
6. BOTANIF GA

- 9SEP1964

FROM BINDERS

$K E W$

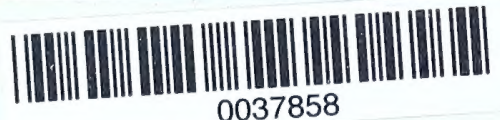

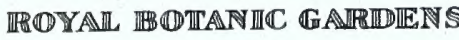

$\mathbb{M} \mathbb{E} \mathbb{E}$

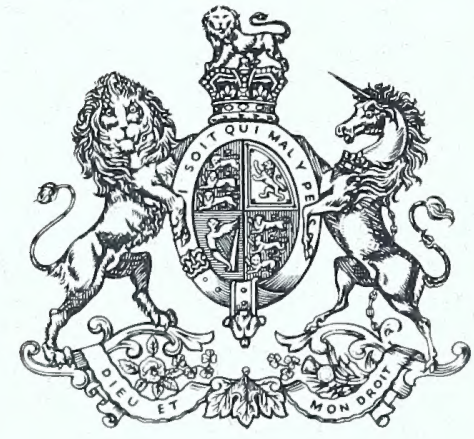

1.

02 


INDEX KEWENSIS

$1886-1895$ 


\section{Digitized by the Internet Archive in 2013}




\title{
INDEX KEWENSIS
}

\section{PLANTARUM PHANEROGAMARUM}

\author{
SUPPLEMENTUM PRIMUM \\ NOMINA ET SYNONYMA OMNIUM GENERUM ET SPECIERUM \\ AB INITIO ANNI MDCCCLXXXVI USQUE AD FINEM \\ ANNI MDCCCXCV COMPLECTENS
}

CONFECERUNT

THEOPHILUS DURAND \& B. DAYDON JACKSON

\author{
BRUXELLIS \\ APUD ALFREDUM CASTAIGNE \\ VIA DICTA BERLAimont, 28 \\ MCMI - MCMVI
}





\section{PREFACE}

THE Index Kewensis is so well-known that it is unnecessary to justify the publication of this first supplement for the decennial period of 1886-1895. There is one thing to be explained - the reason of the delay in its completion. It is a matter of conscience for the author of these lines to absolve Mr B. Daydon Jackson from all responsibility on this point. Shortly after the printing of this volume had begun in Brussels, the state of his own sight, already critical, became so much worse as to cause fear of total blindness. The completion of the work thus only became possible by printing with disheartening slowness, and the correction of proofs during many years, has only been accomplished at the cost of actual suffering.

These circumstances have been the cause of errors which otherwise would not have occurred. The undersigned therefore begs that these defects may not be attributed to his co-author, Mr B. Daydon Jackson, and he relies on the indulgence of all those to whom this work will be of service.

Th. DURAND.

Brussels, June 1906. 


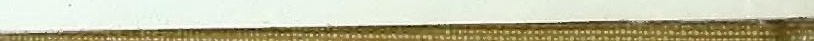




\title{
I N D I IS KEWENSIS
}

\section{SUPPLEMENTUM PRIMUM}

\author{
NOMINA PLANTARUM PHANEROGAMARUM OMNIA \\ A N N IS $1886-1895 \quad$ E D I T A
}

C O M P L E T E N S

\section{AALIUS - ABUTILON}

\section{A}

AALIUS, Rumph. Herb. Amb. iii. (1750) $207=$ Sauropus, Blume (Euphorb.).

androgyna, Kuntze, Rev. Gen. (1891) 591 = S. albicans, Blume.

assimilis, Kuntze, 1. $\mathrm{c}_{\text {. }}=\mathrm{S}$. assimilis, Thw.

brevipes, Kuntze, 1. c. = S. brevipes, Muell. Arg.

Ceratogynum, Kuntze, 1. C. = S. quadrangularis,

Muell. Arg.
compressa, Kuntze, 1. c. =S. compressus, Muell. Arg. forcipata, Kuntze, 1. c. = S. forcipatus, Hook. $f$. lanceolata, Kuntze, 1. c. = S. lanceolatus, Hook.f. macrantha, Kuntze, 1. c. = S. macranthus, Hassk. macrophylla, Kuntze, 1. c. $=$ S. macrophyllus, Hook. $f$. oblongifolia, Kuntze, 1. c. = S. oblongifolius, Hook. $f$. pubescens, Kuntze, 1. c. $=\mathrm{S}$ pubescens, Hook. $f$. quadrangularis, Kuntze, 1. c. = S. quadrangularis, Muell. Arg.

retroversa, Kuntze, 1. c. = S. retroversus, Wight. rhamnodes, Kuntze, 1. c. = S. rhamnoides, Blume. rigida, Kuntze, 1. c. = S. rigidus, Thw.

rostrata, Kuntze, 1. C. = S. Iostratus, Miq. spectabilis, Kuntze, 1. c. = S. spectabilis, Miq. stipitata, Kuntze, 1. c. = S. stipitatus, Hook. $f$. sumatrana, Kuntze, 1. c. = S. sumatranus, Miq. trinervia, Kuntze, 1. c. = S. trinervius, Hook. f. et Thoms.

ABAMA, Adans. = Narthecium, Moehr. (Liliac.). americana, Morong, in Mem. Torrey Bot. Club, v. (1894) $109=\mathrm{N}$. americanum, $\mathrm{Ker}$.

ABATIA, Ruiz et Pav.(Samydac.). - Ind. Kew.i. 1. bnliviana, Britton, in Bull. Torrey Bot.Club, xvii.(1890) 214 (= Graniera boliviana, Mand. et Wedd.).Bolivia.

microphylla, Taub. in Bot. Fahrb. xv, Beibl. 34 (1892) 11. - Bras.

ABELEMIS, Rafin. ex Britton, in Ann. N. Y. Acad. Sc. vi. (1892) $223=$ Anemone, Linn. (Ranunc.). petiolaris, Rafin. ex Britton, I. c. = A. virginiana, Linn.

ABELIA, R. Br. (Caprifol.). - Ind. Kew. i. 2. angustifolia, Bureau et Franch, in Morot, fourn. de Bot. v. (1891) 47. - China.

parvifolia, Hemsl. in foum. Limn. Soc. xxiii. (1888) 358. - China.

mpestris X. Hort. ex Späth, in Gartenfl. (1892) 113 t. 1366. - Hybr. artif.

shikokiana, Makino, in Bot. Mag. Tokyo Soc. vi. (1892) 55 = biflora, Turcz.
ABELICEA, Reichb. = Zelkova, Spach (Urtic.) acuminata, Kuntze, Rev. Gen. (1891) $621=Z$. acuminata, Planch.

cretica, Kuntze, 1. c. $=Z$. cretica, Spach.

ulmodes, Kuntze, 1. c. = Z. crenata, Spach.

ABENA, Neck, = Stachytarpheta, Vahl (Verbenac.).

cayennensis, Hitchc. in Missouri Bot. Gard. Rep.iv. (1893) $117=$ S. cayennensis, Valy.

jamaicensis, Hitchc. 1. c. $=\mathrm{S}$. jamaicensis, Vahl.

ABERIA, Host (Bixin.). - Ind. Kew. i. 2.

hebecarpa, Kuntze, Rev. Gen. (1891) 43 = Gardneri, Clos.

ABIES, Linn. (Conifer.). - Ind. Kew, i, 2

Akatodo, Miyabe, ex Sargent, in Gard. and For, vi. (1898) $525=$ sachalinensis, Mast.

alpestris, Brügor, in Jahresb. Naturf. Ges. Graub. xxix (1886) $126=$ excelsa, $D C$.

lasciocarpa, Sargent, in Gard. and For. ii. (1889) 496 = subalpina, Engelm.

remusta, Sargent, 1. c. = bracteata, Nutt.

ABOLBODA, Humb. et Bonpl. (Xyrid.). - Ind. Kew. i. 3.

Sceptrum, Oliver, in Trans. Linn. Soc.Ser. II, ii (1887) 286; (Oliver, ex im Thurm, in Timehri, v. (1886) 203). - Guian.

ABROMA, Juss. (Stercul.). - Ind. Kew. i. 3. sinuosa, Nichols. Dict. Gard. iv. (1888) 482. - Asia trop.

ABRONIA, Juss. (Nyctagin.). - Ind. Kew. i. 3.

Carletoni, Coult.et Fish. im Coult. Bot. Gaz xvii.(1892) 349. - Colorado.

pogonantha, Heimerl, in Bot. Fahrb. xi. (1890) 87... Calif.

Suksdorfii, Conlt. et Fish. in Coult. Bot. Gaz.xvii. (1892) 338. - Am. bor.

ABROTANELIA, Cass. (Composit.).--Ind. Kew, i. 4 .

caespitosa, Petrie, ex T. Kirk, in Trans. N.Z. Inst. xriv. 1891 (1892) 420. - N. Zel.

muscosa, T. Kirk, l. c. 422, t. 36. - N. Zel.

ABRUS, Linn. (Leguminos.). - Ind. Kew. i. 4. Bottae, Deflers, Voy. Yémen, (1889) 132. - Arab.

Schimperi, Hochst. ex Taub̆. in Engl. Pfanzenw. Ost-Afr.C. (1895) 219 nomen. - Afr, trop.

somalensis, Taub. in Engl. et Pranth, Naturl. Pfanzenfan. iii, 3 (1894) 355. - Somal.
ABSOLMSIA, Kuntze, Rev. Gen. (1891) $417=$ Astrostemma, Benth. (Asclep.).

spartiodes. Kuntze, 1. c. $418 .=$ A. spartioides, Benth.

ABUTILODES, Sieg. Hort. Petrop.i. $(1 / 36)=$ Modiola Moench (Malvac.). carolinianum, Kuntze, Rev.Gen. (1891) 65 = M.multifida, Griseb.

ABUTILON, Tourn. (Malvac.), - Ind. Kew i, 4 Abutilon, Rusby, in Mem. Torrey Bot. Club, v. (1894) $222=\mathrm{A}$. Avicennae, Gartn.

amoenum, K. Schum. in Mart. Fl. Bras, xii. II. (1891) 411. - Bras.

appendiculatum, $K$. Schum. l. c. 408. - Bras.

aristulosum, $K$. Schum. l. c. 379. - Bras.

attenuatum. Rob. et Seaton, in Proc. Am. Acad. xxviii. (1893) 104. - Mexic.

benense, Bak. f. in foum. Bot. xxxi. (1893) 338. Boliv.

bicolor, Philippi, ex K. Schum, in Mart. Fl. Bras. xii. IIr. (1891) 433; et in Anal. Univ. Chit. 1xxxii. (1893) 323. - Chili.

Bridgesii, Bak.f. in foum. Bot. xxxi. (1893) 338.Bolivia.

cinctum, T. S. Brandeg. in Zoe, iii. (1893) $34 \mathrm{~S}=$ Bastardia hirsutiflora. Presl.

cordatum, Garcke et K. Schum. in Mart. Fl. Bras. xii. IIt. (1891) 369. - Peruy.

costicalyx, K. Schum. ex Bak. f. in foum. Bot. xxxi. (1893) 271. - Bras.

discolor, Bak. f. l. c. 73. - Mexic.

Dugesii, S. Wats, in Proc. Am. Acad. xxi. (1886) 447. - Mexic.

Eggersii, Bak. f. in fourn. Bot. xxxi. (1893) \%o. Ins. Baham.

Flueckigerianum, K. Schnm, in Mart. Fl. Bras, xii. IIr. (1891) $370 .-$ Urug.

fluviatile, $K$. Schm?. l. c. 400. - Bras.

Galeottii, Bak.f. in Fourn. Bot. xxxi. (1893) 73. Mexic.

Garckei, Bak, f, l, c, 336, - Chili.

Glaziovii, K. Schum. in Mart. Fl. Bras, xii. II. (1891) 408. - Bras.

Hannii, Bak. f. in fourn. Bot. xxxi. (1893) 268. Austral.

hastatum, Ridl, in Trans. Linn. Soc., Ser. II. iii. (1893) 279. - Penins, Mal.

hirsutum, K. Schum. in Mart. Fl. Bras. xii. III. (1891) 437. - Bras.

Holsti, K. Schum. ex Engl. in Abhand1. Preuss. Akad. Wiss. 1894. (1894) 65 ; et in Engl. Pflanzenw. Ost-Afr. A. (1S95) 110 nomen $=$ intermedium, Hochst.

inaequale, $K$. Schum. in Mart. Fl. Bras. xii. nI.(1S91) $407 .-$ Bras. 


\section{ABUTILON :}

nflatum, Garcke et K. Schum. in Mart. Fl. Bras, xii. III. (1891) 401. - Bras.

lineatum, K. Schun. l. c. 437. - Bras.

Listeri, Bak.f. in fourn. Bot.xxxi.(1893) 269.-Ins, Christmas.

longifolium, $K$. Schum, in Mart. Fl. Bras, xii. III. (1891) 402. - Bras.

malacum, S. Wats, in Proc. Am. Acad. xxi. (1886) 446. - Texas, Mexic

membranaceum, Bak. f. ex 7. N. Rose, in Contrib. U. S. Nat., Herb, iii. (1895) 312. - Mexic. minarum, K. Schum.in Mart.Fl. Bras, xii. III. (1891) 389. - Bras.

molle, Bak. in Kew Bull. (1895) 212. - Afr. trop. or.

monospermum, K. Schum, in Mart. Fl. Bras, xii. II. (1891) 396. - Bras.

Mouraei, K. Schum. l.c. 410. - Bras.

Muelleri-Friderici, Garcke et K. Scmm. l. c. 423.Bras.

Nealleyi, Coult. in Contr. U. S. Nat. Herb. i. (1890) 32 ; et l. f. ii. (1891) 41. - Texas.

neovidense K. Schum. in Mart.Fl. Bras. xii.mr.(1891) 386. - Bras.

Pedrae-brancae, K. Schtmb.l. c. 425. - Bras.

peltatum, K. Schum.l. c. 398. - Bras.

pilosum, $K$. Schum. l. c. 437. - Bras.

purpurascens, $K$. Schm.l. c. 419. - Am. trop

Ranadei, Woodrow et Stapf, in Kew Bull. (1894) 99. - Ind. Or.

reventum, S. Wats, in Proc. Am. Acad. xxi. (1886) 418. - Ariz., Mexic.

Rehmanni, Bak. f. in fourn. Bot.xxxi.(1893) 217. Transv.

rufivellum $K$. Schum. ex Bak.f.l.c. 271 nomen.Bras.

scabridum, K. Schmm.in Mart.Fl.Bras.xii.II.(1891) 413. - Bras.

scabrum, S. Wats, in Proc. An. Acad. xxiv. (1889) 41. - Mexic.

Schenckii, K. Schum. in Mart. Fl. Bras.xii. HI. (1891) 412. - Bras.

senile, $K$. Schum. l. c. 424.- Bras.

silvaticum, $K$. Schum. l. 0.418. - Peruv., Bolivia. sinense, Oliver, in Hook. Icon. Pl. xviii. (1888) t. 1750. - China.

sordidum, K. Schum. in Mart.Fl.Bras, xii.111.(1891) 406. - Argent.

Tiubae, K. Schum. l. c. 381. - Bras.

usanbarense, K. Schum. ex Engl. in Abhandi. Preuss. Akad. Wiss. 1894 (1894) 65; et in Engl. Pflanzenw. Ost-Afr. A. (1895) 110 nomen = longicuspe, Hochst.

virginale, Hort. Damm. ex Regel, in Gartenfl. (1891) 74. (Quid?). - Hab.?

viride, Phil. in Anal. Univ. Chil. Ixxxii. (1893) 323. - Chili.

wissaduloides, Bak. f. ex. F. N. Rose, in Contrib. U. S. Nat. Herb. iii. (1895) 312. - Mexic.

Xanti, A. Gray, in Proc. Am. Acad. xxii. (1887) 301. - Calif.

ACACIA, Linn. (Legumin.). - Ind. Kew. i. 6 .

anisophylla, S. Wats. in Proc. Am. Acad. xxi.(1886) 452. - Mexic.

ataxantha «DC.» ex Taub. in Engl. Pflanzenw. Ost-Afr. C. (1895) 194 (err. typ.) = ataxacantha, $D C$.

Baileyana, F. Muell. in Trans. and Proc. Roy. Soc. Vict. xxiv. (July 1888) 168; et in Gard. Chron. (1894) II. 37 tig. 4. - Austral.

Bakeri, 7. H. Maiden, in Proc. Linn. Soc. N.S.W Wales, Ser. II.x. (Nov. 1895) 337, t. 21. - Austral.

biaciculata, S. Wats, in Proc. Am. Acad.xxi. (1886) 452. - Mexic.

californica, T. S. Brandeg. in Proc. Callf. Acad. Ser. II. iii. 1892. (1893) 221. - Calif.

chrysothrix, Taub. in Engl. Pflanzenw. Ost-Afv. C. (1895) 194. - Afr. trop. or.

cinerea, Schinz, in Verh. Bot. Ver. Brand. xxx. (1888) 240. - Afr. austro-occ.

Cowleana, Tate, in Trans. Roy. Soc. S. Austral. xix. (1895) 81, nomen. - Austral.

craspedocarpa, F. Muell. in Chem. and Drug. Austral. (March 1887) 73. - Austral.

Delavayi, Franch. Pl. Delav. (1890) 194. - Yunnan.

\section{ACACIA}

dulcis, Marl. et Engl. in Bot. Fahrb. x. (1889) 24. Afr. austro-occ.

filiculoides, Trel. ex Branner et Coville, Report Geol. Surv. Ark. 1888, iv.(1891) 178 = filicina, Willd. frumentacea, Tate, in Trans. Roy. Soc. S. Austral. xix. (1895) 81, nomen. - Austral.

glandulifera, S. Wats. in Proc. Am, Acad. xxv. (1890) 14\%. - Mexic

Goeringii, Schinz, in Verh. Bot. Ver. Brand. xxx. (1888) 239. - Afr. austro-occ.

Graffiana, F. Muell. in Chem. and Drug. Austral. (May 1887) 118. - Austral.

hereroensis, Engl. Bot. Fahrb. x. (1889) 20. Afr. austro-occ.

Holstii, Taub. in Engl. Pfanzenw. Ost-Afv. C. (1895) 194. - Afr, or

Howitti, F. Muell, in Vict. Natural. x. (May 1893) 16. - Austral.

Jonesii, F. Muell. et F. H. Maiden, in Proc. Linn. Soc. N. S. Wales, Ser. II, viii. (July 1893) 13 t. 2. - Austral.

kauaiensis, Hillebr. Fl. Haw. Isl. (1885) 113. Ins. Sandvic.

Kelleri, F. Muell. in Proc. Linn. Soc. N. S. Wales, Ser. II. vi. (May 1892) 468. - Austral.

Koaia, Hillebr. Fl. Haw. Isl. (1888) 113. - Ins. Sandvic.

leptosperma, Bello, Estud. A. Porto-Rico, iii. (1885) 154 - Ins. Porto-Rico.

Luederitzii, Engl. Bot. fahwb. x. (1889) 23. - Afr. austro-occ.

lutea, Britton, in Bu11. Torrey Bot. Club, xvi.(1889) $327=$ Mimosa lutea, Mill.

Maidenii, F. Muell, in Macleay Mem. Linn. Soc. N. S. Wales, (1893) 222 t. 29. - Austral.

Maras, Engl. Bot. fahrb. x. (1889) 24. - Afr. austro-occ.

Marlothii, Engl. l. c. 19. - Afr. austro-occ.

melaleucoides, F. M. Bailey, in Proc. Roy. Soc Queensl. v. 121 ex eod. Syn. Queensl. Fl. Suppl. iii. (1890) 23 = Sutherlandi, F. Muell.

Merrallii, F. Muell in Proc. Limn. Soc. N S. Wales, Ser. II, v. (June 1890) 18. - Austral.

nillefolia, S. Wats in Proc. Am. Acad. xxi. (1886) 427. - Mexic,

Muelleriana, F. H. Maidesi et R. F. Baker in Proc. Linn. Soc. N.S. Wales, Ser. II, viii.(June 1894) 515 , t. 25. - Austral.

neglecta, F. H. Maiden et R. F. Baker, l. c. ix. (Sept. 1894) 163 t. 13. - Austral.

O'Shanesii, F. Muell. et F. H. Maiden, l. c. viii. (July 1893) 15 in obs. - Austral.

Pringlei, Rose, in Contrib. U. S. Nat. Herb. iii. (1895) 316. - Mexic.

pumila, F. H. Maiden et R. F. Baker, in Proc. Linn. Soc. N. S. Wales, Ser. II, x. (Nov. 1895) 385, t. 28. - Austral.

Robecchii, Pirotta, in Bull. Soc, bot. Ital. (1893) 61. - Afr.or.

Rossei, F. Muell. in Vict. Natural. x. (July 1893) 55. - Austral.

Spilleriana, f. E. Br. For. Fl. S. Austral. i. t. 44. - Austral.

spinosa, Marl. et Engl. in Bot. Fahrb. x. (1889) 20. - Afr. austro-occ.

spirocarpoides, Engl. Bot. Fahrb. x. (1889) 23. Afr. austr.

spodiosperma, F. Muell. in Trans. Linn. Soc. N.S. Wales, Ser. II, iii. (Jan. 1888) 164. - Austral. occ. Stuhlmannii, Taub. in Engl. Pfanzenw. Ost-Afr. C. (1895) 194. - Afr. or.

Sutherlandi, F. Muell. Ic. Acacia 12th. Decade $(\mathbf{1 8 8 8})=$ Albizzia Sutherlandi, F. Muell.

teitensis, Taub. in Engl. Pflanzenw. Ost-Afr. A. (1895) 49 nomen = subalata, Valke.

tenax, Marl. in Bot. Fahrb. viii. (1887) 254. Afr, austr. (Kalahari).

tequilana, S. Wats. in Proc. Am. Acad.xxii. (1887) 409. - Mexic.

uncinata, Engl. Bot. Fahrb. x. (1889) 21. - Afr. austro-occ.

usambarensis, Taub. in Engl. Pfanzenw. Ost-Afr. C. (1895) 195. - Afr. or.

Willardiana, Rose, in Contrib. U.S. Nat. Herb. i. (1890) 88 (= Prosopis heterophylla, Benth.). Mexic.
ACAGIA :

xiphocarpa, Hochst. ex. Engl. in Abhandl. Preuss. Akad. Wiss. 1891. (1892) 240. - Abyss.

xiphoclada, Bak. in foum. Linn. Soc. xxii. (1887) 468. - Madag.

yunnanensis, Franch. Pl. Delav. (1889) 193. Yunnan.

zanzibarica, Taub. in Eng1. Pflanzenw. Ost-Afr. C. (1895) $195=$ Pithecolobium zanzibaricum, S. Moore.

ACAENA Linn, (Rosac.). - Ind. Kew, i. 13.

apitata Phil. in Anal. Univ. Chil. Ixxxiv. (1894) 623. - Chili.

euacantha, Phil. l. c. 620. - Chili.

fuegina, Phil. l. c.620.- Terr. Fuegia.

leptophylla, Phil. l. c. 622. - Chili.

longifolia, Phil. l. c. 624.-Chili.

macrantha, Colenso, in Trans. N.Z. Inst. xxiii. 1890 (1891) 383, - N. Zel.

montana, F. Muell. in Papers and Proc. Roy. Soc. Tasm. (1891-92) 15. - Tasm.

nivalis, Phil. in Anal. Univ. Chil. 1xxxiv. (1894) 619 - Chili.

parvifolia, Phil. l. c.622.-Chili.

Pearcei, Phil. l. c. 626. - Chili.

petiolulata, Phil. l. c. 624. - Chili

sericea, Phil.l.c.621. - Terr. Fuegia.

ACAL YPHA, Linn. (Euphorb.). - Ind. Kew. i. 14. acmophylla, Hemsl. in foum. Linn. Soc. xxvi. (1894) 436. - China.

acuminata, Baill. Hist. pl. Madag.. Atlas (1891) t. 188. - Madag.

agrestis, Morong, ex Britton, in Ann. N. Y. Acad. So. vii. (1893) 225. - Parag.

albicans, Heyne, ex Hook. f. Fl. Brit. Ind. v. (1887) 417 in syn. = fallax, Muell. Arg.

aliena, Brandeg. in Proc. Calif. Acad. Ser. II. iii. (1891) 172, - Calif.

ambigua, Pax, in Bot. Fahrb. xix. (1894) 96. Angola.

amphigyne, S. Moove, in Trans. Linn. Soc. Ser. II. iv. (1895) $46 \%$ - Bras.

angustissima, Pax, in Bot. fahrb. xix. (1894) 99. Congo.

Bakeriana, Baill. in Bull. Soc. Linn. Par. ii. (1895) 1180. - Madag.

Baurii, Rob. et Greenm. in Am. Foum. Sc. Ser. III. I. (1895) 144. - Ins. Galap.

capillaris, Rusby, in Mem. Torrey Bot. Chub, iv. (1895) 257. - Bolivia.

collina, Hayne, ex Hook. f. Fl. Brit. Ind. v. (1887) 417 in syn. = fallax, Muell. Arg.

comonduana, Millsp. in Proc. Calif. Acad. Ser. II. ii. (1889) 222. - Calif.

comorensis, Pax, in Bot. Fahrb. xix. (1894) 95. Ins. Comor.

crotonoides, Pax, l. c. 97. - Angola.

Dalzellii, Hook. f. Fl. Brit. Ind. v. (188\%) 414.Ind. or.

diminuta, Baill. Hist.pl. Madag., Atlas (1891) t. 194. et in Bull. Soc. Linn. Par. ii. (1895) 1198 et 1281. - Madag.

dioica, S. Wats, in Proc. Am. Acad. xxv (1890) 162. - Mexic.

dissitiflora, S. Wats. l. c. xxvi. (1891) 148. - Mexic erubescens, Rob. et Greenm. in Proc. Am. Acad. xxix. (1894) 393. - Mexic.

filifera, S. Wats. l. c. xxii. (1887) 451. - Mexic.

flavescens, S. Wats. l. c. xxvi. (1891) 149. - Mexic.

floribunda. Heyne, ex Hook. f. Fl. Brit. Ind, v (1887) 417 in syn. = fallax, Muell. Arg.

glandulifera, Rob. et Greenm. in Am. fourn. Sc. Ser III, 1. (1895) 164. - Mexic.

Hamiltoniana, Hort. ex Bruant, Catal. (1895) ex Kew Bull. (1896) 2 - Hab.

haplostyla, Pax, in Bot. fahrb. xix. (1894) 98. - Congo.

hibiscifolia, Britton, in Mem. Torrey Bot. Club, ix. 1895) $25 \%$ - Bolivia.

Hildebrandtii, Baill. in Bull. Soc. Linn. Par. ii. (1892) 1005. - Madag.

Humblotiana, Baill. Hist. pl. Madag., Atlas (1891) t. 190 ; et in Bull. Soc. Linn. Par. ii. (1895) 1198. Madag. 
ACAL YPHA :hypogaea, $S$. Wats. in Proc. Am. Acad. xxii. (1887)
451 . - Mexic.

irazuensis, Kuntze, Rev. Gen. (1891) 616. - CostaRica.

Johnstoni, Pax, in Abhandl. Preuss. Akad. Wiss. 1891. ii. (1892) 283. - Afr. trop.

juliflora, Pax, in Bot. Fahrb. xix. (1894) 95. Madag.

Leoni, Baill. in Bull. Soc. Linn. Par. ii. (1895) 1197. - Madag.

leptomyura, Baill. l. c. ii. (1892) 1004. - Madag.

longipes, S. Wats, in Proc. Am. Acad. xxvi. (1891) 149. - Mexic.

longispica, Warb. in Bot. Falmb. xviii. (1894) 197.Oceania.

Lotsii, f. D. Sm. in Coult. Bot. Gaz. xx.(1895) 544. - Guatem.

madreporica, Baill. Hist. pl. Madag., Atlas (1891) t. 186; et in Bull. Soc. Linn. Par. ii. (1895) 1181. - Madag.

meiodonta, Baill. in Bull. Soc. Linn. Par. ii. (1895) 1197. - Madag.

multispicata, S. Wats, in Proc. Amer, Acad. xxvi. (1891) 148. - Mexic

Noronhae, Ridl. in fourn. Linn. Soc. xxvii. (1890) 59. - Ins Fernando Noronha.

novo-guineensis, Warb. in Bot. fahrb. xiii. (1891) 359. - Oceania.

polynema, Baill. Hist. pl. Madag., Atlas (1891) t. 187; et in Bull. Soc. Linn. Par. ii. (1895) 1197. Madag.

Radula, Baill. l. c. t. 193. - Madag.

ruderalis, Mart. ex Britton, in Ann. N. Y. Acad. Sc. vii. (1893) 225. - Parag.

scandens, Warb. in Bot. Fahrb. xiii. (1891) 359. Oceania.

sessilifolia, S. Wats, in Proc. An, Acad, xxii. (1887) 450. - Mexic

somalensis, Pax, in Bot. Fahrb. xix. (1894) 100.Afr. trop. or.

squarrosa, Pax, l. c. 91. - Madag.

stenophylla, K. Schum. in Bot. Fahrb. ix. (1888) 206. Nov. Guin.

stipularis, Engl. l. c. vii. (1886) 462. - Ins. Fiji.

Stuhlmannii, Pax, l.c.xix. (1894) 99.-Afr.trop.-or.

subviscida, S. Wats, in Proc. Am. Acad.xxi. (1886) 440. - Mexic.

Teusczii, Pax, in Bot. Falzrb. xix. (1894) 98. Angola.

triumphans, L. Lind. et Rodig. in Illustr. Hort. (1888) 55 t. $55 .=$ tricolor, Seem.

urophyla, Pax, in Bot. Fahrb. xix. (1894) 96. Madag.

Volkensii, Pax, in Engl. Pflanzenw. Ost-Afr. C. (1895) 239. - Afr. trop. or.

vulneraria, Baill. in Bull. Soc. Limn. Par.ii. (1895) 1180. - Madag.

ACAMPE, Lindl. (Orchid.). - Ind. Kew i. 17 madagascariensis, Kraenzl. in Gard. Chron. (1891) II. 608. - Madag.

mombasensis, Rendle, in fourn. Linn. Soc. xxx. (1895) 386. - Afr. trop. or.

ACANTHELLA, Hook, f. (Melastom.).-Ind.Kew. i. 17.

conferta, Cogn. in Mart. Fl. Bras, xiv. IV. (1886) 6. - Bras

AGANTHOLIMON, Boiss. (Plumbag.), - Ind. Kew. i. 17

Ecae, Aitch, et Hemsl. in Trans. Limn. Soc., Ser. II iii. (1886) 84. - Turkest.
iit.

sarawschanicum, Golenkin, in Act. Hort. Petrop. xiii. (1894) 85. - Turkest.

speciosissimum, Aitch. et Hemsl, in Trans. Linn. Soc. Ser. 11. iii. (1886) 85. - Turkest.

ACANTHONYCHIA, Rohrb. = Pentacaena, Bartl. (Illecebr.).

ramosissima, Fr. Meigen, in Bot. Jahrb. xvii. (1893) $232=$ P. ramosissima, Hook, et Arn
ACANTHOPANAX, Miq. (Araliac.). - Ind. Kew. i, 18

diversifolium, Hemsl. in foum. Linn. Soc. xxiii. (1888) 340. - China.

etulosum, Franch. in Nouv. Arch. Mus. Paris, Sér. II. viii, 1885 (1886) 249, - China.

ACANTHOPHOENIX, H. Wendl. (Palm.). Ind. Kew. i, 18.

grandis, Hort. ex Illustr. Hortic. (1895) 185. - Bras?

ACANTHOPHYLLUM, C.A. Mey.(Caryoph.) - Ind. Kew. i, 18

brevibracteatum, Lipsky, in Mém. Soc. Natur. Kiew, xii. (1889) 6. - Ross.

kurdicum, Boiss, et Hausskn. ex Boiss. Fl. Or. Suppl. (1888) 90. - Persia.

latifolium, Lipsky, in Mém. Soc. Natur. Kiew, xii. (1889) 6. - Ross.

recurvum, Regel, in Act. Hort. Petrop. ix. (1886) 606 - Turkest.

spinosum, Kuntze, in Act. Hort. Petrop. x. (1887) $172=$ Dianthus spinosus, Desf.

ACANTHOPSIS, Harv.(Acanth.).-Ind.Kew.i, 19 carduifolia, Schinz, in Verh. Bot. Ver. Brand. xxxi. (1890) 200. - Afr. austr.

glauca, Schinz, l, c. 201.-Afr. austr.

spathularis, Schinz, l.c. 201. - Am. bor.

ACANTHOSPERMUM, Schrank (Compos.). Ind. Kew. i, 19

australe, Kuntze, Rev. Gen. (1891) $303=$ brasilum, Schrank

lecocarpoides, Rob. et Greenm. in Am. Fourn. Sc. Ser. III. 1. (1895) 141. - Ins. Galap.

ACANTHOSTACHYS, Link (Bromel.). - Ind Kew. i. 19.

ananassoides, Bak. Handb. Bromel. (1889) 25.Bras.

AGANTHUS, Linn. (Acanth.). - Ind. Kew. i. 19. Boissieri, Hausskn. in Mith. Bot. Ver. Fena, v (1887) 62. - Graecia.

Caroli-Alexandri, Hausskn. in Gartenfl. (1886) 626; et in Mitth. Bot. Ver. Fena, v. (1887) 62. Graecia.

caudatus, Lindau, in Bot. Fahrb. xx. (1894) 33. Angola.

Gaëd, Lindın, l. c. - Afr. trop.-or.

mayaccanus, Buittn, in Verh. Bot. Ver. Brand.xxxii (1890) 37. - Congo.

neo-guineensis, Engl. Bot. Jahrb. vii. (1886) $474=$ ilicifolius, Linnz.

pubescens, Engl. in Abhandl. Preuss. Akad. Wiss. 1891, ii. (1892) 390. - Afr. trop. or.

ACANTHYLLIS, Pomel = Anthyllis, Riv. (Legum.).

armata, Batt. in Batt. et Trab. Fl.de l'Algér.(1889) 251. - Alger.

ACCA, Berg., = Psidium, Linn. (Myrtac.).

Glazioviana, Kiaersk. Enum. Myrtac. Bras. (1893) 115 , t. 10 c. - Bras.

ACER, Linn. (Sapind.). - Ind. Kew. i, 20.

ambiguum, Dippel, Handb. Laubholzk. ii. (1892) 457, fig.218. - Japon.

atropurpureum, Hort. ex Dippel, l. c. $426=\mathrm{A}$ Pseudo-Platanus, Linn.

Bedoi, Borb. Enum, pl. Com. Castrif. (1887) 267; et in Termész. Fiuzet. xiv. (1891) $70=$ campestre, Linn

betulifolium, Maxim, in Act. Hort. Petrop.xi. (1889) 108. - China.

Bornmuelleri $x$, Borb. in Termész. Füzet, xiv. (1891) 70 et $75=$ campestre, Linn.

cordatum, Pax, in Hook. Icon, Pl xix. (1889) sub t. 1897 in nota 6 . - China.

cucullatum, Hort. ex Dippel, Handb. Laubholzk. ii (1892) 45\%, fig. 218. - Japon.

Davidi, Franch, in Nouv. Arch. Mus. Paris, Sér. III viii. (1885) 212. - China.

decompositum, Hort, ex Dippel, Handb. Laubholzk. ii. (1892) $464=$ palmatum, Thunb.

\section{ACER}

denticulatum, Hort. ex Dippel, Handb. Laubholzk ii. (1892) $448=$ monspessulanum, Linn.

Dieckii, Pax, in Bot. Fahrb. xvi. (1893) 402. Hab.

digitatum, Hort. ex Dippel, Handb. Laubholzk. ii. (1892) 577 (Quid?)

divergens, C. Koch et Pax, ex Pax, in Bot. Fahrb. vii. (1886) 234. - Reg. Cauc

Duretti $\times$ Hort. ex Pax, 1. c. xvi. (1893) 397.Hybr. artef.

rosum, Pax, in Hook, Icon, Pl, xix. (1889) sub t. 1897 in nota 10. - China.

erythrocarpum, Hort. ex Dippel, Handb. Laubholzk. ii. (1892) $426=$ A. Pseudo-Platanus, Limn.

euchlorum, Hort, ex Dippel, 1. c. 426. = A. Pseudom Platanus, Limn.

fallax, Pax, in Bot. Fahrb. vii. (1886) 238. - Dalm.

floridanum, Pax, i. c. 243. - Florida.

fulgens, Hort. ex Dippel, Handb. Laubholzk. ii. (1892) $435=$ rubrum, Limn

Francheti, Pax, in Hook. Icon. Pl. xix. (1889) sub t. 1897 , in nota 12. - China.

haplolobum, Borb. in Termész. Füzet, xiv. (1891) 70 et $75=$ campestre, Limn.

Heckianum, Aschers. ex Wesm. in Bull. Soc. bot Belg. xxix. (1890) $51=$ monspessulanum, Linn.

Henryi, Pax, in Hook. Icon. Pl. xix. (1889) t. 1896. - China.

heterotomum, Borb, in Termész, Füzet, xiv. (1891) \%0 et $75=$ campestre, Linn

Inngaricum, Borb. 1. c. xiv. (1891) $70=$ monspessulanum, Linn

incisum. Hort. ex Dippel, Handb. Laubholzk, ii (1892) $464=$ palmatum, Thunb

eucoderme, Small, in Bull. Torrey Bot. Club, xxii. $1895) 367=$ floridanum, $P a x$

liburncum, Hort. ex Dippel, Handb. Laubholzk. ii. (1892) $448=$ monspessulanum, Lim

Lorbergi, Hort. ex Dippel, 1. c. 451 = platanoides, Limn.

Maximowiczii, Pax, in Hook. Icon. Pl. xix. (1889) sub t. 1897 in nota 11. - China.

mexicanum, Pax, in Bot. Jahrb. vii. (1886) $212=$ Negundo mexicanum, $D C$

microphyllum, Pax, $\ell$. c. 180. - Am. bor.

Miyabei, Maxim. in Bull. Acad.Sc.St-Pétersb. xxxii. (1888) 485. - Japon.

molle, Pax, in Bot. Fahrb. xi. (1890) 74. - Reg. Himal.

multiserratum, Maxim, in Act. Hort. Petrop. xi. (1889) 107. - China.

Murrayanum, Hort, ex Dippel, Handb. Laubholzk. ii. (1892) $426=$ macrophyllum, Pursh

nebrodense. Tineo, ex Pax, in Bot. Jahrb. vii. (1886)

$192=$ A. Pseudo-Platanus, Limn.

nepalense, Hort, ex Dippel, Haridb. Laubholz. ii. (1892) $410=$ oblongum, Wall.

oblongifolium, Hort. ex Dippe1, 1. c., $416=$ oblongum, Wall.

Oliverianum, Pax, in Hook. Icon. Pl.xix. (1889) sub t. 1897 in nota $2 .-$ China.

Pavia, Hort, ex Dippel, Handb. Laubholzk. ii. (1892) 436 = dasycarpum, Ehr

Paxii, Franch. in Bull. Soc. bot. Fr. xxxiii, (1886) 464 ; et Pl. Delav. (1889) 144. - Yunnan.

pinnatifidum, Hort. ex Dippel, Handb. Laubholzk. ii. (1892) $464=$ palmatum, Thnnb.

pulverulentum, Hort. ex Dippel, 1. c. 578 (Quid?).

purpureum, Hort. ex Dippel, 1. c. $426 .=$ A. PseudoPlatanus, Linn.

Rafinesquianum, Hort. ex Dippel, 1. c. ii. (1892) $426=$ A. Pseudo-Platanus, Iinn.

Reitenbachii, Hort. ex Dippel, 1. c. 578 (conf. 451) = platanoides, I, inn

ribesifolium, Hort. ex Dippel, 1. c. 578 (conf. 463) = palmatum, Thunb.

Rugelii, $\mathrm{Pax}$, in Bot. Jahrb. vii. (1886) $243=$ ? saccharinum, Wangenh.

Schwerini, Pax, l. c. xvi. (1893) 398. - Reg. Himal.

semiorbiculatum, Pax, l. c. vii. (1886) 181. Am. bor.

sinense, Pax, in Hook. Icon. Pl, xix. (1889) sub t. 1897 in nota $1 . \rightarrow$ China

splendeus, Hort. ex Dippel, Handb. Laubholzk. ii. (1892) $435=$ rubrum, Linn. 
ACER :

sutchuenense, Franch. in Morot, Fourn. de Bot. viii. (1894) 294. - China

tauricum, Hort, ex Dippel, Handb. Laubholzk. ii. (1892) 441 = campestre, Linn

tenellum, Pax, in Hook. Icon. Pl. xix. (1889) t. 1897. - China.

tetramerum, Pax, in Hook. l. co sub t. 1897 in nota 13. - China.

trinerve Hort. ex Dippel, Handb. Laubholzk, ii. (1892) 428. - Japon

Tschonoskii, Maxim. in Bull. Acad. Sc. St-Pétersb. xxxi. (1887). - Japon.

urophyllum, Maxim. in Act. Hort. Petrop. xi. (1889) 105. - China.

velutinum, Hort, ex Pax, in Bot. Jahrb. xvi. (1893)

$395=$ Trautvetteri, Medwedj.

Wagnevi, Hort. ex Wesm, in Bull. Soc. bot. Belg. xxix. (1890) 28 = rubrum, Linn

Willkommii, Wettst. in Sitzb. Akad. Wiss. Wien, xcviii. 1889 (1890) 384 - Asia Min,

Worlee, Hort. ex Dippel, Handb. Laubholzk. ii. (1892) $426=$ A. Pseudo-Platanus, Linn.

zoeschense, Pax, in Bot. Jahrb. vii. (1886) $233=$ neglectum, Lange.

A CERAS, R. Br. (Orchid.) -- Ind. Kew, i. 21. calcarata, G. Beck, in Ann. Nat. Hofmus. Wien, ii. (1887) 55, t. 1 fig. $4=$ Orchis hircina, Crantz. Vayrae X, C. Richt. P1. Europ. i. (1890) 276.Hisp

Vayredae, Rouy, Annot. P1. Europ. $(1890) 276=$

praec.
Weddellii $\times$, G. Camus, in Morot, Journ. de Bot. vi. (1892) 108 in syn. - Gall.

ACERATES Ell. = Gomphocarpus, R. Br. (Asclepiad.).

floridana, Hitchc, in Trans. Acad. Sc. St-Louis, (1892) $508=$ G. longifolius; Spreng.

ACERIPHYLIUM, Eng1, in Engl. et Prantl, Natur1 Pflanzenfam. 1ii.2 a (1890) 52 (Saxifrag.) Bossii, Engl.l. c. 52. - China.

ACETOSELIA, Moehr. (Prim. Lin. Hort. Priv, 4) $(1736)=$ Oxalis, Linn. (Geraniac.).

abyssinica, acuminata, acutifolia, adenodes, adenophylla, adspersa, affinis, aganophila, alata, albicans, algoënsis, alsinodes, amara, amazonica, andicola, angusta, angustifolia, antucensis, approximata, aptera, arachnodea. Arbuscula, arenaria, articulata, asinina. bahiensis balsamifera, Barretieri, Berlandieri, Berteroana, bifolia, bifrons, bifurca, biglandulosa, bipartita, borjensis, breviscapa, Bridgesii, bryodes, buplewrifolia, Burkei, Bustillosii, caesia, caespitosa, caledonica, calliantha, calva, campestris, cana, capillacea, caprina, cearensis, cermua, chrysantha, ciliaris, cineracea, clavifolia, collina, Commersonii, compacta conpressa, confertissima, conorhiza, convexula, coqumpressa, confertissma, conorhiza, convexula, cocrispula, cruentata, Cumingii, cunnulata, daphniformis, debilis, decaphylla, decipiens, delicata densifolia. Deppei, dichondrifolia, dichotomiflora, diffusa, discolor, distans, disticha divaricata, dirergens, Dregei, droserodes, Drummondii, dumetorun, ebracteata, Eckloniana, Ehrenbergii, elatior, elegans, cnneaphylla, evemobia, erioclados, eriorhiza, erythrorhiza, euphorbiodes, excisa, Falconiana, fasciculata, filiformis, fabellifolia, flava, florida, frutes cens, Fruticula, Galeottii, Gardneriana, Gaudichaudii. Gayane, geminata, glabra, glandulosa, glauca, glaucovirens, Glazioviana, glutinosa, goyazensis, gracilis, Govrens, Glazrovana, ghutinosa, goyazensis, gracilis, grisea, gyrorhiza, Haenkeana, hedysarodes, herpestica, heterophylla, hirsuta, hirsutissima, hirta, hispidula, imbricata, incana, incarnata, insipida. facquiniana, japonica laburnifolio laciniata lanata, lasiandra, lasiopetala, lateriflora, Laurcola, laxa, leptocalyx, leptophylla, ligulata, lilacina, limosa, Lindenii, lincaris, lineata, liniflora, livida, lobata, lotodes, lunulata, lupinifolia, luteola, macropus, macrorhiza, magellanica, mallobolba, mandioccana, maritima. medicaginea, megalorhiza, megapotamica, Meisneri, melanosticta, melilotodes, Meyeri, microphylla, minuta, modesta, mollis, monophylla, montevidensis, multicaulis, Mundtii, muscodes, myriophylla, natans, Neaei,

\section{ACETOSELLA :}

nervosa, Nenwiediu, nigrescens, nudiflora, obliquifolia, obtriangulata, obtusa, oregana, ornithopus, Ortgiesii. ovata, oxypteva, pachyphylla, paludosa, papilionacea, paposana, pardalis, parvifolia, Pearcii, pedunculavis, ponicillata, pentantha, pentaphylla, physocalyx, pilo sissima, pilulifera, platensis, platycaulis, platypila, Poeppigii, Pohliana, polyphylla, polytricha, praetexta, primulifolia, prorepens, psilotricha, psoralodes, puberula, pubescens, punctata, purpurata, quinata, radiata, recticaulis, refracta, Regnellii, reticulata, rhombeoovata, rhombifolia, rosea, rosellata, rubra, rubrocincta, rupestris, rusciformis, saliciformis, sarmentosa, saxatilis, scandens, Schomburgkiana, Schraderiana, Sellowiana, semiglandulosa, semiloba, sepium, sericea, serpens, setosa, simulans, spodiophylla, squamata, squarrosa, staphylodes, stellata, stictophylla. strictula, strigulosa, subacaulis, subcarnosa, succulenta, suffruticosa, tenella, tenera, tenuifolia, tephrodes, teretifolia, tetraphylla, tomentella, tomentosa tortuosa, triangularis, trachocalyx, trilliifolia, truncatula, tuberosa, umbraticola, valdiviensis, variabilis, versicolor verticillata villosa, Vinaquillo violacea, virginea, virgosa, Wrightii, xiphophylla, Zeyheri. zonata, Kuntze, Rev. Gen. (1891)90-93, = homonyma omnia Oxalidis.

alba, Kuntze, 1. c. $90=$ O. Acetosella, Lim albida, Kuntze, 1. c. $91=0$. leucotricha, Turcz. ambigua, Kuntze, 1. c. $90=$ O. mutabilis, Sond. arcuata, Kuntze, 1.c. = O. linearis, facq. aureoflara, Kuntze, 1. c. $91=0$. parvifolia, $D C$ Bakeriana, Kuntze, 1. c. = O. villosa, $B a k$. bifida, Kuntze, 1. c. = O. bifida, Thunb

brevicaulis, Kuntze, 1. c. = O. brevicaulis, Sond. brevicaulis, Kuntze, 1. c. = O. brevicaulis, Stend. calligera, Kuntze, 1. c. = O. foveolata, Turcz. chinensis, Kuntze, 1. c. = O. stricta, Linn.

clandestina, Kuntze, Rev. Gen.(1891) $92=0$. clandestina, Phil

comosa, Kuntze, 1. c. $91=$ O. comosa, E. Mey. comosa, Kuntze, 1. c. $92=0$. comosa, Prog. confertifolia, Kuntze, 1. c. $91=0$. densifolia, Zuco. crispa, Kuntze, 1. c. $90=0$. fabaefolia, facq. falcata, Kuntze, 1. c. $91=0$. linearis, facq. fontana, Kuntze, 1. c. = O. corniculata, Limn. gracilicaulis, Kuntze; 1. c. = O. Smithiana, Eckl. et Zeyh.

hapalconidea, Kuntze, 1. c. $92=$ O. geminata, Hook et Arn.

Hernandczii, Kuntze, 1.c. =O. decaphylla, H. B. et $K$ holoserice, Kuntze, 1. c. $91=$ O. holosericea, Sond. holosericea, Kuntze, 1. c. $92=0$. holosericea, Phil. lencantha, Kuntze, 1. c. $91=$ O. alba, D. Don. macrostylis, Kuntze, 1. c. = O. tubiflora, facq. Martiana, Kuntze, 1. c. $90=$ O. corymbosa, $D C$. micrantha, Kuntze, 1. c. $92=$ O. laxa, Hook, et Arn. minima, Kuntze, 1. c. $91=0$. commutata, Sond ornata, Kuntze, 1. c. $92=0$. ornata, Plit.

pentaphyllodes, Kuntze, 1. c. $91=0$. variifolia, Steud. Perdicaria, Kuntze, 1. c. = O. 1obata, Sims.

Phitippiana, Kuntze, 1. c. = O. microphylla, (Phil. in Linnaea, xxxiii. (1864-65) 35.)

polyantha, Kuntze,1.c. $92=$ O.geminata, Hook.et Arn. pracox, Kuntze, 1. c. $93=$ O. praecox, Prog. purpurea, Kuntze, 1. c. $90,91=$ O. purpurea, Linn. pygmaea, Kuntze, 1. c. $92=0$. pygmaea, Phil. ramigera, Kuntze, 1. c, $91=0$. gymnoclada, Turcz. Savignyaua, Kuntze, 1. c. = O. virgosa, Molina? semiglauca, Kuntze, 1. c. $90=0$. goniorhiza, Eckl. et Zeyh

Sonderiane Kuntze, 1. c. $91=0$. minima, Sond. squammosoradiata, Kuntze, 1. c. $92=0$. squamoso-radicosa, Sterd.

stricta, Kuntze, 1. c. $91=$ O. corniculata, Lim.

sulfurea, Kuntze, 1. c. = O. pulchella, facq.

trifoliata, Kuntze, 1. c. $90=$ O. namaquana, Sond. witenhagensis, Kuntze, 1. c. $91=0$. psilopoda, Turcz. viscosa, Kuntze, 1. c. $91=0$. viscosa, E. Mey.

Zuccariniana, Kuntze, 1. c. $93=$ O. Zuccarinii, Prog.

ACHAETOGERON, A. Gray (Composit.). Ind. Kew. i. 21.

affinis, A. Gray, in Proc. Am. Acad, xxi. (1886) 386. - Mexic.

Forreri, Greenc, Pittonia, i. (Jan. 1888) 155.-Mexic. linearifolius, S. Wats, in Proc. Am. Acad. xxvi. (1891) 139. - Nexic.

\section{ACHAETOGERON}

Palmeri, A. Gray, in Proc. Am. Acad. xxi. (1886) 386. - Mexic.

pinnatifidus, A. Gray, in Proc. Am. Acad. xxi. (1886) 386. - Mexic.

ACHARITEA, Benth. (Verbenac.). - Ind. Kew. i. 21

glandulosa, S. Elliot, in fourn. Linn. Soc. xxix. (1891) 43. - Madag.

ACHATOCARPUS, Triana (Amarant.). - Ind. Kew. i. 22.

Balansae, Schinz et Autran, in Bull. Herb. Boiss. i. (1893) 6. - Parag.

bicornutus, Schinz et Autran, l.c.7. - Parag. microcarpus, Schinz et Autran, l. c. 8. - Parag. obovatus, Schinz et Autran.l. c. Parag.

ACHETARIA, Cham, et Schlecht. = Beyrichia, Cham. (Scrophularin.).

erecta, Kuntze, Rev. Gen. (1891) 456. = seq.

crecta, Wettst. in Engl, et Prantl, Natürl. Pflanzenfam. iii. 3 b. (1891) $74=$ B. villosa, Benth.

floribunda, Kuntze, Rev. Gen. (1891) $456=$ B. floribunda, Benth.

ocymodes, Kuntze, 1. c. = seq.

ocymodes, Wettst, in Eng-1. et Prantl, Natürl. Pflanzenfam, iii. 3 b. (1891) $74=$ B. ocymoides, Cham. et Schlecht.

scutellariodes, Kuntze, Rev. Gen. (1891) $456=$ seq. scutcllariodes, Wettst., in Engl. et Prantl, Natürl. Pflanzenfam. iii. 3 b. (1891) = B. scutellarioides, Benth.

ACHILLEA, Linn. (Composit.) - Ind. Kew. i. 22. bsinthoides, Haláczy, in Denkschrift. Akad. Wiss. Wien, 1xi. (1894) 243. - Graec.

acuminata, Fregn. in Oest. Bot. Zeitschr, xlv, (1895) $344=$ A. Ptarmica, Linn.

anthemoides, Freyn et Sint. in Bull. Herb. Boiss, iii. (1895) 346. - Armen.

argyrophylla, Haláczy et Gheorgh. ex Haláczy, in Oest. Bot. Zeitschr. xli. (1891) 221. - Thrac.

aromatica, Velen. in Oest. Bot. Zeitschr. xxxvi. (1886) $355=$ multifida, Griseb.

Baldaccii, Degen, l. c. xlv. (1895) 25. - Alban.

bucharica, C. Winkl. in Act. Hort. Petrop.xi.(1889) 163. - Buchara.

canescens, Formanek, in Verh. naturf. Ver. Brünn, xxxii. 1893 (1894) 15\%. - Maced.

cappadocica, Hausskn. et Bornm. in Mitth. Bot. Ver. Fena, viii. (1890) 18. - Asia Min.

carinata, Formanek, in Deutsche bot. Monatsschr, viii. (1890) 65, 161 et 168 . - Maced.

dacica, Simonk. in Termész. Füzet. x. (1856) 181; et Enum. fl. Transsilv. (1886) $317 .=$ oxyloba, Schultz-Bip.

densifolia, Formanek, in Verh. naturf. Ver. Brünn, xxxii. 1893 (1894) (Beitr. Fl. Serb. und Maced.) 66. - Maced.

eximia (err. typ.? exima), Formanck, in Verh. naturf. Ver. Brïnn, xxxii. 1893 (1894) 156. - Maced.

graja $\times$ Beyer, in Verh. Bot. Ver. Brand. xxxi. (1890) p. xii. - Eur. centr.

griseo-virens, Alboff, Prodr. Al. Colch. (1895) 133. Reg. Cauc.

Hausmanniana $\times$, Suend. in Allg. Bot. Zeitschr. i. (1895) 32. - Eur.

intermedia, Freyn, in Oest. Bot. Zeitsclyr. xli. (1891) 10. - Asia Min.

Kerneri $\times$, Haláczy, in Denkschrift. Akad. Wiss. Wien, Ixi (1894) 243. - Graecia.

melanolepis, Boiss. Fi. Or. Suppl. (1888) 297.-Ins. Cypr

Milli, Heldr. ex Boiss. 1.c. 296= Clavennae, Linn. montenegrina, G. Beck et Szyszyl. in Oest. Bot. Zeitschr, xxxix.(1889) $148=$ abrotanoides, Vis. Muenteriana, Heldr. ex Boiss. Fl. Or. Suppl. (1888) 298. - Graecia.

pindicola, Hausskn. in Nym. Consp. fl. Europ. Suppl. 1889) 167; et in Mitth. Thir. Bot. Ver., N. Folge, vii. (1895) 28. - Graecia.

Schrocteri $\times$ Wolf, in Bull. trav. Soc. Murith. fasc. xvi-xviii. 1887-89 (1890) 27. - Helv.

schugnanica, C. Winkl. in Act. Hort. Petrop. xi. (1859) 164. - Asia centr. 
ACHILLEA :

serbica, Petrovic Addit, ad fl, agri Nyss. (1885) 102, et in Magnier, Scrin. fl. select. viii.(1889) 155.-Serb. Shepardi, Post, in fourn. Linn. Soc. xxiv. (1888) 433. - Asia Min.

thracica, Velen. Fl. Bulg. (1891) 264. - Bulg.

tymphaea $\times$, Hausskn. in Nym. Consp. fl. Europ. Supp1. (1889) 168; et in Mitth. Thür. Bot. Ver. N. Folge, vii. (1895) 28. - Graecia.

Vandasii, Velent ex Oest. Bot. Zeitschr. x1. (1890) 237; et Fl. Bulg. (1891) 265. - Bulg.

ACHILUS, Hems1. in Kew Bull. (1895) 39, et in Hook. Icon. Pl. xxiv. (1895) t. 2370, = Globba

Linn. (Scitamin.). $11 . \mathrm{cc}=$ Globba siamensis, Hemsl.

ACHIMENES，P. Br. (Gesnerac.). - Ind. Kew. i. 24 .

gymnostoma, Fritsch. in Engl. et Prantl, Natürl. Pflanzenf. iv. 3 b (1894) 175. - Argent

pulchella, Hitchc. in Missouri Bot. Gard. Rep. iv (1893) $114=$ coccinea, Pers.

tubiflora, Britton, in Ann. N. Y. Acad. Sc. vii. (1893) $185=$ Gloxinia tubiflora, Hook.

ACHNERIA, P. Beauv. (Gramin.). - Ind. Kew $1,24$.

ampla, Th. Dur. et Schinz, Consp. A. Afr. v. 1894 (1895) 836 (=Eriachne ampla, Nees) - Afr. austr. assimilis, Th. Dur. et Schinz, l.c. $836(=$ Eriachne assimilis, Steud.) - Afr. austr.

microphylla, Th Dur.et Schinz, l.c.836 (=Eviachn microphylla, Nees) - Afr. austr.

pallida, Th. Dur. et Schinz, l. c. 836 (= Eviachne pallida, Nees) - Afr. austr.

tuberculata, Th. Dur.et Schinz, l.c. 836 (= Eviachn tuberculata, Nees) - Afr. austr.

ACHRADOTYPUS, Baill, in Bull. Soc. Linn, Paris ii. (1890) 881. (Sapotac.).

artensis, Baill. l. c. 881 . - Ins. Art.

Vieillardi, Baill.l.c. - N. Caled.

AGHRAS, Linn. (Sapotac.). - Ind. Kew. i. 25. bahamensis, Bak, in Hook. Icon. P1. xviii. (1888) t. 1795. = Mimusops Sieberi, A. DC.

ACHROANTHES, Rafin. = Microstylis, Lindl (Orchid.)

corymbosa. Greene, Pittonia, ii. (Sept. 1891) 184. = $\mathrm{M}$, corymbosa, S. Wats.

floridana, Greene, 1. c. 183. = M. floridana, Chapm maianthemifolia, Greene, 1. c. 184=M. maianthemifolia, Reichb.

monophylla, Greene, 1. c. $183=$ M. monophylla, Lindl.

montana, Greene, 1. c. 183 = M. montana, Rothy

ochreata, Greene, 1. c. $184=$ M. ochreata, S. Wats.

Pringlei, Greene, 1. c. $184=$ M. Pringlei, S. Wats

purpurea, Greene, 1.c. 184 = M. purpurea, S. Wats

umbellulata, Greene, 1. c. $184=$ M. umbellulata, Lindl.

ACHYMUS, Vahl = Streblus, Lour, (Urticac.) patens (err. cal.) "Soland,) ex Hook. f. Fl. Brit. Ind. v. (1888) $489=$ Achymus pallens, Soland.

AGHYRANTHES, Linn. (Amarant.).-Ind. Kew. 1. 25.

elegantissima, Schinz, in Bot. Fahrb. xxi. (1895) 186. - Afr. centr. bor

flabellifera, Boerl. in Nederl. Kruidk. Arch. v. (1891) 421. - Ind. or.

glabra, Heyne, ex Hook. f. Fl. Brit. Ind. iv. (1885) $725=$ Psilotrichum lunulatum, Miq.

lanuginosa, Schinz, in Engl. Pflanzenw. Ost-Afr. C. (1895) 174; et in Bot. fahrb. xxl. (1895) 186. Afr. trop. or

oblanceolata, Schinz, in Bot. Fahvb.xxi. (1895) $18 \%$. - Afr. centr. bor.

Welwitschii, Schinz, in Engl. Pfanzenw. Ost-Afr. C. (1895) 174; et in Bot. Fahrb. xxi. (1895) 187. Afr. trop.
ACHYROCLINE, Less. (Composit.) - Ind, Kew i. 26

deflexa, Rob. et Grenm, in Am. fourn. Sc. Ser. III. 1. (1895) 153. - Mexic

pumila, Schinz, ex Klatt, in Bull. Herb. Boiss.iii.(1895) 429. - Afr. trop. or

ramosissima, Britton, in Bull. Torrey Bot. Club̆, xix. (1892) 148. - Bolivia.

venosa, Rusby, in Mem. Torrey Bot. Club, iii, III. 1893) 57. - Boliv.

virescens, Klatt, in Bot. Fallrb. viii. (1887) 40. N. Granat.

ACHYRODES, Boehmer, in Ludw. Def. (1760) 420, ex Kuntze, Rev. Gen. (1891) 758 = Lamarkia Moench (Gramin.).

aureum, Kuntze, 1. c. (1891) 758. = L. aurea, Moench

ACHYRONIA, Royen = Aspalathus, Linn. $($ Legumin.).

abietina, acanthes, aciphylla, aculeata, acuminata, aemula, affinis, Agardhiana, albens, Alopecurus, angustissima, anthyllodes, arachnodea, araneosa, argentea, argyrea, arida, armata, asparagodes, astroites, Benthamii, bracteata, Burchelliana, calcarata, callosa, canescens, capillaris, capitata, carnosa, Chamissonis, chenopoda, ciliaris, cinerascens, collina, comosa, costulata, crassifolia, cutisodes, dasyantha, densifolia. diffusa; divaricata, elongata, evicifolia, eviophylla, erythrodes, exigua, exilis, falcata, ferox, filicaulis, Forbesii, formicata, galeata, galiodes, garipensis, genistodes, glomerata, grandiflora, hirta. Hystrix. incurva, incurvifolia, facobaea, lactea, lanata, laricifolia, lepida, leptophylla leucophaea linearifolia, longifolia, longipes, lotodes, macrantha, macrocarpa, uarginalis, marginata, Meyeri, microdon, mollis, myrtillifolia, nervosa, nigra, nivea, nodosa, nudiflora obtusata, opaca, orbiculata, pachyloba, pallescens, Pappeana, parviflora, pedicellata, pedunculata, pinea pinguis, polycephala, Priori, propingua, prostrata. psoraleodes, pungents, purpurea, vecurva, retroflexa, rostrata, rubens, nubrofusca, rugosa, sanguinea, sarcantha, sarcodes, securifolia, sevicea, setacea, spinescens, spinosa, stellaris, stenophylla, suaveolens, subulata, suffruticosa, temifolia, teres, thymifolia, tridentata, triquetra, truncata, ulicina, uniflora, variegata, venosa, vermiculata, verrucosa, villosa, vivgata, vulnerans, Willdenowiana, Wurnbeana, Kuntze, Rev. Gen. $157-158=$ homonyma omnia, Aspalathi

alternifolia, Kuntze, Rev. Gen. (1891) $157=$ Asp. alternifolia, Hary.

capitella, Kuntze, 1. c. = Asp. inops, Eckl. et Zeyh. cephalotes, Kuntze, 1. c = Asp. cephalotes, Thunb. spicata, Thunb.

contaminata, Kuntze, 1. c. = Asp. corymbosa E. Mey.

corrudaefolia, Kuntze, 1.c.=Asp.rigescens, E.Mey. fasciculata, Kuntze, 1. c. = Asp. undulata, Eckl. et $Z$ ey/.

frankeniodes, (err. cal. frankeriodes) Kuntze, 1. c. = Asp. frankenioides, $D C$.

incompta, Kuntze, 1.c. = Asp. incomta, Thunb.

spicata, Kuntze, 1. c. = Asp. heterophylla, E. Mey. subtingens, Kantze, 1. c. = Asp. adelphea, Eckl. et Zeyk.

ternata, Kuntze, 1. c. = Asp. ferruginea, Banks.

ACHYRONYGHIA, Torr. et Gray (Illecebr.). -

\section{Ind Kew, i. 26.}

Rixfordii, Brandeg. in Zö̈, i. (1890) 230. - Am. bor. occ.

ACHYROPHORUS, Adans. = Hypochoeris, Linn. (Compos.)

deserticola, Phil, in Anal. Mus. nac. Chili (1891) 36. - Boliv.

ACHYROSPERMUM, Blume (Labiat.) - Ind. Kew. i. 27.

Carvalhi, Gürke, in Engl. Pflanzenes. Ost-Afr. C.

(1895) 343. - Afr. trop. or.

radicans, Gurke, l. c. 343. - Afr. trop. or urens, Baker in Kew Bull. (1893) 14. - Madag.
ACHYROTHALAMUS, O. Hoffm. in Bot. Jahrb. xv. (1893) 541, et in Engl. et Prantl., Natïr1, Pflanzenfam. iv. 5. (1893) 339. (Composit.). marginatus, 0 . Hoffm. l. c. 542. - Atr. trop. or teitensis, $O$. Hoffm. l. c. 542. - Afr. trop. or.

AGIANTHUS, R. Br. (Orchid.) - Ind. Kew. i. 27. ymbalariaefolius, F. Muell. et Kraenzl. ex Kraenzl. in Oest. Bot. Zeitschr. xliv. (1894) 209. - Ocean.

AGIGALYPTUS, A. Gray (Myrtac.). - Ind. Kew.

evgenioides, Niedenzu, in Engl et Prant1, Natiurl. Pflanzenfam, iii, 7 (188\%) $86=$ seq.

eugenioides, Drake, Illustr. Al. Mor. Pacif. (1890) 168. - Ins. Vit.

AGIDANTHERA, Hochst. (Irideae), - Ind. Kew, i. 27.

candida, Rendle, in fourn. Linn. Soc. xxx. (1895) 404. - Afr. trop. or.

capensis, Benth. ex Baker, Handb. Irid. (1892) 187. - Afr. austr.

crispa, Pax, in Engl. et Prant1, Natürl. Pflanzenfam. ii. 5. (1887) 155. = Montbretia lacerata Baker.

Forsythiana, Baker, Handb. Irid. (1892) 186. - Afr. austr.

gracilis, Pax, in Bot. Fahrō. xv. (1893) 154. - Afr. trop. or.

ixioides, Baker, Handb. Irid. (1892) 188.-Afr, austr. laxiflora, Baker, ex Oliver, in fohnst. Kilima-Njaro Exped. (1886) 346; et, in Trans. Linn. Soc. Ser. II, ii. (1887) 350, et Handb. Irid. (1892) 188. - Afr. trop. or

pallida, Pax, in Engl. et Prantl. Natürl. Pfanzenfam. ii. 5. (1887) 155 .

pauciflora, Benth. ex Baker, Handb. Irid. (1892) $18 \%$ - Afr. austr

rosea, Schinz, in Th. Dur. et Schinz, Consp. Fl. Afr. v. 1893 (1895) 198. - Afr. austr.

Tysoni, Baker, Handb. Irid. (1892) 187.-Afr. austr. unicolor, Hochst, ex Engl, in Abhandl. Preuss, Akad. Wiss, Berl. 1891 (1892) 175. - Abyss.

zanzibarica, Baker, Handb. Irid. (1892) 188. = gracilis, $P a x$.

ACIDODENDRON, Kuntze, Rev, Gen. (1891) 950 sphalm. = ACINODENDRON Kuntze = ACI NODENDRUM Linn. = Miconia. Ruiz et Pav. (Melastom.)

ACIDOTON, P. Br. = Securinega, Comm. (Euphorb.).

Acidothamnus, Kuntze, Rev. Gen. (1891) $592=\mathrm{S}$. Acidothamnus, Muell. Arg.

Baillonianus, Kuntze, 1. c. $=$ S. Bailloniana, Muell. Arg.

buxifolius, Kuntze, 1. c. = S. buxifolia, Muell. Arg. congestzs, Kuntze, 1. c. = S. congesta, Muell. Arg. durissimus, Kuntze, 1. c. $\rightleftharpoons$ S. durissima, F. F. Gmel. ellipticus, Kuntze, 1. c. = S. elliptica, Muell. Arg. flexuosus, Kuntze, 1. c. = S. flexurosa, Muell. Arg. flueggeodes, Kuntze, 1. c. = S. fluggeoides, Muell. Arg. griseus, Kuntze, 1. c. = S. grisea, Muell. Arg.

Hilarianus, Kuntze, 1. c. = S. Hilariana, Muell. Arg. Lencopyrus, Kuntze, 1. c. = Fluggea Leucopyrus, Willd

obovatus, Kuntze, 1. c. = Fluggea microcarpa, Blume.

phyllanthodes, Kuntze, 1. c. = S. phyllanthoides, Muell. Arg.

ramiflorus, Kuntze, 1. c. = S. ramiflora, Muell. Arg.

Schuechianus, Kuntze, 1. c. = S. Schuechiana, Muell. Arg.

trichogymus, Kuntze, 1. c. = S. trichogynis, Muell. Arg.

virosus, Kuntze, 1. c. = Fluggea microcarpa, Blame.

ACIELLA, Van Tiegh, in Bull. Soc, bot. Fr. xli. (1894) $435=$ Ioranthus, Linn.

Balansae, Van Tiegh. 1. c. (I894) 439.- N. Caled. dictyophleba, Van Tiegh. 1. c. xlii. (1895) 86 et 445 . $=$ L. dictyophlebus, $F$. Muell. 
ACIELLA :-

Deplanchei, Van Tiegh. 1. c. xli. (1894) 438. N. Caled.

Kingiana, Van Tiegh. 1. c, xlii. (1895) 87 et $445 .=$ L. Kingianus, Van Tiegh.

Ianceolata, Van Tiegh. 1. c. xli (1894) 437. N. Caled.

lifuensis, Van Tiegh. 1. c. (189t) 438. - Ins, Lifu. Pancheri, Van Tiegh. 1. c. (1894) 437. - N. Caled. pyramidata, Van Tiegh. 1. c. (1894) 436. - N. Caled. rubra Van Tiegh. 1. C. (1894) 438. - N. Caled.

tenuifolia, Van Tiegh.1. c. (I894) 439. - N. Caled.

ACINETA, Lindl. (Orchid.). - Ind. Kew. i. 28 Wrighti, Fraser, in Gardening World, v.(1889); et ex Lindenia, iv. (1888) 88=Lacaena spectabilis, Reichb.f.

ACINODENDRON, Kuntze, Rev. Gen. 243(1891) $=$ ACINODENDRUM, Linn. = Miconia, Ruiz et Pav. (Melastomac.)

acalyphodes, Kuntze, 1. c. (1891) $950=$ M. acalyphoides, Naud.

acuminata, Kuntze, 1. c. $949=$ M. striata, Cogn.

acuminiferm, Kuntze, 1. c. 950. = M. acuminifera, Triana.

aegrotans, Kuntze, 1. c. = M. arbutifolia, Naud. aeruginosum, Kuntze, 1. C. = M. desmantha, Benth. affine, Kuntze, 1. c. = M. affinis, Macfad.

alatum, Kuntze, 1. c, = M. alata, DC.

albicans, Kuntze, 1. c. = M. holosericea, Triana.

alborufescens, Kuntze, 1. c. = M. albo-rufescens, Naud.

alternans, Kuntze, 1. c. = M. alternans, Noud. alternifolinm, Kuntze, 1.c. = M. Grisebachii, Triana. altissimum, Kuntze, 1. c. = M. altissima, $\operatorname{Cogn}$. alypifolium, Kuntze, 1. c. = M. alypifolia, Naud. amazonicum, Kuntze, 1. c. = M. amazonica, Triana. ambigum, Kuntze, 1. C. $=\mathrm{M}$. ambigua, $D C$ amblyandrum, Kuntze, 1. c. = M. amblyandra, Naud. anoenum, Kuntze, 1. c. = M. amoena, Triana. amplexans, Kuntze, 1. c. = M. amplexans, Cogn. amplexicaule, Kuntze, 1.c. = M. amplexicaulis, Naud. amplum, Kuntze, 1. c. = M ampla, Triana. ancistrophorum, Kuntze, 1. c. (1891) $950=$ M. ancistrophora, Triana.

andinum, Kuntze, 1. $\mathrm{c} .=\mathrm{M}$. andina, Naud.

Andreanum, Kuntze, 1. C. = M. Andreana, Cogn.

androsaemifolium, Kuntze, 1. $\mathrm{C}_{\text {. }}=\mathrm{M}$. androsaemifolia, Griseb.

angustifolinm, Kuntze, 1. c. = M. angustifolia, Griseb. anisophyllum, Kuntze, 1. c. = M. anisophylla, Triana.

anisotrichum, Kuntze, 1. $\mathrm{c}_{\text {. }}=$ M. Berghesiana, Nand. anmlatum, Kuntze, 1. c. = M. annulata, Triana. aplostachyum, Kuntze, 1. c. = M. aplostachya, DC. aponeurm, Kuntze, 1. c. = M. aponeura, Triana. appendiculatunn, Kuntze, 1. c. = M. appendiculata, Triana.

arboreum, Kuntze, 1. c. = M. calvescens, $D C$. arbutifolium, Kuntze, 1. c. = M. arbutifolia, Naud. argentem, Kuntze, 1. c. = M. argentea, DC. argyraemm, Kuntze, 1. c. = M. argyraea, $\operatorname{Cog}$, argyrophyllum. Kuntze, 1. c。= M. argyrophylla, DC. asclepiadenn, Kuntze, 1. c. = M. aselepiadea, Triana. aspergillare, Kuntze, 1. c. = M. aspergillaris, Naud. asperrimum, Kuntze, 1. c. = M. asperrima, Triana. astrotrichm, Kuntze, I. c, = M. astrotricha, Triana. atratum, Kuntze, 1. c。= M. atrata, Wawra.

atrosanguineum, Kuntze, 1. c. = M. atrosanguinea, Cogni.

Augusti, Kuntze, 1, c. = M. Augusti, Cogn. aulocalyx, Kuntze, 1. c. = M. aulocalyx, Mart. aureodes, Kuntze, 1. C. = M. aureoides, $\operatorname{Cog} n$. aureum, Kuntze, 1. c. = M. aurea, Nard. axilliflorum, Kuntze, 1. c. $949=$ M. axilliflora, Nand. Barbeyanum, Kuntze, 1. c. $950=$ M. Barbeyana, Cogn. barbinerve, Kuntze, 1. c. = M. barbinervis, Triana Benthamianum, Kuntze, 1. c。= M. Benthamiana, Triana.

Beurlingi, Kuntze, 1. $\mathrm{c}_{\circ}=$ M. Beurlingii, Triana. biglomeratum, Kuntze, 1. c。= M. biglomerata, $D C$. biperuliferum, Kuntze, 1. c. = M. biperulifera, Cogn. Boissieranum, Kuntze, 1. c. = M. Boissieriana, Cogn. boliviense, Kuntze, 1. c. = M. boliviensis, Cogn. Bourgeauanum, Kuntze, 1.c. = M. Bourgaeana, Cogn.

\section{ACINODENDRON :}

rachyantherum, Kuntze, Rev. Gen. (1891) $950=$ M. brachyanthera, Triana.

brackivbotryum, Kuntze, 1. c. = M. brachybotrya, Triana.

brachycalyx, Kuntze, 1.c. = M. brachycalyx, Triana. bracteatm, Kuntze, 1. c. = M. bracteata, Triana. bracteolatum, Kuntze, 1. c. = M. bracteolata, DC. brasilzense, Kuntze, 1. $\mathrm{C}_{0}=\mathrm{M}$. brasiliensis, Triana. brevipes, Kuntze, 1. c. = M. brevipes, Benth.

Brittonii, Kuntze, 1. c. = M. Brittonii, Cogn.

brumeum, Kuntze, 1. C. $=$ M. brunnea, DC.

bubalmum, Kuntze, 1. c. = M. bubalina, Naud.

buddlejodes, Kuntze, 1. c. = M. budlejoides, Triana

bullatum, Kuntze, 1.c. = M. bullata, Triana,

Burchelli, Kuntze, 1. c. = M. Burchellii, Triana buxifolium, Kuntze, 1. c. = M. buxifolia, Naud. caelatum, Kuntze, 1. $c_{0}=M_{\text {. caelata. } D C}$ caerulem, Kuntze, 1. c. = M. caerulea, Naud. calophyllum, Kuntze, 1. C. = M. myrtiformis, Naud. campestre, Kuntze, 1.c. = M. campestris, Triana. Candolleanum, Kuntze, 1. c. = M. Candolleana, Triana.

cafitellatum, Kuntze, 1. c. = M. capitellata, Cogn carassanum, Kuntze, 1. c. = M. carassana, Cogn. cardiop $n y n t$
Cog $n$

Carioanum, Kuntze, 1. c. = M. Carioana, Cogn.

carneum, Kuntze, l. c. $=$ M. carnea, Cogn

caryophyllum, Kuntze, 1. c. = M. caryophyllacea, Triana.

castaneaeform, Kuntze, 1. c. = M. castaneaefolia, Naud.

cataractae, Kuntze, 1. c. = M. cataractae, Triana. caudatum, Kuntze, 1. c, = M. caudata, DC

caudigerum, Kuntze, 1. C. = M. caudigera, DC.

cecidophorm, Kuntze, 1. c. = M. cecidophora, Naud.

centrodesmum, Kuntze, 1. c. = M. centrodesma Naud.

centrophom, Kuntze, 1. c. = M. centrophora, Naud. ceramicartum, Kuntze, l. c. = M. ceramicarpa, Cogn cermun, Kuntze, 1. c. = M. cernua, Naud. chactodon, Kuntze, 1. c. = M. desmantha, Benth. Chamissoi, Kuntze, 1. C. = M. Chamissois, Naud. chartaceum, Kuntze, 1. c. = M. chartacea, Triana, chionophyllum, Kuntze, 1. c. = M. chionophila, Naum. chlorocarpum, Kuntze, 1. c. =M. chlorocarpa, Cogn. chysoneurum, Kuntze, 1. c. = M. chysoneura, Triana. chrysophyllum, Kuntze, 1. c. = M. fulva, $D C$ ciliare, Kuntze, 1, c. = M. ciliaris, Triana. ciliatum, Kuntze, 1. c. $949=$ M. fragilis, Naud. cinchonifolium, Kuntze, 1. c. $950=$ M. cinchonifolia, $D C$

cinerascens, Kuntze, 1. c. = M. cinerascens, Miq. cinereum, Kuntze, 1. c. = M. cinerea, $\operatorname{Cog} n$. cimamomifolinm, Kuntze, 1. c. $951=$ M. cinnamomifolia, Triana.

cladranthum, Kuntze, 1. c, = M. clathrantha, Triana. coleste, Kuntze, 1. c, = M. coelestis, Naud.

Cognianxii, Kuntze, 1. c. 950. = M. integrifolia, Cogn comosum, Kuntze, 1. c. 951. = M. comosa, Cogn. compressum, Kuntze, 1. c. = M. compressa, Naud confertum, Kuntze, 1. c. = M. conferta, Cogn. confusum, Kuntze, 1. c. = M. confusa, Cogn. corallinum, Kuntze, 1. c. = M. corallina, Spring. cordatum, Kuntze, 1. $\mathrm{c}_{\mathrm{s}}=\mathrm{M}$. cordata, Triana coriacem, Kuntze, 1. c. = M. coriacea, $D C$. coronatum, Kuntze, 1. C. = M. coronata, $D C$ corymbiforme, Kuntze, I. c. = M. corymbiformis, $\operatorname{Cog} n$ costaricense, Kuntze, 1. c. = M. costaricensis, Cogn crassifolium, Kuntze, 1. c. = M. crassifolia, Triana. crassinerve, Kuntze, 1. c. = M. crassinervia, Cogn. crassipes, Kuntze, 1. c. = M. crassipes, Triana. cremophyllum, Kuntze, 1. c. = M. cremophylla, Naud. crinitum, Kuntze, 1. c. = M. crinita, Naud. croceum, Kuntze, 1. c. = M. crocea, $\Lambda^{\top}$ aud crientum, Kuntze, 1. c. = M. cruenta, Triana. cubense, Kuntze, 1. c. = M. cubensis, Wright. cuneatum, Kuntze, 1. c. = M. cuneata, Triana. cuspidatum, Kuntze, 1. c. = M. cuspidata, Naud. cyanocarpum, Kuntze, 1. c. = M. cyanocarpa, Naud. cyathantherum, Kuntze, 1. c. = M. cyathanthera, Triana.

decipiens, Kuntze, 1. c. = M. decipiens, Cogn.

decussatum, Kuntze, 1. c. $243=$ M. decussata D. Don.

delicatulum, Kuntze, 1. c. 951 = M. delicatula, Rich,

\section{ACINODENDRON :}

densiflorum, Kuntze, Rev. Gen. (1891) $951=$ M. densiflora, $N$ and.

denticulatum, Kuntze, 1, c. = M. denticulata, Naud. depauperatum, Kuntze, 1. c. = M. depauperata, Gaertn.

desmanthum, Kuntze, 1. c. $243=$ M. desmantha, Benth.

dichroum, Kuntze, 1. c. $951=$ M. dichroa, $\operatorname{Cog} n$.

difficile, Kuntze, 1. c. = M. difficilis, Triana.

dipsaceum, Kuntze, 1. $c_{0}=\mathrm{M}$. dipsacea, Naud.

discolor, Kuntze, 1. c. = M. discolor, $D C$.

dispar, Kuntze, 1, c. = M. dispar, Benth.

divaricatum, Kuntze, 1. c. = M. divaricata, Gaertn. divergens, Kuntze, 1. $\mathrm{c}_{0}=\mathrm{M}$. divergens, Triana. dodecandrum, Kuntze, 1. c. = M. dodecandra, $\operatorname{Cog} n$. dolichopodum, Kuntze, 1. c. = M. dolichopoda, Naud. dolichorhynchm, Kuntze, 1.c.=M. dolichorrhyncha, Nand.

doningense, Kuntze, 1. c. = M. domingensis, Cogn. Doniamum, Kuntze, 1. c. = M. Doniana, Nand.

Doriamm, Kuntze, 1. c, = M. Doriana, Cogn.

durum, Kuntze, 1. c. = M. dura, Triana.

egense, Kuntze, 1. c. = M. egensis, Cogn.

Eichlesi, Kuntze, 1. c. = M. Eichlerii, Cogn.

elaeagnodes, Kuntze, 1. c. = M. elaeagnoides, Giseb.

Elacodendron, Kuntze, 1. c. = M. Elaeodendron, Naud.

elaeodes, Kuntze, 1. c. = M. elaeoides, Nand.

clatum, Kuntze, 1. C. = M. elata, $D C$

elegans, Kuntze, 1. c. = M, elegans, $\operatorname{Cog} n$.

ellipticum, Kuntze, 1. c. $950 .=\mathrm{M}$. obovalis, Naud.

elongatum, Kuntze, 1. c. 951. = M. elongata, Cogn.

epiphyticum, Kuntze, l. c. = M. epiphytica, Cogn.

evianthum, Kuntze, 1. c. = M. eriantha, Cogn.

eriocalyx, Kuntze, 1. c. = M. eriocalyx, Cogn.

eviocladum, Kuntze, 1. c. = M. erioclada, Triana.

eviodontum, Kuntze, 1. c. = M. eriodonta, $D C$.

erythranthum, Kuntze, 1. $\mathrm{c}_{\text {. }}=\mathrm{M}$. erythrantha, Naud.

engeniodes, Kuntze, 1. c, = M, eugenioides, Triana.

fallax. Kuntze, 1. C, $244=$ M. fallax, $D C$.

fasciculatum, Kuntze, 1. c. $951=$ M. fasciculata, Gaertn.

favosum, Kuntze, 1. c. = M. favosa, Naud.

Fendleranun, Kuntze, 1. c. = M. Fendleriana, Cogn.

ferruoinatum, Kuntze, 1. C. = M. ferruginata, DC.

forriginenn, Kuntze, 1. c. = M. ferruginea, $D C$

flammenn, Kuntze, 1. c. = M. Hammea, Casar.

flavescens, Kuntze, 1. c. = M. flavescens, Cogn.

floribandum, Kuntze, 1. c. = M. floribunda, DC.

floridum, Kuntze, 1. c. = M. florida, Nand.

foliosum, Kuntze, 1. c. = M. foliosa, Triana.

formosum. Kuntze, 1. c. = M. formosa Cogn.

foveolatum, Kuntze, 1. c. = M. foveolata, Cogn.

fragile, Kuntze, 1. c. $949=$ M. Acinodendron, Sweet.

Francavillanum, Kuntze, 1. c. 951. = M. Francavillana, $\operatorname{Cog} n$.

futrm, Kuntze, 1. c. 950. = M. Solmsii, Cogn.

furforaceum, Kuntze, 1. c. 951. = M. furfuracea, Griseb.

gigantewm, Kuntze, 1. c. = M. gigantea, Cogn. giloum, Kuntze, 1. c. = M. gilva, Cogn .

glaberrimu, Kuntze, 1. c. = M. glaberrima, Naud. glabratm, Kuntze, 1. c. = M. glabrata, Cogn. glanduliferm, Kuntze, 1. c. = M. glandulifera, Cogn. glandulosum, Kuntze, 1. c. $244=$ M. glandulosa, Kuntze.

glaucescons, Kuntze, 1. c. $951=$ M.glaucescens, Triana.

Glaziouanum, Kuntze, 1. c. = M. Glazioviana, Cogn. globuliferm, Kuntze, 1. c. = M. globulifera, Naud. globuliflorum, Kuntze, 1. c. = M. globuliflora, Cham. glomeratum, Kuntze, 1. c. = M. glomerata, Triana. goniocladum, Kuntze, 1. c. = M. gonioclada, Triana. goniostigna, Kuntze, 1. c. = M. goniostigma, Triana. gossypinum, Kuntze, 1. c. = M. gossypina, Triana. Goudotii, Kuntze, 1. c. = M. Goudotii, Naud. gracile, Kuntze, 1. c. = M. gracilis, Triana.

grandiflorwm, Kuntze, 1. c. = M. grandiflora, Cogn. granulosum, Kuntze, 1. C. = M. granulosa, Naud. gratissimum, Kuntze, 1. c. = M. gratissima, Benth. Grayanum, Kuntze, 1.c. = M. Grayana, Cog .

guatenalense, Kuntze, 1. c. = M. guatemalensis, $\operatorname{Cog} n$.

guayaquilense, Kuntze, 1. c. = M. guayaquilensis, D. Don. 
ACINODENDRON :-

guianense, Kuntze, Rev, Gen. (1891) $244=$ M. guianensis, $\operatorname{Cog} n$.

Jaematostemon, Kuntze, 1. c. $951=$ M. haematostemon, Naud.

heliotropodes, Kuntze, 1. c. = M. heliotropoides, Triana.

hemenostigma, Kuntze, 1. c. = M. hemenostigma, Nand.

herpeticum, Kuntze, 1. c. = M. herpetica, $D C$.

heteromerum, Kuntze, 1.c. = M. heteromera, Nand. hirtellum, Kuntze, 1. $\mathrm{e}_{\mathrm{e}}=\mathrm{M}$. hirtella, Cogn.

hispidum, Kuntze, 1. c. = M. hispida, Cogn.

holosericenm, Kuntze, 1. c. 244 (holosericum $)=$ M. holosericea, Turez.

Hookerianum, Kuntze, 1. c. $951=$ M. Hookeriana Triana.

humile, Kuntze, 1. c. = M. humilis, Cognn.

hyemale, Kuntze, 1. c. = M, hyemalis, St-Hil, et Nraud.

kygrophilum, Kuntze, 1. c. = M. hygrophila, Nand .

hymenantherum, Kuntze, 1. c. = M. hymenanthera, Triana.

hymenonerve. Kuntze, 1. c. = M. hymenonervia, $\operatorname{Cog} n$.

hyperprasinum, Kuntze, 1. c. = M. hyperprasina, Naud.

hypoleucum, Kuntze, 1, c. = M. hypoleuca, Triana. ibaguense, Kuntze, 1. c. = M. ibaguensis, Wright. igniarium, Kuntze, 1. c. = M. igniaria, Bonpl.

impetiolare, Kuntze, 1. c. $244=$ M. impetiolaris, D. Don

inaequalifolinm, Kuntze, 1. с. $951=$ M. inaequalifolia, Triana.

inaequidens, Kuntze, 1. c. $=\mathrm{M}$, inaequidens, $N$ ard . inapertum, Kuntze, 1. c. = M. inaperta, Naud. inconspicum, Kuntze, 1. c. = M. inconspicua, Miq. integrifolium, Kuntze, 1. c. 950. = M. multispicata, Naud.

intricatum, Kuntze, 1. c. 951. = M. intricata, Triana.

ioneurum, Kuntze, 1. c. = M. ioneura, Griseb.

Fucunda, Kuntze, 1. c. = M. Jucunda, Triana.

Kappleri, Kuntze, 1. c. = M. Kapplerii, Naud.

Klotzschii, Kuntze, 1. c. = M. Klotzschii, Trana.

Kranzlinii, Kuntze,1. c. = M. Kraenzlinii, $\operatorname{Cog} n$.

Krugii, Kuntze, 1. c. = M. Krugii, $\operatorname{Cog} n$.

lacerum, Kuntze, 1. c. $244=$ M. lacera, Naud

laetum, Kuntze, 1. c. $951=$ M. laeta, Cogn

laevigatum, Kuntze, 1. c. $244=$ M. laevigata, $D C$.

lamprarhenum, Kuntze, 1. с. = M. lamprarrhena, Triana.

lamprophylhtm, Kuntze, 1. c. 951=M. lamprophylla, Triana.

ianatum, Kuntze, 1. c. = M. lanata, Triana.

lanceolatum, Kuntze, 1. c. = M. lanceolata, $D C$.

Langsdorffii, Kuntze, 1. c. $=$ M. Langsdorffi, $\operatorname{Cog} n$.

lappaceum, Kuntze, 1.c. = M. lappacea, Triana.

latifolinm, Kuntze, 1. c. = M. latifolia, Nard.

lauriforme, Kuntze, 1. c. = M. lauriformis, Naud.

laurinum, Kuntze, 1. c. = M. laurina, Nand.

Lechleri, Kuntze, 1. c. = M. Lechleri, Triana.

ledifolium, Kuntze, 1. c. = M. ledifolia, Nand.

Lehmannii, Kuntze, 1. c. $=$ M. Lehmannii, $\operatorname{Cog} n$.

lepidotum, Kuntze, 1. c. = M. lepidota, $D C$

leucocarpum, Kuntze, 1. c. = M. leucocarpa, $D C$.

Liebmannii, Kuntze, 1. c. $=$ M. Liebmannii, Cogn

ligustrinum, Kuntze, 1. $c_{0}=$ M. rhamnoidea, Nand

ligustrodes, Kuntze, 1. c. = M. ligustroides, Naud.

lilacinum, Kuntze, 1. с. = M. lilacina, Triana.

Lindenii, Kuntze, 1. c. = M. desmantha, Benth.

lividum, Kuntze, 1. c. = M. livida, Triana.

lonchophyllum, Kuntze, 1. c. = M. lonchophylla, Naud.

longicaudatum, Kuntze, 1. c. = M. longicaudata, $\operatorname{Cog} n$.

longicuspe, Kuntze, 1. c. = M. longicuspis, $\operatorname{Cog} n$.

longifolium, Kuntze, 1. c. = M. longifolia, DC

longipedunculatum, Kuntze, 1. c. = M. longipedunculata, $\log n$.

longispicatum, Kuntze, 1. c. = M. longispicata, Triana.

Ioreyodes, Kuntze, 1. c. = M. loreyoides, Triana.

loxensis, Kuntze, 1. c. $=$ M. loxensis, $D C$

lucidum, Kuntze, l. c. = M. lucida, Naud.

luvidum, Kuntze, 1. c. = M. lurida, Cogn .

lutescens, Kuntze, 1. c. = M. lutescens, $D C$.
ACINODENDRON :-

macranthrm, Kuntze, Rev, Gen, (1891) $951=\mathrm{M}$. macrantha, Triana.

macrophyllum, Kuntze, 1. c. $244=$ M. macrophylla, Triana.

macrostachynm, Kuntze, 1. c. 951 = M. macrostachya, $D C$.

macrote, Kuntze, 1. c, $244=$ M. macrotis, Cognz, macrothyrsum. Kuntze, 1. c. 951 = M. macrothyrsa, Benth.

Magdalenae, Kuntze, 1. c. = M. Magdalenae, Triana. majale, Kuntze, 1. c. = M. majalis, $\operatorname{Cog} n$.

Mandonii, Kuntze, 1. c. = M. Mandonii, $\operatorname{Cog} n$.

marginatum, Kuntze, 1. c. = M. marginata, Triana.

martinicense, Kuntze, 1, $c,=\mathrm{M}$. martinicensis, $\operatorname{Cog} n$

Martiusianum, Kuntze, 1. c. = M. Martiusiana, DC

Matthaei, Kuntze, 1. c. = M. Matthaei, Nand.

Maximowiczianum, Kuntze, 1. c. = M. Maximowicziana, $\operatorname{Cog} n$.

medium, Kuntze, 1. c. = M. media, Nand.

Melinonii, Kuntze, 1. co = M. Melinonis, Nand.

mellimum, Kuntze, 1. c. = M. mellina, $D C$.

membranacerm, Kuntze, 1. c. 952. = M. membranacea, Triana.

Mendonçaei, Kuntze, 1. c. = M. Mendonçaei, $\operatorname{Cog} n$. meridense, Kuntze, $1_{0} \mathrm{c}_{0}=$ M. meridensis, Triana. metallicum, Kuntze, I. c. $=$ M. metallica, Triana. mexicamum, Kuntze, 1, $\mathrm{c}_{1}=\mathrm{M}$. mexicana, Naud. microcarpum, Kuntze, 1. c. $=$ M. microcarpa, $D C$. micropetalum, Kuntze, $1_{1}$ c. $=$ M. micropetala, $\operatorname{Cog} n$. minutiflorum, Kuntze, 1. c. $245=$ M. minutiflora, $D C$

miocarpum, Kuntze, 1. c. $952=$ M. miocarpa, Naud. molestum, Kuntze, 1. c. $=$ M. molesta, Cogn . molle, Kuntze, 1. $\mathrm{C}=\mathrm{M}$. mollis, Trianc. molliculum, Kuntze, 1. $c_{2}=$ M. mollicula, Triana. molybdenm, Kuntze, 1. c. = M. molybdea, Nand. Mouraei, Kuntze, 1. c. = M. Mouraei, Cognt. mucronatum, Kuntze, 1. c, $244=$ M. mucronata Naud.

multiflorum, Kuntze, 1. c. $952=$ M. multiflora, $\operatorname{Cog} n$. multinerve, Kuntze, 1. c. = M. multinervia, Cogn multinervulosum, Kuntze, $1 . c_{c}=$ M. multinervulosa $\operatorname{Cog} n$

multiplinerve, Kuntze, 1.c. = M. multiplinervia, $\operatorname{Cog} n$. muricatum, Kuntze, 1.c. = M. muricata, Tricusa. mutabile, Kuntze, 1. c. = M. mutabilis, Triana. myrtillifolinm, Kuntze, 1. co = M. myrtillifolia, Naud.

Naudinii, Kuntze, 1. c. 949. = M. fragilis, Nand. neriifolinn, Kuntze, 1. c. $952=$ M. neriifolia, Triana. nevvosum, Kuntze, 1. c. $245=\mathrm{M}$. nervosa, Triana. neurocarpum, Kuntze, 1. c. $952=\mathrm{M}$. neurocarpa, Triana.

neurotrichum, Kuntze, 1. c. = M. neurotricha, $\operatorname{Cog}$ n. nitidissimnm, Kuntze, l. c. $=$ M. nitidissima, $\operatorname{Cog} n$. nitidım, Kuntze, 1. c. = M. nitida, Naud.

nodosum, Kuntze, 1. c. = M. nodosa, $\operatorname{Cog} n$.

notabile, Kuntze, 1. c. $=$ M. notabilis, Triana.

novemnerve, Kuntze, 1. c. $245=$ M. novemnervis, Naud.

oblongifolium. Kuntze, 1. c. $952=$ M. oblongifolia, $\operatorname{Cog} n$.

oboratum, Kuntze, 1. с. = M. obovata, Triana. obscurum, Kuntze, 1. c. = M. obscura, Naud. obtusum, Kuntze, 1. c. = M. obtusa, Triana. ochraceum, Kuntze, 1. c. = M. ochracea, Triana. octopetaltm, Kuntze, 1. c. = M. octopetala, $\operatorname{Cog} n$. octoscenidium, Kuntze, 1. c. = M. octoscenidium, $\operatorname{Cog} n$.

oligotrichnm, Kuntze, 1. c. = M. oligotricha, Naud. orchaeotomum, Kuntze, 1. c. = M. orchaeotoma, Nand.

organense, Kuntze, 1. c. = M. organensis, Gaertn. ovalifolium, Kuntze, 1. c. = M. ovalifolia, $\operatorname{Cog} n$. ovatum, Kuntze, 1. c. = M. ovata, $\operatorname{Cog} n$.

pachyphylhm, Kuntze, 1. c. = M. pachyphylla, $\operatorname{Cog} n$. paleaceum, Kuntze, 1. c. = M. paleacea, $\operatorname{Cog} n$. panduratum, Kuntze, 1. c. = M. pandurata, Triana. paniculatum, Kuntze, 1. c. = M. paniculata, Naud. papillosum, Kuntze, 1. . . = M. papillosa, Naud. paradoxim, Kuntze, 1. c. = M. paradoxa, Triana parviflorum, Kuntze, 1. c. = M. parviflora, $\operatorname{Cog} n$. parvifolium, Kuntze, I. c. = M. parvifolia, Cogn pastoènse, Kuntze, l. c. = M. pastoensis, Triana paucidens, Kuntze, 1. $c_{0}=$ M. paucidens, $D C$. pauciform, Kuntze, 1. c. = M. pauciflora, Triana.
ACINODENDRON :-

pauciglandulosum, Kuntze Rev, Gen. (1891) $952=$ M. pauciglandulosa, Noud.

paulense, Kuntze, 1.c. = M. paulensis, Naud.

pauperculum, Kuntze, 1. c. = M. paupercula, $\operatorname{Cog} n$ Paroniantm, Kuntze, 1. c. = M. Pavoniana, Naud. pedicellatum, Kuntze, 1. c。 = M. pedicellata, Cognt. penduliflorum, Kuntze, 1. c. = M. penduliflora, Cogn pennipile, Kuntze, 1. Co = M. pennipilis, Cogn. Pentlandii, Kuntze, 1. c. = M. Pentlandij, Narid. pepericarpum, Kuntze, 1. c, = M. pepericarpá, $D C$ pergamentaceum, Kuntze, 1. c. = M. pergamentacea, $\operatorname{Cog} n$.

perzettifolium, Kuntze, 1. c. = M. pérnettifolia, rriana.

persicariaefolium, Kuntze, 1. c. = M.' persicarifolia, $\operatorname{Cog} n$

perwianm, Kuntze, 1. c. = M. peruviana, $\operatorname{Cog} n$.

Petronianm, Kuntze, 1. c. = M. Petroniana, $\operatorname{Cog} n$. et Saldn.

petropolitamu, Kuntze, 1. c. = M. petropolitana, $\operatorname{Cog} n$.

phaeophyllum, Kuntze, 1.c, = M. phaeophylla, Triana. phacotrichum, Kuntze, 1. c. = M. phaeotricha, Naud. pichinchense, Kuntze, 1. c. = M. pichinchensis, Benth.

pileatum, Kuntze, 1. c. = M. pileata, $D C$

pinetorum, Kuntze, 1. c. = M. pinetorum, Naud.

piperifolizm. Kuntze, 1. c. = M. piperifolia, Triana.

Pittieri, Kuntze, 1. $\mathrm{c}_{0}=$ M. Pittierii, Cogn.

planinerve, Kuntze, 1. c. = M. planinervia, Nand

plantaginifolinn, Kuntze, 1. c. $950 .=$ M. splendens, Triana.

plethoricum, Kuntze, 1. c. 952. = M. plethorica, Nand.

Plukenetii, Kuntze, 1. c. = M. Plukenetii, Naud.

plumifertm, Kuntze, 1. c. = M. plumifera, Triana.

Poeppigii, Kuntze, 1. c. = M. Poeppigii, Triana

Pohliantm, Kuntze, 1. c. = M. Pohliana, $\operatorname{Cog} n$.

polyandrum, Kuntze, 1. c. = M. polyandra, Gardn

polygamum, Kuntze, 1. c, = M. polygama, $\operatorname{Cog} n$. polyneurum, Kuntze, 1. с. = M. polyneura, Triana. prasinum, Kuntze, 1. c. $245=$ M. prasina, $D C$. psendoaplostachyum, Kuntze, 1. c. $952=$ M. pseudoaplostachya, $\operatorname{Cog} n$.

pseudocentrophorim, Kuntze, 1. c. = M. pseudocentrophora, $\operatorname{Cog} n$.

Pseudo-Eichleri, Kuntze, 1. c. = M. pseudo-Eichleri, $\operatorname{Cog} n$.

pseudonervosum, Kuntze, 1.c. = M. pseudo-nervosa, $\operatorname{Cog} n$

Psendo-Petronianum, Kuntze, 1. c. = M. PseudoPetroniana, $\operatorname{Cog} n$.

psychrophiltzm, Kuntze, 1. c. = M. psychrophila, Cogn.

pterocaulon, Kuntze, 1. c. = M. pterocaulon, Triana. pteropodum, Kuntze, 1. c. = M. pteropoda, Benth.

puberulum, Kuntze, 1. c. = M. puberula, Cognz.

pulchrum, Kuntze, 1.c. = M. pulchra, Cogn.

pulverulentum, Kuntze, 1. $c_{0}=\mathrm{M}$. pulverulenta, $R$. et $P$. punctatum, Kuntze, 1. c. = M. punctata, D. Don.

pusilliflorum, Kuntze, 1. c. = M. Gardneriana, Naud. pustulatum, Kuntze, 1. co = M. pustulata, Nand. pyrifolium, Kuntze, 1. c. = M. pyrifolia, Naud. quadrangulare, Kuntze, 1. c. = M. quadrangularis,

Triana.

quadrifolim, Kuntze, l. c. = M. quadrifolia, Naud. quintuplinerve, Kuntze, 1. с. = M. quintuplinervia, $\operatorname{Cog} n$.

Rabenii, Kuntze, 1. c. = M. Rabenii, Cogn.

vacemiferum, Kuntze, 1. c. = M. racemifera, Triana.

racemosum, Kuntze, 1. c. $245=$ M. racemosa, $D C$

Radula, Kuntze, 1. c. $952=$ M. Radula, $\operatorname{Cog} n$.

radulifolium, Kuntze, $1 . c_{0}=$ M. radulaefolia, $N^{r}$ mud. reclinatum, Kuntze, 1. c. = M. reclinata, Nand. reducens, Kuntze, 1. c. $=$ M. reducens, Triana Regelii, Kuntze, 1. c. = M. Regelii, Cogiz.

Regnellii, Kuntze, l. c. = M. Regnellii, $\operatorname{Cog} n$.

resimum, Kuntze, 1. c. = M. resima, Naud.

resimodes, Kuntze, 1. c. $=$ M. resimoides, $\operatorname{Cog} n$

reticulatum, Kuntze, 1. c. = M. reticulata, Triana. revolutum, Kuntze, 1. $\mathrm{c}_{0}=$ M. revoluta, Miq. rhytidophylhum, Kuntze, 1. c. = M. rhytidophylla, Naud.

Riedelii, Kuntze, 1. с. = M. Riedelii, Nand.

rigens, Kuntze, 1. c. = M. rigens, Nand.

rigidiusculum, Kuntze, 1. c. = M. rigidiuscula, Cog . rigidum, Kuntze, 1. c. = M. rigida, Triana. 
ACINODENDRON :-

imale, Kuntze, Rev. Gen. (1891) $952=$ M. rimalis, Nand.

riparium, Kuntze, 1.c. = M. riparia, Triana

robustum, Kuntze, 1. $\mathrm{c}_{0}=$ M. robusta, $\operatorname{Cog} n$.

robustissimum, Kuntze, 1, c. $=$ M. robustissima, Coggr.

postratum, Kuntze, 1. c. = M. rostrata, $\operatorname{Cog} n$. rotnendifolinm, Kuntze, 1. $\mathrm{c}_{\mathrm{N}}=\mathrm{M}$. rotundifolia, and mabens, Kuntze, 1. c. = M. rubens, Naud. vabiginoskm, Kuntze, I. C. = M. rubiginosa, $D C$. mabricans, Kuntze, 1. $\mathrm{c}_{\text {. }}=$ M. rubricans, Triana nufum, Kuntze, 1. . . = M. rufa, Triana

rufescens, Kuntze, 1. с. = M. rufescens, $D C$.

rufipilum, Kuntze, 1. c. = M. rufipila, Triana. rugifolinm, Kuntze, 1.c. = M. rugifolia, Triana. rugosum, Kuntze, 1. c. = M. rugosa, Triana. Ruizii, Kuntze, 1. c. = M. Ruizii, Nand. Rusbyannn, Kuntze, 1. c. = M. Rusbyana, $\operatorname{Cogn}$. Sagotianum, Kuntze, 1. c. = M. Sagotiana, $\operatorname{Cog} n$. Saldanhae, Kuntze, 1. c. = M. Saldanhaei, Cognz. salicifolium, Kuntze, 1. c, = M. salicifolia, Nond.

Sancti-Philippi, Kuntze, 1. c. = M. Sancti-Philippi, Naud.

sanguineum, Kuntze, 1. c. = M. sanguinea, Triana sarmentosum, Kuntze, 1. c. = M. sarmentosa, $\operatorname{Cog} n$. scabrum, Kuntze, 1. c. = M. scabra, Cogn

Schlechtendalii, Kuntze, 1, c. = M. Schlechtendalii,

$\operatorname{Cog} n$.

Schlimit, Kuntze, 1. c. = M. Schlimii, Triana. Schwackei, Kuntze, 1. c. = M. Schwackei, Cognn. sclerophyllum, Kuntze, 1. . . = M. sclerophylla, Triana. scorpiodes, Kuntze, 1. c. = M. scorpioides, Naud. scrobiculatimn, Kuntze, 1. c. = M. scrobiculata, $\operatorname{Cog} n$.

securdiflorm, Kuntze, 1. c. = M. secundiflora, $\operatorname{Cog} n$. Sellowianm, Kuntze, 1.c. = M. Sellowiana, Naud. seriale, Kuntze, 1. C. = M. serialis, $D C$.

servulatum, Kuntze, 1. c。 = M. galactantha, Naud. sessilifolium, Kuntze, 1. c. = M. sessilifolia, Naud. setinode, Kuntze, 1. C. $=$ M. setinodis, $D C$.

setosociliatun, Kuntze, 1. C. = M. setoso-ciliata, $\operatorname{Cog} n$.

setulosum, Kuntze, 1. c. = M. setulosa, Cogn. simplex, Kuntze, 1. c. = M. simplex, Triana. Sintenisii, Kuntze, 1. c. = M. Sintenisii, Cogn. smaragdintm, Kuntze, 1. c. = M. smaragdina, Nand. sordidum, Kuntze, 1. c. = M. sordida, Triana. speciosum, Kuntze, 1. c. = M. speciosa, $\Lambda^{\top} a u d$. spennerostachyum, Kuntze, 1. c. = M. spennerostam chya, Naud.

spicellatum, Kuntze, 1. co = M. spicellata, Bonpl. spinulosum, Kuntze, 1, $\mathrm{c}_{1}=\mathrm{M}$, spinulosa, Naud.

spireaefolizm, Kuntze, 1. c. = M. spireaefolia, Triana.

Spracei, Kuntze, 1. c. = M. Sprucei, Triana. squamulosum, Kuntze, 1.c. = M. squamulosa, Triana. stamineum, Kuntze, 1, c, = M. staminea, DC.

staphidiodes, Kuntze, 1. c. $953=$ M. staphidioides, Triana.

stelligerum, Kuntze, 1, e. = M. stelligera, Cogn stenobotryum, Kuntze, 1. c. = M. stenobotrys, Naud. stenostachyum, Kuntze, 1. c. = M. stenostachya, DC stenourun, Kuntze, 1. C. = M. stenoura, Triana. stipulare, Kuntze, 1. c. = M. stipularis, Noud. strictim, Kuntze, 1. c. = M. stricta, $\operatorname{Cog} n$. stylosum, Kuntze, 1. c. = M. stylosa, $\operatorname{Cog} n$. subcordatum, Kuntze, 1. c, = M. subcordata. $\operatorname{Cog} n$. subglabrum, Kuntze, 1. c, = M. subglabra, $\operatorname{Cog}$. subnodosum, Kuntze, 1. c. = M subrodosa, Triand. suborbiculare, Kuntze, 1. co = M. suborbicularis, $\operatorname{Cog} n$.

subrernicosum, Kuntze, 1. c. = M. subvernicosa, $\operatorname{Cog} n$.

symplocoidern, Kuntze, 1. c. = Mr. symplocoidea, Triana.

Taquari, Kuntze, 1. c. $950=$ M. latecrenata, Naud. tentaculiferwn, Kuntze, 1. c. $953=$ M. tentaculifera, Naud.

tenue, Kuntze, 1. c. = M. tenuis, Triana.

Terera, Kuntze, 1. c. = M. Terera, Nand.

ternatifotimm, Kuntze, 1.c. = M. ternatifolia, Triana. tetragonum, Kuntze, 1. c. = M. tetragona, $\operatorname{Cog}_{n}$. tetrandrum, Kuntze, $1, c_{0}=\mathrm{M}$, tetrandra, Noud. tetrastomum, Kuntze, 1. c. $=$ M. tetrastoma, Naud. theaeforme, Kuntze, 1. c. $950=$ M. Maximilianea, $D C$. theaezans, Kuntze, I. C. $953=$ M. theaezans, Cogu.

\section{ACINODENDRON :-}

Thomasianm, Kuntze, Rev. Gen. (1891) $953=$ M. Thomasiana, $D C$

thyrsoderm, Kuntze, 1. c. = M. thyrsoidea, Naud. tiliaefolium, Kuntze, 1. c. = M. tiliaefolia, Naud. tinifolinm, Kuntze, 1. c. = M. tinifolia, Nand. Tiri, Kuntze, 1. c. = M. Tiri, Triana.

tomentellum, Kuntze, 1. c. = M. tomentella, Cogn. tomentosum, Kuntze, 1. c. $245=$ M. tomentosa, D. Don

Tonduzii, Kuntze, 1. c. $953=$ M. Tonduzii, $\operatorname{Cog} n$ tovarense, Kuntze, 1. c. = M. tovarensis, Cogn.

Traillii, Kuntze. 1. c. = M. Traillii, Cogn.

Trianae, Kuntze, 1. c. = M. Trianaei, $\operatorname{Cog} n$.

trichodes, Kuntze, 1. c. = M. trichodes, Cogyz

trichotomum, Kuntze, 1. c. $=$ M. trichotoma, $D C$.

trinerve, Kuntze, 1. c. $=$ M. trinervia, D. Don.

triplinerve, Kuntze, 1. c. $245=$ M. triplinervis, $R$. et $P$

triste, Kuntze, 1. c. $953=$ M. tristis, Spreng.

truncatum, Kuntze, 1. c. = M. truncata, Triana.

tuberculatum, Kuntze, 1. c. $245=$ M. tuberculata

Triana.

Tuerckheimii, Kuntze, 1. c. $953=$ M. Tuerckeimii, $\operatorname{Cog} n$.

tunicatum, Kuntze, 1. c. = M. tunicata, Nand. ulnariodes, Kuntze, 1. c. = M. arbutifolia, $\mathrm{Naud}$. umbrosum, Kuntze, 1, c。 = M umbrosa, Cogn. undatum, Kuntze, 1. c. = M. undata, Triana. urophyllum, Kuntze, 1. c. = M. urophylla, DC. urticodes, Kuntze, $1_{\text {. }}$. $=$ M. urticoides, Triana. wiferenn, Kuntze, 1. c. = M. uvifera, Naud. vacciniodes, Kuntze, 1. c. = M. vaccinioides, Naud Vauthieri, Kuntze, 1. с. = M. Valtherii, Naud. velutimum, Kuntze, 1. c. = M. velutina, Triana. verrucosum, Kuntze, 1. c. = M. verrucosa, $\operatorname{Cog} n$. Eersicolor, Kuntze, 1. c. = M. versicolor, Natd. verticillatum, Kuntze, 1. c. = M. verticillata, Triana violaceum, Kuntze, 1. c. = M. violacea, Cogn。

virescens, Kuntze, 1. с. = M. virescens, Triana.

vismiodes, Kuntze, 1. $\mathrm{c}_{0}=\mathrm{M}$. vismioides, Triana. vittatum, Kuntze, 1. c. = M. vittata, $\operatorname{Cog} n$.

vulcanicum, Kuntze, 1. C。 = M. vulcanica, Naud.

Warmingiamm, Kuntze, 1. $\mathrm{c}$. = M. Warmingiana $\operatorname{Cog} n$.

Weddelli, Kuntze, 1. c. = M. Weddellii, Naud.

Willdenowii, Kuntze, 1. c. = M. Willdenowii, Klotzsch.

Wrightii, Kuntze, 1. c. = M. Wrightii, 'Triana.

ACINOS, Rupp. = Galamintha, Lam. (Labiat.). vulgaris, MacMill. Metasp. = Clinopodium vulgare, Limn.

ACIOA, Aubl, = Couepia, Aubl. (Rosac.).

Buchneri, Engl. Bot. Jahrb, xvii. (1893) 88. Congo

campestris, Engl. 1. c. 88. - Afr. trop.

A GIPHYLLA, Forst. (Umbellif.).-Ind. Kew. i. 28. Kirkii, F. Buch. in Trans, N. Z. Inst, xix, 1886 (1887) 214, t. 17. - N. Zel.

simplex, Petrie, in Trans. N.Z. Inst. xxii. 1889 (1890) 440. - N. Zel.

AGISANTHERA, P. Br. (Melastom.).-Ind. Kew. i. 28 .

Goudotii, Cogn. ex Krassiv, in Engl。 et Prantl, Natiirl. Pfanzenf. iii, 7. (1893) 150. - Am. trop.

paraguayensis, Cogn. in Mart. Fl. Brasil, xiv, Iv. (1888) 596. - Parag.

ACKAMA, A. Cunn. (Saxifrag.).-Ind. Kew, i. 29. paniculata, Engl. in Engl, et Prantl, Natiurl. Pflanzenfant. iii. II (1890) 98. - Ind. Or., Austral.

ACNID A, Linn. (Amarant.). - Ind. Kew, i. 29. trmariscina, Kuntze, Rev. Gen. (1891) 535 = tuberculata, $M o q$.

ACNISTUS, Schott (Solanac.). - Ind. Kew. i. 29. oblongifolius, Rusby, in Mem. Torrey Bot.Club, iv, (1895) 232. - Bolivia.

AGOKANTHERA, G. Don (Apocyn.). - Ind, Kew. i. 30.

abessinica, K. Schum. in Engl. et Prantl, Natürl. Pflanzenfam. iv. 2. (1895) $126=$ seq.

\section{ACOKANTHERA :-}

abyssinica, K. Schum, in Engl. Pfanzenw. Ost-Afr. C. (1895) 315. - Abyss.

Deflersii, Schweinf. ex Lewin, in Bot. Fahrb. xvii Beibl. 41 (1893) 44 et 45. - Eritrea, Arab.

Ouabaïo, Cathelineau, ex Lewin, l. c. 44. - Afr. trop. or. (Somal.)

Schimperi, Oliver, in F. Thoms. Through Masai Land Append. (1887) 351. - Afr. trop.

ACONITUM, Tourn. (Ranuncul.). - Ind. Kew. i, 30 .

Baumgartenianum, Simonk. in Termész. Füzet x. (1886) 179; et Enum. fl. Transsilv. (1886) $61=$ A. Lycoctonum, Linn.

bosniacum, G. Beck, in Annal. Naturhist. Hofmus. vi. (1891) 342, t. 10 fig. 1-6. - Bosn.

Delavayi. Franch. in Bull. Soc. bot. Fr. xxxiii.(1886) 381. - Yunnan.

fallacinum, Blocki, in Kneucker, Allg. Bot. Zeitschr. i. (1895) 117. - Austro.-Hung.

Fortunei, Hemst. in fourn. Linn. Soc. xxiii. (1886) 20. - China.

lasianthum, Simonk. Enum. fl. Transs. (1886) $61=$ A. Lycoctonum, Linn.

nanum, Simonk. 1. c. $64=$ A. Napellus, Linn,

noveboracense, A. Gray, ex Coville, in Bull. Torrey Bot. Club, xiii. (1886) 190. - Am. bor.

racemulosum, Franch. in Morot, fourn. de Bot. viii. (1894) 276. - China

Schurii, G. Beck, in Annal. Naturhist. Hofmus. vi. (1891) 343. - Transsilv.

scaposum, Franch., in Morot, fourn. de Bot. viii. (1894) 277. - China.

stenotomum, Borb. in Termész. Füzet, xvi. (1893) $44=$ A. Lycoctonum, Linn.

superbum, Fritsch, in Verh. Zool. Bot. Ges. Wien, xlv. (1895) 370. - Bosnia.

thyraicum, Blocki, in Kneucker, Allg. Bot. Zeitschy, i. (1895) 59. - Carpath.

ACRANTHEMUM, Van Tiegh. in Bull. Soc. bot. Fr. xlii. (1895) $254=$ Loranthus, Linn.

natalitim, Van Tiegh, 1. c. $255=$ L. natalitius, Meissn.

Zeyheri, Van Tiegh. I. c. = L. Zeyheri, Harv.

ACRAITHERA, Arn. (Rubiac.). - Ind. Kew. i. 32 .

Atropella, Stapf, in Trans. Linn. Soc. Ser. II, iv. (1894) 173. - Borneo.

mutabilis, Hemsl., in fourn. Bot. xxv. (1887) 204.Perak.

AGRIDOGARPUS, Guill. et Perr. (Malpighiac.). Ind. Kew. i. 32 .

Humblotii, Baill. Hist.pl. Madag., Atlas (1894)t. 267 - Madag.

ACRIOPSIS, Reinw. (Orchid.).-- Ind. Kew. i. 32. purpurea, Ridl., in Trans. Linn. Soc. Ser. II. iii. (1893) 406. - Penins. Mal.

Ridleyi, Hook. f., Fl. Brit, Ind. vi. (1890) 79. Singap.

ACROGEPHALUS, Benth. (Labiat.). - Ind. Kew. i. 33.

angolensis, Gürke, in Bot. Fahrb. xix. (1894) 198. - Angola.

Buettneri, Gürke, l.c. - Afr. trop. occid.

callianthus, Briq. in Bot. Fahrb. xix. (1894) 169. - Afr. trop. or

campicola, Briq. l. c. - Congo.

elongatus, Briq. l. c. - Congo.

Fischeri, Gürke, in Engl. Pflanzenw. Ost-Afr. C. (1895) 348. - Afr. trop. or.

gracilis, Briq. in Bot. fahrb. xix. (1894) 166. Angola.

Heudelotii, Briq. in Bull. Herb. Boiss. ii. (1894) 689. - Senegamb.

indicus, Kuntze, Rev. Gen. (1891) 511 = capitatus Benth.

iododermis, Briq. in Bot. Fahrb. xix. (1894) 167. - Congo.

lagoensis, Baker, in Kew Bull. (1895) 152. - Lagos. Mechowianus, Briq. in Engl. Bot. fahrb. xix. (1894) 168. - Angola. 


\section{ACROGEPHALUS :}

minor, Briq. Engl. Bot. Fahrb. xix. (1894) 169. Angola.

paniculatus, Briq.l.c.172, - Congo.

Poggeanus, Briq. l. c. 170. - Congo.

praealtus, Briq.l.c. 168. - Angola.

reticulatus, Briq. . . c. 168. - Angola.

Schweinfurthii, Briq. l. c. 171. - Afr. centr.-bor.

sericeus, Briq. l. c. 170. - Angola.

Welwitschii, Briq. . . c. 169. - Angola.

zambesiacus, Giurke, in Engl. Pfanzenw. Ost-Afr.C. (1895) 348. - Afr. trop. or.

ACROCOELIUM, Baill. in Bull. Soc. Linn. Paris, ii. (1892) 988. EUPHORBIACEAE. congolanum, Baill. l.c. - Congo gall.

AGROCOMIA, Mart. (Palm.). - Ind. Kew. i. 33 microcarpa, Barb. Rodr. in Vellosia, 1885-88, ed. 2, i. (1891) 10\% - Bras.

AGRODIGLIDIUMI, Nees (Laurin.) - Ind. Kew, i. 33.

Appelii, Mez, in Bot. Fahrb. xvii. (1893) 519. - Bras. armeniacum, Mez, in fahrb. Bot. Gart. Berl. v. (1889) 85 (= Evonymodaphne armeniaca, Nees). - Peruv.

Canella, Mez, l.c.90 (= Aydendron Canella, Meissn.). - Guian gall.

cayennense, Mez, l.c. 91 (= Aydendron cayennense Meissn. - Guian. gall.

cinnamomoides, Mez, 1. c. $88=$ Nectandra cinnamomoides, Nees.

debile, Mez, I. c. 99. - Guian. gall.

foveolatum, Mez, l. c. 92. - Guian. gall.

geminiforum, Mez, 1. c. $84=$ Goeppertia geminiflora, Meissn.

limbosum, Mez, 1. c. $89=$ Nectandra limbata, Nees.

Martinianum, Mez, 1. c. 93. - Guian. gall.

Meissneri, Mez, l.c. v. - Bras.

pachycarpum, Mez, 1. c. 91 = Aydendron pachycarpum, Meissn.

parviflorum, Mez, 1. c. $85=$ Mespilodaphne parviflora, Meissn.

Puchury-major, Mez, 1. c. $87=$ Nectandra Puchurymajor, Nees.

ACROLASIA, Presl (Loas.). - Ind. Kew. i. 33 elata, Phil., in Anal. Univ, Chil. lxxxv, (1894) 5. Chili.

pinnatifida, Phil. l. c. 6. - Chili.

ACROLOPHIA, Pfitzer in Eng1. et Prantl, Natürl. Pflanzenfam. ii. 6. (1888) 133 = Eulophia, R. Br. (Orchid.)

cochlearis, Schlechter et Bolus, in Journ. Bot. xxxii. (1894) $332=\mathrm{E}$. cochlearis, Lindl.

comosa, Schlechter et Bolus, 1. c. $330=$ E. comosa Sond.

lamellata, Schlechter et Bolus, 1. c. $332=\mathrm{E}$. lamellata, Lindl.

lunata, Schlechter et Bolus, 1. c. $332=$ E. lunata, Schlechter.

micrantha, Schlechter et Bolus, 1. c. $532=$ E. micrantha, Lindl.

sphaerocarpa, Schlechter et Bolus, 1. c. $331=\mathrm{E}$. sphaerocarpa, Sond.

tristis, Schlechter et Bolus, 1. c. $331=\mathrm{E}$. tristis, Spreng.

ustulata, Schlechter et Bolus, 1. c. $332=$ E. ustulata, Bolus.

ACRONYGHIA, Forst. (Rutac.). - Ind. Kew, 1.33

lobocarpa, F. Muell. in fourn. Bot, xxx. (1892) 17. - Papuasia.

ACROSTACHYS, Van Tiegh. in Bull. Soc. bot. Fr. xli. (1894) $504=$ Loranthus, Linn. (Loranth.). Kirkii, Van Tiegh. 1. c. - Zambes.

Sandersoni, Van Tiegh.1. c. - Natal.

ACROSTEPHANUS, Van Tiegh. in Bull. Soc. bot. Fr. xlii.(1895) $268=$ Loranthus, Linn.(Loranth.). Buchneri, Van Tiegh. 1. c. = L. Buchneri, Engl. coronatus, Van Tiegh. 1. c. - Congo gall. dependens, Van Tiegh. 1.c. = L. dependens, Engl.

\section{ACROSTEPHANUS :-}

gorvensis Van Tiegh, in Bull. Soc, bot. Fr, xlii. (1895) $268=$ L. Ogowensis, Engl.

Poggei, Van Tiegh. 1. c. = L. Poggei, Engl.

syringifolins, Van Tiegh, 1. c. = L. syringifolius, Engl.

truncatus, Van Tiegh, 1. c. 268=L. truncatus, Engl. tschintschochensis, Van Tiegh, 1. c. = L. tschintschochensis, Engl.

AGROSTYLIA, Frappier, ex Cordem. FI. Ile Réunion (1895) 22\%. ORCHIDEAE.

paradoxa, Frappier, l. c. 228. - Ins. Borbon.

AGTAEA, Linn. (Ranuncul.). - Ind. Kew. i. 24. acerina, Prantl in Bot. Jahrb. ix.(1888) $246=$ Cimicifuga japonica, Spreng.

americana, Prant1, 1. c. 246=Cimicifuga americana, Michx.

biternata, Prantl, 1. c. 246 = Cimicifuga biternata Miq.

elata, Prant1, 1. c. 246 = Cimicifuga elata, Nutt obtusiloba, Prant1, 1. c. 246=Cimicifuga obtusiloba, Miq.

simplex, Prant1, 1. c. $246=$ Cimicifuga foetida, Limn viridiflora, Greene, Pittonid, ii. (Dec. 1890) 108. Calif.

ACTEPHILA, Blume (Euphorb.). - Ind. Kew 1. 30

nitida, «Benth, et Hook, ) ex Drake Ill, insul. Mar. Pacif. (1892) $17 \%$ et 286. - Ins. Societ.

ACTINEA, Juss. = Cephalophora, Cav. (Com-

acanitis, argentea, biennis, Bigelowii, Brandegei, chrysanthemodes, Cooperi, depressa, Doniana, grandiflora insignis, leptoclada, linearifolia, odorata, Richardsonii, Rusbyi, scaposa, Vaseyi, Kuntze, Rev. Gen (1891) 303 = homtonyma omnia Actinellae.

radiata, Kuntze, 1. c. = C. heterophylla, Less.

ACTINELLA, Nutt. (Composit.).-Ind. Kew, i. 35. texana, Coult, et Rose, in Coult. Bot: Gaz. xvi. (1891) 27; et Contrib. U. S. Nat. Herb. ii. (1892) 231. Texas.

ACTINIDIA, Lindl. (Ternstr.). - - Ind, Kew. i. 35 melanandra, Franch. in Morot, Fourn. de Bot, viii. (1894) 278. - China.

Miquelii, King, in fourn. As. Soc. Beng. lix. (1890) ii. 196. - Malaya

tetramera, Maxim. in Act. Hort. Petrop. xi. (1889) 35. - China.

trichogyna, Franch. in Morot, Fourn. de Bot. viii. (1894) 278. - China.

ACTINODAPHNE, Nees.(Laurin.). - Ind.Kew i. 35 .

ambigua, Hook. f. Fl. Brit. Ind. v. (1886) 153. Zeyl.

campanulata, Hook. f. l. c. 148. - Ind. or.

elegans, Knowbl. in Flora, 1xxi.(1888)394.-Zeylan.

hirsuta, Hook.f. Fl. Brit. Ind. v. (1886) 152. - Malab.

leiantha, Hook. f. l. c. 154. - Tenass.

madraspatana, Bedd. ex Hook. f.l.c. 149. - Deccan

Maingayi, Hook. f. l. c. 151. - Malacca.

malaccensis, Hook. f. l. c. 145. - Malacca.

pisifera, Hook.f. l.c. 151. - Zeylan.

sesquipedalis, Hook. f. et Thoms. ex Hook.f.l.c. 151. - Penins. Mal.

ACTINOMORPHE, Kuntze, Rev. Gen. (1891) 570 sphalm. = Actinodaphne, Nees (Laurin.). ambigua, Kuntze, 1. c. = A. ambigua, Hook. $f$. hirsuta, Kuntze, 1. c. = A. hirsuta, Hook. $f$. madraspatana, Kuntze, 1. c. = A. madraspatana, Bedd.

molochina, Kuntze, 1. c. = A. molochina, Nees.

ACTINOPHLOEUS, Becc, ex K. Schum. et Hollr. FI. Kais. Wilh. Land (1889) 15. PALMAE. Schumanni, Becc, l.c. - N. Guin.

ACTINOPHORA, Wall. = Schoutenia, Korth (Tiliac.).

Godefroyana, Kuntze, Rev. Gen. (1891) $82=$ S. Godefroyana, Baill.

hypoleuca, Kuntze, 1. c. $=$ S. hypoleuca, Pierre.
ACTINOPHYLLUM, Ruiz et Pav, = Trevesia, Miq. (Aral.)

palmatum. Blume, ex Boerl, in Annal. Jard, Buit. vi. (1887) $111=\mathrm{T}$. sundaica, Miq.

AGTINOSTEMON, Mart. (Euphorb.). - Ind. Kew. 1.36.

luquense, Morong, in Ann. N. Y.Acad. Sc, vii. (1893) 228. - Parag.

ACTINOTINUS, Oliver, in Hook, Icon. Pl. xviii. (1888) t. 1740. (Gen. omnino delend, fide cl. Oliver). sinensis, Oliver. 1. c. (vide supra).

ACTINOTUS, Labill. (Umbellif.). - Ind. Kew. i, 36 .

Schwartzii, F. Muell. ex Vict. Natural. v. (1889) (Index) $=$ seq.
Schwarzii, F. Muell, in Trans. Roy. Soc. S. Austral. ix. (1887) 57 nomen; et in Vict. Natural. v. (Aug. 1888) 54. - Austral.

ACUAN(IA), Medic, = Desmanthus, Willd. (Legumin.).

acuminata, Kuntze, Rev. Gen. (1891) $158=$ D. acuminatus, Benth.

arborescens, Kuntze, 1. c. = D. arborescens, Boj. depressa, Kuntze, 1. C. = D. depressus, Humb. et Bonpl.

illinoensis, Kuntze, 1. c. = D. brachylobus, Benth. incurva, Kuntze, 1. c. = D. incurvus, Benth.

Famesii, Kuntze, 1. c. = D. Jamesii, Torr. et Gray. leptoloba, Kuntze, 1.c. = D. leptolobus, Torr. et Gray. veticulata, Kuntze, I. c. $=$ D, reticulatus, Benth.

velutina, Kuntze, 1. c. = D, velutinus, Scheele.

ACUSTELMA, Baill. in Bull. Soc. Linn, Paris, ii, (1889) 804 (err. typ. 84) = Gryptolepis, R. Br. (Asclep.).

Grandidieri, Baill. 1. c. - Madag.

ACYNTHA, Medic, = Sansevieria, Thunb. (Haemod.).

bracteata, Kuntze, Rev. Gen. (1891) $699=$ S. bracteata, $B a k$.

cylindrica, Kuntze, 1. c. = S. cylindrica, Boj. Ehrenbergii, Kuntze, 1. c. = S. Ehrenbergii, Schweinf. lamuginosa, Kuntze, 1. c. $=\mathrm{S}$. lanuginosa, Willd. longiflora, Kuntze, 1. c. = S. longiflora, Sims. nilotica, Kuntze, 1. c, = S. nilotica, Bak.

Roxburghiana, Kuntze, 1. c. = S. Roxburghiana, Schult. $f$.

senegambica, Kuntze, 1. c. = S. senegambica, Bak. thyrsiflora, Kuntze, 1. c。 = S. thyrsiflora, Thunb. zeylanica, Kuntze, 1. c, = S. zeylanica, Willd.

ADA, Lindl. (Orchid.). - Ind. Kew. i. 36. Lehmanni, Rolfe, in Gavd. Chron., (1891) ii. 34. N. Granat.

ADANSONIA, Linn. (Malvac.). - - Ind. Kew. i. 36. Fony, Baill. in Bull. Soc. Linn. Par. ii. (1890) 845. - Madas.

Grandidieri, Baill. Hist. pl. Madag., Atlas (1888) t. 79 E, 79 A. - Madag.

Za, Baill. in Bull. Soc. Linn. Par., ii. (1890) 845 et Hist. pl. Madag. Atlas t. 79 C, 79 D, 79 I. Madag.

ADDISONIA, Rusby, in Bull. Torrey Bot. Club, XX. (1893) 432. COMPOSITAE.

virgata, Rusby, l. c. 432 t. 169. - Bolivia.

ADELANTHUS, Baill. in Bull. Soc. Linn. Paris, i. (1886) 554 , nomen (Olacin.).

ADELIA, P. Br. = Forestiera, Poir. (Oleac.). angustifolia, Kuntze, Rev. Gen. (1891) $410=$ F. angustifolia, Torr.

Burchelliana, Kuntze, 1. c, $=$ F. Burchelliana, Oliv. cassinodes, Kuntze, 1. c. = F. cassinoides, Poir. neomexicana, Kuntze, 1. c. = F. neo-mexicana, A. Gray.

parvifolia, Coville, in Contrib. U. S. Nat. Herb. iv. (1893) $148=\mathrm{F}$. acuminata, Poir.

phillyreodes, Kuntze, Rev. Gen. (1891) $410=\mathrm{F}$. phillyreoides, Torr. 


\section{ADELIA :-}

pubescens, Kuntze, Rev. Gen. (1891) $410=$ F. ligustrina, Poir.

veticulata, Kuntze, 1. C. $=$ F. reticulata, Torr. rhamifolia, Kuntze 1.c. = F. rhamnifolia, Griseb. segregata, Kuntze, 1. c. = F. porulosa, Poir.

sphoerocarta Kuntze, 1.c. = F. sphaerocarpa, Tory.

virgata, T. S. Brandeg. in Zoe, iv. (1894) 406. Calif.

ADELOBOTRYS, DC. (Melastom.). - Ind. Kew. 1. 37.

Boissieriana, Cogn, in Mart. Fl. Bras,, xiv, Iv. (1889) 21. - Peruy.

Spruceana, $\operatorname{Cogn}$., l. c. 18. - Bras.

ADELOPETALUM, Fitzg. in Journ. Bot. xxix. (1891) 152. (Orchid.).

bracteatum, Fitzg., l. c. - Austral.

ADENIA, Forsk.= Modecca, Limn.(Passifl.) aculeata, Engl, Bot. Jahrb. xv. (1893) 572; et in Eng1. et Prantl, Natür1. Pflanzenfam. iii. 6 a. (1893) $84=$ M. aculeata, Oliver.

australis, Eng1. 11. cc. $5 \%$ et $85=\mathrm{M}$. australis, $R . B r$ cardiophilla, Engl. 11, cc. 573 et $84=$ M. cardiophylla, Mast.

cordifolia, Engl. 1. c. $84=$ M. cordifolia, Blume

glauca, Schinz, in Bot. Jahrb. xv. Beib1. n. 33. (1892) 1 - Transv.

globosa, Engl. Bot. Jahrb.xv. (1893)576; et in Engl. et Prantl, Natürl. Pflanzenfam. iii. 6 a. (1893) 85. - Afr. trop.

Kerananthus, Harms, in Engl. et Prant1, 1. c. $84=$ Keramanthus Kirkii, Hook. $f$.

Kirkii, Engl. 1.c. = M. Kirkii, Mast.

lanceolata, Eng1. 11. cc. 572 et 84. - Afr. centr. bor. lobata, Eng1. 1. c. 5\%2 = M. lobata, facq.

palmata, Eng1. 1. c. $84=$ M. palmata, Lam.

panduriformis, Engl. 11. cc. 573 et 84 - Zambes.

populifolia, Engl. 1. c. $573=$ M. populifolia, Blume repanda, Eng1. 1. c. $573=$ M. Paschanthus, Harv. Schweinfurthii, Eng1. 11. cc. 573 et 84 . - Afr. trop. senensis, Engl. 11. CC. = M. senensis, Klotzsch. tvilobata, Engl. 11. cc. = M. trilobata, Roxb.

Volkensii, Harms, in Eng1. Pflanzenw. Ost-Afr. C (1895) 281. - Afr. trop. or.

Welwitschii, Engl. Bot. Jahrb. xv. (1893) 573; et in Engl. et Prantl, Natürl. Pflanzenfam. iii. 6 a (1893) $84=$ M. Welwitschii, Mast.

Wightiana, Engl.11. cc. = M Wightiana, Wall.

ADENIUIM, R. et S. (Apocyn.). - Ind. Kew. i, 38. Boehmianum, Schinz, in Verh. Bot. Ver. Brand. xxx. (1888) 259. - Afr. austro-occ. extratrop.
micranthum, Stapf, in Kew Bull., (1894) 334. Arab.

ADENOCALYMNA, Mart. (Bignon.) - Ind

\section{Kew i. 38}

bullatum, Bur. ex K. Schum. in Engl. et Prantl Natürl. Pfanzenfam., iv. 3 b. (1894) 214. - Bras. croceum, S. Moore, in Trans. Linn. Soc, Ser. II. iv. (1895) 419. - Bras.

foveolatum, $K$. Schum, in Engl. et Prantl, Natürl. Pfanzenfam.iv. 3 b. (1894) 214 fig. 89. - Guian.

helicocalyx, Kuntze, Rev. Gen. (1891) 478, - Ins. Trinit., Venez.

Paulistarum, Bur.ex $K$. Schum. in Engl. et Prantl, Natiirl. Pfanzenfam.iv. 3 b. (1894) 214. - Bras. ocositense, f. D. Sm, in Conlt. Bot, Gaz, xviii. (1893) 209. - Guatem.

portoricense, Stahl, ex Bello, Estud. Al. Porto Rico, vi. (1888) 186. - Ins. Portoric.

reticulatum, Bur. ex K. Schum. in Engl. et Prantl. Natün. Pfanzenfam. iv. 3 b. (1894) 214. - Bras. tephrinocalyx, Bur., l. c. - Bras.

ADENOGARPUS, DC. (Legumin.). - Ind. Kew. i. 38 .

anagyrifolius, Batt. in Batt. et Trab. Fl. de l'Algér. (Dicot.) (1889) 206 in obs. - Afr. bor.

ADENOGHLAENA, Boiss. (Euphorb.). - Ind. Kew. i. 39. - Ind. or.
ADENOLISIANTHUS, Gilg, in Engl. et Prantl, Natîrl. Pflanzenfam, iv, (1895) 98. GENTIANEAE.

arboreus, Gilg, l.c. - Bras.

virgatus, Gilg, l. c. - Bras.

ADENOPHORA, Fisch. (Campanul.). - Ind. Kew. i. 39.

aurita, Franch. in Morot, Fourn. de Bot. ix. (1895) 366. - China.

capillaris, Hemsl. in fourn. Linn. Soc. xxvi. (1889) 10. - China.

himalayana, Feer, in Bot. Fahrb. xii. (1890) 618. Reg. Himal.

jasionifolia, Franch, in Morot, fourn. de Bot. ix. (1895) 365. - China occ.

khasiana, Feer, in Bot Jahrb. xii. (1890) $617=$ Campanula khasiana, Hook. f. et Thoms.

khasyana, Coll. et Hemsl. in fourn. Linn. Soc. xxviii. (1890) 80. - Reg. Himal.

Maximowicziana, Makino, in Bot. Mag. Tokyo Soc. vi. (1892) 54. - Japon.

pubescens, Hemsl. in foum. Linn. Soc. xxvi. (1889) 12. - China.

remotidens, Hemsl. l. c. - China.

rupicola, Hemsl. l. c. 13. - China.

setulosa, Borb. Fl. Comit. Castriferr. (1887) 77 et 204. - Hung.

stenophylla, Hemst. in fourn. Limn. Soc. xxvi (1889) 10 in obs. - Mandchuria.

Turczaninowi, Feer, in Bot. Fahwb.xii. (1890) 618. - Asia centr. bor.

ADENOPHYLLUM, Pers. (Composit.). - Ind.

\section{Kew, i. 40}

ancellatum, Kuntze, Rev. Gen. (1891) 361 sphalm. $=$ Dysodia cancellata, $A$. Gray.

ADENOPUS, Benth. (Cucurb.). - Ind. Kew. i. 40. intermedius, Cognz in Bolet. Soc. Brot. vii. (1889) 227. - Ins. S. Thom. et Princip.

ADENOSTEGIA, Benth * Cordylanthus, Nutt. (Scrophul.)

Bolandevi, Kuntze, Rev. Gen. (1891) $456=$ C. pilosus, A. Gray, var.

canescens, capitata, Kingii, laxiflora, maritima, mollis, Nevinii, Orcuttiana, pilosa, Pringlei, ramosa, tenuis, et Wrightii, Kuntze, Rev。 Gen. (1891) 456-7 omnia homonyma Cordylanthi.

canescens, Greene, Pittonia, ii. (Sept. 1891) 181 = C. canescens, A. Gray.

capitatu, Greene, 1. c. $180=$ C. capitatus, Nutt.

Kingii, Greene, 1. c. 181; Wettst. in Engl. et Prantl, Natürl. Pflanzenfam.iv. 3 b. (1893) 98 $=\mathrm{C}$. Kingii, S. Wats.

Iaxiflora, Greene, 1. co = C. laxiflorus, A. Gray.

Iaxiflora, Wettst, in Eng1, et Prantl, Natürl, Pflanzenfam, iv. 3 b. (1893) $98=$ praec.

maritima, Greene, Pittonia, ii. (Sept. 1891) $181=$ C. maritimus, Nutt.

maritima, Wettst. in Eng1. et Prantl, Natürl. Pflanzenfam, iv, 3 b. (1893) $98=$ praec.

mollis, Greene, Pittonia, ii. (Sept. 1891) $181=\mathrm{C}$. mollis, A. Gray.

mollis, Wettst. in Eng1, et Prant1, Natürl. Pflanzenfam. iv. 3 b. (1893) $98=$ praec.

Nevinii, Greene, Pittonia, ii. (Sept. 1891) $181=\mathrm{C}$. Nevinii, A. Gray.

Orcuttiana, Greene, 1. c. $=$ C. Orcuttianus, $A$. Gray.

Orcuttiana, Wettst. in Engl. et Prantl, Natürl. Pflanzenfam. iv. 3 b. (1893) $98=$ praec

Parryi, Greene, Pittonia, ii. (Sept. 1891) $181=\mathrm{C}$. Parryi, S. Wats.

pilosa, Greene, 1. c. $180=\mathrm{C}$. pilosus, A. Gray.

Pringlei, Greene, 1. c. $181=$ C. Pringlei, $A$. Gray.

ramosa, Greene, 1. c. $180=\mathrm{C}$. ramosus, Nutt.

tenuis, Greene, 1.c. = C. tenuis, A. Gray.

tenuis, Wettst, in Engl. et Prantl, Natürl. Pflanzenfam. iv. 3 b. (1893) $98=$ praec.

Wrightii, Greene, Pittonia, ii. (Sept. 1891) $180=$ C. Wrightii, A. Gray

Wrightii, Wettst. in Engl. et Prantl, Natürl. Pflanzenfam, iv. 3 b. (1893) $98=$ praec
ADENOSTEMMA, Forst. (Composit.). - Ind. Kew, i. 40.

Lavenia, Kuntze, Rev. Gen. (1891) 304 = viscosum, Forst.

Verbesina, Kuntze, 1. c. = Swartzii, Cass.

ADENOSTEPHANUS, Klotzsch = Euplassa, Salisb. (Proteac.).

Glaziovii, Mez, ex Taub, in Bot. Jahrb. xii. Beibl. n. 27. (1890) 10. - Bras.

obversiflorus, Mez, ex Taub. 1. c. 9. - Bras.

rufa, Loesen, in Flora, 1xxii. (1889) 78. - Bras.

ADENOSTYLES, Cass. (Composit.). - Ind. Kew i. 41 .

calcarea, Brügg. in Jahresb. naturf. Ges. Graub. (1886) 55. - Helv.

canescens $\times$, Seenholz, in Oest. Bot. Zeitschr. xxxix. (1889) 332. - Austria.

crassifotia, A. Kern. Sched. Al. Austro-Hung. v. (1888) 78. - Tyrol.

Kerneri, Simonk. in Termész. Füzet. x. (1886) 181; et Enum. fl. Transsilv. (1886) 297. - Transs.

leucophylla, Gremli, Neue Beitr. Fl. Schweiz, v. (1890) 77. - Helv.

polyantha, Kern. in. Pallas, Lexicon (anno?) ex Borb. in Oest. Bot. Zeitschr. xliv. (1894) 399 - Austria.

stenotvicha, Kern. 11. cc. - Austria.

ADESMIA, DC. (Legumin.). - Ind. Kew. i. 41, adenophora, Phil. in Anal. Mus. nac. Chile, (1891) 16. - Am. austr. occ.

brachysemeon, Phil. in Anal. Univ. Chil. 1xxxiv. (1894) 28\%. - Chili.

caespitosa, Phil. in Anal. Mus. nac. Chile, (1891) 16. Am, austr. occ.

calycosa, Phil. in Anal. Univ. Chil. 1xxxiv. (1894) 288. - Chili.

concinna, Phil, in Anal. Mus. nac. Chile (1891) 16. Am. austr. occ.

crassicaulis, Phil. I. . . 17. - Am. austr. occ.

disperma, Phil. in Anal. Univ. Chil. Ixxxiv. (1894) 286. - Chili.

dumosa, Phil. l. c. 433. - Chili.

Fernandezi, Phil.l.c. 284.-Chili.

furcata, Phil. l. c. 434. - Chili.

Grisebachii, Phil.l. c. 285. - Chili.

leucopogon, Phil. in Anal. Mus. nac. Chile (1891) 1\%. - Am. austr. occ.

Medinae, Phil. ex $K$. Reiche, in Bot. Fahrb. xxi. (1895) 47 nomen. - Chili.

melanocaulos, Phil, in Anal. Univ. Chit. Ixxxiv. (1894) 434, - Chili.

melanthes, Phit, in Anal, Mus, nac. Chile (1891) 18. - Am. austr. occ.

microcalyx, Phil. in Anal. Univ. Chil. 1xxxiv. (1894) 286. - Chili.

Palenae, Phil. l.c. 282. - Chili.

pentaphylla, Phil. l.c. 436. - Chili.

polyphylla, Phil. in Anal. Mus. nac. Chile (1891) 18. - Am. austr. occ.

Rahmeri, Phil.l.c.15. - Am. austr. occ.

Remyana, Phil. in Anal. Univ. Chil. 1xxxiv, (1894) 435. - Chili.

senticula, Phil. in Anal. Mus, nac. Chile (1891) 18. - Am. austr. occ

sentis, Phil. l. 0. 18. - Am. austr. occ.

subumbellata, Phil. l. c. 17. - Am. austr. occ.

tenuicaulis, Phil. in Anal. Univ. Chil. 1xxxiv. (1894) 282. - Chili.

tenuis, Phil. l. c. 282. - Chili.

torcaea, Phil. l. c. 287. - Chili.

villosa, Phil.l. c. 287. - Chili.

virens, Phil.l.c. 435 . - Chili.

ADICEA, Rafin. = Pilea, Lind1. (Urtic.). acuminata, Kuntze, Rev. Gen. (1891)622 = P. acu minata, Liebm.

alsinifolia, Kuntze, 1. c. = P. alsinifolia, Wedd. angulata, Kuntze, 1. $\mathrm{c}_{\mathrm{N}}=\mathrm{P}$. stipulosa, Miq. anisophylla, Kuntze, 1. c. = P. anisophylla, Wedd. anomala, Kuntze, 1. c. 622 . = P. anomala, Wedd. approximata, Kuntze', 1. c. $623=\mathrm{P}$. approximata C. B. Clarke

arguta, Kuntze, 1. c. $622=$ P. arguta, Wedd. articulata, Kuntze, 1. c. $=$ P. articulata, Wedd 
ADICEA :-

astrogramma, Kuntze, Rev. Gen. (1891) $622=$ P.

astrogramma, Miq.
atrovividis, Kuntze, I. c. $623=$ P. atroviridis, Baker.

auriculata, Kuntze, 1. c. $622=$ P.auriculata, Liebm. Balfourii, Kuntze, 1. c. $623=$ P. Balfourii, Baker. betulifolia, Kuntze, 1. c. $622=\mathrm{P}$. hederacea, $W$ edd boehmeriades, Kuntze, 1. c. = P. boehmerioides, Wedd.

Troiviniana, Kuntze, 1. c. $=$ P. Boiviniana, Wedd bracteosa, Kuntze, 1. c. = P. bracteosa, Wedd. capitellata, Kuntze, 1. c. = P. capitellata, Wedd. carnosula, Kuntze, 1. c. = P. carnosula, Wedd. clebica, Kuntze, 1. c. = P. celebica, Miq. centradeniodes, Kuntze, 1. c. $=P$. centradenioides, Seem.

cephalantha, Kuntze, 1. c. = P. cephalantha, Wedd. ceratocalyx, Kuntze, 1. c. $=$ P. ceratocalyx, Wedd. ceratomera, Kuntze, 1. c. = P. ceratomera, Wedd. Chamaedrys, Kuntze, 1. c. = P. Chamaedrys, Wedd. chrysospleniodes, Kuntze, 1. c. = P. chrysosplenioides, $W e d d$.

citiaris, Kuntze, 1. c. = P. ciliaris, $W e d d$. ciliata, Kuntze, 1. c. = P. Swartzii, Wedd. citriodora, Kuntze, 1. c. = P. citriodora, $W$ edd. clandestina, Kuntze, 1. c. = P. clandestina, Wedd. Clarkei, Kuntze, 1. c. $623=$ P. Clarkei, Hook.f. consanguinea, Kuntze, 1. c. $622=\mathrm{P}$, consanguinea, Wedd.

cordifolia, Kuntze, 1. c, $623=$ P. cordifolia Hook. $f$. corymbosa, Kuntze, 1. c. 622 . = P. corymbosa, Blume.

crassifolia, Kuntze, 1. c. = P. densiflora, Kunth Cruegeriana, Kuntze, 1. c. = P. Cruegeriana, Wedd. cuneifolia Kuntze, 1. c. = P. cuneifolia, Wedd. cuneiformis, Kuntze, 1. c. $=$ P. cuneiformis, Wedd. dauciodora, Kuntze, 1. c. = P. dauciodora, $W$ edd. danciodora, Kuntze, $1 . \mathrm{c}_{0}=\mathrm{P}$. deltoidea, Liebm. dendrophila, Kuntze, 1. c. = P. dendrophila, Miq. depressa, Kuntze, 1. c. = P. depressa, Blume diffusa, Kuntze, $1 . c_{0}=\mathrm{P}$. diffusa, $W$ edd. diversifolia. Kuntze, 1. c. $=$ P. diversifolia, Wedd. Dombeyana, Kuntze, 1. c. = P. Dombeyana, Wedd. elegans, Kuntze, 1. c. = P. elegans, Wedd. elliptica, Kuntze, 1. c. = P. elliptica, Hook. f. falcata, Kuntze, 1. c. = P. falcata, Liebm

fallax Kuntze, 1. c. = P. fallax, Wedd.

fasciata, Kuntze, 1. c. = P. fasciata, Wedd.

flexwosa, Kuntze, 1. c. = P. flexuosa, Wedd.

Forsythiana, Kuntze, 1. c. = P. Forsythiana, Wedd Franquevilleana, Kuntze, 1. $\mathrm{c}_{\mathrm{i}}=$ P. Franquevilleana, $W e d d$.

fruticosa, Kuntze, 1. c. $623=$ P. fruticosa, Hook. $f$. glomerata, Kuntze, 1. c. $622=\mathrm{P}$. glomerata, Griseb. gnidiodes, Kuntze, 1. c. = P. gnidioides, Griseb.

Goudotiana, Kuntze, 1. c. = P. Goudotiana, Wedd. Goudotiana, Kuntze, 1. c. = P. Goudotiana,
grandifolia, Kuntze, 1. c. = P. grandis, Wedd. grandifolia, Kuntze, 1. c. $=$ P. grandis, Wedd.
Griffithii, Kuntze, 1. c. = P. Griffithii, Blume. guadalupensis, Kuntze, 1. c. = P. guadalupensis, Wedd.

heteronema, Kuntze, 1. c. = P. heteronema, Griseb. Hilariana, Kuntze, 1. c. = P. Hilariana, Wedd.

hirsuta, Kuntze, 1. c. = P. hirsuta, Wedd.

hirtella, Kuntze, 1. c. $=$ P. hirtella, Miq.

Hookeriana, Kuntze, 1. c. = P. Hookeriana, Wedd. hyalina, Kuntze, 1. c. = P. hyalina, Fenzl. hygrophila, Kuntze, 1. c. = P. hygrophila, Blume. inaequalis, Kuntze, $1 . \mathrm{c},=\mathrm{P}$. inaequalis, $W e d d$. iners, Kuntze, 1. c. $=$ P. Maximiliani, Miq. iners, Kuntze, 1. c. $=$ P. Maximiliani, Miq.
insolens, Kuntze, 1. c. $623=\mathrm{P}$. insolens, $W$ edd. integrifolia, Kuntze, 1. c. $=\mathrm{P}$. integrifolia, Liebm. involucrata, Kuntze, 1. c. $622=$ P. pubescens, Liebm.

Kakurang, Kuntze, 1. c. $623=$ P. Kakurang, Blume laevicaulis, Kuntze, 1. c. = P. laevicaulis, Wedd. laevicaulis, Kuntze, l. $_{\text {c. }}=\mathrm{P}$. laevicades, Kuntze, $1 . \mathrm{c}_{0}=\mathrm{P}$. lamioides, $W$ edd. lamiodes, Kuntze, 1. c. $=$ P. lamioides, $W e d d$.
lanceolata, Kuntze, 1. c. $=$ P. lanceolata, Wedd. latifolia, Kuntze, 1. c. = P. latifolia, Wedd. laxa, Kuntze, 1. c. = P. laxa, Wedd

leucophaea, Kuntze, 1. c. = P. leucophaea, Blume. Lindeniana, Kuntze, 1. c. $=$ P. Lindeniana, Wedd. longifolia, Kuntze, 1. c. $623=$ P. longifolia, Baker longipes, Kuntze, 1. c. = P. longipes, Liebm. lucens, Kuntze, 1. c. = P. Iucens, Wedd. lucida, Kuntze, 1. c. = P. Iucida, Blume.

Lundii, Kuntze, 1. c. = P. Lundii, Liebm.
ADICEA :

macrodonta, Kuntze, Rev. Gen. (1891) $623=P$. macrodonta, Baker.

Manniana, Kuntze, 1. c. = P. Manniana, Wedd. marginata, Kuntze, I. c. $=$ P. maroinata, Wedd. melastomodes, Kuntze, 1. c. $622=\mathrm{P}$, trinervia, IVight. mexicana, Kuntze, 1. c. $623=\mathrm{P}$, mexicana, Wedd. microphylla, Kuntze, 1. c. $622=$ P. muscosa, Lindl. modesta, Kuntze, 1. c. $623=$ P. modesta, Baker. mollis, Kuntze, 1. c. $622=\mathrm{P}$. mollis, Wedd. mongolica, Kuntze, 1. c. $623=$ P. mongolica, Wedd. multiflora, Kuntze, 1. c. = P. multiflora, Wedd. nana, Kuntze, 1. c. $=$ P. nana, Liebm. nitida, Kuntze, 1. c. = P. nitida, $W_{e d d}$. nudicaulis, Kuntze, 1.c. = P. nudicaulis, Wedd. nummlariaefolia, Kuntze, 1.c. = P. nummulariaefolia, Wedd.

mutans, Kuntze, 1, $\mathrm{c},=\mathrm{P}$, nutans, Wedd.

obliqua, Kuntze, 1. c. = P. obliqua, Hook. $f$ obtusata, Kuntze, 1. c. = P. obtusata, Liebm. ovalis, Kuntze, 1. c. = P. ovalis, Griseb oxydon, Kuntze, 1. c. = P. bracteosa, $W e d d$. pachycarpa, Kuntze, 1. c. - P. pachycarpa, Wedd. Pavonii, Kuntze, 1. c. = P. Pavonii, Wedd.

peltata, Kuntze, 1. C. = P. peltata, Hance.

pendula, Kuntze, 1. c. = P. pendula, Griseb. peplodes, Kuntze, 1. c. = P. peploides, Hook. et Arn. petiolaris, Kuntze, 1. c. = P. stipulosa, Miq. Poeppigiana. Kuntze, 1. c. = P. Poeppigiana, Wedd. portoricensis, Kuntze, 1. c. $=\mathbf{P}$. portoricensis, $W e d d$. producta, Kuntze, I. c. = P. umbrosa, Wedd. propinqua, Kuntze, 1. c. = P. propinqua, Wedd. pteropodon, Kuntze, 1. c. = P. pteropodon, Wedd. pulegifolia, Kuntze, 1. c. = P. pulegifolia, Wedd. punctata, Kuntze, 1. c. = P. punctata, Wedd. radicans, Kuntze, 1. c. $=\mathrm{P}$. radicans, $W e d d$. repanda, Kuntze, 1. c. = P. repanda, Wedd. repens, Kuntze, 1. c. $622=\mathrm{P}$. repens, Liebm. veticulata, Kuntze, 1. c. $623=$ P. reticulata, Wedd. vhexiodes, Kuntze, 1. c. = P. rhexioides, Liebm. rhizobola, Kuntze, 1. c. = P. rhizobola, Miq. rhombea, Kuntze, 1. c. = P. rhombea, Liebm. rivularis, Kuntze, $1 . \mathrm{c}_{0}=\mathrm{P}$. rivularis, Wedd. rotundata, Kuntze, 1. c. $=$ P. rotundata, Griseb. rubiafolia, Kuntze, 1. c. = P. rubiaefolia, Blume. rufa, Kuntze, 1, c. = P. rufa, Wedd. rugosa, Kuntze, 1. c. = P. rugosa, $W$ edd Sanctaecrucis, Kuntze, 1.c. = P. Sanctae-crucis, Liebm. sarcophylla, Kuntze, 1. c. = P. sarcophylla, Wedd. scripta, Kuntze, 1. c. = P. scripta, Wedd. scrobiculata, Kuntze, 1. c. $=$ P. scrobiculata, Liebm. semidentata, Kuntze, 1. c. = P. semidentata, Wedd. serpyllifolia, Kuntze, 1. c. = P. serpyllifolia, Wedd serratifolia, Kuntze, 1. c. = $\mathrm{P}$. serratifolia, Wedd. serrulata, Kuntze, 1. c. = P. serrulata, Wedd. sessiliflora, Kuntze, 1. $\mathrm{c}_{\text {. }}=\mathrm{P}$. sessiliflora, Wedd. sessilifolia, Kuntze, 1. c. = P. sessilifolia, Wedd smilacifolia, Kuntze, 1. c。 = P. smilacifolia, Wedd. spathulata, Kuntze, 1.c. = P. spathulata, Griseb. Spruceana, Kuntze, 1. c. $=$ P. Spruceana, Wedd. stelluligera, Kuntze, 1. $\mathrm{c}_{\mathrm{v}}=\mathrm{P}$. stelluligera, Wedd. stolonifera, Kuntze, 1. c. = P. stolonifera, Wedd. subcrenata, Kuntze, 1. $\mathrm{c} .=\mathrm{P}$. subcrenata, $W e d d$. sublucens, Kuntze, 1. c. = P. sublucens, Wedd. submissa, Kuntze, 1. c. = P. submissa, Wedd. subserrata; Kuntze, 1. c. = P. subserrata, Wedd. succulenta, Kuntze, 1. $\mathrm{c}_{0}=\mathrm{P}$. succulenta, Wedd. ternifolia, Kuntze, 1. c. = P. ternifolia, Wedd. tetraphylla, Kuntze, 1. c. = P. tetraphylla, Blume. Thoursiana Kuntze, 1. c. $=\mathrm{P}$. Thouarsiana, Wedd. thymifolia, Kuntze, 1. c. $622=$ P. globosa, Wedd. Trianaeana, Kuntze, 1. c. $623=$ P. Trianaeana, Wedd. trichosanthes, Kuntze, 1. c.=P. trichosanthes, Wedd. trichotoma, Kuntze, 1. c. $=$ P. trichotoma, Liebm. trilobata, Kuntze, 1. c. = P. trilobata, Wedd. uliginosa, Kuntze, 1. $\mathrm{c}:=\mathrm{P}$, uliginosa, Phil umbellata, Kuntze, 1. c。 = P. insignis, Blume. umbrosa, Kuntze, 1. c. = P. umbrosa, Wedd. Urticella, Kuntze, 1. c. = P. Urticella, Wedd urticifolia, Kúntze, 1 . c. $622=\mathrm{P}$. rupipendia, $W$ edd. variegata, Kuntze, 1. c. = P. variegata, Seem. venulosa, Kuntze, 1. c. = P. venulosa, Blume verbascifolia, Kuntze, $1 . c_{*}=P$. verbascifolia, Wedd. virgata, Kuntze, 1. c. = P. virgata, Wedd. vulcanica, Kuntze, 1. c. = P. vulcanica, Liebm. Wightii, Kuntze, 1. c, = P. Wightii, Wedd.

Wrightiana, Kuntze, 1. c. = P. Wrightiana, Wedd.
ADINA, Salisb. (Rubiac.). - Ind. Kew. i. 43

Galpini, Oliver, in Hook. Icon. Pl. xxiv. (1895) t. 2386. - Afr. austr.

lasiantha, $K$. Schum. in Engl. Pflanzenw. Ost-Afv. C (1895) 378. - Afr, trop. or

philippinensis, Vidal, Rev.pl. vasc. Filip. (1886) 148. - Ins. Philipp.

pilulifera, Franch. ex Drake, in Morot, Journ. de Bot. ix. (1895) $207=$ globifera, Salisb.

rubescens, Fiemst. in fourn. Bot. xxv. (1887) 204. - Perak.

rubrostipulata, K. Schum. in Engt.Pflanzenw.Ost-Afr. $C$ (1895) 378. - Afr. trop. or.

ADINANDRA, Jack (Ternstroem.). - Ind. Kew.

Hullettii, King, in fourn. As. Soc. Beng. lix. (1890) ii. 192, - Malaya.

Miquelii, KKing, l.c. 192. - Pen. Mal.

verrucosa, Stapf, in Hook. Icon. Pl. xxiii. (1893) 2266. - Borneo.

ADLUMIA, Rafin. (Papaver.). - Ind. Kew. i. 43. fungose Greene, ex Britton, Stern, et Poggenb. Prel. Cat. (1888) $3=$ cirrhosa, Rafm

ADNARIA, Rafin. = Gaylussacia, H. B. et K. (Vacciniac.)

adenochaeta, Kuntze, Rev, Gen. (1891) $383=\mathrm{G}$. adenochaeta, $D C$

amoena, Kuntze, 1, c. = G. amoena, Cham.

angulata, Kuntze, 1. c. = G. allgulata, Gardn

angustifolia, Kuntze, 1.c. = G. angustifolia, Cham. brachycera, Kuntze, 1. $\mathrm{c}_{0}=\mathrm{G}$. brachycera, Torr et Gray.

bracteata, Kuntze, 1. c. = G. bracteata, Gardn.

brasiliensis, Kuntze, 1. c. $382=\mathrm{G}$. Pseudo-Vaccinium, Cham, et Schlecht. caracasana, Kuntze, 1. c. $383=\mathrm{G}$. caracasana, DC. Chamissonis, Kuntze, 1. c. $=$ G. Chamissonis, Meissn.

citiosa, Kuntze, 1. c. = G. ciliosa, Meissn.

crenata, Kuntze, 1. c. = G. crenata, D. Don. decipiens, Kuntze, 1. c. = G. decipiens, Chan. densa, Kuntze, 1. c. = G. densa, Cham.

dependens, Kuntze, 1. c. $=$ G. dependens, G. Don. dumosa, Kuntze, 1. c. $382=\mathrm{G}$. dumosa, Torr. et Gray. fasciculata, Kuntze, 1. c. $383=$ G. fasciculata, Gardn.

frondosa, Kuntze, 1. c. $382=\mathrm{G}$. frondosa, Torr. et Gray.

Gardneri, Kuntze, 1. c. $383=\mathrm{G}$. Gardneri, Meissn. glandulosa, Kuntze, 1. c. $382=\mathrm{G}$. buxifolia, $H$. B.et $K$. hispida, Kuntze, 1. c. $383=\mathrm{G}$. hispida, $D C$.

incana, Kuntze, 1. c. = G. thymelaeoides, Meissn.

Ianceolata, Kuntze, 1. c. = Vaccinium acuminatissimum, Miq.

ledifolia, Kuntze, 1.c.=G. ledifolia, Mart.

Martii, Kuntze, 1. c. $=$ G. Martii, Meissn. montana, Kuntze, 1. c. = G. hispida, DC. myrtillodes, Kuntze, 1. c. = G. hispida, DC nitida, Kuntze, 1. c. = G. nitida, Mart. obscura, Kuntze, 1. c. = G. pallida, Cham. octosperma, Kuntze, 1. c. = G. octosperma, Gardn. oleaefolia, Kuntze, 1.c. = G. oleaefolia, Dunal. pallida, Kuntze, 1. c. = G. pallida, Cham parvifolia, Kuntze, 1. c. = G. parvifolia, Gardn. pinifolia, Kuntze, 1. c. = G. pinifolia, Cham. et pulchra, Kuntze, 1. c. $=\mathrm{G}$. pulchra, Pohl. resinosa, Kuntze, 1. c. = G. resinosa, Torr. et Gray. veticulata, Kuntze, 1. c. = G. reticulata, Mart retusa, Kuntze, 1. c. = G. retusa, Mart. Rhododendron, Kuntze, 1. c. = G. Rhododendron, Cham. et Schlecht.

Riedelii, Kuntze, 1. c. = G. Riedelii, Meissn.

rigida, Kuntze, 1. c. = G. rigida, Casar.

rugosa, Kuntze, 1.c. = G. rugosa, Cham. et Schlecht. salicifolia, Kuntze, 1. c. = G. salicifolia, Cham. et Schlecht.

thymelaeodes, Kuntze, 1. c. = G. thymelaeoides, Meissn.

ursina, Kuntze, 1. c. = G. ursina, Torr. et Gray.

Vauthieri, Kuntze, 1.c.= G. Vauthieti, Meissn.

villosa, Kuntze, 1. c. = G. villosa, Gardn.

virgata, Kuntze, 1. c. = G. virgata, Mart

Vitis-Idaea, Kuntze, 1. c. = G. Vitis-Idaea, Mart. 
ADOLIA, Lam. = Scutia, Comm. (Rhamnac.). arenicola, Kuntze, Rev. Gen. $117=\mathrm{S}$. arenicola, Reiss.

buxifolia, Kuntze, 1. c. = S. buxifolia, Reiss. capensis, Kuntze, 1. c. = S. Commersonii, Brongn. discolor Kuntze, $1, c_{1}=$ Berchemia discolor, Hemsl. myrtina, Kuntze, 1. c. = S. Commersonii, Brongn obcordata, Kuntze, 1. c. = S. obcordata, Bivona.

ADODENDRON, Neck. = Rhodothamnus, Reichb. (Ericac.).

Chamaecistus, Kuntze, Rev. Gen. (1891) $385=$ R. Chamaecistus, Reichb.

ADoNIS, Dill. (Ranunc.). - Ind. Kew. i. 44. abortiva (aborticus), Hausskn. in Mitt. Bot. Ges, fena, v. (18S6) 60. - Graecia.

alpina, Rouy et Fouc. F1. de Fr. ii. (1895) 319 in add, = pyrenaica, $D C$

Barthei, Franch. in Bull. Soc. Phrlom. Sér. VIII, vi. (1894) 89. - Mandchuria.

brevistyla (brevistylus) Franch, in Bull. Soc. bot. Fr. xxxiii. (1886) 372. - Yunnan.

cristata. Stapf, in Sitzb. zool.-bot. Ges. Wien, xxxix (1889) 74 = aleppica, Boiss. = aestivalis, Linn.

Davidi, Franch. in Nouv. Arch. Mus. Sér, II. viii, 1885 (1886) 188. - China.

Delavayi, Franch. in Bull. Soc. Philon. Sér. VIII. vi, (1894) 91 - China occ.

inerninis, Stapf, in Sitzb, zool.-bot. Ges. Wien, xxxix. $\{1889) 74$ = flaminea, $f_{a c q}$, = autumnalis, Limn. = parviflora, Fisch.

involucrata, S. Pons, in Rouy et Fouc. Fl. de Fr. i. (1893) 53 = flammea, facq.

ramosa (ramosus), Franch, in Bull. Soc. Philom. Sér. VIII. vi. (1894) 91. - Japon.

ruthenica, Stapf, in Sitzb. zool.-bot. Ges. Wien, xxxix. (1889) $74=$ amurensis, Regel et Radde, $=$ wolgensis, Stcr.

sutchuenensis, Franch., l.c. 89. - China occ.

ADOPOGON, Neck. = Krigia, Schreb. (Compos.). amplexicaule, Dandelion, nzontanum, occidentale, virginicum, Kuntze, Rev. Gen. (1891) 304. = homonyma omnia Krigiae.

carolinianum, Britton ex Small et Vail, in Mem. Torrey Bot. Club, iv. (1893) 133; et (1894) 346 = Krigia virginica, Willd.

ADORIUM, Rafin。= Musenimm, Nutt. (Umbellif.). divaricatum, Rydberg, in Bot. Surv. Nebraska, ii . (1894) $37=\mathrm{M}$. divaricatum, Pursh.

lucidum, Kuntze, Rev. Gen. (1891) $264=$ M. divaricatum, Nutt.

tenuifolinn, Kuntze, 1. c. = M. tenuifolium, Nutt.

AEGHIMEA, Ruiz et Pav. (Bromel.). - Ind. Kew.

i, 45. Bras.

Alopecurus, Mez, l. c. 367.-Bras.

aguilegioides, Kuntze, Rev. Gen. (1891) 698. Costa-Rica.

armata, Lindman, in Siensk Akad. Handl. xxiv. 8 1891) 33 t. 7 fig. 1-13. - Bras,

aureo-rosea, Baker, Handb. Bromel. (1889) 63. Bras.

Bernoulliana, Wittm. in Bot. Fahrb. xiv. Beibl. n. 32. (1891) 1. - Guatem

billbergioides, Baker, Handb. Bromel. (1889) 38, Bras.

Blanchetii, Baker, l. c. (1889) 43. - Bras.

Blanchetii, Mez, in Mart. Fl. Brasil. iii. iII. (1892) $336=$ Streptocalyx Blanchetii, Baker.

brachycaulis, Baker, Handb. Bromel. (1889) 53. Bras.

brachyclada, Baker, l. c. 37. - Bolivia.

caesia, Éd, Morr. ex Baker, l. c. (1889) 43. - Bras.

candida, Ed. Morr. ex Baker, l.c. 41. - Bras.?

Castelnavii, Baker, l. c. 39. - Bolivia.

caudata, Lindman, in Svensk Akad. Handl. xxiv, 8. (1891) 29 t. 6. fig. 1-9. - Bras.

Chantini, Baker, Handb. Bromel. (1889) 49. - Am austr.

chiriquensis, Baker, in fourn. Bot. xxiv. (1886) 243 - Amer. centr.

\section{AECHMEA :}

hrysocoma, Baker, Handb. Bromel. (1889) 44. Bras.

conglomerata, Hort. Berol. ex Baker, l. c.52.Bras.

conspicuiarmata, Baker, l. c. 47.-Bras.

corallina, Brongn, ex Baker, i.c. 52. - Bras.

corymbosa, Mez, in Mart. F1. Brasil. iii. III. (1892) 216 (= Billbergia corymbosa, Mart.)

crocophylla, Baker, Handl.Bromel. (1889)65. - Bras. crocophylla, Lindman, in Svensk. Akad. Handl. xxiv. 8. (1891) $34=$ praec.?

cylindrata, Lindman, l. c. 32 t. 8 fig. 8-35. - Bras. dealbata, Ed. Morr. ex Baker, Handb. Bromel. (1889) 58. - Bras.

Donnell-Smithii, Baker, in fourn. Bot. xxviii. (1890) 305. - Am. centr.

Drakeana, Éd. André, in Rev. Hortic. (1888) 401; et l. c. (1889) $372 \mathrm{cum}$. icon. et Bromel. Andrean. (1889) 14 t. 6 a. - Ecuad.

eburnea, Baker, Handb. Bromel. (1889) 69. - Bras.

Edmondstonei, Baker, i. c. 38. - Ecuad.

eriantha, Brongn. ex Boker, l. c. 47. - Bras.

exsudans, Baker, l. c. 44. - Bras.

Fendleri, Éd. André, Bromel. Andrean. (1889) 13 in obs. - Venez.

Fernandae, Baker, l, c. 64. - Am. austr.

flexwosa, Baker, in Gard. Chron. (1887) i. $8=$ spectabilis, Brongn.

Fraseri, Baker, Handb. Bromel. (1889) 61. - Ecuad,

Friedrichsthalii, Mez et 7. Donn.-Sm. in Coult. Bot.

Gaz, xix. (1894) 263. - Guatem.

fusca, Baker, l. c. 69.- - Bras.

Galeottii, (err. cal. Galeottei) Baker, l. c. 51. Mexic.

gamosepala, Wittm. in Bol. Fahrb. xiii. Beibl. n. 29. (1891) 3 et 13. - Bras.

Germinyana, Bakey, l. c. 66. - N. Granat.

Germinyana, Lindman, in Svensk. Akad. Handl. xxiv. 8. (1891) $34=$ praec.

gigantea, Baker, Handb. Bromel. (1889) 45. - Hab.? gigantea, Baker, l. c. 65. - Bras.

gigantea, Lindman, l. c. 34. - Bras.

gigas, Éd. Morr. ex Baker, 1. c. $61=$ Lalindei, Linden et Rodig.

glomerata, Mez, in Mart. F1. Brasil. iii. III. (1892) $315=$ conglomerata, Baker.

gracilis, Lindman, in Svensk. Akad. Handl. xxiv. 8, (1891) 30 t. 6 fig. 10-16. - Bras.

grandiceps, Mez, in Mart. Fl. Brasil. iii. 1II. (1892) 346. - Argent.

hamata, Mez, l. c. 347. - Hab.?

Henningsiana, Wittm. in Bot. Fahrb. xiii, Beibl, n. 29. (1891) 12. - Bras.

Hoet.eli, Regel, in Act. Hort. Petrop.x. (1887) $367=$ spectabilis, Brongn.

Hokelii, «Regel», ex Baker, Handb. Bromel. (1889) $52=$ praec.

iguana, Wittm. in Bot. Fahrb. xiv, Beibl. n. 32 . (1891) 3. - Guatem.

immersa, Hort. ex Baker, Handb. Amaryll. (1889) $5=$ Karatas sarmentosa, Baker.

involucrata, Ed. André, in Rev. Hort. (1888) 564; et Bromel. Andrean. (1889) 13 t. 5 fig. a. - Ecuad. sabellina, Baker, in fourn. Bot. xxviii. (1890) 305. - Am. centr.

jucunda, Ed. Morr. ex Baker, Handb. Bromel. (1889) 55. - Bras.

Lagenaria, Mez, in Mort. Fl. Brasil. iii. III. (1892) 372. - Bras.

Lamarchei, Mes, l. c. 372. - Hab.?

laxiflora, Mez, 1. c. $335=$ Streptocalyx laxifora, Baker.

Leopoldi, Hort. ex Baker, Handb. Bromel. (1889) 58 = fasciata, Baker

leucocarpa, Ed. André, in Rev. Hortic. (1888) 563; et Bromel. Andrean. (1889) 10 t. 4 b. $-\mathrm{N}$, Granat.

leucostachys, Baker, Handb. Bromel. (1889) 39. Hab. ?

longicuspis, Bnker, l. c. 60. - N. Granat.

longisepala, Baker, l. c, 48, - Bras.

Luddemanniana, Brongn. ex Baker, 1. c. $50=$ cœrulescens, Baker

macroneottia, Baker, l. c. 68. - Bras.

Magdalenae, Ed. André, ex Baker, l.c. 65.-N. Granat.
AECHMEA :

marmorata, Mez, in Mart. Fl. Brasil. iii. III. (1892) 310 = Billbergia marmorata, Lem.

microthyrsa, Baker, in Kew Bull. (1892) 198. Bras,

miniata, Hort. ex Baker, Handb. Bromel: (1889) 53. - Bras.

myriophylla, Ed. Morr. ex Baker, in Bot Mag. (1887) t. 6939; et Handb. Bromel. (1889) 55.-Bras. Nichollsii, Baker, in Kew Bull. (1892) 128. - Ins. Tobago.

oligosepala, Baker, Handb. Bromel. (1889) 48. Venez.

penduliflora, Éd. André, in Rev. Hortic. (1888) 563 ; et Bromel. Andrean. (1889) 9 t. 4 a. - N. Granat.

phanerophlebia, Baker, l. c. 47. - Bras.

Platznanni, Wittm. in Bot. Jahrb. xiii. Beibl. n. 29 (1891) 2 et 12 = floribunda, Baker.

Plumieri, Bakev, Handb. Bromel. (1889) 50. - Ind. (recid.

Plumieri, Ed. Morr. ex Baker, 1. c. (1889) $45=$ lingulata, Baker.

Poeppioii, Baker, l. c. 37. - Reg. Amaz.

polystachya, Mez, in Mart. Fl. Brasil. iii. III. (1892) 343 = Glaziovii, Baker.

Prieureana, Baker, Handb. Bromel. (1889) 39. Guian. gall.

pulchra, Mez, in Mart. Fl. Brasil. iii. III. (1892) 374. - Bras.

purpurea, Baker, Handb. Bromel. (1889) 69.-Bras. purpurea, Williams, Catal. (1889)22; et ex Kew Bull. (1890) 36. - N. Granat

pycnantha, Baker, Handb. Bromel. (I889) 44. Hab.?

Regelii, Mez, in Mart. Fl. Brasil. iii. III. (1892) 339. Bras.

Ridieyi, Baker, Handb. Bronel. (1889) 47. - Bras. rosea, Baker, l. c. $68 .-$ Bras.

rosea, Hort. ex Baker, 1. c. $42=$ suaveolens, $K n$. et Westc.

Salzmanni, Baker, l. c. 49. - Bras.

Schomburgkii, Baker, l.c. 66. - Guian. brit.

Schultesiana, Mez, in Mart. Fl. Brasil. iii. III. (1892)

334. - Bras.

Selloana, Baker, Handb. Bromel. (1889) 60. - Bras, servitensis, Éd. André, in Rev. Hortic. (1888) 563 ; et Bromel. Andrean. (1889) 11 t. 5 b. - N. Granat. setigera, Hort, ex Baker, Handb. Bromel. (1889) 71 in syn. = Bilbergia thysoidea, Mart.

Skinneri, Baker, in Hook Icon. Pl. xix. (1889) t 1851 ; et Handb. Bromel. (1889) 49. - Guatem.

squarrosa, Baker, in fourn. Bot. xxviii. (1890) 305 Amer. centr.

squarrosa, Baker Handb. Bronzel. (1889)63. - Bras. stenophylla, Baker, l. c. 64. - Bras.

stephanophora, Ed. Morr. ex Baker, 7. c.67-Bras. sulcata, Lindman, in Siensk Akad. Handl. xxiv. 8. (1891) 31 t. 5 fig. 15-21. - Bras.

thyrsiflora, Mez, in Mart. Fl. Brasit. iii. III. (1892) 332. - Bras.

tinctoria, Mez, 1. c. $373=$ conspicuiarmata, Baker. tocantina, Baker. Handh, Bromel. (1889) 39.-Bras. triticina, Mez, in Mart. Fl. Brasil. iii. II. (1892) 369. - Bras.

turbinocalyx, Mez, l. c. 359. - Bras.

Van Houtteana, Mez, 1. c. $366=$ Quesnelia Van Houtteana, Ed. Morr.

virens, Brongn. ex Baker, Handb. Bromel. (1889) 45. - Guian. gall.

vrieseoides, Hort. ex Baker, I. c. 56 = tillandsioides, Baker.

Wittmackiana, Mez, in Mart. Fl. Brasil. iii. III. (1892) $340=$ Quesnelia Wittmackiana, Regel.

Wullschlaegeliana, Me\%, l. c. 380. - Guian. gall xiphophylla, Baker, Handb. Bromel. (Is89) 63. Bras.?

AEGILOPS, Linn. = Triticum, Linn. (Gramin.) Heldreichii, Holzm. ex Nym. Consp. fl. Europ. Suppl. (1889) 342. = T. caudatum, Gren. et Godr.

AEGIPHILA, Jacq. (Verben.).- Ind, Kew. i. 46. falcata, F. D. Sm. in Coult. Bot. Gaz. xviii. (1893) 7. - Guatem.

setiformis, Rusby, in Mem. Torrey Bot. Club, iv. (1895) 245. - Bolivia. 
AEGLE, Correa (Rutac.). - Ind. Kew, i. 47.

Barteri, Hook. f. ex Oliver, in Hook. Icon. Pl. xxiii. (1894) t. 2285. - Afr. trop. occid.

AEGOPODIUM, Knaut (Umbellifer.). - Ind. Kew. i. 47.

tribracteolatum, Schmalh. in Bull. Soc. géogr. Cauc. (1892) 22; et in Ber. deutsch. bot. Ges.x. (1892) 289. - Reg. Cauc.

AEGOPOGON, Beauv. (Gramin.). - Ind. Kew. 1. 47.ilis, Vasey, ex S. Wats, in Proc. Am. Acad. gracilis, Vasey, (1886) 442 nomen; et in Bull. Torrey Bot. Club, xiii. (1886) 230. - Mexic.

AELUROPUS, Trin. (Gramin.).-Ind. Kew.i. 47. mucronatus, Terrac, in Ann. Ist. bot. Roma, V. 1894) 96 = arabicus, Stend.

AEOLANTHUS, Mart. (Labiat.), - Ind. Kew. i. 47.

Buchnerianus, Briq. in Bot. fahro. xix. (1894) 187. - Congo.

Buettneri, Giurke, in Bot. Fahrb. xix. (1894) 222. Afr. trop. occid.

Candelabrum, Briq. in Bot. Fahrb. xix. (1894) 186. - Angola.

canescens, Gürke in Bot. Fahrb. xxii (1895) 147. Afr. trop. et austr.

elongatus, Briq. l. c. 188. - Angola.

elsholtzioides, Briq. l. c. 187. - Angola.

Engleri, Briq. l. c. 189. - Angola.

floribundus, Briq. l. c. 190. - Angola.

fruticosus, Giurke, in Engl. Pfanzenw. Ost-Afr. C 1895) 346. - Afr. trop. or.

Holstii, Giirke, in Bot. Fahrb. xix. (1894) 221. Afr. trop. or.

ndorensis, Schweinf. in Hoehnel, Zum Rudolph See, App. (1892) 6. - Afr. trop.

Njassae, Gürke, in Engl. Pflanzenv. Ost-Afv, C (1895) 346. - Afr. trop. or.

obtusifolius, Briq. in Bot. fahrb. xix. (1894) 189. Angola.

panganensis, Gürke, in Engl. Pfanzenw. Ost-Afr. C (1895) 346. - Afr. trop. or.

Prittwitzianus, Giirke, in Engl. Pflanzenw. Ost-Afr. A (1895) 134. - Afr: trop. or.

Stuhlmannii, Gürke, l. c. 345. - Afr. trop.or.

ukamensis, Giuke in Bot. Fahrb. xxii. (1895) 147.Afr, trop.

virgatus, Gïrke l.c. 146. - Afr. trop.

Welwitschii, Briq. l. c. xix. (1894) 188. - Angola.

AEONIA, Lind1. (Orchid.). - Ind. Kew. i. 47.

macrostachya, Cordem. Fl. Ile Réunion (1895) 551. - Ins. Borbon.

volucris, Cordem, i. c. 550. - Ins. Borbon.

AEONIUM, Webb et Berth. = Sempervivum, Linn. (Crassul.).

Benteju, Webb, ex Christ, in Bot. Jahrb. ix. (1888) $109=$ S. Bentejui, Christ.

Doremae, Webb, 1. c. $110=$ S. mauriqueorum, Christ

giganteum, Webb, 1. c. 111. = S. canariense, Linn. gomeraeum, Webb. 1. c. $=\mathrm{S}$. Paivae, Lorve. macrolepum, Webb 1. c. $112=\mathrm{S}$. macrolepum, Christ.

palmense, Webb, 1. c. $112=$ S. palmense, Christ.

virgineum, Webb, 1. c. $111=\mathrm{S}$. virgineum, Christ.

AËRANTHUS, Reichb. f. = Mystacidium, Lindl. (Orchid.).

brachycentron, Regel, in Act. Hort. Petrop. xi. (1890) 303; Aër, et Gartenfl. (1891) 323. - Hab. ?

Englevianus, Kraenzl, in Bot. Jahrb. xvii. (1893) 62. - Madag.

Gravenreuthii, Kraenzl. 1. c. - Madag.

Hermanni, Frappier, ex Cordem. Fl. Ile Réunion (1895) 193. - Ins. Borbon.

ophioplectron, Reichb. f. in Gard. Chron. (1888) ii. 91. - Madag.

polyanthemus, Ridl. in Journ. Linn. Soc. xxii. (1886) 121. - Madag.

strangulatus, Frappier, ex Cordem. Fl. Ile Réunion (1895) 192. - Ins. Borbon.
AËRANTHUS :-

trichoplectron, Reichb. f. in Gard. Chron. (1888) i. 264. - Madag.

Wawrae, Reichb. f. ex G. Beck, Itin. Princ, Sax, Coburg. ii. (1888) 156. - Bras.

AËRIDES, Lour. (Orchid.). - Ind. Kew. i. 48. Augustianum, Rolfe, in Lindenia v. (1889) 39 tab. 210; et in Gard. Chron.(1890) i. 9 et 233 cum xylogr. - Ins. Philipp.

cristatum, Wall. ex Hook. f. F1. Brit. Ind, vi, (1890) 53 = Vanda cristata, Lindl.

densiflorum, Wall. ex Hook. f. 1. c. $72=$ Cleisostoma spicatum, Lindl.

Godefroyanum, Reichb. f. in Gard. Chron. (1886) i. 814. - Cochin-China.

Huttonii, Veitch, Man. Orchid. Pl. vii. (1891) $70=$ Saccolabium Huttonii, Hook. $f$.

Fansoni X, Rolfe, in Gard. Chron. (1890) i. 66. Burma.

leopardorum, Wall. ex Hook. f. FI. Brit. Ind, vi. (1890) 60 = Saccolabium calceolare, Lindl.

lineare, Hook. f. l. c. 47. - Ind. or.

longicornu, Hook. f. Fl. Brit. Ind. vi. (1890) 44; et Icont. Pl. xxii. (1893) t. 2127. - Reg. Himal.

Picotianum, Hort. ex Reichb. f. in Gard. Chron. (1888) ii. 378 in obs. = Houlletianum, Reicht. $f$. platychilum, Rolfe, in Kew Bull. (1893) 64.- Hab.? racemiferum, Wall, ex Hoolk. f. Fl. Brit. Ind. vi. (1890) $68=$ Sarcanthus pallidus, Lindl.

ramosim. Wall. ex Hook, f, 1. c $72=$ Cleisostoma ramosum, Hook. $f$.

retrofractum, Wall. ex Hook. f. 1. c. $46=$ falcatum, Lindl.

Savageanum, Sand. ex Veitch, Man. Orch. Pl, vii. (1891) 78. - Hab. ?

Warnevi, Hort. ex Hook. f. F1. Brit. Ind. vi. (1890) $46=$ crispum, Lindl.

AERVA, Forsk. (Amarant.). - Ind. Kew. i. 49. Curtisii, Oliver, in Hook. Icon. Pl. xxiii. (1892)t. 2201. - Perak.

desertorum, Engl. Bot. Fahrb. x. (1889) 7.-Afr. austro-occ.

Leubnitziae, Kuntze, in Fahrb. bot. Gavt. Berl. iv, (1889) 272. - Afr. austro-oc.

Pechuelii, Kuntze, l. c. 27\%. - Afr. austro-occ.

AESANDRA, Pierre ex L. Planch. Étud. prod. Sapot. (1888) 26 nomen; et Not. bot. Sapot. (1890) 2. SAPOTACEAE

dongnaiensis, Pierre, l. c. 2. - As, trop.

AESCHRION, Vell.=Picraena, Lindl. (Simarub.). xcelsa, Kuntze, Rev. Gen. (1891) $183=$ P. excelsa, Lindl.

AESGHYNANTHUS, Jack (Gesnerac.). - Ind. Kew. i. 49.

Hildebrandtii, Hemsl. in Bot. Mag. (1894) t. 7365. Burma.

magnifica, Stapf, in Trans. Lim. Soc., Ser. II. iv. (1894) 212. - Borneo

AESGHYNOMENE, Linn. (Leguminos.). - Ind. Kew. i. 50.

abyssinica, Taub. ex Engl. in Abhandl. Preuss. Akad. Wiss. 1891. ii. (1892) $262=$ A. Rueppelii, Baker.

amorphoides, Rose, ex Robinson, in Proc. Am. Acad. xxix. (1894) 315. - Mexic.

arabica, Deflers, in Bull. Soc. Bot. Fr. xlii. (1895) 303. - Arabia.

Elaphroxylon, Taub. in Engl, et Prantl, Natürl. Pflanzenfam. iii. II. (1894) 319-20 fig. $124=$ Herminiera Elaphroxylon, Guill. et Perr.

gracilipes, Taub. in Engl. Pflanzenw. Ost-Afr. C (1895) 214. - Afr. trop. or.

kilimandscharica, Taub. ex Engl. in Abhandl. Preuss. Akad. Wiss. 1891. ii. (1892) 262. - Atr. trop. or, minutiflora, Taub. ex Engl. l. c. (1894) 14; et Pflanzenw. Ost-Afr. C (1895) 214. - Afr. trop. or nivea, T. S. Brandeg. in Proc. Calif. Acad. Ser. II. ii. (1889) 150. - Calif.

petraea, Robinson, in Proc. Am, Acad. xxvii. (1893) 166. - Mexic.

\section{AESGHYNOMENE :}

Pfundii, Tanb. in Engl. Pfanzonw. Ost-Afr. C (1895) 215. - Afr. trop: or

Riedeliana, Taub. in Flora, xxii. (I889) 424.-Bras. rivularis, Frappiev, ex Cordem. Fl. Ile Rémion (1895) 400. - Ins. Borbon.

sansibarica, Taub. in Engl. Pfanzenw. Ost-Afr. C (1895) 214. - Afr. trop. or

shirensis, Taub.l. c. 215. - Afr. trop. or

Telekii, Schweinf. ex Engl. in Abhandl. Preuss. Akad. Wiss. 1891. 1i. (1892) 263; et in Hoehnel, Zum Rudolph-See, App. (1892) 13. - Afr. trop. or.

Vigil, T. S. Brandeg. in Proc. Calif. Acad. Ser. II. iii. (1891) 128. - Calif.

virginica, Britton, Stern et Poggenb. Prelim. Catal. (1888) $13=$ hispida, Willd.

AESGULUS, Linn. (Sapindac.), - Ind. Kew. 1.51. balgiana $\times$, Ed. André, in Rev. Hortic. (1894) 246. - Hybr. artef.

floribunda, Hort. ex Dippel, Handb. Laubholzk. ii. $(1892) 398=$ carnea, Hayn

marylandica, Booth, Catal. ex Dippel, 1. c. $403=$ lutea, Wangenh.

plantierensis X, Ed. André, in Rev. Hortic. (1894) 246. - Hybr. artef.

spectabilis, Hort. ex Dippel, Handb. Laubholzk. ii. (1892) $398=$ carnea, Hayne.

Â̂TANTHUS, Engl, in Engl, et Prantl, Natürl. Pflanzenfam. iii.i. (1889) 189. LORANTHACEAE. Mutisii, Engl.l.o. fig. 128 (=Loranthus Mutisii, H. B. et K.).-Ecuad., N. Granat.

AETHIONEMA, R. Br. (Crucifer.). - Ind. Kew.

creticum, Boiss, et Heldr. ex Boiss. Fl. Or. Suppl. (1888) 61. - Creta, Asia min.

dimorphocarpum, Giraudias, in Bull. Soc. étud. scient. Angers, xxii. (1893) $165=$ pyrenaicum Bout.

gileadense, Post, in fourn. Linn. Soc. xxiv. (1888) 421. - Syria.

glaucescens, Halàcsy, in Zool.-bot. Ges. Wien. Abh. xxxviii (1888) 748. - Graecia.

longistylum, Post, in fourn. Linn. Soc. xxiv. (1888) 421. - Syria.

ovalifolium, Lojacono, F1. Sicul. (1888) $83=$ saxatile, R. Br

schizopterum, Boiss. et Hausskn. ex Boiss. Fl. Or Suppl. (1888) 60. - Persia.

spinosum, Prantl, in Engl. et Prantl, Natürl. Pflanzenfam. iii. 11. (1891) $165=$ Moriera spinosa, Boiss.

varians, Giraudias, in Bull. Soc, étud. scient Angers, xix. (1890) 100. = pyrenaicum, Bout.

AETHONOPOGON, Hackel, ex Kuntze, Rev. Gen. (1891) 788 = Polytrias, Hackel (Gramin.).

praemorsus, Hackel, ex Kuntze, 1. $c_{0}=\mathrm{P}$. praemorsa, Hackel.

AFFONSEA, A. St-Hil. (Legumin.).-Ind. Kew

Lucyi, Kuntze, Rev. Gen. (1891) $158=$ Archidendron Lucyi. F. Muell.

Vaillantii, Kuntze, 1. c. = Archidendron Vaillantii, F. Muell.

AFROMENDONGIA, Gilg, ex Lindau, in Bot. Jahrb. xvii. (1893) 111. ACANTHACEAE.

Gilgiana, Lindau, l. c. - Afr, trop.

Lindaviana, Gilg, l. c. - Afr. trop. occ.

phytocrenoides, Gilg, ex Lindau, l.c.112. - Afr. trop.

AFZELIA, J. F, Gmel. = Seymeria, Pursh (Scrophul.)

bipinnatisecta, Kuntze, Rev. Gen. $457=$ S. bipinnatisecta, Seem.

decurva, Kuntze, 1. c. = S. decurva, Benth. macrophylla, Kuntze, 1. c. = S. macrophylla, Nutt. madagascariensis, Kuntze, 1. c. = S. madagascariensis, Benth, et Hook. f. (fide Kuntze).

pectinata, Kuntze, 1. c. = S. pectinata, Pursh. pinnatifida, Kuntze, 1. $\mathrm{C}_{\mathrm{n}}=\mathrm{S}$. pinnatifida, Hemsl. scabra, Kuntze, 1. c. = S. scabra, A. Gray. virgata, Kuntze, 1. $\mathrm{c}_{\mathrm{N}}=\mathrm{S}$, virgata, Benth. 
AFZELIA, Sm. (Leguminos.). - Ind. Kew. i. 52. australis, Bailey, Syn. Queensl. Fl. Suppl. ii. (1888) 19. - Austral.

bijuga, Raill. Hist. pl. Madag., Atlas (1886) t. 27.Madag.

bijuga, $K$. Schum. in K. Schum, et Hollr. Fl. Kais. Wilh. Land. (1889) 100. - N. Guin.

AGALINA vitiensis "Seem. » in Gartenfl. (1887) $7 \mathbf{1}$. (err. cal.) = Agalma vitiensis, Seem .

AGALLOCHUM, Rumph. = Aquilaria, Lam. (Thymel.).

grastiflorm, Kuntze, Rev. Gen. 283 = Aq. grandiflora, Benth.

malaccense, Kuntze, 1. c. = Aq. malaccensis, Lam. sinense, Kuntze, 1, c. = Aq. Ophispermum, Poir.

AGALLOSTACHYS, Beer = Bromelia, Linn (Bromel.)

givanensis, Beer, ex Baker, Handb. Bromel. (1889) 120 in syn. = Pitcairnia guyanensis, Baker

AGALMA, Miq. = Heplapleurum, Gaert, (Araliac.). ragosum, Boerl. Handl. F1. Ned. Indie, i.
$648 .(=$ Aralia rugosa, Blume). - Java.

AGALMYLA, Blume (Gesnerac.), - Ind. Kew. i. parasitica, Kuntze, Rev. Gen. (1891) 469. = staminea, Blume.

AGANISIA, Lind1. (Orchid.). - Ind. Kew. i. 53 alba, Ridl. ex im Thurm, in Timehri, v. (1886) 204 = Zygopetalum (sp.)

ionoptera, Nichols. Dict. of Gard. i. (1885) 35 Hook. f. in Bot. Mag. (1892) t. 7270. - Peruy. tricolor, N. E. Br. in Lindenia, i. (1885) 95 tab. $45=$ cyanea, Lindl

AGANOSMA, G. Don (Apocyn.). - Ind. Kew. dichotomum, K. Schum. in Eng1. et Prantl, Natürl. Pflanzenfam. iv. 2. (1895) $173=$ caryophyllatum, G. Don.

AGAPANTHUS, L'Herit. (Liliac.), - Ind. Kew. i, 53
africanus, Dur. et Schinz, Consp. Fl. Afr. v. (1893) africanus, Dur. et Schinz, Consp. Fl. Afr. V. (1893)
354. (= A. wmbellatus, L'Hérit. $)=$ Agap. africanus, Hoffmgg.

AGAPETES, G. Don (Vaccin.).-- Ind. Kew. i. 53, acuminatissimum, Nicdenzu, inz Bot. Fahro xi (1890) 201 et 247. (= Vaccinium actminatissimum, Miq.). - Malaya.

Forbesii, F. Muell, in foum. Bot. xxiv. (1886) 290. - N. Guin.

Helence, F. Muell, in Trans. Roy. Soc. Vict. N. S. i. Ir. (1889) 16 = Vaccinium Helenae, F. Muell. lanceolata, Niedenzu, in Bot. fahrb. xi, (1890) 201 et $246=$ Vaccinium acuminatiss imum, $M i q$.

leptantha, Niedenzu, l. c. 201. (= Vaccinium leptanthum, Miq.). - Java, Sumatra.

Mannii, Hemsl. in Gard. Chron. (1892) ii. 364.Reg. Himal.

Meiniana, F. Muell. in Vict. Natural. iii. (March 1887) 158. - Austral.

Moorhousiana, F. Mucll. in Wing, South. Sc. Record, N. S. ii. (Feb. 1886). - N. Guin.

polyantha, Niedenzu, in Bot. Fahrb. xi. (1890) 224 et 246. (= Vaccinium polyanthum, Miq. ined. ?) - Malaya.

vitiensis, “Benth. et Hook.» ex Drake, Illustr. Insul. Maris Pacif. (1892) 223. - Ins. Pacif

yunnanensis, Franch. in Morot, fourn. de Bot. ix. (1895) 366. - China occ

AGARISTA, D. Don (Ericac.). - Ind. Kew. i. 53. angustissima, Taub. in Bot. Jahrb. xvii. (1893) 513. - Bras

ericoides, Taub. 1. c. 512. - Bras.

AGASTACHE, [Clayt. ex] Gronov, Fl. Virg. 88 1762) ex Kuntze, Rev. Gen. (1891) 511 = Lophanthus, Benth. (Labiat.)
AGASTACHE :-

Fanicutum, Kuntze, Rev. Gen. $511=$ L. anisatus, Benth.

Lophanthus, Kuntze, 1. c. = L. chinensis, Benth. nepetodes, Kuntze, 1. c. = L. nepetoides, Benth. rugosa, Kuntze, 1. c. = L. rugosus, Fisch. et Mey. scrophulariaefolia, Kuntze, 1. c. = L. scrophulariaefolius, Benth.

tomentosa, Kuntze, 1. c. = L. tomentosus, Regel. urticifolia, Kuntze, 1. c, = L. urticifolius, Benth.

AGATHIS, Salisb. (Conifer.). - Ind. Kew. i. 54 Palmerstoni, F. Muell. in Vict. Natural. viii (June 1891) 45 in syn.; et ex F. M. Bailey, in Dept. Agric. Bot. Bull. iil. (1891) $17=$ Dammara Palmerstoni.

robusta, F. M. Bailey, Cat. Woods Queensl. (Lond. Col. Ind. Exhib. 1886) $83(=$ Dammara robusta, C. Moore), - Austral.

AGATHOSMA, Willd. (Rutac.).-Ind. Kew. i. 54. Wrightii, Macowan, in fourn. Linn. Soc. xxv, (1890) 386. - Afr. austr.

AGATI, Adans. = Sesbania, Pers. (Legumin.). sericea. Hitchc, in Missouri Bot. Gard. Rep. iv. (1893) $75=$ S. sericea, $D C$.

AGAURIA, Benth. et Hook. f. (Ericac,). - Ind. Kew, i. 55 .

buxifolia, Cordem. (= Andromeda buxifolia, Lam.) Fl. Ile Réunion (1895) $439=$ buxifolia, Baker. callibotrys, Cordem. l. . . 438. - Ins. Borbon. nummularifolia, Baker, in foum. Linn. Soc. xxv. (1890) 332. — Madag.

AGAVE, Linn. (Amaryll.). - Ind. Kew, i. 55.

aurea, T. S. Brandegee, in Proc. Calif. Acad. Ser. II. ii. (1889) 207. - Calif.

Baxteri, Baker, in Gard. Chron. (1888) i. 392; et Handb. Amaryll. (1888) 178. - Mexic.?

brunnea, S. Wats. in Proc. Am. Acad. xxvi. (1891) 156. - Mexic.

Davilloni, Baker, in Keq Bull. (1892) 5. - Patr.?

Engelmanni, Trelease, in Missouri Bot. Gard. Rep. iii. 1891 (1892) 167, t. 55 et 56. - Patr.

Franzosinii $X$, Hort. Hamb. ex W. Wats. in Kew Bull. iii. (1887) 301; et Baker, in Gard. Chron. (1892) ii. 179, fig. 31. - Patr.?

Hanburii, Baker, in Kew Bull. (1892) 3. - Patr.?

Hartmani, S. Wats, in Proc. Am. Acad. xxvi. (1891) 156. - Mexic

Henriquesii, Baker, in Gard. Chron. (1887) i. 732. fig. 70; et Handb. Amaryll. (1888) 170. - Mexic.? huachucaensis, Sarg. in Gard. and For. viii. (1894) 184. - Arizona. (an praec. ?)

huachucensis, Baker, Handb. Amaryll. (1888) 172.Arizona.

integrifolia, Baker, Handb. Amaryll. (1888) 185. Mexic.

longisepala, Tod. Hort. bot. Panorm. (1886) 34 t. 31. - Mexic.

macroculmis, Tod. Ind. sem. hort. Panorm. (1888) 36; et Hort. bot. Panorm.t. 36. - Mexic.

Margaritae, F. S. Brandegee, in Proc. Calif. Acad. Ser. I1. i1. (1889) 206 t. 10. - Calif.

Maximowicziana, Regel, in Act. Hort. Petrop. xi. (1890) 303. - Patr.?

Morrisii, Baker, in Gard Chron. (1887) i. 543 fig. 105; et Handb. Amaryll. (1888) 184. - Jamaica. multilineata, Baker, Handb. Amaryll. (1888), 168. Mexic.

Nickelsi, Hort. Amer. ex Rev. Hortic. (1895) 579. - Texas? vel. Hybr. artef.

planifolia, S. Wats. in Proc. Am. Acad. xxii. (1887) 479. - Mexic.

potosina, Robinson et Greenman, in Proc. Am. Acad. xxix. (1884) 392. - Mexic.

Pringlei, Engelm. ex Baker, Handb. Amaryll. (1888) 182. - Calif.

protuberans, Engelm, ex Baker, 1. c. (1888) $197=$ guttata, Hemsl.

pumila, Hort. De Smet, ex Baker, l. c. 172.-Mexic.? Richardsii, Hort. ex Baker, 1.c. $184=$ striata, Zucc. Romani X. Hort. De Smet, ex Baker, 1. c. 166. Hybr. artef.

saberrima, Hort. Peacock, ex Baker, 1. c. $182=$ Pringlii, Engelm.

\section{AGAVE :}

sebastiana, Greene, in Bull. Calif. Acad. i. (1885) 214. - Calif.

sobria, T. S. Brandegee, in Proc. Calif. Acad. Ser. II. ii. (1889) 20\%. - Calif.

Terraccianoi, Pax, in Gartenfl. (1893) 68 fig. 14. - Mexic.?

Todaroi, Baker, Handb. Amaryll. (1888) 195. Mexic.?

Troubetskoyana, Hort. ex Baker, in Kew Bull. (1892) 5. - Hab.?

vestita, S. Wats, in Proc. Am. Acad. xxv. (1890) 163. - Mexic.

Villarum X. Éd. André, in Rev. Hortic. (1886) 465. - Hybr. artef.

weissenburgensis, "Wittm.» ex Baker, Kew Bull. (1889) $178=$ wiesenbergensis, Wittm.

Wildingii, Tod. Hort. bot. Panorm. (1886) 36 t. 32; Baker, Handb, Anaryll. 18\%. - Mexic.?

AGELAEA, Soland, (Connarac.). - Ind. Kew. 1.57 cmetica, Baill. in Laness. P1. util. col. franç. (1886) 875; et Hist. pl. Madag., Atlas (1886) t. 15. = A. Lamarckii, Planch.

heterophylla, Gilg, in Notizbl. Bot. Gavt. Berl. i. (1895) 66. - Afr. trop. or.

pentagyna, Radlk. in Sitz. math. phys. Cl. Bay. Akad. Wiss. xvi. (1886) 349. = pentagyna, Baill. paradoxa, Gilg, in Engl. et Prantl, Naturl. Pflanzenfum. iii. 3. (1888) 65, fig. 35 - Afr. trop. occ. Poggeana, Gilg, in Notizbl. Bot. Gart. Berl. i. (1895). 65. - Congo merid.

usambarensis, Gilg, ex Engl. Pflanzenw. Ost-Afr. A (1895) $86=$ obliqua, Baker

AGELANTHUS, Van Tiegh. in Bull. Soc. bot. Fr. xlii.(1895)246= Loranthus, Linn. (Loranth.). brumeus, Van Tiegh. 1. c. = L. brunneus, Engl.

Gilgii, Van Tiegh. 1. c. = L. Gilgii, Engl.

gloneratus, Van Tiegh. I. c. = L. glomeratus, Engl.

Henriquesi, Van Tiegh. 1. c. = L. Henriquesii, Engl.

AGERATELLA, A. Gray, ex S. Wats, in Proc. Am. Acad. xxii. (1887) 419. COMPOSITAE. microphylla, A Gray. ex S. Wats. l. c. $(=$ Ageratum microphyllum, Schultz Bip.). - Mexic.

AGERATUM, Linn. (Compos.).-Ind. Kew. i. 58. callosum, S. Wats, in Proc. Am. Acad. xxv. (1890) 153. - Mexic.

intermedium, Hensl. in Biol. centr. Am. iv. (1886) 102. - Ins. Cozumel

rugosum, Coult. ex F. D.-Smith, in Conlt. Bot. Gaz. xx. (1895) 42, - Guat.

AGIABAMPOA, Rose, ex O. Hoffm, in Engl, et Prant, Naturi. Pflanzenfam. iv. 5 (1893) 390. COMPOSITAE.

congesta, Rose, l. c. - Mexic

AGIALID (A), Adans,=Balanites, Delile (Simar.). aegyptiaca, Kuntze, Rev. Gen. (1891) 183 = B aegyptiaca, Delile.

Roxburghii, Kuntze, 1, c. = B. Roxburghii, Planch.

AGLAIA, Lour. (Meliac.). - Ind. Kew. i.

Beccarii, C. DC. in Bull. Herb. Boiss. ii. (1894) 579. - Borneo.

Bergmanni, Warb. in Bot. Fahrb. xiii. (1891) 346. - Oceania

cambodiana, Pierre, F1. For. Cochinch. (1895) sub t. $334 .=$ Milnea cambodiana, Pierre.

cochinchinensis, Pierre, 1. c. t. 334 A. = pyramidata, Hance.

cinerea, King, in fourn. As. Soc. Beng. Ixiv. (1895) ii. 66. - Malacca.

Curtisii, King, l. c.71. - Perak.

Ermischii, Warb. in Bot. Fahrb. xiii (1891) 345. Oceania.

Forbesit, King, in fourn. As. Soc. Beng. 1xiv, (1895) ii. 68. - Malaya.

fusca, King, l. c. 62. - Ins. Andam.

glaucescens, King, l. c. 64. - Ins. Andam.

Goebeliana, Warb. in Bot. Fahrb. xiii. (1891) 345. Oceania.

Harmandiana, Pierre, Fl. For. Cochinch. (1895) t. $333=$ Milnea Harmandiana Pierre. 
AGIAIA : -

heteroclita, King, in fourn. As. Soc. Beng. lxiv. (1895) ii. 78. - Malaya.

Hiernii, King, l. c. 74. - Malaya, Perak.

hoanensis, Pierre, Fl. For. Cochinch. (1895) t. 336. - Cochinch.

humilis, King, in fourn. As. Soc. Beng. 1xiv. (1895) ii. 69. - Perak.

Kunstleri, King, l. c. - Perak.

lanuginosa, King, l.c.71. - Perak.

leucophylla, King, l. .. 66 . - Perak.

macrostigma, King, l. c. 78. - Perak.

membranifolia, King, l. c. 75. - Malaya.

Maingayi, King, l. c. 79. - Malacca, Perak.

rugosa, Pierre, F1. For. Cochinch. (1895) sub. t. $335=$ Milnea rugosa, Pierre.

Scortechinii, King, in fourn. As. Soc. Beng. 1xiv. (1895) ii. 64. - Perak.

sinensis, Pierre, Fl. For. Cochinch. (1895) sub. t. 334 = odorata, Lour.

squamulosa, King, l. c. 65. - Perak.

verrucosa, Pierre, F1. For. Cochinch. (1895) sub.t. $335=$ Milnea verrucosa, Pierre.

Zollingeri, C. DC. in Bull. Herb. Boiss, ii. (1894) 579. - Java.

AGLAONEMA, Schott (Aroid.). - Ind. Kew. i. 59.

angustifolium, N. E. Br. in Kew Bull. (1895) 18. Malaya.

birmanicum, Hook. f. Fl. Brit. Ind. vi. (1893) 529 Burma.

Clarkei, Hook. f. l. c. vi. (1893) 529. - Bengal.

costatum, N. E. Br. in Gard. Chron. (1892) i. 426. - Perak

Helferi, Hook. f. Fl.Brit.Ind.vi.(1893) 529.-Tenass.

minus, Hook. f. l. c. vi. (1893) 530. - Singap.

nanum, Hook. f. l. c. vi. (1893) 530. - Perak.

nebulosum, N.E. Br. in Illustr. Hortic. xxxi. (1887) 67 t. 24. - Java.

nicobaricum, Hook. f. Fl. Brit. Ind. vi. (1893) 530. - Ins. Nicob.

pumilum, Hook, f. l. c. 530 ; et in Veitch. Catal. (1894) 5 cum xylogr. - Burma.

rotunda, N.E. Br.in Gard. Chron. (1893) 86; et fourn. of Hort. (1893) 379 fig. 56. - Malaya?

Scortechinii, Hook. f. Fl. Brit. Ind. vi. (1893) 530. - Perak.

versicolor, Hort, ex Gard, Chron. (1893) i. 414.Ind. or.

AGONIS, Lindl. (Myrtac.). - Ind. Kew. i. 59.

ericoides, F. M. Bailey, in Dept. Agric. Bot. Bull. ii. (1891) 37. - Austral.

1ysicephala, F. M. Bailey, Syn. Oueensl. Fl. Suppl.ii. (1888) 24. (= Melaleuca lysicephala, F. Muell. et Bail.). - Austral.

AGOSERIS, Rafin.$=$ Troximon, Nutt. (Composit.). alpestris, apargiodes, arizonica, aurantiaca, barbellulata, gracilens, grandiflora, heterophylla, humilis, laciniata, Marshallii, parviflora, plebeja, purpurea, retrorsa, Kuntze, Rev. Gen. (1891) $304=$ homonyma omnia Troximonis.

omnia Troximonis.
alpestris, Greene, Pittonia, ii. (Sept. 1891) $177 .=$ T. alpestre, Gray.

apargioides, Greene, 1. c. = T. apargioides, Less. arizonica, Greene, 1. c. 176. $=\mathrm{T}$, arizonicum, Greene. aurantiaca, Greene, 1. c. $17 \%=\mathrm{T}$, aurantiacum, Hook.

barbellulata, Greene, 1. c. = T. barbellulatum, Greene.

chilensis, Greene, 1. c. 178. = Macrorhynchus chilensis, Less.

Dens-leonis, Greene, in Erythea, iii. (1895) 23. Nevada.

elata, Greene, Pittonia, ii. (Sept. 1891) $177=\mathrm{T}$. Nuttallii, A. Gray.

elata, Kuntze, Rev. Gen. (1891) $304 .=$ T. Nuttallii, A. Gray.

glauca, Greene, Pittonia, ii. (Sept. 1891) $176 .=$ T. glaucum, Nutt.

gracilenta. Greene, 1. c. 177.=T. gracilens, $A$. Gray

grandiflora, Greene, 1. c. 178. = T. grandiflorum,

A. Gray.

Greeneana, Kuntze, Rev. Gen. (1891) 304. = T. elatum, Greene.
AGOSERIS : -

heterophylla, Greene, Pittonia, ii. (Sept. 1891) 178. $=\mathrm{T}$. heterophyllum, Greene.

hirsuta, Greene, 1. c. 177. = Leontodon hirsutum. Hook.

intermedia, Greene, in Erythea, i. (I893) 175. Calif.

laciniata, Greene, Pittonia, ii. (Sept. 1891) 178. = T. grandiflorum, var, laciniatum, A. Gray.

laevigata, Greene, 1. c. = Macrorhynchus laevigatus, Fisch.et Mey.

major, Jepson, ex Greene, Pittonia, ii. (Sept. 1891) 179; et in Bull. Torrey Bot. Club. xviii. (1891) $325 .=\mathrm{T}$. elatum, Greene.

Marshallii, Greene, Pittonia, ii. (Sept. 1891) 178. $=\mathrm{T}$. Marshallii, Greene.

parviflora, Greene, 1. c, $176 .=$ T. parviflorum, Nutt.

plebeia, Greene, 1. c. 178. = T. plebeium, Greene. Poeppigii, Greene, 1. c. = Macrorhynchus Poeppigii, $D C$.

purpurea, Greene, Pittonia, ii. (Sept. 1891) 17\%. = T. purpureum, Greene.

scorzoneraefolia, Greene, 1. c. = Ammogeton scorzoneraefolium, Schrad.

retrorsa, Greene, 1. c. 178. = T. retrorsum, A. Gray. rosea, Greene, 1. c. 176. = T. roseum, Nutt.

AGRIMONIA, Tourn. ex Linn. (Rosac.). - Ind. Kew. i. 60.

glandulosa, Murb. in Lunds Univ. Arsskrift. xxvii. v. (1892) $130=$ seq. ?

glandulosa, Simonk. Enum. fl. Transsilv. (1886) 223. $=$ odorata, Linn.

mollis, Britton, in Bull. Torrey Bot.Club. xix.(1892) 221; et in Mem. Torrey Bot. Club. ix. (1895) 116. $=$ A. Eupatoria; Linn.

AGROPYRON, J. Gaert. (Gramin.). - Ind. Kew. i. 60

Buonapartis, Th. Dur. et Schinz Consp. fl. Afric. v, 1894. (1895) 936. (= Triticum Buonapartis, Spreng. - Afr. bor. Reg. Cauc.

desertorum, C. Richt. (an Schult.?) Pl. Europ. i. (1890) 126. (= Triticum desertorm Fisch.) Ross. austr.

distachyum, Vasey, in A. Gray Man. Bot. North. U. S. ed.6. (1890) 671. - Am. bor

duplicatum, C. Richt. Pl. Europ. i. (1890) 126. (= Triticum duplicatum, Steud.). - Graec.

Enysii, T. Kirk, in Trans N.Z. Inst. xxvii. 1894. (1895) 352. - N. Zel

Langei $X$, C. Richt. Pl. Europ. i. (1890) 126. Dania.

piliferum, Benth, ex Aitch. in Trans. Linn. Soc. Ser. II. iii. (1886) 126. - Turkest.

pseudocaninum, Simonk. Enum. fl. Transsylv.(1886) 594. = caninum, Beaw.

ramificum, C. Richt. Pl. Europ.i. (1895) 124 (=Triticum ramificum, Link.). - Graecia.

ramosum. C. Richt. l. c. 126. (= Triticum ramosum, Trin.). - Ross.

Thoroldianum, Oliver, in Hook. Icon. pl. xxiii. (1893) t. 2262. - Tibet

trichophorum, C. Richt. Pl. Europ. i. (1895) 124. (= Triticum trichophorum, Link.). - Litt. Austr. unilaterale, Cassidy, in Bull. Iowa Agric. Exp. Sta. xii. (1890) 63. = caninum, Beauv. var.

violaceum, C. Richt. Pl. Europ.i. (1890) 123. (=Triticum violaceum, Horn.). - Scand.

AGROSTEMMA, Linn. = Lychnis, Linn.(Caryophyll.).

baldense $X$, Porta, ex Tanfani in Bull. Soc, bot. Ital. (1892) 100. - Ital.

Walkeri $\times$, Dickson, in Gartenf. (1890) 529. Hybr. artef.

AGROSTIS, Linn. (Gramin.). - Ind. Kew, i. 61. airoides, Franch. Miss. Sc. Cap Horn. v. (Phan.) (1889) 382 t. 11. - Terr. Magell.

attenuata, Vasey, in Coult. Bot. Gaz. xi. (1886) 337.

Berlandieri, Fourn. Gram. Mexic. 1881 (1886) 96. Mexic.

barbigera, C. Cordem. ex 7. Cordem. Fl. Ile Réunion, (1895) 124. - Ins. Borbon.

\section{AGROSTIS}

borbonica, C. Cordem. ex f Cordem. Fl. He Rénnion (1895) 124. -.. Ins. Borbon.

Bourgaei, Fourn. Gram. Mexic. 1881 (1886) 95. Mexic.

Chinantlae, Fourn. l. c. 96. - Mexic.

curvifolia, Hack. ex Schinz, in Bull. Herb. Boiss. iii. (1895) 384. - Afr. austr.

densiflora, Vasey, in Contrib. U.S. Nat. Herb. iii. (1892) 172; et Grass. Pacif. Slope (1893)t. 30.Calif.

depressa, Vasey, in Bull. Torrey Bot, Club, xiii. (1886) 54. - Colorado.

diegoënsis, Vasey, l.c.55.- Calif.

Dyeri, Petrie, in Trans, N.Z. Inst. xxii. 1889 (1890) 441. - N. Zel.

Elliotii, Hook. ex S. Elliot, in fourn. Linn. Soc. xxix. (1891) 65. - Madag.

exarata, Vasey, in Bull. Torrey Bot. Club, xiii. (1886) 54. - Am. bor. occ.

fallax, Hillebr. Fl. Haw. Isl. (1888) 516. - Ins. Viti. foliosa, Vasey, in Coult. Bot. Gaz. xi. (1886) 337; et xiii. (1886) 55. - Oregon.

gaditana, Coincy, in Morot, Journ. de Bot. (1894) $66=$ A. castillana, Boiss.

Ghiesbreghtii, Foum. Gram. Mexic. 1881 (1886) 97. - Mexic

Hallii, Vasey, in Contrib. U. S. Nat. Herb. iii. (1892)

74; et Grass. Pacif. Slope (1893) t. 32.-Am. bor.

Hegetschweilevi X, C. Richt. P1. Europ. i (1889) 47.Helv.

hiemalis, Britton, Stern. et Poggenb. Prelim. Catal. (1888) 68. = scabra, Willd.

Howellii, Scribn. ex Vasey, in Contrib. U. S. Nat. Herb. iii. (1892) 76. - Oreg.

inflata, Scribner, in Canad. Record. Sc. (Nov. 1894).

152. - Am. bor.

kauaiensis, Hillebr. Fl. Haw. Isl. (1888) 516. Ins. Viti.

Kentrophyllum, $K$. Schum. ex Engl., in Abhandl. Prenss. Akad. Wiss. (1894) 14; et in Pfanzenw. OstAfr. C (1895) 108. - Afr. trop. or.

Liebmanni, Fourn. Gram. Mexic. 1881 (1886) 97. Mexic.

Novae-Angliae, Vasey, $2 n$ Contrib. U. S. Nat. Herb. iii. (1892) \%6. - Am. bor.

oregonensis, Vasey, in Bull. Torrey Bot. Club, xiii. (1886) 56. - Oregon.

Rossae, Vasey, in Contrib. U. S. Nat. Herb. iii. (1892) 76. - Wyoming.

salaziensis, C. Cordem. ex f. Cordem. Fl. Ile Réunion (1895) 124. - Ins. Borbon.

sandwicensis, Hillebr. Fl. Haw. Isl. (1888) 515. Ins. Viti.

Schaffneri, Foum. Gram. Mexic. 1881 (1886) 94. Mexic.

simensis, Hochst ex Engl, in Abhandl. Preuss. Akad. Wiss. 1891 ii. (1892) $128=$ alba, Linn. var. simensis, Engl.

setifolia, Fourn. Gram. Mexic. I881 (1886) 9\%.Mexic.

striata, Colenso, in Trans. N. Z. Inst. xxi. 1888 (1889) 107. - N. Zel.

tacubayensis, Fourn. Gram. Mexic. 1881 (1886) 95. - Mexic.

tenella, Petrie, in Trans. N.Z. Inst. xxii. 1889 (1890) 442. - N, Zel.

Virletii, Fourn.Gram, Mexic. 1881 (1886) 96. Mexic.

AGROSTISTACHYS, Dalz, (Euphorb.). - Ind. Kew. i. 66.

filipendula, Hook. f. Fl. Brit. Ind. v. (1887) 487. Penins. Mal.

Maingayi, Hook. f. l. c. 406. - Malacca.

Massoana, Vidal, Rev. pl.vasc. Filip. (1886) 342. Ins. Philipp.

AGROSTOGRINUM, F. Muell. (Liliac.). - Ind.

scabrum, Baill. in Bull. Soc, Linn. Par. ii. (1893) $1119=$ stypandroides, F. Muell.

AGROSTOPHYILUM, Blume (Orchid.). - Ind. Kew. i. 67.

glumaceum, Hook. f. Fl. Brit. Ind. v. (1890) 824; et Icon.pl. xxi. (1892) t. 2095. - Ind. or. 


\section{AGROSTOPHYLLUM}

majuls. Hoob f. Fl Brit. Ind. v. (1890) 824; et Icon. pl. xxi. (1892) t. 2096. - Ind. or.

pauciflorum, Hook.f. ll. cc. 824; et 2097.- Zeylan. zeylanicum, Hook. f. 7. c. 824. - Zeylan.

AICHRYSON, Webb = Sempervivum, Linn. (Crassul.). Webb, ex Christ, in Bot. Jahrb, ix. (1888) $108,=\mathrm{S}$. immaculatum. Clirist.

AILANTHUS, Desf. (Simarub.),-Ind. Kew. i. 66 calycina, Pierre, Fl. For. Cockinch. (1893) t. 294. (= Pongelion calycimum, Pierre). - Cochinch.

Fauveliana, Pierre, in Laness, Pl, util col franc. (1886) 306; et Fl For. Cochinch. (1893) sub t. 294 et 295 (= Pongelion Fauvelianum, Pierre). Cochinch.

japonica, Hort, ex Dippel, Handb. Laubholzk, ii. (1892) $364 .=$ glaudulosa, Desf.

AINSLIAEA, DC. (Composit.). - Ind. Kew. i. 66 glabra, Henst. in fourn. Linn. Soc. xxii. (1888) 47 t. 14. - China.

gracilis, Franch. in Morot, Fourn. de Bot. viii. (1894) 297. - China.

grossedentata, Franch. l.c. - China.

lancifolia, Franch, in Nouv. Arch. Mus. Par. Sér. UI (1887-88) 41. - China.

nervosa, Franch, in Bull. Mus. Par. i. (1895) 64 - Yunnan.

pertyoides, Franch. in Morot, Foum de Bot.i1. (1889) 70 t. iii. - China.

ramosa, Hensl. in foum. Lmn. Soc. xxii. (1888) 471. - China.

rubrifolia, Franch. in Morot, foum. de Bot, viii. (1894) 296. - China.

sutchuenensis, Franch. l. c. - China

triloba, Makino, in Bot. Mag. Tokyo Soc. vi. (1892) 55. - Japon.

yunnanensis, Franch. in Morot, Fourn, de Bot, ii. (1888) 70 . - Yunnan.

AINSLIEA, Kuntze, Rev. Gen. (1891) 304. = Ainsliaea, DC. (Composit.)

latifolia, Kuntze, 1. c. $305 .=$ A. pteropoda, DC.

AIOUEA, Aubl. (Laurin.).- Ind. Kew. i. 66.

Benthamiana, Mez, in fahrb. bot. Gart. Berl.v. (1889) 48. - Bras.

Burchelliana, Mez, l.c. li. - Bras.

dubia, Mez, 7. c. 34. (= Cryptocarya dubia, H. B. et K.). - Venez.

Gaudichaudii, Mez, l. c. 39. - Bras.

granatensis, Me\%, l. c. 32.-Columb.

hirtella, Mez, l. c. 39. - Bras.

Jelskii, Mez, l. c. 33. - Peruv

Meissneri, Mez, l. c. 46. (= Aydendron tenellum, Meisn.). - Bras.

myristicoides, Mez, l. c. 48, - Bras.

piauhyensis, Mez, l. c. 31. (= Aydendron piawluyense

Meissn.). - Bras.

pruinosa, S. Moove, in Trans. Linn. Soc. Ser. II. iv. (1895) 448. - Bras.

Riedelii, Mez, l. . . 37. - Bras.

Severini, Mez, l. c 31. - Bras.

tambillensis, Me\%, l. c. 33. - Peruy.

tenuiflora, Nees, ex Mez, l. c. 49. (= Ocotea indecora, Schott)

Warmingii, Mez, l. c. 46. - Bras.

AIRA, Linn. (Gramin.). - Ind. Kew. i. 66 aciphylla, Franch. Miss. Sc. Cap Horn, v. Phan. (1889) 384. - Patag.

mexicana, Trin, ex Fourn. Gramin Mexic 1881. (1886) 1ll. in syn. = Eatonia densiflora, Fourn

AJOUEA “Aubl., ) ex Mez, in Jahrb. bot, Gart. Berl. v. (1889) $28=$ Aiouea, Aubl. (Laurin.)

AJUGA, Linn. (Labiat.). - Ind. Kew. i. 69.

Boninsimæ, Maxim. in Bull. Acad. sc. St-Pétersb. xxxii. (1888) 620. - Ins. Boninsim.

brevipoles $X$, Borb. in Termész. Füzetek, xii.(1889) 110. - Austr.-Hung.

breviproles $\times$, Borb. 1, c. - Austr.-Hung.

Hildebrandti, Briq. in Engl. et Prantl, Naturl. Pflanzenfam. ix. 3 a. (1895) 210, nomen.-Madag.
AJUGA :

munitis $X$ Borb, in Termész. Fiizetek, ii. (1889) 110. - Tyrol.

humilis, Porta, in Atti Accad. Agiate ix. (1891) 56 ; ex Willk. Suppl.prodr. A. Hisp. (1893) 158. - Hisp oocephala, Baker, in fourn. Linn. Soc. xxii. (1887) 514. - Madag.

ovalifolia, Bureau et Franch. in Morot, fourn. de Bot. v. (1891) 150. - China.

perbracteata $\times$ Borb. in Termész. Fïzetek, xii. (1889) 111. - Boruss

Postii, Briq. in Bull. Herb. Boiss. ii. (1894) 710; et in Engl. et Prantl, Natür. Pfanzenfam. iv. 3 a. (1895) 210. - Syria.

rhodopea, Velen, in Sitz. Böhn. Ges, Wiss, (1892) 19. - Bulg.

suffrutescens, Lange, in Danske Vidensk. Selsk. Forh. (1893) 196. - Hisp,

turkestancia, Briq. in Bull. Herb. Boiss. ii. (1894) 71 ; et in Engl. et Prantl, Naturl. Pfanzenfam. iv. 3 a. (1895) 210. - Turkest.

ALAFIA, Thou. (Apocyn.). - Ind. Kew, i. 70 Barteri, Oliver, in Hook. Icon. Pl. xx. (1891) t. 1992 - Afr. trop. occ.

caudata, Stapf, in Kew Bull. (1894) 123. - Angola. cuneata, Stapf. l. c. 122. - Angola.

lucida, Stapf, l. c. 122.- Afr. trop. occid.

malouetioides K. Schum, in Engl. et Prantl, Natiinl. Pfanzenfam, iv. 2. (1895) 164. - Ins. Fernando $\mathrm{Po}$.

reticulata, $K$. Schum. l. c. $-\Lambda$ fr. trop. occ

sarmentosa, Stapf, in Kew Bull.(1894) 123.-Angola.

ALAIRIA, Kuntze, Rev. Gen. (1891) 374 sphalm. = Mairia, Nees (Compos.).

percziodes, Kuntze, 1. c. = M. perezioides, Nees.

ALANGIUM, Lam. (Cornac.), - Ind. Kew, i. 70. barbatum "Baill w ex Kuntze Rev Gen. (1891) 273. = Marlea barbata, R. Br

Faberi, Oliver, in Hook. Icon. pl. xviii. (1888) t. 1774. - China.

Zollingeri, «Baill.» ex Kuntze, Rev. Gen. (1891) 273. - Hab.?

ALBERSIA, Kunth = Amarantus, Linn. (Amarant, )

crispa, Aschers. ex Hausskn. in Ber, deutsch. Bot. Ges. viii. (1890) (General Vers.) (121 = Euxolus crispus, Less.) - Am. bor.

emarginata, Aschers, ex Hausskn. 1. c. $=\mathrm{Am}$ viridis, Limn.

ALBERTA, E. Mey. (Rubiac.).- Ind, Kew. i. 71. minor, Baill. ex K. Schum. in Engl, et Prantl, Natïrl. Pfanzenfam. iv. 2. (1895) 89. - Madag.

ALBERTOKUNTZEA, Kuntze, Rev. Gen. (1891) $550=$ Seguiera, Loefl. (Phytolac.).

americana, Kuntze, 1. c. = S. americana, Linn. coriacea, Kuntze, 1. C. = S. coriacea, Benth floribunda, Kuntze, 1. c. = S. floribunda, Benth. foliosa, Kuntze, 1. c. = S. foliosa, Benth. Langsdorffii, Kuntze, 1. c. $=$ S. Langsdorffii, Moq longifolia, Kuntze, 1. c. = S. longifolia, Benth. macrophylla, Kuntze, 1. c. = S. macrophylla, Benth. parvifolia, Kuntze, 1. c. = S. parvifolia, Benth

Vauthievi, Kuntze, 1. c. = S. Vauthieri, Moq.

A.HIZZIA, Durazz.(Legum.). - Ind. Kew, i. 71. brevipes, F. Muell. in Proc. Linn. Soc. N. S. Wales, Ser. II. v. (June 1890) 20 in obs. (= Hausemannia brevipes, F. Muell.) - Austral.

grandibracteata, Taub. in Engl. Pflanzenw. Ost-Afr. C (1895) 193. - Afr trop. or

Hausemanni, F, Muell. in Proc. Linn. Soc. N. S. Wales, Ser. II. v. (June 1890) 20 in obs. (= Hansemannia glabra $\mathrm{K}$. Schum.)

maranguensis, Taub. ex Engl. in Abhandl. Preuss. Akad. Wiss, 1891. ii. (1892) 241. - Afr. trop, or. mollis, F. Muell. in Proc. Linn. Soc. N. S. Wales Ser. II. v. (June 1890) 20 in obs. = Hausemannia mollis, $F$. Muell.

occidentalis, T. S. Brandeg. in Proc. Calif. Acad. Ser. II. ii.. (1892) 222. - Calif.

pseudo-Saponaria, Blume, ex Koorders et Valeton,
ALBIZZIA :-

in Meded. s'Lands Plantentuin no xi. Bidr. n. i. (1894) $295=$ tomentella, Miq.

pubigera, Blume, 1. c. $295=$ tomentella, Miq

Toona, F. M. Bailey, Syn. Queensl. Fl. Suppl. i. (1886) 18. - Austral.

trichopetala, Baker, in fourn. Linn. Soc. xxii. (1887) 468. - Madag.

ALBUCA, Linn. (Liliac.), - Ind. Kew. i. 72.

Allenae, Baker, in Gard. Chron. (1888) i. 10. Zanzib.

Buchanani, Baker, l.c. (1892) 488. - Afr, trop. or. corymbosa, Baker, l. c. (1886) ii. 38. - Afr. austr. Elliotii, Baker, in fourn. Bot, xxix. (1891) 71. Transv.

Fischeri, Engl. in Abhandl. Prenss. Akad. Wiss. 1891 ii. (1892) 165. - Afr. trop. or.

humilis, Baker, in Kew Bull. (1895) 153. - Natal. longebracteata, Engl. Bot. Fahrb. xv. (1893) 472.Afr. trop. or.

Massoni, Baker, in fourn. Bot. xxiv. (1886) 336. Afr. austr.

purpurascens, Engl. Bot. Fahrb. xv. (1893) 473. Afr. centr. bor.

Schweinfurthii, Engl. l. c. 473. - Afr. centr. bor. Steudneri, Schwennf. et Engl.l.c.472. - Afr. trop. or

Tayloriana, Rendle, in fourn. Linn. Soc.xxx. (1895). 424. - Afr. trop. or

trichophylla, Baker, in Gard. Chron. (1889) 94. Natal.

ALCEA, Linn. = Althaea, Linn. (Malvac.). arbelensis. Boiss, et Hausskn. ex Boiss. Fl. Or. Suppl. (1888) 132. - Mesopot.

peduncularis, Boiss. et Hausskn. 1. c. - Persia.

Sibthorpir, Hausskn. in Mitth. Thur. bot, Ges N. Folge, v. (1893) 60. - Graecia.

Tholozani, Stapf, in Denkschr. Akad. Wien (1886) 40. - Asia occ.

ALGHIMILLA, Linn. (Rosac.), - Ind. Kew. i. 73, acutangula, Buser, in Ber. Schweiz. Bot. Ges. iv. (1894) $69=$ vulgaris, Linn.

acutidens, Buser, in Bull. Herb. Boiss, ii. (1894) $104=$ vulgaris, Linn

agoregata, Buser, in Nouv. Mém. Soc. Helv. sc. nat. xxxiv. (1895) 121. - Helv.

anisiana. Wettst. in Luerss. Bibl. Bot. Heft xxvi. (1892) 41; et in Kern. Sched. fl. Austro-Hung vi. (1893) 6 = alpina, Limn.

aroyrophylla, Olizer, in folnst. Kilima-Niaro Exped. (1886) 340; et in Hook Icon. Pl. xvi. (1888) t. 1505. - Afr. trop. or.

asteropliylla, Tausch, ex Buser, in Magnier, Scrin. fi. select. xi. (1891) 250; in Bull. Soc. Dauph. éch. pl. Sér. II. iii. (1892) 93, et in Bull. Herb. Boiss. App. v. (1893) 492 = alpina, Linn.

Bachite, Hochst, ex Engl, in Abhandl. Preuss. Akad. Wiss. 1891 )1892) 237 in syn .= arvensis, Scop.

basaltica, Buser, in Oest. Bot. Zeitschr. xliv. (1894) 476 nomen. - Gall.

cinerea, Engl, Bot. Fahrb. xix, Beibl. n. $47(1894)$ 31. - Afr. trop. or.

colorata. Buser, in Bull. Soc Dauph.éch.pl. Sér. II iii. (1892) 99 ; et in Ber. Schweiz. Bot. Ges. ii. (1892) 131 = vulgaris, Linn.

connivens, Buser, ex C. DC. in Bull. Herb. Boiss. i. (1893) 492; et ii. (1894) $107=$ vulgaris, $\operatorname{Linn}$ coriacea, Buser, in Bull. Soc, Dauph. éch, pl., Sér.

II. iii. (1892) 108; et in Ber. Schweiz. Bot. Ges. ii. (1892) $133=$ vulgaris, Linn.

crinita, Buser, in Magnier, Scrin. fl. select. xi (1892) 256; in Ber. Schweiz. Bot. Ges. ii (1892) 133 et ex C. DC. in Bull. Herb. Boiss. i App. ii. $\{$ 1893) $492=$ vulgaris, Linn.

cuspidens, Buser, in Bull. Herb. Boiss, ii. (1894) 106 in obs. = vulgaris, Linn.

decumbens, Buser, 44 . = vulgaris, Linn.

demissa, Buser, 1. c. 96. - Eur.

effusa, Buser, in Nouv. Mém. Soc. Helv. sc. nat xxxiv (1895) $128=$ vulgaris, $\operatorname{Linn}$.

fallax, Buser, ex M. Besse, in Bull. trav. Soc Murith. fasc. xxi-xxii. (1894) 122 nomen; et in Ber. Schweiz. Bot. Ges, 1ii. (1894) 65. = alpina, Linn. 


\section{ALCHIMILLA : -}

faroensis, Buser, in Ber. Schweiz. Bot. Ges. iv. (1894) 58 in obs. = alpina, Linn

filicaulis, Buser, in Bull. Herb. Boiss. i. (1893) 492 et ii. (1893) 22. - Eur. centr. et occid.

firma, Buser, in Maonier, Scrin. fl. select. xii. (1893) 279; et in Bull. Herb. Boiss. i. (1893) 492 et App. ii. (1893) 34. - Helv.

Fischeri, Engl. in Abhandl. Prenss. Akad. Wiss. 1891, ii. (1892) 236. - Aft. trop. or

fissimima, Buser, in Bull. Herb. Boiss. ii. (1894) 99 $=$ vulgaris, Linn

fabellata, Buser, in Bull. Soc. Dauph. éch. pl., Sér. II, iii. (1892) 101 = vulgaris, Linn.

flavescens, Buser, 1. c. ii. (1894) 197 in obs. = vul garis, Linn

flexicaulis, Buser, ex. C. DC. Bull. Herb. Boiss. i. (1893) 492 ; et App. ii. (1893) 34. - Jurass, Alpes.

frigida, Buser, ex C. DC.,1. c. 491; et ii. (1894) 46 $=$ vulgaris, Lim

fulgens, Buser, in Bull. Soc: Dauph. éch. pl., Sér. II, iii. (1892) 104 ; et in Ber. Schweiz. Bot. Ges. ii. (1892) 132. - Pyren.

gemmia $\times$, Buser, ex C DC in Bull. Herb. Boiss. i. (1893) 491. - Helv.

glomerulans, Buser, 1. c. i. App. ii. (1893) $30=$ vulgaris, Linn.

grossidens, Buser, in Magnier, Scrin. fl. select. xi. (1892) 251; in Bull. Soc. Dauph. éch. pl., Sér. II, iii. (1892) 95; et in Ber. Schweiz. Bot. Ges. ii. (1892) 129 = alpina, Lim

heteropoda. Buser, in Ber. Schweiz. Bot. Ges, iv. (1894) $75=$ vulgaris, Linn.

Holstii, Engl. Bot. Fahrb. xvii. (1893) 86. - Afr. trop. or.

impexa, Buser, ex M. Besse, in Bu1l, trav. Soc Murith. fasc, xxi-xxii. (1894) 124 nomen; et in Nouv. Mém. Soc, Helv, sc, nat, xxxiv, (1895) 130. - Hely.

incisa, Buser, in Magnier, Scrin.fl. select.xi. (1892) 255 et in Ber. Schweiz. Bot. Ges. v. (1892) 132; et ex C. DC. in Bull. Herb. Boiss. i. (1893) 492. - Eur.

inconcinna, Buser, ex C, DC. 1. c. ; et App. ii (1893) $34=$ vulgaris, Linn

Johnstoni, Oliver, in fohnston, Kilima Njaro Exped. (1886) 340; et in Hook. Icon. Pl. xvi. (1888) t. 1504 - Afr. trop. or.

Lapeyrousii, Buser, in Bull. Herb. Boiss, i. App. ii (1893) $18=$ vulgaris, Linn.

lineata, Buser, in Nouv. Mém. Soc. Helv. sc. nat. xxxiv. (1895) $131=$ vulgaris, Limn.

longuiscula, Buser, in Bull. Herb. Boiss. ii. (1894) $101=$ vulgaris, Lisin

micans, Buser, 1. c. i. App. ii. (1893) 28. - Gall., Helv.

multidens, Buser, 1. c. (1893) 6 et 27. - Sabaud.

obtusa, Buser, ex C. DC. 1. c. i. (1893) 492; et in Nouv. Mém. Soc. Helv. sc. nat. xxxiv. (1895) 126 = vulgaris, Limn.

pallens, Buser, in Magnier, Scrin. fl. select. xi. (1892); Bull. Soc. Dauph. éch. pl., Sér. II. (1892) 95; et in Ber. Schweiz. Bot. Ges. ii. (1892) 129 = alpina, Lim

pastoralis, Buser, in Magnier, Bull. Soc. Dauph. éch.p1., Sér. II, iii.(1892) 108; et in Ber. Schweiz. Bot. Ges. ii. (1892) $132=$ vulgaris, $\operatorname{Linn}$.

pilosissima, Simonk. in Oest, Bot. Zeitschr. xxxix. (1889) 137 = vulgaris, Linn

plicata, Buser, in Bull. Herb. Boiss. i. App. ii (1893) 20. - Gall., Bohem., Suec.

psilophylla, Borb. ex Oest. Bot. Zeitschr. xli. (1891) 424. - Austria.

pusilla, Buser, in Bull. Herb. Boiss. i. App. ii. (1893) 6, 19 et 23. - Eur.

racemulosa, Buser,1.c. App. ii. (1893) 31. - Saband. reniformis, Buser, in Nouv. Mém. Soc. Helv. sc. nat. xxxiv. (1895) $127=$ vulgaris, $\operatorname{Lim}$.

saxatilis, Buser, in Magnier, Scrin. fl. select. xi. (1892)250; Buil. Soc. Dauph. éch. pl., Sér, II, iii. (1892) 92 ; et in Ber. Schweiz. Bot. Ges. ii. (1892) $128=$ alpina, Linn.

Schmidelyana, Buser, 11. cc. 254, 101 et 132. Gallia.

semisecta, Buser, in Bull. Herb. Boiss. ii. (1894) 94 = vulgaris, Limn.

\section{ALGHIMILLA :}

sericoneura, Buser, in Ber. Schweiz. Bot. Ges $=$ alpina, Limn

sinuata, Buser, in Bull. Herb. Boiss. ii. (1894) 102 $=$ vulgaris, Linn.

speciosa, Buser, in Magnier, Scrin. fl. select, xii. (1893) 281; et ex C. DC in Bull. Herb. Boiss. i. (1893) 492. - Eur.

splendens $X$, Christ, in Bull. Soc. Vaud. sc. nat xxv. (1889) 52; et in Magnier, Scrin. fl. select. xi. (1892) 253. - Helv.

straminea, Buser, in Nouv. Mém. Soc. Helv. sc, nat. xxxiv. (1895) 117 = vulgaris, Linn.

strigosula, Buser, ex C. DC. in Bull. Herb. Boiss. i. (1893) 492; et ii. App, ii. (1893) 24. - Sabaud. Alp. Marit.

Stuhlmannii, Engl. Bot. Fahrb. xvii. (1893) 86. Afr. centr.

subcrenata, Buser, in Maonier, Scrin. fl. select, xii. (1893) 285; et ex C. DC. in Bull. Herb. Boiss, i. 492. - Eur.

tenuis, Buser, in Ber. Schweiz. Bot. Ges. iv. (1894) $76=$ vulgaris, Linn.

transiens, Buser, 1 . c. 56 = alpina, Linn.

trunciloba. Buser, in Nouv, Mém. Soc. Helv. sc. nat. xxxiv. (1895) $119=$ vulgaris, I inn.

ulugurensis, Engl. Pflanzenw. Ost Afr. A (1895) 131 nomen. - Afr. trop. or.

undulata, Buser, in Bull. Herb. Boiss. i. App. ii 1893) 26. - Sabaud.

rersibila, Buser, 1. c ii. (1894) $112=$ vuloaris, Linn.

Vetteri Buser, ex Oest. Bot Zeitschr xliv. 1894) 470 nomen. - Italia.

Volkensii, Eng1. Bot. Jahrb. xix, Beibl. 47 (1894 30. - Afr. trop, or.

Wichurce, Buser, in Bull. Herb. Boiss, ii. (1894) $110=$ vulgaris, Linn

ALGHORNEA, Sw. (Euphorb.). - Ind. Kew, i. 73. discolor, Hook. f. Fl. Brit. Ind. v. (1887) 420. Penang.

ALECTOROLOPHUS, Moench = Rhinanthus, Linn. (Scrophul.)

Alectorolophus, Sterneck, in Oest. Bot. Zeitschr. xlv. (1895) $11=$ R. major, Ehrh.

atpinus, Sterneck, 1.c. $228=$ R. major, Ehrh

dinaricus, Murb. Beitr. Fl. Sudbosn. und Herceg. (1891) 69 t. 11. - Herceg.

Ilipticus, Sterneck, in Oest. Bot. Zeitschr. xly. 1895) 47 tab. 4. - Tirol.

Freynii, Sterneck, 1. c. $48=$ R. Freynii, Kern. glaber, G. Beck, Fl. Nieder-Oest. ii. (1893) $1068=$ R. Crista-galli, Linn.

glandulosus, Sterneck, in Oest. Bot. Zeitschr. xlv (1895) 98 t. $6=$ R. Crista-galli, Linn

goniotrichus, Borb. ex Sterneck, 1. c. 136 t. 7. Eur. or. et merid.

Kerneri, Sterneck, 1. c. 13 t. 4.-Austria, Ital.

lanceolatus, Sterneck, I. c. $272=$ R. major, Ehrh puberulus $\times$, Fritsch, in Ber. deutsch. bot. Ges. $x$ $(1892)(111)=\mathrm{R}$. puberulus, Fritsch

pubescens, Sterneck, in Oest. Bot. Zeitschr. xlv. (1895) 120 et $126=\mathrm{R}$. pubescens, Boiss. et Heldr. pulcher, Sterneck, 1. c. 225. = R. Crista-galli, Linn. pumilus, Sterneck, 1, c. 49 t. 6.- - Pyren.

ramosus, Sterneck, 1. c. 129 - Monten

serotimus, G. Beck, Fl. Nieder-Oest. ii. (1892) 1069 $=$ R. Crista-Galli, Linn.

Wagneri, Sterneck, in Oest. Bot. Zeitschr. xlv (1895) 102. - Buls.

Wettsteinii Sterneck, 1. c. 129, - Ital.

ALEGTRA, Thunb. (Scrophul.).- - Ind. Kew. i. 74. dentata, Kuntze, Rev. Gen. (1891) $458=$ indica, Benth.

melampyrodes, Kuntze, 1. c. = brasiliensis, Benth

parvifolia, Schinz, in Verh. Bot. Ver. Brand. xxxi, 1889 (1890) 195. - Afr. austro-occ. extratrop.

essiliflora, Kuntze, Rev. Gen. (1891) $458=$ melampyroides, Benth

ALEGTRYON, Gaertn. (Sapind.). - Ind. Kew. i. 74.

macrococcum, Radlk. in Sitz. math.phys. Cl. bayer Akad. Wiss. xx. (1890) 255. - Ins. Haw.

reticulatus, Radlk. l. c.-N. Guin

strigosus, Radlk. l.c. - N. Guin.
ALEPIS, Van Tiegh, in Bull. Soc. bot. Fr. xli. (1894) $604=$ Loranthus, Linn. (Loranth.). flavida, Van Tiegh. 1. c. xli. (1894) $605=$ L. flavidus, Hook.f.

polychroa, Van Tiegh. 1. c. = L. polychrous, Colenso.

ALEPYRUM, Hieron. (non R. Br.) ex Baill. in Bull. Soc. Linn. Par. ii. (1892) $1021=$ Gaimardia, Gaudich. (Centrolepid.).

ALETES, Coult. et Rose, Rev. N. Am. Umbell. (1888) 125 (Umbellif.)

caulis, Coult et Rose, l.c. (=Zizia Hallii, Coult. et Rose), - Am. bor.

ALETRIS, Linn. (Haemodor.). - Ind. Kew. i. 74. arabica, Deflers, Voy. Yemen (1889) 179. - Arabia Delavayi, Franch in Morot, Fourn. de Bot. v. (1891) 157 in obs. (nomen) - China.

Dickinsi, Franch, in Bull, Soc, Philom. Par. Sér. VII. x. (1886) $102=$ foliosa, Bureau et Franch. foliolosa, Stapf, in Trans. Linn. Soc. Ser. II. iv. (1894) 240. - Borneo.

foliosa. Bureau et Franch. in Morot, fourn. de Bot.v. (1891) 156 in obs. - China.

clabra, Bureau et Franch. l. c. - China.

- landulifera, Bwreat et Franch, l. c. - China

khasiana, Hook. f. Fl. Brit. Ind. vi. (1892) 265. Reg. Himal.

lanuginosa, Bureau et Franch. in Morot, Fourn. de Bot.v. (1891) 155. - China.

laxiflora, Buredu et Franch o. C. - China.

nepalensis, Hook. f. Fl. Brit. Ind. vii. (1892) 264.Ind. or.

rigida, Stapf, in Trans. Linn. Soc. Ser. II. iv. (1894) 241. - Borneo.

sikkimensis, Hook. f. Fl. Brit. Ind. vi. (1892) 265.Reg. Himal.

stenoloba, Franch. in Morot, Fourn. de Bot.v. (1891) $15 \%$ in obs. (nomen). - China.

ALEXA, Moq. (Legum.). - Ind. Kew. i. 75. mperatricis, Baker, in Hook. Icon. pl. xviii. (1888) t. 1794. - Guian. angl.

ALGA, Ludw. Def. (1737) 138, fide Kuntze = Posidonia, Kon. (Naiad.). austratis, Kuntze, Rev. Gen. (1891) $744=$
tralis, Hook.f. oceanica, Kuntze, 1. c. = P. Caulini, Konig.

ALGUELAGUM, Kuntze, Rev. Gen. (1891) 511 ex ALGUELAGUEN, Adans. Fam, ii. 505, mutat. ab ALGUE-LAGUEN, Feuillée, Obs. iii. DC. Med. 4. t. 1, nomen aboriginum = Sphacele, Benth. (Labiat.).

acuminatum, Kuntze, 1.c. $512=\mathrm{S}$.acuminata, Griseb alpinum, Kuntze, 1. c。 = S. alpina, Oerst.

bullatum, Kuntze, 1. c. = S. bullata, $H$. B. et $K$.

calycinum, Kuntze, 1. c. $=$ S. calycina, Benth,

chilense, Kuntze, 1. $\mathrm{c}_{0}=$ S. campanulata, Benth.

clinopodiodes, Kuntze, 1. c. = S. clinopodioides,

Griseb.
confertum, Kuntze, 1. c. = S. conferta, Benth.

cordifolium, Kuntze, 1. c. = S. cordifolia, Benth.

floribundum, Kuntze, 1. c. = S. floribunda, Benth.

Grisebachii, Kuntze, 1. c. = S. hastata, Griseb.

hastatum, Kuntze, 1. c. = S. hastata, A. Gray.

lamiifolium, Kuntze, 1. c. = S. lamiifolia, Benth.

mexicamum, Kuntze, 1. c. = S. mexicana, Schauer. muticum, Kuntze, 1, c. $=$ S. mutica, Benth.

paniculatum, Kuntze, 1. c. $=\mathrm{S}$. paniculata, Benth parviflorum, Kuntze, 1. c. = S. parviflora, Benth.

Radula, Kuntze, 1. c. = S. Radula, Benth.

Salviae Kuntze, 1. c. $=$ S. Lindleyi, Benth.

salviaefolium, Kuntze, 1. c. = S. salviaefolia, Benth. salviaefoinm, Kuntze, speciosn, Kunhastata, Benth, suohastatum, Kuntenuiflora, Benth tenuiflorum, Kuntze, 1. C. $=$ S. tenuiflora, Benth,

ALIBERTIA, A. Rich. (Euphorb.). - Ind. Kew.

i. 75 . II. iv. (1895) 370. - Bras.

bertierifolia, K. Sclum. in Mart. Fl. Bras. vi. vi. (1889) 384 . - Bras. 


\section{ALIBERTIA : \\ laviflora, $K$. Schum, in Mart. Fl. Bras, vi. vi (1889) 387. - Peruv. \\ concolor, K. Schum.l. c. 388 (= Gardeniola concolor, \\ Cham.) - Bras. \\ curviflora, K. Schum. l. c. 387.- - Peruv. \\ elliptica, K. Schum. l. c. 389 (= Thieleodoxa elliptica, \\ Cham.). - Bras. \\ humilis, K. Schmm. l.c. 391.- Bras. \\ latifolia, $K$. Sohwm. l. c. 386 (= Cordiera latifolia, Benth.). - Bras. \\ longiflora, $K$. Schum. l. c. 412. - Bras. \\ macrophylla, $K$. Schum. l. c. 394. - Bras. \\ myrciifolia, K. Schum.l. c. 293. - Bras., Guian. \\ obtusa, K. Schum. l. c. 393. - Bras. \\ oligantha, $K$. Schum. .. c. 385. - Bras. \\ rigida, $K$. Schum. l. c. 391 - Bras. \\ rotunda, K. Schum. l. c. 390. - Bras. \\ sessilis, K. Schum. 1. c. $395=$ A. Melloana, Hook. $f$. \\ triflora, $K$. Schum, l, c. 392 (= Cordiera triflora A. Rich.). - Bras. \\ vacciniifolia, K. Schum. (err, cal.?) in Engl, et Prantl, Natür1. Pflanzenfam. iv. 2. (1895) $84=$ seq.? \\ vaccinioides, K. Schum. in Mart. Fl. Bras. vi. vi. (1889) 389. - Bras. \\ verrucosa, S. Moove, in Trans. Lim. Soc. Ser. II iv. (1895) 371 . - Bras.}

ALICASTRUM, P. Br,=Brosimum, Sw. (Urtic.). glaucum, Taub. in Bot. Jahrb. xv. Beibl. n. 34 (1892) $16=$ B. glaucum, Taub.

Glaziori, Taub. 1. c. = B. Glazioxii, Taub.

rubescens, Taub. 1. c. = B. rubescens, Taub.

ALISMA, Linn. (Alismac.). - Ind. Kew. i. 75. batrachiocarpum, St-Lager, in Cariot, Etud. des fleurs, éd. 8,11. (1889) 820= ranunculoides, Linn plantaginifolium, St-Lager, 1. c. $82 \mathrm{l}=\mathrm{A}$. Plantago, Linz?n.

ALISMORCHIS, Thou. = Galanthe, $\mathrm{R}$ Br. (Orchid.).

abbreviata, Kuntze, Rev. Gen. (1891) $650=$ C. abbreviata, Lindl.

alba, Kuntze, 1. c. = C. alba, Reiclib. $f$.

alismifolia, Kuntze, 1. c. = C. alismæfolia, Lindl.

alpina, Kuntze, 1. c. = C. alpina, Hook. $f$.

angraeciflora, Kuntze, 1.c.=C.angræciflora, Reichb.f.

angusta, Kuntze, 1. C. = C. angusta, Lindl.

angustifolia, Kunze, 1. $\mathrm{c} .=\mathrm{C}$, anoustifolia Iindl.

aristulifera, Kuntze, $1, \mathrm{c}=$ aristulifera, Reichb. $f$.

biloba, Kuntze, 1. c. = C. biloba, Lindl.

brevicorm, Kuntze, 1. c. = C. brevicornu, Lindl.

carinata, Kuntze, 1. c. = Eulophia virens, Spreng.

chlorolenca, Kuntze, 1. c. = C. chloroleuca, Lindl.

clarata, Kuntze. 1. c. = C. clavata, Lirdl

conspicua, Kuntze, 1. c. = C. conspicua, Lindl.

cubensis, Kuntze, 1. c. = C. mexicana, Reichb. f.

densiflora, Kuntze, I. c. = C. densiflora, Lindl.

diploxiphion, Kuntze, 1. $\mathrm{C} .=\mathrm{C}$. diploxiphion, Hook.f.

discolor, Kuntze, 1. c. = C. discolor, Lindl.

elytroglossa, Kuntze, 1. C. $=$ C. elytroglossa, Reichb. $f$

emarginata, Kuntze, l. c. = C. emaroinata, Lindl.

Foerstermannii, Kuntze, 1. c. = C. Foerstermannii, Reichb. f.

furcata, Kuntze, 1. c. = C. furcata, Batem.

gigantea, Kuntze, 1. c. = C. gigantea, Hook. f.

gracilis, Kuntze, 1. c. = C. gracilis, Lindl.

gracillima, Kuntze, 1. c. = C. gracillima, Lindl.

granatensis, Kuntze, 1. c. = C. granatensis,

Reichb.f

Griffithi, Kuntze, 1. c. = C. Griffithii, Lindl.

herbacea, Kuntze, 1. c. = C. herbacea, Lindl.

japonica, Kuntze, 1. c. = C. japonica, Bhume.

labrosa, Kuntze, $1 . \mathrm{c} .=\mathrm{C}$. labrosa, Reichb $f$.

Lindleyana, Kuntze, 1. c. = C. plantaginea, Lindl.

longipes, Kuntze, 1. c. = C. longipes, Hook. $f$.

lyroglossa, Kuntze, 1. c. = C. lyroglossa, Reichb. $f$.

Manni, Kuntze, 1. c. = C. Mannii, Hook.f.

Masuca, Kuntze, 1. c. = C. Masuca, Lindl.

mexicana, Kuntze, 1. c。 = C. mexicana, Reichb.f.

ratalensis, Kuntze, 1. c. $=$ C. natalensis, Reichb. $f$.

odora, Kuntze, 1. C. = C. odora, Griff.

pachystalyx, Kuntze, 1. c. = C. pachystalyx, Reichb.f.

parviflora, Kuntze 1. c. = C. parviflora, Lindl

\section{ALISMORCHIS :}

phajodes, Kuntze, Rev. Gen. (1891) $650=\mathrm{C}$ angustifolia, Lindl.

plantaginea, Kuntze, 1.'c. = C. sylvatica, Lindl.

pleiochroma, Kuntze, 1. c. = C. pleiochroma, Reichb.f.

puberula, Kuntze, 1. c. = C. puberula, Lindl.

pulchra, Kuntze, 1. c. = C, pulchra, Lindl.

purpurea, Kuntze, 1. c. = C. purpurea, Lindl.

reflexa, Kuntze, 1. c. = C. reflexa, Maxim.

rosea, Kuntze, 1. C. = C. rosea, Benth

rubens, Kuntze, 1. c. = C. rubens, Huegel.

Scortechinii, Kuntze, 1. c. = C. Scortechinii,

Hook. $f$.

speciosa, Kuntze, 1. c. = C. speciosa, Lindl.

sulphurea, Kuntze, 1. c. = C. sulphurea, Huegel.

Textori, Kuntze, 1. c。 = C. Textori, Miq.

tricarinata, Kuntze, 1. c. = C. tricarinata, Lindl.

tricolor, Kuntze, 1. c. = C. tricolor, Huegel.

twbifera, Kuntze, 1. c. = C. tubifera, Hook. $f$

uncata, Kuntze, 1. c. = C uncata, Lindl.

vaginata, Kuntze, 1. c. = C. vaginata, Lindl.

veratrifolia, Kuntze, 1. C. = C. veratrifolia, $R$. Br.

vestita, Kuntze, 1. c. = C. vestita, Lindl.

Wrayi, Kuntze, 1. c = C. Wrayi, Hook. $f$

Zollingeri, Kuntze, 1. c. = C. Zollingeri, Miq.

ALKANNA, Tausch (Boragin.).-Ind. Kew.i. 76 caliensis, Heldr. ex Boiss. Fl. Or. Suppl. (1888) 353. - Graecia.

Haussknechtii, Bornm. in Oest. Bot. Zeitschr. xliv. (1894) 16. - Asia min.

methanaea, Hausskn. in Mitth. Bot, Ver. Fena, vi. (1886) 32; et $N$. Folge, viii. (1895) 49 (1888) 32. - Graecia.

pindicola, Hausskn. $l l$. cc. - Graecia.

primuliflora, Hausskn. ex Bornm. in Oest. Bot, Zeitschr. xliv. (1894) $16=\mathrm{A}$. Haussknechtii Bornm.

Stribrnyi, Velen. Fl. Bulg. Suppl. (1891) 64\%.Bulg.

ALIAEANTHUS, Thw. (Urtic.)-Ind. Kew, i, 76. Kurzii, Hook. f. Fl. Brit. Ind. v. (1888)? 490. Ind. Or.

A LIAEOPHANIA, Thw. (Rubiac.), - Ind. Kew. i. 76

rugosa, Boevl. Handl. Fl. Ned, Indië, ii. 1.(1891) 124 (= Hedyotis vugosa, Korth.). - Java, Sumatra.

rugosa, Kuntze, Rev. Gen. (1891) $276=$ praec.

ALLAGOPTERA, Nees = Diplothemium, Mart (Palm.).

arenaria, Kuntze, Rev. Gen. (1891) $726=\mathrm{D}$ littorale, Mart, pr, p. et D. maritimum, Mart. campestris, Kuntze, 1. c. $=$ D. littorale, Mart. pr. p. et D. campestre, Mart.

caudescens, Kuntze, 1, c. = D. caudescens, Mart.

leucocalyx, Kuntze, 1. c. = D. lencocalyx, Mart.

Yorallyi, Kuntze, 1. c. = Jubra Yoralli, H. Wendl.

ALLAMANDA, Linn. (Apocyn.) - Ind. Kew 1. 77

magnifica, Williams, Catal. (1888) 19; et Kew Bull. (1889) $75=$ A. Schotti, Poht.

Williamsii, Hort. ex Gard. Chron. (1891) ii. 111 nomen; et ex Garden, x1. (1891) 1642 t. $830=$ cathartica, Linn.

ALLARDTIA, A Dietr. = Tillandsia, Lim. (Bromel.).

Roezlii, Éd. Morr. ex Baker, Handb. Bromel.(1889) 207 = T. Roezlii, Éd. Morr.

ALLENROLFEA, Kuntze, Rev. Gen. (1891) 554 $=$ Spirostachis, S. Wats. (Chenopod.).

occidentalis, Kuntze,1.c. $546=\mathrm{S}$. occidentalis, $S . W$ ats. patagonica, Kuntze, 1. c. = S. patagonica, Griseb. vaginata, Kuntze 1. c. = S. vaginata, Griseb.

ALLIARIA, Adans. = Sisymbrium, Linn. (Crucifer.)

Alliaria, Britton, in Mem. Torrey Bot. Club, v. (1894) $167=$ S. Alliaria, Scop.

Wasabi, Prantl, in Engl, et Prantl, Natürl. Pflanzenfam. iii. 2. (1893) $168=$ Eutrema Wasabi, Maxim.
ALliARIA, Rumph. Amboin. ii. (1741) $4 \mathrm{I}=$ = Dysoxylum, Blume (Meliac.)

acutangula, albicans, arborescens, Balanseana, 'Beccariana, Beddomei, camalensis, caulostachya, chrysophyllina, costulata cuneata, cyrtobotrya, dasyphylla, densiflora, euneura, flavescens, Fraseriana, fraterna, gato. pensis, Gaudichaudiana, glabra, glomerata, grandis, Griffithii, Halmaheirae, Klanderi, Kunthiana, lasiocarpa, latifolia, Lenormandiana, Lessertiana, Lobbii, macrantha, macrocarpa, macrostachya, Maingayi, malabarica, minutiflora, Miqueliana, mollissima, Muelleri, Nageliana, Nernstii, nitida, nutans, oppositifolia, otophora, pachypoda, pallens, Pancheri, parvifolia, procera, ramiflora, Richii, vosea, rufa, rufescens, samoënsis, Schulzii, sessilis, setosa, similis, Spanoghei, specicsx, spectabilis, Teysmannii, trichostyla, Turczaninowii, unijuga, Vieillardii, Vrieseana, Kuntze, Rev. Gen. (1891) 109= homonyma omnia Dysoxyli.

acuminatissima, Kuntze, Rev, Gen. (1891) $108=$ D. alliaceum, Blume.

alliacea, Kuntze, 1. c. = D. Forsteri, C. DC

Ammoorodes, Kuntze 1. C. $=$ D. amooroides, Miq. cauliflora, Kuntze, 1. c. $109=$ D. Cumingianum, C. $D C$

Golodhara, Kuntze, 1. c. =D. binectariferum, Hook. Hiernii, Kuntze, 1. c. = D. cauliflorum, Hiern.

lampongum, Kuntze, 1. c. = D. macrothyrsum, Miq.

mollis, Kunze, 1. c. = D. Hamiltonii, Hiern

multijuga, Kuntze, 1, cit. = D. Blumei, Miq.

pubescens, Kuntze, 1. c. $108=$ D. Becklerianum, C. DC

schizochilodes, Kuntze, 1. c. = D. schizochiloide, C. $D C$.

thyrsoided, Kuntze, 1. c. = D. thyrsoideum, Hiern.

Zippeliana, Kuntze, 1. c. $109=$ D. molle Miq.

ALLIONIA, Loef1. (Nyctagin.). - Ind. Kew, i. 77

Bandurria, Phil. in Anal. Univ. Chil. xli. (1895) 274. - Chili.

angustifolia, Kuntze, Rev.Gen. (1891) $533=$ Oxy baphus angustifolius. Nutt.

Bodini, Morong, in Mem. Torrey Bot. Club, v. (1894) $355=$ Oxybaphus Bodini, Morong.

bracteosa. Kuntze, 1. c. = Oxybaphus bracteosus, Griseb.

Bushi, Britton, in Bull. Torrey Bot. Club, xxii. (1895) 223. - Am. bor.

campestris, Kuntze, Rev. Gen. (1891) $533=$ Oxybaphus campestris. Griseb.

cordifolia, Kuntze, 1. c. = Oxybaphus cordifolius, Kunze.

corymbosa, Kuntze, 1. c. = Oxybaphus glabrifolius, Vahl.

elegans, Kuntze, 1. c.= Oxybaphus elegans, Choisy. excelsa, Kuntze, 1. c. = Oxybaphus micranthus, Choisy.

expansa, Kuntze,1. c. = Oxybaphus expansus, $V a h l$.

floribunda, Kuntze, 1. c. = Oxybaphus floribundus, Choisy.

glabra, Kuntze, 1. c. = Oxybaphus glaber, S. Wats. himalaica, Kunze, 1. c. = Oxybaphus himalaicus, Edgere.

Jarae, Phit.in Anac. Mus.nat.Chite (1891) 72 -Boliv.

linearifolia, Kuntze, Rev. Gen, (1891) 533 = Oxybaphus linearifolius, $S$. Wats.

oxybaphodis, Kuntze, 1. c. = Oxybaphus Wrightii, Hemsl.

prostrata, Kuntze, 1. c. = Oxybaphus prostratus, Vahl.

puberula, Phil. in Anal. Mus. nac. Chile (1891) 71. - Bolivia.

viscosa, Kuntze, Rev. Gen. (1891) $533=$ Oxybaphus viscosus, L'Hérit.

ALLIUM, Linn. (Liliac.). - Ind. Kew. i. 77. Bahri, Regel, in Act. Hort. Petrop. x. (1887) 326. Turkestan.

Barthianum, Aschers. et Schweinf. in Bull. Herb. Boiss. i. (1893) 6\%0. - Afr. bor.

Blomfieldianum, Aschers. et Schweinf. l. c. 671 t. 20. - Afr. bor.

cabulicum, Baker, in Bot. Mag. (1893) t. 7294. Reg. Cabul.

californicum, Rose, in Contrib. U. S. Nat. Herb. i. (1890) 12. - Calif. 
ALLIUM : -

Candolleanum, Alboff, in Bull. Herb. Boiss. iii. (1898) 523 nomen; et Prodr. fl. Colch. (1895) 240 - Reg. Cauc.

chrysocephalum, Regel, in Act. Hort. Petrop. x. (1887) 335. - China occ.

Clarkei, Hook.f. Fl. Brit. Ind. vi. (1892) 344. Reg. Himal.

crispum, Greene, Pittonia, i. (June 1888) 166.-Calif. cyatophorum, Bureau et Franch. in Morot, fourn. de Bot. v. (1891) 154. - China.

dichlamydeum, Greene, Pittonia, i. (June 1888) 166. - Calif,

elatum, Regel, in Gartenfl. (1887) 369 t. 1251. As, centr.

fibrosum, Regel, in Act. Hort. 'Petrop. x. (1887) 322 - Turcom

filifolium, Freyn et Sint. in Oest. Bot. Zeitschr. xliv. (1894) 392. - Asia Min.

filifolium, Regel, in Act. Hort. Petrop. x. (1887) 352 t. 11. - Turkest.

getulum, Batt. et Trab, in Bull. Soc. Bot. Fr, xxxix. (1892) 75; et Fl. de l'Alger, (1895) 62. - Algeria

gracile, Alboff, in Bull. Herb. Boiss. iii. (1895) 523, et Prodr. A. Colch. (1895) 239. - Reg. Cauc.

gracilescens, Sommier et Levier, in Act. Hort. Petrop. xiii. (1893) 51. - Reg. Cauc.

grande, Letsky, l. c. xiii. (1894) 343. - Reg. Cauc. gusaricum, Regel, l. c.x. (1887) 349 t. 3. - Asia centr.

Hendersoni, Robinson et Seaton, in Coult. Bot. Gaz. xviii. (1893) 237. - Am. bor.

Henryi, C. H. Wright, in Kew Bull. (1895) 119.China.

Herderianum, Regel, in Act. Hort. Petrop. x. (1887) 324. - Turcom

hierosolymorum, Regel, l. c. xi. (1890) 301. Palaest.

hyalinum, Curran, ex S. Wats. in Proc. Am. Acad. xxiv. (1889) 87. - Calif

kansuense, Regel, in Act.Hort. Petrop. x. (1887) 590. - China.

kansunense, Baker, in Bot. Mag. (1893), t. $7290=$

praec.
Karyeteini, Post, in Bull. Herb. Boiss. iii. (1895) 165. - Syria.

kaschianum, Regel, in Act. Hort. Petrop. x. (1887) 338 t. 3. - Turkest.

klarputense, Freyn et Sint. in Oest. Bot. Zeitsclur. xlii. (1892) 378. - Armen.

laceratum, Freyn, 1. c. xli. (1891) $60=$ lacerum Freyn.

lacerum, Freyn, l. c, xlii. (1892) 378. - Asia Min.

leucosphaerum, Aitch, et Baker, in Trans. Linn. Soc. Ser. II. iii. (1886) 117. - Afghan.

Loscosii, C. Richt. Pl. Europ. i. (1890) 199.-Hisp.

Machmelianum, Post, Pl. Postianae, iii. (1892) 18. - Syria.

massaessylum, Batt. et Trab. in Bull. Soc. bot. Fr. xxxix. (1892) 74; Atlas fl. Algér. t. 17; et Fl. de l'Algér, 'Monoc.) (1895) 5\%. - Alger.

melananthum, Coincy, in Morot, fourn. de Bot. ix. 336. - Hisp.

monanthum, Maxim. in Bull. Acad. sc. St-Pétersb. xxxi. (1887) 109. - Mandchuria.

monospermum, fepson, ex Groene, Man. Bot. San Frane. Bay, (1894) 321. - Calif.

montenegrinum, G. Beck et Szyszyl. P1. in itin. in Cern. et Alban. lect. (1888) $4 \%$ =carinatum, Linn.

obtusum, Lemmon, in Greene, Pittonia, ii. (May 1890) 69. - Calif.

Pardoi, Loscos, ex Willk. Illustr. fl. Hisp. (1886) t. 96. - Hisp., Alger.

peninsulare, Lemmon, ex Greene, Pittonia, i. (June 1888) 165. - Calif.

petraeum, Genty, in Magnier, Scrin. fl. select. viii. (1889) $151=$ fallax, $R$. et $S$.

platystylum, Regel, in Act. Hort. Petrop. x. (1887) 328 t. 2. fig. 2. - Tibet.

pseudostrictum, Alboff, in Bull. Herb. Boiss. iii. 1895) 523 nomen; et Prodr. fl. Colch. (1895) 238 - Reg. Cauc.

rhodopeum, Velen, in Sitz. Bochm. Ges. Wiss. 1889 (1890) ii. 58; in Oest. Bot. Zeitschr. x1. (1890) 237; et Fl. Bulg. (1891) 560. - Bulg. Roborowskianum, Regel, in Act. Hort. Petrop. x.
(1887) 359 t. 7. - Mongol.

\section{ALLIUM : -}

Rollii, Terrac. in Malpighia iii.(1889) $289=$ sphærocephalum, Linn.

serotinum, Don, ex Hook, f. Fl. Brit, Ind, vii. (1892) 375 = scapiflorum, Wight

simile, Regel, in Act. Hort. Petrop. x. (1S87) 359. Turkest.

Sintenisii, Freyn, in Oest. Bot. Zeitschr. xlii. (1892) 377. - Armenia.

Sprengeri, Regel, in Act. Hort. Petrop. x. (1889) 691 (err. typ. 591). - Syria.

stenanthum, Drew, in Bull. Torrey Bot. Club, xvi. (1889) 152. - Calif.

subangulatum, Regel, in Act. Hort. Petrop.x. (1887) 340 t. 5. - Asia centr.

tanguticum, Regel, l. c.31\%. - China occ.

tekesicolum, Regel, l, c. 350 t. 6. - Turkest.

tenuicaule, Regel, l.c. 348 t. 4.-Buchara.

thracicum, Halácsy et Georgh. in Oest. Bot. Zeitschr. xli. (1891) 223. - Bulg

tortifolium, Batt. in Bull. Soc. Bot. Fr. xxxix (1892) 338; et Fl. de l'Algér. (Monoc.) (1895) 62. Algeria.

Tourneuxii, Chab, in Bull. Soc. Bot. Fr, xxxvi 1889) 319. - Algeria.

triste, Freyn et Sint. in Oest. Bot Zeitschr. xliv. (1894) 393 = tristissimum, Freyn et Sint

tristissimum. Freyn et Sint. l. c. - Asia Min.

tristylum, Regel, in Act. Hort. Pctrop.x. (1887) 333 t. 2. fig. 3. - Turkest.

turcomanicum, Regel, l. c. 305. - Turkest.

ubsicolum, Regel, l. c. 342 t. 5. - Mongol.

unifolium, Viell. ex Greene, Man. Bot. San Franc. Bay. (1894) 321. - Calif.

vancouverense, Macoust, Cat. Canad. Pl.iv (1888) 37. - Ins. Vancouv.

Walteri, Regel, in Act. Hort. Petrop. x. (1887) 357 t vii. - Turkest.

weichanicum, Palibin, in Act. Hort. Petrop. xiv. (1895) 142. - China.

xyphophyllum, Aitch. et Baker, in Trans. Linn. Soc. Ser. II. iii. (1886) 118. - Turkest.

Yatei, Aitch. et Beker, l. c. 117. - Afghan.

AILOGAL YX, Cordem. F1. Ile Réunion (1895) 486. (Scrophular.)

microphylla, Cordenz. l. c. -Ins. Borbon.

ALLOCARYA, Green, Pittonia i. (Feb 1887) 12; et Man. Bot. San Franc. Bay (1894) $258=$ Eritrichium, Schrad. (Boragin.)

albiflora, Greene, in Erythea, iii. (1895) $57=$ E. albiflorum, Griseb.

Austistae, Greene, Pittonia, i. (Feb. 1887) 18. Calif.

australasica. Greene, in Erythea, iii. (1895) $57=$ E. australasicum, $D C$.

brachycarpa, Greene, Pittonia, i. (Feb. 1887) $14=$ Krynitzlia brachycarpa, A. Gray.

califormica, Greene, Pittonia, i. (Feb. 1887) 20 $=$ K. californica, A. Gray.

Chorisiana, Greene, 1. c. $13=\mathrm{K}$. Chorisiana, A. Gray. Cooperi, Greene, 1. c. $19=$ E. Cooperi, A. Gray. Cusickii, Greene, 1. c. 17. - Calif.

diffusa, Greene, 1. cit. 14. - Calif.

Echinoglochin, Greene, 1. c. $15=$ Echinospermum Greene1, A. Gray.

Greenei, Greene, Man. Bot. San Franc. Bay, (1894) $259=$ Echinospermum Greenei, A. Gray Hickmanii, Greene, Pittonia, i. (Feb. 1887) 13. Calif.

hirta, Greene, 1. c. i. (Feb. 1888), 61. - Oregon.

hispidula, Greene, 1. c. i. (Feb. 1887) 14. - Am. bor. occ.

humilis, Greene, 1.c. 17. - E. humile, DC

humistrata, Greene, 1. c. $16=$ Krynitzkia californica, A. Gray. var. subglochidiata, A. Gray.

lithocarya, Greene, 1. c. = Krynitzkia lithocarya, A. Gray.

mollis, Greene, 1. c. $20=$ E, molle, A. Gray.

myriantha, Greene, in Erythea, iii. (1895) 125. Calif.

Nelsoni, Greene, 1. c. 48. - Wyoming

penicillata, Greene, Pittonia, i. (Feb. 1887) 18. Calif.

plebeia, Greene, 1. c. = Krynitzkia plebeia, A. Gray.

\section{ALLOCARYA : -}

procumbens, Greene, Pittonia, i. (Feb 1887) $17=$ Plagiobothrys procumbens, A. Gray.

scopulorm, Greene, 1. c. $16=$ Krynitzkia californica, A. Gray.

Scouleri, Greene, 1. c. $18=$ E. Scouleri, A. DC scripta, Greene, Pittonia, i, Nov. 1887) 142.

sessilifolia, Greene, 1. c. 17 = Eritrichium sessiliflorum, $D C$.

stipitata, Greene, 1. c. 19. - Calif

stricta, Greene, Pittonia, ii. (May 1892) 231. Calif.

temifolia, Greene, in Erythea, iii. (1895) $5 \%=$ Krynitzkia tenuifolia, A. Gray.

trachycarpa, Greene, Pittonia, i. (Feb, 1887) $14=$ Krynitzkia trachycarpa, A. Gray.

aliginosa, Greene, 1. c. $14=$ Eritrichium uligi nosum, Phil.

vestita, Greene, in Erythea, iii. (1895) 125. - Calif.

ALLODAPE, End1. = Lebetanthus, Endl. (Epacrid).

Myrsinites, Kuntze, Rev. Gen. (1891) $391=$ L. americanus, Endl.

ALLOMORPHIA, Blume (Melastom.). - Ind Kew. i. 83.

Balansaei, $\operatorname{Cogn}$. in DC. Monog. Phan. vii. (1891) 1183. - Tonkin.

Beccariana, Cogn. in Boerl. Handl. Fl. Nederl. Indië, i. 2(1890) 531; et in DC. Monog. Phan. vii. (1891) 467 - Borneo.

bullata, Cogn. in DC. Monog. Phan. vii.(1891) 465. - Malacca.

cordifolia, Cogn. in K. Schum. et Holly. Fl. Kais. Wilh. Land, (1889) 87; in Boerl. Handl. Fl. Ned. Indiè, i. 2. (1890) 531; et in DC. Monog. Phan. vii. (1891) 468. - N. Guin.

longifolia, Cogn. in Boerl. Handl. Fl. Ned. Indië, i. 2. (1890) 531; et in DC. Monos. Phan. vii. (1891) 466. - Borneo.

longispicata, Cogn. 27. cc. 531 et 465. - Borneo. macrophylla, Cogn in K. Schum. et Holly. Fl. Kais. Wilh. Land. (1889) 87; in Boerl. Handl. Fl. Ned. Indië, 1. 2. (1890) 537; et in DC. Monog. Phan. vii. (1891) 468. - N. Guin.

multiflora, Cogn. in DC. Monog. Phan. vii. (1891) 1183. - Tonkin.

multinervia, Cogn in Boevl. Handl. Fl. Ned. Indië, i. 2 (1890) 537; et in DC. Monog. Phan. vii. (1891) 531. - Borneo.

quintuplinervia, Cogn. $7 l$. cc. 531 et 466. - Borneo. rosea, Ridl. in Trans. Linn. Soc. Ser. II. iii. (1893) 301. - Penins. Mal.

sertulifera, Cogn. in Boevl. Handl. Fl. Ned. Indië, i. 2. (1890) 531; et in DC. Monog. Phan, vii. (1891) 531. - Borneo.

ALLOPHYLUS, Lam. (Sapindac.). - Ind. Kew. 83 (sens. exten.)

abyssinicus, Radlk. in Engl. et Prantl, Natirr. Pflanzenfam. iii. 5. (1895) 313 (= Schmidelia abyssinica Hochst.). - Afr. trop.

alnifolius, Radlk. ex Engl. in Abhandl. Prenss, Akad. Wiss. (1894) 25; et in Pflanzenw. Ost-Afr. C (1895) 249 (= Schmidelia alnifolia. Baker) - Afr. trop. amazonicus, Radlk. in Engl. et Prantl. Natirr. Pfanzenfam. iii. 5. (1895) 312 (= Schnnidelia amazonica Mart.). - Bras.

angustatus, Radlk. 1. c. (= Schmidelia angustata Triana et Planch.). - N. Granat.

Bojerianus, Radlk.l. c. 31 (= Schmidelia Bojeriana Camb.). - Afr. trop.

chartaceus, Radlk.l. c. 313 (= Schmidelia chartacea Kurz).- Reg. Himal.

concanicus, Radlk. in Sitzungsb. math. phys. Cl bayer. Akad. Wiss. xx. (1890) 230.-As. trop

crassinervis, Radlk. in Engl. et Prantl, Natürl Pflanzenfam. iii. (1895) 312, nomen. - Am. trop. decipiens, Radlk. l. c. 313 (=Schmidelia decipiens, Arn.). - Afr. austr.

devicus, Radlk. i. c. 512 (=Schmidelia devica, Mart.) - Bras.

distachys, Radlk. l. c. 313 (= Schmidelia distachya, DC.). - As. or. 


\section{ALLOPHYLUS:}

edulis, Radlk. ex Warm. in Medd. naturh. Foren. Kjoeb. xxxvii. (1890) 244; et ex S. Moore, in Trans. Linn. Soc. Ser. II. iv. (1895) $340(=$ Solmidelia edulis, St-Hil.). - Bras.

erosus, Radlk, in Engl. et Pyantl, Natür,. Pfanzenfam, iii. 5. (1895) 313 (= Schmidelia erosa, Arn.). - Afr. austr.

excelsus, Radlk. in Sitzungsb. math. pliys. Cl. bayer. Akad.Wiss.xx.(1890)230.iii.5.(1895)312(=Schmidelia excelsa, Triana et Planch.).-Am. trop.

ferruginus, Taub. in Engl. Pflanzenw. Ost-Afr. C (1895) 249. - Afr. trop. or.

floribundus, Radlk, in Engl. et Prantl, Naturl. Pfanzenfam. iii. 5. (1895) 312 (= Schmidelia floribuda, Poepp. et End1.). - Peruvia.

glaber, Boerl. Handl. Fl. Ned. Indië, i. (1892) 284 (= Schmidelia glabra, Roxb.). - As. trop.

glabratus, Radlk. in Engl. et Prantl. Natiirt. Pflanzenfam. iii. 5. (1895) 312 (=Schmidelia glabrata, H. B. et K.). Am. trop.

Goudotii, Radlk, in Sitzungsb. math. phys. Cl. bayer. Akad. Wiss, xx. (1890) 230; et ist Engl. et Prantl. Natuirl. Pflanzenfan. iii. 5. (1895) $312(=$ Schmidelia Goudotii, Triana et Planch.). - Am. trop

grandifolius, Radlk. l.c.313 (= Schmidelia grandifolia, Baker). - Afr. trop.

grossedentatus, Radlk. 1. c. (= Schmidelia grossedentata, Turcz.). - As, or.

guaraniticus, Radlk. 1. c. 312 (= Schmidelia guaranitica, A. St-Hil.).- Bras.

heterophyllus, Radlk. l.c. (=Schmidelia heterophylla, Camb.). - Bras.

hirtellus, Radlk. l. c. (= Schmidclia hirtella, Hook.). - Afr. trop.

kilimandscharicus, Taub. in Engl. Pfanzenw. OstAfr. C (1895) 249. - Afr. trop. or

laevigatus, Radlk. in Engl. et Prantl, Naturl. Pfanzenfam. iii. 5. (1895) $312(=$ Schmidelia lavigata, Turcz:). - Bras.

leptostachyus, Boerl. Handl. Fl. Ned. Indië, i. (1890) 284 (= Schmidelia leptostachya, Blume). - Java.

magicus, Taub. in Engl. Pflanzenw. Ost-Afr.C (1895) 250 in obs. (= Schmidelia magica, Baker). - Afr. trop.

melanocarpus, Radlk. in Engl. et Prantl, Naturl. Pflanzenfam. iii. 5. (1895):313 (= Schmidelia melanocarpa, Arn.). - Afr. austr.

mollis, Radlk. in Sitzungsb. math. phys. Cl. bayor. Akad. Wiss. xx. (1890) 230; et in Engl. et Prant?. Natürl. Pfanzenfam. iii. 5. (1895) 312 (= Schmidelia mollis, Kunth) - N. Granat.

monophyllus, Radlk. ex Taub. in Engl. Pfanzenw. Ost-Afr. C (1895) 250; et in Engl. et Prantl, Naturr. Pfanzenfam. iii. 5. (1895) 312(=Schmidetia nonophylla, Presi). - Afr. trop.

mutabilis, Boerl. Handl. Fl. Ned. Indiè, i. (1890) 284 (= Schmidelia mutabilis, Blume). - Java.

myrianthus, Radlk. in Engl. et Prantl, Natiorl. Pfanzenfan. iii. 5. (1894) 312 (= Schmidelia mollis, Triana et Planch.), - N. Granat.

nitidulus, Radlk.l.c. (= Schmidelia nitidula, Triana et Planch.) - N. Granat.

occidentalis, Radlk. in Sitzungsb. phys, math. Cl.bayer. Akad. Wiss. xx. (1890) 230; et in Engl, et Prantl, Natürl. Pfanzenfan. iii. 5. (1895) 312 (=Schmidelia occidentalis, Sw.). - Am. trop.

paniculatus, Radlk. in Engl. et Prantl, Natürl. Pfanzenfam. iii. 5. (1895) 312 (= Schmidelia paniculata, Poepp. et Endl.). - Peruvia.

petiolatus, (erx. cal.) Radlk. ex Wilh. Müller, in Spengel, Zool. Jahrb. i. (1886) $51=$ seq.

petiolulatus, Radik. Monog. gener. Serjan. suppl. (Abhandl. bayer. Akad. Wiss. xvi. I.) (1886) 181; et in Engl. et Prantl, Natürl. Pflanzenfam. iii. 5. (1895) 312. - Bras.

psilospermus, Radlk. in Sitzungsb. math. phys. Cl. bayer. Akad. Wiss. xx. (1890) 230 in obs.; et in Engl. et Prantl, Natiirl. Pfanzenfam. iii. 5. (1895) 312. - Martinica.

puberulus, Radlk. in Engl. et Prantl, Natürl. Pfanzenfam. iii. 5. (1895) 312 (= Schmidelia puberula, Camb.). - Bras.

punctatus, Radlk.l. c. (=Schmideliapunctata, Poepp. et Endl.). - Peruvia.

quercifolius, Radlk.l. c. (=Schmidelia quercifolia, Mart.). - Bras.

\section{ALLOPHYLUS :}

acemosus, Radlk. in Engl. et Prantl, Natuirl. Pfan zenfam. iii. 5. (1895) 313 (= Schmidelia racemosa Linn.). - As. or.

repandus, Engl. Bot. Fahrb. xvii. (1893) 160 in obs. (= Schmidelia repanda, Baker). - Afr. trop.

reticulatus, Radlk. in Engl. et Prantl, Natiurl. Pfan zenfam. iii. 5. (1895) 312 nomen. - Am. trop.

Rheedii, Radlk. l. c. 313 (= Schmidelia Rheedei Wight). - As. or.

rhoidiphyllus, Balf. $\mathrm{f}$. in Trans. Roy. Soc. Edinb. xxxi. (1888) $60=$ rhusiphyllus, Balf.f.

rhomboidalis, Radlk. in Sitzungsb. math. phys. Cl. bayer. Akad. Wiss. xx. (1890) 230 (= Schmidelia rhomboidalis, Nadeaud). - Ins. Tahit.

rubifolius, Engl. in Abhandl. Preuss. Akad. Wiss. 1891. ii. (1892) 292 (=Schmidelia rubifolia. Hochst.). - Afr. trop.

scrobiculatus, Radlk. in Engl. et Prantl, Natuirl. Pfanzenfan, iii. 5. (1895) 312 (= Schmidelia scro biculata, Poepp. et Endl.). - Peruvia.

semidentatus, Radlk. ex S. Moove, in Trans. Linn. Soc. Ser. II. iv. (1895) 341; et in Engl. et Prantl. Natiurl. Pfanzenfam. iii. 5. (1895) 312 (= Schmidelia semindentata, Miq.). - Bras.

sericeus, Radlk. in Sitzungsb. phys, math. Cl. bayer. Akad. Wiss. xx. (1890) 230; et in Engl. et Prant? Natiirl. Pfanzenfam. iii. 5. (1895) $312(=$ Schnidelia sericea, Camb.).-Am. trop.

simplex, Baill. Hist. pl. Madag., Atlas (1894) t. 247. - Madag.

spicatus, Radlk. in Engl. et Prantl, Nativl. Pfanzenfan. iii. 5. (1895) 312(= Schmidelia spicata, DC. - Afr. trop.

strictus, Radlk.l. c. 312 fig. 162.-Bras.

ternatus, Radlk. l. c. iii. 5. (1895) 313=A. Cobbe, Bl. tomentosus, Bocrl. Handl. Fl. Nederl. Indie, i. (1890) 284 (= Schmidelia tomentosa, Hook. f. - Borneo. trichodesmus, Radlk, in Engl, et Prantl. Natürl. Pfanzenfan. iii. 5. (1895) $313(=$ Schmidelia trichodesma, Boj.). - Ins. Maurit.

villosus, Radik. l. c. iii. 5. (1895) 313 (= Schmidelia villosa, Roxb.). - As. trop.

vitiensis, Radlk. in Sitzungsb. math.phys. Cl. bayer. Akad. Wiss. xx. (1890) 230 in obs. - Ins. Viti.

ALLOPLEGTUS, Mart. (Gesner.). - Ind. Kew. 1.84.

cristatus, Kuntze, Rev. Gen. (1891) $472=$ Pterygoloma cristatum, Grisel.

discolor, Hook. f. in Bot. Mag. cxxii. (1892) ad calc. = A. Lynchei, Hook. $f$.

Lynchei, Hook. f. in Bot. Mag. (1892) t. 7271. -

pubescens, Benth. et Hook. f. ex Kuntze, Rev. Gen. (1891) 472. - Jamaica.

solitarius, Rusby, in Mcm, Torrey Bot. Club, iv. (1895) 238. - Bolivia.

sylvarum, S. Moore, in Trans. Linn. Soc. Ser. II. iv. (1895) 411. - Bras.

ALLUCIA cerma, Klotzsch ex Petersen, in Mart. F1. Bras. III. iii. (1890) 48 in syn. = Renealmia strobilifera, Poepp. ex Endl.

strobilifera, Klotzsch, 1. $\mathrm{c}_{0}=\mathrm{R}$. strobilifera, Poepp et Endl.

ALNASTER, Spach = Alnus, Linn. (Cupulifer.). fruticosa, Somm. (an Ledeb. ?) in Nuov. Giorn. bot. Ital. xxv. (1893) $84=$ Alnus fruticosa, Rupr.

ALNUS, Linn. (Cupulifer.). - Ind. Kew. i. 84 ambigua $X, G$. Beck, in Verh. zool. bot.-Ges, Wien, xxxviii. (1888) '767. - Austria.

Aschersoniana, Callier, in Sitzungsb. Schles. Ges. vaterl. Cult. 1xx. (1891-92) 82; et in Deutsche Bot. Monatsschr. x. (1892) 185. - Germ.

Beckii, Callier, in Deutsche Bot. Monatsschr. vii. (1889) 53. - Germ.

Fiekii $\times$, Callier, in Sitzungsb. Schles. Ges, vaterl. Cult. 1xix. 1891. (1892) 83; et in Deutsche bot. Monatsschr.x. (1892) 186. - Germ.

Figerti $x$, Callier, in Deutsche Bot. Monatsschr. vii. (1889) 56. - Germ.

hybrida X, Hort. ex iDippel, Handb. Laubholzk. ii. (1892) 149. - Germ

\section{ALNUS :}

mperialis, Hort. ex Dippel, Handb. Laubholzk. ii. (1892) $16 \mathrm{I}=$ glutinosa, Linn.

lanceolata, Phil. in Anal. Univ. Chil. xc1. (1895) 514. - Peruvia.

nevvosa; Hort. ex Dippel, Handb. Laubkolzk. ii. (1892) $148=$ cordata, $C$. Koch

occidentalis, Dippel, l. c. 158 fig. 78. - Am. bor. silesiaca $\times$, Fiek, in Sitzungsb. Schles. Ges. vaterl. Cult. 1xix. 1891. (1892) 83. = seq.?

silesiaca $\times$, Fiek. et Pax, in Oest Bot. Zeitschr. (1889) 408. - Germ.

spuria $\times$, Callier, in Sitzungsb. Schles. Ges, vaterl. Cult. lxix. 1891. (1892) 79; et in Kneucker, Allg. Bot. Zeitschr. i. (1895) 105 et 123. - Germ.

Tauschiana $\times$, Callier, in Deutsche Bot.Monatsschr. vii. (1889) 53. - Germ.

ALOGASIA, Neck. (Aroid.). - Ind. Kew. i. 85. aequiloba, N. E. Br. in Kew Bull.(1895) 119. N. Guin.

amabitis, Hort. Bull, ex Hook. f. F1. Brit. Ind. vi. (1893) $527=$ longiloba, Miq.

argyrea, Sander, Catal. (1895) 36. - Hab?

Augustiana, L. Lind. et Rodig. in Illustr. Hort 1886) 61 tab. 593. - Hab. ?

Bachi X. Hort. ex Rodig. in Illustr. Hortic. (1888) 79 et $(1890) 7 \%$ t. 110. - Hybr.artef.

Chantrieri X, Ed. André, in Rev. Hort. (1887) 465 fig. 32. - Hybr. artef.

Chantrieviana $X$, Hort. ex Rev. Hortic. (1887) 465 . - Hybr. artef.

Chantrieriana, Rodig, in Illustr. Hortic. xxv. (1888) 79 t. 64. = praec.?

conspicua X, Ed. André, in Rev. Hortic. (1891) 175 et 367. - Hybr. artef.

cordifolia, Cordem. Fl. Ile Réunion (1895) 136 = Caladium cordifolium, Willd

coriacea, L. Lind. ex Gard. Chron. (1893) i. 475. Hab.?

Curtisii, N. E. Br. in Kew Bull. (1894) 347.Penang.

Dussii, Hort. ex Hook. f. in Bot Mag. (1894) t. 7364 in syn. = Colocasia antiquorum, Schott. Dussii, Dammer, in Gartenft, (1892) 312. - Hab. ? eminens, N.E. Br. in Gard. Chron. (1887) i. 105. - Malaya.

Gaulainii X, Éd. André, ex Wien. I1l. Gartenzeit. (1890) 380. - Hybs. artef. ?

gigas, L. Lind. in L'Hort. Intern. Catal. (1886-87) 41 nomen. - Hab.

grandis, N. E. Br. in Gard. Chron. (1886) ii. 890.Ins. Ind. or.

Lindeni, Rodig. in Illustr. Hortic. (1886) 111 t. 153. - N. Guin.

Luciani X, Pucci, ex Rodig. in Illustr. Hortic. xxxiv. (1887) 75 t. 27. - Hybr. artef.

Margaritae, L. Lind. et Rodig. in Illustr. Hortic. xxxiii. (1886) 155 t. 611 . - Java.

marginata, N.E. Br., in Gard. Chron. (1887) ii. 712. - Bras.

mortfontanensis 入, Ed.André, in Rev. Hortic. (1891) 174. - Hybr. artef.

nobilis, Hort. ex Gard. Chron. (1892) i. 731 nomen. - Hab.?

perakensis, Hemsl, in Journ. Bot. xxv. (1887) 205 princeps, Bull. Catal. (1888) 7, ex Kew Bull. (1889) 76. - Malesia.

Pucciana X, Éd. André, in Rev. Hortic.(1887) 466.Hybr. artef.

reversa, N. E. Br. in Gard. Chron. (1890) ii. 38. - Ins. Philipp.

Rex, Hort. ex Gard. Chron. (1892) i. 731 nomen.$\mathrm{Hab}$.?

Rodigasiana $\times$, Hort. ex Éd. André, in Rev. Hortic. (1890) 114; et (1891) 174. - Hybr. artef.

Sanderiana, Hort. ex Bull, Catal. (1894) 8 cum xylogr. - Malaya.

Villenewrei $\times$, L. Lind, et Rodig. in 1llustr. Hortic. xxxiv. (1889) 59 t. 21. - Hybr. artef.

Watsoniana, Hort. ex Gard. Chron. (1893). i. 442, fig. 83. - Sumatra.

ALOGASIOPHYLLUM, Engl. Bot. Jahrb. xv. (1893) 449 , t. 19. AROIDEAE

kamerunianum, Engl. l. c. - Afr. trop. occid. 
ALÖ̈, (Tourn.) Linn. (Liliac.). - Ind. Kew. i. 85. agavifolia, Schweinf, ex Penzig, in Atti Congr. bot. Genova (1892) 365, nomen. - Exythrea.

aurantiaca, Baker, in Gard. Chron. (1892) i. 780.Afr. austr.

Bakeri, S. Elliot, in foum. Linn. Soc. xxix. (1891) 60. - Madag

Boehmii, Engl. Pfanzenw. Ost-Afr. C (1895) 141. - Afr. trop. or.

Boylei, Baker, in Kew Bull. (1892) 84. - Afr. austr. brachystachys, Baker, in Bot. Mag. (1895) t. 7399. - Zanzib.

Brownii, Baker, in fourn. Bot. xxvii. (1889) 34. Afr. austr.

Buchanani, Baker, in Kew Bull. (1895) 119. Afr. trop. or.

Camperii, Schweinf. in Bull. Herb. Boiss, ii. App, ii. (1894) 66. - Erythrea.

cernua, Tod. Hort.bot. Panorm. ii. (1890) 49 t. 36.Madag.

concinna, Baker, in Kew Bull. (1895) 153. Zanzib.

confusa, Engl. Pfanzenw. Ost-Afr. C (1895) 141. Afr. trop. or.

Derbetzi X, Hort. Deleuil, ex Rev. Hortic. (1894) 147. - Hybr. artef.

haworthioides, Baker, in fourn. Linn. Soc. xxii. (1887) 529. - Madag.

hereroënsis, Engl.Bot.fahrb.x. (1889)2.-Afr.austr.

Hildebrandtii, Baker, in Bot. Mag. (1888) t. 6981. - Afr. trop. or.

imbricata X, Hort. ex Wien. 111. Gartenzeit. (1893) 194. - Hybr, artef.

Johnstoni, Baker, ex Oliver, in Trans. Limn. Soc. Ser. II. ii. (1887) 351. - Afr. trop. or.

Kirkii, Bakev, in Bot. Mag. (1894) t. 7386. - Zanzibar.

kniphofioides, Baker, in Hook. Icon. pl. xx. (1890) t. 1939. - Afr. austr.

Lanzae, Tod. Hort. bot. Panorm. ii. (1890) t. 39. Afr. austr.

lateritia, Engl. Pflanzenzw. Ost-Afr. C (1895) 140. - Afr. trop. or

leptophylla, $N$. E. Br, in Fourn, Bot, xxvii. 1889) 44. - Afr. austr.

longiflora, Baker, in Gard. Chron. (1888) ii. 756. Atr. austr.

Luntii, Baker, in Kew Bull. (1894) 342; et in Bot. Mag. (1895) t. 7448. - Arabia.

minima, Baker, l. c. (1895) 153; et in Hook. Icon. pl. xxv. (1895) t. 2423. - Natal.

Monteiroae, Baker, ex Monteiro, Delagoa Bay, (1891) $174=$ seq.

Monteiroi, Baker, in Gard. Chron. (1889) ii. 523. Mossamb.

rabaiensis, Rendle, in fourn. Linn. Soc. xxx. (1895)

410, - Afr. trop. or. (Rossi). - Madag.

rubroviolacea, Schweinf., in Bull. Herb. Boiss. ii. App. ii. (1894) 71. - Arabia.

sabaea, Schweinf. l. c. 74. - Arabia.

Schoelleri, Schweinf. l. c. 107. - Erythrea.

secundiflora, Engl. Pflanzenw. Ost-Afr. C (1895) 140. - Afr. trop. or.

Simoniana X, Hort. ex Wien. I11. Gartenz. (1893) 194. - Hybr. artef.

Steudneri, Schweinf. ex Penzig, in Atti Congr. bot. Genova (1893) 362 nomen; et in Bull. Herb. Boiss. ii. App. ii. (1894) 73. - Erythrea.

tomentosa, Deflers, Voy. Yémen (1884) 211.-Arabia.

venenosa, Engl. Bot. fahrb. xv. (1893) 87. Congo.

Volkensii, Engl. Pfanzenw. Ost-Afr. C (1895) 141. - Afr. trop. or.

ALONA, Lindl. (Convolvul.). - Ind. Kew. i. 88.

flaccida, Phil. in Anal. Univ. Chil. xci. (1895) 39.Chili.

Foncki, Phil. l. c. 36. - Chili.

grandiftora, Phil. l.c. 37.-Chili.

Miersii, Phil. l. c. 35. - Chili.

patula, Phil. l. c. 39. - Chili.

phylicifolia, Phil. l. c. 36.-Chili

rigida, Phil. l. c. 38. - Chili.

sedifolia, Phil. in Anal. Mus. nac. Chile (1891) 69."Bolivia.
ALOPECURUS, Linn.(Gramin.).-Ind. Kew.i.88. californicus, Vasey, in Bull. Torrey Bot. Club, xv. (1888) 13; et Grass. Pacif. Slope (1893) t. 25. Calif.

Howellii, Vasey, in Bull. Torrey Bot. Club, xi. (1888) 12; in Contrib. U.S. Nat. Herb. iii. (1892) 87; et Grass. Pacif. Slope (1893) t. 27 fig. 1. - Oregon. involucratus, Post, in fourn. Linn. Soc. xxiv. (1888) 440. - As. occ.

Macounii, Vasey, in Bull. Torrey Bot, Club, xiv. (1888) 12; ct Grass. Pacif. Slope (1893) t. 27 fig. 2. - Ins. Vancouv.

mixtus $\times$, C. Richt. P1. Europ. i. (1889) 39.-Helv. occidentalis, Scribn. in Coult. Bot. Gaz. xi. (1886) 170. - Colorado.

sericeus, Alboff, Descr. nonv. esp. Abkasie (1891) 16, in Bull. Herb. Boiss. i. (1893) 25l; et Prodr. f . Colch. (1895) 255. - Reg. Cauc

Stejnegeri, Vasey, in Proc. U. S. Nat. Mus. x. (1887) 153; et Grass. Pacif. Slope (1893) t. 24. Ins. Command. (Mar. Behring.).

ALPHITONIA, Reissek (Rhamn.). - Ind. Kew. ponderosa, Hittebr. Fl. Haw. Isl. (1888) 81. - Ins. Sandvic.

ALPHONSEA, Hook. $f$. et Thoms. (Anonac.). Ind. Kew. i. 89.

Curtisii, King, in fourn. As. Soc. Beng. 1xi. (1892) ii. 127. - Penang.

cylindrica, King. l.c. 127. - Perak.

lucida, King. l. c. 126. - Perak.

subdehiscens, King. i. c. 126, - Perak.

ALPINIA, Linn. (Scitamin.). - Ind. Kew. i. 89. affinis, Ridl. in fourn. Bot. xxiv. (1886) 357.N. Guin.

africana, Ridl. in Bolet. Soc. Brot. vi. (1887) 203.Ins. S. Thom.

aurantiaca, Wall. ex Baker, in Hook. f. F1. Brit. Ind. vi. (1892) $255=\mathrm{A}$. Rafflesiana, $W$ all.

bifida, Warb. in Bot. Fahrb. xiii. (1891) 275 . Oceania.

decurva, Ridl. in Fourn. Bot. xxix. (1886) 357 N. Guin.

decurvata, Baker, in Hook. f. Fl. Brit. Ind. vi. (1892) 25\%. - Perak.

Fraseriana, Oliver, in Hook. Icon. pl. xvi. (188\%) t. 1567. - Borneo.

gracilis, Rich. ex Petersen, in Mart. F1. Bras. iii III. (1890) 47 = Renealmia gracilis, Petersen.

Manii, Baker, in Hook. f. Fl. Brit. Ind. vi. (1892) 253. - Ins. Andam.

petiolata, Baker, l. c. 255. - Perak.

nutans, K. Schum. in K. Schum, et Hollr. Fl. Kais.

Wilh. Land, (1889) 28. - N. Guin.

papilionacea, K. Schum. l.c. 29. - N. Guin

secunda, Baker, in Hook. f. Fl. Brit. Ind. vi. (1892) 257. - Perak.

speciosa, K. Schum. in Bot. Fahrb. xv. (1893) 418 in obs. - Afr. trop.

Wrayi, King, ex Baker, in Hook. f. Fl. Brit, Ind. vi. (1892) 252. - Penang.

zingiberina, Hook. f. in Bot. Mag. (1887) t. 6944. - Siam.

ALSEIS, Schott (Rubiac.). - Ind. Kew. i. 90. involuta, K. Schum. in Mart. Fl. Bras. vi. vi. (1889) 189. - Bras.

labatioides, Karst. ex K. Schum. l.c. 180. - Bras.

ALSEODAPHNE, Nees (Laurin.). - Ind. Kew. i. 90

crassipes, Hook. f. Fl. Brit. Ind. v. (1886) 146.Malacca.

decipiens, Hook. f. l. c. 145. - Malacca.

panduriformis, Hook. f.l. c. - Malacca.

peduncularis, Hook. f. l. c. 144. - Penang

petiolaris, Hook. f.l. c. - Reg. Himal.

umbelliffora, Hook. f. l. c. 145. - Malacca, Ind. bat.

ALSINANTHEMUM, Thalius, ex Greene, Man.Bot. San Franc. Bay (1894) 238 = Trientalis, Linn. (Primulac.).

europaeum, Greene, 1. c. = T europaea, Linn
ALSINASTRUM, Schur= Elatine, Linn. (Elatin.). brachyspermum, Greene, Man. Bot. San Franc. Bay (1894) 62 = E. brachysperma, A. Gray.

ALSINE, Scop. = Arenaria, Linn. (Caryophyll.). Akinfijewi, Schmalh. ex Akinfiew, in Bull. Soc géogr. Cauc. (1892) 12; et in Ber. deutsch. bot. Ges x. (1892) 28\% - Reg. Cauc.

aquatica, Britton, in Mem. Torrey But. Club, v. (IS94) $346=$ Cerastium aquaticum, Linn. baicalensis, Coville, in Contrib. U. S. Nat. Herb. iv. (1893) $70=$ Stellaria umbellulata, Turcz. borealis, Britton, in Mem. Torrey Bot. Club, v. (1894) $149=$ Stellaria borealis, Bigel.

bosniaca, G. Beck, in Ann. Naturh. Hofmus. Wien, vi. (1891) 317 et 321 t. 8 fig. 1-5. - Bosnia.

Brotherana, Boiss. Fl. Or. Suppl. (1888) $112=$ Stellaria Brotherana. Traut

bulgarica, Velen. in Sitzb. K. Bohm. Akad. 1889 (1890) ii. 30; et Fl. Bulg. (1891) 93. - Bulg. ciliata, Schmalh. in Ber. deutsch. bot. Ges. $x$ (1892) 287 t. 17. fig. 1-5. - Reg. Cauc.

circassica, Alboff, in Bull. Herb. Boiss. ii. (1894) 449. - Reg. Transcauc.

crassifolia, Britton, in Mem. Torrey Bot. Club, v. (1894) $150=$ Stellaria crassifolia, Ehrh

crispa, Holzinger, in Contrib. U.S. Nat. Herb. iii. (1895) $216=$ Stellaria crispa, Cham.

dunensis, Corbiére, Nouv. Fl. Norm. (1893) $105=$ Arenaria tenuifolia, Linn.

fontinalis, Britton, in Mem. Torrey Bot. Club, v. (1894) 356 = Stellaria crassifolia, Ehrh.

frutescens, Simonk. Enum. fl. Transs. (1886) $141=$ Arenaria setacea, Thuill.

Garckeana, Aschers. et Sint. ex Boiss. Fl. Or. Suppl. (1888) 112. - Asia Min.

Gayana, Webb, ex Christ, in Bot. Jahrb. ix. (1888) 109 et 159. - Ins. Canar.

graminea, Britton, in Mem. Torrey Bot. Club, v. (2894) $150=$ Stellaria graminea, Linn.

Holostea, Britton, 1. c. = Stellaria Holostea, Linn. humifusa, Britton, 1. c. = Stellaria humifusa, Sw. famesi, Holzinger, in Contrib. U. S. Nat. Herb. iii. (1892) $216=$ Stellaria Jamesii, Torr.

kabirarum, Degen et Halácsy, in Oest. Bot. Zeitschr. xli. (1891) 330. - Ins. Samothr.

lanuginosa, Coste, in Bull. Soc. Bot. Fr. xl. (1893) P. cxvil; et in Magnier, Scrin. $f$. select, xi1. (1894) 318. = Arenaria mucronata, Linn.

littoralis, Greene, Man. Bot. San Franc. Bay (1894) $34=$ Stellaria littoralis, Torr

longifolia, Britton, in Mem. Torrey Bot. Club, v (1894) 150 = Stellaria longifolia, Muhl

longipes, Coville, in Contrib. U. S. Nat. Herb. iv. (1893) $70=$ Stellaria longipes, Goldie.

mediterranea, Fouc, in Soc, étud. fl. Franc. (1892) n. 20, ex Bull. Herb. Boiss. i. App. (1892) $12=$ Arenaria tenuifolia, Linn

nitens, Greene, Man. Bot. San Franc. Bay (1894) $33=$ Stellaria nitens, Nutt.

nivalis, Simonk. Enum. fl. Transsilv. (1886) 142 $=$ Arenaria verna, Linn.

oxypetala, Wolosz. in Spraw Kom. fizyj. Krajowej. xxii. (1883) ii. 214. - Eur.

Paui, Willk. ex Herv. in Magnier, Scrin. fl. select. xi. (1892) 244; et in Rev. gén. Bot. iv. (1892) 152 t. 7 fig. 1. - Hisp.

Pichleri, Boiss. F1. Or. Supp1. (1888) 113. - Pelop. platyphylla, Christ, in Bot. Jahrb. ix. (1888) 102 et 159. - Ins. Canar.

pubera, Britton, in Mem. Torrey Bot. Club, iv. (1893) 107 = Stellaria pubera, Michx.

pungens, Stapf, in Denkschr. Akad. Wien, (1886) 20. - Persia.

pusilla, Stapf, 1. c. 10, - As, Min.

vhaetica, Bruegg. in Jahresb. Nat. Ges. Graub. xxxi. Beil. (1887-88) 29 = Arenaria verna, Linn.

rhodocalyx, Alboff, in Bull. Herb. Boiss. ii. (1894) 255 t. 8. - Reg. Cauc.

rudbarensis, Stapf, in Denkschr. Acad. Wien, (1886) 20. - Persia.

Skorpili, Velen. in Sitzb. Böhm. Ges. Wiss. 1889 (1890) 31; et Fl. Bulg. (1891) 93. - Bulg.

stellata, Halàcsy, in Denkschr. Akad. Wien, lxi (1894) 474. - Graecia.

stenosepala, Stapf, in Denkschr. Akad. Wien, (1886) 9. - As. Min. 
ALSINE:

subuniflora, Alboff, Prodr. fl. Colch. (1895) 35. As. Min.

thessala, Halácsy, in Denkschr. Akad. Wien, 1xi. (1894) 472. - Thessal.

Therenaei, Reut, ex Magnier, Scrin, fl, select, xi. (1892) 242 (conf. Bull. Herb. Boiss. ii. App. ix. (1894) 13. - Gall.

Thomasiana, Somm, in Bull. Soc bot. Ital. Ser. II. ii. (1895) $44=$ Arenaria Villarsii, Balb.

Wiesneri, Stapf, in Denkschr. Akad. Wien, (1886)

20. - Persia

ALSINELLA. Bilb. ex Linn. = Sagina, Linn. (Caryophyll.)

ciliata, Greene, Fl. Francisc. (1891) 126. - Calif. crassicaulis, Greene, 1. c. $125=\mathrm{S}$. crassicaulis, S. Wats.

occidentalis, Greene, 1. c. $=$ S. occidentalis, S. Whats.

saginoides, Greene, 1. c. = Spergula saginoides. Limn.

ALSODEIA, Thou. (Violar.). - Ind. Kew. i. 92. Ancuparia, Welw. ex Buttn. in Verh. Bot. Vev. Brand. xxxi. (1889) 92 in obs. - Angola.

camptoneura, Radlk, in Sitz. math. phys. Cl. bayor. Akad. Wiss. xx. (1890) 187 in obs. - Bras.

capillata, King, in fourn. As. Soc. Beng. Iviii. (1889) ii. $40 \%$ - Penins. Mal.

cinerea, King, l. c. 403. - Penins. Mal.

comosa, King l. c. 407. - Penins. Mal.

condensa, King, 405. - Penins, Mal.

floribunda, King, l. c. 406. - Penins. Mal.

guatemalensis, S. Wats. in Proc. Am. Acad. xxi. (1886) 45s. - Guatem.

Hookeriana, King, in fourn. As. Soc. Beng. 1viii. (1859) ii. 402. - Penins. Mal.

japurana, Radlk., in Sitz. math.phys. Cl.bayer. Akad. Wiss. xx. (1890) 182 in obs. - Bras.

Kunstleriana, King, l. c. 401. - Penins. Mal. membranacea, King, l. c. 402 . - Penins. Mal. ovalifolia, Britton, in Bull. Torrey Bot. Club, xvi. (1889) 18. - Am. austr.

pachycarpa, King, in fourn. As. Soc. Beng. lviii. (1889) ii. 407. - Penins. Mal.

parvifolia, S. Wats. in Proc."Am. Acad. xxv. (1890) 142. - Mexic.

petiolaris, Radlk. in Sitz. math. phiys. Cl.bayer, Akad. Wiss. xx. (1890) 185 in obs. - Afr. trop. occ. Scortechirii, King, in Fourn. As. Soc. Beng. 1viii. (1889) ii. 405. - Penins. Mal.

Stuhlmannii, Engl. Pflansenw. Ost-Afr. C (1895) 276. - Afr. trop. or

usambarensis, Engl. in Abhandl. Preuss. Akad. Wiss. (1894) 36 nomen. - Afr. trop. or.

Woermanniana, Buettn. in Verh. Bot. Ver. Brand. xxxi. (18S9) 90. - Gabon.

Wrayi, King, in fourn. As. Soc. Beng. 1viii. (1889) ii. 403. - Penins. Mal.

ALSODEIIDIUM, Engl. Pflanzenw. Ost-Afr. C (1895) 248. OL ACINEAE.

Schumanii, Engl. 1. c. - Afr. trop. or

ALSODEIOPSIS, Oliver(Olac.).-Ind, Kew. i. 93. Holstii, Engl. in Abhandl. Preuss. Akad. Wiss. (1894) 45; et Pflanzenw. Ost-Afr.C (1895) 248. - Afr. trop. or

Poggei, Engl. Bot. Fahrb. xvii. (1893) 71.-Congo. Schumannii, Engl. in Abhandl. Preuss. Akad. Wiss. (1894) nomen. - Afr. trop. or.

Weissenborniana, $\mathcal{F}$. Braun et $\bar{K}$. Schum. in Mitth. deutsch. Schutzgeb. ii. (1889) 165. - Afr. trop. occ.

ALSOMITRA, M. Roem. (Cucurbit.). - Ind. Kew. i. 93 .

Muelleri, Cogn. in Bull. Acad. Belg. Sér. 3. xiv. (1887) 363. - N. Guin.

suberosa, F. M. Bailey, Syn. Queensl. Fl. Suppl. ii. (1888) 28. - Austra.1.

ALSTONIA, R. Br.(Apocyn.). - Ind. Kew. i. 93. actinophylla, K. Schum. in Eng1. et Prantl, Natürl. Pflanzenfam. iv. 2. (1895) $138=$ verticillosa, F. Muell.

congensis, Engl. Bot. Falırb. viii. (1887) 64. Congo.
ALSTROEMERHA, Linn. (Amaryllid.). - Ind. Kew. i. 93.

apertiflora, Baker, Handb. Amaryll, (1888) 135. Parag.

Bakeri, Pax, in Bot. Fahrb. xi.(1890)335.-Argent. Philippii, Baker, Handb. Amaryll. 140. - Chili. piauhyensis, Gardn. ex Baker, l. c. 136. - Bras.

Schenkiana, Baker, l. c. 134.-Bras.

Volckmanni, Baker, i. c. 139. - Chili.

ALTENSTEINLA, H. B. et K. (Orchid.). - Ind. boliviensis, Rolfe, ex Rusby, in Mem. Torrey Bot. Doliviensis, Rolfe, ex Rusby, in
Club, iv. (1895) 265. - Bolivia.

Hieronymi, Cogn. in Mart. Fl. Bras, iii. III (1895) 245. - Argent.

leucantha, Reichb. f. in Flora, 1xix. (1886) 548. $\mathrm{Hab}$ ?

ALTERNANTHERA, Forsk. (Amarant.), -

Ind Kew i. 95.

boliviana, Rusby, in Mem. Torrey Bot. Club, iv. (1895) 249. - Bolivia.

brasiliana, Kuntze, Rev. Gen. (1891) 537 = Mogiphanes brasiliensis, Mart.

chacoënsis, Morong, in Ann. N. Y. Acad. Sc. vii. (1893) 208. - Parag.

costaricensis, Kuntze, Rev. Gen. (1891) 538. Costarica.

Kerberi, Uline et Bray, in Coult. Bot. Gaz. xx. (1895) 450. - Mexic

Lehmannii, Hieron. in Bot. Fahrb. xx. Beibl. n. 49 (1895) 8. - Columb.

mexicana, Hieron in Bot. Fahrb xx. (1895) Beibl. 11. 49 (1895) 8 in obs. (= Telanthera mexicana, Moq.) - Mexic

multicaulis, Kuntze, Rev. Gen. (1891) $538=$ Mogiphanes straminea, Mart.

porrigens, Kuntze, 1. c. $=$ Telanthera porrigens, IIua.

portoricensis, Kuntze, l. c. 340.- Portorico.

pubiflora, Kuntze, 1. c. $538=$ Telanthera pubiflora, Muq.

repens, Kuntze, 1. c. 536 et $540=$ Alt. Achyrantha, $R . B r$

rigida, Robins, et Greenman, in Am. Fourn. Sc. Ser. III. i. (1895) 143. - Ins. Galapag.

scirpoides, Hook. f. ex Kuntze, Rev. Gen. (1891) 542. - Ins. Galapag.

stellata, Uline et Bray, in Coult. Bot. Gaz. xx. (1895) 451. - Mexic.

ALTHAEA, (Tourn.) Linn. (Malv.). - Ind. Kew. i.

acerifolia, arborea, biennis, cretica, flava, insularis, maritima, micans, microphylla, oblongifolia, occidenttalis, Olbia, phoenicea plebeia, punctata, stenopetala, thuringiaca, triloba, trimestris, unguiculata, venosa Kuntze, Rev. Gen. (1891) 66=homonyma omnia Lavaterae.

arbelensis, Baker $f$. in fourn. Bot. xxviii. (1890) 209. - Mesopot.

assurgentifolia, Kuntze, Rev. Gen. (1891)66 = Lavatera assurgentiflora, Kellogg.

denudata, Baker f. l. c. 208. - Armenia.

dissecta, Baker f. l. c. 143. - Syria.

Haussknechtii, Baker f. l. c. 144.- Syria.

hashmiriana, Kuntze, Rev. Gen. (1891) 66 = Lavatera cachemiriana, Camb.

kragujevacensis, Pancic, ex Kew Bull. (1890) App. i. 3 nomen, - Eur. austro-or.

lasiocalycina, Baker $f$. in fourn. Bot. xxviii. (1890) 144. - Armenia.

Loftusii, Baker f.l.c. 145. - Persia.

mauritiana, Kuntze, Rev. Gen. (1891) 66 = Lavatera mauritanica, Duchartre.

micrantha, Wiesb. ex Borb. in Oest. Bot. Zeitsclux. xliii. (1893) 360 in obs. - Eur.

microchiton, Baker f. in Fourn. Bot, xxviii. (1890) 144. - As. Min.

peduncularis, Baker f. l. c. 209. - Persia.

pontica, Baker f. l. c. 144. - Eur. or

Sintenisii, Hausskn. ex Baker f. l. G. xxxii. (1894) 35. - Armenia. Tholozani, Baker f. l. c. xxviii. (1890) 209. -
Persia.
ALTHENIA Petit (Naiad.).- Ind. Kew. i. 96. australis, Aschers. in Engl. et Prantl, Natül. Pflanzenfam. ii. 1. (1887) 214 (= Lepilaena australis, 7. Drumm.). - Austral.

cylindrocarpa, Aschers, l. c. 213 (=Lepilaena cylindrocarpa, Benth.). - Austral

ALTHOFFIA, K. Schum. in Bot. Jahrb. ix. (1888) 209. TILIACEAE.

tetrapyxis, $K$. Schum. l. c.-N. Guin.

ALVEOLINA, Van Tiegh. in Bull. Soc. bot. Fr. xlii. (1895) $359=$ Loranthus, Linn. (Loranth.) Melinoni, Van Tiegh. 1. c. 360. - Guian. gall.

ALVORDIA, T. S. Brandeg- in Proc. Calif. Acad. Ser.rr. ii. (1889) 174. COMPOSITAE.

glomerata, T. T. Brandeg. 7. o. - Calif.

ALYSSUM, Tourn. ex Linn. (Crucifer.). - Ind. Kew. i. 96.

alpinum, argyreum, auriculatum, Berlandieri, densiflorum, digitatum, Engelmannii, Fondleri, gnaphalodes, Gordonii, gracile, graecum, grandiflonum, lasiocarpum, Lindheimeri, mendocinum, Nuttallii, perpureum, recurvatum, repandum, Shortii, vestitum, Kuntze, Rev. Gen. (1891) 931 = homonyma omnia Vesicariae.

americanum, Greene, Pittonia, ii. (May 1892) 224. - Alaska

Amoris, Coincy, in Bull. Herb. Boiss. iii. (1895) 168 et Eclog. alt. pl. Hisp. (1895) 7. t. 2. - Hisp.

Bernhardii, Wettst, in Luerss, Bibl. Bot. Heft xxv. 1892) 25. - Carinth., Carn.

Bornmuelleri, Hausskn. in Oest. Bot. Zeitschr. x1. (1890) 211 et 393 nomen. - As. Min.

Brasi, Loret, ex Rouy et Fouc. F1. de Fr. ii. (1895) 192 = edentulum, Waldst. et $K$ it.

chlorocarpum, Hausskn, in Mitth. Thiir. Bot. Ver. N. Folge, iii. iv. (1893) 113. - Graecia.

Clastopus, Kuntze, Rev. Gen. (1891) 931 = Clastopus purpurens, Bunge.

clypeatum, Durieu, ex Coss. Comp. f. Atlant. ii. (1886) 236 in syn. = scutigerum, Durieu.

collicolum, Rouy et Fouc.Fl, de Fr. ii. (1895) $180=$ montanum, Limn.

denticulatum, Formanek, in Verh. naturf. Ver. Brimn, xxxii. 1893. (1894) 177. - Maced.

desertorum, Stapf, in Denksclir. Akad. Wien, (1886) 33. - Persia.

Djurdjurae, Chod. in Bull, Soc. Bot. Fr. xxxvi. (1889) 19. - Algeria.

fallacimnnn $\times$, Hausskn. in Mith. Thür. Bot. Ver. N. Folge, iii. et iv. (1893) 114. - Graecia.

Gayasum, Kuntze, Rev. Gen. (1891) $931=$ Vesicaria montana, A. Gray.

Gerardi, Rouy et Fouc. Fl. de Fr, ii. (1895) $177=$ alpestre, Linn.

globosum, Kuntze, Rev. Gen. (1891) 931 = Vesicaria Ludoviciana, $D C$.

Heldreichii, Haussk. in Mitth. Thïr. Bot, Ver. N. Folge, iii. iv. (1893) 113. - Graecia.

fordani, Fouc, et Rouy, F1. de Fr.ii. (1895) $1 \% 6=$ alpestre, Linn.

Moellendorfianum, Aschers. (in Blau. Reis. in Bosnien (1877) p. v. et 22) ex G. Beck, in Ann. Naturh. Hofmus. Wien, ii. (1887) 73 et 174. - Bosnia.

Pichleri, Velen.Fl. Bulg. (1891) 38. - Bulg.

ptilotrichum, Durieu, ex Coss. Comp. Al. Atlant. ii. (1887) 236 in syn. = granatense, Boiss. et Reut. ponticum, Veten. in Sitz. böhm. Ges. Wiss. (1892-93) 10. - BuIg.

pulvinare, Velen. in Sitz. böhm. Ges. Wiss. 1889 (1890) ii. 30; et Fl. Bulg. (1891) 39.-Bulg.

Reisseri, Velen. l. c. (1892-93) 12. - BuIg.

Ruprechti, Boiss. Fl. Or. Suppl. (1888) $51=$ andinum, Rupr.

saxigenum, Timb. in Lucante, Rev, de Bot. x. (1892)

54.-Gall.
scardicum, Wettst. in Luerss. Bibl. Bot. Heft 26. (1892) 24 tab. 1. fig. 20, 21 et 25. - Alban.

Schauerianum, Kuntze, Rev. Gen. (1891) 16=Vesicaria argentea, Schau.

singarense, Boiss, et Hausskn. ex Boiss. Fl. Or. Suppl. (1888) 49. - As. occ.

spathulaefolium, Formanek, in Verh. naturf. Ver. Brïn, xxxii. 1893 (1894) \%6. - Maced. 
ALYSSUM : -

stenophyllum, Kuntze, Rev, Gen. (1891) $931=$ Vesicaria Fendleri, A. Gray.

Stribrnyi, Velen. Fl. Bulg. (1891) 640. - Bulg.

thracicum, Ielen.l.c. 1891) 40. - Bulg.

Troodi, Boiss. ex Boiss. Fl. Or. Suppl. (1888) 49. Cypr.

indob̆onense, G. Beck, Fl. Nieder-Oest. ii. (1892) 469. - Austria.

ALYXIA, Banks (Apocyn.). - Ind. Kew. i. 99. acuminata, $K$. Schum. in K. Schum. et Hollr, Fl. Kais. Wilh. Land, (1894) 110. - N. Guin. composita, Warb. in Bot. Fahrb. xiii. (1891) 404. N. Guin.

lucida, Baker, in fourn. Linn. Soc. xxii. (1887) 503. - Madag.

monilifera, Vidal, Rev. Pl. Vasc. Filip. (1886) 182.Ins. Philipp.

polysperma, S. Elliot, in fourn. Linn. Soc. xxix. (1891) 33. - Madag.

semipallescens, F. Muell. in Trans. Roy. Soc. Vict. i. 2 (1889) 18. - N. Guin.

AMAJOUA, Auct. = Amaioua, Aubl. (Rubiac.).Ind. Kew. i. 99

fusiflora, Spruce, ex K. Schum. in Mart. F1. Bras. vi. vi. (1889) $363=$ Duroia fusifera, Hook. $f$. vi. VI. (1889) $363=$ Duroia fusifera, Hook. $f$.
genipoides, Spruce, ex K. Schum. 1. c. $364=$ Duroi genipoides, Hook. $f$.

petiolaris, Spruce, ex K. Schum. 1. c. $364=$ Duroia petiolaris, Hook f

pilosa, K. Schum. 1. c. 360. - Bras.

AMANOA, Aubl. (Euphorb.). - Ind. Kew. i. 99.

laurifolia, Pax, in Bot. farhb. xi. (1893) 522. - Afr. trop. occ

Stenonia, Baill. Hist. pl. Madag., Atlas (1892) t. 211. - Madag.

AMARANTHUS, Linn. (Amarant.). - Ind. Kew. i. 100 .

acutilobus, Uline et Bray, in Coult. Bot. Gaz, xix. (1894) $320=$ viridis, Limn.

albo-marginatus, Uline et Bray, l. c. 318. - Calif.

Berlandieri, Uline et Bray, 1. c. $268=$ polygonoides, Linn

Bigelovii, Uline et Bray, l. c. 271. - Mexic.

bracteosus, Uline et Bray, l, c. 314. - N. Mexic.

carneus, Greene, Pittonia, ii. (June 1890) 105. Calif.

chihuahensis, S. Wats, in Proc. Am. Acad. xxi. (1886) 436. - Mexic

crispus, Terrac. in Atti Acad. Sc. Napol. Ser. 2. iv. (1890) App. 2. - Italia mer

leucospermus, S. Wats. 1. c. xxii. (1887) $446=$ leucocarpus, S. Wats.

Margaritae, Dam. in Wien. Illustr. Garten-Zeit. (1887) 433-35 fig. 71. - Form, hort.

Pringlei, S. Wats. in Proc. Am. Acad. xxii. (1887) 476. - Mexic.

velutina, Spruce, ex K. Schum. 1. c. $366=$ Duroia velutina, Hook. $f$.

AMARYLLIS, Linn. (Amaryll.). - Ind, Kew. i. 101 .

carnosa, Herb. Ham, ex Hook, f. Fl. Brit. Ind. vi. (1892) $280=$ Crinum asiaticum, Linn.

coenosa, Herb. Ham. ex Hook, f. 1. c, $281=$ Crinum defixum, $K e r$.

Leeana, Williams, Catal. (1889) 22. - Form. hort.

Tettani, Hort. ex Gartenf. (1888) 626. - Form. hort.

AMASONIA, Linn. f. (Verben.). - Ind. Kew. i. 103.

calycina, Hook. f. $2 n$ Bot. Mag. (1887) t. 6915.Guian. angl.

punicea, Hort. ex Hook, f. 1. c. sub t. $6915=$ calycina, Hook. $f$.

AMBAIBA, Barrère, Ess. hist. nat. Fr. équin. (1741) 10 , ex Kuntze, Rev. Gen. (1891) $623=$ Gecropia, Linn. (Urtic.).

acutifolia; Kuntze, Rev. Gen. (1891) $624=$ C. acutifolia, Tréc.

Adenopus, Kuntze, 1. c. = C. adenopus, Mart.
AMBAIBA :-

albicans, Kuntze, Rev. Gen. (1891) $624=$ C. albicans, Tréc.

bicolor, Kuntze, 1, c. = C. bicolor, Klotzsch carbonaria, Kuntze, 1. c. = C. carbonaria, Mart. cinerea, Kuntze, l. c. = C. cinerea, Miq.

commutata, Kuntze, l. c. = C. commutata, Schott. concolor, Kuntze, 1. c. = C. concolor, Willd. costaricensis, Kunte, 623. - Costarica. cyrtostachya, Kuntze, 1. c. $624=$ C. cyrtostachya, Miq.

dentata, Kuntze, 1. c. = C. dentata, Klotzsch.

digitata, Kuntze, 1, c. = C. anoustifolia, Tréc.

Goudotiana, Kuntze, i c $=$ C Goudotiana, Tréc.

Hemsleyana, Kuntze, 1. c. = C. mexicana, Hemsl.

hololenca, Kuntze, 1. c. = C. hololeuca, Miq.

Humboldtiana, Kuntze, 1. c. = C. Humboldtiana Klotzsch.

Klotzschiana, Kuntze, 1. c. $=$ C, Klotzschiana Miq.

latilob̆a, Kuntze, 1. c. = C. latiloba, Miq

lencocoma, Kunze, 1. c. = C. leucocoma, Miq.

leucophaea, Kuntze, 1. c. = C. leucophaea, Poepp.

lyratifiora, Kuntze, 1.c. = C. lyratiloba, Miq.

membranacea, Iuntze, 1. c. = C. membranacea, Tréo.

mexicana, Kuntze, 1. c. $=$ C. mexicana, Hemsl.

nivea, Kuntze, 1. C. $=$ C. nivea, Poepp.

obtusa, Kuntze, 1. c, = C. obtusa, Tréc.

obtusifolia, Kuntze, 1. c. = C. obtusifolia, Bertol.

pachystachya, Kuntze, 1.c. = C. pachystachya, Tréc.

palmata, Kuntze, 1. c. = C. palmata, Willd.

panamensis, Kuntze, l. c. = C. panamensis, Hemsl.

peltata, Kuntze, 1. c. 623. = C. peltata, Linn.

pinnatiloba, Kuntze, 1. c. $624 .=$ C. pinnatiloba Klotzsch.

propinqua, Kuntze, 1. c. = C. propinqua, $M i q$.

Ruiziana, Kuntze, 1. c. = C. Ruiziana, Klotzsch.

Schiedeana, Kuntze, 1. c. =C. Schiedeana, Klotzsch.

Schreberiana, Kuntze, 1. c. =C Schreberiana, Miq. sciadophylla, Kuntze, 1. c。= C. sciadophylla, Mart. strigosa, Kuntze, 1. c. = C. strigosa, Tréc.

surinamensis, Kuntze, 1. c. = C. surinamensis, Miq. Tenoreana, Kuntze, 1. c. = C. digitata, Ten.

tubulosa, Kuntze, 1. C。 = C. tubulosa, Ruiz.

AMBERBOA, Less. = Volutarella, Cass. (Composit.)

Omphalodes, Batt. in Bull. Soc. Bot. Fr. xlii. (1895) $294=$ V. Omphalodes, Benth, et Hook. $f$.

AMBERBOIA, Kuntze, Rev. Gen. (1891) $305=$ $A M B E R B O I$, Adans, = Volutarella, Cass. (Composit.).

divaricata, Kuntze, 1. c. = V. divaricata, Benth. et Hook. $f$.

Omphalodes, Kuntze, 1. c. = V. Omphalodes, Benth. et Hook. $f$.

AMBLYOPAPPUS, Hook, et Arn. (Composit.).-

Ind. Kew. i. 104.

pauciflorus, Phil, in Anal. Univ.Chil., xc. (1895) 29. - Chili.

AMBRINA, Spach = Chenopodium, Linn. (Chenopod.).

andicola, Phil, in Anal.Univ. Chil. xci. (1895) 422. - Chili.

incisa, Phil. 1. c. 422. - Chili.

parvula, Phil. 1. c. 421. - Chili.

AMBRosiA, Linn. (Composit.). - Ind. Kew. i. 105 .

bipinnatifida, Greene, Man. Bot. San Franc. Bay, (1894) $\mathbf{1 8 7}$ = Franseria bipinnatifida, Nutt.

Chamissonis, Greene, 1. c. $188=$ Franseria Chamissonis, Less.

tarapacana, Phil. in Anal. Mus.nac. Chile, (1891) 50. - Bolivia.

AMBROSINIA, Linn. (Aroid.). - Ind. Kew, i. 105. proboscidea, Th. Dur. et Schinz, Consp. fl. Afr. v. 1894. (1895) $482=\mathrm{A}$. Bassii, Linn.

AMBULIA, Lam. = Limnophila, R. Br. (Scrophular.).

fragrans, Drake, Fl. Polyn. franc. (1892) 140 (= Ruellia fragrans, Forst.) = L. serrata, Gaudich.
AMBUIIA : -
hottonioides, Wettst. in Engl. et Prantl, Natürl. Pflanzenfam. iv. 3 b. (1891) 73 fig. 33.- Ind. or

AMBURANA, Schwacke et Taub. in Engl, et Prantl, Naturl. Pflanzenfam. iii. 3. (1894) 387. Prantl, Natur.

Claudii, Schwacke et Taub.l. c.- Bras.

AMELANCHIER, Medic. (Rosac.), - Ind, Kew. i, 105 .

glabra, Greene, Fl. Francisc. (1891) 52 = alnifolia, Nutt.

pallida, Greene, 1. c. = alnifolia, Nutt.

Pringlei, Koehne, in Wissensch. Progr. Falk. Realoymnas. Berlin (1890) $25=$ alnifolia, Nutt. utahensis, Koehne, 1. c. =alnifolia, Nutt.?

AMELLUS, Linn. (Composit.). - Ind. Kew. i

105

epaleaceus, O. Hoffm. ex Schinz, in Bull. Herb. Boiss. i. (1893) 74. - Afr. austr.

AMELLUS, P. Br. = Melanthera, Rohr (Com-

posit.). gens, Kuntze, Rev. Gen. (1891) $306=$ homonyma omnia Melantherae.

augustifolius, Kuntze, 1. c. = Echinocephalum angustifolium, Gardn.

asper, Kuntze, 1. c. $305=$ M. deltoidea, Michx.

discoideus, Kuntze, 1. c. $306=$ Echinocephalum discoideum, Baker.

Echinocephalon, Kuntze, 1.c. = Echinocephalum lanceolatum, Gardn.

latifolius, Kuntze, 1. c. = Echinocephalum latifolium, Gardn.

microphyllus, Kuntze, I. c. = M. lanceolata, Benth niveus, Kuntze, 1, c. = M. hastata, Michx.

scandens, Kuntze, 1. c. = M. Brownei, Sch. Bip.

AMERIMNON, P.Br. = Dalbergia, Linn. $f$ (Legumin.).

acutum, Afzelii, arbutifolium, armatum, assamicum, Bukeri, bracteolatum, brasiliense, calycinum, campe chianum, Championii, confertiflorum, congestum, cujabense, cultratum, densiflorum, densum, discolor, emirnense, foliaceum, glandulosum, glaucescens, glomeviflorum, gracile, Hancei, hircinum, hostile, inundatum, javanicum, funghuhnii, lanceolatum, lateriflorum, latifolium, inzoniense, macrospermum, malifolium, melanoxylon, Milletii, multijugum, nigrum, nitidulum, obovatum, ovatum, paniculatum, pubescens, purpureum, reniforme, rimosum, riparium, rotundifolium, rubiginosum, saxatile, Sissoo, spinosum, Spruceanum, Stocksii, sympatheticum, Thomsonii, villosum, volubile, Kuntze, Rev. Gen. (1891) $159=$ homonyma omnia Dalbergiae.

Benthanianum, Kuntze, 1. C. $159=$ D. polyphylla, Benth

Cumingii, Kuntze, 1. c. = D. Cumingiana, Benth. ferrugineum, Kuntze, l. c. = D. stipulacea, Roxb. frutescens, Kuntze, 1. C. = D. variabilis, Vog. Gardnerianum, Kuntze, 1. c. = D. congesta, R. Grah.

parviflorum, Kuntze, 1. c. = D. Junghuhnif, Benth pinnatum, Kuntze, 1. c. $159,203=\mathrm{D}$. tamarindifolia, Roxb.

polyphyllum, Kuntze, 1. c, 159 = D. foliosa, Benth. Psendosissoo, Kuntze, 1. c. = D. Championii, Thw.

sissoodes, Kuntze, 1. c. = D. latifolia, Roxb.

stipulatum, Kuntze, 1. c. = D. velutina, Benth.

tortum, Kuntze, 1. c. = D. monosperma, Dalz.

violaceum, Kuntze, 1. c. = D. Miscolobium, Benth.

AMICIA, H. B, et K. (Legumin.). - Ind. Kew. i. 106.

Lobbiana, Bentr. ex Rusby, in Mem. Torrey Bot. Club, iii. 3. (1893) 20. - Bolivia.

AMMANIA, Linn. (Lythrar.), - Ind. Kew. i. 106. Koehnei, Britton, in Bull. Torrey Bot. Chub, xvii. (1891) 271. - Am. bor. or.

mexicana, Baill. Hist. pl. Madag., Atlas, (I895) t. 363. - Madag. 
AMIMIOPSIS, Boiss. (Umbellifer.), - Ind, Kew. i. 107

Aristidis, Coss, ex Batt, at Tyab. Fl, de l'Aloérie (Dicot.) (1889) 377. - Algeria.

AMIMOCHARIS, Herb.(Amaryllid.).-Ind. Kew. i. $10 \%$.

coccinea, Pax, in Bot. Fahrb. x. (1889) 3. - Afr.

Taveliana, Schinzz, in Verh. Bot. Ver. Brand. xxxi. (1890) 214, - Afr. austro-occ. extratrop.

AMMODENDRON, Fisch. (Legumin.). - Ind. Kew. i. 107

avgenteum, Kuntze, in Act. Hort. Petrop. x. (1887) 180 ( $=$ Robinia argentea, Siev.) = Ammod. Sieversii, $D C$.

AMMOSELINUM, Torr, et Gray (Umbellifer.). - Ind. Kew. i. 107.

Butleri, Conlt. et Rose, in Coult. Bot. Gaz. vii. (1887) 294; et Contrib. U.S. Nat. Herb.ji. (1891) 144 $(=$ Apium Butleri, Engelm.). - Am. bor.

AMMOSPERMA, Hook. f, (Crucifer,) - Ind. Kew, i 108 .

teretifolium, Prantl, in Engl. et Prantl. Natiul. Pfanzenfam, ii. 2. (1801) 170. - As. occ.

AMMOTHAMNUS, Bunge (Legumin.). - Ind. Kew。i. 108.

intermedius, Kuntze, in Act. Hort. Pctrop. x. (1887) 181. - Turkest.

AMOMIS, Berg. = Pimenta, Lind1. (Myrtac.) caryophyllata, Krug et Urb. ex Urb. in Bot. Jahrb. xix. (1894) 573 (= Myrtus caryophyllata, Jacq.)
$=$ P. acris, Kostel.

AMOMUM, Linn. (Scitamin.). - Ind. Kew. i. 108. alboviolaceum, Ridl. in form. Bot. xxv. (1887) 130. - Angola.

araneosum, Baker, in Hook. f. Fl. Brit, Ind. vi. (1892) 234. - Tenass.

ciliatum, Baker, l. c. 238.,--Zeyl.

crassilabium, $K$. Schum. ex Engl. in Abhandl. Preuss. Akad. Wiss. (1894) 48; et in Pflanzonw. Ost-Afr. $C$ (1895) 149. - Afr. trop. or.

elatterioides, Baker, in Hook, f. Fl. Brit. Ind. vi. (1892) 240. - Malacca

erythrocarpum, Ridl. in Founn. Bot. xxv, (1887) 130. - Angola.

glaucophyllum, $K$. Schum. in Bot. Fahro. xv. (1893) 415. - Afr. trop. occ.

gomphocheilos, Baker, in Hook. f. Fl. Brit. Ind, vi. (1892) 236. - Perak.

humile, Rich, ex Petersen, in Mart, Fl. Bras, iii. III. (1890) $46=$ Renealmia humilis, Pctersen.

Kayserianum, K. Schum. in Bot. Fahrb. xv. (I893) 415. - Afr. trop. occ.

Kingii, Baker, in Hook. f. Fl. Brit. Ind. vi. (1892) 241. - Reg. Himal.

Koenigii, Baker, l. c. 237. - Tenass.

labellosum, $K$. Schum. in $K$. Schnm. et Hollr. Fl. Kais. With. Land, (1889) 27. - N. Guin.

laterale, Ridl. in Trans, I,imn. Soc., Ser. II. iii. (1893) 381. - Penins. Mal.

leptolepis, K. Schum. in Bot. Fahrb. xv. (1893) 414. - Alr. trop. occ

1uteo-album, $K$. Schum. l. c.413. - Afr. centr. bor. macrocheilos, Baker, in Hook. f. Fl. Brit. Ind. vi. (1892) 232. - Malacca.

macrodus, Scortech. in Nuov. Gionn. Bot. Ital. xviii (1886) 309. - Penins. Mal

macrolepis, K. Schum. in Bot. Fahrb. xv. (1893) 416. - Afr. trop. occ

macrostephanum, Baker, in Howk. f. Fl. Brit. Ind. vi. (1892) 243. - Perak.

Maingayi, Bakev, 1. c. 235. - Malacca.

Mala, K. Schum. ex Engl. in Abhandl. Preuss. Akad. Wiss. (1894)53; et in Pfanzento. Ost-Afy.C (1895) 149. - Afr, trop. or

megalocheilos, Baker, in Hook. f. Fl. Brit. Ind. vi. (1892) 236. - Malacca.

metriocheilos, Baker, l. c. 234.-Malacca, Penang.

microstephanum, Baker, l. c. 239. - Concan.

Ophiuchus, Ridl. in Trans. Linn. Soc., Ser. II. iii,

(1893) 381. - Penins. Mal.

\section{AMOMUIN :}

pauciflorum, Baker, in Hook, f. Fl. Brit. Ind, vi. (1892) 238. - Reg. Himal.

polyanthum, $K$. Schum. in Bot. Fa7nb. xv. (1893) 411. - Afr. centr. bor.

Ridleyi, Baker, in Kew Bull. (1892) 128. - Singap. rubro-luteum, Baker, in Hook. f. Fl. Brit. Ind. vi. (1892) 236. - Malacca.

sanouineum, K. Schum. in Bot. Fahwb, xv. (1893) 412. - Afr, centr. bor.

sphaerocephalum, Baker, in Hook. f. Fl. Brit. Ind. vi. (1892) 234. - Penang.

stenoglossum, Baker, l. c. 234. - Perak.

trichanthera, $W a r b$, in Bot. Fahrb. xiii. (1891) $2 \% 6$. - Oceania.

triorgyale, Baker, in Hook. f. Fl. Brit. Ind. vi. (1892) 23\%. - Perak

vittatum, Hance, in fourn. Bot. xxiv. (1886) 53. China

xanthophlebium, Baker, in Hook. f. F. Brit. Ind. vi (1892) 241. - Malacca.

AMOORA, Roxb. (Meliac.). - Ind. Kew. i. 108.

gigantea, Pierre, in Laness. P1. util. Col. franç. (1886) 311. - Cochinchina.

megalophylla, C. DC. in Bull. Herb. Boiss, ii. (1894) 577. - Tonk.

myrmecophila, Warb. in Bot. Falhrb. xviii. (1894) 194. - Oceania.

Naumannii, C. DC. in Bot. Fahrb. vii. (1886) 461.N. Guin.

Ridleyi, King, in fourn. As. Soc. Beng. 1xiv. (1895) ii. 56. - Perak.

salomoniensis, C. DC, in Bot. fahrb. vii. (1886) 461. - Ins. Salomon.

Wallichii, King, in Fourn. As. Soc. Beng, 1xiv. (1S95) ii. 56. - Ins. Andaman.

AMORPHA, Linn. (Legumin.),-Ind. Kew. i. 109. hispidula, Greene, Fl. Francise (I891)14: et Man. Bot. San Franc. Bay (1894) 88. - Calif.

subglabra, Heller, Bot. exp1. S. Texas (1895) $48=$ texana, Buckl.

virgata, Small, in Bull. Torrey Bot. Club, xxi. (1894) 17 t. 171. - Georgia.

AMORPHOPHALLUS, Blume (Aroid.).-- Ind. Kew. i. 109

burmanicus, Hook. f. Fl. Brit. Ind. vi. (1893) 517. - Burma.

chlorospathum, Kurz, ex Hook.f.l.c.516. - Pegu. Doryphorus, Ridl. in fourn. Bot. xxiv. (1886) 305. - Afr. trop. occ.

Eichleri, Hook. f. in Bot. Mag. (1889) t. 7091. Congo

elatus, Hook. f. Fl. Brit. Ind. vi. (1893) 517. Penins Mal.

Elliottii, Hook, f. in Bot. Mag. (1894) t. r3449.Sierra-Leone.

glabra, F. M. Bailey, in Queensl. Dep. Agric. Bot. Bull. vii. (1893) 68; et in Gard. Chron. (1895) I. 484. - Austral.

haematospadix, Hook. f. Fl. Bvit. Ind. vi. (1893) 517. - Penang.

oculatum, Herb. Ham. ex Hook, f. Fl, Brit. Ind. vi. (1893) $515=$ buibifer, Blume.

oncophyllus, Prain, ex Hook. f. Fl. Brit. Ind. vi. (1896) 516; in foum. As. Soc. Beng. 1xii. (1893) ii. 80 ; et Bot. Mag. (1893) t. 7327. - Ins. Andam. Prainii, Hook. f.l. c. 516. - Perak, Penang. purpurascens, Kurz, ex Hook.f.l. c. 515. - Ind. or Rex, Prain, ex Hook.f. 1. c. $514=$ campanulatus, Blume.

sparsiflorus, Hook.f.l.c. 516. - Perak.

taccoides, Herb. Ham. ex Hook. f. 1. c, $515=$ bulbifer, Blume.

AMPACUS, Rumph, Herb. Amb. ii. 168 (I747) ex Kuntze, Rev. Gen. i. (1891) 98 = Evodia, Forst. (Rutac.).

accedens, alata, alba, celastracea, crassinervis, cuspidata, densiflora, discolor, drupacea, elaeodendrodes, floribunda, glabra, hortensis, latifolia, litoralis, madagascariensis, melnaefolia micrococca obtusifolia, pedunculosa, polybotrys, robusta, Roxburghiana, ruticarpa, tetragona, triphylla, viticina, xanthoxylodes, Kuntze, Rev.Gen.(1891)p. 98. =homonyma omnia Evodiae.
AMPACUS : -

angustifolia, Kuntze, Rev. Gen.(1891) $98 \approx \mathrm{E}$. triphylla, $D C$

aromatica, Kuntze, 1. c. = E. glabra, Blume.

Daniellii, Kuntze, 1. c. = Zanthoxylum Danielli, Benn.

grisea, Kuntze, 1. c. = Boninia grisea, Planch, fide, Kuntze, 1. c. (Quid? An sp. ined.?)

incerta, Kuntze, 1. c. = Acronychia Minahassae, Miq.

macrophylla, Kuntze, 1.c.= E. accedens, Blume.

trichotoma, Kuntze, 1. c, = E. fraxinifolia, Hook.f.

AMPALIS, Boj. (Urtic.). - Ind. Kew. i. 110 Greveana, Baill. Hist. pl. Madag., Atlas (1895) t. 293 A. - Madag.

AMPELANUS, Rafin. = Enslenia, Nutt. (Asclepiad.).

albidus, Britton, in Bull. Torrey Bot. Club, xxi. 1894) $314=\mathrm{E}$, albida, Nutt.

igulatus, Heller, Bot. Expl. S. Texas (1895) 79 $=$ E. ligulata, Benth.

AMPELOCISSUS, Planch. = Vitis, Linn. (Ampelid.).

acapulcensis, Planch. in DC. Monog. Phan.v. (1887) 403. - Mexic.

arachnoidea, Planch. 1. c. $375=\mathrm{V}$. indica, Linn. Amottiana, Planch. 1. c. $370(=\mathrm{V}$. indica, $W$. ot Arn.). - Ind. or.

artemisiafolia, Planch. 1. c. 377,-China.

barbata, Planch, 1, c, $372=$ V. barbata, Wall. botryostacliys, Planch. 1. c. 413.-Ins, Philipp. cardiospermoides, Planch. 1. c. 459.- China.

cinnamomea, Planch. 1. c. $408=\mathrm{V}$. cinnamomea, Wall.

compositifolia, Planch. I. c. $412=$ V. compositifolia, M. A. Laws.

cussoniaefolia, Planch. 1. c. 395. - Afr. centr. bor.-OT.

Erdwendbergii, Planch. 1. c. 404. - Mexic.

filipes, Planch. 1. c. 407. - As, trop.

gracilis, Planch. 1. c, = V. gracilis, Wall.

Grantii, Planch. 1. c. $394=$ V. Grantü, Baker,

Helferi, Planch. 1. c. $41 \mathrm{II}=\mathrm{V}$. Helferi, M.A. Laws.

imporialis, Planch. 1. c. $408=\mathrm{V}$. imperialis, Miq.

Kirkiana, Planch. 1. c. 403. - Afr. austro-or.

Korthalsii, Planch. 1. c. 410. - Ind. bat.

Lowii, Planch. 1. c. $412=$ V. Lowii, Hook. $f$.

Martini, Planch. 1. c. 373. - As, trop. or.

Motleyi, Planch. 1. c. $412=$ V. Motleyi, Hook.f.

Mutleviana, Planch, 1 c. 414 - N. Guin.

multistriata, Planch.1. c. $398=\mathrm{V}$. multistriata, Baker . nervosa, Planch. 1. c. $372=V$. nervosa, $M . A$. Laws. nitida, Planch. 1. C. $411=\mathrm{V}$, nitida, $M . A$. Laws. orientalis, Planch. 1. c. $462=\mathrm{V}$. orientalis, Boiss, polystachya, Planch. 1. c. $41 \mathrm{l}=\mathrm{V}$. polystachya, Blume.

pulchra, Gilg, in Engl. Pflanzenw. Ost-Afr. C (1895) 257. - Afr. trop. or.

racemifera, Planch. 1. c, $413=\mathrm{V}$. racemifera, fack.

Robinsonii, Planch. 1. c. $415=$ V. rugosa, Mac Fadyen.

spicigera, Planch. 1. c. $406=$ V. macrostachya,

Miq.
thyrsiflora, Planch. 1. c. $409=$ V. thyrsiflora, Miq. urenaefolia, Planch. 1. c. 385. - Angola.

Volkensii, Gilg, in Pflanzenw. Ost- Afr. C (1895) 257. - Afr. trop. or.

AMPELODESMA, P. Beauv. (Gramin.). - Ind. Kew. i. 110.

mauritanica, Th. Dur. et Schinz, Consp. Al. Afr.v. 1894 (1895) 874 ( = A. tenax, Link). - Reg. Medit. occ.

Thouarii, Th. Dur. et Schinz, l, c. 875 (= A. madagascariensis, Kunth). - Madag.

AMPELOPSIS, Rich. = Vitis, Linn. Ampelid.). aegirophylla, Planch, in DC. Monog. Phan. v. (1887) $454=\mathrm{V}$. aegirophylla, Borss.

arborea, Kochne, Deutsche Dendrol. (1893) 400 (= V. arborea, Linn.

arborea, Rusby, in Mem. Torrey Bot. Club, v. (1894) $221=$ praec. 
AMPELOPSIS : -

brevipedunculata, Koehne, Deutsche Dendrol. (1893) 400 (=Cissus brevipedanculata, Maxim.). - Japon. cantonierisis, Planch. in DC. Monog. Phan. v. (1887) $460=\mathrm{V}$, cantoniensis, Seem.

cardiospermoides, Planch. ex Franch. in Bull. Soc bot. Fr. xxxiii. (1886) 460 ; et Pl. Delav. (1889) 140. - Yunnan.

citrullifolia, Hort, ex Dippel, Handb. Laubholzk. ii. (1892) $565=\mathrm{V}$. heterophylla, Thunb.

citrulloiäes, Hort. ex Dippel, 1. c. $565=\mathrm{V}$. heterophylla, Thunb.

Delavayana, Planch. ex Franch, in Bull. Soc, bot. Fr. xxxiii. (1886) 460; et in DC. Monog. Phan. v. (1887) 458. - Yunnan.

denudata, Planch. 1, c. 619. - Mexic

dissecta, Hort. ex Koehne, Deutsche Dendrol. (1893) $400=\mathrm{V}$. serjaniaefolia, Maxim.

gilgilensis, Koehne, 1. c. 399. - Reg. Himal.

himalayana, Hort. ex Dippel, Handb. Laubholzk. ii. $574=\mathrm{V}$. hederacea, Ehrh.

leeoides, Planch. in DC. Monog. Phan. v. (1887) $462=\mathrm{V}$. leeoides, Maxim.

Loureiroi, Hort. Mazel. ex Plnach. 1. c. 461 in syn. $=\mathrm{V}$. cantoniensis, Seem.

macrophylla. Blume, ex Planch. 1. c. 410 in obs, = V. thyrsifiora, Miq.

macrophylla, Hort. ex Dippel, Handb. Laubholzk. ii. (1892) $574=$ V. hederacea, Ehrh

orientalis, Planch. in DC. Monog. Phan. v. (1887) $462=\mathrm{V}$. orientalis, Boiss.

Regeliana, Hort. ex Dippel, Handb. Laubholzk. ii. (1892) $565=\mathrm{V}$. heterophylla, Thunb.

Roylei, Hort. ex Dippel, 1. c. $5 \%$ et $574=$ V. hederacea, Ehrh

rubifolia, Planch. in DC. Monog. Phan. v. (1887) $463=\mathrm{V}$. rubifolia, Wall.

vubricaulis, Carrière, ex Planch. 1. c. $459=$ V. serjaniaefolia, Maxim.

tomentosa, Planch, ex Franch, in Bull. Soc bot. Fr. xxxiii. (1886) 459; et in DC. Monog. Phan. v. (1887) 457. - Yunnan.

virginiana, Hort. ex Dippel, Handb. Laubholz. ii. (1892) p. $574=$ V. hederacea, Ehrh.

vitifolia, Planch. in DC. Monog. Phan. v. (1887) $454=$ V. persica, Boiss.

AMPELOVITIS, Carr. in Rev. Hortic. (1889) 204 cum icone $=$ Vitis, Linn. (Ampelid.).

Davidi, Carr. 1. c. - China.

intermedia, Carr. 1. c. (1891) 334. - China.

Romaneti, Carr. 1. c. (1892) 94. - China.

AMPHIBIEMMA, Naud. (Melastom.). - Ind. Kew, i. 110.

acaule, $\operatorname{Cogn}$. in Bolet. Soc. Brot. xi. (1893) 89. Angola.

ciliatum, Cogn, in DC. Monog. Phan, vii. (1891) 528. - Congo gall.

lateriflorum, Cogn. . . 0. 529. - Congo gall.

Soyauxii, Cogn.l.c. I184. - Gabon.

AMPHIGARPAEA, Ell. (Legumin.). - Ind. Kew. i. 110 (Amphicarpa).

angustifolia, Tawo. in Engl, et Prantl, Natïrl. Pfanzenfam. iii. 3. (1894) 359 (= Cologania angustifolia. Kunth) - Mexic.

pulchella, Taub. i.c. $(=$ Cologania pulchella, H. B. et K.). - Mexic.

AMPHICARPON, Raf, = Amphicarpam, Kunth (Gramin.).

Ampricarpum, Nash, in Mem. Torrey Bot. Club, v. (1894) $352=$ Purshii, Kunth.

AMPHIDOXA, DC. (Composit.), - Ind. Kew. i. 111

Engleriana, O. Hoffm. in Bot. Fahrb. x. (1889) 274 . - Afr. austr.

villosa, $O$. Hoffm. l.c. xx. (1894) 232.-Afr. trop. or.

AMPHILOPHIUM, Kunth (Bignon.). - Ind. Kew. i. 111 .

Glaziovii, Bureau, ex K. Schum. in Engl. et Prantl, Natürl. Pfanzenfam. iv. 3 b. (1894)

Jelskii, Zahlb. in Annal. Naturhist. Hofmus. Wien, vii. (1892) 9. - Peruvia.
AMPHIPOGON, R. Br. (Gramin.). - Ind. Kew. i. 111.

pentacraspedon, Hack, ex Wawra, Itin. Princ. S. Coburgi, ii. (1888) $102(=$ Pentacraspedon amphipogonoides, Steud.). - Austral.

AMPHORCHIS, Thou, = Gynorchis, Thou. (Or-

discolor, Frappier, ex Cordem. Fl. Ile Réunion (1895) 322. - Ins. Borbon.

reticulata, Frappier, 1. c. 231. - Ins. Borbon.

squamosa, Frappier, 1. c. $23 \mathbf{I}=$ C. squamosa, Lindl.

variegata, Frappier, 1. c, 234. - Ins. Borbon.

\section{AMPHORIGARPUS, Visiani (Composit.). -}

Ind. Kew, i. 112

elegans, Alboff, in Bull. Herb. Boiss. ii. (1894) $21 \%$. - Reg. Cauc.

AMPHOROCALYX, Baker, in Journ. Linn. Soc. xxii. (1887) 476. MELASTOMACEAE.

multiflorus, Baker, l. c. - Madag.

AMSINGKIA, Lehm.(Boragin.).-Ind.Kew.i.112 barbata, Greene, in Erythea, ii. (1894) 192, - Am. bor. occ.

campestris, Greene, Man, Bot. San Franc. Bay, (I894) 262. - Calif.

collina, Grecne, l. c. - Calif.

grandiflora, Kleeb, ex Greene, l. c. - Calif.

microcarpa, Greene, in Erythea, ii. (1894) 191. Am. bor, occ.

AMSONIA, Walt. (Apocyn.). - Ind. Kew. i. 112. Amsonia, Britton, in Mem. Torrey Bot. Club, $\mathrm{v}$. (1894) 262 = Amsonia Tabernaemontana, Walp.

AMYEMA, Van Tiegh, in Bull. Soc, bot. Fr, xli. (1894) $506=$ Loranthus, Linn. (Loranth.)

aurantiaca, Van Tiegh. 1. c. $507=$ L. aurantiacus, Cunz?.

bifurcata, Van Tiegh. 1. c. = L. bifurcatus, Benth cana, Van Tiegh. 1. c. xlii. (1895) 84. - Austral. congener, Van Tiegh. 1. c. = L. pendulus, Sieb. Gaudichandii, Van Tiegh. 1. c. = L. Gaudichaudii, $D C$.

gibberulosa, Van Tiegh. 1. c. = L. gibberulosus, Tate.

Lechenaultii, Van Tiegh. 1. c. - Austral.

linophylla, Van Tiegh. 1. c. xli. (1894) $507=$ L. linophyllus, Fenzt.

Iongifolia, Van Tiegh. 1. c. xlii. (1895) $84=\mathrm{L}$ pendulus, Sieb.

maytenifolia, Van Tiegh. 1. c. xli. (1894) $507=$ L. maytenifolius, A. Gray.

Melaleucae, Van Tiegh. 1. c. xlii. (1895) $84=\mathrm{L}$. pendulus, Sieb.

Miquelii, Van Tiegh. 1. c. xli. (1894) $507=$ L. Miquelii, Lehm.

mutans, Van Tiegh. 1. c. xlii. (1895) $84=$ L. Quandang, Lindl.

pendula, Van Tiegh. 1. c. xli. (1894) $507=$ L. pendulus, Sieb.

Preissii, Van Tiegh. 1. c. xlii. (1895) $84=$ L. linophyllus, Fenzl.

prinosa, Van Tiegh. 1. c. - Austral.

Ouandang, Van Tiegh. 1. c. xli. (1894) $507=$ L. Quandang, Lindl.

scoparia, Van Tiegh. 1. c. xlii. (1895) $84=$ L. linophyllus, Fenzl.

triantha, Van Tiegh. 1. c. xli. (1894) $507=$

L. trianthus, Korth.

tristis, Van Tiegh. 1. c. = L. tristis, Zoll.

AMYGDALUS, Burm. Thes. Zeylan. (1737) $19=$ Heritiera, Dryand. (Stercul.).

angustata, Kuntze, Rev. Gen. (1891) $75=\mathrm{H}$ angustata, Pierre.

litoralis, Kuntze, 1. c. = H. littoralis, Dryand. macrophylla, Kuntze, 1. c. = H. macrophylla, Wall.

minor, Kuntze, 1. c. = H. Fomes, Buch.-Ham

Papilio, Kuntze, 1. c. = H. Papilio, Bedd.

AMYGDALUS, (Tourn.) Linn. = Prunus, Linn. (Rosac.).

Andersonii, Greene, Fl. Francisc. (1894) $49=$ P. Andersonii, A. Gray.

\section{AMYGDALUS :}

Davidiana, Hort. ex Dippel, Handb. Laubholzk. iii (1893) $606=\mathrm{P}$ Persica, Stokes. fasciculata, Greene, Fi. Francisc. (1894) $49=$ Emplectocladus fasciculatus, Torr.

Gessleriana, Hort. ex Dippel, Handb. Lanbholzk. iii. (1893) $606=$ P. nana, Linn.

hippophaoides, Bornm. in Mitth. Thür. Bot. Ver. N. Folge, vi. (1894)66. - Oriens.

AMYLOTHECA, Van Tiegh. in Bull. Soc. bot. Fr xli. (1894) 261 = Loranthus, Linn. (Loranth.). angustifolia, Van Tiegh. 1. c. xlii. (1895) 444. Ins. Salom.

Cumingii, Van Tiegh. 1. c. xli. (1894) 264. - Ins. Philipp.

dictyophleba, Van Tiegh. 1. c. $262=$ L. dictyophlebus, F. Muell.

Hollrungii, Van Tiegh. 1. c. = L. Hollrungii, sumbarensis, Van Tiegh. 1. c. 265. - Ins. Sumbawa.

Zollingeri, Van Tiegh. 1. c. 264.- - Macassar

AMYRIS, P. Br. (Burserac.), - Ind, Kew. i. 113 madrensis, S. Wats. in Proc. Am. Acad. xxv. (1890) 144. - Mexic

parvifolia, A. Gray, l.c. xxiii. (1888) 226. - Texas.

ANACAMPTI-ORCHIS $\times$, G. Camus, in Morot, Journ. de Bot, vi.(1892) 113. ORCHIDEAE.

fallax $\times$, G. Camus, 1. C. = Aracanptis fallax, G. Camus). - Gall.

ANACAMPTIS, Rich. = Orchis, Linn, (Orchid.) fallax $\times, \mathrm{G}$. Camus, Vade-Mecum herb. Paris, ed. 6. (1890) ex Morot. Journ. de Bot. vi. (1892) 113 - Gall.

ANACHYRIS, Nees= Paspalum, Linn. (Gramin.). rosea, Fourn. Gram. Mexic. 1881.(1886) 2. Mexic.

ANAGOLOSA, Blume (Olacin.). - Ind. Kew. i. 115.

Clarkii, Pierre, Fl. For. Cochinch. (1892) t. 266. Cochinch,

ANAGYGLUS, Linn. (Composit.). - Ind. Kew. i 115 .

Freynii, Poxta et Rigo, ex Willk. Suppl. Prodr. fl. Hisp. (1893) 82.- Hisp., Algeria.

ANADENDRUM, Schott (Aroid.), - Ind, Kew. 115

atifolium, Hook. f. Fl. Brit. Ind. vi. (1893) 540. Perak.

ANAEGTOCALYX, Triana (Melastom.). - Ind Kew. i. 115.

latifolia, Cogn. in DC. Monog. Phan. vii. (1891) 713. - Venez.

ANAGALLIS, (Tourn.) Linn. (Primul.). - Ind Kew. i. 115.

acuminata, Welw. ex Schinz, in Bull. Herb. Boiss. ii. (1894) 221. - Angola.

Meyeri, K. Schum. (in H. Meyer, Ostafr. Gletscher fahrten, Anhang 332) ex Engl. in Abhandl. Preuss. Akad. Wiss. 1891 ii. (1892) $330=$ Quartiniana, Engl.

pulchella, Welw, ex Schinz, in Bull. Herb. Boiss. ii. (1894) 221. - Angola.

Quartiniana, Engl. in Abhandl. Preuss. Akad. Wiss 1891 ii. (1892) 330. - Afr. trop.or.

ANAGOSPERMA, Wettst. in Ber. deutsch. bot. Ges. xiii. (1895) $242=$ Euphrasia, Linn. (Scrophul.).

dispermum, Wettst. 1. c. cum xylogr. = E. disperma, Hook. $f$.

ANAMOMIS, Griseb. = Myrtus, Linn. (Myrtac, dichotoma, Sarg. in Gard. and For. vi. (IS93) 130; et N. Am. Sylva, v. 32 t. = Eugenia dichotoma, $D C$.

ANAMOTHECA grandiflora, Hort, Damman, ex Gartenfl. (1893) 412 sphalm. (= Anomotheca grandiflora, Baker?=Lapeyrousia grandiflora, Baker?) 
ANANAS, Tourn. ex Linn. (Bromel.). 一 Ind. Kew. i. 116.

bracamorensis, Hort. Lind. ex Baker, Handb. Bromel. (1889) $23=$ sativus, Schult. $f$.

Bracteatus, Baker, 1. c. = sativus Schult. $f$.

Mensdorfana, Hort. ex Baker, 1. c. $64=$ Aechmea Fernandae, Baker.

microstachys, Lindman, in Kongl. Svensk Vet. Akad. Handl. xxiv. 8. (1891) 39 t. \%. fig. 20-23 = Acanthostachys ananassoides, Baker.

monstrosus. Hort. ex Baker, Handb. Bromel, (1889) 23 = sativus, Schult $f$.

Pancheanus, Ed. André, Bromel. Andrean.(I889) 5. - Columb.

penangensis, Hort. ex Baker, Handb. Bromel. (1889) 23 = sativus, Schult. $f$.

proliferus, Hort. ex Baker, 1.c. = sativus, Schult. $f$.

ANAPHALIS, DC. (Composit.). - Ind. Kew. i 116.

Bodinieri, Franch, in Morot, fourn. de Bot, iv. (1890) 306. - China.

Hellwigii, Warb. in Bot. Fahrb. xvi. (1893) 28. Oceania.

lanata, F. Mnell. in Trans. Roy. Soc. Vict. New Ser. I. ii. (1889) 9 = Gnaphalium japonicum, Thunb.

Mariae, F. Muell. 7. c. 8 - N. Guin.

mucronata, C. B. Clarke, cx Hemsl. in fourn. Linn. Soe. xxx. (1894) 136. - Reg. Himal. et Tibet.

pelliculata, Trimen, Handb. Fl. Ceyl, iii. (1895) 28 et Illustr. Handb. Fl. Ceyl. (1895) t. 58. - Zeylan. saxatilis, Boerl. Handb. Fl. Ned. Indië, ii. 1. (1891) 240 (= Antennaria saxatilis, DC. - Java.)

sordida, Boerl. l. c. (= Antennaria sordida, Sch. Bip.). - Java.

prostrata, F. Muell, in Trans. Roy. Soc. Vict. New Ser. I. ii. (1889) 9 = Helichrysum prostratum, Hook.f.

ivinervis, F. Muell. 1. c. = Gnaphalium trinerve, Forst. $f$.

ANAPHRENIUM, E. Mey, (Anacard.). - Ind. Kew. i. 117.

crassinervium, Engl. Bot. Faht. x. (1889) 37. Afr, austro-bcc. extratrop.

verticillatum, Engl. l. c. xv. (1893) 113. - Angola.

ANARRHINUIM, Desf. (Scrophul.). - Ind. Kew. i. 117 .

arabicum, Eng-1. in Abhandl. Preuss. Akad. Wiss. 1891 ii. (1892) 377 = arabicum, faub. et Spach.

elatum, Kuntze Rev. Gen. (1891) 465. - (Quid.?) an Linaria Elatine, Mill.?

fruticosum, Hochst. ex Engl. in Abhandl. Preuss. Akad. Wiss. 1891. it. (1892) 377 in syn. = arabicum, faub. et Spach.

Pechuelii, Kuntze, in Fahrb. bot. Gavt. Berl. iv. (1886) 269. - Afr. austro-occ. extratrop.

ANARTHROPHYLLUIN, Benth, (Legumin.).Ind. Kew. i. 117.

brevistipula, Phil. in Anal. Univ. Chil. 1xxxiv. (1894) 9. - Chili.

ANASTRAPHIA, D. Don (Composit.). - Ind. Kew. i. 117.

pauciflosculosa, Wright, ex Hitchc. in Missouri Bot. Gard. Rep. iv. (1893) 102. - Ins. Baham.

ANAXAGOREA, St-Hil. (Anonac.). - Ind. Kew. i. 118 .

Scortechinii, King, in fourn. As. Soc. Beng. 1xi. (1892) ii.68. - Perak.

ANCHOMANES, Schott (Aroid.). - Ind. Kew. i 118.

Boehmii, Engl. in Bot. Fahrb. xv. (1893) 454. - Afr. trop. or.

ANCHUSA, Linn. (Boragin.). - Ind. Kew. i. 119 macrocalyx, Hausse. in Mitth. Bot. Ver. Fena, v. 3 (1887) 71; et N. Folge, viii. (1895) 45.-Graecia. moesiaca, Velen. in Sitz. böhm. Ges. Wiss. (1892-93) 44. - Bulg.

obtusifolia, Caruel, in Parl. F1. Ital. vi. (1886) 905 = Nonnea obtusifolia, $D C$.

\section{ANCHUSA : -}

smanica, Velen.in Sitz.böhm. Ges.Wiss.(1885) sep. 32, fide Nym. Consp. fl. Eux. Suppl. ii. (1889 222; et Fl. Bulg. (1891) 391. = officinalis, Linn. palmyrensis, Post, Pl. Postiana, iv. (1892) 9. Syria.

Shattuckii, Post, in fourn. Linn. Soc. xxiv. (1888) 435. - Syria.

setosa, Caruel, in Parl. F1. Ital. vi. (1886) $905=$ Nonnea Iutea, Reich.f.

Tiberiadis, Post, Pl. Postianae, iv. (1892) 9.Syria.

vesicaria, Caruel, in Parl. F1. Ita1. vi. (1886) $906=$ Nonnea nigricans, $D C$,

ANCISTROGLADUS, Wall. (Dipterocarp.). Ind. Kew. i. 119.

Barteri, S. Elliot, in foum. Linn. Soc. xxx. (1894) 73. - Afr. trop. occ.

hanatus, Gilg, in Eng1. et Prantl, Natürl. Pflanzenfam. iii. 6. (1895) $276=$ Vahlii, Arm.

pentagynus, Warb, in Bot. Fahrb. xiii. (1891) 385. - Oceania.

ANGISTROPHYLLUM, G. Mann et $\mathrm{H}$. Wendl. (Palm.). - Ind. Kew. i. 118.

lacve, Drude, in Bot. Jahrb. xxi. (1895) $111=$ seq.

laeve, Th. Dur. et Schinz, Consp. fl. Afr. v. 1893 (1895) 458 (= Laccosperma laeve, G. Mann et $\mathrm{H}$. Wend1.). - Afr. trop. occ.

opacum, Drude, in Bot. Jahrb. xxi. (1895) $111=$ seq.

opacum, Th.Dur. et Schinz, Consp. Al. Afr. v. 1893 (1895) 458 (= Laccosperma opacum, G. Mann et H. Wendl.). - Afr. trop. occ.

ANCYLOCLADUS, Wall. = Willughbeia, Roxb. (Apocyn.).

Beccarianus, Kuntze, Rev. Gen. (1891) 412. Burneo.

celebicus, Kuntze, 1. c. = W. celebica, Blume.

ceylanicus, Kuntze, I. c. $=$ W. ceylanica, Thraites. coriaceus, Kuntze, 1. c. = W. coriacea, Wall

edulis, Kuntze, 1. c. = W. edulis, Raxb.

firmus, Kuntze, 1.c. = W. firma, Blume.

flavescens, Kuntze, 1. c. = W. flavescens, Dyer.

grandiflorus, Kuntze, 1. c. = W. yrandiflora, Dyer.

javanicus, Kuntze, 1. c. = W. javanica, Blume.

oblongus, Kuntze, 1. c. = W. oblonga, Dyer.

rufescens, Kuntze, 1. c. = W. rufescens, Dyer.

temuiflorus, Kuntze, 1. c. = W. tenuiflora, Dyer.

ambrosus, Kuntze, 1. c. $=$ W. umbiosa, Blume.

ANDRACHNE, Linn. (Euphorb.). - Ind. Kew.i. 121.

Clarkei, Hook. f. Fl. Brit. Ind. v. (1887) 285. Ind. or.

nummulariaefolia, Stapf, in|Denkschr. Akad. Wien, 1i. (1886) 314 - As. occ.

phyllanthoides, Coult, in Contrib. U. S. Nat. Herb. ii. (1894) $398=$ Roemeriana, Mutll. Arg.

reflexa, Stapf, in Denkschr. Akad. Wion, li. (1886) 315. - As. occ

Reverchoni, Coult. in Contrib. U. S. Nat. Herb. ii (1894) 396. - Texas.

omalensis, Pax, in Bot. Fahrb. xv. (1893) 322.Afr. trop. or.

polypetala, Kuntze, Rev.Gen. (1891)592. - Anam. virescens, Stapf, in Denkschr. Akad. Wien, 1i. (I887) 314. - As. occ.

ANDREOS-IA. DC. = Dontostemon, Andr. (Crucifer.)

cardaminefolia, Prantl, in Engl. et Prant1, Natür1. Pflanzenfam. iii. ii. (1891) 171 (= Notoceras cardaminefolia, DC.) = Andrzeiowskia Cardamine, Reichb.

ANDROG粱PHAIIUM, Warb, in Bot, Jahrb. xviii. (1894) 196. EUPHORBIACEAE. quercifolium, Warb. l.c.97. - Oceania.

ANDROGYMBIUMI, Willd. (Liliac.),-Ind. Kew. 121 .

europaeum, C. Richt. P1. Europ. i. (1890) $188=$ Erythrostictus europaeus, Lange.

roseum, Engl. Bot. Farhb. x. (1889) 289. - Afr. austro-occ, extratrop.
A NDROGRAPHIS, Wall. (Acanthac.). - Ind. Kew. i. 121 .

laxiflora, Lindau, in Engl. et Prantl. Natür. Pflanzenfam.iv.3 b. (1895) 323 (=Erianthera laxiflora, Blume). - Java.

tenera, Kuntze, Rev. Gen. (1891) $382=$ tenuiflora, T. Anders.

ANDROMACHIA, Humb. et Bonpl. = Liabum, Adans., Composit.). -
Maroni,Ed.André, in Rev.Hortic.(1887) 496.-Bras.

ANDROMEDA, Linn. pr. p. (Ericac.). - Ind. Kew. i. 122.

candida. Hort. ex Dippel, Handb. Laubbholzk. i. (1889) $365=$ Zenobia speciosa. D. Don.

Lobbii, Hort. ex Dippe1, 1. c, $359=$ Leucothoë Davisiae, Torr.

nikoënsis, Maxim. in Bull. Acad. St-Pétersb. xxxii. (1888) 496. - Japon.

ANDROPOGON, Linn. (Gramin.). - Ind. Kew. i. $12^{2} 3$.

acutiusculus, Hack. in DC. Monog. Phan. vi. (1889) 575. - Austral.

fricanus, Franch. in Bull. Soc. hist. nat. Autun, viii. (1895) 325. - Congo gall.

Afzelianum, Rendle, in foum. Bot. xxxi. (1893) 357. - Sierra-Leone.

Alopecurus, Hack. in DC. Monog. Phan. vi. (1889) 381. - Ins. Mascar.

ascinodis, C. B. Clarke, in foum. Linn. Soc. xxv, (1889) 87. t. 36. - Ind. or.

aturensis, Maury, in Morot, fourn. de Bot, iii. (1889) 158. fig. 4. - Am. austr. trop.

Baileyi, F. Muell. in Vict. Natural. viii. (May 1891) 16 (= Sorghum laxiflorum Bailey). - Austral.

Balansae, Hack. in DC. Monog. Phan. vi. (1889) 534. - Parag.

bonangensis, Franch. in Bull. Soc. hist. nat. Autun. viii. (1895) 333. - Congo gall.

Brazzae, Franch, l.o.326. - Congo gall.

Buchneri, Hack. in DC. Monog. Phan. vi. (1889) 649. - Angola.

cambogiensis, Balansa, in Morot, fourn. de Bot. iv. (1890) 114. - Cambod.

chrysopus, Trab. in Batt. et Trab. Fl. de l'Algér. (Monoc.) (1895) $250=$ Aucheri, Boiss.

Clarkei, Hack. in Oest. Bot. Zeitschr. xli. (1891) 49. - Ind. or.

confertus, Trin, ex Fourn. Gram. Mexic. 1881. (1886) 55. - Mexic

congoënsis, Franch, in Bull. Soc. hist. nat. Autun, viii. (1895) 325. - Congo gall.

cryptopus, Trin. ex Hack. in DC. Monog. Phan. vi. (1889) 432 = incanus, Hack.

Cymbachne, Hack. l. c. 450. - Bengal.

Delavayi, Hack. l. c: 404. - China.

digitatum, St-Lager, in Cariot, Étud. desfleurs, éd. 8. ii. (1889) $898=$ A. Ischaemum, Linn.

Dybowskyi, Franch. in Bull. Soc. hist. nat. Autun, viii. (1895) 334. - Congo gall.

elemans, C. Cordenz, ex F. Condenn. Fl. Ile Réunion 1895) 122. - Ins. Borbon

exothecus, Hack. in DC. Monog. Phan. vi. (1889) 632. - Abyss.

floccusus, Schweinf. in Bull. Herb. Boiss. ii. App. ii. 1894) 14. - Erythrea.

formosus, Klotzsch, ex Hack. in DC. Monog. Phan.

vì. (1889) $623=$ Schimperi Hochst.

fragilissimus, Hochst. ex Hack 1. c. 366 sphalm. $=$ exilis, Hochst.

gangeticus, Hack. l. c. 539. - Ind. or.

giganteus, C. Corden. ex 7. Cordem. Fl. Ile Rón. (1895) 122 (giganteum). - Ins. Borbon.

glomeratus, Britton, Stern. et Poggenb. Prel. Catal. (1888) $67=$ macrourus, Michx.

Hallii, Vasey, in Bull. Torrey Bot. Club, xv. (1888) 294 = Hallii, Hack.

helophilus, K. Schum. in Engl. Pflanzenw. Ost-Afr. C (1895) 98. - Afr. trop: or

Hookeri, Munno, ex Hack. in DC. Monog. Phan. vi. (1889) 614. - Ind. or.

Huegelii, Hack. l. c. 492. - Ind. or,

hylophilus, K. Schum. in Abhandl. Preuss. Akad. Wiss. (1894) 38 nomen = helophilus, $K$. Schum. impressus, Hack. in Oest. Bot. Zeitschr. xli. (1891) 49. - Ind, or. 


\section{ANDROPOGON}

incanus, Hack. in DC. Monog. Pran. vi. (1889) 431. - Am. austr.

khasianus, Munro, ex Hack.1.c. $603=$ A. Nardus, Linn. Kunthii, Fourn. Gram. Mexic. 1881 (1886) 59 in obs. - Hab. ?

Kuntzeanus, Hack. in DC. Monog. Phan. vi. (1889) 478. - Ind. or

Lecomtei, Franch. in Bull. Soc. hist.nat. Autun, vii (1895) 329. - Congo gall.

minimus, C. B. Clarke, ex S. Elliot, in fourn. Linn Soc. xxx. (1894) 99. - Afr. trop. occ.

Mohrii, Hack. ex Scribn. in Coult. Bot. Gas xiii. (1888) 295; et ex Vasey, Contrib. U. S. Nat. Herb. iii. (1S92) 11. - Am, bor.

mucronatus, N. F. Anderss.' ex Hack. DC. Monog. Phan. vi. (1889) 577. - Ind. or. ?

multiplex, Hack in DC. l. c. $63 \%$ - Abyss.

Munroi, C. B.Clarke, in fourn. Linn. Soc.xxv. (1889) 87 t. 37 . - Reg. Himal.

nemoralis, Balansa, in Morot, fourn. de Bot. iv. (1890) 113. - Tonkin.

niariensis, Franch. in Bull. Soc, hist. nat. Autun, viii. (1895) 330. - Congo gall.

milagiricus, Hochst, ex Hack in DC. Monog. Phan. vi. (1889) $604=$ A. Nardus, Linn.

Nyassae, Rendle, in fourn. Bot. xxxi. (1883) 358. Afr. trop. or.

oryzetorum, Hack. in DC Monog. Phan. vi. (1889) 477. - Zeyl.

osikensis, Franch, in Bull. Soc, hist, nuat. Autun, viii. (1895) 332. - Congo gall.

pachyarthrus, Hack. in DC. Monog. Phan. vi. (1889) 469. - Ind. or.

pachyneurus, Franch. in Bull. Soc. hist. nat. Autun, viii. (1895) 333. - Congo gall.

pauciflorus, Hack. in DC. Monog. Phan. vi. (1889) 348 (=Sorghum pauciflorum, Chapm.).-Florida. pilosissimus, Hack. l. c.691. - Natal.

platyphyllus, Hack.l. c. 428. - Columb.

polystictus, Hochst. ex Hack. in DC. Monog. Phan. vi. (1889) $584=$ Heteropogon acuminatus, Trin. pratensis, Hochst. ex Hack. l. c. 463. - Abyss.

pteropechys, C. B. Clarke, in fourn. Linn. Soc. xxv. (1889) 88 t. 38. - Ind. or.

Schinzii, Hack. ex Schinz, in Verh. Bot. Ver. Brand. xxx (1888) 139; et in DC. Monog.Phan. vi. (1889) 458 - Afr. austro-occ, extratrop.

spectabilis, F. Muell, ex Hack. in DC. Monog.

Phan. vi. (1889) $597=$ exaltatus, $R . B \gamma$.

tenuiberbis, Hack. in DC. Monog. Phan. vi. (1889) 435. - Afr. trop. centr.

Thollonii, Franch. in Bull. Soc. hist. nat. Autun, viii. (1895) 324 . - Congo gall.

tonkinensis, Balansa, in Morot, fourn. de Bot.iv. (1890) 112.-Tonkin.

trichocladus, Rupr. ex Hack. in DC. Monog. Phan. vi. (1885) 524. - Mexic.

trichospirus, Hack. l. c. 536. - Bras.

tristis, Nees, ex Hack. l. c. 439. - Ind. or

tuberculatus, Hack. l. c. 404. - Ind. or

umbellatus, Hack. l. c. 401. - Zeyl.

unilateralis, Hack. l. c. 533. - Florida.

vulgare, Balansa, in Morot, Journ. de Bot. iv. (1890) $113=$ Sorghum vulgare, Pers.

yunnanensis, Hack. in DC. Monog. Phan. vi. (1889) 440. - Yunnan.

ANDROSACE, (Tourn.) Linn. (Primul.). - Ind.

Kew. i. 128.
acuta, Greene, Man. Bot. San Franc. Bay, (1894) 238. - Calif.

alaschanica, Maxim. in Bull. Acad.St-Pétersb.xxxii. (1888) 503. - Mongol.

alchemilloides, Franch. in Morot, foum. de Bot. ix, (1895) 455. - China.

axillaris, Franch. l. c. - China.

bisulca, Bureau et Franch, in Morot, fourn, de Bot. v. (1891) 103. - China.

britanica, Backh. ex Wien.I1l. Gartenz. (1890) 34; et Kew Bull. (1891) App. ii. 35. - (Quid?)

caucasica, Somm. et Levier, in Gard. Chron. (1892) ii. 399. - Reg. Calic.

cinerascens, Robinson, in Proc. Am. Acad. xxvii. (1893) 180. - Mexic

coccinea, Franch. in Bull. Soc. bot. Fr.xxxiii. (1886) 63, nomen. - Yunnan.

\section{ANDROSAGE :-}

cuscutiformis, Franch. in Morot, fonrn. de Bot. ix. (1895) 454. - China.

Delavayi, Franch. l.c. 456. - Yunnan.

Dieckeana, Hausskn. in Mitth. Bot. Ver. Fena, ix. (1891) 22. - Am. bor. occ.

dissecta, Franch. in Morot, fourn. de Bot. ix. (1895) 454. - China.

flavescens, Maxim. in Bull. Acad. St-Pétersb. xxxii. (1888) 506. - Tibet.

Henryi, Oliver, in Hook. Icon. pl. xx. (1891) 1973. - China.

Mariae, Kanitz, Pl. exped. Szechenyi in As. centr. coll. (1891) 36. - China.

mirabilis, Franch. in Morot, Fourn. de Bot.ix. (1895) 452. - China.

Raddeana, Somm, et Levier, in Act. Hort. Petrop. xiii. (1893) 49. - Reg. Caucas.

squarrosula, Maxim. in Bull. Acad. St-Pétersb. xxxii. (1888) 504. - Tibet.

sutchuenensis, Franch. in Morot, fourn. de Bot. ix. (1895) 454. - China

apete, Maxim. in Bull. Acad. St-Pétersb. xxxii. (1888) 505: - Tibet.

uniflora, Hausskn. in Mitth. Bot. Vey. Zena, ix. (1891) 23. - Am. bor. occ.

Turczaninowii, Freyn. in Oest. Bot. Zeitsehr, xl. (1890) $157=$ maxima, Linn.

ANDROSTEPHIUM, Torr. (Liliac.). - Ind. Kew. i. 129

coevuleum, Greene, Pittonia, ii. (May 1890) $57=$ violaceum, Torr.

ANDROSYCE indica, Wedd. ex Hook. f. Fl. Brit Ind. v. (1888) $563=$ Elatostema ficoides, $W e d d$.

ANDRYALA, Linn. (Composit.), - Ind. Kew. i.

spartioides, Pomel, ex Batt. et Trab. F1. de 1'Algér. (Dicot.) (1889) $566=$ ragusina, Linn.

ANEILEMA, R.Br.(Commelin.).--Ind.Kew.i. 130. bracteatum. Kuntze, Rev. Gen. (1891) 719 = nudiflorum, $R$. Br. var.

Clarkei, Rendle, in foum. Linn. Soc.xxx. (1895) 430. - Afr. trop. or.

humile, Warb. in Bot. Fahrb. xiii. (1891) 2\%0. Oceania.

imberbe, Ridl, in Trans. Linn. Soc., Ser. II. iii. (1893) 389. - Penins. Mal.

imbricatum, Warb. in Bot. Fahrb. xiii. (1891) 270 . Oceania.

Johnstonii, K. Schum. in Engl. Pfanzente. Ost-Afr. $C$ (1895) 135. - Afr, trop. or.

keyense, Warb. in Bot. Fahrb. xiii. (1891) 269. Oceamia.

Kuntzei, C. B. Clarke, ex Kuntze, Rev. Gen. (1891) 719 = bracteatum, Kuntze.

leiocaule, $K$. Schum. in Engl. Pflonzenw. Ost Afr. C (1895) 136. - Afr. trop. or.

papuanum, Warb. in Bot. fahrb. xiii. (1891) 269 - Oceania.

Sacleuxii, Hua, in Bull. Mus. Paris, i. (1895) 121. - Afr. trop. or.

semifoliatum, C. B. Clarke, ex S. Moore, in Trans. Linn. Soc. Ser. Il. iv. (1892) 498. - Bras.

enerum, Baker, in foum. Limn. Soc. xxii. (1887) 530. - Madag.

tetraspermum, K. Schum. in Engl. Pfanzenw. OstAfr. C (1895) 136. - Afr. trop. or.

ANEMONE, Linn. (Ranuncu1.).--Ind. Kew.i.131. ocuta, Vail, ex Britton, in Mem. Torrey Bot. Club, ii. (1890) $42=$ acutiloba, Laws.

ajanensis, Prantl, in Bot. Jahrb, ix. (1888) 249 $(=$ Pulsatilla ajanensis, Regel et Tiling $)=$ vernalis, Linn.

albida, Mariz. in Bolet. Soc. Brot. iv. (1886) $101 \mathrm{t}$. 2. - Lusit.

albiflora, Rouy et Fouc. Fl, de Fr. i. (1893) $46=$ coronaria, Linu.

alpicola, Rouy et Fouc. 1. c. $42=$ alpina, Linn.

amurensis, Korshinsky, in Act. Hort. Petrop. xii. (1892) $292=$ nemorosa, Linn.

chilensis, F. Kurtz, in Bol. Acad. nac. cienc. Córdoba ix. (1886) 369 (= Barneoudia chilensis, J. Gay). Chili.

\section{ANEMONE}

corulescens, Lange, Haandb. Danske F1. ed. 4. (1886-88) 585 = apennina, Linn.

colossea, G. Beck, in Wawra. Itin. Princ.S.Coburgii. (1888) $1=$ Sellowii, Pritz.

cyanea. Freyn, in Deustche Bot. Monatsschr, viii. (1890) $176=$ Grayi, Kell. et Behr.

Davidi, Franch.in Nouv. Arch. Mus. Paris, Sér. II. viii. 1885 (1886) 185. - China.

Delavayi, Franch.in Bull. Soc.bot. Fr. xxxiii. (1886) 366. - Yunnan.

Domeykoana, Fr. Meigen, iu Bot. Fahrb. xvii. (1893) 235 (= Barneoudia Domeykoana, Leyb.) — Chili).

Eunrenia, Hort. ex Bul1. Soc. Tosc. Ortic. (1894) 226. = coronaria, Limn.?

gelida, Maxim. in Act. Hort. Petrop. xi. (1889) 31.China.

glaucifolia, Franch. in Bull. Soc. bot. Fr. xxxiii. (1886) 363. - Yunnan.

Hemsleyi, Britton, in Ann. N.Y.Acad. Sci. vi. (1891) 231 - Mexic.

Henryi, Oliver, in Hook. Icon. pl. xvi. (1887) t. 1570. - China.

hirsutissima, MacMill. Metasp. Minnes. (1892)239= patens, Limn.

imbricata, Maxim. Fl. Tangut. (1889) 8 t. 22 fig. 1-6. - Tibet.

fanczerskii, Giraudias, in Bull. Soc. bot. Fr. xxxviii. (1891) $255=$ Halleri, All

Keiskeana, T. Ito, ex Maxim. in Bull. Acad. St-Pétersb. xxxii. (1888) 4\%8. - Japon.

Limaeana, Rouy et Fouc. Fl. de Fr. i. (1893) 39 $=$ A. Pulsatilla, Linn.

lipsiensis X, G. Beck, Fl. Nied. Oest. (1890) 40\%.Eur, centr.

Lyallii, Britton, in Ann.N.Y.Acad. Sci. vi. (1891) 227. - Am. bor.

major, Fr. Meigen, in Bot. Fahrb. xvii. (1893) 235 et xviii. (1894) 455 (= Barneoudia major, Phil.) - Chili.

mudicaulis, A. Gray, in Coult. Bot. Gaz, xi. (1886)

$17=$ Ranunculus lapponicus, Linn.

oregana, A. Gray, in Proc. Am. Acad. xxii. (1887) 308. - Oregon.

peruviana, Britton, in Ann. N. Y. Acad. Sci. vi. 1891) $22 \%$. - Peruvia.

praecox, Coste, in Bull. Soc. bot. Fr. xxxviii. (1891) p. liii. - Gall.

Regeliana, Maxim. Fl. Tangut. (1889) 10; et Enum. pl. Mongol. (1889)ii. t. 3. - As. centr.

Scherfelii, Ullepitsch, in Oest. Bot. Zeitschr. xxxvii. (1887) 12. - Hung

serotina $x$, Coste, in Bull. Soc, bot. Fr. xxxviii. (1891) p. liii. - Gall.

tetonensis, Porter, ex Britton, in Ann. N. Y. Acad. Sci.vi. (1891) 224. - Idaho.

"esicatoria, Prantl, in Engl. et Prantl, Natiur1. Pflanzenfam. iii. 2. (1891) $62=$ Knowltonia vesicatoria, Sims.

vindobonensis X, G. Beck, F1. Nied. Oest. (1890). 487 - Austria.

Whyteana, Baker f. in Trans. Linn. Soc. Ser. II. iv. (1894) 4. - Afr. trop. austro-or.

ANEMONELLA, Spach = Anemone, Linn. (Ranuncul, )

thalictroides, Trelease, Branner etCoville, in Branner, Rep. Geol. Surv. Ark. iv. 1888. (1891) $162=$ thalictroides, Spach.

ANEMOPAEGIMA, Mart. (Bignon.). - Ind. Kew. i. 132 .

brevipes, S. Moore, in Trans. Limn. Soc. Ser. II, iv. (1895) 420. - Bras.

decorum, S. Moore, l, c. 421. - Bras.

flavum, Morong, in Ann. N. Y. Acad. Sci. vii.(1893) 188. - Parag.

lanceolatum, Bureau, ex K. Schum. in Engl. et Prantl, Naturl. Pfanzenfam. iv. 3 b. (1894) 215 nomen. Bras.

longipes, $K$. Schum. l. c. - Bras.

scandens, Mello, ex K. Schum. l.c. - Bras.

sylvestre, S. Moore, in Trans. Linn. Soc. Ser. II. iv. (1895) 421. - Bras.

ANEMONOSPERMOS, Moehr. Hort. Priv. 16 ex, Kuntze, Rev. Gen. (1891) $306=$ Arctotis, Linn. (Composit.). 
ANEMONOSPERMOS :-

acaulis, adpressa, aenea, amplexicans, angustifolia, aspera, bellidifolia, campanulata, canescens, Cineraria, diffusa, Dregei, clatior, elongata, fastuosa, flaccida, glandulosa, lanceolata, leiocarpa, leptorhiza, leucanthemodes, linearis, oocephala, petiolata, pinnaleucanthemodes, linearis, oocephala, petiolata, pinnatifida, pusilla, pygmaea, reptans, revoluta, stoecha-
difolia, venidiodes, verbascifolia, virgata, Kuntze Rev. Gen. (1891) $306=$ homonyma omnia Arcto tidis.

glabrata, Kuntze, 1, c. = Arct laevis, Thuub.

glaucophylla, Kuntze, 1. c. = Arct. candida, Thunb.

incana, Kuntze, I. c. = Arct. argentea, Thunb.

ANERINGLEISTUS, Korth. (Melastom.). - Ind.

\section{Kew. $; 133$.}

Beccarii, Cogn. in Boerl. Handl. Fl. Ned. Indië, i. 2. (1890) 531; et in DC. Monog. Phan. vii. (1891) 4'78. - Borneo

cordatus, Stapf, in Hook. Icon. pl. xxiv. (1894) t. 2310 (cordata). - Borneo.

Curtisii, Slapf, in Kew Bull. (1892) 196. - Penang. dispar, Cogn. ex Boerl. Handl. Fl. Ned. Indië, i. (1890) 531; et in DC. Monog. Phan. vii. (1891) 479 - Borneo.

ANGELESIA, Korth. = Trichocarya, Miq. (Rosac.).

racemosa, Kuntze, Rev. Gen. (I891) $215=$ T. racemosa, Miq.

ANGELICA, (Riv.) Linn. (Umbellifer.). - Ind. Kew. i. 133.

brachyradia, Freyn, in Abhand1. zool.-bot. Ges. Wien, xxxviii. (1888) $607=$ sylvestris, Linn.

californica, fepson, in Erythea i. (1893) 8; et ex Greene, Man. Bot. San Franc. Bay, (1894) 154. - Calif.

Canbyi, Coult. et Rose, Rev. N.-Am. Unzell. (1888) 40. - Am. bor.

dentata, Coult. et Rose, in Coult. Bot. Ga\%. xii. (1887) 61 (= Archangelica dentata, Chapm.) - Florida.

lata, Velen, in Sitz. bölm. Ges. Wiss. 1890 (1890) ii. 44; et Fl. Bulg. (1891) 201. - Bulg.

globifera, Freyn, in Verh. zool.-bot. Ges. Wien, xxxviii (1888) 607 in syn. = sylvestris, Linn.

Hendersoni, Coult. et Rose, in Coult. Bot. Gaz. xiii. (1888) 80. - Am. bor.

Hermini, Mariz, in Bolet. Soc. Brot. xii. (1895) 215 = lancifolia, Spreng.

koreana, Maxim. in Bull. Acad. St-Pétersb. xxxi. (1887) 51. - Corea.

multisecta, Maxim. l. c. - Japon.

Nelsoni, Coult. et Rose, in Contrib. U. S. Nat. Herb. iii. (1895) 294. - Mexic.

Pancicii, Vandas, ex Velen. in Sitzb. böhm. Ges. Wiss. (1889) 448; et in Fl. Bulg. (1891) 200.-Bulg. Pringlei, Coult. et Rose, in Contrib. U.S. Nat. Herb. 1ii. (1895) 295. - Mexic.

scaberula, Franch. in Bull. Soc. Philom, Paris, Sér. VIII. vi. (1894) 144. - China.

Seatoni, Coult et Rose, in Contrib. U. S. Nat. Herb. iii. (1895) 295. - Mexic.

villosa, Britton, Stern, -et Poggenb. Prelim. Catal. (1888) $22=$ Archangelica hirsuta, Torr. et Gray.

ANGORCHIS, Thou, in Nouv, Bull, Soc. Philom. (1809) 314-19, ex Kuntze, Rev. Gen. (1891) $650=$ Angraecum, Bory (Orchid.)

alcicornis, arachnopus, arcuata, armeniaca, articulata ashantensis, bicaudata, biloba, Boutonii, Brongniartiana, campyloplectron, capitata, candata, Chailluana, citrata, clandestina, clavigere, conchifera, Cowaniz, crassa, cryptodon, aucullata, Curnowiana, eburnea, Ellisii, falcata, fastuosa, fuscata, Galeandrae, gladiifolia, gracilis, Hildebrandtii, implicata, infundibularis, modesta, monodon, palmiformis, parzula, pectinata, pertilsa, physophora, polystachya, pusilla, ramosa, recurva, rhipsalisocia, Rohrii, rostrata, saccifera, Scottiana, sesquepedalis, spathulata, striata, superba temuis, teretifolia, triquetra, vesicata, Kuntze, Rev. Gen. (1891) 651-52=homonyma omnia Angraeci. Criptangis, "Thou. " ex Kuntze, in Bull. Herb. bulss. ii. (1894) $458=$ Angr. cryptodon, Reichb. $f$. Cucullangis, "Thou." ex Kuntze, 1. c. = Angr. cucullatum, Thou.

\section{ANGORCHIS :}

dactyloceras, Kuntze, Rev. Gen. (1891) $651=\mathrm{Li}$ strostachys dactyloceras, Reichb. $f$.

flabellifolia, Kuntze, 1. c. = Aërangis flabellifolia, Reichb. f.

Fragrangis, "Thou, » ex Kuntze, in Bull. Herb. Boiss. ii. (1894) $458=$ Angr. cucullatum, Thon. funalis, Kuntze, Rev. Gen.(1891) $651=$ Dendrophylax funalis, Benth. et Hook. $f$.

hyalodes, Kuntze, 1. c. = Angr. hyaloides, Reichb. $f$. maxillariodes, Kuntze, 1.c. = Angr, maxillarioides, Ridl.

megalorhiza, Kuntze, 1. c. = Angr, megalorrhizum, Reichb. $f$.

Pectangis, "Thou. " ex Kuntze, in Bull. Herb. Boiss. ii. (1894) $459=$ Angr. pectinatum, Thou. Papagayi, Kuntze, Rev. Gen.(1891) 651 = Listrostachys Papagayi, Reichb. $f$

Sedenii, Kuntze, 1. c. 652 = Anor. arcuatum Linld.

Triangis, "Thou. " ex Kuntze, in Bull. Herb. Boiss. ii. (1894) $458=$ Angr. triquetrum, Thou.

Welwitschii, Kuntze, 1. c. = Listrostachys Welwitschii, Reichb. $f$.

ANGRAECUM, Bory (Orchid.).--Ind. Kew.i. 134. acutum, Ridl. in Bolet. Soc. Brot. v. (I887) 199 t. C. fig. b. - Ins. S. Thom.

Althoffii, Kraenzl. in Mitth. Deutsch. Schutzgeb. ii. (1889) 160. - Afr. trop. occ

antennatum, Kraenzl. in Bot. Fahrb. xvii. (1893) 61. - Kamerun.

appendiculatum, Frappier, ex Cordem. Fl. Ile Réunion (1895) 211. - Ins. Borbon.

Aschersonii, Kraenzl. in Mitth. Deutsch. Schutzgeb. ii. (1889) 160. - Afr. trop. occ.

astroarche, Ridl. in Bolet. Soc. Brot. v. (1887) $199 \mathrm{t}$ c. fig. a. - Ins. S. Thom.

avicularium, Reichb. f. in Gard. Chron. (1887) i. 40. - Afr. trop.?

bistortum, Rolfe, in Kew Bull.(1893) 75. - Afr. trop. OCC

Buchholzianum, Kraenzl. in Bot. falırb. vii. (1886) 334. - Kamerun.

Buyssonii, God.-Lebeuf, in L'Orchidophite, (1891) 282 cum xylogr. - Madag.

caffrum, Bolus, Icon. Orchid. austro-afr. i. 1. (1893) t. 8. - Afr. austro-or.

calligerum, Reichb. $f$. in Gard. Chron. (1887) ii. 552. - Hab. ?

cephalotes, Kraenzl. in Mitth. deutsch. Schutzegeb. ii. (1889) 4 (= Listrostachys Metteniae, Kraenzl.) Kamerun.

comorense, Kraenzl. in Bot. Fahrb. xvii. (1893) 60. - Ins. Comor.

costatum, Frappier, ex Corden. Fl. Ile Réunion (1895) 211. - Ins. Borbon.

divaricatum, Frappier, l. c. 177. - Ins. Borbon.

du Buyssonii, God.-Lebeuf, in L'Orchidophile (1887 $280=$ Buyssonii, God.-iebeuf.

elegans, Rolfe, in Bolet. Soc. Brot. ix. (1891) 140. Ins. S. Thom.

Elliotii, Rolfe, ex S. Elliot, in foun. Linn. Soc. xxix. (1891) 54. - Madag.

Englerianum, Kraenzl. in Bot. fatwo. vii. (1886) 333 et xvii. (1893) t. 4(= Listrostachys Engleriana, Kraenzl.). - Kamerun.

fimbriatum, Rendle, in fourn. Linn. Soc. xxx. (1895) 387 t. 32 fig. 11-13. - Afr. trop. or.

Fournierianum, Kraenzl. in Gard. Chron. (1894) i. 808, ii. 43 fig. 7; Éd. André, in Rev. Hortic. (1894) 582 cum icone. - Madag.

Germinyanum, Hort. Sand. ex Hook. f. in Bot. Mag. (1889) t. 7061. - Madag.

Gerrardi, Bolus, Icon. Orchid, Austro-Afr, i. i. (1893) t. 7 = Mystacidium Gerrardi, Bolus. gracillimum, Kraenzl. in Bot. Fahrb. xvii. (1893) 59 t. 5. - Kamerun.

Grandidierianum, Carrièye, in Rev. Hortic.(1887) 42 fig. 9 (= Aerranthus Grandidierianus, Reichb. f.) - Ins. Comor.

grandiflorum, Hort. ex Orchid Album, xi. (1895?) t. 514 sphalm.) = Aëranthus grandiflorus, Lindl. Graventeutii, Kraenzl. in Bot. Fahrb. xvii. (1893) 62. - Kamerun.

Gyriamae, Rendle, in fourn. Linn. Soc. xxx. (1895) 388. - Afr. trop. or.

\section{AIVGRAEGUM :}

Henriquesianum, Ridl. in Bolet. Soc.Brot. v. (1887) 231. - Afr. trop. occ. (Ins. Principis).

Henviquesianum, Rolfe in Gard. Chron. (1890) ii. $466=$ elegans. Rolfe.

Keniae, Kraenzl. in Hoehnel, Zum Rudolph See, App. (1892) 4; at in Bot. Fahrb. xvii. (1893) 59. - Afr. trop. or.

Kimballianum, Hort. ex Kew Bull. App. ii. (1890) $38=$ polystachyum, $A$. Rich

liliodorum, Frappier, ex Cordem. Fl. Ile Réunion (1895) 198. - Ins, Borbon.

longinode, Frappier, l. c. 210. - Ins. Borbon.

luteo-album, Kraenzl. in Bot. Fahrb. (1895) 27; et in Engl. Pflanzenw. Ost-Afr. C (1895) 158. - Afr. trop. or.

macilentum, Früppier, Catal. Orchid. Réunion (1889) 13 nomen; et ex Corden. Fl. Ile Réunion (1895) 210. Ins. Borbon.

malangeanum, Kraenzl. in Bot. Fahrō. xxii. (1895) 26. - Angola.

Maudae, Bolus, Icon. Orchid. Austro-Afr. 1. 1. (1893) t. 9. - Afr. austro-or.

mauritianum, Frappier, Catal. Orchid. Réunion (1889) 13 = gladiifolium, Thou.

minutum, Frappier, ex Cordem. Fl. Ile Rérnion (1895) 209. - Ins. Borbon.

nanum, Frappier, l. c. 208. - Ins. Borbon.

neglectum, Frappier, l. c. 202.- Ins. Borbon.

nutans, Frappier, \%. c. 201. - Ins. Borbon.

Obrienianum, Hort. Sand. ex Gard. Chron. (1892)i. 816, nomen. (Ouid?) - Hab.?

obversifolium, Frappier, ex Cordem. Fl. Ile Réunion (1895) 212. - Ins. Borbon.

pallidum, W. Wats. in Gard. and For. iii. (1890) 78. - Afr. trop. occ.

paniculatum. Frappier, ex Cordem. Fl. Ile Réunion (1895) 215. - Ins. Borbon.

patens, Frappicr, l. c. 206. - Ins. Borbon.

pingue, Frappier, i. c. 214. - Ins. Borbon.

primulinum, Rolfe, in Gard. Chron.(1890) 388.Madag.

pseudopetiolatum, Frappier. ex Cordem. Fl. Ile Réunion (1895) 207. - Ins, Borbon.

pugioniforme, Klotzsch, ex Hook. f. Fl. Brit. Ind. vi. (1890) $70=$ Sarcanthus oxyphyllus, Wall.

Quintasii, Rolfe, in Bolet. Soc. Brot, ix. (1891) 140 - Ins. S. Thom.

Reichenbachianum, Kraenzl. in Reichb. f. Xen. Orchid. iii. 4. (1890) 74 t. 239 , i. fig. 1-3. - Hab.? Sanderianum, Reichb. f. in Gard. Chron. (1888) i. $168=$ modestum, Hook. $f$.

Saundersiae, Bolus, in Hook. Icon. pl.xviii. (1888) t. 1728. - Natal.

Schoellerianum, Kraenzl. ex Schwoeinf. in Bull.Herb. Boiss. ii. App. ii. (1894) 112. - Erythrea.

Scottellii, Rendle, in Fourn. Bot. (1895) 249." - Afr.

trop. or.
Sedeni, L. Lind. et Rodig. in Lindenia, iii. (1887) 81 t. 135 (= Listrostachys Sedeni, Reichb. f.). - Afr. trop. or.

semipedale, Rendle, in fourn. Linn. Soc. xxx. (1895) 389. - Afr. trop. or

Smithii, Rolfe, in Kew Bull. (1895) 37.-Afr. trop.or. stenophyllum, Frappier, ex Cordem. Fl. Ile Réunion (1895) 200. - Ins. Borbon.

stipitatum, Frappier, l. c. 199. - Ins, Borbon. stylosum, Rolfe, in Kew Bull. (1895) 194.- Madag. subclavatum, Rolfe, in Bolet. Soc. Brot. ix. (1891) 141. - Ins. S. Thom.

tenuifolium, Fruppier, Fl. Ile Rémion (1895) 207.Ins. Borbon.

thomense, Rolfe, in Bolet. Soc. Brot. ix. (1891) 141. - Ins. S. Thomé

tricuspe, Bolus, in Fourn. Linn. Soc. xxv. (1889) 163 - Natal.

tridactylites, Rolfe, in Gard. Chron. (1888) ir. 34. Afr. trop. occ.

verrucosum, Rendle, in fourn. Bot.xxxiii. (1895)249. - Afr. trop. austro-or.

verruculosum, Frappier, ex Cordem. Ile Rémion (1895) 204. - Ins. Borbon.

virgula, Kraenzl. in Bot. Fahrb. xxii. (1895) 27; et in Engl. Pfanzenzo. Ost-Afr.C (1895) 15\%. - Afr. trop. or.

Whitfieldii, Rendle, in fourn. Bot. xxxiii. (1895) 249 - Sierra Leone. 
ANGUINA, Mich. ex Linn. = Trichosanthes, Linn. (Cucurbit.).

angulata, Beccariana, bornensis, bracteata, celebica, cordata, coriacea, cucumerina, cucumerodes, cuspidata, dicaelosperma, dioeca, globosa, grandiflora, Hearnii, himalensis, Horsfieldii, incisa, integrifolia, japonica, Kirilowii, Lepiniana, longiflora, multiloba, nervifolia, ovata, ovigera, Patara, pentaphylla, Perrottetiana, pilosa, quinquangulata, subvelutina, sumatrana, tamnifolia, Thwaitesii, tricuspidata, trifoliata, truncata, villosa, villosula, Wallichiana, Wawraei, Kuntze, Rev. Gen. (1891) $254=$ homonyma omnia Trichosanthidis.

anamalayna, Kuntze, 1. c. - T. anaimlaiensis, Bedd.

ANGULOA, Ruiz et Pav. (Orchid.). - Ind. Kew. i. 136

intermediax, Rolfe, in Gard.Chron. (1888). i.798; et in Lindenia, iv. (1888) 8. - Hybr, nat. et artef. Madouxiana $\times$, L. Lind. in Journ. des Orchid. $v$. (1894) 124; et in Lindenia, x. (1894) 7 t. 434 . Hybr. artef.

Mantini, Hort. ex Illustr. Hortic. (1895) $187=$ uniflora. Pers.

ANGURIA, (Tourn.) Linn. (Cucurbit.), - Ind. Kew. i. 36

diversifolia, Cogn. ex f. D.-Smith, in Coult. Bot. Gaz. xvi. (1891) 20. - Guatem.

gloriosa, S. Moore, in Trans. Linn. Soc. Ser. II. iv. (1895) 366. - Bras.

oblongifolia, Cogn ex F. D.-Smith, in Coult. Boi. Gaz. xvi. (1891) 9. - Guatem.

ANHALONIUM, Lem. = Mammillaria, Harv. (Cact.).

furfuracenm, Coult. in Contrib. U. S. Nat. Herb. iii. (1894) $130=$ M. furfuracea, S. Wats.

Fourdanianum, Lewin, in Ber. deutsch. bot. Ges. xii. (1894) 289 in obs. - Hab.?

Lewini, Hennings, ex Gartenf. (1888) 410-11. fig. 92; et Kew Bull. (1889) 77 (= Lophophora Williamsii, Coult.). - Mexic.

ANIBA, Aubl. = Ocotea, Aubl. (Laurin.).

affinis, Mez, in Jahrb. Bot. Gart. Berl. v. (1889) 63 = Aydendron affine, Meissn.

albida. Mez, 1 c. 64 . - Bras.

amazonica, Mez, 1. c. $69=$ Aydendron amazonicum, Meissn.

bracteata, Mez, 1. c. $66=$ Ayd. bracteatum, Nees. Brittonii, Mez, 1. c. 54. - Bras.

Canellila, Mez, 1. c. $53=$ Cryptocarya Canelilla, H. B. K.

citrifolia, Mez, 1. c. $74=$ Aydendron citrifolium, Nees.

desertorum, Mez, 1.c. $76=$ Ayd. desertorum, Nees. firmula, Mez, 1. c. $58=$ Ayd. firmulum, Nees. Gardneri, Mez, 1. c. $60=$ Ayd. Gardneri, Meissn.

Hostmanniana, Mez, 1. c. $67=$ Ayd. Hostmannianum, Nees.

intermedia, Mez, 1. c. $73=$ Ayd. intermedium, Meissn.

fenmani, Mez, 1. c. 70. - Guian. ang1.

Kappleri, Mez, 1. c. 52. - Guian. bat.

laevigata, Mez, 1. c. 59 = Aydendron laevigatum, Meissu.

megaphylla, Mez, 1. c. 6\%.- Guian. gall.

Muca, Mez, 1. c. $57=$ Aydendron Muca, Nees.

Muelleriana, Mez, 1. c. 72. - Guian. gall.

ovalifolta, Mez, 1. c. 77. - Guian. angl.

panurensis, Mez, 1. c. $58=$ Aydendron panurense, Meissn.

parviflora, Mez, 1. c. $56=$ Aydendron parviflorum, Meissn.

permollis, Mez, 1. c. $55=$ Aydendron permolle, Nees.

perutilis, Hemsl. in Kew Bull. (1894) 6. - Columb. Puchury-minor, Mez, in Jahrb. bot. Gart. Berl.v.

(1889) 70 = Nectandra Puchury-minor, Nees. et Mart.

Ramageana, Mez, 1. c. 494. - Antill.

Ridleyana, Mez, 1. c. 77. - Bras.

riparia, Mez, 1. c. $62=$ Aydendron riparium, Nees.
ANIBA : -

robusta, Mez, in Jahrb. bot. Gart. Berl. v. (18s8

$75=$ Aydendron robustur Ness.

Taubertiana, Mez, 1. c. 65. - Guian. gall.

Trinitatis, Mez, 1 c. $68=$ Aydendron Trinitatis, Meissn.

venezuelana, Mez, 1. c. 63. - Venez.

viridis, Mez, 1. c. 61. - Bras.

ANIDRUM, Neck,= Bifora, Hoffm. (Umbellifer.) americanum, Kuntze, Rev. Gen. (I891) $264=$ B. americana, Benth. et Hook.f.

radians, Kunze, 1. C. = B. radians, Bieb.

testiculatum, Kuntze, $1 . c_{0}=$ B. testiculata, Roth.

ANIL(A), Ludw. Defin. pl. (1837) 117 emend. ex Kuntze, Rev. Gen. (1891) 159 et $938=$ Indigotera Linn. (Legtamin.).

acutifolia, adenocarpa, adscendens, affinis, alternans, amoena, angulosa, angustifolia, arabica, arenaria, argyraea, arrecta, aspera, asperifolia, atriceps, atropurpurea, auricoma, australis, Baileyi, Bainesii, purpurea, auricoma, australis, Balley, Bannesi, brachystachya, bracteolata, Brassii, brevidens, Brunoniana, Bungeana, Burchellii, Burkeana, caloneura, Cameronii, campestris, candicans, capitata, cardiophylla, caroliniana, celebica, chinensis, circinnata, complicata, compressa, concava, concinna, congesta, conjugata cordifolia corniculata costaricensis costata, cryptantha, cuneata, cuneifolia, cylindrica, dealbata, declinata, decora, decumbens, densiflora, denudata, depressa, digitata, dimidiata, diphylla, dissitiflora, disticha, divaricata, diversifolia, Dregeana, echinata, efoliata, Elivenbergiana, elliptica, omarginella, endicaphylle, criocarta, crythrogramma, exigua, falcata, fastigiata, filicaulis, filifolia, fliformis, filipes, fabcllata, flaricans, foliusa, frutescens, fulcrata, fulgens, geminata, glandulosa, glaucescens, glomerata, gracilis, grata, grisea, haplophylla, hebepetala, hedranophylla, hedyantha, heterocarpa, heterophylla, heterotricha, Heudelotii, hilaris, hirsuta, hirta, histida, humifusa, humilis, incana, intermedia, intricata, Knoblecheri, leptocarpa, leptosepala, lencoclada, Lindheimeriana, linifolia, Lyallii, macra, macrocalyx, macrocarpa, macrophylla, madagascariensis, malacostachys, marginulata, medicaginea. melanadenia, micrantha, microcarpa, mollis. monophylla, multijuga, Mundiana, mysurensis, nigricans, nigritana, midicaulis, nummularia, obcordata. oligophylla, ovata, ovina, oxalidea, Oxytropis, paniculata, Parkeri, parviflora, parrula, pascuorum, pau ciflora, paucifolia, Pechuelli, pectinata, pedicellata pedunculata, pentaphylla, Perrottetii, pilosa, pinifolia, podophiylla, polycarpa, porrecta, pratonsis, Prieu viana, procera procumbens, pruinosa, psilostachya, pulchella, pungens, Quartiniana, quinquefolia, rhynchocarpa, rhytidocarpa, Rothii, rufescens, rugosa, sabulicola, sarmentosa, saxicola, Schimperi, Schult ziana, secundiflora, senegalensis, sericea, sessiliflora. sessilifolia, seticulosa, setiflora, simplicifolia, sordida. Spachii, sparsa, sphaerocarpa, spicata, spinescens, spinosa, stenophylla, stipularis, stricta, strobilifera, suaveolens, subcorymbosa, subulata. subulifera, sulcata, terminalis, tetragonoloba, tetrasperma, Teysmannii, Thibaudiana, tinctoria, tomentosa, torulosa, trichopoda, trifoliata, triquetra, tristis, trita, truxil lensis, umbonata, uniflora, varia, relutina, venulosa, venusta, vestita, viminea, viscidissima, viscosa,

Welwitschii, Wightii, Zeyheri, Kuntze, Rev. Gen.

(189I) 160 et $938-40=$ homonyma omnia Indigoferae.

amorphodes, Kuntze, 1. c. 938 = I. amorphoides, Faub. ot Spach.

anabaptizata, Kuntze, 1. c, = I. anabaptista, Steud. angustata, Kuntze, 1. c. = I. stenopliylla, Guill. et Perr.

argentea, Kuntze, 1. c。 = I. semitrijuga, Forsk.

argyrodes, Kunze, 1. c. = I. argyroides, E. Mey.

Arnottii, Kuntze, 1.c. = I. tenuifolia, Rotto.

articulata, Kuntze, 1.c. = I. argentea, Wall.

aspalathodes, Kuntze, 1. c. = I. aspalathoides, Vahl.

Bakeriana, Kuntze, 1.c. = I. arrecta, Benth.

benguelensis, Kuntze, 1. c. = I. benguellensis, Baker.

Bongardiau, Kuntze, 1. c. = I. gracilis, Bong.
ANIL(A) :-

coronillifolia, Kuntze, Rev. Gen. (1891),309= I. coronillaefolia, A. Cumn.

coronillodes, Kuntze, 1. c. = I, coronilloides, faub. et Spach.

crotalariodes, Kuntze, 1. c. = I. crotalarioides, Baker.

cytisodes, Kunłze, 1. c. = I. cytisoides, Linn.

daleodes, Kuntze, 1. c. = I. daleoides, Berrth.

Dalzeliana, Kuntze, 1. c. $938=$ I. triquetra, Dalz.

dendrodes, Kuntze, 1. c. $939=$ I. dendroides, 7 acg

dilwyniodis, Kuntze, 1. c. = I. dillwynioides, Benth.

exstipulata, Kuntze, 1. c. 938=I. sarmentosa, Linn.f. galegodes, Kuntze, 1. c. $939 .=$ I. galegrides, $D C$. glabra, Kuntze, 1. c. $938=$ I. pentaphylla, Murr. gonoides, Kuntze, 1. c. $939=$ I. coniodes, Hochst. hippocrepodes, Kuntze, 1. c $=$ Hosackia anoustifolia, G. Don.

Hochstetteri, Kuntze, 1. c. = I. anabaptista, Steud. hololeuca, Kuntze, 1. c. = I. alternans, $D C$.

indica, Kuntze, 1. c. $938=$ I. aspalathoides, Vahl. inhambensis, Kuntze, 1. c. $939=\mathrm{I}$. inhambanensis, Klotzsch.

Kirkiana, Kuntze, 1. c. 938 = 1. torulosa, Bakerr.

Leprieurii, Kuntze 1. c. = I. macrocarpa, Lepr.

lespedesiodes, Kuntze, 1. c. $160=$ I. lespedezioides $H$. B. et $K$

lotodes, Kuntze, 1. c. $938=$ I. lotoides, Lam.

macrostachya, Kuntze, 1. c. = I. macrostachys, Vent.

maritima, (sphalm.) Kuntze, 1. c. = I. maritima Baker.

mawritanica, Kuntze, 1. c. = I. coriacea, Dryand.

mimosodes, Kuntze, 1. c. $939=$ I mimosoides,

Baker.

molucine Kuntze l. $c=$ I. trifoliata, Limn.

mumulariacfolia, Kuntze, 1. c. = I. echinata, Willd.

mithopodiodes, Kuntze, 1. c. = I. ornithopodioides, Cham. et Schlecht.

phyllantrodes, Kuntze, 1. c. = I. phyllanthoides, Baker.

prostrata, Kuntze, 1.c. $938=$ I. enneaphylla, Limn. rapestris, Kuntze, 1. c. = I. poliotes, Eckl. et Zeyh. sutherlandiodes, Kuntze, 1. c. = I, sutherlandioides, Welw.

tenzifolia, Kuntze, 1. c 938. = I. augustifolia, $\operatorname{Linn}$ et I. capillaris, Thunb.

tephrosiodes, Kuntze, 1. c. $940=$ I. tephrosioides, $H$. B. et $K$.

thymodes, Kuntze, 1. c. = I. thymoides, Baker. tribulodes, Kuntze, 1. c. = I. tribuloides, Bois. ultima, Kuntze, 1.c. $938=$ I. vestita, Baker.

viciodes, Kuntze, 1. c. = I. vicioides, Faub. et Spach.

Zollingeriana, Kuntze, 1. c. = I. galegoides, $D C$.

ANISAGANTHUS, Nees. (Acanthac.). - Ind.

\section{Kew i. 137.}

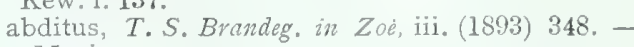
Mexic.

brasiliensis, Iindau, in Bull. Herb. Boiss. iii. (1895) 371. - Bras.

aducifolius, Lindau, in Bot. Fahrb, xix. Beibl.n.48 (1894) 18; ct in Engl. et Prantl, Natürl. Pfanzenfam. iv. 3 b. (1895) 328 (= facobinia caducifolia Griseb.). - Argent.

ruber, Lindau, in Bull. Herb. Boiss. iii. (1895) 371 - Bras.

ANISEIA, Choisy = Ipomoea, Linn. (Coñvolvul.). Hackeliana, Schinz, in Verh. Bot. Ver Brand, xxx, (1888) $273=$ I. Hackeliana, Hallier $f$.

ANISIFOLIUM, Rumpf, Hort. Amboin, ii. (1742) 133 t. 48 = Limonia, Linn. (Rutac.) alatum, Kuntze, Rev. Gen. (1891) $98=$ L. alata, Wall

alternans, Kuntze, 1. c. = L. alternans, Wall. curvispina, Kuntze, 1. c. = L. curvispina, Miq. Limonia, Kuntze, 1. c. = L. acidissima, Linn. pubescens, Kuntze, 1. c. = I. pubescens, Wall. spectabile, Kuntze, 1. c. = L. spectabilis, Miq.

ANISOGHILUS, Wall. (Labiat.). - Ind, Kew. i. 137.

africanus, Baker, ex S. Elliot, in fourn. Lim. Soc. xxx. (1894) 94. - Sierra Leone. 


\section{ANISOCHILUS :}

Englevi, Briq. in Bot. Jahrb. xix. (1894) $190=$ africanus, $B a k c t^{2}$

velutinus, Trim. Handb. Fl.Ccyl. iii, (1895) 377.Zeyl.

ANISOGYGLA, Baill. Hist. pl. Madag., Atlas, (1886) t. 49A; et in Bull. Soc. Linn. Paris, ii. (1893) 1079. MENISPERMACEAE.

Grandidieri, Baill. ll.cc. - Madag.

ANISOMELES, R. Br.(Labiat.),-Ind. Kew. i.137. indica, Kuntze, Rev. Gen. (1891) 512 = ovata, Benth.

secunda, Kuntze, 1. c. = A. Heydeana, R. Br.

ANISOMERIS, Presl= Chomelia, Jacq. (Rubiac.) fasciculata, K. Schum, in Engl. et Prantl, Natürl. Pflanzenfam. iv. 4. (1891) 98. - Ind. occ

obtusa, K. Schum. 1. c. = C. Obtusa, Cham. et Schlecht.

Preslii, K. Schum. 1. c. =C. Anisomeris, Muell. Arg. spinosa, K. Schum. 1. c. = C. spinosa, facq.

ANISOPAPPUS, Hook. et Arn. (Composit.). Ind. Kew, i. 138.

angolensis, O. Hoffm. in Bolet. Soc. Brot. x. (1892) 170. - Angola.

ANISOPETALUM, Hook. = Bulbophylium,

Thou. (Orchid.)
lasianthum, Kuhl, ex Hook. f. Fl. Brit, Ind. vi. (1890) $763=$ B. lasianthum, Lindl.

ANISOPHYLLEA, R. Br. (Rhizophor.). - Ind. Kew. 1. 138.
Boehmii, Engl. Pflanzenw. Ost-Afr. C (I895) $28 \%$. - Afr. trop. or.
fallax, S. Elliot, in Fourn. Linn. Soc. xxix. 16. - Madag.

Thouarsiana, Baill. Hist. pl. Maddg., Atlas (1895) t. 327. - Madag.

ANISOPODA, Baker, in Journ. Linn. Soc, xxv, (1890) 318 t. 1ii. UMBELLIFERAE.

bupleuroides, Baker, l. c. - Madag.

ANISOPTERA, Korth. (Dipterocarp.). - Ind. Kew i. 138.

cochinchinensis, Pierre, in Laness. Pl. util. col. franc. (1886) 29s; et Fl. For. Cochinch. (1890) t. 235A. - Cochinch.

costata, Pierre, in Laness. 1. c. = robusta, Pierre. Curtisii. Dyer, ex King, in foum. As. Soc. Beng. 1xii. (1893) ii. 100. - Penang.

Forbesii, Brandis, in foum. Limn. Soc. xxxi. (1895) 45. - N. Guin.

grandiflora, Brandis, l. c. 43 t. 2 fig. 29.-As. trop. parvifolia, Warb. in Bot. fahrb. xili. (I891) 382.Oceania.

robusta, Pierre, Fl, For. Cochinch. (1890) t. 236. Cochinch.

tomentosa, Brandis, in foum. Linn. Soc. xxxi. (1895) 45. - Ins. Philipp.

Vidaliana, Brandis, l. c. 44, - Ins. Philipp.

ANISOPUS, N. E. Br. in Kew Bull. (1895) 259. ASCLEPIADEAE.

Mannii, N.E. Br. l. c. - Afr. trop. occ.

ANISOSCIADIUM, DC. = Echinophora, Linn. (Umbellif.)

lanatum, Boiss. Fl. Or. Supp1. (I888) 261.-Arabia.

ANISOTES, Nees (Acanth.). - Ind. Kew. i. 139. parvifolius, Oliver, in Hook. Icon. pl. (1886) 346. (sphalm. Anisotis). - Afr, trop. or.

velutinus, Lindau, in Bot. Fahrb. xx. (1894) '76. Afr. trop. or.

ANisotoma, Fenzl (Asclepiad.) - Ind, Kew. i. 139.

mollis, Schlechter, in Bot. Fahrt. xviii. Beibl. n. 45. (1894) 26 (= Lophosiephus nolles, Harv.). Afr. austr.

pedunculata, $N$. E. Br. in Kew Bull. (1895) 150. - Natal.
ANNESLIA (Anneslea, Auct.) Salisb. = Calliandra, Benth. (Legumin.)

calothyrsus, J. D.-Smith, P1. Guat. (1885?) n. $690=$ C. calothyrsa, Miq.

exlophylla, Britton, in Trans. N. Y. Acad. Sc. xiv. (1894) $32=\mathrm{C}$. eriophylla. Benth.

Quetzal, J. D. Smith, in Coult. Bot Gaz, xiii. (1888) 28. - Guatem.

reticulata, Britton, in Trans. N. Y. Acad. Sci. xiv. (1894) $32=\mathrm{C}$ reticulata, $A$. Gray.

tetragona, J. D. Smith, P1. Guat. (1885?) n. 691 $($ Anneslia $)=\mathrm{C}$. tetragona, Binth

ANNESLEYA parvifolia, Britton, in Ann. N. Y. Acad. Sci. vii. (1893) 101 (an Anneslia sp.?) = Inga parvifolia, Hook. et Arm.

ANODA, Cav. (Malv.), - Ind. Kew, i. I39.

abutiloides, S. Wats, in Proc. Am. Acad. xxil. (1887) 300. - Arizona.

arizonica, A. Gray, in Proc. Am. Acad. xxii. (1887) 298. - Arizona.

denudata, K. Schum. in Mart. Fl. Bras, xii. III (1891) $35 \%$ (= Sida denudata, Nees et Mart.). Bras., Parag.

Thurberi, A. Gray, in Proc. Am. Acad.xxii. (1887) 299. - Mexic.

ANODENDRON, A. DC. (Apocyn.). - Ind. Kew. i. 139

Aambe, Warb. in Bot. Fahro. xiii. (1891) 454. Oceania.

Benthamianum, Hemsl, in foum. Linn. Soc. xxvi. (1889) 98. - Formosa

oblongifolium, Henst. in Ann. of Bot. v. (1891) 504; et in Hook. Icon. pl. xxiii. (1892) t. 2207. - Ins. Salom.

ANOECTOCALYX, "Triana » ex Cngn, in DC. Monog. Phan. vii. (1891) 1198 sphalm. = Anaectocalyz, Triana (Melastom.).

ANOEGTOGHILUS, Blume (Orchid.). - Ind. Kew. i. 140.

Griffithii, Hook. f. Fl. Brit. Ind. vi. (1890) 96; et Icon. pl. xxii. (1893) t. 2159. - Reg. Hima1.

javanicus, Hort. ex Ridl. Journ, Linn. Soc. xxiv. (1888) 338 = Microstylis oculata, Reichb $f$.

Lansbergiae, L. Linden, in Illust\%. Hortic. xxxiv. (1887) 7. t. 1; et in Gard. Chron.( 1887) i. 421. Malaya.

nobilis, Hort ex Williams, Orch. Grow. Man. ed. 7 (1894) 696 in syn. = Physurus nobilis, Reichb. $f$.

Sanderianus, Kraenzl, in Gard. Chron. (1895)ii. 484 $=$ Macodes Sanderiana, Rolfe.

Tashiroi, Maxim. in Bull. Acad. St-Pétersb. xxxi. (1887) 103. - Ins. Liukiu.

tetrapterus, Hook. f. Fl. Brit. Ind. vi. (1890) 96. Ind. or.

xanthophyllus, Hort. ex Rolfe, in Journ. Linn. Soc. xxiv. (1887) $1 \% 0$ in syn. = Lobbianus, Planch.

ANOECTOMARIA $\times$, Rolfe, in Journ. Linn. Soc. xxiv. (1888) 170. ORCHIDEAE.

Dominit, Rolfe 1. c. (= Anoctochitus Dominii, Hort.). - Hybr. artef.

ANOGEISSUS, Wall. (Combret.). — Ind. Kew. i. 140.

Bentii, Baker, in Kev Bull. (1894) 332; ot in Hook. Icon. pl. xxiv. (1895) t. 2354. - Arabia

Harmandii, Pierre, $2 n$ Laness. Pl. util. col. franc. (1886) 315. - Cochinch.

ANOGRA, Spach = Oenothera, Linn. (Onagrar.) albicaulis, Britton, in Mem. Torrey Bot. Club, v. (1894) $234=$ O. albicaulis, Pursh.

coronopifolia, Britton, 1. c. $=$ O. coronopifolia, Torr. et Gray.

pallida, Britton, 1. c. = O. pallida, Lindl.

ANOMALOPTERYS, G. Don, = Acridocarpus Guill, et Perr. (Malpigh.)

adenophora, Kuntze, Rev. Gen. (1891) S7 = Ac. adenophorus, $A$. fuss.
ANOMALOPTERYS :-

angolensis, Kuntze, Rev. Gen. (1891) $87=$ Ac. angolensis, $A$. Fuss.

argyrophylla, Kuntze, 1. c. = Ac. argyrophyllus, A. Fuss.

chloroptera, Kuntze, 1. c. = Ac. chloropterus, Oliver. corymbosa, Kuntze, 1. c. =Ac. corymbosus, Hook. $f$. excelsa, Kuntze, 1. c. = Ac, excelsus, A. fuss.

galphimiaefolia, Kuntze, 1, c. = Ac. galphimiaefolius, $A$. Fuss.

natalitia, Kuntze, 1. c. = Ac, natalitius, $A$. fuss.

ovientalis, Kuntze, 1. c. = Ac, orientalis, A. Fuss.

pruriens, Kuntze, 1. c. = Ac. pruriens, A. fuss.

Smeathmanni, Kuntze, 1. c. = Ac. Smeathmanni, Guill. et Perr.

zanzibarica, Kuntze, 1. c. = Ac. zanzibaricus, A. Fuss.

ANONA, Linn. (Anonac.). - Ind. Kew. i, 140.

cordifolia, Poepp. ex Szyszyl. in Diss. math.-nat. Acad. litt. Cracov. xxvii. (1894) $140=$ Rollinia cordifolia, Szyszyl.

latifolia, S. Elliot, in fourn. Linn. So6. xxx. 1894) 69. - Sierra Leone.

longiflora, S. Wats, in Proc. Am. Acad. xxii. (1887) 297. - Mexic.

Rodriguesii, Barb. Rodr. Pl. nov. Fard. bot. Rio iv. (1894) 1 t. 1. - Bras.

Sanctae-crucis, S. Moore, in Trans. Linn. Soc. Ser. II. iv. (1895) 305. - Bras.

Walkeri, S, Moove, l. c.304.-Bras.

ANONYMOS, Gronov. = Galax, Linn, (Diapensias.).

Linn.

ANOPLANTHUS, Endl.= Phelypaea, Tourn. (Orobanch.).

myzorrhizus, Solms, ex G. Beck, in Luers. Bibl. Bot. Heft, xix. (1890) 83 in syn, = Orobanche chilensis, $P$ hil

ANOPLOPHYTUM, Beer = Tillandsia, Linn.

Binoti, Ed. Morr. ex Baker, Handl. Bromel. (1889) $200 .=$ T. brachyphylla, Baker.

bractrypidium, Éd. Morr. ex Baker, 1. c. $196=\mathrm{T}$. Funckiana, Baker.

Krameri, Éd. Morr. ex Baker, 1. c. $197=$ T. Krameri, Baker.

lutemn, Ed. Morr, 1. c. $198=$ T. lutea, Baker.

paniculatum, Éd. Morr. 1. c. $200=$ T. geminiflora, Brongll.,

vefulgens, Éd. Morr. ex Baker, 1. c. $197=$ T. meridionalis, Baker.

straminem, K. Koch, ex Baker, 1. c. $150=$ Caraguata straminea, Baker.

undosum, Ed. Morr. ex Baker, 1. c. $197=$ T. globosa, Warera.

xiphioides, Beer, ex Baker, 1. c. $164=$ T. xiphioides, Ker.

ANOSPORUM, Nees = Cyperus, Linn.(Cyperac.). ablepharum, Maury, ex M. Micheli, in Mém. Soc. sci.phys. Genève, xxxi. (1890) $125(=$ Scir pus ablepharus, Griseb.). - Am. trop.

paraguayense, Maury, 1. c. 124 t. 35. - Parag.

piliferum, Maury, 1. c. t. 34. - Parag:

Schinzi, Boeck. ex Schinz, in Verh. Bot. Ver. Brand. xxix. Abhandl. (1888) 46. - Afr. austroocc. extratrop.

ANOTIS, DC. (Rubiac.). - Ind. Kew. i. 142. nummulariformis, Trim. Syst. Cat. Ceyl. Pl. (1885 42 (= Hedyotis nummulariformis, Arn.) - Zeyl.

ANPLECTRUM, A. Gray (Melastom.). - Ind. Kew. i. 142.

assamicum, C. B. Clarke, in Fourn. Linn. Soc. xxv. (1889) 23. - Reg. Himal.

Beccarianum, Cogn. in DC. Monog. Phan. vii. (1891) 568. - Borneo.

homoeandrum, Stapf, in Trans. Linn. Soc. Ser. II. iv. (1894) 161. - Borneo. 
ANREDERA, Juss.(Chenopod.).-lnd. Kew.i. 142. baselloides, Baill. Hist. des p1. ix. (1888) $147=$ Boussingaulitia baselloides, $H$. $B$. ct $K$.

ANSELLIA, Lindl. (Orchid.). - Ind. Kew. i. 142. confusa, N.E. Br. in Lindenia, ii. (1886) 36 in obs. - Afr. trop. occ.

congoënsis, Rodigas, l. c. 35 t. 64 . - Congo.

humilis, Bull, Catal. (1891) 3; et ex Gartenfl. (1891) 333. - Zambes.

nilotica, N.E. Br. in Lindenia, ii. (1886) 36. Afr. trop. or

ANTENNARIA, Gaertn. (Composit.). - Ind. Kew. i. 143.

Mariae, F. Muell. ex Boerl. Handl. Fl. Ned. Indië, II. i. (1891) $240=$ Anaphalis Mariae, F. Muell,

ANTHAENANTIA, P. Beauv. (Gramin. $)_{0}-$ Ind Kew. i. 143.

glauca, Hack. ex Schinz, in Verh. Bot. Ver. Brand xxx. (1888) 237. - Afr. austro-occ. extratrop.

Hackeli, Arechav, in Anal. Mus. nac. Montevideo, ii. (1894) 96 t. 5. - Urug.

lanata, Hack. ex Schinz, in Verh. Bot. Ver. Brand. xxx. (1888) 237 in obs. = lanata, Benth.

ANTHEMIS, Mich. ex Linn, (Composit.). - Ind. Kew, 1.144.

adulterina $X$, Wallr. ex E. Hallier, in Koch's Syn. Deutsch. F1.ed. 3 (1895) 1392. - Germ.

armeniaca, Freyn et Sint. in Bull. Herb. Boiss, iii. (1895) 348. - Armen. turc.

caulescens, Aitch. et Hemsl. in Trans. Linn. Soc. Ser. II. iii. (1886) 76. - As. centr.

extrarosularis, Freyn, in Oest. Bot. Zeitschy. xliv. (1894) 146. - As. Min.

flabellata, Post, in Bull. Herb. Boiss. i. (1893) 23. -

Syria.
hirtella, C. Winkl. in Act. Hort. Petrop. xi. (1889) 278. - Buchara.

kabylica, batt. et Trab. Fl. de l'Algér. (Dicot.) (1889) 454; et in Bull. Soc. Bot. Fr. xxxix. (1892) 72. Algeria.

macroglossa, Somm. et Levier, in Nuov. Gionn. bot. Ital. Ser. II. ii. (1895) 85. - Reg. Cauc.

melanolepis, Boiss. Fl. Or. Suppl. (1888) 297. Ins. Cypr.

meteorica, Hausshn. ex Nym. Consp. fl. Europ. Suppl. ii. (1889) 165. - Thess.

Muenteriana, Heldr. ex Boiss. Fl. Or. Suppl. (1888) 298. - Graecia.

numidica, Batt. in Batt. et Trab. Fl. de l'Algér. (suppl.) (1890). - Algeria.

ochroleuca X, Celak. f. ex Ber. Deutsch. Bot. Ges. v. (1887) p. cxxiii. -Bohem.

orbelica, Panc. Nov. elem. A. princip. Bulg. (1886) 27. - Bulg.

retusa, Velen. F1. Bulg. (1891) 260 in syn. = Brachmanni, Boiss. et Heldr.

Saportana, Alboff, in Bull. Herb. Boiss. iii. (1895) 92. - Reg. Transcauc.

Sintenisii, Freyn; in Oest. Bot. Zeitschr. xliv. (1894) 147. - As. Min.

Tempskyana, Freyn et Sint. in Bull. Herb. Boiss, iii. (1895) 347. - Armen, turc.

ANTHEPHORA, Schreb. (Gramin.). - Ind.

Kew. i. 146.
cenchroides, K. Schum, in Engl. Pflanzenw. OstAfr. C (1895) $99=$ Hochstetteri, Nees.

hermaphrodita, Kuntze, Rev. Gen. (1891) $759=$ elegans, Schreb.

Schinzii, Hack. ex Schinz, in Verh. Bot. Ver. Brand. xxx (1888) 139. - Afr. austro-occ. extratrop.

ANTHERICOPSIS, Engl. Pflanzenw. Ost-Afr. C (1898) 139. LILIACEAE.

Fischeri, Engl. l. c. - Afr. trop. or.

ANTHERIGUM, Linn. (Liliac.). - Ind. Kew. i. 146.

acuminatum, Rendle, in fourn. Linn. Soc. xxx. (1895) 411. - Afr. trop. or.

apodastanthum, F. D. Smith, in Coult. Bot. Gaz. xix. (1894) 265. - Guatem.

\section{ANTHERICUM}

arvense, Schinz, in Verh. Bot. Ver, Brand.xxxi. (1890) 216. - Afr. austro-occ extratrop.

aurantiacum, Baker, ex Hemsl. Biol. Centr.-Am. iv. (1886) 91; et in Engl. Bot. Fahrb. viii. (1887) 289. - Guatem.

Bragae, Engl. Pfanzenz. Ost-Afr. C (1895) 138. Afr. trop. or.

campestre, Engl. in Abhandl. Prenss. Akad. Wiss. (1894).28; et Pfianzenw. Ost-Afr. C (1895) 138. Afr. trop. or.

crassinerve, Baker, in fourn. Bot, xxix. (1891) 71. - Afr. austro.-occ. extratrop.

dianellaefolium, Baker, in fourn. Linn. Soc. xxii. (IS87) 529. - Madag.

Fischeri, Baker, in Bot. Fahrb. xv. (1S93) 468. Afr. trop. or.

Giryamae, Rendle, in fourn. Limn. Soc. xxx. (1895) 412. - Afr. trop. or.

Gregorianum, Rendle, l.c. 416. - Afr. trop. or.

Lehmanni, Baker, in Bot. Fahrb. viii. (1887)

208. - Ecuad.

leucocomum, Robins. et Greemman, in Am. Fourn. Sci. Ser.III. 1. (1895) 168. - Mexic.

macrophyllum, Baker, ex Hemsl. Biol. Centr,-Am. iv. (1886) 91; et in Bot. Fahrb. viii. (1887) 209 - Guatem.

micranthum, Baker, in fowm. Bot. xxxix. (1891) 71 .

- Transvaal.

milanjianum, Rendle, in Trans. Linn. Soc. Ser. II

iv. (1894) 51. - Afr. trop. or.

Nyassae, Rendle, l. c. 52. - Afr. trop. or

purpuratum, Rendle, in fourn. Linn. Soc. xxx. (1895) 413. - Afr, trop. or.

rubellum, Baker, in Fohnston, Kitimn Njaro Exped.

(1886) 347 nomen; et in Trans. Linn. Soc. Ser. II. ii. (I887) 252. - Afr. trop, or.

serotinum, Baker, in Bot. Fahrb. xv. Beibl. n. 35 (1892) 8. - Arkansas.

speciosum, Rendle, in Fourn. Linn. Soc. xxx, (1895) 413 t. 33. - Afr. trop. or.

Stuhlmanii, Engl. Pfanzenz. Ost-Afr. C (1895)138. - Afr. trop. or.

Taylorianum, Rendle, in fourn. Limn. Soc. xxx. (IS95) 415. - Afr. trop. or.

tuberosum, Herb. Heyne, ex Hook, f, Fl, Brit. Ind. vi. (1892) $334=$ Chlorophytum arundinaceum, Baker.

uyuiense, Rendle, in foum. Linn. Soc. xxx. (1894) 415. - Afr. trop. or.

venulosum, Baker, in fohnston Kilima Njaro Exped. (1886) 347 nomen; et in Trans. Linn. Soc. Ser. II. ii. (1887) 352. - Afr. trop. or.

ANTHEROTOMA, Hook. f. (Melastom.). - Ind Kew. i. 148.

Antherotoma, Krasser, in Engl. et Prantl, Natürl Pflanzenfam. iii. 7. (1893) $154=$ Naudini Hook. $f$.

ANTHISTIRIA, Linn. f. (Gramin.). - Ind. Kew. i. 148 .

Helferi, Munro, ex Hack. in DC. Monog. Phan. vi (1889) 665 (= Themeda Helferi, Hack.). L Tenass Ins. Andam.

vulgaris, Hack. in Engl. et Prantl, Natirnl. Pfanzenfam. II. 2. (1887) $29(=$ Theneda Forshhalii, Hack. - Orb. vet. reg. trop.

ANTHOBRYUM, Phil. in Anal. Mus, nac. Chile (1891) 51. PRIMULACEAE.

aretioides, Phil. l. c. t, 2 fig. 4. - Bolivia.

tetragonum, Phil.l. c. t. 2 fig. 3. - Bolivia.

ANTHOCLEISTA, Afzel. (Logan.). - Ind. Kew. i. 149 .

amplexicaulis, Baker, in fown. Linn. Soc, xxii. (1887) 506. - Madag.

Buchneri, Gilg, in Bot.fahwb. xvii. (1893) 576. Angola.

grandiflora, Gilg, l. c. 582. - Ins. Comor.

Hildebrandtii, Gilg, l. c.583. - Madag.

inermis, Engl. Bot. fahrb. viii. (1887) 63. - Congo.

insignis, Galpin, in Kew Bull. (1895) 150. - Afr austr.

Kalbreyeri, Baker, 7. c. 99. - Afr. trop. occ.

laxiflora, Baker, l. c. - Afr, trop. occ
ANTHOGLEISTA

macrantha, Gilg, in Bot. Fahrb, xvii, (1893) 578, -

Anorola.

magnifica. Gilg, l. c. 584. - Gabon.

niamniamensis, Gilg, l. c.580. - Afr. centr. bor.

orientalis, Gilg, in Engl. Pflanzenw. Ost.-Afr C (1895) 312. - Afr. trop. or

parviflora, Baker, in Kew Bull. (1895) 99. -

Afr. trop. Occ.

(1887) 506. - Madag.

Schweinfurthi

- Afr. trop

Stuhlmannii, Gilg, l. c. 680. - Afr. trop. or

Urbaniana, Gilg, l. c.584. - Madag.

zambesiaca, Baker, in Kew Bull. (1895) 99. Afr. trop. or.

ANTHODISCUS, G. F. W. Mey. (Ternstroem.) - Ind. Kew, i. 149 .

bovatus, Benth. ex Wittm. in Mart. Fl. Bras. xii. 1. (1886) 358. - Bras.

ANTHOLOBUS, Bot. Centrabl. 1xi. (1895) 362 sphalm. = Anthobolus, R. Br. (Santal.).

ANTHOLOMA, Labill. (Tiliac.). - Ind. Kew. i.

149

Tieghemi, F. Muell. in Vict. Natural, viii. (Feb. 1892) 164 nomen; ix. (Nov. 1892) 111; et in fourn. Bot. xxxi. (1893) 322. - N. Guin.

ANTHOLYZA, Linn. (Irid.). - Ind, Kew. i, 149 racilis, Pax ex Engl. in Abhandl. Press. Akad. Wiss. 1891 (1892) 17\%. - Afr. trop. or.

hantamensis, Klatt, in Th. Dur. et Schinz, Consp. Fl. Afr. v. 1893 (1895) 228 (= Hesperantha montana, Klatt). - Afr. austr.

labiata, Pax, in Bot. Fahrb. xv. (1893) 156. - Afr. trop. occ.

Schweinfurthii, Baker, in Gard. Chron.(1894) i. 588. - Abyss.

Steingroeveri, Pax, in Bot. Fahrb. xv. (1893) 156.Afr. austro-occ. extratrop.

Watsoniana, Pax. in Engl. et Prant1, Natürl, Pflanzenfam, ii. 5. (1888) 156 (= Gladiolus Watsonius, Thunb, $=$ revoluta, Burm.

zambesiaca, Baker, Handb. Irid. (1892) 232. - Afr. trop. or.

ANTHOSHOREA, Pierre, F1. For. Cochinch. (1891) sub t. $250=$ Shorea, Roxb, (Dipterocarp.)

Harmandit, Pierre, 1. c. = S. Harmandii, Laness.

ANTHOSPERMUM, Linn. (Rubiac.). - Ind.

Kew. 1. 150.

humile, N.E. Br. in Kew Bull. (1895) 145. Natal.

usambarense, $K$. Schum. in Bot. Fahrb. xvii. (1893) 165 in obs.: et in Abhandl. Preuss. Akad. Wiss. (1894) 69. - Afr. trop. or.

viscosum, Webb, ex Christ, in Bot. Jahrb. ix. (1888) I44 in syn. = Phyllis viscosa, Christ.

Whyteanum, Hiern, in Trans. Linn. Soc., Ser. II., iv. (1894) 16. - Afr. trop. or.

ANTHOSTEMA, A. Juss. (Euphorb.). - Ind. Kew. i. 150 .

Aubryanum, Baill, in Laness. Pl. util. col. franc. (1886) 815 nomen (Anthostemma). - Seneg.

ANTHOTROGHE, Endl. (Solan.). - Ind. Kew.

i. 150

Healeana, F. Muell. in Vict. Natur.viii. (Feb. 1891) 153; et in Bot. Centralbl. xlv. (1S91) 385. Austral.

ANTHOXANTHUM, Linn. (Gramin.). - Ind.

Kew. 1. 150.

nivale, $K$. Schum. in Engl. Pfanzenz. Ost-Afr. C 1895) 107. - Afr. or

ANTHRISGUS, Bernh. (Umbellif.). - Ind. Kew. i. 150 .

Vandasii, Velen. in Sitz, bölm. Ges. Wiss. $1889(1890)$ ii. 35; et Fl. Bulg. (1891) 219. - Bulg.

velutinus, Somm, et Levier, in Nuor', Giorn, bot, Ital. Ser. II. ii. (1895) 73.-Reg. Cauc. 
ANTHROTROCHE Hcaliana, F. Muell. in Vict. Natural, viii (May 1891) 4 nomen, sphalm. = Anthotroche Healiana, F. Muell.

ANTHURIUM, Schott (Aroid.). - Ind. Kew. i.

acutum, N. E. Br. in Gard. Chron. (1887) ii. 776. - Bras.

Allendorfii X, Hort. ex Gartenfl. (1889) 121 t. 1293 fig. e. - Hybr. artef.

brvilobum, N, E. Br. in Gard. Chron. (1887) i 380 = parvum, $N \cdot E \cdot B r$

burfordiense X. Hort. ex Gard. Chron. (1889) i. 700. - Hybr. artef.

Chamberlaini, Mast.in Gard. Chron.(1888) i. 462 fig. 66, 67; Hook. f. in Bot. Mag. (1893) t. 7297.Venez.?

Chantinianum $\times$, Martinet, in Rev. Hortic. (1889) 157. - Hybr. artef.

Crombezianum $\times$, Hort. ex Éd. André, in Rev. Hortic. (1894) 552 cum icone. - Hybr., artef.

cruentum X, Éd. André, 1. c. (1886) 50. - Hybr. artef.

cymbiforme, N. E. Br. in Gard. Chron. (1889) ii. 67. - Am. austr.

Desmetianum X, Hort, ex Rodigas, in Illustr.Hortic. (ISsS) 47 t. lii. - Hybr. artef.

eburneum, Williams, Catal. (1891) 24. - Hybr. artef.

excelsior $\times$, Hort. ex Wien Ill. Gartenzeit. (1890)

307 cum icone. - Hybr. artef.

gandavense $\times$, Hort. ex Gard. Chrón. (1893) i. 415.

- Hyhr. artef.

Goldringi $\times$, Hort. ex Gard. and For. vi. (1893) 269. - Hybr. artef.

Groyanm X.Hort. ex Gard. and For. v. (1892) 525. - Hybr. artef.

Grusoni X, Hort. ex Gartenff. (1889) 121 t. 1293 fig. a. - Hybr. artef.

Hardyanum X, Martinet, in Rev. Hortic. (1889) 157. - Hybr. artef.

Hero X, N. E. Br. in Gard. Chron. (1890) ii. 652. - Hybr. artef.

Hollandi $X$, Hort. ex Gard. and For, vi. (1893) 269. - Hybr. artef.

isarense X, Éd. André, in Rev. Hortic. (1888) 423. - Hybr, artef,

Kolbii X, Hort. ex Gartenf. (1889) 121 t. 1293 fig. b. - Hybr. artef.

Laingi, Hort. ex Wien. Ill. Gartenzeit. (1888) 383. - Form. hort.

Lawrenceanm, Éd, André, in Rev. Hortic. (1888) 12 cum icone. - Hybr. artef.
longispathum, Carvièe, in Rev. Hortic. (1888) 498. - Ins. Guadal.

Mooreanum, N.E.Br. in Gard. Chron. (1886) ii. 2:30. - Hal. ?

Ortgiesii X. Hort. ex Gartenf. (1889) 121 t. 1293

fig. d. - Hybr. artef.
Paradisae X. Williams, Catal. (1891) 24. - Hybr. artef.

punctatum, N.E. Br. in Gard. Chron. (1886) ii, 809. - Ecuad.

purpureum, N.E.Br.l.c.(1887) i. 575. - Bras.

Ridalfianum $\times$, Pucci, in Bull. Soc. Tosc Ortic. (1891) 244 t. 8. - Hybr, artef.

roraimense, N. E. Br. ex Oliver, in Trans. Linn. Soc.. Ser. Ir. ii. (1887) 286 (Oliver, ex im Thurn. in Timehri, v. (1886) 209). - Guian, angl.

rosaeflorum X, Hort. ex Gard. Chron. (1892) i. 731 nomen. - Hybr, artef.

rosenm $x$, Hort. ex Boll. Soc. Tosc. Ortic. (1888) 99. - Hybr. artef.

rotundispathum $\times$, L. Lind. et Rodigas, in Illust. Hortic. (1891) 9 t. 119. - Hybr. artef.

salmonem X, Hort. ex Illustr. Hortic. (1895) 281 t. 42. - Hybr. artef.

subulatum, N.E. Br. in Gard. Chron. Ser. xxvi. (1886) 230. - Columb.

sylvestre, S. Moore, in Trans. Linn. Soc., Ser. II. iv. (1895) 503. - Bras.

Van $W$ ambekeanum $\times$, Hort. ex Illustr. Hortic. xli. (1895) $281=$ Wambeckeanum, Hort.

Wambeckeanum X, Hort. ex Illustr. Hortic. (1895) 185. - Hybr. artef.

Wanbeckianum X, Hort. ex Gard. Chron. (1893) ii. $557 \mathrm{fig} .92=$ Wambeckeanum, Hort.

\section{ANTHURIUIM : -}

Wittmackii X. Hort. ex Gartenfl. (1889) 121 t. 1293 fig.c. - Hybr. artef.

ANTHYLLIS, Riv, ex Linn. (Legumin.). - Ind. Kew. i. 153.

albana, Wettst. in Luerss. Bibl. Bot. Heft xxvi. (1892) 37 t. ii. fig. 24, 26. - Albania.

alpicola, Brügg. in Jahresb. Nat. Ges. Graub. xxix. (1886) $25=$ A. Vulneraria, Limn.

Cherleri, Brügg. 1. C. = A. Vulneraria, Linn. densifolia, Formanek, in Verh. naturf. Ver. Brunn. xxxii. 1893 (1894) 209. - Maced.

depressa, Lange, in Danske Vidensk. Selsk. Forh. (1893) 203. - Hisp.

dinarica, G. Beck, F1. von Südbosn. vi. (1891) 341 t. 19. - Bosnia.

fulgurans, Porta, in Nuov. Giorn. bot. Ital. xix. (1887) 303. - Ins. Balear.

Hegetschweileri, Briigg. ex Killias, in Jahresb. Nat. Ges. Graub, xxxi. Beil. (1887-88) $3.9=$ A. Vulneraria, Linn.

scaruica, Wettst. in Luerss. Bibl. Bot. Heft xxvi. (1892) 37. - Albania

ANTIARIS, Lesch. (Urtic.). - Ind. Kew. i. 153. turbinifera, Hemsl. in fourn. Linn. Soc. xxx. (1894) 215. - Izs. Salom.

ANTIAROPSIS, K. Schum, in K. Schum. Hollr. Fl. Kais. Wilh. Land (1889) 40. URTICEAE.

decipiens, K. Schum.l.c. - N. Guin.

ANTIGHARIS, Endl. (Scrophul.). - Ind. Kew. i. 153.

Aschersoniana, Schinz, in Verh. Bot. Ver. Brand. xxxi. (1890) 188. - Angola.

ebracteata, Schinz, l. c. 187. - Afr. austro-occ extratrop.

imbricata, Schinz, l. c. - Afr. austro-occ. extratrop.

inflata, Marl. et Engl. in Bot. Fahrb. x. (1889) 251 - Afr. austro-occ. extratrop.

longifolia, Marl, et Engl. l. c. 252. - Afr. austroocc. extratrop.

ANTIDESIMA, Burm. (Euphorb.). - Ind. Kew.i. 154

alatum, Hook. f. Fl. Brit. Ind. v. (1887) 358. Penins. Mal.

alnifolia, Baker, in fourn. Linn. Soc. xxii. (1887) 519. - Madag.

andamanicum, Hook. f. Fl. Brit. Ind. v, (1887) 364. - Ins. Andam.

apiculatum, Hemsl. in fourn. Linn. Soc. xxvi. (1894) 430. - China.

arbutifolia, Baker, l. c. xxii. (1887) 519. - Madag. brunneum, Hook. f. Fl Brit. Ind. v. (1887) 359. Zeyl.

brachyscypha, Baker, in fourn. Linn. Soc. xxii (1887) 519. - Madag.

comorense, Vatke et Pax, ex Pax, in Bot. Fahrb. xv. (1893) 529. - Ins. Comor.

erythroxyloides, Baill. Hist. pl. Madag., Atlas (1892) t. 214. - Madag.

Fordii, Hemsl. in Fourn. Limn. Soc. xxvi. (1894) 430. China.

gracilis, Hensl. l. c. 43I. - China.

Helferi, Hook. f. Fl. Brit. Ind. v. (1887) 35\%, Ind. or.

Henryi, Hemsl. in fourn. Linn. Soc. xxvi. (1894) 431. - China.

khasianum, Hook. f. Fl. Brit. Ind. v. (1887) 362. Reg. Himal.

Kingii, Hook. f.l. c. 356. - Perak.

lanceolatum, Hook. f. et Thoms. ex Hook f. 1. c. $362=$ khasianum, Hook. $f$.

leucocladon, Hook. f. l. c. 358. - Penins. Mal.

longipes, Hook. f. l. c. 355 . - Perak

longipes, Pax, in Bot. Fahrb. xv. (1893) 529. Afr. trop. occ

microphyllum, Hemsl, in fourn. Limn. Soc. xxvi. (1894) 432. - China.

oblongum, Wall. ex Hook. f. F1. Brit. Ind. v. (1887) $364=$ martabanicum, Presl.

olivaceum, $K$. Schum, in $K$ Schum. ct Hollv. Fl. Kais. Wilh. Land, (1889) 76. - N. Guin.

\section{ANTIDESMA}

pachystachys, Hook. f. Fl. Brit. Ind. v. (1887) 355. - Penins. Mal.

pendulum, Hook. f.l. c.-- Perak.

pulvinatum, Hillebr. Fl. Haw. Isl. (1888) 403. Schweinfurthii, Pax, in Bot. Fahrb.xv. (1893) 530. - Afr. centr. bor.

Wattii, Hook. f. Fl. Brit. Ind. v (I887) 366. Ind. or.

Wawraeanum, G. Beck, ex Wawra, Itin. Princ. S. Coburg. ii. (I888) 7\%.- Ins. Hawaii.

ANTIGONON, Endl. (Polygon.). - Ind. Kew. i 154.

flavescens, S. Wats. in Proc. Am. Acad. xxii. (188\%) 446. -- Mexic.

ANTIRRHINUM, Tourn, ex Linn. (Scrophul.). - Ind. Kew. i. 155

antirrhiniflom, Hitchic, in Rep. Missouri Bot. Gard. iv. (1893) 113; Heller, Bot. Expl. S. Texas (1895) 91 = Maurandia antirrhiniflora, $W$ illd. asarinum, St-Lager, in Cariot, stud. des fl. éd. 8 ii. (1889) $621=\mathrm{A}$. Asarina, Linn.

Nevinuanum, Orcutt in West Am. Scientist (1891) $208=$ Nevinianum, A. Gray.

Watsoni, Vasey et Rose, in Proc. U. S. Nat.Mus. xi. (1888) 533. - Calif.

ANTOGOERINGIA, Kuntze, Rev. Gen. (1891) 250 = Stenosiphon, Spach (Onagrar.).

linifolia, Kuntze, 1. c. = S. virgatum, Spach.

ANTUNESIA, O. Hoffm, in Bolet. Soc. Brot. x. (1893) 178. COMPOSITAE.

angolensis, O. Hoffm. l. c. 179. - Angola.

ANUBIAS, Schott (Aroid.). - Ind. Kew. i. 157.

hastaefolia, Engl. in Mitt. zu Forschungsr, von Danckelm. ii. 149; et in Bot. Jahrb. xv. (1893) 462. - Afr. trop. occ.

ANYGHIA, Michx (Illecebr.). - Ind. Kew. i. 157. canadensis, Britton, Stern. et Poggenb. Prelim. Catal. (1888) $44=$ capillaris, $D C$.

filiformis, Rafin. ex Britton in Bull. Torrey Bot. Club, xiii. (1886) $187=$ capillaris, $D C$.

APALATOA, Aubl.=Crudia, Schreb. (Legumin.). acuminata, Taub. in Bot. Centralbl. xlvii. (1891) 394. = C. acuminata, Benth.

amazonica, Taub. I. c. = C. amazonica, Spruce. aromatica, Taub. 1. c. = C. aromatica, Willd. bantamensis, Taub. 1. c. $395=$ Pryona bantamensis, Miq.

glaberrima, Taub.1. c. $394=$ C. obliqua, Griseb. oblonga, Taub. 1. c. = C. oblonga, Benth.

pubescens, Taub. 1. c. $=$ C. pubescens, Spruce.

senegalensis, Taub. 1. c. $395=$ C. senegalensis, Planch.

tomentosa, Taub. 1. c. $394=$ C. Parivoa, DC

zeylanica, Taub. 1.c. $395=$ C. zeylanica, Benth

APAMA, Lam. = Bragantia, Lour, (Aristoloch.). corymbosa, Kuntze, Rev. Gen. (1891) $63=$ B. corymbosa, Griff.

Dalzellii, Kuntze, 1. c. = B. Dalzellii, Hook. $f$.

racemosa, Kuntze, 1. c. = B. racemosa, Lour.

tomentosa, Eng1. in Engl. et Prant1, Natür1. Pflanzenfam. III. i. (1888) 272=B. tomentosa, Blume.

APATION purpurascens, Blume, ex Ridl. in Journ. Linn. Soc. xxii. (1886) 279 in syn. = Liparis repens, Ridl.

APEIBA, Aubl. (Tiliac.). - Ind. Kew. i. 158. Schomburgkii, Szyszyl. in Diss. Cl. math.-phys. Acad. litt. Crac. xxvii. (1894) 140. - Guian., Venez.

APERA, Adans. (Gramin.). - Ind. Kew. i. 158. purpurascens, Colenso, in Trans. N.Z. Inst. xxi。 1888. I(889) 106. - N. Zel.

APERULA, Blume = Lindera, Thunb. (Laurin.). Meissneri, Herb. Calc. fide Hook. f, Fl. Brit. Ind. v. (1886) $182=$ L. assamica, $K u v z$. 
APHANAMIXIS, Pierre, Fl. For. Cochinch. (1895) sub t. 334. MELIACEAE

Rohituka, Pierre, l. c. - As. trop austro-or.

APHANANDRIUM, Lindau, in Engl, et Prant1, Natürl. Pflanzenfam.iv. 3 b. (1895) 323. ACANTH ACEAE

Lehmannianum, Lindau, l. c. - Columb

APHANANTHE, Planch. (Urtic.). - Ind. Kew. i. 158.

aspera, Engl. in Engl. et Prantl, Natiirl. Pflanzenfam. iii. 1. (1888) 66. - Japon.

APHANES, Linn. = Alchemilla, Linn. (Rosac.). pusilla, Pomel, ex Batt. et Trab. Fl. de l'Algér. (Dicot.) (1888) $309=$ Al. cornucopioides, Roem. et Schuit.

APHANELYTRUM, Hack. ex Sodiro, Gram. Ecuator. (Anal. Univ, Quito 1889) 7 nomen. GRAMINEAE.

decumbens, Hack. l. c. - Ecuad.

APHANIA, Blume = Sapindus, Linn. (Sapind.). philastreana, Pierre, Fl. For. Cochinch. (1895) t. 329 B. - Cochinch.

viridis, Pierre, 1. c. t. 329 A. - Cochinch.

APHANOGOGGUS, Radlk, in Th. Dur. Ind. Gen. (1888) 74; et in Sitz, math. phys. Cl. bayer. Akad. Wiss. xx. (1890) 283. SAPINDACEAE. celebicus, Radlk. Il. cc. -Ins. Celeb.

APHANOSTEPHUS, DC. (Composit.). - Ind Kew. i. 159.

pinulensis, Coult. ex 7. D. Smith, Enum. pl. Guat. ii. (1891) n. 2407 nomen; et in Coult. Bot Gaz. xvi. (1891) 98. - Guatem.

skirrobasis, Trelease, ex Coville et Branner in Rep. Geol. Surv. Ark. 1888, iv. (1891) $191=$ arkansanus, A. Gray.

APHELANDRA, R. Br. (Acanth.). - Ind. Kew. i. 159 .

amoena, Bull. Catal. (1888) 7; et Kew Bull. (1889) 77 = Blanchetiana, Hook. $f$

Blanchetiana, Hook. f. in Bot. Mag. (1891) t. 7179 - Bras.

chrysops, Bull, Catal. (1887) 7 et 9; et in Gard. Chron. (1887) i., 736 fig. $140=$ squarrosa, Nees, var.

dubia $\times, \mathbf{L}$. Lind, et Rodig. in Illustr. Hortic (1894) 233 t. 15. - Hybr. artef.

gigantiflora, Lindau, in Bull. Herb. Boiss, iii. (1895) 369. - Am. centr

Heydeana, F. D. Smith, in Coult. Bot. Gaz. xviii. (1893) 210 . - Guatem. inaequalis, Lindan, in Bull. Herb. Boiss. iii. (1895)
368. - Bolivia.

Macedoiana, L. Lind. et Rodig, in Illustr. Hortic. (1886) 11 t. 583 . - Bras

macrosiphon, Lindau, in Bull. Herb. Boiss. iii. (1895) 367. - Bolivia.

montana, Lindau, in Engl. et Prantl, Natiurl. Pflanzenfam.iv.3 b.(1895) 322 (=Lagochilium montanum, Nees). - Am. austr.

simplex, Lindau, l. c. 366. - Bolivia.

tomentosa, Lindau, l. i. 369. - Venez.

APHELEXIS, D. Don (Composit.). - Ind. Kew. i. 161 .

flexuosa, Baker, in fourn. Linn. Soc. xxii. (1887) 492. - Madag.

stenoclada, Baker, l. c. 493. - Madag.

sulphurea, Baker, l. c. - Madag.

APHE OIA, Benn. (Bixin.). - Ind. Kew. i. 160. minima, Baker, in fourn. Linn. Soc. xxii. (1887) 444. - Madag.

myrtiflora, Galpin, in Kev Bull. (1895) 142. Transvaal.

APHORA, Neck. = Virgilia,Lam.(Legumin.) (cfr. Ind. Kew.)

argentea, biflora, Burchellii, buxifolia, calyptrata, canescens, cordata, cuneifolia, glauca, lanceolata, micro-
APHORA :-

phylla, orbicularis, reticulata, sericea, speciosa, velutina, Kuntze, Rev. Gen. (1891) I61 = homonyma omnia Podalyriae.

rotundifolia, Kuntze, 1. c. $160=$ P. myrtillifolia, Willd.

APHYLLARUM, S. Moore, in Trams. Linn. Soc. Ser. II. iv. (1895) 501. AROIDEAE.

tuberosum, S. Moore, l. c. t. 35 . fig. 1-12. Bras.

APHYLLON, Mitch. (Orobanch.). - Ind. Kew. 160.

californicum, T. S. Brandeg. in Proc. Calif. Acad., Ser. II, ii. (1889) $192=$ californicum, A. Gray. chilense, Phil. in Anal. Univ. Chil. xc. (1895) 201 (= Myzorrhiza chilensis, Phil.). - Chili.

APHYLLORGHIS, Blume (Orchid.). - Ind. Kew. i. 160.

Odoardi, Reichb.f. in Bot. Centralbl. xxviii. (1886) 345. - N. Guin.

Prainii, Hook. f. Fl. Brit. Ind. vi. (1890) 117; et Icon.pl. xxii. (1894) t. 2192. - Reg. Himal.

vaginata, Hook. f. 11. cc. 117; et t. 2193. - Reg. Himal.

APIASTRUM, Nutt. ex Torr. (Umbellif.) - Ind.

Kew i 160.

patens, Coult. et Rose, Rev. N. Am. Umbell. (1888) 110; et Contrib. U. S. Nat. Herb. ii. (1891) 146 (= Leptocaulis patens, Nutt.). - Am. bor.

APICRA, Willd. (Liliac.), - Ind. Kew. i. 160. turgida, Baker, in fourn. Bot. xxvii. (1889) 44. Afr. austr.

APINELLA, Neck. = Trinia, Hoffm. (Umbellif.). Dufourii, Kuntze, Rev. Gen. (1891) $265=\mathrm{T}$. Dufourei, $D C$.

frigida, Kuntze, 1. c. (= Rumia frigida Boiss. et Heldr ) - Graecia.

glauca, Caruel, in Parl. Fl. Ital. viii. (1889) 503 $=\mathrm{T}$. vulgaris, $D C$

glauca, Kuntze, Rev. Gen. (1891) $265=$ praec.

Guicciardi, Kuntze, 1. c. $(=$ Rumia Guicciardi, Boiss. et Heldr.) - Graecia.

Henningii, Kuntze, 1. c $=$ T. Henningii, Hoffm.

hispida, Kuntze, 1. c. = T. hispida, Hoffm.

Kitaibelii, Kuntze, 1. c. = T. Kitaibelii, Bieb.

Lessingii, Kuntze, 1. c. = T. Lessingii, Reichb. $f$.

scabra, Kuntze, 1. c. = T. scabra, Boiss, et Noé.

seseliodes, Kuntze, 1. c. = E. seselioides, Ledeb.

taurica, Kuntze, 1. c. = Sanicula crithmifolia Willd.

APIOS, Moench (Legumin.). - Ind. Kew. i. 161. Apios, MacMillan, in Bull. Torrey Bot. Club, xix. (1892) $15=$ tuberosa, Moench.

Delavayi, Franch. Pl. Delav.(1890) 180. - Yunnan. macrantha, Oliver, in Hook.Icon. pl.xx. (1890) t.1946. - China.

APIUM, (Tourn.) Linn. (Umbellif.). - Ind. Kew. i. 161 .

alpinum, Caruel, in Parl. Fl. Ital. viii. (1889) 429 = Carum alpinum, Benth. et Hook. $f$.

Ammios, Caruel, 1. c. $435=$ Ptychotis verticillata Duby.

andinum, Phil. in Anal. Univ. Chil. 1xxxv. (1894) 717. - Chili.

anisoides, Caruel. in Parl. Fl. Ital. viii. (1889) 459 $=$ Pimpinella anisoides, Brign.

Berula, Caruel, 1. c. $463=$ Sium erectum, Huds.

Butleri, Engelm.ex S. Wats. in Proc. Am. Acad. xxi. (1886) 453. - Texas, Arkans.

crinitum, Caruel, in Fl. Parl. Ital, viii. (1889) $441=$ Ammi crinitum, Guss.

ferulaceum, Caruel. 1. c $428=$ Carum ferulaefolium, Boiss.

flexuosum, Caruel, 1. c. $433=$ C. flexuosum, Nym. luteum, Caruel, 1. c. 458 = Pimpinella lutea, Desf. montanum, Caruel, 1. c. $429=$ Carum montanum Benth. et Hook. $f$.

\section{APIUM :}

Pimpinella, Caruel, in Parl. Fl. Ital. viii. (1886)

452 = Pimpinella magna, Linn.

Podagraria, Caruel, 1. c. $467=$ Aegopodium Podagraria, Linn

rigidulum, Caruel, 1. c. $434=$ Carum rigidulum Koch.

verticillatum, Caruel,1.c. $430=$ C. verticillatum, Koch

Tragium, Caruel, 1. c. $460=$ Pimpinella Tragium, Desf.

APLECTRUM, Torr. (Orchid.). - Ind. Kew. i. 161

spicatum, Britton, Stern. et Pogg. Prelim. Catal. (1888) $51=$ hiemale, Nutt.

APLOPAPPUS, Cass. (Composit.). - Ind. Kew. i. 162 .

cruentus, Greene, Pittonia, ii. (Nov. I889) 17. Calif.

fasciculatus, Coult. et Rose, in Proc. U. S. Nat. Mus. (1888).

gracitis, T. S. Brandeg. in Proc, Calif. Acad. Ser. II. ii. (1889) = an Aplop. gracilis, A. Gray?

graveolens, Kuntze, Rev. Gen.(1891)313, sphalm. = Bigelowia dracunculoides, DC.

Howelli, A. Gray. Syn Fl. N. Am. ed. 2, Suppl. i. (1886) 446. - Oregon.

interior, Coville, in Proc. Biol. Soc. Wash, vii. (1892) 65. - Calif.

Nealleyi, Coult. in Contrib. U. S. Nat. Herb. i. (1890) 40; et ii. (1892) 186. - Texas

niveus, S. Wats. in Proc. Am. Acad. xxiii. (1888) 277. - Mexic.

spinulosus, T. S. Brandeg, in Proc. Calif. Akad. Ser. II. ii. (I889) 168. - Calif.

tenuilobus, A. Gray, in Proc. Am. Acad. xxi. (1886) 385 et 432 . - Mexic.

texanus, Coult. in Contrib. U. S. Nat. Herb. i. (1890) 40; et ii. (1892) $241=$ Haploesthes Greggii, A. Gray

vernicosus, T. S. Brandeg. in Proc. Calif. Acad. Ser. II. ii. (1889) 168. - Calif.

APLUDA, Linn. (Gramin.). - Ind. Kew. i. 164. varia, Hack, in Engl. et Prantl, Natïrl. Pflanzenfam. ii. 2. (1887) 26; et in DC. Monog, Phan. vi. (1889) 196. - As. et Austral. trop.

APOCOPIS, Nees (Gramin.). - Ind. Kew, i. 164 collina, Balansa, in Morot, fourn. de Bot. iv. (1890)

84. - Tonk.
aginata, Hack. in Oest. Bot. Zeitschr. xli. (1891) 8. - Ind. or.

APOGYNUM (Tourn.) Linn. (Apocyn.). - Ind. Kew, 164

floribundum, Greene, in Erythea, i. (1893) 151. Calif.

pumilum, Greene, Man. Bot. San Franc. Bay. (1894) 240. - Calif.

vestitum, Greene, l.c. - Calif.

APODANTHERA, Arn. (Cucurb.). - Ind. Kew. i. 164 .

crispa, Cogn. in Bull. Acad. roy. Belg. Sér. III. xiv. (1888) 352. - Mexic.

Palmeri, S. Wats. in Proc. Am. Acad. xxiv. (1889) 50. - Mexic.

Pringlei, S. Wats. l. c. xxv. (1890) 149; et in Coult. Bot. Gaz. xvi. (1891) 83. - Mexic.

Roseana, $\operatorname{Cogn}$. ex F. N. Rose, in Contrib. U. S. Nat. Herb. iii. (1895) 317. - Mexic.

APODANTHES, Poit. (Cytin.). - Ind. Kew. i. 164

globosa, S. Wats. ex Robinson, in Coult. Bot. Gaz. xvi. (1891) 83. - Mexic.

Palmeri, S. Wats. in Proc. Am. Acad. xxiv. (1889) 50. - Mexic.

APODINA, Van Tiegh. in Bull. Soc. bot. Fr. xlii. (1895) $353=$ Loranthus, Linn. (Loranth.). cucullaris, Van Tiegh. 1. c. = I. cucullaris, Lam. cupulifer, Van Tiegh. 1. c. = L. cupulifer, $H$. B. et $K$. 
APODINA :-

mexicana, Van Tiegh, in Bull, Soc, bot. Fr, xlii. (1895) $353=$ Loranthus mexicanus, Presl.

APODOGEPHALA, Baker (Composit.). - Ind. Kew. i. 164.

minor, S. Elliot, in Fourn. Linn. Soc. xxix. (1891) 28. - Madag.

APODOLIRION, Baker (Amaryll.). - Ind. Kew. i. 164.

Ettae, Baker, Handb. Amaryll. (1888) 26. - Natal. Macowani, Baker, l. c.-Afr. austr.

APODYTES, E. Mey. (Olacin.). - Ind. Kew. i.

cambodiana, Pierre, Fl. For. Cochinch. (1892) t. 267. - Cochinch.

emirnensis, Baker, in fourn. Linn. Soc. xxii. (1887) 458. - Madag.

Frappieri, Cordem. Fl. Ile Réunion (1895) 377.-Ins. Borbon.

inversa, Baill. Hist. pl. Madag., Atlas (1892) t. 236. - Madag.

Stuhlmanni, Engl. Bot. Fahrb. xvii. (1893) 71. Afr. trop. or.

Thouarsiana, Baill. Hist. pl. Madag., Atlas (1892) t. 237. - Madag.

APOGONIA, Fourn. = Rottboellia, Linn. (Gramin.).

glabrata, Fourn. Gram. Mexic. 1881. (1886) 63. Mexic. (cfr. Ind. Kew, i. 165)

ramosa, Fourn. 1. c. - Mexic. (cfr. 1. c.).

APONOGETON, Linn. f. (Naiad.). - Ind. Kew. i. 165 .

Boehmii, Engl. in Notizbl. bot. Gavt. i. (1895) 26. - Afr. trop. or

flavidum, Ham. ex Hook. f. Fl. Brit. Ind. vi. (1893) 564 in syn. = monostachyum, Linn. $f$.

gracile, Schinz, in Th. Dur. et Schinz, Consp. fl. Afr. v. 1894. (1895) 492. - Transvaal.

Heudelotii, Engl. Bot. Fahrb viii. (1887) 271 (= Ouvirandra Heudelotii, Kunth). - Afr. austr. Kraussianus, Hochst. ex Engl. Bot. Jahrb. viii (1887) $270=$ leptostachyum, E. Mey.

Lagrangei, Éd. André, in Rev. Hortic. (1895) 380 cum icone $=$ distachyum, Thuszb.

lucens, Herb. Madr, ex Hook, f. Fl. Brit. Ind. vi. (1893) 564 in syn. = monostachyum, Limn.f. Stuhlmannii, Engl. in Notizbl. bot. Gart. Berl. i. (1895) 26. - Afr. trop. or

APOROSA, Blume (Euphorb.). - Ind. Kew. i aurea, Hook. f, Fl. Brit. Ind. v, (1887) 351.aurea, roo

Ind. or.
Benthamiana, Hook. f. in Hook. Icon. pl. xvi. (1887) t. 1583. - Penins. Mal.

Bourdillonii, Stapf, in Hook. l. c. xxiii. (1892) t. 2204. - Travanc.

Clellandii, Hook. f. Fl. Brit. Ind. v. (1887) 348. Pegu.

falcifera, Hook. f. l. c. 352. - Perak.

globifera, Hook. f. l. c. 347. - Perak.

Griffithii, Hook. f. . c. 353, - Penins. Mal.

Maingayi, Hook. f. l. c. 348. - Ind. or,

microsphaera, Hook. f. l. c. 350 . - Perak.

nervosa, Hook.f. l. c. 350. - Malacca.

nigricans, Hook f. l. c. 347 . - Perak.

stellifera, Hook. f. l. c. 352. - Penang, Perak.

Wallichii, Hook. f. l. c. 350. - Reg. Himal.

Apostasia, Blume (Orchid.). - Ind. Kew. i. 165.
gracilis, Rolfe, in fourn. Linn. Soc. xxv. (1889) 242.

latifolia, Rolfe, l.c. - Perak.

APPENDICULA, Blume (Orchid.). - Ind. Kew i. 166.

congesta, Ridl. ex Stapf, in Trans. Linn. Soc., Ser. II. iv. (1894) 239. - Borneo.

cordata, Hook. f. Fl. Brit. Ind. vi. (1890) 83; et in Hook. Icon. pl. xxii. (1893) t. 2148. - Perak.

\section{APPENDIGULA :-}

disticha, Ridl, in fourn. Bot. xxiv, (1886) 354 t. 270 - N. Guin.

echinocarpa, Hook. f. Fl. Brit. Ind. vi. (1890) 85; et in Hook. Icon. pl. xxii. (1893) t. 2152. - Penins. Mal.

elongata, Ridl. in Trans. Linn. Soc., Ser. II. iii. (1893) 375. - Penins. Mal.

Koenigii, Hook. f. Fl. Brit. Ind. vi. (1890) 84; et in Hook. Icon. pl. xxii. (1893) t. 2149. - Ind or. lancifolia, Hook. f. ll. cc. 84; et t. 2150.-Perak.

Maingayi, Hook. $f . l l . c c .85$; et t. 2151. - Penins. Mal.

Peyeriana, Kraenzl. in Gard. Chron. ii. (1891) 669 - Sumatra.

APTANDRA, Miers (Olacin.). - Ind. Kew. i. 166

Gora, Hua, in Bull. Mus. Hist. Nat. Paris, i. (1895) 315. - Congo gall.

APTOSIMUM, Burch. (Scrophul.). - Ind. Kew, i. 166 .

albomarginatum, Marl. et Engl. in Bot. Fahrb. x. (1889) 249. - Afr. austr.

arenarium, Engl. l. c. 250. - Afr. austro-occ. extratrop.

decumbens, Schinz, in Verh. Bot. Ver. Brand, xxxi. (1890) 184. - Afr. austro-occ. extratrop.

elongatum, Engl. Bot. Fahrb. x. (1889) 249. - Afr. austr.

lineare, Marl. et Engl. l. c. 250. - Afr. austro-occ. extratrop.

nanum, Engl. l. c. 249. - Afr. austr.

scaberrimum, Schinz, in Verh. Bot. Ver. Brand. xxxi. (1890) 185. - Afr. austro-occ, extratrop.

Steingroeveri, Engl. Bot. Fahrb. xix. (1894) 149. Afr. austro-occ, extratrop.

AQUILARIA, Lam. (Thymel.). - Ind. Kew. i.

Beccariana, Van Tiegh, in Bull. Soc. Bot. Fr. xl. (1893) 77. - Borneo.

borneensis, Van Tiegh. ex Gilg, in Engl. et Prantl, Nativil. Pflanzenfan. iii. 6 a. (1894) 224. Borneo.

sinensis, Gilg, in Engl. Bot. Jahrb. xviii (1894) 506; et in Eno- et Prantl, Natürl. Pflanzenfam. iii. 6 a. (1894) $224=$ grandiflora, Benth.

AQU1LARIELLA, Van Tiegh, in Bull. Soc, bot. Fr.xl. (1893) $77=$ Aquilaria, Lam. (Thymel.). borneensis, $\operatorname{Van}$ Tiegh.1.c. = A. borneensis, Van Tiegh.

malaccensis, Van Tiegh.1. c, = A. malaccensis, Lam. microcarpa, Van Tiegh. 1. c.=A. microcarpa,Baill.

AQUILEGIA, (Tourn.) Linn. (Ranuncul.). - Ind. Kew. i. 166.

afghanica, P. Bruhl, in Fourn. As. Soc. Beng. 1xi. (1893) ii. 309. - Ind. or.

atroviolacea, G. Beck, Fl. von Nieder-Oest. i. (1890) $400=$ vulgaris, Linn

dinarica, G. Beck, in Annal. Naturhist. Hofmus. Wien. vi. (1891) 341 t. 9 fig. 1-5. - Bosnia.

ecalcarata, Eastwood, in Zoe, ii. (1891) 226; iv. 3 t. 259; tt in Proc. Calif. Acad., Ser. II. iv. (1895) 560 - Colorado.

ecalcarata, Maxim. Fl. Tangut. (1889) 20 t. 8 fig. 12. - China.

eynensis, P. Bruhl, in Journ. As. Soc. Beng. Ixi. (1893) I. 293 = vulgaris, Linn.

fabellata, Carrière, in Rev. Hortic. (1887) 548 fig. 116. - Form. hort.

micrantha, Eastwood, in Proc. Calif. Acad. Ser. II. iv. (1895) 559. t. 13. - Utah. . Colorado.

Molleriana, Borb. et Freyn in Foldrajzi Kozleményck (1894) ex Mariz, in Bolet. Soc. Brot. iv. (1886) 108. - Lusit.

pubescens, Cowille, in Contrib. U.S. Nat. Herb. iv. (1893) 56. t. 1. - Calif

recticormu, P. Bruhl, in Journ. As. Soc. Beng, 1xi. (1893) II. 293 = vulgaris, $\operatorname{Linn}$

Ranwolfi, Hort, ex Kew Bull. App. i. (1890) 4. Hab.?

saximontana, Rydberg, ex Robinson Syn. Fl. N.-Amer. i. (1895) 43. - Colorado.

\section{AQUILEGIA :}

Stuarti X.Balf.f.in Garden (1888) 344; et Rev.Hortic. (1888) 539. - Hybr. artef.

suaveolens, P. Bruhl, in Fourn. As. Soc. Beng. lxi. (1893) 11. 309. - Ind. or.

subaphylla, $P$. Bruhl, $l$. $c$. - Ind. or.

Wallichiana, Herb. Calc. ex P. Bruhi, 1. c. $306=$ vulgaris, Linn.

Winterbottomiana, P. Bruhl, 1. c. $309=$ vulgaris, Linn.

ARABIS, Linn. (Crucifer.). - - Ind. Kew. i. 168.

atrorubens, Suksdorf, ex Greene, in Erythea, i. (1893) 223. - Washington.

Beckwithii, S. Wats. in Proc. Am. Acad. xxii. (1887) 467. - Am. bor. occ.

Bolanderi, S. Wats. l. c. - Am. bor. occ.

bosniaca, G. Beck, in Annal. naturh. Hofmus. Wien, v. (1887) 71 = bellidifolia, Crantz.

brachycarpa, Britton, in Mem. Torrey Bot. Club, v. (1894) $174=$ Turritis brachycarpa, Torr. et Gray.

columbiana, Macoun, Catal. Canad. Pl. iv. (1888) 304, - Columb. brit.

confinis, S. Wats. in Proc. Am. Acad. xxii. (1887) 466. - Am. bor.

digenea $\times$, Fritsch, in Verh. zool.-bot. Ges. Wien, xliv. 1894. (1895) 314. - Hybr. artef.

elegans, Tineo, ex Lojacono, Fl. Sicula, i. (1886) 106 - Sicil.

filifolia, Greene, in Bull. Calif. Acad. ii. (1887) 390 (= Cardamine filifolia, Greene). - Calif.

Freynii, Brueg. in Oest. Bot. Zeitschr. xxxix. (1889) 231. - Eur. centr.

grandiflora, Freyn, in Oest. Bot. Zeitschr. (1889) 171 = petraea, Lam.

Howellii, S. Wats. in Proc. Am. Acad. xxv. (1890) 124. - Oregon, Calif.

humifusa, S. Wats. l. c. $(=$ Sisymbritum humifusum, Vahl): - Am. bor.

intermedia, Freyn, in Oest. Bot. Zeitschr. xxxix. (1889) $133=\mathbf{F}$ reynii, Brugg.

juncea, Stapf, in Denkschr. Acad.Wien, li. (1886) 297.

Lemmoni, S. Wats. in Proc. Am. Acad. xxii. (1887) 467; et Contrib. U. S. Nat. Herb. iv. (1893) 61. Am. bor. occ.

Limneana, Wettst, in Luerss. Bibl. Bot. Heft 26. (1892) 18 = alpina, Linn.

longirostris, Eastwood, in Zoë, iii. (1893) 355 , nomen = Streptanthus longirostris, $S$. Wats.

Macouni, S. Wats, in Proc. Am. Acad. xxvi. (1891) 124. - Columb. brit.

Malinvaldiana, Rony et Coincy, in Coincy, Eclog. pl. Hisp. i. (1893) 7 t. 1. - Hisp.

Murrii $\times$. Khek, in Progr. Oberrealsch.Innsbruck (1891) 52; et in Deutsche Bot. Zeitsch. xii. (1894) 92. - Austria,

nana, Simonk. Enum. fl. Transilv. (1886) $75=$ alpina, Linn.

paniculata, Franch. Pl. Delav. (1889) 5\%. Yunnan.

Parishii, S. Wats, in Proc. Am. Acad. xxii. (1887) 468. - Calif.

pectinata, Greene, in Pittonia, i. (April 1889) 287. Calif.

perennans, S. Wats, in Proc. Am. Acad. xxii. (1887) 46\%. - Am. bor. occ.

pleurantha, Phil. in Anal. Univ. Chil. Ixxxii. (1893) 763. - Chili.

pulchra, M. E. fones, ex S. Wats. in Proc. Am. Acad. xxii. (1887) 468. - Calif.

purpurascens, Howell, ex Greene, Pittonia, i. (Feb 1888) 161. - Oregon.

Reverchoni, Freyn, ex Will. Suppl. Prodr. fl. Hisp. (1893) 302; et in Bull. Herb. Boiss. i. (1893) 542.Hisp.

copulorum, T. S. Brandeg. in Proc. Calif. Acad. Ser. II. II. (1889) 165 t. 8. - Calif.

secunda, Howell, in Erythea, iii. (1895) 33. - Am. bor. occ.

stylosa, Boiss, et Balansa, ex Boiss. Fl. Or. Suppl. (1888) 34. - As. Min.

surculosa, Terrac. in Atti Accad. sc. Napoli, Ser.II, iv. (1890) app: n. $2=$ serpyllifolia, Vill. tarapacana, Phil. in Anal. Mus. nac. Chile (1891) 4. -Bolivia. 


\section{ARABIS :}

irginica, Trelease, Branner et Coville, in Branner, Rep. Geol. Surv. Ark. 1988 (1891) 165 (= Cardamini virginica, Linn.) $=A$. Ludoviciana, $C$. A. Mey.

ARACHNANTHE, Blume (Orchid.) - Ind. Kew. i. 170.

alba, Ridl. in Trans. Linn. Soc. Ser. II, iii. (1893) 369. - Penins. Mal.

Clarkei, Rolfe, in Gard. Chron. (1888) ii. 567; Hook. f. in Bot. Mag. (1889) t. 7077. - Reg. Himal.

Maingayi, Hook. f. in Bot. Mag. (1889) sub t. 7077 in obs.; et Fl. Brit. Ind. vi. (1890) 28. Malacca.

ARACHNIS, Blume = Arachnanthe, Blume, (Or:hid.).

Beccarii, Reichb. f., in Bot. Centralb1. xxviii. (1886)

Flos-aëris, Reichb. f., 1. c. = Arachnanthe moschifera, Blume.

Hookeriana, Reichb. f., 1. c. = Renanthera Hookeriana, Reichb. $f$.

labrosa, Reichb. .., 1. c. = Arachnanthe bilinguis, Benth.

Lowei, Reichb. f., 1. c. $344=$ Arachnanthe Lowei, Benth. et Hook. $f$.

Rohaniana, Reichb. f;, 1. c. $344=$ Renanthera Hookeriana, Reichb. $f$.

Sulingi, Reichb. f., 1. c. $343=$ Renanthera Sulingi, Lindl.

ARALIA, Tourn. exLinn. (Aral.). - Ind. Kew. i. 171.

Chabrieri, Hort. ex Carrière, in Rev. Hortic. (1887) 20; et (1891) 224. - N. Caled.

conninna, Hort. ex Truff. in Rev. Hortic. (1891) $224=$ spectabilis Hort.

Kerchovei, Hort. ex Truff, 1. c. 224 fig. 55. - Oceania.

leptophylla, Hort. ex Truff. 1. c. - Melanesia.

longipes, Hort. ex Truff. 1. c. - Austral.

Macdowalli, F. Muell. in Australas. Fourn. Pharm. ii. (1887) 126. in obs; et F. M. Bailey, Syn. Quansl. Fl. Suppl. ii. (1888) 31 (= Panax Macdowalli, F. Muell.) - Austral.

maculata, Hort. ex Truff. in Rev. Hortic. (1891) 224. - Oceania.

monstrosa, Hort. ex Truff. 1. c. fig. 54. - Oceania.

Naumanni, E. March. in Bot. Fahrb. vii. (1886) 469. - N. Guin.

Osyana, Hort. ex Truff. in Rev. Hortic. (1891) 224. - Oceania.

quercifolia, Hort. ex Truff. 1. c. - N. Brit.

Reginae, Hort. ex Truff. 1. c. - N. Hebrid.

rotunda, Hort. ex Truff. 1. c. - Polynesia.

scopulorum, T. S. Brandeg. in Proc. Calif. Acad. Ser. II. ii. (1889) 165 t. 8. - Calif.

splendidissima, Hort. ex Truff. in Rev. Hortic. (1891) - N. Caled.

ternata, Hort, ex Truff, 1. c. 225. - N. Brit.

ARAUGARIA, Juss. (Conifer.). - Ind. Kew. i. 172

Hunsteinii. K. Schum, in K. Schum, et Hollm. Fl. Kais. Wilh. Land. (1889) 11. - N. Guin.

ARAUJIA, Brot. (Asclepiad.). - Ind. Kew. i. 172.

grandiflora, Morong, in Ann. N. Y. Acad. Sc. vii. (1893) 161 (= Schubertia grandiflora, Mart. et Zucc.). - Parag.

graveolens, Mast. in Gard. Chron. (1888) II. 271 fig. 33 (= Schubertia graveolens, Lindl.). - Bras. plumosa, Schlechter, in Oest. Bot. Zeitschr. xlv. (1895) 449 (Arauja). - Argent.

Stormiana, Morong, in Ann. N. Y. Acad. Sci. vii. (1893) 16I. - Parag.

ARBUTUS, (Tourn.) Linn. (Ericac.) - Ind. Kew. i. 172

arizonica, Sarg. in Gard. and For.iv. (1891) 317 fig. 54, et N. Amer. Sylva v. 127 t. 233 (=A. Menziesii, Rothrock). - Arizona, Mexic.

floribunda, Hort. ex Dippel, Handb. Laubholzk. i. (1889) $349=$ Pernettya phillyreaefolia, $D C$.

\section{ARBUTUS :}

nothocomaros, Heldr. ex Nym. Consp. fl. Eur. Suppl. ii. I. (1889) $214=$ A. Unedo, Linn.

ARCANGELINA, Kuntze, Rev, Gen. (1891) $759=$ Kralikia, Coss. et Dur. (Gramin.)

africana, Kuntze, 1. c.=K. africana. Coss. et Dur.

ARGEUTHOBIUM, Bieb. (Loranth.). - Ind. Kew. i. 172.

minutissimum, Hook. f. Fl. Brit. Ind. v. (1886) 227. -Reg. Himal.

ARGHANGELICA, Hoffm. (Umbellif.). - Ind. Kew.i. 173.

villosa, Kuntze, Rev. Gen. (1891) $265=$ hirsuta, Torr. et Gray

ARCHYTAEA, Mart. (Ternstroem.).- Ind. Kew. i. 173 .

alternifolia, Szyszyl. in Engl. et Prantl. Natürl. Pfanzenfam. iii. 6. (1893) 181. - As. trop insul.

ARGTAGRostis, Griseb. (Gramin.). - Ind. Kew. i. 173

humilis, C. Richt. Pl. Europ. i. (1889) 41. - Nov. Semlia.

ARCTIUM, Linn. emend. ex Kuntze, Rev. Gen. (1891) $306=$ Cousinia, Coss. (Composit.)

aciculare, Actinia, adnaium, affne, aintab̄ense, albicaule, albidum, Alepideae, alpinum, amplissimum, arsomalum, Antonowii, araneosum, arctotidifolium, arenarium, atropatanum, Aucheri, aureum, auriculatum, Baberi, bachtiaricum, Belangeri, Bienertii, bipinnatum, Boissieri, Bonvaloti, brachypterum, bucharicum, buphthalmodes, Bungeanum, caesareum, Calcitrapa, calocephalum, Capusii, cardurforme, carduncellodeum. cataonicum, Chamaepeuce, chlorocephalum, chrysacanthum, commutata, concinnum, concolor, congestum, coronatum, crispum, cylindraceum, cylindrocephalum. cymbolepis, decipiens, decurrens, deserti, dichotonum, discolor, dissectum, dolicholepis, elatum, evinaceum, eviobasis, eviocephalum, eviophorum, Falconeri, flavispinum, foliosum, gracile, grande, grandiceps, Griffthianum, Hablitrii, hamosum, helianthum, Hermonis, heterophyllum, Hohenackeri, holoteucum, humile, hypoleucum, hystrix, ilicifolium, incomptum, inflatum, intermedium, integrifolium, involucratum, jassyense, karatavicum, kokanicum, Korolkowii, Krauseanum, lachnosphaerum, lappaceum, lasiandrum, lasiolepis, lepidum, leptocephalum, libanoticum, lucidum, lyratum, macrocephalum, macrolepis, macropterum, microcephalum, molle, monocephalum, multilobum, meurocentrum, Noeanum, obovatum, odontolepis, oligocephahm, Olivieri, outichaschense, pentacanthum pergamaceum, Pestalozzae, pinarocephalum, piptocephalum, platylepis, polycephalum, prasinum, princeps, pseudomolle, pterocarpum, pugioniferum, pulchellum, pulchrum, purpureum, pusillum, pygmaeum, racemosum, Raddeanum, radians, ramosissimum, recurvasum, Raddeanum, radians, ramons, scariosum, Schmalhauseni, Schtschurowskianum, Seidlitzii, Semenowii, Sewerzowii, Smirnowii, squarrosum, stenocephalum, stenolepis, sibmuticum, tabrisianum, tenuifolium, Thomsonii, tomentellum, triflorum, turcomanicum, umbrosum, uncinatum, verbascifolium, verticillare, Verutum, xantha canthum, Kuntze, Rev. Gen. (1891) 307-308= homonnyma omnia Cousiniae.

homonnyma omnia Cousiniae.
actinocephalum, Kuntze, Rev. Gen. (1891) $307=$ C. xiphiolepis, Boiss.

alatum, Kuntze, in Act. Hort. Petrop. x. (1887) $197=$ C. alata, Schvenk.

alpicolum, Kuntze, Rev. Gen. (1891) $307=\mathrm{C}$. alpina, Bunge.

ambigum $x$, Nym. Consp. fl. Eur. Suppl. ii. 1. (1889) 179. - Bohem., Transsilv.

anisopterum, Kuntze, 1. c. = C. calolepis, Boiss arctiodes, Kuntze, 1. c. = C. arctioides, Schrenk. assyriacum, Kuntze, 1. c. = C. leucochlora, Bunge. carlinodes, Kuntze, 1. C. = C. carlinoides, DC centaurodes, Kuntze, 1. C. = C. centauroides, Fisch. et Mey.

cirsiodes, Kuntze, 1. c. = C. cirsiodes, Boiss. et Bal. cynarodes, Kuntze, 1. c. = C. cynaroides, C. $A$. Mey.

eryngiodes, Kuntze, 1. c. = C. eryngioides, Boiss.
ARCTIUM :-
Franchetianum, Kuntze, Rev. Gen. (1891) $30 \%=$ Franchetianum, Kuntze, Rev. Gen. (1891) 507 -
C. canescens, Franch. Karelinii, Kuntze, 1. c. 308 . = C. onopordioides, Ledeb.

Komaroffi, Kuntze, in Act. Hort. Petrop. x. (1887) $197=$ C. Komarowii. C. Winkl.

microcarpum, Kuntze, 1. c. = C. microcárpa, Boiss. minutum, Kuntze, 1. C. = C. minuta, Boiss.

mixtum $x$, Nym. Consp. fl. Eur. Suppl. ii. 1. (1889) $179=$ C. mixta, Simonk

niveum, Kuntze, Rev Gen.(1891) $307=$ C. Trautvetteri, Regel.

nothum $x, \mathrm{E}$. Hallier, in Koch's Syn. deutsch. Fl. ed. 3. (1895) 1512 (= Lappa notha, Rühm.). Germ.

orientale, Kuntze, in Act. Hort. Petrop. x. (1887) $197=$ Auchera orientalis, $D C$

orientale, Kuntze, Rev. Gen. (1891) $367=$ C. Candolleana, Faub. et Spach.

polyacanthum, Kuntze, 1. C. = C. onopordioides, Ledeb.

proliferim, Kuntze, 1. c. = C. prolifera, Faub. et Spach et C. minuta, Boiss.

serratulodes, Kuntze, 1. C. = C. serratuloides, Boiss. silybodes, Kuntze, 1. c. 307 et $308=$ C. Kotschyi,

Boiss.
sphaerocephalum, Kuntze, Rev. Gen. (1891) $307=$ C. Chamaepeuce, Boiss.

subracemosum $X$, Nym. Consp. fl. Eur. Supp1. ii. 1.

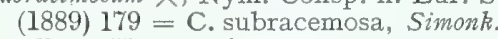

tenellum, Kuntze, in Act. Hort. Petrop. x. (1887)

$197=\mathrm{C}$. tenella, Fisch. et Mey.

trachylepsis, Kuntze, in Act. Hort. Petrop. x. (1887) $197=$ C. trachylepis, Bunge.

thamnodes, Kuntze, Rev. Gen. (1891) = C. thamnoides, Boiss, et Hausskn.

wolgense, Kuntze, 1. c. - Ross. mer.

xiphiolepis, Kuntze, 1. c. = C. xiphiolepis, Boiss.

ARCTOMECON, Torr, et Frém. (Papaver.). Ind. Kew. i. 174

humile, Coville, in Proc. Biol. Soc. Wash. vii. (1892) 67. - Am bor. occ

Merriami, Coville, l. c. 66. - Calif.

ARGTOSTAPHYLOS, Adans. (Ericac.). - Ind.

Kew. i. 174.

bicolor, T. S. Brandeg. in Proc. Calif. Acad. Ser

II. ii. (1889) $181=$ bicolor, A. Gray.?

Caeciliana, Loes, in Bult. Herb. Boiss, ii. (1894) 553. - Mexic.

diversifolia, Parry, ex A. Gray, Syn. Fl. N. Am. II. i. (1886) 397. - Calif.

elegans, fepson, in Erythea, i. (1893) 15. - Calif

insularis, Greene et Parry, in Bull. Calif. Acad. ii (1887) 494. - Calif.

Manzanita, Parry, l. c. 491. (=Arct.pungens, Auct.) - Am. bor. occ.

media, Greene, Pittonia, ii. (Sept. 1891) 171. Washington.

myrtifolia, Parry, in Greene. Pittonia, i. (March. 1887) 34. - Calif.

oppositifolia, Parry, ex A. Gray, Syn. Fl. N. Am. II. i. (I886) 397

Parryana, Lemmon, in Greene, Pịttonia, ii. (May 1890) 68. - Calif.

platyphylla, Kuntze, Rev. Gen. (1891) $385=$ Arct. Manzanita, Parry.

Pringlei, Pary, in Bull. Calif. Acad. ii. (1887) 494 - Mexic.

rupestris, Robinson et Seaton, in Proc. Am. Acad xxviii. (1893) 112. - Mexic.

Stanfordiana, Parry, in Bull. Calif. Acad. ii. (1887) 493. - Calif.

viscida, Parry, l. c. 492. - Am. bor. occ.

ARGTOTIS, Linn. (Composit.). - Ind. Kew. i. 174.

caudata, Kuntze, Rev, Gen. (1891) 306 sphalm. = candida, $T$ hun

Rueppellii, O. Hoffm, in Engl. Pfanzenv. Ost-Afy. C (1895) 419 (= Schnittspahnia Rueppollii, Sch. Bip.). - Afr. trop. or.

scaposa, O. Hoffm. l. c. (= Haplocarpha scaposa, Harv.). - Afr. austr. 
ARCTOUS, Niedenzu, in Engl, et Prantl, Natürl. Pflanzenfam. iv. I. (1889) 48; et in Bot. Jahrb. xi. (1890) $141=$ Arctostaphylos, Adans. (Ericac.).

alpina, Niedenzu, 11. cc. = Arctost. alpina, Spreng.

ARCULUS, Van Tiegh. in Bull. Soc. bot. Fr. xlii (1895) 444 = Loranthus, Linn. (Loranth.).

Duthieamus, Van Tiegh.1. c, $445=$ L. Duthieanus, King.

ARCYTOPHYLLUM, (Willd.) Roem. et Schult. = Mallostoma, Karst. (Rubiac).

cachirense, K. Schum, in Engl, et Prant1, Natürl. Pflanzenfam. iv. 4. (1891) $28=\mathrm{M}$. cachirense Karst.

capitatum, K. Schum. 1. c。 = M. capitatum, Benth.

ARDISIA, Sw. (Myrsin.). - Ind. Kew. i. 174. affinis, Hemsl. in foum. Linn. Soc. xxvi. (1889) 63 - China.

amabilis, Stapf, in Trans. Linn. Soc. Ser. II. iv. (1894) 203. - Borneo.

brachythyrsa, Stapf, l. c. 202. - Borneo.

caudata, Hemsl, in fourn. Linn. Soc. xxvi. (1889) 63. - China.

densiflora, Krueg. et Urban. in Notizbl. Bot. Gart. Berl. i. (1895) 79. - Jamaica.

dissitiflora, Baker, in fourn. Linn. Soc. xxii. (1887) 501. - Madag.

Faberii, Hemsl. l. c. xxvi. (1889) 64. - China.

Fordii, Hemsl. l. c. - China,

Henryi, Hemsl. l. c. 65. - China.

imperialis, K. Schum。 in Bot. fahrb. ix. (1888) 213. -N. Guin.

leptoclada, Baker, in fourn. Linn. Soc. xxii. (1887) 500, - Madag.

Listeri, Stapf, ex Hemsl. l. c. xxx. (1894) 213. Ins. Tonga.

megaphylla, Hemsl. in Kew Bull.(1894) 6; et in Hook. Icon, pl. xxiv. (1894) t. 2316. - Ins. Viti.

micrantha, f. D. Smith, in Coult. Bot. Gaz. xiv. (1889) 27 (= Paratheris micrantha, J. D. Smith). - Guatem.

oocarpa, Stapf, in Trans, Linn. Soc. Ser. II. iv. (1894) 202, - Borneo.

pachyrrhachis, F. Muell, in Vict. Natural. viii. (May 1891) 15; et in Bot. Centralbl. xlvi. (1891) 205 in syn. = Bladhia pachyrrhachis, F. Muell.

paschalis, F. D. Smith, Enmm. pl. Guat. iii. (1891) n. 2465 nomen; et in Coult. Bot.Gaz, xix. (1894) 5 . - Guatem.

pectinata, F. D. Smith, in Coult. l. c. xii. (1887) 132. - Guatem.

picta, Hort. Bull, ex Gartenfl. (1886) 424 cum icone. - Bras.

poranthera, F. Muell. et C. Moore, in fourn. Roy. Soc.N.S. Wales, xx. 1886 (1887) 43.-N. Guin. tachibana, Makino, in Tokyo Bot. Mag. vi, (1892) 53. - Japon.

tuflora, Hemsl. in fourn. Linn.Soc. xxvi. (1889) 67. - China,

Tuerckheimii, f. D. Smith, in Coult. Bot. Gaz. xiii. (1888) 74. - Guatem.

venosa, Mast. ex F. D. Smith, l. c. xviii. (1893) 205. - Guatem.

ARDUINA, Adans. = Kundmannia, Scop. (Umbellif.).

sicula, Kuntze, Rev. Gen. (1891) $265=$ K. sicula, Scop.

ARDUINA, Mill. = Carissa, Linn. (Apocyn.). Carandae, Baill. Hist. des pl. x. (1888) $170 ; \mathrm{K}$. Schum. in Engl. et Prantl Natürl. Pflanzenfam. iv. $2(1895) 127=\mathrm{C}$. Carandae, Linn.

inermis, K. Schum. 1. c. = C. inermis, $V a h l$.

laxiftora, K. Schum. 1. c. $=\mathrm{C}$, laxiflora, Benth

Schimperi, Baill. Hist. des p1. x. (1888) $168=$ C. Schimperi, $A . D C$.

etramera, Sacleux, in Morot, Journ. de Bot. vii. (1893) 312. - Zanzib.

Xylopicron, Baill. Hist. des pl.x. (1888) $170=$ C. Xylopicron, Thou.
AREGA, Linn. (Palm.). - Ind. Kew. i. $17 \%$.

appendiculata, F.M. Bailey, in Dep. Agric. Bot. Bull. iv. (1891) 18. - Austral.

Micholitzii, Hort. ex Sand. Catal. (1895) 46. - N. Guin.

sechellarum, Hort. ex Baill. Hist. des pl. xiii. (1895) $348=$ Stevensonia grandifolia, Duncan。

AREGELIA, Kuntze, Rev. Gen. (1891) $698=$ Karatas, Adans. (Bromel.)

ARENARIA, Rupp. ex Linn. (Caryophyll.). Ind. Kew, i. 178 .

alpicola, G. Beck, in Annal. Naturhist. Hofmus. Wien, vi. (1891) $326=$ serpyllifolia, Linn.

barbata, Franch. in Bull. Soc. bot. Fr. xxxiii. (1886) 430; et Pl. Delav. (1889) 93. - Yunnan.

Boissieri, Pax, in Bot. Fahrb. xviii. (1893) 30 in obs. - Oriens.

brachyphylla, Phil. in Anal. Univ. Chil. 1xxxii. (1893) 762 ou '771. - Chili.

catamarcensis, Pax, in Bot. fahrb. xviii. (1893) 29. - Reg. Argent.

chokaiensis, Yatabé, in Tokyo Bot. Mag. v. (1891) 397 t. 31; et Icon. A. Fapon. ii. (1892) t. 23. Japon.

compacta, Coville, in Proc. Biol. Soc. Wash. vii. (1842) 67; et in Contr. U.S. Nat. Herb. iv. (1893) 70 t. 5. - Calif.

condensata, Lange, Haandb. Danske Fl. ed. 4. (1886-88) $670=$ serpyllifolia, Linn.

crassifolia, Freyn, ex E. Hallier, in Koch, Syn. deutsch. Fl. ed. 3 (1892) $292=$ serpyllifolia, Einn.

Delavayi, Franch. in Bull. Soc.bot. Fr, xxxiii. (1886) 432; et Pl. Delav. (1889) 95. - Yunnan.

edulis, S. Wats, in Proc. Am. Acad. xxi. (1886) 430. - Mexic.

glandulosa, Williams, in Bull. Herb. Boiss. iii. (1895) 603 (=Adenostemma glandulosum, Benth.) = Aren. Benthamii, Edgere. et Hook. $f$.

holosteoides, Franch in Bull. Soc. Philom. Paris, Sér. 6. xv. 241. - China.

Kingii, M. E. Fones, in Proc. Calif. Acad. Ser. II. v. (1895) 627. - Calif

kumaonensis, Maxim. Fl. Tangut. (1889) 86 in obs.

linearifolia, Franch. Pl. Delav. (1889) 96. - Yunnan.

longistyla, Franch. in Bull. Soc. bot. Fr, xxxiii. (1886) 433; et Pl. Delnq. (1889) 96 t. 24 b. Xunnan.

merckioides, Maxim. in Bull. Acad. St-Pétersb.xxxii. (1888) 482, - Japon.

Moritziana, Pax, in Bot. Fahrb. xviii. (1893) 30 in obs. - Columb.

multifida, S. Wats, in Proc. Am. Acad. xxvi (1891) 136. - Mexic

napuligera, Franch. in Bull. Soc. bot. Fr. xxxiii. (1886) 429; et Pl. Delav. (1889) t. 24 a. - Yunnan.

nervosa, Halàcsy et Charrel, in Oest. Bot. Zeitschr. (1892) 272. - Turc.

Nuttallii, Pax, in Bot. Fahrb. xviii. (1893) 30 in obs, - Am. bor. occ.

ovalifolia, Somm. et Levier, in Act. Hort. Petrop. viii. (1893) 40. - Reg. Caucas.

paludicola, Robinson, in Proc. Am. Acad. xxix. (1894) 298. - Calif.

platysperma, Yatabé, in Tokyo Bot. Mag. vi. (1892) 49 et 133 (= Moerhingia platysperma Maxim.). - Japon.

pleurantha, Phil. in Anal. Univ. Chil. 1xxxii. (1893) 763. - Chili.

pusilla, Stapf, in Denkschr. Acad. Wien, 1i. (1886) 355 -As. Min.

pycnophylloides, Pax, in Bot. Fahrb. xviii. (1893) 29. - Reg. Argent.

rhodocalyx, Alboff, in Bull. Herb. Boiss. ii. (1894)

255. - Reg. Cauc.
Roborowskii, Maxim. Fl. Tangut. (1889) 87 t. 29 fig. 8-16. - Tibet.

saginoides, Maxim. I. c. 89 t. 31 fig. 1-17. As. centr.

Stuebelii, Hieron. in Bot. Fahrb. xxi. (1895) 307. Bolivia.
ARENARIA :

tejedensis, Huter, Porto et Rigo, ex Willk. Suppl. Prodr. fl. Hisp. (1893) 275. - - Hisp.

transsilvanica, Simonk. in Erd. Flor. (1886) 148; in Termesz. Fuzet. x. (1886) 180; et Enum. fl.

Transsilv. (1886) $140=$ rotundifolia, Bieb.

trichophora, Franch. in Bull. Soc. bot. Fr. xxxiii. (1886) 431; et Pl. Delav. (1889) 94. - Yunnan. ursina, Robinson, in Proc. Am. Acad. xxix. (1894) 294. - Calif.

vestita, Baker, in Kew Bull. (1895) 212. - Afr. trop. yunnanensis, Franch. in Bull. Soc. bot. Fr. xxxiii.

(1886) 431; et Pl. Delav. (1889) 94. - Yunnan.

ARENGA, Labill. (Palm.). - Ind. Kew. i. 181. brevipes, Becc. Malesia, iii. (1889) 95 et 194. Borneo.

Engleri, Becc.l. c. 184; et in Kew Bull. (1895) 19. Formosa.

Listeri, Becc. in Hook. Icon. pl. xx. (1891) t. 1985. Ins. Christmas.

microcarpa, Bece. in K. Schum. et Hollr. Fl. Kais. Wilh. Land, (1889) 16. - N. Guin.

undulatifolia, Becc. Malesia, iii. (1886) 92 et 192. Borneo.

ARETHUSA, Gronov. (Orchid.). - Ind. Kew. i. 182.

grandiflora, S. Wats, in Proc. Am. Acad. xxvi. (1891) 154. - Mexic

ARETIA, Hall. = Androsace, Linn. (Primul.).

Mathitdae, Caruel, in Parl. F1. Ital. viii. (1889) $658=$ Andr. Mathildae, Levier.

Mathildae, Levier, in Act. Hort. Petrop. xiii. (1893) 50 in obs. = praec.

occidentalis, MacMill. Metasp. Minn. (1892) $411=$ Andr. occidentalis, Pursh.

ARFEUILLEA Pierre, ex Radlk. in Engl. et Prantl, Natürl. Pflanzenfam. iii. 5. (1895) 362; et Fl. For. Cochinch. (1895) t. 322 B. SAPIN. $D A C E A E$.

arborescens, Pierve, $l l . c c .-$ Siam.

ARGEMONE, Tourn. ex Linn. (Papaver.). Ind. Kew, i. 182.

corymbosa, Greene, in Bull. Calif. Acad. ii. (1886) $59=$ mexicana, Linn.

ARGITHAMNIA, Sw. (Euphorb.). - Ind. Kew. i. 182.

purpurascens, S. Moore, in Trans. Limn. Soc. Ser. II. iv. (1895) 466. - Bras.

ARGOMUELLRRA, Pax, in Bot. Jahrb. xix. (1894) 90. EUPHORBIACEAE.

macrophylla, Pax, l. c. - Afr. trop.

ARGOPHYLLUM, Forst. (Saxifrag.). - Ind.

Kew. i. 184.
Grunowii, Zahlbr. in Annal. Naturhist. Hofmus. Wien, iii. (1888) 278 t. 12. - N. Caled.

ARGOSTEMMA, Wall. (Rubiac.). - Ind. Kew. i. 183.

brachyantherum, Stapf, in Trans. Lim. Soc. Ser. I1. iv. (1894) 168. - Borneo.

concinnum, Hemsl. in Hook. Icon. pl. xxiv. (1895) t. 2380; et in Kew. Bull. (1895) 105. - Siam.

gracile, Stapf, in Trans. Linn. Soc. Ser. II. iv. (1894) 168. - Borneo.

involucratum, Hemsl. in Hook. Icon. pl. xvi. (1887) t. 1556. - Perak.

ARGYIIA, D. Don (Bignon.). - Ind. Kew. i. 183.

bifrons, Phil. in Anal. Univ. Chil. xc. (1895) 210. Chili.

digitalina, Phil. l.c. 208. - Chili.

tenella, Phil. l. c. 209.-Chili.

ARGYREIA, Lour. (Convolvul.). - Ind. Kew. i. 183.

Grantii, Bakev, in Kew Bull. (1894) 67. - Afr. trop. Hanningtoni, Baker, l. c. - Afr. trop. or.

laxiflora, Baker, l. c. - Afr. trop. or. 


\section{ARGYREIA}

laxiflora, Prain, in Journ. Linn. Soc. 1xiii. (1894) 92 in syn. = Lettsomia laxiflora, Prain.

macrocalyx, Baker, in Kew Bull. (1894) 67. - Afr. trop. or.

Ridleyi, Prain, in Journ. Linn. Soc. 1xiii. (1894) 98 in syn. = Lettsomia Ridleyi, Prain,

ARGYROCOME, Breyne, Prodr. ii. (1739) 43-44, ex Kuntze, Rev. Gen. (1891) $308=$ Helipterum, DC. (Composit.).

argyropsis, canescens, chlorocephala, Charsleyae, citrina, condensata, corymbiflora, corymbosa, Cotula, dimorpholepis, Dregeana, exigua, eximia, floribunda. Forrestii, Frenchii, Haigii, heterantha, HumboldForresti, Frenchi, Haigi, heterantha, Humboldpolycephala, polygalifolia, polyphylla, pterochaeta, pygmaea, Pyrethrum, rosea, rubella, speciosissima. spicata, sterilescens, stipitata, stricta, tenella, Tietkensii, variegata, virgata, Zeyheri, Kuntze, Rev. Gen. (1891) 308-309 = homonyma omnia Helipteri.

albicans, Kuntze, 1. c. $309=\mathrm{H}$. incanum, DC

anthemodes, Kuntze, 1. c. $=\mathrm{H}$. anthemoides, $D C$.

ferruginea, Kuntze, 1. c. = Helichrysum squamosum, Thunb.

fuscescens, Kuntze, 1. c. = Podotheca fuscescens, Benth.

gnaphalodes, Kuntze, 1. c. = Helipterum gnaphaloides, $D C$.

Margeritae, Kuntze, 1. c. = H. Margarethea, $F$. Muell.

sesamodes, Kuntze, 1. c. $308=$ Helichrysum sesamoides, Willd.

ARGYRODENDRON, F. Muell. = Tarrietia, Blume (Stercul.).

Riedelianum, Pierre, F1. For. Cochinch. (1889) sub t. $\mathbf{1 9 3 - 9 5}$ in obs, $=$ T. Riedeliana, Oliver.

ARGYROLOBIUM, Eckl. et Zeyh. (Legumin.). - Ind. Kew. i. 184.

filicaule, Hochst. ex Engl, in Abhandl. Preuss. Akad. Wiss. 1891. ii. (1892) 249. - Abyss.

Fischeri, Taub. in Engl. Pflanzenw. Ost-Afr. C (1895) 207. - Afr. trop. or.

Harveyanum, Oliver, in Hook. Icon. pl. xvi. (1S86) sub t. 1525 in not. - Afr. austr.

kilimandscharicum, Taub. in Engl. Pfanzenw. Ost. Afr. C (1895) 207. - Afr. trop. or.

marginatum, Bolus, in fourn. Linn. Soc. xxv. (1889) 161. - Afr. austr.

megarhizum, Bolus, l. c. xxiv. (1887) 175. Transvaal.

shirense, Taub., in Engl. Pfanzenw. Ost-Afr. C (1895) 207. - Afr. trop, or.

stenorrhizon, Oliver, in Hook. Icon. pl. xvi.(1886) t. 1525. - Afr. austr.

Stuhlmannii, Taub. in Engl. Pflanzenw. Ost-Afr. C (1895) 207. - Afr. trop.or.

ARGYROTHAMNIA, Muell. Arg. = Argithamnia, Sw. (Euphorb.)

Fridae, Reiche, in Bot. Jahrb. xxi. (1895) 47 nomen. - Chili.

ARGYROXIPHIUM, DC. (Composit.). - Ind. Kew. i. 184.

virescens, Hillebr. Fl. Haw. Isl. (1888) 219. -- Ins. Hawai.

ARGYTHAMNIA, P. Br. = Argithammia, Sw. (Euphorb.).

acalyphifolia, aculeolata, angustissima, bahiensis, buettneriacea, castaneaefolia, cordata. heteropetala, linearifolia, multicostata, paludosa, palustris, Regnellii, Rutenbergii, senegalensis, stenophylla, Kuntze, Rev. Gen. (1891) 593-94 = homonyma omnia Caperoniae.

Brandegei, Millsp. in Proc. Calif. Acad, Ser. II. ii. (1889) 220. - Calif.

corchorodes, Kuntze, Rev. Gen. (1891) $594=$ C. corchoroides, Muell. Arg

heteropetalodes, Kuntze, 1. C. = C. heteropetaloides, Muell. Arg.

Hochstetteri, Kuntze, 1. c. = C. serrata, Presl.

\section{ARGYTHAMNIA :}

Langsdorfi, Kuntze, Rev. Gen. (1891) $594=\mathrm{C}$ Langsdorffi, Muell. Arg.

Muellerargoviana, Kuntze, 1. c. = C. Gardneri Muell. Arg.

Palmeri, S. Wats, in Proc. Am. Acad. xxiv. (1889) 77. - Mexic.

polygama, Kuntze, 1. c. = Argith. lancifolia, Muell. Arg.

savanillensis, Kuntze, 1. c. $593=$ Argithamn. sp Columb.

serrata, T, S. Brandeg, in Proc. Calif. Acad. Ser. II. iii. (1891) 173. - Calif.

ARIA, Jacq. f. = Pyrus, Linn. (Rosac.)

Grantzii, G. Beck, Fl. Nieder-Oest. ii. (1892) 712 $=$ P. Chamaemespilus, Ehrh.

gracilis, Koehne, Deutsch. Dendrol. (1890) $17=\mathrm{P}$ sambucifolia, Cham. et Schlecht.

hybrida, G. Beck, Fl. Nieder-Oest. ii. (1892) $711=$ P. pinnatifida, Ehrh.

semiincisa, G. Beck, 1. c. 714 (= Sorbus semiincisa, Borb.). - Hung

sudetica, G. Beck, 1. c. $711^{\prime}=$ P. Aria, Ehrh.

succica, Koehne, ex Verh. Bot. Ver. Brand. xxxv. 1893 (1894) p. xlix; et Deutsch. Dendrol. (1893) 250 = Pyrus intermedia, Ehrh

thuringiaca $X, G$. Beck, Fl. Nieder-Oest. ii 1892) $711=$ P. pinnatifida, Ehrh.

torminalis, G. Beck, 1. c. $713=$ P. torminalis Ehrh

ARIKURIROBA, Barb, Rodr. Pl.nov. Jard. bot Rio, i. (1891) 5. PALMAE.

Capanemae, Barb. Rodr. l. c. t. 3.-Bras.

ARIOCARPUS, Scheidw.= Mammillaria, Haw (Cact.).

fissuratus, K. Schum. in Engl. et Prantl, Natürl Pflanzenfam. iii. 6 a. (1894) 195 (= Anhalonium Engelmannii, K. Schum.) - Mexic.

sulcatus, K. Schum. 1. c. (= Anhalonium Kotchubeyi, Lem.). - Mexic

ARISA玉MA, Mart. (Aroid.). - Ind. Kew. i. 185. anomalum, Hemsl, in fourn. Bot. (1887) 205; Hook f. in Bot. Mag. (1891) t. 7211. - Penins. Mal. Giraldi, Baroni, in Bull Soc bot Ital (1893) 515; et in Bull. Soc. Tosc. Ortic. (1893) t.12= consanguineum, Schott.

Kunstleri, Hook. f. Fl. Brit. Ind. vi. (1893) 496. Ind. or.

parvum, N. E. Br. ex Hemsl. in fourn. Linn. Soc xxix. (1892) 320. - China.

petiolulatum, Hook. f. Fl. Brit. Ind.vi. (1893) 498 - Reg. Himal.

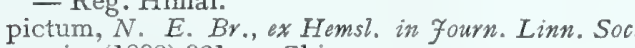
xxix. (1892) 321. - China.

Prazeri, Hook. f. Fl. Brit. Ind. vi. (1893) 501. Burma.

Scortechini, Hook. f. l. c. 503. - Penang, Perak. ternatipartitum, Makino, in Tokyo Bot. Mag.

vi. (1892) 47. - Japon.
Wallichianum, Hook.f. Fl. Brit. Ind. vi. (1893) 500. - Reg. Himal.

Wattii, Hook. f. l. c. 498. - Reg. Himal.

Wrayi, Hemsl. in fourn. Bot. (1887) 205; Hook. f.in Bot. Mag. (1890) t. 7105. - Perak.

ARIST $\mathbf{A}$, (Soland.) Aiton (Irid.). - Ind. Kew. i 186.

abyssinica, Pax, ex Engl. in Abhandl. Preuss. Akad. Wiss. 1891 ii. (1892) 173. - Abyss.

Bakeri, Klatt, in Th. Dur. et Schinz, Consp. fl. Afr. v. 1893 (1895) 169. - Afr. austr.

Cooperi, Baker, Handb. Irid. (1892) 143. - Afr austr.

elata, Baker, ex Engl. in Abhandl. Preuss. Akad. Wiss. (1894) 58. - Afr. trop. or.

flexicaulis, Baker, l.c. 143. - Transvaal.

Johnstoniana, Rendle, in Trans. Linn. Soc. Ser. II iv. (1894) 48 . - Afr. trop. or.

Lastii, Baker, Handb. Irid. (1892) 142. - Afr. trop or.

majubensis, Baker, in fourn. Bot. xxix. (1891) 70 ; et Handb. Irid. (1892) 142. - Natal.
ARISTEA :

oligocephala, Baker, Handb. Irid. (1892) 144. Afr. austr.

paniculata, Baker, l. c. - Afr. austr

paniculata, Pax, in Bot. Fahrb. xv, (1893) 151. Afr.austr.

platycaulis, Baker, in Gard. Chron.(1887) i. 732. Afr. austro-occ. extratrop.

Tayloriana, Rendle, in Trans. Linn. Soc. Ser. II. iv. (1894) 48 in obs. - Afr. trop.

Zeyheri, Baker, Handb. Irid. (1892) 143. - Afr. austr.

ARISTIDA, Linn. (Gramin.). - Ind. Kew. i. 186.

aequighnmis, Hack. ex Schinz, in Bull. Herb. Boiss. iii. (1895) 381. - Transvaal.

alopecuroides, Hack. ex Schinz, in Verh. Bot. Ver. Brand. xxx. (1888) 144. - Afr. austro-occ. appressa, Vasey, in Contrib. U. S. Nat. Herb. i. (1893) 282. - Mexic.

Aristidis, Coss. Miss. scient. Tunisie (1883) ex Batt. et Trab. Fl. de l'Algérie (Monoc.) (1895) 15\%. Tunet.

arizonica, Vasey, in Bull. Torrey Bot. Club. xiii. (1886) 27; et Grass. of the South-West, i. (1891) t. 22. - Arizona.

Cassanellii, A. Terrac. in Ann. bot. Roma, v. (1894) 94. - Eritrea.

divergens, Vasey, in Contrib. U. S. Nat. Herb. ii. (1894) 515; et iii. (1892) 48. - Am. bor. occ.

fugitiva, Vasey, ex S. Wats, in Proc. Am. Acad. xxiv. (1889) 80 nomen. - Caiif. austr.

Havardi, Vasey, in Bull. Torrey Bot. Club, xiii. (1886) 27. - Texas.

herbacea, Steud. ex Th. Dur. et Schinz, Consp. fl. Afric. v. 1894. (1895) 835 = paradoxa, Steud.

Hochstetteriana, G. Beck, ex Hack. in Verh. Bot. Ver. Brand. xxx. (1888) 144. - Afr. austro.occ. Lemmonii, Scribn, in Trans. N. Y. Acad. Sci. xiv. (1894) - Arizona.

longicauda, Hack. in Bolet. Soc. Brot. vii. (1888) 143. - Mossamb.

manzanilloana, Vasey, in Contrib. U. S. Nat. Herb. i. (1893) 282. - Mexic.

Marlothii, Hack. in Bot. Fahvỏ. xi. (1890) 400.Afr. austro-occ. extratrop.

multicaulis, Baker, in fourn. Linn, Soc. xxii. (1887) 533. - Madag.

Nealleyi, Vasey, in Contrib. U. S. Nat. Herb. ii. (1894) 514; et iii. (1892) 45. - Texas.

Orcuttiana, Vasey, in Bull. Torrey Bot. Club, xiii. (1886) 27 - Calif. austr.

palustris, Vasey, in Contrib. U. S. Nat. Herb. iii. (1892) 45. - Florida.

recta, Franch. in Bull. Soc. hist. nat. Autun, viii. (1895) 365. - Congo gall.

redacta, Stapf, in Kew Bull. (1892) 85. - Ind. or.

Reverchonii, Vasey, in Bull. Torrey Bot. Club, xiii. (1886) 52. - Texas.

sahelica, Trab. in Bull. Soc. bot. Fr. xxxiv. (1887) 392. - Algeria.

sericans, Hack. ex Schinz, in Bull. Herb. Boiss. iii. (1895) 381. - Transvaal.

spectabilis, Hack. ex Schinz, l. c. 380. - Transvaal.

Spegazzinii, Arechav. in Anal. Mus. nac. Buenos Aires, iv. (1895) 177 fig. 1. - Urug.

stipitata, Hack. ex Schinz, in Verk. Bot. Ver. Brand. xxx. (1888) 143. - Afr, austro-occ. extratrop.

tunetana, Coss. (Miss. scient. Tunisie, 1883) ex Batt. et Trab. Fl. de l'Algérie (Monoc.) (I895) 157. Tunet.

villosa, Robins, et Greenman, in Am. Fourn. Sci. Ser. III. 1. (1895) 144. - Ins. Galap.

ARISTOLOGHIA, (Tourn.) Linn. (Aristoloch.).Ind. Kew. i. 188.

atropurpurea, Parish, ex Hook. f. Fl Brit. Ind. v (1886) 76. - Tenass.

Cathrartii, Hook. f. l. c. 77. - Reg. Himal.

chrysochlora, Barb. Rodr. in Vellosia, 1885-88, ed. 2 (1891) t. 23 A. - Bras.

Dammeriana, Mast. in Gard. Chron. (1895) i. 452 - Am. centr.

fastidiosa, (D'Almeida?) ex L. Planch. Les Aristol. 1891) 252. - Bras. (Quid?) 


\section{ARISTOLOCHIA}

filipendulina, L. Planch. Les Aristol. (1891) 137 et 191 sphalm. = filipendula, Decne.

guadalajarana, S. Wats. in Proc. Am. Acad. xxii. (1887) 448. - Mexic.

heterophylla, Hensl. in fourn. Linn. Soc. xxvi. (1891) 361. - China.

Holtzei, F. Muell. in Vict. Natural. ix. (Feb. 1893) 160. - Austral.

leonensis, $S$. Elliot, in fourn. Linn. Soc. xxx. (1894) 95. - Sierra Leone.

Linnemanni, Warb. in Bot. Fahrb. xiii. (1891) 301. - Oceania.

longecaudata, S. Wats. in Proc. Am. Acad. xxii. 1887) 447. - Mexic

longipes, S. Wats in Proc. Am. Acad. xxii. (1887) 448. - Mexic.

loriflora, Mast. in Bot. Fahrb. viii. (1887) 220.Guatem.

megalophylla, K. Schum. in K. Schum. et Hollr. Fl. Kais. Wilh. Land, (1889) 104. - N. Guin.

Momandul, $K$. Schum. 1. c. 105. - N. Guin.

monpinensis, Franch. in Nouv. Arch. Mus, Paris, Sér. 2 x. (1887-88) 79. - China.

nana, S. Wats. in Proc. Am. Acad. xxvi. (1891) 145. - Mexic.

Nashij, Kearney, in Bull. Torrey Bot. Club, xxi. (1894) 485. - Florida.

Palmeri, S. Wats in Proc. Am. Acad. xxii. (1887) 447. - Mexic

paransis, (D'Almeida?) ex L. Planch. Les Aristol. (1891) 252. (Quid?). - Bras.

Pearcei, Phil. in Anal. Univ. Chil. xci. (1895) 506. - Chili.

ridicula, N. E. Br., in Gard. Chron. (1886) ii. 360 fig. 73; et in Bot. Mag. (1887) t. 6934. Bras.

salpinx, Mast. in Gard. Chron. ii. (1886) 456 fig. 32. - Parag.

silvatica, Barb. Rodr. in Vellosia, 1885.88. ed, 2. (1891) t. 22 et 23 b. - Bras.

Stuhlmannii, Engl. Pflanzenw. Ost-Afr. C (1895) 169. - Afr. trop. or.

tequilana, S. Wats. in Proc. Am. Acad. xxii. (1887) 447. - Mexic.

Urbaniana, Taub. in Bot. fahrb. xii. Beibl. n. 27. (1890) 14. - Bras

ARISTOTELIA, L'Hérit. (Tiliac.). - Ind. Kew i. 190

gaulteriacea, « F. Muell. » ex Bot. Centralbl. 1. (1892) 195 sphalm. = A. Gaultheria, F. Muell.

Gaultheria, $F$. Muell. in Fourn. Bot. xxix. (1891) 176. - N. Guin.

ARKEZOSTIS, Rafin.= Cayaponia, Manso (Cu* curb.).

alata, amazonica, amevicana, Andreana, angustiloba, attenuata, Bonplandii, Buraecri, calycina, citrullifolia, cordifolia, coriacea, diversifolia, Espelina, excisa, ficifolia, floribunda, fuminensis, glandulosa, Glazioui, gracillima, granatensis, grandiflora, heterophylla, hirsuta, latebrosa, latifolia, Lhotzkiana, longifolia, Maximowiczii, micrantha, Ottoniana, ovata, pedata, pentaphylla, perwviana, petiolulata, piauhiensis, podantha, Poeppigii, racemosa, rigida, Ruizii, Sandia, setulosa, simplicifolia, Tayuya, ternata, Tibiricae, tomentosa, triangularis, trilobata, tubulosa, villosissima, Weddellii, Kuntze, Rev. Gen. (1891) 255 = homonyma omnia Cayaponiae.

bonariensis, Kuntze, 1. c. = C. ficifolia, Cogn.

Cabocla, Kuntze, 1. c. = C. globosa, Silva Manso.

cordatifolia, Kuntze, 1. c. - = C. Martiana, Cog $n$.

Crugeri, Kuntze, 1. C. = C. Crugeri, Cogn.

palmosa, Kuntze, 1. c. = C. palmata, $\operatorname{Cog} n$.

pilosa, Kuntze, l. c. = C. diffusa, Silva Manso.

trifoliata, Kuntze, 1. c. = C. trifoliolata, Cognt.

ARMERIA, Linn. fide Kuntze Rev. Gen. (1891) 432 $=$ Phlox, Linn. (Polemon.).

adsurgens, amoena, bifida, caespitosa, canescens, divaricata, Drummondii, foridana, glaberrima, linearifolia. longifolia, maculata, nana, ovata, paniculata, pilosa, reptans, Richardsonii, Roemeriana, sibirica, speciosa, stellaria, subulata, Kuntze, Rev, Gen. (1891) $432=$ homonyma ommia Phlocis.

bryodes, Kuntze, 1. c. = P. bryoides, Nutt.

\section{ARMERIA :}

Douglasii, Kuntze, Rev. Gen. (1891) $432=$ P. Dowglassii, Hook.

Hordi, Kuntze, 1. c. = P. Hoodii, Rich.

muscodes, Kuntze, 1. c. = P. muscoides, Nutt.

ARMERIA, Linn. (Plumbag.).-Ind. Kew. i. 190 aegiales, Phil. in Anal. Univ. Chil. xci. (1895) 246 - Chili.

canescens, Halâcsy, in Denkschr. Akad. Wiss.

Wien (1894) $481=$ canescens, Boiss.?

Delphini, Phil.l.c. 246. - Chili.

exaristata, Phil. l. c 245. - Chil.

Henriquesii, Daveau, in Bolet. Soc. Brot. vi. (1888) 170 in obs. - Lusit.

Langeana. Henriques, in Bolet. Soc. Brot.v. (1887) 7 cum xylogr. = Henriquesii, Daveau.

longevaginata, Batt. in Batt. et Trab. Fl. de l'Algér. (Dicot.) (1889) 738. - Algér.

patagonica, Phil. en Anal. Univ. Chil. xci. (1895) 244. - Chili.

Rouyana, Daveau, in Bolet. Soc. Brot. vi. (1888) 166 cum icone; et in Bull. Soc. bot. Fr. xxxv. (1888) 331. - Hisp.

tenuifolia, Phil. in Anal. Univ. Chil. xci. (1895) 245. - Chili

trachyphylla, Lange, in Danske Vidensk. Selsk. Forh. (1893) 199. - Hisp.

ARMERIASTRUM, Lindl. = Acantholimon, Boiss. (Plumbag.).

acerosum, acmostegium, araxanum, aristulatum, armemum, aspadanum, atropatanum, auganum, avenaceum, baltanense, Bodeanum, brachyphyllum, brachystachyum, bracteatum, bromifolium, cabulicum, caesareum, Calvertii, caryophyllaceum, cataonicum, cephalotes, curviflorum, cymosum, distachyum, eschkerense, fasciculare, Faustii, festucaceum, flexuosum, glumaceum. Griffthianum, gulistanum, heratense, horridum, Huetii, iconicum, Kavelinii, Kotschyi, latifolium, laxiflorum, libanoticum, longiflorum, lycaonicum, mela nanthum, oliganthum, Olivieri, Peroniii, petraeum, polystachyum, pterostegium, quinquelobum, restiaceum, Ruprechtii, sahendicum, scabrellum, schahrudicum, schirazianum, scirpinum, senganense, setiferum, subulatum, talagonicum, tenuiflorum, tomentellum, tragacanthium, truncatum, ulicinum, viscidulum, Wietragacanthium, truncatum, ulicinum, viscidulum, Wie-
demannii, Kuntze, Rev. Gen. (I891) 393-94 = demannii, Kuntze, Rev. Gen. (I89

assyriacum, Kuntze, 1. c. $393=$ Ac. venustum, Boiss.

Balansae, Kuntze, 1. c. = Ac. armenum, Boiss. et Huet.

dianthifolium, Kuntze, 1. c. = Ac. venustum, Boiss. diapensiodes, Kuntze, 1. c. = Ac. diapensioides, Boiss.

Echinus, Kuntze, 1. c. = Ac. androsaceumn, Boiss. erinacewn, Kuntze, 1.c. = Ac. roseum, Boiss.

ferox, Kuntze, 1. c. = Ac. Scorpius, Boiss.

genistodes, Kuntze, 1. c. = Ac. genistoides, Boiss.

Hausknechtii, Kuntze, 1. c. = Ac. armenum, Boiss. et Huet.

incomptum, Kuntzn, 1. c. = Ac. Scorpius, Boiss.

kurdicum, Kuntze, 1. c. = Ac. brachystachyum, Boiss.

lepturodes, Kuntze, 1. c. = Ac. lepturoides, Boiss. leucacanthum, Kuntze, 1 c. = Ac. Scorpius, Boiss. Listoniae, Kuntze, 1. c. = Ac. acerosum, Boiss. lycopodiodes, Kuntze, 1. c. = Ac. lycopodioides, Boiss.

Pinardii, Kuntze, 1. c. = Ac. acerosum, Boiss.

puberulum, Kuntze, 1. c. $=$ Ac. androsaceum, Boiss.

splendiaum, Kuntze, 1. c. = Ac. bracteatum, Boiss. Stockii, Kuntze, 1. c. = Ac. Stocksii, Boiss. subsessile, Kuntze, 1. c. = Ac. alatavicum, Bunge. tartaricum, Kuntze, 1. c. = Ac. tataricum, Boiss. tenuifolium, Kuntze, 1. c. = Ac. Hohenackeri, Boiss.

ARMORACIA, Gaertn. Mey. et Scherb. = Gochlearia, Linn. (Crucif.).

brassicoides, Scheutz, Pl. vasc. Jeniss. (1888) 82. Sibiria.

ARNEBIA, Forsk. (Boragin.). - Ind. Kew. i. 191.
ARNEBIA :

decumbens, Kuntze, in Act. Hort. Petrop, x. (1887) 211 = decumbens, Coss.

inconspicua, Hemsl. et Lace, in Fourn. Linn. Soc. xxviii. (1891) 326. - Belutsch.

macrothyrsa, Stapf, ex Wien. Ill. Gartenzeit. (1891)

128; et in Gard. Chron. (1891) i. 180 - Armenia.

Széchenyii, Kanitz, Pl. exped. Szechenyi in As. centr. coll. (1891) 42. - As. cent.

ARNICA, Rupp. ex Linn. (Composit.). - Ind. Kew. i. 192

acaulis, Britton, Stern et Poggenb. Prelim. Catal. (1888) $30=$ nudicaulis, Ell.

ARODES, Heist. ex Fabric. Enum. pl. hort. Helmst. (1763) 42, ex Kuntze, Rev. Gen. (1891) $739=$ Richardia, Kunth (Aroid.).

athiopicum, Kuntze, Rev. Gen, $740=$ R. africana, Kunth.

albomaculatum, Kuntze, 1.c. = R, albo-maculata Hook. $f$.

angustilobum, Kuntze, 1. c. = R. angustiloba Schott.

hastatum, Kuntze, 1. $\mathrm{c}=\mathrm{R}$, hastata, $\mathrm{Hook}$

melanoleucum, Kuntze, 1. c. $=$ R. melanoleuca Hook. $f$.

ARONIA, Mitch. = Orontium, Linn. (Aroíd.) aquatica, Baill. Hist. des pl. xiii. (1895) 508 O. aquaticum, Linn.

ARONIA, Pers. = Amelanchier, Lind1. (Rosac.) alpina $\times$, Dippel, Handb. Laubholzk. iii. (1893) 384 (= Pyrus alpina, Willd.). - Hybr. artef.

floribunda, Hort. ex Dippel, 1. c. = Pyrus arbutifolia, Linn.f.

nigra, Britton, in Mem. Torrey Bot. Club, v.(1894) $182=$ Pyrus nigra, Sarg

nigra, Dippel, Handb. Laubholzk. iii. (1893) $384=$ Pyrus arbutifolia, Limn. $f$.

nigra, Koehne, Deutsche Dendrol. (1893) $254=$ P. arbutifolia, Linn. $f$.

ARONICUM, Neck. = Doronicum, Linn. (Composit.).

atlanticum Chabert, in Bull. Soc bot. Fr. xxxvii. (1891) $385=$ D. Pardalianches, Linn.

barcense, Simonk. Enum. fl. Transsilv. (1886) 322 $=\mathrm{D}$. granditlorum, Lam.

ARRABIDARA, DC. (Bignon.) - Ind. Kew. i. 193.

amazonica, K. Schum. in Engl. et Prantl, Natürl. Pflanzenfam. iv. 3 b. (1894) $213=$ conjugata Mart.

arthrerion, Buw. in Baill. Hist. des pl. x. (1888) 28 in adnot. (= Distictis arthrevion, DC.). - Bras.

brachypoda, Bur. in Vidensk. Meddels. naturh. Foren. (1893) 1213 (= Bignonia brachypoda. DC.). Bras.

celastroides, Bur. ex K. Schum. in Engl. et Prantl Naturl. Pfanzenfam.iv. 3 b. (1894)213. - Bras. cinerea, Bur. ex K. Schum. l. c. - Bras.

corymbifera, Bur. ex $K$. Schum. l. c. $(=$ Bignonia corymbifera, Vahl.). - Am. austr.

craterophora, Bur. in Vidensk. Meddels. naturh. Foren. (1893) 100 (= Bignonia craterophora, DC. - Bras.

dichasta, f. D. Smith, in Coult. Bot. Gaz. xx. (1895) 6. - Guatem.

dichotoma, Bur, in Vidensk. Meddels. naturh Foren. (1893) $1212=$ corymbifera, Bur.

dispar, Bur. ex K. Schum. in Engl. et Prantl, Natürl. Pflanzenfam. iv. 3 b. (1894) 215 (= Bignonia Blanchetii, DC.) - Bras.

fagoides, Bur. in Vidensk. Meddels. naturh. Foren. (1893) 97 (= Bignonia fagoides, Cham.). - Bras.

inaequalis, Baill. Hist. des pl. x. (1888) $28 \cdot(=$ Bignonia inaequalis, DC.). - Am. austr.

macrophylla, $K$. Schum. in Engl. et Prantl, Natür Pfanzenfam. iv. 3 b.(1894) 213 (=Arr.platyphylla DC.). - Bras.

minutiflora, K. Schum. l. c. 214. - Am, austr.

mollis, Bur. ex K. Schum. l. c. 213 (= Bignonia mollis, Vahl). - Bras. 


\section{ARRABIDAEA}

bliqua, Bur, in Vidensk. Meddels, naturh. Foren. (1893) $99=$ rotundata, Bur.

potosina, K. Schum. et Loes. in Bull. Herb. Boiss, iii. (1895) 618. - Mexic.

puberula, Bur. in Vidensk. Meddels, naturh. Foren. (1893) 99 (= Cuspidaria puberula, Mart.). - Bras. pulchella, Bur.l. c. (= Bignonia pulchella, Cham.). - Bras.

rotundata, Bur. ex K. Schum. in Engl. et Prantl, Natül. Pfanzenfam. iv. 3 b. (1894) 213 (= Bignonia rotundata, DC.). - Bras.

sciuripabulum, K. Schum. l. c. 224 in obs. Reg. Amaz.

stenothyrus, K. Schum. I. c. $213=$ tuberculata, $D C$. subfastigiata, Bur. in Vidensk. Meddels. naturh. Foren. (1893) 99 (= Adenocalymna foribundum, DC.). - Bras.

triplinervia, Baill. Hist. des pl. x. (1888) 28(= Bignonia triplinervia, Mart.). — Am. austr.

ARRAGAGIA, Bancr. (Umbellif.). - Ind. Kew. i. 193.

andina, Britton, in Bull. Torrey Bot. Club, xviii. (1891) 37. - Am. austr.

bracteata, Coult. et Rose, in Contrib.U.S. Nat. Herb. iii. (1895) 295. - Mexic.

Brandegei, Coult et Rose, in Proc Calif. Acad. Ser. II. ii. (1889) 165. - Calif.

brevipes, Coult. et Rose, in Contrib. U. S. Nat. Herb. iii. (1895) 296. - Mexic.

Coulteri, Rose, 1. c. in obs. = Tauschia Coulteri, A. Gray.

Delavayi, Franch. in Bull. Soc. Philom. Paris, Sér. VIII, vi. (1894) 115. - Yunnan.

Donnell-Smithii, Coult. et Rose, in Coult. Bot. Gaz. xv. (1890) 261 t. 15. - Guatem.

edulis, S. Wats, in Proc. Am. Acad. xxi. (1886) 430. - Mexic.

filiformis, Coult. et Rose, in Contrib. U. S. Nat. Herb. iii. (1895) 296 nomen. - Mexic.

irazuensis, Kuntze, Rev.Gen.(1891)265. - Costarica.

Iuxeana, Coult. et Rose, in Coult. Bot Gaz.xviii. (1893) 54. - Guatem.

Mariana, S. Wats. in Proc. Am. Acad. xxvi. (1891) 136. - Mexic.

multifida, S. Wats. l. c. - Mexic.

Nelsoni, Coult. et Rose, in Contrib. U. S. Nat. Herb iii. (1895) 296. - Mexic.

nudicaulis, Coult. et Rose, in Proc. Am. Acad. xxviii. (1893) 119. - Mexic.

ovata, Coult. et Rose, in Contrib. U. S. Nat. Herb. iii. (1895) 296. - Mexic.

Parishi, Greene, Fl. Francisc. (1892) $318=$ Velaea Parishii, Coult. et Rose.

peucedanifolia, Franch. in Bull. Soc. Philom. Paris, Sér. VIII. vi. (1894) 114. (Arrácacha). - Yunnan.

Pringlei, Coult. ex Rose, in Contrib. U. S. Nat. Herb. iii. (1895) 297. - Mexic.

vaginata, Coult. et Rose, l. c. - Mexic.

ARTABOTRYS, R. Br. (Anonac.). - Ind. Kew. i. 194.

costatus, King, in fourn. As. Soc. Beng. 1xi. (1892) ii. 37. - Perak.

gracilis, King, l. c. 35. - Perak.

grandifolius, King, l. c. 31. - Perak.

Lowianus, King, l. c. 34. - Perak.

madagascariensis, Baill. Hist. pl. Madag., Atlas (1886) t. 5 = madagascariensis, Miq.?

Monteiroae, Olwer, in Hook. Icon. pl. xviii. (1888) t. I796. - Mossamb.

nitida, Engl.Pflanzenw. Ost-Afr. C (1895) 179. Afr. trop. or.

oblongus, King, in fourn. As. Soc. Beng. Ixi. (1892) ii. 33. - Perak.

oxycarpus, King, l. c. 34. - Perak.

Rolfei, Vidal, Revis. pl. vasc. Filip. (1886) $39 .-$ Ins. Philipp.

Scortechinii, King, in fourn. As. Soc. Beng. 1xi. (1892) ii. 32. - Perak.

velutinus, S. Elliot, in fourn. Linn. Soc. $\mathrm{xxx}$ (1894) 71. - Sierra Leone.

venustus, King, in fourn. As. Soc. Beng. 1xi. (1892) ii. 32. - Perak.

Wrayi, King. l. c. 37. - Perak.
ARTANEMA, D. Don (Scrophul.).-Ind. Kew, i 194

longiflorum, Wettst. in Engl. et Prantl, Natürl. Pflanzenfam. iv. $3 \mathrm{~b} .(1891) \% 9=$ sesamoides, Benth.

ARTEMISIA, Linn. (Composit.). - Ind, Kew. i, 195.

Aschurbajewi, C. Winkl. in Act. Hort. Petrop. xi. (1890) 334. - Turkest.

bothnica, Lundstr. ex Nym. Consp. fl. Eur. Suppl. ii. 1 (1889) $170=$ campestris, Linn.

brachanthemoides, C. Winkl. in Act. Hort. Petrop. ix. (1886) 422. - Turkest.

Chamomilla, C. Winkl. l. c. x. (1887) 87. Turkest.

dracunculina, S. Wats. in Proc. Am. Acad. xxiii. (1888) 279. - Mexic.

astigiata, C. Winkl. in Act. Hort. Petrop. xi. (1891) 373. - As. centr.

Forwoodii, S. Wats. in Proc. Am. Acad. xxx. (1890) 133. - Dakota

faeggiana $\times$, Wolf, in Bull. trav. Soc. Murith. fasc. xvi-xviii. (1890) 27. - Helv.

kabylica, Chabert, in Bull. Soc. Bot. Fr. xxxvi, (1889) 27. - Alger.

Kuschakewiczi, C. Winkl. in Act. Hort. Petrop. xi. (1890) 330. - Turkest.

laxa, Fritsch, in Kern. Sched. fl. Austro-Hung. vi. (1893) $88=$ glacialis, facq.

laxiflora, St-Lager, in Cariot, Étud. des fleurs, éd. 8 , ii. (1889) $455=$ A. Mutellina, Vill.

microcephala, Hillebr. Fl. Haw. Isl. (1888) 230. Ins. Hawaii.

pamirica, C. Winkl. in Act. Hort. Petrop. xi. (1890) 329. - Turkest.

Pattersoni, A. Gray, Syn. Fl. N.Am. I. ii. Suppl. (1886) 453. - Colorado.

petrosa, Fritsch, in Kern. Sched. fl. Austro-Hung. vi. (1893) $92=$ Baumgartenii, Bess.

Pewzowi, C. Winkl, in Act. Hort. Petrop. xiii. (1893) 3. - As. centr.-occ.

pygmaea, A. Gray, in Proc. Am, Acad. xxi. (1886) 413. - Am. bor.

redolens, A. Gray, l. c. 393.-Mexic.

rhactica, Brugg. Mitth. neue und krit. Form.

(1886) 75 ex Jahresb. naturf, Gesells, Graub. xxix. $(1884-85)=$ A. Absinthium, Linn

sarawschanica, C. Winkl. in Act. Hort. Petrop. x. (1887) 88. - Turkest.

Seilevix, Wolf, in Archiv. sc. phys, et nat. xxxviii. (1892) 375; et ex Magnier, Scrin. fi. select. xiii. (1894) 324, - Helv.

Skorniakowi, C. Winkl, in Act. Hort. Petrop. xi. (1890) 331. - Turkest

ARTHRAERUA, Schinz, in Engl. et Prantl, Natürl. Pflanzenfam. iii. I a. (1894) 109. AMANATürl. Pflanzer

Leubnitziae, Schinz, l. c. fig. 63. - Afr. austroocc, extratrop.

ARTHRAXON, Beauv. (Gramin.). - Ind. Kew. i. 200 .

breviaristatus, Hack. in DC. Monog. Phan. vi. (1889) 350. - Reg. Himal., Yunnan.

glabrescens, Anderss. ex Hack. 1. c. $35 \%$ = ciliaris, Beaw.

jubatus, Hack. l. c. 358. - Ind. or.

micans, Franch. in Nouv. Arch. Mus. Paris, Sér. ii x. (1887) 109. - Tibet.

nudum, Benth. ex C. B. Clarke, in fourn. Linn. Soc. xxv. (1889) $86(=$ Batratherum nudum. Nees). Bengal.

violaceum, Benth. ex C. B. Clarke, 1. c. - Reg. Himal.

ARTHRAXON, Van Tiegh. in Bull. Soc. bot. Fr. xlii. (1895) $352=$ Loranthus, Linn. (Loranth.). amplexifolium, Van Tiegh. 1. c. 353. - Peruv.

bicalyculatum, Van Tiegh. 1. c. = L. bicalyculatus, Schult.

cardiphyllum, Van Tiegh. 1. c. = L. cardiphyllus, Willd.

chanduyense, Van Tiegh 1. c. = Psittacanthus chanduyensis, Eichl.
ARTHRAXON : (1895) $352=\mathrm{L}$. cordatus, Hoffnssgg.

falcifrons, Van Tiegh. 1. c. = Psittacanthus falcifrons, Mart.

ARTHROCHILIUM, G. Beck, Fl. Nied.-Oest. (1890) $212=$ Epipactis, Adans. (Orchid.). palustre, G. Beck, 1. c. = palustris, Crantz.

ARTHROPODIUM, R. Br. (Liliac.). - Ind. Kew. 1. 200. Colenso, in Trans. N.Z. Inst. xxv. ramulosum, Colenso, in Trans. N. Z. Inst. xxv.

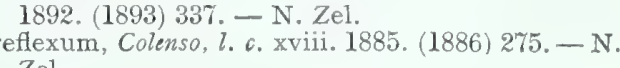

ARTHROSOLEN, C. A. Mey.(Thymel.).-Ind. flavus, Rendle, in Trans. Linn. Soc. Ser. II. iv (I894) 40. - Afr. trop. austro-or.

latifolius, Oliver, in fohnston, Kilima-Njaro Exped. (1886) 345 ; et in Trans. Linn. Ser. II. ii (1887) 348. - Afr, trop. or.

sphaerocephalus, Baker, in Kew Bull. (1894) 341.Arabia.

ARTHROSTEMA, Ruiz et Pav. (Melastom.). Ind Kew i. 200

hirtellum, Cogn.ex F. D. Smith, Enum.pl. Guat. iii. (1893) n. 3328 nomen; et in Coult. Bot. Gaz. xx. (1895) 286. - Guatem

lanceolatum, Cogn. in DC. Monog. Phan. vii. (1891) 142. - Hab.

parvifolium, $\operatorname{Cogn}$. l. c. 143, - Guatem.

ARTHROSTYLIDIUM, Rupx, (Gramin.). Ind. Kew. i. 201

Prestoëi, Munro, in Kew Bull. (1895) 186. - Ins. Trinit.

ARTOGARPUS, Forst. (Urtic.). - Ind. Kew. i. 201

bracteata, King, ex Hook, f. Fl. Brit. Ind. v. (1888) 540 ; et in Ann. Bot. Gard. Calc. ii. (1889) 7 t. 1 b. - Malacca.

Denisoniana, King, $l l$. cc. 544 et 14 t. 8 b. - Perak

Forbesii, King. $l l$. cc. 539; et 7 t. 1 a. - Perak, Sumatra.

involucrata, $K$. Schum. in K. Schum. et Hollr. Fl. Kais. Wilh. Land (1889) 39. - N. Guin.

Kunstleri, King, ex Hook. f. Fl. Brit, Ind. v. (1888) 540; at in Ann. Bot. Gard. Calc. ii. (1889) 9 t. 4. Perak, Malacca.

Maingayi, King, $l l . c c .542$; et 11 t. 8 a. - Perak, Malarca.

Lowii, King, ll. cc. 542; et 10 t. 7 a. - Perak.

Scortechinii, King, Ul.cc. 542; et 12 t. 9. - Perak.

ARUBA, Aubl. = Simaba, Aubl. (Simarub.).

Cedron, crustacea, cuneata, cuspidata, ferruginea, floribunda, glabra, glandulifera, guianensis, macrophylla, Majana, nigrescens, obovata, orinocensis, salubris, suaveolens, subcymosa, suffruticosa, trichiliodes, Warmingiana, Kuntze, Rev. Gen. (1891) 103. = homonyma omnia Simabae.

ARUM, (Tourn.) Linn. (Aroid.). - Ind. Kew. i.

Engleri, Hausskn. in Mitth.Bot.Ver. Fena, ix. (1891) Engleri, Haussk
22. - Persia.

grandiflorum, Ham. ex Hook. f. Fl. Brit. Ind. vi. (1893) 518 in syn.=Thomsonia nepalensis, $W$ all. Magdalenae, Sprenger, in Bull. Soc. Tosc. Ortic. (1894) 227. - Palaest.

modicense, Sprenger, l c, = italicum, Mill.

sanctum, Damm, in Dammann, Catal. (1889) 3 et 5 fig, i; et in Gartenfl. (1889) $655=$ palaestinum, Boiss.

ARUNDARBOR, Rumpf, Herb. Amboin. iv. (1743) 2-18 t. 2-4, ex Kuntze, Rev, Gen. (1891) $760=$ Bambusa, Schreb. (Gramin.)

affinis, agrestis, amahussana, angulata, Apus, aristata, arundinacea, atra, aurea, aurostriata, Balcosa, Beecheyana, Bitung, Blancoi, Blumeana, Brandisi, Cantori, capitata, cornuta, distorta, Falconeri, fera, flexuosa, Fortunei, Griffithiana, Helferi, Horsfieldii, 
ARUNDARBOR :

khasiana, levis, lina, lineata, Lumampao, marantifolia, marginata, Mastersi, maxima, mitis, monogyna, multiplex, nana, nutans, Oldhamii, orientalis, pallida, picta, polymorpha, prava, pungens, pygmaea, regia, remotiflora, Ritcheyi, spinosa, striata, tabacaria, Teba, temis, teres, textoria, vasaria, Kuntze, via, Teba, temis, teres, textoria, vasaria, Kuntze,

Rev. Gen.
Bambusae.

amplexifolia, Kuntze, 1. c. $760=$ Guadua amplexifolia. F. et C. Presl.

argenteostriata, Kuntze, 1. c. $761=$ B, argenteastriata, Regel.

Bambos, Kuntze, L. c. $760=$ B. arundinacea, Willd.

brevifolia, Kuntze, 1. c, = B. breviflora, Munro. diffusa, Kuntze, 1. c. = Guadua distorta, Rupr.

glomerata, Kuntze, 1. c. = Dendrocalamus strictus, Nees.

Guadua, Kuntze, 1. c。 = Guadua angustifolia, Kunth.

kurillensis, Kuntze, 1. c. = Arundinaria kurilensis, Ruspr.

latifolia, Kuntze, 1. c. $761=$ Guadua latifolia, Kunth. longinodes, Kuntze, 1. c。 = B. longinodis, Miq. Luzoniae, Kuntze, 1. c. = B. Luçoniae, Munro. marantifolia, Kuntze, 1. c.= Guadella marantifolia, Franch.

M'Clellandii, Kuntze, 1. c. = B. Mac-Clellandi Munro.

paniculata, Kuntze, 1. c. = Nastūs borbonicus, $\mathcal{f}$. F. Gmel.

rofracta, Kuntze, 1. c. = Guadua refracta, Munvo. Tagoara, Kuntze, 1. c. = Guadua Tagoara, Kuntze.

Trinii, Kuntze, 1. c, $\rightleftharpoons$ Guadua Trinii, Rupr.

Venezuelae, Kuntze, 1. c. = Guadua Venezuelae, Munvo.

virgata, Kuntze, 1. c. = Guadua virgata, Rupr.

ARUNDASTRUM, Rumpf, Herb. Amboin. iv. 22 t. 7 (1744) ex Kuntze, Rev. Gen. (1891) $683=$ Glinogyne, Salisb. (Scitam.).

Benthamianum, Kuntze, 1. c. $684=$ Clinogyne grandis, Benth, et Hook. $f$.

canniforme, Kuntze, 1. c. $683=\mathrm{C}$. dichotoma, Salisb.

cuspidatum, Kuntze, 1. c. 684 (= Donax cuspidata, K. Schum.). - Afr. trop

filipes, Kuntze, 1. co = C. filipes, Benth. et Hook. $f$. grande, Kuntze, 1. c. = C. grandis, Benth. et Hook.f.

romosissimum, Kuntze, 1. c. = Phrynium ramosis simum, Benth.

Schweinfurthianum, Kuntze, 1. c. (= Donax Schweinfurthiana, K. Schum.).- Afr. trop.

virgatum, Kuntze, 1. c. = C. virgata, Benth. et Hook. f.

ARUNDINA, Blume(Orchid.). - Ind. Kew. i. 204. Cantleyi, Hook. f. Fl. Brit. Ind. v. (1890) 858; et Icon. pl. xxil. (1892) t. 2112. - Pexak.

revoluta, Hook. f. l. c. - Perak.

Sanderiana, Kraenzl., in Bot. Fahrb.xvii.(1893) 483. - Sumatra.

ARUNDINARIA, Michx, (Gramin.).-Ind. Kew. i. 204

alpina, $K$. Schum. in Engl. Pflanzenw. Ost-Afr. C (1895) 11\%. - Afr. trop. or.

baviensis, Balansa, in Morot, Fourn. de Bot. iv. (1890) 27. - Tonkin.

nitida, Hort. Kew, ex Kew Bull. Append. ii. (1894) 33 nomen, - Reg. Himal.

quadrangularis, Makino, in Tokyo Bot. Mag. ix. (1895) $71=$ Bambusa quadrangularis, Fenzl.

Sat, Balansa, in Morot, Fourn. de Bot. iv. (1890) 28. - Tonkin.

Sodiroana, Hack. ex Sodiro, Gram. Ecuat. (Anal. Univ. Quito, 1889) 11 nomen. - Ecuad.

ARUNDINELLA, Raddi (Gramin.). - Ind. Kew. 1, 204.

hispida, Kuntze, Rev. Gen. (1891) $\% 61=$ brasiliensis, Radd.

robusta, Fourn. Gram. Mexic. 1881. (1886) 54. Mexic.
ASARCA, Lindl. = Ghloraea, Lind1. (Orchid.)

affinis, alpina, aurea, barbata, Besseri, calopogon, cam pestris, chlorosticta, chrysantha, chrysochlora, collina. Commersonii, crispa, crocata, cuneata, cygnea. cylindrostachya, dasypogon, densa, fimbriata, galeata, Gaudichaudi, Gayana, grandiflora, gymnoglossa heteroglossa, homopetala, incisa, inconspicua, lamellata, Lechleri, litoralis, longipetala, magellanica, medilabia, multiflora, obovata, odontoglossa, patagonica, Pearcei, Poeppigiana, pogonata, prodigiosa, reflexa, Sceptrum, secunda, semibarbata, suaveolens, Unzuiscati, venosa, viridiflora, Kuntze, Rev. Gen. (1891) $652=$ homonyma omnia Chloreae.

bletiodes, Kuntze, 1. C. = C. ulanthoides, Lindl. conspicua, Kuntze, 1. co = C. spectabilis, Phil.

disodes, Kuntze, 1. c. = C. disoides, Lindl.

Fonckii, Kuntze, 1. c. = C. Fonkii, Phil.

insignis, Kuntze, 1. c. = C. speciosa, Poepp.

longibracteata, Kuntze, 1. c. $=$ C. longebracteata, Lindl

Iutea, Kuntze, 1. c. = C. cristata, Lmal.

Philippii, Kuntze; 1. c. = C. Philippi, Reichb. $f$.

rhypaloglossa, Kuntze, 1. c. = C. rypaloglossa, A. Rich.

tuberculata, Kuntze, 1. c, = C. verrucosa, Phil.

virescens, Kuntze, 1. C. = C. Piquichen, Lindl.

ASARUM, (Tourn.) Linn. (Aristol.). - Ind. Kew. i. 206 .

cardiophyllum, Franch. in Bull. Muséum Paris, i. (1895) 65. - Yunnan.

Delavayi, Franch. l. c. 66. - Yunnan.

Forbesii, Maxim. in Bull. Acad. St-Pétersb. xxxi. (1887) 92 . - China.

geophilum, Hemsl. in Gard. Chron. (1890) i. 422; et ex Hook. f. in Bot. Mag. (1891) t. 7168. - China. grandiflorum, Small, in Mem. Torrey Bot. Club, iv. (1894) 150 = virginicum, Linn.var.

macranthum, Hook. f. in Bot. Mag. (1888) t. 7022. - Ins. Formosa

macranthum. Small, in Mem. Torrey Bot. Club, v,

(1894) 136 = virginicum, Linn, var.

maximum, Hemsl. in Gard. Chron. (1890) i.422; et in fourn. Linn. Soc. xxvi. (1891) 359. - China

pulchellum, Hemsl. 11. cc. 422 et $360 .-$ China.

rotundifolium, St-Lager, in Cariot, Étud. des fl. éd. 8, ii. (1889) $720=$ europaeum, Linn.

akawanum, Makino, in Tokyo Bot. Mag. ix. (1895) 260. - Japon.

ASCLEPIAS, Linn. (Asclep.). - Ind. Kew. i 207

aceratoides, Nash, in Bull. Torrey Bot. Club, xxii. (1895) 154 = aceratoides, $M$. Curt.

albicans, S. Wats, in Proc. Am. Acad. xxiv. (1889) 59. - Calif.

albida, N. E. Br. in Kew Bull. (1895) 254. Abyss.

amabilis, N.E. Br.l. c.70.-Afr. trop. or.

Buchenaviana, Schinz, in Vert. Bot. Ver. Brand. xxx. (1888) 261. - Afr. austro-occ, extratrop.

Burchelli, Schlechter, in Journ. Bot. xxxili. (1886) $336=$ Gomphocarpus tomentosus, Burch

californica, Greene, in Erythea, 1. (1893) 92; et Man.

Bot. San Franc. Bay, (1894) 242. - Calif.

cochabambensis, Rusby, in Mem. Torrey Bot. Club, iv. (1895) 221. - Bolivia.

conspicua, N.E. Br. in Kete Bull. (1895) 253. Afr. centr. or.

cultriformis, Schlechter, in Bot. Fahrb. xviii. Beibl. n. 45. (1894) 31. - Afr. austr.

decumbens, K. Schum. in Engl. et Prantl, Natürl. Pflanzenfam. iv, 2. (1895) $239=$ Asclepiodora decumbens, A. Gray.

denticulata, Schlechter, in fourn. Bot. xxxiii. (1895)

334. - Afr. trop.

Dregeana, Schlechter, 1. c. $337=$ Gomphocarpus marginatus, E. Mey.

eximia, Schlechter, l. c. 335. - Afr. trop.

filiformis, "Benth. et Hook. " ex Kuntze, in Jahrb. Bot. Gart. Berl. iv. (1886) 268 (= Lagarinthus filiformis, E. Mey.). - Afr. austr.

flavida, N.E. Br. in Kew Bull. (1895) 255. - Afr trop. or.

fulva, $N . E . B r$. . . c. 254. - Afr. trop. or.

Grantii, Schlechter, in Journ. Bot. xxxiii. (1895) $335=$ Gomphocarpus Grantii, Oliver

\section{ASCLEPIAS}

guatemalensis, 7. D. Smith, in Coult. Bot. Gaz. xviii. (1893) 297. - Guatem.

umilis, Schlechter, in Bot, Jahrb.xx. Beibl, n. 51 1895) $26=$ Gomphocarpus humilis, Decne.

integra, N. E. Br. in Kew Bull. (1895) 219. - Afr

trop. or. 318. - Mexic.

jangadensis, S. Moore, in Trans. Linn. Soc. Ser. II. iv. (1895) 398. - Bras.

Kuntzei, Schlechter, in Oest. Bot. Zeitschr. xIv. (1895) 450. - Bolivia.

labriformis, M. E. Fones, in Proc. Calif. Acad. Ser. II. v. (1895) 708. - Utah.

latifolia, Britton, in Mem. Torrey Bot. Club, v. (1894) $263=$ A. Jamesii, Torr.

leucocarpa, Schlechter, in fourn. Bot, xxxiii. (1895) 335. - Afr. trop.

lineolata, Schlechter, 1. c. $336=$ Gomphocarpus lineolatus, Decne.

macrochila, Schlechter, l. c 355. - Afr. austr.

macroura, A. Gray, in Proc. Am. Acad. xxii. (1887) 436. - Mexic

mashonensis, Schlechter, in fourn. Bot. xxxiii. (1895) 356. - Afr. trop.

palustris, Schlechter, 1. c. $336=$ Gomphocarpus palustris, $K$. Schum

Petherickiana, Schlechter, 1. c. $336=$ Schozoglossum Petherickianum, Oliver.

Philippsiae, N.E. Br. in Kew Bull. (1895) 219. Afr. trop. or

propinqua, $N$. E. Br. l. c. 254. - Afr. trop. or. pseudo-crispa, Schlechter, in fourn. Bot. xxxiii. (1895) $35 \%$ - Afr. austr.

pygmaea, N.E. Br. in Kew Bull. (1895) 255.

Afr. trop. or.

vigida, Schlechter, in Journ, Bot, xxxii. (1895) 357 $=$ Gomphocarpus rigidus, Decne

rubicunda, Schlechter, 1. c. $336=$ fulva, $N . E . B r$

schizoglossoides, Schlechter, in Bot. fahrb. xviii. Beibl.n. 45. (1894) 32. - Afr. austr.

Schweinfurthii, N.E. Br. in Kew Bull. (1895) 253. - Afr. centr.

spectabilis, $N$. E. Br, l. c. 254. - Afr. trop. or.

tenuifolia, N.E.Br.l. c. 255.-Afr. austr

texana, Hellev, Bot. Expl.S. Texas (1895) $7 \%$ t. 4. Texas.

tithymaloides, Greene, in Erythea, i. (1893) 151. Mexic.

Tysoniana, Schlechter, in fourn. Bot. xxxiii. (1895) 358. - Afr. austr.

ASCOLEPIS, Nees (Cyper.). - Ind. Kew. i. 209.

brasiliensis, Benth. ex C. B. Clarke, in Th. Dur. et Schinz, Consp. fl. Afr. v. 1894. (1895) 651 (= Platylepisbrasiliensis, Kunth). - Afr. et Am. trop

Oliveri, Vatke et Hoepfner, ex C. B. Clarke, 1. c. 652 in syn. = speciosa, Welw.

Vatkeana, Boeck. ex C. B. Clarke, 1. c. $652=$ speciosa, Welw.

ASIMINA, Adans. (Anonac.). - Ind. Kew. i. 210.

angustifolia, A. Gray, in Coult. Bot. Gaz. xi. (1886) 163. - Florida.

insularis, Hemsl. in Hook, Icon. pl. xvi. (1886) t. 1514; et Biol. Centr.-Am. i v. (1886) 96. - Yuca$\tan$.

ASPALATHUS, Amm. Stirp. Ruth. (1739) 203-10 t. 35 = Caragana, Lam. (Legumin.).

ambiguus, brevispinus, Bungei, Chamlagu, confertus, crassicaulis, cuneatus, frutescens, Gerardianus, grandiflorus, jubatus, microphyllus, polyacanthus, pygmaeus, Redorski, spinosus, tenuis, ulicinus, Kuntze, Rev. Gen. (1891) 161 = homonyma omnia Caraganae.

Caragana, Kuntze, 1. c. = C. arborescens, Lam. nubigenus, Kuntze, 1, c. $=\mathrm{C}$. crassicaulis, Benth.

triflorus, Kuntze, 1. c. $=$ C. brevispina, Benth?

ASPALATHUS, Linn. (Legumin.). - Ind. Kew. i. 210

argyrella, MacOwan, in fourn. Linn. Soc. xxv. (1890) 387. - Afr. austr. 
ASPALATHUS

humilis, Bolus, MacOwan, in fourn. Linn. Soc. xxv. (1889) 160. - Afr. austr.

leptoptera, Bolus, l. c. - Afr. austr.

ASPARAGUS, Tourn. ex Linn. (Liliac.). - Ind Kew. i. 212.

albanensis, Hort. ex Illustr. Hortic. (1895) 188. Afr. austr.?

Buchanani, Baker, in Kew Bull. (1893) 211. - Afr. trop. or.

comorensis, Hort. ex Wien. Illustr. Gartenz. (1888) 158; et ex Illustr. Hortic. (1895) 60 fig $8=$ crispus, Linn.?

juniperoides, Engl. Bot. Fahrb. x. (1889) 3. Afr, austro-occ, extratrop.

myriocladus, Baker, in fourn. Bot. xxvii. (1889) 43. - Natal.

Saundersiae, Baker, l. c. 42. - Natal.

Sprengeri, Regel, in Act. Hort. Petrop. xi. (1890 302 ; et in Gartenfl. (1890) $490 \mathrm{fig}$. 80 . - Afr austro-or.

Steudneri, Schweinf. ex Engl. in Abhandl. Preuss. Akad. Wiss. 1891 (1892) $169=$ asiaticus, Linn.

Tamaboki, Yatabé, in Tokyo Bot. Mag. vii. (1893) 61 t. 44.- Japon.

zeylanicus, Hook. f. Fl. Brit. Ind. vi. (1892) 317. - Zeylan.

ASPASIA, Lindl. (Orchid.). - Ind. Kew. i. 214 Barclayi, Rolfe, in Kew Bull. (1892) 210. - Hab.

ASPRRULA, Linn. (Rubiac.). - Ind. Kew, i. 214. aristifera, Colenso, in Trans. N.Z. Inst. xxi. 1888 (1889) 88. - N. Zel.

asterocephala, Bornm. in Mitth. Thiir. Bot. Ver. N. Folge, vii. (1895) 7 nomen. - Oriens.

Baenitzii, Heldr. ex Boiss. Fl. Or. Suppl. (1888) 280 - Attica.

baetica, Rouy, in Bull. Soc. Bot. Fr. xxxviii. (1891) 80; et in Magnier, Scrin. A. select.x. (1891) 191. Hisp.

Boissieri, Heldr. ex Boiss. Fl. Or. Suppl. (1888) 281. - Graecia.

breviflora, Batt. in Batt. et Trab. F1. de l'Algér. (Dicot.) (1888) $392=$ aristata, Linn.

dissitiflora, Post, in fourn. Linn. Soc. xxiv. (1888) 432. - Syria.

Doerfleri, Wettst, in Luerss, Bibl. Bot. Heft xxvi. (1892) 59 t. iii. fig. 9-12. - Albania.

Eugeniae, C. Richt, in Oest. Bot. Zeitschr. (1888) 110 - nomen; et in Abhandl.Zool. Bot. Ges. Wien,xxxviii. (1888) 219. - Austria.

ghautensis, Post, Pl. Postianae, iii. (1892) 10. Syria.

Gussoneana, "Boiss, ") ex Ces. Pass, et Gibelli, Comp. fi. 1tal. (1886) $559=$ Gussonei, Boiss. hercegovina, Degen, in Oest. Bot.Zeitschr. xl. (1890) 15. - Herceg.

heteroclada, Hausskn, in Mitth. Thür. Bot. Ver. N. Folge, vi. (1894) 30. - Gallia mer.

leiantha, Kern, ex Wettst. in Murbeck, Beitr. Kennt. F1. Bosn. und Herceg. (1891) 114. - Eur.

Majori, Barbey, in Bull. Herb. Boiss, ii. (1894) 243 t. 6. - Ins. Saria (Cycl.)

majoriflora, Borb. ex Formanek, in Verh. naturf. Ver. Brunn, xxxii. 1893 (1894) 165. - Maced.

oetaea, Heldr. ex Nym. Consp. f.. Eur. Supp1.ii. 1 (1889) $156=$ lutea, Sibth. et Sm.

pilosa, Degen, in Oest. Bot. Zeitschr. x1. (1890) 15 $=$ hexaphylla, All

puberula, Haláczy et Sint. in Oest. Bot. Zeitschr. x1. (1890) 38. - Graecia.

pulvinaris, Heldr. ex Boiss. Fl. Or. Suppl. (1888) 281. - Graecia.

Sheravdi, Höck, ex E. Hallier, in Koch's Syn. deutsch. F1. ed. 3. (1893) $1199=$ Sherar dia arvensis, Linn.

Sintenisii, Halaczy, in Oest. Bot. Zeitschr. xl. (1890) 38 in syn. = puberula, Halaczy et Sint.

sublongiflora, Borb. in Oest. Bot. Zeitschr. xliv. 1894) 399. - Croatia.

taurica, Paczosky, Descr. pl. gubern. Cherson. (1889) 20; et in Act. Hort. Petrop. xiii. (1894) 300. Ross. mer.

Wettsteini, Adamovic, in Deutsche Bot. Monatsschr. vii. (1889) 117. - Eur. or.
ASPHODELINE, Reichb. (Liliac.) - Ind. Kew. i. 215.

recurva, Post, in Bull. Herb. Boiss, iii. (1895) 166.Syria.

ASPHODELIRIS, Moehr. Hort. Priv. (1736) 15 pr. p. ex Kuntze, Rev. Gen. (1891) $706=$ Tofieldia, Huds. (Liliac.)

calyculata, cernua, falcata, glutinosa, gracilis, himalaica, japonica, nuda, nutans, occidentalis, sordida. stenantha, Kuntze, $l$. $c .=$ homonyma omnia Tofieldiae

racemosa, Kuntze, $1 . \mathrm{c} .=\mathrm{T}$. pubens, Willd.

sessiliflora, Kuntze, 1. c. = T. falcata, Pers.

ASPHODELUS (Tourn.) Linn. (Liliac.). - Ind. Kew. i. 215.

comosus, Baker, in Gard. Chron.(1887) i. 799. Reg. Himal.

ASPIDISTRA, Ker-Gawl. (Liliac.). - Ind. Kew. 1. 216.

longifolia, Hook. f. Fl. Brit Ind. vi. (1892) 326. Reg. Himal.

typica, Baill. in Bull. Soc. Linn. Paris, ii. (1894) 1129. - Tonkin.?

ASPIDOPTERYS, A. Juss. (Malpigh.). - Ind.

\section{Kew. i. 216.}

costulata, Pierre, Fl. For. Cochinch. (1893) sub t. 275. - Cochinch.

Harmandiana, Prerre, l. c. t. 275. - Cochinch. tomentosa, Pierre, 1. c, t. $275=$ costulata, Pierre. yemensis, Deflers, Voy. Yémen (1889) 117 (Aspidopteris $)=$ Caucanthus edulis, Forsk.

ASPILIA, Thou. (Compos.). - Ind. Kew. i. 217. albiflora, A. Gray, in Proc. Am. Acad. xxii. (1887) 425. - Mexic.

alternifolia, Klatt, in Ann. naturh. Hofmus. Wien, vii. (1892) 298. - Madag.

angustifolia, A. Gray, in Proc. Am. Acad. xxii. 1887) 425. - Mexic

asperifolia, O. Hoffm. in Engl. Pfanzente. Ost-Afr. $C$ (1895) 413. - Afr. trop. or

costaricensis, Klatt, ex Th.Dur. et Pitt. in Bull. Soc. bot. Belg, xxxi. 1892 (1893) 201. - Costarica.

Fischeri, O. Hoffm, in Engl. Pflanzenw. Ost-Afr. C (1895) 4l3. - Afr. trop or.

Glaziovi, Bakev, in Kew Bull. (1895) 106. - Bras. gondensis, O. Hoffm. in Engl. Pflanzenw. Ost-Afr. C (1895) 413. - Afr, trop. or

Holstii, O. Hoffm. l. c. 411. - Afr. trop. or.

involucrata, O. Hoffm. l.c. 413. - Afr. trop. or

pachyphylla, Klatt, in Leopoldina, Heft xxiii. (1887) 143 = Actinomeris pachyphylla, Sch. Bip.

pluriseta, Schweinf. ex Engl, in Abhandl. Preuss. Akad. Wiss. 1891 (1892) 433; et in Hoehnel, Zum Rudolph Seem, Append. (1892) 10. - Afr. trop. or. Ramagii, Ridl. in fourn. Linn. Soc. xxvix. (1890) 42. - Ins. Fernando Noronha.

subpandurata, O. Hoffm. in Engl. Pfanzenv. OstAfv. C (1895) 413. - Afr. trop. or.

ASPRELLA, Host = Psilurus, Trin. (Gramin.). aristata, Kuntze. Rev. Gen. (1891) $732=$ P. nardoides, Trin.

ASPRELLA, Schreb. = Leersia, Sw. (Gramin.), aristata, Petrie, in Trans. N. Z. Inst. xxvi. 1893. (1894) 272. - N. Zel.

laevis, Petrie, 1. c. xxvii. 1894 (1895) 406.-N. Zel.

ASSONIA, Cav. = Dombeya, Cav. (Stercul.). acevifolia, Ameliae, antsianakensis, Baroni, Bernieri, biumbellata, Boivini, Bojeriana, Breonit, Bruceana, Burgessiae, cannabina, Chapelieri, Coria, irassipes, cuspidata, cymosa, decanthera, densiflora, elliptica, erythroclada, ferruginea, ficulnea, floribunda, glechomifolia, Greveana, guazumifolia, Hildebrandtii, Hilsenbergii, hirsuta, Humblotii, insignis, Kirkii, Lantziana, laurifolia, longicuspis, longifolia, longipes, lucida, lucubensis, macrantha, megaphylla, modesta, mollis, natalensis, obovalis, ovata, Parkeri, parviflora, mollis, natalensis, obovalis, ovata, Parkeri, parvifiora, punctata, repanda, reticulata, Richardii, rigida, rotundifolia, rubifolia, Schimperiana, spectabilis, sti-

\section{ASSONIA :}

pulacea, Thouarsii, tiliacea, tomentosa, triumfettifo lia, umbellata, viburnifolia, Wallichii, xiphosepala, Kuntze, Rev. Gen. (1891) $76=$ homonyma omnia Dombeyae.

angulata, Kuntze, 1. c. $76=$ D. acerifolia, Baker. botryodes, Kuntze, 1. c. = D. botryoides, Baker. manchavica, Kuntze, 1. c. = D. manaharica, Baill. palmata, Kuntze, 1. c. = D. acutangula, Cav. rottlerodes, Kuntze, 1. c, = D, rottleroides, Baill. quinqueseta, Kuntze, 1. c. = D. multiflora, Planch tiliaefolia, Kuntze, 1. c. = D. acutangula, Cav.

ASTELIA. Banks et Soland. (Liliac.).-Ind. Kew. i. 217.

graminifolia, Colenso, in Trans. N. Z. Inst. xix. 1886 (1887) $267=$ spicata, Colenso.

hastata, Colenso, 1. c, $265=$ microsperma, Colenso

Nadeaudi, Drake, Fl. Polyn. franc. (1892) 227; et Illustr. fl. insul. Maris Pacif, (1892) 319. - Ins. Societ.

planifolia, Colenso, in Trans. N. Z. Inst. xx. 1887 (1888) 209. - N. Zel.

subrigida, Colenso, l.c. xix.1886(1887) 268.-N. Zel.

ASTEPHANIA, Oliver, in Hook. Icon. pl. xvi. (1886) t. 1506; et in Trans. Linn. Soc., Ser. II. ii. (1887) 338. COMPOSI TAE

africana, Oliver, $l l . c c$. - Afr. trop. or

ASTEPHANOGARPA, Baker, in Journ. Linn. Soc. xxii. (1887) 493. COMPOSITAE.

arbutifolia, Baker, l. c. - Madag.

ASTEPHANUS, R. Br.(Asclepiad.).-Ind. Kew. i. 218 .

neglectus, Schlechter, in Bot. Fahrb. xviii. Beibl. $\mathbf{n}$, 45. (1894) 26. - Afr. austr.

stenolobus, $K$. Schum. ex Engl. in Abhandl. Preuss. Akad. Wiss. (1894) 15 nomen; et in Engl. Pfanzenv. Ost-Afr. C (1895) 321. - Afr. trop. or

ASTER, Tourn. ex Linn. (Composit.).-Ind. Kew. i. 218 .

abyssinicus, Kuntze, Rev. Gen. (1891) $317=$ Felicia abyssinica, Sch. Bip.

acerosus, Kuntze, 1. c. = Aplopappus acerosus, Bert.

acradenius, Kuntze. 1. c. = Bigelowia acradenia, Greene.

Adelberti, Kuntze, 1. c. $315=$ Aplopappus Chamissonis, $D C$

Aitchisoni, Boiss. Fl. Or. Suppl. (1888) 287. Afghan.

Alamani, Kuntze, Rev, Gen. (1891) $215=$ Soli dago scabrida, $D C$

alatipes, Hemsl. in fourn. Linn. Soc. xxiii. (1888) 407. - China.

albarracinensis, Pau, Not. bot. fl. Espan. i. (1887) 9. - Hisp.

Alberti, Phil. in Anal. Univ. Chil. 1xxxvii. (1894 406. - Chili.

albidus, Kuntze, Rev. Gen. (1891) $315=$ Olearia albida, $\mathrm{Hook}$. $f$

albus, Kuntze, l. c. 317. - Chili.

amplexicaulis, Kuntze, 1. c.=Solidago amplexicaulis, Torr. et Gray.

andinus. Kuntze, 1. с. = Aplopappus pinnatifidus, Nutt.

Angelandyi, Kuntze, 1. c. = Bigelowia Engelmanni, A. Gray.

angulatus, Kuntze, 1. c. = Olearia angulata, T. Kirk.

angustatus, Kuntze, 1. c. = O oleifolia, T. Kirk. anthyllodes, Kuntze, 1. c. 317=Aplopappus anthylloides. Meyen et Walp.

antucensis, Kuntze, l c. - Chili.

apargiodes, Kuntze, 1. c. = Aplopappus apargioides, A. Gray.

araucames, Kuntze, 1. c. =Apl, araucanus, Phil. arborescens, Kuntze, 1. c. $315=$ Olearia nitida, Hook. $f$.

arbutodes, Kuntze, 1. c. $317=$ Aplopappus arbutoides, Remy.

Archeriamus, Kuntze, 1. c. $315=$ Solidago rugosa,

Mill.
arguta, Kuntze, 1. c. $317=$ Sol. arguta, Ait. 
ASTER : -

armenus, Kuntze, Rev. Gen.(1891) 31\% - Armenia. armeriodes, Kuntze, 1.c. = Aplopappus armerioides, A. Gray.

Asae, Kuntze, 1. c. $315=$ Bigelowia paniculata A. Gray.

asperatus, Kuntze, 1. c. = Solidago patula, $M u h l$.

asterodes, Kuntze, 1. c. = Aster Heterochaeta C. B. Clarke.

asteroides, MacMillan, Metasperm. Minn. (1892) $524=$ Sericocarpus conyzoides, Nees.

asteroides, Rusby, in Mem. Torrey Bot. Club, iv.

(1893) $213=$ Baccharis asteroides, Colla.

atacannensis, Kuntze, Rev. Gen. (1891) $315=$ Aplopappus rigidus, Phil.

atenes, Kuntze, 1. c. $(=$ Pyrrocona rigida, Phil. $)$ - Chili.

aureus, Kuntze, 1. c. $317=$ Aplopappus aureus A. Gray.

Autrani, Post, in Bull. Herb. Boiss, iii. (1895) 158. - Syria.

avienniaefolius, Kuntze, Rev. Gen. (1891) $315=$ Olearia avicenniaefolia, Hook. $f$.

baccharodes, Kuntze, 1. c = Solidago occidentalis, Torr, et Gray.

Bangii, Rusby, in Mem. Torrey Bot. Club, iv. (1895) 213 (= Ivibolium conspicum, Lind1.). Bolivia.

Barrelieri, Pau, Not. bot. Al. Espan. iii. (1889) 30 - Hisp.

batangensis, Bur. et Franch. in Morot, fourn. do Bot v. (1891) 50. - China.

Baylahuen, Kuntze, Rev, Gen. (1891) $317=$ Aplopappus Baylahuen, Remy.

Berberidis, Kuntze, 1. c. $=$ Aplopappus Berberidis, A. Gray.

Berlandieri, Kuntze, 1. c. $315=$ Bigelowia Drummondii, A. Gray.

Berteroi, Kuntze, 1. c. $317=$ Aplopappus Berterii DC.

Bezanillana, Kuntze, 1. c. (= Pyrrocoma Beranil lana, Remy).-Chili.

Bidvillii, Kuntze, 1. c. $315=$ Olearia virgata, Hook, f.

Bloomeri, Kuntze, 1. c. $317=$ Aplopappus Bloomeri, A. Gray.

binominatus, Kuntze, 1. c. $315=$ Bigelowia Bige lovii, A. Gray.

Bolanderi, Kuntze, 1. c. $317=$ Big. Bolanderi A. Gray.

Bonplandii, Kuntze, 1. c, $315=$ Solidago simplex H. B. et K.

Bowerii, Henisl. in Fourn. Linn. Soc. xxx. (1894) 113. - Tibet.

brachylepis, Kuntze, Rev, Gen, (1891) 317 = Bigewia brachylepis, $A$. Gray.

Brandegeei, Kuntze, 1. c.=Aplopappus Brandegei, A. Gray.

brickellioides, Greene, Pittonia, ii. (Nov, 1889) 16 (= Sericocarpus tomentellus, Greene) - Oregon.

Brittonii, Kuntze, Rev. Gen. (1891) $315=$ Solidago Bigelovii, A. Gray.

Buchananii, Kuntze, 1.c.=Olearia alpicola, F. Muell.

Buckleyi, Kuntze, 1. c. 317 = Solidago Buckleyi, Torr. et Gray.

bullatus, Klatt, in Annal. Naturh. Hofmus. Wien, ix. (1894) 359. - Mexic.

Bustillosiamus, Kuntze, Gen.Rev.(1891)1.c. $317=$ Aplopappus bustillosianus, Remy.

caesius, Kuntze, 1. c, = Solidago caesia, Linn.

caespitosus, Kuntze, 1. c. $315=$ Aplopappus acaulis, A. Gray.

californicus, Kuntze, 1. c. $314=$ Solidago califor nica, Nutt.

canadensis, Kuntze, 1, c, $317=$ Sol. canadensis, Linn.

Canbyi, Kuntze, 1. c. $315=$ Aplopappus integrifolius, T. C. Porter.

Candollei, Kuntze, 1. c. = Solidago spathulata, DC carnerosanus, S. Wats. in Proc. Am. Acad. xxvi (1891) 139. - Mexic.

carthamodes, Kuntze, Rev. Gen. (1891) $317=$ Aplopappus carthamoides, A. Gray.

Cerberoanus, Kuntze, 1. c. (= Pyrrocoma Cerberoana, Remy). - Chili.

eeruminensis, Kuntze, 1. c.=Bigelowia ceruminosa, A. Gray.
ASTER :

chrysanthemifolius, Kuntze, Rev. Gen. (1891) $317=$ Aplopappus chrysanthemifolius, $D C$.

chryseus, Kuntze, 1. c. 315 (= Pyrrocoma aurea, Phil.). - Chili.

Chy ysothammus, Kuntze, 1. c。= Bigelowia arborescens, A. Gray.

ciliaris, Kuntze, 1. c. = Solidago juncea, Ait.

ciliatus, Kuntze, 1.c. $317=$ Aplopappus ciliatus, $D C$. colchicus, Alboff, in Bull. Herb. Boiss. iii. (1895) 89 et 519. - Reg. Transcauc.

Colensoi, Kuntze, Rev. Gen.(1891) $317=$ Olearia Colensoi, Hook. $f$.

coloratus, Kuntze, 1.c = O colorata, Colenso. commutatus, A. Gray, Syn. Fl. N. Amer. i. 2. (1888) 185. - Am. bor.

commixtus, Kuntze, Rev. Gen. (1891) $315=$ Aster Herveyi, A. Gray.

commutatus, Kuntze, 1.c. = Solidago Chapmanni, A. Gray.

confertiflorus, Kuntze, 1. c. $317=$ Solidago confertiflora, $D C$

confinis, Kuntze, 1. c. = Sol. confinis, A. Gray. Cooperi, Kuntze. 1. c. = Bigelowia Cooperi, A. Gray.

coronopifolius, Kuntze, 1.c. = Big. coronopifolia, A. Gray.

croceus, Kuntze, 1. c. = Aplopappus croceus, A. Gray.

cuneatus, Kuntze, 1. c. = Apl. cuneatus, A. Gray. cuneifolius, Kuntze, 1. c. =Apl. cuneifolius, Nutt. cymbalariodes, Kuntze, 1. c. $315=$ Aster Candollii, Hary.

decenflorus, Kuntze, 1. c. = Solidago Radula, Nutt.

densifolius, Kuntze, 1. c. $317=$ Aplopappus densifolius, Remy.

denticulatus, Kuntze, 1. c. (= Pyrocoma denticulata, Phil.). - Chili.

depressus, Kuntze, 1. c. $318=$ Bigelowia depressa, A. Gray.

Dieteria, Kuntze, 1. c. $315=$ Aplopappus gracilis, A. Gray.

Diplopappus, Kuntze, 1. c. $318=$ Apl. Diplopappus, Remzy.

divaricatus, Kuntze, 1. c. = Apl. divaricatus, A. Gray.

Doellianus, Kuntze, 1. c. = Apl. Doellianus, Phil.

Durandi, Kuntze, 1. c. 916 = Bigelowia teretifolia, A. Gray.

Edwardii, Kuntze, 1 c. = Big. juncea, Greene

elongatus, Kuntze, 1. c. $318 \cong$ Solidago elongata, Nutt.

Elmeri, Greene, Pittonia, ii. (Sept. 1891) 170. Calif.

erectus, Kuntze, Rev, Gen. (1891) 318. Chili.

evicina, Kuntze, 1. c. $313=$ Aplopappus ericoides, $D C$.

eyiophorus, Kuntze, 1. c. $318=$ Leucopsis sericea, Baker.

Euthamia, Kuntze, 1. c. 316 = Solidago tenuifolia, Pursh.

Prorticatus, Kuntze, 1, c, $315=$ Olearia excorticata, F. Buch.

Faxoni, Porter, in Mem. Torrey Bot. Club, v. (1894) 323. - Am. bor.

Ferdinandi, Kuntze, Rev. Gen. (1891) $316=$ Oleariamuricata, Benth.

Fischeri, Kuntze, 1. c。= Aster divaricatus, Nutt.?

fistulosus, Kuntze, 1. c. = Solidago pilosa, Walt.

flavovirens, Kuntze, 1. C. $318=$ Sol. flavovirens, Chapm.

Alexuosus, Kuntze, 1. c. $316=$ Aster Thomsoni, C. B. Clarke.

foliosus, Kuntze, 1.c. $318=$ Aplopappus foliosus, $D C$.

Fordii, Hemsi. in Fourn. Linn. Soc. xxiii. (1888) 410 . - China.

formosus, Kuntze, Rev,Gen. (1891) 316 = Bigelowia pulchella, $A$. Gray.

Forsteri, Kuntze, 1. c. $315=$ Olearia Forsteri, Hook. $f$.

Forwoodii, S. Wats. in Proc. Am. Acad.xxv. (1890) 133. - Dakota.

Frostii, F. Muell. in Vict. Natural. vi. (Feb.-Mar. 1890) 167. - Austral.
ASTER :

rutescens, S. Wats, in Proc. Am. Acad. xxiv. (1889) 55. - Calif.

fulvidus, Kuntze, Rev. Gen. (1891) $315=$ Olearia fulvida (Arch.)

fuscescens, Bur. et Franch. in Morot, fourn. de Bot. v. (1891) 49. - China.

Gagei, "Phil. » ex Bot. Centralbl. v. 4. (1895) 287 sphalm. = Aster Sagei, Phil.

Gattingeri, Kuntze, Rev. Gen. (1891) $318=$ Solidago Gattingeri, Chapm.

Gayanus, Kuntze, 1. c. 316 = Aplopappus velutinus, Reniy.

glabratus, Kuntze, 1. c. $318=$ Apl. glabratus, Phil.

glomeratus, Kuntze, 1. c. = Solidago glomerata Mickx.

glutinosus, Kuntze, 1. c. = Aplopappus glutinosus

$D C$

gracillimus, Kuntze, 1. c. = Solidago gracillima, Torr. et Gray.

graminifolius, Kuntze, 1. c. $316=$ Solidago lanceolata, Linn.

graveolens. Kuntze, Rev. Gen. (1891) $313=$ Bigelowia dracunculoides, $D C$.

Grayanus, Kuntze, 1. c. $316=$ Aplopappus hirtus, A. Gray.

Greenei, Kuntze, 1. c. $318=$ Apl. Greenei, A. Gray. grindeliodes, Kuntze, 1. c. $316=$ Apl. squarrosus, Hook. et Arn.

grindeliodes, Kuntze, 1. c. 318= Apl. grindelioides, DC

griseus, Kuntze, 1. c. 316 (= Pyrrocoma canescens Phil.). - Chili.

Guiradonis, Kuntze, 1. c. 318 = Solidago Guiradonis, A. Gray.

Haastii, Kuntze, 1, c. $315=$ Olearia Haastii, Hook. f.

Haplopappus, Kuntze, 1. c. $316=$ Aplopappus sericeus, $D C$ ?

Harbourii, Kuntze, 1. c. = Bigelowia Parryi A. Gray.

Hartwegii, Kuntze, 1. c. $318=$ Big. Hartwegii, A. Gray.

Harveyanus, Kuntze, l. c. 316. - Afr. austr.

Hectorii, Kuntze, 1. c. $315=$ Olearia Hectori, Hook. $f$.

Hemsleyi, Kuntze, 1.c. 316= Solidago paniculata, $D C$

Hendersoni, Fernald, in Bull. Torrey Bot. Club, xxii. (1895) 273. - Idaho.

Henryi, Hemsl. in fourn. Limn. Soc. xxiii. (1888) 411. - China.

heterophyllzs, Kuntze, Rev. Gen. (1891) $316=$ Bigelowia Wrightii, A. Gray.

hivtellus, Kuntze, 1. c. 318=Aplopappus hirtellus, Phit.

hispidulus, Kuntze, 1. c. $318=\mathrm{Apl}$ hispidulus, $D C$ hispidus, Kuntze, 1.c. $316=$ Solidago nemoralis, Ait

holophyllus, Hemsl. in fourn. Linn. Soc. xxiii. (1888) 412. - As. centr. bor.

Hookerianus, Kuntze, Rev. Gen. (1891) $318=$ Aplopappus Hookerianus, A. Gray.

Hoovebekia, Kuntze, 1. c. = Aplopappus Hoorebekia, $D C$.

Honghtonii, Kuntze, 1. c. = Solidago Houghtoni Torr. et Gray.

Howardi, Kuntze, 1. c. = Bigelowia Howardi, A. Gray.

Howellii, Kuntze, 1. c. 316 - Aplopappus Hallii A. Gray.

ilicifolius, Kuntze, 1. c. $318=$ Apl. ilicifolius, Remy.

illinitus, Kuntze, 1.c. = Apl, illinitus, Phil.

incanopilosus, Sheld, in Bull. Torrey Bot. Club,

xx. $(1893) 286=$ commutatus, A. Gray

inosiatus, Greone, in Erythea, iii. (1895) 119. Calif.

insignis, Kuntze, Rev. Gen. (1891) $315=$ Olearia insignis, Hook. $f$.

invenustus, Greene, Man. Bot. San Franc. Bay, (1894) 179. - Calif.

facksonii, Kuntze, Rev. Gen. (1891) $316=$ Solidago corymbsa, Ellis.

Famesii, Kuntze, 1. c. = Aplopappus Lyallii, A. Gray. 
ASTER

Kernotii, F. Muell. in Trans. Roy. Soc. Vict. N. S. I. ii. (1889) 10. - N. Guin.

lacunosus, Kuntze, Rev. Gen. (1891) $315=$ Olearia lacunosa, Hook. $f$.

laevigatus, Kuntze, $l$. c. 318. - Afr. austr.

lanatus, Kuntze, 1. c. = Aplopappus lanatus, Hook. $f$.

lanceolatus, Kuntze, 1. c. $313=$ Apl. lanceolatus, Torr, et Gray.

lanceolatus, Kuntze, 1, c. 314= Solidago lanceolata, Linn

lancifolius, Kuntze, 1. c. $318=$ Sol. lancifolia Chapm.

lanuginosus, Kuntze, 1. c. $316=$ confusus, Harv. laricifolnu, Kuntze, 1. c. $318=$ Aplopappus laricifolius, A. Gray.

Lastarrianus, Kuntze, 1. c. =Apl. Lastarrianus, Remy.

Jateriflorus, Britton, in Report N. Y. Geol. Surv, ii. (1889) 138; et in Trans. N. Y. Acad. Sci. ix. (1889) $\mathrm{I}=$ Aster diffusus, Ait.

latifolius, Kuntze, Rev. Gen. (1891) $314=$ Solidago latifolia, Linn.

latissimifolius, Kuntze, 1. c. = Sol. elliptica, Ait

Leavenrorthii, Kuntze, 1. c. $318=$ Sol. Leavenworthii, Torr. et Gray.

lecophyllus, Porter, in Bull. Torrey Bot. Club, xx. (1893) $254=$ Aster Lowieanus, Porter

leiospermus, Kuntze, Rev. Gen. (1891) $318=$ Bigelowia leiosperma, A: Gray.

lepidopodus, Robins. et Fernald, in Proc. Am. Acad. xxx. (1895) 117. - Mexic.

lepidus, Kuntze, Rev. Gen. (1891) $318=$ Solidago lepida, $D C$

leptocephalus, Kuntze, 1. c. = Sol. leptocephala. Torr. et Gray.

leucanthemifolius, Greene, in Erythea, iii. (1895) 119. - Nevada.

limosus, Hemsl. in fourn. Linn. Soc. xxiii. (1888) 413. - China

Lindheimeranus, Kuntze, Rev. Gen. (1891) $318=$ Solidago Lindheimeriana, Scheele.

linearifolius, Kuntze, 1. c. = Aplopappus linearifolius, $D C$.

linodes, Kuntze, 1. c. 316 (= Pyrrocoma linifolia, Phil.). - Chili.

longipes, Kuntze, 1. c. 318 (= Pyrrocoma longipes, Phil.). - Chili.

longulus, Sheld. in Minnes, Bot. Stud. i. (1894) 18 t. 2. - Am. bor.

Lowieanus, Porter, in Bull. Torrey Bot. Club, xx1. (1894) 121. - Am. bor.

Lyallii, Kuntze, Rev. Gen. (1891) $315=$ Olearia Lyallii, Hook. $f$.

Mac Dougali, Robins. et Seaton, in Coult. Bot. Gaz. xviii. (1893) 301. - Idaho.

Macraeanus, Kuntze, Rev. Gen. (1891) 318 (=Pyrrocoma Macreana, Remy). - Chili.

macrocephalus, Kuntze, 1. c. = Aplopappus macrocephalus, $D C$

Macronema, Kuntze, 1. c. = Apl. Macronema A. Gray.

Marcusii, Kuntze, 1. c. $316=$ Bigelowia albida, $M$. E. Fones.

marginalis, Kuntze, 1. c. $318=$ Aplopappus mar-

Marshallii, Kuntze, 1. c. = Solidago Marshallii, Roth.

mexicanus, Kuntze, 1. c. = Sol. sempervirens, Linn.

Meyenii, Kuntze, 1. c. = Aplopappus Meyenii, Walp

minor, Kuntze, 1. c. $316=$ Apl. Parryi, A. Gray.

minutus, Kuntze, 1. c. $318=$ Solidago minuta, Limn.

missuriensis, Kuntze, 1. c. = Sol. missouriensis, Nutt.

majus, Porter, in Mem. Torrey Bot. Club, v. (1894) $325=$ Aster modestus, Lindl.

mohavensis, Coult. in Contrib, U.S.Nat, Herb, iv, (1893) 126. - Calif

mohavensis, Kuntze, Rev. Gen. (1891) $318=$ Bigelowia mohavensis, Greene.

monactis, Kuntze, 1. c. = Aplopappus monactis, A. Gray.

monticolus, Kuntze, 1. c. = Solidago monticola Chapm.

\section{ASTER :}

moschatus, Kuntze, Rev. Gen.(1891) $315=$ Olẹaria moschata, Hook. $f$.

Muellenbergianus, Kuntze, 1. c. $316=$ Solidago squarrosa, Muehl.

multicaulis, Kuntze, 1. c. 318 = Aplopappus mul ticaulis, A. Gray.

multibracteolatus, Kuntze, 1. c. $315=$ Olearia mul tibracteolata, Colenso.

multifolius, Kuntze, 1. c. $316(=$ Pyrrocoma foliosa Phil.). - Chili.

multiradiatus, Kuntze, 1. c. $318=$ Solidago multiradiata, Ait.

nanus, Kuntze, 1. c.:= Sol. nana, Nutt.

neozelandicus, Kuntze, 1. c. $316=$ Olearia marginata, Colenso.

nevadensis, Kuntze, 1. c. $318=$ Bigelowia nevaden sis, A. Gray.

Nevinii, Kuntze, 1. c. $316=$ Aplopappus Palmeri, A. Gray.

nitens, Kuntze, l.c. - Chili.

nummulariaefolins, Kuntze, 1. c. $315=$ Olearia nummularifolia, Hook. $f$.

nutatus, Kuntze, 1. c. $318=$ Bigelowia nudata $D C$

Nuttallii, Kuntze, 1. c. = Aplopappus Nuttallii, Torr. et Gray.

ochagaviensis, Kuntze, I.c. = Apl. ochagavianus, Phil.

odorus, Kuntze, 1. c. = Solidago odora, Ait.

ohioënsis, Kuntze, 1. c. = Sol. ohioënsis, Riddell.

Oldhami, Hemsl. in fourn. Linn. Soc. xxiii. (1888) 414. - Formosa.

oleifolius, Kuntze, Rev. Gen. (1891) $315=$ Olearia oleifolia, T. Kirk.

oligodontus, Kuntze, 1. c. $316=$ Aplopappus paucidentatus, $P$ hil.

operinus, Kuntze, 1. c. $315=$ Olearia operina, Hook. $f$.

oppositifolius, Kuntze, 1. c. $318=$ Bigelowia oppositifolia, A. Gray.

Orcuttii, Vasey et Rose, in Coult.Bot. Gaz. xvi. (1891) 113 t. 11. - Calif

tagoënsis, Kuntze, Rev. Gen. (1891) $316=$ Olearia dentata, Hook, $f$

ottomanum, Velen. in Sitzb. boehm. Ges. Wiss. 1890 (1890) ii. 48; et Fl. Bulg. (1891) 27\%. - Bulg.

Parishii, Kuntze, Rev. Gen. (1891) $318=$ Bigelowia Parishii, Greene.

parvifolius, Kuntze, 1. c. (= Pyrrocoma parvifolia DC.) - Chili.

patagoniensis, Kuntze, 1. c. = Aplopappus patagonicus, Phil.

paucicapitatus, Robins, in Proc. Am. Acad. xxix, (1894) 329. - Am. bor.

pauciflocoulosus, Kuntze, Rev. Gen. (1891) $318=$ Solidago pauciflosculosa, Michx

pectinatus, Kuntze, 1. $\mathrm{c}_{\text {a }}=$ Aplopappus pectinatus, Phil.

pedunculosus, Kuntze, 1. c. = Apl. pedunculosus Remy.

perfoliatus, Oliver, in Hook. Icon. pl. xviii. (1887) t. 1717. - Afr. austr

Peteroanus, Phil., in Anal. Univ. 'Chil. lxxxvii (1894) 406. - Chili.

petiolaris, Kuntze, Rev, Gen. (1891) $318=$ Solidag petiolaris, $A$ it

Philippii, Kuntze, 1. c. $316=$ Aplopappus paniculatus, Phil.

phyllocephalus, Kuntze, 1. c. = Aplopappus rubiginosus, Torr. et Gray.

Pickeringii, Kuntze, 1. c. = Aplopappus lanuginosus, A. Gray.

pineus, Kuntze, 1. c. 318 (=Pyrrocoma pinea, Phil.). - Chili.

pinnatifidus, Kuntze, 1. c. 313 et $316=$ Aplopappus spinulosus $D C$

pityphyllus, Kuntze, 1.c. (1891) $316=$ Aplopappus

pinifolius, A.Gray.
polyglossa, Kuntze, 1. c. $318=$ Solidago microglossa, $D C$.

polyphyllus, Kuntze, 1. c. I- Aplopappus polyphiyllus, Phil.

populifolius, Kuntze, 1. c. $315=$ Olearia populifolia, Colenso.

pristiphyllus, Kuntze, 1. c. 318 (= Pyrocoma pristiphylla, Remy). - Chili.

\section{ASTER}

procerus, Hemsl. in fourn. Linn, Soc, xxiii. (1888) 415. - China.

prostratus, Phil. in Anal. Univ. Chil.1xxxvii. (1894) 407. - Chili.

prunellodes, Kuntze, Rev. Gen. (1891) $318=$ Aplopappus prunelloides, $D C$

psammophilus, Klatt, in Arb. Bot. Mus. Hamb. (1890). extr. 4; et in fahrb. Hamb. Wiss. Anstalt 1x. (1892) 126. - Bras

pseudamellus, Hook. f. in Gard. Chron. (1886) ii, 659. - Reg. Himal.

pubens, Kuntze, Rev. Gen. 1891) $316=$ Solidago Curtisii, Torr, et Gray.

pulverulentus, Kuntze, 1. c. 316 et $318=$ Sol, puberula, $N$ utt.

pumilus, Kuntze, 1. c. $318=$ Sol. pumila, Torr. et Gray.

Purschiamus, Kuntze, 1, c, 316=Sol, tortifolia, Ellis

Pyrrhocoma, Kuntze, 1. c. $317=$ Aplopappus race mosus, Torr.

radicans, Kuntze, 1. c. $318=$ Apl. radicans, Remy. Rafinesquii, Kuntze, 1. c. $317=$ Solidago Shortii, Torr. et Gray.

Rani, Kuntze, 1. c. = Olearia Cunninghamii, Hook. $f$.

Remyanus, Kuntze, 1. c. =Aplopappus decurrens Remy.

Remyanus, Kuntze, 1. c. $318=$ Apl. Remyanus, Wedd.

Rengifoanus, Kuntze, 1. c. = Apl. Rengifoanus, Remy.

resinotus, Kuntze, 1. c. $317=$ Apl. nanus, Eaton

retinervius, Kuntze, 1.c. $(=$ Pyrrocoma reticulata, Phil.). - Chil

reversus, Kuntze, 1. c. = Aplopappus reflexus, Phil.

Richardii, Kuntze, 1. c. $318=$ Felicia Richardi, Vatke.

Riddelii, Kuntze, 1. c. $314=$ Solidago Riddellii Frank.

rigidus, Kuntze. 1. c. = Sol. rigida, Linn.

Rothrockii, Kuntze, 1. c. $31 \%=$ Sol. spectabilis A. Gray.

rugosus, Kuntze, 1. c. $318=$ Sol. rugosa, Mill.

upestris, Kuntze 1, $\mathrm{c}=$ Sol, rupestris, Rafin.

Sagei, Phil. in Anal. Univ. Chil. 1xxxvii. (1894) 405. - Axaucania.

Sampsoni, Hemsl. in fourn. Linn. Soc. xxiii. (1888) 415. - China.

Savatieri, Makino, in Tokyo Bot. Mag. viii. (1894) 172. - Japon.

Savianus, Kuntze, Rev. Gen. (1891) $317=$ Solidago littoralis, Savi.

saxatilis, Kuntze, 1. c. 318 (= Pyrrocoma saxatilis, Remy). - Chili.

scaposus, Kuntze, 1. c, = Leucopsis scaposa, Baker. Schumannii, Kuntze, 1. c. $317=$ Aplopappus Poeppigianus, $A$. Gray.

scoparius, Kuntze, l.c. 318. - Sibiria.

scopiformis, Kuntze, 1. c.317=Aplopappus virgatus, Phil.

scrobiculatus, Kuntze, 1. c. $318=$ Apl. scrobiculatus, $D C$.

semiamplexicaulis, Makino, in Tokyo Bot. Mag. vi. (1892) 55. - Japon.

semidentatus, Kuntze, Rev, Gen.(1891)315=Olearia semidentata, Decne.

sempervirens, Kuntze, 1. c. $318=$ Solidago sempervirens, Linn.

Serenoi, Kuntze, 1. c. $317=$ Aplopappus. Watsoni, A. Gray.

setiger, Kuntze, 1. c. $318(=$ Pyrrocoma setigera Phil.). - Chili.

Solanderi, Kuntze, 1. c. $315=$ Olearia Solandri Hook. $f$ :

sonomensis, Greene, Man. Bot. San Franc. Bay (1894) 180. - Calif.

sonoriensis, Kuntze, Rev. Gen. (1891) 317 = Bigelowia diffusa, A. Gray.

sparsiflorus, Kuntze, 1. c. $318=$ Solidago sparsi flora, A. Gray.

speciosus, Kuntze, 1. c. = Sol. speciosa, A. Gray

spinuliger, Kuntze, 1. c. $317=$ Aplopappus spinulosus, Phil.

spithamaeus, Kuntze, 1. c, $318=$ Solidago spithamaea, $M . A$. Curt. 
ASTER :-

stelliger, Kuntze, Rev. Gen. (1891) 317 = Aplopap-

pus stelliger, Remy.
stenophyllus, Kuntze, 1. c. $=$ Apl. stenophyllus, A. Gray.

Stenotus, Kuntze, 1. c. $31 \%=$ Apl. pygmaeus, A. Gray.

Sternbergii, Kuntze, 1. c. (= Pyrrocoma angustifolia, DC.). - Chili.

stewardensis, Kuntze, 1. c. = Olearia angustifolia, Hook.f.

stolonifer, Kuntze, 1. c. $318=$ Aplopappus stoloniferus, $D C$

strictus, Kuntze, 1. c. = Solidago stricta, Ait.

Stuebelii, Hieron., in Bot. Fahrb. xxi. (1895) 334.Peruvia.

sublitoralis, Kuntze, Rev, Gen, (1891) $31 \%$ = Solidago Elliottii, Torr et Gray.

suborbiculatus, Kuntze, 1. c. $315=$ Olearia suborbiculata, Colenso.

suffruticosus, Kuntze, I. c. $318=$ Aplopappus suffruticosus, $A$. Gray.

subtropicus, Morong, in Amn. N. Y. Acad. Sci. vii. :(1893) 139. - Am. bor. et austr.

Terrae-novae, Kuntze, Rev. Gen. (1891). $318=$ Solidago Terrae-Novae, Torr. et Gray.

thermalis, M.E. Fones, in Proc. Calif. Acad. Ser II. v. i. (1895) 694. - Utah.

thyrsoders, Kuntze, Rev, Gen. (1891) $317=$ Solidago macrophylla, Banks.

Tolmieanus, Kuntze, 1. c. $318=$ Sol. Tolmieana, A. Gray.

Torreyi, Kuntze, 1. c. $317=$ Sol. Drummondii, Torr. et Gray.

Torreyi, Porter, in Bull. Torrey Bot. Club, xvii. (1890) 37. - Calif.

trachyticus, Phil. in Anal. Mus, nac. Chile (1891) 37. - Bolivia.

Traillii, Kuntze, Rev. Gen. (1891) $315=$ Olearia Traillii, T. Kirk.

Traversii, Kuntze, 1. c. = O. Traversii, F. Muell.

tuganianus, Alboff, in Bull. Herb. Boiss, ii. (1894) 253. - Reg. Cauc.

tuganus, AIboff, 1. c. iii.(I895) 519 sphalm.= tuganianus, Alboff.

uliginosus, Kuntze, Rev. Gen. (1891) $318=$ Solidago uliginosa, Nutt.

ulmifolius, Kuntze, 1. c。 = Sol. ulmifolia, Muehl.

uncinatus, Kuntze, 1.c. = Aplopappus uncinatus, Phil.

uniflorus, Kuntze, 1. c. $318=$ Apl. uniflorus, Torr et Gray

miligulatus, Kuntze, 1.c. 317 = Solidago neglecta Tory. et Gray.

valparaisanus, Kuntze, 1. c. = Aplopappus pulchellus $D C$.

Vaseyi, Kuntze, 1. c. $318=$ Bigelowia Vaseyi A. Gray.

celutinus, Kuntze, 1. c. = Solidago velutina, $D C$.

venetus, Kuntze, 1. c。 = Bigelowia veneta, $A$ Gray.

venrosus, Kuntze, 1. c. $317=$ Aplopappus reticulatus, Phil.

venustus, M. E. Fones, in Zoë, ii. (1891) 247. Utah, Colorado.

vernus, Kuntze, Rev. Gen. (1891) 318 = Solidago verna, M.A. Curt.

villiger, Kuntze, 1. c. $317=$ Aplopappus villosus, Phil.

Virgaurea, Kuntze, 1. c. $314=$ Solidago Virgaurea Linn.

viscidiflorus, Kuntze, 1. c. $313=$ Bigelowia viscidi flora, $D C$.

Wardii, Kuntze, 1. c. $317=$ Aplopappus Fremonti, A. Gray.

Wattii, C. B. Clarke, in fourn, Linn, Soc, xxy. (1889) 36. - Reg. Himal.

Whitueyi, Kuntze, 1. c. $318=$ Aplopappus Whit neyi, A. Gray.

worcesterensis, Kuntze, $3 \mathbf{1 7}=$ Aster imbricatus, Havo.

ASTERANTHERA, Hanst. (Gesnerac.). - Ind. Kew.1. 224.

orata, Baill. Hist. des pl. x. (1888) $102=$ chiloensis, Hanst.
ASTERISCIUM, Cham, et Schlecht. (Umbellif.). - Ind. Kew. i. 224.

Vidali, Phil, in Anal. Univ. Chil. 1xxxv. (1894) 711, - Chili.

ASTERISCODES, Moehr. = Callistephus, Cass. (Compos.).

chinense, Kuntze, Rev. Gen. (1891) $318=\mathrm{C}$. hortensis, Cass.

ASTERISCUS, Moench=Odontospermum, Neck. (Compos.).

citriodorus, Heldr, et Halâcsy, in Oest. Bot. Zeitschr. (1895) 411. - Ins. Cyclad.

ASTERISCUS, Siegesb. F1. Petrop.(1736) 15 pr.p. ex Kuntze, Rev. Gen. (1891) $318=$ Odontospermum, Neck. (Compos.)

stenophyllus, Kuntze, I. c. $319=$ O. stenophyllum, Sch. Bip.

ASTEROCARPUS, Eck1, et Zeyh.= Pterocelastrus, Meissn. (Celastrin.).

Dregeanus, Kuntze, Rev. Gen. (1891) $113=$ = . Dregeanus, Sond.

tricuspidatus, Kuntze, 1. c. $=$ P. tricuspidatus, Walp.

ASTEROPEIA, Thou (Samyd.). - Ind. Kew. i. 225.

Bakeri, S. Elliot, in fourn. Linn. Soc. xxix. (1891) 6. - Madag.

rhopaloides, Baill. in Bull, Soc. Linn. Paris, i. (1886) $564=$ Rhodoclada rhopaloides, Brker.

sphaerocarpa, Baker, in fourn. Linn. Soc. xxii, (1887) 479. - Madag.

ASTEROSTIGMA, Fisch. et Mey. = Staurostigma, Scheidw. (Aroid.).

luridum, Kuntze, Rev. Gen.(1891) $740=$ S. odorum, Scheidw.

Riedelianum, Kuntze, 1. c. $=\mathrm{S}$ Riedelianum, Engl.

ASTIANTHUS, D.Don=Tecoma, Juss. (Bignon.). viminalis, Baill. Hist. des pl. x. (1888) $44(=$ Bignonia viminalis, $\mathrm{H}$. B.iet $\mathrm{K}$.). - Am. austr.

ASTILBE, Buch.-Ham. (Saxifrag.).- Ind. Kew. i. 326 .

biternata, Britton, in Bull. Torrey Bot. Club, xx, (1893) $475=$ Tiarella biternata, Vent.

Lemoinei $X$, Hort. ex Rev. Hortic. (1895) 567 fig. 185. - Hybr. artef.

pinnata, Franch. in Nouv. Arch. Mus. Paris, Sér. II. x. (1888) 176 in obs.; et Pl. Delav. (1890) 231. Yunnan.

podophylla, Franch. P1. Delav. (1890) 231 in obs. = podophylla, Baill.?

polyandra, Hemsl. in Journ. Linn. Soc. xxii. (1887) 265 et $490=$ Spiraea Aruncus, Linn.?

simplicifolia. Makino, in Tokyo Bot. Mag. vii. (1893) 103. - Japon.

ASTRAGALUS, Tourn. ex Linn. (Legumin.). Ind. Kew. i. 226.

accidens, S. Wats. in Proc. Am. Acad. xxii. (1887) 471. - Oregon.

accumbens, Shald. in Minnes. Bot. Stud. i. (1894) 20 $(=$ Astr. procumbens, S. Wats. $)-\mathrm{N}$. Mexic.

acerbus, Sheld. 1. c. $123=$ A. Dodgianus, $M . E$. Fones.

achtalensis, Conrath et Freyn, in Bull. Herb. Boiss. iii. (1895) 182. - Somchetia.

acrocarpus, Freyn et Sint. in Oest. Bot. Zeitschr. xliv. (1894) 64. - As. Min.

albatus, Sheld. in Minnes. Bot. Stud. i. (1894) 128.Calif.

albifolius, Freyn et Sint. in Oest. Bot. Zeitschr. xlii; (1893) 417. - As Min.

Alboffianus, Freyn, in Bull. Herb. Boiss. iii. (1895) 186. - Daghest.

Alfalfalis, Phil. in Anal. Unit. Chil. 1xxxiv. (1894) 29. - Chili.

algerianus, Sheld. in Minnes. Bot. Stud. i. (1894) 121. = tenuifolius, Desf.

allanaris, Sheld. l. c. 141.-Washingt.

\section{ASTRAGALUS :}

lopecuroideus, St-Lager, in Cariot, Etud. des fleurs, éd. 8. ii. (1889) $188=$ alopecuroides, Linn. alpinus, Sheld. in Minnes. Bot. Stud, i. (1894) 65= frigidus, A. Gray.

ammolotus, Greene, in Erythea, iii. (1895) 76. - Am bor. occ.

amphioxys, Sheld. ex Coville, in Contrib. U. S. Nat. Herb. iv. (1893) 87. - Am. bor. occ.

angustus, $M$. E. Fones, in Proc. Calif. Acad. Ser. II. v. (1895) 634. - Am. bor.

anisus, $M$. E. fones, in $Z$ oé, iv. (1893) 34. - Am. bor. occ

Amunategui, Phil. in Anal. Univ. Chil. Ixxxiv. (1894) 31. - Chili.

apertus, Sheld. in Minnes. Bot. Stud. i. (1894) 166 $=$ ervoides, Haok. et Arn.

apilosus, Sheld.1. c. $22=$ glaber, Michx.

aragonensis, Freyn, exWillk. Suppl.Prodr. fl. Hisp. (1893) $234=$ turolensis, Pau.

araneosus, Sheld. in Minnes. Bot. Stud. i. (1894) 170. - Am. bor. occ.

argillosus, M. E. fones, in Zö̈, ii. (1891) 241. Utah.

argolicus, Hausskn. ex Nym. Consp. fl. Eur. Suppl. II. i. (1889) 98 nomen; et in Mitth. Thiur. Bot. Ver. N. Folge. v. (1893) 81. - Graecia.

argyroides, G. Beck, ex Stapf, in Denkschr. Acad. Wien, 1i. (1886) 341. - As. occ.

arietinus, M. E. Fones, in Proc. Calif. Acad. Ser. II v. (1895) 653. - Utah.

Aristidis, Coss. ex Batt. et Trab. F1. de l'Algérie (Dicot.) (1889) $256=$ cruciatus, Link.

arragonensis, Freyn, in Bull. Herb. Boiss. i. (1893) $544=$ aragonezisis, Freyn.

Artemisiarum, M. E. Fones, in Zoë, iv. (1894) 369. - Am. bor. occ.

asclepiadoides, $M$. E. Fones, l.c. ii. (1891) 238. Utah.

askabadensis, Kuntze, in Act. Hort.Petrop. x. (1887) 182. - Turkest.

astragalinus, Sheld. in Minnes. Bot. Stud. i. (1894) $65=$ alpinus, $\operatorname{Linn}$

assymmetricus, Sheld. 1. c. 23. = leucophyllus, Torr. et Gray.

atropubescens, Coult. et Fish. in Coult. Bot. Gaz. xviii. (1893) 300. - Montana.

Autrani, Baldacci, in Malpighia, viii.(1894) 167; et in Bull. Herb. Boiss, iii. (1895) 196. - Albania.

bajaensis, Sheld. in Minnes, Bot. Stud, i. (1894) 169. - Calif.

Barbeyanus, Freyn, in Bull. Herb. Boiss. iii. (1895) 184. - Reg. Transcauc.

Barbeyanus, Post, l. c. i. (1893) 19. - Syria.

Barceloi, Phil. in Anal. Univ. Chil. 1xxxiv. (1894) 27. - Chili.

barbidens, Freyn, in Bull. Herb. Boiss. iii. (1895) 185. - Daghest.

Barrowianus, Aitch, et Baker, in Trans. Limn. Soc. Ser. II. iii. (1886) 50. - Turkest.

Basineri, Trautv. in Act. Hort. Petrop. ix. (1886) 444. - Turkest.

bernardinus, M. E. Fones, in Proc. Calnf. Acad. Ser. II. v. (1895) 661. - Calif.

Bodini, Sheld. in Minnes. Bot. Stud. i. (1894) 122.Am. bor.

bolivianus, Phil. in Anal. Mus, nac. Chile (1891) 15. - Bolivia.

Bornmuelleri, Frevn, in Oest. Bot. Zettschr. xl. (1890) 403. - As. occ.

Borodini, Krassn. in Script. Hort. Univ. Petrop. ii. 1. (1887-88) I5. - As. occ.

brachycalyx, Phil. in Anal. Mus. nac. Chile (1891) 15. - Bolivia.

brachycephalus, Franch. Pl. Delav. (1890) 161. Yunnan.

brachypetalus, Trantv. in Act. Hort. Petrop. ix. (1886) 446 . - Turkest.

bucharicus, Regel. l. c. ix. (1886) 605. - Bukhara. camptodontus, Franch. Pl. Delav. (IS89) 160 t. 39. Yunnan.

candelarius, Sheld. in Minnes. Bot. Stud. i. (1894) 142. - Am. bor.

candicans, Freyn et Sint. in Oest. Bot. Zeitschr. xlii. (1892) $9=$ Prantlianus, Freyn.

candidissimus, T. S. Brandeg. in Proc. Calif. Acad, Ser. II. ii. (1889) 149. $\rightarrow$ Calif. 


\section{ASTRAGATUS}

Candollianus, Sheld. in Minnes. Bot. Stud. i. (1893) $140=$ Phaca Candolliana, $H$. B. et $K$.

canispinus, Boiss. Fl. Or. Suppl. (1888) 181. Afghan.

capitellus, Britton, in Bull. Torrey Bot. Club, xvi. (1889) 260. - Am. austr.

Celakowskyanus, Freyn, in Oest. Bot. Zeitschr. xlii. (1892) 8. - As. Min.

centralis, Sheld. in Minnes. Bot. Stud. i. (1894) 132 = microcystis, Bunge.

ceramicus, Sheld. 1. c. 19 (=Astr. pictus, A. Gray) - Am. bor. occ.

cerussatus, Sheld.l.c. 139. - Colorado.

cemerinus, G. Beck, ex Stabf, in Denkschr. Acad. Wien, 1i, (1886) 337. - As. occ.

Chamaephaea, Freyn, in Oest. Bot. Zeitschr. xl. 1890) 211 et 402. - As. Min.

chilensis, Sheld. in Minnes. Bot. Stud. i. (1894) 157 = procumbens, Hook. et Arn.

chlorotaenius, Freyn et Sint. in Oest. Bot. Zeitschr. xlii. (1892) 12. - As. Min.

cibarius, Sheld. in Minnes. Bot. Stud. i. (1894) 149 - Am. bor. occ.

Cicadae, M. E. Fones, in Zoë, iv. (1893) 35. - Am. bor. occ.

circumdatus, Greene, Pittonia, i. (June 1888) 173.Calif,

coccineus, T. S. Brandeg. in Zoë, ii. (189I) $72=$ grandiflorus, S. Wats.

colliculus, Rusby, in Mem. Torrey Bot. Club, iii. 3 1893) 19. - Bolivia.

Coltoni, M.E. Fones, in Zö̈, ii. (1891). - Utah.

Conrathi, Freyn, in Bull. Herb̆. Boiss. iii. (1895 182. - Somchetia.

consectus, Sheld. in Minnes. Bot. Stud. i. (1894) 143. - Am. bor. occ.

convallarius, Greene, in Erythea, i. (1893) $207=$ serotinus, A. Gray.

Cottonianus, Aitch.et Baker, in Trans. Linn. Soc., Ser. II, iii. (1886) 51. - Turkest.

crassicarpus, Freyn et Sint. in Oest. Bot. Zeitschr. xliv. (1894) $64=$ Tempskyanus, Freyn et Sint.

crescenticarpus, Sheld. in Minnes. Bot. Stud. i. (1894) 148. - Am. bor. occ.

Crotalariae, Sheld. 1. c. $135=$ Phaca Crotalariae Benth.

cuspidocarpus, Sheld. l. c. 147. - Montana, Wyoming.

curvipes, Trautv. Contrib. Al. Turcom. (1885?) 12; in Act. Hort. Petrop. ix. (1886) 446. - Turkest.

cyclophyllon, G. Beck, ex Stapf, in Denkschr. Acad. Wien, 1i. (1886) 339. - As. occ.

cymboides, $M$. E. Fones, in Proc. Calif. Acad. Ser. II. v. (1895) 650. - Utah.

Daleae, Greene, Pittonia, i. (Jan. 1888) 153.Mexic.

Davidi, Franch. in Nouv. Arch. Mus. Paris, Sér. II. viii. (1885) 214.-China.

demissus, Greene, in Erythea, i. (1893) 221. Nevada.

desperatus, $M$. E. fones, in Zö̈, ii. (1891) 243.Utah.

Dessaueri, Phil. in Anal. Univ. Chil. lxxxiv. (1894) 26. - Chili.

dichroanthus, Freyn et Sint. in Oest. Bot. Zeitschr. xlii. (1892) 13. - Armenia.

diurnus, S. Wats, in Proc. Am. Acad. xxi. (1886) 450. - Oregon.

diversifolius, Trautv.in Act. Hort, Petrop. ix. (1886) 445. - Turkest.

Dodgianus, M. E. fones, in Zö̈, iii. (1893) 289. Utah.

Durandianus, Aitch. et Baker, in Trans. Linn. Soc. Ser. II. iii. (1886) 54.- Persia.

Eastwoodae, $M$. E. fon 6 , in Zoë, iv. (1894) 368. Am. bor. $O C C$

Edmondi, Sheld. in Minnes. Bot. Stud, i. (1894) 131 (= Astr. pectinatus, Boiss.). - Syria.

eginensis, Freyn et Sint. in Oest. Bot. Zeitschr. xli. (1892) 10. - Armenia.

clatiocarpus, Sheld. in Minnes. Bot. Stud. i. (1894) $20=$ lotiflorus, Hook.

elegans, Sheld. 1. c. $154=$ oroboides, Hornem.

elegantulus, Greene, in Erythea, i. (1893) 207 (= Astr.pectinatus, Boiss.).-Syria.

\section{ASTRAGALUS}

Elmeri, Greene, in Erythea, iii. (1895) 98. - Calif.

Engelmanni, Sheld. in Minnes. Bot. Stud. i. (1894) 152. - Texas.

ensiformis, M.E. fones, in Proc. Calif. Acad. Ser. II. v. (1895) 658. - Arizona.

eremicus, Sheld. ex Coult. in Contrib. U. S. Nat. Herb. iv. (1893) 86 sphalm. = eremiticus, Sheld. evemiticus, Sheld. in Minnes. Bot. Stud. i. (1894) $161=$ Coulteri, Benth.

eriocalyx, Freyn, in Oest. Bot. Zeitschr. xI. (1890)

211 et 401 . - As. Min.

erythrocephalus, Freyn et Sint. l. c. xlii. (1892) 10. - Armenia.

erythrosemius, Boiss. Fl. Or. Suppl. (1888) 179. Afghania.

euphraticus, Freyn, in Bull. Herb. Boiss. iii. (1895) 186. - Armenia.

exegicus, Post, Pl. Postianae, iii. (1892) 7. - Syria. famelicus, Sheld. in Minnes. Bot. Stud. i. (1894) 23 $=$ fallax, $S$. Wats.

fissilis, Freyn et Sint. ex Somm。 et Levier, in Bull. Soc. bot. Ital. (1893) 526; et in Oest. Bot. Zeitsclir. xlii. (1893) 414. - Reg. Cauc

fissus, Freyn et Sint. in Oest. Bot. Zeitschr. xliii. (1893) 415 in syn.= fissilis, Freyn et Sint.

fagellaris, Engelm. et Sheld. in Minnes. Bot. Stud. i. (1894) 152 = Engelmanni, Sheld.

flaviflorus, Sheld. 1. c. 158. = flavus, Nutt

flavus, Sheld. 1. c. = Phaca flava, Hook. et Arn

foliolosus, Sheld. i. c. $138=$ pictus, A. Gray, var.

Forwoodii, S. Wats, in Proc. Am. Acad. xxv. (1890) 129. - Dakota.

franciscanus, Sheld. in Minnes. Bot. Stud. i. (1894) 135. = oocarpus, A. Gray.

francisquitensis, M. E. Fones, in Proc. Calif. Acad. Ser. 11. V. (1895) 666. - Calif.

Freynii, Alboff, Prodr. fl. Colch. (1895 61). - Reg. Cauc.

fuliginosus, G. Beck, ex Stapf, in Denkschr. Akad. Wien, 1i, (1886) 340. - As. occ

Gambellianus, Sheld. in Minnes. Bot. Stud. i. (1894) 21 = nigrescens, Nutt.

genuflexus, Freyn et Sint. in Oest. Bot. Zeitschr. xlii (1892) 12 - Armenia.

giganteus, Sheld. in Minnes. Bot. Stud. i. (1894) 65 = alpinus, Linn. var.

gilviflorus, Sheld.1. c. $21=$ triphyllus, Pursh.

glandulosus, G. Beck, ex Stapf, in Denkschr. Akad. Wien, 1i, (1886) 334. - As. occ.

Goreanus, Aitch, et Baker, in Trans. Linn. Soc. Ser. II, iii. (1886) 55. - Afohan.

Grallator, S. Wats, in Zoë, iii. (1892) 52, - Colorado.

grandiflorus, Freyn, in Oest. Bot. Zeitschr. xlii. (1892) 46. - Armenia.

Grisebachianus, Aitch. et Baker, in Trans. Linn. Soc. Ser. II. iji. (1886) 52. - Afohania.

griseopubescens, Sheld, in Minnes, Bot. Stud, i. (1894) $24=$ strigosus, Coult. et Fish.

gypsaceus, G. Beck, ex Stapf, in Denkschr. Akad. Wien, li. (1886) 334. - As. occ.

haesitabundus, Lipsky, in Act. Hort. Petrop. xiii, (1894) 290. - Reg. Cauc.

hamadanus, Boiss. Fl. Or. Suppl. (1888) 186. Persia.

Hasseanus, Sheld. in Minnes. Bot. Stud. i. (1894) 124. - Calif.

Hegelmaieri, Willk. Suppl. Prodr. fl. Hisp. (1893) 235. - Hisp.

Heideri, Wettst. in Oest. Bot. Zeitschy, xxxix. (1889) 157 nomen; et in Sitzungsb. Akad. Wien, xcviii. 1889 (1890) 388 t. 2 fig. 1-7. - As. Min

Hendersoni, S. Wats. in Proc. Am. Acad. xxii. (1887) $471=$ Watsoni, Sheld.

Henryi, Oliver, in Hook. Icon. pl. xx. (1891) t. 1959. - China.

Holdichianus, Aitch. et Baker, in Trans. Linn. Soc. Ser. II. iii. (1886) 54. - Turkest.

holosericeus, M. E. fones, in Proc. Calif. Acad. Ser. II. v. (1895) 638. - Calif.

Hoodianus, Howell, in Erythea, i. (1893) 111. Oregon.

humillimus, Freyn et Sint. in Oest. Bot. Zeitschr. xliv. (1894) 61. - As. Min.

hyalinus, $M$. E. fones. in Proc. Calif. Acad. Ser. II. v. (1895) 648. - Nebraska.

\section{ASTRAGALUS}

ibapensis, M.E. fones, in Zö̈, iii. (1893) 290. Utah

intermedius, $M$. E. fones, in Proc. Calif. Acad. Ser. II. v. (1895) 656. - Arizona.

intonsus, Sheld. in Minnes. Bot. Stud. i. (1894) 23 $=$ villosus, Michx

inversus, M.E. fones, in Zoè, iv. (1893) 276. Calif

inyoensis, Sheld. in Contrib. U. S. Nat. Herb. iv. (1893) 86. - Calif.

Fepsoni, Sheld. in Minnes. Bot. Stud. i. (1894) 22= demissus, Greene.

julianus, M. E. fones, in Proc. Calif. Acad. Ser. II. v. (1895) 667. - Calif

Karoi, Freyn, in Oest. Bot. Zeitschr. xxxix. (1889) 436. - Sibiria.

Kralikii, Coss. ex Batt. et Trab. Fl. de l'Algerie (Dicot.) (1889) 259. - Algeria.

Krugeanus. Freyn et Bornm. in Oest. Bot. Zeitschr xl. (1890) 211 et 443. - As. Min.

Kuntzei, Sheld. in Minnes. Bot. Stud. i. (1894) 123 $=$ tenellus, Bunge.

laetevirens, Phil. in Anal. Univ. Chil. Ixxxiv. (1894) 30. - Chili.

laguroides, Freyn, in Bull. Herb. Boiss, iii. (1895) 180. - Persia

lanocarpus, Sheld. in Minnes. Bot. Stud. i. (1894) 144. - Washington, Nevada.

latus, $M$. E. fones, in Zoë, iv. (1893) 272. - Am. bor. Occ

lectulus, S. Wats. in Proc. Am. Acad. xxii. (188\%) 471. - Calif.

Leibergi, M. E. fones, in Proc. Calif. Acad. Ser. II v. (1895) 663. - Washington.

leucocystis, Greene, in Erythea, iii. (1895) $\% 6=$ lanocarpus, Sheld.

leucolobus, Parry, ex M. E. Fones, in Zoë, iv. (1893) 270 (an Astr. lectulus, S. Wats.?). - Calif.

leucothrix, Freyn et Bornm, in Oest. Bot. Zeitschr. xli. (1891) 406. - As. Min.

Levieri. Freyn, ex Somm. et Levier, in Bull. Soc. bot. Ital. (1893) 527; et in Oest. Bot. Zeitschv. xliv. (1894) 28. - Reg. Cauc.

limatus, Sheld. in Minnes. Bot. Stud. i. (1894) 126. Am. bor. occ.

Lindleyanus, Sheld.l.c. $140(=$ Astr. strobiliferus, Lind1.). - Armenia.

lingulatus, Sheld, l. c. 118, - Am. bor.

litangensis, Bureau et Franch. in Morot, fourn. do Bot. v. (1891) 24. - China.

Loczyi, Kanitz, Pl. exped. Szechenyi in As, centr. coll. (1891) 17. - As. centr.

longibracteatus, Somm, et Levier, in Bull. Soc. bot. Ital. iii. (1894) 31; et in Act. Hort. Petrop. x. (1893) 192. - Reg. Cauc.

longidens, Freyn, in Bull. Herb. Boiss. iii. (1895) 181. - Armenia.

Lumsdenianus, Aitch, et Baker, in Trans. Linn. Soc. Ser. II. iii. (1886) 52. - Turkest., Persia.

Macdougali, Sheld. in Minnes. Bot. Stud. i. (1894) 169. - Arizona.

macedonicus, Heldreich et Hadji, Géogr. bot. Emp. Ottom. (Pl. de Salon.) (1892) 19.-Maced.

macrophysus, Somm. et Levier, in Bull. Soc. bot. Ital, iii. (1894) 31; et in Act. Hort. Petrop. xiii. (1893) 190. - Reg. Cauc.

Magdalenae, Greene, Pittonia, i. (Feb. 1888) 162 (= Astr. candidissimus, S. Wats.). - Calif.

Mandoni, Rusby, in Mem. Torrey, Bot. Club, iii. 3. (1893) 19. - Bolivia.

megalacmus, Freyn et Sint. in Oest. Bot. Zitschr. xliii. (1893) 419. - As. Min.

megalanthus, Freyn et Sint. 1. c. xlii. ( 1892$) 46$ in syn. = grandiflorus, Freyn.

melanogramma, Boiss. Fl. Or. Suppl. (1888) 185.Persia.

metanus, M. E. Fones, in Proc. Calif. Acad. Ser. II, v. (1895) 666. - Calif

miquelensis, Greene, Pittonia, i. (March 1887) $33=$ anemophilus, Greene.

misellus, S. Wats. in Proc. An. Acad. xxi. (1886) 449. - Oregon.

miserandus, Greene, in Erythea, iii. (1895) $76=$ bajaensis, Sheld.

Mitchellii, Post, Pl. Postianate, i. (1890) \%. Syria. 


\section{ASTRAGALUS}

moencoppensis, $\dot{M}, E$. fones, in $Z \circ \ddot{e}$, ii. (1891) 12. Am. bor. occ.

monospermus, Phil. in Anal. Univ. Chil. lxxxiv. (1894) 27. - Chili.

moupinensis, Franch. in Nowv. Arch. Mus. Paris, Sér. 1I. viii. (1885) 213. - China.

muradicoides, Wettst. in Sitzungsb. Akad. Wien, xcviii. 1889 (1889) 387. - As, Min.

Murrii, Huter, in Progr. Oberrealschule Innsbruck. (1891) 53 et 57; et in Deutsche Bot. Monatsschr. xii. (1894) 31. - Tirol.

musiniensis, M. E. Fones, in Proc. Calif. Acad. Ser. II. v. (1895) 67l. - Utah

muticus, Pau, Not, bot. fl. Espan. ii. (1889) 8. Hisp.

myrianthus, G. Beck, ex Stapf, in Denkschr. Akad. Wien, 1i. (1886) 336. - As. occ

Nawabianus, Aitch, et Baker, in Trans. Linn. Soc. Ser. II. iii. (1886) 49. - Afghania, Turkest.

neglectus, Freyn. in Oest. Bot. Zeitschr. xliii. (1893) 415 = fissilis, Freyn et Sint.

neglectus, Sheld. in Minnes. Bot. Stud. i. (1894) 59. $=$ Cooperi, A. Gray.

nemorosus, Batt. in Bull. Soc. Bot. Fr. xl. (1893) 263; et xlii. (1895) 207. - Algeria.

Nevinii, A. Gray, ex Lyon, in Coult. Bot. Gaz. xi. (1886) 331 et 335 nomen; et in Proc. Am. Acad. xxi. (1886) 412, - Calif, austr.

nigrescens, Franch, Pl. Delav. (1890) 162. - Yunnan.

nubigenus, Taub. in Engl. et Prantl, Natürl. Pfanzenfam. iii. 3. (1894) 303 (= Phaca nubigena, E.Mey.). - Chili.

oblatus, Sheld. in Minnes. Bot. Stud. i. (1894) 21 (=Astr, nudus, S, Wats.). -Am. bor. occ. reites, G. Beck, ex Stapf, in Denkschr. Acad. Wien. 1i. (1886) 380. - As, Min.

Orizabae, Seaton, in Proc. Am. Acad. xxviii. (1893) 117.- Mexic

pacificus, Sheld. in Minnes, Bot. Stud. i. (1894) 174 $(=$ Astr. Hendersoni, S. Wats, $)$ - Am. bor, occ.

palans, M. E. Jones, in Zoë, iv. (1893) 37 = lentiginosus, Dougl.

palmyrensis, Post, Pl. Postianae, i. (1890) 6. Syria.

panamintensis, Sheld. ex Coult. in Contrib. U.S. Nat. Herb. iv. (1893) 8\%. - Calif.

paphlagonicus, Freyn et Sint. in Oest. Bot. Zeitschr. xliv. (1894) 65. - As. Min.

paryiflorus, MacMill. Metasp. Minn. (1892) $325=$ gracilis, Nutt.

Paui, Loscos, in Pau, Not.bot. fl. Espan. i. (1887) 8; et in Willk. Suppl. Prodr. fl. Hisp. (I893) 233. Hisp.

Peabodianus, M. E. Fones, in Zoë, iii. (1893) 295. $=\mathrm{Utah}$.

pencanus, Phil. in Anat. Univ. Chil. 1xxxiv. (1894) 30. - Chili.

pentanthus, Boiss. Fl. Or. Suppl.(1888) 187. Persia.

pephragmenus, $M$. E. Fones, in Zoë, iv. (1893) 267. Am. bor. occ.

petropolitanus, Sheld. in Minnes. Bot. Stud. i. (1894) 171 = trichocalyx, Trautv.

phyllostachys, Boiss, Fl. Or. Suppl.-(1886) 183. Persia.

Pichleri, G. Beck, ex Stapf, in Denkschr. Acad. Wien, Ii. (1886) 336. - As. occ. polycladus, Burean et Franch, in Morot, fourn. de Bot. v. (1891) 23. - China.

Pondii, Greene, Pittonia, i. (April 1889) 288. Calif.

praelongus, Sheld. in Minnes. Bot. Stud. i. (1894) 23 (=Astr. procerus, A. Gray). - Am. bor.

praesignis, Sheld. 1. c. 118 in nota $=$ viridis, Bunge.

Prantlianus, Freyn, in Oest.Bot.Zeitschr, xliij. (1893) 415. - Armenia.

Pringlei, S. Wats. in Proc. Am. Acad.xxi. (1886) 449. - Mexic.

protiferus, M. E. Fones, in Zoë, iv. (1893) 275. Calif.

pruniformis, M. E. Fones, in Proc. Calif. Acad. Ser. II. v. (I895) 660. - Oregon.

Purshit, Sheld. ex Coville, in Contrib. U. S. Nat. Herb. iv. (1883) $87=$ leucolobus, $M$. E. fones.

\section{ASTRAGALUS :}

(1886) 450 . - Mexic.

rasus, Shotd in Minnes. Bot Stud. i. (1894) 158. Colorado.

Rawlinsianus, Aitch. et Baker, in Trans. Linn. Soc. Ser. IT. iii. (1886) 51. - Turkest.

remulcus, M. E. Fones, in Proc. Calif. Acad. Ser. II. v. (1895) 658. - Arizona.

Rengifoi, Phil. in Anal. Univ. Chil.1xxxiv. (1894) 25. - Chili.

reventoides, M. E. fones, in Proc. Calif. Acad. Ser. II. $v$ (1895) 661. - Montana.

Richardsoni, Sheld, in Minnes. Bot. Stud. i. (1894 $126=$ Hallii, A. Gray.

Rothrocki1, Sheld.l. c. 174. - Am. bor. occ.

sabulosus, $M$. E. fones, in Zoë, ii. (1891) 239. Utah.

safranbolicus, Sheld. in Minnes. Bot. Stud. i. (1894) $138=$ foliolosus, Bunge.

saguntinus, Pau, Not. bot. fl. Espan. i. (1887) 31 nomen. - Hisp.

salinus, Howell, in Erythea, i. (1893) 111. Oregon.

saxatilis, Freyn et Bornm. in Oest. Bot. Zeitschr. xli. (1891) 495. - As. Min.

scalaris, S. Wats, in Proc. Am. Acad. xxiii. (1888) 270. - Mexic

scobinatulus, Sheld, in Minnes. Bot. Stud. i. (1894) 24 = Haydenianus, A. Gray, var.

Seatoni, M. E. Fones, in Proc. Calif. Acad. Ser. II. v. (1895) 676. - Mexic.

selenaeus, Greene, in Erythea, iii. (1895) $76=$ cres centicarpus, Sheld.

serbicus, Wettst, in.Sitzungsb. Acad. Wien, xcviii 1889, (1889) 390 in obs. nomen. - Serbia

Serenoi, Sheld, in Minnes, Bot. Stud, i. (1894) 130

(= Astr. nudus, S. Wats.). - Am. bor. occ

sericeus, Freyn et Sint. in Oest. Bot. Zeitschr. xli. (1891) 406. - Armenia.

sericopetalus, Trautv. in Act. Hort. Petrop. ix. (1886) 448.- Turkest.

serpens, M.E. fones, in Proc. Calif. Acad. Ser. II v. (1895) 641. - Utah.

Shepardi, Post, Pl. Postianae, i. (1889) 6 et iv (1892) 5. - Syria.

Shockleyi, M.E. Fones, in Proc. Calif. Acad. Ser. II. V. (I895) 659. - Nevada.

Sileranus, M. E. fones, in Zoë, ii. (1891) 242. Utah.

sinaicus, Boiss, Fl. Or. Suppl. (1888) 174. - Reg Medit. or.

sinocarpus, Rusby, in Mem. Torrey Bot, Club, iii. 3 (1893) 19. - Bolivia.

Sintenisii, Freyn, in Oest, Bot. Zeitschy. xli. (1891) 407. - Armenia.

siricus "Ten. ) ex Wettst. in Sitzungsb. Acad. Wien, xcviii. 1889 (1889) 392 sphalm. = sirinicus, Ten.

Skorpili, Velen. Fl. Bulg. (1891) 148. - Bulg.

sofianus, Velen.l.c. 152. - Bulg.

Sommieri, Freyn, ex Somm. et Levier, in Bull. Soc. bot. Ital. (1893) 526; et in Oest. Bot Zeitschr. xliii. (1893) 418. - Reg. Cauc.

sophoroides, M.E. Fones, in Zoë, ii. (1891) 12. Am. bor. occ.

spatulatus, Sheld. in Minnes. Bot. Stud. i. (1894) 22 = caespitosus, $A$. Gray.

stenostachys, G. Beck, ex Stapf, in Denkschr. Acad. Wien, li. (1886) 333. - As. occ.

Stephenianus, Aitch. et Baker, in Trans. Linn. Soc. Ser. II. iii. (1886) 49 - Turkest.

striatiflorus, M. E. Fones, in Proc. Calif. Acad. Ser. II. v. (I895) 643. - Utah.

Stribrnyi, Velen. Fl. Bulg. (1891) 151. - Bulg.

strigosus, Sheld. in Minnes. Bot. Stud. i. (1894) 24 $=$ tener, $A$. Gray.

strigosus, Coult. et Fish, in Coult. Bot. Gaz. xviii. (1893) 299. - Montana.

Suksdorfii, Howell, in Erythea, i. (1893) 11l. - Am. bor. occ

supervacaneus, Greene, in Erythea, i. (1893) 221.Calif.

supervisus, Sheld. in Minnes. Bot. Stud. i.(1894) 140 $=$ Candollianus, Boiss.

sutchuenensis, Franch. Pl. Delav. (1889) 160. Yunnan.

\section{ASTRAGALUS}

uturalis, Sheld. in Minnes. Bot. Stud. i. (1894) 23 = eriocarpus, $S$. Wats.

sylvaticus, S. Wats, in Proc. Am. Acaả, xxiì.(1888) 262. - Oregon

syrticolus, Sheld. in Minnes. Bot. Stud. i. (1894) 22 $=$ Thompsonae, $S$. Wats.

Talbotianus, Aitch. et Baker, in Trans. Linn. Soc. Ser, II. iii. (1886) 56. - Afghania.

tanguticus, Batalin, in Act. Hort. Petrop. xi. (1891) 485. - China

tatsienensis, Bureau et Franch. in Morot, fourn. de Bot.v. (1891) 23. - China

tejonensis $\times, M$. E. Fones, in Proc. Calif. Acad. Ser. II. V. (1895) 644. - Mexic.

Tempskyanus, Freyn, in Oest. Bot. Zeitschr. xl. (1890) 211 et 442 - As. Min.

tepicus, Sheld. in Minnes. Bot. Stud. i. (1894) $172=$ ervoides; Hook. et Arn

texanus, Sheld, 1. c. $65=$ giganteus, S. Wats.

thermalis, Greene, in Erythea, iii. (1895) $76=$ cuspidocarpus, Sheld.

tinctus, Freyn et Sint. in Oest. Bot. Zeitschr. xlii. (1892) 11. - Armenja

Toanus, M. E. fones, in Zö̈, iii. (1893) 296. Am. bor. occ.

tossiensis, Freyn at Sint. in Oest. Bot. Zeitschr. xliii. 1893) 416. - As. Min.

Trabutianus, Batt. in Batt. et Trab. Fl. de l'Algérie (Dicot.) (1889) $256=$ cruciatus. $L i n k$

trachonticus, Post, in foum. Limn. Soc. xxiv. (1888) 426. - Syria.

triflorus, Sheld. in Minnes. Bot. Stud. i. (1894) 140 (= Phaca triflora, DC.). - Am. bor.

turolensis, Pau, Not, bot. A. Espan. i. (1887) 20; et iv. (1891) 29; Willk. Suppl. Prodr. fl. Hisp. (1893) 234. - Hisp.

Tweedyi, Canby, in Conlt. Bot. Gaz. xv. (1890) 150. - Oregon.

Uhlwormianus, Freyn et Bornm. ex Freyn, in Oest. Bot. Zeitschr. xl. (1890) 441. - As. Min.

Ulothrix, G. Beck, ex Stapf, in Denkschr. Acad. Wien, 1i. (1886) 339-As. occ.

uintensis, M. E. Fones, in Proc. Calif. Acad. Ser. II. v. (1895) 670. - Am. bor, occ.

umbraticus, Sheld. in Minnes. Bot. Stud. i. (1894) 23 = sylvaticus, $S$. Wats.

unguiculatus, Freyn, in Oest. Bot. Zeitschr. xliv. (1894) $63=$ Tempskyanus, Freyn et Sint.

uralensis, Letvinoff, in Bull. Soc. Imp. Natur. Moscon (1893) 501. - Reg. Ural.

Vandasii, Velen. in Sitzb. Böhm. Ges. Wiss. 1892 (1893) 34. - Bulg.

velatus, Trautv. in Act. Hort. Petrop. ix. (1886) 450. - Turkest.

vespertimus, Sheld. in Minnes. Bot. Stud. i. (1894) $150=$ amphioxys, A. Gray.

vexilliflexus, Sheld. 1. c. $21=$ pauciflorus, $H o o k$. vexillilongus, Sheld. 1. c. $140=$ Candollianus, Royle virgineus, Sheld. ex Coult. in Contrib. U. S. Nat. Herb. iv. (1893) 88 = sabulorum, A. Gray.

virgultulus, Sheld. in Minnes. Bot. Stud. i. (1894) 165. - Colorado.

viridis, Sheld 1. c. $118=$ A. Kentrophyta, A. Gray. viridissimus, Freyn et Sint. in Oest. Bot. Zeitschr. xlii. (1892) 48. - As. Min.

Watsoni, Sheld. in Minnes. Bot. Stud. i. (1894) 23 = pacificus, Shold.

Watsonianus, Sheld. 1. c. $144=$ eriocarpus, $S$ Wats.

Weirianus, Aitch. et Baker, in Trans. Linn. Soc. Ser. II. iii. (1886) 54. - Turkest.

Wetherilli, M. E. Fones, in Zö̈, iv. (1893) 34. Am. bor. occ.

Wettsteinianus, Freyn et Sint. in Bull. Herb. Boiss. iii. (1895) 183. - Armenia.

Winkleri, Trautv. in Act. Hort. Petrop. ix. (1886) 449. - Turkest.

Wootoni, Sheld. in Minnes. Bot. Stud. i. (1894) 138 = subcinereus, A. Gray.

xanthinus, Freyn et Bornm. in Oest. Bot. Zeitschr. xlii. (1892) 47; et in Bull. Herb. Boiss. iii. (1895) 184. - As. Min.

xylorrhizus, Freyn et Sint. l. c. xlii. (1892) 46.Armenia.

Yaquianus, S. Wats, in Proc. Am. Acad. xxiii. (1888) 270. - Mexic. 
ASTRAGALUS

yunnamensis, Franch. Pl. Delav. (1889) 162. Yunnan.

Zingeri, Korzchinsky, in Act. Hort. Petrop. xi.(1889?) 297. - Rossia med.

Zionis, M.E. Fonés, in Proc. Calif. Acad. Ser. II, v. 1895) 652 - Utah.

onarius, Sheld. in Minnes. Bot. Stud. i. (1894) 124 $=$ collinus, Boiss

ASTRANTIA, (Tourn.) Linn. (Umbellif.) - Ind

Kew. i. 239.

colchica, Alboff, Prodr. Al. Colch. (I895) 100; et Bull. Herb. Boiss. iii. (1895) 519. - Reg. Cauc.

pontica, Alboff, 17 . cc. 99 et 521. - Reg. Cauc.

ASTROGARYUM, G. F. W. Mey.(Palm.).Ind. Kew, i. 240

horridum, Barb. Rodr. in Vellosia, 1885-88, ed. 2 , i. (1891) 104. - Bras.

manaoense, Barb. Rodr. l. c. I05 t. 1. - Bras.

Sechellarum, Hort. ex Baill. Hist. des pl. xiii. (1895) 348 = Stevensonia grandifolia, Duncan.

sociale, Barb. Rodr. in Vellosia, 1885-88, ed. 2. i. 1891) 103. - Bras.

yauaperyense, Barb. Rodr. l.c. - Bras.

ASTROCHLAENA, Hallier f. in Bot. Jahrb. xviii (1894) 120. CONVOLVULACEAE.

cephalantha, Hallier f. l. c. 122. - Afr. trop. or.

Engleriana, Dammer, in Engl. Pfanzenw. Ost-Afr. C (1895) 330. - Afr. trop. or.

floccosa, Hallier f. in Bot. Fahrb. xviii. (1894) 121 (=Ipomoea floccosa, Vatke). - Afr. trop. or.

hyoscyamoides, Hallier $f$. ex Engl. in Abhandl. Preuss. Akad. Wiss. (1894)37; et in Bot. Fahrb. xvii. (1894 121 (= Convolvulus hyoscyamoides, Vatke). - Afr. trop.

lachnusperma, Hallier f.l. c. 121 (= Ipomoea lachnosperma, Choisy). - Afr.trop. or.

malvacea, Hallier f.l. c. (= Convolvulus malvaceus, Oliver). - Afr. austro-or. et trop. or.

melandrioides, Haliier f. $l$. c. 122. - Afr. trop. or

physaloides, Engl (?). Pflanzenw. Ost-Afr. A (1895) 54 nomen. - Afr. trop. or.

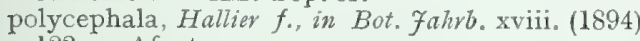
122. - Afr. trop. or.

solanacea, Hallier $f . l$. c. 121.-Afr. trop. or.

Volkensii, Dammer, in Engl. Pflanzenw. Ost-Afr. C (1895) 331. - Afr. trop. or.

ASTRONIA, Noronha (Melastom.). - Ind. Kew. i. 240 .

Beccariana, Cogn. in DC. Monog. Phan, vii. (1891) 1098. - N. Guin.

borneensis, Cogn. in Boerl. Handl. Fl. Ned. Indië, i 2. (1S90) 5.36 nomen. - Borneo.

calycina, Vidal, Rev. pl. vasc. Filip. (1886) 136. Ins. Philipp

Candolleana, Cogn. in DC. Monog. Phan. vii. (1891) 1099. - Ins. Philipp.

Hollnungia, Cogn. in Boerl. Handl. Fl. Ned. Indië, i. 2. (1890) 536 sphalm. = Hollrungii, $\operatorname{Cog} n$.

Hollrungii, $\operatorname{Cog} n$. in $K$. Schnm. et Hollr. Fl. Kais. Wilh. Land (1889) 88; et in DC. Monog. Phan. vii. (1891) 1095. - N. Guin.

Novae-Hannoverae, Engl. Bot. Fałrb. vii. (1886) 468. - Melanesia.

papuana, Cogn. in DC. Monog. Phan. vii.(1895) 1095.

pulchra, Vidal, Revis. pl. vasc. Filip. (1886) 136. Ins. Philipp.

triplinervia, Cogn. in Boevl. Handl. Fl. Ned. Indie, i. 2. (1890) 536. - Ins. Amboin.

ASTROTRICHA, DC. (Araliac.). - Ind. Kew, i. 241.

Biddulphiana, F. Muell, in Vict. Natur. vii. (Dec. 1890) I15; et ex Bot. Centralbl. xliv. (1891) 124. Austral.

cuspidata, Vesque, Epharmosis, iii. (1892) 16; $\operatorname{Cog} n$. in DC. Monog. Phan. vii. (1893) 171. - Bras.

sulphurea, Vesque, in DC. Monog. Phan. vii. (1893) 173 (= Quapoya sulphurea, Poepp. et Endl.). Peruvia.
ASTYDAMIA, DC. (Umbellif.). - Ind. Kew.

latifolia, Kuntze, Rev. Gen.(1891) 265 = latifolia, Baill.

ASYSTASIA, Blume (Acanth.). - Ind. Kew。 i. 241.

Buettneri, Lindau, in Bot. Fahrb. xx. (1894) 37. Afr. trop. occ.

Coleae, Rolfe, in Kew Bull. (1895) 223. - Reg. Somal.

linearis, S. Moore, in Fourn. Bot. (1894) 136.-Afr.

trop. or.
longituba, Lindau, in Bot. Falivb. xxii. (1895) 118.Afr. trop. occ

pusilla, C. B. Clarke, in fourn. Linn. Soc. xxv. (1889) 55 t. 26. - Reg. Himal.

rostrata, Solms, ex Lindar, in Bot. Fahrb. xxii. (1895) 118; et in Engl. Pfanzenw. Ost-Afr. C (1895) 370 (= Calophanes crenata, Schinz). - Afr. austro-occ. extratrop.

varia, N. E. Br. in Gard. Chron. (1892) ii. 760. Afr. austr.

variabilis, Trim. Handb. Fl. Ceyl. iii. (1895) 324. Zeyl.

ASYSTASIELLA, Lindau, in Engl, et Prantl, Natürl. Pflanzenfam. iv, $3 \mathrm{~b}$, (1895) 326. ACANNatürl. Pflan
$T H A C E A E$.

atroviridis, Lindau, l. c. $(=$ Asystasia atroviridis, T. Anders. - Ind, or.

Neesiana, Lindau, $l_{r} c,(=$ Asystasia-Neesiana, Wall.). - Ind. or

ATAENIA, Endl = Carum, Linn. (Umbellif.) Howellii, Greene, in Pittonia. i. (March 1888) 274 $=\mathrm{C}$. Howellii, Coult. et Rose.

Kelloggii, Greene, 1. c. = C. Kelloggii, A. Gray. oregana, Greene, 1. C. = C. oregana, S. Wats.

ATALANTIA, Correa (Rutac.),-Ind. Kew.i. 242. paniculata, Warb, in Bot. Fahrb. xiii. (1891) 340 et xvii. (1893) 173 in obs. - Oceania.

stenocarpa, Drake, in Morot, Fourn. de Bot. vi. (1892) 277. - Tonkin.

ATELEIA, Moç. et Sessé (Legumin.). - Ind. Kew, i. 242.

microcarpa, Millsp, in Field Columb. Museum Bot. Ser. I. (1895) $21=$ microcarpa, D. Dietr.

pterocarpa, Millsp. 1. c. = pterocarpa, Moç.et Sessé?

ATHALMUM, "Neck. " ex Kuntze, Rev. Gen. (1891) $319=$ ATHALMUS, Neck. = Pallenis, Cass. (Compos.)

spinosum, Kuntze, 1. c. = P. spinosa, Cass.

ATHAMANTA, Linn. (Umbellif.).- Ind. Kew, i. 243.

arachnoidea, Boiss, et Orph. ex Boiss, Fl. Or. Suppl. (1888) 262. - Graecia.

Dellacellae, Aschers. et Barbey, ex Coss. in Bull. Soc, bot. Fr. xxxyi. (1889) 101 nomen. - Cyrenaica. grisea, Stapf et Wettst. in Denkschr. Acad. Wien, li. (1886) 319 - As. occ.

hemisphaerica, Stapf et Wettst. l. c. - As, occ

Lobeliv, Caruel, in Parl. F1. Ital. viii.(1889) $348=$ cretensis, Linn.

vestina, A. Kern. Sched. A. Austro-Hung. iv. (1886) 37; E. Hallier, in Koch's, Syn. Deutsch. Fl. ed. 3. (1895) 1085. - Tirol.

ATHANASIA, Linn. (Compos.), - Ind. Kew.i. 243

ramosa, Klatt, ex Schinz, in Bull. Herb. Boiss. iii. (1895) 428. - Reg. Somal.

tridens, Oliver, in Hook. Icon. pl. xxiii. (1892) t. 2232. - Natal.

triloba, Klatt, ex Schinz, in Bull. Herb. Boiss, iii. (1895) 435. - Atr. austro-occ. extratrop.

peruviana, Zahlb. in Ann. Natwh. Hofmus. Wien, vii. (J892) 7. - Peruvia.

subtriflora, Zahlb. l.c. 8 in obs. (= Larnax subtri. flora, Miers). - Peruvia.
ATHEROLEPSIS, Hook. f. (Asclep.). - Ind, Kew, i. 244.

venosa, Collett et Hemsl, in fourn. Linn. Soc. xxviii. (1890) 86 (Atherolepis). - Burma.

ATHRIXIA, Ker-Gawl. (Compos.). - Ind. Kew. i. 244 .

Croniniana, F. Muell. in Vict. Natural.v. (1888) 76 , 54. - Austral.

pinifolia, N. E. Br. in Kew Bull. (I895) 26. Natal.

ATHYANA, Radlk, in Th. Dur. Ind. Gen. (I888) 73; et in Sitz, math. phys. $\mathrm{Cl}$. bayer. Akad. Wiss. xx. (1890) 282. SAPINDACEAE.

weinmannifolia, Radlk. ll.cc, - Parag., Argent.

ATITARA, Barrère, Essai Fr. équinox. (1741) 20 = Desmoncus, Mart. (Palm.)

aculeata, Kuntze, Rev. Gen. (1891) $727=$ D. aculeatus, $W$ endl.

americana, Kuntze, 1. c. = D. americanus, Lodd.

ataxantha, Kuntze, 1. $\mathrm{c}_{0}=$ D. ataxacanthus, Barb. Rodr.

chinantlensis, Kuntze, 1. c. = D. chinantlensis, Liebm.

costaricensis, Kuntze, 1. c. 726. - Costarica.

Drudiana, Kuntze, 1. c. 727. - Mexic.

dubia, Kuntze, 1. c. = D. polyacanthos, Mart.?

granatensis, Kuntze, 1. C. = D. granatensis, Bull

horrida, Kuntze, 1. c. = D. horridus, Splitg.

latifrons, Kuntze, 1. c. = D. latifrons, Bull.

leptospadix, Kuntze, 1. c, = D. leptospadix, Mart.

macracantha, Kuntze, 1. $\mathrm{c}=\mathrm{D}=\mathrm{D}$. macroacanthos, Mart.

major, Kuntze, 1. c. = D. major, Grueg.

mitis, Kuntze, 1. c. = D. mitis, Mart.

oligacantha, Kuntze, 1. c.= D. oligacanthus, Barb Rodr.

orthacantha, Kuntze, 1. C. =D. orthacanthos, Mart. oxyacantha, Kuntze, 1. c. I D. oxyacanthos, Mart. palustris, Kuntze, 1. c. = D. palustris, Trail. phengophylla, Kuntze, I. C. $=$ D. phengophyllus, Drude.

phoenicocarpa, Kuntze, 1. c, = D. pycnacanthos, Mart

polyacantha, Kuntze 1. c. $726=$ D. polyacanthos, Mart.

polyphylia, Kuntze, 1. c. $727=$ D. polyphylla. Poit. prunifera, Kuntze, 1. c. = D. prunifer, Poepp. et Endl.

punila, Kuntze, l. c. = D. pumilus, Trail.

pycnacantha, Kuntze, 1. C.=D. pycnacanthos, Mart. riparia, Kuntze, 1.c. = D. riparius, Spruce.

setosa, Kuntze, 1. c. = D. setosus, Mart.

ATRACTOGARPA, Franch. in Bull. Soc. Linn. Paris, i. (1887) 675. GRAMINEAE.

congolensis, Th. Dur et Schinz, Consp. fl. Afr. y. 1894 (1895) 945 sphalm. = olyraeformis, Franch. olyraeformis, Franch. in Bull. Soc. Linn. Paris i. (1897) 675; et in Bonnier Rev, gene et Bot. (1887) 465 t. 25 (sphalm. olyraefolia). - Congo gall.

ATRACTYLIS, Linn. (Compos.). - Ind. Kew. i.

conformis, Barbey, Karpathos (1895) 115 t. 8. Ins. Karpathos.

Mernephthae, Aschers, Schweinf. et Letourn. Illustr. fl. Egypte (1887) 94. - Aegypt.

ATRAGENE. Linn. (Ranuncul.). - Ind. Kew. i. 245.

tenuiloba, Britton, in Bull. Herb. Boiss, iii. (1895) 206 = Clematis pseudoatragene, Kuntze.

ATRAPHAXIS, Linn. (Polygon.). - Ind. Kew. i. 245 .

Muschketowi, Krassn. Pl.nov. ข. min. $\operatorname{cog} n .(1886)$ 20; et ex Hook. f. in Bot. Mag. (1895) t. 7435. - As. centr.

ATRIPLEX, (Tourn.) Linn. (Chenopod.). - Ind. Kew. i. 245.

amboënse, Schinz, in Verh. Bot. Ver. Brand. xxxi (1890) 211. - Afr. austro-occ, extratrop. angustifolia, Phil. in Anal. Unir.Chil.xci. (1895) 426. - Chili. 


\section{ATRIPLEX}

axillaris, Phil. in Anal. Mus.nac. Chile. (1891) 73.Bolivia.

Barclayana, T. S. Brandeg, in Proc, Caiif, Acad. Ser. II. ii. (1889) $200=$ Barclayana, D. Dietr.? canescens, T. S. Brandeg. 1. C. = canescens, fames? conduplicata, F. Muell. in Australas. Fourn. Pharm i. (Nov. 1886) 429. - Austral.

coquimbana, Phil. in Anal. Univ. Chil. xci. (1895) 425. - Chili. cordulata, Fepson, in Greene, Pittonia, ii. (Sept. 1892)
304. - Calif.

cornuta, $M$. E. fones, in Prov. Calif. Acad. Ser. II v. (1895) 718. - Utah.

corrugata, S. Wats. in Coult. Bot. Gaz.xvi. (1891) 345. - Colorado.

chenopodioides, Batt. in Batt, et Trab. Fl. de l'Al gérie (1889) 755; et in Bull. Soc. bot. Fr. xxxviii. (1891) 315. - Algeria.

costellata, Phil. in Anal. Univ. Chil.xci. (1895) 424 - Chili.

curvidens, T. S. Brandeg, in Proc. Calif. Acad. Ser. II. ii. (1889) 20I. - Calif

densifolia, Phil. in Anal. Univ. Chil. xci. (1895) 428. - Chili.

depressa, Fepson, in Greene, Pittonia, ii. (Sept. 1892) 304. - Calif.

dilatata, Greene, Pittonia, i. (Mar, 1889) 264. Calif.

Ehrenbergii, F. Muell. ex Aschers. et Schweinf (Suppl. Illustr. fl. Egypte) in Mém. Inst. Egypt. ii 1889) 771. - Aegypt.

fruticulosa, fepson, in Greene, Pittonia, ii. (sept. 1892) 306. - Calif.

glaucescens, Phil. in Anal. Mus, nac. Chile (1891)74. - Bolivia.

graciliflora, M. E. Fones, in Proc. Calif. Acad. Ser. II, v. (1895) 717. - Utah.

humilis, Phil. in Anal. Mus.nac, Chile (1891) 74. Bolivia.

Hystrix, Phil. in Anal. Univ. Chil. xci. (1895) 424. - Chili.

leuca, Phil. l. c. 428, - Chili

linearis, S. Wats. in Proc. Am. Acad. xxiv. (1889) 72. - Mexic

lativalve, F. Muell. Icon. Austral. Salsol. Pl. t. 6 ; et in Vict. Natural. ix. (april 1893) 187. - Austral.

lurida, T. S. Brandeg. in Proc. Calif. Acad. Ser. II ii. (1889) 200 - Calif.

Madarcagae, Phil.in Anal. Mus.nac. Chile.(1891)\%3. - Bolivia.

Magdalenae, .T S. Brandeg. in Proc. Calif. Acad. Ser. II. ii. (1889) 200. - Calif.

microcarpa, T. S. Brandeg. 1. c. = microcarpa D. Dietr?

myriophylla, Phit. in Anal. Mus. nac. Chile.(I891) 74. - Bolivia.

nodosa, Greene, in Pittonia, i. (Mar. 1887) 40; et Man. Bot. San Franc. Bay. (1894) 56. - Calif.

oreophila, Phil. in Anal. Univ. Chil. xci. (1895) 427. - Chili

podocarpa, Phil.l.c. - Chili

polyphylla, Phil. in Anal. Mus. nac. Chile (1891) 73. -Bolivia.

Pugae, Phil. in Anal. Univ. Chil. xci. (1895). 426.Chili.

pusilla, Phil. in Anal. Mus, nac. Chile (1891) 73.Bolivia.

Quinii, F. Muell. in Vict. Natural. v. (Nov. 1888) 96 - Austral.

radiata, Coult. in Contrib. U.S. Nat. Herb.ii.(1894) $368=$ Wrightil, S. Wats.

repanda, Phil. in Anal. Univ. Chil. xci. (1895) 425. - Chili.

Rusbyi, Britton, in Mem. Torrey Bot. Club, iv. (1895) 250. - Bolivia.

salaris, Phil. in Anal. Mus, nac. Chile (1891) 74, Bolivia.

subdecumbens, $M$. E. Fones, in Proc. Calif. Acad. Ser. II v. (1895) 716. - Utah.

tridentata, Kuntze, Rev.Gen, (1891) 546. - Utah.

trigonophylla, Phil. in Anal. Univ. Chil. xci. (1895 429. - Chili.

trinervata, Fepson, in Greene, Pittonia, ii (Sept. 1892) 305. - Calif

tuberculata, Coult. in Contrib. U. S. Nat, Herb. ii (1894) $368=$ texana, S. Wats.

\section{ATREPLEX :}

tularensis, Coult, in Contrib. U. S. Nat, Herb. II. iv. (1893) 182. - Calif

verna, fepson, in Greene, Pittonia, ii. (Sept. 1892) 305. - Calif.

ATROPIS, Rupr.=Glyceria, R. Br. (Gramin.) Borreri, C. Richt, Pl. Europ. (1890) $92=\mathrm{G}$. Borreri, $B a b$

festucaeformis, C. Richt. 1, c. $91=\mathrm{G}$. festucaeformis, Heynh.

Kjelmanni, C. Richt. 1. c. $92=\mathrm{G}$. Kjelmanni, Lange. Lemmoni, Vasey, Illustr. N. Am. Grass. ii (1893) t. 90 (= Poa Lemmoni, Vasey) - Am. bor. occ. peisonis, G. Beck, Fl. Nieder-Oest. i. (1890) 89. Austria.

permixta, C. Richt. P1. Europ. i. (1890) $92-\mathrm{G}$. permixta, Guss,

procumbens, C. Richt. 1. c. $=$ G. procumbens, $S m$. tenella, C. Richt. 1. c. = G. tenella, Lange.

tenuifolia, C. Richt. 1. c. $92=\mathrm{G}$. tenuifolia, Boiss. Vahliana, C. Richt. 1. c. = G. Vahliana, Fries.

vilfoidea, C. Richt. 1. c. = G. vilfoidea, Fries.

ATYLOSIA, Wight et Arn. (Legumin.). - Ind. Kew. 1.248.

burmanica, Collett et Hemsl. in fourn. Limn. Soc. xxviii (1890) 49. - Burma.

cajanoides, Cordem. Fl. Ile Réunion (1895) 397. Ins. Borbon.

ATYLUS, Salisb. = Isopogon, R. Br. (Proteac.). adenanthodes, Kuntze, Rev. Gen. (1891) $577=\mathrm{I}$. adenanthoides, Meissn.

anethifolius, Kuntze, 1. C, = I. anethifolius, Knight. asper, Kuntze, 1. c. = I. asper, $R$. Br

attenuatus, Kuntze, 1. c. $=$ I. attenuatus, $R \cdot B r$.

axillaris, Kuntze, 1. c, = I, axillaris, $R, B r$

Baxteri, Kuntze, 1. c. = I. Baxteri, R. Br.

buxifolius, Kuntze, 1. c. $=$ I. buxifolius, $R . B r$

ceratophyllus, Kuntze, 1. c. = I. ceratophyllus, R. Br.

crithmifolius, Kuntze, 1. c. = I. crithmifolius, F. Muell.

cuneatus, Kuntze, 1. c. = I. cuneatus, $R, B r$.

divergens, Kuntze, 1 . c. $=\mathbf{I}$. divergens, $R$. $\dot{B}$ r.

Drummondii, Kuntze, 1. c. = I. Drummondii, Benth.

formosus, Kuntze, 1. c. = I. formosus, $R . B r$. heterophyllus, Kuntze, 1. $c_{0}=\mathrm{I}$, heterophyllus, Meissn. latifolius, Kuntze, 1. c. = I. latifolius, $R, B r$

linearis, Kuntze, 1. c. = I. linearis, Meissn.

longifolius, Kuntze, 1. c. $=\mathrm{I}$. longifolius, $R . B r$.

petiolaris, Kuntze, 1. $\mathrm{c}$. $=\mathrm{I}$. petiolaris, $A$. Cunn

polycephalus, Kuntze, 1, c. $=$ I. polycephalus, $R$. Br

voseus, Kuntze, 1. c $=$ I. roseus, $L$ indl.

scabriusculus, Kuntze, 1.c.=I.scabriusculus, Meissn.

sphaerocephalus, Kuntze, 1. c. = I. sphaerocephalus, Lindl.

teretifolius, Kuntze, 1. c. = I. teretifolius, $R$. $B r$

tridens, Kuntze, 1. c. = I. tridens, $F$. Muell

trilobus, Kuntze, 1. c, = I. trilobus, $R, B r$.

tripartitus, Kuntze, 1, c, = I. tripartitus, $R, B r$.

lacinatus, Kuntze, 1.c. $=I$. uncinatus, $R$. $B$ r.

villosus, Kuntze, 1. c. = I. villosus, Meissn.

AUBERTIELLA, Briq, in Bull. Herb. Boiss, ii.

(1894) 73 sphalm. = Audibertiella, Briq.

AUBLETELLA, Pierre, Not. bot. Sapot. (1891) 47= Chrysophyllum, Linn. (Sapot.)

Macoucou, Pierre, 1. c. = C. Macoucou, Aubl.

AUBRIETIA, Adans.(Crucif.). - Ind. Kew.i. 249.

elwendica, Stapf in Denkschr. Akad. Wien, li. (1886) 301. - Persia.

hybrida, X Hausskn. in Mitth. Thür.Bot. Ver. N. Folge, iil et iv. (1893) 111. - Graecia.

AUDIBERTIA, Benth. (Labiat.). - Ind. Kew. i. 249.

Mearnsii, Britton, in Trans. N. Y. Acad. Sci, viii (1889) '11; et in Bull. Torrey Bot. Club. xvi. (1889) 202. - Arizona.
AUDIBERTIELLA, Briq. in Bull. Herb. Boiss. ii. (1894) 73. LABIATAE

capitata, Briq. l. c. (=Audibertia capitata, A. Gray) - Calif.

Clevelandi, Briq. l. c. ( = Audibertia Clevelandi, A. Gray). - Calif.

Dorrii, Briq. l.c. (= Audibertia Dorrii, Kell.).Calif.

grandiflora, Briq. l. c. (= Audibertia grandiflora Benth.). - Calif

humilis, Briq l. c. (= Audibertia humilis, Benth.) - Calif.

incana, Briq. l. c. = (Audibertia incana, Benth.) Am. bor. occ.

nivea Briq. l.c. (=Audibertia nivea, Benth.).-Calif Palmeri, Briq.l.c. (= Audibertia Palmeri, A. Gray). - Calif.

polystachya, Briq. l.c. $(=$ Audibertia polystachya, Benth.). - Calif.

stachyoides, Briq. l. c. (= Audibertia stachyoides, Benth.). - Calif.

Vaseyi, Briq. l. c. ( $=$ Audibertia Vaseyi, T. C. Por ter). - Calif.

AUGUSTA, Leandr. Sacram. = Stifftia, Mikan (Compos.).

Benthamiana, Kuntze, Rev. Gen. (1891) $319=\mathrm{S}$ Benthamiana, Baker.

condensata, Kuntze, 1. c. = S. condensata, Baker.

Martiana, Kuntze, 1. c. = S. Martiana, Baker.

AUKUBA “Thunb. " ex Koehne, Deutsche Dendrol. (1893) 435 = Aucuba, Thunb. (Cornac.).

AULACOCALYX, Hook. f.(Rubiac.). - -Ind. Kew. 1. 249

trilocularis, S. Elliot, in fown. Linn. Soc. xxx (1894) 81. - Sierra-Leone.

AULACODISGUS, Hook. f. (Rubiac.).-Ind.Kew i. 249 .

enneandrus, Kuntze, Rev. Gen.(189 ..) $301=$ prem noides, Hook. $f$.

AULISGONEMA, Hua, in Morot, Journ de Bot. vi. (1892) 469. LILI ACEAE

aspersa, Hua, 1. c. 471 t. 14 fig. 1 (= Disporopsis fusco-picta, Hance). - China occ.

Pernyi, Hua, l. c. 472 t. $1 \frac{1}{2} \mathrm{fig} .2$ - China.

AUSTRALINA, Gaudich. (Urtic.) - Ind. Kew. i. 251 .

hispidula, Colenso, in Trans. N.Z. Inst. xviii, 1885 (1886) 266. - N. Zel.

AUTRANIA, C. Winkl. et Barbey, in Post, Pl. Postianae, iii. (1892) 11. COMPOSITAE pulchella, C. Winkl. et Barbey, l. c. 12. - Syria

AUXEMMA, Miers (Boragin.).-Ind. Kew.i. 252 Glazioviana, Taub. in Bot. Fahrb. xv. Beibl.n. 34 (1892) 11. - Bras.

oncocalyx, Baill. Hist. des pl. x. (1890) $396=$ Gardneriana, Miers.

oncocalyx, Taub. in Bot. Jahrb. xv, Beibl. n. 34 (1892) 12. = praec

AVRNA, Linn. (Gramin.). - Ind, Kew. i. 252

adzharica, Alboff, Prod. fl. Colch.(1895) 25\%. - Reg Cauc

breviaristata, Barratte, in Batt. et Trab. Fl. de l'Algérie (Monoc.) (1895) 184. - Algeria.

Letourneuxii, Trab in Bull. Soc. bot. Fr. xxxvi. (1889) 411. - Algeria.

pruinosa, Trab. ex. Batt. et Trab. in Bull. Soc. bot. Fr. xxxv. (1888) 343 nomen = breviaristata Barratte.

AVENASTRUM, Jessen= Avena, Linn. (Gramin.) Blavii, G. Beck in Annal. Naturh. Hofmus. Wien v. (1890) 561 = Avena compressa, Heuff.

Parlatorii, G. Beck, F1. Nieder-Oest. i. (1890) 73 = Avena Parlatorii, Woods.

AVICENNIA, Linn. (Verben.).-Ind. Kew. i. 254. spicata, Kuntze, Rev. Gen.(1891) 502. - Penins. Mal. 
AXINAEA, Ruiz et Pav. (Melastom.)-Ind. Kew. 1. 255.

affinis, Cogn. in DC. Monog. Phan. vii. (1891) 449.Am. trop. austr.

costaricencis, $\operatorname{Cogn}$.l.c. 1182 in add, ; et ex Th. Dur. et Schinz, "in Bull. Soc. bot. Belg. xxx. 1891 (1892) 247. - Costarica.

Drakei, Cogn. in DC. l. c. 447.- Ecuad.

Lehmannii, Cogn. in Bot fahrb. vii. (1887) 20. Columb.

pauciflora, Cogn. in DC. Monog. Phan. (1891) 448. Ecuad.

speciosa, Brition, in Bull. Torrey Bot. Club, xvii. (1890) 57; Cogn. en DC. l, c. 1182. - Bolivia.

tomentosa, Cogn.in DC. Monog. Phan.vii. (1891) 451. - Peruvia.

AXINANTHERA. Karst.=Bellucia, Neck. (Melas-

tom.).
Hostmanni, Karst. in Bot. Jahrb. viii. (188\%) $352=$ B. Hostmanni, Naud.

AYENIA, Loefl. (Stercul.). - Ind. Kew. i. 255.

Berlandieri S. Wats, in Proc. Am. Acad.xxi. (1886) 419. - Mexic.

Blanchetiana, K. Schum. in Mart.Fl. Bras. XII. iii, (1886) 105. - Bras.

boliviana, Rusby, in Mem. Torrey Bot. Chub. iii. 3. (1893) 10. - Bolivia.

erecta, Mart. ex K. Schum. in. Mart. Fl. Bras. xm. iii (1886) 103. - Bras.

filiformis, S. Wats, in Proc. Am. Acad. xxiv. (1889) 42. - Mexic.

glabra, S. Wats. l. c. xxii. (1887) 399. - Mexic.

glabrescens, K. Schum. in Mart, Fl. Bras. XII. iii. (1886) 102. - Bras.

jaliscana, S. Wats. in Proc. Am. Acad. xxvi. (1891) 133. - Mexic.

Palmeri, A. Gray, l. c. xxi. (1886) 419. - Mexic.

paniculata, Rose, in Contrib. U S. Nat. Herb. i. (1891) 94. - Mexic.

Riedeliana, $K$. Schum. in Mart. Fl. Bras. x11. ii. (1886) 104. - Bras.

truncata, Rose, in Contrib. U. S. Nat. Herb. i. (1891), 94. - Mexic.

Wrightii, Robins. in Coult. Bot. Gaz. xvi.(1891) 340 . - Mexic.

AZALEA, Linn.=Rhododendron, Linn. (Ericac.). albiflora, Albrechtii, anthopogonodes, arborea, atrovirens, aucubifolia, Augustinii. auviculata, bactica, barbata, Boothii, brachyantha, brachycarpa, Brookeana, bul lata, Bureaui, californica, cammelliaeflora, campanulata, campylocarpa, campylogyna, capitata, catawbiensis, caucasica, cephalantha, Chumpionae, Chapmannii, chrysantha, ciliata, ciliicalyx, citrina, concinna, crassa, daurica, decora, Delavayi, dilatata, Edgeworthii, elliptica, Füberi, Falconneri, Farrerae, fastigiata, ferruginea, formosa. Fortunei, fulgens, glauca, grandis, Griffithiana, haematodes, Hanceana, heliolepis, Henryi, hirsuta, Hodgsonii, Hookeri, hypoglanca, isorata, jasminiflora, kantschatica, Keiskei, Kendrickii, Keysi, lactea, lanata, lepidota, leptocarpa, linearifolia, Lochae, lucida, macrophylla, macrosepala, macrostemon, malayana, Mariae, micrantha, microphyta, moulmeinensis, multicolor, nereiflora, nivalis, nivea, Nuttallii, oleifolia, pendula, pittosporifolia, polyclada, Przervalskii, pumila, Redowskiana, retusa, rhombica, rigida, rigida, rubiginosa, scabrifolia, Schlippenbachii, semibarbata, Seniavini, setosa, Shepherdii, simiarum, staminea, sublanceolata, taliensis, Taschiroi, Teysmannii, Thomsonit, thymifolia, trichoclada, triflora, Tschonoskii, Veitchiana, virgata, Westlandii, Weyrichii. yunanensis, Kuntze, Rev. Gen. (1891) 386-87 = homonyma omnia Rhododendri.

anthopogonodes, Kuntze, 1. c. $38 \%=\mathrm{R}$. anthopogonoides, Maxim.

californica, Hort. ex Dippel, Handb. Laubholzk, i. 1889) $415=\mathrm{R}$. occidentale, A. Gray.

canadensis, Kuntze, Rev. Gen. (1891) $386=\mathbf{R}$. Rhodora, F.F. Gmel.

dianthiflora, Carr. in Rev. Hort. (1889) 391; et (1891) 60 cum ic. et in Wien. Ill. Gartenzeit. (1889) 442:- Japon.

japonica, Kuntze, Rev. Gen. (1891) $386=$ R. Metternichii, Szeb. et $Z u c c$.
AZALEA : -
lamponga, Kuntze, Rev. Gen. (1891) p. $386=\mathrm{R}$ malayanum, fack.

lancifolia, Kuntze, I. c。 = R. ponticum, Linn.

macrocarpa, Kuntze, 1. c. = R. Dalhousiae, Hook.f.

Maddenii, Kuntze, 1. c. $387=$ R. Maddeni, Hook. $f$.

minor, Kuntze, 1. c. $386=\mathrm{R}$. punctatum, Andr.

Oldhamii, Kuntze, 1. c. = R. Oldhami, Maxim.

parvifolia, Kuntze, 1. c. = R. Anthopogon, D. Don.

Roylei, Kuntze, 1. c. = R. cinnabarinum, Hook. $f$

mustica $x$, Hort. ex Rev. Hortic. (1893) 195. Hybr, artef.

squamosa, Kuntze, 1. c. (sphalm. = Azal. squamata, Lindl.) $=$ R. Farrerae, Tate.

sulfurea, Kuntze, 1. c. = R. sulphureum, Franch.

Vervaeneana, Hort. ex Gard. Chron. (1888) i. 799. Form. hort.

vacciniodes, Kuntze, Rev. Gen. (1891) $386=$ R. vaccinioides, Hook. $f$.

Wigthii, Kuntze, 1. c. sphalm. = R. Wightii,

AZALEASTRUM, Hort. = Rhododendron, Linn

(Ericac.)

albiflorwm, Hort, ex Wien. Illustr. Gartenz. (1888) $435=\mathrm{R}$. albiflorum, Hook

AZALEODENDRON $\times$, Rodigas, ex Gard. Chron. (I893) i. $665=$ Azalea $\times$ Rhododendron Hort. (Ericac.).

AZARA, Ruiz et Pav. (Bixin.).- - Ind. Kew. i. 256 Bergi, F. Phil. ex Phil. in Anal. Univ. Chil. 1xxxi. (1893) 337. - Chili.

borealis, F. Phil. ex Phil. l. c. 340. - Chili.

Browneae, F Phil. ex Phit l, c. 335. - Chili

crassifolia, Hort. ex Dippel, Handb. Laubholzk.iii. (1893) $3=$ Gilliesii, Hook. et Arn.

microphylla, Hort. ex Dippel. 1. c. = dentata, Rui\% et $P$ av.

pycnophylla, Phil. in Anal. Univ. Chil. 1xxxi. (1893) 340. - Chili.

subandina, Phil. l. c. 339.-Chili

AZEDARACH, Linn. = Melia, Linn. (Meliac.) elegans, Kuntze, Rev. Gen. (1801) $110=$ M. elegans, Seem

excelsa, Kuntze, 1. c. = M. excelso, fack.

sempervirens, Kuntze, 1. c. $109=$ M. Azedarach, Linn.

tomentosa, Kuntze, 1. c. $110=$ M. tomentosa, Roxb.

AZIMA, Lam. (Salvador.). - Ind. Kew. i. '257.

spinosissima, Engl. Bot. Fahrb. xix. (1894) 147. Afr. austro-OC. extratrop.

AZORELLA, Lam. (Umbellif.). - Ind. Kew. i. 257

albida, Phil. in Anal. Univ. Chil. 1xxxv. (1894) 706. Chili.

clandestina, Phil. l. c. 701. - Chili.

compacta, Phil. in Anal. Mus. nac. Chile (1891) 28. - Bolivia.

crassipes, Phil. in Anal. Univ. Chil. 1xxxv. (1894) 702. - Chili.

elegans, Colenso, in Trans. N. Z. Inst. xxiii. 1890 (1891) 386. - N. Zel.

glacialis, Phil. in Anal. Univ. Chil. Ixxxv. (1894) 704. - Chili.

laevigata, Phil. l. c. 781. - Chili.

Lehmanii, Hieron. in Bot. Fahrb. xx. Beibl. n. 49 (1895) 71. - Columb. vel Ecuad. ?

microdonta, Colenso, in Trans. N. Z. Inst. xxiii, 1890 (1891) $387 .-$ N. Zel.

nitens, Petrie, in Trans, N. Z. Inst. xxv, 1892 (1893) 270. - N. Zel.

nivalis, Phil. in Anal. Univ. Chil. 1xxxv (1894) 703. - Chili.

obtusifolia, Phil. l.c. 701. - Chili

pectinata, Phil. l. c.'700, - Chili.

Rahmeri, Phil.l. c.703. - Chili.

vaginata, Phil. l. c. - Chili.

AZORINA, Feer, in Bot. Jahrb. xii. (1890) 611. $C A M P A N U L A C E A E$.

Vidali, Feer, 1. c. (= Campanula Vidalii, H. C,

Wats.). - Ins. Azor.
B

BABIANA, Ker-Gawl. (Irid.) - Ind. Kew. i. 257. macrantha, Macowan, in fourn. Linn. Soc. xxv. (1890) 394. - Afr. austr.

mononeura, Baker, Handb. Irid. (1892) 182. - Afr.

namaquensis, Baker, l. c. 181.-Afr. austro-occ

occidentalis, Baker, l. c. I83. - Afr, austr.

spiralis, Baker, l. c. - Afr, austr.

BACGAUREA, Lour. (Euphorb.). - Ind. Kew. i.

brevipes, Hook. f. Fl. Brit. Ind. v. (1887) 372. Ind, or. Borneo.

Griffthii, Hook. f. i. c. 371. - Penins. Mal.

latifolia, King, ex Hook. f. l. c. 373. - Perak.

Maingayi, Hook.f.l.c. 370. - Penins. Mal.

malayana, King, ex Hook. f. l. c. 374. - Ind. or.,

Sumatra.

minor, Hook.f.l.c. 370. - Perak.

polyneura, Hook. f. l. c.369.- Penins. Mal

reticulata, Hook. f. l. c. 373 . - Ind. or., Sumatra,

Scortechinii, Hook, f. l. c. 368. - Perak.

sparsiflora, S. Elliot, in fourn. Linn. Soc.xxx.(1894)

97. - Afr. trop. occ.

symplocoides, $I$

376. - Perak.

Wallichii, Hook. f. l.c. 375. - Penins. Mal

Wrayi, King. ex Hook. f. l. c. 374. - Perak.

BACGHARIS, Linn. (Compos.) - Ind.Kew.i.258. araucana, Phil. in Anal. Univ. Chil. Ixxxvii. (1894) 698. - Chili.

cochensis, Hieron. in Bot. Fahrb. xxi. (1895) 343. Columb.

Cuervi, Phil. in Anal. Univ. Chil. Ixxxvii. (1894) 703. - Chili.

cyanosa, Phil. h. c. - Chili.

Gayana, Phil. $l . c, 706$. - Chili

heterothalmoides, Britton, in Bull. Torrey Bot. Club, xix. (1892) 4.- Bolivia.

nvolucrata, Phil. in Anal. Univ. Chil. 1xxxvii.(1894) 707. - Chili.

Itatiaiae, Wawra, Itin. Prine. S. Coburg. ii. (1888) 28. - Bras.

Lehmannii, Klatt in Bot. Fahrb. viii. (1887) 39. Columb.

lejia, Phil. in Anal. Mus. Chile (1S91) 39. - Chili. leptocephala, Phil. in Anal. Univ. Chil. Ixxxvii. (1894) 700. - Chili.

litoralis, Phil. l. c. 699. - Chili.

Montteana, Phil. l. c. 702. - Chili.

Moritziana, Hieron. in Bot. Fahrb. xix. (1894) 50.Columb., Venez.

mucuchiesensis, Hieron. l. c. xxi. (1895) 342 - Columb.

nemorosa, Phil. in Anal. Univ. Chil. Ixxxvii. (1894) 708. - Chili.

ocellata, Phil. l. c. '705. - Chili.

Palenae, Phil. i. c. 708. - Chili.

pascensis, Hieron. in Bot. Fahrb. xxi. (1895) 344. Columb.

polyphylla, Klatt, in Annal. naturh. Hofmus. Wien, ix. (1887) 359. - Ecuad.

pycnantha, Phit, in Anal. Univ. Chil. 1xxxvii. (1894) 701. - Chili.

Santelicis, Phil. in Anal. Mus. nac. Chile (1891) 39 - Am. austr. occ

Stuebelii, Hieron. in Bot. Fahrb. xxi. (1895) 341. Peruvia.

subandina, Phil. in Anal. Univ. Chil. lxxxvi i(1894) 707. - Chili.

subbimera, Hieron. in Bot. fahrb. xxi. (1895) 345. - Peruvia.

tolimensis, Hieron. l. c. 343. - Columb.

trinitensis, Kuntze, Rev. Gen. (1891)319.-Ins. Trinit. viscosa, Kuntze, 1. c. $320=$ glutinosa, Pers.

Vitis-Idea, Oliver, in Trans. Linn. Suc. Ser. II, ii. (1887) 27\%, t. 43 a; (Oliver, ex in Thurm in Tinelur v. (1886) 197, sphalm. Ideaea), - Guian. angl.

Weddelliana, Hieron. in Bot. Fahrb. xxi. (1895) 345 - Columb.

Williamsi, F. Phil. ex Phil. in Anal. Univ. Chil. 1xxxvii. (1894) 701. - Chili. 
BACCHARODES, Kuntze, Rev. Gerı. (1891) $320=$ BACCHAROIDES, Linn. F1. Zeylan. (1747) 196 = Vermonia, Schreb. (Compos.).

brachylepis, calycinum, courtallense, molle, muticum, pedunculatum, phyllolaenum, punctatum, purpureum, veticulatum, Ritchiei, tenue, Kuntze, 1.c.=homonyma omnia, Vernoniae.

frutescens, Kuntze,1.c. (= Decaneurum frutescens, DC.) - Java.

Holtonii, Kuntze, 1. c. $=$ Centratherum Holtonii, Baker.

violaceum, Kuntze, 1. c. $=$ Centr. intermedium, Less.

BACKHOUSIA, Hook, et Harv. (Myrtac.). Ind. Kew, i. 261

Bancroftii, F. M. Bailey et F. Muell, ex F. M. Bailey, Syn. Queensl. Fl. Suppl. I. (1886) 24. - Austral.

BACLEA, Greene in Exythea, i (1893) $238=$ Nemacladus, Nutt. (Campanul.).

oppositifolia, Greene, 1. c. $=$ N. oppositifolius,

BACOPA Aubl. (Scrophul.). - Ind. Kew, i. 261. amplexicaulis, Wettst. in Engl. et Prantl, Natürl. Pflanzenfam. Iv. 3 b. (1891) $76=$ Herpestis amplexicaulis, Pursh.

chamaedryoides, Wettst, $1 . \mathrm{c}_{0}=\mathbf{H}$. chamaedryoides, $H . B$. et $K$

flovibunda, Wettst. 1. c. $17=\mathrm{H}$. floribunda, $R \cdot B r$,

Hamiltoniana, Wettst, 1.c. $77=\mathrm{H}$. Hamiltoniana, Benth.

lanigera, Wettst. 1. c. $=$ H. lanigera, Cham. et Schlecht.

Monniera, Wettst. 1. c. $=$ H. Monniera, Linn

myriophylloides, Wettst. 1.c. $=\mathrm{H}$. myriophylloides, Benth.

nigrescens, Wettst. 1. $\mathrm{c},=\mathrm{H}$. nigrescens, Benth.

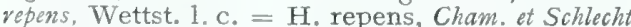

rotundifolia, Wettst. 1. c. $=$ H. rotundifolia, Pursh.

BACTRIS, Jacq. (Palm.) - Ind. Kew. i. 261.

Cohune, S. Wats. in Proc. Am. Acad. xxi. (1886) 467 - Guatem.

insignis, Baill. Hist. des pl. xiii. (1895) 305 (= Guilielma insignis, Mart.). - Am. austr.

BACULARIA, F. Mueil. (Palm.), - Ind. Kew, i. 262.

Albertisiana, Becc. Malesia, iii. (1886) 108, - N. Guin.

Palmeriana, F.M. Bailey, Rep. Exped. Bellenden-Ker, (1889) 61.- Austral.

BADIANIFERA, Linn. Mat. Med. (1749) 180. ex Kuntze, Rev. Gen. (1891) $6=$ Illicium, Linn. (Magnol.).

anisatum, Kuntze, 1. c. = I. anisatum, Linn.

cambodgiana, Kuntze, 1. c. = I.cambodianum, Hance floridana, Kuntze, 1. c. = I. floridanum, Ellis

Griffithi, Kuntze, 1. c. = I. Griffithii, Hook. f. et Thoms.

major, Kuntze, 1. c = I. majus, Hook. $f$. et Thoms. officinarum, Kuntze, 1. c. = I. anisatum, Gaertn.

parviflora, Kuntze, 1. c. = I. parviflorum, Michx.

BADUSA, A. Gray (Rubiac.), - Ind. Kew. i. 263. philippica, Vidal, Revis. pl.vasc. Filip. (1886) 150 (=Exostemma philippicum, Roem. et Schult.) - Ins. Philipp.

BAEGKEA, Linn. (Myrtac.),- Ind, Kew, i. 263.

ambigua, Niedenzu, in Engl. et Prantl, Naturl. Pfanzenfam. iii. 7. (1892) 99. ( = Astartea ambigua F. Muell.).-Austral

fascicularis, Niedenzu, l. c. ( = Ast. fascicularis, DC.). - Austral.

intratropica, Niedenzu, l. c. $(=$ Ast. intratropica, F. Muell.). - Austral

obligomera, "Radlk. »Niedenzu, 1. c., sphalm. = oligomera, Radlk.

BAEOMETRA, Salisb. (Liliac.) - Ind. Kew. i. 264.

Breyniana, Baill. Hist. des pl. xii. (1894) $588=$ columellaris, Salisb.

Breyniana, Th. Dur, et Schinz, Consp. fl. Afr. v. $1893(1895) 414=$ praec.
BAERIA, Fisch et Mey.(Compos.). - Ind. Kew. i. 264 .

Burkei, Greene, in Bull. Calif. Acad. I1. vi. (1886) 151. - Calif.

consanguinea, Greene, Pittonia, i. (March 1889) 284 - Calif.

Parishii, S. Wats. in Proc. Am. Acad. xxiv. (1889) 83. - Calif.

BAGNISIA, Becc. (Burmanniac.). - Ind. Kew. i. 264

episcopalis, Engl. in Engl. et Prantl, Natürl. Planzenfam. ii. 6(I888) 48 (= Geometra episcopalis, Becc.) - Malaya.

Rodwayi, F. Muell, in Proc. Roy, Soc. Tasm, 1890 (1891) 232; et in Bot. Centralb1. xlv.(1891) 257 in syn. = Thismia Rodwayi, F. Muell.

BAHELIA, Kuntze, Rev. Gen. (1891) $458=$ BAHEL Adans. = Artanema, D. Don (Scrophul.) angustifolia, Kuntze, 1. c. = A. angustifolium, Benth.

fimbriata, Kuntze, 1. c. = A. fimbriatum, D. Don

longifolia, Kuntze, 1. c. = A. sesamoides, Benth

BAHIA, Lag. (Compos.). - Ind. Kew. 1. 264. alternifolia, Less. ex Kuntze, Rev. Gen. (1891) 336 in syn. - Hab.?

desertorum, M. E. fones, in Zoë, ii. (1891 249). Utah.

dissecta, Britton, in Trans. N. Y. Acad. Sci. viii. (1889) 68. - Am. bor.

Palmeri, S. Wats, in Proc. Am. Acad. xxiv. (1889)83.

Schaffneri, S. Wats. l, c.xxvi. (1891) 142.--Mexic.

BAIKIAEA, Benth. (Legumin.),-Ind. Kew.ỉ. 264. Eminii, Taub. in Engl. et Prantl. Nativl. Pfanzenfam. iii. 3. (1894) 38\%; et in Engl. Pflanzenw. Ost-Afr. C (1895) 198. - Afr. trop. or.

BAILLONELLA, Pierre, Not. bot. Sapot. (1890) 13. SAPOTACEAE.

toxisperma, Pierre, l. c. 14. - Gabon.

BAILLONIA, Bocq. (Verben.). - Ind. Kew. i. 264

spicata, Baill. in Bull. Soc. Linn. Paris, ii. (1890) 880. - Chili?

BAILLONODENDRON, Heim, in Bull. Soc. Linn. Paris, ii. (1890) 867 = Dryobalanops, Gaertn. (Dipteroc.).

malayanum, Heim, 1. c.; et Recherch. Diptéroc. (1892) $83=\mathrm{D}$. oblongifolia, Dyer.

BAISSEA, A. DC. (Apocỳn.).-Ind. Kew. i. 264. angolensis, Stapf, in Kew Bull. (1894) 126.-Angola. brachyantha, Stapf, l. c. 125; et in Hook. I con. pl. xxiv. (1895), t. 2343 - Afr. trop. occ.

dichotoma, Stapf, l. c. - Afr. trop. occ.

laxiflora, Stapf. l. c. 124; et in Hook. Icon. pl. xxiv. (1894) t. 2342. - Afr. trop. occ

tenuiloba, Stapf, l. c. 124. - Afr. trop. occ.

BAKERELLA, Van Tiegh. in Bull. Soc, bot. Fr. xlii. (1895) $244=$ Loranthus, Linn. (Loranth.). diplocrater, Van Tiegh. 1. c. $246=$ L. diplocrater, Baker.

microcuspis, Van Tiegh. 1. c. = L. microcuspis, Baker.

BAKERIA, Éd. André, in Rev. Hortic. (1889) 84; Baker, Handb. Bromel. (1889) 89. BROMELIA$C E A E$.

tillandsioides, Éd. André, ll. cc. - Bras.?

BALANOGARPUS, Bedd. (Dipteroc.). - Ind. Kew i. 265

acuminatus, Heim, in Mém. Assoc. Franç. Besanç. 1892 (1893) 560. - Malaya.

anomalus, King, in fourn. As. Soc. Beng. 1xii. (1893)

II. 132 (anomala) - Kedah.

Curtisii, King, l.c. 131. - Penang, Perak.

Heimii, King, l. c. 133. - Penang, Perak.

Hemsleyanus, King, l. c. 134. - Penang, Perak.

maximus, King, l. c. 133. - Perak.

penangianus, King, l. c. 131. - Penang, Perak.

\section{BALANOGARPUS :}

sphaerocarpus, Heim, Rech. Diptéroc. (1892) 7\%. Borneo.

Wrayi, King, in fourn. As. Soc. Beng. 1xii. (1893) II. - Perak

zeylanicus, Trimen, in fourn. Bot. (1889) 161; et Handb. Fl. Ceyl. i. (1893) 130 t. 14. - Zeylan.

BALANOPHORA. Forst. (Balanophor.). - Ind.

decurrens, Fawcett, in Trans. Limn. Soc. Ser. II, ii. (1886) 234.- Ins. Philipp.

Forbesii, Fawcett, l. c. 236. - Java.

Henryi, Hemsl. in fourn. Linn. Soc. xxvi.(1894) 410. - China.

Hookeriana, Hemsl. in Kew Bull. (1894) 102. - Reg. Himal.

laxiflora, Hemsl. in Fourn. Linn. Soc. xxvi.(1894) 410 t. 9 fig. 2-3. - China.

minor, Hemsl. l. c. fig. 1. - China.

multibrachiata, Fawcett, in Trans. Linn. Soc. Ser. II. ii. (1886) 236. - Sumatra.

ramosa, Fawcett, l. c. - Java.

Zollingeri, Fawcett, l. c. 234. - Ins. Salayer.

BALFOURINA, Kuntze, Rev. Gen. (1891) $954=$ Didymaea, Hook.f. (Rubiac.).

mexicana, Kuntze, l. c. = D. mexicana, Hook. $f$.

BALIOSPEREUM, Blume (Euphab.). - Ind. Kew. i. 265.

corymbiferum, Hook.f. Fl. Brit. Ind. v. (1888) 463. - Ind. or.

analayanum, Hook. $f . l$. c. - Ind. or.

BALLOTA, Linn. (Labiat.). - Ind. Kew. i. 266. antilibanotica, Post, Pl. Postianae, ii. (1891) 20.Syria.

fruticosa, Baker, in Kew Bull. (1895) 225. - Reg. Himal.

sagittata, Regel, in Act. Hort. Petrop. ix. (1886) 607. - Turkest.

Wettsteinii, Rechinger, in Oest. Bot. Zeitschr. xl. (1890) 153 t. 1. - Ins. Cypr.

BALLS-HEADLEYA stipelosa, F. Muell. ex Bailey, Syn. Queens1. F1. Suppl. i. (1886) 19. - Austral. (Saxifrag. indescript.).

BALSAMEA, Gled. = Commiphora, Jacq. (Bur-

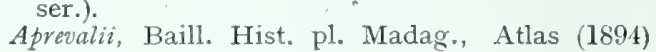
t. $226 \mathrm{~d}$ bis. - Madag.

Greveana, Baill. 1. c. t. 226 c. - Madag.

tetramera, Baill. 1. c. t. 226 d. - Madag.

BALSA MIORHIZA, Hook. (Compos.). - Ind. Kew. i. 267.

invenusta, Coville, in Contrib. U.S. Nat. Herb. iv. (1893) $130(=$ Helianthus invenustus, Greene). Calif.

BALTIMORA, Linn. (Compos.). - Ind. Kew. i. 267.

monocephala, Klatt, in Ann. naturh. Hofmus. Wien, ix. (1894) 360. - Mexic.

BAMBUSA, Schreb. (Gramin.). - Ind. Kew. i. 267.

arnhemica, F. Muell, in Austral. Fourn. Pharm. (Dec. 1886) 447. - Austral.

japonica, Hort. ex Gartenfl. (1889) 167. - Form. hort.

kurilensis, Myabe, in Mem. Bost. Soc. Nat. Hist. iv. vii. (1890) 271 (= Avundinaria kurilensis, Rupr.) - Ins. Kuril.

Mazelii, Hort. ex W. Wats, in Kew Bull. (1889) $298=$ aurea, Siebold?

Moreheadiana, F. M. Bailey, Rep. Exped. BellendenKer (1889) 71. - Austral.

nipponica, Makino, in Tokyo. Bot. Mag. ix. (1895) 72. - Japon.

palmata, Hort. ex Kew Bull. (1889) 79; et ex Gard. Chron. (1890) i. 641 fig. $106=$ tessellata, Munro. remotiflora, Kuntze, Rev. Gen. (1891) 760. - Anam Simoni, Carr. ex Hook. $f$. in Bot. Mag. (1890) subt. $7146=$ Arundinaria Simoni, $A$. et $C$. Rivière. 


\section{BAMBUSA}

tonkinensis, Baill. Hist. des pl.xii.(1894) 147 (= Bonia tonkinensis, Balansa). - Tonkin.

Veitchii, Carr. in Rev. Hortic. (1888) 90; et Gard. Chron. (1888) i. $332=$ tessellata, Manno

Wiesneri, Carr. in Rev. Hortic. lix. (1887) 83. Japon.

Wrayi, Stapf, in Kex Bull. (1893) 114; et in Hook. Icon. pl. xxiii (1893) t. 2253. - Perak.

BANARA, Aubl. (Samyd.), - Ind. Kew. i. 268 pyramidata, Rusby, in Mem. Torrey Bot. Club, iii. 3. (1893) 33. - Bolivia.

serrata, Warb. in Engl. et Prantl,Natürl. Pflanzenfam. iii. 6 a. (1893) $32=$ Vellozii, Gardn.

BANCALUS, Rumpt, Herb. Amboin. iii. (1743) 84 et 755, ex Kuntze, Rev. Gen. (1891) 276 = Nauclea, Linn. (Rubiac.)

affinis, Bartingii, canescens, cordatus, cuspidatus, Forsteri, glaber, glandulifer, gracilis, macrophyllhu, Maingayi, missionis, mollis, obtusus, orientalis, peduncularis, purpureus, sericeus, strigosus, Synkorynes, zeylanicus, Kuntze, 1. c. 276-77=homonyma omnia Naucleae.

grandifolins, Kuntze, 1. c. = Sarcocephalus cordatus, Miq.

rotundifolius, Kuntze, 1. c. = N. Haenkeana, Stend.

BANCROFTIA, Macfad.=Tovaria, Ruiz et Pav, (Capparid.).

pendula, Kuntze; Rev. Gen. (1891) 37=T. pendula, Ruiz et Pav.

BANISTERODES, Kuntze, Rev. Gen. (1891) $45=$ BANISTERIOIDES, Linn. = Xanthophyllum, Roxb. (Polygon.)

affine, ellipticum, excelsum, glaucum, Griffithii, insigne, longifolium, Macintyrii, Maingayi, obscurum, nufum, stipitatam, vitellinum, Kuntze 1. c. = homonyma omnia Xanthophylli.

BANKSIA, Forst. $=$ Pimelea, Banks et Soland (Thymel.).

alpina, altior, ammocharis, angustifolia, argentea, axiflora, Bowmannii, brachyphylla, brevifolia, buxifolia, cinerea, clavata, collina, colorans, concreta, Cornucopiae, curviflora, drupacea, elachantha, Errei, ferruginea, filiformis, flava, floribunda, Forrestiana, glauca, haematostachya, hirsuta, hispida, humilis. imbricata, latifolia, Lehmanniana, leptostachya, ligustrina, linifolia, longiflora, longifolia, Lyallii, microcephala, nervosa, nivea, octophylla, paucifora, petraea, petrophila, Preissii, punicea, pygmaea, rosea, sanguinea, sericea, sericeo-villosa, sericostachya, serpyllifolia, simplex, spathulata, spectabilis, spicata, stricta, sylveitris, Traversii, trichostachya, Urvilleana, villifera, Kuntze, Rev. Gen. (1891) 583= homonyma omnia Pimeleae.

leptospermodes, Kuntze, 1. c. = P. leptospermoides, F. Muell.

Maxwellii, Kuntze, 1. c.=P. Maxwellii, F. Muell. Milliganii, Kuntze, 1. c. = P. Milligani, Meissn. phylicodes, Kuntze, 1. c. $=$ P. phylicoides, Meissn. physodes, Kuntze, 1. c. = P. physoides, Hook. spiculigera, Kuntze, 1. c. = P. spicata, $R$. Br. sulfurea. Kuntze, 1. c. = P. sulphurea, Meissn. tinctoria, Kuntze, 1. c. $=$ P. suaveolens, Meissn. villosa, Kuntze, 1. c. = P. arenaria, A.Cunn.

BANKSIA, Linn. f. (Proteac.).-Ind. Kew. i. 2\%0. Elderiana, F. Muell. et Tate, Elder Exped. Diagn. Nere Pl. [2]; et ex Bot. Ceutralbl. 1v. (1893) 317 . Austral.

BAOBABUS, Kuntze, Rev. Gen. (1891) 66 = BOABAB, Mill. = Adansonia, Linn. (Malvac.). digitata, Kuntze, 1. c. $67=$ A. digitata, Linn. Gregorii, Kuntze, 1. c. $=$ A. Gregorii, F. Muell madagascariensis, Kuntze, 1. c. $=$ A. madagascariensis, Baill.

BAPHIA, Afzel. (Legumin.). - Ind. Kew. i. 271. capparidifolia, Baker. in fourn. Linn. Soc. xxv. (1890) 311. - Madag.

\section{BAPHIA}

ancifolıa, Baill. ex Laness. Pl. util. col. franc. (1886) 340 nomen. - Afr. trop. occ.

massaiensis, Taub, in Enol, Pflanzenw, Ost-Afr. C (1895) 203. - Afr. trop. or.

BAPHIOPSIS, Benth. (Legumin.). - Ind. Kew. i. 271

Stuhlmannii, Taub. in Engl. et Prantl, Natürl. Pflanzenfam.iii. 3. (1895) 388 in add. et in Engl. Pflanzenw. Ost-Afr. C (1895) 203. - Afr. trop. or.

BAPTISTANIA, Barb. Rodr. ex Pfitzer, in Engl. et Prantl, Natïrl. Pflanzenfam. ii. 6 (IS89) 220 sphalm. = Baptistonia, Barb.-Rodr. (Orchid.).

BARATRANTHUS, Miq. = Loranthus, Linn (Loranth.)

acuminatus, Van Tiegh, in Bull. Soc, Bot. Fr. xli. (1894) 538. - Borneo.

Beccarii, Van Tiegh. 1. c. - Borneo.

bicolor, Van Tiegh. 1. c. - Perak

Kingii, Van Tiegh. 1. c, - Perak.

Lobbii, Van Tieoh. I, c. $501=\mathrm{L}$. Lobbii, Hook. $f$ nodiflorus, Van Tiegh. 1. productus, Van Tiegh. 1. c. = L. productus, King. Scortechinii, Van Tiegh. 1. c.538. - Perak.

BARTERIA, Hook. f. (Passifl.). - Ind. Kew.

Braunii, Engl. Bot. fahrb xiv, (1892) 392 et xv. (1893) 588. - Kameran.

BARBAGENIA, Vand. (Amaryll.).- Ind, Kew. i. 272.

aequatorialis, Harms, in Engl. Pflanzenw. Ost-Afr. C (1895) $146=$ Vellozia aequatorialis, Rendle. brevifolia, Taub. in Bot. Fahrb. xii. Beibl. n. 27 (1890) 2. - Bras.

capillaris, Pax, ex Engl, in Abhandl. Preuss. Akad. Wiss. 1891. ii. (1892) $171=$ Xerophyta capillaris, Baker.

Hildebrandtii, Pax, ex Engl. l. c. - Reg. Somal.

Holstii, Harms, ex Engl. in Abhandl. Preuss. Akad.

Wiss. (1894) 57 nomen. - Afr. trop. or.

scabrida, Pax, in Bot. Fahrb. xv. (1893) 144. - Afr. trop, austro-occ.

Spekei, Harms, in Engl. Pflanzenw. Ost-Afr. C (1895) $146=$ Vellozia Spekei, Baker

splendens, Harms, 1. c. = Vell. splendens, Rendle, tomentosa, Pax, in Bot. Fahrb. xv. (1893) 144. Afr. trop. or.

BARBAREA, R. Br. (Crucif,),-Ind. Kew. i. 272. abortiva $X$, Hausskn, in Mitth. Bot. Ver. Jena iii. (1886) 274. - Germ

adulterina $\times$, Hausskn. 1. c. 278. - Germ.

alpicola, Murb. in Lunds Univ. Arsskrift. Xxvir. v. (1892) 170. - Bosnia.

Barbarea, MacMill. Metasp. Minn. (1892) $259=$ vulgaris, $R . B r$.

bosniaca, Murb. in Lunds Univ, Arsskrift xxvII. v. (1891) 169. - Bosnia.

conferta, Boiss, et Heldr. ex Boiss. Fl. Or. Suppl. (1888) 36. - Graecia.

croatica, Borb. et Vukot, in Oest. Bot. Zeitschr. (1888) 421. - Croatia.

Gautieri, Fouc. et Rouy, Fl. de Fr. ii. (1895) 324 in add. = intermedia. Bor.

lippizensis, Caruel, in Parl. Fl. Ital. ix. (1893) $81 \%$ $=$ Nasturtium lippizense, $D C$

pinnata, Lebel, ex Rouy et Fouc. Fl. de Fr. i. (1893) 200. - Gall. occ.

Schulzeana, Hausskn, in Mitth. Bot. Ver. Jena, iii. (1886) 275 . - Germ

BARBEYA, Alboff, in Mém. Sect. Oural. Soc. Russ. Géogr. xiv. (1893), ex Alboff, in Bull. Herb.Boiss ii. (1894) $250=$ Amphoricarpos, Visian (Compos.).

BARBEYA, Schweinf, ex Penzig, in Bull. Soc. bot. Ital. (1892) 269 nomen. URTICEAE. oleoides, Schweinf. l. c.-Abyss.

BARBEYASTRUM, Cogn. in DC. Monog. Phan. vii. (1891) 376. MELASTOMACEAE
corymbosum, $\operatorname{Cogn}$. l. c. - Congo gall.
BARBosA, Becc. in Malpighia, i. (1887), 339 $P A L M A E$.

Pseudo-cocos, Becc., l. c. 352 - Bras.

BARJONIA, Decne (Asclep.). - Ind. Kew. i. 272 recta, K. Schum. in Engl. et Prantl, Natürl. Pflanzenfam. iv. 2. (1891) $285=$ racemosa, Decne

BARKHAUSIA, Moench = Grepis, Linn. $(\mathrm{Com}-$ batica, Colm. Enum. pl. Penins. Iber, iii. (1887) $446=\mathrm{C}$. spathulata, Guss, $446=$ C. spathulata, Guss.
Hackelii, Colm.1. c. $447=$ C. taraxacifolia, Thuill. glanduligera, C. Wink1. in Act. Hort. Petrop. xi. 1890) 325. - As, centr.

BARLERIA, Linn. (Acanth.) - Ind, Kew, i 273.

angustiloba, Lindau, in Bot. Fahrb. xx. (1894) 20.Afr. trop. or.

Antunesi, Lindau, l. c. xxii. (1895) 116. - Angola. blepharoides, Lindau, l. c. xx. (1894) 24.-Afr. trop. or.

Boehmii, Lindau, l. c. 19. - Afr. trop. or

calophylla, Lindau, l. c. 17. - Afr. centr. bor. calophylloides, Lindau, l. c.--Afr. trop, or. comorensis, Lindaw, l. G. 18. - Ins. Comor.

diffusa, Lindau, in Eng-1. et Prantl, Natür1. Pflanzenfam. iv. $3 \mathrm{~b}$. (1895) $315=$ Somalia diffusa, Oliver.

glandulifera, Lindau, in Bot. Fahrb. xx. (1894) 22. - Afr. trop. or.

grandicalyx, Lindau, in Bot. Fahro. xx. (1894) 25. - Afr. centr. bor.

hereroensis, Engl. Bot. Fahrb. x. (1889) 261. Afr. austro-occ. extratrop.

Holstii, Lindan, in Bot. Falirb. xx. (1894) 19.-Afr. trop. or

kilimandscharica, Lindau, l.c. 26. - Afr. trop. or Kitchingi, Baker, in fourn. Linn. Soc.xxi. (1887) 510. - Madas.

latiloba, Engl. Bot. fahrb. x. (1889) 261. - Afr. austro-occ. extratrop.

longifolia, Lindau, in Bot. fahrb. xx. (1894) 32. Afr. trop. OI.

Marlothii, Engl. Bot. fahrb. x. (1889) 262. - Afr austro-occ, extratrop.

mucronata, Lindau, in Bot. Fahrb. xx. (1894) 24. Afr, trop, or.

natalensis, Lindau, l. c. 23. - Natal.

Newtoni, Lindau, l. c. xxii. (1895) 11\%. - Angola. phillyreaefolia, Baker, in fourn. Linn. Soc. xxii 1887) 510. - Madar.

prionitoides, Engl. Bot. fahrb. x. (1889) 262,- $\mathrm{\Lambda fr}$. austro-occ, extratrop.

pulchra, Lindau, l. c. xx. (1894) 18. - Madag.

Sacani, Klotzsch, ex Lindau, in Engl, Pflanzenrw. Ost Afr. C (1895) 368. - Afr. trop. or.

Schenckii, Schinz, in Verh. Bot. Ver. Brand. xxxi. (1890) 199. - Afr. austro occ. extratrop.

Schweinfurthiana, Lindau, in Bot. Fahrb. xx. (1894) 26. - Afr, trop, or.

Stuhlmanni, Lindau, l. c. 20. - Afr. trop. or.

submollis, Lindau, l. c. 21. - Afr. trop. or

sudanica. Itindau, in Engl. Pfanzenw. Ost-Afr. C (1895) 368 (=Dipteracanthus sudanicus, Schweinf.) - Afr. trop.

ukamensis, Lindau, l. c. - Afr, trop. or.

usambarica, Lindau, in Bot. Fahrb. xx. (1894) 21.Afr. trop. or.

vincaefolia, Baker, in Fourn. Linn. Soc. xxv. (1890) 339. - Madag.

Volkensii, Lindau, in Bot. Fahrb. xx. (1894) 22. Afr. trop. or.

yemense, Schweinf. ex Lindau, in Engl. et Prantl. Natürl. Pflanzenfam. iv. 3 b. (1895) 315. - Afr. trop

BARNADESIA, Mutis (Compos.). - Ind. Kew. 1. 275.

Trianae, Hieron. in Bot. Fahrb. xix. (1894) 71. Columb.

BARRING'TONIA, Linn. (Myrtac。).-Ind. Kew. i. 275 .

calyptrocalyx, K. Schum. in K. Schum. et Hollr. Fl. Kais. Wilh. Land (1889) 91. - N. Guin. 


\section{BARRINGTONIA:}

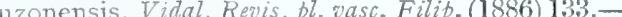
- Ins. Philipp.

rubra, Baill. ex Laness. Pl. util. col. franç. (1886) 621 = acutangula, Gaertn

Schuchardtiana, K. Schum, in K. Schum. et Hollv. Fl. Kais. Wilh. Land (1889) 92. - N. Guin.

BARTONIA, Muhl. (Gentian.).-Ind. Kew.i. 276. Moscri, Robins, et Greenm. ex Gilg, in Engl. et Prant1, Natür1. Pflanzenfam. iv. 2. (1895) $76=$ tenella, Muhl.

virginica, Britton, Stern et Poggenb. Prelim. Catal. (1888) $36=$ tenella, Muhl.

BARTSIA, Linn. (Scrophul.). - Ind. Kew, i. 276. kilimandscharica, Engl. in Abhandl. Preuss. Akad. Wiss. 1891, ii. (1892) 384.- Afr. trop.or.

orerensis, Corden. Fl. Ile Rémion (1895) 488. Ins. Borbon.

BASANACANTHA, Hook. (Rubiac.). - Ind, Kew. 1. 27.

Annae, $K$. Sclum, in Mart. Fl. Bras, vI. vi. (1889) 374 , - Bras

calycina, K. Schum. l. c.375. (= Randia calycina, Cham.). - Bras.

spinosa, K. Schum.l.c.376 (= Mussaenda spinosa Jacq.). - Am. trop.

BASANANTHE, Peyr. (Passiflor.). - Ind. Kew. i. 277.

heterophylla, Schinz, in Verh. Bot. Ver. Brand. xxx. (1888) 252. - Afr. austro-occ, extratrop.

BASELLA, (Rheede) Linn. (Chenopod.). - Ind. Kew. i. $27 \%$.

excavata, S. Elliot, in Fourn.Linn.Soc. xxix. (1891) 44. - Madag.

BASICARPUS, Van Tieg h. in Bull. Soc, bot. Fr. xlii. (1895) $562=$ Loranthus, Linn. (Loranth.) Glaziorii, Van Tiegh. 1. c. 565. - Bras.

BASILICUM, Moench $=$ Moschosma, Reichb (Labiat.).

multiflorm, Kuntze, Rev. Gen. (1891) $512=$ M. multiflorum, Benth.

myriostacliyum, Kuntze, 1. c. = M. myriostachyum, Benth. et Hook. f

riparim, Kuntze, 1. c. = M. riparium, Hochst.

BASILIMA, Rafin. = Spiraea, Linn. (Rosac.). alpina, Koehne, Deutsche Dendrol. (1893) $223=$ S. grandiflora, Sweet.

grandiflor $a$, Kuntze, Rev. Gen.(1891) $215=\mathrm{S}$. salicitolia, Linn.

Kirilowii, Kuntze, 1. c. $=$ = S. sorbifolia, Linn.

Lindleyana, Kuntze, 1. c. = S. Sorbifolia, Linn.

Millefolim, Greene, F1. Francisc. (1891) $57=\mathrm{S}$ Millefolium, Torr.

Millefolium, Kuntze, Rev. Gen.(1891) $215=$ praec.

BASILOXYLON, K. Schum, in Mart. Fl. Bras. xir. iii. (1886) 12 in obs. STERCULIACEAE.

Rex, K. Schum. l. co; et in Ber. deutsch. Bot. Ges. iv. (1886) 82. - Bras.

BASSIA, All. = Chenolea, Thunb. (Chenopod.) dasyphylla, Kuntze, Rev. Gen. (1891) $546=$ Kochia dasyphylla, Fisch. et Mey.

diffusa, Kuntze, 1, c. = Chenolea diffusa, Thunb.

divaricata, Kuntze, 1. c. (= Echinopsiton divaricatus, Kar. et Kir.) - Soongar.

eviantha, Kuntze, 1. c. (=Londesia eriantha, Fisch. et Mey.).- Reg. Casp.

eriophora, Kuntze, 1. c. $547=$ Kochia eriophora Schrad.

hirsuta, Kuntze, 1. c. = K. hirsuta, Nolte.

hyssopifolia. Kuntze, 1. c.=K. hyssopifolia, Schrad. longicuspis, F. Muell. Austral. Salsol. P1. (1891) t. 71; et in Vict. Natural.ix. (1893) 187.-Austral. Luehann, F. Muell. Austral. Salsol. vii. (Aug. 1890) 47; et Bot. Centralbl. xliii. (1890) 371. Austral.

Londesia. F. Muell. 1. c. 48 in obs. = Kochia eriophora, Schrad.

monticola, Kuntze, Rev. Gen. (1891) 547 = Kochia monticola, Boiss.
BASSIA : -

stelligera, «F. Muell. » ex Bot. Centralbl. 1ii. (1892) 168 nomen.

suaedacea, F. Mull, in Vict. Natural. vii. (Aug. 1890) 42 nomen. - Austral.

sedodes, Kuntze, Rev. Gen. (1891) 547 = Kochia sedoides, Schrad.

BASSIA, Koenig (Sapot.). - Ind. Kew. i. $27 \%$ Hollrungii, $K$. Schum, in Bot. Fahrb. ix. (1888) 214 (= Illipe Hollnungii, K. Schum.). - N. Guin. microcalyx, Burck. in Ann. Fard. Buitenz. iii. (1888) 256. - Ins. Stewart.

May, Becc. ex Pierre, Not. bot, Sapot. (1890) 5; et ex Boerl. Handl. Fl. Ned. Indië, ii. 1. (1890) 310 in syn. - Ind. bat.

Tatei, F. Muell. in Vict. Natural. vii. (Sept. 1890) 66. - Austral.

BASSOVIA, Aubl. (Solan.). - Ind. Kew. i. 279 Donnell-Smithii, Conlt. in F. D. Smith, Pl. Guat. ii. (1891) n. 53; et in Bot. Gaz.xvi. (1891) 145. Guatem.

microphylla, Coult. l. c. 145. - Am. centr, et austr. mexicana, Robins in 7 . D Smith PI Guat ii (1891) 53; et in Proc. Am. Acad.xxvi. (1891) 171. - Guatem.

stenoloba, Britton, ex Rusby, in Mem. Torrey Bot. Club, iv, (1895) 232 (= Solanum stenolobum, Van Heurck et Muell.). - Bolivia.

BASTARDIA, H, B. et K. (Malvac.). - Ind. Berlandieri, A. Gray. in Proc.Am. Acad.xxii. (1887) 295. - Mexic

conferta, Garcke et K. Schum, in Mart. Fl. Bras. XII. iii. (1891) 362. - Bras.

elegans, K. Schum.l.c.-Bras.

BATEMANNIA, Lind1. (Orchid.). - Ind. Kew. i. 278.

peruviana, Rolfe, in Kew Bull. (1895)193; et ex Gard. Chron. (1895) i. 551. - Peruvia.

BATHYSA, Presl (Rubiac.) - - Ind. Kew. i. 278. gymnocarpa, $K$. Schum. in Mart. Fl. Bras. vi, vi. (1889) 238. - Bras.

Mendonçaei, K. Schum. l. c. 239. - Bras.

Nicholsonii, K. Schum. l. c. 237 . - Bras.

BATRACHIUM, S. F. Gray = Ranumculus, Linn. (Ranuncul.).

hirtissimum, Prahl, Krit. Fl. Prov. Schles.-Holst. ii. (1890) 4. - Slesv.-Holst.

Lobbianum, Gelert, in Bot. Tidsskr. xix. (1894) 34. - Scand.

sceleratum, Th. Fries, ex A. Pehl, in Bot. Notis.

(1893) $5=$ R. sceleratus, Linn.

BATSCH1A, Vahl.=Humboldtia, Vahl (Legum.). Baillonii, Kuntze, Rev. Gen. (1891) 162= H. Baillonii, Hook. $f$

Brunonis, Kuntze, 1. с. = H. Brunonis, Wall.

unijuga, Kuntze, 1.c. = H. unijuga, Bedd.

Vahliana, Kuntze, 1. c. = H. Vahliana, Wight.

BAUGIS, Phil. in Anal. Univ. Chil. 1xxxv. (1894) 838. COMPOSITAE.

lavandulifolia, Phil.l. c.839. - Chili.

BAUHINIA, Linn. (Legumin.) - Ind. Kew, i. 279 baviensis, Drake, in Morot, fourn. de Bot. v. (1891) 217. - Tonkin.

Benthamiana. Taub. in Engl. et Prantl.Natirl.Pflanzenfam. iii. 3. (1891) 149 (= B. macrostachya Benth.). - Bras.

bryoniflora, Franch.Pl.Delav.(1890) 191. - Yunnan. Burbidgei, Stapf, inz Trans. Linn. Soc. Ser. II. iv. (1894) 143. - Borneo.

corumbensis, S. Moore, l. c. (1895) 348. - Bras,

Delavayi, Franch. Pl. Delav. (1890) 192 t. 43. Yunnan.

densiflora, Franch. Pl. Delav. (1890) 191. Yunnan.

diptera, Collett et Hemsl. in Fourn. Limn. Soc. xxv. (1890) 52. - Burma.

excurrens, Stapf, in Trans. Linn. Soc. Ser. II. iv. (1894) 143. - Borneo.
BAUHINIA : -

Faberi, Oliver, in Hook. Icon. pl. xvili(1888) t. 1790.

- China

Galpini, N. E. Br. l. c. xx. (1891) t. 1994; et in Gard. Chron. (1891) i. 728. - Transv.

Glaziovii, Taub. in Flora, lxxv. (1892) 78. - Bras.

Holzei, F. Muell. in Vict. Natural. viii. (Jan. 1892) 131 nomen. - Austral.

Krugii, Urban, in Stahl,Estud. A. Porto-Rico, iii. (1888) 128. - Ins. Portorico.

Marlothii, Engl. Bot. Fahrb. x. (1889) 26. - Afr. austro-occ. extratrop.

pansamalana, 7. D. Smith, in Coult. Bot. Gaz. xiii. (1888)2\%. - Guatem.

Pechuelii, Kuntze, in Fahrb. Bot. Gart. Berl. iv, (1886) 263. - Afr. austro occ, extratrop.

podopetala, Baker, in fourn. Linn. Soc. xxv. (1890) 313. - Madag.

Pringlei, S. Wats, in Proc. Am. Acad. xxv. (1890) 147. - Mexic.

punctiflora, Baker, in fourn. Linn. Soc. xxv. (1890) 314. - Madag.

pyrrhoclada, Drake, in Morot, fourn. de Bot. v. (1891) 218. - Tonkin.

Rubeleruziana, F. D. Smith, in Coult. Bot. Gaz. xiii. (I888) 27. - Guatem.

Rusbyi, Britton, in Bull. Torrey Bot. Club, xvi. 1889) 326. - Am. austr.

suffruticosa, Ridl. in Trans. Linn. Soc. Ser. II. iii (1893) 295. - Penins. Mal.

taitensis, Taub.in Engl. Pfanzenw.Ost-Afr. C(1895) 200. - Afr. trop. or.

tenuiflora, Watt, ex C. B. Clarke, in fourn. Linn. Soc. xxv, (1889) 18. - Reg. Himal.

tortuosa, Collett et Hemsl. \%. c. xxv. (1890) 52 t. 8. Burma.

uniflora, S. Wats. in Proc. Am. Acad. xxi. (1886) 451. - Mexic.

Urbaniana, Schinz. in Verh. Bot. Ver. Branà. xxx. (1888) 169. - Afr. austro-occ. extratrop.

Vespertilio, S. Moove, in Trans, Limn. Soc Ser. II. iv. (1895) 347 . - Bras.

Volkensii, Taub. in Engl. Pfanzenw. Ost-Afr.C (1895) 200. - Afr. trop, or.

yunnanensis, Franch. Pl. Delav. (I890) 190. Yunnan.

BDELLIUM, Baill, ex Laness. Pl. util, colon. franç. $(1886) 815$ nomen = Commiphora, Jacq. (Burser.).

africanum (err. ca1.? africana) Baill. 1. c, = C. atricanum, Engl.

BEALIA, Scribn. ex Vasey, in Proc. Calif. Acad. Ser. II, ii. (1889) 212 nomen = Muehlenbergia, Schreb. (Gramin.)

mexicana, Scribn. 1. c. - Mexic.

BEAUMONTIA, Wall. (Apocyn.). - Ind. Kew, i.

brevituba, Oliver, in Hook. Icon. pl. xvi. (1887) t. 1582. - Hainan.

campanulata, K. Schum. in Engl. et Prantl, Natürl. Pfianzenfam. iv. 2. (1895) 17\%. - Java.

indecora, Baill. in Bull. Soc. Linn. Paris, i. (1888) 759. - China.

BEAUVISAGEA, Pierre, Not. bot. Sapot. (1890) 15; et ex Baill. Hist. des pl. xi. (1892) 288. SAPOTACEAE.

pomifera, Pierre, $l l . c o$. (= Lucuma pomifera, Zipp.) - N. Guin.

BECCARIANTHUS, Cogn, in Boerl. Hand1. F1. Ned. Indië, I. ii. (1890) 325; et in DC. Monog. Phan. vii. (1891) 1101. MELASTOMACEAE. pulcher, Cogn.li. co. 325 et 1102. - Borneo.

BECCARIELLA, Pierre, Not. bot. Sapot. (1890) $30=$ Sideroxylon, Linn. (Sapotac.). amboinensis, Pierre, 1. c. - Ins. Amboin Aylapi, Pierre, 1. c. - Ins. Amboin. Bilitbitan, Pierre, 1. $\mathrm{c}=\mathrm{S}$. Bilitbitan, Blanco. celebica, Pierre, 1. c. - Ins. Celeb.

Dulitan, Pierre, I. c, = S. Dulitan, Blanco

coriacea, Pierre, 1. c. - N. Caled

firma, Pierre. 1. $\mathrm{c}_{0}=\mathrm{S}$. firmum, Pierre.

microcarpa, Pierre, 1. c. = S. microcarpum, Pierre 
BECCARIELLA :

moluccana, Pierre, Not. bot. Sapot. (1890) $30=$ Sideroxylon moluccanum, Burck.

papuanica, Pierre, 1.c. = Chrysophyllum papuanicum, Pierre.

mbicunda, Pierre, 1. c. - N. Caled.

Seberti, Pierre, 1. c. = Chrys. Seberti, Panch.

BECCARINDA, Kuntze, Rev, Gen。(1891) $470=$ = Slackia, Griff. (Gesner.)

Griffithii, Kuntze, 1. c.=S. Griffithii, C. B. Clarke.

BECCARINA, Van Tiegh. in Bull. Soc. bot. Fr. xlii. (1895) $249=$ Loranthus, Linn. (Loranth.). xiphostachya, Van Tiegh. 1. c. 250. (= Trithecanthera xiphostachya, Van Tiegh.). - Borneo

BECCARIODENDRON, Warb. in Bot. Jahrb. xiii. (1891) 452. ANONACEAE

grandiflorum, Warb. l.c.-- Oceania.

BECLARDIA, A. Rich. = Cryptopus, Lindl.(Orchid.)

evostris, Frappier, Catal. Orchid.Réunion (1880) 12, ex Cordem. Fl. Ile Réunion (1895) 217. - Ins. Borbon.

BEDDOMEA, Hook. f. (Meliac.).-Ind. Kew, i. 283. luzoniensis, Vidal, Rev. pl. vasc. Filip. (1886) 84.Ins. Philipp.

BEFARIA, Mutis (Ericac.) - Ind. Kew. i, 283. decora, Drake, in Morot, fourn. de Bot. iii. (1889) $7 \%$. - Ecuad.

BEGONIA, (Tourn.) Linn. (Begon.), - - Ind. Kew. i. 283

adenostegia, Stapf, in Trans. Linn. Soc. Ser. II. iv. 1894) 164. - Borneo.

Addonis X, Hort. ex Gard. Chron. (1887) ii. 747. Hybr. artef.

adscendens, C. B. Clarke, in fourn. Linn. Soc, xxy. (1889) 26 t. 13. - Reg. Himal.

albo-picta, Hort. ex Gartenfl. (1886) 402 = maculata, Raddi.

AmeliaeX, Bruant, Catal. (1886) 4; et ex Duchartre in Journ. Soc, nat. hortic. (1886), 153, - Hybr. artef.

antioquiensis, Rusby, in Mem. Torrey Bot. Chub, iv. 1893) 207 (= Casparya antioquensis, A. DC.). Columb., Ecuad.

antioquensis, Warb, in Engl. et Prantl, Natürl. Pflanzenfam, iii. 6 a. (1894) $146=$ praec

Baroni, Baker, in fourn. Linn. Soc. xxii. (1887) 480 - Madag.

Baumanni, Lemoine, in Le fardin (1890) 273 cum ic,; et ex Wittmack in Gartenf. (1891) 281 t. 1348 Hab.?

Bertini X, Hort. ex Legros, in Rev. Hortic. (1894) 247 et 294 fig. 93 et $94 .-$ Hybr, artef.

bicolor, S. Wats, in Proc. Am. Acad. xxii. (1887).Mexic.

Bismarcki, Hort. ex. Veitch, Catal. (1888) 10. Form hort.

brevipetala, Warb. in Engl. et Prantl, Natürl. Pfanzenfam, iii. 6 a. (1894) $146(=$ Sassea brevipetala, A. DC.) - Venez.

Burbidgei, Stapf, in Trans. Linn. Soc. Ser. II. iv. (1894) 165. - Borneo.

californica, T. S. Brandeg. in Proc. Calif. Acad. iii. (1891) 140. - Calif.

cataractarum, F. Braun et K. Schum.in Mitth. deutsch. Schutzgeb. ii. (1889) 155. - Afr. trop. occ.

cilio-bracteata, Warb. in Bot. Fakrb. xxii. (1895) 40. - Afr. trop. occ.

Clementinae $\times$, Bruant, in Illustr. Hortic. xxv, (1889) 11 t. 39. - Hybr. artef.

comorensis, Warb. in Engl. et Prantl, Natürl. Pfanzenfam. $11 i \mathrm{a}$ a. (1894) 139; et in Bot. Fahrb. xxii. (1895) 38. - Ins. Comor.

convalliodora, C. DC. in Coult. Bot. Gaz.xx. (1895) 538. - Guatem.

Cooperi, C. DC. . . . 539. - Costarica.

cordifolia, Warb. in Engl, et Prantl, Natirl. Pfanzenfam. iii. 6 a. (1894) $146(=$ Sassea cordifolia,

DC.). - Peruvia.

\section{BEGONIA :}

coronata X, Hort. ex Gard. Chron. (1893) i. 414.Hybr. artef.

crassicaulis, Warb. in Engl. et Prantl, Natïrl. Pfan zenfam. iii. 6a. (1894) 149 (= Casparya crassicaulis, A. DC.). - Java.

Credneri $X$, Haage et Schmidt, ex Gartenfl. (1890) 568 fig. 90.- Hybr. artef

decora, Stapf, ex Kere Bull. (1893) 29.- Form. hort.

Duchartrei $\times$. Bruant, ex Rev Hortic (1892) 29 fig. 7; et ex Kew Bul1.(1893) 29. - Form hort. Dusenii, Warb.in Bot. Fahrb. xxii. (1895) 44. - Afr trop. occ.

egregia, N. E. Br. in Gard. Chron. (1887) i. 346.Bras.

Elianii, Warb. in Bot. Fahrb. xiii. (1891). 387 . Oceania.

Eminii, Warb. in Engl. et Prantl, Natürl. Pfanzenfam. iii. 6 a. (1894) 141; et in Engl. Pfanzenw. Ost Afr. C (1895) 282. -Afr. trop. or.

epilobioides, Warb. in Bot. Fahrb. xxii. (1895) 34. - Afr. trop. Occ. rellensis, $C . D C$

540. - Costarica.

excelsior X, Lind. Catal. n. 123 (1893), ex Kew Bull. (1894) App. ii. 30. - Hybr. artef.

Faureana, Hort. ex Garnier, in Illustr. Hortic, xlii. (1895) 152 t. 34 et 298 t. 43. - Bras.

fracilis, Baker, in fourn. Linn. Soc. xxii. (1887) 479 - Madag.

fuchsiaefolia, Warb. in Engl. et Prantl, Natïrl. Pfanzenfam. iii. 6 a. (1894) 146 (= Stibadotheca fuchsiaefolia, A. DC. ). - Am. trop.

fulvo-villosa, Warb. in Bot.fahrb. xiii. (1891) 386.Oceania.

fusi-alata, Warb.l. c. xxii. (1895) 37. - Afr, trop. occ. geranioides, Hort. ex Gard. Chron. (1888) ii. 501.Form. hort.

glaucophylla, Hook. f. in Bot. Mag. (1892) t. 7219.$\mathrm{Hab}$.

globosa X. Heinemann, ex Gartenfl. (1888) 645. fig. 143. - Hybr, artef.

grewiaefolia, Warb. in Engl. et Prantl,Natürl. Pfanzenfam, iii. 6 a. (1894), 146 (=Casparya grerwiaefolia, A. DC.). - Columb., Ecuad.

Griffithiana, Warb.l.c.142 (= Mezierea Griffithiana,

A. DC.). - Reg. Himal.

Haageana, Hort.ex W. Wats, in Gard. Chron. (1888) i. 49 et $12 \%$ et (1894) ii. 632 fir 81 - Bras Henriquesii, C. DC. in Bolet. Soc. Brot. x. (1892) 123. - Ins. S. Thom.

Henryi, Hemsl. in Fourn. Linn. Soc, xxiii. (1887) 322. - China.

Heydei, C. DC, in Coult, Bot, Gaz, xx.,(1895) 540. Guatem.

Hieronymi, Lindau, in Bot. Fahrb. xix. Beibl. n. 48 (1894) 14. - Argent.

Hoegeana, Regel et Schmidt, in Gartenf. (1886) 398. - Mexic

hybrida X,Hort. ex Rev. Hort. Belge, (1889) 90 cum icone - Hybr. artef.

incomparabilis $\times$, Hort. Ex Gart. Chron. (1895) ii. 680 fig. 112. - Hybr, artef

inostegia, Stapf, in Hook. Icon。 pl. xxiv。 (1894) t. 2309.-Borneo.

faurezi, Laing, in Hamb. Gart. und Blumenzeit. (1894) 364. - Form. hort.

Johnstoni, Oliver, in H. Fohnston, Kilim. Exped. App. (1886) 340 nomen; et in Trans. Linn. Soc. Ser. II. ii. (1887) 331. - Afr. trop.or.

jussiaeicarpa, Warb. in Bot. Fahrb. xxii. (1895) 33. - Afr. trop. occ.

kisuluana, Büttn. in Verh. Bot. Ver.Brand, xxxii. (1890) 45. - Angola.

lacunosa, Warb. in Engl. et Prantl, Natürl. Pfanzenfam. iii. 6a. (1894) 140; et in Bot. Fahrb. xxii. 1895) 42. - Afr. trop. occ.

Landsbergiae, Hort. ex Rev。 Hortic. (1890) 202, $=$ seq.

Lansbergeae, L. Lind, et Rodigas, in Illustr. Hortic. xl. (1893) 41 t. 574 . - Bras.

Lansbergei Hort. ex Gard. Chron. (I893) ii. 479

= praec.
laporteifolia, Warb in Bot. fahrb. xxii. (I895) 41. - Afr. trop. occ.

Le Maouti, Hort. ex Vallerand, in Le Jardin (1889), ex Illustr. Hortic. (1889) 111. - Hab.?
BEGONIA

Lesoudsii X, Éd. André, in Rev. Hortic. (1888) 20 fig. 5. - Hybr. artef.

Luxii, C. DC. exf. D. Smith, in Coult. Bot.Gaz.xx. 1895) 541. - Guatem.

macrocarpa, Warb. in Bot. Fahrb. xxii. (1895) 43.Afr. trop. occ.

macrostyla, Warb. l. c. 37.-Afr. trop. occ.

Meyeri Johannis, Engl. in Abhandl. Preuss. Akad. Wiss. 1891. i1. (1892) 305; et in Engl. et Prantl, Natürl. Pfanzenfam. iii. 6a. (1894) 139.Afr, trop. or.

microsperma, Warb. in Bot. Fahrb. xxii. (1895) 42.

Molleri, Warb. in Engl. et Prantl, Natiirl, Pfanzen. fom, iii. 6 a. (1894) 141. - Ins. S. Thom.

montana, Warb., l. c, 146 (=Sessea montana, A. DC.). - Venez.

myriantha, Britton, in Bull. Torrey Bot. Club, xviii. (1891) 35. - Bolivia.

nepalensis, Warb. in Engl, et Prantl, Natürl. Pfanzenfam. iii. 6 a. (1894) 142 (=Monopteron nepalense, A. DC.). - Ind. or.

Neuberti X, Hort. ex Gard. Chron. (1886) i. 815 et 825 fig. 185. - Hybr, artef.

oblongitolia, Stapf, in Trans. Limn. Soc. Ser. II. iv. (1894) 165. - Borneo.

obversa, C. B. Clavke, in Fourn. Limn. Soc. xxy. 1889) 26 t. 12. - Reg. Himal.

oxyanthera, Warb. in Bot. Fahrb. xxii. (1895) 35

Palmeri, S. Wats. in Proc. Am. Acad. xxi (1886) 429. - Mexic.

pictaviensis X, Bruant, ex Gard. Chron. (1891) i. 334; et ex. Wien. Ill. Gartenz. Zeit. (1891) 155. - Hybr. artef

Poggei, Warb, in Engl, et Prantl, Natirl. Pflanzenfam. iii. 6a. (1894) 141; et in Bot. fahrb. xxil (1895) 35. - Afr. trop.

portillana, S. Wats. in Proc. Am. Acad. xxii. (1887) 414. - Mexic.

Preussii, Warb. in Engl. et Prantl, Natiirl. Pfanzen fam. iii. 6 a. (1894) 141; et in Bot. Fahrb, xxii. (1895) 36. - Afr, trop. occ,

Pringlei, S. Wats, in Proc. Am. Acad. xxvi. (1891). 136. - Mexic.

Prometheus X, Hort. ex Gard. Chron. (1889) ii. 420 - Hybr. artef.

pulvinata, Hort. ex Illustr. Hortic, (1894) $17 \%$ Form. hort.

quadrialata, Warb. in Engl. et Prantl, Natürl. Pfanzenfam. iii, 6 a. (1894) 140 fig. 47; et in Bot. Fahrb. xxii. (1895) 43. - Afr, trop. occ.

Quintasii, C. DC. in Bolet. Soc. Brot. x. (1892) 122 - Ins. S. Thom.

Rajah X, Hort. ex Gard. Chron. (1894) ii. 313. Hybr. artef.

rhopalicarpa, Warb. in Bot. Fahrb, xxii. (1895) 40. - Afr. trop. occ.

Rieckei, Warb. l.c. xiii. (1891) 388. - Oceania.

salaziensis, Warb. in Engl. et Prantl, Natiirl. Pfanzenfam. iii, 6 a. (1894) $139(=$ Mezievea salaziensis, Gaudich.). - Ins. Maurit.

Scharffiana, Hook. f. in Bot. Mag. (1888) sub t. 7028 in obs. sphalm. $=$ Scharffii, Hook. $f$.

Scharffiana, Regel, in Act. Hort. Petrop. x. (1889) 376: et in Gartenfl. (1888) 127, et 661 fig. $146=$ Scharffii, Hook. $f$.

Scharffi, Hook. f. in Bot. Mag. (1888) t. 7028. Bras.

sessilanthera, Warb. in Bot. Fahrb. xxii. (1895) 34. - Afr. trop. occ

Sharpeana, F.Muell. in Proc. Linn. Soc. N.S. Wales, Ser. II. ii. (Nov, 1887) 420, t. \% - N. Guin.

Teusziana, F. Braun et K. Schum. in Mitth. deutsch. Schutzgeb. ii. (1889) 155. - Afr. trop. occ.

Thiemei, C. DC. ex F. D. Smith, in Coult. Bot. Gaz. xx. (1895) 542.- Hondur.

thomeana, C. DC. in Bolet. Soc. Brot. x. (1892) 123. - Ins. S. Thom.

Trianae, Warb. in Engl. et Prantl, Natiirl. Pfanzzersfam. iii. 6a. (1894) 146 - Columb., Ecuad.

trichosepala, C. DC. ex F. D. Smith, in Conlt. Bot. Gaz. xx. (1895) 542. - Guatem.

trispathulata, Warb. in Engl. et Prantl, Natürl. Planzenfam. iii. 6a. (1894) 146 (= Casparya trispathulata A. DC.). - As. trop. 


\section{BEGONIA :}

trisulcata, Warb. in Engl. et Prantl, Natirl. Planzenfam. 1ii. 6 a. (1894) 142 (=Monopteron trisulcatum A. DC.). - As. trop.

Tuerckheimii, C. DC. ex F.D. Smith, in Coult. Bot. Gaz.xx. (1895) 542. - Guatem.

unifiora, S. Wats. in Proc. Am. Acad. xxvi. (1890) 149. - Mexic.

urticifolia, Warb. in Engl. et Prantl, Natïrl. Pfan zenfam. iii. 6 a. (1894) 144 (= Pilderia urticifolia, Klotzsch), - Venez.

versaliensis $\times$. Hort, ex Carr, in Rev. Hortic. (1891) 446. - Hybr. artef.

Warburgiana, Hieron. in Bot. Fahrb. xxi. (1895) 325. - Bolivia.

Wattii, C. B. Clarke, in fourn.Linn. Soc.xxv. (1889) 26 t. 11. - Reg. Himal.

Wrayi, Hemsl. inz foum, Bot. xxv. (1887) 203. Perak.

IVorthiana $\times$, Hort. ex Rev. Horticol. (1894) 247 in obs. - Hybr. artef.

BEHRIA. Greene, in Bull. Calif, Acad, ii. IV (1887) 143. LILIACEAE

tenuiflora, Greene, l.c.-Calif.

BEHURIA Cham. (Melastom.).-Ind. Kew. i. 288. cordifolia, $\operatorname{Cogn}$. in Mart. Fl. Bras, xiv. IV. (1886) 13. - Bras

corymbosa, Cogn. l. c. - Bras.

Glazioviana, $\operatorname{cogn}$. in DC. Monog. Phan. vii. (1891)

415. - Bras.

glutinosa, Cogn. in Mart. Fl. Bras. xiv.rv. (1886) 14. - Bras.

parvifolia, Cogn. l. c. 12. - Bras,

Mouraei, Cogn. in DC. Monog. Phan. vii. (1891) 414 . - Bras.

BEILSGHMIRDIA, Nees,Laurin.), - Ind. Kew. i. 288 .

Brandisii, Hook. f. Fl. Brit. Ind. v. (1886) 123.Reg. Himal.

Cairocan, Vidal, Rev. Pl. Vasc. Filip. 1886) 223.Ins. Philipp.

Clarkei, Hook. f. Fl. Brit. Ind. v. (1886) 122. - Reg. Himal.

elata, S. Elliot, in fourn. Linn. Soc. xxx. (1894) 96 - Afr. trop. occ.

Gammieana, King, ex Hook. f. Fl. Brit. Ind.v. (1886) 125. - Reg. Himal.

grandifolia, Baill. ex Laness. Pl.util.col. franc. (1886) 239 nomen. - N. Caled.

lachnostemonea, F. Muell. in Vict. Natural. ix. (May 1892) 11; et in Bot. Centralb1. li. (1892) 91. Austral.

longipes, Hook. f. Fl. Brit. Ind. v. (1886) 123. Malacca.

malaccensis, Hook.f.l.c. - Malacca

Maingayi, Hook. f. l. c. - Malacca.

odorata, Baill. ex Laness. Pl. util. col. franç. (1886) 239. - N. Caled.

sikkimensis, King, ex Hook. f. Fl. Brit. Ind.v. (1886) 122. - Reg. Himal.

zeylanica, Trim. Syst. Catal. Ceyl. Pl. (1885?) 75; ex Handb. Fl. Ceyl. iii. 440.-Zeyl.

BEKETOWIA, Krassn. in Scripta bot. Hort. Univ. Petrop. II, I (1887-88) 12; Lipsky in Act. Hort. Petrop, xiii. (1894) $365=$ Braya, Sternb. et Hoppe (Crucif.)

tian-shanica, Krassn. 11. cc. - China.

BELANGERA, Cambess. (Saxifrag.).-Ind. Kew. i. 288 .

grandistipularis, Taub. in Bot. Fahrb. xii. Beibl. n. 27 (1890) 17. - Bras.

BELIS, Salisb. = Cunninghamia, R. Br. (Conif.). lanceolata, Kuntze, Rev. Gen. (I891) $798=$ C. sinensis, R. Br.

BELLARDIA, All. = Bartsia, Linn. (Scrophul.). carnea, Wettst. in Engl. et Prantl, Natürl. Pflanzenfam. iv. 3 b. (1891) $102=$ Trixago carnea, Griseb.
BELLEVALIA, Lapeyr. = Hyacinthus, Tourn. (Liliac.).

fuliginosa, Nym. Consp. fl. Eur. Suppl. Ir. i. (1889) $306=$ Muscari fuliginosum, Freyn

longipes, Post, in Bull. Herb. Boiss, iii. (1895) 165. - Syria.

pendulina. Chiovenda, in Bull. Soc.bot. Ital. (1894) 283; et in Ann. Ist. bot. Roma vi. i. (1895) 3\%.I talia centr.

BELLIOPSIS, Pomel = Bellium, Linn. (Compos.) bellidiodes, Kuntze, Rev. Gen. (1891) $321=$ Bellium bellidioides, Linn.

crassifolia, Kuntze, 1. c. = Bellium crassifolium, Mor.

minuta, Kuntze, 1. c. = Bellium minutum, Linn.

BELLIS (Tourn.) Linn. (Compos,).- Ind. Kew. i 289

orthopoda, Robins. et Fernald, in Proc. Am. Acad. xxx. (1895) 117. - Mexic.

purpurascens, Robins. l. c.xxvii. (1893) 172. Mexic.

radicans, Coss, et Durieu, ex Batt. et Trab. Fl. de "'Algér. (Dicot.) (1890) 422. - Algeria.

Vandasii, Velen. ex Nym. Consp. fl. Eur. Suppl. ii. 1. (1889) 179; et Fl. Bulg. (1891) 279. - Bulg.

BELLOTA, C. Gay = Cryptocarya, R. Br. (Laurin.).

costaricensis, Mez, in Jahrb. Bot. Gart. Berl. v. (1889) 27. - Costarica.

BELL UGIA, Neck. (Melastom.). - Ind. Kew. i. 290

circumscissa, Spruce, ex Cogn. in Mart. Fl. Bras. Xiv. iv. (1888) 515. - Bras.

costaricensis, Cogn. ex Th. Dur et Pitt, in Bull. Soc. bot. Belg. xxx. 1891 (1892) 264. - Costarica.

dichotoma, Cogn. in Mart. Fl. Bras. XIV. iv. (1888) 514. - Bras.

imperialis, Sald. et $\operatorname{Cog} n$. ex Cogn. l. c. 515. - Bras.

BELMONTIA, E. Mey.(Gentian.).-Ind. Kew. i 290

emirnensis, Baker, in fourn. Iimn. Soc. xxii. (1887) 507. - Madag

Flanaganii, Schinz, in Bull. Herb. Boiss. iii. (1895) 413. - Afr. austr.

intermedia, Knobl. in Bot. Centralbl. 1x. (1894) 326 - Afr. austr.

Mechowiana, Schinz,in Viertelj. Naturforsch. Gesells. Ziivich, xxxvi. (1891) 333. - Angola.

natalensis, Schinz, in Bull. Herb. Boiss. ii. (1894) 220. - Natal.

platyptera, Baker, in Kew Bull.(1895) 25. - Angola. pumila, Baker, l. c. - Afr. trop. occ.

stricta, Schinz, in Viertelj. Naturforsch. Gesells. Zürich, xxxvi. (1891) 334. - Madag.

Teuszii, Schinz, l. c. 335. - Angola.

zambesiaca, Baker, in Kew Bull. (1895) 25. - Zambesia.

BELOPERONE, Nees (Acanth.). - Ind. Kew. i.

hians, T. S. Brandeg. in Proc. Calif. Acad. Ser. II. ii. (1889) 194. - Calif.

pansamalana, F. D. Smith, in Coult. Bot. Gaz. xiii (1888) 75. - Guatem.

Pringlei, S. Wats, in Proc. Am. Acad. xxv. (1890) 160. - Mexic.

ramulosa, Morong, in Ann. N.Y.Acad. vii (1893) 194

- Parag.

rectiflora, Lindau, in Bull: Herb. Boiss. iii. (1895) 489. - Bras.

riparia, S. Moove, in Trans. Linn. Soc. Ser. II. iv. (1895) 432. - Bras.

squarrosa, Lindau, in Bot. Fahrb. xix. Beibl. n. 48 (1894) 21 (= fusticia squarrosa, Griseb.). - Reg. Argent.

tetramerioides, Lindau, in Bull. Herb. Boiss. iii. (1895) 489. - Bolivia.

velascana, Lindau, l.c. - Bolivia.

BELOTIA, A. Rich. (Tiliac.) - Ind. Kew. i. 290. mexicana, K. Schum. in Engl. et Prantl, Natürl. Pflanzenfam. iii. 6. (1890) 28 = grewiaefolia, A. Rich.
BELUTTAKAKA, Adans. Fam. des pl. ii. (1763) 172 ex Kuntze, Rev. Gen.(1891) $413=$ Ghonemorpha, G. Don (Apocyn.).

Griffithii, Kuntze, 1. c. = C. Griffithii, Hook, $f$ macrophylla, Kuntze, 1. c. =C. macrophylla, G. Don malabarica, Kuntze, 1. c. = C. malabarica, G. Don.

BELVALA, Adans.=Struthiola, Linn. (Thymel.). angustifolia, argentea, chrysantha, dodecapetala, Ecklomiana, hirsuta laxa, longiflora, lucens, Martiana, Mandtii paraiflora rigida striata, tomentosa tuborculosa, virgata, Kuntze, Rev. Gen.(1891) 583-84 = homonyma omnia Struthiolae.

dodecandra, Kuntze, 1. c. $583=$ S. erecta, Linn. glauca, Kuntze, 1, c. $584=$ S. virgata, Linn? juniperina, Kuntze, 1. c. $583=\mathrm{S}$. linearilcba, Meisn. myrsinites, Kuntze, 1. c. = S. ovata, Thunb.

BENEVIDESIA, Sald. et Cogn, ex Cogn. in Mart. FI.Bras. XIv, iv. (1888)604. MELASTOMACEAE. organensis, Sald. et Cogn. l. c. 605. - Bras.

BENJAMINA, Vell.=Dictyoloma, A. Juss. (Simarub.).

perwiana, Kuntze, Rev. Gen. (1891) $103=$ D. peruvianum, Planch.

BENNETTIA, R. Br.=Galearia,Zoll.(Euphorb.). lonoipes. Oliver, in Hook. Icon. pl. xvi. (1887) t. 1596. - Silhet

BENTHAMIELLA, Speg. ex Wettst, in Engl. et Prant1, Natürl. Pflanzenfam. iv. 3b. (1891) 38. SOLANEAE.

patagonica, Speg.l.c. - Patag.

BENTHAMINA, Van Tiegh, in Bull. Soc, bot. Fr. xlii. (1895) $85=$ Loranthus, Linn. (Loranth,). alyxifolia, Van Tiegh. 1. c.=L. alyxifolius, F.Mull.

BENTHAMISTELLA, Kuntze, Rev. Gen. (1891) 458 = Stellularia, Benth. (Scrophu1.).

nigricans, Kuntze, 1. c. = S. nigricans, Benth

BENTIA, Rolfe, in Kew Bull. (1894) 338; Lindau, in Engl. et Prant1, Natürl. Pflanzenfam. iv. $3 \mathrm{~b}$. (1895) 339. ACANTHACEAE.

fruticulosa, Rolfe, $l l . c c$. - Arabia.

BENZOIN, Ludw. = Lindera, Thunb. (Laurin.). acuminatum, Kuntze, Rev. Gen. (1891) $569=$ L. acuminata, Villar.

argenterm, Kuntze, 1. c. (= Daphnidium argenterm, Kurz). - Burma.

assamicum Kuntze, 1. с, $568=$ L. assamica, Kurz Benzoin, Coult. in Mem. Torrey Bot. Club, v. (1894) $164=$ L. Benzoin, Meissn

bibracteatum, Kuntze, 1. c. 569 (= Daphnidium bibracteatum, Nees.).- Java.

Blumeanum, Kuntze, 1. c. (=. Aperula cuspidata Blume) - Ins. Celebes.

bootanicum, Kuntze, 1. c. = L. bootanica, Meissn. caesium, Kuntze, 1. c. = L. caesia, Reine.

caudatum, Kuntze, 1. c. (= Daphnidium caudatum, Nees). - Ind. or.

cuspidatum, Kuntze, 1. c. = L. melastomacea Villar.

gemmiflorum, Kuntze, 1. c. ( = Daphnidiun gemmiflo-

$\quad$ rum, Blume). - Java.
gracile, Kuntze, 1. c. (Daphnid.gracile, Nees).-Hab. Griffithii, Kuntze, 1. c. = L. Griffithii, Meisn. heterophyllum, Kuntze, I. c. = L. heterophylla, Meissn. hypoleucum, Kuntze, 1. c. = L. hypoglauca, Maxim. insigne, Kuntze, 1. c. ( = Aperula insignis, Blume). - Sumatra.

anceolatum, Kuntze, 1. c. $(=$ Aperula lanceolata, Blume). - Java

latifolium, Kuntze, 1. c. = I latifolia, Hook. $f$.

Laureola, Kuntze, 1. c. = I. Laureola, Collett et Hemsl. lucidum, Kuntze, 1. c. (= Aperula lucida, Blume). Java,

macrophyllum, Kuntze, 1. c. = (Daphnidium macrophyllum, Blume).- Java.

malaccense, Kuntze, 1. c. $=$ L. malaccensis, Hook. $f$. megaphyllum, Kuntze, 1. c. ( = Aperula macrophylla, Blume) - Java.

Meisneri, Kuntze, 1. c. $=$ L. Meissneri, King. 
BENZOIN : -

membranaceum, Kuntze, Rev. Gen. (1891) $569=$ Lindera membranacea, Maxim.

Micrantodaphne, Kuntze, 1. c. =L. reticulata, Benth et Hook. $f$.

Myrrha, Kuntze, 1. c. = Litsea trinervia, fuss.? Nacusua, Kuntze, 1. c. = Litsea bifaria, Benth, nevvosum, Kuntze, 1.c. $568=$ Lindera nervosa, $K u r z$. obtusilobum, Kuntze, 1. c. $569=$ L. obtusiloba, Blume.

obtusum, Kuntze, 1. c. = I, obtusa, Franch. et Sav. oxyphyllum, Kuntze, 1. c. $(=$ Aperala oxyphylla, Blume).-Java.

pipericarpum, Kuntze, 1. c. $(=$ Aperula pipericarpa, Meissn.). - Sumatra.

polyanthum, Kuntze.1.c.(=Aperula polyantha,Blume). - Java.

puberulum, Kuntze, 1. c. (=Aperula puberula, Blume). - Java.

pulcherrimum, Kuntze, 1. c. = L. pulcherrima, Benth. reticulatum, Kuntze, 1.c. =L, reticulata, Benth。 et Hook.f.

salicifolium, Kuntze, 1. c. ( = Aperula salicifolia, Blume). - Java.

sikkimense, Kuntze, 1.c. = L. sikkimensis, Meissn . sinense, Kuntze, 1. C. = L. sinensis, Hemsl.

strychnifolium, Kuntze, 1. c. = L. strychnifolia, Villar.

subumbelliferum, Kuntze, 1, c. (= Aperula confusa Meissn.). - Java.

umbellatum, Kuntze, 1. c. $=$ L. umbellata, Thunb.

venosum, Kuntze, 1. c. = L. venosa, Benth.

BERARDA, “Vill. », St-Lager, Étud. des fl., éd. 8. ii. (1889) $437=$ Berardia, Vill. (Compos.).

BERBERIS (Tourn.), Linn. (Berberid.). - Ind. Kew, i. 292.

acuminata, Franch, in Bull. Soc. bot. Fr. xxxiii (1886) $38 \%$. - China

aethnensis, «Presil ex Ces. Pass., et Gibelli, Comp. fl. Ital. ii. (1886) $866=$ aetnensis, Presl.

aurahuacensis, Hort, ex Hook. f. in Bot. Mag.(1889) sub t. 7075 in syn. $=$ B. Lycium, Royle

barandana, Vidal, Rev, pl. vasc, Filip. (1886) 45. Ins. Philipp.

Belstamiana, Hort. ex Hook. f. in Bot. Mag. (1890) sub t. 7116 in syn. = virescens, Hook. $f$

brachyacantha, Phil. ex Reiche, in Bot. Fahrb. xxi. (1895) 45 nomen. - Chili.

dictyophylla, Franch. Pl. Delav. (1889) 39 t. 11.Yunnan.

dictyota, fepson, in Bull. Torrey Bot. Club, xviii. (1891) 319. - Calif.

divaricata Rusby, in Mem. Torrey Bot. Club. iv. (1895). 203. - Bolivia.

Garciae, Pau, Not. bot. fl. Espan. ii. (1889) 6; Willk. Suppl. Prodr. A. Hisp. (1893) 314. - Hisp.

gracilipes, Oliver, in Hook. Icon. pl. xviîi. (1888) t. 1754. - China.

Hakodate, Hort. ex Dippel, Handb. Laubholzk, iii. (1893) $117=$ vulgaris. Linn.

Hallii, Hieron, in Bot. Fahrb. xx. Beibl. n. 49 (1895) 12. - Ecuad.

Holstii, Engl. in Abhandl. Preuss. Akad. Wiss. (1894) 69; et Pflanzenw. Ost-Afr. C (1895) 181. - Afr. trop. oc.

Lehmannii, Hieron. in Bot. Fahrb. xx. Beibl. n. 49 (1895) 15. - Columb.

levis, Franch. in Bull. Soc. Bot. Fr. xxxiii. (1886) 380 ; et in Nouv. Arch. Mus. Paris, Sér. II. x. (1887-8) 183 (=B. Wallichiana, Franch.).- - Tibet. magellanica, Hort. ex Dippel, Handb. Laubholzk. iii. (1893) 135 = buxifolia, Poir.

Moritzii, Hieron. in Bot. Fahrb. xx. Beibl. n. 49 (1895) 16. - Venez.

Nevinii, A. Gray, ex A. Gray et S. Wats. Syn. Fl. N. $A m$. New ed. i. 1. (1895) 69. - Calif.

nigricans, Kuntze, Rev. Gen. (1891) 10.- Costarica.

pachyacantha, Bienert, ex Koehne, Deutsche Dendrol. (1893) $170=$ vulgaris, Linn.

pallens, Franch. Pl. Delav. (1889) 36. - Yunnan. pectinata, Hieron. in Bot. Fahrb. xx. Beibl. n. 49 (1895) 14. - Ecuad.

pindilicensis, Hieron. l.c. - Ecuad. polyantha, Hemsl. in fourn. Linn. Soc. xxix. (1892)
302. - China.

\section{BERBERIS :}

Potanini, Maxim.in Act. Hort.Petrop. xi. (1891) 41 - China.

pruinosa, Franch. in Bull. Soc. bot. Fr. xxxiii. (1886) 38\%. - China.

pumila, Greene, Pittonia, ii. (July 1891) 161. - Am. bor. occ.

pygmaea, Koelne, Deutsche Dendrol. (1893) 166. Chili.

rectinervia, Rusby, in Mem. Torrey Bot. Club, iv. (1895) 204. (an. seq.?). - Bolivia

rectinervis, Rusby, $l$. c. iii, 3. (1S93) 5. - Bolivia.

rigida, Klotzsch, ex Hieron. in Bot.Jahrb. xxi. Beibl. n. 49 (1895) 11 in syn. = rigida, Hieron .

rigida, Hievon. l.c. - Ecuad.

sanguinea, Franch, in Nowv. Arch, Mus. Paris, Sér. II. viii. 1885 (1886?) 194. - Tibet.

serrata, Koelne, Dentsche Dendrol. (1893) 170. Hab.?

Sieboldii, Hort. ex Dippel, Handb. Laubholzk, iii (1893) $117=$ vulgaris, Linn .

sikokiana, Yatabe, in Tokyo Bot. Mag. v. (1891) 283 - Japon.

Stuebelii, Hieron, in Bot. Fahrb. xxi. (1895) 308.Columb.

subtriplinervis, Franch. in Bull. Musérm Paris, i (1895) 63. - Yunnan.

virescens, Hook. f. in Bot, Mag. (1890) t. 7116. Reg. Himal.

vitellina, Hieron. in Bot. Fahrb. xx. Beibl, n, 49 (1895) 15. - Venez

Wagneri, Hort. ex Koehne, Deutsche Dendrol (1893) $164=$ pinnata, Lag.

Warscewiczii, Hieron. in Bot. fahrb. xxi. Beibl. n. 49 (1895) 13. - Ecuad.

Wilcoxii, Kearn, in Trans, N. Y. Acad, xiv, (1894) 23. - Am. bor.

yunnanensis, Franch. in Bull. Soc. bot. Fr. xxxiii (1886) 388. - China.

BERCHEMIA, Neck. (Rhamn.)。 - Ind. Kew. i.

293.

pauciflora, Maxim. in Bull. Acad. Pétersb. xxxii. (1888) 484. - Japon.

philippinensis, Vidal, Rev.pl. vase. Filip. (1886) 91. - Ins. Philipp.

scandens, Trelease, in Trans. St-Louis Acad. v. (1889) 364; et in Rep. Geol. Surv, Arkans, iv. 1888 (1891) $172=$ volubilis, $D C$.

yunnanensis, Franch. in Bull. Soc. bot. Fr. xxxiii. (1886) 456. - China.

BERENDTIA, A. Gray (Scrophul.),-Ind. Kew. i. 294

spinulosa, S. Wats. in Proc. Am. Acad, xxv. (1890) 159. - Mexic

BERGENIA, Moench = Saxifraga, Tourn. (Saxifrag.).

ciliata, Stein, in Gartenfl. (1886) 307; Clos, in Bull. Soc. bot. Fr. xli. (1894) $397=$ S. ciliata, $\operatorname{Lindl}$ crassifolia, Fritsch, in Verh, zool.-bot. Ges. Wien, xxxix. (1889) $587=\mathrm{S}$. crassifolia, Linn.

Delavayi, Eng1. in Engl. et Prantl, Natürl. Pflanzenfam. iii. 2a. (1890) $50=$ S. Delavayi, Franch.

Fortunei, Stein, in Gartenfl. (1886) $307=\mathrm{S}$. Fortunei, Hook

ligulala, Engl. in Engl. et Prantl, Natürl. Pflanzenfam. iii. 2a. (1890) $50=\mathrm{S}$. ligulata, Wall. media, Engl. 1. c. = S. media, Hook. et $f$. Thoms.

Milesii. Stein, in Gartenf. (1886) $307=\mathrm{S}$. ligulata Wall.

orbicularis, Stein, 1. c. = S. orbicularis.

ornata, Stein, 1. C.; Clos in Bull. Soc. bot. Fr. xli. (1894) $397=$ S. ornata, Decne.

Stracheyi, Stein, 1. c.; Engl. in Eng1. et Prant1. Natürl. Pflanzenfam. iii. 2a. (1890) $50=$ S. Stracheyi, Hook. f. et Thoms.

BERGINIA, Harv. (Acanth.). - Ind. Kew. i. 294. Palmeri, Rose, ex Vasey et Rose, in Contrib. U.S. Nat. Herb. i (1890) 86. - Calif.

BERKHEYA, Ehrh. (Compos.).-Ind. Kew. i. 294. Antunesii, O. Hoffm. in Bolet. Soc. Brot. x. (1892) 181. - Angola.

\section{BERKHEYA :}

caffra, MacOwan, in Fourn. Linn. Soc. xxv. (1890)

391. - Afr, austr.

debilis, MacOwan, $l, c$. - Afr, austr.

Echinus, O. Hoffm. in Bolet. Soc. Brot. x. (1892) 181 in obs. = Berkheyopsis Echinus, O. Hoffm. ferox, O. Hoffn. in Bull. Herb. Boiss, ii. (1894) 214. - Afr, austro-occ. extratrop.

Johnstoniana, Britten, in Trans. Linn. Soc., Ser. II. iv. (1894) 22. - Afr, trop, austro-or.

Pechuelii, O. Hoffm. in Bot. Jahrb. x. (1889) $281=$ Berkheyopsis Pechuelii, O. Hoffm

Schenckii, O. Hoffm. ex Schinz, in Bull. Herb. Boiss. ii. (1894) 214. - Afr. austro-occ. extratrop.

Schinzii, O. Hoffm. 1. c. $213=$ Berkheyopsis Schinzii, O. Hoffm.

Welwitschii, O. Hoffm, in Bolet. Soc. Brot. x. (1892) 182. - Angola.

BERKHEYOPSIS, O, Hoffm. in Engl, et Prantl, Natürl. Pflanzenfam. iv. 5. (1893) 311; et in Bolet. Soc. Brot. x. (1892) 179. COMPOSITAE.

aizoides, $O$. Hoffm. $l l . c c$. - Angola.

angolensis, O. Hoffm. l. c. 180. - Angola.

diffusa, O. Hoffm. l. c. 181 (= Gazania diffusa, Oliver). - Afr. trop, or.

Echinus, O. Hoffm.in Engl. et Prantl, Natürl. Pfan. zenfam, iii. 5. (1891) $311=$ Berkheyopsis Echinus, O. Hofm

Pechuelii, O. Hoffm. in Bolet. Soc. Brot. x. (1892) 181 (=Berkheya Pechuelii, Kuntze).- Afr, austroocc. extratrop.

Schinzii, O. Hoffm. l. c. 181 in obs.; et in Bull. Herb. Boiss. i. (1893) 89 (= Berkheya Schinzii, O. Hoffm.). - Afr. austro-occ, extratrop.

BERLINIA, Soland. (Legumin.). - Ind. Kew. i. 205.

Eminii, Taub. in Engl. Pfanzenw. Ost-Afr. C (1895) 199. - Afr. trop. or.

BERMUDIANA, Linn。 = Sisyrinchium, Linn. (Irid.)

acris, angustifolia, arizonica, avenacea, azurea, bogotensis, californica, chilensis, convoluta, cuspidata, fasciculata, filifolia, Glaziovii, gracilis, graminifolia, grandiflora, incurvata, ividifolia, Famesonii, juncea, Luzula, Mandonii, micrantha minutiflora, monosta. chya, nervosa, Nuno, pachyrhiza, palmifolia, patagonica, Pearcei, pilifera, pusilla, quadrangulata, secundiflora, Sellowiana, sessiliflora, setacea, striata, ternifolia, tinctoria, tolucensis, trinervis, unispathacea, vaginata, Weirii, Kuntze, Rev. Gen. (1891) 699$700=$ homonyma omnia Sisyrinchii.

bella, Greene, Man. Bot. San Franc. Bay (1894) $388=$ S. bellum, S. Wats.

Berteroana, Kuntze, Rev. Gen. (1891) $699=$ S. leucanthum, Colla.

congesta, Kuntze, 1. c. = S. palmifolium, Linn.

Hartwegii, Kuntze, 1. c. $700=\mathrm{S}$. tenuifolium, Humb. et Bonpl.

homomalla, Kuntze, 1. c. = S. angustifolium, Mill. Marchio, Kuntze, 1. c. = S. alatum, Hook. marginata, Kuntze, . $_{0} .=\mathrm{S}$. palmifolium, Linn restiodes, Kuntze, 1. c. $=\mathrm{S}$. restioides, Spreng.

scabra, Kuntze, l. c. = S. chilense, Hook.

BERNARDIA, Houst. (Euphorb.), - Ind. Kew. i. 295

Brandegei, T. S. Brandeg. in Proc. Calif. Acad. Ser. II. iii. (1891) 172 nomen =mexicana, Muell. Arg.

viridis, Millsp. in Proc. Calif. Acad. Ser. II. ii. (1889) 223. - Calif.

BERRIA, Roxb. (Tiliac.) - Ind. Kew i. 295 tahitensis, Drake, Fl. Polyn. franç. (1892) 22 (Berrya). - Ins. Tahit.

BERSAMA, Fresen. (Sapind.).-Ind, Kew, i, 295. Engleri, Gürke, ex Engl. in Abhandl. Preuss. Akad. Wiss. 1891. ii. (1892) 293 nomen=Engleriana, Gürke.

Engleriana, Gürke, in Bot. Fahrb. xiv. (1892) 307; et in Engl. et Prantl. Natïrl. PAanzenfam, iii. 5. (1895) 381. - Afr. trop. or. 


\section{BERSAMA}

Holstri, Gürke, in Bot. Fahrb. xix.Beibl. n. 47. (1894) 36. - Afr. trop. or.

lucens, Szyszyl.Pl.Rekmann, ii. (1888) 50 (= Natalia lucens, Hochst.), - Natal.

paullinioides, Baker, ex Engl. Pflanzenw, Ost-Afr. A (1895) 90 nomen = usambarica, Güre.

Tysoniana, Oliver, in Hook. Icon, pl. xxiii. (1894) t. 2267. - Afr. austr.

usambarica, Gürke, in Engl. Pfanzenw. Ost-Afr. C (1895) 252, - Afr. trop. or.

Volkensii, Giirke, in Engl. et Prantl, Natiurl. Pfanzenfam. iii. 5. (1895) 381 nomen. - Afr. trop. or.

BERTIERA, Aubl. (Rubiac.). - Ind. Kew. i. 296. longithyrsa, Baker, in fourn. Linn. Soc, xxv. (1890) 322. - Madag.

parviflora, Spruce, ex K. Schum, in Mart. Fl. Bras. v1. vi. (1889) 325. - Bras.

racemosa, K. Schum. in Bolet. Soc. Brot. x. (1892) 127. - Guinea.

BERTOLONIA, Raddi (Melastom.). - Ind. Kew. i. 296. 56 - Bras.

Mosenii, $\operatorname{Cog}_{72 .}$. . c. 55. - Bras

sanguinea, Sald. ex Cogn. $l$ c. 51 . - Bras.

Ulaei, Cogn, in DC. Monog. Phan, vii. (1891) 1185. - Bras.

BERULA, Hoffm. - Sium, Tourn. (Umbellif.). angustifolia, Greene, Pittonia, i. (July 1887) 88 =angustifolia, Mer.t. et Koch $=\mathrm{S}$. erectum, Huds. erecta, Coville, in Contrib. U. S. Nat. Herb. iv. (1893) 115; et iii. (1895) $160=$ S. erectum, Huds.

BESGHORNERIA, Kunth (Amaryll.). - Ind.Kew. i. 296

argyrophylla, Hort., ex W. Wats. in Kew Bu11. (1889) $302=$ Dekosteriana, C. Koch

glauca, Hort, ex W. Wats. 1. c. - Form, hort

superba, Hort. Hamb. ex Baker, Handb. Amaryll. (1888) 162. - Hab.?

viridifora, Hort. Hamb. ex Kew Bul1. (1892) $7=$ yuccoides, Hook.?

BESLERIA, Plum, ex Linn. (Gesner.),---Ind. Kew. i. 296 .

foliacea, Britton, in Mem. Torrey Bot. Club, iv. (1895) 240. - Bolivia.

montana, Britton, l.c. - Bolivia.

ovalifolia, Britton, l.c. - Bolivia

pansamalana, 7. D. Smith, Pl. Guat, ii. (1891) 56 ;

et in Coult. Bot. Ga\%.xvi. (1891) 197.-Guatem.

BETONICA (Tourn.), Linn. = Stachys (Tourn.), Linn. (Labiat.).

Cernagorae, G. Beck et Szyszyl. Pl. Cern. et Alb. lect. (1888) 140. - Monten.

danica, Lange, Haandb. Danske Fl. ed. 1.(1886-88) $446=$ S. Betonica, Bonth.

Haussknechtii. Uechtr. ex Nym. Consp. fl. Eur. Suppl. I. ii. (1889) $251=$ S. Betonica, Benth.

Kelleri, Formanek, in Verh. naturf. Ver. Brünn. xxx. 1892) 72. - Maced.

BETULA (Tourn.), Linn. (Cupulif.). - Ind. Kew.

Bhojpatra, Hort. ex Koehne, Deutsche Dendrol. (1893) 108 = Ermani, Cham.

Castanae, Buch.-Ham. ex Hook. f. Fl. Brit. Ind. v. (1888) 599 in syn. = utilis, D. Don

globispica, Shirai, in Tokyo Bot, Mag. viii. (1894) 318. - Japon.

hybrida, Bechst. ex Fritsch, in Bot. Centralbl. xlvi. (1891) $91 .-$ Eur

Medwediewi, Regel, in Gartenf. (1887) 383 fig. 95, et in Act. hort. Petrop. x. (1887) 375.-Reg. Cauc. oxytzowiensis, Hort. ex Dippel. Handb. Laubholzk. ii. (1892) $167=$ pendula, Roth.

Potanini, Batalin, in Act. Hort. Petrop. xiii. (1893) 101. - China.

pseudocarpatica $\times$. Simonk. Enum. fl. Transsilv. (1886) 491. - Austria.

Raddeana, Trautv. in Act. Hort. Petrop. x. (1887) 129. - Daghest.

\section{BETULA}

rotundata, G. Beck, F1. Nieder-Oest. i. (1890) 262 $=$ alba, Linn.

pulchella, Hort. ex Dippel, Handb. Laubholzk. ii. (1892) $182=$ pumila, Linn

Sokolovi, Krassn, in Script. bot. Univ. Petrop. i. (1886) 185 nomen (Quid?). - Mont. Altai.

tristis, Hort. ex Dippel, Handb. Laubholzk. ii. (1892) $174=$ alba, Linn

BEURERA, Ehret = Calycanthus, Linn

ferax, Kuntze, Rev. Gen. (1891) 5 = C. laevigatus, Willd

fertilis, Kuntze, 1. c. = C. glaucus, Willd.

florida, Kuntze, 1. c. = C. Hloridus, Linn.

laevigata, Millsp. Fl. West Virgin. (1892) 361 (Beurera $)_{1}=\mathrm{C}$. laevigatus, Willd.

praccox, Kuntze, 1. c. = Chimonanthus fragrans, Lindl.

BEURERIA, «P. Br. » ex Gürke. in Engl.et Prantl, Natürl. Pflanzenfam. iv. 3a. (1891) $87=$ Bourreria, $\mathrm{P} . \mathrm{Br}$. (Boragin.).

Andrieuxii, divaricata, domingensis, exsucca, formosa, grandiflora, havanensis, hwanita, microphylla, vevoluta, succulenta, spinifex, tomentosa, virgata, Gürke, 1. $\mathrm{c}$. = homonima omnia Bourreriae.

eumanensis, Gürke, l. c. = Ehretia, cumanensis, $D C$.

fasciculata, Gürke, 1. c. $=$ Ehretia fasciculata, $H . B$. et $K$.

guatemalensıs, Gürke, 1. c. = Bourreria grandiflora, Bertol.?

velutina, Gürke, 1. c = Bour. tomentosa, G. Don?

BIASOLETTIA, Koch = Ghaerophyllum, Linn (Umbellif.).

balcanica, Velen. in Oest. Bot. Zeitschr. xli. (1891) 399. - Bulg.

pindicola, Hausskn. in Nym. Consp. fl. Eur. Suppl. II. i. (1889) 144. - Graecia.

BIGORNELLA, Lind1. (Orchid.). - Ind. Kew. i.

Schmidtii, Kraenzl. in Bot. Fahrb. xvii. (1893) 67.Ins. Comor.

BICUCULLA, Borckh. = Dicentra, Bernh.. Papaver.)

canadensis, Millsp. in Bull. West Va. Agric. Exp. Sta. ii. (1892) $327=\mathrm{D}$. canadensis, Walp.

Cucullaria, Millsp. 1. c.=D. Cucullaria, Bernh.

eximia, Millsp. 1. c. $=$ D. eximia, Torr.

fungosa, Kuntze, Rev. Gen. (1891) 13 = Adlumia cirrhosa, Raf.

BIDENS (Tourn.), Linn. (Compos.) - Ind. Kew. i. 300

alamosana, Rose, in Contrib. U. S. Nat. Herb. i. (1891) 104, - Mexic.

antiguensis, F.M.Coult. Bot. Gaz.xvi.(1891) 100.Guatem.

aristosa, Britton, in Bull. Torrey Bot. Club, xx. (1893) $281=$ Coreopsis aristosa, Michx.

artemisiaefolius, Kuntze, Rev. Gen. (1891) $321=$ Cosmos sulphureus, Cav.

aurantiacus, Colenso, in Trans, N. Z . Inst, xxvii. 1894 (1895) 388. - N. Zel.

bidentoides, Britton, in Bull. Torrey Bot. Club, xx. (1893) 281 =Coreopsis bidentoides, Torv. ct Gray. croceus, Welw, ex O. Hoffm. in Bolet. Soc, Brot. (1892) 17\%. - Angola.

dahlioides, S. Wats, in Proc. Am. Acad xxvi. (1891) 142. - Mexic.

decipiens, Warnst. in Oest. Bot. Zeitschr.xlv. (1895) 392 et 475 . - Eur.

discoides, Britton, in Bull. Torrey Bot. Club, xx. (1893) 281 = Coreopsis discoides, Torr. et Gray. guatemalensis, Klatt, in Bot. Fakrb. viii. (1887) 44. - Guatem

Hildebrandtii, O. Hoffm. l. c. xx. (1894) 234.- Afr. trop. or.

inermis, S. Wats, in Proc. Am. Aiad. xxiii. (1888) 278. - Mexic

involucrata, Britton, in Bull. Torrey Bot. Club, $\mathrm{xx}$. (1893) 281 = Coreopsis involucrata, Nutt.

\section{BIDENS}

involvens, Phil, in Anal. Mus, nac. Chile (1891) 49. - Am. austr. occ.

aris, Britton, Stern et Porgenb. Prel. Catal. (1888) $29=$ chrysanthemoides, Michx.

ludens, A. Gray, in Proc. Am. Acad.xxi. (1886) 390. - Mexic.

Montsulani, Phil. in Anal. Mus. nac. Chite (1891) 49. - Am. austr. occ

nudata, T. S. Brandeg. in Zoè, i. (1890) 309.-Calif. orientalis, Velen. ex Bornm, in Bot. Centralbl. xxxvi. (1888) 61; et Fl. Bulg. (1891) 250. - Bulg. Palmeri, A. Gray, in Proc. Am. Acad. xxii. (1887) 429. - Mexic

pedunculosus, Phil. in Anal. Mus. nac. Chile (1891) 49. - Am. austr. occ.

refracta, T. S.Brandeg. in Zoé, i. (1890) 310. - Calif. reptans, Hitchc, in Missouri Bot. Gard. Rep. iv. (1893) $101=$ Coreopsis reptans, Linn

trichosperma, Britton, in Bull. Torrey Bot. Club, xx. (1893) 281 = Coreopsis trichosperma, Michx.

Volkensii, O. Hoffm. in Engt. PAlansenw. Ost-Afr. C (1895) 415. - Afr, trop. or.

Xantiana, Rose, ex Vasey et Rose, in Contrib. U.S. Nat. Herb. iii. (1890) 72. - Calif. austr.

BIFRENARIA, Lindi, (Orchid.). - Ind. Kew. i.

Charlesworthii, Rolfe, in Kew Bull. (I 894) 184.--Bras. Dallemagnei, Hort. ex Lindenia, ix. (1893) $3 \mathrm{~L}$ in syn. $=$ tyrianthina, Reichb. $f$.

BIGELOWIA, DC. (Compos.).--Ind. Kew. i. 302. diffusa, T. S. Brandeg. in Proc. Calif. Acad. Ser. II. iii. (1891) 144 (Bigelovia) = diffusa, A. Gray? glareosa, M. E. fones, in Zoë, ii. (1891) 247 (Bigelovia), - Utah.

Macronema, Mr. E. Jones, in Proc, Calif. Acad. Ser. II. V. (1895) 693 (Bigelovia) = Aplopappus, Macronema, A. Gray.

sinuata, T. S. Brandeg. I co iii. (1891) 144.-Calif. turbinata, M. E. Fones, l. c. v. (1895) 691 (Bigelovia). - Am. bor, occ.

BIGNONIA (Tourn.), Linn. (Bignon.),-Ind. Kew. i. 303 .

caudigera, S. Moore, in Trans. Limn. Soc. Ser. II. iv. (1895) 415. - Bras.

columbiana, Morong, in Ann. N. Y. Acad. Sci, vii. (1893) 186. - Parag.

eximia, Morong, l.c. 187. - Parag.

grewioides, S. Moore, in Trans. Linn. Soc. Ser. II. iv. (1895) 413. - Bras.

melioides, S. Moore, l. c. 414. - Bras

modesta, S. Moore, l. c. 416. - Bras.

Morongii, Britton, in Ann. N. Y. Acad. Sci. vii (1893) 185. - Parag.

roseo-alba, Ridl. infourn. Limn.Soc.xxvii. (1890) 52. - Ins. Fernando Noronha.

Rodigasiana, L. Lind.in Illustr. Hortic. xl. (1893) 89 t. 583. - Peruvia.

rubescens, S. Moore, in Trans, Limn. Soc. Ser. II iv. (1895) 412 . - Bras

tomentella, S. Moore, l. c. 413. - Bras.

BIHAI (melius BIHAIA) Mill $=$ Heliconia, Linn. (Scitamin.).

angustifolia, brasiliensis, conferta, curtispatha, dasyantha, densiflora, elegans, episcopalis, FerdinandoCoburgii, glauca, hirsuta, Mariae, metallica, pendula, Poeppigiana, psittacorum, pulverulenta, Schiedeana, vellerigera, villosa, Wagneriana, Kuntze, Rev. Gen. (1891) $684-85$ = homonyma omnia Heliconiae. acuminata, Kuntze, Rev, Gen. (1891) $684=\mathrm{H}$. Bullia, Rich.

Bourgeauana, Kuntze, 1. $\mathrm{c}_{0}=\mathrm{H}$. Bourgaeana. Petersen. cannodea, Kuntze, l. c. $=$ H. hirsuta, Linn.f. imbricata, Kuntze, 1. c. - Costarica.

Iuteofusca, Kuntze, 1. c. = H. Bihai, Linn.

meridensis, Kuntze, 1. $c_{0}=\mathrm{H}$. latispatha, Benth.

BIKKIA, Reinw, ex Blume (Rubiac.) - Ind. Kew. i. 306 .

Commerçoniana, K. Schum. inz Engl. et Prantl, Nativl. Pflanzenfam. iv. 4. (1891) 20. - N. Guin. grandifolia, Kuntze, Rev. Gen. (1891) 279 sphalm. = grandiflora, Reinw. 


\section{BIKKIA :}

macrophylla, K. Schum in Engl. et Prantl, Naturl. Pflanzenfam. iv, 4. (189l) 20 (= Portlandia macrophylla, Brongn, et Gris). - N. Caled.

tetrandra, K. Schum. l. c. (= Portlandia tetrandra, Forst.). - Oceania.

BIKUKULLA, Adans. = Dicentra, Bernh. (Pa-

paver.).
chrysantha, Coville, in Contrib.U.S. Nat. Herb. iv. (1993) $60=$ D. chrysantha, Walp.

Cucullaria, Millsp. in Bull. W. Va. Agr. Exp. Sta. ii. (1892) $327=$ D. Cucullaria, Bernh.

formosa, Coville, in Contrib. U. S. Nat. Herb. iv. (1893) $60=\mathrm{D}$. formosa, Walp.

pauciflora, Coville, 1. c. $=$ D. pauciflora, S. Wats.

BILACUS, Rumpf, Herb. Amboin, i. (1741) 197 t. 81, ex Kuntze, Rev. Gen. (1891) 98 = Aegle, Correa (Rutac.)

decandra, Kuntze, 1. c. 99. = A. decandra, Nares. Marmelos, Kuntze, 1. c. =.A. Marmelos, Linn. trifoliata, Kuntze, 1. c. = Citrus trifoliata, Linn,

BILLBERGIA, Thunb. (Bromel.). - Ind. Kew. i. 306 .

aureo-rosea, Hort. Lind. ex Baker, Handb. Bromel. (1899) 63. = Aechmea aureo-rosea, Baker.

Blireiana X, Éd. André, in Rev. Hortic. (1889) 139. - Hybr. artef.

boliviensis, Baker, Handb. Bromel. (1889) 81. Bolivia:

Burchellii, Baker l. c. 76 - Bras. austr.

caespitosa, Lindman, in Kongl. Svensk. Vet. Akad. Handl. xxiv. vil. (1891) 35 t, 8 fig. 41-46. Bras.

canephora, Hort. cx Baker, Handb. Bromel. (1889) 69 in syn. = Aechmea viridis, Baker.

Cappei, Éd. Morr. ex Baker, 1. c. $83=$ Beauteana, Ed. André.

cylindrostachya, Mez, in Mart. Fl. Bras, iii. III. (1892) 395. - Bras.

distachya, Mez, 1. c. 417. = Burchellii, Baker.

Enderi, Regel, in Gartenfl. 1886) 97 t. 1217; et in Act. Hort. Petrop. ix. (1886) 600.- Bras.

ensifolia, Baker, Handb. Bromel. (1889) 74. - Bras.

farinosa, K. Koch, ex Baker, 1. c. 71 in syn.=pyramidalis, Lindl.

farinosa. Hort. ex Baker, 1. c. 80 = zebrina, Lindl.

Herbaulti, Hort. ex Baker, 1. c. $83=$ Beauteana, Ed. André.

intermedia $\times$, Hort. ex Witte, in Gartenfl. (1891) 563 fig. $101-$ Hybr. artef.

fenischiana $\times$. Wittm. in Engl, et Prantl, Natürl. Pflanzenfam. ii. 4. (1887) 47. - Hybr, artef.

Krameriana X, Wittm. in Gartenfl. (1888) 65\%. Hybr. artef.

Lemoinei, Hort. ex Baker, Handb. Bromel. (1889) 72 = thyrsoides, Mart.

leodiensis $\times$, Hort. ex Th. Witte, in Gartenfl. (1892) 563 fig. 100. - Hybr, artef.

linearifolia, Baker, Handb. Bromel. (1889) 72. Parag.

macrostachya, Brongn. ex Baker, 1. c. 82 in syn. = violacea, Beer.

Morreniana, Baker, l.c. 74. - Hab.?

Perringiana X, Wittm.in Gartenfl.(1890)145 t. 1318. - Hybr. artef.

Pohliana,Mez, in Mart. Fl. Bras, iii. Ir..(1892) 403. - Bras.

Quintusiana, Hort. Makoy, ex Wittm. in Gartenfl, (1890) 202 fig. $49=$ Saundersii, Hort. Bull.

Quintutiana, "Hort. Makoy », ex Baker, Handb. Bromel. (1889) 78 sphalm. = praec.

Reichardti, Hort. Morr. ex Baker. 1. c. $74=$ Morreniana, Baker.

Schimperiana, Wittm. ex Baker, l.c. 79. - Bras

setosa, Hort. ex Baker, 1. c. 71 in syn. = pyramidalis, Lindl.

Skinneri, Hort. Lind, ex Baker, in Hook. Icon.pl. xix (1889) sub t. $1851=$ Aechmea Skinneri Baker.

stipularis,Brongn. ex Baker, Handb.Bromel. (1889) 82 in syn. = violacea, Beer.

tillandsioides, Baker, l. c. 74. - Bras.

Tweedieana, Baker, l. c.73. - Bras.

\section{BILLBERGIA :}

vexillaria, Ed. André, ex Baker, Handb. Bromel, (1889) 84. - Hybr. artef.

Windii $\times$, Hort. ex Baker, 1. c. 83. - Hybr. artef.

Witmackiana $\times$, Hort. ex Th. Witte, in Gartenfl. (1891) $328 \mathrm{fg}$. 69 ; et (1894) 393 t. 1405. Hybr, artef.

Worleana $\times$, Wittm. in Engl, et Prantl, Natür1. Pflanzenfam. II. 4 (1887) 4\%. - Hybr. artef.

Worleyana, "Wittm. » ex Baker, Handb. Bromel. (1889) 83 sphalm. = praec.

BINECTARIA, Forsk. = Imbricaria, Comm. (Sapot.).

borbonica, Kuntze, Rev. Gen. (1891) $406=$ I. maxima, Poir.

fragrans, Kuntze, 1. c. = I. fragrans, Baker.

media, Kuntze, 1. c. = I. media, Boj.

petiolaris, Kuntze, 1. c. = I. petiolaris, A.DC

BIOLETtiA, Greene, Pittonia, ii. (Sept. 1891)215. COMPOSITAE.

riparia, Greene, l. c. 216. - Calif.

BIOPHYTUM, DC. (Geran.). - Ind. Kew. i. $30 \%$. albiflorum, F. Muell. in fourn. Bot. xxxi. (1893) 325. - N. Guin.

crassipes, Engl. Pfanzenw. Ost-Afr. C (1895) 226.Afr. trop, or.

BIOTA, D. Don = Thuya, Linn. (Conif.)

clegantissima, Hort. ex Beissn. Handb. Nadelholzk. (1891) $60=\mathrm{T}$. orientalis, Linn.

semperaurescens, Hort. ex Beissn. 1. c. = T. orientalis, Linn.

BIOVULARIA, Kamienski, in Engl, et Prantl, Natür1. Pflanzenfam. iv. 3 b. (1893) 122. LENTI$B U L A R I E A E$

olivacea, Kamienski, l.c.123 (= Utricularia olivacea, Wright). - Cuba.

BIPINNULA, Comm. (Orchid.). - Ind. Kew.i. 307.

polysyka, Kraenzl. in Bot. Fahro. xi. (1888) 31\%.Urug., Montevid.

BISASCHERSONIA, Kuntze, Rev. Gen. (1891) 408 = Tetraclea, Hiern (Ebenac.).

chusiaefolia, Kuntze, 1. c. = T. clusiaefolia, Hiem.

BISBOECKELERA, Kuntze, Rev. Gen. (1891) 747. = Hoppia, Nees (Cyper.).

angustifolia, Kuntze, 1. c. = H. angustifolia, Boeck. irrigua, Kuntze, 1. c。 = H. irrigua, Nees.

longifolia, Kuntze, 1. c. = H. microcephala, Boeck.

BISGUTELLA, Linn. (Crucif.) - Ind. Kew. i. 308.

angustifolia, Timb. in Lucante, Rev, de Bot. $x$. (1892) 56. - Gall.

brevicalcarata, Batt. in Batt et Trab. Fl, de l'Algém rie (Dicot.) (1888) $39=$ auriculata, Linn.

brevifolia, Rouy et Fouc. F1. de Fx. ii.(1895) $107=$ laevigata, Linn.

nana, Rouy et Fouc. 1. c. 105 et 108 = laevigata, Linn?2.

BISERRULA, Linn. (Legumin.). - Ind, Kew. i. 308

Simeti, Tornab. Fl. Sicula (1887) $200=$ B. Pelecinus, Linm.

BISGOEPPERTIA, Kuntze, Rev, Gen. (1891) 426 = Goeppertia, Griseb. (Gentian.).

gracilis, Kuntze, 1. c. = G. gracilis, Wright.

volubilis, Kuntze, 1. c. = G. volubilis, Griseb.

BIVONAEA, DC. (Crucif.). - Ind. Kew. i. 309. albiflora, Prantl, in Engl. et Prantl, Natürl. Pflanzenfam. iii. 2. (1891) $166=$ Ionopsidium albiflorum, Durieu.

Prolongoi, Prantl, 1. c. = Thlaspi Prolongi, Boiss.

BLAGKIA, Baill. (Euphorb.). - Ind. Kew. i. 309. andamanica, Hook. f. Fl. Brit. Ind. v. (1887) 403. - Ins. Andam.
BLACKSTONIA, Huds.=Chlora Ren. (Gentian.) serotina, G. Beck, Fl. Nieder-Oest. ii. (1892) $934=$ C. serotina, Reichb.

BLADHIA, Thunb. = Ardisia, Sw. (Myrsin.) amboinensis, F. Muell, in Vict. Natural. vili. (May 1891) $16=$ A. amboinensis, Scheff.

brevipedata, F. Muell. 1. c. = A. brevipedata F. Muell.

pachyrhachis, F. Muell. 1. c. 15; et in Bot. Centralbl. xlvi. (1891) 205. - Austral.

paniculata, Sudworth, in Gard. and For. (189I) $239=$ A. Pickeringia, Nutt.

Pseudo-jambosa, F. Muell. in Vict. Natural, viii. (May 1891) 16. - Austral.

reclinata, F. Muell. 1. c. = A. reclinata, Scheff.

BLAERIA, Linn. (Ericac.), - Ind. Kew. i. 309.

Bugonii, Welw. ex Engl. in Abhandl. Preuss. Akad. Wiss. 1891. ii. (1892) 327. - Angola.

flava, Bolus, in Fourn. Bot. xxxi1. (1894) 289.-Afr. austr.

glutinosa, $K$. Schum, et Engl. ex Engl. in Abhandl. Preuss. Akad. Wiss. 1891, ii. (1892) 327. - Afr. trop. or.

Johnstoni, Engl. l. c. 326. - Afr. trop. or,

Meyeri Johannis, K. Schum. et Engl. ex Engl.l. c. Af. trop. or.

setulosa, Welw. ex. Engl. l. c. 328. -Angola.

silvatica, Engl. l. c. 326. - Afr. trop. or.

Whyteana, Engl. Pflanzent. Ost-Afr. A (1895) 132, nomen. - Afr. trop, or.

BLAIN VILLEA, Cass. (Compos.). - Ind. Kew. 1. 310

Dallo-Vedovae, Terrac, in Ann. Ist. bot. Roma, v. (1894) 10\%. - Afr. or.

BLAKEA, P. Br. (Melastom.).- - Ind, Kew, i, 310 amabilis, Cogn. in DC. Monog. Phan. vii. (1891) $10 \% 9$ (= Amaraboya amabitis, Linden).-Columb Andreana, Cogn. in Bull. Acad. Belg. Sér. III. xiv (1887) 769; et in DC. . . c. - Columb.

brasiliensis, Cogn, in Mart. Fl. Bras. xiv, Iv. (1888) 56l. - Bras

Grisebachii, $\operatorname{Cog} n$. in DC. Monog. Phan. vii. (1891) 1071. - Venez.

guatemalensis, f. D. Smith, in Coult. Bot. Gat. xiv. (1889) 25. - Guatem.

longibracteata, Cogn. in DC. Monog. Phan. vii. (1891) 1074. - Venez.

Pittieri, Cogn.l.c. 1080; et ex Th. Dur. et Pitt. in Bull. Soc. bot. Belg. xxx. 1891 (1892) 26\%. Costarica.

princeps, Cogn. in DC. l. c. $1079(=$ Amaraboya princeps, Linden). - Columb.

Spruceana, Cogn. in Mart. Fl. Bras, xiv. IV. (I888) 560. - Bras.

subpeltata, Cogn. in DC. Monog. Phan. vii. (1891) 1075; et ex Th. Dur. et Pitt. in Bull. Soc. bot. Belg. xxx. 1891 (1892) 266. - Costarica.

BLANCOA, Blume= Didymosperma, H. Wend1 (Palm.)

borneensis, Kuntze, Rev. Gen. (1891) $727=$ D. borneensis, Becc.

caudata, Kuntze, 1. c. = D. caudatum, H. Wendl. $e t$ Drude.

hastata, Kuntze, 1. c. = D. hastatum, Becc.

Horsfieldi, Kuntze, 1. c. =D. Horsfieldii, H. Wendl. et Drude.

nana, Kuntze, 1. c. $=$ D. nanum, $H$, Wendl. et Drude.

porphyrocarpa, Kuntze, 1. C. = D. porphyrocarpon, H. Wendl. et Drude.

Reinwardtiana, Kuntze, 1. c. = D. Reinwardtianum H. Wendl. et Drude.

BLASTANIA, Kotschy et Peyr. (Cucurb.).-Ind. Kew. i. 311.

Luederitziana, Cogne ex Schinz, in Verk. Bot. Ver. Brand. xxx. (1SSS) 152. - Afr. austro-occ, extra. trop.

BLASTUS, Lour.(Melastom.). - Ind. Kew, i. 311 borneensis, Cogn. ex Boerl. Handl. Fl. Ned. Indie, i. 2. (1890) 531; et in DC. Monog. Phan. vii (1891) 477. - Borneo. 
BLASTUS :

Cogniauxii, Stapf, in Hook. Icon. ploxxiv. (1894) t. 2311. - Borneo.

BLATTARIA, Burm. = Pentapetes, Linn. (Stercul.).

phoeniced, Kuntze, Rev, Gen. (1891) $6=$ P. phoenicea, Linn.

BLATTI, Adans. = Somneratia, Linn. f. (Lythr.). alba, Kuntze, Rev, Gen, (1891) 238 = S. alba, Sm. apetala, Kuntze, 1. c. = S. apetala, Buch.-Ham. caseolaris, Kuntze, 1. c. $=$ S. acida, Linn. $f$. Griffithii, Kuntze, 1. c. = S. Griffithii, Kurz. leucantha, Kuntze, 1. c. $(=$ Chiratia leucantha, Montr.). - N. Caled.

Pagatpat, Niedenzu, in Engl, et Prantl, Natürl. Pflanzenfam. iii. \%. (1892) $21=$ S. Pagatpat Blume.

BLEGHUM. P. Br. (Acanth.). - Ind. Kew. i. 311 blechioides, Hitchc. in Missouri Bot. Gard, Rep. iv. (1893) 115 = laxiflorum, fuss

BLEPHARIPPAPUS, Hook. (Compos.). Ind. Kew. i. 311

carnosus, Greene, Pittoria, ii. (July 1892) $246=$ Layia carnosa, Torr. et Gray.

chrysanthemoides, Greene, 1. c. 247; et Man. Bot. San Franc. Bay (1894) 201 =Layia chrysanthemoides, A. Gray.

Douglasii, Greene, 11. cc. = Layia Douglasii, Hook. et $A r n$.

elegans, Greene, 11. cc. 246 et 201 = Layia elegans, Torr. et Gray.

Fremonti, Greene,11. cc.=Layia Fremonti, A. Gray. gaillardioides, Greene, 11. cc, 246 et $200=$ Layia gaillardioides, Hook, et Arm.

grareolens, Greene, 11. cc. = Layia heterotricha, Hook. et Arn.

heterotrichus, Greene, 11. cc, 245 et $200=$ Layia heterotricha, Hook. et Arn.

hieracioides, Greene, 11, cc, 246 et $200=$ Layia hieracioides, $H o o k$.

hispidus, Greene, 11. cc. 246 et $201=$ Layia hispida, Greene.

Fonesii, 1. c. 247 = Layia Jonesii, A. Gray.

laevis, A. Gray, in Coult. Bot. Ga\% xiii. (1888) 73.Am, bor austro-oce.

nemorosus, Greene, Man. Bot. San Franc. Bay (1894) 200. - Calif.

mutans, Greene, Pittonia, ii. (July I892) 247 (= Callichroa nutans, Greene). - Calif.

oreganus, Greene, 1. c. 246 = Layia Douglasii, Hook. ct Arn.

fentachaetus, Greene, 1. c. = Layia pentachaeta, A. Gray)

platyglossus, Greene, 1. c. 246 ; et Man. Bot. San Franc. Bay (1894) $201=$ Layia platyglossa A. Gray.

BLEPHARIS, Juss. (Acanth.). - Ind. Kew. i. affinis, Lindau, in Engl. Pfanzenw. Ost-Afr. C (1895) 369. - Afr, trop. or

Buchneri, Lindau, in Bot. Faltro. xx. (1894) 30. Angola, Congo.

chrysotricha, Iindau, l. c. 32. - Afr. trop. or.

dichotoma, Engl. l. c. x. (1889) 260. - Afr. austroocc. extratrop.

Hildebrandtii, Lindau, in Bot. Fahrb. xx. (1894) 29. - Afr. trop. or.

hirta, Martelli, Fl. Bogos. (1886) 65 (=Acanthodium hirtum, Hochst.) - Abyss,

hirtella, Lindau, in Bot. Fahrb. xx. (1894) 28. Angola.

longifolia, Lindau, in Engl. et Prantl, Natiirl. Pfanzenfam. iv. 3 b. (1895) 318 nomen.-Afr. trop. or panduriformis, Lindau, l. c. 30. - Afr. trop. or.

paradoxa, Fritsch, in Ann. Naturhist. Hofmus. Wien, v. (1890) 493. - Madag.

Passargei, Lindau, in Bot. Fahrb. xxii. (1895) 117. - Atr. trop. occ

forsica, Kuntze, Rev. Gen. (1891) $483=$ edulis, Pers

pruincsa, Engl. Bot. Fahrb. x. (1889) 260. - Afr. austro-occ. extratrop.

\section{BLEPHARIS} rupicola, Engl. in Abhandl. Preuss. Akad. Wiss. (1892)
389. - Abyss.

Stuhlmanni, Lindau, in Bot. Fahrb. xx. (1894) 31. - Afr. trop. or.

tetrasticha, Lindau, l. c. 29. - Angola.

trinervis, Deweire, in Bull. Soc. bot. Belg. xxxi, 2. 1894. (1895) 104, nomen. - Congo austro-or.

BLEPHARISPERMUM, Wight (Compos.) Ind. Kew. 1. 312

fruticosum, Klatt, ex Schinz, in Bull. Herb. Boiss. iii. (1895) 429. - Reg. Somal.

lobatum, Klatt, l. c. 428. - Reg. Somal.

BLEPHAROCALYX, Berg = Myrtus, Tourn. (Myrtac.).

aromatica, Niedenzu, in Engl, et Prantl, Natürl. Pflanzenfam. iii. $\%$. (1892) $\% 1=$ Siphoneugenia aromatica, Berg.

Cruckshanksii, Niedenzu, 1. c. = Eugenia Cruckshanksii, Hook. et Arm.

BLEPHARODON, Decne (Asclep.). - Ind, Kew. i. 312

gomphocarpoides, K. Schum. in Engl. et Prantl, Natürl. Pflanzenfam. iv, 2. (1895) 243-Nephrodenia neriifolia, Benth, et Hook.

Rahmeri, Phil. in Ann. Mus, nac. Chile (1891) 52. Am, austr. $O C C$.

trivialis, K. Schum. in Engl, et Prantl, Natürl. Pflanzenfam. iv. 2.(1895) 243 = salicina, Decne.

BLETIA, Ruiz et Pav. (Orchid.). - Ind. Kew. i. 313

alta, Hitchc, in Missouri Bot. Gard. Rep.iv.(1893) 132. = verecunda, $R . B r$

Godseffiana, Kraenzl. in Gard. Chron. (1893) i.442.Bras.?

Palmeri, S. Wats, in Proc. Am. Acad. xxvi. (1891) 153. - Mexic

Pottsii, S. Wats, in T. Brigham, Guatem. App. (1887) 478 nomen, et in Proc. Am. Acad, xxii. (1887) 478. - Guatem.

quadrifida, Herb. Ham. ex Hook. f. F1. Brit, Ind, v (1890) $851=$ Calanthe veratrifolia, $R . B r$.

subaequalis, Reichb.f. in Flora, 1xix. (1886) 553. Ins. Antill.

BLINKWORTHIA, Choisy (Convolv.). - Ind. Kew. i, 313 .

convolvuloides, Prain, in fourn. As. Soc. Beng. 1xiii. (1894) ii. 91. - Burma.

BLITUM, (Tourn.) Linn. = Chenopodium, Linn. (Salsol.).

alsum, Phil. in Anal, Univ. Chil.xci. (1895) 421 - Chili.

BLOOMERIA, Kell. (Liliac.),- Ind. Kew. i. 313. montana, Greene, in Bull. Calif. Acad. i. (1885) 281. - Calif.

BLUMEA. DC. (Compos.). - Ind. Kew. i. 314. Balfourii, Hemsl. in Kew Bull. (1894) 213. - Ins. Salom.

Bojeri, Baker, in Fourn. Linn. Soc. xxv. (1890) $32 \%$. - Madag.

caffra, O. Hoffm. in Bot. Jahrb. x. (1889) 274 $(=$ Conyza caffra, DC. $)=$ natalensis, Sch. Bip.

celebica, Boenl. Handl. Fl. Ned. Indie, ii. i. (1891) 239 (= Conyza celebica, Sch. Bip.) - Ins. Celeb.

dasycoma, Boerl. l.c. (= Conyza dasycoma, Miq.).Sumatra, Java.

floresiana, Boerl. l. c. 238 (= Conyza floresiana, Sch. Bip.) - Ins. Flores.

humifusa, Boerl. l. c. 237 (=Conyza humifusa, Miq.). - Java.

Junghuhniania, Boevl, l. c. 239 (= Conyza funghuhniana, Miq.) - Java.

Korthalsiana, Boerl. l.c. $239(=$ Conyza Korthalsiana, Miq.). - Sumatra.

lanceolata, Warb. in Bot. fahrb. xiii (1891) 446. N. Guin.

moluccana, Bocrl. Handl. Fl. Ned. Indië, ii. I. (1891) 239 ( = Conyza moluccana, Gaudich.) - Ins. Moluce.

\section{BLUMEA :}

spinidens, Boerl. Handl. Fl. Ned. Indië, ii. I. (1891) 237 (=Conyza spinidens, Miq.). - Java, Sumatra. subracemosa, Boerl. l. c. 238 (= Conyza subracemosa Miq.). - Java.

sumbawensis, Boerl.l.c.239(=Conyza sumbarensis, Miq.)... Sumbawa.

ternatensis, Boerl. l. c. 237 ( = Conyza ternatensis, Miq.). - Ins. Ternate.

Zollingeriana, Boevl.l.c. $(=$ Conyza Zollingeriana, Sch. Bip.) - Java.

BLUMELLA, Van Tiegh, in Bull. Soc, bot. Fr. xlii.(1895) 441 = Loranthus, Linn. (Loranth.). capitellata, Van Tiegh. 1. c. = L. capitellatus, Wight et Arn.

diantha, Van Tiegh. 1. c. = L. dianthus, King.

loniceroidas, Van Tiegh. 1. c. = L, loniceroides, Iinn. $f$

psilantha, Van Tiegh. 1.c.=L. psilanthus, Hook. $f$.

BLUMENBACHIA, Schrad.(Loas.).- Ind. Kew. i. 214

Arechavaletae, Urban, in Mart. Fl. Bras, xiii. III. (1889) 217. - Urug.

aspera, Urban, l. c. 222 (= Mentzelia aspera, Vell.)Bras.

Eichleri, Urban, l. c. 218 t, 55. - Bras.

lateritia, Britton, in Bull. Torrey Bot.Club, xvii. (1890 281 ; et in Mem. Torrey Bot. Club, iii. 3. (1893) 37. - Bolivia.

scabra, Urban, in Mart. Fl. Bras. xiii. III. (1889) 219 (= Gripidea scabra, Meis.). - Bras

unens, Urban, 1. c. 214 t. 57 fig. 1 = latifolia, Cam bess.

BLYSMUS, Panz. = Scirpus, Tourn. (Cyperac.). bifolius, Nym. Consp. fl. Eur. Suppl. ii. 1. (1889) $318=$ S. rufus, Schrad.

BLYXA, Noronha (Hydrocharid.). - Ind. Kew. i. 315.

ceylanica, Hook.f. Fl. Brit. Ind.v. (1888) 661. Zeylan.

ceratosperma, Maxim.in Engl. et Prantl, Natür. Pfanzenfam, II. i. (1889) 253. - Japon.

echinosperma. Hook. f. Fl. Brit. Ind. v. (1888) 661 (=Hydrotrophus echinopermus, C.B. Clarke).-Ind. or.

Griffithii, Planch. ex Hook. f. l. c. 660. - Ind. or japonica, Maxim.ex Aschers. ct Gürke, in Engl. et Prantl, Natürl. Pfanzenfan. II. i. (1889) 253.Japon.

lancifolia, Hook. f. Fl. Brit. Ind. v. (1888) 661. Reg. Himal.

malayana, Ridl. in Trans, Linn. Soc. Ser. 11. iii.

(1893) 358, - Penins. Mal.

oryzetorum, Hook. f. Fl. Brit. Ind.v. (1888) 661.As. trop. or,

radicans. Ridl. in Fourn. Linn. Soc. xxii.(1886)236. - Afr. trop.

Talboti, Hook. f. Fl. Brit. Ind. v. (1888) 661.-Ind.

BOBARTIA, Linn. (Irid.). - Ind. Kew. i. 215

anceps, Baker, Handb. Irid. (1892) 121 - Afr. austr. Burchellii, Baker, l. c. 120. - Afr, austr.

macrospatha, Baker, l. c. 119. - Afr. austr.

natalensis, Klatt, in Th. Dur. et Schin\%, Consp. fl. Afr.v. 1893 (1895) 168 (= Keitia natalensis, Regel) - Afr. austr.

robusta, Baker Handb. Ivid. (1892) I20.-Afr, austr.

BOBEA Gaudich. (Rubiac.) - Ind. Kew. i, 315.

Hookeri, Hillebr. Fl. Haw. Isl. (1888) 175 ( $=$ Ry

tidotus sandvicensis, Hool. f.), - Ins. Sandvic.

Mannii, Hillebr. .. c. 173.- Ins. Sandvic.

sandwicensis, Hillebr.l.c. $174(=$ Chomelia sandvicensis, A. Gray) — Ins. Sandvic.

timonioides, Hillebr, l. c. $C=$ Obbea timonioides, Hook. f.). - Ins. Sandvic.

BOGAGEA, St. Hil. (Anonac.) - Ind. Kew. i. 315 aromatica Britton, in Bull. Torrey Bot. Club, xyi. (1889) $14=$ aromatica, Triana et Planch. 
BOCCONIA, Plum. ex Linn. (Papaverac,), - Ind. Kew. i. 315

arborea, S. Wats, in Proc. Am. Acad. xxv. (1890) 141. - Mexic.

latisepala, S. Wats. l.c. - Calif.

microcarpa, Maxim. in Act. Hort. Petrop, xi. (1889) 45. - China.

vulcanica, F. D. Smith, in Coult. Bot.Gaz. xvi. (1891) 1. - Guatem.

BOEA, Comm. ex Lam. (Gesnerac.). - Ind. Kew. i. 315 .

Clarkeana, Hemsl. in fourn. Linn. Soc. xxvi. (1890) 232. - China.

crassifolia, Hemsl. l. c. 233. - China.

Lowesii, H. O. Forbes, in fourn. Bot. xxv. (1887) $348,-N$. Guin.

macrophylla, Drake. in Bull. Soc. Philom. Paris, Sér. VIII. ii. (1890) 130. - Tonkin.

microcarpa, Drake, l. c. - Tonkin.

umbellata, Drake, l.c. 129. - Tonkin

BOEHMERIA, Jacq. (Urtic.). - Ind. Kew. i. 316.

australis, Cheesem, in Trans. N. Z. Inst. xx. 1887 (1888) $173=$ dealbata, Cheesem.

dealbata, Cheesem. l. c. xxiv. 1891 (1892) 410. N. Zel.

Kurzii, Hook. f. Fl. Brit. Ind.v. (1888) 5\%7. - Pegu.

Palmeri, S. Wats. in Proc. Am. Acad. xxii. (1887) 453. - Mexic.

Weddelliana, Vidal, Rev, pl. vasc. Filip. (1886) 256. -Ins. Philipp.

BOEICA, C. B. Clarke, (Gesnerac.), - Ind. Kew. i. 317 .

ferruginea, Drake, in Bull. Soc. Philom, Paris, Sér. VIII. ii. (1890) 129. - Tonkin.

BOERHAA VIA, Vaill. (Nyctagin.).-Ind. Kew. i, 317.

alamasona, Rose, in Contrib. U. S. Nat. Herb. i. (1891) 110. - Mexic.

alata, S. Wats. in Proc. Am. Acad, xxiv. (1889)69. - Calii.

annulata, Coville, in Contrib. U S. Nat. Herb. iv. (1895) 177. - Calif.

capitata, Schweinf. ex Engl. in Abhandl. Prenss. Akad. Wiss. 1891. ii. (1892) 209, nomen.-Afr. trop, or.

elongata, T. S. Brandeg. in Proc. Calif, Acad. Ser.

II. ii. (1889) 199. - Calif.

fallacissima, Heimerl, ex Schinz, in Verh. Bot. Ver. Brand. xxxi. (1890) 223 - Afr. austro-occ. extratrop.

gracillima, Heimerl, in Engl. et Prantl, Natürl, Pflanzenfam. iii. 1b. (1889) 26; et in Bot. Fahrb. xi. (1890) 86. - Mexic.

gypsophiloides, Coult. in Contrib. U. S. Nat. Herb. ii. (1894) $354=$ Senkenbergia annulata, Schau - Mexic

hereroensis, Heimerl, in Bot. Fahrb. x. (1889) 9; et in Engl. et Prantl, Natür. Pfanzenfam. iii. 1b. (1889) 26. - Afr. austro-occ, extratrop.

Marlothii, Heimerl, $l l, c c, 9$ et 26, - Afr. austroocc. extratrop.

octandra, S. Wats, in Proc. Am. Acad, xxvi. (1891)

145. - Mexic

Palmeri, S. Wats, l. c. xxiv. (1889) 69. - Am. bor. Schinzii, Heimerl, ex Schinz, in Verh. Bot. Ver. Brand. xxxi. (1890) 222. - Afr. austro-occ. extratrop.

Sonorae, Rose, in Contrib. U. S. Nat. Herb. i. (1891) 111. - Mexic

tarapacana, Phil. in Am. Mus. nac. Chile (1892) 7l. - Chili. triquetra, S. Wats. in Proc. Am. Acad. xxiv. (1889)
69. - Calif.

Xanti, S. Wats., l. c. - Calif.

BOERLAGEA, Cogn, in Boerl., Handl. Fl. Ned, Indië, i. II. (1890) 522 et 536; et in DC. Monog. Phan. vii. (1891) 611. MELASTOM ACEAE. grandifolia, $\operatorname{Cog} n . l l, c c .523$ et $611 .-$ Borneo.

BOERLAGELLA, Pierre, ex Boerl. in Handl. Fl. Ned. Indië, ii. I. (1891) 305 in obs. = Sideroxy-
lon, Linn. (Sapot.).
BOERLAGIA, Pierre, Not. bot. Sapot. (1890) $33=$ Sideroxylon, Linn. (Sapot.).

spectabilis, Pierre, 1. c. - S. spectabile, Burck.

BOERLAGIODENDRON, Harms, in Eng1. et Prantl, Natürl. Pflanzenfam. iii. 8. (1894) 31 . = ESCHWEILERIA, Zipp. ex Harms, 1. ARALIACEAE.

Boerlagei, Harms, 1.c. 32 in obs. (= Eschweileria Boerlagei, Warb.) = Warburgii, Harms.

barbatum, Harms, l.c.31 (=Eschw.barbata, Zipp.). - Ind. or. bat.

carpophagarum, Harms, l. c. $32(=$ Eschw. carpopha garum, Becc.). - Ind. or. bat.

geelvinkeanum, Harms. l. c. $(=$ Eschw. geelwinkeana, Becc.). - Ind. or, bat.

helleborinum, Harms, l. c.31 (=Eschw. Helleborina. Becc.). - Borneo.

insidiator, Harms, l. c. $(=$ Eschw. insidiator, Becc.). - Borneo.

insigne, Harms, l. c.32 (= Eschw. insignis, Miq.). - Ind. or bat.

novo-guineense, Harms, l.c. 31 (= Eschw. novo-guineensis, Scheff. $)_{0}-\mathrm{N}$. Guin.

palmatum, Harms, l.c.31 (= Eschw. palmata, Zipp.) - Ind or. bat.

Pfeilii, Harms, l. c. 32 (= Eschw. Pfeilii, Warb.). - Ind. or. bat.

pulcherrimum, Harms, l. c. (=Eschw. pulcherrima, Vidal). - Ind. or. bat.

Teysmannii, Harms, l. c. 31 (=Eschw. Teysmannii, Boerl.). - Ind, or, bat.

Warburgii, Harms, l. c. $32(=$ Eschw. Boevlagei, Warb.). - Ind. or. bat.

BOESENBERGIA, Kuntze, Rev. Gen.(1891) $68 \check{\jmath}=$ Gastrochilus, Wall. (Scitam.)

longiflora, Kuntze, 1. c. = G. longiflora, Wall.

minor, Kuntze, l. c. = G. minor, King.

parzula, Kuntze, 1. c. = G. parvula, Wall.

pulcherrima, Kuntze, $1, c_{n}=$ G. pulcherrima, Wall. rubrolutea, Kuntze, 1. c. = G. rubrolutea, Baker. tiliaefolia, Kuntze, 1. c. = G. tiliaefolia, Baker.

tillandsiodes, Kuntze, 1. c. $=$ G. tillandsioidea Baker.

BOISDUVALIA, Spach $=$ Oenothera, Linn. Onagrar

bipartita, Greene, in Erythea, iii. (1895) 119. Calif.

stricta, Greene, Fl. Francisc. (1891) 225; in Contrib. U. S. Nat. Herb. iv. (1893) $106=$ O. Torreyi, S. Wats.

stricta, Trelease, in Missouri Bot. Gard. Rep. v (1894) $117=$ praec.

subulata, Raimann, in Engl, et Prantl, Natürl. Pflanzenfam, iii. 7. (1893) $212=0$. subulata Ruiz et Pav.

BOJERIA, DC. (Compos.). - Ind. Kew. i. 318 vestita, Bakev, in Kew Bull. (1895) 68. - Afr. trop

BOLDUS, Kuntze, Rev. Gen, (1891) $569=$ BOLDU, Feuillée = Bellota, Mez (Lautin.).

costaricensis, Kuntze, 1. c. = B. costaricensis, $M e z$.

BOLELIA, Rafin. = Downingia, Torr. (Campa) nul.).

bicornuta, Greene, Pittonia, ii. (Dec. 1890) $127=$ D. bicornuta, A. Gray.

concolor, Greene, 1. c.; et Man. Bot. San Franc. Bay (1894) $229=$ D. concolor, Greene.

cuspidata, Greene, in Erythea, iii. (1895) 101. Calif

elegans, Greene, Pittonia, ii. (Dec. 1890) 126; et Man. Bot. San Franc. Bay (1894) 228 in obs. = D. elegans, Torr.

humilis, Greene, 11. cc. (May 1892) 226; et 229. Calif.

insignis, Greene, 11. cc. (Dec. 1890) 126; et $228=$ D. insignis, Greene.

laeta, Greene, in Erythea, i. (1893) 238. - Nevada montana, Greene, Pittonia, ii. (Dec. 1890) $127=$ D. montana, Greene.

ornatissima, Greene, 1. c.; et Man. Bot. San Franc, Bay $(1894) 229=\mathrm{D}$. ornatissima, Greene.

pulchella, Greene, 11. cc. 26; et228=D,pulchella, Torr.
BOLELIA : -

pusilla, Greene, Pittonia, ij. (Dec. 1890) 126 (= Clintonia pusillla, G. Don). - Chili.

tricolor, Greene, 1. c. 127; et Man. Bot. San Franc. Bay. (1894) $229=$ D. tricolor, Greene.

BOLLEA, Reichb. f. = Zygopetalum, Hook。 (Orchid.)

Schroederiana, Hort. Sand. ex Gard. Chron. (1895) i. 497 fig. 70. - Columb

Wendlandiana, Hort. ex Gard. and For, i. (1888) $315=$ Zygopetalum Wendlandi, Reichb. $f$.

BOLUSAFRA, Kuntze, Rev. Gen. (1891) $162=$ Fagelia, Neck. (Legumin.)

bituminosa, Kuntze, 1. $\mathrm{c}$. $=\mathrm{F}$. bituminosa, $D C$

BOMAREA, Mirb. (Amaryl1.). - Ind, Kew. 319.

acuminata, Baker, in Bot, fahrb. viii. (1887) 212.Columb.

chimboracensis, Baker, l.c. - Ecuad.

crassifolia, Baker, Handb. Amaryll. (1888) 150.N. Gran.

glaberrima, Pax, in Bot. Fahrb. xi. (1890) 334. Reg. Argent.

Herbertiana, Baker, Handb. Amaryll. (1888) 155. N. Gran,

Hieronymi, Pax, in Bot. Fahrb. xi. (1890) 332. Columb.

Kraenzlinii, Baker, in Bot. Fahrb, viii. (1887) 213.Columb.

macrocephala, Pax, l.c.xi.(1890)331.-Reg. Argent

parvifolia, Baker, Handb. Amaryll. (1888) 154. Peruvia.

Patini, Baker, l. c. 15\% - N. Gran.

phyllostachya, Mast. ex Baker, l. e. 143,- Columb. recurva, Baker, l.c. 145.- Peruvia.

sororia, N. E. Br. in Illustr. Hortic. xxxix. (1892) 19 t. 545. - Am. austr.

stenopetala, Baker, in Bot. Fahrb. viii. (1887) 212; e Handb. Amaryll. (1888) 149. — Columb.

stricta Pax, in Bot. fahrb. xi. (1890) 333. Reg. Argent.

Stuebelii, Pax, l.c. - Peruvia.

vestita, Baker, in Bot. Fahrb. viii. (1887) 213; $e$ Handb. Amaryll. (1888) 152. - Columb.

BOMBAX, Linn. (Malvac.). - Ind. Kew. i. 320 calophyllum, K. Schum. in Mart. Fl. Bras. xil. III. (1886) 227. - Bras.

campestre, K. Schum. l.c. 229. (= Pachira campestris, Decne). - Bras.

Candollianum, $K$. Schum. $l$. c. 218. - Bras.

crenulatum, K. Schum.l.c.219. - Bras.

cyathophorum, K. Schum, l. c. $228(=$ Pachira cyathophora, Casar.).-Bras

gracilipes, $K$. Schum.l. c.221.-Bras.

Jenmani, Oliver, in Hook. Icon. pl. xviii. (1887) t.1720. - Guian. angl.

longiflorum, K. Schum. in Mart. Fl. Bras. vii. UI (1886) 228 (= Pachira longiflora, Decne).-Bras. macrophyllum, K. Schum.l.c. 220. - Bras.

marginatum, K. Schum. l. c. 223 ( = Pachira marginata, St-Hil.).-Bras.

Martianum, K. Schum. l. c. 224 (= Pachira tomentosa, Decne). - Bras.

Palmeri, S. Wats, in Proc. Am. Acad. xxii.(1887) 399. - Mexic.

Poissonianum, K. Schum. in Mart. Fl. Bras, xii. III (1886) 225 (= Pachira nitida, Decne.).-Bras. rhodognaphalon, $K$. Schum. ex Engl. in Abhandl. Prenss. Akad. Wiss, (1894) 34; et in PAlanzenw. OstAfr. C (1895) 269. - Afr. trop. or.

stenopetalum, $K$. Schum. in Mart. Fl. Bras, xii. IIr. (1886) 225 (= Pachiva stenopetala, Casar.).-Bras. tomentosa, Pievre, ex Laness. Pl. util. col, franc (1886) 291, nomen. - Cochinch.

Wittrockianum, K. Schum. in Mart. Fl. Bras, xi . III. (1886) 222, - Bras.

BONAMIA, A. Gray = Breweria, R. Br. (Convolvul.)

agrostopolis, Hallier fo in Bot. Jahrb, Xv. (1893) 563 in obs. et xvi. (1893) $529=\mathrm{Br}$. venulosa, Meissn. 


\section{BONAMIA : -}

Althoffana, Dammer, in Engl. Pflanzenw. Ost-Afr. C (1895) 329. - Afr. trop. or.

Balansae, Hallier f. in Bot. Jahrb. xvi. (1893) 508,

512,513 et 526 in obs. - Parag.

Boivini, Hallierf.1. c. xviii. (1894) 91.- Madag.

Burchelli, Hallier f. 1. c. xv. (1893) 563 in obs.; et xvi. (1893) $529=\mathrm{Br}$. Burchellii, Choisy.

cymosa, Hallier f. 1. c. xviii. (1894) 91 = Ipomoea ramosissima, Choisy.

elegans, Hallier f.l. c. rvi. (1893) $529=\mathrm{Br}$. elegans, Choisy.

ferruginea, Hallier, f. 1. c. xvi. (1893) $530=$ Prevostea ferruginea, Choisy.

glomerata, Hallier f. 1. c. xviii. (1894) $90=\mathrm{Br}$. glomerała, Balf. $f$.

Hernionieri, Hallier f. 1. c. xvi. (1893) 529 in obs. Ins. Guadalup. et Sandvic

Hildebrandtii, Hallier f. 1. c. xviii. (1894) $91=\mathrm{Br}$. Hilldebrandtii, Vatke.

linearis, Hallier f. 1. c. xvi. (1893) 530 et $531=\mathrm{Br}$ linearis, $R . B r$.

mavipoides, Hallier, f. 1. c xvi. (1893) $529(=$ Prevostea spectabilis, Meissn.).-Bras.

media, Hallier f. 1. c. 528 in obs. = Br. media F. Muell.

minor. Hallier f. 1. c. xviii (1894) 91. - Congo.

mossambicensis, Hallier f. 1. c. xviii.(1894) 91 (=Pre vostea mossambicensis, Klotzsch) - Afr, trop. austro-or.

pannosa, Hallier f. 1. c. xvi. (1893) $530=$ Br. pannosa, $R, B r$

rosea, Hallier f. 1. c. xvi. (1893) 528 in obs. $=\mathrm{Br}$ rosea, F. Muell.

semidigyna, Hallier f. l. c. xvi. (1893) 528 ; et xviii. (1894) $90=\mathrm{Br}$. cordata, Blume.

spectabilis, Hallier f. I. c. xvi.(1893) 529; et xviii. (1894) $91=\mathrm{Br}$. spectabilis, Choisy.

sericea, Hallier f. I. c. xvi. (1893) 528 in obs, $=\mathrm{Br}$ sericea, A. Gray.

Thoursii, S. Elliot, in Journ. Linn. Soc, xxix. (1891) 35. - Madag.

Trichantha, Hallier f. in Bot. Jahrb, xvi. (1893) 529,530 et 563 in obs. - Bras.

ambellata, Hallier f. 1. c. xvi. (1893) 530 i=Preqostea umbellata Choisy). - Bras.

Volkensit, Dammer, in Engl. Pflanzenw, Ost-Afr. C (1895) 329. - Afr. trop. or.

BONAPARTEA, Haw. = Agave, Linn. (Ama-

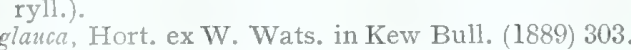
glauca, Hort. ex W. Wats. in Kew Bull.
$\quad=$ Dasylirion glaucophyllum, Hook.

BONATEA, Willd, = Habenaria, Willd. (Orchid.) minor.Mundt, ex Kraenzl. in Bot. Jahrb. xvi. (1893) 79 in syn. = H. Mundtii, Kraenzl.

Samidersiae, Th. Dur. et Schinz, Consp. fl. Afr, v. 1892 (1895) $89=$ H. Saundersiae, Harv.

Stendneri, Th, Dur, et Schinz, 1. c. $90=\mathrm{H}$ Steudneri, Reichb.f.

BONDTIA, Kuntze, Rev. Gen. (1891)500=BONTIA Linn. = Eremophila, R.B. et Pholidia, R.Br (Myoporin.)

adenotricha, Kuntze, 1. c. $501=$ Pholidia adenotricha, F. Muell.

allemifolia, Kuntze, 1. c.=Eremophila alternifolia, R. $B$ r.

minustifolia, Kuntze, 1. c. = Pholidia microtheca, F. A Iuell

Bchrions, Kuntze, 1. $\mathrm{c}=\mathrm{Ph}$. Behriana, F, Mucll. Bcryy, Kuntze, 1. c.=Eremophila Berryi, $F$. Muell. bignoniaciflora, Kuntze, 1. c. = Er. bignoniflora, F. Mucll.

Bowmanni, Kuntze, 1. c. = Er. Bowmani, F. Muell. brevifolia, Kuntze, 1. c, = Pholidia brevifolia, Benth. Christophori, Kuntze, l. c. = Eremophila Christophori, F. Muell.

Clarke, Kuntze, 1, c, = Er. Clarkei, Oldfield.

crassifolia, Kuntze, 1. c. = Pholidia crassifolia, F. MIucll.

Dalyana, Kuntze, 1.c. = Ph. Dalyana, F. Muell.

Dolisseri, Kuntze, 1. c. = Ph. Delisserii, F. Mucll.

Dimpsicri, Kuntze, 1. c. = Eremophila Dempsteri, F. Mluill.

\section{BONDTIA : -}

densifolia, Kuntze, Rev. Gen. (1891) 501 = Pholidia densifolia, F. Muell.

denticulata, Kuntze, 1. c. = Eremophila denticulata F. Muell.

divaricata, Kuntze, $1 . c_{0}=$ Pholidia divaricatd, F. Muell.

Drummondi, Kuntze, 1. c. = Eremophila Drum mondi, $F$. Muell.

Duttonii, Kuntze, 1. c. = Er. Duttoni, F. Muell.

Elderi, Kuntze, 1. c. = Er. Elderi, F. Muell.

eviocalyx, Kuntze, 1. c. = Er, eriocalyx, $F$. Muell

exilifiora, Kuntze, 1. c. = Er. exilifolia, F Muell.

Forrestii, Kuntze, 1. c. = Er. Forrestii, F. Muell

Fraseri, Kurtze, 1, c, = Er. Fraseri, F. Mull.

Freelingii, Kuntze, 1. c. $=$ Er. Freelingii, $F$. Muell.

gibbosifolia, Kuntze, 1.c. $=$ Pholidia gibbifolia, F. Muell.

Gibsonii, Kuntze, 1. c. = Eremophila Gibsonj, F. Muell.

Gilesii, Kuntze, 1. c. = Er. Gilesii, F. Muell.

glabra, Kuntze, 1. c. $=$ Er. Brownii, F, Muell.

Goodwinii, Kuntze, 1. c, = Er. Goodwinii, F Muell.

graciliflora, Kuntze, 1. c.=Er, graciliflora, F. Muell.

Hughesii, Kuntze, 1. c. = Er. Hughesii, F.Muell.

imbricata, Kuntze, 1. c. = Pholidia imbricata, Benth.

Latrobei, Kuntze, 1. c. = Eremophila Latrobei, F. Muell.

leucophylla, Kuntze, 1. c. = Er. leucophylla, Benth. longifolia Kuntze, 1. c. $=$ Er longifolia, $F$. Muell. Macdonellii, Kuntze, 1. c. =Er.Macdonelli, F. Muell. Mackinlayi, Kuntze, 1. c.=Er.Mackinlayi, F.Muell. maculata, Kuntze, 1. c. = Er. maculata, F. Muell Maitlandii, Kuntze, 1, c = Er. Maitlandi, F. Muell. Mitchelli, Kuntze, 1.c. = Er. Mitchelli, Benth.

Oldficldii, Kuntze, 1. c. =Er. Oldfieldii, F, Muell.

oppositifolia, Kuntze, 1. c.= Er. oppositifolia, R. Br.

Paisleyi, Kuntze, 1. c. = Er. Paisleyi, F. Muell.

Pantonii, Kuntze, 1. c. = Er. Pantoni, F. Muell.

platycalyx, Kuntze, 1. c, = Er. platycalyx, $F$. Muell.

polyclada, Kuntze, 1. c. = Er. polyclada, F. Muell.

resinosa, Kuntze, 1. c. = Pholidia resinosa, Engl.

rotundifolia, Kuntze, 1. c. = Eremophila rotunditolia, F. Muell.

santalina, Kuntze, 1. c. = Pholidia santalina, F. Muell.

scoparia, Kuntze, 1. c. $=\mathrm{Ph}$. scoparia, $R \cdot B r$

serrulata, Kuntze, 1.c. = Eremophila latifolia, $F$. Mucll.

strongylophylla, Kuntze, 1. c. = Er. strongylophylla F. Muell.

Sturtii, Kuntze, 1. c, = Er. Sturtii, $R . B r$.

subfloccosa, Kuntze, 1. c. =Er. subfloccosa, F. Muell.

Turtonii, Kuntze, 1.c. = Er. Turtoni, F. Muell.

riscida, Kuntze, 1. c = Er, viscida, Endl.

Weldii, Kuntze, 1. c. = Er. Weldii, F. Muell

Willsii, Kuntze, 1. c. = Er. Willsii, F. Muell

Woolsiana, Kuntze, 1. c。 = Pholidia Woollsiana, F. Muell.

Youngii, Kuntze, 1. c. = Eremophila Youngii, F. Muell.

BONIA, Balansa, in Morot, Journ. de Bot. ix. (1890) 29. GRAMINEAE

tonkinensis, Balansa, l. co 一 Tonkin.

BONINIA, grisea, Planch. ex Kuntze, Rev. Gen. (1891) $98^{\circ}=$ Evodia grisea, Kuntze.

BONNETIA, Mart, et Zucc. (Ternstroem.), Ind. Kew. i. 32l.

Roraimae, Oliver,in Trans.Linn. Soc.Ser.II.ii.(1887) 272, (Oliver, ex im Thurn, in Timehri, v.(1886) 190). - Guian. angl.

BOOPIS. Juss. (Calycer.).- Ind. Kew. i. 322. ustralis, Phil. in Anal. Univ.Chil.1xxxv. (1894) 818.

- Chili.

bicolor, Phil. 7.c.813. - Chili.

breviflora, Phil.l.c. 814. - Chili.

breviscapa, Phil. l. c. 818 . - Chili.

dubia, Phil. l. c. 815 . - Chili.

integrifolia, Phil. l.c. $814-$ Chili.

Miersii, Fr. Meigen, in Bot. Fahrb. xvii. (1893) 277 (= Nastanthus Miersii, Phil.). - Chili.

Miersii, Phil, in Anal. Univ. Chil. 1xxxy. (1894) 817 $=$ praec.

\section{BOOPIS :}

monocephala, Phil. in Anal. Mus.nac. Chile (1891) 30 - Am. austr. occ.

Reichei, Phil. in Anal. Univ, Chil. 1xxxv. (1894) 815. - Chili.

BоOтTIA, Wall. (Hydrocharid.). - Ind. Kew. i. 322

abyssinica, Ridl.in fourn. Linn. Soc. xxii. (1886) 239. - Abyss.

crassifolia, Ridl. ? c - Angola.

exserta, Ridl.l.c. 240. - Zambesia, Madag.

Fischeri, Gïrke, in Engl. Pfanzenw. Ost-Afr. C (1895) 95. - Afr. trop. or.

Rohrbachiana, Aschers. et Gürke, in Engl. et Prant?, Natür. Pflanzenfam. II. i. (1889) 256.-Afr. centr.

Schinziana, Aschers ot Gürke ex Sching in Bull. Herb. Boiss. iii. (1895) 376. - Afr. austro-occ. extratrop.

BORDEREA, Miégev. = Dioscorea, Lam. (Dioshumilis, Pax, en Engl, et Prantl, Natürl. Pflanzenfam. iii. 5. (1887) $133=$ D. humilis, Bort.

BORETTA, Neck, = Daboecia, D. Don (Ericac.) cantabrica, Kuntze, Rev. Gen. (1891) $387=\mathrm{D}$. polifolia, D. Don

Daboecii, Baill. Hist. des pl. xi. (1892) $173=\mathrm{D}$ polifolia, D. Don .

BORONIA, Sm.(Rutac.). - Ind. Kew. i. 323. Adamsiana, F. Muell. in Proc.Linn.Soc. N.S. Wales, Ser. II. v. (June 1890) 15. - Austral.

BORRERIA, G. F. W. Mey,= Spermacoce, Linn. (Rubiac.)

Baurii, Robins. et Greenm. in Am. Journ. Sc Ser. III. 1. (1895) 140. - Ins. Galap.

compacta, K. Schum. in Engl. et Prantl, Natürl. Pflanzenfam. iv, 4. (1891) $144=$ S. compacta Hochst.

decipiens, K. Schum. in Mart. F1. Bras, vi. vi.(1888) 57. - Bras.

exserta, K. Schum, in Engl. et Prantl, Natürl. Pflanzenfam. iv. 4. (1891) $144=$ S. exserta, Benth.

fastigiata, K. Schum. in Mart. Fl. Bras, vi. vi. (1888) 68. - Bras.

filifolia, K. Schum.in Engl, et Prantl, Natürl. Pflanzenfam. iv. 4. (1891) $144=$ Octodon filifolium, Schum. et Thonn.

galapageia, Robins, et Greenm. in Am. Journ. Sc Ser. III. 1. (1895) 140. — Ins. Galap.

hispida, K. Schum in Eng1. et Prantl, Natür1. Pflanzenfam. iv. 4. (1891) $144=$ S. hispida, Lim. hispida, Spruce, ex K. Schum. in Mart. F1. Bras. vi. vi (1889) 62. - Bras.

inaperta, K. Schum. in Engl, et Prantl, Natürl. Pflanzenfam. iv. 4. (1831) $144=$ S. inaperta, F. Muell.

Kotschyana, K. Schum. in Engl. Pflanzenw. OstAfr. C (1895) $394=$ S. Kotschyana, Oliver.

Lagurus, S. Moore, in Trans. Linn. Soc. Ser. II. iv. (1895) 383. - Bras.

latifolia, K. Schum, in Mart. F1. Bras, vi, v1.(1888) $61=$ S. latifolia, $A u b l$

leiophylla, K. Schum. 1. c. 66. - Bras.

leucadea, K. Schum. in Engl. et Prantl, Natürl. Pflanzenfam. iv, 4. (1891) $144=$ S. leucadea Hochst.

monodon, K. Schum. in Mart. Fl. Bras. vi. vi. (1890) 63. - Bras.

pacifica, Robins, et Greenm. in Am. Journ. Sc. Ser. III, 1. (1895) 140. - Ins. Galap.

pogostoma, K. Schum. in Engl. et Prantl, Natürl. Pflanzenfam. iv. 4. (1891) $144=$ S. pogostoma, Benth.

pygnaea, Spruce, ex K. Schum. in Mart. Fl. Bras. vi. vi. (1888) 58. - Venez.

Runkii, K. Schum. 1. c. 42 . - Bras.

scabra, K. Schum. in Eng1. Pflanzenw, Ost-Afr. C (1895) $394=\mathrm{S}$. Ruelliae, $D C$.

senensis, K. Schum, in Abhandl.Preuss. Akad.Wiss. (1894) 23; et in Engl. Pflanzenw. Ost-Afr. C (1895) $394=\mathrm{S}$. senensis, Hiern. 
BORRERIA : -

setosa, K. Schum. in Enol: et Prantl, Natürl. Pflanzenfam, iv, 4. (1891) $144=$ Octodon setosum, Hiern.

stricta, K. Schum. 1, c. $143=$ S. stricta, Linn. $f$.

tenuissima, K. Schum. 1. c. $144=$ S. tenuissima, Hochst.

Warmingii, K. Schum. in Mart. F1. Bras. vi. v1. (1888) 42. - Bras

Wunschmanni, K. Schum. 1. c. 53. - Bras.

BORAGINELLA, Siegesb. Fl. Petrop. (1736) 20, ex Kuntze, Rev. Gen. (1891) $435=$ Trichodesma, R. Br. (Borag.)

africana, ambacensis, amplexicaulis, angustifolia, Aucheri, calcarata, Ehrenbergii, heliocharis, incana, indica, khasiana, latisepala, laxiflora, microcalyx, mollis, stricta, zeylanica, Kuntze 1. c. 435-36= homonyma omnia Trichodesmatis.

physalodes, Kuntze, 1. c. $=$ T. physaloides, $A . D C$. Scottii, Kuntze, 1. c. $=$ T. Scotti, Balf. f.

trichodesma, Kuntze, 1. c. $=$ T. calathiformis, Hochst.

BosciA, Lam. (Capparid.). - Ind. Kew. i, 325. Carsoni, Baker, in Kew Bull. (1895) 288. - Afr. centr. austr.

coriacea, Pax, in Engl. et Prantl. Natürl. Pflanzenfam. iii. 2. (1891) 232; et in Bot. Fahrb.xiv. (1592) 299. - Afr. trop. or

corymbosa, Gilg, in Engl. Pfanzenw. Ost-Afr. C (1895) 186. - Afr. or.

Fischeri, Pax, in Engl. l. c. 186. - Afr, trop. or foetida, Schinz, in Abhandl. bot. Ver. Prov. Brand. xxix. (1888) 49. - Afr. austro-occ. extratrop. grandiflora, Gilg, in Engl. Pfanzenw. Ost-Afr. C

(1895) 186, - Afr. or.

Holstii, Pax, ex Engl. in Abhandl. Preuss. Akad. Wiss. (1894) 40; et in Engl. Pflanzenw. Ost-Afr. C (1895) 186. - Afr. or

Pechuelii, Kuntze, in Fahrb. Bot. Gart. Berl. iv. (1886) 261. - Afr. austro-occ, extratrop.

puberula, Pax, in Bot. Fahrb. xix. (1894) 134. - Afr. austro-occ. extratrop.

pungens. Gilg, in Engl.Pflanzenw. Ost-Afr. C (1895) 186. - Afr. trop. or.

rotundifolia, Pax, in Bot. Fahrb. xiv. (1892) 299. Afr. trop. or

teitensis, Gilg, in Engl. Pfanzenw. Ost-Afr. C (1895) 186. - Afr. or.

variabilis, Collett et Hemsl. in fourn. Linn. Soc. xxviii. (1890) 18 t. 1. - Burma.

BOSSIAEA, Ventenat. (Legumin.). - - Ind. Kew. i. 325 .

Stephensonii, F. Mull. in Proc. Linn. Soc. N.S. Wales, Ser. II. i. (Feb, 1887) 1107. - Austral.

BOSWELLIA, Roxb. (Burserac.). - Ind. Kew. i. 325 .

campestris, Engl. Pflanzenw. Ost-Afr. A (1895) 41 nomen = Hildebrandtii, Engl.

Hildebrandtii, Engl. Bot. fahrb. xv. (1893) 98. Afr. trop. austro-or.

BOTOR, Adans. = Psophocarpus, Neck. (Legumin.).

palustris, Kuntze, Rev. Gen. (1891) $163=$ P.palustris, Desv.

tetragonoloba, Kuntze, 1. c. $162=\mathrm{P}$. tetragonolobus, $D C$.

BOTHRIOGHLOA, Kuntze, Rev. Gen. (189I)762, GRAMINEAE anamitica, Kuntze, l.c. - Anam.

BOTHRIOGHLINE, Oliver (Compos.). - Ind. Kew. i. 326.

alternifolia, O. Hoffm. in Engl. Pflanzenw. Ost-Afr. C (1895) 403. - Afr. trop or

cordifolia, Engl. l.c. A (1895) 110 nomen. - Afr. trop. or.

diversifolia, O. Hoffn. ex Engl. l. c. C (1895) 403.Afr. trop. or.

laxa, N. E. Br. in Kerw Bull. (1894) 388. - Afr. trop. et austr.

\section{BOTHRIOCHLINE}

longipes, $N$. F Br, l. c 389 - Afr. centr. bor. marginata, $O$. Hoffm. in Engl. Pfianzenv. Ost-Afr. $C$ (1895) 403 (=Vernonia marginata, Oliver). Afr. trop.

Meyeri, O.Hoffm. ex Engl. in Abhandl. Preuss. Akad. Wiss. (1894)62, et in Pflanzenw. Ost-Afr. A (1895) 111 nomen. - Afr. trop. or.

oramballae, O. Hoffm, in Engl. l. c. C (1895) 403

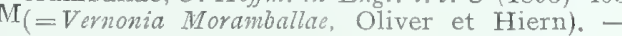
Afr. trop.

BOTRYANTHES, Kunth= Muscari,Mill.(Liliac.) granatensis, Nym. Consp. fl. Eur. Suppl. ii. I.(1889) $307=$ M. granatensis, Freyn

Kerneri, Nym.1. c. = M. botryoides, $D C$.

speciosus, Nym.1. c. = M. neglectum, Guss

Strangwaisii, Nym. 1. c. = M. botryoides, $D C$

BOTRYOSPORA, Hook. f. Fl. Brit. Ind.v. (1888) 476. EUPHORBIACEAE

Kingii, Hook.f. l. c. - Perak

BOUCEPOSIA, Wight et Arn. (Asclepiad.) - Ind. Kew. i. 326.

Aaronis, H. C. Hart, Fauna and Fl. of Sinai (1891) 100, t. 4 (sphalm. Aavonis, in text.) - Arabia. adenensis, Deflers, in Rerue d'Egypte, (1894), ex Bull. Soc. bot. Fr. xlii. (1895) 689, nomen. - Arabia Awdeliana, Deflers, $l l$. cc. nomen. - Arabia.

BOUGHEA, Cham. (Verbenac.), - Ind. Kew. i 327.

dissecta, S.Wats. in Proc. Am. Acad.xxiv.(1889) 68 - Calif.

prismatica, Kuntze, Rev. Gen. (1891) $502=$ Ehrenbergii, Cham,

prismatica, Bria, in Engl. et Prantl, Natürl. Pflan zenfam. iv. 3a. (1895) $154=$ praec.

pterygosperma, Engl. Pflanzenw. Ost-Afr. A (1895) sphalm. = pterygocarpa, Schauer.

BOUCHETIA, DC. (Solan.). - Ind. Kew.i. $32 \%$. nomala, Britton et Rusby, in Trans. N. Y. Acad. Sc. vii. (1887) $12=$ erecta, $D C$.

BOUGAINVILLEA, Comm. (Nyctagin.). - Ind. Kew. i. 327.

refulgens, Bull, Catal. (1887) 9, nomen. - Bras. spinosa, Heimerl, in Engl. et Prantl, Natuirl. Pfanzenfan, iii, 1b. (1889) 27 (= Tricycla spinosa Cav.). - Reg. Argent.

BOURDONIA, Greene, in Exythea, i. (1893) 207 = Keerlia, A. Gray (Compos.)

bellidifolia, Greene, 1. c.=K. bellidifolia, A. Gray.

effusa, Greene, 1. c. = K. effusa, A. Gray.

BOURNEA, Oliver, in Hook. Icon. pl. xxiii. (1893) t. 2254. GESNERACEAE.

sinensis, Oliver, l. c. - China.

BOUTONIA, DC. = Periblema, DC. (Bignon.). cuspiatata, Kuntze, Rev. Gen. (1891) 483= P. cus pidata, $D C$ BOURRERIA, P. Br. (Boragin.): - Ind. Kew. i.

Sonorae, S. Wats, in Proc. Am. Acad. xxiv. (1889) 62. - Calif. BOUTELOUA, Lag. (Gramin.). - Ind Kew. i.
32\%.

alamosana, Vasey, ex Rose, in Contrib. U. S. Nat. Herb. i. (1891) 115. - Mexic.

americana, Scribn, in Proc. Acad. Philad. (1891) 306; Hitchc, in Missouri Bot. Gard. Rep. iv. (1893) $148=$ litigiosa, Lag.

arenosa, Vasey, ex S. Wats, in Proc. Am. Acad. xxiv. (1889) 81 nomen; et Ill. N. Am. Grass. i. (1891) t. 34. - Mexic.

breviseta, Vasey, ex Coult. in Contrib. U.S. Nat. Herb. i. (1890) 58; et iii. (1894) 531. - Texas

\section{BOUTELOUA :}

Fournierana, Vasey, in Proc. Am, Acad. xxii. (1887) 461 nomen; et ex Scribn, in Bull. Torrey Bot. Club, xvii. (1890) 229(= Pentaraphis Fournievana, Hack. et Scribn.) - Mexic

hirta, Scribn. ex Vasey, 1. c. 531 = hirsuta, tao Tumilis, Hack. ex Sodiro, Gram. Ecuator. (Anal. Univ. Quito, 1889) 8(= Chondrosium humile, Kunth) = prostrata, Lag.?

major, Vasey, in Bull. Torrey Bot. Club, xiv. (1887) 10 in obs. = oligostachya, Torr

microstachya, Dewey, ex Coult.in Contrib. U.S. Nat. Herb. ii. (1894) 531 (= Chondrosinm microstachym, Fourn.) - Mexic., Texas.

Palmeri, Vasey, in Bull. Torvey Bot. Club, xiv. (1887) 9 in obs. = hirsuta, $L a g$.

Rahmeri, Phil. in Ann. Mus. nac. Chile (1892) 85.Chili.

ramosa, Scribn. in Vasey, Illustr. N. Am. Grass. i. 1. (1891) t. 44. - Am. bor. austro-occ.

stolonifera, Scribn in Proc. Acad. Philad. (1891) 306. et in Bull. Torrey Bot.Club. xviii. (1891) 314.?-Ca.lif.

stricta, Vasey, in Bull. Torrey Bot. Club, xv (1888) 49; et in Illustr. N. Am. Grass. i. I. (1890) t. 45. Texas

Triaena, Scribn. in Proc. Acad. Phil. (1891) 30\%; et in Bull. Torrey Bot. Club, xviii. (1891) 314 $(=$ Atheropogon Triaena, Spreng. $)=\mathrm{B}$. Triathera, Benth.

uniflora, Vasey, in Contrib. U. S. Nat. Herb. ii. (1894) 533. - Texas.

vestita, Scribn. ex Coult. in Contrib. U. S. Nat. Herb. ii. (1894) 531. - Texas.

BoUvardia, Salisb. (Rubiac.). - Ind. Kew, i.

Flos-Joannis, K. Schum, ex Loes, in Bull. Herb. Boiss. iii. (1895) 621. - Mexic.

gracilis, A. Gray, in Proc. Am. Acad. xxii. (1887) 306. - Mexic.

Hogarthi, Hort. ex Gard. Chron. (1889) ii. 718 nomen, - Form, hort.

hybrida, Hort. ex Gartenfl. (1887) 289 t. 1248. Form, hort.

BOWKERIA, Harv. (Scrophul.), - Ind. Kew. i.

cymosa, Macowan, in foum. Limn. Soc. xxv. (1890) 390. - Transvaal.

simplicifolia, MacOwan, l.c.-Afr. austr.

BOWLESIA, Ruiz et Pav. (Umbellif.)...- Ind, Kew.

i. 328 .

axilliflora, Phil. in Anal. Univ. Chit. 1xxxv: (1894) 513. - Chili.

cana, Phil. l. c. 510. - Chili.

cirrosa, Phil. l. c. 699. - Chili.

digitata, Phil. l. c. - Chili.

dumetorum, Phil. l. c. 514 (err. cal.? dunetoreum). - Chili.

glandulosa, Kuntze, Rev. Gen. (1891) $265=$ oppo sitifolia, Buch.

Mandoni, Rusby, in Men. Torrey Bot. Club, iii. 3 (1893) 41. - Bolivia.

Reichei, Phil. in Anal. Univ. Chil. lxxxv. (1894) 512 - Chili.

BOYKINIA, Nutt. (Saxifr.). - Ind. Kew. i. 329.

elata, Greene, Fl. Francisc. (1891) $183=$ occidentalis, Torr. et Gray.

Famesii, Engl. in Engl. et Prantl, Natürl. Pflanzenfam. iii. 2a. (1890) 51 (= Saxifraga fanesic Torr.). - Am. bor. oc.

lycoctonifolia, Engl. l. c. $(=$ Sax lycoctonifolia, Maxim.). - As. or.

Nuttalli, Macoun. Canad. Board of Sc. (July 1895) extr. = occidentalis, Torr. et Gray.

ranunculifolia, Greene, F1. Francisc. (1891) $190=$ Saxifragra ranunculifolia, Hook.

BRAGHIONIDIUM, Lindl. (Orchid.). - Ind.

Kew. 1. 329

Sherringii, Rolfe, in Kew Bull. (1893) 4. - Ins. Grenada. 
BRAGEA, King, in Journ. As. Soc. Beng. 1xiv. (1898) ii. 101. OLACINEAE.

paniculata, King, l.c. - Perak.

BRACHISTUS, Miers (Solan.). - Ind. Kew, i. 329. escuintlensis, Coult, in F. D. Smith, Pl. Guat.ii. (1891) 53; et Bot. Ga\% xvi. (1891) 144. - Guatem. Pringlei, S. Wats. in Proc. Am. Acad. xxv. (1890) 159. - Mexic

BRAGHYACHAENIUM, Baker, in Journ. Linn. SoC. Xxv. (1890) 330. COMPOSITAE.

incanum, Baker, l. c. t. 53. - Madag.

BRACHYACTIS, Ledeb. (Compos.). - Ind. Kew. i. 329.

chinensis, Bur. et Franch. in Morot, fourn. de Bot. v. (1891) 69. - Tibet.

linearifolia, C.Winkl. in Act. Hort. Petrop. xiv. (1895) 123. - Mongolia.

BRACHYCHAETA, Torr, et Gray (Compos.). Ind. Kew. i. 320.

sphacelata, Britton, ex Kearn. in Bull. Torrey Bot. Club, xx. (1893) $484=$ cordata, Torr. et Gray.

sphacelata, Greene, in Erythea, ii. (1894) $58=$ praec.

BRACHYGHILUM, O, G. Petersen, in Bot. Tidskr. (1893) 262. SCI TAMINEAE.

Horsfieldii, O. G. Petersen, l. c, t. 17; Baker, in Gard. Chron. (1894) i. 652 (= Hedychinm Horsficldii, R. Br.). - Java.

BRACHYCHITON, Schott et Endl. = Sterculia, Linn. (Stercul.).

Carruthersii, F. Muell, in Vict. Natural. iii. (Augr. 1886) 50. - N. Guin.

rupestris, K. Schum, in Engl. Naturi. Pflanzenfam. iii. 6. (1893) $96 .=$ S. rupestris, Lindl.

BRACHYCOME, Cass, (Compos.). - Ind. Kew, i. 330 .

cuneifolia, Tate, in Trans. and Proc. Roy. Soc. S. Austral. xi. (1889) 83. - Austral.

hispida, Klatt, in Leopoldina, Heft Xxv. (1889) 108. - Bolivia.

BRAGHYGORYTHIS, Lind1. (Orchid.). - Ind.

Kew. i, 330 .

Engleriana, Kracnzl. in Bot. Fahrb. xxii.(1895).20. - Kamerun.

BRACHYELYTRUM, Beauv. (Gramin.), - Ind. Kew. i. 330 .

africanum, Hack. ex Schinz, in Bull. Herb. Boiss. iii (1895) 382, - Transvaal.

aristosum, Trelease, Branner et Coville, in Branner, Rep. Geol. Surv. Ark. iv. 1888 (1891) $235=$ erectum, Beanv.

BRACHYLOPHON, Oliver, in Hook. Icon. pl. xvi. (1887) t. 1566. MALPIGHIACEAE.

Curtisii, Oliver, l. c. - Penang.

Hulletti, King, in fourn. As. Soc. Beng. 1xii. (1893) ii. 196. - Malacca.

Scortechini, King, l. c. 197.-Perak.

BRAGHYOTUM. Triana(Melastom.).-Ind.Kew. i. 831 .

alpinum, Cogn, in DC. Monog. Phan. vii. (1891) 167. - Ecuad.

Andreanum, Cogn。 in Bull. Acad. Belg. Sér. III. xiv. (1887) 938. - Ecuad.

Barbeyanum, Cogn,in DC. Monog. Phan. vii. (1891) 148. - Peruvia.

Grisebachii, Cogn. l. c. 153. - Peruvia.

Lindenii, Cogn. l. c. 159. - N. Gran.

Maximowiczii, Cogn. l. c. 154. - Bolivia.

rotundifolium, Cogn. in Bull. Acad. Belg. Sér. III. xiv. (1887) 937. - Ecuad.

Trianaei, Cogn. in DC. Monog. Phan.vii.j(1891) 167. - Peruvia.

BRACHYPODIUM, Beauv. (Gramin.). - Ind. Kew. i. 331.

andinum, Hack. ex Sodiro, Gram. Ecuator. (Anal. Uniø. Quito, 1889) 10 nomen. - Ecuad.

\section{BRAGHYPODIUM}

glaucorivens, Murb. in Lunds Univ. Arsskrift, xxvii. v. (1892) $22=$ sylvaticum, Huds.

multiflorum, K. Schum. ex Engl. in Abhandl. Preuss. Akad. Wiss. (1894) 58; et Pflanzenw. Ost-Afr. A 1895) $100=$ Bromus russorensis, K. Schum.

ponticum, Velen, in Sitz. Boehm. Ges. Wiss. 1892 (1893) 71.-As. Min.

pubescens, K. Schum ex Engl. Pflanzenw. Ost-Afr. A (1895) $128=$ Bromus russoriensis, K. Schum. Quartinianum, Hack, ex Engl. in Abhandl, Preuss. Akad. Wiss. 1891 ii. (1892) $137(=$ Festuca Quartiniana, A. Rich.). - Abyss.

Wattii, C. B. Clavke, in fourn. Linn. Soc. xxv. (1889) 90. - Reg. Himal.

BRACHYSIPHON, A. Juss. = Sarcocolla, Linn.

(Penaeac.).
fucatus, Gilg, in Bot. Jahrb. xviii. (1894) 520 ; et in Engl, et Prantl. Natürl. Pflanzenfam. iii. 6 a. (1894) $212=$ S. fucata, Endl.

BRACHYST EGIA, Benth。(Legumin.). - Ind. Kew. i. 332,

Boehmii, Taub. in Engl. Pfanzenu. Ost-Afr. C (1895) 197. - Afr. or.

Fischeri, Taub. l. c ; et in Engl. et Prantl, Natür. Planzenfam. iii. 3 (1894) 387. - Afr. or

flagristipulata, Tanb. l. c. 198. - Afr. or.

itoliensis, Taub. l. c, 197 ; et in Engl. et Prantl. Natür? Pfanzenfam. iii. 3. (1894) 387. - Afr. or

Oliveri, Taub. l. c. 97. - Afr. or.

stipulacea, Taub. in Engl. et Prantl, Natiirl. Pfan zenfam. iii. 3 (1894) 387. - Afr. trop.

Welwitschii, Taub. l. c.-Angola.

BRACHYSTELMA, R, Br. (Asclep.). - Ind. Kew.i. 332.

Buchanani, N.E.Br.in Kew Bull. (1895) 263. Afr. trop. alistro-or.

caffrum, N. E. Br. in Gard. Chron, (1894) ii. 62. Afr. austr.

caffrum, Schlechter, in Bot. Fahrb. xviii Beibl. n. 45 (1894) 13. - Afr. austr.

caudatum, N. E. Br. ex K. Schum. in Engl. et Prantl, Natürl. Pflanzenfam. iv. 2. (1891) $268=$ crispum, $R$. Grah.

edulis, Collett et Henst. in Founn. Linn. Soc, xxviii. (1890) 89 t. 14. - Burma

eiranthum, "Schlecter» ex K. Schum. in Engl, et Prantl, Natürl, Pflanzenfam. iv. 2 (1891) 268 sphalm. = oianthum, Schlechter.

euphorbioides, $K$. Schum. in Bot. Fahrb. xvii. (1893) 149. - Afr. centr. bor.

foetidum, Schlechter, in Bot. Fahro. xx. Beibl. n. 51 (1895) 52. - Afr. austr.

keniense, Schweinf. in Hoehnel, zum Rudolph See, Append. (1892) 8; et in Abhandl. Preuss. Akad. Wiss. 1891. ii. (1892) 344. - Afr. trop. or.

magicum, N.E. Br. in Kew Bull. (1895) 263. Afr. centr. or

occidentale, Schlechter, in Verh. Bot. Ver, Brand. xxxv. (1893) 53. - Afr. austr.

oianthum, Schlechter, in Bot. Fahro. xx. Beibl. n. $51(1895)$ 53. - Afr. austr.

phyteumoides, K. Schum. l. c. xvii. (1893) 149, Afr. centr. bor.

pulchellum, Schlechter, l. c. xx, Beibl. n. 51 (1895) 53 ( = Micraster pulchellus, Haw.) - Afr. austr.

Schoenlandianum, Schlechter, in Bot. Fahrb. xviii.

Beibl. n. 45. (1894) 35. - Afr. austr.

shivense, Schlechter, in Journ. Bot. xxxiii. (1895) $339=$ Buchanani, $N$. E. Br.

BRACHYSTELRARIA, Schlechter, in Bot. Jahrb. xx. Beibl. n. 5I. (1895) 50. ASCLEPIA$D E A E$.

Gerrardi, Schlechter, l. c. 50.-Afr. austr.

longifolia, Schlechter, l. c. - Afr. austr.

macropetala, Schlechter, l. c. 51. - Afr. austr.

natalensis, Schlechter, l. c. 50. - Afr. austr.

ramosissima, Schlechter, $l$. c. - Afr. austr.

BRACHYSTEPHANUS, Nees (Acanth.). - Ind.

Kew. i. 332.

africanus, S. Moove, in Trans. Linn. Soc., Ser. II. iv. (1894) 3l. - Afr. trop. austro-or.
BRACHYSTEPHANUS cuspidatus, Baker, in fourn. Linn. Soc. xxv. (1890)
339. - Madag.

Holstii, Lindau, in Abhandl. Preuss. Akad. Wiss. (1894) 69; et in Bot. Fahrb xx. (1894) 53. - Afr. trop, or.

jaundensis, Lindan, in Bot. Fahrb. xxii. (1895) 125. - Kamerun.

longiflorus, Lindau, l. c. xx. (1894) 53; et in Engl. et Prantl, Natiorl. Pfanzenfan. iv. 3 b. (1895) 344. Afr. trop. occ.

occidentalis, Lindau, $l l . c c$. - Ins. S. Thom

yaudensis, Lindau, in Engl. et Prant1, Natürl. Pflanzenfam. iv. 3 b. (1895) 344 . = jaundensis, Lindau.

BRAGKENRIDGEA. A. Gray (Ochnac.).- Ind.

Kew. i, 332.
Hookerii, Gilg, in Engl. et Prantl, Naturl. Pflanzenfam. iii.6. (1893) 143 (=Gomphia Hookeri, Planch.).
- Penang.

BRADBURYA, Rafin, = Centrosema, Benth, (Legumin.).

angustifolia, arenaria, bifida, bracteosa, brasiliana, conjugata, coriacea, dasyantha, fasciculata, ferruginea, grandiflora, heptaphylla, macrocarpa, pascuorum platycarpa, Plumieri, pubescens, rotustifolia, simmata, venosa, vetula, vexillata, virginium, Kuntze, Rev. Gen. (1891) $164=$ homonyma omnia Centrosematis.

acutifolia, Kuntze, 1. c. = Centrosema brasilianum, Benth.

biflora, Kuntze, 1. c. = C. virginianum, Benth. decumbens, Kuntze, 1. co = C. virginianum, Benth。 dubia, Kuntze, 1. c. = C. hastatum, Benth.

glabra, Kuntze, 1. c. = C. coriaceum, Benth.

insulana, Kuntze, 1. c. = C. brasilianum, Benth.

longifolia, Kuntze, I. c. = C. angustifolium, Benth. oblonga, Kuntze, 1. C. = C. coriaceum, Benth.

triquetra, Kuntze, 1, c. = C. triquetrum, Benth. fide Kuntze.

BRADLEYA, Vell. = Amphyrrhox, Spreng. (Violar.).

latifolia, Kuntze, Rev. Gen. (1891) $40=$ A. latifolia, Mart.

longtfolia, Kuntze, 1. c. = A. longifolia, Spreng.

surinamensis, Kuntze, 1. c. = A. surinamensis, Eichl.

BRadshawia, F. Muell. in Proc. Linn. Soc. N. S. Wales, Ser. II. vi. (May, I892) $473=$ Rhamphicarpa, Benth. (Scrophul.).

macrosiphonia, F. Muell. 1. c. = R. macrosiphonia, F. Muell.

BRAGANTIA, Lour. (Aristol.). - Ind. Kew, i. 393.

Dalzellii, Hook. f. Fl. Brit. Ind.v. (1886) 73. - Ind. or.

BRAHEA, Mart. (Palm.), - Ind. Kew. i. 333 filifera, Hort. ex W. Wats. in Kew Bull. (1889) 296 = Washingtonia filifera, H. Wendl.

BRAMIA, Lour. = Herpestis, Gaertn. f. (Scro-

Mhun.). Gratiola Monniera, Linn.

BRANDEGEA, Cogn. in Proc, Calif. Acad. Ser. II. iii. (1890) 58. CUCURBITACEAE.

Bigelovil, Cogn. l. c. 58 (= Elaterium Bigelovii, S. Wats.). - Colorado.

monosperma, Cogn. l. c. 59 (= Cyclanthera monosperma, Brandeg.). - Calif.

BRANDISIA, Hook. f, et Thoms. (Scrophul.). Ind. Kew. i. 333

racemosa, Hemsl. in Hook. Icon. pl. xxv. (1895) t. 2383, et in Kew Bull. (1895) 114. - China.

BRASENTA Schreb. (Nymphaeacae).-Ind. Kew: i. 333 .

pelta, “Pers. ) ex Casp. in Engl. et Prant1, Natürl. Pflanzenfam. iii. 2. (1886)6 sphalm. = peltata, Pers. 
BRASILETTIA, Kuntze, Rev. Gen. (1891) $164=$ Peltophorum, Walp. (Legumin.).

adnata, Kuntze, 1. c. = P. adnatum, Griseb. africana, Kuntze, 1. c. = P. africanum, Sond. brasiliensis, Kuntze, 1. c. = P. Linnaei, Benth. dasyrhachis, Kuntze, 1. c. = P. dasyrachis, Kurz. dubia, Kuntze, 1. c. = P. Vogelianum, $W$ alp.

ferruginea, Kuntze, 1. c. $=$ P. ferrugineum, Benth

BRASSAIOPSIS, Decne et Planch. (Araliac.). Ind. Kew, i. 334

glomerulata, Kuntze, Rev. Gen. (1891) $271=$ glomerulata, Regel.

BRASSAVOLA, R. Br. (Orchid.). - - Ind. Kew, i. 342

stricta, Hort. ex Gard. Chron. (1885) i. 501 et 505 fig. 92 ; et (1889) ii. 355. - Form. hort.

BRASSIA, R. Br. (Orchid.). - Ind. Kew. i. 334 bicolor, Rolfe, in Lindenia, viii. (1892) 87 t. 378. Peruvia. Leursii, Rolfe, in Orchid Review, i. (1893) 149. -
Hab?

BRASSICA, (Tourn.) Linn. (Crucifer.). - Ind Kew. i. 334 .

acris, Kuntze, Rev. Gen. (1891) 17, $19=$ Diplotaxis Sieberi, Presl.

amplexicaulis, Batt. in Batt. et Trab. Fl. de l'Algé vie (Dicot.) (1888) 59. - Alger.

angustifolia, Kuntze, Rev. Gen, (1891) 20 = frutescens, Soland.?

arvensis, Kuntze, in Act. Hort. Petrop. x. (1887) 164; et Rev. Gen. (1891) 19 = B. Sinapistrum Boiss.

aurasiaca, Coss. et Kralik, ex Coss, Illustr. Al. Atlant. i. 31 t. 22; et Comp. Al. Atlant. ii. (1887) 199 . Algeria.

Bourgeaui, Kuntze, Rev. Gen. (1891)20.--ins. Canar

Dianae, Lacaita, ex Willk. Suppl. Prod, fl. Hisp. (1893) 309. in syn. = Diplotaxis maritima, Rouy. erucastroides, Stapf, in Denkschr. Acad. Wien, Ii. (1886) 36. - Persia.

erucodes, Kuntze, Rev. Gen. (1891) 17 = Diplotaxis erucoides, $D C$

frutescens, Kuntze. 1. c. $20=$ frutescens, Soland.? glauca, Kuntze, l.c. - Ins. Canar.

griquensis, N.E. Br. in Kew. Bull. (1894) 353. Afr. austr.

juncea, Czern. ex Palibin, in Act Hort. Petrop. xiv. (1895) $109=$ juncea, Coss.

lasiocalycina, Boiss. Fl. Or. Suppl. (1888) 66

(= Erucastrum lasiocalycinum, Boiss.). - As. Min.

Munbyana, Coss. et Durieu, ex Coss. Comp. fl Atlant. ii, (1887) 199 in syn. = setulosa, Coss.

palmensis, Kuntze, Rev. Gen. (1891) 20. - Ins. Palma.

Persoonii, Rouy et Fouc. Fl, de Fr. ii. (1895) $5 \mathbf{l}=$ sinapoides, Roth.

radicata, Batt. in Batt. et Trab. F1. de l'Algérie (Dicot.) (1888) $59=$ fruticulosa, Cyril.

Richeri, St-Lager, in Cariot, Étud, des $\mathrm{fl}$ éd. 8 , ii, (1889) $54=$ Richeri, Vill.

rupestris, Kuntze, Rev. Gen. (1891) 20. - Ins. Mader.

setulosa, Coss. Illustr. Al. Atlant. i. 32 t. 23; et Comp.

f. Atlant. ii. (1887) 199. - Algeria.

Souliei, Batt. in Bull. Soc. Bot.Fr. xi. (1893) 262 - Algeria.

turgida, Rouy et Fouc. F1, de Fr. ii. (1895) $51=$ sinapoides, Roth.

Vogelii, Kuntze, Rev. Gen. (1890) 20. - Ins. Cap, Virid.

BRASSO-CATTLEYA $\times$, Rolfe, in Gard. Chron. (1889) ii. 78; et (1890) ii. 241. ORCHIDEAE.

Lindleyana $\times$, Rolfe, 11. cc. (= Laelia Lindleyana Veitch.). - Hybr, artef.

BRAUNERIA, Neck. = Echinacea, Moench $($ Composit.).

pallida, Britton, in Mem. Torrey Bot. Club, v. (1894) 334. = E. angustifolia, DC

purpurea, Britton, 1. c. $334=$ E. purpurea, Moench.
BRAVAISIA, DC. (Acanth.),-Ind, Kew. i. 336. tubiflora, Hemsl. in Hook. Icon. pl, xvi. (1886) t. 1516; et Biol. Centr.-Am.iv. (1886) 106. - Ins. Cozumel (Yucatan).

BRAVOA, Lex. (Amaryll.). - Ind. Kew. i. 336. densiflora, Robins, et Fernald, in Proc. Am. Acad. xxx. (1895) 122. - Mexic.

singuliflora, S. Wats. l. c. xxii. (1887) 479, Mexic.

BRAYA, Sternb, et Hoppe(Crucifer.).- Ind. Kew. i. 336 .

pectinata, Greene, in Erythea, iii. (1895) 69. - Calif. rubicunda, Franch. in Bull. Soc bot. Fr. xxxiii. (1889) 403. - China occ.

sinensis, Hemsl. in fourn. Linn. Soc. xxx. (1892) 303. - China occ.

sinuata, Maxim. Fl. Tangut. (1889) 69 t. 28 fig 24. 33. - Tibet.

BRAzzera, Baill. in Bull. Soc. Linn. Paris, i. (1886) 609. TILIACEAE.

congoensis, Baill. l. c. - Congo gall.

Tholloni, Baill. l. c. ii. (1890) 868. - Congo gall,

BREDEMEYERA, Willd. (Polygal.) - Ind. Kew 1. 327

Autrani, Chod, in Bull. Herb. Boiss. ii.(1894), 171.Bras.

Barbeyana, Chod. l. c. 183. - Bras.

confusa, Chod. l.c. - Bras.

Huberiana, Chod. l. c. 172. - Bras.

Isabelliana, Barb. Rodr. in Vellosia, i, (1885-8) Sec. edic. (1891) 5 t. 4. b. - Bras.

BREDIA, Blume (Melastom.) - Ind. Kew. i. 337. quadrangularis, Cogn. in DC. Monog. Phan. vii. (1891) 473. - China.

BREVOORTIA, Wood (Liliac.). - Ind. Kew. i. 337.

venusta, Greene, Pittonia, ii. (May 1892) $230=$ Brodiaea venusta, Greene.

BREWERIA, R. Br. (Convolvul.). - Ind. Kew. $33 \%$.

angustifolia, Nash, in Bull. Torrey Bot. Club, xxii. (1895) 155. - Florida.

argentea, Terrac, in Ann. Ist, bot. Roma, v. (1894) 104. - Afr. or.

baccharoides, Baker, in Kew Bull. (1894) 68. Zambesia.

buddleoides, Baker, l, c. 69. - Afr. trop. or.

campanulata, Baker, l. 6.68. - Gabon.

campanulata, $K$. Schum, ex Hallier f. in Bot. Zahrb. xviii. (1894) 92 (= Prevostea campanulata, K. Schum.). - Afr. trop.

Codonanthus, Baker, ex Oliver, in Hook. f. Icon.pl. xxiii. (1894) sub t. 2276 in obs. (= Prevostea africana, Benth.). - Afr, trop.

conglomerata. Baker, in Kew Bull. (1894) 68. Angola.

densiflora, Baker, in fourn. Limn. Soc. xxv. (1890) 336. - Madag.

Heudelotii, Baker, ex Oliver, in Hook. Icon. pl. xxiii. (1894) t. 2276 ; et in Kew Bull. (1894) 68. - Afr. trop. occ.

latifolia, Terrac. in Ann. Ist. bot. Roma, v. (1894) 104 (= Seddera latifolia, Hochst. et Steud.). Afr. trop. or.

microcephala, Baker, in Kew Bull. (1894) 68. Angola.

mirabilis, Baker, ex Oliver, in Hook. f. Icon. pl. xxiii. sub t. 2276 in obs. - Gabon.

montevidensis, Peter, in Engl. et Prantl, Natiirl. Pfanzenfam. iv, 3a. (1891) 16. - Reg. Argent.

rotundifolia, S. Wats. in Proc. Am, Acad. xxiii. (1888) 281. - Mexic.

semidigyna, Kuntze, Rev. Gen.(1891) $440=$ cordata, Blume.

sessiliflora, Baker, in Kew Bull. (1894) 68. - Zambezia.

suffruticosa, Schinz, in Verh. Bot. Ver. Brand. xxx. (1888) 275. - Afr. austro-occ, extratrop.

tenella, Peter, in Engl. et Prantl, Natirrl. Pfanzenfam. iv. 3a. (189l) 16. - Georg., Florida.

\section{BREWERIA}

tiliaefolia, Baker, in fourn. Linn. Soc. xxii. (1887) 508. - Madag.

villosa, Nash, in Bull. Torrey Bot. Club, xxii. (1895) 154. - Florida.

BREYNIA, Forst. (Euphorb.). - Ind. Kew. 337.

angustifolia, Hook. f. Fl. Brit. Ind. v. (I887) 330.-Ind. or.

coronata, Hook. f.l. c.-Perak.

officinalis, Hemst. in fourn. Linn. Soc. xxvi. (1894) 427. - China

reclinata, Hook. f. Fl. Brit. Ind. v. (1887) 331. As. trop.

vestita, Warb. in Bot. Fahrb. xiii. (1891) 354 . Oceania.

BRICKELLIA, E11. (Compos.). - Ind. Kew. i.

brachiata, A. Gray, in Proc. Ant. Acad. xxi. (1886) 431 nomen. - Mexic.

cuspidata, A. Gray, l. c. xxii. (1887) 421.- Mexic. desertorum, Coville, in Proc. Biol. Soc. Wash vii. (1892) 68 (= Coleosanthus desertorum, Coville). Am. bor. occ

glutinosa, S. Wats. in Proc. Am. Acad. xxi. (1886) 385. - Mexic

Knappiana, E. C. Drew, in Greene, Pittonia, i. (Oct. 1888) 260. - Calif.

lanciifolia, Robins. et Greenm, in Am. foum. So. Ser. III. i. (1895) 152. - Mexic

nutans, Robins, et Greenm. l. c. - Mexic.

orizabensis, Klatt, in Annal. naturh. Hofmus. Wicn, ix. (1894) 358. - Mexic.

pacayensis, Coult. Bot. Gaz. xvi. (1891) 98 (= Coleosanthus pacayensis, Coult.) - Guatem.

rhomboidea, Greene, Pittonia, ii. (June 1890) 103.Calif.

solidaginifolia, A. Gray, in Proc. Am. Acad. xxii. (1887) 306. - Mexic

squarrosa, Robins. et Seaton, in Proc. Am. Acad. xxviii. (1893) 108. - Mexic.

BRIDELIA, Willd. (Euphorb.).- Ind. Kew. i. 338. burmanica, Hook. f. Fl. Brit. Ind. v. (1887) 269 . Burma.

cinnamomea, Hook. f. l. c. 273. - Perak.

Curtisii, Hook. f.l.c. -. Penang

Fischeri, Pax, in Bot. Fahrb. xv. (1893) 53. - Afr. trop. or.

Fordii, Hemsl. in fourn. Linn. Soc. xxvi. (1894) 419. - China.

Griffithii, Hook. f. Fl. Brit. Ind. v. (1887) 272. Ind. or.

Kurzii, Hook.f.l. c. - Ins. Nicob.

minutiflora, Hook. f. l. c. 273. - As. trop. insul.

parvifolia, Kuntze, Rev. Gen.(1891) 594. - Anam

penangiana, Hook. f. Fl. Brit. Ind. v. (1887) 272.Penang

pustulata, Hook.f. I. c. 271. - Malacca.

rufa, Hook.f.l. c. 273. - Penang.

scleroneuroides, Pax, in Bot. Fahrb, xv, (1893) 532. - Afr. centr. bor.

taitensis, Vatke et Pax, ex Pax, l. c.531.-Afr. trop.

zanzibarensis, Vatke et Pax, l. c. 530. - Zanzib.

BRILLANTAISIA, Beauv. (Acanth.). - Ind. Kew. i. 339.

anomala, Lindau, in Engl. Pflanzenw. Ost-Afr. C (1895) 366; et in Engl. ot Prantl, Natürl. Pfanzenzfam. iv. 3 b. (1895) 296. - Afr. trop. or.

cicatricosa, Lindau, in Engl. Bot. fahrb. xx. (1894) 4. - Afr. trop. or.

Emini, Lindau, l. c. xvii (1893) 103. - Afr. centr. or

lancifolia, Lindau, l. c. 98. - Afr. trop. or

madagascariensis, T. Anders. ex Lindau, l. c. xvii 103. - Madag.

Molleri, Lindau, l. c. 99. - Ins. S. Thom.

nitens, Lindau, l. c. 102. - Afr. trop. occ

Palisotii, Lindan, l. c 99. - Afr. trop.

Preussii, Lindau, l. c. 100. - Kamerun.

salviflora, Lindau, l. c. 101 ; et in Engl. et Prantl. Natür. Pfanzenfam. iv. 3b. (1895) 296. - Afr. trop. occ. 


\section{BRILLANTAISIA}

chumanniana, Lindau, in Bot. Fahrb. xx. (1894) 102:- - Kamerun.

Soyauxii, Lindau, l. c. 101. - Gabon.

spicata, Lindau, ex Engl. in Abhandl. Prenss. Akad. Wiss. (1894) 50 et 54 ; et in Bot. Fahrb. xx. (1894) 4 . - Afr. trop. or.

nlugurica, Lindau, in Engl. Pfanzenfam. Ost-Afr. A (1895) 91 nomen; et l. c. xxil. (1895) 112. - Afr trop. or.

verruculosa, Lindau, l. c. 113. - Kamerun.

BRINTONIA, Greene, in Erythea, iii. (1895) $89=$ Solidago, Vaill. (Compos.).

discoidea, Greene, 1. c. = S. discoidea, Torr. et Gray.

BRITOA, Berg = Campomanesia, Ruiz et Pav. (Rubiac.)

Glasioviand, Kiaersk. Enum. Myrt. Bras, (1893) 6 . - Bras.

Langsdorffi, Niedenzu, in Engl. et Prantl, Natür1. Pflanzenfam. iii. 7. (1892) 74 (= Acrandra Langsdorffi, Berg, fide Kuntze). - Bras.

Lundiana, Kiaersk. Enum. Myrt. Bras. (1893) 7. Bras.

BRITTENIA, Cogn, in Boer1. Handl. Fl. Ned. Indië 1. ii. (1890) 5l5; et in DC. Monog. Phan. vii. (1891) 519. MELASTOMACEAE

subacaulis, Cogn. ll. cc. - Borneo

BRITTONAMRA, Kuntze, Rev. Gen. (1891) $164=$ Cracca, Benth. (Legumin.).

carbaca, Kuntze, 1. c. = C. caribaea, Benth.

sericea, Kearn., in Trans. N. Y. Acad. Sc. xiv

(1894) $32=$ C. sericea, A. Gray.

BRITTONELLA, Rusby, in Bull. Torrey Bot. Club. xx. (1893) 429. MALPIGHTACEAE.

pilosa, Rusby, l.c. 430 t. 147. - Bolivia.

BRITTONIA, Kuntze, Rev.Gen. (1891) 173 sphalm. $=$ BRISSONIA, Neck. = Indigofera, Linn (Legumin.).

BRIZA, Linn. (Gramin.). - Ind. Kew. i. 339. gracilss, Hort. ex Kew Bull. (1892) Append. i. 4 - (Quid?).

BRIZOPYRUM, J. Presl = Distichlis, Rafin. uninerinum, Fourn. Gramin. Mexic. 1881 (1886) 121 $=$ Eragrostis uninervia, Stend.

BROCCHIA, Vis. = Cotula, Linn. (Compos.) erea, Batt. in Batt, et Trab. Fl. de l'Algér. Dicot.) $(1890) 467(=B$. cinerea, Vis. $)=C$. cinerea, Delile.

BROGGHINIA, Schult. f. (Bromel.), - Ind. Kew.

Andreana, Hort. ex Baker, Handb. Bromel. (1889; $\mathrm{S} S=$ cordylinoides, Baker.

demerarensis $x$. Hort. ex Baker, 1. $c$. = cordylinoides, Bakex.

BROCCHONEURA, Warb, in Abhandl. Preuss. Akad. IViss, (1894) 44 nomen : et in Engl. Pflanzenw. Ost-Afr, C (1895) 179. MYRISTICACEAE. pterocarpa, Warb. in Ber. Deutsch. bot. Ges, xiii. (1895) [89]. - Afr. trop.

isambarensis, Warb. in Abhandl. Preuss. Akad. Wiss. (1894) 44 ; et in Engl. Pflanzenw. Ost-Afr. C (1895) 180. - Afr. trop. or.

BRODIAEA, Sm. (Liliac.). — Ind. Kew. i. 340.

bivalvis, Fr. Meigent, in Bot. Fahrb, xvii. (1893) 224 (= Milla bivalvis, Baker). - Chili.

Bridgesii, S. Wats, in Gard. and For. i. (18S8) 125. - Calif.

Hendersoni, Howell, ex Grecne, Pittonia, i. (Feb. 1888) 164. - Oregon.

Hendersoni, S. Wats, in Proc. Am. Acad. xviii. (1888) $366=$ praec

I da Maia, Greene, Pittonia, ii. (July 1892) 250 = Brevoortia Ida-Maia, Wood.

\section{BRODIAEA}

nsularıs, Greene, in Bull. Calif. Acad. ii. (1886)

134. - Am. bor, austro-occ.

Palmeri, S. Wats. in Proc. Am. Acad. xxiv. (1889) 78. - Calif.

Poeppigiana, Kurtz, in Verh. Bot. Ver.Brand, xxxv. (1894) $112=$ Milla Poeppigiana, Baker.

porrifolia, Fr. Meigen, in Bot. Jarhb. xvii. (1893) $225=$ Milla porrifolia, Baker

pulchella, Greene, in Bull. Calif. Acad.ii. (1886) 133 $=$ congesta, Sm.

sessilis, Fr. Meigen, in Bot. Jahrb. xvii. (1893) 225 = Milla sessiliftora, Baker.

uniflora, Eng1, in Engl, et Prantl, Natürl. Pflanzenfam. iii. 5. (1887) 57 = Milla uniflora, $R$. Grah.

venusta, Greene, Pittonia, ii. (July 1892) 250 (=Brevoortia venusta, Greene). - Calif.

BROMELIA, (Plum.)Linn. (Bromel.).--Ind. Kew. i. 340

argentina, Baker, in Kew Bull. (1892) 194 ; et in Hook. Icon. pl, xxiii. (1893) t. 2228. - Reg. Argent. Balansae, Mez, in Mart. Fl.Bras. iii. III. (1891) 181. - Parag.

Desmetiana, Hort, ex Baker, in Bot. Mag. (1894) sub t. 7340 in syn. = Dyckia Desmetiana, Baker. Hieronymi, Mez, in Mart. Fl. Bras. iii. III. (1891) 199. - Reg. Argent.

Lagopus, Mez,l.c.188 (= Karatas Lagopus, Ed. Morr.). - Panam

Legrellae, $\mathrm{Mez}, 1$. c. $179=$ Karatas Legrellae, Ed. Morr

Lindmani, Mez, l. c. (1894) 621. - Bras.

macrodosa, Hort. ex Baker, Handb. Bromel. (1889) 24 in syn. = Ananas macrodontes, Ed. Morr

Moensii, (sphalm.? Moensis) Éd. Morr. ex Baker,

1. c. $14=$ Distiacanthus Morrenianus, Baker.

Morreniana, Mez, in Mart. Fl. Bras. iii. II. (1891) $186=$ Distiacanthus Morrenianus, Baker.

Poeppigii, Mez, l. c. 188. - Peruvia.

Regnelli, Mez, l.c. 194. - Bras.

reversacantha, Mez.l.c. 198. - Bras.

sylvicola, S. Moove, in Trans. Linn. Soc. Ser. II, iv. (1895) 490. - Bras.

undulata, Hort. ex Baker, Handb. Bromel. (1889) 23 in syn. = Ananas macradontes, Ed. Morr.

BROMHEADIA, Lindl. (Orchid.). - Ind, Kew.

1.icola, Ridl. in fourn. Linn, Soc. xxviii. (1891)

alticola, Ridl. in fourn. Linn
338 t. 42. - Penins. Mal.

rigida, Ridl. ex Stapf, in Trans. Linn. Soc. Ser. II. iv. (1893) 239. - Borneo.

sylvestris, Ridl. in foum. Limn. Soc. xxviii. (1891)

337. - Penins. Mal.

BROMUS, Dill. ex Linn: (Gramin.). - Ind. Kew. i. 341 .

adjaricus, Somm et Levier, in Act. Hort. Petrop. xiii. (1893) 51. - Reg. Cauc.

barcensis, Simonk. Enum. fl. Transsilv. (1886) 584 $=$ erectus, Linn.

Benekeni, G. Beck, Fl. Nieder-Oest. i. (1890) $107=$ asper, Murr.

demissus, Portu, in Nuon. Giom, bot. Ital. xix. (1887) 328. - Ins. Balear.

eburonensis, C. Richt. Pl. Eurup. i. (1890) $117=$ arduennensis, Dumort.

hannoveranus X, C. Richt. 1, c, - Germ.

interruptus, G. C. Druce, in fourn. Bot. xxxii. (1895) 344. - Brit.

Macounii, Vasey, in Bull. Torrey Bot. Club, xv. (1S88) 48. - Ins. Vancouv.

macrantherts, Hack, in Bull. Soc, bot. Fr. xxxiv. (1887) 395 in obs. = rigidus, Roth.

macrantherus, Trab. in Batt, et Trab. Fl. de l'Al. gérie (Monoc.) ((1895) $226=$ praec

milanjianus, Rcndle, in Trans. Linn. Soc. Ser. II iv. (1894) 59. - Afr. trop. austro-or.

mutans, St-Lager, in Cariot, Étud. des fl. éd. 8 ii. (1889) $945=$ tectorum, I inn.

Porteri, Nash, in Bull. Torrey Bot. Club, xxii. (1895) 512. - Am. bor.

Punpelli, Scribn, in Bull. Torrey Bot. Club, xv, (1888) 9 xylogr. = Pumpellianus, Scribn.

Pumpellianus, Scribn. l. c.9 t. '76, fig. d. - Am. bor.occ.

\section{BROMUS :}

unssoroensis, $K$. Schum. in Engl. Pflanzenw. OstAfr.C (1895) 116. - Afr. trop or.

scaberrimus, St-Lager, in Cariot, Etud. des fl. éd. 8 ii. (1889) 946 = sterilis, $\operatorname{Linn}$.

splendens, Velen. in Sitz. boehm. Ges. Wiss. (1886) 46 sep. ex Nym. Consp. fl. Eur. Suppl. II. i. (1889) 387 = arvensis, Linn.

tunetanus, Hack. ex Trab. in Batt. et Trab. F1. de l'Algérie (Monoc.) (1895) $228=$ mollis, Linn.

BRONGNIARTIA, H. B. et K. (Legumin.). -

Ind. Kew. i. 344 .
inconstans, S. Wats, in Proc. Am. Acad. xxii. (I887) 404. - Mexic.

lupinoides, Taub. in Bull. Herb. Boiss. iii. (1895) $613=$ Peraltea lupinoides, Kunth.

nudiflora, S. Wats. in Proc. Am. Acad, xxv. (1890) 146. - Mexic

Palmeri, Rose, in Contrib. U.S. Nat. Herb. i. (1891) 97. - Mexic.

BROOKEA, Benth. (Scrophul.). - Ind. Kew. i. 444

albicans, Stapf, in Trans. Linn. Soc. Ser. II. iv, (1894) 211. - Borneo

BROSIMOPSIS, S. Moore, in Trans. Linn. Soc. Ser. II. iv. (1895) 473, - URTICEAE.

lactescens, $S$. Moove, l. c. t. 31.-Bras.

BROSIMUM, Sw. (Urtic.). - Ind. Kew. i. 344. glaucum, Taub. in Bot. Fahrb. xii. Beibl. n. 27 (1890) 4. - Bras.

Glaziovii, Taub.l.c. 3. - Bras.

rubescens, Taub. l. $c_{0}$ - Bras.

BROSSEA, Kuntze, Rev. Gen. (1891) $387=$ BROS SAEA, Plum. = Gaultheria, Kalm (Ericac.). acuminata, adenothrix, anastomosans, antarctica, brachybotrys, bracteatu, buxifolia, caespitosa, candida, conferta, crenulata, elliptica, erecta, fagifolia, ferruginea, foliolosa, formosa, fragrantissima, glabra, glaucifolia, Griffithiana, hirtiflora, hispida, insipida. lanceolata, lanigera, leucocarpa, Lindeniana, loxensis, microphylla, mucronata, nitida, odorata, oppositifolia, organensis. ovata, pichinchensis, Poeppigii, procumbens, purpurascens, ramosissima, reticulata, rigida, Roraimae, rufescens, rupestris, scabra, secunda, Shatlon, strigosa, tomentosa, trichocalycina, trichophylla, triquetra, venusta et vestita, Kuntze, Rev. Gen. (1891) 387 = homonyma ommia Gaultheriae.

antipoda, Kuntze, 1. c. = G. microphylla, Hook. $f$. bandongensis, Kuntze, 1. c. = G. leucocarpa, Blume. mummlariodes, Kuntze, 1. $\mathrm{c}=\mathrm{G}$. nummularioides, D. Don.

Philippiana, Kuntze, 1.c. = G. mucronata, Phil.

pyrolifolia, Kuntze, 1. c. = G. pyrolaefolia, Hook.f. pyrolodes, Kuntze, 1. c. = G pyrolaefolia, Hook. $f$. scabra, Kuntze, 1. c. = G. odorata, Willd.

BROTEROA, Kuntze, Rev. Gen. (1891) $322=$ BROTERA, Willd.=Cardopatium, Juss. (Compos.). amcthystina, Kuntze, 1. c.=C. amethystinum, Spach. atractylodes, Kuntze, 1.c. = C. atractyloides, Winkl. Boryi, Kuntze, 1. c. = C. Boryi, Spach.

BROUGHTONIA, R. Br. (Orchid.). - Ind. Kew. i. 344 .

domingensis, Rolfe, in Gard. Chron. (1889) i. 491 $(=$ Cattleya domingensis, Lindl.). - Ind. occ.

fusca, Wall. ex Hook. f. Fl. Brit. Ind. V. (1890) 844 $=$ Otochilus fusca, $L$ indl.

linearis, Wall. ex. Hook. f. 1. c. $836=$ Coelogyne ovalis, Linal.

pendula, Wall. ex Hook. f. 1. c. $843=$ Coel. alba, Lindl.

BROUSEMICHEA Balansa, in Morot, Journ. de Bot. iv. (1890) 163. GRAMINEAE.

seslerioides, Balansa l.c. - Tonkin.

BROUSSONETIA, L'Hérit. (Urticac.). - Ind. Kew.i. 344 .

Kasi, Hort. ex Dippel, Handb. Laubholzk. ii. (1892) $17=$ papyrifera, $V$ ent. 
BROWNEA, Jacq. (Legumin.). - Ind. Kew. i. 344

Crawfordi, $\times$ W. Wats, in Gard, Chron. (1891) i. 398. - Hybr. artef

BROWNLEEA, Harv. (Orchid.). - Ind. Kew. i. 345.

Galpini, Bolus, Icon. Orchid. Austro-Afr.1.i. (1893) t. 42. - Afr. austr.

madagascarica, Ridl. in Journ. Linn. Soc. xxii. (1886) 126 = coerulea, Havv.

monophylla, Schlechter, in Bot. Jahrb. xx. Beibl. n. 50 (1895) $18=$ caerulea, Harv.

BROWNLOWIA, Roxb. (Tiliac.). - Ind. Kew. i. -345 .

lepidota, Warb. in Bot. Fahrb. xviii. (18.94) 200. Oceania.

BRUGEA, J. S. Mill. (Simarub.). - Ind. Kew. i. 345

tenuifolia, Engl. in Abhandl. Preuss. Akad. Wiss (1894) 44; et Pfanzenw. Ost-Afr. A (1895) 12 nomen - Afr. trop. or.

BRUGMANSIA, Pers.=Datura, Linn. (Solanac.) aurea, Lagerh. in Gartenfl. (1893) 33. - Ecuad. chlorantha, Hort ex Garden (1894) $528=\mathrm{D}$. arborea, Linn.

cornigera, Lagerh. in Bot. Jahrb. xx. (1895) $663=$ D. cornigera, Hook.

dolichocarpa, Lagerh. 1. c. 665. - Ecuad.

longifolia, Lagerh. 1. c. 666. - Ecuad.

versicolor, Lagerh. 1. c. - Ecuad.

BRUNELLA, Tourn, ex Linn, = Prunella, Linn. (Labiat.).

bicolor X, G. Beck, in Oest. Bot. Zeitschr. (1890) 237. - Eur. centr.

capitellata, G. Beck, in Ann. Naturh. Hofmus. Wien, ii. (1887) $146=\mathrm{P}$. vulgaris, Linn.

elatior $火, \mathrm{G}$. Beck, 1.c. Bosnia.

integerrima, G. Beck, 1. c. = P. laciniata, Limn.

spuria X, Stapf, in Kern. Sched. fl. Austro-Hung. iv. (1886) 69. - Austria.

vulgaris, Greene, Man. Bot. San Franc. Bay (1892) $293(=$ B. vulgaris, Benth.). = P. vulgaris. Linn.

BRUNELLIA, Rujz et Pav. (Simarub.). - Ind Kew. i. 345.

boliviana, Britton, ex Rusby, in Mem. Torrey Bot. Club, III. iii. (1893) 13. - Bolivia.

integrifolia, Szyszyl. in Diss, math.-nat. Acad. litt. Cracov. xxvii. (1894) 141. - Venez.

Oliverii. Britton, in Bull. Torrey Bot. Club, xvi. (1889) 160. - Bolivia.

Stuebelii, Hieron. in Bot. Fahrb. xxi. (1895) 317. N. Gran.

BRUNSVIGIA, Heist. (Amaryll.).- Ind. Kew. i. 346.

Banksiana, Th. Dur. et Schinz, Consp. fl. Afr. v. 1893 (1895) 253 = Slateriana Benth, et Hook. $f$.

Kirkii, Baker, Handb. Amaryll. (1888) 99. - Afr. trop. or.

Massaiana, L. Lind. et Rodigas, in Illustr. Hortic. xxxiv. (1887) 55 t. $19=$ Crinum Massaianum N.E. Br.

BRYA, R. Br. (Legumin.). - Ind. Kew. i. 347. morphoides, S. Wats. in Proc. Am. Acad. xxii (1887) 406 (= Aeschynomene amorphoides, Rose). Mexic.

BRYANTHUS, S. G. Gmel. (Ericac.).--Ind. Kew. i. 347 .

coeruleus Dippel, Handb. Laubholzk. i. (1889) 385 $=$ taxifolius, $A$. Gray.

BRYODES, Benth. (Scrophul.). - Ind. Kew. i. 347.

minutissima, Phil. in Anal. Univ. Chil. xci. (1895). 503. - Chili.

BRYONIA, Linn. (Cucurbit.). - Ind. Kew. i. 347. marmorata, E. Petit, in Bot. Tidskr. xvii. (1889) 242.

\section{BRYONIA}

monoica, Aitch. et Hemsl., in Trans. Linn. Soc. Ser. II. 111. (1886) 65, - Turkest

BRYOPHYLLUM, Salisb. (Crassul.). - Ind. Kew, i. 348 .

pinnatum, Aschers. et Schweinf. Illustr.fl. Égypte, ex Mém. Inst. égypt. ii. (1887) $79=$ calycinum, Salisb.

rubellum, Baker, in fourn. Linn. Soc. xxv.(1890) 314 - Madag.

BUCEPHALON, Linn. = Trophis Linn. (Urtic.). glabratum, Kuntze, Rev. Gen. (1891) $624=$ T. glabrata, Liebm.

mexicanum, Kuntze, 1. c. = T. mexicana, Bur.

BUCEPHALOPHORA, Pau, Not. bot. fl. Espan. i. (1887) 24 = Rumex, Linn. (Polygon.). aculeata. Pau, 1. c. = R. bucephalophorus, Linn.

BUCERAS, P. Br, = Terminalia, Linn. (Combretac.)

angustifolia, Hitchc, in Missouri Bot. Gard. Rep. iv. (1893) $85=$ T. Buceras, Wright.

Catappa, Hitchc. 1. c. = T. Catappa, Linn.

BUCHANANIA, Spreng. (Anacard.).-- Ind. Kew.

i. 349 . 363. - Oceania.

BUCHENROEDERA, Eckl. et Zeyh. (Legumin.). - Ind. Kew. i. 349.

lotononoides, S. Elliot, in Fourn. Bot. xxix.(1891) 68 . - Afr. austr.

BUCHHOLZIA, Engl. Bot. Jahrb. vii. (1886) 335. CAPPARIDEAE.

coriacea, Engl, l. c. - Kamerun.

macrophylla, Pax, in Engl. et Prantl, Natürl. Pfanzenfam. iii. 2. (1891) 232, et in Bot. Jahrb. xiv. (1892) 300. - Gabon.

Tholloniana, Hua, in Bull. Soc. Philom. Paris, Sér. VIII, vii. (1895) 78. - Afr. trop. occ.

BUGHNERA, Linn. (Scrophul.). - Ind. Kew. i. angolensis, Eugl. Bot. Fahrb. xviii. (1894) 70. Angola.

Bragaana, Engl. Pfanzenw. Ost-Afr. C (1895) 360. (err. cal.? Bragaeana, loc. cit. ad calc.) - Afr. trop. or.

Browniana, Schinz, in Verh. Bot. Ver. Brand. xxxi. (1890) 195. - Afr, austro-occ. extratrop.

Buettneri, Engl. Bot. Fahrb. xviii. (1894) 72. - Afr. trop. occ.

ciliolata, Engl. l. c. 69. - Angola

Henriquesii, Engl.l.c. - Angola.

Klingii, Engl. l.c. - Afr, trop, occ.

Lastii, Engl. Pflanzenw. Ost-Afr. C (1895) 359.Afr. trop, or.

longespicata, Schinz, in Verh. Bot. Ver. Brand. xxxi. (1890) 193. - Afr, austro-occ. extratrop.

multicaulis, Engl. Bot. Fahrb. xviii. (1894) 69. Angola, Congo.

Poggei, Engl.l. c. - Angola.

quadrifaria, Baker, in Kew Bull. (1895) 71. - Afr. centr. or.

quangensis, Engl. Bot. fahrb. xviii. (1894) 71.Congo mer.

Reissiana, Buettn ex Engl. l. c. 68 in obs. - Hab.? splendens, Engl. l.c. 71. - Angola.

subcapitata, Engl. l. c.- Angola.

Welwitschii, Engl. l.c. 70. - Angola.

BUGHNERODENDRON, Gürke, in Bot. Jahrb. xviii. (1894) 161. BIXINEAE.

speciosum, Gürke, l.c. - Congo.

BUDA, Adans. = Spergularia, C. et J. Presl $(\mathrm{Ca}$

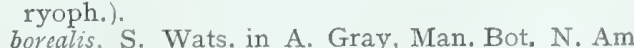
borealis, S. Wats. in A. Gray, Man. Bot. N. Am
Stat. ed. vi. (1890) $90=$ S. rubra, f. et C. Presl. diandra, Kuntze, Rev. Gen. (1891) $50=$ S. diandra Boiss.

macrothece, Kuntze, 1. c. = S. macrotheca. Horn. platensis, Kuntze, 1. c. = S. platensis, Camb.
BUDA :

rupestris, F. Hanb: Lond. Cat. Pl. ed. ix. $12=$ S. rupestris, Guss.

BUDDLEIA, Houst. ex Linn. (Loganiac.). - Ind. Kew. i. 351 .

albiflora, Hemsl. in fourn. Linn. Soc. xxvi. (1889) 118. - China.

andina, Britton, ex Rusby, in Mem. Torrey Bot. Club, iv. (I893) 222 - Bolivia.

chapalana, Robins. in Proc. Am. Acad. xxvi. (1891) 169. - Mexic.

cuspidata, Baker, in Kew Bull.(1895) 113. - Madag.

Davidi, Franch. in Nouv.Arch. Mus. Paris, Sér. II. x 1887-88) 65. - China.

Geisseana, Phil. in Anal. Univ. Chil. xci. (1895). 111 (Buddleja). - Chili.

Glaziovii, Taub, in Bot, fahrb, xvii. (1893) 514. Bras.

insignis, Hort. ex Dippel, Handb. Laubholzk. i, (1889) $\mathbf{1 5 4}=$ Lindleyana, Fortune.

japonica, Hemsl. in fourn. Linn. Soc. xxvi. (1889) 119 in obs. - Japon.

Nettoana, Taub. in Bot. Fahrb. xvii. (1893) 514. Bras.

pulchella, N.E.Br. in Kew Bull. (1894) 389. - Afr austr.

salicifolia, Hort. ex Dippel, Handb. Laubholzk. i. (1889, $153=$ Lindleyana, Fortune.

speciosissima, Taub. in Bot. fahrb. xvii. (1893) 513. - Bras.

sphaerocalyx, Baker, in fourn. Linn.Soc. xxii. (1887) 505. - Madag.

Szyszylowiczii, A. Zahlbr.in Ann. naturh. Hofmus. Wien, vii. (1892) 6. - Peruvia.

usambarensis, Gilg, ex Engl. in Abhandl. Preuss. Akad. Wiss. (1894) 40 et 63 nomen; et in Pfanzenw. Ost-Afr. C (1895) 313. - Afr, trop. or.

utahensis, Coville, in Proc. Biol. Soc. Wash. vii. (1892) 69; et in Contv. U.S.Nat. Herb. iv. (1895) 149 t. 12. - Calif.

variabilis, Hemsl. in fourn. Linn. Soc. xxvi. (1889) 120. - China

Wrightii, Robins, in Coult. Bot. Gaz. xvi. (1891) 341. - Mexic.

BUECHNERA, "Linn. " ex Wettst. in Engl. et Prantl, Natürl. Pflanzenfam. iv. 3 b. (1891) 94 sphalm. = Buchnera, Linn. (Scrophul.).

BUETTNERIA, Loefl. (Stercul.). - Ind. Kew. i. 352.

amazonica, Poepp. ex K. Schum. in Mart. F1. Bras. xii. III. (1886) 92 = catalpaefolia, 7 aiq.

bauhinioides, Baker, in fourn. Linn. Soc, xxii. (1887) 451 (Byttneria). - Madag.

benensis, in Bull. Torrey Bot. Club, xvi. (1889) 155 - Bolivia.

Beyrichiana, K. Schum, in Mart. Fl. Bras. xII. iii. 1886) 96. - Bras.

boliviana, Britton, in Bull. Torrey Bot. Club, xvi. (1889) I55. - Bolivia.

campestris, S. Moore, in Trans. Linn. Soc. Ser. II. iv. (1895) 318 (Byttneria). - Bras

charagmocarpa, S. Moove, l. c. 320 (Byttneria). Bras.

coriacea, Britton, in Bull. Torrey Bot. Club, xvi. (1889) 156. - Bolivia.

Curtisii, Oliver, in Hook. Icon, pz, xviii.(1888)t. 1761. - Penang.

filipes, Mart. ex K. Schum. in Mart. Fl.Bras, xii. III. (1886) 95 . - Bras,

fruticosa, $K$. Schum. ex Engl. in Abhandl. Prenss. Akad. Wiss. (1894) 33 ; et in Pflanzenv. Ost-Afr. C (1895) 271. - Afr. trop. or

glabra, Mart. ex K. Schum. in Mart. Fl. Bras. xii III. (1886) 94 in obs. (sp. dub.), - Bras.

Leesoni, S. Moore, in Trans. Linn. Soc. Ser. II. iv. (1895) 319 (Byttneria). - Bras

Martiana, K. Schum, in Mart. Fl. Bras. xii. III. (1886) 94. - Bras.

melantha, Mart. ex K. Schum. l. c. (1886; 98. Bras.

Melleri, Baker, in fourn. Linn. Soc. xxii. (18ST) 154 (Byttneria). - Madag.

muricata, S. Moore, in Trans. Linn. Soc. Ser. II. iv. (I895) 319 (Byttneria). - Bras. 


\section{BUETTNERIA :}

nitidula, Baker, in Fourn. Linn. Soc. xxv。(1889) 384 (Byttneria). - Madag.

pentagona, Spruce, ex K. Schum, in Mart. Fl. Bras. xii. III. (1886) $90=$ jaculifolia, Pohl.

pescapraeifolia, Britton, in Bull. Torrey Bot. Clnb, xvi. (1889) 155. - Bolivia.

Spruceana, K. Schum, in Mart. Fl. Bras. xii. III. (1886) 97. - Bras.

uaupensis, Spruce, ex K. Schum.l. c. 93.- Bras.

urticifolia, K. Schum. l. c. 98. - Bras.

BUFONIA, Sauv. ex Linn. (Caryoph.). - Ind.

Kew.t. 352 .

arcuata, Stapf, in Denkschr. Akad. Wien, 1i. (1886) 285 (Buffonia). - Persia.

calycina, Boiss. et Hausskn. in Boiss. Fl. Or. Suppl. 1888) 110. - Turkest.

capsularis, Borss. et Hausskn. ex Boiss.l. 111. (Buffonia). - Persia.

micrantha, Boiss. et Hausskn. in Boiss, l. c. (Buffonia). - Persia.

Teneriffae, Christ, in Engl. Bot. Fahrb. ix. (1888) 101. - Teneriffa.

tuberculata, Loscos, Trat. pl. Arag. iii. suppl. 8. (1886) 104; Willk. Suppl. Prodr. Al. Hisp. (1893) 273 (Buffonia).- Hisp.

valentina, Pau, Not. bot. fl. Espan. i. (1887) 15 in syn. = tuberculata, Loscos

virgata, Stapf, in Denkschr. Akad. Wien, li. (1886) 285. (Buffonia), - Persia.

BUFORRESTIA, C. B. Clarke (Commelin.). Ind. Kew. I. 353

minor, K. Schum. ex Engl. in Abhandl. Prenss. Akad Wiss. (1894) 45 nomen; et in Pflanzenw. Ost-Afr. C (1895) 136. - Afr. trop. or.

BUINALIS, Rafin.= Siphonychia, Torr, et Gray (Illecebr.)

americana, Kuntze, Rev. Gen. (1891) $534=$ S.americana, Torr. et Gray.

diffusa, Kuntze, 1. c. = S. diffusa, Chapm.

erecta, Kuntze, 1. c. = S. erecta, Chapnz.

Rugelii, Kuntze, 1. c. = S. Rugelii, Chapm

BULBINE, Linn. (Liliac,). - Ind. Kew, i. 353.

platyphylla, Baker, in Bot. fahrb.xv. (1893) 468.Afr. trop. or.

BULBINELLA, Kunth (Liliac.). - Ind. Kew. i.

Aitoni, Th. Dur. et Schinz, Consp. Al. Afr.v. 1893 (1895) 334 ( = Anthericum Aitoni, Baker). - Afr. austr.

carnosa, Th. Dur. et Schinz, l.c. 334 (= Anth.car nosum, Baker). - Afr. austr.

Cauda-felis, Th. Dur. et Schinz, l. c. 334 (= Anth Cauda-felis, Linn, f.). - Afr. austr.

foribunda, Th. Dur. et Schinz, l. c. $335(=$ Anth floribundwm, Ait.). - Afr. austr.

nutans, Th. Dur. et Schinz, l.c. $(=$ Anth. nutans, Thunb.). - Afr. austr.

setosa, Th. Dur. et Schinz, l. c. (= Anth. setosum, Willd.). - Afr。 austr.

BULBOCODIUM, Ludw. Def. pl. (1787) 12, ex Kuntze, Rev. Gen. (1891) 700 = Romulea. Maratti (Irid.)

arenarium, barbatum, camerunianum, chloroleucum, Clusianum, Columnae, corsicum, crocifolinm, cruciatum, cupreum, elongatum, filifolium, grandiscapum, latifolium, ligusticum, Linaresii, longifolium, neglecinm, numidicum, purpurascens, ramiflorum, Requienii, roseun, simile, spirale, subluteum, tortuosum, Kuntze, I. $\mathrm{c}$. =homonyna omnia Romuleae.

campantatum, Kuntze, 1. c. = R. hirsuta, Eckl,

collinum, Kuntze, 1. c. $=$ R. Bulbocodium, Seb. et Maur.

dichotomum, Kuntze, 1. c. = R, rosea, Eckl.

flavm, Kuntze, I. c. = R. bulbocodioides, Eckl.

Macowanii, Kuntze, 1. c. = R. Macowani, Baker.

pudicum, Kuntze, 1. c. = R. rosea, Eckl.

Revelier, Kuntze, 1. c. = R. bulbocodioides, Eckl.

Rollii, Kuntze, 1. c. = R. ramiflora, Ten.

spcciosum, Kuntze, 1. c. = R. rosea, Eckl.
BULBOPHYLLUM, Thou. (Orchid.). - Ind.Kew. i. 354 .

albidum, Hook. f. Fl. Brit. Ind. v. (1890) 756. Perak.

altispex, Ridl. ex Stapf, in Trans. Linn. Soc. Ser.II, iv. (1894) 236. - Borneo.

anceps, Rolfe, in Lindenia, viii. (1892) 33 t. 351. Borneo.

apodum, Hook. f. Fl. Brit. Ind. v. (1890) 766; et in Hook. Icon. pl. xxi. (1890) t. 2043. - Penins. Mal.

approximatum, Ridl. in fourn. Linn. Soc. xxii. (1886) 117. - Madag.

bicolor, Hook. f. Fl. Brit. Ind. v. (1890) 770.-Reg. Himal.

bracteatum, F. M. Bailey, in Dep. Agric. Bot. Bull. iv. (1891) 17. - Austral.

breviflorum, Ridl ex Stapf, in Trans. Linn. Soc. Ser. II. iv. (1894) 236. - Borneo.

calyptratum, Kraenzl, in Bot. Fahrb̈, xxii. (1895) 24. - Kamerun.

candidum, Hook. f. Fl. Brit. Ind. v. (1890) $7 \% 0$; et in Hook. Icon. pl. xxi. (1890) t. 2050. - Reg. Himal.

carinatum, $\operatorname{Cogn}$. in fourn. des Orchid. vi. (1895) 216; et in Lindenia,xi. (1895) 20. et 33 t. 495. Borneo.

catenarium, Ridl. in Trans. Iinn. Soc. Ser. II. iv. (1894) 235. - Borneo.

cauliflorum, Hook. f. Fi. Brit. Ind.v. (1890) 758. - Reg. Himal.

cirrhatum, Hook.f.l. c. - Reg. Himal.

Clarkeanum, King et Pantling, in fourn. As. Soc. Beng. 1xiv. (1895) ii, 333. - Ind, or.

Clarkei, Reichb. f. in Flova, 1xxi. (1888) 155; et in fourn. Limn. Soc. xxv. (1889) 72. - Reg. Himal. Cominsii, Rolfe, in Kew Bull. (1898) 138. - Ins. Salom.

comosum, Collett et Hemsl, in Fourn. Iinn. Soc. xxviii. (1890) 130 t. 19; in Hook. f. Fl. Brit. Ind. v. (1890) 762; et ex Hook. f. in Bot. Mag. (1893) t. 7283. - Burma.

compactum, Kraenzl. in Bot. Fahrb. xvii. (1893) 48. - Ins. Comor.

compressum, Fraptier, ex Cordem. Fl. Ile Réunion (1895) 172. - Ins. Borbon.

onchilioides, Ridl. in foum.Limn. Soc. xxii. (1886) 117. - Madag.

concinnum, Hook.f. Icon. pl. xxi. (1890) t. 2038 a; et Fl. Brit. Ind. vi. (1890) 187. - Ind. or.

confertum, Hook.f.ll.cc. v. (1890) 757; et t. 2035 - Reg. Himal.

Cordemoyi, Frappier, ex Cordem. Fl. Ile Reinion (1895) 172.- Ins. Borbon.

coriaceum, Ridl. ex Stapf, in Trans. Linn. Soc. Ser. II. iv. (1894) 235. - Borneo.

coriophorum, Ridl, in fourn. Linn. Soc. xxii. (1886) 119. - Madag.

cornutum, Ridl. in fourn. Bot. xxiv. (1886) 325.N. Guin.

crassipes, Hook. f. Fl. Brit. Ind. v. (1890) 760.Ind. or.

curvibulbum, Frappier, ex Cordem. Fl. Ile Réunion (1895) 171. - Ins. Borbon.

cylindrocarpum, Frappier, l. c. 174.-Ins. Borbon.

Dearei, Reichb. f. in Flora, 1xxi. (1888) 156. - Borneo.

Dearei, Veitch, Man. Orch. Pl, iii. (I888) 95. Ins. Philipp,

densiflorum, Rolfe, in Kew Bull. (1892) 139; et (1895) 7. - Laos, Siam.

denticulatum, Rolfe, l. c. (1891) 197 et in Gard. Chron. (1894) ii. 213. - Sierra-Leone.

Elliotti, Rolfe, ex S. Elliot, in fourn. Linn. Soc. xxix. (1891) 51. - Madag.

Epicrianthes, Hook.f. Fl. Brit. Ind.v. (1890)753. - Java, Tenass.

Ericssoni, Kraenzl. in Gard. Chron. (1893) ii. 522. - Hab.?

fallax, Rolfe, l. c. (1889) ii. 558. - Assam.

filiforme, Kraenzl. in Bot. Fahrb. xxii. (1895) 25 (Bolbophyllum). - Kamerun.

Gamblei, Hook f. Fl. Brit. Ind. vi, 1890 187; et in Hook. Icon. pl, xxi (1890) t 2039b. - Reg. Himal.

Gerlandianum, Kraenzl. in Bot. Fahrb. vii. (1886) 437. - N. Guin.
BULBOPHYLLUM

Globulus, Hook, $f$, Fl. Brit. Ind. v. (I890) 767; et in Hook. Icon. pl. xxi. (1890) t. 2047 - Perak. gymnopus, Hook. f. l. c. 764; et in Hook. Icon. pl. xxi. (1890)t. 2040. - Reg. Himal.

Hamelini, Hort. ex Gard. and For. vi. (1893) 386; et ex Kew Bull.(1894) App. II, 30. - Madag.

Hellwigianum, Kraenzl. ex Warb. in Bot. Fahrb. xvi. (1893) 17. - Oceania.

Herbula, Frappier, ex Corden. Fl. Ile Réunion (I895) 169. - Ins. Borbon.

Hookerianum, Kratenzl. in Bot. fahrb. xvii. (1893) 49; Wendl. ex Kraenzl. in Gard Chron. (1894) i. 685. - Afr. trop.

Humblotti, Rolfe, ex S. Elliot. in fourn. Linn. Soc. xxix. (1891) 50. - Madag.

hymenanthum, Hook. f. Fl. Brit. Ind. v. (1890) 767; et in Hook. Icon. pl. xxi. (1890 t. 2046-Reg Himal.

ichthyostomum, Colenso, in Trans. N.Z. Inst. xxvi. 1893 (1894) 319. - N. Zel.

inaequale, Reichb. $f$. in Flora, 1xix. (1886) 553. Gabon.

inconspicuum, Maxim. in Bull. Acad. Pétersb. xxxi. (1887) 102. - Japon.

inflatum, Rolfe, in Kew Bull. (1891) 234; et in Gard. Chron. (1891) i. 334. - Sierra-Leone.

Johannis, Kraenal, in Gard, Chron. (1894) ii. 592. Madag.

kermesinum, Ridl. in fourn. Bot, xxiv. (1889) 325. - N. Guin.

Kingii, Hook.f. Fl. Bvit. Ind. v. (1890) 760.--Reg. Himal.

lemniscatoides, Rolfe, in Gard. Chron. (1890) i. 672. - Java?

leptanthum, Hook. f. Fl. Brit. Ind. v. (1890) 759; t in Hook. Icon. pl. xxi. (1890 t. 2030 a. - Reg. Himal.

leptosepalum, Hook.f. l. c. 767; et in Hook. Icon. pl. xxi. (1890) t. 2045. - Penins. Mal

lineare, Frappier, ex Cordem. Fl. Ile Réunion (1895) 170. - Ins. Borbon.

longispicatum, Cogn. in fourn. des Orchid. iv. (1893) 265. - Bras.

macrocarpum, Frappier, ex Cordem. Fl. Ile Rénnion, (1895) 173. - Ins. Borbon.

membranifolium, Hook. f. Fl. Brit. Ind. v. (1890) 756; et in Hook. Icon. pl. xxi. (1890) t. 2034. Perak.

Micholitzianum, Kraenzl. in Bot. Fahrb. xvii. (1893) 484. - Sumatra.

micranthum, Hook. f. Fl. Brit. Ind. v. (1890) 768; et in Hook. Icone pl. xxi. (1890) t. 2048. - Tenass. mishmeense, Hook. f. l.c. 769. - Reg. Himal.

modestum, Hook.f. l. c.759; et in Hook. Icon. pl. xxii. (1890) t. 2038b. - Perak.

Molossus, Reicho. f. in Flova, Ixxi. (1888) 155. Madag.

montense, Ridl. ex Stapf in Trans. Linn. Soc. Ser. II, iv. (1894) 234. - Borneo.

montigenum, Ridl. l. c. - Borneo.

nervulosum, Frappier, ex Cordem. Fl. Ile Réunion (1895) 170. - Ins, Borbon.

nigripetalum, Rolfe, in Kew Bull. (1891) 197; et in Gard. Chron. (1891) ii. 215. - Afr. trop. occ.

O'Brienianum, Rolfe, in Gard. Chron. (1892) ii. 332 et in Kew Bull. (1893) Append. II. 30 nomen. Reg. Himal.

Odoardi, Pfitz. in Engl. et Prantl, Natïrl. Pfanzen-

fam, iii. 6. (1888) 179. - Borneo.

oncidiochitum. Kraenzl. in Bot. Jahrb. xviii. (1894) 485 = Latourea oncidiochila, Kraenzl.

Ophiuchus, Ridl. in fourn. Limi. Soc. xxii. (1886) 118, - Madag.

paniculatum, Ridl. in foum. Bot. xxiv. (1889) 326. - N. Guin.

patens, King, in Hook. f. Fl. Brit. Ind. vi. (1890)

187 in add.; Hook. f. in Hook. Icon. pl, xxi. (1891) t. 2054 sub B. vermiculare. - Perak.

Pechei, Bull, Catal. 1891, ex Gard. Chron. (1891) i. 676; et Bot. Mag. (1893) t. 7286. - Burma.

perpusillum, Kraenzl. in Gard. Chron. (1894) ii. 592 - Madag.

Pervillei, Rolfe, ex S. Elliot, in fourn. Linn. Soc.

xxix. (1891) 51. - Madag.
porphyroglossum, Kraenzl. in Bot. faltrb. xxii. (1895) 24 (Bolbophyllum). - Kamerun. 


\section{BULBOPHYLLUM :}

protractum, Hook. f. Fl. Brit. Ind. v. (1890) 758; t in Hook. Icon. pl. xxi. (1890) 2037. - Tenass.?

psittacoglossum, Reichb. f. ex Hook. l. c. 754. Tenass.

pteriphilum, Rolfe, in Kew Bull.(1894)391.-Penang - Ins. S. Thom.

racemosum, Rolfe, in Kew Bull. (1893)61.-Borneo. resupinatum, Ridl. in Bolet. Soc. Brot. v. (1887) 198. - Ins. S. Thom.

rufilabrum, Parish, ex Hook. f. Fi. Brit. Ind. v.(1890) 761. - Tenass.

Sanderianum, Rolfe, in Kew Bull. (1893) 4; et ex Gard. Chron. (1893) i. 291. - Bras.

scaberulum, Bolus, in fourn. Linn. Soc. xxv. (1889) 181 (= Megaclinium scabenulum, Rolfe). - Afr. austr.

secundum, Hook. f. Fl. Brit. Ind. v. (1890) 764; et in Hook. Icou. pl. xxi. (1898) t. 2042. - Reg. Himal.

spathaceum, Rolfe, in Kew Bull. (1893) 170. Burma.

stenopetalum, Kraenzl. in Bot. Fahrb. xxii. (1895) 25. - Kamerun.

stenorhachis, Kraenzl.l.c. - Kamerun.

striatellum. Ridl. in Ann. of Bot. iv. (1890) 335 Hook. f. Fl. Brit. Ind. vi. (1890) 189 in add. Singap.

suavissimum, Rolfe, $m$ Gard. Chron. (1889). i. 297 et Hook. f. Fl. Brit. Ind. v. (1890) 768.-Burma.

Thomsoni, Hook. f. l. c. 764; et in Hook. Icon. pl. (1890) t. 2041. - Reg. Himal.

Toressae, F.M. Bailey, Rep. Exped. Bellenden-Ker, (1889) 62. - Austral.

trachyanthum, Kraenzl. in Oest. Bot. Zeitschr. xliv. (1894) 336. - N. Hibern.

vermiculare, Hook. f. Fl. Brit. Ind. vi. (1890) 188 in obs. - Penins. Mal.

virens, Hook. f. Fl. Brit. Ind. v. (1890) 7\%0. Assam.

viride, Rolfe, in Kew Bull. (1893) 170. - Afr. trop. occ.

vitiense, Rolfe, l. c. 5; et ex Gard. Chron. (1893) i. 291. - Ins. Viti.

Watsonianum, Reichb. f. in Flora, 1xxi, (1888) 155 - Ins. Hongkong.

Wrayi, Hook. f. Fl. Brit. Ind. v. (1890) 766; et in Hook. Icon. pl. xxi. (1890) t. 2844. - Perak.

BULGA, Linn. Syst. ed. I. (1735) 14, ex Kuntze, Rev. Gen. (1891) 512 = Ajuga, Linn. (Labiat.).

brachystemon, Chamaeeistus, flaccida, incisa, Iva, japonica, lobata, macrosperma, oblongata, oocephala, orientalis, parviflora, pyramidalis, robusta, salicifolia, Kuntze, 1. c. 512 et 513 = homonyma omnia Ajugae.

Chamaepitys, Kuntze, 1. c. = A. Chamaepytis, Schreb.

Laxmannii, Kuntze, 1. c. = A. Laxmanni, Benth.

scoparia, Kuntze, I, c. = A. Chamaecistus, Ging.

BULBOSTYLIS, Kunth (Cyper.). - Ind. Kew.

abortiva, C. B. Clarke, in F. Buchan. Nyassaland (1889) 21; et in Th. Dur, et Schinz, Consp. Al. Afr. v. 1894 (1895) 610 (=Fimbristylis abortiva, Steud.) - Afr. trop.

andongensis, C. B. Clarke, in Th. Dur.et Schinz,l. c. 611 (= Fimbr. andongensis, Ridl.). - Afr. trop. occ.

aphyllanthoides, C. B. Clarke, in Th. Dur. et Schinz, l. c. (=Finnbr. aphyllanthoides, Welw.).-Afr. trop. occ.

barbata, C. B. Clarke, in Hook. f. Fl. Brit. Ind, vi. (1893) 651; et in Th. Dur. et Schinz. l. c. - Reg. calid. orb. vet.

Boivini, C. B. Clarke, in Th. Dur. et Schinz, l. c. 612. - Ins. Comor.

breviculmis. C. B. Clarke, l.c. $(=$ Isolepis breviculmis, Kunth). - Afr. austr.

Buchanani, C. B. Clarke, in F. Buchan. Nyassaland (1889) 21 nomen. - Afr. trop. austro-or.

Burchellii, C. B. Clarke, in Th. Dur. et Schinz, Consp. Al. Afv. v. 1894 (1895) 612 (= Fimbristylis Burchellit, Ficalho et Hiern). - Afr. austr.
BULBOSTYLIS :

cardiocarpa $C$. B Clarke in Th Dur et Schinz, Consp.f. Afr. v. 1894 (1895) 612 (= Fimbristylis cardiocarpa, Rid1.). - Afr, trop

cinnamomea, C. B. Clarke, in $\tilde{f}$. Buchan, Nyssaland (1889) 21; et in Th. Dur. et Schinz l. c. $(=$ Scirpus cinnamomeus, Boeck.).-Afr. austr. et trop. austro-or.

coleotricha, C. B. Clarke, in Th. Dur, et Schinz, l.c. 613 (= Fimbristylis coleotricha, Hochst.). Abyss.

collina, C.B. Clarke, l.c. (= Isolepis collina, Kunth), - Afr. austr., Madag

cylindrica, C. B. Clarke, l. c. - Angola.

festucoides, C. B. Clarke, l. c. (= Scirpus festucoides, Poir.). - Madag., Borbon.

filamentosa, C. B, Clarke, l.c. $(=$ Scirpus filamentosus, Vahl). - Afr. trop.

humilis, C. B. Clarke, l. c. 614(= Isolepis humilis,

Kunth). - Afr. austro-or, et austr

Kirkii, C. B. Clarke, l. c. - Natal.

laniceps, C. B. Clarke, l.c. - Afr. trop. occ

Lichtensteiniana, C. B. Clarke, l. c. $(=$ Isolepis Lichtensteiniana, Kunth). - Ins. S. Helena.

macra, C. B. Clarke, l. c. (= Fimbristylis macra, Ridl.). - Angola.

megastachys, C. B. Clarke, l. c. (= Fimbr. megastam chya, Ridl.). - Angola.

melanocephala, C. B. Clarke, l. c. 615 (= Fimbr. melanocephala, Ridl.). - Angola.

neglecta, C. B. Clarke, l. c. (= Fimbr. neglecta, Hemsl.). - Ins. S. Helena.

oligostachya, C. B. Clarke, l. c. (= Scirpus oligostachyus, Boeck.). - Abyss.

oritrephes, C. B. Clarke, in Trans. Linn. Soc. Ser. II. iv. (1894) 54; et in Th. Dur. et Schinz, l. c. (= Fimbristylis oritrephes, Ridl.). - Angola.

parva, C. B. Clarke, in Th. Dur. et Schinz, l. c. (=Fimbr. parva, Ridl.). - Angola.

puberula, C. B. Clarke, in Hook. f. Fl. Brit. Ind. vi.

(1893) 652; et in Th. Dur. et Schinz, l. c. - As. et Afr. trop.

pusilla, C. B. Clarke, in Th. Dur. et Schinz, $l$. c. (= Fimbristylis pusilla, Hochst.). - Abyss.

rarissima, C. B. Clarke, l. c. $(=$ Cyperus rarissimus, Steud.). - Abyss.

Rehmanni, C. B. Clarke, l. c. - Transvaal

Renschii, C. B. Clarke, l. C. (=Scirpus Renschii, Boeck.). - Madag.

Schimperiana, C. B. Clarke, l. c 616. (=Isolepis Schimperiana, Hochst.). - Abyss.

schoenoides, C. B. Clarke, in Trans. Linn, Soc. Ser. II. iv. (1894) 54; et in Th. Dur. et Schinz, l. c. (= Isolepis schoenoides, Kunth). - Afr. austr. et trop. occ.

sphaerocarpa, C. B. Clarke, in Th. Dur et Schinz, l.c. ( = Scirpus sphaerocarpus, Boeck.) - Afr. austr.

striatella, C. B. Clarke, l. c. - Afr. austr, et trop. or.

subspinescens, C. B. Clarke, in Hook. f. Fl. Brit. Ind. vi. (1893) 652. - Ind. or.

trichobasis, C. B. Clarke, in Th. Dur. et Schinz, Consp. fl. Afr. v. 1894 (1895) 616 (= Scirpus trichobasis. Baker) - Madag.

Taylori, C. B. Clarke, l.c. Z Zanzibar.

trabeculata, C. B. Clarke, l. c. - Angola.

zambesica, C. B. Clarke, l, c. - Zambesia.

Zeyheri, C. B. Clarke, l. c. (= Scirpus Zeyheri,

Boeck.). - Afr. austr. et austro-or.

BULNESIA, C: Gay (Zygophyll.). - Ind. Kew. i.

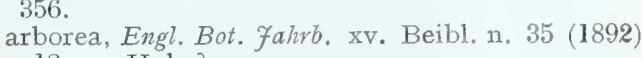
12. - Hab.?

BUMELIA, Sw. (Sapot.) - Ind. Kew. i. 356.

fragrans, Ridl. in fourn. Linn. Soc. xxvii. (1890) 43. Ins. Fernando Noronha

leiogyna, F. D. Smith, in Coult. Bot. Gaz, xviii. (1893) 4. - Guatem.

mexicana, Engl. Bot. fahrb. xii. (1890) 519. Mexic.

Palmeri, Rose, in Gard. and For. vii. (1894) 195 fig. 35. - Mexic.

pleistochasia, F. D. Smith, in Coult. Bot. Gaz, xviii. (1893) 4. - Guatem
BUNGHOSIA, Rich. (Malpigh.), - Ind. Kew, i

357.

guadalajarensis, S. Wats, in Proc. Am. Acad.xxii. (1887) 401. - Mexic.

Lanieri, S. Wats. l. c. xxi (1886) 461; et in T. Brigh. Guatem. App. (1887) 427. - Guatem,

Palmeri, S. Wats. l. c. xxii. (1887) 401. - Mexic. parvifolia, S. Wats. l. c. xxiv, (1889) 42. - Calif.

Pringlei, S. Wats. l. c. xxvi. (1891) 133. - Mexic.

sonorensis, Rose, in Contrib. U.S. Nat.Herb.i. (1891). - Mexic.

BUNIOTRINIA, Stapf et Wettst. ex Stapf, in Denkschr. Akad. Wien, li. (1886) 315. UMBELLIFERAE.

juncea, Stapf et Wettst. l. c. - As. Occ.

BUNIUM, Linn. = Carum, Linn. (Umbellif.) Bourgaei, Freyn et Sint, in Oest. Bot. Zeitschr. xliv. (1894) 99. - As. Min.

cataonicum, Stapf et Wettst. Beitr. Fl. Lyc. (1886) 261. - As. Min.

cylindraceum, Freyn, in Oest, Bot. Zeitschr. xlii. (1892) 83 = C. cylindricum, Boiss. et Hochst.

dancoides, Haussk. in Mitth. Thur. Bot. Ver. N. Folge, v. (1893) $114=\mathrm{C}$. daucoides, Boiss. elegans, Freyn, in Oest. Bot. Zeitschr. xlii. (1892) 83. - Armenia.

fallax, Freyn, 1. c. x1. (1890) 211; et xli. (1891) 10.As. Min.

filipes, Freyn et Conrath, in Bull. Herb. Boiss. iii (1895) 305. - Reg. Cauc

incrassatum, Batt. in Batt. et Trab. Fl. de 1'Algérie (Dicot.) $(1888) 346=\mathrm{C}$. incrassatum, Boiss

mawitanicum, Batt. 1. c. =C. mauritanicum, Boiss. et Reut.

microcarpum, Freyn et Bornm. ex Freyn, in Oest Bot. Zeitschr. xil. (1891) 10 in obs.; et xliv. (1894) 99 - C. microcarpum, Boiss

Tempskyanum, Freyn et Sint. in Bull. Herb. Boiss. iii. (1895) 384. - Armenia.

tenerum, Hausskn, in Nym. Consp. fl. Eur. Suppl. II. i. (1889) 144. - Graecia.

BUPHANE, Herb. (Amaryll. . - - Ind. Kew. i. 358. longepedicellata, Pax, in Bot. Fahrb. x. (1889) 4.Afr. austr.

BUPLEURUM, [ Tourn.] Linn. (Umbellif.) - Ind. Kew. i. 359

americanum, Coult. et Rose, Rev.N.Am. Umbell. (1888) 115. - Am. bor. occ

antiochium, Post, in fown. Linn. Soc. xxiv. (1888) 427. - Syria.

Boissieri, Post; l. c. 426; et ex Boiss. Fl. Or. Suppl. (1888) 251. - Syria

caricinum, Cabanès, in Bull. Soc. sc, nat. Nîmes, xix. (1891) 30. - Gall, mer.

laxum, Veten. in Oest. Bot. Zeitschr. xli. (1891) 396. - Bulg.

mauritanicum, Batt. in Bull. Soc. bot. Fr. xxxv. (1888) 386. - Algeria

orbelicum, Velen.in Sitz. Boehm. Ges. Wiss. 1890 (1890) 407; et Fl. Bulg. (1891) 222. - Bulg.

pekinense, Franch ex Hemsl. in fourn. Linn. Soc. xxiii. (1887) 327 nomen; at in Nouv. Arch. Mus. Paris, Ser. II. x. (1888) 183. - China.

petiolatum, Franch. in Bull. Soc. Philom. Paris, Sér VIII. vi. (1894) 117. -- Yunnan.

polymorphum, Alboff, Prodr, Al. Colch. (1895) 101. - Reg. Cauc.

quadridentatum, Wettst. in Luers. Bibl. Bot. Heft xxvi. (1892) 48 t. 3 fig. 16-19. - Maced., Albania. ramunculoideum, St Lager, in Cariot, Etud. des fl. éd. 8. ii. (1889) 337 = ranunculoides, Linn.

Rischawi, Alboff, in Bull. Herb̆. Boiss, ii. (1894) 450 . - Reg. Cauc

Rischavianum, Alboff, 1. c, iii. (1895) 521 sphalm. $=$ Rischawi, Alboff

thracicum, Velen. in Sit\%. Boehm. Ges. Wiss, 1892 (1893) 381. - Turc.

yunnanense, Franch. in Bull. Soc. Philom. Paris, Sér. VIII. vi. (1894) 117. - Yunnan.

BURASAIA, Thou. (Menisperm.). - Ind. Kew. i. 360

australis, S. Elliot, in fourn. Iinn. Soc. xxix. (1891) 2. - Madag. 
BURCKELLA, Pierre, Not. bot. Sapot. (1890) 3 = Bassia, Koenig (Sapot.)

Cocoa, Pierre, 1. c. Bassia Cocco, Scheff.

Erskineana, Pierre, 1. c. 4; et ex Boerl. Handl. Fl Ned. Indië, ii. 1. (1891) $311=$ Bassia Erskineana, F. Muell.

Hollungii, Pierre, 11. cc. = Bassia Hollrungii, K. Schtm.

May, Pierre,1. c. = Bassia May, Becc

obovata, Pierre, 1. c. = Bassia obovata, Forst.

BUREA VELLA, Pierre, Not. bot. Sapot. (1890) 16. SAPOTACEAE

Macleyana, Pierre, l. c. $(=$ Bassia Maclayana, F. Muell. in Victor Ranval. i. (1885) 168, nomen.).- N. Guin.

BURLINGTONIA, Lindl. = Rodriguezia, Ruiz et Pav. (Orchid.).

caloplectron, "Reichb. f. ) ex Williams, Cata1. (1887) $21=\mathrm{R}$. caloplectron, Reichb. $f$.

BURMANNIA, Linn.(Burmanniac.).-Ind. Kew. i. 361 .

bifurca, Ham. ex Hook. f. Fl. Brit. Ind. v. (1888) $665=$ coelestis, Don

candida, Griff. ex Hook. f. l. c. - As. trop. or. gracilis, Ridl, in fourn. As. Soc. Straits Branch, (1890) 335. - Ind or.

nepalensis, Hook. f. Fl. Brit Ind. v. (1888) 666. As. trop. or.

papillosa, Stapf, in Trans. Linn. Soc. Ser. II, iv. (1894) 232. - Borneo.

Wallichii, Hook,f. Fl. Brit Ind. v. (1888) 666.As. trop. or.

BURMEISTERA, Karst. et Triana (Campanul.). - Ind. Kew, i. 361 .

cyclostigmata, 7. D. Smith, in Coult. Bot. Gaz.xx. (1895) 291. - Costarica.

BURSA, Weber = Capsella, Medic. (Crucif.)

antipoda, cochlearina, diwaricata. Drummondii, grandifora, humistrata, mexicana, pilosula, procumbens, pubens, tasmanica, Kuntze, Rev. Gen. (1891) 20-21 = homonyma omnia Capsellae.

panciflora, Kuntze, 1. c. $20=$ Hutchinsia pauciflora, Nym.

Prostii, Kuntze, 1. c. = Hutch. Prostii, 7 . Gay.

tibetica, Kuntze, 1. c. = Capsella Thomsoni, Hook. $f$.

BURSERA, Jacq. (Burser.).-1nd, Kew. i. 362.

Eracouchii, Baill, ex Laness. P1. util. col, franc. (1886) $367=$ Icica heterophylla, $D C$.

australasica, F. M. Bailey, in Dept. Agric., Queensl. Bot. Bull. v. (1892) 8. - Austral.

Beandou, Baill. Hist. pl. Madag. Atlas, (1892) t. 226 b. - Madag.

cerasifolia, T.S. Brandeg. in Proc. Calif. Acad. Ser, II. iii. (189i) 121. - Calif.

fracilis, S. Wats. in Proc. Am. Acad. xxi. (1886) 422 . - Mexic.

glabrescens, Rose, in Contrib. U.S Nat. Herb, iii. (1895) 313. - Mexic.

Jonesii, Rose, l. c. 314. - Am. bor. occ.

Hindsiand, T. S. Brandeg. in Proc. Calif. Acad. Ser. II. iii. (1891) 121. - Calif

laxiflora, Kuntze, Rev. Gen. (1891) $108=$ seq.

laxiflora, S. Wats, in Proc. Am. Acad. xxiv. (1889) 44. - Calif.

Nelsoni, Rose, in Contrib. U.S. Nat. Herb. iii. (1895) 314. - Mexic.

odorata, T. S. Brandeg. in Proc. Calif. Acad. Ser. II. ii. (1889) 138. = fagaroides, Engl.

Palmeri, S. Wats, in Proc. Am. Acad. xxii. (1887) 402. - Mexic.

Pringlei, S. Wats, 7. c. xxy, (1890) 145 - Mexic.

pubescens, S. Wats. l. c. xxiv. (1889) 44. - Calif.

Schaffneri, S. Wats. l. c. xxii. (1887) 469.- - Mexic.

Simanba, Sarg. in Gard. and For. iii. (1890) 260 ; et N. Am. Sylva, i. 97 t. 41 et $42=$ gummifera, facq.

tenuifolia. Engl. ex Kuntre, Rev. Gen. (1891) 10\%. Mexic.

tenuifolia, Rose, in Contrib. U.S. Nat. Herb. iii. 1895 ) 314 (an praec.?). - Mexic.
BUSERIA, Th. Dur. Ind, Gen. (1888) 501. RUBIA$C E A E$

resinosa, Th. Dur. ex K. Schum. in Engl. et Prantl, Natiul. Pfanzenfam. iv. 4. (189I) 108 (= Leiochilus resinosus, Hook. f.). - Madag.

BUTEA, Koen. (Legumin.). - Ind, Kew. i. 362. monosperma. Kuntze, Rev. Gen.(1891) $202=$ frondosa, Roxb.

monosperma, Taub. in Engl. et Prantl, Natürl. Pflanzenfam. iii, 3 (1894) $366=$ praec.

BUTTNERIA, Duham. = Galycanthus, Linn. (Calycanth.).

fertilis, Kearney, in Bull. Torrey Bot. Club, xxi. (1894) 175 (Buettneria) $=\mathrm{C}$. fertilis, Walt

flovida, Kearney, 1. c. 175 (Buettneria) $=$ C floridus Linn.

occidentalis, Greene, in Erythea, i. (1893) 207; et Man. Bot. San Franc. Bay (1894) $119=$ C. occidentalis, Hook. et Arn.

BUXUS, Linn. (Euphorb.). - Ind. Kew. i. 362 bahamensis, Baker, in Hook. Icon. pl. xix, (1889) t. 1806. - Ins. Baham.

chinensis, Hort ex Dippel, Handb. Laubholzk. iii. (1893) $80=$ lon ifolia, Boiss.

macrophylla, Hort, ex Dippel, 1.c. = sempervirens, Linn.

Macowani, Oliver, in Hook. Icon. pl. xvi. (1886) t. 1518. - Afr. austr.

Rolfei, Vidal, Pl. vaso. Filip. (1886) 233. - Ins. Philipp.

BYRSOCARPUS, Schum. et Thonn. (Connar.). - Ind. Kew. i. 363.

Baroni, Baker, in fourn. Linn. Soc. xxii. (1887) 462 - Madag.

BYRSONIMA, Rich. (Malpigh.). - Ind. Kew. i. 363.

indorum, S. Moore, in Trans. Linn. Soc. Ser. II iv. (1895) 323 . - Bras.

\section{G}

GACABUS, Benth. (Solan.), - Ind. Kew. i. 365. integrifolius, Phil. in Anal. Mus. nac. Chile (1892) 63. - Chili.

Miersii, Wettst. in Engl. et Prantl, Natürl, Pflanzenfam.iv. 3 b. (1891) 16 (= Dictyocalyx Miersii Hook. f.). - Peruv

parviflorus, Rusby in Mem. Torrey Bot. Chub, iv. (1895) 233. - Bolivia.

CACALIA, Burm. Thes, Zeyl. (1737) 52 t. 21 Kuntze, Rev. Gen. (1891) $323=$ Vernonia Schreb. (Compos.).

abyssinica, accedens, acilepis, acuminata, acutangula, adamantium, adenophylla, adoënsis, affinis, alpestris, ambigua, ammophila, amygdalina, angulifolia, angustifolia, aphantha, apiculata, Aplinii, apocynifolia. appendiculata, araneosa, aravana, araripensis, arborea, arborescens, arenaria, argentea, arguta, argyrophylla, argyrotvicha, arkansana, Aschenborniana, asteriflora, attenuata, aueva, auriculata, bahamensis Bainesi, barbata, barbinervis, Benthamiana, Beyrichii, Biafrae, blanda, Bolleana, borneensis, brachiata. brachylepis, brachycypha, bracteata, brevifolia, brevipetiolata, Buchingeri, buddleiaefolia, bullata, buxifolia, Calvoana, Candolleana, Candollei, canescens, capituliflora, carduodes, chalybaea, Chamaedrys, Chamaepeuce, Chamissonis, chiliantha, cincta, cinerea, claciata, clivorum, cognata, compacta, compactiflora conferta, cordata, cordiaefolia, cordigera, coriacea, corymbiformis, corymbosa, Cotoneaster, Coulonii, cuiabensis, Cumingiana, cuneifolia, cylindrica, cymosa, decumbens, delapsa, demulans, dersiflora, Deppeana, desertorum, discolor, dissoluta, divergens, diversifolia, Doniana, dura, echitifolia, Ehrenbergiana, ehretiaefolia, elaeagnifolia, elegans, evemo phila, evioclada, eviolepis, erythrophila, esculenta. exilis, extensa, fagifolia, favinosa, fasciculata, fastigiata, fernginea, filigera, firma, flexuosa, floccosa foliosa, fragrans, Francavillana, frondosa, fruticosa,
CACALIA : -

fruticulosa, fulta, fuscopilosa, Gardnevi, geminata, glabra, glabrata, glandulosa, glutinosa, Gomphrena, gracilis, Grantii, gratiosa, grisea, guineensis, gymhexantha, hirtiflora, Hochstetterii, holosericea, Hookkeriana, koreasfolia, hymenolepis, Hypochaeris, hypolenca, ignobilis, immunis, incana, indica, infundibularis, insignis, interjecta, intermedia, isotricha, jugalis, karaguensis, Karunshiana, Kirkii, Kotschyana, Kroneana, lacunosa, lanceolaris, lappodes, latifolia, laurifolia, laxa, Leiboldiana, leiocarpa, Leopoldi, Lettermannit, leucophylla, lilacina, Lindbergii, Lindheimeri, linearifolia, linearis, Livingstoniana, Lobbii, lucida, Lyallii, macrocephala, macrophylla, madagascariensis, malabarica, Mansoana, Mariana, megapotamica, Melleri, mespilifolia, mexicana, micradenia, microcephala, misera, mollis, mollissima, moluccensis, Monosis, monticola, Moritziana, mossambicensis, mucronifolia, mucronulata, muricata, myriantha, myriocephala, nemoralis, nitens, novae-boracensis, mudiflora, obconica, obovata. obscura, obtusata, obtusifolia, ochroleuca, octantha. oligolepis, ovata, oxylepis, paludosa, pandurata, paniculata, patens, pauciflora, pectiniformis, pedunculata, peguensis, pellita, pentacantha, Perrottetii, petiolaris, platensis, polyanthes, populifolia, psilophylla, psilostachya, pteropoda, puberula, pulverulenta, pumila, punctata. pungens, pycnostachya, pyrifolia, Quartiniana, quinqueflora, Radula, reflexa, Reinwardtiana, remotifiora, revoluta, Riedelii, rigiophylla, rosea, rosmarinifolia, Rothit, rubricaulis, rubriramea, ruficoma, rugosa, rugulnsa, rupestris, salicifolia, saligna, Salrinae, saxicola, scapigera, scariosa, Schiedeana Schimperi, Schreinfurthii, schwenkialfolia, sechellensis, seiunda, secundifolia, Seemanniana, Sellowii, senegalensis, sericea, serrata, sessilifolia, shivensis, simplex, simulata, Smithiana, solanifolia, sparsiflora, Spixiana, squamulosa, Steetzii, stellaris, stenocephala, stenophylla, Stoechas, stricta, suaveolens, subsessilis, subsimplex, subulata, subverticillata, syncephala, talaumifolia, tanalensis, tarchonantifolia, terniflora, Teysmanniana, theophrastifolia. Thomae, Thomsoniana. Thwaitesii, tigrensis, toluccana, tomentella, tragiaefolia, travancorica, triantha, tricephala, triflosculosa, turbinata, Tweedieana, uncinata, undulata unionis varroniaefolia, venosissima, vepretorum, verbascifolia, vestita, vialis, virens, virgulata, viscidula, volkameriaefolia, Warmingiana, Westiniana, xanthophylla, zeylanica Zuccariniana, Kuntze, Rev. Gen. (1891) 323 et 968-71 = homonyma omnia Vernoniae.

acaulis, Kuntze, 1. c. $968=\mathrm{V}$, oligophylla, Michx. adproximata, Kuntze, 1. c. $969=\mathrm{V}$. diffusa, Less. africana, Kuntze, 1. c. = V. Vernonella, Harv. Alamani, Kuntze, 1. c. = V. Alamani, $D C$. Andersanii, Kuntze, 1. c. = V. Cumingiana, Benth. angustifolia, Kuntze, 1. c. $968=$ V. Poskeana, Vatke. anisochactodes, Kuntze, 1. c. $969=$ V. anisuchaetoides, Sond.

argvropappa, Kuntze, 1. c. = V. Salzmanni, DC.

aristata, Kuntze, 1. c. $968=$ V. natalensis, Sch. Bip. bacchariodes, Kuntze, 1. c. $969=$ V. baccharioides, H. B. et $K$.

Baldwinii, Kuntze, 1. $\mathrm{c}=\mathrm{V}$. Baldwini, Torr. baptisanda, Kuntze, 1. c. $968=$ V. uniflora, Sch. Bip. bardanodes, Kuntze, 1. c. $969=$ V. bardanoides, Less.

Baronii, Kuntze, 1. c. = V. Baroni, Baker.

Beddomii, Kuntze. 1. c. $=$ V. Beddomei, Hook. $f$.

Bipontini, Kuntze, 1. c. = V. affinis, Sch. Bip.

blumeodes, Kuntze, 1. c. $969=$ V. blumeoides. Hook.f.

brasiliana, Kuntze, 1. c. 323 et $968=$ V. scabra, Pers.

burmanica, Kuntze, 1. c. 323. - Burma.

Burtoniz, Kuntze, 1. c, =V. Burtoni, Oliver et Hiern. capensis, Kuntze $1, c_{0}=\mathrm{V}$. pinifolia, Less.

capitata, Kuntze, 1. c. $969(=$ Distephanus capitatus, Boj.). - Madag.

chlorolepis. Kuntze, 1.c. $968=$ V. Steetziana, Oliver et Hiern.

cladantha, Kuntze, Rev. Gen. (1891) 968 = Piptocarpha Sellowii, Baker.

Clarkeand, Kuntze, I. c. $323=$ Centratherum

Hookeri, C. B. Clarke.

colorata, Kuntze, 1. c. $968=$ V. senegalensis, Less. crotonodes, Kuntze, 1. c。 = V. crotonoides, Sch.Bip. 
CACALIA : -

cymosa, Kuntze. Rev. Gen. (1891) 968 = Vernonia missionis, Gardn.

arphnodes, Kuntze, 1. c. $970=\mathrm{V}$. daphnoides, Waip. debilis, Kuntze, 1. c. = V. Cotoneaster, Less,

divaricata, Kuntze, 1. c. $968=\mathrm{V}$. diffusa, Lees.

eleaegnodes, Kuntze, 1. c. = V. Kraussii, Sch.Bip.

erigerodes, Kuntze, 1. c. $970=\mathrm{V}$. cinerea, Less.

crubescens, Kuntze, 1. c. $968=\mathrm{V}$. Aschersonii, Sck. Bip.

eupatoriodes, Kuntze, 1. c. $324=$ V. eupatorioides, Blume.

fotowiodes, Kuntze, 1. c. $970=\mathrm{V}$. flotowioides, Baker.

frangulifolia, Kuntze, 1. c. = V. frangulaefolia, $H$. B. et $K$.

fruticosa, Kuntze, 1. c. $968=$ V. rigida, Sw

gerberiformis, Kuntze, 1. c. $=$ V. Gerberae, Oliver et Hiern.

Gerrardii, Kuntze, 1. c. $968=$ V. Gerrardi, Haro. gigantea, Kuntze, 1. c. $324=\mathrm{V}$. altissima, Nutt.

Glazionana, Kuntze, 1. c. $968=$ V. Glazioviana, Baker.

graphalodes, Kuntze, 1. c. = V. gnaphaloides, Sch. Bip.

gochnatiodes, Kuntze, 1. c. = V. gochnatioides, Hook. et Arn.

graminifolia, Kuntze, 1. $\mathrm{c}=\mathrm{V}$. angustifolia, Mich $x$.

graminifolia, Kuntze, 1. c. $970=$ V. graminifolia, Gardn.

Hookerii, Kuntze, 1. c. = Centratherum Hookeri, C. B. Clarke.

inulifolia, Kuntze, 1. c. = V. inulaefolia, Steud.

inulodes, Kuntze, $1 . \mathrm{c}_{0}=\mathrm{V}$. inuloides, $D C$.

lappodes, Kuntze, 1. $c_{0}=$ V. lappoides, Baker.

latifolia, Kuntze, 1. c. $968=$ V. Petersii, Oliver et Hiern.

Lessingiana, Kuntze, 1. c. = V. barbata, Less.

lessingoides, Kuntze, 1. c. = V. lessingioides, Sch. Bip.

liatrodes, Kuntze, 1. $\mathrm{C}_{\mathrm{c}}=\mathrm{V}$. liatroides, $D C$.

ligulifolia, Kuntze, 1. c. = V. ligulaefolia, Mart.

lithospermodes, Kuntze, 1. c, = V. lithospermoides, Baker.

marginata, Kuntze, 1. c. $=$ V. Jamesii, Torr, et Gray.

marginata, Kuntze, 1. c. $970=\mathrm{V}$. marginata, Oliver et Hiern.

monocephala, Kuntze, 1. c. = V. monocephala, Harv.

montevidensis, Kuntze, 1. c. $=\mathrm{V}$. nitidula, Less.

moquiniodes, Kuntze, 1. c. $970=$ V. moquinioides, Baker.

neriifolia, Kuntze, 1. c. $968=$ V. ruficoma, Schlecht.

nigritana, Kuntze, 1. c. $970=$ V. nigritiana, Oliver et Hiern.

nudicanlis, Kuntze, 1. c. $968=$ V. Dregeana, $S c h$. Bip.

mudicaulis, Kuntze, 1. c. $970=\mathrm{V}$. nudicaulis, Less, octangularis, Kuntze, 1. c. = Baccharis Meyeniana, Walp.

oligatodes, Kuntze, 1. c. $=$ V. oligatoides, Less.

oligophylla, Kuntze, 1. c. $968=$ V. Cephalotes, $D C$.

onopordiodes, Kuntze, 1. c. $970=\mathrm{V}$. onopordioides, Baker.

patula, Kuntze, 1. c. $324=\mathrm{V}$. chinensis, Less.

piptocarphodes, Kuntze, 1. c. = V. piptocarphoides,

Baker.

plantaginodes, Kuntze, 1. c. $969=\mathrm{V}$. plantagi-

Poeppigiana, Kuntze, 1. c. $971=$ Piptocarpha Poeppigiana, Baker.

polycephala, Kuntze. 1. c. $=\mathrm{V}$. ferruginea, Less.

pumila, Kuntze, 1. c. $969=$ V. grandiflora, Less.

pyramidale, Kuntze, $1, \mathrm{c}=\mathrm{V}$. Roxburobii, Less.

quadrifolia, Kuntze, 1. c. $971=$ V. quadriflora,

Baker.

ramiflora, Kuntze, 1. c. $969=$ Piptocarpha rami-

flora, Baker. Richardiana, Kuntze, 1. c. $967=$ V. myriocephala,
A.Rich.

rhaponticodes, Kuntze, 1. c. $971=$ V. rhaponticoides, Baker.

salviaefolia, Kuntze, 1. c。 = V. salvifolia, Wight.

Salzmanni, Kuntze, 1. c. = V. Salzmanni, DC.

scorpiodes, Kuntze, 1. c. $=$ V. scorpioides, Pers.

scorpioides, Kuntze, 1. c. $324=$ V. scorpioides, $P$ ers.

senegalensis, Kuntze, 1. c. $969=$ V. Tenoreana,

\section{CACALIA :}

serratulodes, Kuntze, Rev. Gen. (1891) $969=$ Vernonia serratuloides, $H$. B. et $K$

Sinclairi, Kuntze, 1. c. = V. Sinclairii, Benth sororia, Kuntze, 1. c. = V. scurpioides, Pers. spathulata, Kuntze, 1. c. $969=$ V. atriplicifolia, 7aub. et Spach.

squarrosa, Kuntze, 1. c, = V. teres, Wall.

stahelinodes, Kuntze, 1. c. $971=$ V. stahelinoides. Harv.

stellata, Kuntze, 1. c. $969=\mathrm{V}$. oppositifolia, Less. Sutherlandii, Kuntze, 1. c. $=$ V. Sutherlandi, Harv. Thomsonii, Kuntze, 1. c. = V. Thomsoni, Hook. $f$. Tinneana, Kuntze, 1. c. =V. pumila, Kotschy et Peyr. tomentosa, Kuntze, 1. c. $969=$ V. Monosis, Sch.Bip. toumefortiodes, Kuntze, 1. c. $971=$ V. tournefortioides, $H$. $B$. et $K$.

trinervis, Kuntze, 1. c. (= Distephanus trinervis, Boj.). - Madag.

uniflora, Kuntzt; 1. c. $969=\mathrm{V}$, remotiflora, Rich. urticifolia, Kuntze, 1. c. $971=$ V. urticaefolia, A. Rich.

vagans, Kuntze, 1. c. $969=\mathrm{V}$. scandens, $D C$.

verbascodes, Kuntze, $1 . \mathrm{c}_{\mathrm{C}}=\mathrm{V}$. verbascoides, $W$ alp vernoniodes, Kuntze, 1. c. $=$ V. dicarpa, Less. zanzibariensis, Kuntze, 1.c. = V. zanzibarensis, Less.

ollingerianodes, Kuntze, 1. c. = V. zollingerianoides, Sch. Bip.

CACALIA, Linn. = Senecio, Tourn. (Compos.)

aurea, MacMill. Metasp. Minnes. (1892) $556=\mathrm{S}$. aureus, $\operatorname{Linn}$

globosa, Robins, et Fernald, in Proc. Am. Acad. xxx. (1895) 119. - Mexic.

integerrima, MacMill. Metasp. Minnes. (1892) 556 $=\mathrm{S}$. integerrimus, Nutt.

longipetiolata, Robins, et Greenm, in Am. Journ. Sci. Ser. III. 1. (1895) 157. - Mexic.

lugens, MacMill. Metasp. Minnes. (1892) $555=\mathrm{S}$. lugens, Richards.

megaphylla, Robins, et Greenm, in Am. Journ. Sci. Ser. III. 1. (1895) 157. - Mexic.

obtusiloba, Robins, et Greenm. 1. c, 158. - Mexic.

Palmeri, Greene, Pittonia, i. (Oct. 1888) 219. Mexic.

paucispicata, Robins, et Greenm. in Am. Journ. Sci. Ser. III. 1. (1895) 158. - Mexic.

peltata, Robins. et Greenm. 1. c.=S. megaphylla, Robins, et Greenm.

peltigera, Robins. et Seaton, in Proc. Am. Acad. xxviii. (1893) 111, - Mexic.

platylepis, Robins, et Seaton, 1. c. 110. - Mexic

poculifera, S. Wats, in Proc. Am. Acad, xxvi. (1891). 143. - Mexic

Pringlei, S. Wats. 1. c. xxv. (1890) 156. - Mexic.

silphiffolia, Robins, et Greenm. in Am. Journ. Sci. Ser. iii. 1. (1895) 158. - Mexic

tridactylites, Robins. et Greenm. 1. c. 159.-Mexic

CACARA, Rumpf = Pachyrhizus, Rich. (Legu-

erosa, Kuntze, Rev. Gen. (1891) I65 = P. angulatus, Rich.

palmatiloba, Kuntze, 1. c.=P. palmatilobus, Benth. et Hook. $f$.

CACCINIA, Savi (Boragin.). - Ind. Kew. 1. 367 crassifolia, Kuntze, in Act. Hort. Petrop. x. (1887) 212 = glauca, Savi.

GACOUCIA, Aubl. (Combret.), --Ind. Kew i. 367. littorea, Engl. Pfanzenze. Ost-Afr. C (1895) 293 .Afr. trop. or.

longispicata, Engl.l. c. - Afr. trop. or.

platyptera, Welw. ex Oliver, in Hook. Icon. pl, xxiii. (1892) t. 2203 in obs. = paniculata, Laws.

CACTUS, “Linn. » ex Kuntze, Rev. Gen. (189I) $258=$ Mammillaria. Haw, (Cact.).

acanthophlegma, acanthostephes, acicularis, aciculatus, actinopleus, deruginosus, affinis, alpinus, amabilis, ancistrius, anguineus, areolosus, argenteus, atroruber. atrosanguineus, aulacanthus, aulacothele, aureiceps, auricomus, auroreus, barbatus, Barloweiz, bellatulus, biglandulosus, bihamatus, Bockii brevimamma, bre visetus, calcaratus, carneus, Celsianus, centricirrhus,

\section{CACTUS:-}

centrispinus, cephalophorus, ceratrocentrus, chrysacanthus, cirrhifer, clarus, compactus, compressus, conicus, conopsens, comifer, corollarius, crassispinus, crebrispinus, crinitus, crocidalus, cruciger, curvispinus, dasyacanthus, dealbatus, decipiens, depressus, Diadema, discolor, divaricatus, divergens, dolichocen trus, eborinus. Echimus, Ehrenbergii, elearans, ele phantidens, erectus, erectacanthus, eriacanthus, enclorus, eximius, fasciculatus, Fellneri, Fischeri, floribundus, Foersteri, formosus, forcolatus, fulvispinus, Funckii, fuscatus, geminatus, gibbosus, glabratus, gladiatus, glanduliger, glaucus, glochidiatus, gracilis, Grahami, grandicornis, grandiflorus, granulatus, grisents, gummifer, Haageanus haematactinus, hamatus, Heinei, heteromorphus, hexasanthus, Heyderi. Hum boldtii, Hystrix, incurvus, intertextus, irregularis, isabellinus, jucundus, Karwinskianus, Kleinii, Krameri, Kunthii, lactescens, lanifer, lasiacanthus, leucocentrus, leucodasis, leucodictyus, leucotrichus, Linkearus, lividus, longimantma longisatus loricates, Iudwigii, macromeris, macrothele. Martianus, maschalacanthus, megacanthus, meiacanthus, melaleucus, micans, micracanthus, microceras, micromeris, mini mus, mirabilis, missouvensis, mitis, mucronatus, Muehlenpfordtii, multiceps, mutabilis, Mystax. Neumannianus, niger, nigricans, nivosus, nobilis, mudus, obliquns, obvallatus, octacanthus, Odieranus, olorinus, oothele, Ottonis, ovimamma, pallescens, Parkinsonii, parvimamma, pallescens, Pazzanii, pectinatus, pentacanthus, Pfeifferianus, phacacanthus, phaeotrichus, phellospermus, phymatothele, pictus, Plaschnickit Plecostigma, pleiocephalus, polycentrus, polycephalus, polyedrus, polygonus, polymorphus, polythele, polytrichus, pomaceus, Pottsii, pretiosus, prismaticus, procerus, pugionacanthus, pulchellus, pulcher, purpureus, pusillus, pycnacanthus, pyrrhocephalus, pyrrochroacanthns, quadrispinus, vadians, vecurvatus, recurvispinus, recurvus, regius, retusus, rhaphidacanthus, rhodanthus, rhodeocentrus, robustispinus, vufidulus, rufocroceus, rutilus, Salmdyckianus, saxatilis, scepontocentrus, Schaeferi, Scheerii. Scheidvveilavianus, Schelhasii, Schiedeanus, Schlechtendalii, Seemannii, Seidelii, Seitzianus, Sempervivi, setosus, Severinii. sororius, spectabilis, sphacelatus, sphaericus, sphaerotrichus, spinaureus, spinosissimus, squarrosus, Stellaaurata, stenocephalus, strobiliformis, Stueberi, subangularis, subcroceus, subechinatus, subpolyedrus, subtetragonus, subulifer, sulcolanatus, supertextus, tectus, tentaculatus, tenuis, tetracanthus, tomentosus, triacanthus, tubinatus, uberiformis, umbrinus, uncinatus, variamamma, versicolor, vetulus, villifer, virens, viridis, vulpinus, Webbianus, Wegeneri, Wildianus, Winkleri, woburnensis, Wrightii, xanthotrichus. Zegschwitzii, Zepnickii, Kuntze, Rev. Gen. (1891) 259-261 = homonyma omnia Mammillariae.

alternatus, Coult. in Contrib. U. S. Nat. Herb. iii. 1894) 95. - Mexic.

ancistracanthus, Kuntze, Rev, Gen. (1891) $261=$ M. rhaphidacantha, Lerr.

ancistrodes, Kuntze, 1. $\mathrm{c}_{1}=\mathrm{M}$. ancistroides, $\mathrm{Lem}$. atratus, Kuntze, 1. c. $259=$ M. rhodantha, Link et Otto

Beneckei, Kuntze, 1. c. $260=$ M. Goodrighii, Scheer.

bocasanus, Coult in Contrib. U. S. Nat. Herb. iii. (1894) $104=$ M. bocasana, Poselg.

Brandegei, Coult, 1. c. 96. - Calif. inf.

brunneus, Coult. 1. c, 11\% - Mexic

caespititius, Kuntze, Rev. Gen. (1891) $260=$ Mammillaria multiceps, Salm-Dyck.

capillaris, Coult. in Contrib. U. S. Nat. Herb.

jii. (1894) 107 (= Mam, lanifera, Salm-Dyck). Mexic

conoidens, Kuntze, Rev. Gen. (1891) 260=M. conoidea, $D C$.

coronatus, Kuntze, 1.c. $261=$ M. crebrispina, $D C$ cylindracens, Kuntze, 1. c. $260=$ M. eriacantha, Hort.

densus, Kuntze, 1. C = M. echinata, $D C$.

densispinns, Coult, in Contrib. U.S. Nat. Herb. iii. (1894) 96. - Mexic

disciformis, Kuntze, Rev. Gen. (1891) $260=$ Echinocactus turbiniformis, Pfeiff.

Dyckianus, Kuntze, I. c. = M. acanthophlegma, Iehm.

Echinaria, Kuntze, 1.c。 = M. echinata, $D C$. 


\section{CACTUS :}

echinocactodes, Kuntze, Rev. Gen. (1891) $260=$ Mammillaria conoidea, $D C$

elongatus, Kuntze, 1, c. = M. elongata, $D C$.

Engelmanni, Kuntze, 1. c. = M. recurvata, Engelm. Eschanzieri, Coult in Contrib. U.S. Nat. Herb. iii. 1894) 104. - Mexic

exudans, Kuntze, 1. c. = M. exsudans, Zucc.

Gabbii, Coult. in Contrib. U. S. Nat, Herb, iii (1894) $109=$ M. Gabbii, Engelm.

geminispinus, Kuntze, Rev. Gen. (1891) $260=$ M. bicolor. Lehm

Goodridgii, Kuntze, 1. C. = M. Goodridgii, Scheer. Guillennianus, Kuntze, 1. c. $261=$ M. decipiens, Scheidw.

Halei, Coult, in Contrib. U. S. Nat. Herb, iii. (1894) $106=$ M. Halei; T. S. Brandeg.

Staworthianus, Kuntze, Rev. Gen. (1891) $259=$ M. stellata, Haw.

Kotschubeyi, Kuntze, 1. c. $260=$ M. sulcata, Salm Dyck.

Klugii, Kuntze, 1. c, = M. elegans, $D C$.

latimamma, Kuntze, 1. C. = M. pycnacantha, Mart.

Lehmanni, Kuntze, 1. c. = M. recurva, Lehm.

macracantizus, Kuntze, 1. C. = M. macracantha, DC. maculatus, Coult. in Contrib. U. S. Nat. Herb. iii. (1894) 117. - Mexic

Meissneri, Kuntze, Rev. Gen. (1891) $261=\mathrm{M}$. acanthophlegma, Lehm.

multisectus, Kuntze, 1. c. = M. multiceps, SalmDyck

nivers, Kuntze, 1. c. $259=$ M. bicolor, i ehm

obconella, Kuntze, 1.c. = M. dolichocentra, Lehm.

Palmeri, Coult in Contrib. U. S. Nat Herb, iii. 1896) 108. - Mexic.

persicanus, Kuntze, Rev. Gen. (1891) 261= M. persicina, Ehrenb.

Pondii, Coult, in Contrib. U. S. Not. Herb. iii. 1894) $102=$ M. Pondii, Greene.

Praelii, Kuntze, Rev. Gen. (1891) 261 = M viridis, Salm-Dyck.

Pringlei, Coult. in Contrib. U. S. Nat. Herb. iii. (1894) 109. - Mexic.

pulcherrimus, Kuntze, Rev, Gen. (1891) 261. = M. pulcherima, Ehrenb.

pulvilliger. Kuntze, 1. c. $260=$ M. elongata, $D C$ ?

radiosus, Coult, in Contrib. U. S. Nat. Herb. iii. (1894) $120=$ M. vivipara, Engelm.

rosea, Kuntze, Rev. Gen.(1891) $261=$ M. rosea, Scheidw.

Roseanus, Coult, in Contrib. U. S. Nat. Herb. iii. (1894) $105=$ M. setispina, Engelm.

Rueschianus, Kuntze, Rev, Gen, (1891) 261. = M. Ruschiana, Regel.

muficeps, Kuntze, 1. c. = M. rhodantha, Link et Otto.

scolymodes, Kuntze, 1. $\mathrm{c}=\mathrm{M}$, scolymoides, Scheidw

setispinus, Coult in Contrib. U. S. Nat. Herb. iii 1894) $106=\mathrm{M}$. setispina, Engelm.

senilis, Kuntze, Rev. Gen. (1891)261 = M. senilis, Lodd.

subcurvatus, Kuntze, 1. c. = M. subcurvata, A. Dietr.

tetracentrus. Kuntze, 1. c. = M tetracentra, Hort. Beral.

tetrancistrus, Coult, in Contrib. U. S. Nat. Herb. iii. (1894) $104=$ M. phellosperma, Engelm.

texensis, Kuntze, Rev. Gen. (1891) = M. Heyderi, Muchlenpf.

tuberculosus, Kuntze, 1. c. = M. strobuliformis, Scheer.

Vrieseanus, Kuntze. 1. c. $260=$ M. speciosa, De Vriese.

zephyranthodes, Kuntze, 1, c.=M. zephyranthoides, Scheidit.

CADABA, Forsk. (Capparid.). - Ind. Kew. i, 369. juncea, Szyszyl. Polypet. Rehmann.(1887) $18=$ juncea, Hart.

scandens, Pax, in Bot. Fahrb. xiv. (1892) 361. Afr. trop. or.

CAESALPINIA, Linn. (Legumin.). - Ind. Kew. i. 370 .

Andreana, M. Micheli, in Morot, Fourn. de Bot. vi. (1892) 193. - N. Gran

\section{CAESALPINIA}

aphylla, Phil. in Anal. Mus. nac. Chile (1891) 19.Chili.

Bangii, Rusby, in Mem. Torrey Bot. Club, iii. 3 (1893) $22=$ Hoffmanseggiae sp

brachycarpa. Fisher, in Coult. Bot. Gaz. xviii.(1893) $123=\mathrm{H} \cap \mathrm{ffm}$. brachycarpa, A. Gray.

canescens, Fisher, 1.c. = Hoffm. canescens, Fisher. candata, Fisher, 1. c. = Hoffm, caudata, A. Gray.

drepanocarpa. Fisher, 1. c. $122=$ Hoffm. drepano carpa, A. Gray.

Drummondii. Fisher, 1. c. $123=\mathrm{H}$ offm. Drum mondii, Torr, et Gray.

falcaria, Fisher, 1. c, $122=$ Hoffm, falcaria, Cav Fisheriana, Rusby, in Mem. Torrey Bot. Club, iii. 3. (1893) $23=$ Hoffmanseggiae sp.

fruticosa, Fisher, in Coult. Bot. Gaz. xviii. (1893) $123=$ Hoffm. fruticosa, S. Wats.

gladiata, Fisher, 1. c, 122=Hoffm. gladiata, Benth Godefroyana, Kuntze, Rev.Gen.(1891) 166.-Cochin. Grisebachiana, Kuntze, 1. c. = C. Bonduc, Linn?

intricata, Fisher, in Coult. Bot. Gaz, xviii. (1893) 123 = Hoffmannseggia glabra, Fisher.

famesii, Fisher, 1. c. $123=$ Hoffm. Jamesii, Torr e Gray

melanosticta, Fisher, 1, c, = Hoffm. melanosticta, A. Gray.

multiflora, Robins, in Proc, Am. Acad. xxvii. (1893) 16\%. - Mexic.

multijuga, Fisher, 1. c. = Hoffmanseggia multijuga S. Wats.

oxycarpa, Fisher, in Coult. Bot. Gaz. xviii. (1893) $122=$ Hoffm. oxycarpa., Benth.

Palmeri, S. Wats, in Proc. Am. Acad, xxiv, (1889) 47. - Calif.

pannosa, T. S. Brandeg. in Proc. Calif. Acad.Ser. II. ii. (1889) 150. - Calif.

paucijuga, Benth. ex Hook. Icon. pl. xx. (1891) t. 1977 - Ins. Trinit.

placida, T. S. Brandeg. in Proc. Calif. Acad. Ser II. iii. (1891) 131. - Calif.

platycarpa, Fisher, in Coult. Bot. Gaz, xviii. (1893) $122=$ Hoffmanseggia platycarpa, Benth

platyloba, S. Wats in Proc. Am. Acad. xxi. (1886) 425. - Mexic.

repens, Eastwood, in Zö̈, iv. (1893) 116 t. 26. Utah.

rosulata, Rusby, in Mem. Torrey Bot. Club, iii. 3. (1893) 23; et IV. (1895) $206=$ Fisheriana, Rusby. essilifolia, S. Wats, in Proc. Am. Acad. xxi. (1886) 450. - Mexic

texana. Fisher, in Coult. Bot. Gaz, xviii. (1893) 123 $=$ Hoffmanseggia texana, Fisher.

Taubertiana, S. Moore, in Trans. Limn. Soc. Ser. II. iv. (1895) 345 - Bras.

virgata, Fisher, in Coult. Bot. Gaz, xviii. (1893) 123 = Hoffmanseggia microphylla, Torr

Watsoni, Fisher, 1. c. $122=$ Hoffm. gracilis, S. Wats.

CAESALPINIODES, Kuntze, Rev. Gen. (1891) 166 = CAESALPINOIDES, Linn. = Gleditschia Clayton (Legumin.)

africanum, australe, caspium, heterophyllum, japonicum, macracanthum, monospermum, sinense, Kuntze, Rev. Gen. (1891) $167=$ homonyma omnia Gleditschiae. triacanthum, Kuntze, 1. c. = G. triacanthos, Linn.

GAESIA, R. Br. (Liliac.). - Ind. Kew, i. 371.

brevicaulis, Th. Dur et Schinz, Consp. $f$. Afv. v. 1893 (1895) 353 (= Anthericum.brevicaule, Baker) - Afr. austr.

brevifolia, Th. Dur. et Schinz, l. c. $(=$ Anth. brevifolium, Thunb.). - Afr. austr.

contorta, Th. Duv. et Schinz, l.c. $(=A n t h$. contortum Linn. ... . - Afr, austr.

scilliflora, Th. Dur. et Schinz, l. c. 354 $=$ Anth. scilliflorum, Eck1.). - Afr. austr.

subulata, Baker, in fourn. Linn. Soc, xxii. (1887) 530. - Madag.

Zeyheri, Th. Dur. et Schinz, Consp. Al. Afr. v. 1893 (1895) (= Anthericum Zeyheri, Baker). - Afr. austr.

CAIOPHORA, Presl = Blumenbachia, Schrad.
CAIOPHORA : -

albiflora, Urban et Gilg, in Engl. et Prant1, Natür1. Pflanzenfam. iii 6a (1894) 119. - Reg. Aroent. anemonoides, Urban et Gilg, 1, c. 119. - Chili.

Arechavaletae, Urban, I. C. 120.- Urug.

boliviana, Urban et Gilg, 1. c. 119. - Bolivia

Buraeavi, Urban et Gilg, ex Rusby, in Mem. Torrey Bot. Club, iij. 3. (1893) 37. - Bolivia.

canarinoides, Urban et Gilg, in Engl, et Prantl, Natürl. Pflanzentam. iii. 6a. (1894) 119. Bolivia.

cernua, Urban et Gilg, ex Kurtz, in Revista Museo La Plata, v. (1893) 829, et Sert. Cordob. (1893) I1; et in Engl. et Prantl, 1. c. = Blumenbachia cernua, Griseb.

contorta, Urban et Gilg, in Eng1. et Prantl, Natürl. Pflanzenfam. iii. 6a. (1894) 119. - Chili, Peruvia.

dissecta, Urban et Gilg. 1. c. 120. - Chili

Eichleri, Urban, 1. c. 121. - Bras.

Espigneira, Urban et Gilg, 1. c. Blumenbachia Eepigneera, C. Gay.

heptomera, Urban et Gilg. 1. c. - Bolivia.

hibiscifolia, Urban et Gilg, 1. c. 119. - Reg. Argent.

horrida, Urban et Gilg, ex Rusby, in Mem. Torrey Bot. Club, iii. 3. (1893) 36. - Bolivia.

Kurtzii, Utban et Gilg, ex Kurtz, in Verh. Bot. Ver. Brand. xxxy. (1894) 10\%. - Reg. Argent. macrocarpa, Urban et Gilg, in Engl. et Prantl, Natürl. Pflanzenfam. iii. 6a. (I894) 119. - Reg. Argent.

mollis, Urban et Gilg, 1. c. - Reg. Argent.

Orbignyana. Urban et Gilg, 1. c. - Bolivia.

Pavonii, Urban et Gilg, 1. C. - Peruvia.

Prietea, Urban et Gilg, 1. c. $120=$ Blumenbachia Prietea, C. Gay.

pulchella, Uxban et Gilo, ex Kurtz, in Verh. Bot Ver, Brand. xxxv. (1894) 111 nomen. - Reg. Argent.

Rahmeri, Phil. in Anal. Mus. nac. Chile (1891) 23. - Chili.

Rusbyana, Urban et Gilg, ex Rusby, in Mem. Torrey Bot. Club, iii, 3. (1893) 35. - Bolivia.

rosulata, Urban et Gilg, in Engl. et Prantl, Natür1. Pflanzenfam. iii. 6 a (1894) 119. - Peruvia. scabra, Urban, 1. c. 121. - Bras.

superba, Phil. in Anal. Mus, nac. Chile (1891) 23.Chili.

CAJU, Kuntze, Rev, Gen. (1891) $167=$ CAJUM Rumpf = Pongamia, Vent. (Legumin.). pinnatum, Kuntze, 1. C. = P. glabra, Vent.

CALACANTHUS, Kuntze, Rev. Gen. (1891) 483 = Galacantha, T. Anders. (Acanth.).

grandiflorus, Kuntze, 1. C. = C. Dalzelliana, T. Anders.

GALADENIA, R. Br. (Orchid.). - Ind. Kew. i. 372

cardiochila, Tate, in Trans, et Proc. Roy. Soc. S. Austral. ix. (1887) $60=$ Cavinsiana, F. Muell. macrophylla, Colenso, in Trans, $N, Z$. Inst, xxvii. 1894 (1895) 396. - N. Zel.

tentaculata, Tate, in Trans. et Proc. Roy. Soc. S. Austral. xî. (1889) 130. - Austral.

toxochila, Tate, l. c. 129. - Austral.

GALADIUM, Vent (Aroid.). - Ind. Kew. i. 372. adamantinum, L. Lind. in Illustr. Hortic. (1890) 71 t. 532. - Peruvia.

amboinense, Ham. ex Hook, f. Fl. Brit. Ind, vi. 1893) 532 in syn. = Homalomena caerulescens, fungh.

heterotypicum, S. Moore, in Trans. Linn. Soc. Ser. II. iv. (1895) 500 t. 35 fig. 13. - Bras.

lilliputiense, Rodigas, in Illustr. Hortic. (1895) 363 t. 47. - Venez.

medio-radiatum, L. Lind. et Rodigas, l. c. (IS90) 51 t. 528. - N, Gran.

ovatum, Ham, ex Hook. f. Fl. Brit. Ind. vi. (1893) 519 in syn. = Ariopsis peltata, Nimmo

rubescens, N.E. Br. in Gard. Chron. (1893) ii. 86. - Bras.

sagittatum, L. Lind. et Rodigas, in Illustr. Hortic. (1890) 101 t. 538. - Bras. 
GALADIUM

venosum, N. E. Br. in Gard. Chron. (1893) ii. 86. - Rras.

CALAIS, DC. = Microseris, D. Don (Compos.). Clevelandi, Greene, in Bull. Calif. Acad. ii. vI. (1886) 153. - Calif.

Kelloggii, Greene, 1. c. ii. (1886) 49. - Calif.

Parryi, Greene, 1. C. = Clevelandi, Greene.

pluriseta, Greene, Pittonia (Mar. 1887) 34. - Calif

submembranacea, Fernald, in Coult. Bot. Gaz. xx. (1895) 535. - Mexic

CALAMAgROSTIS, Adans. (Gramin.). - Ind Kew. I. 374.

arctica, Vasey, Illustr. N. A. Grass, ii. (1893) t. 55 et in Contrib. U.S. Nat. Herb. i. (1893) 268.-Am. arct.

aurea, Hack. ex Sodiro, Gram. Ecuator. (Anal. Univ.

Quito, 1884) 8(=Deyeuxia aurea, Munro).-Ecuad.

bihariensis, Simonk, in Termész. Füzet. x. (1886) I84; et Enum. pl. Transsilv. (1886) 566. Transs.

breviseta, Scribn. in Mem. Torrey Bot. Club, vi. (1894) 41 = Pickeringii, A. Gray.

cimnoides, Scribn. 1. c. 42 (=C. cimnoides, Spreng.) $=$ Deyeuxia Nuttalliana, Vasey.

collina, Franch. in Nouv. Arch. Mus. Paris, Sér. II. x. (1887-88) 105. - China.

crassifolia, Hack. ex Sodiro, Gram. Ecuator. (Anal.

Univ. Quito, 1889) 8 nomen. - Ecuad.

Curtisii, Vasey, in Coult. Bot. Gaz. xv. (1890) 269 in obs. et in Contrib. U. S. Nat. Herb. i. (1892) 209 - Am. bor.

densa, Vasey, in Coult. Bot. Gaz. xvi. (1891) 147 (densus), et Illustr. N. Am.Grass, ii. (1892) t. 40.Calif.

dubia, Scribn. in Contvib. U. S. Nat. Herb, i. (1892) 249. - Am. bor

emirnensis, Th. Dur. et Schinz, Consp. Al. Afr. v. 1894 (1895) 831 (= Deyeuxia emirnensis, Baker). - Madag.

epigea, "Roth » ex St-Lager, in Cariot, Etud. des f. éd. 8 , ii. (1889) $905=$ epigeios, Roth.

Haussknechtiana $\times$, Torges, in Mitth. Thür. Bot Ver. N. Folge, viii. (1895) 16. - Germ

Indagata $\times$, Torges et Hausskn. 1. c. 26. - Germ.

irazuensis, Kuntze, Rev. Gen.(1891) 763.-Costarica

koelerioides, Vasey, in Coult. Bot. Gaz. xvi. (I891) 147. - Calif.

longearistata, Hack. ex Sodero, Gram. Ecuator. (Anal. Univ. Quito, 1889) 8(= Deyeuxia longearistata Wedd.). - Ecuad.

Macouniana, Vasey, in Contrib. U. S. Nat, Herb, i. (1892) 249, et iii. (1892) 81. - Am. bor.

Mannii, Engl, in Abhandl. Preuss. Akad. Wiss. 1891 ii. (1892) = Deyeuxia Mannii, Hook. f.

Matsumurae, Maxim. in Bull. Acad. Pétersb. xxxii. (1888) 628. - Japon,

montanensis, Schribn. ex Vasey, in Contrib. U.S Nat. Herb. i. (1892) 249, et iii. (1892) 82. - Am. bor.

moupinensis, Franch, in Nowv. Arch. Mus. Paris, Sér. II, x. (1888) 106. - China

pallida, Vasey et Scribn. in Contrib. U. S. Nat. Herb. i. (1892) 249; et iii. (1892) 79. - Am. bor. (Washington).

paradoxa, Lipsky, in Act. Hort. Petrop. xiii. (1894) 346. - Reg. Cauc.

robusta, Vasey, in Contrib. U. S. Nat. Herb. i. (1892) 249; et iii. (1892) 82. - Am. bor.

scabrescens, Franch. in Nouv. Arch. Mus. Paris, Sér. II - X. (1898) 105. - China.

copulorum, M. E. fones, in Proc. Calif. Acad. Ser. II. $v .(1895) 722 .-U$ tah.

Sodiroana, Hack. ex Sodiro, Gram. Ecuator. (Anal. Univ. Quito, 1889) 8 nomen. - Ecuad.

Spruceana, Haik. ex Sodiro, Gram. Ecuator. (Anal. Univ. Quito, 1889) 8(= Deyeuxia Spruceana, Wedd.). - Ecuad.

Suksdorfii, Scribn. ex Vasey, in Contrib. U. S. Nat. Herb. i. (1892) 249; et iii. (1892) 82. - Am. bor Torgesiana X, Hausskn. in Mitth. Thür. Bot. Ver. N. Folge, vi. (1894) 69.- Germ.

Tweedyi, Scribn. in Contrib. U. S. Nat. Herb. i. (1892) 249; t. iii. (1892) 83; et in Vasey, Ill. N. Am. Grass. ii. (1892) t. 44. - Washingt.

\section{CALAMAGROSTIS}

illosa, St-Lager, in Cariot, Etud. des fl. éd. 8, ii. 1889) $906=$ Halleriana, $D C$.

Wirtgeniana $\times$, Hausskn, in Mitth. Thür, Bot, Ver. N. Folge, vi (1894) 68. - Germ.

Yatabei, Maxim. in Bull. Acad. Pétersb. xxxii. (1888) 627. - Japon.

GALAMINTHA, (Tourn.) Linn.(Labiat.), - Ind. Kew. 1. 375.

baborensis, Batt. in Batt. et Trab. Fl. de l'Algér. [Dicot.] (1889) 679; et in Bull. Soc.bot. Fr. xxxvi. (1889) 64. - Algeria.

Baumgarteni, Nym Consp. fl. Eur. Suppl. II. i. (1889) $255=$ alpina, Lam.

glabra, Trelease, ex Branner et Coville, in Ann. Rep. Geol. Surv. Arkans. 1888, i. (1891) 211 - Nuttallii, Bentr.

hungarica, Simonk. in Termész. Füzet. x. (1886) 182. - Eur. or.

hungavica, Nym. Consp. fl. Eur. Suppl. II. i. (1889) $255=$ praec

intermedia, H. Braun, in Verh. zool.-bot, Ges. Wien, xxxix. (1889) $220=$ sylvatica, Bromef.

Kilimandschari, Gürke, ex Engl. in Abhandl. Preuss. Akad. Wiss. 1891. ii. (1892) 366. - Afr. trop. or. mixta $\times$. Ausserdorfer, ex H. Braun. et Sennh. in Oest. Bot. Zeitschr. x. (1890) 158; G. Beck, F1. Nieder-Oest. ii. ( 892) 999. - Austria.

origanifolia, St-Lager, in Cariot. Etud. des fl. éd. 8 ,ii. (1889) 665, sphalm. = Clinopodlum origanifolium, Labill.

CALAMOVILFA Hack. True Grasses (1890) 113. GRAMINEAE

brevipilis, Hack. l. c. (= Calamagrostis brevipilis, A. Gray). - Am. bor.

longifolia, Hack. l. c.; et ex S. Wats. in A. Gray, Man. N.Am. Bot. ed. 6. (1890) 651 $(=$ Calamagrostis longifolia, Hook.). — Am. bor.

CALAMUS, Linn. (Palm.).-- Ind. Kew. i. 376. armensis. Becc. Matesia, iii. (1886) 61. -Ins, A rm. axillaris, Becc. in Hook. f. Fl. Brit. Ind. vi. (1893) 456. - Perak.

Barteri, Drude, in Bot. Fahrb. xxi. (1895) 111 nomen. - Sierra-Leone.

Brandisii, Becc. in Hook. f. Fl. Brit. Ind. vi. (1892) 448. - Travanc.

conirostris, Becc. l. c. 461. - Perak.

Cuthbertsoni, Becc. in Nuov. Giorn. bot. Ital. xx. (1888) $179,-N$. Guin.

densiflorus, Becc. in Hook.f. Fl. Brit. Ind. vi. (1892) 445. - Perak.

digitatus, Becc. l. c. 442. - Zeyl.

diffusus, Becc. l. c. 447 . - Penins. Mal.

Doriaei, Becc.l. c. 456. - Burma.

filipendulus, Becc.l.c. 443 . - Perak

Feanus, Becc.l.c. 448 . - Tenass.

flabellatus, Becc. Malesia, iii. (1886) 62. - Borneo.

Gamblei, Becc, in Hook. f. Fl, Brit. Ind. vi. (1893)

453. - Ind. or

giganteus, Becc.i.c. 460. - Perak

grandis, Hort. ex Iilustr. Hortic. (1895) 223. Borneo?

Heudelotii, Becc. et Drude, in Bot. Fahrb. xxi. (1895) 112 et 134. - Guinea.

Holltungii, Becc in $K$. Schum et Hollv, Fl. Kais. Wilh. Land (1889) 17. - N. Guin.

interruptus, Becc. Malesia, iii. (1886) 60.-N. Guin.

Lobbianus, Becc. in Hook. f. Fi. Brit. Ind. vi. (1893) 451. - Penins. Mal.

luridus, Becc. $l$ c. 445 . - Perak.

Martianus, Becc.l. c. 459. - Penang.

melanocarpus, Ridl. in Trans. Linn. Soc. Ser. II. iii. (1893) 392. - Penins. Mal.

myrianthus, Becc. in Hook. f. Fl. Brit. Ind. vi. (1894) 451. - Burma.

neglectus, Becc. l. c. 458. - Malacca

nicobaricus, Becc. l. c. 446 . - Ins. Nicob.

pallidulus, Becc. l. c. 457. - Perak.

papuanus, Becc. Malesia, iii. (1886) 60. - N. Guin

paspalanthus, Becc. in Hook. f. Fl. Brit. Ind. vi (1893) 450. - Perak.

perakensis, Becc. l. c. 451 . - Perak.

Pseudosepal, Becc.l. o. 465. - Perak

pseudo-tenuis, Becc. l. c. 445. - Zeyl.

\section{GALAMUS}

pygmaeus, Becc. Malesia, iii. (1886) 8. - Borneo, radulosus, Becc. in Hook. f. Fl. Brit. Ind. vi. (1892) 443. - Perak.

rugosus, Becc. l. c. 443. - Perak.

robustus, L. Lind. et Rodigas, in Illustr. Hortic. (1893) 19 t. 569. - Borneo

serrulatus, Becc. Malesia, iii. (1886) 61. - N. Guin, simplex, Becc. in Hook. f. Fl. Brit. Ind. vi. (1893) 456. - Perak.

singaporensis, Becc. l. c. 454.- Penins. Mal

Thwaitesii, Becc. l. c. 441. - Zeyl.

tomentosus, Beec.l. c. 455. - Perak

travancoricus, Bedd. ex Hook. f. Fl. Brit. Ind. vi. (1894) 452. - Deccan.

triqueter, Beco. Malesia, iii. (1886) 62. - Borneo.

vestitus, Becc. l. c. 59, - N. Guin.

viridispinus, Becc. in Hook. f. Fl. Brit. Ind vi (1893) 458. - Perak

zebrinus, Becc. Malesia, iii. (1886) 59. - N. Guin. zeylanicus, Becc. in Hook. f. Fl. Brit.Ind. vi. (1893) 455. - Zeyl

GALANDRINIA, H. B. et K. (Portul.). - Ind.

ambigua, Howell, in Erythea, i. (1893) $34=$ sesuvioides, A. Gray.

armeriifolia, Phil. in Anal. Mus. nac. Chile (1891) 25. - Chili.

calocephala, Phil. l. ., - Chili.

capiapina, Phil.l. c. - Chili.

Howellii, S. Wats. in Proc. Am. Acad. xxiii. (1888) 262. - Oreg.

sesuvioides, A. Gray, l. c. xxii. (1887) 278. - Calif. spicigera, Phil. in Anal, Mus. nac. Chile (1891) 25.

GALANTHE, R. Br. (Orchid.). - Ind. Kew. i. 378.

Augusti-Reigneri, Hort. ex Rev. Hortic. (1894) 134 $=$ Regnieri, Reichb. $f$.

buccinifera, Rolfe, ex Hemsl. in fourn. Linn. Soc. xxix. (1892) 318. - China

Darblayana $\times$. Hort. Maron, ex God.-Leboeuf, in l'Orchidophile (1889) 178 cum ic. - Hybr. artef. Davidi, Franch. in Nouv. Arch. Mus. Paris, Sér. II. $\mathrm{x}$. (1888) 85. - China.

curantigoides, Kuntze, Rev. Gen. (1891) 650 sphalm. $=$ curculigroides, $L$ indl.

delphinioides, Kraenzl. in Bot. Fahrb. xvii. (1893) 55. - Kamerun.

diploxiphion, Hook. f. Fl. Brit. Ind. v. (1890) 849. - Perak

ecarinata, Rolfe, ex Hemsl. in fourn. Linn. Soc. xxix. (1892) 318. - China.

elytroglossa, Reichb. f. ex Hook. f. Fl. Brit. Ind. v. (1890) 853. - Reg. Himal.

Eyermanii $\times$, Hort. ex Gard. and For. iv. (1891) 16 fig. 3. - Hybr. artet.

fimbriata, Franch. in Nouv. Arch. Mus, Paris, Sér. II. x. (1887) 86. - China.

Fineti $\times$, Hort. ex Rev. Hortic. (1894) 134.= Hybr. artef.

giganteâ, Hook. f. Fl. Brit. Ind. v. (1890) 856 . Perak.

gigas $\times$, Hort. ex Gartenfl. (1894) 24. - Hybr,

Halli $\times$, Hort. ex Wien. Illustr. Garten-Zeit. (1888) 108. - Hybr. artef.

inquitina $\times$, Rolfe, in Journ. Linn. Soc, xxix. (1887) 168 (= Phaius vestitus, Reichb.f.).-Hybr. artef.

kirishimensis, Yatabé, in Tokyo Bot. Mag. vi. (1893) 253 t. 7. - Japon.

labrosa, Hook, f. Fl. Brit. Ind.v. (1890) 856.Tenass.

Mannii, Hook. f. l. c. 850. - Reg. Himal.

megalopha, Franch. in Nouv. Arch. Mus. Paris, Sér. II. x. (1887) 85. - China.

Muelleri, Kraenzl. in Bot. Falırb. xvii. (1893) 486.

Mylesii X, Williams, in Warn. et Will. Orchid Alb. ix. (1891) t. 402. - Hybr. artef.

ovalifolia, Ridl. ex Stapf, in Trans. Linn. Soc., Ser. II. iv. (1894) 239. - Borneo.

pachystalix, Reichb. f. ex Hook. f. Fl. Brit. Ind. v. (1890) 850. - Reg. Himal. 
CALANTHE :-

rubens, Ridl. in Gard. Chron. (1890) i. 576. Penins. Mal.

Sanderiana, Williams, Catal. (1887)21. - Cochinchina.

Scortechinii, Hook, f. Fl. Brit. Ind. v. (1890) 854 - Perak.

tubifera, Hook. f. l. c. 855.-Burma

Wrayi, Hook. f. l. c. v. (1890) 850.- Perak.

CALANTHIDIUM, Pfitzer, in Engl. et Prantl, Natiirl. Pflanzenfam ii, 6, (1888) 153. ORCHI $D E A E$

labrosum, Pfitzer, l. c.; et in Bull. Herb. Boiss. ii. (1894) 49. - Moulm.

CALANTIGA, Jaub. (Samyd.) - - Ind. Kew. i.

fanberti, Baill: in Bull. Soc. Linn. Par. i. (1886)

fanberti, Baill. in Bull. Soc. Lin
$573=$ Bivinia Jaubertia, Tul.

lucida, S. Elliot, in fourn. Linn. Soc. xxix. (1891) 20. - Madag.

Mantini x, Hort. ex Rev. Hort. (1894) 134. Hybr. artef.

CALAPPA, Rumpf, Herb. Amboin. i. (1741) 9/12 ex Kuntze, Rev. Gen. (1891) $982=$ Cocos, Linn. (Palm.).

acaulis, acrocomiodes, amara, australis, botryophora, campestris, capitata, comosa coronata. Datil, erios patha, flexwosa, graminifolia, insignis, leiospatha. Martiana, Mikaniana, nucifera, oleracea, orinocensis, petraea, pityrophylla, plumosa, Procopiana, Romanzoffana, schizophylla, speciosa, Weddellii. Yatay, Kuntze, 1. c. = homonyma ommia generis Cocos.

coccodes, Kuntze, 1. c. = Cocos Syagrus, Drude.

elegantina, Kuntze, 1. c. = Cocos Weddelliana, Drude.

Sancona, Kuntze, 1.c. (= Syagrus Sancona, Karst.). - N. Gran.

CALATheA, G. F. W. Mey. (Scitam.). - Ind Kew. i. 379 .

Achira, Petersen, in Mart. Fl. Bras. iii. III. (1890) 108 (= Phrynium Achira, Poepp. et Endl.). Bras.

albicans, A. Brongn. ex Peterseis, 1. c. 97 nomen, = undulata, Lind. et É d. André.

amplissima, Petersen, l. c. 115. - Bras.

Bakeri, C. B. Clarke, ex Tonduz, in Bull. Herb. Boiss, 1895) 464 nomen. - Am. centr.

barbata, Petersen, in Mart. Fl. Bras. iii. III. (1898) 110. - Bras.

concolor, Eichl. ex Petersen, l. c. 126. - Hab.

crotalifera, S. Wats. in Proc. Am. Acad. xxiv. (1889) 86. - Guatem.

cyclophora, Baker, in Kew Bull. (1895) 17. Guian. angl.

discolor, G. F.W. Mey. ex Eggers, in Bot. Centralbl. liii. (1893) 307. - Baloo.

Eichleri, Petersen, in Mart. Fl. Bras. II. iii. (1890) 108. - Bras.

Gardneri, Baker, in Kew Bull. (1895) 18. - Bras.

Glaziovii, Petersen, in Mart. Fl. Bras, iii. III. (1890) 111. - Bras.

gracilis, Petersen, in Ved. Meddel naturh. Foren. (1889) 328. - Bras.

grandis, Petersen, in Mart. Fl. Bras, III. iii. (1890) 124. - Guian. batav.

humilis, S. Moore, in Trans. Linn. Soc. Ser. II. iv. (1895) 489. - Bras.

inocephala, Kuntze, Rev. Gen.(1891) 694.-Panama. insignis, Petersenz, ex Eggers, in Bot. Centralbl. liii. (1893) 307. - Baloo.

insignis, Petersen, in Mart. Fl. Bras, iii. III. (1890) 1:4. - Panama.

Koernickeana, Petersen, in Vid. Meddel. naturh. Foren. (1889) 330, - Bras.

lanata. Petersen, in Mart. Fl. Bras. iii. III.(1890) 119 - Bras.

Lindbergii, Petersen, 2. c. 113. - Bras.

Marcelli, Hort. ex Petersen, 1. c. $118=$ virginalis, Lind.

Neoviedii, Petersen, l. c. 117. - Bras.

Petersenii, Eggers, in Bot. Centralbl. liii. (1893) 304. t. 1. - Baloo.

\section{CALATHEA}

praecox, S. Moove, in Trans. Linn. Soc. Ser. II iv. (1895) 488. - Bras.

propinqua, Hort. ex Petersen, in Mart. Fl. Bras. iii. II. (1890) $127=$ Koernickeana, Regel.

rhizantha, $K$. Schum. in Bot. Fahrb. xv. (1893) 433 - Gabon.

sciuroides, Petersen, in Vid. Meddel. naturh. Foren. (1889) 329. - Bras.

Sodiroi, Eggers, in Bot. Centralbl. 1iii. (1893) 306. Baloo.

straminea, Petersen, in Mart. Fl. Bras, iii. II. (1890) 118. - Bras.

subtilis, S. Moore, in Trans. Linn. Soc. Ser. II. iv. (1895) 487 . - Bras.

vaginata. Petersen, in Vid. Meddel. naturh. Foren. (1889) 331. - Bras.

CALGEOLARIA, Linn. (Scrophul.).- Ind. Kew.

i. 380 . 150. - Chili.

algarrobensis, Phil.l.c. 136, - Chili.

arachnoideo-crenatiflora, Rodigas, in Illustr. Hortic. (1888) 51 t. 54 . - Form. hort.

asperula, Phil. in An. Univ. Chil. xci. (1895) 153.Chili.

auriculata, Phil.l. c. 151. - Chili

bigemina, Phil. l. c. 158, - Chili.

bipartita, Phil. l. c. 156. - Chili.

Borchersi, Phil.l. c. 149. - Chili.

brunellifolia, Phil.l. c. 155. - Chili.

Burbidgei $x$, Hort. ex Gard. Chron. (1886) 464. Hybr. artef.

albula, Colenso, in Trans. N. Z. Inst. xxvii. 1894 (1895) 391. - N.Zel.

Campanae, Phil in An, Univ, Chil, xci. (1895) 152. - Chili.

cheiranthoides, Phil. ex Reiche, in Bot. Fahrb. xxi. (1895) 49. - Chili.

compacta, Phil. in An. Univ. Chil. xci. (1894) 139. - Chili.

cordata, Phil. l.c. 159. - Chili.

crocea, Phil. l. c. 139. - Chili.

cuspidata, Phil. 1. c. $148=$ petiolaris, Cav.?

dumetorum, Phil. l. c. 144. - Chili.

effusa, Phil. l. c. 147. - Chili.

Georgiana, Phil.l. c. 138. - Chili.

glutinosa, Fr. Meigen, in Bot. Fahrö. xvii. (1893) nomen, et xviii. (1894) 483. - Chili.

Gmelini, Phil. in Anal. Univ. Chil. xci. (1895) 134 $=$ integrifolia, Linn.

irazuensis, F. D. Smith, in Coult. Bot. Gaz. xx. 1895) 292. - Costarica.

Kingi, Phil, in An. Univ, Chil, xci. (1895) 149.Chili.

lepida, Phil. l. c. 140. - Chili

longepetiolata, Phil. l. c. 144.-Chili.

Oreas, Phil. l.c. 137. - Chili

Palenae, Phil. l. c. 155. - Chili.

pallida, Phil. l. c. 144. - Chili.

parvifolia, Phil. l. c. 136. - Chili.

Poeppigiana, Phil.l. c. 153. - Chili.

pristiphylla, Phil. l.c. 138. - Chili.

pubescens, Plit. l. c. 139. - Chili.

pulchella, Phil. in Anal. Mus. nac. Chile (1892) 70 - Chili.

rupicola, Fr. Meigen, in Bot. Fuhrb. xvii. (1893) 273 et 290 nomen; et xviii. (1894) 483. - Chili. salicariifolia, Phil. in Anal. Univ. Chil. xci. (1895) 135. - Chili.

stachydifolia, Phil, l, c, 143, - Chili.

stellarifolia, Phil, in An. Mus, nac. Chile (1892)

70. - Chili.

Sturmii, Colenso, in Trans. N. Z. Inst. xxvii. 1894 (1895) 392, - N. Zel.

tenerifolia, Phil. in An. Univ. Chil. xci. (1895) $15 \%$. - Chili.

villosa, Phil. l. c. 142. - Chili

Williamsi, Phil. l. c. 158. - Chili.

CALCEOLARIA, Loefl. Iter Hisp. (1758) ex Kuntze Rev. Gen. (1891) 40 = Ionidium, Vent. (Violar.).

alba, anomala, atropurpurea, bicolor, bigibbosa, brevicaulis, caffra, calycina, capensis, communis, concolor, debilissima, elata, filiformis, floribunda, truticulosa,
CALCEOLARIA :-

glutinosa, gracilis, heterosepala, Hieronymi, Ipeca. cuanha, lamata, lasiocarpa, linearis, longifolia, Lon rentziana, Maximiliani, oppositifolia, Poaya, procumbens, ramosissima, setigera, Sprucei, stricta, thymifolia, verbenacea, Vernonii, villosissima, Kuntze, Rev. Gen. (1891) 40-41 = homonyma omnia Ionidii.

angustata, Kuntze, 1. c 4l=Ionidium angustatum, Klotzsch, fide Kuntze.

arborea. Kuntze, 1. c. = Corynostylis Loeflingii, Spreng.

Bangii, Rusby, in Mem. Torrey Bot. Club, iii. 3. 1893) 6. - Bolivia.

Botteri, Kuntze, 1. c. = I. Botterii, Turcz.

brasiliensis, Britton, in Ann. N. Y. Acad. Sc. vi1.

(1892) $5 \mathrm{I}=\mathrm{I}$. album, St-Hil.

circaeodes, Kuntze, 1, c. = I. circaeoides, $H, B$. et $K$

enneasperma, Kuntze, 1. c. = I. heterophyllum, Vent.

Lehmannii, Hieron. in Bot. Jahrb. xx. Beibl. n. 49

(1895) 57 in obs. = I. Lehmannii, Hieron.

lobeliodes, Kuntze, 1. c. = I. lobelioides, Schlecht.

microphylla, Kuntze, l. c. = 1. glutinosum, Vent.

Mocinoana, Kuntze, 1. c. = I. calceolarium, Ging.

occulta, Kuntze, 1. c. = I. occulatum, Polak.

parvifolia. Kuntze, 1. c. = I. glutinosum, Vent.

phyllanthodes, Kuntze, I. c. = I. phyllanthoides,

Planch. et Lind.

viparia, Kuntze, 1. c. = I. oppositifolium, Roem.et Schult.

Tatei, Kuntze, 1, c. (=Hybanthus Tatei, F. Muell.). - Austral.

verticillata, Kuntze, 1. c. = I. polygalaefolium, Vent.

CALCEOLUS, (Tourn.) Adans.= Cypripedium, Linn. (Orchid.).

alternifolius, St-Lager, in Cariot, Etud. des fl. éd. 8. ii. (1889) $816=$ Cypripedium Calceolus, Linn.

CALDASIA, Mutis = Helosis, Rich. (Balanophor.). brasiliensis, Kuntze, Rev. Gen. (1891) $590=$ H. guyanensis, Rich.

mexicana, Kuntze, 1. c. = H. mexicana, Lehm.

CALEA, Linn. (Compos.). - Ind. Kew. i. 384

angosturana, Hieron. in Bot. Fahrb. xix.(1894) 56. - Columb.

caracasana, Hieron. 1. $\mathrm{c}_{\mathrm{s}}$ in obs, = seq.

caracasana, Kuntze, Rev. Gen. (1891) 324 (= Allocarpus caracasanus, H. B. et K.). - Venez.

floribunda, Baker, in Kew Bull. (I893) 15\%. Bras.

glomerata, Klatt, in Bot. Fahrb. viii. (1887) 45. Columb.

Liebmannii, Sch. Bip. ex Klatt, in Leopoldina, Heft xxiii. (1887) 145. - Mexic。

multiradiata, Robins, et Seaton, in Proc. Am. Acad. xxiii. (1893) 120. - Mexic.

orizabaensis, Klatt, in Leopoldina, Heft xxiii. (188\%) 145. - Mexic.

pachensis, Hieron. in Bot. Fahrb. xix. (1894! 56. Columb.

Palmeri, A. Gray, in Proc, Am. Acad. xxii. (1887) 430. - Mexic.

pellucidinerva, Klatt, ex Th. Dur. et Pitt. in Bull. Soc. Bot. Belg. xxxi. 1892 (1893) 207. - Costarica.

robusta, Britton, in Bull. Torrev Bot. Club, xix. (1892) 151. - Bolivia.

sillaensis, Kuntze, Rev. Gen. (1891) 324.-Venez.

ternifolia, Oliver, in Trans. Linn. Soc. Ser. II. ii. (1887) $27 \%$ t. 43b. (Oliver, ex im Thurm, in Timehri, v. [1886] 197.), - Guian, angl.

tolimana, Hieron. in Bot. Fahrb. xix. (1894) 57. Columb.

Trianae, Hievon, $l$. c, 58, - Columb

trichotoma, F. D. Smith, in Coult. Bot. Gaz. xiii. (1889) 299. - Guatem.

CALENDULA, Linn. (Compos.). - Ind. Kew. i.

foliosa, Batt. in Batt. et Trab. El. de l'Algér. (Dicot.) (1888) 479. - Algeria. 
GALENDULA :-

microphylla, Lange, ex Nym. Consp. fl. Eur. Suppl. I. i. (1889) $178=$ microphyla, Lange.

GALEPINA, Adans. (Crucif.). - Ind. Kew. i. 334. cochlearioides, Kern. Sched. fl. Austro-Hung. vi. (1893) $15=$ C. Corvini, Desv.

CALESIUM, Kuntze, Rev. Gen. (1891) 151=CALESIAM, Adans. = Odina, Roxb. (Anacard.).

acidum, asplenifolium, Barteri, discolor, edule, fruticosum, humile, obovatum, ornifolium, Schimperi. Schweinfurthii, speciosum, triphyllum, velutinum Kuntze, 1. c. = homonyma omnia Odinae.

alatum, Engl, in Engl. et Prant1, Natiurl. Pflanzenfam. iii. 5. (1892) 153. - Reg. Somal

cinereum, Engl. 1. c. - Reg. Somal.

ensifoliolatum, Eng1.1. c. - Reg. Somal.

fulvum, Engl. 1.c. - Afr. trop. or.

grande, Kuntze, Rev. Gen. (1891) $151=$ O. Wadiae, Roxb.

obcordatum, Eng1. in Engl. et Prantl, Natürl. Pflanzenfam. iii. 5. (1892) 153. - Reg. Somal.

tomentosum, Eng1. 1. c. - - Afr. trop. or.

CALETIA, Baill. = Micrantheum, Desf. (Euphorb.).

ericodes, Kuntze, Rev. Gen. (1891) $595=$ M. ericoides, Desf.

CALIMERIS, Nees $=$ Aster, Tourn, $($ Compos. $)$. fruticosa, C. Winkl. in Aet. Hort. Petrop. ix. (1886) 419. - As. centr.

GALLA, Linn. (Aroid.). - Ind. Kew, i. 384.

Pentlandi, Hort. ex Kew Bull. (1893) Append. ii. $30=$ Richardia Pentlandi, Hort.

GALLIANDRA, Benth. (Legumin.). - Ind. Kew. boliviana, Britton, in Bull. Torrey Bot. Club, xvi. (1889) $32 \%$ - Bolivia.
boliviana, Britton, $2 n$ B

Chapadae, S. Moore, in Trans. Linn. Soc. Ser. II, iv. (1895) 349. - Bras.

cinerea, Taub. in Flora, 1xxv. (1892) 70. - Bras.

Glaziovii, Taub. l. c. 71. - Bras.

nitida, S. Wats, in Proc, Am. Acad. xxii. (1887) 410 , - Mexic.

Palmeri, S Wats. l.c.- Mexic.

Schwackeana, Taub. in Flora, 1xxv. (1892) 69. Bras.

tolimensis, Taub. ex Hieron. in Bot. Fahrb. xxi. (1895) 314. - N. Gran.

GALLIANTHEMUM, C. A. Mey. (Ranuncul.),

-Ind. Kew. i. 386.
anemonoides, Kern. Sched. fl. Austro-Hung. v. (1888) 35 = rutaefolium, Reichô.

anemonoides, Zahlbr. in Engl, et Prantl, Natürl. Pflanzenfam. iii. 2. (1888) $57=$ praec.

Kernerianum, Freyn, ex Kern. Sched. fl, AustroHung.v. (1888) 36. - Austria.

GALIIGARPA, Linn. (Verben.), - Ind. Kew. i. 386.

caudata, Maxim. in Bull. Acad. Pétersb. xxxi. (1887) 76 . - Ins. Philipp.

pilosissima, Maxim l. c. - Ins. Formos.

shikokiana, Makino, in Tokyo Bot. Mag. vi. (1892)

54. - Japon.

tosaënsis, Makino, l.c. 181. - Japon.

GALLIGHLAMYS, Miq. (Bignon.). - Ind. Kew.

i. 386.
latifolia, K. Schum, in Engl. et Prantl, Natürl. Pfanzenfam. iv. 3b. (1894) 223. - Bras.

Peckoltii, Bur. ex K. Schum. l. c. fig. 88. - Bras.

CALLICHROA, Fisch. et Mey.=Layia, Hook, et Arn. (Compos.).

fonesii, Greene, Pittonia, ii. (May 1892) $228=$

Layia Jonesii, $A$. Gray.

nutans, Greene, 1. c. 227. - Calif.
CALIPHRURIA, Herb. (Amaryll.). - Ind. Kew.

i. 384 .

Bonplandii, Baill. in Bull. Soc. Linn. Paris, ii. (1894) 1136 (Calliphruria) $=$ Hymenocallis Bonplandii, Kunth

candida, Baill. 1. c. (Calliphruria) $=$ Eucharis candida, Planch, et Lind.

Castelnaeana, Baill. l. c. 1135 (Calliphruria.). Peruvia.

tenera, Baker, Handb. Amaryll. (158s) 112. N. Gran.

CALLIGONUM, Linn. (Polygon.). - Ind. Kew. 1. 387

minimum, Lipski, Exc. bot. au delà Mer Casp. (1889) 19. - Rossia.

CALLIPRORA, Lindl. = Brodiaea, Sm. (Liliac. $)$ ixiodes, Greene, Man. Bot. San Franc. Bay (1894) $318=$ B. ixioides, $S$. Wats.

lugens, Greene, 1. c. $319=$ B. lugens, Greene.

scabra, Greene, in Erythea, iii. (1895) 126. - Calif

CALLISTA, Lour. = Dendrobium, Sw.(Orchid.). acerosa, acicularis, acinaciformis, acrobatica, acuminatissima, Adae, adunca, aemula, affinis, aggregata, agrostophylla, albosanguinea, alpestris, amboinensis, amethystoglossa, amoena, ampla, anceps, angulata, angustifolia, antennata, Aphrodite, appendiculata, aquea, Avachnites, attenuata, aurantiaca, aurorosea, Baileyi, Bairdiana, bambusifolia, barbatula, Bensoniae, bicamerata, bicaudata, bifalcis, bifaria, biflora, bigibba, biloba, Binnendykii, binocularis, bolboflora, Boothii, brachypetala, Brachypus, bursigera, calophylla, Calopogon, canaliculata, candida capillipes, Cathcarthii, chrysantha, chrysocrepis, chrysotoxa, ciliata, clavata, clavipes, Coelogyne, comata, connata, convexa, cornuta, crepidata, cretacea, crocata, cruenta, crumenata, crystallina, cucumevina, cumulata, cuspidata, densiflora, denudans, Devoniana, dicupha, Diodon, distachya, disticha, dixantha, Draconis, elongata, eviceflora, erosa, eulophota. euphlebia, excavata, Falconeri, fimbriata, Findlayana, Fitrgeraldii, flavescens, flavidula, floribunda, Foelschei, foliosa, formosa, fugax, funiformis, furcata, fuscescens, Fytcheana, geminata. Gibsonii glossotis, Gouldii, gracilicaulis, gracilis, graminifolia, grandiflora, grandis gratissima, Griffthiana, haemoglossa, Harveyana, Hasseltii, herbacea, hercoglossa, heterocarpa, heterodea, Heyneana, hispida, Hookerana, Hornei, hymenantha, hymenoptera incrassata, incurva, indivisa, Infundibulum, inssignis, intermedia, javanica, ferdoniana, fohannis, juncea, kentrochila kentrophylla. Kingiana, Kuenstlevi, Kuhlii, labuana, lamellata, lancifolia, lasioglossa, Laviana, Leonis, leucochlora, leucolophota, lilacina, Linawiana, lituiflora, lobata, Lobbii, Loddigesii, lonchophylla, longicollis, longipes, Lubbersiana, lucens, Lowiz, lunata, luteola, Macfarlanei, Macraei, macrantha, macrophylla, macropoda, Macropus, macrostachya, marginata, marmorata, megaceras, meta chilina, microbullon, misera, moniliformis, monophylla, Moorei, Mortii, moutmeinensis, mutabilis, nana, Nathanielis, nitidissima, nobilis, normalis, nuda, nutans, ochreata, ochrolenca, ophioglossa, pachyglossa, Palpebrae, pandurata, panduriformis, parca, Parishit, parviflora, pendula, perakensis, Perula, Phalaenopsis, platygastria, porphyrochila, praecincta, primulina, pugioniformis, pulchella, pumila, purpurea, pusilla, pycnostachya, pygmaea, quadrangularis, radians, ramosa, Reichenbachii, reptans, revoluta, rhodocentra, rhodopterygia, rigida, rotundata, Ruckeri, vugosa, salaccense, sanguinolenta, sarcantha, scabrilinguis, Scortechinii, sculpta, se cunda, senilis, simuata, Smilliae, Spatella, spathacea. speciosa, spectabilis, spinescens, Stratiotes, strebloceras, Stricklandiana, striolata, strongylantha, Stuar tii, stuposa, subacaulis, subulata, sulcata, Sumneri superbiens. taurina, tenella, tenuicaulis, teres, teretifolia, terminalis, tetraedris, tetragona, tetrodon, thyrsodes, Tmesipteris, tortilis, transparens, Treacheriana, trichotoma, tricuspis, tridentifera, triflora, trigonopus, tropaeoliflora, truncata, tuberifera, uncata, undulata, unguiculata, Veitchians, veratrifolia, vexabilis, villosula, virginea. Wattii, Williamsonii, xantholenca, xanthophlebia, Kuntze, Rev. Gen. (1891) $653-55=$ homonyma omnia Dendrobii.
CALLISTA :-

aloefolia, Kuntze, Rev. Gen. (1891) $653=$ D. Serra, Lindl.

angulata, Kuntze, 1. c. $654=$ D. homonymum, Sterd.

anosma, Kuntze, 1. c. $653=$ D. superbum, Reichb. $f$. aphylla, Kuntze, 1.c. = D. Pierardi, Roxb.

aurea, Kuntze, 1, $C_{1}=\mathrm{D}$, heterocarpum, Wall.

Beckleri, Kuntze, 1. c. $654=$ D. Mortii, F. Muell. bicolor, Kuntze, 1, c, $653=$ D, subulatum, Hook, $f$. borneoênsis, Kuntze, 1. c. $654=$ D. Teysmanni, Miq.

Boxaleiz, Kuntze, 1. c. = D. gratiosissimum, Reichb. $f$.

Greciflora, Kuntze, 1. c. = D. bicameratum, Lizzdl. Brymerana, Kuntze, 1. $\mathrm{c}_{0}=$ D. Brymerianum, Reichb. $f$

Calceola, Kuntze, 1. c. = D. Calceolaria, Carey. carrnifera, Kuntze, 1. $\mathrm{c}_{\mathrm{r}}=\mathrm{D}$. carinatum, Willd. carnosa, Kuntze, 1. c. = D. atropurpureum, Miq. commutata, Kuntze, 1. c. 653 = D. homonymum, Steud.

conostalyx, Kuntze, 1. c. $654=$ D. conostalix, Reichb. $f$

crassinodis, Kuntze, 1. $\mathrm{c}_{*}=$ D. pendulum, Roxb.

Cunninghamii, Kuntze, 1. c. = D. Cunninghami, Lindl.

cymbidiodes, Kuntze, 1. c. = D. cymbidioides, Lindl. Dearii, Kuntze, 1. C. = D. Dearei, Reichb.

eviaeodes, Kuntze, 1. c. $=$ D. eriaeoides, F. M. Bailey.

Fairfaxii, Kuntze, 1. c. = D. teretifolium, $R$. Br.
falconirostris, Kuntze, I. c. $=$ D. falcorostrum,

falconirostris

Farmeri, Kuntze, 1. c. = D. Farmerii, Paxt.

flabella, Kuntze, 1. c. = D. Macraei, Lindl.

Fytcheana, Kuntze, 1. c. = D. Fytchianum, Batem.

Gordonii, Kuntze, 1. c. = D. Gordoni, S. Moore.

Huttonii, Kuntze, 1. c. = D. Huttoni, Reichb. f.

hymenophylla, Kuntze, 1. c. = D. Hymenophyllum, Lindl.

jabonica, Kuntze, 1. c. $=$ D. moniliforme, $S m$.

Fenkinsii, Kuntze, 1. c. = D. parciflorum, Reichb.f.

Fonopus, Kuntze, 1. c. 655 . = D. ionopus, Reichb. $f$.

linguiformis, Kuntze, 1. c. = D. linguaeforme, Sw. longicornis, Kuntze, 1. c. = D. longicornu, Lindl.

lycopodiodes, Kuntze, 1. c. = D. lycopodioides, Lindl.

Macarthiae, Kuntze, 1. c. = D. MacCarthiae, Thw. micrantha, Kuntze, 1. c. = D. Serra, Lindl.

Mirbelliana, Kuntze, 1. c. = D. Mirbelianum, Gaudich.

moschata, Kuntze, 1. c. = D. Calceolaria, Carey.

oculata, Kuntze, 1. c. $653=$ D. fimbriatum, Hook

arlata, Kuntze, 1. c. = D. chlorops, Lindl.

oxystophylla, Kuntze, 1. c. $654=$ D. rigidum, R. Br.

pachyphylla, Kuntze, 1. c. = D. carnosum, Teijsm. et Binn.

Reinwardtii, Kuntze, 1. c, $655=$ D. Reinwardti, Lindl.

rigescens, Kuntze, 1. c. $=$ D. formum, Stend.

suavissima, Kuntze, 1. c. = D. chysotoxum, Lindl. subteres, Kuntze, 1. C. $=$ D. acerosum, Lindl.

Tattoniana, Kuntze, 1. c. = D. canaliculatum, R. $B r$.

Teysmannii, Kuntze, 1. c. $=$ D Teysmanni, Miq.

Wardiana, Kuntze, 1. c. = D. pendulum, Roxb.

CALLISTACHYS, Vent. = Oxylobium, Andr. (Legumin.).

aciculifera, acuta, alpestris, atropurpurea, capitata, cordifolia, cuneata, hamulosa, heterophylla, microphylla, obtusifolia, parviflora, procumbens, Pulteneae, reticulata, scandens, spectabilis, staurophylla, tricuspidata, Kuntze, Rev. Gen. (1891) $168=$ homonyma omnia Oxylobii.

coriacea, Kuntze, 1. c. $=$ O. retusum. $R$. Br.

ilicifolia, Kuntze, 1. c. = O. trilobatum, Benth.

retusa, Kuntze, 1. c. = O. virgatum, Hort. Kew. ex Benth.

CALLISTEMma, Boiss. = Scabiosa, Tourn. (Dipsac.).

palaestinum, Halàcsy, in Denkschr. Akad. Wien, ix. (1894) $477=\mathrm{S}$. palaestina, Limn。 
CALLITRIGHE, Linn。(Halorag.), - Ind. Kew. i. 388 .

bifida, Morong, in Mem. Torrey Bot. Club, v. (1894) 215 = autumnalis, Linn.

longipedunculata, Morong, in Bull. Torrey Bot. Ciub, xviii. (1891) 236. - Calif.

longistyla, Norm. in Christiana Vidensk.-Selsk. Forliandl. (1892) extr. 28. - Nouv.

microphylla, Colenso, in Trans. N. Z. Inst. xx. 1887. (1888) 190. - N. Zel.

panormitana, Tornab. Fl. Sicula (1887) 245. Sicilia.

GALLITRIS, Vent. (Conifer.). - Ind. Kew. i. 389

Commersonii, Th. Dur. et Schinz, Consp. fl. Afr. v. 1894 (1895) 951 ( = Pachylepis Commersonii, Brongn.) - Ins. Maurit, et Madag.

juniperoides, Th. Dur.et Schinz, l.c. $(=$ Cupressus juniperoides, Linn.). - Afr. austr.

GALLOPSIS Volkensii, Engl。 in Abhandl. Preuss. Akad. Wiss. (1894) 47 nomen. - Afr, trop. or.

GALIUNA, Salisb. (Ericac.). - Ind. Kew. i. 389. Beleziana, Rouy, in Bull. Soc. Bot. Fx, xlii. (1895) $500=$ vulgaris, Salisb.

GALOCEPHALUS, R. Br. (Composit.) - Ind. Kew. 1. 390.

Dittrichii, F. Muell, in Wing, South. Sc. Record, N.S. ii. (May 1886). - Austral.

CALOGHILUS, R. Br. (Orchid.). - Ind. Kew. i.

Holtzei, F. Muell. in Bot. Centralbl. 1. (1892) 127. Austral.

GALOGHORTUS, Pursh (Liliac.). - Ind. Kew. i. 390 .

amoenus, Greene, Pittonia, ii. (May 1898) 71. Am. bor. occ.

ciliatus, Robins, et Seaton, in Coult. Bot. Gaz. xviii. (1898) 238. - Washingt.

collinus, Lemmon, in Erythea, iii.(1895) 49. - Calif. excavatus, Greene, Pittonia, ii. (May 1890) 71. Calif.

Holtzei, F. Muell. in Vict. Natural, viii. (Mar. 1892) 180. - Austral.

Howellii, S. Wats. in Proc. Am. Acad. xxiii. (1888) 266; et in Gard. and For. iii. (1890) 348. Oregon.

invenustus, Grcene, Pittonia, ii. (May 1890) 71. Calif.

Lyoni, S. Wats. in Proc. Am. Acad. xxi。 (1886) 455. - Calif.

madrensis, S. Wats. l. c. xxiii. (1888) 283; et ex Gard. Chron. (1890) ii. 391 fig. 78. - Mexic.

obispoënsis, Lemmon, in Coult. Bot. Gaz. xi. (1886) 180. - Calif.

Plummerae, Greene, Pittonia, ii. (May 1890) ro. Calif.

venustulus, Greene, l.c. i.(Jan. 1888) 158. - Mexic.

COLOGRATER, K. Schum. in Engl. et Prantl, Natiirl. Pflanzenfam. iv. 2. (1895) 175. APOCYNEAE.

Preussii, K. Schum. l. c. - Kamerun

CALOLISIANTHUS, Gilg, in Eng1. et Prant1, Natürl. Pflanzenfam. iv. 2. (1895) 99. GENTIANEAE.

acutangulus, Gilg, 1. c. 100 (= Lisianthus acutangulus, Mart.) - Bras.

amplissimus, Gilg, 1.c. (= Lis, amplissimus, Mart.). - Bras.

frigidus, Gilg, 1. c. (= Lis. frigidus, Sw.). - Ind. occ.

pendunculatus, Gilg, 1. c. (= Lis. pedunculatus, Cham. et Schlecht.). - Bras.

pendulus, Gilg, 1. c. (= Lis, pendulus, Mart. $).$ Bras.

pulcherrimus, Gilg, 1. c. $(=$ Lis. pulcherrimus, Mart.). - Bras.

speciosus, Gilg, 1. c. $(=$ Lis, speciosus, Cham. et Schlecht - Bras.
CALOMERIA, Vent. = Humea, Sm. (Compos.) cassiniaeformis, Kuntze, Rev. Gen.(1891) $325=$ H. cassiniacea, F. Muell.

ozothamnodes, Kuntze, 1. c. = H. ozothamnoides, F. Muell.

punctulata, Kuntze, 1. C. $=$ H. punctulata, F. Muell squanata, Kuntze, 1. c. = H. squamata, F. Muell

CALONYCTION, Choisy $=$ Ipomoea, Linn. $($ Convolvul.).

ventricosum, Hallier $f$, in Bot. Jahrb. xvi. (1893) 556 nomen. - Mexic.

GALOPHAGA, Fisch. (Legumin.). - Ind, Kew i. 391 .

depressa, Oliver, in Hook. Icon. pl. xxiv. (1894) 2301 - Kashmir.

grandiflora, Regel, in Act. Hort. Petrop. ix. (1886) 607 ; et in Gartenfl. 1886) 517 t. 1231. - Buchara

GALOPHANES, D. Don (Acanthac.). - Ind. Kew, i. 391

californica, Rose, ex Vasey et Rose, in Contrib.U.S Nat. Herb. i. (1890) 85. - Calif

crenata, Schinz, in Bull. Herb. Boiss. iii. (1895) 415. - Natal.

fasciculiflora, Martelli, in Nuov. Giorn. bot. Ital. xx. (1888) 390 (= Linostylis fasciculiflora, Fenzl). Afr. trop.

Palmeri, A. Gray, ex S. Wats. in Proc. Am. Acad. xxii. (1887) 443. - Mexic.

peninsularis, Rose, ex Vasey et Rose, in Contrib. U. S. Nat. Herb. i. (1890) 75. - Mexic.

CALOPHYLLUM, Linn. (Guttifer.). - Ind. Kew. i. 391 .

australianum, F. Muell. ex Vesque, Epharm. ii. (1889) t. 22; et in DC. Monog. Phan. viii. (1893) 574 - Austral.

borneense, Vesque, ll. cc. 580. - Borneo.

buxifolium, Vesque. Il. cc. 9 t. 18; et 56\%. - Ins. Philipp.

cerasiferum, Vesque, $l l . c c .10$ t. 32 ; et 585.-Ins. Vit Curtisii, King, in fourn. As. Soc. Beng. lix. (1890) ii. 176. - Malaya.

inophylloide, King, l.c. t. 88; Vesque, in DC. Monog. Phan. viii. (1893) 549. - Malaya

Kingianum, Engl.in Engl.et Prantl, Natürl. Pfanzenfam. iii. 6. (1893) 221 ( $=$ C. microphyllumT. Anders.). - Ind or.

Kunstleri, King, in fourn. As. Soc. Beng. lix. (1890) ii. 174; Vesque, in DC. Monog. Phan. viii. (1893) 607. - Malaya.

lanceolatum, Warb. in Bot. Jahrb. xiii. (1891) $381=$ Warburgii, Engl.

medium, Zoll. ex Vesque, in DC. Monog. Phan. viii. (1893) 579 in syn. = Teysmanni, Zoll.

Miqueli, Vesque, l. c. $60 \%$ - Sumatra.

molle, King, in fourn. As. Soc. Beng. lix. (1890) ii. 177. - Malaya.

nodosum, Vesque, Epharm. ii. (1889) 8 t. 10; et in DC Monog. Phan. viii. (1893) 559. - Borneo.

parvifolium, Vesque, l. c. $604(=$ C. macrophyllum, 'T. Anders.). - Penins. Mal.

Prainianum, King, in fourn. As. Soc. Beng. lix. (1890) ii. 175; Vesque, in DC. Monog. Phan, viii. 1893) 550. - Malaya.

revolutum, L. C. Rich. ex Vesque, 1. c, $596=$ lucidum, Benth.

rupicolum, Ridl. in Trans. Linn. Soc. Ser. II iii (1893) 278. - Penins. Mal.

Schefferi, Vesque, in DC. Monog. Phan. viii. (1893) 609. - Ins, Gébéh (Ind. bat.)

sclerophyllum, Vesque, Epharm, ii. (1889) t. 33; et in DC. Monog. Phan. viii. (1893) 587. - Borneo.

venustum, King, in fourn. As. Soc. Beng, lix. (1890) ii. 180; Vesque, in DC. Monog. Phan. viii. (1893) 549. - Penins. Mal.

Vidali, Ceron, in Vidal, Revis. pl. vasc. Filip. (1892) 229. - Ins. Philipp.

Warburgii, Engl.in Engl. et Prantl, Natürl. Pflanz enf $m$. iii. 6. (1893) $221 \quad(=C$. lanceolatum. Warb.). - Ins. Key

CALOPOGON, R. Br.(Orchid.). - Ind. Kew. i, 392. toerosus, Britton, Stern et Pogg. Prelim. Catal, (18*8) $52=$ pulchellus, $R . B r$. GALOPOGONIUM Desv. (Legumin.). - Ind.

racemosum, M. Micheli, in Morot, fourn, de Bot. vi. (1892) 187. t. 7. - N. Gran.

CALOPYXIS, Tul. = Combretum, Linn. malifolia, Baker, in Journ. Linn. Soc. xxii. (1887) 474. - Madag.

subumbellatı, Baker, 1. c. xxv. (1890) 316.-Madag. trichophylla, Baker, 1. c. - Madag.

GALORHABDOS, Benth. (Scrophul.). - Ind.

\section{Kew. i. 392.}

latifolia, Hemsl. in fourn. Linn. Soc. xxvi. (1890) 196. t. 4. - China.

stenostachya, Hemsl. l. c. - China.

venosa, Hemsl. l. c. 197. - China.

CALOROPHUS, Labill. = Hypolaena, R. Br. (Restiac.).

anceps, asper, Benthamii, Burchellii, exsulcus, fascioulatus, filiformis, gracilis, impolitus, laxiflorus, pubescens, tenuis, vestitus, virgatus, Kuntze, Rev. Gen. (1891) 747 = homonyma omnia Hypolaenae.

clavatus, Kuntze, 1. $\mathrm{c}=\mathrm{H}$. fastigiata, $R . B r$.

digitatus, Kuntze, 1. c. = H. Eckloniana, Nees.

CALOSPERMUM, Pierre, Not. bot. Sapot. (1890) 11 = Lucuma, Molina (Sapot.).

manmosum, Pierre, 1.c. $13=\mathrm{L}$. mammosa, $A . D C$. parvum, Pierre, 1. c. - Mexic.

CALOSTEPHANE, Benth. (Compos.). - Ind.

Kew. i. 392.

foliosa, Klatt, ex Schinz, in Bull. Herb. Boiss. iii. (1895) 436. - Afr, austro-occ. extratrop.

Marlothiana, O. Hoffm. in Bot. fahrb. x. (1889) 276. - Afr, austro-occ. extratrop.

Schinzii, O. Hoffm. ex Schinz, in Bull. Herb. Boiss. i. (1893) 77. - Afr. austro-occ. extratrop.

CALOSTYLIS, Kuntze, Rev. Gen. (1891) 679 in syn. sphalm. = CALLOSTYLIS, Blume = Eria, Lindl. (Orchid.).

GALOTIS, R. Br. (Compos.). - Ind. Kew. i. 398. latiuscula, F. Muell. et Tate, in Trans. and Proc. Roy. Soc. S. Austral. xiii. (1890) 107. - Austral.

CALTHA (Rupp.) Linn. (Ranuncul.). - Ind. Kew. i. 393.

Freyniana, Heldr. ex G. Beck, in Verh. zool.-bot. Ges. Wien, xxxvi. (1886) 349 in syn. = palustris, Linn.

longirostris, G. Beck, l.c. 348; et in Annal. naturh. Hofmus. Wien, v. (1887) 69.- Bosnia.

marginata, Colenso in Trans. N.Z. Inst. xxiii. 1890 (1891) 382. - N. Zel.

procumbens, Huth, in Baenitz, Prosp. Herb. Eur. (1894) p. 13; et ex Osst. Bot. Zeitschr., (1893) xliii. 438. - Germ.

stagnalis, Magnier, ex Rouy et Fouc, Fl. de Fr. i (1893) $114=$ palustris, Linn.

GALVOA, Hook. f. (Melastom.).-Ind. Kew.i. 394 grandifolia, $\operatorname{Cog} n$. in DC. Monog. Phan. vii. (1891) 424. - Ins. Rolas (Afr. trop. occ.).

Henriquesii, $\operatorname{Cogn}$. l. c. 526. - Ins. S. Thom.

integrifolia, Cogn.l. c. 525. - Ins. S. Thom.

orientalis, Taub, in Abhandl. Preuss. Akad. Wiss. (1894) 46; et in Engl. Pfanzenw. Ost-Afr. C (1895) 296. - Afr. trop. or.

GALYGACANTHUS, K. Schum. F1. Kais. Wilh Land (1889) 126; et in Engl. et Prantl, Natürl. Pflanzenfam. iv. 3 b. (1895) 337. ACANTHACEAE.

Magnusianus, K. Schum. ll.cc. - N. Guin

CALYGOGONIUM, DC. (Melastom.),-Ind. Kew.

biflorum, Cogn. in fahrb. Bot. Gart. Berl. iv. (1886) 276. - Ins. Portoric.

hispidulum, Cogn. in DC. Monog. Phan. vii. (1891) 944. - Ins. S. Doming.

Krugii, Cogn. in fahrb. Bot. Gart. Berl. iv. (1886) 279. - Ins. Portoric. 
CAL YCOGONIUM

obliquum, Cogn. in DC. Monog. Phan. vii. (1891) 947 (= Charianthus obliquus, Griseb.). - Cuba. squamulosum, Cogn. in fahrb. Bot. Gart. Berl. iv. (1886) 277. - Ins. Portoric.

CALYGORECTES, Berg (Myrtac.). - Ind, Kew. I. 39.5.

densifiorus, Niedenzu, in Engl. et Prantl, Natïrl. Pflanzenfam. iii. 7. (1893) 82(=Siphoneugenia densiflora, Berg). - Bras.

Pohlianus, Kiuersk. Enum. Myrt. Bras. (1893) 117 (= Schizocalyx Pohlianus, Berg). - Bras.

Widgrenianus, Niedenzu, in Engl. et Prantl, Natürl. Pfanzenfam. iii. 7. (1893) 82 (= Siphoneugenia Widgreniana, Berg). - Bras.

CALYCOTHRIX, Meissn. = Calythrix, Labill. (Myrtac.)

Sullivani, F. Muell. ex Sullivan, in Rep. Austral. Assoc. Advanc. Sc. (1890) 507, nomen = Calyt. Sullivani, F. Muell.

CALYGOTOME, Link (Legumin.). - Ind. Kew. i. 395 .

hispanica, Rouy, in Bull. Soc. Bot. Fr. xxxvii. (1890) 162. - Hisp.

CALYPSO, Salisb. (Orchid.). - Ind. Kew. i. 396 ulbosa, Britton, in Bull. Torrey Bot. Club (1889) $203=$ borealis, Salisb.

CAL YPTRANTHES, Sw. (Myrtac.).-Ind, Kew. angustifol a, Kiaersk. Enum. Myrt. Bras. (1893) 42 angustifol

Bergii, Krueg et Urban, ex Urban, in Bot. Fahrb. xix. (1895) 601. - Cuba.

elegans, Krueg, l. c. 599. - Ins. Antill.

Fawcettii, Krueg, l. c. 600. - Ins. Antill

ferruginea, Krueg et Urban, l. c. 603 (= Eugenia ferruginea, Rich.). - Cuba.

Glazioviana, Kiaersk, Enum. Myrt. Bras. (1893) 35. - Bras.

Krugii, Kiaersk. in Bot. Tidsskr. xvii. (1889) 248 t.

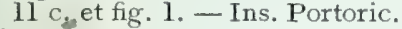

obovata, Kiaersk. Enum. Myrt. Bras. (1893) 38. Bras.

obovata, Krueg et Urban, ex Urban, in Bot. Fahrb. xix. (1895) 600. - Ins, Antill.

Picardae, Krueg et Urban, ex Urban, l. c. 595. Ins. Haiti.

Sintenisii, Kiaersk. in Bot. Tidsskr. xvii. (1889) 250. t. 11 b. - Ins. Portoric.

tobagensis, Krueg et Urban, ex Urban, in Bot. fahrb. xix. (1895) 593. - Ins. Antill.

umbelliformis, Krueg et Urban, ex Urban, l. c. 596 - Jamaic.

Warmingiana, Kiaersk. Enum. Myrt. Bras. (1893) 40. - Bras.

GALYPTRIDIUM, Nutt. (Portul.). - Ind. Kew i. 397

monospermum, Greene, in Erythea, iii. (1895) 63 (= Spraguea umbellata, Coville). - Am. bor.

nudum, Greene, Pittonia, i. (July 188\%) 64. - Calif.

Parryi, A. Gray, in Proc. Am. Acad. xxii. (1887) 285. - Calif.

paniculatum, Greene, in Bull. Torrey Bot. Club, xiii. (1886) 144 (= Spraguea paniculata, Kell.). - Am. bor. occ.

umbellatum, Greene, l. c. (= Spraguea umbellata, Torr.). - N. Mexic.

CALYPTRION, Ging. = Corynostylis, Mart. (Violar.).

excelsum, Taub. in Engl. et Prantl, Natürl. Pflanzenfam. iii. 6. (1895) $332=$ Coryn. Hybanthus, Mart.

Hybanthus, Millsp. in Field Columb. Mus. Bot. Ser. I (1895) $32=$ Coryn. Hybanthus, Mart.

GALYPTROGALYX, Blume (Palm.). - Ind. Kew.i. 396

elegans, Becc.ex K. Schum. et Hollr. Fl. Kais. Wilh. Land (1889) 16. - N. Guin.
GALYPTROCHILUM, Kraenzl. in Bot. Jahrb.

xxii. (1895) 30. ORCHIDEAE

Preussii, Kraenzl. l.c.-Afr. trop. occ.

CALYPTROPSIDIUM, Berg = Psidium, Linn. Myrtac.)

Sartorianum, Krueg et Urban, ex Urban, in Bot. Jahrb. xix. (1894) 581 (= Mitranthes Sartoriamus, Berg). - Mexic.

Sintenisii, Kiaersk. in Bot. Tidsskr. xvii. (1890) 280. t. 12b. et fig. 10. - Ins. Portoric.

CALYSACCION, Wight $=$ Ochrocarpos, Thou. (Guttifer.).

eugenioides, Planch. et Triana, ex Vesque, in DC. Monog. Phan, viii. (1893) $524=$ O. eugenioides, Vesque

CALYSTEGIA, R. Br.(Convolvul.). - Ind. Kew. 1. 398 .

abyssinica, Engl. in Abhandl. Preuss, Akad. Wiss, 1891. ii. (1892) 347. - Abyss.

CAMARA, Plum. ex Linn. = Lantana, Linn. (Verben.).

alba, brasiliensis, canescens, chamaedrifolia, involucrata, Kisi, lucida, Lunduana, macrophylla, macropoda, Maximiliani, microcephala, mollis, Petitiana, Pohliana, procurrens, purpurea, Radula, rugulosa, salicifolia, Sellowiana, spicata, Spiraeastrum, stricta, tiliaefolia, trifolia, undulata, velutina, viscosa, Kuntze, Rev. Gen. (1891) 371 et 503-504 = homonyma omnia Lantanae.

aculeata, Kuntze, l.ic. $371=$ L. Camara, Linn. lippiodes, Kuntze, 1. c. $504=$ L. lippioides, Spreng. salviaefolia, Kuntze, 1. c. = L. salvifolia, facq.

Salzmannii, Kuntze, 1, c. = L. Salzmanni, Schau.

CAMAREA, St Hil. (Malpigh.). - Ind. Kew. i. 399.

lanata, Chod. in Arch. sc.phys. et nat. (1890), ex Chod. in Mém. Soc. sc. phys. Genève, xxxi. 2. (1892) n. 3. 20 t. 49. - Parag

robusta, Chod. il. cc. 21 t. 48. - Parag.

salicifolia, Chod. ll. cc. 20 t. 47. - Parag.

CAMARIDIUM, Lindl. (Orchid.). - Ind. Kew, i. 399.

boliviense, Rolfe, ex Stapf, in Mem. Torrey Bot. Club, iv. (1895) 264. - Bolivia

Lawrenceanum, Rolfe, in Kew Bull. (1894, 185; et ex Rev. Hortic. (1894) 361. - Hab.

GAMAROTEA S. Elliot, in Journ. Linn. Soc xxix. (1891) 37. ACANTHACEAE.

romiensis, S. Elliot, l. c. 38. - Madag.

CAMASSIA, Lindl. (Liliac.). - - Ind. Kew. i. 398. Cusickii, S. Wats, in Proc. Am. Acad. xxii. (1887) 479; et in Gard. and For. 1. (1888) 172 et 174 fig. 32. - Oregon.

Engelmannii, Sprenger, in Bollet. Soc. Tosc. Ortic (1889) 101. - Am. bor

Howellii, S. Wats, in Proc Am. Acad, xxv, (1890) 135. - Oregon.

Quamash, Greene, Man. Bot. San Franc. Bay, (1894) $313=$ esculenta, Lindl.

GAMELINA, Crantz (Crucifer.). - Ind. Kew.i. 399

ambigua, Fouc. et Rouy, Fl. de Fr. ii. (1895) 233 $=$ foetida, Fries

confusa, Rouy et Fouc. 1, c. $235=$ silvestris, Wallv

rumelica, Velen, in Sitz. Boehm. Ges. Wiss, xli. (1891) 123; et Fl. Bulg. (1891) 43. - Rumel.

Souliei, (err. cal.? Soulieri), Batt. in Bull. Soc. Bot. Fv, xxxvi. (1889) p. ccxviii; et xl. (1893) 262; et in Batt. et Trab. Fl. de l'Algérie, App: ii. (1889) p.ii. (= Brassica Souliei, Batt.) - Algeria.

GAMELLIA, Linn. (Ternstroem.). - Ind. Kew. i. 400.

chinensis, Kuntze, Rev. Gen. (1891) $64=$ C.

Thea, Link.

Donkelaari, Hort. ex Rev. Hort. (1893) $412=$ seq.

\section{CAMELLIA}

Donkelaaris, Hort. ex Gard. Chron. (1889) 429 cum xyl. - Form. hort.

sinensis, Kuntze, in Act. Hort. Petrop. x. (1887) 195 in obs. $=$ C. Thea, Link.

GAMILLEUGENIA, Frappier, ex Cordem. F1. île Réunion (1895) 234. ORCHIDEAE.

coccinellides, Frappier, $l$. c. 234. - Madag.

GAMPANEA, Decne. (Gesner.). - Ind. Kew. i. 400

picturata, 7. D. Smith, in Bull. Torrey Bot. Club, xv. $(1890) 28$ t. 3. - Guatem.

CAMERIUM, Rumph. = Aleurites, Forst. (Euphorb.).

cordatum, Kuntze, Rev. Gen. (1891) $595=$ A. cor-

data, Steud.

moluccanum, Kuntze, 1. c. = A. triloba, Forst.

trispermum, Kuntze, 1. c。= A. triloba, Forst.

CAMPANOPSIS, Kuntze, Rev. Gen.(I89I) $378=$ Wahlenbergia, Schrad. (Campanul.). acaulis, adpressa, androsacea, angustifolia, annularis, liensis, Burchellii, caffra, caledonica, capensis, capillacea, cartilaginea, cermua, costata, dalmatica, debilis, decipiens, denudata, dicentrifolia, divergens, Ecklonii, emirmensis, epacridea, etbaica, exilis, fernandeziana, flaccida, graminifolia, hederacea, Hilsenbergii, homal lanthina, huillana, humilis, inconspicua, ingrata, inambanensis, Kitaibelii, linifolia, madagascariensis, Mannii, Meyeri, montana, nudicaulis, oocarpa, oppositifolia, oxyphylla, paniculata, patula, pauciflora, peduncularis, pilosa, procumbens, prostrata, Pumilio, pusilla ramulosa riparia, robusta, Roxburghii, saxicola, silenodes, spinulosa, tenuifolia, tenuis, tuberosa, ondulata, Wyleyana, Zeyheri, Kuntze, 1. c 378-79 = homonyma omnia Wahlenbergiae.

Bowkerae, Kuntze, 1. c. $379=$ W. Bowkeriae, Sind. campanulodes, Kuntze, 1. c. $378=$ W. Cervicina, A. DC.

dichotoma, Kuntze, 1. c. $379=$ W. androsacea A. $D C$

linariodes, Kuntze, 1. c。 $=\mathrm{W}$. linarioides, $A . D C$ lobeliodes, Kuntze, 1. c. = W. pendula, Schrad. marginata, Kuntze, 1. c. = W. gracilis, Schrad. namaquana, Kuntze, 1. c. = W. annularis, $A$. DC. serpillifolia, Kuntze, 1. c. = Campanula serpyllifolia, $V i$ s.

stellariodes, Kuntze, 1. c. = W. stellarioides, Cham

GAMPANULA, [Tourn.] Linn. (Campanul.). Ind. Kew, i. 400

Amasiae, Post, in fourn. Linn. Soc.xxiv. (1888) 435. - As. Min

atlantica, Coss. et Durieu, ex Batt. in Batt. et Trab. Fl. de l'Algérie (Dicot.) (1888) $573(=$. C. afganica, Pomel). - Algeria.

aurita, Greene, Pittonia, i.(Oct. 1888) 221.-Alaska.

Autraniana, Alboff, in Bull. Herb. Boiss. ii. (1894) 115; et iii. (1895) 519. - Reg. Cauc.

Barbeyi, Feer, in fourn. Bot. xxviii. (1890) 271. Italia.

bosmiaca, Murb in Lunds Univ. Arsskrift, xxvii. v. (1892) 97 = pseudo-phrygia, C. A. Mey.

brassicifolia, Somm. et Levier, in Nuov. Giom. bot. Ital. Ser. II, ii. (1895) 94. - Reg. Cauc.

breynina, G. Beck, F1. Nieder-Oest. ii. (1892)-1105 in obs. = rotundifolia, Linn.

brodensis, Formanek, in Oest. Bot. Zeitschr. xl. (1890) 81 = patula, Linn.

Brotherorum, Feer, in fourn. Bot. xxviii. (1890) 273 - Reg. Cauc.

calcarata, Somm, et Levier, in Nwov. Giorn. bot. Ital. Ser. II, ii. (1895) 96. - Reg. Cauc.

calycantherrea, Hort., Veitch, ex Gard. Chron. (1889) ii. 718. - Form. hort.?

cana, Simonk. Enum. fl. Transs. (1886) $383=$ bononiensis, Linn.

cantabrica, Feer, in fourn. Bot. xxriii. (1S90) 774; ct ex Willk. Suphl. Prodr. fi. Hisp. (1S9:3) 12?.Hisp.

castellana, Pau, Not. bot. fl. Espan. i. (1887) $24=$ C. Rapunculus, Linn. 


\section{GAMPANUIA :}

catinensis, Tornab. Fl. Sicula (1887) 357 = dichotoma, Limn

cephallenica, Feer, in foum. Bot. xxiviii. (1890) 273. - Ins. Cephallen.

chrysosplenifolia, Franch. in Morot, fourn. de Bot. ix. (1895) 364. - Yunnan:

crassa, Formanek, in Verh. naturf. Ver. Brünn, (1894) 11 = expansa, Frivald.

crenulata, Franch, in Morot, fourn. de Bot. ix. (1895) 365. - Yunnan.

Delavayi, Franch.l. c. 364. - Yunnan.

Dieckii, Lange, in Dansk Vidensk. Selsk. Fork. (1893) 195. - Hisp.

Dzaakii, Alboff, in Bull. Herb. Boiss, ii. (1894) 118 iii. (1895) 90 et 519; et Prodr. A. Colch. (1895) 156. - Reg. Caur.

epigaea, Fanka, ex Degen, in Oest. Bot. Zeitschr. xli. (1891) 194. - Thracia.

erucifolia, Feer, in fourn. Bot. xxviii. (1890) 268. Ins. Karpathos.

exigua, Formanek, in Verti. naturf. Ver. Brinn, xxxii. (1894). - Maced.

éxigua, Rattan, in Coult. Bot. Gaz. xi. (1886) 339', et in Bot. San Franc. Bay (I894) 230. - Calif.

farinulenta, Ken. et Wettst. in Oest. Bot. Zeitschr. xxxvii. (1887) 80. - Dalm.

fenestrellata, Feer, in fourn. Bot, xixviii, (1890)272.

- Litt. Austriac

flagellaris, Halacsy, in Denksohr. Akad. Wien, lxi. (1894) 248. - Graecia.

Fondervisii, Alboff, in Bull. Herb. Boiss. ì. (1894) 117. - Reg. Cauc.

groenlandica, Berl. in Ofvers. Vet. Akad. Förh. (1884) n. 7 p. 50 ; Lange, Comp. Al. Groenl. ii. (1887) 269. - Groenl.

Halacsyana, Baldacci, in Malpighia, viii. (1894) 280. - Albania.

Hawkinsiana, Hausskn. et Heldr. ex Hausskn. in Mitth. Bot. Ver. Fena, v. (1887) 8\%; Halacsy, in Dentschr. Akad. Wien, 1xi. (1894) 479. - Graecia.

hercegovina, Degen et Fiala, in Dést. Bot. Zeitschr. xliv. (1894) 303. - Herceg.

istriaca, Feer, in fourn. Bot. xxviii. (1890) 371; Hallier, Syn. Deitschl. Flora, ed. 3 (1895) 1276. Istria.

laciniata, Boiss. F1. Or. Suppl. (1886) $339=$ erucifolia, Feer.

lepida, Feer, in fourn. Bot.xxviii.(1890) 273.-Dalm.

lyratella, Feer, l. . . 269. - Sauria.

mirabilis, Alboff, in Bull. Herb. Boiss. iii. (1895) 228; et Prodr. Al. Colch. (1895) 158. - Reg. Cauc.

moesiaca, Velen. in Sitzungsb. Boehm. Ges. Wiss. 1892 (1893) 385. - Bulg.

Oliveri, Rouy et Gautier, ex Rony, in Bull. Soc. Bot. Fr. xli. (1894) 326. - Pyren.

picturata, F. D. Smith, in Coult. Bot, Gaz. xv. (1898) 28 t. 3. - Guatem.

pontica, Alboff, in Bull. Herb. Boiss, ii. (1894) 116 - Reg. Calic

praecox, Miégev. in Bull. Soc. Bot. Fr. xl. (1893) 304. - Pyten.

praesignis, G. Beck, Fl. Nieder-Oest. i1. (1892) $1105=$ roturidifolia, Limn.

pulvinaris; Haussk. et Bornin, in Mitth.Bot. Ver. fena, ix. (1891) 19. - Cappadoc.

rapunculiformis, St Lager, in Cariot, Etud: des $\mathrm{fl}$ éd. 8 , ii. (1889) $547=$ rapunculoides; Linn.

serpylliformis, Batt。e te Trab. Atlas fl. d'Algeivie, (1886) t. 6; et Fl. de l'Algérié, (Dicot.) (1890) 573 - Algeria.

Shepardi, Post, in Bull. Herb. Boiss. i. (1893) 25. Syria.

solstitialis, A. Kern. in Verh. zool.-bot. Ges. Wien, xxxviii. (1888) 669. - Austria.

Songeoni, Chabert, in Bull. Herb, Boiss, iii. (1895) 146. - Sabaud.

sporadum. Feer, in fourn. Bot, xxviii. (1890) 269.Ins. Sporad.

tymphaea, Hausshn. in Mitth. Bot. Ver. Fenia, v. (1887) 87. - Graecia.

Velenowskyi, Adamovic, in Oest. Bot. Zeitschr, xlii. (1892) 408. - Serbia.

velutina, Velen. in Sitzunsgb, Boehm. Ges. Wiss. 1889 (1890) ii. $54=$ lanata, Frivald

Villanii, Nym. Consp. fl. Eur. Suppl. I1, i. (1889) = caespitosa, Scop.

\section{GAMPANULA}

Wettsteinii, Halácsy, et Baldacci ex Halàcsy, in Oest. Bot. Zeitschr. xli. (1891) 371 in syn.= Edraianthus Wettsteinii, Halacsy et Baldacci.

CAMPANUMOEA, Blume (Campanul.). - Ind.

\section{Kew. 1. 407.}

axillaris, Oliver, in Hook.Icon.pl.xviii. (1888) t. 1775. - China.

CAMPHORATA, Ludwig $=$ Camphorosma Linn. (Chenop.).

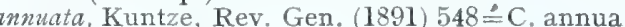
Pall.

monandra, Kuntze, I. c. = C. monandrum, Bunge. ovatum, Kuntze, 1. c. = C. ovatum, Waldst. et Kit.

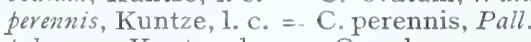

polygama, Kuntze, 1. c. = C. polygamum, Bunge.

ruthenica, Kuntze, 1. c. = C. Iuthenicum, Bieb.

GAMPOMANESIA, Ruiz et Pav, (Myrtac.), Ind. Kew i. 408

Beaurepairiana, Kiaerske. Enum. Myrt. Bras. (1893) 15. - Bras.

bracteolata, Kiaersk, l. c. 10. - Bras,

Cagaiteira, Kiaersk, l. c. 12. - Bras.

chrysophylla, Niedenzu, in Engl. et Prantl, Natürl. Pflanzenfam. iii. 7. (1893) 73. - Bras.

Glazioviana, Kiaersk. Enum. Myrt. Bras. (1893) 16 - Bras.

Guaviruba, Kiaevzk. l.c. $81=$ Abbevillea Guaviruba, Berg.; an C. Guavinuba Benth. et Hook. f.?) Bras.

itánarensis, Kiaersk. Enum. Myrt. Bras. (1893) 8; et ex Engl. et Prantl, Natiirl. Pfanzenfam. iii. $\%$. (1893) 73 (= Ab6. rugosa, Berg). - Bras.

maschalantha, Kiaersk. l. c. (1893) 8 (Abb. mascha lantha, Berg). - Bras.

neriifolia, Niedenzu, in Engl. et Prantl, Natürl. Pfanzenfam. iii. 7. (1893) 73. (= Abb. neriflora, Berg). - Bras.

prosthecesepala, Kiaersk. Enum. Myrt. Bras. (1893) i1. - Bras.

psidioides, Niedenzu, in Engl. et Prantl, Natürl. Pfanzenfam. iii. 7. (1893) $73(\Leftrightarrow$ Abbevillea Langsdorffi, Berg). - Bras.

Rabeniana, Kidersk. Enum. Myrt. Bras. (1893) 11. - Bras.

recurvata, Niedenzu, in Engl. et Prantl, Natirl. Pflanzenfam. iii.7(1893) $73(=$ Abbevillea recurvata, Berg): - Bras.

Regeliana, Kiaersk. Enum. Myrt. Bras. (1893) 8 (Abb. Regeliana, Berg). - Bras.

rivularis, Niedenzu, in Engl. ex Prantl, Naturl. Pfanzenfam. iii. \%:(1893) 73 (= Abb. Fenzliana, Berg). - Bras.

rufa, Niedenzu, l. c. $\{=A b b$. vufa, Berg). - Bras. Schlechtendaliana, Niedenzu, l.c. - Bras.

stictopetala, Kiaersk. Enum. Myrt. Bras. (1893) 8. - Bras,

Warmingianà, Ǩaersk. l. c. 14.- Bras.

CAMPSIS, Lour. Tecoma, Juss. (Bignon.). grandiflora, K. Schum. in Engl. et Prantl, Natürl. Pflanzenfám. iv. 3b. (1894)230= T. grandiflora, Thunb.

CAMPSONEURA debilis, Warb. in Ber. deutsch. Bot. Ges. xiii. (1895) [84]. - (Quid?)

CAMPTOSEMA, Hook. et Arn. (Legumin.). Ind. Kew. i. 408.

isopetalum, Taub. in Engl. et Prantl, Natürl. Pflanzenfam. iii. 3. (1894) 369 (= erythrinoides, Benth.

pentaphyllum, Taub. in Filora, Ixxii. (1889) 428. Bras.

GAMPTOSTEMON, Mast. (Malvac.). - Ind. Kew, i. 408.

aruense, Bécc. Malesia, iui. (1889) 274. - Ins. Aru. philippinense, Becc. l.c. $273(=$ Cumingia philippinensis, Vidal). - Ins. Philipp.

CAMPULOSUS,Desv. = Ctenium,Panz.(Gramin.). aromaticus, Scribn. in Mem. Torrey Bot. Club, v. 1864) $45=$ aromaticus, Trin.
CAMPULOSUS :

canescens, Kuntze, Rev. Gen. (1891) $764=$ Ct. canescens, Benth.

concinnus, Kuntze, i. c. = Ct. concinnum, Nees. elegans, Kuntze, 1. c. = Ct. elegans, Kunth. gangitis, Kuntze, 1. $\mathrm{c}$, $=\mathrm{Ct}$. caroliniannm, Pan\%. rupestris, Kuntze, $1 . \mathrm{c} .=\mathrm{Ct}$, rupestre, $7 . A$. Schmidt. serpentium, Kuntze, 1. c. $=\mathrm{Ct}$. serpentinum, Steud.

CAMPYLANDRA, Baker = Tupistra, Ker-Gawl. (Liliac.).

Fargesii, Baill. in Bull. Soc. Linn. Paris, ii. (1893) 1113 in obs. = Tupistra Fargesii, Baill.

Fargesiana, Baill. 1. c. 1114 sphalm. = práec. tonkinensis, Baill. 1. c. 1113. - Tonk.

Wattii, C. B. Clarke, in Journ. Linn. Soc, xxv. (1889) 78 t. 32. - Reg. Himal.

CAMPYLOTHECA, Cass. = Coreopsis, Linn.? (Compos.).

cosmoides, Hillebr. Fl. Haw. Isl. (1888) $213=$ Cor, cosmoides, A. Gray.

dichotoma, Hillebr. 1. c. 212. - Ins. Hawaii.

hawaiiensis, Hillebr. 1. c, $214=$ Bidens hawaiiensis, A. Gray.

macrocarpa, Hillebr. 1. c, = Cor. macrocarpa, A. Gray.

maniensis, Hillebr. 1. c. $213=$ Cor. mauiensis, A. Gray.

Menziesii, Hillebr 1. c. $216=$ Cor. Menziesii, A. Gray.

molokaiensis, Hillebr. 1, c, 212, - Ins. Hawaii.

pulchella, Hillebr. 1.c. (=Adenolepis pulchella, Less.).

- Ins. Hawaii.

Remyi, Hillebr. 1. c. - Ins. Hawaii.

sandwicensis, Hillebr. 1. c. $214=$ Bidens sandwicensis, Less.

CAMP INEMANTHE, Baill, in Bull. Soc. Linn. Paris, ii. (1893) 1109; et Hist. des pl. xii. (1894) 592. IILIACEAE.

viridiflora, Baill. $l l . c c .-$ N. Caled.

CAMUNIUM, Adans. = Aglaia, Lour. (Meliac.). sinense, Pierre, Fl. For. Cochinch. (1895) sub t. 334 in syn. = chinense, Roxb.

CAMUNIUM, Rumpf, = Murraya, Koen. (Rutac.). elongatum, Kuntze, Rev, Gen.(1891) $99=$ M. elongata, $A . D C$

exoticum, Kuntze, 1. c. $=$ M. exoticum, Limn heptaphylla. Kuntze, 1. c. = M. heptaphylla, Span. Koenigii, Kuntze, 1: c. = M. Koenigii, Spreng.

longifolia, Kuntze, 1. c. $=$ M. longifolia, Blume.

GANANGA, Rumph. (Anonac.). - Ind. Kew. i. 410

Scortechinii, King, in fourn. As. Soc. Beng. 1xi. (1892) ii. 42. - Perak.

GANARINA, Linn. (Campanu1.). - Ind. Kew. ii. 410 .

canariensis, Kuntze, Rev. Gen. (1891) $379=$ campanulata, Linn.

Eminii, Aschers. et Schweinf. in Sitzb. Ges.naturf. Fr. (1892) 173. - Afr. trop.

CANARIUM, (Rumph.). Linn. (Burser.), - Ind. Kew. i. 410.

Buettneri, Engl. Bot. Fahrb, xv, (1893) 101. Afr. trop. occid.

caudatum, King, in fourn, As. Soc. Beng. 1xii. (1893) ii. 240.'- Perak.

edule, Eng1. Pflanzenw. Ost-Afr. B (1895) $200=$ edule, Hook. $f$.

Kunstleri, King, in Fourn. As. Soc. Beng. Ixii. (1893) ii. 248. - Perak.

Manii, King, l. c. 247. - Ins. Andam.

obtusifolium, S. Elliot, in Fourn. Linn. Soc. xxix. (1891) 10. - Madag.

Planchoni, King, in fourn. As. Soc. Beng. 1xii. (1893) i. 240 (= Sastoria Planchonii, A. W. Benn.). - Malaya.

polyphyllum, $K$. Schum. in K. Schum et Holl. Fl. Kais. Wilh, Land (1889)63. - N. Guin. 


\section{CANARIUM}

resiniferum, Bruce, ex King, in fourn. As. Soc Beng. 1xii. (1893) ii. 188. - Reg. Himal.

Saphu, Engl. Bot. Fahrb. xv. (1893) 99. - Kametrun.

sapidum, Hemsl. in Ann. of Bot. v. (1891) 504. Ins. Salom.

sikkimense, King, in fourn. As. Soc. Beng. lxii. (1893) ii. 187 t. 12 . - Perak.

CANAVALIA, DC. (Legumin.). - Ind. Kew. i. 411.

tortilis, Frappier. ex Cordem. Fl. Ile Réunion (1895) 396. - Ins. Borbon.

versicolor, Rodr. Pl. nov. Fard. bot. Rio, iv. (1894) 5 t. 2. - Bras.

CANBYA, Parry (Papaverac.). - Ind. Kew. i. 411.

aurea, S. Wats. in Proc. Am. Acad. xxi. (1886) 445. - Mexic.

CANNA, Linn. (Scitam.). - Ind. Kew. i. 412.

Verloti, Hort. Huber. ex Petersen, in Mart. F1. Bras. iii. II (1890) 78, nomen = indica, Linn.

CANCRINIA, Kar. et Kir. (Compos.). - Ind. Kew. i. 411.

brachypappos, Winkl. in Act. Hort. Petrop. xii. (1892) 29. - Mongolia.

lasiantha, C. Winkl. l. c. xiii. (1894) 235. Turkest.

lasiocarpa, C. Winkl. l. c. xii. (1892) 30. - Mongolia.

Maximowiczi, C. Winkl. l. c. 29. - Mongolia.

paradoxa, C. Winkl. l. c. xi. (1891) 371.- Turkest.

CANDOLLEA, Labill. = Stylidium, Sw.

Morrallii, F. Muell. in Vict. Natural. v. (Oct. 1888) $76=$ S. Morrallii, F. Muell.

Tepperi, F. Muell. (sphalm. J.) in Mitth. Bot. Ver Jena, vi. (1888) $5=$ Tepperiana, F. Muell.

Tepperiana, F. Muell. in Chem. and Drug. of Austral. (Jan. 1887) ex Bot. Centralbl. xxxvi. (1888) 374. - Austral

CANDOLLINA, Van Tiegh. in Bull. Soc. bot. Fr. xlii. (I895) 269 = Lorantbus, Linn.

Haenkeana, Van Tiegh. 1. c. xlii. (1895) $269=$ L. Haenkeanus, Presl.

malifolia, Van Tiegh. 1. c. = L. malifolius, Presl.

CANISTRUM, Éd. Morr. = Aechmea, Ruiz et Pav. (Bromel.).

amazonicum, Mez, in Mart. Fl. Bras. III. iii. (1891)

$249=$ Karatas amazonica, Baker.

cyathiformis, Mez, 1. c. 252. - Bras.

Lindeni, Mez,1. c. $256=$ Ae. eburnea, Baker.

superbum, Mez, 1. c. 621 in obs. = Wittrockia superba, $\operatorname{Lindm}$.

CANNABINA, Ludw. = Datisca, Linn

glomerata, Kuntze, Rev. Gen. (1891) $258=$ D. glomerata, Baill

CANSCORA, Lam. (Gentian.). - Ind. Kew. i. 413.

heteroclita, Gilg, in Engl. et Prantl, Natürl. Pflanzenfam.iv. 2(1895) p. 76 (= Gentiana heteroclita, Linn.). - Ind. or.

tetragona, Schinz, in Viertelj. Naturforsch. Ges. Zürich, xxxvi. (1891) 338. - Angola.

CANSJERA, Juss. (Olacin.). - Ind. Kew. i. 413. Helferiana, Valeton, Crit. overz. Olac. (1886) 159. Tenass.

CANTHAROSPERMUM, Wight. et Arn. = Aty losia, Wight et Arn. (Legumin.)

molle, Taub. in Engl, et Prantl, Natürl. Pflanzenfam. iii. 3. (1894) 373 (mollis) = A. mollis, Benth. trineurum, Taub. 1. c. = A. Candollei, Wight et Arn.

CANTHIUM, Lam.= Plectronia, Linn. (Rubiac.). brevifolium, Engl. Bot. Jahrb. viii. (1887) 67. Congo.
CANTUA, Juss. (Polemon.). - Ind. Kew. i. 414. lanceolata, Peter, in Engl. et Prantl, Naturr. Pfanzenfam. iv. 3 a (1891) 45. - Peruvia.

CANTUFFA, J. F. Gmel. = Pterolobium, R. Br. (Legumin.).

hexapetala, Kuntze, Rev. Gen. (1891) $168=$ P. indicum, A. Rich.

indica, Kuntze, 1. c. $=\mathrm{P}$. indicum, A. Rich

lacerans, Taub. in Engl, et Prantl, Natürl. Pflanzenfam. iii. 3 (1892) $172=\mathrm{P}$. lacerans, Roxb macrophylla, Kuntze, Rev. Gen. (1891) 168. P. indicum, A. Rich.

microphylla, Kuntze, 1. c. = P. indicum, A. Rich

nitens, Kuntze, 1. c. = P. nitens, F. Muell.

punctata, Kuntze, 1, c. $=$ P. punctatum, Hemsl.

subvestita, Kuntze, 1. c. $=$ P. subvestitum. Hance.

CAOPIA, Adans = Vismia, Vand. (Hyperic

acuminata, affinis, Billbergiana, brasiliensis, cayennensis, confertiflora, dealbata, decipiens, ferruginea, frondosa, glabra, jupurensis laesis, latifolia lauriformis, laxiflora. leonensis, macrophilla, magnoriformis, laxiflora, leonensis, macrophyta, magnopanamensis, parviflora, petiolata, mubescens, sessiiifolia, tomentosa, viridiflora, Kuntze, Rev. Gen. (1891) $59=$ homonyma omnia Vismiae.

arborescens, Kuntze, 1. c. $59=$ Cratoxylon Blancoi, Blume.

baccifera, Kuntze, 1. c. = V. guianensis, Pers.

crassa, Rusby, in Mem. Torrey Bot. Club, iy. (1895) 204. - Bolivia.

gracilis, Hieron. in Bot. Jahrb. xx. Beibl. n. 49 (1895) 52 in obs. = V. gracilis, Hieron.

Mandurr, Hieron. 1. c. 54 in obs. = V. Mandurr, Hieron.

panamensis, Kuntze, Rev. Gen. (1891) $59=$ V. fer ruginca $H$. B. et $K$.

petiolata, Kuntze, 1. c, = V. laurifolia. Pers.

Reichardiana, Kuntze, 1. c. =V. bacc1fera, Reichardt

CAPERONIA, St-Hil. (Urtic.). - Ind. Kew. i. 415

latifolia, Pax, in Bolet. Soc. Brot. x. (1892) 159.Ins. S. Thom.

Stuhlmanni, Pax, in Bot. Fahrb. xix. (1894)81. Afr, trop. or.

CAPITAINYA, Schweinf. ex Penzig, Atti Congr. bot Genova (1893) 355; et ex Giurke, in Bot. Jahrb. xxi. (1895) 105. LABIATAE. rogieoides, Schweinf. l. c. 355 nomen. - Erithrea. ostegioides, Gurke, l.c. 106 t. 1. - Afr. or.

CAPNODES,Adans.= Corydalis, Vent.(Papaver.). adiantifolium, aduncum, ambiguum, angustifolium, aureum. bracteatum, breviflorum, Bungeanum, Burmanni, Caseanum, chaerophyllum, claviculatum, conorhizum. cornutum, Cracca, crassifolium, crithmi folium, crystallinum, curvisitiqua, dasypterum, decumbens, edule, elegans, Falconeri, Fedschenkoanum, fibrosum, flabellatum, flaccidum, flavulum, fumariaefolium, Gebleri, giganteum, glaucescens, Gortschakowii, Govanianum, gracile, incisum, inconspicuum, junceum, Kavelinianum, kaschgaricum, latiflorum, laxum, leptocarpum, Marschallianum, meifolium, mela rochlorum, micropodum, Moorcroftianum, ochotense, ophiocarpum, pallidum, paniculigerum, pauciflorum, persicum, polygalinum, pruinosum. pulchellum, pumilum, racemosum, Raddeanum, ramosum, roseum, rupestre, rutifolium, Schelesnowianum, Scouleri, Semenowii, senanensis, Sewerzowii, Sheareri, sibiricum, streptocarpum, strictum, suaveolens, tenellum, tibeticum, trachycarpum, Turczaninowii, uralense, Vernyi, Kuntze, Rev. Gen. (1891) 14-15 = homonyma omnia Corydalidis.

acaule, Kuntze, 1. c. $14=$ Corydaliso chroleuca, Engelm.

biternatum, Kuntze, 1. c. = Cor. pauciflora, Pers cachemirianum. Kuntze, 1. c. = Cor. cashmeriana, Royle.

curviflorum, Kuntze, 1. c. = Cor. curviflora, Maxim. heterocarpum, Kuntze, 1. c. = Cor. pallida, Pers. intermedium, Kuntze, 1. c. = Cor. fabacea, Pers jesoënse, Kuntze, 1. c. = Cor. jesoënsis, impatiens, Kuntze, 1. c. = Cor. sibirica, Pers.
CAPNODES :

linariodes, Kuntze, Rev. Gen. (1891) $15=$ Corydalis linarioides, Maxim.

lenense, Kuntze, 1. c, $14=$ Cor. paeoniaefolia, Pers.

oppositifotinm, Kuntze, $1 \quad c$. = Cor. rutaefolia, $D C$. rutaefolium, Kuntze, 1, c. = Cor. rutaefolia, DC.

remotum, Kuntze, 1. c. $14=$ Cor. bulbosa, $D C$.

Savatieri, Kuntze, 1. c, = Cor, Iaxa, Franch.

Schanginii, Kuntze, 1. c. = Cor. longiflora, Pers.

speciosum, Kuntze, 1.C. $15=$ Cor. pallida, Pers.

speciosum, Kuntze, 1. c. $15=$ Cor. pallida, Pers.
stramineum. Kuntze, 1. c. $=$ Cor. straminea, Maxim.

verticillare, Kuntze, 1. c. = Cor, rutaefolia, DC

vesicarium, Kuntze, 1. c. $14=$ Cor. versicaria, Pers.

Wilfordii, Kuntze, 1, c. $15=$ Cor. pallida, Pers.

CAPNOIDES, Tourn. = CAPNODES, Adans. ex Kuntze = Corydalis, Vent. (Papaver.).

Bidwellianum, Greene, F1. Francisc. (1891) $280=$ Cor. Bidwelliana, S. Wats.

Caseanum, Greene, 1. c. = Cor. Caseana, A. Gray. micranthum, Britton, in Mem. Torrey Bot. Club, v. (1894) $166=$ Cor. micrantha, A. Gray.

montanum, Britton, 1. c. = Cor. montana, Engelm.

GAPNOPHYLLUM, Gaertn. (Umbellif.). - Ind.

\section{Kew. i. 415.}

peregrinum. Kuntze, Rev. Gen. (1891) 265 = peregrinum, Lange.

CAPNORCHIS, Ludw. = Dicentra, Bernh. (Pa-

pav.).
canadensis, chrysantha, Cucullavia, eximia, formosa, pusilla, Roylei, scandens, thalictrifolia, torulosa, unifiora, Kuntze, Rev, Gen. (1891) 15 = homonyma omnia Dicentrae.

ochroleuca, Greene, Fl. Francisc. (1891) p. $279=$ D. ochroleuca, Engelm.

pauciflora, Greene, 1. c. = D. pauciflora, S. Wats.

peregrina, Kuntze, Rev. Gen. (1891) $15=$ D. lachenaliaeflora, Ledeb.

CAPNOREA, Rafin.= Nicotiana, Linn. (Solanac.). ciliata, Greene, in Erythea, ii. (1894) $193=$ Hesperochiron ciliatus, Greene.

pumila, Greene, 1. c. = Hesp. pumilus, Porler.

CAPPARIS, (Tourn.) Linn. (Capparid.). - Ind. Kew. i. 415.

Afzelii, Pax, in Bot. Fahrb. xiv. (1892) 299. - Afr trop. occ.

boscioides, Pax, l. c. 297. - Abyss.

brachyandra, Pax, in Engl. Pflanzenw. Ost-Afr. C (1895) 185. - Afr, trop. or.

burmanica, Coll. et Hemsl. in fourn. Linn. Soc xxviii. (1890) 19 t. 2. - Ind. or.

Carvalhoana, Gilg, in Engl. Pflanzenw. Ost-Afr. C (1895) 185. - Afr. trop. or.

cucurbitina, King, in fourn, Linn. Soc. lviii. (1889) ii. 395. - Malaya.

decidua, Pax, in Engl. et Prantl, Natiirl. Pflanzentam. iir. 2. (1891) $231=$ C. Sodada, Forsk.

elliptica, Hausskn. èt Bornm. ex Bornm. in Mitth Thiur. Bot. Ver. N. Folge, vi. (1894) 49. Oriens.

Fischeri, Pax, in Bot. Fahrb. xiv. (1892) 298. Afr, trop. or.

hainanensis, Oliver, in Hook. Ic, pl.xvi. (1887) t. 1588. - Hainan.

hereroënsis, Schinz, in Bull. Herb. Boiss. iii. (1895)

396. - Afr, austro-occ. extratrop.

Heydeana, F. D. Smith, in Coult. Bot. Gaz. xviii. (1893) 197. - Guatem

Kunstleri, King, in fourn. As. Soc. Beng. lviii. (1889) i1. 396. - Malaga.

larutensis, King, l. c. 393. - Malaya.

Poggei, Pax, in Bot. Fahrb. xiv. (1892) 298. Congo.

salicifolia Hort. Par, ex Vesque, Epharm, i. (1889) t. 71 . n. $79=$ nerifolia, Radlk?

Scortechinii, King, in fourn. As. Soc. Beng. lviii. (1889) ii. 394. - Malaya.

urens, Rodr. in Vellozia, i. (1884-88) Sec. edic. (1891) 2 t. 2. - Bras. 


\section{CAPPARIS}

Volkensii, Gilg, in Engl. Pflanzenw. Ost-Afr. C (1895) 185. - Afr. trop. or.

xanthophylla, Coll. et Hemsl. in fourn. Linn. Soc. xxvili. (1980) 20. - Burma.

CAPRARIA, [Tourn.] Linn. (Scrophul.). - Ind Kew. i.p. 418 .
annua, Kuntze, Rev. Gen. (1891) $459=$ Scoparia annua, Cham. et Schlecht.

dulcis, Kuntze, 1. c. = S. dulcis, Linn.

elliptica, Kuntze, 1. C. = S. elliptica, Cham.

evicacea, Kuntze, 1. c $=$ S. ericacea, Cham, et Schlecht.

montevidensis, Kuntze, 1. c. = S. flava, Cham. et Schlecht.

pinnatifida, Kunfze, 1. c. = S. flava, Cham. et Schlecht.

CAPRIFOLIUM, Tourn. = Lonicera, Linn. (Caprifol.).

acuminatum, Altmannii, angustifolium, arboreum, aspevifolium, Aucheri, biflorum, Bournei, bracteolare, Brandtii, cancasicum, cerasinum, Chamissoi, chrysanthum, eiliatum, coerulescens, conjugiale, decipiens, dimorphum, Elisae. Ferdinandi. flavescens, floribun dum, fragrantissimum, gibbiflorum, glabratum, glaw cum, Glehni, glutinosun, gracilipes, gynochlamy deum, Henryi, hellenicum, heterophyllum, hirsutum, hispidum, humile, hypoleucum, ibericum, involucratum, japonicum, Kavelinii, leianthum, Leschenaultii, ligustrinum, linderifolium, Maackii, macranthum, Maxi. mowiczit, micranthum, microphyllum, nervosum, Nummularia, nummulartaefolium, obovatum, Olgae, orientale, oratum, parvifolium, phyllocarpum, pileatum, purpurascens, quinqueloculare, ramosissimum, reticulatum, rupicolum, Ruprechtianum, Schmitziamum, segreziense, Semenowii simile spinosum, splendidum, Stabianum, Standishii, Sullioantii, sumatranum, syringanthum, tangutinum, tataricum, tenuiflo. rum, tomentellum, Tschonoskii, turcomanicum, uta hense, venulosum, Vidalii, Xylostewm, Kuntze, Rev. Gen. (1891) 273-74 = homonyma omnia Lonicerae. adenocarpum, Kuntze, Rev. Gen. $274=$ L. implexa, Soland.

americanum, Kuntze, 1. c. = L.grata, Soland.

Amherstii, Kuntze, 1. c. = L. pilosa, Maxim.

Borbasianum, Kuntze, 1. c. = L. reticulata, Borbas.

Bungeanum, Kuntze, 1. C. = L. microphylla, Willd.

cyrenaicum, Kuntze, 1. c. = L. etrusca, Santi

dumosum, Kuntze, 1. c. = L, albiflora, Torr. et Gray.

fuschsiodes, Kuntze, 1. c. = L. fuchsioides, Torr. et Gray.

Hemsleyanum, Kuntze, 1. c. - China.

hypoglaucum, Kuntze, 1. c. = L. affinis, Hook. et Arn. interrutptum, Greene, Fl. Francis. (1892) 347; et in

Man. Bot. San. Franc. Bay (1894) $164=$ L. interrupta, Benth.

Ledebvurit, Greene, 1. c. $346=$ L. involucrata, Banks.

Magnevilleae, Hort. ex Dippel, Handb. Laubholzk. i. (1889) $203=$ L. Caprifolium, Linn.

nrexicannm, Kuntze, Rev. Gen. (1891) $274=$ L. gibbosa, Willd.

mollissinum, Kuntze, 1. $\mathrm{c}_{\mathrm{o}}=\mathrm{L}$. affinis, Hook. et Arn. Morrowii, Kuntze, 1. c. = L. chrysantha, Turcz.

pilosum, Hort, ex Dippel, Handb. Laubholz. i

(1889) $210=$ L. hirsuta, Eaton.

praecox, Kuntze, 1. c. - China.

puniceum, Kuntze, 1. c. = Symphoricarpus puniceus, Stend.

semperflorens, Hort. ex Dippel, Handb. Laubholzk. i. (1889) $204=$ L. Periclymenum, Linn.

subspicatum, Greene, Fl. Francisc. (1892) $348=$

L. hispidula, Dougl.

Tartarinowii, Kuntze, Rev, Gen.(1891) $274=\mathrm{L}$.

Tatarinowii, Maxim.

Thomsonit, Kuntze, 1. c. = L. glauca, Hook. f. et Thoms.

tragopliyllum, Kuntze, 1. c.=L. tragophylla, Hemsl. valentinum, Pau, Not. bot. fl. Espan. iii. (1889) 30 nomen. - Hisp.

CAPRIOLA, Adans. = Cynodon, Rich. (Gramin.). ciliavis, Kuntze, Rev. Gen. (1891) $764=$ Cyn. ciliaris, Benth.

convergens, Kuntze, 1. c. $=$ Cyn. convergens,
CAPRIOLA : -

Dactylon, Kuntze, 1. c.; Baill. Hist. des p1. xii. (1894) $159=$ Cyn. Dactylon, Pers

tenella, Kuntze, 1. c. = Cyn. tenellus, $R . B r$

GAPSELLA, Medic, (Crucifer.). - Ind. Kew i. 418.

abortiva $\times$, Hausskn. in Mitth. Thür. Bot Ver. N. Folge, iii. et iv. (1893) 116. - Graecia.

alpina, Ces. Passer, et Gibelli, Comp. fl. Ital. ii. (1886) 824 = Hutchinsia alpina, $R \cdot B r$.

humilis, Rouy et Fouc. F1. de Fr. ii. (1895) $96=$ C. Bursa-pastoris, Moench

lycia, Stapf, in Denkschr. Akad. Wien, li. (1886) 362. - As. Min.

stellata, S. Wats. in Proc. Am. Acad. xxv. (1890) 142. - Mexic.

thracica, Velen, in Sitzungsb. Boehm. Ges, Wiss. 1893. (1893) 11. - Thracia.

villosula, F. Muell. et Tate, in Trans, Roy. Soc. S. Austral. xix. (1895) 80, nomen.-Austral.

CAPSICUM, [Tourn.] Linn. (Solan.). - Ind. Kew. i. 419.

fasciculatum, Sturtevant, in Bull. Torrey Bot. Club, xv. (1888) 133. - Hab.?

GARACASIA, Szyszyl. in Engl. et Prantl, Natürl, Pflanzenfam, iii, 6a, (1894) 164. TERNSTROE$M I A C E A E$

Tremadena, Szyszyl. l.c. $(=$ Vargasia Tremadena, Ernst). - Venez.

viridiflora, Szyszyl. l. c. $(=$ Varg. viridiflora, Ernst.). - Venez.

GARAGANA, Lam. (Legumin.), - Ind. Kew.i. 419 .

aurantiaca, Koehne, Deutsche Dendrol. (1893) 340. As. centr.

decorticans, Hemsl. in Hook. Icon. pl. xviii. (1887) t. 1825. - Afghan.

pendula, Carr. in Rev. Hortic. (1887) $268=$ arborescens, Lam.

GARAGUATA, [Plum.], Lindl, (Bromel.), - Ind. Kew. i. 420

acorifolia, Ed. André, in Rev. Hortic, (1888) 565; et Brom. Andr. 56 t. 16 fig. b; Baker, Handb. Brom. 146. - Columb.

Bakeri, Wittm. in Bot. Fahrb. xi. (1890) 59. Columb.

Beleana, $\dot{E} d$. André, in Rev. Hortic. (1893) $114 \mathrm{fig}$ 27. - Hab.?

bracteosa, Ed. André, l. c. (1888) 565; et Brom. Andr, 47 t. 14 fig, a; Baker. Handb. Brom. 146. - Ecuad,

Candelabrum, Éd. Andvé, ll. cc. 565; et 55 t. 19 fig. a; Baker, l. c. 148. - Columb

conifera. Ed. André, 11 . cc. 565 ; et 47 t. 15 Baker, l. c. 144; et in Bot Mag. (1894) t. 7359 Ecuad.

Devansayana, Ed. Morr. ex Baker, Handb. Bromel (1889) 144 (=Guzmannia Deransayana, Éd. Morr.). - Ecuad.

gloriosa, Ed. André, in Rev. Hortic. (1888) 565; et Brom. Andr. 48 t. 17 fig. c; Baher, l.c. 147. Ecuad.

grandiflora, Bakev, l. c. (1889) 145. - Ins, PortoRico,

hygrometrica, Éd. André, in Rev. Hortic. (1888) 565; et Brom, Andr. 59 t. 18 fig. c; Baker, l. c. 152. N. Gran.

Lehmanniana, Baker, Handb. Bromel. (1889) 150 (= Schlumbergeria Lehmanniana, Wittm.). N. Gran,

lepidota, Ed. André, in Rev. Hortic. (1888) 565; et Brom. Andr. 57 t. 19 fig. b.; Baker, l. c. 149. Ecuad.

Lindeni, Baker, l. c. (1889) 151 (= Schlumbergeria Lindeni, Ed. Morr.) - Peruvia.

magnifica, Hort. ex Baker, 1. c. $142=$ Osyana, Ed. Morr.

magnifica $x$, Hort. ex Baker, 1. c. 148. - Hybr. artef.

Melinonis, Ed. Morr. ex Bakcr, l. c. 145 (= Guzman nia Melinoni, Regel). - Guian. gall.
CARAGUATA

Morreniana, Éd. André, in Rev. Hortic. (1886) 12 cum. ic.; et Brom. Andr. 51; Baker, l. c. 147. Ecuad.

Mosquerae, Wittm. in Bot. fahrb.xi. (1890) 58. Columb.

multiflora, Éd. André, in Rev. Hortic. (1888) 565; et Brom. Andr. 54 t. 18 fig. 9 h.; Baker, Handb. Brom. 148. - Columb

palustris, Wittm. in Bot. Fahrb. xi. (1890) 58. Columb.

pulchella, Ed. André, in Rev. Hortic. (1888) 565; et Brom. Andr. 49 t. 17; Baker, Handb. Brom. 144. Ecuad.

Schlumbergerii, Baker, l. c. (1889) 151 (Schlumbergeria Morreniana, Ed. Morr.). - Reg. Andina.

Sintenisii, Baker, l. c. 145. - Ins. Antill.

sphaeroidea, Éd. André, in Rev. Hortic. (1888) 565 . et Brom. Andr. 58 t. 19 fig. c; Baker, l. c. 149. Columb.

straminea, Baker, l. c. (1889) 150. (= Anoplophyton stramineum, C. Koch). - Hab.

violacea, Éd. André, in Rev. Hortic. (1888) 565; et Brom. Andr. 50 t. 18 fig. a; Baker, Handb. Brom. 147. - Ecuad.

virescens, Baker, l.c. (1889) 151 (= Puya virescens, Hook.). - Peruvia.

vittata, Baker, l. c. 146 (=Bonapartea vittata, Mart.) - Reg. Amazon.

CARAIPA, Aubl. (Ternstroem.). - Ind. Kew. i. 420 .

insidiosa, Rodr. in Vellozia, Sec. edic. (1891). 9. - Bras.

Lacerdaei Rodr.l.c.9.-Bras.

palustris, Rodr. l. c. 8 t. 5 a. - Bras.

silvatica, Rodr, l, c. 8 t. 5 b. - Bras.

spuria, Rodr. l. c.8 t. 5 c. - Bras.

CARALLUMA, R. Br.(Asclep.), - Ind, Kew, i 420

Aaronis, N. E. Br. in Gard. Chron. (1892) ii. 369 (= Bowirosia Aaronis, Hart). - Arabia.

acutangula, N.E. Br.l. c. (=B. acutangula. Decne). - Seneg.

Ango, N. E. Br.l.c. (= Stapelia Angn Rich.), Abyss.

aperta, N. E. Br, in Hook. Icon. pl. xx. (1890) t. 1905 a. (= Stapelia aperta, Masson). - Afr. austr.

arabica, N. E. Br. in Kew Bull. (1895) 318 . Arabia.

arida, N. E. Br. in Gard. Chron. (1892) ii. 369 (= Stapelia arida, Masson). - Afr. austr.

armata, N. $E, B r$ in Hook. Icon. pl. xx. (1890) t. 1962. - Afr. austro-occ. extratrop.

Aucheriana, N. E. Br. in Gard. Chron. (1892) ii. 369 (= Boucerosia Aucheriana, Decne). - Arabia. campanulata, N. E. Br.l. c. fig. 61; Hook. f. in Bot. Mag. (1893) t. $7274(=$ Bouc. campanulata. Wight). - Zeyl.

chlorantha, Schlechter, in Bot. Fahrb. xviii. Beibl. n. 45 (1894) 37. - Afr. austr.

cicatricosa, N. E. Br. in Gard. Chron. (1892) ii 369 (= Bouc. cicatricosa, Deflers). - Arabia.

Decaisneana, N.E. Br.l.c. $(=$ Bouc. Decaisneana,

Lem.). - Seneg.

codonoides, $K$. Schum. in Engl. Pflanzenw. Ost-Afr. $C$ (1895) 328. - Afr. trop. or.

dependens, N. E. Br. in Hook. Icon.pl. xx. (1890) t. 1903. - Afr. austr.

diffusa, N.E. Br. in Gard. Chron. (1892) ii. 369 (= Boncerosiadiffusa, Wight). - Travanc

Edithae, N. E. Br. in Kew Bull. (1895) 219. Reg. Somal.

europaea, N. E Br, in Gard. Chron. (1892) ii. 369 (=Bouc. exropaea, Hook. f.). - Eur.; Afr. bor. flava, N.E. Br. in Kew Bull. (1894) 335. - Arabia. gracilipes, $K$. Schum, in Engl. et Prantl, Natürl. Pflanzenfam iv. 2. (1895) 278; et in Engl. Pfanzenw. Ost-Afr. $C$ (1895) 328. - Afr. trop. or.

hirtiflora, N. E. Br. in Kew Bull. (1895) 264.Ins. Hanich (Mare Rubr.).

hottentorum, N. E. Br. in Hook. Icon. pl. xx. (1890) sub t. 1903 (= Quaqua hottentorum, N.E. Br.). Afr, austro-occ. extratrop. 
CARALLUMA :

carnata, N. E. Br, in Gard. Chron. (1892) ii. 369 (= Boucerosia incarnata, N. E. Br.). - Afr austr. indica, N.E.Br.l.c. (= Bouc. Hutchinia, Decne.). - Ind. or.

lasiantha, N. E. Br. l. c. (= Bouc. lasiantha, Wight). - Ind. or

linearis, N. E. Br. in Hook. Icon. pl. xx. (1890) t. 1903 fig. a. - Afr. austr.

longidens, N.E. Br. in Gard. Chron. (1892) ii. 369. - Nubia.

Luntii, N. E. Br. in Kew Bull. (1894) 335. Arabia.

lutea, N.E. Br.in Hook. Icon. pl. xx. (1890) t. 1901 . - Afr. austr.

mammillaris, N.E. Br. in Hook. l. c. sub t. 1902. (= Boucerosia mammillaris, N. E. Br.). - Afr. austro-occ. extratrop.

maroccana, N.E. Br. in Gard. Chron. (1892) ii. 278 (=Bouc. maroccana, Hook. f.). - Marocco.

Munbyana, N.E.Br. l. c. (= Bouc. Munbyana, Decne.). - Algeria.

parviflora, N. E. Br.l. c. (= Stapelia parviflora, Masson). - Afr. austro-occ. extratrop.

pauciflora, N.E.Br.l.c. (= Boucerosia panciflora, Wight). - Ind. or

penicillata, N.E. Br. l. $c .(=$ Bouc. penicillata, Deflers.). - Arabia.

pruinosa, N. E. Br. l. c. (= Stapelia pruinosa, Masson). - Afr. austro-occ. extratrop.

quadrangula, N.E.Br.l.c. (= Boucerosia quadrangula, Decne). - Arabia.

ramosa, N. E. Br. in Hook Icon pl. xx. (1890) t. 1904 (= Stapelia ramosa, Masson.). - Afr. austr. retrospiciens, N.E. Br. in Gard. Chron. (1892) ii. 370 (= Desmidorchis retrospiciens, Ehrenb.). Abyss.

socotrana, N. Br. l. c. (= Boucerosia socotrana, Balf. f.). - Ins. Socotra.

somalica, N. E. Br. in Kew Bull. (1895) 264. Reg. Somal.

speciosa, N. E. Br. l. c. (= Sarcocodon speciosum, N. E. Br.). - Reg, Somal.

Sprengeri, N. E. Br. in Kew Bull. (1895) 263 (= Huernia Sprengeri, Schweinf.). - Abyss.

valida, N. E. in Kew Bull. (1895) 264. - Afr. (sine loco).

tuberculata, N.E.Br. l.c. (= Boucerosia Aucheriana, Hook. f.). - Belutsch., Afghan.

GARDAMINE, [Tourn.] Linn. (Crucif.). - Ind. Kew. i. 420.

amethystea, Pancic, Nov. elem. fl. Princ. Bulg. (1886) 15. - Bulg.

andicola, Phil. in Anal. Mus. nac. Chile (1891) 1. - Chili.

andina, Phil. in Anal. Univ. Chil, Ixxxi. (1893) 71. - Chili.

angelorum, S. Wats. in Proc. Am. Acad.xxiv. (1889) 39. - Calif.

arenicola, Britton, in Bull. Torrey Bot. Club, xix. (1892) 220 (=A virginiana, Michx.). - Am. bor.

barbaraeoides, Haláczy, in Denkschr. Akad. Wien. 1xi. (1894) 228. - Mont. Rhodop.

bracteata, Phil. in Anal. Univ. Chil. 1xxxi. (1893) 85. - Chili.

bulbosa, Britton, Stern et Pogg. Prelim. Catal. (1888) $4=$ rhomboidea, $D C$.

caespitosa, Phil. in Anal. Univ. Chil. 1xxxi. (1893) 79. - Chili.

californica, Greene, Fl. Francisc. (1891) 266; et Man. Bot. San Franc. Bay (1894) $19=$ paucisecta, Benth.

cardiophylla, Greene, Man. Bot. San Franc. Bay (1894) 19. - Calif.

ciliata, Phil. in Anal. Univ. Chil.1xxxi. (1893) 77. - Chili.

Delavayi, Franch. in Bull. Soc. Bot. Fr, xxxiii. (1886) 397. - China occ.

deserticola, Phil. in Anal. Univ. Chil. 1xxxi. (1893) 86. - Chili.

Douglassii, Britton, in Trans. N. Y. Acad. Sci, ix. (1889) $8=$ Arabis Douglassii, Torr.

ecuadorensis, Hieron. in Bot. fahrb. xx. (1895) 19. - Ecuad.

Fauriae, Franch. in Bull. Soc. Philom. Paris, Sér. VII. xii. (1888) 83. - Japon.

\section{CARDAMINE :}

Ferrariz X Burnat, Fl. Alpes Marit. (1892) 184 in obs. - Pedem.

filifolia, Greene, Pittonia, i. (Feb. 1887) $30=$ Arabis filifolia, Greene.

gemmata, Greene, l. c. i. (Feb. 1888) 162. Oregon.

hispidula, Phil. in Anal. Univ. Chil. lxxxi. (1893) 79. - Chili

insularis, Rouy et Fouc. Fl. de Fr. i. (1893) $241=$ resedifolia, Linn.

integrifolia, Phil. in Anal. Univ. Chil. 1xxxi. (1893) 71. - Chili.

integrifolia, Greene, in Bull. Calif. Acad. (1887) 389 $=$ paucisecta, Benth.

Johnstoni, Oliver, in H. Fohnston, The Kilim. Exped. Append. (1886) 337 nomen; et in Trans. Linn. Soc. Ser. II. ii. (1887) 328. - Afr, trop. or.

Killiasii $\times$, Brügg. (ubi?) (conf. Ber. deutsch. bot. Ges. vii. (1889) [131]). - Hely.

kopaonikensis, Pancic, ex Wettst. in Luerss. Bibl. Bot., Heft xxvi. (1892) $20=$ glauca, Spreng

Larembergiana $x$, Rouy et Four. Fl. de Fr. (1893) 235. - Gall.

lazica, Boiss. et Bal., ex Boiss. Fl. Or. Suppl. (1888) 31. - As. Min

Lehmanii, Hieron. in Bot. Fahrb, xx, Beibl.n. 49 (1895) 19. - Columb.

Leibergii, Holzinger, in Contrib. U.S. Nat. Herb. iii. 4. (1895) 212. - Am. bor.

Lyallii, S. Wats. in Proc. Am. Acad.xxii. (1887) 466. - Amer. bor. occ.

macrostachya, Phil in Anal. Univ. Chil. lxxxi. (1893) 75, - Chili.

micropetala, Phil.l.c. 76. - Chili.

monticosa, Phil. i.c. 72.-Chil.

multijuga, Franch. in Bull. Soc. Bot, Fr. xxxiii. (1886) 399. - China occ

Nuttallii, Greene, in Bull. Calif. Acad, ii. (1887) 389 in obs. (= Dentaria tenella, Pursh). - Calif.

ochroleuca, Stapf, in Denkschr. Akad. Wien, li. (1886) 297. - Persia.

ovata, Phil. in Anal. Univ. Chil. Ixxxi. (1893) 69.Chile.

Palenae, Phil. l. c. 80. - Chili.

Palmeri, S. Wats, in Proc. Am. Acad, xxiv. (1889) 38. - Calif.

Peteroana, Phil. in Anal Univ. Chil. Ixxxi. (1893) 74. - Chili.

polemonioides, Rouy, Fl. de Fr. i. (1893) 234 in obs, - Eur. arct.

pulcherrima, Greene, in Erythea, i. (1893) 148. -

Am. bor. occ.

quercetorum, Howell, in Erythea, iii. (1895) 33. Oregon.

Sandbergii, Holzinger, in Contrib. U. S. Nat.

Herb. iii. (1895) tab. $3=$ Leibergii, Holzinger.

Seedlitziana, Alboff, in Bull. Herb. Boiss, ii. (1894) 448. - Reg. Cauc.

sinuata, Greene, in Erythea, i. (1893) 148. - Calif.

Skorpili, Velen. in Sitzungsb. Boehm. Ges. Wiss. 1889 (1896) ii. 29; et Fl. Bulg. (1891) 29. - Bulg.

Soehrensi, Phil. in Anal. Univ. Chil. 1xxxi. (1893) 84. - Chili.

speciosa, Britton, in Bull. Torrey Bot. Club, vix. 1889) 16. - Bolivia.

stenoloba, Hemsl, in fourn. Linn. Soc. xxix. (1892) 303. - China.

stricta Phil. in Anal. Univ. Chil. 1xxxi. (1893) 77.Chili.

thalictroidea, St Lager, in Cariot, Étud. des fl. éd. 8. ii. (1889) $46=$ thalictroides, $A l l$.

tridens, Phil. in Anal. Univ. Chil. (1893) 74. Chili.

triphylla, Phil. l.c. 72. - Chili.

yunnanensis, Franch. in Bull. Soc. Bot. Fr. xxxiii. (1886) 398. - China.

CARDAMOMUM, Rumph. Hist. Amboin. v, (1745-47) 152 t. 65 fig. 1; ex Kuntze, Rev. Gen. (1891) $685=$ Amomum, Linn. (Scitam.)

aculeatum, angustifolium, aromaticum, arundinaceum, biflorum, capitatum, cereum, Ceruga, ciliatum, Clusii, coccineum, corynostachyum, costatum, Dallachyi, dealbatum, echinatum. Fenzlei, floribundum, foetens, giganteum, glaberrimum, globosum, gramineum, graminifolium, Grana-paradisi, hemisphaericum, heteran-
CARDAMOMUM : -

tum, hirsutum, involucratum, Koenigii, latifolium, Leonurus, limbatum, linguiforme, longiscapum, magnifucum, Mannii, marginatum, naximum, Melegueta, molle, nemorale, palustre pilosum, pterocarpum, roseum, rubrum, rufescens, Sceptrum, spurium, subsericeum, subrlatum. tomentosum, uliginosum, villosim vitellinum, et Walang, Kuntze, Rev. Gen. (1891) $685-87=$ homonyma omnia Amomi.

Afzelii, Kuntze, l. c. $685=$ Amomum Granumparadisii, Linn.

album, Kuntze, 1.c. = Elettaria alba, Blume

anthodiodes, Kuntze, l. $\mathrm{c}_{\mathrm{r}}=\mathrm{E}$. anthodiodes, Teijsm. et Binn.

arboreum, Kuntze, 1. c. = Costus Loureiri, Haran.

Beccarianum, Kuntze, 1. c. - Java.

Binnendijkii, Kuntze, 1. c. $68 \%$ (= Donacodes villosa

Teijsm, et Binn.) = Amomum villosum, Lour.

cannicarpum, Kuntze, 1. c. $687=$ Am. cannaecarpum, Benth, et Hook. f.

citratum, Kuntze, 1, c. = Am cereum, Hook if

Danielli, Kuntze, 1. c. = Am. Danielli, Hook.

eriocarpum, Kuntze, 1. c. - Java.

grandiflortm, Kuntze, 1. c, = Amomum Granumparadisi, Linn.

litorale, Kuntze, 1.c. = Am. littorale, Koen.

macrocephalum, Kuntze, 1. c. 687 (= Donacodes ma crocephala, Zoll. et Mor. - Java.

masticatorum, Kuntze, 1. c. = Am. masticatorium Thw.

minus, Kuntze, 1. c. $685=$ Am. Cardamomum Linn

mimus, Kuntze, 1, c, $687=$ Elettaria minor Blume.

minutum, Kuntze, 1. c. = El. minuta, Blume.

pallidum, Kuntze, 1, c. = El. pallida, Blume.

palludosum, Kuntze, 1. c. = El. paludosa, Miq.

parviflorum, Kuntze, 1. c. = Alpinia parviflora

Rolfe.

Pininga, Kuntze, Rev. Gen. (1891) 687 = Alpinia Pininga, D. Dietr.

Scottii, Kuntze, 1. c. = Elettaria Scottiana, F.Mull.

Scyphus, Kuntze, 1.c. = Amomum scyphiferum Koen.

sericeum, Kuntze, I.c. = Am. dealbatum, Roxb.

solare, Kuntze, 1. c. = Elettaria solaris, Blume

speciosum, Kuntze, 1. c. $686=\mathrm{El}$. speciosa, Bhm.

tridentatum, Kuntze, 1.c. - Java.

xanthiodes, Kuntze, 1. c. $687=$ Amomum xanthioides, Wall.

CARDAMON, G. Beck, Fl. Nieder-Oest. ii. (189\%) $495=$ Lepidium, Linn. (Crucifer.)

satirum, G. Beck, 1. c. = L. sativum, Linm.

GARDIANDRA, Sieb. et Zucc. (Saxifrag.). Ind. Kew. i. 423

alternifolia, Hort. ex Dippel, Handb. Laubholzk

i. (1889) $\mathbf{1 8}=$ Ehretia acuminata, R. Br.

GARDIOGHLAMYS, Oliver (Convolv.). - Ind Kew. i. $42: 3$.

velutina, Hallier f. in Bot. Fahrb. xviii. (1894) 94. Madag.

CARDIOSPERMUM, Linn. (Sapind.). - Ind. Kew. i. 423.

dissectum, Radlk. in Engl. et Prantl. Natïrl. Pfanzenfam. iii. 5. (1895) $308(=$ Urvillea dissecta, S. Wats.). - Am. bor.

giganteum, Rodr Pl. nov. fard. bot. Rio, iii. (1893) 9 t. 2. - Bras.

integerrimum, Radlk. in Engl. et Prantl, Natiinl. Pfanzenfam. iii. 5. (1895) 307. - Bras.

Palmeri, Vasey et Rose, in Proc. U. S. Nat. Mus xiii. (1890) 147. - Ins. Clarion (Calif.).

Pechuelii, Kuntze, in. Fahrb. Bot. Gart, Berl. iv. (1886) 262. - Afr. austro-occ.

spinosum, Radlk, in Engl. et Prantl, Natür, Pflanzenfam. iii. 5. (1895) 308. - Calif.

CARDOPATIUM, Juss. (Compos.) - Ind. Kew.

atractyloides, C. Winkl. in Act. Hort. Petrop. ix. (1886) 517 - As. centr. 
GARDUNGELLUS, Adans. (Compos.). - Ind Kew, i, 424

caespitosus, Batt. et Trab. in Bull. Sec. bot. Fr. xxxv. (1888) 343 et 390 . - Algeria.

Choulettianus, Pomel, ex Batt. in Bull. Assoc. franc. sci. (1889) 489; et Fl. de l'Algérie (Dicot.) (1889) 515. - Algeria.

cryptocephalus, Baker, in Kew Bull. (1895) 217, Reg. Somal.

Duvauxii, Batt. et Trab. in Bull. Soc. bot. Fr. xxxy. (1888) 341 et 390. - Algeria

kentrophylloides, Baker, in Kew Bull. (1895) 182. Arabia.

Pomelianus, Batt. in Bull. Soc. bot. Fr.xxxiii. (1886) 354; et Atlas fl. Algérie (1880) 8 t. 3. - Algeria.

Reboudianus, Batt. l. c. xxyvi. (1889) P. ccxxi ; et in Bull.

CARDUUS [Tourn.] Linn. (Compos.). - Ind. Kew, i. 424

acantholepis, Greene, in Proc. Acad. Sci. Philad. 1892 (1892) $363=$ Cnicus acantholepis, Hemsi. agrestis, A. Kern. in Koch, Syn. deutsch. Fl. ed. $3(1895) 1525$ in syn.$=$ crispus, Lim

americams, Greene in Proc. Acad. Sci. Philad. $1892(1892) 362=$ Cnicus americanus, A. Gray. amplifolius, Greene, 1. c.; et Man. Bot. San Franc. Bay (1894) 217 = Cnicus amplifolius, Greene.

Andersonii, Greene, 1. c. $362=$ Cnicus Andersonii, A. Gray.

arizonicus, Greene, 1. c. $=$ Cnicus arizonicus, A. Gray.

Assoi, Willk. Suppl. Prodr. fl. Hisp. (1893) $105=$ nigrescens, Vill.

baldschuanicus, C. Winkl. in Act. Hort. Petrop. ix. (1886) 152. - Buchara.

Burbergii $\times$, Haussm. ex Kern. Sched. fl. AustroHung. v. (1888) 65. - Austria.

bernardinus, Greene, in Proc. Acad. Sci. Philad, 1892 (1892) 361. - Calif.

Breweri, Greene, 1. c. $363=$ Cnicus Breweri, A. Gray.

californicus, Greene, 1. c. 359 in obs. et Man. Bot. San Franc. Bay (1894) 217 = Cnicus californicus, A. Gray.

candidissimus, Greene, l. c.359. - Calif

Choulettianus, Batt. in Batt. et Trab. Fl, de l'Algérie (Dicot.) (1888) 515 (= Lamottea Choulettiana, Pomel). - Algeria.

colchicus, Alboff, Prodr. Al. Colch. (1895) 142. Reg. Cauc.

controversus, Sudre, in Lucante, in Rev. de Bot. xii. (1894) 22. - Gall.

crassicaulis, Greene, in Proc. Acad. Sci. Philad. 1892 (1892) 357; et Man. Bot. San Franc. Bay (1894) 217. - Calif.

Drummondii, Coville, in Contrib. U. S. Nat. Herb. iv. (1892) 142 = Cnicus Drummondii, A. Gray. edulis, Greene, in Proc. Acad. Sci. Philad. 1892 (1892) 362; et Man. Bot. San Franc. Bay (1894) $217=$ Cnicus edulis, $A$. Gray.

eriocephalus, C. Winkl. in Act. Hort. Petrop. ix. 1886) 520 . As, centr.

excelsior, Greene. in Proc. Acad. Sci. Philad. 1892 (1892) $364=$ Cnicus excelsior, Robins.

fontinalis, Greene, in Proc. Acad. Sci. Philad. 1892 (1892) 363; et Man. Bot. San Franc. Bay (1894216 = Cnicus fontinalis, Greene.

Fussii, Kern. ex Simonk, in Termész. Füzét. $\mathrm{x}$. (1886) 181; et Enum. fl. Transilv. (1886) 337 in syn. = Kerneri, Simonk.

Gentyanus $\times$, Gillot, Herbor. Jura central. 1890 (1891). - Helv.

Grahami, Greene, in Proc Acad Sci Philad. 1892 (1892) $363=$ Cirsium Grahami, A. Gray.

groedigensis $X$, Fritsch, in Sitz. zool.-bot. Ges. Wier, xxxix. (1889) 89; et ex Bot. Centralb1. xli. (1890) 84. - Austria.

Haussknechtii $\times$, Bornm, in Mitth. Thür. Bot. Ver. N. Folge, viii. (1895) 37. - Germ.

heterolepsis, Greene, in Proc. Acad. Sci, Philad. 1892 (1892) 363. - Mexic

heteromorphus $x$, Sennholz, in Sitz. zool.-bot. Ges. Wien, xxxvii. (1887) 7\%. - Carinthia.

Hilli, Porter, in Mem. Torxey Bot, Club,

(1894) 344 = Cnicus Hillii, Canby.

\section{GARDUUS :}

hydrophilus, Greene, in Proc. Acad. Sci. Philad. 1892 358; et Man. Bot. San Frano. Bay (1894) 218. Calif.

intercedens $\times$, Hausskn. in Mitth. Thür. Bot. Ver. T. Folge, vii. (1893) 41. - Graecia

Zuratgkae X, G. Beck, F1. Nieder-Oest. I. ii. (1892) 1231. - Austria.

Kernevi $\times$, Simonk, in Termész. Füzét. x. (1886) 181; et Enum. fi. Transsilv. (1886) 337.--Transs. Khekii X, Murr, in Oest. Bot. Zeitschr. xlii. (1892) 214; et in Deutsche Bot. Monatsschr. xii. (1894) $94=$ Schulzeanus, G. Ruhmer.

laniceps, C. Winkl. in Act. Hort. Petrop. ix. (1886) 519. - As. centr.

latisquamus, Freyn et Conrath, ex Freyn, in Bull. Herb. Boiss, iii. (1895) 357 = nutans, Limn.

lecophyllus, Petrov. ex Bormm. in Bot. Centralbl. xxxvi..(1888) 88. - Bulg.

linearifolius, Greene, in Proc. Acad. Sci. Philad. $1892(1892) 563=$ Cnicus linearitolius, S. Wats.

longifolius, C. Winkl. in Act. Hort. Petrop. xi. (1890 378. - As. centr.

macedonicus, Charrel, in Oest. Bot. Zeitschr. xlii. (1892) 340 nomen; et Pl. de Salonique (1892) 27. Maced.

mexicanus, Greene, in Proc. Acad. Sci. Philad. $1892(1892) 363=$ Cnicus mexicanus, Hemss. mixtus $\times$. Corbière, Nouv. Fl. Norm. (1893) 348. - Gall. occ.

mohavensis, Greene, in Proc. Acad. Sci. Philad. 1892 (1892) 361. - Calif.

Muellneri $X$, Sennholz, in Sitz. zool.-bot. Ges. Wien, xxxvii. (1887) 70. - Austria.

neo-mexicanus, Greene, in Proc. Acad. Sci. Philad. 1892 (1892) 362 = Cirsium neo-mexicanum A. Gray.

niveus, C. Winkl. in Act. Hort. Petrop. xi. (1890) 378. - As. centr.

ochrocentrus, Greene, in Proc, Acad. Sci. Philad. 1892 (1893) $363=$ Cnicus ochrocentrus, A. Gray. odoratus, Porter, in Mem. Torrey Bot. Club, v.

(1894) $345=$ Cnicus pumilus, Torr.

Parryi Greene, in Proc Acad. Sci. Philad. 1892 (1892) $362=$ Cnicus Parryi, A. Gray.

phyllolepis, Willk. in Oest. Bot. Zeitschr. xli. (1891) 51. - Hisp.

pindicolus, Hausskn. in Mitth. Bot. Ver. Fena, v. (1887) 86. - Graecia.

Pitcheri, Porter, in Mem. Torrey Bot. Club, v. (1894) $345=$ Cnicus Pitcheri, Torr

plattensis, Rydberg, in Contrib. U. S. Nat. Herb. iii 3. (1895) 167 t.2. - Nebraska.

potosinus, Greene, in Proc. Acad. Sci. Philad. 1892 (1892) 364. - Mexic.

praticolus X, G. Beck, Fl. Nieder-Oest. II. i. (1892) 1232. - Austria.

Pringlei, Greene, in Proc. Acad. Sci. Philad 1892 (1892) $364=$ Cnicus Pringlei, S. Wats

propinquus, Pomel, ex Batt. et Trab. Fl. de l'Algér.

(Dicot.). (1889) 524. - Algeria.

pseudohamulosus $X, G$. Beck, Fl. Nieder-Oest. ii. (1892) 1232. - Austria.

quercetoram, Greene, in Proc. Acad. Sci. Philad. 1892 (1892) 362; et Man Bot. San Franc. Bay (1894) $218=$ Cnicus quercetorum, A. Gray.

raphilepis, Greene, 1. c. $363=$ Cnicus raphilepis, Hemisl.

Rothrockit, Greene, in Proc. Acad. Sci. Philad. 1892 (1892) $362=$ Cnicus Rothrockii, A. Gray. Rusbyi, Greene, b.c. 361. - Arizona.

Schultzeanus, Ruhm. in Oest. Bot. Zeitschr. xliii (1893) 177 sphalm. = Schulzeanus $\times$, Ruhm

scopulorum, Greene, in Proc. Acad. Sci. Philad. 1892 (1892) $362=$ Cnicus eriocephalus, A. Gray.

sepincolus, Hausskn. in Mitth. Thïr. Bot. Ver. N. Folge, vi. (1894) 25. - Graecia

tiriacus $\times$, G. Beck, Fl. Nieder-Oest. i. if. (1892) 1233. - Stiria.

umbrosus $\times$, Simonk. Enum. Al. Transsilv. (1886) 329. - Transs.

velatus, Greene, in Proc. Acad. Sci. Philad. 1892 (1892) $363=$ Cnicus velatus, $S$. Wats.

venustus, Greene, 1. c. 359; et Man. Bot. San Franc Bay (1894) 218. - Calif.

vindabonensis $X$, G. Beck, F1. Nieder-Oest. ii. II. (1893) 1238. - Austria.
CARELIA, Moehring, Hort, Priv, (1736)

Kuntze, Rev. Gen. (1891) $325=$ CARELIA, Adans. = Agreratum, Linn. (Compos.).

adscendens, albida, arbutifolia, brachystephana, conferta. corymbosa, domingensis, glandulifera Houstoniana, isocarphodes, latifolia, matricariodes, melissifolia, microcephala, mutica, paleacea, petiolata, purpurea, salicifolia, scabriuscula, sessilifolia, stricta, tomentosa, Kuntze, Rev. Gen. (1891) $325=$ homonyma omnia Agerati.

Agrianthus, Kuntze, 1. c. = Agrianthus corymbosus, $D C$

conyzodes, Kuntze, 1. c. = Ageratum conyzoides, Linn.

echiodes, Kuntze, 1. c. = Ager. echioides, Hemsl.

maritima, Kuntze, 1. c. = Ager. conyzoides, Linn.

matricariodes, Kuntze, 1. c. = Ager, matricarioides, Less.

GAREX [Dill.] Linn. (Cyperac.). - Ind. Kew. i. 427.

abacta, L. H. Bailey, in Bull. Torrey Bot. Club, xx. (1893) $427=$ Michauxiana, Boeck.

acuta L. H. Bailey in Proc. Am. Acad, xxii. (1886) 86 = acutina, L. H. Bailey.

acutina, L. H. Bailey, in Mem. Torrey Bot. Club, i. (I889) 52, - Am. bor.

affinis, F. Nyl, ex Nym. Consp. f. Eur. Suppl. II. i. (1890) $323=$ saiina, $W$ ahlenb.

akanensis, Franch, in Bull. Soc. Philom. Paris, Sér. VIII. vii. (1895) 51. - Japon.

albata, L. H. Bailey, in Macoun, Cat. Canad. Pl. iv. (1888)

albida, L. H. Bailey, in Mem. Torrey Bot. Club, i. (1889) 9. - Am, bor.

albursina, Sheld. in Bull. Torrey Bot. Club. xx. (1893) 284 = laxiflora, Lam.

alma, L. H. Bailey, in Mem. Torrey Bot. Club, i. (1889) 50. - Calif.

alsatica X, Zahn, in Oest. Bot. Zeitschr. xl. (1890) 363. - Eur.

alterniflora, Franch, in Bull. Soc. Philon. Paris, Sér. VIII. vii. (1895) 51. - Japon.

angustisquama, Franch.l. c. 39. - Japon.

Appeliana $x$, Zahn, in Oest. Bot. Zeitschr. xl. (1890) 364 . - Alsatia.

arcuata, Franch. in Bull. Soc. Philom. Paris, Sér. VII.x. (1886) 106. - Japon.

arrhyncha, Franch. l.c. Sér. VIII. vii. (1895) 30.Japon

arridens, C. B. Clarke, hn Hook. f. Fl. Brit, Ind. vi. (1894) 726. - Penins. Mal.

Arthuriana $\times$, Beckm. et Figert, in Ber. deutsche bot. Ges. vii. (1889) 30; et in Deutsche Bot. Monatsschr. x. (1892) 176. - Germ.

Asa-Grayi, L. H. Bailey, in Bull. Torrey Bot. Club, xx. (1893) $427=$ Grayii, Carey.

assiniboimensis, $W$. Boott, in Coult. Bot. Gaz. ix. (1884) 91. - Am. bor.

attantica, L. H. Bailey, in Bull. Torrey But. Club, xx. (1893) 425 = echinata, $M$ urv

atractiformis, Britton, in Bull. Torrey Bot. Club, xxii. (1895) 222. - Am. bor.

Augustinowiczii, Meinsh. in Act. Hort. Petrop. xii. (1892) 411. - As. bor.-or.

auriculata, L. H. Bailey, in Mem. Torrey Bot. Club, i. (1889) 19. - Am. bor.

auriculata, Franch, in Bull. Soc. Philom. Paris, Sér. VII. x. (1886) 106. - Japon.

australis, T. Kirk, in Trans. N.Z. Inst. xxvi. 1893 (1894) 262. - N. Zel.

austro-caroliniana, L. H. Bailey, in Bull. Torrey Bot. Club, xx. (1893) $428=$ caroliniana, Buckley. axillaris, Becc. in Hook. f. Fl. Brit. Ind. vi. (1893) 456. - Perak

Baeuerlenii, F. Muell. ex Maiden, in Proc. Linn. Soe. N. S. Wales, iv. (May 1889) 110 et 111, nomen. - Austral

Baileyi, Britton, in Bull. Torrey Bot. Club, xxii. (1895) 220. - Am. bor.

Bebbii, Olney, ex Britton, in Mem. Torrey Bot. Club, i. (1889) 55; etv. (1894) 97 =tribuloides, Wahlenb. Beckmanniana $X$, Figert, in Deutsche Bot. Monatsschr, vii. (1889) 185. - Germ.

bella, L. H. Bailey, in Coult. Bot. Gaz. xvii. (1892) 152. - Am. bor.-occ 


\section{CAREX}

Berggreni, Petrie, in Trans. N. Z. Inst. xviii. 1885 (1886) 297 . - N. Zel.

bidentula, Franch in Bull Soc, Philow, Payis, Sẻr. VIII. vii. (1895) 41. - Japon.

behurica $X$, Simonk. Enum. fl. Transsilv. (1886) 548. - Transs.

binensis, Franch. in Bull. Soc. Philom. Paris, Sér. VIII. vii. (1895) 28. - Japon.

blepharicarpa, Franch. l. c. 46. - Japon.

Bndinteri. Franch.l. c. 85. - Ins, Hong-Kong.

botasgdensis $X$, Kükenth, in Mitth. Thür. Bot. Ver. N. Folge, v. (1893) I9. - Norv.

bostrychostigma, Maxim. in Bull. Acad. Pétersb. xxxi. (1887) 118. - Mandchur.

brachysandra, Franch, in Bull. Soc, Philom. Paris, Sér. VIII. vii. (1894) 40. - Japon.

breviscapa, C. B. Clarke, in Hook. f. Fl. Brit. Ind. vi. (1894) 736. - Zeyl.

Brittoniana, Coult. in Contrib.U. S. Nat. Herb. ii. (1894) 484. - Texas.

Brongniartii, L. H. Bailey, in Proc, Am. Acad, xxii, (1886) $137=$ vicaria, $L . H$. Bailey.

Bruceana, Boott, ex C. B. Clarke, in Hook. f. Fl. Brit. Ind. vi. (1894) 717 in syn. = continua, C. B. Clarke.

Brueckneri $\times$, Kủkenth. in Deutsche Bot. Monatsschr. viii. (1890) 107. - Germ.

Brueggeri X, C. Richt. Pl. Europ. i. (1890) 170. Helv.

Calcitrapa, Franch, in Bull. Soc. Philom. Paris, Sér. VIII. vii. (1895) 30. - Japon.

californica, L. H. Bailey in Mem. Torr. Bot. Club, i. (1889) 9. - Calif.

capilliformis, Franch, in Bull. Soc. Philom, Paris, Sér. VIII. vii. (1895) 89. - China.

capitulata, Boott, ex C. B. Clarke, in Hook. f, FI. Brit. Ind.vi.(1894) 721 in syn. = rhizomatosa, Steud.

capituliformis, Meinsh. ex Maxim. in Bull. Acad. Pétersb. xxxi. (1887) 115. - Japon.

capricornis, Meinsh. l. c. xxxi. (1887) 119. Mandchur.

castaneostachya, K. Schum. in Engl. Pflanzenw. Ost. Afr. A (1895), 131 nomen. - Afr. trop. or.

cercostachys, Franch, in Bull. Soc. Philom. Paris, Sér. VIII. vii. (1895) 27. - Yunnan.

Chevalieri $x$, Corbière, in Bull. Soc. Linn. Norm. Sér. IV, ix. (1895) 76. - Gall. occ.

chinensis. Munro, ex Hook. f. Fl. Brit. Ind. vi. (1894) 738 = Munroi, Boott.

chlamydea, Norm. in Christian. Vidensk.-Selsk. Forhandl. (1893) extr. 45. - Norv.

chloroleuca, Meinsh. in Act.Hort. Petrop. xii. (1892) 411 nomen; et in Bot. Centralbl. 1v. (1893) 196. Sibiria.

Christii $\times$, Boeck. in Bot. Centralbl. xlii. (1890) 134 - Helv.

ciliolata, Franch. in Bull. Soc. Philom. Paris, Sér VIII. vii. (1895) 38. - Japon.

cincta, Franch. l. c. 35. - Japon.

communis, L. H. Baley, in Mem. Torrey Bot. Club. i. (1889) 41 = varia, A. Gray.

conferto-spicata, Boeck. in Bot. Fahrb. viii. (1887) 206. - Columb.

continua, C. B. Clarke, in Hook. f. Fl. Brit. Ind. vi. (1894) 717. - Reg. Himal.

eontracta, Boeck. Cyp. Nov. ii. (1890) 34. - Japon. cooptanda, C. B. Clarke, in Hook. f. Fl. Brit. Ind. vi. (1894) 707. - Reg. Himal.

Coreana, L. H. Bailey, in Mem. Torrey Bot. Club, i. (1889) 8. - Am. bor

crassinervia, Franch. in Bull. Soc. Philom. Paris, Sér. VIII. vii. (1895) 38. - Japon.

cremostachys, Franch.l. c. 34. - Yunnan.

csomadensis $X$, Simonk. Enum. fl. Transsilv.(1886) 556. - Transs.

curticeps, C. B. Clarke, in Hook. f. Fl. Brit. Ind. vi. (1894) 729. - Reg. Himal.

curvifolia, Boeck. Cyp. Nov. i. (1888) 41. - Reg. Argent.

cyclocystis, Boeck. l. c. 47; C. B. Clarke, in Hook. Fl. Brit. Ind. vi. 748 in obs, (cycloristis.). Tibet.

cylindrostachys, Franch. in Bull. Soc. Philom. Paris, Sér. VIII. vii. (1895) 32. - Tonkin.
CAREX :

Dallii, T. Kirk, in Trans, N.Z. Inst. xxvi. 1893 (1894) 26I. - N. Zel.

decurtata, Cheesem, in Trans, N $Z$. Inst, xxiv. 1891 (1892) 414 = cryptocarpa, Cheesem.

Delavayi, Franch. in Bull. Soc. Philom. Paris, Sér. VIII. vii. (1895) 29. - Yunnan.

densa, L. H. Bailey, in Mem. Torrey Bot. Club, i. (1889) 50. - Am. bor

dichroa, Franch. in Bull. Soc. Philom. Paris, Sér. VIIl. vii. (1895) $86=$ thibetica, Franch

dichroa, Freyn, in Oest. Bot. Zeitschr. xl. (1890 $304=$ vesicaria, $\operatorname{Linn}$

dicuspis, Franch. in Bull. Soc. Philom. Paris, Sér. vii. (1895) 42. - Japon.

Dieckii, Boeck. Cyp. Nov. ii. (1890) 33. - Columb. angl.

diffusa, Boott, ex C. B. Clarke, in Hook. f, Fl. Brit. Ind. vi. (1894) $717=$ vesiculosa, Boott

diminuta, Boeck. Cyp. Nov. ii. (1890) 36. - China.

dimorpha, Boek. l. c. i. (1888) 45. - Reg. Himal

dinarica, Simonk. Enum. $f$. Transsilv. (1886) 533.Transs.

dissitiflora, Franch. in Bull. Soc. Philom. Paris, Sér. VIII. vii. (1895) 32. - Japon.

distracta, C. B. Clarke, in Hook. Fl. Brit. Ind. vi (1894) 715. - Reg. Himal.

dolicophylla, Link, ex C. B. Clarke, in Bot. Mag. (1893) t. 7288 in syn. = baccans, Nees.

Donnell-Smithii, L. H. Bailey, in Mem. Torrey Bot. Club, i. (1889) 56. - Guatem.

drepanorhyncha, Franch. in Nouv. Arch. Mus Paris, Sér. II. x. (1887-88) 183. - China.

Duermbergeri $\times$, Ritzberger, in Oest. Bot. Zeitschr. xli. (1891) 246. - Austria

Dufftii X, Hausskn. in Mitth. Bot. Ver. Jena, vi (1888) 10.- Eur.

durifolia, L. H. Bailey, in Bull. Torrey Bot. Club, xx. (1893) $428=$ Backii, Boott.

Dussiana, Boeck. Cyp. Nov. ii. (1890) 36. - Ins. Martin.

Duthiei, C. B. Clarke, in Hook. f. Fl. Brit. Ind vi (1804) 831. - Ind, or

ecostata, C. B. Clarke, l. c. 720 . - Ind. or

Eleocharis, L. H. Bailey, in Mem. Torvey Bot. Club, i. (1889) 6. - Saskatch.

erostrata, Boott, ex C. B. Clarke, in Hook. f. Fl. Brit. Ind. vi. (1894) 711. - Reg. Himal.

exsiccata, L. H. Bailey, in Mem. Torrey Bot. Club i. 1889) 6. - Am. bor.

Fargesii, Franch. in Bull. Soc. Philom. Paris, Sér. VIII. vii. (1895) 34. - China.

fastigiata, Franch. l. c.34. - Yunnan.

Fauriei, Franch. 1. c. Sér. VII. x. (1886) 105

(sphalm. Fauriae), - Japon.

Favrati $\times$, Christ, ex Ber. Deutsche. bot. Ges. viii (1890) [173]. - Helv.

feta, L. H. Bailey, in Bull. Torrey Bot. Club, xx. (1893) 417. - Am, bor.-occ

filicina, Boeck. ex C. B. Clarke, in Hook. f. Fl. Brit. Ind. vi. (1894) 717 in syn, = stramentitia, Boott.

Fischeri, K. Schum. in Engl. Pflanzenw. Ost-Afr. C (1895) 130. - Afr. trop. or

fissitis, Boott, ex C. B. Clarke, in Hook, f. F1. Brit Ind. vi. (1894) 714 et 715 in syn = indica Linn et distracta, C. B. Clarke.

Fritschii, Waisbecker, in Verh. zool.bot. Ges. Wien, xliv. (1895) 51. - Hung.

fucata, Boott, ex C. B. Clarke, Hook.f. Fl. Brit. Ind vi. (1894) 710. - Sikkim.

fulta, Franch. in Bull. Soc. Philom. Paris, Sér. VIII. vii. (1895) 28. - Japon.

funicularis, Franch. l. c. 57. - Japon.

fuscifructus, C. B. Clarke, in Hook. f. Fl. Brit. Ind vi. (1894) 742. - Assam.

fuscolutea. Boeck. in Bot. Fahrb. vii. (1886) 278. Mexic.

Fussii $\times$, Simonk. Enum. A. Transsilv. (1886) 548. - Transs.

Fyllae, Holm, in Bot. fahrb. viii. (1887) 294; et Consp. fl. Groenl. iii. 2. (1887) 291. - Groenland. gansuensis, Franch. in Bull. Soc. Philom. Paris, Sér. VII1. vii. (1895) 39. - Japon.

gentilis, Franch. l.c.84. - Yunnan.

Gerhaldti $\times$, Figert, in Deutsche Bot. Monatsschr. iv. (1886) 153. - Germ.

\section{CAREX :}

germanica $\times$, C. Richt. P1. Europ, i. (1890) 169. Germ

gifuensis, Franch, in Bull. Soc, Philom. Paris, Sér. VIII. vii. (1895) 47. - Japon.

grallatoria, Maxim. in Bull. Acad. Pétersb. xxxi. (1887) 113. - Ins. Kiu-Siu

grandis, L. H, Bailey, in Mem. Torrey Bot. Club, i. $(1889) 13$ = gigantea, Dewey.

grandisquama, Franch. in Bull. Soc. Philom. Paris, Sér. VIII. vii. (1895) 50. - Japon

gravida, L. H. Bailey, in Mem. Torrey Bot. Club, i. 1889) 5. - Am. bor.

hobkodensis, Franch. in Bull. Soc. Philom. Paris, Sér. VIII, vii. (1895) 28. - Japon.

Hectori, Petrie in Trans. N.Z. Inst, xxvii. 1894 (1895) 405 - N. Zel

Henningsiana, Boeck. Cyp. Nov. i. (1888) $42=$ vulpinaria, Raes.

herbariorum, L. H. Bailey, in Coult. Bot. Gaz, xvii. 1892) 150. - Am. bor

heteroclita, Franch. in Bull. Soc. Philom. Pars, Sér. VIII. vii. (1995) 28. - Japon

heterolepis, Boeck. Cyp. Nov. i. (1888) 48. - Tibet.

Hieronymi, Boeck. l. c. 46. - Reg. Argent.

Howellii, L. H. Bailey, in Mem. Torrey Bol. Club, i, 1889) 45. - Oreg.

illota, L. H. Bailey, l. c. 15, - Am. bor.

inaequalis, Boott, ex C. B. Clarke, in Hook. f. Fl. Brit. Ind. vi. (1894) 726. - Reg. Himal. inclinis, Boott, l.c. 728. - Reg. Himal.

incompta, Franch. Miss. scient. Cap. Horn, v. [Phan.] (1889) 376 t. 6. - Reg. Magell.

indagata $\times$, Torges et Hausskn. in Mitth. Bot. Ver. Jena, ix. (1891) 26. - Eur.

insignis, Phil. ex K. Reiche, in Bot. Fahrb.xxi.(1895) 43 , nomen. - Chili.

interior, L. H. Bailey, in Bull. Torrey Bot. Club, xx, (1873) 426. - Am. bor.

isomadensis, Simonk. ex K. Richt. Pl. Eur.i. (1890) - Transs.

javanica, Boeck. Cyp. Nov. i. (1888) 43. - Java.

Johnstonii, Boeck. in Bot. fahrb. vii. (1886) 278. Afr. trop. or.

Bailey, in Mem. Torrey Bot. Club. i. (1889) 16. - Am. bor.

kamikawensis, Franch. in Bull. Soc. Philom. Paris, Sér. VIII. vii. (1895) 48. - Japon.

Karoi, Freyn, in Oest. Bot. Zeitschr. xl. (1890) 303 = capillaris, Linn.

kashmirensis, C. B. Clarke, in Hook. Fl. Brit. Ind. vi. (1894) 743. - Cachem.

Kirkii, Petrie, in Trans, N, Z. Inst, xviii, 1885 (1886) 297. - N. Zel

Kneuckeriana $\times$, Zahn, in Oest. Bot.Zeitschr. xl. 1890) 412. - Austria.

Kohtsii $\times$, C. Richt. Pl. Europ, i. (1890) 170 . Silesia.

Krausei, Boeck, in Bot. Jahrb, vii. (1886) $279=$ capillaris, Linn.

Krebsiana, Boeck. Cyp. Nov. ii. (1890) 32. - Ja-

pon.
Kuntzeana, Boeck.l. c. 51. - Java

laeviculmis, Meinsh. in Bot. Centralbl. 1v. (1893) 195. - Kamtchatka.

lamprosandra, Franch. in Bull. Soc. Philom. Paris, Sér. VIII. vii. (1895) 45. - Yunnan.

lancea, Baill. Hist. des pl. xii. (1894) $341=$ Schoenus lanceus, Thunb.

lasiolepis, Franch, in Bull. Soc. Philom. Paris, Sér. VIII. vii. (1895) 46. - Japon.

laticuspis, Franch. 1. c. $58=$ cryptocarpa, C. A. Mey.

lazica, Boiss, et Balansa, ex Alboff, in Bull. Herb. Boiss. iii. (1895) $93=$ pontica, Alboff.

leiogona, Franch. iu Bull. Soc. Philom. Paris, Sér. VIII. vii. (1865) 88. - Japon.

leptocarpa, C. B. Clarke, in Hook. f. Fl. Brit. Ind. vi. (1894) 719 (leptocarpus). - Ind or.

Leutzii $\times$. Kneuck, ex Ber. Deutsch. Bot. Ges. x. (1992) [131]. - Germ.

levicaulis, Franch, in Bull. Soc. Philom. Paris, Sér. VIII. vii. (1895) 37. - Japon.

limnogena $\times$, Appel, ex Callier, in Deutsche Bot. Monatsschr. x. (1892) 168. - Germ.

litorhyncha, Franch. in Bull. Soc. Philom. Paris, Sér. VIII. vii. (1895) 84. - Yunnan. 


\section{CAREX}

lc ngepedicellata, Bocck. Cyp. Nov. i. (1888) 41. Tibet.

ngiacuminata, Colenso, in Trans. N. Z. Inst. xxi. 1888 (1889) $104,-\mathrm{N} . \mathrm{Zel}$

lungibracteata, St-Lager, in Cariot, Étud. des fl. éd. 8. ii. (1889) $863=$ C. Pseudo-Cyperus, Linn. (ngicuspis, Boeck.l. c. 49. - Tibet

longipedunculata, $K$. Schum. in Engl. Pflanzenw. Ost-Afr. C (1895) 130. - Afr. trop. or

1cnghiensis, Franch. in Bull. Soc. Philonn. Paris, Sér. VIII vii. (1895) 85. - Yunnan.

lonisianica, L. H. Bailey, in Bull. Torrey Bot. Club, xx. (1893) $428=$ Halei, Carey.

incidula, Franch in Bull. Soc. Philom. Paris, Sér. VIII, vii. (1895) 48 = recticulmis, Franch.

Imida, L. H. Bailey, in Proc. Am. Acad. xxii. (1886) 63 = lupulina, Muht.

lurida, C. B. Clarke, in Hook. f. Fl. Brit. Ind. vi. (1894) 742. - Reg. Himal.

Lycurus, $K$. Schntm. ex Engl. in Abhandl. Preuss. Akad. Wiss. (1894) 58; et in Engl. Pfanzenw. OstAfr. C. (1895) 129. - Afr. trop, or.

Lyoni, F. Kurtz, in Bot. Fahrb. xix. (1894) 419. Alaska.

Macounii, A. Bennett, in Macoun, Catal, Can. Pl. iv. (1888) 147. - Canada.

macrantha, Boeck. Cyp. Nov. i. (1888) 49. - Tibet. macrochlamys, Franch in Bull Soc Philom. Paris, Sér. VIII. vii. (1895) 49. - Japon.

macrocystis, Boeck. Cyp. Nov. i. (1888) 50. - Afr. austr.

macrorhiza, Boeck. Cyp. Nov. i. (1888) 43. - Reg. Argent.

mahinoensis, Franch.l. c. 47. - Japon.

malaccensis, C. B. Clarke, in Hook.f. Ft. Brit. Ind. vi. (1894) 722. - Penins. Mal.

mandshurica, Meinsh. in Bot. Centralbl. Iv. (1893) 197. - Mandchuria.

marginaria, Franch. in Bull. Soc. Philom. Paris, Ser. VIII. vii. (1895) 40. - Japon.

Matsumurae, Franch.l.c. 50. - Japon.

Meadii, Porter, in Bull. Torrey Bot. Club, xxi. (1894) 122. - Am. bor.or.

melanolepis, Boeck. Cyp. Nov. i. (1888) 47. - Reg. Himal.

membranopacta, L. H. Bailey, 1. cr xx. (1893) $428=$ $=$ compacta, $R \cdot B r$

microstoma, Franch. in Bull. Soc. Philom. Paris, Sér. VIII. vii. (1895) $48=$ pallescens, Linn

Milne, Boott, ex C. B. Clarke, in Hook. f. Fl Brit. Ind.vi. (1894) $715=$ indica, Linn. var.

minutiflora, Boeck. Cyp. Nov. i. (1888) 51. - Reg. Himal.

minuta, Franeh, in Bull. Soc. Philom. Paris, Sér VIII. vii. (1895) 41.- Japon.

misera, Franch. l. . 51. - Japon.

Mithala X, Callier, in Deutsche Bot. Monatsschr. vi. (1888) 40. - Scand

mitrata, Franch. in Bull. Soc. Philom, Paris, Sér. VIII. vii. (1895) 88. - Japon.

mixta $\times$, Corbière, Nouv, FI. Norm. (1893) 607. Gall. occ

moniliformis, Britton, in Geol. Surv. N. Jersey, ii. (1889) 278 = silicea, Olney.

montanensis, L. H. Bailey, in Coult. Bot. Gaz, xvii. (1892) 152. - Am. bor.-occ

Montis Eeka, Hillebr. Fl. Haw. Isl. (1888) 486. Ins. Sandvic.

mosognensis, Franch, in Bull. Soc. Philom, Paris, Sér. VIIl. vii. (1895) 31. - Yunnan.

moupinensis, Franch. in Nouv. Arch. Mus. Paris, Sér. II, x. (1887-8) 102. - China.

Muelleri, Petrie, in Trants. N. Z. Inst. xviii. 1885 (1886) $298(=$ C. vividis, Petrie) - N. Zel.

munipoorensis, C. B. Clarke, in Hook. f. Fl. Brit. Ind. vi. (1894) 729. - Ind. or.

Munroi, Boott, ex C. B. Clarke, 7. c. 738. - Ind. ov

Murrii $\times$, Appel, in Oest. Bot. Zeitschr. xli. (1891) 124 ; et in Deutsche Bot. Monatsschr. xii. (1894) 100. - Austria.

mutans, Boott, ex C. B. Claske, in Hook, f. Fr. Brit. Ind. vi. (1894) 695 in syn. = Kobresia seticulmis, Boeck.

monosperna, Macoun, Cat. Canad. Pl. ii. (1888) 109 in syn. = chordorrhiza, Linn. $f$.

\section{CAREX}

Myabei, Franch. in Bull. Soc. Philom. Paris, Sér. VIII. vii. (1895) 52.- Japon.

Naegelii $x$, Bruegg. ex Sennholz, in Verh, zool. bot Ges. Wien, xxxvii, (188\%) 72 - Hely. Austria.

nambuensis, Franch. in Bull. Soc. Philon. Paris Sér. VIII. vii. (1895) 44. - Japon.

nemurensis, Franch.l. c. 30. - Japon.

Niederleiniana, Boeck. Cyp. Nov. i. (1888) 50.Reg. Argent.

Norämanni, Kern, ex Palla, in Verh. zool.-bot. Ges. Wien. xxxviii. (1888) Sitzungsb. $69=$ tomentosa Linn.

Novae-Zelandiae, Petrie, in Trans. N. Z. Inst. xxy. 1892 (1893) 273. - N. Zel.

oaluensis, Hillebr. F1. Haw. Is1. (1888) 487 =wahuensis, C. A. Mey.

obnupta, L. H. Balley, in Proc. Calif. Acad. Ser. II. iii. (1891) 104. - Calif.

occidentalis, L. H. Bailey, in Mem. Torrey Bot. Club̆, i. (1889) 14. - Am. bor.

Ohuboi, Franch. in Bull. Soc. Phitom. Paris, Sér. VIII. vii (1895) 43. - Japon.

oligantha, Phil. in Anal. Mus. nac. Chile (1892) 80 - Chili.

oligocarpa, C. B. Clarke, in Hook. f. Fl. Brit. Ind. vi. (1894) 746. - Tibet

oligoplyylla, Freyn, in Oest. Bot. Zeitschr. xl. (1890) $305=$ caespitosa, $\operatorname{Lim}$.

oligostachys, Meinsh. ex Maxim in Bull. Acad. Pétersb. xxxi. (1887) 117. - Mandchur.

oranensis, Trab. in Batt. et Trab. Fl. de 1'Algérie (Monoc.) $(1895) 111=$ distans, Limm.

otaruensis, Franch, in Bull. Soc, Philom. Paris, Sér. VIII. vii. (I895) 34. - Japon

pachyrrhiza, Franch. l. c. 45. - Yunnan.

pandanophylla, C. B. Clarke, in Hook. f. Fl. Brit Ind. vi. (1894) 714. - Pegu.

Pannewitziana $\times$, Figert, in Deutsche Bot. Monatsschr.v. (1887) 9\%. - Germ.

Paponii X. Muret, ex Th. Dux, et Pitt. in Bull Soc. Bot. Belg. xxi. (1882) 285 nomen; et $x x v$ 1 (1886) 336. -- Helv.

paraguayensis, Maury, ex M. Micheli, in Mém. Soc. sc. phys. Genèv. xxxi. (1890) n. 1, 151 t. 45.Parag.

parvigluma, C. B. Clarke, in Hook. f. Fl. Brit. Ind. vi. (1894) 716. - Reg. Himal.

patens, Franch. in Bull. Soc. Philom. Paris, Sér V1II. vii. (1895) 90. - Japon.

Peckii, E. C. Howe, in 47th As nual Report N. York, State Museum, 1893 (1894) 166. - Am, bor

bedicellata, Britton, in Mem Torrey Bot. Club, v. (1894) 87 = ouria, Dewey.

peraffinis $\times$, Appel, in Ber. Deutsch. Bot. Ges. x. (1892) [77]. - Silesia.

perakensis, C. B Clarke, in Hook. f. Fl. Brit. Ind. (1894)720. - Perak.

pertenuis, L. H. Bailey, in Mem. Torrey Bot. Club, i. (1889). - Mexic

Petrae-fu FaeX, Murr, in Progr. K. K Oberrealschule Insbr. (1891) 5\%; et in Kneuck. Allg. Bot. Zeitschr. 1. (1895) 76. - Tirol.

phoenocarpa, Franch. in Bull. Soc. Philom. Paris, Sér. VIII. vii. (1895) 90. - Yunnan.

picea, Franch. l. c. 39. - Japon.

picta, Colenso, in Trans. N. Z. Inst. xxi. 1888 (1889) 103. - N. Zel.

pinguis, L. H. Bailey, in Bull. iii. Geol. and Nat. Hist. Surv. Minn. (1887) 22 = adusta, Boott

platyphylla, Franch. in Bull. Soc. Philom. Paris, Sér. VIII, vii. (1895) $50=$ siderosticha, Hance.

plebeia, C. B. Clarke, in Hook. $f$. Fl. Brit. Ind. vi. (1894) 178. - Ind. or.

plocamostyla, Maxim. in Bull. Acad. Pétersb. xxxi. 1887) 117. - Japon.

polygyna, Boeck. Cyp. Nov. i. (1888) 40. - Reg. Himal.

polyneura, Colenso, in Trans. N.Z. Inst. xxi. 1888 (1889) 184. - N. Zel.

pontica, Alboff, in Bull. Herb. Boiss, iii (1895) 93. - Reg. Cauc.

Portae, C. Richt. Pl. Europ. i. (1890) 165. - Ins. Balear.

praelonga, C. B. Clarke, in Hook. f. Fl. Brit. Ind. vi. (1894) 70\%. - Reg. Himal.

\section{CAREX}

praestans, C. B. Clarke, in Hook. f. Fl. Brit. Ind. vi. (1894) 723. - Ind. or.

Pratti, Franch. in Bull. Soc. Philon. Paris, Sér VIII. vii. (1895) 32, - China.

Pringlei, L. H. Bailey, in Coult. Bot. Gaz. xvii. 151. - Mexic.

prionocarpa, Franch. in Bull. Soc. Philom. Paris, Sér. VIII. vii. (1895) 8\%. - Japon.

Provoti. Franch l. . 52, - China.

psendoaxillaris X. C. Richt. Pl. Europ. i. (1890) 168. - Europ.

pseudo-echinata, Boeck. Cyp. Nov. i. (1888) 34. Reg. Argent.

pseudohelrola, Kihlm. in Meddel. Soc. Faun, et Fl. Fenn. (1888-91) 71; et in Hjelt, Consp. fl. Fenn. (1892) $256=$ helvola, Blytt.

pseudo-Mairii X, G. Camus, in Bull. Soc. Bot. Fr. xxxiii. (1886) 479. - Gall.

pserdornlpina $X$, C. Richt. P1. Europ. i. (1890) 168. Germ.

quadritida, I. H. Bailey, in Proc. Calif. Acad. Ser. II. iii. (1891) 104. - Calif

qualiounensis, L. P. Bailey, in Bull. Torrey Bot. Club, xx. (1893) $428=$ Macounii, A.Benn.

recticulmis, Franch. in Bull. Soc. Philom. Paris; Sér. VIII, vii. (1895) 48. - Japon.

Regnelliana, Boeck. Cyp. Nov. 1. (1888) 34. - Bras. repanda, $C$ B. Clarke, in Hook f. Fl."Brit. Ind. vi. (1894) 720. - Reg. Himal

resectans, Cheesem. in Trans. N. Z. Inst. xxiv. 1891 (1892) 413 ( = C. inversa, R. Br. var. radicata, Cheesem.). - N. Zel.

rhizopoda, Maxim, in Bull. Acad. Pétersb. xxxi. 18S7) 114. - Japon.

rhyncophora, Franch, in Bull. Soc. Philom. Paris, Sér. VIII. vii. (1895) 90. - China.

iishirensis, Franch.l.c.81. - Japon.

rorulenta, Porta, in Nuov. Giorn. bot. Ital. xix. 1887) 321. - Ins. Balear.

Rouyana, Franch, in Bull. Soc. Philom. Paris, Sér. VIII. vii. (1895) 51. - Japon.

rubro-brunnea, C. B. Clarke, in Hook.f. Fl. Brit. Ind. vi. (1894)710. - Khasia.

rufa, Baill. Hist, des pl. xii. (1894) $340=$ Schoenoxiphium rufum, Nees.

rufo-variegata, Bo.ck. Cyp. Nov. i. (1888) 33. Columb. angl.

runssoroensis, K. Schum, in Engl. Pflanzenw. OstAfr. C (1895) 129. - Afr. trop. or.

sadoensis, Franch. in Bull. Soc. Philom. Paris, Sér. VIII, vii. (1895) 41. - Japon.

saltuensis X, L. H. Bailey, in Mem. Torrey Bot. Club, i. (1889) \%.- Am. bor.

Sanionis $\times$, C. Richt P1. Europ. i. (1890) 170.Germ.

saruensis, Franch. in Bull. Soc. Philom. Paris. Sér. VIII. vii. (1895) 85. - Japon.

scabrinervia, Franch.l. c.37. - Japon.

Schenkiana, Boeck. Cyp. Now i. (1888) 36. - Bras. scirpoides, Sartwell, in Bull. Torrey Bot. Chub, xx. 1893) 426 (an C. scirpoides, Michx?). - Am. bor. scita, Maxim. in Bull. Acad. Pétersó. xxxi. (1887) 115. - Japon.

Schlagintweitiana, Boeck. Cyp. Nov. i. (1888) 48.Reg. Himal.

sclerocarpa, Franch. in Bull. Soc. Philom. Paris, Sèr. VIII. vii. (1895) 91. - China.

sendaica, Franch. l. c. 42. - Japon.

Sewelli, A. Bennett et C. B. Clarke, in Trans. Bot. Soc. Edinb. xvii. (1889) 456 t. 8. - Sibiria.

sharensis, Franch, in Bull. Soc. Philom. Paris, Sér. VIII, vii. (1895) 90. - Japon.

shikokiana, Makino, in Tokyo Bot. Mag. vi. (1892) 47. - Japon.

shimidzensis, Franch. in Bull. Soc. Philom. Paris, Sér. VIII, vii, (1895) $33=$ cernua, Boot

sikkimensis, C. B. Clarke, in Hook. f. Fl. Brit. Ind. vi. (1894) 708. - Reg, Himal.

silesiaca $X$, Figert, in Deutsche Bot. Monatsschr vi. (1888) 146 . - Germ.

Sismani, Velen. in Sitzungsb. Boehm. Ges. Wiss. 1892 (1893) 67. - Bulg.

smaragdina, Colenso, in Trans, N.Z. Inst, xxvii. 1894 (1895) 398. - N. Zel.

solstitialis $\times$, Figert, in Deutsche Bot. Monatsschr. vii. (1889) 86. - Germ. 
CAREX:-

Souliei, Franch, in Bull. Soc, Philom, Paris, Sér. VIII. vii. (1895) 35. - China.

spathulatus, Becc. in Hook. f. Fi. Brit, Ind. vi. (1893) 559. - Malacca.

specifixa, L. H. Bailey, in Mem. Torrey Bot. Chub, i, (1889) 21. - Calif.

spicato-paniculata, Boeck. cx C. B. Clarke, in Th. Dur. et Schinz, Consp. A. Afr。 v. 1891 (1895) 690 nomem. - Afr. austr.

spiralis, Ewing, in Trans, nat. hist. Soc. Glasgow, ii. 1886-87 (1888) 110. - Scotia.

spissa, L. H. Bailey, ex Hemsl. Biol. Centr.-Amer. iv. (1886) 94 . - Am. bor, austro-occ

spreta, L. H. Bailey, in Mem. Torrey Bot. Chub, i. (1889) 6. - Am. bor.

stachydesma, Franch. in Bull. Soc. Phitom. Paris, Sér. VIII. vii. (1895) 85. - Yunnan.

stipitinux, C. B. Clarke, ex Franch. in Bull. Soc. Philom. Paris, Sér. VIII. vii. (1894-95) 31. China.

straminiformis, L. H. Bailey, in Mem. Torrey Bot. Club, i. (1889) 24 - Am. bor.

subnivalis, Arv.-Tour. ex Ber. Deutsch. Bot. Ges, vii. (1890) [169], - Gall.

subsabulosa, Norm. in Christian. Vidensk-Setsk. Forhandl. (1893) extr. 48. - Norw.

sutchuensis, Franch. in Butl. Soc. Philom. Paris, Sér. VIII. vii. (1895) 45. - China.

taliensis, F,anch. i.c. 34. - Yunnan.

tapinzensis, Franch. l.c. 44.- - Yunnan.

taraspensis, Bruege, et Killias, in Jahresb. Naturf Ges. Graub. xxx1. (1888) Beil, 193. - Helvet.

tarumensis, Franch. in Bull. Soc. Philom. Paris, Sér. VIII. vii. (1895) 86. - Japon.

tenerrina, Mury et Appel, in Oest. Bot. Zeitschr. xli. (1891) 124. - Tirol

tenuiseta, Franch in Bull. Soc. Philom. Paris, Sér. VIII. vii. (1895) 43. - Japon.

tetrasticha, Boeck. Cyp. Nov. i. (1888) 35. - Reg. Argent.

texensis, L. H. Bailey, in Mem. Torrey Bot. Chub, v. (1894) 97. - Am. bor.

texensis, Coult, in Contríb. U. S. Nan. Herb. ii. (1894) 485. - Texas

thibetica, Franun. in Nowv. Arch. Mus. Paris, Sér. II. x. (1887-88) 103. - Chinà.

Thomsoni, Petrie, in Trans. N. Z. Inst, xviri. 1885 (1886) 298. - N. Zel.

tonkinensis, Franch in Bulh Soc Philom. Paris, Sér. VIII. vii. (1895) 33. — Tonkin.

toezensis $\times$, Simonk. in Oest. Bot. Zeitschr. xli. (1891) 426. - Hung.

trachycarpa, Cheesem. in Trans. N. Z. Inst. xxiv, 1891 (1892) 413 (=C. muricata, Cheesem.). N. Zel.

trappistarum, Franch. in Morot, fown. de Bot. iv, (1890) 320. - China.

Traversii, T. Kirk, in Trans. N. Z. Inst. xxvi. 1893 (1894) 262. - N. Zel.

trichopoda, Franch. in Bull. Soc. Philum. Paris, Sér. VIII. vii. (1895) 43. - Japon.

tricolor, Velen, in Sitzb. Boehm. Ges, Wiss, 1889 (1890) ii. 58; et in Oest. bot. Zeitschr. xl. (1890) 237. - Bulg.

triquetrifolia, Bock. in Bot. Fahrb. vii. (1886) 279 . - Afr. aequat. or.

trispiculata, Boock, Cyp. Nov. i. (1888) 45. - Reg. Himal.

tsangensis, Franch.in Bull. Soc. Philom. Paris, Sér. VIII. vii. (1895) 44. - Yunnan.

Turczaninowiana, Meinsh. ex Korshinsky, in Act. Hort. Petrop. xiii. (1892) 411. - As. bor.-or.

Uechtritziana X, C. Richt. Pl. Europ. i. (1896) 170. - Germ.

Uleana, Boeek. Cyp. Nov. i. (188S) 42. - Bras.

Urbani, Boeck. in Bot. Jahrb. vii. (1886) $280=$ flava, $\operatorname{Linn}$

unciniiformis, Boeck. Cyp. Nov. i. (1888) 40, - Reg. Himal.

urolepis, Franch. Miss. scient. Cap Horn, vo Bot. (1889) 376 t. 5. - Patag.

urolepis, Franch. in Bull. Soc. Philom. Paris, Sér. VIII, vii. (1895) $36=$ xanthathera, Franch.

urostachys, Franch. l.c. 35. - Japon.

uruguensis, Boeck, in Bot. Fakrb. vii. (1886) 27\% Reg. Argent.

\section{CAREX :}

usta, L. H. Bailey, in Mem. Torrey Bot. Club, i. (1889) 20. - Am. bor.

usta, Franch, in Bull. Soc. Philom. Paris, Sér. VIII vii. (1895) 41. - Japon.

Vallis-Rosetta, $K$. Schum, in Engt. Pfanzenw. OstAfv. C (1895) 130. - Afr. trop. or

variabilis, L. H. Bailey, in Mem. Torrey Bot. Chwb i. (1889) 18. - Am. bor.

ventricosa, Franch in Bull. Soc. Philom. Paris, Sér. VIII. vii. (1895) 91. - Japon.

vernacula. L. H. Bailey, in Bull. Torrey Bot. Chub, xx. (1893) 417. - Am. bor. -oc

vicaria, I. H. Bailev, in Mem. Torrey Bot. Club, i. (1889) 49. - Am. bor.

vidua, Boott, ex C. B Clarke, in Hook. f. Fl. Brit. Ind. vi. (1894) 7l3. - Sikkim.

vimariensis $\times$. Hausskn. ex Ber. Deutsch. Bot. Ges.

x. (1890) [131]. - Germ.

Volkensii, $K$. Schum, in Engt. Pfanzenu. Ost-Afr. C (1895) 130. - Afr. trop. Or.

vilgaris, L. H. Bailey [conf. Mac Mill. Metasp.

Minn. (1892) 123] = stricta, Lam.

Walteriana, L. H. Bailey, in Bull. Torrey Bot. Club, xx. (1893) $420=$ striata, Michx.

Warmingii, Holm in Lanoe, Consp. fl. Groenl. ii (1887) 290; et ex Eng1, Bot. Jahrb, viii. (1887) $244=$ Bigelovii, Torr

Winterbottomi. C. B. Clarke, in Hook. f. Fl. Brit. Ind. vi. (1894) 727. - Reg. Himal.

Wrightii, Franch. in Bull, Soc. Philon. Paris, Sér. VIIl. vii. (1895) 4\% - Japon.

xanthathera, Franch. l. c. 88. - Japon.

xerantica, L. H. Bailey, in Coult. Bot. Gaz. xvii. (1892) 151. - Am. brit.

yesinensis, Franch. in Bull. Soc. Phelom. Paris, Sér.

VIII. vii. (1895) 88. - Japon.

yosemitana, L. H. Bailey, in Mem. Torrey Bot. Club, i. $(\mathbf{1 8 8 9})=$ Sartwelliana, Olney.

yunnanensis, Franch. in Bull. Soc. Philom. Paris, Sér. VIII. vii. (1895) 31. - Yunnan.

Zahnii X, Kneuck. in Deutsch. bot. Monatsschr. ix. (1891) 60; et in Bull. Trav. Soc. Murith. fasc xix-xx. (1892) 78. - Helv.

GA RIGA, Linn. (Passifl.). - Ind. Kew. i. 441. aurantiaca, Bull, ex Solms, in Mart. Fl. Bras, xiii. II. (1889) 186 (= Vasconcellia aurantiaca, Regel). - N. Gran.

Bonplandiana, Hort. Par. ex Solms, 1. c. 178=quercifolia, Solms.

Bourgeaui, Solms, in Engl. et Prantl, Natiirl. Pflanzenfam, iii. 6 a. (1894) 98. - Am. trop

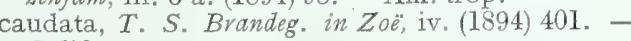
Calif.

cestriflora, Solms, in Mart. Fl. Bras. xiii. III. (1889) (= an C. cestriflora, A. DC.). - N. Gran.

cubensis, Solms, l. c. $17 \%$ - Ins, Antill.

gracilis, l. c. 182 (= Papaya gracilis, Regel). Ecuad.

hastaefolia, Hort, ex Solms, 1. c. 179 in obs. = quercifolia Solms.

Manihot, Solms, l. c. 186 (= Vasconcellia Manihot, Triana et Planch.). - N. Gran.

platanifolia, Solms, l. c, 177 et 182 . - Peruvia.

pubescens, Solms, l.c. $185(=$ V asconcellia pubescens, A DC.). - Peruvia.

quercifolia, Solms, l. c. $178(=$ Vasconcellia querci folia, St-Hil..). - Am. austr.

rviloba, Mast. ex Solms, 1. c. in syn. = heterophylla Poepp. et Endl.

CARICINA, St-Lager, in Cariot, Etud. des fleurs, éd, 8. ii. (1889) $880=$ Carex. Linn. (Cyperac.). approximata, St-Lager, 1. c. $879=$ C. approximata, Hoppe.

brizoidea, St-Lager, 1. c. $877=$ C. brizoides, Limn canescens, St-Lagcr, 1. C. $=\mathrm{C}$, canescens, Linn. chordorrhiza, St-Lager, 1. C. 874 in obs. = C. chordorrhiza, Ehrh.

disticha, St-Lager, 1. c. $880=$ C. disticha, Huds. divisa, St-Lager, 1. c. $874=$ C. divisa, Huds. divulsa. St-Lager, 1. c. $875=$ C. divulsa, Good. compacta, St-Lager, 1.c. $874=$ C. compacta, Wimm.

curvula, St-Lager, 1. c. $876=$ Carex curula, v $A l l$.
CARICINA :cyperoides, St-Lager, in Cariot, Etud. des
ii. (1889) 879 = Carex cyperoides, Limn elongata, St-Lager, 1. c. $8 \div 8=$ C, elongata, Linm. foetida, St-Lager, 1. c. = C. foetida. All. incirva, St-Laoer, 1. c. $873=$ C. incurva, Lightf microstyla, St-Lager, 1. c. $873=$ C. microstyla, Gay

multicaulis, St-Lager, 1. c. $877=$ C. Schreberi, muricata, St-Lager, 1. c. $875=$ C. muricata, Linn. oralis, St-Lager, 1, c. $878=\mathrm{C}$, ovalis, Good. paniculata, St-Lager, 1. c. $876=$ C. paniculata,

paradoxa, St-Lager, 1. c. = C. paradoxa, Willd. remota, St-Lager, 1, c. $879=$ C. remota, Linn. setifolia, St-Lager, 1. c. $874=\mathrm{C}$. divisa, Huds stellutata, St-Lager, 1. c. $870=$ C. stellulata, Good. teretiuscila, St-Lager, 1. c. $875=$ C. teretiuscula, Good.

CARICINELLA, St-Lager, in Cariot. Étud. des fleurs, éd. 8. il. (1889) $880=$ Garex, Linn. (Cyperac.) alvis, St-Lager, 1. c. = C, dioica, Linn.

microglochin, St-Lager, 1. c. $880=$ C. microglochin, Wallenb.

pauciflora, St-Lager, 1. C. $88 \mathrm{I}=$ C. pauciflora, Lightf.

pulicaris, St-Lager, 1. c. = C. pulicaris, Linn.

scabra. St. Lager, I. c. $880=$ C. scabra, Forst.

GARISSA, Linn. (Apocyn.). - - Ind. Kew. i. 441.

pilosa, Schinz, in Verh. Bot. Ver. Brand. xxx. (1888)

259. - Afr. austro-occ. extratrop.

revoluta, S. Elliot, in fourn. Linn. Soc. xxix. (1891) 33. - Madag.

GARLINA, Linn. (Compos.). - Ind. Kew. i. 441. anthophylla, Hausskn. mitth. Bot. Ver. Fena, v.
(1887) 85; et ex Nym. Const. fl. Eur. ii. 1. (1889) (1887) 85; et ex
78. - Graecia.

longicaulis, Somm, et Levier, in Nuov. Giorn. bot. Ital. Ser. II, ii. (1895) 91. - Reg Cauc.

olympica, Form. in Verh. Natur. Ver, Brünn, xxix. (1891). - Graecia.

pallescens, Wettst. in Sitzungsb. zool.-bot. Ges. Wien, xcviii. 1889. (1889) 371 fig. 1-8. - As. Min.

semiamplexicaulis, Form in Oest. Bot. Zeitschr. xl. (1890) 86; et Kueténa, iii. (1892) 593. - Moravia. sudecurvens, Vandas, 1. c. xxxviii. (1888) $413=$ aggregata, Willd.

thracica, Velen. in Sitzungsb. Boehm. Ges, Wiss, 1892 ,1893) 384. - Thracia.

CARLOMOHRIA, Greene, in Erythea, i. (1893) 246 $=$ Halesia, Linn. (Styrac.).

carolina, Greene, 1. c. = H. tetraptera, Ellis.

diptera, Greene, 1. c. = H. diptera, Ellis.

parviflora, Greene, 1. c. = H. parviflora, Michx.

GARLOWRIGHTIA, A. Gray (Acanth.). - Ind.

Kew. i. 442. 406. - Mexic.
Merdifolia, A. Gray.

corymbosa, Colenso, in Trans. N.Z. Inst. xxi. 1888 (1889) $80 .-$ N. Zel.

fimbriata, T. S. Brandeg. in Proc. Calif. Acad. Ser. II. iii. (1891) 161. - Calif.

glabrata, Fernald, in Coult. Bot. Gaz. xx. (1895) 536. - Mexic.

ovata, A. Gray, in Proc. Am. Acad. xxi. (1886) 406. - Mexic.

pectinata, T.S. Brandeg. in Proc. Calif. Acad. Ser. II, iii. (1891) 160. - Calif

pubens, A. Gray, in Proc. Am. Acad. xxi. (1886) 406. - Mexic.

serpyllifolia, A. Gray, l. c. 405.-Mexic.

GARLUDOVIGA, Ruiz et Pav. (Cyclanth.). -

Ind. Kew. i. 442.
Caput-Medusae, Hook. f. in Bot, Mag. (1890) t. 7118. - Hab. ?

Drudei, Mast. in Engl. et Prantl, Naturl. Pfanzenfam. ii. 3. (188\%) 99. - Am. centr.

gigantea, Kuntze, Rev. Gen. (1891) 737 et738, Panama. 


\section{CARLUDOVICA :}

Hookeri, H. Wendl. ex Kuntze, Rev.Gen. (1891) 738 = latifolia, Rwiz et Pav.

humilis, Kuntze, 1. c. = palmata, Ruiz. et Pav. microcephala, Hort. Berol. ex Hook. f. in Bot. Mag. (1892) t. 7263. - Costar.

palmifalia, Kuntze, Rev. Gen. (1891) $738=$ Plumierii, Kunth.

rotundifolia. H. Wendl. ex Hook. f. in Bot. Mag.

(1889) t. 7083. - Costar.

CARMELITA, C. Gay = Chaetanthera, Ruiz et Pav. (Compos.).

spathulata, Phil. in Anal. Univ. Chil. 1xxxv. (1894) 831. - Chili.

CARMICHAELIA, $\mathrm{R}$ - $\mathrm{Br}$. (Legumin.) * - Ind.

Kew. i. 442.
curta, Petrie, in Trans. N. Z. Inst. xxv. 1892 (1893) 271. - N. Zel.

diffusa, Petrie, $l . c .972 .-\mathrm{N} . Z \mathrm{el}$.

micrantha, Colenso, l. c. xxvi. 1893 (1894) 313. N. Zel.

Muelleriana, Regel, in Gartenfl. (1887) 611 ; et in Act. Hort. Petrop. x. (1889) 377 . - N. Zel.?

multicaulis, Colenso, in Trans. N. Z. Inst. xxv. 1892 (1893) 329. - N. Zel.

orbiculata, Colenso, l. c.xxii. 1889 (1890) 459. - N. Zel.

prona, T.Kirk, l.c. xxvii, 1894(1895) 350--N. Zel.

Suteri, Colenso, l. c. xxii. 1890 (1891) $383 .-\mathrm{N}$. Zel.

GAROPODIUM, Stapf et Wettst. ex Stapf, in Denkschr. Acad. Wien. 1i. (1886) 31\%. UMBELLIFERAE.

meoides, Stapf et Wettst. l. c.- As. occ.

CARPESIUM, Linn. (Compos.). - Ind. Kew. i. 443.

Atkinsonianum, Hemsl. in Ker Bull. (1892) 15\%. China.

eximium, C. Winkl. in Act. Hort. Pctrop. xiv. (1895) 58. - China.

Faberi, C. Winkl.l. c.-China.

humile, C. Winkl. l. c. 70. - China.

Lipskyi, C. Winkl. i. c. 68. - China.

minus, Hemsl. in fourn. Linn. Soc. xxiii. (1888) 431 tab. 13. - China.

velutinum, C. Winkl. in Act. Hort, Petrop. xiv. (1895) 73. - China

CARPHA, Banks et Soland. (Cyperac.). - Ind Kew. i. 443.

bracteosa, C. B, Clarke, in Th. Dur. et Schinz, Consp. Fl. Afr.v. 1894 (1895) 656. - Afr. austr.

CARPINUS, Linn. (Cupulif.). - Ind. Kew. i. 443. Carpinus, Sargent, in Gard, and For. vi. (1893) 364 $=$ japonica, Blume.

umifolia, St-Lager, in Cariot, Étud. des fl. éd. 8. ii. (1889) $742=$ C. Betulus, Linn.

virginiana, Sudw. in Bull. Torrey Bot. Club, xx. (1893) 43; et in Mem. Torrey Bot. Club, iv (1894) 153 = caroliniana, Walt.

GARPODINUS, R. Br. (Apocyn,). - Ind. Kew.

Barteri, Stapf, in Kew Bull. (I894) 19. - Afr. trop. occ.

calabaricus, Stapf, l.c.-Afr. trop. occ.

camptoloba, K. Schum. in Engl. et Prantl, Natür. Pflanzenfam. iv. 2. (1895) 132. - Congo.

complicata, K. Schum. .. c.-Hab.?

incerta, $K$. Schum. l. c.-Togo.

lanceolata, $K$. Schum. in Engl, et Prantl, Natürl. PAanzenfam. iv. 2. (1895) 132. - Congo.

leptantha, $\mathbb{K}$. Schum. l. c. - Gabon.

papuanus, F. Muell. l. c. 1x. (1894) 226 nomen. N. Guin.

parviflorus, Stapf, in Kew Bull. (1894) 19. - Afr. trop. occ.

pauciflora, K. Schum. in Engl. et Prantl, Natür. Pfanzenfam. iv. 2. (1895) 131. - Togo.

subrepanda, $K$. Schum. l. c. 132. - Kamerun

uniflorus, Stapf, in Hook. Icon. pl. xxiv. (1894) t

2340; et in Kew Bull. (1894) 19. - Afr. trop. occ
GARRIGHTERA, Adans. (Crucif). - Ind. Kew. i. 444 .

annua, Prantl, in Engl. et Prantl, Natürl. Pflanzenfam. iii. 2. (1891) $173=\mathrm{C}$. Vella, $D C$

CARRUTHIA, Kuntze, Rev. Gen. (1891) $141=$ Aitonia, Thunb. (Sapind.).

capensis, Kuntze, 1 c. $142=$ A. capensis, Thunb.

CARTHAMODES, Manetti, Virid. Florent. (1751), ex Kuntze, Rev. Gen. (1891) $325=$ Carduncellus, Adans. (Compos.).

araneosum, eriocephalum, mitissimum, pectinatum, pinnatum, Kuntze, 1. c. 325-26=homonyma omnia Carduncelli.

Carduncellus, Kuntze, 1. c. = Card. monspeliensis, All.

coevuleus, Kuntze, 1. c. = Card. caeruleus, Less

hispanicum, Kuntze, 1. c. = Card. caeruleus, Less.

GARTHAMUS, [Tourn.] Linn, (Compos.), - Ind. Kew. i. 444.

calvus, Batt. in Bull. Assoc. franc. Avanc. sci. (1889) 489 ; et in Batt. et Trab. Fl. de l'Algérie [Dicot.] (1889) 510 (= Cavanncellus calvus, Boiss. et Reut.). - Algeria.

carlinoides, Batt. in Batt. et Trab. l, c. $510(=$ Onobroma carlinoides, Pomel). - Algeria,

carthamoides, Batt. l. c. $511(=0$. carthamoides, Pomel). Algeria.

strictus, Batt.l. c.510. - Algeria

CARUELINA, Kuntze, Rev. Gen. $277(1891)=$ Ghomelia, Jacq. (Rubiac.).

angustifolia, anisomeris, brasiliana, estrellana, fasciculata, flipes, hirsuta, intercedens, Martiana, obtusa, occidintalis, oligantha, parviflora, pedunculosa, Pohliana pubescens, sericea, sessilis, spinosa, tenuiftora, transiens, tristis, Vauthieri, vulpina, Kuntze, 1. c. = homonyma omnia Chomeliae.

malaneodes, Kuntze, 1. c。= C. malaneoides, Muell. Arg.

ribesiodes, Kuntze, 1. c. = C. ribesioides, Benth.

GARUM, Rupp. (Umbellif.). -Ind. Kew. i. 445.

acuminatum, Franch. in Bull. Soc. Philom. Paris Sér. VIII, vi. (1894) 23 in obs. = Pimpinella acuminata, C. B. Clarke.

ancelicaefolium, Baker, in fourn. Linn. Soc. xxy. (1890) 319. - Madag:

brachyactis, Post, in fourn. Linn. Soc. xxiv. (1888) 428. - Syria.

caespitosum, Boiss. Fl, Or. Suppl. (1886) 256. As. Min.

Candolleanum, Franch. in Bull. Soc. Philom. Paris, Sér. VIII. vi. (1894) $128=$ Pimpinella Candolleana, Wight et Arn

cardiocarpum, Franch.l.c. 120. - Yunnan.

caudatum, Franch. l. c. 126. - Yunnan.

Chaberti, Batt. in Bull. Soc. Bot. Fr. xxxv. (1888) 387. - Algeria.

coriaceum, Franch. in Bull. Soc. Philon. Paris, Sér. VIII. vi. (1894) 127. - Yunnan.

cruciatum, Franch.l.c. 124. - Yunnan.

Delavayi, Franch.l. c. 120. - Yunnan.

dissectum, Franch.l. c. 123. - Yunnan.

filicinum, Franch. in Bull. Soc. Philom. Paris, Sér, VIII. vi. (1894) 121. - Yunnan.

flaccidum, Franch. 1. c. $126=$ Pimpinella flaccida, C. B. Clarke.

gracile, Boiss. F1. Or. Suppl. (1888) 258 in syn.= rupestre, Boiss. et Heldr.

Heyneanum, Franch. in Bull. Soc. Philom. Paris, Sér. VIII. vi. (1894) 127 in obs, = Pimpinella Heyneana, Wall.

holopetalum, Maxim. in Bull. Acad. Pétersb. xxxi. (1887) 48. - Japon

Hookeri, Franch. in Bull. Soc. Philom. Paris, Sér. VIII. vi. (1894) 122 = Pimpinella Hookeri, C. B. Clarke.

Howellii, Coult, et Rose, Revis, N. Am. Umbell. (1888) 129. - Oregon

imbricatum, Schinz, in Bull. Herb. Boiss, ii. (1894) 208. - Afr. trop. austro-occ.

involucratum, Kuntze, Rev. Gen. (1891)265 (=C.invoIncratuu, Baill.) = Roxburghianum, Benth.

\section{CARUM}

Lemmoni, Coult, et Rose, in Coult. Bot. Gaz, xiv. (1889) 283. - Calif.

leptocladum, Aitch. et Hemsl. in Trans. Linn. Soc Ser. II. iii. (1886) 66 t。22. - Afghan.

loloense, Franch. in Bull. Soc. Philom. Parts, Sér VIII. vi. (1894) 125. - Yunnan.

molle, Franch. l.c. 120. - Yunnan.

nudum, Post, in fourn. Linn. Soc. xxiv. (1888) 428. - Syria.

olympicum, Boiss. Fl. Or. Suppl. (1888) 255. - As. Min.

paniculatum, Franch, in Bull. Soc. Philom. Paris Sér. VIII.vi. (1894) 122. - Yunnan.

purpureum, Franch. l. c. 127. - Yunnan.

saxicolum, Alboff, Prodr. Al. Colch. (1895) 103; et in Bull, Herb. Boiss. (1895) 523. - Reg. Cauc

scaberulum, Franch. in Bull. Soc. Philom. Paris, Sér. VIII. vi.(1894) 125. - Yunnan.

schizopetalum, Franch. l. c. Sér. VIII. ii. (1890) 198. - China.

segetum, Kuntze, Rev. Gen.(1891) $26 \%=$ C. Ridolfia, Benth, et Hook.f

sinense, Franch. in Bull. Soc. Philom. Paris, Sér. VIII. vi. (1894) 119. - Yunnan.

tenerum, Franch.1.c. $122=$ Pimpinella tenera, Benth. et Hook. $f$

trichomanifolium, Franch. in Bull. Musénm Paris, i. (1895) 64. - Yunnan.

yunnanense, Franch. in Bull. Soc. Philom. Paris, Ser. VIII. vi. (1894) 128. - Yunnan.

CARUMBIUM, Reinw. $=$ Homalanthus, A. Juss.

(Euphorb.).
novo-guineense, Warb. in Bot. Jahrb. xviii. (1894) 199. - N. Guin.

CARUSIA, Mart. ex Niedenzu, in Engl, et Prantl, Natürl. Pflanzenfam. iii, 4. (1890) $73=$ Bnrdachia, Mart. (Malpigh.).

CARVALHOA, K. Schum, in Engl, et Prant1, Natürl. Pflanzenfam. iv. 2 (1895) 189. APOCY' $N E A E$.

campanulata, K. Schum.l. c. - Mossamb.

GARYA, Nutt. (Jugland.). - Ind. Kew. i. 446. alba, Britton, Stern et Pogg. Prelim. Catal. (1888) $49=$ tomentosa, Nutt.

Fernowiana, Sudworth, Trees of Washingt. (1891) 6 . - Am. bor.

minima, Britton, Stern et Pogg. Prelim. Catal. (1888) $49=$ amara, Nutt.

ovata, Britton, Stern et Pogg. 1. c. = alba, Nutt.

CARYELLA madagascariensis, Bourn. ex Parment. Histol. comp. Ebenac. (1892) 114. (Quid?). Madag.

CARYOGAR, Linn. (Ternstroem.), - Ind. Kew. i. 446.

coriaceum, Wittm. in Mart. Fl. Bras. vii. I. (1886) 352. - Bras.

crenatum, Wittm. l. c. 351. - Bras.

cuneatum, Wittm.l. c. 352. - Bras.

gracile, Wittm. l.c. 350.-Bras.

intermedium, Wittm. l. c. 352.- Bras.

toxifera, Rodr. in Vellozia, i. (1885-88) Sec, ediçâo, (1891) 11. - Bras

CARYOCHLOA, Spreng. = Oryzopsis, Michx. Gramin.).

panicodes, Kuntze, Rev. Gen. (1891) $775=$ O. setacea, Rich.

setifolia, Kuntze, 1. c. 764 (= Uvachne simplex, Trin. et Rupr.). - Chili.

stipodes, Kuntze, 1. c. 765 (= Piptathenm sphacelatum.

Boiss.). - Persia.

trichotoma, Kuntze, 1, c. $(=$ Arachne trichotoma, Trin.). - Bras.

CARYOPTERIS, Bunge (Verben.). - Ind. Kew. i. 446 .

ningpoënsis, Hemsl. in fourn. Linn. Soc. xxvi. (1890) 264. - China

parvifolia, Batalin. in Act. Hort. Petrop. xiii. (1893) 98. - China. 


\section{CARYOPTERIS :-}

inensis, Dippel, Handb. Laubholzk, i. (1889 59 fig. $24=$ C. Mastacanthus, Schat.

CARYOSPERMUM, Blume, (Celastr.). - Ind. Kew. i. 447 .

alpestre, Kuntze, Rev. Gen. (1891) $113=$ Celastrus alpestris, Blume.

philippinense, Vidal, Rev. Pl. Vasc. Filip.(1886) 89. - Ins. Philipp

CARYOTA, Linn. (Palm.). - Ind. Kew. i. 447 mitis Herb. Calc. ex Hook f, Fl Brit. Ind. vi. (1892) $419=$ Wallichia disłicha, $T$. Anders.

CASEARIA, Jacq. (Samyd.), - Ind. Kew. i. 449. Bangii, Rusby, in Mem. Torrey Bot. Club, iii. 3. (1893) 34. - Bolivia.

Brighami, S. Wats. in Proc. Am. Acad. xxi. (1886) 459. - Guatem.

gelonioides, Baill. in Bull. Soc. Linn. Paris, i, (1886) 567. - Madag.

gelonioides, Warb, in Engl, et Prantl, Natürl. Ptlanzenfam. iii. 6 a. (1893) $51=$ praec

laetioides, $W a r b$. l.c. - Guatem.

membranacea, Britton, in Bull. Torrey Bot. Club, xvii. (1890)214. - Bolivia.

mollis, K. Schum, in K. Schum, et Hollv. Fl. Kais, With. Land. (1889) 50. - N. Guin.

riparia, S. Moore, in Trans. Linn. Soc. Ser. MI. iv. (1895) 363. - Bras.

Tulasneana, Warb, in Engl. et Prantl, Natiirl. Pfanzenfam. iii. 6 a (1893) 51 (= Pitumba Tulasneana, Baill.). - Ins. Maurit.

Zahlbruckneri, Szyszyl, in Diss. Cl. math.-phys. Acad. litt. Cracov. xxix. (1894) 226. - Peruvia.

CASSANDRA, D. Don (Ericac.).-Ind.Kew. i.449. ferruginea, Niedenzu, in Bot. Jahrb. xi.(1890) 184 $=$ Lyonia ferruginea, Nutt

jamaicensis, Niedenzu, 1. c. = Lyonia jamaicensis, D. Don.

CASSEBEERIA, Dennst. = Sonerila, Roxb. (Melastom.).

angustata, arguta, Bensonii, biflora, Brunonis, elegans, erecta, Fordii, Gardneri, grandiflora, Griffithi, Harveyi, hirsutula, insignis, funghuhniana, khasiana, laeviuscula, lanceolata, linearis, magnifica, moluccana, nudiscapa, obliqua, pedunculosa, picta, pilosula, robusta, rotundifolia, scapigera, secunda, squarrusa, stricta, tenera, tenuifolia, Teysmanniana, tomentella, travancorica, Wallichii, Wightiana, versicolor, viotravancorica, Wallichii, Wightiana, versicolor, vio-
lifolia, zeylanica, Kuntze, Rev. Gen.(1891) 245. $46=$ homonyma omnia Sonerilae.

affinis, Kuntze, 1. c. $245=$ S. zeylanica, Wight et Arn.

amabilis, Kuntze, 1. c. (=S. amabilis, Bedd. $)=$ S. Clarkei, $\operatorname{Cog} n$.

amabilis, Kuntze, 1. c. $953=$ S. amabilis, Kurz.

Arnottiana, Kuntze, 1. c. $245=\mathrm{S}$. Wightiana, Arm axillaris, Kuntze, 1. c. $953=\mathrm{S}$. versicolor, Wight. Beccariana, Knntze, 1. c. = S. Beccariana, Cogn.

borneensis, Kuntze, 1. c. = S. borneensis, $\operatorname{Cog} n$.

brachyandra, Kuntze, 1. c, $245=$ S. tenera, Royle

Clarke, Kuntze, 1. c. = S. Clarkei, Cogn

cordifolia, Kuntze, 1. c. $953=\mathrm{S}$. cordifolia, Cogn. emaculata, Kuntzè, 1. c. 245 = S. emaculata, Roxb.

glaberrima, Kuntze, 1. c. $953=\mathrm{S}$. zeylanica, Wight et $A r n$.

Gunneratnei, Kuntze, 1. c. = S. linearis, Hook. $f$

hirtella, Kuntze, 1. c. = S. hirtella, $\operatorname{Cog} n$.

heterostemon, Kuntze, 1. c. $=\mathrm{S}$. obliqua, Korth

heterophylla, Kuntze, 1. c. $245=$ S. heterophylla, facq.

Hookeviana, Kuntze, 1. c. $245=$ S. Wightiana, Arn.

impatiens, Kuntze, 1. c. = S. Impatiens, Becc.

Kurzii, Kuntze, 1. c. $246=$ S. amabilis, Kurz.

margaritacea, Kuntze, 1. c. $953=$ S. margaritacea, Lindl.

margaritacea, Krasser, in Engl. et Prantl, Natürl. Pflanzenfam, iii. 7. (1893) $177=$ praec.

pałuana, Kuntze, Rev. Gen. (1891) 953 = S. parviflora, $\operatorname{Cog} n$.

parviflora, Kuntze, 1. c. = S. parviflora, $\operatorname{Cog} n$.
CASSEBEERIA :-

peperomiaefolia, Kuntze, Rev, Gen, (1891) $353=$ S. peperomiaefolia, Oliver.

pumila, Kunize, 1. c. = S. zeylanica, Wight et Arn. purpurascens, iruntze, 1. c. = S. purpurascens, Beco Thombifolia, Kuntze, 1. c. $246=\mathrm{S}$ zeylanica Wight et Arn

rostrata, Kuntze, 1, c. = S. zeylanica, Wight et Arr. triflora, Kuntze, 1. c. $953=$ S. triflora, $\operatorname{Cog} n$.

tuberculifera, Kuntze, 1. c. = S. tuberculifera, Cogn velutina, Kuntze, 1. c. = S. velutina, $\operatorname{Cog} n$.

CASSIA, [Tourn.] Linn. (Legumin.). - Ind. Kew. i. 449

Cuthbertsoni, F. Muell. in Vict. Naturalist, (Oct. 1888) 75. - Austral

densistipulata, Taub. in Engl. Pfanzenw. Ost-Afr

C (1895) 200. - Afr. or.

depressa, Pollard, in Bull. Torrey Bot. Club, xxii. (1895) 515 t. 25l. - Am. bor.

mississipiensis, Pollard, l.c. xxi. (1894) 219. - Am. bor.

Morongii, Britton, in Ann. N. Y. Acad. Sci, vii (1892) 91. - Parag.

multipinnata, Pollard, in Bull. Torrey Bot. Club, xxii. (1895) 515 t. 250. - Am. bor.

oocarpa, Baker, in Kerv Bull. (1895) 181. - Arabia. Palmeri, S. Wats. in Proc. Am. Acad. xxii. (1887) 409. - Mexic.

Simpsoni, Pollard, in Bull. Torrey Bot. Club, xxi. (1894) 221. - Florida.

Stuhlmannii, Taub. in Engl. Pfanzenv. Ost-Afr. C (1895) 201. - Afr. or.

tarapacana, Phil. in Anal. Mus.nac. Chile (1891) 20 - Chili.

usambarensis, Taub. ex Engl. in Abhandl. Preuss. Akad. Wiss. (1894) 57; et in Engl. Pfanzenw. OstAfr. C (1895) 201. - Afr. trop. or.

zygophylloides, Taub. in Flora, lxxv, (1892) 79. Bras.

CASSIDISPERMUM. Hemsl, in Ann, of Bot. vi. (1892) 208. SAPOTACEAE.

megahilum, Hemsl. l. . . t. 14 - Ins. Salomon.

GASSINE, Linn. (Celastr.). - Ind. Kew. i. 454 attenuata, Kuntze, Rev. Gen. (1891) $114=$ Elaeodendron attenuatum, A. Rich

australis, Kuntze, 1. c. = E. australe, Vent.

Buchananii, Loes. in Bot. Fahrb. xvii. (1893) 551.Afr. trop. austro-or.

Burchellii, Loes, ex Schinz, in Bull. Herb. Boiss, ii (1894) 193. - Afr. austr.

Burkeana, Kuntze, Rev. Gen. (1891) 114 (= Mystroxylon Barkeamm, Sond.) =E. Rehmanni, Szyzzyl. comorensis, Loes. in Bot. Fahrb, xvii. (1893) 551 . Ins. Comor.

confertiflora, Loes. l.c. 553 (= Mystroxylon conferflorum, Tul.). - Afr. trop.

crocea, Kuntze. Rev. Gen. (189I) $114=$ E. croceum, $D C$

curtipetala, Kuntze, 1. c. = E. curtipendulum, Endl.

dentata, Kuntze, 1. c. =Elaeocarpus dentatus, $V a h l$ elliptica, Kuntze, 1. c. = Elaeodendron ellipticum Decne.

Engleriana, Loes. in Bor. Fahrb. xvii. (1893) 552.Zanzib.

excleaeformis, Kuntze, Rev. Gen. (1891) 114 (= Mys-

troxylon eucleaeforme, Sond.). - Afr. austr.

Fortunei, Kuntze, 1. c. = Elaeodendron Fortunei, Turcz.

glauca, Kuntze, 1. c. = E. glaucum, Pers

gymosporiodes, Kuntze, l. c. = E. glaucum, Pers. Holstii, Loes, ex Engl. in Abhandl. Preuss. Akad. Wiss. (1894) 16; et in Bot. Fahrb. xix. (1894) 233. - Zanzib.

Hookeriana, Kuntze, Rev. Gen. (1891) $114=$ Elaeocarpus Hookerianus, Raoul.

japonica, Kuntze, 1. c. = Elaeodendron japonicum, Franch.

lyciodes, Küntze, 1. c. = E. lycioides, Baker.

macrocarpa, Kuntze, 1. c. (= Mystroxylon macrocarpum, Sond.) - Afr. austr.

megalophylla, Kuntze, 1. c. 150 sub Makrocenia = Turpinia megaphylla, Tul.
CASSINE

melanocarpa, Kuntze, Rev, Gen, (1891) $114=$ Elaeodendron melanocarpum, F. Muell. micrantha, Loes. in Bot. fahrb. xvii. (1893) 551 (= Elacodendron micranthum, Tul. - Habs? nitidula, Kuntze. 1. c. = E. nitidulum, Baker. oligantha, Kuntze, 1. c. = E. oliganthum, Baker orientalis, Kuntze, 1. c. = E. orientale, facq. papillosa, Kuntze, 1. c. = E. capense, Eckl. et Zeyh. pauciflora, Loes. in Bot. Fahrb. xvii. (1893) 551 (= Elacodendron panciflorm, Tul.). - Hab.? pilosa, Kuntze, 1. c. = E. pilosum, Baker.

pubescens, Kuntze, 1. c. (= Mystroxylon pubescens, Eckl. et Zeyh.). - Afr. austr.

quadrangulata, Kuntze, 1. c. = Elaeodendron quadrangulatum, Reiss.

Rehmanni, Kuntze, 1. c. (= Mystroxylon Burkeanum, Sond.) = E. Rehmanni, Szyszyl.

rotmdata, Kuntze, 1. c. = E. rotundatum, $D C$

Schweinfurthiana, Loes, in Bot. fahrb. xvii. (1893) 550. - Afr. trop. or.

sphaerophylla, Kuntze, Rev. Gen. (1891)114=Elaeodendron sphaerophyllum, Presl.

Szyszylowiczli, Kuntze, 1. c. = E. glaucum, Szyszyl.

tomentosa, Kuntze, 1. c. = Cervantesia tomentosa Ruiz et $P a v$.

trachyclada, Kuntze, 1. c. = Elaeodendron trachycladum, Baker.

"acciniodes, Kuntze 1 c, = E. vaccinioides, Baker. Zollingeri, Kuntze, 1. c. 150 in syn. sub Maurocenia Zollingevi, Kuntze $=$ Triceros cochinchinensis, Zoll.

CASSINIA, R. Br. (Compos.). - Ind. Kew. i.

454.
rubra, F. Buch." in Trans. N. Z. Inst. xix. 1886 (1887) $216 .-$ N. Zel.

spatmulata, Colenso, 1. c. xxii. $1889(1890) 572=$ leptophylla, $R . B r$.

CASSIPOUREA, Aubl, (Rhizophor.). - Ind.

Kew. 1. 455

erticillata, N. E. Br. in Kew Bull. (1894) 5. Bras.

GASSUPE, Humb. et Bonpl. (Rubiac.). - - Ind Kew, 1. 455. fam. iv. 4. (1891) 63. - N. Gran

CASSUVIUM, Rumpf $=$ Semecarpus, Linn. f. (Anacard.)

acuminatum albescens, Anacardium, aruense, auricula tum, australiense, Balansae, cochinchinense, coviaceun, cuneatum, Forstenii, fulvinerve, Gardnevi, glaucum, heterophyllum, Kurzii, laevigatum, marginatum, Moonit, neocaledonicum, nicobarense, nigroviride, obovatum, obscurum, punduratum, parvifolium, Perrotteti, philippinense, pubescens, Roxburghii, scabridum. subpeltatum, subracemosum, travancoricum, Walkeri Kuntze, Rev. Gen. (1891) 151-52 = homonyma omnia Semecarpi.

atrum, Kuntze, 1. c $151=$ Oncocarpus vitiensis, A. Gray.

caesium, Kuntze 1. c. = S, heterophylla, Blume.

longifolium, Kuntze, 1. c. = S. Anacardium Linn. f. vel S. Cassavica, Roxb.?

Spanogheanum, Kuntze, 1. c. = S. longifolia, Blume vitiense, Kuntze, 1. c. $152=$ Oncocarpus vitiensis A. Gray.

CASSYTHA, Linn. (Laurin.). - Ind. Kew. i. 455 Tepperiana, Ludw. ex Tepper, in Bot. Centralbl. xxxvi. (1888) 342. - Ins. Kangaroo.

CASTALIA, Salisb. = Nymphaea, Linn. alba, Greene, in Bull. Torrey Bot. Club, xv, (1888) $85=$ N. alba, $\operatorname{Lin} n$

elegans, Greene, 1. c. = N. elegans, Hook

flava, Greene, 1. $\mathrm{c}=\mathrm{N}$. flava, Leitn.

gigantea, Britten, in Journ. Bot. xxvi. (1888) $9=$ N. gigantea, Hook,

Gilbertii, Morong, in Ann. N. Y. Acad. Sci. vii. (1892) 48. - Parag

Leibergii, Morong, in Coult. Bot. Gaz, xiii. (1888 $124=\mathrm{N}$. tetragona, Georgi? 
CASTALIA

Mexicana, Coult. in Contrib. U. S. Nat. Herb, ii. (1891) $12=$ Nymphaea mexicana, Zucc

odorata, Greene, in Bull. Torrey Bot. Club, xv. (18.88) $85=\mathrm{N}$. alba, Linn

polysepala, Greene, 1.c. $84=$ Nuphar polysepalum, Engelm.

reniformis, Trelease, ex Branner et Coville, in Ann. Rep. Geol. Surv. Arkans. for 1888 i. (1888) i. (1891) $164=$ Nym, reniformis, $D C$

reniformis, Nash, in Bull. Torrey Bot. Club, xxii. (1895) $147=$ praec.

rubrodisca, Greene, 1. c xv. (1888) $85=$ Nuphar rubrodiscum, Morong.

tuberosa, Greene, 1. c. = N. tuberosa, Pame.

CASTANEA, Tourn. ex Linn, (Cupulif,). - Ind. Kew, i, 455.

Castanea, Sudworth, in Bul1. Torrey Bot. Club, xix. (1892) 152 = sativa, Mill.

dentata, Sudworth, 1. c. 154; et in Mem. Torrey Bot. Club, iv. (1893) 154 = sativa, Mill.

GASTANEOPSIS, Spach (Cupulff.). - In"d, Kew. i. 456 .

argyrophylla, King, ex Hook. f. Fl. Brit. Inu. v. (1888) 622. - Ind. ang1.

borneensis, King, in Amn. Bot. Gard. Calc. ii. (1889 99. t. 90 - Borneo.

catalpaefolia, King, ex Hook, f. Fl. Brit. Ind. v. (1888) 621. - Perak.

Clarkei, Hook. f. l. c. 623. - Reg. Himal

Curtisii, King, in Ann. Boi. Gard. Calc. ii. (1889) 107 t. 103. - Penang

diversifolia, King, ex Hook. f. Fl. Brit. Ind. v. (1888) 620. - As, trop or

Hullettii, King, ex Hook. f. .. c. 623. - As. trop. or. Mottleyana, King, in Amzn. Bot. Gard. Calc. ii. (1889) 96 t. 86. - Borneo.

nephelioides, King, ex Hook, f. Fl. Brit. Ind. v. (1888) 624. - Perak.

turbinata, Stapf, in Trans, Limn, Soc. Ser. II. iv. (1894) 232. - Borneo.

Wallichii, King, ex Hook.f. Fl. Brit. Ind. v. (1888) 624. - Penins. Mal

CASTILLEJA, Mutis (Scrophul.), - Ind. Kew, 1. Bryanti, T. S Brandeg. in Proc. Calif. Acad. Ser. Bryanti, T.S Brandeg. in
II. ii. (1889) 192. - Calif.

gloriosa, Britton, in Bull, Torrey Bot. Club, xvi. (1889) 203. - Am. bor.

hololeuca, Greene, in West-Am. Scientist, iii. (1886) 3; et in Pittonia, i. (Mar. 1887) 38. - Calif

macrostigma, S. Wats. in Proc. Am. Acad. xxvi. (1891) 173. - Mexic.

mexicana, A. Gray, l. c. xxi. (1886) 404. - Mexic. Suksdorfii, A. Gray, l. c. xxii. (1887) 311. - Washingt. (Am. bor.).

CATABRosA, P. Beauv. (Gramin.). - Ind. Kew. i. 458 .

araratica, Lipsky, in Act. Hort. Petrop. xiii. (1894) 358. - Armenia.

caucasica, Alboff, Prodr. fl. Colch. (1895) 259. Reg. Cauc.

colchica, Alboff, l. c. - Reg. Cauc.

hierochloides, Bornm, in Mitth. Thür. Bot. Ver. N. Folge, vi. (1894) $67=$ Colpodium hierochloides, Hausskn. et Bormm.

latifolia, Phil. in Anal. Mus. nac. Chi1, (1892) 85 in obs. = aquatica, $P$. Beawv.

GATALPA. Scop. (Bignon.). - Ind. Kew. i. 450. Bungei, Hort. ex Dippel, Handb. Laubholzk. i. 1889) $49=$ ovata, G. Don.

Catalpa, Sudworth, in Gard. and For. ii. (1891) 166 $(=\text { Cat. Catalpa, Karst. })_{\text {, }}=$ biononioides, Walt.

Fargesi, Bur. in Nowv. Arch. Mus. Paris, Sér. II. vii. (1894) 195. - China

himalayaca, Hort. ex Dippel, Handb. Laubholzk. i. (1889) 50 = ovata, G. Don.

himalayensis, Hort. ex Dippel. 1. co = ovata, G. Don.

nana, Hort. ex Dippel, 1. c. 51 = ovata, G. Don.

pumila, Hort. ex Wien. Illustr. Gartenzeit. (1890) 317 nomen. - Form. hort.

\section{GATALPA}

Thunbergii, Hort. ex Wien. Illusir. Gartenzeit. (1890)

318 nomen. - Form, hort.

umbraculifera, Hort. ex Bull. Soc. Tosc. Ortic. (1888) 330 - China

Wallichiana, Hort. ex Wien. Illustr. Gartenz.(1890) $318=$ Kaempferi, Sieb. et Zucc.

CATANANCE, St-Lager, in Cariot, Etud, des fl, éd. 8. ii. (1889) 531 = Gatananche, Linn. (Compos.).

GATANTHERA, F. Muell, in Journ. Bot. xxiv (18S6) 289. VACCINIACEAE,

lysipetala, F. Muell. l.c. - N. Guin.

CATAPODIUM, Link = Festuca, Linn. $($ Gramin,$)$. Lolinm, Hack, in Engl. et Prantl, Natürl. Pflanzenfam. iii. 2. (1887) $75=$ Festuca Lolium, Balansa.

Lolium, Trab. in Batt. et Trab. Fl. de l'Algér, (Monoc.) (1895) $233=$ praec.

GATASETUMI, Rich.(Orchid.). - Ind. Kew. i. 458.

apertum, Rolfe, in Kew Bull. (1895) 284. - Hab, ? Bungerothi, N. E. Br. in Lindenia, ii. (1886) $21 \mathrm{t}$ 57 ; et in Illustr. Hortic, xxxiv. (1887) 31 t. 10. Am, austr.

chloranthum, Cogn. in fourn. des Orchid. v. (1894) 251. - Peruvia.

Claesianum, L. Lind. et Cogn. l. c. iv. (1893) 267. - Bras.

Cognianxii, L. Lind. 1. c. vi. (1895) 223 nomen $=$ fimbriatum, Lindl. et Paxt.

collare, $\operatorname{Cog}$ n. I.c. vi. (1895) 154. - Venez.

comosum, Cogn. 7. c. 266. - Venez.

costatum, Reichb. f. in Gard. Chron. (1887) i. 72. Am. austr.

Darwinianum, Rolfe, l.c. (1889) i. 394. - Guian. angl.

decipiens, Reichb. f. in Lindenia, iii. (1887) 99 t. 144. - Venez.

ferox, Kraenzl. in Gard. Chron. (1895) ii. 262. $\mathrm{Hab}$ ?

Finetianum, L. Lind. et Cogn. in fourn. des Orchid. iv. (1894) 362, - Columb.

fuliginosum, Rolfe, in-Gard. Chron. (1887) $473=$ Darwinianum, Rolfe.

galeritum, Reichb. f.l.c. (1886) ii. 616; et in Lindenia ii. (I886) 41 t. $67 .-\mathrm{Hab}$. ?

Garnettianum, Rolfe, l. c. (1888) ii. 692; Hook. f. in Bot. Mag. (1889) t. 7069. - Am. austr.

hymenophorum, Cogn. in fourn. des Orchid. vi (1895) 215; et in Lindenia, xi. (1895) 14 et 24. Am. austr.

imperiale, L. Lind. et Cognn. in fourn. des Orchid. $\mathrm{v}$. (1895) 316; et in Lindenia, x. (1890) 50 t. 460; inz Gard. Chron. (1895) i. 328 - Bras. (an hybr. spont.?).

Imschootianum, L. Lind. et Cogn. l. c. iv. (1893) 266; et in Lindenia, ix. (1893) 41 t. 403. - Bras. Lehmanni, Regel, in Act. Hort. Petrop. ix. (1886 602 ; et in Gartenfl. (1886) 289 t. 1223. - Columb. Lemosii, Rolfe, in Kew Bull. (1894) 394 ; et ex Hook f. in Bot. Mag. (1895) t. 7444 . - Bras.

Lichtensteinii, Kraenzl. in Gard. Chron. (1892) i, 171 ; et in Reichb. $f$. Xen. Orchrd. iii. 6 (1892). Hab. ?

Lindeni, Cogn. in fourn. des Orchid. v. (1895) 365. - Bras.

Luciani, Cogn. l. c.; et in Lindenia, x. (1895) 47 t. 454. - Am. austr.

mirabile, Cogn. $2 l$. cc. 355 ; et 55 t. 458 . - Bras. ? (an hybr. spont.?).

pallidum, Cogn, in fourn. des Orchid. v. (1894) 252. - N. Gran.

pileatum, Reichb. fo in Gard: Chron. (1886) ii .616. Hab.

pulchrum, $N$. E. Br. in Lindenia, iii. (1887) $51 \mathrm{t}$ 120 ; et in Gard. Chron. (1888) i. 10. - Bras.

punctatum, Rolfe, in Kew Bull. (1894) 364 ; et in Lindenia, xi. (1895) 35 t. 496. - Bras.

quadricolor, $\operatorname{Cogn}$, in foum, des Orchid. vi. (1895) 73. - Am. austr.

quorms, Hort. ex Hamb. Gart. und Blum. (1888) 285 sphalm. $=$ C. Gnomus, Reichb. $f$.

\section{GATASETUM :}

Randii, Rolfe, in Kew Bull. (1894) 394. - Bras. revolutum, Cogn. in fourn. des Orchid. v. (1894) 303. - Bras

Rodigasianum, Rolfe, in Lindenia, v, (1889) $41 \mathrm{t}$ 259. - Bras.

semirosewn $X$, G. Beck, in Wien. Illustr. Gart Zeit. (1895) 415. - Hybr. artef.

splendens, Coon. in fourn. des Orchid. v. (1894) 302 ; et in Iindenia, x. (1895) 49 et 51 t. 455 et 456 . Bras.? (an hybr. spont.?)

stupendum, Cogn. ll. cc. vi. (1895) 13; xi. (1895) 17 t. $48 \%$. - Peruvia?

tapiriceps, Reichb. f. in Gard. Chron.(1888) i. 136 - Bras.

uncatum, Rolfe, in Ken Bull. (1895) 283. - Bras.

CATEVALA, Medic. = Haworthia, Duval (Liliac.).

affuis, altilinea, angolensis, angustifolia, asperiuscula, asperula, attemuata, bilineata, Bolusi, chlorocantha, coarctata, Cooperi, cordifolia, cuspidata, cymbiformis, denticulata, fasciata, glabrata, glauca, Grenii, hy brida, icosiphylla, laeterirens, margaritifera, minima mivabilis, nigra, pallida, papillosa, Peacockii, pilifera, polyphylla, Radula, recurva, reticulata, rigida, rugosa, scabra, semiglabrata, sordida, subattenuata, subfasciata, subregularis, subrigida, subulata, tessellata, Tislcyi, tortuosa, translucens, turgida, venosa, viscosa, vittata, Kuntze, Rev. Gen. (1891) $707=$ homonyma onnia Haworthiae.

arachnodes, Kuntze, 1. c. = H. arachnoidea, Dural. marginata, Kuntze, 1. c. $=\mathrm{H}$. albicans, Haw.

Reinwardti, Kuntze, 1. c. = H. Reinwardti, Haw. setosa, Kuntze, 1. c. = H. setata, Haw.

GATHGARTHIA, Hook. f. (Papaver.). - Ind. Kew. i. 460

Delavayi, Franch. in Bull. Soc. Bot. Fr. xxxiii. (1886) 390 (= Meconopsis Delavayi, Franch.). China.

lancifolia, Franch, l. c. 391 (= M. Tancifolia, Franch.). - China.

CATHEA, Salisb. = Calopogon, R. Br. (Orchid.). uberosa, Morong, in Bull. Torrey Bot. Club, xx. (1893) $34=$ C. pulchellus, R. Br.

GATHEDRA, Miers (Olacin.). - Ind. Kew, i. 460

grandiflora, Loes. in Flova, 1xxii. (1889) 75. Bras.

CATopsis, Griseb. (Bromel.). - Ind. Kew. i.

alba, É. Morr. ex Baker, Handb. Bromel. (1889) 192 = Tillandsia monadelpha, Baker.

aloides, Baker, l. c. $156(=$ Tillandsia aloides, Cham. et Schlecht.). - Mexic

apicroides, Baker, in. Fourn. Bot. (1887) 175; et Handb. Bromel.' (1889) 154 (= Tillandsia apicroides, Cham, et Schlecht.). - Mexic

Fendleri, Baker, ll. cc. 175; et 155. - Venez.

flexuosa, Baker, ll. co. 175; et 154. - Bolivia.

Garckeana, Wittm. in Bot. Fahrb. xi. (1890) 70. Columb.

Hahnii, Baker, in Fourn. Bot. (1887) 175 ; et Handb. Bromel. (1889) 155. - Mexic.

inconspicua, Baker, $7 l$. co. 174; et 153 (= Pogospermum inconspicunm, Brongn.). - Guian. gall.

maculata, Ed. Morr. ex Baker, l. c. 155. - Bras austr.

nitida, Baker, in Fourn. Bot. (1887) 174; et Handb. Bromel. (1889) 154; et in Kew Bull. (1893) 280 (= Tillandsia nitida, Hook.). - Am. trop. et subtrop.

nutans, Baker, in Fourn. Bot. (1887) 176; et Handb. Bromel. (1889) 156 (= Tillandsia nutans, Sw.). Am. trop.

pendula, Baker, Handb. Bromel. (1889) 155. Mexic.

Schumanniana, Wittm. in Bot. Fahrb. xi. (1890) 70; Baker, Handb. Bromel. (1889) 154. - N. Gran. stenopetala, Baker, in fourn. Bot. (1887) 176; tt Handb. Bromel. (1889) 156. - Guatem.

tripinnata, Baker, Handb. Bromel. (1889) 156. Am. trop. austr. 


\section{CATOPSIS}

itellina, Baker, in Fourn. Bot. (1887) 176 pr.p.; et Handb. Bromel. (1889) 156. - Venez.

CATTIMARUS, Rumpf, Herb. Amboin. iii. (1743) $177 \mathrm{t} .113$, ex Kuntze, Rev. Gen, (1891) $76=$ Kleinhovia, Linn. (Stercul.).

hospitus, Kuntze, 1. c. $77=$ K. hospita, Linn.

CATTLEYA, Lindl. (Orchid.). - Ind. Kew. i. 460.

Albertii X, Hort. ex God.-Lebœuf, L'Orchidophile (1890) 321 cum ic. - Hybr. artef.

Alexandrae, L. Lind. et Rolfe, 'in Gard. Chron. (1892) i. 522 ; et Lindenia, viii. (1892) 45 et 47 t. 357 et 35s. - Bras.

Aliciae $\times$, L. Lind. 1. c. xi. (1895) 31 t. 494.-Hybr spont?

Amesiae, Hort. Sand. ex Kew Bull. (1893) $30=$ an seq. ?

Amesiana, Hort. ex Williams, Orchid. Grow. Man. ed 6 (1885) $173=$ Laelia amesiana, Reichb. $f$.

amoena $\times$, Hort. ex God.-Lebouf, L'Orchido(1891) $273 \mathrm{cum}$ ic. - Hybr, artef.

Aquinii, Rodr. Pl.nov. Fard. bot. Rio, i. (1891) $23 \mathrm{t}$. 4 c. - Bras.

Arthuriana X, O'Brien, in Gard. Chron. (1894) i. 103. - Hybr. artef.

autumnalis, Hort. ex Orchid Alb. vii. (1888) sub t. $323=$ Bowringiana, Veitch.

Balantiniana $\times$. Reichb. f. in Gard. Chron. (1889) i. 264; et in Reichenbachia, ii. t. 91. - Hybr. artef.

Batalini, Sander et Kraenzl.l. c. (1892) ii. 332.-Bras.

Behrensiana X, Hort. ex Gartenfl. (1892) 183. Hybr. artef

blesensis X, Hort. Gall. ex Rev. Hortic. (1892) 416 $=$ Laelio-Cattleya blesensis, Warn. et Will.

Bramnae X. Hort, ex Rev. Hortic. (1895) 63. Hybr. artef.

Brownii, Rolfe, in Kew Bull. (1894) 156. - Bras.

Bullieri, Carr. in Rev. Hortic. (1886) $444=$ labiata Lindl.

Burberryana X, Hort. ex Kew Bull. (1893) 30. Hybr. artef.

Buyssoniana X, Hort. ex O'Brien, in Gard. Chron. (1890) ii. 588 fig. 116 = granulosa, Lindl.

Cassandra $\times$, Rolfe, 1. c. (1888) i. 596. - Hybr artef.

Chloris $\times$, Hort. 1. c. (1893) ii. 525 fig. 88. - Hybr. artef.

citrino-intermedia $\times$, Rolfe; ex Gartenfl. (1888) 423 - Hybr. artef

Dallei X. Hort. ex Rev. Hortic. (1894) 292. Hybr. artef.

Dallemagnei X, Hort. 1. c. 334. - Hybr. artef.

Dukeana, Reichb. f. in Gard. Chron. (1887) i. 576.$\mathrm{Hab}$,?

epidendroides, Hort. ex Rolfe, 1. c. (1889)i. $619=$ luteola, Lindl.

flaveola, Reichb. f. l. c. (1888) ii. 473. - Hab. ?

Fowleri $\times$, Sander et Kraenzl. 1. c. (1895) ii. 178.Hybr. artef.

Frithii $X$, Hort. Veitch, 1. c. (1889) i. 8. - Hybr. artef.

Gibeziae, L. Lind, et Rodigas, in Lindenia iii (1887) 77 t. $133=$ intermedia, R. Grah.

hackbridgensis $X$, Hort. ex Gard. Chron. (1890) ii 8. - Hybr. artef.

Harrisi $\times$. Hort. 1. c. (1887) i. 104. - Hybr. artef.

funo X, L. Barron, 1. c. (1895) ii. 118. - Hybr. artef.

Kienastiana X, Hort. ex Rev. Hortic. (1895) 63. Hybr. artef.

Kimballiana, L. Lind. et Rodig. in Lindenia, ii (1886) 85 t. 89. - Venez.

Kraenzlini $\times$, Hort. ex Gartenfl. (1892) 183. Hybr. artef.

Krameriana, Reichb. f. in Gard. Chron. (1888) ii, 323. - Bras.

leucoglossa $\times$, Hort. ex Kew Bull. (1893) 30 . Hybr. artef.

Lindeni, Hort. Lind, ex Journ. of Hort. xxi. (1890) 491 fig. 64 = gigas, Lind. et André.

Lourryana $X$, Hort. ex Gard. and For. (1891) 293 et ex Gartenf. (1892) 183. - Hybr. artef.

\section{GATTLEYA}

Maloriana Lind in Illustr. Hortic, (1886) 102 nomen = maxima, Lindl.

Mantinix, Mant in in Rev. Hortic. (1834) 234,558 et $(1895) 63,129 \mathrm{fig} .35$. - Hybr. artef.

Massaiana, Warn. et Williams, Orchid Alb. visi. (1889) t. 362 (an Hybr. spont.?). - Columb.

Measuresin X, Reichb. f. in Grard. Chron. (1886) ii. 526. - Hybr. artef.

Mendeli, L. Lind. et Rodigas, in Lindenia, ii. (1886) 17 t. $55 .-\mathrm{Hab}$. ?

Minacia $\times$, Hort. ex Kew Bull. (1893) App. ii. 31. - Hybr. atef.

O'Brieniana, Hort. ex Journ. of Hort. xx. (1890) 25 fig. 4 = intermedia, $R$. Grah.

Oweniana X. Hort. ex Kew Bull. (1893) 30. Hybr. artef.

Parthenia X, Bleu, in Lindenia, vi. (1890) 75 t. 276; et in Reichenbachia, Ser. II. ii. 39 t. 67. Hybr. artef.

Phile X, Hort. ex Kew Bull. (1893) 30. - Hybr. artef.

Princeps $\times$, Hort. 1. c. - Hybr. artef.

Rex, O'Brien, in Gard. Cliron. (1890) ii. 684; et in Lindenia, vi. (1890) 53 t. 265. - Am. austr.

rochellensii, Reichb. f. 1. c. (1888) ii. 533 in syn.= labiata, Lindl.

Schroederae, Reichb.f.1.c. (1887) i. $512=$ Schroederiana, Rechb. $f$.

Sororia X, Reichb. f. 1. c. 40 ; et ex Orchid Alb. ii. (1888) t. 307 . - Hybr. artef.

splendidissima $\times$, Hort. ex Gard. Chron. (1886) ii. 10. - Hybr. artef.

Statteriana X. Hort. ex Kew Bull. (1893) App.ii. 21; et L. Lind. in Lindenia, x. (1894) 97 in obs. - Hybr. artef.

uavior X. Reichb. f, ex Veitch, Man Orch. Pl. ii. (1888) 92. - Hybr. artef.

sulphurea $\times$, Hort. ex Gard. Chron. (1889) i. $802=$ luteola, Lindl.

Vedasti $X$, Perren. ex God.-Lebouf, L'Orchidophile (1891) 48 cum ic. - Hybr. artef.

Victoria Regina X. Hort. ex Gard. Chron. (1892) i. 586 et 809 fig. 115 et 116 ; et in Reichenbachia t. 85. - Hab.?

violacea, Rolfe, l. c. (1889) i. $802(=$ C. superba, Schomb.). - Am. trop. austr.

violacea, Maury, in Morot Journ. de Bot. iii. (1889) $272=$ superba, Schomb.

Wagneri, Hort. ex Gard. Chron. (1886) ii. $10=$ Wageneri, Reichb. $f$ ?

Warocqueana, L. Lind. in Journ. des Orchid. (1890) $189=$ labiata, Lindl.

Zenobia X, Rolfe, in Gard. Chron.(1887) ii. 552.Hybr, artef.

CATUTSJERON, (COIr. EX KATOUTSJEROË)

Adans.= Holigarna, Buch. Ham

Arnottianum, Kuntze, Rev. Gen. $152=\mathrm{H}$. Arnottiana, Hook. $f$.

Beddomei, Kuntze, 1. c. = H. Beddomei, Hook. f

ferrugineum, Kuntze, 1. c. = H. ferruginea March.

Grahami, Kuntze, 1. c. = H. Grahamii, Hook. $f$

Helferi, Kuntze, 1. c. = H. Helferi, Hook. $f$. GAUCALIS, Linn. (Umbellif.) - Ind. Kew. i
462.

pedunculata, Baker, $f$. in Trans. Linn. Soc., Ser. II

iv. (1894) 15. - Afr. trop. or.

Sintenisii, Freyn in Oest. Bot. Zeitschr. xliv. (1894) 144. - As. Min.

Torgesiana, Hausskn. in Nym. Consp. Suppl. II. I (1889) 135; et in Mitth. Thür. Bot. Ver N. Folge, v. (1893) 10\%. - Graecia.

turgenioides, Stapf et Wettst. ex Stapf, in Denkschr. Akad. Wien, li. (1886) 372. - As. Min

GAULANTHUS, S. Wats. (Crucif.), - Ind. Kew.

i. 462

Lemmoni, S. Wats. in Proc. Am. Acad. xxiii. (1888) 261. - Calif.

CAULINIA, Moench = Kennedya, Vent. $($ Legu $\min$.)
CAULINIA : -

Beckxiana, eximia, glabrata, macrophylla, microphylla, nigricans, procurrens, provepens, retusa, Stirlingii Kuntze, Rev. Gen. (1891) $171=$ homonyma ommia Kennedyae.

bimaculata, Kuntze, 1. $\mathrm{c}_{\circ}=$ Hardenbergia monophylla, Benth.

bracteata, Kuntze, 1. C. $=K$. prostrata, $R . B r$

carinata, Kuntze. 1. c. = K. parviflora, Meisn.

coccinea, Kuntze, 1. c。 = K. prostrata, R. Br.

Comptoniana, Kuntze, 1. e. = Hardenbergia Comp-

toniana, Benth.

inopliylla, Kuntze, 1. c。 = K. coccinea, Vent.

CAVANILLESIA, Ruiz et Pav. (Malvac.) Ind. Kew. i. 463 .

arbcrea, K. Schum. in Mart. Fl. Bras, xii, I1. (1886) 237 (= Pourretia tuberculatu, Mart, et Zucc.). Bras.

CAVANILLA, Thunb. = Pyrenacantha, Wight grandiflora, Kunze, Rev. Gen. (1891) 111= P. grandiflora, Baill

kamassana, Kuntze, 1. c. = P. kamassana, Baill.

Kirkii, Kuntze, 1. c. = P. Kirkii, Baill,

Vogeliana, Kuntze, 1. c. = P. Vogeliana, Baill.

rolubilis, Kuntze, 1. c. = P. volubilis, Wight.

GAVENDISHIA, Lindl. (Vacciniac.).- Ind. Kew. i. 463

callista, F. D. Smith, in Coult. Bot. Gaz. xx. (1895) 5 t. 2. Guatem.

Klotzschiana, Niedenzu, in Bot, Fahrb. xi. (1890) $206(=$ Socratesia melastomoides, Klotzsch). - Am. austr. trop.

paniculata, Rusby, in Mem. Torrey Bot. Club, iv. (1893) 215. - Bolivia.

pubescens, Britton, in Bull. Torrey Bot. Clut, xx. (1893) 138 (= Thibaudia pubescens, H. B. et K.). - Bolivia.

GEANOTHUS, Linn. (Rhamn.).-Ind. Kew.i. 464. arboreus, Greene, in Bull. Calif. Acad. ii. (1886) 144. - Calif.

Arnoldi $\times$, Hort. ex Dippel, Handb. Laubholzk. ii. (1892) 536 in obs. - Hybr. artef.

Arnouldi $x$, Hort. ex Koehne, Deutsche Dendrol. (1893) $396=$ praec

californicus, Kell. ex $K$. Brandeg. in Proc. Calif. Acad. iv. (1894) 181. - Calif.

connivens, Greene, Pittonia, ii. (Nov. 1889) 16. -

Calif.
cuneatus, K. Brandeg. in Proc. Calif. Acad. iv. 1894) 204. - Calit.

eglandulosus, Trelease, in Proc. Calif. Acad. Ser. II. i. (1888) $110=$ cordulatus, Kell.

grandiflorus, Hort. ex Dippel, Handb. Laubholzk. (1892) $534=$ ovalis, Bigel.

impressus, Trelease, in Proc, Calif, Acad. Ser, II, i. 1888) 112, - Calif.

intermedius $\times$, Hort. ex Koehne, Deutsche Dendrol. (1893) 396. - Hybr. artef.

Jepsonii, Greene, Man. Bot. San Franc. Bay (1894) 78. - Calif.

lencodermis, Greene, in Keq Bull. (1895) 15 Calif.

macropliyllus, Hort. ex Dippel, Handb. Laubholzk. $533=$ americanus, Linn.

multiflorus, Hort. ex Dippel, I. C. = americanus, Linn.

megacarpus, K. Brandeg. in Proc. Calif. Acad. iv. (1894) $205=$ macrocarpus, Nutt

nevadensis, Kell. ex K. Brandeg. l. c. 181. - Calif.

Orcuttii, Parry, in Proc. Davenp. Acad. Sci. v. (1889) 194. - Calif.

oreganus, Nutt.ex K. Brandeg. in Proc. Calif. Acad iv. (1894) 180 in obs. - Oreg.

pallidus $\times$, Hort. ex Koehne, Deutsche Dendrol. (1893) 396. - Hybr, artef.

Palmeri, Trelease, in Proc. Calif. Acad. Ser. II, i. (1888) 109. - Calif.

Parryi, Trelease, l. c. - Calif.

parvifolius, Coult, in Contrib. U.S. Nat. Hevb. iv. 1893) 79 (an seq.?). - Calif.

parvifolius, Trelease, in Proc. Calif. Acad. Ser. II. (1888) 110. - Am. bor. occ, 


\section{GEANOTHUS :}

pinetorum, Coult. in Contrib. U.S. Nat. Herb. iv (1893) 80 - Calif.

pumilus, Greene, in Erythea, i. (1893) 149. Oregon.

roseus, Hort. ex Koehne, Deutsche Dendrol. (1893) 395. - Hybr. artef.

rugosus $\times$, Greene, Fl. Francisc. (1891) 88. Calif.

sorediatus, W. S. Lyon, in Coult. Bot. Gaz. xi. (1886) 204 et $333=$ arboreus, Greene.

tomentosus, Parry, in Proc. Davenp. Acad. v. (1889) 190. - Am. bor.

vestitus, Greene, Pittonia, ii. (June 1890) 101. Calif.

GEGROPIA, Linn. (Urtic.). - Ind. Kew. i. 464.

Bureauiana, Alad. Richt. ex Bot. Centralbl. 1i. (1892) 238. - Hab.?

dealbata, Williams, Catal. (1887) 21. - N, Gran.

Juranyana, Alad. Richt. ex Bot. Centralbl. 1i. (1892) 238. - Guiana.

Levyana, Alad. Richt. l.c.-Nicarao

Radlkoferana, Alad. Richt. l. c.-Columb.

scabrifolia, Alad. Richt. l. c. - Nicarag.

GEDRELA, P. Br. (Meliac。). - Ind. Kew。 i. 465. barbata, C. DC. in Bull. Herb. Boiss, ii. (1894) 575. - Bras.

GEDRELopsis, Baill. Hist. pl. Madag., Atlas. (1893) t. 257. MELIACEAE.

Grevei, Baill. l. c. - Madag.

CEDRONELLA, Riv. (Labiat.). - Ind. Kew. i. 465.

aurantiaca, A. Gray, in Proc, Am. Acad.xxi. (1886) 435 nomen; et l. c. xxii. (1886) 408. - Mexic. coccinea, Greene, Pittonia, i. (Jan, 1888) 157. Mexic

rupestris, Greene, l. c. (Feb. 1888) $164(=C$. cana, Hook. var. lanceolata, A. Gray). - N. Mexic.

GEDRUS, [Tourn.] Mill. (Conif.). - Ind. Kew, i. 465.

sempervirens, Mast. ex Bolet. Soc. Brot. xii. (1895) 54. - Hab. ?

torulosa, Mast.l. . .53. - Ind. lusit

CEIB 1, Medic. = Friodendron, DC. (Malvac.) Burchellii. K. Schum. in Mart. Fl. Bras, xii. m. (1886) 211. - Bras.

evianthos, K. Schum. 1. C. $=$ E. leiantherum, DC. jasminodora, K. Schum.1.c. $213=\mathrm{E}$. jasminodorum, St-Hil.

phaeosantha, K. Schum. 1. C. $214=$ E. phaeosanthum, Decne.

pubiflora, K. Schum. 1. c. $213=$ E. pubiflorum St-Hil.

Rivieri, K. Schum. 1. c. $212=$ E. Rivieri, Decne

Samaima, K. Schum.1. c. $210=$ E. Samauma, Mart.

GELASTRUS, Linn. (Celastr.), - Ind. Kew. i.

articulata, Hort, ex Koehne, Deutsche Dendrol. (1893) $363=$ orbiculata, Thunb

baccatus, S. Elliot, in fourn. Linn. Soc. xxix. (1891) 11. - Madag.

diversifolius, Hensl. l. c. xxiii. (1886) 123.-China. latifolius, Henrsl l. c. - China.

hypoglaucus, Hemsl. in Ann. of Bot. ix. (1895) 150. - China.

maritimus, Bolus, l. c. xxiv.(1887) 173. - Afr. austr. papuana, Warb., in Bot. fahrb. xiii. (1891) 366. Oceania.

racemulosa. Franch, in Bull. Soc. Bot. Fr. xxxiii. (1886) 455. - China occ.

variabilis, Hemsl. in fourn. Limn. Soc. xxiii. (1886) 124. - China.

CELMISIA, Cass, (Compos.), - Ind. Kew, i. 467 Adamsii, T Kirk in Trans, N.Z. Inst. xxvii. 1894 (1895) 329. - N. Zel.

Armstrongii, Petrie, l. c. xxvi. 1893 (1894) 269.N. Zel.

\section{GELMISIA}

Brownii, F, R. Chapm. in Trans, N. Z. Inst. xxii. (1890) 444. - N. Zel.

campbellensis, F, R. Chapm. l, c. xxiii. 1890 (I891) 407. - N. Zel.

Chapmanni, T. Kirk, in Gard. Chron. (1891) i. 731 146. - N. Zel

Macmahoni, T.Kirk, in Trans. N. Z. Inst. xxvii. $1894(1895) 327$ - N. Zel.

Martini, 7. Buch. l. c. xix. 1886 (1887) 213. N. Zel.

membranacea, Colenso, l. c. xxii. 1889 (1890) 470.N. Zel.

parva, T. Kivk, l. c. xxvii. 1894 (1895) 328. N. Zel.

perpusilla, Colenso, l. c. xxii. 1889 (1890) 470. N. Zel.

prorepens, Petrie, l.c. xix, 1886 (1887) 326. N. Zel.

robusta, f. Buch. l. c. xix. 1886 (1887) 215 t. 18. N. Zel.

ruahinensis, Colenso, l. c. xxvii. 1894 (1895) 388. N. Zel.

Rutlandii, T.Kivk, l. c. xxvii. 1894 (1895) 329. N. Zel.

setacea, Colenso, l. c. xxi. 1888 (1889) 88. - N. Zel.

GELOSIA, Linn. (Amarant.). - Ind. Kew, i. 467. angustifolia, Schinz, in Bot. Fahrb. xxi. (1895) 179. - Madag.

Freynii, Sint. ex Freyn, in Oest. Bot. Zeitschr. xliv. (1894) 297. - As. Min.

intermedia, Schinz, in Bot. Fahrb. xxi.(1895) 179. - Afr. austro-occ. extratrop.

micrantha, Baker, in Fourn. Linn. Soc. xxii. (1887) 514. - Madag.

pleiogyna, Kuntze, Rev.Gen.(1891) 541.-Costarica.

Schweinfurthiana, Schinz, in Bot. Fahrb, xxi. (1895) 17; et in Engl. Pfanzenw. Ost-Afr. C (1895) 172.Afr. trop, or.

spathulaefolia, Engl. Bot. Fahrb. x. (1889) 6.-Afr. austro-occ. extratrop.

Swinhoei, Hemsl, in fourn. Linn. Soc. xxvi. (1891) 318 - Hainan.

triuncinella, Schinz, in Bot. Fahrb. xxi. (1895) 189. - Madag

Welwitschii, Schinz, l. c. 179. - Angola.

GELSIA, Linn. (Scrophul.).- Ind. Kew. i. 468.

Berneti, Post, in fourn. Linn. Soc. xxiv. (1888) 437. - Oriens.

brevipedicellata, Engl. in Abhandl. Preuss. Akad. Wiss. 1891, ii. (1892) 376. - Afr. trop. or.

floccosa, Porta, in Nuov. Giorn. bot. Ital. xix. (1887) 313 = Verbascum Portae, Willk.

Freynii, Sint. in Dest. Bot. Zeitschr. xliv. (1894) 297. - As. Min.

glandulifera, Post, Pl. Postianae, ii. (1891) 19. Syria.

parviflora, Engl. ex Wettst. in Enel, et Prantl, Natïnl. Pfanzenfam, iv, $3 \mathrm{~b}$. (1891) 52 sphalm.? = parvifolia, Engl.

parvifolia, Engl. Bot. Fahrb. x. (1889) 252. - Afr. austro-occ, extratrop.

roripifolia, Haláczy, in Oest. Bot. Zeitschr. xl. (1890) 404. - Thracia.

Sedgwickiana, Schimp. ex Engl. in Abhandl. Prenss. Akad. Wiss. 1891. ii (1892) 3\%6. - Abyss.

CELTIDOPSIS, Fr. Priemer, in Bot. Jahrb. xvii. 1893429 et $470=$ Celtis, Linn. (Urtic.).

citrifolia, Fr. Priemer, 1. c. ( = Mertensia citrifolia, Kunth) $=$ Celtis pubescens, $H$. B. et $K$.

GELTIS, Tourn. ex Linn. (Urtic.). - Ind. Kew. i. 469 .

betulaefolia, Vandas, in Oest. Bot. Zeitschr. xxxix. (1889) 22I. - Herce?

gomphophylla, Baker, in fourn. Linn. Soc. xxii. (1887) 521 . - Mada

grewioides, Warb. in Bot fahrb. xiii. (1891) 287.Oceania.

iguanaeus, Sarg. Silv. N.-Amer. vii. (1895) $64=$ aculeatd, Sw.

ilicifolia, Engl. Pfanzenw. Ost.-Afr. C (1895) 160. - Afr. trop. or.
GELTIS :

nervosa, Hensl. in foum. Limn. Soc xxvi. (1894) 450. - Formosa.

scabra, Hort, ex Dippel, Handb. Laubholzk, ii. (1892) $44=$ occidentalis, Linn.

serrata, Hort. ex Dippel, 1. c. $43=$ australis, Linn.

GENCHRUS, Linn. (Gramin.). - Ind. Kew. i 470 .

gracillimus, Nash, in Bull. Torrey Bot. Club, xxii. (1895) 300. - Florida.

Palmeri, Vasey, in Proc. Am. Acad. xxiv. (1889) 80 nomen; in Proc. Calif. Acad. Ser. II. ii. (1889) 211 ; et in Illustr. N. Am. Grass. ii. t. 3. - Calif.

GENTA UREA, Linn. (Compos.). - Ind. Kew. i. 470.

adjarica, Alboff, in Bull. Herb. Boiss. ii. (1894) 639. - Reg. Transcauc

albispina, Aitch. et Hensl. in Trans. Linn. Soc. Ser. II. iii. (1886) 81. - Afghan.

Amani, Post, in fourn. Linn. Sov. xxiv. (1888) 434 et in Bull. Herb. Boiss. i. (1893) 23. - Syria.

amphiloba $\times$, Hausskn. in Mitth. bot. Ver. Jena iii. 2 et 3 (1884) 229. - Eur.

argyrocephala, Freyn et Sint. in Oest. Bot. Zeitschr. xlii. (1892) 240. - Armenia.

arisitensis $X$, Coste et Sennen, in Bull. Soc Bot. Fr. xli. (1894) 573. - Gall

Aschersoniana X, Vetter, ex Ber. deutsch. hot. Ges. (1890) [144]. - Helv.

austriacoides $\times$, Wolosz. in Spraw. Kom. fizyj. Krajowei. xxvii. (1892) 206; et in Oest. Bot. Zeitschr. xliii, (1893) 108. - Eur

Aylmeri, Baker, in Kero Bull. (1895) 218. - Reg. Somal.

balsamitoidea, Post, Pl. Postianae, ii. (1891) 15. Syria.

Beckiana $\times$, Muellner, in Verh. zool.-bot. Ges. Wien, xxxvii. (1888) 27. - Austria.

Bertolonii, Hausskn. in Mitth. Thür. Bot. Ver N. Folge, vi. (1894) 34. - Eur.

biformis, Timb. in Lucante, Rev. de Bot. x. (1892) 262 = maculosa, Lam

Bolleana, Bolle, in Bot. Jahrb. xiv. (1892) 234 (= Amberboa Bollei, Sch. Bip.). - Ins. Canar.

borina. Velen. in Sitzungsb̆. Boehm. Ges. Wiss. 1889 (1890) ii. 36. - Eur.

bosniaca, Murb. In Lunds Univ. Arsskrift, xxvii v. (1892) $97=$ pseudophrygia, C. A. Mey.

brevispina, Hausskn. in Nym. Consp. Al. Eur. Suppl. II. i. (1889) 187; et in Mitth. Thïr. Bot. Ver. N. Folge, vii. (1895) 46. - Graecia.

carpatica, Formanek, in Osst. Bot. Zeitsch. xxxvii. (1887) 153. - Bucov.

Charrelii, Halacsy et Dörfer, in Falw.-Katal. Wien bot. Tauschver. (1894) 6. - Maced.

Claryi, Debeaux, in Soc, hist. nat. Toulouse (Mars 1889) ex Batt. et Trab. Fl. de l'Algérie (Dicot.) (1889) $496=$ pullata, Linn.

confusa $X$, Coste et Sennen, in Bull. Soc. Bot. Fr. xli. (1894) 578 . - Gall.

Cossoniana, Batt. l. c. xxxv. (1888) 341. Algeria.

crispatula, Timb. in Lucante, Rev, de Bot. $x$. (1892) 262 in syn. = maculosa, Lam.

dhofarica, Baker, in Kew Bull. (1895) 182. -Arabia. Doddsii, Post, ex Boiss. Fl. Or. Suppl. (1888) 515; et in fourn. Linn. Soc. xxiv. (1888) 434. - Syria. Duvauxii, Batt. in Bull. Soc Bot. Fr. xxxv. (1888) 341 et 390. - Algeria.

epapposa, Simonk. Enum. fl. Transsilv. (1886) 350 $=$ Biebersteinii, $D C$.

euxina, Velen. in Sitzb. Boetm. Ges. Wiss. 1889 (1890) ii. 50. - Eur.

Formanekii, Halacsy, ex Form. in Verh. Naturf. Ver. Brïnn. xxx. (1892) extr. 15; et in Oest. Bot. Zeitschr. xliii. (1893) 55. - Maced.

Freynii, Sint. et Freyn, in Bull. Herb. Boiss. iii. (1892) 472. - Armenia,

Funkii, Pau, Not. bot. fl. Espan. i. (1887) $34=$ Paui, Loscos.

genuensis $X$, Hausskn. in Mitth. Thür. Bot. Ver N. Folge, vi. (1894) 35. - Italia.

Theorghieffii, Halacsy, in Oest. Bot. Zeitschr. xli. (1891) 222. - Bulg. 


\section{CENTAUREA :-}

halkensis, F. Major et Barbey, Halki (1891) 4 t. 1.Ins. Halki.

Heldreichii, Halàczy, in Denkschr. Akad. Wien, lxi. (1894) 315. - Graecia.

Holzmanniana, Heldr. ex Boiss. Fl. Or. Suppl. (1888) 316 in syn. = iberica, Trautv

hortorum, Pau, Not. bot.fl. Espan. i. (1887) 12. Hisp.

illapelina, Phil. in Anal. Univ. Chil. xc. (1895) 43. - Chili.

javornikiensis, Formanek, in Oest. Bot. Zeitschr. xxxvii. (1887) 153; et in Krétena ii. (1892) 578. Moravia.

hroumirensis, Coss, ex Batt. et Trab., Fl. del'Algér. (Dicot.) (1889) $500=$ nicaeensis, All.

lacera, Simonk. Enum. fl. Transilv. (1886) $345=$ C. Jacea, Linn.

lanata, Formanek, in Oest. Bot. Zeitschr, xxxviii. (1888) 146 nomen. - Herceg.

lapsanifolia, Freyn, in Bull. Herb. Boiss, iii. (I895) 473. - As. Min.

leptocephala $\times$, Coste et Senren, in Bull. Soc. Bot. Fr. xli. (1894) 575. - Gall.

Loret $\times$, Coste et Sennen, 1. c. 377. - Gall

Ludovici $X$, Borb, in Oest, Bot. Zeitschr, xli. (I891) 186; et in Termész. Füzet. xv. I. (1892) 244. - Hung.

macedonica, Halaczy, in Denkschr. Akad. Wien, 1xi. (1894) 244. - Graecia.

macracantha, Coss. et Durieu, ex Batt. et Trab. Fl. de l'Algér. [Dicot.] (1889) $501=$ pungens, Pomel.

Malinvaldiana, Batt. in Bull. Soc. Bot. Fr. xxxiii. (1886) 355; et in Batt. et Trab. Atlas Al. Algér. (1886) 15 t. 11. - Algeria.

Margaritae, Hort. ex Gard. Chron. (1891) ii. 741 fig. $108=$ odorata, Burm. $f$

melanocalathia, Borb. in Oest. Bot. Zeitschr. xxxix. (1889) $235=$ C. Jacea, Linn.

microcarpa, Coss. et Durieu, ex Batt. et Trab. Fl. de l'Algér. (Dicot.) (1889) 500. — Algeria.

mirabilis $\times$, Rouy, in Bull. Soc. Bot, Fr, xxxvi. (1889) 425. - Lusit.

Noulii $\times$, Franch. ex Coste, in Bull. Soc. Bot. Fr. xl. (1893) 285. - Gall.

Omphalodes, O. Hoffm. in Engl. et Prantl, Natürl. Pfanzenfam. iv. 5. (1893) $330(=$ Stephanochilus Omphalodes, Coss. et Durieu). - Alger.

omphalotricha, Coss. et Durieu, ex Batt. et Trab. Fl. de l'Algér. [Dicot.] (1889) 497. - Afr. bor., Hisp.

Pecho, Alboff, in Bull. Herb. Boiss, ii. (1894) 640. Reg. Transcauc.

pentelica, Hausskn. in Mith. Thür. Bot, Ver. N. Folge, vii. (1895) 45. - Graecia.

peregrina $\times$, Coste et Sennen, in Bull. Soc. Bot. Fr. xli. (1893) 574; et in Bull. Herb. Boiss. iii. App. i. (1895) 14. - Gall.

Perlakyana $\times$. Borb. in Termész. Füzet. xv. I. (1892) 244. - Hung.
Pinae, Pau, Not. bot. fl. Espan. i. (1887) 12. Hisp.

plumosa, Aitch. et Hemsl. in Trans, Linn. Soc. Ser. II. iii. (1886) 81. - Persia.

psephelloides, Freyn et Sint. in Oest. Bot. Zeitschr. xlii. (1892) 237. - Armenia.

pseudosolstitialis, Debeaux, Not. pl. nouv. ou peu conn. rég. Médit. (1895); ex Bull Soc. Bot. Fr. xlii. (1895) 376 . - Gall.

ramosissima, Freyn et Sint. ex Freyn, in Oest. Bot. Zeitschr. xliv. (1894) 220. - As. Min.

redempta, Heldr. in Bull. Soc. Bot. Fr. xxxvii. (1890) 243. - Creta.

similata $\times$, Hausskn, in Mitth. Bot. Ver. Jena, iii. 2 et 3 (1884) 229. - Eur

Sintenisii, Freyn, in Oest. Bot. Zeitschr. xlii. (1892) 238. - Armenia.

subcordata, Freyn et Sint. 1. c. $237=$ nigrescens. Willd.

tartarea, Velen. in Abhandl. Böhm. Ges. Wiss. (1886) $25=$ affinis, Friv.

Tempskyana, Freyn et Sint. ex Freyn, in Bull. Herb. Boiss. iii. (1895) 471. - Armenia.

thessala, Hausskn. in Mitth. Bot. Ver. Fena, v. (1889) 86. - Graecia.

tossiensis, Freyn et Sint. ex Freyn, in Oest. Bot. Zeitschr. xliv. (1894) 258. - As. Min.

\section{GENTAUREA :-}

trachonitica, Post, in fourn. Linn. Soc. xxiv. (1888) 434. - Syria.

Tuba, Somm. et Levier, in Act. Hort. Petrop. xii. (1892) 156. - Cauc

tymphaea, Hausskn. in Nynt. Consp. Fl. Eur. Suppl. II. i. (1889) 186; et in Mitth. Thiir. Bot. Ver. N. Folge vii. (1895) 44. - Graecia.

Vandasii, Velen. in Oest. Bot. Zeitschr. xlv. (1895) 72. - Eur. or.

Velenovskyi, Adamovic, l. c. xliii. (1893) 172. Serbia

vicentina, Welw. ex Henriquès, in Bolet. Soc. Brot. x. (1892) 223 t. 2. = fraylensis, Sch. Bip.

vicina, Lipsky, in Act. Hort. Petrop, xiii. (1894) 312. - Reg. Cauc.

CENTAURIUM, Gilib.= Erythraea, Borkh. (Gentian.).

linariaefolium, G. Beck, Fl. Nieder-Oest. ii. (1892) $934=$ E. linarifolia, Pers

GENTEMA, Hook. f. (Amarant.) - Ind. Kew, i 477.

biflora, Schinz, in Engl. et Prantl, Natürl. Pflanzen. fam. iii. la (1893) 107; et in Bot. Fahrb. xxi. (1895) 183, - Afr. trop.

cruciata, Schinz, 7. c. 184. - Transv.

GENTIPEDA, Lour. (Compos.). - Ind. Kew. i 477

minima, Kuntze, Rev. Gen. (I891) $326(=$ C. minima, Al. Br. 1867) = orbicularis, Lour. minuta, Drake, Fl. Polyn. Franc. (1892) 110 (an C. minuta, C. B. Clarke?). - Orb. vet, reg, trop.

GENTOTHECA, Desv. (Gramin.), - Ind. Kew i. 478 .

madagascariensis, Hack. ex $S$. Elliot, in Fourn Linn. Soc. xxix. (1891) 66 (= Poa madagascarien sis, Lam.). - Madag.

mucronata, Kuntze, Rev. Gen. (1891) $765=$ praec.

GENTRADENIA, G. Don (Melastom.). - Ind. Kew. i. 478.

Bernoullii, Cario, ex Cogn. in DC. Monog. Phan. vii. (1891) 118. - San Salv.

GENTRANTHUS, DC. (Valerian.). - Ind. Kew. i. 478 .

Sieberi, Heldr. in Verh. zool.-bot. Ges. Wien, xl. (1890) 295. - Creta.

GENTROPOGON, Presl (Campanul.). - Ind.

\section{Kew i 470 .}

erythraeus, Drake, in Morot, fourn. de Bot, iii. (1889) 237. - Am. austr.

gamosepalus, Zahlbr. in Ann. naturh. Hofmus. Wien, vi. (1891) 434. - Peruvia.

gesneraeformis, Drake, in Morot, fourn. de Bot. iii. (1889) 239. - Ecuad.

gracilis, Drake, l. c. 238. - Ecuad.

grandidentatus, Zahlbr. in Annal. Naturh. Hofmus Wien, vi. (1891) 439 (= Lobelia grandidentata, Schlecht.). - Mexic.

guatemalensis, Robins. ex 7. D. Smith, in Coult. Bot. Gaz.xx. (1895) 4. - Guatem.

hirtiflorus, Drake, in Morot, Fourn. de Bot. iii. (1889 239. - Ecuad

Karstenii, Zahlbr. in Ann. naturh. Hofmus. Wien, vi. (1891) 436. - Ecuad.

laciniatus, Zahlbr. ex Loes. in Bull. Herb. Boiss. iii. (1895) 623. - Mexic.

longipes, Zahlbr. in Ann. naturh. Hofmus. Wien, vi (1891) 439 (= Siphocampylus longipes, Vatke). Venez.

Lucyanus, Schoenland, in Engl. et Prantl, Naturl. Pfanzenfam, iv. 5. (1889) 65, - Hab.?

Mandonis, Zahlbr. in Ann. naturh. Hofmus. Wien, vi. (1891) 438. - Bolivia.

pallidus, Drake, in Morot, fourn. de Bot. iii. (1889) Ecuad.

reticulatus, Drake, l. c. 238. - Ecuad

sciaphilus, Zahlbr. in Ann. naturh. Hofmus. Wien, vi. (1891) 435. - Peruvia.

vernicosus, Zahlbr.l. c. 440 , - Peruvia.

yungasense, Britton, in Bull. Torrey Bot. Chub, xix. (1892) 3\%1. - Bolivia
GEPHAËLIS, Sw. (Rubiac.), - Ind. Kew. i. 480.

Bearii, "Linden ) ex Hamb. Gartenzeit. (an C. Beerii, Teijsm. et Binn. ?) (1888) 571. - Mexic

Beeriana, Fenzl, ex Pokorny, in Verh. zool.-bot. Ges Wien, xxxvi. (1886) 292. - Bras.

glomerulata, f. D. Smith, in Coult. Bot. Ga\%. xvi. 1891) 12 t. 1. - Guatem.

GEPHALANTHERA, Rich. (Orchid.).:- Ind.

Kew. i. 481 .

alba, Fritsch, in Oest. Bot. Zeitsch. xxxviii. (1888) $81=$ seq.

alba, Simonk. Enum. fl. Transsilv. (1886) $504=$ pallens, Rich.

angustifolia, Simonk. 1. c. $505=$ ensifolia, Rich.

Andrusi, Post, in Bull. Herb. Boiss, iii.(1895) 163.Mesopot.

kurdica, Bormm. ex Kraenzl. in Bull. Herb. Boiss. iii. (1895) 143. - Kurdist.

longifolia, Fritsch, in Oest. Bot. Zeitschr. xxxviii. 1888) 81 = ensifolia, Rich.

CEPHALANTHUS, Linn, (Rubiac.). - Ind.

\section{Kew. i. 481}

augustifolius, Hort. ex Dippel, Handb. Laubholzk. i. (1889) $164=$ occidentalis, Linn.

breviflorus, Spruce, ex K. Schum. in Mart. Fl. Bras. vi. VI. (1889) 129. - Bras.

coriaceus, $K$. Schum, in Engl. et Prantl, Natürl. Pfanzenfam. iv. 4. (1891) 58. - Afr. trop. occ. glabratus, $\mathrm{K}$ Schum. in Mart. Fl. Bras. vi. vi (1889) $128=$ C. Sarandi, Cham. et Schlecht.

peruvianus, Spruce, ex K. Schum. l. c. 129. Peruvia.

GEPHALARIA, Schrad. (Dipsac.). - Ind. Kew. i. 481 .

atlantica, Coss. et Dur. ex Batt. et Trab. Fl. de l'Algér. (Dicot.) (1889) $417=$ mauritanica

calcarea, Alboff, Prodv.Al.Colch. (1895) 126. - Reg. Cauc.

maroccana, Coss. ex Batt. et Trab. Fl. de l'Algér. (Dicot.) (1889) 417. - Marocco.

salicifolia, Post, in Bull. Soc. Vaud. sc. nat. $\mathrm{xxv}$. (1889) 59. - Syria.

Sintenisii, Freyn, in Oest. Bot. Zeitschr, xliv. (1894) 144. - As. Min.

tenella, Payne, List. Pl. East. Palest. 108 ; ex Boiss. Fl. Or. Suppl. (1888) 285. - Palaest.

CEPHALOCEREUS, Pfeiff. = Cereus, Haw

(Cact.).

californicus, Hort. ex K. Schum. in Engl. et Prantl, Natürl. Pflanzenfam. iii. 6a. (1894) 182. Calif.

chrysomallus, K. Schum, 1. c. = C. chrysomallus, Hemsl.

Columna, K. Schum, 1. c. = C. Columna-Trajani, Karw.

Hoppenstedii, K. Schum.1. c. (= Pilocereas Hoppenstedtii, Roezl.). - Mexic.

Melocactus, K. Schum. in Mart. Fl. Bras. vi. II (1890) 215 ; et 1. c. $181=$ C. fluminensis, Miq.

pasacanus, Weber [Paris.], ex K. Schum. in Engl. et Prantl, Natür1. Pffanzenfam. iii. 6a. (1894). 182. - Am. austro-occ.

CEPHALOGROTON, Hochst. (Euphorb.) Ind. Kew. i. 481.

cordifolius, Baker, in fourn. Linn. Soc. xxii. (1887) 520. - Madag.

CEPHALOPHORA, Cav. (Compos.). - Ind

Kew. i. 483

Barchesi, Phil. in Anal. Univ. Chil. xc. (1895) 33.Chili.

gracilis Phil.l.c.34.-Chili.

lanceolata, Phil. l.c. 35. - Chili

Leguiffei, Phil. $l . c .30$ - Chili.

Peraltae, Phil. l. c. 31. - Chili.

robusta, Rusby, in Mem. Torrey Bot. Chub, iii. III. (1893) 63. - Bolivia.

spathulata, F. Phil. ex Anal. Phil. Unir. Chil. xc.

(1895) 33. - Chili.

Stolpi, Phil. l. c. 34. - Chili.

vallenariensis, Phil. l. c. 32 . - Chili. 
CEPHAIORRHYNCHUS, Boiss = Lactuca Tourn. (Compos.).

confertus, Conrath et Freyn, ex Freyn, in Bull. Herb. Boiss. iii. (1895) 477. - As. Min.

GEPHAL OSTIGMA, A. DC. (Campanul.). Ind. Kew i, 482

Fockeanum, Schinz, in Verh. Bot. Ver, Brand. $\mathrm{xxx}$ (1888) 25\%. - Afr. austro-occ. extratrop.

CEPHALOTAXUS, Sieb, et Zucc. (Conifer.). Ind. Kew. 1. 482.

adpressa, Hort ex Beissn. Handb. Nadelholzk. (1891) $174=$ Taxus baccata, Linn.

brevifolia, Hort. ex Beissn. 1. c, $174=\mathrm{T}$. baccata, Linn.

Griffithii, Hook. f. Fl. Brit. Ind. v. (1888) 648. - Reg. Himal.

koraiana, Hort, ex Beissn. Handb. Nadelholzk. (1891) $\mathbf{1 S 1}=$ pedunculata, Sieb. et Zucc

Mannii, Hook. f. in Hook. Icon. pl. xvi. (1886) t. 1523. - Khasia.

CERASTIUM [Dill.] Linn. (Caryophyll.). - Ind, Kew i. 483 .

adenotrichum, Celak, in Oest. Bot, Zeitschr, xxxyii. (1887) 338. - As. Min.

algericum, Batt. in Batt. et Trab. Fl. de l'Algér, (Dicot.) (1888) $149=$ pumilum, Curt.

alpicolum, Brügg. in Jahresb. Nat. Ges. Graub. xxxi. Beil. (1887-88) $34=$ arvense, Linn.

amblyodontum, Colenso, in Trans. N. Z. Inst. xxvii. 1894 (1895) 384 - N. Zel.

balcanicum, Vandas, in Nym. Consp. A. Eur. ii. 1. (1889) 62; et ex Velen. Fl. Bulg. (1891) 87. Bulg.

Blyttii $\times$, Baenitz, in Oest. Bot. Zeitschr. xl. (1890) 365. - Nory.

bosniacum, G. Beck, in Annal. naturh. Hofmus. Wien, ii. (1886) $62=$ tomentosum, Linn.

brachycarpum, Stapf, in Denkschr. Akad. Wien, 1xi. (1886) 355. - As. Min.

brachyodon, Celak. in Oest. Bot. Zeitschr. xxxvii. (1887) 338. - Armenia.

brachypodum, Robins. ex Britton, in Mem. Torrey Bot. Club, v. (1894) 150; et in Proc. Am. Acad. xxix. (1894) 27\%. - Am. bor

cerastoides, Britton, 1. c. $152=$ Stellaria cerastoides, Linn.

dinaricum, G. Beck et Szyszyl. Pl. Cern, et Alban. lect. (1888) 62; et ex Bull. Soc. Bot. Fr. xxxvi. (1889) 11\%. - Monten.

Dollineri, G. Beck, in Annal. naturh. Hofmus. Wien, ii. (1887) $62=$ lanigerum, Clem

evectum, Britton, in Bull. Torrey Bot. Club, xviii. (1891) $268 i=C$. evectum, Coss, et Germ. $)=$ quater nellum, Fenz?.

grande, Greene, Pittonia, ii. (May 1892) 229. Alaska.

Hieronymi, Pax, in Bot. fahrb. xviii. (1893) 26. Reg. Argent.

Kochii, Wettst, in Luerss. Bibl. Bot. Heft xxvi. (1892) 35 = alpinum, Linn

Laestadianum $\times, H$. Samzelius, in Bot. Notis. (1890) 177. - Scand.

lazicum, Boiss. Fl. Or. Suppl. (1888) 121. - Persia. madagascariense, Pax, in Bot. Fahrb, xvii. (1893) 588. - Madag.

madrense, $S$. Wats, in Proc. Am. Acad, xxiii. (1888) 269. - Mexic

mixtum $\times$, Huter, ex Hallier, in Koch, Syn. Deutsch. F1. ed. 3 (1892) 31\%. - Germ.

montenegrinum, G. Beck et Szyszyl. Pl. Cern. et Alban. lect. (1888) $62=$ odontolepis, $G$. Beck et Szyszyl.

oblongifolium, C. Anders. Cat. P1. Nev. $118=$ nutans, Rafin.

odontolepis, G. Beck et Szyszyl. Pl. Cern. et Alban. lect. (1888) 62. - Monten.

orbelicum, Velen. in Sitzb. Böhm. Ges.Wiss, 1890 (1890) ii. 42; et Fl. Bulg. (1891) 88, - Bulg

pauciflorum, Phil. in Anal. Univ. Chil. Ixxxii.(1893) 772. - Chili.

phiysospermum, C. Gay, ex Nym. Consp. Fl. Eur. Suppl. (188:) 62 = Boissieri, Nym.

Poeliannm, Brügg. in Jahresb. Nat. Ges. Graub. xxxi. Beil. (1887-88) 34 in syn, = arvense, Linn.

\section{CERASTIUM :}

ponticum, Alboff, in Bull. Herb. Boiss. ii. (1894) 449; et Prodr. Al. Colch. (1895) 37. - Reg. Cauc schizopetalum, Maxim. in Bull. Acad. Pétersb. xxxii. (1888) 483. - Japon.

Sellowii, "Cham. et Schlecht. " ex Ann. N. Y. Acad. Sci. vii. (1892) $53=$ Sellowi, Schlecht.

texanum, Britton, in Bull. Torrey Bot. Club, xv. (1888) 97. - Texas

truncatulum, Colenso, in Trans, N.Z. Inst, xxy. $1892(1893) 32 \%$ - N. Zel.

tucumanense, Pax, in Bot. Fahrb. xviii. (1893) 25. - Reg. Argent

undulatifolium, Somm et Levier, in Act. Hort.

Petrop. xiii. (1893) 41. - Reg. Cauc.

CERASUS, [Tourn.] Linn. = Prunus, Linn.

(Rosac.).

Anti-Libani, Post, P1. Postianae, i. (1890) 8. Syria.

emarginata, Greene, F1. Francisc. (1891) 50 (non Doug1.) = P. emarginata, $W$ alp.

californica, Greene, 1. c. = P. marginata, Walp

Facquemontii, Boiss. Fl. Or. Suppl. (1888) 198. -

Reg. Himal., Afghan.

racemosa. St-Lager, in Cariot, Etud des fl. éd. 8 , ii. (1889) $217=$ P. Padus, Linn.

occidentalis, Greene, in Bull. Calif. Acad. ii. vil. (1887) $396(=$. occidentalis. Loisel. $)=\mathrm{P}$. occidentalis, $S w$.

GERATANDRA, Eckl. (Orchid.), - Ind, Kew. i. 487.

atrata, Th. Dur. et Schinz, Consp. Fl. Afr. v $1892(1895) 123=$ ochroleuca, Eckl.

CERATANTHERA, Hornem. = Globba, Linn (Scitam.)

Beaumetzii, Ed. Heckel, in Ann. Fac. sci. Marseille, i. 1. (1891) 27. - Afr, trop. occ.

CERATOCHILUS, Blume= Saccolabium, Blume (Orchid.).

papuanus, Kraenzl. ex Warb. in Bot. Jahrb. xvi. (1893) 19. - Oceania.

GERATODISGUS, Batalin, in Act. Hort. Petrop. xi. (1892) 176. GESNERACEAE.

conchaefolius, Batalin, l, c. - China.

CERATOCEPHAI,US, Burm. ex Kuntze, Rev, Gen (1891) $326=$ Spilanthes, Jacq. (Compos.).

Acmella, anactinus, Beccabunga, bicolor, caespitosus, ciliatus, commutatus, exasperatus, fimbriatus, insipidus, javanicus, Karvinskianus, leiocarpus, leucanthus, macropodus, nitidus, papposus, parvifolius, Poeppigiz ramosus, repens, sessilis, subhirsutus, urens, Kuntze Rev. Gen. (1891) $326=$ homonyma omnia Spilanthes.

americanus, Kuntze, 1. c. $=$ S. Mutisii, $H$. B. et $K$. arnicodes, Kuntze, 1. c. $=\mathrm{S}$. arnicoides, $D C$. debilis, Kuntze, 1. $\mathrm{c}_{0}=\mathrm{S}$. Acmella, Murr. decumbens, Kuntze, 1. c. = S. arnicoides, $D C$. diffusus, Kuntze, 1. c. = S. diffusus, Poepp. et Endl. ecliptodes, Kuntze, 1. $\mathrm{c}$. = Jaegeria hirta, Less. grandiflora, Kuntze, 1. c. = S. Acmella, Murv.

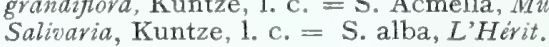
sessilifolius, Kuntze, 1. c. = Jaegeria hirta, Less. tenellus, Kuntze, 1. c. = S. Acmella, Murr. wedeliodes, Kuntze, 1. c. = Ecliptera elliptica, DC.

CERATODES, Kuntze, Rev. Gen. (1891) $548=$ CERATOIDES Kramer, Tent. Bot. (1744) $146=$ Ceratocarpus, Buxb. (Chenopod.).

arenavium, Kuntze, 1. c. $548=$ Ceratoc. arenarius, Linn.

GERATOLOBUS, Blume (Palm.). - Ind. Kew. i. 487 .

discolor, Becc. Malesia, iii. (1886) 63. - Borneo.

CERATOPETALUM, Sm. (Saxifrag.). - Ind. Kew. i. 487 .

Virchowii, F. Muell, in Vict. Natural. vii. (Mar. 1891) 181. - Austral.
GERATOPHYLLUM, Linn, (Ceratophyll.). Ind. Kew. i. 488.

cristatum, Spruce, ex K. Schum, in Mart. Fl. Bras. III. iii. (1894) $748=$ demersum, Linn.

GERATOSANTHES, Burm. (Cucurbit.). - Ind. Kew. i. 488.

angustiloba, Ridl. in fourn. Linn. Soc. xxvii. (1890) 37. - Ins. Fernando Noronha.

parviflora, $\operatorname{Cogn}$. in Bull. Acad. Belg. Sér. III. xvi (1888) 232. - Bras.

cuneata, Ridl. in fourn. Linn. Soc. xxvii. (1890) 37. - Ins. Fernando Noronha.

rupicola, Ridl. l. c. 38. - Ins. Fernando Noronha.

GERATOSEPALUM, Oliver, in Hook. Icon. pl. xxiv. (1894) t. 2307. TILIACEAE.

digitatum, Oliver, l. c. - Afr. trop. or

CERATOSTEMA, Juss. (Vaccin.). - Ind. Kew, 1. 488 .

Andreana, Drake, in Morot, fourn. de Bot.iii. (1889) 75. - Peruvia.

Hookeri, Britton, in Bull. Torrey Bot. Club, xx (1892) 137. - Bolivia.

Mandoni, Britton, l. c. - Bolivia

mutans, Niedenzu, in Bot. fahrb. xi. (1890) 207 (= Thibaudia mutans, Klotszch). — Guian.

serrata, Bvitton, in Bull. Torvey Bot.Club, xx. (1893) 138. - Bolivia.

GERATOSTYLIS, Blume (Orchid.).- Ind. Kew i. 488 .

ampullacea Kraenzl. in Bot. Fahrb. xvij. (1893) 487. - Sumatra?

clathrata, Hook. f. Fl. Brit. Ind. v. (1890) 825; et in Hook. Icon. pl. xxi. (1891) t. 2099. - Perak.

eriaeoides, Hook. f. l. c.(1891) t. 2074 b (=Eria pygmaea, Hook. f.). - Perak.

lancifolia, Hook. f. Fl. Brit. Ind. v. (1890) 826. Perak.

himalaica, Hook. f. l. c. - Reg. Himal.

malaccensis, Hook f l, c.823; et in Hook. Icon. pl. vxi. (1892) t. 2098. - Penins. Mal.

pellita, Reichb. f. ex Hook. f. F1. Brit. Ind. v. (1890) 809 in syn. = Eria leiophylla, Linn,

pendula, Hook. f. l. c. 826 ; et in Hook. Icon. pl. xxi, (1892) t. 2100. - Perak.

robusta, Hook. f. l. c. 827. - Perak.

GeratothecA, Endl. (Pedalin.). - Ind. Kew. i. 488 .

integribracteata, Engl. Bot. Fahrb. xix. (1894) 156. - Angola.

lamiifolia, Engl. l.c. - Afr. trop,

GERBERA, Linn. (Apocyn.). - Ind. Kew. i.

floribunda, K. Schum. in K. Schum. et Hollv. Fl. Kais. Wilh. Land, (1889) 111. - N. Guin.

GERGESTIS, Schott (Aroid.). - Ind. Kew. i, 489. Congensis, Engl. Bot. fahrb. xv. (1893) 448. Congo.

GERCIDIUM, Tul. (Legumin.). - Ind. Kew. i. 489 .

Torreyamum, Sarg. in Gard. and Fnr. ii. (1889) 388; et Sylva N. Amer. iii, 85 t. $130=$ Parkinsonia Torreyana, S. Wats.

viride, Taub. in Engl. et Prantl, Natürl. Pflanzenfam. iii. 3. (1892) 172 (= Retinophloeum vivide, Karst.). - Am. austr.

GERGIS, Linn. (Legumin.). - Ind. Kew. i. 489. racemosa, Oliver, in Hook. Icon. pl. xix. (1889) t. 1894. - China.

texensis, Sarg. in Gard. and For. iv. (1891) 448 et Sylva N. Amer. iii. 97 t. $135=$ reniformis, S. Wats

GERGOGARPUS, H. B, et K. (Rosac.). - Ind. Kew. i. 489.

arizonicus, M. E. Jones, in Zoë, ii. (1891) $14=$ ledifolius, $N u t t$

involutus, Greene, Pittonia, i. (April 1889) 190. Calif.

paucidentatus, Britton, in Trans. N. Y. Acad. Sc. xiv. (1894) $31=$ parvifolius, Nutt 
CEREFOLIUM, Riv. = Anthriscus, Hoffm. (Umbellif.).

Anthriscus. G. Beck, in Annal. naturh. Hofmus. Wien, x. (1895) $210=$ A. vulgaris, Bernh.

fumarioides, G. Beck, in Schubert, Park von Abbazia (1894) $97=$ A. fumarioides. Spreng.

siculum, G. Beck, in Annal. naturh. Hofmus. Wien, x. (1895) 211 in obs. = A. sicula, $D C$. enuifolium, G. Beck 1. c. $210=$ A. sylvestris, Hoffm.

CEREUS. Mill. (Cact.). - Ind. Kew, i. 489

Arendtii, Hildm. et Mathes, in Monats, für Kakteenk. iv. (1894) 173. - Urug.

Balansaei, K. Schum. in Mart. Fl. Bras. ix. I1. (1890) 210. - Parag.

Baumanni, Fenzl, in Verh. zool.bot. Ges. Wien, xxxvi. (1886) 294. - Bras.

chalybaeus, Hort. Berol. ex K. Schum, in Engl. et Prantl, Natïl. Pflanzenfam. iii, 6a. (1894) 176 $(=C$. chalibaeus, Hort.). - Bras.?

Cochal, Orcutt, in West Am. Scientist, vi. (1889) 29 ; et ex $K$. Schum. in Monats. für Kakteenk. v. (1895) 74. - Calif.

Cumengii, Weber [Puris.], in Bull. Mus. Paris, i. (1895) 317. - Calif.

Digueti, Weber, l. c. 319. - Calif.

eriocarpus, Phil. in Anal. Mus. nac. Chile (1891) 27. - Chili.

Eruca, T. S. Brandeg. in Proc. Calif. Acad. Ser. II. ii. (1889) 163 t. 7; et ex K.Schum. in Monats. fiur Kakteenk. v. (1895) 73. - Calif.

Glaziovii, K. Schum. in Mart. Fl. Bras. iv, II (1890) 200. - Bras

gummosus, Hort. ex Weber [Paris.], in Bull. Mus. Paris, i. (1895) 317 in obs. = Cumengii, Webes [Paris.]?

Hermannianus, Suring, in Versl. Kon, Akad. Wet, Amsterd. Ser. III. ii. 1885 (1886) 194. - Ind. Amster.

Hildmannianus, K. Schum, in Mart. Fl. Bras, vi. 11. (1898) 202; et in Monats. für Kakteenk. ii. (1892) 55 cum ic. - Bras

Hoppenstedtii, K. Schum. in Engl, et Prantl, Natiurl. Pflanzenfam. iii. 6 a. (1894) 181. - Mexic

Kreggii, K. Schum. in Monats. fir Kakteenk. v. (1895) $149 .-\mathrm{Hab} . ?$

lasianthus, K. Schum. in Mem. Torrey Bot. Club, iv. (1895) 208. - Am. austr.

melanotrichus, K. Schum, l.c. - Am, austr.

melanurus, $K$. Schum. in Mart. Fl. Bras, vi. II (1890) 200. - Bras.

microsphaericus, K. Schum.l. c. 197. - Bras.

monstruosus, Hort. ex K. Schum. in Engl. et Prantl, Natür1. Pfianzenfam. iii. 6a. (1894) 178 = monstrosus, Steud.?

obtusangulus, K. Schum. in Mart. Fl. Bras. iv. I1. (1890) 198. - Bras.

Plmeri, Hort. ex Weber, [Paris.], in Bull. Mus. Paris, i. (1895) 318 = Schottii, Engelm.

parvulus, K. Schum. in Mart. Fl. Bras. iv. II. (1890) 197. - Bras.

Pecten-aborigenum, "Engelm. » ex Gard. and For. (1894) 335 fig. $51=$ seq.

Pecten-aboriginum, Engelm. ex S. Wats. in Proc. Am. Acad. xxi. (1886) 429. - Mexic.

queretaroënsis, Weber [Paris.], ex Mathes, in Monats. für Kakteenk. i. (1891; 27. - Mexic.

Sargentianus, Orcutt, in Gard. and For. iv. (1891) 436 fig. 69. - Calif.

saxicolus, Morong, in Ann. N. Y. Acad. Sci. vii. (1893) 121. - Parag.

speciosus, K. Schum. in Engl. et Prantl, Natürl. Pfanzenfam. iii. 6a. (1894) 179 (= Cactus speciosus, Cav.). - Mexic.

striatus, T. S. Brandeg. in Zoë", ii. (1891) 19. -Calif.

Warmingii, K. Schum, in Mart. Fl. Bras, iv, II. (1890) 204. - Bras.

GERINTHE, [Tourn.] Linn. (Boragin.). - Ind. Kew. i. 492.

lamprocarpa, Murb. in Lunds Univ. Arsskrift, vii. v. (1992) 86. - Herceg

oranensis, Batt. in Bull. Assoc. franc. avanc. sci. (Congr. Tou1.) (1887) extr. 6 t. 81; et in Bull. Soc. Dauph. Sér. II, i. (1890) 24. - Algeria.
CERIN'THODES, Ludwig, Defin. Gen. (1737) 5, ex Kuntze, Rev. Gen. (1891) 436 = Mertensia Roth (Boragin.)

alpinum, ellipticum, lanceolatum, longistylum, maritimum, oblongifolium, paniculatum, vivulare, serrulatum, sibiricum, simplicissimum, stylosum, Kuntze, 1. c. = homonyma omnia Mertensiae

davuricum, Kuntze, 1. c. = M. dahurica, D. Don

virginicum, Kuntze, 1. c. = M. pulmonarioides, Roth

GEROPEGIA, Linn. (Asclepiad.). - Ind. Kew. i. 493

angusta, N. E. Br. in Kew Bull. (1895) 261 Angola.

antennifera, Schlechter, in Bot. Fahrb. xx. Beibl. n 51 (1895) 46. - Afr. austr.

Beccariana, Martelli, Fl. Bogos. (1886) 56. Abyss.

caffrorum, Schlechter, in fourn. Bot. xxxii. (1894) 358. - Afr. austr.

constricta, N.E. Br. in Kew Bull. (1895) 260. Afr. centr. or.

crassifolia, Schlechter, in fourn. Bot. xxxiii. (1895) 273. - Afr. austr.

debilis, N.E. Br, in Gard. Chron. (1895) ii. 358. Afr. trop. austro-or.

denticulata, $K$. Schum. ex Engl. in Abhandl. Preuss. Akad. Wiss. (1894) 38; et in Engl. Pfanzenw. OstAfr. C (1895) 327. - Afr. trop. or

distincta, N. E. Br. in Kev Bull. (1895) 262 . Zanzib.

filipendula, K. Schum. in Bot. Fahrb. xvii. (1893) 150. - Angola.

Galpinii, Schlechter, l. c. xviii. Beibl. n. 45(1894) 23. - Afr, austr.

leucotaenia, $K$. Schum, l. c. xvii. (1893) 151. Angola.

loranthiflora, $K$.Schum. l. c. 150. - Abyss.

medoènsis, N.E. Br. in Kew Bull. (1895) 263. Afr. or

Meyeri-Johannis, Engl. in Abhandl. Prenss. Akad. Wiss. 1891, ii. (1892) 343. - Afr. trop. or.

Monteiroae, Hook. f. in Bot. Mag. (1887) t. 6927; et in Monteiro, Delagoa Bay (1891) 175. - Mos samb.

mozambicensis, Schlechter, in fourn, Bot. xxxiii (1895! 273. - Afr. trop. or

nana, Coll. et Hemsl. in fourn. Linn, Soc xxviii. (1890) 89 t. 13. - Burma.

nigra, N. E. Br. in Kew Bull. (1895) 261. - Reg. Nigrit.

pachystelma, Schlechter, in Bot. Fahrb. xx. Beibl. n. 51 (1895) 47. - Afr. austr.

parviflora, Trim. in. fourn. Bot. xxvii.(1889) 164 ; Plat. illust. Fl. of Ceyl. (1895) t. 63. - Zeyl.

purpurascens, $K$. Schum. in Bot. fakrb. xvii. (1893) 152. - Angola.

pygmaea, Schinz, in Verh. Bot. Ver. Brand. xxx.

(1888) 265. - Afr. austro-occ, extratrop.

racemosa, N.E. Br. in Kew Bull. (1895) 262. Afr. centr, bor.

radicans, Schlechter, in Bot. Fahrb. xviii. Beibl. n 45 (1894) 12. - Afr. austr.

Rendallii, N.E. Br. in Kew Bull. (1894) 100. Transv.

Sandersoniae, Hook, f, in Bot. Mag. (1887) t. 6927. = Sandersoni, Decne.

scandens, N. E. Br. in Kew Bull. (1895) 262. Angola.

setifera, Schlechter, in Bot. Fahrb. xx. Beibl. n. 51 1895) 48. - Afr. austr.

sobolifera, N.E. Br. in Kew Bull. (1895) 261. Abyss.

stenantha, K. Schum. in Bot. fahrb. xvii. (1893) 152. - Afr. centr. bor.

subtruncata, N.E.Br, in Kew Bull. (1895) 260. Abyss.

tentaculata, N. E. Br, l. c. 260. - Afr, austro-occ extratrop.

tomentosa, Schlechter, in Bot. Fahrb. xviii. Beibl. $\mathrm{n}$ 45 (1894) 33. - Afr. austr.

umbraticola, K. Schum. l. c. xvii. (1893) 153. Angola.

volubilis, N. E. Br. n Kew Bull. (1895) 261. Angola.

Woodii, Schlechter, in Bot. Fahrb. xviii. Beibl, n 45 (1894) 34. - Afr. austr.
CESTICHIS, Thou. = Liparis, Rich. (Orchid.). decurrens, Pfitzer, in Engl, et Prantl, Natürl. Pflanzenfam. ii. 6. (1888) $131=$ Platystylis decurrens, Lindl.

disticha, Pfitzer, 1. c. = L. disticha, $L$ indl

latifolia, Pfitzer, 1. c, = L, latifolia, Lindl

pendula, Pfitzer, 1. c. = L. longipes, Lindl.

GESTRUM, Linn. (Solanac.). - Ind. Kew. i. 494

fasciculiflorum, Taub. in Bot. Fahrb. xv. Beibl. n. 38 (1893) 17. - Bras.

irazuense, Kuntze, Rev. Gen.(1891) 450. - Costarica.

rigidum, Rusby, in Mem. Torrey Bot.Chub, iv. (1895) 234. - Bolivia.

GHADSIA, Grandidieri, Baill. Hist. pl. Madag Atlas (1886) t. 38. - Madag.

granitica, Baill. l. c. tab. 39. - Madag.

GHAENAGTIS, DC. (Composit.). - Ind. Kew. i. 496

alpina, $M$. E. Fones, in Proc. Calif. Acad. Sér. IT. v. (1895) 699. - Utah.

lacera, Greene, Pittonia, i. (April 1889) 291. Calif.

scaposa, Eastrood, in Zoë, ii. (1891) 231. - Colorado.

CHAENANTHE, Lindl. = Diadenium, Poepp. et Endl. (Orchid.).

micrantha, Kuntze, Rev. Gen. (1891) $656=$ D. micranthum, Poepp. et Endl.

Parkeri, Kuntze, 1. c. = D. Barkeri, Benth. et Hook. $f$.

GHA ENOGEPHALUS, Griseb. (Composit.). Ind. Kew. i. 497.

arboreus, O. Hoffm. in Engl. et Prantl, Natürl. Pfanzenfam. iv. 5. (1890) 239(=Verbesina arboren, H. B. et K.). - Ecuad.

CHAENOMELES, Lindl.=Pyrus, Linn. (Rosac.) alpina, Koehne, in Gartenfl. (1891) 61 ; et Deutsche Dendrol. (1893) $262=$ P. japonica, Thunb.

chinensis, Koehne, 11. cc. $=$ P. sinensis, Poir.

GHAENOSTOMA, Benth. (Scrophul.). - Ind. Kew. i. 497.

canariense, Wettst. in Engl. et Prantl, Natürl. Pflanzenfam. iv. 3b. (1891) $69=$ Lyperia canariensis, $W e b b$.

corymbosum, Marl. et Engl. in Bot. Fahrb. x. (1889) 253. - Afr. austro-occ. extratrop.

fruticosum, Wettst. in Engl. et Prantl, Natürl. Pflanzenfam. iv. 3b. (1891) $69=$ Lyperia fruticosa, Benth.

hereroënse, Engl. Bot. fahrb. xix. (1894) 150. Afr. austro-occ. extratrop.

lyperiaeflorum, Wettst. 1. c. = Urbania lyperiaeflora, Vatke.

lyperioides, Engl. Bot. Fahrb. x. (1889) 253. - Afr austro-ocć. extratrop.

pedicellatum, Eng1. 1. c. = Lyperia pedicellata, $K$ l micranthum, Engl, in Engl. Pflanzenw. Ost-Afr. (1895) 356. = Lyperia micrantha, Klotzsch.

triste, Wettst. in Engl. et Prant1. Natürl. Pflanzenfam. iv. 3b. (1891) $69=$ Lyperia tristis Linn.

GHAEROPHYLLUM, Linn. (Umbellif.). - Ind

Kew. i. 497.

aurantiacum, Post, Pl. Postianae, iii. (1892) 8. Syria.

balcanicum, Velen. in Sitzb. Boehm. Ges. Wiss. 1892 (1893) 30. - Bulg.

Biasolettii, G. Beck, in Annal. naturh. Hofmus. Wien, x. (1895) $212=$ Biasolettia tuberosa Koch.

Borodini, Alboff, in Bull. Herb. Boiss. ii. (1894 451 ; et Prodr. fl. Colch. (1895) 106. - Reg. Cauc Borodinianum, Alboff, 1. c. iii. (1895) $521=$ praec gagausorum, Velen. in Bot. Centralb?. xxxvi. (1888) 60. - Bulg.

ghilanicum, Stapf et Wettst, in Denkschr. Akad. Wien 1xi. (1886) 54. - Asia occ. 


\section{CHAEROPHYLLUM :}

racile, Freyn et Sint. in Oest. Bot. Zeitschr. xlii. (1892) 120. - Armenia.

oligocarpum, Past, ex Boiss. Fl. Or. Suppl. (1888) 258 ; et in fourn. Linn. Soc. xxiv. (1888) 429. Syria.

rubellum, Alboff, Prodr. A. Colch. (1895) 105. Reg. Cauc.

Schmalhauseni, Alboff, in Bull. Herb. Boiss. ii. (1894) 451. - Reg. Cauc.

CHAETACANTHUS, Nees = Calophanes, D. Don (Acanthac.).

setiger, Lindau, in Bot. Jahrb. xviii. (1894) 38; in Engl. et Prantl, Naturil. Pflanzenfam. lv. $3 \mathrm{~b}$. (1894) 302; et in Eng1. Pflanzenw. Ost-Afr. C. (1895) $367^{\circ}(=$ Ch. setigera, Nees $)=$ Cal. Persoonii, Nees.

CHAETAEA, Jacq. = Buettneria, Loefl. (Stercul.).

hirsuta, Rusby, in Mem. Torrey Bot. Club, iii. MI. (1893) $10=$ B. hirsuta, Ruiz et Pav.

paraguayensis, Britton, in Ann. N. Y. Acad. sci. vii. (1892) 63. - Parag.

CHAETANTHERA, Ruiz et Pav.(Compos.). Ind. Kew. i. 498

andina, Phil. in Anal. Univ. Chil. 1xxxvii. (1894) 6. - Chili.

apiculata, Fr. Meigen, in Bot. Jahrb. xviii. (1894) 456 = Egania apiculata, Remy.

araucana, Phil. in Anal. Univ. Chil. 1xxxvi?. (1894) 10. - Chili.

brachylepis. Phil. l.c. 12.-Chili.

comata, Phil. l. c.8. - Chili

crenata, Fr. Meigen, in Bot. Jahrb. xviii. (1894) $456=$ Chondrochilus crenatus, Phil.

delicatula, Phil. in Anal. Univ. Chil. Ixxxvii. (1894) 13. - Chili.

elata, Phil. l. c. 9. - Chili.

euphrasioides, Fr. Meigen, in Bot. Fahrb. xvii.(1893) 284 (= Elachia euphrasioides, DC.). - Chili.

foliosa, Phit. in Anal. Univ. Chil. 1xxxvii. (1894) 11. - Chili.

glabraia, Fr. Meigen, in Bot. Jahrb. xviii. (1894) 456 = Tylloma glabratum. DC.

involucrata, Phil. in Anal. Univ. Chil. Ixxxvii. (1894) 6. - Chili.

lanigera. Phil. l. c. 9. - Chili.

montana, Phil.l. c. 10. - Chili.

nana, Phil. l.c. 7. - Chili.

obtusata, Phil. l. c. - Chili.

pentapetala, Phil. l. .. 13. - Chili.

pratensis, Phil. l. c. 12, - Chili.

Stuebelii, Hieron. in Bot. Fahrb. xxi. (1895) 368. Peruvia.

GHAETOCALYX, DC. (Legumin.), - Ind, Kew. i. 499

Glaziovii, Taub. in Flora. 1xxii. (1889) 425. - Bras. ilheotica, Taub. l. c. - Bras.

CHAETOCARPUS, Thw. (Euphorb.). - Ind. Kew. i. 499.

africanus, Pax, in Bot. Fahrb. xix. (1894) 113. Congo.

pubescens, Hook. f. Fl. Brit. Ind. v. (1887) 461. Zeylan.

GHAETOCHLAMYS, Lindau, in Bull. Herb. Boiss. iii. (1895) 490 ; et in Engl. et Prantl, Natürl. Pflanzenfam. iv. 3b. (1895) 354. ACAN THACEAE

macrosiphon, Lindau, ll. cc. - Bolivia.

marginata, Lindau, $l l$. cc. 491 et \$54. - Bolivia.

Rusbyi, Lindau, ll. co.-Bolivia.

CHAETOGASTRA, DC. = Tibouchina, Aubl. (Melast.).

galipensis, Klotzsch, ex Kuntze, Rev. Gen. (1891) $248=$ T. longifolia, Baill.

GHAETOLEPIS, Miq. (Melast.). - Ind. Kew, i 500 .

brevistrigillosa, Cogn. in DC. Monog. Phan. vii (1891) 172. - Cuba.

Grisebachii, $\operatorname{Cog} n . l, c,-$ Cuba.
CHAETOSPORA, R. Br. = Schoenus, Linn (Cyper.).

intermedia, G. Beck, F1. Nieder-Oest. i. (1890) 128 in syn. = S. intermedius, Brugg.

CHAETOSTOMA, DC. (Melast.). - Ind. Kew, i. 501.

Joanae, Glaziou, ex Cogn. in DC. Monog. Phan, vii. (1891) 28. - Bras

luteum, Cogn. in Mart. Fl. Bras. xiv. IV. (1888) 590 - Bras.

Petronianum, Sald. et Cogn. ex Cogn.l.c.591. Bras.

trauninense, Cogn.in DC. Monog. Phan. vii. (1891) 30. - Bras.

CHAETOTHYLAX, Nees (Acanth.) - Ind. Kew. i. 501.

boliviensis, Lindau, in Bull. Hevb. Boiss, jii. (1895) 492. - Bolivia.

Rothschuhi, Lindau, l. c. - Nicarag.

CHAETURUS morrubifolius, St-Lager, in Cariot, Etud. des fl. éd. 8. ii. (1889) 681 (= Chaicurus Marrubiastrum, Spenn.) = Leonurus Marrubiastrum, Linn.

GHAILLETIA, DC. (Chailletiac.). - Ind, Kew. i. 501

andamanica, King, in fourn. As. Soc. Beng. 1xiv. (1895) ii. 93. - Ins. Andam.

Bocageana, Henriques, in Bolet. Soc. Brot. x. (1892) 107. - Ins. S. Thom.

capitulifera, Spruce, ex Baill. in Mart. F1. Bras, xii. 1. (1886) $376=$ Tapura capitulifera, Baill.

Hookeri, King, in fourn. As. Soc. Beng. lxiv. (1895) ii. 91. - Penins. Mal.

latifolia, Spruce, ex Baill. in Mart. Fl. Bras, vii. I. (1886) 371 (= Dichapetalum latifolium, Baill.). Bras.

odorata, Spruce, ex Baill. l. c. (= Dichapetalum odoratum, Baill.) - Bras.

oleifolia, Baker, in fourn. Linn. Soc. xxv. (1889) 306. - Madag.

tenuifolia, King, in fouru. As. Soc. Beng. lxiv. (I895) ii. 91. - Perak.

CHALCAS, Linn. = Murraya, Koen. (Rutac.). exotica, Millsp. in Field Columb. Mus. Bot. Ser. i. (1895) $25=$ M. exotica, Linn.

CHAMAECERASUS, [Tourn.] Medic. = Lonicera, Linn. (Caprifol.).

Alberti, Späth, in Rev. Hortic. (1886) $547=$ Lonicera (sp.)

Niagerilli, Hort. ex Dippel, Handb. Laubholzk. i. (1889) $226=$ L. fragrantissima, Carr.

CHAMAECISTUS, S. F. Gray = Loiseleuria, DC. (Ericac.)

procumbens, Kuntze, Rev. Gen. (1891) $388=$ L. procumbens, Desf.

CHAMAECYPARIS, Spach = Thuya, Tourn. (Conif.).

acuta, Hort. ex Beissn. Handb. Nadelholzk. (1891) $92=$ T. obtusa, Benth. et Hook. f.

atrovirens, Hort. ex Beissn. 1. c. $69=$ T. sphaeroidalis, Rich.

plumosa, Hort. ex Beissn. 1. c. $87=\mathrm{T}$. pisifera, Benth. et Hook. f.

thyoides, Sargent, in Gard. and For. ii. (1889) 484 $=$ T. sphaeroidalis, Rich.

CHAMAEDAPHNE, Catesby, Nat. Hist. Carol. ii. (1740-43) t. 98 App.t. 17, ex Kuntze, Rev. Gen. (1891) 388 = Kalmia, Linn. (Ericac.).

angustifolia, cuneata, glanca, hirsuta, latifolia, Kuntze, 1. $\mathrm{c}$. = homonyma omnia Kalmiae.

ericodes, Kuntze, 1. c. = K. ericoides, Griseb.

CHAMAEDAPHNE, Moench. = Cassandra, D. Don (Ericac.).

calyculata, Baill. Hist. Pl. xi. (1892) $179=$ Cass. calyculata, G. Don
CHAMAEDOREA, Willd. (Palm.). - Ind. Kew. i. 502 .

Pringlei, S, Wats. in Proc. Am. Acad. xxvi. (1891) 157. - Mexic.

stolonifera, H. Wendl, ex Hook. f. in Bot. Mag. (1892) t. 7265. - Mexic.

CHAMAEDREA stolonifera « $\mathrm{H}$. Wendl, »e Hook. f. in Bot. Mag. (1892) sub t. 7265 sphalm. = Chamaedorea stolonifera, $H$. Wendl.

CHAMAEDRYFOLIA, Dill. Cat. Pl. Afr. Shawii (1738) n. 133, ex Kuntze, Rev. Gen. (1891) $625=$ Forskohlea, Linn. (Urtic.)

angustifolia, candida, procridifolia, tenacissima, viridis, Kuntze, 1. c. =homonyma omnia Forskohleae.

CHAMAEJASME, Amm. Ruth. (1739) 16. t. 2 ex Kuntze, Rev. Gen. (1891) $584=$ Stellera J. G. Gmel. (Thymel.).

Lessertii, Kuntze, 1. c. = S. Lessertii, C. A. Mey. stachyodes, Kuntze, 1. c. = S. Lessertii, C. A. Mey. Stelleriana, Kuntze, 1. c. = S. Chamaejasme, Linn.

CHAMAEMELUM, Vis, = Matricaria, Linn. (Compos.).

heterolepis, Freyn et Sint. ex Sint. in Bull. Herb. Boiss. iii. (1895) 349.- Armenia.

repens, Freyn et Sint. 1. c. - Armenia.

rupestre, Somm et Levier, in Nuov. Giorn. Bot. Ital. Ser. II, ii. (1895) 86. - Reg. Cauc.

CHAMAENERIUM, [Tourn.] Adans. = Epilo bium, Linn. (Onagrar.).

latifolium, Helm, in Bot. Jahrb, viii. (1887) $305=$ E. latifolium, Sweet.

CHAMAERAPHIS, R. Br. = Setaria, P. Beauv. (Gramin.)

corrugata, effusa, glanca, italica, latiglumis, paniculifera, pauciseta, Schiedeana, setosa, sulcata, uniseta, Kuntze, Rev. Gen. (1891) 771 = homonyma omnia Setariae.

brachiariaformis, Kuntze, 1. c. = Panicum brachiariaeforme, Steud.

caudata, Britton, in Ann. N. Y. Acad. Sci. vii (1894) 264. - Parag.

cirrhosa, Kuntze, Rev. Gen. (1891) 770 = S. cirrosa, Fourn.

costata, Kuntze, 1. c . 771 = Panicum flavescens, Sw. Crus-Ardeae, Kuntze, 1. c. = P. Crus-Ardeae, Willd. excurrens, Kuntze, 1, c. $=$ P. plicatum, Lam.

Forbesiana, Kuntze, 1. c. (= P. Forbesianum, Nees $)$. - Ind. or.

fuergensii, Kuntze, 1. c. $770=$ S. Jurgensenii, Fourn.

Lindenbergiana, Kuntze, 1. c. $771=$ P. Lindenbergianum, Ness.

musaefolia, kuntze, 1. c. || P. musaefolium, Klotzsch. nepalensis, Kuntze, 1. c. = P. plicatum, Lam.

neurodes, Kuntze, 1. c, = P. plicatum, Lam.

palmifolia, Kuntze, 1. c. = P. palmifolium, Poir.

paucifolia, Morong, in Ann. N. Y. Acad. Sci. vii. (1893) 265 (paucifolius). - Parag.

plicata. Kuntze, Rev. Gen. (1891) $768=$ Panicum plicatum, Lam.

prostrata, Kuntze, 1. c. $770=$ P. Leptachyrium, Doell.

speciosa, Kuntze, 1. c. = P. speciosum, $R . B r$. verticillata, Porter, in Bull. Torrey Bot. Club, xx. (1893) $196=$ S. verticillata, $P$. Beaw

viatica, Kuntze, Rev. Gen. (1891) $770=$ Panicum prostratum, Beauv

viridis, Millsp. F1. West Virgin. (1892)466; Porter, in Bull. Torrey Bot. Club, xx. (1893) $196=$ S. viridis, Beauv.

CHAMAERIPHES, Dill, = Hyphaene, Gaertn. (Palm.).

benguelensis, compressa, coriacea, crinita, macrosperma, thebaica, turbinata, ventricosa, Kuntze, Rev. Gen. (1891) $728=$ homonyma omnia Hyphaenes.

coriace, Baill. Hist. Pl. xiii. (1892) $298=$ coriacea, Kuntze [vide supra].

guineensis, Baill. 1. c. = seq.

guineensis, Kuntze, Rev. Gen. $728=\mathrm{H}$. thebaica, Mart. 
GHAMAESARACHA, A. Gray (Solan.). - Ind. Kew. i. 505 .

coniodes, Britton, in Mem. Torrey Bot. Club, v. (1894) $287=$ conoides, Benth。et Hook.

echinata, Yatabé, in Tokyo Bot. Mag. v. (1891) 355. - Japon.

heterophylla, Hemsl. in fourn. Linn. Soc. xxvi. (1890) 174. - China.

potosina, Robins, et Greenm. in Am. Fourn. Sci. Ser.

1II. 1. (1895) 161. - Mexic.

sinensis, Hemst. in fourn. Linn. Soc. xxvi. (1390) 174. - China.

Watanabaei, Yatabé, in Tokyo Bot.Mag.v. (1891) 315 t. 29. - Japon.

CHAMAESPHACOS, Schrenk (Labiat.). - Ind, Kew. i. 505.

afghanicus. Aitch. et Hensl. in Trans. Linn. Soc. Ser. II. iii. (1886) 97. - Afghan.

CHAMAETHRINAX, H. Wendl. ex R. Pfister, Beitr. vergl. Anat. Sabaleenblätter (1891) 19 nomen. $P A L M A E$

Hookeriana, H. Wend1. ex Pfister, 1. c. 46. - Hab.?

CHAMELUM, Phil. (Irid.). - Ind. Kew, i. 505.

Bodenbenderi, Kurtz, in Verh. Bot. Ver. Brand. xxxv. (1894) 112 nomen. - Chili.

CHAMISSONIA, Lindl. = Oenothera, Linn. (Onagrar.).

cheivanthifolia, Raim. in Engl, et Prantl, Natürl, Pflanzenfam. iii. 7. (1893) $17=0$. cheiranthifolia Hornem.?

conforta, Kearn = O. strigulosa, Torr. et Gray.

tenuifolia, Fr. Meigen, in Bot. Jahtb. xviii. (1894) $445=$ seq.

tenuifolia, Raim. in Engl. et Prantl, Natürl. Pflanzenfam. iii. 7. (1893) $217=$ O. tenuifolia, Cav.

CHAMISSOMNEIA, Kuntze, Rev. Gen. (1891) 326 = Schlechtendalia, Less. (Compos.)

luzulifolia, Kuntze, 1. c. $327=$ S. luzulaefolia. Less.

CHAMORCHIS, Rich. = Herminium, Linn. (Orchid.).

alpina, Simonk. Enum. fl. Transs. (1886) $504=$ H. alpina, Rich.

CHAMPEREIA, Griff. (Sarital.). - Ind. Kew. i. 506.

Gaudichaudiana, Van Tiegh. in Bull. Soc. Bot.Fr. xli. (1894) 70. - Malacca.

CHAPELIERIA, A. Rich. (Rubia 1, - Ind. Kew. i. 506.

Mellevi, K. Schum. in Engl. et Prantl, Natürl. Pflanzenfam. iv. 4. (1891) 78 (Chapeliera) = Tamatavia Melleri, Hook. $f$.

CHARDINIA, Desf. (Compos.). - Ind. Kew. i. 506.

orientalis, Kuntze, in Act. Hort. Petrop. x. (1887) $261=$ xeranthemoides, Desf.

CHARIANTHUS, D. Don (Melast.). - Ind. Kew. i. 506.

corymbosus, Cogn. in DC. Monog. Phan. vii. (1891) 714 (= Melastoma corymbosa, L. C. Rich.). Am. trop.

longifolius, $\operatorname{Cogn}$.l.c. 715. - Dominica.

CHARIESSA, Miq. = Villaresia, Ruiz et Pav. (Olacin,).

Morei, Engl. in Engl. et Prantl, Natürl. Pflanzenfam. iii. 5. (1893) 245. - Austral.

samoënsis, Engl. 1. c. (= Pleuropetalon samoènse, A. Gray). - Ins. Samoens.

CHARISTEMMA, Janka, in Termész. Fuzëtek, x. (1886) 62 = Scilla, Linn. (Liliac.)

fastigiata, Janka, 1. c. = S. fastigiata, Viv.
CHASALIA, Comm. (Rubiac.). - Ind. Kew.i. 507 gracilis, Stapf, in Trans. Linn. Soc. Ser. II. iv. (1894) 183. - Borneo.

ivens, K. Schum. in Bolet. Soc. Brot. x. (1892) $133=$ Psychotria virens, Hiern.

CHASMANTHERA, Hochst. (Menisperm.) Ind. Kew. i. 507.

Bakis, Baill. ex Laness. PI. util. col. franç. (1886) $803=$ Tinospora Bakis, Miers.

CHASMIA, Schott. = Arrabidaea, DC. (Bignon.). Rego, Kuntze, Rev. Gen. (1891) $479=$ A. Agnuscastus, $D C$.

Salzmannii, Kuntze, 1. c. = A. Salzmanni, $D C$.

CHATINIA, Van Tiegh, in Bull. Soc. Bot. Fr xlii. (1895) $350=$ Loranthus, Linn.

auviculata, Van Tiegh.1. c. $351=$ L. auriculatus, Oliver.

calyculata, Van Tiegh. 1. c. = L. calyculatus, DC.

Kerberi, Van Tiegh. 1. c. = L. Kerberi, Fonrn

Schiedeana, Van Tiegh. 1. c. = L. Schiedeanus, Cham, et Schlecht.

CHAUNOSTOMA, J. D.Smith, in Coult. Bot. Gaz xx. (1895) 9. LABIATAE

mecistandrum, 7. D. Smith, l. c.t. 3. - Guatem

GHEILOTHECA, Hook. f. (Monotrop.). - Ind. Kew. i. 508.

malayana, Scortech. ex Hook. f. in Hook. Icon. pl. xvi. (1887) t. 1564. - Penins. Mal.

GHEIRANTHUS, Linn. (Crucif,), - Ind. Kew. i. 508 .

luteus, St-Lager, in Cariot, Etud. des fl. éd. 8, II (1889) $37=$ luteus, Dulac.

occidentalis, S. Wats. in Proc. Am. Acad. xxiii. (1888) 261. - Am. bor. occ

roseus, Maxim. Fl. Tangut. (1889) 57 t. 21 fig. 1-12. - China.

CHEIROSTYIIS, Blume (Orchid.). - Ind. Kew i. 510

Franchetiana, King et Pantling, in fourn. As. Soc. Beng. lxiv. (1895) ii, 341. - Ind. or.

GHELIDONIUM, Tourn, ex Linn. (Papaver.). Ind. Kew. i. 510.

lasiocarpum, Oliver, in Hook. Icon.pl. xviii. (1888) t. 1739. - China.

sutchuenense, Franch, in Morot, Journ, de Bot. viii. (1894, $293=$ Stylophorum sutchuenense Franch.

CHELONANTHUS, Gilg = Lisianthus, Linn. (Gentian.).

acutangulus, Gilg, in Engl. et Prantl, Natürl Pflanzenfam. iv. 2. (1895) $98=$ L. tetragonus Benth.

angustifolius, Gilg, 1. c. = L. angustifolius, H. B. et $K$.

bifidus, Gilg, 1. c. = L. bifidus, $H$. B. et $K$

campanulatus, Gilg, 1. c. = L. campanuloides, Spruce.

chelonoides, Gilg, 1.c. = L. chelonioides, Linn.

fistulosus, Gilg, 1. c, = L. fistulosus, Poir.

Schomburgkii, Gilg, 1. c. = I. Schomburgkii, Griseb.

uliginosus, Gilg, 1.c. = L. uliginosus, Griseb.

viridiflons, Gilg, 1. c. = L. viridiflorus, Mart.

GHELONESPERMUM, Hemsl, in Ann. of Bot. vi. (July 1892) 205. SAPOT ACEAE. fijiense, Hemsl. l. c. 207. - Ins. Fiji. majus, Hemsl. l. c. 286. - Ins. Salomen. minus, Hemsl. l.c. 207. - Ins Salomon. unguiculatum, Hemsl. l. c. - Hab.

GHELONOPSIS, Miq. (Labiat.). - Ind. Kew. i. 511 .

Benthamiana, Hemsl. in fourn. Linn. Soc. xxvi. (1890) 298 (= Bostrychanthera deflexa, Benth.). China.
GHENOLEA, Thunb. (Chenopod.). - Ind. Kew. 1. 511

Cornischiana, F. Muell, in Bot. Centralbl. xxyi. (1889) 228 in syn. = Bassia Cormishiana, F. Muell.

divaricata, Hook.f. Fl. Bri. Ind. v. (1886) 10. As, centr.

eriophora, Aitch. et Hemsl. in Trans. Linn. Soc. Ser。 II. iii. (1886) 102, - Afghan.

sedoides, Hook. f. Fl. Brit. Ind. v. (1886) 10. Eur, Asia.

GHENOPODIUM, [Tourn.] Linn. (Chenopod.).Ind. Kew. i. 511 .

acutifolium, Phil. in Ann. Univ. Chil. xci. (1895) 420. - Chili.

aromaticum. Hort. ex Kew Bull. (1892) Append. i. 6. - Germ.

Borbasii $x$, Murr, in Progr. Realsch. Innsbr. (1891) 56; et in Deutsche Bot. Monatsschr. xi. (1893) 9 et xii. (1894) 99. - Tirol.

bryoniaefolium, A. Bunge, in Act. Hort. Petrop. xiii. (1893) 16. - As, bor. or

Buchanani, T. Kirk, in fourn. Bot. xxvii. (1889) 139; et in Trans. N. Z. Inst. xxii. 1889 (1890) 446= 467. - N. Zel.

capitatum, S. Wats. ex Britton, in Geol. Surv. N. Jersey, ii. (1889) 207 = capitatum, Aschers. chilense, Phil. in Anal. Uniw. Chil. xci. (1895) 418. - Chili.

hastatum, St-Lager, in Cariot, Étud. des A. éd. 8. ii. (1889) $703=$ C. Bonus-Henricus, Linn.

latifolium, Phil. in Anal. Univ. Chil. xci. (1895) 418. - Chili.

patagonicum, Phil.l. c. 419. - Patagon.

prostratum, Bunge, ex Herder, in Act. Hort. Petrop. x. (1889) 594. - Sibiria.

prostratum, Roxb. ex Hook. f. Fl. Brit. Ind. v. (1886) $14=$ Suaeda nudiflora, Moq.

sparsiflorum, Phil. in Anal. Univ. Chil. xci. (1895) 419. - Chili.

subaphyllum, Phil. l.c. 421. - Chili.

trifurcatum, Phil. l. c. 418, - Chili

GHERSODOMA, Phil, in Anal. Mus, nac. Chile (1891) 32. COMPOSITAE

candida, Phil.l.c. tab. 1. fig. 6. - Chili.

CHEVALIERIA, Gaudich.= Aechmea, Ruiz et Pav. (Bromel.).

Fernandae, Hort. ex Baker, Handb. Bromel. (1889) 64 in syn. = Ae. Fernandae, Baker.

gigantea, Maury, in Bull. Assoc. Franç. (Congr. de Toulouse) 1887 (1888; 556 ; in Le Jardin (1888) 8 171 cum xylogr.; et in Rev. Hortic. (1888) 370 fig. $83=$ Ae. gigantea, Baker.

Magdalenae, Ed. André, in Rev. Hortic. (1888) 503; et Bromel. Andr. $65=$ Ae. Magdalenae, É. André.

CHIANTHEMUM, Sieg. Fl. Petrop. (1736) 31pr.p. ex Kuntze, Rev. Gen. (1891) 703 = Galanthus, Linn. (Amaryll.).

Elwesii, Kuntze, 1. c. = G. Elwesii, Hook. $f$.

graecum, Kuntze, 1. $c_{0}=\mathrm{G}$. graecus, Orph.

nivale, Kuntze, 1. c. = G. nivalis, Linn.

Olgae, Kuntze, 1. c. = G. Olgae, Orph.

plicatum, Kuntze, 1. c. = G. nivalis, Linn.

CHILIOTRICHUM, Cass. (Compos.). - Ind.

Kew. i. 514

anoustifolium, Phil. in Anal. Univ, Chil. 1xxxvii. (1894) 401. - Chili.

longifolium, Phil. l.c. - Chili.

tenue, Phil. l. c. - Chili.

GHIMARFHIS, Jacq. (Rubiac.), - Ind. Kew. i.

515.

Hookeri, K. Schum. in Mart. Fl. Bras, vii. vi. (1889) 259. - Peruvia.

pisoniaeformis, "Baill. » ex K. Schum. 1. c. $226=$ Sickingia pisoniaeformis, Baill.

CHIMONANTHUS, Lind1. (Calycanth.). - Ind. Kew. i. 515.

nitens, Oliver, in Hook. Icon. pl. xvi. (1887) t. 1600 . - China. 
CHIOCOCCA, P. Br, (Rubiac.) - Ind. Kew, i. 515.

alba, Hitchc, in Missouri Bot. Gard. Rep. iv 1893) $94=$ racemosa, $\operatorname{Linn}$.

CHIOGENES, Salisb. (Vaccin.). - Ind, Kew. i. hispidula, Baill. Hist. Pl. xi. (1892) $184=$ hishispidula, Baill. Hist.
pidula, Torr. et Gray.

GHIONACHNE, R. Br. (Gramin.). - Ind. Kew. 1. 515 .

Massii, Balansa, in Morot, fourn. de Bot. iv. (1890) 78. - Tonk

Sclerachne, F. M. Bailey, in Dept. Agric. Bot. Bull. [ii.] (1891) 21.- Austral.

GHIONODOXA, Boiss. (Liliac.). - Ind. Kew, i. 516. sardensis, Barr et Sugden, Catal. (1883), ex Garden, (1888) 371. - As. Min.

CHIONOGRAPHIS, Maxim. (Liliac.). - Ind Kew. i. 516.

lutea, Baill. Hist. Pl. xii. (1894) 593 = japonica Maxim.

Chionolaena, DC. (Compos.). - Ind. Kew i. 516 .

eleagnoides, Klatt, in Leopoldina, Heft xxiii. (1887) 88. - Mexic.

innovans, Warera, Itin. Princ. S. Coburg. ii. (1888) 30. - Bras.

Sartorii, Klatt, in Leopoldina, Heft xxiii. (1887) 89. - Mexic.

CHIRIDIUM, Van Tiegh. in Bull. Soc. bot. Fr xli. (1894) 483 = Loranthus, Linn.

Beccarii, Van Tiegh. 1. c. xli. (1894) 541. Borneo.

Lijndenianum, Van Tiegh. I. c. $484=$ L. Lijndenianus, Zoll.

longissinum, Van Tiegh. 1. c. 541. - Sumatra.

setigerum, Van Tiegh. 1. c. $484=$ L. setigerus, Korth.

speciosum, Van Tiegh. 1. c. = L. speciosus, Wall.

verticillatum, Van Tiegh.1. c. 541. - Perak.

GHIRITA, Buch.-Ham. (Gesner.), - Ind. Kew.i.

516.

Balansae, Drake, in Bull. Soc. Philom. Sér. VIII. ii. (1890) 138. - Tonkin.

bracteosa, Drake, l. c. 39. - Tonkin

depressa, Hook. f. in Bot. Mag. (1892) t. 7213. China.

CHIRONIA, Linn. (Gentian.).-- Ind. Kew. i. 516. densiflora, S. Elliot, in fourn. Bot. xxix. (1891) 69. - Afr. austr.

fruticosa, Kuntze, Rev. Gen. (1891) 432 sphalm. = Orphium frutescens, E. Mey.

lancifolia, Baker, in Fourn. Linn. Soc. xxv. (1898) 334. - Madag.

laxiflora, Baker, in Kew Bull. (1894) 25. - Zambesia.

CHIROPETALUM, A. Juss, = Argithamnia, Sw. (Euphorb.)

Pavonianum, Pax, in Engl.et Prantl, Natür1. Pflanzenfam. iii. 5 (1890) $45=$ A. Pavoniana, Muell. Avg.

Schiedeanum, Pax, 1. c. = A. Schiedeana, Muell. $A$ rg

Sponiclla, Pax, 1, c. = A. sponiella. Muell. Arg.

GHISOCHETON, Blume(Meliac.). - Ind. Kew. i. 517

annulatus, King, in fourn. As. Soc. Beng. 1xiv. (1895) ii. 31. (Chizocheton). - Perak.

Balansae, C. DC. in Bull. Herb. Boiss, ii. (1894) 578. - Tonk.

Kunstleri, King, in fourn. As. Soc. Beng. 1xiv. (1895) ii. 27. - Perak.

laxiflorus, King, l. . . 33. - Perak.

macrophyllus, King, l. c. 22. - Penang

macrothyrsus, King. l. c. 33. - Perak.

\section{GHISOCHETON : -}

Princeps, Hemsl. in Hook. Icon. pl. xix. (1889) t. 1844. - Penang.

pauciflorus, King, in fourn. As. Soc. Beng. 1xiv. (1895) ii. 2\%. - Perak

rubiginosus, King, l. c. 29. - Perak.

GHLAMIDACANTHUS, Lindau, in Bot. Jahrb xviii. (1894) 58; et in Eng1. et Prantl, Natürl. Pflanzenfam. iv. 3b. (1895) 343. ACANTHA$C E A E$

euphorbioides, Lindau, ll. cc. 109, 61 et $343 \mathrm{fig}$. 137. - Madag.

GHLAMYDOGARDIA, Lindau, in Bot. Jahrb. $\mathrm{xx}$. 1894) 39 ; et in Engl, et Prantl, Natürl. Pflanzenfam. iv. 3b. (1895) 329. ACANTHACEAE.

Buettneri, Lindau, $l l . c c$. - Afr, trop. occ.

subrhomboidea, Lindau, l. c. xxii. (1895) 119. Kamerun.

GHLAMYDOCARYA, Baill. (Olacin.). - Ind Kew. i. 518.

Soyauxii, Engl. Bot. Falwb. xxii. (1893) 73. Gabon.

CHLAMYPHORUS, Klatt, in Leopoldina, Heft xxv. (1889) 106. COMPOSIT AE.

obvallatus, Klatt, l. c. 10\%.- Bras.

CHLAMYSPORUM, Salisb. = Thysanotus, $\mathrm{R} . \mathrm{Br}$ (Liliac.)

anceps, arbusculum, asperum, Baueri, dichotomum, Drummondii, exiliflorum, glaucum, isantherum, jun ceum, pauciflorum, scabrum, tenue, tuberosum, Kuntze Rev. Gen. (1891) $708=$ homonyma omnia Thysanoti.

chrysantherum, Kuntze, 1. $\mathrm{C},=\mathrm{T}$. chinensis, $D C$

Menziesii, Kuntze, 1. $c_{2}=$ T. Patersonii, R. $B r$.

thyrsodeum, Kuntze, 1. c. $=$ T. thyrsoideus, Baker

CHLEV $A X$ athous, Cesati, ex Boiss. Fl. Or. Suppl. (1888) 265 in syn. = Ferula meoides, Linn

CHLOANTHES, R. Br.(Verben.). - Ind. Kew 1. 518

coeruleus, F. Muell. et Tate, in Elder Exped. Diagn. new. pl. [1]; et ex Bot. Centralbl. 1v, (1893) 317. Austral.

Teckiana, F. Muell. in Vict. Natural. vi. (Oct. 1889) 104; et ex Bot. Centralbl, x1. (1889) 268. Austral.

GHLORAEA, Lind1. (Orchid.). - Ind. Kew. i 518.

Arechavaletae, Kraenzl. in Bot. Fahrb. ix (1888) 316: Cogn. in Mart. Fl. Bras. iii. IV. (1895) 107 t. 20 fig. 2. - Reg. Argent.

Bugainvilleana, Franch. Miss. scient. Cap Horn, v. (Phan.) (1889) 366. - Reg. Magell.

Pigichen, Kuntze, Rev. Gen. (1891) 652 sphalm. = C. Piquichen, Lindl.

Teixeirana, Cogn. in Mart.Fl. Bras, iii, Iv. (1893) 107 t. 18 fig. 4 (= Geoblasta Teixeirana, Rodr.). - Bras.

Ulantha, Rolfe, in Kew Bull. (1893) 278 (= Ulantha grandiflora, Hook.). - Ins. S. Vinc.

CHLORANTHUS, Sm. (Chloranth.).-Ind. Kew. i. 519 .

angustifolius, Oliver, in Hook. Icon. pl. xvi. (1886) t. 1580. - China.

Henryi, Henssl. in fourn. Linn. Soc. xxvi.(1891) 367. - China.

nervusus, Collett et Hemsl. l: G. xxviii. (1890) 118. Burma.

CHLORIS, Sw. (Gramin.) - Ind. Kew, i. 519. cenchriformis, Baill. in Bull. Soc. Linn. Pavis, ii. (1893) 1070 (= Lepidopyronia cenchriformis, A. Rich.). - Abyss.

longifolia, Vasey, in Contrib. U.S. Nat. Herb. i (1893) 284 t. 19. - Mexic

neglecta, Nash, in Bull. Torrey Bot.Club, xxii. (1895) 423. - Florida.
CHLORIS

obtusifolia, Balansa, in Morot, fourn. de Bot. iv. (1890) 166. - Tonk.

Savatieri, Baill. in Bull. Soc. Linn. Paris, ii. (1893) 1070. - Ins. Cap. Virid.

spathacea, Baill. l. C. (an C. spathacea, Hochst.?).Arabia.

GHLOROCODON, Hook. f. (Asclep.) - Ind. Kew. i. 520 .

ecornutum, N. E. Br. in Kew Bull. (1895) 111 (ecornuta). - Afr. trop. austro-or

CHLOROCYATHUS, Oliver, in Hook. Icon. pl xvi. (1887) t. 1557. ASCLEPIADEAE.

Monteiroae, Oliver, l.c.; Monteiro, Delagoa Bay (1891) 176. - Mossamb.

GHLOROGALUM, Kunth (Liliac.). - Ind. Kew. i. 520 . purpureum, T. S. Brandeg. in Zoe, iv. (1893) 159.Calif.

GHLOROLUMA, Baill. Hist. pl. xi. (1892) 294. SAPOTACEAE

GHLOROPHORA, Gaudich. (Urtic.). - Ind Kew, i. 520 . tenuifolia, Engl. Bot. Fahrb. xx. (1894) 139. - Ins. S. Thom.

GHLOROPHXTUM, Ker-Gawl. (Liliac.). - Ind. Kew. i. 520 .

africanum, Engl. Bot. Jahrb. xv. (1893) $470=$ Dasystachys Grantii, Benth. et Hook. $f$.

aureum, Engl. Bot. Fahrb. l.c. 469. - Afr. centr. bor.

brachystachyum, Baker, in Gard.Chron. (1893) i 711. - Reg. Nyass.

bukobense, Engl. Pfanzenw. Ost-Afr. C (1895) 139 - Afr. trop. or.

campanulatum, Engl, in Abhandl. Preuss. Akad. Wiss. 1891 (1892) $161=$ Dasystachys campanulata, Baker.

chinense, Bureau et Franch, in Morot, fourn. de Bot. v. (1891) 154. - China

chloranthum, Baker, in fourn. Linn. Soc. xxii. (1887) 529. - Madag.

colubrinum, Engl. in Abhandl. Preuss. Akad. Wiss. 1891 (1892) $162 \doteq$ Dasystachys colubrina, Baker.

cordatum, Engl. Bot. Fahrb. xv. (1893) 468. - Afr. centr. bor.

densiflorum, Engl.l.c. 470, - Angola.

elongatum, Baker, in Bot. Fahrb. xv. Beibl. n. 35 1892) 9. - Bras.

falcatum, Engl. in Abhandl. Preuss. Akad. Wiss 1891 (1892) $161=$ Dasystachys falcata, Baker.

fusiforme, Rendle, in fourn. Limn. Soc. xxx. (1895) 419. - Afr. trop. or.

gracile, Bakev, $l . e$. xxv, (1890) 348. - Madag.

Holstii, Engl. in Abhandl. Prenss. Akad. Wiss. (1894) 29 ; et Pfanzenw. Ost-Afr. C (1895) 140. - Afr. trop. or.

khasianum, Hook. f. Fl. Brit. Ind. vi. (1892) 334.Khasia.

marginatum, Rendle, in fourn. Linn. Soc. xxx. (1895) 422. - Afr. trop. or

miserum, Rendle, l. c. 420 .- Afr. trop. or.

moniliforme, Rendle, $l$. .. 418 . - Afr. trop. or

papillosum, Rendle, l. c. 423. - Afr. trop. or.

pleiostachyum, Th. Dur, et Schinz, Consp. Fl. Afr. v. 1893 (1895) 352 = Dasystachys pleiostachya, Baker.

puberulum, Engl. Pflanzenw. Ost-Afr. C (1895) 139. - Afr. trop. or.

ramiferum, Rendle, in fourn. Linn. Soc. xxx. (1895) 521. - Afr. trop. or.

Schimperi, Engl. in Abhandl. Preuss. Akad. Wiss. 1891 (1892) 161. - Abyss.

somaliense, Baker, in Bot. Fahrb. xv. (1893) 469. Reg. Somal.

tenuifolium, Baker, in Kew Bull. (1895) 228. - Reg. Somal.

viridescens, Engl. Pfanzenw. Ost-Afr. C (1895) 140. - Afr, trop. or. 
CHLOROPSIS, Hackel $=$ Trichloris, Fourn. $($ Gra$\min$.).

Blanchardiana, J. Gay, ex Vasey, Ill. N. Am. Grass. I. ii. (1891) sub t. 25 in syn. $=T$, verticillata [vel potius, fasciculata] Fourn.

Blanchardiana, Kuntze, Rev. Gen. (1891) $771=$ praec.

crinita, Kuntze, 1. $c_{.}=$Chloris crinita, Lag.

fasciculata, Kuntze, 1. c. = T. fasciculata, Fourn

pluriflora, Kuntze, 1. c. = T. pluriflora, Fourn.

Pumilio, Kuntze, 1. c. = Chloris Pumilio, $R . B r$.

CHLOROSTELMA, fritillarioides, Welw. ex Rendle. in Journ. Bot. xxxii. (1894) 162 in syn.=Xysmalobium fritillarioides, Rendle.

GHOISYA, H. B. et K. (Rutac.), - Ind. Kew. i, 520.

dumosa, A. Gray, in Proc. Am. Acad. xxiii. (1888) 224. - Am. bor.

GHOMELIA, Jacq. (Rubiac.). - Ind. Kew. i 521.

affinis, $K$. Schum. in Engl. Pfanzenw. Ost-Afr. C (1895) 380 . - Afr. trop. or.

angolensis, Kuntze, Rev. Gen. (1891) $278=$ Tarenna angolensis, Hiern.

asiatica, Kuntze, 1. c. = T. zeylanica, Gaertn

Buchananii, K. Schum. in Engl. Pflanzenw. Ost.-Afr. C (1895) 380. - Afr. trop. or.

conferta, Kuntze, Rev. Gen. (1891) $27=$ Tarenna conferta, Hiern.

congensis, Kuntze, 1. c. = T. congensis, Hiern.

coriacea, K. Schum. ex Engl, in Abhandl. Preuss Akad. Wiss. (1894) 19; et in Engl. Pflanzenw. Ost-Afr. A (1895) $17=$ Enterospermum nigxi cans, Hook.f.

corymbosa, K. Schum, in Engl. et Prantl, Natürl. Pflanzenfam. iv. 4 (1891) $74=$ Tarenna zeylanica, Gaertn.

cuspidata, Kuntze, Rev. Gen. (1891) 278 (= Stylocoryna cuspidata, E. Mey.). - Afr. austral.

Dallachiana, Kuntze, 1. c. (= Webera Dallachiana, F. Muell.). - Austral.

fragrans, K. Schum. in Engl. et Prantl, Natürl. Pflanzenfam. iv. 4 (1891) $/ 4$ (= Wahlenbergia fragrans, Blume). - Malaya.

grandiflora, Kuntze, Rev. Gen. (1891) $278=$ Tarenna grandiflora, Hiern.

mollissima. Kuntze, 1. c. (= Webera mollissima, Benth.). - China.

Morongii, Britton, in Ann. N. Y. Acad. Sci, vii. (1893) 127. - Parag.

mosambicensis, Kuntze, Rev, Gen. (1891) $278=$ Tarenna mossambicensis, Hiern.

mossambicensis, K. Schum, in Engl. Pflanzenw. Ost-Afr. C (1895) $379=$ praec.

myrtifolia, $S$. Moore, in Trans. Linn. Soc. Ser. II. iv. (1895) 373. - Bras.

nigrescens, K. Schum. in Abhandl. Preuss, Akad. Wiss. (1894) 36 ; et in Engl. Pflanzenw. Ost.-Afr C $(1895) 380=$ Coptosperma nigrescens, Hook. $f$.

nigrescens, Kuntze, Rev. Gen. (1891) 278 = Tarenna nigrescens, Hiern.

nilotica, Kuntze, 1. c. = T. nilotica, Hiern.

nitidula, Kuntze, 1. c. = T. nitidula, Hiern.

pallidula, Kuntze, 1. c. = T. pallidula, Hiern.

Pringlei, S. Wats. in Proc. Am. Acad. xxvi. (1891) 137. - Mexic

sambucina, Kuntze, Rev. Gel. (1891) $278=\mathrm{Pa}$ vetta sambucina, $D C$.

sechellensis, Kuntze, 1. c. (= Webera sechellensis, Baker). - Ins. Seychell.

tetramera, Kuntze, Rev. Gen. (1891) $278=$ T. tetramera, Hiern.

tetramera, K. Schum. in Engl. et Prantl, Natürl. Pflanzenfam. iv. 4 (1891) $74=$ Tarenna tetramera, Hiern.

GHONDRILLA, [Tourn.] Linn. (Compos.). Ind. Kew, i. 522.

Albertoregelia, C. Winkl. in Act. Hort. Petrop. xi. (1890) 337. - Buchara.
CHONDROCHILUS, Phil. = Chaetanthera, Ruiz et Pav. (Compos.).

grandiflorus, Phil. in Anal, Univ. Chil. 1xxxvii. (1894) 15. - Chili.

lanatus, Phil.1. c. 14. - Chili.

CHONDROPHORA Rafin. New Fl. N. Am. iv. (1836) 79 ex Britton, in Mem. Torrey Bot. Club, v. (1894) $317=$ Bigelowia, DC. (Compos.).

Drummondii, Heller, Bot, Explor.S. Texas i.(1895)

$101=$ B. Drummondii, $A$. Gray.

Engelmanni, Britton, in Mem. Torrey Bot. Club, v. (1894) $317=$ B. Engelmanni, A. Gray.

Howardi, Britton, 1. c. = B. Howardi, A. Gray.

nauseosa, Britton, 1. c. = B. graveolens, A. Gray.

nudata, Britton, 1. c. = B. nudata, $D C$

virgata. Greene, in Erythea, iii. (1895) $91=$ B. nudata, $D C$.

CHONDRORHYNCHA, Lindl. (Orchid.). - Ind. Kew. i. 522 .

bicolor, Rolfe, in Kew Bull. (1894) 393. - Costarica.

Lendyana, Reichb, f. in Gard. Chron. (1886) ii. 103. - Hab.?

CHONDRosum, Desv. = Bouteloua, Lag. (Gramin.).

Drummondii, Fourn. Gramin. Mexic, 1881 (1886) 137. - Mexic

Trinii, Fourn. 1. c. 135. - Mexic.

CHONOLEA, Kuntze, Rev. Gen. (1891) 546 err, typ. = Chenolea, Thunb. (Chenop.).

CHORILAENA, Endl. (Rutac.). - Ind. Kew. i. 523.

Hasseltii, F. Muell. in Vict. Natural. vi. (Sept. 1889) 87; et ex Bot. Centralbl. xl. (1889) 94. - Austral.

GHORIOLUMA, Baill. in Bull. Soc. Linn. Paris, ii. (1892) 892; et Hist. pl. xi. (1892) 287. SAPOTACEAE.

coriacea, Baill.l.c. (=Sideroxylon coriaceum, Baill. $)$. - N. Caled.

GHORISIA, H. B. et K. (Malv.). - Ind. Kew. i. 523.

soluta, F. D. Smith, in Coult. Bot. Gaz.xvi. (1891) 1. - Guatem

CHORISPERMUM, R. Br. = Chorispora, DC. (Crucif.)

exscapum, ibericum, persicum, sibiricum, syriacum, Kuntze, Rev. Gen. (1891) 26 = homonyma omnia Chorisporae.

elegans, Kuntze, 1. c. $26=$ Chorispora sabulosa, Cambess.

strictum, Kuntze, 1. c = Diptychocarpus strictus. Trauty.

CHORISTIGMA, Baill. Hist. des pl. xl. (1892) 454 = Schoepfia, Schreb. (Olacin.)

grandifolium, Baill. Hist. des pl. xi. (1892) $454=$ S. grandifolia, Baill.

CHORISTYLIS, Harv, (Saxifrag.). - Ind. Kew. i. 524 .

shirensis, Baker f. in Trans. Linn. Soc. Ser. II. iv. (1894) 13. - Reg. Nyass.

virescens, Baker f.l. c. - Reg. Nyass.

GHORIzANTHE, R. Br. (Polygon.). - Ind. Kew. i. 524.

Andersoni, Parry, in Proc. Davenp.Acad. v. (1889) 176. - Am. bor. occ.

densa, Phil. in Anal. Univ. Chil. xci. (1895) 496 et 499. - Chili.

deserticola, Phil. l. c. 298. - Chili.

Douglasii, Parry, in Proc. Davenp. Acad. v. (1889) I76 = Douglasii, Benth.?

fasciculata, Phil. in Anal. Univ. Chil. xci. (1895) 497. - Chili.

flava, T. S. Brandeg. in Proc. Calif. Acad.Ser. II. ii. (1889) 202. - Calif.

\section{CHORIZANTHE : -}

humilis, Phil. in Anal. Univ. Chil.xci. (1895) 495.Chili.

illapelina, Phil.l. c. 497. - Chili.

insignis, Curran, in Bull. Calif. Acad, i. (1885) 275 - Calif.

intricata, Phil. in Anal. Univ. Chil. xcl. (1895) 495 . - Chili.

mutabilis, T. S. Brandeg. in Proc. Calif. Acad. Ser. II. ii. (I889) 203. - Calif

Nortoni, Greene, Pittonia, ii. (July 1891) 164. Calif

parviflora, Phil. in Anal. Univ. Chil. xci. (1895) 494 - Chili.

pauciflora, Phil. l. c. 495. - Chili.

pulchella, T.S. Brandeg. in Proc. Calif. Acad. Ser.

II. ii. (1889) 203, - Calif.

robusta, Parry, in Proc. Davenp. Acad. v. (1889) 176. - Am. bor occ

tenuis, Phil. in Anal. Univ. Chil. xci. (1895) 499. Chili.

Vaseyi, Parry et Rose, in Coult. Bot. Gaz.xv. (1890) 64 t. 10 . Calif

viridis, Phil in Anal Univ, Chil. xci. (1895) 498,Chili

Vortriedei, T. S. Brandeg. in Zoë, iv. (1893) 158. Calif.

CHOROZEMA, Sm.= Ghorizema, Labill. (Legumin.).

Lowii $\times$, Hort. ex Rev. hort. Belge, xx. (1892) 265 cum ic. - Hybr. artef.

CHRISTOPHORIANA, Burm, Afr, dec. (1738) 145-7 t. 51, ex Kuntze, Rev. Gen. (1891) 1. Knowitonia, Salisb. (Ranuncul.)

capensis, daucifolia, gracilis, hirsuta, vesicatoria, Kuntze, Rev. Gen. (1891) 1 = homonyma omnia Knowltoniae.

rotundifolia, Kuntze, 1. c. $931=\mathrm{K}$. rotundifolia, Huth.

CHROSPERMA, Rafin. = Zygadenus, Michx. (Liliac.).

muscaetoxicum, Kuntze, Rev. Gen. (1891) \%08 = Z. muscitoxicum, Regel.

GHRYSACTINIA, A. Gray (Compos.). - Ind

Kew. 1. 525.

pinnata, S. Wats. in Proc. Am. Acad. xxv. (1890) 153. - Mexic

truncata, S. Wats. l. . . - Mexic.

CHRYSAMPHORA; Greene, Pittonia, ii. (Sept 1891) 191 = Darlingtonia, Torr. (Sarracen.) californica, Greene, 1. C. = D. californica, Torr.

GHRYSANTHELLUM, Rich. (Compos.). - Ind. Kew. i. 525

americanum, Hitchc. in Missouri Bot. Gard. Rep. iv. (1893) $10 \mathrm{I}=$ procumbens, $\mathrm{R} i \mathrm{ch}$

CHRYSANTHEMUM, [Tourn,] Linn. (Compos.), - Ind. Kew. i. 526

achilleifolium, Kuntze, in Act. Hort. Petrop. x. (1887) $200=$ achilleaefolium, $D C$

arassanicum, C. Winkl. in Act. Hort. Petrop. xi. 1890) 372. - Turkest

canariense, Christ, in Bot. Fahrb. ix. (1888) 146 (=Preauxia canariensis, Sch. Bip.), - Ins. Canar.

Clausonis, Batt. in Batt. et Trab. Fl. de l'Algér.

[Dicot.] (1889) 463. - Algeria.

crithmifolium Christ, in Bot. Tahrb. ix. (1888) 146 $=$ crithmifolium, Brouss.

Decaisneanum, N.E. Br. in Kew Bull.ii. (1888) 98. - Japon.

Dugourii. Christ, in Bot. Falırb. ix. (1888) 146 (= Preauxia Dugourii, C. Bolle).-Ins. Canar. filifolium, Christ, l. c. 168 (= Monoptera filifolia, Sch. Bip.). - Ins. Canar.

Gayanum, Batt. in Batt. et Trab. Fl. de l'Algér. [Dicot.] (1889) $466=$ Pyrethrum Gayanum, Coss, et Durieu.

gloriosum, Hort ex Gard. Chron. (1886) ii. 749. Form. hort. 


\section{CHRYSANTHEMUM :}

grandiflorum Batt in Batt et Trab. Fl. de l'Algér. [Dicot.] (1889) 464 (= Balsamita grandiflora, Desf.). - Afr. bor.

huronense, Kuntze, Rev. Gen. (1891) $327=$ Tanacetum huronense, Nutt.

jacobaeifolium, Christ, in Bot. Fahrb. ix. (1888) 168 (= Preauxia jacobaeifolia, Sch. Bip.). - Ins. Canar.

macrocarpum, Coss, et Kral. ex Batt. et Trab. Fl. de l'Algér. [Dicot.] (1889) 460. - Afr. bor.

Marschallii, Aschers. ex O. Hoffm. in Engl, et Prantl. Natür. Pfanzenfam. iv. 5 (1893) 373 (=Pyrethrum roseum, Bieb.). - As. occ.

ochrolencum, C. Bolle, in Bot. Jahrb. xiv. (1892) 244 =ochroleucum, Masf.

Perralderii, Christ, in Bot. Jahrb. ix. (1888) $168=$ Perralderii, Sch.Bip.

richterioides, Winkl. in Act. Hort. Petrop. x. (1887) 86. - Turkest.

tatsienense, Bureau et Franch. in Morot, Fourn. de Bot.v. (1891) 72, - China.

tenuissimum, C. Winkl. in Act. Hort. Petrop. xi. (1889) $123(=$ Pyrethrum tenuissimm, Trautv.). Turkest.

Tchihatcheffii, Hort. ex Kew Bull. (1893) Append. i. 6 (= Pyrethrum Tchihatchewi, Hort.). - Oriens?

trichophyllum, Kuntze, in Act. Hort. Petrop. x. (1887) 202 = Tanacetum trichophyllum, Regel et Schmalh.

Walteri, C. Winkl. in Act. Hort. Petrop. x. (1887) 123 t. 3 fig. 3. - Turkest.

Webbii, Christ, in Bot. Jahrb. ix. (1888) $168=$ Webbii, Masf.

GHRYSOBALANUS, Linn. (Rosac.). - Ind. Kew. i. 527.

Stuhlmannii, Engl. Pfanzenw. Ost-Afr. C (1895) 191 - Afr. or.

GHRYSOCHLAIIYS, Poepp. et End1. (Guttifer.). - Ind. Kew. i. 528

guatemalticana, F. D. Smith, in Coult. Bot. Gaz. xiii. (1888) 26. - Guatem.

CHRYSOCOME, St-Lager, in Cariot, Etud. des f. ed. 8, ii. (1889) $446=$ Ghrysocoma, Linn. (Compos.).

GHRYSOGLOSSUM, Blume (Orchid.). - Ind. Kew. i. 529 .

assamicum, Hook. f. Fl. Brit. Ind.v. (1890) 784 ; in Hook. Icon. pl. xxi. (1891) t. 2063. - Assam. erraticum, Hook, f. ll.cc. 784 ; et t. 2062. - Reg. Himal.

macrophyllum, King et Panting, in fourn. As. Soc Beng. 1xiv. (1895) ii. 335. - Penins. Mal.

maculatum, Hook. f. $l l$. ec. 784 ; et t. 2064. Zeylan.

CHRYSOMA, Nutt. = Solidago, Vaill. (Compos.) arborescens, Greene, in Erythea, iii. (1895) $10=$ Bigelowia arborescens, A. Gray.

brachylepis, Greene, 1.c. $12=$ Big. brachylepis, A. Gray.

Cooperi, Greene, 1. c. = Big. Cooperi, A. Gray.

cuneata, Greene, 1. c. $11=$ Aplopappus cuneàtus. A. Gray.

diffusa, Greene, 1. c. 10=Bigelowia diffusa, $A$. Gray. domingensis, Greene, 1.c. = Gundlachia domin gensis, A. Gray.

exicoides, Greene, 1. c. $11=$ Aplopappus ericoides, $D C$

laricifolia, Greene, 1. c. $14=\mathrm{Apl}$. laricifolius, A. Gray.

nana, Greene, 1. c. $10=$ Apl. nanus, Eaton.

Palmeri, Greene, 1. c. $12=$ Apl. Palmeri, A. Grav. paniculata, Greene, 1, c. 12=Bigelowia paniculata A. Gray.

Parishii, Greene, 1. c. $10=$ Big. Parishii, Greene.

pauciflosculosa, Greene, 1. c. $8=$ Sol, paucifiosculosa, Michx.

pinifolia, Greene, 1. c. 12= Aplopappus pinifolius, A. Gray.

teretifolia, Greene, 1. c. 12 = Bigelowia teretifolia, A. Gray
GHRYSOPHYLLUM, Linn. (Sapot.). - Ind.

Kew. i. 529

alnifolium, Engl. Bot. Falwb. xii. (1890) 522. Guiana gall.

Balansae, Baill. in Bull. Soc. Linn. Paris, ii. (1891) 901. - N. Caled,

cinereum, Engl. Bot. Fahrb. xii. (1890) 522. Angola.

Deplanchei, Baill. in Bull. Soc. Linn. Paris, ii. (1890) 899. - N. Caled.

dioicum, Koorders et Valeton, in Mededeel. s'Lands Plantent.n. xi. Bijdr. n. i. (1894) 131.- Java.

elegans, Raunkler ex Warm. in Vid. Medd. naturh. Foren. (1889) 9.) - Bras.

onocarpum, Engl, Bot. 7ahrb. xii. (1890) 523 (= Sapota gonocarpa, Mart. et Eckl. - Bras.

glaucescens, Engl. l. c. 521. - Bras.

intermedium, Baill, in Bull. Soc. Linn. Paris, ii. (1891) 898. - N. Caled.

lissophyllum, Pierre, ex Baill. l. c. 903. - N. Caled.

longipes, Baill. l. c. 900. - N. Caled.

macrocarpum, Baill. l. c. 901. - N. Caled.

marginatum, Radlk. in Act. Congr. bot. Anvers (1887) 170 (= Myrsine marginata, Hook. et Arn.). Bras.

Melinoni, Engl. Bot. Fahrb. xii. (1890) 521. Guian. gall.

Msolo, Engl. in Abhandl. Prenss. Akad. Wiss. (1894) 44 et 52 ; et in Pflanzenw. Ost-Afr. C (1895) 306 t. 37. - Afr. trop. or

papuanicum, Pierre, Not. bot. Sapot. (1890) $30=$ Beccariella papuanica, Pierre.

polynesicum, Hillebr, Fl. Haw. Isl. (1888) 277. Ins. Hawai.

pyriforme, Baill. in Bull. Soc.Linn. Paris, ii. (1891) 899 (= Epiluma pyriformis, Baill.). - N. Caled. reticulatum, Engl. Bot. Fahrb. xii. (1890) 522. Bras.

Stuhlmannii, Engl. Pfanzenw. Ost-Afr. C (1895) 306. - Afr. trop. or.

Welwitschii, Engl. Bot. Fahrb. xii. (1890) 521. Angola.

GHRYSOPOGON, Trin. (Gramin.). - Ind. Kew. i. 530

minor, Vasey, in Proc. Am. Acad. xxii. (1887) 460 nomen. - Mexic.

verticillatus, St-Lager, in Cariot, Étud. des fl. ed. 8. ii. (1889) $899^{\circ}=$ A. Gryllus, Linm.

villosulis, Vidal, Revis. pl. vasc. Filip. (1886) 291 $=$ violascens, Irin

GHRYSOPSIS, Ell. (Compos.). - Ind. Kew. i. 530

Berlandievi, Greene, in Erythea, ii. (1894) $96=$ villosa, $D C$

caespitosa, M. E. Fones, in Proc. Calif. Acad. Ser. II. v. (1895) 694 [non Nutt.] - Utah.

columbiana, Greene, in Erythea, ii. (1894) 95. - Am. bor. occ.

Nuttallii, Britton, in Mem. Torrey Bot. Club, v. (1894) 316. - Am. bor.

pilosa, Britton, 1. c. = gossypina, Nutt.

pumila, Greene, in Erythea, ii. (1894) 95. Colorado.

Rutteri, Greene, 1. c. $96=$ villosa, $D C$

rudis, Greene, Man. Bot. San Franc. Bay (1894) 174. - Calif.

stenophylla, Greene, in Erythea ii. (1894) $96=$ villosa, DC.

viscida, Greene, 1. c. $105=$ villosa, $D C$.

CHRYSOSPERMA, Rafin. = Zygadenus, Michx (Liliac.).

muscatoxicum, Kuntze, Rev. Gen.(1891) $703=$ 2 muscatoxicum, Regel.

GHRYSOSPLENIUM, Tourn. ex Linn. (Saxifrag.). - Ind. Kew. i. 531.

aomorense, Franch, in Bull. Soc, Philom. Paris, Sér. VIII. ii. (1890) 103. - Japon.

aomorense, Tokubuchi, ex Makino, in Tokio Bot. Mag. ix. (1895) 334 nomen (an sp. praec. ?). - Japon.

Calcitrapa, Franch. in Bull. Soc. Philom. Paris. Sér. VIII. ii. (1890) 104. 一 Japon.

\section{CHRYSOSPLENIUM}

ciliatum, Franch, in Bull. Soc Philom, Paris, Sér. VIII. ii. (1890) 102; et in Nouv. Archiv. Mus. Paris, Sér. VIII. ii. (1890) 108 t. 30.-China.

corrugatum, Franch. in Bull. Soc. Philom. Paris, Sér VII. x. (1886) $102=$ costulatum, Franch.

costulatum, Franch. l. c. 101. - Japon.

crenulatum, Franch. l. c. 102. - Japon.

gracile, Franch. in Nowv, Archiv. Mus. Paris, Sér.

II. viii. (1886) 234. - China.

Henryi, Franch. l. c. Sér. III. ii. (1890) 112 t. 4b et in Bull. Soc. Philom. Paris, Sér. VIII. ii. (1890) 102. - China.

macrophyllum, Oliver, in Hook. Icon. pl. xviii. (1888) t. 1744 - China.

microspermum, Franch. in Nouv. Mém. Mus. Pavis, Sér. III. ii. (1890) 109; et in Bull. Soc. Philom. Paris, Sér. VIII. ii. (1890) 162. China.

nodulosum, Franch. 1. c. Sér. VIII, ii. (1890) 103 = costulatum. Franch.

nodulosum, Tokubuchi, in Tokyo Bot. Mag. ix.(1895) 334 nomen (an sp. praec.?). - Japon.

pumilum, Franch. Pl. Delav. i. (1889) 249. China.

shiobarense, Franch. in Bull. Soc. Philom. Paris, Sér. VIII. ii. (1890) 104. - Japon.

sibericum, Stephen, ex Franch. in Nouv. Arch. Mus. Paris, Sér. III. ii. (1890) 107 in syn. = alternifolium, Linn.

stamineum, Franch. in Bull. Soc. Philom. Paris, Sér. VII. x. (1886) 103. - Japon.

tian-schanicum, Krassn, in Script. Hort. bot. Univ. Petrop. ii. I. (1887-88) 16. - China.

tosaënse, Makino, in Tokyo Bot. Mag. vi. (1892) 52. - Japon.

villosum, Franch. in Morot, fourn. de Bot. iv. (1890) 305. - China.

CHRYSOTHAMNUS, Nutt. = Bigelowia, DC. (Compos.).

albidus, Greene, in Erythea, iii. (1895) $107=\mathrm{B}$. albida, $M$. E. fones.

Bigelovii, Greene, 1. c. $112=$ B. Bigelovii, A. Gray.

Bloomeri, Greene, 1.c. $115=$ Aplopappus Bloomeri, A. Gray.

Bolandevi, Greene, 1. c. $111=$ B. Bolanderi A. Gray.

californicus, Greene, 1. c. = B. dracunculoides, DC.

ceruminosus, Greene, 1. c. $94=$ B. ceruminosa A. Gray.

elegans, Greene, 1. c. - Colorado.

frigidus, Greene, 1. c. 112. - Am. bor. occ graveolens, Greene, 1. c. $108=$ B. dracunculoides, $D C$.

Greenei, Greene, 1. c. $94=$ B. Greenei, A. Gray.

Howardi, Greene, 1. c. 113 = B. Howardii, A. Gray.

junceus, Greene, 1. c. $113=$ B. juncea, Greene

leiospermus, Greene, 1. c. =B. leiosperma, A. Gray. mohavensis, Greene, 1. c. = B. mohavensis, Greme. nevadensis, Greene, 1. c. $114=$ B. nevadensis, A. Gray.

Parryi, Greene, 1. c. $113=$ B. Parryi, A. Gray

puberulus, Greene, 1. c. $93=\mathrm{B}$. viscidiflora, $D C$. var.

pulchellus, Greene, 1. c. $107=$ B. pulchella, A. Gray stenophyllus, Greene, 1. c. $94=\mathrm{B}$. viscidiflora, $D C$ Vaseyi, Greene, 1. c. $96=$ B. Vaseyi, A. Gray.

CHRYSOXYLON, Wedd.= Fogonopus, Klotzsch (Rubiac.)

speciosum, Kuntze, Rev. Gen. (1891) $278=$ P. speciosus, Schan.

tubulosum, Kuntze, 1. c. = P. tubulosus, Schau.

CHUPALON, Adans. = Thibardia, Ruiz et Pav (Vaccin.).

acuminatum, Kuntze, Rev. Gen.(1891) 383 = Cavendishia acuminata, Benth.

alatum, Kuntze, 1. c. 384 (=Proclesia alata, Klotzsch). - Peruvia.

alnifolium, Kuntze, 1. c. (=Pr. alnifolia, Klotzsch). -Venezuela.

Benthamianm, Kuntze, 1, c. =Cavendishia acuminata. Benth. 
CHUPALON :-

bracteatum, Kuntze, Rev. Gen. (1891) 383. (= Proclesia bracteata, Klotzsch). - Peruvia.

capitatum, Kuntze, 1. c. $384=$ Cavendishia nobilis. Lindl.

complectens, Kuntze, 1. c. $383=$ Cav. complectens, Hemsl.

cordatum, Kuntze, 1. c. 384 (=Proclesia cordata,

Klotzsch). - Venezuela.

cordifolium, Kuntze, 1. c. (=Pr. cordifolia, Klotzsch). - N. Granat.

crassifolium, Kuntze, 1. c. $383=$ Cavendishia crassifolia, Hemsl.

Endresii, Kuntze, 1. c. = Cav. Endresii, Hemsl.

formosum, Kuntze, 1. c. = Psammisia formosa,

Klotzsch.

guianense, Kuntze, 1. c. $384=$ Ps, guianensis, Klotzsch. - Ecuador.

Hartwegianum, Kuntze, 1. c. (= Proclesia Hartwegiana, Klotzsch.

latifolium, Kuntze, 1. c. $383=$ Cavendishia latifolia, Hemsl.

laurifolium, Kuntze, 1. c. = Cav, laurifolia, Benth et Hook. $f$.

leucostomum, Kuntze, 1. c. $384=$ Psammisia leucostoma, Benth.

melastomodes, Kuntze, 1. c. 383 = Cavendishia melastomoides, Benth , et Hook, f.

nobilis, Kuntze, 1, c. $384=$ Cav, nobilis, Lindl

pendulliflonum, Kuntze, 1. c. $383=$ Psammisia penduliflora, Klotzsch.

pseudopubescens, Kuntze, 1. c. 384 (= Proclesia Psendo-pubescens, Klotzsch). - N. Granat.

pubescens, Kuntze, 1. c. $383=$ Cavendishia pubes cens, Hems?.

Quereme, Kuntze. 1. c. $384=$ Cav. Querema, Benth et Hook. $f$.

scabriusculum, Kuntze, 1. c. (=Proclesia scabriuscula Klotzsch). - Ecuador.

splendens, Kuntze, 1. c. (=Pr. splendens, Klotzsch $)$. - N. Granat.

strobilijerum, Kuntze, 1. c. (= Pr. strobilifera, Klotzsch). - N. Granat.

arapotanum, Kuntze, 1. c. = Cavendishia tarapotana, Benth. et Hook. $f$

eraguense, Kuntze, 1. c. $383=$ Cav, veraguensis, Hemsl.

Warscewiczii, Kuntze, 1. c. = Cav. Warscewiczii, Hemsl.

AHUQUIRAGA, Juss. (Compos.). - Ind. Kew. i. 532

alpestris, Rodr. Pl. nov. Fard. bot. Rio, iv. (1894) 20 t. 5. (Chuquiragua).- Bras.

chapadensis, S. Moore, in Trans. Linn. Soc. Ser II. iv. (1895) 389. - Bras.

ferox, Britton, in Bull. Torrey Bot. Club, xix. (1892). 266 (Chuquiragua) (= Flotoria ferox, Wedd.). Reg. Andin.

glabra, Phit. in Anal. Mus. nac. Chile (1891) 30 (Chuquiragua). - Chili.

incana, Phil. in Anal. Univ. Chil. 1xxxv. (1894) 829 - Chili.

juniperina, Phil. l.c. 830. - Chili.

retinens, S. Moore, in Trans. Linn. Soc. Ser. II iv. (1895) 390. - Bras.

GHUSQUEA, Kunth (Gramin.).- Ind. Kew. i. 532. Caamanoi, Sodiro, Gram. Ecuat. (Anal. Univ. Quito 1889) 11 nomen. - Ecuad.

Maurofernandeziana, Pitt. et Hack. in Anal. Inst. fis.-geogr. nac. S. fosé (1891) sep. (Viajo valle R. Grande de Terraba) 15 nomen. - Costarica quitensis, Sodiro, Gram. Ecuat. (Anal. Univ. Quito, 1889) 11 nomen. - Ecuad.

Spencei, Ernst, in Rev. cient. mens. Univers. centr. Venez. i. (1887) 132. - Venez.

CHYMSYDIA, Alboff, in Bull. Herb. Boiss. iii. (1895) 235; et Prodr. fl. Colch. (1895) 110. UMBEL LIFERAE

agasylloides, Alboff, Il.cc. - Reg. Cauc.

CHYTRACULIA, P. Br. = Calyptranthes, Sw. (Myrtac.)

affinis, anceps, aromatica, axillaris, bimarginatu, bipennis, Blanchetiana, brasiliensis, bullata, cau-

\section{CHYTRACULIA : -}

data, cephalantha, chisiaefolia, concinna, cordata costaricensis, cubensis, cuprea, cuspidata. densiflora, dichotoma, eviopoda, fasciculata, fastigiata, Forsteri, glomerata, grandifolia, Karwinskyana, lanceolata, Langsdorfii, Lindeniana, longifolia, loranthifolia, lucida, macrophylla, Martiusiana, maschalantha, melanoclada, multiflora, mutabilis, nigricans, Nummularia, obscura, obversa, Ottonis, ovalifolia, ovata paniculata, pauciflora, platyphylla, Poeppigiana, Pohliana, polyantha, pteropoda pulchella, Regeliana, vigida, rufa, Ruiziana, Schiedeana, Schlechtendaliana, scoparia, Spruceana, strigipes, tetraptera. Thomasiana, tuberculata, Tussaceana, variabilis, Widgreniana, Kuntze, Rev. Gen. (1891) 238 = homonyma omnia generis Calyptranthes.

arborea, Kuntze, 1. c. = Cal. Chytraculia, Sw.

Bergiana, Kuntze, 1. c. (= Mitranthes Langsdorffi, Berg). - Bras.

Browneana, Kuntze, 1. c. (= M. Browniana, Berg). - Bras.

enteniodes, Kuntze, 1. c, = Cal, eugenioides, Camb. Gardneriana, Kuntze, 1. c. (- Mitranthes Gardne riana, Berg). - Bras.

grammica, Kuntze, 1. c. = Cal. musciflora, Berg. pendula, Kuntze, 1. c. = Cal. Chytraculia, Sw.

Riedeliana, Kuntze, 1. c. (= Mitranthes Riedeliana, Berg). - Bras.

Sartoriana. Kuntze, 1. c. (= M. Sartoriana, Berg) - Mexic

Selloana, Kuntze, 1. c. (= M. ovalifolia, Berg). Bras.

Suzygiun, Kuntze, 1. c. = Cal. Syzygium, Su.

GHYTRANTHUS, Hook. f. (Sapind.). - Ind Kew. i. 533

setosus, Radlk. in Sitz. Math. phys. Akad. Muench xx. (1890) 232 et 240. - Afr. trop. occ.

CICCA, Adans. = Julocroton, Mart. (Euphorb.) Ackermanniana, argentea, conspurcata, decaloba, doratophylla, fuscescens, Gardneri, geraënsis, hondensis, humilis, lanceolata, microcalyx, montevidensis, nervosa, peruviana, pycnophylla, Riedeliana, solanacea, triquetra, verbascifolia, Kuntze, Rev. Gen. (1891) 595 = homonyma omnia Julocrotonis.

CICHLANTHUS, Van Tiegh. in Bull. Soc. Bot. Fr. xlii. (1895) $253=$ Loranthus, Linn.

atropurpureus, Van Tiegh.1.c.=L. atropurpureus, Blumue.

chinensis, Van Tiegh 1. c. = L. chinensis, $D C$.

chrysanthus, Van Tiegh. 1. c. = L. chrysanthus, Blume.

ferrugineus, Van Tiegh. 1. c. = L. ferrugineus, Roxb.

fuscus, Van Tiegh. 1. c. = L fuscus, Blume.

Fadoriki, Van Tiegh. I. c. = L. Jadoriki, Sieb.

lepidotus, Van Tiegh. 1. c. = L. lepidotus, Blume.

philippinensis, Van Tiegh. 1. c. $=$ L. philippinensis, Cham。et Schlecht.

putverulentus, Van Tiegh. 1. c. = L. pulverulentus, Wall.

repandus, Van Tiegh. 1. c, = L. repandus, Blume, Schultesii, Van Tieoh. 1. c. = L. Schultesii, Blume. Scurrula, Van Tiegh. 1. c. = L. Scurrula, Linn.

umbellifer, Van Tiegh. 1. c. = L. umbellifer, Schult.

GIGHORIUM, [Tourn.] Linn. (Compos.). - Ind. Kew. i. 534.

balearicum, Porta, in Nuov. Giorn. Bot. Ital xix. (1887) 311 . - Ins. Balear.

GICUTA, [Tourn.] Linn. (Umbellif.). - Ind. Kew. i. 534 .

californica, Greene, Pittonia, i. (Mar. 1889) 271 (non A. Gray) = Oenanthe californica, S. Wats. linearifolia, S. Wats. in Proc. Am. Acad, xxii. (1887) 415 (= Prionosciadium linearifolinm, Coult. et Rose). - Mexic.

occidentalis, Greene, Pittonia, ii. (Nov, 1889) 7. Calif.

pumila, F. Behm, in Bot. Notiz. (1887) 180.Scand.

purpurata, Greene, Pittonia, ii. (Nov. 1889) S. Am. bor. occ

vagans, Greene, l. c. 9. - Am. bor. occ
CICUTARIA, Mill. = Molopospermum, Koch (Umbellif.)

peloponnesiaca, Kuntze, Rev, Gen. (189I) $266=$ $=\mathrm{M}$. cicutarium, $D C$.

CIENFUEGOSIA, Cav. = Fugosia, Juss. (Malvac,

anomala, Gilg, in Bot. Jahrb. xix. Beibl. n. 48 (1894) $2=$ Gossypium anomalum, Wawra et Peyr.

argentina, Gürke, in Mart. F1. Bras. xii, III. (1892) 579. - Reg. Argent.

pentaphylla, K. Schum, in Bot. Jahrb. x. (1889) 48. - Afr. austro-occ. cxtratrop.

Riedelii, Gürke, in Mart. Fl. Bras, vii. IIl. (1892) 576. - Bras.

tripartita, Gürke, 1. c. $578=$ Redoutea tripartita, H. B. et $K$.

GIMIGIFUGA, Linn. (Ranuncul.), - lnd. Kew. í. calthaefolia, Maxim. ex Oliver, in Hook. Icon. pl. xviii. (1888) t. 1746. - China.

dahurica, Huth, in Bot. Fahrb̆. xvi, (1893) 316 (= Actinospora dahwrica, Turcz.). - As. centr.

GINERARIA, Linn. (Compos.). - Ind. Kew. i. 537.

albicans, N. E. Br. in Gard. Chron. (1895) i. 39.Afr. austr.

Anampoza, Baker, in Journ. Linn. Soc. xxii. (1887) $496=$ Senecio Anampoza, Baker.

arnautorum, Nym. Consp. F1. Eur. Suppl. ii. I. 163. - Bulgar.

Aspasia, Hort, ex Gard, Chron. (1888)i.799 nomen. - Form. hort.

aurita. Hort ex Garden, xxxviii. (1890) 252t. $770=$ lanata, Curtis.

bosniaca, G. Beck, in Ann. Naturh. Hofmus. Wien, ii. (1887) 163. - Bosnia

Coincyi, Willd. Suppl. Prodr.Af. Hisp. (1893) 86 (= Senecio Coincyi, Rouy). - Hisp.

Eminii, Aschers, ex Schreeinf. in Sitzb. Ges. naturf. Fr. Berl. (1892) 173. - Afr. trop.

flatnitzensis, Pacher, Nachtr. Fl. Karnt. (1894) 59.Carinthia.

hygrophila, Klatt, in Annal. natwh. Hofmus. Wien, vii. (1892) 299 (= Senecio hygrophilus, Klatt). Madag.

kilimandscharica, Engl. in Abhandl. Preuss. Akad. Wiss. 1891. ii. (1892) 439. - Afr. trop. or.

seminuda, Klatt, ex Schinz, in Bull. Herb. Boiss, iii. (1895) 438. - Afr. austro-occ, extratrop.

GINNA, Linn. (Gramin.). - Ind. Kew, i. 539.

miliacea, Griseb. ex Fourn. Gramin. Mexic. 1881. (1886) 91 in syn. - Mexic

GINNAMOIMUM, [Tourn.] Linn.(Laurin.). - Ind. Kew.1.539.

Cinnamomum, Cockerell, in Bull. Torrey Bot. Club, xvii. (1890) 94 = zeylanicum, Nees.

gracile, Hook. f. Fi. Brit. Ind. v. (1886) 134. Deccan

macrocarpum, Hook. f. l. c. 133. - Canara.

Mercadoi, Vidal, Rev. Pl. Vasc. Filip. (1886) 224.Ins, Philip.

mollissimum, Hook, f. Fl, Brit. Ind. v。 (1886) 131 Penang

Oliveri, F. M. Bailey, in Dep. Agric, Bot. Bull.v. (1892) 24. - Austral.

CINNASTRUM, Fourn. = Deyeuxia, Clar. (Gramin.).

miliaceum, Fourn. Gramin. Mexic. 1881. (1886) 91 = Cinna miliacea, Griseb.

poaeforme, Fourn. 1. c. =D. poaeformis, $H, B$. et $K$.

CIRCINUS, Medic. = Hymenocarpos, Savi (Legumin.).

circinatus, Kuntze, Rev. Gen. (I891) $171=\mathrm{H}$. cirm cinnatus, $W$ illd.

GIRRHOPETALUM, Lindi. (Orchid.). - Ind, Kew, i. 540 


\section{CIRRHOPETALUM :}

Amesianum, Rolfe, in Lindenia, vii. (1891) 55 t. 314 - Ind. bat.

Andersoni, Hook, f. Fl. Brit. Ind. v. (1890) $77 \%$; et in Hook. Icon. H. xxi. (1891) t. 2055. - Reg. Himal.

aureum, Hook. f. Il. cc. 777 ; et sub t. 2056; et t. 2057 b. - Malabar

Blepharistes, Hook. f. l. c. 779 (= Bolbophyllum Blepharistes, Reichb. f.). - Ind. or.

brevipes, Hook. f.l. c. 777 ; et in Hook. Icon. pl. xxi. (189I) t. 2056. - Reg. Himal.

Brienianum, Rolfe, in Kew Bull. (1893) 62. Borneo.

Collettianum. Hems!. ex Collett et Hemsl. in Journ. Linn. Soc, xxviii. (1890) t. 20. sphalm. = seq.

Collettii. Hemsl in fourn, Linn. Soc, xxviii. (1890) 131 t. 20; at in Hook. f. Fl. Brit. Ind. v. (1890) 773. - Burma.

compactum, Rolfe, in Kew Bull. (1895) 281. Tenass.

concinnum, Hook, f. Fl. Brit. Ind, vi (1890) 190 ; et in Hook. Icon. pl. xxi. (1891, t. 2060b.-Penins. Mal.

Dyerianum, King et Pantling, in Journ. As. Soc Beng. lxiv. (1895) ii. $335=$ pumilum, Hook $f$.

elatum, Hook. f. Fl. Brit. Ind. v. (1890) 775 . -

Reg. Himal.

elegantulum, Rolfe, in Gard. Chron. (1891) i. 552; et in Kew Bull. (1892) App. 23. - Ind. or

Gamblei, Hook. f. Fl. Brit. Ind.v. (1890) 1778; et in Hook. Icon. pl. xxi. (1891) t. 2058. - Reg. Neilgherr.

guttulatum, Hook. f.l. c. 776 . - Reg. Himal.

gracillimum, Rolfe, in Kew Bull. (1895) 34. Burma?

japonicum, Makino, Illustr. Fl. of fapon (1891) t. 42. - Japon

Layardi, F. Muell. et Kraenzl. ex Kraenzl. in Oest. Bot. Zeitschr. xliv. (1894)210. - N. Caled.

Lendyanum, Reichb. f. in Gard. Chron. (1887) ii. 70 (= Bulbophyllum Lendyanum, Reichb. f.).Hab.?

Mastersianum, Rolfe, in Lindenia, vi. (1890) 33 t. $255 .-$ Ind. bat.

mundulum, Hort. Bull, ex Gard. Chron. (1891) i. 676. - As. trop.

mysorense, Rolfe, in Kew Bull. (1895) 34. - Ind. or. austr.

nodosum, Rolfe, l. c. 35. - Ind. or

parvulum, Hooh. f. Fl. Brit. Ind. v. (1890) 778; et in Hook. Icon, pl. xxi. (1891) t. 2060a. - Reg. Himal.

Peyerianum, Kraenzl. in Bot. fahrb, xvii. (1893) 485. - Sumatra

planibulbe, Ridl. iu Trans. Linn. Soc. Ser. II. iij. 1893) 364. - Penins. Mal.

pulchrum, N. E. Br. in Illustr. Hortic, xxxiii. (1886) 139 t. 608; ei in Lindenia, iv. (1888) 45 t. 145 . Ins. Halmaheira.

Restrepia, Ridl. in Trans. Linn. Soc. Ser. II. iii (189:3) 365. - Penins. Mal.

Rothschildianum, O'Brien, in Gard.Chron. (1895) ii. 608 fig. 102. - Hab.

sarcophyllum, King et Pantling, in fourn. As. Soc. Beng. Ixiv. (1895) ii. 335. - Ind, or.

setiferum, Rolfe, in Kew Bull. (1895) 35. - Reg. Himal.

strangularium, Reichb.f. in Gard. Chron. (1887) ii. 186 et 214; et ex Gartenfl xxxvii. (18x8) 37 i= an C. putchrum, Rolfe?). - Hab.

taeniophyllum, Hook. f. Fl. Brit. Ind. v. (1890) 786 Tenass.

Thomsoni, Hook. f.l. c. 786; et in Hook. Icon. pl. xxi. (1891) t. 2059. - Reg. Neilgherr.

umbellatum. Frappier, ex Cordem. Fl. Ile Réu. nion (1895) 176 (Cirropetalum) = Thouarsii, Lindl.

viridiflorum, Hook. f. Fl. Brit. Ind. v. (1890) I79; et in Hook. Icon. pl. xxi. (1091) t. 2061. - Reg. Himal.

Wendlandianum, Kraenzl. in Gard. Chron. (1891)i. 612 ; et in Reichb. f. Xen. Orchid. iii. 5. (1892) 79 4. 243 fig. 1-5. - Ind. or

Whiteanum, Rolfe, in Kew Bull. (1895) \%. - Ins. Molucc.
CIRSIUM, [Tourn.] Adans, = Cnicus, Tourn. (Compos.).

albamun, Wettst. in Luerss. Bibl. Bot, Heft xxvi. (1892) 71 t. 5. fig. $24=$ Cirsium ligulare Boiss.

Albowianum, Somm, et Levier, in Act. Hort. Petrop. xii. (1892) 153; et in Nuov. Giorn. Bot. Ital. Ser. II. i1. (1895) 19. - Reg. Cauc.

aleutrense, Porta, ex Kern. Sched. F1. Austro-Hung, v. (1888) 64. - Austria.

albidum, Velen, in Sitzb. Boehm. Ges. Wiss, (1888) 53. (sep.) ex Nym. Consp. Fl, Eur. ii. I. 180 . Bulg.

armatum, Velen. 11. cc. 52; et 180. - Bulg

auriculatum, G. Camus, ex Pelèze, in Bull. Soc. Bot. Fr. xlii. (1895) $503=$ Cn. pratensis, Willd balearicum, Porta, in Nuov. Giorn, Bot. Ital. xix. (1887) 309. - Ins. Balear.

baleavicum, Willk. Illustr. F1. Hisp. ii. (1886) 20 in obs. = crinitum, Boiss.

Benzii X, Murr, in Oest. Bot. Zeitschr. (1888) 205 (1893) 177; et in Deutsche Bot, Monatsschr. xii. (1894) 95, - Tirol.

Boulayi $\times$ G. Camus, in Bull. Soc, Bot. Fr, xxxyiii. (1891) 106. - Gall,

Caput-Mcdusae, Somm. et Levier, in Nuov. Giorn. Bot. Ital. Ser. II. ii. (1895) 10. - Reg. Cauc.

Castriferrer $\mathcal{X}$, Borbas, Enum. pl. Castrif. (1889) 195. - Hung.

chlorocomos, Somm, et Levier, in Act. Hort. Petrop. xii. (1893) 154; et in Nuov. Giorn. Bot. Ital. Ser. II. ii. (1895) 14. - Reg. Cauc.

costaricensis, Klatt, ex Th. Dur. et Piit. in Bull. Soc. Bot. Belg. xxxi. 1892 (1893) 214. - Costarica.

czepeliense X, Herb. Rouy, ex G. Camus, in Bull. Soc. Bot. Fr. xxxviii. (1891) 81 in obs. - Hung. elbrusense, Somm. et Levier, in Nuov. Giorn. Bor. Ital. Ser, II. ii. (1895) 16. - Reg. Cauc.

evisithaloides, Murr, in Oest. Bot. Zeitschr. (1893) 178; et in Deutsche Bot. Monatsschr, xiii. (1894) 95. - Tirol.

extraneum ×, G. Beck, Fl. Nieder-Oest. ii.(1992) 1242. - Austria.

Fabim $X$, Porta, ex Kern. Sched. Fl. Austro-

Hung. v. (1888) 63. - Austria.

finissimum, Rota, ex Rodegher, in Bull. Soc. Bot Ital. (1893) 519 nomen. - Italia

foliosum $x$, Rhiner, in Verh. zool, bot, Ges. Wien, xxxvii. (1887) Sitzb. 72.-Helv. Carinthia. galaticum, Freyn, in Bull. Herb. Boiss. iii. (1895) $467=$ Sintenisii, Freyn.

Galissierianum, G. Camus, in Bull. Soc. Bot. Fr. xxxviii. (1891) 104 et 107 - Gall.

Gollevi, Huter, ex Oest. Bot, Zeitschr. (1895) 399. - Tirol.

Grenerix, Roury, in Bull. Soc. Bot. Fr. xxxviii, (J 891$) 107$ in obs. - Gall.

Grecescui, Rouy, 1. c. xxxvii. (1890) 164. - Eur. or.

Halacsyi, Formanek, in Verh. naturf. Ver. Brïnn, xxx. (1892) 63. - Maced

Haynaldi $X$, Borbas, in Oest. Bot. Zeitschr. xtii. 1892) 250; G. Beck, Fl. Nieder-Oest. ii. (1892) 1202. - Hung.

Heldreichii, Halaczy, 1. c. x1. (1890) 114. Graecia.

horridum, Formanek, in Verh. naturf. Ver. Brünn, xxxiii. (1895) 28. - Epiria,

Fouffroyi $\times$, Neyra et $G$. Camus, in Bull. Herb. Boiss. i. App. ii. (1893) 41. - Gallia.

Khekir X, Murr, in Oest. Bot. Zeitschr. (1893) 117; et in Deutsche Bot. Monatsschr. xii. (1894) 95.-Tirol.

Kusnezowianum, Somm, et Levier, in Act. Hort. Petrop. xii. (1892) 155; et in Nuov. Giorn. Bot. Ital. Ser. II. ii. (1895) 16.-Reg. Cauc,

Lanottei $Y$, Neyra et G. Camus, in Bull. Herb. Boiss. i. App. ii. (1893) 40. - Gallia.

Liebmanni, Sch.-Bip. ex Klatt, in Leopoldina, Hett xxiv. (1888) 128 in syn. - Mexic

Lojkae, Somm, et Levier, in Nuov, Giorn. Bot. Ital. Ser. II. ii. (1895) 15. - Reg. Cauc.

lokense, Conrath et Freyn, ex Freyn, in Bull. Herb. Boiss. iii. (1895) 468. - Armenia.

macedonicum, Formanek, in Verh. naturf. Ver. Brünn, xxx. (1892) 64; et xxxii. (1894). Maced
CIRSIUM : -

Mailhoi, Giraudias, in Bull. Assoc. pyrén. éch. pl i. (1891), ex Bull. Soc. Bot. Fr. xl. (1893) Bibl. 175. - Pyren,

Morrisii X, Bicknell, in Malpighia, viii. (1894) 392. - Italia.

Neyrae X, G. Camus, in Bull. Herb. Boiss. i. App. ii. (1893) 41. - Gallia.

Noli-tangere, Somm. et Levier, in Nuov. Giorn. Bot. Ital. Ser. II. ii. (1895) 11. - Reg. Cauc.

orizabense, Klatt, in Leopoldina, Heft xxiv. (1888)

128 in syn. - Mexic.

paniculatum, Porta, in Atti Accad. Agiati, ix. (1891) 38; Willk. Suppl. Prodr. Fl. Hisp. (1893) 104. - Hisp.

persimile $X$, G. Beck, Fl. Nieder-Oest. ii. (1892) 1244. - Austria.

pindicolum, Hausskn, in Nym. Consp. Suppl. II. i. (1889) 181; et in Mitth. Thür. Bot. Ver. N. Folge vii. (1895) 39. - Graecia.

pisidium, Wettst. in Sitzungsb. Akad. Wiss. Wien. xcviii. 1889 (1890) 370 t. 3 fig. 9-12. - As. Min.

Przybylskii X, Eichenfeld, in Oest. Bot. Zeitschr. xxxvii. (1887) $37 \%$. - Stiria.

pugnax, Somm. et Levier, in Nuov. Gior... Bot. Ital. Ser. II ii. (1895) 12. - Reg. Cauc.

pulchrum $x$, G. Camus, in Bull. Soc. Bot. Fr. xxxvi1i. (1891) 81. - Gallia.

reglense, Sch.Bip. ex Klatt, in Leopoldina, Heft xxiv (1888) 128. - Mexic.

Sintenisii, Freyn, in Bull. Herb. Boiss. iii. (I895) 466. - As. Min.

Spitzneri, Formanek, in Verh, naturf. Ver. Brünn. xxxii, (1894) 66. - Maced.

Stoderianum X, Diirrnberger, in Oest. Bot. Zeitsch. xl. (1890) 410. - Austria.

Stonum $\times$ Porta, ex Kern. Sched.Fl. Austro-Hung. v. (1888) 63. - Austria.

Straussianum, Hausskn, in Mitth. Bot. Ver. Jena, ix (1891) 18. - Persia.

subcanum $\times, G$. Beck, F1. Nieder-Oest. ii. (1892) 1244. - Austria.

suberisithales $X, G$. Beck, 1. c. 1246. - Austria

submedium $X$, Hy, in Bull. Herb. Boiss. iii. App I. (1895) 13. - Gallia.

subrivulare $X, G$. Beck, F1. Nieder-Oest. ii. (1892) 1244. - Austria.

suspiciosum $\times, G$. Beck, 1. c. 1243. - Austria.

svaneticum, Summ, et Levier, in Nuov, Giorn. Bot. Ital. Ser. II. ii (1895) 20. - Reg. Cauc.

Treninfelsianum $\times$, Ausserdorfer, in Herb. Norm. sched. ad cent. xxxi. (1894) 18; et ex Murr, in Deutsche Bot. Monatsschr, xii. (1894) 100. Tyrol.

triste, A. Kern. Sched. Fl. Austro-Hung, v. (1888) 62. - Austria.

tymphaeum, Hausskn. in Nym, Consp. Suppl. ii. I. 181; et in Mitth. Thür. Bot. Ver. N. Folge vii. (1895) 38. - Graecia.

urbanum $\times$, G. Beck, Fl, Nieder-Oest, ii. (1892) 1242. - Austria

valentinum, Porta, in Atti Accad. Agiati, ix. 1891 (1892) 38. - Hisp.

Velenowsky, Vand. in Sitzb. Boehm. Ges. Wiss. 1889. (1890) ii. 268. - Eur. or.

indobonense $\times$. Halacsy, in Bot. Centralbl, xxxii. (1887) 381. - Austria.

viride, Velen. ex Nym. Consp. Suppl. ii. I. 181; Bornm, in Bot. Centralbl. xxxvi. (1888) 88 - Bulg.

Waisbeckeri $\times$, Simonk. in Köszeo oidék, edényes, ex Oest. Bot. Zeitschr. xli. (1891) 381. Hung.

Willkomianum, «Porta et Rigo » ex Batt. et Trab. in Bull Soc. Bot. Fr. xxxv. (1888) $344=$ seq.

Willkommianum, Porta, ex Willk. Illustr. Fl. Hisp.

ii. (1886) 19; et in Nuov. Glorn. Bot. Ital. xix. (1887) 309. - Ins. Balear.

CISSUS, Linn. = Vitis, Tourn. (Ampelid.).

acris, Planch, in DC. Monog. Phan. v. (1887) 576. $=\mathrm{V}$. acris, F. Muell.

acutissima, Gilg, in Eng1. Pflanzenw. Ost-Afr. C (1895) 259. - Afr. trop. or.

adenocaulis, Steud. ex Planch. in DC. Monog. Phan. v. (1887) 586. - Afr. trop.

Agnus-Castus, Planch.1. c. 598.-Zambes. 
CISSUS :-

alnifolia, Schweinf. ex Planch, in DC. Monog. Phan. v. (188 i) 577. - Afr. centr. bor.

Mboinensis, Zippel, ex Planch. 1. c. 448 (= Tetrastigma amboinensis, Planch.). - Ins. Amboin. amplexa, Planch. 1. c. $593=\mathrm{V}$, amplexa, Baker. andongensis, Planch. 1. c. $572=\mathrm{V}$. andongensis, Welw.

Andraeana, Planch. 1. c. 533. - N. Gran.

aralioides, Planch. 1 . c. $513=\mathrm{V}$. aralioides, Baker aristolochioides, Planch. 1. c. 508. - Siam.

aristolochiaefolia, Planch. 1. c. 488. - Zambes.

asperifolia, Planch. 1. c. 539. - Bras.

Bakeriana, Planch. 1. c. 599. - Afr. trop.

Barterii, Planch. 1. c. $491=$ V. Barterii, Baker.

Bauerleni, Planch. 1. c. 515. - N. Guin

bignonioides, Schweinf. ex Planch.1. c. $481=$ C. suberosa, Planch.

Blanchetiana, Planch. 1. c. 556. - Bras

Bodiniana, Hort. Par., sphálm. ex Planch. 1. c 517 (= Baudiniana, Brouss.) = V. antarctica Benth.

Boivinii, Planch. 1. c. 498, - Madag.

brachypoda, Planch. 1. c. $520=$ V. brachypoda, F. Muell.

Buchananii, Planch. 1. c. 601. - Afr. trop.

bukobensis, Gilg, in Engl. Pflanzenw. Ost-Afr. C (1895) 258. - Afr. trop. or.

Burchellii, Planch in DC. Monog. Phan. v. (1887) $537=\mathrm{V}$. Burchellii, Baker.

sactiformis, Gilg, in Engl. Pflanzenw. Ost-Afr. C (1895) 258. - Afr. trop. or.

campestris, Planch. in DC. Monog. Phan. v. (1887) $536=\mathrm{V}$. cämpestris, Bakev.

canarensis, Planch. 1. c. 620 in add. $=\mathrm{V}$. canarensis, Dalz.

cerasiformis, Planch. 1. c. 621 in add. = V. cerasiformis, Teysm. et Binn.

chlorolenca, Planch. 1. c, $592=\mathrm{V}$, chloroleuca, Welw.

chontalensis, Planch 1. c. 624 in add. $=$ V. chontalensis, Seem

chrysadenia. Gilg, in Bot. Jahrb. xix. Beibl. n. 47 (1894) 39. - Afr. trop. or

clematidea, Planch. in DC. Monog. Phan. v. (1887) $566=\mathrm{V}$. clematidea, F. Muell

coccinea, Mart. ex Planch. 1. c. 557. - Bras

cocciniaefolia, Schweinf. ex Planch. 1. c. $674=$ V. palmatifida, Baker.

congesta, Planch. 1. c. $590=$ V. congesta, Baker.

convolvulacea, Planch. 1. c 501. - Siam.

cornifolia, Planch. 1. c. $492=\mathrm{V}$. cornifolia, Baker

corylifolia, Planch, 1. c. $484=\mathrm{V}$. corylifolia Baker.

Crameriana, Schinz, in Verh. Bot. Ver. Brand. xxx. (1888) 241. - Afr. austro-occ. extratrop. crassifolia, Planch. in DC. Monog. Phan. v. (1887 $508=$ V. crassifolia, Baker.

crassiuscula, Planch. 1. c. $608=\mathrm{V}$. crassiuscula Baker.

crinita, Planch. 1. c, 581. - Afr. centr. bor.

crotalarioides, Planch. 1. c. 577. - Afr. trop.

cucumerifolia, Planch. 1. c. 474 . - Afr. trop. or

curvipoda, Planch. 1. c. 573. - Afr. trop. occ

cuspidata, Planch. in DC. Monog. Phan. v. (1887) 498. - Madag.

cussonioides, Schinz, in Bull. Herb. Boiss. ii. (1894 195. - Natal.

cussoniaefolia, Schweinf, ex Frnch. 1. c. 395 (= Ampelocissus cussoniaefolza, Planch.). - Afr. trop.

debilis, Planch. 1. c. $569=$ V. debilis, Baker.

diffusiflora, Planch. 1. c. $496=$ V. diffusiflora, Baker.

Duparquetii, Planch. 1. c. 599. - Zanzib.

egregia, Gilg, in Engl. Pflanzenw. Ost-Afr. C (1895) 259. - Afr. trop. or.

Eminii, Gilg, 1. c. - Afr. trop. or.

Erdwendbergii, Planch. in DC. Monog. Phan. v (1887) 405 in obs. (= Ampelocissus Erdwendbergii Planch.). - Mexic.

erythrochlora, Gilg, in Bot. Jahrb, xix. Beibl. n. 47 (1894) 38. - Afr. trop. or.

farinosa, Planch. in DC. Monog. Phan. v. (1887) $488=\mathrm{V}$ farinosa, Baker.

Fischeri, Gilg, in Engl. Pflanzenw. Ost-Afr. C (1895) 259. - Afr. trop. or.
CISSUS : -

flavicans, Planch. in DC. Monog. Phan. v. (1887)

$591=\mathrm{V}$. flavicans, Baker.

floribunda, Planch. 1. c, $493=\mathrm{V}$. floribunda, Baker.

Forsteniana, Planch, 1. c. $500=$ V. Forsteniana, IIiq.

furcata, Ridl, in Trans. Linn. Soc. Ser. II. iii. (1893) 287. - Bras

gastropus, Welw. ex Planch. in DC. Monog. Phan. v. (1887) 583 in syn. = V. macropus, Hook.

Gibertii, Planch. 1. c. $543=$ V. Gibertii, Baker.

gigantea, Planch. 1. c. 622 in add. = V. gigantea, Bedd.

glaberrima, Planch. 1. c. 498. - Penang.

glaucoramea, Planch.1. c. 506. - N. Caled.

Goudotii, Planch. 1. c. 586. - Madag.

grisea, Planch. 1. c. 622 in add $=$ V. grisea, Baker.

Grisebachii, Planch. 1. c. 541.-Cuba.

grandifolia, Warb. in Eng1. Bot. Jahrb. xviii. (1894) 199. - Oceania.

astata, Planch. in DC. Monog: Phan. v. (1887) $502=\mathrm{V}$. hastata, $\mathrm{Miq}$.

hebecarpa. Hochst. ex Planch, 1. c, 606 in syn. = V. Thonningii, Baher pr.p

hederaefolia, Planch. 1. c.514. - Afr. trop. occ.

hexangularis, Thorel, ex Planch. 1. c. 511. Cochinch.

Heyneana, Planch. 1. c. $476=\mathrm{V}$. Heyneana, Wall hibiscinus, Delile, ex Planch. 1. c. $384=\mathrm{V}$. ipomeaefolia, Baker.

Hildebrandtii, Gilg, in Eng1. Pflanzenw. Ost-Afr C (1895) 260 t. 17 a-c. - Afr, trop, or.

hispida, Planch. in DC. Monog. Phan. v. (1887) 623 in add. = V. hispida, Eckl. et Zeyh.

Hochstetteri, Planch. 1, c. $480=\mathrm{V}$. Hochstetteri, Miq.

Hooker, Ridl. in Trans. Linn, Soc. Ser. II. iii (1893) 287. - Penins. Mal

mumilis, Planch. in DC. Monog. Phan. v. (1887) 629 in add. $=$ V. humilis, N.E. Br.

inaequilaterus, E. Mey, ex Szyszyl, Pl. Rehmann, ii (1888) 44 in syn, = cuneifolia, Eckl. et Zeyh.

integrifolia, Planch. in DC. Monog. Phan. v. (1887) $483=\mathrm{V}$. integrifolia, Baker.

inusidata, Planch. 1. c. $537=$ V. inundata, Baker. jatrophoides, Planch. 1. c. $579=$ V. jatrophoides, Welwe

javalensis, Planch. 1. c. 624 in add. = V. javalensis, Bull.

karaguensis, Gilg, in Engl. Pflanzenw. Ost-Afr. C Beibl. n. 47 (1895) 261. - Afr. trop. or:

kilimandscharica, Gilo, in Engl. Bot. Jahrb, xix. (1894) 39. - Afr, trop. or.

Kirkiana, Planch. in DC. Monog. Phan. v. (1887) 601. - Afr. trop. or.

Knittelii, Gilg, in Engl. Pflanzenw. Ost-Afr. C (1895) 260. - Afr. trop. or

Koehneana, Fred. Hoffm. Beitr. Kenntn. Fl. Centr. Afr. (1889) 22. - Afr. centr. or.

Lentiana, Volk. et Gilg, in Engl. Pflanzenw. OstAfr. C (I895) 260. - Afr, trop. or.

lineata, Warb. in Engl. Bot. Jahrb. xiii. (1891) 370. - Oceania.

Mannii, Planch. in DC. Monog. Phan. v. (1887) $610=$ V. Mannii, Buker.

maranguensis, Gilg, in Bot. Jahrb. xix. Beibl. n. 47 (1894) 38. - Afr, trop. or.

meliaefolia, Planch. in DC. Monog. Phan. v. (1887) 558. - Bras.

mexicana, Hort. ex Bull. Soc. Tosc. Ortic. (1888) 298 fig. 25 (an C. mexicana, Moç. et Sessé?). Mexic.

microdiptera, Planch. in DC. Monog. Phan. v (1887) 629 in add. = V. microdiptera, Baker

microdonta, Planch. in DC. 1. c. $482=\mathrm{V}$. micro donta, Baker.

modeccoides, Planch. 1. c. 503. - Cochinch.

morifolia, Planch. 1. c. 478. - Angola.

Muelleri, Planch. 1. c. 516. - Austral

nervosa, Planch. 1. c. 564.-N. Guin

novemfolia, Planch. 1. c. $519=$ V. novemfolia, Wall.

nymphaeifolia, Planch. 1. c. $484=$ V. nymphaeifolia, Welw.

oblonga, Planch. 1. с. $517=$ V.oblonga, Benth.

odontadenia; Gilg, in Engl. Pflanzenw, Ost-Afr. C (1895) 261. - Afr. trop. or.
CISSUS :-

Oliveri, Gilg, ex Eng1. in Abhand1. Preuss. Akad. Wiss. (1894) $46=$ Oliveriana, Gilo.

Oliveriana, Gilg, in Engl. Pflanzenw. Ost-Afr. C 1895) 258. - Afr. trop. or

oliviformis, Planch. in DC. Monrg. Phan. v. (1887) 513. - Sierra-Leone

opaca, Planch.1.c. $518=$ V. opaca, F. Muell.

orientalis, A. Gray, in Proc. Am. Acad. xxiii. (1888) 227 in obs. $(=$ C. orientalis, Lam. $)=\mathrm{V}$. arborea, Linn.

pallida, Planch. in DC. Monog. Phan. v. (1887) 477 $=\mathrm{V}$. pallida, Wight et Arn.

palmatifida, Planch. 1. c. $473=$ V. palmatifida, Baker.

paniculata, Planch. 1. c. $481=\mathrm{V}$, paniculata, Balf.f. pannosa, Planch. 1.c. $539=\mathrm{V}$. pannosa, Baker.

paraguayensis, Planch. 1. c. 554. - Parag.

Parkeri, Planch. 1.c. $550=$ V. Parkeri, Baker.

pauciflora, Eckl. et Zeyh. ex Szyszyl. Pl, Rehmann. ii. (1888) $44=$ pauciflora, DC.

pauciflora, Burch. ex Planch. 1. c. 469 in syn. (- Rhoicissus pauciflora, Planch.). - Afr.austr. pendula, Planch. in DC. Monog. Phan. V. (1887) $594=\mathrm{V}$. pendula, $W$ elw

Planchoniana, Gilg, in Engl. Pflanzenw. Ost-Afr. C (1895) 258. - Afr, trop. or.

Plumeri, Planch. in DC. Monog. Phan. v, (1887) 532. - Ins. S. Doming-

penninervis, Planch. 1. C. $520=$ V. penninervis, F. Muell.

Pohli, Planch. 1. c. $520=$ V. Pohlii, Baker.

polydactyla, Planch. 1, c. $560=$ V. polydactyla, Miq.

praecox, Schweinf, ex Planch. 1. c. 492 in syn. = V. cornifolia, Baker

pruriens, Planch. 1. c. $595=\mathrm{V}$. pruriens, Welw.

pisicarpa, Zippel, ex Planch. 1. c. $441=$ Tetrastigma pisicarpum, Planch.

psoralifolia, Planch. 1. c. $567=$ V. psoralifolia, F. Muell.

purpurascens, Zippel, ex Planch. 1. c. 500 in syn. = V. rostrata, Miq.

Rafflesiae, Korth. ex Planch. 1. c. 443 in syn.= V. Rafflesiae, Miq.

reticulata, Blume, ex Planch, 1. c. 574. - Java.

retivenia, Planch. 1 , c. $576=\mathrm{V}$. reticulata, $M$. Lares

rhamnoided Planch. 1. c. 516. - N. Guin

rheifolia, Planch.1. c. 507. - Cambod

vostrata, Korth. ex Planch. 1. c. $500=$ V.rostrata Miq.

Roxburghii, Planch. 1. c. $572=$ V. Roxburghii, Wight et Arn.

Roylei, Hort. Kew. ex Planch. 1. c. $45 \mathrm{l}$ in obs. (= Parthenocissus himalayana, Planch.?). - Reg. Himal.

rubifolia, Planch. 1. c. 596 in obs. = V. pruriens, Planch.?

rubiginosa, Planch. 1. c. $486=$ V. rubiginosa, Baker.

Saponaria, Planch.1. c. $574=$ V. Saponaria, Benth sarcocephala, Schweinf. ex Planch. 1. c. 405 (=Ampelocissus sarcocephala, Planch.).-Afr. centr scabra, Planch. 1. c. $549=$ V. scabra, Baker.

scabricaulis, Planch. 1. c. 543. - Bras.

Schimperi, Hochst. ex Planch. 1. c. $589=$ V. oxyphylla, A. Rich.

Schweinfurthii, Planch. 1. c. 591. - Afr. centr. bor sciaphila, Gilg, in Abhandl. Preuss. Akad. Wiss.

(1894) 46 nomen; et in Engl. Pflanzenw. Ost-

Afr. C (1895) 258 - Afr. trop. or.

Selloana, Planch. in DC. Monog. Phan. v, (1887) $521=\mathrm{V}$. Selloana, Baker.

semivirgata, Planch. 1. c. 538. - Bras.

serjanioides, Planch. 1 c. 588 . - Abyss

serpens, Hochst. ex Planch. 1. c. 606 in syn. = V. Thonningii, Baker pr. p.

sesquipedalis, Gilg. in Engl. Pflanzenw. Ost-Afr. (1895) 259. - Afr. trop. or.

siamica, Planch. in DC. Monog. Phan. V. (1887) 506. - Siam.

Smithiana, Planch. 1. c. $491=$ V. Smithiana, Baker.

spectabilis, Hochst. ex Planch. 1. c. 609 in obs. $(=$ C. nivea, Hochst, $)$ - - Abyss.

spectabilis, Planch. 1. c. 507. - Reg. Himal.

stipulacea, Planch. 1. c. $597=\mathrm{V}$. stipulacea, Bake 
CISSUS :-

stenotoba, Planch. in DC. Monog. Phan. v. (I887) $578=$ V. stenoloba, Welw

sterculifolia, Planch. 1. c. $519=\mathrm{V}$. sterculifolia, F. Muell.

Stuhlinnminiz Gilo in Engl. Pflanzenw. Ost-Afr. C (1895) 260. - Afr. trop. or.

subarenzia, Planch. in DC. Monog. Phan. v. (1887) 241. - Cuba

subciliata, Planch. I. c. $594=$ V. subciliata, Baker. suberosa, Planch. 1. c. $481=\mathrm{V}$. suberosa, Baker. subolaucescens, Planch, 1. c. 591. - Reg. Zambes. subrhomboidea. Planch. 1. с. $547=$ V. subrhomboidea, Baker.

subtetragona, Planch. 1. c. 499. - Tonk.

sulcicaulis, Planch 1. c. $547=\mathrm{V}$. sulcicaulis, Baker.

ternata. Planch. 1, c $558=\mathrm{V}$. ternata, Baker.

thalictrifolia, Planch. 1. c. 560, - Madag.

Thomsoni. Planch. 1. c. $565=$ V. Thomsoni, Laz'son.

Threaitesit, Planch. 1. c. 502. - Zeyl,

tiliaefolia, Planch. 1. c. 491. - Afr. trop. centr.

Trianae, Planch.1. c. 555. - N. Gran.

tricuspis, Burch. ex Planch. 1. c. $=\mathrm{V}$. tricuspis, Baker.

trifolia, K. Schum. in K. Schum, et Hollr. Fl. Kais. Wilh. Land (1889) $71=$ V. trifolia, Limm.

Tweedieana, Planch. in DC. Monog. Phan. v. (1887)

$534 .=\mathrm{V}$. Tweedieana, Baker.

ukerewensis, Gilg, in Engl. Pflanzenw. Ost-Afr. C (1895) 260. - Afr. trop. or.

ulmifolia, Planch. in DC. Monog. Phan. v. (1887) $552=\mathrm{V}$. ulmifolia, Baker

usambarensis, Gilo, ex Engl. in Abhandl. Preuss. Akad. Wiss. (1894) 44; et in Engl. Pflanzenw. Ost-Afr. A (1895) $3 \mathrm{I}=$ Oliveriana, Gilg.

Viticella, Webb, ex Planch. in DC. Monog. Phan. v. (1887) 587 in syn. $=$ V. adenocaulis, Miq. Volkensii, Gilg, in Bot. Jahrb. xix. Beibl. n, 47 (1894) 37. - Afr. trop, or.

Welvertschii, Planch, in DC. Monog. Phan. v.(1887) $489=$ V. Welwitschii, Baker.

Wightii, Planch. 1. c. 478. - Ind. or.

Wrightiana, Planch. 1. c. 536. - Cuba.

CLASTOPUS, Bunge = Vesicaria, Tourn. (Cru-

cif.).
bicolor, Stapf, in Denkschr. Acad. Wien, (1886) 33. - Persia.

GLATHROSPERIMUM, Planch. (Anonac.) Ind. Kew. i. 55 .

Baillonii, S. Elliot, in fourn. Linn. Soc. xxx. (1894) 70. - Afr, trop. occ.

Heudelotii, S. Elliot, 1. c. 71. - Afr, trop. occ.

CLAUSENA, Burm. f. (Rutac.). - Ind. Kew, i. 553.

Hildebrandtii, Engl, Pfanzenw. Ost-Afr. C (1895) 229. - Afr. trop. or.

lenis, Drake, in Morot, fourn. de Bot. vi. (1892) 276. - Tonk.

CLAvigA, Regel, in Act. Hort. Petrop. xi. (1890) 311 sphalm。= Glavija, Ruiz et Pav.

cauliflora, Regel, 1. c. = Clavija cauliflora, Regel.

CLAvIJA, Ruiz et Pav. (Myrsin.). - Ind. Kew. i. 554 .

antioquensis, Radlk. in Math.-Phys. Sitzb. Akad. Muench.xix. (1889)255. (= Theophrasta antioquensis, Linden), - Venez.

cauliflora, Rcgel, in Act. Hort. Petrop. x. (1889) 696. - N. Granat.

Ernestii, "Hook f. » ex Rev. Hortic. (1888) $239=$ Ernstii, Hook, f.

Ernstii, Hook f. in Bot. Mag. (1887) t. 6928. Venez.

Jelskii, Szyszyl, in Diss, Cl. math.-phys. Acad. litt. Cracov. xxix. (1894) 225. - Peruvia.

GLAYTONIA, Gronov. ex Linn. (Portul.). - Ind. Kew. i. 554 .

aurantiaca, brevifolia, calycina, mneifolia, Limavia, mexicana, minima, napiformis, reflexa, sarmentosa, spinescents, teretifolia, trigona, Kuntze, Rev. Gen. (1891) 57 = homonyma onmia Talini.

\section{GLAYTONIA}

acaulis, affinis, alba, arenaria, aurea, axilliflora, Berteroana, cachinalensis, caespitosa, calycotricha, capitata, caulessens, colchaguensis, compacta, compressa, conferta, coquimbensis, corymbosa, Cumingii, demissa, denticulata, dianthodes, diffusa, discolor, erythrocoma, fasciculata, Fenzlii, ferruginea, flovibunda, frigida, Gaudichaudi, Gilliesii, glomerata, graminifolia, grandiflora, hivtella, Landbeckii, leucocephala, lingulata, litoralis, longiscapa, macilenta, megarhiza, Meyeniana, minutissima, modesta, mucromulata, mul ticaulis, nitida, oblongifolia occulta, paniculata, pilosiuscula, Poeppigiana, polyclados, procumbens, prostrata, ramosissima, nupestris, Saxifraga, sericea setosa, spectabilis, spicata, splendens, tenuifolia, tricolor, trifida, tuberosa, umbellata, virgata, Kuntze, Rev. Gen. (1891) 57 = homonyma ommia Calandriniae.

arenicola, Henderson, in Bull. Torrey Bot. Club, xxii (1895) 49. - Am. bor.

atacamensis, Kuntze, Rev. Gen. (1891) 57 = Calandrinia calycina, Phil.

Barneoudi, Kuntze, 1. c. $56=$ Cal. Chamissoi, Bam.

Bonplandiana, Kuntze, 1. c. $57=$ Talinum lineare, R. Br.

Bodini, Holzinger, in Contrib. U. S. Nat. Herb. i. (1893) 288. - Texas

Breweri, Kuntze, Rev Gen. (1891) $5 \%$ = Calandrinia Breweri, S. Wats.

caffra, Kuntze, 1. c. = Portulaca caffra, Thun .

ciliata, Kuntze, 1. $c_{0}=$ Calandrinia ciliata, $D C$.

cistiflora, Kuntze, 1.c. = Cal. cistiflora, Gill.

Collana, Kuntze, 1. c. = Talinum diffusum, Colla

densiflora, Kuntze, 1. c. = Calandrinia densiflora, Barn.

Gayana, Kuntze, 1. co = Cal. biflora, Meyen.

Grayana, Kuntze, 1. c. = Cal. nevadensis, A. Gray.

Hallii, A. Gray, in Proc. Am. Acad.xxii. (1887) 283. - Calif.

Humboldtiana, Kuntze, Rev. Gen. (1891) $57=\mathrm{Ca}-$ landrinia acaulis, $H . B$, et $K$.

latifolia, Sheld. in Minnes. Bot. Stud, i. (1894) 15 = caroliniana, Michx.

maritima, Kuntze, Rev. Gen. (1891) 57 = Calan-

drinia maritima, Nutt.

Menziesii, Kuntze, 1. c. = Cal. Menziesii, Torr. et Gray,

mutandra, Kuntze, 1. c. $56=$ Cal. calycina, Phil.

nubigrena, Greene, Pittonia, ii. (Sept. 1892) 294. Calif.

Nuttaliana, Kuntze, Rev. Gen. (1891) $5 \%$ = Talinum parviflorum, Nutt

parva, Kuntze, 1. c. = Cal. pygmaea, A. Gray.

parvifolia, Mocino, ex A. Gray, in Proc. Am. Akad. xxii. (1887) 283. - Am. bor.

patens, Kuntze, 1. c. $56=$ Talinum patens, Willd.

peruviana, Kuntze, 1. c. $57=$ Calandrinia Phacosperma, $D C$

Philippiana, Kuntze, 1. c. = Cal, densiflora, Phil picta, Kuntze, 1. c. = Cal. arenaria, Cham.

polycarpodes, Kuntze, 1. c. = Cal. polycarpoides Phit.

potentillodes, Kuntze, 1. c. = Cal. potentilloides, Barn.

pusilla, Kuntze, 1. c. = Cal. pusilla, Barn.

salsolodes, Kuntze, 1. C. = Cal. salsoloides, Barn.

saxosa, T. S. Brandeg. in Zoé, iv. (1893) 150.Calif.

speciosa, Kuntze, 1. c, = Cal, discolor, Lindl.

tenuis, Kuntze, 1. $c_{0}=$ Talinum gracile, Colla.

triangularis. Kuntze, 1, c. $56=\mathrm{T}$. triangulare, Willd.

CLEisostoma, Blume (Orchid.). - Ind. Kew.

i. 555 .

andamanicum, Hook. f. Fl. Brit. Ind. vi. (1890) 71. - Ins. Andam.

bicuspidatum, Hook.f. l.c. 75. - Himal.

bipunctatum, Hook. f. l. c. 73. - Tenass.

brevipes, Hook. f. l.c., et in Ann. Bot. Gard. Cale. v. 1. (1895) 55 t. 82. - Sikkim. Assam.

congesta, F. M. Bailey, in Proc. Roy. Soc. Queensl. xi. I. (1895) 1\%. - Austral.

cristatum, Ridl. in Trans, Linn.Soc. Ser. II. iii, (1893) 370. - Penins, Mal.
GLEISOSTOMA

firmulum, Reichb. $f$. in Bot. Centralbl. xxviii. (1886) 344. - N. Guin.

Hansemanni, Kraenzl. in Oest. Bot. Zeitschr. xliv. (1894) 254. - N. Guin.

Kunstleri, Hook. f. in Hook. Icon. pl. xxiv. (1894) t. 2335. - Perak.

marsupiale, Kraenzl. in K. Schum, et Hollr. Fl. Kais. Wilh. Land. (1889) 34. - N. Guin.

Micholitzii, Kraenzl. in Oest. Bot. Zeitschr. xliv. (1894) 462. -

Nugentii, F. M. Bailey, in Proc. Roy. Soc. Oueensl. xi. I. (1895) 17. - Austral.

ramosum, Hooh. f. Fl. Brit. Ind. vi. (1890) 72. Reg. Himal

ringens, Reichb. f. in Gard. Chron. (1888) ii. 724. Ins. Philipp.

tenerum, Hook. f. Fl. Brit. Ind. vi. (1890) 73. Ind. or. - Zeyl.

uteriferum, Hook. f. l.c. 74. - Perak.

CLEISTANTHES, Kuntze, Rev. Gen. (1891) $60 \%$ sphalm. = Gleistanthus, Hook. f. (Euphorb.).

GLEISTANTHUS, Hook. f. (Euphorb.). - Ind.

\section{Kew. 1. 5.5.}

Blancoi, Vidal, Rev. Pl. Vasc. Filip. (1886) 234.Ins. Phillp.

cupreus, Vidal, l. c. 235. - Ins. Philip.

decurrens, Hook. f. Fl. Brit. Ind. v. (1887) 278. Perak.

ellipticus, Hook.f.l.c. 281. - Perak.

gracilis, Hook. f. l.c. 277. - Penins. Mal.

Helferi, Hook. f. l. c. 280. - Tenass.

heterophyllus, Hook. f. l. c. 276. - Malacca.

hirsutulus, Hook. f. l. c. 278. - Perak.

laevis, Hook. f. l. c. 277. - Penins. Mal.

lancifolius, Hook. f. l.c. - Tenass.

macrophyllus, Hook. f. . c. 278. - Perak.

Maingayi, Hook. f. l. c. 280. - Penins. Mal.

malaccensis, Hook. f. l. c. 277. - Penins. Mal

membranaceus, Hook. f. l. c. 278. - Perak.

nitidus, Hook. f. l. c. 280, - Penins. Mal.

parvifolius, Hook. f. l. c. 281. - Perak.

pedicellatus, Hook, f.l. c. - Penins. Mal.

podocarpus, Hook, f. l. c. - Perak.

stipulatus, Hook.f.l.c. - Perak.

GLEMATIGISSUS, Planch. in DC. Monog. Phan. ఛ. (1887) 422. AMPELIDEAE.

angustissima, Planch. l. c. (=Vitis angustissima. F. Muell.). - Austral.

GLEMATIS, Dill. ex Linn. (Ranuncul.). - Ind. Kew, i. 556

Addisonii, Britton, ex A. M. Vail, in Mem. Torrey Bot. Chub, ii. (1890) 28. - Virginia.

anemoniflora, Hort. ex Koehne, Deutsche Dendrol. (1893) 157 = florida, Thunb.

aphylla, Colenso, in Trans. N. Z. Inst, xix. 1886 (1887) 259. - N. Zel.

atragenoides, Batalin, in Act. Hort. Petrop. xi. (1891) 481. - China.

australis, T. Kirk, Specim. Stud. Handb. N. Zeal. Fl. (1889) 5. - N. Zel.

Bangii, Rusby, in Mem. Torrey Bot. Club, iii. 3. (1893) 3. - Bolivia.

Benthamiana, Hemsl. in fourn. Limn. Soc. xxiii. (1886) 2. - China.

brevicaudata, Hort. [an DC. ?] ex Gard. and For. v. (I892) 739 t. 138. - As.

chrysocoma, Franch. in Bull. Soc. Bot. Fr. xxxiii. (1886) 362. - China.

cochabambensis, Rusby, in Mem. Torrey Bot. Club,

iii. 3. (1893) 3. - Bolivia.

dasyandra, Maxim. in Act. Hort. Petrop. xi. (1890) 7. - China.

Delavayi, Franch. in Bull. Soc. Bot. Fr, xxxiii, (1885) 360. - China occ.

elata, Bureau et Franch. in Morot, Fourn. de Bot. v. (1891) 20. - Tibet.

Fargesii, Franch. l.c. viii. (1894) 273. - China. fasciculiffora, Franch. Pl. Delan?. i. (1889) 5, China.

formosanà, Kuntze, in Hook. Icon. pl. xx. (1896) t. 1945. - Ins. Formos. 


\section{CLEMATIS}

Hendersoni $X$. Hort. ex Koehne, Deutsche Dendrol. (1893) 160. - Hybr. artef.

Henryi, Oliver, in Hook. Icon pl. xix. (1889) t. 1819. - China.

ianthina, Koehne, Deutsche Dendrol. (1893) 159. - Reg. Amur.

lancifolia, Bureau et Franch. in Morot, fourn. de Bot v. (I891) 18. - China.

leiocarpa, Oliver, in Hook. Icon.pl. xvi. (1888) t. 1533. - China.

longifoliolata, Kuntze in Verhand1. zool.-bot. Ges Wien, xxxviii. (1887) $49=$ hexapetala, Linn. $f$. obscura, Maxim. in Act. Hort. Petrop. xi. (1890) 6 - China.

orientalis, Hort, ex Gartenfl. (1894) $610=$ graveolens, Lindl.

ovalifolia, Ito, ex Maxim. in Bull. Acad. Sci. Pétersb. xxxi. (1887) 12. - Japon.

Palmeri, N.E. Rose, in Contrib.U. S. Nat. Herb. i (1891) 118. - Ariz.

Pieroti, Hort. ex Gard, and For, i. (1888) $359=$ brevicaudata, $D C$

pogonandra, Maxim. in Act. Hort. Petrop. xi. (1890) 8. - China.

Potanini, Maxim. l. c. 9. - China

Prattii, Hemsl. in Kew Bull. (1892) 82. - China.

pseudoflammula, Schmalh. ex Lipsky, in Act. Hort. Petrop. xiii. (1894) 276. - Reg. Cauc.

ranunculoides, Franch. in Bull. Soc. Bot. Fr, xxxiii. (1886) 360. - China occ.

hodochlora, Ed. Andvé, in Rev. Hortic. Iix. (1887) 449. - Japon (vel form. hort.).

Sargenti, Lavallée, ex Gard. and For. i. (1888) 344 $=$ Pitcheri,

Stuhlmannii, Hieron, in Engl. Pflanzenw. Ost-Afr. C (1895) 180. - Afr. trop. or.

Suksdorfi, Robins, in A. Gray Syn. Fl. N. Am. I. (1895) 4. - Washingt.

Tashiroi, Maxim. in Bull. Acad. Sci. Peitersb. xxxii (1888) 477. - Japon.

tosaensis, Makino, in Tokyo Bot. Mag. vi. (1897):50 nomen. - Japon.

Traversiana, Kuntze, in Verh.zool.-bot. Ges. Wien, xxxvii. (1887) $50=$ hexapetala

viornioides $\times$. Britton, in Mem. Torrey Bot. Club, iii. (1890) 42. - Hybr. artef,

yunnanensis, Franch, in Bull. Soc. Bot. Fr. xxxiii (1886) 361. - China.

CLEMATOGLETHRA, Maxim, in Act, Hort Petrop. xi. (1889) 36. TERSTROEMIACEAE. actinidioides, Maxim. l. c. 38. - China.

cordifolia, Franch. in Morot, fourn. de Bot. viii. (1894) 279. - China.

Faberi, Franch. l. c. - China.

Hemsleyi, Baill. in Bull. Soc. Linn. Paris, ii. (1890) 873. - China.

integrifolia, Maxim. in Act. Hort. Petrop. xi. (1890) 38. - China.

lasioclada, Maxim. l. c.-China.

Maximowiczii, Baill. in Bull. Soc. Linn. Paris, ii. 1890) 873. - China.

candens, Maxim. in Act. Hort. Petrop. xi. (1890) 38. - China.

strigillosa, Franch. in Morot, fourn, de Bot. viii. (1894) 280. - China.

tomentella, Franch.l.c. - China

GLEOME, Linn.(Capparid.). - Ind. Kew. i. 558 arborea, T. S. Brandeg. in Proc. Calif. Acad. Ser. II. i1. (1889) $128=$ Isomeris arborea, Nutt.

areysiana, Deflers, in Bull. Soc. Bot. Fr. xlii. (1895) 297. - Arabia.

brachystyla, Deflers, in Morot, fourn. de Bot. i. (1887) 39; et in Bull. Soc. Bot. Fr.xxxiv. (1887) 65. - Arabia.

ephemera, T. S. Brandeg. in Proc. Calif. Acad. Ser II. iii. (1891) 112. - Calif.

glandulosissima, Gilg in Engl. Pflanzenw. Ost-Afv. C (1895) 184. - Afr. trop, or.

grandifolia, F. Muell. in Syst. Cens. Austral. Pl. Third Suppl. (1886) 3. - Austral.

Hanburyana, Penzig, in Atti Congr, bot. Genova (1893) 330. - Erithrea.

hispida, Deflers, in Bull. Soc. Bot. Fr. xxxii. (1888) $346=$ polytricha, Defiers.

\section{GLEOME}

ispida, Ehrenb. ex Franch. in Morot, Journ. de Bot. i. (1887) $39=$ brachystyla, Deflers.

Hulletii, King in fourn. As. Sos. Beng lviii (1889) II, 392, - Malaya.

Isomeris, Greene, Pittonia, i. (June 1888) 200. = lsomeris arborea, Nutt.

Luederitziana, Schinz, in Verh. Bot. Ver. Brand. xxix. Abhandl. (1888) 51. - Afr. austro-occ extratrop.

lutea, E. Mey. ex Szyszyl. Polypet. Thalam. Rehmann. (1888) $17=$ Polanisia lutea, Sond

macedonica, Heldr. ex Nadji, Emp. Ottom. Geogr. bot (1892) 11 [conf. Oest. Bot. Zeitschr. (1892)271]. Maced.

maculata, Szyszyl. Polyp. Thalam. Rehmann.(188\%) 17 = Polanisia maculata, Sond.

melanosperma, S. Wats. in Proc. Am. Acad. xxi. (1886) 415. - Mexic.

ovalifolia, Deflers, in Morot, fourn. de Bot. i. (18s7) 40. - Afr. trop. Jr.

platycarpa, Schinz, in Verh. bot. Ver. Prov. Brand. xxix. Abhandl (1888) 50 - Afr austro-occ. extratrop.

polytricha, Franch. in Morot, fourn. de Bot. i 1887) 41. - Arabia.

potosina, Robins. in Proc. Am. Acad. xxvii. (1893) 165. - Mexic.

Schimperi, Pax, in Bot fahrb. xiv. (1892) 294. Abyss.

serrulata, Pax, 7. c. 293. - Afr. trop. or.

suffruticosa, Schinz, in Verh. Bot. Ver. Prov. Brand. xxix. Abhandl. (1888) 50. - Afr. austro-occ. extratrop.

tenuis, S. Wats. in Proc. Am. Acad. xxiv. (1889) 39 - Calif.

usambarica, Pax, ex Engl. in Abhandl. Preuss. Akad. Wiss. (1894) 14 et 60 ; et ex Engl. Pfanzenx. Ost Afr. C (1895) 184. - Atr. trop. or.

GLEOMELLA, DC. (Capparid.). - Ind. Kew. i. 560 .

Palmerana, M.E. fones, in Zoë, ii. (1891) 236. Utah.

GLEOMODENDRON, Pax, in Ber. deutsch. bot. Gesells. ix. (1891) 38; et in Eng1. et Prant1, Natür1. Pflanzenfam. iii. 2. (1891) 276. CAPPA RIDACEAE

somalense, Pax, $7 l$. cc. 33 et 276 ; et in Bot. Fahrb. xiv. (1892) 224. - Afr. trop. or.

GLERMONTIA, Gaudich. (Campanul.). - Ind Kew. i. 560

arborescens, Hillebr. Fl. Haw. Isl. (1888) $242=$ Cyanea arborescens, Mann

coerulea. Hillebr. l. c. - Ins. Sandvic.

Gaudichaudii, Hillebr. 1. c. $243=$ Delissea clermontioides, Gaudich.

multiflora, Hillebr. l. c. 242. - Ins, Sandvic.

pallida, Hillebr. l. c. 241. - Ins. Sandvic.

pyrularia, Hillebr. l. c. 243. - Ins. Sandvic.

GLERODENDRON, Linn. (Verben.). - Ind. Kew. i. 560.

aggregatum, Givke, in Bot. Fahvb. xviii. (1894) 177. - Madag.

alatum, Gürke, l, c. 182, - Afr trop.

aucubifolium, Hemsl. in Ker Bull. (1894) 102. Madag.

Bakeri, Gürke, in Bot. Fahrb. xviii. (1894) 175. Congo.

Balfouri, Hort. ex Gartenfl. (1886) 139 in syn. = Thomsoni, Balf.

Baronianum, Oliver, in Hook. Icon. pl. xxiii. (1892) t. 2241. - Madag.

breviflorum, Ridl. in foum. Bot. xxxiii. (1895) 43 (breviflora.). - Ind. or.

Buchholzii, Gürke, in Bot. Falırb. xviii. (1894) 176. - Afr. trop. occ.

Buchneri, Gürke, l. c. 172. - Angola, Congo

Buettneri, Gïrke, l. c. 174. - Gabon.

bukobense, Gürke, l. c. 182. - Afr, trop. or.

caeruleum, N.E. Br. in Kew Bull. (1895) 115. Arr. austr.

\section{CLERODENDRON}

ephalanthum, Oliver, in Hook. Icon. pl. xvi. (1887) t. 1550; et in Gard. Chron. (1888) i. 652, - Ins.

congense, Baker, in Kew. Bull.(1892) $127=$ Bakeri, Giurke.

Congense, Engl. Bot. Fahrb. viii. (1887) 65 (congensis). - Conoro.

Dinklagei, Gürke, l. c. xviii. (1894) 175.-Kamerun

eriophyllum, Gïrke, l. c. 178. - Afr. trop. or.

eucalycinum, Oliver, in Hook. Icon. pl. xxiii. (1892) t. 2242. - Madag.

Fischeri, Gürke, ex Engl. in Abhandl. Preuss, Akad. Wiss. (1894) 27; et in Bot. Fahrb. xviii. (1894) 172. - Afr. trop. or.

formicarum, Gürke, l. c, xviii. (1894) 179. - Afr. trop.

formosanum, Maxim. in Bull. Acad. Sci. Pétersb. xxxi. (1887) 85. - Ins. Formos.

Fortunei, Hemsl. in foum. Linn. Soc. xxvi. (1890) 259. - China.

fuscum, Giirke, in Bot. Faltrb. xviii. (1894) 175 . Afr, trop. or

Godefroyi, Kuntze, Rev. Gen. (1891) 505. Cochinch.

grandifolium, Gürke, in Bot. Fahrb. xviii. (1894) 173. - Congo

Holstii Gürke, in Abrandl. Preuss. Akad. Wiss. (1894) 27 nomen. - Afr. trop. or.

Holtzei, F. Muell. in fourn. Roy. Soc. N. S. Wales, xxiv. (1891) 75. - Austral.

indicum, Kuntze, Rev. Gen.(1891) $586=$ C. Siphonanthus, R. Br.

Johnstoni, Oliver, in $H$. fohnst. Kitim. Exped. Append. (1886) 344, nomen; et in Trans. Linn. Soc. Ser. II. ii. (1887) 346. - Afr. trop. or.

kinabaluense, Stapf, in Trans. Linn. Soc. Ser. II. iv. (1894) 216. - Borneo.

lanceolatum, Gürke, in Bot. fahrb. xviii. (1894) 181. - Afr. trop. or.

longipetiolatum, Gürke, l. c. 178. - Ins. Zanzib.

magnificum, Warb. l. c. xiii. (1891) 428. - Oceania.

melanocrater, Gürke, l. c. xviii. (1894) 180.-- Afr. centr. or.

micans, Gürke, l. c. 180. - Madag.

minutiflorum, Baker, in Kew Bull. (1894) 150. Ins. Aldabra.

mirabile, Baker, in fourn. Linn. Soc. xxii. (1887) 513. - Madag.

moupinense, Franch. in Nouv. Arch. Mus. Paris, Sér. II, x. (1888) $68=$ Microtaena moupinensis, Franch.

myricoides, Gürke, in Engl. et Prantl, Natiurl. Pfanzenfam. iv. 3a. (1895) $\mathbf{1 7 6}=$ myricoides, $R \cdot B r$. myrmecophila, Ridl. in fourn. Bot. xxxiii. (1895) 42. - Penins, Mal.

natalense, Gürke, in Bot. Fahrb.xviii. (1894) 183.Natal.

ovalifolium, Engl., Pflanzenw. Ost-Afr. A (1895) 124 sphalm. = ovale, Klotzsch.

pleiosciadium, Güre, in Bot. Fahrb. xviii. (1894) 177. - Ins, Zanzib.

polycephalum, Baker, in Kew Bull. (1895) 116. Lagos

Poggei, Giirke, in Bot. Farhb. xviii. (1894) 181. 171. - Afr, trop.

Preussii, Guirke, l. c. 175. - Kamerun

pulverulentum, Engl., Pflanzenr. Ost-Afr. A (1895) 94 nomen. - Afr. trop. or.

Rumphianum, Bull, Catal. (1887) 9. - Java.

sansibarense, Gürke, in Bot. Fahrb. xviii. (1894) 181 tex Engl. in Abhandl. Preuss. Akad. (1894) 27 nomen. - Ins. Zansib.

Schweinfurthii, Giirke, in Bot. Fahrb. xviii. (1894) 177. - Afr. trop.

serotinum, Hort, ex Dippel, Deutsch. Dendrol. i. 1889) $58=$ trichotomum, Thunb.

Sieboldii, Kuntze, Rev. Gen. (1891) 505 = Caryopteris divaricata, Maxim.

Silvaeanum, Henriques, in Bolet. Soc. Brot. x. (1892) 148. - Ins. S. Thom.

speciosum, Gurke, in Bot. Fahrb. xvixi. (1894) 171. - Angola.

spinescens, Gürkc 1. c. $180=$ Cyclonema spinescens, Oliver.

Stuhlmanni, Gïrke.l. c. 173. - Afr. troo. or. 


\section{GLERODENDRON}

subpandurifolium, Kuntze, Rev. Gen.(1891) 506. Assam.

sylvaticum, Briq. in Engl. et Prantl, Natürl. Pflanzenfam. iv. 3a.(1895) $176=$ Cyclonema sylvaticum, Hochst.

tanganyikense, Baker, in Kew Bull. (1895) \%1. Afr. trop. or

ternatum, Schinz, in Verh. Bot. Ver. Brand, xxxi. (1890) 205. - Afr, austro-occ extratrop.

toxicarium, Baker, ex Gürke, in Engl. Pflanzenw. Ost-Afr. C (I895) 341. - Afr trop. or.

triplinerve, Rolfe, in Bolet. Soc. Brot. xi. (1893) 87 = formicarum, Givke.

uncinatum, Schinz, in Verh. Bot. Ver. Brand.xxxi. (1890) 206. - Afr. austr. (pars bor.)

Welwitschii, Gïrke, in Bot. Fahrb. xviii. (1894) 174 - Angola.

GLETHRA, Gronov, ex Linn, (Ericac.).- Ind. Kew. i. 562. (Ericac.)

cutervoana, Szyszyl. in Disss. Cl. math-phys. Acad. litt. Cracor xxix. (1894)227 - Peruvia.

Delavayi, Franch. in Morot Fourn, de Bot.ix. (1895) 370. - Yunnan.

Fargesii, Franch.l. c.369. - China.

occidentalis, Kuntze, Rev. Gen. (1891) $389=$ tinifolia. Sw.

peruviana, Szyszyl, in Diss, Cl, math-phy's. Acad. litt. Craco\%. xxix. (1894) 227. - Peruvia.

Pringlei, S. Wats. in Proc. Am. Acad. xxy. (1890) 15\%. - Mexic.

scandens, Franch. in Nouv. Arch. Mus. Paris, Sér. II. x. (1888) $53=$ Clematoclethra scandens. Maxim

CLEVELANDIA, Greene, ex T. S. Brandeg. in Proc. Calit. Acad. Ser. II. iii. (1891) 15\%, et ex O. Hoffm. in Eng1. et Prantl. Natur1. Pflanzenfam. iv. 3b. (1893) 99. SCROPHULARINEAE.

Beldingi, Greene, $l l . c c$. - Calif.

CLEYERA, DC. (Ternstroem.).-Ind. Kew. i. 562 Fortunei, Hook. f. in Gard. Chron. (1895) i. 10\%; et in Bot. Mag.(1895)t. 7434. - Japon.

CLIANTHUS, Banks et Soland.(Legumin.). Ind. Kew. i. 562

maximus, Colenso, in Trans. N. Z. Inst. xviii. 1885 (1886) 294. - N. Zel.

GLIBADIUM, Linn. (Compos.). - Ind. Kew. i. 562.

arboreum, 7. D. Smith. in Coult. Bot. Gaz. xiv. (1889) 26. - Guatem

asperum, Baill. ex Laness. P1. util. col. franc (1886) 406. = Baillieria aspera, Aubt

Donnell-Smithii, Coult. Bot. Gaz. xvi. (1891) 98. Guatem

CLIONE integrifolia, C. A. White, in Am. Natural xii. (1888) 1029 sphalm. = Cleome integrifolia Torr. et Gray

CLIDEMIA, D. Don (Melastom.). - Ind. Kew. i. 563

acutifolia. Cogn. ex Rusby, in Mem. Torrey Bot. Chub, iii. 3 (1893) 32. - Bolivia.

affinis, Cogn. in Mart. Fl. Bras. xiv, Iv. (1888) 493 (= Staphidium affne, Naud.). - Bras.

ampla, Cogn. l. c. 1023. - Columb. Venez.

attenuata, Cogn. l. c.1006 (= Staphidiastum attenuatum, Naud.). - Ins. S. Thom (Am.)

Barbeyana, Cogn. l. c. 1014. - Cuba.

Biolleyana, Cogn. l. c. 1193; et ex Th. Dur. et Pitt. in Bull. Soc. Bot. Belg. xxx. 1891 (1892) 264. Costarica.

boliviensis, Cogn. ex Britton, in Bull. Torrey Bot. Club, xvii. (1890) 94. - Bolivia.

Bonplandii, Cogn. in Mart. Fl. Bras xiv, IV. (1888) 501 (= Sagraea Bonplandii, Triana). - Am. trop.

bullosa, Cogn. l. c. 490 (= Melastoma bullosum, Spreng.). - Bras., Guian.

Candolleana, $\operatorname{Cogn}$. . . c. - Bras.

capilliflora, Cogn. l. c. 308 (= Sagraea capilliflora, T-iana). - Bras.

\section{CLIDEMIA}

capillipes, Cogn. in Mart. Fl. Bras. xiv. IV. (1888) 509 (= Sagraea capillipes, Triana). - Bras.

capituliflora, $\operatorname{Cogn}$.l. c. 1021. - Cuba.

cordata, Cognn ex Britton: in Bull. Torrey Bot. Club, xvii. (1890) 211. - Bolivia.

coriacea, Cogn. in Mart. Fl. Bras, xiv. Iv. (1888)

510 (=Sagraea coriacea, Triana). - Guian. ang1.

cubensis, Cogn. in DC. Monog. Phan. vii. (1891) 1021. - Cuba.

cymifera, F. D. Smith, in Coult. Bot.Gaz. xiv. (1889) 25. - Guatem.

discolor, Cogn. in DC. Monog. Phan. vii. (1891) 1025 (= Sagraea discolor, Triana). - N. Granat.

dispar, Cognz. in Mart. Fl. Bras. xiv, Iv. (1888) 497 (= Calophysa dispar, 'Triana). - Peruvia.

divaricata, Cogn. in DC. Monog. Phan. vii. (1891) 1015. - Cuba.

domingensis, Cogn. in fahrō. Bot. Gavt. Berl. iv, (1886) 283 (= Sagraea domingensis, DC.). - Ins. Antill.

Donnell-Smithii, Cogn. ex F. D. Smith, in Coult. Bot. Gaz. xvi. (1891) 5. - Guatem.

epiphytica, Cogn, in DC. Monog. Phan, vii. (1891) 1025. - N. Gran

Fendleri, Cogn.l. c. 1016. - Venez

flexuosa, Cogn. l. c. 1103 (=Calophysa flexuosa, Triana). - Venez.

Francavillana, Cogn, in Mart. Fl, Bras, xiv. Iv. (1888) 502. - Bras

glandulifera, Cogn. ex F. D. Smith, in Coult. Bot. Gaz. xx. (1895) 289. — Guatem.

grandifolia, Cogn. in DC. Monog. Phan. vii. (1891) 1018. - Antill. Venez.

Grisebachii, Cogn. l.c. 1009. -- Jamaica.

heteroneura, Cogn. in Mart. Fl. Bras. xiv. IV. (1888) 506 (- Sagraea heteronewra, Triana). - Bras. Ecuad.

impetiolaris, Cogn. in DC. Monog Phan. vii.(1891) 1016 (= Staphidiastrum impetiolare, Naud.). Am. austr.

Kapplerii, Cogn. in Mart. Fl. Bras, xiv, IV. (1888) 496. - Guian. bat

macrandra, Cogn. in DC. Monog. Phan. vii. (1891) 1013. - Cuba.

melanophylla, Cogn. in Mart. Fl. Bras, xiv. IV (1888) 511 (= Sagraea melanophylla, Triana). Bras.

minutiflora, Cogn. in Mart. Fl. Bras. xiv, Iv. (1888) 507 (= Sagraea minutiflora, Triana). - Bras.

Naudiniana, Cogn. in DC. Monog. Phan. vii. (1891) 990 (= Staphidium dependens, Naud.). Mexic

pilosa, Cogn.l.c. 1023 (= Sagraea pilosa, DC.).Jamaica.

platyphylla, Cogn. in Mart. Fl. Bras. xiv. Iv. (1888) 499 (= Sagraea platyphylla, Triana). - Bras.

obliqua, Cogn. in DC. Monog. Phan. vii. (1891) 1017 (= Staphidiastrum obliqum, Naud.). - Am austr.

ossaeaeformis, $\operatorname{Cog} n$. l. c. 1011 (= Miconia ossaeiformis, Naud.). - Antill.

pilosissima, Cogn. ex Britton, in Bull. Torrey Bot. Club, xvi. (1890) 211. - Bolivia.

pleiostemon, Cogn. in DC. Monog. Phan, vii. (1891) $1000(=$ C. variflora. Benth.). - Bras.

polystachya, Cogn.l. c. 1021 (= Staphidiustrum polystachyum, Naud.). - Porto-Rico.

purpureo-violacea, $\operatorname{Cog} n$, ex Th. Dur. et Pitt. in Bull. Soc. Bot. Belg. xxx. 1891 (1892) 263. - Costarica.

pusilliflora, Cogn, in DC. Monog. Phan. vii. (1891) 1010. - Ins, S. Doming.

Raddiana, Cogn. in Mart. Fl. Bras. xiv, Iv. (1888) 509. - Bras.

radicans, $\operatorname{Cog} n$, ex F. D. Smith, in Coult. Bot. Gaz. xx. (1895) 288. - Costarica.

rariflora, Cogn. in DC. Monog. Phan. vii. (1891) 1017 (= Melastoma yariflora, Bonpl.). - Venez. rubrinervis, Cogn. Monog. Phan. vii. (1891) 1013 (= Staphidiastrum rubrinerve, Naud.). - Cuba.

Rusbyi, Cogn。ex Britton, in Bull. Torrey Bot. Club, xvii. (1890) 211. - Bolivia.

salicifolia, Cogn. in DC. Monog. Phan. vii. (1891) 1009 (=Ossaea salicifolia, Crueg.). - Ins. Trinit. septuplinervia, Cogn. in Mart. Fl. Bras. xiv. Iv. (1888) 506. - Peruvia.

\section{CLIDEMIA}

(5erpens, Cogn. in DC. Monog. Phan. vii. (1891) 1025. - N. Gran.

sessiliffora, Cogn. iu Mart. Fl. Bras, xiv, Iv. (1888) 505. - Peruvia.

sparsiflora, Griseb. (Veget. Carib. n. 565), ex Cogn. in DC. Monog, Phan. vii. (1891) 1043 in syn.

(= Henriettella lateriflora. Triana.).-Ins. Antill. trichodes, Sagot, ex $\operatorname{Cog} n$. in Mart. Fl. Bras. xiv. Iv. $(1888) 612=$ Miconia robusta, $\operatorname{Cog} n$.

trichopetala, Cogn. in DC. Monog. Phan, vii. (1891) 1013. - Cuba.

umbrosa, Cogn. l.c. $1019(=$ Melastoma umbrosa, Sw.). - Antill.

CLIFFORTIA, Linn. (Rosac.). - Ind. Kew. i.

pilifera, Bolus, in fourn. Limn. Soc. xxv. (1889) 162. - Afr. austr.

GLIFTONIA, Banks (Cyrill.), - Ind. Kew. i.

monophylla, Britton, sec. Sargent N. Amer. Sylva, ii. (1892) 7 t. 51, cum cit. erron. [Conf. Bull. Torr. Bot. Club, xvi. (1889) 310] = ligustrina, Spreng.

GLINAGANTHUS, Nees (Acanth.). - Ind. Kew. i. 565

mutans, Lindau, in Bot. Jahrb. xviii. (1894) $63=$ C. Burmanni, Nees

GLINOGYNE, Salisb. (Scitam.). - Ind. Kew. i.

565.
dichotoma, Kuntze, Rev. Gen. (1891) 684 sphalm.= Maranta grandis, Miq. = dichotoma, Salisb. purpurea, Ridl. in fourn. Bot. xxv. (1887) 132. Angola.

CLINOPODIUM, Linn. = Calamintha, Tourn. (Labiat.).

abyssinicum, Kuntze, Rev. Gen. (1891) 515 = Cal abyssinica, $A$. Rich.

Acinos, Kuntze, 1. c. $513,515=$ Cal. Acinos, Clairy

aduense, Kuntze, 1. c. = Cal. aduensis, Strobl.

alpinum, Kuntze, 1. c. = Cal. alpina, Lam

alternipilosum, Kuntze, 1. c. = Satureia alternipilosa, C. Koch.

annum, Kuntze, 1. c. = Cal, annua, Schrenk.

approximatum, Kuntze, 1. c. = Satureia approximata, Frivald.

Benthamii, Kuntze, 1. c. = Micromeria Benthami, Webb et Berth.

betulifolium, Kuntze, 1. c. = Cal. betulifolia, Boiss. et Bal.

biflorm, Kuntze, 1. c. = Micromeria biflora, Benth. boivianum, Kuntze, 1. c. = M. boliviana, Benth.

bonariense, Kuntze, 1. c. = M. bonariensis, Fisch. et Mey.

Bourgeauanum, Kuntze, 1. c. = M. Bourgaeana, Webb.

bracteolatum, Kuntze, 1. c. = M. bracteolata, Benth.

Brownei, Kuntze, 1. c. $514=$ M. Brownei, Benth.

Calamintha, Baill. Hist. despl. xi. (1892) 24 et $32=$ seq.

Calamintha, Kuntze, Rev. Gen. (1891) $515=$ Cal. officinalis, Moench.

Campanella, Kuntze, 1. c. = Satureia Campanella, Ehrenb.

candidissimum, Kuntze, 1. c. = Cal. candidissima, Munby.

canum, Kuntze, 1. c. = Cal, graveolens, Benth. capitellatum, Kuntze, I. c. = Micromeria capitellata, Benth.

chinense, Kuntze, 1. c. = Cal, chinensis, Benth.

coccineum, Kuntze. 1. c. = Cal. coccinea, Benth.

coerulescens, Kuntze, 1. c. = Cal. caerulescens, Wedd.

confine, Kuntze, 1. c. = Cal. confinis, Hance.

congestum, Kuntze, 1. c. = Micromeria congesta Boiss. et Hausskn.

consentinum, Kuntze, 1, c. = M. graeca, Benth.

cordatum Kuntze, I $\mathrm{c}_{0}-\mathrm{M}$ cordata, Moris.

cremnophilum, Kuntze, 1. c. = M. cremnophila, Boiss, et Heldr.

creticum, Kuntze, 1. c. = Cal, cretica, Benth. 
CLINOPODIUM :-

cristatum, Kuntze, Rev, Gen. (1891) 515 = Micromeria cristata, Griseb.

cryptanthum, Kuntze, 1. c. = Cal. cryptantha, Vatke.

cuneifolium, Kuntze, 1. c. = Satureia cuneifolia, Ten.

cymuligerum, Kuntze, 1. c. = Micromeria cymuligera, Boiss. et Hausskn

Darwini, Kuntze, 1. c. = M. Darwinii, Benth

debile, Kuntze, 1. c. = Cal, debilis, Benth.

densiflorum, Kuntze. 1. c.= Micromeria densiflora, Benth.

dentatum, Kuntze, 1. c. = Cal. dentata, Chapm.

depauperatum, Kuntze, 1. c. = Cal. depauperata, Bunge.

Douglasi, Kuntze, 1, c. = Micromeria Douglasii, Benth.

ellipticum, Kuntze, 1. c. = M. elliptica, C. Koch.

ericifolium, Knntze, 1. c. $514=$ M. varia Benth.

filiforme, Kuntze, 1. C. $515=$ M. filiformis, Benth.

floridum, Kuntze, 1.c. = Cal. florida, Boiss.

Forbesii. Kuntze, 1. c. = Micromeria Forbesii, Benth.

fruticosum, Kuntze, 1 c. = M. marifolia, Benth.

Gilliesii, Kuntze, 1. c. = M. Gilliesii, Benth.

glabellum, Kuntze, 1 c. = Cal. glabella, Benth .

glabrum, Kuntze, 1.c. = Cal. Nuttallii, Berth

glandulesum, Kuntze, 1. c. = Cal. glandulosa,

Benth.

gracile, Kuntze, 1. c. $514=$ Cal. gracilis, Benth.

graecum, Kuntze, ․ c. $515=$ Micromeria canescens, Benth.

grandiflorum, Kuntze, 1. c, = Cal. grandiflora, Moench.

graveolens, Kuntze, 1. c. = Cal, graveolens, Benth.

Haussknechtii, Kuntze, 1. c. = Cal. Haussknechti, Bunge.

helianthemifolium, Kuntze. 1. $\dot{c}$. = Micromeria helianthemifolia, $W e b b$ et Berth

hispidum, Kuntze, 1. $\mathrm{c}=\mathrm{M}$. hispida, Boiss, et Heldr. hortense, Kuntze, 1. c. = Satureia hortensis, Linn. Hydaspidis, Kuntze, 1. c。= Micromeria Hydaspidis, Falc.

imbricatum, Kuntze, 1, c. = M. Forskàhlei, Benth. incanum, Kuntze, 1. c. = Cal. incana, Boiss

inodorum, Kuntze, 1. c. = Micromeria inodora, Benth.

intermedium, Kuntze, 1. c. = Satureia intermedia, C. A. Mey.

julianodes, Kuntze, 1. c. = Micromeria julianoides, Webjo et Berth

julianum, Kuntze, 1. c. = M. Juliana, Benth.

lanatum, Kuntze, 1. c = M. lanata, Benth.

lepidum, Kuntze, 1. c. = M. lepida, Webb et Berth.

libanoticum, Kuntze, 1. $c_{*}=$ M. libanotica, Boiss.

macrostemum, Kuntze, 1. c. = Cal. macrostema, Benth.

maritinnum, Kuntze, 1, c. = Cal, maritima, Benth

microplyllum, Kuntze, 1. c. = Micromeria microphylla, Benth

mimulodes, Kuntze, 1. c. = Cal. mimuloides, Benth. molle, Kuntze, 1. c. = Micromeria mollis, Benth.

montanum, Kuntze, 1. c. = Satureia montana, Linn.

multicaule, Kuntze, 1. c. = Cal, multicaulis, Maxim.

Nepeta, Kuntze, 1. c. = Cal. Nepeta, Savi.

nevvosum, Kuntze, 1. c. = Micromeria nervosa, Benth.

niteum, Kuntze, 1. c. = Cal. nivea. Boiss

mubigenum, Kuntze, 1.c. = Micromeria nubigena, Benth.

nummulariaefolium, Kuntze, 1. c. = M. nummularifolia, Boiss

Olla, Kuntze, 1. c. = Satureia Olla, Ehrenb.

pachyphyllum, Kuntze, 1. c。 = Satureia hortensis, Linn.

Palmeri, Kuntze, 1, c = Cal Palmeri, A. Gray

parvifolium, Kuntze, 1. c. = Micromeria parviflora, Rezclib.

patainum, Kuntze, 1. c. = Cal. patavina, Host.

Pomelianum. Kuntze, 1. c. = Cal. nervosa, Pomel.

purpureum, Kuntze, 1. c. (purpurea) = Micromeria purpurea, A. Gray.

rigidum, Kuntze, 1. c. = Satureia rigida, Bartr.

rotundifolium, Kuntze, 1. c。= Ziziphora acinoides, Linn.

\section{CLINOPODIUM : -}

Salzmannii, Kuntze, Rev. Gen.(1891) $515=$ Satu-

reia inodora, Salzm.

serpyllifolium, Kuntze, 1. c. = Micromeria serpyllifolia, Boiss.

simense, Kuntze, 1.c. $516=$ Cal. simensis, Benth

sinaicum, Kuntze, 1. c. = Micromeria sinaica, Benth.

spicigerum, Kuntze, 1. c. = Satureia alternipilosa, C. IKoch

spinosum, Kuntze, 1. c. = Sat. approximata, Frivald. stamineum, Kuntze, 1. c. = Cal, staminea, Boiss.

stoloniferum, Kuntze, 1. c. = Micromeria stolonifera, Benth.

suaveolens, Kuntze, 1. c. = Cal. suaveolens, Boiss, sumudum, Kuntze, 1. c. = Micromeria Pulegium, Benth.

tenue, Kuntze, 1. c. = M. tenuis, Benth

tenuifolium, Kuntze, 1. c. = M. graeca, Benth

terebenthinaceum, Kuntze, 1. c. $514=$ M. Teneriffae, Benth.

teydense. Kuntze, 1. c. $516=$ M. teydensis, C. Bolle.

Thymbra, Kuntze, 1. c. = Satureia Thymbra, Linn. thymifolium, Kuntze, 1. c. = Cal. thymifolia, Host. thymodes, Kuntze, 1. c. = Micromeria thymoides, De Not.

mbrosum, Kuntze, 1. c. = 514 Cal. umbrosa, Fisch, et Mey.

usuriense, Kuntze, 1. c. $516=$ Càl. usuriensis, Regel et Maack.

viminerm, Kuntze, 1. c. = Micromeria obovata, Benth.

Walterianum, Kuntze, 1. c. = Cal. caroliniana, Sweet.

xalapense, Kuntze, 1. c. = Micromeria Brownei, Benth.

GLITANDRA, Benth. (Apocyn.), - Ind. Kew. i.

Barteri, Stapf, in Kew Bull. (1895) 20. - Afr. trop.

occ.

Mannii, Stapf, l. c. - Afr. trop. occ.

orientalis, K. Schum, in Engl. Pflanzenw. Ost-Afr, C (1895) 315. - Afr. trop. or.

robustior, $K$. Schum. in Engl. et Prantl, Naturl. Pfanzenfam. iv. 2. (1895) 130. - Congo

Schweinfurthii, Stapf, in Kew Bull. (1895) 20. Afr. centr. bor.

GLITORIA, Linn. (Legumin.). - Ind, Kew. i.

Hanceana, Hemsl. in Fourn, Limn. Soc. xxiii. (1887)

I87. - China.

sericea, S. Wats. in Proc. Am. Acad. xxii. (1887) 407. - Mexic

triflora, S. Wats. l. c. - Amer. bor.

CLIVEOCHARIS $\times$, Hort, ex Gartenf, (1891) 416 = Gliveucharis, Rodigas,

CLIVEUCHARIS $\times$, Rodigas, ex Rev. Hortic, lxiii. (1891) 316 et ex Gard: Chron. (1891) I. 708 (sphalm. Clivencharis). - AMARYLLIDEAE

pulchra $\times$. Hort, 11. cc. - Hybr. artef.

CLIVIA, Lindl. (Liliac.). - Ind, Kew. i. 566 sulphurea, Laing, ex Wien. I11. Gartenzeit. (1888) $275=$ miniata, Regel

CLOMPANUS, Rumpf, Herb, Amboin. ii, 168-170 (1743); ex Kuntze, Rev. Gen. $77(1891)=$ Sterculia, Linn.

affmis, alata, Alexandri, arabica, Barteri, bicolor, Bidwillii, Blumei, caribaea, caudata, ceramica, Chicha, cinerea, coloratu, comosa, cuneata, cuspidata, discolor, ensifolia, ferruginea, frondosa, fulgens, gracilis, grandifolia, linearicarpa, linearis, linguifolia, lurida, macrophylla, madagascariensis, mexicana, oblonga, macrophylla, madagascariensis, mexicana, oblonga, folia, propinqua, punctata, purpurascens, quadrifida, Roxburghii, rufa, rugosa, rupestris, scaphigera, Spanglevi, stipularis, stipulata, striata, striatiflora, subpeltata Thwaitesii tululata urens, versicolor villosa, Zippelii, Kuntze, Rev. Gen. (1891) $78=$ hamonyma

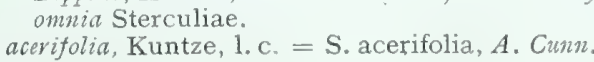

CLOMPANUS : -

africana, Kuntze, Rev. Gen. (1891) $77=\mathrm{S}$. Triphaca. R. Br.

apetala, Kuntze, 1. c. $78=$ S. carthaginensis, Cav. armata, Kuntze, 1. c. = S. ornata, Wall.

australis, Kuntze, 1. c. = S. Trichosiphon, Benth coccinea, Kuntze, 1. c. $77=\mathrm{S}$. coccinea, Roxb. cochinchinensis, Kuntze, 1.c. $78=$ S. cochinchinensis, Pierre.

cordata, Kuntze, 1, c. $77=$ S. javanica, $R . B r$. cordifolia, Kuntze, 1. c. 78 = S. cordifolia, Blanco. diversifolia, Kuntze, 1. c = S. diversifolia, G. Don. dongnaiensis, Kuntze, 1. $\mathrm{c}$. = S. dongnaiensis, Pierre.

excelsa, Kuntze, 1. c. $77=$ S. excelsa, Mart.

foetida, Kuntze, 1. c. = S. foetida, Linn.

gracilipes, Kuntze, 1. c. $78=$ S. gracilipes, Pierre.

Gregorii, Kuntze, 1, c. = S. diversifolia, G. Don.

Haenkeana, Kuntze, 1.c. = S. acerifolia, Hemsl.

Hamiltonii, Kuntze, 1. c. $77=\mathrm{S}$. coccinea, Roxb.

Harmandii, Kuntze, 1. c. $78=$ S. Harmandii,

Pierre.

hypoihra, Kuntze, 1. c. = S. hypochrea, Pierve.

javanica, Kuntze, 1. c. $77=$ S. campanulata, Wall.

issophylla, Kuntze, 1. c. $78=\mathrm{S}$. lissophylla, Pierre. longifolia, Kuntze, 1. c. = Cola acuminata, Schott. et Endl.

malabarica, Kuntze, 1. c. 77 = S. guttata, Roxb.

Mastersii, Kuntze, 1. c. $78=$ S. Mastersii, Mart.

monusperma, Kuntze, 1. c. = S. nobilis, Sm.

paradoxa, Kuntze, 1. c. = S. ramiflora, Benth.

peltata, Kuntze, 1. c. = Pterospermum heterophyllum, Hance.

Pexa, Kuntze, 1. co = S. Pexa, Pierre.

pruviens, Kuntze, 1. c. = S. Ivira, Sw.

pubescens, Kuntze, 1. c. $77=$ S. Tragacantha, Lindl.

pyriformis, Kuntze, 1. c. $78=$ S. platanifolia, Linn. $f$.

mbiainosa, Kuntze, I, c. 77 = S. Iubiginosa, Vent. simplex, Kuntze, 1. c. = S. platanifolia, Linn, $f$. speciosa, Kuntze, 1. c. $78=\mathrm{S}$. speciosa, $K$. Schum. stigmarota, Kuntze, 1. C. = S. stigmarota, Pierre. Thorellii, Kuntze, 1. c. = S. Thorellii, Pierre. tomentosa, Kuntze, 1. c. =S. tomentosa, Guill, et Perr.

GLOSIA, Remy, (Compos.). - Ind. Kew. i. 566.

brachypetala, Phil. in Anal. Univ. Chil. 1xxxvii. (1895) 711. - Chili.

digitata, Phil.l. c. 710. - Chili.

elata, Phil. [Iter Atac, n. 197). l. . - Chili.

foliosa, Phil. l. c. 709. - Chili

villosa, Phil. l. c. 712. - Chili.

viridis, Phil $\bar{c}$ c. $710,-$ Chili.

GLUSIA, Linn. (Guttif.). - Ind. Kew. i. 567

noustifolia, Engl. in Mart. Fl. Bras, xii. I. (1888)

420. - Bras.

articulata, Vesque, in DC. Monog. Phan. viii. (1893) 124. - Columbia.

axillaris, Engl. in Mart. Fl. Bras. xii. I. (1888) 413. - Bras

Burchellii, Engl.l.c. 416. - Bras.

calyptrata, Vesque, Epharm, iii. (1892) 8 t. 20; et in DC. Monog. Phan. viir. (1893) 76. - Ins. Portoric.

carachensis, Vesque, in DC. Monog. Phan. viii. (1893) 139. - Venez.

cartilaginea, Vesque, l.c. 97. - - Ins, S. Doming.

colorans, Engl. in Mart. Fl. Bras. xii. I. (1888) 426. = Guian. angl.

columnaris, Engl. l. c. 432. - Bras.

Conleti, Duchassaing, ex Vesque, in DC. Monog. Phan, viii. (1893) 95 in syn. = minor, Linn. crubescens, Vesque, 1. c. 63 sphalm. = erubescens,

Ve que.
cyclanthera, Vesque, 1. c. 136 in syn. = columnaris, Engl.

deperdens, Pav. ex Vesque, 1. c. 177 in syn.=Chrysochlamys dependens, Planch. et Triana. erubescens, (err. cal. crubescens) Vesque, l. c. 63.Columb.

grandifolia, Engl. in Mart. Fl. Bras. xii. I. (1888) 429. - Bras.

Jenmani, Engl. l. c. 432. - Guian. angl. 


\section{GLUSIA}

Lehmanni, Vesque, in DC. Monog. Phan, viii. (1893) 65. - Columb

macropoda, Klotzsch, ex Engl. in Mart. Fl. Bras, xii. 1. (1888) 424. - Guian. angl.

Martiana, Engl. l.c. 411. - Bras.

Martini, Sagot, ex Engl. 1. c. $425=$ palmicida, L.C. Rich.

mexicana, Vesque, Epharm. iii. (1892) 9 t. 24 et 25 et in DC. Monog. Phan. viii. (1893) 84. - Mexic. microphylla, Engl, in Mart. Fl. Bras, xii. 1. (1888) 426. - Guian. angl.

pallida, Engl.l.c. 414. - Peruvia

parvicapsula, Vesque, Epharm. iii. (1892) 10 t. 34; et in DC. Monog. Phan. viii. (1893) 98. - Peruvia. parviflora, [Sald. mss.] Engl. in Mart. Fl. Bras. xii. I. (1888) 407; et in Engl. et Prantl Natiirl. Pfanzenfam. iii. 6. (1898) 225. - Bras

peruviana, Szyszyl。 in Diss. Cl. Mat.-phys. Acad. litt. Cracoi'. xxix. (1894) 225. - Peruvia.

penduliflora, Engl, in Mart. Fl. Bras, xii. I. (1888) 412. - Bras.

petiolata, Klotzsch, ex Engl. 1. c. $423=$ grandiflora, Splitg.

Planchoniana, Engl. l. c. 431 (= Polythecandra Spruceana, Planch. et Triana). - Bras.

Poeppigiana, Engl. in Engl, et Prantl, Natiurl. Pfanzenfam. iii. 6.(1895) 225 (=C. alba, Ruiz et Pav.). - Peruria.

polysepala, Engl. in Mart. Fl. Bras, xii. I. (1888) 427. - Bras.

prismandra, Vesque, in DC. Monog. Phan. viii. (1893) 80 in syn. = penduliffora, Engl.

pulcherrima, Engl. in Mart. Fl. Bras. xii. I. (1883) 414. - Ecuad.

purpurea, Engl. l. c. 416 (= Avrudea purpurea, Splitg., - Guian. bat.

ramosa, Rusby, in Mem. Torrey Bot. Club, iv. (1895) 204. - Bolivia.

Riedeliana, Engl. in Mart. Fl.Bras. xii. I. (1888) 410. - Bras.

viparia, Sagot, ex Engi. 1. c, $405=$ cuneata, Benth Schomburgkii, Vesque, Epharm. iii. (1892) 7 t. 94 et 95; et in DC. Monog. Phan. viii. (1893) 69. Guian. angl.

sessilis, Klotzsch, ex Engl. ex Mart. Fl. Bras. xii. I. (1888) 405 . - Guian. ancl.

spathulaefolia, Engl, l. c. 412. - Bras.

tetrastigma, Vesque, Epharm. iii. (1892) 7t. 16 et 17 ; et in DC. Monog. Phan。 viii. (1893) 71. Cuba.

trochiformis, Vesque, $l i . c c .4$, tab. 3 et 47 (= Tovomitopsis Sbruceana, Engl.). - Peruvia.

viscida, Engl, in Mart. Fl. Bras, xii. I. (1888) 422.Bras

CLUSIANTHEMUM, Vieill, = Garcinia, Linn. (Guttifer.)

coriacenn, Vieill. ex Vesque, in DC. Monog. Phan. viii. (1893) 418 in syn.=G. Mungotia, Deplanche. densiflorum, Vieill. 1. c. $420=\mathrm{G}$. densiflora, Vicill. pedicellatum, Vieill, 1. c. $=$ G. Mungotia, Deplanche.

GLUYTIA, Boerh. ex Linn. (Euphorb.). - Ind. Kew. i. 568.

kilimandscharica, Engl. in Hoeknel, zum Rudolph See, Append. (1892) 5 ; et in Abhandl. Preuss. Akad. Wiss. 1891 (1892) 285. - Afr. trop. or.

leuconeura, Pax, in Bot. Fahrb. xix. (1894) 112. Afr. trop. or.

mollis, Pax, l. c.; et in Abhandl. Prenss. Akad. Wiss. (1894) 64. - Atr, trop, or.

robusta, Pax, in Engl. Pflanzenw. Ost-Afr. C (1895) 241. - Afr. trop. or.

Stuhlmanni, Pax, in Bot. Fahrb. xix. (1894) 112. - Afr. trop. or.

CLYPEOLA, Linn. (Crucifer.), - Ind. Kew. i. 568.

minima, Stapf, in Denkschr. Acad. Wien, (1886) 35. - Persia.

Raddeana, Alboff, in Bull. Herb. Boiss. ii. (1894) 448. - Reg. Cauc.

CNESTIS, Juss. (Connarac.). - Ind, Kew, i. 569. bullata, Baill. Hist. pl. Madag. Atlas, (1886) t. $1 \%$ - Madag.

\section{CNESTIS}

alocarpa, Gilg, in Engl. Pfanzenw. Ost-Afr. C (1895) 192. - Afr. or.

confertiflora, Gilg, l. c. 193. - Afr. or

urens, Gilg, in Engl. et Prantl, Natïr. Pflanzenfam. iii. 3. (1891) 67; et in Engl. Bot. Fahrb. xiv. (1892) 330. - Kamerun

GNIGUS, Linn. (Composit.). - Ind. Kew. i. 569. amplifolius, Greene, Pittonia, i. (July 1887) 70.Calif.

calcareus, M. E. Fones, in Proc. Calif. Acad. Ser. II. v. (1895) 704. - Utah

Chrismarii, Klatt, in Leopoldina, Heft xxv. (1889) 108. - Mexic

Clarkei X. H. C. Wats, ex F. E. Hanb. Lond. Cat P1. ed. ix. (1895) 24. - Brit.

clavatus, M. E. Fones, in Proc. Calif. Acad. Ser. II v. (1895) 704. -- Utah.

darwasicus, C. Winkl. in Act. Hort. Petrop. ix. (18s6) 427. - Buchara

Echinus, Kuntze, Rev。Gen. (1891) $328=$ carlinoides, Fisch.

excelsior, Robins, un Proc. Am. Acad. xxvii. (1893) 179. - Mexic

fontinalis, Greene, in Bull. Calif. Acad. ii. vi. (1886) 151. - Calif.

glabrifolius, C. Winkl, in Act. Hort. Petrop. ix. (1886) 5\%3. - As. centr.

Hillii, Canby, in Gard, and For. iv. (1891) 101. Am. bor.

imbricatus, Robins. ex Greenm, in Am. Fourn. Sci. Ser. III. 1. (1895) 159. - Mexic

jucundus, C. Winkl. in Act. Hort. Petrop. ix. (1886) 427. - Buchara.

Liebmanni, Klalt, in Leopoldina, Heft xxiv. (1888) 128 (= Cirsum Liebnanni, Sch.-Bip.).-Mexic.

lilacinus, Greene, in Bull. Calif. Acad. ii. 7. (1887) $404=$ occidentalis, A. Gray.

linearifolius, S. Wats, in Proc. An. Acad, xxvi. (1891) 143. - Mexic

neglectus, Parish, ex Greene, in Bull. Calif. Acad. 1i. 7. (1887) 404 in obs. = lilacinus, Parish

nidulus, M. E. fones, in Proc. Calif. Acad. Ser. II v. (1895) 705. - Utah.

odoratus, Britton, Stern et Pogg. Prelim. Cat. (1888) $30=$ pumilus, Torr.

orizabensis, Klatt, in Leopoldina, Heft xxiv. (1888) 128 (= Cirsim orizabense, Sch.-Bip.). - Mexic. portoricensis, Kuntze, Rev. Gen. (1891) 329. - Ins. Portoric

Pringlei, S. Wats. in Proc. Am. Acad. xxv. (1890) 156. - Mexic.

reglensis, Klatt, in Leopoldina, Heft xxiv. (1888) 128 (= Cirsium reglense, Sch,-Bip.). - Mexic.

sairamensis, C. Winkl. in Act. Hort. Petrop. ix. $(1886) 522$. - As. centr.

Semenowi, C. Winkl. l.c. 522 in obs. - As. centr. tolucanus, Robins, et Seaton, in Proc. Am. Acad. Exviii. (1893) 111. - Mexic

velatus, S. Wats. l, c. xxvi. (1891) 143. - Mexic

Woodreardii X, H. C. Wats. ex F. J. Hanb. Lond. Cat. P1 ed. 9 (1895) 24. - Brit.

CNIDIUM, Cusson = Selinum, Linn. (Umbellif.) apioideum, St-Lacer, in Cariot, tud, des fl, éd. 8. ii. (1889) 351 = Carum rigidulum, Koch.

pauciradum, Somm: et Levier, in Nuov. Giorn. Bot, Ital. Ser. II. ii. (I895) 76. - Reg. Cauc.

Reichenbachii, Huter, ex Nym. Consp. Fl. Eur, ii. 1. (1889; 140. - Dalm.

GOAXANA, Coult, et Rose, in Contrib. U. S. Nat Herb. iii. 5. (1895) 297. UMBEL LIFERAE. purpurea, Coult, et Rose, l. c. t. 5. - Mexic.

COBAEA, Cav. (Polemon.). - Ind, Kew, i.5\%2 penduliflora, Peter, in Engl. et Prantl, Natürl. Pflanzenfam. iv. 3a. (1891) $44=$ penduliflora, Hook. $f$.

triflora, 7. D. Smith, in Coult. Bot.Gaz. xiii. (1888) 75. - Guatem.

COGGINIA, Wight et Arn. (Cucurbit.). - Ind. Kew. i. 572

Buettneriana, $\operatorname{Cog} n$. in Bull. Acad. Belg. Sér. III. xiv. (1887) 351. - Gabon.
COCCINIA

grandiflora, Cogn.ex Engl, in Abhandl. Preuss. Akad. Wiss. (1894) 34; et in Bot. Falirb. xxi. (1895) 211 - Afr. trop. ot.

lalambensis, Penzig, in Atti Congr. Bot. Genova(1893) 342. - Erithrea.

Rehmannii, Cogn. in Bull. Herb. Boiss. iii. (1895) 418. - Transv.

rigida, Cogn. in Bot. Fahrb. xxi. (1895) 211. - Afr. trop. or.

Schinzii, Cogn.ex Schinz, in Bull. Herb. Boiss. iii. 1895) 419. - Transv.

GOCGOCYPSELUM, R. Br. (Rubiac.). - Ind. Kew, i. 573 .

anomalum, K. Schum. in Mart, Fl. Bras, vi. vI. (1889) 311. - Bras

discolor, Hort. ex Hook. f. in Bot. Mag. (1893) t. 7278 in syn. = hirsutum, Barth.

glabrum, Britton, in Bull. Torrey Bot. Club, xviii. (1891) 108. - Bolivia.

guianense, K. Schum. in Mart. Fl. Bras. vi. vi. (1889) 315 (= Tontanea guianensis, Aubl.). Guian.

macropodum, Britton, in Bull. Torrey Bot. Club, xviii. (1891) $16=$ Geophila mactopoda, $D C$.

GOGGOLOBA, Linn. (Polygon.). - Ind, Kew.

Barbeyana, Lindau, in Bot. Fahrb. xiii. (1890) 185. - Peruvia.

Billbergii, Lindau, l. c. 219. - Columb.

cozumelensis, Hensl. Biol. Centr.-Amer. iv. (1886) 108. - Ins. Cozumel.

Cruegeri, Lindau, in Bot. Fahrb. xiii. (1890) 209. - Ins. Trinit.

Curtisii, Lindau, l. c. $159(=$ C. laurifolia, Jacq.).Florida.

cylindrostachys, Lindau, l. c. 163.-- Bras.

dioica, Karst. ex Lindau, l. c. 170. - Venez.

Eggersiana, Lindau, l. c. 153. - Ins. S. Doming.

fallax, Lindau, l. c. 172. - Ins. Trinit.

floribunda, Lindau, l. c. 217 (= Campderia floribunda, Benth.). - Guatem.

geniculata, Lindau, l.c. 141.-Cuba.

Glaziovii, Lindau, l.c. 163. - Bras.

grandiflora, Lindau, l. c. 175. - Bras.

Grisebachiana, Lindau, l. c. 195. - - Ins. Trinit.

jamaicensis, Lindau, l. c. 206. - Jamaica.

furgenseni, Lindau, 1. c. 188. = Schiedeana, Lindau. - Mexic

Krugii, Lindau, l, c. 145. - Antill.

laxiflora, Lindan, l. c. 191. - Bras.

Lehmannii, Lindau, ex Hieron. l. c. xx. (1895) 7.Columb.

leptostachyoides, Lindau, l. c. xiii. (1890) 207.Jamaica.

Liebmanni, Lindau, l. c. 189. - Mexic

Lindeniana, Lindau, 1. c. $182(=$ Campderia Lindeniana, Benth.). - Mexic.

longipes, S. Moore, in Trans. Linn. Soc. Ser. II. iv. (1895) 446. - Bras.

microphylla, Morong, in Ann. N.Y.Acad. Sci. vii. (1893) 213. - Parag.

Moritziana, Klotzsch, ex Lindau, in Bot. Fahro. xiii. (1890) 2I6 ( - C. ovata, Benth.). - Guiana. Mosenii, Lindau, l. c. 173. - Bras.

nematostachya, Lindau, l. c. 208 (= Campderia nematostachya, Griseb.). - Panama.

nigrescens, Lindau, $l$, c. 192. - Ins. Trinit,

nodosa, Lindau, l. c. 147. - Ins. S. Doming.

novogranatensis, Lindan, l. c. 192.-Columb

oblonga, Lindau, l. c. 136. - - Bras.

Orizabae, Lindau, l. c. 189.- Mexic

paraguariensis, Lindau, l. c. 215.-Paraguay.

pendula, Salzm, ex Lindau, l. c. $180(=$ C. nitida,

H. B. et K.). - N. Granat.

peruviana, Lindan, l. c. 213. - Peruvia.

praecox, Wright, ex Lindau, l. c. 142. - Cuba.

recurva. Newm. ex Lindau, 1. c. $180(=$ C. nitida,

II. B. et K.). - N. Granat.

reflexa, Lindau, $l$ c. 141. - Cuba.

rubiginosa, Mart.ex Lindau, l. c. 138 (= C. acrostichoides, Cham.). - Bras.

Ruiziana, Lindau, l.c. 215. - Am. trop.

Sagotii, Lindau, l. c. 184. - Guan. gall. 


\section{COCCOLOBA}

sarmentosa, S. Moore, in Trans, Linn. Soc. Ser. II. iv. (1895) 446. - Bras.

Schiedeana, Lindau, in Engl. Bot. fahrb. xiii. (1890) 187. - Mexic.

Schwackeana, Lindau, l. s. 200. - Bras.

scrobiculata, Lindau, l. c. 140 . - Ins. S. Doming. Sintenisii, Urban, ex Lindau, l. c. 15\%. - Ins. Portorico.

sparsifolia, Lindau, l. c. 195. - Bras.

sphaerococca, Lindau, l. c. 185. - Peruvia.

spinescens, Morong, in Ann. N. Y.Acad. Sci. vii. (1893) 212. - Parag.

Spruceana, Lindau, in Engl. Bot. Fahrb. xiii. (1890) 162. - Venez.

subcordata, Lindau, l. c. 131 (=Erythroxylon subcordatum, DC.). - Ins. S. Doming.

tenuiflora, Lindau, l. c. 190. - Bras.

tiliacea, Lindau, l. c. 198. - Reg. Argent

Trianaei, Lindau, l. c. 213. - N. Granat.

Trinitatis, Lindau, l. c. 142. - Ins. Trinit

Urbaniana, Lindau, l. c. 155. - Ins. Antill.

verruculosa, Lindau, l. c. 154. - Ins. Antill.

Wrightii, Lindau, l. c. 151. - Cuba.

yucatana, Lindau, l. c. 190. - Mexic.

COCCULUS, DC. (Menisp.). - Ind. Kew. i. 574. affinis, Oliver in Hook. Icon, pl. xviii, (1888) t. 1760. - China.

lonchophyllus, Hillebr. Fl. Haw. Isl. (1888) 8 (= Holopeira lonchophylla, Miers $=$ C. Ferrandianus, Gaudich, ?). - Ins. Sandvic.

integer, Hillebr. l. c. 7. - Ins. Sandvic.

Kunstleri, King, in fourn. As. Soc, lviii. (1889) ii. 384. - Malaya.

Selwynii, F. M. Bailey, Syn. Queensl. Fl. Suppl. iii. (1890) 6 (= Hypserpa Selwyni, F. Muell.). Austral.

virgatus, Hillebr. Fl. Haw. Isl. (1888) 8. - - Ins. Sandvic.

GOCHLEARIA, Tourn. ex Linn. (Crucif.), - Ind. Kew, 1. 475

Conwayi, Hemsl. in Kew Bull. (1894) 4. - Reg. Himal.

micacea, E. S. Marshall, in Journ. Bot. xxxii. (1894) 289 t. $346=$ groenlandica, Linn.

stenocarpa, Rouy et Fouc. Fl. de Fr. ii. (1895) 202 $=$ anglica, Linn.

GOCHLIODA, Lindl. (Orchid.). - Ind. Kew. i. 575 .

Noezliana, Rolfe, in Lindenia, vi. (1890) 55 t. 266; et in Orchid Alb. xi. (1895) t. 509. - Am. austr.

Notzliana " Rolfe» ex l'Or hidophile (1892) 272 cum ic., sphalm. = Noezliana, Rolfe.

COCHRANEA, Miers (Borag.). - - Ind. Kew. i. 576.

anchusaefolia, Gürke, in Engl. et Prantl, Natürl. Pflanzenfam. iv. 3a. (1894) 97 (= Heliotropium anchusaefolium, Poir.). - Bras., Reg. Argent.

crassifolia, Phil. in Anal. Univ. Chil. xc. (1895) 349 (= Heliotropium crassifolium, Phil.). - Chili. glutinosa, Phil. l. c. (= Heliotropium glutinosum Linn.). - Chili.

Kingi, Phil. l. c. 350. - Chili.

longistyla, Phil. l. c. 349 (= Heliotropium longisty. lum, Phil.).- Chiii.

parviflora, Phil. l. c. 350 . - Chili.

sentis, Phil. l. c. 351. - Chili.

taltalensis, Phil. l. c. 349. - Chili.

Cocos, Linn. (Paim.). - Ind. Kew. i. 576.

australis, Drude et Brandt. (an Mart. ?) in Gartenf. xxxviii. (1889) 451 fig. 72. - Form. hort.

Chavisiana, Rodr. ex Bece. in Malpighia, i. (1887) 445. - Bras.

Chiragua, Becc., l. c. 446. - Am. trop

Drudei, Becc., l. c. 445 . - Am. trop.

odorata, Rodr. Pl. nov. Fard. bot. Rio, i. (1891) $11 \mathrm{t}$. $4 \mathrm{a}$ et $5 \mathrm{c}$. - Bras.

Orbignyana, Becc, in Malpighia, ii. (1888) 147. Am. trop.

\section{cocos}

picrophylla, Rodr. Les Palm. 26 et t. 3 fig. 2 ab. ex Becc. in Malpighia, i. (1889) 448. - Bras.

Pynaertii, Hort. ex Gard. Chron. (1891) i 683 = Weddelliana, $H$. Wendi.

pulposa, Rodr. Pl. nov. Fard. bot. Rio, i. (1891) 14 t. 4 b. - Bras.

CODARIA, Linn. = Lerchea, Kalm (Rubiac.). interrupta, Kuntze, Rev. Gen. (1891) $279=\mathrm{L}$. interrupta, Korth.

longicauda, Kuntze, 1. c. = L. longicauda, Linn.

CODIAEUM, Rumph. (Euphorb.). - Ind. Kew. i.

Stellingianum, Warb. in Bot. Fahrb. xiii. (1891) 353. - Oceania.

CODON, Linn. (Hydrophy11.). - Ind. Kew, i. $57 \%$. Schenckii, Schinz, in Verh. Bot, Ver. Brand. xxx. (1888) 173. - Afr. austro-occ. extratrop.

GODONOGEPHALUM, Fenzl (Compos.). Ind Kew i. $57 \%$

Peacockeanum, Aitch. et Hemsl. in Trans. Linn. Soc. Ser. II. ini. (1886) .5 t. 31 et 32 . - Persia.

CODONOPSIS, Wall. (Campanul.). - Ind. Kew。 Henryi, Oliver, in Hook.Icon.pl. xx. (1891) t. 1967. - China.

Tangshen, Oliver, l. c. t. 1966. - China.

ussuriensis, Hemst. in fourn. Linn. Soc. xxvi. (1889) 6. - As. bor. temp.

GOELACHNE, R. Br. (Gramin.), - Ind. Kew。i.

madagascariensis, Baker, in fourn. Bot. xxv. (1890) 348. - Madag.

COELACHYRUM, Nees = Eragrostis, P. Beauv . (Gramin.).

indicum, Hack. in Engl. et Prantl, Natürl. Pflanzenfam. ii. 2 (1887) $61=\mathrm{E}$. brevifolia, Benth.

COELOGARPUM, Balf. f. [sphalm. COELOCARPUS] (Verben.). - Ind. Kew.i. 578.

madagascariensis, S. Elliot, in Fourn. Linn. Soc. xxix. (1891) 43. - Madag

COELOCARYON, Warb. in Ber. deutsch. Bot. Ges. xiii 1895) (85)

Preussii, Warb.l.c. - Afr. trop. occ

COELODEPAS, Hassk. (Euphorb.). - Ind. Kew. i. 578 .

ferrugineum, Hook. f. Fl, Brit. Ind. v. (1887) 420 . - Malacca.

longifolium, Hook.f.l, c. - Perak.

COELOGYNE, Lindl. (Orchid.). - Ind. Kew. i. 578.

anceps, Hook. f. Fl. Brit. Ind. v. (1890) 840.Perak.

Beccarii, Reichb. f. in Bot. Centralbl. xxviii. (1886) 345. - N. Guin.

borneensis, Rolfe, in Kew Bull. (1893) 62. Borneo.

bulbocodioides, Franch. in Nout. Arch. Mus. Paris, Sér. II. x. (1888) 84. - China occ.

carinata, Rolfe, in Kew Bull. (1895) 191. - N. Guin. carnea, Hook f. Fl. Brit. Ind v. (1890) 838. Perak.

Clarkei, Kraenzl. in Gard. Chron. (1893) i. 740. Hab.?

cuprea, Wendl. et Kraenzl. in Gard. Chron. (1892) i. 618: et in Reichb. f. Xen. Orchid. iii. 6 (1893) 110 t. 263 fig $1-8$ - Malacca?

Edelfeldtii, F. Muell. et Kraenzl. in Oest. Bot. Zeitschr. xliv, (1894) 421. - N. Guin.

elegans, Reichb. $f$. in Flora (1886) 561; et in Gard. Chron. (1887) i. 145. - Tibet.

flavida, Wall. ex Hook. f. FI. Brit Ind. v. (1890) 839 = flavida, Hook. $f$

flexuosa, Rolfe, in Kew Bull. (1892) 209. - Java.

Foerstermanni, Reichb. f. in Gard. Chron. (1886) ii. 262 et (1887) i. 798. - Archip. Sund,
COELOGYNE

Griffithii, Hook. f. Fl. Brit. Ind.v. (1890) 638. Ind. or.

Kingii, Hook.f. in Ann. Bot. Gard. Calc. v. I (1895) 25 t. 38. - Perak.

lactea, Reichb. $f$. in Gard. Chron. (1888) i. 521. Burma

lamellata, Rolfe, in Kew Bull. (1895) 36. - N. Hebrid.

longibracteata, Hook. f. Fl. Brit. Ind. vi. (1890) 19 in add.; et in Ann. Bot. Gard. Calc. v. 1. (1895) 25 t. 39. - Perak

longipes, Hook. f.l.c. $195 \mathrm{in}$ add. - Reg. Himal. lycastoides, F. Muell. et Kraenzl. in Oest. Bot. Zeitschr. xlv. (1895) 179. - Ins. Samoens.

Mac Donaldi, F. Muell. et Kraenzl. l. c. xliv. (1894) 209. - Hab.?

macrobulbon, Hook, f. Fl. Brit. Ind. v. (1890) 830 - Penins. Mal., Borneo.

Maingayi, Hook.f. l. c.831. - Malacca.

Micholicziana, Kraenzl. in Gard. Chron. (1891) ii. 300 ; et in Reichb. f. Xen. Orchid. iii. 6. (1892) 100 t. 256. - N. Guin.

Mossiae, Rolfe, in Kew Bull. (1894) 156; et in Gard.

Chron. (1894) i. 400 fig.49. - Ind. or.

occultata, Hook. f. Fl. Brit. Ind. v. (1890) 832. Reg. Himal.

papillosa, Ridl. ex Stapf, in Trans. Linn, Soc., Ser. II. iv. (1894) 238. - Borneo.

purpurascens, Hook.f. Fl. Brit. Ind. v. (1890) 842. - Zeyl.

pustulosa, Ridl. in fourn. Bot. xxiv. (1886) 353. N. Guin

rubens, Ridl. in Gard. Chron. (1890) i, 576; Hook. f Fl. Brit. Ind. vi. (1890) 195. - Ins. Langkavi.

Sanderae, Kraenzl. ex O'Brien, in Gard.Chron. (1893 i. 360 et 547; et in Reichenbachia (1893) t. 56 . Hab.?

Sanderiana, Hort. ex Gard.Chron. (1893) i. 361 fig. 52 sphalm. (non Reichb. f.) = Sanderae, Kraenzl.

Sanderiana, Reichb. f. in Gard. Chron.(1887) i, 764. - Archip. Sundaic

stellaris, Reichb. f. l. c. (1886) i. 8 et 73. - Am centr.

stenochila, Hook. f. Fl. Brit. Ind. v. (1890) 83\%. Perak.

suaveolens, Hook.f. l. c. 832. - Reg. Himal.

Swaniana, Rolfe, in Kew Bull. (1894) 183; et in Reichenbachia, ii. 2. (1895?) t. 92. - Ins. Philipp. tenuis, Rolfe, l. c. (1893) 171. - Borneo.

Treutleri, Hook.f. Fl. Brit. Ind. v. (1890) 194 ; et in Hook. Icon. pl. xxii. (1892) t. 2105. - Ind. or. xylobioides, Kraenzl. in Bot. fahrb. xvii. (1893) 482. - Sumatra.

Veitchii, Rolfe, in Kew Bull. (1895) 282.- N. Guin.

COELONEURUM, Radlk. in Sitzb. Math.-phys. Akad. Muench. xix. (1889) 280. SOLANACEAE. Eggersii, Radll. l. c. 281. - Ins. Antill

lineare, Radlk. i. . . - Ins. Antill.

COELOPLEURUM, Ledeb. = Archangelica, Hoffm. (Umbellif.)

maritimum, J. D. Smith, in Coult. Bot. Gaz. xiii. (1888) 148, et Rev. N. Am. Umbell,(1888) 91. Terr. Washingt.

COELOSTEGIA, Benth. (Malv.). - - Ind. Kew. i. 579

borneensis, Bect. Malesia, iii. (1889) 272.-Borneo. sumatrana, Becc. l. c.- Sumatra.

COELOSTYLIS, Kuntze, Rev. Gen. (1891) $8 \%=$ Echinopterys, A. Juss. (Malpigh.) glandulosa, Kuntze, 1. c. = E. Lappula, A. fuss.

COFFEA, Linn. (Rubiac.). - Ind. Kew. i. 579 baviensis, Drake, in Morot, fourn. de Bot.x. (1895) 235. - Tonk.

Floresiana, Boerl, Handb. Fl. Ned. Indië, ii. I. (1891) 136 nomen. - Ins. Flores.

liberica, Bull. ex K. Schum. in Engl. et PrantI. Natürl. Pflanzenfam. iv. 2. (1898) $105=$ liberica. Hiern.

sumatrana, Becc. Malesia, iii. (1S89) 272.-Sumatra. triflora. Boerl. Handl. Fl. Ned. Indië, ii. I. (1891) 


\section{COFFEA}

136 (= Lachnostoma triflorum, Korth.). = kha siana, Hook. $f$

unitora, K. Schum. in K. Schum. et Holly, Fl. Kais, Wilh. Land (1889) 132. - N. Guin.

COGNIAUXIA, Baill. (Cucurb.). - Ind. Kew. 580

ampla, Cogn. in Bull. Acad. Belg. Sér. III. xiv. (1887) 349. - Gabon.

Brazzaei, Cogn.l.c. Sér. III. xvi.. (1888). 237. Congo. gall.

cordifolia, Cogn. l. c. Sér. III. xiv. (188\%) 350.Gabon.

COHNIA, Kunth = Cordyline, Comm. (Liliac.) flabelliformis, Cordem. in Bonnier, Rev. gén. Bot. IV. (1892). 369. = Cord. flabelliformis, Cordem.

COHNIELLA, Pfitz. in Eng1. et Prantl, Natürl Pflanzenfam. 1i. 6. (1889) 194. ORCHIDEAE. quekettioides, Pfitz. l. c. - Guatem.

COILOTAPALUS, P. Br. = Cecropia, Loefl (Urtic.).

peltata, Britton, in Ann. N. Y. Acad. Sci.vii.(1893) $230=$ Cecr. peltata, Linn

COINCYA, Rouy, in Deyrolle, Le Naturaliste, Sér II, xiii. (1891) 248. CRUCIFERAE

rupestris, Rouy, l. c. (= Raphanus nupestris, Porta et Rigo). - Hisp.

COINOGHLAMYS, T. Anders. (Acanth.) Ind. Kew. i. 580

gabonica, Solered. in Engl. et Prantl, Natürl. Pflan zenfam. iv. 2. (1892) 29 (= Mostuea gabonica Baill.). - Gabon.

Poggeana, Gilg, in Bot. Fahrb. xvii. (1893) 558.Congo.

Schweinfurthii, Gilg, l. c. 560. - Afr. centr. bor.

COIX, Linn. (Gramin.). - Ind. Kew. i. 580.

lingulata, Hack. in Oest. Bot. Zeitsihr. xli. (1891) 5. - Burma

puellarum, "Balansa, in Morot, fourn. de Bot. iv (1890) 77. - Tonk.

stenocarpa, Balansa, l. c. -- Tonk.

tubulosa, Hack. ex Warb. in Bot. fahrb. xiii. (1891) 260. - Oceania.

COLA, Schott et Endl. (Stercul.). - Ind. Kew.

Ballayi, Cornu, ex Heckel, in Anz. Inst. bot.-géol. Marseille, i. (1893) 101 et $104 \mathrm{fig}$.9.- Afr. trop. occ

crispiflora, $K$. Schum. in Bot. Fahrb.xv. (1893) 136. - Afr. trop. occ

Duparquetiana, Baill, ex Heckel, in Ann. Inst. bot.géol. Marseille, i. (1892) 150 nomen. - Hab.?

lepidota, K. Schum. in Bot. Fahrb. xv. (1893) 136. - Kamerun.

macrantha, K. Schum.l. c. 137. - Gabon.

pachycarpa, K. Schum.l.c. - Kamerun.

sphaerosperma, Heckel, in Ann. Inst. bot.-géol. Marseille, j. (1893) 154. - Afr. trop.

COLCHIGUM, Linn. (Liliac.). - Ind, Kew. i. 581 .

algeriense, Batt. in Batt. et Trab. Fl. de l'Algér. (Monoc.). (1895) 76. - Algeria.

Bornmuelleri, Freyn, in Ber. Deutsch, Bot. Ges. vii. (1889) 319 ; et in Oest. Bot. Zeitschr. xlii. (1892) 379. - As. Min.

Gruessfeldtianum. Aschers, et Schreeinf. in (Suppl. Illustr, fl. Egypte) Mém. Inst. Egypt. ii. (1889) 774. - Aegypt.

hungaricum, Fanka, in Termész. Füzetek, x. (1886) 75. - Hung.

merenderoides, Perrier et Songeon, in Bull. Herb. Boiss. ii. (1894) 429. - Sabaud.

procurrens, Baker, in Gard. Chron. (1890) i. 192. As. Min

Psaridis, Heldr. ex Nym. Consp. Fl. Eur. Suppl. ii. 1. (1889). - Graecia.
GOLDENIA, Linn. (Boragin.). - Ind, Kew,

382.

angelica, S. Wats. in Proc. Am. Acad.xxiv. (1889) 62. - Calif

brevicalyx, S. Wats, l. c. - Am. bor. austro occ. Darwini, Gürke, in Engl. et Prantl, Natürl. Pflanzenfam.iv. 3a. (1891) 90 (= Galapagoa Darwinii, Hook, f.). - Ins. Galapag.

fusca, Gürke, l. c. (= Gul. fusca, Hook. f.). - Ins. Galap.

glabra, Phil. in Anal. Univ. Chil. xc, (1895) 230. Chili.

grandiflora, Phil. in Anal. Mus, nac. Chite, (1892) 55. - Chili.

mitis, Phil. in Anal. Univ. Chil. xc. (1895) 229. Chili.

paronychioides, Phil. in Anal. Mus. nac. Chile, (1892) 55. - Chili.

phaenocarpa, Phil. l. c.56. -.. Chili.

parviflora, Phil. l. c. - Chili.

plicata, Coville, in Contrib. U.S. Nat. Herb. iv. (1895) $163=$ Nuttallii, Hook

tenuis, Phil. in Anal. Mus.nac. Chile (1892)55.Chili.

virens, Phil. in Anal. Unw.Chil. x.. (1895) 229. Chili.

GOLEA. Boj. (Bignon.). - Ind. Kew, i. 582.

aberrans, Baill. in Bull. Soc. Linn. Paris, i. (1887) 687. - Madag.

Boivini, Baill. l. c. 685. - Madag.

coccinea, S. Elliot, in fourn. Linn. Soc. xxix. (1891) 36. - Madag.

compressa, K. Schum. in Engl. et Prantl, Natürl. Pflanzenfam. iv. 3 b. (1895) 248 (= Bignonia compressa, Lam.). = decora, Boj.

concinna, Baker, in fourn. Bot. xxv. (1890) 337. Madag.

Humblotiana, Baill. in Bull. Soc. Limn. Paris, i. (1887) 68\%. - Madag.

Lantziana, Baill.l. c. - Madag.

longepetiolata, Baker, in fourn. Bot. xxv. (1890) 338. - Madao.

macrantha, Baker, l. c. 337. - Madag.

macrophylla, Baker, l. c. - Madag.

Poivrei, Baill. in Bull. Soc. Linn. Paris, i. (1887) 685. - Madag.

racemosa, Baill. 1. c. = decora, Boj.

racemosa, Baker, in fourn. Bot, xxv。(1890) 336. Madag.

COLEOSANTHUS, Cass, = Brickellia, Ell. (Compos.).

baccharideus, betonicifolius, brachyphyllus, californicus, cordifolins, corymbosus, Coulteri, cylindraceus, dentatatus, diffusus, floribundus, fructescens, Galeottii, grandiflorus, Greenei, hastatus, hebecarpus, hymenochlaenus, incanus, lanatus, Lemmonii, linifolius, longifolius, microphyllus, mohavensis, multiflorus, oblongifolius, oliganthus, Palmevi, Parryi, faroulus, pendulus, pinifolius, Pringlei, reticulatus, scoparius, secundiflorus, Seemannii, simplex, spinulosus, squamulosus, thyrsiflorus, tomentellus, veronicifolius, Wislizenii, Kuntze, Rev. Gen, (1891) $328=$ homonyma omnia Brickelliae.

atractylodes, Kuntze, 1. C. = B. atractyloides, A. Gray.

cedrosensis, Greene, in Erythea, i. (1893) $54=$ B. cedrosensis, Greene.

cuspidatus, Greene, 1. c。 = B. cuspidata, A. Gray. desertorum, Coville, in Contrib. U. S. Nat. Herb. iv. (1895) $119=\mathrm{B}$. desertorum, Coville.

glandulosus, Kuntze, Rev, Gen, (1891) $328=$ B. Rosalesia, Benth. et Hook. $f$

Knappianus, Greene, in Erythea, i. (1893) $54=$ B. Knappiana, Drew.

laciniatus, Kuntze, Rev. Gen.(1891)328= B. dentata, Sch. Bip.

pacayensis, Coult. Bot. Gaz, xx, (1895) 46.Guatem.

rhomboidea, Greene, in Erythea, i. (1893) $54=$ B. rhomboidea, Greene.

vigidus, Kuntze, Rev. Gen. (1891) $328=$ B. Hartwegi, A. Gray.

Rusbyi, Kuntze, 1, c. = B. Rusbyi, A, Gray

squarrosus, Kuntze, 1. C. = B. Cavanillesii, A. Gray. tener, Kuntze, 1. c. = B. Wrightii, Dur, et Hilg.
COLEOSANTHUS : -

Wrighti, Britton, in Bull. Torrey Bot. Club, xiv . (1894) $43=$ B. Wrightii, A. Gray.

GOLEOTRYPE, C. B. Clarke (Commelin.). Ind. Kew, i. 582.

Baroni, Baker, in fourn. Linn. Soc. xxi1. (1887) 530. - Madag.

GOLEUS, Lour. (Labiat.). = Ind. Kew. i. 583. aquaticus, Gïrke, in Bot. Fahrb. xix. (1894) 218. Afr. trop. or.

Autrani, Briq. in Bull. Herb. Boiss. ii. (1894) 129.Abyss.

Bernieri, Briq. l. c. 128. - Madag.

camporum, Girke, in Bot. Fahrb. xix. (1894) 214.Afr. trop.or.

coeruleus, Gürke, ex Engl. in Abhandl. Preuss. Akad. Wiss. (1894) 37; et in Bot. Fahrb. xix. (1894) 217. - Afr. trop. or.

comosus, Hochst. ex Gürke l. c. 212. - Abyss.

decumbens, Güke, l. c. 211. - $\Lambda$ fr. trop. or.

decurrens, Gürke, l. c. 215. - Kamerun.

dissitiflorus, Gürke, l. c. 21\%. - Kamerun.

dysentericus, Baker, in Kew Bull. (1894) 10. Nigrit.

elongatus, Trimen, in fourn. Bot. xxvii. (1889) 165. - Zeylan.

Eureka X. Hort. ex Gard. Chron. (1889) i. 808. Form. hort.

Alavo-virens, Gürke, in Engl. Pflanzenw. Ost-Afr. C (1895) 347. - Afr. trop. or.

gomphophylius, Baker, in Kow Bull. (1895) 225. Reg. Somal.

Goudoti, Briq. in Bull. Herb. Boiss. ii. (1894) 126.Madag.

gracilifolius, Briq. l. c. 127. - Madag.

gymnostomus, Gürke, in Bot. Fahrb. xix. (1894) 212. - Afr. trop. or.

Kilimandschari, Gürke, ex Engl. in Abhandl. Preuss. Akad. Wiss. 1891 ii. (1892) 359; et (1894) 37. Afr. trop. or.

lanuginosus, Hochst. ex Engl.l. c. 1891 ii. (1892) 360 nomen. - Abyss.

lasianthus, Gürke, in Bot. fahrb. xix. (1894) 212. Afr. trop. or.

latifolius, Hochst. ex Engl, in Abhandl. Preuss. Akad. Wiss. 1891 ii. (1891) 361 nomen. - Afr. trop. or. leucophyllus, Baker, in Kew Bull. (1895) 292. Afr. centr. austro-or.

longipetiolatus, Gürke, ex Engl. in Abhandl. Preuss. Akad. Wrss. (1894) 65; et in Bot. fahrb. xix. (1894) 214. - Afr. trop. or.

maculatus, Gürke, in Bot. fahrb. xix. (1894) 210. Afr. trop. OI.

maranguensis, Gürke, l. c, 216.-Afr. trop. or.

Mechowianus, Briq. l.c. 183. - Angola.

membranaceus, Briq. l.c. 182. - Congo mer

mirabilis, Briq. l. c. 183. - Angola, Congo.

montanus, Gürke, l. c. 218. - Kamerun.

nervosus, Briq. l. c. - Congo centr.

Penzigii, Schweinf. ex Penzig, in Att. Congr. bot Genova (1893) 355 nomen; Baker, in Gard. Chron. (1893) ii. 616. - Erithrea.

Poggeanus, Briq. in Bot. Fahrb. xix. (1894) 182. Congo merid.

Preussii, Gürke, l. c. 219. - Afr. trop. occ.

punctatus, Baker, in Kew Bull. (1895) 291. - Afr. centr. austr.

repens, Gürke, in Bot. Fahrb. (1894) 213. - Afr. trop. occ

rupestris, Hochst. [in Schimp. P1. Abyss. (185.3) n. 21727, ex Briq. in Bull. Herb. Boiss, ii. (1894) $131=\mathrm{C}$. Schimperi, Vatke.

salagensis, Guirke, in Bot. Fahrb. xix. (1894) 220. Afr. trop. occ.

scandens, Gürke, ex Engl. in Abhandl. Preuss, Akad. Wiss. (1894) 51 ; et l.c.221. - Afr. trop. or.

Schweinfurthii, Briq. in Bot. Fahrb. xix. (1894) 181. - Afr. centr. bor.

shirensis, Gurke, l. c.216. - Afr. trop. or

silvaticus, Gürke, ex Engl. in Abhandl. Preuss. Akad. Wiss. (1894) 51 ; et l. c. 213. - Afr. trop. or. tricholobus, Gürke, $l l$ cc. 62 et 220 . - Afr. trop. or.

trichophorus, Briq. in Bull. Herb. Boiss. ii. (1894) 130. - Abyss. 


\section{COLEUS}

vestitus, Baker, in Kev Bull. (1895) 224. - Reg. Somal.

viridis, Briq. in Bot. Fahrb. xix. (1894) 181. Congo merid.

Welwitschii, Briq. l. c. 185. - Angola.

COLINIL, Adans. = Tephrosia, Pers. (Legumin.)

cinereum, Hitchc. in Missouri Bot. Gard, Rep. iv. (I893) $75=\mathrm{T}$. cinerea, Pers.

roseum, Hitchc. 1. c. $=$ T. grandiflora, Pers.

COLLABIUM, Blume (Orchid.). - Ind. Kew. i. 583.

Wrayi, Hook. f. Fl. Brit. Ind. v. (1890) 784; et in Icon. pl. xxi. (1891) 2065. - Perak.

COLLETIA, Comm. (Ramn.). - Ind. Kew. i. 584. campanulata, Phil. in Anal. Univ. Chil. lxxxiv. (1893) 6. = Chili.

dumosa, Phil. l.c. 7. - Chili.

foliosa, Rusby, in Mem. Torrey Bot. Chub, iii. 3. (1893) 16. - Bolivia.

COLLINSIA, Nutt. (Scrophul.). - Ind. Kew. i. 584

arvensis, Greene, Pittonia, ii. (May 1892) 232. Calif.

concolor, Greene, in Erythea, iii. (1895) 49. Calif.

Davidsonii, S.B. Parish, in Zoë, iv.(1893)147.-Calif. floribunda, Greene, Pittonia, i. (July 1887) 55 (= Tonella floribunda, A. Gray). - Calif.

franciscana, Bioletti, in Erythea, i. (1893) 17; et in

Man. Bot. San Franc. Bay (1894) 272.= Calif.

Greenei, A. Gray ex Greene, Man. Bot. San Franc.

Bay (1894) 272. - Calif.

Rattani, A. Gray, l.c.-Calif.

stricta, Greene, Pittonia, ii. (Nov. 1889) 23. Calif.

Wrightii, S. Wats. in Proc. Am. Acad. xxiv. (1889) 84. - Calif.

COLLOMIA, Nutt. (Polemon.). - Ind. Kew. i. 584 .

atacamensis, Phil, in Anal. Univ. Chil. xc. (1895) 217. - Chili.

debilis, Greene, Pittonia, i. (Nov, 1887) $127(=G i$ lia debilis, S. Wats.). - Am. bor. occ.

diversifolia, Greene, Pittonia, i. (Nov, 1887) 128. Calif.

linearis, Phil. in Anal. Univ. Chil. xi. (1895) $217=$ coccinea, Lehm.

Pringlei, Peter, in Engl. et Prantl, Natiurl. Pfanzen fam. iv. 3 a. (1891) 48. - Mexic.

Rawsoniana, Greene, Pittonia, i. (Oct. 1888) 221. Calif.

Soehrensi, Phil, in Anal. Univ. Chil. xc. (1895) 218. - Chili.

COLLOTAPALUS, « $\mathrm{P} . \mathrm{Br}$. » sphalm. = COI LOTAPALUS, P. Br. = Cecropia, Loefl. (Urtic.).

peltata, Hitchc. in Missouri Bot, Gard, Rep. iv. (1893) $\mathrm{I} 30=$ Cecr. peltata, Linn.

GOLOBANTHUS, Bartl. (Caryophyll.). - Ind. Kew. i. 585.

alatus, Pax, in Bot. Fahrb. xviii. (1893) 28. - Reg. Argent.

brevisepalus, $T$. Kirk, in Trans. N. Z. Inst. xxvii 1894 (1895) 35\%; et in fourn. Bot. xxxiii. (1895) 175. - N. Zel

Buchanani, T. Kirk, ll.cc. 358 et 175 - N. Zel.

caespitosus, Colenso, in Trans. N. Z. Inst. xxvii. 1894 (1895) 384. 一 N. Zel.

canaliculatus, $T$, Kirk, l. c. 357; et in fourn. Bot. xxxiii. (1895) 174. - N, Zel.

Meigeni, Phil. ex Fr: Meigen, in Bot. Fahrb. xviii. (1894) 459 nomen. - Chili.

Muelleri, T. Kirk, in Trans. N. Z. Inst. xxvii. (1895) 356 ; et in fourn. Bot. xxxiii. (1895) 174. N. Zel.

repens, Colenso. in Trans. N. Z. Inst. xix. 1886 (1887) 261. - N. Zel.
COLOCASIA, Schott (Aroid.). - Ind. Kew. i. 585. Devansayana, L. Lind. et Rodigas, in Illustr. Krortic. xxxiv. (I886) 97 t, 50l - N Guin.

gigantea, Hook. f. Fl. Brit. Ind vi. (1893) 524 As. trop.

Mannii, Hook. f.Fl. Brit. Ind. vi. (1893) 524.Assam.

Wendlandii, Engl. ex Hook, f, FI. Brit. Ind, vi, (1893) 524 in syn. = fallax, Schott

GOLOGANIA, Kunth (Legumin.), - Ind. Kew. i. 585.

hirta, N.E. Rose, in Contrib. U. S. Nat. Herb, iii (1895) 315 (= Galactia hirta, Mart, et Gal.), Mexic.

Pringlei, S. Wats. in Proc. Am. Acad. xxiii. (1888) 271 ; et xxv. (1890) 147. - Mexic

GOLOPTERA, Coult, et Rose, Revis, N. Am. Umbeliif. (1888) 49. UMBELLIFERAE

Jonesii, Coult. et Rose, l. c 58. - Utah.

Newberryi, Coult. et Rose, l. c. 49. - Am. bor. occ. Parryi, Coult.et Rose, l.c.50 (= Cymopterus glomeratus, DC.). - Wyoming.

GOLPODIUM, Trin.(Gramin.). - Ind, Kew, i 585

hierochloides, Hausskn. et Bornm. ex Bornm. in Mitth. Thür. Bot.Ver., N. Folge, vi. (1894) 67.Oriens.

COLQUHOUNIA, Wall. (Labiat.). - Ind. Kew i. 586 .

martabanica, Kurz, ex Prain, in Journ. As. Soc. Beng. 1xii. (1893) ii. 38 = elegans, Wall.

COLUBRINA, Rich. (Ramn.). - Ind. Kew. i. 586 arborea, T. S. Brandeg. in Zoë, iv. (1894) 401. Calif

Beccariana, Warb, in Bot. Fahrb. xiii. (1891) $36 \%$ N. Guin.

glabra, S. Wats. in Proc. Am. Acad. xxiv. (1889) 44 - Calif.

mexicana, N. E. Rose, in Contrib. U. S. Nat. Herb. iii. (1895) 315. - Mexic.

COLUMBARIA, J. et C. Presl = Scabiosa Tourn. (Dipsac.)

fissa, Timb. in Lucante, Rev.de Bot. x. (1892) 250. - Gall.

Guitardi, Timb. 1. c. - Gall

gramuntia, Timb. 1. c. = S. gramuntia, Linn

COLUMBIA, Pers. (Tiliac.). - Ind. Kew. i. 586. integrifolia, Warb. in Bot. Fahrb. xiii, (1891) 372.Oceania.

GOLUMNEA, Plum. ex Linn. (Gesnerac.). - Ind. Kew. i. 586.

angustifolia, bicolor, capitata, chrysantha, circinnata, coccinea, coriacea, corymbosa, cristata, dichroa, dimi diata, Foseithii, ichthyoderma, lanata, meridensis, multiflora, Patrisii, peltata, pubescens, Schlimii, semicordata, sparsiflora tetragona tigrina villosa, Kuntze, Rev. Gen. (1891) 471-72= homonyma omnia Alloplecti.

aggregata, Kuntze, 1. c. $472=$ Codonanthe aggre gata, Hanst.

ascendens, Britton, ex Rusby, in Mem. Torrey Bot. Club iv. (1895) 239. - Bolivia.

Benthamiana, Kuntze, Rev. Gen. (1891) $4 \% 1=$ Alloplectus tenuis, Benth.

boliviana, Britton, ex Rusby, in Mem. Torrey Bot. Club, iv. (1895) 238. - Bolivia.

chloroneura, Kuntze, Rev. Gen. (1891) $472=$ Nematanthus longipes, $D C$.

ciliosa, Kuntze, 1. c. = Episcia ciliosa, Hanst.

congesta, Kuntze, 1. c. = Alloplectus congestus, Deone, ex f. Linden, Catal, n.5 (1850)

corticicola, Kuntze, 1. c. = Nematanthus corticicola, Schrad.

costaricensis, Kunze, l. c. 471. - Costarica.

Endlicheriana, Kuntze, 1. c, $472=$ Alloplectus pendulus, Poepp. et Endl.

gracilis, Kuntze, 1. c. = Hypocyrta gracilis Hook.

\section{COLUMNEA}

Grisebachiana, Kuntze, Rev, Gen. (1891) $472=$

Alloplectus cristatus, Mart.

Hansteiniana, Kuntze, I. $c=$ A11. strigosus, Hanst.

Hookeriana, Kuntze, 1. c. = Hypocyrta glabra, Hook.

Humboldtiana, Kuntze, 1. c. $471=$ Alloplectus hispidus, Mart.

Klotzschiana, Kuntze, 1. c. $172=$ All. villosus, Hanst.

latisepala, Rusby, in Mem. Torrey Bot. Club, iv. (1895) 239. - Bolivia.

Lindenii, Kuntze, Rev. Gen.(1891) 471. - N. Granat.

longipes, Kuntze, 1. c. $472=$ Nematanthus longipes, $D C$.

macrocalyx, Kuntze, 1, c. = Hypocyrta macrocalyx, Hanst.

macrophylla, Kuntze, l. c. = Hyp. macrophylla, Poepp. et Endl.

Martiana, Kuntze, 1. c. = Hyp. hirsuta, Mart.

Mocinoana, Kuntze, 1. c. $471=$ Alloplectus glaber $D C$.

Nummularia, Kuntze, 1. c. = Hypocyrta Nummularia, Hanst.

peruviana, Zahlbr. in Ann. naturh. Hofmus. Wien, vii (1892) 8. - Peruvia.

Poeppigiana, Kuntze, Rev. Gen. (1891) $471=$ Alloplectus speciosus, Poepp. et Endl.

Presliana, Kuntze, 1. c. $=$ Nematanthus radicans, Presl.

radicans, Kuntze, 1. c. = Hypocyrta radicans, Klotzsch et Hanst.

scabrida, Kuntze, 1. c. = Hyp. scabrida, Lem.

Schlimii, Kuntze, 1. c. $471=\mathrm{Col}$. Lindenii, Kuntze.

Selloana, Kuntze, 1. c. $472=$ Hypocyrta Selloana Klotzsch et Hanst.

sericea, Kuntze, 1. c. = Hyp. sericea, Hanst.

serrulata, Kuntze, 1. c. = Nematanthus serrulatus, Presl.

Sprucei, Kuntze, 1. c. 471. - Ecuad.

strigillosa, Kuntze, 1. c. $472=$ Hypocyrta strigillosa, Mart.

Weirii, Kuntze, l. c. 471. - N. Granat.

GOLURIA, R. Br. (Rosac.). - Ind. Kew. i. 587. Henryi, Batalin, in Act. Hort. Petrop. xiii. (1893) 94. - China.

GOLUTEA, [Tourn.] Linn. (Legumin.). - Ind Kew. i. 587

armata, Hemsl. et Lace, in fourn. Linn. Soc, xxviii. 322 t. 39. - Belutsch.

Delavayi, Franch. Pl. Delav. (I889) 158 t. 38. Yunnan.

uniflora, G. Beck, ex Stapf, in Denkschr. Akad. Wien, (1886) 64. - As. occ.

COLUTEASTRUM, Moehr. = Lesserti, DC (Legumin.)

abbreviatum, anmulare, argenteum, brachystachyum, candidum, capitatum, carnosum, depressum, excisum, flexuosum, fruticosum, inflatum, lanatum, macrostachium, obtusatum, Pappeanum, physodes, polystachinu, procumbens, prostratum, pubescens, spinescens, stenolobum, subumbellatum, sulcatum, temifolium. Kuntze, Rev. Gen. (1891) $172=$ homonyma omnia Lessertiae.

capessse, Kuntze, 1.c. $171=$ L. pulchra, Sims. dubium, Kuntze, 1. c. = L. diffusa, $R$. Br. glabratum, Kuntze, 1. c. = L. brachypus, Haw.

herbaceum, Kuntze, 1. c = L. linearis, $D C$.

humile, Kuntze, 1. c. $=$ L. falciformis. $D C$.

parviflorum, Kuntze, 1. c. 172 [sphalm.] = L. pauciflora, Haw.

perennans, Kuntze, 1. c. $171=\mathrm{L}$. perennans, $D C$

vesicarium, Kuntze, 1. C. = L. tomentosa, DC. et vesicaria, $D C$.

COMAROSTAPHYLIS, Zucc. = Arctostaphylos, Adans. (Ericac.)

diversifolia, Greene, in Bull. Calif. Acad. ii. vir. (1887) $406=\mathrm{A}$. diversifolia, Parry

COMBRETOPSIS, K. Schum. in K. Schum, et 


\section{COMBRETOPSIS}

Hollr. Fl. Kais. Wilh. Land (1889) 69. OLACINEAE.

pentaptera, K. Schum. l. i. (= Lophopyxis pentaptera, Engl.). - N. Guin.

COMBRETUM, Linn. (Combret.). - Ind. Kew. i. 588

abbreviatum, Engl. Pflanzenw. Ost-Afr. C (1895) 292. - Afr. trop. or

bacciferum, Pierre, ex Laness. Pl. util. col. frane (1886) 316 nomen (baccifera). - Cochinch.

Boehmi, Engl. in Abhandl. Preuss. Akad. Wiss, (1894) 36; et Pflanzenw, Ost-Afr. A (1895) 75 numen $=$ C. Nyikae, Engl.

bracteosum, Brandis, ex Engl. in Engl. et Prantl Natiirl. Pflanzenfam. iii. 7 (1893) 123 nomen. Ind. or.

Bragae, Engl. Pfanzenw. Ost-Afr. C (1895) 289.Afr. trop. or.

camporum, Engl. Bot. Fahrb. viii. (1887) 62. Congo.

Carvalhi, Engl. Pflanzenw. Ost-Afr. C (1895) 292. Afr. trop. or.

coriaceum, Schinz, in Verh. Bot. Ver. Brand. xxx. (1888) 247. - Afr. austro-occ, extratrop.

deciduum, Collett et Hems?. in . Fourn. I inn. Soc. xxy. (1890) 58. - Burma.

deserti, Engl. Pflanzenw. Ost-Afr. C (1895) 289. Afr. trop. or.

discolor, Taub. in Bot. Fahrb. xv. Beibl. n. 34 (1893) 9. - Bras.

Eilkerianum, Schinz, in Verh. Bot. Ver. Brand. xxx. (1888) 246. - Afr. austro-occ. extratrop.

exalatum, Engl. Pfanzenw. Ost-Afr. C (1895) 290. Afr. trop. or

Fischeri, Engl. l. c. - Afr, trop. or.

fragrans, $F$, Hoffm. Beitr. Kenntn. Fl. Centr.=Ost Afr. (1889) 31. - Afr. centr.

glandulosum, F. Hoffm. l. c. 33. - Afr. centr.

gondense, $F$. Hoffm. l. c. 32. - Afr. centr

grandifolium, $F$. Hoffm. l. c. 29. - Afr. centr.

glutinosum, Engl. Pflanzenw. Ost-Afr. B (1895) 404

nomen. - Afr. trop. or.

hereroense, Schinz, in Verh. Bot. Ver. Brand. $\mathrm{xxx}$ (1888) 245. - Afr. austro-occ. extratrop.

Hildebrandtii, Engl. Pflanzent. Ost-Afr. C (1895) 289. - Afr. trop. or.

Holstii, Engl. in Abhandl. Preuss. Akad. Wiss. (1894) 36; et Pflanzenw。Ost-Afr. C (1895) 291. - Afr. trop. or.

Illairei, Engl. in Abhandl. Preuss. Akad. Wiss. (1894) 15 nomen. - Afr, trop. or

Illairii, Engl. Pfanzenw. Ost-Afr. C (1895)289. Afr. trop. or.

infundibuliforme, Engl. Pflanzenv. Ost-Afr. C (1895) 292. - Afr. trop. or.

laurifolium, Engl. l. c. - Afr. trop. or.

Leuconili, Schweinf. in Hoehnel, zum Rudolph See, Append. (1892) 12. - Afr. trop.

littoreum, Engl, in Abhandl. Preuss, Akad. Wiss. (1894) 18; et Pflanzenw. Ost-Afr. A (I895) 17 nomen. - Afr trop, or.

meruense, Engl. in Abhandl. Preuss. Akad. Wiss. (1894) 34; et Pfanzenw. Ost-Afr. C (1895) 291.Afr. trop. or.

microlepidotum, Engl.l.c. 290. - Afr. trop. or

mossambicense, Engl. l.c. 292 (= Poivrea mossam-

bicensis, Klotzsch). - Mossamb.

mweroense, Baker, in Ker Bull. (1895) 290. - Afr. centr. austr.

Nyikae, Engl. in Abhandl. Preuss. Akad. Wiss. (1894) 36; ct Pfanzenw. Ost-Afr. C (1895) 289. Afr. trop. or.

oblongum, F. Hoffm. Beitr. Kenntn. Fl. Centr. OstAfr. (1889) 34. - Afr. centr.

obovatum, F. Hoffm. l. c. 28. - Afr. centr.

olivaceum, Engl. Pflanzenw. Ost-Afr. C (1895) 288. - Afr. trop. or

Oliverianum, Engl. l. c. 424 in add, - Afr, trop.

parvifolium, Engl, Pflanzenw. Ost-Afr. C (1895) 290. - Afr. trop. or.

Petersii, Engl. l. c. (= Argyrodendron Petersii, Klotzsch). - Mossamb.

phaneropetalum, Baker, in fourn. Iim. Soc. xxv. (1890) 315. - Madag.

\section{COMBRETUM}

pisoniiflorum, Engl. Pflanzenw. Ost-Afr. C (1895) 293 ( = Sheadendron pisoniiflorum, Klotzsch). Mossamb

pisonioides, Taub. in Bot. Fahrb. xv. Beibl. n. 34 1892) 10. - Bras.

primigenum, Marl. in Bot. Fahrb. x. (1889) 49.-

Afr. austro-occ. extratrop.

purpureifloruni, Engl. Pflanzenzw. Ost-Afr. C (1895) 292 - Afr. trop. or

Raimbaulti, Heckel, in Les remèd. et Repert. de Pharm. (1891) = micranthum, G. Don.

rupicolum, Ridl, in fourn. Linn. Soc. xxvii. (1890) 28. - Ins. Fernando-Nonorha.

Schelei, Engl. in Abhandl. Prouss. Akad. Wiss. (1894) 27 nomen; et Pflanzenw.Ost-Afr. C (1895) 291. - Afr. trop. or.

Schumannii, Engl. in Abhandl. Preuss. Akad. Wiss. (1894) 34; et Pflanzenv. Ost-Afr. C (1895) 289. Afr. trop. or.

splendens, Engl. Pfanzenw. Ost-Afr. C (1895) 289. - Afr. trop. or.

taborense, Engl. l. c. 290. - Afr.trop. or.

tenuispiscatum, Engl. in Abhandl. Preuss. Akad. Wiss. (1894) 34; et Pflanzenw, Ost-Afr. C (1895) 291. - Afr. trop. or

transvaalense, Schinz, in Bull. Herb. Boiss, ii. (1894) 202. - Transy

trichopetalum, Engl. Pflanzenw. Ost-Afr. C (1895) 292. - Afr. trop. or.

trichophyllum, Baker, in fourn. Linn. Soc. xxv. (1890) 315. - Madag.

truncatum, Eng1. Pflanzenw, Ost-Afr. C (1895) 288 $=$ Oliverianum. Engl.

turbinatum, F. Hoffm. Beitr. Fl. Centr.-Ost-Afr (1889) 28. - Afr. centr.

ukambense, Engl. Pfanzenw. Ost-Afr. C (1895) 291 - Afr. trop. or

umbricola, Engl. in Abhandl. Preuss. Akad. Wiss. (1894) 17 nomen; et Pflanzenw. Ost-Afr. C (1895) 288. - Afr. trop. or.

usaramense, Engl. l. c. 290. - Afr. trop. or.

Volkensii, Engl. in Abhandl. Preuss. Akad. Wiss, (1894) 18; et Pflanenw. Ost-Afr.C (1895) 290。Afr. trop. or.

Wakefieldii, Engl. Pfanzenw. Ost-Afr. C (1895) 291. - Afr. trop. or.

GOMINSIA, Hems1, in Ann. of Bot, v. (1891) 507 t 28; et ex Gartenfl.(1891) 109. SCITAMINEAE. Guppyi, Hemsl. $l l . c e .-$ Ins. Salom.

COMMELINA, Plum. ex Linn. (Commel.). - Ind

Kew. 1. 590

anoustissima, $K$. Schum, in Engl. Pfanzenw, Ost Afr. C (1895) ] 35 - Afr. trop. or

Beccariana. Martelli, Fl, Bogos. (1886) 87. - Ahyss

Boehmiana, K. Schum. in Engl. Pfanzenw. Ost Afr. C (1895) 135. - Afr. trop. or.

echinosperma, K. Schum.l. c.- Afr. trop, or.

Elliotii, C. B. Clarke et Rendle, ex S. Elliot in fourn. Linn. Soc. xxx. (1894) 98. - Afr. trop.

esculenta, Heyne, ex Hook. f. F1. Brit. Ind. vi. (1892) $37 \%$ in syn. = Aneilema esculentum, Wall.

guineensis, Hua, in Bull. Mus. Paris, i. (1895) 118. - Afr. trop. occ.

kilimandscharica. $K$. Schum in Engl. Pflansenw. Ost.-Afr. C (1895) 134. - Afr. trop. or.

lanuginosa, Heyne, ex Hook. f. Fl. Brit. Ind. vi, (1892) 380 in syn. = Aneilema lanuginosum Wall.

lunata, Heyne, 1. c, 374 in syn.= ensifolia, $R \cdot B r$

lutea, Cordemoy, Fl. Ile Réun. (1895) 147. Ins. Borb

montana, K. Schum, ex Engl. in Abhandl. Preuss.

Akad. Wiss, 1891 (1892) 156 nomen. - Abyss.

obscura, K. Schum. in Engl. Pfanzenw. Ost-Afr. C (1895) 135. - Afr. trop. or.

Schinzii, C. B. Clarke, in Th. Dur. et Schinz, Consp. Fl. Afr. v. 1893 (1895) 428. - Madag

speciosa, Heller, Bot. Expl. S. Texas, 22, sphalm = leiandra, C. B. Clarke.

Swingleana, Nash, in Bull. Torrey Bot. Club, xxii. (1895) 160. - Florida

trilobosperma, K. Schum. in Engl. Pfianzenw. Ost Afr. C (1895) 134. - Afr. trop. or
COMMERÇONIA, F. Muell. ex Tate, in Trans, Proc. Roy. Soc. S. Austral. xi. (1889) $82=$ Gommersonia, Forst. (Stercul.).

COMMERSONIA, Forst. (Stercul.). - Ind. Kew. i 593 .

Tatei, F. Muell. ex Tate, in Trans. Proc. Roy. Soc. S. Austral. xi. (1889; 82 (Commerçonia). Austral.

GOMMIPHORA, Jacq. (Burser.). - Ind. Kew. i. 593.

campestris, Engl. Bot. Fahrb.xv. (1893) 97. - Afr. trop. or,

caryaefolia, Oliver, in Hook. Icon. pl.xxiii. (1894) t. 2287. - Afr. austr.

cinerea, Engl. Bot. Fahrb. xix. (1894) 139. - Afr. austro-occ. extratrop.

crenato-serrata, Engl. l.c. 140. - Afr. austro-occ. extratrop.

cuneifolia, Baker, in fourn. Linn. Soc. xxv. (1899) 304. - Madag.

dulcis, Engl. Bot. Fahrb. xix. (1894) 141. - Afr. austro-occ. extratrop.

Eminii, Engl. Pflanzenw. Ost-Afr. C (1895) 230.Afr. trop. or.

Fischeri, Engl. Bot. Fahrb. xx. (1893) 97. - Afr. trop, or.

fraxinifolia, Baker, in fourn. Linn. Soc. xxii. (1887) 459. - Madag.

glaucescens, Engl. Bot. Fahrb. x. (1889) 283. -

Afr. austro-occ. extratrop.

Guerichiania, Engl. Bot. Fahrb. xix. (1890) 141.Afr. austro-occ. extratrop.

Holstii, Engl. in Abhandl. Preuss. Akad. Wiss. (1894) 16 et 25 ; et in Pflanzenw. Ost-Afr. C (1895) 229. - Afr. trop. or.

kilimandscharica, Engl. Pfanzenw. Ost-Afr. C (1895) 230. - Afr. trop. or.

laxiflora, Engl. l. . - - Afr. trop. or.

laxiflora, Baker, in fourn. Linn. Soc. xxii. (1887) 459. - Madag.

mollis, F. Hoffm. Beitr. Kenntn. Fl. Centr. Ost-Afr. (1889) 21. - Afr. centr. or.

pteleifolia, Engl, in Abhandl. Preuss. Akad. Wiss. (1894) 16 nomen; et in Pfanzenw. Ost-Afr. C (1895) 229. - Afr. trop or.

resiniflua, Martelli, Fl. Bogos. (1886) 15. - Abyss. saxicola, Engl. Bot. fahrb. x. (1889) 283. - Afr. austro-occ. extratrop.

serrulata, Engl. l. c. xv. (1893) 96. - Reg. Somal.

somalensis, Engl. l. c. - Reg. Somal.

spathulifoliolata, Engl. l. c. xix. (1894) 140. - Afr. austro-occ. extratrop.

Stuhlmannii, Engl. Pflanzenw. Ost-Afr. C (1895) 230. - Afr. trop. or

virgata, Engl. Bot. fahrb. xix. (1894) 139. - Afr. austro-occ. extratrop.

Woodii, Engl. l.c.xv. (1893) 9\% - Natal.

GOMOLIA, DC. (Melast.). - Ind, Kew. i. 593. parvifolia, Cogn. in DC. Monog. Phan. vii. (1891) 283. - Bras.

tetraquetra, Cogn. in Mart. Fl. Bras. xiv. IV. (1888) 603. - Bras.

GOMOCLA DIA, P. Br. (Anacard.). - Ind. Kew. i. 593 .

Engleriana, Loesen, in Bull. Herb. Boiss. ïi. (1895) 615. - Mexic.

GOMOROA, Oliver, in Hook. Icon. pl. xxv. (1895) t. 2408. RUTACEAE

pisocarpa, Oliver, l. c. - Ins. Comor.

COMPERIA, C. Koch = Orchis, Linn

karduchorum, Bornm. et Kraenzl. ex Kraenzl. in Bull. Herb. Boiss. iii. (1895) 141. - Persia.

COMPSOA, D. Don = Tricyrtis, Wall. (Liliac.). flava, Kuntze, Rev. Gen. (1891) $708=$ T. flava, Maxim.

formosana, Kuntze, 1. c. = T. formosana, Baker.

hirta, Kuntze, 1. c. $=$ T. hirta. Hook.

latifolia, Kuntze, 1, c. = T, latifolia, Maxim

macropoda, Kuntze, 1. c. $=$ T. macropoda, Miq. 
COMPTONIA, Banks = Myrica, Linn

peregrina, Coulter, in Mem. Torrey Bot. Club. v. (1894) $127=$ M. asplenifolia. Linn.

CONANTHERA, Ruiz et Pav. (Haemodor.). Ind. Kew. i. 594

trimaculata, Fr. Meigen, in Bot. Jahrb. xvii. (1893) 226. et. xviii. (1894) 436 (= Cumingia trimaculata, D. Don), - Chili.

variegata, Fenzl, ex H.W. Reichardt, in Verh. zool.n bot. Ges. Wien, xxxvi. (1886) 29J. - Chili.

CONGHOPETALUM, Radlk. in Th. Dur. Ind. Gen. (1888) 81; et in Sitzb. Akad. Muench. xx. (1890) 295. SAPINDACEAE.

madagascariense, Radlk. l. c. - Madag.

madagascariense, Baill. Hist. pl. Madag., Atlas (1893) t. $250 \mathrm{a}=$ praec

CONDALIA, Cav. (Rhamn.). - Ind. Kew. i. 594.

lycioides, Weberbauer, in Engl. et Prantl. Natürl. Pflanzenfam. iii. 5 (1895) 404 (= Zizyphus lycioides, A. Gray). - Mexic.

obtusifolia, Weberbaner, l. c. $(=Z$. obtusifolia, A. Gray). - Am. bor

Parryi, Weberbauer, l. c. $(=Z$. Parryi, Torr.). Calif.

CONIOSELINUM, Fisch. = Ligusticum, Linn. (Umbellif.).

bipinnatum, Britton, in Bull. Torrey Bot, Club, xiv. (1887) 233 = Selinum canadense, Michx.

chinense, Britton, Stern et Pogg. Prelim. Catal.(1888) $22=$ Sel. canadense, Michx.

CONNAROPSIS, Planch. (Geran.). - Ind. Kew. i. 594 .

macrophylla, King, in fourn. As. Soc. Beng. 1xii. (1893) ii. 201. - Perak.

CONNARUS, Linn. (Connar.). - Ind. Kew. i Englerianus, Gilg, in Bot. Fahrb. xiv. (1892) 316.Englerianus, Gitg

longistipitatus, Gilg, in Engl. Pfanzenw. Ost-Afr. C (1895) 191. - Atr. or.

nigrensis, Gilg, in Bot.7ahrb.xiv.(1892)317.-Nigrit

pachyneurus, Radlk: in Sitzb. math.-phys. Akad. Muench.xvi.(1886) 365.-Bras.

Pottsii, S. Wats, in Proc. Am. Acad. xxi.(1886) 463 Guatem.

pseudoracemosus, Gilg, in Bot. Fahrb. xiv. (1892) 317. - Gabon.

Stuhlmannianus, Gilg, in Engl.Pfanzenw. Ost-Afr. C (1895) 192. - Afr. trop. or.

CONOCEPHALUS, Blume (Urtic.). - Ind. Kew. i. 596 .

amboinensis, Warb. in Bot. Fahrb. xviii. (1894) 183 (= Poikilospermum amboinense, Zipp.). - Ins. Amboin

amoenus, King, ex Hook. f. Fl. Brit. Ind. v. (1888 545. - Penins. Mal.

Scortechinii, King, l. c, 545. - Penins. Mal.

CONOMORPHA, A. DC. (Myrsin.). - Ind. Kew. i. 597 .

verticillata, Zahlbr. in Ann. naturh. Hofm. Wien, vii. (1892) 3. - Peruvia.

CONOPODIUM, Koch (Umbellif.). - Ind. Kew. i. 597.

elatum, Willk. in Oest. Bot. Zeitschr. xiii. (1891) 83 ; et Suppl. Prodr. Al. Hisp. (1893) 205. - Hisp.

pyrenaeum, Jeanb. et Timb.-Lagr.Le Capsir, (1887) ex Bull. Soc. Bot. Fr. xxxiv. (1887) 157.-Pyren.

Richteri, Rouy, in Bull. Soc. Bot. Fr. xxxix. (1892) 231. - Gall merid.

CONOSTEGIA, D. Don (Melast.). - Ind. Kew. 1. 598 .

Bernoulliana, Cogn. in DC: Monog. Phan. vii. (1891) 698. - Am. centr.

bigibbosa, Cogn. in Th. Dur. et Pitt. in Bull. Soc. Bot. Belg.xxx. 1891 (1892) 252. - Costarica.

\section{CONOSTEGIA}

Cooperii, Cogn. in DC. Monog. Phan. vii. (1891) 705. - Costarica.

Donell-Smithif, Cogn.l.c. 706 : et ex Th. Dur.et Pitt. in Bull. Soc. Bot. Belg. xxx. 1891 (1892) 252. Costarica.

Grisebachij, Cogn.l. c. 700. - Jamaica.

hirtella, Cogn. in Coult. Bot. Gaz. xvi. (1891) 4 ; et in DC. Monog. Phan. vii. (1891)711. - Guatem.

lanceolata, Cogn. l. c. 708; et ex Th. Dur. et Pitt. in Bull. Soc. Bot. Belg. xxx. 1891 (1892) 253. - Costarica.

Lindenii, $\operatorname{Cogn}$. l. c. 705. - Cuba.

mexicana. Cogn.l.c.707. - Mexic

Monteleagreana, $\operatorname{Cogn} . l$. c 1189 [Append.]; et ex Th. Dur. et Pitt. in Bull. Suc. Bot. Belg. xxx, 1891 (1892) 251. = Costarica.

Pittieri, Cogn. ex Th. Dur. in Bull. Soc. Bot. Belg. xxvii. (1888) 176. - Costarica.

Poeppigii, Cogn. in Mart. Fl. Bras, xiv. IV. (1887) 211. - Bras.

puberula, Cogn. in DC. Monog.Phan. (1891) 703.Am. centr.

Trianaei, $\operatorname{Cog} n$. l. c. 702. - N. Granat.

viridis, Cogn. ex F. D. Smith, in Coult. Bot. Gaz. xx. (1895) 286. - Guatem.

CONVALLARIA, Linn.(Liliac.). - Ind. Kew. i. 599.

aetnea, Tornab. Fl. Sicula (1887) 534. - Sicil.

polygonata, St-Lager, in Cariot, Etud. des fl. èd. 8 ii. (1889) $768=$ Polygonatum officinale, $A l l$.

CONVOLVULUS, [Tourn.]. Linn. (Convolv.), Ind. Kew. i. 597.

agrestis, Hallier f. in Bot. fahrb. xviii. (1894) 101 (=Evolvulus agrestis, Schweinf.). - Afr. trop. angolensis, Baker, in Kew Bull. (1894) 6\%. Angola.

arabicus, Hochst. ex Hallier f. in Bot. Jahrb. xviii. (1894) $100=$ glomeratus, Choisy.

Aschersoni, Engl. in Abhandl. Preuss. Akad. Wiss. 1891. ii. (1892) 349. - Abyss.

Binghamiae, Greene, in Bull. Calif. Acad. ii. vir, (1887) 417. - Calif.

Boedeckerianus, Peter, in Engl. et Prantl, Natürl. Pfanzenfam. iv. 3 a. (1891) 18. - Afr. austr.

Bornmuelleri, Hausskn. an Mitth. Thür. Bot. Ver. N. Folge, vi. (1894) 56. - Oriens.

chrysorhizus, Forst, ex Wien. Illustr. Gartenz. (1888) 288 = Ipomoea Batatas, Linn

fastigiatus, Hallier $f$. in Bot. Fahrb. xviii. (1894) 97 (= Breweriafastigiata, Balf. $\mathrm{f}_{0}$ ). - Ins. Socotr.

Fauroti, Franch. in Morot, fourn. de Bot.i. (1887) 121. - Afr. or.

geranioides, Phil. in Anal. Univ. Chil. xc. (1895) 222. - Chili.

glandulosus, Hallier $f$. in Bot. Fahrb. xviii. (1894) $102(=$ Rhodorrhiza glandulosa, Webb). - Ins. Canar.

hadramauticus, Baker, in Kew Bull. (1894) 337. Arabia.

hamphilahensis, Terracc. in Ann. Inst.bot. Roma, v. (1894) 105. - Afr. or

inconspicuus, Hallier f. in Bot. Fahrb, xviii. (1894) 106. - Afro austr.

kentrocaulos, Steud. ex Hallier f. in Bot. Jahrb. xviii. (1893) $119=$ Ipomoea tuberosa, Rich.

Kilimandschari, Engl. in Abhandl. Preuss. Akad. Wiss. 1891. ii. (1892) 348. - Afr. trop. or.

macrocalycinus, Hausskn. et Bornm. ex Bornm, in Mitth. Thür. Bot. Ver. N. Folge, vi. (1894) $66=$ holosericeus, Bieb.

mucronatus, Engl. Bot. fahrb. x. (1889) 246. Afr. austr.

ndorensis, Schweinf. ex Engl. in Abhandl. Prenss, Akad. Wiss. 1891. ii. (1892) 351, nomen.-Afr. trop. or.

ornatus, Engl. Bot. Fahrö. x. (1889) 247. - Afr. austr.

ovatus, Phil. in Anal. Univ, Chil, xc. (1895) 221. Chili.

Parishii, Peter, ex Hallier f. in Bot. Fahrb. xvi.(1893) 533 nomen. - Californ

Philippsiae, Baker, in Kew Bull. (1895) 221. - Reg. Somal

\section{CONVOLVULUS :}

praelongus, S. Moove, in Trans, Linn. Soc Ser. II iv. (1895) 403. - Bras.

rhynchophyllus, Baker, ex Engl. Bot. Fahrb. x. (1889) 247, nomen. - Afr. austr.

Schimperi. Engl. in Abhand. Preuss. Akad. Wiss. 1891. ii. (1892) 347. - Abyss.

Schweinfurthii, Engl.l. c. 348. - Abyss.

segobricencis, Pau, Not. bot. H. Espan. i. (1887) 7; Willk. Suppl. Prod. Fl. Hisp. (1874) 168, in obs. [sphalm. segrobricensis] $=$ aroensis, Linn. sinuatodentatus, Collett et Hemsl. in fourn. Linn. Soc. xxviii. (1890) 98. - Burma.

Sintenisii, Boiss. Fl. Or. Suppl. (1888) 349. - Ins. Cypr.

sphaerophorus, Baker, in Kew Bull. (1895) 221. Reg. Somal.

spicatus, Peter, ex Hallier f. in Bot. Fahrb. xviii. (1894) 99. -- Arabia.

Steudneri, Engl. in Abh.ndl. Preuss. Akad. Wiss. 1891. ii. (1892) 350. - Abyss.

subacculis, Greene, Man. Bot. San Franc. Bay, (1894) 265.

Thomsoni, Baker, ln Kew Bull.(1894) 6\%. - Afr. trop. austro-or.

truncatella, Colenso, in Trans. $N . Z$. Inst, xxi. 1888 (1889) 495. - N. Zel

alosepalus, Hallier f. in Bot. Fahrb. xviii. (1894) 103. - Afr. austr.

venosus, Hallier f. l. c. 109. - Teneriffa

verticillatus, Pavon, ex Hallier f. in Bot. Jahrb. xvi. (1893) $543=$ Jacquemontia polyantha, Hallier $f$.

CONYZA, Linn. (Composit.). - Ind. Kew. i. 607. amplexicaulis, Baker, in fourn. Linn. Soc. xxii. (1887) 489. - Madag.

andicola, Phil. in Anal. Mus. nac. Chile, (1891) 38. - Am. austr. occ.

araucana, Phil. in Anal. Univ. Chil. 1xxxvii. (1894) 696. - Chili

armeriifolia, Phil. l. c. 680.-Chili.

australis, Phil. Reconoc. Rio Palena (1886) 125 ; ex Anal. Univ. Chil. lxxxii. (1894) 683. - Patag.

Bocconi, Tornab. Fl. Sicula (1887) 303. - Sicil

capillipes, S. Moore, in Trans. Linn. Soc. Ser. II. iv. (1895) 387. - Bras.

colinensis, Phil. in Anal. Univ. Chil. Ixxxvii. (1895) 688. - Chili.

conglomerata, Phil. l.c.68\% - Chili.

copiapina, Phil.l. c. 686. - Chili.

Coxi, Phil. l. c. 690.-Chili.

cyanea, Engl. Pflanzenr. Ost-Afr. A (1895) 125 nomen. - Afr. trop. or.

cylindrica, Baker, in Kew Bull. (1895) 317. Arabia.

depilis, Phil. in Anal. Univ. Chil. 1xxxvii. (1894) 691. - Chili.

deserticola, Phil. in Anal. Mus.nac. Chile, (1891) 38 - Am. austr.-OCC

elata, F. M. Bailey, in Dept. Agric. Bot. Bull. viii. (1893) 78. - Austral.

Ellisii, Baker, in Journ. Linn. Soc. xxii. (1887) $489=$ C. Garnierii, Klatt.

foliosa, Phil. in Anal. Univ. Chil. 1xxxvii. (1894) 692. - Chili.

gigantea, O. Hoffm. in Engl. Pflanzenw, Ost-Afr. C (1895) 408. - Afr. trop. or.

glabrata, Phil. in Anal. Univ. Chil. 1xxxvii. (1894) 690. - Chili.

lateralis, Phil. 1. c. 679. - Chili.

longipedunculata, Klatt, in Bot. Fahrb. xii. Beibl. n 27 (1890) 22. - Madag.

miniata, Klatt, l. c. 23. - Madag.

minutiflora, Phil. in Anal. Univ. Chil. Ixxxvii. (1894) 692. - Chili

Moelleri, Phit. l. c. 686. - Chili.

monocephala, Phil. l. c. 680 . Chili.

monticola, Phil. l. c. 685. - Chili.

nemoralis, Phil. l. c.689. - Chili.

patens, Phil. l.c. 691. - Chili.

Paulseni, Phil.l.c.682. - Chili.

pencana, Phil. l. c.695. - Chili.

plebeja, Phil.l, c.685.-Chili.

pulsatilloides, 0 . Hoffm. in Bot. Fahrb. xx. (1894) 225. - Afr. aequat. or. 


\section{CONYZA}

pycnophylla, Phil. in Anal. Univ. Chil. lxxxvii, (1894) 693. - Chili.

ruderalis, Phil.l c. 694. - Chili.

serratifolia, Baker, in fourn. Linn. Soc, xxii. (1887) 488. - Madag.

setulosa, F. Phil. ex Phil. in Anal. Univ. Chil. 1xxxvii. (1894) - Chili.

spartioides. O. Hoffm. in Bot. Fahrb. xx, (1894) 224. - Afr, trop. or.

spicata, Phil. in Anal. Univ. Chil. lxxxvii. (1894) 679. - Chili.

spicata, Phil. l. c. xci. (1895) 679. - Chili.

stenodonta, Baker, in Kew Bull. (1895) 316.-Arabia. stenophylla, Phil. in Anal. Unis. Chil. 1xxxvii. (1894) 687. - Chili.

subscaposa, O. Hoffm. in Bot. Fahrb, xx. (1894) 225. - Afr. trop. or.

tamborensis, Boerl. Handl. Fl. Ned Indie,. ii. I. (1891) 237. - Sumbawa.

Telekii, Schweinf. ex Engl. in Abhandl. Preuss. Akad. Wiss. 1891. ii. (1892) 421 nomen; et in Hoelm. zum Rudolph See, Append. (1892) 10. - Afr. trop. or.

tenera, Phil. in Anal. Univ. Chil. Ixxxvii, (1895) 682. - Chili.

tenera, Phil. l. c. 684. - Chili

thermarum, Baker, in fourn. Linn. Soc. xxv。(1890)

327. - Madag

valdisiana, Phil, in Anal. Univ. Chil. Ixxxvii. (1894) 697 - Chili.

Volkensii, O. Hoffm. in Bot. Fahrb. xx. (1894) 224 - Afr. trop. or.

yungasensis, Rusby, in Mem. Torrey Bot. Club, iii.

3 (1893) 55. - Bolivia

COPAICA, Mill. = Gopacfera, Linn. (Legumin.). bijuga, Kuntze, Rev. Geń. (1891) $172=$ C. bijuha, Wild.

bracteata, Kuntze, 1. c. = C. bracteata, Benth

coleosperma, Kuntze, 1. c. = C. coleosperma, Benth confertiflora, Kuntze, 1. c. = C. confertiflora, Benth conjugata, Kuntze, 1. c. = C. Gorskiana. Benth. copallifera, Kuntze, .. c. = C. Guibourtiana, Benth. coriacea, Kuntze, 1. c. = C. coriacea, Mart. disperma, Kuntze, 1. c. = C. disperma, Willem. elliptica, Kuntze, 1. c. = C. elliptica, Mart.

guianensis. Kuntze, l. C. = C. guyanensis, Dest hymrenaeifolia, Kuntzc, 1, c. = C. hymenaeifolia, Moric

Fussieui, Kuntze, 1. c. = C. Jussieui, Hayae. Langsdorfii, Kuntze, 1. c. = C. Langsdorfii. Desf. marginata, Kunte, 1. C. = C. marginata, Benth

Martii, Kuntze, 1. c. = C. Martii, Hayne.

Mopane, Kuntze, 1. c, = C. Mopane, 7.Kurk.

multijuga, Kuntze, 1.c. = C. multijuga, Hayne.

oblongifolia, Kuntze, I. c. = C. oblongifolia, Mart. officinalis, Kuntze, Kuntze, 1.c. = offlcinalis, Linn rigida, Kuntze, 1. $c_{0}=$ C. rigida, Benth.

trapezifolia Kuntze, I. $\mathrm{C}=\mathrm{C}$. trapezifolia, Hayne.

GOPAIFERA. Linn.(Legum.) - Ind. Kew, i. 510

Cornui, Heckel, in Ann, Fac, sci. Marseille, fasc, i, (1891) 15. - Afr, trop.

Gorskia, Schinz, in Verh. Bot. Ver. Brand. xxx. 1888 (1889) 172 sphalm. = C Gorskiana, Benth Salikounda, Heckel, in Ann. Fac. soi. Marseille, iii. (1891) 4. t. 16. - Afr. trop.

COPERNIGIA, Mart, (Palm.).-- Ind. Kew. i, 610 alba, Morong, in Ann. N. Y. Acad. Sci, vii. (1893) 246. - Parag.

rubra, Morong, i. c. 247. - Parag.

COPROSMA, Forst.(Rubiac.).--Ind. Kew, i. 611. alba, Colenso, in Trans. N. Z. Inst.xxiv. 1891 (1892) 388, - N. Zel.

areolata, Cheesem, l.c. xviii, 1885 (1886) 315. N. Zel.

aurantiaca, Colenso, l. c. xxii. 1889 (1890) 464.N. Zel.

autumnalis, Colenso, l. c. xix. 1886 (1887) 263.N. Zel.

Buchanani, T. Kirk, l. c. xxiv. 1891 (1892) 424. N. Zel.

coffaeoides, Colenso, l. c. xxi. 1888 (1889) 87.-N. Zel.

crassicaulis, Stapf, in Trans. Limn. Soc. Ser, II. vi, 1894) 186. - Borneo.

\section{GOPROSMA}

ymosa, Hillebr. Fl. Haw. Isl. (1888) 186. -- Ins. Sandvic.

heterophylla, Colenso, in Trans. N. Z. Inst. xviii. $1885(1886) 263=$ rhamnoides, $A$. Cunn

Hookeri, Stapf, in Trans. Linn. Soc. Ser. II iv. (1894) 187. - Borneo.

latifolia, Colenso, ex Cheesem, in Trans. N.Z. Inst. xix. 1886 (1887) 229 = grandifolia, Hook. f.

lentissima, Colenzo, l.c. xxii. 1889 (1890) 465. N. Zel.

macrocarpa, Cheesem, l. c. xx. 1887 (1888) 147 N. Zel.

montana, Hillebr. Fl. Haw. Isl. (1888) 185. - Ins. Sandvic.

multiflora, Colenso, in Trans, N.Z. Inst, xxi. 1888 (1889) 86. - N. Zel.

orbiculata, Colenso, l. c. xxii. $1889(1890) 465$. N. Zel.

pendula, Colenso, l. c. xxi. 1888 (1889) 84. N. Zel.

perpusilla, Colenso, l. c. xxii. 1889 (1890) 466. N. Zel.

Petriei, Cheesem.l.c. xviii. 1885 (1886) 316; ct ex Bot. Centralbl. xlviii, (1891) 28. - N. Zel.

pubens, Petrie, 1. c. xxvi. 1893 (1894) $267=$ ramulosa, Petrie.

ramulosa, Petrie, l. c. xxvii. 1894 (1895) 406, N. Zel.

retusa, Petrie, l. c. xxvi. 1893 (1894)268. - N. Zel. rigida, Cheesem.l. c. xix. $1886(1887) 243 .-\mathrm{N}$. Zel. rufescens, Colenso, 1. c. xviii. 1885 (1886) $261=$ rotundifolia, A. Cunn.

stephanocarpa, Hillebr. Fl. Haw. Isl. (1888) 18\%. Ins. Sandvic.

tenuifolia. Cheesem, in Trans. N. Z. Inst. xviii. 1885 (1886) 315. - N. Zel.

turbinata, Colenso, l. c. xxiv. 1891 (1892) 389. N. Zel.

COPTOSPELTA, Korth. (Rubiac.), - Ind. Kew. i. 611

macrophylla, K. Schum. in Engl. et Prantl, Natürl. Pflanzenfam, iv. 4 (1892) 51 = flavescens, Roxb.

CORALLOGARPUS, Welw. (Cucurbit.). - Ind. Kew. i. 612

glomeruliforus, Schweinf. ex Deflers, in Bull. Soc. Bot. Fr.xlii. (1895) 304 in syn. = Phialocarpus glomerulifforus, Deflers.

Schinzii, Cogn. ex Sckinz, in Verh. Bot. Ver. Brand. xxx. (1888) 153. - Afr, austro-occ. extratrop.

sphaerocarpus. Cogn. l. c. 154. - Afr. austro-occ extratrop.

CORALLODENDRON, Tourn. = Erythrina Linn. (Legumin.).

abyssinicum, acanthocarpum, arborescens, bracteatum. breviflorum, Brucei, caffrum, Crista-Galli, divaricatum, excelsum, falcatum, fuscum, glaucum, herbaceum, holosericeum, horridum, huillense, leptorhizum, lithospermum, Livinostonianum. lobulatum, longipes, mite, monospermum, Mulungu, nervosum, ovalifolium, patens, princeps, resupinatum, reticulatum, roseum, rubrinerve, senegalense, setosum, spathacenm, strictum, suberifora, suberosum, sumatranum, umbrosum, velutinum, Vespertilio, Zeyheri, Kuntze, Rev. Gen. (1891) $172-173$ = homonyma omnia Erythrinae. americanum, Kuntze, 1. с. $172=\mathrm{E}$. corneà, Ait. australe, Kuntze, 1. c。= E. Corallodendron, Limm. var.

corallodes, Kuntze, 1. c. $=$ E. coralloides, $D C$.

Humei, Kuntze, 1. c. $173=$ E. Humeana, Spreng.

latissinum, Kuntze $1, c=E$ tomentosa $R \cdot B r$. occidentale, Kuntze, 1. с. $172=\mathrm{E}$. Corallodendron, Linn. var. occidentalis, Linn.

orientale, Kuntze, 1. C. = E. indica, Lam.

GORALLODISGUS, Batalin, in Engl. et Prant1, Natürl. Pflanzenfam. iv. 3 b. (1894) 145. GESNE$R A C E A E$.

conchaefolius, Batalin, l.c. - China.

GORALLORHIZA, Hall. (Orchid.). - Ind. Kew. i. 612

Corallorhiza, Mac Millan, Metasp. Minn. (1892) 174 ; et in Bull. Torrey Bot. Club, xix, (1892) 15 $(=C$. Corallowhiza, Karst. $) .=$ innata, $R, B r$
GORGHORUS, [Tourn.] Linn. (Tiliac.). - Ind. Kew. i. 612.

Allenii, F. Muell, in Vict. Natural. viii. (Oct. 1891) 85. nomen; et in Proc. Linn. Soc. N. S. Wales, Ser II. vi. 1891 (May 1892) 462. - Austral.

cinerascens, Deflers, in Bull. Soc. Bot. Fr. xlii. (1895) 300. - Arabia.

Elderi, F. Muell. in Trans, et Proc, Roy, Soc. S. Austral. ix. (1987) 58. - Austral.

hamatus, Baker, in foum n. Linn. Soc. xxii. (1887) 458. - Madag.

GORDIA, Linn. (Boragin.). - Ind. Kew. i. 613.

Andersonii, Gürke, in Engl. et Prantt, Natürl. Pflanzenfam. iv. 3a (1891) 83 (= Varronia canescens, Anderss.). - Ins. Galap.

atrofusca, Taub. in Bot. Fahrb. xv, Beibl.n. 38 (1893) 12. - Bras.

aurantiaca, Baker, in Kerv Bull. (1894) 26. - Afr. trop.

Blancoi, Vidal, Rèv. Pl. Vasc. Filip. (1886) 192. Ins. Philip.

Caput-Medusae, Taub. in Bot. Fahrb. xv. Beibl.n. 28 (1893) 15. - Bras.

chrysocarpa, Baker, in Kerv Bull. (1895) 27. Angold.

dichotona, Gürke, in Engl, et Prantl, Natürl. Pflanzenfam. iv 3a (1891) $84=$ C. bifurcata, Roem. et Schult.

Fischeri, Gürke, in Engl. Pflaznenw. Ost-Afr. C (1895) 335. - Afr. trop. or.

flava, Gürke, in Engl. et Prantl, Natürl. Pfanzenfam. iv. 3 a (1891) 83 (= Varronia flava, Anderss.). Ins. Galap.

galapagensis, Gürke, l.c. (=V. seaberrima, Anderss.). - Ins. Galap.

Glaziovii, Taub. in Bot. Fahrb. xv. Beibl. n, 38 (1893) 14 (= Patagonula Glaziovii, Mez), - Bras.

Haenkeana, Mez, in Bot. Fahwb. xii. (1890) 560. Peruv.

harara, G. Beck, in Paulitschke, Harrar (1888) 357.-

Afr. trop. or.
Heudelotii, Baker, in Kew Bull. (1894) 27. - Afr. trop. occ.

Holstii, Gürke, ex Engl, in Abhandl, Preuss. Akad. Wiss. (1894) 51; et in Engl. PAanzenw. Ost-Afr. C (1895) 335. - Afr. trop. or.

Hookeriana, Gürke, in Engl. et Prantl, Natürl. Pflanfam. iv. 3 a (1891) 83 (= C. linearis, Hook. f.).- Ins, Galap.

Irvingii, Baker, in Kew Bull. (1895) 113. - Lagos. jucunda, S. Moore, in Trans. Limn. Soc. Ser. II, iv. (1895) 401. - Bras.

Kirkii, Baker, in Kew Bull. (1894) 28. - Zambesia. leucomalla, Taub., in Bot. Fahrb. xv. Beibl. n. 38 (1893) 14. - Bras.

longipeda, Mez, l. c. xii. (1890) 550. - Bras.

longipes, Baker, in Kew Bull. (1894) 27. - Angola.

Meziana, Gürke, in Engl. et Prantl. Natürl. Pfanzenfam. iv. 3 a $(1891) 84(=$ C. amplifolia, Mez $)$.

- Am. trop.
Millenii, Baker, in Kew Bull. (1894) 27. - Lagos.

Nettoan, Taub in Rot. Fahrb, xv, Beibl, n. 38 1893) 11. - Bras.

obovata, Baker, in Kew Bull. (1894) 28. - Abyss.

Palmeri. S. Wats. in Proc. Am. Acad. xxiv. (1889) 62. - Calif.

Palmeri, Rose, in Contrib. U. S. Nat. Herb. i. (1691) tab 9 -C. Sonorae, Rose.

pilosissima, Baker, in Kew Bull. (1894) 28. Angola.

platythyrsa, Baker, l.c. 28. - Afr. trop. occ.

populifolia, Baker, l. c. 2\%. - Afr. trop. occ.

Pringlei, Rob̆ins, in Proc, Am. Acad. xxvi. (1891) 169. - Mexic

quarensis, Guirke, in Engl. Pflanzenw. Ost-Afr. C (1895) 335. - Afr, trop. or.

senegalensis, Hochst. ex Baker, in Kew Bull. (1894) 28 = obovata, Baker.

serrata. Gürke, in Engl. et Prantl, Natürl. Pflanzenfam. iv. 3 a (1891) 83. - Am. austr.

somaliensis, Baker, in Kew Bull. (1894) 28. - Reg.

Somal.
Sonorae, N. E. Rose, in Contrib. U. S. Nat. Herb. 1. (1891) 106. - Mexic 
CORDIA

Sprucei, Mez, in Bot. Fahrb. xii. (1890) 549. Bras.

Stuhlmannii, Gurke, in Engl. Pflanzenw. Ost-Afr. C (1895) 335. - Afr. trop. or.

thyrsiflora, Hort. ex Dippel, Handb. Laubholzk, i. (1889) $18=$ Ehretia serrata, Roxb.

venosa, Hemsl. in fourn. Linn. Soc. xxvi. (1890 143. - China.

Watsoni, N.E. Rose, ex Vasey et Rose, in Contrib. U. S. Nat. Herb i. (1890) 89. - Mexic.

Zedambae, Martelli, Fl. Bogos. (1886) 58. - Abyss.

CORDIERA, A. Rich. = Alibertia, A. Rich. (Rubiac.).

bertierifolia claviflora concolor curviflora, edulis, elliptica, humilis, longiflora, macrophylla, obtusa, oligantha, rigida, sessilis, vinosa, Kuntze, Rev. Gen. (1891) $279=$ homonyma omnia Alibertiae.

Garapatica, Kuntze, 1. c. = A. edulis, A. Rich.

hexagyna, Kuntze, 1. $r_{\text {, }}=$ A. hexagyna, Karst.

jacquiniodes, Kuntze, 1. $\mathrm{c}_{0}=\mathrm{A}$. jacquinioides, Griseb.

myricifolia, Spruce, ex K. Schum. in Mart. Fl. Bras. vi.vi.(1889) $393=$ A. myricifolia, K. Schum. acciniodes, Kuntze Rev Gen.279.=A.vaccinioides,

K.Schum.

CORDYLINE, Royn (Liliac.). - Ind. Kew. i.

flabelliformis, Cordem. Fl. Ile Réun. (1895) 151 (an C. flabelliformis, Kunth?) - Ins. Borbon.

Hectori, Colenso, in Trans. N.Z. Inst. xxv. 1892 (1893) 334. - N. Zel.

lineata, Hort. ex Rodigas, in Illustr. Hort. x1. (1893) 121 t. $590=$ indivisa, Steud.

macrophylla, Cordem. Fl. île Réun. (1895) $153=$ C. macrophylla, C. Koch

Rashleighana $\times$, Hort. ex Gard. Chron. (1886) i. 818. - Hybr, artef.

COREOPSIS, Linn. (Composit.). - Ind. Kew. i. 616.

arizonica, O. Hoffm. in Engl. et Prantl, Natürl. Pflanzenfam. iv. 5. (1890) $243=$ Leptosyne arizonica, A. Gray.

Buchneri, Klatt, Leopoldina, Heft xxv. (1889) 107.Angola.

Buchneri, Klatt, in Ann. naturh. Hofmus. Wien, vii. (1892) 103 (an praec?). - Angola.

cordifolia, Drake, F1. Polyn. franç. (1892) $109=$ Bidens cordifolia, Sch.-Bip.

cordylocarpa, A. Gray, in Proc. Am. Acad.xxii. (1887) 428. - Mexic.

coriacea, O. Hoffm. in Engl. Pfanzenw. Ost-Afr. C (1899) $414 .-$ Afr. trop. or.

exaristata, O. Hoffm. l. c. - Afr. trop. or.

Fischeri, O. Hoffm. l. c. - Afr. trop. or.

frondosa, $O . H$. Hofm. $l . c .-$ Afr. trop, or.

Holstii, O. Hoff $w$. l. c. 415. - Afr. trop. or.

fardini, Drake, F1. Polyn. franç. (1892) $109=$ Bidens Jardini, Sch. Bip.

kilimandscharica, O. Hoffm. in Bot. Fahrb. xx. (1894) 234. - Afr. trop. or.

lineata, Klatt, in Ann. naturh. Hofmus, Wien, vii. (1892) 103. - Angola.

longifolia, Small, in Bull. Torrey Bot. Club, xxii. (1895) 47. - Am. bor.-or.

muecensis, Heller, Bot. Expl. S, Texas, (1895) 106 = coronata, Hook.

oligantha, Klatt, in Ann. naturh. Hofmus. Wien, vii. (1892) 103. - Angola.

oligoflora, Klatt, in Leopoldina, Heft xxv. (I889) 107. - Angola.

polycephala, Drake, Fl. Polyn. franç. (1892) $108=$ Bidens polycephala, Sch. Bip.

petrophila, A. Gray, in Proc. Am. Acad. xxii. (1887) 428. - Mexic.

serrulata, Drake, F1. Polyn. franç. (1892) $109=$ Bidens serrulata, Sch. Bip.

simplicifolia, Engl. in Abhandl. Preuss. Akad. Wiss. 1891 ii. (1892) 435. - Abyss.

Stuhlmannii, O. Hoffm, in Engl. Pflanzenw. Ost-Afr. C (1895) 415. - Afr. trop. or.

trilobata, Vahl, ex Klatt, in Leopoldina, Heft xxiii. (1887) 90 in syn. = Montania pauciflora, Klatt.
CORETHROGYNE, DC. (Composit.). - Ind. Kew.i. 617

cana, Greene, in Bull. Calif. Acad. i. 1885 (1886) 223. - Calif.

CORIARIA, Niss. ex Linn. (Coriar.). - Ind. Kew. i. 618

papuana, Warb. in Bot. Fahrb. xvi. (1893) 22.Oceania.

terminalis, Hemsl. in Hook. Icon. pl. xxiv. (1892) t 2220. - China.

CORION, Mitch. = Spergularia, J. et C. Pres? (Caryophyll.).

medium, N. E. Br. in Bot. Exch. Club Brit. Isles, Report for $1892(1893)=$ Spergularia media.

GORIS, Tourn. ex. Linn. (Primul.). - Ind. Kew, i. 618

purpurea, St-Lager, in Cariot, Etud. des fl. éd. 8. ii. (1889) $576=$ monspeliensis, Linn.

CORMIGONUS, Rafin.=-Bikkia, Reinw.(Rubiac). campanulata, Kuntze, Rev. Gen.(1891)279(= Grisid campanulata, Brongn.). - N. Caled.

carneus, Kuntze, 1. c. - N. Caled.

Deplanchei, Kuntże, 1. c. - N. Caled.

fritillariodes, Kuntze, 1. c. (= Grisia fritillarioides, Brongn.). - N. Caled.

macrophylla, Kuntze, 1.c. (=G.macrophylla,Brongn.) - N. Caled.

neriifolia. Kuntze. 1.c. (=G. neriffolia, Brongn.).N. Caled.

Pancheri, Kuntze, 1. c. (= Bikkiopsis Pancheria).N. Caled.

portlandiodes, Kuntze, 1. c. (= Tatea portlandioides, Seem.). - N. Caled.

tetrandus, Kuntze, 1. C. = B. grandiflora, Reinw.

CORMONEMA, Reissek (Rhamn.). - - Ind. Kew.i. 618.

mexicana, N. E. Rose, in Contrib. U. S. Nat. Herb. III. (1895) 315 . - Mexic.

Nelsoni, Coult., l. c. - Mexic.

CORMUS, Spach = Pyrus, Linn. (Rosac.). crenata, Koehne, in Gartenfl. (1891) 59; et Deutsche Dendrol. (1893) $255=$ P. crenata, D. Don.

lanata, Koehne, 1. c. 59 et $254=$ P. lanata, $D$. Don.

CORNIDIA, Ruiz et Pav. = Hydrangea, Linn. (Saxifrag.).

integerrima. Hort ex Koehne, Deutsche Dendrol. (1893) $\mathbf{1 8 9}=$ Schizophragma hydrangeoides, Sieb. et Zucc.

CORNUELIA, Pierre, Not. bot. Sapot, (1891) 66 . $S A P O T A C E A E$ venezuelanensis, Pierre, l. c.(1891)68. - Venez.

GORNUS, [Tourn.] Linn. (Cornac.) - Ind. Kew. i. 619.

Baileyi, Coult. et Evans, in Coult. Bot.Gaz.xv. (1890) 37 ; et in Gard, and For. iii. (1890) 464. fig. 58. Am. bor.

Greenei, Coult. et Evans, in Conlt. Bot. Gaz. Xv. (1890) 36; et ex Greene, Man. Bot. San Franc. Bay (1894) 159 (sphalm. ? Coult. et Rose). - Calif.

hongkongensis, Hemsl. in fourn. Linn. Soc. xxiii. (1888) 345. - China.

Nuttalli, Hort. ex Koehne, Deutsche Dendrol. (1893) 436 = glabrata, Benth.?

occidentalis, Coville, in Contrib. U. S. Nat. Herb. IV. (1893) $117=$ pubescens, Nutt.

scabridus, Franch. in Nouv. Arch. Mus. Paris, Sér. III. viii. 1885 (1886) 250. - China.

Volkensii, Harms, in Engl. Pfanzenw. Ost-Afr. C (1895) 301. - Afr. trop. or

CORONILLA, Tourn. ex Linn. (Legumin.). Ind. Kew. i. 620.

Pomeli, Batt. ex Bull. Soc, Bot. Fr, xxxiii. (1886) 353 ; et in Batt. et Trab. F1. de l'Algér. (1889) $288=$ juncea, $\operatorname{Linn}$

scorpioidec, St-Lager, in Cariot, Étud. des fl. éd. 8 ii. $(1889) 311=$ scorpioides, Koch.
CORONOPUS, Rupp. = Senebiera DC. (Crucif.). Coronopus, Britton, in Bull. Torrey Bot. Club, xviii (1891) $265(=$ C. Coronopus, Karst. $)=\mathrm{S}$. Coronopus, Poir.

Helenianus, Kuntze, Rev. Gen. (1891) $27=$ S, pinnatifida, $D C$

integrifolius, Prantl, in Engl, et Prantl, Natiirl. Pflanzenfano. iii. 2. (1891) 161 (= C. integrifolius Spreng.) $=\mathrm{S}$, integrifolia, $D C$.

lepidiodes, Kuntze, Rev. Gen.(1891) $27=$ S. lepidioides, Coss.

linodes, Kuntze, 1. c. $26=\mathrm{S}$. integrifolia, $D C$

niloticus, Prantl, in Engl. et Prantl, Natürl. Pflanzenfam. iii. 2. (1891)161 (=C.niloticus, Spreng.) = S. nilotica. Delile

pectinatus, Kuntze, Rev. Gen.(1891)27 = S. pinnatifida, $D C$.

pinnatifidus, Fr. Meigen, in Bot. Jahrb. xvii. (1893) $238(=\mathrm{C}$. pinnatifidus, Dulac $)=\mathrm{S}$.pinnatifida, $D C$. violacers, Kuntze, Rev. Gen.(1891) $27=$ S. violacea Munby.

GORTUSA, Linn. (Primul.). - Ind. Kew. i. 620 . pekinensis, A. Richt. in Termerzet. Fiizétek (1894) 130. - China.

CORUNASTYLIS, Fitzg. Austral. Orchids, ii, III. (Dec. 1888). ORCHIDEAE. [ = Anticheirostylis, Fitze.. 1891].

apostasioides, Fitzg.l.c. - Austral.

CORYANTHES, Hook. (Orchid.). - Ind. Kew i. 621

Bungerothii, Rolfe, in Gard. Chron. (1890) ii. 210 et in Lindenia vi. (1890) 11. t. 244.-Venez.

leucocorys, Rolfe, l. c. vii. (1891) 13 t. 293. - Pe. ruvia.

macrocorys, Rolfe, l. c. viii. (1892) 17. t. 342.Peruvia.

orbiculata, Colenso, in Trans. N. Z. Inst. xxiii. 1890 (1891) 389. - N. Zel.

GORYGIUM, Sw. (Orchid.). - Ind. Kew. i. 621. tricuspidatum, Bolus, in fourn. Linn. Soc. Xxv. (1889) 176 et 2075 fig. 13. - Afr. austr.

GORYDALIS, Vent. (Papaver.). - Ind. Kew. I. 621.

anthriscifolia, Franch. in Nouv. Arch. Mus. Paris, Sér. IMY. viii. 1885 (1886) 196. - China.

balcanica, Velen. in Sitzb. Boehm. Ges. Wiss. 1889 (1890) 1i. 28; et Fl. Bulg, (1891) 23. - Bulg.

bicalcarata, Velen. Fl. Bulg. (1891) 20, - Bulg

Boweri, Hemsl. in fourn. Linn. Soc. xxx. (1894) 108. - Tibet.

cachemiriana, Franch. in Bull. Soc. Bot. Fr, xxxvii. (1886) $392=$ pachycentra, Franch

calcarea, Alboff, Prod. A. Colchic. (1895) 1\%.- Reg. transcauc.

capillipes, Franch. in Bull.Soc. Phil. Paris, Sér. vii. x. (1886) 139. - Japon.

cheilanthifolia, Hemsl. in fourn. Linn. Soc. Xxix. (1892) 302. - China.

cheirifolia, Franch, in Morot, fourn. de Bot, viii. (1894) 285. - Yunnan.

conspersa, Maxim. Fl. Tangut. (1389) 49 t. 25 fis. 1-5. - Tibet.

Crista-galli, Maxim. l.c. 47 t. 25. fig. 26-31.-Tibet. cristata, Maxim. in Act. Hort. Petrop. xi.(1890) 47. - China.

curviflora, Maxim. ex Hemsl. in Fourn. Linn. Soc. xiii. 1886) 37, nomen; et Fl. Tangut.(1889) 41.t 20. fig. 1-11.- China.

Davidi, Franch. in Nouv. Arch. Mus. Paris, Sér. III viii. 1885 (1886) 198. - China.

Delavayi, Franch, in Bull. Soc. Bot. Fr, xxxiii. (1886) 393. - China.

Duthiei, Maxim. Fl.Tangut.(1889)49, in obs, t. 25 . fig. 12-17. - Reg. Himal

echinocarpa, Franch. in Bull. Soc. Bot. Fr, xxxiii. (1886) 393. - China.

elata, Bureau et Franch. in Morot, Fourn. de Bot, v. (1891) 20. - China.

Fargesii, Franch. l. c. viii. (1894) 290. - China.

flexuosa, Franch, in Nouv. Arch. Mus. Paris, Sér.

III. viii. 1885 (1886) 197. - China. 


\section{GORYDALIS}

glareosa, Somm et Ievier, in Act. Hort. Petrop. xiii. (1893) 27 . Cauc

gracilis, Franch. in Bull. Soc, Bot. Fr. xxxiii. (1886) 395. = China

hamata, Franch. in Morot, fonrn. de Bot.viii. (1894) 291. - Tibet.

Hannae, Kanitz, Pl. exp. Szechenyi in Asia centr. coll. (1891) 7. - Asia centr.

Hendersonii, Hemsl. in fourn. Limn. Soc. xxx. (1894) 109. - Tibet.

leiosperma, Conrath, in Oest. Bot. Zeitschr, xxxviii. (1888) 50. - Bosnia.

livida, Maxim . Fl. Tangut. (1889) 49 - China.

lopinensis, Franch. in Morot, fourn. de Bot. viii. (1894) 283. - China.

micrantha, A. Gray, ex Coult. Bot. Gaz. xi. (1886) 189. - Amer. bor, austr.

moupinensis, Franch. in Nouv. Arch. Mus. Paris, Sér. III. viii. 1885 (1886) 198.-China.

mucronata, Franch.l. c. 197. - China.

mucronifera, Maxim.Fl. Tangut.(1889) 51. t. 24. fig. 19-21. - Tibet.

oxypetala, Franch, in Bull. Soc. Bot. Fr. xxxiii. (1886) 392. - China.

pachycentra, Franch. Pl. Delav. (1889) 45. - Yunnan.

petrophila, Franch. l.c. 47. - Yunnan.

Potanini, Maxim. Fl. Tangut. (1889) 48, - China.

Prattii, Franch, in Morot, fourn, de Bot. viii. (1894) 284. - China.

pulchella, Franch. Pl. Delav. (1889) 44. - Yunnan. scaberula, Maxim. Fl. Tangut. (1889) 40 t. 24 fig. 1-11. - Tibet.

scandens, Franch. in Bull. Soc. Bot. Fr. xxxiii. (1886) 391 = Dicentra scandens, Walp.

slivenensis, Velen, ex Nym. Consp. Fl. Eur. et $\mathrm{Fl}$. Bulg. (1891) 20. - Bulg.

Souliei, Franch, in Morot, fourn. de Bot. viii. (1894) 283. - China.

stenantha, Franch. Pl. Delav. (1889) 49. - Yunnan. straminea, Maxim. ex Hemsl. in fourn. Linn. Soc. xxiii. (1886) 38. nomen; et Fl. Tangut. (1889) 44. t. 20, fig. 17-24. - China.

swanetica, Krassnow, Enum. pl. nowv. Swanétie (1891) 15. - Reg. Caucas

stenantha, Franch. Pl. Delav. (1889) 49. - China. taliensis, Franch.l.c. 48. - Yunnan.

temulifolia, Franch. in Morot, Fourn, de Bot, viii. (1894) 290. - China.

thalictrifolia, Franch. l. c. 291. - China.

tomentella, Franch. l. c. 292. - China.

tongolensis, Franch. l. c. 285. - China.

trifoliolata, Franch. in Bull. Soc. Bot. Fr. xxxiii. (1886) 392, - China.

trisecta, Franch. in Morot, fourn. de Bot. viii. (1894) 284. - China.

triternata, Franch. l. c. 290. - Yunnan.

yunnanensis, Franch, in Bull. Soc. Bot. Fr, xxxiii, (1886) 394. - China.

GORYLUS, [Tourn.] Linn.(Cupulif.). - Ind. Kew, i. 622 .

calyculata, Dippel, Handb. Laubrolzk. ii. (1K92) 132 fig. 63. - Am bor.

colchica, Alboff, Prod. fl. Colch. (1895) 219. - Reg. Cauc.

rostrata, Hort. ex Dippel, Handb. Laubholzk. ii. (1892) $132=$ calyculata, Dippel.

serotina, Hort, ex Dippel. 1. co = americana, Walt. tibetica, Batalin, in Act. Hort. Petrop. xiii. (1893) 102. - China.

urtizaefolia, Hort. ex Dippel, Handb. Laubholzk. ii. (1892) $128=$ C. Avellana, Linn.

virginiana, Hort, ex Dippel, 1. c. $132=$ calyculata, Dippel.

GORYMBIS, Thou. (Orchid.).-Ind. Kew, i, 623. brevistylis, Hook. Fl. Brit. Ind. vi. (1890) 92. Perak.

decumbens, Cogn, in Mart. Fl. Bras iii. vi. (1895 276. t. 67 (=Chloidia decumbens, Lind1.). - Am. austr

leptantha, Kraenzl, ex Engl. in Abh. Preuss. Akad. Wiss. (1894) 45 et 53; et ex Engl. Pflanzenw. Ost-Afr. A (1895) 83 et $89=$ corymbosa, Thou.

\section{CORYMBIS :}

longiflora, Hook. f. Fl. Brit. Ind. vi. (1890) 92. Penins. Mal.

rhytidocarpa, Hook. f. l. o. - Perak.

CORYNOLOBUS brachycarpus, Rouy, in Bull. Soc. Bot. Fr, xxxiii (1886) 524 in syn. = Erucastrum brachycarpum, Rouy.

CORYNOPHALLUS,Schott $=$ Amorphophallus Blume (Aroid.)

angolensis, Kuntze, Rev. Gen. (1891) 741 (= Hy drosme angolensis, Schotí). - Afr. trop.

consimilis, Kuntze, 1, c. = A. consimilis, Blume,

Fontanesii, Kuntze, 1. $\mathrm{c}_{-}=$A. Fontanesii, Kunth. gratus, Kuntze, 1.c. (= Hydrosme grata, Engl.). - Afr. trop.

Hohenackeri, Kuntze, 1. с. = Rhaphiophallus Hohenackeri, Schott.

maximus, Kuntze, 1.c. (= Hydrosme maxima, Engl.). - Afr. trop.

mossambicensis, Kuntze, 1. c. = A. mossambicensis, Klotasch

GORYNOSTYLIS, Mart. (Violar.). - Ind. Kew. i. 623.

palustris, Rodr. in Vellozia, i. (1885-88), Sec. edic. (1891) 4. t. 3.- - Bras

pubescens, S. Moore, in. Trans. Linn. Soc. Ser. II. iv. (1895) 306.- Bras.

CORYPHA, Linn. (Palm.), - Ind. Kew, i. 623

decora, Hort. Bull, Catal. (1887) 10; et exW. Wats. in Kew Bull. iii. (1889) $294=$ Livistona inermis, R. Br.

Martiana, Becc. ex Hook.f. Fl. Brit. Ind, vi. (1892) 429. - Burma

GORYTHEA, S. Wats, in Proc. Am. Acad, xxii (1887) 451. EUPHORBIACEAE.

filipes, S. Wats, l. c. - Mexic.

CORYTHOLOMA, Decne, = Gesneria, Mart (Gesnerac.).

allagophyllum, Fritsch, in Engl. et Prantl, Naturl. Pflanzenfam, iv. 3b. (1894) $180=G_{\text {. allago- }}$ phylla, Mart.

maculatum, Fritsch, 1. c. = G. maculata, Mart. magnificum, Fritsch, 1. c. = G. magnifica, Otto et Dietr.

splendens, Fritsch, 1. c. fig. $79=$ G. splendens, Van Houtte.

tuberosum, Fritsch, 1. c. = G. tuberosa, Mart.

cardinale, Fritsch, $1, \mathrm{c},=\mathrm{G}$, cardinalis, Lehm.

COSMOS, Cav. (Composit.). - Ind. Kew. i. 624. aurantiaca, Klatt, in Leopoldina, Heft xxv. (1889) 105. - Guatem

exiguus, A. Gray, in Proc. Am. Acad. xxii. (1887) 429. - Mexic.

hybridus, Hort. ex Gard, and For. i. (1888) 474. Mexic.

COSSIGNIA, “ Comm." ex Radlk. in Engl, et Prantl,! Natïrl. Pflanzenfam, iii. 5 (1895) $354=$ Cossinia, Comm. (Sapind.).

COSSONIA.Durieu= Raffenaldia, Godr. (Crucif.). intermedia, Coss. Ill. fl. Atlant. i. (1884) 53 ; et Comp. fl. Atl, ii. (1887) 224. - Marocc.

platycarpa,Coss.1. c. i. 54. t. 37; et ii. (1887) 225. Marocc.

CostaeA, A. Rich. = Purdiaea, Planch (Cyrill.).

nutans, Gilg, in Engl, et Prantl, Natürl. Pflanzenfam. iii. 5 (1892) $182=$ Purdiaea nutans, Planch.

GOSTULARIA, C.B. Clarke, in Th. Dur. etSchinz, Consp. Fl.Afr.v. 1894 (1895)658. CYPERACEAE. Baroni, C. B. Clarke, l.c. - Madagasc.

Melleri, C. B. Clarke, l. c. - Madagasc natalensis, C. B. Clarke, l. . . - Natal.

pantopoda, C. B. Clarke, l.c. (= Cladium pantopodum, Baker, pr. p ).-Madagasc.

recurva, C.B. Clarke, l.c. (= Rhynchospora leucocarpa, Ridl.). - Madagasc.
CosTUS, Linn. (Scitamin.). - Ind. Kew. i. 625. acaulis, S. Moore, in Trans. Linn. Soc. Ser. II. iv (1895) 481. t. 33. fig. 1-5. - Bras.

bicolor, 7. Braun et K. Schum. in Mitth. deutsch. Schutzgeb. ii. (1889) 151. - Kamerun

elegans, Hort. ex Petersen, in Mart. F1. Bras. iii. III. (1390) $52=$ Malortieanus, Wendl.

Englerianus, K. Schum. in Bot. fahrb. xv. (1893 419; et in Monatsschr. Kakteenk. iii. (1893) 13. Kamerun.

Friedrichsenii, Petersen, in Bot. Tidskr. xviii. (1893) 260 t. 15. - Hab.

giganteus, Kuntze, Rev. Gen. (1891) 687 = Kuntzei, K. Schum.

giganteus, Welw. mss. ex Ridl. in fourn. Bot. xxv. (1887) 131. - Angola

Kingii, Baker, in Hook. f. Fl. Brit. Ind. vi. (1893) 250. - Perak.

Kuntzei, $K$. Schum. in Bot. Fahrb. xv. (1893) 422 in obs. ( = C. giganteus, Kuntze). - Costa-Rica, lanceolatus, Petersen, in Mart. Fl. Bras. iii. III (1890) 56. - - Bras.

laxus, Petersen, l. c. - Costarica.

Lucanusianus, f. Braun et K. Schum. in Ber. deutsch. Schutrgeb. ii. (1889) 151; et ex K. Schum. in Gartenfl. xli. (1892) 482. t. 1379. - Kamerun.

mexicanus, Liebm, ex Petersen, in Mart. Fl. Bras, iii. U1. (1890) 59 nomen; et in Bot. Tidskr. xviii. (1893) 261 t. 16. - Mexic.

mosaicus, Bull, Catal. (1887) 10. - Congo.

pauciflorus, $K$. Schum. in Bot. Fahrb. xv. (1893) 421. - Gabon.

phyllocephalus, $K$. Schum. l. c. 420.-Angola.

pistiifolius, $K$. Schum. l. c. 424. - Angola.

pubescens, S. Moore, in Trans. Linn. Soc. Ser. II

iv. (1895) 481 . - Bras.

pumilus, Petersen, in Mart. Fl. Bras. iii. III. (1890) 58. - Bras.

spectabilis, K. Schum. in Bot. Jahrb. xv. (1893) 422 = Kaempferia spectabilis, Fenzl.

Tappenbeckianus, 7. Braun et K. Schum. in Ber. deutsch. Schutzgeb. 1i. (1889) 152. - Kamerun.

trachyphyllus, K. Schum. in Bot. Fahrb. xv. (1893) 420. - Afr. trop. centr. bor.

unifolius, N. E. Br. in Gard. Chron. (1892) ii. 696 $=$ Englerianus, $K$. Sichum.

Warmingii, Petersen, in Mart. Fl. Bras. iii. III. (1890) 57. - Bras.

COTINUS, [Tourn.] Linn. = Rhus, Linn. (Anacard.).

cotinoides, Britton, in Mem. Torrey Bot. Club, v. (1894) 216. = R. Cotinoides, Nutt.

Cotinus, Sargent, in Gard. and For. iv. (1891) $340=\mathrm{R}$. Cotinus, Linn

COTONEASTER, Rupp. (Rosac.). - Ind. Kew. i. 625 .
angustifolia, Franch. Pl. Delav. (1890) 221. - Yun-

cordata, Focke, in Engl. et Prantl, Natürl. Pflanzenfam. iii. 3. (1888) $21=$ Crataegus cordata, Soland.

coriacea, Franch. Pl. Delav. (1890) 222. - Yunnan. glaucophylla, Franch. l, c. - Yunnan.

intermedia, Coste, in Bull. Soc. Bot. Fr. xl. (1893) p. cxxii. = tomentosa, Lindl.

moupinensis, Franch. in Nouv. Arch. Mus. Paris, Sér. III. viii. 1885 (1886) 224. - China.

mucronata, Franch. Pl. Delav. (1889) 223.- China.

pannosa, Franch.l. c. - Yunnan.

sikkimensis, Hort. ex Wien. Illustr. Gartenz. (1890) 248. - Reg. Himal.

salicifolia, Franch. in Now. Arch. Mus. Paris, Sér. III. viii. 1885 (1886) 225.- China.

COTTENDORFIA, Schult. f. (Bromel.). - Ind. Kew.i. 626.

guianensis, Klotzsch, ex Baker, Handb. Bromel. (1889) 129 ( = Anoplophyton guianense, Beer).

- Guiana

neogranatensis, Baker, l. c.- N. Gran.

Pearcei, Baker, l. c. 128. - Am. austr. trop.

Weddelliana, Brongn. ex Baker, l. c. 129. - Bolivia.

COTULA, [Tourn.] Linn. (Compos.). - Ind. Kew. i. 626 . 
COTULA :

Goyeni, Petrie, in Trans. N.Z. Inst. xviii. 1885 (1886) $295,-\mathrm{N}$. Zel.

Hombroni, Franch. Miss, scient. Cap Horn (1886) 345. - Fret. Magell.

scariosa, Franch. 1. c. $334=$ Leptinella scariosa Cass.

venosa, Colenso, in Trans. N.Z. Inst. xxiii. 1890 (1891) $388 .-\mathrm{N}$, Zel.

COTYLANTHERA, Blume (Gentian.). - Ind. Kew i. 626 .

tenella, Gilg, in Engl. et Prantl, Natürl. Pflanzenfam. iv. 2, (1895) 64 (= Eophylon tenellum, A. Gray). - lns. Pacif.

GOTYLEDON, Tourn. ex Linn. (Crassul.). Ind. Kew. i. 627

Aizoon, Schoenl. in Engl. et Prantl, Natürl. Pflanzenfam. III. 2a. (1890) 33 (=Umbilicus Aizoon, Ferizl). - As.min.

alsinoides, Engl, in Abh. Preuss. Akad. Wiss, 1891 (1892) 231 = Tillaea alsinoides, Hook $f$.

attenuata S. Wats. in Proc. Am. Acad. xxii. (1887) 472. - Calif.

Barbeyi, Schweinf. ex Penzig, in Att. Congr. Bot. Genov. (1893) 341; W. Wats. in Gard. Chron. (1893) i. 624. - Arabia, Erithrea.

lanceolata, Greene, Pittonia, i. (1889) $264=$ linearis, Greene.

linearis, Greene, Pittonia, i. (1889) 285. - Calif.

nubigena, T. S. Brandeg. in Proc. Calif. Acad. Ser. I1. iii (1891) 136. - Calif.

patens, Batt. in Batt. et Trab. Fl. de l'Algér.

[Dicot.] (1888) $329=\mathrm{C}$. Umbilicus, Linn.

pendulinus, Batt. 1. $\mathrm{c}_{2}=\mathrm{C}$. Umbilicus, Linn

Pringlei, S. Wats. in Proc. Am. Acad. xxv. (1890) 148. - Mexic.

rubens, T.S. Brandeg. in Proc. Calif. Acad. Ser. II. ii. (1889) 155 . - Calif.

sikokiana, Makino, in Tokyo Bot. Mag. v. (1891) 213 nomen. - Japon.

subrigidum, Robins; et Seaton, in Proc. Am. Acad. xxviii. (1893) 105. - Mexic.

COTYLELOBIOPSIS, Heim, Rech. Diptéroc, (1892) 125. DIPTEROCARPEAE.

Beccariana, Heim, l. c. (an Cotylelobium Beccarii, Pierre?). - Borneo.

GOTYLELOBIUM, Pierre, Fl. For. Cochinch. (1889) sub t. 235. DIPTEROCARPEAE.

Beccarianum, Heim, Rech. Diptéroc. (1892) 122 [an sp. seq. ?]. - Borneo.

Beccarii, Pierre, l.c. (1891) t. 258 b. (=Vatica Beccariana, Heim). - Borneo.

Burckii, Heim, Rech. Diptéroc. (1892) $122=$ flavum, Pierre.

flavum, Pierre, Fl. For. Cochinch. (1891) t. 258 a (=Vatica Burckii. Heim). - Cochinch.

Harmandii, Heim, Rech. Diptéroc. (1892) 122 ( = Vatica Harmandii, Heim). - - Borneo.

hopeifolium, Heim, in Bull. Soc. Linu. Paris, ii. (1891) $971=$ Hopea Heimiana, Brandis.

Melanoxylon, Pierre, Fl. For. Cochinch. (1889) sub. t. 235 (= Anisoptera? Melanoxylon, Hook.). Borneo.

philippinense, Heim, ex Brandis, in Journ. Linn. Soc. xxxi. (1895) $134=$ Shorea Mangachapoi, Blume.

scabriusculum, Brandis, in Fourn. Linn Soc, xxxi. (1895) 114; et in Engl. et Prantl, Natürl. Pflanzenfam. III. 6 (1895) $268(=$ Vatica scabriuscula, A. DC.). - As. trop.

COUBlandia, Aubl. = Muellera. Linn. $\mathrm{f}$. (Legumin.).

mexicana, Kuntze, Rev. Gen. (1891) $173=$ seq. mexicana, Taub. in Bot. Centralbl. xlvii. (1891) 389 = M. mexicana, Benth.

COUEPIA, Aubl. (Rosac.). - Ind. Kew. i. 628. amazonica, Fritsch, in Ann. naturh.Hofmus, Wien. v. (1890) 12. - Bras.

floccosa, Fritsch, l. c. - Guatem.

insignis, Fritsch, l. c. xi. - Bras.

Schottii, Fritsch, l.c. xiii. - Bras.
COULTERELLA, Vasey et Rose, in Contrib. U.S. Nat. Herb. i. (1890) 71; et ex O. Hoffm. in Engl. et Prantl, Natïrl. Pflanzenfam. iv. 5 . (1890) 390. COMPOSITAE

capitata, Vasey et Rose, $l l . c c$, t. 1. ; et 390. - Calif. Vaseyi, Rose, ex O.Hoffm. l.c. iv. 5. (1893) 390.-

COULTERINA, Kuntze, Rev. Gen. (1891) 931 = Physaria, A. Gray (Crucifo).

didymocarpa, Geyeri, Newberryi, oregana, Kuntze, 1.c. = homonyma omnia Physariae.

GOULTEROPHYTUM. Robins. in Proc. Am. Acad. xxiii. (1893) 168. UMBELLIFERAE.

laxum, Robins. l. c. 169. - Mexic.

Coumarouna. Aubl. = Dipteryx, Schreb. (Legumin.).

alata, Taub. in Bot. Centralbl. xlvii. (1891) $389=$ D. alata, Vogel.

coriacea, Taub. 1. c. $=$ D. nudipes, $T$.

crassifolia, Taub. 1. c. = D. crassifolia, Benth

oleifera, Taub. 1. C。 = D. oleifera, Benth. et Hook. f.

oppositifolia Taub. 1. c. = D. oppositifolia, Willd.

reticulata, Taub. 1. $c_{0}=$ D. reticulata, Benth.

rosea, Taub. 1. c. = D. rosea, Spruce.

tetraphylla, Taub. I. c. = D. tetraphylla, spruce.

GOURSETIA, DC. (Legumin.). - Ind. Kew。 i. 629

axillaris, Coult. et Rose, ex Coult. in Contrib. U.S. Nat. Herb. ii. (1891) 81. - Texas.

mexicana, S. Wats, in Proc. Am. Acad. xxi. (1886) $424=$ Willardia mexicana, Rose

GoURtoisia, Nees (Cyper.). - Ind. Kew. i. 629

assimilis, C. B. Clarke, in Th. Dur. et Schinz. Consp. Fl. Afr.v. 1894 (1895) 596 (= Cyperus assimilis, Steud.). - Abyss.

COUSINIA, Cass. (Compos.). - Ind. Kew. i, 629. afghanica, C. Winkl. in Act. Hort. Petrop. xii. (1892) 273. - Afghan.

Aitchisoni, Boiss. Fl. Or. Suppl. (1888) 308. Afghan., Persia.

Aitchisoni, C. Winkl. in Act. Hort. Petrop. xii, (1892) 275. - Afghan.

Albertoregelia, C. Winkl. l. co.x. (1887) 91. Turkest.

alpicola, Borszczow, ex C. Wink1. 1. c. xii. (1892) 282 = alpina, Bunge.

amara, C. Wink kl. l. C. x. (1887) 88. - Turkest. amoena, C. Winkl.l.c. xiii. (1894) 237. - Turkest.

Antonowi, C. Winkl. l. c. xi. (1889) 135 t. 2 fig. 2. Turkest.

arbelensis, C. Winkl. et Bornm. in Bull. Herb. Boiss. iii. (1895) 566 et 567, t. 14. - Kurdist.

arida, C. Winkl. in Act. Hort. Petrop. xv. (1892) 190. - Persia

aurea, C. Winkl. l. c. x. (1887) 475. - Turkest

Barbeyi, C. Winkl. l. c. xii. (1892) 274. - Persia. Batalini, C. Winkl. l. c. 248. - Buchara.

Beckeri, Trautv, l.c. ix. (1886) 45\%.- Turkest.

bicolor. Freyn et Sint, in Oest. Bot. Zeitschr. xlii. (1892) 204. - Armenia

bucharica, C. Winkl. in Act. Hort. Petrop. x. (1887) 473 et 477. - Buchara

caespitosa, C. Winkl. l. c. x. (1887) 93. - Turkest. carduchorum, C. Winkl. et Bornm. in Bull. Herb.

Boiss. iii (1895) 566 et 568 t. 15. - Kurdist.

corymbosa, C. Winkl, in Act. Hort. Petrop, x. (1887) 89. - Turkest.

cynaroides, C. Winkl. ex Aitch. et Hemsl. in Trans. Linn. Soc. Ser. II. iii. (1886) $79=$ afghanica, C. Winkl.

darwasica, C. Winkl. in Act. Hort. Petrop. xii. (1892) 249. - Buchara.

Dayi, Post, Pl. Postianae, ii. (1891) 13. - Syria.

decolorans, Freyn et Sint. in Oest. Bot. Zeitschr. xlii. (1892) 206. - Armenia.

deserti, Aitch. et Hemsl. in Trans. Linn. Soc. Ser. II. iii. (1886) $77=$ arida, C. Winkl.

dichacantha, Lipsky, Exc. bot, au delà Mer Casp. (1889) 12, - Rossia.

divaricata, C. Winkl. in Act. Hort. Petrop. xi. (1890) 334. - Turkest.
GOUSINIA

fallax, C. Winkl. in Act. Hort. Petrop. x. (1887) 471. - As. centr.

Fetissowi, C. Winkl. l. c. xii.(1892) 247. - Turkest.

Francheti, C. Winkl. l. c. x. (1887) 578 in obs (=C. canescens, Franch.). - China.

Gilesi, C. Winkl. l. c. xii. (1892) 251. - As. centr. Gmelini, C. Winkl. l. c. 241. - Persia.

hastifolia, C. Winkl. l.c.x. (1887) 571. - As. centr.

Haussknechti, C. Winkl. l. c. xii. (1892) 238. Persia.

Hemsleyana, C. Winkl. l. c. 228. - Afghan.

hissarica, C. Winkl. l. c. x. (1887) 93. - Buchara.

interrupta, C. Winkl. l. c. xii. (1892) 229. Turkest

intertexta, Freyn et Sint. in Oest. Bot. Zeitschr. xlii. (1892) 169. - Armenia.

jassyensis, C. Winkl. in Act. Hort. Petrop. x. (1887) 472. - Turkest.

Komarowii, C. Winkl.l.c. 470 in obs, - As. centr. kurdica C. Winkl. et Bornm. in Bull. Herb̆. Boiss. iii. (1895) 564 et 567. t. 13, - Kurdist.

laetevirens, C. Winkl. in Act. Hort. Petrop. x. (1887) 576. - Turkest.

lanata, C. Winkl. l. c. xiii. (1894) 238. - Turkest. lancifolia, C. Winkl.l.c.x. (1887) 572.-As. centr. Layardi, Ball et Barbey, [Note sur le] Cousinia Layardi (1890) 2 cum ic.; C. Winkl. in Act. Hort. Petrop. xii. (1892) 196.-Kurdist.

lyratitolia, C. Winkl. l. c. x. (1887) 90. - Turkest.

Massalskyi, C. Winkl. l. c. xi. (1889) 131 in obs.Armenia.

Newesskyana, C. Winkl. in Act. Hort. Petrop.xi. (1890) 333. - Turkest

nivea, C. Winkl. l. c. xii. (1892) 261 - As. centr. Onopordon, Freyn et Sint. in Oest. Bot. Zeitschr. xlii. (1892) 207. - Armenia.

orientalis, O. Hoffm. in Engl. et Prantl, Natürl. Pflanzenfam.iv. 5 (1890) $319=$ Auchera orientalis, $D C$.

pannosa, C. Winkl. in Act. Hort. Petrop. x. (1887) 578. - Turkest

perennis, C. Winkl.l.c.xi. (1892) 192. - Afghan. persarum, C. Winkl. l.c. xli. (1892) 22\%. - Persia

poliothrix, C. Winkl. l.c.x. (1887) 577. - Turkest.

Postiana, C. Winkl. l. c. xii. (1892) 223. - Syria. pseudomollis, C. Winkl. l. c. x. (1887) 470 . -

As. centr

pulchra, C. Winkl. l. c. 478. - Buchara.

pusilla, C. Winkl.l. c. 468. - Buchara.

pygmaea, C. Winkl.l. c. 467. - Buchara.

Raddeana, C. Winkl.l. c. 473 in obs.; et xi. (1889) 132 t. 1. - Turkest.

rotundifolia, C. Winkl. l. c. x. (1887) 579. Turkest.

sarawschanica, C. Winkl. l. c. ix. (1886) 424. As. centr.

Schlagintweiti, C. Winkl. l. c. xii. (1892) 262.Ind. or.

Schmalhauseni, C. Winkl. l. c.x. (1887) 474. As. centr.

semidecurrens, C. Winkl. l. c. x. (1837) 574.Turkest.

simulatrix, C.Winkl.l. c.x. (1887) 573. - Turcom.

Sintenisii, Freyn, in Oest. Bot. Zeitschr. xlii. (1892) 205. - Armenia.

speciosa, C. Winkl. in Act. Hort. Petrop. x. (1887) 579. - As. centr.

splendida, C. Winkl. l. c. xiii. (1894) 240. Turkest.

Stapfiana, Freyn et Sint. ex Freyn, in Oest. Bot. Zeitschr. xliv. (1894) 218. - As. Min.

stephanophora, C. Winkl. in Act. Hort. Petrop. x. (1887) 575 . - Buchara.

Stocksi, C. Winkl. l. c. xii. (1892) 216. - Belutchist.

tomentella, C. Winkl. l.c.x. (1887) 469. - Turkest. turcomanica, C. Winkl. l. c. xi. (1889) 133 tab. \& fig. 1. - Turkest.

Wesheni, Post, Pl. Postianae, ii. (1S91) 13. - Syria. Winkleriana, Aitch. et Hemsl. in Trans. Limn. Soc. Ser. II. iii. (1886) 79. - Afghan.

GoussapoA, Aubl. (Urtic.).- Ind. Kew, i. 630. Leopoldi, Hort. ex Rev. Hortic. (1894) 251.-Bras. 
CoussareA, Aub1. (Rubiac.). - Ind. Kew. i. 630.

frondosa, S, Moore, in Trans. Linn. Soc. Ser. II. iv. (1895) 374. - Bras.

CoUTAREA, Aubl.(Rubiac.).- Ind. Kew. i. 631. hexandra $F$. Schum. in Mart. F1. Bras. vi. vi.
(1889) 1 ; et in Bot. Jahrb. x. (1889) $315=$ speciosa, Aubl.

octomera, Hemsl. Biol. Centr.-Amer. iv. (1886) 101. - Ins. Cozumel.

CoUThoviA, A. Gray (Logan.). - Ind. Kew. 1. 631

densiflora, K. Schum. in Bot. Jahrb. ix. (1888) 215. - N. Guin.

(gOUtoubea, Aubl. (Gentian.). - Ind. Kew. i. 631.

scandens, Knobl. in Bot. Centralbl. 1x. (1894) $356 .=$ volubilis, Mart

COVILLEA, M. Vail, in Bull. Torrey Bot. Club,

xxii. (1895) $229=$ Larrea, Cav. (Ficoid.).
divaricata, Coville, 1. c. = L. divaricata, Cav.

GRABBEA, Harv, (Acanth.), - Ind. Kew, i. 631 undulatifolia, Engl. Bot. Fahrb. x. (1889) 263.Afr, austr.

velutina, S. Moore, in fourn. Bot. xxxii. (1894) 135. - Afr. trop. or.

CRACCA, Benth. (Legumin.).- Ind. Kew.i.631 bicolor, M. Micheli, in Bull. Herb. Boiss, ii. (1894) 444. $\mathrm{t}$. 11. - Guatem.

micrantha, M. Micheli, ex Th. Dur. et Pitt. in Bull. Soc. Bot. Belg. xxx. 1891 (1892) 286.-Costarica.

CRACCA, Linn. = Tephrosia, Pers. (Legumin.). acaciaefolia, adunca, aemula, aequilata, ambigua, amoena, andongensis, angustissima, Ansellii, arabica, astragalina, barbigera, Bidwilli, brachycarpa, brachystachya, bracteolata, brevipes, brunnea, calophylla, canescens, capensis, capillipes, chrysophylla, cephalantha, concinna, coriacea, crassifolia, crocea. dasyphylla, decumbens, densiflora, dichotoma, dichrocarpa, diffusa, dimorphophylla, discolor, disperma, dolichocarpa, Dregeana, elegans, elongata, eriocarpa, falcata, fasciculata, filiformis, filipes, flammea, flexuosa, Forrestiana, frutescens, fruticosa, fulvinergis, glomerwliflora, gracilipes, graminifolia, grandiflora, heterantha, hispidula, huillensis, humilis, juncea, Kirkii, Kraussiana, laevigata, lamprolobiodes, lanata, leiniarpa, leptoclada, leucantha, Lindheimeri, linearis, longipes, lupinifolia, lurida macrocarpa, macropoda, madrensis, mariana, melanocalyx, myrtifolia, nana, nematophylla, nicaraguensis, nitens, noctiflora, mubica, obcordata, oblongata, oblongifolia, oligophylla, pallens, paniculata, pedicellata. Perriniana, phaecosperma, platycar pa, fogonostigma, polysperma, polystachya, polyzyga, porrecta, pulchella, pusilla, radicans, remotiflora, reptans, reticulata, rigidula, rosea, secunda, semiglabra, Senna, senticosa, sericea, simplicifolia, sphaeroperma, spicata, spinosa, stipularis, Stuartii, subtriflora, temuis, totta, toxicaria, uniovulata, velutina, venosa. vestita, virginiana, Vogelii, Kuntze, Rev. Gen. (1891) 174-175 = homonyma omnia Tephrosiae.

antliyllodes, Kuntze, Rev. Gen.(1891) $174=\mathrm{T}$ anthylloides, Hochst.

astragalodes, Kuntze, I. c. = T. astragaloides, Benth.

candida, Kuntze, 1. c. $173=$ T. singuliflora. F Muell.

cimerea, Morong, in Ann. N. Y. Acad, Sci, vii. (1892) $79=$ T. cinerea, Pers

conferta, Kuntze, Rev. Gen. (1891) $174=\mathrm{T} \cdot \sin$ guliflora, F. Muell,

emerodes, Kuntze, 1. $c_{0}=\Upsilon$. emeroides, A. Rich foridana, M. Vail, in Bull. Torrey Bot. Club, xxii. (1895) 35. - Florida.

intermedia, Small, 1. c. xxi. (1894) 303. - Florida. lathyrodes, Kuntze, Rev. Gen. $(\mathbf{1 8 9 1}) 175=$ T. lathyroides, Guill. et Perr.

leptostachya, Rusby, in Mem. Torrey Bot. Club, iii.

3. (1893) $18=$ 'T. leptostachya, $D C$.

\section{CRACCA : -}

onobrychodes, Kuntze, Rev. Gen. (1891) $175=$ T. onnbrychoides, Nutt.

orobodes, Kuntze, 1. c. $=$ T. oroboides, $H$. B. et $K$ oxygera, Kuntze, 1. c. = T. oxygona, Walp.

Richardiana, Kuntze, 1, c. = T. vicioides, A. Rich. rigida, Kuntze. 1. c. = T. rigida, Baker

Schottii, M. Vail, in Bull. Torrey Bot. Club, xxii. (1895) 25 in obs. - Columb.

Smallii, M. Vail 1, c. 33. - Am. bor or.

sophorodes, Kuntze, Rev. Gen. (1891) 175. = T sophoroides, $D C$.

viciodes, Kuntze, 1. c. = T. vicioides, Schlecht.

CRAMBE, Tourn, ex Linn. (Crucif.). - Ind. Kew.

\section{i. 632}

arborea, Webb, ex Christ, in Bot. Fahrb. ix. (1888) 94. - Ins. Canar

gomeraea, Webb ex Christ, l.c. - Ins, Canar

laevigata, DC. ex Christ, l, c. - Ins. Canar.

Viraeana, Webb, ex Christ, in Bot. Jahrb. ix (1888) $93=$ Pritzelii, C. Bolle.

GRANICHIS, Sw. (Orchid.). - Ind. Kew. i. 632 , candida, Cogn. in Mart. F1. Bras. iii. vI. (1895) $248=$ similis, Reichb. $f$.

multiflora, $\operatorname{Cog} n .1, \mathrm{c}$, = foliosa, Lindl.

GRANIOTOME, Reichb. (Labiat.). - Ind, Kew i. 633

furcata, Kuntze, Rev. Gen. (1891) 516 = versicolor Reichb.

CRANOCARPUS, Benth. (Legumin.). - Ind

Kew. i. 633.
Mezii, Taub. in Flora, 1xxii. (1889) 128 et $426 .-$ Bras.

CRANTZIA, Schreb. = Toddalia, Juss. (Rutac.). asiatica, bilocularis, densiflora, lanceolata, macrophylla, micracantha, natalensis, nobilis, paniculata, pilosa, Willdenowii, Kuntze, Rev. Gen. (1891) $99=$ homonyma omnia Toddaliae.

nitida, Kuntze, 1. c. = T. aculeata, Pers,

schmideliodes, Kuntze, 1. c. $=$ T. schmidelioides, Baker.

CRANTZIA, Scop. = Alloplectus, Mart. (Gesnerac.).

capitata, circinnata, coccinea, congesta, coriacea, corymbosa, costaricensis, dichrus, ichthyoderma. I indenit, multiflora, parviftora, Patrisii, pendula, semicordata speciosa, Sprucei, strigosa, tetragona, tigrina, vil losa, Wrinii, Fritsch, in Engl. et Prant1, Natürl. Ptlanzenfam. IV. $3 \mathrm{~b} .(1894) 168=$ homonyma omnia Alloplecti.

CRASSINA, Scepin. = Zinnia, Linn. (Compos.). acerosa, angustifolia, anomala, bicolor, elegans, grandiflora, juniperifolia, linearis. maritima, pumila, verticillata. Kuntze, Rev. Gen. (1891) 331 = homo nyma omnia Zinniae.

intermedia, Kuntze, 1. $c_{0}=Z$. pauciflora, Linn.

leptopoda, Kuntze, 1. c. = Z. pauciflora, Linn. multiflora, Kuntze, 1.c. = Z. pauciflora, Linn. peruviana, Kuntze, 1. c。 = Z. pauciflora, Linn. temuiflora, Kuntze, 1. c. = Z. pauciflora, Linn.

CRASSOCEPHALUM, Moench = Gynura, Cass. (Compos.)

aurantiacum, Kuntze, Rev. Gen. (1891) $331=$ G. aurantiaca, DC.

Cusimbua, Kuntze, 1. c. $=\mathrm{G}$. angulosa, $D C$. densifolium, Kuntze, 1. c. $=\mathrm{G}$. dencifolia, Miq. Pseudochina, Kuntze, 1. c. = G. Pseudo-China, DC pubigerum, Kuntze, 1. c. $332=\mathrm{G}$. sarmentosa, $D C$. Teysmannianum, Kuntze, 1. c. 331.- Java.

CRASSULA, Dill. ex Linn.(Crassu1.).- Ind. Kew i. 633

acinaciformis, Schinz, in Bull. Herb. Boiss, ii. (1894) 204. - Transv.

alsinoides, Eng1. in Abhand1. Preus. Akad. Wiss. 1891, ii.(1892) 231 = Tillaea alsinoides, Hook.f. andicola, Fr. Meigen, in Bot. Jahrb. xvii. (1893) $239=\mathrm{T}$. andicola, Phil.

aquatica, Schoenl. in Engl, et Prant1, Natürl.

\section{CRASSULA}

Pflanzenfam. iii. 2. (1891) $37=$ T. aquatica Linn.

Coleae, Baker, in Kew Bull. (1895) 214. - Reg Somal.

cordifolia, Baker, in fourn. Linn. Soc. xxv. (1890) 315. - Madag.

curta, N.E.Br. in Kew Bull. (1895) 144. - Natal. fragilis, Baker, in fourn. Linn. Soc. xxii. (1887) 469. - Madag.

heterotricha, Schinz, in Bull. Herb. Boiss. ii. (1894) 203. - Natal

Holstii, Pax, ex Engl. in Abhandl. Preuss. Akad. Wiss. (1894) 59 nomen. - Afr. trop.

Macowani, S. Elliot, in Fourn, Bot, xxix. (1891) 69. - Afr, austr.

peduncularis, Fr. Meigen, in Bot. Jahrb. xvii. (1893) 239; et xviii. (1894) $417=$ Tillaea peduncularis, Smith.

pentandra, Schoenl. in Engl, et Prant1, Natürl. Pflanzenfam. iii. 2. (1891) $37=T$. pentandra Royle.

pharnaceoides, Schoenl. 1. c. $(=C$. pharnaceoides, C. A. Mey.) = T. pharnaceoides, Hochst.

recurva, N. E. Br. in Gard. Chron. (1890) ii.

684. - Afr. austr.

rhomboidea, N.E. Br, 1, c, (1886) ii. 712, Afr, austr.

Schmidtii, Regel, in Act. Hort. Petrop. ix. (1886) 602; et in Gartenfl. xxxv. (1886) 345 t. 1225 $=$ C. impressa. N. E. Br., non Dietr.). Afr, austr.

Solieri, Fr. Meigen, in Bot. Jahrb. xvii. (1893) $239=$ Tillaea Solieri, Gay.

Schweinfurthii, Hort. Dammann, ex Gartenfl. xli (1892) 525. - Abyss.

umbraticola, N.E. Br. in Kew Bull. (1895) 145.Natal.

Volkensii, Engl.Pflanzenw. Ost-Afr. C (1895) 189 - Afr. trop. or

GRATAEGUS, Tourn. ex Linn. (Rosac.). - Ind. Kew. i. 635

Carrierei, Hort. Vauvel, ex Kew Bull. (1892) Append. i. 24; Koehne, Deutsche Dendrol. 1893) 234. - Hybr. artif

dahurica, Hort. ex Koehne, Deutsche Dendrol 1893) $240=$ pinnatifida. Bunge.

Dippeliana, Lange, in Bot. Tidsskr. xix. (1895) 261 - Hab.?

Douglasi, Macoun, Cat. Canad. Pl. i. (1886) 523 $=$ coccinea, $\operatorname{Linn}$

Downingii, Hort. ex Kew Bull. (1892) Append. i 24. - Form. hort

flicifolia, Hort. ex Kochne, Deutsche Dendrol. (1893) $238=$ monogyna, facq.

flexispina, Sarg. in Gard, and For. ii. (1889) $424=$ flava, Ait

florida, Hort, ex Koehne, Deutsche Dendrol (1893) 231 = parvifolia, Soland

germanica, Kuntze, Rev. Gen. (1891) $215=$ Pyrus germanica, Hook. $f$.

grignoniensis, Mouillef, ex Wien. Illustr. Gartenzeit. (1890) 248. - Form, hort.

intermixta, G. Beck, Fl. Nied. Oest. ii. I. (1892) 706. - Austria

intricata, Lange, in Bot. Tidssk.xi. (1895) 264.Am. bor.

Lavallei, Hort. Paris, ex Sarg. N. Amer. Sylva. vi (1892) 91 in syn, = C. Crus-galli, Linn.

oxyacanthoidea, St-Lager, in Cariot, Etud. des $\mathrm{fl}$ éd. 8. ii. (1889) $291=$ C. Oxyacantha, Linn.

paucifoliata, Pau, Not. bot. fl. Espan. i. (1887) 22 = C. Oxyacantha, Linn.

Philippii, Hort. ex Koehne, Deutsche Dendrol. (1893) $240 .=$ pinnatifida, Bunge.

Wattiana, Hemsl. et Lace, in fourn. Linn. Soc xxvii. (1891) 323 t. 40. - Belutsch,

CRATAEVA, Linn. (Capparid.). - Ind. Kew. i.

mucronata, Kuntze, Rev. Gen. (189l) $38=$ Niebuhria mucronata, Kuntze.

CRATERICARPIUM, Spach = 0enothera, Linn. (Onagrar.)

subulatum, Raimann, in Engl. et Prantl, Natürl. 
CRATERICARPIUM :

Pflanzenfam, iii. 7. (1893) 212, sphalm. $=\mathrm{Oe}$ subulata, Ruiz et Pav.

CRATERISPERMUM, Benth. (Rubiac.). - Ind Kew. i $63 \%$.

orientale, K. Schum. in Engl. Pflanzenw. Ost-Afr. C (1895) 387. - Afr. trop. or.

CRATEROSIPHON, Engl. et Gilg, in Bot. Jahrb. xix. (1894) 275; et in Engl. et Prantl, Natürl. Pflanzenfam. iii. 6. (1894) 233. THYMELAEA $C E A E$.

scandens, Engl. et Gilg. Il. cc. - Kamerun.

CRATEROSTEMMA, K. Schum, in Bot, Jahrb. xvii. (1893) 154; et in Engl. et Prantl, Natürl Pflanzenfam. iv.2. (1895) 266. ASCLEPIADEAE. Schinzii, $K$. Schum. ll. cc. - Afr. austro-occ. extratrop.

CRATEROSTIGMA, Hochst. (Scrophul.). Ind. Kew. i. 637.

nanum, Engl. Pflanzenw. Ost-Afr. C (1895) 357 $=$ Torenia nana, Benth.

GRA WFURDIA. Wall. (Gentian.), - Ind. Kew.

i. 6.37.
luzoniensis, Vidal, Rev.Pl. Vasc. Filip.(1886) 191.Ins. Philipp.

volubilis, Gilg, in Engl. et Prantl, Natürl. Pfanzenfam. iv, 2. (1895) 79 ( = Pterygocalyx volubilis, Maxim.). - As. centr. bor.

GREMANTHODIUM, Benth. (Compos.). - Ind. Kew.i. 638.

Potanini, C. Winkl. in Act. Hort. Petrop. xiv. (1895) 150. - China.

CREMASPORA, Benth. (Rubiac.), - Ind, Kew. i 6.38 .

confluens, K. Schum. in Engl. Pflanzenw. Ost-Afr. C (1895) 383. - Afr. trop. or.

heterophylla, $K$. Schum. l. c. - Afr. trop. or.

triflora, $\mathrm{K}$. Schum, in Engl, et Prantl, Natürl Pflanzenfam. iv, 4. (1891) 88 = africana, Benth.

CREMASTUS, Miers = Bignonia, Linn.

pulchra, Bureau, ex K. Schum. in Engl. et Prantl, Natürl. Pflanzenfam. iv. 3 b. (1894) 222. - Bras.

CREMOCARPUS, K. Schum, in Engl, et Prantl. Natür1. Pflanzenfam. iv. 4. (1891) $133=$ Cremocarpon, Boiss. (Rubiac.).

Boivinianus, K. Schum. 1. c. = Cremocarpon Boivinianum, Bull.

CREMOLOBUS, DC. (Crucif.). - Ind. Kew. i. 638 .

bolivianus, Britton, in Bull. Torrey Bot. Club, xvi. (1889) 17. - Bolivia.

CREPIDOCARPUS, Klotzsch = Scirpus, Linn.

(Cyper.).
Schinzii, Klotzsch, ex Boeck. in Verh. Bot. Ver. Brand. xxix. (1888, 46=S.cubensis.Poepp. et Kth,

CREPINELLA, Marchal (ex Oliver) in Trans, Linn. Soc., Ser. II. ii. (1887) 275 (Oliver, ex im Thurn, in Timehri, v. (1886) 194). ARALIACE\&E.

gracilis, Marchal, $l l . c c .275$ et 195. - Guian. angl.

CREPINODENDRON, Pierre, Not. bot. Sapot. $(\mathbf{1} 890,28$. SAPOT ACE AE

crotonoides, Pierre 1. c. (1890) $28=$ Chrysophyllum crotonoides, Klotzsch CREPIS, [Vaill.] Linn. (Compos.). - Ind. Kew. i,
-

Aitchisoni, Boiss. Fl. Or. Suppl. (1888) 324. Afghan.

Bakeri, Greene, in Erythea, iii. (1895) 73.-Calif.

balcanica, Velen. zolastni otisk Vestnik (1890); et Fl. Bulg. (1891) 334. - Bulg.

Baldaccii, Halàcsy, in Verh. zool. bot. Ges. Wien, xlii. 1892 (1893) 57\%. - Albania.

\section{CREPIS}

blattarifolia, St-Lager, in Cariot, Étud, des fl, éd. 8 ii. (1889) $502=$ blattarioides, Vill.

bupleurifolia, Freyn et Sint. in Oest. Bot. Zeitschr. xlii. (1892) $268=$ Sonchus bupleurifolius, Boiss. et Kotschy.

chloroclada, Collett et Hemsl. in Fourn. Linn. Soc. xxviii. (1890) 78. - Burma.

Claryi, Batt. in Batt. et Trab. Fl. de l'Algér. (Dicot.) 1888) 563. - Algeria

confusa, Wolosz. in Spraw. Kom. fizyj. Krakow. xxi. (1888) ii. 126 = grandiflora, Tausch.

cylindrica, St-Lager, in Cariot, Etud. des fl. éd. 8 ii. (1889) 500 .

dinarica, G. Beck, in Annal, naturh. Hofmus, Wien, ii. (1887) 169 t. 3 fig. $2=$ incarnata, Tausch.

Geisseana, Phil. in Anal. Univ. Chil. 1xxxvii. (1894) 328. - Chili.

geracioides, Hausskn. ex Nym. Consp. Fl. Eur. Suppl. II. i. (1889) 201; et in Mitth. Thür. Bot. Ver. N. Fislge, vii. (1895) 52, - Graecia.

heterophylla, Hemsl. in fourn. Linn. Soc. xxiii. (1888) 475. - China.

heterophylla, Klatt, in Annal. naturh. Hofmus. Wien, ix. (1894) 368. - Mexic

hispanica, Pau, Not.bot. fl. Espan, i. (1887) 11 et ii. (I889) 30. - Hisp.

hyemalis, Ces. Passer, et Gibelli, Comp. Fl. Ital. ii (1886) 452 (= Barkhausia hyemalis, Biv. $)=\mathrm{C}$ taraxacifolia, Thuill.

kilimandscharica, $O$. Hoffm. in Engl. Pflanzenw Ost-Afr. C (1895) 402, - Afr. trop. or

longipes. Hemsl. in fourn. Linn. Soc. xxiii. (1888) 476. - China.

modocensis, Greene, in Erythea, iii. (1895) 48. Calit.

moesiaca, Degen et Baldacci, in Oest. Bot. Zeitschr. xliv. (1894) 302. - Monten., Herceg.

mucronata. Ces. Passer. et Gibelli, Comp. Fl. Ital ii. (1886) $252(=$ Barkhausia mucronata, Bertol. $)$ $=$ C. alpestris, Reichb.

Murmanni, Boiss. Fl. Or. Suppl. (1888) 325 = lampsanoides, Froel.

nigra, Velen, in Act. Soc. Sci. Bohem. (1887) 23, ex Nym Consp. Fl. Eur. Suppl. ii. (1889) $201=$ viscidula, Froel

oenipontana X. J. Murr, in Oest. Bot. Zeitschr, xlii (1893) 178 ; et in Deutsche Bot. Monatsschr.xil (1894) 19. - Tirol.

oligophylla, Klatt. ex Schinz, in Bull. Herb. Boiss. iii. (1895) 426. - Angola.

orbelica, Velen, Zolastni otisk Vestnika (1890); et Fl. Bulg. (1891) 334. - Bulg.

prenanthoides, Hemsl. in fourn. Linn. Soc, xxiii. (1888) 477. - China.

scorzoneroides, Rouy, in Bull. Soc. Bot. Fr xxxy. (1888) 120. - Hisp.

sorocephala, Hemsl. in fourn. Linn. Soc. xxx. (1894) 116 t. 4 fig. 1-4. - Tibet

Stocksiana, Aitch. et Hemsl. in Trans. Linn. Soc. Ser. II, iii. (1886) 82 - Afghania.

suberostris, Batt, in Batt. et Trab. Fl de l"Aloér. (1889) 561 (= Barkhausia suberostris, Coss. et Durieu). - Algeria.

subscaposa, Collett et Hemsl. in fourn. Linn. Soc. xxviii. (1890) 78. - Burma.

trichocarpa, Franch. in Morot, fourn. de Bot. ix. (1895) 25\%. - China.

turicensis $X$, Bruegg. ex Nym. Consp. F1. Eur. Suppl. (1886) 202. - Helv.

Umbrella, Franch. in Morot, fourn. de Bot.ix. (1895) 255. - Yunnan.

valentina, Willk. Suppl. Fl. Hisp. (1893) $116=$ pulchra, Linn.

CRESSA, Linn. [Convolvul.]. - Ind. Kew. i. 642. aphylla, Heller, in Contrib. Herb. Frankl. and Marsh. Coll. i. (1895) 80 t. 5. - Texas.

Ballii, Batt. in Batt. et Trab. Fl. de l'Algér. (Dicot.) (1888) 629. - Algeria.

CRINODENDRON. Molina = Tricuspidaria, Ruiz et Pav. (Tiliac.)

dependens, Kuntze, Rev. Gen. (1891) $82=$ T. dependens, Ruiz et Pav.
GRINUM, Linn. (Amaryll.). - Ind. Kew. i. 642. angolense, Benth. ex Baker, Handb. Amaryll. (1888) 80. - Angola.

angustifolium, Tate, in Trans. et Proc. Roy. Soc S. Austral. xii. (1889) 117 nomen $=$ flaccidum, Herb.

argentinum, Pax, in Bot. Fahrb. xi. (1890) 325. Reg. Argent.

Bakeri, K. Schum. in Bot. Fahrb. ix. (1888) 194. As. or. insul.

Colensoi, Hort. ex Baker, Handb. Amaryll. (1888) 93. = C. Moorei, Hook. f.

crassicaule, Baker, l. $c .85$. - Afr. trop. austro-or. crassipes, Baker, in Gard. Chron. (1837) ii. 126 ; et l. c. $90 .-\mathrm{Hab}$.

Douglasii, F. M. Bailey, in Dept. Agric. Bot. Bull. x. (1895) 27. - Austral.

jemenicum, Hort. ex Dammann, in Gartenfl. (1892) 26 fig. $12 .=$ latifolium, $\operatorname{Linn}$.

jemense "Hort. Damman " ex Gard. Chron. (1893) i. $658=$ praec.

Kunthianum, Hort. Dammann, ex Wien. Illustr. Gartenz. (1890) $358 \mathrm{fig} .76$; et in Kew Bull. (1891) App. ii, 46. - Hab.?

Lastii, Baker, Handb. Amaryll. (1888) 79. - Afr. trop. or.

longitubum, Pax, in Bot. Fahrb.xv. (1893) 141.Angola.

Mackenii, Hort. ex Baker. Handb. Amaryll, (1888) $93=$ C. Moorei Hook. $f$.

macrantherum, Engl. Bot. Fahrb. vii. (1886) 448 - Melanesia.

Makoyanum, Hort. ex Rev. hort. Belg., xiii. (1887) 241 cum xylogr. = C. Moorei, Hook. $f$.

Massaianum, N. E. Br. in Kew Bull. ii. (1888) 100. - Zanzib.

modestum, Baker, in fourn. Linn. Soc. xxii. (1887, 528. - Madag.

natalense, Hort. ex Baker, Handb. Amaryll. (1888) 93. = C. Moorei, Hook. $f$.

pauciflorum, Miq. ex Hook. f. Fl. Brit. Ind. vi. (1892) 285 in syn. = Pancratium triflorum, Roxb. pedicellatum, Pax, in Bot. Fahrb. xv. (1893) 142. Afr, trop, or.

pedunculatum, Tate, in Trans, et Proc, Roy. Soc. S. Austral xii. (1889) 117 nomen $=$ flaccidum Herb.

Poggei, Pax, in Bot. Fahrb. xv. (1893) 141. - Afr.

trop.
Powelliz $\times$, Hort. ex Baker, Handb. Amaryll. (1888) 95. - Hybr, artef.

Rautanenianum, Schinz, in Th. Dur. et Schinz, Consp. Fl. Afr. v. 1893 (1895) 250. - Afr. austroocc. extratrop.

Roozenianum, O'Brien, in Gard. Chron.(1891) i 701. - Jamaica

Schimperi, Vatke, ex K. Schum. in Gartenfl. xxxviii. 1889) 561 t. 1309; et ex Bot. Mag. (1895) t.7417.Abyss.

Thruppii, Baker, ex Oliver, in F. L. Fames, Unkn. Horn of Afr., Append. (1888) 322; et Handb. A maryll. (1888) 79. - Reg. Somal.

Wattii, Baker, l. c. 76 . - Ind, or

yemense, Hort. Dammann, in Gard. Chron. (1893) i $658 i=C$, jemenicum, Hort. Damman $)=$ latifolium, Linn.

GRISTARIA, Cav, (Malv.) - Ind. Kew. i. 643 cyanea, Phit. ex Baker $f$ in Fourn. Bot. xxx. (1892) 76. - Chili.

divaricata, Phil. l. . . 77. - Chili.

flexuosa, Phil. in Anal.Mus, nac. Chilie. (1891) 10.Am. austr. occ.

grandidentata, Phil. ex Baker f. in fourn. Bot. xxx. (1892) 77. - Chili

microptera, Phil. ex Baker f. l, c. xxxii. (1894) 37. - Chili.

ranunculifolia, Phi.ex Baker f. l. c. xxx. (1S92) 78 - Chili.

saniculaefolia, Phil. l. c. 77. - Chili

CROCODILODES, Adans. = Berkheya, Ehrh. (Compos,).

annectens, coriaceum, corymbosum, cruciatum, itthatum. Dregei, Ecklonis, eryngiffolium, palmatum. anitim. pungens, purpurcum, seminivenm, setiferan, Spcisit- 


\section{CROCODILODES :}

num. subulatum, umbellatum, Kuntze, Rev, Gen. (1891) $332-3$ = homonyma omnia Berkheyae.

acanthopodum, aristosum, bilobum, bipinnatifidum, cardopatifolium, carlinifolium, cirsiifolutm, discolor, chinaceum, echinopodum, epitrachys, Eviobasis, erysithales, Gerrardii, glabratum, glabriusculum, grandifolium, Stlianthiflorum, heterophyllum, M'Kenii, membran i, olium, microcephalum, multijugum, onopordifolium, petiolatum, pinnatifidum, platypterum, polyacanthum, Radula, rhaponticum, vigidum, sonchifolium, speciosum, sphaerocephalum, viscosum, Ceyheri, Kuntze, Rev. Gen. (1891) 332-3= homonyma omnia Stobaeae [ = Berkheya].

acarnodes, Kuntze, 1. c: (= Stobaea acarnoides, DC. - Afr. austr

aculeatum, Kuntze, 1, с, $332=$ B, obovata, Willd angustifolimm, Kuntze, $1 \mathrm{c},=\mathrm{B}$. lanceolata, Willd. armatum, Kuntze, 1. c. = B. carthamoides, Willd. atractylodes, Kuntze, I. c. = B. carlinoides, Willd barbatum, Kuntze, 1. c。 = B. carlinoides, Willd. decurrens, Kuntze, 1. c. = B. scolymoides, $D C$. fruticosum, Kuntze, 1. $\mathrm{C}_{0}=\mathrm{B}$. fruticosa, Ehrh. gazaniodes, Kuntze, 1. c. = B. gazanioides, Havv. gorterodes, Kuntze, 1. C. = B. gorteroides. Oliver et Hienn

Harreyanum, Kuntze, 1. c. = B. seminivea, Harv. herbaceum, Kuntze, 1. c. = B. cynaroides, Willd. herpiciodes, Kuntze, 1. c. = B. herpicioides, Sond. insignis, Kuntze, 1. c. = B. subulata, Harv. minus, Kuntze, 1. c. = [Quid.?] - Afr. austr. onobromodes, Kuntze, 1. C. ( = Stobaea onobromoides DC.),

oppositifolium, Kuntze, 1. c. = B. grandiflora Willd.

scolymodes, Kuntze, 1.c. (= Stobaea scolymoides, DC.). - Afr. austr.

spinosum, Kuntze, 1. c. ( = Stobaea oppositifolia DC, ). - Afr, austr.

stobaeodes, Kuntze, 1. c. = B. stobaeoides, Harv.

CROCOPSIS, Pax, in Bot. Jahrb, xi. (1890) 324

AMARY L LIDEAE.
argentinum, Pax, l.c. xi. (1889) 325.- Reg.Argent. fulgens, $P a x$, l.c. - Reg. Argent.

GROCUS, [Tourn.] Linn. (Irid.). - Ind. Kew。 i 644.

Autrani, Alboff, in Bull. Herb. Boiss. i. (1893) 242. Reg. Cauc.

Mouradi, Whittall, in The Garden, xxxv。(1889) 373. - As. Min

officinalis, G. Beck, Fl. Nieder-Oest. i. (1890) 187. Austria.

Vilmae, Fiala, in Oest. Bot. Zeitschr. xl. (1890) 247 et in Wissensch. Mitth. Bosn. und Herceg. i. (1893) 562 cum ic. - Bosnia.

GROIXIA, Pierre, Not, bot. Sapot, (1890) 32 SAPOTACEAE

Beccariana, Pierre, (err. cal.? Beccanaria) l.c. 33. Born., Penins. Mal.

CROSSANDRA, Salisb. (Acanth.). - Ind. Kew. 1. 646 .

brachystachys, Lindau, in Eng1, et Prantl, Natürl. Pflanzenfam. vi. 3 b. (1845) 319 . = nilotica, Oliver.

leikipiensis, Schweinf. in Hoelnel, zum Rodolph See, Append. (1892) 7. - Afr. trop. or.

likiphinsis, Schweinf. ex Engl. in Abhandl. Preuss, Akad. Wiss, 1891 ii. (1892) $391=$ praec

mucronata, Lindan, in Bot. Fahrb. xx. (1894) 35. Afr. trop. or

parvifolia, Lindan, l. c. 37. - Afr. trop. or.

primuloides, Lindan, l. c. 36. - Angola.

pungens, Lindan, l.c. - Afr. trop. or.

Stenandrium, Lindau, in Engl, et Prant1. Natürl. Pflanzenfam, iv, 3 b. (1895) $319(=$ Polythrix Stcnandrium, Nees) = C. madagascariensis, T. Anders.

tridentata, Lindau, in Engl, Pfanzenw. Ost-Afr. C (1895) 370. - Afr. trop. or.

CROSSOPETALUM, P, Br, = Myginda, Linn. (Celastr.).

Bredemeyeri, distichum, ilicifolium, integrifolium, lati-

\section{CROSSOPETALUM}

folium, microphyllum, pallens, rotundatum, scoparium, Kuntze, Rev。Gen. (1891) 116 = homonyma omnia Mygindae.

aquifolium, Hitchc, in Missouri Bot. Gard. Rep. iv. (1893) $70=$ M. aquifolia, Griseb.

gonocladum, Kuntze, Rev. Gen. (1891) 70. - Antill. myrsinodes, Kuntze, $1 . \mathrm{c}$. $=\mathrm{M}$. myxsinoides, $H . B$. et $K$

pallens, Millsp. Field Columb. Mus. Bot. Ser. I. (1895) $32=$ M. pallens, Sm.

Rhacoma, Hitchc, in Missouri Bot. Gard. Rep. iv.

(1893) $70(=$ C. Rhaeoma, Crantz) $=$ M. Rhacoma, Sw.

theodes, Kuntze, (Rev. Gen. (1891) $116=$ M. theoides, Benth

CROSSOPTERYX, Fenzl (Rubiac.). - Ind. Kew. i. 646.

africana, K. Schum, in Engl. Pflanzenw. OstAfr. C (1895) 378 (= C. africana, Baill.) = Kotschyana, Fenzl.

GROSSOSOMA, Nutt, (Dilleniac.). - Ind, Kew. i. 646 .

parviflora, Robins, et Fernald. in Proc. Am. Acad. xxx. (1895) 114. - Mexic.

CROSSOSTYLIS, Forst. (Rhizophor.). - Ind. Kew. i. 646.

Cominsii, Hemsl, in fourn. Linn, Soc, xxx. (1894) 212 t. 10.

Seemannii, A. F. W. Schimp. in Engl. et Prantl, Natürl. Pflanzenfam. iii. 7. (1893) $51=$ Hoplopetalum Seemanni, A. Gray.

GROTALARIA, Dill.ex Linn.(Legumin.).- Ind.

adenocarpoides, Taub. in Engl. Pfanzenw. Ost.-Afr. C. (1895) 206. - Afr. trop, or.

agatiflora, Schweinf. ex Engl. in Abhandl. Preuss. Akad. Wiss, 1891, ii. (1892) 244 nomen; et in Hoehnel, zum Rudolph See, Append. (1892) 13.Afr. trop. or.

aurantiaca, Baker, in Kew Bull. (1895) 213. Reg. Somal.

Belckii, Schinz, in Verh.Bot.Ver. Brand, xxx. (1888) 159. - Afr. austro-occ, extratrop.

Boehmii, Taub, in Engl. Pfanzenw. Ost-Afr. (1895) 204.-Afr, trop. or.

burmanica, Collett et Hemsl, in fourn. Linn. Soc. xxviii. (1890) 38. - Burma.

Cornetii, Taub. et Deweirye, in Bull. Soc. Bot. Belg. xxxiji, 2, 1894 (1895) 99; et xxxiv. 2 (1895) 94. Congo.

damarensis, Engl. Bot. Fahrb.x. (1889) 27. - Afr. austro-occ. extratrop.

uspidata, Tanto in Engl. Pflanzenw Ost-Afr. C. 1895) 205. - Afr. trop. or.

Fischeri, Taub.l.c. - Afr. trop. or.

grandibracteata, Tanb. in Abhandl. Preuss. Akad. Wiss. (1894) 48 ; et l.c. 206. - Afr. trop. or.

griquensis, Bolus, in fourn. Linn. Soc. xxiv. (1887) 174. - Afr. austr.

Harmsiana, Taub, in Engl. Pflanzenw. Ost.-Afr. C (1895) 205. - Afr. trop, or

Holstii, Taub. ex Engl. in Abhandl. Preuss. Acad Wiss. (1894) 63 et 64 ; et in Pfanzenw. Ost.-Afr. A (1895) 104 et 106 nomen. - Afr, trop, or.

huillensis, Taub. in Engl. Pflanzenw. Ost-Afr. C (1895) 205 in obs. = ramosissima, Baker

imperialis, Taub. I. c. 206. - Afr, trop. or.

Jamesii, Oliver, in Hook. Icon, pl. (1886) t. 1530; et in F. L. Fames, Unkn. Horn of Afr, Append. (1888) 319 t. 5. - Reg. Somal.

karagowensis, Taub. in Engl. Pfanzenw. Ost-Afr. C (1895) 204, - Afr. trop. or.

katangensis, Dewèvre, in Bull. Soc. Bot. Belg. xxxiii 1894. 2 (1895) 99. - Congo.

kilimandscharica, Taub. ex. Engl, in Abhandl. Preuss. Akad.Wiss. 1891 (1892) 246. - Afr. trop. or.

lachnocarpoides, Engl, l. o. - - Abyss.

laxiflora, Baker, in Kev Bull. (1895) 64. - Afr. trop. austro-or.

Leubnitziana, Schinz, in Verh. Bot. Ver. Brand. xxx. (1888) 158. - Afr. austro-occ. extratrop.

\section{GROTALARIA}

eucoclada, Baker, in Kew Bull. (1895) 214. - Reg Somal.

(teo-rubella, Baker, in fourn. Linn. Soc. xxis. (1887) 462. - Madag.

macrocarpa, Penzig, in Atti Congr. Bot. Genova (1893) 338. - Abyss. [Erithrea].

macropoda, Baker, in fourn. Linn. Soc. xxii. (1887) 463. - Madag

Marlothii, Engl. Bot. Fahrb. x. (1889) 27. - Afr. austro-occ, extratrop.

massaiensis, Taub. in Engl. Pflanzenw. Ost-Afr. C (1895) 205. - Afr. trop, or

megistantha, Taub. i. c. 206. -- Afr. trop. or,

mesopontica, Taub. l.c. 207.--Afr, trop. or.

parvula, G. Beck, in Paulitschke, Harrar (1888) 45 fig. 7. - Afr. trop. or. [Harrar].

passerinoides, Taub. in Engl. Pfanzenw. Ost-Afr. C (1895) 204. - Afr. trop. or

Pechueliana, Schinz, in Verh Bot. Ver. Brand. xxx. (1888) 15\%. - Afr. austro-occ, extratrop.

perpusilla, Collett et Hemsl. in fourn. Linn. Soc. xxviii. (1890) 37 t. 5. - Burma.

Phillipsiae, Baker, in Kew Bull. (1895) 213. - Reg. Somal.

picensis, Phil. in Anal. Mus. nac, Chite (1891) 13.Am. austr. occ.

pilulicarpa, Taub. in Engl. Pfanzenw. Ost-Afr. C. (1895) 204. - Afr. trop, or

polychotoma, Taub. ex Engl, in Abhandl. Preuss. Akad. Wiss. (1894) 16 et 24; et in Pflanzenw. Ost Afr. A (1895) 16 et 23 nomen. - Afr. trop. or.

reptans, Taub. in Engl. Pflanzenw. Ost-Afr. (1895) 204. - Afr, trop. or.

similis, Hemsl. in Ann. of Bot. ix. (1895) 152. Ins. Form.

Schweinfurthii, Taub. ex Engl. Pfanzenw. Ost-Afr $A$ (1895) 64, nomen. - Atr. trop. or.

Stuhlmannii, Taub. in Engl. Pfanzenw. Ost-Afr. C (1895) 204. - Afr. trop. or.

aguenensis, Taub, l. c. 206. - Afr. trop. or.

Urbaniana, Tauö. in Flora, 1xxii. (1889) 423. Bras.

Vatkeana, Engl. in Abhandl. Preuss. Akad. Wiss 1891 (1892) 245. - Abyss.

yunnanensis, Franch. Pl. Delav. (1889) 151. China.

GROTON, Linn. (Euphorb.), - Ind. Kew. i. 651 affinis, Maiden et R. T. Baker, in Proc. Limn. Soc. N. S. Wales, Ser. II. ix. (Sept. 1894) 160 t. 12, Austral.

aigburtenszs, Hort. ex Gard. Chron.(1886) ii. 749. Form, hort.

alamosanum, N. E. Rose, in Contrib. U. S. Nat. Herb. i. (1891) 111. - Mexic.

ardisioides, Hook.f. Fl. Brit. Ind. v. (1887) 393.-Penins. Mal., Borneo.

Bakerianus, Baill. in Bull. Soc. Linn. Paris, ii (1890) 849. - Madag.

Bangii, Rusby, in Mem. Torrey Bot. Club, iv. (1895) 256. - Bolivia

Baroni, Baill. in Bull. Soc. Linn. Pavis, ii. (1890 863. - Madag

Bernievi, Baill. Hist. pl. Madag., Atlas (1891 t. $163=$ C. Berniera, Raill.

calomeris, Baill. in Bull. Soc. Linn. Paris, ii, (1890) 860 ; et l. c. 1891) t. 164. - Madag.

calvescens, S. Wats, in Proc. Am. Acad. xxvi. (1891 147. - Mexic.

Campenoni, Baill, in Bull. Soc, Linn. Paris, ii. (1890) 847; et Hist. pl. Madag., Atlas (1891) t. 161 - Madag.

Catati, Baill. Il.co. 851; et t. 158. - Madag,

comanthus, S. Moore, in Trans. Limn. Soc. Ser. II iv. (1895) 460. - Bras.

confertum, Baker, in Kew Bull. (1895) 186. Arabia.

corumbensis, S. Moore, in Trans. Limn. Soc. Ser. II iv. (1895) 457. - Bras.

costaricensis, Kuntze, Rev. Gen. (1891) 614 . Costa-Rica.

delphinianus, Baill. in Bull. Soc. Linn. Paris, ii (1891) 928. - Madag.

dissimilis, Baill. l.c. ii. (1890) 86I. - Madas.

Doctoris, S. Moove, in Trans. Linn. Soc. Ser.II. iv (1895) 456. - Bras. 
CROTON

Elaeagni, Baill. in Bull. Soc. Linn. Paris, ii. (1890) 848; et Hist. pl. Madag., Atlas (1890) t. 156. Madag.

elaeagnoides, $S$, Wats, in Proc. Am. Acad, xxyi. 1891) 147. - Mexic,

Elliotianus, Baill. in Bull. Soc. Linn. Paris, ii (1890) 863. - Madag.

eluterioides, Lotsy, in Coult. Bot. Gaz. xx. (1895) 352 t. 25 fig. 7-10. - Guatem.

erythrostachys, Hook, f. Fl. Brit. Ind. v. (1887) 391. - Malacca.

Evansianum, Hort. ex Rev. Hortic. (1894) 534. Form. hort.

furcellatus, Baill. in Bull. Soc. Linn. Paris, ii. (1891) $96 \%$ - Madag.

fuscirameus, Baill.l. c. 927. - Madag

Greveanus, Baill. l. c. ii. (1890) S48; et Hist.pl. Madag., Atlas (1890) t. 157. - Madag.

Griffithii, Hook, f. Fl. Brit. Ind. v. (1887) 392. Ind. or.

guatemalensis, Lotsy, in Coult. Bot. Gaz. xx. (1895) 353, t. 25. fig. 1-6. - Guatem.

heterochrous, Baill. in Bull. Soc. Linn. Paris, ii 1890) 862. - Madag.

hilaris, Baill. l. c. ii. (1891) 927. - Madag.

Hildebrandtii, Baill. l. c. ii. (1890) 847. - Madag.

horridulus, Baill. l. c. ii. (1891) 977. - Madag.

Humblotii, Baill. l.c. ii. (1890) 846; et Hist. pl. Madag., Atlas (1890) t. 155. - Madag.

hypochalibaeum, Baill. l. c. ii. (1890) 862. Madag.

incisum, Baill. Hist. pl. Madag., Atlas (1891)

t. 16z. - Madag.
inops, Baill. in Bull. Soc. Linn. Paris, ii. (1890) 864. - Madag.

lasiopyrus, Baill.l. c. ii. (1891) 926. - Madag.

leuconeurus, Pax, in Bot. Fahrb. xv. (1893) 533. Afr. trop. centr.

longipes, $M$. E. Fones, in Proc. Calif. Acad. Ser. II. v. (1895) 721. Calif.

macrobuxus, Baill. in Bull. Soc. Linn. Paris, ii. (1890) 863. - Maday.

macrochlamys, Baill. l. c. - Madag.

microprunus, Baill. l. c. 861. - Madag

Magdalenae, Millsp. in Proc. Calif. Acad. Ser. II ii. (1889) 220. - Calif.

microbotryus, Pax, in Bot. Fahrb. x. (1889) 35. Afr. autr.

mimeticus, S. Moove, in Trans. Linn. Soc. Ser. II, iv. (1895) 453. - Bras.

mollivelum, Baill. in Bull. Soc, Linn, Paris, ii. (189]) 926. - Madag.

Muelleri, Coult, in Contrib. U. S. Nat. Herb. ii (1894;399. - Texas.

myriaster, S. Elliot, in Bull. Soc. Linn. Paris, ii (1891) 967 in syn. = Scotti, Baill.

Neremannii, Hort. Bull, Catal. (1887) 10 et 6 cum icone $=$ Codiaeum variegatum, Blume.

nigritanum, S. Elliot, in fourn. Limn. Soc. xxx. (1894) 97. - Afr. trop. occ.

nivifer, S. Moore, in Trans, Linn, Soc. Ser. II iv. (1895) 456. - Bras

odoratus, Ridl. in fourn. Linn. Soc. xxvii. (1890) 58. - Ins. Fernando-Noronha.

pachecensis, S. Moore, in Trans. Linn. Soc. Ser. II, iv. (1895) 459. - Bras.

picturatum, Éd. André, in Rev. Hortic. (1888) 423 = Codiaeum variegatum, Blume

piluliferum, Rusby, in Mem. Torrey Bot. Club, iv. (1895) 256. - Bolivia.

Poggei, Pax, in Bot. Fahrb. xv. (1893) 534. Congo.

polytrichus, Pax, l. c. 533. - Afr. trop. centr.

Regeli, Hort. ex Rev. Hortic. (1894) 534. - Form. hort.

salviformis, Baill. in Bull. Soc. Linn. Paris, ii. (1891) 926. - Madaz.

Sanctae-Crucis, S. Moore, in Trans. Linn. Soc. Ser. II. iv. (1895) 455. - Bras

sarcopetaloides, S. Moore, l. c. 454. - Bras.

Scarciesii, S. Elliot, in fourn. Linn. Soc. $\mathrm{xxx}$ (1894) 96. - Afr. trop. occ.

sclerodorum. Baill. in Bull. Soc. Linn. Paris, ii. (1891) 968. - Madag.

Scotti, Baill. l. c. 967. - Madag.

\section{GROTON}

omalensis, Vatke et Pax ex Pax, in Bot. Fahrb. xv. (1893) 535. - Reg. Somal.

sparsiflorus, Morong, in Ann. N.Y.Acad. Sci. vii. 1893) 221. - Parag.

stanneum, Baill. in Bull. Soc, Linn. Paris, ii. (1890) 850. - Madag.

Stuhlmanni, Pax, in Bot. Fahrb. xix. (1894) 80. Afr. trop. or.

subaemulans, Baill. in Bull. Soc. Linn. Paris, ii. (1890) 851. - Madag.

submetallicum, Baill ? c ii (1891) 966 - Madag. tenuicuspis, Baill.l.c.927. - Madag.

tenuilobus, S. Wats. in Proc. Am. Acad. xxi. (1886 439. - Mexic

turneraefolius, S. Moore, in Trans. Linn. Soc. Ser. II. iv. (1895) 458. - Bras.

Turrialva, Kuntze, Rev, Gen, (1891) 614, Costarica.

vernicosus, Baker, in fourn. Linn. Soc. xxii. (1887) 519. - Madag.

GROTONOGYNE, Muell. Arg. (Euphorb.). Ind. Kew. i, 657 .

angustifolia, Pax, in Bot. Fahrb. xx. (1894) 83.Gabun.

gabunensis, Pax, l. c. 82. - Gabon.

Poggei, Pax, l. c.84.- Congo.

CROTONOPSIS, Michx (Euphorb.). - Ind. Kew. i. 658 .

spinosa, Nash, in Bull. Torrey Bot. Club, xxii, (1895) 15\%. - Florida

CROZOPHORA, A. Juss. = Ghrozophora Neck (Euphorb.)

Warionii, Coss, ex Batt, et Trab. F1, de l'Algér. (Dicot.) (1888) 804. - Algérie.

GRUGKSHANKSIA, Hook, (Rubiac.). - Ind. Kew. i. 658 .

Darapskyana, Phil. in Anal. Univ. Chil. Ixxxv. (1894) 738. - Chili.

Geisseana, Phil. l.c. 737. - Chili.

oblonga, Fr. Meigen, in Bot. Fahrb. xvii. (1893) 275 (= Oreopolus oblongus, Phil.). - Chili.

paradoxa, Phit. in Anal. Univ. Chil. 1xxxv. (1894) 738. - Chili.

verticillata, Phil.l.c.737. - Chili.

CRUMINIUM, Desv.= Centrosema DC. (Legumin.).

virginianum, Britton, in Bull. Torrey Bot. Club, xviii. (1891) $269=$ Clitoria virginiana, Linn.

CRUSEA, Cham, et Schlecht, (Rubiac.). - Ind. Kew i. 659

aphylla, Heller, Bot. Expl. S. Texas, (1895) 80 t. 5. - Texas.

coronata, Robins. et Greenm. in Proc. Am. Acad xxix. (1894) 387. - Mexic.

cruciata, S. Wats. l. c. xxv. (1890) 152. - Mexic megalocarpa, S. Wats. l.c. xxvi. (1891) 137. Mexic.

Palmeri, A.Gray, l.c. xxi.(1886) 381 et 431 , nomen. - Mexic.

tricocca, Heller, Bot. Expl. S. Texas, i. (1895) $97=$ allococca, $A$. Gray.

villosa, S. Wats, in Proc. Am. Acad. xxv. (1890) 152. - Mexic.

GRUZIA, Phil. in Anal. Univ. Chil. xc. (1895) 558. LABIATAE

serpyllacea, Phil. l. c. - Patagonia.

GRYPSIS, Ait. (Gramin.).- Ind, Kew, i. 659. alopecuroidea, St-Lager, in Cariot, Etud. des $\mathrm{fl}$ éd. 8. ii. (1889) 887 (= alopecuroides, Schrad.) $=$ Heleochloa alopecuroides.

GRYPTANDRA, Sm. (Rhamn.). - Ind. Kew. i. 6.99.

scabrida, Tate, in Trans, et Proc. Roy. Soc. S. Austral. xii. (Dec. 1889) 129.- Austral.
CRYPTANGIUM, Schrad. ex Nees (Cyper.). Ind. Kew, i. 660.

brevifolium, Boeck. in Kneuck. Allgem. Bot. Zeitschr. 1. (1895) 24. - Bras.

ciliatum, Boeck. Cyp. Nov, ii. (1890) 28. - Bras.

dioicum, Boeck. in Kneuck. Allgem. Bot. Zeitschr. i. (1895) 24 . - Bras

distichophyllum, Boeck. Cyp. Nov. ii. (1890) 28. Bras.

griseum, Boeck. in Kneuck. Allgem. Bot. Zeitschr. i. (1895) 23. - Bras.

insigne, Boeck. l. c. 23. - Bras.

Kuntzeanum, Boeck. Cyp. Nov. i. (1888) 32.Ins. Trinit.

melanocarpum, Boeck. l.c. ii. (1890) 28. - Bras.

parviflorum, Boeck. in Kneuck, Allgem. Bot. Zeitschr. 1. (1895) 23. - Bras.

Schenckianum, Boeck.Cyp. Nov。 ii. (1890) 27.Bras.

tenuifolium, Boeck.l.c. i. (1888) 32. - Bras

tremulum,Boeck, in Kneuck.Allgem.Bot.Zeitschr.i. 1895) 24 in obs. = Lagenocarpus tremulus, Nees.

CRYPTANTHE, Benth. et Hook, f. (= Cryptantha, Lehm.) = Krynitzkia, Fisch, et Mey. (Boragin.) affinis, Greene, Pittonia, i. (Nov. 1887) $119=\mathrm{K}$ affinis, A. Gray.

ambigua, Greene, 1. c. $113=\mathrm{K}$. ambigua, A. Gray. anoustifolia, Greene, 1. c. 112 = K. angustifolia, A. Gray,

barbigera, Greene, 1. c. $114=$ K. barbigera, A. Gray.

Bartolomaei, Greene, 1. c. ii. (May 1892) 232.Calif.

cedrosensis, Greene, 1. c. i. (Nov. 1887) $117=$ K. cedrosensis, Greene.

Clevelandi, Greene, 1. c. - Calif

congesta, Greene, 1. c. $111=$ Eritrichium congestum, $D C$.

crassisepala, Greene, 1. c. $112=\mathrm{K}$. crassisepala, A. Gray.

crinita, Greene, in Erythea, iii. (1895) 66. - Calif.

cycloptera, Greene, Pittonia, i. (Nov. 1887) $120=$ K. cycloptera, Greene.

denticulata, Greene, 1. c. $114=\mathrm{K}$. denticulata, Greene.

dimorpha, Greene, 1. c. 112. = Eritrichium dimorphum, Phil.

dumetorum, Greene 1. c. =- K. dumetorum, Greene.

echinella, Greene, 1. c. 115. - Am, bor. occ

Fendleri, Greene, 1. c, $120=\mathrm{K}$. Fendleri, A. Gray.

faccida, Greene, 1. c. $115=\mathrm{K}$. oxycarya, A. Gray.

foliosa, Greene, 1. c. $113=\mathrm{K}$. foliosa, Greene.

geminata. Greene, 1. c. 119. - Calif

glaveosa, Greene, 1. c. $111=$ Eritrichium glareosum, Phil.

glomeriflora, Greene, 1. c. 116. - Calif

hispidissima, Greene, 1. c. 118. - Calif

intermedia, Greene, 1. c. 114. = K. intermedia, A. Gray.

fonesii, Greene, 1. c. $113=$ K. Jonesii, A. Gray.

Kelseyana, Greene, 1. c. ii. (May 1892) 232. - Am bor. occ.

laxiflora, Phil. in Anal. Univ. Chil. xci. (1895) 503: - Chili.

leiocarpa, Greene, Pittonia, i. (Nov. 1887) $117=$ K. leiocarpa, Fisch. et Mey

linearis, Greene, 1. c. $111=\mathrm{K}$. linearis, A. Gray. maritima, Greene, 1. c. $117=$ K. maritima, Greene micromeres, Greene, 1. c. $113=\mathrm{K}$. micromeres, A. Gray.

microstachys, Greene, 1. c. $116=\mathrm{K}$. microstachya, Greene.

mohavensis, Greene, 1.c.120=K.mohavensis, Greene muriculata, Greene, 1. c. $113=\mathrm{K}$. muriculata, A. Gray.

nemaclada, Greene, 1.c. 118.-- Calif.

oxygona, Greene, 1. c. $120=\mathrm{K}$. oxygona, A. Gray. Pattersoni, Greene, 1. c, = K. Pattersoni, A. Gray. patula, Greene, 1. c. i. (Mar. 1889) 265. - Calif.

polycarpa, Greene, 1. c. i. (Nov. 1887) 1]4. - Calif Pondii, Greene, 1. c. i. (April 1889) 291.-Calif. pterocarya, Greene, 1. c. i. (Nov. 185\%) $120=$

K. pterocarya, A. Gray.

pusilla, Greene, 1. c. $115=$ K. pusilla, A. Gray.

racemosa, Greene, 1. c。 = K racemosa, Grene 
CRYPTANTHE :-

ramosa, Greene, 1. c. $=$ K. ramosa, $A$. Gray. ramosissima, Greene, 1. c. $116=\mathrm{K}$. racemosa, Greene.

Rattani, Greene, 1. c. i. (Jan. 1888) 160. - Calif. recurvata, Coville, in Contr. U.S. Nat. Herb. iv (1895) 167. - Calif.

rostellata, Greene, 1. c. $116=\mathrm{K}$. rostellata, Greene sparsiflora, Greene, 1.c. = K. sparsiflora, Greene.

submollis, Coville, in Contr. U. S. Nat. Herb. iv. (1895) $167=\mathrm{K}$. holoptera, A. Gray.

texana, Greene, Pittonia, i. (Nov. 1887) $112=$ K. texana, A. Gray.

Torreyana, Greene, 1. c. $118=\mathrm{K}$. Torreyana, A Gray.

utahensis, Greene, 1. c. $120=\mathrm{K}$. utahensis, A. Gray.

Watsoni, Greene, 1. C. $=$ K. Watsoni, A. Gray,

GRYPTANTHUS, Otto et Dietr. (Bromel.). - Ind. Kew. i. 660.

andicola, Moritz, ex Baker, Handb. Bromel. (1889) 4 syn. = Karatas albo-rosea, Baker?

angustifolius, Baker, l.c. $15-$ Guian. Brit.

clavatus, Hort. ex Baker, 1. c. 68 in syn. = Aechmea aurantiaca, Baker.

cochleatus, Éd. Morr. ex Baker, l. c. 17. - Bras.

emergens, Lindm, in Kongl. Svensk Vet. Akad. Handl. xxiv. 8 (1891) 19 t. 2 fig. 1-12. - Bras. Glaziovii, Mez, in Mart.Fl. Bras. iii. In, (1891) 202. - Bras.

Lubbersianus, Éd. Morr. ex Baker. Handb. Bromel. (1889) 17. - Bras.

Makoyanus, Baker, i.c. 16.-- Bras.

Morrenianus, Regel, in GartenH. (1888) 157; et in Act. Hort. Petrop. x. (1889) $693=$ Diștiacanthus Morrenianus, Baker.

praetextus, Ed. Morr. ex Baker, Handb. Bromel. (1889) 16. - Bras.

Regelii, Hort. Makoy, ex Baker, 1. c. 17 nomen. (Quid?)

testaceus, Ed. Morr. ex Baker, 1. c. $15=$ undulatus, Otto et Dietr.

suaveolens, Ed. Morr, ex Baker, 1. c. 16. - Bras.

Schwackeanus, Mez, in Mart. Fl. Bras. III, iii. (1891) 203. - Bras.

GRYPTOCARPUS, H. B. et K. (Nyctagin.).Ind. Kew. i. 660

capitatus, S. Wats. in Proc. Am. Acad. xxiv. (1889) 71. - Calif.

CRYPTOGARYA, R. Br. (Laurin.). - Ind Kew. i. 660.

andamanica, Hook. f. Fl. Brit. Ind. v. (1886) 118. - Ins. Andam.

Andersoni, King, ex Hook.f. l.c. 120.- Reg.Himal

Aschersoniana, Mez, in fahrb. Bot. Gart. Berlin, v. (1889) 11. - Bras.

Bancroftii, F. M. Bailey, in Dept. Agric. Bot. Bull. [ii] (1891) 16. - Austral.

Burckeana, Warb. in Bot. Fahrb. xiii. (1891) 315. Oceania.

chinensis, Hemsl. in fourn. Linn. Soc. xxvi. (1891) $370(=$ Beilschmiedia chinensis, Ham.). - China depressa, Warb. in Bot. Fahrb. xiii. (1891) 316. Oceania.

enervis. Hook. f. Fl. Brit. Ind. v. (1886) 119. Malacca.

Ferrarsi, King, ex Hook. f. l. c. 118.- Ins. Andam

glaucosepala, S. Elliot, in fourn. Linn. Soc. xxix. (1891) 45. - Madag.

graveolens, F. M. Bailey, in Dept. Agric. Bot. Bull. [ii] (1891) 16. - Austral.

ilocana, Vidal, Revis, Pl. Vasc. Filip. (1886, 223. Ins. Philipp.

insignis, F. M. Bailey, in Dept. Agr. Bot. Bull. [ii] (1891) 15. - Austral.

Kurzii, Hook. f. Fl. Brit. Ind. v. (1886) 119. Tenass

longistylis, Mez, in Bot. Fahrb. xvii. (1893) 518. Bras.

luzoniensis, Vidal, Revis. Pl. Vasc. Fitip. (1886) 223. - Ins, Philipp.

Mannii, Hillebr, Fl. Have, Isl. (1888) 382. - Ins Sandvic.

\section{CRYPTOCARYA}

minima, Mez, in Jahrb. bot. Gart. Berlin, v. (1889) 14 = Aydendron floribundum, Meissn.

oblata, F. M. Bailey, in Dep. Agric. Bot. Bull. ix. 1894) 11. - Austral.

Palmerstoni, F. M. Bailey, l. c. [ii] (1891) 16. Austral.

pauciflora, Baker, in fourn. Linn. Soc. xxii. (1887) 515. - Madag.

rugulosa, Hook. f. Fl. Brit. Ind. v. (1886) 118. Malacca.

saligna, Mez, in fahrb. bot. Gart. Berlin. v. (1889) 13. - Bras.

Villarii, Vidal, Revis. Pl. Vasc. Fitip. (1886) 223.Ins. Philipp.

GRYPTOGORYNE, Fisch. (Aroid.). - Ind. Kew. i. 660 ,

affinis, N. E. Br. ex Hook. f. Fl. Brit. Ind. vi. (1893) 494. - Perak.

elliptica, N.E. Br. l. c. 495. - Perak.

CRYPTOLAPPA [A. Juss.] Kuntze, Rev. Gen. (1891) $88=$ Camarea, St-Hil. (Malpigh.).

affinis, axillaris, discolor. hirsuta, lincarifolia, pulchella, sericea, triphylla, Kuntze, 1, c. = homonyma omnia Camareae.

ericodes, Kuntze, 1, c. = C. ericoides, St-Hil.

CRYPTOLEPIS, R. Br. (Asclep.). - Ind. Kew 1. 660

apiculata, $K$. Schum. ex Engl, in Abh. Preuss, Akad. Wiss. (1894) 26 nomen; et in Pfanzenw. Ost-Afr. C. $(1895) 320$. - Afr. trop. or

Barteri, K. Schum. in Engl. et Prantl, Natür, Pflan zenfam. iii. 2. (1895) 219 nomen. - Afr. trop. occ capensis, Schlechter, in Verh. Bot. Ver. Brand. xxxv. 1893) 47. - Afr. austr.

Elliotii, Schlechter, in fourn. Bot, xxxiii. (1895) 300 . - Afr. trop. or

hypoglauca, K. Schum, ex Engl. in Abh. Preuss. Akad. Wiss. (1894) 28 nomen; et in Pfanzenw. Ost-Afr. C. (1895) 320, - Afr, trop. or,

Monteiroae, Oliver, in Hook. Icon. pl. xvi. (1887) t. 1591 - Mossamb.

obtusa, K. Schum. in Engl. Pflanzenw. Ost-Afr. C. (1895) 320. - Atr. trop. or.

obtusa, N.E. Br. in Kew Bull. (1895) 110. - Afr. trop. austro-or.

Sizenandi, Rolfe, in Bolet. Soc. Brot, xi. (1893) 86.Angola.

triangularis, N.E. Br. in fourn. Linn. Soc. $\mathrm{xxx}$. (1894) 92. - Afr. trop. occ.

Welwitschii, Schlechter, in Fourn. Bot. xxxiii (1895 301. - Afr. trop. or.

GRYPTOMERIA, D. Don. (Conif.).-- Ind. Kew

\section{i. 662}

araucarioides, Carrière, in Rev. Hortic. (1890) 518 et Hort.ex Beissn.Handb. Nadelholzk. (1891) 146 = japonica, D. Don.

compacta, Hort. ex Beissn. 1. c. $147=$ japonica D. Don.

Lobbii, Hort. ex Beissn. 1. c. $146=$ japonica D. Don.

mucronata, Hort. ex Beissn. 1. c. $146=$ japonica D. Don.

ariegata, Hort. ex Beissn. 1. c. $147=$ japonica, D. Don.

pungens, Hort. ex Beissn. 1.c. = japonica, D. Don viridis, Hort. ex Beissn. 1. c. $146=$ japonica, D. Don

CRYPTOPHASEOLUS, Kuntze, Rev. Gen. (1891) 176. LEGUMINOSAE anamensis, Kuntze, l. .. 177. - Anam.

GRYPTOPHORANTHUS, Rodr. Gen. et $\mathrm{sp}$ Orch. nov. ii. (1881) p. 79 ORCHIDEAE.

atropurpureus, Rolfe in Gard. Chron. (1887) ii. 693 (= Pleurothallis atropurpurea, Lindl.). - Jamaica Cuba.

Dayanus, Rolfe, l. c. 693 fig. 134 et in Illustr. Hortic. xxxix (1892) 21 t. $546(=$ Masdevallia Duyana Reichb, f.). - N. Gran.

gracilentus, Rolfe, l.c. $(=$ Masdevallia gracilenta, Reichb. f.). - Costarica.

\section{GRYPTOPHORANTHUS}

hypodiscus, Rolfe in Gard. Chron. (1889) ii. 693 (= Masdevallia hypodiscus, Reichb, f.) - Hab, ? maculatus, Rolfe, $l$. $c$. - Bras.

minutus, Rolfe, in Kew Bull. (1895) 5. - Hab. ?

oblongifolius, Rolfe, l. c. 5. - Am. austr

GRYPTOPHRAGMIUM, Nees = Gymnostachyum, Nees (Acanth.).

affine, ceylanicum, Cumingianum, febrifugum, hirsutum, leptostachyum. paniculatum, polyanthum, Thwaitesii, tomentosum, Kuntze, Rev. Gen. (1891) $483=$ homonyma omnia Gymnostachii.

CRYPTOSTEPHANUS, Welw. (Amaryll.). Ind. Kew. i. 662.

haemanthoides, Pax, in Bot. Fahrb. xv. (1893) 142. - Afr. trop. or.

CTENANTHE, Eichl. (Scitamin.). - Ind. Kew, i. 662

casupoides, Petersen, in Mart. Fl. Bras. iii. III. (1890) 162. - Bras.

lanceolata, Petersen, 1, c. 163. - Bras

Lubbersiana, Eichl. ex Petersen, 1. c. $159=$ Stromanthe Lubbersiana, Ed. Morr.

Muelleri, Petersen, l.c. 161.- Bras.

GTENIUM, Panz. (Gramin.). - Ind. Kew. i. 662. Newtonii, Hack. in Bolet. Soc. Brot.v. (1887) 229.Dahomey,

CUGUMIS, [Tourn:] Linn. (Cucurbit.). - Ind. Kew. i. 664.

aculeatus, Cogn. in Bot. Fahrb. xxi. (1895) 209. Afr. trop. or,

parvifolius, $\operatorname{Cogn}$. ex S. Elliot, in fourn. Linn. Soc. xxix. (1891) 19. - Madag.

Sacleuxii, Hort. ex Wien. Illust. Gartenz. (1890) 298; et ex Kew Bull. (I891). Add. ii. 40. Zanzib.

CUCULLARIA, Kramer, Tent. (1744) $10=$ Callipeltis, Stev, (Rubiac.).

aperta, Kuntze, Rev. Gen. (1891) $279=$ Call. aperta, Boiss

microstegia, Kuntze, 1. c. = Call. microstegia, Boiss.

GUGURBITA [Tourn,] Linn. (Cucurbit.). - Ind.

Kew. i. 665 .

cordata, S, Wats, in Proc. Am. Acad. xxiv. (1889) 50. - Calif.

mexicana, Dammann, Catal. (1890-91) 42 ; et ex Kew Bull. (1891) Add. ii, 40. - Mexic.

CUDRANUS, Rumph. = Cudrania, Tréc. (Euphorb.).

spinosus, Kuntze, Rev, Gen. (1891) $623=$ Cudrania javanensis, Tréc.

GULCASIA, Beauv, (Aroid.) - Ind Kew, i. 666. Mannii Engl, in Enol et Prantl, Natürl. Pflanzenfam. ii. 3. (1887) 116; et in Gartenfl. (1887) $84=$ Denhamia Mannii, Hook. $f$.

tenuifolia, Engl. Bot. fahrb. xv. (1893) 447. Kamerun.

CULCITIUM, Humb. et Bonpl. (Compos.). - Ind, Kew. i. 666 ,

ferrugineum, Klatt, in Annal. naturh. Hofmus. Wien, ix. (1894) 363. - Am. centr.

peruvianum, Klatt, l. c. - Peruvia.

CUMARUna. J. F. Gmel = Dipteryx, Schreb. (Legumin.).

alata, crassifoliw, nudipes, oleifera, oppositifolia, reticulata, rosea, tetraplyylla, Kuntze, Rev. Gen.(1891) $\mathbf{1 7 7}=$ homonyma omnia Dipterygis.

GUMINUM [Tourn.] Linn. (Umbellif.). - Ind.

Kew. i. 666 .
cuminodes, Kuntze, Rev. Gen. (1891) $266=$ Lagoecia cuminoides, Linn.

GUNILA, Linn. (Labiat.), - Ind. Kew. i. 667. 


\section{CUNILA}

longiflora, A. Gray, ex S. Wats. in Proc. Am. Acad. xxii. (1887) 444. - Mexic.

origanoides, Britton, in Mem. Torrey Bot. Club, v. (1894) $278=$ C. Mariana, Linn.

pycnantha, Robins et Greenm. in Proc. Am. Acad xxix. (1894) 391. - Mexic.

CUPANIA, Plum. ex Linn. (Sapind.). - Ind. Kew. i. 667 .

andronensis, Baker, in fourn. Linn. Soc. xxv, (1890; 308. - Madag.

dissitiflora, Baker, l.c. - Madag.

clegans, L. Lind. ex Gard. Chron. (1893) i. 474 ; et ex Rev. Hurtic. (1893) 339, - Form. hort.

flagelliformis, F. M. Bailey, in Dep. Agric. Bot. Bull. viii. (1893; 73. - Austral.

pleurophylla, F. Muell. in Vict. Natural. iii, (April 1887) 170, nomen. - Austral.

sericolignis, F. M. Bailey, in Dep. Agric. Bot. Bull. v. (1892) 11. - Austral.

Shirleyana, F. M. Bailey, Syn. Queensl. Fl.Suppl. ii. (1888) 15. - Austral.

GUPANIOPSIS, Radlk. (Sapind.). - Ind. Kew.

i. 668 . Muench. xx. (1890) 359 - N. Guin.

macropetala, Radlk. l. c. 357.- N. Guin

platycarpa, Radlk, l. c. 359. - N, Guin.

subserrata, Radlk. l. c.- N. Guin.

CUPHEA, P. Br. (Lythrar.). - Ind. Kew. i. 668 avigera, Robins, et Seaton, in Proc. Am. Acad. xxviii. (1893) 105. - Mexic.

Glaziovii, Koehne, ex Taub, in Bot. fahrb. xv. Beibl. n. 38 (1893) 5. - Bras.

Heydei, Koehne, in Coult. Bot. Gaz. xix. (1894) 256. - Guatem.

Lehmanni, Koehne, in Bot. Fahrb. viii. (1887) 244. Columb.

mesochloa, Greene, Pittonia, i. (Nov. 1887) 141 (=C. vividostoma, S. Wats.). - Mexic

Niederleinii, Koehne, ex Taub. in Bot. fahrb. xv Beibl. n. 38 (1893) 5. - Reg. Argent.

Palmeri, S. Wats. in Proc. Am. Acad. xxi. (1886) 429. - Mexic

persistens, Koehne, in Verh. Bot.Ver. Brand. xxx. (1888) 277. - Reg. Argent

Pringlei, S. Wats., l. c. xxv. (1890) 149. - Mexic,

Reipublicae, Robins. et Seaton, l. c. xxviii. (1893) 106. - Mexic.

retroscabra, S. Wats, l. c. xxii. (1897) 413.-Mexic

Schwackei, Koehne, ex Schwacke, in Bot. Fahrb. xii. Beibl. n. 28 (1890) 9 nomen; et xv. Beibl, n. 38 (1893) 6. - Bras.

viridostoma, $\mathrm{S}$. Wats, in Proc. Am. Acad. xxii (1887) 412 = mesochloa, Greene.

GUPRESSUS, Tourn. ex Linn, (Conifer.). - Ind. Kew. i. 671

Corneyana, Hort. ex Dangeard, Le Botaniste, Sér. iii. (1893) 177. - Form, hort.

Devoniana, Hort, ex Beissn. Handb. Nadelholzk. (1891) $116=$ Juniperus phoenicea, Limn

Doniana Hort, ex Hook, f. Fl. Brit. Ind. v. (1888) $645=$ sempervirens, Linn.

evicoides, Hort. ex Beissn. Handb. Nadelholzk. (1891) $67=$ Chamaecyparis sphaeroidea, Spach.

filiformis, Hort. ex Beissn. 1. c. $63=$ Biota orientalis, Endl.

orientalis, Hort. ex Beissn. 1. c. $102=$ C. sempervirens, $\operatorname{Linn}$.

pendulata, Hort. ex Beissn. 1. c. $63=$ Biota orientalis, Endl.

Reinwardti. Hort. ex Beissn. 1. c. $103=$ C. macrocarpa, Hartw.

CUPUIA, Aubl. = Coupoui, Aubl. (Apocyn.). Martiniana, Kuntze, Rev. Gen. (1891) 414 (= Coupuia Martiniana; Miers). - Am. aust.

GURA TELLA, Linn. (Dilleniac.). - Ind. Kew. i 671.

imperialis, Hort. ex Baill. Hist, des pl. xi. (1892) 296 = Martiusella imperialis, Pierre.
GURGULIGO, Gaertn. (Amaryll.), - Ind. Kew. i. 671 .

capitulata, Kuntze, Rev, Gen. (1891) 703 = recurvata, Dryand.

rhizophylla, Th. Dur. et Schinz, Consp. Fl. Afr.v. 1893 (1895) $237=$ Hypoxis thizophylla, Baker

CUSPIDOCARPUS, Spenn. = Micromeria, Benth (Labiat.).

thymifolius, Kuntze, Rev. Gen. (1891) $514=$ M. rupestris.

CYBELE, Sạlisb. et Knight = Stenocarpus,R.Br Proteac.).

Cunninghamii, elegans, gracilis, heterophylla, intermedia, laurina, Milner, vubiginosa, saligna, sinuata, villosa, Kuntze, Rev. Gen. (1891) $577-78=$ homonyma omnia Stenocarpi.

dareodes, Kuntze, 1. c. $578=$ S. dareoides, Brongn et Gris.

umbellata, Kuntze, 1, c, $577=$ S, Forsteri, $R . B r$

GURGUMA, Linn. (Scitamin.). - Ind. Kew. i. 672.

Bakeriana, Hemsl. in Gard. Chron. (1892) i. 682. - N. Guin.

coccinea, Wall. ex Hook f. Fl. Brii. Ind. vi. (1890) 216 in syn. = Roscoeana, Benth.

sylvestris, Ridl. in Trans. Linn. Soc. Ser. II. iii (1893) 378, - Penins. Mal.

urceolata, Rich. ex Petersen, in Mart. Fl. Bras, iii. Iit $(1890) 167=$ Saranthe urceolata, Petersen

GURTIA, Cham. (Gentian.). - Ind. Kew.i. 672 conferta, Knobl. in Bot. Centralbl. 1x. (1894) 357 $(=S$. conferta, Mart.),-Bras.

intermedia, Knobl. l. c. $(=$ S. intermedia, Prog. $) .-$ Bras.

obtusifolia,Knobl. l. c. ( = S. obtusifolia, Benth, ). Bras.

patula, Knobl. l.c. ( = S. patula, Mart.). - Bras pusilla, Knobl.l.c. $(=S$. pusilla, Griseb.). - Bras tenuifolia, Knobl, l. c.323 ( = Exacum tenuifolium, Aubl.). - Am. trop.

verticillaris, Knobl.1. c. = gentianoides, Cham. et Schlecht.

GUSGUTA, [Tourn.] Linn. (Convolvul.). - Ind. Kew. i. 672.

andina, Phil. in Anal. Univ. Chil. xc. (1895) 224.Chili.

aurea, Phil. l.c.-Chili.

candicans, Genn. ex Nym. Consp. Suppl. ii. I. (1889) 221 = planiflora, Ten.

globosa, Ridl. in fourn. Linn. Soc. xxvii. (1890) 48. - Ins. Fernando Noronha.

Kilimanjari, Oliver, in H. fohnston, The Kilim Exped. Append. (1886) 343 nomen; et in Trans. Linn. Soc. Ser. II. ii. (1887) 343. - Afr. trop. or.

ndorensis, Schweinf in Hoehnel, zum Rudolph See, Append. (1892) \%. - Afr. trop. or.

Palmeri, S. Wats. in Proc. Am. Acad. xxiv. (1889) 64. - Calif.

purpurata, Phil. in Anal. Univ. Chil. xc, (1895) 225. - Chili.

Veatchii, T.S. Brandeg. in Proc. Calif. Acad. Ser. II. ii. (1889) 189. - Calif.

GUSPARIA, Humb. (Rutac.).-Ind. Kew. i. 674 Engleriana, Taub. in Bot. Fahrb. xv. Beib1. n. 34 (1892) 4.- Bras.

Glazioviana, Taub̆.l. c.5.-- Bras

undulata, Hemsl, in Gard. Chron. (1892) ii. 396. Bras

CUSPIDARIA, DC. (Bignon.). - Ind. Kew. i, 674 .

bracteata, Bureau, ex Baill. Hist. des pl.x. (1888) in nota $5 .=$ Setilobus bracteatus, Baill.

corymbifera, Baill. ex K. Schum. in Engl. e Prant1, Natürl. Pflanzenfam. iv, 3b, (1894) 216 $=$ trifoliata $D C$

hibiscifolia, Bureau, in Baill. Hist. des pl.x. (1888) 29 $(=$ Bignonia hibiscifolia, Cham.). - Bras.

pulciiella, Baill. 1. c. in nota = Arrabidaea pulchella, Bureau.
CUSPIDARIA

ulchella, $K$. Schum, in Engl. et Prantl, Natiurl. Pflanzenfam. iv. 3b(1894)216(an praec.?).-Bras.

CUSSAMBIUM, Rumpf, = Schleichera Will. (Sapind.).

oleosum, Kuntze, Rev. Gen. (1891) $143=\mathrm{S}$. trijuga, Willd.

CUSSONIA, Thunb. (Aral.). - Ind. Kew. i. 674 chartacea, Schinz, in Bull. Herb. Boiss. ii. (1894) 211. - Natal.

Holstii, Harms, ex Engl. in Abh. Preuss. Akad. Wiss. (1894) 64; et in Pflanzenw.-Ost-Afr. C (1895) 298. - Afr. trop. or.

lanceolata, Harms, l. c. A (1895) 130 nomer. Afr. trop. or.

GUTANDIA, Willk. (Gramin.).- Ind. Kew. i.

divaricata, C. Richt. Pl. Europ. i (1889) $78=$ divaricata, Benth.

memphitica, C. Richt. 1. c. 77 (= C. memphitica, Benth.). = scleropoides, Willk.

GUVIERA, DC. (Rubiac.), - Ind. Kew. i. 675. physinodes, K. Schum. in Engl. et Prantl, Natürl. Pfanzenfam. iv. 4.(1891) 94.-Gabon.

GYAMOPSIS, DC. (Legumin.), - Ind. Kew。i. 675.

serrata, Schinz, in Verh. Bot. Ver. Brand. xxx. (1888) 161. - Afr. austro-occ. extratrop.

tetragonolobus, Taub, in Engl, et Prantl, Natürl. Pflanzenfam. iii. 3. (1894) 259 ( = Psoralea tetragonoloba, Linn.) = psoraloides, $D C$.

GYANANDRIUM, Stapf, in Hook. Icon. pl, xxv. (1895) t. 2419. MELASTOMACEAE guttatum, Stapf. l. c. - Borneo. rufum, Stapf, $l, c$. sub t. 2419. - Borneo.

GYANANTHUS, Wall. (Campanul.). - Ind Kew.i.

Delavayi, Franch. in Morot. Fourn. de Bot. i. (1887) 280. - ( =C, barbatus, Franch.). - Yunnan. longiflorus, Franch.l. c. - Yunnan? macrocalyx, Franch.l.c. 279. - Yunnan. petiolatus, Franch. in Bull. Soc. Phil. Paris, Sér VIII. iii. (1891) 147. - China occ

GYANASTRUMI, Oliver, in Hook, Icon. pl. xx (1891) t. 1965. HAEMODORACEAE.

cordifolium, Oliver, $l$. $c$ - Afr. trop. occ

GYANEA, Gaudich. (Campanul.). - Ind. Kew.i.

acuminata, Hillebr. Fl. Haw.Isl. (1888)254 ( $=$ Delissea acuminata, Gaudich.). - Ins. Sandvic.

angustifolia, Fillebr. l. c. $253(=$ D. angustifolia, Presl). - Ins. Sandvic.

arborea, Hillebr. l. c. 261. - Ins. Sandvic,

asplenifolia, Hillebr.l.c. $260(=$ Delissea asplenifolia, Mann). - Ins. Sandvic.

atra, Hillebr, l. c. 263. - Ins. Sandvic.

comata, Hillebr. l. c. 256. - Ins. Sandvic

coriacea, Hillebr. l. c. $254(=$ Delissea coriacea, A. Gray). - Ins. Sandvic.

ferox, Hillebr. l. c. 259. - Ins. Sandvic.

fissa, Hillebr. l. c. 255 (= Delissea fissa, Mann).Ins. Sandvic.

Gibsonii, Hillebr, l. c. 263. - Ins. Sandvic

hirtella, Hillebr. l. c. 255. ( = Delissea hirtella, Mann). - Ins. Sandvic.

holophylla, Hillebr. l. c. 257. - Ins. Sandvic.

Kunthiana, Hillebr.l.c. 264 ( = Delissea Kunthiana, Gaudich. ?). - Ins. Sandvic.

macrostegia, Hilleb. l. c. 263. - Ins. Sandvic

Mannii, Hillebr. l. c. 253 (= Delissea Mannii, W.T. Brigham). - Ins. Sandvic.

procera, Hillebr. b. c. 262. - Ins. Sandvic

obtusa, Hillebr. l. c. $256(=$ Delissea obtusa, A. Gray). - Ins. Sandvic

platyphylla,. Hellebr. $l_{0} c_{0}(=D$. platyphylla, A. Gray), - Ins, Sandvic.

recta, Hillebr. l. c. $255(=D$. recta, Wawra. $)$. Ins. Sandvic. 


\section{GYANEA}

scabra, Hillebr. Fl. Haw. Isl. (1888) 256. - Ins. Sandvic

solanacea, Hillebr. l. c. 259. - Ins. Sandvic.

solenocalyx, Hillebr. l. c. 258. - Ins. Sandvic.

GYANELLA, Linn. (Haemodor.). - Ind. Kew. i. 675

racemosa, Schinz, in Bull. Herb. Boiss, iii. (1895) 394. - Afr, austr.

GYANOGARPUS, F. M. Bailey, Rep. Exped. Bellenden-Ker, (1889) 55. PROTEACEAE.

Nortoniana, F. M. Bailey, l. c. - Austral.

CYANOPHYLLUM, Naud. = Miconia, Ruiz et Pav. (Melastom.)

aspersum. L. Lind. ex Gard. Chron. (1893) i. 475 et ex Rev. Hortic. (1893) 339, - Am. trop

CYANOTIS, D. Don (Commelin.). - Ind. Kew. i. 676.

Dybowskii, Hua, in Bull. Mus. Paris, i. (1895) 122 - Congo gall.

somaliensis, C. B. Clarke, in Kew Bull. (1895) 229. - Reg. Somal.

CYATHISCUS, Van Tiegh. in Bull. Soc. Bot. Fr xli. (1894) 538 = Loranthus, Linn.

nodiflorus, Van Tiegh. 1. c. $539=$ L. nodiflorus, Ther

productus, Van Tiegh. 1. c. = L. productus, King.

CYATHOGALYX, Cham. (Anonac.). - Ind. Kew i. 676

virgata, King, in Journ. As. Soc, Beng. 1xi. (1892) II. 28 = Cananga virgata, Hook. f. et Thoms.

CYATHOGLINE, Cass. (Compos.). - Ind. Kew. purpurea, Kuntze, Rev. Gen. (1891) $333=$ lyrata,

CYATHOPUS, Brongn, et Gris (Epacrid.).-Ind. Kew. i. $67 \%$.

sikkimensis, Stapf, in Hook. Icon. pl. xxv. (1895) t. 2395. - Reg. Himal.

CYATHOSTEMMA, Griff. (Anonac.). - Ind. Kew, i. 677

acuminatum, King, in fourn. As. Soc. Beng. Ixi. (1892) I. 4 et in Ann.Gard.Calc.I. 13 t.41-Perak. Hookeri, King. ll. ca. 61 et 10 t. 40. - Malaya.

Scortechini, King. $l l . c c .61$ et 12 t. 38.- Malaya.

Wrayi, King. ll. cc. 61 et 12 t. 39. - Malaya,

CYATHULA, Lour. (Amarant.). - Ind. Kew. i. 677.

crispa, Schinz, in Bot. Fahrb. xxi. (1895) 188. Transv.

erinacea, Schimz, l.c. 189; et in Engl. Pflanzenw, OstAfr. C (1895) 173. - Afr. trop. or.

lanceolata, Schinz, $l i . c c .188$ et 173. - Afr, trop. or. orthacantha, Schin\%, in Engl. et Prantl, Natürl. Pfanzenfam. iii. Ia. (1893) 108 ( = Pupalia orthacantha, Hochst.). - Abyss.

GYBIANTHUS, Mart. (Myrsin.). - Ind. Kew, i. 677.

collinus, S. Moore, in Trans. Linn. Soc. Ser. II. iv. (1895) 391. - Bras.

GYBISTAX, Mart. (Bignon.). - Ind. Kew, i. 677. Sprucei, K. Schum, in Engl. et Prantl, Natürl. Pfanzenfam. iv. 3b (1894) 240. - Peruv.

subtomentosa, $K$. Schum. l. c. - Bras.

CYCAS, Linn. (Cycad.). - Ind. Kew. i. 67\%

Béddomei, Hort, ex Hook. f. Fl. Brit. Ind. v. (I888) $650=$ circinalis, $\operatorname{Linn}$

Bellefonti, L. Lind, et Rodig. in Illustr. Hortic. xxxiii. (1886) 27 t. 586. - Tonk

rillosa, Herb. Van Royen, fide A. DC. ex Th. Dur. et Schinz, Consp. Fl. Afr. v. 1894 (1895) 957 in syn. = Encephalartos caffer, Miq. var.
GYGLAMEN, [Tourn.] Linn. (Primul.); - Ind. Kew.i. 678.

alpinum, Hort. Dammann, ex Gartenfl. (1892) 526. - Hab. ?

Pentelici, F. Hildeb. in Bot. Fahrb. xviii, Beibl. n. 44 (1894). - Graecia.

punicum, Pomel, in Bull. Soc. Bot, Fr, xxxvi. (1889) 356. - Tunet.

rotundifolium, St Lager, in Cariot, Etud. des fl. ed. 8. ii. (1889) $573=$ europaeum, Linn.

saldense, Pomel, in Bull. Soc. Bot. Fr. xxxvi. (1889) 354; et in Batt. et Trab. Fl.de l'Algérie (Dicot.) (1889, 720 = africanum, Boiss. et Reut.

tauricum, Hort.Dammann, ex Gartenf. (1892) 526. - As. min.

CYCLAMINUS, [Hall.] Aschers, in Ber, deutsch. bot Gesells, x. (1892) $235=$ Gyclamen, Tourn (Primul.).

coa, Aschers. 1. c. = C. coum, Mill.

europaea, Aschers. 1.c. $(=$ Cyclaminus europaeus, Scop.) $=$ C. europaeum, Linn

graeca, Aschers, 1. $\mathrm{c}=\mathrm{C}$ graecum, $\mathrm{I}_{\mathrm{inz}}$

neapolitana. Aschers. 1. c. $=$ C. neapolitanum, Ten. persica, Bonnet, in Morot, Journ. de Bot. vii. (1893) $195=$ seq.

persica, Aschers. in Ber. deutsch. bot. Gesells. x. (1892) $235=$ C. latifolium, Sibth. et Sm.

repanda, Aschers, 1 c. = C. hederaefolium, Ait.

CYGLANTHERA, Schrad. (Cucurbit.). - Ind. Kew.1. 778 .

Donnell-Smithii, $\operatorname{Cogn}$. ex F. D. Smith, in Coult. Bot. Gaz. xx. (1895) 290. - Guatem.

micrantha, $\operatorname{Cog} n$. ex Rose, in Contrib. U. S. Nat Herb. iii. (1895) 319. - Mexic.

monospersna, T. S. Brandeg. in Proc. Calif. Acad. Ser. II. ii. (1889) $159=$ Brandegea Bigelovii, Cogn.

Pittieri, Cogn. ex Th. Dur, et Pitt. in Bull. Soc. Bot. Belg. xxx. 1891 (1892) 275. - Costarica.

Pringlei, Robins. et Seaton, in Proc. Am. Acad. xxviii. (1893) 106. - Mexic.

Rusbyi, Britton, in Bull. Torrey Bot. Club, xviii (1890) 284. - Bolivia.

Siemiradzkii, Szyszyl. in Diss. Cl. Math.-phys, Acad. litt. Cracov. xxix, (1894) 231. - Peruvia.

testudinea, T. S. Brandeg. in Proc. Calif. Acad. Ser. II. iii. (1891) 138. - Calif.

Tonduzii, Cogn, ex. Th. Dur, et Pitt. in Bull. Soc. Bot. Belg. xxx. 1891 (1892) 274. - Costarica.

GYGLANTHUS, Poit. (Cyclanthac.).- Ind. Kew.i. 678.

Godseffianus, Hort. Sander, ex Gard.Chron. (1892)i. 731. - Hab. ?

CYGLEA, Arn.(Menisperm.). - Ind, Kew. i. 678. elegans, King, in fourn. As. Soc. Beng. lviii. (1889) II. 387. - Penins. Mal.

madasascariensis, Baker, in fourn. Iinn. Soc xxii. (1887) 443. - Madag.

racemosa, Oliver, in Hook. Icon. pl. xx. (1890) t. 1938. - China.

CYCLOCHEILON, Oliver, in Kew Bull, (1895) $222=$ Holmskioldia, Retz. (Verbenac). somaliense, Oliver, 1. c.; et in Hook. Icon. pl. t. 2439 (somalense). - Afr, trop.

CYGLOLOMA, Moq. (Chenopod.). - Ind, Kew. i. 679

atviplicifolium, Coulter, in Mem. Torrey Bot. Club, v. (1894) 143; et in Contrib. U. S. Nat. Herb. ii (1894) 366 = platyphyllum, Moq.

CYGLOSTEMON, Blume (Euphorb.). - Ind. Kew. t. 680

aquifolium, S. Elliot, in fourn. Linn, Soc. xxix. (1891) 49. - Madag.

assamicus, Hook. f. Fl. Brit. Ind.v. (1887) 342.Reg. Himal.

calocarpus, Hook.f.l. c. 343. - Ins. Andam.

confertiflerus, Hook.f.l. c. 341. - Canara.

Curtisii, Hook.f.l. c. 343. - Penang.

ellipticus, Hook. $f . l, c .342$. - Ind. or
CYGLOSTEMON

glaber, Pax, in Bot. Fahrb. xv. (1893) 527. - Ins.

Griffithii, Hosk. f. Fl. Brit. Ind. v. (1887) 340.Reg. Himal.

Helferi, Hook.f. l. c. 343. - Ind. or.

Henriquesii, Pax, in Bolet. Soc. Brot. x. (1892) 158. - Ins. S. Thom

lancifolius, Hook.f. Fl. Brit. Ind. v. (1887) 340. Reg. Himal

nervosus, Hook. f.l. . .342. - Perak.

nitidus, Pax, in Bot. Fahrb. xv. (1893) 527.Ins. Comor.

GYGNIUM, E. Mey. (Scrophul.). - Ind. Kew. i. 680

ajugaefolium, Engl. Bot. Fahrb. xviii. (1894) 74. - Afr. trop. or.

Buchneri, Engl. l.c. 73. - Angola.

cameroonianum, Engl, Pflanzenw, Ost-Afr. C. (1895) $361=$ Rhamphicarpa camerooniana, Oliver.

camporum, Engl. Bot. Fahrb. xviii. (1894) 73. Afr. trop.

Carvalhi, Engl, Pflanzenw. Ost-Afr. C (1895) 360.Afr. trop, or

Herzfeldianum, Engl, in Abh. Preuss, Akad. Wiss. (1894) 58; et in Bot. Fahrb. xviii. (1894) $74=$ Rhamphicarpa Herzfeldiana, Vatke.

Heuglinì, Engl. Pfanzenw. Ost-Afr. C (1895) 361. - Afr trop or.

Meyeri-Johannis, Engl, in Abh. Preuss, Ahad. Wiss. 1891, ii. (1892) 383; et in Engl. Pflanzenw. OstAfr. C (1895) 361 (an C. Herzfeldianum, Eng1.?). - Afr. trop. or.

pratense, Engl. Pfanzenw. Ost-Afr. C (1895) 361, Afr trop. or.

recurvum, Engl. 1. c. = Rhamphicarpa recurva, Oliver.

servatum, Eng1. 1, c. $360=$ R. serrata, Klotzsch.

tubulosum, Eng1. 1. c. $361=$ R. tubulosa, Benth.

veronicifolium, Engl. 1. c。 $=\mathrm{R}$. veronicifolia, Vatke.

Volkensii, Engl. l. c. 360. - Afr. trop. or.

GYGNOGHES, Lindl. (Orchid.). - Ind. Kew. i. 680 .

chlorochilum, Rolfe, in Gard.Chron. (1888) i. 144 cum ic, in fourn. of Hort. (1888) 462 cum xylogr. et in Gard. and For. v. (1892) 88 [chlorochilon]. - Guiana, Venez.

glanduliferum, Rolfe, in Gard. and For.v. (1892) 90. - Mexic

peruvianum, Rolfe, in Lindenia, vii. (1891) 29 t. 301; et in Gard, and For. v. (1892) p. 90. - Peruvia. Rossianum, Rolfe, in Gard. Chron. (1891) i. 456; at in Gard. and For. v. (1892) 90. - Hab.?

versicolor, Reichb. f. in Gard. Chron. (1888) ii. 596 ; et in Gard, and For. v. (1892) 88. - Bras.

CYLINDROLEPIS, Boeck, in Bot, Centralbl. xxxix.(1889) $75=$ Mariscus, Gaertn. (Cyperac.). Rehmanniana, Boeck, in Bot. Centralbl, xxxix. (1889) $73=$ M. Rehmannianus, C. B. Clarke.

CYMBALARIA, Medik = Linaria, Mill. (Scrophul.).

Cymbalaria, Wettst. in Engl. et Prantl, Natiirl. Pflanzenfam. iv. 3b. (1891) $58=$ L. Cymbalaria, Linn.

hepaticaefolia, Wettst. 1. c. = L. hepaticaefolia, Spreng.

microcalix, Wettst. 1.c. = L. microcalyx, Boiss.

pallida, Wettst. 1. c. = L. pallida, Ten.

CYMBIDIUM, Sw. (Orchid.). - Ind. Kew. i. 682. Gammieanum, King et Pantling, in fourn. As. Soc. Beng. 1xiv. (1895) II. 339. - As. trop.

Humblotii, Rolfe, in Gard. Chron. (1892) ii. 8. Madag.

minimifolium, Thw. ex Hook. f. F1. Brit. Ind. vi. (1890) 37 in syn. = Sarcochilus minimifolius, Hook, $f$.

Munronianum, King et Pantling, in Fourn. As. Soc. Beng. 1xiv. (1895) II. 238. - As. trop.

pulcherrimum, Hort. Sander, ex Gard. Chron. (1891) ii. 712. - Ind. or. 
GYMBIDIUM

sikkimense, Hook. f. Fl. Brit. Ind. vi. (1890) 9. Reg. Himal.

Simonsianum, King et Pantling, in fourn. As. Soc. Beng. 1xiv. II. (1895) 239. - As. trop.

Tracyanum, Hort. ex Gard. Chron. (1890) ii. 702 et 718; et (1891) i. fig. 34 [Traceyanum] = grandiflorum, Griff.

Winnianum $x$, Hort. ex Reichenbachia, ii. 6 . (1894) t. 75. - Hybr. artef.

GYMBOPETALUM, Benth. (Anonac.). - Ind. Kew. i. 683.

odoratissimum, Rodr. in Vellozia, i. (1885-88) Sec. ediç. (1891) i. t. 1. - Bras.

stenophyllum, F. D. Smith, in Coult. Bot. Gaz. xx. (1895) 2. - Guatem.

CYMBOPOGON, Spreng. = Andropogon, Linn. (Gramin.).

circinnatus, Hochst. ex Hack, in DC. Monog. Phan. vi. (1889) $599=$ A. laniger, Desf.

GYMBOSEPALUM, Baker, in Kew Bull. (1895) 103. LEGUMINOSAE.

Baroni, Bakey, l. c. - Madag.

GYMOPTERUS, Rafin. (Umbellif.). - Ind. Kew. i. 684 .

acaulis, Rydberg, Bot. Surv. Nebr. iii. (1894) 38 $=$ glomeratus, $D C$.

decipiens, M. E. Jones, in Zoë, ii. (1891) $246=$ glomeratus, $D C$.

ibapensis, M. E. fones, l. c. iii (1893) 302.-Am. bor. occ.

Jonesii, Coult. et Rose, Rev. N. Am. Umbell. (1888) 80. - Utah.

megacephalus, $M, E$. fones, in Zoê, ii. (1891) 14. Arizona.

Newberryi, M. E. Jones, 1; c. iv. (1893) 47. $=$ Ferula Newberryi, S. Wats.

panamintensis, Coult: et Rose, ex Coville, in Contrib. U.S. Nat. Herb. iv, (1895) 116. - Calif.

Parryi, M. E. Jones, in Zoë, iv. (1893) 48 t. 25 $=$ C. Fendleri, A. Gray.

purpurascens, M. E. Jones, 1. c. iv. (1893) 277. $=$ montanus, Torr. et Gray, var.

utahensis, M.E. Fones, in Proc. Calif. Acad. Ser. II. v. (1889) 685. - Utah.

GYNANCHUM, Linn. (Asclepiad.). - Ind. Kew. i. 684 .

abyssinicum, K. Schum. in Engl, et Prantl, Natürl. Pflanzenfam. iv. 2. (1895) $253=$ abyssinicum, Decne.

acuminatifolium, Hemsl. in Fourn. Linn. Soc, xxvi. (1889) 104. - ( = Vincetoxicum acuminatum, Decne.). - China.

acuminatum, K. Schum. in Engl. et Prantl, Natïrl. Pfanzenfam. iv. 2 (1895) 253 ( = Cynoctonum ackminatum, Benth.). - Afr.trop. occ.

Adalinae, $K$. Schum. l. c. - Afr. trop. occ.

affine, Hemsl. in fourn. Linn. Soc. xxvi.(1889) 104.China.

altiscandens, $K$. Schum. in Abh. Preuss. Akad. Wiss. (1894) 64; et in Engl. Pfanzenw. Ost-Afr. C (1895) 324. - Afr. trop. or.

amplexicaule, Hemsl. in fourn. Linn. Soc. xxvi. (1889) 104. (=Vincetoxicum amplexicaule, Sieb. et Zucc.). - As. centr. et or.

arenosum, K. Schum. in Engl. et Prantl, Natürl. Pfanzenfam. iv. 2(1895) 252(= Orthosia arenosa, Decne). - Bras.

brevidens, N.E. Br. in Kew Bull. (1895) 25\%. Congo, Zambes.

canescens, K. Schum. in Engl. et Prantl, Natürl. Pflanzenfam. iv. 2(1895) $252=$ Vincetoxicum canescens, Willd.

complexum, N. E. Br. in Kew Bull. (1895) 256 et 337 = mossambicense, $K$. Schum

Eichleri, K. Schum. in Engl, et Prantl, Natiurl. Pflanzenfam. iv, 2 (1895) 253 (= Orthosia Eichleri, Fourn.). - Bras.

eurychitoides, K. Schum. l. c. - Madag.

Eurychiton, $K$. Schum. l.c. (= Cynoctonum eurychiton, Decne). - Madag.

\section{GYNANCHUM}

flavidens, N. E. Br. in Kew Bull. (1895) 256. Reg. Somal.

Fordii, Hemsl. in fourn. Linn. Soc. xxvi. (1889)

106. - China.

formosanum, Hemsl.l.c. (= Cynoctonum formosanum, Maxim.). - Formosa.

formosum, N.E. Br. in Kew Bull. (1895) 112. Peruvia, Ecuad.

fraternum, N.E. Br.l. c. 256. - Abyss.

fuscatum, K. Schum. in Engl, et Prantl, Natürl. Pflanzenfam. iv 2 (1895) 252 = Vincetoxicum fuscatum, Reichb.

grandifolium, Hemsl. in fourn. Linn. Soc. xxvi. (1889) 106. (= Vincetoxicum macrophyllum. Sieb. et Zucc.). - As. or.

hastifolium, N.E. Br. in Kew Bull. (1895) 297. Abyss.

hastifolium, K. Schum. in Engl. et Prantl, Natürl. Pfanzenfam. iv. 2(1895)253 [an praec.?]. - Abyss. Holstii, K. Schum. 1. c. - Afr. trop. or.

Huteri, K. Schum. 1. c. 252. = Vincetoxicum Huteri, Vis. et Aschers.

insulanum, Hemsl. in fourn. Linn. Soc. xxvi. (1889) 107. - ( = Cynoctonum insulanum, Hance $).-$ Hainan.

insulanum, K. Schum. in Engl, et Prantl, Natür1. Pflanzenfam. iv. 2 (1895) $253=$ praec.

japonicum, Hemsl. in Fourn. Linn. Soc xxvi. (1889)

107 ( = Vincetoxicum japonicum, Morr. et Decne.). - Corea, Japon.

kenowiense, K. Schum. in Engl. et Prantl, Natürl. Pflanzenfam. iv. 2 (1895) $252(=$ Vincetoxicum kenowiense, Wight $)=\mathrm{V}$. officinale, Moench.

laeve, K. Schum.l. c. - Java.

leucanthum, K. Schum. l. c. 253 fig. 73 g. - Madag. inearifolium, Hemsl. in fourn. Linn. Soc. xxvi. (1889) 107. - China.

madagascariense, K. Schum. in Engl. et Prantl, Natiur. Pfanzenfam iv. 2 (1895) 253.- Madag. mandshuricum, Hemst. in fourn. Linn. Soc. Xxvi.

(1889, 107 (=Vincetoxicum mands furicum, Hance). - China

medium, K. Schum, in Engl. et Prantl, Natürl. Pflanzenfam. iv. 2 (1895) $252=$ Vincetoxicum medium, Decne.

mensense, K.Schum. 1.c.253; et in Eng1. Pflanzenw.

Ost-Afr. C. 324 in obs. = V. mensense, Schreing

Meyeri, Schlechter, in Bot. Jahrb. xx. Beib1. n. 51 (1895) 2( = Cynoctonum Meyeri, Decne $)=$ V. Meyeri, Benth. et Hook, $f$.

minutiflorum, K. Schum. in Engl. et Prantl, Natürl. Pfanzenfam, iv. 2 (1895) 252. - Afr. or.

mongolicum, Hemst, in fourn. Limn. Soc. xxvi. (1889) 107 (= Vincetoxicum mongolicum, Maxim.). - China.

Mooreanum, Hemsl. l. e. $108(=\mathrm{V}$. chinense. S. Moore). - China.

mossambicense, $K$. Schum. in Engl. Pfanzenw. Ost Afr. C (1895) 323; et in Engl. et Prantl, Natür. Pfanzenfam. iv. 2 (1895) 254. - Afr. trop. or.

multiflorum, $K$. Schum.l.c. $252(=$ Orthosia multiflora, Fourn.). - Mexic., Bras.

natalitium, Schlechter, in Bot. Fahrb. xviii, Beibl. n. 45 (1894) 32. - Afr. austr.

nivale, G. Beck, in Ann. Naturh, Hofmus. Wien, ii.(1887) $\mathbf{I} 1$ = Vincetoxicum nivale, Boiss.et Heldr. obscurum, $K$. Schum. in Engl. et Prantl, Natïrl. Pfanzenfam. iv. 2 (1895) 253. - Angola.

pachyphyllum, $K$. Schum. l. c. $(=$ Cynoctonum pachyphyllum, Decne.).- Chili

parviflorum, K. Schum. 1. c. $252=\mathrm{V}$. parviflorum Decne.

petrense, Hemsl. et Lace, in fourn. Linn. Soc. xxviii. (1891) 326. - Belutch., Afghan

polyanthum, $K$. Schum. in Engl. et Prantl., Natürt. Pfanzenfam.iv. 2 (1895) 253. - Afr. centr.

purpureum, K. Schum. 1. c. $=$ roseum, $R . B r$.

repandum, $K$. Schum. l. c. $(=$ Cynoctonum repandum, Decne.). - Madag.

sarcostemmatoides, K. Schum. in Engl. Pflanzenw. Ost-Afr. C (1895)323; et in Engl.et Prantl, Natürl. Pflanzenfam.iv.2 (1895) 252. - Afr. trop. or.

schistoglossum, Schlechter, in fourn. Bot. xxxiii. (1895) 271. - Afr. austr.

stenophyllum, Hemsl. in fourn. Linn. Soc. xxvi. (1889) 108. - China.

\section{CYNANGHUM}

thesioides, K. Schum. in Engl. et Prantl, Natür1 Pflanzenfam. iv. 2 (1895) 252 = Vincetoxicum thesioides, Freyn.

tmoleum, K. Schum. 1. c. = V. tmoleum, Boiss.

umbrosum, $K$. Schum. l. c. $(=$ Orthosia umbrosa Decne). - Bras.

undulatum, K. Schum. l.c. (= Cyzoctonum wndulatum, Decne). - Chili.

urceolatum, $K$. Schum. l.c. $253(=$ Orthosia urceolata, Fourn.). - Bras.

vagum, N. E. Br. in Kew Bull. (1895) 25\%.Congo.

verticillatum, Hemst. in fourn. Linn. Soc. xxvi (1889) 109. - China.

volubile, Hemsl. l.c. $(=V$ incetoxicum volubile, Decne $)$ - Corea, Mandshuria.

Zeyheri, Schlechter, in 'Bot. Zahrb. xx. Beib1. n. 51 (1895) 3. - Afr. austr.

GYNARA, Vaill. (Compos.).- Ind. Kew. i. 684. aranitica, Post, in Bull. Herb. Boiss. i. (1893) 400. - Syria.

CYNOCRAMBE, Tourn. = Theligonum, Linn (Urtic.).

macrantha, Poulsen, in Engl. et Prant1, Natüri Pflanzenfam, iii. 1a (1893) $124=\mathrm{T}$. macranthum, Franch.

CYNOCTONUM, E. Mey. = Vincetoxicum, Moench (Asclep.).

acutifolium, Phil, in Anal. Univ. Chil. xe. (1895) 201. - Chili.

Mitreola, Britton, in Mem. Torrey Bot. Club, v. (1894) $258=$ Mitreola petiolata. Torr. et Gray.

CYNOGLCSSOSPERMUM, Siegesb. Fl. Petrop. (1736) 40, ex Kuntze, Rev。 Gen. (1891) $436=$ Echinospermum, Sw. (Boragin.)

affine, anisacanthum, brachycentrum, Bungei, capense, concavum, consanguinewm, cynosum, deflexum, diffu sum, diploloma, divaricatum, Lappula, latifoliwm, macranthum, marginatum, mexicanum, microcarpum. oligacanthum, patulum, Redowskii, semicinctum, semiglabrum, sessiliflorum, sinaicum, spathulatum, strictum, temue, virginicum, Kuntze, Rev. Gen. (1891) 436-37 = homonyma onnia Echinospermi.

caspicum, Kuntze, 1. c. $437=\mathrm{E}$. semiglabrum, Ledeb

cristatum, Kuntze, 1. c. = Paracaryum cristatum, Boiss.

cynoglossodes, Kuntze, 1. c. = E. cynoglossoides, Lehm.

echinophorum, Kuntze, 1. c. = Lappula echinophora, Kuntze

omphalodes, Kuntze, 1. c. = E. omphaloides, Schrenk. spinocarpum, Kuntze, 1. c. = E. Vahlianum, Lehm.

GYNOGLOSSUM, [Tourn.] Linn. (Boragin.). Ind Kew i 686

abyssinicum, Hochst, ex Engt. in Abh. Prenss. Akad. Wiss. 1891. ii. (1892) 353.- - Abyss.

Azocarti, Phit. in Anal. Univ. Chil. 1xv. (1884) 62, et xc. (1895) 553. - Chili.

heterocarpum, Kuntze, ex Wilik. Illustr. Fl. Hisp. ii. (1892?) 121 t. 160; et Suppl. Prodr. F1. Hisp. $166=$ arundanum, Coss

Hochstetteri, Vatke, ex Engl. in Abh. Prouss. Akad.

$W$ iss. 1891, ii. (1892) 353 nomen. - Abyss.

Johnstoni, Baker, in Kew Bull. (1894) 29. - Afr. trop. or.

punctatum, Borb. in Oest. Bot. Zeitschr, xxxviii (1888) 44. - Transsilv.

rotatum, Velen. in Sitzb. Boerm. Ges. Wiss. (1892) 3. - Bulo.

GYNOMETRA, Linn. (Legumin.). - Ind. Kew. i. 688 .

Glaziovii, Taub. in Flora, 1xxv. (1892) 76. - Bras. Lyallii, Baker, in Kew Bull. (1894) 344. - Madag. minutiflora, F. Mull. in Austral. Fourn. Pharm. (April 1886) 123; et ex Bot. Centralbl. xxyii. (1886) 21. - N. Guin.

ramifora, F. M. Bailey, Cat. Woods Queensi. (Lond. Col. Ind. Exhib. 1886) $24=$ Afzelia australis, Bailey. 
GYNORCHIS, Thou. (Orchid.). - Ind, Kew. i. 688

anacamptoides, Kraenzl. in Bot. Fahrb. xxii. (1895) 18. - Afr. trop, or

Baronii, Rolfe, ex S. Elliot, in fourn. Linn. Soc. xxix. (1891) 58. - Madag.

compacta, Reichib. f. in Flora, 1xxi. (1888) 149.Natal.

Cordemoyi, Frappier, ex Cordem. Fl. Ile Réun.(1895) 229. - Ins. Borbon.

elata, Rolfe, ex S. Elliot, in fourn. Linn. Soc, xxix. (1891) 58. - Madag.

pauciflora, Rolfe, 1. c. - Madag.

Volkensii, Kraenzl. in Bot. Fahrb. xxii. (1895) 18.Afr. trop. or.

CYNOSORCHIS, Thou. = Gynorchis, Thou. (Orchid.)

anacamptoides, Kränz1. in Eng1. Pflanzenw. OstAfr. C (1895) $151=\mathrm{C}$. anacamptoides, Kraenzl. angustipetala, Th. Dur. et Schinz, Consp. F1. Afr. v. 1892 (1893) $90=$ Cynorchis angustipetala, Ridl.

annottioides, Reichb. f, ex Th. Dur, et Schinz, 1. c. $=$ Cynorchis arnottioides, Reichb. $f$.

aurantiaca, Ridl, in Journ. Linn. Soc. xxii. (1886) 123. - Madag.

Baroniz, Th. Dur. et Schinz, Consp. Fl. Afr. v. 1892 (1895) $90=$ Cynorchis Baronii, Rolfe

Brauniana, Kraenzl. in Bot. Jahrb. xvil. (1893) 62. - Madag.

brevicornu, Th. Dur. et Schinz, Consp. F1. Afr. y, 1892 (1893) 90 = Cynorchis brevicornu, Redl.

calanthoides, Th. Dur. et Schinz, 1. c. = Cynorchis calanthoides, Kraenzl.

calcarata, Th. Dur. et Schinz, 1. c. = Cynorchis squamosa, $L$ indl.

elegans, Reichb.f. in Flora, 1xxi, (1888) 150; et in Gard. Chron. (1888) i. 424. - Madag.

glandulosa, Ridl. in Journ. Linn. Soc, xxii. (1886) 123. - Madag.

grandiflora, Th, Dur, et Schinz, Consp. Fl. Afr.v 1892 (1895) $91=$ Cynorchis grandiflora, Ridl.

hispidula, Th. Dur. et Schinz, 1. c.= Cynorchis hispidula, Ridl.

laxiflora, Th. Dur, et Schinz, 1. c. $(=$ Amphorchis laxiflora, Blume). - Ins. Borbon.

lilacina, Th. Dur. et Schinz, 1. c. $92=$ Cynorchis lilacina, Rzdl.

Lowiana, Reichb. f. in Flora, 1xxi.(1888) 150; et in Gard. Chron. (1S88) i. 424. - Madag.

occidentalis, Th. Dur, et Schinz, Consp. F1. Afr. v. 189 (1895) 92 (=Amphorchis occidentalis, Lind1.). - Afr. trop. occ,

parviflorx, Reichb. f. ex Th. Dur. et Schinz, 1. c 92 in obs. - Ins. Borb.

Ridleyi, Th. Dur. et Schinz, 1. C. ( $=$ Amphorchis lilacina, Rid1.). - Madag.

speciosa, Ridl. in Journ. Linn. Soc. xxii. (1886) 122. - Madag

stenoglossa, Kraenzl. in Bot. Jahrb. xvii. (1893) 63. - Madag.

tenella, Ridl, in Journ. Linn. Soc, xxii. (1886) 124. Madag.

Volkensi, Kraenzl, in Engl. Pflanzenw. Ost-Afr.C (1895) 151. - Afr. trop. or

CYNOSURUS, Linn. (Gramin.). - Ind. Kew. i. pygmaeus, Porta, in Nuov. Giorn. Bot. Ital. xix. (1887) 322. - Ins. Balear.

GYPELLA, Herb. (Irid.). - Ind. Kew. i. 689. linearis, Baker, Handb. Irid. (1892) $65(=$ Moraea linearis, $\mathrm{H}$. B. et $\mathrm{K}$.). - Venez.

CYPERELLA, Kramer, Tentam. bot. (1744) 41 = Luzala, DC. (Juncac.).

campestris, Mac Mill. Metasp. Minnes. (1892) 143 $=\mathrm{L}$. campestris, $D C$.

GYPERUS, [Mich.], Linn. (Cyperac.). - Ind. Kew. i. 689.

Adansoni, C. B. Clarke, in Th. Dur. et Schinz. Consp. Fl. Afr.v. 1894 (1895) 546. - Senegal.

alboviridis, C. B. Clarke, ex S. Elliot, in fourn Linn. Soc. xxix. (1891) 62. - Madag.

\section{GYPERUS}

alpestris, K. Schum. in Engl. Pflanzenw. Ost-Afr. C (1895) 122. - Afr. trop. or.

amomodorus, $K$. Schum. l. c. - Afr. trop. or.

Andreanus, Maury, in Morot, fourn. de Bot. ii. (1888) 393. - Ecuad.

Arechavaletae, Boeck. Cyp. Nov。 i. (1888) 9. Urug.

arrhizus, Boeck. ex C. B. Clarke, in Th. Dur. et

Schinz, Consp. Fl. Afr. v. 1894 (1895) 577 $=$ sphaerospermus, Schrad.

atroviridis, C. $B$. Clarke, 1. c. 548. - Fernando-Po. aurescens, Boeck. Cyp. Nov. i. (1888) 8. - Reg. Argent

Baikiei, C. B. Clarke in Th. Dur. et Schinz, Consp. Fl, Afr. v. 1894 (1895) 550. - Afr. trop. occ.

Balansae, Maury, in Mèm. Soc. Sc.phys. Genève, xxxi. (1890) 130 t. 39. - Parag.

betschuanus, Boeck. in Bot. Fahrb.xi. (1890) 406.Afr. austr.

bivadiatus, Boeck. in Kneuck. Aligem. Bot. Zeitschr. i. (1895) 186 (= Pycreus, sp.). - Bras.

Blodgettii, Britton, in Bull. Torrey Bot. Club, xvii. (1890) 316. - Am. bor

Bolusii, Boeck. ex C. B. Clarke, in Th. Dur. et Schinz, Consp. F1. Afr. v. 1894 (1895) $585=$ Mariscus Bolusii, C. B. Clarke.

Bonianus, Boeck. in Kneuck. Allgem. Bot. Zeitschr. i. (1895) $\mathbf{1 8 6}$ (= Pycreus, sp.). - Tonk.

Botteri, Boeck. in Kneuck. 1. c. 227. - Mexic.

brunneo-vaginatus, Boeck. in Bot. fahro. xi. (1890) 407. - Afr. austr.

brunnescens, Bocik. Cyp. Nov. ii. (1890) 3.Singap.

Buchanani, Boeck. l. c. i. (1888) 4,- Afr. trop. or.

Buchholzii, Boeck. l. c. 3. - Kamerun.

Buckleyi, Britton, ex Coult. in Contrib. U. S. Nat. Herb. ii. (1894) 461. - Am. bor. occ

Buettmeri, Boeck. Cyp. Nov. i. (1888) 3. - Afr. trop. occ.

bulbosus, Boeck. ex C. B. Clarke, in Th. Dur. et Schinz, Consp. Fl. Afr. v. 1894 (1895) $581=$ usitatus, Burch.

Cadamosti, Bolle, ex E. H. L. Krause, in Bot. Fahrb. xiv. (1892) 400. - Ins. S. Vinc.

calcaratus, S. Wats, in A. Gray, Man. N. Am. Bot. ed. $6(1890) 5 \% 0=$ pseudovegetus, Steud.

capitinduensis, Maury, ex M. Micheli, in Mém. Soc. Sc. phys. Genive, xxxi (1890) n. 1, 129 t. 38.Parag.

Carruthii, Wood, in B. B. Snith, Check list pl. Kansas, (1892) 26. - Kansas.

catharinensis, Boeck. Cyp. Nov, ii. (1890) 9. - Bras. celluloso-reticulatus, Boeck. in Kneuck. Allgem. Bot. Zeitschr. i. (1895) 202. - Bras.

ciliolatus, Boeck. Cyp. Nov. ii. (1890) 5. - Bras.

cinereus, Maury, ex M. Micheli, in Mém. Soc. Sc. phys. Genève, xxxi. (1890) n. 1, 127 t. 36 B.Parag

circinatus, Ridl. in foum. Linn. Soc. xxvii. (1890) 64 t. 2 fig. 1, 2。 - Ins. Fernando-Noronha.

Clarkeanus, K. Schum. in Engl. Pflanzenw. OstAfr. C (1895) $123=$ Mariscus Taylori, C. B. Clarke.

lavinux, C. B. Clarke, in Th. Dur. et Schinz, Consp. Fl. Afr. v. 1894 (1895) 551. - Bornou.

compresso-triqueter, Boeck. Cyp. Nov. i. (1888) 10 $(=$ Mariscus, sp. $)$ - - Ins. Portoric.

cuspidatus, Baker, in fourn. Linn. Soc. xxii. (1887) 532. - Madag.

cylindricus, Britton, ex Coult. in Contrib. U. S. Nat. Herb. ii. (1894) 466. - Texas.

cylindrostachyus, Boeck. ex Tonduz, in Bull. Hevo. Boiss. iii. (1895) 451 nomen. - Costarica.

debilissimus, Baker, in fourn. Linn. Soc. xxii. (188\%) 532. - Madas

decipiens, Hillebr. Fl. Hav. Isl. (1888) 46\% - Ins. Sandvic

deremensis, K. Schum. ex Engl. in Abh. Prouss. Akad. Wiss. (1894) 50 ; et in Engl. Pfanzenw. Ost Afr. C (1895) 119. - Afr. trop. or.

discolor, Boeck. Cyp. Nov, i. (1888) 7. - Ins. S. Thomas.

Donianus, Boeck. in Kneuck. Allg. Bot. Zeitschr. i. (1895) 165. - Tonk.

Durandii, Boeck. 1. c. $185=$ Pycreus flavescens, P. Beauv.

\section{CYPERUS}

Dussii, Boeck. Cyp.Nov. ii. (1890) 37.-Ins. Martin. echinatus, Britton, in Bull. Torrey Bot. Club, xv. (1888) $99=$ Baldwinii, Tory

efoliatus, Boeck. in Kneuck. Allgem. Bot. Zeitschr. i (1895) 226. - Costarica.

Eggersii, Boeck. Cyp. Nov. i. (1888) 53. - Ins. Portoric.

elephantinus, C. B. Clarke, in Th. Dur, et Schinz, Consp. Fl. Afr. v. 1894 (1895) 559, - Natal. ferrugineus, Boeck. in Kneuck. Alloem. Bot. Zeitschr. i. (1895) 225. - Bras.

flexibilis, Maury, in Morot, fourn. de Bot. ii. (1888) 392. - Columb.

foliosissimus, Boeck. Cyp. Nov. ii. (1890) 7.-Reg. Argent.

Frerei, C.B. Clavke, in Th. Duy, et Schinz, Consp. Fl. Afr. v. 1894 (1895) 563. - Zanzibar.

friburgensis, Bock. Cyp. Nov, ii. (1890) 2. - Bras. frionensis, Boeck. l.c. 10.-Bras.

fulgens, C.B. Clarke, in Th. Dur. et Schnz, Consp. Fl. Afr. v. 1894 (1895) 563. - Afr. trop.

fusco-ater, Meinsh. ex Korshinshy, in

Petrop. xii. (1892) 406. - As. bor. or. Zeitschr. i. (1895) 226. - Bras.

galapagensis, Caruel, in Rendic. Accad. Lincei, v. (1889) 621. - Ins. Galapagos.

glaucophyllus, Boeck. Cyp. Nov. i. (1888) 4. - Afr. trop. or.

glaucoviridis, Boeck, in Allgem. Bot. Zeitschr. i. (1895) 230. - Afr. trop.

gondanws, Boeck. Cyp. Nov. i. (1888) $3=$ Mariscus diurensis, C. B. Clarke.

grandis, C.B. Clarke, in Th. Dur. et Schinz, Consp. Fl. Afr. v. 1894 (1895) 564; et ex Engl. Pfanzenw. Ost-Afr. C (1895) 121. - Zanzibar.

Grantii, Boeck. ex Engl. Pfanzenw. Ost-Afr. A (1895) 102 et 108. - Afr. trop. or.

grossarius, Heyne, ex C. B. Clarke, in Hook.

F1. Brit. Ind. vi. (1894) 590 in syn. = Pycreus sanguinolentus, C. B. Clarke.

haematocephalus, Boeck. ex C. B. Clarke, in Th. Dur. et Schinz, Consp. Fl. Afr. v. 1894 (1895) 564. - Afr. austro-or. extratrop.

Halei, Torr. ex Britton, in Bull. Torrey Bot. Club, xiii. (1886) 213. - Florida.

Hallii, Britton, l. c. 211. - Texas.

Harla, Boeck. ex Tonduz, in Bull. Herb. Boiss. iii. (1895) 451 nomen. - Costarica.

Hartii, Boeck. Cyp. Nov. i. (1888) $9=$ Mariscus flabelliformis, $H$. B. et $K$.

haspanoides, C. B. Clarke, in Th. Dur. et Schinz, Consp. Fl.Afr.v. 1894 (1895) 565.-Afr. aequat. or. hawaicensis, Hillebr. Fl. Haw. IsI. (1888) $470=$ Maxiscus hawaiiensis, Mann.

Hieronymi, Boeck. Cyp. Nov. i. (1888) \%, - Reg. Argent.

Hillebrandi, Boeck. ex Hillebr. Fl. Haw. Isl. (1888) 464. - Ins. Sandvic.

Hildebrandtii, $K$. Schum, in Engl. Pfanzenw. OstAfr.C (1895) 118. - Afr. trop. or.

hypochlorus, Hillebr. Fl. Hav. Isl. (1888) 468.Ins. Sandvic.

ibeensis, C. B. Clarke, in Th. Dur. et Schinz, Consp. Fl. Afr. v. 1894 (1895) 565. - Afr. trop. or.

indicus, Boeck. Cyp. Nov. i. (1888) 6.- Reg. Himal. intricato-ramosus, Boeck. in Kneuck. Allgem. Bot. Zeitschr. i. (1885) $186=$ Pycreus melanostachyus, C. B. Clarke.

Iwasakii, Makino, in Tokyo Bot. Mag. vi. (1892) 47. - Japon.

ixiocarpus, F. Mucll. in Trans. et Proc. Roy. Soc. Vict. xxiii. (April 1887) 55. - Austral.

faeggii, Boeck. Cyp. Nov. i. (1888) 2(= Pycreus. sp.). - Montevid.

Jenmani, C. B. Clarke, ex Morong, in Ann. N.Y. Acad. Sc. vii. (1893) 252. - Parag.

Kamphoeveneri, Boeck. Cyp. Nor. i. (1888) 5.Ins. Nicobar.

Kleinianus, Hochst. ex C. B. Clarke, in Th. Dur. et Schinz, Consp. Fl. Afr. v. 1894 (1895) 596 in syn. = Courtoisia cyperoides, Nees.

Krebsii, Boeck. Cyp. Nov. ii. (1890) 2. - Japon.

Krugii, Boeck. l. c. i. (1888) 8. - Ins. Portoric. Kunthianus, Hillebr. F1. Haw. Isl. (1888) 468. = Mariscus Kunthianus, Gaudich. 


\section{CYPERUS}

Kuntzei, Boeck, Cyp. Nov. i. (1888) I: (= Pycreus. sp.). - Anam

leptophyllus, Boeck. ex C. B. Clarke, in Th. Dur. et Schinz, Consp. Fl. Afr. V. 1894 (1895) 595 $=$ Mariscus vestitus, C. B. Clarke.

Jeucostachys, Boj. ex C. B. Clarke, 1. c. $653=$ Rynchospora adscendens, C. B. Clarke.

limbatus, Maury, ex M. Micheli, in Mém. Soc.Sc.phys. Genève, xxxi. (1890) n. 1, 129 t. 37. - Parag.

locuples, C. B. Clarke, in Th. Dur. et Schinz, Consp. Fl. Afr. v. 1894 (1895) 566. - Reg. Nigrit

lomatophyllus, Engl. Pflanzenw. Ost-Afr. A (1895) 125 [Quid ?.] - Afr. trop. or.

longifolius, Boeck, ex C. B. Clarke, in Th. Dur. et Schinz, Consp. Fl.Afr. v. 1894 (1895) 581= zambesiensis, C. B. Clarke.

longicaulis, Boeck, in Kneuck. Allgem. Bot. Zeitschr. i. (1895) 202. - Am. trop. ?

longespicatus, Boeck. l. c. 229. - Bras.

lucentinigricans, $K$. Schum, ex Engl. in Abh. Prenss. Akad. Wiss. (1894) 59 ; et in Engl. Pflanzent. OstAfr. $C(1895) 119$. - Afr. trop. or.

macrolepis, Boech. in Knenck. Allgem. Bot. Zeitschr. i. (1895) 226. - Costarica.

macropus, K. Schum. ex C. B. Clarke, in Th. Dur. et Schinz, Consp. Fl. Afr. v. 1894 (1895) $570=$ niveoides, C. B. Clarke.

manilensis, Boeck. ex Warb. in Bot. Fahrb. xiii (1891) 264. - Oceania

Mannii. C. B. Clarke, in Th. Dur. et Schinz, Consp. Fl. Afr. v. 1894 (1895) 568. - Kamerun, Fernando-Po.

mapanioides, C. B. Clarke, l. c. - Congo

maranguensis, $K$. Schum. in Engl. PAlanzenw. Ost Afr. C (1895) 120. - Afr, trop. or.

Marlothii, Boeck. in Bot. Jahrb.:xi. (1889-90) 407 $=$ Mariscus Marlothii, C.B. Clarke.

Martindalei, Britton, in Bull. Torrey Bot. Club, xv. (1888) 98. - Florida.

martinicensis, Boeck. Cyp. Nov. ii. (1890) 38. Ins. Martin.

maucensis, Hillebr. Fl. Haw. Isl. (1888) 469.-- Ins. Sandvic.

Mendoncae, Boeck. Cýp. Nov. ii. (1890) 9. - Bras. Minarum, Boeck.l. c. 5. - Bras.

mollipes, K. Schum. in Eng1. Pflanzenw. Ost-Afr. C (1895) $122=$ Mariscus mollipes, C. B. Clarke. monocephalus, Baker, in fourn. Linn. Soc. xxii. (1887) 531. - Madag.

montanus, Boeck. Cyp. Nov. ii. (1890) 4. - Reg. Argent

Montis-Sellae, K. Schum. ex Warb. in Bot. Fahrb. xviii. (1894) 186. - Oceania.

natalensis, Hort. ex Gard, and For. iii. (1890) 469 = Mariscus sparganifolius, C. B. Clarke? (conf. Kew Bull. [1891] Add. II, 40).

Niederleinianus, Boeck. Cyp. Nov. i. (1888) (= Pycreus, sp.). - Reg. Argent.

niveoides, C. B. Clarke, inTh. Dur. et Schinz, Consp. Fl. Afr. V. 1894 (1895) 570. - Congo.

Noronhae, Ridl, in fourn. Limn. Soc. xxvii. (1890) 66. - Ins. Fernando-Noronha.

Oatesii, C. B. Clarke, in Hook. f. Fl. Brit. Ind. vi. (1893) 618. - Burma.

ochrocarpus, K. Schum. in Engl. Pfanzenw. OstAfr. C (1895) 122. - Afr. trop. or.

uchrocephalus, C. B. Clarke, in Trans. Linn. Soc. Ser. II, iv. (1894) 53 ; et in Th. Dur. et Schinz, Consp. FI. Afr. v. 1894 (1895) 571. - Afr. trop occ.

oleraceus, Roxb. ex C. B. Clarke, in Hook. f. F1. Brit. Ind, vi. (1894) 611 in syn. = bulbosus, Vahl.

oxycarioides, Britton, ex Coult, in Contrib. U.S Nat. Herb. ii. (1894) 465. - Texas.

paniceus, Boeck. Cyp. Nov. ii. (1890) 38. - Ind. or.

parvispiculatus, Boeck. l. c. i. (1888) 7. - Ins. S. Thomas.

pectinatus, Hilsenb. et Boj. ex C. B. Clarke, in Th. Dur. et Schinz, Consp. Fl. Afr. v. 1894 (1895) 581 in syn. = uncinatus, Poir.

pergracilis, Boeck. Cyp. Nov. ii. (1890) I. - Reg. Argent.

Pethericki, C. B. Clarke, in Th. Dur. et Schinz, Consp. Fl. Afr. v. 1894 (1895) 571. - Afr. trop. bor. or.

\section{GYPERUS :}

phaeorhizus, K. Schum, in Engl. Pfanzenw. Ost Afr. C (1895) 119. - Afr. trop. or.

phleoides, Hillebr. Fl. Haw. Isl. (1888) $469=$ Mariscus phleoides, Nees.

Picardae, Boeck. in Knenck. Allgem. Bot. Zeitschr. i, (1895) 229. - Ins. Haiti.

Pittieri, Boeck, ex Tonduz, in Bull. Heyb. Boiss, iii. (1895) 6, nomen; et in Kneuck. Allgem. Bot.Zeitschr. i. (1895) 230. - Costarica.

platycaulis, Baker, in fourn. Linn. Soc. xxii. (1887) 532. - Madag.

protractus, C. B. Clarke, in Th. Dur. et Schinz, Consp. Fl. Afr. v. 1894 (1895) $572(=C$. tegetum. Balf. f.), - Ims. Socotra.

pseudocephalus, Boeck. ex Tonduz, in Bull. Herb. Boiss, iii. (1895) 464 nomen. - Costarica.

pseudo-Haspan, Makino, in Tokyo Bot. Mag. vi. (1892) 47. - Japon.

pseudo-niveus, Boeck, in Verh -bot, Ver. Prow. Brand. xxix. Abh. (1888) 45. - Afr. austro-occ. extratrop.

pseudosphacelatus, Boeck. Cyp. Nov. ii. (1890) \%.Ins. Trinit.

psendosurinamensis, Boeck. in Kneuck. Allgem. Bot. Zeitschr. i. (1895) 201 (= Pycreus, sp.). - Ins. Martin

punctorizs, Schrad., ex C. B. Clarke, in Th. Dur. et Schinz, Consp. Fl. Afr, v. 1894 (1895) $580=$ textilis, Thun b.

pungens, Boeck. ex Aitch, et Hemsl. in Trans, Linn. Soc. Ser. II iii. (1886) 191 _- Belutsch

purpureo-vaginatus, Boeck. Cyp. Nov. ii. (1890) 8. - Bras.

purpureo-variegatus, Boeck. l.c. 37.-- Ins. Martin. purpureus, Boeck. inz Verh. bot. Ver. Prov, Brand. xxix. Abh. (1888) 45. - Afr. austro-occ. extratrop.

quinquespicatus, Boeck. in Krenck. Allgem. Bot, Zeitschr. i. (1895) 226. - Bras.

Randuzii, Boeck. l.c. 228 [err. typ. = Tonduzii]. Costarica.

redolen's, Moury ex M. Micheli, in Mém. Soc. Sc. phys. Genève, xxxi. (1890) n. 1, 126 t. 36. - Parag. regiomontanus, Britton, in Contrib. Nat. Herb. i. (1895) 362 = Mariscus Haenkei, Prest

Rehmannianus, Boeck. ex C. B. Clarke, in Th. Dur. et Schinz, Consp. Fl. Afr. v. 1894 (1895) 542 = Pycreus Rehmannianus, C. B. Clarke.

rionensis, Boeck. Cyp. Nov, i. (1888) ]2. - Bras.

rufostriatus, C. B. Clarke, in Th. Dur. et Schine, Consp. Fl. Afr.v. 1894 (1895) 575. - Madag.

Rusbyi, Britton, in Contrib. U. S. Nat. Herb. ii. (1894) 461. - Texas, N. Mexic.

scaberrimus, Boeck. Cyp. Nov. ii. (1890) 3. - Bras.

Schaffneri, Boeck. in Bot. fahro. vii. (1886) 273.Mexic.

Schenckianus, Boeck. Cyp. Nov. ii. (1890) 4. Bras.

Schinzii, Boeck. in Verh. bot. Ver. Prov. Brand. xxix

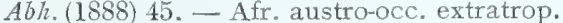

Schmitzianus, Boeck. in Knenck. Allgem. Bot. Zeitschr. i. (1895) 226. - Mexic.

senegalensis, C. B. Clarke, in Th. Dur. et Schinz, Consp. Fl. Afr. v. 1894 (1895) 577. - Senegal.

Serrae, Boeck. in Kneuck. Allgem. Bot. Zeitschr.i. (1895) 227. - Bras.

setiformis, Korshinsky, in Act. Hort. Petrop. xii (1892) 405 (= Pycreus, sp.). - As. bor. or.

Sintenisii, Boeck. Cyp. Nov. i. (1888) 12 (= Mariscus, sp.). - Ins. Portoric.

socialis, C. B. Clarke, in Th. Dur. et Schinz, Consp. Fl.Afr.v. 1894 (1895) 577 (=C. latifolius, Ridl.) - Angola.

Solmsii, Boeck. in Kneuck, Allgem. Bot. Zeitschr. i. (1895) 228. - Hab.?

somaliensis, C. D̃. Clarke, in Kew Bull. (1895) 229. - Reg. Somal.

spiculatus, Wood, in B. B. Smyth, Check list pl. Kansas (1892) 26. - Kansas.

spongioso-vaginatus. Boeck. Cyp. Nov. i. (1888) 5. - Bengal.

Stuhlmanni, C. B. Clarke, in Th. Dur. et Schinz, Consp. Fl. Afr. v. 1894 (1895) 578; et ex Engl. Pfanzenw. Ost-Afr. C (1895) 118.- Afr. trop. or. subaequalis, Baker, in fourn. Linn. Soc, xxii. (1887) 531. - Madag.

\section{GYPERUS :}

Daphyllus, Boeck, ex Schinz, in Verh. Bot. Ver. Brand, xxx. (1888) 139. - Afr. austro-occ. extratrop

subcapitatus, C. B. Clarke, in Hook. f. Fl. Brit. Ind. vi. (1893) 616. - Ind or

Swartzii, Boeck. Cyp. Nov. i. (1888) 10 in obs. $=$ Kyllingia filiformis, $S w$.

sylvicola, Ridl. in Bolet. Soc. Brot.v. (1887) 208 t. L. fig. 4. - Ins. S. Thom.

Tauberti, Boeck, in Kneuck. Allgem. Bot. Zeitschr. i. (1895) 185 (= Pycreus, sp.). - Bras.

Taylori, C. B. Clarke, in Th. Dur. et Sohinz, Consp. Fl. Afr, v, 1894 (1895) 578. - Mombassa.

tomaiophylhus, K. Schum, ex C. B. Clarke, 1. c. 594 ; et ex Engl. Pflanzenw. Ost-Afr. C (1895) 122 $=$ Mariscus tomaiophyllus, C. B. Clarke.

Tonduzianus, Boeck. in Knenck. Allgern. Bot. Zeitschr. i. (1895) 187. - Costarica.

Torrevi, Britton, in Bull. Torrey Bot. Club, xiii. (1886) $215=$ cylindricus, Britton.

tosaensis, Makino, in Tokyo Bot. Mag. vi. (1892) 47. - Japon.

trigonus, Boeck. Cyp. Nov. i. (1888) 11. - Ins.

Tridadensis, Boeck.Cyp. Nov. ii. (1890) 7. - Ins Trin.

tucumanensis, Boeck. in Bot. Fahrb. vii. (1886)274. - Argent.

Uleanus, Boeck. Cyp. Nov. ii. (1890) 5. - Bras. mbellatus, Hillebr. Fl. Haw. Isl. (1888) $470=$ Mariscus umbellatus, $\mathrm{Vahl}$.

umbilensis, Boeck. ex C. B. Clarke, in Th. Dur. et Schinz, Consp. Fl. Afr. v. 1894 (1895) $595=$ Mariscus umbilensis, C. B. Clarke.

Urbani, Boeck. Cyp. Nov.i. (1888) 10 (= Mariscus, sp.). - Ins, Portoric

vaginatissimus, $K$. Schrm. in Engt. Pflanzenze. OstAfr. C (1895) 121. - Afr, trop, or.

validus, Boeck. in Allgem. Bot. Zeitschr. i. (1895) 229. - Bras

varius, Boeck. in Knenck. Allgem. Bot. Zeitschr, i, (1895) 202: - Reg. Argent.

vialis, Ridl, in Fourn. Limn, Soc. xxvii. (1890) 65.Ins. Fernando-Noronha.

virens, Boeck. Cyp. Nov. ii. (1890) 6. - Reg. Argent.

viridispicatus, Boeck. l. c. 8. - Reg. Urug.

Wrightii, Britton, in Bull, Torrey Bot. Club, xiii. (1886) 215. - N. Mexic.

zambesiensis, C. B. Clarke in Trans, Limn. Soc. Ser. II. iv. (1894) 53 ; et ex Th. Dur. et Schinz, Consp. Fl. Afr. v. 1894 (1895) 581. - Afr. trop. austro-or.

zanzibarensis, C. B. Clarke, in Th. Dur. et Schinz, Consp. Fl. Afr. v. 1894 (1895) 58I. - Zanzibar.

GXPHIA, Berg. (Campanul.). - Ind. Kew. i. '700. tortilis, N. E. Br. in Kevw Bull. (1894) 356. - Afr. austr.

GYPHOKENTIA, Brongn. (Palm.). - Ind. Kew.

Heanei, Hort. ex Rev. Hortic. 1viii. (1886) 230. IIab.

GYPHOMANDRA, Mart. (Solan.). - Ind. Kew. 700

dichotoma, Rusby, in Mem. Toryey Bot. Chub, iv. (1895) 231 - Boliv.

heterophylla, Taub. in Bot. Falrb. xv. Beibl. n. 38 (1893) 16. - Bras.

CYPRIPEDILON, St-Lager, in Cariot, Etud, des fl. éd. 8 = Gypripedium, Linn. (Orchid.).

Marianus, Rouy, in Morot, Journ. de Bot.viii. (IS94) $58=$ Cypripedium Calceolus, Lim

GYPRIPEDIUM, Linn. (Orchid.). - Ind. Kew.

Adonis, $\mathcal{}$, Hort. Will. ex Williams, Cat, new pl. (1893) 7 ; et Orchid Alb. xi. (1895) t. 500. Hybr. artef.

Albertianum, X, J. Hye, in Gard. Chron. (1892) ii. 672; Rev. Hortic. Belg. xix. (1893) 3 cum ic. Hybr. artef. 


\section{GYPRIPEDIUM :}

album, Reichb. f. in Gard. Chron. (1887) i. 512. Hybr. artef.

Alcides $\times$, Rolfe, in Gard. Chron. (1891) i. 40. Hybr. artef.

Alfredi $X, \mathrm{~N} . \mathrm{E} . \mathrm{Br}$. in Gard. Chron. (1890) ii. 294. - Hybr, artef.

Alice X, N. E. Br. in Gard. Chron. (1890) ii. 294. - Hybr. artef.

almum X. Reichb.f. 1.c. (1887) i. 512. - Hybr. artef.

amabile $\times$, A. Bleu, in Rev. Hort. 1xiii. (1891) 406 cum ic. - Hybr. artef.

amandum $\times$. Reichb. $f$, in Gard. Chron. (1887) i 174. - Hybr. artef.

Amesianum $\times$, Williams, Cat new pl. (1887) 22; et Orchid Alb, viii. (1889) t. 340, - Hybr. artef.

Antigone $\times$, Rolfe, in Gard. Chron. (1890) ii. 716. - Hybr, artet.

apiculatum X. Hort. Veitch, ex Reichb. $\mathrm{f}$, in Gard

Chron. (1886) i. 617. - Hybr. artef.

Arnoldiae X. Hort. ex Gard. and For. viii. (1894) 425 fig. 67 (an seq.?). - Hybr. artef

Arnoldianum X. Hort. ex W. A. Manda, in Gard. Chron. (1890) ii. 632. - Hybr. artef.

Atys $\times$, Reichb, f. in Gard. Chron. (1888) ii. 6. Hybr. artef.

Aylingii X, L. Castle, in Journ. of Hortic. (1890) 480 fig. 74; Rolfe, in Gard. Chron. (1890) 1.792 fig. 131. - Hyb. artef.

Baconis $\times$, Kraenzl. in Gard. Chron. (1892) i. 170. - Hybr. artef.

Barteti $\times$. Hort. ex Carr in Rev Hortic, lviii. (1886) 84; God.-Lebœuf, L'Orchidophile (1886) 121 cum $x y \log x$. - Hybr. artef.

Beatrice $X$, N. E. Br. in Gard. Chron. (1889) ii. 266. - Hybr. artef.

bellatulum, Reichb. f. in Gard. Chron. (1888) i. 746 et 749 fig. 99 ; Lindenia, iv. (1888) t. 149. - As. trop.or.

Berenice X, Rolfe, in Gard. Chron. (1891) i. 136. - Hybr. artef.

Berggrenianum $\times$, Reichb.f. 1. c. (1888) i. 788.Hybr, artef.

Binoti, Hort ex Illustr. Hortic, xxxiv. (1887) 19. et I,'Orchidophile (1890) 111 cum icone = Selenipedium vittatum, Reichb. $f$.

Bragaianum $X$, L. Lind. in Lindenia, vi. (1890) 81 t. 279; et ex Gard. Chron. (1891) i, 406 et 784. - Hybr. artef.

Brownii X. Hort. ex Gard. Chron. (1891) ii. 49. Orchid Rev. i. (1893) 326. - Hybr. artef.

Buchananianum $x$, Hort. Measur, ex Rolfe, 1. c (1890) i. 73. - Hybr, artef.

Buchanianum $x$, Gower, in The Garden, xxxv. (1889) 8; Will. Orch. Grow. Man. ed. 7, 236.Hybr. artef.

burfordiense $X$, Reichb. $f$. in Gard. Chron. (1888) ii. 724. - Hybr. artef.

caligare X, Reichb. f. 1, c. (1888) i. 264. - Hybr. artef.

callosum. Reichb. f. l. c. (1886) ii, 326, (1887) i. 314 fig. 64, Lindenia ii. (1886) 53 t. 73. - Siam vel Cochinch.

calurum X, Reichb. f. 1. c. (1886) i. 73. - Hybr. artef

cambridgeanum, Hort. ex fourn. Hort. xiv. (1887) 376 t. 66; Will. Orch. Grow. Man.ed. 7 (1893) 238. - Hab.

barbati-Veitchianum $X$, Bleu, in Lindenia, v. (1889) 75 t. 238. - Hybr. artef.

Canhamiae X, Hort. ex Gard. Chron. (1887) ii. 746; et (1894) ii. 667 fig. 86. - Hybr, artef.

Cannartianum, Hort. ex Lindenia, iii. (1887) 93 t. $141\left(=C\right.$. Roebelinzi, Reichb. $\left.\mathrm{f}_{0}\right)=$ philippinense, Reichb. $f$.

cardinale $\times$, Reichb. f. in Gard. Chron. (1886) ii. 526; et (1890) i. 558; Orchid Alb. viii. (1889) t. 370. - Hybr, artef.

Carrievei $\times$, Hort. Gall. ex Le Monit. d'Hortic. (1887) 54; Will. Orch. Grow. Man. ed. 7, 239.Hybr, artef.

Cassiope X, Rolfe, in Gard. Chron.(1889) i. 200.Hybr. artef.

Castleanum X, Rolfe, 1. c. (1891) i. 39 et 70 ;

\section{GYPRIPEDIUM}

et in Reichenbachia, Ser. II. (1892) 97 t. 45 - Hybr. artef.

Celia ' ', Rolfe, 1. c. (1891) i. 104. - Hybr. artef

Ceres X, N. E. Br. I. C, 360, (1892) i. 214 - Hybr, artef.

Chamberlainianum, O'Brien, l.c. (1892) i. 234 ; et ex Rev. Hortic. (1892) $104 \mathrm{fig} .27$ et 28. N. Guin.

Charlesianum $\times$, Hort. ex Gard. Chron. (1894) ii. 430. - Hybr. artef.

Charlesworthii, Rolfe, in Orchid Rev, i. (1893) 303 ; Lindenia, x. (1894) 25 t. 443; Bot.Mag.(1895) t. 7416 . - Ind. or.

chelseense $\times$, Reichb. f. in Gard. Chron. (1888) ii. 407. - Hybr, artef.

chinense, Franch. in Morot, Journ. de Bot. viii (1894) 230. = Henryi, Rolfe.

chlorops $X$, Reichb, $f$, in Gard. Chron. (1888) i. 584. - Hybr. artef.

claptonense X Reichb.f.1. c. (1889) i. 168; Rev Hortic. (1891) 533 [claptoniense]. - Hyb. artef. Claudii $\times$, L. Linden, in Lindenia, ix. (1893) 29 t. 397 . - Hybr, artef.

Cleofatra X, Hort. ex Gard. Chron. (1892)i.458.Hybr. artef.

Clinkaberryanum X. Hort. ex O'Brien, 1. c. (1893) ii. 86. fig. 18. - Hybr. artef.

concinnum $\times$, Bull, Catal (1887) 16. - Hybr artef conco-Lawre, $\times$, Hort, ex Orchid Rev, ii. (1894) 339; Lindenia, ix. (1894) 51 t. 408; Orchid Alb. xi. (1895) t. 506. - Hybr. artef.

conspicum $\times$, Reichb. f. 1.c. (1888) i. 521; Will Orch. Grow. Man. ed. 7, 248. - Hybr. artef.

Constance X, N. E. Br. 1. c. (1890) ii. 294. Hybr. artef

Coppinianum $X$, Hort. ex Gartenfl. (1892) 183 nomen. - Hybr. artef.

Corningianum X. Hort. ex Garten Mag. (1891) 495 Orchid Rev. i. (1893) 327. - Hybr. artef.

corrugatum, Franch. in Morot, Fourn. de Bot. viii 1894) 251. - China.

Cowleyanum X, Hort. ex O'Brien, in Gard. Chron (1892) i. 72; Will. Orch. Grow. Man. ed. 7, 248 - Hybr. artef.

Cytheva X, Hort. ex Rolfe, 1.c. (1890) i. 72. Hybr. artef.

Dallemagnei $X$, Hort. ex Lindenia, ix. (1894) $5^{\circ}$ t. 411 . Hybr artef.

Daisyae $\times$, Hort. ex Gard. Chron. (1892) ii. 301 et ex Gard. and For, v. (I892) 463 fig. 79. Hybr. artef.

Deboisianum X. Hort. 1. c. (1890) ii. $747=$ Desboisianum, Hort.

delicatulum $\times$, Reichb. f. 1. c. (1887) ii. 552. Hybr. artef.

delicatum X, Hort. ex Will. Orch. Grow. Man, ed. 7, (1894) 251. - Hybr. artef.

Denisianum X, O'Brien, 1. c. (1894) ii. 118. Hybr, artef.

Desboisianum X, Ch.de Bosschere, in Gard. Chron. (1890) ii. 747 (Deboisianum); in Lindenia, vi (1890) 77 t. 27\%; et ex Gard. Chron. (1891) i. 731. - Hybr, artef.

Dibdin X, Hort. ex Gard. Chron. (1893) i, 162, Hybr,artef.

dilectum, Reichb. f. l. c. (1888) i. 330 [an hybr. spont.?. - Hab.

discolor X, Reichb. f. [ubi?] ex Will. Orch. Grow. Man. ed. 7 (1893) 253. - Hybr. artef.

doliare $\times$, Reichb.f. I. c. (1887) i. 447. - Hybr artef.

Doris $\times$, Hort. ex Rolfe, 1. c. (1890) ii. 716. Hybr. artef.

Edithae X, Kraenz1. 1. c. (1892) ii. 458. - Hybr. artef.

Electra X Rolfe, 1. c. (1888) 1. 297. - Hybr. artef. elegans, Reichb. f.in Flora, lxix. (1886) 560.-Tibet. Elinor X, N. E. Br. in Gard. Chron. (1890) ii. 38 Will. Orch. Grow. Man. ed. 7 (1894) 255. Hybr. artef.

Elliottianum, O'Bren (an Reichb. $f$. ?) in Gard. Chron. (1888) ii. 501 et 532: Iindenia iv (1888) $8^{\text {r7 }}$ t. 186; Orchid Alb. ix. (1891) t. 397. - Ins. Philipp.

enficldiense $X$, Hort. ex Gard. Chron. (1892) i. 88 . - Hybr. artef.

\section{GYPRIPEDIUN}

Engelhavdtae $\times$, L. Linden, in Lindenia, vi. (1890) 81 et 93 t. 285. - Hybr. artef.

Ernestianum $X$, Hort. ex Journ, of Hort. xiv. 1887) 375 fig. 6\%; Will. Orch. Grow, Man. ed. 7, 256. - Hybr. artef.

Eucharis $X$, Desbois, in Gard. Chron. (1893) i. 195; Will. Orch. Grow. Man. ed. 7 256. Hybr. artef

Euryale $\times$, Veitch, Man. Cyprip. (1889) 83; et ex Kew Bull. (1890) Add. ii. 43. - Hybr. artef. exul, O'Brien, in Gard. Chron. (1892) i. 522 fig. 77. - Nepal

Eyermannianum $\times$, Rolfe, 1. c. (1890) ii. 746; et ex Reichenbachia, Ser. II. i. (1892) t. 38 fig. 2. - Hybr. artef.

Fargesii, Franch. in Morot, fourn. de Bot. viii. (1894) 267. - China.

fascinatum $\times$, Hort. ex Rev. Hortic. Belg. (1894) 25. - Hybr. artef.

fasciolatum, Franch, in Morot, fourn. de Bot. viii. (1894) 232. - China.

Figaro X. O'Brien, in Gard. Chron. (1889) ii. 750. - Hybr. artef.

Fitchianum $X$, Will. New pl. catal. (1888) 20; et in Warn. et Will. Orchid Alb. viii. (1889) t. 350 .- Hybr. artef.

Fraseri $x$, "Reichb. f." ex Lindenia, vi. (1890) 29 t. 253. - Hybr. artef.

Galatea X. Rolfe, in Gard. Chron. (1888) i. 168. Hybr. artef.

Gaskellianum $\times$, Gower, in Garden (1890) 150; $=$ C. Niobe, Rolfe.

Germinyanum $\times$, Hort. Veitch, ex Reichb. f. in Gard. Chron. (1886) i. 200. - Hybr. artef.

Gibezianum $\times$, L. Linden, in Lindenia, ix. (1894) 85 t. 425. - Hybr. artef.

gigas $\times$,O'Brien, in Gard.Chron.(1892)i. 136; Journ. of Hort. xxiv, (1892) 257 fig. 42. - Hybr. artef. Godseffanum X, Hort. ex Gard. Chron. (1888) i. 296; et ex Rev. Hortic. Belg. (1892) 85. Hybr. artef

Gravesiae X, R. M. Grey, in Gard. Chron. (1894) i. 298 fig. 34. - Hybr. artef.

Henryi, Rolfe, in Kew Bull. (1892) 211. - China.

Hephaestus X, A. H. Kent, ex Gard. Chron. (1888) i. 425. - Hybr. artet.

Hera X, Rolfe, 1. c. (1890) i. 104 et 105; Will. Orch. Grow. Man. ed. 7, 264. - Hybr. artef. Hermione X. Hort. ex O'Brien, 1. c. (1893) ii. 682. - Hybr. artef.

himalaicum, Rolfe, ex Hemsl. in fourn. Linn. Soc. xxix. (1892) 319. - China occ., Sikkim, Nepal.

Hornianum X, Reichb. f. in Gard. Chron. (1887) 428. - Hybr. artef.

Horneri $x$, Hort. ex. Orchid Rev. ii. (1894) 80. Hybr. artef.

Houtteanum X, Hort. ex Gard. Chron. (1888) i. $561=\mathrm{C}$. Van Houtteanum, Hye.

Huybrechtsianum $\times$, Hort. Vervaet, ex Ch. de Bosschere, in Gard. Chron. (1892) i. 554; Will. Orch. Grow. Man. ed. 7. (1893) 206 [Huybrechtianum]. - Hybr. artef.

Hyeanum X, L. Linden et Rodigas, ex Gard. Chron. (1886) i. 567, 590 et 680 . - Hybr. artef. insigne, Ridl. l. .. (1891) ii. 94. - Nepal

Inspirator $X$, de Kerchove, in Rev. Hort. Belg. (1894) 25. - Hybr. artef.

Io $\times$, Reichb. f, in Gard. Chron. (1886) i. 488. Hybr. artef.

Isabelianum, Pucci, Les Cypriped. (1891) $123=$ Selenipedium Isabelianum, Rod.

fanus $X$, Hort, ex Gard, and For. viii. (1895) 64.- Hybr. artef.

foungianum $X$, Hort, ex Gartenfl. (1892) 183 (an. C. Youngianum, Rolfe?). - Hybr. artef.

funo X, N. E. Bro in Gard. Chron. (1891) i. 360. - Hybr. artef.

Kimballianum, L. Linden, in Iindenia, ii. (1886) 42 in nota. - Burma.

Kranevianum $\times$, Hort. ex Gartenfl. (1892) 183 nomen. - Hybr. artef.

Lathami X, Hort. ex Journ. of Hortic. (1888) 174. - Hybr. artef.

Lathamianum X, Reichb. f. in Gard. Chron. (1888) i. 360 ; et ex Gartenfl. (1889) 528 fig. 79. Hybr, artef. 


\section{GYPRIPEDIUM}

Laucheanum $X$, Hort. ex Gartenfl. (1892) 183 nomen. - Hybr. artef.

Laurae $\times$, Hort. ex Orchid Rev, ii. (1894) 80 . Hybr. artef.

Laurebel $x$, Hort. ex Gard. Chron. (1892) i. 502 560 et $561 \mathrm{fig} .82$; et ex Lindenia, ix. (1893) 49 t. $407=$ Laurebellum, Hort.

Laurebellum $\times$, Lawrence 1. c.(1892) i. 502 ; et (1892) i. 561.- Hybr. artef.

Lebaudyanum X, Hort. 1. c. (1895) ii. 90. - Hybr. artef.

Leda X. Hort. 1. c. (1892) i. 202. - Hybr. artef.

Lemoineanum $X$, Reichb. f. 1. c. (1886) i. 558 . Hybr. artef

Lemoinierianum $\times$, Reichb. f. 1. c. (1888) i. 712; et in Reichenbachia ii. t. 89. - Hybr. artef.

Leonae X, L. Linden, in Lindenia, viii. (1892) 51 t. 360. - Hybr. artef

Leysenianum $\times$, Hort. ex Rev. Hortic. Belg. xx. 1894) 169 cum ic. - Hybr, artef.

lineolare $\times$, Reichb. f. ex Gard. Chron. (1887) i. 447. - Hybr. artef

Littleanum X. Hort. 1. c. (1895) ii. 36.-Hybr. artef.

Leopoldianum $\times$, Hort. ex Gard.Chron.(1895) i. 333 - Hybr. artef.

Iucienianum $\times$, Hort. ex Lindenia, viii. (1892) 55. t. 362. - Hybr. artef.

luteum, Franch. in Nour. Arch. Mus, Paris, Sér. II. x. (1888) 88. - China.

Macfarlanei $\times$, Kraenzl. in Gard. Chron. (1891) ii. 300. - Hybr. artef.

macrochilum $\times$, Hort. 1. c. (1894) ii. 343. - Hybr artef.

Maeserelianum $\times$, Hort. ex Rodigas, in Illustr. Hortic. (1887) 23 t. 77 ; et (1889) 23 cum ic. Hybr. artef

Magdalana $\times$, Hort. ex O'Brien, in Gard. Chron. (1895) i. 228. - Hybr. artef.

Malyanum X, Hort. ex Gartenfl. (1892) 183 nomen. - Hybr. artef.

margaritaceum, Franch, in Bull. Soc. Phil. Paris, Sér. VII. xii. (1888) 141; et in Morot, fourn. d Bot. viii. (1894) 265; L'Orchidophile (1888) 368 cum. ic. - China.

marmoratum $\times$, Hort. ex Gard. Chron. (1887) 576 fig. 109. - Hybr. artef.

Massainum X, Hort. ex Weathers, 1. c. (1893) ii $267 \mathrm{fig}$. 48. - Hybr. artef.

Maynardi $\times$,Rolfe, 1.c.(1890) ii. 702 ; in Reichenbachia (1892) t. 43 fig. I; Will. Orch. Grow. Man ed. 7, (1893) 293. - Hybr. artef.

Measuresianum $\times$, Will. New pl. catal. (1887) 18 et 22 cum ic.; et Orchid Alb. vii. (1888) 304 Rev. Hort. Belg. (1888) 266 cum ic. - Hybr artef.

memoria-Moensi X, L. Linden, in Lindenia, viii. 1892) 53 t. 461; Will. Orch. Grow. Man. ed. 7 282. - Hybr. artef

micranthum, Franch. in Morot, fourn. de Bot. viii. (1894) 265. - China.

Minerva $\times$, Rolfe, in Gard. Chron. (1889) ii. 464 Will. Orch. Grow. Man. ed. 7. 283; God. Lebœuf, in L'Orchidophile (1890) 35. - Hybr. artef.

Minos $\times$. Hort. Veitch, ex Will, Orch. Grow. Man. ed. 7, (1893) 283. - Hybr. artef.

Miteananum, L. Lind. et Rodigas, in Lindenia, iv. 1887) 7 t. 146; et in Gard. Chron. (1888) ii. 326 = ciliolare, Reichb. $f$

Moensianum, Hort. ex Lindenia, iii. (1887) 69 t. 129 et in Gard. Chron. (1888) i. 561. - Ins. Philipp. Murillo X, Desbois, in Gard. Ghron. (1893) i. 163 - Hybr. artef.

neo-guineense, L. Linden, (1888) i. 505 nomen $=$ Rothschildianum, Reichb. $f$.

Nicholsonianum $\times$, Hort. ex Orchid Rev. i. (1893) 374 [sphalm. Nicholsianum] et 379.-Hyb.arter

Niobe X, Rolfe, ex Gard. Chron. (1890) i. 91 Orchid Alb. x. (1893) tab. 438. - Hybr, artef nitidissimum X, Reichb. f. 1. c. (1888) ii. 6; ; et in Reichenbachia, Ser. II, i. t. 2\% - Hybr, artef

Numa X, Hort. 1. c. (1890) i. 608; et $(1890)$ ii. 7 [Numae]. - Hybr. artef.

obscurum X, Reichb. f. 1. c. (1887) i. 8.-Hybr. artef

Oenone X, Hort. ex Rolfe, 1. c. (1890) i. 260; Will. Orch. Grow. Man. ed. 7287 . - Hybr, artef.

\section{CYPRIPEDIUM}

Clenus X, Hort, Measures ex Gard. Chron.(1895) i.

613. - Hybr, artef.

orbum $\times$, Rolfe, 1. c. (1887) ii. 772 - Hybr, artef

ornatum $\times$, Hort. 1. c. (1892) i, 428. - Hybr artef. orphanorum $x$. Hort. 1. c. (1887) ii. 747 [an seq. ?] - Hybr. artef.

Orphanum $\times$, Hort. Veitch, ex Reichb. f. 1. (1886) ii. 166; Orchid Alb. x. (1893) t. 455. Hybr. artef.

Orpheus $\times$, Rolfe, 1.c. (1891) i. 39: Will. Orch. Grow. Man. ed. 7, 288. - Hybr, artef

Pageanum $X$, Reichb. f. 1. c. (1888) ii. 164. Hybr. artef.

Pallas X, N. E. Br. 1. c. (1891) i. 360. - Hybr artef.

Paris $\times$, Rolfe, in Orchid Rev, i. (1893) p. 88 fig. 6. - Hybr. artef.

Parksianum X, Hort. ex Gard. Chron. (1892) i. 88 - Hybr. artef.

pavoninum $\times$, Reichb. f. 1. c. (1888) i. 264. Hybr. artef.

Pardeti, Hort. ex Rev. Hort. lviii. (1886) 85 in obs. = Barteti, Hort

Peetersianum $x$, Reichb. f. in Gard. Chron. 1. c. (1888) i. 331. - Hybr, artef.

Penelaus $x$, Hort. ex Journ. of Hort, xxvi. (1892) 319 fig. 45; et ex Will. Orch. Grow. Man. ed. 7 290. - Hybr artef.

Peteri $\times$, Reichb.f. 1. c. (1887) i. 577 fig. 110. $\mathrm{Hybr}$. artef

picturatum X, Hort, ex Gartenfl. (1892) 183; et ex Will. Orch. Grow. Man. ed. 7 (1893) 290. Hybr. artef,

Pitcherianum, Manda, in Am. Florist, iii. (1887) $178=$ C. Argus, Reichb. $f$.

Pitcherianum X. Reichb. f. in Gard. Chron. (1888) i. 42 ; et (1889) i. 72 fig. 10 ; Orchid Alb. (1893) t. 453. - Hybr. artef.

pleistochlorum X, Reichb. f. 1. c. (1887) ii. 552.Hybr. artef.

plunerum $x$, Reichb. f. 1. c. (1887) i. 40. - Hybr artef.

politum $\times$. Hort. 1. c. (1887) i. 764 fig. 143; et ex Gartenfl. (1887) 499. - Hybr. artef.

Pollettianum $x$, Rolfe, in Journ. of Hort xxiii. 1891) 559 t. 101; in Reichenbachia, (1892) t. 43 fig. 2. - Hybr, artef.

polystigmaticum X, Reichb. f. 1. c. (1888) ii. 407.Hybr, artef.

porphyrospilum, Hort. ex Will. Orch. Grow. Man. ed. 7 (1893) $293=$ pycnopterum, Reichb. $f$

praestans, Reichb. f. in Gard. Chron. (1886) ii. 776; et (1887) ii. 242; et in Illustr. Hortic. xxxii (1887) 35 et 73 t. 26. - Borneo.

Pryorianum $\times$, Hort. ex Will. Orch. Grow. Man. ed. 7 (1893) 293. - Hybr. artef.

pusillum, Rolfe, in Kew Bull. (1892) 211. - Florida. regale $X$, Bull, Catal. (1887) 10. - Hybr. artef.

Richardsoni X, Hort. ex Will. Orch. Grow." Man. ed. 7 (1893) 295. - Hybr. artef.

robustius X, Reichb. f. in Gard. Chron. (1889) i. 394; Will. Orch. Grow. Man. ed. \%, 295. Hybr. artef.

Reichenbachianum, Hort ex Lindenia, iii. (1887) 90. $=$ longifolium, Warn. et Reichb. $f$

Robinianum $\times$, Hort. ex Orchid Rev. ii. (1894) 79. - Hybr, artef.

Robinsonianum $\times$ Hort. ex Gartenfl. (1892) 183 nomen. - Hybr. artef.

Rothschildianum, Reichb. f. in Gard. Chron. (1888) i. 457 et 554; Hook. f. in Bot. Mag. (1890) t. 7102 - N. Guin.

rubrum X., Hort. ex Will. Orch. Grow. Man. ed. 7 (1894) 296. - Hybr. artef.

Sanderae $\times$, Hort. ex Rev. Hortic. (1895) 249 et $250=$ Sanderianum, Reichb. $f$.

Sanderianum $\times$, Reichb. $f$. in Gard. Chron. (1888) ii. 273; et in Reichenbachia, i. t. 3. - Hybr artef.

Saundersianum $\times$, O'Brien, 1. c. (1888) ii. 40\%. Hybr.artef

Savageanum $\times$, Reichb. f, 1. c. (1888) ii. 407.Hybr. artef.

Schroederae $\times$, Reichb, $\mathrm{f}$. in Orchid Alb. v. (1886) t. 196: Veitch, Man, Orch, Pl. iv. 105. - Hybr. artef.

\section{GYPRIPEDIUN}

Seegerianum $X$, Hort. ex Will. Orch. Grow. Man. ed. $7(1894) 300=$ Siegerianum, Hort. siamense, Rolfe, in Gard. Chron. (1890) i. 161.Siam.

sibyrolense $X$, L. Linden, in Illustr. Hort, xi. (1893) 69 t. 579. - Hybr artef.

Siegerianum $\times$, Hort, ex Gard. Chron. (1894) ii. 431. - Hybr. artef.

Simoni $X$, Hort. ex Rev. Hort. (1890) 190. Hybr. artef.

Smithii $\times$. Hort. ex Will. Orch. Grow. Man. ed. 7 (1893) 301. - Hybr. artef.

southgatense $x$, Hort. ex Journ. of Hort. xxv. (1892) 39 fig. 6. - Hybr. artef.

Statterianum $\times$. Hort. ex Journ. of Hort. xxvii. (1893) 417 fig. 611; et ex Will. Orch. Grow. Man. ed. 7 (1893). - Hybr. artef.

stenophyllum ;, Reichb. f. ex Will. 1. c. 303.- Hybr. artef.

superciliare $\times$, Hort. ex Gard. Chron. (1887) ii. 747; Will. 1. c. 305. - Hybr. artef.

Swinburnei $\times$, Hort. 1. c. (1892) i.88 et 136 . Hybr. artef.

Sylvia X, Hort. ex O'Brien, 1. c. (1893) i. 682.Hybr, artef.

Taganti $\times$, God.-Lebœuf, in L'Orchidophile(1887) 64. - Hab. ? vel Hybr. artef

Tautzianum X, Hort. ex Gard. Chron. (1886) ii. 681; et Reichenbachia, ii. (1889) t. 65. - Hybr artef.

Thibautianum $\times$, [Hort. Veitch] ex Reichb.f. 1. c. (1886) i. 104. - Hybr. artef.

tibeticum, King, ex Hemsl. in fourn. Linn. Soc. xxix. (1892) 320. - China, occ. India.

tonkinense, Hort. ex Lindenia ii. (1886) 61 t. 77 $=$ concolor, Benth

triumphans X, O'Brien, in Gard. Chron. (1894) i. 198. - Hybr, artef.

turpe $\times$, Hort. ex God.-Lebœuf, in L'Orchidophile (1888) 87 nomen. - Hybr. artef.

Van Houtteanum $\times$, Hye, ex Lindenia, iii. (1887) 71 t. $130 .-$ Hybr, artef.

variopictum $\times$; Reichb. $f$. in Gard, Chron. (1888) ii. 407. - Hybr. artef

Vervactianum X, Reichb. f. 1. c. (1888) i. $712=$ C. Euryale, Veitch.

Vipani X, Hort. ex Kew Bull. (1891) Add. ii.41, et ex Journ. of Hort. xxiv. (1892) $421 \mathrm{fgg} .73 .-$ Hybr, artef.

Volonteanum, Hort. ex Reichb. f. in Gard. Chron. (1890) ii. 7 et $66=$ C. Hookerae, Reichb.

Weathersianum $\times$. L. Linden, in Lindenia, ix. (1894) 29 t. 397. - Hybr. artet.

Weidlichianum $\times$, Hort. ex Gartenfl. (1892) 183. Hybr. artef.

Wendlandi, Hort. ex Gartenfl. (1892) 183; et ex Rev. Hort. Belg, xix. (1893) 48. - Hybr. artef.

Winnianum $x$, Reichb. $f$. in Gard. Chron. (1886) i. 362; Journ, of Hort, xxii. (1893) 71 fig, 12 Will. Orch. Grow. Man. ed. 7, 314. - Hybr. artef.

Wolterianum, Kraenzl. in Gard. Chron. (1895) i. 166. - Hab. ? (an hybr. spont.?)

Youngianum $\times$, Rolfe, 1. c. (1890) ii. 183; et in Reichenbachia, Ser. I, i. (1891) t. 31. - Hybr. artet.

yunnanense, Franch. in Morot, fourn. de Bot. viii. (1894) 231. - China.

Yvonnde $\times$. Hort, ex Garnier, in Illustr. Hortic xlii. (1895) 23 t. 26; et Rev. Hortic. (1895) 392 [Yvonae].- Hybr. artef.

CYPSELOCARPUS, F. Muell. (Chenopod.). Ind. Kew. i. T02.

haloragoides, Baill. Hist. des pl. ix. (1888) $180=$ haloragoides, F. Muell.

GYRTANDRA, Forst. (Gesnerac.).- - Ind. Kew i. 702 .

Baileyi, F. Muell. in F. M. Bailey, Syn. Queensl. Fi. Suppl. III. (1890) 51. - Austral.

begoniaefolia, Hilleby. Fl. Haw. Isl. (1858) 328. Ins. Sandvic.

biserrata, Hillebr. l. c. 329. - Ins. Sandvic

bracteata, Warb. in Bot. Fahrb. xiii. (1891) 417. Oceania. 


\section{GYRTANDRA :}

Clarkei, Stapf, in Trans. Linn. Soc. Ser. II. iv. (1894) 213. - Borneo.

Cuminsii, Hensl. in Kew Bull.(1895) 137. - Ins. Salom.

dubiosa, Kuntze, Rev. Gen. (1891) 472. - Java.

filipes, Hillebr. Fl. Har'. Isl. (1888) 336. - Ins. Sandvic.

gracilis, Hillebr. l. c. 333.- Ins. Sandvic.

Groyana, Hillebr. . . c. 330. - Ins. Sandvic.

Hellwigii, Warb. in Bot. fahrb. xvi. (1893) 2\%. Oceania.

Hillebrandi, Oliver, ex Hillebr. Fl. Haw. Isl. (1888) 331. - Ins. Sandvic

latebrosa, Hillebr. l. c. 337. - Ins, Sandvic

Listeri, Hemsl. in fourn. Linn. Soc. xxv. (1894) 213: - Ins. Pacif.

Lydgatei, Hillebr. Fl. Haw. Isl. (1888) 335. - Ins. Sandvic.

Iysiosepala, Hillebr. l. c. 330. - Ins. Sandvic. macrocalyx, Hillebr. l. c. 329. - Ins. Sandvic paritiifolia, Hillebr. .. c. 328. - Ins. Sandvic. procera, Hillebr. l. c. 329. - Ins. Sandvic. Schraderi, K. Schum. in Bot. fahrb. ix. (1888) 217. - N. Guin.

suffruticosa, Ridl. in Trans, Linn. Soc. Ser. II. iii. (1893) 330. - Penins. Mal.

Terrae-Guilelmi, K. Schum. in Bot. Fahrb. ix. (1888) 217. - N. Guin.

Wawrae, Hillebr. Fl. Haw. Isl. (1888) 328 (=C. peltata, Wawra). - Ins. Sandvic

GXRTANDRONOEA, Zoli. (Gesnerac.). - Ind. Kew. i. 703.

megaphylla, Hensl. in Hook. Icon. pl. xvi. (1886) t. 1555 . - Perak.

CYRTANTHUS, Ait. (Amaryll.). - Ind. Kew. i.

brachyscyphus, Baker, Handb. Amaryll. (1888) 55. - Afr. austr.

Galpin1, Baker, in Kew Bull. (1892) 83. - Afr. austr.

Huttoni, Baker, Handb. Amaryll. (1888) 55. - Afr. austral.

intermedia X, Hort. Bull, ex Gard. Chron. (1893) i. 413. - Hybr. artef.

lutescens, Hort. ex Kew Bull. (1889) 77 = Anoiganthus breviflorus, Baker.

parviflorus, Baker. in Gard. Chron. (1891) i. 104. Afr, austr.

rectiflorus, Baker, Handb. Amaryll. (1888) 55.Afr. austr.

CYRTOPERA, Lindl. = Eulophia, R. Br. (Or-

flexuosa, Rolfe, in Kew Bu1l. (1894) 363. - Afx. trop. or.

Holstiana, Kraenzl., ex Engl. in Abh. Preuss. Akad. Wiss. (1894) 41. - Afr. trop, or.

papuana, Ridl. in Journ. Bot. xxv.(1886) 354. N. Guin.

papillosa, Rolfe, in Kew Bull. (1893) 336. - Natal. Regnieri, Reichb.f. in Gard. Chron. (1886) ii. 294; L'Orchidophile (1886) 223 cum ic. - Cochinch.

GYRTOPODIUM, R. Br. (Orchid.). - Ind. Kew,

Aliciae, L. Iinden et Rolfb, in Lindenia, viii. (1892) 23 t. 371. - Bras.

flavescens, Cogn. in Mart. Fl. Bras. vi. (1895) 74. Guian.

Parkinsonii, F. Muell. et Kraenzl. in Oest. Bot. Zeitschr. xliv. (1894) 256. - N. Brit.

plantagineum, Cordem. Fl. Ile Réun. (1895) 225 $(=$ Limodorum plantagineum, Thou.). - Ins. Borb.

Saintlegerianum, Hort.ex Gard. Chron.(1888) ii.180; et ex Gartenfl. xxxvii. (1888) 597 = punctatum, Lindl.

CYRTORHYNCHA, Nutt. = Ranunculus, Tourn. Cymbalaria, Britton, in Mem. Torrey Bot. Club, v. (1894) $161=\mathrm{R}$. Cymbalaria, Linn.

GYRTOSPERMA, Griff.(Aroid.). - Ind. Kew.

\section{GYRTOSPERIMA}

ferox, N.E. Brawn et I: Iind in Illustr. Hortic xxxix. (1892) 39 t. 153; et ex Gard. Chron. (1892) ii. 123. - Borneo.

CYRTANTHE, R. Br. = Richea, R. Br. (Epacrid.).

dracophylla, Gunnii, pandanifolia, et scoparia, Kuntze, Rev. Gen. (1891) 391 = homononyma omnia Richeae.

CYSTOPUS, Blume $=$ Odontochilus, Blume (Orchid.).

brevistylis, calcaratus, Clarkei, crispus, Elwesii, flavescens, grandiflorus, Fauberti, lanceolatus, longiflorus, macranthus, pectinatus, pumilus, Kuntze, Rev. Gen. (1891) $658=$ homonyma omnia Odontochili. flavus, Kuntze, 1. c。= O. lanceolatus, Blune.

CYSTOSTEMIN, Balf. f. (Boragin.). - Ind. Kew. 亡. 705 .

socotvense, “ Baif. f. » ex Engl. et Prantl, Natürl. Pflanzenfam. iv. 3a (1894) $126=$ socotranum, Balf.f.

GYTINUS, Linn. (Cytin.), 一 Ind, Kew, 706. Baroni, Baker f. in fourn. Linn. Soc. xxiv. (1888) 469. - Madag.

oxylepis, Robins. in Proc. An. Acad.xxix.(1894) 321. - Mexic.

GYTISOPSIS, Jaub. et Spach (Legumin).- Ind. Kew. i. 706.

spinosa, Conrath, in Bull. Herb. Boiss, ii. (1894) 327. - Armen

GYTISUS, Linn. (Legumin.).- - Ind. Kew. i. 706 absinthioides, Velen. ex Degen, in Oest. Bot. Zeitschr. xliii. (1893) 423 in syn.; Briq. Etud. Cytis. Alp. Marit. (1894) $181=$ supinus, Linn. var.

ganipilus, Veten. ex Nadji, Géogr. bot. Emp. Otiom. (1892) 17 nomen. - Thrac

ambiguus, Adannovic, in Oest. Bot. Zeitschr. xlii. (1892) 406. - Serb.

arenarius, Simonk. in Math. és Termész. Kozlem. xxii. (1888) 361, ex Briq. Etud. Cytis. Alp. Marit. (1894) 173 = supinus, Linn.

austratis, A. Kern. ex Wohlfarth. in Koch, Syn. Deutsch1. Fl. ed 3 (1892) $509=$ nigricans, Limn.

Boissieri, Briq. Etud. Cytis. Alp. Marit. (1894) 148 $(=$ Sarothammus eriocarpus, Boiss, et Reut.). Hisp.

bosniacus, G. Beck, in Annal. Naturh. Hofmus. Wien, ii. (1887) $119=$ ciliatus, Willd.

bucovinensis, Simonk. in Math. és Termész. Kozlem. xxii. (1888) 361; ex Briq. Etud. Cytis. Alp. Marit. (1894) $173=$ supinus, Linz.

cascariensis, Greene, Man. Bot. San Franc. Bay (1894) $102=$ canariensis, Steud.

cananensis, Kuntze, Rev. Gen. (1891) 178 sphalm. $=$ canariensis, Steud.

cantabricus, "Reichb." ex Briq. Etud. Cytis. Alp. Marit. (1894) 147. - Hispan.

catalaunicus, Briq. l. c. $149(=$ Sarothamnus catalannicus, Webb). - Hisp.

cetius X, G. Beck, Fl. Nied.-Oest. ii. (1892) 833. Austria.

colchicus, Alboff, Prod. Fl. Colch. (1895) 53. - Reg. Cauc

danubialis, Velen, in Abh. Böhm. Ges. Wiss. (1890) ii. 43 ; et F1. Bulg. (1891) $130=$ supinus, Linn. var.

Frivaldszkyanus, Degen, in Oest. Bot. Zeistchr. xliii. (1893) 422; Briq. Etud. Cytis. Alp. Marit. (1894) $175=$ hirsutus Linn. subsp. pallidus, Briq.

Haynaldi, Simonk. Enum. fl. Transsilv. (1886) 173; Briq. 1. c. $170=$ hirsutus, Linn. var

Hillebrandtii, Briq.l. c. 137 ( = Genista Hillebrandtii, Christ). - Ins. Canar.

insubricus, Wettst. ex Briq. I. c. $124=$ Laburnum anagyroides, Medic.

Facquinianus, Kern. Sched. Fl. Austro-Hung. vi. (1893) $5=$ seq.

facquinianus, Wettst: in Oest. Bot. Zeitschr. x1. (1890) 438 = Laburnum, anagyroides, Medic.
GYTISUS

Fankar, Velen. in Abh. Boehm. Ges. Wiss. 1889 (1890) 31 ; et F1. Bulg. (189I) $129=$ supinus, Linn. var.

Kerneri, Blocki, in Kneuck, Allgem. Bot. Zeitschr. i. (1895) 137 ; et in Oest. Bot. Zeirschr. xliii. (1893) 10\%. - Eur. centr.

Kernevi, Mugg. Kan, et Knapp [Die bish. bek. Pfl, Slav. (1866) 1607 ex Briq. Etud. Cytis. Alp. Marit. (1894) 166 et $173=$ supinus, Linn. et hirsutus, Linn.

kosmariensis, "Ball» ex Koehne, in Just, Bot. Jahresb. xvi1. (1889) I66, sphalm.= osmariensis, Ball.

leiotrichus, Borb. P1. Com. Temés. (1884) 78, ex Briq. Etud. Cytis. Alp. Marit. (1894) $176=$ austriacus, Linn.

Linneanus, Wettst. in Oest. Bot. Zeitschr. x1. (1890) 437 et (1891) 173 et 264 fig. $7-12$ et $21=$ Laburnum anagyroides, Medic.

monopestulanus, Briq. 1.c. 94 sphalm. = monspessulanus, Linn.

mutabilis, Loscos, ex Briq. 1. c. 143 in syn. = patens, Linn.

Nö̈anus, Reichb. ex Briq. 1. c. $182=$ supinus, Linn.

osmariensis, “ Ball » ex Briq. 1. c. $113=$ hosmariensis, Ball.

pannonicus, Simonk, in Math. és Termész. Kozlem. xxii. (1888) 361 ex Briq. 1. c. $173=$ supinus, Linn.

podolicus, Blocki, in Kneuck. Allgem. Bot. Zeitschr. i. (1895) 137; et in Oest. Bot. Zeitschr. xliii. (1893) 109. - Eur, centr.

praecox $\times$, ex Kew Bull. (1892) Append. i.24. Hybr. artef. ?

vhodopeus, Wagn. ex Degen, in Oest. Bot. Zeitschr. xliii. (1893) 423; et in syn. Briq. Etud.Cytis. Alp, Marit. (1894) 180 in obs. = supinus, Limn var.

Rocheli, Hort. ex Koehne, Deutsche Dendrol. (1893) $332=$ capitatus, facq.

Sauzeanus, Burn. et Briq. Etud. Cytis. Alp. Marit. (1894) 27 et 15\%. - Gall.

shipkaënsis, Dippel, Neuh. Offerte Nation. Arboret. 1892-3) 27 nomen. - Reg. Balkan.

Spachianus, Kuntze, Rev, Gen. (1891) 17S= Genista Spachiana, Webb.

stenopetains, Christ, in Bot. Jahrb. ix. (1887) 162; Briq. Etud. Cytis. Alp.-Mar. $138=$ maderensis, Masf.

subspinescens, Briq. l. c. 60 et 163. - Eur.

siprambius, Kuntze, Rev. Gen. (1891) $178=$ fragrans, Lam.

szeplighettis, Koehne, ex Briq. 1. c. 188. - (Quid?) tridentatus, Batt, in Batt et Trab. F1. de 1'Algér. (Decot.) (1888) $206=$ Genista tridentata, Lim. tridentatus, Taub, in Engl. et Prantl, Natürl. Pflanzenfam. iii. 3. (1893) $239=$ praec.

trifolius, Briq. Etud. Cytis. Alp.-Mar. 107 sphalm. = trifforus. Linn.

versicolor $x$, Briq. 1. c. 165 in obs. - Hybr. artef. vivens, Velen. Fl. Bulg. (1891) 128; Briq. 1. c. 178 et $179=$ supinus, Lim. var.

virescens, Wohlfarth, in Koch, Syn. Deutschl. F1. ed. 3. (1892) 511. - Austria.

virescens $x, G$. Beck, F1. Nied.-Oest. ii. (1892) 834. - Austria.

Watereri $x$, Wettst. in Oest. Bot. Zeitschr, xli. (1891) 129 t. 4; Briq. Étud. Cytis A'p.-Marit. (1894) $124=$ Laburnum Watereri $\times$, Briq.

Weissmanni, Wettst.in Oest. Bot. Zeitschr. xli. (1891) 449 ad calc. ex Briq. 1. c. $124129=$ insubricus Wettst.?

\section{D}

DACRYDIUM, Soland. (Conifer.). - Ind. Kew.

i. 708. (=Lepidothamnus Foncki, Phil.). - Am. austr.

Hookerianum, Eichl. in Engl. et Prantl, Natürl. Pflanzenfam. ii. 1. (1887) 10\% = Pherosphaera Hookeriana, Archer. 
DACTYLAENA, Schrad. (Capparid,) - Ind Kew. i. 708 .

Glazioviana, Taub. in Bot. Fahrb. xv. Beibl. n. 34 (1892) 1. - Bras.

DACTYLOPHORA, Van Tiegh, in Bull. Soc. Bot. Fr. xli. (1894) $549=$ Loranthus, Linn. verticillata, Van Tiegh, 1. c. $550=$ Dendrophthoë verticillata, Schiff.

DACTYLODES, Zanoni-Monti, Rar. Stirp. (1743 94-95 t. 66, ex Kuntze, Rev. Gen. (1891) $772=$ Tripsacum, Linn. (Gramin.)

angulatum, Kuntze, Rev. Gen. (1891) $773=\mathrm{T}$. dac tyloides, Linn.

fasciculatum, Kuntze, 1. c. = T. fasciculatum, Trin.

DACTYLOCLADUS, Oliver, in Hook. Icon. pl xxiv. (1895) t. 2341. MELASTOMACEAE. stenostachya, Oliver, l. c.-Borneo.

DACTYLOCTENIUM, Willd. = Eleusine, Gaertn (Gramin.), aegyptium, Richt. P1. Europ. i. (1889) 68. $(=D$ aegyptiaum, Willd.). = E. aegyptiaca, Desf.

DACTYLOPETALUM, Benth. (Rhizophor.). Ind. Kew. i. 709

parvifolium, S. Elliot, in fourn. Linn. Soc. xxx. (1894) 78. - Afr. trop. occ.

DACTYLOSTELMA, Schlechter, in Oest. Bot. Zeitschr. xlv. (1895) 452. ASCLEPIADEAE boliviense, Schlechter, l. . . - Bolivia.

DAEMIA, R. Br. (Asclepiad.). - Ind. Kew. i. 709. barbata, Schlechter, in Bot. Fahrb. xx. Beibl. n. 5l, (1895) 43. - Afr. austr.

cordifolia, K. Schum. ex Engl in Abhand1. Preuss. Akad. Wiss. (1894) 17; et in Engl. Pflanzenw. Ost-Afr. C (1895) $324=$ extensa, R. Br.

DAEMONOROPS, Blume (Palm.). - Ind. Kew. i. 710 .

didymophylla, Becc. in Hook. f. Fl. Brit. Ind. vi. (I893) 468. - Penins. Mal., Sumatra.

Kunstleri, Becc. in Hook. f. 1. c. 469. - Perak

Kurzianus, Hook. f. l. c. 463. - Ins. Andam.

macrophyllus, Becc. in Hook. f. l. c. 470. - Perak.

Manii, Becc. in Hook. f. l. c. 463 . - Ins. Andam.

micracanthus, Becc. in Hook.f.l.c. 467. - Malacca.

oligophyllus, Becc. in Hook.f. l. c. - Perak.

propinquus. Becc. in Hook. f. l. c. 467. - Penins. Mal., Sumatra.

Sabut, Becc. in Hook.f. l. c. 469. - Perak.

Sepal, Becc. in Hook. f. l. c. 465. - Perak

tabacinus, Becc. in Hook. f.l. c. 456. - Perak.

vagans, Becc. in Hook. f. l. c. 469. - Perak.

DAHLIA, Cav. (Composit.). - Ind. Kew. i. 710.

dissecta, S. Wats. in Proc. Am. Acad. xxvi. (1891) 141. - Mexic.

Lehmanni, Hieron. in Bot. Fahrb. xix. (1894) 55. Columb.

pubescens, S. Wats. in Proc. Am. Acad. xxvi. (1891) 142. - Mexic.

DAIS, Royen (Thymel.). - Ind. Kew. i. 710 anthylloides, Eckl. et Zeyh. ex Hook, f. in Bot.Mag. (1893) t.7303 = Lasiosiphon anthylloides, Meissn. rhamnifolia, Baill. Hist. pl. Madag., Atlas (1895) t. 318. - Madag.

DALBERGIA, Linn. f. (Legum.). - Ind, Kew. i. 710

Boehmii, Taub. in Engl. Pflanzenw. Ost-Afr. C (1895) 218. - Afr, trop, or.

cochinchinensis, Pierre, ex Laness. Pl. util. col. franc. (1886) 289. - Cochinch.

Delavayi. Franch. Pl. Delav. i. (1889) 186.-China.

Ecastophyllum, Taub, in Engl. et Prantl, Natürl. Pflanzenfam. iii. 3. (1894) 335. = Hecastaphy1lum Brownei, Pers.

Fischeri, Taub. in Engl. Pfanzenw. Ost-Afr. C (1895) 218. - Afr. trop. or.

frutescens, Britton, in Bull. Torrey Bot. Club, xvi, (1889) 324 = variabilis, Vogel.

\section{DALBGRGIA}

mimosoides, Franch. Pl. Delav. i. (1889) 187. - China.

Muelleri, Taub. in Engl. et Prantl, Natürl. Pfangenfam, iii. 3. (1894) 336 - Orb. vet, reg. trop. myriabotrys, Baker, in fourn. Bot. xxy. (1890) 311 - Madas

pterocarpiflora, Baker, l. c.312. - Madag.

scorpioides, Baker, in fourn. Linn. Soc. xxii. (1887) 466. - Madag.

Stuhlmannii, Taub, in Engl. Pfanzenw, Ost-Afr, C (1895) 217. - Afr. trop. or.

trichocarpa, Baker, in fourn. Bot. xxv. (1890) 311 - Madag.

yunnanensis, Franch. Pl. Delav. i. (1889) 187. Yunnan.

Wattii, C. B. Clarke, in foum. Linn. Soc.xxy. (1895) 17 t. 5. - Reg. Hímal.

DALEA, Linn. (Legumin.). - Ind. Kew. i. 712. anmu, Kuntze, Rev. Gen. (1891) $178=$ alopecuroides, Willd.

Benthami, T. S. Brandeg, in Proc. Calif. Acad. Ser. II. ii. (1889) 148. - Calif

boliviana, Britton, in Bull. Torrey Bot. Club, xvi. (1889) 259. - Bolivia.

capitata, S. Wats. in Proc. Am. Acad. xxv. (1890) 146. - Mexic

cutervoana, Szyszyl. in Diss. Cl. math.phys. Acad. litt. Cracor. xxix. (1894) 222. - Peruvia

cyanea, Greene, Pittonia, i. (Jan. 1888) 153. Mexic.

Dalea, Mac Mill. Metasp. Minn. (1892) 330. = alopecuroïdes, Willd.

evanescens, T. S. Brandeg, in Proc. Calif. Acad. Ser. II. ii. (1889) 146. - Calif.

filiciformis, Robins, et Greenm, in Proc. Am. Acad. xxix. (1894) 382. - Mexic.

glaberrima, S. Wats. l. c. xxii. (1887) 470.-Mexi oracillima, S. Wats. l. c. 404. - Mexic

Lumholtzii, Robins, et Fernald, l. c. xxx. (1895) 115. - Mexic.

maritima, T. S. Brandeg. in Proc. Calif. Acad. Ser. II. ii. (1891) 125. - Calif.

neglecta, Robins, in Proc. Am. Acad, xxix. (1894) 329. - Mexic

pazensis, Rusby, in Mem. Torrey Bot. Club, iii. 3. (1893) 18. - Bolivia.

plumosa, S. Wats. in Proc. Am Acad.xxi. (1886) 448. - Mexic.

revoluta, S. Wats, l. c. xxii. (1887) 404. - Mexic. Seemanni, S. Wats. ex C.R. Orcutt, in West Am. Scientist, ii (1886) 55 nomen; et in Proc. Am. Acad. xxii. (June 25 1887), 470. - Calif.

tinctoria, T. S. Brandeg. in Proc. Calif. Acad. Ser. II. ii (1889) 147. - Calif.

trochilina, T. S. Brandeg. l.c. Ser. II, iii. (1893) 220. - Calif.

unifoliolata, Robins, et Greenm, in Proc. Am, Acad xxix. (1894) 383. - Mexic

vetula, T.S. Brandeg. in Proc. Calif. Acad. Ser. II. ii. (1889) 146. - Calif.

virgata, Alboff, in Bull. Herb. Boiss, ii. (1894) 442 t. 9. - Costarica.

viridiflora, S. Wats, in Proc. Am. Acad. xxi. (1886) 448. - Mexic

DALEGHAMPIA, Plum. ex Linn. (Euphorb.). Ind. Kew. i. 713.

cynanchoides, S. Moore, in Trans. Limn. Soc. Ser. II. iv. (1895) 468 . - Bras.

Didierei, Baill. Hist. pl. Madag., Atlas (1891) t. 198. - Madag.

Hildebrandti, Pax, in Abhandl. Preuss. Akad. Wiss. (1894) 28; et in Bot. Fahrb. xix. (1894) 107. Ins. Zanzib.

Kurzii, Hook.f. Fl. Brit. Ind. v. (1888) 468. - Ind. or.

sylvestris, S. Moove, in Trans. Linn. Soc. Ser. II iv. (1895) 467. - Bras.

DAMAPANA, Adans.= Smithia, Ait. (Legumin.) aeschymomenodes, bigemina blanda, capitata capituli fera, ciliare, coerulescens, dichotoma, gracilis, gran dis, japonica, nodulosa, purpurea, salsuginea, sensitiva, setulosa, strigosa, strobilantha, Kuntze, Rev. Gen. (1891) $179^{\circ}=$ homonyma onnia Smithiae.
DAMAPANA : africana, Kuntze,
schii, Benth.

conferta. Kuntze, 1. c. = S, geminiflora, Roth.

picnantha, Kuntze, 1. c. = S. pycnantha, Benth.

DAMMARA, [Rumph.]= Agathis, Salisb.(Conif.) Palmerstoni, F. Muell. Syst. Cens. Austral. P1. Suppl. iv. (1889) 4 nomen; in Vict. Natural. viii. (June 1891) 45; et in Bot. Centrabl. xlviii. (1891) $221=$ Agathis Palmerstoni F. Muell.

DAMMAROPSIS, Warb, in Bot. Jahrb, xiii. (1891) 296. URTICEAE

Kingiana, Warb.l.c.-Oceania.

DANAIS, Comm. (Rubiac.). - Ind. Kew. i. 715 Lyallii, Baker, in fourn. Linn. Sor, xxii. (1887) 481 .
- Madag.

nummularifolia, Baker, l. c. - Madas.

DANTHONIA, DC. (Gramin.). - Ind. Kew. i. 715 .

avistata, St-Lager, Étud. des fl. éd. 8. ii. (1889) 936. = Triodia decumbens, Beauv.

Bachmanni, Hack. ex Schinz, in Bull. Herb. Boiss. ii1. (1895) 385. - Afr. austr.

borussica, K. Schum. in Engl. Pfanzenw. Ost-Afr. C (1894) 109. - Afr. trop. or.

chrysurus. K. Schum. l. c. 110 - Afr. trop. or.

lasiantha, Baker, in Fourn. Bot. xxv. (1890) 349.Madag.

longearistata, Engl. in Abhandl. Prenss. Akad. Wiss. 1891 (1892) 131 ( = Trisetum Iongiaristum, A. Rich.). - Abyss.

nana, Engl. l. c. - Abyss.

nardoides, Phil. in Anal. Mus, nac. Chile (1892) 84. - Chili.

oreophila, Petrie, in Trans. N.Z. Inst. xxvii. 1894 (1895) 406 (=D. pallida, Petrie). - N. Zel. pallida, Petrie, 1. c. xxvi. 1893 (1894) $271=$ oreophila, Petrie.

DAPANIA, Korth. (Geran.). - Ind. Kew, i. 716. scandens, Stapf, in Hook. Icon.pl.xx. (1891) t. 1997. - Perak.

DAPHNANDRA, Benth. (Monimiac.) - Ind. Kew. i. 716

aromatica, F. M. Bailey, Syn. Queensl. Fl. Suppl. i. (1886) 46. - Austral.

DAPHNE, Tourn, ex Linn. (Thymel.). - Ind. Kew. I 716.

cantabrica, Willk. Ill. Fl. Hisp. (1890?) 108 t. 152; et ex Oest. Bot. Zeitschr. (1890) 459. - Hisp. composita, Gilg, in Engl. et Prantl, Natürl. Pflanzenfam. iii. 6a (1894) $238=$ pendula, Lin.

kabylica: Chab, in Bull. Soc. Bot. Fr, xxxvi. (1889) 30. - Alger.

papyracia, Hort. ex Koehne, Deutsche Dendrol. (1893) 422 in obs. = Edgeworthia chrysantha, Lindl.

retusa, Hemsl, in Fourn. Linn. Soc. xxix. (1892) 318. enera. Phil. in Anal. Univ. Chil. xci. (1895) 505. Chili.

Chili.
tenuiflora, Bureau et Franch. in Morot, fourn. de Bot.v. (1891) 151. - China.

DAPHNIPHYLUUM, Blume (Euphorb.). - Ind.

\section{Kew. 1. 718}

borneense, Stapf, in Trans, Limn. Soc, Ser. II. iv. (1894) 224. - Borneo

conglutinosum, Hemsl. in Kew Bull. (1895) 137.Ins. Salom.

Kingii, Hook. f. Fl. Brit. Ind. v. (1887) 354.Perak

lancifolium, Hook. f. l.c. - Perak.

Scortechinii, Hook. f. l. c. - Perak.

DAPHNOPSIS, Mart, et Zucc. (Thymel.). Ind. Kew. i. 718 .

Beta, Taub. in Bot. Fahrb. xii Beibl, n, 27 (1S90) 5. - Bras.

coriacea, Taib. l.c. 7. - Bras.

tmarginata, Gilg, in Eng-1. et Prantl, Natürl. Pflanzenfam. iii. 6a, (1894) $236=\mathrm{D}$. Pavoni, Missu. 


\section{DAPHNOPSIS :}

longifolia, Taub. in Bot. Fahrb. xii, Beibl, n. 27 (1890) 9. - Bras

macrophylla, Gilg, in Engl. et Prantl, Natürl. Pflanzenfam. iil. 6a (1894) $236=$ D. Humboldtii, Meissn.

occidentalis, Krug et Urb., in Bot. Fahrb. xv. (1893) 349 (= Daphne occidentalis, $\mathrm{Sw}$.).

Jamaica.
Philippiana, Krug et Urb. 1. c. 348. - Ins, PortoRico.

radiata, F. D. Smith, in Coult. Bot. Gaz. xiv. (1889) 30. - Guatem.

Schwackeana, Taub. in Bot. Fahrb. xii. Beibl. n. 27 (1890) 61, et xv. Beibl. n. 38 (1893) 8. Bras.

Sellowiana, Taub. in Bot. Jahrb. xv. Beibl. n. 38 (1893) 7 - Bras.

sessiliflora. Gris. ex Taub. l, c. 18. - Bras.

Tuerckheimiana, f. D. Smith, in Coult. Bot. Gaz xvi. (1891) 13. - Guatem.

DARBYA, A. Gray = Buckleya, Torr, (Santal.) umbellata, Kuntze, Rev. Gen, (1891) 589 in syn. sphalm. = umbellulata, $A$. Gray.

DASYLEPIS, Oliver (Bixin.). - Ind. Kew, 1 719

integra, Warb, ex Engl, in Abr. Preus.s. Akad. Wiss. (1894) 44 ; et in Engl. Pflanzenz. Ost-Afr. C (1895) 27\%. - Afr. trop. or

leonensis, Warb. in Eng1. et Prant1, Natur1. Pflanzenfam. iii. 6a (1893) $15=$ Scottellia leonensis Oliver.

DASYLIRION, Zucc, (Liliac.). - Ind, Kew.i 719.

inerme, S. Wats. in Proc. Am. Acad. xxvi. (1891) 167. - Mexic

juncacfolim, Hort. ex W. Wats, in Kew Bull. (1889) $303=$ quadrangulatum, S. Wats

DASYNEMA, Schott = Sloanea, Linn. (Tiliac.). surinamensis, Endl. ex K. Schum. in Mart. FI. Bras. xii, III. (1886) 194 in obs, = Sagotia racemosa, Baill.

DASYSTACHYS, Baker (Liliac.). - Ind. Kew。 i. ¿I!

densiflora, Baker, ex Eng1. in Bot. Jahrb. xv.(1893) $470=$ Chlorophytum densiflorum, Engl.

DASYSTOMA, Rafin. = Dasistoma, Rafin. = Gerardia, Linn. (Scrophul.).

laevigata, Britton, ex Morong, in Bull.Torrey Bot. Club, xx. (1893) $483=\mathrm{G}$. laevigata, Rafin. virginica, Britton, in Mem. Torrey Bot. Club, v (1894) $295=\mathrm{G}$. quercifolia, Bentt.

DATURA, Linn. (Solan.). - Ind. Kew, i. 720. Cornucopia, Hort. ex The Garden (1894) 224. Form, hort.

tarapacana, Phil. in Ann.Mus. nac. Chili, (1892) 63. - Chili

DAUGUS, [Tourn.] Linn. (Umbellif.). - Ind. Kew. i. 720.

Aristidis, Coss. ex Batt. et Trab. F1. de l'Algér. [Dicot.] (1888) 377 in syn.=Ammiopsis Aristidis, Batt.

jordanicus, Post, in fourn. Linn. Soc. xxiv. (1888) 431. - Syria.

Masclefii, Corbière, Nouv. F1. Norm. (1893) 264 = gummifer, Lan.

ponticus, Velen. in Sitzb. Boehm, Ges. Wiss. 1889 (1890) 34; et Fl. Bulg. (1891) 198. - Bulg.

pumilus, Caruel, in Parl. Fl. Ital. viii. (1889) 534 $=$ Caucalis pumila, Linn

Reboudii, Coss. ex Batt. et Trab. Fl. de l'Algér. [Dicot.] (1888) 379. - Algéria.

setifolius, Kuntze, in Act. Hort. Petrop. x. (1887) 191 = Psammogeton setifolium, Boiss

stenopterus, Batt. in Batt. et Trab. Fl, de l'Algér. [Dicot.] (1888) 379. - Algeria.

subsessilis, Boiss, Fl. Or. Suppl. (1888) 272. - Ins. Cypr.
DAVEANA, Willk, ex Maris, in Bolet, Soc, Brot ix. (1891) 220 et 243; et in Magnier. Scrin. Al ix. (1891) 220 et 243 ; et in Magnie
select. xii. (1893). COMPOSITAE. anthemoides, Maris, 1. c. 220 et 244. - Lusit.

DAVIESIA, Sm. (Legumin.). - Ind. Kew, i. 721 Croniniana, F. Muell. in Vict. Natural. x. (April 1894) 194 ; et ex Bot. Centralbl. lviii. (1894) 189. Austral.

DAYDONIA, Britten, in Journ. Bot. xxvi. (1888) 11 = Anneslea, Wall. (Legum.).

crassipes, Britten, 1. c. $=\AA$. crassipes, Hook.

fragrans, Britten. 1: c. = A. fragrans, Wall.

DEANEA, Coult. et N. E. Rose, in Coult. Bot. Gaz. xx. (1895) 372; et in Contrib. U. S. Nat. Herb. iii. 3. (1895) 298, UMBELLIFERAE. nudicaulis, Coult et N.E. Rose,ll, cc, t. 6. -. Mexic tuberosa, Coult. et N.E. Rose, l. c. 373. - Mexic.

DEBESIA, Kuntze, Rev. Gen. (1891) 708 = Acro spira, Welw. (Liliac.)

asphodelodes, Kuntze, 1.c. $=$ A. asphodeloides, Baker.

DEBREGEASIA, Gaudich. (Urtic.). - Ind. Kew i. 722 .

ceylanica, Hook. f. Fl. Brit, Ind.v. (1888) 592. Zeylan.

dentata, Hook. f. l. c. 59I. - Ind. or

squamata, King, ex Hook.l.c.-Perak.

DECABELONE, Decne. (Asclep.). - Ind, Kew I. 722 .

grandiflora, $K$. Schum, in Engl. et Prantl, Natürl. Pfanzenfam. iv. 2 (1895) 276. - Afr. austr.

DECACERAS, Harv, = Anisotoma, Fenzl (Asclep.).

Arnoldii, Schlechter, in Bot. Jahrb. xviii. Beibl. 45 (1894) 26 in obs. = Brachystelma Arnoldii, Baker.

Arnottii, K. Schum. in Engl. et Prant1, Natürl. Pflanzenfam. iv. 2. (1895) $267(=$ D. Arnoldii, Schlecht.). = A. Arnoldii, Baker.

DEGAISNEA, Hook. f. et Thoms. (Berberid.). Ind. Kew, i, 722

Fargesii, Franch. in Morot, Fourn. de Bot. vi. (1892) 233; et ex Rev. Hortic. (1893) 447. - Chin.

DECAISNELLA, Kuntze, Rev. Gen. (1891) $584=$ Gyrinopsis. Decne. (Thymel.).

Cumingiana, Kuntze, 1.c. = G. Cumingiana, Decne.

DECAISNINA, VanTiegh, in Bull, Soc. Bot. Fr.xlii. (1895) $435=$ Loranthus, Linn. (Loranth.). alata, Van Tiegh. 1. c, xlif. (I895) 437. - Ins. Moluce.

amplexans, Van Tiegh. 1. c. $436=$ L. amplexans, Van Tiggh.

Beccarii, Van Tiegh. 1. c. 487. - N. Guin.

glanca, Van Tiegh 1. c. 456. - Timor.

Honbroni, Van Tiegh. 1. c. - Timor.

Muelleyiana, Van Tiegh. 1. c. $=$ L. Muellerianus, Van Tiegh.

triflora, Van Tiegh. 1. c. $=$ L. triflorus, Spanh

signata, Van Tiegh. 1. c. = L. signatus, Van Tiegh.

DECASPORA, R. Br. = Trochocarpa, R. Br. (Epacrid.).

laurina, Kuntze, Rev. Gen. (1891) $391=$ T. laurina, $R . B r$.

DEGASGHISTIA, Wight et Arn. (Malvac.). Ind. Kew. i. 723.

affinis, Pierre, en $K$. Schum. in Engl. et Prantl, Natürl. Pfanzenfam, iii. 6. (1899) 47.-Cochinch. ficifolia, Mart. in Gard. Chron. (1888) ii. 565, et 1890 ii. 628 fig. 122. - Burma.

DECASPERMUM, Forst. (Myrt.). - Ind. Kew, i. 793 .

Vitis-Idaea, Stapf, in Trans. Linn. Soc. Ser. II. iv. (1894) 150. - Borneo.
DEGATOCA, F. Muell, in Trans. Roy. Soc. Vict New Ser. I, ii. (1889) 25; Baill. Hist. des pl. xi. (1892) 203

Spencerii, F, Muell. Il. cc. 26 et 203. - N. Guin.

DECKERA, Sch. Bip. = Picris, Linn. (Composit.) comosa, Batt. in Batt, et Trab. Fl. de l'Algér. [Dicot.] (1889) 544 ( = Helminthia comosa Boiss.) - Hisp., Algér.

DEGLIEUXIA, $H . B$. et $K$. (Rubiac.). - Ind Kew i. 723.

Alfredi, Ernst, in Rev. cient. mens. Univ. Vener. i (1887) 222. - Venez.

fruticosa, Kuntze, Rev. Gen. (1891) $279=$ chiococ coides, $H$. B. et $K$.

DECODON, J. F. Gmel. = Nesaea, Comm (Lythrar.).

myrtifolius, Kuntze, Rev. Gen. (1891) $249=\mathrm{N}$ myrtifolia, Dest.

salicifolius, Kuntze, 1, $\mathrm{c}=\mathrm{N}$. salicifolia, $H$. B. et $K$

DEGUMARIA, Linn. (Saxifrag.). - Ind. Kew. i. 724

inensis, Oliver, in Hook. Icon. pl. xviii. (1888) t. 1741. - China.

DERRINGIA, R. Br. (Amarant.). - Ind. Kew, i.

holostachya, Baker, in fourn. Limn. Soc. xxv. (1890) 342. - Madag.

DEERINGIA, Kuntze, Rev. Gen. (1891) $267=$ Deringa, Adans. = Gryptotaenia, DC. (Umbel lif.).

canadensis, Kuntze, 1. c. $266=\mathrm{C}$. canadensis, $D C$

DEFIERSIA, Schweinf, ex Penzig, in Atti Congr bot. Genova (1893) 359 nomen. EUPHORBIA $C E A E$.

erythrococca, Schweinf. l.c.- Erithrea.

DEGUELIA, Aubl. = Derris, Lour. (Legumin.) acumnata, amoena, brachyptera, brevipes, canarensis, chinensis, Cumingii, cuneifolia discolor, elegans, elliprica, eualata, ferruginea. floribunda, glabrato, Heyneana, javanica, Korthalsiana, laxiflora, longifolia, lucida, macroloba, macrophylla, Maingayana, marginata, microptera, montana, multiflora, negren sis, nobilis, oblonga, panicula, parviflora, platyptera, polyantha, polybliylla, polystachya, pubinervis, pyrrothyrsa, robusta, secunda, sinuata, Spanogheana, subavenus, sumatrana, thyrsiflora, trifoliata, vestita. Wightii, Taub. in Bot. Centralbl. xlvii. (1891) $386=$ homonyma omnia generis Derreos

Hanceana, Taub. 1. c. = D. oblonga, Hance.

Stuhlmannit, Taub. in Engl. Pflanzenw. Ost-Afr. C (1895) 218. - Afr, trop. or.

timoriensis, Taub. in Bot. Centralbl. xlvii. (1891) $386=$ D. guyanensis, Benth.

DEHAASIA, Blume (Laurin.).- Ind. Kew, i. 724 Kurzii, King, ex Hook. f. Fl. Brit. Ind. v. (1886) 125. - Tenass., Ins. Andam.

DEINBOLLIA, Schum, et Thonn. (Sapind.). Ind. Kew. i. 724

kilimandscharica, Taub. in Engl. Pfanzenw. OstAfr. C (1895) 250. - Afr. trop. or.

ramiflora, Taub.l.c. - Afr. trop. or.

DELAVA YA, Franch. in Bull.Soc. Bot. Fr, xxxiii (1886) 462. SAPINDACEAE.

toxocarpa, Franch. 1. c. (nomen improprium) = yunnanensis, Franch

yunnanensis, Franch. Pl. Delav. (1889) 142. Yunnan.

DELILEA, Spreng. = Elvira, Cass. (Compos.). biflora, Kuntze, Rev. Gen.(1891) $333=$ E. Mar tyni, Cass.

inelegans, Kuntze, 1. c. ( = Desmocephalum inelegan Hook. f.). Ins. Gâlap.

repens, Kuntze, 1. c. $(=$ Microcoeciarepens, Hook. $f$. - Ins. Galap. 
DELIMA, Linn . = Tetracera, Linn. (Dillen.) laevis, Maingay, ex King, in Journ.As. Soc. Beng. 1xiii. (1889) II. 362. - Malaya.

DELISSEA, Gaudich. (Campanu1.). - Ind. Kew. i. 795

fallax, Hillebr. Fl. Haw. Isl. (1885) 251. - Ins. Sandvic.

laciniata, Hillebr. l. c. 249. - Ins. Sandvic. parviflora, Hillebr. l. c. 251. - Ins. Sandvic

sinuata, Hillebr, l. c. 250. - Ins. Sandvıc.

DELOSTOMA, D. Don (Bignon.). - Ind. Kew

roseum, K. Schum, in Engl. et Prantl, Natiurl. Pflanzenfam. iv. 3b. (1894) 239 (= Codazzia rosea Karst. et Triana). - Columb,

speciosum, K. Schum. l.c. ( = Codazzia speciosa Karst.). - N. Gran.

DELPHINIUM, Tourn. ex Linn. (Ranunc.). Ind. Kew. i. 725.

Aitchisonii, Huth, in Bot. Fahrb. xx. (1895) 395. Cachem.

Amani, Post.. in Bull. Herb. Boiss. iii. (1895) 152 et ex Huth, l.c. 444. - Syria.

apetalum, Huth, l. c. 398. - Turkest.

apiculatum, Greene, Pittonia, i. (April 1889) 285. Calif.

armeniacum, Stapf, ex Huth, in Bot. Fahrb. xx. (1895) 380. - Armenia

Barbeyi, Huth, in Bull. Herb. Boiss. i. (1893) 3335 t. 17. - Colorado.

Batalini, Huth, in Bot. Fahrb. xx. (1895) 432. Turkest.

biternatum, Huth, l.c. 422. - Turkest.

Blochmanae, Greene, in Erythea, i. (1893) $247=(D$ ornatum, Greene, Fl. Francisc. 304). - Calif.

Bonvaloti. Franch. in Bull. Soc. Philom. Paris, Sér. VIII. v. (1893) 165. - China.

Borbasii, Formanek, in Verh. Natürf. Ver. Brunn. xxxii. (1894) 175. - Maced.

bracteosum, Somm, et Levier in Act. Hort. Petrop. xiii. (1893) 25. - Reg. Cauc

Burkei, Greene, in Erythea, i1. (1894) 183. - Am. bor, occ.

caerulescens, Freyn, ex Stapf, in Denkschr. Akad. Wien (1886) 25. - Persia.

camporum, Greene, in Erythea, ii. (1894) 183.Am. bor. occ.

campylocentrum, Maxim. in Act. Hort. Petrop. x. (1887) 31. - China.

campylopodum, Freyn, ex Stapf, in Denkschr. Acad. Wien (1886) 19. - As. Min.

ceratophorum, Franch. in Bull. Soc. Bot. Fr. xxxiii. (1886) 377. - Chin. occ.

chefoense, Franch. in Bull. Soc. Philom. Paris, Sér. VIII, v. (1893) 170. - China.

coelestinum, Franch, in Morot, fourn, de Bot. viii. (1894) 276. - China.

columbianum, Greene, in Erythea, ii. (1894) 193 $(=D$. Nuttallii, A. Gray). - Am. bor. Occ.

Davidi, Franch. in Bull. Soc. Phil. Paris, Sér. VIII. v. (1893) 179. - China.

Delavayi, Franch. in Bull. Soc. Bot. Fr. xxxiii. (1886) 379. - Chin.

densiflorum, Duthie, ex Huth, in Bot. Fahrb. xx. (1895) 393. - Cachem., India, China.

dinaricum, G. Beck. et Szyszyl. Pl. Cern. et Alb. lect. (1888) 91. - Monten.

dissectum, Huth, in Bot. Farhb.xx. (1895) 403.Mongolia.

Duhmbergii, Huth, in Bull. Herb. Boiss. i. (1893) 330 t. 16. - Ross, mer.

Ehrenbergii, Huth, l. c. 336 t. 17. - Mexic.

elatum, Franch. Pl. Delav. (1889) $28=$ taliense, Franch.

Emiliae, Greene, in Erythea, ii. (1894) 120 et Syn. Fl. N.Am. I. i. (1895) 51 ; Gard. Chron. (1894) ii. 434 - Calif.

Englerianum, Huth, in Bot. Fahrb. xx. (1895) 418. - Ross., Turkest. Reg. Cauc.

Fargesii, Franch. in Bull. Soc. Philom. Paris, Sér. VIII, v. (1893) 164. - China.

Freynii, Huth, in Bot. Jahrb. xx. (1895) $372=$ halophilum, Huth.

\section{DELPHINIUM}

Geyeri, Greene in Erythea, ii. (1894) 189. - Am. bor. occ.

grandiflorum, Franch. P1. Delav. (1885) $24=$ mosoynense, Franch.

halophilum, Huth, in Bot. Fahrb. xx. (1895) 48\%.Persia.

hamatum, Franch. Pl. Delav. (1889) 28. - Yunnan.

Henryi, Franch, in Bull Soc. Philom. Paris, Sér VII1, v.(1893) 177 - China

Hirschfeldianum, Heldr, et Holzm. ex Boiss. Fl. Or Suppl. (1888) 19. - Ins Aegina.

hirticaule, Franch. in Morot, Fourn, de Bot. viii. (1894) 275 . - China

iliense, Huth, in Bot. Fahrb. xx. (1895), 462. Turkest., Sibiria.

kumaonense, Huth, in Bull. Herb. Boiss. 1. (1893) 333. - Reg, Himal.

lankongense, Franch. Pl. Delav.(1889)26.-Yunnan.

laxiflorum. Freyn, ex Stapf, in Denkschr. Acad. Wien (1886) 25. - Persia.

leiocarpum, Huth, in Helios, xi. (1873) 73 ; et in Bull. Herb. Boiss. i. (1844) 334. - Eur, or., As. occ.

Leroyi, Franch. ex Huth, l. c.; et in Bot. Fahrb. xx. (1895) 474. - Kilim N'Jaro.

leucophaeum, Greene, in Erythea, iii. (1895) 118. Am. bor. occ.

likiangense, Franch. in Bull. Soc. Philom. Paris, Sér. VIII, v. (1893) 180. - China.

longipes, Franch. in Nouv. Arch. Mus. Paris, Sér. III. viii. 1885 (1886) $191=$ Davidi, Franch

macedonicum, Halàcsy et Charyel, ex Charrel, in Oest. Bot. Zeitschr. xi. (1891) 374 nomen; et in Charrel [Nadji Effendi] Emp. Ottom., Géogr.bot. (1892) 8. - Maced.

macrostachyum, Boiss, ex Huth, in Bot. Fahrb. xx. (1895) 441. - Kurdist.

madrense, S. Wats, in Proc, Am. Acad, xxv, (1890) 141. - Mexic

Maximowiczii, Franch. in Bull. Soc. Philom. Paris, Sér. VII1. v. (1893) 164.- - China.

mosoynense, Franch. in Bull. Soc, Philom. Paris, Sér. VIII. v. (1893) 168. - China.

narbonense, Huih, in Bull. Herb. Boiss. i. (1893) 333. - Gallia.

oliganthum, Franch. P1. Delav. i. (1889) $29=$ likiangense. Franch.

oreophilum, Huth, in Bot. Fahrb. xx. (1895) 412. Turkest.

ornatum, Greene, Fl. Francisc. (1892) 304. - Calif.

orthocentrum, Franch. in Bull. Soc. Phil. Paris, Sér. VIII. v. (1893) 178. - China.

oxysepalum, Pax et Borbas, in Term. tudom. közl. xxii. (1890) 647; Pax, in Verh, bot. Ver. Prov. Brand. xxxiii. (1892) 88. - Carpath.

pachycentrum, Hemsl. in foum. Linn. Soc. xxix. (1892) 301. - China.

paphlagonicum, Huth, in Bull. Herb. Boiss. i. (1893) 328. - As. Min.

pauperculum. Greene, Pittonia, i. (Mar. 1889) 284. - Am. bor. occ

Penardi, Huth, in Abh. und Vortr. Gesammigeb. d. Naturw. iv. (1892) 18; in Helios, $\mathrm{x}$. (1893) 34; et in Bull. Herb. Boiss, iii. (1895) 206. - Am. bor.

Penhardi, "Huth " ex Robins. in A. Gray et S. Wats. Syn. Fl. N. Am. I. I. (1895) 46 in obs. sphalm. = Penardi, Huth

ponticum, Hausskn. et Bornm. in Oest. Bot. Zeitschr. x1. (1890) 211, nomen. - As. Min.

Potanini, Huth, in Bull. Herb. Boiss. i. (1893) 332 t. 14. - China.

Przewalskii, Huth, in Bot. Fahrb. xx. (1895) 407.— Mongolia.

pycnocentrum, Franch. in Bull. Soc. Bot. Fr. xxxiii. (1836) 379 . - China

pyramidatum, Alboff, Descr. nouv. esp.pl. (1891) II. [Trav. Soc. Hort. Odessa (1891)].-Reg. Cauc. quercetorum, Boiss. et Hausskn. ex Boiss. Fl. Or. Suppl. (1888) 20. - Persia

recurvatum, Greene, Pittonia, i. (April 1889) 285. - Calif.

rossicum, Rouy, in Rouy et Fouc. Fl, de Fr. i. (1893) 134 in obs. = fissum, Waldst. et $K$ it. saccatum, Huth, in Bull. Herb. Boiss, i. (1893) 328 t. 16. - Persia.

Schlagintweiti, Huth, l.c. 329. - Cachem

Schmalhauseni, Alboff, Deser. nowv. esp. pl. (1891)

\section{DELPHINIUM}

II, [Trav. Soc. hort. Odessa (1891)]; et Prod. $A$. Colchw. (1895) 11; Huth, in Bot. Fahrb. xx. (1895) 441. - Reg. Transcauc.

sertiferum, Franch. in Bull. Soc. Plhilom, Paris, Sér. VIII, v. (1893) 171. - China.

Sintenisii, Freyn, in Oest. Bot. Zeitschr. xliii. (1893) 374. - As. Min

siwanense, Franch. in Bull. Soc. Philom. Paris, Sér. VIII, v. (I893) 162. $(=D$. cheilanthum, Franch. P1. David, i, 22). - China.

somcheticum, Conrath et Freyn, ex Freyn, in Bull. Herb. Boiss, iii. (1895) 37. - As. Min.

Souliei, Franch. in Bull. Soc. Philom. Paris, Sér. VIII, v. (1893) 172. - China.

suave, Huth, in Bot Fahrb. Xx. (1895) 470.-Afghan. sutchuenense, Franch, in Bull. Soc, Philom. Paris. Sér. VIII, v. (1893) 178. - China.

syncarpum, Freyn ex Stapf, in Denkschr. Akad. Wien (1886) 26. - Persia

taliense, Franch, in Bull. Soc. Philom. Paris, Sér. VIII, v. (1893) 1\%4. - China

tanguticum, Huth, in Bull. Herb. Boiss. i. (1893) 331 t. 15. - China.

tatsienense, Franch in Bull. Soc. Philom. Paris, Sér. VIII, v. (1893) 169. - China.

tenuisectum, Greene, in Erythea, ii. (1894) 184. Mexic.

ternatum, Huth, in Bot. Fahrb. xx. (1895) 421. Turkest.

thessalonicum, Charrel [Nadii] Géogr. bot.'Emp. Ottom. [Pl. de Sal.] (1892) 46 nomen, - Oriens. tongolense, Franch. in Bull. Soc. Philom, Paris, Sér. VIII, v. (1893) 166. 一 China.

trichophorum, Franch.l. c. - China.

trilobatum, Huth, in Bull. Herb. Boiss. i. (1893) 330.

- Reg. Himal.

turkestanicum, Huth, in Bot. Fahrb. xx. (1895) 420. - Turkest.

Uechtritzianum, Pancic, ex Huth, in Bot. Fahrb. xx. (1895) 278. - Serbia, Albania.

viride, S. Wats, in Proc. Am. Acad. xxiii. (1888) 268 ; et in Gard. and For. i. (1888) 149. Mexic.

Winklerianum, Futh, in Bot. Fahrb. xx. (1895) 419. - Turkest.

yunnanense, Franch. in Bull. Soc. Philom. Paris, Sér, VIII, v, (1893) 173. - China.

Zalil, Aitch, et Hemsl. in Trans. Linn.Soc. Ser. II. iii. (1886) 30 t. 3. - Persia.

DELPYA, Pierre F1. For. Coch, (1895) t. 328 = Paranephelium Miq. (Sapind.)

muricata, Pierre 1.c. $=$ P. muricatum, Pierre.

DENDROBIUM, Sw. (Orchid.). - Ind. Kew. i.

727 .

albiflorum, Ridl. in fourn. Bot. xxiv. (1886) 323. N. Guin.

Apollo X, O'Brien, in Gard. Chron. (1895) i. 294. - Hybr, artef.

appendiculiforme, Kraenzl. in Oest. Bot. Zeitschr. xliv. (1894) 335. - N. Guin.

Aspasia X. Hort, ex Gard. Chron. (1892) i, 214. Hybr. artef.

troviolaceum, Rolfe, in Gard. Chron. (1890) i. 512 et (1892) i. 214; Hook. f. Bot.Mag. (1894) t. 7371. - N. Guin.

Augustae-Victoriae, Kraenzl. in Gartenfl. (1894) 115. - N. Guin.

aurantiacum, Reichb. f. in Gard. Chron. (1887) ii. 98. - Assam.

Baeuerleni, F. Muell. et Kraenzl.ex Kraenzl. in Oest. Bot. Zeitschr xliv. (1894) 162. - N. Guin.

Benita $\times$, Hort. ex O'Brien, in Gard. Chron. (1893) i. 355. - Hybr. artef.

bolboflorum, Falc. ex Hook. f. Fl. Brit. Ind. v. (1890) 729. - Reg. Himal.

brachythecum, F. Muell. et Kraenzl. ex Kraenzl. in Oest. Bot. Zeitschr. xliv, (1894) 161. - N. Guin.

bracteosum, Reichb. $f$. in Gard. Chron. (IS86) ii. 809; et in Lindenia, ii. (1886) 55 t. $71 .-\mathrm{N}$. Guin.

Broomfieldii, Fitzg. Austral. Orchids, ii. II. (Dec.

$1888)=$ undulatum, $R \cdot B r$.

caespitosum, King et Pantling, in fourn. As. Soc. Beng. (1895) ii. 332. - Ind. or. 


\section{DENDROBIUM}

Cassiope $\times$, Hort. ex Rolfe, in Gard. Chron. (1889) i. 200 ; et $(1890)$ ii. $620 .-\mathrm{Hybr}$. artef.

Cathcartii, Hook. f. Fl. Brit. Ind. v. (1890) 1727; et Icon. pl. (1890) t. 2022. - Reg. Himal.

cerasinum, Ridl. in fourn. Bot. xxiv. (1889) 334. N. Guin.

chryseum, Rolfe, in Gard. Chron. (1888) i. 233; Ridl. in fourn. Limn. Soc. xxvi. (1888) 392 Hoock. f. Fl. Brit. Ind. v. (1890) 738. - Reg. Himal.

chrysocephalum, Kraenzl. in Gard. Chron. (1893) ii 122. - Hab.?

chrysodiscus $\times$, Hort. ex Rolfe, in Gard. Chron. (1889) i. 197. - Hybr. artef.

chrysolabium, Rolfe, l. c. 770. - N. Guin.

clavipes, Hook. f. Fl. Brit. Ind.v. (1890) 728.Perak, Java.

Cogniauxianum, Kraenal. ex Warb, in Bot. fahrb. xiii. (1891) 280.- N. Guin.

Copelandianum, F. Muell. et Kraenzl. ex Kraenzl. in Oest. Bot. Zeitschr. xlv. (1895) 179. - N. Guin.

cornutum, Hook.f. Fl. Brit. Ind. v. (1890) 730; et Icon.pl. (1890) t. 2029. - Perak

crocatum, Hook. f. l. c. vi. (1890) 185. - Perak.

curviflorum, Rolfe, in Kew Bull. (1895) 281. Reg. Himal.

Cuthbertsoni, F. Muell. in Trans. and Proc, Roy. Soc. Vict. xxiv. (July 1888) 175. - N. Guin.

Cybele X, Rolfe, in Gard. Chron. (1887) ii. 778. Hybr. artef.

delicatulum, Kraenzl. ex Warb. in Bot. Fahrb. xvi. (1893) 17; et in Oest. Bot. Zeitschr. xliv. (1894) 162. - Oceania.

Doreyanum, L. Linden, in L'Hortic. intern. Catal. (1888-89) 48, nomen. - N. Guin.

eboracense, Kraenzl. in Oest. Bot. Zeitschr. xliv. (1894) 419.

eriaeoides, F. M. Bailey, Syn. Queensl. Fl. Suppl. ii, (1888) 56. - Austral.

Fairfaxii, Rolfe, in Gard. Chron. (1889) i. 798.Ins. N. Hebrid,

flavidulum, Ridl. ex Hook. f. Fl. Brit. Ind. vi. (1890) 185 in add. - Singap.

Forbesii, Ridl. in fourn. Bot. xxiv. (1886) 323.N. Guin.

Friedricksianum, Reichb. f. in Gard. Chron.(1887) ii. 648. - Siam.

Gazellae, Kraenzl. in Bot. Fahrb. vii. (1886) 436. N. Guin

glomeratum, Hort. Veitch, ex Gard. Chron. (1894) i. 653. - N. Guin.

glomeratum, Rolfe, in Kew Bull. (1894) 155. - Ins. Molucc.

glomeriflorum, Kraenzl. in Gard. Chron. (1895) ii. 200. - Hab.?

gracilicaule, Kraenzl. ex Warb. in Bot. fahrb. xvii. (1894) 187. - Oceania.

grande, Hook. f. Fl. Brit. Ind.v. (1890) 724. - As. trop. or.

hamatum, Rolfe, in Kew Bull. (1894) 183. Cochinch.

Hellwigianum, Kraenzl. ex Warb. in Bot. Fahrb. xvi. (1893) 16. - Oceania.

hercoglossum, Reichb. f. in Gard. Chron. (1886) ii. 487; ct ex Hook.f. Fl. Brit. Ind. vi. (1890) 185. - Malacca.

Hildebrandii, Rolfe, in Kew Bull. (1894) 182. Ind. or.

Hollrungii, Kraenzl. in Schum. et Holly. Fl. Kais, Wilh, Land. (1889) 32. - N. Guin.

Hosei, Ridl, in Trans, Iinn. Soc, Ser. II, iii. (1893) 36:3. - Penins, Mal.

hynenanthnm, Hook. t. Fl. Brit. Ind. v. (1890) 732 et vi. (1890) $185=$ hymenopterum. Hook. $f$.

hymenopterum, Hook. f. Icon.pl. (1890) t. 2032; et in Fl. Brit. Ind. vi, 185 in obs. (=D. Jiymenanthum, Hook. f.). - Ind, angl.

hyperanthiflorum, Kraenzl. in Oest. Bot. Zeitschr.

hyperanthiforum, Kraenzl. in
xliv. (1894) 333. - N. Brit.

illustre $X$, Hort. ex Gard. Chron. (1895) ii. 14, fig. 4.- Hybr. artef.

inarditum, Reich. f. 1. c. (1886) ii. 552; et in Lindenia, ii. (1886) 66 = longicolle, Lindl.

inflatum, Rolfe, in Kew Bull. (1895) 6. - Java.

isochiloides, Kraenzl. in Oest. Bot. Zeitschr. xliv. (1894) 334. - Ins. Pacif.

\section{DENDROBIUM :}

Jofftii, F. M. Bailey, Syn. Queensl. Fl. Suppl. iii. (1890) 71. - Austral.

Kaernbachii, Kraenzl. in Oest. Bot. Zeitschr. xliv. (1894) 163. - N. Guin.

kentrochilum, Hook. f. Fl. Brit. Ind.v. (1890) 731 et Icon. pl. $(1890)$ t. 2030 - Perak.

kentrophylem, Hook. f. Fl. Brit. Ind. v. (1890) 725. - Perak

kinabaluense, Ridl. ex Stapf, in Trans. Linn. Soc. Ser. II. iv. (1894) 234. - Borneo.

Kunstleri, Hook. f. Fl. Brit. Ind. v. (1890) r14. Perak.

lacteum, Kraenzl, in Oest. Bot. Zeitschr. xliv. (1894) $334 .-$ N. Hibern.

Leeanum, O'Brien, in Gard. Chron.(1894) ii.640, fig. 88. - Hab. ?

lineale, Rolfe, in Gard. Chron. (1889) ii. 381. N. Guin.

listeroglossum, Kraenzl. in Reichb. f. Xen. Orch. iii. 6. (1892) 108 t. 260 II. fig. 9, 16. - As, trop. or Loddigesii, Rolfe, in Gard. Chron. (1887) ii. 155 ( =D. pulchellum, Lodd.). - Hab.

lonchophyllum, Hook, f. Fl. Brit. Ind. v. (1890) 714 ; et Icon. pl. (1890) t. 2018. - Perak, ? Java. longipes, Hook. f. l. c. 713; et Icon. pl. (1890) t. 2017. - Perak

Mac Carthiae, Pfitz, in Engl. et Prantl, Natürl. Pflanzenfam. ii. 6. (1888) $174=$ D. Macarthiae Thw.

Mac Gregorii, F. Muell. et Kraenzl. ex Kraensl. in Oest. Bot. Zeitschr. xliv. (1894) 301; et in Gard. Chron. (1894) ii. 90. -

macropodum, Hook. f. Fl. Brit. Ind. v. (1888) 713 et Icon. pl. (1890) t, 2020. - Perak

megaceras, Hook. f. 11. cc. 713 ; et 2031. - Malacea.

melanodiscus $\times$, Hort. ex Rolfe, in Gard. Chron. (1889) i. 297 et 300. - Hybr. artef.

melanophthalmum $\times$, Reichb. $f$. ex Gard. Chron (1886) i. 426. - Hybr. spont.

Meltkeaeum, Kraenzl, l. c. (1894) ii, 306 - Hab. moulmeinense, Parish, ex Hook. f. Fl. Brit. Ind. v. (1890) 746; et Icon.pl. (1810) t. 2033. - Tenass. moulmeinense, Hort. Low, ex Warn. et Will. Orchid. Alb.x. (1893) t. $448=$ infundibulum, Lindl.

murhiniacum X, Reichb. $\mathrm{f}$, in Gard. Chron. (1888) i. 551. - Hybr. artef.

nanum, Hook. f. Icon. pl. xix. (1889) t. 1853; et Fl. Brit. Ind. v. (1898) 717. - Malabar.

Nestor $\times$, O'Brien, in Gard. Chron. (1892) i. 718 - Hybr. artef.

niveum, Rolfe, in Gard. Chron.(1891) i. $104(=D$ Macfarlanei, Reichb.f.). - Austral.

Novae-Hiberniae, Kracnzl. in Oest. Bot. Zeitschr. xliv. (1894) 301. - N. Hibern.

nycteridoglossum, Reichb. f. in Gard. Chron. (1886) ii. $616 .-\mathrm{N}$. Guin.

O'Brienianum, Kraenzl. l. c. (1892) i. 266. Ins. Philipp.

Owenianum X, Hort. ex O'Brien, 1. c. (1893) i. 226.- Hybr. artef.

pachyceras, F. Muell. et Kraenzl. ex Kraenzl. in Oest. Bot. Zeitschr, xliv, (1894) 164, - N. Guin. panduriferum, Hook. f. Fl. Brit. Ind. vi. (1890) 186. - Pegu.

perakense, Hook. f. Fl. Brit. Ind. v. (1890) 712; et Icon. pl. (1890) t. 2019. - Perak.

percnanthum, Reichb. f. in Gard. Chron. (1886) ii. 70 ; et in Lindenia, ii. (1886) 28. - Ins. Molucc. Pitcherianum X, Reichb. f. in Gard. Chron. (1888) i. 392, - Hybr. artef

platycaulon, Rolfe, in Kew Bull. (1892) 139. - Ins. Philipp.

pleurothalloides, Kraenzl. in Oest. Bot. Zeitschr. xlv. (1895) 178. - N. Guin.

podagraria, Hook.f. Fl. Brit. Ind. v. (1890) 7£8; et Icon. pl. (1890) t. 2026. - Burma, Tenrss.

pogoniates, Reichb. f. in Gard. Chron. (1886) ii. 199. - Borneo.

polyphlebium, Reichb. f. 1. c. (188\%) ii. $242=$ rhodopterygium, Reichb. $f$.

prionochilum, F. Muell. et Kraenzl. ex Kraenzl. in Oest. Bot. Zeitschr. xliv, (1894) 162. - N. Guin.

pumilum, Parish, et Reichb. f. in Trans. Linn. Soc. xxx. (1894) 150 t. $31=$ quadrangulare Parish.
DENDROBIUM

puniceum, Ridl. in fourn. Bot. xxiv. (1886) 324. N. Guin.

psychrophilum, F. Muell. in Trans. Roy. Soc. Vict. New Ser. ii. (1889) 24. - N. Guin.

pyropum, Ridl, in Trans. Linn. Soc. Ser. II iii. (1893) 362. - Penins. Mal.

quadrangulare, Parish, ex Hook, f. Fl. Brit. Ind. vi. (1890) 714. - Tenass.

quadrangulare, Reichb, $f$. in Flora, 1xix. (1886) 553. - Burma.

Regnieri $\times$, Regnier, ex Rev. Hortic. (1894) 192. Hybr. artef.

reptans, Ridl. in fourn. Bot. xxvi. (1886) 323.N. Guin.

rhodostele, Ridl. in Trans. Linn. Soc. Ser. II. iii. 1893) 360. - Penins. Mal.

rhodostictum, F, Muell, et Kraenzl. ex Kraenzl, in Oest. Bot. Zeitschr. xliv. (1894) 300. - N. Guin. robustum, Rolfe, in Keve Bull. (1895) 33.-N. Guin. Rolfeae X, Rolfe, in Gard. Chron. (1892) i. 522. Hybr, artef.

rubens $\times$, Hort. ex O'Brien, 1. c. (1893) i. 226.Hybr, artef.

rutriferum, Reichb. f.l.c. (1887) ii. 746; et in Lindenia, iii. (1887) 49 t. 119. - N. Guin

Sanderianum, Rolfe, in Kew Bull. (1894) 155. Borneo.

sanguineum, Rolfe, in Gard. Chron. (1895) ii. 292.Borneo.

Schneiderae, F. M. Bailey, Occas. Pap. n. I. 7, et Syn. Queensl. Fl. Suppl. 1I, (1888) 57, - Austral.

Schneiderianum $\times$, Reichb. $f$. in Gard. Chron. (1887) i. 209. - Hybr. artef.

Scortechini, Hook. f. Fl. Brit. Ind. v. (1890) 741.Perak.

seriatum, Wall. ex Hook. f. F1. Brit. Ind. v. (1890) 796 = Eria acervata, Lindl

serpens, Hook. f. in Ann. Bot. Gard. Calc. v. 1, (1895) 10 t. 16. - Perak.

speciossimum, Hort, ex Rev. Hortic. (1895) 415. Borneo.

sphenochilum, F. Muell. et Kraensl. ex Kraenzl. in Oest. Bot. Zeitschr. xliv. (1894) 254. - N. Guin.

Stratiotes, Reichb. f. in Gard. Chron. (1886) i. 266; et (1886) ii. 176 fig. 34; et in Illustr. Hortic. xxxiv. (1886) 109 t. 602. - Ins. Sund.

strebloceras, Reichb. f. l. c. (1886) i. 266. - Ins Sund.

subclausum, Rolfe, in Kew Bull. (1894) 361. - Ins. Molucc.

subulatum «Hook. f.) Fl, Brit. Ind. v. (1890) '726 sphalm. = subulatum, Lindl.

tenuicaule, Hook, f.l. c. vi. (1890) 184 in add. Ins. Andam.

tigrinum, Rolfe, ex Hennsl. in Ann. of Bot. v. (1891) 507. - Ins. Salomon.

tosaense, Makino, Ill. Bot. Fap. (1891), ex fourn. Bot. (1891) 383. - Japon

trigonopus, Reichb. f. in Gard. Chron. (1887) ii. 682. - Burma.

tripterum, Wall. ex Hook. f. Fl. Brit. Ind. v. 1890) $790=$ Trias oblonga, Lindl.

triquetrum, Ridl. in fourn. Bot.xxiv. (1886) 322 - N. Guin.

tropaeoliflorum, Hook. f. Fl. Brit. Ind. vi. (1890) 186, in add. - Perak.

tuberiferum, Hook. f. l. c. v. (1890) 728; et Icon. pl. (1890) t. 2025. - Perals.

velutinum, Rolfe, in Kew Bull. (1895) 33. - Burma.

Vemus $\times$. Hort ex Rolfe, in Gard. Chron.(1890) i. 608; et (1893) i. 290. - Hybr. artef.

versicolor, Cogn, in foum. des Onch. vi. (1895) 153. - Assam.

Warburgianum, Kraenzl. ex Warb. in Bot. fahrb. xiii. (1891) 280, - N. Guin.

Wattii. Reichb f in Gard. Chron. (1888) ii, 725; et in Hook. f. Fi. Brit. Ind.v. (1890) 721. - Munni-

Wore. 334. - Hybr, artef.

DENDROCALAMUS, Nees. (Gramin.). - Ind. Kew. i. 731 .

maximus, Kuntze, Rev. Gen. (1891) $773=$ Hamiltonii, Nees et Arn. 
DENDROCALAMUS

sikkimensis, Gamble, ex Oliver, in Hook. Icon, pl.xviii. (1888) t. 1770. - Reg. Himal.

DENDROCHILUM, Blume (Orchid.). - Ind.

cobolbine, Reichb. f. in Flora, Ixxxi. (1888) 151. Java.

conopseum, Ridl. ex Stapf, in Trans. Linn.Soc., Ser. II. iv. (1894) 336. - Borneo.

linearifolium, Hook. f. Icon.pl. xix. (1889) t. 1850; et Fl. Brit. Ind. v. (1890) 782. - Perak.

Micholitzianum, Kraenzl. in Bot. Fahrb̆. xvii. (1893) 486. - Sumatra.

pallidiflorum, Hook. f. Fl. Brit. Ind. v. (1890) 782 sphalm. = pallidiflavens, Blume.

DENDROMEGON, Benth. (Papaver.) - Ind. Kew, i. 732 .

flexile, Greene, in Bull. Torrey Bot. Club, xiii. (1886) 216 = rigidum, Benth

Harfordii, Kell. ex Greene, 1. c. $217=$ rigidum, Benth.

DENDROPEMON, Blume = Loranthus, Linn. alatus, Van Tiegh. in Bull. Soc. bot. Fr.xlii. (1895) 170. - Ins. S. Doming.

cubensis, Van Tiegh. 1. C xli. (1894) 69 ; et xlii (1895) $170=\mathrm{L}$. cubensis, Grisel.

domingensis, Van Tiegh. 1. c. xli. (1894) 69; et xlii. (1895) $170=\mathrm{L}$. domingensis, Desv

laxiflorus, Van Tiegh. 1. c. xlii. (1895) $170=$ L. laxiflorus, Desv

loranthoideus, Van Tiegh. 1. c, xli. (1894) 70. - Ind. occ.?

parvifolius, Van Tiegh. 1. c. xlii. (1895) $170=$ L. parvifolius, Sw

pauciftorus. Van Tiegh. 1. c. xli. (1894) 69; et xlii. (1895) $170=$ L. panciflorus, Sw.

1ortoricensis, Van Tiegh.11. cc. = L. portoricensis, $D C$.

psilobotrys, Van Tiegh. 11. cc. = L. psilobotrys, $D C$

DENDROPHTHOË, Mart. = Loranthus, Linn. acacioides, Van Tiegh in Bull. Soc bot. Fr. xlii. (1895) 85 et $252=\mathrm{L}$. acacioides, $A$. Cunn.

angustifolius, Van Tiegh. 1. c. (1895) $85=$ L. angustifolius, R. Br.

curvatus, Van Tiegh. I. c. $252=$ L. curvatus, Blume.

longiflorus, Van Tiegh. 1. c. (1895) 85 et $252=$ L. longiflorus, Desr.

orbicularis, Van Tiegh. 1. c. 252. - Hab.?

pentandrus, Van Tiegh. 1. c. = L. pentandrus, Linn.

praelongus, Van Tiegh. 1. c. = L. praelongus, Blume.

vitellinus, Van Tiegh. 1. c. 85 et $252=$ L. vitellinus, $F$. Muell.

ligulatus, Van Tiegh. 1. c. = L. ligulatus, Thw.

nilgherrensis, Van Tiegh. 1. c. xlii. (1895) $252-$ $=\mathrm{L}$. nilgherrensis, Wight.

odontocalyx, Van Tiegh. 1. c. $85=\mathbf{L}$. odontocalyx, F. Muell.

DENDROPHYLAX, Reichb. f. (Orchid,). - Ind. Kew. i. 733.

Fawcetti, Rolfe, in Gavd. Chon.(1888) ii. 533.Ind. occ.

DENDRORCHIS, Thou, in Nouv. Bull. Soc. Philom. Paris (1809) 314-19, ex Kuntze Rev. Gen. (1891) $658=$ Polystachya. Hook.(Orchid.).

acutifolia, Adansoniae, affinis, alpina, anceps, Bennettiana, bifida, bracteosa, caduca, caloglossa, caracasana, carea, clavata, coriscencis, elastica, elegans, estrellensis, extinctoria, foliosa, galericuluta, golungensis, Fussieuana, laxiflora, leonensis, lineata, nana. odorata. Ottoniana, pachyglossa, paulensis, puberula. pubescens, purpurea, pyramidalis, ramulosa, reflexa. rhodoptera, rosea, rosellata, rufinula, setifera, shirensis, similis, Steudneri, superposita, tessellata, virescens, Wightii, Zollingeri, Kuntze,1.c. = homonyma omnia Polystachyae.

caperisis, Kuntze, 1. c. = P. Ottoniana, Reichb. $f$.
DENDRORCHIS : -

dendrobiflora, Kuntze Rev. Gen. (1891) 658. = P. dendrobiiflora, Reichts. $f$.

galeata, Kuntze, 1. c. = P.grandiflora, Lindl. masayensis, Kuntze,1.c. = P.masasayensis, Reichb.f. membranacea, Kuntze,1.c. $=$ (Chloidia vernalis, Lindl. $)$ - Ind. occ.

minuta, Kuntze, 1. c. = P. zeylanica, Lindl. minutiflora, Kuntze, l. c. $=$ P. zeylanica, Lindl.

polystachyon, Kuntze, 1.c. = P. zeylanica, Lindl.

DENDRORCHIS, polydendris, “Thou. » ex Bull. Herb. Boiss. ii. (1894) 459 ( = Dendrobinm poly stachys, Thou. $)=$ Polystachya mauritiana, Spreng.

DENDROSTELLERA, Van Tiegh. in Bull. Soc. bot. Fr. xl. (1893) $74=$ Stellera, J. G. Gmel. (Thymel.)

Griffithi, Van Tiegh. 1. c. $75=$ S. Lessertii, C. A. Mey.

Lessertii, Van Tiegh. 1. $\mathrm{c} .=\mathrm{S}$. Lessertii, $C . A$. Mey.

spicata, Van Tiegh. 1. c. = S. Lessertii, C. A. Mey.

stachyoides, Van Tiegh. 1. c. = S. Lessertii, C. A. Mey.

DENHAMIA, Meisn. (Celastr.). - Ind. Kew.i. 733

viridissima, F.M. Bailey et F. Muell. Rep. Exped. Bellenden-Ker (1889) 35. - Austral.

DENTARIA, [Tourn.] Linn. = Cardamine, Linn. (Crucif.).

cardiophylla, Robins. Syn. F1. N. Am. 1 i. (1895) 155. = C. cardiophylla, Greene.

gemmata, Howell, ex Greene, Pittonia, i. (Feb.1888) $162=$ C. gemmata, Greene.

Rapini X, Rouy et Fouc. Fl. de Fr. i. (1893) 245 = digenea, Gremli

pachystigma, S. Wats. Syn. F1. N. Am. 1. i. (1895) $155=$ C. californica Greene, var.

DENTIMETULA, Van Tiegh. in Bull. Soc, bot. Fr. xlii. (1895) $265=$ Loranthus, Linn

dodoneaefolia, Van Tiegh. 1. c. = L. dodoneaefolius, $D C$.

DERMATOBOTRYS, Bolus, in Hook. Icon. pl, xx. (1890) t. 1940. - SCROPHULARIACEAE Saundersii, Bolus, l.c.; et in Bot. Mag. (1894) t. 7369. - Afr. austro-or.
t

DEROEMERA, Reichb. f. = Habenaria, Willd (Orchid.)

acuminata, Rendle et Schlechter, in Journ, xxxiii. (1895) 277 (Deroemeria). - Afr. trop. or.

aphylla, Schlechter et Rendle, in Journ. Bot. xxxiii. (1895) 277 in obs. = H. aphylla, Reichb. $f$.

DERRIS, Lour. (Legumin.). - Ind. Kew. i. 734 Fordii, Oliver, in Hook. Icon. pl. xviii. (1888) t. 1771. - China.

grandiflora, Kuntze, Rev. Gen. (1891) 203. - Java Koolgibberah, F. M. Bailey, Rep. Exped. BellendenKer (1889) 38. - Austral.

polyphylla, Baker, in fourn. Linn. Soc. xxv. (1890) 312. - Madag.

DESCHAMPSIA, P. Beauv. (Gramin.). - Ind. Kew. i. 734.

Berteroana, Fr. Meigen, in Bot. Jahrb. xvii. (1893) $228=$ Berteroiana, Trin.?

Chapmani, Petrie, in Trans, N.Z. Inst, xxiii. 1890 (1891) 401. - N. Zel.

gracillima, T. Kirk, in fourn. Bot. xxiv. (1891) 237. - Ins. Auckland.

Hookeri, T. Kirk l. c. 238. - N. Zel.

Hookeriana, Scribn. in Coult. Bot. Gaz. xi. (1886)

97 in obs. ( = Aira latifolia, Hook.). - Am. bor. mexicana, Scribn. in Proc. Acad. Phit. (1891) 300 - Mexic.

Novae-Zelandiae, Petrie, in Trans, N. Z. Inst. xxiii. 1890 (1891) $402 .-\mathrm{N}$. Zel.

nubigena, Hillebr. Fl. Haw. Isl. (1888) 521. Ins Sandvic.

pallens, Hillebr., l. c. 520. - Ins. Sandvic.
DESCHAMPSIA

paludosa, C. Richt, Pl. Europ. i. (1889) 56 (Airo Wibeliana. Sond.). - Germ.

penicillata, T.Kirk, in Trans. N.Z. Inst. xxvii 1894 (1895) 354. - N. Zel.

Pringlei, Scribn. in Proc. Acad. Phil. (1891) 300. Mexic.

pusilla, Petrie, in Trans. N.Z. Inst. xxiii. 1890 (1891) 403. - N. Zel.

setacea, C. Richt. P1. Europ. i. (1889) $57=$ discolor, Roem. et Schult.

tenella, Petrie, in Trans. N.Z. Inst. xxiii. 1890 (1891) 402. - N. Zel,

DESCURAINIA, Webb et Berth. = Sisymbrium Linn. (Crucif.)

Bourgaeana, Webb, ex Christ, in Bot. Jahrb. ix. (1888) $89=\mathrm{S}$. Bourgaeanum, Fourn.

canescens, Prantl, in Engl. et Prantl, Natür1, Pflanzenfam. iii. 2. (1891) $192=$ Erysimum pinnatum, Nutt.

Cumingiana, Prant1, 1. c. $=\mathrm{S}$. Cumingianum Fisch. et Mey.

Hartwegiana, Britton, in Mem. Torrey Bot. Club, v. (1894) $173=\mathrm{S}$. Hartweoianum, Fourn.

incisa, Britton, 1. c. = S. incisum, Engelm.

pinnata, Britton, 1. c. = Erysimum pinnatum Nutt.

Preauxiana, Webb, ex Christ, in Bot. Jahrb, ix (1888) $90=$ Sisymbrium Preauxianum, $W e b b$ Sophia, Webb, ex Prantl, in Engl. et Prantl, Natürl. Pflanzenfam. iii. 2. (1892) $192=\mathrm{S}$ Sophia, Linn

tanacetifolia. Prantl, in Engl. et Prantl, 1. c. = S. tanacetifolium, Linn

DESDEMONA, S. Moore, in Trans. Linn. Soc. Ser. iv. II. (1895) 408. SCROPHULARIACEAE. pulchella, S. Moore, l. c. t. 27 fig. 2-9. - Bras.

DESMANTHODIUM, Benth. (Compos.). - Ind Kew. i. 735

Trianea, Hieron, in Bot. Fahrb. xix. (1894) 52. Columb.

DESMANTHUS, Willd. (Legumin.) - Ind. Kew. i. 735.
bicornutus, S. Wats. in Proc. Am. Acad. xxi. (1886) 426. - Mexic.

Cooleyi, Trelease, ex Branner et Coville, in Ann. Rep. Geol. Surv. Arkans, for 1888, i. (1891) $178=$ Jamesii, Torr. et Gray.

fruticosus, $N . E$ Rose, in Contrib. U. S, Nat. Herb. i. (1892) 131, t. 13. - Ins. Carmen.

illinoënsis, Mac Mill. Metasp. Minn. (1892) 388 $(=$ Acuania illinoensis, Kuntze $)=\mathrm{D}$. brachylobus, Benth.

ligospermus, T. S. Brandeg. in Proc. Calif. Acad. Ser. II. iii. (1891) 133. - Calif.

paucifoliolatus, S. Elliot, in fourn. Linn. Soc. xxix. (1891) 14. - Marag.

DESMARIA, Van Tiegh. in Bull. Soc. bot. Fr. xlii. (1895) $458=$ Loranthus, Linn.

mutabilis, Van Tiegh. 1. c. $=$ L. mutabilis, Poepp. at Endl.

DESMAZERIA, Dum. = Demazeria, Dum. (Gramin.).

acutiflora, Th. Dur. et Schinz, Consp. Fl. Afr.v.

1894 (1895) 900 (= Brizopyrum acutiflorum, Nees). - Afr. austr.

alternans, Th. Dur, et Schinz, 1. C. $(=B$, alternans, Nees). - Ins. S. Hel.

balearica, Willk. in Oest. Bot. Zeitschr. xl. (1890)

134. - Ins. Balear.

triticea, Presl, ex Willk. l. c. 135.--Sicil.

DESMIDORCHIS, Ehrenb. = Boucerosia, Wight et Arn. (Asclep.).

Aucheriana, Kuntze, Rev. Gen. (1891) $418=\mathrm{B}$.

Aucheriana, Decne:

cremulata, Kuntze, 1. c. = B. crenulata, Wight.

Decaisneana, Kuntze, 1. c. = B. Decaisniana, Lem.

diffusa, Kuntze, 1. c. $=$ B. diffusa, Wight.

europaea, Kuntze, 1. c, = B. Gussoniana, Hook. 
DESMIDORCHIS : -

indica, Kuntze, Rev. Gen. (1891) 418 = B. Hutchinia, Decne.

panciflora, Kuntze, 1. c, = B. pauciflora, Wight. quadrangula, Kuntze, 1. c. = B. Forskalii Decne

Stocksiana, Kuntze, 1. c. = Caralluma edulis, Benth.

umbellata, Kuntze, 1. Co = B. umbellata, Wight et Arn.

DESMrODIUM, Desv. (Legumin.).- - Ind. Kew. i. 736 .

albiflorum, Cordem. Fl. Ile Réun. (1895) 403.Ins. Borbon.

amans, S. Wats. in Proc. Am. Acad, xxvi, (1891) 135. - Mexic.

bioculatum, S. Wats. l. c. 425. - Mexic.

callianthum, Franch. Pl. Delav. (1890) 173. Yunnan.

cinerascens, Franch. l.c. 174. - China.

Godefroyanum, Kuntze, Rev。Gen。(1891) 196. Cochinch

guadalajaranum, S. Wats, in Proc. Am. Acad. xxv. (1890) 147. - Mexic.

hamulatum, Franch. Plant. Delav. (1889) 175. Yunnan.

hispidum, Franch. l. c. 174. - Yunnan.

hondurense, M. Micheli, ex F. D. Smith, in Coult. Bot. Gaz. xx. (1895) 284. - Hondur.

jaliscanum, S. Wats. in Proc. Am. Acad. xxii. (1887) 406. - Mexic.

Lindheimeri, M. A. Vail, in Bull. Torrey Bot. Chub, xviii. (1891) 120. - Mexic.

Mandoni, Britton, l. c. xvi. (1889) 261. - Boliv

mexicanum, S. Wats. in Proc. Am. Acad. xxiii. (1888) 271. - Mexic.

Pringlei, S. Wats. $l_{\text {. }}$. o $_{0}$ - Mexic.

procumbens, Hitchcook, in Missouri Bot. Gard. Rep. iv. (1893) $76=$ spirale, $D C$

prostratum, T. S. Brandeg. in Proc. Calif. Acad. Ser. II. iii. (1891) 128. - Calif.

thabdocladum, Franch. Plant. Delav. (1889) 173. - China.

scopulorum, S. Wats, in Proc. Am. Acad. xxiv. (1886) 47. - Calif. inf.

Stuhlmannii, Taub. in Engl. Pflanzenw. Ost-Afr.C. (1895) $21 \%$ - Afr. trop. or.

subsessile, Robins. et Seaton, in Proc. Am. Acad. xxviii. (1893) 118. - Mexic.

subspicatum, S. Wats. l. c. xxvi. (1891) 135. Mexic.

tanganyikense, Baker, in Kew Bull. (1895) 65. Afr, trop.

Tweedyi, Britton, in Trans. N. Y. Acad. Sci.vii. (1890) 183. - Texas.

youngasense, Britton, in Bull. Torrey Bot. Club, xvi. (1889) 261. - Bolivia.

yunnanense, Franch. Plant. Delav. (1889) 172. - Yunnan.

DESMOSTACHYS, Planch. (Olacin.). - Ind. Kew. i. 739 .

nitidus, Planch. ex Valeton, Crit. Overs. Olacin. (1886) $205=$ Planchonianus, Miers.

Preussii, Engt. Bot. Fahrb. xv. (1893) 70. Kamerun.

DESROUSSEA UXIA, Van Tiegh. in Bull. Soc. bot. Fr, xlii. (1895) $358=$ Loranthus, Linn. nodosa, Van Tiegh. 1. c. $=$ L. nodosus, Desc

DETANDRA, Miers = Sychnosepalum, Eichl. (Menisperm.).

paraènsis, K. Schum. ex Taub. in Bot. Jahrb. xv. Beibl.n. 38 (1893) $5=$ S. paraënse, Eichl.

pubistaminea, K. Schum. 1. c. 4. - Bras.

Sagotiana, K. Schum. 1. c. 5 = S. Sagotianum, Eichl.

DEUTERocohniA, Mez, in Mart. FI. Bras. iii. III. (1894) 507. BROMELIACEAE.

longipetala, Mez. 1. c. (1894) 507 ( = Dyckia longipetala, Baker). - Am. austr. trop. DEUTZIA, Thunb: (Saxifrag.). - Ind. Kew.i.
739.

\section{DEUTZIA :}

albida, Batalin, in Act. Hort. Petrop. xiii. (1893)

97. - China.

discolor, Hemsl. in Fourn. Itnn. Soc. xxiii. (1887) 275. - China.

discolor, Maximi. in Bull. Acad. Pétersb. xxxii. 487. - Japon.

glomeriflora, Franch. in Nouv. Arch. Mus. Paris, Sér. 1I. viii. (1886) 236. - China occ.

Lemoinei $X$, Hort. Lemoine, ex Rev. Hortic. (1894) 214; et ex Gartenfl. (1895) 566 fig. 105. Hybr. artef.

longifolia, Franch, in Nowv. Arch. Mus, Paris, Sér. II, viii. 1885 (1886) 235. - China.

Maximowicziana, Makino, in Tokyo Bot. Mag. vi. (1892) 52 et viii (1894) 505; = hypoleuca, Maxim.

pulchra, Vidal, Revis. Fl. Vasc. Filip. (1886) 124. - Ins. Philipp.

Wateveri $x$, Hort. ex Koehne, Deutsche Dendrol. (1893) 185. - Hybr. artef.

Wellsi $\times$, Hort. ex Koehne, 1. c. - Hybr. artef.

DEYEUXIA, Clar. (Gramin.). - Ind. Kew. i. 739.

arundina, Phil. in Anal. Mus. nac. Chile (1892) 84. - Chili.

borealis, Macoun, Cat. Can. Pl. (1888) 207, nomen = vancouverensis, Vasey.

breviaristata, Vasey, in Bull. Torrey Bot. Club, xv. (1888) 48. - Ins. Vancouv.

chrysophylla, Phil. in Anal. Mus, nac. Chile, (1892) 83. - Chili.

columbiana, Macoun. Cat. Can. Pl. (1888) 207, nomen - Columb. brit.

dubia, Soribn. in Coult. Bot. Gaz. xi. (1886) 174. Am. bor. occ.

emirnensis, Baker, in fourn. Linn. Soc. xxii, (1887) 533. - Madag.

epileuca, Stapf, in Trans. Linn. Soc., Ser. II. iv. (1894) 247 t. 20 c 10-16. - Borneo.

glomerata, Vasey, ex Macoun, in Coult. Bot. Gaz. xvi. (1891) 288 nomen. - Canada.

Hillebrandi, Munvo, ex Hillebr. Fl. Haw. Isl. (1888) 519. - Ins. Sandvic

javanica, Boerl. in Ann. Jard. Buit. viii. (1889) 71 = Calamagrostis javanica, Steud.

laxiflora, Phil. in Anal. Mus, nac. Chile (1892) 83.Chili.

nardifolia, Phil.l. c. - Chili,

tenuifolia, Phil. i. c. - Chili.

Treutleri, Stapf, in Hook. Icon. pl. xxv. (1895) t. 2396. - Reg. Himal.

trisetoides, Phil. in Anal. Mus. nac. Chile, (1892) 83. - Chili.

variegata, Phil. l. . . - Chili.

vancouverensis, Vasey, in Bull. Torrey Bot. Club, $\mathrm{xv}$. (1888) $48-$ Am. bor. occ.

DIALIUM, Linn. (Legumin.). - Ind. Kew. i. 741. madagascariense, Baill. Hist. pl. Madag., Atlas (1886) t. 30 B. - Madag.

DIALYANTHERA, Warb. in Ber. Deutsch. Bot. Ges. xiii. (1885) 89. ANONACEAE.

Otoba, Warb. 1. c. - Am. austr. trop.

DIANELLA, Lam. (Lillac.), - Ind. Kew.i. 711. reflexa, Colenso, in Trans. N.Z. Inst. xxvii. 1894 (1895) 396. - N. Zel

straminea, Yatabé, in Tokyo Bot. Mag. vii. (Jan. 1893) 435 t. I. - Japon.

DIANTHERA, Gronov. (Acanth.). - Ind. Kew. i. 741 .

bicolor, Pax, in Bot. fahrb. x. (1889) 15. - Afr. austro-occ. extratrop.

bullata, N. E. Br. in Illustr. Hort. (1886) 43 t. 589. - Borneo.

carnosa, Pax, in Bot. Falırb. x. (1889) 14. - Afr. austro-occ. extratrop.

incerta, T. S, Brandeg. in Proc. Calif. Acad. Ser. II. iii. (1893) 226. - Calif.

lactevirens, Baill. Hist, des pl. x. (1891) $446=$ Galesia laetevirens, A. Gray.

\section{DIANTHERA}

aevilinguis, Lindau, in Bot. Jahrb. xix. Beibl. n. 48 (1894) $20=$ Rhytiglossa laevilinguis, Nees.

obtusifolia, Morong, in Ann. N. Y. Acad. Sci, vii. (1893) $195=$ Rhytoglossa obtusifolia, Nees.

ovata, Trelease, ex Branner et Coville, in Ann. Rep. Geol. Surv. Arkans. for 1888. i. (1891) 210 $=$ humilis, Engelm. et Gray.

paludosa, S. Moore, in Trans. Linn. Soc. Ser. II, iv. (1895) 432. - Bras.

polygaloides, S. Moore, l. c. 433. - Bras.

Sonorae, S. Wats, in Proc. Am. Acad. xxiv. (1889) 67. - Calif.

Sonorae, T. S. Brandeg. in Proc. Calif. Acad. Ser. II. ii. (1889) 195 nomen = Tetramerium ovalifolium, Oerst.

violacea, Kuntze, Rev. Gen. (1891) $979=$ Beioperone violacea, Planch. et Linden.

DIANTHUS, Linn. (Caryoph.). - Ind. Kew.i.

acrochlonis, Stapf, in Denkschr. Acad. Wien. (1886) 5. - As. Min.

albanicus, Wettst. in Luerss, Bibl. Bot. Heft xxvi. (1892) 34. - Alban.

angolensis, Hiern, ex Williams, in fourn. Bot, xxiv. (1886) 301. - Angola.

Aristıdis, Batt. in Batt, et Trab. Fl. de l'Algér. (Dicot.) (1888), append. 2 p. v. - Algeria.

auraniticus, Post. in Fourn. Bot. xxiv. (1888) 422. Syria.

basianicus, Boiss. et Hausskn. ex Boiss. Fl. Or. Suppl. (1885) \%\%. - Mesopot.

Borbasii, Vandas, in Oest. Bot. Zeitschr. xxxvi. (18S6) 193. - Volhyn.

Bornmuelleri, Hausskn. in Mlth. Bot. Ver. Fena, ix. (1891) 16; et ex Williams in fourn. Linn. Soc. xxix. (1893) 460. - As. Min.

brevicalyx, G. Beck, in Ann. Naturh. Hofmus. Wien, ii. (1887) $63=$ inodorus, Linn.

carpathicus, Borb. in Termesz. Fuzét, xii. (1889) 44 ; et in Oest. Bot. Zeitschr, xli. (1891) 75 in syn. = spiculifolius, Schur.

carpathicus, Wolosz. in Spraw. Kom. fizyj. Krajowei xxii. (1888) ii. 214. - Reg. Carpath.

curticeps, Borb. in Oest. Bot. Zeitschr. x1. (1890) 97. - Bosnia.

Deserti, Post, Pl. Postianae, ii. (1891) 6. - Syria.

Endressi, Zahlbr. ex Conrath, in Oest. Bot Zeitschr. xxxviii. (1888) $51=$ deltoides, Linn.

Engleri, Hausskn, et Borm, in Mitth. Bot. Ver. Fena, ix. (1891) 15; et ex Williams in fourn. Linn. Soc. xxix. (1893) 410. - As. Min.

eretmopetalus, Stapf, in Denkschr. Akad. Wien, (1886) 349. - As. Min.

Formanekii, Borb. ex Formanek, in Verh. Naturf. Vev. Brunn. xxxii. (1894) 39. - Maced.

Freynii, Vandas, in Sit\%. Böhm. Ges. Wiss, 1889 (1890) ii. 255 t. 9 fig. 6; G.Beck. in Annal. NaturhHofmus. Wien, vi. (1891) 332. - Bosnia.

giganteiformis, Borb. in Oest. Bot.Zeitschr. xli. (1891) 32. - Hung.

Giuliae, “ Janka » ex Nym. Consp. Fl. Eur. Suppl. ii. I (1889) 59 sphalm. = D. Guliae, fanka.

Hanryi $\times$, Burnat, F1. Alp. Marit. (1892) 223. - Alp. Marit.

Holzmannianus, Heldr. et Hausskn. ex Nym. Consp. Fl. Eur. Suppl. ii. 1 (1889) 58 nomen.Graecia.

Hubnevi $X$ Seehaus, in Verh. bot. Ver. Prov. Brand. xxxiii. (1892) 95. - Germ.

kastembeluensis, Freyn et Sint. in Oest. Bot. Zeitschr. xliii. (1893) 375. - As. Min.

Kitaibelii, Janka, ex G. Beck, in Annal. Naturh. Hofmus. Wien, ii. (1889) $192=$ petraeus, $W$. et $K$.

Laucheanus $\times$, Bolle, ex Bolle et Aschers. in Verh. bot. Ver. Prov. Brand, xxxiii. Abhandl. (1892) 102 - Germ.

Lisae, X, Burnat, F1. Alp. Marit. (1892) 233. Alp. Marit.

Iumitzeri Wiesb. Schles, bot. Tauschver. (I882) ex Bot. Centralbl. xxvi. (1886) 85 = plumarius, Linn.

marginatus, Lacaita, in Nuov. Giorn. bot. Ital. xix. (1887) 130 nomen, - Ital. 


\section{DIANTHUS}

Maris, Willd ex. Willians, in fourn. Linn. Soc. xxix. (1893) 415. - Alpes.

marisensis, Simonk. in Termész. Fizzét. ix. (1885) 37; ex Enum.pl. Transs. (1886) 118. - Trans.

mecistocalyx, Williams, in fourn. Bot. xxvii. (1889) 199. - Transv

medunensis, G. Beck et Szyszyl., Pl. Cern. (1888) 65 et in Bull. Soc. bot. Fr. xxxvi. (1889) 118. Monten.

melandrioides $\times$, Pau, Not. bot. fl. Espan. i. (1887) 29; et ii. (1889) 15. - Hisp.

Monteuilii, Burnat, Fl. Alp. Marit. (1891; 221. Alp. Marit.

moviensis, Williams, in fourn. Bot. xxvii. (1889) 199. - Transy.

narbonensis, Rouy, in Morot, Journ. de Bot. vi. (1892) 64 in syn. = brachyanthus, Boiss.

Nassireddini, Staff, in Denkschr. Akad. Wien (1886) 279. - Persia.

Nelsoni, Williams, in fourn. Bot.xxvii. (1889) 200. - Transv.

Nicolai, Beck et Ssysyl. Pl. Cern. (1888) 65 t. 3 ; et in Bull. Soc. bot. Fr. xxxvi. (1889) 117.-Monten. oetaeus, Heldr. ex Nym. Consp. ii. 1. (1889) 57 , nomen $=$ gracilis, Sibth. et Sm.

pachypetalus, Stapf, in Denkschr. Akad. Wien (1886) 278. - As. occ.

Pancicii, Velen. in Sitz. Boehm. Ges. Wiss. (1886) extr. 9; et Fl. Bulg. (1891) 79. - Bulg.

persicus, Hausskn. in Mitth. Bot. Ver. Fena, ix. (1891) 16. - Persia.

praevertens, Williams, in fourn. Linn. Soc. xxix. (1893) 408 (= D. servulatus, Schloss). - Croatia. pulverulentus, Stapf, in Denkschr. Akad. Wien, (1886) 279. - Persia.

pulverulentus, Wettst. in Sitzungsb. Akad. Wien xcviii. 1889 (1890) 382. - As. Min

purpureo-luteus, Velen. Fl. Bulg. (1891) 73. Bulg.

pusillus, Freyn et Sint. ex Freyn, in Bull. Herb. Boiss. iii. (1895) 75. - Armen.

quadrangulus, Velen. in Sitz: Boehm. Ges. Wiss. 1891 (1893) 372. - Bulg.

rhodopeus, Velen. l. c. (1890) 40 ; et Fl. Bulg. (1891) 69. - Bulg.

roseo-luteus, Velen, in Oest. Bot Zeitschr. xxxvi. (1886) 226; et Fl. Bulg. (1891) 72 in syn.Rumel,

rumelicus, Velen. Fl. Bulg. (1891) 78. - Bulg.

scardicus, Wettst. in Luerss. Bibl. Bot. Heft xxvi. (1892) 31 t. II. fig. 1-5. - Alban.

Seehausianis $X$, Aschers, ex K. A. Seehaus, in Verh. bot. Ver. Prov. Brand. xxxiv. (1893) 12. - Germ.

semperflorens, Hort. ex A. Voss, in Gartenfl. (1895) $514=$ D. carthusianorum, Linn

serbicus, Wettst. in Luerss. Bibl. Bot. Heft xxvi. (1892) $34=$ pinifolius, Sm

serresianus, [Charrel] Nadji, Emp. Ottom. Géogr. bot. (1892) 12 nomen; Halcasy et Charvel, ex Oest. Bot. Zeitschr. xlii. (1892) p. 271. - Turc

sessiliflorus, Boiss, Fl. Or.Suppl. (1888) 78.-Armenia.

setisquamosus, Hausskn. et Bornm. ex Hausskn. in Mitth. Bot. Ver. Fena, ix. (1891). 15. - As. Min.

Sintenisii, Freyn, in Oest. Bot. Zeitschr. xliii. (1893) 376. - As, Min.

Skorpili, Velen. in Sitz. Boehm. Ges, Wiss. (1890) ii 40; et Fl. Bulg. (1891) 68. - Bulg.

slavonicus, Williams, in fourn. Linn. Soc. xxix. (1893) 380. - Slavonia.

Smithii, Wettst. in Luerss. Bibl. Bot. Heft xxvi. (1892) $33=$ pinifolius, $S m$

Stribrnyi, Velen. in Sitz. Boehm. Ges, Wiss, 1892 (1893) 15. - Bulg.

subulosus, Conrath, et Freyn, ex Freyn, in Bull. Herb. Boiss, iii. (1895) 76. - As. Min.

Tatrae, Borb. in Oest. Bot. Zeitschr. xli. (1891) 32. Hung.

tergestinus, Simonk. in Magyar Növenyt. Lapok, xii. (1888) $2 i$ [an Reichb. ?]. - Croat.

tristis, Velen, in Sitzb. Boehm. Ges. Wiss. (1890) ii. 41 ; et Fl. Bulg. (1891) 80. - Bulg.

turcicus, Velen. l. c. 1892 (1893) 273. - Eur. autro-or.

Vandasii, Velen. l.c. 1892 (1893) 16. - Bulg.

\section{DIANTHUS}

elebiticus, Borb. ex Velen. in Sitzb. Boehm. Ges. Wiss. 1892 (1893) 275 nomen. - Bulg.

Velenowskyi, Borb. in Termész. Fuzét. xiv. (1893) 46. - Eur. or.

Wawrae, Freyn, ex Boiss, Fl. Or. Suppl. (1888) 79 - As. Min.

DIARRHENA, Jeauv. (Gramin.). - Ind, Kew. i. 746.

diandra, Hitchc, in Kansas Acad. Sci. (1891) 529 et in Trans. Acad. Sci. St-Louis, v. (1892) 529 = americana, Beauv.

mandshurica, Maxim. in Bull. Acad. Pétersb. xxxii. (1888) 628. - China.

DIASGIA, Link et Otto (Sorophu1.) - Ind. Kew. i. 746 .

cordata, N.E. Br. in Kew Bull. (1895) 151. Natal.

purpurea, N.E.Br. l.c.(1895) 151. - Natal. ramosa, S. Elliot, in fourn. Bot. xxix. (I891) 69. Afr. austr.

DIASPERUS, Linn. = Phyllanthus, Linn. (Eu-

phorb.).
abnormis, acidissimus, acuminatus, acutifolius, acutissimus, acutus, Adami, adenodiscus, adenophyllus, aeneus, affinis, albiflorus, albus, almadensis, amentuliger, anubaptizatus, Andersonii, angolensis, angustifolius, angustissimus, anisolobus, arborescens, arenicolus, arvensis, asper, assamicus, Augustinii, australis, avicularis, axillaris, bahiensis, Baillonianus, baladensis, benguelensis, Berteroanus, bicolor, birmanicus, Blanchetianus, Blancoanus, Bojerianus, bonneensis, botryanthus, Bourgeoisii, brevipes, buxifolius, cacuminum, calycinus, capillaris, carnosulus, carolinensis, Carpentariae, casticum, cataractarum, caudatus, cauliflorus, Chamaecerasus, chlorophaeus, chrysanthus, cinereus, cladanthus, cladotrichus, Clarkei, Claussenii, cochinchinensis, columnaris, compressus, consanguineus, corcovadensis, coriaceus, cornutus, crassifolius, cryptophilus, cuspidatus, cyanospernus, cyclanthera, debilis, decipiens, dictyospermus, diffusus, discoideus, discolor, distichus, dumetosus, elegans, ellipticus, Emblica, Epiphyllanthus, erythrinus, Faguetii, fallax, fasciculatus, fastigiatus, Ferdinandi, fimbriatus, flagelliformis, fluitans, Francavilleanus, frondosus, Fuernrohrii, fuscoluridus, fuscus, Galeottianus, Gasstroemii, glabrescens, gladiatus, glancescens, glaucinus, glancophyllus, glaucus, Glazioui, glomerulatus, gomphocarpus, Goudotianus, gracilentus, gracilipes, gracilis, grandifolius, grandisepalus, graveolens, Grayanus, Griffithii, Griesebachianus, Gueinzii Gunnii, Hamvur, Hasskartianus, Helferi heliotropus, heteradenius, heterodoxus, heterophyllus, hirtellus, hogkalensis, hypoleucus, hyssopifolius, incurvus, indicus, insignis, jacobinensis, janeirensis, javanicus, junceus, khasicus, Kivkianus, Klotzschianus, Kollmanianus, Korthalsii, Kuenstleri, Kutzianus, lacteus, launarius, laevigatus, lagoensis, lamprophyllus, lanceolatus, lasiogynus, latifolius, Lawii, laxiflorus, leptocaulos, leptocladus, leptophyllus. Leschenaultii, leucogynus, Liebmannianus. Lindbergit, linearis, loandensis, longifolius, Macraei, macrocalyx, macropus, madagascariensis, maderaspatensis, mammillosus, Mannianus, Manono, marianus, Martiz, Melleri, Meyerianus, micrandrus, micrantlius, nicrocladus, Microdendron, microphyllinus, microphyllus, minutiflorus, minutulus, mirabilis, Missionis, Moci nianus, mollis, montanus, montevidensis, multicaulis, multiflorus, myrianthus, Myrsinites, myrtacens, myrtifolius, nanogynus, nanus, nemorum, neogranatersis, neopeltandrus, neurocarpus, nigrescens, Niruri, nitidulus, nummulariacfolius, nutans, obtusatus, octomerus, odontadenius, oligotrichus, oppositifolius, orbiculavis, orbiculatus, oreophitus, ovalifolizs, ovatus, oxycarpus, pacificus, pallidus, parvifolius, Pavonianus, pectinatus, pendulus, pentandrus, perpusillus, persimilis, Pervilleanus, petiolavis, phillyreaefolins, physocarpus, pilosus, pinifolius, piscatontm, plaryca lyx, podocarpus, Pohtianus, polycarpus, polyphylius, pomiferus, prostratus, pruinosus, Psendocicoa, Psewdoconami, Pseudoniruri, pulcher, pumilus, purpureus quercinus, racemiger, ramillosus, ramosissimus, Regnellianus, Reinuardtii, reticulatus, rhabdocarpus, Rheedii, rhytidospermus, Riedelianus, vigens, vigidu-

\section{DIASPERUS : -}

lus, Roeperianus, rosellus, rosmarinifolius, votundatus, rotundifolius, Roxburghii, rubellus, ruber, rufidulus, rufoglaucus, rupestris, ruscifolius. salicifolius, salviaefolius, samarensis, sandwicensis, scaber, scabrifolius, scandens. Schomburgkianus, scoparius, Seemannianus, Sellowianus, semicordatus, senensis, sericeus, silheticus, similis, simplicicaulis, singalensis, societatis, spathulifolins, speciosus, sponiaefolius, Spruceamus, squamifolius, stenopterus, subcarnosus, subcrenu latus, subemarginatus, suberosus, sublanatus, subobscurus, subscandens, sundaicus, tenellus, tenuicaulis, Teysmannii, Thomsonii, Thwaitesianns, torrentium, trachyspermus, tremulus, umbraeus, urceolatus, Urinaria, vacciniifolius, venulosus, Vieillardii, villosus, virens, virgulatus, vitiensis, wagapensis, Welwitschianus, Wilkesianus, Wrightii, Zippellianus. - Kuntze, Rev. Gen. (1891) 596-603 = homonyma omnia Phyllanthi.

adiantodes, Kuntze, 1. c. $598=\mathrm{P}$. adiantoides, Klotzsch.

albizziodes, Kuntze, 1. c. $601=$ P. albizzioides, Hook. $f$.

ananiticus, Kuntze, 1. c. = Glochidion anamiticum Kuntze.

andamanicus, Kuntze, 1. c. = P. Helferi, Muell. Arg.

antillanus, Kuntze, 1. c. $597=$ P. nobilis, Muell. Arg.

arboreus, Kuntze, 1.c. $597=$ Glochidion arboreum, Wight.

Avnottianus, Kuntze, 1. c. $=$ Gl. Arnottianum, Muell. Arg.

asper, Kuntze, 1. c. = P. asperus, Muell. Avg baeobotryodes, Kuntze, 1. c. = P. baeobotryoides, Wall.

Beckleri, Kuntze, 1, c. = P. simplex, Retz.

Benthamianus, Kuntze, 1. c. = Glochidion macrophyllum, Benth.

Bernievanus, Kuntze, 1. c. $=$ P. Bernerianus, Baill. Berryanus, Kuntze, 1. c. $597=$ P. indicus, Mull. Arg.

Billardieri, Kuntze, 1. c. $598=$ Glochidion Billardieri, Baill.

brachylobus, Kuntze, 1. c. = G1. brachylobum, Mivell. Arg.

brasiliensis, Kuntze, 1. c. = P. Conami, Sw

brunneus, Kuntze, 1. c. $601=$ Gl. brunneum,

Hook. $f$.

bupleurodes, Kuntze, 1, c, $598=$ P. buplerroides, Baill.

Burchelli, Kuntze, 1. c. = P. Burchelli, Muell. Avg. caledonicus, Kuntze, 1. c. = Glochidion caledonicum, Muell. Arg.

calocarpus, Kuntze, 1. c. $598=$ G1. zeylanicum, A. Fuss,

celastrodes, Kuntze, 1. c. = P. celastroides, Muell. Arg.

choretrodes, Kuntze, 1. C. = P. choretroides, Muell. Arg.

ciccodes, Kuntze, 1. c. = P. ciccoides, Mull. Arg.

cinerascens, Kuntze, 1. c. = Glochidion cineras cens, Miq.

coccineus, Kuntze, 1. c. = G1. coccineum, Muell. Arg.

coluteodes, Kuntze, 1. c. $599=$ P. colutaeoidea Baill.

compressicaulis, Kuntze, 1, c. = Glochidion compressicaule, Kurz.

concolor, Kuntze, 1. c. = G1. concolor, Muell. Arg. conterminus, Kuntze, 1. $\mathrm{c}_{\mathrm{a}}=\mathrm{P}$. simplex, Retz.

cordatus, Kuntze, 1. c. = Glochidion cordatum Seen

coronatus, Kuntze, 1, c. $597=\mathrm{P}$, penangensis, Muell. Arg.

crotalayiodes, Kuntze, 1. c. $599=$ P. crotalarioides Zipp.

Cumingii, Kuntze, 1.c. = Glochidion Cumingii, Muell. Arg.

Curtisii, Kuntze, 1. c, $601=$ G1. Curtisii, Hook. $f$ cyonorum, Kuntze, 1. c, $599=\mathrm{P}$. calycinus, $\mathrm{La}$ bill.

cyrtophyllodes, Kuntze, 1. c. = P. cyrtophyiloides, Muell. Arg.

cyrtophylhus, Kuntze, 1. c. = Glochidion cyrtophyllum, Miq.

cyrtostylus, Kuntze, 1. c. = G1. cyrtostylum, Miq. 
DIASPERUS : -

dalbergiodes, Kuntze, Rev, Gen.(1891) $597=$ P. reticulatus, Poir.

Daltonii, Kuntze, 1. c. $599=$ Glochidion Daltoni Kierz.

dasyanthus, Kuntze, 1. c. = G1. dasyanthum, Kierz. dasystylus, Kuntze, 1. c. $601=$ Gl. dasystylum, Kurz.

depressus, Kuntze, 1. c. $599=$ P. pedunculatus, Kostel.

desmocarpus, Kuntze, 1. c. $601=\mathrm{Pl}$. desmocarpus Hook $f$.

desmogyne, Kuntze, 1. c。 $=\mathrm{Pl}$, desmogyne, Hook. $f$.

ditassodes, Kuntze, 1. c. $599=$ P. ditassoides, Muell. Arg.

emblicodes, Kuntze, 1. c. = P. polyphyllus, Willd

ericodes, Kuntze, 1. c. $=$ P. ericoides, Torr.

eriocarpus, Kuntze, l. c. = Glochidion eriocarpum Champ.

erythroxylodes, Kuntze, 1. c, = P. erythroxyloides, Muell. Avg.

fagifolius, Kuntze, 1. c. = Glochidion sphaerogy num, Kierz.

Fagueti, Kuntze, 1, c. = G1. Fagueti, Muell. Arg.

Finlaysonianus, Kuntze, 1.c. 602 = G1. superbum, Beull.

flavidus, Kuntze, 1. c. $599=$ Gl. flavidum, Kurz.

flexuosus, Kuntze, 1. c. = P. japonicus, Mwell. Arg.

floriburdus, Kuntze, 1. c. $597=$ P. Wightianus, Muell. Avg.

freggeaeformis, Kuntze, 1. c. $599=$ P. glaucus, Wall.

fulvirameus, Kuntze, 1. c. = Glochidion fulvirameum, Miq.

Gamblei. Kuntze, l. c. $601=$ Gl. Gamblei, Hook. $f$.

Gardneri, Kuntze, 1. c. $597=$ Gl. Gardneri, Thw.

Gaudichandii, Kuntze, 1. c. 599 = Gl, marianum, Muell. Arg.

genistodes, Kuntze, 1. c. = P. genistoides, Sond.

glaucifolius, Kuntze, 1. c. = Glochidion glaucifolium,

glaucogymzs, Kuntze,1. c. = G1. Mooni, Thw.

goniocarpus, Kuntze, 1. c. = G1. goniocarpum, Hook. f.

guyanensis, Kuntze, 1. c. = P. attenuatus, Miq.

heteranthus, Kuntze, 1. c. $597=$ Glochidion Wallichianum, Muell. Arg.

Heyneanus, Kuntze, l. c. $599=$ Gl. Heyneanum Wight.

hirsutus, Kuntze, 1. c. = G1. hirsutum, Voigt.

Hohenacheri, Kuntze, 1. c. = G1. Hohenackeri, Bedd.

hongkongensis, Kuntze, 1. c. = G1. hongkongense Muell. Arg.

Hookeri, Kuntze, 1. c. = P. Urinaria, Lmn.

impubes, Kuntze, 1. c. $598=$ Glochidion sinicum Hook, et Arn.

insuldanus, Kuntze, 1. с. $599=$ G1, insulanum, Muell. Arg.

jabbalpurensis, Kuntze, 1. c. $602[=$ Phyllanthi, sp.]. - Ind. or.

Fardinii, Kuntze, 1. c. $599=$ P. Jardini, Mwell. Arg.

folnustonei, Kuntze, 1. c. 601 = Glochidion Johnstuni, Hook, f.

Fussieuanus, Kuntze, 1. c. $599=$ G1. rigidum, Muell. Arg.

kanalansts, Kuntze, 1. c. $=$ Gl. Lenormandi, Muell. Arg.

kanalophilus, Kuntze, 1. co = G1. kanalense, Baill.

Kipareh, Kuntze, 1. c. 599 et $602=$ Gl. glaucum Blume.

Lambertianus, Kuntze, 1. c. = G1. Lambertianum, Muell. Arg.

lanceolarius, Kuntze, 1. c. = Bradieia lanceolaria Roxb.

lathyrodes, Kuntze, 1. $\mathrm{C}_{0}=$ P. lathyroides. $H . B$. et $K$.

leiostylus, Kuntze, 1. c. $601=$ Glochidion leiostylum, Kurz.

litoralis, Kuntze, 1. c. $599=$ G1. littorale, Blume.

Llanosii, Kuntze, 1.c. = G. Llanosi, Muell. Arg.

loranthodes, Kuntze, 1. c. = P. loranthoides, Baill.

lucidus, Kuntze, 1. c. = Glochidion lucidum, Blume.

lutescens, Kuntze, 1. $\mathrm{c}_{0}=$ G1. 1utescens, Bhume.

macrocarpus, Kuntze, 1. c. = Gl. macrocarpum, Blume.
DIASPERUS : -

macrochorion, Kuntze, Rev. Gen, (1891) $599=$ G1. macrochorion, Muell. Arg.

macrophyllus, Kuntze, 1.c. = G1. macrophyllum Mueli. Arg.

macrostigma, Kuntze, 1. c. = G1. macrostigmum Hook. $f$.

micrantheodes, Kuntze, 1. c. = Phyll, micrantheoides, Baill.

malabaricus, Knntze, 1. c. = P. malabaricum Muell. Arg.

microbotrys, Kuntze, 1. c. $601=$ Gl. microbotrys, Hook. $f$.

mimasodes, Kuntze, 1. c. $600=\mathrm{P}$. mimosoides, $S w$

Miquelianus, Kuntze, 1. c. $600=$ P. simplex, Retz

mishmiensis, Kuntze, 1. c. $601=$ Glochidion mishmiense, Hook. $f$.

moluccanns, Kuntze, 1. c. = G1. moluccanum Blamie.

Moonit, Kuntze, 1. $\mathrm{c}_{\mathrm{N}}=\mathrm{G}$. Moonii, Thw.

Muellerianus, Kuntze, 1. c. $597=$ P. floribundus, Muell. Arg

muitilacularis, Kuntze, 1. c. 600 et $602=$ Glochidion multiloculare, Voigt.

myrtillodes, Kuntze, 1. c. $600=$ P. myrtilloides, Griseb.

neilgerrhensis, Kuntze, 1. c. = Glochidion neilgherrense Wight.

nemoralis, Kuntze, 1. $\mathrm{c}_{0}=$ G1. nemorale, Thw.

neocaledonicus, Kuntze, 1. c. $597=$ P. Vieillardi, Baill.

Neohollandiae, Kuntze, 1. c. $600=$ P.Novae-Holiandiae, Mull, Ary.

mepalensis, Kuntze, I. c. = Glochidion velutinum Muell. Avg.

nephradenius, Kuntze, 1. c. = P. longiflorus, Heyne

niruriodes, Kuntze, 1, c, = P, nirurioides, Muell. Arg.

nitidus, Kuntze, I, c, $601=$ Glochidion zeylanicum, $A$. Fuss.

mubigenus, Kuntze, 1. c. = Gl. nubigenum, Hook. $f$. nummulariodes, I. c. $600=\mathrm{P}$. nummularioides, Muell, Arg.

oblatus, Kuntze, 1. c. $601=$ Glochidion oblatum, Hook. $f$.

obliquus, Kuntze, 1. c. $600=$ Glochidion zeylanicum, A. Fuss.

obovatus, Kuntze, 1. c. = G1. obovatum, Sieb. et Zucc.

obscurus, Kuntze, 1. c. = G1. obscurum, Blume.

ornatus, Kuntze, 1, c. = G1. ornatum, Kurz.

pallidifolins, Kuntze, 1. c. = P. pulcher, Wall .

Pancherianus, Kuntze, 1. c. = Glochidion Pancherianum, Buell, Arg.

pedunculatus, Kuntze, 1. с. $597=$ P. longipes, Muell. Arg.

Peltandra, Kuntze, 1. c, $600=$ P. Thwaitesianus, Muell. Arg.

peperomiodes. Kuntze, 1. c. $597=$ P. Finlaysonianus, Wall.

perakensis, Kuntze, 1. c. $597=$ Glochidion perakense, Hook. f.

permixtus, Kuntze, 1. c. $598=$ Gl. coriaceum, Thw Perottetianus, Kuntze, 1. c. $600=$ Gl. neilgherrense Wight.

philippinensis, Kuntze, 1. c. = G1. philippinense, Benth.

pinnatus, Kuntze, 1.c. $597=$ Flueggea microcarpa, Blume.

Poeppigianus, Kuntze, 1. c. = Glochidion Poeppigianum, Muell. Arg.

polygonodes, Kuntze, 1. c. $=\mathrm{P}$. polygonoides, Spruce.

portoricensis, Kuntze, 1. c. 602. - Ins. Antiil.

praetervisus, Kuntze, 1. c. $600=$ P. parvifolius, Buch.-Ham.

pycnocarpus, Kuntze, 1. c. = Glochidion pycrocarpum, Bedd.

pycrophyllus, Kuntze, 1. c. = G1. microphyllum, Mwell. Arg.

Ralphii, Kuntze, 1. c. 601 et $603=$ G1. Ralphii Hook. $f$.

vamiforus, Kuntze, 1. c. $600=$ G1. ramiflorum, Forst.

rhombodalis, Kuntze, 1. $\mathrm{c}_{0}=$ P. rhomboidalis, Muell. Arg.

sclerophyllus, Kuntze, 1.c. $601=$ Glochidion sclerophyllum, Hook. $f$.
DIASPERUS : -

sikimensis, Kuntze, Rev, Gen, (1891) $601=\mathrm{P}$. Hamiltonianus, Muell. Arg.

sphaerogynus, Kuntze, 1. c. = Glochidion sphaerogynum, Kurz.

spinulosus, Kuntze, 1. c. $597=$ P. Lauri, f. Grah, stellatus, Kuntze. l. c. = Glochidion rigidum. Muell. Arg.

stenocladus, Kuntze, 1. c. = P. Adami, Muell. Arg.

Stocksii, Kuntze, 1. c. = P. indicus, Muell. Arg.

stylosus, Kuntze, 1. c。 = P. Griffithii, Muell. Arg.

symplocodes, Kuntze, 1. c. = Glochidion montanum, Thw.

symphoricarpodes, Kuntze, 1. c. = P. symphoricarpoides, $H$. B. et $K$

taitensis, Kuntze, 1. c. = G1. taitense, Baill.

tetrandrus, Kuntze, 1. c. = P. Teysmanni, Muell. Arg.

thymodes, Kuntze, 1. c. $601=$ P. thymoides, Sieb.

tomentosus, Kuntze, 1. c. $=$ Glochidion tomentosum, Dalz.

triandrus, Kuntze, 1. c. = Gl. eleutherostylum, Muell. Arg.

trichogynus, Kuntze, 1. c. = G1. trichogynum, Muell. Arg.

varians, Kuntze, 1. c. $=$ G1. varians, $M i q$.

velutinus, Kuntze, 1.c. = G1. velutinum, Wight.

vernucosus, Kuntze, 1. c. (= Securinegae sp.). Afr. austr.

Vespertilio, Kuntze, 1. c. = Glochidion Vespertilio, Muell. Arg.

villicaulis, Kuntze, 1. c. = GI, villicaule, Hook. $f$.

virgatus, Kuntze, 1. c. 601 et $603=$ P. simplex, Retz

Wightianus, Kuntze, 1. c. $597=$ Glochidion ellipticum, Wight.

Wightianus, Kuntze, 1. c. $603=$ G1. rubrum, Blume.

williamiodes, Kuntze, 1. c, $601=$ P. williamsioides, Griseb.

zeylanicus, Kuntze, 1. c. 601 et $603=$ Glochidion zeylanicum, $A$. Fuss.

Zollingeri, Kuntze, 1. c. = GI. Zollingeri, Miq.

zygophyllodes, Kuntze, 1. c. = P. zygophylloides, Muell. Arg.

DIASPIS. Niedenzu, in Bot. Jahrb. xiv. (1892) 314, $M A L P I G H I A C E A E$

albida, Niedenzu, l.c. - Afr. trop. or.

DIASTEMA, Benth. (Gesnerac.). - Ind. Kew. i.

Lehmanni, Regel, in Act. Hort. Petrop. x. (1889) 695. - N. Granat.

picta, Regel, in Gartenfl. xxxvii. (1888) 241. Columb.

DIGELLA. Griseb. (Malpigh.). - Ind. Kew.i. 747.

nudiflora, Chod. in Arch. sci. phys. et nat. (1890), ex Chad. in Mém. Soc.phys. Genève, xxxi. 2 (1892) n. 3, 23. - Parag.

DIGENTRA. Bernh. (Papav.). - Ind. Kew. i. 748.

macrantha, Oliver, in Hook. Icon. pl. xx. (1890) t. 1937. - China.

DIGHAEA. Lindl, (Orchid.). - Ind, Kew. i. 1748. cornuta, S. Moore, in Trans. Linn. Soc., Ser. II. iv. (1894) 479 t. 32 fig. 1-3. - Bras.

hamata, Rolfe, ex Stapf, in Mem. Torrey Bot. Club, iv. (1895) 264. - Bolivia.

DICHAELIA, Harv. = Brachystelma. R. Br. (Asclep.).

breviflora, Schlechter, in Bot. Jahrb. xx. Beibl. n. 51. (1895) 49. - Afr. austr.

elongata, Schlechter, 1. c. xviii. Beibl. n. 45 (1884) 35. - Afr. austr.

Galpinii, Schlechter, 1. c. 25. - Afr. austr.

natalensis, Schlechter, 1. c. $35=$ B. natalensis, Schlechter.

pallida, Schlechter, 1. c. xx. Beibl. n. 51 (1895) 49. - Afr. autr.

pygmaea, Schlechter, in Tourn. Bot. xxxii. (1894) 262. - Afr. austr. 
DICHAELIA : -

undulata, Schlechter, in Bot. Jahrb. xviii. Beibl. n. 45 (1894) 36. - Afr. austr.

villosa, Schlechter, 1. c. 25. - Afr. austr.

DICHAEOPSIS, Pfitzer, Entwurf Natürl, anordn. Orch. (1887) 107; et-in Engl. et Prantl, Natürl. Pflanzenfam. ii. 6, (1889) $207=$ Dichaea Lindl. (Orchid.).

DICHAESPERMUM, aurantiacim, Hassk. ex Hook f. Fl, Brit. Ind, vi, (1892) 378 in syn = Aneilema pauciflorum, Wight.

Koenigii, Hassk. ex Hook. f. 1. c. $381=$ A. Koenigii. Wall.

paniculatum, Hook. f, et Thoms. ex Hook. f. 1. c, $=$ A. paniculatum, Wall.

DICHAET ANTHERA. Endl. (Melast.). - Ind. Kew. i. 748 .

altissima, Cogn. in DC. Monog. Phan. vii. (1891) 382. - Madag.

asperrima, $\operatorname{Cog}$ 2. l. c. 381. - Madag.

crassinodis, Baker, in fourn. Linn. Soc. xxii. (1887) 476; Cogn. l. c. - Madag.

grandifolia, Cogn. in DC. Monog. Phan. vii. (1891) 1180 (append.).; et ex S. Elliot, in Fourn. Linn. Soc. xxix (1891) 17 - Madag.

lanceolata, Cogn. in DC. Monog. Phan. vii. (1891) 383. - Madag.

latifolia, Cogn.l. c. 380. - Madag.

parvifolia, Cogn. .. c. - Madag.

reticulata, $\operatorname{Cog} n$. .. c. 381. - Madag.

rosea, Cogn. .. c. 381. - Madag,

DICHAPETALUM, Thou. = Chailletia, DC. angolense, Chod. in Bull. Herb. Boiss. iii. (1895) 672. - Angola.

Browni, Baill. Hist. p1. Madag.. Atlas (1892) t. 205. - Madag.

crassifolium, Chod in Bull. Herb. Boiss, iii. (1895) 672. - Angola.

deflexum, Engl. Pflanzenw. Ost-Afr. C (1895) 235 $=$ C. deflexa, Klotzsch.

latifolium, Baill. in Mart. Fl. Bras. xii. I. (1886) 370. - Bras.

Lautzianum, Baill. Hist. pl. Madag., Atlas (1892) t. 205. - Madag.

mossambicense, Engl. Pflanzenw. Ost-Afr. C (1895) $235=$ C. mossambicensis, Klotzsch.

nigrescens, Baill. Hist. pl. Madag., Atlas (1892) t. 207. - Madag.

odoratum, Baill, in Mart. F1. Bras, xii. I. (1886) 371. - Bras.

Spruceanum, Baill. 1. c. 371.- Peruvia.

subsessilifolium, Chod. in Bull. Herb. Boiss. 1ii (1895) 671. - Angola.

umbellatum, Chod. 1 c. - Angola.

vestitum, Baill, in Mart. F1. Bras, xii. I. (1886) 371. - Bras., Guian.

DICHELOSTEMMA, Kunth. = Brodiaea, Sw (Liliac.).

Ida-Maia, Greene, Man. Bot. San Franc. Bay (1894) $318=$ B. Ida-Maia, Wood

DICHONDRA, Forst. (Convolvul.). - - Ind. Kew. v1. 749

volvulacea, Britton, in Mem. Torrey Bot. Club, v. (1694) $268=$ repens, Forst.

DIGHOPSIS, Thw. (Sapot.). - Ind. Kew. i. 749 Lamponga, Pierve, ex L. Planch. Etud. prod. Sapot. (1888) 47 nomen. - Cambodia.

DICHORISANDRA, Mikan (Commel.). - Ind Kew, i. 749.

acaulis, Cogn. in Illustr. Hortic. xli. (1894) 297. t. 19. - Bras.

angustifolia, L. Lind. et Rodig. l. c. xxxix. (1892) 81 t. 158. - Ecuad.

Glaziovii, Taub. in Bot. Fahrb. xii. Beibl. n. 27 (1890) 2. - Bras.

DICHOSTYLIS, Beauy. = Scirpus, Linn Cyper.).
DICHOSTYLIS :

aristata, Palla, in Bot. Jahrb. x. (1888) $299=$ Cyperus aristatus, Rottb.

Baldwinii, Palla, 1. $\mathrm{c}$. = C. Baldwinii, Torr congesta, Palla, 1. c. = Fimbristylis Vablii, Link.

DrCHOTOMA, Sch. Bip. = Sclerocarpus, Jacq (Compos.)

coffececola, Sch. Bip. ex Klatt, in Annal Naturh. Hofmus. Wien, ix. (1894) 360 in syn., nomen = S. coffeaecolus, Klatt.

DIGHROGEPHALA, L'Hérit. (Compos.). - Ind. Kew. i. 750

gossypina, Baker, in fourn. Linn. Soc. xxv. (1890) 326. - Madag.

integrifolia. Kuntze, Rev. Gen. (1891) $333=$ Hippia integrifolia, Limn. $f$.

linearifolia, O. Hoffm. in Engl. Pflanzenw. Ost-Afr. C 1895) 406. - Afr. trop, or.

DIGHROMENA, Michx. (Cyper.).- Ind. Kew. 1.750

canescens, Maury, ex M. Micheli, in Mém. Soc. Sci. pliys. Genéve, xxxi. (1890) n. 1, 143 t. 42 - Bras. Parag.

cephalotes, Britton, in Bull. Torrey Bot. Club, xv (1888) $100=$ leucocephala, Michx.

colovata, Hitchc. in Missouri, Bot. Gard. Rep. iv. 1893) $141=$ leucocephala, Michix

fasciata, Maury. in Morot, fourn. de Bot.ii. (1888) 396. - Columb

nivea, Boeck, in Contrib. Herb. Frankl. I. (1895) $20=$ D. Reverchoni. S. H. Wright.

nivea, Britton, in Bull. Torrey Bot. Club, xv. (1888) $101=$ diphylla, Tory

Reverchoni, S.H.Wright.1. c. ix, 1882) 86 - Am. bor.

Watsoni, Britton, in Bull. Torrey Bot. Club, xv (1888) 101. - Guatem.

DICHROSTACHYS, Wight et Arn.(Legumin.) - Ind. Kew. i. 751

myriophylla, Baǩer, in fourn. Linn. Soc. xxv. (1890 314. - Madag.

nyassana, Taub, in Enol. Pflanzenw. Ost-Afr. C (1895) 195. - Afr. or.

unijuga, Baker, in fourn. Linn. Soc. xxii. (1887) 467. - Madag.

DIGHROTRIGHUM, Reinw. (Gesnerac.), - Ind

\section{Kew i. 751.}

bracteatum, Stapf, in Trans. Linn. Soc. Ser. II iv. (1894) 212. - Borneo.

DICKINSIA, Franch. in Nouv. Mém. Mus. Paris, Sér. II, viii. 1885 (1886) 244. UMBELLIFERAE. hydrocotyloides, Franch.l. c.t. 8 fig.a.-China.

DICLIDOCARPUS, A. Gray = Trichospermum Blume (Tiliac.).

javanicus, Kuntze, Rev. Gen. (1891) $83=$ T. javanicum, Blume.

DICLIPTERA, Juss. (Acanth.). - Ind. Kew. i. 751

alternans, Lindau, in Bot. Fahrb. xx. (1894) 47. Afr. trop. occ

Carvalhoi, Lindau, in Engl. Pfanzenw. Ost-Afr.C (1895) 371. - Afr. trop. or.

cochabambensis, Lindau, in Bull. Herb. Boiss, iii. (1895) 479 - Bolivia.

Ehrenbergii, Lindau, l. c. 480.- Mexic

falciflora, Lindau, l. c. - Bras.

formosa, T.S. Brandeg. in Proc. Calif. Acad. iii (1891) 162. - Calif.

Hensii, Lindau, in Bot. Fahrb. xxii. (1895) 120.Congo.

kamerunensis, Lindan, l. c.121. - Af: trop. occ.

Maclearii, Hemsl. in foum. Linn. Soc. Xxv. (1890 356. - Ins. Christmas.

magnibracteata, Collett et Hemsl. l. c. xxviii. (1890) 108. - Burma.

Marlothii, Engl. Bot. Fahrb. x. (1889) 265. - Afr. austro-occ. extratrop.
DICLIPTERA :

Muelleri Ferdinandi. Lindau, Bot. Falıvb. xix (1894) 5. - N. Guin.

Niederleiniana, Lindau, l.c. xix. Beibl. n. 48 (1894) 18. - Reg. Argent.

papuana, Warb. in Bot, fahrb. xviii. (1894) 207. N. Guin.

Quintasii, Lindau, l. c. xxii. (1895) 121. - Natal.

Schumanniana, Schinz, in Verh. Bot. Ver, Brand. xxxi. (1890) 204. - Afr. austro-occ. extratrop. usambarica, Lindau, in Bot. Fahrb. xx. (1894) 46. - Afr. trop. or.

DICOMA, Cass. (Compos.). - Ind, Kew, i. 752

legans, Welw. ex O. Hoffm. m Bolet. Soc. Brot. x. 1892) 184; it in Bot. Fahrb. xv. (1893) 544. Angola.

foliosa, O. Hoffm. $7 l . c c .184$ et 543. - Angola.

incana, O. Hoffm. in Engl. et Prantl, Natürl. Pflanzenfam. iv. 5 (1893) $339=$ Brachyachaenium incanum, Baker.

Nachtigalii, O. Hoffm. in Bot. Fahrb. xv. (1893) $545 ;$ et l. c. - Afr. austro-occid.

plantaginifolia, O. Hoffm. l. c. 546. - Angold.

Poggei, O. Hoffm. $l$. c. - Angola.

quinquenervia, Baker, in Kew Bull. (1895) 290. Afr. centr, austr.

Schinzii, O. Hoffm, in Bot. Fahvb.xv. (1893) 543.Afr. austro-occid.

Schimperi, Baill. ex O. Hoffm, in Engl. et Prantl. Naturl. Pflanzenfam. iv. 5. (1893) $339=$ Hoch stetteria Schimperi, $D C$

Welwitschii, O. Hoffm, in Bolet. Soc. Brot. x. (1892) 184; et in Bot. fahrb. xv. (1893) 544. - Angola.

DICLYTRA, Borkh. = Dicentra, Bernh. (Papav.). Clirysantha, orchroleuca, pauciflora et uniflora, Greene, Pittonia, i. (June 1888) 187 = homonyma ommia, Dicentrae.

DICORYPHE, Thou. (Hamamelid.). - Ind. Kew

guatteriaefolia, Baker, in fourn. Linn. Soc. xxii. (1887) 473. - Madag.

laurifolia, Baker, l. c. 474. - Madag-

retusa, Baker, l. c. 473. - Madag.

stipulacea, Baill. Hist. pl. Madag. Atlas (1886) t. $60=($ an D. stipulacea, Jaume St-Hil.?). Madag.

DICRAEA, Thou. = Podostemon, Michx. (Podostemac).

quangensis, Eng1. in Bot. Jahrb. (1894) 134. Congo.

Warmingii, Engl. 1. c. 135. - Congo.

DICRANOLEPIS, Planch. (Thymel.). - Ind.

Kew, i, 753.

Benthamiana, Van Tiegh. in Ann. Sc. Nat. Sér. VII. xvii. (1893) 197 [cf. Gilg, in Bot. Jahrb. xviii. (1894) 513 in obs.]. - Kamerun.

Buchholzii, Engl. et Gilg, l. c. xix. (1894) 273. Kamerun.

cerasifera, Gilg, l. c. 272. - Afr. centr. bor.

convalliodora, Gilg, l. c. 271. - Congo.

grandiflora, Engl. l. c. vii. (1886) 338. - Ins. Fernando-Po.

oligantha, Gilg, l.c. xix. (1894) 274. - Gabon.

Schweinfurthii, Gilg, l. c. 271. - Afr. centr. bor. Soyauxii, Enol l. c. vii. (1885) 337. - Gabon.

thomensis, Engl. et Gils, l. c. xix. (1894) 273. - Ins. S. Thom.

usambarica, Gilg, l. c. xix. (1894) 272. - Afr. trop. or.

vestita, Engl. l. c. vii. (1886) 337. - Kamerun.

DIGRASTYLIS, Drum. (Verben.). - Ind. Kew i. 753.

Costelloi. F. M. Bailey, in Dept. Agric. Quecnsl. Bot. Bull. iv. (189]) 14.- Austral. A

Weddii, F. M. Bailey, l.c.x. (1895) 24. - AustraI.

DIGRAURUS, Hook. f. (Amarant.). - Ind. Kew.

diffusus, Baill. Hist. des pl. ix. (1888) $214=$ leptocladus, Hook. $\mathrm{f}$. 
DIGTYANTHUS, Decne. (Asclep.). - Ind. Kew. ceratspetala, 7. D. Smith, in Coult. Bot. Gaz, xviii. (1893) 208 . - Guatem.

tuberosus, Robins. in Proc. Am. Acad. xxvii. (1893) 180. - Mexic

DICTYOSTEGA, Miers (Burmann.), - Ind. Kew. i. 754 .

isambarica, Engl, in Abh. Preuss. Akad. Wiss, (1894) 45 (Dictyostegia $)=$ Gymnosiohon usambaricus, Engl.

DIDELOTIA, Baill. (Legumin.). - Ind. Kew. i. 754 .

Afzelii, Taub. in Engl. et Prantl, Natürl. Pflanzenfam. iii. 3, (1894) 38\%. - Sierra Léone.

DIDIEREA, Baill. in Bull. Mus. Hist. Nat. Paris, i. (1895) 22. SAPINDACEAE.

madagascariensis, Baill. l. c. 22.; et Hist. pl. Madag. Atlas (1895) t. 261-62. - Madag.

mirabilis, Baill. l.c. 23; in Bull. Soc. Limn. Paris, ii. (1894?) 1182 ; et l.c. t. 262 A-D. - Madag.

DIDISCUS, DC. = Trachymene, Rudge (Umbel1. f.).

Croninianus, F. Muell. in Victor. Natural. vi. (Feb. 1895) 144; et ex Bot. Centralbl. 1xii. (1895) 29 et $93=\mathrm{T}$. Croninian., F. Muell.

elackocarpus, F. Muell, 1. c. ix. (Aug, 1892) 58 et 1. c. 1i. (1892) 397. - Austral.

Gillenae, Tate, in Trans. Roy. Soc. S. Austral. xix. (1895) 81 nomen. - Austral.

DIDISSANDRA, C.B. Clarke (Cyrtandr.). - Ind. Kew. i. 754

aspera, Drake in Bull. Soc. Phìlom. Paris, Sér. VIII. ii. (1890) 127. - Tonkin.

confertiflora, Drake l. c. - Tonkin.

glandulosa, Batalin, in Act. Hort. Petrop. xii. (1892) 175. - China.

lancifolia, Franch. in Nowv. Arch. Mus. Paris, Sér II, x. (1887-88) 63. - China.

longifolia, Franch. l.c. - China.

longipes, Hemsl. in Kerw Bull. (1895) 115; et in Hook. Icon. pl. xxv, (1895) t. 2379. - China.

primulaeflora, Batalin, in Act. Hort. Petrop, xiv. (1895) 176. - Tibet

saxatilis, Hemsl. in Fourn. Linn. Soc. xxvi. (1890 227. - China

sesquifolia, C. B. Clarke, in Hook. Icona. pl. xviii. (1888) t. 1797. - China.

speciosa, Hemsl. in fourn. Linn. Soc. xxvi. (1890) 2:28. - China.

DIDYMIA, Philippi, in Bot. Jahrb, viii. (1887) 57 cyperomorpha, Phil. 1.c. t. 1. = Mariscus flavus, Vahl.

DIDYMOGARPUS, Wall. (Gesnerac.). - Ind Kew. i. 755.

albomarginatus, Hensl. in fourn. Bot. xxv. (1887) 204. - Perak.

areolatus, Stapf, in Trans. Limn. Soc., Ser. Ir, iv. (1894) 213. - Borneo.

atrosanguinea, Ridl.l.c. iii. (1893) 328. - Penins. Mal.

flavobrunnea, Ridl. l. c. 329 - Penins. Mal.

Fordii, Hensl. in fourn. Linn. Soc. xxvi. (1890) 22. - China.

Hancei, Hentsl. l. c. - China.

heterophylla, Ridl. in Trans. Linn. Soc. Sér. II, iii. (1893) 329. - Penins. Mal.

kamerunensis, Engl. in Bot. falwb. xviii. (1894) 79. - Afr. trop. occ,

Kinnearii, F. Muell. in Vict. Natural. iii. (March 1887) 159; et ex Bot Centralbl. xxx. (1887) 278. Austral.

lacunosa, Hook.f. in Bot. Mag. (1892) t. 7236; et ex Gard. Chron. (1893) ii. 120 et 211 fig. 38. Penang.

lilacina, Ridl. in Trans. Linn. Soc. Ser. II, iii (1893) 330. - Penins. Mal.

\section{DIDYMOCARPUS :}

neurophylla, Coll. et Hemsl. in fouru. Linn. Soc. xxviii. (1890) 102. - Burma.

pectinata, C. B. Clarke, in Hook. Icon. pl. xxiii. (1892) t. 226. - Perak.

pusillus, Baker, in fourn. Linn. Soc. xxii. (1887) 508. - Madag.

pyroliflora, Ridl. in Trans. Limn. Soc. Ser. II, iii. (1893) 330. - Penins. Mal.

quinquevulnera, Ridl. l. c. 328, - Penins, Mal.

rotundifnlia, Hemsl. in fourn. Linn. Soc. xxvi. (1890) 230. - China.

salicina, Rial. in Trans. Linn. Soc. Sér. II, iii 1893) 329. - Penins. Mal.

stenanthos, C. B. Clarke, in Hook. Icon.pl. xviii. (1888) t. 1799. - China.

Zollingeri, Kuntze, Rev. Gen. (1891) 4.7 sphalm. $=$ Chirita Zollingeri, C. B. Clarke.

DIDYMOPANAX, Decne. (Araliac.). - Ind.

\section{Kew i. 1756}

acuminatum, E. March. in Bull. Sor. Bot. Belg. xxviii?. (1889) 52.- Bras.

anomalum, Taub. in Bot. Fahrb, xvii. (1893) 511. Bras.

cordatum, Taub. 7. c. 509. - Bras

falcatum. E. March. in Bull. Soc. Bot. Belg. xxxviii 2. (1889) 51. - Bras.

Glaziovi, Taub. in Bot. fahvb. xvii. (1893) 510 . Bras.

Pittieri, E. March. ex Th. Dur. et Pitt. in Bull. Soc. Bot. Belg. xxx, 1891 (1892) 280. - Costarica.

Urbanianum, E. March. ex Urban, in Bot. Fahrb. xv. (1893) 326. - Ins. Martinica

venulorum, Taub. in Bot. Fahrb. xvii. (1893) 510.Bras.

DIDYMOSPERMA, H.Wendl, et Drude (Palm.).

\section{Ind Kew i. $756^{\circ}$}

borneensis, Becc. Malesia, iii. (1889) 197. - Borneo.

gracilis, Hook. f. Fl. Brit. Ind. vi. (1892) 420.Assam.

hastata, Bece. Malesia, iii. (1889) 199. - Penins. Mal.

Hookeriana, Becc. l. c. 186. - Penins. Mal.

DIERBACHIA, Spreng. = Dunalia, H. B. et K. (Solan.)

acnistodes, Kuntze, Rev. Gen. (1891) $451=$ Dun acnistoides, Miers.

brachyacantha, Kuntze, 1.c. = Dun. brachyacantha, Miers.

cyanea, Kuntze, 1. c. ¿- Dun, cyanea, Rows.

lilacina, Kuntze, 1. c. = Dun, lilacina, Miers.

lyciodes, Kuntze, 1. c. = Dun. lycioides, Miers.

ramiflora, Kuntze, 1. c. = Dun. ramiflora, Miers

serzticosa, Kuntze, 1. c. = Dun. senticosa, Miers.

DIEFFENBACHIA, Schott (Aroid.).- Ind, Kew i. 756.

Fournieri, Hort. ex Gard. Chron. (1890) ii. 70.Columb.

Leoncae, Hort. ex Rev.Hort. (1894) 251. - Columb.

Makoyana, Hort. ex Gard. Chron. (1890) ii. 70. Columb.

Meleagris, L. Linden et Rodig. in Illustr. Hort. xxxix. (1892) t. 559. - Ecuad.

Olbia, L. Linden et Rodig. l. c. 31 t. 548. - Peruvia

picturata, L. Linder et Rodig. l. c. $101 \mathrm{t} .562$. Venez.

Seguine, Baill. Hist. des pl. xiii. (1895) $439=\mathrm{D}$. Seguine, Schott?

DIERVILLA, Tourn, ex Linn. (Caprif o1.). Ind. Kew. i. 757.

Dievillla, Macmill. in Bull. Torrey Bot. Club, xix. (1892) $15=$ trifida, Moench.

fallax, Boerl. Handb. Fl. Ned. Indie ii. 1. (1891) 6 (=Weigelia fallax, Miq.). - Java.

hybrida X, Hort. ex Dippel, Deutsch. Dendrol. i. (1889) 274. - Hybr. artef.

rivularis, Gattinger, in Coult. Bot. Gas. xiii. (1888) 191.

DIETES, Salisb. = Moraea, Linn. (Irid.).
DIETES : -

Macleaii, Hort. ex Baker, Handb. Irid. (1892) 60 in obs. = Moraea iridioides, Linn.

DIGITALIS, [Tourn.] Linn. (Scrophul.). - Ind Kew. i. 757.

Charrelii, Heldr. ex Charrel, in Oest. Bot. Zeitschr. xlii. (1892). - Maced.

Nadji, Heldr. et Nadji [Charrel] Emp. Ottom. (Pl. de Salon.) (1892) 33. - Oriens.

DIGITARIA, Heist. ex Adans. = Panicum, Linn (Gramin.).

tarapacana, Phil. in Ann. Mus. nac. Chile (1892) 80. - Chil.

thyrsoidea, Balansa, in Morot, Journ. de Bot. iv. (1890) 138. - Tonk.

timorensis, Balansa, 1. C. = P. timorense, Kunth

DILKEA, Mast. (Passiflor.).- - Ind. Kew. i. 758.

Johannesii, Rodr. in Vellosia, Sec. ediç. i. (1885-88) 22. - Bras.

DILLENIA, Linn. (Dilleniac.). - Ind. Kew. 759. alata, Gilg, in Engl. et Prantl, Natürl. Pflanzenfam. iii. 6a. (1893) $\mathbf{1 2 3}=$ alata, Banks.

Albertisiana. Martelli, in Becc. Malesia iii. (1886) 161. - N. Guin.

apetala, Martelli, 1. c. $163=$ Wormia apetala, Gaudich.

artocarpifolia, Martelli, 1. c. = W. artocarpaefolia, Baker.

auriculata, Martelli, l.c.159. - N. Guin

Baillonii, Pierre ex Laness. Pl. util. Colon. Franc (1886) 81; et ex Gilg, in Engl. et Prantl, Natür. Pfanzenfam. iii. 6 (1893) 128 (= D. pentagyna, Plerre). - Cochinch.

Beccariana, Martelli, in Becc. Malesia, iii. (1886) 158. - Borneo.

biflora, Martelli, 1. c. $163=$ Wormia biflora, 1. Gray.

Burbidgei, Martelli, 1. c.; Gilg, in Engl. et Prantl, Natïrl. Pflanzenfam. iii. 6. (1893) $123=\mathrm{W}$. Burbidgei, Hook. 'f

castaneaefolia, Martelli, 1. c. = W. castaneaefolia, Miq.

crassisepala, Martelli. l. c. 156. - Borneo.

elata, Pierre, ex Gilg., in Engl. et Prantl, Natiurl. Pfanzenfam, iii. 6. (1893) 125. - Ind.

excelsa, Martelli, in Becc. Malesia, iii. (1886) 163; Gilg, 1.c. $123=$ W. excelsa, fack.

ferruginea, Gilg, 1.c. = W. ferruginea, Gilg.

glabra, Martelli, in Becc. Malesia, i1i. (1886) 157. Borneo.

Hookeri, Pierre, ex Gilg, in Engl. et Prantl, Natürl. Pfanzenfam. iii. 6. (1893) 125. - Cochinch.

luzoniensis, Martelli, in Becc. Malesia, iii. (1886) $163=$ W. luzoniensis, Vidal.

Macdonaldi, Martelli, 1. c. $=$ W. Macdonaldi, F. Muell.

macrocarpa, Ruiz, ex Vesque, in DC. Monog. Phan. viii. (1893) $62=$ Clusia Pavoni, Planch. et Triana

madagascariensis, Martelli, in Beccari, Malesia, iii. (1886) $163=$ Wormia madagascariensis, DC.

magnicapsula, Pav. ex Vesque, in DC. Monog Phan. viii. (1893) 62 = Clusia Pavonii, Planch. et Triana.

magnoliaefolia, Martelli, in Becc. Malesia iii. (1886) 155. - Sumatra.

mattadens1s, Martelli, l. c. 160. - Borneo.

meliosmaefolia, Pierre, ex Gilg, in Engl. et Prantl, Natürl. Pflanzenfam.iij.6. (1893) $123=$ meliosmaefolia, Hook. $f$.

menbranifolia, Martelli, in Becc. Malesia, iii. (188\%) 163 = Wormia membranifolia, Seem.

micrantha, Martelli, l.c. 156. - Borneo.

minor, Gilg, in Engl. et Prantl. Natürl. Pflanzenfam. iii.6a. (1893) $125=$ Wormia minor, Zoll:

oblonga, Martelli, in Becc. Malesia, iii. (1886) 163; Gilg, 1. c. $123=$ W. oblonga, Wall,

ochreata, Gilg, in Eng1. et Prantl, Natür1. Pflanzenfam. iii. 6. (1893) $123=$ W. ochreata. Miq.

papuana, Martelli, in Becc. Malesia, iii. (1886) 1506. - Borneo. 


\section{DILLENIA :}

magnoliaefolia, Martelli, in Becc. Malesia, iii. (1886) 155. - Sumatra.

parvifolia, Martelli, l. c. 158. - Borneo.

pauciflora, Gilg, in Engl. \& Prantl, Natürl. Pflanzenfam. iii. 6. (1893) $123=$ Wormia pauciflora, Zoll. et Mor.

pulchella, Gilg, 1. c. = W. pulchella, fack.

reticulata, King, in fourn. As. Soc. Beng. 1viii. (1859) 11. 367. - Malaya.

rubescens, Ruiz, ex Vesque, in DC.Monog. Phan. viii. (1893) 63 in syn. = Clusia elliptica, $H$. B. et $K$.

speciosa, Gilg, in Engl. \& Prantl, Natürl. Pflanzenfam. iii. 6 a. (1893) $124=$ Reifferscheidia speciosa, Presl.

suffruticosa, Martelli, in Becc. Malesia, iii. (1886) $163 ;$ GIIg, 1. c. 123 = Wormia suffruticosa, Griff. thurifera. Pav, ex Vesque, in DC. Monog. Phan. viii. (1893) 59 in syn. $=$ Clusia thurifera, Planch. et Triana.

tomentella, Martelli, in Becc. Malesia, iii. (I886) 159. - Borneo.

triquetra, Gilg. in Engl. \& Prantl, Natürl. Pflanzenfam. iii. 6. (1893) $123=$ W. triquetra, Rottb.

DILOPHIA, T. Thoms.(Crucif.) - Ind. Kew.i.759. ebracteata, Maxim. Fl. Tangut. (1S89) 72. t. 28 fig. 34-45. - Tibet.

sinuata, Maxim.l. c. fig. 46-54. - Tibet.

DIMERESIA. A Gray, in Proc. Am. Acad. xxi. (1886) 411 ; et in Syn. F1. N. Am. i. 1. Suppl. (1886) 448. COMPOSITAE

Howellii, A. Gray. ll. cc. 411 et 449. - Oreg.

DIMERIA, R. Br. (Gramin.) - Ind. Kew, i. 760. connivens, Hack. in DC. Monog. Phan. vi. (1889) 689. in add. - Ind. or.

falcata, Hack. l. c. 85. - China.

glabriuscula, F. M. Bailey, Syz. Queenel. Fl.:Suppl. iii. (1890) 83. - Austral.

Lehmanni, Hack. in DC. Monog. Phan. vi. (1889) 82. - Zeylan.

leptorhachis, Hack. l.c.87.- Zeylan.

pubescens, Hack. l. c. 83. - Zeylan.

Thwaitesii, Hack. i. c. 78. - Zeylan

Woodrowii, Stapf, in Hook. Icon. pl. xxiv. (1894) t. $2312 .-$ India.

DIMEROCOSTUS, Kuntze, Rev. Gen. (1891) $68 \%$. SCIT AMINEAE.

strobilacea, Kuntze, l. c. - Panama.

DIMORPHANDRA, Schott (Legumin.). - Ind. Kew. i. 760.

megacarpa, Rolfe, in Kew Bull. (1894) 345. - Bras,

DIMORPHANTHERA, F. Muell, in Wing, South Sci. Record, N. S. ii. (Feb. 1886) in obs.; et in Trans. Roy. Soc. Vict. i. Ii. (1889) 19. $V A C C I N^{\top} I C E A E$

amblyornidis, F. Muell. l. c. (1886) in obs. ( = Agapetes amblyornidis, Becc.) - Borneo.

meliphagidum, F. Muell.l.c. $(=$ A. meliphagidum, Becc. - Malaya.

Moorhousiana. F. Muell. l. c. ; et ex Bot. Centralbl. xxvi. (1886) 163. (= A. Moorhousiana, F. Muell.) - Austral.

DIMORPHOGALYX, Thw. (Euphorb.) - Ind. Kew i 760.

capillipes, Hook. f. Fl. Brit. Ind. v. (1887) 405. - Singap.

Kunstleri, King, ex Hook. f. l. c. - Penang

Lawianus, Hook. f. l.c, 404. - Ind. or

malayanus, Hook, f., l.c.- Ind. or., Borneo.

DINAEBA, Delile = Bouteloua, Lag. (Gramin.). pubescens. K. Schum. in Engl. Pflanzenw. Ost-Afr. C. (1895) 111. - Afr. trop. or.

DINEMAGONUM, A. Juss. (Malpigh.) - Ind. Kew. i. 761.

maculigerum, Phil. in Anal. Univ. Chil. Ixxxii. (1893) 725. - Chili.
DINOCHLOA, Buese (Gramin.) - Ind. Kew. i. 761 scandens, Kuntze, Rev. Gen. (1891) $773=\mathrm{D}$ Tjankorreh, Buese.

DIOCLEA, H. B. et K. (Composit.) - Ind. Kew. i. 761 .

comosa, Kuntze, Rev. Gen. (1891) $179=$ guianensis, Berth.

coriacea, Rusby, in Mem. Torrey Bot, Club, iii. 3 (1893) 22. = coriacea, Benth.

DIODIA, Gronov. (Rubiac.) - Ind. Kew. i. 761. apiculata, K. Schum, in Bot. Jahrb. x. (1889) 313 $=$ Spermacoce tenella, $H$. $B$. et $K$.

assurgens, K. Schum, in Mart. Fl. Bras. vi. vi (1888) $22=\mathrm{S}$. tenella, $H$. B. et $K$

aulacosperma, $K$. Schum, in Engl. Pfanzenw. Ost Afr. C. (1895) 394. - Afr. trop. or.

dichotoma, K. Schum, in Mart. F1. Bras, vi, vi. (1888) $10=$ glabra, Willd

Gardneri, K. Schum. l. c. 402. - Bras.

gymnocephala, K. Schm. 1. c. $16 \%$ Borreria gymnocephala, DC.). - Bras.

Kuntzei, K. Schum. l. c, 15. - Bras.

macrophylla, K. Schum. l. c. 401. - Bras.

riparia, Sagot, ex $\mathrm{K}$. Schum. 1. c. $27=$ sarmentosa, $S w$.

saponarifolia, K. Schum. l. c. 16. (= Borreria sapomariaefolia Cham, et Schlecht.) - Bras.

spicata, K. Schum. 1. c. $23=$ spicata, Miq.

DIONCOPHYLLUM, Baill, in Bull. Soc. Linn Paris, ii. (1890) 870 . BIXACEAE.

Tholloni, Baill. l. c.-Congo Gall.

DIONYCHIA, Naud. (Melast.) - Ind. Kew. i. 762 gracilis, Cogn. in DC. Monog. Phan. vii. (1891) 338. - Madag.

DIOSGOREA, Plum. ex Linn. (Dioscor.). - Ind Kew, i. 762

Beccariana, Martelli, Fl. Bogos. (1886) 83.-Abyss

Bisantaca, Ham. ex Hook. f. Fl. Brit. Ind. vi. 1892) 296 in syn. = alata, Linn.

Buchholziana, Engl. Bot. Fahrb. vii. (1886) 333. Kamerun.

Burchellii, Baker, in fourn. Bot. xxvii. (18S9) 1. Afr. austr.

calyculata, 7. D. Smith, in Coult. Bot. Gaz. xx. (1895) 295. - Am. centr.

caucasica, Lipsky, in Bull. Soc. Natur. Kieff, (1893) 143 t. 6-7; Alboff, in Act. Hort. Petrop. xii. (1893) 439 ; ct in Bull. Herb. Boiss. i. (1893) 263. - Reg. Cauc.

Cerubulium, Herb. Ham. ex Hook. f, F1. Brit. Ind. vi. (1892) 291 in $\operatorname{syn} .=$ spinosa, Roxb.

Collettii, Hook. f. l. c. 290.-Burma.

colocasiaefolia, Pax, in Bot. Fahrb. xv. (1893) 145. - Kamerun.

coriacea, Wight, ex Hook, $f$. Fl, Brit. Ind, vi. (1892) 292 in syn. = oppositifolia, Linn

crepitans, Ham. ex Hook. f. 1. c. $294=$ glabra, Roxb.

cryptantha, Baker, in fourn. Limn. Soc. xxii. (1887) 5:8. - Madao

cyanisticta, 7. D. Smith, in Coult. Bot. Gaz.xx. (1895) 10. - Costarica.

decemangularis, Ham. ex Hook. f. Fl. Brit. Ind, vi. (1892) 295 = sativa, Linn.

decipiens, Hook. f. l. c. 293. - Burma.

deflexa, Hook. f. l. c. - Penins, Mal.

Devipata, Ham. ex Hook, f. 1. c. $296=a^{2} a t a$, Linn. dicranandra, 7. D. Smith, in Conlt. Bot. Gaz. xix. (1S94) 13. - Guatem.

Dregeana. Th. Dur. et Schinz, Consp. Tl. Afr. v. 1893 (1895) 274. (= Helmia Dregeana, Kunth). Afr. austr.

Dugesii, Robins. in Proc. Am. Acad. xxix. (1894) 330. - Mexic.

dumetorum, Th. Dur, et Schinz, Consp. F1. Afr. v. $1893(1895) 274=$ seq.

dumetorum, Pax, in Engl, \& Prantl, Natürl. Pflanzenfam. ii. 5. (1887) 133. (= Heimia dumetorm, Kunth) = triphylla, Schimp.

Forbesii, Baker, in foum. Bot. xxvii. (1889) 2. Afr, trop. austro-or.

\section{DIOSCOREA :}

gibbiflora, Hook. f., Fl. Brit. Ind. vi. (1892) 294.Ind. or.

Hamiltoni, Hook. f. l. c. - Ind. or.

hirsuticaulis, Robins, in Proc. Am. Acad. xxix. (1894) 324. - Mexic.

Hoffa, Cordem. Fl. Ile Rérn. (1895) 159. - Ins. Borbon.

holmioidea, Maury, in Morot, Fourn. de Bot, iii. 1889) 267 fig. 11. - Am. austr. trop.

Holstii, Harms, in Engl. Pflanzenw. Ost-Afr.C (1895) 147. - Afr trop or.

Hurchusia, Ham, et Hook. f. F1. Brit. Ind. vi. (1892) 296 in syn. = alata, Linn

hybrida $\times$ Hort. ex Nichols. Dict. of Gard. iv. (1888) 537. - Form. hort.

hylophila, Harms, ex Engl. in Abh. Preuss. Akad. Wiss. (1894) 51, et in Engl. Pfanzenz. Ost-Afr. C (1895) 146. - Afr. trop. or.

incrassata, Ham. ex Hook. f. Fl. Brit Ind. vi. (1892) $295=$ Hamiltoni, Hook. $f$.

Jacquemontii, Hook. f.l. . . 296. - Concan

jaliscana, S. Wats. in Proc. Am. Acad. xxii. (1S87) 438. - Mexic.

lancolata, Heyne, ex Hook. f. F1. Brit. Ind. vi. (1892) 292 in syn. = oppositifolia. Limn.

lucida, S. Elliot, in fourn. Limn. Soc. xxix. (1891) 60. - Madag.

malifolia, Baker, in fourn. Bot. xxvii. (1889) 1. Afr. austr.

militaris, Robins, in Proc. Am. Acad. xxix.(I894) 324. - Mexic

minima, Robins. et Seaton, l. c. xxviii (1893) 115. Mexic.

minutiflora, Engl. Bot. Fahrb. vii. (1S86) 332 ; et xv 146 (err cal. multiflora) t. 8. - Kamerun

monadelpha, Pax, in Engl. Eo Prantl. N'atiinl. Pflanzonfam. ii. 5 (1887) 133 = monadelpha, Griseb.

multiflora, Engl. ex Pax, in Bot. Jahrb. xv. (1893)

146 sphalm. = minutiflora, Engl.

Mundtii, Baker, in fourn. Bot. xxvii. (1889) 1.Afr. austr.

nipponica, Makino, Ill. Fl. Fap. (1891) t. 45 ; et ex fourn. Bot. xxix (1891) 383. - Japon.

obcuneata, Hook. f. Fl. Brit. Ind. vi. (1892) 293. Zeylan.

octangularis, Ham. ex Hook. f. 1. c. 296 in syn. $=$ alata $L$ inn.

odoratissima, Pax, in Bot. Fahrb. xv. (1893) 146. Afr. trop. occ

orbiculata, Hook.f. Fl. Brit. Ind. vi. (1892) 292. Penang.

ovata, Ham. ex Hook. f. 1. c. 292. = Hamiltoni, Hook.f.

papuana, Warb. in Bot. Fahrb. xiii. (1891) 273. N. Guin

pedicellata, Morong, in Ann. N.Y.Acad. Sci. vii. (1893) 240. - Parag.

perdicum, Taub. in Bot. Falirb. xv. Beibl. n. 34 (1892) 13. - Bras.

phaseoloides, Pax, in Bot. Falub. xv. (1893) 149 - Afr. centr. or.

plumifera, Robins. in Proc. Am. Acad. xxix. (1894) 324. - Mexic

polyclados, Hook.f. Fl. Brit. Ind. vi. (1892) 294. Singap. Java.

Preussii, Pax, in Bot. Fahrb xv. (1893) 147. Kamerun.

Pringlei, Robins. in Proc. Am. Acad. xxix. (1894) 323. - Mexic

rhipogonoides, Oliver, in Hook. Icon. pl. xix. (1889) t. 1868. - Ins. Hongliong.

sagittata, Royle, ex Hook f Fl, Brit. Ind. vi. (1892) $294=$ glabra, Roxb.

sagittifolia, Pax, in Bot. Fahrb. xv. (1893) 14\%. Afr. centr. or.

sansibarensis, Pax, l. c. 146. - Afr. trop. or.

Schweinfurthiana, Pax, l. c. 149. - Afr. centr. or. Stuhlmannii, Harms, in Engl, Pfanzenw. Ost-Afr. C (1895) 146. - Afr. trop. or

thamnoidea, Hort. ex Correns, in Sitzungsō. Akad. Wien, xcvii (1S59) 672 et 673 nomen, (Quid ?).

Tokoro, Makino, ex Miyabé, in Tokyo Bot. Mag. viii. (1894) 485 nomen. - Japon.

Tumgd Ham, ex Hook, f. Fl, Brit. Ind, vi. (1\$92) 295 in syn. = sativa, Lim 


\section{DIOSCOREA}

Tysoni, Baker, in fourn. Bot. xxvii. (1889) 2. Afr, austr.

undatiloba, Baker, l. . . 8. - Natal.

versicolor, Ham. ex Hook. f. F1. Brit. Ind.vi. (1892) 295 in syn. (sphalm versicola $)=$ sativa, Linn.

Wallichii, Hook. f. l. c. - Ind. or.

Wightii, Hook. f. l. c. 291. - Travanc.

DIOSCOREOPHYLLUM, Engl. Pflanzenw. OstAfr. C 180') 181. MENISPERMACEAE.

Volkensii, Engl.l. c. 182. - Afr. trop. or.

DIOSCORIDA, St, Lager, in Cariot, Etud. des fi. éd. 8. ii. (1889) $764=$ Dioscorea, Plum.

DIOSPHAERA, Feer, in Bull. Herb. Boiss, ii (1894) 519 = Trachelium, Journ. (Campanul.). asperuloides, Feer, 1. c. $523 .=\mathrm{T}$. asperuloides, Boiss.

chalcidica, Feer, 1. c. 521.- Graec

dubia, Feer, 1, c. 522 = T. rumelicum, Boiss.

Facquini, Feer, 1. c. $520=$ T. Jacquini, Boiss.

DIOSPYROS, Linn. (Ebenac.). - Ind. Kew. i.

766. Hemsl. in Kew Bull. (1895) 136. - Ins.

acris, $H$

armata, Hensl. in foum. Linn. Soc. xxvi. (1889) 69. - China.

aurantium. Hort, ex.Ed. André, in Rev. Hort. (1887) $349=$ D. Kaki, I.inn.f.

Bertii, André, 1. c. = D. Kaki, Limu. $f$.

bilocularis, Otiver, in Hook. Icon. pl. xxiv. (1894) t. 2336. - Singap.

caliginosa, Ridl, in Trans. Linn. Soc, Ser. II, iii. (1893) 318. - Penins. Mal.

calycina, Hort. ex Dippel, Handb. Laubholzk. i. (1889) $306 .=$ D. Lotus, Lim,

conocarpa, Gürke, ex K. Schum. in Bot. fahrb. xiv, (1892) 311. - Gabon.

coreacea, "Hiern, » ex Boerl. Handl. Fl. Ned. Indie ii. I. (1891) 317 sphalm. = coriacea, Hiem

Cuningii, Giirke, in Engl. \& Prantl, Natürl. Pflanzenfam. iv. 1. (1891) $162=$ philippinensis, A. $D C$.

dictyonewra, “Hiern » ex Boerl. Handl. Fl. Ned. Indiè, ii. 1.(1891) 316 sphalm. = dictyonema Hiern

elliptica. Hort, ex Ed. André, in Rev. Hortic, lix. (1887) $349 .=$ D. Kaki, Linn. $f$

Fischeri, Giorke, in Bot. Fahrb. xiv. (1892) 311. Afr. trop. or

guianensis, Gürke, in Erigl. \& Prantl, Natürl Pflanzenfam. iv, I (1891) $163=$ D. Paralea Sterd.

Hildebrandtii, Gürke, in Bot- Fahrb. xiv.(1892) 312. - Madag.

laxa. K. Schum. in.K. Schum. et Hollr. Fl. Kais. Wilh. Land (1894) $108=$ maritima, Elume.

lenticellata, Baker, in fourn. Limn. Soc. xxv. (1890) 333. - Madas.

melanoxylon, Ces., Passer, et Gibelli, Comp. F1. Ital. ii. (1886) $403(=$ D. melanoxylon, Willd. $)=$ D. Ebenum, Koen.

microcarpa, Gürke, in Engl. \& Prantl, Natiirl. Pflanzenfam. iv. 1 (1891) $163=$ D. Cargillia, F. Muell.

mollis, Gürke, 1. c. 162 (= Gunisanthus mollis, Kurz) $=$ martabanica, C. B. Clarke.

Oldhami, Maxim. in Bull. Acad Sci. Pétersb. xxxi. (1887) 67. - Ins. Formos

peregrina, Gürke, in Eng1. \& Prantl, Natürl. Pflanzenfam. iv. I (1891) 164 fig. 87 (= Embryopteris peregrina, Gaertn.). = D. Embryopteris, Pers.

pergamacea, "Hiern. " ex Boerl. Hand1. F1. Ned. Indië, ii. 1. (1891) 317 sphalm。= pergamena, Hiern.

philippcnsis, Gürke, in Engl, \& Prantl. Natïrl. Pflanzenfam, iv, 1. (1891) $164=$ discolor, Willd.

Preussii, Giirle, in Bot. Fahrb. xiv. (1892) 313.Kamerun.

psendebenus, Parment. Histol. comp. Ebénac. (1892) $29=$ Euclea pseudebenus, E. Mey.

\section{DIOSPYROS}

psudo-ebenum, Koerd. et Valet. in Mededeel. s'Lands Plantent. n. xi, Bijdr. n. 1 (1894) $58=$ Euclea pseudebenus, E. Mey.

thombifolia, Hemsl. in foum. Linn. Soc. xxvi. (1889) 70. - China.

Sahuti, Hort. ex Éd. André, in Rev. Hortic. lix. (1887) $349=$ D. Kaki, Linn. $f$.

sinensis, Hemsl, in foum. Linn. Soc.xxvi.(1889) 71. - China.

Soyauxi, Gürthe et $K$. Schum. ex Giurke, in Bot. Fahrb. xiv. (1892) 312. - Gabon.

Stuhlmannii, Gürke, in Engl. Pflanzenw. Ost-Afr.C 1895) 306. - Afr. trop. or.

utilis, Hemsl.in Ann. of Bot. ix.(1895) 154 - Formos.

Walkerii, Gürke, in Eng1. \& Prant1, Natürl. Pflanzenfam. iv. 1. (1891) 162 (= Patonia Walkerii, Wight $)=\mathrm{D}$. Gardneri, Thw.

Wieseneri, Carrière, in Rev. Hortic. lix. (1887) S3. $=$ D. Kaki, Limn. $f$.

DIPGADI, Medic. (Liliac.), - Ind. Kew. i. 768

Bakerianum, Schinz, in Verh. Bot.Vor. Brand. xxxi. (1890) $21 \%$ - Afr. austrn-occ. extratrop.

Clarkeanum, Schinz, l. c. 218. - Afr. austro-occ. extratrop.

Durandianum, Schinz, in Th. Dur. et Schinz, Const. Fl. Afr. v. 1893 (1895) 374. - Afr. austro-occ. extratrop.

longibracteatum, Schinz, in Verh. Bot. Ver. Brand. xxxi. (1890) 218. - Afr. austro-occ. extratrop.

Marlothii, Engl. Bot. Fahrb. x. (I889) 3. - Afr. austr.

minor, Hook, $t$, Fl, Brit. Ind. vi, (1892) 346. Concan.

occidentale, Baker, in Kew Bull. (1895) 119. Afr. trop. occ.

sansibaricum, Engl. Pflanzenw. Ost-Afr. C (1895) 142. - Afr. trop or.

spirale, Baker, in Bot. Fahrb.xv. Beibl.n. 35 (1892) 7. - Afr. austr.

DIPELTA, Maxim. (Caprifol.) - Ind. Kew. i. 769. elegans, Batalin, in Act. Hort. Petrop. xiv. (1895) 174. - China.

DIPETALIA, Rafin. = Oligomeris, Cambess. (Resed.)

Burchellii, Kuntze, Rev. Gen. (IS91) $39 .=$ O. Bur chellii, Harv.

Dregeania, Kuntze, 1. c. = O. Dregeana, Mucll. Arg. spathulata, Kuntze, 1. c. = O. spathulata, E: Mcy. subulata, Kuntze, 1. c. = O. glaucescens, Cambess.

DIPHACA, Lour. = Ormocarpum, Beauv (Legumin.).

coerulea, Taub. in Eng1. \& Prantl, Natür1, Pflanzenfam. iii. 3. (1894)319. = O. caeruleum, Balf. $f$. gracilis, Taub. 1. c. = Arthrocarpum gracile, Balf. $f$.

Tervicosa, Taub. 1. c. - Afr. trop. occ.

Kirkii, Taub.1. c. = O. Kirkii, S. Moore.

mimosoides, Taub, in Engl. Pflanzenw. Ost-Afr, C (1895) 213. = O. mimosoides, S. Moore.

trachycarpa. Taub. 1. c. - Afr trop. or.

trichocarpa, Taub. 1. c. 213. - Afr. trop. or.

verrucosa, Taub. in Engl. \& Prantl, Natürl. Pflanzenfam. iji. 3. (1894) 319. = O. verrucosum, Beauv.

DIPHRYLLUM, Rafin. = Listera, R. Br. (Orchid.).

australe, Kuntze, Rev. Gen. (1891) $659 .=$ L. australis, Lindl.

convallariodes, Kuntze, 1. c. = L convallarioides, Nutt.

cordatum, Kuntze, 1. c. = L. cordata, R. Br.

Eschscholtzianum, Kuntze, 1. c. = L. Eschscholziana, Cham, et Schlecht.

japonicum, Kuntze, 1. c. = L. japonica, Blume

micranthum, Kuntze, 1. c. = L. micrantha, Lindl. ovatum, Kuntze, 1. c. = L. ovata, R. Br.

pinetorum. Kuntze, 1. c. = L. pinetorum, Lindl.

DIPHYLAX, Hook. f. in Hook. Icon, pl. xix. (1889). t. 1865. ORCHIDEAE.

\section{DIPHYLAX :}

rceolata, Hook. f. in Hook. Icon. pl. xix. (1889) t. 1865 (= Habenaria urceolata, Hook. f.) - Reg. Himal.

DIPHYSA, Jacq. (Legumin.). - Ind. Kew. i. 769. racemosa, N.E.Rose, in Contrib.U.S. Nat. Herb. i (1891) 97 t. 3. - Am. bor. occ

suberosa, S. Wats. in Proc. Am. Acad.xxii.(18S7) 405. - Mexic

DIPLACHNE, Beauv. (Gramin.). - Ind. Kew. i. 769

aristata, Baker, in fourn. Linn. Soc. xxis. (1S87) 534. - Madag.

biflora, Hack. ex Schinz, in Bull. Herb. Boiss, iii. (1895) 387. - Transv.

Brandegei, Vasey, in Proc. Calif. Acad. Ser, 2. ii (1889) 213. - Calif.

bulgarica, Bornm. in Bot. Centralbl. xxxvi. (1888) 156 ; et Ixi. (1890) 165; et in Bull. Soc. Dauph. (1890) 28 = serotina, Lint $_{\text {. }}$

caudata, K. Schum, in Engl. Pfanzenw. Ost-Afr. C (1895) 113. - Afr. trop. or.

cinerea, Hack. in Bot. Fahrb. xi. (1890) 403. - Afr. austro-occ extratrop.

grandiglumis, Hack. 1. c. 404. (= Leptochloa granidighnnis, Nees). - Afr. austr.

pallida, Hack. ex Schinz, in Bull. Herb. Boiss, iii. (1895) $38 \%$. - Transv.

patula. St. Lager, in Cariot, Étud. des fl. éd. 8. ii. (18S9) 937 = serotina, Link.

Reverchoni, Vasey, in Bull. Torrey Bot. Club, xiii. (1886) 118 ; et Illustr. N. Am. Grass. i. 11. (1891) t. 43. - Texas.

rigida, Vasey, l. ...t. $44=$ rigida, Benth。

saccharoides, Baker, in fourn. Linn. Soc. xxv. (1890 349. - Madas.

squarrosa, C. Richt. P1. Europ. i. (1889) ¿2 $^{2}=$ Molinia squarrosa, Trin.

tarapacana, Phil. in Anal. Mus. nac. Chile. (1892) 88. - Am. austr. occ.

Thoroldi, Stapf, ex Hemsl. in Fourn. Limn. Soc. xxx. (1894) 121. - Tibet.

Tracyi, Vasey, in Bull. Torvey Bot. Club, xv, (1888) 49. (= Leptochloa Tracyi, Beal). - N. Mexic.

Vulpiastrum, Aschers. ex Engl, in Abhandl. Preuss. Akad. Wiss. (1894) 35 et $38=$ (Rabdochloa Vulpiastrum, De Not.). - Afr. trop.

DIPLACRUM, R. Br. = Scleria, Berg (Cyper. ifricanum, C. B. Clarke, in Th. Dur, et Schinz, Consp. Fi. Afr. v. 1894 (1895) 668. - Afr. trop. longifolium, C. B. Clarke, 1. c. $669(=$ Pteroscleria longifolia, Griseb.). - Bras., Afr. trop. occ.

DIPLACUS, Nutt. = Mimulus, Linn. (Scrophul.) grandiflorus, Greene, Pittonia, ii. (Dec. 1890) 150 (=D. Iongiflons Greene, non Nutt.). - Calif. linearis, Greene, 1. c. = M. linearis, Benth. parviflorus, 'Greene; 1, c. i. (Mar. 1887) 36. Calif.

speciosus, Davy, in Erythea, ii. (1894) 101. - Calif.

DIPLADENIA, A. DC. (Apocyn.). - Ind. Kew. i. $7 \% 0$.

congesta, K. Schum, in Engl. Es Prantl, Natiml. Pfanzenfam iv. 2. (1895) 169. - Eruad.

eximia, Hensl. in Gard. Chron. (1893) ii. 120. Am. austr.

Marie-Henriettae, Hort. Sand. ex Gard. Chron. (1892) i. $731=$ atropurpurea, $A . D C$.

Myriophyllum, Taub. ex Ule, in Cruls, Rapp. expl. plat. centr. Brésil (1894) 355 et 361; 11 Feb. 1896. - Bras.

tenuifolia, K. Schum. in Engl. \& Prantl, Natürl. Pflanzenfam. iv. 2. (1895) $169=$ polymorpha Muell. Arg.

velutina, K. Schum. 1. c. = grentiànoides, Mwell. Arg.

DIPLANTHERA, Banks et Soland. (Bignon.). Ind. Kew. i. 770 .

speciosa, K. Schum. in Engl. of Prantl, Natürl. Pfanzenfan. iv. 3b. (1894) 235. (= Deplanched speciosa, Vieill.). - N Caled. 
DIPLATTA Van Tiegh, in Bull. Soc. Bot. Fr, xli. 1894) 501 . = Loranthus, Linn

Alberticii. Van Tiegh. 1. c. xlii. (1895) 88. - N. Guin. grandibractea, Van Tiegh. 1.-c. xli. (1894) 502. = L. grandibracteus, F. Muell.

tenuifolia, Van Tiegh. 1. c. - Austral.

DIPLECTRIA, Kuntze, Rev. Gen. (1891) 246 $=$ Anplectrum, A. Gray, (Melast.). annulata, assamica, biligulata, confinis, Korthalsii, latifolia, ligulata, nodosa, pallens, reformata, rostrata, stipularis, viminalis, Kuntze, Rev. Gen. (1891) $246=$ homonyma omnia Anplectri.

Beccariana, Kuntze, 1. c. 953 = A Beccarianum, $\operatorname{Cog} n$.

bibracteata, Kuntze, 1. c. $246=$ Creochiton bibracteata, Blume.

Ganocarpa, Kuntze, 1. c. = A. glaucum, Triana divaricata, Kuntze, 1. $c_{-}=$A. divaricatùm, Triana. myrtifolia, Kuntze, 1. c. = Medinilla myrtiformis, Triana.

pudibunda, Kuntze, 1. c. = Creochiton pudibunda, Bhume.

tetrandra, Kuntze, 1. c. $=$ A. glaucum, Triana.

DiPlocyathus, K. Schum. in Eng1. \& Prantl, Natüri. Pflanzenfam. iv. 2 (1895) $281=$ Diplocyatha, N. E. Br. (Asclep.).

DIPLOGATHA, "N. E. Br. » ex K. Schum. in Encl, \& Prantl, Natürl. Pflanzenfam. iv. 2. (1895) 281 sphalm. = Diplocyatha, N. E. Br. (Asclep.).

DIPLOGLOTTIS, Hook. f. (Sapind. ?) - -Ind. Kew. i.7.7.

diphyllostegia, F. M. Bailey, Syn. Queensl. Fl. First Suppl. (1886) 14 (= Cupania diphyllostegia, F. Muell.). - Austral.

DIPLOGON, Rafin, = Chrysopsis, Nutt. (Compos.) Breweri, graminifolium, hyssopifolium, oreganzm, pilosum, pinifolium, scabrellum, trichophyllum, villosum, Kuntze, Rev. Gen. (1891) $334=$ homonyma omnia Chrysopseos.

falcatum, Kuntze, 1. c. = C. villosa, $D C$

Nuttallianum, Kuntze, 1. c. = C. pilosa, Nutt.

DIPLOMORPHA, Griff. = Agyneia, Linn. (Euphorb.).

bacciformis, Kuntze, Rev, Gen. (1891) $603=$ A. bacciformis, $A$. f uss.

DIPLOPAPPUS, Cass. = Aster, Tourn. (Compos.). chrysophylhus, Hort. ex Koehne, Deutsche Dendrol. (1893) 562 in syn. = Cassinia fulvida, Hook. $f$.

DIPLOPELTIS, Endl. (Sapind.). - Ind. Kew. i. 772 .

madagascariensis, Radlk, in Engl. E Prantl, Natïrt. Pflanzenfam. iii. 5. (1895) 35\%. - Madag.

DIPLOPHRAGTUM, Desf. (Tiliac.). - Ind.

Kew. i. 773. Vidal, Revis. Pl. Vasc. Filip. (1886)
philippinense. Vidat. 71. - Ins. Philipp.

DIPLORRHYNGHUS, Welw. (Apocyn.). - Ind. Kew. i. 773 .

angolensis, Buettn. in Verh. Bot. Ver. Brand. xxxi. (1589) 85. - - Angola.

Poggei, K. Schum. in Engl. \& Prantl, Natürl. Pfanzenfam. iv. 2. (1895) 142 fig. 540. - Congo.

Welwitschii, Rolfe, in Bolet. Soc. Brot. xi. (1893) 85 $=$ angolensis, Buettn .

DIPLOSPORA, DC. (Rubiac.) - Ind. Kew.i. 773 fruticosa, Hemsl. in fourn. Linn. Soc. xxiii. (1888) 283. - China.

parvifolia, Kuntze, Rev. Gen. (1891) 280. - As, trop.

DIPLOSTEPHIUM, H. B. et $K$. (Composit.), - Ind. Kew. i. 773 .

antisanense, Hieron. in Bot. Fahrb. xxi. (1895) 338. - Ecuad.

\section{DIPLOSTEPHIUM}

cochense, Hieron. in Bot. Fahrb. xxi (1895) 341. N. Gran.

glandulosum, Hieron. l. c. 339. - Am. austr.

Hartwegii, Hieron. l. c. 337. - N. Gran.

incanum, Hieron. l. c. 340. - Peruvia.

ochroleucum, Klatt, . c. viii. (1887) 37 -Columb. rhododendroides, Hieron. l. c. xxi. (1S95) 340.N. Granat.

tacorense, Hieron. l. c. 33\% - Peruvia.

DIPLOSTIGIA, K. Schum, in Eng1. PHanzenw. Ost-Afr. C (1895) 334; et in Engl. \& Prantl, Natürl. Pflanzenfam, iv. 2. (1895) 256. ASCLE$P I A D E A E$.

canescens, $K$. Schum. $l l$. cc. 334 et 25\%. - Afr trop. or.

DIPLOTAXIS, DC. (Crucif.) - Ind. Kew. i. 773 Blancoana, Giraudias, in Bull. Soc. sc. Angers (1881) = Brassica Blancoana, Boiss.

Delagei, Ponel, ex Batt. in Bull. Soc. Bot. Fr. xxxiii. (1886) 476. - Algeria.

fruticulosa, Tod. ex Caruel, in Parl. Fl. Ital. ix. (1893) 962. - Ins, Melit.

heterophylla, Porta et Rigo, ex Porta. in Atti Accad. Agiati, ix. 1891 (1892) sep. 7; Willk. Suppl. Prodr. A. Hisp. (1893) 309. - Hisp.

Rouvana, Janka, ex Willk. Suppl. Prodr. fl. Hisp. (1893) 309 in syn. = maritima. Routy

segobricensis, Par, Not. bot. fl. Espan. i. (1857) 28 nomen. - Hisp.

stenocarpa, Rouy et Fouc. F1. de Fr. ii. (1895) $46=$ Erucastrum obtusangulum, Reichi.

valentina, Paw, Not. bot. fl. Espan. i. (1887) 9 Willk. Suppl. Prodr. fl. Hisp. (1893) 309. - Hisp.

DIPLOTHEMIUM, Mart. (Palm.). - Ind. Kew i. 774 .

jangadense, S. Moove, in Trans. Linn. Soc. Ser. II. iv. (1895) 499 t. 36. - Bras.

DIPLYGosia, Blume (Ericac.) - Ind. Kew. i. 774 .

chrysothrix, Stapf, in Trans. Linn. Soc. Ser. II. iv. (1894) 191. - Borneo.

cinnamomifolia, Stapf, 1. c. 195. - Borneo.

kinabaluensis, Stapf, l. c. 193.- Borneo.

memecyloides, Stapf, l. c. 194. - Borneo.

Myrtillus, Stapf, l. c. 192 - Borneo.

penduliflora, Stapf, l. c. 193.- Borneo

pinifolia, Stapf. l. c. 192. - Borneo.

punctulata, Stapf, l. c. 193. - Borneo.

rufa, Stapf, l. c. 191. - Borneo,

urceolata, Stapf, l. c. - Borneo.

DIPODOPHYLLUM, Van Tiegh, in Bull. Soc. Bot Fr. xli. $r(1895) 177=$ Loranthus, Linn.

Digueti, Van Tiegh. 1. c. 178. - Calif.

DIPOMA, Franch, in Bull. Soc. Bot. Fr. xxxiii. (1886) 404 ; etPl. Delav. (1889)63. CRUCIFERAE.

iberideum, Franch. 77 . cc. 405 ; et 64 t. 17. i. Yunnan.

DIPORIDIUM, Wendl. f. = Ochna. Linn.

Afzelii, brevipes, ciliatum, Kirkii, leptocladum, leucophaeum, macrocalyx, madagascariense, mauritianum, Mechowianum, membranaceum, mossambicense, multiflorum, tolycarpum, pulchrum, pumilum, serratifolium, squarrosum. Wallichii, Wightianum, Kuntze, Rev. Gen. (1891) 105 = homonyma omnia Ochnae.

andravinense, Kuntze, 1. c. $105=\mathrm{O}$. andravinensis, Baill.

ardisiodes, Kuntze, 1. c. = O. ardisioides, $W c b b$.

Bernieri, Kuntze, 1. $\mathrm{c}_{2}=$ O. Bernieri, Baill.

Boivinianum, Kuntze, 1. c. = O. Boiviniana, Baill. brachypodum, Kuntze, 1. c. $=$ O. brachypoda, Baill comorense, Kuntze, 1. c. = O. comorense, Baill.

fascicularis, Kuntze, 1. c. = O. fascicularis, Blanco. Humblotianum, Kuntze, 1. c. $=$ O. Humblotiana, Baill.

macranthum, Kuntze, 1. c. = O. macrantha, Baker. micropetalum, Klintze, 1. c. = O. micropetala, Hochst.
DIPORIDIUM :

obovatum, Kuntze, Rev. Gen. (1891) $105=0$. obovata. Baill.

parvifolium, Kuntze, 1. c. = O. parvifolia, Baker. Pervilleanum, Kuntze, 1. c. = O. Pervilleana. Baill. quangense, Kuntze, 1. c. = O. quangensis, $R$, Buettn. accinoides, Kuntze, 1. c. - O. vaccinioides, Baker.

DIPSAGUS, Linn. (Dipsac.). - Ind. Kew. i, 775. chinensis, Batalin, in Act. Hort. Petrop. xiii. (1894) 377. - China.

DIPTERYGIA, Presl = Asteriscium, Cham, et Schlecht (Umbellif.

aemocarpa, chilensis. flexuosa, polycephala, ramosissima, Kuntze, Rev. Gen. (1891) $267=$ homonyma ommia Asterisiscii.

anthodes, Kuntze, 1. c. = A. anethoides, Turcz.

Closii, Kuntze, 1. c. = A. chilense, Cham, et Schlecht.

foliosa, Kuntze, 1.c. (=Gymophyton foliosum, Phil.). - Chili.

Hensleyana, Kuntze. 1. c. = A. flexuosum, Hems7.

Kingii, Kuntze, 1. c. (= Gymnophyton Kingi, Phil.) - Chili.

muda, Kuntze, 1. c. (= Tritaenicum nudum, Jurcz.). - Chili.

Philippiana, Kuntze, 1. c. (= Eremocharis fruticosa, Phil.). - Chili.

pozzodes, Kuntze, 1. c. = A. pozzoides, Clos.

spinescens, Kuntzc, 1. c. (= Gymnophyton spinescens,

Phil.): - Chili.

spinosissima, Kuntze, 1. c. (= Gymnophyton spinosis-

simum, Phil.). - Chili.
verrocosa, Kuntze, 1. c. = A. chilense, Cham. et Schlechit.

DIRICHLETIA, Klotzsch (Rubiac). - Ind. Kew.

asperula, K. Schum. in Engl. Pfanzenน. Ost-Afr. C (1895) 378. - Afr. trop. or.

DISCOSPERMUM, Dalz. = Diplospora, DC (Rubiac.)

confusum, Griffithi, javanicum, malaccense, pubescens, singulare, Kuntze, Rev. Gen. (1891) 281 = homonyma omnia Diplosporae.

biloculare, Kuntze, 1. c. = Dip1. Kurzii, Hook. $f$.

dubium, Kuntze, 1. c. = Dipl. viridiflora, $D C$

fruticosum, Kuntze, 1. c. = Dipl. fruticosa, Hemsl.

parvifolim, Kuntze, 1. c. $280=$ Dipl. parvifolia, Kuntze.

DIPTEROCARPUS, Gaertn. (Dipteroc.) - Ind. Kew. i. 776.

ffinis, Brandis, in fourn. Linn. Soc. xxxi. (1895) 31. - Ins. Philipp.

artocarpifolius, Picrre, ex Laness. Pl. util. Colon. Fr. (1886) 297. nomen; et Fl. For. Cochinch. fasc. 14 (1889) t. $213 \mathrm{~A}$. - Cochinch.

bancanus, Burck, in Annal. Fard. Buit. vi. (1887) 196. - Ins. Bangka.

Bourdilloni, Brandis, in Hook. Icon. pl. xxv. (1895) t. 2403. - Travanc.

cancanus, "Burck. », ex Brandis, in Journ. Linn. Soc. xxxi. (1895) 31, sphalm. = bancanus, Burck. condorensis, Pierre, Fl. Fr. Cochinch., fasc. I4 (1889) t. $244 \mathrm{c},-$ Cochinch.

Duperreana, Pierre, ex Laness. Pl. util. Col. Fr. (1886) 297 ; et Fl. For. Cochinch. fasc. 14 (1889) t. 219. - Cochinch.

Dyeri, Pierre, ll. cc. 297; et t. 216-17. - Cochinch.

Jourdainit, Pierre, ll.cc. 298; et t. 220. - Cochinch. Kerrii, King, in fourn. As. Soc. Beng. 1xii. (1893) ii. 93. - Malacca.

Kunstleri, King, l. c. 93. - Perak

pulchérimus, Ridl, in Trans. Linn. Soc. Ser. II, iii. (1893) 283 = oblongifolius, Blume.

punctulatus, Pierre, Fl. For. Cochinch. fasc. 14 (1889) t. 221. - Cochinch.

Scortechiniî, King, in foum. As. Soc. Bung. 1xii. (1893) ii. 91. - Perak.

Skinneri, King, l.c.- Penang.

speciosus, Brandis, in fourn. Linn. Soc. xxxv. (1895) 38. - Ins. Philipp.

Thorelii, Pierre, ex Laness. P1. util. Col. Fr. (1886) 297, nomen, - Cochinch. 


\section{DIPTEROCARPUS :}

velutinus, Vidal, $P l$. vasc. Filip.(1886) 59. - Ins. Philipp.

Warburgii, Brandis, in foum. Linn. Soc. xxxi. (1895) 32. - Ins. Philipp.

DIPTERONIA, Oliver, in Hook. Icon. pl. xix. (1889) t. 1898. SAPINDACEAE.

sinensis, Oliver, l. c. - China.

DIRICHLETIA, Klotzsch (Rubiac.), - Ind. Kew. i. 777.

insignis, K. Schum, in Engl. \& Prantl, Natirl: Pfanzenfam, iv. 4(1891) 30 fig. 8. - [an D. insignis, Vatke?] - Madag.

involucrata, Baker, in fourn. Linn. Soc. xxi3. (1887) 482. - Madas.

leucophlebia, Baker, l.c.xxv. (1890) 321. - Madag. sphaerocephala, Baker, l. . - - Madag

ternitolia, Bakcr, l. c. xxii. (1887) 482.- Madag.

trichophlebia, Baker, l. c. 483. - Madag.

DISA, Berg (Orchid.). - Ind. Kew. i. 777.

apetala. Kraenzl. in Bot. Fahrb. xxii. (1895) 21 ; et in Engl. Pflanzenw. Ost-Afr.C (1895) 153. Afr. trop. or.

basutorum, Schlechter, in Bot. Fahrb. xx. Beibl. n. 50 (1895) 17. - Afr. austr.

Baurii, Bolus, in Fourn. Limn. Soc. xxv, (1889) 174 fig. 12. Afr, austr.

biraliata, Th. Dur, et Schinz, Consp. Fl Afr.v. (1892-1895) 100 (= Ophrys bivalvata, Linn.) = D. melaleuca. Sw.

brevicornis, Bolus in fourn. Linn. Soc. xxv. (18S!) 196. (= Monadonia brevicornis, Lindl.) - Afr. austr.

caffra, Bolus, 1.c. 171. fig. 9 - Afr. austr.

clavigera, Bolus, [Orch. Cape Penins.] in Trans. South. Afr, phil. Soc. V. I. (1888) 140; (= Schizodiun clarigerum, Lindl.). - Afr. austr.

conferta, Bolus, Icon. Orchid. austro-afric. i. 3. (1893) t. 28. - Afr. austr.

Culveri, Schlechter, in Bot. Fahrb. xx. Beibl. n. 50 (1895) 17. - Afr. austr

delphinoides, Haw, ex Schlechter, in Bot. Jahrb. xx. Beibl, n. 50 (1895) $39=$ aconitoides, Sond. densiflora, Bolus, in foum. Linn. Soc. xxv. (1889) 197 (= Monademia densiflora, Lindl.) - Afr. austr.

Emini, Kraenzl. in Bot. fahrb. xix. (1894) 248. Afr. trop. or,

erubescens, Rendle, in foum. Bot. xxxiii. (1895) 297. - Afr. trop. or.

falcata, Schlechter, in Verh. Bot. Ver. Brand. xxxy. (1893) 46. - Afr. austr.

fallax, Kraenzl. in Bot. Fahrb. xvii. (1893) 64.Madas.

fragrans, Schlechter, 7. C. xx. Beibl. n. 50 (1895) 40. - Atr. austr.

frigida, Schlechter, l. c. 18. - Afr. austr.

Gregoriana, Rendle, in fourn. Bot. xxx. (1895) 398. - Afr. trop. or.

Gueinzii, Bolus, in fourn. Linn. Soc. xxv. (1889) 201 (= Schizodium Gueinzii, Reichb. f.). - Afr. austr. hamatopetala, Rendle, in Trans. Lim. Soc., Ser. II. iv. (1894) 47. - Afr. trop.

Rewensis X, Hort. ex W. Wats, in Gard. Chron. (1893) i. 625 ; et (1895) ii. $273 \mathrm{fig} .51$. - Hybr. artef.

kilimanjarica, Rendle, in fourn. Linn. Soc, xxx. (1895) 399. - Afr. trop. or.

Langleyensis $\times$. Hort. ex Gard. Chron. (1894) ii. 35 fig. 5. - Hybr. artef.

longipetala, Bolus, in fourn. Linn. Soc. xxv. (1889) 201 (= Schizodium longipetalum, Lind1.). - Afr. austr.

macrostachya, Bolus, l. c. 197 (= Monadenia macrostachya, Lindl.). - Afr. austr.

micrantha, Bolus, [Orch. Cape Penins.] in Trans. South Afr. phil. Soc. v. I. (1888) 142, et 1. c. 196 (= Monadenia micrantha, Lindl.) - Afr. austr.

micropetala, Schlechter, in Bot. Fahrb. xx. Beibl. n. 50 (1895) 7. - Afr. austr.

multiflora, Bolus, [Orch. Cape Penins.] in Trans. South Afr. phil. Soc.v. 1. (1888) 140; et in fourn. Linn. Soc. xxv. (1889) 196 (= Monadenia multiflora, Lind1.). - Afr. austr.
DISA :

obliqua, Bolus, in Trans. South Afr. phil. Soc.v. T. (1888) 162; et in Fourn. Linn. Soc. $\mathrm{xxv}$ (1889) 201 - (= Schizodium obliqum, Lindl. $)$ - Afr. austr.

Oliveriana, Reichb. f. in Flora, 1xix. (1886) 54\%. Hab.?

ophrydea, Bolus, [Orch. Cape Penins.] in Trans. South. Afr. phil. Soc. v. I. (1SS8) 142 ; et in fourn. Linn. Soc. xxv. (1889) 196 (= Monadenia ophrydea, Lindl.). - Afr. austr.

oreophila, Bolus, l. c. xxv. (1889) 170 fig. 8. - Afr. austr.

Papilio, Th. Dur. et Schinz, Consp. Fl. Afr. v. 1892 (1895) 105 (= Penthea Papilio, Lind1.). - Afr. austr.

Preussii, Kraenzl. in Bot. Fahrb. xvii. (1893) 64.Kamerun.

rodantha, Schlechter, l. c.xx. Beibl. n. 50 (1895) 40 . - Transv.

sabulosa, Bolus, Icon, Orchid. Austro-Afr. i. 1. (1893) t. 27. - Afr. austr.

saxicola, Schlochter, in Bot. Fahrb. xx. Beibl. n. 50 (1895) 41. - Afr. austr.

Stairsii, Kraenzl. in Gard. Chron. (1892) ii. 72S.Afr. trop. or.

stenoglossa, Bolus, in fourn. Lim. Soc. xxv. (1889) $173 \mathrm{fig} .11$. - Natal.

tripetaloides, N. E. Br. in Gard: Chron.(1889) i. 360 (= Orchis tripetaloides, Linn. f.). - Afr. austr.

Tysoni, Bolus, in fourn. Linn. Soc. xxv. (1890) 172 fig. 10. - Afr, austr.

Vasselotii, Bolus, ex Schlechter, in Verh. Bot. Ver. Brand. xxxv. (1893) 47 nomen. - Afr. austr.

Veitchi $x$. Hort. ex Gard. and For. iv. (1891) 305 ; The Garden, xlii. (1892) 408 t. 882; Gard. Chron. (1894) ii. 93. - Hybr, artef.

Wissmannii, Kränzl, in Bot. Jahrb, xxii. (1895) ii et in Engl. Pflanzenw. Ost-Afr. C (1895) 154.= Gregoriana, Rendle.

zombaensis, Rendle, in Trans. Limn. Soc., Ser. II. iv. (1894) 47. - Afr. trop.

DISGHIDIA, R. Br. (Asclepiad.). Ind. Kew. i. ntennifera, Becc. Malesia, ii. (1886) 270 t. 63 , fig. 8-12. - Borneo.
fignifera, Becc. Mates.

borneensis, Becc.l.c. 262.t. 47 fig. 7-12. -- Borneo digitiformis, Becc. l. c. 265. - Ins. Celeb. ericaeflora, Becc.l.c. 266. t. 63fig. 18-20. - Borneo. Hellwigii, Warb. in Bot. Fahrb. xviii. (1894) 205. Oceania.

imbricata. Warb. 1. c. 206 in obs. (= Conchophyllum imbricatum, Blume) $=$ D. Collyria, $W$ all .

kutschinensis, "Becc." ex K. Schum. in Engl. \& Prantl, Natürl. Pflanzenfam. iv. 2. (1895) 288. $=$ seq.

kutcinensis, Becc. Malesia, ii. (1886). 266. Borneo.

longiflora, Becc. l. c. 263 t. 62 fig. 1-6. - Ins. Molucc.

longifolia, Becc. l. c. 271. - N. Guin.

merguiensis, Becc.l. c. 266. - Mergui.

micrantha, Beco. l. c. 270.- Borneo, Sumalra

Milnei, Henst. in Ann. of Bot. v. (1891) 506; et in Kew Bull. (1895) 137. - Ins. Solom.

papuana, Warb. in Bot. Fahrb. xviii. (1894) 205.Oceania.

pedunculata, Warb.l.c. 206. - Oceania.

retusa, Becc. Malesia, ii. (1886) 270. - Ins. Kei

ruscifolia, Decne. ex Becc. 1. c. 272. - Ins. Philipp.

soronensis, Becc.l.c. 271. - N. Guin.

squamulosa, Becc. l. c. 266. - Borneo.

DISCHISTOCALYX, Lindau, in Bot. Jahrb. $\mathrm{xx}$. $(1894)=$ Distichocalyx. T. Anders. (Acanth.) bignoniiflorus, Lindau, in Engl. \& Prantl, Natiunl. Pfanzenfam. iv. 3 b. (1895) $30 \%$ = Ruellia bignoniaeflora, S. Moore.

Bucliholzii, Lindau, in Bot. Jahrb. xx. (1894) 14. Afr. trop. occ.

confcrtiforus, Lindau, 1. с. 13. - Afr. trop. or.

laxiflorus, Lindau, 1. c, 13.-Afr. trop. or.
DISCOCACTUS, Pfeiff. (Cact.). - Ind. Kew. I.

alteolens, K. Schum. in Engl. \& Prantl, Natürl. Pflanzenfam. iii.6 a. (1894) 190 in obs, = alteolens, Lem.

placentiformis, K. Schum. 1. c. = insignis, Pfeiff.

DISCOLOBIUM, Benth. (Legumin.). - Ind. Kew. i. 778

junceum, M. Micheli, in Mím. Soc. scienc. pliys. Genéc', xxx. (1889) n. 7, 80 tab. 24. - Parag.

DISCOLUMA, Baill. Hist. des pl. xi. (1852) 290. SAPOTACEAE.

Gardneri, Baill. l. c. (= Chrysophyllum Gardneri, Mart, et Eichl.), - Bras.

DISGOPLEURA, DC.(Umbell.).-Ind Kew. i. 779. major, Britt. Stern et Pogg. Prel. Cat. (1888) $22=$ capillacea, $D C$.

DISEPALUM, Hook. f. (Anonac.). - Ind. Kew. i. \%(

longipes, King, in Fourn. As. Soc. Beng. 1xi. (1892) ii. 69. - As. trop.

DISOXYLUM, Blume (Meliac.). - Ind. Kew, i. 806.

andamanicum, King, in fourn. As. Soc. Beng. 1xiv. (1895) ii. 49. - Ins. Andam.

angustifolium, King, l. c. 39. - Pahans.

Baillonii, Pierre ex Laness. Pl. util. Col. Franc. (1856) 309. - Cochinch.

dumosum, Kirg, in fourn. As. Soc. Beng. 1xiv. (1895) II. 39. - Perak.

interruptum, King, l. c. 40. - Perak.

Loureirit, Pierre, ex Laness. Pl. util. Col. Franc. (1886) 309. - Cochinch

megalanthum, Hemsl. in foum. Linn. Soc. xxx. 1894) 211 t. 9. - Ins. Pacif.

microbotrys, King, in fourn. As. Soc. Beng. lxiv. (1895) 11. 47. - Ins. Andam. et Nicobar

papillosum, King, l.c.50.-Perak.

racemosum, King, l. c. 4\%. - Ins. Andam. et Nicobar.

rugulosum, King, l. c. 49.- Perak

turbinatum, King, l. c. 43. - Perak

venulosum, King. l. c. 42. - Perak.

DISPERIS, Sw. (Orchid.). - Ind, Kew. i. 780. circumflexa, Th. Dur. et Schinz. Consp. F1. Afr.v. $1892(1895) 118=$ secunda, Sw.

concinna, Schlechter, in Bot. Fahrb. xx. Beibl. n. 50 (1895) 43. - Afr. austr.

disaeformis, Schlchter, in Verh. Bot. Vor. Brand. xxxv. (1893) 47. - Afr. austr.

gracilis, Schlechter, in Bot. Fahrb. xx. Beibl. n. 50 (1895) 44. - Afr, austr.

guttata, Frappier, ex Cordem. Fl. Ile Rézun. (1895) 255. - Ins. Borbon.

Johnstoni, Reichb. f. ex Otiver, in H. Fohnston, The Kilim. Exped., Append. (1886) 346 nomen ; et in Trans. Linn. Soc. Ser. II. ii. (1887) 349. - Afr. trop. or.

kilimanjarica, Rendle, in fourn. Linn. Soc. xxx. (1895) 400 t. 32 fig. 8-10. - Afr. trop. or.

nemorosd, Rendle, in fourn. Bot. xxxiii. (1895) 297. - Afr. trop. or. germ.

stenoglossa, Schlechter, in Bot. Fahrb. xx. Beibl. n. 50 (1895) 19. - Afr. austr.

Thorncrofti, Schlechter, l. c. - Afr. austr.

DISPORUM, Salisb. (Liliac). - Ind. Kew. i. 780. chinense, Kuntze, Rev. Gen.(1891) 708 = pullum, Salisb.

Hookeri, Britton, in Bull. Torr. Bot. Club, xv. (1888) $188=$ Hookeri, Nichols.

lanuginosum, Britton, 1. c. = lanuginosum, Nichols. latipetalum, Collett et Hemsl. in fourn. Linn. Soc. xxviii. (1890) 139. - Burma.

maculatum, Britton, in Bull. Torr. Bot. Club, xv. (1888) 188 (= Prosartes maculata, A. Gray). - Am. bor.

majus, Britton, l. c. $188(=P$. oregana, S. Wats.) - Am. bor. occ. 


\section{DISPORUM}

Menziesii, Britton, in Bull. Torr. Bot. Club, xv. (1888) $188=$ Menziesii, Nichols.

parvifolium, Britton, l. c. (= Prosartes parvifolia, S. Wats.). - Calif

trachyandrum, Britton, 1. c. = lanuginosum, Nichols.

DISSANTHELIUM, Trin. (Gramin.). - Ind. Kew. i. 780.

Bourgaei, Fourn. Gramin. Mexic. 1881 (1886) 113. - Mexic

DISSOCHAETA, Blume(Melastom.).-Ind. Kew. i. 780 .

Beccariana, Cogn. in DC. Monog. Phan. vii. (1891) 559. - Borneo.

marumioides. $\operatorname{Cog} n$. . . c. 556. - Sumatra.

montana, $\operatorname{Cogn}$. l. c. 558. - Sumatra.

quintuplinervis, $\operatorname{Cogn}$. in Boerl. Hand1." F1. Ned. Indië, i. II. (1890) 533 ; et l. c. 550. = Hederella quintuplinervis, Stapf.

Schumannii, Cogn. in DC. Monog. Phan. vii. (1891) 563 ; et in K. Schum. et Hollv. Fl. Kais. WillLand. 88. - N. Guin.

DISSOCHONDRUS, Kuntze, Rev. Gen. (1891) 770 = Setaria, Beauv. (Gramin).

bifidus, Kuntze, 1. c. [sphalm. ?] = S. biflora, Hillebr.

DISSOTIS, Benth. (Melastom.). - Ind. Kew. i. 781 .

alpestris, Taub. in Engl. Pfanzenw. Ost-Afr. C (1895) 295. - Afr. trop. or.

angolensis, Cogn. in DC. Monog. Phan, vii. (1891) 371. - Angola.

Autraniana, $\operatorname{Cog} n$. l. c. vii. (1891) 1180 (Append.) - Congo.

Brazzaei, Cogn. l. c. 372. - Congo gall.

Candolleana, Cogn. l. c. 373. - Angola.

crenulata, Cogn l. c.376. - Ancola.

cryptantha, Baker, in Kew Bull. (1894) 345. - Afr. trop. or.

gracilis, Cogn. in DC. Monog. Phan. vii. (1S91) 366 - Angola.

Hensii, Cogn. l. c. 372. - Congo.

Johnstoniana, Baker $f$, in Trans. Limn. Soc. Ser. II. iv. (1894) 14. - Afr. trop.

lanceolata, Cogn. in DC. Monog. Phan. vii. (1891). 366. - Angola.

longicaudata, Cogn . l. c. 373. - Angola.

Sizenandi, Cognn, in Bolet. Soc. Brot. xi. (1893) 88. - Afr. centr. austr.

speciosa, Taub. in Engl. Pflanzente. Ost-Afr. C (1895) 295. - Afr. trop. or.

Thollonii, Cogn. ex Büttn. in Verh, Bot. Ver. Brand. xxxi. (1889) 96; et in DC. Monog. Phan. vii. (1891) 373. - Congo gall.

tristemmoides, Cogn. l. c: 370. - Afr, trop. occ.

Welwitschii, Cogn. l. c. 371. - Angola.

DISTASIS, DC. = Chaetopappa, DC. (Compos.). asterodes, Kuntze, Rev. Gen. (1891) $334=$ C. asteroides, $D C$.

Parryi, Kuntze, 1. c. = C. Parryi, A. Gray.

DISTEGANTHUS, Lem. (Bromel.), - Ind. Kew. i 781 .

Moensi. Hort. ex Regel, in Act. Hort. Petrop. x. (1888 ?) 693 in syn. = Cryptanthus Morrenianus, Regel.

DISTEGIA, Rafin. = Lonicera, Linn, (Caprifol.) Ledebourii, Greene, Man, Bot. San Franc. Bay (1894) $164=$ L. Ledebourii, Eschs.

DISTERIGMA, Niedenzu, ex Drude, in Engl. \& Prantl, Natürl. Pflanzenfam. iv. 1. (1889) 52; et in Bot. Jahrh. xi. (1896) $209=$ Vaccinium, Linn.

acuminatum, Niedenzu, 1. c. $209=$ V. acuminatum, H. B. et $K$.

agathosmoides, Niedenzu, 1. c. $224=$ V. agathosmoides, Willd.
DISTERIGMA :

cuspidatum, Niedenzu, in Bot. Fahrb. xi. (1896) 220 $=\mathrm{V}$. cuspidatum, Planch.

dendrophilum, Niedenzu, 1. c。 $=\mathrm{V}$. dendrophilum, Benth.

empetrifolium. Niedenzu, ex Drude, in Engl. \& Prantl, Natürl. Pflanzenfam. iv. 1. (1889) $52=$ V. empetrifolium, $H$. B. et $K$.

cpacridifolium, Niedenzu, in Bot. Fahrb. xi. (1896)

$210=\mathrm{V}$. epacridifolium, Benth

Humboldtii, Niedenzu, 1. c. $224=\mathrm{V}$. Humboldtii, Klotzsch.

penaeoides, Niedenzu, 1. c. $210=$ V. penaeoides, $H$. B. et $K$.

pernettyoides, Niedenzu, 1. c. $224=\mathrm{V}$.pernettyoides, Griseb.

staphelioides, Niedenzu, 1. c. $210=\mathrm{V}$. staphelioides, Planch.

terniflorum, Niedenzu, 1. c. $224=$ V. terniflorum, Dunal.

DISTIACANTHUS, Baker, Handb. Bromel. (1889) 18. BROMELIACEAE

Morrenianus, Baker, l.c. 14 (= Cryptanthus Morrenianus, Regel) - Peruvia.

scarlatinus, Hort. Linden, ex Baker, l. c. (= Bromelia scarlatina, Ed. Morr.). - Am. austr.

DISTIGHLIS, Rafin. (Gramin.) - Ind. Kew. i. 782 humilis, Phil. in Anal. Mus. nac. Chile (1892) S6. Chili.

marginata, Phil. l, c. - Chili

misera, Phil. l. c. - Chili.

spicata Greene, in Bull Calif Acad ii. v1l. (1857) 415 = maritima, Rafin.

spicata, Kuntze, Rev. Gen. (1891) 773 = spicata, Greens.

DISTIGHOCALYX, T. Anders. (Acanth.). Ind. Kew. i. 782 [Conf, etiam DISCHISTOCA$[Y X$, Lindau].

DISTICTIS, Mart.(Bignon.). - Ind.!Kew. 1. 782. clongata, Bureau, ex $K$. Schum. in Engl. \& Pranti, Natïrl. Pflanzenfam. iv. 3 b. (1894) $218=\mathrm{Big}-$ nonia elongata, $V a h l$.

Mansoana, Baill. Hist. des pl. x. (1888) 35. - Bras. Mansoana, Bureau. in Vid. Meddel.naturh. Forer. Kjoeb. (1892-3) 422 ; et 1. c. (1894) $218=$ praec. Rovirosana, 7. D. Smith, in Coult. Bot. Gaz. xx. (1895) 7. - Am. centr.

DISTIGOCARPUS, Sarg. in Gard. \& For. vi. (1893) 364, sphalm. = DISTEGOCARPUS; Sieb. et Zucc, = Carpinus, Linn. (Cupul.).

DISTOECHA, Phil. in Ann. Mus, Nac. Chile.(1891) 36. COMPOSITAE

taraxacoides, Phil. l. c. t. 2 fig. 2. - Chili.

DISTYLIUIM, Sieb. et Zucc. (Hamamel.), - Ind. Kew. i. 782 .

stellare, Kuntze, Rev. Gen. (1891) 233. - Java.

DITASSA, R. Br. (Asclep.). - Ind. Kew. i. 782. humilis, Morong, in Ann. N. Y.Acad. Sci. vii.'(189.3) 163. - Parag.

rotundifolia, Baili. Hist. des pl. x. (1890) 255 in obs.; et Engl. \& Prantl, Natïrl. Pflanzenfam. iv. 2 (1895) $242=$ Husnotia rotundifolia, Fourn.

tassadioides, Schlechter, in Oest. Bot. Zeitsch.xlv. (1895) 451. - Bolivia.

DITAXIS, Vahl = Argythamnia, Sw. (Euphorb.). aphoroides, Pax, in Engl. \& Prantl, Natürl. Pflanzenfam. iii. $5(1890) 45=$ A. aphoroides, Muell. Arg.

Blodgetti, Pax, 1. c. (= Aphora Blodgetti, Torr.).Florida.

catamarcensis, $\mathrm{Pax}, 1 . \mathrm{c} .=\mathrm{A}$. catamarcensis, Hieron.

Inmilis, Pax, in Engl. \& Prantl, Natürl. Pflanzenfam. iii. 5 (1890) $45=$ A. humilis, Muell. Ang. mercurialina, Coulter, in Mem. Torrey Bot. Club, v. (1894) $213=$ A. mercurialina, Muell. Arg.
DITAXIS :

monteridensis, Pax. in Engl. \& Prant1, Natürl. Pflanzenfam. iii. $5(1890) 45=$ A. montevidensis, Muell. Arg.

DITHECINA, Van Tiegh. in Bull. Soc. Bot. Fr. xlii (1895) $489=$ Loranthus, Linn. (Loranth.) Balansae, Van Tiegh. 1. c. - Tonk.

coccinea, Van Tiegh. = I. coccineus, fack.

ligustrina, Van Tiegh. 1. c. = L. ligustrinus, Wall. racemifera, Van Tiegh. 1. c. $=$ L. coccineus, fack.

terrestris, Van Tiegh. 1. c. $=\mathrm{L}$. terrestris, Hook. $f$.

DIURIS, Sm. (Orchid.).-- Ind. Kew. i. 783.

bracteata, Fitzg. Austral. Orchids, ii, iv, (1891). Austral.

cuneata, Fitzo, $l, c,-$ Austral.

platichilus, Fitzg. l.c. - Austral.

Sheaffiana, Fitzg. l. c. - Austral.

spathulata, Fitzg. l. c. - Austral.

DIZYGOSTEMON, Radlk, ex Wettst, in Engl, \& Prantl, Natiirl. Pflanzenfam, iv. 3b. (1891) $\% 4$ SCROPHULARINEAE.

floribundum, Radlk.l.c. $(=$ Beyrictia floribunda Benth.). - Bras.

DIZYGOTHEGA, N. E. Br. in Kew Bull. (1892) 197. ARALIACEEE

leptophylla, Hemsl. l. c. (1893) $156=$ Aratia leptophylla. Veitch.) - Hab.?

Nilsonii, N.E. Br. l. c. (1892) 19\%; et in Hook. Icon. pl. xxiv. (1894)t. 2323. - N. Caled.

Reginae, Hemsl. in Kew Bull. (1895) I81. - N. Caled.

DOBINEA, Buch.-Ham. (Sapind.). - Ind, Kew. i. 783

Delavayi, Baill. in Bull. Soc. Limn. Par. ii. (1890) 835. (= Podoon Delavayi, Baill. ) - China.

Delavayi, Radlk, in Sitz. math.-phys. Cl. bayer. Akad Wiss. xx. (1890) 339 in obs. (= Podoon Delavayi, Baill.) - China.

DODEGADENIA, Nees (Laurin.) - In 1 . Kew. 1. 784

Griffithii, Hook. f. Fl. Brit. Ind. v. (1886) 181.Reg. Himal.

paniculata, Hook. f. l. c.- Reg. Himal,

DODECATHEON, Linn. (Primu1.), - Ind. Kew 1. 784 .

alpinum, Greene, in Erythea, iii. (1895) $39(=D$. Feffreyi, Coult.). - Calif.

Clevelandi, Greene, Pittonia, i. (June 1888) 213.Calif.

conjugens, Greene, in Erythea, iii. (1895) 40. - Am. bor. occ.

crenatum, Greene, Pittonia, ii. (May 1890) 74. Washington.

cruciatum, Greene, 1. c. i. (June 188s) 213. - Calif. cruciferum. K. Brandeg. in Zoë, i. (1890) 18, 20 sphalm. = cruciatum, Greene.

Cusickii, Greerie, Pittonia, ii. (May 1890) \%3. - Am bor, occ

glastifolium, Greene, in Erythea, iii. (1895) \%1. Calif.

Hendersoni. A. Gray, in Coult. Bot. Gaz. xi. (1886) 233. - Washington

Media, Greene, Pittonia, i. (June 1888, 209, sphalm. = D. Meadia, Limn.

patulum, Greene, 1. c. 211. - Am. bor. occ.

pauciflorm, Greene, 1.c. Ii. (May 1890) $72=\mathrm{D}$. Meadia, Linn. var.

radicatum, Greene, in Erythea, iii. (1895) 37. Am. bor. occ.

splendidum, Hort. ex Wien. Gart. Mas. (1888) 20.5-06 fig. $44=$ D. Meadia. Lim

tetrandrum, Suksdorf, ex Greene, in Erythea, iii. (1895) 40. - Am. bor. occ.

viviparum, Greene, in Erythea, iii. (1595) $38(=D$. crenatum, Greene). - Am. bor. occ.

DODONAEA, Linn (Sapind.). - Ind. Kew。.i. 784 Hansenii, F. Muell. in Vict. Natural. viil. (Oct. 1891) 93. - Austral. 


\section{DODONAEA}

pachyneura, F. Muell. in Trans. et Proc. Roy. Scc. Vict. xxiii. (April 1887) 51. - Austral.

petiolaris, F. Muell. Pl. coll. Capric. (1886) 2. Austral. occ.

stenoptera, Hillebr. Fl. Haw. Isl. (1S\&S). \&8. Ins. Sandvic

DOELLOCHLOA, Kuntze, Rev. Gen. (1891) $773=$ Monochaete, Doell (Gramin.)

fastigiata, Kuntze, 1. c. = M. fastigiata, Doell.

DOLIA, Lind1. (Convolvul.). - - Ind. Kew. i. 785. albescens, Phil. in Anal. Univ. Chil. xci. (1895) 44. [an seq. ?] - Chili.

albescens, Wettst. in Engl. E Prantl, Natürl. Pfanzenfam. iv. 3b. (1891) 4. - Chili.

canescens, Phil, in Anal. Univ. Chil. xci. (1895) 46. - Chili.

eremobia, Phit. l. c. 45. - Chili.

foliosa, Phil. in Anal. Mus.nac. Chile, (1891) 68. Am, austr. occ.

incana, Wettst. in Engl. \& Prantl, Natiul, Pfanzenzfam. iv. 3b. (1891) 4 (= Alibrexia incana, Phil.) - Chili.

grandiflora, Phil. in Anal. Univ. Chil. xci. (1895) 44. - Chili.

hirsutula, Phil.l.c. 46. - Chili.

macrocalyx, Phil. i. e. 45. - Chili.

puberula, Phil.l.c. 43. - Chili.

tarapacana, Phil. in Anal. Mus. nac. Chile, (1892) 68. - Chili.

DOLIGHANDRONE, Fenzl (Bignon.). - Ind, Kew. i. 785. Atrooivens, K. Schum. Seent.

Hildebrandtii, Baker, in Kew Bull. (1894) 31.Atr. or.

hirsuta, Baker, l.c. - Zambes.

latifolia, Bakev, l. . - Afr. trop. or.

longissima, K Schum. in Engl. \& Prantl, Natürl. Pflanzenfam. iv. 3 b. (1894) 240. = D. Rheedii, Seeni.

obtusifolia, Baker, in Kew Bull. (1894) 31.-Afr. trop. or.

platycalyx, Baker, l.c.30. - Afr. or.

Smithii, Baker, l. . . - Zambes.

spathacea, K. Schum. F1. Kais. Wilh. Land, (1889) $123=$ D. Rheedii. Scem.

DOLICHOGYNE, DC. = Nardophyllum, Hook. (Compos.).

glabra, Phil. in Anal, Mus, nac, Chile (1891) 39. $\longrightarrow$ Chili.

DOLIGHOS, Linn. (Legumin.). - Ind. Kew. i. 185

Eminiana, Taub. in Engl, E Prantl, Natürl. Pfanzenfan, iii. 3. (1894) 383. - Afr. centr. or.

pratensis, Taub. 1. c. = D. Chloryllis, Hary.

erectus, Baker f. in Trans. Linn. Soc. Ser. II. iv (1894) 10. - Afr. trop.

kilimandscharicus, Taub. in Bot. Fahrb. xix. Beibl. n. 47. (1894) 32. - Afr. trop. or.

lupinoides, Bake, in Kew Bull. (1895) 66. - Afr. centr. or

maranguensis, Taub. ex Engl. in Abhandl. Prouss. Akad. Wiss. 1891 (1892) 271 ; et (1894) 59. Afr, trop. or

monophyllus, Taub, in Enol, \& Prantl, Natïr. Pflanzenfann. iii. 3. (1894) 383; et in Engl. Pflanzenw. Ost-Afr. C (1895) 224. - Afr. trop.or.

pratensis, Taub. 1. c. iii. 3. (1894) 383.= D. Chlo ryllis, Haro.

platypus, Baker, in Kew Bull. (1895) 289. - Afr. centr. austro-or.

pteropus, Bakcr, l. c. 66. - Afr. centr. or.

Schweinfurthii, Tanb. in Engl. \&. Prantl, Natim. Pfanzenfam.jii. 3. (1894) 383. - Afr. centr. or. simplicitolius, Hook. f.in Bot.Mag. (1893)t.7318.Afr, trop. or.

Volkensii, Taub. in Engl. Pfanzonw. Ost-Afr C (1895) 224. - Afr. trop. Or.
DOLICHOS xiphophyllus, Bakev, in Kew Bull. (1895) 66. - Afr.
centr. or.

DOLIOCARPUS, Roland, (Dilleniac.). - Ind. Kew. i. 787 .

calineoides, Gilg, in Engl. of Prantl, Natïrl. Pfanzenfam. jii. 6. (1893) 114 (= Pinzana calineoides Eichl.) - Bras.

castaneifolius, Gilg, 1. c. $115=$ grandiftorus, Eichl. coriacea, Gilg, 1. c. 114. = Pinzana coriacea, Mart. et Zucc.

Eichlerianus, Gilg, 1. c. = castaneifolius, Mart. guyanensis, Gilg, 1.c. = D. Soramia, $D C$.

oaxacanus. Szyszyl. in Diss, math, nat. Acad litt. Cracov. xxvii (1894) 139. - Mexic.

scandens, Gilg, in Engl, E Prantl, Natürl. Pflanzenfam. iii. 6a. (1\$93) $114=$ D. Calinea, F. F. Gmel.

DOMBEYA, Cav, (Stercul.). - Ind. Kew, i. 787. acerifolia, Baker. in fourn. Linn. Soc. xxii. (1887) 449. - Madag.

arabica, Baker, in Kew Bull. (1895) 315. - Arabia. australis, S. Elliot, in foum. Linn. Soc. xxix. (1891) 8. - Madag.

Baroni, Baker, l. c. xxii. (1887) 450. - Madag.

biumbellata, Baker, l. c. - Madas.

blattiolens, Frappier, ex Cordem. Fl. Ile Rém. (1895) 311. - Ins. Borbon

botryoides, Baker, in fourn. Linn. Soc. xxv. (1889) 298. - Madas.

Buettneri, K. Schum. in Bot. Fahrb.xv. (1893) 133. - Afr. trop. occ

ciliata, Cordem. Fl. Ile Réun. (1895) 312. - Ins. Borbon.

cincinnata, K. Schum. ex Engl. in Abh. Preuss. Akad. Wiss. (1894) 24, 25 et 36 ; et in Pfanzent. Ost-Afr. C (1895) 271. - Afr. trop. or

crassipes, Baill. Hist.pl. Madag, Atlas (1888) t. 73. - Madag.

elegans, Cordem. Fl. The Rúm. (1895) 310. - Ins. Borbon.

Frappierana, Cordem. l. c. 312. - Ins. Borbon. gemina, Baker, in fourn. Limn. Soc. xxv. (1859) 297. - Madag

Gilgiana, K. Schum. ex Engl, in Abh. Preuss. Akad. Wiss. (1894) 24, 25 et 36 nomen. ; et in Pflanzenw. Ost-Afr. C (1895) 270. - Afr. or.

hirsuta, $\mathbf{K}$. Schum. in Engl, \& Prantl, Natürl. Pflanzenfam. iii. 6. (1890) $78=$ Schimperiana, Rich.

insignis, Baker, in foum. Linn. Soc. xxii. (1887) 450. - Madag.

lancea, Frappier, ex Cordem. Fl. Ile Réun. (1895) 313. - Ins. Borbon.

Lastii. K. Schnm. in Engl. Pfanzenw. Ost-Afr. C (1895) $270 .-$ Afr.trop. or

leucoderma, $K$. Schum. l. c. 270. - Afr. trop. or.

lucubensis "Baill. » ex Kuntze, Rev. Gen. (1891) $76=$ loucoubensis, Baill.

megaphylla, Baker, in foum. Linn. Soc, xxii. (1887) 449. - Madag.

obovata, Cordem. Fl. Ile Rérn. (1895) 313. - Ins. Borbon.

orbicularis, Cordem. l. c. 315. - Ins. Borbon.

pedunculata, $K$. Schum. in Engl. Pfanzenw. Ost Afv. C (1895) 269. - Afr. trop. or.

pilosa, Cordem. Fl. Ile Rém. (1895) 312. - Ins. Borbon.

pulchra, N. E. PBr. in Kew Bull. (1895) 142. Transv.

reclinata, Cordem." Fl. Ile Ríun. (1895) 315. - Ins. Borbon.

Richardi, Baill. Hist. pl. Madag., Atlas (IS88) t. 75. - Madas.

Richardiara, Cordem. Fl. Ile Rém. (1895) 31S.Ins. Borbon.

scabrida, Cordem. l. c. 315. - Ins. Borbon.

Thonarsii, Baill. Hist, pl. Madag., Atlas (1888) t. 77. - Madag.

viburnoides, Cordem. Fl. Ile Rimn, (1895) $309:=$ Assonia viburnoides, DC.j. - Ins. Borbon.

xiphosepala, Baker, in foum. Linn. Soc. xxv. (1889) ¿9s. - Madag.
DONAX, Lour: = Glinogyne, Salisb. (Scitam. arillata, K. Schum. in Bot. Jahrb. xv. (1893) 438. Kamerun.

azurea, K Schum, 1. c, 434. - Afr. trop.

Blumei, K. Schum. 1. c, 435 in obs, - Hab.

canniformis, K. Schum, 1. c. 440 in obs, = Thalia canniformis, Forst.

comorejtsis, Baill. in Bull. Soc. Linn. Paris, ii. (1895) $1200=$ Marantochloa comorensis, Brongn. congensis, K. Schum, in Bot. Jahrb. xv. (1893). Congo.

cuspidata, K. Schum. 1. c. 440 in obs. = Maranta cuspidata, Rosc.

filipes, K. Schum. 1. c. 436 in obs. = Clinogyne filipes, Benth.

gracilis, K. Schum. 1. c. 440 in obs. = C. gracilis, Benth. et Hook.f.

leucantha. K. Schum. in Bot. Jahrb. xv. (1893) 436. - Kamerun.

oligantha, K. Schum. 1. c. 435. - Gabon.

purpurea, K. Schum. 1. c. 440 in obs. = Clinogyne purpurea, Rial.

Schweinfurthiana, K. Schum. 1. c. 437.--Afr. trop. virgata, K. Schum. 1. c. 440 in obs.= Maranta virgata, Wall.

ugandensis, K. Schum. in Engl. Pflanzenw. OstAfr. C (1895) 150.- Afr. trop. or.

DONELLA, Pierre, ex Baill. Hist, des pl. $x$. (1892) 294. - SAPOT ACEAE.

DONIOPHYTUM, Wedd. (Compos.).--Ind. Kew. i. 788.

anomalum, Kurtz, in Verh. Bot. Ver. Brand. xxxv. (1894) $108=$ Chuquiraga anomala, D. Don. -

DONNELLSMITHIA. Coult. et Rose, in Coult. Bot. Gaz. Xv. (1890) 15. UMBELLIFERAE. guatemalensis, Conlt. et Rose, l. c. t. 2. - Guatem.

DONTOSTEMON, Andrz. (Crucif.).-- Ind. Kew. 1. 789. elegans, Maxim. Enumn. Pl. Mongol. (1889) 57. - Mongol.

DOONA, Thev. (Dipteroc.). - Ind. Kew, i. 789 disticha, Heim, in Bull. Soc. Bot. Fr, xxxix. (1892) 153 ; et Rech. Diptéroc. (1892) $72=$ seq.

disticha, Pierre., F1. For. Cochinch. (1890) sub t. 237 in obs. = Vatica disticha, A. DC.

javanica, Burck, in Ann. Fard. Buit. vi. (1887) 235 t. 29 fig. 7. - Java.

micrantha, Burck, l.c.234. (= Petalandra micrantha, Hassk.). - Java, Sumatra.

multiflora, Burck, 1, c. $231=$ Hopea multiflora, Brandis.

nitida, Heim, in Bull. Soc. Bot. Fr. xxxix. (1892) 153; et Rech. Diptéroc. (1892) $72=$ Vateria nitida, Thw.

odorata, Burck, in Ann. Jard. Buit. vi. (1887) 233 $=$ Hopea odorata, Roxb.

DOPATRIUMI, Buch.-Ham. (Scrophul.). - Ind.

Kew. i. 789 .
nanum, S. Elliot, in foum. Linn. Soc. xxx. (1894) 94. - Afr. trop. occ.

Schweinfurthii, Wettst. in Engl. \& Prantl, Natiur. Pflanzenfam. iv. 3b. (1891) 75. - Afr. trop.

tricolor, Wettst. l. c. - Afr. trop.

DOREMA, D. Don (Umbellif.). - Ind. Kew. i. 789 .

serratum, Aitch.et Hemsl. in Trans. Linn. Soc Ser. II. iii. (1886) 70. - Afghan.

DORITIS, Lindi. (Orchid.). - Ind. Kew, i. 789. Braceana, Hook, f. Fl. Brit. Ind. vi. (1S90) 196 in obs. - Reg. Himal.

DORONICUM, Tourn, ex Linn. (Compos.). Ind. Kew. i. 789 .

atlanticum, Chab. in Bull. Soc. Bot. Fr, xxxviii. (1891) 385 in syn. = D. Pardalianches, Linn. atlanticum, Rouy, in Bull. Soc. Bot. Fr. xl. (1893) Is7 [an praec, ?] - Algeria. 


\section{DORONICUM}

Halacsyi, $\times$ Eichenfeld, in Verh. zool.-bot. Ges. Wien, xxxix. (1889) 10. - Austria.

macrolepis, Freyn et Sint. ex Freyn, in Bull. Herb. Boiss. iii. (1895) 351. - Armen.

pilosum, Simonk. Enum. fl. Transsilv. (1886) 322 $=$ cordatum, $W$ ulf

Tournefortii, Rouy, in Bull. Soc. Bot, Fr. x1. (1893) 186. - Lusit.

DORSTENIA, Plum. ex Linn. (Urtic.), - Ind. Kew. i. 790.

bicuspis, "Schweinf, ) ex Bureau, in Bull. Mus. Paris, i. (1895) 62, sphalm. = bicornis, Schweinf.

Buchanani, Engl. Bot. Fahrb. xx. (1894) 142.Afr. trop. or.

caulescens, Schweinf.ex. Engl. Bot. Fahrb. xx. (1894). Afr. centr. bor.

choconiana, S. Wats. in Proc. Am. Acad. xxii. (1887) 477. - Guatem.

crispata, S. Wats. l. c. 452.-Mexic.

debilis, Baill. Hist. pl. Madag., Atlas (1895) t. 294 c. - Madag.

Dinklagei, Engl. Bot. Fahrb. xx. (1894) 143. Afr. trop. occ.

Hildebrandtii, Engl. l. c. 146. - Afr. aequat. or

Holstii, Engl. l. c. 145. - Afr. trop. or.

Humblotiana, Baill. Hist.pl. Madag., Atlas (1895) t. 294 b. - Madag.

kameruniana, Engt. Bot. Fahrb. xx. (1894) 142. Afr. trop. occ.

Massoni, Burecu, in Bull. Soc. Bot. Fr. xxxiii. (1886) 70. - Gabon.

mungensis, Engl. Bot. Falirb. xx. (1894) 145. - Afr, trop. occ.

ophiocoma, K. Schum. ex Engl.l.c. - Afr. trop. occ

palmata, Engl. l. c. 146. - Afr. centr. bor.

Poggei, Engl. l.c. - Congo

poinsettifolia, Engl. l.c. 142.- - Afr. trop. occ.

Preussii, Engl. l. c. 143. - Sierra-Leone.

prorepens, Engl. l. c. 144. - Afr. trop. occ.

Richardi, Baill, Hist, pl. Madag., Atlas (1888) t. 75. - Madag.

scabra, Engl. Bot. Fahrb. xx. (1894) 142. - Afr. trop. occ.

scaphigera, Bureau, in Bull. Mus. Paris, i. (1895) 60. - Congo Gall.

Telekii, Schweinf. ex Engl. in Abh. Prenss, Akad. Wiss. 1891 (1892) 190 nomen; et in Hoeknel, Zum Rudolph See (1892) App. 4. - Afr. trop. or.

ulugurensis, Engl. Pflanzenz. Ost-Afr. A (1895) 92 nomen. - Afr. trop. or.

Volkensii, Engl. Bot. fahrb. xx. (1894) 143. - Afr. trop. or.

Walleri, Hemsl. in Gard. Chron. (1893) ii. 178. Afr, trop.

zanzibarica, Oliver, in Hook. Icon. pl. xvi. (1886) t. 1581. - Ins. Zanzib.

DORTMANNIA Linn. = Lobelia, Plum. (Campanul.).

acuminata, acutidens, alpina, amoena, anygdalina anceps, appendiculata, aquatica, assurgens, Bergiana, Berlandieri, Boivinii, Boykinit, brevifolia, Breynii. Bridgesii, camporum, Canbyi, capillifolia, cardinalis, chinensis, chireensis, cirsiitolia Cliffortiana, collina, colorata, columnaris, concolor, conglobata, cordigera, coronopifolia, corymbosa, Cymbalaria, decipiens, Deckenii, decurrens, dentata. depressa, divaricata, diversifolia, Dregeana, Eckloniana, Elwenbergii, ensiformis, erecta, Erinus, fastigiata, Feayana. fenestralis, fervens, fistulosa, fulgens. Gardneviana, Gau dichaudii, Ghiesbreghtii, Giberroa, gibbosa, glandulosa, gracilis, graminea, Griffithii, gruma, Haenkeana, heterophylla, hirsuta, hyssopifolia, inconspicua, infesta. inflata, Kalmii, lasiantha, laxiflora, leptostachys, linearis, longifolia, loxensis, Lucaeana, ludoviciana, macrostachys, madagascariensis, Melleri, membranacea, microsperma, minutiflora, mishmica, modesta. mollis, monticola. mucronata, nana, neglecta, nerifolia, Nuttallii, Orizabae, parviflora, patula, pauciflora, phyllostachya, pinifolia, polyphylla, puberula, pubescens, pulchella, purpurascens, purpurea, pusilla. pyramidalis, quadrangularis, racemosa, radicans, reticulata, retrorsa, rhombifolia, rhytidosperma, robusta, rosea, rotundifolia, Roughii, rupestris, Sartorii,

\section{DORTMANNIA :-}

scaevolifolia, Schimperi, senegalensis, sessilifolia, setacea, sonchifolia, spicata, stencephylla, stricta. subnuda, subpubera, succulenta, syphilitica, tenera, tenuior, tomentosa, trigona, trigonocaulis, trinitensis, triquetra, trullifolia, Tupa, urens, zagans, valdiirana, Warczewiczii, zeylanica, Kuntze, Rev. Gen. (1891) 379-80 et 972-73 = homonyma omnia Lobeliae. alsinodes, Kuntze 1; c. $972=$ L. alsinoides, Lam: arguta. Kuntze, 1. c. = Siphocampylus giganteus, G. Don.

Berteroi, Kuntze, 1. c. = I. serrata, Meyen. Besseriana, Kuntze, 1. c. = L. polyphylla, Hook blanda, Kuntze, 1. c. (= Tupa blanda, D. Don).Chili.

bracteosa, Kuntze, 1. c. = L. polyphylla, Hook. Browniana, Kuntze, 1. c. = L. gibbosa, Labill. campanulodes, Kuntze, 1. c. $=$ L. radicans, Thun b. candatz, Kuntze, 1.c. (= Tupa caudata, Griseb.).Ind. occ.

chamaedrifolia, Kuntze, 1. c. = L. chamaedryfolia, A. DC.

circaeodes, Kuntze, 1. c. $=\mathrm{L}$. circaeoides, $A . D C$.

cordata, Kuntze, 1. c. $971=$ L. Preslii, A. DC

cyphodes, Kuntze, 1. c. $972=$ L. cyphioides, Haw. digitalifolia, Kuntze, 1. c. (= Tupa digitalifolia Griseb.). - Ind.

dioeca, Kuntze, 1. c. = L, dioica, R. Br.

Doniana. Kuntze, 1. c. $971=$ L. secunda, Linn.f.

Encelmanniana, Kuntze, 1. c. 972 = L mucronata, Engelm.

ensifolia, Kuntze, 1. c. (= Tuparensifolia," A. DC.). - Ins. S. Doming.

erinodes, Kuntze, 1. c. = Laurentia erinoides, Nichols.

cxaltata, Kuntze, 1. c, = Haynaldia exaltata, Kanitz. excelsa, Kuntze, 1. c. $=$ L, salicifolia, Sweet. filiformis, Kuntze, 1. c. = L. serpens, Lam. favescens, Kuntze, 1. c. = L. conglobata, Lam. Acxrosa, Kuntze, 1.c. = L. natalensis, A. DC. Gattingerii, Kuntze, 1. c. = L. Gattingeri, A. Gray. Hartwegii, Kuntze, 1. c. = L Hartwegi, Benth

Hilaiveana, Kuntze, 1. c. = Haynaldia Hilaireana, Kanitz.

Inumifusa, Kuntze, 1. c. = L. alsinoides, Lam. imberbis, Kuntze, 1. c. (= Tupa imberbis, Griseb.). - Ind. occ.

Zavendulacea, Kuntze, 1. co = L. triquetra, Limn.

Leschenaultiana, Kuntze, 1. c. = L. excelsa, Leschen.

linariodes, Kuntze, 1. c. = L. linarioides, $A . D C$.

Martagon, Kuntze, 1. Co (= Tupa Martagon, Griseb.). - Ind. occ.

mexicana, Kuntze, $1 . \mathrm{c}_{\mathrm{c}}=\mathrm{L}$. flexuosa, $A . D C$. micrantha, Kuntze, I. c。 = I. trigona, Roxb.

montana, Kuntze, 1. c. = L. Rhynchopetalum Hemsl.

muscodes, Kuntze, 1. c. = L. muscoides, Cham.

nicotianifolia, Kuntze, 1. c. 973. = L. nicotianaefolia, Heyne.

mumnulariodes, Kuntze, 1.c. = L. nummularioides, Cham.

obovata, Kuntze, 1. c. = L. incana, Ruiz et Pav.

ocimodes, Kuntze, 1. c, = L. ocimoides, Kuntze.

organensis, Kuntze, 1. c. = Haynaldia orcanensis, Kanitz.

avata, Kuntze, 1. c. (= Tupa ovata, G. Don). Peruv.

persicifolia, Kuntze, 1. c. = L. persicaefolia, Cav Philippiana, Kuntze, 1. c. 972. (= Tupa montana Phil.). - Chili.

pratiodes, Kuntze, 1, c, 973 . = L pratioides, Benth. rapunculodes, Kuntze, 1. c. = L. rapunculoides, $H$. B. et $K$.

Reinwardtiana, Kuntze, 1. c. = L. trigona, Roxb.

Sonderiana, Kuntze, 1. c. 972. (= Mezleria Dreseana Sond.). - Afr. austr.

spartiodes, Kuntze, 1. c. $973 .=$ L. spartioides, D. Dietr.

splendens, Kuntze, 1. c. = L. fulgens, Willd.

subcuneata, Kuntze, 1. c. = L. affinis, Wall.

subdentata, Kuntze, 1. C. = L. polyphylla, Hook, et Arn.

subrepens, Kuntze, 1. c. = L. surrepens, Hook. $f$.

thapsodea, Kuntze, 1. c. = Haynaldia thapsoides, Kanitz.
DORTMANNIA : -

thermalis, Kuntze; Rev, Gen. (1891) $973=$ L. leptocarpa, Griseb.

trialata, Kuntze, 1, c, = L trigona, Roxb.

uranocoma, Kuntze, I. c. $973=$ Haynaldia uranocoma, Kanitz,

xalapensis Kuntze, 1. c. = L. Cliffortiana, Linn.

yuccodes, Kuntze, 1. c. $=$ L. yuccoides, Hillebr.

DORYALIS “ E. Mey." » = Dovyalis, E. Mèy.

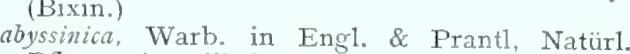

Pflanzenfam. iii. 6 a. (1893) 44.= Aberia abyssinica, Clos

caffra, Warb. 1. c. 44. = A. caffra, Harv, et Sond. hebecarpa, Warb. 1. c. = A. Gardneri, Clos. longispina, Warb. 1. c. = A. longispina, Hara. macrocalyx, Warb. 1. c。 = A. macrocalyx, Oliver. mollis, Warb. 1. c. = A. mollis, Olizer.

rhamnoides, Eng1. Pflanzenw. Ost-Afr. A (1895) 217. (- Doryalis rhamnoides Burch. $)=$ ziziphoi-

rotundifolia Engl. 1. c. $(=D$ rotundifolia, Haro $)$ $=$ celastroides, Sond

tristis, Warb. in Engl. \& Prantl, Natürl. Pflanzenfam. iii. 6 a. (1893) 44 . = A. mollis, Sond. Eermucosa, Warb. 1. c. = A. verrucosa, Hochst.

Zeyheri, Warb. 1. c. = A. Zeyheri, Sond.

DORYANTHES, Correa (Amaryll.). - Ind. Kew. i. 791

Guilfoylei, F. M. Bailey, in Australasian of Melbourne (Nov. 1892) cum ic.; et in Dep. Agric. Bot Bull. vii. (1893) 67; Rec'. Hortic. (1893) 391. Austral.

Larkini, C. Moore, Handb. Fl. N. S. Wales (1893) 413. - Austral.

DORYCNIUM,Linn.(Legumin.).-Ind:Kew.i.791 hispanicum, Pau, Not. bot. fl. Espan, i. (1887) 15 [sp. collect.]. - Hisp.

iberccum, Hort. ex Kochne, Deutsche Dendrol. (1893) 333 in obs. = Lotus tenuifolius, Reichb.

DOWNINGIA, Torr. (Campanul.). - Ind. Kew

bicornuta, A. Gray, Syn. Fl. N. An. ii. 1. Suppl. (1886) 395. - Calif.

concolor, Greene, in Bull. Calif. Acad. ii. vr. (1886) $153,-$ Calif

insignis, Greene, Pittonia, (May 1890) 80. - Calif. ornatissima, Greene, l.c. 80. - Calif.

tricolor, Greene, l.c. 79. - Calif.

DRABA. Dill. (Crucif.). 一 Ind. Kew. i. 792

affghanica, Boiss. Fl. Or. Suppl. (1888) 55. Afghan.

alpina, Wormskj. ex Lange; Consp. fl. Groenl, ii. (1887) 247 in syn, = aurea, $M . V a h$. amplexicaulis, Franch, in Bull. Soc. Bot. Fr xxxiii. (1886). 403. - China.

aurea, M. Vahl, ex Lange, Consp. Fl. Groent. ii, (1887) 247. - Groen1.

Beleziana X, G. Camus, in Morot, Journ. de Bot. v. (1891) 198. - Gallia.

Boissierii, Baldacii, in Nuov. Gion, Bot. Ital. Ser. II, i. (1894) 115. - Eur. mer., Algeriạ.

bosniaca, G. Beck, in Ann. naturh. Hofmus. Wien, ii. (1887) 75 . = lasiocarpa, Rockel.

bracteata, Batalin, in Act. Hort. Petrop. xi. (1891) 482. = Coelonema draboides, Maxim.

Breweri, S. Wats, in Proc. Am. Acad, xxiii (1888) - Am. bor.

Candollei, Rouy et Fouc. Fl. de Fr. ii.(1895) 208 et 210. = aizoides, Linn.

claviformis, Fouc. et Rouy, 1. c. $225=$ verna, Linn. corsica, Stein, in Gartenfl. $(1886) 423(=$ D. olympica, Auct. Ital.). - Cors.

Crockeri, Lemmon, in Bull. Torrey Bot. Club, xvi (1889) 221. - Calif.

dentata, Rouy et Fonc. Fl, de Fr. ii. (1895) $224=$ verna, Linn

Doerfleri, Wettst. in Luerss. Bibl. Bot. Heft xxvi. (1892) 22 t. 1 fig. 4-8. - Albania.

elegans, Maxim. Enum. pl. Mongol. (1889) 57 t 7 fig. 1-4. - China. 


\section{DRABA :}

erostra, Haláczy, in Denkschr. Akad. Wient, 1xi. (1894) 495. - Graecia.

furcipila, Rouy et Fouc. Fl. de Fr, ii. (1895) 224 = verna, Linn

glabrescens, Rouy et Fouc. 1. c. 220 et $228=$ verna, Linn.

grandiflora, Franch. in Bull. Soc. Philom. Paris, Sér. VII, xii. (1888) S3. - Japon.

grassensis, Rouy et Fouc. Fl. de Fr. ii. (1895) 209 $=$ aizuides, Linn.

hirtella, Rouy et Fouc. 1. c. $220=$ verna, Linn.

intricatissima, Phil. in Anal. Mus.nac. Chile, (1891) 5. - Am. austr. ccc.

Lacaitae, Boiss. Fl. or. Suppl. (1888) 53. - Graecia. lanciformis, Rouy et Fouc. F1. de Fr. ii. (1895) 213 $=$ tomentosa, Wahlenb.

Ledebourit, Rouy et Fouc. 1. c, 217 = incana, $\operatorname{Linh}$ leptophylla, Rouy et Fouc, 1. c. 221 et $223=$ verna Linn.

longisiliqua, Schmalh. ex Akinferw in Bull. Soc. geogr. Cauc. (1892) 10; et Fl. Cauc. centr. (1894 69 ; et in Ber. deutsch.bot. Ges. xi (1892) 286 t. 16 fig. 3-6. - Reg. Cauc.

majuscula, Roriy et Fouc. Fl. de Fr, ii (1895) $221=$ verna, Limn.

Montbretiana, Somm. et Levier, in Act. Hort. Petrop. xiii. (1893) 33. - Reg. Cauc.

moupinensis, Franch. in Nouv. Arch. Mus. Paris, Sér. II viii. (1SS6) 200 - China.

nana, Stapf, in Denkschr. Akad. Wien, (1886) 17. As. Min.

remzoralis, "Linn, » Franch, in Nouv. Arch, Mus, Paris, Sèr. II, x. (1887-8) 200 sphalm。 = nemorosa, Limn.

ossetica, Somm, et Levier, in Act. Hort. Petrop. xiii. (1893) 30. - Reg. Cauc.

Palanderiana, Kjellm. Fanerog. Vest-Eskim. Land, 45 t. 3. - Am. bor. occ

Revelieri, Rouy et Fouc. Fl. de Fr. ii. (1895) $228=$ verna, Limn.

Saffordi, Phil, in Britton, Fl. Straits Magell. ex Bull. Torrey Bot. Club, xvii. (1890) 82. - Am. austr. Schoenleini, Fr. Meigen, in Bot. Falirb. xvii. (1893) 290, nomen; et xviii (1894) 454. - Chili.

sessilis, S. Wats. in Proc. Am. Acad. xxiii. (18s8) 255. - Calif.

Sonorae, Greene, in Bull. Calif. Acad. ii. v. (1S86) 63. - Mexic.

subnitens, Rouy et Fouc, Fl. de Fr. ii. (1895) 230 = verna, $\operatorname{Limn}$.

subrotunda, Rouy et Fouc., 1. c. $228=$ verna Linz

subsecunda, Somm et Levier, in Act. Hort. Petrop. xiii. (1893) 35. - Reg. Cauc.

subsessilis, S. Wats. in Proc. Am. Acad, xxiv. (1888) 25.5. - Calif.

surculosa, Franch. in Bull. Soc. Bot. Fr. xxxiii. (1886) 401 - Chin . Ccc .

Toepferi $\times$, Stein, in Gartenfl. (1886) 424. - Hybr. spont.

rivescens, Rouy et Fouc. F1. de Fr. ii. (1895) 230 $=$ verna, Limn.

anlgavis, Rouy et Fouc., 1. c. 221 et 224. Linn.

yunnanensis, Franch, in Bull. Soc. Bot. Fr. xx xiii. (1886) 40\%. - Yunnan.

DRABOPSIS, C. Koch $=$ Sisymbrium, Tourn (Crucif.).

oronticum, Stapf, in Denkschr. Akad. Wien, (18S6) $\therefore 0,-$ Persia.

DRAGAENA, Vand. (Liliac.). - Ind. Kew. i. 795 merleyense, Hort, ex Rev. Hortic. Belg. xix. (1893) 257. - Hybr, artef.

arbenteo-striata, Hort. Bull, Catal. (1888)S; et ex Gard. Chron. (1888) ii, 273. - Ins, Maris austr.

Bakeri, S. Elliot, in foum. Limn. Soc. xxix. (1891) 60. - Madag.

Barteti X, Carr. in Rev. Hortic lviii. (1886) 178 Hybr. artef.

Bergmani $\times$, Hort. ex Rev. Hortic. Belg. x1x. (1893 ¿5\%. - Hybr, artef.

brachystachys, Hook. f. Fl. Brit. Ind.vi. (1892) 388 - Penang.

\section{DRACAENA :}

Braunii, Engl. Bot fahrb. xv。 (1893) 479 - Kamerun.

Buettneri, Engl. l. c. 478. - Gabon,

congesta, Ridl. in Trans. Linn. Soc. Ser. II. iii. (1893) 388. - Penins. Mal.

Coullingii, Hort. ex Gard. Chron. (1892) i. 731. - Form. hort.

cuprea, L. Lind. et Rodig, in Iliustr. Hortic. x1. (1893) 9 t. 56\%. - Ind. or.

Donceti, Hort. ex Gard. Chron. (1889) i. 808 ; et ex Rev. Hortic. Belg. xix. (1893) 257. - Form. hort

Duchneri, (an potius Buchneri ?) Hort. ex Rev Hortic. (1894) 251. - Ins. Fernando-Po.

Fischeri, Baker, in Bot. fahrb. xv. (1893) 477 - Afr. trop. or

Godseffiana, Hort. ex Rev. Hortic. (1890) 201 ; et ex Rev. Hortic, Belg. xix. (1893) 113; et ex Gard. Chron. (1894) ii. 212. - Afr. trop. occ.

Goldieana, Hort. ex Illustr. Hortic. xlii. (1895) 256 fig. 36. - Afr, trop. occ.

granulata, Hook. f. Fl. Brit. Ind. vi. (1892) 32\%.Perak.

laxissima, Engl. Bot。 fahrb. xv。 (1893) 478. Congo.

longifrilia, Ridr, in Trans. Limn. Soc. Ser. II. iii. (is93) 385. - Penins. Mal.

Maingayi, Hook.f. Fl. Brit. Ind. vi. (1892) 392. Penins. Mal.

marmorata, Baker, in Bot. Mag. (1889) t. 7078. Singap.

nutans, Ridl. in Trans. Linn. Soc. Ser. II. iii. (1893) 406. - Penins. Mal.

Papahu, Engl. Pflanzenw. Ost-Afr. C (1895) 143. Afr. trop. or.

petiolata, Hook. f. Fl. Brit. Ind. vi. (1892) 331. Assam.

Poggei, Engl. Bot. Fahrb. xv. (1893) 478. - Congo. Poubellei, Hort. ex Rev. Hort. (1888) 530. - Form. hort.

Preussii, Engl. Bot, Fahrb, xv, (1893) 477. Kamerun.

Sanderiana, Hort. Sand. ex Rev, Hortic. (1890) 201 ; et ex Gard. Chron. (1893) i. 443 et 445 . fig. 65 . - Atr. trop. occ

sepiaria, Danm., in Gurtenfl.(1887) 136. - Ins. Viti. serrulata, Baker, in Kew Bull. (1894) 342, - Arabia. Steudneri, Engl. Pflanzenw. Ost-Afr. C (1895) 143. - Afr. trop. or.

usambarensis, Engl. in Abh. Preuss. Akad. Wiss. (1894) 30; et Pflansenw. Ost-Afr。C (1895) 144. Afr. trop. or

DRACAENOPSIS, Planch. = Cordyline, Comm. (Liliac.).

lineata, Rodig. in Mllustr. Hortic. x1. (1893) 121 in obs. = C. indivisa, Steud.

DRACO, Heist. [1748] = Dracaena, Vand. (Liliac.). Afzelii, angustifolia, arborea, aurea, bicolor, cameruniana, cincta, cinnabari, concina, cylindrica, densiflora, elliptica, fragrans, fruticosa, slomerata, Goldieana, Hookeriana, humilis, Kirkii, Kochiana, Manni, marginata, ovata, Porteri, refexa, schizantha, spicata, stenophylla, surculosa, timorensis, wmbraculifera, Kuntze, Rev. Gen. (1891) $710=$ homonyma ommia Dracaenae.

atropurpurea, Kuntze, 1. c. = D. elliptica, Thunb.

dragonalis, Kuntze, 1. c. = D. Draco, Limn.

Finlaysonit, Kuntze, 1. c. = D. Finlaysonii, Baker.

Fontanesii, Runtze 1. c. = D. Fontanesiana Schull.

Hookeriana, Kuntze, 1. c. = D. Hookeriana, C. Koch.

Ombet, Kuntze, I. $c_{0}=$ D. Draco, Limn.

Perottetii, Kuntze, 1. c, = D. Perrottetii, Baker

phryniodes, Kuntze, 1. c. = D. phrynioides, Hook

Saposchnikowii, Kuntze, 1. c. = D. Saposchnikowi Regel.

thatiodes, Kuntze, 1. c. = D. thalioides, Hort. Makoy. Thworitesii, Kuntze, 1. c. = D. spicata, Roxb̆.

DRACOCEPHALUM, Linn.(Labiat.). - Ind. Kew, i. 796

caucasicum, Lipsky et Akinficf, in Act. Hort. Petrop. xiv. (1894) 326. - Reg. Caucas.
DRACOCEPHALUM :

Faberii, Hemsl. in fourn, Limn. Soc. xxvi. (1890) 291. - China.

Gobi, Krassn. in Script. Hort. Unio. Petrop. ii. I. (1887-88) 19. - China.

prunelliforme, Maxim, in Bull. Acad. Sci. Pétersb. xxx. (1887) 90. - Japon.

villosum, Krassn. in Script. Hort. Univ. Petrop. ii. 1. (1887-88) 20. - China.

DRACONTOCEPHALUM, St, Lager, in Cariot tud. des fl. éd. 8. ii. (1889) 671 = DRACON TOCEPHALUM, Hassk, = Dracocephalum. Linn. (Labiat.).

integrifolium, St Lager, 1, c. = Dracocephalum Ruyschiana, Linn.

lacineatum, St Lager, 1. c. = Dracoc, austriacum. Linnt.

DRACONTOMELON [Dracontomelum], Blume (Anacard.). - Ind. Kew. i. $79 \%$.

laxum, K. Schum, in K. Schum. et Holly. Fl. Kais. Wilh. Land. (1889) 65. - N. Guin.

vitiense, $K$. Schum. in Engl \& Prantl, Natïrl. Pfanzenfam. iii. 5. (1891) 151 (an D. vitiense, Engl.?) - Ins. Viti.

DRACOPHYLLUM, Labill. (Epacrid.). - Ind Kew, i. 797

Featonianum, Colenso, in Trans. N. Z. Inst. xxii. 1889 (1890) 477. - N. Zel.

imbricatum, Colenso, 1. c. xxv. 1892 (1893) 331. N. Zel.

recurvatum, Colenso, 1. c. xxi. 1888 (1889) $92=$ lati folium, A.Cunn.

rubrum, Colenso, l. c. xx. 1887 (1888) 200. - N. Zel

Sayeri, F. Muell, in Australas. Fourn. Pharm. ii

(Mar. 1887) 85; et in Bot. Centraibl. xxx. (1887) 356. - Austral.

tenuicaulis, Colenso, l. c. xxii. 1889 (1890) 476.N. Zel.

DRAKAEA, Lindl. (Orchid.). - Ind. Kew. i. 797 Huntiana, F. Mucll. in Vict. Natural.v. (April 1889) 174. - Austral.

DRAPETES, Banks (Thymel.). - Ind. Kew. i. 798 macrantha, Colenso, in Trans. N.Z. Inst. xxii. 1889 (1890) 487. - N. Zel.

DREGEA, E. Mey. (Asclep.). - Ind. Kew. i. 798 byssinica, K. Schum. in Engl. Pflanzenw. Ost-Afr C (1895) 326; et in Engl. \& Pranti, Natürl. Pflanzenfam. iv. 2 (1895) 293. = Hoya africana, Decne.

africana, Martelli, Fl. Bogos. (1886) 55. = Hoya africana, Decne.

rubicunda, $K$. Schum, in Bot. Fahrb. xvii. (1S93) 147. - Afr. trop.

sinensis, Hemsl. in fourn. Linn. Soc, xxvi. (1889) 115. - China.

DREPANOPHYLLUM, Wibel = Falcaria, Hort. (Umbellif.).

Falcaria, Simonk. Enum. fl. Transs. (1SS6) 251. = Sium Falcaria, Linn

DRIESSENIA, Korth. (Melast.). - Ind. Kew. i. 798.

ciliata, Bece. ex Cogn, in Boerl. Handl. Fl. Ned. Indië, i. II. (1890)531; ct in DC. Monog. Phan. vi. (1891) 476. - Borneo.

crystallina, Stapf, in Hook. Icon. pl. xxv. (1895) sub. t. 2414. - Borneo.

glanduligera, Stapf, l. c. xxiii. (1894) t. 2291. Borneo.

microthrix, Stapf. l. c. t. 2292, - Borneo.

scorpioides, Stapf, l.c. xxv.(1895)t. 2414. - Borneo.

Teysmannii. Cogn. ex Boerl. Handl. Fl. Ned. Indi i. 1:. (1S90) 531 ; et in DC. Monog. Phan. vii. (1891) 475. - Borneo.

DRIMIA, Jacq. (Liliac.). - Ind. Kew. i. 798 angustitepala, Engl. Bot. Fahrb. xv. (1893.) 475. [Drimya] - Atr. trop. or. 
DRIMIA

Hildebrandtii, Baker, in Bot. Falirb. xv. (1893) 474 [Drimya]. - Afr. trop. or.

macrantha, Baker, l. c. Beibl. n. 35 (I892) 7 in obs. (= Ornithogalum macranthum, Baker) - Afr. austr.

pauciflora, Baker, l. c.6. - Afr. autr.

DRIMIOPSIS, Lindl. et Paxt. (Liliac.). - Ind. Kew. i. 799.

Holstii, Engl. in Abh. Prenss. Akad. Wiss. (1894 62 ; et Pfunzenw. Ost-Afr. C (1S95) 143, - Afr. trop. or.

DRIMYS, Forst. (Dilleniac.). - Ind. Kew. i. 799 semecarpoides, F. Muell. in Vict. Natural. viii (May 1891) 15; et ex Bot. Centralbl. xIvi. (1891) 204. - Austral.

DROGUETIA, Gaudich. (Urtic.). - Ind. Kew. i. 799.

parvifiora, Eng1. Pflanzenw. Ost-Afr., Index (1895) $17=$ pauciflora, Wedd.

umbricola, Engl. 1. c. C(1895) 164. - Afr. trop. or.

DROSERA, Linn. (Droser.). - Ind. Kew. i. 799 Beleziana X, G. Camus, in Bull. Soc. Bot. Fr. (1895) 496. - Gail.

chrysolepis, Tanib. in Bot. Fahrb. xvii. (1893) 505. - Bras.

circinervia, Colenso, in Trans. N. Z. Inst. xxvi. $1893(1894) 314,-$ N. Zel.

flagellifera, Colenso, l. c. xxiii. 1890 (1891) 384. N. Zel.

Lovellae, F. M. Bailey, in Dep. Agric. Bot. Bull. vii. (1893) 61. - Austral.

minutula, Colenso, in Trans. N. Z. Inst. xxi. 1888 (1889) 81. - N. Zel.

polyneura, Colenso, l. c. xxii. 1889 (1890) 460.N. Zel.

praefolia, Tepper, in Bot. Centralbl. 1. (1892). 353. - Austral.

triflora, Colenso, in Trans. N. Z. Inst. xxii. 1889 (1820) 461. - N. Zel.

DRYADAEA, Linn. = Dryas, Linn, (Rosac.)

Drummondii, Kuntze, Rev. Gen. (1891) $215=$

Dryas Drummondii, Richards.

octopetala, Kuntze, 1. c. = Dryas octopetala, Lim.

DRYAS, Linn. (Rosac.). - Ind. Kew. i. 801.

lanata, Stein, ex Correv. in Gard. Chron. (1891) i.

$340=$ octopetala, Linn

DRYMARIA, Willd. (Caryoph.). - Ind. Kew. i. 801 .

anomala, S. Wats. in Proc. Am. Acad. xxv. (1890) 143. - Mexic

carinata, T.S. Brandeg. in Zoë, ii. (1891) 70. Calif

debilis, T. S. Brandeg. in Proc. Calif. Acad. Ser, ii. II (1889) 131. - Calif.

diffusa, N.E. Rose, in Contrib. U. S. Nat. Herb. i. (1892) 130 t. 12. - Ins. Carmen.

filiformis, Robins. et Seaton, in Proc. Am. Acad. xxviii. (1893) 11\% - Mexic.

longepedunculata, S.W Wts. l. c. xxv. (1890) 142. Mexic.

oxalidea, Pax, in Bot. Fahrb. xviii. (1893) 31. Mexic.

polystachya, T. S. Brandeg. in Zö̈, ii. (1891) 70. Calif.

procumbens, N. E. Rose, in Contrib. U. S. Nat. Herb. i. (1895) 304. - Mexic.

tenuis, S. Wats, in Proc. Am. Acad. xxv. (1890) 142. - Mexic

Veatchii, Curran, in Proc. Calif. Acad. Ser. ij, 1. (1888) $227=$ crassifolia, Benth

viscosa, S. Wats. ex C. R. Orcutt, in West Am. Sciontist, ii. (1886) 57 nomen; et in Proc. Am. Acad. xxii. (1887) 469. - Calif.

DRYMONIA, Mart. (Gesner.). - Ind. Kew. i. 801. maculata, S. Moore, in Trans. Linn. Soc. Ser. II, iv. (1S95) 410. - Bras.
DRYMOPHLOEUS, Zipp.(Palm.), - Ind, Kew.

olivaeformis, W. Wats, in Gard. and For. (1891) $330 \mathrm{fig} .57=$ appendiculatus, Miq.

DRYOBALANOPS, Gaertn. f. (Dipteroc.). Ind. Kew, i. 802.

Halli, Korth. ex Burck, in Ann. Jard. Buit, vi. (1887) 243 = Anisoptera costata, Korth

lanceolata, Burck, l. c. 244. - Borneo.

neglectus, Korth. ex Burck, 1. c. 243 in obs. = Hopea sericea, Blume.

DRYPETES, Vahl (Euphorb.). - Ind. Kew. I. 802

diversifolia, Krug et Urb. in Bot. Fahrb. xv. (1893) 353. - Ins. Baham.

Dussii, Krug et Urb. 1. c. 355. - Ins. Martinica, ilicifolia, Kng et Urb. 1. c. 352. - Ins. Puerto Rico.

keyenzis, Krug et Urb. 354 ; Sarg. Sylra N. Am. vii (1895) 25 t. 307 (=D. glanca, Chapm.). Florida.

lateriflora, Krug et Urb. 11. cc. 354 ; et 27 t. 308 - crocea, Poit.

serrata, Krug et Urb. 1. c. 35̃ $4=$ glomerata, Griseb.

DRYPIS, Mich. (Caryoph.). - Ind. Kew. i. 802 ,

facquiniana, Murb, et Wettst. in Luerss. Bibl. Bot. Heft xxvi (1892) 28; et in Oest. Bot, Zeitschr. (1891) 239 ; et (1892.) $358=$ spinosa, Linn.

Limeana, Murb, et Wettst. 11. cc. 28 et $239=$ spinosa, Linn.

DUBANUS, Rumpf = Pometia, Forst. (Sapind.) acumnatus, Kuntze, Rev. Gen. (1891) 143 = Nephelium acuminatum, Hook. $f$.

pinnatus, Kuntze, 1. c. = P. pinnata, Forst.

tomentosus, Kuntze, 1. c. = P. eximia, Bedd.

DUBAUTIA, Gaudich. (Compos.). - Ind. Kew. i. 802

Knudsenii, Hillebr. Fl. Haw. Isl. (1888) 223. - Ins. Sandvic.

raïllardioides, Hillebr. l. c. 224. - Ins. Sandvic.

DUCHARTRELLA; Kuntze, Rev。 Gen. (1891) $563=$ Holostylis, Duch. (Aristol.).

reniformis, Kuntze, 1. c. $564=\mathrm{H}$. reniformis, Duchartre.

DUCHESNEA, Focke, in Eng1. \& Prantl, Naturl. Pflanzenfam. iii. 3. (1888) $33=$ DUCHESNEA Sm. = Fragaria, Linn. (Rosac,

filipendula, Focke, 1. c. = F. filjpendula, Hemsl. indica, Focke, 1.c. = F. indica, Andr.

DUGUETIA, A. St-Hil. (Anonac.). - Ind. Kew i. 803 .

glabra, Britton, in Bull. Torrey Bot. Club, xvi. (1889) 14. - Bolivia.

leiophylla, F. D. Smith, in Coult. Bot.Gaz. xx. (1895) 281. - Hondur.

Sanctae-Crucis, S. Moore, in Trans. Linn. Soc Ser. II, iv. (1895) 299. - Bras.

DULACIA, Neck, = Couepia, Aubl. (Legumin.). Glazioviana, Taub. in Bot. Jahrb. xv. Beibl. n. 34 (1892) \%. - Bras.

DULACIA, Vell. = Liriosma, Poepp. \& Endl. (Olacin.).

acuta, adhaerens, candida, Gardneriana, grandiflora, guianensis, inopiflora, macrophylla, orita, pallida, panciflora, Pohliana, Spruceana, Kuntze, Rev. Gen. (1891) $111=$ homonyma omnia Liriosmae.

DULIGHIUM, Pers. (Cyper.). - Ind. Kew. i. mundinaceum, Heller, in Bull. Torrey Bot. Club. xxi. (1894) $29=$ spathaceum, Pers.

DUNALIA, Spreng. = Lucya, DC. (Rubiac.).

tetrandra, Kuntze, Rev. Gen. (1891) $281=$ L. tuberosa, $D C$
DUNBARIA, Wight et Arn, (Legumin.), - Ind Kew i 804 .

singuliflora, $F$. Muell. in fourn. Roy. Soc. N. S . Wales, xxiv, 1890 (1891) 74. - Austral.

DUPATYA, Vell. = Paepalanthus, Mart. (Eriocaul.).

aciphylla, affinis, alpina, amoena, andicola, angustifolia. anomala, anthemidiflora, appressa, arenaria, argentea, Argyrolinon, Armeria, atrovirens, bahiensis, bifida, bisulcata, Blanchetiana, blepharophora. Bongardii, Brachypus, brasiliensis, caespititia, caespitusa, calia, canescens, capillacea. capillaris, Capito, caulescens, ciliata, circinnata, Clausseniana, compacta, conduplicata, confusa, consanguinea, corymbosa, crassicaulis, crassifolia curvifolia decussa demsa. densiflora, denudata, dichotoma, distichophylla, diva ricata, dubia, cburnea, elata, elegans, ensifolia. Erigeron, eriophylla, exigua, falcifolia, fastigiata, fertilis, flaccida, flagellaris, favescers, flaviceps, flavidula, fuitans, foliosa, fuscoater, Gardneriana, géniculata, glareosa, glaucescens, goyazensis, gracilis, graminea, granatensis, guyanensis, heterophylla, Hilairei, hirsuta, homomalla, Humboldtii, imbricata, incana, intermedia, inumdata, ithyphilla, Kegeliana, Klotzschiana, Lamarckii, lanato-alba, lanceolata, Langsdorffi, lanuginosa, laricifolia, latifolia, laxifolia, leucoblephara, Liebmanniana, lingulata, longifolia, Lundie, luxurians, macrocephala. Martiana, melaleuca, mevidensis, microphylla, minarum, minu tula, mucronata, muscosa, myocephala, neglecta, nitens, nitida, nivea, nubigena, oblonga, obtusifolia, ochrocephala, Oerstedtiana, oligocephala, ovata, oxyphylla, pachyphilla, pauciflora, perpusilla, petraea, pilifera, pilosa, pillulifera, Plantago, plumosa, polyantha, polygona, prolifera, propinqua, prostrata, puberula, pubescens, pulchra, pulla, pusilla, ramosa, reclinata, regalis, Regeliana, rigida, vigidula, rufula, Ruprechtiana, saxatilis, saxicola, Schlechtendali, Schlimii, Schomburgkii, Schuechiana, scirpea, Sellowiana, sessiliflora, simplex, spadicea, spathulata. speciosa, spiralis, stricta, subtilis, succisa, supina, speciosa, spiralis, stricta, subtilis, succisa, supina, truxillensis, tuberosa, umbellata, uncinata, raginata, verticillata, willosula, viridis, vivipara, Wahlbergii Weddelliana, Widgreniana, Kuntze, Rev. Gen. (1891) 745-46 = homonyma omnia Paepalanthi.

bisumbellata, Kuntze, 1. c. $745=$ P. Steudelianus, Koern.

bryodes, Kuntze, 1. c. = P. bryoides, Kunth centaurodes, Kuntze, 1. c. = P. centauroides, Koerm. chrysantha, Kuntze, 1. c. = P. morulus, Kunth. dendrodes, Kuntze, 1. c. = P. dendroides, Kunth. dianthodes, Kuntze, 1. c. $=\mathrm{P}$. dianthoides, Mart. elongata, Kuntze, 1. c. = P. helichrysoides, Kunth fasciculata, Kuntze, 1. c. $=$ P. congestus, Kunth.

Fischeriana, Kuntze, 1. c. = P. nardifolius, Kunth. Freyreissii, Kuntze, 1. c. $=$ P. paludosus, Kunth.

Funkeana, Kuntze, 1. c. $=$ P. Funckeanus, Koern. holminthorhira, Kuntze, $1_{1} \mathrm{c}_{\mathrm{v}}=\mathrm{P}$, helminthorhizus, Mart.

macrorhiza, Kuntze, 1. c. $746=$ P. macrorrhizus, Kunth.

pedunculata, Kuntze, 1. c. = P. falcatus, Nees.

philodicodes, Kuntze, 1. c. $=$ P. philodicoides, Koern.

planifolia, Kuntze, 1. c. = P. monticola, Mart.

plantaginea. Kuntze, 1. co = P. zosterifolius. Kunth. plantaginodes, Kuntze, 1. c。= P. plantaginoides, Koern.

polytrichodes, Kuntze, 1. c. = P. polytrichoides, Kunth.

Riedeliand, Kuntze, 1. c. $=\mathrm{P}$. Vauthierianus, Kunth.

scdodes, Kuntze, 1. c. = P. sedoides, Koorn.

selaginodes, Kuntze, 1. c. $=$ P. selaginoides, Koom, Spixiana, Kuntze, 1. c. = Eriocaulon quinquangulare, Linn.

vellozicdes, Kuntze, 1. c. = P. vellozioides, Koern. vernoniodes, Kuntze, 1. c. $=$ P. vernonioides, Kunth xeranthemodes, Kuntze, 1. c. $=$ P. xeranthemoides, Koern.

DUPINIA, Scop, = Ternstroemia, Linn. $f$ (Ternstroem.) 
DUPINIA : -

japonica, Franch. in Bull. Soc. Bot. Fr. xxxiii, (1886) $439=$ T. japonica, Thunb.

DURANDEA, Planch.(Lincae).--Ind. Kew. i. 804 pallida, K. Schum, in K. Schum, et Hollv. Fl. Kais. Wilh. Land (1889) 56. - N. Guin.

DURANDEELDEA, Kuntze, Rev. Gen. (1891) 603. $=$ Acidoton, Sw. (Euphorb.).

urens, Kuntze, 1. c. = A. urens, Sw.

DURANTA, Linn. (Verben.). - Ind. Kew.i. 804 Benthami, Briq. in Engl. \& Prantl, Natïr. Pflanzenfam.iv. 3a. (1895) 160. - Bolivia.

DURIO, Adans. (Malv.). - Ind. Kew. i. 804. affinis, Becc. Malesia, iii. (1889) 246. - Borneo. conicus, Becc.l. c. 241. - Borneo.

dulcis, Becc.l. c. 243 t. 14. - Borneo.

gratissimus, Becc. l. c. 244 t. 22. - Borneo.

graveolens, Bccc.l. c. 242. - Borneo.

kutejensis, Becc.l.c.251 (=Lahia kutejensis, Hassk.). - Borneo.

sumatranus, Becc. 7. c, 249 t, 23. - Sumatra.

testudinarius, Becc. l. c. 244 t. 13,14 et 36 f. 17 19. - Borneo.

DURoIA, Linn. f. (Rubiac.) - Ind. Kew, i. 804 firsuta, K. Schum, in Mart, Fl. Bras, vi. VI. (1889) 367 = Amajoua hirsuta, Pocpp. \& Endl.

DUSSIA, Krug et Urb. ex Taub. in Engl \& Prantl, Natürl. Pflanzenfam. iii. 3. (1892) 193 LEGUMINOSAE.

martinicensis, Krug et Urb., 1. c. - Ins. Martin.

DUTHIEA. Hack. ex. Procop.-Procop, in Verh. Zool.-Bot. Ges, Wien, xlv (1895) 200. GRAMINEAE.

bromoides, Hack. l. c. - Ind. angl

DUVALIA, Haw. (Asclep.) - Ind. Kew, i. 804 dentata, N. E. Br. in Kew Bull. (1895) 365. Afr. austr.

transvaalensis, Schlechtor, in Bot. Fahrb. xx. Beibl. n. 51 (1895) 54. - Afr. austr.

DUVALIELLA, Heim, in Bull. Soc. Linn. Paris, ii. (1892) 1011, et Rech. Diptéroc. (1892) 72. DIPTEROCARPEAE.

problematica, Heim, $l l$. cc.-Penang.

DUVAUA, Kunth = Schinus, Linn. (Anacard.) spinosa, Britton, in Ann. N. Y. Acad. Sci. vii. (1892) $76=$ S. spinosus, Engl

DUVERNOYA, E. Mey. = Adhatoda, Nees (Acanth.)

Andromeda, Lindau, in Bot. Jahrb. xx. (1894) 42 - Afr. trop. occ.

Buchiolzi, Lindau, 1. c, - Afr. trop. occ.

Descampsii, Dewevre, in Bull. Soc. Bot. Belg. xxxiii.? 1894 (1895) 104, (nomen) - Afr. austro-or extensa, Lindau, in Engl. Pflanzenw, Ost-Afr. (1895) $372=$ Justicia extensa, T. Anders.

intermpta, Lindau, in Bot. Jahrb. xxii. (1895) 123. - Afr. trop. or.

orbicularis, Lindau, 1. c. - Kamer.

paniculata, Lindau, 1. c. xx. (1894) $43=$ A. paniculata, Bcnth.

punila, Lindau, 1. c. 44. - Afr, trop.

pyramidata, Lindau, 1. c. xxii, (1895) 124. - Kamer.

salviiflora, Lindau, 1. c. xx (1894) 42. - Afr trop. or.

Stachytarpheta. Lindau, in Engl. \& Prantl, Natürl. Pflanzenfam.iv. 3 b. (1895) 339 [an seq. ?]. Afr. trop.

stachytarphetoides, Lindau, in Engl. Pflanzenw. Ost-Afr. C (1895) 37\%. - Afr. trop. or.

Stuhlmannii, Lindau, in Bot. Jahrb. xx. (1894) 43 et 1. c. A (1895) 95; et C (1895) $372=$ Justicia extensa, T. Anders.

tcnuis, Lindau, in Bot. Jahrb. xx. (1894) 44. Afr. trop. occ.

trichocalyx, Lindau, 1. c. xxii. (1895) 122. - Natal.
DYGKIA. Schult, f. (Bromel.) - Ind. Kew i. 805 acaulis, Baker. Handb. Bromel. (1889) 137 (= Navia acaulis, Mart.).-. Am. austr.

affinis, Baker, l.c. 133. - Parag.

argentea, Mez, in Mart. Fl. Bras. iii, III. (1894) 492. - Bras.

Augustae, Baker, Handb. Bromel. (1889) 135 (= Encholivion Augustae, Schomb.). - Guian. brit. biflora, Mez, in Mart. Fl. Bras. iii, III. (1894) 486. - Bras.

bracteata, Mez, l. c. 476. - Bras.

Burchellii, Baker, Handb. Bromel. (1889) 131. Montevideo.

caulescens, Baker, l. c. 137 (= Navia caulescens. Mart.). - Am. austr.

cinerea. Mez, in Mart.Fl. Bras. iii, III. (1894) 469. - Bras.

coccinea, Mez, l. c. 491. - Bras,

consimilis, Mez, 7.479 - Bras.

decomposita, Baker, Handb. Bronel. (1889) 136. Reg. Argent.

Desmetiana, Baker, in Bot. Mag. (1894) t. 7340, Bras.?

gcmellaria, Hort. ex Baker, Handb. Bromel. (1889) $131=$ sulphurea, $K . K$ och

Gilliesii, Baker, l. c. 136. - Reg. Argent.

Glaziovii, Baker, l, c. 133. - Bras.

grandifolia, Baker. l. c. 136. - Bras.

Grisebachii, Baker, l. c. 130.- Reg, Argent.

agoensis, Mez, in Mart. Fl. Bras. iii, III. (1894) 483. - Bras.

linearifolia, Baker, Handb. Bromel. (1889) 131. Bras.

longipetala, Baker, 1. c. 135. - Am. austr, trop. macracantha, Baker. l. c. 137. - Bras.

maritima, Baker, l. c. 136. - Bras, austr.

micracantha, Baker, l. c. 135. - Bras, austr.

microcalyx, Baker, l. c. 133. - Parag.

minarum, Mer, in Mart.Fl. Bras. iii, III. (1894) 483. - Bras.

missionum, Mez, l. c. 47\%. - Reg. Argent.

Morreniana, Mez, l, c. 496. - Hab. ?

myriostachya, Baker, Handb. Bromel. (1889) 137.Bras.

Niederleinii, Mez, in Mart. Fl. Bras. iii, III. (1894) 474. - Reg. Argent.

orobanchoides, Mez, l. c. 475. - Bras.

racemosa, Baker, Handb. Bromel. (1889) 132. Bras.

ramosa, Hort., ex Balker, 1, c. $134=$ altissima, Lindl.

regalis, Linden et Ed. Morr. ex Baker, 1.c. $134=$ frigida, Hook. $f$.

rubra. Wittm, in Bot. Fahrb. xiii. Beibl, n. 29 (1891)

16. - Bras.

Schwackeana, Mez, in Mart Fl. Bras, iii, III. (1894) 478. - Bras.

Selloa, Baker, Handb. Bromel. (1889) 136 (= Prionophyllum Selloum, K. Koch). - Bras.

sordida, Baker, 7 c 134 . - Bras.

spectabilis. Baker, l. c. 138 (= Encholirion spectabile, Mart.). - Bras.

subinermis, Mez, in Mart. Fl. Bras, iii, III. (1894) 48\%. - Bras.

subsecunda. Baker, Handb. Bromel. (1889) 135 Bras.

tenuis, Mez, in Mart. Fl. Bras. iii, III. (1894) 485. Bras.

trichostachya, Baker, Handb. Bromel. (1889) 133. Bras.

Tweediei, Mez, in Mart. Fl. Bras, i3i, III. (1894) 485. - Urue

vaginosa, Mez. l. c. 490. - Bras.

velascana, Mez, l. c. 476. - Reg. Argent

Warmingii, Mez, l. c. 481. - Bras

Weddelliana, Baker, Handb. Bromel. (1889) 132. Bras.

DYERA, Hook. f. (Apocyn.).-- Ind. Kew. i. 805. porneensis, Baill, in Bull. Soc. Linm. Paris, i. (1888) 751. - Borneo

DYERELLA, Heim, Rech. Diptéroc. (1892) $123=$ Vateria, Linn. (Dipteroc.)

scabriuscula, Heim, 1. c.; et in Bull. Soc, Bot. Fr. xxxix.(1892) $153=$ V. scabriuscula, Thw
DYEROPHYTUM, Kuntze, Rev. Gen. (1891) 394 Vogelia. Lam (Plumbag.),

africanum, Kuntze, 1. c. = V. africana, Lam.

indicum, Kuntze, l. $\mathrm{c}_{0}=\overline{\mathrm{V}}$. indica, Gits.

pendulum, Kuntze, 1.c. $=\mathrm{V}$. pendula, Balf. $f$.

DYPSIDIUM, Baill, in Bull. Soc, Linn. Paris, ii (1893) 1172 ; et Hist. des pl. xiii. (1895) 371. $P A L M A E$.

Catatianum, Baill. in Bull. Soc. Linn. Paris, ii (I893) 1173. - Madag.

emirnense, Baill. l. c. - Madag.

Vilersianum, Baill. l. c. Madag.

DYPSIS, Noronha (Palm.). - Ind. Kew. i. 80.

Boiviniana. Baill. in Bull. Soc. Linn. Paris, ii.(1893) 1164. - Madag.

concinna, Baker. in Fourn. Linn. Soc. xxii. (J88\%) 526. - Madag.

Curtisii, Baker, i. c. - Madag.

heterophylla, Baker, l. c. 552. - Madag.

Lantzeana, Baill. in Bull. Soc. Lim. Paris, ii. (1893) 1163. - Madag.

polystachya, Baker, in foum. Linn. Soc. xxii (1S87) 525. - Madag.

rhodotricha, Baker, l. c. - Madag.

Thouarsiana, Baill. in Bull. Soc. Linn. Paris, ii. (1893) 1163. - Madas.

Vilersiana, Baill. l. c. 1165. - Madag.

DYSCHORISTE, Nees $=$ Calophanes, D. Don (Acanth.).

adscendens, ancena, augustifolia, bilabiata, capitata, ciliata, costata, crinita, decumbens, gracitis, Heudelotiana, hirsutissima, humistrata, hyssopifolia, lavandulacea, linearis, madagascariensis, Maranhonis, microphylla, multicaulis, natalensis, oblongifolia, Persoonii, Pulegium, quadrangularis, quitensis, radicans, repens, Schiedeana, Serpyllum, setosa, siphonantha, Tweediana et vagans, Kuntze, Rev. Gen. (1891) 485-86 = homonyma omnia generis Calophaneos.

Burchellii, Kuntze, 1. c. $485=$ C. Burkei, T. Anders, erectà, Kuntze, 1. c. $=$ C. Nagehana, Nees

crythrorhiza, Lindau, in Engl. \& Prantl, Natürl. Pflanzenfam. IV. 3 b (1895) $302=$ Homotropium erythrorhizum, Necs.

Fischeri, Lindau, in Bot. Jahrb. xx. (1894) 11. Afr. trop. or.

glandulosa, Kuntze, Rev, Gen. (1891) $486=$ C. Per soonii, T. Anders.

Hildebrandti, Lindau, ex Engl. in Abh. Preuss. Akad. Wiss. (1894) 26,39 et $41=\mathrm{C}$. Hildebrand tii, S. Moore.

Thmilis, Lindau, in Bot. Jahrb, xix. Beibl. n. 48 (1894) 15. - Reg. Argent.

hygrophyllodes, Kuntze, Rev. Gen. (1891) $486=$ C. hygrophylloides, Nees.

fasminum, I. c. $=$ C. Jasminum-mexicanum, Nees.

kilimandscharica, Lindau, in Eng1. Pflanzenw. OstAfr. C (1895) 36\%. - Afr. trop. or

madurensis, Kuntze, Rev. Gen. (1891) $486=$ C. littoralis, T. Anders.

mauritiana, Kuntze, 1. c. = Hypoestes serpens, R. Br.

Niederleinii. Lindau, in Bot. Jahrb. xix. Beibl. n. 48 (1894) 15. - Reg. Argent.

ovata, Kuntze, Rev. Gen. (1891) $486=$ C. linearis, A. Gray.

Perrottettii, Kuntze, 1. . c. = C. Perrotteti: Nees.

rufopila, Boiv, ex Baill. Hist. des pl. x. (1890) 443 in syn. = Synchoriste rufopila, Baill.

tenera, Lindau, in Bot. Jahrb. xxii. (1895) 116. Angola.

thunbergifflora, Lindau, in Encr. Pflanzenw. OstAfr. C (1895) $36 \%=C$. thunbergiaeflora, $S$. Moore.

trichocalyx, Lindau, 1. c. = C. trichocalyx, Oliver.

DYsodia, Cav. (Compos,). - Ind, Kew, i. 805.

glandulosa, O. Hoffm. in Engl. (i. Prantl, Natürl. Pflanzenfam. iv. 5. (I890) 266 [an Cav. vel Less.? (= Willdenowa glandulosa, Cav.), - Ecuad. 
DYSODIA :

papposa, Kuntze, Rev. Gen. (1891) $334=$ chrysanthemoides, Lag.

papposa, Hitchcork, in Trans. Acad. Sc, St-Louis, v. (1892) $503=$ praec.

DYSOPHYLLA, Blume (Labiat.). - Ind. Kew。i. S06.

communis, Collett et Hemsl. in Journ. Linn. Soc. xxviii. (1890) 114 = auriculata, Bhume.

Andersoni, Prain, in Fourn. As. Soc. Beng. lix. (1891) II. 298. - Sikkim,

peguana, Prain, l. c. 299. - Sikkim.

porophyllodes, Kuntze, Rev. Gen. (1891) 530, sphalm. $=$ Dysodia porophylloides, A. Grag.

DYSOXYLUM, Blume (Meliac.) - Ind. Kew, i,

Arnoldianum, K. Schum. in K. Schum. et Hollr. Fl. Kais. Wilh. Land (1889) $61-\mathrm{N}$. Guin.

Forsythianum, Warb in Bot. Fahrb. xiii (1891) 343 [Dysoxylon]. - N. Guin.

novo-guineeuse, Warb.l. c. 344. $-\mathrm{N}$. Guin.

Pettigrewianum, F. M. Bailey, in Dep. Agric. Bot. Bull.v (1892) 9. [Dysoxylon]. - Austral

vestitum, Warb. in Bot. fahrb. xiii. (1891) $343-\mathrm{N}$. Guin

DYSPHANIA R. Br. (Illecebr.) - Ind. Kew. i. 806.

simulans, F. Muell, et Tate, ex Tate, in Trans. et Proc.

Roy. Soc, S. Austral. viii (1886) 71. - Austral.

\section{E}

EARINA, Lind1, (Orchid.). - Ind. Kew, i. 807. alba, Colenso, in Trans. N. Z. Inst, xviii. 1885 (I886) 26\%. - N Zel.

samoensiana, F. Muell. et Kraenzl. in Oest. Bot. Zeitschr. xliv. (1894) 211, - Ins. Samoens.

EASTW OODIA, T. S. Brandeg. in Zoë, iv, (1894) 397 t. 30. COMPOSITAE.

elegans, T. S. Brandeg. l. c. - Calif

EATONIA, Rafin. (Gramin.). - Ind. Kew. i. 807. densiflora, Fow'sn, Gramin. Mexic. 1881 (1886) 111. - Mexic.

Dudleyi, Vasey, in Coult. Bot. Gaz, xi. (1886) $116=$ nitida, Nash.

nitida, Nash, in Bull. Torrey Bot. Club, xxii. (189?) $511=$ purpurascens, Rafin.

EBELINGIA, Reichb. = Harrisonia, R. Br. abyssinica, Kuntze, Rev. Gen. (1891) $103=\mathrm{H}$. abyssinica, Oliver.

paucijuga, Kuntze, $1, c_{.}=\mathrm{H}$. paucijuga, Benn.

EBENIDIUM, Jaub. et Spach = Ebenus, Linn. (Legumin.).

Bourgeani, creticum, depressum, longipes, macrophylhum, pinnatum, phumosum, Sibthorpii, Kuntze, Rev. Gen. (1891) 180 = nomonyma omnia Ebeni.

Monbrettii, Kuntze, 1. c. = Ebenus Montbretii, faub. E Spach.

pogonotropis, Kuntze, 1. c. = Ebenus barbigera, Boiss.

tragacanthodes, Kuntze, 1. c. = Ebenus stellata, Boiss.

EBENUS. Linn. (Leguminos.). - Ind. Kew. i. 807.

Armitagei, Schweinf. et Taub. ex Schweinf. et Aschers. in Bull. Herb̆. Boiss. i. (1893).645. - Afr. bor. candidus, G. Beck, ex Stapf, in Denkschr. Akad. Wien (1886) 38. - As. Min.

EBENUS, Rumpf. ex Burm. Thes. Zeyl. (1737) 91, ex Kuntze, Rev. Gen. (1891) $408=$ Maba Forst. (Ebenac.)
EBENUS :-

abyssinica, acapulcensis, acuminata, albens, andama nica, Andersoni, Beccarii, brexifolia, caribaea, cauliflora, compacta, confertiflora, cordata, diffusa, elliptica fasciculosa foliosa, geminata, Grisebachii Hilairei, Hillebrandi, humilis, inconstans, intricata, javanica, lamponga, lancea, lanceolata, laurina, Maingayi, major, Manni, Mellinoni, mersuensis, micrantha. Motleyi, myrmecocalyx, myrmecocarpa, natalensis. nigrescens, oblongifolia, oborata, ovalifolia, Pavonii. punctata, quiloënsis, reticulata, rufa, ruminata, salicifolia, sandwicensis, sericea, seychellarum, sumatrana, Kuntze, 1. c. $408=$ homonyma omnia Mabae.

hemicyclodes, Kuntze, I. c. = M. hemicycloides, F. Muell.

hermaphrodica, Kuntze, 1. c. = M. hermaphroditica, Zoll.

Mualata, Kuntze, 1, c. = M. Mualala, Welr.

Teysmannii, Kuntze, 1. c. = M. Teysmanni Frassk.

Vieillardii, Kuntze. 1. c. = M. Vieillardi, Hiern。

ECBOLIUM, Kurz. (Acanthac.). - Ind. Kew. i 808.

amplexicaule, S. Moore, in fourn. Bot. xxxii. (1894) 136. - Afr, trop. or

barlerioides, Lindau, in Bot. Jahrb xx. (1894) 42 in obs, = Isoglossa barlerioides, S. Moore.

ECBOLIUM, Riv, ex Linn, = Justicia, Linn, (Acanth.).

abyssinicum, Kuntze, Rev, Gen. (1891) $980=$ J glabra, Koen.

acuminatissimum, Kuntze. 1. c. (= Rhytiglossa acumimatissima, Miq.). - Guian.

acuminatum, Kuntze, 1, c. = Adhatoda acuminata, Nees.

adenostachyum, Kuntze, I. c. (= Tyloglossa adenosta chya, Nees). - Bras.

Adhatoda, Kuntze, 1. c, $487=$ Adhatoda Vasica Nees.

adscendens, Kuntze, 1. c. $979=$ A. Lindeniana, Nees.

aequilabre, Kuntze, 1. c. 980 (= Amphiscopia aequi labris, Nees). - Bras.

alterum, Kuntze, 1. c. 979 (= Diantherae sp.). Borneo.

amaranthodes, Kuntze, 1, c. $978=$ J. ceylanica, T. Anders.

amazonicum, Kuntze, 1. c. 980 (= Rhytiglossa ama zonica, Nees). - Bras.

americantm, Kuntze, 1. c. = Dianthera americana Linn.

Amherstiae, Kuntze, 1, c. $=$ D. nodosa, Benth, 6 Hook. $f$.

Anagallis, Kuntze, 1. C. = D. Anagallis, Hemsl.

anagallodes, Kuntze, 1. c. = Adhatoda anagalloides, Nees.

Andersonii, Kuntze, 1. c. $978=$ Dianthera virgata Benth.

andrographiodes, Kuntze, 1. c. $980=\mathrm{J}$. andrographioides, C. B. Clarke.

androsaemifolium, Kuntze, 1. c, = Dianthera androsaemifolia Griseb.

angustatum, Kuntze, 1. с. = J. angustata, Warb.

angustifolium, Kuntze, 1. c. $=$ Dianthera angustifolia, Benth. \& Hook. f.

Ansellianum, Kuntze, 1. c. = D. Anselliana, Benth. \& Hook. $f$.

arabicum, Kuntze, 1. c, $979=$ Adhatoda leptostachya, Nees.

arenicolum, Kuntze, 1. c. $980=$ J. arenicola. Engl. argyrostachyum, Kuntze, 1. c. = J. argyrostachya T. Anders.

Arnottianum, Kuntze, 1.c. (= Rhytiglossa Arnottiana Nees). - Bras.

asclepiaderm, Kuntze, 1. с. (= Simonisia asclepiadea, Nees) - Bras.

asperum, Kuntze, 1. c. = Adhatoda aspera, Nees.

assamicum, Kuntze, 1. c. = J. assamica, C. B. Clarke. Atherstonii, Kuntze, I. $_{0}=\mathrm{J}$. Atherstonei, T. Anders. Atkinsonii, Kuntze, 1. c. = J. Atkinsoni, T. Anders. auriculata, Kuntze, 1, $c_{0}=$ Adhatoda auriculata, Nees.

axillare, Kunize, 1. c. (= Rhytiglossa axillaris, Nees). - Bras.

\section{ECBOLIUM}

bahiense, Kuntze, Rev. Gen.(1891) $980=$ Adhatoda bahiensis, Nees.

Balfourii, Kuntze, 1. c. $979=$ J. rigida, Balf. $f$.

Barteri, Kuntze, 1. c. = J. Barteri, T. Anders.

barbatum, Kuntze, 1. c. 980 (= J. barbata, Bertol.). - Guatem.

Beddomei, Kuntze, 1. c. = Adhatoda. Beddomei, C. B. Clarke

Betonica, Kuntze, 1. c. $487=$ J. Betonica, Linn.

Beyrichii, Kuntze, 1. c. $980=$ J. nummularia, Mart blepharosteginm, Kuntze, 1. c. = J. debilis, Lam. botrhaaviaefolium. Kuntze, 1. c. = Adhatoda boerhaaviaefolia, Nees.

Bojeri, Kuntze, 1. c. (= Anisostachya Bojeri, Nees). - Madag.

Bojerianum, Kuntze, 1. c $=$ Adhatoda Bojeriana, Nees.

Bmneyanum, Kuntze, 1.c. = J. Bonneyana, F. Mwell.

borneense, Kuntze, 1. c. 979 (=Diantherae sp.). Borneo.

brachystachynm. Kuntze, 1. c. $980=$ J. brachystachya, Thorr.

Brandisii, Kuntze, 1, $\mathrm{c}=\mathrm{J}$. Brandisii, T. Anders breviforum, Kuntze, 1. c. = Dianthera breviflora, Hemsl.

burmanicum, Kuntze, 1. c. = J. burmanica, C.B Clarke.

caloneurzm, Kuntze, 1. c. = J. caloneura, Kurz.

calycinum, Kuntze, 1. c. $=$ Dianthera calycina, Benth. \& Hook. f.

campestre, Kuntze, 1. c. = D. campestris, Benth. \& Hook. $f$.

campylostemon, Kuntze, 1, c. = J, campylostemon, T. Anders.

Candelariae, Kuntze, 1, c, = Dianthera Candelariae, Hensl.

candicans, Kuntze, 1. c. = D. candicans, Benth. \& Hook. f.

caracasanum, Kuntze,1. c. = Beloperone caracasana. Fenzl.

carthaginense, Kuntze, 1. c. = Beloperone violacea, Planch. \& Lind.

cavernarum, Kuntze, 1.c. = J. cavernarum, F.Muell. cayennense, Kuntze, 1. c. = Dianthera cayennensis, Griseb.

chamaed'yodes, Kuntze, 1.c. (= Rhytiglossa chamaedryoides, Nees). - Bras.

chamaeranthemodes, Kuntze, 1. c. 487.-Costarica. Championii, Kuntze, 1. c. = J. Championi, $T$. Anders.

chapadanum, Kuntze, 1. c. $979=$ Aphelandra pectinata, Willd.

chloropterm, Kuntze, 1. c. $980=$ J. chloroptera, Baker.

chrysotrichomum, Kuntze, 1. c. (= Tyloglossa chrysotrichoma, Nees). - Bras.

ciliatum, Kuntze, 1. c. (= T. ciliata, Nees).-Bras. Clarkeanum, Kuntze, 1. c. $979=$ Dianthera debilis, C. B. Clarke.

collinum, Kuntze, 1. c. $980=$ D. collina, C. B. Clarke. comatum Kuntze, 1 c. $487=$ D. comata, Linn.

congruum, Kuntze, 1. c. 980 = Adhatoda congrua, Nees.

cordatum, Kuntze. I. c. = J. cordata, T. Anders.

cordifolium, Kuntze 1. c. = Rhytiglossa cordifolia, Nees). - Bras.

corymbulosum, Kuntze, 1. c. (= F. corymbulosa, Bertol.) - Guatem

crassifolium, Kuntze, 1. c。 = Dianthera crassifolia Chapm.

crinitum, Kuntze, 1. c. $978=$ J. micrantha, Heyne. cuneatum, Kuntze, 1, c. $980=$ J. cuneata, Vahl. cuneiforme, Kuntze, 1. c. $979=\mathrm{J}$. cuneifolia, Nees. cuspidulatum, Kuntze, 1. c. $980 \stackrel{=}{=}$ Rhytiglossa cuspidatum, Nees). - Bras.

cydoniaefolinm, Kuntze, 1. c, = Adhatoda cydoniaefolia. Nees.

dasycarpun, Kuntze, 1. c. = J. dasycarpa, Kurz.

dasyclados, Kuntze, 1. c. = Dianthera dasyclados, Benth. \& Hook. $f$.

debile, Kuntze, 1. C. = J. debilis, Lam decussatua, Kuntze, 1. с, = J. decussata, Roxb. depauperatum, Kuntze, 1.-c. $=$ T. depauperata, T. Anders.

desertortm, Kuntze, 1. c. = J. desertorum, Engl. 


\section{ECBOLIUM :}

dichotomum, Kuntze, Rev. Gen. (189I) 487 et $980=$ Dianthera dichotoma, $C, B$, Clarke,

diffusum, Kuntze, 1. c. $487=$ = . diffusa, Willd .

distortum, Kuntze, 1. c. $980=$ Dianthera distorta, Benth. \& Hook. f.

divergens, Kuntze, 1. c. 487 et 980 (= Rhytigloss divergens, Nees). - Bras.

Ecklonianum, Kuntze, 1. c. 980 (= Rhytiglossa Eckloniana, Nees). - Afr. austr.

elegans, Kuntze, 1. c. = J. elegans, Poh.

eranthemodes, Kuntze, 1. c. = J. eranthemoides, F. Muell.

Esenbeckit, Kuntze, 1. c. 979 (= Amfhiscopia mon tana, Nees). - Bras.

Eustachianum, Kuntze, 1. c. $980=$ Dicliptera Vahliana, Nees

extensum, Kuntze, 1. c. = J. extensa, T. Anders.

fasciatum, Kuntze, 1. c. = J. fasciata, E. Mey.

Felisbertianum, Kuntze, 1. c. = Adhatoda Felisbertiana, Nees.

flaccidum, Kuntze, 1. c. = J. flaccida, Kurz.

flagelliforme, Kuntze, I. c. = J. flagelliformis, C. B. Clarke.

flavm, Kuntze, 1. c. = Barleria flava, facq.

flexusum, Kuntze, 1. c. = Adhatoda flexuosa Nees.

fragile, Kuntze, 1. $c_{0}=$ J. fragilis, Wall.

furcatum, Kuntze, 1. c. = J. furcata, facd.

Gendarussa, Kuntze, 1. c. $487=$ J. Gendarussa, Burm.f.

geniculatum, Kuntze, 1. c. = Dianthera secunda Griseb.

genistifolium, Kuntze, 1. c. = J. genistifolia, Engl. genistiforme, Kuntze, 1. c, = Adhatoda genistiformis, Nees.

genuflexum, Kuntze, 1. c. $(=7$. genuflexa, Nees et Mart.). - Bras.

Gilliesii, Kuntze, 1. c. = Adhatoda Gilliesii, Nees. glandulosum, Kuntze, 1. c. = Adh. glandulosa, Nees.

glaucescens, Kuntze, 1. c. $979=\Lambda$ dh. ciliata, Nees. glaucum, Kuntze, 1. c. $980=$ J. glauca, Rottl.

grandifolium, Kuntze, 1. c. = J. grandifolia, $T$. Anders.

Griffithii, Kuntze, 1. c. = Dianthera Griffithii Benth.

Grisebachianum, Kuntze, 1. c, $979=$ Dianthera glandulosa, Griseb.

grossum, Kuntze, 1. c. $980=\mathrm{J}$. grossa, C. B. Clarke.

Tharanense, Kuntze, 1. c. = Dianthera comata, Limn.

Helferi, Kuntze, 1. c. = J. Helferi. C. B. Clarke.

heveroënse, Knntze, 1. c. $980=\mathrm{J}$. hereroënsis Engl.

Hemsleyanum, Kuntze, 1. c. 978 (= Ruellia leptostachya, Wall.). - Ins. Philipp.

heterantherum, Kuntze, 1. с. $979=$ Beloperone violacea, Planch. Es Lind.

heterocarpum, Kuntze, 1. c. $980=$ J. heterocarpa, T. Anders.

hirsutolabiatum, Kuntze, 1. c. 979 (= Rhaphidospora tenella, Nees). - Java.

hirsutum, Kuntze, 1. c. 980 (= Rhytiglossa hirsuta, Nees). - Peruv.

holosericeum, Kuntze, 1. c. = Adhatoda holosericea, Nees.

Hookerianum, Kuntze, 1. c, = Dianthera Hookeriana, Benth. \& Hook. $f$.

hygrophilodes, Kuntze, 1. c. = J. hygrophiloides, F. Muell.

hyssopifolium, Kuntze, 1. c. $487=\mathrm{J}$. hyssopifolia, Linn.

Hyssopus, Kuntze, 1. c. 980 (= Rhytiglossa Hyssopus,

Nees). - Bras.

ilhense, Kuntze, 1.c. (= Rhytiglossa ilhensis, Moric.). - Bras.

inaequale, Kuntze, 1.c. = Dianthera inaequalis, Benth. \& Hook. $f$.

incanum, Kuntze, 1. c. = Adhatoda incana, $N^{\top} e e s$. indicum, Kuntze, 1. c. = Dianthera indica, $C . B$. Clarke.

inficiens, Kuntze, 1. c. = J. inficiens, $V_{a} h l$

insulare, Kuntze, 1. c. = J. insularis, T. Anders.

Kempeanum, Kuntze, 1. C. $=$ J. Kempeana, $F$. Muell.

\section{ECBOLIUM :}

hhasiana, Kuntze, Rev. Gen. (1891) $980=$ J. khasiana, C. B. Clarke.

Kirkianum, Kuntze, 1. c. = J. Kirkiana, T. Anders.

Kotschyi, Kuntze, 1. c. $(=$ Tyloglossa Kotsihyi, Hochst.). - Afr. trop.

Kurzianum, Kuntze, 1. c. $979=$ J. flava, Kurz.

Kuraii, Kuntze, 1. c. $980=$ J. Kurzii, C. B. Clarke.

laetum, Kuntze, 1: c. = Dianthera laeta, Hicrn.

laevilingue, Kuntze, 1. C. (= Rhytiglossa laevilinguis,

Nees). - Bras.

lancifolium, Kuntze, 1. c. (= Amphiscopia lancifolia, Nees). - Peruv.

latiflorm, Kuntze, 1. c. = J. latiflora, Hemsl.

latifolium, Kuntze, 1. c. = Dianthera latifolia, Benth. E Hookf.

lavandulifolim, Kuntze, 1. c. (= Rhytiglossa lavandulaefolia, Nees), - Bras.

laxun, Kuntze, 1. $\mathrm{c}_{n}=\mathrm{J}$. laxa, T. Anders.

leptanthum, Kuntze. 1. c. = J. leptantha, T. Anders, leptostachym, Kuntze, 1.c. = Dianthera Wallichii, Benth. En Hook. f.

Linaria, Kuntze, 1. c. $=$ J. Linaria, T. Anders.

Lindeniamun, Kuntze, 1. c. = Dianthera Lindeniana, Hemisl.

lineare, Kuntze, 1.c. (= Rhytiglossa lincaris, Nees). - Bras.

lineolatm, Kuntze, 1. c. = J. lineolata, Ruiz \& Pav.

lithospermifolinm, Kuntze, 1. c. = Hygrophila guianensis, Nees.

longiflonm, Kuntze, 1.c. = Dianthera longiflora, Benth. \& Hook.f.

longifolim, Kuntze, 1. c. = Adhatoda longifolia, Nees.

lucidum, Kuntze, 1.c. = Dianthera secunda, Griseb.

Maingayi, Kuntze, I. c. = J. Maingayi, C. $B$. Clarke

majus, Kuntze, 1. c. = Adhatoda major, Nees.

Mannii, Kuntze, 1, $\mathrm{c}_{\text {, }}=\mathrm{J}$. Mannii. T. Anders

Martianum, Kuntze, 1.c. = Adhatoda Martiana, Nees.

maynense, Kuntze, 1. c. (= Rhytiglossa mayncnsis, Nees). - Bras.

membranifolinn, Kuntze, 1. c. $(=$ Rhaphidospora membranifolia. Miq.). - Java.

menthodes, Kuntze, 1.c.(= Rhytiglossa monthoides, Nees), - Bras.

Meyenianum, Kuntze, 1.c. = Beloperone Meyeniana, Nees

mexicamm, Kuntze, 1.c. = Dianthera mexicana, Benth. \& Hookf.

microstachyum, Kuntze, 1. c. (= Rhytiglossa microstachya, Nees). - Perut.

Middletonii, Kuntze, 1. c. $978=\mathrm{J}$. haplostachya, T. Anders.

minus, Kuntze, 1. c $980:=\mathrm{J}$. minor, T. Anders.

molle, Kuntze, 1. c. = J. mollis, E. Mey.

montanum, Kuntze, 1. c. = J. montana, Wall.

Moricandianum, Kuntze, 1. c. $(=$ Rhytiglossa Moricandiana, Nees). - Guian.

Moritzianum, Kuntze, 1. c. $979=$ Dianthera comara, Linn.

Moritzianum, Kuntze. 1. c. $980=$ Adhatoda Morit ziana, Nees.

nanum, Kuntze, 1 . c. (= Rhytiglossa nand, Nees). Mexic.

matalense, Kuntze, I. c. $=$ Adhatoda natalensis, Nees.

Neesianum, Kuntze, 1. c. = J. Neesiana, Wall.

neuranthm, Kuntze, I. c. = J. neurantha, Collett \&o Hensl.

nilgerrhense, Kuntze, 1. c. = J. nilgherrensis, Wall nodosum, Kuntze, 1, c. = Dianthera nodosa, Benth. of Hook. $f$

nothum, Kuntze, 1.c. = Ji notha, C. B. Clarke.

nudum, Kuntze, 1. c. = Adhatoda nuda, Nees.

oblongum, Kuntze, 1. c. $(=$ Rhytiglossa oblonga, Nees). - N. Granat.

obtusifolim, Kuntze, 1, c. = Dianthera ovata, Walt. odorum, Kuntze, 1. c. = T. odora, Vahl.

Ocrstedtii, Kuntze, 1. c. $978=$ Dianthera glabra Benth. E Hook. $f$.

Orbigniamm, Kuntze, 1. c. $981=$ Adhatoda Orbigniana, Nees

orchiodes, Kuntze, 1. c. $=$ J. orchioides, Limn. $f$.

\section{ECBOLIUM : -}

oreophilum, Kuntze, Rev. Gen. (1891) $981=\mathrm{J}$. oreophila, C. B. Clarke.

origanodes, Kuntze, 1. c $=$ Adhatoda origanoides, Necs.

Orthotactus, Kuntze, 1. c. 979 ( $=$ Amphiscopia Moricandiana, Nees). - Bras.

ovatum, Kuntze, 1. c. $978=$ Dianthera ovata. Walt pacificum, Kuntze, 1. c. 981 = J. pacifica, Hemsl. palustre, Kuntze, 1. c. $=$ J. palustris, T. Anders, - Bras.

paniculainm, Kuntze, 1.c. (= Rhytiglossa paniculata Nees). - Bras.

parifflorum, Kuntze, 1. c. = Dianthera parviflora A. Gray.

parrifolimn, Kuntze, I. c. = D. parvifolia, Benits. \& Hook. f.

patulum, Kuntze, 1. c. = Adhatoda patula, Nees. - Bras.

pancifiorum, Kuntze, 1. c, (= Rhytiglossa pauciflora. Nees). - Bras.

pectorale. Kuntze, 1. c. $487=$ Dianthera pectoralis, F. F. Gmel.

peplodes, Kuntze, 1. c. $981=$ D. peploides Griseb.

periplocifolium, Kuntze, 1. c. = Adhatoda periplocifolia, Nees.

petiolare, Kuntze, 1. c. $981=\mathrm{J}$. petiolaris, E. Mes. plicatum. Kuntze, 1. c, = Adhatoda plicata, Nees. Poeppigianum, Kuntze, 1. c. $=$ (Rhytiglossa Poeppi giana, Nees). - Bras.

Pohlianim, Kuntze, 1. c. (= Amphiscopia Pohliana, Nees). - Bras.

polyonodes, Kuntze, I. c. $(=7$. polygonoides, H. B. $\& \mathrm{~K}$. . . N. Granat.

polystachyum, Kuntze, 1. c. 488 et $981=\mathrm{J}$. polystachya, Lam.

procumbens, Kuntze, 1. c. $48 S=$ J. procumbens, Linns.

protractum, Kuntze, 1. c. $981=$ Adhatoda protracta, Nees.

psychtriodes, Kuntze, 1.c. = J. psychotrioides, Thou ptychostomum, Kuntze. 1. c. $=$ J. ptychostoma Wall.

pubigtrum, Kuntze, 1. $c_{0}=\mathrm{J}$. pubicera, Wall pundnanum, Kuntze, 1. c. 4s8 = J. punduana, Wall punctatum, Kuntze, 1. c.981= Dianthera punctata. Vahl.

quadrifarium, Kuntze, 1. c. = J. quadrifaria, Wall quinquangulare, Kuntze, 1. c。 = J. quinqueangularis, Koenz.

racomosum, Kuntze, 1.c. = J. racemosa, Ruiz $E$ Pao.

reflexiflorm, Kuntze, 1. c. 487 = Adhatoda reflexiflora, Nees.

repens, Kuntze, 1.c.981 (= Rhytiglossa repens, Nees). - Bras.

refractifolium, Kuntze, 1. c. 487. - Costarica.

reptans, Kuntze. l. c. $=$ Dianthera reptans, $\mathcal{F} . F$ Gmel.

retusum, Kuntze, 1, c. = J. retusa, Vahl.

rhodopterum, Kuntze, 1. c. $=$ J. rhodoptera, Baker rigidum, Kuntze, 1. c. = Dianthera rigida, Benth. et Hook. $f$.

roseum, Kuntze, 1. c. (= Amphiscopia rosea, Nees). Bras.

rostratum, Kuntze, 1. c. = J. rostrata, Bertol.

Rostellaria, Kuntze, 1. c. $979=$ J. neglecta T. Anders.

rotundifolinm, Kuntze, 1. c, $981=\mathrm{J}$. rotundifolia, E. Mey.

Ruizianun, Kuntze, 1. c. = Dianthera lineolata Tafalla.

rungiodes, Kuntze, 1. c. 488. - Java.

salicifolium, Kuntze 1. c. $981=\mathrm{I}$. salicifolia T. Anders.

salsolodes, Kuntze, 1. c. = J. salsoloides, T. Andors. salviaefolium, Kuntze, 1. c. 488 et $981=\mathrm{J}$. salviaeflora, $H . B$. \& $K$.

sarmentosum, Kuntze, 1. c. 981 (= Rhytzglossa sarmentosa, Nees). - Bras.

scabrum, Kuntze, 1.c. 488 = Adhatoda scabra, Nees.

Schimperianum, Kuntze, 1. c. $981=$ Adhatoda Schimperiana, Hochst.

secundum, Kuntze, 1. c. $488=$ Dianthera secunda Gris,b. 
ECBOLIUM:

Sellinii, Kuntze, Rev. Gen. (1891)979 (= Amphiscopia ciliata, Nees). - Reg. Argent.

sessile, Kuntze, 1. c. $488=$ Dianthera sessilis, f.F. Gmel.

setaceum, Kuntze, 1. c. $979=$ Dianthera ciliata, Benth. \& Hook. $f$.

simplex, Kuntze, 1. c. $488=$ J. simplex, D. Don

spartiodes, Kuntze, 1. c. $981=$ J. spartioides,

T. Anders.

speciosum, Kuntze, 1. c. $488=$ Dianthera speciosa, Benth. \& Hook. $f$

spergulifolium, Kuntze, 1. c. $981=\mathrm{J}$. spergulaefolia, T. Anders

sphaerospermum, Kuntze, 1. c. $979=$ J. sphaerosperma, $V a h l$.

speciosum, Kuntze, 1 c. $48 \mathrm{~S}=$ Dianthera speciosa, Benth. \& Hook. f

spicatum, Kintze, 1. c. $979=$ Adhatoda spicata, Nees.

squarrosum, Kuntze, 1. c. = Dianthera nodosa, Benth. \& Hook. f.

strobilaceum, Kuntze, 1. c. (= Amphiscopia strobilacea, Nees) - Bras.

subserratum, Kuntze, 1. c. = J. Gendarussa, Burm. $f$. sulcatum, Kuntze, 1. c. = Adhatoda sulcata, Nees. Swartzii, Kuntze, 1. c. $979=$ Adh. divergens, Nees.

symphyanthum, Kuntze, 1. c. 981 (= Rhytiglossa symphyantha, Nees). - Bras.

tenellum, Kuntze, 1. c. $=$ J. tenella, T. Anders.

temifion, Kuntze, 1. c. = J. tenuiflora, Ruiz. \& Pai

thymifolium, Kuntze, 1. c. = Adhatoda thymifolia, Nees.

tranquebariense, Kuntze, 1. c. = J.tranquebariensis, Linn. $f$.

trichotomum, Kuntze, 1. c. 488. - Costarica.

trifoliodes, Kuntze, 1. c. $981=\mathrm{J}$. trifolioides, $T$. Anders.

trinervium, Kuntze, 1. c. = J. trinervia, $V a h l$.

triste, Kuntze, 1. $\mathrm{c}=$ Adhatoda tristis, Nees.

Tweedieanum, Kuntze, 1. c. = Adh. Tweediana, Nees.

umbrosum, Kuntze, 1. c. = Adh. umbrosa, Nees.

vagans, Kuntze, 1. c. = J. vagans, Collett \& Henst.

vasculosum, Kuntze, 1, c. = J. vasculosa, Wall.

Velasquezii. Kuntze, 1. c. = J. Velasquezii, Bertol.

velutinum, Kuntze, 1. c. (= Anisostachya velutina,

Nees). - Madag.

venosum. Kuntze, 1. c. = J. cristata, Pohl.

E'entricosum, Kuntze, 1. c. = J. ventricosa, Wall.

virticillare, Kuntze, 1. c. (= Rhytiglossa verticillaris,

Nees). - Ins. Puerto-Rico.

villosum, Kuntze, 1. c. 978 = Adhatoda divaricata, Nees.

violaceum, Kuntze, 1. c. $981=\mathrm{J}$. violacea, Vahl.

virgatum, Kuntze, 1. c. = Dianthera virgata. Benth.

Willdenowii, Kuntze, 1. c. (= Rhytiglossa scabra,

Nees). - Hab. ?

Wrightii, Kuntze, 1. c. $981=\mathrm{J}$. Wrightii, A. Gray. wynadense, Kuntze, 1. c. $=$ J. wynaadensis, Heyne. xipotense, Kuntze, 1. c. 979 (= Rhytiglossa lewcophloea, Nees). - Bras.

Zeylanicum, Kuntze, 1. c. $978=\mathrm{J}$. Hookeriana, $T$. Anders.

Zollingerianum, Kuntze, 1. c. $981=\mathrm{J}$. Zollingeriana, C. B. Clarke.

ECCLINUSA, Mart. (Sapot.). - Ind. Kew i. 808. brevipes, Pierre. Not. bot. Sapot. (1891) 57. - Bras. costaí, Pierre, l. c. 56. - Bras.

Glaziovii, Pierre, l. c. - Bras.

Grisebachii, Pierre, l. c. 5\%, - Ins. Trinit.

lanceolata, Pierre. l. c. $(=$ Passaveria lanceolata Mart. \& Eichl.). - Bras.

sanguinolenta, Pierre, 1. c. 50 in obs. (= Ragala sanguinolenta, Pierre). - Hab.?

ECDYSANTHERA, Hook, et Arn. (Apocyn.). Ind. Kew. i. 808 .

inflata, K. Schum. in Engl. \& Prantl, Natïrl. Pflanzenfam iv. 2. (1895) $163=$ Anodendron inflatum, Hassk.

myrtifolia, K. Schum. 1. c. (= Dendrocharis myrtifolia, Mik.). - Malaya.
ECHEANDIA, Orteg. (Liliac.). - Ind. Kew. i. 808

brevifolia, S. Wats. in Proc. Am. Acad. xxi. (1886) 441. - Mexic.

nodosa, S. Wats. I. c. xxvi. (1891) 156. - Mexic. parviflora, Baker, ex Hemsl. Biol. Centr.-Am. iv. (1886) 91 ; et in Bot. Falirb. viii. (1887) 209. Guatem.

ECHEVERIA, DC. = Cotyledon, Linn. (Crassu1,) bracteosa, K. Schum. ex T. Rümpler, Die Sukkulenten (1892) 77. - Hab.

ECHIDNOPSIS. Hook. f. (Asclep.). - Ind. Kew i. 809 .

Dammanniana, Sprenger, in Dammann, Catal. (1892) 4 fig. 5; Wien. Illustr. Gartenz. (1892) 351 fig. 59 Gartenf, (1892) 526 fig $10 \%$ N.E. Br. in Gard. Chron. (1894) ii. 530.- Eritrea.

Dammanniana, Schweinf. ex Penzig, in Atti Congr. Bot. Genova (1893) 349 nomen = praec

nubica, N.E.Br. in Kew Bull. (1895) 263. - Nubia. tessellata, K. Schum. in Engl. \& Prantl, Natürl. Pflanzenfam, iv, 2 (1895) 274 = cereiformis, Hook. $f$.

Virchowii, K.Schm.in Monatssclir.f. Kakteenk.(1893) 98 cum ic.; et in Engl. Pfanzenz', Ost-Afr.C (1895) 328. - Afr. trop, or.

E(HINAGANTHUS, Nees (Acanth.). - Ind. Kew. i. 809. ichotomus, Kuntze, Rev. Gen. (1S91) 489. - Java. dichotomus, Kuntze, Rev. Gen.
javanicus, Kuntze, l. c.- Java.

ECHINOCACTUS, Link et Otto (Cact.). - Ind.

\section{Kew. i. 809 .}

alteolens, K. Schum. in Mart. F1. Bras, iv, II (1890) $246=$ Discocactus alteolens, Lam.

bolans1s, Runge, in Gartenf. (1889) 106 fig. 21. Hab.?

constrictus X. Hildm. in Monatsschr. f. Kakteenk. i. (1891) 15. - Hybr. artef.

disciformis, K. Schum. in Engl. \& Prantl, Natürl, Pflanzenfam. iii, 6 a. $(1894) 189=$ turbiniformis, Pfeiff. et Otto.

Dregeanus, Hort. ex W. Mocller, in Rev. Hort. (1895) 186. - Hab.

Grusonii, Hildm in Monatsschr. f. Kakteenk. i. (1891) 4 et 45 cum ic. - Mexic,

Haselbergii, Foerst. Handb. d. Cacteenk. i.(1S86) 563; et ex Hook.f. iu Bot. Mag. (1888) t. 7009. - Hab.? leucotrichus, Phit. in Anal. Mus, nac. Chile (1891) 27. - Chile.

Lewisii, K. Schum. in Monatsschr. f. Kaktcenk, v. (1895) 11 (= Anhalonium Lereisii, Hennings) — Mexic

Macdowellii, C. R. Orcutt, in West-Am. Scientist (1894) 118 cum xylogr. - Mexic.

Mac Dowellii, Rebut, ex Monatsschr. f. Kahteenk, iv. (1894) 133 ian praec, ?). - Hab.

mitis, Phil. in Anal. Unir.Chil.1xxxv. (1894). 493. - Chili.

multicostatus, Hildm.ex K. Schum.in Engl. E Prantl, Natürl. Pflanzenfam. iii.6a (1894) 187; W. Moell. in Rer. Hort. (1895) 186. - Mexic

Orcuttii, Engelm. ex C. R. Orcutt, in West-Am. Sciontist, ii. (1886) 46 cum fig. - Calif.

Peninsulae, L. Weber, in Bull. Mus. Paris, i. (1895) 320. - Calif.

placentiformis, K. Schum. in Mart. Fl. Bras, iv, II (1890) $246(=$ E. placentiformis, Lehm. $)=$ Discocactus insignis, Pfeiff.

rinconadensis, K. Schum. in Engl. \& Prantl, Natürl. Pflanzenfam iii. 6a (1894) 189 in obs. = rinconensis, Poselg.

Schumannianus, Nicolai, in Monatsschr. $f$. Kakteenk iii. (1893) 175. - Paras

senilis, Phil. in Gartenf. (1886) 485 t. 1230 a. Chili.

Trollietii, Rebut, ex $K$ : Schum. in Monatsschr. $f$. Kakteenk. v. (1895) 184.- Mexic.

ECHINOGARPUS, Blume (Tiliac.). - Ind. Kew. sinensis, Hemsl. in Ann. Bot. ix. (1895) 147 [an E. sinensis. Hance?] - China.
ECHINOCEREUS, Engelm. = Cereus, Haw (Cact.).

amoenus, K. Schum. in Engl. \& Prantl, Natürl. Pflanzenfam, iii. 6a (1894) $185=\mathrm{C}$. amoenus, Hemsl.

bicolor, "Galeotti, » ex Wien. 1llustr. Gartenzeit. (1893) 83. [Quid?]. - Mexic.

cinnabarinus, K. Schum, in Engl. \& Prant1, Natürl. Pflanzenfam, iii.6 a. (1894) 185 (= Echinopsis cinnabarina, Labour.). - Bolivia.

claratus, K. Schum. in Monatsschr, f. Kàkteenk. 1895) 123. - Am, austr.

Hildmanni, Arendt, in Monatsschr. f. Kakteenk i. (1891) 146. - Hab. ?

hypogaeus, A. Weber, ex K. Schum. in Engl. \& Prantl, Natïrl, Pflanzenfam, iii. 6a (1894) 185 (= Eulychia clavata, Phil.). - Chili.

Knippelianus, Liebner, in Monatsschr. f. Kakteenk v. (1895) 170. - Mexic

leonensis, Mathsfon, 1. c. i. (1891) 66. - Mexic

Pentlandii, K. Schum. in Engl. \& Prantl, Naturl. Pflanzenfam. iii. 6a (1894) 185 (= Echimopsis Pentlandii, Salm-Dyck). - Peruvia.

pulchellus, K. Schum. 1. c. = Cereus pulchellus, Pfeiff.

Rungei, $K$. Schum. in Monatsschr, f. Kakteenk (1895) 124 (=E.texensis, Runge). - Texas.

ECHINOCHLOA, Beauv. = Panicum, Linn (Gramin.)

disticha, St, Lager, in Cariot, Etud. des $\mathrm{fl}$ éd, 8 ii. (1889) $\$ 92=$ P. Crus-galli, Linn.

oryzoides, Fritsch, in Verh. zool.-bot. Ges. Wien, xli. (1891) $742=$ P. Crus-galli, Limn.

EGHINOGYSTIS, Torr. \& Gray (Cucurbit.). Ind. Kew i. $81 \%$

Brandegei, Cogn. in Proc. Calif. Acad. Ser. II, ii (1859) 215; et iii. (1890) 59 (= Vaseyanthus Bige lorit, N. E. Rose) = Brandegea Bigelovii $\operatorname{Cog} n$.

cirrhopedunculata, N.E. Rose, in Contrib. U.S Nat. Herb. i. (1891) 100 in obs. - Mexic

Coulteri, T. S. Brandeg. in Zoé, iv. (1894) 402. Calif.

cchinata, Britton, Stern \& Pogg. Prelim. Cat. (1888) $20=$ lobata, Torr. ot Gray.

macrocarpus, Britton, in Bull. Torrcy Bot. Club, xvii. 1890) 284. - Bolivia.

minima. T. S. Brandeg. in Proc. Calif. Acad. Ser. ii. II. (1889) 159 et 216 . - Calif.

ECHINOPANAX, Decne et Planch. = Fatsia Decne et Planch. (Araliac.).

japonicum, Kuntze, Rev. Gen.(i891) $271=\mathrm{F}$. japonica, Decne et Planch.

papyriferum, Kuntze, 1. c. = F. papyrifera, Benth. \& Hook. $f$.

ECHINOPEPON, Naud. = Echinocystis, Torr. et Gray (Cucurbit.).

cirrhopedunculatus, N. E. Rose, in Contrib. U. S. Nat. Herb. i. (1891) $100=$ Echinoc, cirrhopedunculatus, N.E. Rose

insularis, S. Wats. in Proc. Am. Acad. xxiv. (1889) 51. - Ins. S. Pedro Martin (Calif, austr.).

Palmevi, S. Wats. 1. c. 52. - Mexic.

ECHINOPHORA, Tourn. ex Linn. (Umbellif.). Ind. Kew, i. 814.

chrysantha, Freyn \& Sint, in Oest. Bot, Zeitschr. xlii. (1892) 121. - Armen.

ECHINOPS, Linn. (Compos.).- Ind. Kew. i. 814 bipinnatus, Freyn et Sint. in Oest. Bot. Zeitschr. xliv. (1894) 21\%. - As. Min.

chaetocephalus, Pomel. ex Batt. et Trab. Fl. de l'Algér. [Dicot.] (1890) 482. - Algeria.

Conrathi, Freyn, in Bull. Herb. Boiss. iii. (1895) 356. - As. occ.

eryngiifolius, O.Hoffm, in Engl. Pfansenve. Ost-Afr. C (1895) 419. - Afr. trop. or.

galaticus, Freyn, in Bull. Herb. Boiss. iii. (1895) 355. - As. Min. 


\section{FGHINOPS :}

heterocephalus, Frevn, in Oest. Bot, Zeitschr xli (1891) 11. - As. Min.

Hoehnelii, Schweinf. in v. Hochnel, Zum Rudolph See, Append. (1892) 11. - Afr. trop. or.

macedonicus, Formanek, in Verhonaturf.Ver. Briunn, xxxii. (1894) 166. - Maced,

major, St Lager, in Cariot, Etud. des fl. éd, 8. ii. (1889) $412=$ sphaerocephalus, Linn

minor, St Lager, 1. c. $413=$ E. Ritro, Linn.

nirens, Henderson, in Act. Hort. Petrop. xii. (1892)

$261=$ Cousinia nivea, C. Winkl.

quercifolius, Freyn, in Bull. Herb. Boiss, iii. (1895)

$356=$ bannaticus, Rechel.

Sintenisii, Freyn, 1. c. - Armen.

spinosissimus, Freyn, 1. c. 354. - As. Min.

thracicus, Velen. in Sitz. Bochn. Gen. Wiss. 1890 (1890) ii. 49 ; et Vestrika 49. - Thracia.

ECHINOPSILON, Moq. - Ghenolea, Thunb. (Chenop.).

tibeticus, Hook. f. \& Thoms. ex Hook. f. Fl. Brit. Ind. v. (1886) $10=$ C. divaricata, Hook. $f$.

LCHINOPSIS, Zucc, = Cereus, Haw. (Cact.). gemata, K. Schum. in Mart. Fl. Bras, iv, II. (1890) $231=$ C. turbinatus, Pfeiff

lcucantha, K. Schum, in Engl. \& Prantl, Natürl. Planzenfam. iii. 6a (1894) $184=$ C. leucanthus, Pfeiff.

abrepandus, K. Schum. 1. c. (= Echinocactus obretandus, Salm-Dyck). - Bolivia.

minuscula, Cat. Rebut, ex K. Schum. in Monatsschr.

f. Kakteenk. v. (1895) $105=$ Rebutia minuscula, K. Schum.

Salmiana, Hort. Germ. ex Rud. Meyer. in Monatss. f. Kakteenk. v. (1895) 155 - Hab.

ECHINOPUS, Tourn. ex Adans. = Echinops, Linn. (Compos.)

galalensis, Schweinf. in Aschers. \& Schweinf. (Suppl. Illustr. fl. Egypte) in Mém. Inst. Égypt. ii. (1889) 762. - Aegypt.

ECHINOSPERMUM, Sw. (Boras.). - Ind. Kew. i. 816 .

virginianum. Britton, Stern. \& Pogg. Prelim. Cat. (1888) $37=$ virginicum., Lehm.

rapateri, Pau, ex Magnier, Scrin. fl, select, xiii. (1895) $72=$ barbatum, Lehn.

ECHINOSTACHYS, Brongn.= Aechmea, Ruiz et Pav. (Bromel.).

Hystrix, Wittm, in Bot. Jahrb. xiii. Beibl. n. 29. (1891) $4=$ A. hystrix, Ed. Morr.

Prieureana, Brongn, ex Baker, Handb. Bromel. (1889) $39=$ A. Prieureana, Baker.

ECHINOTHAMNUS, Engl, Bot, Jahrb, xiv. (1892) 383. PASSIFLOREAE

Pechuëlii, Engl. l. c.; K. Schum。in Monatsschr. $f$. Kaktcenk. v. (1895) 54. - Afr. austro-occ, extratrop

ECHINUS, Lour. = Mallotus, Lour. (Euphorb.). Bailloniants, Baill. in Bull. Soc. Linn. Paris, ii. (1891) 977 : et Hist. pl. Madag., Atlas (1891) t. $175=$ M. Baillonianus, Muell. Arg.

integrifolius, Baill, 1. c. $978=$ M. integrifolius, Muell. Arg.

oppositifolizs, Baill. 1. c. ; et Hist. pl. Madag., Atlas (1891) t. $174=$ Croton oppositifolius, Geisel.

ECHITES, P. Br. (Apocyn.). - Ind. Kew, i, 817 pocynifolia, A. Gray, in Proc. Am. Acad. xxii. (1887) 435. - Mexic

boliviana, Britton, ex Rusby, in Mcm. Torrey Bot. Club, iv. (1893) 219. - Bolivia

comosa, Kuntze, Rev. Gen. (1891) 414. - Am. centr.

contorta, K. Schum. in Engl. \& Prantl. Natiol. PAanzenfam, iv. 2 (1895) 166. - Columb.

macrophylla, Zallzbr. in Annal. Hofnns. WVien, ii (1892) 5. - Peruvia
EGHIUM, Tourn. ex Linn.(Borag.), - Ind. Kew.

\section{820 .}

Argentae. Pau. Not. bot. fl. Espân. i. (1887) $22=$ vulgare, Linn.

balearicum, Porta, in Nuov. Giorn. Bot Ital. xix. (1887) 318. - Ins. Balear.

Bourgaeanum, Webb, ex Christ, in Bot. Jahrb. ix. (1888) $126=$ Auberianum, Webb et Berth.

fruticescens, Coincy, in Morot, Fourn. de Bot. viii. (1894) 65. - Hisp.

horridum, Batt. in Bull. Soc. Bot. Fr. xxxix. (1892) 336. - Algeria.

ECLIPTICA, Rumpf, Herb. Amboin. vi. (1750) 48 f. 18.1; ex Kuntze. Rev. Gen. (1891) $334=$ Eclipta, Linn. (Compos.).

alba, elliptica, lanceolata, platyolossa, Kuntze, 1. c. = homonyma omnia Ecliptae.

latifolia, Kuntze, 1. c. = Blainvillea rhomboidea, Cass.

EGTADIOPSIS, Benth. (Asclep.). - Ind. Kew. i. 822.

Buettneri, K. Schum. in Engl. \& Prantl, Nation. Pflanzenfam iv. 2. (1895) 219. - Congo.

cryptolepioides, Schlechter, in Bot. Fahrb. xx. Beibl n. 51 (1895) 10. - Afr, austr.

lanceolata, Baill. in Bull. Soc. Linn. Paris, ii. (1889) 803. - Angola.

nigritiana, K. Schum. in Engl. \& Prantl, Natürl Pflanzenfam, iv. 2. (1895) $219=$ nigritana Benth.?

scandens, $K$. Schum. l, c. - Anorola.

Welwitschii, Baill. in Bull. Soc. Linn. Paris, ii, (1889) 803. - Angola.

EGTINOGLADUS, Benth. (Apocyn.).- Ind. Kew. 1. 822 .

Benthami, Baill. Hist. des pl. x. (1888) 211 ; Oliver in Hook. Icon. pl. xxiv. (1894) t. 2341. - Afr trop. occ.

EDITHCOLEA, N. E. Br., in Kew Bull. (1895) 220. ASCLEPIADEAE

grandis, N.E. Br.l.c. - Reg. Somal.

EDRAIANTHUS, A. DC. = Wahlenbergia Schrad. (Campanul.).

pumiliorum, Maly, ex Wettst. Monog. Edraj. (188i) 192 in syn. = Hedreanthus dinaricus, Wettst.

Wettstemii, Halácsy \& Baldacci, ex Halácsy, in Oest. Bot. Zeitsch. xli. (1891) 377.-Montenegro.

EDWARDIA, Rafin. = Cola, Schott et Endl (Stercul.)

acuminata, argented, cauliflora, clacata, digitata, fici folia. gabonensis, heterophylla, lawrifolia, quinqueloba, Kuntze, Rev. Gen. (1891) $79=$ homonyma omni Colae.

caricifolia, Kuntze, 1. c. = C. Afzelii. Mart.

EGANIA, Remy = Chaetanthera, Ruiz et Pav. (Compos.)

appressa. Phil. in Anal. Mus. Nac. Chile (1891) 34 - Chili.

veroluta, Phil, 1. c. - Chili.

EGLETES, Cass. (Compos.).- Ind. Kew. i. 822. prostrata, Kuntze, Rev. Gen. (1891) $334=$ domingensis, Cass.

EHPETIA, Linn. (Borag.). - Ind. Kew. i. 823. acutifolia, Baker, in Kew Bull. (1894) 28. - Afr. trop. occ

angolensis, Baker, l. c. 29. - Angola.

cordifolia, Robins. in Proc. Am. Acad. xxix. (1894) 319; ct ex Pringle, in Gard. and For. vii. (1894) 153 - Mexic.

divaricata, Baker, in Kew Bull.(1894)24. - Zambes. Fischeri, Giirke, in Engl. Pfanzene. Ost-Afr. C (1895) 336. - Afr. trop. or

tormosana, Hemsl. in Fourn. Linn. Soc. xxvi, (1890) 144. -- Ins. Formos.

Hancenna, Hemsl, l.c. 145. - China.

keyensis, Warb. in Bot. Fahrb. xiii (1891) 424. Oceania.
EHRETIA :

littoralis, Gurke, in Abh. Prenss, Ahad, Wiss, (1894) 16 nomen; et in Engl. \& Prantl, Natürl. Pflanzenfam C (1895) 335. - Afr. trop. or.

Luxiana, F. D. Smith, in Coult. Bot. Gaz. xvii I (1893) 5, - Guatem.

macrophylla, Baker, in Kew Bull. (1891) 29. - Afr. trop, or.

mexicana, S. Wats, in Proc. Am. Acad. xxvi (1891) 144. - Mexic.

Navesii, Vidal, Rev. Pl.Vasc. Filip. (1S86) 194. Ins. Philipp.

nemoralis, Gürke, in Abh. Preuss. Akad. Wiss. (1894) 26 nomen, et in Engl. Pfanzenw. Ost-Afr. C (1895) 336 - Afr trop or

silvatica, Gürke, l. c. (189:3) 63 nomen; th in Bot. fahrb. xix Beibl. n. 47 (1894) 46. - Afr. trop. or.

Stuhlmannii, Gürke, in Engl.Pylanzenw. Ost-Afr. C (1895) 336. - Afr. trop. or.

teitensis, Giurke, in Abh. Preuss. Akad. Wiss. (1894) 31 nomen; et in Engl.l. c. - Afr. trop.or.

EHRHARTA, Thunb. (Gramin.). - Ind. Kew. i.

unislumis, Fenzl, ex Th. Dur. \& Schinz. Consp. Fl Afr. V. 1894 (1895) 770 in syn. = Tricholaena uniglumis, Feuzl.

EICHLERINA, Van Tiegh, in Bull, Soc. Bot. Fr. xlii. (1895) $174=$ Loranthus, Linn.

densiflora. Van Tiegh. 1. c. 175. = L. densiflorus, Benth.

Deppeana, Van Tiegh. 1. c. = L. Deppeanus, Cham. Es Schlecht.

elegans, Van Tiegh. 1.c. = L. elegans, Mart.

Licbmanni, Van Tiegh. 1. c. = L. Liebmanni, Oliver

orbicularis, Van Tiegh. 1. c. $=\mathrm{L}$. orbicularis, $H$. $B$. \& $K$.

rhynchophylla, Van Tiegh, 1. c。= L. rhynchophyllus, Eichl.

vulgaris, Van Tiegh. 1. c. = L. vulgaris, Mart.

EKEBERGIA, Sparrm. (Meliac.). - Ind. Kew. i. $8 \% 4$

suavis, Baill. Hist. pl. Madag., Atlas (1893) t. 256, Madag.

ELACHANTHERA, F. Muell, in Vict. Natural, iii. (Dec, 1886) 108. LILIACEAE.

Sewelliae, F. Aluell. ll. cc. - Austral.

ELACHOLOMA, F. Mull, et Tate, in Vict. Natural xii. (June 1895) 14. PEDALINEAE.

Hornii, F. Muell. Eo Tate, l. c. "'et in Trans, Roy. Soc. S. Austral. xix. (1895) 82. - Austral.

ELAEAGIA, Wedd. (Rubiac.). - Ind. Kew, i. 824

grandis, Rusby, in Mem. Torrey Bot. Club, iv. (1895) U8. - Bolivia

ELAEAGNUS, [Tourn.] Linn. (Elaeagn.). - Ind Kew. i. 825.

Davidi, Franch. in Nouv. Arch. Mus. Paris, Sér. II x. (1887-88) 77. - Tibet

pyriformis, Hook. f. Fl. Brit. Iud. v. (ISS6) 202 . Reg. Himal.

sativa, Hort. ex Dippel, Handb. Laubholzh. iii. (1893) $20 \%$. = augustifolia, Linn.

sincnsis, Hort. ex Koehne, Deutsche Dendrol. (1893) $428=$ pungens, Thunb

ELAEIS, Jacq. (Palm.). - Ind. Kew. i. 825.

Dybowski, Hua, in Bull. Mus. Paris, i. (1S95) 315. - Congo gall.

ELAEOGARPUS, Burm. ex Linn. (Tiliac.). Ind. Kew, i. 825 .

acuminatus, Korders \& Valeton, in Mededcel. s' Lands Plantent. n. xi, Bijdr. n. i (1894) 258. - Javą? Braceanus, Watt, ex C. B. Clarke, in fourn. Linn. Soc. xxv. (1889) 8. - Ind. or.

culminicola, Warb. in Bot. Fahrb. xvi. (1893) 23. Oceania. 


\section{ELAEOCARPUS}

dalechampioides, Baker, in fourn. Linn. Soc. xxii. (1887) 452. - Madag.

decipiens, Hemsl. ex Forbes \& Hemsl. in fourn. Linn. Soc. xxiii. (1886) 94. - As. or.

Eumundi, F. M. Bailey, in Proc. Roy. Soc. Queenst. (1894) 5. - Austral

Hildebrandtii, Baill. in Bull. Soc. Linn. Paris i. (1886) 562; et Hist. pl. Madag., Atlas (1889) t. 93. - Madag.

Humblotii, Baill. $7 l$ cc. 562 et 94. - Madao.

facki, F. Muell. in Trans. Roy. Soc. Vict. N. S. I. ii. (1889) 3. = ferrugineus, Steud.

Kirtonii, F. Muell. ex F. M. Bailey, Syn. Quensl. Fl., Suppl. i. (1886) 8. - Austral.

latescens, F. Muell. in Trans. Roy. Soc. Vict. N. S. I, ii. (I889) 2. - N. Guin.

Iongifolia, C. Moore, Handb. Fl. N. S. Wales (1893) 6\%. - Austral

Parkinsonii, Warb. in Bot. Fahrb. xiii. (1891) 377. - Oceania.

Reedyi, F. Muell. in Trans. of Proc. Roy. Soc. Vict. xxiv, (July 1888) 175 in obs. - N, Fruin.

Thodanthoides, Baill, in Bull. Soc. Linn. Paris, i. (1886) 560; et Hist. pl. Madag., Atlas (1889) t. 91. - Madag.

Richardi, Baill. ll. co. 563; et t. 94. - Madag.

Sayeri, F. Muell. in Trans. \& Proc. Roy. Soc. Vict. xxiv. (July 1888) 174. - N. Guin.

sericeus, Stapf, in Trans. Linn. Soc. Ser. II, iv. (1894) 137. - Borneo.

sphaericus, K. Schum. in Engl. \& Prantl, Natürl. Ptlanzenfam. iii. 6. $(1890) 5=$ E. Ganitrus, Roxb.

Thouarsii, Baill. in Bull. Soc. Linn. Paris, i. 1886 563. et Hist. pl. Madag., Atlas (1889) t. 96. Madag.

undulatus, Warb. in Bot. Fahrb. xiii. (1891) 378. Oceania

viscosus, Warb. l. c. xviii. (1894) 201. = Oceania

ELAEODENDRON, Jacq. f. (Celastr.). - Ind. Kew. i. 826 .

confertifolium, Szyszyl. Pl. Rehmann. ii. (1888) 37 (= Mystroxylon confertifolium, Eckl. \& Zeyh.). Afr. austr.

glaucus, Szyszyl. l. c. 36. - Afr. austr.

gymnosporoides, Baker, in fourn. Linn. Soc. xxii. (1887) 460. - Madag.

lycioides, Baker, l. c. xxv. (1889) 306. - Madag.

Rehmanni, Szyszyl. Pl. Rehmann. ii. (1888) 3\%. Afr. austr.

somalense, Engl. ex Loesen. in Bot. Jahrb. xvii, (1893) 550 in syn. = Cassine Schweinfurtiana Loesen.

zanzibaricum, Schweinf. ex Loesen. 1. c. = C. Schweinfurthiana, Loesen.

ELAEOLUMA, Baill. Hist. des pl. xi. (1892) 293. SAPOTACEAE.

Schomburgkiana, Baill. $l . c .(=$ Myrsine Schomburgkiana, Miq.). - Bras.

ELAEOSELINUM, Koch (Umbellif.). - Ind. Kew. i. 827.

polygamum, Caruel, in Parl. F1. Ital. viii. (1889) 509 = Laserpitium polygamum, Linn.

ELATERIUM, Jacq. (Cucurb.). - Ind. Kew. i. 827.

longisepalum, Cogn. ex N. E. Rose, in Contrib.U.S. Nat. Herb. iii. (1895) 318. - Mexic.

pauciflorum, $\operatorname{Cog} n$. ex Th. Dur. \& Pitt. in. Bull. Soc. Bot. Belg. Xxx 1891 (1892) 276. - Costarica.

ELATINE, Linn. (Elatin.). - Ind. Kew. i. 827. aetolica, Haláczy \& Wettst. ex Wettst. in Denkschr. Akad. Wien, lxi. (1894) 312. - Graecia.

inaperta, Lloyd, ex Kuntze, Rev. Gen. (1891) 58. Gall.

tetrandra, Maxim. in Bull. Acad. St-Pétersb. xxxí. (1888) 484. - Japon.

ELATINOIDES, Wettst. in Engl. \& Prantl, Natürl. Pflanzenfam. iv. 3 b (1891) $58=$ Linaria, [Tourn.] Mill. (Scrophul.)
ELATINOIDES : -

aegyptiaca, Brunneri, cirrhosa, commutata, dichondraefolia, Elatine, ramosissima, spartioides, spuria, Wettst. I. c. = homonyma omnia Linariae.

ELATOSTEMA, Forst. (Urtic.). - Ind. Kew. i. 828.

ciliatum, C. B. Clarke, ex Hook. f. Fl. Brit. Ind. v. (1888) 574. - Ind. or

bulbothrix, Stapf, in Trans. Linn. Soc, Ser. II. iv. 1894) 230 [Elatostemma]. - Borneo.

Clarkei, Hook, f. . Fl. Brit. Ind. v. (1888) 569. Bengal.

Griffithii, Hook.f.l.c. - Assam

filicinum, Baker, ex Focke, in Abh. Nature. Ver Bremen, xiii. (1895) 164 in obs. - Hab.?

Finisterrae, Warb. in Bot. Fahrb. xvi. (1893) 19

[Elatostemma]. - Oceania.

hexadontum, Baker, in fourn. Linn. Soc, xxii, (1887) 524. - Madag.

lineare, Stapf, in Trans. Linn. Soc., Ser. ii. IV. (1894) 228. - Borneo.

lithoneurum, Stapf, l. c. 230 [Elatostemma]. Bormeo.

Lowi, Stapf, l. c. 229. - Borneo

nasutum, Hook. f. Fl. Brit. Ind. v. (1888) 571. Reg. Himal.

novo-guineense, Warb. in Bot. Falırb. xiii. (1891) 290 [Elatostemma]. - N. Guin.

orientale, Engl. Pflanzenw. Ost-Afr. C (1895) 164 [Elatostemma]. - Afr. trop. or.

pusillum, C. B. Clarke, ex Hook. f. Fl. Brit. Ind. v. (1888) 56s. - Reg. Himal.

reptans, Hook.f. l. c. 567. - Ind. or

stellatum, Hook.f. l. c. 572. - Reg. Himal.

thalictroides: Stapf, in Trans. Lim. Soc. Ser. ii IV. (1894) 229. - Borneo.

thomense, Henriques, $2 n$ Bolet. Soc. Brot. x. (1892) 163. - Ins. S. Thom.

Treutleri, Hook. f. Fl. Brit. Ind. v. (1888) 57l. Reg. Himal.

Walkerae, Hook. f. l. c. 566. - Zeyl.

Wightii, Hook. f. l. c. 570 . - Ind. or.

ELATTOSTACHYS, Radik. (Sapind.). - Ind. Kew. i. 828.

tetraporandra, Radlk. in Sitz. Math. Phys. Acad. Muench.xx. (1890) 267. - Oceania.

ELGOMARHIZA, Rodr. ex K. Schum. in Eng1. \& Prantl. Natürl. Pflanzenfam. IV. 2. (I 895$) 305$. in obs. ASCLIPIADEAE.

amilacea, Rodr, l. c. - Bras.

ELEMIFERA, Linn = Amyris, $\mathrm{P}, \mathrm{Br}$. (Burser.) balsamifera, decandra, lineata, maritima, Plumier, silvatica, Tecomaca, terebinthifolia, thyrsiflora, Kuntze, Rev. Gen. (1891) $100=$ homonyma onnia Amirydis.

bipinnata, Kuntze, 1. c. = Bursera bipinnata. Engl. hexandra, Kuntze, 1. c. = Dacryodes hexandra, Griseb.

ELEOCHARIS, R. Br. (Cyper.).-Ind. Kew. i. amphibia, C. B. Clarke, in foum. Bot. xxv (1887) $2 \% 0$ (= Heleocharis amphibia. Durieu) - Eur.occ. amphibia, Nym. Consp. F1. Eur. Suppl. ii. 1. (1889) $320=$ praec

anceps, C. B. Clarke, in Th. Dur. \& Schinz. Consp. Fl. Afr. v. 1894 (1895) 596 (= Heleocharis anceps, Ridl.). - Afr. trop.

carniolica, C. B. Clavke, in fourn. Bot. xxv. (1887) 269 (= Heleocharis carniolica. Koch). - Eur. austr

comosa, C. Richt. P1. Europ. i. (1890) 143 = acicularis, R. Br.

complanata, C. B. Clarke, in Th. Dur. E Schinz, Consp. Fl. Afr. v. 1894 (1895) 598 (= Heleocharis complanata, Boeck.): - Afr. trop.

contracta, Maury. ex M. Micheli, in Mém. Soc. sci. phys. Geneve, xxxi. (1890) n. 1, 139 t. 41 C. Parag.

flexifolia, Reichb. ex. C. B. Clarke, in Th. Dur. \& Schinz, Corsp. Fl. Afr. v. 1894 (1895) $622=$ Scirpus flaccifolius, Stend.
ELECHARIS :

Hildebrandtii, C. B. Clarke, in Th. Dur. \& Schinz Consp. F1. Afr. v. 1894 (1895) 598 (= Heleocharis Hildebrandtii, Boeck.). - Afr. trop.

intermedia, Maury, ex $M$ Micheli: in Mém. Soc sci. phys. Geneve, xxxi. (1890) n. 1, 138 t. 41 A.-Parag.

mitrata, C. B. Clarke, in Th. Dur. E Schinz, Consp. Fl. Afr. v, 1894 (1895) $599(=$ Scirpus mitratus, Griseb.). - Am. et Afr. trop.

Naumanniana, C. B. Clarke, l. c. $(=$ Heleocharis Naumanniana, Boeck.). - Afr. trop.

neo-zelandica, C. B. Clarke, ex T. Kirk, in Trans. N. Z. Inst. xxvi. 1893 (1894) 260. - N. Zel

paraguayensis, Maury, ex M. Micheli, in Mém. Soc. sci.phys. Genive, xxxi.(1890) n. 1. 137. t. 41 B.Parag.

Parishii, Britton, in fourn. N. Y. Microsc. Soc. v. (1889) 111. - Calif

sanguinea, Maury, ex M. Micheli, in Mém. Soc. sci. phys. Genève, xxxi. (1890) n. 1, 135 t. 40 c. Parag.

subvivipara, C. B. Clarke, ex Hook. f. Fl. Brit. Ind. vi. (1893) 629; et in Th. Dur. E Schinz, Consp. Fl. Afr.v. 1894 (1895) 601 (= Heleocharis subvivipara, Boeck.) - Ind. or., Madas.

trilophus, C. B. Clarke, l. ..601. - Senegal.

villaricensis. Maury, ex M. Micheli, in Mem. Soc. sci. phys. Genève, xxxi (1890) n. 1, 138 t. 40 B.Parag.

Wolfii, A. Gray, ex Britton, in Journ. N. Y. Micros. Soc. v. (1889) $105=$ Scirpus Wolfi, $A$. Gray.

ELEPHANTOPUS, Linn. (Compos.). - Ind.

Kew. i. 831.
angolensis, O. Hoffm. in Bolct. Soc. Brot. x. (1892) 172. - Angola.

ELETTAPIOPSIS, Baker, in Hook. f. Fl. Brit Ind. vi. (1992) 251. SCITAMINEAE.

Curtisii, Baker, l. c. 252.- - Penang.

exserta, Baker, l. c. 251. - Penins. Mal.

longituba, Ridl. in Trans. Linn. Soc. Ser. II. iii. (1893) 382. - Penins. Mal.

serpentina, Baker, m Hook. f. Fl. Brit. Ind. vi (1892) 252. - Penang.

ELEUSINE, Gaertn. (Gramin.). - Ind, Kew.j.

blepharoglumis, $K$. Schum, in Engl. Pflanzenw. Ost-Afr. C (1S!5) 113. - Afr. trop. or.

ELEUTHERANTHERA, Poit. (Compos.).-

Ind. Kew. i. $83 \%$.
areolata, Klatt, in Leopoldina, Heft xxv. (1889) $10 \%$. Am. austr

divaricata, Millsp. Field Columb. Mus. Bot. Ser. I (1895) 53 = Mclampodium divaricatum, $D C$. rdevalis, Hitche. in Missouri Bot. Gard. Rep. iv (1893) 99 = Ogiera ruderalis, Griseb.

ELEUTHEROGOGGUS, Maxim. (Arai.).-- Ind. Henryi, Oliver. in Hook. Icon. pl. xvili. (1887).t.

leucorrhizus, Oliner, l. c. - China.

FIIONURUS, Humb. et Bonp1. (Gramin.).Ind. Kew, i, 832

barbiculmis, Hack. ex Scribn. in Coult. Bot. Gaz. xiii. (1888) 296; ct in DC. Monog. Phan. vi. (1889) 339. - Am. bor. OCC

hirtifolius, Hack. in DC. 1. c. 341. - Afr. trop.

lividus, Hack. l. c. 333\%. - Paras.

platypus, Hack. l. c. 335. (= Andropogon platypus, Trin.). - Sierra-Leone.

tristis, Hack. l. c. 331. - Madag:

ELLEANTHUS, Presl (Orchid.), - Ind. Kew. i 833.

yungasensis, Rolfe, cx Rusby, in Men. Torrey Bol. Club, iv. (1895) 262.-- Bolivia. 
ELLERTONIA, Wight (Apocyn.). - Ind. Kew. i. 833 .

sessilis, K. Sclinm, in Eugl, \& Prantl, Natiurl. Pfanzenfam. iv. 2 (1895) 144. — Ins. Mayotte.

ELLIPANTHUS, Hook. f. (Orchid.). - Ind, Kew. i. 833 .

Luzoniensis, Vidal, Reris, Pl. Vase, Filip. (1886) 104. - Ins. Philipp.

sterculiaefolius, Prain, in fourn. As. Soc. Beng. lix. (1890) ii. 209 t. 8. - Burma.

ELLIPEIA, Hook. f. \& Thoms. (Anon.). - Ind. Kew. i. 833 .

costata, King, in fourn. As. Soc. Beng. 1xi. (1892) ii. 26. - Burma.

leptopoda, King, l. c. 25. - Perak.

pumila, King, l. c. 27. - Perak.

mundulata, Scortech. ex King, 1. c. 56 in syn. = Polyalthia Scortechinii, King.

ELODEA, Michx (Hydrochar.), - Ind. Kew. i. 834

chimensis, Casp. in Engl, \& Prantl, Natürl. Pflanzenfam. ii. 1 (1889) 251, sphalm. = chilensis, Casp.

ELSHOLTZIA, Willd. (Labiat.). - Ind. Kew. i. Oldhami, Henst, in foum. Limn. Soc. xxvi. (1890) 277. - Formosa.

Patrini, Kuntze, Rev. Gen. (1891) $517=$ cristata, Benth.

rugulosa, Honsl. in Fourn. Limn. Soc. xxv1. (1890) 278. - China.

ELSOTA, Adans.= Securidaca, Linn. (Polygal.). acuminata, bialata, bracteata, complicata, Gondotiana, Hostmanni, Lamarckii, lanceolata, lateralis, longifolia, longipcdunculata, macrocarpa, major, marginata, ovalifolia, pubescens, rivinifolia, rufescens, Schlechtendaliana, Sellowiana, silvestris, tavoyana, tomentosa, sirgata, s'olubilis, Welwitschii, Kuntze, Rev. Gen. (1891) 46 = homonyma omnia Securidacae.

calophylla, Kuntze, 1. c, $46=$ S. Corytholobium, A. W. Benn.

corymbosa, Kuntze, 1. c. = S. corymbosa, Triana \& Planch.

corymbosa, Kuntze, 1. c. = S. Cumingii, Hassk.

mollis, Kuntze, 1. c. $=\mathrm{S}$. volubilis, Linn

retusa, Kuntze, I. c. $=$ S. retusa, Spruce.

ELVASIA, DC. (Ochnac.). - Ind. Kew. i. 834 clvasioides Gilg, in Engl, \& Prantl, Natürl. Pflanzenfam. iii. 6 (1893) 145 in obs. = E. Hostmannia, Planch.

Hostmanniana, Planch. ex Gilg, 1. c. sphalm. = E. Hostmannia, Planch.

ELYMUS, Linn, (Gramin.). - Ind. Kew, i. 834 mbicuus, Vazey \& Scribn, ex Vasey, inz Contrib. U. S. Nat. Herb, i. (1893) 280. - Colorado.

americanus, Vasey \& Scribn. ex Macoua, Catal. Canad. Pl. iv. (1888) 245; et 1. c. 280 in syn.= rlaucus, Buckl.

attenuatus, C. Richt, Pl. Europ. i. (1890 $132-$ Rossia.

lymoides, Swezey, Cat. Nebraska Pl. (1891) $15=$ E. Sitanion, Schult.

erianthus, Phil, in Anal. Mus, nac. Chile (1892) 13 t. 5. - Chili.

Macounii, Vasey, in Bull. Torrey Bot.Club, xiii. (1886) 119, - Am. bor, occ.

nitidus, Vasey, 7. c. 120.-- Orecon

salinus, MI. E. Fones, in Proc, Calif. Acad. Ser. II. v. (1895) 725. - Am. bor. occ.

vancourerensis, Macoun, ex Vasey, in Bull. Torrey Bot. Chub, xr. (1888) 48. - Ins. Vancouv.

LLYNA, Schrad. = Kobresia. Wildd.(Cyper.). cirpina. Pax, in Engl. \& Prant1, Natür1. Pflanzenfam. is. $2(1887) 122=K$, scirpina, Willd.
ELYNANTHUS, Nees = Tetraria, Beauv. (Cyper.).

microstachyus, Nees, ex C. B. Clarke in Th, Dur. \& Schinz, Consp. Fl. Afr. v. 1894 (1895) 659 in syn. $=\mathrm{T}$. aristata, C. B. Clarke.

sodalium, Franch. Miss. scient. Cap Horn. v. (1889) 375. t. 8. - Reg. Magell.

usambarensis, K. Schum. ex Engl. in Abh. Preuss. Akad. Wiss. (1894) 59 nomen. - Afr. trop. or.

ustulatus, Nees, ex C. B. Clarke, in Th. Dur. \& Schinz. Consp. Fl, Afr. v. 1894 (1895) $663=$ T. rottboelliodes, C. B. Clarke.

ELYTRANTHE, Blume = Loranthus, Linn ampullacea, Engl, in Engl. \& Prantl, Natürl. PflanZemfam iii. I (1889) $188=\mathrm{L}$. ampullaceus, $R 0 \times b$ Arnottiana, Van Tiegh. in Bull. Soc. Bot. Fr. xlii. (1695) $439=$ L. Arnottianus, Korth.

Brandisiana, Engl. in Engl. \& Prantl, Natürl. Planzenfam. iil. 1. (1889) $188=$ L. Brandisianus, Kurz.

capitellata, Eng1.1. c. $189=$ L. capitellatus, Wight \& $A r n$.

globosa, Engl. 1. c. = L. g-1obosus, Roxb

leucosiphon, Van Tiegh. in Bull. Soc. Bot. Fr. xlii. (1895) $439=$ L. leucosiphon, Griff.

Maingayi, Van Tiegh. 1. c. = L. Maingayi, Hook.f.

trigona, Engl, in Engl. \& Prantl, Natürl. Pflanzentam.1ii. 1. (1889) $188=$ L. trigonus, Wight E. Arn.

EMBBLIA, Burn. f. (Myrsin.). - Ind. Kew. i. 836.

Flueckigeri, F. Muell. in Vict. Natural. viii. (April 1892) 200; et in Bot. Centralbl. 1. (1892) 313. Austral.

furfuracea, Coll. \& Hensl. in foum. Linn. Soc. xxviii. (1890) 82, - Ind. or.

kilimandscharica, Gilg, in Bot. Fahrb. xix. Beibl. n. 4\%. (1894) 45. - Afr. trop. or.

longifolia, Hemsl. in fourn. Linn. Soc. xxvi. (1890 62. (= Samara longifolia, Benth.). - Ins. Hongkong

minutifolia, Stapf, in Trans. Limn.Soc. Ser. II iv. (1894) 201. - Borneo.

oblongifolia, Honsl. in fourn. Limn. Soc. xxvi. (1889) 62. - China.

obovata, Hemsl. l.c. (= Samara obovata, Benth. $)$ - China.

pacifica, Hillebr. Fl. Haw. Isl. (1888) 282. - Ins Sandvic

phaeadenia, Stapf, in Trans. Linn. Soc. Ser. II. iv. (1894) 201. - Borneo.

spiraeoides, Stapf, l.c.- Borneo.

tortuosa, Stapf, l. c. 200. - Borneo.

EMERUS, Burm, = Sesbania, Scop. (Legumin.) brachycarpus, exasperatus, grandiflorus, longifolnus, macropterus, procumbens, puniceus, simpliciusculus, tetrapterus, Thwberi, tomentosus, Kuntze, Rev. Gen. (1891) $180-81=$ hominyma omnia Ses baniae.

Sesban, Kuntze, 1. c. 180. = S. aegyptiaca, Poir. sphaerospermus, Kuntze, 1. c. 1S1. $=\mathrm{S}$. sphaerocarpa, Welw.

resicarius, Kuntze, 1. C. = S. platycarpa, Pers

EMILIA, Cass. (Compos.). - Ind. Kew. i. 837. integrifolia, Baker, in Krw Bull. (1895) 69. - Afr. centr. or.

EMINIA, Taub. in Ber. deutsch. bot. Ges, ix. (1891) 29; et in Engl \& Prantl, Natürl. Pflanzenfam. iii. 3. (1894) 359 = Rhynchosia, (Legumin.) antenmulifera, Taub. in Bot. Centralb1. xlv. (1891) 349: Hemsl, in Ann. Bot. V. (1S9I) 408 Taub, in Engl. \& Prantl. Natürl. Pflanzenfam. iii. $3(1894) 360=\mathrm{R}$. antennulifera, Baker.

eminens, Taub. in Ber. deutsch. bot. Ges. ix. (1891) 30 t. 2 et 3 ; et 1 . c. $360=$ antennulifera, Taub.

EMINIUM, Blume = Helicophyllum, Schott (Aroid.).

intortum, Kuntze, Rev. Gen. (1891) $741=\mathrm{H}$. Rauwolffii, Schott

Lchmannit, Kuntze, 1. c. = H. Lehmanni, Regel. spiculatum, Kuntze, I. c, = H. crassipes, Schott.
EMMENANTHE, Benth. (Hydrophyll.), - Ind. Kew. i. 837.

foliosa, M. E. fones, in Zoë, iv. (1893) 278. - Utah.

EMMENOPTERYS, Oliver, in Hock. Icon. p1. xix. (1889) t. 1823. RUBIACEAE.

Henryi, Olizer, l.c. - China.

EMMEORHIZA, Endl. = Emeorhiza, PohI (Umbell.).

umbellata, K. Schum. 1. c, 408, - Bras.

EMPETRUM, [Tourn.] Linn. (Empetr.), - Ind. Kew, i. 837.

bilobum, Phil. ex Oest. Bot. Zcitschr. XLIII (1893)

27. - Chili.

ENALLAGMA, Baili. Hist. des p1. x. (18s8) 54. $B I G N O N I A C E A E$

cucurbitina, Baill. ex K. Schum. in Engl. \& Prantl, Natür. Pfanzenfam.iv. 3 b. (1895) 247 (=Crescentia cucurbitina, Linn.). - Am. trop.

oborata, Baill. 1. c. $(=$ C. oborata, Benth. $)=$ cucurbitina, Baill.

ENALUS, Aschers \& Garcke, in Engl. \& Prantl, Naturl. Pflanzenfam.ii. I. (1889)254=Enhalus L. C. Rich. (Hydrochar.)

acoroides, Aschers. \& Garcke, 1. c. = Enh. Koenigii, L. C. Rich.

ENANTIOPHYLLA, Coult. \& N.E. Rose, in Coult. Bot. Gaz. xviii. (IS93) 55. UMBELLIFERAE.

Heydeana, Conlt. \& N. E. Rose, 1. c. 56 t. 5.Guatem.

ENARGEA, Banks = Luzuriaga, Ruiz \& Pav. (Liliac.)

polyphylla, F. Muell. in Vict. Natural. iv. (Dec.1886) $109=$ L. erecta, $K u n t h$.

radicans, F. Muell. 1. c. = L. radicans, Ruiz Eo $P a v$.

ENARTHROGARPUS, Labill. (Crucif.). - Ind. Kew. i. 838

tragicerus, Boiss. \& Hausshn. ex Boiss. Fl. Or. Suppl. (1888) 67. - Persia

ENGELIA, Adans. (Compos.). - Ind. Kew. 838. cedrosensic, N.E. Rose, in Contrib. U.S. Nat. Hcrb. i. (1890) 17. - Calif. [Ins Cedros].

fruticulosa, Hieron. in Bot. Fahrb, xix. (1894) 54 (= Hopkirkia fruticulosa, Spreng.). - Am. austr.

glutinosa, Robins. E Greenm. in Am. Foum. Sci. Ser. III. 1. (1895) 155. - Mexic.

grandifora, M. E. Fones, in Proc, Calif. Acad. Ser. II. V. (1895) 702 (= Helianthella argophylla, Coville). - Calif

hypargyrea, Robins. \& Greenm, in Am. Fourn. Sci. Ser. II. 1. (1895) 155.- Mexic.

laciniata, Vasey \& $N$. E. Rose. in Proc. U. S. Nat. Mus. xi. (1888) 535. - Calif.

nutans, Eastwood, in Zoé, ii. (1891) 230.-Colorado.

oblonga, Robins. E Fernald, in Proc. An. Acad.xxx. (1895) 118. - Mexic

Palmeri, Vasey of N. E. Rose, in Proc. U.S. Nat. Mus. xi. (1888) 535. - Mexic., Calif.

pleistocephala, F. D. Smith, in Conlt. Bot. Gaz. xiii. (1888) 189. - Guatem.

radians, T. S. Brandeg. in Proc. Calif. Acad. Ser. II. ii. (1889) 176. - Calif

rhombifolia, Robins. \& Greenm. in Am. Fourn. Sci. Ser. III. 1. (1895) 155. - Mexic.

stricta, Seaton, in Proc. Am. Acad. xxviii. (1893) 120. - Mexic.

ventorum, T. S. Brandeg. in Proc. Calif. Acad. Ser. II. ii. (1889) 175. — Calif

ENCEPHALARTOS, Lehm. (Cycad.). - Ind. Kew. i. 838 .

septentrionalis, Schweinf.ex Eichl. in Engl. E Prantl. Naturl. Pfanzenfam. II. 1. (1887) 22. - Afr. trop. bor 
ENCHOLIRION, Benth, \& Hook.f. = ENCHOLIRIUM, Mart. = Dyckia, Schult. f. (Bromel.) Glaziovii, Mez, in Mart. Fl. Bras. iii. III. (1894) 505. - Bras

ENDEGANTHUS, Humblotii, Baill. Hist. pl. Madag., Atlas (1892) t. 241. - Madag.

ENDIANDRA, R.Br.(Laurin.).-Ind. Kew.i. 839. Cowleyana, F. M. Bailey, in Dept. Brisbane, Agric. Bot. Bull. v. (1892) 23. - Austral.

dichrophylla, F. Muell. in Vict. Natural. ix. (May 1892) 12; et ex Bot. Centralbl. 1i. (1892) 91. Austral.

exostemonea, F. Muell. l. c. (June 1892) 42; et l.c. 1. (1892) 251. - Austral,

Sankeyana, F. M. Bailey, in Dept. Brisbane, Agric. Bot. Bull. viii. (1893) 82. - Austral.

Lowiana, F. M. Bailey, 1. C.v. (1892) 24.-Austral.

Maingayi, Hook. f. Fl. Brit. Ind. v. (1886) 127. Malacca.

ENDLICHERA, Presl = Emmeorhiza, Pohl (Rubiac.).

umbellata, K. Schum. in Mart. Fl. Bras, vi. vI. (1888) 38. = Emm. brasiliensis, Walp.

ENDLICHERIA, Nees = Aydendron, Nees (Laurin.)

armeifiora, Mez, in Jahrb. bot. Gart. Berlin. v. (1889) 131 = Ampelodaphne arunciflora, Meissn.

Browniana, Mez, 1. c. $115=$ Aydendron macrophyllum, Meissn.

columbiana, Mez, 1. c. 115 (= Oreodaphne cohmbiana, Meissn.) - Columb.

dysodantha, Mez, 1. c. 118 (= Goeppertia dysodantha, Nees). - Peruvia.

glomerata. Mez, 1. c. 127. - Bras.

gracilis, Mez, 1. C. 124. - Guian, gall.

guadalupensis, Mez, 1. c. 124. - Ins. Guadalup.

impressa, Mez, 1. c. $132=$ Phoebe impressa, Meissn.

Lhotzkyi, Mez, 1. c. $122=$ Ocotea Lhotskyi, Nees.

longifolia, Mez, 1. c. 119 (= Goeppertia longifolia Nees). - Peruv.

macrophylla, Mez, 1. c. $128=$ Ampelodaphne macrophylla, Meissn.

multiflora, Mez, 1.c. $130=$ Amp. dasyantha, Meissn.

pannicularis,-Mez, 1. c. 128 (= Goeppertia panicularis, Nees). - Bras.

paradoxa, Mez, 1. c. 114. - Peruvia

piriformis, Mez, 1. c. 116 (= Mespilodaphne prriformis, Nees). - Guian. gall.

refleitens, Mez, 1. c. 126 (= Goeppertia reflectens, Nees). - Guian. ang1.

rubiflora, Mez, 1. c. $494 .-\mathrm{Columb}$

Sprucei, Mez, 1. c. 125 (= Goeppertia Sprucei, Meissn. - Bras.

rubiflora, Mez, 1. c. 495. - N. Granat.

Szyszylowiczii, Mez, 1. c. - Peruvia.

tomentella, Mez, 1. c. 115. - Peruvia

villosa, Mez, 1. c. 129. - Ins. Jamaic.

ENDONEMA, A. Juss, (Penacac.). - Ind. Kew. i. 840 .

lateriflora, Gilg, in Eng1. \& Prantl, Natürl. Pflanzenfam. iii. 6 a. (1s!t) $210=$ Thunbergii, $A$. fuss .

ENDOSPERMUM, Benth. (Euphorb.). - Ind. Kew, i. 840

perakense, King, ex Hook. f. Fl. Brit. Ind. v. (1887) 458. - Perak.

ENDUSA, Miers (Olacin.). - Ind. Kew. i. 840. punctata, Radlk. in Sitzb. Phys.-Math.Cl. Akad. Muench. xvi. (1886) 313. - Peruvia.

ENDYMION, Dum, = Scilla, Linn. (Liliac.) Lacaillei, Corbière, Nouv. Fl. Norm. (1893) 574. = S. festalis, Salisb.

ENGELHARDTIA, Leschen. (Jugland.). - Ind. Kew. i. 841 .

nudiflora, Hook. f. Fl. Brit. Ind. v. (1888) 597 ; et in Hook. Icon. pl. xviii. (1888) t. 1747. - Penang. pterococca, Kuntze, Rev. Gen. (1891) 637 = spicata Blume.
ENGLERASTRUM, Briq. in Bot, Jahrb, xix, (1894) 178. LABIATAE

Schweinfurthii, Briq.l.c. - Afr. centr. bor.

ENGLERELLA, Pierre, Not. bot. Sapot. (1891) 46. SAPOTACEAE

macrocarpa, Pierre, l.c. 47. - Guian. gall.

ENGLERIA, O. Hoffm. in Bot. Jahrb. x. (1889) 273 ; et in Engl. \& Prantl, Natürl. Pflanzenfam. iv. 4. (1890) 152. COMPOSITAE.

africana, O. Hoffm. $l l . c c_{0}$; Oliver, in Hook. Icon. pl. xxiii. (1892) t. 2205. - Afr. austro-occ. extratrop.

ENGLERINA, Van Tiegh. in Buil. Soc. Bot. Fr. xlii. (1895) 257 = Loranthus, Linn.

Holstii, Van Tiegh. 1. c. = L. Holstii, Engl.

ENGLERODAPHNE, Gilg, in Bot, Jahrb. xix. (1894) 274; et in Engl. \& Prantl, Natürl. Pflanzenfam iii. 6a (1894) 236 fig. 81. THYMELAEACEAE.

leiosiphon, Gilg, 11.cc. - Afr, trop, or.

ENGLEROPHOENIX. Kuntze, Rev. Gen. (1891) 728 = Maximiliana, Mart. (Palm.).

caribaeum. Kuntze, 1. c. = M. caribaea, Griseb. \&. H. Wendl.

Maripa, Kuntze, 1. с. = M. Maripa, Drude

regia, Kuntze, 1. c. = M. regia, Mart.

ENIGOSTEMA, Blume (Gentian.). - Ind. Kew。 i 841 .

verticillare, Baill. Hist. des p1. x. (1888) $131=$ littorale, Blume.

verticillatum, Engl, Pflanzenw, Ost-Afr, C (1895) 313 = littorale, Bhme.

ENKIANTHUS, Lour. (Ericac.). - Ind. Kew. i. 841.

brachyphyllus, Franch, in Morot, fourn. de Bot, ix. (18951 371. - Yunnan.

chinensis, Franch, l. E. - Yunnan.

nikoensis, Makino, in Tokyo Bot. Mag. viii. (1894) $215=$ Andromeda nikcensis, Miq.

subsessilis, Makino. 1. c. = A. subsessilis, Maxim.

ENSLENIA, Nutt. (Asclep.). - Ind. Kew。 i. 841 racemosa, Millsp. Field Columb. Mus. Bot. Ser. i. Jacquini, Decne.

ENTANDROPHRAGMA, C. DC, in Bull. Herb. Boiss. ii. (1894) 582 et 58:3. MELIACEAE.

angolense, C. DC. l. c. - Angola.

ENTEROLOBIUM, Mart, (Legumin.). - Ind. Kew. i. 842

contortisiliqunm, Morong, in Ann. N. Y. Acad. Sci vii. (1892) 102. = E. Timbouva, Benth. et Hook. $f$

ENTEROPOGON, Nees (Gramin.). - Ind. Kew. i. 843 ,

macrostachyus, K Schum, ex Engl, in Abh. Preuss. Akad. Wiss. (1894) 31 nomen (an E. macrostachym, Munro?) - Afr. trop. or.

sonostachyus, K. Schum. 1. c. 17 ; et in Eng1. Pflanzenw. Ost-Afr. C (1895) $110=$ Leptochloa mono stachya, Rocm, Eo Schult.

sechellense, «Benth。 ") ex Th. Dur. Eo Schinn: Consp. Fl. Afr. v. 1894. (1895, 859 [nom. mutat. ]. (= Ctenium sechellense, Baker). $=E$. seychellarum. (Benth.). - Ins. Seychell.

FOMECON, Hance (Papav.). - Ind. Kew. i. 842 hionantha, Bull, Catal. (1888) ex Gard. Chron. (1888) ii. 273 . -

EPACRIS, Forst. (Epacrid.). - Ind. Kew, i. 842 affinis, Colenso, in Trans. N. Z. Inst. xx. 1887 (1888) 199. — N. Zel.

EPAILAGE, DC. (Compos.). - Ind. Kew. i. 843. dissitifolia, Baker, in fourn. Linn. Soc. xxii. (1887) 494. - Madag:
EPERUA, Aubl. (Legumin.). - Ind. Kew. i. 843. Jenmani, Oliver, in Hook. Icon. pl. xx. (1891) t. 1955. - Guian, brit.

EPHEDRA, Tourn. ex Linn. (Gnet.). - Ind. Kew, i. 843

araucana, Phil. in Anal. Univ. Chil. xci. (1895) 520. - Chili.

breana. Phil. . . . 519. - Chili.

Limnaei. Stapf, ex Koehne, Deutsche Dendrol. (1893). 58 et 579 ad calc $=$ distachya, Limn.

multiflora, Phil. ex Stapf, in Denkschr. Akad. Wiss. Wien. (1887) 43; et in Anal. Mus. nac. Chile, (1891). 7\%. - Chili.

Przewalskii, Stapf, in Denkschr. Akad. Wiss. Wien. (1889) 40. - As. centr.

sarcocarpa, Aitch et Hemsl. in Trans. Linn. Soc. Ser. II. iii. (1886) 1l2; Stapf in Denkschr Akad. Wiss Wien. (1889) 61. - Afghania.

(159) Coville, in Contrib. U. S. Nat. Herb. IY. 1893) $220=$ nevadensis, S. Wats

EPICAMPES, J. et C. Pres1 (Gramin.). - Ind. Kew. i. 844 .

ligulata, Scribn, ex Vasey, Illustr. N. Am. Guin. I ii. (1891) add. ; et in Contrib. U. S. Nat.Herb.III. i. (1892) 58. - Ariz., Mexic.

rigens. Phil, in Anal. Mus. nac. Chile (1891) 82 $=$ Sporobolus rigens, E. Desv.

EPICATTLEYA X, Rolfe, in Gard. Chron. (1889). I. 491. ORCHIDEAE.

gratemalensis X. Rolfe, 1. c. (= Cattleya guatemalensis, T. Nioore). - Guatem.

EPICHROXANTHA, Eckl. et Zeyh. ex Van Tiegh. in Bull. Soc Bot, Fr xl (1893) $76=$ EPICHROCANTHA, Eckl, et Zeyh. = Gnidia, Linn. (Thymel.).

EPICLASTOPELMA, Lindav, in Bot. Jahrb. xxii. (1895) 114; et in Engl. \& Prantl, Natürl,
Pflanzenfam. 1v. 3 b (1895) 353. ACANTHA$C E A E$.

glandulosum, Lindau, $l l$. cc. - Afr. trop. or.

EPIDENDRUM, Linn.(Orchid.). - Ind. Kew. i. 845

alsum, Ridl. ex Oliver, in Trans. Linn. Soc. Ser. II ii. (1887) 281 [Oliver, ex im Thurn, in Timnelivi, v. (1886) 202]. - Guian, angl.

amabile. Hort. ex God.-Leboeuf in L'Orchidophile (1887) 304 cum ic. = dichromum, Lindl. auriculigerum, Reichb.f. in Gard. Chron. (1888) ii. 34. - Hab.

Barbeyanum, Kraenzl. in Bull. Herb. Boiss. iii. (1895) 607. - Costarica.

Gituberculatum, Rolfe, in Kew Bull. (1892) 209. $\mathrm{Hab}$.

calceolare, Ham, ex Hook. f. Fl. Brit, Ind, vi. (1890) $60=$ Saccolabium calceolare, Lindl. Capartianum, L. Lind. in Lindenia, vii. (1891) 93. t. 333. - Bras.

dellense $X$. O. Brten, in Gard. Chron. (1891) i. 584 ; et ex Gartenfl. (1891) 360. - Hybr. artef. Ellisii, Rolfe, in Kew Bull. (1894) 184. - Columb. Endresio-Wallisii $X$, Hort. ex Rev. Hortic. (1895) 250. - Hybr. artef.

falsum, Reichto f. in Flora, 1xix. (1886) 553. N. Granat.

geniculatum, Herb. Ham. ex Hook. f. F1. Brit. Ind. vi. (1890) 45 in syn, = Aerides multiflorum, Roxb.

Godseffianum, Rolfe, in Gard. Chron. (1892) i. 136. - Bras.

Hartii, Rolfe, in Kev Bull. (1894) 157. - Ins. Trinit.

Imthurmüs, Ridl. ex Oliver, in Trans. Linn. Soc., Ser. II, ii. (I887) '282 t. 46 a. [Oliver, ex in Thurn, in Timekri, v. (IS86) 203 (im Thurnii).] —Guian. angl.

Laucheanum, Rolfe, in Gartenf. (1892) 183; et in Kew Bull. (1893) 63. - N. Granat.

longipetalum, God. Le eboonf. in L'Orchidophile (1892) 25\%. - Guatem. 


\section{EPIDENDRUIM : -}

Mantinianum, Rolfeo in Illustr. Hortic. xxxix. (1892) 43. t. 550. - Hab. ?

montigena, Ridl. ex Oliver, in Trans. Linn. Soc., Ser. II, ii. (1887) 282. [Oliver, ex im Thun, in Timehri, v. (1886) 203]. - Guian. ang1.

Mooreanum, Rolte, in Kew Bull. (1891) 190. Costarica.

O'Brienianum X, Rolfe, in Gard, Chron. (1888) I 770-71 fig. 103 ; et (1889) 8. - Hybr. artef

Ortgiesi, Regl, in Act. Hort. Potrop. xi. (1891) 473. - Hab.

Palmeri, Rolfo, in Kero Bull. (1893) 6. - Mexic. Pfavii, Rolfe, l.c. (1894) 392. - Costarica.

pristes, Reichb. f. in Gard. Chron. (1886) Ir. 262. $\mathrm{Hab}$.

pugioniforme, Regel, in Act. Hort. Petrop. xi (1890) 305. - Mexic

pumilum, Rolfe, in Kere Bull. (1893) 1\%1. Costarica.

pusillum, Rolfe, in Gard. Chron. (1894) 11. 669.Bras.

tricolor, Rolfe, in Kew Bull. (1893) 63. - Venez. tridentatum, W. Fawcett, in fontn. Bot. xxxiii. (1895) 12. - Ins. Jamaic.

Umlaufti, Zahlbr. in Wien. Illustr. Gart.Zeit. (1893) t. 2; ex Gartenf. (1893) 503 cum ic. - Hab.

violascens, Ridl. ex Oliver, in Trans. Linn. Soc Ser. II, ii. (1887) 282. [Oliver, ex im Thum, in Timehri, v. (1886) 203]. - Guian. angl.

Wendlandianum, Kraenzl. in Gard. Chron. (1893) II 58; et in Reichb. f. Xen. Orchid. iii. 8 (1894) 129. t. 274 i. et ii. fig. 1-3. - Mexic.

yungasense, Rolfe, ex Rusby, in Mom. Torrey Bot. Club, iv. 3. (1895) 262. - Bolivia.

EPIDORCHIS, Thou in Nouv. Bull, Soc Philom (1809) 3149; ex Kuntze, Rev. Gen. (1891) 659 $=$ Mystacidium, Lind1. (Orchid.)

aphylla, Kuntze, 1. c. $660=$ M. aphyllum, Benth. brachystachya, 1. c. 659 . = Aëonia brachystachya I izidl.

Burchelli, Kuntze, 1. c. $660=$ Angraecum Burchellii, Reichb. $f$

Calceolus, Kuntze, 1. c. = A. Calceolus, Thou

carpophora, Kuntze, 1. c. = A. carpophorum, Thon canlcscens, Kuntze, 1. c. = M. caulescens, Ridl. disticha, Kuntze, 1, $\mathrm{c}_{\mathrm{*}}=\mathrm{M}$. distichum, Pfitz.

erythropollinia, Kuntze, 1. c。 = M. erythropollinium, Reichb.f.

exilis, Kuntze, 1. c. = M. exile, Th. Dur. E Schinz.

expansa, Kuntze, 1. c. = Angraecum expansum, Thout.

fragrans, Kuntze, 1. c. = A. fragrans, Thou.

fragrantissima, Kuntze, 1. c. = Listrostachis fragrantissima, Reichb. $f$.

Gorrardi, Kuntze, 1. C. = M. Gerrardi, Bolus.

Gilpinae, Kuntze, 1. c. = M. Gilpinae, Th. Dur. et Schinz.

graninifolia, Kuntze, I. c. = M. graminifolium, Ridl.

Guoyaniana, Kuntze, 1. c. = M. radicosum, Th. Dur. \& Schinz.

ichneumonea, Kuntze, 1. c. = Angraecum ichneumoneum, Lindl.

imbricata, Kuntze, 1. c. = A. imbricatum, Lindl.

inaperta, Kuntze, 1. c。= M. inapertum, Ridl.

Lansbergii, Kuntze, 1. c $=$ Angraecum Lans

bergii, Reichb. $f$.

Lehmannii, Kuntze, 1. c. (= Aeranthus Lchmannii, Reichb, f.)

Tongicornis, Kuntze, 1. c. = M. longicornu, Th. Dur. of Schinz.

macrostachya, Kuntze, 1. c. $659=$ Aëonia macrostachya, Lindl.

megalorhiza, Kuntze, 3. c. $660=$ Angraecum megalorrhizon, Reichb. $f$

micrantha, Kuntze, 1. c. $=$ M. micranthum, $T h_{2}$ Dur. E Schinz.

multiflora, Kuntze, 1. c. = M. caulescens, Ridl. muscicola, Kuntze, 1. c. = M. muscicolum. Th. Dur. E Schinz.

ochracea, Kuntze, 1. c. = M. ochraceum, Ridl. parviflora, Kuntze, 1. c. = Angraecum parviflo-
rum, Thou.
EPIDORCHIS : -

pectinata, Kuntze, Rev. Gen. (1891) $660=$ M. pectinatum. Benth. \& Hook. $f$.

pellucida, Kuntze, 1. c. = M. pellucidum, Benth. \& Hook. $f$.

physophora, Kuntze, 1. c. = M. physophorum, $T h$. Dur. \& Schinz.

polystachya, Kuntze, 1. c. $659=$ Aëonia polystachya Benth. \& Hook. f.

recta, Kuntze, 1. c. $660=$ Angraecum rectum, Thou.

saccifera, Kuntze, 1. c. = A. sacciferum, Lindl.

subulata, Kuntze, 1. c. = A. subulatum, Lindl.

tenella, Kuntze, 1. c. = M. tenel'um, Ridl.

tridens, Kuntze, 1. c. = Angraecum tridens, Lindl.

vagans, Kuntze, 1. c. = A. vagans, Lindl.

vestita, Kuntze, 1. c. = A. vestitum, Lindl.

viridis, Kuntze, 1, $\mathrm{c}_{n}=\mathrm{M}$. viride, Ridl.

colucris, Kuntze, 1. c. $659=$ Aëonia Auberti, Lindl.

xanthopollinia, Kuntze, 1, c. = M. xanthopollinium, Reichb.f.

EPYGYNUM, Wight(Apocyn.),-Ind, Kew. i. 851. Beccarii, $K$ Schum, in Engl, \& Prantl, Naturl. Pfanzenfam.iv. 2. (1895) 178. - Borneo.

EPILASIA, Benth. \& Hook. f. (Compos.), - Ind. Kew. i. 851.

hemilasia, Kuntze, in Act. Hort. Petrop, x. $2021=$ E. hemilasia, C. B. Clarke) $=$ Bungei, C. B. Clarke.

EPILOBIUM, Dill. ex Linn. (Onagrar.). - Ind. Kew. i. 851

alpestre, G. Beck, Fl. Nied.-Oest. II. i. (1892) $689=$ triconum. Sclnzozk.

anglicum $X$, Marsh in Journ. Bot, xxix. (1891) $8 .-$ Brit.

biharicum X, Simonk. in Termész. Fuzétek, x.(1886) 181; et Enum. fl. Transsilv. (1886)228. - Transsilv.

Castriferrei, Borb. Geogr. aiq. cmum. pl. Castrif. (1887-88) 274. - Hung.

clavatum, Trelease, in Missouri Bot. Gard. Rep. ii, (1891) 111, t. 48. - Am, bor. occ.

colchicum, Alboff, Prodr.Fl.Colch.(1S95)86. - Reg. Canc.

Darreri X, C. Richt, in Verh. zool.-bot. Ges. Wien, xli (1891) Sitzb. 21. - Austria.

delicatum, Trelease, in Missouri Bot. Gard. Rep. ii. (1891) 99. t. 28. - Oregon.

exaltaium, Drew, in Bull. Torrey Bot. Chub, xvi. (1889) 151. - Calif.

glaucum, Howell, Coll. Pacif. Coast Pl. (1887); ex Bull. Torrey. Bot. Club, xv. (1887) 24; Greene, Pittonia, i. (Oct. 1888) $225=$ oreganum, Greene.

gracilipes, T. Kirk, in Trans. N. Z. Inst. xxvii. 1894 (1895) 351 - N. Zel.

holosericeum, Trelease, in Missonvi Bot. Gard. Rep. ii. (1891) 91. t. 17. - Calif.

madrense, S. Wats in Proc. Am. Acad. xxiii. (1888) 274. - Mexic

Marshallianum X, Hausskn. in Bot. Exch. Club Brit.-Isl., Report for 1891 (1892) 336. - Brit.

miguelense, Leveillé, in Le Monde des pl. iii. (1894) 91 - Ins, Azor.

Muellerianum, Leveillé, l.c. 275. - Austral.

nanum, Colenso, in Trans. N.Z. Inst. xxvi. 1893 1894) 315. - N. Zel.

Nassirelinulci, Stapf, in Denkschr. Akad,Wiss. Wien, (1886) 57. - As. occ.

niveum, T. S. Brandeg. in Zoë, iii. (1892) 242 t. 24. - Calif.

oreganum, Greene, Pittonia, i. (Oct. 1888) $225=$ subcaesium, Greene.

Parishii, Trelease, in Zoë, i. (1890) 210; et in Missouvi Bot. Gard. Rep, ii, (1892) 97. t. 2\% - Calif. percollinum $y$, Simonk, in Oest. Bot. Zeitschr. xli. (1891) 182. - Hung.

prostratum, Warb. in Bot. Fahrb. xvi. (1893) 23. Oceania.

Pringleanum, Hausskn. in Mitth. Bot. Ver. Fena, vii. (1888-89) 5. - Am. bor. occ.

pycnotrichum $\times$, Borb. in Akad. Ertok, ix. (1888?) 7; et Geogr, atq. enum. pl. Castrif. (1888-89) 272. - Hung

\section{EPILOBIUM :}

Radoi, Borb. Geogr. atq. enum. pl. Castrif. (1888-89) 273. - Hung.

rioulare $X$, Celak. ex Sagerski et Schneid. F1. Centr. Carpath. 180. - Hung,

Schmalhansenianum $X$; M. Schulze in Mitth. Bot. Ver. Jena, vi. (1888) 37 ; viii. (1890) 8. - Eur. stenophyllum X.Borb. Geogr. atq. enum. pl.Castrif (1888-89) 273. - Hung.

subcaesium, Greene, Pittonia, ii. (Sept. 1892) 295 (=E. oreganum, Greene). - Oregon.

Tarni X, de Laremb. ex Nym. Consp. F1. Eur Suppl. I1. 1. (1889) 122. - Gall.

tiarogynum, Norm. in Christ. Vidensk.-Selsk. Forh. (1893) extr. 25; ex Oest. Bot. Zeitschr. xlv. (1895) 117. - Norv.

ursinum, Parish, ex Trelease, in Missouri Bot. Gard. Rep. ii. (1891) 100. t. 31. - Calif.

EPILUMA, Baill. Hist. des pl. xi. (1892) $28 \%$ SAPOT ACEAE.

pyriformis, Baill. 1. c. (= Chry sophyllum pyriforme, Baill.). - N. Caled.

EPIMEDIUM, [Tourn.] Linn. (Berber.). - Ind. Kew. i. 854.

acuminatum, Franch. in Bull. Soc. Bot. Fr. xxxiii. (1886) 109. - China.

brevicornu, Maxim. in Act. Hort. Petrop. xi. (1889) 42. - China.

Davidi, Franch. in Nouv. Arch. Mus. Paris. Sér. II. viii. 1885 (1886) 195. - Tibet.

Fargesii, Franch. in Morot, fourn. de Bct. viii. 1894) 281. - China.

sutchuenensé, Franch. l. c. 282. - China.

EPIPACTIS, Adans. (Orchid,).--Ind. Kew, i. 855. africana, Rondle, in fourn. Bot. xxxiii. (1895) 252. - Afr. trop. or.

Austinae, Wettst. in Oest. Bot. Zeitschr. xxxix. (1889) 429. = Chloraea Austinae, A. Gray.

chloidophylla Wettst. 1. c. $428=$ Cephalanthera chloidophylla, Reichb. $f$.

cucullata. Wettst. 1. c. $429=$ C. cucullata, Boiss et Helds.

grandiflora, Lloyd et Fouc. Fl. Ouest Fr. éd. 4 (1886) $341=$ grandiflora, Sm.

longibracteata, Wettst in Oest. Bot. Zeitschr, xxxix (1889) $428=$ Cephalanthera longibracteata, Blume.

ochroleuca, St. Lager, in Cariot, Etud, des fl. éd. 8. ii. (1889) 811 (= E. ochrolanca, Baumg.) $=$ C. pallens, Rich.

orbicularis, C. Richt, in Verh. zool.-bot. Ges. Wien, (1887) 190. - Austria.

oregana, Wettst, in Oest. Bot. Zeitschr. xxxix. 1889) $429=$ Cephalanthera oregana, Reichb. $f$. Schmalhausenii $X$, C. Richt. P1. Europ. i. (1890) 284. - Rossia.

speciosa $\times$, Wettst. in Oest. Bot. Zeitschr. xxxviii. (1889) 396 t. 3 fig. 1 et 427 ; G. Beck, Fl. Nied.Oest. i. (1890) 214. - Austria.

EPIPETRUM, Phil = Dioscorea, Linn

bilobum, Phil. in Anal. Mus, nac. Chile, (1892) 11. t. 3. - Chili.

polyanthes, Reiche, in Bot. Jahrb. xxi. (1895) 44 nomen. - Chili.

EPIPHYLLUM, Haw. (Cact.). - Ind. Kew.i. acuminatum, K. Schum. in Mart. Fl. Bras, iv. II. (1890) 222. t. 45. - Bras.

Gaertneri, K. Schum. l.c. 218. - Bras.

Gibsoni, Hort. ex Rev, Hortic. 1xiii. (1886) 28.3 sphalm. = Russelianum, Hook.

Makoyanum, Hort. ex Rev. Hortic. Belg. xv. (1889) $229=$ Russellianum. Hook.

obtusangulum, Lindl. ex K. Schum. in Mart. Fl. Bras. iv. II. (1890) $198=$ Cereus obtusangulus. K. Schum.

EPIPOGON, Ledeb.= Epipogum, S. G. Gmel. (Orchid.)

Epipogon, Kern. Sched. Fl. Austro-Hung.vi. (1893) $105=$ aphyllum, Sw. 
EPIPREMNUM, Schott (Aroid.). - Ind. Kew. i. humile, Hook. f. Fl. Brit. Ind, vi. (1893) 549 ( Anadryum humile, Schott). — Penins. Mal. Anadryu

EPISGHOENUS, C. B. Clarke, in Th. Dur. \& Schinz Consp. FI. Afr. v. 1894 (1895) 657. CYPERACEAE

quadrangularis, C. B. Clarke, l. c. - Afr. austr.

EPISGIA, Mart. (Gesner.). - Ind. Kew. i. 856

densa, C. H. Wright, in Ker Bull. (1895) 17. Guian. brit.

Fendleriana, Kuntze, Rev. Gen. (1891) 473. - Costarica, Panama.

EPISTEPHIUMI, Kunth (Orchid.). - Ind. Kew. i. 856 .

lucidum, Cognz. in Mart. Fl. Bras. iii. IV. (1893) 141 , t. 30. - Bras

EPITHEMA, Blume (Gesner.) - - Ind. Kew. i. 856 thomense, Henriques, in Bolet. Soc. Brot. x. (1892). 145. - Ins. S. Thom.

ERAGROSTIS, Host (Gramin.). - Ind. Kew. i. 857 .

alopecuroides, Balansa, in Morot, fourn. de Bot. iv. (1890) 168. - As. trop. occ.

amabilis, Kuntze, Rev. Gen. (1891) 773 et $774=$ plumosa, Link.

annulata, Rendle, ex S. Elliot, in fourn. Bot. xxix. (189L) 72. - Afr. austro. occ. extratrop.

atropioides, Hillebr. Fl. Haw. Isl. (1888) 531. Ins. Sandvic.

bahamensis, Hitcho. Pl. of Bahamas (1893) 149; et in Missouri Bot. Gard. Rep. iv. (1893) 149. - Ins. Baham.

barbinodis, Hack. ex Sclinz, in Bull. Herb. Boiss. iii. (1895) 390. - Transv.

Barrelieri, Davean, in Morot, Fourn. de Bot. viii. (1894) 289 ; et in Bull. Herb. Boiss. ii. (1894) 651. - Eur. mer., Afr. bor.

Beyrichii, 7. G. Smith, in Missouri Bot. Gard. Rep. vi. (1895) 117 t. 56. - Arkans., Texas

biflora, Hack. ex Schinz, in Bull. Herb. Boiss. iii. (1895) 390. - Afr. austr.

bipinnata, K. Schum. in Engl. Pflanzenw. OstAfr. C (1895) 113 (= Briza bipinnata, Limn.) $=$ cynosuroides, Beawo

Botteri, Fourn. Gram. Mexic. 1881 (1886) 115. = poaloides, Beauv.

Buchanani, K. Schum. in Engl. Pflanzenw. Ost-Afr. C (1895) 114. - Afr. trop. or.

caroliniana, Scribn. in Mem. Torrey Bot. Club, v. (1894) 49. ( $=$ Poa caroliniana Spreng.) $=\mathrm{E}$ Purshii, Hort. ex Schrad.

collocarpa, K. Schum. ex Engl. in Abh. Prenss. Ahad. Wiss. (1894) 64 ; et in Engl. Pflanzenw. Ost Afr. C (1895) 114. - Afr. trop. or.

densiflora, Hack. ex Sodiro, Gram. Ecuator. (Anal. Univ. Quito, 1889) 9 nomen. - Ecuad.

densissima, Sodiro, l. c. - Ecuad.

denudata, Hack. ex Schinz, in Bull. Herb. Boiss. iii (1895) 392. - Transv.

diversiflora; Vasey, in Contrib. U. S. Nat. Herb. i. (1893) 285. - Mexic.

emarginata, Hack, ex Schinz, in Verh. Bot. Ver. Brand. xxx. (1888) 238. - Afr. austro. occ.

enodis, Hack. l. c. 148. - Afr. austro-occ.

Eragrostis, Karst. Deutschl. Fl. (1880-83) 389 Macmill. Metasp. Minn. (1892) 75 (= Brizu Eragrostis, Linn.) $=$ minor, Host.

glomerata, L. H. Dewey, ex Coult in Contrib, U. S. Nat. Herb. ii. (1894) $543=$ conferta, Trin. grandiflora, f. G. Smith \& Bush, ex f. G. Smith, in Missouri Bot. Gavd. Rep. vi. (1895) 117 t. 56. Indiana, Texas.

grandis, Hillebr. Fl. Haw. Isl: (1888) 528. - Ins. Sandvic.

hawaiiensis, Hillebr. I. c. 530. - Ins. Sandvic.

hispida, K. Schum, in Engl. Pflanzenw. Ost-Afr. C (1895) 114. - Afr. trop. or.

hypnodes, Kuntze, Rev. Gen. (1891) $774=$ seq.

\section{ERAGROSTIS}

ynoides, Britton, Stern \& Poggenb. Prelim. Cat. (1888) 69. (= Poa hypnoides, Lam) = reptans, Nees. namoena, $K$. Schum. in Engl. Pfanzenter Ost-Afr. C (1895) 115. - Afr. trop. or.

incana, Maury, in Morot, Fourn. de Bor, iii. (1889) $163 \mathrm{fig}$. 6. - Am. austr. trop.

internupta, Trelease, ex Branner \& Coville, in Ann. Rep. Geol. Surv, Arkansas, 1885. (1891) $237^{\circ}=$ oxylepis, Trin.

Kennedyae, F. Turner, in Proc. Linn. Soc. N.S. Wales, Ser. II. viii. (June 1894) 535. - Austra1. laetevirens, K. Schum, in Abh. Preuss. Akad. Wiss (1894) 12. - Afr. trop.

asiophylla, K. Schum. in Engl. Pfanzenw. Ost-Afr. C (1895) 114. - Afr trop.

Iaxissima, K. Schum. ex Engl, in Abh. Preuss. Akad. Wiss. (1894) 58 ; et in Pflanzenw. Ost Afr. A (1895) $99=$ macilenta, Stend.

Marlothii, Hack. in Bot. Fahb. xi. (1890) 404.-Afr austr.

meoalostachya, St. Lacer, in Cariot, Etud. des fl. éd. 8. ii (1889) $935=$ major, Host

membranacea, Hack. ex Schinz, in Verh. Bot. Ver Brand. xxx. (1888) 148. - Afr. austro-occ

micrantha. Hack. ex Schinz, in Bull. Herb. Boiss, iii 1895) 388. - Afr. austr.

montana, Balansa, in Morot, fourn. de Bot. iv. (1890) 168. - As. trop. occ

monticola, Hillebr. Fl. Haw. Isl. (1888) 531 (= Poa monticola, Gaudich.). - Ins. Sandvic.

mucronata, Deflers, in Bull. Soc. Bot. Fr, xxxiv. (1887) 69 (= Uniola mucronata, Linn.). - Arab.

olivacea, $K$. Schun, ex Enol. in Abh. Prenss. Akad. Wiss. (1894)57; et in Pfanzenw. Ost-Afr. C (1895) 114. - Afr. trop. or

Oreuttiana, Vasey, in Contr. U.S. Nat. Herb. i. (1893) 269. - Calif

Palisoti, Th. Dur. \& Schinz, Consp. Fl. Afr. v. 1894 (1895) 887.

pallens. Hack. ex Schinz, in Bull. Herb. Boiss, iii. 1895) 392. - Transv.

pallida, Vasey, in Contrib. U S. Nat, Herb. i. (1893) 285. - Mexic.

patentíssima, Hack. ex Schinz, in Bull. Herb. Boiss. iii. (1895) 391. - Transv

perbella, K. Schum. ex Engl. in Abh, Preuss. Akad. Wiss. (1894) 38 ; et in Pflanzenw. Ost-Afr. C (1895) 115. - Afr. trop. or

phleoides, Hillebr. Fl. Haw. Isl. (1888) $530=$ Ins. Sandvic.

Rahmeri, Phil. in Anal, Mus. nuc, Chile (1891) 88 - Am. austr. occ

Rankingi, F. M. Baitey, in Dept. Agric. Brisbane, Bot. Bull. ii. (1891) 22. - Austral.

refracta, Scribn. in Mem. Torrey Bot. Club, v.

(1894) 49 (= Poa refracta, Muh1.) = pectinacea

rigida, Scribn. in Proc. Acad. Philad. (1891) 304 Vasey, Grass. South-West (1891) t. $41=$ sessilispica, Buckl.

rigidifolia, Hochst. ex Engl, in Abh. Prenss. Akad.

Wiss. 1891 (1892) 133. - Abyss.

Scotelliana, S. Elliot, in fourn. Linn. Soc. xxx. (1894) 99. - Sierra Leone.

spicata, Vasey, in Coult. Bot. Ga\%. xvi. (1891) 146. - Calif. inf.

sporoboloides, 7. G. Smith et Buch, ex 7. G. Smith, in Missouri Bot. Gard. Rep. vi. (1895) 116 t. 54. - Indian.. Texas.

stricta, F. M. Bailey, in Dept. Agric. Brisbane, Bot. Bull. iii. (1891) 19. - Austral.

Thunbergii, Baill. Hist. des pl. xii. (1894) $222=$ cynosuroides, Roem. et Schult.

Thunbergii, Franch, in Bull. Soc. Limn. Paris, ii. (1892) 1055 [an praec, ?] - Afr. austr.

thyrsoidea, Hillebr. Fl. Haw. Ist. (1888) 529. Ins. Sandvic

trichodes, Nash, in Bull. Torrey Bot. Club, xxii. (1895) 465. = Geyeri, Steud.

truncata, Hack. in Bot. Fahrb. xi. (1890), 405. Atr. austr.

Warburgii, Hack. I. c. xiii. (1891) 262. - Oceania.

ERANTHEMUM, Linn. (Acanth.), - Ind. Kew. i. 859 .
ERANTHEMUM : -

affine, Warb. in Bot. Fahrb. xiii. (1891) 420. Oceania.

fastigiatum, Kuntze, Rev, Gen. (1891) $489=$ Daedalacanthus montanus, T. Anders.

lateriflorum, C. B. Clavke, in fourn. Linn. Soc. xxv. (1889) 55 t. 27. - Ind. or.

Ludovicianum, Büttn. in Verh. Bot. Ver. Brand. xxxii. (1890) 41 = Pseuderanthemum Ludovicianum, Radlk.

pacificum, Engl. Bot. Fahrb. vii. (1886) 475 . N. Hannov.

parviflorum. Warb. in Bot. Fahrb. xiii. (1891) 420 . - Oceania.

plumbaginoides, Maury, in Morot, fourn. de Bot. ii. (1888) 264 cum xylogx. — Gabon.

polyanthum, C. B. Clarke, ex Oliver, in Hook, Icon. pl. xx, (1891) t. 2000. - Assam.

polyneurum, C. B. Clarke, ex Kuntze, Rev. Gen. (1891) 495. - Ava.

tubiflorum, Radlk, ex Lindau, in Eng1. \& Prantl, Natürl. Pflanzenfam. iv. 3 b. (1895) $311=$ Daedalacanthus tubifiorus, $T$. Anders.

Whartonianum, Hemsl. in Kew Bull. (1894) 214.Ins. Salom.

ERANTHIS, Salisb. (Ranunc.) - Ind. Kew. i. 860

albiflora, Franch. in Nouv. Arch. Mus. Faris, Sér II. viii. 1885 (1886) 191. - Tibet.

ERATICA Gumi, Hort. ex Dippel, Handb. Laubholzk i. (1889) $292=$ Olearia Gunniana, Hook.

ERECHTITES, Rafin.(Compos.). - Ind. Kew, i. 860

diversifolia. Petrie, in Trans. N. Z. Inst. xix. 1886 (1887) $324 .-$ N. Zel.

EREICOCTIS, Kuntze, Rev. Gen. (1S91) $281=$ Mallostoma Karst. (Rubiac.).

acerosa, Kuntze, 1. $\mathrm{c}_{\mathrm{n}}=$ Houstonia acerosa, Benth et Hook. $f$.

capitata, Kuntze, 1. c. = Hedyotis Hartwegiana, Wedd.

caracasana, Kuntze, 1, c. = Mallostoma caracasanum, Benth. G Hook. f.

Cervantesii, Kuntze, 1. c。= Hedyotis Cervantesii $H . B$. \& $K$.

conferta, Kuntze, 1. c. = Mallostoma confertum, Benth. \& Hook. $f$.

crassifolia, Kuntze, 1, $c$. = Hedyntis crassifolia, Spruce, fide Kuntze.

cricodes, Kuntze, 1. c. = H. ericoides, Willd.

filiformis, Kuntze, 1. c. = Mallostoma filiforme, Benth. \& Hook. f.

hypnodes, Kuntze, 1. C. = Hedyotis hypnoides, H. B. \& $K$

hyssopifolia, Kuntze, 1. c. = Mallostoma hyssopifolium, Benth. Go Hook. f.

uniperifolia, Kuntze, 1. c. = M. juniperifolium, Benth. \& Hook.f.

aricifolia, Kuntze, $1, c_{=}=$Mallostoma laricifolium, Benth. \& Hook. f.

microphylla, Kuntze, 1. c. = Hedyotis microphylla, H. $B . \& K$

mitida, Kuntze, 1. c. = Mallostoma nitidum, Benth. E Hook. $f$.

setosa, Kuntze, 1. c. = M. setosum, Benth. \& Hookf. thymifolia, Kuntze, 1. c. = M. thymifolium, Benth. of Hook. $f$.

EREMANTHUS, Less. (Compos.).-- Ind. Kew. i. 861.

purpurascens, Oliver, in Hook. Icon, pl. xxiii. (1894) t. 2282, - Bras.

EREMIASTRUM, A. Gray (Compos.). - Ind. Kew. i. 861 .

Orcuttii, S. Wats. in Proc. Am. Acad. xxv. (1890) 132. - Calif.

EREMINULA, Greene, Pittonia, ii. (July 1892) $248=$ Dimeresia, A. Gray (Compos.). Howellit, Greene, 1. c. = D. Howellii, A. Gray. 
EREMOCARYA, Greene, Pittonia, i. (July 1887 ) 58 = Eritrichium, Schrad. (Borag.)

Ictide Greene, 1. c. $59=$ E. micranthum, Phil. var.

micrantha, Greene, 1. c. $59=$ E. micranthum Phil. var.

EREMOCHLOA, S. Wats. (Gramin.). - Ind. Kew, i. S61.

bimaculata, Hack. in DC. Monog. Phan. vi. (1889) 265. - Ind. or.

ciliatifolia, Hack. l. c. - Ind, or.

falcata, Hack. l. c. 263 (= Ischaemum falcatum, Nees). - China.

leersioides, Hack. l. c. $264(=$ I. leersioides, Munro). - China.

muricata, Hack. l. c. $262(=I$. pectinatum, Trin.). - Ind. or.. Austral.

ophiuroides, Hack.l.c. 261 (=I. ophinwoides, Munro). - China.

zevlanica, Hack. .. c.263 (= I. falcatum, Thw.).Zeylan.

EREMOGRINUM, M. E. Jones, in Zoë, iv. (1893) 53. t. 25 ; Baill. Hist. des pl. xii. (1894) 536 IILI ACEAE.

albomarginatum, M. E. fones, $l l . c$. . (= Hesperanthus albonarginatus, M. E. Jones). - Calif.

EREMOLEPIS, Griseb. (Loranth.).-Ind. Kew.i. 861

microcalyx, Ernst, in Rev. cient. mens, Univ, centr. Venez. i. (1887) 133. - Venez.

EREMOLOBIUM, aegyptiacum, Aschers, ex Boiss. F1. Or. Suppl. (1888) $30-$ Malcolmia aegyp tiaca, Spreng.

EREMOLUMA, Baill. in Bull. Soc. Linn. Paris, ii. 925 ; et Hist. des pl. xi. (1892) 291. SAPOTA$C E A E$.

Sagotiana, Baill, Il. cc. 925 et 292. - Guian.

EREMOMASTAX, Lindau, in Bot. Jahrb, xx. (1894) 8; et in Engl. \& Prantl, Natürl, Pflanzenfam. iv. 3 b. (IS95) $297=$ Paulo-Wilhelmia, Hochst. (Acanth.).

crossandriflora, Lindau, 11. cc. = P. Sclerochiton, Lindau.

EREMOPHILA, R. Br. (Myopor.). - Ind. Kew. i. 861 .

Battii, F. Muell. in Proc. Linn. Soc. N. S. Wales. Ser. II. v. (Tune 1890) 187. - Austral.

Merralli, F. Muell. in Vict. Natural. ix. (Sept. 1892) 6.3 nomen. - Austral.

Phillipsii, F. Muell. l.c.76.- Austral.

Tietkensiz, F. Muell. \& Tate, in Trans. et Proc. Roy. Soc. S. Austral. xiii. (1890) $109=$ E. Latrobei F. Muell.

EREMOSPARTUM, Fisch. \& Mey. [Eremosparton] (Legum.). - Ind. Kew. i. 862

Schumanni, Kuntze, in Act. Hort. Petrop. x. (1\&87) 184. - Turkest.

EREMosPATHA, Mann \& H. Wendl. (Palm.). - Ind. Kew. i. 862

decrata, Th. Dur. \& Schinz, Consp. Fl. Afr. v. 1893 (1895) $458=$ Calamus deerratus, Mann \&. H. Wendl.

EREMOSTAGHYS, Bunge (Labiat.) - Ind. Kew. 1. 62.

adpressa. Regel, in Act. Hort. Petrop. ix. (1886) ว.3s. - Turkest.

Alberti, Regel, l. c.537. t. 8. - Turkest.

Beckeri, Regel. l. c. 561.t. 7.-Persia,

Boissieriana, Regel, l. c. 559. - Turkest.

cordifolia, Regel, l.c.550.t.5.- Turkest.

desertorum, Regel.l.c. 563.t. 7. - Turkest.

eriocalyx, Regel, l. c. 564. t. 9. - Turkest.

Fetisowi, Regel, l.c.547.t. 5 (= Phlomis Alberti,

Regel). - Turkest.

hissarica, Regel, l.c. 542, t. 4. - Turkest.

nuda, Regel, l. c.540t. 3. - Turkest.

\section{EREMOSTACHYS}

pauciflora, Kuntze, in Act. Hort. Petrop. x. (1887) 226. - Turkest.

persimilis, Aitch. E. Hemsl. in Trans. Linn. Soc. Ser. II. 1ii(1886) 98. - Turkest.

Regeliana, Aitch. \& Hemsl. l. c. 99. - Atghan.

sarawschanica, Regel, in Act. Hort. Petrop. ix (1886) 548 t.5. - Turkest.

transiliensis, Regel, l. c. 556 t. 6. - - Songar.

Trautvetteriana, Regel, l. c. 551 t. 5. - Turkest.

uniflora, Regel, l. c. 558 t. 7. - Turkest.

EREMOTHAMNUS, O. Hoffm, in Bot. Jahrb. x. (1889) 278. COMPOSITAE.

Marlothianus, O. Hoffm. l. c. 279. - Afr. austroocc. extratrop.

EREMURUS, Bieb. (Liliac.). - Ind. Kew. i. 862. Aschersoni, Euntze, in Act. Hort. Petrop.x. (1887) 243. - Turkest.

parviflorus, Regel, in Act. Hort. Petrop. ix. (1886) 609. - Buchara.

ERIA, Lind1. (Orchid.). - Ind. Kew. i. 862.

albiflora, Rolfe, in Kew Bull. (1893) 170. - Ind. or,

andamanica, Hook of Fl Brit, Ind v (1890) 801 ; et in Hook. Icon, pl. xxi. (1891) t. 2073. - Ins. Andam.

Andersoni, Hook. f. ll. cc.795; et t. 2069. - Reg. Himal.

augustifolia, Ridl. ex Stapf, in Trans. Linn. Soc. Ser. II. iv. (1894) 23\%. - Borneo

aporina, Hook. f. Fl. Brit. Ind.v. (1890) 808; et in Hook. Icon. pl. xxi. (1892) t. 2081. - Perak.

australiensis, F.M. Bailey. Occas. Pap. no 1. 8; Syn. Queensl. Fl. Suppl. ii. 57. - Austral.

calamifolia, Hook.f. Fl. Brit. Ind.vi. (1890) 191.Assam.

cinnabarina, Rolfe, in Kew Bull. (1894) 183; et in Lindenia, x. (1894) 35. t. 448, -- Borneo.

choniana, Kraenzl. in Bot. Fahro. viii.(1887) 203. Ind, or. ?

confusa, Hook. f, in Hook. Icon. pl. xix, (1889) t. 1850 ; et Fl. Brit. Ind. v. (1899) 796. - Ind or

crassicaulis, Hook.f, $l l . c c .805$; et t. 2076. - Bengal.

cristata. Rolfe, in Kew Bull. (1892) 139. - Moulmein.

elata, Hook. f. in Hook. Icon. pl. xix. (1S89) t. 1848; et Fl. Brit. Ind. v. (1890) 794. - Perak.

exilis, Hook. f. Il.cc. Tis ; et (1891) t. 2074. - Travanc

Fordii. Rolfe, in Gard. Chron. (1\&86) 11.584= carinata, Gibs.

gracilis, Hook. f. Fl. Brit. Ind. V. (1S90) 806; ot in Hook. Icon. pl. XXI. (1891) t. 2078. - Perak.

grandis, Ridl. ex Staff, in Trans. Limn. Soc. Ser. II. iv. (1894) 237. - Borneo.

iridifolia, Hook. f. Fl. Brit. Ind. v. (1850) r90; et in Hook. Icon. pl. XXI. (1891) t. 2067. - Pexak.

japonica, Maxim. in Bull. Acad. Sci. St Pétersb. xxxi. (1887) 103. - Japon.

Kingii, Hook. f. F1. Brit. Ind, v. (189S) 790 ; et in Hook. Icon. pl. (1891) t. $2067=$ Scortechinii, Stapf,

Kurzii, T. Anders, ex Hook. f. 1. c. (1890) $797=$ bractescens, Lindl.

lancifolia, Hook. f. l. c. (1890) S04; et in Hook. Icon. pl. XXI. (1891) t. 2075. - Perak.

Laucheana, Kracnzl. in Gard. Chron. (1892) 1. 809. - Hab.?

leptocarpa, Hook. f. Fl. Brit. Ind. v. (1890) 805 ; et in Hook Icon. pl. XXI. (1891) t. 2077. - Perak

longifolia, Hook. f. 7l. cc. 790; et (1891) t. 2068. Perak.

Iuchuensis, Yatabé, in Tokyo Bot. Mag. vii. (1892) 131. - Japon.

Maingayi, Hook. f. Fl. Brit. Ind. v. (1890) 798 ; et in Hook. Icon. pl. XXI. (1891) t. 2072. - Penang. major, Ridl. ex Stapf, in Trans. Linn. Soc. Ser. II iv. (1894) 237. - Borneo.

marginata, Rolfe, in Gard. Chron. (1889) I. 200; et cx Hook. f. in Bot. Mag. (1892) t. 7238. - Burma. Mathervsi, Drake, Fl. Polyn. franç. (1892) $213=$ Phreatia Mathewsij, Reichb. $f$.

Micholitzii, Kraenzl. in Oest. Bot. Zeitschr. xliv, (1894) 460, - N. Guin.
ERIA :

monticola, Hook. f. Fl. Brit. Ind, v. (1890) 806 (= Trichotosia biflora, Griff.). - Malaccd.

oligantha, Hook. f. l. c. 807 et in Hook. Icon. pl. XXI. (1892) t. 2079. - Penang.

pellipes, Reichb. f. ex Hook. f. l. c. 802. - As. trop. puberula, Ridl. in fourn. Bot. xxiv. (1886) 226. N. Guin.

pygmaea. Hook. f. F1. Brit. Ind. v. (1890) $804=$ Ceratostylis eriaeoides, Hook. $f$.

ramosissima. Wall. ex Hook, f. 1. c. $826=\mathrm{C}$. himalaica, Hook. f.

recurvata, Hook. f. l. c.797; et in Hook. Icon.pl. XXI. (1891) t. 2070. - Perak.

saccifera, Hook. f. 17, cc.797 et t. 2071 - Perak Scortechinii, Hook. f. ll. cc. S09; et (1892) t. 2082. - Perak.

Scortechinii, Stapf, in Trans. Limn. Soc, Ser. II iv. (1894) 23\%. - Borneo.

striolata, Reichb. f. in Gard. Chron. (1888) i. 554; et in Illustr. Hort: xxxv. (1888) 35 t. 48. N. Guin.

Thwaitesii, Hook. f. Fl. Brit. Ind. v. (1890) 803 (= Eria vchutina, Thw.). - Zeyl.

tomentusa, Hook. f. l. c. 803 (= Epidendrum tomentosum, Koen.). - Ind. or.

tuberosa, Hook. f. i.c. 807 ; et in Hook. Icon. pl. XxI. (1892) t. 2080. - Perak.

umbonata, F. Muell. et Kraenzl. ex Kraenzl. in Oest. Bot. Zeitsch. xliv. (1894) 163. - N. Guin.

ERIACHNE, R. Br.(Gramin.). - Ind. Kew.i. 865.

aurea, Th. Dur. \& Schinz, Consp. Fl. Afr. v. 1894 (1895) $836=$ aurea, Nees.

capensis, Th. Dur. \& Schinz, 1. c. = capensis, Steud.

Eckloni, Th. Dur. \& Schinz, 1. c. = Eckloni, Nees.

ERIANTHEMUM, Van Tiegh. in Bull. Soc. Bot. Fx. xlii. (1895) 248 = Loranthus, Linn.

Dregei, Van Tiegh. 1. c. = L. Dregei, Eckl. et Zeyh Schelei, Van Tiegh. 1. c. = L. Schelei, Engl.

taborensis, Van Tiegh. 1. c. = L. taborensis, Engl.

ERIANTHUS, Michx.(Gramin.). - Ind. Kew. i. 864 .

Balansae, Hack. m DC. Monog. Phan. vi. (1889) 133. - Parag.

chrysothrix, Hack. in Oest. Bot. Zeitschr. xli. (1891) 6. - Ind. or

compactus, Nash, in Bull. Torrey Bot. Club, xxii. (1895) 419. - Am. bor.

flavescens, $K$. Schum. in Engl. Pflanzenw. Ost-Afr. C (1895) 96. - Afr. trop. or.

Hookeri, Hack. in DC. Monog. Phan. vi. (1889) 143 - Ind. or.

pallens, Hack. l. c. 143. - Reg. Himal,

pedicellaris, Hack. l. c. 137 (= Saccharum pedice?lare, Trin.). - N. Caled.

Trinii, Hack. l. c. 135. - Mexic., Am, austr.

violacens, K. Schum. in Engl. Pfanzenw. Ost-Afy. C (1895) 96. - Afr. trop. or.

ERICA, [Tourn.] Linn. (Ericac). - Ind. Kew. i.

denophylla, Bolus, in fourn. Limn. Soc. xxir.

(1887) 181. - Afr. austr.

algida, Bolus, in fourn. Bot. xxxii. (189t) 238. Afr. austr.

aspalathifolia, Bolus, in fourn. Linn. Soc. xxiv. (188\%) 182. - Afr, austr.

barbertona, Galpin, in Kow Bull. (1895) 148. Transvaal.

Baurii, Bolus, in fourn. Linn. Soc. xxiv. (1887 178. - Afr. austr.

Brownleeae, Bolus, l. c. 185. - Afr. austr.

caffrorum, Bolus, $l$. c. 184. - Afr. austr.

Cooperi, Bolus, l. c. 179. - Afr. austr.

eriopodon, Bolus, l. c. 186. - Afr. austr.

Fairii, Bolus, in fourn. Bot. xxxii. (1894) 236. Afr, austr.

Flanagani, Bolus, l. c. 238. - Afr. austr.

flava, Bolus, l. c. 239. - Afr. austr.

frigida, Bolus, l. c. 235. - Afr. anstr. 


\section{ERICA :}

Guthriei, Bolus, in fourn. Bot. xxxii. (1894) 234. Afr. austr.

haemantha, Bolus, in fourn. Linn. Soc. xxiv. (18s7) 181. - Afr. austr.

inops, Bolus, $l$. c. $186,-$ Afr. austr.

Johnstoniana, Britten, in Trans. Limn. Soc. Ser. II. iv. (1894) 23. - Afr. trop.

Junonis, Bolus, in fourn. Bot. xxxii. (1894) 234. Afr. austr.

Lerouxiae, Bolus, in fourn. Linn. Soc. xxiv. (1887) 182. - Afr. austr.

maesta, Bolus, in fourn. Bot. xxxii. (1894), 239. Afr. Austr.

Marlothii, Bolus, l. c. 237. - Afr. austr.

missionis, Bolus, in fourn. Linn. Soc. xxiv. (1887)

179. - Afr, austr.

natalitia, Bolus, l. c. 187. - Natal.

nubigena, Bolus, in fourn. Bot. xxxii. (1894) 236. Afr. austr.

oresigena, Bolus, l. c. 238. - Afr. austr.

Rhodopis, Bolus, l. c. 239. - Afr. austr.

satureioides, Sond. ex Bolus, in Journ. Linn. Soc. xxiv. (188T) $18 \%=$ Tysoni, Bolus.

Schlechteri, Bolus, in fourn. Bot. xxxii. (1894) 235. - Afr. austr.

tetrastigmata, Bolus, in fourn. Linn. Soc. xxiv. (1887) 178. - Afr. austr.

trichadenia, Bolus, l.c. 183. - Afr. austr.

Tysoni, Bolus, l. c. 181. - Afr. austr.

Urna-viridis, Bolus, l. c. 180. - Afr. austr.

Vilmoriana, Hort. ex Carr. 1. c. in obs. = Wilmorei. Knowl. et Westc.

Vilmoriniana, Hort. ex Carr. in Rev. Hort. (1891) 235. in obs. = Wilmorei, Knowl. et Westc.

Whyteana, Britten, in Trans. Linn. Soc. Ser. II iv. (1894) 24. - Afr. trop.

Willmoreana, Hort. ex Carr. in Rev. Hortic. (1891) 235. in obs. = Wilmorei, Knowl.et Westc.

Willmoriana, Hort. ex Carr. 1. c. in obs. = Wilmorei, Knowl. et Westc.

Woodii, Bolus, in fourn. Bot. xxxii. (1894) 237. Afr, austr.

ERICAMERIA, Nutt. = Aplopappus, Cass. $($ Compos.).

arborescens, Greene, Man. Bot. San Franc. Bay (1894) 175 = Bigelovia arborescens, A. Gray. cuneata, McClatchie, in Erythea, ii. (1894) $124=$ Aplopappus cuneatus, A. Gray.

monactis, McClatchie, $l . c_{0}=$ A. monactis, $A$. Gray.

ERICODES, Moehr. = Erica, [Tourn.] Linn. (Eric.).

abietinum, accomodatum, acutum, adenophorum, adenostemun, aduncun, aequale, affine, aggregatum, Aitonianum, albens, albescens, ampullaceum, andromediflorum, angustatum, Aphanes, appressum, arboreum, ardens, argenteum, aristatum, aristifolium, armatum, articulare, aurenm, australe, axilliflorum, azaleaefolium, azoricum, baccans, Banksii, barbatum, barbigerum, Bartlngianum, Benthamianum, Bergianum, bicolor, blandum, Blanfordiznum, blennum borboniaefolium. Bowieanum, brachiale, brachycentrum, bracteatum, brevifolium, Broadleyanum, bruniodes, bruniaefolium, Burchelliz, caducum, caledonicum, campanulatum, canaliculatum, capillare, capitatum, carduifolium, carinatum, cephalotes, cernum, cerviciflorum, Chamissonis, chlamydiflorum, chlorolomum, chlorosepalum, chrysanthum, ciliare, cinerascens, cinereum, cistifolium, claviferum, coarctatum, coccineum, colorans, comosum, condensatum, confertum, conicum, conspicuum, Constantia, cordatum, corifolium, coroniferum, Corydalis, crassifolium, crassisepalum, cruentum, cubicum, cumuliflorum, curviflorum, curvfolium, curvirostre, cymosum, daphniflorum, decipiens, decorum, deflexum, deliciosum, demissum, denticulatum, depressum, desmanthum, dianthifolium, dilatatum, diosmifolium, diotiflorum, discolor, distans, distortum, dumosum, dysanthum, elegans, empetrifolium, Eriopus, exiguum, exsurgens, fabrile, fasciculare, fastigiatum, faustum, flamentosa filiforme, filipendulum, fimbriatum, flaccum, flammeum, favicans, favicomum, flexicaule, flocciflorum, floccosum, flcribundum, floridum, foliaceum, formosum, fragrans, fucatum, fulgidum, gibbosum, gigan-

\section{ERICODES :}

teum, Gillii, gilvum, glanduliferum, glandulosum, glaucum, globosum, glomeratum, glutinosum, gnaphalodes, grandiflorum, Halicacaba, hebecalyx, Hesseanum, hirsutum, hirtum, hirtiflorum, hispidulum. humifusum, humile, imbricatum, incarnatum, inclusum, incomtum, inconspicuum, incurvum, inflatum, insultum, intermedium, intervallave, intolucratum, involvens, Irbyanum, irregulare, ixantherum, jasminziflorum, Kraussianum, lachnaeum, lactiflorum, laetum, laevigatum, lamprotes, lanatum, lanuginosum, lascirum, latifolium, Lau'sonianum, laxum, Lehmannii, leiophyllum, leptopus, leucantheram. leucodesmium, lineatum, longiaristatum, longifolium, lungipes, lucidrm, luteum, macrolomum, macropliyllum. mammosum, margaritaceum, marifolium, medium, melantherum, Mertensianun. Meyerianum, minutissinum, mirum, modestum, nolle, monadelphum, Monsonianum, moschatun, mucosum, mucronatum, multiflorum, Muscari, nanum, nidularium, nigritum, nitens, nitıdum, nivale, niveum, nodiflorum, nudiflorum. nutans, obliqunm, oblongiflorum, obtusatum, odoratum, oophyllum, opulentum, orinum, oxycoccifolium, pallens, palliiflonum, paniculatum, parile, parviflorum, Passerinae, patens, patulum, pedicellatum, pedunculare, peltatum, penicillatum, persolutun, perspicumm, petiolatum, physanthum, physodes, pliysophyllum, piliferum, piluliferum, planifolium, phunosum, podophyllum, pogonantherum, polifolium, polyanthum, polycodon, polycomum, pracox, praestans, procumn. bens, propendens, protrudens, puberulum, pubescens. pubigerum, pulchellum, punilum, purpureum, pusillum, pycnanthum, pyramidale, pyramidiforme, quadraeflorum, racemosum, ramentaceum, recurvatum regerminans, regium, retortum, Roxburghil, Nobns, sagittatum, salax, scabriusculum, scoparium, selaginifolium, senile, seriphiifolium, serratifolium, setanifolium, senile, seriphiifolium, serratifolium, seta-
coum, setiferum, setosum, setulosum, sexfarium, sitiens, socciflorum, speciosum, spectabile, sphaerocephalum, spicatum, spumosum, squamosum, squarrosum, stamineum, Steinbergianum, stellatum, stenanthum, stenophyllum, strigosum, stylare, subterminale, subulatum, suffultum, sulcatum, taxifolium, tenellum, tenue, tenuicaule. tenuiflorum, tenuifolium, teretiusculum, tetragonum, Tetralix, teucriifolium, Thunbergii, thymifolium, tomentosum, transparens, triceps, trichophorum, trichophyllum, triflorum, triphyllum, triste, turbiniflonum, turgidum, turmale, turrigerum, umbellatum, umbelliflorum, unibracteatum. unilaterale, vagans, variabile, ravium, velitare, ventricosum, verecundum, vernicifhum, versicolor, verticillatum, vesiculare, restiflum, vestitum, vallosum, virescens, virginale, viridiflorum, viridipurpureum, viscarium, Walkeri, Wendlandianum, Willdenowii, Zeyheri, Kuntze; Rev. Gen. (1891) 963-68 = homonyma omnia Ericae.

arborenn, Kuntze, 1. c. $389=\mathrm{E}$. arborea, Linn. caffrum, Kuntze, 1. c. $965=$ E. urceolaris, Berg. calycina, Kuntze, 1. c. $965=$ E. vespertina, Linn. $f$ calyculata, Kuntze, 1. c. = E. penicilliflora, Salisb. capax, Kuntze, 1. c。 = E. oblata, $A n d r$. caterviflorum, Kuntze, 1.c.= E. catervaeflora, Salisb. cerinthodes, Kuntze, 1. c. E. cerinthoides, Limn. cratervifiorum, Kuntze, 1. c. [Quid?] an E. catervaeflora, Salisb.

cristiflorum, Kuntze, 1. c. = E. cristaeflora, Salisb. cylindricum, Kuntze, 1. c. = E. tenuiflora, Andr. cyrilliflorum, Kunze, 1. c. = E. palustris, Andr. densifolium, Kuntze, 1. c, = E. Uhria, Andr. dichroum, Kuntze, 1. c. $966=$ E. dichrus, Spreng. doliiforme, Kuntze, 1. c, $965=\mathrm{E}$. blanda, $A n d r$. empetrodes, Kuntze, 1. c, $966=\mathrm{E}$, empetroides, $A n d r$. genistifolium, Kuntze, 1. c. = E. genistaefolia, Salisb.

glomiflorum, Kuntze, 1. c. $965=$ E. reflexa, Link. glumiflorum, Kuntze, 1. c. $966=\mathrm{E}$. glumaellora, Klotzsch.

herbaceum, Kuntze, 1. c. 963. = E. carnea, Linn.

herrenlanusiense, Kuntze, 1. c. $965=\mathrm{E}$, cylindrica, Wendl.

Hibbertianum, Kuntze, 1. c. = E. Hibbertia, Andr. insultum, Kuntze, 1. c。=E. insulsa, Forbes.

lachnaeodes, Kuntze, 1. c. = E. lachnaeoides, G.Don. lavendulifolium, Kuntze, 1. c. = E. lavandulaefolium, Salisb.
ERICODES :

Leeantm, Kuntze, Rev. Gen. (1891) $000=$ E. Leea Andr.

luteoalbum, Kuntze, 1. c. = E, leucantha, Linzk. lycopodiodes, Kintze, 1. c. = E. lycopodioides, Hor

Mackeyi, Kuntze, 1. c. = E. Tetralix, Linn,

Massonii, Kuntze, 1, c. = E. Massoni, Linn.f. melastomun. Kuntze, 1.c. = E. Petiverii. Wild Meuronii, Kuntze, 1. c. $967=$ E. Meuroni. Benth. minus, Kuntze, 1. c. 905 . = E. perlata, Forbes. Nirenii, Kuntze, 1. c. = E. Nivenia, Andr.
onosmiflorm, Kuntze, 1. c. = E. onosmaeflora, Salisb.

pallidopurpureum, Kuntze, 1. c. $963=$ E. vagans, Linn.

pavettiflorum, Kuntze, 1. c. $967=\mathrm{E}$. pavettaeflora,

pectinifolium, Kuntze. 1. c. $965=\mathrm{E}$, erubescens, Andr.

pellucidum, Kuntze, 1. c. = E. venusta, Forbes

pendulum, Kuntze, 1. c. = E. stricta, Donn.

periplociflorm, Kuntze, 1.c. $967=\mathrm{E}$. periplocaeflora Salisb.

Petiveri, Kuntze, 1. c. $965=$ E. Sebana, Donn.

placentiflorum, Kuntze.1. c. $=$ E. tiaraeflora, Andr. Plukenetii, Kuntze, 1. c. $967=$ E. Plukeneti, Linn. polygaliflon, Kuntze, 1. c. = E. polysalaeflora, Klotzsch.

polytrichofolizm, Kuntze, 1. c, = E, lusitanica Rudolph.

Savileanum, Kuntze, 1.c. = E. Savilea, Andr.

scoparium, Kuntze, 1. c. $390=$ E. scoparia, Linn. Shannonianum, Kuntze, 1. c. = E. Shannonea, Andr. sicifolimm, Kuntze, 1. C. = E. sicaefolia, Salisb. simplicifolinm. Kuntze, 1. c. = E. brucinaeformis, Salisb.

Solandrianum, Kuntze, 1. c. = E. Solandra, Andr. Sparmanii, Kuntze, 1. c。 = E. Sparmani, Limn. $f$. spaeranthum, [sphalm. = sphaeranthum?] $=\mathrm{E}$. sphaerantha, Spreng.

splendens, Kuntze, 1. c.965.= E. tumida, Ker-Gawl. stagnale, Kuntze, 1. C. $=$ E. sulphurea, $A n d r$. strigiliolium, Kuntze, 1. c, = E. elongata, Lodd. tenuissimum, Kuntze, 1. c。= E. gracilis, Salisb. tetrathecodes, Kuntze, 1. c. $967=\mathrm{E}$. tetrathecoides, Benth.

traguliferum, Kuntze, 1. c. $965=\mathrm{E}$. nitida, Andr. trichromum. Kuntze, 1. c. $967=\mathrm{E}$. trichoma, Benth. tubiflorum. Kuntze, 1. c. $965=$ E. ignescens. Andr.

ERIGERODES. Linn. Fl. Zeyl. (1747) 197, ex Kuntze, Rev. Gen. (1891) $335=$ Epaltes, Cass. (Compos.).

australe, brasiliense, Cunninghamii divaricatum, garie pinum, Harrisii, mexicanum, pleiochaetum, pygmaeum, Tatei, Kuntze, Rev, Gen. (1891) $335=$ hononyma omnia generis Epa'tis.

ERIGERON, Linn. (Compos.). - Ind. Kew. i. 873. lomosanus, N. E. Rose, in Contrib. U.S. Nat. Herb. i. (1891) 102. - Mexic

Alinae, Boerl. Handl. Fl. Ned. Indië, ii, r. (1891) 237 = Vittadinia Alinae, F. Muell.

andryaloides, Boiss. Fl. Or. Suppl. (1888) 288 (= Conyza andryaloides, DC.).- Reg. Himal., Tibet. angustata, Greene, Man. Bot. San Franc. Bay (1894) 181. - Calif.

angustifolia, Phil. in Anal. Univ. Chil. Ixxxvii. (1894). 418. - Chili.

araucanus, Phil. 1. c. 142. - Chili

aristhales, Phil. l. c. 412. - Chili.

aureus, Greene, Pittonia, ii. (Sept, 1S91) 169,

Aplopappus Brandegei, A. Gray.

Austinae, Greene, in Erythea, iii. (1895) 100. Calif.

barbellulatus, Greene, l.c.65. - Calif.

Biolettii, Greene, Man. Bot. San Franc. Bay (1894) 181. - Calif.

Blasdalei, Greene, in Erythea, iii. (1895) 124. Calif.

Bonplandii, 7. Buchan. in Trans. N.Z. Inst. xix. 1886 (1887) 213. - N. Zel.

bracliycomoides, Boerl. Handl. Fl. Ned. Indië, ii, 1. (1891) $237=$ Vittadinia brachycomoides, F. Muell 


\section{ERIGERON}

Branderei, Millsp, in Proc. Calif. Acad. Ser. II. ii. (1859) 226. - Calif.

brevicaulis, Phil. in Anal. Univ. Chil. Ixxxvii. (1894) 416. - Chili.

Brittonianus, Rusby, in Mem. Torrcy Bot. Club, ii. 3. (1893) 54. - Bolivia.

alifornicus, fepson, in Bull. Torrey Bot. Club, xviii. (1891) 324. - Calif.

calvus, Coville, in Proc. Biol. Soc. Wash. vii. (1892) 69. - Calif

chihnahamus, Greene, Pittonia, ii, (Sept 1891 ) 169 = Achaetogeron pinnatifidus, A. Gray.

cochlearifolius, Phil. in Anal. Univ. Chil. lxxxvii. (1894) 414. - Chili.

colinensis, Phil. l. c. 420 - Chili.

comonduanus, Millsp. in Proc. Calif. Acad. Ser. II ii. (1889) $229,-$ Calif.

conjunctus, Millsp. l. c. 227. - Calif

continis, Howell, in Erythea, iii. (1895) 35. - Am. bor, occ.

coronarius, Greene, Pittonia, ii. (Sept. 1891) $16 \%$. - Mexic.

Covillei. Grocne, in Erythea, iii. (1895) 20. - Calif cupularoides, Freyn, in Oest. Bot.Zeitschr. xlv. (1895) 343. - Dahuria.

depilis, Phil. in Anal. Univ. Chil. lxxxvii. (1894) 417. - Chili.

ecuadoriensis, Hieron.in Bot. Fa7rb. xxi. (1895) 336 - Ecuad.

elegantulus, Greene, in Erythea, iii. (1895) 65. Calit.

exilis, A. Gray, ex S. Wats, in Proc. Am. Acad. xxii. (1887) 422. - Mexic

Fernandezi, Phil. in Anal. Uniz. Chil. 1xxxvii (1894 418. - Chili.

Forreri, Greene, Pittonia, ii. (Sept. 1891) 169. = Achaetogeron Forreri, Greene.

fratermus, Greene, 1. c. = A. affinis, A. Gray.

Galeottii, Greene, 1. c. $168=$ A. Galeottii, A. Gray.

Gandini, Bruegg. in Jahresb. Naturf, Ges. Graub. xxxi. (1887-88) $85=$ Villarsii, Bell.

geminilobus, Millsp, in Proc. Calif. Acad. Ser. II. ii. (1889) 228. - Calif.

glabrescens $\times$, Bruegg. in Jahresb. Naturf. Ges. Graub. xxix. (1886) 86; Nym. Consp. Fl. Eur. Suppl. 174. - Helv.

Hartwegi, Greene, in Erythia, iii. (1895)21. - Calif Heleniastrum, Greene, l. c. i. (1893) 150. - Mexic. heteromorphus, Robins, in Proc. Am. Acad. xxvii. (1893) 173. - Mexic.

hirtopilosus, Hicron, in Bot. Fahrb. xxi. (1895) 336 - Peruvia.

hybridus, Hieron. l. c. 334.- N. Granat

hyperboreus, Greene, Pittonia, ii. (May 1892) 227. Alaska.

Ibari, Phit. in Anal. Univ. Chil. 1xxxvii. (1894) 413. - Reg. Magellan.

illapelinus, Phil. l. c. 411.-Chili.

inconspicurs, Mac Mill. Metasp. Minn. (1892) 268 $=$ asper, Nutt.

inoptatus, A. Gray. in Proc. Am. Acad. xxi. (1886) 387. - Mexic.

involutus, Millsp, in Proc, Calif. Acad. Ser. II. ii. (1889) 227. - Calif.

lacarensis, Phil. in Anal. Univ'.Chil. 1xxxvii. (1894) 424. - Chili.

Lehmanni, Hieron, in Bot.Jahrb.xix. (1894) $49=$ loxensis, Hieron.

leptophyllus, Grecne, Pittonia, ii. (May 1892) 226. Colorado.

loxensis, Hieron. in Bot. Fahrb. xxi. (1895) 335. N. Granat.

macer, Boerl. Handl. Fl. Ned. Indië, II. i. (189I) 237 = Vittadinia macra, F, Muell.

mendocinus, Greene, in Erythea, ii. (1894) $106(=$ C. andicola, Phil., non DC.). - Am. OcC.

Ioelleri, Phit. in Anal. Univ. Chil. lxxxvii. (I894) 419. - Chili.

moupinensis, Franch. in Nont. Arch. Mus. Paris. Sér. II. viii. 1885 (1886) 36. - Tibet.

multiceps, Greene, Pittonia, ii. (Sept. 1891) 167 (= E. caespitosus, Vasey et N. E. Rose, non Nutt.). - Calif.

nemoralis, Phil. in Anal. Unv. Chil. Ixxxvii. (1894) 420. - Patagon

\section{ERIGERON}

nubgenus, Phil, in Anal. Univ. Chil. 1xxxvii.,(1894) 423. - Chili.

oxyphyllus, Greene, in Erythea, iii. (1895) 20. - Arizona

Parryi, Canby et N. E. Rose, in Coult. Bot. Gaz. xv. 1890) 65. - Montana.

parviflorus $\times$, Bruegg, in Jahresb. Naturf. Ges. Graub. xxix, (1886) 86. in syn; et xxxi. Beil. (1887-88) 86. - Helv.

patagonicus, Phil. in Anal. Univ. Chil. 1xxxvii. (1894) 414. - Patagon

pellitus, Hieron. in Bot. Jahrb. xix. (1 $\div 94) 49 .=$ hybridus, Hicron.

petrocallis, Greene, in Erythea, iii. (1895) 21. - Nevada.

petrophilus, Greene, Pittonia, i. (Oct. 1888) 218; et Man. Bot. San Franc. Bay (1894) 181. Calif.

pratensis, Phil. in Anal. Univ. Chil. lxxxvii. (1894). 419. - Chili.

Pugae, Phit. l. c. 416. - Chili

purisimanus, Millsp.in Proc. Calif. Acad. Ser. II. ii. 1889) 225. - Calif.

amosus, Britton, Stern et Pogg. Prelim. Cat.

(1888) $27=$ strigosus. Muell.

robustum, Boiss. F1. Or. Suppl. (1888) $290=$ Brachyactis robusta, Benth.

sanctarum, S. Wats, ex T.S. Brandeg. in Proc. Calif, Acad. Ser. II. i. (Oct. 11. 1888) 212 nomen; S. Wats. in Proc. Am. Acad. xxiv. (Jan. 31. 1889) 83. - Calif.

scabrellus, Greene, in Erythea, ii. (1894) 108. Calif.

Schleicheri, Gremli, F1. anal. Suisse (1886) $280=$ Villarsii, Bell.

Semannii, Greene, Pittonia, ii. (Sept. 1891) $168=$ Achaetogeron Seemannii, A. Gray.

setiferus, Post, ex Boiss. Fl. Or. Suppl. (1888) 289; et in fourn. Linn. Soc. xxiv. (1888) 433. Syria.

Shepardi, Post, in Bull. Herb. Boiss. i. (1893) 22.Syria.

Sonnei, Greene, Pittonia, i. (Oct. 1888) 218. Calif.

stolonifer, Greene, l. c. ii. (Sept. 1891) 169. - Am. bor. occ

strigulosus, Greene, 1. c. $169=$ Achaetogeron Palmeri, A. Gray.

Stuebelii, Hieron. in Bot. Fahrb. xxi. (1895) 335.N. Granat.

subtrinervis, Rydberg, in Mem. Torrey Bot. Club, v. (1894) 328. - Am. bor.

Telekii, Schwcinf, ex Engl. in Abh. Preuss. Akad. Wiss. 1891 (1892) 418 nomen; et in Hoehnel, zum Rudoph See, App. (1892) 9. - Afr. trop. or.

tener, M. E. Jones, in Zoë, ii. (1891) 248. = E. Eatoni, A. Gray.

Turneri, Grene, Pittonia, ii. (May 1892) 227.Alaska.

Tweedyanus, Canby \& N.E. Rose, in Coult. Bot. Gaz, xv. (1890) 65. - Montana.

Tweedyi, Canby, 1. c. xiii. (1888) $1 \%=$ tener, $A$. Gray.

umbrosus, Boiss. Fl. Or. Suppl. (1888) 290 (= Conyza Roylei, Kar. et Kir.) - Afghan.

Vidali, Phil. in Anal. Univ. Chil. Ixxxvii. (1894) 410. - Chili.

visidulus, Greene, Pittonia, i. (June, 1888) 174.Calif.

Williamsi, Phil. in Anal. Univ, Chit. Ixxxvii. (1894), 413. - Chili.

Wislizeni, Greene, Pittonia, ii. (Sept. 1891) $168=$ Achaetogeron Wislizeni, A. Gray.

Xanti, Engelm, ex Mallsp. in Proc. Calif. Acad. Ser. II. ii. (1889) 228, - Calif.

ERIOBOTRYA, Lindl. (Rosac.). - Ind. Kew. i.

Griffithi, Franch. P1. Delav, i. (1890) $224=$ Photinia Griffithii, Decne.

lasiogyna, Franch. l. c. 225. - China.

philippinensis, Vidal, Revis. Pl. Vasc. Filip. (Is86) 623. - Ins. Philipp.

prionophylla, Franct. Pl. Delav. i. (1890) 225 t. 46. - Yunnan.
ERIOCARPUM, Nutt. = Aplopappus, Cass. (Compos.).

australe, Greene, in Erythea, ii. (1894) 108. - Am. bor. austro-occ

blephariphyllum, Greene, 1. c. iii. (1895) $14=\mathrm{A}$ blephariphyllus, A. Gray.

coloradense, Greene, 1. c. ii. (1894) $110=$ Aster coloradoensis, A. Gray.

gracile, Greene, 1. c. $109=$ Aplopappus gracilis, A. Gray.

gymnocephalum, Greene, 1.c. = A. gymnocephalus. $D C$.

juncem, Greene, 1.c. $108=$ A. junceus, Greene.

phyllocephalum, Greene, 1. c. iii. (1895) $15=\mathrm{A}$ phyllocephalus, $D C$

mubiginosum, Britton, in Mem. Torrey. Bot. Club v. (1894) $316=$ A. rubiginosus, Torr. et Gray. rubiginosum, Greene, in Erythea, iii. (1895) $15=$ praec.

spinulosum, Greene, 1. c. ii. (1894) $108=$ A. spinu-

losus, $D C$.

stenolobum, Greene, 1. c. 109.-Mexic

ERIOGAULON, Linn. (Eriocaul.).-- Ind. Kew. i.

alpestre, Hook. f. \& Thoms, ex Hook. Fl. Brit. Ind. vi. (1893) 578. - Reg. Himal.

articulatum, Morong, in Bull. Torrey. Bot. Club, xviii. (1891) $353=$ septangulare, With.

bilobatum, Morong, 1. c. xix. (1892) 226. - Mexic.

Capillus-naiadis, Hook. f. Fl. Brit. Ind. vi. (1893) 572. - As. trop.

Carsoni, F. Muell, in Proc. Limn. Soc. N. S. Wales, Ser. II. v. (Sept. 1890) 250; et ex Bot. Centralbl. xliv. (1890) 302. - Austral.

Collettii, Hook. f. Fl. Brit. Ind. vi. (1893) $575 .-$ Burma.

collinum, Hook. f. l. c. 584. - Ind, or.

decemflorum, Maxim, in Bull. Acad sci. St-Pétersb. viii. (93) 7. - China,

dicline, Maxim., l. c. - China.

Duthier, Hook. f. Fl. Brit. Ind, vi. (1893) 578. Ind. or.

elegantulum. Engl.iu Abh. Preuss. Akad. Wiss. (1894 14 nomen; et Pflanzenv. Ost-Afr. C (1895) 133. Afr. trop. or

graphitinum. F. Mucll. E Tate, in Trans, Roy. Soc. S. Austral. xix. (1895) 82 nomen. - Austral.

Helferi, Hook.f. Fl. Brit. Ind. vi. (1893) 583.Tenass.

Hookerianum, Stapf, in Trans, Linn. Soc. Ser. II. iv. (1894) 243. - Borneo.

kiusianum. Maxim. ex Hook. f. F1. Brit. Ind. vi. (1693) $578=$ alpestre, Hook. f. et Thoms.

jaliscanum, S. Wats. in Proc.Am.Acad. xxvi. (1891) 157. - Mexic

Kiusianum, Maxim. in Bull. Acad. sci. St-Pétersb. viii. (93) 22. - China.

leptodictyon, A. Gray, ex S. Wats. in Proc. Am. Acad. xxii. (1887) 420. - Mexic.

longicuspis, Hook. f. Fl. Brit. Ind. vi. (1893) 573.Zeylan.

minutum, Hook. f. l. c. 579. - Ind. or.

mitophylum, Hook. f. l. c. 575. - Khasia

nipponicum, Maxim, in Bull. Acad. sci. St-Pitersb. viii. (93) 9. - Japon.

Philippo-Coburgi, Szyszyl.exWawra, Itin. Princ.S. Coburg. ii. (1888) 96. - Zeylan.

polycephalum, Hook. f. Fl. Brit. Ind. vi. (1893) 573. - Ind. or

Pringlei, S. Wats. in Proc. Am. Acad. xxiii. (1888) 283. - Mexic.

Pumilio, Hook. f. Fl. Brit, Ind. vi. (1893) 581. Reg. Himal.

Schimperi, Koern. ex Engl. in Abh. Preuss. Akad. Wiss. 1891 (1892) 154 nomen. - Abyss.

sexangulare. Heyne, ex Hook. f. Fl. Brit. Ind. vi. (1893) 576 in syn. = Wightianum, Mart.

sikolianum, Maxim. in Bull. Acad. sci. St-Póicrsb. viii. (93) 10. - Japon.

subcaulescens, Hook. f. Fl. Brit Ind. vi. (1893) 573. - Zeylan.

Volkensii, Engl. Pfanzenw. Ost-Afr. C (1895) 133.Afr. trop. or.

Walkeri, Hook. f. Fl. Brit. Ind. vi. (1893) 583. Zeylan. 
ERIOCEPHALUS, Linn.(Compos.), - Ind. Kew. i. 880 .

Luederitzianus. O. Hoffm. in Bull. Herb. Boiss i. (1893) 86; et in Engl. \& Prantl. Natïr. Pfanzenfam. iv. 5. (1894) 270. - Afr. austro-occ. extratrop.

pinnatus, O. Hoffm. in Bot. Fahrb. x. (1889) 277. Afr. austro-occ. extratrop.

ERIOCHLOA, H. B. \& K. (Gramin.). - Ind. Kew i. 881 .

aristata, Vasey, in Bull. Torrey Bot. Club, xiii. (1886) 229. - Mexic

bolbodes, Schweinf. in Bull. Herb. Boiss. ii Append. ii. (1894) 17 (= Helopus bolbodes, Hochst.), Abyss.

Lemmoni, Vasey or Scribn. ex S. Wats, in Proc. Am. Acad. xxi. (1886) 442 nomen; et in Contrib. U.S. Nat. Herb. iii. (1892) 21. - Am. bor. austro-occ. longifolia, Vasey, l. c. 21. - Florida.

ramosa, Kuntze, Rev. Gen. (1891) 775 = annulata, Kunth et polystachya $H . B . \& K$.

sericea, Munro, ex Vasey, l.c. 21. - Am. bor. austroocc.

ERIOGNEMA, Naud. (Melast.).- - Ind. Kew. i. 880.

Sanderae X, Hort. ex Rev. Hortic. (1895) 249. Hybr, artef.

ERIOCOMA, H.B. et $\mathrm{K}$. =Montanoa, Cerv. (Compos.).

Aschenbornii, clematidea, crenata, elegans, gracilis, hibiscifolia, Karwinskyi, microcephala, mollissima, Olivae, nvalifolia, pyramidata, speciosa, ternifolia, tomentosa, triloba, uncinata, xanthiifolia, Kuntze, Rev. Gen. (1891) 336 = homonyma omnia Montanoae.

atriplicifolia, Kuntze, I. c. = M. arborescens, $C$, Koch.

Hartwegiana, Kuntze, 1. c. = M. grandiflora, Hemsl. Hemsleyana. Kuntze, 1. c. = M. gràndiflora, Hemsl. Moritziana, Kuntze, 1. c. = M. Moritziana, Sch. Bip. in Herb. Kew.

ERIODENDRON, DC. (Malv.). - Ind. Kew. i. 880 .

acuminatum, S. Wats, in Proc. An. Acad. xxi. (1886) 418. - Mexic.

tomentosa, Robins, ex Pringle, in Gard, and For, vii. (1894) 153; t in Proc. Am. Acad. xxix. (1894) 314 - Mexic. = Ceiba tomentosa, Britton \& E. G. Baker.

hypoleucum, Spruce, ex Kuntze, Rev. Gen. (1891) 75. - [Quid?]. Nab ?

ERIOCOMA, H. B. \& K.= Montanoa, La Llave. (Compos.).

Lehmannii, Hieron. in Bot. Falrb. xix. (1894) 55. Columb.

ERIODICTYON, Benth. (Hydrophyll.). - Ind. Kew. i. 881.

californicnm, Greene, Pittonia, ii. (Nov. 1889) 23; et Man. Bot. San Franc. Bay. (1894) $256=$ glutinosum, Benth.

Parryi, Greene, 1. c. $22=$ Nama Parryi, A. Gray.

ERIOGLOSSUM, Blume (Sapind.). - Ind. Kew. i. 881 .

rubiginosum, Radlk, in Sitzb. Math.-Phys. Akad. Muench. xx. (1890)236. = rubiginosum, Brandis?

ERIOGONUM, Michx (Polygon.). - Ind, Kew. i. 881.

agninum, Greene, Pittonia, ii. (July 1891) 165. Calif.

Alleni, S. Wats, in A. Gray, Man. N. Am. Bot. ed. 6. (1890) 734; et in Proc. Am. Acad.xxv, (1890) 134. - Virginia.

aureum, M.E. Fones, in Proc. Calif. Acad. Ser. II. v. (1895) \%18. - Utah.

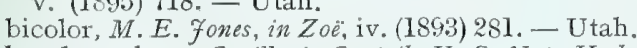

brachyanthum, Coville, in Contrib. U. S. Nat. Herb. iv. (1893) 185. - Calif.

\section{ERIOGONUM :}

citharaeforme, S. Wats in Proc. Am. Acad. xxiii. (1888) 266. - Calif

coriaceum, Coult. \& E. M. Fish. in Contrib. U.S Nat. Herb. ii. (1894) $375(=$ E. texanum, Coult \& E. M. Fish.). - Texas.

Davidsonii, Greene, Pittonia, ii. (Sept. $18921295=$ molestum, S. Wats.

denudatum, Curran, in Bull. Calif. Acad. i. (1885) 274. = Nemacaulis Nuttallii. Benth.

deserticola, S. Wats. in Proc. Am. Acad. xxvi. (1891) 125. - Calif.

elegans. Greene, Pittonia, ii. (Sept. 1891) 173.Calif.

esmeraldense, S. Wats. in Proc. Am. Acad. xxiv. (1889) 85. - Nevada.

fastigiatum, Parry, in West-Am. Scientist, vi, (1889) 102. - Calif.

flexum, M. E. Fones, in Zoë, ii. (1891) 15. - Am. bor. occ.

gracilipes, S. Wats. in Proc. Am. Acad. xxiv. (1889) 85. - Calif.

grande, Greene, Pittonia.i. (Mar. 1887) 38. - Calif Haussknechtii, Dammer, in Gartenfl. (1891) 493 fig. 92. - Am. bor.

irretitum, T. S. Brandeg. in Proc. Calif. Acad. Ser. II. ii. (I889) 202. - Calif.

Jonesi1, S. Wats. in Proc. Am. Acad. xxi. (1886) 455. - Calif.

longilobum, M. E. Fones, in Proc. Calif. Acad. Ser. II. v. (1895) 720. - U tah

Mearnsii. Parry, in Trans. N.Y.Acad. Sci. viii. (1889) 72. - Am. bor.

minutiflorum, S. Wats. in Proc. Am. Acad. xxvi. (1891) 125. - Calif.

molle, Greene, Pittonia, i. (June 1888) 207. - Ins Cedros.

Nealleyi, Coult. in Contrib. U.S. Nat. Herb. i. (1890) 48, et ii. (1891) 391. - Texas.

ridularium, Coville. l. c. iv. (1893) 186. - Calif.

nivale, Canby, ex Coville, l. c. 187. - Calif.

Nortoni Greene, Pittonia, ii. (July 1891) I65; Man. Bot. San Franc. Bay. (1894) 46. - Calif.

Ordii, S. Wats, in Proc. Am. Acad. xxi. (1886) 468. - Ariz.

pendulum, S. Wats. l. c. xxiii. (1888)265. - Oregon

Pondii, Grecne, Pittonia, i. (Mar. 1889) 267. Calif.

Pringlei, Coult. \& E. M. Fish. in Coult. Bot. Gaz. xvii. (1892) 351. - Ariz

rubescens, Greene, Pittonia, i. (Mar. 18s7) 39. Calif.

rubiflorum, M. E. fones, in Zoë, iv. (1893) 281 . Utah.

speciosum, Drew, in Bull. Torrey Bot. Club, xvi. (1889) 152. - Calif

taxifolium, Greene, Pittonia, i. (Mar. 1889) $267=$ Wrightii, Tory, var.

texanm. Coult. \& E. M. Fish. in Coult. Bot. Gaz. xvii. (1891) $350=$ coriaceum, Coult. E. E. M. Fish

tripodum, Greene, Pittonia, i. (Mar. 1887) 39. Calif.

ERIOGYNIA, Hook. = Spiraea, Linn. (Rosac.) caespitosa, S. Wats. in Coult. Bot. Gaz. xv. (1890) $242=$ S. caespitosa, $N u t$.

Hendersonii, Canby \& Greene, Pittonia, ii. (May 1892) 219. - Calif.

uniflora, S. Wats. in Proc. Am. Acad. xxv. (1890) 130; et in Coult. Bot. Gaz. xv. (1890) 242. - Montana.

ERIOPE, Humb. (Labiat.). - Ind. Kew. i. 882.

elegans, Briq. in Bull. Soc. Bot. Genève, v. (1889) 114. - Parag

nudicaulis, Briq. l. c. 116. - Parag.

trichopoda, Briq. l. c. 115. - Parag.

ERIOPHORUM, Linn. (Cyper.). - Ind. Kew. i.

quatile, Norm. in Christ. Vidensk.-Selsk. Forh. (1893) extr. 43. - Norv.

japonicum, Maxim. in Bull. Acad. sci. St-Pétersb. xxxi. (1887) 111. - Japon.

Kerneri, Ullepitssh, in Oest. Bot. Zeitschr. xliii. (1893) 421. - Hung
ERIOPHYLLUM, Lag. (Compos.). - Ind, Kew

absinthiaefolium, biternatum, neomexicanum, nudicaule. oblongifolium, oppositifolium, pedatum, sinuata, Woodhousi, Kuntze, Rev. Gen. (1891) 336-37 = homonyma ommia Bahiae.

achillaeoides, Greene, Man. Bot. San Franc. Bay. (1894) 207. - Calif.

alternifolium, Kuntze, Rev. Gen. (1891) 336. - Am. bor.

ambrosiodes, Kuntze, 1. c. = Bahia ambrosioides, Lag.

anthemodes, Kuntze, 1. c. = B. anthemoides, A. Gray.

arachnoideum, Greene, Man. Bot. San Franc. Bay (1894) 207. - Calif.

artemisiaefolium, Kuntze. Rev. Gen. (1891) $336=$ Bahia stoechadifolia, DC

Bigelowii, Kuntze, 1. c. $337=$ B. Bigelovii, $A$ Gray.

chrysanthemodes, Kuntze. Rev. Gen. (1891) $337=$ B. chrysanthemoides, A. Gray.

croceum, Greene, in Erythea, iii. (1895) 124.-Calif

Jepsonii, Greene, Pittonia,ii. (July 1891) 165; et Man. Bot. San Franc. Bay (1894) 207. - Calif.

Nevinii, A. Gray, ex Lyon, in Coult. Bot. Ga\%. xi. (1886) 335. nomen, et Syn. Fl. N.Am. i. II. Suppl. 1886) 452. - Calif

obovatum, Greene, in Erythea, iii. (1895) 123. Calif.

resinosum, Kuntze, Rev. Gen. (1891) $336=$ Galinsoga resinosa, $D C$

speciosum, Greene, l. c. i. (1893) 149. - Calif.

tanacetiflorum, Greene, Pittonia, ii. (Nov. 1889, 21 - Calif.

ERIOSEMA, DC. (Legumin.).--Ind. Kew. i. 883. andongense, Hiern, ex Baker f. in fourn. Bot xxxii (1895) 148. - Angola.

Buchanani, Baker, f.l. . . 145. - Afr. trop

cyclophyllum, Welw, ex Baker f. l. c. - Angola.

Elliotii, Baker f. l. c. 229. - Afr trop. or.

exythrocarpon, G. Beck, in Paulitschka, Harrar (1888) 455 . t. $10=$ Flemingia rhodocarpa, Baker.

filipendulum, Welw. ex Bakerf. in Fourn. Bot.xxxiii (1895) 235. - Angola.

gracillimum, Baker f. l. c. 232. - Angola.

holophyllum, Baker f.l. c. 99. - Afr. centr.

leucanthum, Welw, ex Baker f. l. c. 234. - Angola.

linifolium, Baker f. l.c.228. - Afr. centr.

macrostipula, Baker f. l. c. 142. - Afr. centr.

montanum, Bakerf. l. c. - Afr. trop.

multiflorum, Robins. ex Pringle, in Gard. and For vii. (1894) 153; et in Proc. Am. Acad. xxix. (1894) 316. - Mexic

Palmeri, S. Wats, in Proc. Am. Acad. xxii. (1887) 408. - Mexic

prunelloides, Welw. ex Bakerf. in fourn. Bot.xxxiii (1895) 232, - Angola.

psiloblepharum, Welw. ex Baker f. l. c. 233. Angola.

pulcherrimum, Baker f. l. c. 99. - Afr. centr.

pulcherrimum, Taub. in Engl. \& Prantl, Natiurl. Pfanzenfam. ii. 3. (1894) 375. - Afr. centr.

ramosum, Baker f. in Fourn. Bot. xxxiii. (1895) 146. - Angola.

Schweinfurthii, Baker f. l. c. 231. - Afr. trop.

scioanum, Avetta, ex Nuov. Giorn. Bot. Ital. xxi. 1889) 346; et in Annuar. Ist. bot. Roma, vi. (1895) 49. - Afr. trop. or.

shirense, Baker $f$. in Trans. Linn. Soc. Ser. II. iv. (1894) 11. - Afr. trop. or.

sparsiflorum, Baker f. in foum. Bot. xxxiii. (1895) 144. - Afr. centr.

terniflorum, Hiern, ex Baker f. l. c.234. - Angola. Welwitschii, Hiern, ex Baker f. l. c. 229. - Angola.

ERIOSOLENA, Blume = Daphne, Linn. (Thymel.) longifolia, Van Tiegh. in Bull. Soc. Bot. Fr. xl (1893) 69. = D. longifolia, Meins.

ERIOSPERMUM, Jacq. (Liliac.). Ind. Kew. i. 884.

Bakerianum, Schinz, in Verh. Bot. Ver. Brand, xxxi. (1890) 215 - Afr. austro-occ. extratrop. 


\section{ERIOSPERMUM :}

confertum, Baker, in Bot. Falurb.xv, Beibl. n. 35. (1892) 5. - Afr. austr.

porphyrovalve, Baker, in fourn. Bot. xxix. (1891) 7i. - Transvaal.

triphyllum, Baker, in Bot. Fahrỏ. xv. (1893) 471. Afr. trop. or.

ERIOSPORA, Hochst. (Cyper.). - Ind, Kew. i. 854.

Oliveri, C. B. Clarke, in Th. Dur. E Schinz, C.nsp. Fl. Afr. v. 1894 (1895) $676(=$ Trilepis Oliveri, Boeck.) - Afr. trop. or.

Rehmanniana, C. B. Clarke, in Trans. Limn. Soc. Ser. II. iv. (1894) 54 ; et 1. c.676 $(=$ Tr. Rekmanmiana, Boeck.). - Transvvaal.

Schweinfurthiana, Benth. ex C. B. Clarke, l. c. 676. (-Carpha Schroeinfurthiana, Boeck.)..-Afr. centr. setifera, C. B. Clarke, l. c. $676(=$ Fintelmannia setifera, Ridi.). - Madag.

villosula, C. B. Clarke, in Trans. Linn. Soc., Ser. II. iv (1894) 54; et l. c. 676. - Afr, trop. virgata, K. Schum. in Engl. Pfanzenzer Ost-Afr. C (1895) 128. - Afr. trop. or.

ERIOSTEMON, Sm. (Rutac.).- Ind. Kew. i. rgyreus, F. Muell. Eo Tate, in Trans. et Proc. Roy. argyreus, F. Muell. Fo Tate, in Trans. et Proc.
Soc. S. Austral, xi. (1S90) $10 \%$. Austral.

Carruthersi, F. Muell. in Vict. Natural. vii. (Aug. 1890) 46; et ex Bot. Centralbl. xliii. (1890) 371. Austral.

ERIOTRICHUM, St-Lager, in Cariot, Étud. des fl. éd. S. ii. (1889) $609=$ Eritrichium, Schrad. (Borag.).

ERISMANTHUS, Wall. (Euphōrb.). - Ind. Kew, 1. S85. in Hook. Icon. pl. xvi. (1887) t. 1578. - Ins. Hainan.

ERITRIGHIUM, Schrad. (Borag.). - Ind. Kew. i. 885.
affine, Phil, in Anal. Univ. Chil.xc, (18 5). 523.Chili.

alfalfalis, Phit. l.c. 525. - Chili. armeriffoiium, Phil. l. c. 551. - Chili.

axillare. Phil, in Anal. Mus. nac. Chile, (1891) 57. Am. anstr-occ.

Bouchersii, Phil. int Anal. Univ. Chil, xc. (1895). 531 - Chili

bracteatum, Phil. . c. 548, - Chili.

Bridgesii, Phil.l. c. 515. - Chili.

calandrinioides, Phil. l. c. 541. - Chili.

carrizalense, Phil. l. c.526. - Chili

cephalanthum, Phil. l. c. 520. - Chili.

cinereum, Phil. l. c.545. - Chili.

Closii, Phil. 7. c. 528. - Chili.

debile, Phil. in Anal. Mus. nac. Chile (1891) 5\%.Chili.

delicatulum, Phil. in Anal. Unir. Chil, xc. (1895) 544. - Chili

denudatum, Phil. l. c. 527. - Chili

Dichita, Phil. I. . .516. - Chili.

diplasiantnum, Phil. l. c. 530. - Chili

divaricatum, Phil. in Anal. Univ. Chil. xc. (1895). 534. - Chili

dolichophyllum, Phil. I. c. 520. - Chili.

dolichophyllum, Phit. l. . 522. - Chili.

fallax, Phil. ..c. 518, - Chili.

filagineum, Phil.l. c. 536. - Chili.

flavicans, Phil. l.c. 544. - Chili.

floribundum, Phit. l. c. 532. - Chili.

foliosum, Phil. ex Reiche, in Bot. Fahrb. xxi. (1895) 49 nomen ; et l.c. 5333. - Chili.

Germaini, Phil, in Anal. Univ. Chil, xc. (1895) 550 . - Chili.

glabratum, Phil, in Anal. Mus.nac. Chile. (1891) 56. - Chili.

glomeruliferum, Phil. in Anal. Univ. Chil. xc.

(1895). 521. - Chili.

gracile, Plit. l. c. 519. - Chili.

rraminifolium, Phil. l. c. 547. - Chili.

haplostachyum, Phil.7.c.537. - Chili.
ERITRICHIUM : -

illapelinum, Phil. in Anal. Univ. Chil. xc. (1865) 548. - Chili.

inconspicuum. Phil. l. c, 534. - Chili.

fankae, Simonk. Enum. fl. Transs. (1886) $408=$ nanum, Schrad.

Kingi, Phit. in Anal. Univ. Chil. xc. (1895). 516. Chili.

laxiflorum, Phil. l. c. 527. - Chili.

lignosum, Phil. l. c. 524. - Chili.

limonium, Phil. l. c. 566.-Chili.

longifolium, Phil. l. c.522. - Chili.

macrocalyx, Phil. l. c. 536. - Chili.

microphyllum, Phil, in Anal. Mus, nac. Chile, (1891) 57. - Chili.

Mite, Phil. in Anal. Univ. Chil. xc. (1895). 539. Chili.

oliganthum, Phil. l. c. 535. - Chili.

oppositifolium, Phil.l.c.542. - Chili.

parvulum, Phil.l.c. - Chili.

pedicellare, Phil. l. c. 549. - Chili.

polycaule, Phil. l. . .542. - Chili.

Pugae. Phil. l. c. 532. - Chili.

pulchellum, Phil. l. c. 545. - Chili.

pustulosum, Phil.l.c. 537. - Chili.

Rengifoanum, Phil, l. c.529. - Chili

rigidum, Phil. l. c. - Chili.

sessilifolim, Greene, Pittonia, i. (1887) 17 sphalm. $=$ sessiliflorum, $D C$.

spathulatum, Phil. in Anal. Univ. Chil. xc. (1895) 517 . - Chili.

sphaerophorum, Phil. l. c. 539. - Chili.

talquinum, Phil. l. c. 517.-Chili.

uspallatense, Phil.l. c. 521.-Chili.

vernum, Phil. l. c.550, - Chili.

Vidali, Phil. l. c. 525. - Chili.

virens, Phil. l.c. 519. - Chili.

ERLANGEA, Sch. Bip. (Compos.). - Ind. Kew. i. 886 .

Schinzii, O. Hoffn. ex Schinz, in Bull. Herb. Boiss, i. (1893) 71. - Afr. austro-occ. extratrop.

ERNESTIA, DC. (Melast.). - Ind. Kew, i. 886 ovata, $\operatorname{Cog} n$. in Bull. Acad. Belg. Sér. III. xiv. (1887) 929... N. Granat.

ERNSTAMRA, Kuntze, Rev. Gen. (1891) 434. = Wigandia, H. B. \& K. (Hydrophyll) caracasana. Kuntze, 1. c, = W. caracassana, $H . B$. E. $K$

crispa. Kuntze, 1. c. = W. crispa, H.B. $6 K$ herbacea, Kuntze, 1. c. = W. herbacea, Choisy. macropliylla, Kuntze, 1. c. $=$ W. urens, $H . B$. E. $K$.

scorpiodes, Kuntze, 1. c. = W. scorpiodes, Choisy.

urens, Kuntze, I. c. $=$ W. urens, Choisy.

ERODIUM, L'Hérit. (Geran.). - Ind. Kew. i. 887.

aragonense, Loscos, Trat.pl. Arag. ii. (187\%-79 ?) 228.; ex Willk. Suppl. Prodr. Fl. Hisp. (1893) 266 - Hisp.

californicum, Greene, Fl. Francisc. (1991) 97 et Man. Bot. San Franc. Bay. (1894) 70. - Calif.

Choulettianum, Coss. ex Batt. in Bull. Soc. Bot. Fr. xxxiv. (1887) 386. - Algeria.

fuliani, Batt. 1. c. in obs.= Choulettianum, Coss.

EROTEUM, Sw.= Freziera, Sw. (Ternstroem.). subintegrifolizm, Rusby, in Mem. Torrey Bot. Club, iii. 3. (1893) 9. - Bolivia.

yzngasium, Rusby, 1. c. = F. yungasia Tul.

ERPORCHIS, Thou. = Platylepis, A. Rich. (Orchid.).

bractcata, glandulosa, heteromorpha, sechellarum, Kuntze, Rev. Gen. (1891) $660=$ homonyma omnia Platylepidis.

Cryptorpis, Thou, ex Bull. Herb. Boiss. ii. (1894) $462=$ Platylepis goodyeroides.

ERRERANA, Kuntze, Rev. Gen. (1891) 937. = Pleiococca, F. Muell. (Rutac.).

Wilcoxiana, Kuntze, 1. c. $938=$ P. Wilcoxiana, F. Muell.
ERTELA, Adans, = Monnieria, Linn. (Rutac.) bahicnsis, Kuntze, Rev. Gen. (189I) $100=$ M. bahiensis, Engl.

trifolia, Kuntze, 1. c. = M. trifolia, Linn.

ERUCA, Tourn. ex Adans. (Crucif.). - Ind. Kew. i. 885 .

drepanensis, Carwel, in N. Giorn. Bot. Ital. xxiii. (1891) 240 ; ct Fl. Ital. ix. (1891) 773. - Sicilia. macrocapa, Caruel, $l l$. cc. (= Brassica macrocarpa, Guss, ). - Sicilia.

ERUCAGO, Tourn, ex Adans. = Bunias, Linn. (Crucif.)

segetum, Tourn. ex Coss. Comp.F1. Atlant. ii. (1887) 363 in syn. = B. Erucago, Linn.

ERUCARIA, Gaertn. (Crucif.). - Ind. Kew. i. 889. Reboudii, Coss. Comp. Fl. Atlant. ii. (1S57) 212 in syn. = Reboudia erucariodes, Coss. \& Durieu. rupestris, Huter, in Bull. Soc. Bot. Fr. x1. (1893) litt. 51 (= Coincya rupestris, Rouy). - Hisp.

ERUCASTRUM, Presl = Brassica, Tourn, (Crucif.).

brachycarpum, Rouy, in Bull. Soc. Bot. Fr. xxxiii. (1ss6) 524. - Hisp.

bracteatum, St. Lager, in Cariot, Etud. des fl. éd. 8. ii. (IS89) $54=$ B. Erucastrum, Linn.

cardaminoides, Webb, ex. C. Bolle, in Bot. Jahrb. xiv. (18?2) 231 in obs. = canariense, Webb.

leptopetulu' Engl, in Abh. Preuss. Akad. Wiss. (1894) bir; et Pflanzenw. Ost-Afr. C (1895) 183 B. leptopetala, Sond.

ERVUM, Tourn. = Vicia, Tourn. (Legumin.).

longepedunculatum, Willk. et Costa, ex Debeaux, Not. plus, pl. nouv. ou peu conn. Rég. Médit. (1895), ex Bull. Soc. Bot. Fr. xlii. (1895) $375=$ V. gracilis. Loisel.

nemorale, Giraudias in Magnier, Scrin. fl. select.vi. 115 ; et in Bull. Soc. Dauph. xv. (1888) 604. - Gallia

ERYGIBE, Roxb. (Convolv.). - Ind. Kew. i. 890. aenea, Prain, in fourn. As. Soc. Beng. 1xiii. (1894) I1. 85. - Perak.

albida Prain, l.c.87. - Penins. Mal

anculata, Prain, l. c. 84. - Malaya.

angustifolia, Hallier $f$. in Bot. Fahrb. xvi. (1893) 524 nomen. - Borneo.

festiva, Prain, in Fourn. As. Soc. Beng. 1xiii. (1894) ii. 87. - Penins. Mal.

Hellwigii, Prain, l. c. 84 inobs.-N. Guin.

micrantha, Hallier f. in Bot. Fahrb. xvi. (1893) 503 et 524 nomen. - Ins. Philipp.

peguensis, Prain, in fourn. As. Soc. Beng. Ixiii. (1894) ii. 83. - Pegu.

praecipua, Prain, l.c. 86. - Penang.

Stapfiana, Prain, l. c. 87. - Perak, Teríass.

ERYNGIUM, [Tourn.] Linn. (Umbellif.). - Ind. Kew. i. 890 .

alismaefolium, Greene, in Erythea, iii. (1895) 64. Calif.

alternatum, Coult. E. N.E. Rose, in Contrib.U.S.Nat. Herb. iii. 3. (1895) 298. Mexic

aristulatum, fepson, in Erythea, i. (1893) 62. - Calif. armatum, Coult. \& N.E. Rose, in Coult. Bot.Gaz.xiii (188S) 141 ; et Rer. N. Am. Umbell. (18S8) 96. Am. bor. occ.

armatum, Csato, ex Simonk. Enum. fl. Transsilv. (1886) $249=$ planum, Linn

coquienbanum, Phit. in Anal. Univ. Chil. 1xxxvii. (1894).713. - Chili:

digitifolium, Stapf \& Wettst, ex Stapf, in Denksch. Akad. Wien, (1886) 26. - As, Min.

floridanum, Coult. of N. E. Rose, in Coult. Bot. Gaz. xiii. (1888) 142 in obs; et Rev. N. Am. Umbell. (1888) 96. - Florida.

Harknessii, Curran, ex Greene, Man, Bot, San Franc. Bay. (1894) 148. - Calif.

Huteri, Porta \& Rigo, ex Porta, in Atti Accad. Agiati ix. 1891 (1892) extr. 29; ct Willk. Suppl. Prodr. Fl. (1893) 196. - Hisp. 


\section{ERYNGIUM}

involucratum, Conlt. \& N. E. Rose, in Contrib. U.S. Nat. Herb. iïi. 3 (1895) 299. - Mexic.

Lemmoni, Coult. \& N. E. Rose, in Coult. Bot. Gaz. xiv. (1889) 279. - Arizona.

lycium, Stapf \& Wettst. ex Stapf, in Denkschr. Akad. Wien (1886) 25. - As. Mir.

Iudovicianum, Morong, in Bull. Torrey Bot. Club, xiv. (1887) $51=$ virgatum, Lam. var. Lam.

macracanthum, Plit. in Anal. Univ. Chil. 1xxxvii. (1894) 715. - Chili.

madrense, S. Wats, in Proc. An. Acad. xxiii. (1888) 274. - Mexic.

mexicanum, S. Wats, l. c. xxvi. (1891) 136. Mexic.

montanum, Coult. \&N. E. Rose, in Contrib. U.S. Nat. Herb, iii. 3 (1895) 300. - Mexic.

multicapitatum, Morong, in Ann. N. Y. Acad. Sci. vii. (1893) 124. - Parag.

Telsoni, Coult. EN. E. Rose, in Contrib. U. S. Nat. Herb̆, iii. 3 (1895) 300. - Mexic.

orientale, Stapf \& Wettst. in Denkschr. Akad. Wien (1888) 47 . - As, occ.

pulchellum, Pliil, in Anal. Univ. Chil. 1xxxvii. (1894) 715 . - Chili.

Seatoni, Conlt. \& N. E. Rose, in Proc. Am. Acad. xxviii. (1893) 118 ; et in Contrib. U. S. Nat. Her. iii. 3. (1895) 300. - Mexic,

spinosissimum, Stapf \& Wettst.ex Stapf.in Dentschr. Akad. Wien (1886) 25. - As. Min.

thessalonicum, Nadji, [Charrel] Emp, Ottom. $[\mathrm{Pl}$. de Salon.] (1892) 22. - Thessal.

Vaseyi, Coult. E. N.E. Rose, in Coult. Bot.Gaz, xiii. (1888) 142; et Rev. N. An. Umboll. (18S8) 97. Am. bor. occ

ERYSIMUMI, [Tourn.] Linn.(Crucif.) - Ind. Kew. i. 892.

albiflorum, Wettst. in Oest. Bot. Zeitschr. xxxix. (1889) $283=$ Cheiranthus albiflorus, T. Anders, altaicum, Maxim. Enum. p1. Mongol. (1889) $64=$ Sisymbrium altaicum, C. A. Mey,

arenicola, S. Wats in Proc. Am. Acad, xxvi. (1891) 124 (= Cheiranthus arenicola, Greene). - Washington.

austriacum. Maxim. Enum. pl. Mongol. (1889) 65 (= Cheiranthus austriacus, Bunge). - As. centr.

Blancheanum, Boiss. Fl. Or. Suppl. (1888) 38. As. occ.

brevistylum, Somm, et Levier. in Act. Hort. Petrop. xiii. (1893) 29. - Reg. Cauc.

Burnati, Vidal, in Magnier. Scrin. fl. select. xiv. (1895) 340. - Gall.

califurnicum, Greene, in Erythea, iii. (1895) 69. Calif.

callicarpum, Litski, in Mèm. Soc. hist. Nat. Kiew, xi. (1891) extr. 17 ; $e_{t}^{2}$ in Act. Ilort, Petrop. xiii. (1894) 280. - Reg. Cauc.

capitatum, Greene, Fl. Francisc. (1891) 269 ; et Man. Bot. San Franc. Bay (1894) 21 = Cheiranthus capitatus, Dougl.

chamaephyton, Maxim. Fl. Tanout. (1889) 63. Tibet.

cinerenm, Wettst. in Oest. Bot. Zeitscht, xxxix. (1889) 283 = Cheiranthus scoparius, Brouss.

contractum, Sonin. E Levier, in Act. Hort. Petrop.

xiii. (1893) 30. - Reg. Cauc.

corinthinun, Wettst, in Oest. Bot. Zeitschr, xxxix. (1889) 283 (cornthius) $=$ Cheir. corinthius, Boiss. cuspidatum, Velen. F1. Bulg. (1891) $32=$ Syrenia cuspidata, Reichb.

filifolium, Boiss. E Hausskn. ex Boiss. Fl. Or. Suppl. (1888) 4l. - Pers.

frigidum, Boiss. \& Hausskn. l. c. 39. - Pers.

gladiiferum, Boiss. \& Hausskn. l. c. 40. - Pers.

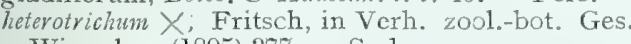
Wien, 1xv. (1895) $37 \%$. - Serb.

himalayense, Wettst, in Oest. Bot. Zeitschr. xxxix. (1889) 283 = Cheiranthus himalayensis, Canb.

hirschfeldioides, Boiss. Ef Hausskn. ex Boiss. Fl. Or. Suppl. (1888) 39. - Mesopot.

inconspicuum, Mac Millian, Metasp. Minn. (1892) $208=$ parviflorum, $N u t$.

insulare, Greene, in Bull. Torrey Bot. Club, xiii. (1886) $218=$ Cheiranthus insularis, Greene.

\section{ERYSIMUM :}

Intermedium $Y$, Wettst, in Oest. Bot, Zeitschr. xxxix. (1889) 244. t. 1. - Austria.

Knowlesii, Wettst. 1. c. 283. = Cheiranthus Knowlesii, Walp.

kurdicum, Boiss. \& Hausskn. ex Boiss. Fl. Or. Suppl. (1888' 38. - Pers.

libanoticum, post, Pl. Postianae, iii, (1892) 5. Syria.

linifolium, M. E, fones, in Proc. Calif. Acad. Ser. II. v. (1895) 622. (= Sisymbrium linifolinm, Nutt.). Am. bor.

Menziesit, Wettst, in Oest. Bot. Zeitschr, xxxix. (1889) 283 , = Cheiranthus Menziesii, Benth。 $e$ Hook. $f$.

microstyhum $\times$, Hausskn. in Mitth. Thür. Bot. Ver. N. Folge, iii et iv. (1893) 109. - Graecia. mutabile, Wettst. in Oest. Bot. Zeitschr. xxxix (1889) 283 = Cheiranthus mutabilis, L'Hérit. nasturtioides, Boiss, \& Hausskn. ex Boiss, Fl. Or. Suppl. (1888) 40. - Pers.

nitrarinm, Wettst. in Oest. Bot. Zeitschr. xxxix. (1889) 283 = Cheiranthus nitrarius, Pall. parryoides, Wettst. 1. c. = C. parryoides, Kurz. patens, Loscos, Trat pl. Aras. iii. suppl. 7o (1886) 71: Willk. Suppl. Prodr. Fl. Hisp. (1893) 299. Hisp.

scoparium, Wettst. in Oest. Bot. Zeitschr. xxxix. (1889) 283. = C. scoparius, Willd.

semperforens, Wettst. 1. c. = C. semperflorens, Schousb.

Senoneri, Wettst. 1. c。 = C. Senoneri, Heldr. et Surt. Stervartii Wettst. 1. C. = C. Stewartii, T. Anders. syrticolum, Sheld. in Bull. Torrey Bot. Club, xx. (1893) $285=$ C. syrticola, Greene.

tenuifolinm, Wettst. in Oest. Bot. Zeitschr. xxxix 1889) $283=$ Cheiranthus tenuifolius, L'Hérit. Thatianum, Fritsch, in Bot. Centralbl, xliii. (1890) 14: G. Beek, Fl. Nied.-Oestr. II. i. (1892) 480(= E. Thaliamm, Kitt.) $=$ Sisymbrium Thalianum f. Gay.

irescens, Wettst in Oest. Bot. Zeitschr. xxxix. (1889) $283=\mathrm{C}$. virescens, $W e b 3$.

Wahlenbergii, Simonk. Enum. fl. Transylv. (1886) 85 = hieracifolium, Linn

yunnanense, Franch. in Bull. Soc. Bot. Fr., xxxiii. (1886) 404. - China.

ERYSIMUM, [Tourn.] Linn. ex Kuntze, Rev. Gen. (1891) 27 et 931 [Gen. collect.] (Crucif.).

Allioniz, alpestre, amplexicaule, androsaceum, arcuatum, arenosun, Aucheri, auriculatum, blepharophyllum, Cadmea, Carduchorum, cebennense, collinum, crassifolium, decumbens, dentatum, drabaeforme, Dregeanum Drummondii, eriopodum, evubescens, flagellosum, flaviflorum, Halleri, hirsutum, Holboellii, ionocalyx, laevigatum, laxum, longirostre, ludoricianum, lusitanicum, lyratum, Montbretianum, murale, neglectum, ochroleucum, pachyrhizum, parvulum, patens, patulum, pendulum, petiolare, petraeum, Piasezkiz, platyspermum, procurrens, Pseudoturrita, pubicalyx, purpureum, resediflorum, saxatile, serpyllifolium, serratum, simu atum spathulatum, Stelleri, Stevenianum, strictum, tibeticum, trichopodun, Turrita, vermum, okoscenyse, Kuntze, Rev. Gen. (1891) 933-34 = homonyme omnia Arabidis.

albidum, Kuntze, 1. c. $28=$ Arabis aibyda Stev. et alpina, Linn.

alyssodes. Kuntze, 1. c, 933 (= Stevenia alyssoides, Adams \& Fisch.). --Sibir.

ambignnm, Kuntze, 1. c. = A. petraea, Limn aubrietiodes, Kuntze, 1. c. = A. aubrietioides, Boiss. bracteatum, Kuntze, 1. c. = Streptanthus bracteatus, A. Gray.

Breweri, Kuntze, 1. c. = S. Breweri, A. Gray. bryodes, Kuntze, 1. c. $=$ Arabis bryoides, Boiss. canadense, Kuntze, 1. c. $28=$ A. canadensis, Linn. carinatum, Kuntze, 1. c, $933=$ Streptanthus carinatus, Wright.

ciliatum, Kuntze, 1. c. = A. Scopoliana, Boiss.

conringiodes, Kuntze, 1. c. = A. conringioides, Ball . cordatum, Kuntze, 1. c. = Streptanthus cordatus, Torr.

erysimodes, Kuntze, 1. c. = Arabis erysimoides, Kar. \&o Kir.

falcatum, Kuntze, 1. c. $=$ A. Turczaninowii, Leder.
ERYSIMUM :

falklandicum, Kuntze, Rev. Gen. (1891) $933=$ Arabis macloviana, Hook

flavescens, Kuntze, 1. c. = Streptanthus flavescens, Hook

frutescens, Kuntze, 1. c. = A. fruticulosa, C. A. Mey. fruticulosum, Kuntze, 1, c, = A incarnata, Lamb. glabrum, Kuntze, 1.c. = A. perfoliata, Linn.

glandulosum, Kuntze, 1. c. = Streptanthus glandulosus, Hook.

Heritieri, Kuntze, 1, c. $29=$ Cheiranthus mutabilis, L'Hérit.

heterophyllum, Kuntze, 1. c. $933=$ Caulanthus Coulteri, S. Wats.

hyacinthodes, Kuntze, 1. c. = Streptanthus hyacin thoides, Hook

hispidwm, Kuntze, 1. c. = S. hispidus, A. Gray.

Karelinianum, Kuntze, 1. c. = Arabis glandulosa, Kar. \& Kir.

Iycicum, Kuntze, 1, $c_{1}=$ A. deflexa, Boiss.

maculatum, Kuntze, 1. c. = Streptanthus maculatus, Nutt.

molle, Kuntze, 1. c. = Arabis vochinensis, Spreng. mepetifolim, Kuntze, 1. c. = A. nepetaefolia, Boiss. madicaule, Kuntze, 1. c. = A. nudiuscula, E. Mey. mudum, Kuntze, 1. c. - Sisymbrium nudum, Boiss.

Nuttallianum, Kuntze.1. c. = Streptanthus repandus, Niutt.

Nuttallii, Kuntze, 1. c. = A. spathulatum, Nutt.

platycarpum, Kuntze, 1. c. = Streptanthus platycarpus, A. Gray.

polygalodes, Kuntze, 1. c. = Strep. polygaloides, A. Gray.

Preslianm, Kuntze, 1.c. = Arabis Turrita, Limn. puberulum, Kuntze, 1. c. = A. canescens, Nutt. resediflom, Kuntze, 1. c. 25 et $933=$ Nasturtium arabiforme, $D C$

rupestre, Kunzzc, 1. c, $933=$ Arabis ciliata, $R, B$ r. sulfuremm, Kuntze, 1. c. $934=$ A. sulphurea, Boiss taraxacifolium, Kuntze, 1, c. $=$ A. arvensis, Edgew. tortwosum, Kuntze, 1. c. = Streptanthus tortuosus, Kell.

Wettsteinianum, Kuntze, 1. c. $933=$ Arabis alpina, Linn.

ERYTHRAEA, Renealm. (Gentian.). - Ind. Kew 1. 894 .

Carueliana, Terrac in Bull. Soc. Bot. Ital. iv (1394) 179 (sp. coll.). - Eur., Asia, Afr, bor. curvistaminea, Wittr. in Bot.Centralbl. xxvi. (1886) 317.

divaricata, Porta, in Nuov. Giorn. Bot. Ital. xix. (1887) 312. - Ins. Balear

exaltata, Coville, Contrib. U. S. Nat. Herb. iv,

(1893) $150=$ E. Douglasii, A. Gray.

caltata, Britton, in Mem. Torrey Bot. Club, (1894) $258=$ praec

japonica, Maxim. in Bull. Acad. St-Pétersb. xxxi. (1887) $6 \%$ - Japon

Irovievi, Corbière, in INém. Soc. sc. nat. Cherb. xxy. (1887) 269-71; et Nouv. Fl. Norm. (1893) $334=$ ramosissima, Pers.

subspicata, Velen, in Sitz. Boehm. Ges. Wiss. 1889. (1890) II. 37. - Bulg.

turcica, Velen. ex Nym. Consp. Fl. Eur. Suppl. (1886) $219=$ glomerata, Wittr.

ERYTHPINA, Linn. (Legumin.). - Ind. Kew。 i.

aurantiaca, Ridl. in fourn. Linn. Soc. xxvii. (1890) 30. t. I. - Ins. Fernando Noronha.

costa-ricensis, M. Micheli, in Bull. Herb. Boiss. ii. (1894) 445. - Costarica.

edulis, Triana, ex M. Micheli, in Morot, fourn. do Bot. vi. (1892) 145. - Columb.

flabelliformis, Kearn. in Trans. N. Y. Acad. Sci. xiv. (1894) 32. - Arizona.

Humei, [N.E. Br.] in Monteiro, Delagoa Bay (1891) 159. nomen (an E. Humeana, Spreng.? ? Mossamb.

ERYTHROCEPHALUM, Benth. (Compos.) Ind. Kew, i. 896.

dianthiflorum, O. Hoffm. in Bolet Soc. Brot. x. (1892) 183 ; et in Bot. Fahrb. xv. (1S93) 541.Angola. 


\section{ERYTHROCEPHALUM}

Stuhlmannii, O. Hoffm. in Engl. Pflanzenw. Ost-Afr. C (1895) 420. - Afr. trop. or.

ERYTHROCHLAMYS, Guerke in Bot. Jahrb. Tix. (1894) 222. LABIATAE.

spectabilis, Guerke, l. c. - Afr. trop. or.

ERYTHROGOGGA, Benth. (Euphorb.). - Ind. Kew. i. 896.

abyssinica, Pax, in Bot. Fahrb. xix. (1894) 87. Abyss.

bongensis, Pax, l. $c .88$. - Afr. trop.

Fischeri, Pax, l. c. - Afr. trop. or.

mitis, Pax, in Engl. Pfanzenw. Ost-Afr. C (1895) 238. - Afr, trop. or.

ERYTHRONIUM, Linn. (Liliac.). - Ind. Kew. i. 896.

citrinum, S. Wats, in Proc. Am. Acad. xxii. (1887) 480. - Oreg.

Hendersoni, S. Wats. 1. c. 479; et ex Hook. fo in Bot. Mag. (IS88) t. 7017 = grandiflorum, Pursh.

Howellii, S, Wats, l, c, 480, - Am, bor.

Johnsonii, H. N. Bolander, in Erythea, iii. (1895) 127. - Oregon.

mesochoreum, Knerr, in B.B. Snyth, Chech List pl. Kansas (1892) 26. - Kansas.

montanum, S. Wats, in Proc. Am. Acad. xxvi. (1891) 130. - Am. bor. occ.

ERYTHROPHLOEUM, Afzel. (Legumin.). Ind. Kew. i. 897 .

chlorostachys, Hennings, ex Taub. in Engl. \& Prantl, Natürl. Pflanzenfam. iii. 3 (1892) 127 (=E. chlorostachys, Baill $)=E$. Laboucherii, F. Mucll.

Dinklagei, Taub. l. . .386. - Kamer.

gabunense, Tanb. l. $\iota_{0}$ - Gabon.

pubistamineum, Hennings, in Gartenfl. xxxviii. (1889) 39 fig. 8. - Angola.

ERYTHROSPERMUM, Lam. (Bixin.).- Ind

\section{Kew i. 897.}

ampullaceum, Baker, in foum. Limn. Soc. xxii (1887) 455. - Madag.

bancanum, Burck, in Annal. fard. Buitenz. xi (1893) 192 t. xvi. - Ins. Banka.

Boivinianum, Baill. in Bull. Soc. Iinn. Paris, i. (1886) 599 ; et Hist.pl. Madag. Atlas, t. 118. Madag.

capitatum, Baker, in foum. Linn. Soc. xxv. (1889) 302. - Madac.

coffeaefolium, Baill, in Bull. Sor. Iinn. Paris, i. (1886) 605. - Madag.

corymbosum, Baill. l. c. 606; et Hist pl. Madag, Atlas, t. 120. - Madag

crassipes, Baill. l. c. 605. - Madag.

ecarinatum, Burck, in Annal. fard. Buitenz. xi. 1813) 191 t. xv. - Ins. Molucc.

elegans, Baill. in Bull. Soc. Linn. Paris, i. (1886) 600. - Ins. Comor.

Fischeri, Engl. Pflanzenw. Ost-Afr. C (1895) 226 - Afr. trop. or.

hypoleucum, Oliver, in Hook. Icon.ph. xix. (1889) t. 1899. - China.

latifolium, Burck. in Annal. Fard. Buitenz, xi. (1893) 192. - Ins. Lingru.

Laurei, Baill. in Bull. Soc. Linn. Paris, i. (1886) 600. - Madag.

longistipulatum, Burck, in Annal. Fard. Buitenz. xi. (1S93) 193. - Archip. Malay

montanum, Teysm. \& Binn. ex Burck, in Annal. Jard. Buitenz, xiii. (1893) $191=$ ecarinatum, Burck.

nossibeense, Baill. in Bull. Soc. Linn. Paris, i (1886) 600. - Madar.

novo-granatense, Hicron. in Bot. Falirb. xx. Beibl. n. $49(1895) 35$ - Columb.

Pervillei, Baill. in Bull. Soc. Linn. Paris, i. (1886) 606. - Madag.

recurvifolium, Baker, in fourn. Limn. Soc. xxv.

(1889) 301. - Madag.

Richardianum, Baill. in Bull. Soc. Linn. Paris, i.

(1886) 605. - Madag.

Rignyanum, Baill. l. c.- Madag.

\section{ERYTHROSPERMUM: -}

Scortechinii, King, in foum. As. Soc. Beng. lix. (1890) ii. 116. - Malaya.

sparsiflorum, Baker, in fourn. Linn. Soc, xxii

(1887) 455. - Madag.

ESCALLONIA, Mutis (Saxifr.). - Ind. Kew i. 898 .

andina; Phit. in Annal. Univ. Chil. 1xxxv. (1894 502. - Chili.

bracteata, Phil. l. c. 500. - Chili.

glutinosa, Plil. l. c. 499. - Chili.

Mandoni, Rusby, in Menn. Torrey Bot. Club. iii. 3 (1893) 25. - Boliv.

promaucana, Phil. in Anal. Univ. Chil. Ixxxy. (1894) 500. 一 Chili.

Pugae, Phil. l. c. 501. - Chili.

Rahmeri, Phil. l. c.502. - Chili

rigida, Phil. . . c. 503. - Chili.

sparsiflora, Phil. l. . .505. - Chili.

ESGHSGHOLTZIA, Cham. (Papav.). - Ind Kew. i. 899

ambigua, Greene, Fl. Francisc. (1896) 286 ; et Man Bot. San Franc. Bay (1894) 11. - Calif.

cucullata, Greene, in Erythea, ii. (1894) 120; et ex Gard. Chron. (1894) iI. 434. - Calif.

glauca, Grecne, Pittonia, i. (Mar. 1887) 45. - Calif.

Lemmoni, Greene, in West-Am. Scientist. iii. (1887) 157; et Fl. Francisc. (1892) 28\% - Calif.

leptandra, Greene, Pittonia, i.(June 1888) 170. Am. bor. occ.

maritima, Greene, l. c., i. (July 1887) 60. - Calif

minutiflora, Parish, ex Greene, 1. c. i. (June 1888) $169=$ modesta, Grente.

modesta, Greene, l. c.-Calif

Palmeri, N. E. Rose, in Contrib. U. S. Nat. Herb. i. (1890) 23. - Ins. Guadal. (Calif.).

ramosa, Greene, in Bull. Torrey Bot. Clutb, xiii. (1886) 21\%. - Calif.

rhombipetala, Greene, Man. Bot. San Franc. Bay, (1894) 12. - Calif.

tenuisecta, Greene, Pittonia, i. (June 1888) $169=$ californica, Cham。 et Schlecht.

ESCHWEILERA, Mart. = Lecythis, Linn. (Myrtac.).

amara, Niedenzu, in Eng1. \& Prantl, Natür1. Pflanzenfam. iii. 7 (1892) $40=$ amara, Berg?

Idatimon, Niedenzu, I. C. $=$ L. Idatimon, $A u b l$. ovalifolia, Niedenzu, 1. c. = L. ovalifolia, $D C$.

Poiteaui, Niedenzu, 1. c。 = L. Poiteaui, Berg.

retusa, Niedenzu, 1. c. $=$ L. retusa, Spruce.

salebrosa, Niedenzu, 1. c. = L. salebrosa, Berr.

Schomburgkii, Niedenzu, 1. c. = L. Schomburgkii Bcrg.

Spruceana, Niedenzu, 1. c. = L. Spruceana, Berg.

turbinata, Niedenzu, 1. c. = L. turbinata, Berg.

valida, Niedenzu, 1.C. (=Chytronia valida, Miers).

- N. Granat.

ESCHWEILERIA, Zipp. ex Boerl. in Annal. Jard. Buit. vi. (1887) 112 [OSMOXYLON, Blume pr.p. $=$ Boerlagiodendron. Burck (Aral.) barbata, Boer1. 1. c. 117 (= O. bavbatum, Becc) $=$ B. barbatum, Harms.
$=$.

Boerlagei, Warb. in Bot. Jahrb. xiii. (1891) $295=$ B. Warburgii, Harms.

carpophagarum, Boerl. in Annal. Jard. Buit. vi.

(1887) $120(=0$. carpophagarum Becc. $)=\mathrm{B}$. carpophagarum, Harms.

Gelwinkiana, Boerl. 1. c. 120 (= O. Gelwinkianum, Becc. $)=$ B. Gelwinkianum, Harms

helleborinum, Boerl. 1. c. 115 (= O. helleborinum, Becc.) = B. helleborinum, Harms.

insidiatrix, Boerl. 1. c. $120(=$ O. insidiator, Becc.). $=\mathrm{B}$. insidiator, Harms.

msignis, Boer1. 1. c. $122(=0$. insigno, Becc. $)=$ B. insigne, Harns.

novo-guineensis, Boerl. 1. c. $118(=0$.novo-guineense. Becc. $)=$ B. novo-guineense, Harms.

palmata, Zipp. ex Boerl. 1. c. $116=$ = B. palmatum, Harms.

Pfeiti, Warb. in Bot. Jahrb, xiii. (1891) $396=$ B. Pfeilii, Harms
ESCHWEILERIA : -

pulcherrima. Boerl. in Annal. Jard. Buit. vi (1857) $123(=0$. pulcherrimum, Vidal $)=\mathrm{B}$ pulcherrimum, Harnis

Teysmannii, BoerI. 1. c. $119=$ B. Teysmannii, Boerl.

ESENBEGKIA, H. B. \& K. (Rutac.). - Ind. Kew i. 899

flava, T. S. Brandeg. in Zoë, i. (1890) 378 t. 12. Calif.

Hartmanii, Robins. E Fernald, in Proc. Am. Acad. xxx. (1895) 115. - Mexic.

ESMERALDA, Reichb. f. = Arachnanthe, Blume (Orchid.).

bella, Reichb. f. in Gard. Chron. (1888) i. 136. Hab.?

Clarkei, Reichb.f. 1. c. (I8S6) ii. 55\% = A. Clarkei, Rolfe.

ETAERIA, Blume = Hetaeria, Blume (Orchid.) clongata, Hcok. f. in Hook. Icon. p1. xxii (1894 t. 2190. - Penins. Mal.

E'THANIUM, Salisb. = Renealmia, Linn, f (Scitam.)

africanum, bracteosum. breviscapum, exaltatum, macran thum, Mannii, mexicanum, Kuntze, Rev. Gen, (1891) $690=$ homonyma ommia Renealmiae.

aromaticum, Kuntze, 1. C. $689=$ R. occidentalis, Swect.

cincinnatum, K. Schum. in Bot. Jahrb. xv. (1893) 424. - Gabon.

Pacoseroca Kuntze, Rev. Gen. (1891) $689=\mathrm{R}$, Pacosecora, Horan.

racemosum, Kuntze, 1. c. = R. breviscapa, Poepp. Es Endl.

silvestre, Kuntze, 1. c. = R. sylvestris, Horan.

thyrsodcum, Kuntze. 1. c. = R. thyrsoidea. Pocpp. \& Endl.

EUADENIA, Oliver (Capparid.). - Ind. Kew. i. 901.

alimensis, Hua, in Bull. Soc. Philom. Paris, Sér. VIII. vii. (1895) 81. - Afr. trop. occ.

major, Hua, l. c. 82.-Guin.

EUBRACHION, Hcok, f. (Loranth.). - Ind. Kew. i. 901.

ambiguum, Engl. in Engl. \& Prantl, Natïrl. Pfanzenfam. III. 1. (1889) 192 (= Viscum ambigum. Hook. \& Arn.). - Urug.

EUCALYPTUS, L'Hérit. (Myrt.). - Ind, Kew. i. 901.

Andreana, Carr. in Rev. Hortic. (1890) $346 \mathrm{fig}$. 104 et 105. - Tasman.

Bauerlesii, F. Mucll, in Vict. Natural. vii. (Oct. 1890) 76 ; et ex Bot. Centralbl. xliv. (1890) 236.Austral.

Bosistoana, F. Muell. in Australas. Fourn. Pharm.x. (1895) 293; et ex Bot. Centralbl. 1xiv. (1895) 365. - Austral.

Kruseana, F. Mull. l. c. x. (1895) 233. - Austral.

Lansdowneana, F. Muell. \& F. E. Brown, in 7. E. Brown, For. Fl. S. Austral. pt. 9 (1890) [t. 31]. Austral.

Maideni, F. Muell. in Proc. Limn. Soc. N. S. Wales, Ser. II. iii. (Feb. 1890) 1020 tt. 28, 29. Austral.

Muelleri, 7. B. Moore, in Proc. Roy. Soc. Tasman 1886 (1887) 208. - Tasmania.

Naudiniana, F. Muell. in Australas. Fourn. Pharm. (July 1886) 239 ; et ex Bot. Centralbl. xxviii. (1886) 179. - N. Brit.

Rameliana X. Trabut. in Mém. Assoç. Franc, Marseille, 1891 (1892) 463. - Hybr. artef.

EUCHARIS, Planch. (Amaryll.). - Ind. Kew. i. $90: 3$.

Bakeriana, N.E. Br. in Gard. Chron. (1890) i. 416. fig. 61 ; ct ex Hook. f. in Bot, Mag. (1890) t. 7144 . - N. Granat.

Lehmanni, Regel, in Gartenfl. xxxviii. (1889) 313 t. 1300 fig. 1; et in Act. Hort. Petrop. x. (1889) 591 (691, err. typ.). - Columb. 


\section{EUCHARIS :}

Lowil, Baker, in Gard. Chron.(1893) i. 538, fig. 78 - N. Granat.

Stevcnsi X, Hort. ex 1. c. (1890) i. 640.-Hybr. artef.

EUCHRESTA, Benn. (Legum.). - Ind. Kew. i 903.

tenuifolia, Hemsl. ex Forb. E Hemsl. in foum: Linn. Soo. xxiii. (1887) 200. - China.

EUCLEA, Murr. (Eben.). - Ind. Kew. i. 903. karaguensis, Guerke, in Engl. Pfanzenw. Ost-Afr C (1895) 305. - Afr. trop. or.

microcarpa, Guerke, l. c. - Afr. trop. or.

oppositifolia, Parment. Histol. comp. Ebénac (1892) $142=$ Diospyrosa oppositifolia. Thiw.

Stuhlmannii, Guerke, l. c. Afr. trop. or.

suberifolia, Parment. Histol. comp. Ebénac. (1892) 116 et $142=$ Diospyros suberifolia, Decne.

urijiensis, Hienn, in fourn. Bot. xxxiii. (1895) 179 - Afr. trop. or.

EUCNIDE, Zucc. = Mentzelia, Linn. (Loas.). grandiflora, N. E. Rose, in Contrib. U. S. Nat. Herb. iii. 5 (1895) 317 [Eucnida] (= Microsperma grandiflora, Groenl.) - Mexic,

EUCOMIS, L'Hérit. (Liliac.) - Ind. Kew i. 90. humilis, Baker, in Kew Bull. (1895) 152. - Natal. pallidiflora, Baker, in Gard. Chron. (1887) ii. $15 !$ - Afr. austr.

robusta, Baker, l.c. (1894) ii. 562. - Natal.

zambesiaca, Reichb. f. l. c. (1886) ii. 8. - Zambes.

EUCOMMIA, Oliver, in Hook. Icon. p1. xx. (1890) t. 1950 ; et xxiv. (1895) t. 2361. MAGNOLIA$C E A E$.

ulmoides, Oliver, l. c, - China

EUCROSIA, Ker-Gawl. (Amaryll.). - Ind. Kew. i. 904

eucrosioides, Pax, in Engl. \& Prantl, Natiurl. Pfanzenfam. ii. 5 (1887) 115 (= Callipsyche cucrosioides, Herb.). - Am, austr.

EUCRYPHIA, Cav. (Rosac.). - Ind. Kew. i. 904. glutinosa, Focke, in Engl. \& Prantl, Natiorl. Pfanzenfam. iii. 6 (1893) 131. - Chili.

EUGEISSONA, Griff. (Palm.). - Ind. Kew. i.

major, Becc. Malesia, iii. (1886) 3 (Eugeissonia). - Borneo.

EUGENIA, Mitch. ex Linn. (Myrt.).- Ind, Kew. i. 904 .

acutiflora, Kiaersk. Enum. Myrt. Bras.(1893) 164.

- Bras.
acutangula, K. Schum. in K. Sinum. \& Holly. Fl. Kais. Wilh. Land (1889) 89. - N. Guin.

adenodes, Kiaersh. Enwm. Myrt. Bras. (1893) 176. - Bras.

aggregata, Kiaersk. 1. c. 162 (= Phyllocalyx cerasiflora, Berg). - Bras.

aggregata, Baker, in foum. Limn. Soc. xxii. (1887) 475. - Madag.

agrostophylla, F. M. Bailey, in Proc. Roy. Soc. Queensl. xi. i. (1895) 16. - Austral.

alegrensis, Kiaersh. Enum. Myrt. Bras. (1893) 180. $(=$ Myrciaria capitata, Berg). - Bras.

Alexandri, Kmg \& Urb. ex Urb. in Bot. Fahrb. xix. (1895) 626. - Jamaica.

amplectens, Niedenzu, in Engl. \& Prantl, Natiurt. Pflanzenfam. iii. 7 (1893) 81 (= Stenocalyx sessitifolius, Berg). - Bras.

ampullaria, Stapf, in Trans. Linn. Soc, Ser. II. iv. (1894) 153. - Borneo.

antiseptica, Kuntze, Rev. Gen. (1S91) 238. - Java. apiculata, Niedenzu, in Ensl. \& Prantl, Natürl. Pfanzenfam. iii. 7(1893) 81 (= Myrcianthes apiculata, Berg). - Bras.

apodophylla, F. Muell. in Vict. Natural. viii. (April 1א92) 197; et ex Bot. Centralbl. 1. (1892) 311 . Austral.

aprica, Trim. Handb. Fl. Ceyl. ii. (1894) 186. Zeyl.

\section{EUGENIA:}

argyrocalyx, Warb. in Bot. fahrb. xiii. (1891) 391. - Oceania.

aromatica, Kuntze, Rev. Gen. (1891) 239 = caryophyllata, Thunzb.

Asa-Grayi, Krug \& Urb. ex Urb. in Bot. Fahrb. xix. (1895) 658. - Cuba.

Aschersoniana, F. Hoffn. Beitr. Kenntn. Fl. Centr. Ost-Afr. (1889) 35. - Afr. trop.

augustana, Kiaersk. Emum. Myrt. Bras. (1893) 153 - Bras.

Baeuerleinii, F. Muell. in Australas. Fourn. Pharm, (June 1886) 19; et ex Bot. Centralbl. xxviii. (1886) 149. - N. Guin.

bahamensis, Kiaerske, in Bot. Tidskr. xvii. (1890) 266. t. $8 \mathrm{~A}$ et fig, 4 - Ins. Baham.

Bellonis, Krug \& Urb. ex Urb. in Bot. Fahrb. xix. (1895) 611. - Ins. Puerto-Rico.

biseriata, Kiaersk. Enum. Myrt. Bras.(1893) 180 (= Myrciaria disticha, Berg). - Bras.

Blumeana, Kuntze, Rev. Gen. (1891) $239=$ ramosissima, Wall.

boliviensis, Rusby, in Mem. Torrey Bot. Club, iii. 3 (1893) 28. - Boliv.

botequimensis, Kiaersk. Enum. Myrt. Bras, (1893) 156. - Bras.

brachymischa, Kiaersk. l. c. 165. - Bras

brachysepala Kinersk. l. c. 125, - Bras.

brevipedunculata, Kiaersk.l. c. 139 - Bras

brunea, Niedenzu. in Engl. \&o Prantl, Naturl. Pfan zenfam. iii. 7 (1893) 81 - Bras.

Buettneriana, K. Schum. in K. Schum, \& Hollv. Fl Kais. Wilh. Land (1889) 89. - N. Guin.

bunchosiifolia, Niedenzu, in Engl. Eo Prantl, Natiml. Pfanzenfam. iii. 7 (1893) 82 (= Phyllocalyx grandifolius, Berg). - Bras.

Cabelludo, Kiaersh. Enum. Myrt. Bras. (1893) 180 (= Myrciaria glomerata, Berg). - Bras.

caldensis, Kiaersk. l. . . (I893) 162 (= Phyllocalys limbatus, Berg). - Bras.

calystegia, Niedenzu, in Engl. Eo Prantl, Natürl. Pfanzenfam. iii. 7 (1893) \&2 (= Phyllocalyx caly stegius. Berg) - Bras.

cambucarana, Kiaersk. Ennm. Myrt. Bras. (1893) 151. - Bras.

camporum, Morong, in Ann, N, Y. Acad. Sci, vii. (1893) 106. - Parag.

cauliflora, Ridl. in Trans. I. inn. Soc. Ser. II. iii. (1893) 299. - Penins. Mal.

Championi, Hemsl. ex Forb. \& Hemsl. in foum Linn. Soc. xxiii.(1887)296 (= Acmena Championi. Benth.). - Ins. Honkong.

chnoosepala, Kiaersk. Enum. Myrt. Bras. (1893) 174 - Bras.

christovana, Kiaersk. l. c. 184. - Bras.

cleyeraefolia, Yatabé, in Tokyo Bot. Mag. vi. (1892) 405. t. 13. - Japon.

Coolminiana, C Moore Handb. Fl. NT. S. Wales (1893) 207. - Austral.

corcovadensis, Kiaersk. Enum. Myrt. Bras. (1893) 126. - Bras.

crassiflora, Kiaersk. l. c. 132. - Bras.

Cruegeri, Krug \& Urb. ex Urb. in Bot. Fahrb. xix. (1895) 625. - Ins. Antill

cuprea, Niedenzu, in Engl. of Prantl, Natiirl. Pfanzenfam. iii. 7 (1893) 82 (= Phyllocalyx cupreus Berg). - Bras.

dentata, Niedenzu,l.c. (= Stenocalyx dentatus, Berg $)$. - Bras.

dasyblasta. Niedanzu, in Engl. \& Prantl. Natïrl. Pfanzenfan. iii. 7 (1893) 82 (= Stenocalyx dasy blastus, Berg). - Bras.

diaphana, Kiaersk.Enum. Myrt. Bras. (1893) 154. Bras.

dolichophylla, Kiaersk. l. c. 157. - Bras.

Dussii, Krug \& Urb. ex Urb. in Bot, fahrb. xix (1895) 646. - Ins. Guadalup.

edulis, Kiaersk. Enum. Myrt. Bras. (1893) 162 (= Phyllocalyx edulis, Berg). - Bras.

Eggersii, Kiaersk. in Bot. Tidskr. xvii. (1890) 368 t. 12 et fig. 5. - Ins. Puerto-Rico.

ellipsoidea, Kiacrsk. Enum. Myrt. Bras.(1893) 134. - Bras.

elongata, Nicdenzu, in Engl. \& Prantl, Natïrl. Pflanzenfam. iii. 7. (1893) 82 (= Phyllocalyx racemosus, Berg). - Bras.
EUGENIA :

eurysepala, Kiaersk. Enmm. Myrt. Bras. (1893) 117. - Bras.

Fadyenii, Krug \& Urb. ex Urb.in Bot. Fahrb. xix. (1895) 622. - Ins. Antill

Fergusoni, Irim. Handb. Fl, Ceyl, ii. (1894) 172 et Pl. illustr, Handb. Fl. Cevl. (1894) t. 38 -Zeyl.

filipes, Baill. Hist. pl. Madag. Atlas (1895) t. 328. - Madas.

Fitzgeraldi, F.Mull. \& Bailey, in Vict. Natural. viii. (June 1891) 45; et ex Bot. Centralbl. xlvii. (1891 221. - Austral.

fluviatilis, Hemsl. ex Forb. E Hemsl. in foum. Linn. Soc. xxiii. (1887) 296. - China austr.

fuscopunctata, Kiaersk. Enmm. Myrt. Bras. (1893) 155 (= Stenocalyx grandifolius, Berg). - Bras. galalonensis, Krug \& Urb. ex Urb. in Bot. Fahrb. xix. (1895) 641. - Cuba.

Garberi, Sarg, in Gard, and For, ii. (1889) 28 fig. 87; et N. Am. Sylva, v. 49 t. CCIX = procera, Poir. glanduliflora, Kiaersk. Enum. Myrt. Bras, (1893) 180. - Bras.

glandulosissima, Kiacysk.l. c. 147. -- Bras.

Glazioviana, Kiaersk. l. c. 128. - Bras.

glomerata, Warb. in Bot. Fahrb. xiii. (1891) 390. Oceania.

goyazensis, Nicdenzu, m Engl. Eo Prantl. Natiurl. Pflinzenfam. iii. \%. (1893) S2 (= Phyllocalyx Regelianzs, Berg). — Bras.

gracilipes, Kiaersk. Enum. Myrt. Bras. (1893) 158. - Bras

gracillima, Kiacrsk. l. c. 120, - Bras.

grandiglandulosa, Kiacrsk, l; c. 181 ( = Myrciaria Spruceana, Berg). - Bras.

Grisebachii, Krug \& Urb. ex Urb. in Bot. Fahrb. xix. (1895) 627. - Cuba.

gryposperma, Krag \& Urb. ex Urb. I. c. 650. - Ins. Martinic.

Guaquiea, Kiaersk. Enum. Myrt. Bras. (1893) 181. - Bras.

guineensis, Baill. ex Laness. P1. util. Colon. Franç. (1856) 822 (= Syzyginn guinecuse. DC.) - Afr。 trop. occ.

Hagendorffii, Kiaersk. Enum. Myrt. Bras. (1893) 179 (= Myrciaria Hagendorfi, Berg). - Bras.

haitiensis, Krug of Urb. ex Urb. in Bot fahrb. xix. (1895) 616. - Ins. Haiti.

Harrisii, Knig E Urb.l. c. 632. - Antill.

Hartii, Kiaersh. in Bot. Tidskr. xvii. 271. t. 9 B et fig. 6. - Jamaica.

hedraiophylla, F. Muell. in Vict. Natuval. viii. (April 1892) 198; et ex Bot. Centralbl. I, (1892) 312. - Antill.

Holtzei, F. Muell. in Australas. Fourn. Pharm. (June 1886) 199; et ex Bot. Centralbl. xxviii. (1886) 148. - Austral.

ilalensis, Hicrom. in Bot. Fahrb. xxi. (1895) 326. Ecuad.

iteophylla, Krug \&o Urb. ex Urb. l. c. xix. (1895) 611.

-Cuba.
Isabeliana, Kiaersk. in Bot. Tidskr. xvii. (1890) 272 t. 8 B et fig. 7. - Ins. S. Doming.

itaguahiensis, Niedenzu, in Engl. \& Prantl, Natiirl. PAanzenfam, iii. 7 (1893) 81 (= Stenocalyx Langsdorffi, Berg). - Bras.

itatiaiensis, Kiaersh. Enum. Myrt. Bras. (1893) 166. - Bras.

Jaboticaba, Kiaersk. l. c. 185 (= Myrciaria faboticaba, Berg). - Bras.

Johnsoni, F. Mucll. in Vict. Natural. viii. (April 1892) 199; et ex Bot. Centralbl. 1. (1892) 312. Austral.

jurujubensis, Kiaersk. Enum. Myrt. Bras. (1893) 143. - Bras.

kinabaluensis, Stapf, in Trans. Lim. Soc., Ser. II. iv. (1894) 152. - Borneo,

Krugii, Kiaersk. in Bot. Tidskr. xvii. (1S90) 259.Ins. Puerto-Rico.

lagoënsis, Kiacrsk. Enum. Nyrt. Bras. (1893) 123. - Bras,

leiocarpa, Krug \&o Urb. ex Urb. in Bot. Fahrb. xix, (1895) 662 (= Anamomis forrmgmea, Griseb.). Cubar

leptomischa, Kiaterk. Enmm. Myrt. Bras. (1893) 121. - Bras. 
EUGENIA :

Icucophloea, Kiaersk. Enum. Myrt. Bras. (1893) 183 (= Myrciaria leucophloea. Berg). - Bras.

longipedunculata, Niedenzu, in Engl. \& Prantl, Naturh. Pfanzenfam.iii. 7 (1893) 81 (= Stenocalyx longipes, Berg). - Bras.

longipes, Warb. in Bot. Fahrb. xiii. (1S91) 391. Uceania.

longiracemosa, Kiaersk. Enum. Mrrt. Bras. (1893) 149. - Bras.

lucescens, Niedenzu, in Engl. \& Prantl, Naturl. Pflanzenfam. iii. 7 (189:3) 82 (= Phyllocalyx Luschnatianus, Berg). - Bras.

Luehmanni, F. Muell. in Vict. Natural. ix. (May 1892) 10 ; et ex Bot. Centralbl. 1i. (1842) 90. Austral.

Lundiana, Kiaersk. Enum. Myrt. Bras. (1893) 16? (= Phyllocalyx Regelianus, Berg). - Bras.

Macoorai, F. M. Bailey, in Dept. Agric. Brisbane Bot. Bull. v. (1892) 15. - Austral.

magnifolia, Kiaersk. Enzm. Myrt. Bras. (1893) 136. - Bras.

malangensis, Niedenzu, in Engl. \& Prant, Natiur. Pfanzenfam. iii. 7 (1893) 81 (= Myrtopsis malangensis, O. Hoffm.). - Angola.

Marshiana, Krug \& Urb. ex Urb. in Bot. Jahrb. xix. (1895) 652 (=E. Marshiana, Griseb.?) Ins. Antill.

maranhensis, Kiaersh. Enum. Myrt. Bras. (1893) 183 (= Myrciaria maranhonsis, Berg). - Bras. maschalantha, Kiacrsh.l.c. 183. - Bras.

media, Niedenzu, in Engl. \& Prantl, Naturrl. Pfanzenfam. iii. $\tau$ (1893) 79 (= Catinga media, Sagot). - Guian.

melanadenia, Krug \& Urb. ex Urb. in Bot. Fahrb. xix. (1895) 607. - Cuba.

membranifolia, Niedenzu, in Engl. \& Prantl, Natuirt. Pfanzenfam. iii. 7 (1893) $82(=$ Philocalyx mem branaceus, Berg). - Bras.

Milletiana, Hensl. ex Forb. E Hensl. in fourn. Linn. Soc. xxiii. (1887) 297 (= Syzyginm odoratum, Hook. \& Arn.). - China.

minensis, Kiacrsk. Enum. Myrt. Bras. (1893) 184 (= Myrciaria mineszsis, Berg). - Bras.

minutuliffora, F. Muell. in Vict. Natural. viii. (April 1892) 197; et ex Bot. Centralbl. 1. (1892) 311. Austral.

moschata, Niedenzu, in Engl. E Prantl, Natür. Pflanzenfam. iii. 7 (1893) 79 (= Catinga moschata, Aubl.). - Am. austr.

mutabilis, Nicdenzr, $l, c, 8(=$ Stonocalyx mutabilis, Berg). - Bras.

Myrcianthes, Niedenzu, l. c. (=Myrcianthes edulis, Berg). - Bras.

myrsinocarpa, F. Muell. in Vict. Natural.ix. (May 1892) 5 nomen. - Austral.

Myrtillus, Stapf, in Trans. Linn. Soc. Ser. II, iv. (1894) 153. - Borneo.

Nettoana, Kiaersh. Enum. Myrt. Bras. (1893) 179 - Bras.

neurocalyx, $K$. Schum. $m$. Schum. \& Holly. Fl, Kois. Wilh. Land (1889) 90. - N. Guin.

nutans, $K$. Solnmm, l. c. - N. Guin.

oblongifolia. Niedenzu. in Engl. \& Prantt, Natürt. Pfanzenfam. iii. 7 (1893) 82 (= Stenocalyx oblongifolius, Berg). - Bras.

oblongifolia, Niedenzu, l. c. 79 (= Catinga oblongifolia, Sagot). - Am. austr.

obtusiflora, Kiaersk. Enum. Myrt. Bras. (1893) 168. - Bras.

octopleura, Krug \& Urb. ex Urb. in Bot. Fahrb. xix. (1895) 653. - Antill

odoratissima, F. M. Bailey, in Dept Arric. Brisbane Bot. Bull. iii. (1891) 12 in obs, = E. Fitzgeraldi, F. Muell.

oligandra, Krug \& Urb. exUrb. in Bot. Fahrb. xix. (1895) 612. - Cuba

oligantha. Baker, in fourn. Linn. Soc. xxii. (1857) 474. - Madag.

ophthalmantha, Kiacrsk. Enum. Myrt. Bras. (189\%) 159 (= Stenocalyx geminiftorus, Berg). Bras.

ovalifolia, Warb. in Bot. Fahrb. xiii. (189I) 390 (= fambosa oralifolia, Blume). - N. Guin.

oxyoëntophylla, Kiaersh. Enmm. Myrt. Riras. (1893)

145. - Bras.

\section{EUGENIA}

pallescens, Kiaersh. Enum. Myrt. Bras. (1893) 162. - Bras.

Parodiana, Moromg, in Ann. N. Y.Acad. Sci.vii (1893) 107. - Parag

parvifolia, C. Moore, Hando. Fl. N. S. Wales (1893) 207, in obs; et in fourn. Roy. Soc. N. S. Wales, xxvii. 1893 (1894) 85. - Austral.

pedunculata, Trim, in fonm, Bot, xxvii. (1889) 162 - Zeyl.

phitrantha, Kiaersk. Enum. Myrt. Bras. (1893) 185. - Bras.

phiebotomonides, Kiaersk. 1. c. 159 (= Stenocalyx lanceolata, Berg). - Bras.

Picardae, Krnu E Urb, ex Urb. in Bot. Fahrb. xix. (1895) 608 (= Engenia microphylla, L. C. Rich.) - Ins. S. Doming.

piedadensis, Kiaersh. Enum. Myrt Bras. (1S93) 176. - Bras.

pilosula, Krug of Urb. ex Urb. in Bot. Fahrb. xix. (1895) 612. (=E. angustifolia Berg). - Ins. Haiti.

pilotantha, Kiatsk. Enum. Myrt. Bras. (1893) 169. - Bras

Pitanga, Kiacrsk. 2. c. 155; Niedenzu, in Engl. E Prantl, Natiorl. Pfanzenfam. iii. 7 (1893) 82 (= Stenocalyx Pitanga, Berg), — Bras.

plicata. Niedenzu, l, c, 81 (= Stenocalyx Riedelianus, Berg). - Bras.

Plumieri, Niedenzu, l.c. 82 = Myrcia glomerata Berg). - Ins. Martin.

Prenleloupii. Kiacrsk. in Bot. Tidskr. xvii. (1890) 275. t. 7. B et fig. 8. - Ins. S. Doming.

pseudodichasiantha, Kiacrsk. Emm. Myrt. Bras. (1893) 177. - Bras

pseudoverticillata, Kiaersk. l. c. 140. - Bras.

puberula, Nicdenzu, in Engl. E Prantl, Natürl. Pfanzenfan. iii. 7 (1893) 82 (= Phyllocalyx pubescons.

Berg). - Bras.

pulcherrima, Kiaersk. Enmm. Myrt. Bras. (1893) 159. - Bras.

Rabeniana Kiaersk.l. c.186(= Myrciaria trunciflora, Berg). - Bras.

reticulata. Trim. Hanlb. Fl. Ceyl. ii. (1894) 185.Zeyl.

retusa, Niedcnzu, in Engl. \& Prantl, Natür. Pflanzenfam. iii. 7 (1893) 82 (= Pliyllocalyx retusus, Berg). - Urug.

thombea, Krug \& Urb. ex Urb. en Bot. Fahrb. xix.

(1895) 644. - Florida, Antill.

robusto-venosa, Kialsk. Enmm. Myrt. Bras. (1893) 137. - Bras.

rotundata, Trimen, Fiandb. Fl. Coyl. ii. (1894) 185. - Zeylan.

salomonensis. Hemsl. un fourn. Linn. Soc. xxx,

(1894) 212. - Ins. Salom.

sandreiconsis, Hillebr. Fl. Haw. Isl. (1888) $129=$ sandwicensis, A. Gray.

santensis, Kiaersk. Enum. Myrt. Bras. (1893) $163 \%=$ Phyllocalyx grandifolius, Berg). - Bras.

Sauvallei, Krig \& Urb. ex Urb. in Bot. falrb. xix. (1895) 661. -.. Cuba.

Sayeri, F. Muell. in Vict. Naturalix. (May 1892) 5, nomen. - Austral.

seriato-pedunculata, Kiacrsk. Enum. Myrt. Bras. (1893) 170. - Bras.

seriato-racemosa, Kiaersk. l.c. 151. - Bras.

seriato-ramosa, Kiaersk. l. c. 170. - Bras.

sericea, Kiaersk. l. c. 129. - Bras.

Serrasuela, Krug of Urb. ex Urb. in Dot. Fahrb. xix. (1895) 652, - Ins, Puerto-Rico.

sinensis, Hemsl. ex Forb. \& Homsl. in fourn. Linn. Soc. xxiii. (1887) 298 (= Syzygizm buxifolim, Hook. \& Arn.). - China.

Sintenisii, Kiaerse, in Bot. Tidskr. xvii. (1890) 263 t. 7 c. et fig. 3. - Ind. occ.

Sintenisii, Krug of Urb. ex Urb. in Bot. fahrb. xix. (1895) 650. - Ins. Puerto-Rico.

sordida, F. M. Bailey, in Dept Agric. Brisbane Bot. Bull. v. (1892) 15. - Austral.

Stahlii, Krug \& Urb. ex Urb. in Bot. Fahrb. xix. (1895) 650. - Porto- Rico.

stenosepala, Kiacrsk. Eumm. Myrt. Bras. (1893) 155. - Bras.

sticheromischa, Kiaersk. l. c.172. - Bras.

stictosepala, Kiaersk. l. c. 119.-Bras.

\section{EUGENIA}

irpiflora, Krug \& Urb. ex Urb. in Bot. Fahrb. xix. (1894) 672(= Myrciaria stirpiflora, Berg). - Ins, Antill.

stricta, Kiaersh. Enum. Myrt. Bras. (1893) $163=$ Phyllocalyx strictus, Berg-) - Bras

subundulata, Kiacrsk. l.c. 129. - Bras.

suffrutescens, Niedenzu, in Engl. E Prantl, Natürl.

Pfansenfam. iii. \%(1893) 82 (= Phyllocalyx herbaceus, Berg). - Bras.

sulcivenia, Krug Eo Urb. ex Uro. in Bot. Fahrb. xix. (1895) 632. - Jamaica.

enuipedunculata. Kiaersk. Enum. Myrt. Bras. (1893) 131. - Bras.

Theodorae, Kiaersk. l. c. 160. - Bras.

umbellulifera, Knug \&o Urb. cx Urb. in Bot. Fahrb. xix. (1895) 665 (= Myrcia umbellulifera, Berg). Am. trop.

undulatifolia, Niedenzu, in Engl. \& Prantl, Naturl. Pflanzenfam. iii, 7 (1893) 82 (= Phyllocalyx lint batus, Berg). - Bras.

velutiflora, Kiaersk. Enum. Myrt. Bras. (1893) 144. - Bras.

Villae-Novae, Kiaersk. l. c. 141. - Bras

vicentina. Kmg \& Uvb. ex Urb. in Bot. Fahrb. xix, (1895) 621. - Ins. S. Vincent.

Warmingiana, Kiacrsk. Enumn. Myrt, Bras, (1893) 138 (= E. bimarginata, Berg). - Bras.

Widgreniana, Kiaersk. l.c. $175(=$ Siphoneugenia Widgreniana, Berg). - Bras.

Willdenowii, Nicdenzu, in Engl. \& Prantl, Natürl. Pfanzenfam, iii. \% (1893) 81 (= Stenocalyx Psendopsidinm, Berg). - Ins. Martinica.

EUGENIODES, Kuntze = EUGENOIDES, Linn. = Symplocos, Jacq. (Styrac.).

acuminatum, acutum, adenopliyllum, Adenopus, angustatum, apicale, arboreun, Arechea, bahicnse, bancanum. bapticum, bracteale, caerulescens, caudatum, celastrifolium, celastrineum, cerasifolium, cernum, ciliatum, Claussenii, coccineum, congestum, cordifolium, coriaceum, coronatum, costaricanum, costatum, crassifolium, crassipes, cubense, cuneatum, decorum, dryophyllum, elegans, estrellense, fasciculatum, ferrugineum, foliosum, Fordii, glaucescens, glomeratum, gracile, grandiflorum, hebanthum, hirsutum, hispidulum, Hohenackeri, Hookeri, jucuzidum, kurgense, laetum, lancifolizm, latiflorum, laxiflorum, leiostachyum, Lenormandianum, loucantlunn, lucidunn, Iundii, macrocarpum, macrophyllam, Maingayi, marginale, Martii. martinicense, microphyllum, minus, monanthum, montanum, mucronatum, myrtacoum, nerifolium, nicobaricum, nitens, nitidum, nudum, obovatum, obtusum, octopetalum, odoratissimum, oligandrum, ophirense, oxyphyllum. paniculatum, parviflorum, pauciflorum, pendulums. phacocladon, platyphyllum, prionophyllum, pubescens. pulchrum, pycnanthum, pycnobotryum, pyrifolium, racemosum, ramentacoum, veflexum, repandulum, reoolutum, rhamnifolium, Ribes, rigidum, roseum, rotundifolium, rubiginosum, rufescens, Schicdeanum, serrulatum, sessile, sinicum, speciosum, sulcatum, Sumuntia, tetrandrum, theaefolium, Thwaitesii, tinctorium, tomentosum, uniflorm, urceolare, variabile, versicolor. Kuntze, Rev. Gen. (1891) $975=$ homonyma ommia gencris Symploci.

anamalayanum, Kuntze, 1. c. = S. anamallayana Bedd.

Beddomei, Kuntze, 1. c. = S. reticulata; 7. Grah

Benthamianum, Funtze, 1. c. = S. ciliata, Benth.

Brongniartianum, Kuntze, 1. c. = S. Lenorman diana, Brongn. \& Gris.

ciliatum, Kuntze, 1. c. = S. ciliata, Miq.

crataegeodes, Kuntze, 1. c. = S. crataegoides, BuchsHam.

crenatum, Kuntze, 1. $\mathrm{c},=\mathrm{S}$. lanceolata, $A . D C$

diengense, Kuntze, 1. c. 409.-Java.

fasciculatum, Kuntze, 1. c. = S. fasciculata, Zoll.

guianense, Kuntze, 1. c. $975=\mathrm{S}$. Ciponima, L'Hérit.

Hartwegii, Kuntze, 1. $\mathrm{C}_{\mathrm{o}}=\mathrm{S}$. Hartwegi, A. DC.

Henschelii, Kuntze, 1. c. = S. Henscheli, Benth.

fuergensenii, Kuntze, 1. c. = S. Jurgensenii, Hemsl. lachnobotryum, Kuntze, 1. c。 = S. ferruginea, Roxb. laurinum, Kuntze, 1. c. $409=\mathrm{S}$. spicata, Roxb.

Matthewsi, Kuntze, 1. c. $975=\mathrm{S}$. Mathewsii, DC. 


\section{EUGENIODES :}

pallidum, Kuntze, Rev. Gen. (1891) $975=$ S. crataegoides, Buch,-Ham.

paraënse, Kuntze, 1. c. = S. Ciponima, L'Hérit.

ramosissimum, Kuntze, 1. c. $409=\mathrm{S}$. ramosissima, IVall.

salaccense, Kuntze, 1. c. $=$ S. salaccensis, Miq. sessifolium, Kuntze, 1. c. $=\mathrm{S}$. subsessilis, Choisv.

spicatum, Kuntze,1.c. $975=$ S. caryophylloides, $Z$ otl Stavellii, Kuntze, 1. c. $976=$ S. spicata, Roxb.

stravadiodes. Kuntze, 1. $\mathrm{c}=\mathrm{S}$. stravadioides, Brongn. \& Gris.

theaefolinm, Kuntze. 1. c. $409=$ S. theaefolia, D. Don.

theaeforme, Kuntze, 1. c. = S. Alstonia, L'Hérit.

wyradense, Kuntze, 1. c. $975=\mathrm{S}$. acuminata, Bedd.

EULALIA, Kunth = Pollinia. Trin. (Gramin.) ciliata, dispar, eucnemis, fimbriata, gracillima, grata hirtiflora, irritans, Mackinlayi, mollis, monanthe, muda, pallens, phaeothrix, quadrenervis, rufispica speciosa, spectabilis, tenuis, Thwaitesii, vagans, velutimza, Kuntze, Rev. Gen. (1891) $775=$ homonymu omnia Polliniae.

contorta, Kuntze, 1. c. = P. articulata, Trin.

fulva, Kuntze, 1. c. = P. Cumingii, Nees.

tristachya, Kuntze, 1. c. = P. argentea. Trin.

vimenea, Kuntze, 1. c. = P. imberbis, Nees.

EULOPHIA, R. Br. (Orchid.). - Ind. Kew. i. 912

aemula, Schlechter, in Bot. fahrb. xx. Beibl. n. 50 (1895) 26. - Atr. austr.

aequalis, Bolus, in Journ. Linn, Soc, xxv. (18s9)

$182=$ Lissochilus aequalis, $\operatorname{Lindl}$.

Antunesii, Rolfe, in Bolet, Soc. Brot. vii. (1889) 236. - Angola.

arenaria, Bolus, in Journ. Linn. Soc. Xxv. (1889) $185=$ Lissochilus arenarius, Lindl.

aristata, Rendle, in fourn. Bot. xxxiii. (1895) 169.Afr. trop. or.

bella, N. E. Br. in Gard. Chron. (1889) ii. 210 Rolfe, in Kew Bull. (1890) 45. - Zambesia.

bilamellata, Schlechter, in Bot. Fahrb. xx. Beibl. n. 50 (1895) 1. et 26. - Transvaal.

bicarinata, Hook. f. Fl. Brit. Ind. vi. (1890) $6(=$ Cyrtopera bicarinata, Lind1.). - Ind. or.

Buchanani, Bolus, in Journ. Linn. Soc. xxy. (1889) $185=$ Lissochilus Buchanani, Reichb. $f$.

Buchanani, Th. Dur. \& Schinz, Consp. Fl. Afr. v 1892 (1895) $19=$ Cymbidium Buchanani Reichb. $f$.

burmanica, Hook. f. Fl. Brit. Ind. vi. (1890) 5. Burma.

calanthoides, Schlechter, in Bot. Fahrb. xx. Beibl. n. 50 (1895) 1. - Natal.

candida, Hook. f. Fl. Brit. Ind. vi. (1890) 6 (= Cyrtopera candida, Lind1.). - Reg. Himal.

chlorantha, Schlechter, in Bot. Fahrb. xx. Beibl. n. 50 (1895) 9. - Afr, austr.

clitellifer, Bolus, in Journ. Linn. Soc. xxv. (1889) $184=$ Lissochilus clitellifer, Reichb. $f$.

chrysantha, Schlechter, in Bot. Fahrb. xx. Beibl. n. 50 (1895) 2. - Natal.

congoënsis, Cognz, in fourn. des Orchid. vi. (1895) 155. ; et in Lindenia xi. (1895) 15. t. 486. - Congo.

corallorhiziformis, Schlechter, in Bot. Fahrb. xx. Beibl. n. 50 (1895) 9. - Afr. austr.

deflexa, Rolfe, in Kew Bull. (1895) 192. - Natal.

dispersa, [N.E.Br.] in Monteiro, Delagoa Bay (1891 174 ; et in Kew Bull. (1892) $127=$ Lissochilus dispersus, Rolfe.

Dusenii, Kraenzl. in Bot. Fahrb. xix. (1894) 254. Kamer.

elata, Hook. f. Fl. Brit. Ind. vi. (1890) 3. - Perak. Elliotii, Rolfe, cx S. Elliot, in foum. Linn. Soc. xxix (1891) 52. - Madag.

flaccida, Schlechter, in Bot. Fahro. xx. Beibl. n. 50. (1895) 3. - Natal.

flava, Hook. f. Fl. Brit. Ind. vi. (1890) \% (=Cyr topera flava, Lind1.). - Reg. Himal., Ins. HongKong.

flexuosa, Gilg, in Engl. Pflanzenw. Ost-Afr. C (I895) 157 - Cyrtopera flexuosa, Rolfe.

fragrans, Schlechter, in Bot. Fahrb. xx. Beibl. n. 50 (1895) 27. - Afr. austr.

Galpini, Schlechter, l. c. 10. - Afr. austr.

\section{EULOPHIA}

grantea, N. E. Br. in Gard. Chron. (1888) I. 616. fig. 83 ; et in Kew Bull. (1889) 90 = Lissochilus giganteus, $W$ elw.

gracillima, Ridl, in fourn. Bot. xxiv. (1886) 292. Calabar.

holochila, Collett \&o Hemsl. in foum. Linn. Soc, xxviii. (1890) 132; Hook. f. Fl. Brit. Ind. vi. (1890) 196. - Burma.

humilis, Rendle, in Fotern. Bot.xxxiii, (1895) 165.. Afr. trop. or.

Holstiana, Kraenzl. in Bot. Falrob. xxii. (1895) 23; et in Engl. Pfanzenw. Ost-Afr. C (1895) 157. Afr. trop. or.

Ifoltäi, F. Muell. in Vict. Natural, vi. (Juli 1889) 55 = Pachystoma Holtzei, F, Mutl.

naequalis, Schlechter, in Bot. fahrb. xx, Beibl. n. 50 (1895) 3. - Natal.

Krebsii, Bolus, in Journ. Linn. Soc. xxv. (1889) $185=$ Lissochilus Krebsii, Reichb. $f$.

achnocheila, Hook. f. Fl. Brit. Ind. vi. (1890) 2. Burma.

latifolia, Rulfe, in Bolet. Soc. Brot, ix. (1891) 139 et in Gard. Chron. (1892) ii. 583. - Ins. S. Thoma.

laxiflora, Schlechter, in Bot. Fahrb. xx. Beibl. n. 50 1895) 4. - Natal.

Ledienzi, Stein, in Verh. Schles, Ges. Vaterl. Kult. (1886), ex Stein, in Gartenfl. xxxvii. (1888) 609 in syn.; N. E. Br. in Kew Bull. (1889) $90=$ maculata, Reichb. $f$.

longepedunculata, Rendle, in foum. Linn. Soc. xxx. (1895) 383. - Afr. trop. or.

longibracteata, Th. Dur. E Schinz, Consp. Fl. Afr. v. $1892(1595) 22=$ Galeandra longibracteata, Lindl.

longisepala. Rendle, in Trans, Limn. Soc., Ser. II, iv. (1894) 43. - Afr. trop.

Lunata, Schlechter, in Verh. Bot. Ver. Brand. xxxv. (1893) 45. - Afr, austr.

Mackenii, Rolfe, in Gard. Chron. (1892) ii. 583. Natal.

macra. Ridl. in fourn. Linn. Soc. xxii. (1886) 120. - Madag.

macrobulbon, Hook. f. Fl. Brit. Ind. vi. (1890) 7 (= Cyrtopera macrobulbon, Parish \& Reichb. f.). - Ind. or.

macrorhizon, Hook. f. l. c. - Reg. Himal

Mannii, Hook. f. l. c. 4 (= Cyrtopera Mannii, Reichb. f.). - Assam

Mechorwi, Th. Dur. \& Schinz, Consp. Fl. Afr. v. 1892 (1895) $23=$ Orthochilus Mechowii, Reichb.f. milanjiana, Rendle, in Trans, Linn. Soc., Ser. II iv. (1894) 44. - Afr. trop,

missionis, Rendle, in fourn. Bot. xxxiii. (1895) 168 - Afr. trop. or.

nigricans, Schlechter, in Bot. Fahrb. xx. Beib1. n. 50 (1895) 5. - Natal.

Nyasae, Rendle, in Trans, Limn. Soc., Ser. II, iv. (1894) 44. - Afr. trop.

obtusa, Hook. f. Fi. Brit. Ind. vi. (1890) 3 (= Cyr topera obtusa. Lindl.). - Ind. or.

Oliveriana, Bolus, in Journ. Linn. Soc. xxv. (1889) $185=$ Cyrtopera Oliveriana, Reichb. $f$.

pandurata, Rolfe, ex S. Elliot, in fourn. Linn. Soc. xxix. (1891) 52. - Madag.

porphyroglossa. Bolus, in Journ. Linn. Soc. xxy (1889) $185=$ Lissochilus porphyroglossus, Reichb.f.

praestans, Rendle, in fourn. Bot, xxxiii. (1895) 166. -Zambesia.

Preussi, Kraenzl., in Bot. Fahrb. xvii. (1893) 54. Sierra-Leoni.

Reichenbachiana, Bolus, in Journ, Linn. Soc. xxy. (1889) 185 = Cymbidium Buchanani, Reichb. $f$

Renschiana, Th. Dur. \& Schinz, Consp. Fl. Afr. v. 1892 (1895) $25=$ Orthochilus Renschianus, Reichb. $f$.

ruwenzoriensis, Rendle, in fourn. Bot, xxxiii. (1895) 166. - Afr, trop. or

sanguinea, Hook. f. Fl. Brit. Ind. vi. (1890) $8(=$ Cyrtopera santoumea, Lindl.). - Reg. Himal.

Schweinfurthii, Kraenzl. in Bot. Fahrb. xvii. (1893) 54. - Afr. trop.

Shupangae, Gilg, in Engl. Pflanzenw. Ost-Afr. C (1895) $157=$ Cyrtopera Shupangae, Reichb. $f$.
EULOPHIA :

speciosa, Bolus, in Journ, Linn, Soc xxy. (1889)

$184=$ Lissochilus speciosus, $R$. Br.

stenantha, Schlechter, in Bot. Falrb. xx. Beibl. n. 5( (1895) 2\%. - Afr, austr.

triata, Rolfe, ex S. Elliot, in Journ. Linn. Soc xxix. (1891) $53=$ pulchra, Lindl

subulata, Rendle, in fourn. Bot, xxxiii. (1895) 167.

- Afr. trop. or.

abularis, Bolus, in Trans, South Afr. phit. Soc. v. I. (1888) 108. - Afr. austr.

(berculata, Bolus, in Journ. Linn. Soc. xxv. (1889) $184=$ Lissochilus platypetalus, Lindl.

ustulata, Bohus in Trans. South Afr. phit. Soc, v. I. (IS88) 110 ; et l. c. - Afr, austr.

Walleri, Gilg, in Engl, Pflanzenw. Ost-Afr. C (1895) $157=$ Cyrtopera Walleri, Reichb. $f$.

Warburgiana, Kraenzl. in Reichb. f. Xen. Orchid. iii, 6. (1893) 115 t. 266 II. fig. 8-12. - Ins. Philipp.

, Rolte, in Bolet. Soc. Brot, vii (1889) $236=$ Orthochilus Welwitschii, Reichb. f.

Woodii, Schlechter, in Bot. Jahrb. xx. Beibl n 50 (1895) 5. - Natal.

EULOPHidduM, Pfitz. in Engl. \& Prant1, Natiorl Pflanzenfam. ii, VI. (1888) 188 = Eulophia R. Br. (Orchid.).

maculatım, Pfitz. 1. $\mathrm{c}_{0}=$ Eulophia maculata, Iindl.

EULOPHIELLA, Rolfe, in Lindenia vii. (1891) 77. ORCHIDEAE

Elisabethae, Rolfe, l. c. t. 325; Hook. f. in Bot. Mag. (1894) t. 7387. - Madag.

EULOPHIOPSIS. Pfitz. Entwurf. Natürl. anordn. Orchid. (1887) 105; et in Engl. \& Prantl, Natürl. Pflanzenfam. ii. 6. (1888) 183. - Eulophia, R. Br. (Orchid.).

pripta, Pfitz. 1. c. 183 (= Eulophia scripta, Lindi.) - Ins. Mascar.

EULOPHUS, Nutt. (Umbell.). - Ind. Kew. i. 913

Bolanderi, Coult. \& N. E. Rose, Revis. N. Am. Umbell. (1888) 112 = Peucedanum Bolanderi. A. Gray.

californicus, Coult. \& N. E. Rose, I. c. $114=$ P. californicum, A. Gray.

Parishii, Coult. \& N. E. Rose, l. c. $112(=$ Pimpi nella Parishit, Coult. \& N. E. Rose). - Calif. Pringlei, Coult. \& N. E. Rose, l. c. - Am, bor austro-occ.

tenuifolius, S.Wats, in Proc. Am.Acad. xxiii. (1888) $276(=$ Museniopsis tennifolia, Coult. \& N. E. Rose). - Mexic.

ternatus, S. Wats. l. c. $(=$ Museniopsis ternatd. S. Wats.).-Mexic.

EULYGHNIA, Phil. (Cact.), - Ind. Kew.,i. 913. clavata, Phil. ex K. Schum, in Enol. \& Prantl Natiirl. Pfanzenfam, i1i. 6a (1894) $185(=$ Echinocereus hypogaeus, Weber), - Chili.

EUNANUS, Benth。 $=$ Mimulus, Linn. (Scrophul.). angustifolius, Greene, Pittonia, ii. (Nov. 1889) 23. - Neva la.

Austinae. Greene, 1. c. i. (Mar. 1887) 36. - Calif. Congdoni, Greene, in Erythea, i. (1893) 247 . M. Congdoni, Robins.

Cusickii. Greene, Pittonia, i. (Mar. 1887) 36. Am. bor. occ.

namus, Holzinger, in Contrib. U. S. Nat. Herb, if (1895) $244=\mathrm{M}$. nanus, Hook. \& Am.

pulchcllus, Drew, ex Greene, Pittonia, ii. (June 1890। 104, - Calif,

ubsecundus, Greene, l. c., i. (Mar, 1887) $37=$ M. subsecundus, $A$. Gray.

subuniflorus, Greene, Man. Bot. San Franc. Bay. (1894) $275=$ M. Douglasii, A. Gray'.

EUONYMUS, Linn. (Celastr.). - Ind. Kew, i. 913

acanthocarpus, Franch. P\%. Dilav. (1889) 129 (Evonymus). - Yunnan. 


\section{EUONYMUS :}

culeatus. Hemusl. inn Kore Bull (1893) 209. China.

amygdalifolius, Franch. in Bull. Soc. Bot. Fr. xxxiii. (1886) 453 (Evonymus). - China.

carnosus, Hemsl. in fowm. Linn. Soc. xxiii. (1886) 118. - Formosa.

Carrierei, Hort. ex Dippel, Handb. Laubholzk. ii, (1892) 495 (Evonymus) = japonica, Thunb cornutus, Hemsl. in Kew Bull. (1893) 209. - China. fimbriatus, Baill. ex Laness. P1. util. Colon. Franç (1886) 312 (Evonymus) = Lophopetalum fim briatum, Wight

gracillimus, Henst. in fourn. Linn. Soc.xxiii, (1886) 118. - China.

Hamiltonianus, Dippel, ex Koehne, Deutsche Dendrol. (1893) 365 (Evonymus) $=$ Sieboldianus, Blume.

ilicifolius, Franch in Bull. Soc. Bot. Fr. xxxiii. (1886) 453 (Evonymus). - China.

linearifolius, Franch., l. c. 455. - China.

lanceolatus, Yatabé, in Tokyo Bot. Mag. vi. (1893) 179. - Japon.

macrocarpus, Gamble, ex Oliver, in Hook. Icon. pl. xvi1i. (1885) t. 1763. - Ind. or.

linifolius, Hort. ex Dippel, Handb. Laubholzk, ii. (1892) 491 (Evonymus) = nanus, Biøb.

myrianthus, Hemsl. in Kew Bull. (1893) 210.China.

Parishii, Trelcase, in Trans. Acad. Sci. St. Louis, v. 1859 (1892) 354 - Calif

putchellus, Hort. ex Dippel, Handb. Laubholzk, ii. (1892) 495 (Evonymus) = japonicus, Linn. $f$.

pyramidalis, Hort. ex Carr. in Rev. Hortic, lix. (1887) 89 in syn. (Evonymus) = japonicus, Linn. $f$.

radicans, Hort. ex Dippel, Handb. Laubholzk. ii. (1892) 495 (Evonymus) = japonicus, Linn.f.

Tanakae, Maxim. in Bull. Acad. Sci. St. Péterb, xxxi. (1887) 22. - Japon.

Tashiroi, Maxim.l.c.23. - Japon.

venosus, Hemsl. in Kew Bull. (1893) 210. - China.

yunnanensis, Franch, in Bull. Soc. Bot. Fr. xxxiii. (1886) 454 (Evonymus). - China.

EUOSMA, Andr. = Logania, R. Br.

buxifolia, callosa, campanulata, cordifolia, crassifolia, depressa, fasciculata, flaviflora, latifolia, linifolia, longifolia, micrantha, mida, ovata, pusilla, serpyllifolia, spermacocca, stenophylla, Kuntze. Rev. Gen. (1891) 425 = homonyma onnia Loganiae.

ciliolata, Kuntze, 1. c. [Vernoniae sp.]. - N. Zel.

tetragona, Kuntze, 1. c. [Vernoniae sp.]. - N. Zel.

EUPATORIOPHALACRON, Adans. = Eclipta (Compos.)

albun, Hitchcock, in Missouri Bot. Gard. Rep. iv. (1893) $99=$ Ecl. erecta, Linn.

EUPATORIOPSIS. Hieron. in Bot. Jahrb. xviii. Beibl. n. 43 (189:3) 46. COMPOSIT AE.

Iloffmanniana, Hieron. l.c. - Bras.

EUPATORIUM, [Tourn.]. Linn. (Compos.). Ind. Kew. i. 915 .

abronium, Klatt, in Ann. naturh. Hofmus. Wien, ix. (1894) 355. - Mexic

nisochromum, Klatt, ex Th, Dur. \& Pitt, in Bull. Soc. Bot. Belg. xxxi. I892 (1893) 186. - Costarica. badium, Klatt, \& Th. Dur et Pitt.l. c.-Costarica. brickellioides, Klatt, in Arb. Bot. Mus. Hambr. $(1890)$ extr. 2. - Bras.

bullatum, Klatt, in Bot. Fahro. viii. (18s7) 34.Columb

capillifolinm, Small, in Mem. Torrey Bot. Club, v. $(1894): 311=$ foeniculaceum, Willd.

carnosum, Kuntze, Rev. Gen. (1891) 337. - Costarica.

chlorophylium, Klatt, ex Th, Dur, \& Pitt, in Bull. Soc. Bot. Belg. xxxi. 1892 (189:3) 187. - Costarica. chrysocephalum, Kiatt, Bot. Bcibl. zur Leopoldina. (1895) 2. - Costarica.

clibadioides, Baker, in Krow Bull. (1895) 105. Bras.

collodes. Robins. E Grenc, in Ann. Fourn. Sci. Ser III. 1. (1895) 152. - Mexic.

\section{EUPATORIUM}

nstipatiflorum, Klatt in Ann, naturh. Hofmus. Wien, ix. (1894) 355. - Mexic.

coperense, Hieron. in Bot. Fahrb. xxi. (1895) 330. N. Granat.

Costaricense, Kuntze, Rev. Gen. (1891) 337. - Costarica.

cotacachense, Hieron. in Bot, Fahrb. xxi. (1895) 331. - Ecuad.

dasycarpum, A. Gray, ex S. Wats, in Proc. Am. Acad. xxii. (1887) 420. - Mexic

densiflorum, Morong, in Ann. N.Y. Acad. Sci. vii. (1893) 136. - Parag.

didymum, Klatt, in Ann. naturh. Hofmus, Wien, ix. (1894) 356. - Bolivia.

Donnell-Smithii, Coult. Bot. Gaz, xvi. (1891) 95. Guatem.

drepanophyllum, Klatt, in Ann. natuvh. Hofmus, Wien, ix. (1894) 356. - Yucatan.

Durandi, Klatt, ex Th. Dur, et Pitt, in Bull. Soc. Bot. Belg. xxxi. 1892 (1893) 189. - Costarica.

Ecuadorae, Klatt, in Ann. naturh. Hofnus. Wien, ix. (1894) 356. - Ecuad.

eleutheranthemum, Rusby. in Mem. Torrey Bot. Club, iii. 3. (1893) 53. - Bolivia.

filicaule, Sch. Bip.ex A. Gray, in Proc. Am. Acad. xxi. (1886) 384 in obs, ; et xxvii. (1893) 170.Mexic.

Fraseri, Hort. ex Kew Bull. iii. (1889) 40 (=E. Frasier, Poit.) = ageratoides, Linn.

griseum, Coult. Bot. Gaz.xx. (1895) 43. - Guatem. guanaiense, Britton, in Bull. Toryey Bot. Club, xviii. (1891) 333. - Bolivia.

hymenophyllum, Klatt, ex Th. Dur. \& Pitt. in Bull. Soc. Bot. Belg. xxxi. 1892 (1893) 190. - Costarica. Lehmannianum, Klatt, in Bot. fahrb. viii. (1887) 34. - Columb.

leivense, Hieron. in Bot. Fahwb. xxi. (1895) 329. N. Granat.

Lemmoni, Robinson, in Proc. An. Acad. xxvii. (1893) 171. - Mexic

Lobbii, Klatt, in Ann, naturh. Hofmus. Wien, ix. (1894) 355. - Mexic.

loxense, Hicron in Bot. Fahrb. xxi. (1895) 331.Eucad.

loxense, Klatt, in Ann. naturh. Hofmus. Wien. ix. (1894) 357. - Ecuad.

lyratum, Coult. Bot.Gas. xvi. (1891) 96. - Guatem. madrense. S. Wats. in Proc. Am. Acad. xxvi. (189l) 137. - Mexic.

malachophyllum, Klatt, in Arb. Bot. Mus. Hamb. (1890) extr. 3. - Bras.

microphyllum, A. Gray, in Proc. Am. Acad, xxi. (1886) 384 in obs, - Mexic

myrianthum, Klatt, in Bot. Bcibl. zur Leopoldina (1895) 3. - Costarica.

myriocephalum, Klatt, in Leopoldina. Heft xxv. (1889) 104. - Costarica.

nemorosum, Klatt, in Bot. Fahrb. viii. (188\%) 35. Columb.

pacacanum, Klatt, in Bot, Beibl, zur Lcopoldina (1895) 3. - Costarica.

Palmeri, A. Gray, in Proc. Am. Acad. xxi. (1886) 383. - Mexic.

parasiticum, Klatt, in Ann. naturh. Hofmns. Wien,

ix. (1894) 357. - Costarica.

pellium Klatt ? c. - Venez.

phyllocephalum, Klatt, l. c. 358. - Bolivia.

Pittieri, Klatt, ex Th. Dur. \& Pitt. in Bull, Soc. Bot. Belg. xxxi. 1892 (1893) 192. - Costarica.

polanthum, Klatt, in Bot. Beibl. zur Leopoldina (1895) 3. - Costarica.

pratense, Klatt, ex Th. Dur, Eo Pitt. in Bull. Soc. Bot. Belg. xxxi, 1892 (1893) 193. - Costarica.

Pringlei, Robins, \& Grenm. in Am, foum. Sci. Ser. III. 1. (1895) 152. - Mexic

probum, N. E. Br. in Gard. Chron. (1890) i. 321 fig. 48. - Peruvia.

rafaèlense, Conlt. Bot. Gaz. xvi. (1891) 9\%.Guatem.

Robinsonianum, Greene, in Erythea, i. (1893) 150.Mexic.

roseum, Klatt, ex Th. Dur. \& Pitt. in Bull. Soc. Bot. Belg. xxxi. 1892 (1893) 194. - Costarica.

Rusbyi, Britton, in Bull. Torrey Bot. Club, xviii. (1891) 334.- Bolivia

\section{EUPATORIUM}

Saltivari1, Soln. Bip ex Robins of Seat in Proc. Am. Acad, xxviii. (1893) 108. - Mexic.

Schaffneri, Sch. Bip. ex Robinson, l. c. xxvii. (1893) 171. - Mexic.

Sipolisii, N.E.Br. in Kew Bull. (1893) 158. - Bras. soratense, Hievon. in Bot. Fahrb. xxi. (1895) 333. N. Granat.

stipuliferum, Rusby, in Mem. Torrey Bot.Club, iv. (1893) 210. - Bolivia.

strictum, A. Gray. in Proc. Am. Acad. xxi. (1886) 384. - Mexic.

Stuebelii, Hieron. in Bot. Fahro. xxi. (1895) 329. Am. austr.

tacotanum, Klatt, in Bot. Fahrb. viii. (1887) 35. Columb.

thymifolium, Britton, in Bull. Torrey Bot. Club, xix. (1892) 1. - Boliv,

inctorimn, Pohl, ex Oliver, in Kew Bull. (1892) $179=$ laeve, $D C$.

tolimense, Hieron. in Bot. Fahrb. xix. (1894) 45.Columb.

Thieleanum, Klatt, ex Th. Dur. E Pitt. in Bull. Soc. Bot. Belg. xxxi. 1892 (1893) 191. - Costarica.

Tonduzii, Klatt, in Bot. Beibl. zur Leopoldina (1895) 4. - Costarica.

turbacense, Hieron. in Bot. Fahrb. xxi. (1895) 332 - N. Granat.

umbrosum, Klatt, l. c. viii. (1887) 35. - Columb.

Valverdeanum, Klatt, ex Th. Dur. Go Pitt. in Bull. Soc. Bot. Belg. xxxi. 1892 (1893) I88. - Costarica. renulosum, 1. Gray, in Proc. Am. Acad. xxi. (1886) 384. - Mexic.

Vaseyi, Porter, in Bull. Torrey Bot. Chub, xix. (1892) 128. - Am. bor.

vernonioides, Coult. Bot. Gaz. xx, IS95\} 45.Guatem.

EUPHORBIA, Linn. (Euphorb.). - Ind. Kew. I.

Abbottii, Baker, in Kew Bull. (1894) 150 ; et in Hook Icon. pl. xxiv, (1894) t. 2347. - Ins. Aldabra.

abortiva, Porta, in Atti Accad. Agiati, ix. 1891 (1892) 67 ; et ex Willk. Suppl. Prodr. Fl. Hisp. (1893) 262. - Hisp.

adenensis, Deflers, in Bull. Soc. Bot. Fr. xxxiv. (1887) 67. - Arab.

akdaghensis, Stapf, in Denkschr. Akad. Wien (1886) 24. - As. min.

alcicornis, Baker, in foum. Linn. Soc. xxii. (1887) 517 . - Madag

anagalloides, Baker, l. c. xxv. (1890) 344. - Madag. angolensis, Pax, in Bot. Fahrb. xix. (1894) 117. Angola.

aprica, Baill. in Bull. Soc. Linn. Paris, i. (1886) 616. - Madag.

araucana. Phil. in Anal. Univ. Chil. xci. (1895) 508. - Chili.

aristata, Schmalh. in Ber. dentsch. bot. Ges. x. (1892) 292 t. 17 fig. 13. - Reg. Cauc.

Armourii, Millsp. Field Columb. Mus. Bot. Set. I (1895) 28 t. 2. - Yucatan.

assamica, Hook. f. Fl. Brit. Ind. v. (1887) 269. Reg. Himal.

Bakeriana, Baill, in Bull. Soc. Linn. Paris, i. (1886) 623. - Madag.

Bartolomaei, Grcene, Pittonia, i. (April 1889) 290. - Calif.

benedicta, Greene, l.c. (Mar. 1889) 263. - Calif.

betacea, Baill. in Bull. Soc. Linn. Paris, i. (1886) 623. - Madag.

biserrata, Millsp. in Zoë, i. (1890) 347. - Calif.

blepharostipula, Millsp. ex N. E. Rose in Contrib. U. S. Nat. Herb. i. (1890) 7\%. - Calif.

Blodgettii, Engelm. ex Hitchcock, Missouri Bot. Gard. Rep. iv. (1893) 126. - Ins. Baham.

Brandegei, Millsp. in Proc. Calif. Acad. Ser. II. ii. 1889) 226. - Calif.

burmanica, Hook. $f$ in Hook. Icon. pl. xvi. (1886) t. 1546. - Burma.

calderensis, Phil. in Anal. Univ. Chil. xci. (1895) 510. - Chili.

carmenensis, N. E. Rose, in Contrib. U.S. Nat. Hcrb. i. (1892) 133. - Ins, Carmen.

carpatica, Woloszczak, in Spraw. Kom. fiz. xxvii. (1892) 153. - Reg. Carpath. 
EUPHORBIA :

carthaginensis, Porta et Rigo, in Atti Accad. Agiati ix. 1891 (1892) 66; Willk. Illustr. Fl. Hisp. ii. (1886-92) 154 t. 183. - Hisp.

cervicornu, Baill. in Bull. Soc. Linn. Paris, ii (1890) 878. - Congo gall.

chamaepeploides, Lotsy, in Coult. Bot. Gaz. xx. (1895) 351. - Guatem.

Clarkeana, Hook. f. Fl. Brit. Ind. v. (1887) 253.Ind. bor. occ.

Commersonii, Baill. in Bull. Soc. Linn. Paris, i. (1886) 623. - Madag.

comonduana, Millsp. in Proc. Calif. Acad. Ser. II. ii. (1889) 229. - Calif

complanata, Warb. in Bot. Fahrb. xviii. (1894) 196. - Oceania.

conjuncta, Millsp. in Proc. Calif. Acad. Ser. II. ii. (1859) 227. - Calif.

corynoclada, F. Muell. in Wing South. Sc. Record, N. S. ii. (April 1886). - Austral.

cymbiformis, Rusby, in Mem. Torrey Bot. Club, iv. (1895) 255. - Bolivia.

cyparissioides, Pax, in Bot. Fa色b. xix. (1894) 123. - Afr. or.

daphnoides, Baill. in Bull. Soc. Limn. Paris, i. (1887) 671. - Madag.

demnatensis, Coss. ex Batt. Eo Trab. Fl. de l'Algér. [Dicot.] (1888) 803, nomen. - Marocc

digitata, S. Wats, in Proc. Am. Acad. xxvi. (1891) 146. - Mexic.

djurensis, Schweinf. ex Pax, in Bot. Fahrb. xix. (1894) 119. - Afr. trop.

Elquiensii, Phil. in Anal. Univ. Chit. xci. (1895) 509. - Chili.

elwendica, Stapf, in Denkschr. Akad. Wien (1886) 45. - As. occ.

Emodi, Hook. f. Fl. Brit. Ind. v. (1887) 250.Reg. Himal.

Engleri, in Engl. Pfanzenw. Ost-Afr, C (1895) 242. - Afr. trop. or.

Erythraea, Hensl. in fourn. Limn. Soc. xxvi. (1891) 412. - China.

espinosa, Pax, in Bot. Fahrb. xix. (1894) 120. - Afr. trop. OI.

esuloides, Velen, ex Nym. Consp. Fl. Eur. Suppl. (1886) 276 ; et Fl. Bulg. (1891) 505. - Bulg.

Fauroti, Franch, in Morot, fourn. de Bot.i. (188i) 135. - Afr. or.

Fischeri, Pax, in Bot. Fahrb. xix. (1894) 11\%.Afr. trop. or.

Fournieri, Hort. ex Rev. Hortic. (1895) 249.-Hab.?

galapageia, Robins. E Greenm. in Am. Foum. Sci. Ser. III. 1. (1895) 144. - Ins. Galapag.

geminiloba, Millsp. in Proc. Calif. Acad. Ser. II. ii. (1889) 228. - Calif.

glanduligera, Pax, in Bot. Fahrb. xix. (1894) 142. - Afr. austro-occ. extratrop.

gossypina, Pax, l. c. 119. - Afr. trop. or

grandicornis, Goebel, Pfanzenbiol. Schilderungen, i. 62. - Afr. austr. ?

Grandidieri, Baill. in Bull. Soc. Linn, Paris, i. (I886) 615. - Madag.

Greenei, Millsp. in Greene, Pittonia, ii. (May 1890) 88. - Am, bor. occ.

Griffithii, Hook. f. Fl. Brit. Ind. v. (1887) 259.Reg. Himal.

Guerichiana, Pax, ex Engl.in Bot. Fahrb. xix. (1894) 143. - Afr. austro-occ. extratrop.

gracillima, S. Wats. in Proc. Am. Acad. xxi. (1886) 438. - Mexic.

guadalajarana, S. Wats. l. c. xxii. (1887) 449. Mexic.

hadramautica, Baker, in Kew Bull. (1894) 341.Arab.

Halácsyi, Formanek in Verk. naturw. Ges. Brunn, xxxiii. 1894 (1895) 128. - Eur. or.

Henryi, Hemsl. in fourn. Linn. Soc. xxvi. (1891) 413. - China.

hereroensis, Pax, in Bot. Fahrb, x. (1889) 35. Afr. austro-occ. extratrop.

heterochroma, Pax, in Engl. Pfanzenw. Ost-Afr. C (1895) 242. - Afr. trop. or.

hexagonoides, S. Wats, in Proc. Am. Acad. xxv. (1890) 161. - Mexic.

Hildebrandtii, Baill. in Bull. Soc. Linn. Paris, i. (1886) 615. - Madag.

\section{EUPHORBIA}

ippocrepica Henusl. un fourn. I inn Sec xyvi. 1891) 414. - China.

Hochstetteriana, Pax, in Bot. Fahrb. xix. (1894) 123 in obs. (=E. Schimperi Boiss.). - As.

Holstii, Pax, in Bot. fahrb̆. xix. (1894) 121. - Afr. trop. or.

incerta, T. S. Brandeg, in Proc. Calif. Acad. Ser. II iii. (1891) 171. - Calif.

intermixta, S. Wats, in Proc. Am. Acad, xxiv. (18s9 74. - Mexic.

involuta, Millsp. in Proc. Calif. Acad. Ser. II. ii. 1889) 227. - Calif

Jonesii, Millsp. in Greene, Pittonia, ii. (May 1890 ) 89. - Arizona.

kilimandscharica, Pax, ex Engl. in Abh. Preuss Akad. Wiss. 1891 ii. (1892) 28\%. - Afr. trop. or Kralickii, Coss. ex Batt. et Trab. Fl. de l'Aloér. [Dicot.] (1889) 791. - Afr. bor.

anceolata, Phil. in Anal. Univ. Chil. xci. (1895) 508. - Chili.

laredana, Millsp. ex Coult. in Greene, Pittonia, ii (May 1890) 8S; et ex Conlt. in Contrib. U. S. Nat Herb. ii. (1894) 390. - Texas.

leucocephala, Lotsy, in Coult. Bot. Gaz, xx. (1895) 350 t. 24. - Guatem.

lineata, S. Wats, in Proc. Am. Acad. xxi. (1886) 455. - Mexic.

lohaënsis, Baill. in Bull. Soc. Linn, Paris, i. (1887 671. - Madag.

longecornuta, Pax, ex Engl, in Ab\%. Preuss. Akad. Wiss. 1891 (1892) 286. - Abyss.

longecornuta, S. Wats in Proc. Am, Acad. xxy. 1890) 161. - Mexic

longeramosa, S. Wats. l. c.-Mexic.

lorifolia, Hillebr. Fl. Haw. Isl. (1888) 395. - Ins. Sandvic.

lyciopsis, Pax, in Engl. Pfanzenw. Ost-Afr. C (1895) 242. - Afr. trop. or.

macrophylla, Pax, in Bot. Fahrb. xix. (1894) 122 - Afr. trop.

macropodoides, Robins. et Greenn. in An. fourn. Sci. Ser. III. 1. (1895) 164. - Mexic.

macraulonia, Phil. in Anal. Univ, Chil. xci. (1895) 507. - Chili.

mancinella, Baill. in Bull. Soc. Linn. Paris, i. (1886) 623. - Madag.

mandshurica, Maxim. in Act. Hort. Petrop. xi. 1891) 360 -- Songar.

Marlothii. Pax, in Bot. Fahrb.x. (1889) 36. - Afr. austro-occ. extratrop.

membranacea, Pax, in Engl. Pflanzenw. Ost.-Afr. C (I895) 242. - Afr. trop. or.

microappendiculata, Lotsy, in Coult. Bot. Gaz. xx. (1895) 349. - Guatem.

minuta, Phil. in Anal. Mus, nac. Chile (1891) 76. - Am. austr. occ.

misella, S. Wats. in Proc. Am. Acad. xxvi. (1891) 146. - Mexic

Nealleyi, Coult. of Fisher, in Conlt. Bot. Gaz. xvii. (1892) 351; et in Contrib.U.S. Nat. Herb ii. (1894) 391. - Texas.

neo-mexicana, Greene, in Bull. Calif. Acad. II. v. (1886) 56 (=E. inaequilatera, Engelm. pr.p.). N. Mexic.

niciciana, Borb. in Term. Fuzét. xiv. (1893) 53.Serb.

Normanni, Schmalh, ex Lipslzy, in Mim. Soc. hist. nat. Odessa, xi. (1891) extr. 35 ; et in Ber. deutsch. bot. Gesells. x. (1892) 293 t. 16 fig. 15. - Reg. Cauc.

noxia, Pas, in Bot. Fahrb. xix. (1894) 124. - Reĝ. Somal.

Nyikae. Pax, ex Engl, in Ablt. Prenss, Akad. Wiss. (1894) 31, 33, 39 et 40; et in Engl. Pflanzenw. Ost-Afr. C (1895) 242. - Afr. trop. or.

oblongicaulis, Baker, in Kew Bull. (1895) $185=$ hadramautica, Baker.

occidentalis, Drew, in Bull. Torrey Bot. Club, xvi. (1889) 152. - Calif.

ornata. Stapf, in Denkschr. Acad. Wien (1886) 44. As. occ.

orthoclada, Haker, in foum. Linn. Soc. xxii. (1887) 517. - Madao

ovalleana, Phil. in Anal. Univ, Chil.xci. (1895) 508. - Chili.

\section{EUPHORBIA :}

pachysantha, Baill. in Bult. Soc Limn. Paris, (1886) 623. - Madag.

Parishii, Greene, in Bull. Calif. Acad. ii. V. (1886) 56. - Calif.

pectinata, Alboff, in Bull. Herb. Boiss. ii. (1894) 640 - Reo. Transcauc.

petrina, S. Wats, in Proc. Am. Acad. xxiv. (1889) 75. - Ins. S. Pedro Martin (Calif. austr.).

Pirottae, Terrac. in Ann. Ist. Bot.Rom. v. (1894) 97 - Afr. trop. or.

platycephala, Pax, in Bot. Fahrö.xix. (1894) 122 - Afr, trop.

plicata, S. Wats, in Proc. Am. Acad. xxi. (1886) $4: 38$; et xxii. (1887) 450. - Mexic.

Poggei, Pax, in Bot. Fahrb.xix. (1894)118. - Congo poiyphylla, Engolm. ex N.E. Rose, in Contrib. U. S. Nat. Herb. 1. (1892) 215. - Am. bor.

Pondii, Millsp. ex Vasey \& N.E. Rose, in Contrib

U. S. Nat. Herb. i. (1890) 12. - Calif. austr.

porphyrantha, Phil. in Anal. Univ. Chil. xci. (1895) 510. - Chili.

portulana, S. Wats. in Proc, Am. Acad. xxiv. (1889) 73. - Mexic.

Preussii, Pax, in Bot. Fahrb.xix. (1894) 123.Kamer.

pseudoserpyllifolia, Millsp. in Greene, Pittonia, ii (May 1890) 87. - Am. bor. occ.

purisimana. Millsp. in Proc. Calif. Acad. Ser. II ii. (1889) 225. - Calif.

pusillima, Post, in Bull. Hevb. Boiss. iii. (1895) 162. - Syria.

quadrangularis, Pax, in Bot. Fahrb. xix. (1894) 119. - Afr, trop. or.

Quintasii, Pax, in Bolet. Sor. Brot. x. (1892) 156. Ins. S. Thom.

ramosa, Seaton, in Proc. Am. Acad. xxviii. (1893) 121. - Mexic.

Reboudiana, Coss. ex Batt. E Trab. Fl. de l'Algér [Dicot.] (1889) 794. - Algeria.

reflexa, Formanek in Verh. Naturw. Ges. Brün xxxiii. 1894 (1895) 22. - Eur, or.

retroscabra, S. Wats. in Proc. Am. Acad. xxii. 1887) 449. - Mexic

rubrosperma. Lotsy, in Coult. Bot. Gaz. xx. (1895) 349. - Guatem

rugulosa, Greene, Man. Bot. San Franc. Bay (1894) 81 ; et Fl. Francisc. (1891) $92=$ serpyllifolia Pers, var.

Rusbyi, Greene, in Bull. Calif. Acad. ii. I. (1886) 57. - Arizona.

sapiifolia, Baill. in Bull. Soc. Limn. Paris, i. (1886) 616. - Madag.

sarmentosa, Welw. ex Pax, in Bot. Fahro. xix 1894) 121. - Angola

Schleintzii, Engl. in Engl. E Prantl, Natïr. Pfanzenfam iii. 5 (1890) 105. - Austral.

Schurii $\times$, Simonk。 in Termész Fuzét. x. (1886) 183. - Transsilv

scripta. Somm. \& Leqier, in Act. Hort. Petrop, xii. 1892) 159. - Reg. Cauc

shirensis, Baker, f. in Trans. Linn. Soc. Ser. II. iv. (1894) 38. - Afr. trop.

Sipolisii, N.E. Br. in Kew Bull. (1893) 158. Bras.

spinescens, Pax, in Bot. Falub. xix. (1894) 120. Afr. trop or.

stenoclada, Baill. in Bull. Soc. Linn. Paris, 1. (188i) 672 ; et Hist. pl. Madag., Atlas, t. 152. Madag.

strictior, Holzinger, in Contrib. U.S. Nat Herb, (1892) 214 t. 18. - Am. bor

subapoda, Baill, in Bull. Soc. Limn. Paris, i. (1887) 671. - Madas.

subpeltata, S. Wats, in Proc. Am. Acad. xxvi.(1891) 146. - Mexic.

subreniformis, S. Wats, l. C. xxi. (18S6) 439 (subreniforme). - Mexic

systyloides, Pax, in Bot. Fahró. xix. (1894) 121. Zanzib.

tacnensis, Phil. in Anal. Mus, nac, Chite (1891) 7 . - Peruvia.

tanaitica, Paczosky, Mat. fl. stepp. proc'. Don (1891) 78. - Ross.

tarapacana, Phil. in Anal. Mus. nac. Chile (1891) 76. - Chili. 


\section{EUPHORBIA}

Tele, Schweinf. ex Pax, in Bot. Fahrb. xix. (1894)

118. - Afr. trop.

tomentulosa, S. Wats, in Proc. An. Acad. xxii. (1887) 476. - Calif.

trichadenia, Pax, in Bot. Fahrb. xix. (IS94) 125. Angola.

uberosa, N. E. Rose, in Contrib. U. S. Nat. Herb. i. (1891) 111. - Mexic

uniclandulosa, S. Wats. in Proc. Am, Acad, xxii. (1887) 476. - Mexic.

usambarica, Pax, in Bot. Fahrb.xix. (1994) 122.Afr. trop. or.

Vaseyi, Coult. in Contrib. U. S. Nat. Herb. i. (1890) 18 (= Ricinella Vaseyi, Coult.). - Texas.

relutina, Greene, in Bull. Calif. Acad. ii. v. (1886) 57. - Calif.

velutina, Pax, in Engl. Pflanzenw. Ost-Afr. C (1895) 242. - Afr. trop. or.

velutina, K. Schmm. in K. Schmm. ot Hollr. Fl. Kais Wilh. Land (1889) 74. - N. Guin.

verna, Phil. in Anal. Univ. Chil. xci. (1895) 506.Chili.

villosula, Pax, in Bot. Fa7ro. xix. (1894) 118. - Afr. trop. or.

Volkensii, Pax, in Engl. Pfanzenw. Ost-Afr. C (1895) 242. - Afr. trop, or.

Wallichii, Hook. f. Fl. Brit. Ind. v. (1887) 258.Rec. Himal.

Watsonii, Millsp. in Zoer, i. (1890) 347. - Calif.

Wightiana, Hook. f. Fl. Brit. Ind. v. (1887) 248. Deccan

TVhyteana, Baker f. in Trans. Linns. Soc, Ser. II iv. (1894) 39. - Afr. trop.

EUPHRASIA, Linn. (Scrophul.), - Ind. Kew. i. 931.

alpestris, Harz, in Bot. Centralbl. xlv. (1891) 136. - Bohem.

alpinc, Gremli Excursionsf. f. d. Schw ed I (1893) $318(=E$. alpina, Lam. $)=$ officinalis, Linn.

aurea, F. Phil. ex Phil. in Anal. Unin. Chil. xci. (1895). 113. - Chili.

borneensis, Stapf, in Trans. Limn. Soc, Ser. II, iv. 1894) 210 - Borneo.

Brandisii, Freyn, ex Freyn et Brandis, in Verh. zool.-bot. Ges. Wien, xxxviii. (1888) $622=$ officinalis, Linn.

brevipila, Burn. et Gremli in Journ. Bot. (1884) 167. - Helv.

caespitosa, Phil, in Anal. Univ, Chil. xci. (1895). 116. - Chili.

calvescens $\chi^{\prime}$, G. Beck, F1. Nied.-Oest. II. ii. (1893) 1060. - Austria.

capitulata, Townsend, in Journ. Bot. xxviii. (1890) 164 = officinalis. Linm.

carpatica. Zapal. in Spraw, Kom. fizyj. Krajowei xxiv. () 889) 270. - Hung.

Christi $\times$, Favrat, in Gremli, Neue Beitr. iv 1S87) 27 ; et in Nouv. Mem. Soc. Helv. sci. nat xxxiv. (1895) 28. - Helv.

Cockayniana, Petrie, in Trans. N.Z. Inst xxvi. 1893 (1894) 269. - N. Ze1.

dinarica, G. Beck, in Ann. Naturhist. Hofm. Wien, i. (1887) 140 t. vI. fig. 4-6; Murb. in Lunds Univers. Arskrift, xxvii. (1891) $72=$ tricuspidata, Lim

drosocalyx, Freyn. in Oest. Bot. Zeitschr. xliv. (1894) 289.

Favrati $X$, Wettst, in Oest. Bot, Zeitschr. xliv. (1894) 451 . - Hung.

flavicans, Phil. in Anal. Univ. Chil. xci. (1895) 114. - Chili.

Freynii $X$, Wettst. in Oest. Bot. Zeitschr, xliv. (1594) 452. - Tirch.

cracilis, Phit. in Anal. Univ. Chil. xci. (1895) 115. - Chili

Grcmlii X. Wettst. in Oest. Bot. Zeitschr, xliv. (1894) 453. - Tirol.

humitis, Harz, in Bot. Centralb1. xlv. (IS91) 136. Bohem.

Zrbrida $\lambda$. Wettst. in Oest. Bot, Zeitschr. xliv. (1894) 454. - Austro-Hung-

illyrica, Wettst. 1. c. xliii. (1893) 1.31; Borb. in Bot. Centralbl. liv. (1893) 130 in obs. - Austria.

\section{EUPHRASIA}

tercedens X. Wettst. in Oest. Bot. Zeitschr. xliv. (1894) 455. - Eur. centr.

jabalambrensis, Pau, Not. bot. fl. Espan. ii. (1889) 33 nomen. - Hisp.

Faeggii $X$. Wettst. in Oest. Bot. Zeitschr. xliv. (1894) 450 . - Tirol.

fordani X. Wettst. 1. c. 454. - Tirol.

Kerneri, Wettst. in Engl. \& Prantl. Natür1. Pflanzenfam. iv. 3b (1891) 101; G. Beck. Fl. Nied. Oest. ii. 2 (1893) 1060. - Austria.

liburnica, Wettst. in Oest. Bot. Zeitschr. xliv (1894) 172. - Austro-Hung.

Maximowiczii, Wettst. ex Pubalin in Act. Hort. Petrop. xiv. (1895) 133 nomen. - China.

montana, Phil, in Anal. Univ, Chil, xci, (1895) 116 $=$ E. Philippii, Weitst.

multicuspidata, Kostel. ex Wettst. in Oest. Bot. Zeitschr.xliv. (1894)376 insyn, $=$ = officinalis, Linn. olympica, Hálacsy et Sint. 1. c. x1. (1890) $39=$ officinalis, Linn.

paludosa. Townsend, in The Bot. Exch. Club Brit Isles Report for 1890 (1891) 307; et in Journ Bot. xxix. (1891) $161=$ officinalis, Limn.

parrula, Wettst. in Eng1. \& Prantl, Natürl. Pflanzenfam. iv. 3b (1893) 101. = officinalis, L inn.

permixta, Gremli, ex Wettst. 1.c, - Hely.

Plizippii. Wettst, in Eng1, \& Prantl, Natuirl. Pflanzentam. iv. 3b (1893) $101=$ montana Phil.

picta, G. Beck, F1. Nied.-Oest. ii. 2 (1893) 1059. $=$ picta.

Portae, Wettst. in Oest. Bot. Zeitschr, xliii. (1893) 196. - Austro-Hung.

pubibunda, Simonk. Enum. fl. Transsilv. (1S86) 432 $=$ officinalis, Linn

Rechingeri $X$, Wettst, in Oest. Bot. Zeitschr, xliv. (1894) 454. - Austro-Hung

rigida, Harz, in Bot. Centralbl, xlv. (1891) 136. Bohem.

Sintenisit, Halácsy, in Engl, \& Prantl, Natürl, Pflanzenfam. iv. $3 \mathrm{~b}$ (1893) $107=$ officinalis, Linn.

stivaca, Wettst. in Oest. Bot. Zeitschr. xliii. (1893) 239. - Austro-Hung.

stricta, G. Beck. \& Szyszyl. Pl. Cernag. lect (1888) $130=$ officinalis, Limn.

Tatrae, Wettst. in Oest. Bot. Zeitschr, xliv. (1894) $248=$ officinalis, Linn.

tenuifolia, Phil. in Anal. Univ.Chil. xci. (1895) 117. - Chili.

tenuis, Wettst. in Engl. \& Prantl, Natïrl. Pfanzenfam. iv. 3b (1893) 101 (= E. gracilis, Phil.). Chili.

Townsendiana, Freyn, ex Wettst in Eng1. \& Prantl. Natürl. Pflanzenfam. iv. 3b (1893) $101=$ offici nalis, Linn.

transiens, Borb. in Bot. Centralb1. liv. (1893) $129=$ officinalis, Limn.

tricolor, Colenso, in Trans. N. Z. Inst. xix. 1880 (1887) 264. - N. Zel.

variabilis, Freyn. in Kern. Sched. Fl. Austro-Hung: iv. (1886) 55.- Austria.

vestinensis $X$. Wettst. in Oest. Bot. Zeitschr. xliv. (1894) 452, - Tirol.

villaricensis, Phil. in Anal. Univ. Chnl. xci. (1895) 114. - Chili.

EUPOMATIA, R. Br. (Anon.). - Ind. Kew. i. 932.

Belgraveana, F. Muell. in Australas. Founn. Pharm. ii. (June 1887) 4; et in Bot. Centralbl. xxx. (1887) 325. - Austral.

EURAPHIS, Trin. = Pappophorum, Schreb, (Gramin.).

Pumilio, Kuntze, Rev. Gen. (1891) $776=$ B. bromoides, Hochst. \& Stend.

EUREIANDRA, Hook. f. (Cucurb.).-Ind. Kew. 1. 933

Balfourii, Cogn. in Bull. Acad. Belg. Ser. III. jy. (1887) 348. - Ins, Socotra.

EUROTIA, Adans (Chenop.). - Ind. Kew. i. 933. anata, T. S. Brandeg, in Proc. Calif. Acad. Ser. II. ii. (1889) $199=$ lanata, Mog.?
EUROTIUM, Sw. = Freziera, Sw. (Ternstroem.). arbutifolinm, boliviense, calophyllum, candicans, canescens, cordatum, Dombeyanum, ferrugineun, guianense, lanatum, longipes, macrophyllum, nevoosum, reticulatum, sericeum, suberosum, tonuentosum, undulatum, Kuntze, Rev. Gen. (1891) $62=$ homonyma omnia Frezierae.

theodes, Kuntze, 1, c. $62=$ Cleyera theoides, Choisy. omentosum, Kuntze, 1. c. = F. sericea, Hunz, \& Bonpl.

EURYA, Thunb. (Ternstroem.). - Ind. Kew. i. 933.

angulosa. Szyszyl. in Engl. \& Prantl. Natürl. Pflanzenfam. iii. 6 (1893) $190=$ Freziera angulosa, Tul.

arbutifolia, Szyszy1. 1. c. $=$ F, arbutifolia, Planch. E Triana.

boliviensis, Szyszyl. 1. c. = F. boliviensis, Wawra. calophylla, Szyszy1. 1. c. = F. calophylla, Triana \& Planch.

candicans, Szyszyl. 1. c. $=\mathrm{F}$. candicans, Tul.

canescens, Szyszyl. 1. c. $=\mathrm{F}$. canescens, Humb. \& Bonpl.

castaneifolia.Vesque, in Bull. Soc. Bot. Fr. xlii. (1895) 155 et 158 . - Reg. Himal.

cavinervis, Vesque, l. c. - Reg. Himal.

cermua, Szylzyl, in Enol, \& Prantl, Naturl. Pflanzenfam. iii. 6 (1893) 190 = Freziera cernua, Tul. cordata, Szyszy1.1. c. $190=$ cordata, Tul.

distichophylla, Hemsl. ex Forb. \& Hemsl. in fourn. Lim. Suc. xxi1i. (1886) 77. ... China.

Dombeyana, Szyszyl. in Engl. \& Prantl, Natürl. Pflanzenfam. iii. 6 (1893) $190=$ F. Dombeyana, Tul.

ferruginca, Szyszy1. 1. c. = F. ferruginea, Wawra. Friedrichsthaliana, Szyszyl, l. c. - Guatem. guianensis, Szyszyl. 1. c. = F. guianensis, Wawra. gynandra, Vesque, in Bull. Soc. Bot. Fr. xlii. (1895) 160. - China.

integrifolia, Szyszyl. in Engl. \& Prantl, Natürl. Pflanzenfam. iii. 6 (1893) $189=$ Freziera integrifolia, Benth.

Karsteniana, Szyszyl. l. c. 190. - Guatem.

Korthalsiana, Vesque, in Bull. Soc. Bot. Fr. xlii. (1895) 155 et $15 \%$. - Java.

Lehmannii. Hicron. in Bot. Fahrb. xx. (1895) Beibl. 49. - Columb

longipes, Szyszyl. in Eng1. \& Exantl, Natürl. Pflanzenfam. iii. 6 (1893) $190=$ Freziera longipes, $T u l$.

macroplyzlla, Szyszyl. 1. c. = F. macrophylla, Tul. mexicana, Szyszyl. 1, c. $189=$ F. mexicana, Turcz. nervosa, Szyszyl. 1. c. $190=$ F. nervosa, Humb. \& Bonpl.

nitida, Hicron. in Bot fahrb. xx. (1895) 50. Columb.

ochnacea, Szyszyl. in Engl. E Prantl, Natürt. Pfanzenfam, iii. 6 (1893) $189=$ Cleyera ochnacea, $D C$. reticulata, Szyszyl.1. c. $190=$ Freziera reticulata, Humb. \& Bonpl.

roramensis, Szyszyl. 1. c. $=\mathrm{F}$. roraimensis, $T u$. sanguinea, Vesque, in Bull. Soc. Bot. Fr. xlii. (1894) 159. - Ins. Samoëns.

sericea, Szyszyl, in Eng1. \& Prant1. Natür1. Pflanzenfam. iii. 6 (1893) $190=$ Freziera sericea, Humb. \& Bonpl.

suberosa, Szyszyl. 1. c. = F. suberosa, Tul.

syphilitica, Szyszyl. 1. c. $189=$ Cleyera siphilitica, Choisy.

theoides, Szyszyl. 1. c. = Freziera theoides, Sw.

undulata, Szyszyl. 1. c. $190=$ F. undulata, Willd:

varians, Vesque, in Bull. Soc. Bot. Fr. xlii. (1895) 155 et 157 . - Java

verncosa, Hieron, in Bot. Fahrb. xx. (1895) Beibl. 51. - Columb. vel Ecuad.

Wrayi, King, in foum. As. Soc. Beng. lix. (1890) II. 196. - Perak.

Yungasiae, Szyszyl. in Engl. \& Prantl, Natürl. Pflanzenfam, iii. 6(1893) $190=$ Freziera Yungasia, Tul.

EURYBIA, Cass.= Olearia, Moench. (Compos.). iticifolia. Hert. ex Dippel, Handb. Laubholzk. i. (1889) $290(=$ E. errbescens, DC. $)=$ Olearia myrsinoides. 
EURYGANIA, Klotzsch (Vaccin.). - Ind, Kew. i. 934

subcrenulata, Niedenzu, in Bot. Jahrb. xi. (1890) 207 $=\mathrm{V}$. subcrenulatum, Klotzsch.

EURYOPS, Cass. (Compos.). - Ind. Kew. i. 934. dacrydioides, Oliver, in Hook. Icon, pl, xvi. (18S6) t. 1508 ; et in Trans. Linn. Soc. Ser. II. ii. (1887) 340. - Afr. trop. or.

pedunculatus. N.E. Br. in Kew Bull. (1895) 147.-Afr. austr.

Schenckii, O. Hoffm. in Bull. Herŏ. Boiss. i. (1893) 88. - Afr. austró-occ. extratrop.

EUSCAPHIS, Sieb. \& Zucc. (Sapind.). - Ind. Kew. i. 935.

aponica, Pax, in Engl. \& Prantl, Natür1. Pflanzenfam. iii. 5 (1893) 262; Koehne, Deutsche Dendro:. (1893) $366=$ staphyleoides, Sieb. \& Zucc.

EUSTEGIA, R. Br. (Asclep.). - Ind. Kew. i. 9:37. macropetala, Schlechter, in fourn. Bot. xxxiii. (1895), 358. - Afr. austr.

plicata, Schinz, in Bull. Herb. Boiss. ii. (1894) 218 - Afr. austr.

EUSTEPHIA, Cav.(Amary11.). - Ind. Kew, i 936

argentina, Pax, in Bot. Fahrb. xi. (1890) 32s.Reg. Argent.

marginata, $P a x, l . c,-$ Reg. Argent.

EUSTIGMA, Gardn. \& Chapm. (Hamamel.). Ind. Kew. i. 936.

Balansae, Oliver, in Hook. Icon.pl.xx. (1891) t. 1954 - Tonkin.

EUTOCA, R. Br. = Phacelia, Juss. (Hydrophyll.) diversicolor, Baill. in Bull. Soc. Linn. Paris, ii. (1890) 830. - Hab. ?

grandis. Phil. in Anal. Univ. Chil. xc. (1895) 226. Chili.

litoralis, Phil. l. c. 228. - Chili.

lomarifolia, Phil. in Anal. Mus. nac. Chile (1891) 54. - Am. austro-occ.

pedunculosa Phil. l. c. - Chili.

Peraltae, Plit. in Anal. Univ. Chil. xc. (1895) 227. - Chili.

EUTREMA, R. Br. (Crucif.). - Ind. Kew. i. $93 \%$. Eschscholtziamum, Robinson, Syn. Fl. N. Am. i. I. (1895) $135=$ Braya Eschscholtziana, Hook. of Arn. Przewalskii, Maxim. Fl. Tangut. (18S9) 68. China.

thibeticum, Franch. in Nonv. Arch. Mus. Paris, Sér. II. viii. 1885 (1886) 201. - Tibet.

yunnanense, Franch. Pl. Delas. (1889) 61. - Yunnan.

EUTRIANA, Trin.= Bouteloua, Lag.(Gramin.). racemosa, Trin. ex Fourn. Gram. Mexic, 1881 (1886) 141 in syn. = B. Triathera, Benth.

EUXENIA, Cham. = PodantIns, Lag. (Compos.). ovalifolia, Kuntze, Rev. Gen. (1891) 338 = P. ovatifolius, $L$ ag.

EVAGIDIUIM, Pomel (Compos.), - Ind. Kew.i.

Heldreichii, Pomel, in Bull. Soc. Bot. Fr. xxxy. (1888) $313=$ atlanticum, Ponel.

EVACOPSIS, Pomel = Evax, Gaertn. (Compos.). angustifolia, Pomel, in Bull. Soc. Bot. Fr. xxxv. (1888) 333. - Algeria.

mareotica, Pomel, 1. c. $334=$ Filago mareotica, Delile.

EVAX, Gaertn. (Compos.). - Ind. Kew. i. 938. acaulis, Greene, Man. Bot. San Franc. Bay (1894) 184. - Calif.

Cavanillesii, Rouy, in Le Naturaliste (1884) $557=$ carpetana, Lange.

involucrata. Greene, Man. Bot. San Franc. Bay (1894) $185=$ Psilocarphus caulescens, Benth.

\section{EVAX:-}

gallica, Rouy, in Bull, Soc, Bot, Fr. xxxvii. (1890) p. xvii in syn. = E. Cavanillesii, Rouy.

linearifolia, Pomel, in Bull. Soc. Bot. Fr. xxxy, (1888) 333. - Algeria.

mucronata, Pomel, 1. c. - Tunet.

psilantha, Pomel, 1. c. - Algeria.

EVERARDIA, Ridl. ex Oliver, in Trans, Linn, Soc., Ser. II. ii. (1887) 287 [Oliver, ex im Thurn, in Timehri, v. (1886) 210]. CYPERACEAE.

montana, Ridl. l. c. t. 52 (Ridl. ex im Thurn. err. cal, montano). - Guian. ang-1.

EVODIA, Forst. (Rutac.). - Ind. Kew. i. 939.

Belahe, Baill. in Bull. Soc. Linn. Paris, i. (1886) 590 ; et Hist. pl. Madag.. Atlas (1891) t. 166.Madag.

Boiviniana, Baill. $7 l . c c .591$; et t. 168. - Ins. Comor.

Bojeriana, Baill. Hist. pl. Madag., Atlas (1891) t. 169. - Madas.

crassinervis, $K$. Schum, in K. Schum. \& Hollr. Fl.

Kais. Wilh. Land (1889) 59. - N. Guin.

cuspidata, $K$. Schum. l, c.57 - N. Guin.

Daniellii, Hemsl. ex Forb. \& Hensl, in fourn. Linn. Soc. xxiii. (1886) 104 (= Zanthoxylum Danisllii Benn.) - China.

discolor, Baker, in fourn. Linn. Soc. xxii (188\%) 456. - Madag.

floribunda, Baker, l. c. 45\%. - Madag.

grisea, Kuntze, Rev. Gen. (1891) $98^{\circ}=$ Boninia grisea, Planch.

lobocarpa. F. Muell. in Journ. Bot. xxx. (1892) $17=$ Acronychia lobocarpa, F. Muell.

macrocarpa, King, in fourn. As. Soc. Beng. lxii. (1893) II. 209. - Perak.

magnifolia. Baill. in Bull. Soc. Linn. Paris, i. (1886) 590 ; et Hist. pl. Madag., Atlas (1891) t. 167. Madag.

mollis, Warb. in Bot. fahrb. xiii. (1891) 339. Oceania.

Nadeauli, Drake, Fl. Polyn. Franc. (1893) 2\% $1=$ Melicope tahitensis, Nadeaud). - Ins. Societ.

pachyphylla, King, in fourn. As. Soc. Beng. lxii. (189:3) II. 210. - Penins. Mal.

pilulifera, King, l, c.-Perak.

Schullei, Warb., in Bot. Fahrb. xiii. (1891) 338. Oceania.

subunifoliolata, Stapf, in Trans. Linn. Soc., Ser. Ir. iv. (1894) 138. - Borneo.

tenuistyla, Stapf, l. c. 137. - Borneo.

tetragona, $K$. Schum. in $K$. Schum. \& Holl. Fl. Kais. Wilh. Land (1889) 57. - N. Guin.

viridans, Drake, in Morot, foncm. de Bot. vi. (1892) 273. - Tonk.

EVOLVULUS, Linn. (Convolv.). - Ind. Kew. i. 939

Karstenii, Peter, in Engl. ct Prantl, Natürl. Pfanzenzfam. iv. 3a (1891) 19 (= Majera coerulea, Karst.). - Columb

prostratus, Robins. in Proc. Ant. Acad. xxix. (1894) 320. - Mexic.

Lavae, Schweinf, ex Penzig, in Atti Congr. bot. Genova (1893) 351. - Erithea.

rotundifolius, Hallier fo in Bot. Jahrb. xvi. (1893) $530=$ Breweria rotundifolia, S. Wats.

EXACULUM, Caruel, in Parl. F1. Ital. vi. (1887) 743 ; et Epit. F1. Eur. ii. (1894) $141=$ Cicendia, Griseb. (Gentian.).

EXACUM, Linn. (Gentian.). - Ind. Kew. i. 940 , Hoffmannii, Schinz, in Viertelj. Naturforsch. Gesells. Zurich, xxxvi. (1891) 327. - Madag.

EXARRHENA, R. Br. = Myosotis, Linn.(Borag.). Colensoi, $T$. Kirk, in Trans. N. Z. Inst. xxvii. 1894 (1895) 351. - N. Zel.

EXCOECARIA, Linn. (Euphorb.). - Ind. Kew。i. 941.

glaucescens, S. Elliot, in fourn. Linn. Soc. xxix. (1891) 48. - Madag.
EXCOEGARIA :

glomeriflora. Pax, in Engl. Pflanzenw. Ost-Afr. C (1895) 241. - Afr. trop. or.

lissophylla, Baill. Hist. pl. Madag., Atlas (1S91) t. 203. - Madag.

rectinervis, Kuyz, ex Hook.f. Fl. Brit. Ind. v. (1888) 473 (= Actephila rectinervis, Kurz). - Ins. Nicob.

robusta, Hook. f. l. c. 474. - Concan

venenifera, Pax, in Bot. Fahrb. xix. (1894) 113.Afr. trop. or.

EXOCARPUS, Labill. (Santa1.). - Ind. Kew.i. 942.

brachystachys, Hillebr. Fl. Haw. Isl. (1888) 391. Ins. Sandvic.

EXOGONIUM, Choisy = Ipomoea, Linn. (Convolvul.).

Uhdeanm, Fenzl, ex Hallier f. in Bot. Jahrb. xvi. (18.13) $559=1$. tubulosa, Henns?

villosum, Peter, in Engl. \& Prantl, Natürl. Pflanzenfam. iv. 3a (1891) 2S (=I. villosa, Meissn. ex Mart.). - Bras.

EXOTHEA, Macfad. = Hypelate, P. Br. (Sapind.).

Copalillo, Radlk. in Th. Dur. Ind. Gen. Phan. (1888) 81. -

paniculata, Radlk.l.c. $(=$ E. paniculata, Walp.) $=$

H. paniculata, Cambess.

\section{F}

FABERIA, Hemsl. ex Forb. \& Hemsl. in Journ. Linn. Soc. xxiii. (1S38) 479. COMPOSITAE sinensis, Hemsl.l. c. et in Hook. Icon.pl.xix. (1889) t. 1815. - China.

FABIANA, Ruiz \& Pav. (Solan.). - Ind. Kew. i. 944 .

axaucana, Phil. in Anal. Univ, Chil. xc. (1895) 759. - Am. austr.

Barrisi, Phil. l. c. 763. - Chili.

lutescens, Phil. l. c. 760. - Chili

squamata, Phil. in Anal. Mus. nac. Chile (1891) 61. - Am. austr. occ.

FABRICIA, Scop. = Alysicarpus, Neck. (Legumin.).

belgaumensis, bupleurifolia, ferruginea, hamosa, Icngifolia, monilifera, porrecta, pubescens, nugosa, tetragonoloba, Zcyheri, Kuntze, Rev. Gen. (1891) is1-82 = homonyma omnia Alysicarpi.

cylindrica, Kuntze, I. c. $182=\mathrm{A}$. rugosus, $D C$.

mummulariaefolia, Kuntze, 1. c. $181=\mathrm{A}$. vaginalis, $D C$.

FAGELIA, Schrank = Galceolaria, Linn. 'Scrophul.).

adscendens, alba, alternifolia, amplexicaulis, andina, angusitifora, argentea, bellidifolia, bicolor, bicrenata. biflora, calycina, cana, canescens, cerasifolia, corymbosa, crenata, crenatiflora, cuneiformis, Darwinit, deflexa, dentata, dilatata, divaricata, erioclada, deflexa, dentata, dilatata, dlexuosa, Fothergillii, excelsa, extensa, ferriginea, flexuosa, Fotnergilli, glandulosa, glauca, gossypina, gracilis, graminifolia, Hyssopifolia, integrifolia, involuta, lamiifolia, lanata, lanceolata, latifolia, laxa, linearis, lobata, Matthewsii, nexicana, montana, Morisii, nana, nivalis, mudicaulis, oblonga, ovata, padifolia, paralia, parjiflora, perfoliata, petiolaris, pinifolia, pinnata, pisacomensis, plectranthifolia, polifolia, polyrhiza, pulverulenta, punctata, punicea, purpurea, racemosa, rosmarinifolia, rotundifolia, salicifolia, saxatilis, scabra scapiflora, serrata, sessilis, Sinclairii, stricta. scabra, scapifora, serrata, sessilis, sinclairiv, striota, triandra, trifida, tripartita, undulata, uniflora, 


\section{FAGELIA : -}

Gerticillata violacea, virgata, viscosa, viscosissima, Kuntze, Rev. Gen. (1891) $459-60$ = homonyma ommia Calceolariae.

arachnodea. Kuntze, 1. c. $459=$ C. arachnoidea, R. Grah.

Bangii, Rusby, in Mem. Torrey Bot. Club, iv, (1895) 236. - Bolivia.

bartsiacfolia, Rusby, 1. c. 235. - Bolivia.

Berteroi, Kuntze, Rev. Gen. (1891) $459-60=\mathrm{C}$. Berterii. Colla.

chalidoniodes, Kuntze, 1. c. = C. chelidonioides, H. B. \& $K$

cricodes, Kuntze, 1, c. $=\mathrm{C}$. ericoides, fuss.

helianthemodes, Kuntze, 1. $\mathrm{c} .=\mathrm{C}$. helianthemoides, H. B. \& $K$

inflexa, Kunlze, 1. c. $460=$ C. serrata, Lam.

lavandulifolia, Kuntze, 1, $\mathrm{C}$, = C. lavandulaefolia, H. B. \& $K$.

melissifolia, Kuntze, 1. $c_{0}=\mathrm{C}$. melissaefolia, Benth.

mollissima, Kuntze, 1. c. = C. integrifolia, Mum

nitida, Kuntze, 1. c. = C. adscendens, Lindl.

Paronia, Kuntze, 1. c. = C. Pavonii, Benth.

scabiosifolia, Kuntze, 1. C. = C. scabiosaefolia,

$$
\text { Sims. }
$$

scabra Rusby, in Mem. Torrey Bot. Club, iv. (1895) 236 in obs. = scabra, Kuntze.

sibthorpiodes, Kuntze, Rev. Gen. (1891) 459-60= Calceolaria sibthorpioides, $H . B$. \& $K$.

temiflora, Kuntze, 1. c. sphalm. = C. terniflora, Car.

utviculariodes, Kuntze, 1. c, = C. utricularioides, Hook.

FAGONIA, Tourn, ex Linn. (Zygophyll.), -- Ind. Kew, i. 944.

Iuntii, Baker, in Kew Bull. (1894) 330. - Arabia. minutistipula, Engl. Bot. fahrb. x. (1889) 33.Afr. austro-occ, extratrop.

nummulatifolia, Baker, in Kew Bull. (1895) 181. Arabia.

Palmeri, Vasey et N.E. Rose, in Contrib. U. S. Nat. Herb. i. (1890) 82. - Calif, inf.

subaphylla, Phil. in Anal. Mus, nac. Chite (1891) 12. - Chili.

FAGRAEA, Thunb. (Logan.). - Ind. Kew, i. 945. Alteniana, F. Mull, in Vict. Natural. vi. (July 1889) 45 nomen. - Austral.

Woodiana, F. Muell, in Austrolas. Fourn. Pharm. (Sept. 1886) 323; et ex Bot. Centralbl. xxix. (1887) ¿41. - N. Guin.

FAGUS, [Tourn.] Linn. (Cupulif.). - Ind. Kew. i. 945 .

asiatica, "DC, ex Koehne, Deutsche Dendrol. (1893) 121 et 580 ad calc. = F. Sieboldii, Endl

atropunicea, Sudw in Bull. Torrey Bot. Club, xix. (1893) 43 ; et in Mem. Torrey Bot. Club, iv. (1893) $153=$ ferruginea, Ait.

Carroni, C. Moore, Handb. F1. N. S. Wales (1893) $85=\mathrm{F}$. Moorei, F. Muell.

crispa, Hort. ex Dippel, Handb. Laubholzk ii. (1892) $52=$ sylvatica, Linn.

cucullata, Hort, ex Dippel, 1. c。 = sylvatica. Linn.

incisa, Hort, ex Dippel, 1, c, $51=$ sylvatica, Limn.

japonica, Maxim. in Bull. Acad. sci. St. Pétersb. xxxi. (1887) 101. - Japon.

quercïdes, “Pers, ) ex Dippel, Handb. Laubholzk. ii. (1892) 51 et $581=$ sylvatica, Lim.

FALCARIA. Riv.(Umbellif.). - Ind. Kew. i. 946. persica, Stapf ct Wettst. ex Stapf, in Denkschr. Akad. Wien (1856) 48. - Persia.

servata, St Lager, in Cariot, Etud. des fl. éd. 8. ii. (1889) $360=$ vulgaris, Bcrnh.

FALCATA, J.F. Gmel。= Amphicarpaea, Eil. (Legumin.)

conosa, Kuntze, Rev. Gen. (1891) $182=$ A. monoica, Ell.

Edgeworthii, Kuntze, 1. c. = A. Edgeworthii. Benth.

Pitcheri, Kuntze, 1. c. = A. Pitcheri, Torr. \& Gray.
FALKIA, Linn. (Convolv). - Ind. Kew. i. 946. abyssinica, Engl, in Abh. Preuss. Akad. Wiss, 1891 (1842) 344. - Abyss.

diffusa, Hallier f. in Bot. Fahrb. xviii. (1894) 85. Afr. austr.

villosa, Hallicr f. l. . . - Afr. austr.

FARADAYA, F. Muell. (Verben.). - Ind. Kew. i. 946 .

Albertisii, F. Mull. Papuan Pl. viii. (1886). N. Guin.

parviflora, Warb. in Bot. Fahrb. xviii. (1894) 208. - Oceania.

ternifolia, F. Mucll. Papuan Pl. viii. (1886) 46. N. Guin.

FARAMEA, Aubl. (Rubiac.).-Ind. Kew. i. 946. amevicana, Kuntze, Rev. Gen. (1891) $282=$ odoratissima, $D C$.

Bangii, Rusby, in Menu. Torrey Bot.Club. iii. 3 (1893) 45. - Bolivia.

breviflora, Benth. ex Brillon in Bull. Torrey Bot. Chib, xviii. (1891) 109.-Bolivia.

FARFUGIUM, Lind1. = Senecio, Tourn. (Compos.)

gigantem, Hort. Dammann, ex Gartenfl. (1892) 525 $=$ S. Kaempferi, $D C$

FARGESIA, Franch, in Bull. Soc, Linn. Paris, ii. (1893) 1067; Baill. Hist. des pl. xii. (1894) 251. GRAMINEAE.

spathacea, Franch. ll. cc. - China,

FAROA. Welw. (Gentian.). - Ind. Kew. i. 947. Boehmii, Engl. Pfanzenw. Ost-Afy. C (1895) 313. Afr. trop.or.

Buchanani. Baker in Kow Bull. (1894) 26. - Afr. trop. or.

gomphrenoides, Engl. Pfanzenw. Ost-Afr. C (1895) 313. - Afr. trop. or.

graveolens, Baker, in Kew Bull. (1894) 26. - Afr. trop. or.

involucrata, Knobl. in Bot. Centralbl. 1x. (1894) 331. - Afr. trop.

pusilla, Baker, in Kew Bull. (1894) 26. - Afr. trop. or.

Schweinfurthii, Knobl. in Bot. Contralbt. 1x. (1894) 330. - Afr. trop

FARSETIA, Turra (Crucif.). - Ind. Kew. i. 947 italica, Ces., Pass et Gibelli, Comp. Fl. Ital. ii. (1886) 837 = Aulrietia deltoidea, Guss.

longistyla, Baker, in Kew Bull. (1895) 211. - Reg. Somal.

ramosissima, Hcldr. ex Boiss. Fl. Or. Suppl. (1888) 30. - Aegypt

FAUREA, Harv, (Proteac.). - Ind. Kew, i. 948 arborea, Engl. Bot. Fahrb. xix. Beibl. n. 47 (1894) 29. - Afr. aequat. or.

usambarensis, Engl.l.c. - Afr. trop. or.

FAURIA, Franch, in Bull. Soc. Philom. Paris, Sér. vii. X. (1886) 140. SAXIFRAGEAE. japonica, Franch, l. c. 141. - Japon.

FAVRATIA, Feer, in Bot. Jahrb. xii. (1890) $610=$ Campanula, Linn. Zoysii, Feer, 1. C. = C. Zoysii, Wulf.

FAXONIA, T. S. Brandeg, in Zoë, iv. (1894) 403 t. 31. COMPOSITAE

pusilla, T.S. Brandeg. l.c.-Calif

FEDIA, Adans. = Patrinia, Juss. (Valer.) cungustifolia, gibbosa, hetorophylla, monandra, palmata, saniculifolia, scabra, Kuntze, Rev, Gen. (I891) $302=$ homonyma onnia Patriniae.

orata, Kuntze, 1. c. = P. villosa, fuss

FEERIA, Buser, in Bull. Herb. Boiss. ii. (1894) 517. CAMPANULACEAE.

angustifolia, Buscr, l. c.518 (= Tracheliun angustifolim, Schousb.). - Marocc.
FEIJOA, Berg (Myrt.). - Ind. Kew. i. 949.

Schenckiana, Kiacrs. Enum. Myrt. Bras. (1891) 186. - Bras.

FELICIA, Cass. (Compos.). - Ind. Kew. i. 949. Boehmii, O. Hoffm。 in Engl.Pflanzenw. Ost-Afr. C (1895) 407. - Afr, trop. or.

Cameronii, F. Muell. in Trans, Roy. Soc. Vict. N. S. I. ii. (1889) 7. - N. Guin.

Fischeri, O. Hoffm. in Engl. Pflanzenw. Ost-Afr. C (1895) 407. - Afr. trop. or.

linearis, N.E. Br. in Kcw Bull. (1895) 146. - Natal.

FERDINANDUSA, Pohl (Rubiac.). - Ind. Kew. i. 949 .

Goudotiana, K. Schum, in Mart. Fl. Bras, vi. VI. (1889) 211. - Guiana angl.

Guianiae, Spricce, сx K. Schum. l. c. 208. - Bras.

lanceolata, K. Schum. l. c. 209. - Bras.

Sprucei, K. Schum.l. c. 210. - Bras.

uaupensis, Spruce, ex K. Schum. l.c. 212, - Bras,

FERNANDIA, Baill. Hist. des pl. x. (1888) $47=$ Heterophragma, DC. (Bignon.).

Fernandi, Baill. ex K. Schum. in Engl. \& Prantl, Natür1. Pflanzenfam. iv. 3b (1895) 243 = Ferdinandoa superba, Seem.

superba, Baill. 1. c. $48=$ Ferdinandoa superba Scem.

FERNSEEA, Baker, Handb. Bromel. (1889) 20. BROMELIACEAE.

Itatiaiae, Baker, l. c. 21. $(=$ Bromelia Itatiaia Wawra). - Bres.

FEROLIA, Barrère, = Parinarium, Aubl, (Rosac.).

asperula, brasiliensis, capensis, chrysophylla, cordata, coriacea, corymbosa, costata, curatcllifolia, excelsa, Gardneri, glaberrima, glabra, Griffithana, indica, fackiana, macrophylla, Mobola, montana, nitida. Nonda, oblongifolia, obtusifolia, Pohlii, polyandra, polyneura, robusta, salicifolia, scabra, Sprucei, subcordata, trasancorica, Kuntze, Rev. Gen. (1891) 216 = homonyma omnia Parinarii.

anazonica, Kuntze, 1.c. = P. excelsum, Sabine. campestris, Kuntze, 1. c. = P. campestre, Aubl. minutiflora, Kuntze, 1. c. = P. Griffithianum, Benth. sumatrana, Kuntze, 1. c. = P. costatum, Blumze.

FERRARIA, Linn. (Irid.). - Ind, Kew. i. 950 Welwitschii, Baker, Handb. Irid. (1892) 74. Angola.

FERULA, Tourn, ex Linn. (Umbell.). - Ind. Kew. i. 950.

Barbeyi, Post, Pl. Postianac, ii. (iS91) 10. - Syria. Bilasi, Post, l. c. 9. - Syria.

Cossoniana, Batt. in Bull. Soc. Bot. Fr. xxxy. (1888) 340 et 388 nomen $=$ longipes, Coss .

Erythraeae, Schweinf. ex Pentig, in Atti Congr. Bot. Genova (1893) 343 nomen. - Erithrea.

hispanica, Rouy, in Bull. Soc. Bot. Fr. xxxv. (1888) 116 - Hisp.

longipes, Coss. ex Bonn. \& Maury. in Morot, Fourn. de Bot. ii. (1888) 314; et ex Batt. in Bull. Soc. Bot. Fr. xxxv. (1888) 388. - Algeria.

Loscosii, Willk. [Dolect. sem. Hort. bot. Prag. (1882)] ex ej. Suppl. Prodr, Fl. Hisp. (1893) 206. - Hisp. marmarica, Aschers. \& Taub. ex Aschers. \& Schweinf. in Bull. Herb. Boiss. i. (1893) 649. - Afr. bor.

parva, Freyn \& Bormm. ex Freyn, in Oest.-Bot. Zeitschr.xhii. (1892) 121.- Armen.

purpurea, S. Wats. in Proc. Am. Acad. xxi. (1886) 453. - Am. bor. occ

suaveolens, Aitch. \& Hemsl. in Trans. Linn. Soo Ser, II. iii. (1886) 69 t. 20 et 21. - Persia.

tunetana, Pomel. ex Batt. in Bull. Soc. Bot. Fr. axxiii. (1886) 478. - Algeria.

FERULAGO, Koch = Ferula, Linn. (Umbell.). Amani, Post. ex Boiss. Fl. Or. Suppl. (1888) 264 et in Journ. Linn. Soc. xxiv. (1SS8) 439. Syria.

asporula, Freyn \& Sint. ex Sint. in Oest. Bot. Zeitschr. xlii. (1892) 122. - Armen. 
FERULAGO : -

aurantiaca, Post, in Journ. Linn. Soc. xxiv. (1888) 430. - Syria.

Blancheana, Post, ex Boiss. Fl, Or. Suppl. (1888) 265 ; et 1. c. 430. - Syria.

resceritensis, Coss. \& Durieu, ex Batt, \& Trab. Fl. de l'Algér. [Dicot.] (1888) 368. - Algeria.

FESTUCA [Tourn.] Linn. (Gramin.). - Ind. Kew.

aetnensis, C. Richt. P1. Europ. i. (1889) 108 (=F. aetnensis, Walp.j = ciliata, Pers,

algeriensis, Trab, in Batt. \& Trab. Fl. de l'Algér. [Monoc.] (1895) 212. - Algeria.

aurasiaca, Trab. 1. c. $215=$ rubra, Linn

Brannii X, C. Richt. P1. Europ. i. (1889) 103.Germ.

casapaltensis, Ball, in fourn. Limn. Soc. xxv. (1885) 62. - Peruvia.

californica, Vasey, in Contrib. U. S. Nat. Herb. i. (1893) 277. - Calif

chrysophylla, Phil. in Anal. Mus. nac. Chile (1891 88. - Chili.

Commersonii, Franch. Miss. scient. Cap Horn. v. Bot. (1889) 388 t. 8 fig. c. - Fret. Magell.

contracta, $T$. Kirk, in Trans. N. Z . Inst xrvii. 1894 (1895) 353. - N. Zel.

flava, Hack. ex Sediro, Gram. Enator. [Anal. Unir. Quito, 1889$] 10$ nomen. - Ecuad

glaucantha, Blocki, in Oest. Bot. Zeitschr. xxxix. 1889) 155 = ovina, Linn.

glumosa, Hack. ex Sodiro, Gram, Euator. [Anal. Unir. Quito, 1889] 10. - Ecuad.

grandis, Trab. in Batt. et Trab. Fl. de l'Algér [Monoc.] (1895) 216= rubra, Limn.

Hackelii X, G. Beck, Fl. Nied.-Oest. i. (1890) 97 [an seq. ?]. - Austria.

Hackelii, C. Richt. P1. Europ, i. (1889) 101. Austria.

Hansshechtii $X$, Torges, in Mitth. Bot. Ver. Jena, vii. (1889) 6.- Europ.

hispanica, C. Richt. Pl. Europ. i. (1889) 109 (= Nar durus montamus, Boiss.). [an Kunth ?]. - Hisp

hyprophila, Phil. in Anal. Mus, nac. Chile (1891) 89. - Am. austro-occ.

infesta, Hack. ex Batt. et Trab. in Bull. Soc. Bot. Fr. xxxv. (1888) 347 nomen. - Algeria.

Jonesii, Vasey, in Contrib. U. S. Nat. Herb. i. (1893) 278. - Am. bor. austro-ocic

juncea, Phil. in Anal. Mus. nac. Chile (1891) 88.Chili.

lamprophylla, Trab. in Bull. Soc. Bot. Fr. xxxvi. (1889) 64, nomen. - Algeria.

leioclada, Hack: ex Sodiro, Gram. Ecuator. [Anal. Univ. Quito, 1889] 10. - Ecuad.

maroccana, Trab. in Batt. et Trab. F1, de l'Algér. [Monoc.] (1895) $215=$ rubra, Linn

milanjiana, Rendle, in Trans. Linn. Soc., Ser. II iv. (1894) 5\%. - Afr. trop

minor, St. Layer, in Cariot, Etud. des $\mathrm{Al}$, éd. 8. ii. (1889, $940=\mathrm{F}$. Halleri, All.

numidica, Trab. in Batt. et Trab. Fl. de l'Algér. [Monoc.] (1895) 214. - Algeria.

bovalis, Willa. ex Fourn. Gramin. Mexic, 1881 (1886) 124 sphalm.?] (= Diplachne procera Spreng. $=$ orgyalis, Willd.

oregona, "Vasey »ex Holzinger, in Contrib. U. S. Nat. Herb. iii. 4 (1894) 264, sphalm. = oregana Vasey.

patens, C. Richt. Pl. Europ. i. (1890) 110 (=Brachypodium patens, Nym.). - Lusit.

paupera, Phil. in Anal. Mus. nac. Chile (1891) 89. - Am. austro-occ.

Pichinchae, Hack. ex Sodiro, Gram. Ecuator. [Anal. Univ. Quito, 1889710 nomen, - Ecuad.

pogonantha, Franch. Min. scient. Cap Horn, v. Bot 1889) 387. - Patag.

pseudooina, G. Beck, F1. Nied.-Oest. i. (1890) 103 [an F. Pseudorina, Hack. ?] = ovina, Linn

rigidior, C. Richt. Pl. Europ. i. (1889) $105=$ pumila, Vill.

rupicaprina, G. Beck, Fl. Nied.-Oest. i. (1890) 104 - ovina, Lim

salinaria, Simonk, in Termész. Füzét. x. (1886) 184 ; et Enum. F1. Transsilv. (1886) $586=\mathrm{Gly}$ ceria distans, Wahlenb.

\section{FESTUCA}

alzmanni, C. Richt. PI. Europ. i. (1890) $110=$ F. Salzmanni, Boiss.

sardoa, Frack. in Barb. Comp. Fl. Sard. (1884) 71. Sard.

scabrescens, Hack, ex Trab, in Batt, et Trab, Fl. de l'Algér. [Monoc.] (1895) $215=$ rubra, Linn. Sodiroana, Hack, ex Sodiro, Gram. Ecuator. [Anal. Univ. Quito, 1889] 10, nomen. - Ecuad.

stenantha, G. Beck, Fl, Nied.-Oestr. i. (1890) 104 [an $F$. stenantha, Nym. ?] = ovina, Limn.

sulcata, G. Beck, 1. c. 103 [an F. sulcata, Hack. ?] = ovina, Limm.

texana, Vasey, in Bull. Torrey Bot. Chub, xiii. (JS86) 119. - Texas.

tuberculosa, C. Richt. Pl. Europ, i. (1890) $110=$ tuberculosa, Coss. \& Durieu.

viridula, Vasey, Ill. N, Am. Grass, ii, (1893) t. 93 et Contrib. U.S. Nat. Herb. i. (1893) 279. Calif.

FEUILLEEA, Kuntze, Rev. Gen. (1891) $182=$ Fevillaea, Linn. 1735 [non FEVILLEA Linn. 1737], gen. collect. (Legumin.)

amara, angolensis, anthelmintica, basaltica, Boivini, brachycalyx, coriaria, elliptica, ferruginea, Forbesii, fulgens, glabrescens, glomeriflora, gramulosa, faubertiana, Fulibrissin, Lebbek, liloralis, lucida, montana, obovata, odoratissima, paicina, pallida, Petersiana, polyphylla, procera, Ouartiniana, retusa, rhombifolia, rotundata, rufa, salajeriana, saponaria, Schimperii, stipulata, subfalcata. Thozetiana, tomentella, versicolor, viridis, Welwitschii, Kuntze. Rev. Gen. (1891) 187-189 = homonyma omnza Albizziae.

abbreviata, aculeata, alternans, amazonica, angelica, angustifolia, axillaris, bella, bicolor, Blanchetii, bombycina, brevipes, californica, calothyrsa, calycina, canescens, capillata, caracasana, carbonaria, chilensis, codonandra, comosa, crassipes, Cruegeri, Cumingii, depauperata, dysantha, emarginata, criophylla, expansa, falcata, foliolosa, formosa, Gardneri, glomerulata glyphoxylon, gracilis, grandiflora, Griffithit, Guildingii, haematocepliala, haematomma, Harrisii, Guildingii, haematocepliala, hamatomm, Harrisii, lanata, laxa, leptopoda, linearis, longipes, longipinna, macroccphala, Magdalenae, malacophylla, mollissima, myriopliylla, Pacara, Peckoltii, pedicellata, portoricensis, prostrata, Purdiaci, purpukea, reticulata, rigida, scutellifera. Seemanui, squarrosa, subnervosa, subspicata, taxifolia, tenuiflora, tergemina, tetragona, tetraphylla, trinervia, turbinata, Twecdii, umbrosa, virgata, viscidula, Wendlandii, Kuntze, Rev. Gen. (1891) 187-89 = homonyma omnia Calliandrae

acrocephala, acuminata, affnis, aggregata, alba, bahionsis, barbata, Billbergiana, Blanchetiana, Bonplandiana, brachyptera, bracteosa, bullata, campanulata, capitata, carnosa, cayennensis, chartacea, ciliata. cinnamomea, conferta, cornscans, cylindrica, densiflora, diadema, disticha, dominicensis, edulis, fagifoliu, fastuosa. Fendleriana, ferngineo-hirta, flagelliformis, globulifera, graciliflora, Guilleminiana, Hayesi, heterophylla, heteroptera, hispida, insignis, juglandifolia, lallensis, lanceacfolia, lateriflora, laurina, leiocalycina, lenticellata, lentiscifolia, leptantha, leptoloba, Lindeniana, lineata, Luschnathiana, macrophylla, maritima, martinicensis, Mathewsiana, mayazensis, Veisneriana, membranacea, multicaulis, multijuga, myriantha, negrensis, nobilis, muda, obtusata, Oerstedtiuna, panamensis, Pavoniana, pezizifera, platyptera, plumifera, Poeppigiana, pruriens, punctata, quaternata, rubiginosa, rufescens, rufinervis, Ruiziana, Salzmanniana, scabrizscula, schinifolia, Sciadion, sessilis, setifera, setosa, speciosa, spectabilis, splendens, spuria, stenocalyx, stenoptera, stipularis, strigillosa, subnuda, tarapotensis, tenuifolia, Thibaudiana, tomentosa, tubulifera, umbellifera, umbratica, uruguensis, velutina, venosa, vestita, villosissina, virescens, virgultosa, vismiacfolia, mulpina, xalapensis, Kuntze, Rev. Gen. (1891) 187-189=homonyma omnia Ingae.

acattensis, albicans, altissima, ampla, asplenifolia, auriculata, Bertholonii, bigemina, boneensis, brevifolia, bubalina, campestris, cauliflora, circinalis, clypearia, coccinea, cochleata, cognata, contorta, corymbosa, daulensis, divaricata, diversifolia, dulcis, dumosa, excelsa, filamentosa, filicifolia, filipes, flori-

\section{FEUILLEEA :}

bunda, Fournieri, furcata, Glazioui, Hendersoniz, inymeneaefolia, Hystrix, inaequalis, incurialis, fungJuhniana, Kegelii, laeta Ianosdorfii, latifolia, laxiflora, lencophylla, ligustrina, lindseacfolia, longiflora, lusoria, macrostachya, Mathewsii, micradenia, micrantha, microcalyx, microcarpa, monilifera, montana, Mottleyana, multiflora, oblonga, obovalis, panurensis, paraguensis, pedicellaris, Pervilleana, prehensilis, pruinosa, pubescens, ramiflora, rhombea, rostrata, Saman, sanguinea, scalaris, Selloi, simabifolia, sophorocarpa, Spruceana, subacuta, subcoriacea, torta, triflora, unbellata, Unguis-Cati, mnifoliolata, Kuntze, Rev. Gen. (1891) 187-89 = homonyma omnia Pithecolobii.

aeschynomenodes, Kuntze, 1. c. = Calliandra aeschynomenoides, Benth

alata, Kuntze, I. c. 184 = Inga brevipes, Benth.

amplebracteosa, Kuntze, 1. c. = Calliandra bracteosa. Benth.

aspleniodes, Kuntze, 1. c. = C. mertensioides, Benth. bahiensis, Kuntze, 1.c. = Pithecolobium foliolosum, Benth.

Bakeriana, Kuntze, 1. c. = Albizzia pedicellata, Baker.

Beccariana, Kuntze, 1. c. = Pithecolobium fasciculatum, Benth.

Benthamiana, Kuntze, 1. c. = Calliandra fasciculata, Benth.

Berteroana, Kuntze, I. c.= Pithecolobium fragrans, Benth.

Bourgoni, Kuntze, 1. c. $187=$ Inga Buorgoni, $D C$.

brerispicata, Kuntze, 1. c. $184=$ I. dumosa Benth.

ampanulata, Kuntze, 1. c. = Albizzia lentiscifolia, Benth.

Cataractae, Kuntze, 1. c. $185=$ Pithecolobium glomeratum, Benth.

Catharinae, Funtze, 1. c. = Inga striata, Benth.

caviflora, Kuntze, 1. c. 187, sphalm.= Pithecolobium claviflorum, Spruce.

cearana, Kuntze, 1. c. $185=$ Calliandra umbellifera, Benth.

Championii, Kuntze, I. c. = Pithecolobium lucidum, Benthe.

chrysantha, Kuntze, 1. c. $18 \%=$ Acacia chrysantha, DC.

cochlocarpa, Kuntze, I. c. $185=$ Pithecolobium Anaremotemo, Mart.

colletiodes, Kuntze, 1. c. = Calliandra colletioides, Griseb.

commutata, Kuntze, 1. c. = Serianthes myriadenia, Planch.

contortisiliqua, Kuntze, 1. c. = Enterolobium 'Tim boüva, Mart.

coriacea, Kuntze, 1. c. = Inga sertulifera, $D C$.

corniculata, Kuntze, 1. c. = Albizzia Milleti, Benth.

cyclocarpa, Kuntze, 1. c. I87 = Enterolobium cyclocarpum, Griseb.

cynometrodes, Kuntze, 1. c. = Inga cynometroides, Bedd.

darienensis, Kuntze, 1. co = I. dariensis, Seem.

dimidiata, Kuntze, 1. c. $185=$ Calliandra filipes Benth.

discolor, Kuntze, 1. c. = Pithecolobium adianthifolium, Benth.

distachya, Kuntze, 1. c. = Albizzia lophantha Benth.

dubia, Kuntze, 1. c. = Pithecolobium marginatum, Spruce.

elliptica, Kuntze, 1. c. $187=$ Albizzia elliptica, Fourzz.

Endlicheri, Kuntze, 1. c. 185 = Inga fasciculata, Poepp Eo Endl.

fasciculata, Kuntze, 1. c. = Calliandra surinamensis, Benth.

flexuosa, Kuntze, 1. c, = Pithecolobium geminatum, Benth.

fulvescens, Kuntze, 1. c. = P. ferrugineum, Benth. gummifera, Kuntze, 1. c. $185=$ Enterolobium ellipticum, Benth.

heterophylla, Kuntze, 1, c. = Pithecolobium angulatum, Benth.

hymeneaeodes, Kuntze, 1. c $=$ Calliandra hymenaeoides, Benth. 
FEUILLÉEA : -

hypolenca, Kuntze, Rev。 Gen. (1891) $188=$ Albizzia Harveyi, Fourn.

ignota, Kuntze, 1. c. 185 = Inga longiflora, Spruce. incana, Kuntze, 1. $\mathrm{c}_{0}=$ Albizzia canescens, Benth. incerta, Kuntze, 1. $\mathrm{c}_{0}=$ Pithecolobium Blancheti, Benth.

indurata, Kuntze, 1. c. = P. stipulare, Benth. Inga, Kuntze, 1. c. 182-184 = Inga vera, $W$ illd.

ingodes, Kuntze, 1. c. = I. ingoides, Willd.

finicul, Kuntze, 1. c. $188=$ I. Jinicuil, Cham。 \& Schlecht.

firing $a$, Kuntze, 1. c: $185=$ Pithecolobium lobatum. Benth.

Fupunba, Kuntze, 1, c. = P. trapezifolium, Benth lebbekodes, Kuntze, 1. c. $188=$ Albizzia odoratissima. Benth。

longifolia, Kuntze, 1. c, $185=$ Pithecolobium Vahlianum, Benth.

malaccensis, Kuntze, 1. c. $186=P$. confertum Benth.

mangensis, Kuntze, 1. c. = P. parvifolium, Benth. marginata, Kuntze, 1. c. 188 = Inga marginata Willd.

media. Kuntze, 1. c. $186=$ I. micradenia, Spruce.

microphylla, Kuntze, 1. c. = Albizzia myriophylla Benth.

multifoliolata, Kuntze, 1: c. = Calliandra microphylla, Benth

mutata, Kuntze, 1. c。 = Inga panurensis, Sprace.

mutica, Kuntze, 1. c. = Calliandra sessilis, Benth

myriadenia, Kuntze, 1. c. $188=$ Serianthes myriadenia, Planch.

neocaledonica, Kuntze, 1. c. $186=$ S. calycina, Benth.

nova, Kuntze, 1. c. = Inga microcalyx, Spruce.

pachyloma, Kuntze, 1. c, = Calliandra parviflora Benth.

periviana, Kuntze, 1. c. = Inga longipes, Benth.

pilosula, Kuntze, 1. c, = I. pilosiuscula, Desv.

plana. Kuntze, l. c. = I. cordistipula, Mart.

platyloba, Kuntze, 1. c. $=$ Pithecolobium serici florum, Benth.

polycephala, Kuntze, 1. c. $188=$ Enterolobium polycephalum, Griseb.

quassiaefolia, Kuntze, 1. c, $186=$ Inga nitida Willd.

Quitaro, Kuntze, 1. c. $186=$ Calliandra stipulacea Benth.

veticulata, Kuntze, 1. c. = Inga Feuillei, DC.

rtbra, Kuntze, 1. C. = Albizzia purpurea, Boiv.

saltum, Kuntze, 1. $\mathrm{c},=\mathrm{A}$. montana, Benth

sapinodes, Kuntze, 1. Co = Inga sapindoides, Willd.

Sassa, Kuntze, I. c. = Albizzia fastigiata, Oliver

Schomburghit, Kuntze, 1. c. $189=$ Enterolobium Schomburgkii, Benth.

Selloana, Kuntze, 1. c. = Inga Sellowiana, Benth

Serianthes, Kuntze, 1. c. $186=$ Serianthes grandiflora, Benth.

Sesseana, Kuntze, 1. c. = Inga coriacea, G. Don sessiliflora, Kuntze, 1. c. = I. dysantha, Benth.

Sesuya, Kuntze, 1. C. = I. laxiflora, Benth.

similis, Kuntze, 1. C, = Pithecolobium affine, Baker. stipulacea, Kuntze, l. C, = Inga rufiseta, Benth

Sarapota, Kuntze, 1. co = Pithecolobium macrophyllum, Spruce.

tenuis, Kuntze, 1. c. = Inga nutans, Mart.

terminalis, Kuntze. 1. c. $187=$ Pithecolobium polycephalum, Benth.

texana, Kuntze, 1, $c_{0}=$ Calliandra conferta, Benth.

Tozeri, Kuntze, l, c. = Pithecolobium grandiflorum, Benth.

vitiensis, Kuntze, 1. c. $189=$ Serianthes vitiensis A. Gray.

Zygia, Kuntze, 1. c. $187=$ Albizzia Brownei, Walp.

FICARIA, [Dill.] Hall. = Ranunculus Linn. pumila, Velen, in N. Beitr. Kenntn. F1. Ost-Rumel, und Bulg. ex Bornm. in Oest. Bot. Zeitschr. xxxviii. (1888) $108=\mathrm{R}$. Ficaria, Linnz.

FICINIA, Schrad. (Cyper.). - Ind, Kew. i. 957. acrostachys, C. B. Clarke, in Th. Dur. E. Schinz, Consp. Fl. Afr, v. 1894 (1895) $635(=$ Scirtus acrostachys, Steud.). - Afr, austr.

\section{FICINIA}

angustifolia, C. B. Clarke, in Th. Dur. E Schinz, Consp. Fl. Afr. v. 1894 (1895) 635 (= Hemichlacsa angustifolia, Schrad.). - Afr. austr.

capillaris, Nees, ex C. B. Clarke, 1. c. $636=$ F. Bergiana, Kunth

capillifolia, C. B. Clarke, 1. C. 637 (= Hemichlaena capillifolia, Schrad.). - Afr. austr.

cinnamomea, C. B. Clarke, l. c. - Afr. austrowocc. et austr.

ferruginea, C. B. Clarke, l. c. 638 (= Acrolepis fer. ruginea, Nees). - Afr. austr.

fimbriata, E. Mey. ex C. B. Clarke, 1. c. $641=$ paradoxa, Nees.

ignorata, Boeck, Cyp. Nov, ii. (1890) 18. - Afr. austr. leiocarpa, Zeyh, ex C. B. Clarke, in Th. Dur. \& Schinz, Consp. Fl, Afr, v. 1894 (1895) $643=$ sylvatica, Kunt is

longifolia, C. B. Clarke, l.c.640 (= Hemichlaena longifolia, Nees). - Afr. austr.

lucida, C. B. Clarke, l. c. 640. - Afr, austr.

Macowani, C. B. Clarke, l. ., - Afr, austr.

micrantha, Boeck. ex C. B. Clarke, 1, c. $635=$ angustifolia, $C, B$. Clarke.

pusilla, C. B. Clarke, l. c. 641. - Afr, austr

Rehmanniana, Boeck. ex C. B. Clarke, 1. c. $635=$ angustifolia, C. B. Clarke.

Schinziana, Boeck. in Verh. Bot. Ver. Brand. xxix. (1888) 47 = Scirpus diabolicus, Stend.

tenuis, C. B. Clarke, in Th. Dur. E. Schinz, Consp. Fl. Afr. v. 1894 (1895) 645 (= Melanoranis temuis, Eck1.). - Afr. austr.

FIGUS, Tourn, ex Linn, (Urtic.). - Ind, Kew. . 957

albidula, Baker, in fourn. Limn. Soc. xxii. (1887) 523. - Madag

aldabrensis, Baker, in Kew Bull. (1894) 15I. - Ins. Aldabra.

araneosa, King, ex Hook.f. Fl. Brit. Ind. v. (1888) 529. - Perak.

ardisioides, Warb. in Bot. Fahrb. xx. (1894). Congo.

Armiti, King, inz fourn. As, Soc. Beng. 1v. (1887) II. 404. - N. Grim.

artocarpifolia, Roxb, ex Hook f. Fl. Brit. Ind. v. (1888) 517 in syn. = callosa, Willd

assimilis, Baker, in fourn. Limn. Soc. xxv. (1890) 345. - Madag.

Baeuerleinii, King, in fourn. As. Soc. Beng. Iv. (1887) II. 408, - N. Guin.

barbata, Warb. in Bot. Fakrb. xx. (1894) 168.Angola.

Bellengeri, C. Moore, Handb. Fl. N. S. Wales, (1893) 81. - Austral.

Bernaysii, King, in fourn. As. Soc. Beng. 1v. (1887) II, 406. - N, Guin.

bhotanica, King, ex Hook. f. Fl. Brit. Ind.v. (1888) 519. - Ind. or

bongoënsis, Warb. in Bot. fahrb. xx. (1894) 166. Atr. centr. bor.

botryoides, Baker, in fourn. Linn. Soc. xxii. (1887) 523. - Madag.

brachiata, King, in fourn. As. Soc. Beng. Ivi. (1888) II. 65. - Sumatra.

broussonnetiaefolia, Baker, in fourn. Linn. Soc. xxv. (1890) 345. - Madag,

Buchneri, Warb. in Bot. Falrb. xx. (1894) 15\%. Afr. trop.

Buettneri, Warb. l. c. - Afr. trop. occ.

Canoni, N. E. Br. in Gard. Chron. (1888) i. 9 (= Artocarpus Canoni, Hort. Bull1). - Ins. Societ. asearioides, King, in fourn. As. Soc. Beng. Iv. (1887) II. 403. - N. Guin.

Cavroni, Carrière, in Rev. Hortic. (1887) 329. - Bras.

Chalmersii, King, in Founn. As, Soc. Beng, lv. (1887) II. 406,- N. Guin.

chlamydodora, Warb, ex Engl, in Abh. Preuss. Akad. Wiss. (1894) 40; et in Bot. fahirb. xx. (1894) 163. - Afr, trop.

chrysocerasus, Welw. ex Warb. in Bot. Falrrb. xx. (1894) 167. - Angola.

Clarkei, King, ex Hook. f. Fl, Brit. Ind. v. (1888) 536. - Khasia.

occulifolia, Baker, in fourn. Linn. Soc. xxii. (1887) 521. - Madag.

\section{FICUS :}

omorensis, Warb. in Bot. fahrb. xx. (1894) 152.Ins. Comor.

congensis, Engl. l. c. viii. (1887) 59. - Congo.

conglobata, King, ex Hook, f. Fl. Brit. Ind, v. (1888) 525. - Ind. or.

crassipes, F. M. Bailey, Rep. Exped. Bellenden-Ker (1889) 60. - Austral.

cyathistipula, Warb. in Bot. fahrb. xx. (1894) 17: - Afr. trop. or.

damarensis, Engl. l. c. x. (1886) 5. - Afr. austroocc. extratrop.

dimorpha, King, in fourn. As. Soc. Beng. Ivi. (1888) II. 66. - Sumatra.

dumosa, King, 7. c. 67. -- Sumatra.

duriuscula, King, l. c. lv. (1887) II. 408. N. Guin.

Dusenii. Warb. in Bot. Fahrb. xx. (1894) 168.Afr. trop. occ.

Edelfeltii, King, in Fourn. As. Soc, Beng. 1v。 (1887) II. $402,-$ N. Guin.

excavata, King, ex Hook.f. Fl. Brit. Ind.v. (1888) 526. - As. trop.

excentrica, Warb. in Bot. Fahrb. xx. (1894) 168. Afr. trop. occ.

fasciculata, King, ex Hook. f. Fl. Brit. Ind.v. (1888) 524. - Perak.

fasciculata, Warb. in Bot. fahrb. xx. (1894) 175. Zanzib.

fasciculata, S. Wats. in Proc. Am. Acad. xxiv. (1889) 78 ; et xxvi. (1891) 152. - Mexic

Forbesii, King, in fourn. As. Soc. Beng. 1vi. (1888) II. 66. - Sumatra.

furcata, Warb. in Bot. Fahrb. xx. (1894) 173. Congo bor.-or.

Gazellae, Engl. i. c. vii. (1886) 452. - Ins.

gracilipes, F.M. Bailey, in Dept. Agric. Brisbane Bot. Bull. [iii]. (1891) 16. - Austral.

Grevei, Baill. Hist. pl. Madag. Atlas (1894) t. 298. - Madag.

guadalajarana, S. Wats, in Proc, Am. Acad, xxvi. (1891) 151. - Mexic.

guatteriaefolia, Baker, in fourn. Linn. Soc. xxv. (1890) 346. - Madag.

Guerichiana, Engl. Bot. Fahrb. xix. (1894) 130.Afr. austro-occ, extratrop.

guttata, Kurz. ex Hook. f. Fl. Brit. Ind. v. (1888) 534 (= Covellia guttata, Wight). - Ind. or.

hesperidiiformis, King, in fourn. As. Soc. Beng. 1v. (1887) II. 401. - N. Guin.

Hillii, F. M. Bailey, in Dept. Agric. Brisbane Bot. Bull. [iii] (1891) 16. - Austral.

Holstii, Warb, in Bot, fahrb. xx. (1894) 160.Afr. trop, or.

jaliscana, S. Wats. in Proc. Am. Acad. xxvi. (1891) 150. - Mexic.

kinabaluensis, Stapf, in Trans, Linn. Soc. Ser. II iv. (1894) 226. - Borneo.

lanigera, Warb. in Bot. fahvo.xx. (1894) 162. Afr. trop. or.

Laurus, Baill. Hist. pl. Madag. Atlas (1894) t. 301. - Madag.

Lawesii, King, in fourn. As. Soc. Beng. lv. (1887) II. 403. - N. Guin.

lyrata, Warb. in Bot. Fahrb. xx. (1894) 172. - Afr. trop. occ.

malifolia, Warb. l. c. 165. - Afr. trop. or.

mallotocarpa, Warb. l. c. 154. - Afr, trop. or.

medullaris, Warb. l. c. 169. - Afr. trop. or.

Miquelii, King, in fourn. As. Soc. Beng. 1v. (1887) II. 405; Hook. f. Fl. Brit. Ind. v. (1888) 524

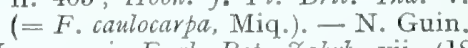

Naumanni, Engl. Bot. fahrb. vii. (1886) 451. N. Guin.

nigrescens, King, ex Hook. y. Fl. Brit. Ind. v. (1888) 520. - Ind, or.

Novae-Hannoverae, Engl. Bot. Fahrb. vii. (1886) 453. - Ins. N. Hannov.

obpyramidata, King, ex Hook. f. Fl. Brit. Ind. v, (1888) 525. - Perak.

Odoardi, King, in fourn. As. Soc. Beng. 1v. (1887) 409. - N. Guin.

oxystipula, Baker, in foum. Linn. Soc. xxv. (1890) 345. - Madag.

pachyclada, Baker, l. c. xxii. (1887) 522 ; et $\mathrm{xxx}$ (1890) 345. - Madag. 
FICUS

Palmeri, S. W'ats, in Proc. Am, Acad, xxiv. (1889)

77. - Ins. S. Pedro Martin (Calif. austr.)

Pantoniana, King, in fourn. As. Soc. Beng. lv, (1887) II. 407. - N. Guin

pauper, King, l. c. 410. - N. Guin.

persicifolia, Welw. ex Warb. in Bot. Fahrb. xx. (1894) 162. - Afr, trop.

Petersii, Warb. l. c. 164. - Mossamb.

phanerophlebia, Baker, in foum. Linn. Soc. xxii. (1887) 522. - Madag.

Preussii, Warb. in Bot. Fallrb. xx. (1894) 156. Afr. trop. occ.

Pringlei, S. Wats, in Proc. Am. Acad. xxvi. (1891) 150. - Mexic.

Pringsheimiana, F. Braun \& K. Schum. in Ber. deutsch. Schutzgeb.ii. (1889) 153. - Afr. trop. occ.

pulvinata, Warb. in Bot. Fahrb. xx. (1894) 169. Zanzib.

pulvinifera, Baker, in fourn. Linn. Soc. xxii. (1887) 5?2. - Madag.

Radula, Morong, in Ann. N. Y. Acad. Sci. vii. (1893) 229 (= Pharmacosyce Radula, Miq.) - Am. trop. radulina, S. Wats. in Proc. Am. Acad. xxvi. (1891) 151. - Mexic

rhizophoraephylla, King, in foum. As. Soc. Beng. lv. (1887) II. 410. - N. Guin.

Rokko, Warb. et Schweinff. in Bot. Fahrb. xx. (1894) 164. - Afr. trop.

Sakalavarum, Baker, in fourn. Linn. Soc. xxii. (1887) 523. - Madag.

sansibarica, Warb. in Bot. Fahrb. xx. (1894) 171 . - Zanzib.

Scratchleyana, King, in fourn. As. Soc. Beng. lv. (1887) II. 404. - N. Guin.

segaarensis, Engl. Bot. Fahrb. vii. (1886) 453. N. Guin.

setiflorus, Stapf, in Trans. Linn. Soc. Ser. II. iv. (1894) 226. - Borneo.

Sonorae, S. Wats. in Proc. Am. Acad.xxiv. (1889) 78. - Mexic.

soronensis, King, in fourn. As. Soc. Beng. 1v. (1887) II. 411. - N. Guin.

subcalcarata, Warb. et Schweinf. in Bot. Fahrb. xx. (1894) 155. - Afr. centr. bor.

stellulata, $W a r b$. l. c. 152 . - Afr. trop. occ

stenoclada, Baker, in fourn. Limn. Soc. xxy. (1890)

346. - Madag.

sterculioides, Warb. in Bot. Fahrb. xx. (1894) 175. - Afr. trop. or.

Stuhlmannii, Warb. l. c. 161.-- Afr. trop. or.

syringifolia, Warb. l. c. 170. - Afr. trop.

Tashiroi, Maxim. in Bull. Acad. sci. St. Pétersb.

xxxii. (1888) 621. - Archip. Ya-Yama.

tesselata, Warb. in Bot. Fahrb. xx. (1894) 156. -

Afr. trop. occ

Ti-Koua, Bureau, in Morot, Fourn. de Bot. ii. (1888) 213 t. 7. - Yunnan.

tremula, Warb. in Bot. Fahrb. xx. (1894) 171. Zanzib.

triangularis, Warb.l. c. 170. - Afr, trop. occ.

trichoclada, Baker, in fourn. Linn. Soc. xxii. (1887) 524. - Madag.

truncata, King, [an Miq. ?] ex Hook. f. Fl. Brit. Ind. v. (1888) 507 (= Urostigma truncatum, Miq.).As. trop.

umbilicata, Bureau, ex Drake, Fl. Polyn. Franc. (1892) 195. - Ins. Mangarewa.

usambarensis, Warb. in Bot. fahrb. xx. (1894) 159. - Afr. trop. or. (Zanzib.)

vestito-bracteata, Warb.l. c. 159. - Ins. Comor.

verruculosa, Warb. l. c. 166. - Angola.

Vohsenii, Warb. l. c. 155. - Afr. trop. occ

Volkensii, Warb. l. c. 167. - Afr, trop. or.

vulcanica, Wawra, Itin. Princ. S. Coburg. ii. (1888) 78. - Java.

Watkinsiana, F. M. Bailey, in Dept. Agric. Brisbane Bot. Bull. [ii] (1891) 18. - Austral.

Welwitschii, Warb. in Bot. Fahrb. xx. (1894) 160. - Angola.

zanzibarica. Boech. ex Engl. in Abh. Preuss. Acad. Wiss. (1894) 20. - Zanzib.

FILAGo, Linn. (Compos.). - Ind. Kew, i. 965. aetnensis, Tormab. Fl. Sicula (1887) 323. - Sicil.

\section{FILAGO}

angustifolia, Batt, in Batt, et 'Trab, Fl de l'Algér. [Dicot.] (1889) $441=$ exigua, Sibth.

dichotoma, Pomel, ex Batt. et Trab. 1. c. = F Cupaniana, Parl.

Heldreichii, Batt, in Batt. et Trab. 1. c. 439 (=Evax Heldreichii, Parl.). - Afr. bor.

intermedia $X$, Hausskn. in Nym. Consp Fl. Eur. Suppl. (1889) 173; et in Mitth. Bot. Ver. Jena. N. Folge, vii. (1895) 30. - Graecia

milicaulis, Heller, [Bot. Explor. S. Texas] in Contrib. Herb. Frankl. and Marsh. Coll. i (1895) $102=$ Evax multicaulis, $D C$.

numidica, Pomel, in Bull. Soc. Bot. Fr, xxxy. 1888) 336 ; et ex Batt. et Trab. Fl. de l'Algér. [Dicot.] (1S89) 440. - Algeria.

Pomeli, Batt. in Batt. et Trab. l. c. 442 (= Evacopsis montana, Pomel). - Algeria.

prolifera, Britton, in Mem. Torrey Bot. Club, y. (1894) 329 = Evax prolifera, Nutt.

smilata $X$, Hausskn. in Nym. Consp. F1. Eur. Suppl. (1889) 173; et in Mitth. Bot. Ver. Jena, N. Folge, vii. (1895) 30. - Graecia,

FILETIA, Miq. (Acanth.). - Ind. Kew. i. 966 fricana, Lindau, in Bot. Fahrb. xx. (1894) 41: Afr. trop. occ

FILICIUM, Thw. (Burser.). - Ind. Kew, i. 966 abbreviatum, Radlk. in Sitz. math,-phys. Akad. Muench.xx. (1840) 277. - Madag.

elongatum, Radlk. ex Taub, in Enol. Pflanzenw. OstAfr. C (1895) 252; et in Engl. Go Prantl, Natürl. Pfanzenfam. iii. 5 (1895) 360. - Afr. trop. or.

FILIPENDULA, Tourn. ex Linn. = Spiraea Linn. (Rosac.).

denudata, Fritsch, in Verh. zool.-bot. Ges. Wien, xxxix. (1889) $591=$ S. Ulmaria, Linn

subdenudata, Fritsch, 1. c. = S. Ulmaria, Linn.

FIMBRISTEMMA, Turcz. (Asclep.). - Ind.

calycosa, F. D. Smith, in Coult. Bot. Gaz. xvi. (1891) 196 t. 16. - Guatem.

stenosepala, f.D. Smith, l. c. xviii. (1S93) 208.Guatem.

FIMBRISTYLIS, Vahl (Cyper.). - Ind. Kew. i.

966.
Actinoschoenus, C. B. Clarke, in Hook. f. Fl. Brit Ind. vi. (1893) 650 (= Actinoschoenus filiformis, Benth.). - Zeylan.

africana, C. B. Clarke, in Th. Dur. \& Schinz, Consp Fl. Afr.v. 1894 (1895) 691 (= Abildgaardia pilusa Nees). - Afr. trop.

albo-viridis, C. B. Clarke, in Hook. f. Fl. Brit. Ind. vi. (1893) 638. - Ind. or.

atrosanguinea, C. B. Clarke, in Th. Dur. E. Schinz, Consp.Fl. Afr. v. 1894 (1895) 611 (= Scirpus atrosanguineus, Boeck.). - Afr. aequat. or.

atrosanguinea, K. Schum. in Engl. Pflanzenw. Ost-Afr. C (1895) $125=$ praec.

ciliatifolia, Britton, ex S. Wats. in Proc. Am. Acad xxii. (1S87) 459 nomen. - Mexic

cinnamomea, $K$. Schum. in Engl. Pflanzenw. Ost Afr. C (1895) 125 (= Scirpus cinnamomeus, Boeck.). - Afr. trop.

Eggersii, Bock, Cyp. Nov. ii. (1890) 17. - Ins. Baham.

faulensis, G. Beck, in Annal. Natur. Hofmus. Wien, iii. (1888) 252. - Ins. Stewart.

filamentosa, $K$. Sihtm. in Engl. Pfanzenw. Ost-Afr C (1895) 125 (= Scirpus filamentosus, Vahl). Afr. trop.

fuscinux, C. B. Clarke, ex Hook. f. Fl. Brit. Ind. vi. (1893) 638. - Ind. or

Gambleana, Bock. Cyp.Nov. ii. (1890) 40.-Ind. or hawaiiensis, Hillebr. Fl. Haw. Isl. (1888) $472 .-$ Ins. Sandvic.

junciformis, Maury, in Morot, fourn. de Bot. iii. (1889) 197 (= Isolepis junciformis, H. B. \& K.). Am. trop.

Kingii, Gamble, Cyp. Nov. ii. (1890) 40. - Ind. or

Kingii, C. B. Clarke, in Hook. f. Fl. Brit. Ind. vi. (1893) 633. - Ind. or.

\section{FIMBRISTYLIS :}

aniceps, K. Schum. in Engl. Pflanzenw. Ost-Afr. C (1895) $125=$ Bulbostylis laniceps, C. B. Clarke. lanifera, K. Schum. 1. C. = Scirpus lanifere, Boeck. laxiflora, C. B. Clarke, in Th. Dur. of Schinz, Consp. Fl. Afr, v. 1894 (1895) 607. - Madag.

maxima, K. Schum. Fl. Kais, Wilh. Land (18S9) 24. - N. Guin.

merguens1s, C. B. Clarke, in Hook. f. Fl. Brit. Ind. vi. (1893) 642. - Penins-Mal.

nigritana, C. B. Clarke, in Th. Dur. E Schinz. Consp. Fl. Afr. v. 1894 (1895) 608. - Afr, trop. occ. nipponensis, Makino, in Tokyo Bot. Mag. vi. (1892) 47. -- Japon.

oligostachya, K. Schum. in Engl. Pylanzenw. Ost-Afr. C (1895) 125 (= Scirpus oligostachyus, Boeck.). Abyss.

pilosa, K. Schum. 1. c. 124 (= Schoenus pilosus,

Wilid.). - Afr, trop.

purpureo-atra, C. B. Clarke, ex Engl, in Abh. Preuss. Akad. Wiss. 1891 II. (1892) 149; et in Th. Dur, \&o Schinz, Consp. Fl. Afr. v. 1894 (1895) 609 (= Scirpus purpureo-ater, Boeck.). - Abyss. pycnocephala, Hillebr. Fl. Haw. Isl. (1888) 473. Ins. Sandvic

recta, F. M. Bailey, Syn. Queensl. Fl. Suppl. iii. (1890) $80=$ monostachya, Hassk.

Schimperiana. K. Schum, in Engl. Pflanzenw. OstAfr. C (1895) $125=$ Bulbostylis Schimperiana. C. B. Clarke.

Schinzii, Boeck, in Verh. Bot, Ver. Brand. xxix, (1888) 47 (=? Scirpus modosus, Rottb.). - Afr. austro-occ, extratrop

choenoides, K. Schum, in Engl. Pflanzenw. OstAfr. C (1895) 125 (= Isolepis schoenoides, Kunth). - Afr. austr.

semihirsuta, Boeck. Cyp. Nov.ii. (I890) 18. - China. setacea, Leprieur. ex C. B. Clarke, in Th. Dur. \& Schinz, Consp. Fl. Afr. v. 1894 (1895) $604=$ diphylla, Vahl.

Sintenisii, Boeck. in Bot. Fahrb. vii. (1886) 276 . Ins. Portoric

sphaerocarpa, K. Schum, in Engl. Pfanzenw. OstAfr. C (1895) 125 (= Scirpus sphacrocarpus, Boeck.). - Afr. trop.

stolonifera, C. B. Clarke, in Hook. f. Fl. Brit. Ind. vi. (1893) 637. - Ind. or.

subbulbosa, Boeck.Cyp. Nor.ii. (1890) 39.-As, trop. subtrabeculata, C. B. Clarke, in Hook. f. Fl. Brit. Ind. vi. (1893) 633. - Ind. or.

subumbellata, K. Schum. in Engl. Pfanzenw. OstAfr. C (1895) 125. - Afr. trop. or.

temifolia, Nees, ex C. B. Clarke, in Hook. f. Fl. Brit. Ind. vi. (1893) 639 in syn. = compressa, Boeck.

tokyoënsis, Makino, in Tokyo Bot. Mag. vi. (1892) 47. - JaDon.

tonensis, Makino, l. c. ix (18.5) 260. - Japon.

transiens, $K$. Schum. in Engl. Pfanzenw. Ost-Afr. C (1895) 124. - Afr, trop. or

trichophora, Steud. ex C. B. Clarke, in Th. Dur. \& Schinz, Consp. Fi. Afr. v. 1894 (1895) 605 $=$ exilis, Rocm. E Schult.

triflora, K. Schum. ex Engl. in Abh. Preuss. Akad. Wiss. (1894) 14; et in Pfanzenw. Ost-Afr, C (1895) 124 (= Cyperus triflorus, Linn.). - Afr. trop.

caginata, Boiv, ex C. B. Clarke, in Th. Dur. \& Schinz, Consp. F1. Afr, v. 1894 (1895) $606=$ ferruginea, $V a h l$.

verrucifera, Makino, in Tokyo Bot. Mag. ix. (1895) 259 (= Isolepis verrucifera, Maxim.). - Japon.

Warburgii, K. Schum. ex Warb. in Bot. fahrb. xiii. (1891) 265. - Oceania.

zambesiua, K. Schum, in Engl. Pflanzenw. Ost-Afr C $(1895) 125=$ Bulbostylis zambesica, C. $B$. Clarke.

FINSCHIA, Warb. in Bot. Jahrb. xiii. (1891) 297. PROTEACEAE

rufa, Warb.l.c. - Oceania.

FIRMIANA, Marsigli = Sterculia, Linn

Barteri, K. Schum. in Engl. \& Prantl, Natürl. Pflanzenfam, iii. 6 (1893) $97=\mathrm{S}$. Barteri. Must fulgens, K. Schum. 1. c. = S. fulgens, Mast. 
FISCHERIA. DC. (Asclep.), - Ind. Kew. i. 969 crishifol $\mathrm{K}$ Schum in Enyl \& Prantl Natür. 1.tlanzentam, iv. 2. (1\$95) $2300=$ scandens, $D C$.

FISSILIA, Comm. = Olax, Linn

Qisparilis, Comm. ex Valeton, Crit, orer\%. Olac. (1siti) 121 in syn, = O. psittacorum, $D C$.

FISTULARIA, Linn. = Rhinanthrs, Linn (Scrophul.)

Alectorolophus. Wettst. in Engl, \& Prantl, Natürl. Pflanzentam.iv. 3b (189:3) $103=\mathrm{R}$. major. Ehrh. rar.

alpina. Wettst, 1, c, $=$ R, minor, Elyrh, var.

emgustifolia, Wettst. $1 . \mathrm{c}_{0}=\mathrm{R}$. angustifolius, $C$. C Gmel.

Crista-galli, Kuntze, Rev. Gen.(1891) $460=\mathrm{R}$ major et minor, Ehrh.

Crasta-galli, Wettst, in Engl. \& Prantl, Natiirl. PAlanzentam, iv $\left.3 \mathrm{~b}(189)^{*}\right) 10.3=\mathrm{R}$ minor, Elirh.

dinarica, Wettst. 1. C. $=\mathrm{R}$. dinaricus, MIurb.

major, Wettst. 1. c. = R. major, Elrh.

minor. Kuntze, Rev. Gen. (1S)1) $460=$ R. minor. Ehrh.

mbescons, Wottst, in Engl. \& Prantl, Natïrl. Pflanzenfam. iv, 3 b $(1893103=$ R. major, Ehw var. umelica. Wettst. 1 c $=$ R. rumelicus, Velen.

scrotina, Wettst 1. $\mathrm{c}_{0}=\mathrm{R}$, serotinus, Obom

FLAGOURTIA, [Comm.]. L'Hérit.(Bixin.) - Ind. Kíew. i. 96!)

elliptica, Warb. mn Engl. E Prantl, Natür. Pfanzenfam. iii. 6a (1893) 43 $1=$ Xylosma ellipticum, Tul.). - Zanzib

FLANAGANIA. Schlechter, in Bot. Jahrb, xviii. Beib1. n. 45 (1894) 10. ASCLEPIADEAE.

orangeana, Schlchiter, 7.c. - Afr, austr.

FLAVERIA, Juss. (Compos.). - Ind. Kew i. 970. anomala, Robinson, in Proc. An. Acad.xxvii. (1893) 178. - Mexic.

elata. Klatt, in Leopoldina, Heft xxiii. (1887) 146.Mexic.

perfoliata, Sch.-Bip. ex Klatt, l.c. - Mexic

amosissima, Klatt, l.c.-Mexic

FLEMINGIA, Roxb. (Legumin.). - Ind, Kew, i. macrocalyx, Baker f in Trans. Linn. Soc.. Ser. II. iv. (1894) 12. - Afr. trop

yumnanensis, Franch. Pl. Delai. i. (1888) 185.Yunnan.

FIEURYA. Gaudich. (Urtic.), - Ind Kew, i. 970. rlaberrima, G. Beck, in Annal. Natur. Hofmus. Wien, iii. (18s8) 253. - Ins. Stewart.

anceolata, Engl. in Abh. Prenss. Akad. Wiss. (1894) 37; ct un Pfanzent. Ost-Afr. C (1895) 163. - Afr. trop. or.

FLOERKEA, Willd. (Geran.). - Ind. Kew, i. 970. $a l b a$, Greene. Fl. Francisc. (1891) $100=$ Limnanthes alba. Hartw

osea, Greene, 1. c. = L. Insea, Hartw

versicolor, Greene, in Erythea, iii. (1895) 62. - Calif.

FLOScopA, Lour. (Commelin.). - Ind. Kew. i. (1) 1 .

aquatica, IIua, in Bull. Mus. Paris, i. (1895) I22. Congo gall.

Clarkeana, Kuntze, Rev.Gen.(1891) 720.-Costarica.

FLUCKIGERA, Kuntze, Rev, Gen. (1891) 551 = Ledenbergia, Klotzsch (Phytol.)

iguierodes, Kuntze, 1. c.=L. seguierioides, Klotasch.

FLUCKIGERIA, Rusby, in Bull. 'Torrey Bot. Club, xxi. (1895) 488. COMPOSITAE.

Fritschi, Rusby, l. c.-Bolivia.

FLUGGEA, Will. (Euphorb.). - Ind. Kew, i 971 .

Bailloniana, Pax, in Bot falırb. xix. (1894) f6 in obs. $(=$ Securinega Bailloniana, Muell. Arg.). Afr. irop.

\section{FLUGGEA :}

facitolid, Pax, in İngl. Pfanzente. Ost-Afr, C (1895) 2306. - Atr. tro p) or.

nitida, Pax in Bot. Fahrb. xix. (1894) 76. Mossimb.

FOCKEA, Endl. (Asclep.), 一 Ind. Kew. i. 972. augustifulia, K. Schum, in Bot. Falwb. xvii. (1894) 146 (= Brachistelma circinnatum, Marl.). - Afr. austr.

crispa. K. Schum, in Eng1. \& Prant1, Natürl. Pflanzenfam. iv. (1895) $296=$ capensis, Endl.

edulis, $K$. Sclumb.l. c. - Afr, austr.

multiflora, K. Schnm. in Bot. fahrb. xvii (1893) 145. - Afr. trop

Schinzii, N. E. Br. in Kew Bull. (1895) 259. Anvola.

sessiliflura, Sihlechter, in Bot, Fanrb. xx. Beibl. n. 51 (159) 44 - Transvaal.

undulata. N. E. Br. in Kew Bull. (1895) 260.Transväal

FOETIDA, Comm. (Myrtac.). - Ind. Kew. i. (1)

clusivides, Eaker, in Kew Bull. (1895) 104. Maclas

FONTARTs iA, Labill, (Oleac.). - Ind. Kew. i. ()

angu tifolia, Dippel, Handb. Laubholzk. i. (1SS9) 104 Hig. 5\%. - Hab. ?

angustifolia. Hayne, ex Koehne, Deutsche Dendrol. (1893) 505 Lan praec. ?] = phillyraeoides, Labili californica, IIort, ex Dippel, Handb. Laubholzk. i. $(1889)^{2} 06=\mathrm{F}$. Fortunei, Carr

FONTBRUNEA, Pierre, Not bot. Sapot. (1890) 31 = Sideroxylon, [Dill.] Linn. (Sapot.).

malaccensis, Pierre 1. $c .=\mathrm{S}$. malaccense, $C, B$. Clarke.

FORGIPELLA Baill. Hist. des p1, x. (1890) 444; Lindau, in Engl. \& Prantl, Natürl. Pflanzenfam. iv. 3b (1895) 343. ACANTHACEAE. madagascariensis, Baill. ll.cc. - Madag.

FORDIA, Hemsl. ex Forb. \& Hemsl. in Journ. Limm. Soc zxiii. (1886) 160, LEGUMINOSAE. canliflura, Hemsl.l. c. t. x. - China.

FORDIOPHYTON, Stapf, in Ann. Bot. vii, (1892) 314. MELASTOMACEAE.

cantuncnse, Stapf, l. c. 314. $(=$ Sonerila Fordic Oliver). - China.

Faberi, Stapf, l. c.314. - China.

Fordii, Krasser, in Engl. \& Prantl, Natürl. Pflan zentam. iii. 7 (1893) $175=$ cantonense, Stapf. integrifolium, Stapf, in Ann. Bol. vii. (1892)314. Persk.

FORESTIERA, Poir. (Oleac.). - Ind. Kew. i.

Engersiana, Krug, in Bot. Fahrb. xv. (1893) 339. Ins. S. Thom.

macrocarpa, T. S. Brandeg. in Zö̈, iv. (1894) 404 . - Calif.

racemosa, S. Wats, in Proc. Am. Acad. xxv. (1890) 1.j8. - Mexic.

segregata, Krug \&o Uvb. in Bot. Fahw. xv. (1893) 339 (= Myrica segregata, Jacq.). - Florida, Antill.

tomentosa, S. Wats, in Proc. Am. Acad. xxv. (1890) 158. - Mexic.

FORSELLESIA, Greene, in Erythea, i. (1893) 206 $=$ Glossopetalon, A. Gray (Celastr.).

novadensis, Greene, 1. c. $=\mathrm{G}$. nevadense, $A$ Gray.

spinescens, Greene, 1. c. $=\mathrm{G}$. spinescens, A. Gray.

FORSTERA, Linn. f. (Stylid.). - Ind. Kew. i. 973.

truncatella, Colenso, in Trans. N.Z. Inst. xx. 1887 (1888) 196. - N. Zel. FORSTERoniA, G. F. W. Mey. (Apocyn.).-

mollis, Rusby, in Mem. Torvey Bot. Club, iv. (1893) 218. - Boliv.

obscura, Rusby, l. c. 219. - Boliv.

paniculata, Casar. ex K. Schum. in Mart. F1. Bras. vi. VI. (1889) 200 in syn. = Molopanthera paniculata, Turcz.

FORSYTHIA. Vahl (Oleac.). - Ind. Kew. i. 973. intermedia X, Zabel, in Gartenfl. (1885) 36; Dippel, Handb. Laubholzk. i. (1889) 108. - Hybr, artef. Sieboldii, Hort. ex Dippel, l. c. $109 \mathrm{fig}$. 63. - China.

FORSYTHIOPSIS, Baker (Acanth.). - Ind. Kew. i. 973 .

australis, S. Elliot, in Fourn. Limn. Soc. xix. (1891) 37. - Madag.

FotherGILLA, Murr. (Hamamel.). - Ind. Kew. i. 973 .

Carolina, Britton, in Mem. Torrey Bot. Club, v. (1894) $180=$ F. Gardeni, Murv.

FOUQUIERA, H. B. \& K. (Tamarisc.). - Ind. Kew, i. 973.

gigantea, C. R. Orcutt, in West-Am. Scientist, ii. (1886) $48=$ columnaris, $K$ Kell.

FOURCIOYA, Spreng. = Furcraea, Vent. (Amaryll.)

Bedinghausii, Ed. André, in Rev. Hortic. (1895) 468 fig. 154 \& $155=$ Furcraea Bedinghausii, $C$. Koch.

Roezlii, Ed. André, 1. c. (1887) 353 fig. 71. - Mexic. gigantea, Engl. Pflanzenw. Ost- Afr. B (1895) 369 $=\mathrm{F}$. gigantea, Vent.

FRADINIA, Pomel $=$ Mecomischus, Coss. (Com-

pos.).
hatimifolia, Batt. in Batt. et Trab. Fl. de l'Algér. (Decot.) (1889) $450=$ Anthemis halimifolia, Munby.

FRAGARIA, [Tourn.] Linn. (Rosac.). - Ind. Kew. i. 974.

americana, Britton, in Bu11. Torrey Bot. Club, xix. (1892) 222; et in Mem. Torrey Bot. Club, iv. (1893) 116 = vesca, Limn.

filipendula. Hemsl, cx Forb. et Hemsl. in fourn. Limn. Soc. xxiii. (1887) 239. - China.

illinoënsis, Prince, ex Hitchc in Trans. Acad. Sc. St. Louis, v. (1892) $493=$ virginiana, Duchesne. praestabilis X, G. Beck, F1. Nied.-Oest, ii. I. (1892) 748. - Austria.

Zapateriana, Pau, Not. bot. Fl. Espan. iii. (1889) 18 = elatior, Ehrh

FRANCA, Michel, = Frankenia, Linn.

grandifolia, Greene, Man. Bot. San Franc, Bay (1894) $38=$ F. grandifolia, Cham. \& Schlecht.

FRANCHETELLA, Kuntze, Rev, Gen. (1891) $26 \%$ $=$ Heteromorpha, Cham, \& Schlecht. (Umbellif.).

arborescens, Kuntze, 1. $\mathrm{c}=\mathrm{H}$. arborescens, Cham. E Schlecht.

FRANCHETELLA, Pierre, Not. bot. Sapot. (1890) 24; Baill. Hist. des pl. xi. (1892) $291=$ Lucuma, Molina (Sapot.).

tarapotensis, Pierre, 11. cc. = L. tarapotensis, Eichl.

FRANSERIA, Cav. (Compos.). - Ind. Kew. i. 976.

acanthicarpa, Coville, in Contrib. U. S. Nat. Herb. iv. (1893) $129=$ Franseria Hookeriana, Nutt. acuminata, T. S. Brandeg, in Proc. Calif. Acad. Ser. I1. ii. (1S89) 171. - Calif

andina, Phil. in Anal. Univ. Chil. xc. (1895) 40.Chili.

Bryanti, M. K. Curran, in Proc. Calif. Acad. Ser. II. i. (1858) 232. - Calif.

divaricata, T.S. Brandeg. zn Proc. Calif. Acad. Ser. 1I. ii. (1889) 171. - Calif. 
FRANSERIA :

exigua, Wawra, Itin. Princ. S. Coburg. ii. (1888) 41. - Am. bor.

fruticosa, Phil. in Anal. Mus. nac. Chile (1891) 50. - Am, austro-occ

Magdalenae, T.S. Brandeg. in Proc. Calif. Acad. Ser. II. ii. (1889) 170. - Calif.

nivea, Robinson et Fermald, in Proc. Am. Acad. xxx. (1895) 117. - Mexic

FRASERA, Walt. (Gentian.). - Ind. Kew. i. 976

coerulea, A. F. Mulford, in Coult. Bot. Gaz. xix. (1894) 118. - Am. bor.

Cusickii, A. Gray, in Proc. Am. Acad. xxii. (1887) 310. - Oreg.

montana, A. $\dot{f}$. Mulford, in Coult. Bot. Ga\%.xix. (1894) 119. - Am. bor.

tubulosa, Coville, in Proc. Biol. Soc. Wash, vii. (1S92) 71 - Calif.

utahensis, M. E. fones, in Zö̈, ii. (1891) 13. Am. bor. occ.

FRAXINUS, Tourn. ex Linn, (Oleac.). - Ind. Kew. i. 976.

acutifolia, Hort. ex Dippel, Handb. Laubholzk, i. (1889) S5 et 442 ad calc, = excelsio-, Iinn.

amarissima, Hort. ex Dippel, 1. c. $84=$ excelsior Linn.

americana, Marsh. Arboret. Am. (1785) 50; ex Dippel, 1. c. $79=$ caroliniana, Mitl.

arbutifolia, Hort. ex Dippel, 1. c. $76=$ pubescens, Lam.

aucubaefolia, Hort, ex Dippel, 1. c. $77=$ pubescens, Lam.

bracteata, Hemsl, in fourn. Limn. Soc. xxvi. (1890) 84. - China.

calabrica, Hort, ex Dippel, Handb. Laubholzk. i. (1889) $90=$ ancustifolia, Vahl.

californica, Hort. ex Dippel, 1. c. $80=$ oresana, Nutt.

ciliata, Dippel, 1, c. 72; Koehne, Deutsche Dendrol. (1893) $509=$ dipetala, Hook. et Am.

concavaefolia, Hort. ex Dippel, 1. c. $83=$ excelsior, Linn

cucullata, Balt. ex Dippe1, 1. c. 83 et 442 ad calc. = excelsior, Linn.

edentata, Hort. ex Dippe1, 1. c. $90 \Longrightarrow$ oxycarpa, Willd.

Elonza, Dippel, Handb. Laubholz. i. (1889) $87 \mathrm{fig.}$ 46; Koehne, Dentsche Dendrol. (1893) 513. - Hab.

exoniensis, Hort, ex Dippel, 1. c. 85 et 442 ad calc. $=$ excelsior, $L$ inn

globosa, Hort. ex Dippel, 1. c. $83=$ excelsior, Linn.

glomerata, Hort. ex Dippe1, 1. c. $83=$ excelsior, Linn.

humilis, Hort. ex Dippe1, 1. c. = excelsior, Linn

insularis, Hemsl. in foum. Linn. Soc. xxvi. (1889) 86. - China.

intermedia, Hort. ex Dippel, Handb. Laubholzk. i. (1889) $84=$ excelsior, Linn.

linearis, Hort. ex DippeI, 1. c. 85 et 410 ad calc. $=$ excelsior, Linn.

lncida, Hort. ex Dippel, 1. c: = excelsior. Lim.

lutea, Lodd. ex Dippel, 1. c. $86=$ excelsior, Linn.

Mentha, Hort. ex Dippe1, 1. c. $94=$ parvifolia, Lan.

nana, «Dippel. ) ex Koehne, Deutsche Dendrol. (1893) 514 et 580 ad calc. = oxyphylla, Bieb.

numidica, Dippel, Handb. Laubholzk. i. (1889) 96 ; Koehne, l. c.515. - Algeria.

oxvacanthifolia. Hort. ex Dippel, 1. c. $70=$ xanthoxyloides, $W$ all.

parvifolia, Dippel, 1. c. 82 in obs.; Koehne, Deutsche Dendrol.(1893) $599=\mathrm{F}$. Bungeana, DC

platypoda, Oliver, in Hook. Icon. pl. xx. (1890) t. 1929. - China.

pumila, Hort. ex Dippel, Handb. Laubholzk. i. (1889) $83=$ excelsior, Linn.

Regeli, Dippel, l. c. 97 fig. 53; Kochne, Deutsche Dendrol. (1893) 515. - Turkest.

Schiedei, Hort, ex Dippel, Handb. Laubholzk, i. (1889) $172=$ ciliata. Dippel.

scolopendrifolia, Hort. ex Dippel, 1. c. 83 = excelsior, Linn

\section{FRAXINUS :}

colopendrinm, Hort, ex Dippel, Handb. Laubholzk. i. (1889) $83=$ excelsior, Linn

spectabilis, Hort. ex Dippel, 1. c. $84=$ excelsior Linn.

taurica. Hort. ex Dippel, 1. c. $90=$ oxycarpa Willd.

texensis, Sarg. N. Am. Sylva, vi. (1894) 47t. $260=$ americana, Lim

tortuosa, Hort. ex Dippel, Handb. Laubholzk. i. 1889) $84=$ excelsior, $\operatorname{Lin} n$

turkestanica, Carrière, in Rev. Hort. (1887) $63=$ angustifolia, $\mathrm{Vah}$.

verticillata, Lodd. ex Dippel, Handb. Laubholzk. i. (1889) 85 et 410 ad calc, = excelsior, Linn.

Willdenowiana, Kochue, Deutsche Dendrol.(1893)515. - Hab.

FREESIA, Klatt (Irid.). - Ind. Kew.i. 977.

alba, Hort. ex Baker, Handb. Irid. (1892) $167=$ refracta, Klatt.

angolensis, Klatt, in Th. Dur. \& Schinz, Consp. F1. Afr. v. 1893 (1894) 187 (= Anomatheca angolensis, Baker). - Afr. austr.

cruenta, Klatt, 1. c. $(=$ A. cruenta, Lind1. $)$ - Afr. austr.

curvifolia, Klatt, l. c., nomen - Afr, austr.

grandiflora, Klatt, 1. C. (= Anomatheca grandiflora, Baker). - Afr. austr.

iuncea, Klatt, 1. c. = Lapeyrousia juncea, Pourr

uncifolia, Klatt, 1. c. 188 (= Morphixia juncifolia, Baker). - Afr. austr.

FREMONTODENDRON, Coult, in Contrib. U.S. Nat. Herb. iv. (1893) $74=$ Fremontia, Torr. Stercul.).

californicum, Coult.1. c, = F. californica, Torr.

FRESENIA, DC. (Compos.). - Ind. Kew. i. 978 foliosa, Klatt, ex Schinz, in Bull. Herb. Boess. iii. (1895) 431. - Afr, austro-occ. extratrop.

pinnatilobata, Klutt, ex Schinz, l. c. 432. - Afr. austro-occ, extratrop.

FREYGINETIA, Gaudich.(Pandan.). - Ind Kew i 978. Gaudich. (Pandan.). angustissima, Ridl. in fourn. Bot. xxiv. (1886) 359 - Guin.

Carolana, F, Muell, in Australas. Journ. Pharm. ii. (1887) 126 in obs, = insionis, Blume.

Forbesii, Ridl. in fourn. Bot. xxiv. (1886) 359.N. Guin

FREYERA, Reichb. = Chaerophyllum, Linn. Umbell.).

balcanica, Halácsy, in Oest. Bot. Zeitschr xlii. (1892) $3 \% 0(=$ Biasolettia balcanica, Velen.). Bulg.

balcanica, "Velen. ) ex Nadji, [Charrel] P1. de Salon. [Emp. Ottom.] (1892) $23=$ praec.

longiradia, Halácsy, in Oest. Bot. Zeitschr. xlii. 1892) 370 in syn. = balcanica. Halácsy.

FREZIERA, Sw.(Ternstroem.). - Ind. Kew, i.

boliviensis, Wawra, in Mart. Fl. Bras, xii. I. (1886) 284. - Boliv.

ferruginea, Wawra, l.c. - Peruv.

guianensis, Wawra, l.c. - Guian, angl.

inaequilatera, Britton, in Bull. Torrey Bot. Club, xvi. (1889) 63. - Bolivia.

FRITILLARIA, [Tourn.] Linn. (Liliac.). - Ind. Kew. i. 979.

aintabensis, Post, in Bull. Herb. Boiss, iii (1895) 164. - Syria.

agrestis, Greene, in Erythea, iii. (1895) 67. - Calif. alpina, Freyn \&o Sint. in Oest. Bot. Zeitschr. xliv. (1894) 32\%. - As. Min.

Bornmuelleri, Hansskn. in Oest. Bot. Zeitschr. xl. (1890) 393. - As, mir.

canaliculata; Baker, in Gard. Chron.(1890) i. 288. - Kurdist.

citrina, Baker, l. c. (1893) i. 538, - As. Min

coccinea, Greene, Pittonia, ii. (July 1892) 250 ; et Man. Bot. San Franc. Bay (1894) 310. - Calif.

\section{FRITILLARIA}

contorta, Hort. ex Baker in Gavd. Chron. (1886) 1. $6 \mathrm{S1}$ - Hab.

Davidi, Franch. in Nouv. Arch. Mus. Paris, Sér. II x. (1887-88) 93 t. 16, fig. B. - Tibet.

glauca, Greene, in Erythea, i. (1893) 153. - Oregon. hericaulis, Baker, in Gard. Chron. (1889) ii. 38. As. Min.

inearis, Coult. \&o Fisher, in Coult, Bot. Gaz. xvii. 1892) 352. - Dakota.

lophophora, Bureau \& Franch. in Morot, Fourn. de Bot.v. (189I) 153; Oliver, in Hook. Icon, pl. xxiii. (1892) t. 2219. - China.

Perryi X. Hort. ex Reuthe, in Gartenfl. xxxy.(1886) 117. - Calif

Przewalskii, Maxim. ex Batalin, in Aot. Hort. Petrop. xiii. (1893) 105. - China

Raddeana, Regel. l. c.x. (1887) 365 ; et in Gartenfl. xxxvi. (1887) 583. - Turkest.

Regis-Georgii, Heldr. \& Holzm. ex Rouy, in Bull. Soc. Bot. Fr, xxxviii. (1891) 184 in obs. Graecia.

Stracheyi, Hook. f. Fl. Brit. Ind. vi. (1892) 353. Reg. Himal.

Stribrnyi, Velen. in Sitzb. Boehm. Ges. Wiss. 1892 (1893) 61. - Bulg.

viridiflora, Post, in Bull. Herb. Boiss, iii. (1895) 164. - Syria.

Whittallii, Baker, in Gord. Chron. (1893) i. 506. As. Min.

agrica, Stapf, in Verh.zool.-bot. Ges. Wien, xxxviii. (1888) 351; Baker, in Gard. Chron. (1893) i. 568. - Persia.

FROELICHIA, Moench (Amaryll.). - Ind. Kew. i. 980 .

alata, S. Wats, in Proc. Am. Acad. xxi. (1886) $43 \%$ - Mexic.

juncea, Robinson of Grecnm, in Am. Fourn. So Ser. III. 1. (1895) 143. - Ins, Galap.

texana, Conlt. et Fisher, in Coult. Bot. Gaz. xvii. (1892) 350.-Texas.

texana, Coult. \&N. E. Rose, ex Coult in Contrib.U.S Nat. Herb. ii. (1894) 363 [an praec.?]. - Texas

FUCHSIA, [Plum.] Linn. (Onagr.). - Ind. Kew i. 980

boliviana, Britton, in Bull. Torrey Bot. Club, xvii. (1890) 214. - Bolivia.

Garleppiana, Kuntze \& Wittm. in Gavtenf. xlii. (1893) 461 fio. 96. - Bolivia.

Glazioviana, Taub, in Bot. Fahrb. xv. Beibl. n. 34 (1892) 16. - Bras.

myrtifolia, Hort. ex Koehne, Deutsche Dendrol (1893) $429=$ discolor, Lindl.

Pringlei, Robinson \& Seaton, in Proc. Am. Acad. xxviii (1893) 106. Mexic.

Riccartoniana, Hort, ex Koehne, Deutsche Dendrol. (1893) $429=$ globosa, Lindl.

semperforens $X$, Rozain, in Wien. Illustr. Gartenz. (1888) 244. - Hybr. artef.

splendens. Hort. ex Dippel, Handb. Laubholzk. iii. (1893) 226 in obs. = microphylla, $H$. B. \& $K$.

Thompsoni, Hort. ex Koehne, Deutsche Dendrol. 1893) $430=$ gracilis, Lindl.

FUGOSIA, Juss. (Malvac.). - Ind. Kew. i. 981. reysiana, Deflers, in Bull. Soc. Bot. Fr. xlii. (1895) 299. - Arabia.

FUIRENA, Rottb. (Cyper.). - Ind. Kew. i. 981 calolepis, K. Schum. in Abh. Preuss. Akad. Wiss. 1894) 20 et 21 ; et in Engl. Pflanzenw. Ost-Afr. C (1895) 126. - Afr. trop. or

ciliaris, K. Schum., 1. c. $126=$ Scirpus ciliaris, Iinn.

glauca, Boeck, ex C. B. Clarke, in Th. Dur, \& Schinz, Consp. F1. Afr. v, 1894 (1895) $646=$ coerulescens, Stend.

macrostachya, Boeck. in Eng1. Pflanzenw. Ost-Afr. A. (1895) $67=$ pachyrrhiza, Rendle

repens, Boech. in Bot. Fahrb. vii. (1886) 27\%.Mexic.

temifolia, Boeck, ex C. B. Clarke, in Th. Dur. \& Schinz, Consp. F1. Afr. v. 1894 (1895) $648=$ pubescens, Kunth. 


\section{FUIRENA :}

Trilobites, C. B. Clarke, in Hook, f. Fl. Brit. Ind vi. (1893) 666. - Deccan.

Welwitschii, Engl. Pfanzenw. Ost-Afr. A (1895) 132. - Afr. trop.

FUMANA, Spach = Helianthemum, Tourn. Barrelieri, Rouy \& Fouc, F1. de Fr, ii, (1895) 313 $=$ H. glutinosum, Pers. ricoides, Pau, Not. Bot. F1, Espan. ii. (1889) $12=$ H. ericoides, Dunal.

FUMARIA, Tourn. (Papav.). - Ind. Kew, i. 982 abortiva $\times$, Hausskn. in Mitth. Thuir. Bot. Ver. N. Folge, iii. et iv. (1893) 102. - Graecia. 4 lberti $x$, Fouc. \& Rouy, Fl. de Fr. i. (1893) 178. - Gall

atiantica, Coss. \& Durieu, ex Coss. Comp. Fl. Atlant. ii. (1887) $90=$ anraria, Lag. grandiftora, Nym. Consp. Fl. Eur., Suppl. (1889) 18 = Sarcocapnos grandiflora, Rouy.

FUNCKIA, Willd, = Astelia, Banks \& Soland. (Liliac.).

albicans, alpina, Cunninghamii, fragrans, graminifolia, grandis, hastata, Menziesiana, microsperma, montana, merrosa, polyneuron, pumila, Solandri, spicata, subrigida, trinervia, Kuntze, Rev, Gen. (1891) $711=$ homonyma omnia Asteliae.

Hookeriana, Kuntze, 1. c, = A. Cunninghamii, Hook.

Waiadealae, Kintze, 1. c. = A. Waialealia, Warera.

FURCILLA, Van Tiegh, in Bull. Soc. Bot. Fr. xlii. (1895) $85=$ Loranthus, Linn.

Bidwillii, Van Tiegh. 1. c. = L. Bidwillii, Benth. myrtifolia, Van Tiegh. 1. c. = L. myrtifolius, $R$. Br.

FURCRAEA, Vent. (Amary11.). - Ind. Kew, i. 981

albispina, Hort. Palerm. ex Baker, in Gard. Chron. (1893) 11. 584. - Hab.?

pubescens, Baker, Handb. Amaryll. (1888) 201 ; et in Bot. Mag. (1892) t. 7250. - Mexic.

Roezlii, Éd. André, in Rev. Hort. (1887) 353 fig. I $=$ F. Bedinghausii, C. Koch.

FUSANUS, R. Br. (Santa1.)。 - Ind. Kew. i. 984 cignorum, Kuntze, Rev. Gen. (1891) $589=$ spicatus R.Br.

\section{G}

GAEDAWAKKA, Lin1. Fl. Zeyl. (1747) 203; ex Kuntze, Rev. Gen. (1891) $606^{\circ}=$ Chaetocarpus Thw. (Euphorb.).

Blanchetii, coriacea, Pohlii, pubescens, Kuntze, 1. c. = homonyma omnia Chaetocarpi.

globosa, Kuntze, 1. c. = Mettenia globosa, Griseb. Schomburgkiana, Kuntze, 1. c. - Am. austr.

GAERTNERA, Iam. (Logan.). - Ind. Kew. i. morindoides, Baker, in Kew Bull. (1892) 83. Guinea.

rufmervis, Stapf, in Trans Limn. Soc., Ser. II. iv. (1894) 183. - Borneo.

GAERTNERlA, Medic. = Franseria, Cav. (Compos.)

bipinnatifida, Chamissonis, cordifolia, discolor, dunosa. eviocentra, fruticosa, hispida, Hookeriana, ilicifolia, tenuifolia, tomentosa, Kuntze. Rev. Gen. (1891) $339=$ homonyma onmia Franseriae.

acanthicarpa, Britton, in Mem. Torrey Bot. Club, v. $(\mathbf{1 8 9 4}) 332=$ F. Hookeriana, Nutt.

anibrosiodes, Kuntze, Rev, Gen. (1891) $339=\mathrm{F}$ ambrosioides, $\mathrm{Ca}$ \%

artcmisiodes, Kuntze, 1. c. = F. artemisioides Meyen \& Walp.

deltodes, Kuntze. 1. c, = F. deltoidea, $T(r r$

Mejeniana, Kuntze, 1. c. $=$ F. artemisioides. Meyen \&W Walp.
GAGEA, Salisb. (Liliac.). - Ind. Kew. i. 985. alceriensis, Chub in Bull. Soc. Bot. Fr. xxxvi. (1889) 320 in syn. $=$ G. Liottardi, Schult. $f$

glanca, Blocki, in Deutsche Bot. Monatsschr. v (1887) 65.- Eur. centr.-or.

Haccklii X. Dufft et M. Schulze, in Mitth. Geogr Ges. Jena iii, 2 et 31884 (1885) 224. - Germ.

pomeranica, Ruithe, in Verh. bot. Ver. Prov. Brand. xxxiv. (1893) 15. - Germ.

puymaurensis, H. \& A. Marcailh. d'Aym, in Revue de Bot. ix. (1891) 229 et $291=$ foliosa, Schult. $f$. szepusiana, Ullepitsch, in Oest. Bot. Zeitschr. xxxvi. (1886) 399. - Hung.

Welwitschi, G. Beck, F1. Nied.-Oestr. i. (1890) 175 in syn. = hybrida, Schur

GAGNEBINA, Neck. (Legumin.). - Ind. Kew. i. 985.

lutescens, Vell. FI. Flum, i.t. 116 text. ed. Netto, $45=$ Manettia lutescens, $K$. Schum.

GAHNIA, Forst. (Cyper.). - Ind. Kew. i. 986.

Boninsimae. Maxim. in Bull. Acad. sci. St. Pétersb. xxxi. (1887) 112. - Japon.

exioua, Colenso, in Trans. N. Z. Inst. xviii. 1885 (1886) $279=$ rio:da, T.Kirk.

Manni, Hillebr. Fl. Haw. Isl. (I8S8) 48\%, - Ins. Sandvic

multiglumis. Colenso, in Trans. N. Z. Inst. xviii $1885(1886) 280=$ setifolia. Stend.

pariflora, Colenso, 1. c. $279=$ setitolia, Stond.

robusta. T. Kirk, l. c. xxvi. 1893 (1894) 261. N. Zel.

scaberula, Colenso, 1. c. ${ }^{x v i i i} .1885$ (1886) $278=$ setifolia, Stend.

GAIADENDRON, G. Don = Loranthus, Linn. breviflorm, Hieron. in Bot. Jahrb. $x x$, Beibl. n. 45 (1895) 5. - Columb.

ligustrinum, Engl. in Engl. \& Prant1, Natürl. Pflanzenfam. 11I. i. (1889) $178=$ L. ligustrinus, Wall.

Tagua, Engl. 1. c. = L. Tagua, ${ }^{r} H . B$. $6 K$.

GAILLARDIA, Fouger. (Compos.). - Ind, Kew i 986.

Richardsoni, Hort. ex Kew Bull. iii. (1S89) $41=$ aristata, Pursh.

suavis, Britton \& Rusby, in Trans. N. Y. Acad. Sci. vii. (1887) $11=$ simplex Scheele.

GAILLONIA, A. Rich. (Rubiac.), - Ind. Kew。i. 986.

dubia, Aitch. E Honsl, in Trans. Linn. Soc. Ser. II iii. (1886) 73 t. 30. - Afghan,

GAIMARDIA, Gaudich, (Centrolepid.).-- Ind, Kew. i. 986.

minima, Colenso, in Trans. N. Z. Inst. xxii. 1889 1S90) 491. - N. Zel.

GAIANUS, Rumpf, ex Kuntze, Rev. Gen. (1891) 189 = Inocarpus, Forst. (Legumin).

edulis, Kuntze, 1. c. = I, edulis, Mart. guianensis, Kuntze, 1. c. = I. edulis, Mart. lanceolata, Kuntze, 1. c. = I. edulis, Mart.

provacensis, Kuntze, 1. c. $\{=$ Bocod prouacensis, Aubl.). - Guian

GALACTIA, P. Br. (Legumin.). - Ind. Kew. i. 986.

Aschersoniana, Taub. in Flora, 1xxii. (18s9) 427.Bras.

crassifolia, Taub. in Engl. \& Prant1, Natür1. Pflanzenfam. iii. 3 (1894) 368 (= Collaea crassifolia, Benth.). - Bras.

discolor, F. D. Smith, in Coult. Bot. Gaz, xvi. (1S91) 194. - Guatem.

erecta, Vail, in Bull. Torrey Bot. Club, xxii. (1895) 502 = sessiliflora, Torr. \& Gray.

fasciculata, Vail, l. c. - Florida.

Galactia, Vail, 1. c. 500 in obs. = pendula, Pers galactioides, Hitchcock, in Missouri Bot. Gard. Rep. iv. (1893) $77=$ impressa, Wright,

Grayi, Vail, in Bull. Torrey Bot. Club, xxii. (1895) $503=$ heterophylla, A. Gray.
GALACTIA

grewiacfolia, Taub in Engl. \& Prantl, Natürl. Pflanzenfam, iii. 3 (1894) 368 (= Collaea grewiaefolia. Benth.). - Bras.

heterophylla, Vail, in Bull. Torrey Bot. Club, xxii. (1895) $502=$ marginalis, Benth.

macropizylla, Taub. in Engl. \& Prantl, Natürl. Pflanzenfam. iii. 3 (1894) 378 (= Collaca macroploylla, Benth.). - Bras.

montana, Britton, in Bull. Torrey Bot. Club, xvi. (1889) 334. - Bolivia.

multiflora, Robinson, in Proc. Am. Acad.xxix. (1894) 315. - Mexic.

regularis, Britton, Stern \& Pogg. Prelim. Catal. (1888) $14=$ glabella, Michx.

rotundifolia, M. Micheti, in Morot, fourn. de Bot. vi. (1892) 188 t. 8. - N. Granat.

scarlatina, Taub. in Eng1. \& Prantl, Natürl. Pflanzenfam. iii. 3 (1894) 378 (= Collaea scarlatzna, Benth.). - Bras.

speciosa. Britton, in Bull. Torrey Bot. Club, xvi. (1889) $262=$ Collaea speciosa, DC.

Tashiroi, Maxim. in Bull. Acad. sci. St. Pétersó. xxxi. (1887) 34. - Ins. Liukiu.

tenera, Kuntze, Rev. Gen. (1891) $190=$ Genista virgata, $\operatorname{Linh}$

varians, F. M. Bailey, in Dept. Agric. Brisbane Bot. Bull, x. (1895) 22. - Austral.

volubilis, Britton, in Mem. Torrey Bot. Club, v. (1894) 208; et Vail, in Bull. Torrey Bot. Club, xxii. (1895) $507=$ pilosa, Ell.

GALAGTITES, Moench (Compos.). - Ind. Kew.

i. 987. pumila, Porta, in Atti Accad. Agiati, ix. 1891 (1892) 39 [sphalm. Galactitis]; Willk. Suppl. Prody. Fl Hisp. (1893) 107. - Hisp.

GALACTOXYLON, Pierre, Not, bot. Sapot. (1890) 6; Baill. Hist. des pl. xi. (1892) 300 SAPOTACEAE.

Pierrei, Baill.l.c. (= Bassia Galactoxylon, F. Muell.) - Archip. Ind.

GALACTOXYLUM, “Pierre » ex L. Planch. Étud prod. Sapot. (1888) $26=$ praec

GALANTHUS, Linn. (Amaryll.) - Ind. Kew. i. lleni, Baker, in Gard. Chron. (1891) i. 298. - Reg. Cauc.

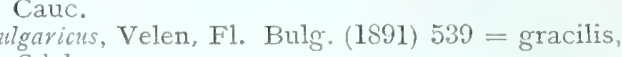
Celak.

byzantinus, Baker, in Gard. Clron. (1893) i. 226. Eur. or.

caucasicus. Baker, 1. c. (1887) i. 312; et Handb. Amary11. (1888) 17 = nivalis, Lim.var.

corcyrensis, Leichtl, ex Le Jardin (188S) $139=$ nivalis, Limn.

Fosteri, Baker, in Gard. Chron. (1889) i. 458. As. Min.

globosis, Wilks, in Garden (1887) i. $393=$ G. Elwesii, Hook. f.

gracilis, Celak, in Sitz. Boelım. Ges. Wiss. (1891) i. 195 t. 9; Velen, Fl. Bulg. (1891) 539. - Bulg. Ikariae, Baker, in Gard. Chron. (1893) i. 506. Ins. Nikaria.

maximus, Volen, Fl. Bulg. 1891) 540. - Bulg.

Olgae-Reginae, Hort. ex Gard. and For. i. (1888 $499=\mathrm{G}$. Olgae, Orph

Perryi, Hort. ex Baker, in Gard. Chron. (1893) i. 258 - Reg. Cauc.

Reginae-Olgae, Hort, ex Le Jardin (1888) $140=$ G. Olıae, Orph.

Sharlocki, Casp. ex Gard. Chron. (1888) i. $243=$ nivalis, Linn.

Sharloki, "Casp. " ex Baker, Handb. Amaryll. (1888) 17 = nivalis, Limn.

GALATEA, Salisb. = Eleutherine, Herb. (Irid.). americana, Kuntze, Rev. Gen. (1891) $701=$ E. plicata, Herb.

GALATELLA, Cass. = Aster, Tourn. (Compos.). illyrica, Murb. in Lunds Univ. Arsskrift, xxvii. 5 (1897) $104=$ A. trinervis, Desf. 
GALAXIA. Thunb. (Irid.). - Ind. Kew. i. 988. purpurea, Klatt, in Th, Dur. Eo Schinz, Consp. Fl. Afr. v. 1893 (1895) 161. - Afr. austr.

GALBULIMIMA. F. M. Bailey, in Dept. Agric, Brisbane Bot. Bull. ix. (1894) 5. MAGNOLIA$C E A E$.

baccata, F. M. Bailey, l. c. - Austral.

GALE, Tourn. = Myrica, Lin1

californica, Greene, Man. Bot. San Franc. Bay 1894) $298=-$ M. californica, Cham.

GALEANDRA, Lindl (Orchid.).-Ind. Kew. i. 988. andamanensis, Rolfe, in Gard. Chron. (1895) ii. 581. - Ins. Andam., Tenass.

Batemanii, Rolfe, l.c. (1892) II. 431 (= G. Bauer Batem.); Cogn. in Mart. Fl. Bras. iii. IV. (1895) 294. - Am. centr.

bituberculata, Rolfe, l.c. (1895) II. 581.- Hab.

Claesii, Cogn. in fourn. des Orchid. iv. (1893) 202

in Lindenia, ix. (1893) 17 t. 391; et in Mart. Fl. Bras. iii. IV. (1895) 301. - Bras.

d'Escagnolleana, Reichb. f, in Illustr. Hort xxxiv. (1887) 63 t. 22 ; et in Gard. Chron. (1892) II. $4: 31=$ palustris, Rodr.

d'Escragnolleana, Hort. ex Gard. Chron. (1888) II. 328 sphalm. = G. d'Escagnolleana, Reichb. $f$.

flaveola, Reichb. f. in Gard. Chron. (1887) I. 51:. $\mathrm{Hab}$.?

GALEARIA. Zoll, \& Mor. (Euphorb.). - Ind. Kew , i. 988 .

Helferi, Hook.f. Fl. Brit. Ind. v. (1887) 378. Tenass.

Lindleyana, Hook. f.l. c. 379. - Penang

Maingayi, Hook. f. l. c. 377. - Malacca.

subulata, Hook. f. l. c. 379. - Penang, Perak.

GALEDUPA, Lam.= Pongamia, Vent.(Legumin.) pinnata, Taub, in Engl. \& Prantl, Natürl. Pflanzenfam. iii. 3 (1894) $344=$ P. glabra, Vent.

GALEGA, Tourn. ex Linn. (Legumin.). - Ind. Kew i. 989.

coronilloides, Freyn \& Sint. in Oest. Bot. Zeitschr. xliii. (1893) 413. - As. Min.

GALEOLA, Lour. (Orchid.). - Ind. Kew, i. 990. Cathcartii, Hook. f. Fl. Brit. Ind. vi. (1890) 89. Reg. Himal.

Falconeri, Hook.f. l. c. S8. - Reg. Hima!

pusilla, Hook. f. l. c. 89 . - Pegu.

GALEOPSIS, Linn. (Labiat.).- Ind. Kew. i. 990. balatonensis, Borb. in Termész. Füzét. xvii. (1894) $66=\mathrm{G}$. Ladanum, Linn. var. crenifrons, Borb. 1. c, $65=$ speciosa, Mill. var.

Eversiana, Murr, in Deutsch. Bot. Monatsschr. xii. (1894) 20. - Tirol.

flanatica, Borb. in Termész. Füzét. xvii. (1894) $68=\mathrm{G}$. Ladanum, Linn. var.

flarescens, Borb. Enum. pl. Com. Castriferr. (1887) 346 ; et in Oest. Bot. Zeitschr. xxxix. (1889) 346 = speciosa, Mill. var.

hispida, Borb. in Termész. Füzét. xvii. (1894) 65 = speciosa, Mill. var.

ionantha, Borb. 1. c. $65=\mathrm{G}$. Tetrahit, Linn. var.

lactiflora, Borb. 1. c. = G. Tetrabit, Limn. var.

leiotricha, Borb. (Békésvarmegye flóraja (1881-88) ex Oest. Bot. Zeitschr. xxxix. (1889) $234=$ speciosa, Mill. var.

litoralis, Borb. in Termész. Fuizét. xvii. (1894) 6.5 = G. Ladanum, Linn.var.

longiflora, Timb. \& Marçais, in Magnier, Scrinia H. select. vi. (1S87) $116=\mathrm{G}$. Ladanum, Linn

Marrubiastrum, Borb. in Termész. Füzét. xvii (1894) $65=\mathrm{G}$. Ladanum, Linn.

Murriana, Borb. \& Wettst. ex Murr, in Oest. Bot Zeitschr. xxxviii. (1\$88) 238 ; et in Progr. Innstr. Ober-Real Schule $(1890-91)=$ pubescens, Bess. var.

oclirerythrea X, Prahl, Krit. Fl. Prov. Schlesw. Holst. ii. (1890) $170=\mathrm{G}$. Wirtgeni, Ludw. $\times$. pallens $X$, Briq. in Bull. Herb. Boiss. i. (1893) 389 - Eur.

\section{GALEOPSIS}

Pernhofferi $\times$, Wettst, in Kern. Sched, Fl, AustroHung, vi. (1893) 41 = pallens, Briq. $X$

persetosa, Borb., in Termész. Füzèt. xvii. (1894) 65 $=\mathrm{G}$. Tetrahit, Linn, var.

polychroma $\times, G$. Beck, Fl. Nied.-Oest. II. ii (1893) 1016. - Austria.

silvestris, Borb. in Termész. Füzét. xvii. (1894)73 $=\mathrm{G}$. Tetrahit, Linn. var.

subspeciosa, Borb. 1. c. $65=$ pubescens, Bess, var. subtatrensis, Borb.1. c. $66=\mathrm{G}$. Tetrahit, Linn. var Timbali $X$, Hariot, in Bull. Herb. Boiss. 1 Append. i. (1893) 39. - Gall

GALEOTTIA, Nees= Glockeria, Nees (Acanth.) glandulosa, Kuntze, Rev. Gen. (1891) $490=\mathrm{Gl}$ glandulosa, Oerst.

haematodes, Kuntze, 1. c. = G1, haematodes, Oerst.

sessilifolia, Kuntze, 1. c. = Gl. sessilifolia, Oerst.

GALINSOGA, Ruiz \& Pav. (Compos.). - Ind. calva, Rusby, in Mem. Torrey Bot.!Club, iii. 3 (1893) 61. - Buliv.

GALINSOGAEA, Himpel, F1. Elsass-Lothr. (1891) $187=$ Galinsoga, Cav. (Compos.).

GALIPEA, Aub1. (Rutac.). - Ind. Kew. i. 991 ciliata, Taub. in Bot. Fahrb. xv. Beibl, n. 34 (1892) 3. - Bras

GALIUM Linn, (Rubiac) - Ind. Kew i. 991 berrans X, G. Beck, Fl. Nied.-Oest. II. ii. (1893) 1123. - Austria.

anfractum, Sommier Es Levier, in Bull. Soc. Bot. Ital. Ser. II. iii. (1894) 29. - Reg. Cauc.

araucanum, Phil. in Anal. Univ. Chil. 1xxxv. (1894) 731. - Chili.

Baldaccii, Halácsy, in Oest. Bot. Zeitschr. xl. (1890) 165. - Montenegro.

Baumgartncri, G. Beck, Fl. Nied.-Oest. II. ii. (1893) 1124. - Austria.

bulgaricum, Velen, Fl. Bulg. (1891) 231. - Bulg-

bullatum, Lipsky, in Act. Hort. Petrop. xiii. (1894) 300. - Reg. Cauc

buxifolium, Greene, in Bull. Calif. Acad. II. vi. (1886) 150 et 400. - Ins. S. Cruz. (Calif.)

catalinense, A. Gray, Syn. Fl. N.Am. I. ii. Suppl. 1886) 445. - Calif

cymulosum, Post, in Fourn. Linn. Soc, xxiv. (1888) 432. - As. occ

dacicum, Rouy, in Bull, Soc. Bot. Fr. xxxvii. (1890) 163 = aspertiliflorum, Borb.

Degenii, Baldacci, in Oest. Bot. Zeitschr. xlv. (1895) 131. - Alban.

ffulgents X, G. Beck, Fl. Nied.-Oest. II. ii. (1893) 1124. - Austria.

elegans $\times$, Blocki, in Oest. Bot. Zeitschr. xlii. 1892) 351 ; et xliii. (1893) 108. - Austro-Hung. fistulosum, Sommier of Levier, in Bull. Soc. Bot. Ital. Ser. II. iii. (1894) 31 ; et in Act. Hort. Petrop. xiii. 1894) 195 - Reg. Cauc.

flaccidum, Greene Pittonia, i. (Mar. 1887) 34. - Calif.

Forsteri, Phil. in Anal. Univ. Chil. Ixxxy. (1894) 735. - Reg. Magrellanic

grande, Mcblatchie, in Erythea, ii. (1894)124.-. Calif Guillemotii X. Corbière, .Nouv. Fl. Norm. (1893) 301. - Gall. occ

Honoratae $\times$, Blocki, in Oest. Bot. Zeitschr, xliii. (1S93) 108. - Austro-Hung.

farynae $X$, Woloszczak, 1. c. xxxvii. (1887) 227.Galicia.

lanatum, Boiss. Fl. Or. Suppl. (1888) 282 (= Vaillantia lanata, Delile). - Erypt.

lanuginosum, Post. in fourn. Linn. Soc. xxiv. (1888) 432. - As. occ

laxum, Phil. in Anal. Univ. Chil. 1xxxv. (1894) 732 - Chili.

leptum, Phil. l.c. 734. - Chili.

Leyboldii, Kern. Sched. Fl. Austr. vi. (1893) $80=$ rubrum, Linn.

luteum, St Lager, in Cariot, Etud. des fl. éd. S. ii (1889) $387^{\circ}=$ verum, Linn

Mandoni, Britton, in Bull. Torrey Bot. Club, xviii. (1891) 263, - Bolivia.

\section{GALIUM}

mavisense, Simonk, Enum. Fl. Transsilv, (1886) 281 - Transsilv.

miguelense, Greene, Pittonia, i. (Mar, 1887) 34. Calif.

occidentale, Mcblatchie, in Erythea, Ji. (1894) 124 - Calif.

oligotrichum, Simonk. Enum. F1. Transsilv. (1886) $285=$ pseudo-aristatum, Schur.

ovalleanum, Phil. in Anal, Univ. Chil. 1xxxy, (1894) 734. - Chili.

pabulosum, Sommier et Levier, in Bull. Soc. Bot. Ital. Ser. II. ii. (1894) 31. - Reg. Cauc.

peregrimu, Britt., Stern et Pogg. Prel. Catal. (1888) $24=$ hispidulum, Michx

Peteroanum, Phil.in Anal. Univ.Chil. lxxxv.(1894) 733. - Chili.

plumosum, Rusby, in Mem. Torrey Bot. Club, iii. 3 (1893) 49. - Bolivia.

polonicum, Blocki, in Oest. Bot. Zeitschr. xxxvii. (1887) 189. - Eur. centr.

pseudo-Polycarpon. Sonmier \& Levier, in Bull. Soc. Bot. Ital. Ser. II. iii. (1894) 30. - Reg Cauc.

pucnotrichum, Kern. Sched. Fl. Austro-Hung. vi (1893) $70=\mathrm{G}$. Mollugo, Linn

Reiseri, Halácsy, in Oest. Bot. Zeitschr. xlv. (1895) 338 t. 18. - Ins. Sporad.

rodoperm, Velen, in Sitz. Boehm. Ges, Wiss. 1892-93) 32. - Bulg

Schiedeanum $X$, Prahl, Krit. Fl. Prov. Schlesw. Holst. Theil ii. (1890) 114. - Slesv,-Holst.

spectabile $\times$, G. Beck, FI. Nied.-Oest, II, ii. (1893) 1123. - Austria.

stenophyllum, Baker, in Kew Bull. (1895) 69. Afr. trop.

subuliferum, Sommier \& Levier, in Act. Hort. Petrop.xii. (1892) 151. - Reg. Cauc

telanthos, Phil. in Anal. Univ. Chil. 1xxxv. (1894) 732. - Chili.

turcicum, Velen, F1. Bulg. (1891) $231=$ G. Heuffelii, Borb.

Volckmanni, Phil. in Anal. Univ. Chil. 1xxxv. (1894) 732. - Chili.

Wettsteini, Ullepitsch, in Oest. Bot. Zeitschr, xliui (1893) 421 - Hung

Willkommianum, Batt, in Bull. Soc. Bot, Fr. xxxiii. (1886) 354 in syn.; et in Batt. et Trab. Fl. de l'Algér. [Dicot.] = parisiense, Lim.

GALPHIMIA. Cav. (Malpigh.). - Ind. Kew, i. 996. australis, Chod in Arch, scienc. phys, et nat. (1890) ex Chod. in Mem. Soc. sc. phys. Gen. xxxi, 2 (1892) n. 3, 22. - Parag.

platyphylla, Chod. in Arch. sc. phys. et nat. (1890): ex Chod. in Mem. Soc. sc. phys. Gen. xxxi. 2 (1892) n. 3, 23. - Parag.

sessilifolia, N.E. Rose, in Contrib. U. S. Nat. Herb. iii. 5 (1895) 313. - Mexic

vestita, S. Wats, in Proc. Am, Acad, xxi. (1886) 421. - Mexic.

GALPINIA, N. E. Br. in Kew Bull. (1894) 345. LYTHRARIEAE

transvaalica, N. E Br, l, c. 346; Oliver, in Hook. Icon.pl. xxiv. (1895) t. 2375. - Transvaal.

GALPINSIA, Britton, in Mem. Torrey Bot. Club, v. (1894) $236=$ Oenothera, Linn. (Onagrar.). Hartwegil, Britton 1. c. $=$ Oe. Hartwegii, Benth.

GALVEZIA, Domb.(Scrophul,).- - Ind. Kew. i. 996. uncea, T. S. Brandeg. in Proc. Calif. Acad. Ser. II. iii. (1891) $225=\mathrm{seq}$.

juncea, A. Gray, in Proc. Am. Acad. xxii. (1887) 311 (= Maurandia juncea, Benth.) - Chili

speciosa, A. Gray, l. co in obs. (= Antisrhimum speciosum, A. Gray). - Chili.

GAMBEYA, Pierre, Not. bot. Sapot. (1891) 61 Baill. Hist. des pl. xi. (1892) 296. SAPOTA$C E A E$.

africana, Pierre, l.c. $63(=$ Chrysophyllum africanum, G. Don). - Ins. Fernando-Po

Boiviniana, Pierre, l. c. $(=$ Chrys. Boivinianum, Hartig.). - Madag. 


\section{GAIMBEYA :-}

mammosa, Pierre, Not. bot. Sapot. (1891) 61 (= Lucuma mammosa, Gaertn. f.). - Am. austr.

subnuda, Pierre, l.c. (= Chrys, subnudum, Baker). - Afr. trop.

GAMOPODA, Baker, in Journ. Linn. Soc. xxii. (1887) 443; Prant1, in Engl. \& Prant1, Natürl. Pflanzenfam. iii. 2 (1891) 275. MENISPER$M A C E A E$.

densiflora, Baker, l. c. - Madag.

GANDASULIUM, Rumpf, Herb. Amboin. v. (184547) 175 ; ex Kuntze, Rev, Gen. (1891) $690=$ Hedychium, Koen.(Scitam.),

coccineum, coronarium, densiflorum, ellipticum, Gomezianum, gracile, Griffithianum, Hasseltii, Horsfieldii, intermedium, lanatum, lingulatum, palembanicum, peregrinum, Roxburghii, simile, Spanogheanum. speciosum, spicatum, sumatranum, thyrsiforme, renustum, Kuntze, 1.c. = homonyma omnia Hedychii. angustifolium, Kuntze, 1. c. $=$ H. coccineum, Buch.-Ham.

flavum, Kuntze, 1. c. = H. coronarium, Koen,

Sieboldii, Kuntze, 1. c。 = H. spicatum, Smith?

GANSBIUM, Adans. = Erophila, DC. (Crucif.). vernum, Kuntze, Rev. Gen. (1891) $30=\mathrm{E}$, vulgaris, $D C$

GARCINIA, Linn. (Guttif.). - Ind. Kew. i 997.

andamanica. King, in fourn. As. Soc. Beng. lix. (1890) II. 170; Vesque, in DC. Monog. Phanz. viii. (1893) 3ะ8. - Ins. Andam.

angolensis, Vesque, Epharmosis, ii. (1889) 13; et in DC. . . . 335. - Angola.

aphancphlebia. Baker, in fourn. Linn. Soc. xxv. (1889) 295. - Madag.

Baikieana, Vesque, Epharmosis, ii. (1889) 13 ; et in DC. Monog. Phan. viii. (1893) 336. - Afr. trop. occ.

Balansae, Baill. in Bull. Soc. Linn. Paris, ii. $(18,0) 8 \% 7=$ tonkinensis, Vesque.

Boeringii, Pievre, ex Vesque, in DC. Monog. Phan. viii. (1893) 363. - Java?

bosoboscensis, Pierre, ex Vesque, in DC. l.c. 484 (=G. Maingayi, Vidal). - Ins, Philipp.

Buchanani, Baker, in Kev Bull. (1894) 354. - Afr trop.

Cadelliana, King, in Journ. As. Soc. Beng. lix. (1890) $11.154=\mathrm{G}$, Lanessanii, Pierre.

cambodgiënsis, Vesque, Epharmosis, ii. (1889) 14 t. 92 et $93(=G$. Andersoni, Pierre); et in DC. Monog. Phan, viii. (1893) 316. - Cambod.

cauliflora. Baker, in fourn. Linn. Soc. xxii. (1887) 446. - Madag.

cernua, Baker, l. c. - Madag.

Commersonij, Vesque, in DC. Monog. Phan. viii. (1893) 484 ( = Rheedia Commersonii, Planch. et Triana). - Madag.

costata, Hcmsl. ex King, in fourn. As. Soc. Beng. lix. (1890) 11. 161; Vesque, in DC. Monog. Phan. viii. (1893) 409; - Perak.

curvinervis, Vesque, Epharmosis, ii. (1889) 14; et in DC. .. c. 331 . - Gabon.

cuspidata, King, in fourn. As. Soc. Beng. lix. (1890) II. 152; Vesque, in DC. l. c. 365. - Malaya.

decipiens, Vesque, in DC. l. c. 482 (= Ochrocarpus dizersifolius, Baill.). - Ins. Nossibe.

densiflora, King, in fourn. As. Soc. Beng. lix. (1890) 11. 171. - Malaya.

disepala, Vesque, Epharmosis, ii. (1889) t. 159; et in DC. Monog. Phan. viii. (1893) 48. - Madag.

diversitolia, King. in fourn. As. Soc. Beng. lix.

(18!0) п. 153; Vesque, in DC. Monog. Phan, viii (1893) 351. - Malaya.

dumosa, King, l. c. 167; Vesque, l. c. 465. Malaya.

floribunda, Mast. ex Vesque, l. c. 488. - Lagos.

Forlesii, King, in fourn. As. Soc. Beng. lix. (1890)

ii. 162 ; Vesque, l. c, 486. - Sumatra.

glomerata, Vesque, l. c. 320 (= G. densiflora, King). - Perak

guineensis, Vesque, l. c. 335 (= Stalagmites guineensis, Don). - Afr. trop. occ

\section{GARCINIA.}

Havilandii, Stapf, in Trans. Linn. Soc. Ser. II. iv (1894) 132. - Borneo.

Kingii, Pierre, ex Vesque, in DC. Monog. Phan. viii. (1893) 407. - Ins. Andam.

Kunstleri, King, in fourn. As. Soc. Beng. lix. (1890) 11. 165 ; Vesque, l. c. 485 . - Perak.

lucida, Vesque, l. c. 311. - Afr. trop. occ

Mestoni, F. M. Bailey, Rep. Exped. Bellenden-Ker, (1889) 31 ; et Syn. Queensl. Fl. Suppl. iii. 8.Austral.

moulmeinensis, Pierre, ex Vesque, in DC. Monog. Phan. viii. (1893) 392, - Moulmein.

novo-guineensis, Vesque, l. c. 643. - N. Guin.

opaca, King, in fourn. As. Soc. Beng lix. (1890) !I. 160 ; et in DC. Monog. Phan, viii. (1893) 411. Malaya.

orthoclada, Baker. in foum. Linn. Soc. xxii. (1887) 446. - Madag.

ovalifolia, Baill. ex Vesque, in DC. Monog. Phan viii. (1893) 331 in syn. = curvinervis, Vesque.

pachyphylla, Baker, in fourn. Linn. Soc. xxv. (1889) 295. - Madag.

Pervillei, Vesque, in DC. Monog. Phan. viii. (1893) 485 (= Rheedia Pervillei, Planch. et Triana). Madag.

polyphlebia, Baker, in fourn. Linn. Soc. xxii. (1887) 447. - Madag.

Prainiana, King, in fourn. As. Soc. Beng, lix. (1890) 11. 171 ; Vesque, in DC. Monog. Phan. viii. (1893) 329. - Malaya

Roxburghii, Herb. Kew, ex Vesque, I. c. $456=$ G. Horsfieldiana, Pierve

Scortechinit, King, in Journ. As. Soc. Beng. lix. (1894) I. $166=$ G. Gaudichaudii, Planch. et Triana, var.

tonkinensis, Vesque, in DC. Monog. Phan. viii. (1891) 379 (=G. Balansac, Baill.), - Tonkin

ulugurensis, Engl. Pflanzenथ. Ost,-Afr. A (1895) 92 nomen. - Afr. trop.

uniflora, King. in fourn. As. Soc. Beng. lix. (1890) 11. 167; Vesque, in DC. Monog. Phan. viii. (1893) 476. - Perak

urophylla, Scortech. ex King, l. c. 167 ; et Vesque, l. c. 467 . - Malaya.

Vilersierna, Pierre, ex Laness. P1. util. Col. Franc. (1886) 319 , sphalm. = G. Velersiana, Picrre.

Volkensii, Engl. Pflanzenw. Ost.-Afr. C (1895) 275 - Afr. trop. or.

Vrieseana, Pierre, ex Vesque, in DC. Monog. Phan. viii. (1893) 328. - Celebes.

Warrenii, F. Mucll. in Vict. Natural. viii. (Nov. 1891) 109; in Bot. Centralbl. xlix. (1891) 362 ; et ex Vesque, in DC. Monog. Phan, viil. (1893) 641. - Austral.

Wrayi, King, in Journ. As. Soc. Beng. lix. (1890) 11.152 = merguensis, Wright, var.

GARDENIA, Ellis (Rubiac.)。 - Ind. Kew. i 999.

Campanula, Ridl. in Trans. Linn. Soc. Ser. II. iii. (1893) 310. - Penins. Mal.

Gossleriana, 7. Braun of $K$. Schum, in Ber. deutsch. Schutzgeb. ii. (1S89) 157. - Kamerun.

Hansemannii, K. Schum. in Bot. Fahrb. ix. (1888) $220-$ N. Guin.

Hiernii, S. Elliot, in fourn. Linn. Soc. xxx. (1894) 50. - Sierra Leone.

longiflora, Vidal, Revis."Pl.Vasc. Filip. (1886) 153. - Ins. Philipp.

obscura, Rolfe, in fourn. Bot. xxiv. (1886) 349, in obs. - Ins. Philipp.

ovularis, F. M. Bailey, in Dep. Agric. Brisbane Bot. Bull, vii. (1893) 64. - Austral.

riparia, K. Schum. in Engl. Pflanzenw. Ost-Afr. C (1895) 381. - Afr. trop. or.

succosa. Baker, in fourn. Linn. Soc. xxii. (1887) 483. - Madag.

GARDNERIA, Wall. (Logan。). - Ind. Kew. i. 1000 .

multiflora, Makino, in Tokyo Bot. Mag.vi. (1892) 53. - Japon.

GARNOTIA, Brongn. (Gramin.). - Ind. Kew, i. 1001.

\section{GARNOTIA}

Fergusonii, Trim. in fourn. Bot. xxvii. (1889) 170. - Zeyl.

panicoides, Trim.l.c. - Zeyl.

sandwicensis, Hillebr. Fl. Haw. Isl. (1888) 513. Ins. Sandvic

GARULEUM, Cass. (Compos,). - Ind. Kew, i. 1001 .

Schinzii, O. Hoffm. ex Schinz, in Bull. Herb. Boiss. i. (1893) 74. - Afr. austro-occ, extratrop. Woodii, Schinz;, l. c. iii. (1895) 440. - Natal.

GASTERIA, Duval (Liliac.). - Ind. Kew. i. 1001

radulosa, Baker, in fourn. Bot. xxvii. (1889) 43. $\mathrm{Hab}$ ?

transvaalensis, Baker, l. c. 44. - Transvaal.

GASTONIA, Comm. (Aral.). - Ind. Kew. i. 100\%. sechellarum, Harms, in Eng1. \& Prantl, Natürl. Pflanzenfam, iii. 8 (1894) $43=$ Polyscias Sechellarum, Baker.

simplicifolia, Zipp. ex Boerl. in Annal. Jard. Buit. vi. (1887) $125=$ Osmoxylon Miquelii, Boerl.

GASTROCHILUS, D. Don = Saccolabium, Blume (Orchid.)

acaulis, acuminatus, acutifolius, ampullaceus, bellinus. bifidus, bigibbus, brevifolius, cephalotes, chionanthus, clavatus, compressus, congestus, constrictus, curvifolius, distichus, fasciculatus, fliformis, flavus, flexuosus, fragrans, gemmatus, graculis, Helferi, inconspicurs, intermedius, ferdonianus, lanatus, longifolius, maculatus, miniatus, minimiflorus, nilagivicus, niveus, obliquus, obtusifolius, ochraceus, pachyglossus, papitlosus, Pechei, penangianus, perpusillus. Pumilio, pusillus, quinquefidus, retusus, roseus, rostellatus, tenuicaulis, viridiflorus, Kuntze, Rev. Gen. (1891) 661 = homonyma omnia Saccolabii.

adscendens, Kuntze. 1. c. = S. ascendens, Lindl.

aphyllus, Kuntze, 1.c. = Angraecum aphyllum Thou.

biglandulosus, Kuntze, 1. c. = S. distichum, Lindl.? bipunctatus, Kuntze, 1. $\mathrm{c}_{0}=\mathrm{S}$. bipunctatum, Par. \& Reichb. $f$

Blumei, Kuntze, 1. c. = Rhynchostylis retusa, Blume. coriaceus, Kuntze, 1. c. - Aërides coriaceum, Sw. Dasypogon, Kuntze, 1. c. = S. calceolare, Lindl. ? densiflorus, Kuntze, 1. c. = Cleisostoma spicatum. Lindl.

dentatus, Kuntze, 1. c, = S. acutifoliam, Lindl.

denticulatus, Kuntze, 1. c. = S. acutifolium, Lindl. giganteus, Kuntze, 1. c. = Vanda densiflora Lindl.

gorwaticus, Kuntze, 1. c. = Rhynchostylis retusa, Blume.

Griffthii, Kuntze, 1, c. = Microsaccus javensis Blume.

laxiflorus, Kuntze, 1. c. = S. lineare, Lindl.

micranthus, Kuntze, 1. c. = Omoea micrantha, Blume.

paniculatus, Kuntze, 1. c. = S. ramosum, Lindl.

paniculatus, Kuntze, 1. $c_{0}=$ S. lineare, Lindl.

parviflorus, Kuntze, 1. c. $=\mathrm{S}$. micranthum, Lindl paromlus, Kuntze, 1. 1. c. = S. buccosum, Reichb. $f$ praemorsus, Kuntze, 1. c. = Rhynchostylis retusa Blume.

racemiferus, Kuntze, 1. c. = Sarcanthus pallidus, Lindl.

ramosus, Kuntze, 1. c. = S. ramosum, Lindl.

reflexus, Kuntze, 1. c。= Renanthera elongata Lindl.

retusus, Kuntze, 1. c. = Rhynchostylis retusa Blume.

Rhecdei, Kuntze, 1, c. = Rh. retusa, Blume

ringens, Kuntze, 1. c. = Aërides radicosum A. Rich.

speciosus, Kuntze, 1. c. = Aërides maculosum, Lindl. spicatus, Kuntze, 1. c. = Rhynchostylis retusa。 Blume.

strichus, Kuntze, 1. c. = Angraecum striatum, Thon. trichromus, Kuntze, 1. C. = S. pallens, Cathcart. undulatus, Kuntze, 1. c. = Cleisostoma undulatum Reichb. $f$. 
GASTROCHILUS :-

violaceus, Kuntze, Rev. Gen. (1891) $661=$ Rhynchostylis violacea, Reichb. $f$.

Wightianus, Kuntze, 1. c. = Aërides radicosum, A. Rich,

GASTROGHILUS, Wall. (Scitam.). - Ind. Kew. i. 1002 .

albo-lutea, Baker, in Gard. Chron. (1894) ii. 34. Ins. Andam.

biloba, Ridl, in Trans. Linn. Soc. Ser. II. iii. (1893) 379. - Penins, Mal.

Curtisii, Hook. f. in Bot. Mag. (1894) t. 7363. Penins. Mal

minor, King, ex Baker, in Hook. f. Fl. Brit. Ind. vi. (1890) 21\%. - Perak.

rubro-lutea, Baker, l. . . 218. - Khasia

tiliaefolia, Baker, l. c. - Khasia.

tillandsioides, Baker, l. c. - Perak.

GAstrodia, R. Br. (Orchid.). - Ind. Kew。 i. 1002

exilis, Hook. f. Fl. Brit. Ind. vi. (1890) 123.Khasia.

Hectori, F. Buch. in Trans. N.Z. Inst. xix. 1886 (1887) 214 t. 15. - N. Zel.

minor, Petrie, l. c. xxv. 1892 (1893) 273 t. 20 ff. $5-7$. - N. Zel.

leucopetala, Colenso, l. c. xviii. 1885 (1886) 268. N. Zel.

sesamoides, Petrie, l. c. xxvi. 1893 (1894) 272. - N. Zel

shikokiana, Makino, in Tokyo Bot. Mag. vi. (1892) 48. - Japon.

GAUDICHAUDIA, H. B. \& K. (Malpigh.)。 - Ind. Kew, i. 1003 .

Palmeri, S. Wats. in Proc. Am. Acad. xxi. (1886) 421. - Mexic.

Uhdeana, Niedenzu, in Bot. Falirb. xiv. Beibl. n. 30 (1891) 3. - Mexic

GAUdINIA, Beauv. (Gramin.). - Ind. Kew. i. 1003

coarctata, Th. Dur. E Schinz, Consp. Fl. Afr.v. 1894 (1895) 845 (= Avena geminiflora, Kunth). Ins. Azor.

filiformis, Albert, in Magnier, Sorin. ft. select. vi (1887) 120. - Gall.

GAULTHERIA, Kalm, ex Linn. (Ericac.). - Ind, Kew. i. 1003 .

Blumii, F. Muell. in Trans. Roy. Soc. Vict. N. S. i. ii. (1889) 21 (= Diplycosia microphylla, Becc.). Malaya.

borneensis, Stapf, in Trans. Linn. Soc. Ser. II. iv. (1894) 190. - Borneo.

discolor, F. Muell. in Trans. Roy. Soc, Vict. N. S. i, ii. (1889) 21. - N. Guin.

divergens, Colenso, in Trans. N. Z. Inst. xx. 1887 (1888) 198 . - N Zel.

epiphyta, Colenso, l. c. xxii. 1889 (1890) 474. - N Zel.

florida, Plii. in Anal. Uuiv. Chil. 1xxxvii. (1894). 192. - Chili.

glabra, Kuntze, Rev. Gen. (1891) 388 sphalm. = scabra, Willd.

hidalgensis, Loesen. in Bull. Herb. Boiss, ii. (1894) 552. - Mexic

Jelskii, Zahlbr, in Diss. Cl. math.-phys. Acad. litt. Cracov. xxix. (1894) 229. - Peruv.

lanceolata, Phil. in Anal. Univ. Chil. lxxxvii. (1894) 193. - Chili.

mundula, F. Muell. in Trans, Roy. Soc, Vict. N.S. i. ii. (1889) 21. - N. Guin.

salicifolia, Phil. in Anal. Univ. Chil. 1xxxvii. (1894) 192. - Chili.

subcorymbosa, Colenso, in Trans. N. Z. Inst. xxii. 1889 (1890) 476. - N. Zel.

GAURA, Linn. (Onagrar.). - Ind. Kew。 i. 1004 Nealleyi, Coult. in Contrib. U. S. Nat. Herb. i (1890) 38; et ii. (1891)118. - Texas.

GAUTIERA, Rafin = Gaultheria, Kalm. (Ericac. $)$
GAUTIERA :-

procumbens, Torr. Fl. N: Y. (1843) 433 ; ex Dippel, Handb. Laubholzk. i. (1889) $350=$ Gaultheria procumbens, I,inn.

GAYA, H. B. \& K, (Malv。), - Ind. Kew, i. 1004 gracilipes, $K$. Schum。 in Mart. Fl. Bras. xii. III (1891) 348. - Bras

Guerkeana, K. Schum. l. c. 354. - Bras,

pilosa, K. Schum. l. c. 355 . - Bras.

GAYLUSSAGIA, H, B。 \& K. (Vaccin.)。 - Ind Kew。 i. 1005

hirtella, Klotzsch, ex Dippel. Handb. Laubholzk. i. (1889) 323 (= G. hivtella, Torr. \& Gray) = dumosa, Torr. \& Gray.

pruinosa, Loesen. in Flora, 1xxii. (1889) 77. — Bras.

GAYOPHYTUM, A. Juss. (Onagrar.). - Ind. Kew. i. 1005.

riospermum, Coville, in Contrib. U. S. Nat. Herb. iv. (1893) 103. - Calif.

lasiospermum, Greene, Pittonia, ii. (July 1891) 164 - Calif.

GAZANIA, Gaertn. (Compos.)。 - Ind. Kew. 1005

bracteata, N. E. Br. in Gard. Chron. (1894) I. 620 - Natal?

diffusa, Oliver, in H. Fohnst. The Kilim. Exped. (1886) 342, nomen; et in Trans. Linn. Soc. Ser. II ii. (1887) 340 t. 61. - Afr. trop.

Pechuelii, Kuntze, in Jahrb. Bot. Gart. Berl, iv. (1886) $267=$ Berkheyopsis Pechuelii, O. Hoffm

Schenkii, O. Hoffm. ex Schinz, in Bull. Herb. Boiss ii. (1894) 216. - Afr. austro-occ. extratrop.

Schinzii, O. Hoffm. l. . 215. - Afr. austro-occ extratrop.

GEIGERIA, Griessel. (Compos.). - Ind. Kew。 i 1006.

acicularis, O. Hoffm. in Bolet. Soc. Brot. x. (1892) 175 ; et in Bull. Herb. Boiss, i. (I893) 82 , Angola.

angolensis, O. Hoffm. $l l . c c .175$ et 85. - Angrola.

Luederitziana, O. Hoffm。 in Bull. Herb. Boiss, i. (1893) 81. - Afr. austro-occ. extratrop.

odontoptera, O. Hoffm. l. c. 85. - Afr. austro-occ. extratrop.

ornativa, O. Hoffm. in Engl, et Prantl, Natürl. Pfan zenfam. iv, 5 (1890) 208; et in Bull. Herb. Boiss. i. (1893) 82. - Afr. austro-occ, extratrop.

rigida, $0 . H o f f m . \quad$ l. o. 84. - A Afr, austro-occ extratrop.

Schinzii, O. Hoffm. l. c. 80. - Afr. austro-occ extratrop.

spinosa, O. Hoffm, in Bolet, Soc. Brot. x. (1892) 175 Angola.

vigintisquamea, O. Hoffm. in Bull. Herb. Boiss. i (1893) 83. - Afr. austro-occ. extratrop.

GEIJERA, Schott (Rutac.). - Ind. Kew. i. 1006. salicifolia, Tate, in Trans. \& Proc. Roy. Soc, S. Austral. xii.(1889) 74 , nomen = parviflora, $L$ indl

GEISSANTHUS, Hook. f. (Myrsin.). - Ind Kew. i. 1006

Bangii, Rusby, in Mem. Torrey Bot. Club, iv. (1893) 217. - Bolivia

boliviana, Britton, in Bull. 'Torrey Bot. Club, xx. (1893) 140. - Bolivia.

GEISSASPIS, Wight (Legumin.). - Ind. Kew。 i 1006

psittacorhyncha, Taub. in Engl. et Prantl, Natïl. Pflanzenfam. iii. 3 (1894) 321. - Afr, trop. occ.

GEISSOLEPIS, Robinson, in Proc. Am. Acad. xxvii. (1893) 17\%. COMPOSITAE. suaedaefolia, Robinson, l. c. - Mexic

GEISSOMERIA, Lindl. (Acanth.). - Ind. Kew. i. 1006.

mexicana, Lindau, in Bull. Herb. Boiss, iii. (1895) 369. - Mexic
GEISSORHIZA, Ker-Gaw1. (Irid.). - Ind. Kew, i. 1006.

Bellendeni, Macowan, in Fourn. Linn. Soc, xxy. (1890) 393 ; et Baker. Handb. Irid. (1892) 156, Afr. austr.

Bolusii, Baker, l. c. 158. - Afr. austr.

Dregei, Baker, l. . . - - Afr. austr.

geminata, E. Meyer, ex Baker, l.c. 159. - Afr, austr.

gracilis, Baker, l. c. 155. - Afr. austr.

graminifolia, Baker, l. c. - Afr. austr.

Pappei, Baker, l. c. 154. - Afr。 austr.

GEISSOSPERMUM, Allem. (Bignon.). - Ind. Kew. i. 1007

laeve, Baill. in Engl, \& Prantl, Natürl. Pflanzen fam.iv. 2(1895) $146(=$ G. lacve, Miers $)=G$ 。 Vellozii, Fr. Allem.

GELASINE, Herb. (Irid.). - Ind. Kew. i. $100 \%$ richantha, Baker, in Bot. Fakrb, viii. (1887) 215. Guatem.

GELONIUM. Gaertn. = Ratonia, DC. (Sapind,) arborea, Kuntze, Rev.Gen.(189l) 144 = Cupania laevis, Pers.

brevipes, Kuntze, 1. c. (= Molinaea brevipes, Radlk. $)$. - Madag.

cupaniodes, Kuntze, l. c. $=$ Cupania laevis, Pers,

macrantha, Kuntze, l. c (= Molinaea macranthe, Radlk.). - Ins, Maurit.

petiolaris, Kuntze, 1. c. (= Mol. petiolaris, Radlk.). - Madag.

retusa, Kuntze, I, c. (= Mol, retusa, Radlk.) Madag.

Tolambitu, Kuntze, 1. c。 = Cupania Tolambitou, Cambess.

GELONIUM, Roxb. (Euphorb.). - Ind. Kew. i. 1007.

bifarium, Wight, ex Hook. f. Fl. Brit. Ind. v. (1887) 459 in syn. = lanceolatum, Willd.

GELSEMIUM, Weinm. Phytant. iii. (1742) 13-15 t. 530 f. c.; ex Kuntze, Rev。 Gen. (1891) $479=$ Tecoma, Juss. (Bignon.)

amboinense, capense, dendrophilum, fulgens, fulvum, Gaudichaudi, grandiflorum, Hilli, hirtum, insigne, leptophyllum, Maximiliani, molle, radicans, stans, undulatum, valdivianum, viminale, Kuntze, 1. c. 478-80 = homonyma omnia Tecomatis.

alatum, Kuntze, 1. c. $479=\mathrm{T}$. Guarume, $D C$

azaleaeflorum, Kuntze, 1, c, $=$ T. rosaetolia, $H . B . \delta \cdot K$. cuspidatum, Kuntze, 1. $\mathrm{c}_{2}=$ Nyctocalos brunfelsiaeflorus, Teijsm. \& Binn.

jasminodes, Kuntze, l. c. $=$ T. jasminoides, Lindl. ochroxanthum, Kuntze, 1. c. $=$ T. australis, $R . B r$ Pandorea, Kuntze, 1. $c_{0}=$ T, australis, $R$. $B r$. rosifolizm, Kuntze, $1 . c_{0}=T$. rosaefolia, $H . B . \& K$ sambucifolium, Kuntze, 1. c. = T. stans, fuss.

GEMMiNGlA, Heist. ex Fabr, Enum. Pl. Helmst. (1759); ex Kuntze, Rev。 Gen. (1891) $701=$ Belamcanda, Adans. (Irid.)

chinersis, Kuntze, 1. c. = B. punctata, Moench.

GENIOSPORUM, Wall. (Labiat.). - Ind. Kew。 i. 1008.

afane, Guerke, in.Bot. Fahrb. xix. (1894) 19\%. - Afr. trop.

angolense, Briq. l.c. 164. - Angola.

coloratum, Kuntze, Rev. Gen. (1891) 517 = strobiliferum, Wall.

glabrum, Guerke, in Bot. Fahrb. xix. (1894) 196. Madag.

lasiostachyum, Briq. l. c. 164. - Angola.

membranaceum, Briq. in Bull, Horb. Boiss, ii. (1894) 122 - Madag.

rotundifolium, Briq. in Bot. Fakrb. xix. (1894) 26:3. - Angola.

scabridum, Briq. . . c. 165. - Afr. trop. occ

GENIOSTOMA, Forst. (Logan.)。 - Ind. Kew. i. 1008 .

arboretm, Kuntze, Rev. Gen.(189I) $425=$ rupestre, Forst. 
GENIPA, [Tourn.]. Linn. (Rubiac.). - Ind. Kew. i. 1008

echinocarpa, A. Gray, in Proc. Am. Acad. xxv. (1886) 380 (= Randia echinocarpa, DC.) - Mexic.

GENISTA, Linn. (Legumin。). - Ind. Kew. i. 1009.

abyssinica, Briq. Etud. Cytis. Alp. Marit. (1894) 120 = Argyrolobium abyssinicum, faub. \& Spach. acquinoctialis, Briq. 1.c. $121=$ Arg. acquinoctiale Welw.

affghanica, Briq. 1. c. $120=$ Arg. stenophyllum, Boiss.

africana, Briq. 1. c. $119=$ Arg. uniflorum, Hart. anab̄aptizata, Briq. 1. c, $121=$ Arg. virgatum. Baker.

Andreana, A. Puiss, in Rev. Hortic. 1viii. (1886) 372 ; et Rev. Hortic. Belge, xix (1893) 127 cum ic. = Cytisus scoparius, Link.

angulata, Taub. in Engl. \& Pranth, Naturl. Pflanzenfam. iii. 3 (1893) 234 = parviflora, Poir.

arabica, Briq. Etud. Cytis. Alp. Marit. (1894) 120; et 183 = Argyrolobium arabicum, faub. E. Spach. ascendens, Briq. Etud. Cytis. Alp. Marit. (1894) 120 = Argyrolobium ascendens, Walp.

Aucheri, Briq. 1. c. $121=$ Arg. prostratum, Boiss.

austriaca, Scheele in Flora, xxvi. (1843) 438, fide Briq. Etud. Cytis, Alp. Marit. (1894) 175 in syn. = Cytisus supinus, Limn, var

Bakeri, Briq. 1. c. $121=$ Argyrolobium ramosissimum, Baker.

Ballii, Briq. 1.c. $120=$ Arg. stipulaceum, Ball.

Bottae, Briq. 1. c. = Arg. Bottae, Faub. \& Spach. calycina, Briq. 1. c. = Arg. calycinum, faub. \&s Spach.

Charegia, Coss. ex Batt. in Batt. \& Trab. Fl, de 1'Algér. [Dicot.]. (1889) $201=$ ferox, Poir collma, Briq. Etud. Cytis. Alp. Marit. (1894) 119 = Argyrolobium collinum, Eckl. E Zeyh. connata, Briq. 1. $\mathrm{c}_{0}=$ Arg. connatum, Harv.

Cossoniana Batt. in Batt. \& Trab. Fl, de l'Algér. [Dicot.] (1889) 197. - Algeria.

crassifolia. Briq. Etud. Cytis. Alp. Marit. (1895) 119 - Argyrolobium crassifolium, Eckl. \& Zeyh.

crotalarioides, Briq. 1. c. $120=$ Arg. crotolarioides, 7aub. Es Spach.

demnatensis, Coss, ex Batt. \& Trab. Fl. de l'Algér. [Dicot] (1886) 201. nomen. - Marocco.

dorycnioides, Briq. Etud. Cytis. Alp. Marit. (1894) $120=$ Argyrolobium dorycnioides, Baker.

Eckloniana, Briq. 1. c. = Argyrolobium patens, Eckl. \& Z Zeyh.

alongata, Scheele, in Flora, xxvi, (1843) 438; Briq. 1. c. $168=$ Cytisus hirsutus, Linn.var

emirnensis, Briq. 1. c. $121=$ Argyrolobium emirnensis, Baker.

fliformis, Briq. 1. c, $120=$ Arg. filiforme, Eckl. of Zeyh.

facrida, Briq. 1, c. = Arg. flaccidum, 7aub. \& Spach.

formosa, Hort. ex Carr. in Rev. Hortic. (1890; 227 $=$ Cytisus racemosus, Carr

Harreyi, Briq. Etud. Cytis. Alp. Marit. (1893) 119 $=$ Argyrolobium pilosum, Harw.

Hillebrandit. Christ, in Bot. Jahrb. ix. (1888) $121=$ Cytisus Hillebrandtii, Briq.

Hillebrandtit, "Christ. "ex Briq. Etud. Cytis. Alp Marit. (1894) sphalm. = praec

incana, Briq. Etud. Cytis, Alp. Marit. (1894)119= Argyrolobium incanum, Eckl. \& $Z$ eyh.

involucrata, Briq. Etud. Cytis. Atp. Marit. (1894) $120=$ Arg. involucratum, Harr.

facquiniana, Scheele, in Flora, xxvi. (1843) 438 Rriq.1. c. $167=$ Cytisus hirsutus, Linn. var.

kabylica, Coss, ex Batt. in Bull. Soc. Bot. Fr. xxxvi. (1888) p. 225 in obs. = G. Vepres, Pomel.

Kotschyi, Briq. Etud. Cytis, Alp. Marit. (1894) 121 = Argyrolobium Kotschyi. Boiss.

Junaris, Briq. 1. c. $120=\mathrm{Arg}$. lanceolatum, Echl. E. Zeyh.

maroccana, Briq.1. c. = Arg. microphyllum, Ball. microsoma. Briq. 1. c。 = Arg. pumilum, Eckl. है Zeyh.

Milli, Heldr. ex Boiss. Fl. Cr. Suppl. (1ES8) 160.Graecia.

\section{GENISTA}

mingrelica. Alboff, Prodr. Fl. Colch.(1895) 52. Reg. Cauc.

moesiaca, Velen. in Sitz. Boehm. Ges. Wiss, 189 1893) $19=$ depressa, Bieb.

migricans, Scheele, ex Briq. Etud. Cytis. Alp. Marit. 1894) $19=$ Cytisus nigricans, Linn.

nyssana, Petrov. in Magnier, Scrin. $f$. select. viii. 1889) 54. - Serbia

obsoleta, Briq. Étud. Cytis. Alp. Marit. (1894) 119 = Argyrolobium obsoletum, Eckl. \& Zeyh.

onithopodioides, Briq. 1. c. $121=$ Arg. ornithopodioides, Faub. \& Spach

pauciflorum, Briq. 1. c. $119=$ Arg. petiolare, $W$ alp Petitiana, Briq. 1. c. = Arg. Petitianum. A. Rich polyphylla, Briq. 1. c. $119=$ Argyrolobium poly phyllum, Eckl. \& Zeyh.

polysperma, Briq. 1. c. 120 et $188=$ Arg. Andrewsianum, Stend.

pteroclada, Taub. in Engl. \& Prantl, Natürl. Pflanzenfam. iii. 3 (1893) $234=$ parviflora, Poir.

pubescens, Bourg. ex Perez Lara, Fl. Gadit. (1886-92 $489=$ hirsuta, Vahl

vamentacea, Briq. Etud. Cytis. Alp. Marit. (1894) $123=$ Petteria ramentacea, Presl.

vémota, Briq. 1. c. $120=$ Argyrolobium remotum Hockst.

rhodopea, Velen. in Sitzb. Boehm. Ges. Wiss. 1892 1893) 20. - Bulg

rosea, Briq. Etud. Cytis. Alp. Marit. (1S94) 121 et 187 = Argyrolobium roseum, fanb. \& Spach.

rumelica, Velen. in Sitz. Boehm. Ges. Wiss. 1890 (1890) II. 43. - Rumel.

salicifolia, Hort. ex Dippel, Handb. Laubholzk. iii (1893) $666=$ tinctoria, Linn.

Schimperiana, Briq. Etud. Cytis. Alp. Marit. (1894) $121=$ Argyrolobium Schimperianum, Hochst.

sessiliflora, Briq. 1. c. $119=$ Argyrolobium candi cans, Eckl. \& Zeyh.

stenocarpa, Janka, in Termész. Füzet. viij. (1884) $70 ;$ Briq. 1. c. $134=$ Cytisus tridentatus, Vukot.

stipulacea, Briq. 1. c. $119=$ Argyrolobium stipulaceum, Eckl. \& Zeyh.

supina, Scheele [in Flora, xxvi. (1843) 438;] ex Briq. 1. c. 179 in syn. = Cytisus supinus, Linn. var.

tenuis, Briq. 1. c. $120=$ Argyrolobium, tenue, Eckl. \& $Z$ eyh

Thunbergii, Briq. 1. c. $119=$ Arg. sericeum. Eckl. G Zeyh.

trigonelloides, Briq.1. c. 121 et $186=$ Arg. trigonelloides, Faub. E Spach.

uniflora, Briq. 1. c. 120 et $188=$ Arg. uniflorum, Faub. \& Spach.

velutina, Briq 1. c. $119=$ Arg. velutinum. Eckl. \& Zeyh.

Walpersiana, Briq. 1. c, $120=$ Arg. rupestre, $W$ alp. Weldeniana, Scheele [in Flora(1843) 438] ex Briq

1. c. (1894) $123=$ Petteria ramentacea, Presl. Zeyheri, Briq. 1. c. $120=$ Argyrolobium molle, Eckl. \& Zeyh.

GENOSIRIS, Labill. = Patersonia, R. Br. (Irid.) Drummondii, graminea, inaequalis. limbata, longiscapa. macrantha, Maxwellii, Kuntze, Rev, Gen. (1891) 701 = homonyma omnia Patersoniae.

babianodes, Kuntze, 1. c. = P. babianoides, Benth,

GENTIANA, Tourn, ex Linn. (Gentian.). - Ind. KCw. i. 1010.

ajanensis, Murb, in Act. Hort. Berg, ii. 3 (1892) 24. - Silesia.

alba, Freyn, in Oest. Bot. Zeitschr. xl. (1890) 124 = aquatica, Linn

albescens, Frans. ex Kusnezow, Etud. monog. Sousgenve Eugentiana (1894) 266. - China.

albida, Freyn, in Oest. Bot. Zeitschr. xlv. (1895) 468. - Europ

amevicana, Macmill. Metasp. Minnes. (1892) $421=$ crinita, Froel

anisodonta, Borb. in Oest. Bot. Zeitschr.xlv. (I885) 122. et in Termész. Füzet. $(1893)=$ obtusifolia, Willd.

antarctica, $T$. Kirk, in Trans. $\Lambda^{\top}$. Z. Inst. xxvii. 1894 (1895) 339. - N. Zel.

\section{GENTIANA}

antecedens, Wettst. in Oest. Bot. Zeitschr, xlii. (1892) $232=$ germanica, Willd.

antipoda, T. Kirk, in Trans. N. Z. Inst. xxii. 1890 (1891) 440 nomen; et xxvii. 1894 (1865) $340 .-$ N. Zel

araucana, Phil. in Anal. Univ. Chil.xc. (1895) 205. - Chili.

arrecta, Franch. ex Hemsl. in fourn. Linn. Soc. xxvi. (1890) 124. - Yunnan

baltica, Murb. in Act. Hort. Berg. ii. 3 (1892) 4. Eur.

bella Franch. ex Hemsl, in fourn. Linn. Soc, xxvi, (1890) 124. - Yunnan.

biflora, Regel, ex Kusnezow, in Act. Hort. Petrop. xiii. (1893) 62; et Etud. monog. Sous-genve Eugentiana 1894) 176. - As. centr

brevidens, Regel, in Act. Hort. Petrop. x. (1887) 376. - Reg. Himal.

bulgarica, Velen. in Sitz. Boehm. Ges. Wiss, (1886) 457; et F1. Bulg. (1891) 382. - Bulg.

californica, Kusnezow, in Act. Hort. Petrop. xiii, 1893) 69. - Calif

calycina, Wettst. in Oest. Bot. Zeitschr. xli. (1891) 567 = obtusifolia, Willd

carpatica, Wettst, in Oest. Bot. Zeitschr. xlii.(1392) 4 ; Kern. Sched. Fl. Austro-Hung. vi. (1893) 55. Austro-Hung.

castanetarum, Borb, in Oest. Bot. Zeitschr. xlii. (1892) 286, sphalm = castanetorum, Borb

caucasica, Simonk. Enum. Fl. Transsylv. (I886) $398=$ carpatica, Wettst

cephalantha, Franch. ex Hemsl. in fourn. Linn. Soc. xxvi. (1890) 125. - Yunnan.

chalybaea, G. Beck, in Annal. Naturhist. Hofmus. Wien, i1. (1887) 130 t. 5 fig. 1 = verna, Linn.

chinensis, Kusnezow, in Bull. Acad. sci. St. Pétersb. xxxv. (1894) 250 ; et Etud, monog. Sous-genve Eugentiana, (1894) 133. - As. centr.

Clarkei, Kusnezow. Etud. monog. Sous-ganve Eugen. tiana (1894) $276(=$ G. pygmaea, C. B. Clarke). - Reg. Himal.

coriacea. St. Lager, in Cariot, Etud. des fl., éd. 8 . (1895) $586=$ acaulis, Linn.

corymbifera, T. Kirk, in Trans. N.Z. Inst, xxvii. 1894 (1895) 336. - N. Zel.

crassuloides, Bureau \&o Franch. in Morot, Fourn. de Bot.v. (1891) 104. - China.

crassuloides, Franch. in Bull. Soc. Philom. Paris, Ser. VIII. iii. (1891) 148 [an praec.] Tibet.

cynanchiflora, Franch. ex Hemsl. in fourn. Linn. Soc. xxvi. (I890) 126. - Yunnan.

dimarica, G. Beck, in Ann. Naturh. Hofmus, Wien. ii. (18S7) 128 t. 4 fig. $10=$ acaulis, Linn.

Ettingshauseni, F. Mucll. in Trans. Roy. Soc. Vict. N.S. I. ii. (1889) $2 \%$ - N. Guin.

Fatrae, Borb. in Oest. Bot. Zeitschr. xliii. (1893) $69=$ germanica, Willd.

Favrati, Rittener, ex Favrat, in Bull. trav. Soc. Murith. Fasc, xiii-xv. (1887) $62=$ verna, Limn. filicaulis, Hensl. in fourn. Limn. Soc. xxvi. (1890) 127. - China

foliiformis, Borb. in Termész. Füzet. xvi. (1893) $5 \mathrm{I}$ in ohs. = calycina, Boiss. \& Hauss

Franchetiana, Kusnezow, Etud. Monog. Sous-genve Eugentiana (1894) 243. - As. centr.

Freyniana, Bormm. ex Freyn, in Oest. Bot. Zeitsch, xlii. (1892) 345. - As. Min.

frondisefala, Borb. 1.c. $219=$ rhaetica, A. \& f.Kern.

gelida, Hort. ex Kew Bull. iii. (1859) $41=$ septemfida, Pall.

glomerata, Kusnezow, in Bull. Acad. sci. St. Pétersb. xxxiv. (1892) 507. - Turkest.

Grayi, Kusnezow, in Act. Hort. Petrop. xiii. (1893) 59. - Am. bor.

Grombczewskii, Kusnezon in Bull. Acad. sci. St Pétersb. xxxv. (1894) 349; et Etud. Monog. Sous genre Eugentiana (1894) 167. -- Turkest.

Grunnii, Kusnezow, in Act. Hort. Petrop, xiii. (1893) 63 ; et Etud. monog. Sous-genve Eugentiana 1894 246. - As. centr.

Haengsti, Hausm. ex Kew Bull. iii. (1889) $91=$ Kummeriana, Sendt.

Haynaldi, Kanitz, Pl. exped. Szechenyi in As centr. coll. (1891) $39=$ linoides, Franch. 


\section{GENTIANA}

Henryi, Hemsl. in foum. Limn. Soc. xxvi. (1890) 128. - China.

hexaphylla, Maxim. in Kusnerow, in Bu?l. Acad. sci. St. Pétersb. xxxr. (1894) 349; et Etud, monog. Sousgenve Eugentiana (1894) 126. - As centr.

Huxleyi, Kusnezow, in Act. Hort. Petrop. xiii. (1893) 64 ; et l. c. 280. - As. centr.

irrorota. Franch. ex Kusnezow, Etud. monog. Sous-genre Engentiana (1894) 102 in syn. = otophora, Franch.

fankae, Kanitz, Pl. exped. Szechenyi in As. centr. coll. (1891) $41=$ rhodantha, Franch

Jamesii, Hensl. in fourn. Linn. Sor. xxvi. (1890) 128. - China.

Kummeriana $\times$.Sendt. ex Le Jardin (1888) 76 ; et ex Nym. Consp. Fl. Eur, Suppl. ii. (1889) 218. - Eur.

lactea, Phil. in Anal. Univ. Chil. xc. (1895) 206. - Chili.

leucomelaena, Maxim, in Mél. biol. Acad. Imp. xiii. (1891) 175; et in Bull, Acad. sci. St. Pétersb, xxxiv. (1892) 505. - Mongol., Tibet.

lineata, T. Kivk, in Trans. N.Z. Inst. xxvii. 1894 (1895) 334 t. $27 .-\mathrm{N} . \mathrm{Zel}$.

linoides, Franch, ex Hemsl. in fourn, Limn. Soc. xxvi. (1890) 129. - Yunnan.

Lipskyi, Kusnezow, in Act. Hort. Petrop. xiii. (1894) 361. - Reg. Cauc

longepetiolata, Kusnezow, l. c. (1893)62: et Étud. monog. Sous-genre Eugentiana (1894) 137. - As. centr.

lutescens, Velen, in Sitz. Boehm. Ges, Wiss, (1888) sep. 89 ; et Fl. Bulg. (1891) 383. - Bulg.

lycopodioides, Stapf, iu Trans. Linn. Soc., Ser. II. iv. (1894) 208. - Borneo.

macrocalyx, Celak. in Sitz. Boehm. Ges. Wiss. (1890) $44 \%$; et ex Wettst. in Oest. Bot. Zeitschr. xlii. (1892) $157=$ germanica, Willd.

Makinoi, Kusnezow, in Act. Hort. Petrop. xiii. (1893) 60 ; et Etud. Monog. Sous-genve Eugentiana (1894) 89. - Japon.

Maximowiczii, Kanitz, P1. exped. Szechenyi in As. centr. coll. (1891) $39=$ aperta, Maxim.

Maximowiczi, Kusnezore, in Bull. Acad. sci. St.

Pétersb. xxxiv. (1892) 505 ; et Etud. Sous-genre Eugentiana (1894) 236. - China.

melandrifolia, Franch. ex Hemsl. in fourn. Linn. Soc. xxvi. (1890) 129. - Yunnan.

microdonta, Franch. ex Hemsl. l. c. 130. China.

microphyta, Franch. ex Hemsl. l. c. - Yunnan.

multibracteolata, Colenso, in Trans. N. Z. Inst. xxiv. 1891 (1892) 389. - N. Zel

neapolitana, Wettst. in Oest. Bot. Zeitschr. xlii. (1892) $44=\mathrm{G}$. Columnae, Ten.

nipponica, Maxim. in Bull. Acad. sci. St. Pétersb. xxxii. (1858) 507. - Japon.

norica, A. \& J. Kern. in Kern. Sched. Fl. AustroHung. vi. (1893) $56=$ germanica, Willd.

otophora, Franch. ex Hemsl, in Fourn. Linn. Soc, xxvi. (1890) 130. - Yunnan.

ovatiloba, Kusnezow, in Act. Hort. Petrop. xiii. (1893) 60. - Mexic

palustris, St. Lager, in Cariot, Étud. des fl. éd. 8 ii. (1889) $584=\mathrm{G}$. Pneumonanthe, Linn.

paradoxa, Alboff, in Bull. Herb. Boiss. iii. (1894) 230 ; et Prodr. Fl. Colch. (1895) 173. - Reg. Cauc.

picta, Franch. ex Hemsl. in fourn. Linn. Soc. xxvi. (1890) 131. - Yunnan.

pilosa, Wettst. in Oest. Bot. Zeitschr. xlii. (1892) $42=$ germanica, Willd .

praccox, A. \& J. Kern. ex A. Kern in Verh. zool.bot. Ges. Wien, xxxviii. Abh. (1888) 669 ; et Sched. Fl. Austro-Hung. vi. (1893) 61. Austria

praeflorens, Wettst, in Oest. Bot. Zeitschr. xlii. (1892) $234=$ germanica. Willd.

praematura, Borb, ex Oest. Bot. Zeitschr. xliv. (1894) 494 ad calc, = germanica, Willd.

Prattii, Kusnezow, in Act. Hort. Petrop. xiii. (1893) 63 ; et Etud. monog. Sous-genre Eugentiana (1894) 245. - As. centr.

pseudoaquatica, Kusnezow, $l l . c c .63$; et 246 . As. centr.

\section{GENTIANA :}

pseudogermanica, Gelmi, Prosp. Fl. Trentina (1893) = germanica, Willd

pterocalyx, Franch. ex Hemsl. in fourn, Linn. Soo xxvi. (1890) 132. - Yunnan.

puberuia, Franch.ex Hemsl. l.c.- - Yunnan

pulla. Franch. ex Hemsi. 1 c. $133=$ Franchetiana, Kusnezore.

purpurata, Maxim. ex Kusnerow, in Bull. Acad. sci. St, Pétersb. xxxiv. (1892) 506; et Etud. monog. Sous-genre Eugentiana (1894) 251. - As centr.

ramiflora, Szábó, in Oest. Bot. Zeitschr. xliv 1894) $474=$ asclepiadea, $L$ inz

Regeli, Krusnezow, in Bull. Acad. sci. St. Pétersb. xxxiv. (1892) 507; et Etud. monog. Sous-genve Eugentiana (1894) 156. - As. centr.

rhodantha, Franch, ex Hemsl. in fourn. Linn. Soc. xxvi. (1890) 133. - China.

rigescens, Franch, ex Hemsl. l. c. 134. - Yunnan.

Rockhillii, Hemsl. l. c. xxx. (1894) 137. - Sierra Leone.

rosularis, Franch, in Bull. Soc. Philom. Paris, Sér. VIII. iii. (1891) $148=\mathrm{G}$. Szechenyi Kanitz.

rubicunda, Franch. in Nouv. Archiv, Mus, Paris Sér. II, x。 (1888) 62. - China occ.

Rusbyi, Greene, ex Kusnezow, Étud, monog. Sous-genre Eugentiana (1894) 54.- N. Mexic

scaberrima. Kusnezow, in Act. Hort. Petrop. xiii (1893) 59. - Am. bor.

sikokiana, Maxim. in Bull. Acad. sci. St. Pétersb. xxxii. (1888) 508. - Japon.

siphonantha, Maxim.ex Kusnezow, l. c. xxxiv. (1892 506 ; et Étud. monog. Sous-genve Eugentiana (1894 171. - Mongol.

spathulifolia, Kusnezow, $l l . c c . x x x v .(1894) 351 .-$ China centr.

Spenceri, T. Kirk, in Trans. N. Z. Inst. xxvii 1894 (1895) 335. - N. Zel.

stellariaefolia, Franch. ex Hemsl. in Fourn. Linn Soc. xxvi. (1890) 135. - Yunnan.

stiviaca, Wettst. in Oest. Bot. Zeitschr, xlii. (1892) 1. $\mathrm{t} .3 \mathrm{fig}, 1$ = germanica, Willd

stecica. Murb. in Act. Hort. Berg. ii. 3 (1892) $10=$ campestris, Linn

superba, Greene, Pittonia, i. (Jan. 1888) 155. Mexic.

sutchuenensis, Franch. ex Hemsl. in fourn. Linn Soc. xxvi. (1890) 136. - China.

smphyandra, Murb. in Lunds Univ. Arsskrift xxvii, v. (1892) $89=$ Iutea, Linn

Széchenyii, Kanitz, $\mathrm{Pl}$. exped. Szechenyt in $A$ s. centr. coll. (1891) 40. - As. centr

tergestina. G. Beck, in Annal. Naturh. Hofmus. Wien, i1. (1887) 130; et F1. Nied.-Oest. ii.11. (1893) $239=$ verna, $\operatorname{Linn}$.

thermalis, Kuntze, Rev. Gen. (1891) 42\%. - Am. bor .

tetraphylla, Kusnezow, in Bull. Acad. sci. St. Pétersb xxxv. (1894) 350 ; et Etud. monog. Sous-genv Eugentiana (1894) 125. - China.

tortuosa, M. E. Fones, in Proc. Calif. Acad. Ser. II. v. (1895) 707 . - Utah.

trichotoma, Kusnezow, in Act. Hovt. Petrop. xiii. (1893) 61 ; et Etud. monog. Sous-genve Eugentiana (1894) 137. - As. centr

Uechtritzii, Wettst, in Oest. Bot. Zeitschr. xlii (1892) 69 = germanica, Willd.

valdiviana, Phil. in Anal. Univ. Chil. xc. (1895) 206. - Chili.

vandellioides, Hemsl. in fourn. Linn. Soc. xxvi. (1890) 137. - China.

venosa, Hemsl. l. c, t. 3. - China

Wettsteinii, Woloszczak, in Spraw. kom. fiz. xxviii (1892); ex Oest. Bot. Zeitschr. xliii. (1893) 108 $=$ carpatica, Wettst.

GEOBLASTA, Rodr. in Vellozia, ed. 2 (1891) 133 = Chloraea. Lindl. (Orchid.)

Teixeirana, Rodr. 1.c. = Chloraea Teixeirana, Cogn

GEODORUM, Jacks. (Orchid.). - Ind. Kew. i. 1016.

formosanum, Rolfe, ex Hemsl. in Ann. Bot. ix. (1895) 157. - Ins. Formosa.
GEOFFROYA, Murr. = Geoffraea, Linn. (Legumin.).

striata, Morong, in Ann. N. Y. Acad. Sci, vi (1892) $87=$ Geoffraea superba, Humb. \& Bonpl.

GEONOMA. Willd. (Palm.). - Ind. Kew. i. 1016 ecora, L. Lind. \& Rodigas, in Illustr. Hortic. xli (1894) 364 t. 23. - Bras.

Martiana. Hort ex Baill. Hist. des pl. xiii, (1895) 388 = Asterogyne sp

GEOPHILA, D. Don (Rubiac.). - Ind. Kew. i

Aschersoniana, Buettn, in Verh. Bot, Ver. Brand. xxxi. (1839) 74. - Congo.

herbacea, Kuntze, Rev. Gen. (1891) $300=$ reniformis, Cham. \& Schlecht.

herbacea, K. Schum. in Engl. \& Prantl, Natürl. Pflanzenfam. iv, 4 (1891) 119: Morong, in Ann. N. Y. Acad. Sci, vij. (1893) $129=$ praec ides, $K$. Schum, in Engl. Pfanzenw. Ost-Afr. C (1895) 392, - Afr. trop, or.

melanocarpa, Ridl. in Trans. Linn. Soc. Ser. II iii. (1893) 313. - Penins. Mal.

GEOSIRIS, Baill, in Bull. Soc. Linn. Paris, ii (1890) 1149 ; et Hist. des pl. xiii. (1895) 152. IRIDEAE

aphylla, Baill. l. c. - Madag.

GERANIOSPERMUM, Siegesb * = Pelargonium L'Hérit. (Geran.)

abrotanifolium, acetosum, aconitophyllum, alpinum, alternans, amatymbicum, anethifolium, angustifolium, anti-dysentericum, apiifolium, appendiculatum, artemisiaefolium, articulatum, asarifolium, astragalifolium, attenuatum, australe, betulinum, bicolor, bifolium, bubonifolium, caffrum, campestre, candicans, capillare, capitatum, carnosum, caucalifolium, ceratophyllum, chamaedrifolium, Chelidonium, clavatum, confusum, coronopifolium, crassicaule, crassipes, crinitum, crispum, crithmifolium, cucculatum, dasy caulon, delphinifolium, denticulatum, dipetalum, dis sectum, distans, divaricatum, echinatum, elegans, Endlicherianum, ensatum, exstipulatum, ferulaceum, fissifolium, flabellifolium, flavum, floribundum, fulgidum, gibbosum, glaucum, glutinosum, grandiflorum, Grenvilleae, heterophyllum, hispidum, Hystrix, incisum, incrassatum, inquinans, ionidiflorum, laevigatum, lateripes, lobatum, longifolium, Meyeri, minimum, moniliforme, multibracteatum, multicaule, multivadiatum, myrrhifolium, nervifolium, Nivenii, oblongatum, ochroleucum, odoratissimum, Oenotherae, ovale, oxal difolium, papilionaceum, patulum, peltatum, penniforme, pilosum, pinnatum, pulchellum, pulverulentum, punctatzm, quercifoliun, quinatum, quinquelobatum, quinquesulnerum, radicatum, Radula, ramosissimum, rapaceun, reflexum, reniforme. verolutrem, ribifolium, Rodncyanum, roseum, sanguineum, scabrum, scandens, schizopetalum, sericeum, setosum. sibthorpiaefolium spathulatum, spinosum, stipulaceum, ternatum, tetragonum, tomentosim, trifidum, trifoliatum, iriphyllum, triste, urbanum, craviegatum, velutinum, viscosissimum ritifolium, Zeyheri, zonale, Kuntze, Rev, Gen. (1891) $93-95$ = homonyma omnia Pelargonii.

adulterinum, Kuntze, 1. c. $94=$ P. adulterinum L'Hérit.

alchemillodes, Kuntze, 1. c. = P. alchemilloides, L'Hirit.

althaeodes, Kuntze, 1. c. = P. althaeoides, L'Hérit angulosum, Kuntze, 1. c. = P. acerifolium, L'Hérit. athantanthodes, Kuntze, 1. C. = P. athamanthoides, L'Hérit.

cardiophyllum, Kuntze, 1. c. = P. setulosum, Turca carinatum, Kuntze, 1. c, $=$ P. carinatum, Sweet. centaurodes, Kuntze, l. c. $=$ P. centauroides, L'Hérit.

cordifolium, Kuntze, 1. c. $=$ P. cordatum, L'Hérit cortusifolizm, Kuntze. 1. c. = P. cortusaefolium L'Hérit.

dichondrifolium, Kuntze, 1. c. = P. dichondraefolium, $D C$.

elongatum, Kuntze, 1. c, = P. tabulare, L'Hérit. fragile, Kuntze, 1. c. = P. tripartitum, IVilld. fumariodes, Kuntze, 1. c. = P. fumarioides, L'Hirit. glechomodes, Kuntze, 1. c. = P.glechomoides, A.Rich. 
GERANIOSPERMUM :-

grossulariodes, Kuntze Rev, Gen. (1891) $95=$ Pelarconium australe, Willd.

heracleitorme, Kuntze, 1. ca $=$ P. heracleifolium Lodd.

hirsutun, Kuntze, 1.c. = P. atrum, L'Hérit hirtum, Kuntze, 1. c. = P. tenuifolium, L'Hérit. 7nymzifusunv Kuntze, 1. c. $94=\mathrm{P}$. parvulum, DC. jatropifolinm, Kuntze, 1, c. $95=\mathrm{P}$. jatrophaefolium, $D C$.

malvifolium, Kuntze, 1. C。= P. malvaefolium, facq. $f$.

multifidum, Kuntze, 1.c. = P. multifidum, Harv. mzunitum, Kuntze, 1, $c$ - P crithmifolium Sw. oxalodes, Kuntze, 1. $\mathrm{c}=\mathrm{F}$. oxaloides, Willd pinnatifidum, Kuntze, 1. c. $94=$ P. carneum, facq proliferm, Kuntze. 1. c. = P. barbatum, facq. radulifolim, Kuntze, 1. co = P. radulaefolium Stend.

seneciodes, Kuntze, 1. c $=\mathrm{P}$. senecioides, L'Hérit tabulare, Kuntze, 1. c $=\mathrm{P}$, saniculaefolium Willd.

terebintacem, Kuntze, 1. c. = P. graveolens, I'Hinl.

tricolor, Kuntze, 1. c. $95=\mathrm{P}$. violareum, 7 acq. qioliflorum, Kuntze, 1. C. $=\mathrm{P}$. violaeflorum, $D C$.

GERANIUM, [Tourn.]. Linn. (Geran.). - Ind. Kew.i. $101 \%$

armenizm, Hort, ex Éd. André, in Rev. Hortic 1xiii. (1891) $350 \mathrm{cum}$ ic. = armenum, Boiss

Bangii, Hieron, in Bot. Fahrb. xxi. (1895) 314. Bolivia.

Delavayi, Franch.in Bull. Soc.Bot. Fr.xxxiil.(1886) 442. - China occ

decipiens $X$, Hausskn. in Mitth. Bot. Ver. Jena, N. Folge, v. (1893) 65. - Graecia.

ecuadoriense, Hicron. in Bot. Falwb. xx. Beibl. n. 49 (1895) 30 - Ecuad.

humile, Hillcbr. Fl. Haw. Isl. (1888) 56. - Ins. Sandvic.

hybridum X. Hausskn. in Mith. Bot. Ges. Jena, iii. 278. - Germ.

kilimandscharicum, Engl. in Abh. Preuss. Akad. Wiss. 1891 (1892) II. 274. - Afr, trop. or

melanandrum, Franch. Pl. Delav.(J889) 112. Yunnan.

moupinense, Franch. in Nouv. Arch. Mus. Paris, Sér. II. viii. 1885. (1886) 208. - Tibet.

nanum, Coss, ex Batt. et Trab. Fl. de l'Algér. [Dicot.] (1888) 119, nomen. - Marocco.

napuligerum, Franch, Pl. Delav. (1889) 115. Yunnan.

neapolitanum, Terrac. Prodr. FI. Lucan. i. (1893) $90=\mathrm{G}$. Robertianum, Linn.

niveum, S. Wats. in Proc. An. Acad. xxi. (1886) 421. - Mexic.

ocnense $\times$, Borbas, in Prog. Ober-Real Schule Innsbruck (1891) 53; et in Deutsche Bot. Monatsschr. xii. (1894) 93. - Tirol.

peruvianum, Hievon. in Bot. Fahw. xxi. (1895) 316. - Peruv.

platypetalum, Franch. Pl. Delav. (1889) 111. Xunnan.

pogonanthum, Franch.l.c.- Yunnan.

pulchrum, N.E.Br。in Kew Bull. (1895) 143.Natal.

renifolium, Hieron. in Bot. Fahrb. xxi. (1895) 315. - Peruv

Ruizii, Hievon. l. c. xx. Beibl. n. 49 (1895) $31 .-$ Peruv

sepalo-roseum, Rusby, in Mem. Torrey Bot. Club, iii, 3 (1893) 12. - Bolivia.

Sintenisii, Freyn, in Bull. Herb. Boiss. iii. (1895) 104. - Armen.

strigosum, Franch, in Bull. Soc. Bot. Fr. xxxiii. (1886) 442. - China occ.

Stuebelii, Hieron. in Bot. Fahrb. xxi. (1895) 316. Peruv.

tridens, Hillebr. Fl. Har\%. Isl. (1888) 55. - Ins. Sandvic.

umbelliforme, Franch. Pl. Delav. (1889) 115 t. 25. - Yunnan.

yunnanense, Franch. l. c. 114. - Yunnan.

Wislizen.. S. Wats. in Proc. Am. Acad. xxi. (1886) 421. - Mexic
GERARDIA, Linn. (Scrophul.). - Ind. Kew. i. I02\%.

Besseyana. Britton, in Mem. Torrey Bot. Club, v. (1894) 295. - Am. bor

paupercula, Britton, 1. c. = purpurea, Linn.

punctata, Robinson, in Proc. Am. Acad. xxvi. (1891) 172 ; et xxvii. (1893) 183. - Mexic.

virginica, Britton, Stern \& Pogg. Prelim. Catal, (1888) $40=$ quercifolia, Pursh

virginica. Kuntze, Rev. Gen. (1891) $460=$ praec.

GERARDIOPSIS, Eng1. Pflanzenw. Ost-Afr.C (1895) 359, SCROPHULARINEAE

Fischeri, Engl. l. c. - Afr. trop. or

GERBERA, Gronov. (Compos.). - Ind. Kew.i. 1923.

Delavayi, Franch. in Morot, Foum. de Bot.ii. (1888) 68. - China.

emirnensis, Baker, in foum. Linn. Soc. xxii. (1887) 498. - Madag.

Jamesoni. Bolus, ex Gard. Chron. (1889) r. 772 fig. 122 ; te ex Hook. f. in Bot. Mag. (1889) t. 7087. Transvaal.

nepalensis, O. Hoffm. in Engl. E Prantl, Natïrl. Pflanzenfam, iv. 5 (1893) $345=$ Clustanthium nepalense, Kuntze.

parva, N.E. Br. in Kew Bull. (1895) 27 ; Oliver, in Hook. Icon, pl, xxiv. (1895) t. 2379 - Afr. austr. raphanifolia, Franch. in Morot, Fourn. de Bot. ii. (1888) 67. - China.

ruficoma, Franch.l.c. 68. - China.

Tanantii, Franch. l... vii. (1893) 155. - China.

GERMAINIA, Balansa \& Poitrass, = Anthistiria, Linn. f. (Gramin.).

khasyana, Hack. in Oest. Bot. Zeitschr. xli. (1891) 50. - Reg. Himal.

GESNERA, Plum. ex Adans. = Gesneria, Linn sulcata, Rusby, in Mem. Torrey Bot. Club, iv (1895) 237. - Bolivia.

GESNERIA. Linn. (Gesner.). - Ind. Kew. i. 1024.

albiflora, Kuntze, Rev, Gen. (1891) $473=$ Penta rhaphia albiflora, Decne.

angustior, Kuntze, 1. C. = P. longiflora, Lindl.

auriculata, Kuntze, 1. c. = Rhytidophyllum auriculatum, Hook.

Berteroana, Kuntze, 1. c. = R. Berteroanum, Mart. calycosa, Kuntze, 1. C. = Pentarhaphia calycosa, Decne.

catalpiflora, Kuntze, 1. c. = P. catalpaeflora, Decne. cubensis, Kuntze, 1. c. = P. cubensis, Decne.

cumanensis, Kuntze, 1. C. = P. cumanensis, Hanst. cuncifolia, Fritsch, in Engl. \& Prantl, Natürl. Pflanzenfam.iv. 3b (1894) $184=\mathrm{P}$. cuneifolia, Moc. É Sessé.

fruticosa, Kuntze, Rev. Gen. (1891) $473=$ P. craniolaria, Decne.

Hahni, Hort. Paris, ex Baill, in Bull. Soc Linn. Paris, i. (1887) $719=$ Isoloma Hahnii, Hort. Paris. Herminieri, Kuntze, Rev. Gen. (1891) 473 = Pentarhaphia longiflora, Lindt

hispida, Kuntze, 1. c. = P. Sloanei, Hanst.

Lessertiana, Kuntze, 1. c. = P. catalpaeflora, Decne.

leucomalla, Kuntze, 1. c. = Rhytidophyllum leucomallon, Hanst.

Lindleyana, Kuntze, 1.c.= Pentarhaphia longiffora Lindl.

montana, Kuntze, 1. c. = P. longiflora, Lindl.

neglecta, Kuntze, 1. c. = P. neglecta, Hanst.

parviflora, Kuntze, 1. c, = P. catalpaeflora, Decne.

petiolaris, Kuntze, l. c. = Rhytidophyllum petiolare, $D C$.

Plumieriana, Kuntze, 1. c. $=\mathrm{R}$. Plumerianum, $D C$. tencra, Kuntze, 1. c, = Pentarhaphia tenera, Hanst. verrucosa, Kuntze, 1. c. = P. verrucosa, Decne.

viridiflora, Kuntze, 1, c. $=$ P. viridiflora, Hanst.

GETHYLLIS, Plum. ex Linn. (Amaryll.). - Ind. Kew. i. 1025.

fusiformis, Ham. ex Hook. f. Fl. Brit. Ind vi, (1892) 279 in syn. = orchioides, Gaertu.
GEUM, Linn. (Rosac.). - Ind. Kew. i. 1025.

albarracinense, Pau, Not, bot. Fl. Españ. i. (1887)

23. - Hisp.
alpinum, F. Buch. in Trans. N. Z. Inst. xix. 1886 (1887) 216 [alpina]. - N. Zel.

Billieti X. Gillot, in Rev. scient. Bourb. (1894); 136 . Bull. Soc. Bot. Fr. xlii. (1895) 521. - Gall, centr. hirtigenum $\mathrm{X}$, Borb. in Termész. Füzét, xiv. (1893) 48. - Bulg.

fankae $X, G$. Beck, in Verh. zool.-bot. Ges. Wien, xlv. (1895) 104. - Mont. Rhodop.

Kolbianum, Obrist \& Stein, ex Stein, in Gartenfl. (1886) 461 in syn. = rhaeticum, Bruegg.

latilobum, Sommier E Levier, in Act. Hort. Petrop. xiii. (1893) 44. - Reg. Cauc

leiospermum, Petrie, in Trans. N.Z. Inst. xxvi. 1893 (1894) 26\% - N. Zel.

macedonicum, Formanek, in Verh. naturf. Ver. Brünn, xxx. (1892) = nitidostylum, Formanek.

nitidostylum, Formanek, l.c. xxxiii. (1895) 53.Maced.

pratense $X$, Pau, Not. bot. F1. Espan. i. (1887) 22 ; et iii. 13. - Hisp.

speciosum, Alboff, in Bull. Herb. Boiss. i, (1893) 244 ; et Prodr. Fl. Colch. (1895) 80. - Reg. Cauc Sredinskianum, Krassnow, Enum. pl, now, Swanétic [Bull. Soc. Natur. Khark.] (1891) 21; Alboff, l. c. 245. - Reg. Cauc.

teszlense $X$. Simonk. Enum. F1. Transsilv, (1886) 215. - Transsilv.

Velenovskyi $\times$, Borb. in Termész. Füzét. xiv. (1893) 48. - Bulg.

waldsteinioides, Alboff, Prodr.Fl. Colch. (1895) 79 - Reg. Cauc.

GEUNSIA, Blume (Verben.). - Ind. Kew. i. 1026.

Beccariana, Briq. in Engl. of Prantl. Natürl. Pfanzenfam. iv. 3a (1894) 165. - Borneo.

GIFOLARIa, Pomel, in Bull. Soc. Bot. Fr, xxxy. (1888) $335=$ Filago, Linn. (Compos.)

floribunda, Kralik, ex Pomel, 1. c. xxxv. (1888) 335 - Tunet.

GIGALOBIUM, P. Br。 = Entada, Adans. (Legumin.).

scandens, Hitchcock, in Missouri Bot. Gard. Rep. iv. (1893) $82=\mathrm{E}$. scandens, Benth.

GILGIA, Pax, in Bot. Jahrb. xix. (1894) 80. EUPHORBIACEAE.

candida, Pax, l. c. (1894) 81. - Afr. trop. or.

GILIA, Ruiz et Pav, (Polem.).- Ind. Kew, i. $102 \%$ abrotanifolia, Nutt, ex Greene, in Erythea, iii. (1895) 104. - Calif.

ambigua, Rattan, in Conlt. Bot. Gaz. xi. (1886) 339. - Calif.

Chamissonis, Greene, in Erythea, iii. (1895) 105 (= G. achilleacfolia, A. Gray). - Calif.

copiapina, Phil. in Anal. Univ. Chil. xc. (1895) 213. - Chili.

gilioides, Greene, in Erythea, i. (1893) $93=$ Collo mia gilioides, Benth.

glabrata, Phil. in Anal. Univ. Chil. xc. (1895) 213. - Chili.

gloriosa, T. S. Brandeg. in Proc. Calif. Acad. Ser. II. ii. (1889) 184 t. 9. - Calif.

glutinosa, Phil. in Anal. Univ. Chil. xc. (1895) 212. - Chili.

gracilis, Phil. l. c. 214. - Chili.

Howardi, $M$. E. Fones, in Zoë, ii. (1891) 250.Utah.

involucrata, Plill. in Anal. Mus, nac. Chile (1891) 53. - Am. austr. occ.

Johowi, Fr. Meigen, in Bot. Fahrb. xvi. (1893) 291 - Chili.

lanigera, Phil. in Anal. Univ. Chil. xc. (1895) 215. - Chili.

laxa, Vasey \& N. E. Rose, in Proc. U. S. Nat. Mus. xi. (1886) 531. - Calif.

maculata, Farish, in Bull. Torrey Bot. Club, xix. (1892) 93. - Calif.

Mc Vickerae, M. E. Fones, in Proc. Calif. Acad. Ser II. v. (1895) 712. - Utah. 
GILIA

mellita, Greene, Pittonia, i. (July 1887) 71. - Calif. modesta, Phil. in Anal. Univ. Chil. xc. (1895) 212. - Chili.

Nevini, A. Gray, ex Lyon, in Conlt, Bot. Gaz, xi. (1886) 335 , nomen. - Ins. Cata1.

nudicaulis, Phil. in Anal. Univ. Chil. xc. (1895) 211. - Chili.

Palmeri. S. Wats. in Proc. Am. Acad. xxiv. (1889) 61. - Calif austr.

parvula, Greene, Pittonia, i. (July 1887) 72. Calif.

pentstemnnoides, M.E. Fones, in Zoē, iv. (1893) 279. - Colorado.

Pringlei, A. Gray, in Proc. Am. Acad. xxi. (1886) 401. - Mexic.

ramosissima, Phil, in Anal. Mus. nac. Chite (1891) 53. - Am. austro-occ

rubra, Heller, in Contrib. Herb. Frankl. and Marsh. Coll. [Bot. Expl. S. Texas] i. (1895) $81=$ coronopifolia, Pers

Sonorae, N.E. Rose, in Contrib. U. S. Nat. Herb. i. (1890) 90. - Calif, inf.

staminea, Greene, in Erythed, iii. (1895) 105. Calif.

superba, Eastwood. in Zoë, iv. (1893) 122, 296 t. 27 $=$ subnuda, Torr.

Triodon, Eastwood, l.c. 121. - Am. bor, occ

GILIBERTIA, Ruiz \& Pav. (Aral.). - Ind. Kew. i. 1028 .

arborea, E. March. ex Th. Dur. \& Pitt. in Bull. Acad. roy. Belg. xxx. 1891 (1892) 281. - Am. trop. japonica, Harms, in Engl. \& Prantl, Natür. Pflanzenfam. iii. 8 (1894) 41. - Japon.

parviflora, Harms, $l$. $c_{0}(=$ Dendropanax parriflorum, Benth.). - As. trop. et subtrop.

protea, Harms, l. c. (= Dendropanax proteum, Benth.). - China.

GILLENIA, Moench (Rosac.), - Ind, Kew. i. 1028.

stipulata, Trelease, ex Branner \& Coville, in Ann. Rep. Geol. Surv. Arkans, iv. 1888 (1891) $179=$ stipulacea, Nutt.

GILLIESIA, Lind1. (Liliac.), - Ind. Kew, i. monophylla, Reiche, in Bot. Fahrb. xvi. (1893) 276.

GINALLOA, Korth. (Loranth.). - Ind. Kew, i. 1028 .

Beccariana, Van Tiegh. in Bull. Soc. Bot. Fr. xlii. (1895) 647. - Bormeo.

tenuifolia, Van Tiegh. l. c. - Borneo.

Zullingeri, Van Tiegh.l. c. - Borneo.

GINURA, Vidal, Rev. Pl. Vasc. Filip. (1886) 163, sphalm. = Gynura, Cass. (Compos.).

GIRARDINIA, Gaudich. (Urtic.). - Ind. Kew. i. 1029.

vitifolia, Franch. in Nouv. Arch. Mus. Paris, Ser. II. x. $(\mathbf{1 8 8 7 - 8 )} 80$. - Tibet.

GITHAGO, Adanson = Lychnis, Linn. (Caryophyll.).

gracilis, Haussk, in Mitth. Thur. Bot. Ver. N. Folge, v. (1893) $47=$ Agrost. gracilis, Boiss.

GIVOTIA, Griff. (Euphorbiac.). - Ind. Kew. i.
1029 . madagascariensis; Baill. in Bull. Soc. Linn. Paris, i. (1889) 810. - Madag.

GLADIOLUS, [Tourn.] Linn. (Irid.). - Ind. Kew. i. 1029 .

Adlami, Baker, in Gard. Chron. (1889) i. 233; et Handb. Irid. (1892) 219. - Transvaal.

antholyzoides, Baker, in fourn. Bot. xxix. (1891) 70 ; et l. c. 227. - Transvaal

Bakeri, Klatt, in Th. Dur. \& Schinz, Consp. Fl. Afr. v. 1893 (1895) 213. - Afr. trop.

\section{GLADIOLUS}

Bolusii, Baker, Handb. Irid.(1892)208. - Afr.austr. brachyscyphus, Baker, l. c. 210. - Afr. austr. brevispathus, Klatt, in Th. Dur. E Schinz, Consp. Fl. Afr. v. 1893 (1895) 214. - Ancola.

Buchanani, Baker, Handb. Irid. (1892) 212. Zambesia

Buettneri. Pax, in Bot. Fahrb. xv, (1893) 155 Baker, Handb. Irid. (1822) 220. - Afr. trop. occ. caudatus, Baker, in Kew Bull. (1895) 74. - Afr. centr, or

Carsoni, Baker, l, c. - Afr. centr. or

Elliotii, Baker, in Fourn. Bot. xxix. (1891) 70; Handb. Irid. (1892) 215. - Transvaal

erectiflorus, Baker, in Kew Bull. (1895) 293. - Afr. centr. austr.

flexuosus, Bakcr, l. c. (1894) 390. - Afr. centr. or.

gracillimus, Baker, l. c. (1895) 74. - Afr. centr. or.

Grantii, Baker, Handb. Irid. (1892) 206. - Afr centr. or.

Hanningtoni, Baker, l. c. 212. - Afr. trop. or.

Hibbertii, Hort. ex Baker, 1. c. $217=$ blandus, Aiton.

hybridus X. Hort ex Illustr. Hortic, xxxvii. (1890) 107 t. 512. - Hybr. artef.

inandensis, Bakcr, Handb. Irid. (1892) 207. - Natal.

kilimandscharicus, Pax, ex Engl. in Abh. Preuss. Akad. Wiss, 1891 (1892) 175. - Afr. trop. or.

Kirkii, Baker, in Gard. Chron. (1890) ii. 524; Handb. Irid, (1892) 222, - Afr, austr

Leichtlini, Baker, 2l. cc. (1889) ii. 154 ; et 114.Transvaal.

Lemoinei X, Hort. ex Baker, Handb. Irid. (1892) 224. - Hybr. artef.

lucidor, Baker, l. c. $227 i=$ Homoglossum lncidor, Baker). - Afr, austr.

Macowani, Baker, l. c. 217. - Afr. austr

Massonii, Klatt, in Th. Dur. E Schinz, Consp. Fl Afr.v. 1893 (1895) 220. - Afr, austr.

micranthus, Baker, Handb. Irid. (1892) 212. - Afr. austr

micranthus, Stapf, in Denkschr. Akad. Wien, i.(1885) 82. - As. Min.

microphyllus, Baker, Handb. Irid. (1892) 206. Afr. austr.

manceianus X. Hort. ex Baker, 1. c. 229; et in Gard. Chron. (1893) I. 130 fig. 21. - Hybr. artef.

nervosus, Baker, l. c. 228 (= Antholyza nevvosa, Thunb.), - Afr. austr.

Niveni, Baker, l. c. 210.- - Afr, austr

Oatesii, Rolfe, in Oates, Matebeleland, ed. ii. (1889) 410; Baker, l. c 226. - Afr. austr.

oligophlebius, Baker, in Kew Bull. (1895) 73. - Afr. centr.-or.

oppositifolius, Hort. ex Gard, Chron. (1893) i. 291 fig. 4l, sphalm. = oppositiflorus, Herb.

paludosus, Baker, in fourn. Bot. xxix. (1891) 70 ; et Handb. Irid. (1892) 209. - Transvaal.

Pappei, Baker, l. .. 208. - Afr. austr

pauciflorus, Baker, ex Otiver, in H. Folnston, Th Kilim. Exped. Append. (1886) 346 nomen; et in Trans. Linn. Soc. Ser. II. ii. (1887) 350 ; et Handb. Irid. 206. - Afr. trop.

Paxii, Klatt, in Th. Dur, \&o Schinz, Consp. Fl. Afr. v. 1893 (1895) 224. - Angola.

platyphyllus, Baker, in Gard. Chron. (1893) ii. 456. - Afr. austr..

primulinus, Baker, l. c. (1890) ii. 122; et Handb. Ivid. (1892) 222. - Afr. trop, austro-or

pubescens, Pax, in Bot. Fahrb. xv. (1893) 154. Angola.

Rehmanni, Baker, Handb. Irid. (1892) 216 . Transvaal.

Rogersii, Baker, l.c 208. - Afr. austr.

salmoneus, Baker, l. c. 217.-Afr. austr.

scaphochlamys, Baker, l. c. - Afr, austr.

Scullyi, Baker, l.c. 224. - Afr. austro-occ. extratrop.

Sintenisii, Baker, l. c. 202. - Armenia turc

spathaceus, Pappe, ex Baker, l.c. 208. - Afr. austr.

spathulatus, Baker, l.c. 223. - Afr. austr.

splendidus, Rendle, in fourn. Linn. Soc. xxx. \{1895 406. - Afr. trop. or

sulphureus, Baker, ex Oliver in H. Fohnston, The

Kilim. Exped. Append. (1886) 346 nomen; et in Trans, Linn. Soc. Ser. II. ii. (1887) 350. - Afr. trop.

\section{GLADIOLUS :}

Taylorianus, Rendle, in foum. Linn. Soc. xxx. (1895) 405. - Afr trop, or.

Thomsoni, Baker, Handb. Irid. (1892) 223. - Afr. trop.

tritomoides, Baker, in Kew Bull. (1895) 74. - Afr. centr, -or.

turicensis X. Hort. ex Gard. Chron. (1880) ii. 183. - Hybr. artef.

Tysoni, Baker, Handb. Irid, (1892) 220. - Afr. rysin.

victorialis $X$. Sprenger, ex Gard. Chron. (189.3) 596 ; et ex Gartenfl. (1893) 730. - Hybr. artef. Woodii, Baker, Handb. Irid. (1892) 207. - Natal zambesiacus, Baker, l. c. 212. - Zambesia.

GLANDULIFOLIA, Wendl. = Adenandra Willd. (Rutac.)

amoena, biseviata, brachyplivlla, ciliata, coriacea, fragrans, gracilis, humilis, Krausii, lasiantha, macrado nia, marginata, obtusata, pubescens, rotundifolia serpyllucea, viscida, Kuntze, Rev. Gen. (1891) 100 = homonyma ommia Adenandrae.

mundtiaefolia, Kuntze, 1. c, = A. mundiaefolia, Eckl. \& Zeyh.

villosa. Kuntze, 1. c. = A. cusoidata, E. Mey.

GLASTARIA, Boiss.= Texiera, Jaub. \& Spach (Crucif.).

glastifolia, Kuntze, Rev. Gen. (1891) $30=$ T. glastifolia, faub. \& Spach.

GLAUGIUM, Tourn. ex Hall, (Papav.). - Ind Kew, i, 1032

acutidentatum. Hausskn. \& Bornm. ex Bornm. in Mitth. Bot.Ver. Feno, N. Folge. vi. (1894) 65. Oriens,

caricum, Stapf, in Denkschr. Akad. Wien (1886) 16 - As. Min.

pulchrum, Stapf, l. c. 27. - Persia

GLAUX, [Tourn.]. Linn. (Primu1.). - Ind. Kew. 1. 10.32 .

densiflora, Phil. in Anal. Mus, nac, Chile (1891) 51. - Am. austr. occ.

mucronata, Phil. l. c. 50. - Am. austro. occ

GLAZIOPHYTON, Franch. in Morot, Journ. de Bot. iii. (1889) 27\%. GRAMINEAE.

mirabile, Franch. l. c. - Bras.

GLAZIOVIA, Benth, \& Hook, f. = Glaziova Bureau (Bignon.)

bauhinioides, Bureau, ex Baill. Hist. des pl. x. (1888) 38. - Bras

GLECHOMA, Linn = Nepeta, Linn, (Labiat.) agrestis, andrica, annua, Apuleji, aristata, azurea. Balbisii, barbata, biloba, bombaiensis, brevifolia, cadmea, caesarea, calycina, campestris, camphorata, Cataria, cephalotes, chionophila, ciliaris, Clarkei. concolor, connata, crinita, crispa, cryptantha, curoidens, curviflora cyanea, daënensis, dasyanoula, densiflora, denutata, depauperata, discolor, distans, elliptica, erecta, eviostachys, foliosa, Fordii, glabrescens glomerata, glutinosa, Govaniana, gracilescens, gracili flora, granatensis, grandiflora, grata, heliotropifolica. hispanica, hymenodonta, isaurica, ispahanica, italica. japonica, juncea, kokamivica, kokanica. Kotschyi, lagopsis, lamiifolia, lamiopsis, laxiflora, leptantha leptoclada, leucolaena, leucophylla, leucostegia, linearis longibracteata, macrosiphon, mallophora, maracandia Mariae, marifolia, micrantha, mollis, multibracteata. mepalensis, Nepetella, nervosa, muda. Olgae, Orhchiana, oxyodonta, parnassica, Perretii, persica, petraea, podostachys, prostrata, pubescens, pungens. racemosa, vaphanorhiza, reticulata, rugosa, sacchu rata, salviaefolia, schirazana. Schtschurowskiana, scordotis, septemorenata, sessilifolia, Sewerzowir sibirica, Sibthorpii, spathulifera, speciosa, Sprwneri stenantira, subhastata, subincisa, subsessilis, supina stenuifolia teucriifolia terdea timolea. Trantuetteri

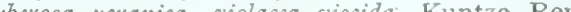
Gen. (1891) $518-19=$ homonyma ommia Nepetae. 


\section{GLECHOMA : -}

ballotifolia, Kuntze, Rev. Gen.(1891)518= Nepeta ballotaefolia, Hochst.

Eenthamii, Kuntze, 1. $c_{0}=\mathrm{N}$. gracilis, Salis',

betonicifolia, Kuntze, 1. $\mathrm{c}$. $=\mathbf{N}$. betonicaefolia, C. A. Mey.

bulgarica, Borb. in Termész. Fuzét. xiv. (1893) 51 $=$ N. Glechoma, Benth.

calaminthodes, Kuntze, Rev. Gen, (1891) j18 = N. ruderalis, Buch.-Ham.

Calvertii, Kuntze, 1. c, = N. Calverti, Boiss

canescens, Kuntze, 1. c. $=$ N. italica, Limn.

cilicia, Kuntze, 1. $\mathrm{c}=\mathrm{N}$. cilicica, Boiss

Ererardi, Kuntze, 1. c. = N. Everardi. S. Moore.

globulata, Hazsl. [Mag. Edeny nov. 238, sphalm]

ex Oest. Bot, Zeitschr, xxxix (IS89) $310=G$

lobulata, Kit. $)=$ N. Glechoma, Benth

hamilis, Kuntze, Rev Gen. (1891) $518=\mathrm{N}$. bracteata, Benth.

laevigata, Kuntze, 1. c. = N. spicata, Benth.

macrura Kuntze, 1. $\mathrm{c}=\mathrm{N}$ Cataria Limm.

marrubiodes, Kuntze, l. c, = N marrubioides, Boiss. \& Heldr.

melisszfolia, Kuntze, 1. c. $=$ N. melissaefolia, Lam.

multifida, Kuntze, 1 c. $=$ N. lavandulacea, Linn.

Mussinii, Kuntze. 1. c. = N. Mussini, Spreng.

pusilla, Kuntze 1. $\mathrm{c}_{0}=\mathrm{N}$. puncens. Benth.

pycnantha. Kuntze, 1. c. = N. cilicica, Boiss.

rotundifolia, Kuntze, 1. c. $=$ N. floccosa, Benth.

Ruprechtii, Kuntze, 1. c. = N. Ruprechti, Boiss.

scrbica, Halácsy \& Wettst. in Verh. zool.-bot. Ges.

Wien, xxxviti, Sitz. (1888) 71; et ex Bot. Centralbl, xxxy, $(1888,61=$ N. Glechoma, Benth

teucriodes, Kuntze, Rev. Gen. (1891) $518=$ N. lasciocephala, Benth.

Thomsonii, Kuntze, 1. c. = N. Thomsoni, Benth.

GLEDITSCHIA, Clayton, ex Linn. (Legumin.). - Ind. Kew. i. 1033

amorphoides, Taub. in Ber. deutsch. bot. Ges, x. 1892) 638. - Reg. Argent., Bolivia.

australis, Hemsl. ex Forb. E Hemsl, in foum. Linn. Soc.xxiii. (1887) 208 t. 5. - China.

cccinea, Hort. ex Koehne, Deutsche Dendrol. (1893) $320=$ japonica, Miq.

Delavayi, Franch. Pl. Delai. (1890) 189. Yunnan.

nuna. Hort. ex Dippel, Handb. Laubholzk, iii. (18:43) $658=$ sinensis, Lam.

officinalis, Hemsl. in Kew Bull. (1892) 82. - China.

pachycarpa, Balansa, ex Drake, in Morot, Fourn. de Bot.v. (1891) 217, nomen. - Tonk.

Rolfei, Vidal, Revis, Pl. Vasc, Filip. (18s6) 115. Ins. Philipp.

GLINUS, Linn. = Mollugo, Linn. (Ficoid.)

Bainesii, Pax, in Engl. \& Prantl, Natürl. Pflanzenfam. iii. lb (1889) 40. - Afr. centr.

Spergula, Pax, 1. c. $(=G$ Spergula, Steud. $)=\mathbf{M}$. oppositifolia, Lim

GLIRICIDIA, H. B. \& K. (Legumin.) - - Ind. Kew. i. 10:33.

guatemalensis, M. Micheli, in Bull. Herb. Boiss. ii. (1894) 442 t. 10. - Guatem

I.ambii, Fernald, in Coult. Bot, Gaz. xx. (1895) 533 - Mexic

GLOBBA, Linn.(Scitam.), - Ind. Kew. i. 10:33. alba, Ed. Morren, in Belg. Hort. xxxv. (1885) 286 t. $₹ 0=$ albobracteata, N. E. Br.

Andersoni, C. B. Clarke, ex Baker, in Hook. f. Fl. Brit. Ind. vi. (1890) 202. - Rer. Himal.

atrosangunea X. Hort. ex Rev. Hortic. lix. (1887) 346. - Hybr, artef.

brachycarpa, Baker, in Hook. f. Fl. Brit. Ind. vi. (18:0) 205. - Perak.

canarensis, Baker, .. c. 206. - Canara.

cernua, Baker, l. c. 205, - Penins. Mal.

Clarkei, Baker, l.c. 210. - Ind or

elongata. Baker, 1. c. 203, in syn. = uliginosa, Miq. Aloribunda, Bakcr, l. c. - Penins. Mal.

Hookeri, C. B. Clarke ex Baker, ì. c. 202. - Reg. Himal.

\section{GLOBBA}

Kingii, Bakev, in Hook. f. Fl. Brit. Ind, vi. (1890)

204 . - Penins. Mal.

pallidiflora, Baker, l,c - Penins, Mal

pauciftora, King, ex Baker, l, c. 205. - Ins, Andam. platystachya, Baker, l. c. 206. - Canara

pulchella, $K$. Schum. in $K$. Schum. \& Hollr. Fl. Kais. Wilh, Land (1889) 26. - N. Guin.

refractibulbigera, Kuntze, Rec'. Gen. (1891) 690.Burma.

siamensis, Hemsl, in Kerv Bull. (1895) 204. - Siam. Cambod.

stenothyrsa, Baker, in Hook. f. Fl. Brit. Ind. vi (1890) 204. - Tenass.

subscaposa, Collett of Hemsl. in foum. Linn. Soc. xxviii. (1890) 135. - Burma.

substrimosa, King, ex Baker in Hook, $f$ Fl Brit Ind. vi. (1890) 202. - Tenass

variabilis, Ridl, in Trans, Lim. Soc. Ser. II. ii (1893) 378. - Penins. Mal.

Wallichii, Baker, in Hook. f. Fl. Brit, Ind. vi. (1890) 203. - Penang.

GLOBIFERA, J. F. Gmel. = Micranthemum Michx (Scrophul.).

adenandra, Kuntze, Rev. Gen. (1891) 461 (= Homi anthus adenander, Wright).- - Cuba.

arenariodes. Kuntze, 1. c. $(=$ Amphiolanthus arenuroides, Griseb.). - Cuba.

bryodes, Kuntze, 1.c. $(=$ A.bryoides, Griseb. $)$ Cuba.

callitrichodes, Kuntze, 1. c. = M. callitrichoides, Wright.

ciliolata, Kuntze, 1. c, = M. riliolatum. Wright.

elatinodes, Kuntze, 1. c. = M. elatinoides, Wright. crosa, Kuntze, 1. c. (= Hemianthus multiflorus, Wright). - Cuba.

micranthemodes, Kuntze, 1. co = M. Nuttallii, $A$, Gray.

punctata, Kuntze, 1. c. $(=$ Hemianthus punctatus. Wright). - Cuba

reflexa, Kuntze, 1.c = M, reflexum, Wright.

rotundata, Kuntze, 1. c. = M. rodundatum, Griseb tetrandra, Kuntze, 1. c。= M. tetrandrum, Wright trisetosa, Kuntze, 1. c $1=$ Hemianthus trisetosus. Wright). - Cuba.

GLOBIMET ULA, Van Tiegh. in Bull. Soc. Bot. Fr. xlii. (1895) $264=$ Loranthus. Linn.

Branni, Van Tiegh. 1. c. $265=$ L. Braunii, Engl. cupulata. Van Tiegh. 1. c. $264=\mathrm{L}$. cupulatus, $D C$. Dinklagei, Van Tiegh. 1. c. $265=$ L. Dinklagei Engl.

oreophilus, Van Tiegh. 1, C. = I, oreophilus, Oliver. unguiformis, Van Tiegh. 1.c. = L. unguitormis, Engl.

Zenkeri, Van Tiegh. 1. c. = L. Zenkeri, Engl.

GLOBOCARPUS, Carnel, in Parl, FI, Ital, viii (1889) 239: et Epit. Fl. Ital: i1. (1894) $262=$ Oenanthe [Tourn.]. Linn. (Umbell.).

oenanthoides, Caruel, 11. =c。= O. slobulosa, Limn

GLOBULARIA. Tourn, ex Linn. (Selag ), - Ind. Kew.i. 1034

Cambessedii, Willk. Suppl. Prodr. Fl. Hisp. (1893) 140. - Hisp

fuxcensis X. Giraudias, in Bull. Soc. But. Rochel. xi. (1889)-90) 208. - Gall. Galissieri $\vee$ Giraudias, 1. c: - Gall.

Sintenisii, Hausskn. \& Wettst. ex Wettst. $2 n$ Bull. Herb. Boiss, iii. (1895) 274 t. 7 fig. 1-5. - Kurdist.

GLOCHIDION, Forst. (Euphorb.). - Ind. Kew .

\section{i. 1034}

anamiticum, Kuntze, Rev. Gen. (1891) 601. Anam,

assamicum, Hook.f. Fl. Brit. Ind.v. (18S7) 319.Reg. Himal.

brunneum, Hook. f. l. c.312. - Penins, Mal.

celastroides, Pax, in Engl. \& Prantl, Natür, Pfanzenfam. iii. 5 (1890) 24. - Java.

coronatum, Hook.f.Fl. Brit. Ind. v. (1887) 326. lnd or.

Curtisii, Hook. f. l. c. 327. - Penang.

\section{GLOCHIDION}

desmocarpum, Hook. f. Fl. Brit. Ind. v. (1887) 318. - Ind. or.

desmogvne, Hook.f.l.c.310, - Tenass.

Gamblei, Hook. f. l.c.-Reg. Himal.

goniocarpum, Hook.f. l. c. 309. - Penins. Mat.

Helferi, Hook. f.l. c. 311 . - Tenass.

Helferi, Pax, in Engl. \& Prantl, Natiirl. Pflanzentam, iii. $5(1890) 24=$ praec

insulare, Hook, f. Fl. Brt. Ind. v. (1887) 310. Penang.

Johnstonei, Hook. f.l.c.314.- - Ind. or khasicum, Hook. f. l, c. 324, - Reg. Himal laevigatum, Hook.f.l. c.319. - Ind. or. macrostigma, Hook.f. l. c. 313 . - Penang. microbotrys, Hook $f, l$ c 319 - Penins. Mal. mishmiënse, Hook, f. l. c. 327. - Reg. Himal. nanogynum, Houk. f.l.c. 318. - Ind. or: nubigenum, Hook. f. l. c. 315. - Reg. Himal. oblatum, Hook.f.l.c. 312. - Reg. Himal.

perakense, Hook.f.l.c.317. - Perak.

Ralphii, Hook.f.l.c. 314. - Ind or

sclerophyllum, Hook. f l. c. 313. - Penins. Mal.

sericeum, Hook. f. l. c. 326. - Penins. Mal.

sericeum, Pax, in Engl. \& Prant, Natürl. Pflanzenfam. iii. $5(\mathbf{1 8 9 0}) 24=$ praec

Talboti, Hook. f. Fl. Brit. Ind. v. (188\%) $310=$ tomentosum. Dalz.

tenuistylum, Stapf. in Trans. Linn. Soc., Ser. II, iv. (1894) 223. - Borneo.

Thomsoni, Hook. f. Fl. Brit. Ind. v. (1887) 318. Reg. Himal.

villicaule, Hook. f. l. c. 3\&6. - Ind. or., Yunnan.

GLORIOSA, Linn. (Liliac.). - Ind. Kew. i. 1035. speciosa, Engl. in Abh. Preuss. Akad. Wiss. 1891 ii. (1892) 158 (= Clinostylis speciosa, Hochst.) = abyssinica, $A$. Rich.

GLOssideA, Van Tiegh. in Bull. Soc. Bot. Fr. xlii. (1895) $349=$ Loranthus, Linn

biternata, Van Tiegh. 1. c. $350=$ L. biternatus, Hoffmannssegg.

glaucocoma, Van Tiegh. 1. c. = Psittacanthus glaucocoma, Eichl.

grandifolia, Van Tiegh. 1. c. $=$ P. grandifolius, Mart.

peronopetalus, Van Tiegh. I. c. = P. peronopetalus, Eichl.

GLOSSOGARYA, Wa ${ }^{1}$ l。 (Verben.). - Ind, Kew. i. 1035 .

scandens, Trim. Syst. Catal. Ceyl. Pl. (1885) 69; Handb. Fl. Ceyl. i1i. (1895) 324; ct Illustr. (1895) t. 73. - Zeyl

GLOSSOGYNE, Cass, (Compos,)..-Ind. Kew. i. 103.5

orthochaeta, F. Muell. in Vict. Natural. viii. (Nov. 1891) 110; et ex Bot. Centralbl. xlix. (1891) 363. Austral.

GLosSONEMA, Decne (Asclep.). - Ind. Kew. i. 1036.

affine, $\Lambda^{\top}$. E. Br. in Kew Bull, (1895) 249. - Abyss. edule, N.E. Br. l. c. 183. - Arabia.

Elliotii, Schlechter, in Fourn. Bot. xxxiii. (1895) 304. - Afr. trop. or.

Thruppii, Olizer, in F. L. Fames, Unkn. Horn of Afr. Append. (1888) 320. - Reg. Somal.

GLOSSOPETALON, A. Gray (Celastr.) - Ind Kew, i. 1030

meionandrum, Koehne, in Gartenf. xliii. (1894) 237 fig. 52. - Colorado.

GLOSSORHYNCHA, Ridl, in Journ. Linn. Soc. xxviii. (1891) 341. ORCHIDEAE

amboinensis, Ridl.l.c. 342 t. 44. - Amboina.

GLOSSOSTELMA. Schlechter, in Journ. Bot. xxxiii. (1895) 321. ASCI-EPIADEAE.

angolense, Schlchter, l. c. 322 t. 352b. - Angola.

GLOSSOSTIGMA. Wight et Arn.(Scrophul.).Ind. Kew. i. 1036 . 


\section{GLOSSOSTIGMA}

diandrum, Kuntze, Rev.Gen. (1891) $461=$ spathulatum, Wight \& Arn.

submersum, Petrie, in Trans. N. Z. Inst, xxiii. 1890 (1891) 401. - N. Zel.

trichodes, F. Muell. in Vict. Natural.ix. (Dec, 1892 ) 128 ; et in Bot. Centralbl. liii. 125. - Austral.

GLUTA, Linn. (Anacard.). - Ind. Kew, i. 1038. Harmandiana, Pierre, ex Laness, Pl. util. Colon. Franc. (1886) 307, nomen. - Cochinch.

GLYCERIA, R. Br. (Gramin.).- Ind. Kew, i $103 \%$

altissima, Garcke, Deutschl. F1. ed. 16 (1830) 500 in syn, = aquatica, Wahlenb.

anoustata, Vasey, in Bubl. Torrey Bot. Club, xv. (isss) 48 (= Atropis angustata Griseb.). - Oreson. festucaeformis, Degen, ex Sommier, in Bull. Soc. Bot. Ital. Ser. II. ii. (1895) $51(=$ G. festucaeformis Heynh.) = distans, Wahlenb.

grandis, S. Wats, in A. Gray, Man. N. U. St. A. Bot. ed. 6 (1890) 667; et in Proc. Am. Acad. xxv. (1890) $140=$ aquatica, IV ahlenb.

laxa, Scribn. ex L. Rand \& F. H. Redficld, Prel. Cat. pl. Mount Desert (1890) 180. - Am. bor.

pumila, Macoun, ex Vasey, in Bull. Torrey Bot. Club $\mathrm{xy}$ (1888) 4S, nomen. - Ins. Vanconv.

retinosa, Velen. ex Nym. Consp. Fl. Eur. Suppl. (1889) 359 = arundinacea, $M$. Bicb.

GLYCINE, Linn. (Legumin.).-Ind, Kew. i. 1037 maranguensis, Taub. in Engl. Pfanzenw. Ost-Afr. C (1895) 220, - Afr, trop. or.

pseudojavanica, Taub. l. c. - Afr. trop. or.

repens, Taub.l.c. - Afr. trop. or.

GLYCINOPSIS, Kuntze, Rev. Gen.(1891) $190=$ Periandra, Mart. (Legumin.)

acutifolia, Berteroana, coccinea, densiffora, heteropliylli, Kuntze, $1 . \mathrm{c}$. = homonyma ommia Periandrae.

mediterramea, Kuntze, $1 . \mathrm{c},=\mathrm{P}$. dulcis, Mart.

GLYCOSMIS, Correa (Rutac.). - Ind. Kew. i. 1039

montana, Pierre, Fl. For. Cockinch. Fasc. 17 (1892) t. 285b. - Corhinch.

GLYCYRRHIZA, Tourn. ex Linn.(Legumin.), - Ind. Kew. j 1039.

inflata, Batalin, in Act. Hort. Petrop.xi. (1891) 484 - China.

GLYPHAEA, Hook. f. (Tiliac.). - Ind. Kew. i. 1039

Boivini, Baill. in Bull. Soc. Limn. Paris, i. (1856) 550. - Madag.

chalybaea, Baill. l. c. - Madag.

GLYPTOPETALUM, Thw. (Celastr.). - Ind. Kew. i. 1039

calocarpum, Prain, in fourn. As. Soc. Beng. 1x. (1891) II. 209. - As. trop

Griffithii, Prain, l. c. - Ind. or

GLYPTOSTROBUS, Endl. = Taxodium, Rich (Conif.).

columnaris, Carrière, in Rev. Hort. (1881) $528=$ T. distichum, Rich.

GMELINA, Linn.(Verben.). - - Ind. Kew. i. 1039 hainanensis, Oliver, in Hook. Icon. Pl. xix. (1889) sub t. $18 \% 4$. - Hainan.

uniflora; Stapf, in Hook. l. c. xxiv. (1895) t. 2391: Borneo.

GNAPHALIUM, Linn. (Compos.), - Ind. Kew i. 1040 .

acutifolium, Phit. in Anal. Univ. Chil. xc. (1895) 12. - Chili.

agreste, Pliil. l.c. 22. - Chili.

americanum, Greene, Man. Bot. San Franc. Bay $(1894>185)=$ Anaphalis margaritacea, $R . B r$.

Andersoni, Franch. in Bull. Soc. Bot. Fr. xxxix. (1892) $132=$ Leontopodium Andersoni, C. B Clarke.

\section{GNAPHALIUM :}

ndicola, Phil. in Anal. Univ.Chil. xc. (1895) 17 - Chili

andinum. Phil. l, c, 24, - Chili.

antennarioides, Franch, in Bull. Soc. Bot. Fr, xxxix. (1892) 135. - Am, mer

argyrolepis, Phil. in Anal. Mus. nac. Chite (1891) 46. - Chile.

bellidifolium, Phil. in Anal. Univ. Chil. xc. (1895)

19. - Chili

bicolor, Bioletti, in Erythea, i. (1S93) 16. - Calif. canum, Phil, in Anal, Univ, Chil, xc, (1895) 11. - Chili.

columbianum, Hieron. in Bot. Fallrb. xix. (1894) 52. - Columb

corymbosum, Burean et Franch. in Morot, Fourn. de Bot. v. (1891) 71. - China.

Dedekcnsii, Burcau ct Fraszch I c 70 - China.

depilatum, Phil. in Anal. Univ. Chil. xc. (1895) 10. - Chili.

diffusum, Baker, in fourn. Linn. Soc. xxii. (188\%) 490. - Madac

cuadoriense, Hieron, in Bot, fahrb. xxi. (1895) 347. - Ecuad.

fastigiatum, Phil. in Anal. Univ. Chil. 1xxxviii 1894) 15. - Chili.

Griffithi, Kuntze, Rev. Gen. (1891) $339=$ Anaphalis Griffithii, Hook

Helleri, Britton, in Bull. Torrey Bot.Chb, xx. (1893) 280 - Am. bor. or.

heterophyllum, Phil. in Anal. Univ. Chil. xc. 1895) 14. - Chili.

imbaburense, Hieron, in Bot. Fahrb. xxi. (1895) 347 - Ecuad.

Julieti, Phil. in Anal. Univ. Chil. xc. (1895) 23. - Chili.

lanceolatum, Hort. ex S. Mottet in Rev. Hortic 1894) 459 in obs. = Helichrysum rupestre DC

Liebmannii, Sch, Bip, ex Klatt, in Leopoldina, Heft. xxiii. (1887) 89. - Mexic.

linearifolium, Franch, in Bull. Soc. Bot. Fr, xxxix. (1892) $135=$ Leontopodium linearifolium, Benth Hook. $f$.

longifolium, Phil. in Anal. Univ. Chil. xc. (1895) 13. - Chili.

maximum Kuntze, Rev, Gen. (1891) 340.- Java.

minutula, Colenso, in Trans. N. Z. Inst. xxii. 1889 (1890) 472. - N. Zel.

Moelleri, Phil. in Anal. Univ, Chit, xc. (1895) 11 - Chili.

mucronatum, Phil.l. c. 50 . - Chili.

nivale, Phil. l.c. 21. - Chili.

nobile, Bureau et Franch. in Morot, Fourn. de Bot. v 1891) 70. - China occ

obconicum, Kuntze, Rev. Gen. (1891) $340=$ Heli chrysum obconicum, $D C$

obscurum, Phit. in Anal. Univ. Chil. xc. (1895) 26. - Chili.

paludosum, Petrie, in Trans. N. Z. Inst. xxi1. 1889 (1890) $441 .-$ N. Zel.

Peteroanum, Phil. in Anal. Univ. Chil. xc. (1895) 21. - Chili.

Pichleri, Murb. in Lunds Unï. Arsskrift, xxvii. v. (1892) 106. - Herceg.

polybotryum, Phil. in Anal. Unir. Chil. xc. (1895) 24. - Chili.

Pringlei, A. Gray, in Proc. Am. Acad. xxi. (1886 38\%. - Mexic.

procumbens, Phil, in Anal. Univ, Chit, xc. (1895) 25. - Chili

pterigoideum, Klatt, in Bot. Fahrb. xii. Beibl. n. 27 (1890) 24. - Madag.

Remyanum, Phil. in Anal., Unic'. Chil.xc. (1895) 8. - Chili.

robustum, Phil. l. c. 16. - Chili.

Serranoi, Phil.l.c. 7.- Chili.

Sieboldianum, Franch, in Bull. Soc. Bot. Fr, xxxix. (1892) 133 = Leontopodium alpinum, Cass

sinense, Franch., 1. c. $133=\mathbf{L}$. sinense, Hemsl.

spathulatum, Phil. in Anal. Univ. Chil. xc. (1895) 20. - Chili.

Stracheyi, Franch, in Bull, Soc. Bot. Fr. xxxix. (1892) 133. - Himalaya, China.

subnudum, Phit. in Anal. Univ. Chit. xc. (1895) 15. - Chili.
GNAPHALIUN :

subulatum, Franch, in Bull. Soc, Bot. Fir. xxxix. 1892) 130. - China.

tarapacanum, Fhil. in. Anal. Mus, nac. Chile (I891) 46. - Chile.

thibeticum, Burean et Franch, in Morot, Fourn. de Bot.v. (1891) 72. - China.

tomentosum, Hort. ex S. Mottet, in Rev. Hortic (1894) 459, in obs. = Helichrysum rupestre, $D C$ Villarroeli, Phil. in Anal. Uniq. Chil.xc. (1895) 9. - Chili.

Weddellianum, Rusby, in Mem. Torrey Bot. Club, iii. 3 (1893) 57. - Bolivia.

GNAPHALODES, A. Grày (Compos,) - - Ind. Kew.i. 1046

amplibola, Greene, Man. Bot. San Franc, Bay (1S94) 183 = Micropus amphibolus, A. Gray. californica, Greene, 1. C. = M. californicus, Fisch. et Mey.

GNEMON, Rumpf, Herb. Amboin. (1741) 1181 t. 71,72; ex Kuntze. Rev. Gen. (1891) $796=$ Gnetum, Linn

amazonica, cuspidata, latifolia, leptostachya, microsta. chya, neglecti, nigra, nodiflora, paniculata, urens, venosa, Kuntze, Rev, Gen, (1891) $736=$ homo nyma omnia Gneti.

Brinoniana, Kuntze, 1. c. = Gnet. Gnemon, Linn cdulis, Kuntze, l. c. = Gnet. scandens, Rox.b. Griffitii, Kuntze, 1.c. = Gnet. Gnemon, Linn. indica, Kuntze, 1. c. = Gnet, funiculare, illume. Leyboldii, Kuntze, 1, c. = Gnet. Leyboldi, Tul. oralifolia, Kuntze, 1. c. = Gnet. Gnemon, Limn

GNETUM, Linn. (Gnet.), - Ind, Kew, i. 1040. ostatum, K. Schum, in K. Schum, et Holly. Fl. Kais. Wilh. Land (1889) 13. - N. Guin.

macrostachyum, Hook.f. Fl. Brit. Ind. v. (1888) 642. - Penins. Mal.

microcarpum, F. Muell. m Bot. Centralbl. 1. (1892) 195, nomen. - N. Guin.

ovalifolium, Karst, in Amal. Fard. Buit. xl, (1893) 215. - Ins. Ceram.

verrucosum, Karst. l. c. 216. - Archip. Mal.

GNIDIA, Linn. (Thymel.). - Ind. Kew, i, 1046. anthylloides, Gilg, in Bot. Jahrb, xix. (1894) 265 in obs. = Lasiosiphon anthylloides, Meissn

apiculata, Gilg, l. c. 263. - Afr. trop.

Bakeri, Gilo, in Engl, et Prantl, Natuirl. Pflanzenfam. ili, 6a (1894) 227 = Dais gnidioides, Baker.

Bojeriana, Baill. Hist. pl. Madag., Atlas (1895) t. 312. - Madag.

Buchananii, Gilg, iu Bot. Falro. xix. (1894) 261. Afr. trop, or

Burchellii, Gilg, in Encl. et Prantl, Natürl, Pflanzenfam. iii, 6a (1894) $229=$ Lasiosiphon Burchellii, Moissn.

calocephala Gilg, in Bot. Jahrb. xix. (1894) 265 in $\mathrm{obs}=$ Arthrosolen calocephalus, C.A.Mey chrysantha, Gilg, im. Bot. fahrb. xix. (1894) 258. Afr. centr. hor.

deserticola, Gilg, in Bot. Fahro, xix. (1894) 263.Afr. trop. or.

dichotoma. Gilg, in Engl. et Prantl, Natuirl. Pfan¿enfan. iii. 6a (1894) 229. - A fr. austr.

djurica, Gilg, in Bot. Fahro. xix. (1894) 268. - Afr. trop.

dschurica, Gilg, in Engl. \& Prantl, Natïrl. Pflanzenfam. iii. 6a (1894) $228=$ praec

Emini, Engl. \& Gilg, in Bot. Fahrb. xix. (1894)265. - Afr. trop.

fastigiata, Rendle, in Trans. Limm. Soc., Ser. II. iv (1894) 4l. - Afr. trop.

Fischeri, Engl. \& Gilg, in Bot. Fahrb. xix. (1S94) 266. - Afr. trop. or.

fava, Gilg, in Bot. Jahrb. xix. (1894) 258 in obs. et in Engl. \& Prantl, Natirirl. Pflanzenfam. iil 6a $(1894) 227=$ flava, Lindl.

genistifolía, Engl. \& Gilg, l, c. 26\%, - Angrola, glauca, Gilg, 1. c. 265, in obs = Lasiosiphon slaucus, Fresen

glancescens, Gilg, in Eng-1. Pflanzenw. Ost- Afr. C (1895) 283 = Arthrosolen glaucescens, Olis't 


\section{GNIDIA :}

gymostachya, Gilg, in Engl. \& Prantl, Natürl, Pflanzenfam. iii. 6a (1894) $228=$ Arthrosolen cymnostachys, C. A Mey.

Iildcbrandtii, Gilg, I. c. $=\mathrm{G}$. Hildebrantii, S. Elliot.

Hoepfneriana, Gilg, in Bot. Falnb. xix. (1894) 268. - Afr. austro-occ, extratrop.

Holstii, Engl. \& Gilg, in Bot. Fahrb. xix.(1894) 257: ct in Engl. \& Prantl, Natürl. Pfanzenfam. iii. 6a (1894) 226. - Afr. trop. or.

ignea. Gilg, in Bot. Fahrb. xix. (1894) 258. - Afr. trop. or.

katangensis, Gilg. Eo Dewerve, l. c. 2\%6; et in Bull. Soc. Bot. Belg. xxxiii. 2. 1894 (1895) 105. - Congo austro.or.

lamprantha, Gilg, l. c.264. - Afr.trop. or.

latifolra, Gilg, in Engl. Pflanzenw, Ost.-Afr. C (1895) $283=$ Arthrosolen latifolius, Oliver.

Iaxa, Gilg, in Engl. \& Prantl, Natuirl. Planzenfam. iii. 6a (1894) $226=$ Arthrosolen laxus, C. A. Mey.

leiantha, Gilg, in Bot. Fahrb. xix. (1894) 261.Afr. trop.

macrorhiza, Gilg, 1. c. 264.-Afr. trop. occ

madagascariensis, Baill. Hist. pl. Madag., Atlas (1895) t. 313. - Madag.

Mittuorum, Gilg, in Bot. Fahrb. xix. (1894) 260. Afr. trop.

Oliveriana, Engl. \& Gilg, l. c. 262, - Afr. trop. OCC.

Poggei, Gilg, l. c. 259. - Afr. trop. occ

polyantha, Gilg, l. c. 265. - Natal.

polycephala, Gilg, ex Engl. 1. c. 138 et 264, in obs. $=$ Arthrosolen polycephalus, C.A.Mey.

pubescens, Baill. Hist. pl. Madag., Atlas (1895) t. 314. - Madag.

Rehmannii, Szyszyl. ex Engl. in Abh. Preuss. Akad. Wiss. (1894) 16. - Afr, austr.

rubrocincta, Gilg, in Bot. Falirb. xix. (1894) 259. Afr, trop. occ.

Schweinfurthii, Gilg, 2. c. 261. - Afr. trop.

socotrana, Gilg, in Engl. \& Prantl, Natürl. Pflanzenfam. 1ii. 6a (18:4) 228; et in Engl. Pflanzenw . Ost -Afr. B (1895) $335=$ socotranum, Balf. $f$.

spicata, Gilg, 1. c. iii, 6a (1894) $228=$ Arthrosolen spicatus, C. A. Mey.

stenophylla, Gilg, in Bot. Fahyb. xix. (1894) 258. Afr. trop, or.

stenosiphon, Gilg, l. c. 258. - Afr. trop. bor.-or. Stuhlmanni, Gilg, l.c. 266. - Afr. trop. or,

usinjensis, Gilg, l. c. 269. - Afr. trop. or.

Vatkeana, Engl. \& Gilg, ex Gilg, $l$ c. 267. - Afr. trop.

GNIDIOPS1S, Van Tiegh. in Bull. Soc. Bot. Fr. xl. (1893) 75 = Gnidia, Linn. (Thymel.).

albicans, Burmanni, carinafa, coriacea, decurrens, hypericina, juniperifolia, linoides, microcephala, monticola, obtusissima, oppositifolia, parviftora, scabra, styphelioides, subulata. Van Tiegh. 1. c. 76-77= homonyma onnia Gnjdiae.

insularis, Van Tiegh. 1. c. $77=$ Lasiosiphon insulare, $\mathrm{Miq}$.

GOCHNATIA, H. B.\& K. (Compos.). - Ind. Kew. i. 1047.

australis, Phil, in Anal. Univ, Chil. 1xxxv. (1894) 834. - Chili.

Berteroana, Phil. l. c. 835. - Chili.

curviflora, O. Hoffm. in Engl \& Prantl, Natürl, Pflanzenfam.iv, 5 (189.3) 337 = Moquinia curviflora, Griseb.

cuspidata, Phil. in Anal. Univ. Chil. Ixxxv. (1894) 833. - Chili.

integerrima, Phil.l.c. - Chili.

laxiflora, Phil. l. c. 835 . - Chili

litoralis, Phil. l. c. 832 - Chili.

multiflora, F. Phil. ex Phil. l. c. 836. - Chili.

racemosa, Phil. l. c. 834 . - Chili.

tarapacana, Phil. in Anal. Mus, nac. Chile (1891) 34. - Chili.

GODETIA, Spach = Oenothera, Linn, (Onagrar.).

micropetala, Greene, Pittonia, i. (Feb, 1887) 32; t Man. Bot. San Franc. Bay (1894) 134. - Calif.
GODETIA : -

pulchirima, Greene, Pittonia, ii. (Sept. 1891) 217. - Calif.

GOEBELIA, Bunge = Sophora, Linn. (Legumin.).

reticulata, Freyn. \& Sint. in Oest. Bot. Zeitschr. xiliv. (1894) 66. - As. Min

GOETHEA, Nees (Malv.), - Ind. Kew. i. 1048. canliflora, Hort. ex Rev. Hortic. $(1890) 466=$ strictiflora. Hook.

GOETZEA, Wydl. (Solan.), - Ind. Kew.i. 1048. Eggersii, Urban, ex Radlk, in Sitz, math.-phys. Akad. Muench.xix. (1889) 281 in syn.= Coeloneurum Eggersii, Radlh.

GOLDBAGHIA, DC. (Crucif.). 一 Ind. Kew, i 1048 .

lancifolia, Franch in Bull. Soc. Bot. Fr. xxxiii. (1886) 408. - China.

GOLIONEMA, "S. Wats. » ex O. Hoffm. in Engl \& Prantl. Natuirl. Pflanzenfam. iv. 5 (1893) 389 - Oligonema. S. Wats. (Compos.).

beterophylla, "S. Wats. "1. c. $=$ O. heterophylla, S. Wats.

GOMIDESIA, Ber $\%$ = Myrcia. DC. (Myrt.)

Cerqueiria, Nicdenzu, in Engl. \& Prantl, Natirl. Pflanzenfam. iii. 7 (1893) $78(=$ Cerqueiria Sello wiana, Berg.). - Bras,

crocea, Niedenzu, 1. c. $77=$ Jacquiniana, Berg.

mitida, Niedenzu, 1. c. = Chamissoana, Berg.

GOMPHANDRA, Wall. (Olacin.),-Ind. Kew. i 1049 .

andamanica, King, m fourn. As. Soc, Beng. 1xiv. (1895) II. 115. - As, trop. ins.

comosa, King. l. c. 112. - Ins, Andam.

Cumingiana, Valeton, Crit. overz. Olacin. (1886) 229 [Cumingianus]. = Gomphandra Cumingiana Villar.

gracilis, King, in Foum. As. Soc. Beng. lxiv. (1895) II. 115 - Perak.

javaniá, Valeton. Crit. overz. Olacin. (1886) $217=$ Lasianthera javanica, Miq.

lanceolata, King, in fourn. As. Soc. Beng. 1xiv."(1895) II. 112. - Penins. Mal.

lysipetala, Stapf, in Trans. Linn. Soc, Ser, 1I, iv. (1894) 139. - Borneo.

Maingayi, King, in fourn. As. Soc. Beng. 1xiv. (I895) II. 114. - Penins. Mal.

mappioides. Valeton, Crit. overz. Olacin. (1886) 227. - Ins. Soemba (As. trop. or.)

nyssifolia, King, in foum. As. Soc. Beng. 1xiv (1895) 11. 114. - Penins. Mal

pavviflora, Valeton, Crit. overz, Olacin. (1886) 218 $=$ Lasianthera parviflora, Miq.

vitiensis, Valeton, l: c. 230 (= Stemonurus vitiensis, Seem.). - Ins.

GOMPHIA, Schreb.(Ochn.), - Ind. Kew. i. 1049, guatemalensis, Engl. ex T. Brigham. Guatcm. App. (1887) 426, nomen. - Guatem.

GOMPHILUMA, Baill. Hist. des pl, xi. (1892) 285 SAPOTACEAE

Martiana, Baill.l.c. (= Lucuma gompliaefolia, Mart. et Miq.). - Bras.

GOMPHOGALYX, Baker, in Journ, Linn. Soc. xxii. (1887) 485. RUTACEAE.

herniarioides, Baker, l. c. 486. - Madag

GONPHOCARPUS, R. Br. (Asclep.). - Ind Kew, i. 1050

acerateoides, Schlechter, in Bot. Fahrb. xviii. Beibl. n. 45 (1894) 16. - Afr. austr.

adscendens, Schlechter, l. c. - Afr. austr.

affinis, Schlechter, l. c. xx. Beibl. n. 51 (1895) 27. Afr. austr.

alatus, Schlechter, in Verh. Bot. Ver. Brand. xxxv. (1893) 51. - Afr. austr

\section{GOMPHOCARPUS}

amoenus, K. Schmm. in Bot. fahrb. xvii. (1893) 124 - Angola.

arenarius, Schlechter, in Verh. Bot. Ver. Brand, xxxv. (1893) 52. - Afr. austr.

asclepiaceus, Schlechter, in Bot. Fahrb, xviri. Beibl, n. 45 (1894) 7. - Afr. austr.

aureus, Schlechter, l. c. - Afr. austr.

auriculatus, K. Schum, in Encl. \& Prantl, Natürl. Pflanzenfam.iv, 2(1895) 2:36 (= Acerates auriculata, Eugelm.). - Am. bor.

bisacculatus Oliver, in H. Fohnston, The Kilim. Exped.App. (1896) 343, nomen; ct in Trans. Lim. Soc. Ser. 1I. 1i. (1887) 341. - Afr. austr.

brevipes, Schlechter, in Bot. Falvb. xx. Beibl. n. 51 (1895) 28. - Afr. austr.

concinmus, Schlechter, in fourn. Bot. xxxiii. (1895) 270. - Afr, austr.

cornutus, $K$. Scham, in Bot. Fahrb. xvii. (1893) 132. - Afr. trop.

cucullatus, Schlechter, in Bot. Fahrb. xviii. Beill. n. 45 (1894) 17. - Afr. austr.

cultriformis. Harv, ex Schlechter, 1. c. $31=$ Asclepias cultriformis, Schlechter.

dependens, $K$. Schum, in Bot. Fahrb. xvii. (189;) 125. - Angola.

depressus Schlechter, l. $c$, xx. Beibl. n. 51 (1895) 29. - Afr. austr.

fallax, Schlechter, l. c. - Afr. austr.

foliosus, K. Schum. l. c. xvii. (1893) 126. - Afr, trop.

fragrans, Schlechter, l. c. xx. Beibl. n. 51 (1895) 30. - Afr. austr.

Galpinii, Schlechter, l.c. xviii. Beibl. n. 45 (1S94 18. - Afr. austr

geminatus, Schlechter, l. c.8.-Afr. austr

geminiflorus, Schlecliter, l. c. xx. Beibl. n.51 (1895 31. - Afr austr.

glaucophyllus, Schlechter, l. c. xviii. Beibl, n. 45 (1894) 19. - Afr, austr.

grandiflorus, K. Schum, in Engl. \& Prantl. Natïrl. Pflanzenfam. iv, $2(\mathbf{1 8 9 5}) 237=$ grandiflorus, Decne.

Grantii, Schlechter, in Journ. Bot. xxxiii. (1895) 269 , in obs, = Schizoglossum Grantii, Oliver.

Harveyanus, Schlechter, 1 c. $270=$ Xysmalobium pedunculatum, Harv.

insignis, Schlechter, l. c. xx. Beibl. n. 51 (1895) 32 - Afr. austr.

involucratus, Schlechter, $l$. c. xviii. Beibl, n. 4.5 (1894) $8=$ Xysmalobium involucratum, Decne.

longifolius, K, Schum. in Engl. \& Prantl, Natürl. Pflanzenfam. iv. 2 (1895) $236=$ longifolius, Spreng.

longifulius, Schlechter, in Bot. Jahrb. xviii. Beibl. n. 45 (1894) $9=$ Xysmalobium, tromphocarpoides, Decne.

macropus, Schlechter, in foum. Bot. xxxi. (1894) 353. - Atr. austr.

meliodorus, Schlechter, in Bot. Falirb xx. Beibl. n. 51 (1895) 33. - Afr. austr.

Meyerianus, Schlechter, $l, c,-$ Afr. austr.

ochroleucus, Schlechter, l. c. xviii Beibl. n, 45 1894) 30. - Natal.

orbicularis, Schlechter, 1. c. xx. Beibl. n. 51 (1895)

$34=$ Xysmalobium orbiculare, E. Mey.

ovatus, Schlchter, l. c. xviii. Beibl, n. 45 (1894) 20. - Afr. austr.

pachyglossus, Schlechter, l. c. xx. Beibl. n. 51 (1895) 35. - Afr. austr.

pachystephanus, Schlechter, in Verh. Bot. Ver. Brand. xxxy, (1893) 52. - Afr. austr. extratrop. Palmeri, A. Gray, in Proc. Am. Acad.xxii. (1887) 436. - Mexic.

palustris, K. Schum. in Bot. Fahw. xvii. (1893) 127; et in Engl. Pflanzenw. Ost-Afr. A (1895) 115 . Angola.

parviflorus, Schlechter, 1. c. xx, Beibl. n. 5 I (1895) 35 = Xysmalobium parviflorum, Harv.

rectinervis, Schlechter, l. c. 38. - Afr. austr.

rhinophyllus, $K$. Schum, in Engl. Pflanzenw. Ost-Afr. $\mathrm{C}(1895)$ 322. - Afr. trop. or.

rivularis, Schlechter, in Bot. Fahrb. xx. Beibl. n. 51 , (1895) 36. - Afr. austr.

robustus, Schlechter, l. c. 37 , nomen. - Afr. austr. 


\section{GOMPHOGARPUS}

roseus, K. Schrm. in Bot. Falvbo. xvii, (1893)-12\%; et in Engl. \& Prantl, Natürl. PAanzenfam: iv. 2 (1395) 23\%. - Angola.

scaber, K. Schum. I.c. $124=$ rhizophyllus, Engl.

Schinziantes, Selkechter, in Fourn. Bot. xxxiii. (1S95) 356 in obs.; et l. C. xx. Beibl. H. $5 \mathbf{1}($ I895) 3\%. Afr. austr.

schizoglossoides, Schlechter, l. c. xviii. Beibl. n. 45 (1894) 21. - Afr. austr.

semiamplectens, K. Schum. l. c. xvii. (1893) 128, Afr. trop.

simplex, Schlechter, l. c. xviii. Beibl, n. 45 (1894) 21. - Afr. austr.

spathulatus, Schlechtcr, in Journ. Bot. xxxiii. (1895 269 in obs, = Schizoglossum spathulatum, $K$ Sihum.

stenoglossis, Schlechter, 1. c. xxxii. (1894) 257; et in Bot, Jahrb. x*. Beibl. n. 51 (1895) $40=$ Krebsia stenoglossa, Schlechter.

stockenstromensis, Schlechter, 1. c. $40=$ Xysmalobium stockenstromensis, S, Elliot.

suaveolens, Schlechter, l.c. 38. - Afr. austr.

trachyphyllus, $K$. Schum. l. c. 237; et in Engl. \& Prantl, Natürl. Pfanzenfam. iv. 2.'(1895) $23 \%$ (= G. scaber, K. Schum.), - Afr. trop. or.

transvaalensis, Schlechter, l.c. xviii, Beibl. n. 45 (1S94) 22. - Afr. austr.

trifurcatus, Schlechter, 1. c. $9=$ Woodia trifurcata Schlechter.

undulatus, Schlechter, 1. c. 10 = Xysmalobium undulatum, $R, B$ r.

validus, Schlechter, l. c. 23. - Afr austr.

velutinus, Schlechter, l. c. 22, - Afr. austr.

viridiforks, $\mathrm{K}$. Schum. in Engl. \& Prantl, Natür1. Pflanzenfam. iv. 2 (1895) $236=$ viridiflorus, Spreng.:

Woodii, Schlechter, in fourn, Bot.xxxii. (1894) 258 - Afr. austr.

GOMPHOLOBIUM, Sm. (Legumin.), - Ind. Kew. i. 1050.

Eatoniae, F. Muell. in Vict. Natural.vi. (May-June 1859) 38. - Austral.

GOMPHOSTEMMA, Wall. (Labiat.). - Ind. Kew. i. 1051.

Curtisii, Prain, in fourn. As. Soc. Beng. lix. (1891) 11. 315; et in Ann. Bot. Gard. Calc. iii. 2 (1891) 266. - Penins. Mal.

Hemsleyanum, Prain, ex Collett et Hemsl. in fourn. Linn. Soc, xxviii. (1890) 116. - Ind. angl.

microcalyx, Prain, in fourn. As. Soc. Beng. lix. (I891) 11. 316; et in Ann. Bot. Gard. Calc. iii, (1891) 251. - Penins. Mal.

rugosum, Prain, l. c. iii. 2 (1891) 262.' - As. trop:

Scortechinii, Prain, in fourn. As. Soc. Bong. lix (1891) II. 315; et l. c. 260.- Penins. Mal

Wallichii, Prain, ll. cc. 314 ; et 245 . - Ind. or.

GOMPHOSTIGMA, Turcz. (Logan.), - Ind. Kew. i. 1051

irgatum, Baill. Hist. des pl. ix. (18S8) $348=$ scoparioides, Turcz.

GOMPHRENA, Linn. (Amarant.). - Ind. Kew i. 1051.

lecipiens, S. Wats. in Proc. Am. Acad, xxi. (1886) $437=\mathrm{G}$. Sonorae, Torr

Nealleyi, Coult. \& Fisclier. in Coult. Bot. Gaz. xvii. 349? et in Contrib. U. S. Nat. Herb. ii. (1894) 362. - Texas.

nitida, Coult, in Contrib. U. S. Nat. Herb, ii. (1890) $48=$ G. Neallyi, Coult. \& Fisch.

platandra, F. Muell, in Trans. \& Proc. Roy. Soc. Vict. xxiii. (April 1887) 52, - Austral.

Pringlei, Coult. \& Fisch, in Coult. Bot. Gaz. xvii, (1892) 349. - Mexic.

Tuerckheimii, Uline \& Bray, in Coult. Bot. Gaz. xx. (1895) 161. - Guatem.

GONGORA, Ruiz \& Pav. (̧Orchid.). - Ind. Kew. i. 1053 .

flaveola, Reichb. f. in Gard.Chron. (1886) ii. 456.Hab. ?
GONGRONEMA, Decne (Asclep.),- Ind. Kew. i. 1053 .

glabriflora, Warb. in Bot. Fahrb. xiii. (1891) 411. N. Guin.

Welwitschii, K. Schum. 1. c. xvii. (1833) $145=$ Sphaerocodon obtusifolium, Benth。

GONGXLOGARPUS, Cham, \& Schlect. (Onagrar.). - Ind. Kew. i. 1053

fratescens, M. K. Curran, in Proc. Calif. Acad. Ser. II. i. (1888) $231=$ Gaura fruticulosa, Benth.

fruticulosis, T. S. Brandeg. 1. c. Ser. II. ii. (1889) 158 t. 5 = Uaura fruticulosa, Benth.

GONIOLIMON, Boiss, = Statice. Tourn. (Plumbag.).

Heldreichii, Halácsy, in Verh. zool.-bot. Ges, Wien, (1886) $241=$ S. Heldreichii. Halácsy.

GONIOLOBIUM, G. Beek, in Verh, zool.-bot. Ges, Wien, Setz. (1890) 1; ; et Fl. Nied.-Oest, II. i. (1892) 478 ; Fritsch, in Bot. Centralbl. xliii. (1890) 13 = Conringia, Hist. (Crucif.).

austriacum, G. Beck, 11. cc. 19; et 479= C. austriaca, Sweet.

GONIORRHAGHIS, Taub, in Flora, lxxv, (1892) 77 ; et in Eng1. \& Prantl, Natïrl. Pflanzenfam. iii. 3. (1892) 137. LEGUMINOSAE.

marginata, Taub. $l l . c c .-$ Bras.

GONIOTHALAMUS, Hook. f. \& Thoms. (Anon.). - Ind. Kew. i. 1053

cauliflorus, K. Schmm. in K. Schum. \& Hollr. Fl, Kais. Wilh. Land I (1889) 48, - N, Guin.

Curtisii, King, in fourn. As. Soc. Beng. 1xi. (1892) II. 75. - Perak.

Kunstleri, King, l. C. 73. - Perak

mollis, Warb. in Bot. fahrb. xiii. (1891) 306. Oceania.

Prainianus. King, in foum. As. Soc. Beng. Ixi (1892) Ir. 72. - Perak

Ridleyi, King, l. c.76. - Singap.

roseus, Stapf, in Trans, Linn. Soc., Ser, II. iv. (1894) 130. - Borneo.

Scortechinii, King, in fourn. As. Soc. Beng. lix. (1892) II. \%7. - Perak.

stenopetalus, Stapf, in Trans. Linn. Soc, Ser. II. iv. (1894) 129. - Borneo.

subevenius, King, in fourn. As. Soc. Beng. 1xi. (1892) II. 71. - Perak.

tenuifolius, King, l.c. - Perak.

uvarioides, King, l.c. 78. - Malaya,

Wrayi, King, l. c. - Perak.

GONOCARYUM, Miq. (Ins. sed.). - Ind. Kew. i. 1054

Harmandianum, Pierre, Fl. For, Cochinch. Fasc. xvii. (1892) t. 368a. - Cochinch.

lobospermum, Valeton, Crit. overz, Olac. (1886) 249 [lobosperma] $=$ Phlebocalymna lobosperma, F. Muell.

longeracemosum, King, in founn. As. Soc, Beng, 1xiv. (1895) II. 120. - Singap., Perak

subrostratum, Pierre, Fl, For. Cochinch. Fasc. xvii. (1892) t. 268b. - Cochinch.

GONOCRYPTA, Baill. in Bull. Soc. Linn. Paris, ii. (1889) 804 (err. cal. 84) = Gryptolepis, R. Br. (Thymel.).

Grevei, Baill. 1. c. - Madag.

GONOLOBUS, Michx (Asclep.). - Ind. Kew. i. 1054 .

acuminatus, A. Gray, in Proc. An. Acad. xxi. (1886) 399. - Mexic.

ancustifolitis, K. Schum. in Engl. \& Prantl, Natïr?. PAanzenfam, iv. 2 (1895) 302.-Cuba

atratus, A. Gray, in Proc. Am. Acad. xxii. (1887) 436. - Mexic.

caudatus, A. Gray, l. c. xxi. (1886) 399. Mexic.

chihuahuensis, A. Gray, 7. c. 398. - Mexic.

\section{GONOLOBUS :}

ellipticus, Rusby, in Mem. Torrey Bot. Club, iv (1895) 22\% [elliptica]. - Bolivia.

guatemalensis, K. Schum. in Engl. \& Prantl, Natiir. Pfanzenfan. iv. 2 (1895) $302(=$ G. velutinus, J. D. Smith). - Guatem.

Haussknechtii, K. Schrum, l. . - Mexic.

petiolaris, A. Gray, in Proc. Am. Acad. xxi. $\{1886\}$ 396. - Mexic

scaber, K. Schum. in Engl. \& Prantl, Natiurl. Pfanzenfam. iv 2 (1895) 302. - Venez.

sororius, A. Gray, ex S. Wats, in Proc. Am. Acad. xxii. (1887) 431. - Mexic.

stenopetalus, A. Gray, l. co xxi. (1886) 39. -- Mexic. suberiferus, Robinson, l. c. xxvii. (1893) 181. Mexic.

GONYSTYLUS, Teijsm. \& Binn. (Thymel.). Ind. Kew. i. 1054.

affinis, Radlk, in Sitr. Akad. Wiss. Muench, xvi. 1886) 329. - Borneo.

pluricornis, Radlk, l. . . - Borneo.

Maingayi, Hook. f. Fl. Brit. Ind. v. (1886) 200.Malacca.

GONZALAGUNEA, Ruiz et Pav. fide Kuntze = Gonzalea, Pers. (Rubiac.).

incanescens, nivea, parriftora, pulverulenta, secunda. tomentosa, Kuntze, Rev. Gen. (1891) $284=$ homonyma ommia Gonzaleae.

GONZALAGUNiA, Ruiz \& Pav。

Gonzalea Pers. (Rubiac.).

hirsuta, K. Schum. in Mart. Fl. Bras, vi. VI. (1889) 291 = Gonzalea spicata, $D C$.

mollis, Spruce, ex K. Schum. 1. c. 290. - Ecuad.

GONZALEA, Pers. (Rubiac) ) - Ind, Kew。i. 1055 .

glabra, S. Wats, in Proc. Am. Acad. xxv. (1890) 152 - Mexic.

thyrsoidea, F. D. Smith, in Coult. Bot. Gaz.xiii. (1888) 188. - Guatem.

GOODENIA, Sm, (Gooden.). - Ind. Kew. i. 1055 cirrifica, F. Muell, in Austral, fourn. Pharm. (March 1886) 81. - Austral.

Elderi, F. Muell. E Tate, in Bot. Centralbl. liii. (1893) 268. - Austral

fascicularis, F. Muell. \& Tate, in Trans. En Proc Roy. Soc. S. Austral. xiii. (1890) 108. - Austral. Forestii, F. Muell. in Vict. Natural. ix. (Aug. 1892) 58 ; et 'Sept. 1892) 63 [Foresti]]; et in Bot. Centralbl. lii. (1892) 46. - Austral.

Horniana, Tate \& F. Muell. $n$ Trans, Roy. Soc. S. Austral xix (1805) 82, nomen. - Austral.

O'Donnellii, F. Muell. in Australas. Fourn. Pharm. (Aug. 1886); et ex Bot. Centralbl, xxvii, (1886) 54. - Austral.

Pumilla, R. Br。 ex Bot. Centralbl. xlv. (1891) 30 , sphalm = pumila, $R . B r$.

pusilliflora, F. Muell, in Vict. Natural. v, (May 1888 ) 11: et in Bot. Centralbl, xxxv. (1888) 99. - Austral. Stephensoni, F. Muell.l. c. iii. (Feb. 1887) $138 ;$ ed l. c. xxx. (1887) 242 - Austral.

subintegra, F. Muell. l. c. v. (May 1888) 13. Austral.

Watsoni, F. Muell. G Tate, in Bot. Centralbl. liii, (1893) 268. - Austral.

GOODYERA, R. Br. (Orchid.). - Ind. Kew. i, 1056. biflora, Hook.f. Fl. Brit. Ind. vi. (1890) 114.Reg. Himal.

cordata, Benth. ex Hook, f. l. c. : Hook. f. Icon. pl. xxii. (1894) t. 2187 (=Georchis cordata, Lindl.). Ind. or

foliosa, Benth. ex Hook. f. Fl. Brit. Ind. vio( (1890) 113 (= Gecrchis foliosa, Lindl.). - Ind, or.

formosana, Rolfe, ex Hemsh, in Am. Bot, ix。 (1895) 159. - Ins. Formos.

fusca, Hook, f. Fl. Brit. Ind vi. (1890) 112。 - Regr Himal.

gracilis, Hook.f.l.c. 112, - Perak

hachijoensis, Yatabe, in Tokyo Bot. Mug. Vo (1891) 1 t. 19. - Japon. 


\section{GOODYERA}

papuana, Ridl. in foum. Bot. xxiv. (1856) 35.5. N. Guin.

Prainii, Hook. f. Fl. Brit. Ind. vi. (1890) 112. Assam.

pendula, Maxim. in Bull. Acad. Sci. St, Pctersb.xxxii. (1888) 623. - Japon.

robusta. Hook. F. Fl. Brit. Ind. vi. (1890) 113. Khasia.

Rodigasciana, L. Linden. in Illustr. Hort. xxxiv. (1886) 175 t. 616. - N. Guin.

vittata, Benth. ex Hook. f. Fl. Brit. Ind. vi. (1890) 113; et Icon. pl. xxii。 (1894) t. 2185. - Reg Himal.

GORDONIA, Ellis (Ternstroem.).-- Ind. Kew, is 1057

acuminata, Vidal, Reris, Pl, Vasc, Filip. (1886) is --Ins. Philipp.

Altamahn, Sary, in Gard, and For. (1889) 616 Dippel, Handb. Laubholzk. iii. (1893) $31=$ pubescens, L'Hérit.

axillaris, Szyszyl in Enst. \& Prantl, Natürl. Pflanzenfam. iii. 6 (1893) $185=$ anumala, Spreng.

grandis, King, in foum. As. Soc, Beng. lix. (1890) II. 203. - Perak.

imbricata, Ktng, l. c. 204.-Perak.

Lesiertii, Szyszyl. in Engl. \& Prantl, Natürl. Pflanzenfam. iii. 6 (1893) $\mathbf{1 8 5}=$ anomala Spreng.

Iuzonica, Vidal, Revis, Pl. Vasi, Fitip. (1886) 57. Ins. Philip.

multinervis, King, in fourn. As. Soc. Beng, lix. (1890) II. 205. - Perak.

Scortechinii, King, l. c. 204. - Perak

Vidalii, Szyszyl。 in Engl. \& Prantl, Natirl. Pfanzenfam, iii, 6 (1893) 185 (= G. acuminata, Vidal)

- Ins. Philipp.

GOSSYPIANTHUS, Hook. (Amarant.). - Ind Kew. i. 1057.

decipiens, Kuntze, Rev, Gen.(1891)543= Hebanthe decipiens, Hook. f.

guticnensis, Kuntze, 1. c. = H. guianensis, Klotrsch. Hookerianus, Kuntze, l. c. = H, Hoolieriana, Hemsl.

mollis, Kuntze, 1. c. $=$ H. mollis, Himsl.

submudus, Kuntze, 1. с. = H. sulnuda, Hemsl.

GOSSYPIUN, Linn. (Malv.). - Ind. Kew. i. 1057 areysianum, Deflers, Esq. géogr. bot. (1895?) 49 ; et in Bull. Soc. Bot。 Fr。 xlii. (1895) 299, in syn. = Fugosia areysiana, Deflers.

Harknessii, T. S. Brandeg. in Proc. Calif. Acad. Ser. II. ii. (1889) 136. - Calif.

lanceaeforme, Micrs, ex Britten, in fourn. Boto xxxi (1893) 331. - Mexic

multiglandulosum, Phit. in Anal. Mus, nac. Chite (1891) 10. - Chili

GOTHOFREDA, Vent. = Oxypetalum, R. Br.

aequaliflora, albiflora, ampliftora, appcudiculata, Arnottiana, Banksii, brevipes. Brunonis, capitata, coalita, coerulea, confertiflora, coriacea, corymbifera, crispa, densiffora, dentata, Dombeyana, crecta, eriantha, erostris, foliosa, glomerata, grandifora, Guilleminiana, Hilariana, incana, integriloba, facobinae lagoënsis, lanata, ligulata. linearis, I Iuschnalhii, lugoènsis, lanata, ligulata, linearis, Luschnalhit, microstemma, minarum, mollis, monantha, montana, mucronata, mutica, nigrescens, pachyglossa, pachygyna, pallida, paludosa, pannosa, pardensis, putviflora, patula, paupercula, pedicellata, propinqua pulcra, Schottit, Selloana, Siliculae, squamilata. stigmatosa, stricta, suaceolens, sublivtella, ternifolia tomentosa, villosa, Wightiana, Kuntze, Rev. Gen. (1891) 419-20 = Homonyma omnia Oxypetali.

andina, Rusby, in Mem. Torrey Bot. Club, iv. 1895) 220. - Bolivia.

(rachnodea, Kuntze, Rev. Gen. (1891) $419=0$. arachnoidum, Fourn.

birostrata, Kuntze, 1. c. $420=0$. Hookeri Decne.

deltodea, Kuntze, 1. c. = O. deltoideum, Foum
GOTHOFREDA : -

Fournieriana, Kuntze, Rev, Gen. (1891) $420=0$. parvifolium, Fourn.

gracilis, Rusby, in Mem. Torrey Bot. Club, vii. 1893) 162. - Parag.

multicaulis, Kuntze, 1, $c_{0}=$ O. campestre, Decne.

nitida, Kuntze, 1. c. = O. umbellatum, Gardn.

obliquifolia, Kuntze, 1. c. = O. saxatile, Decme

oblongifolia, Rusby, in Mem. Torrey Bot. Club,

vii. (1893) 162. - Parag.

probiscidia, Kuntze, Rev, Gen, (1891) $420=0$. proboscideum, Fourn.

solanodes, Kuntze, 1. c。 = O. solanoides, Hook。 \& Arn.

ultima, Kuntze, l. c, = O. multicaule, Foum.

GOUANIA, Jacq. (Rhamn.). - Ind. Kew. i, 1058. Bishopii, Hillebr. Fi. Haw. Isl. (1888) 83. - Ins. Sandvic.

Hillebrandi, Olizer, ex Hillcorr. l.c. - Ins. Sandvic

Lehmannii, Hieron, $21 n$ Bot, fahrb, xx. Beibl, n. 49 (1895) 41 - Columb.

longispicata, Engl. Pfanzemw. Ost-Afr. C (1895) 256 . - Afr. trop. or.

mexicana, N. E. Rose, in Contrib. U. S. Nat. Herb. iii. 5 (1895) 314. - Mexic

GouldiA, A. Gray (Rubiac.). - Ind. Kew. i. 10.99

coriacea, Hillebr. Fl, Haw, Isl, (1888) l68 (= Petesia coriacea. Hook, \& Arn.). - Ins, Sandvic. hirtella, Hillcbr. I. c. 169. - Ins. Sandvic. macrocarpa, Hillebr. l. c. 170.- Ins. Sandvic terminalis, Hillebr. l. c. $168(=$ Petesia terminalis,

Hook, \& Arn.). - Ins. Sandvic.

GOUPIA, Aubl. (Celastr.). - Ind. Kew. i. 1059: cinerascens, Poepp. ex Baill. in Mart. Fl. Bras. xiii. (1886) $372=$ Dichapetalum vestitum, Baill.

GOVENIA, Lindl. (Orchid.). - Ind. Kew. i, 1059

boliviensis, Rolfe, in Menr. Torrey Bot. Club, iv. ? (1895) 263. - Bolivia.

elliptica, S. Wats, in Proc. Ann. Acad. xxvi. (1891) $153 .-$

GRADERIA, Benth. (Scrophul.). - Ind. Kew. i. 1059 .

ubintegra, Mast. in Gard. Chron.(1893) ii: 799 fig. 122. - Afr, austr.

GRAFFENRIEDA DC. (Melast.). - Ind. Kew. i. 1059

boliviensis, Cogn。ex Rusby, in Mcm. Torrey Bot. Club, iii. 3 (1893) 28. - Bolivia.

GRAMMANTHES, DC. (Crassul.). - Ind, Kew.

Heylandiana, Webb, ex Christ, in Bot, fahrb. ix. (1888) $162(=$ Umbilicus Heylandianus, Webb \& Berth ). - Ins. Canar.

GRAMMATOPHYLLUM, Blume (Orchid.), -

Ind. Kew, i, 1059 . Ins. Salom.

Guilelmi, Kraenzl, in Gartenfl. (1894) 114. - N. Guin.

leopardinum, Reichb, f. in Flora, lxxxi. (1888) 151. - Ins. Moluce.

Scegerianum X, Hort. e:: Gard. Chron. (1891) II. 49. - Hybr, artet.

GRAMMOSCIADIUM, DC, =- Chaerophyllum, Linn. (Umbellif.).

pauciradium, Freyn \& Sint, in Oest. Bot. Zeitschr. xlii. (1892) $120=$ G. Aucheri, Boiss,

GRANATUM; Rumph. = Carapa, Aubl. (Meliac.). guzanense, moluccense, nicaraguense, proserum, surinamense, Kuntze, Rev. Gen. (1891) $110=$ homonyma omnia Carapae

oboratum, Kuntze, 1. c. = C. moluccensis, Lam.
GRANTIA, Griff, = Wolffia, Horkel (Lemn.) brasiliensis, Mac Mill. Metasp. Minn. (1892) $134=$ W. brasiliensis, Wedd.

columbiana, Mac Mill. 1. c. $135=$ W. columbiana, Karst.

GRANTIA, Boiss. (Compos.). - Ind. Kew, i. 1060. enecionoides, Baker, in Kew Bull. (1895) 31\%. Arabia.

GRAPHISTEMMA, Champ.(Asclep.). - Ind. Kew i. 1051 .

pictum, Baill. Hist. des pl. x. (is90) $253=$ pictum, Champ.

GRAPHORCHIS, Thou, in Nouv. Bull. Sor Philom. Paris (1809) 314-19; ex Kuntze, Rev Gen. (1891) 661 = Eulophia, R. Br. (Orchid.) abysinica, adamanensis, aloifolia, articulata, Arundi nae, atrovirens, baginsensis, beracensis, bicavinata, bicolor, bracteosa, burmanica, caffra, callichroma. campestris, candida, cochlearis, comosa. concolor. cristata densiflora, Dreaeana, elata, ensata, exaltata. explanata, filicaulis, Filzalani, fac'a, galbana, gracilis, graminea, guinecnsis, hians, holochila, Holtzci. lachnocheila, lamellata, lurida, lutea, macrcbulbon, macrorliza, macrostachya, maculata, madagascariensis, Mannii, Meleagris, micrantha, Milnei, natalensis, muda, mutans, obtusa, ochreata, ovalis, parilabris, Petersii, pileata, platypetala, pratensis, pitlchra, ramosa, reticulata, nupestris, Rutenbergiana, sanguinca, Saundersiana, scripta, sphacrocarpa, squalida, stachyodes, stenopetala, sumatrana, tenella, tristis, vaginata, venosa, eemulosa, violacea, virens, Zeyheriana, Kuntze, Rev. Gen. (1891) 662 = homonym omia Eulophiae.

bicolor, Kuntze, 1. c. 663. = E. herbacea, Lindl.

Blumeana, Kuntze, 1. c. = E. emarginata, Blume.

capensis, Kuntze, 1. c. $662=$ E. barbata, Spreng.

ciliata, Kuntze, 1. c. = E. gracilis, Lindl.

claricornis, Kuntze, 1 c. = E. hians, Spreng.

calographis, Thou, ex Bull. Herb. Boiss. ii. (1894) $459=$ E. pulchra, Lindl.

cucullata, Kuntze, 1, c. = Polystachya grandiflora, Lindl.

decipiens, Kuntze, 1. c. = E, graminea, Lindl.

dipodiformis, Kuntze, 1. c. = E. dipodiiformis, Reichb $f$.

dubia, Kuntze, l. c. = E. campestris, Wall.

emarginata, Kuntze, 1. c。 = E. hians, Spreno.

flabellata, Kuntze, 1. c, = Cyrtopodium flabellatum Spreng

inconspicua, Kuntze, 1. c. = E. graminea, Lindl.

lissochilodes, Kuntze, 1. c. = E. lissochiloides, Lindl.

Monographis, Thou. ex Bull. Herb. Boiss. ii. $(1894$ $459=$ E. scripta, Lindl. var.

odontoglossa, Kuntze, 1. c. = E, aculeata, Sprons.

ovalis, Kuntze, 1. c. = E. barbata, Spreng.

plantaginea. Kuntze, 1. c.= Cyrtopodium plantagineum, Benth.

rufa, Kuntze, 1. c. (= Cyrtopera rufa, Thw.). = sanguinea, Lindl.

GRATIOLA, [Rupp.]. Linn. (Scrophul.). - Ind. Kew. i. 1060.

adenocaula, Maxim, in Bull. Acad, sci. St. Potersb. xxxii. (1888) 513. - Japon,

concinna, Colenso, in Trans. N. Z. Inst. xix. 1886 (1887) 264.- N. Zel.

mexicana, S. Wats. in Proc. Am. Acad. xxv. (1890) 159. - Mexic

GRATWICKIA, F, Muell. in Chem, \& Drug. Australas. (Nov, 1895); et ex Bot. Centralbl. lxiv. (1895) 445. COMPOSITAE.

monochaeta, F. Muell. ll.ce. - Austral.

GRAVESIA. Naud, (Melast). - Ind. Kew. 1. 1061

angustifolia, Cogn, in DC. Monog, Phan. vii. (1891) 522. - Madas.

Humblotii, $\operatorname{Cogn}$. l. c. 521. - Madag.

porphyrovalvis, Buker, in fourn. Limn, Soc. xxii.

(1887) 477; Cogn. l. c. 522. - Madag.

primuloides, $\operatorname{Cog} n$. . . c. 523. - Madag. 


\section{GRAVESIA}

pusilla, Cogn. in DC. Monog. Phan. vii. (1891) 523 - Madas.

reticulata, Cogn l. c.521. - Madas.

Rutenbergiana, Baill. ex Cogn. .. c. 5\%2. - Madag.

GRAVISIA, Mez, in Mart. F1. Bras. iii, I1. (189? 298 = Aechmea, Ruiz \& Pai'. (Bromel.).

chrysocoma, Mez, 1. c. $301=$ Ae. chrysocoma, Baker. exsudans, Mez, 1. c. $300=$ Ae. exstidans, Baker.

GREENEA, Wight \& Arn. (Rubiac.). - 1nd. Kew. i. 1061 .

corymbosa, K. Schum. in Eng1. \& Prantl, Natïrl Pflanzenfam.iv. 4.(1891) $37=\mathrm{G}$. Jackii, Wight E. Am .

GREENEINA, Kuntze, Rev. Gen. (1891) $628=$ Helicostylis, Tréc. (Urtic.).

affinis, Kuntze, 1. $c_{0}=$ H. Poeppigiana, Trec.

Poeppigiana, Kuntze, 1.c. = H. Poeppigiana. Trec

GREENELLA, A. Gray (Compos.). - Ind, Kew. i. 1061 .

ramulosa, Greene, Pittonia, i. (May 1889) 202. Calif.

GREENONIA, Webb \& Berth.= Sempervivum Rupp. (Crassui.)

forrea, Webb, ex Christ, in Bot. Jahrb. ix. (1888) $114=\mathrm{S}$. ferreum, Christ.

polypharmica, Webb, 1. c. = S. polysphaericum Christ.

quadrantalis, Webb, 1. c. = S. Aizoon, Christ.

rupifraga, Webb, 1. c。= S. rupitragum, Christ.

sedifolia, Webb, 1.c. $115=\mathrm{S}$. sedifolium, Christ.

GREIGIA, Regel (Bromel.). - Ind. Kew, i. 1062 vulcanica, Ed. André, in Rev. Hortic. 1x. (18ES 563; Baker, Handb. Bromel. (1889) 13. - Columb

GREVELLINA, Baill. in Bull. Soc, Linn. Paris ii. (1894) 1160. MELIACEAE.

scoparia, Baill. l. c. - Madag.

GREVILLEA，R. Br. (Proteac.). - Ind. Kew. i 1062.

Kennedyana, F. Muell. in Trans. \& Proc. Roy. Soc Vict. xxiv. (July 1888) 172. - Austral.

pinnatifida, F.M. Bailey, Syn. Queensl. Fl. Suppl. ii. (1888) 52 (= Kermadecia pinnatifida, F. M Bailey). - Austral.

Renwickiana, F Muell, in Proc, Limn, Soc. N. S. Wales, Ser. II. i. (Feb. 1887) 1105. - Austral.

scoparia, Baill. Hist. pl. Madag., Atlas (1893) t. 258. - Madag.

Van Houtteana, Hort. ex Hook. f, in Bot. Mas (1889) sub t. $707(\mathrm{O}$, in syn. = asplenifolia, Knight.

Williamsoni. F, Muell. in Vict. Natural. x, (Dec. 1893) 129. - Austral.

GREWIA, Linn. (Tiliac.). - Ind. Kew. i, 1064 aldabrensis, Baker, in Kew Bull. (1894) 147. - Ins. Aldabr.

ambongensis, Baill. in Bull. Soc. Linn. Paris, i. (1886) 559. - Madag.

amplifolia, Baill. l. c. 5.58. - Madag.

astropetala, Pierre, Fl. For. Cochinch. Fasc. x. 18S8) t, 161. - Cochinch.

Bakeriana, Baill. in Bull. Soc. Linn. Paris, i. (1886) 559. - Madag.

barombiensis, K. Schum。 in Bot, fahrb. xv. (1893) 124. - Afr. trop. occ.

betulaefolia, Baill. in Bull. Soc, Limn. Paris, i. (1886)

548. - Madag.

Boehmiana, Fred. Hoffm. Beitr. Kenntu.: Fl. Centr. Ost-Afr. (1889) ]5. - Afr. centr.-or,

botryantha, Baill. in Bull. Soc. Limn. Paris, i. (1886 557. - Madag.

bracteata, Baker, in fourn. Linn. Soc. xxv. (1889)

300. - Madao

Celle, Baill. in Bull. Soc. Linn. Pavis, i. (1886) 550 - Madag.

celtidifolia, Baker, in fourn. Linn. Soc. xxv. (1889) 301. - Madag.

\section{GREWIA :}

cernua, Baker, in fourn. Limn. Soc, xxv. (1889) 300 - Madag.

coerulea, K. Schun, in Engl. Pfanzcnw. Ost-Afr. C (1895) 263. - Afr trop. or.

chalybaea, Baill. Hist. pl. Madag., Atlas (1888) t. 85. - Madas.

comorensis, Baill. in Bull. Soc. Linn. Payis, i. (1885) - Ins. Comor.

conocarpa, K. Schum, in Engl. Pfanzenw. Ost-Afr. C (1895) 264. - Afr. trop. or

cyclea, Ball. in Bull. Soc. Linn. Paris, i. (1886) 559: et Hist. pl. Madag., Atlas (1888) 86. Madas

discolor, Baill. in Bull. Soc. Linn. Paris, i. (1886) 5.jl. - Madag

discolor, Baker, in Fomm. Limn. Soc. xxy. (188!) 300 - Maday.

densa, K. Schum. in Bot. Fahrb.xv. (1893) 122. Afr. trop or.

dubia, Deflers, in Bull. Soc. Bot. Fr. xlii. (1895) 300. - Arabia.

elatostemoides, Collett Eo Hemsl. in Fourn. Lim. Soi. xxviii. (1890) 27. - Burma

fallax, $K$. Schum. in Bot. Fahrb. xv, (1893) 116.Afr. trop. or.

Havicans, Boir, ex Baill, in Bull. Soc, Limn. Paris, i. (1886) 548, - Madag.

gonioclinia, K. Schum. in Bot. Fahrb. xv, (1893) 119. - Afr. trop. or.

glyphaeoidcs, Baill. in Bull. Soc. Linn. Paris, i. (1586) 552. - Madag.

Hildebrandtii, Baill. l. c. 551. - Madag.

Humblotii, Baill. l, c. 549. - Madag.

hypoglauca, $K$. Schum, in Engl. Pfanzenw. Ost-Afr. C (1895) 263. - Afr. trop. or.

hypotephra, Pierre, Fl. For Cochinch. Fasc. x. 1888) t. 157. - Cambod,

lavanalensis, Baill. in Bull. Soc. Linn. Paris, i. (1886) 548; et Hist. pl. Madag., Atlas (1888) t. 84. Madas

lorifolia, Baill. l. c. t. 83. - Madag.

mayottensis. Baill. in Bull. Soc. Linn. Paris, i. 1886) 557. - Madas.

minutiflora, Baill. l. c.55l.- Madag.

nodisepala, K. Schum. in Bot. fahrb. xv, (1893) 120.

- Afr. trop. or

nossibeensis, Baill. in Bull. Soc. Linn. Paris, i. (1886) 549. - Madag.

obovata, K. Schum. ex Engl. in Abh. Preuss. Ahad Wiss. (1894) 18; ct in Engl. Pfanzonw. Ost.-Afr. C (1895) 263. - Afr trop or

oligandra, Pierre, Fl. For. Cochinch. Fasc, x. (18s8) t. 163.- Cochinch.

pachycalyx, K. Sihum. in Bot. Fahrb. xv. $(1893)$ 123. - Afr. trop. or.

pedunculata, K. Schnm, in Engl. Pfanzenw. Ost$A f r . \mathrm{C}(1895) 263$. - Afr. trop. or

penninervis, Boic. ex Baill. in Bull. Soc. Linn, Paris, i. (1886) 552. - Madag.

Pervillei, Baill. l. c. 548. - Madag.

picta, Baill. l. c. 557. - Madas

plagiophylla, K. Schum. in Bot. Fahrb.xv. (1893) 119. - Afr. trop. or.

praecox, K. Schum, in Bot. Fahrb.xv, (1893) 117. Afr. trop. or.

Puttkameri, Warb. in Bot. Fahrb. xiii. (1891) 3\%1. Oceania.

Radula, Baker, in fourn. Limn. Soc, xxv. (1889) 299. - Madas.

repanda, Baker, l. c, - Madar

rhytidophylla, K. Solnum. in Bot. Fahro. xv, (1893) 122. - Afr. trop. or.

Richardiana, Baill, in Bull. Soc, Limn. Paris, i.

(1886) 358. - Madag.

Schinzii, $K$. Schum, in Bot. Fahrb. xv, (1893) 124 .

Afr. austro-occ. extratrop.

serratula, Baill. in Bull. Soc. Linn. Paris, i. (1886) 549. - Madag.

similis, K. Schum. in Bot. Fahrb. xv. (1893) 118. -

Afr. trop. or.

Stuhlmannii. K. Scmm.l.c. 121. - Zanzib.

tiliaecarpa, Baill. in Bull. Soc. Limn. Paris, i. (1886) 552. - Madag.

triflora, Baill. . . c.587 (= Vincentia triflora, $130 j$.$) .$ - Madas.

\section{GREWIA}

tristis, K. Schum. in Bot. Fahrb. xv. (1893) 116. Afr, trop, or.

viscosa, Boir, ex Baill, in Bull. Soc. I innz, Paris, i. (1886) 557. - Madag

zizyphifolia, Baill. l. c.550. - Madag.

GREYIA, Hook. \& Harv. (Sapind.). - Ind, Kew. i. 1065

Flanagani, Bohus, in Hook. Icon. pl, xxiv, (1894) sub t. 2349, in text - Afr austr.

Flanigani, Bolus, 1. c. t. 2349, sphalm. = prace Radlkoferi, S\%yszyl. Pl. Rehmann. ii. (1888) 49 - Transvaal.

GRIAS, Linn. (Myrt.). - Ind. Kew。 i. 106.5.

tetrapetala, Niedenzu, in Engl. \& Prantl, Natïrl. Pflanzentam. iii.7 (1892;39= Aubletiana, Miors.

GRIELUM, Linn. (Rosac.). - Ind. Kew. i. 1060 Marlothii, Engl. Bot. Fahrb. x. (1889) 16. - Afr austro-occ. extratrop.

GRIFFON1A, Baill. = Bandeiraea, Welw, $\{$ Le gum.)

speciosa, Taub. in Engl. \& Prantl, Natriil. Pllanzenfam. iii. $3(1892) 147=$ B. speciosa. Welw

GRINDELIA, Willd. (Compos.). - Ind. Kew. i 1066

amporum, Grcene, Man. Bot. San Franc. Bay (1894 171. - Calif.

Hendersoni. Greene, Pitlonia, ii. (Nov, los?) is. Am. bor. occ.

lanata, Greene, l. c. ii. (Sept. 1892) $290-$ Am. bor

montana, Phil. in Ancl. Univ. Chil, lxxxvii. (1894 429. - Chili.

paludosa, Greene, Man. Bot. San Franc, Bay (1894) 172. - Calif

patens, Grcene, Pittonia ii (Sept 1892) . 200. Man. Bot. San Franc. Bay (1894) 172.-Calif

procera, Greene, Man. Bot. San Franc. Bay (1894 172. - Calit.

tarapacana, Phil, in Anal. Nus, nac. Chile (1891) iss. - Chili.

GRISELINIA, Forst, f. (Cornac) :- Ind, Kew, i $106 \%$

alata, Ball, in foum. Linn. Soc. xxii. (1886) 16:3Chili.

jodinifolia, Taub, in Bot. Jahrb, xvi. (1893) $390=$ Decostea jodinifolia, Griseb.

racemosa, Taub. 1. c. = D. racemosa, Phil

ruscifolia. Ball, in fourn. Linn. Soc.xxii. (1886) 16\%; K. Schum, in Mart. Fl. Bras. iii. I1. (1894) $779=$ D. ruscifolia, Clos.

ruscifolia, Taub, in Bot, Jahrb, xvi. (1893) 391 = praec.

candens, Taub. 1. c. $398=$ Decostea scandens, Ruiz \& Pai.

GROBYA, Lindl. (Orchid.). - Ind. Kew: i. 1067. fascifera, Reichb. f. in Flora, lxix. (1886) 551. Hab.

GRUMILEA, Gaertn。 = Psychotria, Lim (Rubiac.).

exserta, K. Schum. in Engl. Pflanzenw. Ost.-Afr. C (1895).392, - Afr. trop or

laviacea, K. Schum. 1. c. - Afr. trop. or

mesoplita, K. Schum, in Engl, \& Prantl, Natiirl. Pflanzenfam.iv. 4 (1891) $116=$ nesophiła, $F$ Mull.

platyphylla, K. Schum. in Engl. PAansenw. Ost.-Afn. C (1895) 392. - Afr. trop.or.

Purtschelleri. K. Schum, ex Engl, in Abh. Prcuss. Akad. Wiss. 1891 (1892) 401. - Afr. trop

serpens, K. Schum. in Engl, \&. Pranti, Natiirt Ptlanzenfam. iv. $4(1891) 116=\mathrm{P}$. serpens Lini stricta. K. Schim. 1. c. - N. Guin.

GRUSONIA Hort Nicolai, ex Ti Schum. in Monats schr. f. Kakteenk iv. (1894) 110. CACTEAE cereiformis. Hort. Nicolui, cx K. Simun.l. co-Hal 
GUADELLA, Franch, in Bull. Soc, Linn. Paris, i. (1887) 676, GRAIILNEAE.

marantifolia, Franch. l. c. - Gabon.

GUAIAGUM, Plum. ex Linn. (Zygophyll.). - Ind. Kew, i. 1068.

watemalense. Herb. Kew. ox T. Brigham, Guatem. App. (1887) 427, nomen. - Guatem.

GUAJAVA, Moehr. = Psidium. Linn. (Myrtac.) ctcukngula, aeruginea, alata, albida, amplexicaulis. anceps, anthomega, arborea, aquatica, argentea, aus tralis, basantha, Benthamiana, buxifolia, ciliata. cinerea, costaricensis, crenata, cuncata, cuprea, decussata, densicoma, Domiana, eleogns, firma, fluviatilis, Gardnuviana, glaucescens, grandifolia, herbacea, hians, humilis, inaequilatera, inconescens, indica, itanarensis, Iactea, lanceolata, Langsdorfi, Larnotteana, laurifolia, leptoclada, marahensis, macrosperma, maronhensis, mengahiensis, microcarpa, mollis. montana. Moritziana, Myrsinites, mutans, oblongata, oblong folia, Oerstediana, oligosperma, oioidea, ovatifolia paraènsis, paranemsis, pareiffora, persicifoliat, Pohliana. polycarpa, pumila, radicans, refracta, whombea Richardiana, Riedeliana, rifaria, robusta. rubescens Ruiziana, salutarss. Schiedeana, sericea. Sieberiana, sorocabensis, Sprucei, suffruticosa, turbiniflora, umbrosa. Widgreniana, ypanemensis, Kuntze Rev. Gen. (1891) 239-40 = homonyma ommia Psidii.

Bepteroana, Kuntze, 1. c. $240=$ P. Berterianum. Berg.

amponanesiodes, Kuntze, 1. c。 = P. campomanisioides, Berg.

Cattleyana, Kuntze, 1.c. $239=$ P. Cattleianum Surbine.

gluajabita, Kuntze, 1, C. $240=$ P. Guayabita, A. Rich.

guineensis, Kuntze, 1. c. 239 = P. Araça, Radd

marihensis, Kuntze, $1 . c_{c}=P$. maribense, Mart.

multiflora, Kuntze, 1. c, = Campomanesia multiflora, Blume.

myrsinodes, Kuntze, 1. C. $=$ P. myrsinoides, Berg (borata, Kuntze, 1.c. $=$ P. Cattleianumr, Sabine. myrtodes, Kuntze, 1. c. = P. myrtoides, Berg. pilosa, Kuntze, 1. $\mathrm{c}_{0}=\mathrm{P}$. rufum, Mart.

pyrifera, Kuntze, 1. co = P. Guajava, Linn.

salicifolia, Kuntze, 1. c. $240=$ P. crenatum Birg. striatula, Kuntze, 1. c. $239[$ sphalm. triatula $]=\mathrm{P}$ striatulum, $D C$

GUAPEBA, Gomez = GUAPEIBA, Gomez = Lucuma. Juss. (Sapot.).

mazonica, Pierre, Not. bot. Sapot.(1891) $43=$ Pouteria, amazonica, Radls.

Camito, Pierre, 1. c, $42=\mathrm{L}$. Cainito, $A, D C$

coracea, Pierre, 1. c, - Bras.?

crassifolia, Pierre, 1. c. $43=$ Pouteria amazonica, Radlk.

fragans, Pierre, 1. c. 41. - Parag.

Glazioreana, Pierre, L c, 43 nomen, - Bras.

glomeratc, Pierre, 1. c。 = L. glomerata, Miq.

gumphiaefolia, Pierre, 1. c. $43=$ Pouteria gomphiacfoliae, Radlk

laevigata, Pierre, 1. c, $42=\mathrm{L}$. laevigata, $A . D C$. lasiocarpa. Pierre, 1. c. = L. lasiocarpa, A. DC. Tucens, Pierre, 1. c, $43=\mathrm{L}$. lucens, Mart. E Miq. nestifolia, Pierre, 1 . c, 42 = L neriifolia, Hook of Arn.

mitida, Pierre, $1 . \mathrm{c}_{0}=\mathrm{L}$. nitida, $A . D C$

chosperma, Pierre, 1.c. $43=$ Pouteria amazonica Radli.

farmarioides, Pierre, 1. c. = L. parinarioides, Radlk.

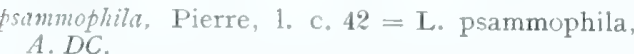

alicifolia, Pierre, 1. c, = Labatia salicifolia, Mart. semecarpifolia, Pierre, 1. c. 43 , nomen. - Ins. Martin.

tylosa, Pierre, 1. c. 42, - Panama.

forta, Pierre, 1. c. $43=$ L. torta, $A . D C$

GUARDIOLA, Cerv. (Compos.)。 - Ind, Kew, i. logs rotundifolia, Robinson, in Proc. Am. Acad. xxíx. 1894) 317 . Mexic
GUAREA, Allem. (Meliac.), - Ind. Kew. i. 1068. Balansae, C. DC. in Bull. Herb. Boiss, ii. (1894) 5 ris. - Paraw.

Bilibil. C. DC. . . c.570. - Columb.

dumetorum, C. DC. . . c. 569. - Parag.

frutescens, C. DC. i. c. 56\%. - Paras

Jaeggiana, C. DC. . . c. 570. - Bras.

leucantha, C. DC. l. c. 568. - Paras,

L'Herminieri, C. DC. l. c.5 5.1. - Ins. Guadal.

Luxii, C. DC, ex F. D. Snith, in Coult, Bot.Ga\%. xix. (1894) 2. - Guatem.

nemorensis, C.DC, in Bull, Herb. Boiss, ii. (1894) 569. - Parag.

Palmeri, N. E. Rose, ex C. DC. in Coult. l. co xix. (1894) 39. - Mexic

GUATTERIA, Ruiz \& Pav. (Anon.). - Ind. Kew. i. 1069 .

grandiflora, F. D. Smith, in Coult. Bot, Gaz, xiv. 1889) 25. - Guatem.

GUAZUMA. Plum, ex Adans, (Stercul.). - Ind. Kew。 i. 1070.

Guazuma, Cockerell, in Bull, Torrey Bot. Club, xix. (18:2) $95=$ tomentosa, $H . B . \& K$.

GUERKEA, K. Schum, in Engl, \& Prantl, Natürl. Pflanzenfam. iv. 2(1895) 180. APOCYNEAE.

floribunda, K. Schum.l.c. - Gabon.

GUETTARDA, Linn, (Rubiac.). - Ind. Kew。 i.

1.ricensis, K. Schum, ex Tonduz, in Bull, Horb. Boiss, ii. $(1895) \tau$, nomen. - Costarica.

Leai, Ridl. in fourn. Linn. Soc, xxvii. (1890) 40. Ins. Fernando Noronha.

macrosperma, f. D. Smith, in Coult. Bot. Gaz, xviii. (1893) 204. - Guatem.

GUIDONIA, P, Br. = Laetia, Adans, Bixin. .

apetala, calophylla, coriacea, corymbulosa, cupulata, lucida, procera, suatcolcns, Thamna, Kuntze, Rev. Gen. (1×91) 44 = homonyma omnia Laetiae.

cosandra, Kuntze, l. c. = L" Guidonia, Sw.

serrata, Kuntze, I. c. = Aphloia mauritiana, Baker.

ternstroemiodes, Kuntze, 1, c. = L. ternstroemioides, Griseb.

GUIDONIA, Plum. ex Adans, = Casearia, Jacq. (Samyd.).

amplissima, Baill. in Bull. Soc, Linn. Paris, i, (1886) $567=\mathrm{C}$. amplissima, $T_{u}$.

elliptica, Baill. 1. co = C. elliptica, Tul.

fragilis, Cordem. Fl. Ile Réunion $(18 \%) 35 \tau=\mathrm{C}$. tragilis, $V a h l$.

nigrescens, Baill. in Bull. Soc. Linn. Paris, i. (1886) $567=$ C. nigrescens, $T u l$.

orata, Baill. ex Laness. Pl, util. Colon. Franç. (1886) 379. - Afr trop. occ.

Tulasneana, Baill. in Bull. Soc, Linn. Paris, i. (1886) 566. - Madag.

GUILLANDINODES, Kuntze, Rev. Gen. (1891) $190=$ Schotia . Jacq. (Legumin.).

brachypetalum, capitatum, Forbesianum, latifolium, Kuntze, 1. c. $190=$ homonyma omnia Schotiae

afrum, Kuntze, 1. c. $190=\mathrm{S}$. speciosa, facq .

humboldtiodes, Kuntze, 1, c, = S. humboldtioides, oliver.

GUIOA, Cav. = Cupania, Linn. (Sapind.).

aryterifolia, Radlk. in Sitzb. Math.-Phys. Acad. Muench, xx. (1890) 357. - N. Guin.

cambodiana, Pierre, F1. For Cochinch. Fasc, $\mathrm{xx}$ 1894) t. 317a. - Cochinch.

comesperma, Radik. in Sitzb. Math.-Phys. Acad. Muench, xx. (1890) 357. - N. Guin

curvidens, Radlk. 1 c. 359. - N. Guil.

dictyophylla, Radlk。1. c. 360.--N. Guin.

hospita, Radlk. in Engl. \& Prantl, Natürl. Pflanzenfam. iii. 5 (1895) $346 .-\mathrm{N}$. Guin.

macropetala, Radlk. in Sitzb. Math.-Phys. Acad. Muench. xx. (1890) 357. - N. Guin.

platycarpa, Radlk. 1. c. 359.-N. Guin.

plurinervis, Radlk. in Engl. \& Prantl, Natürl, Pflanzenfam. iii. 5 (1895) 346. - N. Guin. subserrata, Radlk, in Sitz. Math-Phys. Acad. Muench, xx. (1890) 358. - N. Guin.
GULDENSTAEDTIA, Dum. = Gueldenstaedtia Fisch. \& Mey. (Legumin.)

junnanensis, Franch. Pl. Delav. (1890) 164 t. 40. Yunnan.

GUMIRA, Rumph.= Premna, Linn. (Verben.) abbreriata, acuminata, adenosticta, amplectens, attenuata, barbata. bengalensis, bracteata, cardiophylla, ceramensis, cordifolia, coriacea, corymbosa, Cumingiana, cyclophylla, Dallachyana, divaricata, esculenta, ferru ginea, facescens, grossa, herbacea, hispida, integerrima, interrupta, japonica, khasiana, laevigata. leucostoma, limbata, longifolia, lucidula, macrophylla. marianarm, nicrantha, microphylla, milleflora, nauscosa, nitida, oblongata, opulifotia, philiptinensis, pinguis, proiumbens, pubescens, punctulata, punduana purpurascens, pyramidata, quadrifolia, racemosa, resinosa, scandens, senensis, taitensis, Thwaitesii, restita, villosa, Wightiana, Kuntze, Rev, Gen. (1891) 507 $08=$ homonyma ommia Premnae

mollissima, Kuntze, 1. c. $508=$ P. latifolía, Roxb. odorata, Kuntze, 1. c. = P. pubescens, Blume. thyrsodea, Kuntze, 1. c。 = P. thyrsoidea, Wight. trichostoma, Kuntze, 1. c. = P. parasitica, Blume. truncata, Kuntze, 1. c. $=$ P. corymbosa, Rottl. $\delta$ IVilld.

riburnodes, Kuntze, 1. c. = P. viburnoides, A. Rich

GUNDELIA, [Tourn.]. Linn. (Compos.). - Ind. Kew. i. 1072.

tenuisecta, Freyn \& Sint. in Oest. Bot. Zeitsclsr. xlii. (1892) 168. - Armen.

GUNNERA, Linn. (Halorag.), - Ind. Kew. is 1072 .

arenaria, Cheesem.ex T.Kirk, in Trans. N.Z. Inst, xxvii. 1894 (1895) 348. - N. Zel.

dentata, T. Kirk, l. c. 346.- N. Zel.

elongata, $T$, Kirk, 1, c, $345=$ flavida, Colenso

microcarpa, T. Kirk, l.c.348. - N. Zel.

mixta, T. Kirk, l. c. 344. - N, Zel.

orata, Petrie, 1. c. xxv. 1892 (1893) $274=\operatorname{mixta} \&$ flavida, Colenso.

GUNNIOPSIS, Pax, in Engl. \& Prantl, Natürl. Pflanzenfam. iii. 1b (1889) $44=$ Aizoon, Linn (Ficoid.).

quadrifaria, $\mathrm{Pax}, 1 . \mathrm{c} .=\mathrm{A}$. quadrifarium, $F$. Muell.

GURANIA, Cogn. (Cucurbit.). - Ind. Kew. i. 1072.

boliviana, Rusby, in Mem. Torrey Bot. Club, iii. 3 (1893) 38. - Bolivia.

Cogniauxiana, Rodr. Pl. non'. Fard. bot. Rio, iv (1894 16 t. 4. - Bras.

Donnell-Smithii, Cogn.ex F. D. Snith, in Coult. Bot. Ga\%, xvi. (1891) 10. - Guatem

macrophylla, Rodr. Pl.nov. Fard.bot. Rio, iv, (1894) 10 t. 3. - Bras.

GUSSONIA, Spreng. = Actinostemon, Mart. (Euphorb.).

angustifolia, Kuntze, Rev, Gen, (1891) $606=\mathrm{A}$ caribaeus, Griscb. ?

australis. Kuntze, 1. c. (= Dactylostemon australis, Muell. Arg.). - Bras

brasiliensis, Kuntze, 1. c. = A. Sprengelii, Baill.

bundiana, Kuntze, 1. c. (= Dactylostemon Lundianus,

Didr $)=$ A. lasiocarpoides, Baill.

cumeata, Kuntze, 1. $\mathrm{c}=\mathrm{A}$, cuneatus, Baill.

desertorum, Kuntze, 1. c. (= Dactylostenon descrtorum, Muell. Arg.). - Bras

cchinata, Kuntze, 1. c. = A. echinatus, Muell. Arg. estrellensis, Kuntze, 1.c. (= Dactylostemon estrellensis. Muell. Arg.), - Bras.

Gadneri, Kuntze, 1. c. $(=$ D. Gardneri, Muell. Arg.). - Bras.

grandifolia, Kuntze, 1. c. (= D. grandifolius, Klotzsch) = A. Klotzschianus, Baill.

imbricata, Kuntze, 1. c. = A. imbricatus, Muell. Arg.

Iagoënsis, Kuntze, 1. c. (= Dactylostemon lagoënszs, Muell. Arg.). - Bras.

lanceolata. Kuntze, 1. c. $=$ A. lanceolatus, Saldanka. lasiocarta, Kuntze, 1. c. = A. lasiocarpus, Baill. 
GUSSONIA :-

Leptopus, Kuntze, Rev. Gen. (1891) 606 (= Dactylostemon leptopus, Muell. Arg.). - Bras.

macrocarpa, Kuntze, 1. c. = A. macrocarpus, Muell. Arg,

mandiocana, Kuntze, 1. c. (= Dactylostemon mandiocamus, Muell. Arg.). - Bras.

multiflora, Kuntze, 1. c. = A. caribaeus, Griseb,

oligandra, Kuntze, 1. с. = A. oligandrus, Baill.

sparsifolia, Kuntze, 1. c. (= Dactylostemon sparsifolins, Muell. Arg.). - Bras.

trachycarpa, Kuntze, 1. c. = A. trachycarpus, Mulll. Arg.

rerticillata, Kuntze, 1. c. A. verticillatus, Baill.

GUSTAVIA, Linn. (Myrt.). - Ind. Kew。i 1073 .

hexapetala, Hook, ex Urb. in Bot. Jahrb. xix. (1894) $669=$ antillana, Miers.

GUTENBERGIA, Sch. Bip. (Compos.), - - Ind Kew. i. 1073

leiocarpa, O. Hoffm, in Engl. Pflanzenw. Ost,-Afr. C (1895) 402. - Afr. trop, or.

GUTIERREZIA. Lag. (Compos.), - Ind. Kew. i. 1073.

baccharoides, Phil. in Anal. Univ. Chil, 1xxxvii (1894) 428. - Chili.

compacta, Phil. l. c. $42 \%$ - Chili.

copiapina, Phil. l. c, 425, - Chili.

Iserni, Phil. l. c. 427 (= Brackyris Iserni, Phil.) Chili.

paniculata, Fr. Meigen, in Bot. Jahrb, xvii. (1893) 281 ; et xviii. (1894) 444 [an $G$. paniculata, A Gray ?]-- Chili.

Sarothrae, Britton \& Rusby, in Trans. N. Y. Acad. Sci. vii. (1887) $10=$ G. Enthamia, Torr. \& Gray.

Sarotihrae, Kuntze, Rev. Gen. (1891) $341=$ praec. spathulata. Phil. in Anal. Univ. Chil. lxxxvii. (1894) 426. - Chili.

taltalensis, Phil. l. c. - Chili.

GUZMANIA, Ruiz \& Pav, (Bromel.). - Ind. Kew. i. 1074 .

angustifolia, Wittm. in Bot. Jahrb. xi. (1890) $62=$ Caraguata angustifolia, Baker.

Bulliana, Ed. André, in Rev. Hortic. (1886) $324=$ C. angustifolia, Baker.

crispa, Baker, in fourn. Bot. xxv. (1887) 173; t Handb. Bromel. (1889) 153. - N. Granat.

Furstenbergiand, Wittm. in Bot. Jahrb. xi. (1890) 61 = Caraguata Furstenbergiana, Kirch. \& Wittm. grandis, Hort, Lind, ex Baker, Handb. Bromel. (1889) $50=$ Aechmea mexicana, Baker.

imperialis, Hort. ex Éd. André, Bromel. Andrean. (1889) 96 , in syn $=$ Tillandsia nigrescens, $E d$. André.

Kraenzliniana, Wittm. in Bot. Fahrb. xi. (1890) 62. - Columb

maculata, Hort. ex Baker, Handb. Bromel. (1889) 47 = Aechmea augusta, Baker.

spectabilis, Hort. ex Baker, 1. c. $51=$ Aechmea spectabilis, Brongn.

GYMINDA, Sarg. in Gard. and For. iv, (1891) $4=$ Myginda. Jacq. (Celastr.)

Grisebachii, Sarg. 1. c. = M. integrifolia, Poir.

GYMNAGRANTHERA. Warb. in Ber. Deutsch. Bot. Ges. xiii. (1895) [94.] MYRISTICACEAE.

GYMNADENIA, R. Br. = Habenaria, Willd. (Orchid.).

Aschersoni $\times$, Bruegg. \& Killias, in Jahresb. Naturf Ges. Graub. xxxi. Beil. (1887-88) 175. - Helv.

Aschersoniana, “Bruegg. \& Killias 》 ex Nym. Consp. Fl. Europ. Suppl. ii. i. (1889) $293=$ praec.

cyclochila, Korshinsky, in Act. Hort. Petrop. xii. (1892) $396=$ H. cyclochila, Franch. \& Sav.

Heuflevi, X, Wettst. in Ber. Deutsch. bot. Ges, vii. (1889) $=\mathrm{H}$. nigra, $R . \mathrm{Br}$

Le Grandiana X, G. Camus. in Bull. Soc, Bot. Fr. xxxvii. (1890) 217. - Gall.
GYMNADEN゙IA :

Mac Owaniana, Schlechter, in Verh. Bot. Ver. Brand. xxxv. (1893) $46=$ Brachycorythis Mac Owaniana, Reichb. f.

micrantha, Wettst, in Ber. Deutsch. Bot. Ges, vii. (1889) $308=$ micrantha, Kern.

nigra, Wettst. in Verh. zool.-bot. Ges, Wien (1889) 83; et in Ber. Deutsch. Bot. Ges, vii. (1Ss9) 308 $=\mathrm{H}$ nimra, $R \cdot B$

pyrencica, Girandias, in Morot, Jcurn. de Bot. vi. (1892) $4 \% 9=$ pyrenaica, Philitpe.

rubra, Wettst. in Verh. zool.-bot Ges. Wien, (1889) 83 ; et in Ber. Deutsch. Bot. Ges. vii. (1889) = Nigritella rubra, C. Richt.

sesamoides, Parish, in Grant, Orchids of Burma, 1895) 326. - Burma.

souppensis $X, G$. Camus, in Bull. Soc. Bot. Fr. xxxviij. (1891) 167; et Atlas Occh. env. Paris t. $35 .-$ Gall.

Stracheyi, Hook, f. Fl. Brit. Ind, vi. (1830) 128. Reg. Himal.

suaveolens, Wettst. in Ber. Deutsch. Bot. Ges. vii. (1889) 317 in obs, = H. nigra, $R, B r$.

GYMNAGATHIS, Stapf, in Ann. Bot, vi. (1892) 315. MELASTOMACEAE

peperomüfolia, Stapf, l.c. $(=$ Sonerila peperomiifolia, Oliver). - China.

GYMNANTHERA, R. Br. (Asclep.). - Ind. Kew. i. 1075 .

paludosa, K. Schum. in Eng1, \& Prantl, Natiirl. Pflanzenfam. iv. 2 (1895) 213 = Dicerolepis paludosa, Blume.

GYMNEMA, R, Br. (Asclep,), - Ind.-Kew. i. 1075.

cuspidatum, Kuntze, Rev. Gen.(1891) $420=$ pergularioides, Wight \& Gardu.

cuspidatum, K, Schum. in Engl. \& Prantl. Natür1. Pflanzenfan. iv. $2(\mathbf{1 8 9 5}) 284=$ praec

longepedunculata, Schweinf. in Hoelhnel, zum Rudolph See. App. (1892) 8 [longepedunculatum]. - Afr. trop.

parvifolium. Oliver, in $H$. folmston, The Kilim. Exped., App. (1856) 343, nomen; et in Trans. Limn. Soc. Ser. II, ii. (1887) 342 - Afr. trop, or.

GYMNIGRITELLA $X, G$. Camus, in Morot, Journ. de Bot. vi. (1892) 484 (Orchid.).

Heufleri $X, \mathrm{G}$. Camus, 1. c. (= Nigritella, Henfleri, Kern. $)=$ Habenaria nigra, $R . B r$.

suaveolsns $\bar{X}, \mathrm{G}$. Camus, 1. C. $(=$ Nigritella suaveolens Koch) $=\mathrm{H}$. nigra, $R . B r$.

GYMNOGARPOS, Forsk. (Illecebr.). - Ind. hew

i. 1076.
salsoloides, Webb, ex Christ, in Bot. Fahrb. ix. (1888) 104. - Ins: Canar.

G YMNOLOMiA, H. B. \& K. (Compos.)。 - Ind.

Kew. i. 1076.
canescens, Robinson, in Proc. An. Acad. xxvii. (1893) 174. - Mexic.

decumbens, S.Wats. l. c. xxvi. (1891) 165. - Mexic.

decurrens, Fratt, in Leopoldina, Heft xxiii. (1887) 90. - Mexic

Ehrenbergiana, Klatt, l. c. - Mexic.

hirsuta, Klatt, in Bot. falkb. viii. (I887) 42. Ecuad.

Liebmannii, Klati, in Leopoldina, Heft xxiii. (188i) 90. - Mexic.

rudis, A. Gray, in Proc. Am. Acad. xxii. (1887) 424. - Mexic.

sericea, Klatt, in Leopoldina. Heft xxiii. (1887) 90. - Mexic.

silvatica, Klatt, l. c, xxv。(1889) 104 ; et ex Th, Dur. et Pitt. in Bull. Soc. Bot. Belg. xxxi。 (1893) 199 [sylvatica]. - Costarica.

tripartita, Robinson, \& Greenm. in An. fourn. Sci. Ser. III. 1. (1895) 154, - Mesic.

GYMNOLUMA, Baill. Hist. des pl. xi. (1892) $292=$ Lucuma, Molina (Sapot.).

glabrescens, Baill. 1. co = L. glabrescens, Mart. \& Eichl.
GYMNOPENTZIA, Benth. (Compos.). - Ind. Kew, j. 1076

pilifera, N. E. Br. in Kew Bull. (1895) 26. - Natal.

GYMNOPETALUM, Arn.(Cucurbit.). - Ind. Kew. i. 1076

lemcostichum Cogn. in Boerl. Handl. Fl. Ved Indië, I. ii. (1890) $595=$ leucostictum, Miq.

GYMNOPOGON, Beauv. (Gramin.). - Ind. Kew

ambiguns, Britton, Stern \& Pogg. Prelim. Catal. (1888) $69=$ racemosus, Bean?

mesense, Schweinf. in Bull. Herb̆. Boiss, ii. App. 2 (1894) 32. - Abyss.

rupestre, Ridl. in fourn. Linn. Soc. xxrii. (1890) is - Ins. Fernando Noronha.

GYMNOSIPHON, Blume (Burmann.). - Ind Kew, i. 1077

Trinitatis, fohow, in Pringsh. fahrb.xx. (1889) 477 - Ins. Trinit.

usambaricus, Engl. Bot. Fahrb. xx. (1894) 138.Afr. trop, or.

GYMNOSPORIA. Benth. \& Hook. f. (Celastr.) Ind. Kew i $10 \%$.

acuminata, Szyszyl. Pl. Rehmann. ii. (188s) :3: = Celastrus acuminatus, Linn

ambonensis, Loesen, in Bot. Falurb. xix. (189t) 231 - Afr. trop. or.

Bachmannii, Loes 7. c. 232 - Afr austr -

buxifolia, Szyszyl.P1. Rehmann. ii.(1888) $34=$ Celastrus buxifolius, Limn.

crenulata, Engl. Bot. Fahrb. x. (1889) 38. - Afr austro-occ. extratrop.

cuneifolia, Baker, in funm. Linn. Soc, xxii. (1887) 460. - Madag.

fasiculata, Loesen, in Bot. Fahrb. xix. (1894) $232(=$ Catha fasciculata, Tul.). - Malaya.

gracilipes, Loesen, in Engl. Pflanzenw. Ost.-Afr. C (1895) $246=$ gracilipes, $W$ elw.

gracilis, Pierre, Fl. For. Cochinch. Fasc, xix. (18??) t. $304 \mathrm{~b} .-$ Cochinch.

Juillensis, Szyszy]. P1. Rehmann. ii. (1888) $35=$ Celastrus huillensis, $W$ clw.

laurina, Szyszyl. 1. c. $=$ C. laurinus, Thunb

luteola, Szyszyl. 1. c. = C. luteolus, Deli? 。

mekongensis, Pierre, Fl. For. Cachinch. Fasc. xix. (1893) t. 303a. - Cochinch.

nemorosa, Szyszyl. 1. c. = C. nemornsus, Eikl. E Zeyh.

obscura, Engl. Pfanzenw. Ost.-Afr. B (1895) 509 nomen. - Afr, trop.

pallida, Collett of Hensl. in fourn. Linn. Soc. xxirii (1890) 32. - Burma.

polyacantha. Szyszyl. Pl. Rehmann. ii. (18S81:3:3= Celastrus polyacanthus, Sond

putterlickioides, Loesen. ex Engl. in Abh. Prouss. Akad. Wiss. (1894) 25 et 51. - Afr. trop

Rehmannii, Szyszyl. Pl. Rehmann。ij.(1888) 34.Natal.

Schlechteri, Loesen. in Bull. Herb. Boiss, ii. 1894 193. - Afr. austr.

stylosa, Pierre, Fl. For. Cochinch. Fasc. xix. (1893) t. 304a, - Cochinch.

temispina. Szyszyl. Pl. Rehmann. ii. (1888) $33=$ Celastrus tenuispinus, Sond.

undata, Szyszyl. 1. c. $33=\mathrm{C}$. undatus, Thunb.

Woodii, Szyszyl, i. c. 35. - Natal

Zeyheri, Szyszyl. 1. c. $33=$ Cel. Zeyheri, Sond.

GYMNOSTACHYUM, Nees (Acanth.). - Ind

Kew. 1. 1077 .

decurrens, Stapf, in Kew Bull. (1894)35\%. - Pahang.

GYMNOTHRIX, Spreng. = GYMNOTRIX, Beanv. Pennisetum, Pers, (Gramin.)

cladodes, Hochst. ex Engl. in Abh. Preuss, Akad.

Wiss. $1891 \mathrm{ii}$. (1892) 123, in syn。 $=\mathrm{P}_{\text {. slaucifo- }}$ lium, Hochst.

GYNANDRIRIS, Parl. = Iris, Tourn

sicula, Todaro, Hort. bot. Panorm. ii. (18?(3) 4:? in syn. (Gynandrisis) = Moraea sicula, Todirw. 
GYNERIUM. Humb. \& Bonpl. (Gramin.).- Ind Kew, i, 1078.

triaristatum, Sodiro, Gram. Ecuator. (Anal. Univ. Quito, 1889) 8, nomen. - Ecuad.

IVolfii, Sodiro, l. c. - Ecuad.

GYNOCHTHODES, Blume (Rubiac.). - Ind. Kew i 10 to

ctrandra, Kuntze, Rev, Gen. (1891) $284=$ sublanceolata, Miq.

GYNOPLEURA, Cav, (Passifl.), - Ind. Kew。 i. 1079 .

ungosa, Ball, in foum. Linn. Soc. xxv. (1886) 159 $i=$ Malesherbia rugosa, C. Gay). - Chili.

GYNOPOGON, Forst. - Alyxia. Banks (Apocyn.). acuminatus, K. Schum. in Engl. \& Prant1, Natürl. Phanzenfam. iv. 2(1895) 151. - N. Guin.

breripes, Baill, in Bull. Soc. Linn. Paris, i. (1889) 7\%6. - N. Caled.

buxitolius, K. Schum, in Engl. \& Prantl, Natürl. Pflanzenfam. iv. $2(1895) 151=$ A. buxifolia, IR. $B$ r.

culetioides, Baill. in Buil, Soc. Linn. Paris, i. (1889) 781. - N. Caled.

colastrinus, Baill. 1, c. [colastrinm ] - N. Caled.

clusiophyllus, Baill. 1.C.[chusiophylhum] - N. Caled

coriacers, K. Schum, in Engl. \& Prantl, Natürl. Pflanzenfam. iv. $2(1895) 151=\mathrm{A}$. coriacea, IVall.

crythrocarpus, K. Schum. 1, c. = A. erythrocarpa, Vathe.

fascicularis, K. Schum. 1. c. $151=$ A. fascicularis, Benth.

gracilis. K. Schum. 1. C. = A. gracilis, Benth.

ilicifolius, K. Schum. 1. $\mathrm{c}$. $=$ A. ilicifolia, $F$. Aruell.

Labillardieri, K. Schum. 1. c. = A. stellata, Roem. E Schult.

linurincus, K. Schum. 1. c, = A. laurina, Gandich.

lutrinus, Baill, in Bull. Soc. Linn. Paris, i. (1889) 781 [laurinum]. - N. Caled.

madagascariensis. K. Schum, in End. \& Prantl, Natïrl. Pflanzenfam, iv, $2(1895) 151=\mathrm{A}$. madagascariensis, A. DC.

Microbuxus, Baill, in Bull. Soc, Linn. Paris, i. (1889) 7\%6. - N. Caled.

pumilus, K. Schum. in Engl. \& Prantl, Natürl. Pflanzenfam. iv. 2 (1895) $151=$ A. pumila, Hook. $f$.

rosmarinifolius, Baill. in Bull. Soc, Linn. Paris, i. (1889) 781 [rosmarinifolizm]. - N. Caled.

mbricaule, Baill, 1. c. 776. - N. Caled.

ruscifolia, K. Schum. in Engl. \& Prantl, Natürl. Pflanzenfam.iv, $2(1895) 151=$ A. ruscifolia R. Br.

supiifolins, Baill. in Bull. Sòc. Linn. Paris, i. (1889) 775 [sapiifolium]. - N. Caled.

cmperflorens, K. Schum. in Eng1. \& Prantl, Natürl. Pflanzenfam. iv. 2 (1895) $151=$ A. semperflorens, Panch. [fide Kuntze].

cllatus, Baill. Hist. des pl. x. (I888) 1\%1, in nota [ stellatum $]=$ stellatum, Forst.

ravis, Baill, in Bull. Soc. Linn. Paris, i. (1889) 775 [suave $]$ - N. Caled.

torquatus, 1. c. 781. - N. Caled.

reylanicus, K. Schum. in Engl. \& Prantl, Natürl. Pflanzenfam. iv. $2(1895) 151=\mathrm{A}$. ceylanica IVight.

GYNOSTEMMA, Blume (Curcurbit.) - Ind Kew, 1. 1079.

cardiosperma, Cogn.ex Oliver, in Hook. Icon.pl.xxiii 1892) t. 2225. - China.

GYNOXYS, Cass. (Compos.). - Ind. K w. j. 1079. Hallii, Hieron. in Bot, fahrb, xix (1894) 64. licuad

nervosa, Hicron. l. c. xxi. (1895) 354.- N. Granat. psilophylla, Klatt, in Amal. Natim. Hofmus. Wien ix. (1894) 357. - Bolivia.

Stuebelii, Hieron. in Bot. Fahrb. xxi. (1895) 355.Jicuad.

Trianae, Hieron.l c $3.3-\mathrm{N}$ Granat.
GYNURA, Cass. (Compos). - Ind. Kew, i. 1079. auriculata, Klatt, ex Schinz, in Bull. Herb. Boiss, iii. (18.5) 426. - Angola.

aurita, C. Winkl, in Act. Hort. Petrop. xiv. (1895) 151. - China.

coerulea, O. Hoffm. in Bull. Herb. Boiss. i. (1893) 86. - Afr, austro-occ, extratrop.

Fischeri. O. Hoffn, in Engl, Pfanzenw. Ost-Afr. C (1895) 4l6, - Afr. trop. or.

Meyeri-Johannis, $O$. Hoffm.. . c. - Afr. trop. or

purpurascens, Vidal, Rev. Pl. Vasi. Filip. (1886) 164. - Ins. Philip.

scandens, O. Hoffm. in Engl. Pflanzenw. Ost-Afr. C (1895) 416. - Afr, trop. or.

sonchifolia, Baker, in foum. Limi. Soc. xxii. (1887) 495. - Madag.

Valeriana, Olizer, in Hook. Icon, pl.xvi. (1886) t 1507; et in Trans. Limn. Soc. Ser. II. ii. (1887 339. - Atr. trop. or

zeylanica, Trim. Handb. Fl. Ceyl iii. (1895) 44; et Pl. illustr. Handb. Fl. Ceylon (1895) t. 58. - Zeyl.

GYPSOPHILA, Linn. (Caryophyil.). - Ind. Kew i. 1080 .

antilibanotica, Post. Pl. Postianae, ii. (1891) 6. Syria.

arsusiana, Williams, in foum Bot, xxvii. (1889) 322 (= Ankyropetalum arsusianum, Kotschy). - Syria. biovulata, Stapf, in Hook. Icon. fl. xxiv. (1894) t. 2332. - Persia.

capillipes, Freyn of Sint. ex Freyn, in Dest. Bot. Zeitschr, xli. (1891) 363. - As, Min.

cuelosyriaca, Williams, in fourn, Bot. xxvii. (1889) 322. (= Ankyropetalum coelosyriacum, Boiss. \& Hausskn.). - Oriens.

digenea X. Borb, in Termész. Füzet. xiii. (d890) 84. - Hung

Haussknechti, Boiss. Fl. Or., Suppl. (18S8) S6.Mesopot.

herniarioides, Boiss. l. c. 84. - Afghan

hygrophila, Post, Pl. Postianae, ii, (1891) 6. Syria.

hungarica, Borb, in Doerfler, Herb. norm., Sched. ad Cent xxxi. (1894); ex Uest. Bot. Zeitschy. xliv. (1894) $462=$ paniculata, Lim.

Jaubertiana, Boiss. Fl. Or. Suppl. (1888) $89(=G$ spergulaefolia, Boiss.). - As. Minor.

laconica, Boiss. \& Heldr.ex Boiss. l.c.88. - Graecia. lignosa, Hemsl. \& Lace, in Fourn. Limn. Soc. xxviii. (1891) 322. - Belutch. brit

pallida, Stapf, in Denkschr. Acad. Wien (1886) 13.Persia.

pinifolia. Boiss, et Hausskn, ex Boiss. Fl. Or. Suppl.

(1888) 87. - As. Min.

platyphylla, Boiss. l. c. - Turkest.

producta, Stapf, in Denkschr. Acad. Wien (1886) 12. - Persia

pulchra, Stapf, l. c. 13. - Persia.

Raddeana, Regel. in Act. Hort. Petrop.x. ( ) 698 ; et in Gartenf. xli. (1892) 89 fig. 3-8. - Turkest.

Reuteri, Willians, in fourn. Bot, xxvii. (1889) 32? (=Aukyropetalum Reuteri, Boiss. \& Hausskn.).Oriens

GYROSTACHYS, Pers. = Spiranthes, Rich. (1818) (Orchid.)

acutata, aguacatensis, apiculata, aprica, Arrabidae assurgens, aurantiaca, balanophorostachya, bicola bonariensis, bracteosa, brevifolia, brevilabris, campunum, cermu, chilensis, chlorops, cinnabarina, comosa congesta, costaricensis, cuculligera, cuspidata, dilatata. cnsitolia, Engenii, gracilis, graminca, grandiflora, gutturosa, hemichroa, hirta, homalogastra, inaequilagutturosa, hemichroa, harta, homalogastra, inaequilapetiolata, lupulina, macrantha, macrostachya, ma drensis, Mandonii, mechoacana, minor, minutiflora, montana, nesophila, neuroptera, odorata, ocstrifera. orthosepala, ovalis, pauciflora, peruviana, picta, plantaginea, polyantha, porrifolia, prasopliylla, pterygantha, pyramidalis, ramentacea, rupestris, saccata, sagittata, sancta, Schaffneri, Scopulariae, simplex, Smithii, stylites, tenuis, thelymitra, trilineata, truncata coginata vermalis, villose. Warmingii, Kuntze, Rev. Gen. (1891) 663-64 = homonyma ommia Spirantheos.

afhylla, Kuntze, 1, c. $664=\mathrm{S}$. orchioides, A. Rich.
GYROSTACHYS : -

chloriformis, Kuntze, Rev. Gen. (1891) $664=\mathrm{S}$ chloreaeformis, A. Rich. \& Gal.

Funkiana, Kuntze. 1. c. $=$ S. Funckiana, $A$. A. Rich. \& Gal.

gemmipara. Kuntze, 1. c. = S. Romanzoffiana, Cham. Es Schlecht.

Haenkeana, Kuntze, 1. c. $663=$ S. peruviana, Presl.

Pruntze, 1. c. $664=$ S. Hostmanni. Reichb. $f$.

lanceolata, Kuntze, 1. c. $663=\mathrm{S}$. orchioides, $A$. Rich.

lanceolata, Kuntze, 1. c. $664=\mathrm{S}$. orchioides, $A$. Ricil

nowifuburgcnsis, Kuntze, $1, \mathrm{c},=\mathrm{S}$, australis, Lindl. orchiodes, Kuntze, 1. c. = S. orchioides, A. Rich. oíalifolia, Kuntze, 1. c, = S. Preslii, Lindl.

papulosa, Kuntze, 1. c. $\longleftrightarrow=$ Stenorhynchus papulosus Lind1.). - Mexic

praecox, Kuntze, 1.c. $663=$ S. gracilis, Beck.

Romanzoffana, MacMill. Metasp. Minn. (1892) 71 $=\mathrm{S}$. Romanzoffiana, Chan .

sarcoglossis, Kuntze, Rev. Gen. (1891) $663=\mathrm{S}$. speciosa, Lindl.

sceptrodes, Kuntze, 1. c. $664=$ S. sceptroides, Reichb. $f$.

speciosa, Kuntze, 1, c, = S. colorata, N.E. Br.

spiralis, Kuntze. 1. $\mathrm{c},=\mathrm{S}$. autumnalis, Rich.

Stenorliynchus, Kuntze, 1. c. = S. australis, Lindl.

sulfurea, Kuntze, 1. c. = S. sulphurea, Hemsl.

milateralis, Kuntze, 1. c. $663=\mathrm{S}$. diuretica, Lindl.

Vightiana, Kuntze, 1. c. = S. australis, Lindl.

GYROSTEMON, Desf. (Phytolacc.). - Ind. Kew. i. 11981 .

australasicum, Heimerl, in Eng1. \& Prantl, Natürl. Pflanzenfam. iii. 1b (1889) $12=$ G. Cyclotheca, Benth.

GYROTHECA, Salisb. = Lachnanthes, Ell. (Haemod.)

capitata, Morong, in Bull. Torrey Bot. Club, $\mathrm{xx}$. 1893 472; et in Mem. Torrey Bot. Club, v. (1894) $11 \%=\mathrm{L}$. tinctoria, Ell.

\section{$\mathrm{H}$}

HAASTIA, Hook. (Compos.). - Ind. Kew. i. 1082. montana, 7. Buch. in Trans. N. Z. Inst. xix. 1886 (1885) $215 .-\mathrm{N}$. Zel

HABENARIA. Willd, (Orchid.), - Ind. Kew, i. 1022

achalensis, Kraenzl. in Bot. Fahro. xvi. (1893) 133. - Reg. Argent.

aequatorialis, Rendle, in fourn. Linn. Soc. xxx, (1895) 391. - Afr. trop. or

Aitchisoni, Reichb. f. ex Aith. E Hemsl. in Trans, Linn. Soc. Ser. II. iii. (1886) 113; Boiss. Fl. Or. Suppl. (1858) 370 [Aitchisonii]. - Afghan.

alpestris, Cogn. in Mart. Fl. Bras, iii. IV. (1893) 74 . - Bras.

altior, Rendle, in foum. Limn. Soc. xxx. (1895) 394. - Afr. trop. or

amalfitana, Lchm. \& Kraenzl. ex Kraenzl, in Bot. Fahrb. xvi. (1893) 113. - Columb.

andamanica, Hook. f. Fl. Brit. Ind. vi. (1890) 134. - ]ns. Andam.

ancuiceps, Bolus, in fourn. Limn, Soc. xxy. (1889) 164. fig. 2. - Afr. austr.

angustata, Kuntze, Rev. Gen. (1891) 664. - Java.

anomala, Lindl. ex Kraenzl. in Bot. Fahrb. xri. 1843) 206.- - Abyss.

arachnoides, Macowan, ex Kraenzl, 1. c. 150 in syn. $=$ H. MacOwaniana, Kraenzl.

arcuata, Hook. f. Fl. Brit. Ind. vi. (1890) 155, Reg. Himal.

Arechavaletae, Kracnzl. in Bot. Falwo. xvi. (1893)

185. - Urug.

arietina, Hook.f. Fl. Brit. Ind. vi. (1890) 138.-

Reg. Himal,

aristata, Hook. f. l. c. 158. - Ind, or, Zeyl. 
HABENARIA :

aurea, Kracusl. in Bot. Fahrb. xvi. (1893) 209. Afr. trop. occ

avana, Hook. f. Fl. Brit. Ind. vi. (1890) 148.Burma.

Barberae, Schlechter, in Bot. Fahrb. xx. Beib1, n. 50 (1895) 7. - Afr. austr.

barrina, Ridl. in Bolet. Soc. Brot. v. (188T) 202 t. d fig. b. - Ins. S. Thom.

Bauerleni, F. Muell. E Kraenzl. ex Kraenzl. in Bot, fahrb. xvii. (1893) 488. - N. Guin

bicornuta, Hook. f. Fl. Brit. Ind. vi. (1590) 150.Ind. or.

Blumei, Kuntze, Rev. Gen. (1891) 664 (= Platanthera Blumei, Lind1.). - Java.

Bonatea, Pfitz. in Engl. \& Prantl, Natürl. Pflanzenfam ii. 6. (1888) $95=\mathrm{H}$. Bonatea, Reicht. $f$

borneensis. Rial. ex Stapf, in Trans. Linn. Soc. Ser. II. iv. (1894) 240. - Borneo.

brachyphylla, Reichb. f. ex Aitch. \& Hemsl. l.c. Ser. II. iii. (1886) $113=$ brachyphylla, Aitch.

brachyphylla, Kraenal. in Bot. Falhrb. xvi. (1893) 153 (= Platanthera brachyphylla, Kraenzl.). Ind. or.

bracteata, Matsudaira, in Tokyo Bot. Mag. ix. (1895) 4\%0. - Japon.

Brandisii, Hook. f. Fl. Brit. Ind. vi. (1890) 160. Pegu.

breviloba, Hook. f. l. c. 159. - Zeyl.

Buchananiana, Kraenal. in Bot. fahrb. xix. (1894) 247. - Afr. trop.

Buettneriana, Kraenzl.l. c.xvi. (1893) 68. - Togo.

caldensis, Kraenzl. l. c. $128(=H$. paludosa, Rodr.). - Bras.

camptoceras, Rolfe, ex Hemsl. in Fourn. Limn. Soi. xxix, (1892) 319. - China occ.

candida, Lindl. ex Kracnzl. in Bot. Fahrb. xvi. (1893) 217. - Afr. trop. occ

Candolleana, Cogn. in Mart. Fl. Bras, iii. IV. (1893) 73. - Bras.

cardiochila, Kraenzl, ex Engl, in Abls. Prenss, Akad. Wiss, 1991. ii. (1892) 182, nomen; et in Bot fahrt. xvi. (1893) 144. - Afr. trop. or.

carnea, N.E.Br. in Gard. Chron. (1891) ii. 729, fig 105 ; et (1892) ii. $300 \mathrm{fig.} \mathrm{51.} \mathrm{-} \mathrm{Penang.}$

Childori, Makino, in Tokyo Bot. Mag. vi. (1892) 48. - Japon.

chloroleuca, Frapp, ex Cordem. Fl. Ile Rénnion (1895) 257. - Ins. Borbon

ciliolaris, Kraenzl. in Bot. Falırb. xvi.(1893) 169. Ins. Hongkong

cinnabarina, Rolfe, in Kew Bull. (1893) 173.Madag.

Clarkei Kracnzl. in Bot. Fahrb. xvi.(1893) 148. Ind, or.

combrista, Rill. in fourn. Bot. xxiv. (1886) 294. Abyss.

Commersoniana, Cordem. Fl. lle Réunion (1895) $259=$ seq.

Commersoniana, Th. Dur. \& Schinz, Consp. Fl. Afr. v. 1892 (1895) 75 (= Gymnadenia Commersoniana, A. Rich.). - Ins. Borbon.

concinna, Hook. f. Fl. Brit. Ind. vi. (1890) 155 et in Hook. Icon. pl. xxv. (1894) t. 2320. Khasia.

confusa, Cogn, in Mart. Fl. Bras, iii. iv. (1893) 65 - Bras

conopodes, Ridl. in foum. Linn. Soc. xxii. (1886) 124. - Madag.

constricta, Hook. f. Fl. Brit. Ind. vi. (1890) 161 (= Peristylus constrictus, Lindl.) - Ind, or.

corcovadensis, Kraenzl, in Bot. Fahrb, xvi. (1893) 120. - Bras.

120.- Bras. 278. - Afr. trop. or.

cultriformis, Kraenzl. ex Engl. in Abh. Prenss. Akad. Wiss. 1891 ii. (1892) 181, nomen; et in Bot. Fahrb. xvi. (1893) 89. - Afr. trop. or.

Culveri, Schlechter, in Bot. fahrb. xx. Beibl, n. 50 (1895) 14. - Afr. austr.

dauphinensis, Rolfe, ex S. Elliot, in fourn. Iinn. Soc. xxix. (1891) 56. - Madag.

Davidi, Franch, in Nouv. Arch. Mus. Paris, Sér. II.

x. $(1887-88) 86 .-$ Tibet.
decipiens, Hook. f, F1. Brit. Ind, vi. (1890) 165 et $197 \geqslant$ H. Griffithii, Hook. $f$.

\section{HABENARIA}

deflexa, Hochst. [in Schimp. Pl. Abyss. exsicc 1853 n. 606] ex Engl, in Abl. Prenss. Akad. Wiss 1891 (1892) 183, nomen; th in Bot. Fahrb. xvi $1893)$ 146. - Abyss.

diphylla, Th. Dur, \& Schinz, Consp. F1. Afr. v. $1892(1895) 76=$ cordata, $R . B r$

ditricha, Hook. f. Fl. Brit. Ind. vi. (1890) 151. Tenass.

eburnea, Ridl. in Fourn. Bot. xxiv. (1886) 293. Afr. trop. occ.

ecaudata, Kraenzl. ex Engl, in Engl. Pfanzenz?. Ost Afr. C (1895) 152; et in Bot. Fahrb. xxii. (1895 19. - Afr. trop. or

Elliotii, Rolfe, ex S. Elliot, in fourn. Linn. Soc. xxix 1891) 57 t. 12 sub fals, nom. Holothr. madagasca vientsis, Rolfe. - Madag.

Elliotii, Rolfe, ex Kraenzl. in Bot. Fahrb xvi (1893) 70 [an praec.?]. - Madag.

Emini, Kraenal. . . c. xix. (1894) 245. - Afr. trop.

Engleriana, Kraenzl. l. c. xvii. (1893) 68. - Afr trop. occ.

erinaçea, Cordem. Fl. Ile Rémion (1895) 261 (= Pe vistylus evinaceus, Frapp.). - Ins. Borbon.

filifera, S. Wats, in Proc. An. Acad xxvi, (1891) 154. - Mexic.

flagellifera, Makino, in Tokyo Bot. Mag. vi. (1892) 48 (= Coeloglossum flagelliferm, Maxim.). Japon

flavescens, Hook.f. Fl. Brit. Ind. vi. (1890) 150.Concan.

flexa, Reichb.f. ex Kracnsl. in Bot. Fahrb. xvi (1893) 97. - Bras.

foliosa, Reichb. ex Kraenzl.1. c. $214=$ polyphylla Reicilb. $f$.

Foxii, Ridl, in fourn. Linn, Soc. xxii. (1886) 124.Madag.

furfuracea, Hook.f. Fl. Brit. Ind.vi (1890) 144. Khasia.

fusifera, Hook. f.l. c. 147. - Travanc.

Galpini, Bolus, Icon. Orchid. Austro-Afr. i. i. (1893)

t. 17. - Transvaal.

Gardneri, Hook. f. Fl. Brit. Ind, vi. (1890) 158, .. Zeyl.

genuflexa, Rendle, in fourn. Bot. xxxiii. (1895) 279 - Afr. trop.

Gibsoni, Hook.f. Fl. Bvit. Ind. vi. (1890) 135; ct in Hook. Icon. pl. xxiv. (1894) t. 239. - Concan

gigas, Hook. f. l. c. 160, - Perak

glaucifolia, Burean of Franch. in Morot, Fourn. de Bot. v. (1891) 152, - China occ

Glazioviana, Kinenzl. ex Cogn. in Mart. Fl, Bras. iii. IV. (1893) 84. - Bras.

goyazensis, $\operatorname{Cog} n$. . . . 77. - Bras.

gracillima, Hook. f. Fl. Brit. Ind. vi. (1890) 163. Khasia.

guadalajarana, S. Wats. in Proc. Am. Acad xxii (1887) $456=$ clypeata, Lind.

Hamiltoniana, Hook, f. Fl. Brit, Ind, vi, (1890) 160 (= Herminium Hamiltonianum, Lind.). Ind. or

Helferi, Hook. f. l. c. $164(=$ Gymnadenia Helferi Reichb. f.). - Ind. or.

Hieronymi, Kraensl. in Bot. Fahrb, xvi. (1893) 187. - Reg. Argent.

Hochstetteriana, Kraenzl. ex Engl. in Abh. Prenss. Akad. Wiss. 1891. ii. (1892) $180(=H$, replicata Hochst.); et in Bot. Fahrb. xvi. (1S93) 73. - Afr trop. or.

holochila, Hillebr. Fl. Haw. Ist. (188s) 432. - Ins. Sandvic.

Holstii, Kraenzl. ex Engl. in Abh. Prenss. Akad. Wiss. (1894) 53 ; ct in Bot. Fahrb, xix. (1894) 246. - Afr trop. or.

Holtzei, F. Muell. in fourn. Roy. Soc. N. S. Wales, xxiv. 1890 (1801) 128. - Austral.

Horsfieldiana, Kraena?, in Bot. Fahrb. xvi. (1893) 167. - Java.

humilis, Cogn, in Mart. Fl. Bras iii. IV. (1893) 67. - Bras.

ichneumoniformis, Ridl. in fourn. Linn. Soc. xxii. (1886) 125. - Madag.

ingrata, Rendle, in Fourn. Bor. xxxiii. (1895) 279.Afr, trop. or.

insignis, Schlechter, in Bot. Fahrb. xx. Beibl. n. 50 (1895) 32. - Afr. austr.

\section{HABENARIA}

nvoluta, Bolus, in fourn. Limn. Soc. xxv. (1889)

165 fig. 3. - Natal.

jaliscana, S. Wats, in Proc. Am. Acad, xxii, (1887) 45.). - Mexic

janeirensis, Kracnal, in Bot. fahb. xvi. (1893) 127. - Bras.

javanica, Kraenzl. l. c. 162.- Java

Johannae, Kraenzl. 7. c.77. - Ins. Comor.

Kayseri, Kraenzl. ex Engl. in Abh. Prenss. Akad. Wiss. (1894) 62; et l. c. xix. (1894) 246. - Afr. trop. or.

khasiana, Hook. f. Fl. Brit. Ind. vi. (1890) 151. Khasia.

Kingii, Hook.f. l. c. 144. - Perak.

Korthalsiana, Kracnal. in Bot. Fahr. xvi. (1893) 170. - Java

Kraenzliniana, Schlechter l c rx Beibl, n. 50 (1895) 35. - Afr. austr.

Lagunae-sanctae, Kraenzl. 7. c. xvi. (1893) 11\%. Bras.

latifolia, Th. Dur. \& Schinz, Consp. Fl. Afr. $1892(1895) 80$ (= Satyrium latifolinn, Thou.) $=$ chlorantha, Sprenzo.

latifolia, Cordem. Fl. Ile Rémion (1895) $260(=P$ ristylus latifolius, Thou.). - Ins. Mascar

latilabris, Hook. f. Fl. Brit. Ind. vi. (1890) 153. Ind. or.

Lawii, Hook.f.l.c. 162 (= Peristylus Lavii, Wight). - Ind. or.

Lecardi, Kraenzl. in Bot. Fahrb. xvi. (1894) 150. Seneg.

Lefebriana, Th. Dur. \& Schinz, Consp. Fl. Afr.v 1892 (1895) $80=$ Herminium Lefeburianum A. Rich.

Lehmanni, Kraenal, in But. Fahrb. xvi. (1893) $97=$ seq

Lehmanniana, Kraenzl.l. c.-Columb.

leonensis, "Kraenzl. in Bot. Jahrb. xvi. (1892) 217 Sierra Leone [cit, falsa] "ex Th. Dur. \& Schinz. Consp. Fl. Afr, v. (1895) $80=$ candida, Lindl.

leptobrachiata, Ridl. in Form. Bot, xxiv, (1886) 293. - Abyss.

leptocaulon, Hook. f. Fl. Brit. Ind. vi. (1890) 154.Reg. Himal

longa, Cordem. Fl. Ile Rémnion (1895) 261 (= Peri stylus longus, Frapp.). - Ins. Borbon.

longibracteata, Hook. f. Fl. Brit. Ind. vi. (1890) 166 (= Plutanthera longibractcata, Lindl.). Burma.

lucaecapensis, M. L. Fernald, in Zoë, iv. (1894 379. - Calif.

MacOwaniana, Reichb, fo in Gard. Cliron. (1889) i $\mathrm{I68}$ (= Brachycorythis MacOwanana, Reichb. $\mathrm{f}$.) - Afr. austr.

MacOwaniana, Kracn\%l. in Bot. Fahrb. xvi. (1893) 150. - Afr. austr. extratrop.

macroceratitis, Rottl. ex Hook. f. Fl. Brit. Ind. vi (1890) 141 , in syn. = longicalcarata, A. Rich. macrochlamys, Baker, in Hook. f. Fl. Brit. Ind. vi (1890) 223. - Tenass.

macrura, Kraenzl. ex Engl. in Abh. Preuss. Akad. Wiss. 1391 (1892) 183, nomen; et in Bot. Fahrb xvi. (1893) 152. - Angola.

malabarica, Hook.f. Fl. Brit. Ind. vi. (1890) 159.Ind. or.

malleifera. Hook" f. l, c. 143. - Ind. or.

Mandersii, Collett \& Hemsl. $2 n$ foum. Linn. Soc xxviii. (1890) 133; it in Hook. f. l. c. 146. Burma.

maritima, Greene, Pittonia, ii. (Sept. 1892) 298; Man. Bot. San Frane. Bay (1894) 306. - Calit.

Medusa. Kracnzl. in Bot. Fahro. xvi. (I8:3) 203. Java?

Melvillei, Ridl. cx Kraenzl.l.c.203. - Bras

microcorys, Hochst. [in Schimp. P1. Abyss. exsicc 1853 n. 634] ex Engl. in Abh. Preuss. Akad. Wiss. 1891 (1892) 183; Kraenzl. in Bot. Jahrb. xvi. (1893) $152=$ vaginata, $A$. Rich

microrhynchos, Schlechter, in Bof. Fahrb. xx. Beibl n. 50 (1895) 36. - Afr. austr

Millari, F, M. Bailey, in Dept. Agric. Brisbane Bot. Bull. [iii]. (1891) 18. - Austral

monophylla, Collett of Hemsl. in Fourn. Linn. Sor xxviii. (1890) 134; et in Hook. f. Fl. Brit. Ind. vi. (1890) 143, - Burma. 


\section{HABENARIA}

militaris, Reichb. f. in Gavd. Chron. (1886) ii. 518; Rolfe, in Lindenia, vii. (1891) 63 t. 318, - Cam bodia.

montana, Th, Dur. \& Schinz, Consp. Fl. Afr. v. 1892 (1895) 82 (= Platanthera chlorantha, Cust.) - Eur., Afr. bor.

Montulivaea, Kracnal.cx Engl. in Abh. Preuss. Akad. Wiss. 1891. if. (1892) 183; et in Bot. Fahrb. xvi. (1893) 172 (= Montolizaea degans, Reichb. f.) - Abyss.

Moritzii, Ridl. in Trans, Linn. Soc., Ser. II. ii. (1887) 284 [Oliver, cx in Thurn, in Timehri, v. (1886) 2061. - Guian., Venez.

Muelleriana, Cogn. in .Mort. Fl. Bras. iii. Iv, (1893 72. - Bras

multipartita, Blume, cx Kracnst. in Bot. Fahrb. xvi (1893) 194. - Java.

Mundtii, Kraenzl. l. c. 79. - Afr, austr.

muricata. Reichb f. ex Kraenal. l. c. 140. - Ins Philipp

Murtoni, Hook. f. Fl. Brit. Ind. vi. (1890) 144. Penins. Mal.

ndiana, Rendle in foun. Limn. Soc. xxx, (1895) 393. - Afr. trop. or.

nematocaulon. Hook. f. Fl. Brit. Ind. vi. (1890 154. - Reg. Himal.

mda, Kraenzl. in Bot. Jahrb. xvi. (1892) ge $=$ H. Sprucei, $\operatorname{Cog} n$.

njamnjamica, Kraenzl, in Bot. Fahrb. xvi. (1893 106. - Afr, trop

Oldhami, Kraenzl. l. c. 205. - Japon.

oligantha, Hochst. ex Engl. in Abh. Preuss. Akad. Wiss, 1891 (1892) 18\%, in syn. = perbella Reichb.f.

liorantha, Hook f. Fl. Brit. Ind. vi, (1890) 154. Reg. Himal.

Orchidis, Hook.f.l.c. $142(=$ Platanthera Orchidis Lind1.):- Reg. Himal.

pachycaulon, Hook, f, l, c, 154. - Reg. Himal.

pantothrix, Kracnzl, ex Engl, in Abh. Prenss. Akad. Wiss. 1891. ii. (1892) 181, nomen; at in Bot. fahb. xvi. (189:3) 89. - Afr. trop.

papuana, Kraenzl. in Bot. Fahrb. xvi. (1893) 179 et xviii. (1894) 188. - N. Guin.

Parishii, Hook. f. Fl. Brit. Ind. vi. (1890) 161. Tenass.

Pervillei, Kraenzl. in Bot. Fahrb xvi. (1893) 209 - Madag

Petitiana, Th. Du. \& Schinz, Consp. Fl. Afr.w. 1892 (1895) 83 (= Peristylus Petitianus, A. Rich.) - Abyss.

Philippsi1, Rolfe, in Kew Bull. (1895) 227. - Reg. Somal

Poggeana, Kraenzl. in Bot. Fahrb. xvi. (1893) 207 - Congo mer.

polyantha, Kxaenzl. 1. co xxii. (1895) 19 ; ot in Engl. Pflanzenw. Ost-Afr. C (1895) 15\%. - Afr. trop.

polyodon. Hook. f. Fl. Brit. Ind. vi. (1890) 139. Ind. or.

polypliylla, Boiv. ex Cordem. Fl. Ile Réunion (1895) 258 , in syn. $=$ H. sigillum, Thou.

polyphylla, Kracnal. in Bot. Fahrb, xvi。(1893) 214. - Atr. austr.

porrecta, Bohns, in Fourn. Limn. Soc. xxv, (1889) $167 \mathrm{fig} . \overline{5} .-\mathrm{Natal}$.

praestans, Rendle, in Fourn. Bot.-xxxiii. (1895) 203. - Afr. trop. or.

Praini, Hook. f. Fl. Brit. Ind. vi. (1890) 159.Ind. or.

Pringlei, Robinson, in Proc, Ant. Acad. xxvii. (1893) 184 - Mexic

quadrifolia, Frapp. ex Corden. Fl. Ile Rémion (1895 259. - Ins. Borbon

rabaiensis, Rendle, in foum. Limn. Soc. xxx. (1895) 390. - Afr. trop. or.

ranicolorata, Reichb. f. ex Oliver, in Johnston, Kilima-njaro Exped. (1886) 346, nomen = seq. raricolorata, Reichb, $f$. ex Oliver, in Trans. Linn. Soc. Ser. II. ii. (1887) 350, nomen. Afr. trop.

Regnellii, Cogn. in Mart. Fl. Bras. iii. Ir. (1893) 60. - Bras.

Rehmanni, Bolus, in Fourn. Lim. Soc. xxv. (1889) I69 fig. 6. - Transvaal.

\section{HABENARIA}

(1890) 152 (= Herminium reniforme, Lindl.). - Ind. or. - China.

retroflexa, F. Muell. E Kraenzl. ex Kracnzl. in Bot. fahrb. xvii. (1893) 488. - N. Guin.

rhynchocarpa, Hook. f. Fl. Brit. Ind. vi. (1890) 145 (= Platunthera rhynchocarpa, Thw.). Zeyl.

Richardi, Cordent. Fl. Ile Réunion (1895) 259 (= Platanthera Richardi, Frapp.). - Ins. Borbon.

Ridleyana, Kraenzl. ex Engl, in Abh. Prenss. Akad. Wiss, 1891. ii. (1892) 179. - Afr, trop.

Ridleyana, Kraenzl. in Bot. Falirb. xvi. (1893) 65 [an praec. ?]. - Abyss.

Riedelii, Cogn. in Mart. Fl. Bras, iii. IV. (1893) 80. - Bras.

robustior, Hook. f. Fl. Brit. Ind, vi. (1890) 160 (= Peristylus robustior. Wieht). - Ind or

Rodriguesii, Cogn. in Mart.Fl. Bras, iii.w. (1893) 42 t. 7 fig. 3. - Bras.

Roemeriana, Th. Dur. \& Schinz, Consp. Fl. Afr v. 1892 (1895) 85 (= Peristylus Quartinianus A. Rich.) - Abyss.

uwenzoriensis, Rendle, in foum. Bot. xxxii. (1895) 280 - Afr. trop. or

saccata, Greene, in Erythea, iii. (I895) 49. - Calif. sacculata. Th. Dur. \& Schinz, Consp. Fl. Afr. v, 1892 (1895) 85 (= Peristylus sacculatus, Balf. f.). - Ins. Borbon.

samoensis. F. Mucll. \& Kracnzl. ex Kraenzl. in Bot. fahrb. xvii. (1893) 487. - Ins. Samoens.

Schaffneri, S. Wats. in Proc. Am. Acad. xxiii, (1888) 283; Kraenzl. in Bot, Fahrb. xvi. (1893) 135. - Mexic.

Schlechteri, Kraensl. of Sihlechter, in Bot. Fahrb. xx. Beibl. n 50 (1895) 35. - Afr. austr.

Schenckij, Cogn. in Mart. Fl. Bras, iii. IV. (1893) 61. - Bras.

secundiflora, Cordem. Fl. Ile Réunion (1895) 260 (= Peristylus secundiflorus, Frapp.). - Ins, Borbon. secundiflora, Hook. f. Fl. Brit. Ind. vi, (1890) 165 et in Hook. Icon. pl. xxiv. (1894) t. 2321. - Reg. Himal.

sikkimensis, Hook.f.l. c. 155. - Reg. Himal

socotrana, Reichb. f. ex Kraenst. in Bot. Fahrb. xvi.

(1893) 144. - Socotra

Soyauxii, Kraensl. 1. c. xvi."(1893) 93. - Afr. trop. occ.

spathulifera, Cogn, in Mart. Fl. Bras, iii. IV. (1893) 86. - Bras.

spiralis, Cordem. Fl. Tle Réunion (1895) $260(=P e-$ vistylus spiralis, S. Moore). - Ins. Borbon.

spiraloides, Cordem. $7 . c$. 551, in add. - Ins. Borbon.

splendens, Rendle, in Fourn, Linn. Soc. xxx. (1895) 395. - Afr. trop. or.

Sprucei, Cogn. in Mart. Fl. Bras. iii. IV. (1893) 40. - Bras.

stenantha, Hook. f. Fl. Brit. Ind. vi. (1890) 15\%3.Reg. Himal

tauroglossa, Kracnzl, in K. Schnm. \& Hollr, Fl. Kais. Wilh. Land (1889) 35. - N. Guin.

stenorhynchos, Schlechter, in Bot. Falub. xx. Beibl. n. 50 (1895) 33. - Afr. austr.

Stoliczkae, Kraenzl. l. c. xvi. (1893) 215. - Ind. or.

Stocksii, Hook. f. Fl. Brit. Ind. vi. (1890) 158. Ind. or.

Suzannae X. Hort. ex Gard. Chron. (1894) ii. 278 fig. 38. - Hybr. artef.

Taubertiana, Cogn, in Mart. Fl. Bras, iii. IV. (1893) 69. - Bras

temicomis, Wall. ex Hook. f. Fl. Brit. Ind. vi. (1890), 149, in syn. = furcifera, Lindl.

tentaculata, Pfitr. in Engl. \& Prantl, N ativl. Pfanzcnfam. i1. 6 (1888) 95 (= Glossula tentaculata, Lindl.). - China.

tenuicaulis, Rendle, in fourn. Linn. Soc.xxx. (1895) 396. - Afr. trop. or.

tenuispica, Rendle, l. c. xxxiii. (1895) 293. - Afr. trop. or.

tetrapetaloides, Schlecter, in Bot. Fahrb. xx. Beibl. n. 50 (1895) 34. - Afr. austr.

Thomsoni, Reichb. f. ex Oliver, in 7. Thoms. Through Masai Land Append. (1887) 353, nomen. - Afr. trop.
HABENARIA

Thouarsii, Th. Dur. Es Schinz, Consp. Fl. Afr. v. 1892 (1895) 87 (= Satyrinn flexuosum, Thou.). Ins. Mascar.

torta, Hook. f. Fl. Brit. Ind, vi. (1890) 159. - Ind. or., Zeyl.

tosaensis, Makimo, in Tokyo Bot. Mag. vi. (1892) 4S. - Japon

transvaalensis, Schlechter, in Bot. Fahró. xx. Beibl. n. 50 (1895) 6. - Transvaal.

travancorica, Hook. f. Fl. Brit. Ind. vi. (1890) 135. - Tenass.

trifürcata, Hook.f. l. c. 135. - Khasia

Tysoni, Bolus, in foum-Eimu. Soc. xxv. (1889) 166. fig. 4. - Afr. austr.

Ulaei, Cogn, in Mart, Fl. Bras, iii. IV. (1893) 74. Bras.

undulata, Frapp. ex Cordem. Fl. Ile Réunion (1895) 256. - Ins. Borbon.

unidentata, Bhmc. ex Krathal. in Bot. Falmu. xvi. 1893) 158. - Java

Uxbaniana, Cogn. in Mart. Fl. Bras. iii. IV. (1893) 45. - Bras.

urceolata, C. B. Clarke, in fourn. Limn, Soc. xxv. (1889) 73 t 30. Hook f Fl. Brit Ind vi. (1890) $165(=$ Diphylax urceolata. Hook. f. $)$ - Reg. Himal.

Usambarae, Kraenal. cx Engl, in Abh. Preuss. Akad. Wiss. (1894) 57; ot Engl. Pfanzenw. Ost-Afr. A (1895) 98. - Afr. trop. or.

variabilis, Ridl. in foum. Bot. xxiv. (1886) 294. Abyss.

ventricosa, Frapp. ex Cordem. Fl. Ile Rémnion (1895) 257. - - Ins. Borbon.

viridi-aurea, Lindl. ex Kraenzl, in Bot. Jahrb. xvi. (1893) 102 = heptadactyla, Reichb $f$

Vogelii, Ridl. in fourn, Bot, xxiv, (1886) 295.Afr. trop. occ

Volkensiana, Kracnzl. in Bot. Fahrb. xix. (1894) 244. - Afr. trop. ox.

Wilfordii, Ridl. in fourn, Bot. xxiv. (1886) 295. Sierra-Leone.

Zenkeriana, Kracuzl. in Bot. Fahrb, xix. (1894) 247. - Kamerun.

zosterostyloides, Hook. f. Fl. Brit. Iild. vi. (1890) 155. - Penins. Mal.

HABRACANTHUS Nees (Acanth.) - Ind. Kew. i. 1085

pyramidalis, Lindau, in Bull. Herb. Boiss, iii. (1895) 484. - Am. trop.

HACKELOCHLOA, Kuntze, Rev, Gen. (1891) 7/6 = Manisuris, Sw. (Gramin.).

gramularis, Kuntze, 1. c. $=$ M. granularis, $S w$.

HAEMANTHUS, [Tourn.]. Linn. (Amaryll.). Ind, Kew. i. $1080^{\circ}$

bivalvis, G. Beck, in Paulitschk. Harrar (1888) 452 fig. 1. - Afr. trop. or.

callosus, Burchell, ex Baker, Handb. Amaryll. (1888) \%. - Afr. austr.

Cooperi, Baker, l. c. 70. - Afr. austr.

eurysiphon, Harms, in Bot. Fahrb. xix, Beibl. n. 4 i 1894) 27. - Afr, trop, or.

Germarianus, 7. Brann \& $K$. Schum, in Mith. deutsch. Schutzgeb. ii. (1889) extr. 1. - Kamerun. Katherinae, N.E. Br. in Montivo, Delagoa Bay (1891) 170. [an Baker ?]. - Mossamb.

Kundianus, 7. Brann \& $K$. Schum. in Mitth. doutsch. Schutregeb.ii. (1889) extr. 1. - Kamerun.

Lindeni, N.E. Br. in Illustr. Hortic. xxxvii. (1890) 89 t. 512 et xli. (1894) 13 fig. 3 ; et in Gard. Chron. (1890) ii. 436 fig. 85 ; et $(1893)$ i. 483 Congo.

longipes, Engl. Bot. Fahrb. vii. (1886) 332. Kamerun.

Mackenii, Bakcr, Handb. Amaryll. (1888) 69. Natal.

micrantherus, Pax, in Bot. Fahrb. xv. (1893) 140. - Afr. trop.

robustus, Pax, l. c. 140, - Afr. trop. or.

somaliensis, Baker, in Kow Bull. (1895) 227. - Reg. Somal.

superbus, Hort. ex Baker, Handb. Amaryll. (18s8. $66=$ magnificus, Herb. 
HAEMARIA, Lindl. (Orchid.), - Ind, Kew. i. 1087.

Otletae, Rolfe, in rllustr. Hort. xxxriii, (1891) 31 t. 524. - As. trop, or.

Olletae, "Rolfe », ex Gard. Chron. (1891) i. 469 , sphalm. = praec.

HAEMASTEGIA, Klatt, in Ann, Naturh. Hofmus, Wien, vii. (1892) 102 = Erythrocephalum,

Benth. (Compos.).
foliosa, Klatt, 1. C. $=$ E. foliosum, O. I1offm

HAEMATOXYLON. Linn. (Légumin.), - Ind. Kew. i. 1087

boreale, S. Wats. in Proc. An. Akat. xxi. (1886) 426. - Mexic.

HAEMOCHARIS, Salisb. = Laplacea, H. B. \& K. (Ternstroem.).

acutifolia, Mart, ex Wawra, in Mart. Fl. Bras, xii. I. $(1886) 290=\mathrm{L}$, semiserrata, Camb.

anceps, Kuntze. Rev. Gen. (1891) $62=$ Bonnetia anceps, Mart.

buxifolia, Szyszyl. in Engl. \& Prantl, Natirl. Pflanzenfam. iii. 6 (1893) 184. - Sumatra.

camelliodes, Kuntze, Rev, Gen, (1891) $62=\mathrm{I}$. camellioides, Sond.

Courtyana, Kuntze 1. c. = L. Curtyana, A, Rich, marginata, Kuntze, 1. c $63=$ L. marginata, Choisy. obovata, Mart. ex Wawra, in Mart. F1. Bras, xii. 1. (1886) 290 = Laplacea semiserrata, Camb.

oralis, Kuntze, Rev. Gen. (1891) $63=$ L. ovalis, Choisy.

praemorsa, Kuntze, 1. c. $62=$ L. praemorsa, Splitg.

pubescess. Hieron, in Bot. Jahrb. xx. (1895) $48=$ L. pubescens, Triana \& Planch.

sessilis, Kuntze, Rev. Gen. (1891) $62=$ Bonnetia sessilis, Benth.

stricta, Kuntze, 1. c. = B. stricta, Nees \& Mart.

symplocodes, Kuntze, 1. c. = L. symplocoides, Triana E Planch.

venulosa, Kuntze, 1. c. $=$ Bonnetia venulosa, Mart. inlcania, Kuntze, 1. c. = L. vulcanica, Kinth.

HAENELIA, Walp, = Amellus, Tourn, (Compos.). anisata, coclopodia, hispida. Lychnutis, microglossa. nana, scabrida, strigosa, Kuntze, Rev. Gen. (1891) $341=$ homonyma omria Amelli.

HAENIANTUS, Griseb. = Linociera、Sw. (Oleac.)

obovatus, Krug \& Urb. in Bot. Jahrb. xv. (1893) 342. - Ins. Puerto-Rico.

HAHNIA. Medic. = Pyrus, Linn. (Rosac.).

Hostii, Dippel, Handb. Laubholzk, iii. (1893) 378 $=$ P. Aria, Elirh

succica, Dippel, 1. с. $37 \%=$ P. intermedia, Ehrh.

HAKEA, Schrad. (Proteac.). - Ind. Kew, i. 1087 Bakeriana, F. Muell. Er Maiden, in Macleay Momor. Vol. Limn. Soc. N. S. Wales (1893) 226 t. 30 ; et ex Bot. Centralbl. lix. (1894) 303. - Austral.

breviflora Wawra, Itin. Princ. Sax.-Coburg, ii. (1888) 73. - Austral.

Brookeana, F. Muell, in Australas. Fourn. Pharm. i. (Nov, 1886) 430; et ex Bot. Centralbl, xxix. (18s7) 114. - Austral.

Macraeana, F. Muell.ll. cc. - Austral.

Persiehana, F. Mucll.ll co. 430; et 115. - Austral

HALENIA, Borekh. (Gentian.). - Ind. Kew. i. 1089.

candida, Ramirez, in Inform. Secret. Foment. Mexic (Excurs. Mont. Ajusєo) (1895) 34. - Mexic.

crassiuscula, Robinson of Seaton, in Proc, Am. Akad. xxviii. (1893) 113. - Mexic.

Palmeri, A. Gray, l. c. xxi. (1886) 401. - Mexic

Pringlei, Robinson Eo Seaton, l. c. xxviii. (1893) 113. - Mexic.

HALESIA. Linn. (Styrac.) - Ind. Kew. i. 1089. Fortunei, Hemsl. in fourn. Linn, Soc. xxvi. (1290) 75. - China
HALGANIA, Gaudich. (Borag.). - Ind, Kew. ì. 1089.

Gustafseni, F. Muell. in Proc. Linn. Soc. N. S Wales, Ser. II. V. (June, 1890) 188. - Austral.

HALIMOGNEMIS, C. A. Mey. (Chenopod.).Ind. Kew. i. 1089

ribbosa, Woluszczak, ex Stapf, in Denkschr. Akad. Wien (1886) 9. - Persia.

HALIMUS, Rumpf, Herb. Amboin. vi. (1\%48-50 165. t. 72 f. i. ; ex Kuntze, Rev, Gen. (1891) 26. = Sesuvium, Linn. (Ficoid).

congensis, crystallinus, Edmonstonit, Portulacastrum, Kuntze, 1. c。 = homonyma onnia Sesuvii.

maritima, Kuntze, 1. c. = S. Portulacastrum. Linn.:

sesuriodes, Kuntze, 1. c, = S. digynum, Welw

HALLACKIA, Harv. = Huttonaea, Harv. (Or chid.).

pulclira, Kuntze, Rev. Gen. (1891) $665=$ Hutt. pulchra, Hari.

HALLOMUELLERA, Kuntze, Rev. Gen. (1891) 267 = Crantzia, Nutt. (Umbell.)

lineata, Kuntze, 1. c. = C. lineata, Nutt.

HALLOSCHULZIA, Kuntze, Rev, Gen. (1891) 705 = Stenomeris, Planch. (Dioscor.).

Cumingiana, Kuntze, 1. c。= S. Cumingiana, Bece

diescoreaefolia, Kuntze, 1.c. = S. dioscoreaefolia, Pianch.

HALOGNEMUM, Bieb. (Chenopod:). - Ind Kew. i. 1090.

cruciatum, Baill. Hist. des pl. ix. (1888) 185 [an H. cruciatum, Tod. ?] = Salicornia cruciata, Forsh.

HALORAGIS, Forst. (Halorag.). - Ind, Kew, i 1091

Baeuerleinii, F. Mutll. in Trans. et Proc. Roy. Soc. Vict. xxiv. (July 1888) 132; et ex Bot. Centralbl. xxxii. (1887) 147. - Austral.

bibracteolata, Colenso, in Trans, N. Z. Inst, xxii. $1889(1890) 462 .-\mathrm{N}$. Zel.

exalata, F. Muell. in Trans. et Proc. Roy. Soc. Vict. xxiv. (July 1888) 133, in obs. $(=H$. alata Jacq. pr. p.). - Austral.

Meionectes, F. Muell. l. c. 127 (Meionectes Brownii Hook. f.). - Austral.

minima, Colenso, in Trans. N. Z. Inst. xviii. 188. (1886) 259. - N. Zel.

pycnostachya, F. Muell. in Trans. et Proc. Roy. Soc Vict. xxiv. (July 1888) 135. - Austral.

sclopetifera, F. Muell. l. c. 136. - Austral.

spicata, Petrie, in Trans. N. Z. Inst. xix. 1886 (1887) $325 .-$ N. Zel.

HALOSTACHYS, C. A. Mey. (Chenopod.).Ind. Kew. i. 1091.

caspica, Baill. Hist. des pl. ix. (1888) $\mathbf{1 8 6}=$ caspia, C. A. Mey.

HALOXYLON, Bunge (Chenopod.). - lnd. Kew. i. 1091 .

Schweinfurthii, Aschers. ex Aschers, of Schweinf. Illustr. Fl. Egypt. [Mém.Inst. Egybt. ii. (1887) 128] (= Anabasis articulata, Moq.-Tand.). Aegypt.

HAMAMELIS. Gronov. (Hamamel.). - Ind. Kew. i. 1092.

mollis, Oliver, ex Forb. E Hensl, in Fourn. Linn. Soc. xxiii. (1887) 291, nomen; th in Hook. Icon. pl. xviii. (1888) t. 1742. - China.

HAMELIA. Jacq. (Rubiac.). - Ind. Kew. i. 1092. calycosa, F. D. Smith, in Coult. Bot. Ga\%. xii. (1887) 132. - Guatem.

versicolor, A. Gray, cx S. Wats, in Proc. Am. Acad, xx1. (1886) 416. - Mexic.

jerocarpa, Kuntze, Rec.Gm.(1891) 284. - Costa-
HAMMARBYA, Kuntze, Rev. Gen, (1891) 66:

Malaxis, Soland, Orchid.

paludosa, Kuntze, 1. c. = M. paludosa, Sw.

\section{HAMMATOLOBIUM, Fenzl (Legumin.).} Ind. Kew. i. 1092 .

Lndoricia, Batt. in Batt. \& Trab. Fl. de l'Algér. [Dicot.]. (1889) $288=$ Ludovicia Kremeriana Coss.

HAMPEA, Schlecht. (Malv.). - Ind. Kew. i. 1092. stipitata, S. Wats, in Proc. Am, Acad. xxi. (1886) 461. - Guatem.

HANBURIA, Seem. (Cucurbit.). - Ind. Kew. 1002

parviflora, F. D. Smith, in Conlt. Bot. Gas. xiit. (1888) 209; et xv. (1890) 27. - Guatem.

HANGEA, Hemsl, in Journ. Linn. Soc. xxyi. (1891) 309. LABIATAE.

inensis, Hemsl. l. c. 310 t. 6. - China.

HANCEA, Pierre, FI. For. Cochinch., Fasc. 16 (1891) sub t. 244 = Hopea, Roxb. (Dipteroc.). Beccariana, Pierre, 1. c. = Hop. Beccariana, Burck. Beccarii, Pierre, 1. c. = Hop. Beccarii, Burck.

cornua, Pierre, 1. c. = Hop. cernua Teijsm. \& Binn.

dryobalanoides, Pierre, 1. c. = Hop. dryobalanoides Miq.

Griffihii, Pierre, 1. c. = Hop. Griffithii, Kur

Meogaraian, Pierre, 1. c. = Hop. Meogaravan, Miq.

micrantha, Pierre, $1 . c_{0}=$ Hop. micrantha, Hook. $f$. microptera, Pierre, 1. c. = Hop. microptera, Dycr. Piervei, Pierre, 1. c. et sub t. $248=$ Hop. Pierrei, Hance.

HANSEMANNIA. K. Schum, in Bot. Jahrb, ix (1888) 201; Taub. in Engl. \& Prant1, Natïrl.Pflanzenzentam. iii. "3 (1891) 102. LEGUMINOSAE. aruensis, Warb. l.c. xiii. (1891) 334. - Oceania. brevipes, K. Schum. in K. Schum. \& Hollr. Fl. Kais. Wilh. Land (1889) 103. - N. Guin.

glabra, K. Schtm. in Bot. Fahmb. ix. (1888) 201. N. Guin.

mollis, K. Schnm.l.c. 202, - N. Guin.

oblonga; Hemsl. in Kew Bull. (1892) 125. - Ins. Salom

pachycarpa, Warb. in Bot. Fahrb. xiii. (1891) 333. - Oceania

HANSTEINIA, Oerst. (Acanth.), - Ind. Kew, i. 1093.

crenulata, Britton, ex Rusby, in Mom. Torrey Bot. Club, iv, (1895) 242. - Bolivia.

gracilis, Lindau, in Engl. \& Prantl, Natürl. Pfanzenfam. iv. 3b (1895) 345; et in Bot. Falirb. xviii. (1894) 58 (= Glockeria gracilis, Nees). - Mexic

Oerstedii, Lindan, $l l . c c .(=H$. gracilis, Oerst.).Am. centr.

HAPALINE, Schott (Aroid.)。 - Ind. Kew, i. 1093. Brownii, Hook. f. Fl. Brit. Ind. vi. (1893) 521 ; et in Bot. Mag. (1893)t. $7325 .-$ Penins. Mal.

HAPLOGOELUM, Radlk. (Sapind.). - Ind. trigonocarpum, Radlk. in Sitzb. Math.-Phys, Akad. Muench, xx. (1890) 249. - Zanzib.

HAPLODISCUS, Benth. \& Hook. f., fide Phil. (Comdensifolins, Phil. in Anal. Univ. Chil. 1xxxrii. (1895) 624. - Chili

elatus, Phil. 1. c, 617. - Chili.

exserens, Phil.1. c. 614. - Chili

fallax, Phil, 1. c. 622. - Chili

graveolens, Phil. 1. c. 619. - Chili

humitis, Phil. 1. c. 621. - Chili

Ischnos, Phil. 1. c. 616. - Chili.

Kingi, Phil, 1. c, 615.-Chili.

Landbecki, Phil. 1. c. 616. - Chili

latifolius, Phil. 1. c. 623, - Chili

longiscapus, Phil. 1. c. 6:0.-Chil 
HAPLODISCUS:-

pachyphyllus, Phil, in Anal. Univ, Chil, lxxxvii. $1895) 614 .-$ Chili

Peteroanus, Phil. 1. c. 620.-Chili.

polycladus, Phil. 1. C. 622. - Chili

sphacelatus, Phil. 1. c. 613. - Chili,

temuifolins, Phil, 1. C. - Chili.

vernicosus, Phil, 1. c.618. - Chili.

Zanartui, Phil. 1. c. - Chili.

HAPLODYPSIS, Baill. in Bull. Soc. Linn. Paris ii. (1894) 1167; et Hist. des pl. xiii. (1895) 370. PALMAE.

Pervillei, Boill. l.c. 1167. - Madag.

HAPLOPAPPUS, Endl. = Aplopappus, Cass. (Compos.).

ucanthodon, Phil. in Anal. Univ. Chil. 1xxrvii. (1Sno) 603. - Chili.

ancthifolins, Phil. 1. c. 595. - Chili.

armerioides, Phil, 1. c. $59 \%$ - Chili.

mustralis, Phil. 1. C. 598 - Chili

axilliflorus, Phil. 1 c. 611. - Chili.

baccharidifolins, Phil. 1. c. 606. - Chil

bellidifolius, Phil, 1. c. 593. - Chili.

brachylepis, Phil. 1. c. 594. - Chili.

Candollei, Phil. 1. c. 599. - Chili.

cormiculatus, Phil. 1. c.609. - Chili.

deserticola, Phil, 1. c 592, - Chili.

Domeykoi, Phil. 1. c. 590. - Chili.

Fluelmanni, Phil.1. c. - Chili.

Foncki, Phil. 1. c. 606. - Chili.

formosus, Phil. 1. c. 601.-Chili.

heteroconus, Phil.1. c. 608. - Chili.

keterophysus, Phil. 1. c. 60\%. - Chili.

hirsutus, Phil. 1. c. 600 - - Chili.

incolucratus, Phil. 1. c. 593. - Chili.

lewcanthemifolints, Phil. 1. c. $60.5,-$ Chili.

limarensis, Phil. 1. c. 602. - Chili.

litoralis, Phil. 1. c. 610. - Chili.

obucatus, Phil. 1. c. 604. - Chili.

pallidus, Phil. 1. c. 596. - Chili.

Peteroamus, Phil. l. c. 609. - Chili.

platylepis, Phil. 1. c.591. - Chili.

setigerus, Fr. Meigen, in Bot. Jahrb, xvii. (1893)

$281=$ Pyrrhocoma setigera, Phil.

stenophyllus, Phil. in Anat. Univ. Chil. 1xxxvii. (1894) 604. - Chili.

Stolpi, Phil. 1. c. 595. - Chili

subandinus, Phil. 1. c. 598. - Chili.

Vidali, Phil.1. c. 601.-Chili.

Villanuevae, Phil. 1. c. 592. - Chili.

HAPLOPHLOGA. Baill, in Bull. Soc, Linn. Paris, ii. (1894) 1168; et Hist. des pl. xiit. (1895) 370. - PALMAE.

Bernjersana. Brill.l. c. 1171. - Madag.

comorensis, Baill.l.c. - Ins. Comur.

loncoubensis, Baill. \%. c. - Nossibe.

Poivreana, Baill.l.c.1168. - Madag.

HAPLOPHYLLUM, Reichb. = APLOPHYL LUM, A. Tuss, = Ruta, Linn。

angustifolinn, Pau, Not. Bot. Fl. Espan, i. (1887)

$15=\mathrm{R}$, rosmarinifolia, fuss

Bopmmuelleri, Freyn, in Oest. Bot. Zeitschr, xl. 1890) 401. - As. Min.

chaborasinm, Boiss. \& Hausskn. in Boiss, Fl. Or, Suppl. (1888) 148. - As. occ.

grentophilum, Boiss. \& Hausskn. in Boiss. 1. c, 149. - Persia.

eriocarpum, Freyn, in Bull. Herb. Boiss, iii. (189;) 106. - As. Min

Haussknechtii, Boiss. F1. Or. Suppl. (I888) 148. As. occ.

untifolim, Pau, Not. Bot, Fl. Espan. i. (1887) 15 = R. pubescens, Willd.

Teiocarpum, Freyn, in Bull. Herb. Boiss。 i1i. (1895) 1. $107=\mathrm{R}$. villosa, Bieb.

fycnanthum, Boiss. \& Hausskn. in Boiss. Fl. Or, Suppl. (1888) 148. - Persia.

HAPLOSTACHYS, Hillehr. Fl. Haw. Isl. (1888) 346. LABIATAE.

\section{HAPLOSTACHYS}

Grayana, Hillebr. Fl. Haw. Isl. (1888) 346 (= Phyllostegia haplostachya, A. Gray). - Ins. Sandvic.

rosmarinifolia, Hillebr. l. c.34\% - Ins, Sandvic truncata, Hillebr. l. c. $(=$ Phyllostegia truncata, A.

Gray). - Ins. Sandv c

HAPLOSTIGHANTHUS, F. Muell, in Vict. Natural. vii. (Mar. 1891) 180. ANON ACEAE. Johnsoni, F. Muell. l. c. - Austral.

HARBoURIA, Coult, \& N. E. Rose, Revis, N. Am. Umbell. (1888) 125. UMBELLIFERAE trachypleura, Coult. \&N.E.Rose, l.c. $(=$ Thaspium trachypleurum, A. Gray). - Am. bor, austro-occ.

HARFORDIA, Greene \& Parry, in Proc. Davenp. Acad. Nat. Sci. v. (1888) 27. POL YGONEAE. fruticosa, Grene \& Pary, l. c. $28(=$ Pterosteria jruticosa, Greene). - Calif.

macroptera, Greme \& Parry, l. c. $(=$ Pterostegia macroptera, Benth.). - Calif.

HARIOTA, Adans. = Rhipsalis, Gaertn. (Cact.). cereiformis, conferta, coriacea, crispata, cylindrica, fasciculata, floccosa, horvida, Houlletiana, Knightii, macrocarpa: micrantha, monacantha, pachyptera, paradoxa, penduliflora, pentaptera, platycarpa, ramulosa, vhombea, Riedeliana, robusta. spathulata, teres, trigona, Kuntze, Rev. Gen, (1891) 262-6:3 = homonyma omnia Rhipsalidis.

aluta, Kuntze, 1. c. $262=\mathrm{R}$. Swartziana, Pfeiff

boliviana, Britton, in Mem. Torrey Bot. Club, iii.

3 (1893) 40, - Bolivia.

cererscula, Kuntze, Rev. Gen. (IS91) $262=\mathrm{R}$. Saglionis, Otto

cinerea, Britton, in Bull. Torrey Bot. Club, xviii. (1891) 35. - Bolivia

cruciformis, Kuntze, Rev. Gen.(1891) $262=\mathrm{R}$. cereiformis. Foerst.

grandiflora, Kuntze, 1. c, = R. funalis, Salm.-Dyck.

lumbricalis, Kuntze, 1. c. $=\mathrm{R}$. sarmentacea, Otto \& Dietr.

moscmbryanthemodes, Kuntze, $1 . \mathrm{c},=\mathrm{R}$. mesembryanthemoides, Haw.

parasitica, Kuntze, 1. c. = R. Cassytha, Gaertu.

ramosisina, Kuntze, 1. c. $263(=$ Lepisminm ramosissimum, Lem.). - Bras.

vugosa, Kuntze, 1. c。= R. rugulosa, Len

sallicorniodes, Kuntze, I. co = R. salicornioides, Haw. squamulosa, Kuntze, 1. c, $=$ R. Mittleri, Foerst.

triquetra, Kuntze, l. c, $(=$ Lehisnuinm fluminense, Miq.). - Bras.

villigera, K. Schum, in Mart. Fl. Bras. iv. II. (1890) - Bras.

HARMANDIA, Pierre, ex Baill, in Bull. Soc. Linn. Paris, ii. (1889) 770; Baill. Hist. des pl. xi. (1892) 452. OL ACINEAE

flavescens, Pierre, ex Hein, in fourn. Limn. Soc. xxxi. (1895) $123(=$ Vatica Harmandiana, Laness.). - Cochinch.

Kunstleri, King, in fown. As. Soc. Beng. 1xiv. (1895) II. 100. - Perak.

mekongensis, Baill, in Bull. Soc. Lim. Paris, ii. 1889) 770. - Laos.

HARPAGOPHYTUM, DC. (Pedalin.)。 - Ind. Kew, i. 1094.

abbreviatum, Baill, in Bull. Soc. Linn. Paris, i. (1887) 670. - Madag.

dimidiatum, Baill.l. c.669. - Madag.

Grandidieri, Baill. l.c. - Madag

peltatum, Baker, in fourn. Linn. Soc. xxv. (1890) 341 - Madag.

pinnatifidum, Engl. Bot. Fahrb. x. (1889) 255.Afr. austr.

HARPALYCE, [Moç. \& Sessé ex] DC. (Legumin.). - Ind. Kew. i. 1094.

hidalgensis, Tanb. in Bull. Herb. Boiss. iii. (1895) 613. - Mexic

Loeseneriana, Taub. l. c. 612. - Mexic.

rupicola, F. D. Smith, in Coult. Bot. Gaz. xiii. (1888) 26. - Guatem.
HARPECHLOA, Kunth (Gramin.). - Ind. Kew. i. 1094

altera, Rendle, in Trans. Linn.Soc., Ser. II. iv, (1894) 57. - Afr. trop., Transvaal.

Falx, Kuntze, Rev. Gen. (1891) $764=$ capensis, Kunth

HARPULLIA, Roxb. (Sapind.).- - Ind, Kew, i. 1094 .

aeruginosa, Radlk, in Sitz3. Math,-Phys. Akad. Wuench. xx. (1890)278. - N. Guin.

arborea, Radlk. l. c.xvi.(1886) $404(=$ Ptelea arbovea, Blanco). - Ins. Philipp.

camptonetra, Radlh, l. c. xx,- (1890)-360.-Mexic.

cochinchinensis, Pierre, Fl. For. Cochinch. fas a.xxi. (1895) t. 332 A. - Cnchinch.

condorensis, Pierre, l. c.t. 332. - Cochinch

crustacea, Radlk in K. Schmm. \& Hollr. Fl. Kais. Wilh. Land (1S89) 67. - N. Guin

divaricata, Radlk, in Sitz3. Math.-Phiss. Alow Muench. xx. (1890) 279. - Austr.

frutescens, F. M. Bailey, Rep. Exped. Bellenden-Kcr, (1889) 36. - Austral.

leptococca, Radlh. in Sitzb. Math.-Phys. Ahad. Mucuch.xx. (1890) 278. - N. Guin.

marginata, Radlk. in Engl. E Prantl, Natirrl. Pfanzenfan. iii. 5 (1895) 362. - Austr.

oococca. Radlk. in Sitzo. Math.-Phys. Akad. Mucnch. xx. (1890)278, - N. Guin

pedicellaris, Radlk. l. c. 279. - N. Guin.

ramiflora, Radlk. l. c. 278. - N. Guin.

rhachiptera, Radlk.l.c. - N. Guin.

zanguebarica, Radlk. l. c. $279(=$ Majidea zinguebarica, J. Kirk), - Afr. trop. or.

HARTOGHIA, capensis, Hort. ex Gard. Kew, i Polypet. (1895) $237=$ Prunus Lauro-Cerasus, Linn.

HARTOGIA, Linn. = Agathosma, Willd. (Rutac) acerosa, acutifolia, adenocanlis, affinis, alaris, amomala, asperifolia bisulca, capitata, chortopliylla. ciliata. collina, craspedata, crassifolia, cuspiduta, decumbens, Dregeana, Eckloniana, clata, elegans, crecta, fastigiata, florida, florulenta, foliosa, fraudulenta, Gillivrayt, glabrata, glandulosa, gonaquensis, gracilicaulis, hirta, hirtella, Hookeri, humilis, involucrata, foubertiana, juniperifolia, juniperina, lancifolia, latipetala; lediforms, linifolia, marifolia, Martiana, microphylla, minuta, montana, monticola, mucronulata, Mundtii, nigra, nigromontana. Nivenii, orbicularis, parviflora. patula, pentachotoma, pilifera, planifolia, prolifera. propinqua, pubescens, pubigera, punctata, recurvifolia, robusta, vubra, sabulosa, sedifolia, serpyllacea, spinosa, squamosa, tabularis, temus, thymifolia, Ventenatiana, villosa, virgata, Kuntze, Rev. Gen.(1891) $100-02=$ homonyma omia, A arathosmatis.

ambigua, Kuntze, 1. c. $101=$ A. ambigua, Sond. apiculata. Kuntze. I. c. $=$ A. apiculata, G. F.W. Mey.

aulonophylla, Kuntze, 1. c. = A. commutata. Sond. barosmifolia, Kuntze, 1. $\mathrm{c}_{0}=\mathrm{A}$, barosmaefolia Eckl. \& Zeyh.

barosmodes, Kuntze, 1. c. = A. barosmoides, Sond.

blaeriodes, Kuntze, 1. c. = A. blaerioides. Cham. cephalotes, Kuntze 1. c. = A. globutiflora, Presl.

cercfolia, Kuntze, 1. c. $=$ A. Cerefolium, Bartl.

eriantha, Kuntze, 1. c. = A. Schlechtendalii, Sond.

evicodes. Kuntze, 1. c. = A. ericodes, Schlecht.

leptospermodes, Kuntze, 1. c. = A. aristata, Presl.

lycopodiodes, Kuntze, 1. c. = A. lycopodioides,

Bartl. \&o Wendl.

melaleucodes, Kuntze, 1. c. = A. melaleucoides, Sond.

platypetala, Kuntze, 1. c. = A. platypetala, Echl. \& Zeyh.

puberila, Kuntze, 1. c. = A. gnidioides, Schlecht. stenopetala, Kuntze. 1. c. $=$ A. filipetala, Eckl. \& Zeyls.

Thunbergiana, Kuntze, 1. c. = A. Thunbergiana, Bartl. \& Wendl, var.?

umbellata, Kuntze, 1. c. = A. bifida, Bartl. \& Wendl. 
HARTogia, Linn. f. (Celastr.). - Ind. Kew。 i. 1095 .

lanceolata, Eckl. \& Zeyh. ex Szyszyl. P1. Rehmann. ii. $(1888) 32=$ capensis, Linn. $f$.

HARTWRIGHTIA. A. Gray, ex S. Wats, in Proc. Am. Acad. xxiii. (1888) 264. COMPOSI$T A E$.

floridana, A. Gray, l.c. 65. - Florida

HARVEYA, Hook。(Scrophul.), 一 Ind. Kew, i. 1095.

foliosa, Sohweinf. ex Penzig, in Atti Congr. Bot. Genoi'a (1893) 352, nomen. - Erithrea.

versicolor, Engl. Pfanzenw. Ost-Afr. C (1895) 362. - Afr. trop. or.

hasseltia, H. B. \& K. (Tiliac.). - Ind. Kew. i. 1095 .

guatemalensis, Warb. in Engl, et Prantl, Natiirt. Pfanzenfam. iir.6a (1893) 32. - Guatem.

HAUYA, [Moç. \& Sessé] ex DC. (Onagrar.). Ind. Kew. i. 1096.

arborea, Curran, in Proc. Calif, Acad, Ser. II. i. (1S88) 253 = Oenothera arborea, Kell. arborca, T. S. Brandes. 1. c. ii. $(1889) 15 \%=$ praec. californica, S. Wats. 1. c. Ser. II. 1. (1888) 2.5. $3=$ Oenothera arborea, Kell.

Heydeana, f. D. Smith, in Coult. Bot. Gaz. xviii. (1893) 3. - Guatem

Rodriguezii, F. D. Smith, l. c. - Guatem.

HAVETIA, H. B. \& k. (Guttif.). - Ind. Kew. i. 1096 .

caryophylloides, Vesque, in Morot, Fourn. de Bot. v. (1891) 327 ; Epharmos. iii. (1892) t. 73 ; et in DC. Monog. Phan, viii. (1893) 158 (= Havetiopsis caryophylloïdes, Planch. \& Triana). - N. Granat.

hippocrateoides, Vesque, $7 l . c c .327$; t. 73 ; et $15 \%$ (= Havetiopsis hippocrateoides, Planch. et Triana) - Peruv.

Martii, Vesque, $l l . c c .327,15$ t. 73 ; et 154 (= Havetiopsis Martii, Planch. et Triana). - Bras.

obovata, Spruce, ex Vesque, in DC. Monog. Phan. viii. (1891) 161, in syn. = Oedematopus obov'. tus, Plancin et Triana.

HAVETIOPSIS, Planch. et Triana (Guttif.) Ind. Kew, i. 1096.

laurifolia, Engl. in Mart. Fl. Bras, xii. I. (1888) 438 ( = Havetia laurifolia, Mart.). - Bras.

obovata, Spruce, ex Engl. 1. c. $437=$ Oedematopus obovatus, Planch. et Trima.

HAVILANDia, Stapf, in Trans. Linn. Soc. Ser. II. iv. (1894),209. BORAGINEAE.

borreensis, Stapf. l. c. - Borneo.

HAWORTHIA, Dunal (Liliac.), - Ind. Kew. i. 1096.

columnaris, Baker, in fourn. Bot. xxvii. (1889) 45. - Hab. ?

stenophylla, Baker, in Hook. Icon. pl. xx. (1891) t. 1974 - Transvaal.

tenuifolia, Engl. Bot. falırb. x. (1889) 2. - Afr. austr.

HAYNALDiA, Schur = Agropyron, J. Gaertn. (Gramin.).

hordeacea, Hack, in Engl. \& Prantl, Natürl, Pflanzenfam. ii. 2 (1887) $80=$ A. orientale, Roem. Ev Schutt.

hordeacea, Trab. in Batt. et Trab. Fl. de l'Algér. [Monoc.] (1895) $242=$ A. orientale, Roem. \& Sclizult.

HAZARDIA, Greene, Pittonia, i. (Feb. 1887) $28=$ Aplopappus, Cass. (Compos.).

Berberidis, Greene, in Erythea, ii. (1894) $112=$ A. Berberidis, A. Gray.

cana, Greene, Pittonia, i. (Feb. 1887) $29=$ Diplostephium canum, A. Gray.

crucnta, Greene, in Erythea, ii. (1894) $112=$ A. cruentus, Greene.
HAZARDIA : -

detonsa, Greene, Pittonia i. (1887) $29=$ Diplo stephum canum, Greenz

Orcuttii, Greene, in Erythea, ii. (1894) $112=$ A. Orcuttii, A. Gray.

serrata, Greene, in Pittonia, i. (1887) 30. Calif.

squarrosa, Greene, in Erythea, ii. (1894) $112=$ A. squarrosus, Hook. \& $A \gamma n$.

HEARNIA, F. Muell. (Meliac.). - Ind. Kew. i 1097

aquatica, Pierre, Fl. For. Cochinch. Fasc. 21 (1895

t. 3333 b. - Cochinch.

Balansae, C. DC. in Bull. Herb. Boiss. ii. (1894) 580. - Tonkin.

HEBANTHE, Mart. (Amarant.). - Ind. Kew. i. 1097.

Philippo-Coburgi, Zahlbr. ex Wanya, Itin. Princ Sax.-Coüurg. i..(18S8) 5\%. - Bras.

HEBENSTREITIA, Linn. (Selag.). - Ind. Kew i. $109 \%$.

angolensis, Rolfe, in foun. Bot. xxiv, (1886) 1\%4. - Angola.

rariflora, Tervac. in Buil. Soc. Bot. Ital. (1892) 424 - Afi. trop. or.

HECASTOPHYLLUM, H. B. \& K. = Ecasta phyllum P. Br. (Lesumin.).

amazonicum, Radlk, Ueber anal. Char, Dalbero. (1892) 40. - Bras.

megrense, Radlk. I. c. - Bras.

Riedelii, Radlk. 1. c. - Bras.

HECATACTIS. F. Muell, in Trans. Roy. Soc. Vict. N. S. I. ii. (1889) 13 = Myriactis, Less. (Compos.)

HECHTIA, Klotzsch (Bromel.). - Ind. Kew. i. 1095 .

Besseriana, Hort, ex Baker, Handb. Bromel. (1889)

$140=$ stenopetala, Klotisch.

longifolia, Hort. ex Baker, l. c. - Hab.

rosea, Ed. Morr. ex Baker, i.c. - Mexic.

pedicellata, S. Wats. in Proc. Am. Acad. xxvi (1891) 155. - Mexic.

Pringlei, Robinson \& Greenm, in An. Foum. Sci. Ser. III. 1. (1895) 16\%. - Mexic.

HEDEOMA, Pers. (Labiat.) - Ind. Kew. i. 1098. jucunda, Greene, Pittonia, i, (1888) 156. - Mexic.

HEDERA, Tourn. ex Linn. (Aral.). - Ind. Kew. i. 1098.

acuta, Hort. ex Gard. Kew, i. [Polypet.] (1895) 243 $=$ H. Helix, Lim

algeriensis, Hort. ex Rev. Hortic. (1890) 164; Dippel, Handb. Laubholzk, iii. (1893) $241=\mathrm{H}$ Helix, I, im .

angularis, Hort. 1. c. $163=\mathrm{H}$. Helix, Linn.

arborea, Hort. 1. c. $164=\mathrm{H}$. Helix, Limn.

aurantiaca, Hort. 1. c. ; Dippel, Handb. Laubholzk. iii. (1893) $241=$ H. Helix, Linn.

azorica, IIort. 1. c, $164=\mathrm{H}$. Helix, Linn。

baccifera, Hort, ex Gard. Kew, i. [Polypet.] (1895) $243=$ H. Helix, Linn.

cambwoodiana, Hort. ex Rev. Hortic. (1890) $162=$ H. Helix. Linn.

canariensis, Hort. 1. c. $163=\mathrm{H}$. Helix, Lim. cancasica, Hort. 1. c. $164=$ H. Helix, Linn. chrysocarpa, Hort. 1. c. $163=$ H. Helix, Linn.

chrysopliylla, Hort, 1. c. $=$ H. Helix, Lim.

conglomerata, Hort. $\mathrm{i}$. c. $=\mathrm{H}$. Helix, Lim.

contracta, Hort. 1. $\mathrm{c}_{\mathrm{i}}=\mathrm{H}$. Helix, Linn.

cordata, Hort. 1. c. $164=$ H. Helix, Lim.

cordifolia, Hort. ex Gard. Kew, i. [Polypet.] (1895) $247=$ H. Fielix, Linn.

dentata, Hort. ex Rev. Hortic, (1S:0) $162=\mathrm{H}$ Helix, Linn.

elegantissima, Hort. ex Gard. Kew, i. [Polypet.] (189) $24 \tau=$ H. Helix, Linn。

Glimii, Hort. 1. c. $249=$ H. Helix, Linn.

gracilis, Hort. ex Rev. Hortic, $(1590) \quad 163=\mathrm{H}$. Helix, Linn.
HEDERA :

grandifolia, Hort. ex Gard. Kew, i. [Polypet.] (1895) $243=\mathrm{H}$. Helix, Linn

hibermica, Hort. ex Rev. Hortic. (1890) 163: Dippel, Handb. Laubholzk, iii. (1893) $241=\mathrm{H}$. Helix I inn?.

Gimalaica, Hort. 1. C, $164=\mathrm{H}$. Helix. Limm.

japonica, Hort. 1. c. 162 et $164=\mathrm{H}$. Helix, Lim .

maderensis, Hort. ex Dippel, Handb. Laubholzk. iii. (I893) $241=$ H. Helix, Linnt.

palmata, Hort. ex Rev. Hortic. (1890) $163=\mathrm{H}$ Helix, Lim

pennsylanica, Hort. ex Gard. Kew, i. [Polypet.] (1895) $245=$ H. Helix, Linn.

poetica, Hort. ex Rev. Hortic. (1890) $163=\mathrm{H}$. Helix, Linn.

purpurea, Hort. 1. c, $=$ H. Helix, Limn.

rhomber, Hort. 1. c. $16 t=\mathrm{H}$. Helix, Limn.

Rocgneriana, Hort, ex Dippel, Handb. Laubholzk. iii. (1893) $242=\mathrm{H}$. Helix, Limn.

submarginata, Hort. ex Gard. Kew, i. [Polypel. (1895) $24 \tau=$ H. Helix, Linn.

tarurica, Hort. ex Rev. Hortic. (1890) 164; Dippel, Handb. Laubholzk. jii. (1893) $243=\mathrm{H}$. Helix

Fegcta, Hort. ex Gard. Kew, i. [Polypet.] (1895) $243=$ H. Helix, Limn

ciridis, Hort. 1. c. = H. Helix, Linn.

vitifolia, Hort. 1. c. $245=$ H. Helix, Limn.

IVillsiana, Hort. 1. c. $247=\mathrm{H}$. Helix, Linn.

HEDERELLA, Stapf, in Hook. Icon, pl xxv (1895) sub t. 2415. MELASTOMACEAE, Forbesii, Stapf, l.c.- N. Guin.

multiflora, Stapf, l.c.t. 2415. - Borneo.

quintuplinervis, Stapf, l. c.t. $2416(=$ Dissochacta quintuplinervis, $\operatorname{Cog} n$.$) - Borneo.$

tetrandra, Stapf, l.c. t. 2415. - Borneo.

HEDREANTHUS, Griseb. = EDRAIANTHUS A. DC. = Wahlenbergia, Schrad. (Campanul.).

caricinus, Wettst, in Denkschr. Akad. Wien, Iiii. 1887) 204 (= E. caricinus, Schott, Nym. \& Kotschy) $=$ W. tenutolia, A.DC.

croaticus, Wettst. 1. c. 202. (= E.croaticus, Kern.) $=$ W. Kitaibelii, A. DC.

dalnaticus, Wettst. 1. c. 205 (=E. dalmatious, A.

DC. $=$ W. dalmatica, $A . D C$.

dinaricus, Wettst. 1. c. 192. - Eur. centr.

graminifolius, Wettst. 1. c. $200(=\mathrm{E}$. graninifolius A. DC. $=\mathrm{W}$. graminifolia, $A . D C$

Kitaibelii, Wettst. 1. C. 196 (E. Kitaibelii, Wettst. $)=$ W. Kitaibelii, A. DC

Murbeckii X. Wettst, in Fysiorr, Sällskop. Handl. ii. (1891) 98; et ex Murb. in Lunds Univ. Arskrift, xxvii. v. (1892) 93. - Herceg., Bosn.

nivers, G. Beck, in Wien. I11. Gartenzeit. (1893) 296 . - Busn.

Pumilio. Wettst. in Denkschr. Akad. Wien, liii (1887) $190(=$ E. Punilio, A. DC. $)=$ W. Pumilio A. $D C$.

sevbicus, "Petrov, " ex G. Beck, in Wien. Ill. Gartenzeit. (1893) $289=$ seq

serbicus, Wettst. in Denkschr. Akad. Wien, liii (1887) 206 (=E. serbicus, Petrov.) - - Serb

serpyllifolius, Wettst. 1. c. 193 (=E., serpyllifolius, A.

DC. $=$ Campanula, serpyllifolia, $V$ is.

temuifolius, Wettst. 1. c. $197(=$ E. temuifolius, A DC. $=$ W. tenuifolia, $A . D C$

Wettsteini, Halácsy \& Bald. ex Halácsy, in Oest. Bot. Zeitschr. xli. (1891) 311; et Wien. Ill. Crartenzeit. (1893) 292. - Austro-Hung.

HEDYCARYA, Forst. (MIonim.), - Ind. Kew. i 1099 .

alternifolia, Hemsl. in foum. Limn. Soc. xxx. (1894 215. - Ins. Tonga.

salomonensis, Hensl. in Kev Bull. (1895) 137. Ins. Salom.

HEDYCHIUM, Koen. (Scitam.). - Ind. Kew. i. 1099.

aureum. C. B. Chirke Er Mann, ex Buker, in Hook. f.

Fl. Brit. Ind. vi. (1892) 229. - Ind. or.

crassifolium, Buker, l. c. 228, - Perak. 


\section{HEDYCHIUM}

Elwesil, Baker, in IIook.f. Fl. Bril. Ind. vi. (1892) 226. - Khasia.

Hookeri, C. B. Clarke, cx Baker, 7, c. 230. Khasid.

longicornutum, Griff. cx Baker, l. c. 228. - Malac-

luteum, Herb. Calc.cx Bakcr, l. c. 232. - Assam. maroinatum, C. B. Clarke, in fonm. Linn. Soc, xxy. (1589) 75 t. 31: Baker, 7. c. 236. - Ind, or.

Wilkeanum X. Hort. ex W. Wats, in Gard. Chron. (1894) ii. 276. - Hybr, artef.

HEDYOSMOS, Mitchell = Gunila Linn. (Labiat. moustifolius, Kuntze, Rer, Gen.(1891) $520=\mathrm{C}$. angustifolia, Benth.

fasciculatus, Kuntze, 1. c. = C. fasciculata, Benth, galiodes, Kuntze, 1. c. = C. galioides, Benth. incanus. Kuntze, 1. c. = C. incana, Benth.

incisus, Kuntze, 1, c $=\mathrm{C}$. incisa, Benth

loncanthus. Kuntze. 1, c. = C. leucantha. Benth.

lythrifolius. Kuntze, 1. c. = C. lythrifolia, Bonth.

menthodes, Kuntze, 1. c。= C. menthoides, Benth.

miorocephalus, Kuntze, 1. c. = C. microcephala Benth.

origanodes, Kuntze, 1. c. = C. Mariana, Linn.

polyanthus, Kuntze, 1. C. = C. polyantha, Benth.

secumdus Kuntze, 1. C, = C. secunda, S. Wats.

secundus Kuntze, 1. c, = C secunda,
spicatus, Kuntze, 1. C. $=$ C. spicata, Benth.

stachyodes, Kuntze, 1. c, = C. stachyoides, Mart. \& Gal.

stricfus, Kuntze, 1. $\mathrm{c}=\mathrm{C}$. stricta, Benth

HEDYOTIS, Linn. (Rubiac.).-Ind. Kew. i. 1100

athroantha, Collett \& Hemsl. in fourn. Limn. Soc xxviii. (1890) 65. - Ind. or.

brachypetala, Plil. in Anal. Unir. Chil. Ixxxv. (1894) 740. - Chili.

coprosmoides, Trim. Syst. Cat. Ceyl. (1885) 42; Handb, Fl. Coyl. ii. (1894) 306. - Zeyl.

inconspicua, F. Phil. cx Phil, in Anal. Unia. Chil. lxxxy, (1894) 739 , - Chili

Johnstoni, Oliver, in H. Fohnst. The Kilim. Exped. App. $(1886,341$; ot in Trans, Linn, Soc. Ser. II. ii (1887) 335, - Afr. trop. or.

Inacrostegia, Staff, l. c. Ser. II. iv. (1894) 170. Borneo.

protrusa, Stapf, l. c. 169.- Borneo.

pulchella, Stapf, l. c. - Borneo.

tenuipes, Hennsl. ex Forb. et Hensl. in foum. Linn. Soc.xxiii. (1888)375. - China.

HEDYSARUM. [Tourn.] Linn. (Legumin.). lnd. Kew. i. $110 \%$

americanm, Britton, in Mem. Torrey Bot. Club, (1894) $201=-$ boreale, $N^{\top} u t t$

candidum, Freyn, in Oest. Bot. Zcitschr. xlii. (1892) 80. - Armen.

cyprium, Boiss. Fl. Or. Suppl. (1888) 189. - Ins Cypr

ecbatanum, G. Beck, ex Stapf, in Denkschr. Akad. Wien (1886) i4. - Persia.

flavescens. Conlt, et Fisher, in Coult Bot. Gar. xviii. (1893) 300. - Am. bor.

Maitlandianum, Aitch. \& Baker, in Trans. Linn. Soc. Ser. II. iii. (1886) 57. - Turkest.

Wrightianum, Aitch. \& Baker, l. c. - Afghan. Turkest.

xanthinum, Freyn, in Ocst. Bot. Zeitschr. xlii. (189\%) 49. - As. Min,

HEERIA, Meissn. = Anaphrenium, E. Mey. (Anacard.).

concolor, dispar, paniculosa, pulcherrima, Kuntze, Rev. Gen. (1891) 152 = homonyma ommia Anaphrenii.

insignis, Kuntze, 1. c。= A. mucronatum, Bernh,

HEERIA, Schlecht. (Melast.).- Ind. Kew. i. $110 \%$ axillaris, Cogn. in DC. Monog. Phan. vii. (1891) 138 (= Hetcrocentron axillate. Naud.). - Mexic. Am. centr.

HEINSIA, DC, (Rubiac) - Ind, Kew, i. 1108 puchella. K. Schum. in Engl, et Prantl, Naturr. Pfanzenfam, iv, 4 (1891) $84=$ jasminiflora, $D C$.
HEISTERA, Linn. = Muraltia, Neck。(Polyg.): acicularis, acipetala, angulosa. anthospermifolia, asparagifolia, Beiliana, breicormu, calycina, carnosa, ciliaris, cliffortiacfolia crassifolia depressa diraricata, Dregei, dumosa, evicifolia, fasciculata, filiformis, humilis, incompta, juniperifolia, lancifolia, laricifolia. laxa, leptortiza, longicuspis, macrocarpa, macroceras, macropetala, micrantha, mixta, obovata. ononidifolia, Pappeana, parvitlora, panciflora, pilosa, Poirctii, pubescens, rigida, squarrosa, stifulacea, Poireth, pubescens, rigida, squarrosa, stifulaced, Gen.(1891) 47 = homonyma ommia Muraltiae.

alopecurodes, Kuntze, 1. C. = M. alopecuroides D. C

Candollei, Kuntze, 1. c. = M. De Candollei, Eckl. \& $Z$ cy/h.

conferta. Kuntze $1 \mathrm{c}=\mathrm{M}$, satureioides, Burch diffusa. Kuntze, 1. c. = M. stipulacea, Burch.

ericodes. Kuntze. 1. c. = M. Burmanni, DC

metalasiaefolia, Kuntze, 1. c. = M. rubeacea, Eckl. \& $Z e y / 7$.

phylicodes, Kuntze, 1. c. = M. phylicoides, DC.

reticulata, Kuntze, 1. c. = M. origanoides, Presl.

saturejodes, Kuntze, 1. c. = M. saturejoides, Burch.

serpyllodes, Kuntze, 1. c. = M. serpylloides, $D C$.

HEISTERIA, Jacq. (Olacin), - Ind. Kew. i. 1108. costaricensis, F. D. Smith, in Conlt. Bot. Gaz xix. (1894) 255, - Costarica.

microcalyx Sagot, ex Kuntze. Rer.Gen. (1891) 112. - Am. austr.

HELENIASTRUM, Mill. Gard. Dict. (1739) = Helenium, Linn. (Compos.)

amphilobum, autumnale, Bigelowii. Bolanderi, brevifolium, Curtisii, clegans, - fimbriatum, Hoopesii, integrifolinm, laciniatun, mexicanum, microcephalum, mudiforum, ooclininun, puberulum, quadridentatum, tenufolium, Thurberi, vernale, Kuntze, Rev, Gen. (1891) $342=$ homonyma omnia Helenii.

Helenimu, Kuntze, 1. c. = H. Nuttallii, A. Gray.

occidcntale, Greene, Man. Bot. San Franç. Bay 1894) 202. - Calif.

pariflom, Kuntze, Rev. Gen. (1891) $341=$ Helenium nudiflorum, Nutt.

arim, Kuntze, 1. $c_{0}=$ H. mexicanum, H. B. \& $K$.

HELENIUM, Linn. Syst, i. (1735) 16 [non 1753] = Inula, Linn. (Compos; )

acaule, acuminatum, africanum, ammobhilum, anatolicum angustifolium, Arbuscula, Aschersonianum, Aucherianum, auriculatum, bifrons britamicum, candidum, Cappa, caspinm, confertiflorum, cordatum, cuspidatum, cnsifolium, Falconeri, fragile, germanicum, glomeratum, gyande, grandiflorum, graveolens, Griffithii, heterolepis, hivtum, Hookeri, Kalapani, limonifolim, macrophylla, macrospermum, Mannii, Montbretianum, montanum, multicaule, nercosum, obtusifolium, Oculus-Christi, polygonatum, racemosum, rhizocephalum, Royleamum, rubricaule, salicinum, Seidlitzii, Simonsii, somalense, squarrosum, suaceolens, Vaillantii, viscosum, Kuntze, Rev. Gen. (1891) $342-43=$ homonyma ommia Inulae.

crithmodes, Kuntze, 1. c. = I. crithmoides. Lim. Csatoi, Kuntze 1. c. $343=$ I. Csatoi $\times$, Borb.

cupatoriodes, Kuntze, 1. c. = I. eupatorioides, $D C$. grantiodes, Kuntze, 1. c = I. grantioides, Bern. heleniodes, Kuntze, 1. c. = I. helenioides, DC. hispidum, Kuntze, 1. c. = I, squarrosa, Limm. intermedium, Funtze, 1. c. = I. intermedia Strud.

Kanitzii, Kuntze, 1. c. $342=$ I. Oculus-Christi, Linn.

litorale, Kuntze. 1. c, $343=$ I. litoralis X, Borb macrocephalum, Kuntze, 1. $C_{*}=$ I. Royleana, $D C$. macrolcpis, Kuntze, 1. c. = I. britannica, Linn. microcephalum, Kuntze, 1. c. = I. microcephala X, Borb.

officinale, Kuntze, 1. c. $342=$ I. Helenium, Linn.

orientale, Kuntze, 1. c. = I. glandulosa, Puschk.

repandum, Kuntze, 1. c. $343=$ I. britannica, Linn. revolutum, Kuntze; 1. c. = Pulicaria revoluta, Nym. rhizocephalodes, Kuntze, 1. c. = I. rhizocephaloides, C. B. Clarke.

salviodorm, Kuntze, 1, c. = I. Cappa, DC.
HELENIUM :-

sericenm, Kuntze, Rev. Gen. (1891) $342=(=$ Schizogyne abtutsifolia, Cass.). - Ins. Canar.

strictum, Kuntze, 1. c. $343=$ I, stricta, Tausch.

thapsodes, Kuntze, 1. $c=$ I. thapsoides, Boiss.

Vrabclyianm, Kuntze, 1. c. $(=I$. Vrabolyianum $X$ Kern.) = I. stricta, Tausch.

'ulgare, Kuntze, 1. c. $342=1$. Conyza, $D C$.

HELENIUM, Linn. (Compos.), - Ind. Kew. i. 1108

collinum, Fr. Meigen, in Bot. Jahrb. xvii. (1893) 281 = Cephalophora collina, Plit.

setigerum, Britton \& Robinson, in Trans. $N . V$. Acad. Sci. vii. (1887) 11 (= Amblyolepis setigera, DC.). - Texas.

HELEOCHARIS, Lestib. = Eleocharis, R. Br. (Cyper.).

bahamensis, Boeck. Cyper. Nov. ii. (1890) 11. Ins. Baham.

brasilientsis, Boeck. 1. c. 13. - Bras.

caduca, Aschers, ex C. B. Clarke, in Th. Dur. \& Schinz, Consp, F1. Afr.v. (1895) $597=\mathrm{E}$. capitata, $R$. Br.

crisporaginata, Boeck. in Bot. Jahrb, viii.-(1887) 206. - Ecuad.

cubensis, Boeck. Cyper. Nov, ii. (1890) 10. - Cuba.

hyalino-vaginata, Boeck. ex Reiche, in Bot. Jahrb. xxi. (1895) 43, nomen. - Chili.

Kuntzci, Boeck.1. C. 1. (1888) $14^{-}=$E. afflata, Stcud.

Lehmanniana, Boeck. in Bot. Jahrb. viii. (1887) 205. - Ecuad.

Loefgreniana, Boeck. Cyper. Nov. ii. (1890) 12. Bras.

Mendoncac, Boeck. 1. c. - Bras.

Minarm. Boeck. 1. c. - Bras.

minutiflora, Boeck. in Bot. Jahrb. vii. (1886) 274. - Ins. S. Thom.

paracicularis, Boeck. 1. c. 275 , in obs. = Scirpus paracicularis, Wright

plantaginea, R. Br. ex Boeck. Cyper. Nov. ii (1s:0) $14=\mathrm{E}$. plantaginea, $R . B r$

punctata, Boeck. ex Tonduz, in Bull. Herb, Boiss. iii. (1895) 464. - Costarica

Reichei, Boeck. ex Reiche, in Bot. Jahrb. xxi. (1895) 43, nomen. - Chili.

Scriaffneri, Boeck. 1. c. vii. (1886) 2\%4. - Mexic.

Schenckii, Boeck. Cyper. Nov. ii. (1890) 13, - Bras. squamata, Boeck. 1. C. 11.-Bras.

striata, Hochst, ex Engl, in Abh. Preuss, Akad. Wiss. 1891 (1892) $149=\mathrm{E}$. palustris, $R$. $B r$.

Vulcani, Boeck, in Bot. Jahrb. viii. (188\%) 206.Columb.

HELEOCHLOA, Host (Gramin, ). - Ind, Kew i. 1109

brachystachys, C. Richt. Pl, Europ. i. (1889) 35 (= Vilfa brachystachys, Presi). - Sicil.

compacta, Th. Dur. \& Schinz, Consp. Fl. Afr.v. 1894 (1895) 814 (=Crypsis compacta, Steud.). Sener.

Myosurus, Th. Dur. \& Schinz, l. c. $(=$ Crypsis Myosurus. Nees). - Aegypt.

HELIA, Mart. = Lisianthus, Linn.(Gentian.) alata, alba, alpestris, amplissima, angustifolia, arboren, auriculata, bifida, campanulacea, coevulescens, ciassi caulis, densiflora, elegans, Elisabcthac, fistulosa, frigida, glabra, glandulosa, grandiflora, macrantha macrophyzla, Mathewsii, obtusifolia, oralis, panin lata, pondula, pratensis, Princeps, pulcherrima, piilcha, pumila, purpurascens, ramosissima, revoluta, Schomburgkii, speciosa, splendens, Spruceana, tenuifolia, tetragona, trifidus, uliginosa, rasculosa, sirgata, viridiflora, viscosa, Kuntze, Rev. Gen. (IE!) 427-28 = homonyma omnia Lisianthi.

acutangula, Kuntze, 1. c. $427=\mathrm{L}$. trifidus, $H . B . K$. amoena, Kuntze, 1. c. $428=$ L. uliginosus, Grises campanulodes, Kuntze, 1. c. $=$ L. campanuloides, Spruce.

chelonodes, Kuntze, 1. c. $42 \%=$ L. chelonoides, Linu. $f$.

cujabana, Kuntze, 1. c. = L. acutansulus, Mat, daturodes, Kuntze, 1. c. $428=$ L. daturcides, Griseb. 
HELIA : -

gracilis, Kuntze, Rev.Gen.(1S91) $428=$ L. uliginosus. Griseb.

loranthodes, Kuntze, 1. c. = L. loranthoides, Griseb. Marti, Gilg, in Eng1. \& Prantl, Natürl. Pflanzenfam. iv. $2(1895) 101=$ L. Martii, Griseb. nemorosa, Kuntze, Rev. Gen.(1891) $428 ;=$ Irlbachia Bonplandiana, Fenzl). - N. Granat.

neviodes, Kuntze, 1. c。 = L. nerioides, Griseb.

Oerstedti, Kuntze, 1. C. = L. alatus, Aubl.

spathulata, Gilg, in Eng1. \& Prantl, Natürl. Pflan zenfam. iv. 3 (1895) $101=\mathrm{L}$. spathulatus, $H$ $B$. \& $K$.

thamnodes, Kuntze, 1. c. - L, thamnoides Griseb.

HELIANTHELLA, Torr. \& Gray (Compos.). lnd. Kew, i. 1109

Aldersonii, Grcene, in Erythea, i. (1893) 259. Calif.

castanea, Greene, l. c. 127 ; ot Man. Bot. San Franc. Bay (1894) 190. - Calif

madrensis, S. Wats, in Proc. Am. Acad. xxiii. (188s) 278. - Mexic

Pringlei. S. Wats. l. c.xxi. (1886) 389. - Mexic.

HELIA NTHEMUM, Tourn. ex Hall. (Cistin.). Ind. Kew. i. 1109.

affine, Fouc. \& Rouy, Fl. de Fr, ii. (1895) $304=$ hirtum, Pers.

argyreum, Baker, in Kew Bull. (1894) 329; ct in Hook Icon.pl. xxiv. (1895) t. 2360. - Arabia.

Chatenieri, Fonc. \& Roncy, Fl. de Fr. ii. (1895) 307 - Gall. mer.

chihuahuanum. S. Wats. in Proc. Am. Acad. xxiii (1SS8) 268. - Mexic.

digenenm $X$, Rouy \& Fouc. FI. de Fr. ii. (1895) 306. - Gall. mer

hercegoimum, G. Beck, in Annal. Naturh. Hofmus. Wien, ii. (1887) 83 = vulgare, Gaertn.

hirtiforme $X$, Rouy et Fouc. Fl. de Fr. ii. (1895) 306. - Gall. mer.

littorale, Rouy \& Fouc, 1. c. 286 et $288=$ guttatum, Mill.

majus, Britton, Stern \& Pogs. Prelim. Catal. (1888) 6 = canadense, Michx.

majus, Bicknell, in Bull. Torrey Bot. Club, xxi. (18.14) 257 [an praec. ?]. - Am. bor.

metlilense, Coss. \& Durieu ex Batt. \& Trab. Fl. do l'Algér. [Dicot.] (1889) 96, nomen; et Ill. Fl. Atlant. i. 112 t. $\% 1$ = getulum, Ponel.

Milleri, Rouy \& Fouc. Fl, de Fr. ii. (1895) $285=$ guttatum, Mill.

monspessulanum $X$, Rouy \& Fouc, Fl. de Fr. ii (1895) 311. - Gall. mer.

Nashi, Britton, in Bull. Torrey Bot. Chub, xxii. (1895) 147. - Florida.

nutans, T. S. Brandeg, in Proc. Calif. Akad. Ser. II. ii. (1889) 129. - Calif

occidentale, Greene, in Bull. Calif. Acad. ii. vi. (1886) 144. - Ins. S. Cruz. (Calif.).

ochroleucum $X$, Rouy \& Fouc. Fl. de Fr. ii. (1895) 303. - Gall.

Pringlei, S. Wats, in Proc. An. Acad. xxiii. (1888) 268. - Mexic

rosmarinifolium, Hort. ex Gard. Kew. i. [Polypet.] $33=$ H. Libanotis, Willd.

Sancti-Antonit, Schweinf. ex Aschers. \& Schweinf. Ill. Fl. Egypte [Mém. Inst. Egypt.] ii. (1887) 45 et $748=$ ventusum, Boiss.

Scopolii, Rouy \& Fouc. F1. de Fr. ii. (1895) 295 et 298 = vulgare, Gacrn.

shericense, Simonk. in Termész. Füzet. x. (1886) 180 = rupifragum, $A$. Kern.

HELIANTHUS, Linn, (Compos.). - Ind. Kew. 1112

atacamensis, Phil. in Anal. Mus. nac. Chile (1891) 48. - Chili

araucanus, Phil. in Anal. Univ. Chil. xc. (1894) 39 - Chili.

australis, Phil. l. c. 39. - Chili.

copiapinus, Phil.l.c.37. - Chili.

Cusickii, A. Gray, in Proc. Am. Acad. xxi. (1886) 415. - Oreg.

Gayanus, Phil. in Anal. Univ. Chil. xc. (1895) 39.

\section{HELIANTHUS}

imbaburensis, Hicron. in Bot. Fahro:xxi. (1895) 348. - Ecuad.

incenustus, Greene, Pittonia, i. (Mar. 1889) 28t= Balsamorhiza invenusta, Cooille.

Navarri, Phil. in Anal. Univ, Chil. xc. (1895) 3\%.Chili.

mivens, T. S. Brandeg. in Proc. Calif. Acad. Ser. II. ii, (1889) 173 = Encelia nivea, Benth.

niveus, Hieron in Bot, fallzb. xxi. (1895) 350. Peruv.

Stuebelii, Hicron. l. c. 349. - Peruv.

HELIGHR YSUM, Vail].(Compos.).-Ind. Kew.

i. 111

achryroclinoides, Baker, in fourn. Linn. Soc, xxv. 1890) 328. - Madag.

album, N. E. Br. in Kee Bull. (1895) 24. - Natal. argyrolepis, MacOwan, in foum. Limn. Soc. xxy. (1890) $38 \%$ - Afr. austr.

mplexicaule, Baker, l, c. xxii. (188 ü) 491 Madas.

Antandroi, S. Elliot, l.c.xxix. (1891) 29. - Madas araneosum, Baker, l. c. xxii. (1887) 491. - Madas argyranthum, O. Hoffm. un Engl. Pfanzenw. Ost Afr. C (1895) 410. - Afr. trop. or.

arnicoides, Cordem. Fl. Ile Remion (1875) $5331=$ Gnaphalium arnicoides, Lam.). - Ins. Borbon.

betsiliense, Klatt, in Bot. Fahrb. xii. Beibl. n. 27 (1890) 24. - Madag

biterrense, Coste \& Mouret, in Bull. Soc. Bot. Fr. xl. $(18,3)$ p. cxli. $=$ H. Strechas, $D C$

Buchanani, Engl. in Abh. Prenss, Akad. Wiss. 1891 (1892) 429. - Zambesia

confertum, N. E. Br. in Kew Bull. (1895) 25. Natal.

cordatum, [Engl.?] Pflanzenw, Ost-Afr. A (1895) 132 [Quid ?]. - Afr. trop.

rispo-marcinatum, Baker, $2 n$ fou'n, I inn, Soc. xxy. (1890) 328. - Madag.

lamarense, O. Hoffm. in Bot. Fahrb. x. (1889) 275. - Afr. austro-occ. extratrop.

decorum, [N.E.Br.in] Monteiro, Delagoa Bay (1891) 170 [an DC. ?]. - Mossamb.

devium, 7. Y. Folnson, in Gard. Clron. (1888) ii. 62. - Madera

densiflorum, Oliver, in Hook. Icon. pl. xxiii. (1894) t. 2286. - Afr. trop. austro-or.

dracunculifolium, Boiss, Fl. Or. Suppl. (1888) 292. - Persia.

Engleri, O. Hoffm. in Bot. Falirb. xx. (1894) 232. Afr. trop. or

ericifolium, Baker, in fourn. Linn. Soc. xxy. (1890) 329. - Madas.

Faradifani, S. Elliot, in foum. Limn. Soc. xxix. (1891) 29. - Madas.

farinosum Baker, l. c xxii. (1887) 491. - Madac. fulvum, N. E. Br. in Kew Bull. (1895) 146. - Natal. geminatum, Klatt, in Ann. Naturh.Hofmus. Wien, vii. (1892) 101. - Angola.

Guilelmi, Engl. in Abh. Prenss. Akad. Wiss. 1891 (1892) 426. - Afr. trop. or

Hoehnelii, Schweinf. in Hochnel, zum Rudolph See. App. (1892) 10; et ex Engl. in Abh. Prenss. Akad. Wiss. 1891 (1892) 426, nomen. - Afr. trop. or.

Humblotii, Klatt, in Am. Naturh. Hofmus, Wien. vii. (1892) 297. - Ins. Comor.

Kilimanjari, Oliver, in folnst. Kitin. Exped., App. (1886) 342 ; et in Trans. Linn. Soc, Ser. II. ii, (1887) 338. - Afr. trop or

Lastii, Engl. in Abh. Prenss. Akad. Wiss. 1891 (1892) 430. - Afr. trop. or

Lentii, Volk. \& O. Hoffm. in Engl. PAanzenw. OstAfr. C (1895) 410. - Afr. trop. or.

leimanthium, Klatt, in Ann. Natnrh. Hofmus, Wim, vii. (1892) 101. - Angola.

leptolepis, [N.E. Br. in Monteiro, Delogoa Bay (1891) I68. - Mossamb

maranguense. O. Hoffm. in Engl. Pflanzenv. OstAfr. C (1895) 411. - Afr. trop. or.

Marlothianum, O. Hoffm. in Bot. Fahrb. x. (1889) 275. - Afr. austro-occ, extratrop.

Mechowianum, Klatt, in Ann. Naturh. Hofmus. Wien. vii. (1892) 101. - Angola.

Meyeri-Johannis, Engl. in Abh. Preuss. Akad: Wiss, 1891 (1892) 427. - Afr. trop, or

\section{HELICHRYSUM :}

milanjlense Britton, in Trans I inn Soc, Ser. II. iv. (1894) 19. - Afr'. trop.

chraceum, Klatt, in Am. Naturh. Hofmus. Wien, vii. (1892) 297. - Ins. Comor.

parviflorum. [N. E. Br. in] Monteiro, Delagoa Bay (1891) 16\%. - Mossamb.

pauciflorum, T. Kirk, in Trans, N. Z. Inst, xxvii. $1894(1895) 351 .-$ N. Zel

phaceloma, F. Mucll. \& Tate, in Trans. Roy. Soc. S Austral. xix. (1895) 81, nomen, - Austrai.

Pichleri, Barbey, in Bull. Soc. vaud. sci, nat. xxi. (1885) 00. - Ins. Karpathos.

platycephalum, Baker, in foum, Linn, Soc. xxii. 1887) 492. - Madao

Purdiei, Petrie, in Trans. N. Z. Inst. xxii. 1889 1890) 440 ; et xxvi. 1893 (1894) 273. - N. Zel.

pygmaeum, Post, Pl. Postianae, ii. (I891) 1\%. Syria.

reflexum, N. E. Br. in Kur Bull. (1894) 3506. Transvaal.

roseo-niveum, Marloth \&o O. Hoffm. in Bot. Fahrb. . (1889) 275. - Afr. austro-occ. extratrop

sarmentosum, O. Hoffnt. in Engl. Pfanzenw. Ost-Afr. C (1895) 411. - Afr. trop. or

Sleudnevi, Schweinf. ex Engr. in Abh. Prenss. Akad. Wiss. 1891 (1892) 430 , in syn. = fruticosum Vatk

Stirlingii, F. Muell. in Vict. Natural. vi. (Feb.-Mar. 1890) 166: et in Bot. Centralbl, xli, (1890) 398. Austral.

Stuhlmannii, O. Hoffm. in Bot. Fahrb. xx. (1894) 232. - Afr. trop. or

valentinum, Rouy, in Bull. Soc. Bot. Fr. xxxv. (1888 117. - Hisp.

Volkensii, O. Hoffm, in Engl. Pflanzenw. Ost-Afr. C 1895) 410. - Afr. trop. or.

Webbit. Christ, in Bot. Jahrb. ix. (1888) 168 (= Gnaphalim Wcbbii, Sch. Bip.) = gossypinum, Sch. Bip.

Whyteanum, Britten, in Trans. Linn. Soc. Ser. II iv. (1894) 19. - Afr. trop.

HELICIA, Lour. (Proteac.). - Ind. Kew. 1. 1117 rratica, Hook. f. Fl. Brit. Ind. v. (18S6) 189. Reg. Himal.

Forbesiana, F. Mull. in Vict. Natural. iii. (Sept 1886) 63 ; ct ex Bot. Ceutralbl. xxix. (1887) 84 . N. Guin

formosana, Hensl, in Fourn, Limn, Soc xxvi. (1891) 394; et in Annal. Bot. ix. 1895$) 156$. - Ins. For mos.

Sayeriana, F. Muell. in Vict. Natural. iii. (Nov. 1886) 93. - Austral.

travancorica, Bedd. ex Hook. f. Fl. Brit. Ind.v. 1886) 191. - Deccan

Whelani, F. M. Bailey, Rep. Exped. Bellenden-Ker 1889) 55. - Austral.

HELICODEA, Lem. = Billbergia. Thunb. (Bromel.).

Baraquiniana, Lem. ex Baker, Handb. Bromel. (1889) 81 , sphalm. (=H. Bariquiana, Lem.) $=$ B. decora, Pecpp. E Endl.

HELICONIA, Linn. (Scitam.). - Ind, Kew. i $111 \%$

Bourgaeana, Petersen, in Mart. Fl. Bras, iii. III. 1890) 14. - Mexic.

Burchellii, Baker, in Ann. Bot. vii, (1893) 197. Bras. centr.

choconiana, S. Wats, in Proc. Am. Acad. xxiii. (1S88) 284 ; et in Gard. and For. i. (1888) 161 fig. 31. - Guatem.

conferta, Petersen, in Mart. Fl. Bras. iii. III. (1890) 13. - Ins. Guadalup.

curtispatha, Petersen, l. c. 15. - Panama

elegans, Petersen. l. c. 12. - Am. trop

Ferdinando-Coburgi, Szyszyl. ex Wawra, Itin. Princ. Sax. Coburg. ii. (1888) 88. - Bras

illustris. Hort. Bull. ex Gard. Chron. (1893) i. 413 ; et ex Illustr. Hort. xlii. (1895̃) 288. - Ins. Maris austr.

imbricata, Baker, in Ann. Bot. vii. (1893) 191 (= Bihai mbricata, Xuntze). - Costarica.

platystachys, Baker, l. i. 199. - Columb., Guatem 


\section{HELICONIA :}

roseostriata Hort ex Illustr. Hortic xlii. (1895) 98. - Form, hort

spectabilis, L. Lindl. \& Rodigas, in Illustr. Hortic. xxxix. (1892) 61 t. 556 . - As. trop. austr.

Wasneriana, Petersen, in Mast. Fl. Bras, iii. III. (1890) 13. - Panama.

HELICTERES, Pluk, ex Linn. (Stercul.). - Ind. Kew. i. $111 \%$

uneata, K. Schm. in Mart. Fl. Bras. xii. I!I. (1886) 24 . - Bras

Eichleri, K. Scmmm. l. c. 16. - Bras.

Lhotzlyana, K. Schmm. l. c. 19.-Bras.

longepedunculata, K. Schum. l. c. 26. - Bras.

microphylla, K. Schm.l. c.2S. - Bras

mollis, $K$, Schum. l.c. 22. - Bras.

Rusbyi, Britton, in Bull. Torrey Bot. Club, xvi. (1839) 155. - Bolivia.

Urbani, K. Schum. in Mart Fl. Bras. xii. II. (1886 22. - Guian. ang1.

velutina, $K$. Schum.l. c. - Bras

HELIETTA, Tul. (Rutac。) - Ind. Kew, i. 1118 oncifoliata, Britton, in Ann, N.Y.Acad, Sci, vil. (is92) 69. - Parag.

HELINUS. E. Mey. (Rhamn.). - Ind. Kew. i. 1118

integrifolius, Kuntze, Rev. Gen. (1891) 120, in syn = ovatus, E.Mcy.

HeLIOCARPUS, Linn. (Tiliac.). - Ind. Kew, i. 1118.

ttenuatus, S. Wats, in Proc. Am. Acad. xxi. (1886) 420. - Mexic

Palmeri, S. Wats . . c - Mexic.

polyandrus, S. Wats.l. c.-Mexic.

HELIOPHILA, Burm. f. (Crucif.). - Ind. Kew. i. 1118

patens, Olicer, in Hook, Icon.ploxxiv, (1894) t. 2325. - Afr. austr.

tenuis, N.E, Br.in Kew Bull. (1894) 99. - Afr austr.

HELIOPSIS. Pers. (Compos.). - Ind. Kew. i. III?.

buphthalmoides, T. S. Brandeg. in Proc. Calif, Acad. Ser. II. ii. (1889) $172=$ bupthalmoides, Dum

filifolia, S. Wats. in Proc. Am. Acad. xxv. (1890) 153. - Mexic

helianthodes, Kuntze, Rev. Gen.(1891) $343=$ seq.

helianthoides, Britton, Stern \& Pogg. Prelim, Catal. (1888) $28=$ laevis, Pers

HELIOTROPIUM, [Tourn.] Linn. (Borag.). Ind. Kew i. 1119

abbreviatum, Rusby, in Mem. Torrey Bot. Club, iv. (1895) 224. - Bolivia.

albiflorum, Engl. Bot. Fahr, x. (1889) 267. - Afr. austro-occ. extratrop.

albohispidum, Baker, in Kew Bull. (1895) 220.Reg. Somal.

album, St. Lager, in Cariot, Etud. des fl. éd. 8. ii (1889) $614=$ europaeum, Linn.

andinum, Rusby, in Men. Torrey Bot. Club, iv. (1893) 224. - Bolivia.

auratum. Plit. in Anal. Mus.nac. Chilc (1891) 56. - Am. austr. occ

Balfouri, Guerke, in Engl. E Prantl, Natiur. Pflanrenfam, iv. 3a (1894) 97 (= H. odorm, Ball, f.). - Ins. Socotr.

Boissieri, Guevke, l.c. $96(=H$ confertiflornm, Boiss. et Noé). - Persia.

bolivianum Rusby, in Mcm. Torrey Bot. Chub, iv. (189.5) 225. - Bolivia.

brachystachyum, Gueske, in Engl. Eo Prantl, Natirl. Pflanzenfam. iv. 3a (1894) 96 (= Heliophytum brachystachyum, DC.). - Peruv.

Breanum, Phil, in Anal. Univ. Chil, xc. (1895):35\%. - Chili.

brevifolium, Phil.l. c. -- Chili.

Bridgesii, Rusby, in Men. Torrey Bot. Club, iv, (1895) 224. - Rolivia

\section{HELIOTROPIUM}

anum, Phil, in Anal. Univ', Chit., xc, (1895) :556.Chili.

congestum, Bakcr, in Kow Ball. (1894) 336. Arabia.

crispulum, Guerke, in Engl. \& Prantl, Natür. Pfanzenfam.iv, 3a (1894) $96(=$ Heliopliytum crispulum, Fresen - Bras

drepanophyllum, Baker, in Kew Bull. (1894) 336. - Arabia.

Eduardi. Martelli, Fl. Bogos. (1886) 59. - Abyss.

Fresenii, Guerke, in Engl. \& Prantl, Naturl. Pfanzenfam. iv, 3a (1894) 97 (=H. incannm, Fresen.).Abyss

Fumana, Guerke, l. c, $(=$ Schleidenia Fumand, Fresen.). - Bras.

Gardneri, Guerke, l.c. (= S. Gardneri, Fresen.).Bras.

Geissei, F. Phil. ex Phil. in Anal, Univ. Chil. xc. (1895) 352. - Chili.

glomeratum, Terrac, in Bull. Soc. Bot. Ital. (1892) 424. - Reg. Somal.

gymnostomum, Homsl. in Hook. Icon. pl. xviii. (1888) t. 1755. - Giloit.

hispidulum, Phil, in Anal. Unir, Chil, xc. (1895) 356. - Chili.

Izagae, Phil. l. c. 355. - Chili.

Kolschyi, Guerke, in Engl. \& Prant1, Natürl. Pflanzentam. iv. 3a (1893) 95 (= Holiophytum Kotschyi Bunge $=$ tuberculosum. Boiss.

lagoense, Gucrke, l. c. 97 (= Schlcidcnia lagoensis, Warm - Bras.

leiocarpum, Morong, in Ann. N. Y. Acad. Sci. vii. (1893) 168. — Parag.

leptostachyum, Gucke, in Engl. \& Prantl, Natiirl. Pflanzenfan. iv. 3a (1894) 97 (= Schleidenia leptostachya, Fresen.). - Bras.

lineare, Guerke, l. c. 96 (= Heliophytum lineare, A. DC.). - Afr, austr.

linifolium, Guerke, l. c. 97 (= Preslea linifolia, A. St. Hil.). - Bras.

longiflorum, Phil. in Anal. Unir. Chil, xc, (1895) 354. - Chili.

longipetiolatum, Guerke, in Engl. \& Prantl, Naturl. Pflanzenfam. iv. 3a (1893) 97 (= Schleidonia longipetiolata, Fresen.). - Bras.

macranthum, Guerke, l. c. 97 (= Schlcidenia macrantha, Fresen.).-Bras.

mactodon, Gucrke, l, c. 97 ( $=$ S, macrodon, Fresen.) - Bras.

macrostachyum, Guerke, 1.c. $96=$ macrostachyum Henisl.

Martii, Guckk, l. c. 97 $=$ H. dasycarpum, Fresen.). - Bras.

messerschmidiodes, Kuntze, Rev, Gen. (1891) $438=$ Tournefortia fruticosa, Ker-Gaw?.

messerschmidioides, Guerke, in Engl. \& Prantl Natür1. Pflanzenfam. iv. 3a (1893) $94=$ praec odorum, Guerke, l. c. 96 (= Heliopliytum odorum, Fresen.). - Bras.

Oliverianum, Schinz, in Verh. Bot. Ver. Brand. xxx. (1888) 268. - Afr. austro-occ extratrop.

paradoxum, Guerke, in Engl. \& Prantl, Natiorl. Pflanzenfam.iv. 3a (1894) $\vartheta_{1}(=$ Schleidenia para doxa, Mart.). 一 Bras.

parciflorum, Gucrke, l.c. $(=$ S. parciflora, Mart. $)$ - Bras.

persicariaefolim, Britton, in Ann. N. Y. Acad. Sci. vii. (1893) $169=$ monostachyum, Cham.

phyllosepalum, Baker, in Kew Bull. (1894) 30. Zambesia.

piauhiense, Guerke, in Engl. Eo Prantl, Natür. PAanzenfam. iv. 3a $(1893) 97(=H$. oralifolium, Fresen.). - Bras

Pringlei, Robinson, in Proi. Am.Acad. xxvi. (1891 170. - Mexic

pubescens, Gurke, in Engl. \& Prantl, Natürl. Pfanzenfan. iv. 3a (1893) 97 (- Schleidenia pubescens. Fresen.). - Bras.

pullulans, Guerkc, l.c. (= Sihleid.pullulans, Fresen.). - Bras.

Schweinfurthi, Boiss. Fl. Or. Suppl. (1858) 350. Syria:

stenostachyum, Guerke, in Engl. Eo Prantl, Natiml. Pfanzenfam.iv. 3a (1893) $97^{\circ}$ (= Preslaea stenosta chya, A. St. Hil.). - Bras.

\section{HELIOTROPIUM :}

Subracemosum Guerke in Eng7 of Prantl, Natün. Pfanzenfam。iv. 3a (1893) 97 (- Schleidenia subracemosa, Warm.). - Bras.

subulatum, Hochst. ex Martelli, Fl. Bogos. (1886 59 = zeylanicum, Lam.

tuberculatum, Guerke, in Engl. Es Prantl, Natür. Pflanzenfam. iv. 3a (1893) 94 (= Messerschmiedtio tuberculata, Cham.). - Afr. austr.

Vatkei, Guerke, l. c. 96 (= H. calcareum, Vatke). Afr. trop.

vernicosum, Phil. in Anal. Unir. Chil. xc. (1895) 35.5. - Chili.

HELIPTERUM, DC. (Compos.). - Ind. Kew. i 1122

Battii, F. Muell. in Vict. Natural. x. (Jan. 1894) 144. - Austral.

Fitzgibboni, F. Muell. in Trans. et Proc. Roy Soc S. Austral. xiii. (1890) 170; et ex Bot. Centralbl xlii. (1890) 276; et xlv. (1891) 122. - Austral.

Jesseni, F. Muell. in Vict. Natural. vii. (Aug. 1890) 45 ; et ex Bot. Centralbl. xliii. (1890) 372. Austral.

Troedelii, F. Mull. ll.cc. vii. (Oct. 1890) r6; et xliv. (1890) 237. - Austral.

HELLEBORINE, Martyn, Hist. Pl. (1736) t. 50; ex Kuntze, Rev.Gen, (1891) 665 = Galopogon, R. $\mathrm{Br}$ (Orchid.).

graminifolia, Kuntze, 1, c. = C. parviflorus, Lindl. multiflora, Kuntze, 1. C. $=$ C. multiflorus, Lmdl. pallida, Kuntze, 1. c。= C. pallidus, Chapman. tuberosa, Kuntze, 1, c, = C. pulchellus, $R$. $B r$.

HELLEBORODES, Moehring = Exanthis, Salisb. (Rantnc.).

cilicicum, Kuntze, Rev. Gen. (1891)3= E. culicica, Schott \& Kotschy.

liycmale, Kuntze, 1. c. = E. hyemalis, Salisb.

sibiricum, Kuntze, 1 , c. = E, sibirica, $D C$.

uncinatum, Kuntze, 1. $\mathrm{c}=\mathrm{E}=\mathrm{E}$. uncinata, Turcz.

HELLEBORUS, [Tourn.] Linn. (Ranuncul,). Ind. Kew, i. 1123.

Banmgarteni, Kovats, in Bot. Jahrb. xi. $(1890,322$ = purpurascens, Waldst. \& Kit.

chinensis, Maxim. in Act, Hort. Petrop. xi. (1889) 27. - China.

fissus $X$, Schiffn. in Denkschr. Akad. Naturforsch. lvi. (1890) 175. - Eur. or.

Heyderi $X$, Hort. ex Schiffn. 1. c. 169. - Reg. Callcas

kamtschatensis $X$, Hort. ex Schiffn. 1. c. 173. Hybr, artef.

Kochii, Schiffn. 1. c. 85; et in Bot. Jahrb. xi. (1890) $108=$ orientalis, Lam

lncidus $X$, Hort, ex Schiffn. 1. c. 175. - Hybr. artef.

macranthus, Freyn, ex Schiffn. 1. c. 76 ; et in Bot Jahrb. xi. (1890) $105=$ niger Linn.

Personati, Masclef, in Bonnier, Rev. sén. Bot. (1889) 606; et in Magnier, Scrin. fl. select. xi. (1892) 238 = viridis, Limn.

siculus, Schiffn. in Denschr. Akad. Naturforsch. Ivi (1890) 123 t. 6. - Sicil.

pinescens, Tausch, ex Schiffn. in Bot. Jahrb. xi. 103, in syn. = corsicus, Willd.

thibetanus, Franch.in Nouv. Arch. Mus. Paris, Sér. II. viii. 1885 (1886) 190. — Tibet

viridescens $X$, Schiffn. in Denkschr. Akad. Naturforsch. lvi. (1890) 176. - Europ. centr.

HELLWIGIA, Warb, in Bot. Jahrb. xiii. (1891) 279. ZINGIBERACEAE.

pulchra, Warb.l.c. - Oceania.

HELODEA, Caruel, Epit. Fl. Europ. i. (1892) $106=$ HEODEA, Reichb. = Elodea. Michx (Hydrochar.).

HELODES, St. Lager = ELODES, Adans. = Hypericum, [Tourn.]. Linn.

glandulosum, St. Lager, in Morot, Journ. de Bot viii. (1894) $84=$ H. Elodes, Huds 
HELOPHYLLUM, Hook. f. = Phyllachne, Forst. (Stylid.).

muscoides, Colenso, in Trans. N. Z. Inst. xxvi. 1893 (1894) 318. - N. Zel.

HELOSYIADIUM, Koch = Apium, Tourn. (Umbell.).

biternatum, Phil. in Anal. Univ. Chil. Ixxxv. (1894) ส18. - Chili.

simense, Hochst. ex Engl, in Abh. Preuss, Akad. Wiss, 1891 (1892) 318, in syn. = Pimpinella simensis, Benth. \& Hook.f.

HELWINGIA, Willd, (Aral.). - Ind. Kew. i. 1125. chinensis, Batalin, in Act. Hort. Petrop. xiii. (1893) 97. - China.

- HelXine, Linn. = Fagopyrum, Tourn. (Poly-

gon.).
acutata, Kuntze, Rev. Gen. (1891) $553=$ F. cymosum, Meissn.

Fagopyrum, Kuntze, 1. cos = F. esculentum, Moench. tartarica, Kuntze, 1.c. = F. tataricum, Gacrtn.

HEMEROGALLIS, Linn. (Liliac.). - Ind. Kew. i. 1125.

aurantiaca, Baker, in Gard. Chron. (1890) ii. 24. Hab.?

serotina, Focke, in Abr. Naturw. Ver. Brem, x. (1888) 158. - Hab. ?

Thunbersii, Baker, in Gard. Chron. (1890) ii, 94. Japon.

HEMIARTHRON, Van Tiesh. in Bull. Soc. Bot. Fr. xlii. (1895) $352=$ Loranthus, Linn.

divaricatum, Van Tiegh. 1. c. = L. divaricatus, $H, B . \& K$,

HEMIBOEA, C. B. Clarke, in Hook. Icon, pl. xvíii. (18S8) t. 1798. GESAERACEAE. follicularis, C. B. Clarke, l. c. sub t. 1798. - China. Henryi, C. B. Clarke, 1. c t. 1798. - China. subcapitata, C. B. Clarke, 1. c. sub to 1798. China.

HEMICARPHA, Nees \& Arn. = Seirpus, Tourn. (Cyperac.).

axillaris, Britton; in Bull. Torrey Bot. Club, xv. (1888) $104=\mathrm{S}$. micranthus, $V a h$.

micrantha, Britton, 1. c.; et xxi. (1894) $35=$ S. micranthus, Valll.

HEMICYCLIA, Wight \& Arn. (Euphorb.). - Ind. Kew. i. 1126

Wightii, Hook. f. Fl. Brit. Ind. v. (1887) 339, Deccan.

HEMIDIODIA, K. Schum, in Mart, Fl. Bras, vi. vI. (1888) 29)= Spermacoce, Dill. (Rubiac.)

ocimifolia, K. Sçhum. 1. c. = S. ocimifolia, Willd.

HEMIGENIA, R. Br. (Labiat.). - Ind. Kew。 i. 1126.

Biddulphiana, F. Muell. in Vict. Natural, vii. (Sept. 1890) 6\%. - Austral.

Tysoni, F. Muell.l.c. x. (Nov. 1893) 109; ct cx Bot. Centralbl. lvii. (1894) 62. - Austral.

HEMIGRAPHIS, Nees (Acanth.). - Ind, Kew. i. 1120.

Blumeana, K. Schum. inz K. Si.hum. Er Hollr. Fr. Kais. Wilh. Land (18S9) 124. - N. Guin.

chinensis, $T$. Anders. ex Hemsl. in foum. Linn. Soc. xxvi. (1891) 238 (= Ruellia chinensis, Nees). China.

primulifolia, K. Schum. in Bot. Jahrb. ix. (1888) $219=$ primulaefolia, Vell.

reptans, Engl. 1. c. vii. (1886) $474=$ reptans, T. Anders.

szechuanica, Batalin, in Act. Hort. Petrop. xiii. (1894) 384, - China.

HEMILOPHIA, Franch. P1. Delav. (1889) 65 ; Pax, in Engl. \& Prantl, Natürl. Pflanzenfam. iii. 2 (1891) 164. CRUCIFERAE.

pulchella, Franch, ll. cc. - Yunnan.
HEMIORCHIS, Kurz (Scitam.). - Ind. Kew. i. 1127.

Godefroyi, Baill. in Bull. Soc, Linn. Paris, ii. (1895) 1196. - As, trop. or.

Harmandi, Baill. l. c. - As, trop. or.

Thoreliana, Baill. l. c. - As, trop. or

HEMIPERIS, Frapp. ex. Cordem. FI. Ile Réunion (1895) 235 = Habenaria, Willd. (Orchid.). brachycentra, Frapp. 1. c. 250. - Ins, Borbon. breviplectra, Frapp. 1. c. 244. - Ins. Borbon. calcaripotens, Frapp. 1. c. 252. - Ins. Borbun. clavata. Frapp. 1. c. 247. - Ins, Borbon, constellata, Frapp. 1. c. 246. - Ins. Borbon. crispa, Frapp. 1. c. 241. - Ins. Borbon. exilis, Frapp. 1. c. 238. - Ins. Borbon. falcata, Frapp. 1. c. 241. - Ins. Burbon. fissirostris, Frapp. 1. c. 228, in syn. = Acrostylis paradoxa, Frapp.

globulosa, Frapp. 1. c. 249. - Ins, Borbon.

imbellis, Frapp. 1. c. 244. - Ins. Borbon.

ludens, Frapp.1.c. 239. - Ins. Borbon.

micrantha. Frapp. 1. c. - Ins. Borbon.

nevilabris, Frapp. 1. c. 250. - Ins. Borbon.

nitida, Frapp. 1. c, 245. - Ins. Borbon

pelicanides, Frapp. 1. c. 251. - Ins. Burbon.

pleiades, Frapp. 1. c. 243. - Ins. Borbon.

purpurea, Frapp. 1. c. - 251. - Ins. Borbon.

ringens, Frapp. 1. c. 245. - Ins. Borbon.

simplex, Frapp. 1. c. 248. - Ins. Borbon.

tenella, Frapp. 1. c. 237. - Ins. Borbon.

trilinguis, Frapp. 1. c. 542 . - Ins. Borbon.

HEMIPILIA, Lindl. (Orchid.),-Ind, Kew. i.112\% flabellata, Burcau \& Franch. in Morot, Fourn. de Bot. v. (18.11) 152. - China occ.

HEMISTEPTA, Bunge = Saussurea, DC. (Compos.).
carthamodes, Kuntze, Rev. Gen. (1S91) $344=$ arthamodes, Kuntze,
S. affinis, Spreng.

HEMrTomes, A. Gray = Newberrya, Torr. (Monotrop.).

pumilum, Greene, in Erythea, ii. (1894) 121. - Calif.

HEMIZONIA, DC. (Compos.).-Ind. Kew.i.1127, anomala, A. Gray, Syn. Fl. N. Am. i. ii. Suppl. (1886) 451. - Calif.

citrina, Greene, Man. Bot. San Franc. Bay (1894) 194. - Calif.

Clevelandi. Greene, l. c. - Calif.

Greeneana, $\lambda^{2}$. E. Rose, in Contrib, U. S. Nat. Horb. i. (1890) 24. - Ins. S. Benito.

Heermanni, Greene, Man. Bot. San Franc. Bay (1894) 194. - Calif.

Kelloggii, Grene, l co-Calif.

Palmeri, N. E. Rose, in Contrib. U. S. Nat. Herb. i. (1890) 24. - Calif.

scabrella, Drew, in Bull. Torrey Bot. Chub, xvi. (1889) 151. - Calif.

HEMSLEYA, Cogn. ex Forb. \& Fems1. in Journ Linn. Soc, xxiii. (1888) 490 ; et in Hook. Icon. pl. xix. (1859) t. 1822. CUCURBITACEAE.

chinensis, $\operatorname{Cog} n$. ll. cc. - China.

tonkinensis, Cogn. in Bull. Hert. Boiss, i. (1893) 613. - Tonkin.

HEMSLEYNA, Kuntze, Rev. Gen. (1891) $88=$ Thryallis, Mart, (Malpigh,).

brachystachya, Kuntze, 1. c. = T. brachystachy"a, Lindl.

latifolia, Kuntze, 1. c. = T. latifolia, Mart.

longifoli.t, Kuntze, 1. c. = T. longitolia, Mart.

HENNINGSOCARPUM, Kuntze, Rev, Gen. (1891) 117 = Llavea, Liebm. (Celastr.).

integrifolium, Kuntze, 1. co = L. integrifolia, Hemsl. viscosum, Kuntze, 1. c. = L. viscosa, Liebm.

HENOSIS, Hook. f. Fl. Brit. Ind. v. (1890) $7 \gamma$; ; vi. (1890) 189; et in Hook. Icon. pi. xxi. (1891) t. 2051. ORCHIDEAE.

longipes, Hook. f. ll. cc. (= Bulbophyllum longipes, Reichb. f.). - Tenass.
HENRIBAILLONIA, Kuntze, Rev. Gen. (1891) $606=$ Cometia. Thou. (Euphorh.).

Iucida, Kuntze. 1. c. $\cot =$ C. Iucida, Baill.

Thouarsi, Kuntze, 1, c. = C. Thouarsii, Baill.

HENRIETTEA, DC. (Melast.). - Ind. Kew.

Glazioviana, Cogn. in Mart. Fl. Bras. xiv. IV. (1888) 532. - Bras.

Saldanhaei, Cogn. l. c. - Bras.

Spruceana, Cogn. l. c. 530.-- Bras.

HENRINTTELLA, Naud. (Melast.). - Ind

Kew. 1. 1128 . 1045. - Bolivia.

glabra, Cogn. in Mart. F1. Bras. xiv. IV. (1SS8) 5,38 = umbellifiora, Triana.

Glazioviana, $\operatorname{Cogn}$. l. c. 539. - Bras.

hispidula. Cogn, in Bot. Fahrb. viii. (1887) 30 ; et in DC. Monog. Phan. viii. (1891) ) 046. - Columb. membranifolia, Cogn. [in Sint. Pl. Portoric. n. 5730 et 5968] in DC, l. c. 1042. - Ins. Portorii.

ovata, Cogn. in Mart. Fl. Bras, xiv. IV. (188S) 540. - Bras.

tovarensis. $\operatorname{Cog} n$. in DC. Monog. Phan, vii. (1891) 1044. - Venez.

HENRIQUEZIA. Spruce (Rubiac.). - Ind. Kew. i. 112 ?

Jenmani, K. Schum, in Mart. Fl. Bras, vi. vi (1889) 135. - Guiana ang1.

HENRYA, Hemsl, in Journ. Linn. Soc. xxvi (1889) 111 ; et in Hook. Icon. pl, xx. (1891) t $10 \pi 1$ APOCYNEAE.

Augustiniana, Hemsl. ll.co - China.

HENRYA, Nees = Fetramerium, Nees (Acanth.). costata, A. Gray, in Proc. Am. Acad. xxi. (1586) 406. - Mexic.

grandifolia, Fernald, in Conlt. Bot. Gaz. xx. (189.)) 537. - Mexic

imbricans, J. D. Smith, in Coult. 1. c. xvi. (1891) 198. - Guatem.

HENSLOVIA. Blume (Santal.). - Ind. Kew. 1129.

sessiliftora, Hemsl. in fourn. Linn. Soc xxvi. (189!) 409. - China.

HEPATICA, Dill ex Linn. = Anemone, Linn. (Ranunc.).

acuta, Britton, in Ann. N. Y. Acad. Sci. vi. (1891) $234=\mathrm{A}$. acutiloba, Laws.

modia $X$. Simonk. Enum. F1. Transsilv. (1856) 58: et in Termész. Füzet. x. (1886) 179. - Transsilv.

HEPPIELLA, Regrel (Gesnerac.). - Ind. Kew. i. 1122

ciscida, Fritsch. in Engl. \& Prantl, Natïrl. Pflanzenfam. iv. 3b (1894) $176=$ atrosanguinea, Regel.

HEPT APLEURUMI, Gaertn. (Aral.). - Ind Kew. i. 1129.

gymnocarpum, Drake, Ill. Ins, Mar. Pacif. Fasc. 6 (1890) 183 (= Pterotropis gymnocarpa, Hillebr.). - Ins. Sandvic

impressum. C. B. Clarke, ex Gard. Kew, i. Polypet. (1894) 243. - Reg. Himal.

littorale, Boerl. Handl. Fl. Ned. Indië, i. ii. (1890) 647 (= Parapanax littorale, Miq.). - Sumatra.

octophyllum, Kuntze. Rev. Gen. (1891) $271=$ octophyllum, Benth. \& Hook. f.

redivinm, Boerl. Handl. Fl. Ned. Indië, i. ji. (1890) 648 (= Agalma redivinm, Seem.). - Borneo.

rugosum, Bourl. l. c. $(=$ A. mgosmm, Miq. $)$. Java.

moosum, Kuntze, Rev. Gen.(1S91) $271=$ praec.

samoense, Benth. \& Hook. f. ex Drake, Ill. Ins, Mill

Pacif. Fasc. 6 (1890) 183 (= Paratropis samo:ntsis,

A. Gray). - Ins. Samoa. 


\section{HEPTAPLEURUM}

scssile, Boerl. Handl. Fl, Ned. Indië, i, ii. (1891) 648 (= Brassaic sessilis, Seem.) - Sumatra.

vitiense, Benth. E. Hook.f. ex Drake, Ill. Ins. Mar. Pacif. Fasc. 7 (1892) 409, in add. (= Agalma viticnse, Seem.), - Ins. Fiji.

Volkensii, Harms, in Bot. Fahrb. xix. Beibl. n. 47 (1894) 4l (= Scheffera Volkensii, Harms). - Afr. trop. or.

HERAGLEUM, Linn. (Umbell.). - Ind. Kew. i. $11: 30$.

acuminatum, Franch, in Bull. Soc. Philom, Paris, Sér. VIII. vi. (1894) 144. - Yunnan.

atlanticum, Coss, ex Batt. \& Trab, Fl, de l'Algér. [Dicot.]. (1889) $370=\mathrm{H}$. Sphondylium, Limn.

Builletianm, Timb.-Lagr. \& Marçais, in Lucante, Rev. de Bot. vii. (1888-\$9) 331. - Gall austroocc.

calcareum, Alboff, Prodr. Fl. Colch, (1895) 116. Reg. Cauc.

macranthum, Borb. Enum. pl. Comit. Castrif. (1888) $236=\mathrm{H}$. Sphonaylium, Linn

massyciticum, Stapf \& Wettst. ex Stapf, in Denkschr. Akad. Wicn (1886) 27. - As, Min.

Rapula, Franch. in Bull. Soc. Philonn. Paris, Sér. VIII. vi. (1894) 145. - Yunnan.

scabridum, Franch.l.c. -- Yunnan.

scabrum, Alboff, Prodr. Fl. Colch. (1S95) 115. Reg. Cauc.

simplicifolium, Wettst. in Spraw Kom. Fizyjogr. Krajow. xxii. (1828) II. 210. - Hung.

Jrnatum, Velen, in Sitzb. Boehm. Ges. Wiss, 1890 (1890) 11.46; et Vestnika (1893) 46. - Bulg

verticillatum, Pancic, ex Boiss. Fl. Or. Suppl. (1888) 269. - Maced.

yunnanense. Franch, in Bull, Soc. Phizom. Paris, Sér. VIII. vi. (1894) 143, - Yunnan.

HERBERTIA, Sweet (Irideae), - Ind. Kew。 $i_{;}$ 1]:31.

Watsoni, Baker, Handb. Irid. (1892) 71. - Texas.

HERITIERA, [Dryand.] Ait. (Stercul.). - Ind. Kew, i. Il30.
sylvatica, Vidal, Revis. Pl. Vasc. Filip. (1886) 66. Ins, Philipp.

HERMANNIA, Linn. (Stercul.). - Ind. Kew, i. 1131 .

atyssinica, K. Schum. ex Schinz, in Verh. Bot. Ver. Brand, xxx. (18\&8) $2: 6$, in obs.= Mahernia abyssinica, Hockst.

affinis, K. Sclum, cx Schinz, l. c. xxxi. (1890) 180. - Afr. austro-occ, extratre p.

amabilis, Marloth, co K. Sclum, in Bo: Fal.rb. x. (1889) 42. - Afr, austrc-occ. extratrop.

Bolusii, Szyszyl. Polypet. Relimann. (IS87) 49. Atr, austr.

cana, K. Schum, in Bot. Falirb.x. (1889) 42. - Air. austr.

cristata, Bolus, in fourn Linn. Soc, xxv, (18E9) 156 ; et ex Hook. f. in Bot. Mag. (1891) t. 7173. - Afr. austr.

diffusa, K. Schum. in Engl. \& Prant1, Natürl. Pflanzenfam. iii. $6(1890) \quad 80=$ diffusa, Linn. f.

cxappendiculata, K. Schimo. cx Engl。 in Abh. Prenss. Akad. Wiss. (i894)*5 [Quid?]. - Afr. trop.

Fischeri, K. Scl.um? in Bot. Ful.rb. Xv. (189:3) 134. Afr. trop. or.

fruticulosa, K. Sclum. sx Sclinz, in Verh. Bot, Ver .

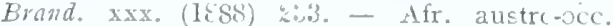
extratrop.

Guerkeana, K. Sclum, ex Sclimiz, l. c. 231. - Alr. austro-occ, extratrop.

glandulignera, K. Sclum。 cx Sclinz, l. c. 232. - Afr. austro-occ. cxtratrop.

granclitolia, N. E. Lr. in Kev Bull. (1825) 143, Transtaal.

Helianthemum, K. Sclum. in Bot. Fahrb. x (18En) 44. - Afr. austri-occ. extratrcp.

namoera, K. Sclim. in Engl. Pfanzenw. Ost-Ajo. C (1895) ETU. - Alr. tre.p.or.

lancifolia, Szyszyl. I oigtct. Relmann (IEST 141.Iransvaal

\section{HERMANNIA :}

limnacoides, K. Schum. in Bot. Jahrb. x. (1889) 42 $=$ Mahernia gracilis, Harr

malvaefolia, N.E.Br. in Kew Bull. (1895) 24. Natal.

montana, N.E. Br. l.c. 143. - Transvaal.

Oliveri, K. Schum. in Bot. Fahrb. xv. (1893) 134. Afr. trop. or.

Palmeri, N. E. Rose, in Contrib. U. S. Nat. Herb. i. (1890) 67. - Calif.

Rehmannii, Szyszyl, Polypet. Rehmann. (1887) 47, Afr. atistr.

Schinzii, K. Sclizm, ex Schinz, in Verh. Bot, Ver. Brand. xxx. (188s) 235. - Afr, austro-occ. extratrop.

solaniflora, K. Schum. in Bot. Fahrb. x. (1889) 43. - Afr. austro-occ, extratrop.

stellulata, K. Schum. 1. c. $42=$ Mahernia stellulata, Hare?

tigrensis, F. Hoffm. Beitr. Kennt. Fl. Centr. Ost-Afr. (1889) 13. - Afr. centr. or.

verticillata, K. Schum, in Engl. \& Prant1, Natürl. Pflanzenfam. iii. 6 (1890) $80=$ Mahernia verticillata, Limn

HERMBSTAEDTIA, Reichb.(Amarant.).-Ind, Kew. j. 11333

argenteiformis, Schinz, in Verh. Bot. Ver. Brand. xxxi. (1890) 209. - Afr. austro-occ, extratrop.

linearis, Schinz, l. c. 210. - Afr. austro-oce. extratrop.

scabra, Schinz, l.c. 209. - Afr. austro-occ, extratrop.

HERMESIAS, Loefl. = Brownea,Jacq. (Legumin.). Ariza, Kuntze, Rev. Gen. (1891) 191 = B. Ariza Benth。

capitellata, Kuntze, 1. c. = B. capitella, facq. canlifora, Kuntze, 1. c. = B. cauliflora, Pocpp. E Endl.

coccinea, Kuntze, 1. c. = B. coccinea, Loeft

grandiceps, Kuntze, 1. $\mathrm{C}_{0}=\mathrm{B}$, grandiceps, $f a c q$. latifolia, Kuntze, I. c, = B. latifolia, facq.

lencantha. Kuntze, l. c. = B. leucantha, Facg.

leucantha, Taub. in Engl. \& Prantl, Natiirl. Pflanzenfam, iii, $3(1892) 146=$ praec.

megrensis, Taub. 1. c. = B. negrensis, Benth.

racemosa, Kuntze, Rev. Gen. (1891) $191=$ B. racemosa, facq.

Rosa, Kuntze, 1. c, = B. Rosa-de-monte, Berg.

speciosa, Kuntze, 1. c. = B. Rosa-de-monte, Berg.

HERMINIUM, Linn. (Orchid.), - Ind. Kew. i. 1133

alaschanicum. Maxim. in Bull. Aad. sci. St. Pétersb. xxxi. (1887) 105. - Mongol.

biporosum, Maxim. l.c. 106. - Reg. Tangut.

Duthiei, Hook.f. Fl. Brit. Ind. vi., (1890) 130. Reg. Himal.

failax. Hook. f. 1. c. $129=$ fallax, Lindl.

grandiflorum, Lindl, ex Hook. f. 1. C. = H. Josephi, Reichb. f.

orbiculare, Hook. f. Fl. Brit. Ind. vi. (1890) 129. Reg. Himal.

pugioniforme, Lindl. ex Hook. f.l.c. 130. - Reg. Himal.

IIERMIONE, Salisb,$=$ Narcissus, 'Tourn. $[$ Amaryll.).

laclicolor, Baker, Handb. Amaryll. (1888) $7=$ N. Tazetta, Limn. var.

HERMUPOA, Loef, = Steriphoma, Spreng (Capparid.).

elliptica, Kuntze, Rev. Gen。 (1891) $38=\mathrm{S}$. elliFtica, Spreng.

paradoxa, Kuntze, 1. c. = S. paradoxa, Endl.

fericiana, Kuntze, 1. c. $39=$ S. peruviana, Spruce.

HERNANDIA, Plum, ex Linn. (Laurin.), -.- Ind. Kew. i. 1134

beninensis, Wolev. ex Henriques, in Bolet. Soc. Brot. x. (1892) 155. - Ins. S. Thom.
HERNIARIA, [Tourn.] Linn. (Illecebr.). - Ind Kew. i. 1134.

Hartungii, Parl ex C. Bolle, in Bot. Fahrb. xiv. (1892) 234. - Ins. Canar.

maskatensis, Bornm. in Mitth. Thïr. Bot. Ver. N. Folge, vi. (1894) 51. - Arabia.

HERPESTIS. Gaertn. f. (Scrophul.). - Ind. Kew, i. 1134

auriculata, Robinson, in Proc. Ane. Acad. xxvi. (1891) 172. - Mexic

caroliniana, Britton, Stern \& Pogg. Prelim. Catal. (1888) 39 = amplexicaulis, Pursh.

Eiseni, Greene, Man. Bot. San Franc, Bay (1894) $278(=$ Ranapalus Eiscnii, Kell. $)$ = rotundifolia, Pursh.

exilis, T. S. Brandeg. in Proc, Calif. Acad. Ser. II. ii. (1889) 191. - Calif

HERSCHELIA. Lindl. = Disa, Berg. (Orchid.) graminifolia, Th. Dur. \& Schinz, Consp. Fl. Afr。v. $1892(1895) 111=\mathrm{D}$. graminifolia, Ker-Gawl.

HERTIA, Neck, = Othonnopsis, Jaub \& Spach (Compos.).

angustifolia. cheirifolia, cilnata, chutiaefolia, cneorifolia, intermedia, pallens, Kuntze, Rev. Gen. (1891) $344=$ homonyma omnia Othonnopsidis.

servulata, Kuntze, 1, c. - Afr, austr.

HERYA, Cordem. F1, Ile Réunion (1895) 410 . CELASTRINEAE.

anomala, Cordem. l. $c$. - Ins. Borbon.

HERZOGIA, K. Schum. in K. Schum. \& Hollr. Fl. Kais. Wilh. Land (1889) 60; Boerl. Handi. Fl. Ned. Indië, i. II. (1890) 669 = Evodia, Forst. (Rutac.).

odorifera, K. Schum. 11, cc. 60 ; et $670=$ E. hortensis, Forst.

HESPERALCEA, Greene, Pittonia, ii, (Sept 1892) $301=$ Sidalcea, A. Gray $($ Malv.

malachroides. Greene, 1. c.; E. G. Baker, in Journ. Bot. (1894) $36=$ S. malachroides, A. Gray.

HESPERALOË, Engelm. (Liliac.). - Ind. Kew. i. 1136 .

pareiffora, Coult. in Contrib, U. S. Nat. Herb. ii. (1994) $436=$ yuceaefolia, Engelm.

HESPERANTHA, Ker-Gawl. (Irid.). - Ind. Kew. 1. 1136.

albomarginata. M. E. Jones, in Zoë, ii. (1891) 251 = Eremocrinum albomarginatum, $M$. E. Fones.

alpina, Pax, in Abh. Preuss. Alkad. Wiss. 1891 (1892) $174=$ Geissorhiza alpina, Hook, $f$

candida, Baker, Handb. Irid. (1892! 151. - Afr. austr.

fibrosa, Baker, l. c. 149. - Natal.

gracilis, Baker, l. c. - Afr. austr.

kilimanjarica, Rendle, in fourn. Linn. Soc. xxx. (1895) 40\%. - Afr, trop. or.

lactea, Baker, Handb. Irid. (1892) 151. - Natal.

leucantha, Baker, l. c. 150. - Natal.

modesta. Baker, l. c. 150. - Natal.

namaquensis, Baker, l. c. 149. - Afr. austro-occ. extratrop.

pulchra, Baker, l. c. - Afr. austr.

Tysoni, Baker, l. c. - Afr. austr.

Volkensii, Harms, in Bot. Fahrb. xix. Beibl. n. 47 (1894) 28. - Afr. trop. or

Woodii, Baker, Handb, Irid. (1892) 150. - Natal.

HESPERANTHEMUM, Kuntze, Rev, Gen. (1891) $490=$ Anthacanthus, Nees (Acanth. $)$.

aciculare, armatum, microphyllum, purpurascens, spinosum, tetrastichum, Kuntze, 1, C, = homonyma omnia Anthacanthi.

HESPERIDOPSIS, Kuntze, Rev, Gen. (1891) 30 gen. coll. Crucier

breripes, Kuntze, 1. c. = Malcomia hrevipes, Boiss. circinatus, Kuntze, 1. co. = M. circinata, Boiss.

dentatus, Kuntze, 1. c. = Dontostemon dentatus, Ledeb 
HESPERIDOPSIS :-

eglundulosus, Kuntze, Rev, Gen. (1891) $30=$ Dontostemon dentatus, Ledeb.

integrifolins, Kuntze, 1. C. = D. integrifolius, Ledeb. micranthus, Kuntze, 1. c. = D. micranthus, C. A. Mey.

oblongifolius, Kuntze, 1. C $=$ D, dentatus, Ledez

perennis Kuntze, 1.c. = D. perennis, C.A. Mey.

pinnatifidus, Kuntze, $1, \mathrm{C}=\mathrm{D}$. pectinatus, $C \cdot A$ Mey.

scorpiodes, Kuntze, 1. c. = Malcomia scorpioides, Boiss.

HESPERIS, Linn. (Crucif.).- Ind. Kew, i. 1136 aintabica, Post, in fourn. Limn. Soc. xxiv. (1888 420. - Syria.

aladabadensis, Stapf, in Denkschr. Akad. Wien (1886) 32. - Persia.

carpatica, Zapalowicz, in Spraw Kom. Fizyjogr. Krajowei, xxiv. (1889) 106. - Eur

desertorum, Velen, in Sitzb. Boehm. Ges. Wiss. (1892 93) 7. - Buls

dinarica, G. Beck, in falireslat. Wien. bot. Tauschver (1894) 6 et in Ammal. Naturn Hofmus. Wienz, x. (1895) 174. - Born.

nivalis, Boiss. E Hausskn. ex Boiss. Fl. Or. Suppl. (1888) 45. - Persia.

meda, Stapf, in Denkschr. Akad. Wien (1S86) 32. Persia.

sabauda, Rouy \& Fouc. Fl. de Fr. ii. (1895) $3=$ matronalis, Linn.

HESPERIS, Linn. (1835) emend. ex Kuntze, Rev. Gen. (1891) 30-33 et 934-36= gen. collect. Crucif abyssinica, altissima, amplexicaulis, andina, anomala, antarctica, arctica. Arnottiana, arindana, Assoana, athrocarpa, auriculata, axillaris, Belangeri, Berlandieri. Berteroana, brachycarpa, Bungei, calycina, capensis, ciliolata, confusa, contorta, corymbosa, corniculata, Coulteri, crassifolia, Cumingiana, dahurica, domascena, decipiens, diffusa, dumulosa elliptica, Eschscholtziana, exasperata, foliosa, fragilis, fugax, fuscescens, garicpina, glauca, gracilis, granasensis, Griffithiana, lalophila, heteromalla, himalaica, hispanica, hispidula, imbricatimalla, himalaica, hispanica, hispidula, imbricatiloba, laxiflora, Lechleri, Ledebouri, leptocarpa, Limosella, linifolia, Loeselii, magellanica, Mandonii, minutiflora, mollissima, mvriophylla, nivea, officinalis, oligantha, Orbignyana, orientalis, orophila. Palmeri, Parryi, parvifolia, patula, pauciflora, peruviana, petraea, Piasezkii, pinnatifida, polyceratia, polysperma, Preauxiana, pumila, pusilla, ramosa, ramulosa. reflexa, Remyana, sagittata, salsuginea, Schaffneri, scholaris, septacea, solidaginea, Sophia, spectabilis, stenophylla, streptocarpa, strictissima, stricta, subspinescens, subu!ata, suffruticosa, supina, tanacetifolia, Thaliana, tibetica, Tilingii, toxophylla, tripinnata, Turczaninowii, uniflora, serna, versicolor, virgata, Virlettii, Wallichii, Weddellii, wolgense, Kuntze, Rev. Gen. (1891) 934-36 = homonyma omnia Sisymbrii

aculeolata, bicolor, Bungei, cabulica, circinna:a, cymbalaria, flexuosa, graeca, Ledebouri, Meyeri, nana, Orsiniana, strigosa, torulosa, Kuntze, 1. c. 934-36 = homonyma ommia Malcolmiae.

arabica, aspera, chenopodifolia, damascena, dumulosa, elliptica, farinosa, fenestralis, flavida, fragrans, glandulosi, incana, livida, lunata, montana, obovata, ovatifolia, revoluta, robusta, Stoddartii, thessala, varia, Kuntze, I. c. = homonyma omnia Matthiolae.

acaulis, Kuntze, Rev. Gen. (1891) $934=$ Matthiola humilis, $D C$.

alpina, Kuntze, 1. c. = Braya alpina, Sternb.

Bourgeauna, Kuntze, 1. c. = Sisymbrium Bourgaeanum, Fourn.

brachycarpa, Kuntze, 1. c. = S. canescens, Nutt.

brassiciformis, Kuntze, l. c. $=\mathrm{S}$. brassicaeforme C. A. Mey.

brevipes, Kuntze, 1. c. = S. nudum. Boiss

Broussonetii, Kuntze, 1. c. $935=$ Malcolmia littorea R. Br.

iabulica, Kuntze, 1. c, $934=$ Sisymbrium pum: lum, Steph.

\section{HESPERIS :-}

chorastanica, Kuntze, Rev, Gen. (1891) $935=$ Matthiola chorassanica, Bunge.

ciliolata, Kuntze, 1, c. $934=$ Sisymbrium ciliolatum, Fonrn.

cochalguensis, Kuntze, 1. c. = S. cochalguense, Wedd.

Columnae, Kuntze, 1. c. $33=\mathrm{S}$. orientale, Linn confusissima, Kuntze, 1. c. $936=$ Malcolmia nana, Boiss.

deltodea, Kuntze, 1. c. $934=$ Sisymbrium deltoideum, Hook.

dubia, Kuntze, 1. c. 935 = Braya rosea, Bunge

erysimodes, Kuntze, 1. c. $33=$ Sisymbrium erysimoides, Desf.

Eschscholtziana, Kuntze, 1. c. 935 = Braya Eschscholtziana, Benth. \& Hook. f.

exacodes, Kuntze, 1. c. = Malcolmia exacoides, Spreng.

falcosa, Kuntze, 1. c. $934=$ Sisymbrium falcatum, Fourn.

flacissima, Kuntze, 1, c. $=$ Smelowskia flavissima Kar. E Kir.

Galleotiana, Kuntze, 1. c. = Sisymbrium Galeottianum, Fourn

glabella, Kuntze, 1. c. 935 = Braya alpina, Sternb. glabra, Kuntze, 1. c. $936=$ Matthiola incana, $R . B r$. grandiflora, Kuntze, 1. c. = Malcolmia Bungei, Boiss.

Hartwegiana, Kuntze, 1. c. = Sisymbrium incisum, Engelm.

Hermanniana, Kuntze, 1. c. $936=$ S. persicum, Schrad.

Inumifusa, Kuntze, 1, c. $934=$ Arabis lyrata, Linn Jygrophylla, Kuntze, 1. c. $936=$ Sisymbrium humile, C. A. Mey.

integrifolia, Kuntze, 1. c. $=$ Matthiola crassifolia Boiss. \& Gay.

involucrata, Kuntze, 1. c. 935 = Braya involucrata Ledeb.

iriodes, Kuntze, 1. c. $934=$ Sisymbrium Irio Linn.

limosellodes, Kuntze, 1. c. $935=$ S. Limosella, Fourn. littoralis, Kuntze, 1. c. = S. litorale, Plill.

longepedicellata, Kuntze, 1, c, $934=\mathrm{S}$, incisum Engelm.

maderensis, Kuntze, 1. c. $33=$ Matthiola maderensis, Lowe.

malcolmiodes, Kuntze, 1. c。 = Sisymbrium malcolmioides, Coss. \& Dur.

maxima, Kuntze, 1. c. $=$ S. Irio, Linn.

Meyeri, Kuntze, 1. c. = Malcolmia Ledebourii Boiss.

micrantha, Kuntze, 1. c. $935=$ Matthiola parvi flora, $R . B r$.

millefolia, Kuntze, 1, c. $33=$ Sisymbrium millefolium, Ait.

niagarensis, Kuntze, 1. c. $935=\mathrm{S}$. officinale Scop.

mubigina, Kuntze, 1. c. (= Entrema nubigena, Humb \& Bonpl.). - Ecuador.

pandurifolia, Kuntze, 1. c. = Sisymbrium pan durifolium, Kuntze.

pilosa. Kuntze, 1. c. $935=$ Braya pilosa. Hook.

pinnata, Kuntze, 1. c. 936 = Sisymbrium canes cens, Nutt.

Planchoniana, Kuntze, 1. c. (= Eudema grandiflora Planch.). - Am, austr

primulifolia, Kuntze, 1. c. $035=$ Eutrema primulaefolia, Hook. f. \&o Thams.

promontorii, Kuntze, 1. c. $936=$ Sisymbrium capense, Thunb.

pubcscens, Kuntze, 1.c. = S. pinnatum, Barn. pyrentica. Kuntze, 1. c. = S.-austriacum, facq. rigidula, $\mathrm{K}$ untze, 1. c. $935=\mathrm{S}$. altissimum, Limn rosea, Kuntze, 1. c. $936=$ Braya rosea, Bunge. ruderalis. Kuntze, 1. c. $=$ Sisymbrium officinale Scop.

runawurensis, Kuntze, 1. c. = S. rupestre, Edgere. rupestris, Kuntze, 1. c. $935=$ Eutrema Humboldtii, Spreng.

septulata, Kuntze, 1. c. = Sisymbrium altissimum Linn.

siliquosa, Kuntze, 1. c. = Braya siliquosa, Bunge

silvestris, Kuntze, 1. c. = Sisymbrium lyratum Burm.
HESPERIS : -

spathulifolia, Kuntze, Rev, Gen, (1891) $935=$ Sisymbrium spathulaefolium, A. Gray.

stelligera, Kuntze, 1. c. = Matthiola turulosa, DC

Thomsonit, Kuntze, 1. c. $=\mathrm{S}$. Thomsonii, Hook. titicatense, Kuntze, 1. c. = S, titicacense, Walp

versicolor, Kuntze, 1. c. = Braya versicolor, Turcz.

Villarsii, Kuntze, 1. c. = Sisymbrium austriacum Facq.

Zanoni, Kuntze, 1. c. = S. pinnatifidum, $D C$

HESPEROGHIRON, S. Wats. (Hydrophyll.) Ind. Kew, 1, 1137.

iliatus, Grecue, Pittonia, i. (Mar. 1889) 282. Nevada.

nanus, Greene, in Bull. Torrey Bot. Club, xv 1888) $110=$ californicus, S. Wats

HESPEROMANNIA, A. Gray (Compos.). Ind. Kew, i. 1137.

arbuscula, Hillebr. Fl. Haw, Isl. (1888) 232. - Ins Sandvic.

HESPEROPEUCE, Lemmon, Third Rep. Calif St. Board Forest $(1890), 100,126$ t. $9=$ Tsuga Carr. (Conif.)

Pattoniana, Lemmon, $1, \mathrm{c},=\mathrm{T}$. Pattoniana Engelm.

HESSEA, Herb. (Amaryl1.). - Ind. Kew. i. 1137 Rehmanni, Baker, Handb. Amaryll. (1888) 22.Transvaal.

spiralis, Baker, $i$ c. 22. - Afr, austr

Zeyheri, Baker, l. c. - Afr. austr.

HetAERIA, Blume (Orchid.). - Ind. Kew.

\section{7.}

elata. Hook. f. Fl. Brit. Ind. vi. (1890) 116. Perak

Helferi, Hook. f. l. c. 115. - Tenass

occulta, Th: Dur. \& Schinz, Consp. Fl. Afr.v. 1892

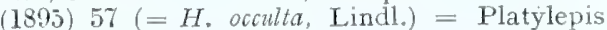
goodyeroides, Reichb. $f$

mbicunda, Drake, Fl. Polyn. Franc. (1892) 218, in obs. (= H. rubicunda, Reichb. f); et Ill. Ins. Mar. Pacif. Fasc. 7 (1892) $312=$ Ramphidia rubicunda, Reichb. $f$.

Societatis, Drake, $l l$. cc..-Ins, Societ.

Eaginalis, Th. Dur. \& Schinz, Consp. Fl. Afr. v $1892(1895) 58=$ vaginalis, $R$ eich. $f$.

HETERADELPHIA, Lindau, in Bot. Jahrb xvii. (1893) 108; et in Engl. \& Prantl, Natiirl. Pflanzenfam, iv, $3 \mathrm{~b}(1895)$ 302. ACANTHA$C E A E$.

Paulowilhelmia, Lindau, $l l . c c .-$ Ins. S. Thom.

HETERANTHERA, Ruiz \& Pav. (Ponteder.). - Ind. Kew, i. 1138

dubia, Mac Mill. Metasp. Minn. (1892) $138=$ graminea, Vahl.

dubia, Morong, in Mem. Torrey Bot. Club, v. (1894) $105=$ praec

HETEROCENTRUM, Hemsl. = HETEROCEN$T R O N$, Hook. \& Arn. = Heeria, Schlecht (Melast.).

Arstedii, Cogn. in Mart. Fl. Bras. xiv. HI. (1885) $297=$ H. Oerstedii, $\operatorname{Cog} n$

clegans, Kuntze, Rev, Gen. (1891) 247 [Heterocentron] = Heeria elegans, Schlecht.

Oerstedii, $\operatorname{Cogn}$. in Mart. Fl. Bras, xiv. IV. (18S3) 597 - Am. centr.

HETERODERIS, Boiss, = Grepis, Vaill. (Com-

pos.). [Suppl. Illustr Fl. Egypte] in Mém. Inst. Egypt. ii. (1889, 766. - Aegypt.

HETEROGAURA, Rothrock (Onagrar.), - Ind. Kew. i. 1139

heterandra. Coville, in Contrib. U:S. Nat, Herb. iv. (1893) 106 = californica, Rothrock. 
HETEROMORPHA, Cass, = Heterolepis, Cass. (Compos.).

aliena, Kuntze, Rev, Gen, (1891) $344=\mathrm{H}$. decipiens, Cass.

imuloides, Kuntze, 1.c, sphalm. $=\mathrm{H}$. decipiens, Cass, mitis. Kuntze, 1. e. = H. mitis, $D C$.

peduncularis, Kuntze, 1. c. $=\mathrm{H}$. peduncularis, $D C$.

HETEROMORPHA, Cham. \& Schlecht. (Umbell.). - Ind. Kew. i. 11:39.

stenophylla, Welw, ex Engl. in Abh. Preuss. Ahad. Wiss. 1891 (1892) 317, nomen. - Angola.

HETEROPHRAGMA, DC. (Bignon.). - Ind.

Kiew. i 1140.
longipes, Baker, in Kow Bull. (1894) 31.-Zambesia. quadriloculare, K. Schum. in Engl. \& Prantl, Natïrl. Pflanzenfam. iv. 3b (1895) $243=$ H. Roxburghii, DC.

HETEROPOGON, Pers. (Gramin.). - Ind. Kew, i. 1140.

melanocarfus, Dewey, ex Coult. in Contrib. U. S. Nat. Herb. ii. (1894) $493=$ acuminatus, Trin.

HETEROPSIS, Kunth (Aroid.). - Ind. Kew。 i. 1140 .

Jexmani, Oln'er, in Hook. Icon. pl. xx. (1890) t. 1949. - Guian. angl.

HETEROPTERIS, H. B. \& K. (Malpigh.).lnd. Kew. i. 1140 .

amplexicaulis.Alorong, in Ann. N.Y. Acad. Sch. vii. (1892) 67. - Parags.

cultriformis, Chod. in Mém. Soc, sci. priss. Genère, xxxi. 2. n. $3(1892)$ 18. - Parag.

pirayuensis, Morong, in Am. N. Y. Acad. Sci. vii. (189\%) 66. - Parag.

portillana, S. Wals. in Proc. Am. Acad, xxii. (1887) 40\%. - Mexic

pseudoangustifolia, Chod. in Arch. sci. phys. En nat. (1S!O); cx Chod. in Mim. Soc. sci. pliys. Geneve, xxxi.2. n. 3(1892) 17. - Parag.

retusa, F. D. Snith, in Coult. Bot. Gaz. xvi. (1891) 2. - Guatem.

HETEROPYXIS, Harv.(Lythrar.). - Ind. Kew i. 1141 .

canescens, Cliver, in Hook. Icon, pl. xxv. (1895) t. 2407. - Transiaal.

HETLROSAMARA, Kuntze, Rev. Gen. (1891) 4 Polygala, [Tourn.]. Linn.

birnamica, Kuntze, 1. c. = P. birmanica, Chod.

FETEROSGIADIUM, Lange, ex Willk. Suppl. Prudr. Fl. Hisp. (1593) 198. UMBEL LIFERAE androphilnm, Lange, 1. c. - Hisp.

HeterothecA, Cass. (Compos.). - Ind. Kew. 1. 1141 .

deltoidea, Klatt, in Ann. Naturh. Hofmns, Wim, ix. (1824):35\%. - Peruvia.

subaxillaris, Britton \& Rusby, in Trans. N. Y Acad. Sci. vii. (list) $10=$ H. Lamarkii, Cass. subaxillaris, Trclease, ex Branner \& Coville, in Ann. Rep. Gcul. Surv. Arkans. i. (1891) $190=$ praec.

IETEROTCMA, Zucc. (Campanul.),-Ind. Kew. i. 1142

aurita, T. S. Branaleg in Proc. Calif. Acad. Scr. II. iii. (1S91) 14\%. - Calif.

gibbosa, S. Wais. in I'roc. Am. Acad. xxiii. (18SS) 2ะ0. - Mcxic.

HETEROTRICHUM, DC. (Mclast.). - Ind. Kew. 1. 1142.

Egracrii, Cogn. ex Stahl, Esizd, Fl, Puevto-Rico iv. (1886) !4; in falirb. Eot. Gart. Berl. iv. (18s6) ise; at in DC. Monog. Plan. vii. (1801) 956.Ins. Puertu-Rico.

glandulosum, Cogn. in DC. l.c. 95.s. - Venez.

rloluliflorumi, Cogn. in Lull. Soc. Bot. Belg. xxvii. 2 (1858) 176 ; ot in DC.? $i$. $155^{\circ}$. - Costur1cis
HEUCHERA, Linn. (Saxifr.). - Ind. Kew. i. 1142 .

Drmmmondii, Hort. ex Gard. Kew, Herbac. P1 (1895) $227 .-\mathrm{Hab}$. ?

Hapcmani, Coult. \& Fischer, in Coult. Bot. Gaz. xvii. (1892) 348 (= Sullivantia Hapemani, Coult.). - Am. bor

maxima, Greene, in Bull. Calif. Acad. ii. vi. (18s6) 149. - Ins. S. Cruz (Calif.)

novo-mexicana, Wheelock, in Bull. Torrey Bot. Club, xvii. (1890) 200. - N. Mexic

Williamsii, Eaton, in Coult. Bot. Gaz, xv. (1890) 62. - Montana.

HEURNIA, “ R. Br., » ex K. Schum. (1895) 280; et in Engl. \& Prantl, Natürl. Pflanzenfam. iv. 2. (1895) 280 [sphalm. ?] = Huernia, R. Br. (Asclep.).

HEWITTIA. Wight \& Arn. (Convolvul.). Ind. Kew, i. 1142.

Barbeyana. Chod. \& Roulet, in Bull. Herb. Boiss, i. (1893) 191. - Seneg.

sublnbata, Kuntze, Rev. Gen. (1891) $441=$ bicolor, Wight \& Arn.

HEXALECTRIS, Rafin. (Orchid.). - Ind. Kew. i. 1143

aphillits. A. Gray, Man. N. Am. Bot, ed, 6 (1890) $501=$ aphylla, Rafin.

HEXAPORA, Curtisi, Hook. f. Fl. Brit, Ind. v. (1886) 189 , in obs。 = Micropora Curtisii, Hook. $f$

HEXAPTERA, Hook. (Crucif.). - Ind. Kew, i. 1143.

Constitutionis, Phil. in Anal. Univ. Chil. (1893) 335. - Chili.

tridens, Phil, in Anal. Wus, nac, Chile (1891) 6. Chili.

virens, Phil. l.c. - Chili.

HEYDIA, Dennst. = Scleropyrum. Arn. (Santal.). Maingayi, Kuntze, Rev。Gen. (1S91) $587=\mathrm{S}$. Maingayi. Hook. $f$.

FIBBBERTA, Andr, (Dillen.), - Ind. Kew. i. 1144.

Auberti, Gilg, in Engl \& Prantl, Natïrl. Pflanzenfam, iii. $6(1893) 119=$ coriacea, Baill.

Brongniartii, Gilg, 1. c. $115=$ Trisema salicifolia, Brongn. \& Gris.

conspicur, Gilg, 1. c. 118= Pachynema conspicuum, Diamm. \& Hare.

coriacea, Gilg, 1. c. $115=$ Trisema coriacea, Hook.f. cuneiformis, Gilg, 1.c. $118=$ Candollea cuneiformis, Labill.

Drummondii, Gilg, 1. c. $116=$ H. Ochrolasia, Benth.

Fordinandi-Mullevi, Gilg, 1. c. 11 \% = glaberrima, F. Muell.

glaberrina, Gilg, 1. c. $118=$ polygonoides, $F$. Muell. Millari, F. M. Bailey, Syn. Qucensl. Fl. Suppl. ii (18Ł8) 5, - Austral.

raccmosa, Gilg, in Engl, \& Prantl, Natürl. Pflanzenfam, iii. 6 (1893) $118=$ Candollea pedunculata, $R \cdot B r$.

Readii, Hort. ex Gilg, l. c. 120. - Hab.

scandens, Gilg, 1. c. $117=$ volubilis, $A n d r$

tetrandra, Gilg, 1. c. $118=$ Candollea tetrandra Lindl.

Vicillardii, Gilg, 1. c. $115=$ Trisema Vieillardi, Brongn. \& Gris.

Wayapii, Gilg, l. c. - N. Caled.

HIBISCUS, Linn. (Malv.). - Ind. Kew. i. 1145. albifloras, Kuntze, Rev, Gen. (1891) $68=$ Gossy. pium rosenm, Tod.

anomalus, Kuntze, 1. c. = G. anomalum, Wawra $\mathscr{E}$ Peyr.

argutus, Bater, in Kew Bull. (1895) 212. - Reg. Sumal.

australis, Kuntze, Rev. Gen. (1891) $69=$ Fugosia australis. Benth.

barbadensis, Kuntze. 1. c. $67=$ Gossypium barbadence, Lim.
HIBISCUS

biseptus, S. Wats. in Proc. Am. Acad. xxi. (1886) 418. - Mexic

Blumei, Kuntze, Rev. Gen. (1891) $69=$ Thespesia macrophylla, Blume.

Burtonii, F. M. Bailey, in Dept. Agric. Brisbane Bot. Bull. ii. (1891) 7. - Austral

campestris, Kuntze, Rev. Gen. (1891) $69=$ Fugosia campestris, Benth.

Cavanillesii, Kuntze, 1. c. $=\mathrm{F}$. digitata, Pers.

cornums, Kuntze, 1. c. $68=$ Gossypium cernuum, Tod.

cytisifolius, Baker, in foum. Linn. Soc. xxii. (1887) 447. - Madag.

dcciduns, Kuntze, Rev.Gen.(1891) $68=$ Gossypium barbadense, Linn.

Drammondii, Kuntze, 1, c. 69 - Fugosia Drummondii, A. Gray

drynariodes, Kuntze, 1.c.= Gossypium drynarioides, Se'm.

Engleri, K. Schum. l.c. - Afr. austro-occ. extratrop.

flaiflorus, Kuntze, Rev, Gen, (189]) 69 [flaviflorum] = Fugosia flaviflora, F. Muell.

Fleckii, Guerke, ex Schimz, in Bull. Herb. Boiss. iii (1895) 404. - Afr. austro-occ. extratrop.

fruticulosus; Kuntze, Rev. Gen. (1901) $65=$ Gossypium fruticulosum, Tod.

geminiforus' Ernst, in Rev. cicnt. mens. Univ, centr. Vencz. i. (1857) 219. - Venez.

gossypiodes, Kuntze, Rev. Gen. (1891) $69=$ Gossypium Sturtii, F. Muell.

gravacfolius, G. Kuntze, in Bot. Centralbl. xlv. (1891) 198, sphalm. = grewiaefolius, Hassk.?

Henningsianus, Guerke, in Mart. Fl. Bras. xii. III. (1892) 5.59 - Bras.

Hilairii, Kuntze, Rev, Gen, (1891) $69=$ Fugosia phlomidifolia, $A$. Fuss

Ingenhousii. Kuntze, 1. c. $69=$ Ingenhouzia triloba, Moç. É Sessé

fussieni, Kuntze, 1. c. = Fugosia sulfurea, St. Hil.

latifolius, Kuntze, I. c. = F. latifolia, Benth.

Lebelei, Naud. in Rev. Hortic. (I893) 449. China.

Marlothianus, K. Schmm. in Bot. Fahrb. x. (1889) 46.

-Afr. austr.
Mesnyi, Picre, ex Laness. Pl. util. Colon. Franc, (1886) 291. - Cochinch.

micranthela, "Cav. " ex (4. Kuntze, in Bot. Centralb1. xlv. (1891) 198. [Quid ?].

myriaster, S. Elliot, in Fourn. Linn. Soc. xxix. (1891) 7. - Madag.

Nangking, Kuntze, Rev. Gen. (1891) $68=$ Gossy= pium herbaceum, Linn.

nummularifolius, Baker, in Fonm. Linn. Soc xxii. (1.887) 448. - Madag.

oblatus, Baker, l.c. - Madag.

oligospermus, Kuntze, Rev. Gen. (1891) 68 = Gossypium barbaderise, Linm.

Peterianus, Guerke, in Mart. Fl. Bras. xil. III. (1892) 547. - Bras.

phanerandrus, Baker, in foum. Limn. Soc. xxv, (1889) 29\%. - Madas.

phlomidifolins, Kuntze, Rev. Gen. (1891) 69 [phlomidifnlia $]=$ Fugosia phlomidifolia, $A$. Fuss.

Pohlii, Guerke, in Mart. Fi. Bras. xii. II. (1892) 564. - Bras.

populifolizs, Kuntze, Rev. Gen. (1891) $69=$ Fugosia populifolia, Benth.

Prestii, Kuntze, Rev. Gen. (1891) $69=$ Thespesia tomentosa. Presl.

purpurascens, Kuntze, 1. c. $68=$ Gossypium arboreum, Lmm.

racemosus, Kuntze, 1. c. $=\mathrm{G}$. barladense. Linn. Redoutci, Kuntze, 1. c. $69=$ Fugosia heterophylla, Spach.

religiosus, Kuntze, 1. c. $68=$ Gossypium herbaceum, Limn?

rhodanthus, Gucke, ex Schinz, in Bull. Herb. Boiss. iii. (1895) 405. - Afr. trop.

Robinsonii, Kuntze, Rev. Gen. (1891) 69) = Gossypium Robinsoni, E. Muell.

Schinzii, Guerke ex Schinz, in Verh. Bot. Ver. Brand. xxx. (1888) 176. - Afr. austro-occ. extratrop. 


\section{HIBISGUS :}

Scotellii, E. G. Baker, in fourn. Linn. Soc. xxx. (1894) 74. - Sierra Leone.

Selloi, Guerke, in Mart. Fl. Bras, xii. III. (1892) 554 - Bras.

tomentosus, Kuntze, Rev. Gen. (1891) $68=$ Gossypium tomentosum. $N u t t$

tripartitus, Kuntze, 1. c. 69 [tripartita] = Fugosia tripartita, Steud.

Upingtoniae, Guerke, ex Schinz, in Verh. Bot. Vor. Brand, xxx. (18s8) 178. - Afr. austro-occ. extratrop.

Volkensii, Guerke, in Engl. Pfanzenw. Ost-Afr.C (1895) 266. - Afr. trop. or.

xiphocuspis. Baker, in fourn, Linn. Sor. xxii. (1887) 447, - Madag.

HICKORIA, olivaeformis \& Peccan, C. Mohr, in Pharm. Rundsch. visi. 56 [splualm.] $=\mathrm{HiCO}$ RIA, Rafin.= Hicoria, Nutt.

HICORIA, Rafin. = HICORIUS, Rafin. = Carya Nutt. (Jugland.)

acumnata, Dippel, Handb. Laubholzk. ii. (1892) $336=$ C. sulcata, Nutt.

alba, Britton, in Bull. Torrey Bot. Club, xv. (1S88) $284=$ C. alba, Nutt

aquatica, Britton, 1. C. = C. aquatica, Nutt

Fernowiana, Sudworth, Trees of Wash. (1891), ex Sarg. Sylva N. Am. vii. (1895) $145=$ C. myristicaetormis, Nult.

glabra, Britton, in Bull. Torrey Bot, Club, xv. (1888) $284=\mathrm{C}$. glabra, Mill.

laciniosa, Sarg. in Mem. Torrey Bot. Club, v. (1894) 354 : et Sylva N. Am. vii. (1895) 157 t. 398-99= C. sulcata, Nutt.

mexicana. Britton, in Bull. Torrey Bot. Club, xv. (1888) 283 = C. mexicana, Engelm.

microcarpa, Britton, 1. c. = C. microcarpa, Nutt. minima, Britton, 1. c. $284=$ C. amara, $N^{\top} u t t$.

myristicaeformis, Britton, 1. c. $284=$ C. myristicaeformis, Nutt.

odorata, Dippel, Handb. Laubholzk. ii. (1892) 332 $=$ C. microcarpa, Nutt.

vvata, Britton, in Bull. Torrey Bot. Club, xv. (1Ss8) $283=$ C. alba, Nutt.

Pecan. Britton, 1. c. $282=$ C. olivaeformis, $N^{\gamma} u t t$.

sulcata, Britton, 1. C. $283=$ C. sulcata, Nutt.

HICORIUS, Rafin. = Carya, Nutt. (Jugland.)

albus, Sarg, in Gard. and For. ii. (18s9) $460=$ C. alba, Nutt.

aquaticus, Sarg. 1. c. $(=H$. aquaticus, Rafin. $)=$ C. aquatica, Nutt.

glaber, Sarg. 1. C. = C. porcina, Nutt.

minimus, Sarg. 1. c. $460==$ C. amara, Nutt. myristicaeformis, Sarg. 1. c. ${ }^{\prime}=$ C. myristicaeformis,

Nutt.

odoratus, Sarg. 1. c. = C. microcarpa, Nutt.?

ovatus, Sarg. 1. c. = C. alba, Nutt.

Pecan, Sarg. 1. co = C. olivaeformis, Nutt

sulcatus, Sarg. 1. c. = C. suIcata, Nutt

HIERACIODES, Moehr. Hort. Priv. (1736) 48, ex Kuntze, Rev. Gen. (1891) $344=$ Crepis, Vaill (Compos.).

acaule, aculeatum, acuminalum, albidum, alpestre, alpinum, Andersonii, arabicum, armenum, asperum, athoum, aureum, bellidifolium, bithynicum; bulbosum Burenianum, bursifolium, caspitosum, carbonarium, caucasicum, chrysanthum, ciliatum. Columnae, corniculatum, creticum, crocifolium, decumbens, depressum, dioviticum, Dioscorzdis, djimilense, elbrusense, eleoans, erucifolium, fallax, flexuosum, foetens, foetidum, erucifolium, fallax, flexuosum, foetens, foctidum, fuscipappun, glomeratum, Gmelini, gracilipes, heterokerianum, Huctii, incanum, insulare, integrum, intermedium, japonicum, jubatum, Keiskeanum, khorassanicum, Kitaibelii, Kotsclyyanum, longipes, lyratum, macrophyllum, macropus, multicaule, multilyratum, macrophyllum, macropus, multicaule, mult-
florum, nanum, neglectum, Newii, occidentale, olympicum, oreades, paludosum, pinnatifidum, praemorsum, pulchrum, pulmonariaefolium, furpureum, pygmaeum, racemiferum, Raulinii, Reuterianum, rigens, rubrum,

\section{HIERACIODES:}

numicifolium, runcinatum, Ruprechtii, Sahendi, Schimperi, Schultzii, setosum, sibircum, Sibthorpiamum, Sicberi, silletense smyruaeum, spathulatum, Stenoma, Stoliczkai, Suffrenianum, taraxactolim, Stenoma, Stoliczka, Suffrenamum, taraxactolimn, viscidulum, Kuntze, Rev. Gen. (IS91) 344-46= homonyma omnia Crepidis.

abyssinicum. Kuntze, 1. c, $345=$ Crepis Rueppellii, Sch. Bip.

achyrophorodes, Kuntze, 1. c. = C. achyrophoroides, Vaike.

andryalodes, Kuntze, 1. c. = C. chondrilloides, filiq.

auriculifolium, Kuntze, 1. c. = C. auriculaefolia,

canlescens, Kuntze, 1. c. = C. glauca. Torr. \& Gray.

clondrillodes, Kuntze, l. c. = C. Jacquini, Tausch.

connosum. Kuntze, 1. c. = C, comata, Banks of Soland.

conyzifolinm, Kuntze, 1.c. = C. grandiflora, Tausch. croceum, Kuntze, 1, c, = C. Pallasil, Turcz.

ditaricatum, Kuntze, 1. c. $346=$ C. divaricata, F. Schultz.

glabrum, Kuntze, 1. c. = C. glabra, Boiss.

Heldreichiann, Kuntze, 1. C, $345=\mathrm{C}$, divaricata, íoiss. \&f Heldr.

hiemale, Kuntze, 1. c, $346=$ C. taraxacifolia Thuill.

Kochianum, Kuntze, 1. c. = C. Kochii, Tchihatch.

lampsanodes, Kuntze, 1. $\mathrm{C}_{0}=\mathrm{C}$. lampsanoides, Froel.

latiale, Kuntzc, 1, c, $345=\mathrm{C}$ lacera, Tenore.

leonlodontodes. I. c $=$ C. leontodontoides $A$.ll.

Loweanm, Kuntze, 1. c. = C. andryaloides, Laws

Marschallii, Kuntze, I. c. = C. Marschallii, Sch. Bip.

molle, Kuntze, 1. c, = C succisaefolia, Tausch

montanum, Kuntze. 1. C. = C. incarnata, Tausch.

Oliverianum, Kuntze, 1. c. = C. Hookeriana, Oliver E Hiern.

oporinodes, Kuntze, 1, c. = C. oporinoides, Boiss,

pannonicam, Kuntze, $\mathrm{l}, \mathrm{c}=\mathrm{C}$. rigida, Waldst. 6 Kit.

patulum, Kuntze, 1. c. $346=$ Lapsana virgata, Desf.

pontanm, Kuntze, 1. c. $345=$ C. montana, Reichb

prenanthodes, Kuntze, 1. c。 $=$ C. prenanthoides, Henrsl.

pterothecodes, Kuntze, 1. c. = C. pterothecoides, Boiss.

pusillum, Kuntze, 1. c $346(=$ Heteroderis pusilla, Boiss.). - Persia

pyrenaicum, Kuntze, 1. c. $345=$ C. blattarioides, Vill.

ramosissimnm, Kuntze, 1, c. $346=$ C. ramosissima, Uri.

robertiodes, Kuntze, 1. c. = C. robertioides, Boiss seneciodes, Kuntze, 1. C. = C. senecioides, Delite, strictum, Kuntze, 1. c. $345=$ C. Bungei, Ledeb.

tergloviense, Kuntze, .1. c. = C. hyoseridifolia, Reichb.

Turcranizowii, Kuntze, 1. c. $346=$ C. Pallasii, Turcz.

willemetiodes, Kuntze, 1. c. = C. willemetioides, Boiss.

HIERAGIUM, [Tourn ]. Linn. (Compos.). - Ind.

Kew. i. 1149 .
abruptifolium, Vukot. ex G. Beck, F1. Nied.-Oest. ii. (1893) 1309, in syn. = racemosum, Waldst. \& Kit.

acanthodon, Arv. \& Gautier, in Bull. Soc. Bot. Fr. xli. (1894) 361. - Gall.

acrogymnon, Malme, in Bot. Notiser (1891) 178; et in

K. Svensk. Vet. Alkad. Handl. xxvi. 3 (1894) 248 = vulgatum, Fries

acroleucum, Stenstr. Värmzl. Archierac. (1889) 55 ; et Dahlst. in K.Siensk.Vet.Akad. Handl. xxvi.(1889) 69. - Scandinav.

acutulum, Dahlst. in Act. Hort. Berg. ii. 4 (1894) = H. Pilosella, Linn.

adenocephalum, Britton, in Bull. Torrey Bot. Chub xix. (1892) $3 \% 1$ (= Pilosella admocephala, Sch Bip.). - Bolivia.

\section{HIERACIUM :}

adenoclinium, Ara, Hier. Alt. (1888) 108.

Cors.

adspersum, Dahlst, in Act. Hort. Berg, ii. 4 (1894 45. - Scandinav.

aemulum, Aro. in Bull. Soc. Bot. Fr. xli. (1894) 331 - Pyren.

afingense X. Murr, in Prosr. Ober-Realsch. Innsbruck (1891) 54; et in Deutsche Bot. Monatsschr. xiii. (1891) : 77 - Tirol.

agronomon X, G. Beck, in Annal. Naturh. Hofmus. Wien, ii. (1887) $171=$ florentinum, All.

albanicum X, Freyn, in Bull. Herb. Boiss. iii. (1895 6.5 l et 660 . - Albania.

albaticeps, Dahlst. in Bot. Notiser (1892) $165=\mathrm{mu}-$ rorum, Linn.

albidulum, Stenstr. Värml. Archierac, (1S90) 18. Scandinav.

alboviride, $M$. Brenner, in Medd. Soc. Faun. et Fl. Fenn. 1891-02 (1892) 112. - Europ.

Alfenzinum, Evers, in Oest. Bot. Zeitschr. xliii. 1893 425. - Austria.

amblyocephaloides, Dahlst, in Act. Hort Berg. i. (1891) 13; et ii. 4 (1894)31-Scandinav.

amblyphyllarium, Dithlst. l. c. ii. 4 (1894) 58. Scandinav.

amblyphyllum, Dahlst. 1. c., in syn. = amblyphyllarium, Dalhst.

amphibulum $\times$, A. Rehm, in Oest. Bot Zeitsch xliv. (1894) 241. - Austria.

amphigenum, Arv, ex Briq. in Bull. Soc. Bot. Genère. v. (1889) 211 ; et in Bull. Herb. Boiss. v. 623.Sabaud.

ampliceps, Stenstr. Värmz. Archierac. (1889) 32. Scandinav.

amplifolium, Almq. ex Elfstr. in Bihang Siensk. Vet. Akad. Handl. xvi. iii. (1890) 69. - Scandinav.

amplifolium, Arv. Hier. Alp. (1888) 105. - Gall.

amplum, Greene, in Erythea, iii. (1895) 101.

Washington.

amygdalinum, Arv. m Bull. Soc. Bot. Fr.xli. (1824 370. - Pyren.

anacraspedon, A. Rehm. in Verh. zool.-bot. Ges. Wien, xlii. (1895) $330=$ flagellare, Willd.

anadenium, Arv. Hier. Alp. (1888) 41 = subnivale, Gren. \&o Godr.

anatolicum, Freyn \& Sint. in Oest. Bot. Zeitschr. xliv. (1894) 263. - As. Min.

anchusoides, Arv. Hier. Alp. (1888) 13. - Europ anchusoidcun, St. Lager, in Cariot, Etud, des H. éd. 8, ii. (1889) $508=$ anchusoides, Arz

Andrzejowskii, Blocki, in Oest. Bot. Zeitschr. xxxviiz. (1888) 153; et in Woloszczak in Spraw kom. fizyjogr. Krajowci (1888) ii. 203. Europ.

anfractiforme, E. S. Marshall, in Journ. Bot. xxx, (1892) $183=$ subanfractum, E. S. Marsirall.

anfractiforme, Almq. [Dahlstedt. Hierac, exsicc. Fasc. iii. (1889)], ex Dahlst, in K. Svensk. Vet, Akad. Handl. xxv, 3 (1893) $108=$ vulgatum, Fries.

angulatum, Stcnstr. Värml. Archievac. (1889) 59. - Scandinav.

angusticeps, $M$. Brenner, in Medd. Soc. Fann. \& Fl. Fenn. 1891-92 (1892) 107. - Europ.

anisocephalum, A. Rehm. in Verh. zool.-bot. Ges. Wien, xlv. (1895) $326=$ prussicum, Naeg. \& Peter.

anthelatphilum, A. Rehm. 1. c. $334=$ bifurcum. Bisb.

anthyllidifolium, Murr, in Deutsche Bot. Monastsschr. viii. (1890); et in Oest. Bot. Zeitschr. xliii. (1893) 222, in obs; et xlv. (18.55) 222. Austria.

apariaeforme Elfstr in Bihang Suensk. Vet. Akad Handl, xvi, iii. 7 (1890) 41; et xx. iii. 1 (1894) 12 [apargiaeforme?]; et Hier. Alp. Mittl. Skund. (1893) 38. - Scandinav.

apenninum. Levier, ex Sommier et Levier, in Nruon. Giom. Bot. Ital. xxiii. (1891) 261. - Italia. aphyllum. Naeg. et Peter, Hievac, ii. (1886) 234.Europ.

aproximatum, A, Rehm. in Verh zool.-bot. Ges.

Wien. xlv. (1895) $343=$ leptophyton, Naeg. E Peter. 


\section{HIERAGIL'M :}

apricorann Wiesb ex G. Beck, F1. Nied,-Oest, ii. II. (1893) $1294=$ gadense, Wiesb.

aquiloninm, Elfstr. in Bihang Svensk. Vet. Akad. Handl, xx. sii. 1 (1894) $9=$ alpinum, Linn.

aracioides, Arv. E Gautier, in Bull. Soc. Bot. Fr. xli. 1894) 354, - Pyren

araneosum, Arv. Hier, Alp. (1888) $49=$ pulmonarivides, Vill.

arctogenum, Norrl, ex Nym. Consp. Fl. Europ. Suppl. ii. i. (1889) $199(=$ Pilosella arclogena Norr1.) = cymosum, Linn。

arcuatum, Arv. Hier. Alp. (1888) $44=$ heterodon. Arel

arenicola, Blocki, in Oest. Bot. Zeitschr. xxxviii. (1888) 297, nomen. - Austria.

arense $\times$, Dahlst. in K. Svensk. Vet. Akad. Handl. xxiii. $15(1890) 19$ - - Scandinav

argothrix, Naeg. \& Peter, Hierdc. ii. (1889) 303. Europ.

arcyreum. Aro, \& Gautier, in Bull. Soc. Bot. Fr, xli. (1894) 333. - Hisp.

argyrotrichum, Freyn, in Velen. Fl. Bulg. (1891) 340; et in Oest. Bot. Zeitschr, xlii. (1892) 345. Bulg

Trmenum, Frenn. \&. Sint. ex Freyn, l. c. 344. - As. Tin.

Arnelli, Dahlst. in Act. Hort. Berg. ii. 4 (1893) 97. - Norv.

aronicifolium, Arv. Hier. Alp. (1888) 102. Ga1l.

arrectipes, Almq. ex Elfstr, in Bihang Srensk. Vet. Ahad. Handl. xvi. iii. 7 ; 1890) 43 ; 'et Hier. Alp. Mittl. Skand. (1893) 41 - Scandinav.

arrosum. Stchstr. Väml. Archierac. (1889) 14.Scandinav.

asteriforme, Arv. \& Lamotte, ex Arv, Hier. Alp. (1888) $116=$ conieum, Aro

asterinum, Arr. \& Briq. ex Briq. in Bull. Herb. Boiss, ii. (1894) 622. - Sabaud.

astolonum, Vukot, ex Peter, in Engl. \& Prantl, Natürl. Pflanzenfam. iv. 5 (1893):380 = florentinum, Hall.

atratiforme, Simonk. Enum. Fl. Transsilv. (1886) 371 = nigrescens, $W$ illd

atricapillum, Blocki, in Oest. Bot. Zeischr, xxxviii. 1888) 297 , in obs. - Hung.

atricomum. M. Brenner, in Medd. Soc. Famn. et Fl. Fenn. 1891-92 (1892) 105. - Europ.

atrocephalum, Schmalh, in Ber. dentsch, bot. Gezells. x. (1892) 290. - Reg. Cauc.

atrocrocem, Peter, in Oest. Bot. Zeitschr. xxxvi. 18\&6) $45=$ auricula, Lim

atrocladrm, A. Rehm, in Verh. zool.-bot. Ges. Wien, xlv. (1845) $342=$ brachiatum, Bert.

attractum, Arr, in Full. Soc. Bot. Fr, xli. (1894) 34). - Gall. mer.

anrantiacoides, Ari. Hier. Alp. (1888) 9. Europ.

aureo-purpurcum, Freyn, in Oest, Bot. Zeitschr. xli. (1891) $11=$ bifircum, Bieb.

auriculifolium, Arv. et Briq. ex Briq. in Bull. Herb. Boiss. ii. (1894) 626. - Sabaud.

auriculinum, Almq. ex Dalist. in Act. Hort. Berg. 1. 7 (1891) 16 ; et ii. 4 (1894) 38 et 40 ; et ins K. Swensk. Vat. Akad. Handl. xxiii. 15 (1890) 102. - Scandinav.

agriculinztm X.G. Beck, FI. Nied,-Oest, ii. IL (1893) 1283. - Europ.

anssigense. Wiesb. [in. Baenitz, Herb. Europ. n. 6.319] ex Oest. Bot. Zeitschr, xl。(1890) $466=$ bifidum, Waldst, \& Kit.

austriacum, Britton, ex Nym. Consp, F1. Eur. Suppl. ii. 1. (1889) 195; G. Beck, F1. Nied.-Oest. ii. II. (1893) $1295=$ H. Dollineri, F. Schultz.

austriacum, Uechtr. ex Peter, in Engl. of Prantl. Natiir. Pfanzenfam. iv. 5 (1893) 382. Austria.

Autrani, Post, in Bull. Herb. Boiss. i. (1893) 25.Syria.

axiflorum, Arv. Go Briq. ex Briq. l. c. ii. (1894) 624. - Sabaud.

Aymericianum, Arr. in Bull. Soc. Bot. Fr. xli, (1894) 346. - Pyren.

Backhousei, Hanbury, in fourn. Bot. xxvii. (1889) 74. - Brit.

\section{HIERACIUM}

baeticum, Arv \& Reierch, ex Herv, in Rev, gén. bot. iv. (1892) 154. ot in Bull. Soc Bot. Fr xli. (1894) 331; Willk, Suppl. Prodr. Fl. Hisp. (1893) 120. - Hisp

Baldacciamum X, Freyn, in Malpighia, vi. (1892); et in Bull. Herb. Boiss. iii. (1895) 650 et 664 . Albania.

Baldaccii, Haläcsy, in Oest. Bot. Zeitschr. xli. (I891) 223. - Montenerro.

Bangii, Rusby, in Mem. Torrey Bot. Club. iii. 3 (1893) 66. - Bolivia.

Barbeyi, Post, in Bull. Herb. Boiss. i. (1893) 24 et 411. - Syria.

Barteranum. Aro. \& Mailho, in Bull. Soc. Bot. Fr. xli. (1894) 338. - Gall. iner.

basifolium, Almq. in Stenstr. Värml. Archierac (1889) 43; et ex Dahlst. in K. Svensk. Vet. Akad. Handl. xxvi. 3 (1894) $38=$ caesimm. Fries

batycomum, Dahlst. [Herb. Hier. Scand. Cent. v. (1893) n. 15] in Act.Hort. Berg. ii. 4 (1893) 133. - Scandinav.

Beckianum, Freyn et Sint. ex Freyn, in Bull. Herb Boiss, iii. (1895) 669. - Armen.

bellulum, Dahlst. in Act. Hort. Berg. ii. 4 (1894) 3S. - Scandinav.

benulum, Magnusson, ex Elfstr. Hier. Alp. Mittl. Skand. (189:3) 34. - Scandinav.

Berardianum, Aro. Hier. Alp. (1888) 59. - Gall

berdoense, Woloszczak, in Spraw Kom. fizyjogr. Krajowei (1888) ii. 202. - Hung.

biflorm, Arv. Hier. Alp. (1888): $=\mathrm{H}$. Peleterianum, Mérat.

bifrons, Aro, in Bull. Soc. Dauph. xiii. (1886) 555 ; ct l. c. 97. - Europ.

bipes, Dahlst. [Herb. Hier. Scand. Cent, iii. (1893 n. 34] ; et in Act. Hort. Berg. i1. 4 (1893) 102. Scandinay.

boreum, Elfstr. in Bihang Svensk. Vet, Akad. Handl, xxiii. 1 (1894) 20 =alpinum, Linn.

Bornmuelleri, Freyn, in Oest. Bot. Zeitschr. xli (1891) 54 ; et in Bull. Herb. Boiss. iii. (1895) 510 - As. Min.

bosniacum, G. Beck, in Annal. Naturh. Hofmus, Wien, ii (1857) $171=$ magyaricum, Naeg. \& Peter.

bosniacum, Frejn, in Bull. Herb. Boiss, iii. (1895) 508 et 654 . - Bosnia.

Boswelli, E. F. \& W. R. Linton, in fourn. Bot. xxxi. (1893) 178. - Scotia.

Boutignyanum, Aro, in Bull. Soc, Bot. Fr. xli. (1894) 335. - Pyren.

brachyacron, A. Rehm. in Verh. zool.-bot. Ges. Wien, xIv. $(1895) 327$ = flagellare, Willd

brachycephalum, Norr1. ex Nym. Consp. F1. Eur. Suppl. ii. I. (1889) 200 (= Pilosella brachycephala Norrl.) = suecicum, Fries.

brachypodarium, Dahlst. in Act. Hort. Berg. ii 4 (1593) 130. - Scandinav.

Brandisii $X$, Freyn, in Bull. Herb. Boiss, iii. (1895) 646 et 664. Bosnia.

brassicoides, Arv. ox Wilczek, in Bull. Soc. Bot. Fr. xli. (1894) p. cclxviii. - Valesia.

breadalbanense, Hanbury, in Fou'n. Bot. xxx. (1892) 261. - Scotia.

Briquetianum, Aro. ex Briq. in Bull. Herb. Boiss. ii. (1894) 627. - Sabaud.

britannicum, Hanbury, in fourn. Bot. xxx. (1892) 366. - Anglia.

brumale, Ari, Hier. Alp. (188s) 71. - Gall.

brunellaeforme, Arv. l. c. 69 . - Europ.

brunopolitanum, Murr, in Oest. Bot. Zeitschr. xly. (1895) $425=$ glaucopsis, Fries.

Bublae, Blocki, ex Oest. Bot. Zeitschr. xxxviii. (18s8) 154, in obs. - Austro-Hung.

buglossoides, Arv. Hier. Alp. (1888) $72=$ onosmoides, Fries.

bulgaricum, Freyn, in Velen. Fl. Bulg. (1891) $34 \pi$ et in Oest. Bot. Zeitschr. xlii. (1892) 344 . Bulg

Burnati, Arv. Hier. Alp. (18s8) 24. - Pedem.

Burserianum, Arv. in Bull. Soc. Bot. Fr. xl. (1894) 256. - Pyren.

caerulaceum, Arv. Hier. Alp. (1888) 73. - Gall

caesiiceps, M. Brenner, in Medd. Soc. Faunn et Fl. Fenn 1891-92 (1892) 118. - Europ.
HIERACIUM :

caesiomurorum, Linzlo, ex Stenstr. Värml. Archierac. (1889) 35; Dahlst. in K. Siensk. Vet. Akad, Handl. xxvi. 3 (1894) 44. - Scandinav.

caesiovirens, Dahlst. [Herb. Hier. Scand. Cent. iii. (1892) n. 43 in Act. Hort. Berg. ii. 4 (1893) 122. Scandinav.

caespitans, Dahlst.l. c.i.7(1894) 31. - Scandinav. caespitosum, Dahl.t. 1. c. ii. 4 (1894) 42, in syn. = pleiocaulon, Dalhst.

calcidicum, "Boiss. \& Heldr. » ex Oest. Bot. Zeitschr. (1890) 490, ad calc. = chalcidicum, Boiss. \& Heldr.

caledonicum, Hanbury, in fourn. Bot. xxvii. (1889) 75. - Brit.

Calisii, Evers, ex Huter, in Oest. Bot. Zeitschr. xlii. (1892) 70 , in obs. = leucocephalum, Bartl. callistophyllum, Hunbury, in fourn. Bot.xxx. (1892) 168. - Scotia.

calomelanum, A. Rehm, in Verh. zool.-bot, Ges. Wien, xlv. (1895) 333 = glomeratum, Fries.

calophyllum, Uechtr. ex Peter, $n$ Engl. \& Prantl, Natiirl. Pfanzenfam. iv. 5 (1893) 384.-Europ.or. cambricum, Hanbury, in fourn. Bot. xxxii. (1894) 226. - Brit.

campylopodum, Dahlst. Herb. Hier. Scand. Cent. v. (1893) n. 7; et in Act. Hort. Berg. ii. 4 (1893) 93 et 142, in obs. - Scandinav.

canaliculatum, M. Brenner, in Medd. Soc. Faunn ct Fl. Fenn. 1891-92 (1892) 104. - Europ.

caniceps, Hanbury, in foum. Bot. xxx. (1892) 368. - Scotia.

canipes, Almq. ex Stenstr. Värml. Archicrac. (1889) 3l. - Scandinav.

canitiosum, Dahlst. in Bot. Notiser (1892) $155=$ vuløatum, Fries.

cantianum, Hanbury, in Fouru. Bot. xxxii. (1894) 232. - Brit.

canum, Peter, in Engl. E Prantl, Natiirl. Pfanzenfam. iv. 5 (1893) 379. - Europ.

capnoides, Kern.ex Naeg. E Peter, Hierac. ii. (1886) 231. - Europ.

capnostylum, Dahlst. \& Elfstr. ex Dahlst. in Act. Hort. Berg. ii. 4 (1893) 6l et 63; et Hier. Alp. Mittl. Skand. (1893) 38. - Scandinav.

cappadocicum, Freyn, in Oest. Bot. Zeitschr. xli. (1891) 55; et in Bull. Horb. Boiss. iii. (1895) 507. - As. Min.

Carenorum, Hanbury, in fourn. Bot. xxxii. (1894) $227 .-$ Brit.

caricinum, Arr. Hier. Alp. (18s8) 17. - Europ.

Castriferrei, Borb. Geogr. atq. cmum. pl. Comit. Castrif. (1889) 201. - Hung.

cataractarum, Arv. ex Willk. Suppl. Prodr. Fl. Hisp. (1893) 121, nomen; et in Bull. Soc. Bot. Fr. xli. (1894) 330 . - Hisp.

caucasicum, Noteg. \& Peter, ex Peter, in Engl. \& Prantl, Natuirl. Pflanzenfam. iv. 5 (1893) 380.Reg. Cauc

cebennense, Arv. ex Martin, in Bull. Soc. Bot. Fr. xl. (1893) 19. - Gall

cenisium, Are. in Bull. Soc. Daupl. xiv. (188\%) 580 ; et Hier. Alp. (1888) 32. - Gall.

centripetale, Hanbury, in fourn. Bot. xxx. (1892) 166. - Brit.

cepenthum, Naeg. \& Peter, Hievac, ii. (1889) 338. Bavar.

ce:atodon, Arr. Hier: Alp. (1888) 69. - Europ.

ceratophyllum, Arv. 1. c. $68=$ rupicolum, Fries.

ceramotum, Stenstr. Värml. Archierac. (1889) 52. Scandinav.

cerinthiforme, Backh. ex Hanbury, in fourn. Bot. xx.r. (1892) 169. - Brit.

Chaberti X, F. O Wolf, in Bull. Soc. Bot. Fr. xli. (1894) 175. - Vales.

Chaboissaei, Arv. ex Nym. Consp. Fl. Eur. Suppl. ji. I. (1889) $196=$ pallidum, Fries.

chaetodon, Dahlst. in Act. Hort. Berg. ii. 4 (1893) 23. - Scandinav.

chalybaeum, Aro, in Bull. Soc. Bot. Fr. xli. (1894) 360. - Gall. centr.

chiclense, Ball, in Fourn. Linn. Soc. xxii. (1885) 47. - Peruvia.

chloropoides, A. Rehm. in Verh. zool.-bot. Ges, Wien, xlv (1895) $324=$ prussicum, N'alg. E Peter. 


\section{HIERACIUM}

chloroleucum, Dahlst. [Hier. exsicc Fasc. 1. (1889) n. 93] in Act. Hort. Berg. i. 7 (1891) 37. Scandinav.

chloromelanum $\times$, Peter, in Jahrb. Schweiz. Alpenclub, xxxii. (1857) 352-59.- Helv.

chnoodes $X$. Peter, 1. c. - Helv.

chondrilloideum, St. Lager, in Cariot, Etud, des $\mathrm{fl}$. éd, 8, ii. $(1889) 510=$ chondrilloides, Vill.

christianiense, Dahlst, ex Stenstr. Värml. Archierac. (1889) 11. - Norv.

chrysocephalum, Norrl. ex Nym. Consp. Fl. Eur. Suppl. ii. 1 (1859) 200 (= Pilosella chrysocephala. Norr1.) = suecicum, Frics.

chrysostylum, Linder, ex Elfstr. Bot. utflygter (1890) 67 ; et Hier. Alp. Mittl. Skand. (1893) 53. Scandinav.

cichoriacem, Arv. Hier. Alp. (1888) $92=$ juranum, Fries.

Cieselskii, Blocki, in Oest. Bot. Zeitschr. xxxviii. (18s8) 297, in obs, - Hung.

ciliatidens, Elfstr. in Bihang Svensk. Vet. Akad. Handl. xxiii. 1 (1894) 31, ad calc. = petiolatum, Elfstr.

ciliatum X. Blocki, in Oest. Bot. Zeitschr. xxxvij. (1887) 227. - Hung.

ciliiferum, A. Rehm, in Verh zool.-bot. Ges. Wien, xlv. (1895) $345=$ paragogum, Naeg. \& Peter.

cincinnulatum, M. Brenner, in Medd. Soc. Fann. et Fl. Fenn. $1891-92$ (1892) 119. - Europ.

cinericeps, $M$. Brenner, l. c. 92. - Europ.

clovense, E. F. Linton, in fourn. Bot. xxxi. (189:3) 178. - Scotia.

coalescens, Norrl. ex Nym. Consp. Fl. Eur. Suppl. ii. I. $(1889)(=$ Pilosella coalescens, Noril.) $=$ H. Pilosella, Linn

coarctatum, Arv. Hier. Alp. (1888) 92 = juranum, Fries.

cochleare X. Kern. ex Naeg. \& Peter, Hierac. ii. (1889) 258. - Europ.

cochleatiforme, Dahlst, in Act. Hort. Berg. ii. 4 (1894) $10=$ H. Blyttianum, Fries.

coderianum, Arv. E Gautier, in Bull. Soc. Bot. Fr. xli. (1894) 350. - Pyren.

coevulacem, Arv. in Bull. Soc. Dauph. xiii. (1886) $557=$ caerulaceum, Arv

cololepium, Dahlst. in Act. Hort, Berg. ii. 4 (1893) 94. - Scandinav.

colophyllum, Naeg. \& Peter, Hierac, ii. (1889) 309

columnare, Arv. Hier. Alp. (1888) 86. -. Gall.

comminutum, Dahlst. in Act. Hort. Berg. ii. 4. (1893) 113. - Scandinav.

comosum, Elfstr. in Bikang Svensk. Vet.-Akad. Handl. xx. 3 (1895) 17. - Scandinav

congestum, Freyn, in Oest. Bot. Zeitschr. xli. (1891) 56; et in Bull. Herb. Boiss. iii. (1894) $509=$ cappadocicum, Freyn.

conforme, M. Brenner, in Medd. Soc. Faun. et Fl. Fenn. 1891-92 (1892) 116. - Europ

conjunctum. $X$, G. Schneid, in Deutsche Bot, Monatsschr. vi. (1888) 122. - Europ.

conringiaefolium, Arv. Hier. Alp. (1888) 106. Gall.

conyzoides, Arv. in Bull. Soc. Bot. Fr. xxi. (1894 369. - Pyren

copidophyllum, Dahlst. in Act. Hort. Berg. ii. 4 (1893) 72. - Scandinav

copulatum X, G.Schneid. in Deutsche Bot. Monatsschr. vi. (1888) 123. - Europ.

coracinum, Dahlst. in Act. Hort. Berg. ii, 4 (1894) 64. - Norv.

coriifolium, Arv. Hier. Alp. (1886) 78. - Gall.

coronariaefolium, Ari. l. c. 56. - Gall.

coronarium, M. Brenner, in Medd. Soc. Fann. et Fl. Fenn. 1891-92 (1892) 106. - Europ.

corrubtum $X, G$. Schneid. in Deusche Bot. Monats schr. vi. (18SS) 123. - Europ.

corymbuliferum, Ars. Hier. Alp. (1888) 8.Europ.

ottianum, Ary, in Bull. Soc. Dauph. xiii. (1886) 557 ; et Hier. Alp. (1888) 102. - Europ.

creperum, Stenstr. Värml. Archierac. (1889) 64. Scandinav.

crepidifolium, Arv. Hier. Alp. (1888) 89. - Gall.

\section{HIERAGIUM}

chum, Dahlst. [Hier, exs, Fasc i, (1889) n.61] in K. Svensk, Vet, Akad. Handl xxy, 3 (1893) 89 , in syn. = vulgatum, Fries.

crispum, Elfstr, ex Dahlst. in Act. Hort. Berg, ii. 4 (1893) 45; et Hier. Alp. Mittl. Skand. (1893) 14 = alpinum, Limn.

croccum, Dahlst. 1. c. ii. 4 (1893) $18=$ floribundum. Wimm. \& Grab.

cruentatum, Lïbcch, ex Stenstr. Värm?. Archierac. (1889) 44. - Scandinav.

cruentifolium, Dahlst. E Libbeck. ex Dahlst. in $K$. Svensk. Vet. Akad. Handl. xxxi. 3 (1894) 144. - Scandinav.

cruentum, Naeg \&o Peter, ex Sagorski of Schneid. Fi. Centralkarp. ii. (1891) 303; et ex Engl. Ex Prantl. Natiirl. Phanzenfam. iv. 5 (1893) 380. - Europ.

cryptadenum. Arv. in Bull. Soc. Bot. Fr. xli. (1894) 329. - Gall.

cryptanthum, Arv, \& Marc d'Aym. in Lucante, Rev. de Bot. ix. (1891) 38. - Pyren. gall.

umbriense, Hanbury, in fourn. Bot. xxxii. (1894) 226 . - Scotia.

cuneatum, Arv. E Gautier, in Bull. Soc. Bot. Fr. xli (1894) 342. - Gall. mer.

cuneolatum, Stenstr Värml. Archierac. (1889) 39. Scandinav.

curvatiforme, Dahlst. in Act. Hort. Berg. ii. 4 (1893) 67. - Scandinay

curcatipes, Elfstr. in Bihang Svensk. Vet Akad. Handl. xx, III, 1 (1894) 19, in obs.= alpinum, Linn.

curvatum, Elfstr. Bot. Utflyoter (1890) 47; et Hier. Alp, Mittl. Skand. (1893) 45. - Scandinav.

Custoris X. Bruegg. ex Killias, in Jahresb. Naturf. Ges. Graub. xxxi. Beil. (18S7-S8) 114. - Helv.

cyaneum, Arv. Hier. Alp. (1888)69. - Europ.

cynodon, M. Brenner, in Medd. Soc. Fann. et Fl.

Fenn.1891-92 (1892) 103. - Eirop. bor.

Czetzianum X Simonk. Enum. Fl Transsily. (1886) 367. - Transsilv

Dalhstedtii, Almq. ex Elfstr. Hier. Alp. Mittl Shand. (1893) 60. - Scandinav.

delicatulum. Arv. ex Murr, in Bot. Deutsche Monats. schr, viii. (1890) 108. - Tirol.

delphinale, Arv. Hier, Alp. (1888) 47. - Gall.

Delpinoi, Baldacci, in Malpighia, vi. (1892) et $e x$ Freyn, in Bull. Herb. Boiss. iii. (1895) 649. Montenegro.

deltophyllum, Arv. Hier. Alp. (1888) 120. - Gall.

depilatiforme, Dahlst. in Act. Hort. Berg, ii. 4 (1893) 140. - Scandinav

depilatum, Alnq. ex Elfstr. Bot. Utflygter (1890) 66; e Hier. Alp. Mittl. Skand. (1893) 51. - Scandinav

diabolicum $X$, Naeg. \& Peter, Hierac. ii. (1886) 235. - Europ

digeneum, G. Beck, ex Pcter, in Engl, \& Prant?, Natür. Pfanzenfam. iv. 5 (1893) 381. Europ.

dilwviale, A. Rehm, in Verh. zool -bot. Ges. Wien, xiv. (1895) $341=$ brachiatum, Bert.

dimorphoides, Norrl. ex Nym. Consp. Fl. Eur. Suppl. ii. I. (1889) 199 (= Pilosella dimorphoides, Norrl.) $=$ flammeum, Fries

dissimile, Lindeb. ex Elfstr. Hier. Alp. Mittl. Skand. (1893) 60. - Scandinav.

dissquamatum, Elfstr. 1. c. $19=$ alpinum, Linn. distinctum, Stenstr. Värml. Archierac. (1889) 30. Scandinav.

divaricans, M. Brenner, in Medd. Soc. Fann. et Fl. Fenn. 1891-92 (1892) 124. - Europ.

divergens, Naeg. \& Peter, Hierac. ii. (1889) 332. Europ.

doronicifolium, Arv. Hier. Alp. (1888) 98. - Gall. doronicoides, Arv, in Bull. Soc. Bot, Fr, xl. (1894) 340. - Gall. mer.

drazeticum, Ars. \& Marc. d'Aym. l. c. 364. Pyren.

dublanense, A. Rehm. in Verh. zool.-bot. Ges. Wien, xlv. $(1895): 323=$ collinum, Gochn

dubiosum $\times, G$. Schneid. in Deutsche Bot. Monatsschr.vi.(1888) 122. - Europ.

duplicatum, Almq. [in Dahlst. Hier. exsicc. Fasc, ii. (I889) n. 84.] in Act. Hort. Berg. i. 7 (1891) 38. - Scandinav.

duriceps, Hanbury, in fourn. Bot.xxx. (1892) 260. - Scotia.

\section{HIERAGIUM :}

ybowskianum, A. Rehm, in Verh. zool.-bot. Ges, Wien, xlv. (1895) $346=$ trigenes, Naeg. E Peter ectradoriense, Arvo ex Peter. in Engl. E Prantl. Natirl. Pfanzenfam. iv. 5 (1893) 387. Ecuad.

effusum, Arv. \& Briq. ex Briq in Bull. Herb. Boiss. ii. (1894) 631. - Sabaud.

eginense, Freyn \& Sint. in Oest. Bot. Zeitschr. xlii. (1892) 270. - Armen. turc.

elatius X, A. Rehm. in Verh. zool.-bot. Ges. Wien, xlv. (1895) 332. - Europ.

elegantulum, Dahlst. in Act. Hort. Berg. ii. 4 (1898) 24. - Scandinav.

Elfstrandii, Dahlst. l. c. 79 ; Elfstr. Hier. Alp. Mittl. Skand. (1893) 2\%. - Scandinav.

Elisaeanum, Arv. cx Willh. Suppl. Prodr. Fl. Hisp. (1893) 120; et in Bull. Soc. Bot. Fr. xli. (1894) 332 . - Hisp.

enginense, Arv. Hier. Alp. (1888) $101=$ mollitum,

epacrum, Stcnstr. Vürml. Archicrac. (1890) 70. Scandinav

ericetorum, Freyn, in Oest. Bot. Zeitschr. xxxvii, (1887) 391. - Tirol

Vicetorum, Ravaud, ex Nym. Consp. Fl. Eur. Suppl. ii. 1. (1889) $\mathbf{1 9 3}=$ vulgatum. Fries.

erigerontinum. Arv. in Bull. Soc. Bot. Fr xli. (1894) 328. - Gall.

erioleion, Naeg. \& Peter, Hicrac. ii, (1889) 296. -.. Europ.

riopodum, Kern, in Oest, Rot. Zeitschr, xxyix (1889) 12; et xlv. (1895) $394=$ illyricum, Naeg. E. Peter.

eriostachynm, Borb. ex Nym. Consp. Fl. Eur. Suppl. ii. I. (1889) $192=$ anisophyllum, Boiss.

erucoïdes, Arv, in Bull. Soc. Bot. Fr, xli. (1894) 360. - Alp.

erysibodes, Dahlst, in Act. Hort. Berg. i. 7 (1891) 33. - Scandina

erythrellum, Aro. in Bull. Soc. Bot. Fr. xli. (1894) 359. - Pyren.

pthrommoum, A. Rehm, in Verh. zool -bot. Ges.

Wien, xlv. (1895) $337=$ brachiatum. Bert.

erythrotrichum, A. Rehm. 1. c. = brachiatum, Bert.

esketanense, Stenstr. Värml. Archicrac. (1898) 60. Scandinav.

eudaedalium, Stenstr. ex Dahlst. in K. Siensh. Vet Akad. Handl. xxvi. 3 (1894) 249 - Scandinav.

euprepes, Hanbury, in fourn. Bot. xxx. (1892) 206

eurycibe, Dahlst. [Horb. Hier. Scand. Cent, ii (1892) n. 59l in $K$ Siensh. Vel. Akad. Handl. xxvi. $3(1894) 150 .-$ Scandinav.

eustales, E. F. \& $W$. R. Linton, in foum: Bot xxxi. (1893) 195. - Scotia,

exacutum, Dalzlst. l. c. xxiii. 15 (1890) $33=\mathrm{seq}$.

exacutum, Norrl. ex Nym. Consp. Fl. Eur., Suppl ii. I. (1889) 200 (= Pilosella exacuta, Norrl.) = H. Pilosella, Lim

exaltatum, Arv. Spicil. Hier. Suppl. i. (1886) 41. Pyren.

exaltatum, Dahlst. in Stenstr. Värml. Archierac 1889) 42 ; et in K. Svensk. Vet. Akad. Handl. xxxi. 3(1894) $35=$ caesium, Fries

exaltatum, Dahlst. ex Andersson, in Bot. Notiser (1890) 92 [an praec. ?] = murorum, Linn。

exilentum, Arv. Hier. Alp. (1888) $90=$ epimedium, Fries.

eximiiforme, Dahlst, in Act. Hort. Berg. i. 7 (1891) 21 ; et ii. 4 (18 4) $71=$ alpinum, Linn

expallens, Arv. Hier. Alp. (1888) $78=$ subincisum, $A ; 0$.

expallidiforme, Dahlst. ex Stenstr. Värml. Archierac. 1890) 26. - Scandinav.

expansiceps, Elfstr. Hier. Alp. Mittl. Skand. (1893) 43. - Scandinav.

expansum, Dahlst. [Herb. Hierac. Scand, Cent. iij. (1892-93) n 22] in Act. Hort. Berg, ii. 4 (1894) $61=$ alpinum. Linn.

extensiforme, Dahlst.in K. Suensk.Vat, Akad. Handl. xxvi. 3 (1894) 197 - Scandinav.

extrorsifrons, Elfstr. Hier. Alp. Mittl. Skand. (1898) $20=$ alpinum, Linn.

farinaceum, Stenstr. Värml. Archierac. (1890) 33. Scandinav. 


\section{HIERAGIUM}

farinicchs, Dahlst. in Act. Hort. Berg. ij. 4 (1894) 30 - Nory.

farrense, Hambury, in fourn. Bot. xxvii. (1889) 75. - Brit.

Fatrae, Pax. in Oest. Bot. Zeitschr. xlv. (1895) 42. - Carpath

Fanmei Arv, Hierac. Alp. (1888) 5 ; et in Bull. Herb. Boiss, ii. (1894, 619) - Gall.

Fatreanum, Arv. 1 c. (1888) $39=$ glanduliferum, Hoppe.

Ferdinandi X, G. Beck, F1. Nied.-Oest, ii. II. (1893) 1287. - Austria

Fichii, Uechtr. ex Nym. Consp. F1. Eur. Suppl, ii. 1 (1889) $191=$ corymbosum, Fries.

finmarkicum, Elfstr, in Bihang Srensk. Vet, Akad. Handl. xx, 11.1 (1894) $133^{\circ}=$ alpinum, Linn.

firmipes, A. Rehm. in Verh. zool.bot. Ges. Wien, xlv. (1895) $331=$ macrostolonum, G. Schmeid

fistulosum, A. Rehm. 1. c. $346=$ nigriceps, Naeg. of Peter.

flaccidum, M. Bromer. un Medl. Soc. Fann. et Fl. Fon. 1801-02 (1802)!) - Eur 1).

Flammula. Arr. Hier. Alp. (18s8) 9. Europ.

faricaule, A. Rehm. in Verh. zool.-bot. Ges. Wien, xiv. (1895) $3: 37$ = brachiatum, Bert.

flaciforme, A. Rehm. 1. c. $340=$ brachiatum, Bert. fexile X. Kotula, ex Oest. Bot. Zeitschx. xli. (1891) 119, 140 et 251. - Hung.

flexicaule X. Freyn \& Vandas, ex Freyn, in Bull, Hexb. Boiss. iii. (1895) 645 et 606 . - Oriens.

flocciferum, Arc, in Lucante, Rer' de bot, ix. B1. Gall.

floccifrons, Elfstr. Bot. Utflygter (1890) $61=$ dissimili. Lindes.

floccosum, Ar. Hier. Alp. (1888) 57. - Gall.

florentinoides, Arv. l. c. 16. - Europ.

folioliferum, Elfstr. in Bihang Siensh. Vet. Akad. Handl. xx. III. 1 (1894) 8. - Scandinav.

formicarim, Th. Fries, ex Elfstr. 1. c. $29=$ rulgatum, Fries.

Foucandianum, Arr. in Bull. Soc. Bot. Fr. xli. (1894) 337. - Pyren

fronditerum. Elfstr. Bot. Utflygter $(1890) 38$; et Hier. Alp, Mitll. Skand. (1893)21. - Scandinav.

fuciflorm, Arv. Hier. Alp.(18ss) $4=\mathrm{H}$. Peleterianum. Mirat.

fulcratum, Aro. cx Briq. in Bull. Herb. Boiss. ii. 1894) 621. - Sabaud

fuliginosum, Laest. in Eifstr. Pot. Utflygter (1890) ; et Hirr. Alp. Mittl. Skand. (1893) $24=$ fulininosum, Anders.?

furculatum, Elfstr. Bot. Utfygter (1890) 66 ; et Hier. Alp. Mittl. Shand. (1893) 59. - Scandinav.

furvicolor, M. Brenner, in Medd. Soc. Fonn. et Fl. Fenn.1891-92 (1892) 108. - Europ.

fuscatum. Elfstr. Bot. Utflygter (1890) 56; ct Hier. Alp. Mittl. Skand. (189:3) 49. - Scandinav.

gadense, Wiesb. ex Nym. Consp. Fl. Eur. Suppl. ii. i. (1889) 198 = staticaefolium, Vill.

galaticum, Freyn, in Oest. Bot. Zeitschr. xli. (1891) 11 = macranthum, Ten.

galbanm, Dahlst, ex Andersson, in Bot. Notiser 1890) $92=$ murorum, Linn.

galbeum, $M$. Brenner, in Medd. Soc. Faun. et Fl. Fenn. (1892) 11:\% - Eurou.

calicience, Blocki, in Oest. Bot. Zeitschr. xxxviii. 1888) 7i, in obs. - Austro-Hung.

garganum, Arv. Hier. Alp. (1888) $92=$ juranum, Fries.

Gelmianum. Samtheim, in Oest. Bot. Zeitschr. xliv. (1894) 275. - Venetia.

gemellum, Alna. cx Elfstr. Hier. Alp. Mittl. Skand. 1893) 65. - Scandinav.

glabclum, Dahlst. in Bot. Notiser (1886) 140; et ex Bot. Centralbl. xxvi. (1886) $174=$ dovrense, Fries.

glabratoides, Murr, in Oest. Bot. Zeitschr, xliii. (1893) 221; xlv. (1895) 428; et in Deutsche Bot. Monatsschr. xii. (1894) $98=$ glabratum, Hoppe.

glabriceps, G. Beck, in Ann. Naturh. Hofmus. Wien, ii. (1887) $170=$ florentinum, All.

glabridens, Elfsir, in Bihang Siensk. Vet. Akad. Handl. xx. 11: 1 (1894) 18, - Scandinay.

glandulatum, Elfstr. 7. c. xvi. 11. 7 (1890) 42; et Hier. Alp. Mittl. Shand. (1893) 28. - Scandinav.

\section{HIERACIUM}

glandulosodentatum, G. Schneid, in Oest. Bot. Zeit schr. xxxvi.(IS86) $24=$ vulgatum, Frics.

glaucicolor, Dahlst. in Bot. Notiser (1886) 139; et in Bot. Centralbl. xxvi. (1886) $174=$ dovrense Fries.

glaucocehhalum X, Naeg. \& Peter, Hierac. ii. (1886) 78. - Europ.

glaucochlorm, A. Rehm, in Verh, zool.-bot. Ges. Wien, xlv. (1895) $328=$ flagellare, Willd.

glaucovircns, Dahlst. in Stenstr. Värml. Archierac (1889) 5.5; et in K. Svensk. Vet. Akad. Handl. xxvi. $3(1894) 169=$ diaphanum, Fries.

globiceps, Dahlst. in Act. Hort. Borg. ii. 4 (1894) 51. - Scandinav.

globularifolium, Are. IJier. A7p. (1888) 6. - Gall glossodes, Dahlst. in Act. Hort. Berg. ii. 4 (1893) 134. - Scandinar.

gnaphatium, A. Rehm, in Verh, zool.-bot. Ges. Wien, xlv. (1895) $325=$ prussicum, Nagg. \& Peter.

Godryi, Orphanides, [Fl. Graec. exsicc. n 347] ex Naeg. \& Peter, Hierac. ii. (1889) $331=$ H. Gaudryi Boiss,

Grabounshimnun \& Peter, Hierac, ii. (1886) 207. - Europ.

gracillimum, Dahlst. in Act. Hort. Berg. ii. 4 (189:3) 142; Elfstr. in Bihang Srensk. Vet. Akad. Handl. xx. w, 1 (1894) $6=$ alpinum, Iimz.

grammophyllum, Stensty. in Bot. Notiser (1895) 216. - Scandinay.

grandidens, Dahlst. in K. Svensk. Vet. Akad. Handl. xxy. 3 (1893) 136; Elfstr. in Bihans Svensk. Vet. Akad. Handl, xx. III. I (1894) $27=$ alpinum, Linn.

graniticolum. Linton, in fourn. Bot. xxxi. (1893) 145. - Scotia

Greenii, Porter \& Britton, in Bull. Torrey Bot. Chub xx. (1893) $120(=$ Pilosella spathntata, Sch. Bip.) - Am. bor. occ.

Gremlii, Arv, Hier. Alp. (1SSS) $35=$ dentatum, Hoppe.

grisancense, Bejer, in Wiss. Beil. Progr. Andrcas Realgymn. Berl. (1891), cx Oest. Bot. Zeitschr, xli (1891) 177. - Europ.

sriselliceps, M. Brenner, in Medd. Soc, Fann. et Fl. Fonn. 1891-92 (1892) 90. - Europ.

grivastcllam, Dahlst. [Hier. exs., Fase. i. (1889 n. So et 81 j in K. Svensk. Vet. Akad. Handl. xxvi. 3 (1894) $41=$ caesium, Fries.

Grofac, Woloszczak, in Spraw $\mathrm{K} \cap \mathrm{m}$, fizyjogr. Krajowei, xxvii. (1892) 142. - Europ

Gussembanerianum, Pacher, Nacht. Fl. Karnt. (1894) 71. - Carinth

gypsicola, Blocki, in Oest. Bot. Zeitschr. xxxviii, (1888) $996=$ praealtum. Gochn.

gyroflexum, Arv. Hier. Alp. (1S88) $54=$ vogesiacum, Mong.

halense, Murr, in Oest. Bot. Zeitschr. xly. (1895) 429 Tirol.

handoclcnse, Dahlst, in Act. Hort. Berg. ii. 4 (1894) 73. - Scandinav

hanense X, Dahlst. in K. Svensk. Vet. Akad. Handl, xxiii. 15 (1890) 19. - Scandinav.

Hankae, A. Rehm, in Verh. zool.-bot. Ges. Wien, xlr. (1895) $342=$ venetianum, $N$ acg. \& Peter.

hastatulum, Elfstr. Hier. Alp. Mittl. Skand. (1893) 40; et in Act. Hort. Berg. ii. 4 (1894) 76. Scandinav.

hastatum, Ravaud, ex Arv. Hier, Alp.(IS88) $22=$ inclinatum, Aro

hastile, Aro. \& Gautier, in Bull. Soc.Bot. Fr. xli. 1894) 34\%. - Pyren.

Hecri, Bruegr. ex Killias, in Jahresb. Naturf. Ges. Graub. xxxi. Beii. (1887-88) $112=$ humile facq.

hclobium, A. Rehm. in Verh. zool.-bot. Ges. Wien, xlv. (1895) $329=$ flagellare, Willd.

helveolum, Dahlst, in Act. Hort. Berg. ii. 4 (1894) 13 = floribundum, Wimm. E Grab

helceticum, Arv. ex Nym. Consp. Fl. Eur. Suppl.ii. 1 (1889) 192 = picroides, Vill.

helvopurpureum, Dahlst. [Hier. exsicc. Fasc, iv. (1891) n. 21] in Act. Hort. Berg. i. 7 (1891) 9. Scandinav.

\section{HIERAGIUM}

hemipsilum, M. Brenner, in Medd. Soc. Fanne et Fl. Fem, 1891-92 (1892) 106. - Europ.

hepaticolor, Stenstr. Värml. Archicrac. (1889) 28. Fennia.

hercegovinm. G. Beck, in Annal. Naturh. Hofmus. Wien ii. (1887) $172=$ umbelliferum, Naeg. 6 Petcr.

herccgoomicum, Freyn, in Bull. Herb. Boiss. iii. (1895) $644=$ marmoreum. Vis. \& Pancic

herjedalicum, Dahlst. in Act. Hort. Berg. ii. 4 (1894) 7 = cernum, Fries.

Hereicri, Arv, in Bull. Soc. Dauph. Ser. II. ii (1\$91) 57 = boreale, Frics.

heterodon, Am. Hicr. Alp. (188S) 45. - Gall

heterophyllum, Ari. l. c. 4S. - Gáll.

hibernicum, Hanbury, in Fourn. Bot. xxx. (1892) 258. - Hibern.

Jivticaula. Norrl. ex Nym. Consp. Fl. Eur. Suppl. ii. 1. (1889) 199 (= Pilosella hirticula, Norrl.) = pratense, Tausch

hispidulum, Arv. Hier. Alp. (1SSS) 43 = humile, facq.

hoglandicum, M. Brenner, in Medd. Soc. Fann, et Fl. Fenn. 1891-92 (1892) 88. - Europ

holophyllum, M. Brenter, l. c. 127. - Europ

holophyllum, Linton, in foum. Bot. xxviii. (1890) 376; ct in The Bot. Exch. Clut Brtt. Istes. Report for 1890 (18!) 304 . - Brit.

holoskcnse, A. Rehm, in Verh. zool.-bot, Ges. Wien, xlv. (1895):320 = H. Pilosella, Limn.

Hostianm, Wiesb. [in Ges, Doubl. Verz. Schles. Tausch. 188:3-84] ex G. Beck, Fl. Nied.-Oest. ii. (189:3) $1307=$ laevîgatum, Willd. ?

Howellii, A. Gray, in Conlt. Bot. Gaz, xiii. (18S8) 73.- - Oregon.

hugeliense, Dahlst. in Ait. Hort. Berg. i. 7 (189I) 27. - Scandinav.

Jungaricum $X$, Simonk. Enum. F1. Transs. (1886) 365. - Transsilv.

hyalinum, M. Brenner, in Medd. Soc. Fam, et Fl. Fenn. 1881-92 (1892) 100. - Europ.

hygrophilum, Dahlst. in Act. Hort. Berg. ii. 4 (1894) 81. - Norv.

hypareticum, Alnq. [ex Ang. Berlin, Karli Svenska exped. Grönland (1883)] ex Elfstr Hier. Alp. Mittl. Skand. (1893)50. - Groenl, Scandinar.

Jypoleucum, Arv. Hier. Alp. $(188 s)=$ H. Faurei, Are'.

hyponaerum, Dahlst. in Act. Hort. Berg. ii."4 (1893) 106. - Scandinav.

gneum, Freyn, in Oest. Bot. Zeitschr, xlii. (1892) $268(=H$. aureopurpurcum, Freyn).-Armen. turc imitans, M. Brenner, in Medd. Soc. Fann. et Fl Fenn. 1891-92 (1892) 102. - Europ.

intressiforme, Dahlst. in Bot. Notiser (1892) $161=$ murorum, Linn.

incanescens, Blocki, in Oest. Bot. Zeitschy, xxixviii (1888) 297, nomen.-Hung.

incertum $X, G$. Schneid, in Deutsche Bot. Monatsschr. vi. (18s8) 123.-- Europ

inclinatum, Arr. Hior. Alp. (1888) 21.-Gall incrassatum X. Blocki, in Oest. Zeitschr. xlii. (1892) 350. - Austro-Hung.

informe, Stenstr. Värml. Archicrac (1889) 23 Fennia.

inlingulatum, Elfstr. in Bihang Sienss. Vet. Akad Handl. xx. 111 (1894)7. - Scandinav.

insignitum, Dahlst, in Act. Hort. Berg. ii. 4 (1894) 70. - Norv

integratum, Dahlst. in K. Sicnsk. Vet. Akad. Handl. xxviii. (1893) 112. - Scandinav

integrifolium, Dahlst. ex Stenstr. Värml. Archierac (1889) 21. - Scandinav.

intormedium $\times$, G. Schneid, in Deutsche Bot. Monatsschr. vi. (18S8) 122. - Europ.

intermixtum, M. Brenner, in Medd. Soc, Fann. et Fl. Fenn. 1891-92 (1892) 103. - Europ.

intermixtum, Dahlst. [Hier. exsicc. Fasc. iv. (1891) n. 22] in Act. Hort. Berg. i. 7 (1891) 10. Scandinav.

intertextum, Ar\%.Hier. Alp. (1888) 53 - Gall. intricatum, Arv. ex Nym. Consp. Fl. Eur. ii. I (1889) $195=$ pallidum, Biv.

intumescons $X$. Naeg. \& Peter, Hierac. ii. (1886) 230. - Europ. 


\section{HIERAGIUM}

irriguum, Sienstr. Värml. Archierac.(1859) 50; Dahlst. in K. Siensh. Vet. Akad. Handl. xxxvi. 3 (1894) 139 (an H. irrigum, Griseb. ?) - Scandinav.

ischnophilum, A. Rehm, in Verh. zool.-bot. Ges. Wien, xlv. (1895) $339=$ brachiatum, Bert.

1slandicum, Dahlst. in Act. Hort. Berg. ii. 4 (1893) $15=$ floribundum, Wimm. \& Grab.

istriacum, Freyn, ex Nym. Consp. Fl. Eur. Suppl. ii. 1 (1889) 191 = barbatum, Tausch.

jablonicense, Woloszczak, in Spraw. Kom. fizyjogr. Krajozei, xxv. (1890) 1.66. - Hung.

jaceoides, Arv. Hir. Alp. (1888) 91. - Tirol.

javalambrense, Pau, Not. Bot. Fl. Espan. iii. (1889)

22; Willk. Suppl Prodr. Fl. Hisp. (1893) 123. Hisp.

jemtlandicum, Norrl. ex Nym. Consp. Fl. Eur. ii. 1 (1889) 119 (= Pilosella jemtlandica, Norrl.) = flammeum, Lindeb.

joconianum, Aro. in Bull. Soc. Bot. Fr. xli. (1894) 385. - Europ.

fordani, Arv. Hier. Alp. (18s8) $60=$ lanatum, Vill.

juratense, Gremli, ex Nym. Consp. F1. Eur. Suppl. ii. 1 (1889) $198=$ bupleuroides, Gmel.

Kindbergii $X$, Dahlst. in K. Svensk. Vet. Akad. Handl xxiii. 15 (1890) 56. - Scandinav.

Kloeber, A. Rehm, in Verh. zool.-bot. Ges. Wien, xlv. (1S95) $329=$ flagellare, Willd.

mantiaefolium, Arv. Hier. Alp. (18S8) $83=$ murorum, Linn.

Koracis, Boiss. F1. Or., Supp1. (18s8) $328=$ bracteolatum, Sibth. \& Sm.

Krasani, Woloszizak, in Spraw. Kom, fizyjogr. Krajoreci, xxv. (1S\%0) । . 65. - Hung.

kiynaviense, Woloszczak, l. c. xxii. (1888) II. 204. Hung.

lacerifolium, Almq. ex Stenstr. Värml. Archierac. (1888) 19; Dahlst. in K. Svensk. Vet. Akad. Handl. xxv. 3 (1S93) 72. - Scandinav.

lachnopsilon, Arí. iu Eull. Soc. Bot. Fr. xli. (1894) 351 - Pyren.

laciniaefolium, M. Brenner, in Medd. Soc. Fann. et Fl. Fenn. 1891-92 (1892) 109. - Europ

lacistophyllum, Dallst. in Act. Hort, Berg. ii. 4 (1893) 104. - Scandinav.

laete-virens, Sommier \& Levier, in Boll. Soc. Bot. Ital. (1893) 526; et in Act. Hort. Petrop. xiy. (1894) 196. - Reg. Cauc.

lagarophyllum, A. Rehm. in Verh. zool.-bot. Ges.

Wien, xlv. (1895) $320=$ brachiatum, Bert.

lagarophyton, A. Rehm. 1. c. 321 = auriculiforme, Fries.

lamprodes, Dahlst. in Act. Hort. Berg. ii. 4 (1893) 66. - Scandinav.

langwellense, F. Hanbury, in Fourn. Bot. xxvi. (18s8)

206. - Brit.
lanifolium, Naeg. \& Peter, in Bull. Herb. Boiss. iii. (1895) $663=\mathrm{H}$. Waldsteinii, Tausch.

lansicum, Arv. \& Raraud, iu Arv. Hier. Alp. (1888) 58. - Gail

lappachense. Murr, in Kneucker, Allgem. Bot. Zeitschr. i. (1895) 231. - Tirol.

laricentse, Gautier \& Timb. in Bull Soc. Dauph. xii. (18.5) 512, in syn. = sonchoides, Arr

latilobum, Almq. ex Daklst in K. Secnsl. Vet. Akad. Handl. xxv. 3. (1893) 166. - Scandinav.

lautumiarum, Dahlst. in Act. Hort. Berg, i. 7 (IS91) 6. - Scandinav

leiophanum, Dahlst. 1. c. ii. 4 (1893) $11=$ floribundum, Wimm. \& Grab.

leiosoma $X$, Naeg. \& Peter, Hierac. ii (1886)62. Europ.

Leithneri, Heldr. E Sart. cx Poter, in Engl. E Prantl, Naturl. Pfanzenfam, iv. 5 (1893) 384. Graecia.

lemanianum, Ari. ex Briq. in Bull. Soc. Bot. Genére, v. (1889) 214. - Sabaud.

- leontodontoides, Arv. \& Briq. in Bull. Herb. Boiss. ir. (1894)625. - Sabaud.

lepidiforme, Stenstr. Värml. Archierac. (1898) 47. Scandinav.

lepidotum, Stenstr. l. c. 45; Dahlst. in K. Siensk. Akad. Handl xxvi, 3 (18!4) 118. - Scandinav.

lepidulum, Stenstr. $l$. cc. 50; et 131. - Scandinav.

\section{HIERACIUM}

lepidum, Arv. Hier. Alp. (1888) $79=$ caesium,

eptoglossum. Dahlst. ex Elfstr. Hier. Alp. Mittl. Skand. (1893) 25; et in Act. Hort. Berg. ii. 4 (1893) 5:3. - Scandinay.

leucense K, F. O. Wolf, in Bull. trav. Soc. Murith. Fasc. 21-22 (1894) 132. - Helv.

leucocheilos, A. Rehm. in Verh. zool -bot. Ges. Wien, xlv. (1895) $344=$ sulphureum, Doell.

leucochlorum, Arv. Hier. Alp. (1888) $30=$ piliferum, Hoppe.

leucopelmatum $\times$, Naeg. \& Peter, Hierac, ii. (1886) 80. - Europ.

leucopsis, Arv. Hier. Alp. (18S8) $40=$ glanduliferum, Hoppe.

leucothecum, Uechtr. ex Freyn, in Oest. Bot. Zeitschr. xlii. (1892) 343. - As. Min.

Leyi, F. Hanbury, in fourn. Bot. xxxii. (1894) 226. - Brit.

ligulellum, Elfstr, in Bihang Svensk. Vet. Akad. Handl, xxiii. 1 (1894) 11 = alpinum, Linn.

lima, F. Hanbury, in fourn. Bot. xxx. (1892) 206. - Brit.

lincopiense $X$. Dahlst. in K. Svensk. Vet. Akad. Handl. xxiii. 15 (1890) 46. - Scandinay

Linderi X, F. O. Wolf, in Bull. Soc. Bot. Fr, xli. 1894) p. 155. - Vales.

lineatum. Almq. ex Stenstr. Värml. Archierac. (1889) 72; Dahlst. in K. Svensk. Vet. Akad. Handl. xxvi. 3 (1894) 241 = rigidum, Hartm.

lineatum, Arv. Hier. Alp. (1888) $80=$ caesium, Fries.

linguatum, Dahlst. in Act. Hort. Berg. ii. 4 (1893) $4=$ H. Pilosella. Linn

liopogon, Gren. ex St. Lager, in Cariot, Étud. des fl. éd. 8, ii. (1889) $51 \%$ (= = H. leiopogon, Gren.) = saxetanum, Fries.

lipnckianun, A Rehm. in Verh. zool.-bot. Ges, Wien, xlv. (1895) $325=$ prussicum, Naeg. \& Peter.

lithophilum, Arv. Hier. Alp. (1888) 68. - Gall.

litigiosum, Arv. 1. c $\mathbf{1 0 2}=$ valdepilosum, Vill.

lobulatum, M. Brenner, in Medd. Soc. Fann. it Fl. Fenn. 1891-92 (1892) 120. - Europ.

lomnicense $\times$. Woloszczak, [Spraw. köm. fizyjogr. Krajowei, xxv. I. (1891)] ex Oest. Bot. Zeitschr xli. (1S91) 111 et 140. - Europ.

longipes, Freyn \& Sint. in Oest. Bot. Zeitschr. xliv. 1894) 262; et in Bull. Herb. Boiss. iii. (1895) 504 et 668 . - As. Min.

lorophyllum, Arv. ex Nym. Consp. Fl. Eur. Suppl. ii. 1 (1889) $196=$ alpinum, Linn.

lugubre. G. O. Anflersson, in Bot. Notiser (1890 93 ; et in Bot. Centralbl. xlvi. (1891) $258=$ murorum, Limn.

lustratum, Ary. \& Guilhot, in Bull. Soc. Bot. Fr. li. (1894) 342. - Gall.

lycodontum, 1re. E Gautier, in Bril. Soc. Bot. Fr xli. (1894) 329. - Pyren.

macilentum, Arv. Hier, Alp.(1888) $90=$ epimedium Aro'.

macrantheloides, Dalilst. (Hier. exsicc. Fasc, iv 1891) n. 26) in Act. Hort. Berg. i. 7 (1891) 17. Scandinas.

macroglossum, A. Rehm. in Verh. zool.-bot. Ges Wien, xlv. (1895) $324=$ prussicum, N'acg. \& Pcter

macrolepideum, Norrl in Act. Soc, Faun. \& Fl. Fenn, iii. (18S8) $18=\mathrm{H}$. Peleterianum, Mcrat. macrostolonum $X, G$. Schneid. ex Formanek, Kvêtena, ii. (1892) 373. - Moravia

macrotonum. Dahlst. [Hier. exs, Fasc. ii. (18s9) n. 98 et 991 in K. Svensk. Vet. Akad. Handl. xxvi. 3 (1894) 83 et 86. - Scandinav.

maculosum Dahlst, ex Stenstr. Värml. Archierac. 1890) 12. - Scandinav

Magmussonii $\times$, Dahlst. in Act. Hort. Berg. i. '7 1891) 4 - - Scandinav.

mallotum, Stenstr. in Bot. Notiser (1895) 215. -

Malmei, Dahlst. 1. c. (1S92) $158=$ vulgatum, Fries

Mandoni, Britton, in Bull. Torrey Bot. Club, xix (1892) 266. (= Pilosella Mandoni, Sch. Bip.). Bolivia.

\section{HIERACIUM}

mapirense Britton, in Bull. Torrey Bot. Club, xix. (1892) 371. - Bolivia

marginellum, Dahlst. ex Stenstr. Värml. Archierac (1890) 28; et ex Anderss. in Bo:. Notiser (1890) 91. - Scandinav.

Marshalli, Linton, in foum. Bot. xxix. (1891) 271. - Brit

Martrini, Arv, in Lucante, Rev. de Bot. xii. (1894) 25. - Gall.

Massoniae, Favrat, in Bull. Soc Vaud. sci. nat. xxviii. (1892) 38; et in Ber. Schweiz. Bot. Ges. iii. (1893) $124=$ boreale, Fries.

medifforme, G. O. Andersson, in Bot. Notiser (1890) 91 ; et in Bot. Centralbl. xlvi. (1891) 257 - vuluatum. Fries.

medionigrescens, Almq. ex Elfstr. in Bihang Svensk. Vet. Akad. Handl. xvi. iii. 7 (1890) 53 = atratum, Fries

megalocephalon, Nash, in Bull. Torrey Bot. Chb, xxii. (1895) 152. - Florida.

melainon, Elfsir. in Bihang Siensk Vet Akad. Handl. xvi. iii. 7 (1890) 50. - Scandinav.

melandryfolium, Arv. Hier. Alp. (1888) 57. Gall.

melanocalathium, A. Rehm, in Verh, zool.-bot. Ges. Wien, xlv. (I 895$) 321=H$. Auricula, Lam. mclanolepis, Norrl, in Act. Soc, Faun. \& Fl. Fenn. iii. (1889) 90. - Fennia.

melanomallum, Dahlst. in Act. Hort. Berg. ii. 4 (1894) 57. - Scandinav.

melanophilum, A. Rehm. in Verh. zool.-bot. Ges. Wien, xlv. (1895) $343=$ leptophyton, Naeg. $\mathscr{0}$ Peter.

melanops, Arv, in Bull. Soc. Dauph. xiii. (1886) 558 ; et Hier. Alp. (1888) 75. - Delph.

menthaefolium, Arv. Hier. Alp. (1888) 55. - Gall. meridionale, Dahlst. [Herb. Hier. Scand., Cent. iv,

(1893) n. 25] in K. Svensk. Vet. Akad. Handl. xxyi. (1894, 252; et in Act. Hort. Berg. ii. 4 (1893) 34. - Scandinav.

mesodicoides, Dahlst. l. c. ii. 4 (1894) 34. - Scan dinav.

mesodicum, Dahlst. (Hier. exsicc. Fasc, iv. (1891) n. 16) ; et 1. c. i. 7 (1S91) 14. - Scand.

mespilifolim. Arv. Hier. Alp. (1888) 93 = prenanthoides, Vill.

Michaeli X, G. Beck, F1. Nied.-Oest. ii. II. (1893) 1280. - Austria.

Mickiewiczii, A. Rehm, in Verh. zool.-bot. Ges.

Wien, xlv, (1895) $323=$ stolonifforum, $W$. \& $K$. mikrosabinum, G. Beck, in Annal. Naturh. Hofmus. Wien, ii. (188\%) $1 \% 0=$ cymosum, Linn.

nisancinum X. Naeg. \& Peter; Hierac. ii. (1886) 238. - Europ

modestum, Ravaud, Guid. bot. Dauph. 12e excurs, (1891) $49=$ prenanthoides, Vill.

Tokragorae, Naes. \& Peter, in Bull Herb. Boiss, iii. (1895) 456. - Serbia

molybdium, Stenstr. Vännl. Archierac. (1890) 15. - Scandinav.

molybdochroum, Dahlst. iu Act. Hort. Berg. ii. 4 (1893) 86. - Scandinav.

montanum, G. Schneid. in Oest. Bot. Zeitschr. xxxvi. (1886) $22=$ alpinum, Linn

montenegrinum $>$ Freyn, in Bull. Herb. Boiss. iil. (1895) 648 et 665 . - Oriens.

multifrons, M. Brenner, in Medd. Soc. Fann. \& Fit Fenn. 1891-92 (1892) 121. - Europ.

mucescens, Dahlst. in Act. Hort, Berg. i. 7 (189] 30. - Scandinav.

muranense, A. Renm. in Verh. zool.-bot. Ges. Wien, xlv. (1895) $335=$ brachiatum, Bert

Murrianum, Ary. ex Murr, in Oest. Bot. Zeitschr. xliii. (1893) 222; Briq. in Bull. Herb. Boiss, ii. 1894) 629. - Tirol. Sabaud.

Muteli, Arv, Hier. Alp. (18S8) 25. - Gall.

mutilatum, Almq. ex Elfstr. in Bihang Siensk. Vot. Akad. Handl. xvi. iii. 7 (1S90, 74. - Scandinav. maszodense X, Simonk. Enum. F1. Transs. (1886) 366. - Transsilv.

mocollinum, A. Rehm in Verh. zool.-Dot. Ges. IVien. xlv. (1895) $331=$ spathiphyllum, Niteg. of Peler.

Nataiae, Borb. in Tormész. Fiñotck, xIv. (1893) 50 - Eirrop. 


\section{HIERACIUM :}

nematoclados. A. Rehm, in Verh, zool -bot. Ges. Wien, xlv. (1895) 342 = leptophyton, Naeg. E Peler.

neodoronicum, Ara. E Gautier, in Bull. Soc. Bot. Fr. xli. (1894) 337. - Pyren.

neoprenanthes, Aro. in Bull. Soc. Dauph, xiii. (IS86) 560 ; et Hicr. A7p. (1888) 94. - Gall.

neviophyllum, Arr, Hier. Alp. (1888) 100. - Gall.

Neyraeanum, Ars. l. c. 20. - Gall.

miankoricnse, A. Rehm. in Verh. zool.-bet. Ges. Wien, xlv. (1895) $328=$ flagellare, Willd.

nigrelln, Arv. Hier. Alp. (1885) $38=$ armerioides, Ari'

migribractem, A. Rehm, in Verh zool.-bot. Ges. Wien, xlv. (1895) $336=$ brachiatum, Bertol.

nigricanticeps, Stenstr. Värml. Archicrac. (1890) 27. - Scandinav.

nigriteilum, Arv. Hier, Alp. (1888) $37=$ ustulatum,

nigrocollinum, $S$. Wats. in Proc. Am. Akad, xxv. (1890) 133, - Dakota.

nivipinm, A. Rehm. in Verh. zool.-bot. Ges. Wien, xlv. (1895) $335=$ fallax, Naeg. E Peter.

nordlandicum, Dahlst. in Act. Hort. Berg. ii. 4 (1893) 98. - Scandinav

midieps, Pernhoffer, in Oest. Bot. Zeitschr. xliv. (1894) 477 = vulgatum, Fries

mdum. Nym. Consp. Fl. Eur., Suppl. II. i. (18S9) $197=$ scorzoneraefolium, Vill.

mdum, Kern. ex Peter, in Engl. \& Prantl. Natür1. Pflanzenfam. iv. 5 (1893) $381=$ glabratum", Hoppe.

Nylanderianum. M. Bremer, in Medd. Soc. Fann. et Fl. Fenn. 1891-92 (1892) 117. - Europ.

obscurans, Elfstr. Bot. Utflygter (1890) 37 ; et Hier. Alp. Mittl. Skand. (1S93) 35. - Scandinav.

obtusulum, Stenstr. Värml. Archierac. (1890) 57. Scandinav.

odontophyllum, Freyn \& Sint. ex Freyn, in Oest. Bot. Zeitschr. xlii. (1892) 270; et in Bull. Herb. Boiss. iii. (1895) 506. - Oriens.

odontotrichum, Freyn, in Velen. Fl. Bulg. (1891) 342 ; et in Oest. Bot. Zeitschr. xlii. (1892) 342. - Buls.

oligodon $X$, Naeg. \& Peter, Hierac. ii. (1S86) 51. - Europ.

oligolepium, Stcnstr. Värml. Archierac. (1889) 34. - Scandinav.

onegense, Norrl. ex Nym, Consp, Fl. Eur, ii. I. (1899) 199 (= Pilosella onegense, Norr1.).-Europ. opeatodontum, Stenstr. Värml. Archierac. (I889) 20. - Scandinav.

orbicans, Almq. ex Stenstr. 1. C. 23; Dahlst. in K. Seensk. Vet. Akad. Handl. xxv, 3 (1893) 162.Scand.

orbolense Stenstr.1. c. 62. - Scandinav.

orcadense, $W . R$. Linton, in fourn. Bot. xxxi. (1893) 196. - Ins. Orcad.

orthopodum, Dahlst. in Act. Hort. Berg. ii. 4 (1893) $117=$ atratum, Fries

oraliceps, Norrl. in Act. Soc, et FI. Fenn. iii. 4 (1888) $82=$ alpinum, Linn

ovatum, Aro. in Bull. Soc. Bot. Fr. xli. (1S94) 341. - Gall. mer.

pachyphyllum, M. Bromer, in Medd. Soc. Fann. E Fl. Fenn. 1891-92 (1892) 115. - Europ.

panaeolum, Dahlst. in K. Siensh. Vet. Ahad. Handl. xxv. $3(1893)$ 123. - Scandinav.

pannosiforme, Frenn \&o Sint. ex Fregn, in Bull. Herb. Boiss. iii. (1895) 504 et 66\%. - Armen.

pannulatum, Dahlst. in Act. Hort. Berg. ii. 4 (1893) 109. - Scandinav.

pantepsilon, A. Rehm. in Verh. zool,-bot. Ges. Wien, xlv. (1895) $339=$ brachiatum, Bert.

Paolovicii, Naeg. \& Peter, in Bull. Herb. Boiss. iii. (1895) 663.-

paphlagonicum, Freyn \& Sint. ex Freyn, in Oest. Bot. Zeitschr. xliv. (1894) 260 ; et in Bull. Herb. Boiss. jii. (1895) 506. - Oriens.

paraguayense, Arc. ex Pcter, in Engl. E Prantl, Nalürl. Pfanzenfam. iv. 5 (189:3) 386. - Parac. parcepilosum, Ari. in Bull. Soc. Danph. xiii. (1586) 560: et Hierac. Alp. (LSSS) $103(=\mathrm{H}$. brejninum, A. Kern.). - Gall.

parcidentatum, M. Bremur, in Medd. Soc. Fann. E Fl. Fcnn. 1891-92 (1892) 110. - Europ.

\section{HIERACIUM}

pardalinum, Dahlst. [Herb. Hier. Scand., Cent, iii. (1892?) n. 100] in K. Sientsk. Vet. Akad. Handl. xxvi. 3 (1894) 255. - Scandinav.

parvuliceps, M. Brenner, in Medd. Soc. Faun. et Fl. Fenn 1891-92 (1892) 9\%. - Europ.

patentissimum, Frcyn \& Sint. ex Frejn. in Bull. Herb. Boiss iii. (1895) 651 et 656. - Armen.

peculiare, Dahlst. in Act. Hort. Berg. ii. 4 (1893) 125. - Scandinav.

pedosum, Elfstr. Hier. Alp. Mittl. Skand. (1893) 32 ; et in Bihang Svensk. Vet. Akad. Handl. $\mathrm{xx}$, III $\mathrm{n} .1$ (1894) 24 , in obs, = alpinum, Linn. Pellatianum, Arv. Hier. Alp. (18:8) $28=$ elongatum, IVilld.

pellucidun, Almq. ex Elfstr, in Bihang Svensk. Vet. Akad. Handl. xvi. iii. 7 (1S90) 55 = vulgatum, Fries.

penicillatum, M. Erenner, in Medd. Soc. Faun. ct Fl. Fenn. 1891-92 (1892) 98. - Europ.

pennimum X, Naeg. \& Peter, Hierac. ii. (1886) 165. - Europ.

perciliatum, Elfstr. in Bihang Sicnsh. Vet. Akad. Handl. xx. III. 1 (1894) $16=$ alpinum, Linn. Dereffusun, Elfstr. 1. c. $24=$ alpinum, Linn.

periplecum, Ara. \& Gautier, in Bull. Soc. Bot. Fr. xli. (1894) 355. - Pyren.

personatiforme, Dahlst. in Act. Hort. Berg. ii. 4 1894) 106. - Scandinav

petiolatum, M. Brenner, in Medd. Soc. Fann. et Fl. Fenn. 1891-92 (1892) 100. - Europ.

petiolatum, Elfstr. Botaniska Utfligter (1890) 36 et Hier. Alp. Mittl. Skand. (1893) 18. - Scandinav.

petroplizim, Arv. Hier. Alp. (1888) $50=$ amplexicaule, Linn.

philanthrax, Stenstr. Värml. Archierac. (1899) 25. - Scandinav.

phomidifolim, Arv. Hier. Alp. (1888) 56 = thapsoides. Aru.

pholidotum, Stenstr. Värml. Archievac, (1889) 46. Scandinav.

pictisquamum, A. Rehm, in Verh. zool.-bot. Ges. Wien, xlv. (1895) $322=$ auriculiforme, Fries

picinum, Dahlst. Herb, Hier. Scand. Cent. iii. 1893) n. 39] in Act. Hort. Berg. ii. 4 (1893) 112. - Scandinav.

Pictorum, W. R. Linton, in foum. Bot. xxix. (1891) 271. - Brit.

piliperdum. A. Rehm. in Verh. zool.-bot. Ges. Wien, xlv. (1895) $321=$ H. Pilosella, Linn.

pinetorum, A. Rehm. 1. c. $341=$ brachiatum, Bert.

pimatifidun, Lönnr. ex Dahlst. in Bot. Notiser 1892) $163=$ murorum, Linn.

plaicense X, Woloszczak, in Spraw. Kom. fizyjogr. Krajow. xxii. (1888) II. 201. - Hung.

plantagineum, Ars. in Bull. Soc. Dauph. xiii. (1886) 560 ; ct Hier. Alp. (18S8) 31 - Gall.

platyphyllum, Arv. Hier. Alp. (1888) $124=$ boreale, Fries.

plecophyllum, Ari, et Gautier, in Bull. Soc. Iot. Fr. xli. (1894) 354. - Pyren.

pleiocaulon, Dahlst. in Act. Hort. Berg. ii. 4 (IS93) 42. - Scandinav.

pleiophyllum, (Auct,?) ex G. Beck, in Annal. Naturh. Hofmus. Wien, ii. (1887) 174, nomen. Bosnia.

plicato-acuminatum, A. Rehm, in Verh, zool.-bot. Ges. Wien, xlv. (1895) $339=$ brachiatum, Bert. plumiterum, $\lambda^{\top}$ aeg. E Peter. Hicrac. ii. (1589) 322. - Europ.

poecilochroum, Dahlst. |Herb. Hier. Sand. Cent, v. (1893) n. 13] l. c. 128; et in Act. Hort. Berg. ii. 4 (1893) 128. - Scandinav.

poecilophyllum, Dahlst. et A. Magnuss, ex Dahlst. l. c. 134. - Scandinav.

poecilostictum, Dahlst. Hier. exsicc. Fasc. iv. (1891) n. 50. - Scandinay

pogonatum, Aro. in Bull. Soc. Bot. Fr, xli. (1894) 344. - Pyren.

pogonites, Naeg. Eo Peter, Hierac. ii. (1889) 306. Europ.

poliodermum, Dahlst. in K. Sicnsk. Vet. Akad, Handl. xxiii. 15 (1890) 119. - Scandinav.

pollinarium, F. Hanbury, in foum. Bot,xxyi. (1888) 206. - Brit.

\section{HIERACIUM}

polonicum, Blocki, in Oest. Bot. Zeitschr. xxxvii. (1887) 303. - Europ.

polymorphum, G. Schneid, in Oest. Bot, Zeitschr. xxxvii (1887) 240 ; et in Deutsclie Bot. Monatsschr. vi. (1888) 16: - Europ.

polysarcon, A. Rehm. in Verh. zool.-bot. Ges. Wien, xlv. (1895) $332=$ spathophyllum, Naeg. 6 Peter.

porrigens, Almq. ex Elfsty. in Bihang Siensk. Vet. Akad. Handl. xvi. III. 7 (1890) 61 ; et xxvi. 3 (1894) 48. - Scandinav.

porimense, Fycyn \&o Vandas, in Bull. Herb. Boiss. iii. (1895) 668, - Hercegov.

Portae, Willk. Suppl. Prodr. Fl. Hisp. (1893) 118. Hisp.

potamophilon, Elfstr. Hier. Alp. Mittl. Skand. (1893) 29. - Scandinav.

praematurum. Elfstr. l. c. 24 ; et in Act. Hort. Berg. ii. 4 (1893) 142. - Scandinav.

praesteneriforme, Almg. ex Dahlst. [Hier. exsicc. fasc. it. (1809) n. S6ך; et in Act. Hort. Berg. i. ? (1891) 40. - Scandinav

praetenellum, Elfstr. in Bihang Siensk. Vet. Akad. Handl. xvi. iii. 7 (18\%0) 77. - Scandinav.

praetenerum, Almg, ex Dahlst. in K. Siensk. Vet. Akad. Handl. xxy. 3 (1893) 153. - Scandinav.

praetubulosm, Dahlst. [Hier. exsicc. Fasc. iv. (1891) n. 25] in Act. Hort. Berg. i. 7 (1891) $19=$ fuscum, Vill.

praeustum, Arv. Hier. Alp. (1888) $75=$ melanops, Argt.

praeustum, Dahlst. in Bot. Notiser (1886) 140 ; et in Bot. Centralbl. xxvi. (1886) $174=$ dovrense Fries.

prasinatum, Norrl, ex Nym. Consp. F1. Afr. Eur. ii. I. $(1889) 200=\mathrm{H}$. Pilosella, Linn.

prasiophaeum. Arv. \& Gautser, in Bull. Soc. Bot. Fr. xli. (1894) 349. - Pyren.

prasoides, Dahlst. [Herb. Hier. Scand. Cent. iv. (1893) n. 3] in Act. Hort. Berg. ii. 4 (1893) 88 in syn。= intumescens, Norrl.

prenanthoideum, St. Lager, in Cariot, Etud. des fl. éd. 8 , ii. (1889) $520=$ prenanthoides, Vill.

pronanthomorphun $X$, Naeg. \& Peter, Hierac. ii. (1886) 163. - Europ.

primulaeforme $\times$ Arv. Hier. Alp. (1S88) 5. - Gall. prionatum, Arv. 1. c. $35=$ dentatum, Hoppe.

prclixoides, M. Brenner, in Medd. Soc. Fann. ct Fl. Fenn. 1891-22 (1892) 102. - Europ.

prolixum, Norrl. in Act. Soc. Faun. et Fl. Fenn. iii. 4 (1888) $94=$ murorum, Linn.

proximum, F. Hanbury, in fourn. Bott. xxvii. (1889) 76. - Brit.

pseudeximium, Dahlst, in Act. Hort, Bero, ii. 4 (1893) 75. - Norv.

pseudoatratum, Woloszczak, in Spraw. Kom, fizyjoge, Krajow. xxii. (1888) ii. 201. - Hung.

pseudobifidum, Blocki, in Oest. Bot. Zeitschr. xxxviii. (IS88) 48 et 49. - Ross. mer.

pseudoboreale, Arv. Hierac. Alp. (188s) $124=$ boreale, Fries.

psendobupleuroides $X$, Naeg. \& Peter, Hierac. ii. (1886) 74. - Europ.

pseudodecipiens, G. Schncid. in Deutsche Bol. Monatsschr. vi. (1888) 122. - Europ.

pseudodepilatum. Almo ex Elfstr. Hier. Alp. IIitt Skand. (1893) 54. - Scandinav.

pseudoeriophorum, Loret \& Timb. ex Peter, in Engl. E Prantl, Natürl. Pfanzenfam.iv. 5 (1893) 384. Gall.

psendofammenn, Dahlst. in Act. Hort. Berg. ii. 4 (1S93) $27=$ fuscum. Vill.

pseudoglomeratum, Woloszczak, in Spraw. Kom. fizyjogr. Krajow. xxii. (1888) II. 203. - Hung:

pseudogracile, A. Rehm. in Verh. zool.-bot. Ges. Wien, xlv. (1895) $334=$ bifurcum, Bieb.

psendo-hybridum, Ari, in Lucantc, Rer. de Bot, xiii. (1895) 70 (356). - Gall.

pseudojuranum, Ari. Hier. Alp. (1888) 92. Gall

pseudolanatum, Are. l. c. 60.-Gall.

pseudonigyescens, Almq. et Dahlst. [in Dahlst. Hier. exs. Fasc. 1ii. (1889) n. 22] ex Eltstr. in Bihang Svensk. Vet. Akad. Hand1. xvi. III. 7 (1890) 5.3 = atratum, Fries. 


\section{HIERAGIUM}

pseudonosmoides, Dahlst. [Hier. exsicc. Fasc. iii. (1889) n. 26 et 27 in Act. Hort. Berg. i. 7 (1891) 25. - Scandinav.

pseudopersonatum, G. Schneid. in Oest. Bot. Zeitschr. xxxvi. (1886) 23. - Moravia.

pseudopicris, Arv. Hier. Alp. (1888) $110=$ cydoniaefolium, $V$ ill.

pseudoporrectum, Naeg. \& Pefer, ex Murr, in Deutsche Bot. Monatsschr. vii. (1890), - Tirol.

pseudopratense, Uechtr. ex Freyn, in Oest. Bot, Zeitschr. xl. (1890) 237. - Europ.

pseudo-prenanthoides. Wilczek, ex Cottet \& Castella, in Bull. Soc. Frib, sci. nat. 188\%-90 (1891) 230, in syn. = strictum, Fries.

pseudo-pulmonarioides, Pacher, ex Nym. Consp. Fl. Eur. Suppl. ii. 1 (1889) 197 = amplexicaule, Linn.?

pseudo-Wimmeri X, G. Schneid. in Deutsche Bot. Monatsschr. vi. (1888) 122. - Europ.

psilophyllum X. G. Andersson, in K. Svensk. Vet. Akad. Handl. xxiii. 15 (1890) 47. - Scandinav.

pteropogon, Ara. Hier. Alp. (1888) 59, - Gall.

ptychopliyllum, Dahlst. in Bot. Notiser (1892) $156=$ vulgatum, Fries.

pubescens, Dahlst. in Act. Hort. Berg. ii. 4 (1893) 42. - Scandinav.

pulchrum, Arvo in Bull. Soc. Danth. xiv. (188\%) 583 ; et Hier. Alp. (1888) 30. - Gall.

pullatum, Dahlst. [Hier, exsicc. Fasc. i. n. 997 in K. Svensk. Vet. Akad. Handl. xxvi. 3 (1894) 239, in syn. = rigidum, Hartm

pullulum, M. Brenner, in Medd. Soc. Foun et Fl. Fenn. 1891-92 (1892) 92. - Europ.

pulvinatum. Norrl ex Nym. Consp. F1. Eur. ii. I. (1889) 199 (= Pilosella pulvinata, Norrl.) = flammeum, Waldst. \& Kit.

purpurifolium, Elfstr. Botanisha Utflygter (1890) 35. - Scandinav.

pycnophyllum, Peter, in Engl. \& Prantl, Natürl. Pfanzenfam. iv. 5 (1893) 385. - Europ. centr.

querciticum, Freyn, ex Ber. Deutsch. Bot. Ges. iv. $(1886) 194$, in syn. = graniticum, Sch. Bip. Rackii, "Vukot. " ex Oest. Bot. Zeitschr. xxxix. (1889) $176=$ H. Racskii, Vukot.

radiosum, M. Brenner, in Medd. Soc. Famn.et Fl. Fenu. 1891-92 (1892) 95. - Europ.

Ravaudii X. Arv. Hier. Alp. (1858) 58. - Gall. ravidum, M. Brenner, in Medd. Soc. Faun. et Fl. Fenn. 1891-92 (1892) 113. - Europ.

Reboudianum, Aro. Hier. Alp. (1888) 63. - Gall reductum, Freyn \&o Sint. in Bull, Herb. Boiss. iij. (1895) 667. - Armen.

Rehmanni, Woloszczal, ex Oest. Bot, Zeitschr. xli. (1891) $111=$ juranum, Fries?

remanens, Malme, in Bot. Notiser (1891) $178=$ vulgatum, Fries.

repandifrons, M. Brenner, in Medd. Soc. Faun. et Fl. Fenn. 1891-92 (1892) 123. - Europ.

resupinatum, Almq. ex Stenstr. Värml. Archierac. (1-89) 58; Dahlst. in K. Svensk. Vet. Akad. Handl, xxvi. 3 (1894) $58=$ porrigens, Almq.

reticulatum, Naeg. \& Peter, in Ball. Herb. Boiss, iii

(1895) $663 .-$

rhombifolium, Arv. Hier. Alp. (1888) $47=$ urticaceum, Arv.

rigidifolium, Elfstr. in Bihang Svensk. Vet. Akad. Handl. Xx. III 1 1894) $15=$ alpinum, Linn.

Rostafinskii X, Blocki, in Oest. Bot. Zeitschr, xlii. (1892) 350. - Europ.

Rostani X, Naeg. \& Peter, Hierac, ii. (1886) 229. - Europ.

Ronyanum X, F. O. Wolf, in Isull. Soc. Bot. Fr. sli. (1894) p. 176. - Valesia.

rubens, Dahlst. in Act. Hort. Berg. ii. 4 (1893)Norv.

rubicundum, F. F. H. Moffat, ex F. Hanbury in Rep. Bot. Exch. Club Brit: Isles for 1885 (1886) 376; F, Hanbury, in fourn. Bot.xxx. (1892) 208. - Brit. rubiginosum, F. Hanbury, 1. c. xxxii. (1594) $229=$ vulgatum, Fries.

rubristylum. A. Rehm. in Verh. zool.-bot. Ges, Wien, xlv. (1895) $345=$ calomastix, Naeg. \& Peter. rupicoloides, Woloszczak, in Spraw. Kom. fizyjogr. Krajow. xxii. (1888! II. 204. - Hung.

\section{HIERAGIUM :}

rupigenum, Arv. Hier. Alp. (18s8) 46. - Gall.

Rusbyi, Greene, ex Conlt. in Contrib. U. S. Nat. Herb. ii. (1894) 248. - N. Mex., Texas

sagittatum, Lindb. ex Stenstr. Värml. Archierac. (1889) 24 ; Dahlst. in K. Srensk, Vet. Akad. Handl. xxv. 3 (1893) 179. - Scandinay.

Sagorskii X, G. Schneid. in Deutsche Bot. Monatsschr. vi. (18s8) 122. - Europ.

salicifolium, Reverch, in Arv. Hier. Alp. (1888) 126 = umbellatum, Linn.

salvifolium, Arv. E Gautier, in Bull. Soc. Bot. Fr. xli. (1894) 352. - Pyren.

sanctum $X$, Naeg. \& Peter, Hierac. ii. (1886) 69. Europ.

Sandbergii, Elfstr. in Bihang Svensk. Vet. Akad. Handl. xx. "11. 1 (1894) 21, in obs. = nigrum,

Sapiehae, Blocki, in Oest. Bot.Zeitschr. xxxvii. (1888) 297, nomen. - Hung

sarcophyllum, Stenstr. Värml. Archierac. (188.?) 15 Daklst. in K. Siensk. Vet. Akad. Handl. xxv. (1893) 171. - Scandinav.

saussureoides, Arv. Hier. Alp. (1888) $3=\mathrm{H}$. Peleterianum, Mérat.

saxigenum, M. Brenner, in Medd. Soc. Fann. et Fl. Fenn. 1891-92 (1892) 89. - Europ.

scandinavicum, Dahlst. in Act. Hort. Berg. i. 7 1891) 11 ; et ii. 4 (1893) 31. - Scandinav.

scanicum, Dahlst. [Hier. exsicc. Fasc, ii. (1889) n. 73-75] in K. Svensk. Vet, Akad. Handl, xxvi, 3 (1894) 89. - Scandinav.

scapiforme, M. Brenner, in Medd. Soc. Faun. et Fl. Fenn. 1891-92 (1892) 117. - Europ.

scaposum, Arv. in Bull, Soc, Bot. Fr. xli. (1894) 330. - Pyren.

scariolaceum, Arv. I. c. 367. - Alp.

scavioluefolizm, Arv. Hier. Alp. (18\$S) $108=$ viscosum, Arv.

scepusiense. Simonk. in Term. tud. Közl. (1890) 490 $=\mathrm{H}$. Ullepicii, Uechtr.

schoenbrnnnense $\mathrm{X}$, G. Beck, F1. Nied.-Oest. ii. II. (1893) 1298. - Austria

sciadophornm X, G. Schneid. in Deutsche Bot. Monatssch. vi. (1888) $2 \%$. Europ.

Scribneri. Small, in Bull. Torrey Bot. Chub, xxi. (1894) 20. - Tennessee.

scitulum, Woloszciak, in Spraw, fizyjogr. Kom. Krajowei xxi. (1888) 128. - Hung. sclerotrichum, Arv. Hier. Alp. (1888) 15 = fallax, Willd.

scorpioidenm, Arv. 1.c. $71=$ brumale, Arit.

scoticum, F. Hanbury, in fourn. Bot. xxvi. (1888) 206. - Scotia.

seckauense $X$, Pernh. in Oest. Bot. Zeitschr, xliv. (1894) 364 . - Stiria.

seidense, Elfstr. in Bihang Svensk. Vet. Akad. Handl. xx. 3 (1895) 21. - Scandinav.

segureum, Are. Hier. Alp. (1888) 90. - Gall.

semiauricula $\times, G$. Schneid, in Deutsche Bot. Monatsschr. v. (1887) 20. - Germ.

semidovrense, Elfstr, in Bihang Svensk. Vet. Akad. Handl. xvi. 111. 7 (1890) 64; et Hier. Alp. Mittl. Skand. (1893) 5, 6 et 57. - Scandinav.

semiglobosum, Stenstr. Värnt. Archierac. (1889) r1. - Scandinav.

semilanatum, Arr. Hier. Alp. (1888) $61=$ psendolanatum, Arv.

semiplanum, A. Rehm, in Verh. zool.-Bot. Ges. Wien, xly. (1895) $338=$ brachiatum. Bert. seneciflorum. Arv. Hier. Alp. (1888) 99 = doronicifolium, Arv.

septentrionale, Arv. 1. c. $86=$ columnare, Arv.

serratifrons, Almq. ex Dahlst. in K. Svensk. Vet. Akad. Handl. xxv. 3 (1893) 82. - Scandinav.

sertuliferum, M. Brenner.in Medd. Soc, Fann。 et Fl. Fenn. 1891-92 (1892) 126. - Europ.

serratum X, Naeg. \& Peter, Hierac, ii. (1886) 200. - Europ.

seteheriforme, A. Rehm. in Verh, zool.-bot. Ges. Wien, xlv. (1895) 344 = leptophyton, Nalg. \& Peter.

seusanum, Arv. Hier. Alp. (18\$8) 65. - Gall.

Scheppigianum $X$, Freyn, in Bull. Herb. Boiss. iii. (1995) 651 et 665 . - Oriens.

\section{HIERAGIUM :}

scissiforme, Dahlst. in Act. Hort. Berg. ii. 4 (1893) $1 \tau$ = floribundum, Wimm. \& Grab.

seidense, Elfstr. in Bihang Svensk. Vet. Akad. Handl. xx. 14. l (1894) 21 = alpinum, Linn.

septentrionis, Elfstr. I. c. 31, ad calc, = praematurum, Elfstr.

siliginellum, Dahlst. ex Porat, in Bot. Notiser (1894) $40=$ vulgatum, Fries.

silsinm X, Naeg. \& Peter, Hierac, ii. (1886) $22 \%$. - Europ.

Sintenisii, Freyn, in Oest. Bot. Zeitsckr. xlii。(1892) 269. - Armen, turc

sinuasifrons, Almq. [Dahlst. Hier.exs. Fasc. 1 (1888) n. 10-13] ex Dahlst. in K. Svensh. Vet. Akad. Handl. xxy. 3 (1893) 53. - Scandinav.

sipikorense, Freyn \& Sint. in Oest. Bot. Zeitschr, xlii. (1892) $270=\mathrm{H}$. Sintenisii, Freyn \&. Sint.

Solilapidis, Evers, l. c. xliii. (1893) 86 et 426 . Tirol.

sinuans, F. Hanbury, in Fourn. Bot.xxx. (1882) 167. - Scotia

Smithii $\times$, Arv. Hier. Alp. (1888) 8. - Gall.

sonchoides, Arv. Suppl.Monog. Pilos. \& Hier. (1886) 8. - Gall.

sparsidens, Dahlst. in K. Svensk, Vet. Akad. Handl. xxv. 3. (1893) 138. - Scandinav.

sparsiramum X, Naeg. \& Peter, Hierac. ii. (1886) 70. - Europ.

spectandum, Timb, in Jeanbern. \& Timb. Le Capsir (1887) 153 (Bull. Soc. sci. phys. \& nat. Toul. vii. 1886). - Pyren.

spelaeum, Arv. ex Briq. in Bull. Soc, bot. Genère, vii. (1894) 11r. [an seq. ?]. - Gallia.

speluncarium. Arv. Hier. Alp. (1888) $50=$ amplexicaule. I-inn.

spicatifolium, Arv. 1. c. 97 = lancelatum, Vill.

splendens, Elfetr. in Bihang Svensk. Vet. Akad. Handl. xvi. H. 7 (1890) 70. - Scandinav

splendidum, Dahlst. in Act. Hort. Berg. ii, 4 (1893) 116. - Scandinav.

spurium $X$, Bruegrg. in Jahresb. Naturf. Ges. Graub. xxix. (1886) 133; et xxxi. Beil.(1887-88) 218. - Hely.

squalidun X, Arv. Hier. Alp. (1888) 45. - Gall.

squamatum, Arv, in Bull. Soc. Bot. Fr. xli. (1894) 329. - Gall.

stachyoideum, Arv, ex Peter, in Engl. \&o Prantl, Natuirl, PAdnzenfam, iv, 5 (1893) 387. - Bolivia.

stellulatum, Simonk. Enum. Fl. Transsilv. (1886) $369=$ H. Bauhini, Schult

stenoclinium, Ari' \& Gcutier, in Bull. Soc. Bot. Fr. xli. (1894) 335. - Pyren.

stenodon, Elfstr, in Bikang Siensk. Vet, Akad. Hand?. xvi. 111. 7 (1890)52 - Scandinay.

stenophyes, $W . R$. Linton, in fourn. Bot. xxxi. (1893) 181. - Scotia.

stenoplecum, Arv. E Huter, in Bull. Soc. Bot. Fr. xli. (1894) 363. - Tyrol.

stipatum, Stenstr. Värml. Archierac. (1890) 48े. Scandinav.

stiriacum, Kern. ex Peter, in Engl. E Prantl, Natiir?. Pflanzenfam. iv. 5 (1893) 384. - Stiria.

storliense, Norrl. in Act. Soc. Faun. et EI. Fenn. iji. 4 (1888) $105=$ vulgatum, Fries.

stricticeps, Dahlst, in Stenstr. Värml. Archierac. (1889) 56; et in K. Svensk. Vet. Akad. Handl xxvi. 3 (1894) 73. — Scandinav.

strigulosum, Arr. Hier. Alp. (18S8) 103. Europ.

strigulosum, Post, in Bull. Herb. Boiss. i. (1893) 25. - Syria.

strigosum, Arv. Hier. Alp. (1888) 103 = cottianum. Arr.

siyriacum, Kern. ex Oest. Bot. Zeitschr. (1895) 233 $=$ racemosum, Waldst. \& $K$ it.

subalpestre, Norrl, in Act. Soc. Faun, et Fl, Fenn, iii. 4 (1888) 111 = vulgatum, Fries.

subalpinum, Arv. Hier. Alp. (1888) 88. - Europ. subanfractum, E. S. Marshall, in foum. Bot xxx. (I892) 183, - Brit,

subauriculaeforme, Lönnr. ex Daklst. in K. Seensk. Vet. Akad. Handl, xxiii. 15 (1890) 20. - Scandinav.

subauriculoides, Blocki, in Oest. Bot Zi:tsclir. xxxviii. (18ss) 190. - Europ. 


\section{HIERACIUM}

(1893) 1309 = racemosum, Waldst. \&o Kit

subcaesium, Formanek, Kvetena, ii. (1892) $473=$ mucrum, Linn.

subcanipes, Dahlst. in Act. Hort.Berg. i. 7 (1891) 29. - Scandinav.

subcaulescens, $\mathrm{N}_{\mathrm{aeg}}$. \& Peter, ex Oest. Bot. Zeitschr. (1889) 451. - Eur, centr.

subcordatum, Dahlst. in Act. Hort. Berg. ii. 4 (1893) 1]5. - Scandinav

suburcatum, Elfstr. in Bihang Svensk. Vet. Akad Hand1. $\mathrm{xx} .111 .1$ (1894) $23=$ alpinum, Linn

sulhdecolorans, Dahlst, in Act. Hort. Berg. ji. 4 (1893) 23. - Scandinav.

subellipticum, Elfstr. in Bihang Svensk. Vet. Akad. HandI. xx. 11. 1 (1894) $23=$ alpinum, Lim

sublongatum X, Naeg. \& Peter, Hierac. ii. (1886) 225. - Europ.

subforibundun' Dahlst in Act Hort Bere it 4 (1893) 35 = floribundum, Wimm. \& Grab

subfurculatum. Elfstr. in Bihang Svensk. Vet. Akad. Handl. xx. 11, n. 1 (1894) 31 , ad calc. = finmarkicum, Elfstr.

sublabratum X, G. Beck, F1. Nied.-Ocst, ii. I (1893) 1203 - Aistria.

subincisum, Arr. Hier. Alp. (1888) 77. - Europ.

subintegratum, Elfstr, in Bihang Svensk. Vet. Akad. Handl. xx, 14. 1 (1894) 31, ad calc. $=$ comosum. Elfstr.

subiryigunm, Dahlst, ex Porat, in Bot. Notiser (1894) $42=$ murorum, Linn.

sublactcum $\times$ Arv, \& Gautier, in Bull. Soc. Bot. Fr. x1. (1893) p. 236. - Gall. mer

sublacie, Arv. Hier. Alp. (1888) $72=$ buglossoides Aretion.

Mblacie, Freyn \& Bornm. ex Freyn. in Oest. Bot Zeitschr x'i. (1891) $364=$ scalurum, Lim

sublanatum, Arv. ex Nym. Consp. Fl. Eur., Suppl. ii. 1 (1889) $196=$ pellitum, Frics.

sublineatum, Elfstr. in Biliang Siensk. Vet. Akad Handl. xx. 111. I (1894) 10. - Scandinav.

subnigrescens, Dahlst, in Act. Hort. Berg, ii. 4 (1893) 131 - Scandinav.

subobscurans, Dahlst. ex Porat, in Bot. Notiser (18:94) $4 \mathrm{l}=$ serratifroms, $A$ lniq.

subortum X, G. Schneid, in Deutsche Bot. Monatsschr. vi. (1888) 122. - Europ.

subperfoliatum, Arv. Hier. Alp. (ISSS) $92=$ juranum, Fries.

subpratense, Norrl. ex Nym Consp. Fl. Eur. Sufpl. ii. 1 (1889) 200 (= Pilosella subrateme's, Norrl.), = suecicum, Naeg. \& Peter.

snbrioidum, Almo ex Stonstr. Värml. Archierac (1889) 61. - Scandinav.

subrosulatum, Frewn \& Sint. ex Freyn, in Eull. Herb. Boiss. iii. (1895) 503. - Armen

subrubns, Arv. Hier. Alp. (1888) $5=$ H. Taurci Arit.

mbrude, Arv, 1. c. $72=$ buglossoides, Ay:

subsinuatum, Borb. in Vortrag Bot. Fachoonf. Un oar. Naturh. Gesells. $18^{\circ} 12$ (1893) 46; et in Oest. Bot. Zeitschr. xliii. (1893) 69. - Hung.

ubspeciosum X, Naeg, in Naeg. \& Peter, Hierac ii. (1886) 147. - Europ.

smbstellatum $\times$. Ary. \& Gautier, in Bull. Soc. Bot. Fr. xl. (189:3) 2:36, nomen. - Gall.

substoloniflorum, Peter, in Engl. \& Prantl, Natürl. Pfanzenfan. iv. 5(1893) 3\%9. - Alp. Eur.

cubtriangulare, Stcnstr. Värml. Archierac. (1889) 17 - Scandinar.

Eubtubulasens, Dahlst. [Hicy. Cxsicc. Fasc, iii. (1887) n. 121 in Act. Hort. Bcrg. i. T (1891) 16. - Scandinav.

subrestitum. Timb. in Jeanbern. \& Timb. Le Cap $\operatorname{sir}(1887) 154$ [Bull. Soc, sci. phys. \& nat. Toul. vii. 1886$]$. - Pyren.

subvillosum, Fremn, in Vcicn. FI. Bulg. (1891) 345 in 391 ; ct in Oest. Bot. Zeitsclir. xlii. (Is!2) 343. Bulg.

subvirens, Arv. Hicr. Alp. (1S8S) 121.-Gall.

suecicum, Norrl. ex Nynn. Consp. Fl. Eur. Suppl. ii. 1. (1889) 200. - Fennia.

suivalense, Norrl.ex Dahlst.in K. Sicnsk. Vet. Akud.

Handl. xxiij. 15 (1890) 41 (= Pilosella suiralensis,

Norrl.). - Scandinav.

\section{HIERACIUM}

Simatr. in Bihang Svensk. Vet. Akad. Handl. xvi. 111.7 (1890) 45; et Hier. Alp. Mittl. Skand. (1893) $32=$ alpinum, Linn

sumense, Norrl. ex Nym. Consp. Fl. Eur, Suppl. ii. 1. (1889) $199(=$ Pilosella suomense, Norrl.) $=$ cymosum, I.imn

supplicatum. Elfstr. Hier. Alp. Mitll. Skand. (1893) 62. - Scandinav.

surrejanum, F.Hanbury, in fourn. Bot, xxxii. (1894) 230 . - Brit

sylvaticum, Porta, in Atti Accad. Agiati, ix. 1891 (1892) 45. - Hisp.

symphytaceum, Arv, in Bull. Soc. Dauph, xiii.(1886) 561 ; et Hier. Alp. (188S) 112. - Gall.

sympodiale, Bork. ex Oest. Bot. Zeitschr, xlii. (IS92) 186, nomen. - Hung.

szepusiense, Simonk. e\% Termész. Közlöny (1S90) 490 $(=$ H. rhodopaenm, Auct. Hung.). - Hune

tanense, Elfstr. in Bihang Svensk. Vet, Akad.

Handl. xx, 111. 1 (1894) $14=$ alpinum, Lim.

turaxaciforme, Arv Suppl. Monog. Hier, (1S86) 15 et Hier. Alp. (18\&8) $80=$ bifidum, Kit.

arnense, Arv, et Sudre, in Lucante. Rev, de Bot. xii. (18.4) 25. t. 2; et in Bull. Soc. Bot. Fr. xli. (1895) 199 - Gall.

Tatrae, Borf, in Bot. Centralbl. 1vii. (1894) 100, nomen. - Huns.

tempedense, Frejn \& Sint. ex Freyn, in Bull. Herb. Boiss. iii. (18\%5) 504. - Armen.

tenebricosum, Danlst. cx Stenstr. Värml. Archicrac. (1889) 31; et in K. Siensh. Vet. Akad. Handl. xxv. 3 (1893) 148. - Scandinav.

cnebrosum, Norrl. in Act. Soc. Faun, et Fl, Fenn. iii. 4 (1888) $106=$ vulgatum, Fries

tenuilingua. Norrl. ex Nym. Consp. FI. Eur. Suppl 11. 1 (1889) (= Pilosella tenuilingua, Norrl.) $=$ H. Pilosella, Limn.

Hussimum, A. Rehm, in Verh, zool-bot, Ges xlv. (1895) $336=$ brachiatum, Bert.

thapsilolium, Arv. Hier. Alp. (1888) 55. Gall.

thapsiforme, Uechtr. ex Naeg. \& Peter. Hicrac. ii (1889) 290. - Europ.

7napsigenum X, Naer. \& Peter, Hierac. ii. (1889) 39. - Bavar

thapsoides, Arv. Hier. Alp. (1888) 56. - Gall. Therenii, Timb. in Jeanbern. \& Timb. Le Capsir

(1887) 153 [Bull. Soc, sci. phys, et nat. Toul. vii. (1886)]. - Pyren.

thyraicum, Blocki, in Oest. Bot. Zeitschr. (1SS9) T4. - Transsilv.

Timbalianum, Aw. \& Gautier, in Bu?l. Soc. Bot. Fr. xli. (1894) 348. - Pyren.

tolpidifolium, Are. l. c. 343. - Pyren.

omentcllum $\times$, Naer. \& Peter, Hierac, ii, (1886) 79. - Europ

tómósense $\times$. Simonk, Enum. Fl, Transsilv. (1883) 3\%1. - Transsilv

tómósenze $X$. Simonk. ex Nym. Consp. Fl. Eur Suppl. ii. 1. (1859) $200=$ praec.

Simonk ex Oest Bot Zeitschr xli. 1891) in = tómósense, Simomb.

Torrepandoi, Willk. Suppl. Prodr. Fl. Hisp. (1893) 123. - Hisp.

ransalpinum, Arv. Hier. Alp. (1888) $97=$ lanceolatum, Vill.

ransiens, Dahlst. in Act. Hort. Berg. ii. 4 (1S93) 111. - Scandinav.

transiens, Frejn, in Oest. Bot. Zeitschr. xliv. (1894) 262. - Bulg.

translucens, Arw. Hier, Alp. (1888) 84.-Gall.

triangulare, Almo. ex Stenstr. Värml. Archicr. (1889) 17 ; Dahlst. in K. Sicnsk. Vet.Akad. Handl. xxv, 3 (1893) 69. - Scandinav.

trichocerinthe, Aro. in Bull. Soc. Bot. Fr. xli. (1894) 334. - Pyren.

vichocladum, Arv. Hier. Alp. (1888) $38=$ armerioides, Arv.

trichoderma, A. Rehm. in Verh. zool.-bot. Ges. Wien, xlv (1895) $322=$ collinum, Goct. $n$.

trichodermum, Aro. \& Gauticr, in Bull. Soc, Bot. Fr. xli. (1894) 345. - Pyren.

trichodontum, Britton, in Bull. Torrey Bot.Club, xix. (1892) 266 (= Pilosella trichodonta, Sch. Bip.). Bolivia.

\section{HIERACIUM :}

icholepidum Ar". \& Gantier, in Bull. Soc. But. Fr. xli. (1894) 362. - Alp. Marit.

trichoneurum, Prantl, ex Nym. Consp. Fl, Eur. Suppl. ii. 1 (1889) $196=$ glabratum. Hoppe.

tuberculatum, Freyn, in Oest. Bot. Zeitschr. xliv (1894) 260; et in Bull. Herb. Boiss. iii. (1895) 505 - As. Min.

tumescens, Norrl Bidr, till Shand. Hier.flora (1S8S) 80 ; et ex Dahlst. in Act. Hort. Berg. ii. 4 (1893) SS. - Scandinav.

turbiniceps, Dahst. [Hiev. cxsicc. fasc. iv. (1891 n. 801 in $K$. Svensk. Vet. Akad. Handl. xxvi. B (1894) 96. - Scandinav.

turritifolium, Arv. in Bull. Soc. Bot. Fr. xhi. (1894) 36i3. - Pyren.

Twardowskianum, A. Rehm, \& Woloszczak, in Oest. Bot. Zeitschr. xlit. (1892) $190=$ H. Pilosella, Limn.

werans $X$. Murr, in Oest. Bot. Zeitschr, xxxviii. (1888) 205, et xliii. (1893) 179); et in Deutsche Bot. Monatsschr. xii. (1894) 97. - Tirol.

uconicum, Arv. Hier. Alp. (1888) 52 = saxatile, Vill. Uechtritrianum, G. Schneid. in Oest. Bot. Zeitschr. xxxvi. (1886) $23=$ eximium. Backh.

Ullepicii, Blocki, in Deutsche Bot. Monatsschr. (1887) 24. - Hung.

umbelluliferum, Arv. ex Nym. Consp. Fl. Eur. Suppl, ii. 1 (1889) $198=$ cymosum, Linn.

urticaceum, Arv. Hier. Alp. (18ss) 47. - Gall.

urticaefrons, Dallst. in Act. Hort. Berg. i. 7 (1891)

35. - Scandinav.

ustulatum, Ara. in Bull. Soc. Dauph, xiii. (1SS6) 561 ; et Hier. Alp. (1888) 36. - Gall

vacllistense, Elfstr. Hier. Alp. Mittl. Skand. (1893) 15 = alpinum, Linn.

ialbonnense. Arv. Hier. Alp. (1888) $48=$ pedemontanum, Burn of Growiti.

Valdelievrei, Mur, in Progr. Ober. Realsch. Innsbr. (1890-91) ex. Oest. Bot. Zeitschr. (1891) 280. Tirol.

valentinum, Arv' \& Rererch. ex Herv, in Rev. gén. bot. (1892) 156; Willk. Suppl, Prodr. Fl. Hisp. (1893) 119. - Hisp.

alidum, Arv, in Herv, Rech fl bass, Loire, 4e livr. (1885?) $34=$ boreale, Fries.

valsianum $X$. Sarnth. ex Oest. Bot. Zeitschr. xliii (1893) 179. -- Europ.

Vandasii. Freyn, in Velen. Fl. Bulg. (1891) 343; et in Oest. Bot. Zeitschr, xlii. (1892) 343. - Bulg.

carangerense, Elfstr. in Bihang Svensk. Vet. Akad. Handl. xx. II. n. 1 (1894) 31, ad calc: = gracilentum, Backh

Garatinense, Woloszczal, in Spraw. Kom fizyjogr. Krajowei, xxii. (1\&88) $\because 202=\mathrm{H}$. Bauhini, Dolliner.

variicolor, Dahlst. ex Stcristr. Värnul. Archicrac. (1800) 22. - Suec

vatricosum, Dahlst, in Act. Hort. Berg. ii. 4 (1893) 84. - Scandinav.

Velenovskyi, Freyn, in Velen, Fl. Bulg. (1891):346 et in Oest. Bot. Zeitschr, xlii. (1892) 344. - Buly. enetum, "Boiss. \& Reut, " ex Oest. Bot. Zeitschr. xli. (1891) 455, ad calc. = vestitum, Boiss. E Reut rerbenacum. Arv. ex Nym. Consp. Fl. Eur. Suppl, ii. I (1889) $191(=H$. ierbenacum, Arv. $)=u m-$ bellatum. Linn.

vernantianum, Arv. Eo Briq. ex Briq, in Bull. Herb. Boiss. ij. (1S94) 630. - Sabaud.

versifolium, M. Brenner, in Medd. Soc. Fann.et Fl. Fenn. 1891-92 (1892) 117. - Europ.

estmannicum, Dahlst. ex Porat, in Bot. Notiser ( 854$) 42=$ rigidum, Hartm

viduatum, Aro, in Bull. Soc. Bot. Fr. xli. (18?4) 348. - Pyren

villiceps, M. Brenner, in Mcdd. Soc. Fann. et Fl. Fonn. 1891-92 (1892) 114. - Europ.

villiferum, Naes. of Peter, Hierac. ii. (1889) 329); Europ.

Eillipes, Dahlst. in Act. Hort. Berg. ii. 4 (1S93) 6 $=$ H. Pilosella, Linu.

villosiceps, Nacg. \& Petcr. Hierac. ii. (18S6) 10.5. Europ.

cizlosiflormm, Dahlst et A Magnuss, ex Dahlst in Act. Hort. Berg. ii. 4 (1893) 47 = alpinum Linn. 


\section{HIERACIUM}

villosipes, Pax, int Oest. Bot. Zeitschr. xlv. (1895) 42. - Carpath.

violascens, Almq. ex Dahlst. in Bot. Notiser (I8\&6) 164 [Hier. exsicc. Fasc. ii. n. 95] ; et in K. Svensk. Vet. Akad. Handl. xxvi. 3 (1894) $136=$ murorum, Linn

riolascens, Borb. ex Nym. Consp. Fl. Eur. Suppl. ii. 1 (1889) $192=$ prenanthoides, Linn.

Eirgatum, Peter, ex O. Hoffm, in Engl. \& Prantl,

Natürl. Pflanzenfam. iv. 5 (1893) 385. - Eur. centr.

rirgicaule $X$, Naeg. \& Peter, Hierac. ii. (1S86) 72. - Europ.

viride, Arr' in Bull. Soc. Dauph. xiii. (1886) 561; of Hier. Alp. (1888) 73. - Gall.

viridiceps, M. Brenner, in Medd. Soc. Fann. et Fl. Fenn.1891-92 (1892) 96. - Europ.

viscidum, Arv. ex Peter, in Engl. E Prantl, Natiurl. Pfanzenfam. iv. 5 (1893) 383. - Europ.

ritellicolor, Eltstr. Hier. Alp. Mittl. Skand. (1893) $36=$ alpinum, Limn.

rlasitschense X, Freyn, in Bull. Herb. Boiss, iij. (1895) 646. - Bosnia.

Wahlenbergii. Pax. in Oest. Bot. Zeitschr. xlv. (1896) 43. - Carpath.

Weberi $\times$. G. Schneider, in Sagorski \& Schneider, F1. Centralkarp. (1891) 275 et 36:.- Europ.

Wiesbaurianum, Uechtr. in Deutsche Bot. Monatsschr. (1884) 102; G. Beck, Fl. Nied-Oest. ii. 11. (1893) 1293. - Austr.

Woloszczakii, Blocki, in Oest. Bot. Zeitsily, xxxviii. (1888) 297, nomen. - Hung.

aulkense, A, Rehm. in Verh, zool,-bot, Ges. Wien. xliv. (1895) $330=$ macrostolonum, G. Schneid.

Xatardianum. Arv. in Bull. Soc. Bot. Fr. xli. (1894) 353. - Gall. mer.

Zapalowicksii $X$. Woloszczak. in Spraw. Kom. fizyjogr. Krajowei, xvvii. (1892) II. 208. - Europ. zetlandicum. Beeby, in foum. Bot.xxix. (1S91) 243. —Ins. Zetland.

ziljevanum, Oborny, ex Murb. in Lunds, Univ. Arsskrift. xxvii. V. (1892) $95=$ H. Fussianum, Schur.

HIEROBOTANA, Briq. in Eng1. \& Prantl, Natïrl. Pflanzenfam.iv.3a (1894) 148. VERBENACEAE.
nflata, Briq. l. c. (= Verbena inflata, Kunth). Columb.

HIERAPICRA, Siegesb, Fl. Petrop, (1736) 54 ex Kuntze, Rev. Gen. (1891) 346 = Carben:a Adans. (Compos.).

benedicta, Kuntze, 1. c. $347=$ C. benedicta, Adans

HIEROGHLOË, S. G. Gmel. (Gramin.). - Ind Kew i, 1161.

Hookeri, Maxim. in Bull. Acad. Sci. St. Pétersb. xxxi1. (1888)627 (= Ataxia Hookeri, Griseb.). Ind. or.

Horsfieldii, Maxim l.c. (=A. Horsficldis, Kunth). - Java.

japonica, Maxim, l.c. 626. - Japon.

odorata, Britton, Stērn \& Pogs. Prelim. Catal. (1888) $67=$ borealis, Roem. E Schult.

repens, Simonk. Enum. F1. Transs. (1886) $560(=$ Holcus repens, Host) = borealis, Roem. \& Schult.

sikkimensis, Maxim. in Bull. Acad. Sci. St. Pétersob. xxxii. (1888) 626. - Reg. Himal.

tenuis, Th. Dur. E Schinz, Consp. Fl. Afr. v. 1894 (1895) 798 (=Ataxia tonuis Trin.). - Afr. austr.

HIERONYMA, Baill. = Hyeronima, Allem. (Euphorb.).

reticulata, Britton, ex Rusby. in Mem. Torrey Bot. Club, iv. (1895) 25. (= Antidesma riticulata, Planch.). - Bolivia.

HIERONYMIELLA, Pax, in Bot. Jahrb. xi. (1890) 327. AMARYLLIDEAE.

clidanthoides, Pax, l. c. - Reg. Argent.

HILARIA, H. B. \& K. (Gramin.). - Ind. Kew. i. 1161.

rigida, Scribn. ex Vasey, Illustr. Am. Gram. i. Ir. (1891) t. 2; et in Contrib. U. S. Nat. Herb. iii. (1892) 14 = rigida, Vasey,
HILDEBRANDTIA, Vatke (Convolv.). - Ind: Kew, i. 1161

somalensis, Engl. Bot. Fahrb. xviii. (18:4) 87. Afr, trop. or.

HILLERA, Kuntze, Rev。Gen, (1891) $5.51=$ HII LERIA. Vell. = Mohlana, Mart. (Phytol.).

secunda, Kuntze, 1.c. = M. nemoralis, Mart.

HILLIA, Jacq. (Rubiac,), - Ind. Kew, i, 1161 boliviana, Britton, in Mem. Torrey Bot. Club, iii. 3 1893) 43. - Boliv

illustris, K. Schum, in Mart. F1. Bras vi. vı. (I889) $202=$ tubaeflora. Clum

Saldanhaei, K. Schum. l. c. 201. - Bras.

HIMANTANDRA, F. Muell. in Australas. Journ. Pharm. ii. (1887) $5=$ Eupomatia, R. Br (Anonac.).

HIMANTOGHILUS, T; Anders. (Acanth.) Ind. Kew i. 1161 .

comorensis, Lindau, in Bot. Fahrb. xx. (1894) 61.Ins. Comor.

macrophyllus, Lindau, l.c. 60. - Afr. trop. or.

marginatus, Lindau, l. c. - Afr. trop. or.

Zenkeri, Lindau. t. c. 60. - Afr. trop. occ.

HIMANTOPHYLLUM, Spreng. = Clivia, Lindl. (Amaryll.).

atrosanguneum, Williams, Catal. (188S) $20=\mathrm{C}$. miniata, Regel.

HIN DSIA, Benth. (Rubiac.) - Ind. Kew. i. 1162 breviflora, $K$. Sihum, in Mart. Fl. Bras. vi. vi.(I8S9) 165. - Bras.

glabra, K. Schum.l.c-Bras.

phyllocalyx, $K$. Schum. l. c. 169 - Bras.

HIPPAGROSTIS, Rumpf, Herb. Amboin. vi. (1749) 14 t. 5, ex Kuntze, Rev. Gen. (1S91) $776=$ Oplismenus, Beauv. (Gramin).

Burmanni, Kuntze, Rev. Ger. (1891) $77 \%=0$. Burmanii, Beati.

composita, Kuntze, 1, c. = O. compositus, Beaw

hivtella, Kuntze, 1. c. = O. rompositus, Beauv.

loliacea, Kuntze, 1. c. $=\mathrm{O}$ comprositus, Bearr

setaria, Kuntze, 1. c. = O. undulatifolius, Beaw.

undulatifolia, Kuntze, 1. c. = O. undulatifolıus, Beawo.

HIPPEASTRUM, Herb. (Amaryll.). - Ind. Kew.

i. 1162.
africamun, Welw. ex Baker, Handb. Amaryll.(1888) 49, in ols. $=\mathrm{H}$. Reginae, Herb.

angustifolium, Pax, in Bot. Fahrs. xi. (1890) 321 Reg. Argent

brachyandrum, Baker, Handb. Amaryll. (1888) 4?, in Gard. Chron. (1890) ii. 154; ct in Bot. IIag. (1894) t. $7344 .-A m$, austr. extratrop.

Mandoni, Baker, l. c. 49. - Bolivia.

pallidum, Pax, in Bot. Fahrb. xi. (1890) 321 Habrantius pallidus. Lndd.)

petiolatum, $P$ ax, l. c. 330. - Reg. Argent.

purpureum, Kuntze, Rev. Gen.(1891) $703=$ equestre, Herb.

scopulorum, Baker, Handb. Amaryll. (1888) 49. Bolivia.

soratense, Baker, $l$, c. 42. - Bolivia,

tubispathum, Pax, in Bot. Fahrb. xi. (1890) 329. Reg. Argent

Wolteri, Wiltm. in Gartenfl. (1895) 201 fig. 49 et 465 t. $1418=$ equestre, Herb.

HIPPIONUM, Kuntze, Rev, Gen, (1891) $428=$ HIPPION, F. W. Schmidt, = Enicostema Blume (Asclip.).

revicillatum, Kuntze, Rev. Gen. (1891) 428 (= Hippion ierticillatum, F. W. Schmidt). = E. littorale, Blutite.

HIPPOBROMUS, Eck1. \& Zeyh. (Sapind.). Ind. Kew. i. 116\%

apetalus, Cordem. Fl. Ile Rémion (1895) 381 (= Melicocca apetala, Poir.). - Ins. Borbon.

pauciflorus, Radlk, in Engl. E Prantl, Natürl. Pfanzenfam. iii. 5 (1895) - Afr. austr.
HIPPOCASTANUM, Toum, ex Rupp. = Aescu lus, Linn. (Sapind,

californicum, Greene, Man. Bot. San Franc. Bay (1894) 73. - Spach.

HIPPOGRATEA, Linn. (Celastr.). - Ind. Kew. 1. 110.3 .

Buchananii, Loesen. in Bot. Fahrb. xix. (1894) 285. - Afr. trop. or

Buchholzii, Loesen. l. c. 234. - Kamerun.

cambodiana, Pierre, Fl. For Cochinch. Fasc. 19 (1893) t. 302 B. - Cambodia.

Chesseana, Pierre, l. c. \& 381 B. - Cochinch.

crenata, K. Schum \& Loesen. ex Loesen. in Engl. \& Prantl, Naturl. PHanzenfam. iii. 5 (1893) 228 = Gymnema crenatum, Klotzsch,

dinhensis, Pierre, Fl. For. Cochinih. Fasc, 19 (1893) t. $301 \mathrm{~A}$. - Cochinch.

Grisebachii, Loesen. l. c. 227 ( = H. vernucosa. Griseb.) - Parag.

malifolia, Baker, in fourn. Linn. Soc. xxy, (1890) :307 - Madar

micrantha, Baker, l. c. 307. - Madag.

Miersii, Loesen, in Engl. Ev Prantl, Natuirl. Pfanzenfam. iii. 5 (1893) 228 (= Pristimera apiculata Miers). - Am. austr.

Pogerei, Loesen. in Bot. Fahrb. xix. (1894) 238. Congo merid.

Rowlandii, Loesen. l. c. 238. - Afr. trop. occ.

Stuhlmanniana, Loesen. in Engl. \& Prantl, Natiul Pfanzenfam. iii. 5 (1893) 228. - Zanzib.

Volkensii, Loesen. in Bot. Fahrb. xix. (1394) 238.Afr. trop. or.

Zenkeri, Loesen. l. c, - Kamerun.

HIPPOGREPIS, Lindl. (Legumin.). - Ind. Kew i. 1164 .

Bornmuelleri, Hausskn. ex Bornm. in Mittl. Thiir Bat. Ver. N. Folge, vi. (1894) 53. - Persia.

elongatula, Hochst. ex Boiss. Fl. Or. Suppl. (ISSS) 171 , in syn. = constricta. Kuntze

fructicosa, Rony, in Bull. Soc, Bot. Fr. xxxv. (1SSS) 116. - Hisp.

HIPPODAMIA, Decne = Solenophora, Benth (Gesner.).

Endliclieriana, Fritsch, in Enc1. \& Prant1, Natür1. Pflanzenfam.iv. 3b (1894) $183=\mathrm{S}$. Endlicheriana, Hanst.

insignis, Fritsch, 1. c. = S. insignis, Hanst.

obscura, Fritsch, l. c. = S. obscura, Hanst.

HIPPOPHA angustifolic, "Lodd. " ex Dippel, Handb. Laubholzk, iii. (1893) $214=$ rhamnoides, Linn.

rhamnoidea, St. Lager, in Cariot, Etud, des fl. éd 8 ii. (1889) $720=$ rhamnoides, Limn.

aurica, Hort, ex Dippel, Handb. Lanbholzb. iii. (1893) $214=$ rhamnoides, Lim.

HIPPOTIS, Ruiz \& Pav, (Rubiac.). - Ind. Kew i. 1165 .

brevipes, Spruce, ex K. Schum, in Mart. Fl. Bras, vi. v. (1889) 298 . - Peruv.

tubiflora, Spruce, ex K. Schum. l. c. - Peruv.

HIPTAGE, Gaertn, (Malpigh.).-Ind. Kew, i. 116.) bengalensis, Kuntze, Rev, Gen.(1891) $88=\mathrm{H}$. Ma dablota, Gaertn.

calycina, Pierre, Fl. For. Cochinch. Fasc. 17 (1892) t. $272 \mathrm{~A}$. - Cochinch.

elliptica, Pierre, l. c. t. 272 B. - Cochinch.

Harmandiana, Pierre, l. c. t. 270 B. - Cochinch.

lucida, Pierre, l. c. Fasc, 18 (1593) t. 273 t. Cochinch.

macrocarpa, Chodat, in. Archin. sci. phins. En nat. (1890) in Bull. Soc. Bot. Suisse i. 35: et in Mél. Soc. sci. phys. \& nat. Gentèe, xxi, 2 n. 3 (1893) 116 t. 46. - Parag

microcarpa, Pierre, Fl. For. Conhinch. Fasc is (1893) t. 274 B. - Cochinch.

parvifolia, Nivdenzu, in Bot. Fahr. Beibl, n. 30 (1891) 2. - Bras

pulcherrima, Morong, in Ann. N. Y. Aud. Sui, vi (1892) 67. - Parag

triacantha, Pierre, Fl. For. Coilinith. Fasc, Is (1893) t. 273 A. - Cochinch. 
HIRNELLIA, Cass. = Myriocephalus, Benth. (Compos.)

atpendiculata, gracilis, nuda, rhizocephala, Rudallii, Simartic, suffruticosa, Kuntze, Rev. Gen. (1891) $346=$ homonyma ommia Myrcocephali.

helichrysodes, Kuntze, 1. c. = M. helichrysoides, A. Gray.

Querinae, Kuntze, 1. c。 = M. Querinae, F. Muell.

HIRSCHIA, Baker, in Kew Bull. (1895) 317 . COMPOSITEAE

anthemidifolia, Baker, l. c. - Arabia.

HIRSCHFELDIA, Moench = Brassica, Town (Crucif.)

consobuna, Pomel, F1. de l'Algér. [Dicot.] (1888) 61 $=\mathrm{B}$. adpressa, Boiss

HIRTELLA, Linn. (Saxifr.), - Ind, Kew。 i. 1166. Burchellii, Britton, in Bull. Torrey Bot. Club, xvii. (1890) 10. - Bolivia.

erensis, Fritsch, in Amzal. Naturl. Hofmus. Wien. v. (1890) 10. - Bras.

Glaziovii, Taub, in Bot. Fahrb. xv. Beibl. n. 34 (1892) 8. - Bras.

pulchra, Fritsch. in Amal. Naturl. Hofmus, Wien, v. (1890) 9. - Bras.

Thonarsiana, Baill. ex Laness. Pl. util. Colon. Franc. (1886) 874; et Hist. pl. Madag. Atlas (1886) t. 13. - Madag.

HITCHENIA, Wall, (Scitam). - Ind. Kew, i. 1167 caulina, Baker, in Hook. f. Fl. Brit. Ind. vi, (1892) 2:4. - Concan.

musacea, Bakcr, l. c. 225 (= Curcuma musacea Wall.). - Penins. Mal.

HOEHNELIA, Schweinf, ex Engl, in Abh. Preuss, Akad. Wiss, 1891. ii. (1892) 422, nomen; in Hoehnel, Zum Rudolph See, Append. (1892) 9 ; O. Hoffm. in Engl. \& Prantl. Naturl. Pflanzenfam. iv. 5 (1893) 388. COMPOSITAE.

vernonioides, Schweinf. $l l . c c .-$ Afr. trop.

HOFERIA, Scop。= Ternstroemia, Linn, $\mathrm{f}_{\text {。 }}$

japonica, Franch. Pl, Delav, (1889) $105=T$, japonica, Thunb.

HOFFMANNIA, Sw. (Rubiac.) - Ind. Kew。 i. .

brachycarpa, Britton, in Bull. Torrey Bot. Club, xviii. (1891) 108. - Bolivia.

gesneriodes, Kuntze, Rev. Gen. (1891) 285 = Ophryococcus gesnerioides, Oerst.

latifolia, Kmitze, I. c. 284. - Peruv., Costarica.

pallida, Rusby, in Mem. Torrey Bot. Club, iii. (1893) 44. - Bolivia.

Pearcei, Rusby, l.c. - Bolivia.

Peckii, K. Schum, in Mart. Fl. Bras, vi. vi. (1889) 32\%. - Bras.

rotata, f. D. Smitth, in Coult. Bot. Gaz.xviii. (1893) 204. - Guatem.

HOFFMANSEGGIA, Cav。(Legumin.) - Ind Kew, i. 1168 .

andina, Phil, in Anal, Mus. nac, Chile (1891) 19. Chili.

canescens, Fisher, in Contrib. U. S. Nat. Herb. i. (1892) 149. - Mexic

truticosa, S. Wats, in Proc. Am, Akad, xxi. (1886) 4. 1. - Mexic

glabra, Fisher, in Contrib. U. S. Nat. Hcrb. i. (1892) 147. - Calif

gladiata, Fisher, I.c. 146. - Mexic.

intricata, T. S. Brandeg, in Proc, Calif. Akad, Ser.

II. ii. (1889) 151. - Calif.

multijuga, S. Wats. in Proc. Am. Acad. xxi. (1886) 451. - Mexic

parviflora, M. Micheli, in Méme Soc Hele' sci. nat. xxx. (1889) n.7, 87 t. 25. - Parag

platycarpa, Fisher, in Contrib. U.S. Nat. Herb. i. (1892) 146 - Mexic

rubra, Engl. Bot. Fahrb. x. (1889) 25. - Afr. austro-occ, extratrop.

ternata, Phil. in Anal. Mus. nac. Chile (I891) 19. Chili.

\section{HOFFMANSEGGIA}

texensis, Fisher, in Contrib. U. S. Nat. Herb. i. (1892) 147. - Texas

HOFMEISTERIA, Walp. (Compos.) - Ind, Kew.

\section{i. 1168 .}

crassifolia, S. Wats. in Proc. Am. Acad. xxiv. (1889) 53. - Mexic.

fasciculata, T. S. Brandeg. in Proc. Calif. Akad. Ser. II. ii. (1889) 167 = fasciculata, Walp.

pubescens, S. Wats. in Proc. Am. Acad, xxiv. (1889) 54. - Mexic.

HOHENBERGiA, Schult. fo = Aechmea, Ruiz et Pav. (Bromel.)

augusta, Mez, in Mart. Fl. Bras, iii. 1:1. (1891) 270 $=$ A. multiceps, Baker.

Blanchetii. Ed. Morr, ex Baker, Handb. Bromel. (188:3) 49 = A. Blanchetii, Ed. Morr.

chrysocona, Ed. Morr. ex Baker, 1. c. $44=\mathrm{A}$ chrysocoma, Baker.

eriantha, Mez, in Mart. Fl. Bras, iii. I11. (1891) 269 $=$ A. eriantha, Bronyn.

gnetacea, Mez, 1. c. 272. - Bras.

membranostrobilus, Mez, 1. c. 269. - Bras.

pycnantha Mez, 1. c. $273=\mathrm{A}$. pycnantha, Buker.

Ridleyi, Mez, 1. c. - Bras.

Salzmanni. Éd. Morr, ex Baker, Handb. Bromel. (1889) $49=$ A. Salzmanni, Baker.

HOILBRENCKIA, formosa, Hort. ex Gard. Kew i. Polypet. (1894) 101. = Staphylea colchica. Stev.

HOLALAFIA, Stapf, in Kew Bull. (1894) 123; et in Hook, Icon. pl. xxiv. (1894) t. 2350. APOCY $N E A E$

multiflora. Stapf, $l l . c c$. - Afr. trop. occ.

HOLARRHENA, R. Br. (Apocyn.), - Ind. Kew. i. 1168

Fischeri, K. Schum. in Engl, Pfanzenu. Ost-Afr.C. (1895) 316 ; et in Engl. E Prantl, Natirl. Pflanzenfam, iv. 2 (1895) 13\%. - Afr. trop. or.

HOLBOELLIA, Wall. (Berber.), - Ind, Kew. i. 1168.

cuneata, Oliver, in Hook. Icon. pl, xix. (1889), t. 1811. - China.

HoLCUS, Linn. (Gramin.). - Ind. Kew, i. 1168 Iongiaristatus, St. Lager, in Cariot, Étud. des fl. éd. 8. ii. (1889) $907=$ mollis, Linn.

HOLLANDAEA, F. Muell. in Chem, and Drug. Australas. (June 1887) 173. PROTEACEAE,

Sayeri, F.Muell.l.c. (= Helicia Sayeri, F. Muell.). - Austral.

HOLLRUNGIA, K, Schum, in Bot. Jahrb. ix. (1888) 212 ; et xv. (1893) 564 ; et in Engr \& Prantl, Natürl Pflanzenfam. iii. 6a (1893) 88 PASSIFLORAE

aurantioides, K. Schum. ll.cc. - N. Guin.

HOLOCARYA, Th. Dur. Ind. Gen. (1888) 184, sphalm。 = Holocarpa, Baker (Rubiac).

HOLODISCUS, Maxim.= Spiraea, Linn.(Rosac.) ariaefolzus, Greene. Man. Bot. San Eranç. Bay (1894) $113=\mathrm{S}$. ariaefolia, Smith.

HOLOLAFIA. “ Stapf » ex K. Schum, in Engl. \& Prantl, Natürl. Pfanzenfam. iv. 2. (1895) 188, sphalm. = Holalafia Stapf $($ Apocyn. $)$.

HOLOSTACHYS, Greene, Fl. Francisc. (1891) 173 in syn, sphalm. = Halostachys, C. A. Mey. (Chenop.).

HolostemmA, R. Br. (Asclep.). - Ind. Kew, i. 1170 .

ammularis, K. Schum, in Engl, \& Prantl, Natürl. Pflanzenfam. iv. 2 (1895) $250=\mathrm{H}$. Rheedei, Wall.

sinense, Hemsl. in fourn. Linn. Soc, xxvi. (1889) 103 (= Metaplexis Hemsleyana, Oliver). - China.
HOLOSTEUM. Dill. ex Linn. (Caryoph.), - Ind Kew. i. 1170.

macropetalum, Hausskn. \& Bornm. ex Hausskn. in Mitth. Bot.Ver. Fena, ix. (1891) 15. - As. Min

HOLOTHRIX, Rich. (Orchid.).-Ind. Kew. i. 1170.

arachnoidea. Th. Dur. \& Schinz, Consp. F1 Afr. v. (1892) $69=$ Peristylus arachnoideus. A. Ricl. glaberrima, Ridl. in Fourn. Linn Soc. xxii. (1886) 125 - Madag.

hispidula, Th. Dur. \& Schinz, Consp. Fl, Afr, v. 1892 (1895) $70=$ parvifolia, Lindl.

longiflora, Rolfe, in Bolet. Soc. Brot. vii. (1889) 237. - Angola.

madagascariensis, Rolfe, ex S. Elliot, in Fourn. Linn. Soc. xxix, (1891) 55. - Madag.

micrantha, Schlechter, in Bot. Fahrb. xx. Beibl. n. 50 (1895) 31. - Atr. austr.

montigena, Ridl in fourn. Bot. xxiv. (1886) 295.Abyss.

multisecta, Bolus, in fourn. Linn. Soi. xxv. (1889) ] 70 fir. 7. - Afr. austr.

platydaityla, Kraensh. in Bot. Fatrrb. xvii. (1893) 66. - Kamerun.

pleistodactyla, Kraenzl. in Engl. Pfanzenw. OstAfr. C (1895) 151; et in Bot. Fahrb. xxii. (1895) 17. - Afr'trop. or.

puberula, Rendle, in Fourn. Bot. xxxiii. (1895) 278. - Afr. trop. or.

Schmidtii, Kraenzl. in Bot. Fahrb. xvii. (1893) 66. - Ins. Comor.

Usambarae, Kraenzl. l. c. xix. (1894) 248. - Afr. trop. or.

HolozoniA, Greene, Man. Bot San Franc. Bay (1894) 199 = Lagophylla. Nutt. (Compos.).

filipes, Greene 1. c. = L. filipes, A. Gray.

HOOKERA, Salisb。= Brodiaea. Sm. (Liliac.).

aurea, Kuntze, Rev. Gen. (1891) 712= Milla aurea Baker.

bivalvis, Kuntze, 1. c. = M. bivalvis, Baker.

brevipes, Kuntze. 1. c. = M. brevipes, Baker.

Bridoesii, Kuntze, 1. c, = B. Bridgesii, S. Wats.

californica, Greene, in Bull. Calif. Acad. ii. vi. (1886) $1362=$ B. californica, Lindl.

capitata, Kuntze, Rev. Gen. (1891) $138=$ B. capitata, Benth.

crocea, Kuntze, 1. c. = B. crocea, S. Wats.

gracilis, Kuntze, 1. c. = B. gracilis, $S$. Wats

grandiflora, Kuntze, 1. c. = B. grandiflora, $S_{n}$.

hirtella, Kuntze, 1. c. = Milla hirtella, Baker.

hyacinthina, Kuntze, 1. C. = B. lactea, S. W Wats

ixiodes, Kuntze, 1. c. = B. ixioides, S. Wats

laxa, Kuntze, 1. c. = B. laxa, S. Wats

lcptandra, Greene, Pittonia, i. (July 1887) 74. Calif.

macropoda, Kuntze, Rev. Gen. (1891) $138=\mathrm{B}$. terrestris, Kellogg.

minor, Britton, ex Greene, Man. Bot. San Franc. Bay (1891) $318=$ seq

minor, Kuntze, Rev. Gen. (1S9l) $138=$ B. minor, S. Wats.

multiflora, Britten, in Journ. Bot. xxiv. (1886) 51 $=$ B. multiflora, Benth.

Orcuttii, Greene, in Bull. Calif. Acad. ii. vı. (1886) 138. - Calif.

paraiflora, Kuntze, 1. c. $711=$ B. multiflora, Benth.

patagonica, Kuntze, 1. c. $712=$ Milla patagonica, Baker.

peduncularis, Kuntze, 1. c. $=$ B. peduncularis, S. Wats

Poeppigiana, Kuntze, 1. c. = Milla Poeppigiana Baker.

porrifolia, Kuntze, 1. c. = M. porrifolia, Baker.

rosea, Greene in Bull. Calif. Acad. ii. VI. (1S86 137. - Calif.

Sellowiana, Kuntze, Rev. Gen. (1891) $712=$ Milla Sellowiana, Bakcr.

sessilis, Kuntze, 1. C. = M. sessiliflora, Baker

setacer, Kuntze, 1. c. = M. setacea, Baker.

stellaris, Greene, in Bull. Calif. Acad. ii. VI. (1886) $137=$ Brodiæa stellaris, S. Wats.

subbiflora, Kuntze, Rev, Gen. (1891) $711=$ Milla subbiflora, Baker. 
HOOKERA : -

errestris, Britton, ex Greene Man, Bot. San Franc. Bay (1894) $319=$ Brodiaea terrestris, Kell uniflora, Kuntze, Rev. Gen.(1891) $711=$ Milla uniflora, $R$. Grah.

HOMAIDA, Adans = Biarum, Schott(Aroid.).

Bovei, Carduchorum, eximia, Olivieri. Pyrami, Spruneri. tenuifolia, Kuntze, Rev. Gen. (1891) $742=$ homonyma omnia Biari.

Bovei, Baill. Hist. des pl. xiii. (1895) $456=$ B. Bovei, Blume.

graminea, Kuntze, Rev. Gen. (1891) $\% 42=\mathrm{B}$. tenuifolium, Schott.

Russelliana, Baill. Hist. des pl. xiii. (1895) $456=$ B. Russellianum Schott.

tenuifolium, Baill. 1. c. = B. tenuifolium, Schott.

HOMALANTHUS, A. Juss. (Euphorb.). - Ind. Kew. i. 1171

Moerenhoutianus, Benth. E Hook. f. ex Drake, Ill. Ins. Maris Pacif (1892) $293 \quad(=$ Carumbium Moerenhoutianum, Muell. Arg.). - Ins. Tahit.

nutans, Benth. Eo. Hook. f. ex Drake, l. c. $(=C$. nutans, Muell. Arg.). - Ins, Vitiens.

populneus, Pax, in Engl. E Prantl, Natirl. Pfanzenfam. iii. $5(1592) 96(=C$. populneam, Muell. Arg.). - As. trop.

HOMALIUM, Jacq. (Samyd.). - Ind. Kew. i. 1171 lbiflorum, Baill. in Bull. Soc. Linn. Paris, i. (1886) 575 (= Nisa albiflora, Boivo) = albiflorum, O. Hoffm, ?

axillare, Baill. $l . c, 574=$ axillare, Benth

Bailloni, S. Elliot, in fourn, Linn. Soc, xxix. (1891) 23. - Madag.

brachystylum, Baill. in Bull. Soc. Linn. Paris, i. (IS86) 573 (= Blackwëllia brachystylis, Tul.). Madag.

brevipedunculatum, S. Elliot, in fourn. Lim. Soc. xxix. (1891) 21. - Madas.

Buchholzii, Warb. in Engl. \& Prantl, Natür. Pfanzenfam. iii. 6a (1893) 36 - Afr. trop.

circumpinnatum, F.M. Bailey, in Dept. Agric. Brisbane Bot. Bull. v. (1892) 17. - Austral.

cymosulum, S. Elliot, in fourn. Linn. Soc, xxix. (1891) 22. - Madag.

dasyanthum, Warb. in Engl. \& Prantl, Natürl. Pfianzenfam. iii. 6a (1893) $36=$ Griffithianum Kurz.

Deplanchei, Warb.l.c.36 (= Blackwellia Deplanchei, Vieill.): - N. Caled.

dictyoneurum, Warb. 1. c. $36=$ Pierrea dictyoneura, Hance.

erianthum. Baill. in Bull. Sor. Linn. Paris, i. (1886) 574 ; et Hist.pl. Madag., Atlas, t. $132(=$ Blackwellia eviantha, Tul.). - Madag.

fasciculatum, S. Elliot, in fourn. Limn. Soc. xxix. (1891) 21. - Madag.

frutescens, Warb. in Engl. \& Prantl, Natïrl. Pfanzenfam. iii. 6a (1893) 36. - Java.

guianense, Warb. 1. c. = H. Racoubea, Sw.

Hildebrandtii, Baill. in Bull. Soc. Linn. Paris, i. (1886) $5 \pi 6=$ involucratum. O. Hoffm

Hoffmannianum, Baill. l. c. 575. - Madag.

hondurense, F. D. Smith, in Coult. Bot. Gaz. xx. (1895) 4. - Am. centr.

Humblotii, Baill. in Bull. Soc. Linn. Paris, i. (1886) 574. - Madar.

integrifolium, Baill. 1. c. = paniculatum, Eenth

integrifolium, S. Elliot, in Journ. Linn. Soc. xxix. (1891) $24=$ praec.

lanceolatum, S. Elliot, l. c. 23. - Madag.

laxiflorum, Baill. in Bull. Soc. Linn. Paris, i. (1886) 575 ; et Hist. pl. Madag., Atlas (1889) t. 126 (= Myriantheia laxiflora. Tul.). - Madas.

leucophlaeum, Baill. ll. co. 576; et t. 12S $(=$ Nisa leucophlaeum, Baill. ll. cc. 576
lencophloea, Tul.) - Madag.

lucidum, S. Elliot, in fourn. Linn. Soc, xxix. (1891) 24. - Madag.

nobile, Baill. in Bull. Soc.Linn. Paris, i. (1889) 575 et Hist. pl. Madag. Atlas (1859) t. 12\%. - Madag. nudiflorum, Baill. l.c. (= Nisa nudiflora, DC.). Madag.

oppositifolium, Baill.l.c. (= Myriantheia oppositifolia, Tul.). - Madas:

\section{HOMALIUM}

aniculatum, Baill. in Bull. Soc. Linn. Paris, $i$. (1886) 574 = paniculatum, Benth

planiflorum, Baill.l. c.; et Hist.pl. Madag. Atlas (1889) t. 133 (= Blackwellia planiflora, Boiv.).Madag

polyandrum, Warb. in Engl. \& Prantl, Naturl. Pfanzenfam. iii. 6a (1893) 36. - N. Calcd.

rubiginosum, Warb.l. c. (= Blackwellia nubiginosa, Vieill.). - N. Caled.

sanouineum, Baill. in Bull. Soc Linn. Paris, i. (1886) 575; et Hist. pl, Madag., Atlas (1889) t. 122 ( = Nisa sangunea, Boiv.). - Madas.

scleroxylon, Baill. Il. cc. 575; et t. 121 (= Nisa scleroxylon, Tul.). - Madag.

Stuhlmannii, Warb. in Engl. PAanzenw. Ost.-Afr.C (1895) 278. - Afr. trop, or.

Thouarsianum, Baill. in Bull. Soc. Linn. Paris, i. (1886) 571 a (= Blackwellia Thonarsiana, Tul,). Madas.

urceolatum, S. Elliot, in foum. Linn. Soc. xxix. (1891) 22. - Madag.

Villarianum, Vidal, Revis. Pl. Vasc. Filip. (1886) 142. - Ins. Philipp.

HOMALOCENCHRUS, Mieg. ex Hall. Hist. Stirp. Helv. ii. (1768), ex Kuntze, Rev. Gen. 1891) 777 = Leersia, Soland. (Gramin.). angustifolius, Kuntze, 1. c. - Afr. centr

Gowini, Kuntze, 1. c. = L. Gouini, Fourn.

lenticularis, Kuntze, 1. c. = L. lenticularis, Michx. lenticularis, Scribn. in Bull. Torrey Bot. Club, v. (1894) $33=$ praec

ligularis, Kuntze, Rev Gen. (1891) 777 = L. ligularis, Trin.

monandrus, Kuntze, 1, c, = L. monandra, Sw

ovatus, Kuntze, 1. C. = L. ovata, Poir.

rivginicus, Britton, in Trans. N. Y. Acad. Sci. ix. 1889) $14=\mathrm{L}$. virginica, $W_{\text {illd. }}$

HOMALOMENA, Schott (Aroid.). - Ind. Kew. i. 1171

angustifolia, Hook. f. Fl. Brit. Ind. vi. (1893) 533 (= Calla angustifolia, Jack). - Perak.

deltoidea, Hook. f.l.c 536.- Perak.

elliptica, Hook. f. l. c. - Perak

Griffithii, Hook. f. l. c. 534. - Malacca, Borneo

humilis, Hook, f. l. c.533-Penins. Mal., Borneo

Kingii, Hook. $f$, l. c. $535 .-$ Penins. Mal.

lancifolia, Hook. f. l. c. 533. - Penins, Mal,

nutans, Hook, f. l. c 525. - Perak.

obliquata, Hook ff l. c.534. - Penins, Mal.

ovata. Hook, f.l. c. 536 (= Chamaecladon ovatzm Schott). - Penins. Mal.

paludosa, Hook. f. l. c. 531. - Perak

pontederaefolia, Griff. ex Hook.f.l. c. 533. - Penins. Mal.

pumila, Hook. f.l. c. - Penins. Mal.

Scortechinii, Hook. f. l. c. 534. - Perak

trapezifolia, Hook.f.l. c. = Perak

truncata, Hook. f. l. c. 535 (= Chamaecladon trimcatum, Schott). - Penins. Mal.

velutina, Scortech. ex Hook. f. l. c. 534. - Perak.

HORMOLOTUS, Oliver, in Johnston, Kilima-njaro Exped.(1886) 337 et 339, nomen = Ornithopus, Linn. (Legumin.)

folmstoni, Oliver, 1. c. nomen $=0$. coriandrinus, Hochst. \& Steud.

HOMERIA, Vent. (Irid.). - Ind. Kew. i. 1172

bicolor, Klatt, in Th. Dur. Eo Schinz, Consp. Fl. Afr v. 1893 (1895) 15\% - Afr. austr

pallida, Baker, Handb. Ir d. (1892) 75.-Afr. austr.

HOMILACANTHUS, S. Moore, in Journ. Bot, xxrii. (1894) 129. ACANTHACEAE.

Gregorii, S. Moore, l.c. t. 343. - Afr. trop. or.

HOMOEANTHUS, Spreng, = HOMOIANTHUS, Bonpl. = Perezia. Lag. (Compos.).

bellidifolius, Phil, in Ann. Univ. Chil. 1xxxvii, (1894) 306. - Chili.

brevicanlis, Phil. 1. c. 309. - Chili

calophyllus, Phil. 1. c. $305 .-C h i 1$.

capito, Phil. 1. c, 309 - - Chili.
HOMOEANTHUS : -

humilis, Phil. in Anal Univ. Chil. lxxxvii. (1894) 307. - Chili.

miralis, Phil. 1. c. 308. - Chili.

Remyanus, Phil. I. c. 310 - Chili

triceps, Phil 1. c. 307 . Chili.

variabilis, Fhil. 1. c. 306. - Chili.

HOMOTROPA macranthum, Schuttl. ex Small, in Mem. Torrey Bot. Club., iii. (1893) 11, in syn. et iv. (1894) $150=$ Asarum virginicum, Linn.

HONGKENYA, Willd. (Tiliac.), - Ind. Kew. i. 1172 .

parva, K. Schum. in Bot. Fahrb. xv. (1893) 115. Afr. trop. occ

HONDBESSEION, Kuntze, Rey, Gen, (1891) "85 HONDBESSEN, Adans. = Paederia, Rupp. (Adans.)

calycinum, densiflorm, foetidum, Gardneri, lamuginosum, lineare, piliferum, tomentosum, rerticillatum, Wallichii, Kuntze, Rev. Gen. (189I) 285ั-6 $=$ homonyma omnia Paederiae,

HOODIA, Sweet (Asclep.). - Ind. Kew, i. 1172 parviflora, N.E. Br. in Kew Bull. (1895) 265. Angola,

HOOIBRENKIA formosa, Hort. ex Dippel, Handb. Jaubholzk. ii. (1892) $473=$ Staphylea colchica Stov.

HOOKERELLA, Van Tierh in Bull Soc, Bot. Fr. xlii. (1895) $26=$ Loranthus, Linn

temiflora, Van Tiegh. 1. c. $26=$ L. tenuiflorus. Hook. $f$

HOOKERINA, Kuntze, Rev. Gen. (1891) $718=$ Hydrothrix, Hook. f. (Ponted.)

Gardneri, Kuntze, 1. c. = Hydr. Gardneri, Hook.f.

HOPEA, Roxb. (Dipterocarp.).-Ind. Kew. i. 1173. Beccariana, Burck, in Ann. Fard. Buit.vi. (1887) 240. - Borneo.

borneensis, Heim, in Bull. Soc. Linn. Paris, ii. (1891) 972. - Borneo.

bracteata, Burck, in Ann. Fard. Buit.vi. (1887) 239 (= Balanocarpus Curtisii, King). - Borneo. celebica, Burck, l. c. vi. (1887) 23\%. - Ins. Celeb. cordifolia, Trim. Handb. Fl. Ceyl. i. (1S93) 126. Zeyl.

coriacea, Burck, in Ann. Fard. Buit. vi. (1887) $23 \%$. - Borneo.

Curtisii, King, in Fourn. As. Soc. Beng. Ixii, (1893) II. 124. - Perak.

Dyeri, Heim, in Bull. Suc. Linn. Paris, ii. (1891) 972 - Borneo.

ferrea, Lanessan, Pl. util. Colon. Franc. (1886) 300 Pierre, Fl. For. Cochinch, Fasc. 16 (1891) t. 249. - Cochinch.

ferrea, Heim, Recherch.Diptéroc.(18:2)62= praec. globosa, Brandis, in foun. Limn. Soc. xxxi. (1805) 61. - Perak.

orisea, Brandis, 7. c. 63. - Borneo.

Hasskarliana, Heim, Rech. Diptéroc. (1892) $64=$ micrantha. Hassk.

Heimiana, Brandis, in fourn. Limn. Soc. xxxi (1S95) 63 (= Cotglelobium hofeifolinm, Heim). Borneo.

Helferi, Brandis, l, c. 62 (= Vatica Helferi, Dyer) - Mernui.

intermedia. King, in fourn. As. Soc. Beng. 1xii (1893) II. 126. - Penang.

javanica, Burck, in foum. Lim. Soc. xxxi. (IS95) 64. - Java.

jaranica. Heim, Rech. Dipteroc. (1892) $64=$ Doona javanica, Burck

longiflora, Brandis, in fourn. Linn. Soc, xxxi. (189.5 63. - Borneo

Lowii, Dyer, ex Brandis, l. c. - Bolneo, Sumatra. microcarpa Heinn, in Bull. Soc. Limn. Paris, il. (1891) 954. - Borneo.

microptera, Dyer, ex Brandis, in Journ. Linn. Soc xxxi. (1895) $68=$ H. Dyeri, Him. 


\section{HOPEA}

multiflora, Brandis, in fourn, Limn. Soc. xxxi. 1895) 60. - Sumatra.

nervosa, King, in fourn. As, Sor. Beng. 1xii (1S93) II. 124. - Perak.

Ticholsoni, Heim, in Bull, Soc, Linn. Paris, ii. 1891) $971=$ H. Beccariana, Burck.

nigra, Burck, in Ann. Fard. Buit. vi. (1887) 238. Borneo

placrata, Vidal, Revis, Pl, Vasc, Filip. (1886) 62 (- Anicoptera pl-gata. Blume) - Ins. Philipp.

Recopei, Picrre, ex Laness. Pl. util. Colon. Franc (1886) 301 ; et Fl. For. Cochinch.Fasc. 16 (1891) t. 24\%. - Cochinch.

sarawakensis, Heim, in Bull. Soc. Limn. Paris, ii. (1891) 971. - Borneo

suaris, Kurz, ex Brandis, in Journ. Linn. Soc, xxxi. (1895) 62, in obs. = H. Helferi, Brandis.

Thorelii, Pierre, Fl. For, Cochinch. Fasc. 16 (1891) t. 245. - Cochinch

Treubii, Heim, in Bull. Soc. Linn. Paris, ii. (1891) 955 ; et Recherch. Diptéroc. (1892) 62. - Borneo.

Vesquei, Heim, in Bull. Soc. Linn. Paris, ii. (1891) 97. - Borneo.

HOPLOPHYTUM, Beer = Aechmea, Ruiz et Pav. (Bromel.)

dealbatum, Ed. Morr. ex Baker, Handb. Bromel. (1859) $58=$ A. dealbata, Ed. Morr.

grande, Ed. Morr. ex Baker, 1. c. $50=$ A. mexicana, Baker.

lincatum, Hort. Bull, ex Gard, Chron. (1893) i 4l4. [lineatus]. - Hab.

iuterm, Éd. Morr. ex Baker, Handb. Bromel. (1889) 42. = A. floribunda, Marl

Makoyanum, Hort. ex Rev.Hortic.(1894) 250.-Bras.

HORDEUM, [Tourn.] Linn. (Gramin.). - Ind kew. I. 1173.

Caput-Mcdusae, IIack. in Ens1. \& Prantl, Natïrl. Pflanzenfam, iii, 2 (1887) $83 \Leftrightarrow$ H. Caput-Me dusae, Loret \&o Barr.) = Elymus Caput-Medusae Limn.

crinitum, St. Lager, in Cariot, Etud. des fl. éd. 8 . ii. (1889) 910, in obs. ( $=H$. crinitum, Desf. $)=$ E. Caput-Medusae, Limn

cylindricum, St. Lager, 1. c. $09=\mathrm{H}$. cylindricum, Mure.

Delileamunn, Hack, in Engl.\& Prantl, Natürl. Pflanzenfam. ii. 2 (1887) $88=$ Elymus Delileanus Schult.

satirum, Jessen, Deutsche Excurs. F1. 55l ; ex G. Beck, Fl. Nied,-Oest. i. (1890) $117=$ sativum, Pirs.

HORKELIA, Cham. \& Schlecht. = Potentilla Linn. (Rosac.).

Kelloggii, Greene. in Bull. Calif. Acad ii. 11 .(1887) 4l6. - Calif.

Parryi, Greene, 1. c. - Calif.

HORSFIELDIA, Willd. = Myristica, Linn

glabra. Warb. in Ber. deutsch. Bot. Ges, xiii (189.) $[83]=$ M. glabra, Blune.

Irya, Warb.1.c. [85] = M. Irya, Gaevtn.

Teptocurpa, Warb. 1. c. [89], nomen. - Hab. ?

HORSFORDIA. A. Gray, in Proc. Am. Acad. xxii. (1857) 296. MALVACEAE.

alata, A.Gray.l.c.(=Sida alata, S.Wats.).-Mexic.

Newberryi, A.Gray, l. c. $(=$ Abutilon Newberyi,

Newberryi, A. Gray,

I'almeri, S. Wats, in Proc. Am. Acad, xxiv, Isso 40 - Calif. austr.

Purisimac, T. S. Brandeg. in Proc. Calif. Acad. Ser. II. ii. (1889) $135=$ rotundifolia. S. IV Wts. rotundifolia, S. Wats. in Prac. Am. Aad. xxiv. (1889) 40. - Calif.

IIORTENSIA, Comm. = Hydrangea, Linn. (Saxifr.).

ispera, Ham. ex Dippel, Haidb, LauLholzk, iii. (189.3) $319=$ Hydr. aspera, Dou.

HORTIA, Vand. (Rutac.) - Ind. Kew, i. 1115. megaphylla, Taub. in Bot. Fahrb. xv. 13cibl, n. 34. (IS92) 6. - Bras.
HORTONIA, Wight (Monim.).-Ind. Kew. i. 1175. augustifolia, Trim. Syst. Cat. Ceyl. Pl. (1885) 75 et Handl. Fl. Ceyl. iii. 43\%. - Zeyl.

HOSAGKIA, Dougl. (Legumin.). - Ind. Kew. i.

1175.
alamosana. N.E Rose, in Contrib. U.S. N'at. Hero. alamosana. $N . E$ Rose, in
i. (1891) $96 .-$ - Mexic.

Bryanti, T. S. Brandeg. in Proc. Calif. Acad. Ser. II. ii. (1889) 144. - Calif.

chihuahuana, S. Wats, in Proc. Am. Acad. xxiii. (1888) 270, - Mexic

denticulata, Drew, in Bull. Torrey Bot. Club, xvi. (1889) 151. - Calif.

Haydoni, C. R. Orcutt, in West Am. Sci. vi. (1S89) 63. - Am. bor $=0 \mathrm{Cc}$

maritima, Greene, Pittonia, i. (April 1889) $288=$ Lotus humilis, Greene.

nivea, S. Wats. in Proc. Am. Acad.xxii. (1887) 470. - Calif.

nudata, Vasey \& $\Lambda^{\top}$. E. Rose, in Contrib. U.S. Nat. Herb. i. (1890) 14 (= Syrmatinm matum, Greene). - Calif.

occulta, Greene, in Bull. Calif. Acad. ii. VII. (1887) 394. - Ins. S. Cruz (Calif.)

Palmeri, Vasey of N.E. Rose, in Proc. U. S. Nat. Mus. xi. (1888) 529. - Calif.

plebeia, T. S. Brandeg. in Proc. Calif. Acad. Ser. II, ii. (1889) 144. - Calif.

sericea, Trelease, ex Branner \& Coville, in Ann. Rep. Geol. Surv. Arkansas, iv. 1888. (1891) 174 $=$ H. Purshiana, Benth.

Waltoni, Vasey \& $N$. E. Rose, in Proc, U. S, N'at. Mus. xi. (1888) 528. - Calif.

HOSTA, Tratt. = Funkia, Spreng. (Liliac.) lancifolia, Engl, in Engl. \& Pranti, Natürl. Pflanzenfam. ii. 5 (1887) 40 = lancifolia, Tratt.

Sieboldinana, Engl. 1. c。 = F. Sieboldiana, Hook.

HORNEA, Baill. ( rassiflor.) - Ind. Kew. i. $11 \% 6$. guineensis, Warb. in Engl. \& Prantl, Natürl. Pflanzenfam. iii. 6a (1893) $26=$ Paropsia guineensis, Oliver.

HOUSTONIA, Gronov, ex Linn. (Rubiac.). Ind. Kew. i. 1176.

arenaria, N. E. Rose, ex Coult. G N. E. Rose, in Contrib. U.S. Nat. Herb. i. (1890) 700 - Calif, inf. asperuloidis, T. S. Brandeg. in Proc. Calif. Acad. Ser. II. iri. (1891) 142. - Calif.

Brandegeana, N. E. Rose, ex Cou?t. \& N.E. Rose, in Contrib. U. S. Nat. Herb. i. (1890) 83. - Calif. inf.

brevipes, $N . E$. Rose, l. c. 83. - Calif, inf.

Croftiae, Britton et Rusby, in Trans. N.Y. Aiad. Sci. vii. (1887) 10. - Texas.

fruticosa, $\Lambda^{\top}$. E. Rose, in Contrib. U.S. Nat. Herb. i. (1892) 132. - Ins. Carmen.

minor, Britton, in Mem. Torrey Bot. Club, v. (1894) $302=$ patens, Ell.

polypremoides, A. Gray, in Proc. Am. Acad. xxi. (1886) 379. - Mexic

salenia, Heller, [Bot. Explor. S. Tcxas] in Contrib. Herb. Frankl. and Marsch. Coll. i. (1895) 96. t. 9. - Texas.

HOUTTUYNiA, Thunb.(Piper.). - Ind Kew. i. 1176.

californica. T. S. Brandeg. in Proc. Calif. Acad. Ser. II. iii. (1891) $168=$ californica, Benth. \& Hook. $f$.

HOWELLIA A. Gray (Campanul.). - Ind. Kew. j. 1171 .

limosa, Greene, Pittonia, ii. (May 1890) 8I : et Man. Bot. San. Franc. Bay (1894) 228. - Calif.

HOYA, R. Br. (Asclep.). - Ind. Kew, i. $117 \%$.

affinis, Fiensl. in Kow Bull. (1892) 126: Olicer, in Hook. Icon. $f$. xxiii. (1892) t. 2247 B. - Ins. Salom

Aldrichii, Hemsl. in fourn, Limn. Soc. xxv. (1890) 355. - Ins. Christmas.

Cominsii, Hemsl, in Ann. Bot. v. (1891) 505 ; ct in Hook. Icon. pl. xxiii. (1892) t. 2248. - Ins. Salom.
HOYA

Guppyi, Olizer, in Guppy, Salom. Isl. 298; et in Hook. Icon. pl. xxiii. (1892) t. $2247 \mathrm{~A}$. - Ins, Salom. inconspicua, Hemsl. in Kew Bull. (1894). 213. Ins. Salom.

neo-guineensis, Engl. Bot. Fahrb. vii. (1886) 471.— N. Guin.

HUBERIA DC. (Melast.). - Ind. Kew. i. $11 \% 8$ glabrata, Cogn. in DC. Monog. Phan, vii. (1891) 409. - Bras.

Glazioviana, $\operatorname{Cog} n . l . c .-$ Bras.

minor, $\operatorname{Cog} n . l . c .-$ Bras.

parvifolia, $\operatorname{Cog} n$. l. c. 410. - Bras.

peruviana, Cogn. in Mart. Fl. Bras, xiv. IV. (1886) 10. - Peruv

triplinervis, Cogn. in DC. Monog. Phan. vii. (1891) 410 . - Bras.

HUERNIA, R. Br. (Asclep.). - Ind. Kew. i. 1178. arabica, N. E. Br, in Kew Bull. (1895) 265. - Arabia. aspera, N. E. Br. in Gard. Chron. (188\%) ii. 364; et in Bot. Mag. (1888) t. 7000. - Zanzib.

Engleri, Terrac. in Amn. Ist. Bot. Roma, v, (1894) 105. - Afr, trop. or.

Loeseneriana, Schlachter, in Bot. Fahrb.xx. Beibl, n. 51. (1895) 55. - Afr. austr.

macrocarpa, Schweinf. ex $K$. Schum. in Gavtenfl. (1892) 526 fig. 108; (1895) 353 t. 1416; ct in Monatssch. f. Kakteenk. iv. (1894) 155. - Eritrea.

Penzigii, N.E. Br, in Gard. Chron. (1822) i. 719. Afr. bor. or

Penzigii, Baker, ex Penzig, in Att. Congr. bot. Genova (1893) $349=$ praec.

primulina, N.E. Br. in Hook. Icon, pl. xx. (1890) t. 1906. - Afr. austr.

similis, N.E. Br. in Kew Bull. (1895) 265. - Angola.

Sprengeri, Schweinf, ex Dammann, Catal. (1893) 46: K. Schum. in Montasschr. f. Kakteenk. iii. (1893) 74 et 104 ; et ex Gard. Chron. (1893) i. $414=$ Caralluma Sprengeri, $N, E . B r$.

stapelioides. Schlechter, in Bot. Falirb, xx. Beibl. n. 51 (1895) 55, - Afr, austr.

HUFELANDIA, Nees = Beilschmiedia, Nees (Laurin.)

curviramea, Mez. in Jahrb. Bot. Gart. Berlin, v (1889) 18 = Aydendron curvirameum, Meissn.

emarginata, Mez, 1. c. 18 = Cryptocarya emarginata, Meissn

mexicana. Mez, 1. c. 20.-Mexic.

rigida, Mez, ex Taub. in Bot. Jahrb. xvii. (1893) 519. - Bras.

HUGONIA Linn. (Lineae). - Ind. Kew. i. 117s brewerioides, Baker, in foum, Linn. Soc. Xxy. (1859) 301. - Madag.

castanea, Baill. in Bull. Soc. Linn. Paris, i. (1886) 599 ; el Hist. pl. Madag., Atlas t. 117. - Madag. lancifnlia, Baill. l. c. 598. - Madag.

montana, Plerre, Fl. For. Cochincl. Fasc. 13 (1893) t. 281 A. - Cochinch.

sphaerocarpa, Baill, in Bull. Soc. Linm. Paris, i. (1856) 598 ; et Hist. pl. Mutag., Atlas t. 11\%. Madag.

HULLETIA, King, ex Hook. f. Fl. Brit, Ind. v. (1888) 547. URTICEAE.

dumosa. King l. c. - Perak.

Griffithiana, King, l. c. $(=$ Dorstestia Griffithiana, Kurz). - Perak.

HUMBLotiA, Baili, in Bull. Soc. Linn. Paris, i, (1886) 593 ; et Hist. pl. Madag., Atlas (1892) t 220 : Pax, in Encl. \& Prantl, Natïrl. Pflanzenfam. iii. 5 (1890) 23. EUPHORBIACEAE. comorensis, Baill.ll. cc. - Ins. Comor.

HUMBOLDTIA, Ruiz \& Pav, = Pleurothallis, R. Br. (Orchid.

aidanthera, acuminata, acutissima, affinis, agatopliylla, alpestris, amoena, angustifolia, antennifera, apiculata arachnantha, Arbuscula, Archidonae, arcuata, aris tata, articulata, asperilinguis, atropurpurea, aurca, auriculata, barbata, Barberiana, barbulata, Beyrichiz,

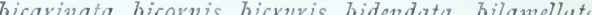
Bisorma, binalits, boliviana, brevifora, brevipes. 
HUMBOLDTIA : -

Bufonis, cabellensis, capillaris, cardiostola, cardiothallis, Cardium, casapensis, Cassidis, caulescens. cauliflora, Centranthera, Chamaelepanthes, chamensis, chloidophylla, chlorolenca, chrysantha, cilixta, circumplexa, clandestina, cochlearis, conanthera, consoluta, cordata, cordifolia, coriacardia, corniculata, crassifolia, crassipes, crenata, crepidophylla, crocodiliceps. cubensis, cyclochila, declivis, decurrens, decurva, delicatula, dendrophila, diffusa, Dinotherii, diptera, dubia, dutra, elegans, elongata, emarginata, endotrachya, ephemera, erinacea, exasperata, expansa, filifera, fimbriata, flexuosa, floribunda, floripecten, Horulenta, Fockei, foetcus, foliata, fonsfornm, foveata, fragilis, fraterna, Fritillaria, Fugi, fulgens, galeata, gelida, geniculata, gigantea, glanduligera, Glossopogon, ghumacea, gracillima, grandiflora, gratiosa, Grobyi, harhophylla, Hartwegii, hastulata, hemirhoda, hians, Hoffmannseggiana, hymenantha, hypnicola, Hystrix, immersa, Imrayi, inalequalis, incompta, incuria, insignis, intricata, Kefersteiniana. Klotzschiana, Krameriana, lavoigata, lamellaris, Lanceana, Lanceola, lanceolata, lateritia, laurifolza, laxa, leontoglossa. leucopyramis, ligulata, Lindenii, Linngua, linguifera longicaulis, longilabris, longerostris, loranthophylla, luctuosa, macra, macrocaydia, macrophylla, macrorhiza, Magdalenae, malachantha, Mandonii, margizalis, marginata, Matthewsi, memor, mevidana, microcardia, microlepanthes, microphylla, mimutalis. Miqueliana, misera, modestissima, monocardia, Moritzi, moschata, maramensis, navicularis, navilingins, nicaraguensis, mittiorhyncha, oborata, ochreata, orbicularis, pachyglossa, tachyphylla, palmiformis, pandurifera, Pantasmi, papillosa, parvifolia, pectinata peduncularis, pedunculata, perpusilla, pliyllocardia, picta, pilifera, pisifera, plantaginea, plumosa, Poeppigii, polylivia, polystachya, pristeoglossa, procumbens, prolifera, prostrata, pruizzosa, pubescens, pulchella, punctata, punctulata, pusilla, pyrsodes, quadrifida quitensis, vacemiflora, ramulosa, recurva, retusa. vigidifolia, Roezlei, roseopunctata, rostriflora, rubens, rubrovividis, ruberrima, rufobrunnea, rupestris, ruscifolia, saltatoria, Sanderana, sarcophylla, santocephala, scabrata, scabrilinguis, scabripes, scariosa, Schiedei, sclerophylla, secunda, segoviensis, semipellucida, semiscabra, scmperflorens, seriata, serrifera, setigera, sicrria, Sirene, Smithiana, soratana, sphenochila, spiculifera. Sprucei, stenopetala, stenostaclyy, striata, strupifolia, subsinuata, tentaculata, tenuissima, teres, tricarinata, trichophora, trichopoda, tridentata, trifida, trilineata, tripterantha, tripterygia, Trulla truncata, truxillensis, tubulosa, undulata, uniflora univaginata, velaticaulis, velatipes, ventricosa, verntcosa, villosa, violacea, viridula, vittata, Warmingii, Weddelliana, Wilsonii, xanthochlora, xiphochila, zephyrina, Kuntze, Rev. Gen. (1891) 666-68= homonyma omnia Pleurothalleos.

aspasiensis, Kuntze, 1. c. $66 \tau=$ Pleurothallis aspasicensis, Reichb. $f$.

biflora, Kuntze, 1. c. $=\mathrm{P}$. orbicularis, Lindl.

ceratothallis, Kuntze, 1.c. = P. ceratathallis, Reichb.f. discodea. Kuntze, 1. c. $=$ P. discoidea, $L$ indl.

Gardneri, Kuntze, 1. c. = Restrepia Gardneri, Benth.

famesonii, Kuntze, 1. c。 = Pleurothallis Jamiesoni, Lindl.

lepanthiformis, Kuntze, 1. c. = P. villosa, Knowul. E Westc.

longissima, Kuntze, 1. c. = P. racemiflora, Lindl.

Miersii, Kuntze, 1, c, $668=$ Restrepia Miersii

Reichb.f.

monoplyylla, Kuntze, 1. c. $667=$ Pleurothallis emarginata, Lindl.

Mosenii, Kuntze, 1. c. = P. Moseni, Reichb.f. muscodea, Kuntze, 1. c. = P. muscoidea, Lindl.

octomeriodes, Kuntze, 1. c. = P. octomerioides, Lindl.

pachyphylla, Kuntze, 1. c. $666=$ P. crassifolia, H.C. Focke.

phalangifera, Kuntze, 1. c. $667=$ P. Mathewsii, Linal.

polygonodes, Kuntze, 1. c. = P. polygonoides, Griseb.

Reichenbachiana, Kuntze, 1.c. = P. Roezlii, Reichb.f. restrepiodes, Kuntze, 1. c. = P. restrepioides, $L$ indl. Reymondi, Kuntze, 1. c. = P. Raymondi, Reichb. $f$.

\section{HUMBOLDTIA}

sertulariodes, Kuntze, Rev. Gen. (1891) $668=$ Plenrothallis sertularioides, Spreng.

subellucida, Kuntze, 1. c. $66^{\circ}=$ P. loranthophylla Reichb. $f$.

testifolia, Kuntze, 1, co = P, testaefolia, Lindl.

tribulodes, Kuntze, 1.c. $=$ P. tribuloides, Lindl.

ujarensis, Kuntze, l c. = Restrepia ujarensis, Reichb. $f$.

villipensa, Kuntze. 1. c. = Pleurothallis vilipensa, Reichb.f.

HUMBOLDTIA, Vahl (Legumin.). - Ind. Kew. 1179

decurrens. Bedd. ex Oliver, in Hook. Icon. pl. xxiv. (1895) t. 2368. - Travanc.

HUMEA, Sm. (Compos.). - Ind. Kew。 i. 1179 corymbulosa, F. Muell, in Vict. Natural, ix. (Jan. (1893) $397^{\circ}$ (= Pithocarta corymbastoso, Lindl ). Austral.

gracillima, $F$, Muell, $l l . c c,-$ Austral

macra, F. Muell. ll.cc. (= Acomis macra, F. Muell. $)$ - Austral.

rutidosis, F. Muell. ll. cc. (= Acomis rutidosea,

F. Muell.). - Austral.

HUNTERIA, Roxb. (Apocyn.). - Ind. Kew. i. 1179

africana, K. Schum, in Engl. Pfanzenw. Ost-Afr. C (1895) 31\%. - Afr. trop. or.

HUSSONIA, Boiss, = Enarthrocarpus, Labill. (Crucif.).

Sonisii, Pomel, ex Coss. Comp. Fl. Atlant. ii, (1887) 216, in syn, = Erucaria Aegiceras,' 'f. Gay.

HUTChINSIA, [R. Br.] Ait. (Crucif) - - Ind. Kew. i. 1180.

gracilis, Hort. ex Kew Bull. iii. (1889) 43, nomen. - Hab.

panciftora, Cabanès, in Bull. Soc. sci. nat. Nimes xix. (1891) $18=$ Capsella pauciflora, Koch. perpusilla, Hemsl. in Hook. Icon。 pl. xvi. (1887) t. 1599. - Gilgit.

HUTERA. Porta, in Atti Accad. Agiati, ix. 1891 (1892) 6; Willk. Suppl. Prodr. Fl. Hisp. (1893) 293. UMBELLIFERAE.

rupestris, Porta, l. c. (= Coincya mupestris, Rouy $)$. - Hisp.

HYACINTHELLA, Caruel, Epit. FI, Eur, i. (1892) $46=$ HYACINTHELLA, Schur = Hyacinthus, Tourn. (Liliac.).

HYAGINTHUS, [Tourn.] Linn, (Liliac.). -- Ind. Kew. i. 1180 .

Battandieri, Th. Dur. E Schinz, Consp. Fl. Afr. v. 1893 (1895) 386 (= Belleralia Battandieri, Freyn). - Algeria.

fallax, Th. Dur, \& Schinz, l. c. $387=$ ( $=$, fallax, Pomel). - Algeria.

mauritanicus, Th. Dur. Eo Schinz. l.c. (= B. manvitanica, Pomel). - Algeria

Pechuelii, Kuntze, in fahrb. Bot. Gart. Berl. iv, (1886) 274 (= Psendogaltonia Pechuelii, Kuntze). - Afr. austro-occ. extratrop.

variabilis, Th. Dur. of Schinz, Consp. Fl. Afr.v. 1893 (1895) 388 (= Bellevalia variabilis, Freyn). - Algeria.

HYBANTHUS, Jacq. =- Ionidium, Vent. (Violar.). albus, Taub. in Erigl. \& Prantl, Natürl. Pflanzenfam. iii. 6 (1895) $333=\mathrm{I}$. album, A. St . Hil. bicolor, Taub. 1. $c_{0}=\mathrm{I}$. bicolor, A. St. Hil. brevicaulis, Taub. 1. c. = I. brevicaule, Mart brexifolizs, Baill. in Bull. Soc, Linn. Paris, i. (1886) 584 (= Viola buxifolia, Poir.). - Madag. communis, Taub, in Engl. \& Prantl, Natürl. Pflanzenfam. iii. 6 (1893) $333=\mathrm{I}$. commune, $A$. St. Hil.

Ipecacuanha, Baill. ex Laness. Pl. util. Colon. Franç, (1886) $401=1$. Ipecacuanha, Vent
HYBANTHUS:-

lanatus, Taub. in Engl, \& Prantl, Natürl. Pflan-
zenfam. iii. 6 (1893) $333=$ Ionidium lanatum. A. St. Hil.

linifolins, Baill. in Bull. Soc. Linn. Paris, i: (1886) $584=\mathrm{I}$. linifolium, $D C$.

miniatus, F. Muell. \& Tate, in Trans. et Proc. Roy. Soc. S. Austral. xiii. (June 1890) 97; xix. (July 1895) $83=\mathrm{I}$. heterophyllus, Vent.

Poya, Taub. in Engl. \& Prantl, Natürl. Pflanzenfam. iii. 6 (1893) $333=$ I. Pooya, A. St. Hil.

suffruticosus, Baill. ex Laness. Pl. util. Colon. Franc. ( I886) $606=\mathrm{I}$. heterophyllum, Vent.

villosissimus, Taub, in Engl, \& Prant1, Natürl. Pflanzenfam. iii. 6 (1895) $333=\mathrm{I}$. villosissimum, A. St. Hil.

HYBOPHRYNIUM, $K$. Schum. in Bot. Jahrb. xv. (1893) 428. MARANTACEAE.

Braunianum, K. Schum. l. c. - Afr。 trop.

HYDNOGARPUS, Gaertn. f。 (Bixin.). - Ind.

\section{Kew, i. 1182.}

anthelminthicus, Pierre, ex Laness, Pl. util. Colon. Franc. (1886) 303. [sphalm. Hydrocarpus]. Cochinch.

cucurbitina, King, in fourn. As. Soc, Beng. lix. (1890) I. 120. - Malaya.

Curtisii, King, l.c. 119. - Malaya

Kingii, Warb. in Engl. \& Prantl, Natürl. Pflanzenfam. iii. 6a (1893) $21=$ Scortechinii, King. Kuenstleri, Warb. 1. c. = Taraktogenos Kunstleri, King.

Kurzii, Warb. 1. c. $=$ F. Kurzii, King.

macrocarpa, Warb. 1. c. = Asteriastigma macrocarpa, Bedd.

nana, King, in fourn. As. Soc. Beng. lix. (1890) If. 118. - Malaya.

Scortechinii, King, l. c. 118, - Malaya.

serrata, Warb. in Engl, \& Prantl. Natiirl. PAlanzenfam. iii. 6a (1893) 21. - Cochinch.

tomentosa, Warb. 1. c. = Taraktogenos tomentosa, King.

Wrayi, King, in foum. As. Soc. Beng. lix. (1890) II. 121. - Malaya.

HYDNOPHYTUM, Jack (Rubiac.). — Ind. Kew.

1. 1rari, K. Schum, in Bot. Fahrb. ix. (1888) 221 N. Guin.

costatum, Drake, in Morot. Fourn. de Bot.x. (1895) 240. - Tonk

Forbesii, Hook. f. in Bot. Mag. (1892) t. 7218. N. Guin.

Hellwigii, Warb. in Bot. Fahrb. xviii. (1894) 209. Oceania.

laurifolium, Warb. l. c. 210. - N. Grin.

macrophyllum, Warb. l. c. xiii. (1891) 441. Oceania.

HYDNORA, Thunb. (Cytin.). - Ind. Kew. i. 1182 bogonensis, "Becc." Martelli, Fl. Bogos. (1886) 70 = bogotensis, Becc.

HYDRAGONUM, Sieg, Fl. Petr. (1736), ex Kuntze, Rev.Gen. (1891) 390 = Cassandra, D. Don (Ericac.).

calyculatum, Kuntze, 1. c. = C. calyculata, D. Don.

HYDRANGEA, Gronov, (Saxifr.). - Ind. Kew.

\section{i. $118 \%$.}

Bretschneiderii, Dippel, Handb. Laubholzk. iii.(1894) 320. fig. 171. - China.

cyanea, Hort. ex Gard. Kew, i. Polypet. (1894) 223 $=\mathrm{H}$. Thunbergii, Sieb.

cyanoclada, Hort. 1. c. $221=$ H. Hortensia, DC. var.

Davidi, Franch. in Nowv. Archiv, Mus. Paris, Sér. II viii, 1885. (1886) 22\% - Tibet.

integerrima, Engl. in Eng1. \& Prantl, Natürl. Pflanzenfam. iii. $2 a(1891) 76=$ scandens, Pocpp Jelskii, Zahlbr. in Diss. Cl. matho-physs, Acad. litt. Cracov. xxix. (1894) 218. - Peruv.

longipes, Franch, in Nowe. Arch. MIus. Paris, Sér. II viii. (1886) $22 \%$ - China o 


\section{HYDRANGEA}

longipes, Henisl. ex Forb. 'E Hemsl. in fourn, Linn. Soc xxiil. (1887) 273 , - China.

macrocephala, Hort, ex Dippel, Handb, Laubholzk. iii. (1893) $322=$ opuloides, Lam.

mandschurica, Hort. ex Dippel, 1. c. 323; Koehne, Deutsche Dendrol. (1893) $18 \%=$ opuloides, I anin.

migra, Hort. ex Dippel, 1. c. = opuloides, Lam.

peckinensis, Hort. ex Dippel, 1. c. $320=\mathrm{H}$. Breitschneideri, Dippel.

roseo-alba, Hort. ex F1. des Serres (1894) 221, t. $1649-50=\mathrm{H}$. Hortensia, $D C$.

sinensis, Hort. ex Gard. Kew, i. Polypet (1894) 221 = radiata, Walt.

serratifolia, Engl, in Engl \& Prantl, Natürl. P'llanzenfam. iii. 2a (1891) $76=$ serratifclia. Plizil. f.

Sieboldii, Hort, ex Dippel, Handb. Laubholzk. iii. (1893) $323=$ opuloides, Lam.

sikokiana, Maxim, in Bull. Acad, sci. St. Pétersb. xxxi. (1887) 45. - Japon.

sinensis, Hort ex Dippel, Handb. Laubholzk. iii. (1893) $322=$ opuloides, Lam.

urticafolia. Hort. ex Dippel, 1. c. 314 ; et ex Gard. Kew, i. Polypet. $(1894) 219=$ arborescens, $L$ inn.

HYDRIASTELE, H. Wend1. \& Drude (Palm.). - Ind. Kew i. 1183.

Wendlandiana, Baill. Hist. des pl. xiii. (1895) $342=$ H. Wendlandiana, H. Wendl. \& Dride.

HYDROCOTYLE, [Tourn.] Linn: (Umbcll.):Ind. Kew. i. 1183

alsophila, Colenso, in Trans, $N, Z$. Inst, xviii, 1885 (18S6) 261. - N. Zel.

ambigua, Britton, Stern \& Pogg. Prelim. Catal. (1888) $21=$ umbellata, Linn.

amoena, Colenso, in Trans. N. Z. Inst, xxi. 1888 (1889) 83. - N. Zel.

araucana, Phil. in Anal. Unir. Chil. Ixxxv. (1894) 509. - Chili.

Canbyi, Conlt. \& N. E. Rose, in Bot. Gaz: xii. (1887) 103; et Rev. N. Am. Umbell. (1888) 135. - Civit Foed.

capensis, Kuntze, Rev. Gen, (1891) 268 = H. Solan-

dra, Linn.f.

Carrerae, Phil. in Anal. Univ. Chil. 1xxxv. (1894) 507 . - Chili.

colorata, Colenso, in Trans. N.Z. Inst. xviii. I885 (1886) 260. - N. Zel.

comocarpa, F. Muell. in Vict. Natural. iii. (June

1887) 127 ; et ex Bot. Centralbl. xxx. (1887) 214. -

Austral.

corynophora, F. Muell. in Proc. Linn. Soc. N. S. Wales, Ser. II. v. (June 1890) 20. Austral.

eccentrica, Britton, in Bull. Torrey Bot. Club, xviij. (1890) 36. - Bolivia.

echinella, Colenso, in Trans. N. Z. Inst. xx. 1887 (1888) 191. - N. Zel

ecostata, Collett \& Hemsl, in Fourn. Linn. Soc. xxvi11. (1890) 62. - Ind. or.

heterophylla, Schin\%, in Bunl. Herb. Boiss. nii. (1895) 410. - Afr. austr.

involucrata, Colcnso, in Trans. N. Z. Inst. xix. $1886(1887) 26 \% .-\mathrm{N} . \mathrm{Zel}$

Lechleri, Phil. in Anal. Unia. Chil. Ixxxv, (IS:4) 508. - Chili.

nitens, Colcnso, in Trans, N. Z. Inst, xxiii, 1890 (1891) 386. - N. Zel.

novo-guineensis, Warb. in Bot. Fañb. xvi. (IS93) 24. - N. Guin.

nuanavoides, F. Muell, in Bot. Contralbl. 1. (1892) 194, nomen. - N. Guin.

pauciflora, Phil, in Anal. Univ. Chil. 1xxxy. (1894) 508. - Chili.

Rahmeri, Phil. l. c.50\% - Chili.

ramiflora, Maxim. in Bull. Acad. sci. St. Pitersb. xxxi. (1887) 46. - Japon.

rubescens, Franch. in Bull. Soc. Phitom, Paris

Ser. VIII. vi. (1894) 108. - Yunnan.

septemloba, Schinz, in Bull. Hcrb. Boiss. iii. (1895) 410.- Afr. austr

sibthorpioides, Colenso, in Trans. N. Z. Inst. xxi. 1888 (1889) S3. - N. Zel.

\section{HYDROCOTYLE :}

sylvicola, Cordem. Fl. Ile Réunion (1895) 434. Ins. Borbon.

uliginosa, Phil. in Anal. Univ. Chil. 1xxxv. (1894) 509. - Chilj.

Wilfordi, Maxim. in Bull. Acad. sci. St. Pétersb. xxxi. (1887) 45. - Japon.

HYDROLEA, Linn. (Hydrophyll.). - Ind. Kew. i. 1184

sansibarica, Gilg, in Engl. Pfanzenw. Ost-Afr. C (1895) 335 . - Afr. trop. or.

HYDROSME, Schott $=$ Amorphophallus, Blu me (Aroid.).

borneensis, Engl. Bot. Jahrb. xv. (1893) 458, nomen. - Borneo.

dracontioides, Engl. 1. c. 461. - Afr. trop. or.

Fischeri, Engl. 1. c. 460.- Afr. trop. or.

Hohenackeri, Engl. in Engl. \& Prantl, Natiirl. Pflanzenfam. ii. 3 (1887) 128. - Hab

Leopoldiana, Mast. in Gard. Chron. (1887) i 542 et 544 fir. 122 et 123 ; et in Illustr. Hortic xxxiv. (1887) 65 t. 23. - Congo.

Preussi, Engl. Bot. Jahrb. xv, (1893) 459. Kamerun.

sparsiftora, Engl. 1 c. 462. - Afr. trop.

HYDROSTACHYS, Thou. (Podost.). - Ind. Kew, i. 1186.

Bismarckii, Engl. Bot. Fahrb. xx. (1894) 137. Congo.

Hildebrandtii, Engl. l. c. 136. - Madar

multipinnata, Engl. l. c. 137. - Afr. trop, or.

nana, Engl. l. c. 136. - Madag.

pinnatifolia, Engl. l.c. 137. - Madag.

Rutenbergii, Buchenau, in Abh. naturw. V'er. Brem. x. (1889) 375, t. 6 fig. 1-8. - Madar.

HYDROTAENIA, Lindl. (Irid.). - Ind. Kew. i. 1186

Van Houttei, Baker, Handb. Irid. (I892) $69(=$ Tigridia Van Houttei, Roez1). - Mexic.

HYDROTHRIX. Hook, fo in Ann, Bot. i. (1887) 889: Schoenl, in Engl. \& Prantl, Naturl. Pflanzenfam. ii. 3 (1887) 75. PONTEDERIACEAE. Gardneti, Hook. f. ll. cc. 90, t. 7, et 75 - Bras.

HYGROPHILA, R. Br.'Acanth.). - Ind. Kew.

\section{i. 1186.}

asteracanthoides, Lindau, in Bot. Fahrb. xx. (1894) 6. - Abyss.

coevulea, Martelli, in Nuov. Giorn. Bot. Ital. xx. 1888) $390=$ coerulea, T. Anders

crenata, Lindau, in Bot. Fahrb. xx. (1894) 6. - Afr. trop. or.

glandulosa, Lindau, in Eng1. Pflanzenw. Ost-Afr C (1895) $367=$ Nomaphila glandulosa, Klotzsch. lacvis, Lindau, in Engl. \& Prantl. Natürl. Pflanzenfam. iii. 3b (1895) $297=\mathrm{N}$. laevis, Nees.

parviflora, Lindau, in Bot. Fahrb. xx. (1894) 7. Afr. trop. or.

petiolata, Lindau, in Engl. \& Prantl, Natürl. Pflanzenfam. iii. 3b (1895) 297 = Nomaphila petio lata, Decne.

quadrangularis, Lindau, in Eng1. Pflanzenw. OstAfr. C (IS95) $367=\mathrm{N}$. quadrangularis, Klotzsch. saxatilis, Ridl. in Trans. I imn. Soc. Ser. II. iii (1893) 333. - Penins. Mal.

spiciformis, Lindan, in Bot. Fahrb. xx. (1894) 5. Afr. trop. or.

stricta, Lindau, in Engl. \& Prantl, Natürl. Pflanzenfam. iv. 3b (1895) $297=$ Nomaphila stricta, N'ees.

Teuszii, Lindau, l. c. 5. - Angola.

Volkensii. Lindaw, l. c. xix. Beibl, n. 47 (1894) 46 . $\rightarrow$ Afr. irop.or.

HYLODENDRON, Taub, in Engl. \& Prantl, Natiirl. Pflanzenfam. 1ii. 3 (1894) 386. LEGUMI NOSAE.

gabunense, Taub. l. c. - Gabon.

HYLOGYNE, Salisb. \& Knight = Telopea, R. Br (Proteac.).
HYLOGYNE : -

oreades, Kuntze, Rev. Gen. (1891) $5 \% 8=$ Telopea oreades, F. Muell.

spathulata, Kuntze, l, c. $=$ T. speciosisssima, $R . B r$. truncata, Kuntze, 1, c. $=\mathrm{T}$. truncata, $R . B r$.

HYLOMECON, Maxim. = Stylophorum, Nutt. (Papaver.).

japonicum, Prantl, in Engl. \& Prantl. Natürl. Pflanzenfam. iii, $2(1889) 1: 39=\mathrm{S}$. japonicum, Miq.

HYLOPHILA, Lindl. (Orchid.). - Ind. Kew. i. $118 \%$

lanceolata, Hook. f. Fl. Brit. Ind. vi.(1890) $110=$ lanceolata Miq.

HyMENACHNE, Beauv. = Panicum, Linn. tGramin.)

polymorpha, Balansa, in Morot, Journ. de Rot, iv (1890) 143, - Cochinch.

HYMENAEA, Allem. (Legumin.), - Ind. Kew. i. 1187 microphylla, Rodr. Hort. Flumin. 1893 (1895) $14 \%$. - Bras.

HYMENANTHERA, R. Br. (Violar.). - Ind. Kew, i. 1187.

obovata, T. Kirk, in Trans. N. Z. Inst. xxvii, 18,4 (1895) $350 .-\mathrm{N}$. Zel.

HYMENATHERUM, Cass. (Compos.). - Ind.

\section{Kew. i. 1187.}

anomalum, Canby \& N. E. Rose, in Contrib. U. S. Nat. Herb. i. (1891) 105. - Mexic.

HYMENOCALLIS, Salisb. (Amary11.). - Ind, Kew.1.1187.

concinna, Baker, in Gard. Chron. (1893) ii. 150. Mexic.

deflexa, Baker, Handb. Anaryll. (18S8) 12S (= Ismene deflexa, Herb.). - Peruvia.

Deleuilii, Hort. ex Rev. Hortic. (1894) 218. - Tonkin.

galvestonensis, Baker, Handb. Amaryll. (1888) 121. - Texas.

Horsmanni, Baker, l. c. 125, - Mexic

Niederleinii, Pax, in Bot. fahrb. xi. (1890) 326. Rég. Argent.

nutans, Baker, Handb. Amaryll. (1888) 128 (= Ismene nutans, Herb.). - Am. austr.?

HYMENOGARDIA, Wall. (Euphorb.). - Ind. Kew. i. 1188

lasiophylla, Pax, in Bot. Fahrb. xix. (1894) 79. Afr. trop. or

mollis, Pax, l. c. xv. (1893) 528. - Afr. trop.

Poggei, Pax, l. c. 529. - Afr. trop.

HYMENOCHARIS, Salisb. = Ischnosiphon, Koern. (Scitam.).

Arouma, bambusacea, densiflora, farinosa, grocilis, guianensis, hirsuta, Koernickiana, laxa, lencophaea, orbiculata, ovata, Parkeri, plurispicata, rotundifolia, secunda, smaragdina, spicata, surinamensis, Kuntze, Rev. Gen. (1891) 691 = homonyma onnia generis Ischnosiphonos.

faiquinii, Kuntze, 1. c. = I. polyphyllus, Koorn.

HYMENOPAPPUS, L'Hérit. (Compos.). - Ind. Kew. i. 1189.

caroliniensis, Porter, in Mem. Torrey Bot. Club, v. (1894) $338=$ scabrescens, L'Hérit.

radiata, N. E. Rose, in Contrib. U.S. Nat. Herb, i. (1891) 122. - Arizona.

HYMENOTHRIX, A. Gray (Compos.). - Ind. Kew. i, 118?.

glandulosa, S. Wats, in Proc. Am. Acad. xxiii. (18S8) 278. - Mexic.

Palmeri, A. Gray, l. c. xxi. (18S6) 391. - Mexic.

HYMENOXYS, Cass. (Compos.). - Ind, Kew. i 1189.

Schaffneri, Sch. Bip. ex Klatt, in Leopoldinc. Heft xxiii. (1887) 146. - Mexic. 
HYOSGYAMUS, [Tourn.] Linn. (Solan.). - Ind. Kew. i. 1189.

Boceanus Aschers. \& Schweinf. (Illustr. Fl. Égypt.) in Mém. Inst. Egypt. ii. (1887) 113 = Scopolia Boveana, Dunal.

flaccidus, Wright. in Kew Bull. (1895) 1S4. Arabia.

saguntinus, Pau, Not. Bot. Fl. Españ. iii. (1889) 34, nomen. - Hisp.

IIYPAELYPTUM, Tahl = Hypolytrum, Rich. (Cyper.).

albiceps, K Schum. in Engl. Pflanzenw. Ost-Afr. C (1895) $127=$ Lipocarpha albiceps, Ridl.

fulcherrimum. K. Schum. 1. c. = L. pulcherrima, Rial.

senegalense, K. Schum. 1. c. = L. argentea, R. Br.

HYPECOUM, Tourn. ex Linn. (Papaver.). - Ind. Kew: i. 1190.

acgyptiacum, Aschers. et Schweinf. (Illustr. Fl. Egypt.) in Mém. Inst. Ésypt. ii. (1887) $37=$ imberbe, Sibth.

ponticum, Velen. in Silzb. Boelin. Ges. Wiss, 1893 (1894) ii. 37. - As. Min.

IIYPERICOIDES, gummifera, Cambess, ex Vesque in DC. Monog. Phan. viii. (1893) 334, in syn. = Garcinia Smeathmanni, Olizer.

HYRERIGUM, Tourn, ex Linn. (Hyper.). - Ind. Kew. i. 1191.

aetneum, Tornab. Fl. Sicula (1987) 171. - Sicil.

Ardasenovi, Keller of Alboff, in Bull. Herb. Boiss. ii. (1894) 450 - - Reg. Cauc.

bacciferum, St Lager, in Cariot, Étud. des fl. éd. 8, ii. (1889) $140=\mathrm{H}$. Androsaemum, Linn.

boreale, Bicknell, in Bull. Torrey Bot. Club, xxii. (1890) $211=$ mutilum, Linn, var

Decaisneanum, Coss. \& Dareau, in Bull. Sor. Bot. Fr. xxxvi. (1889) 104. - Cyren.

depilatum, Freyn \& Bornm. ex Freyn, in Oest. Bot. Zeitschr. xli. (1891) 360 = origanifolium, Willd.

fimbriatum, St Lager, in Cariot, Étud. des fl. éd. 8, ii. (1889) 138 = fimbriatum, Lam.

galioides, Freyn \& Sint. in Bull. Herb. Boiss. iii (1895) 103. - Armen.

geminiflorum, Himsl. in Ann. Bot. ix. (1895) 144. - Ins. Formosa.

gentianoides, Britton, Stern \& Pogg. Prelim. Catal. (1888) $9=\mathrm{H}$. Sarothra, Michx.

Gumbletoni, Hort. Segrez. ex Gard. Kew, i. Polypet. (1894) $39=$ patulum, Thunb.

haplophylloides, Haláczy \&o Baldacci, in Verh. zool. bot. Ges. Wien, xlii. 1892 (1893) 578. Albania.

irazuense, Kuntze, Rev. Gen. (1891) $61=$ stenopetalum, Turcz.

Jankae, Nym. Consp. Fl. Eur., Suppl. ii. 1. (1889) 75. - Thrac.

kemense, Schwoinf. in Hoelnel, Zum Rudolph See, Append. (1892) 15. - Afr. trop. or

kiboènse, Oliver, in Trans. Linn. Soc., Ser. II. ii. (1887) 329. - Afr. trop. or.

kiloënse, Oliver, in $H$. fohnston, The Kitim. Exped. Append. (1886) 338, nomen (an praec.?). - Afr. trop.

lobocarpum, Gattinger, The Tennessee Flora (1887) 28 [labocarpum]; et in Coult. Bot. Ga\%.xi. (1886) 275. - Am. bor.

longistylum, Oliver, in Hook. Icon. pl. xvi. (1886) t. 1534. - China.

Macgregorii, F. Muell, in Trans. Roy. Soc. Vict. N. S. i. H. (1889) 2. - N. Guin.

macrocalyx, Freyn, in Bull. Herb. Boiss, iii. (1895) 103. - - As. Min.

majus, Britton, in Mem. Torrey Bot. Club, v. (1894) $225=$ canadense, Linn.

modestum, Boiss. Fl. Or. Suppl. (18S8) 126. - Ins. Cypr.

Moscrianum $\chi$, Éd. André, in Rev. Hortic. 1xi. (1888) 463, fig. 110 et 111: Le Jardin (1889) 209; et ex Gard. Chron. (1894) ii. 333, fig. 38. Hybr. artef.

\section{HYPERIGUM}

minus, Hort. ex Gard. Kew, i. Polypet. (1894) 39 $=$ hircinum, Linn.

maltiforum, Hort, ex Dippel, Handb. Laubholzk. iii. (1893) 39= elatum, [Dryander in $]$ Ait.

myricariifolium, Hieron. in Bot. Fahrb. xxi. (1895) 321. - N. Granat

Noëanum, Boiss. Fl. Or. Suppl. (18S8) 130. Thracia.

opacum, Sarg. in Gard. and For.v. (1892) 304, cum ic. = cistifolium, Lam.

orbiculare, Halacsy, in Oest. Bot. Zcitschr. xI. (1890) 405. - Thrac

pachyphyllum, Collett \& Hemst. in fourn. Linn. Soc, xxviii. 1890$) 24$ t. 3.-Burma.

parvulum, Greene, Pittonia, i. (Jan. 1888) 154. Mexic.

paucifolium, S. Wats. in Proc. Am. Acad. xxv. (1890) 143. - Mexic

ponticum, Lipsky, in Mem. Soc. hist. nat. Kiew, xii. (1892) extr. 16: et in Act. Hort. Petrop. xiii. (1894) 282. - Reg. Cauc

portoricense, Kuntze, Rer. Gen. (1891) 60. - Ins, Puerto Rico.

Prattii, Hemsl. in fonm. Limn. Soc, xxix.(1892) 303. China.

pruinatum, Boiss. E Balınsa, ex Boiss. Fl. Or. Suppl. (1888) 128. - As. Min.

Pumilio, Bornm. in Mitth. Thïr. Bot. Ver. N. Folge, vi. (1894) 65. - Oriens.

Pringlei, S. Wats, in Proc. Am. Acad, xxv. (1890) 143. - Mexic,

Roberti, Coss, ex Batt. E Trab. Fl. de l'Algér. [Dicot.] (1889) 183, nomen. - Algeria.

Sancti-Antonii, Schweinf. ex Boiss. Fl. Or. Suppl. (18S8) 70. - Desert. Aegypt.-Arab.

sanctum, Degen, in Oest. Bot. Zeitschr. xli. (1891) 333. - Ins. Samothr.

senanense, Maxim. in Bull. Acad. sci. St. Pétersb. xxxi. (1887) 16. - Japon.

Sintenisii, Freyn, in Oest. Bot. Zeitschr. xli. (1891) 36.5. - Armen.

Stuebelii, Hieron. in Bot. Fahwb. xxi. (1895) 320. Peruvia.

Tauberti. Aschers. \& Barb, ex Coss, in Bull. Soc. Bot. Fr. xxxvi. (1859) $104=$ H. Decaisneanum, Coss. \& Daveau.

Tempskyanum, Freyn \& Sint. in Bull. Herb. Boiss. iii. (1895) 102. - Armen.

tomentellum, Freyn \& Sint: in Oest. Bot. Zeitschr. xli. (1891) 365. - Armen.

trinervium, Hemsl. in Ann. Bot. ix, (1895) 144. Ins. Formos.

vermiculare, Boiss. \& Hausskn. ex Boiss. Fl. Or. Suppl. (1888) 129. - Mesopot.

Webbianum, Hort. ex Gard. Kew,

$37=$ H. Androsaemum, Linn.

yezoënse, Maxim. in Bull. Acad. sci. St. Pétersb. xxxi. (1857) 16. - Japon.

yumnanense, Franch. Pl. Delar. (1889), 103. Yunnan

HYPOGALYMNA, Meissn. (Myrtac.). - Ind. Kew. i. 1196

dimorphandrum, Niedenzu, in Engl. \& Prantl, Natïr. Pflanzenfam. iii. 7 (1893) $99=$ Baeckea dimorphandra, F. Mucll.

Drummondii, Niedenzu, 1. c. $99=$ B. Drummondii, Benth.

fumanum, Niedenzu, 1. c. = B. fumana, F. Muell.

oxycoccoides, Niedenzu, 1. c. = B. oxycoccoides, Benth.

platystemon, Niedenzu, 1. c. = B. piatystemona, Benth.

schollerifolium, Niedenzu, 1. c. = B. scholleraefolia, Lethm.

HYPOCALYPTUS, Thunb. (Legumin.). - Ind. Kew. 1. 1190.

cordifolius, Taub, in Engl. \& Prant1, Natiirl. Pflanzenfam. iii. 3 (1893) $240=$ obcordatus, Thunb.

HYPOGHAERIS, Linn. (Compos.). - Ind. Kew. i. 1196.

acaulis, Britton, in Bull. Torrey Bot.Clus, xix. (IS92) $3 \pi 1$ (= Achyrophorus acturis. Remy). - Am. austr.

\section{HYPOGHAERIS :}

arpathica, Pax. in Oest. Bot. Zeitschr. xlv. (1895) 26. - Mont. Carpath.

chilensis, Britton, in Bull. Torrey. Bot. Club, xix 1892) 371 (= Achyrophonus chilensis, Sch. Bip.). Chili.

Claryi. Batt. in Bull. Soc. Bot. Fr. xxxvi. (1889) p.222; et in Batt. E Trab. Fl. de l'Algér. [Dicot.] (1889) 536. - Alger.

coronopifolius, Franch. Miss. scient. Cap Horn, v 1889) 350 (= Achyrophortis coronopifolius, Sch. Bip.). - Reg. Marrell.

cupressarum, F. Phil. ex Phil. in Anal. Univ. Chil. lxxxvii. (1894) 313. - Chili.

deserticola, Phil. l.c. 318. - Chili.

eurylepis, Phil. l. c. 31\%. - Chili.

glabrata, Phil. l. c. 315 . - Chili.

graminifolia, Phil. l. c. 320, - Chili.

grandiflora, F. Phil. ex Phil. l. c. 313. - Chili

hirta, Phil.l. c. 319. - Chili.

hispidula, Phil. l. c. 316. - Chili,

Hookeri, Phil. l, c. 314. - Chili.

Ibari, Phil. l. c. 320.- Reg. Magell.

laciniosa, Phil. l. c. 319. - Chili

lutea, Britton, in Ann. N. Y. Acad. Sci, vii. (1893) 153 = brasiliensis, Griseb.

melanolepis, Phil. in Anal. Univ. Chil. 1xxxvii. (1894) 321. - Chili.

Nahuelvutae, Phil. l. c. 315. - Chili.

nana, Phil. l. c. 323. - Chili.

pumila, Phil. l. c.522. - Chili.

pygmaea, Phil. l. c. 321. - Chili.

Shermanum, Phil. l, c. 323, - Chili.

taraxacoides, Ball, in fourn. Limn. Soc. xxii. (1885)

49 [sphalm. ?] (= Oreophila turaxacifolia, Meyen). - Peruvia.

taraxacoides, Britton, in Bull. Torrey Bot. Club, xix (1892) 371 = taraxacoides, Benth. \& Hook. f.

Volckmanni, Phil, in Anal. Univ, Chil. Ixxxvii. (1894) 317 (= Achyrophonus Volcknanni, Phil.), Chili.

HYPOCRYPTA, Mart. (Gesner.), - Ind. Kew. i 1196

pulchra, N.E. Br. in Gard. Chron. (1894) 244. Columb.

HYPOCISTIS, Ludw。= Cytinus, Linn.

americana, Kuntze, Rev, Gen. (1891) $563=\mathrm{C}$. americanus, $R$. Br.

Andrienxii, Kuntze, 1. C, = C. Andrieuxii, Homsl.

sangumea, Kuntze, 1. $\mathrm{C}_{0}=\mathrm{C}$. dioicus, fuss,

HYPOGYLIX, Woloszczak, ex Stapf, in Denkschr. Acad. Wien (1886) 7. SALSOLACEAE.

Kerneri, Woloszczak, l. c. 8.- Persia.

HYPOËSTES, Soland. (Acanth.). - Ind. Kew. i. 1197.

acuminata, Baker, in fourn. Limn. Soc. xxii, (1887) 512. - Madag.

aldabrensis, Baher, in Kew Bull. (1894) 150. - Ins Aldabra.

chloroclada, Baker, in fourn. Limn, Soc.xxii. (1887) 513. - Madas.

ciliata. Lindau, in Bot. Fahrb. xx. (1894),51, - Afr. trop. occ.

congestiflora, Baker, in foum. Linn. Soc, xxii. (1887) 511. - Madag

consanguinea, Lindau, in Bot. Fahrb. xx. (1894) 50 . - Air. trop, occ.

depauperata, Lindau. l. c. 52. - Transvaal.

echioides, Lindau, l. c. = Afr. trop. or,

glandulitera, S. Elliot, in fourn. Limn. Soc. xxix. (1891) 41. - Madag.

grandifolia, Lindau, in Bot. Falirb. xx. (1894) 49. Afr. centr. bor.

Hildebrandtii, Lindan, l. c. 4S. - Afr, trop. or.

inaequalis, Lindau, l. c. 50. - Afr. trop. occ

incompta, S. Elliot, in foum. Limn. Soc. xxix. (1891) 41. - Madag.

kilimandscharica, Lindau, in Bot. Fahrb. xix. Beibl, n. 47 (1894) 47. - Afr. trop. or.

longilatiata, S. Elliot, in foum. Limn. Sor. xxix, (1891) 4\%. - Madag.

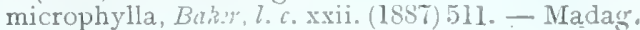




\section{HYPOËSTES :}

moschata, F. Muell. in Vict. Natural, viii. (Dec, 1891) 115, nomen. - Austral.

Neesiana, Kuntze, Rev. Gen. (1891) 491.-Afr. trop.

nummularifolia, Baker, in fourn. Linn. Soc. xxv, (1890) 340. - Madag.

obtusifolia, Baker, l. c. xxi1. (1887) 512. - Madag. phaylopsoides, S. Moove, in Trans. Limn. Soc. Ser. II. iv. (1894) 34. - Afr. trop.

phyllostachya, Baker, in Foum. Linn. Soc. xxii. (1887) 511. - Madas.

Preussii, Lindau, in Bot. Fahrb. xx. (1894) 48. Afr. trop. occ.

pulchra, N.E. Br. in Gard. Chron. (1894) ij. 244. - N. Granat

salicifolia, Kuntze, Rev.Gon. (1891) 491.- Java.

sessilifolia, Baker, in foum. Linn. Soc. xxii. (1887) 512. - Madag.

Staudtii, Lindan, in Bot. Fahrb. xxii. (1895) 122. - Kamerun.

tenuispica, Delile, ex Martelli, in Nuov, Giorn. Bot. Ital, xx. (1888) 395, in syn. $=\mathrm{H}$. Forskalei, $R, B r$

triticea, Lindau, in Bot. Fahrb. xx. (1894) 51. - Afr. trop. occ.

Volkensii, Lindan, l. c. xix. Beibl. n. 47 (1894) 47 - Afr. trop. or.

HYPOLYTRUM, Rich. (Cyyer.). - Ind. Kew. i 1198.

Kuntzeanum, Boeck. Cyper. Nov, i. (18S8) $23=\mathrm{Cla}$ dium jamaicense, Crantz.

madagascariense, C. B. Clarke, in Th. Dur. E Schinz, Consp. Fl. Afr. v. 1894 (1895) 666, nomen. - Madas.

nemorum, C. B. Clarke, l. c. (= Hypaelyptum nemorum, Beauv.). - Afr. trop.

penangense, C. B. Clarke, ex Hook. f. Fl. Brit. Ind vi. (1894) 679. - Penang.

Schraderianm, Hort. Bull, ex Gard. Chron. (1893) i. $414=$ Schraderianum, Nees

testaccum, C. B. Clarke, in Th.Dur. E. Schinz, Consp Fl. Afr. v. 1894 (1895) 667, nomen. - Madag.

turgidum, C. B. Clarke, cx Hook. f. Fl. Brit. Ind.vi. (1894) 679. - Zeylan.

HYPOPITYS, Dill. ex Adans. (Monotropeae). Ind. Kew, i. $1190^{\circ}$

Hypopitys, Small, in Mem. Torrey Bot. Club, iv. (1893) $137=$ M. Hypopitys, Linn.

Rivini, Rupp. jun. ex Cess. Passer. \& Gibelli, Comp. Fl. Ital. ii. (1886) $418=$ M. Hypopitys, Limn.

HYPOXIS, Linn. (Amaryl1.). - Ind. Kew. i. 1195. cuminata, Baker, in foum. Bot.xxvii. (1889) 3.Natal.

colchicifolia, Baker. l. c. - Hab.

curculigoides, Bolus, in Hook. Icon. pl. xxiii. (1893) " t. 2259. - Afr. austr.

Fischeri, Pax, in Bot. Falub. xv. (1893) 143. - Afr. trop. or.

floccosa, Baker, in Kew Bull. (1894) 35\%. - Afr. austr.

Gregoriana, Rendle, in foum. Linn. Soc. xxx. (1895) 408. - Afr, trop. or.

Girsuta, Coville, in Mem. Torrey Bot. Club, v. (1894) $118=$ erecta, Linn.

laikipiensis, Rendle, in fourn. Limn. Soc. xxx. (1895) 407. - Afr. trop. or.

oligotricha, Baker, in foum. Bot. xxvii. (1889) 3. Natal.

olivacea, Engl. Pfanzenw. Ost-Afr. A (1895) 9s, nomen. - Afr. trop.

racemosa. 7. D. Smuth, in Conlt. Bot. Gaz. xiv. (1889) 30. - Guatem.

Saarpata, Ham. ex Hook. f. F1. Brit. Ind. vi. (1892) 278 , in syn. = Curculigo recurvata, Dryand.

Schlechteri, Bolus, in Hook. Icon. pl. xxiii. (1893) t. 2250 B. - Afr. austr.

Scullyi, Baker, in fourn. Bot. xxvii. (1889) 2.Afr. austro-occ. extratrop.

subspicata, Pax, in Bot. fališ. xv. (1893) 143. Afr. trop. austro-occ

Woodii, Baker, in fourn. Bot. xxvii. (18s9) 3. Natal.
HYPSELODENDRON, Sclimperi Hochst, ex Engl. in Abh. Preuss. Akad. Wiss. 1891 (1892) 192, in syn. = Urera Hypselodendron, Wedd.

HYPSOPHILA, F. Muell, in Vict. Natural, iii (April. 1887) 168. CELASTRINEAE.

Halleyana, F. Muell, $l$. c. - Austral.

oppositiftora, F. Muell. l. c. ix. (May 1892) 11. Austral.

oppositifolia, "F. Muell. » ex Bot. Centralbl. li. (1892) 91, sphalm. = praec

HYPTIS, Jacq. (Labiat.). - Ind. Kew. i. 1200. ammotricha, Kuntze, Rev. Gen. (IS91) 526, sphalm. $=$ ammotropha, Griseb.

Balansae. Briq. in Bull. Soc. Bot. Genère, v. (1889) 113. - Parag.

cinerea, Morong, in Ann, N. Y.Acad. Sci, vii. (1893) 200. - Parag.

collina, T. S. Brandcg. in Proc. Calif. Acad. Ser. II iii. (1891) 164. - Calif

dumetorum, Morong, in Am. N. Y Acad. Sci. vii. (1893) 200. - Paras.

Glaziovii, Briq. in Bull. Hert. Boiss, ii. (1894) 716 . - Bras.

gracilipes, Britton, in Ann. N. Y. Acad. Sci. vii. (1893) 201. - Parag.

incana, Briq. in Bull. Soc. Bot. Gene'e, v. (1889) 111. - Parag.

mirabilis, Briq.l. c. 113. - Parag.

Muelleri, Briq. i. c. - Parag.

Palmeri, S. Wats. in Pruc. Am. Acad. xxiv. (1889) 68. - Mexic.

Seemannii, A. Gray, l. c. xxi. (1886) 407. - Mexic. tripartita, Briq. in Bull. Soc. Bot. Genere, v. (1889) 111. - Parag.

HYSSOPUS, [Tourn.]. Linn. (Labiat.) - Ind. Kew. i. 1202 .

cinereus, Pau, Not. Bot. F1. Espan. i. (1888) $23=$ officinalis, Limm.

HYSTRIX, Moench $=$ Asprella, Humb. (Gramin.). califormica, Kuntze, Rev. Gen.(1891) $778=\mathbf{A}$ californica, Benth.

gracilis, Kuntze, 1. c. = Gymnostachyum gracile, Hook.f.

Hystrix, MacMill. Metasp. Minn. (1892) 89; Millsp. F1. West Virgin. (1892) $474=\mathrm{A}$. Hys trix, Willd.

sibirica, Kuntze, Rev, Gen. (1891) 778 = A. sibirica, Tranto.

\section{I}

IBERIS, Dill. ex Linn. (Crucif.). - Ind. Kew. i 1202 .

aniensis, Fouc. \& Rouy, F1. de Fr. ii. (1895) $123=$ spathulata, 7. P, Bers.

Badali, Pau, Not. Bot. Fl. Espan. ii. (1889) $11=$ Lagascana, $D C$.

Costei, Fouc. \& Rouy, Fl. de Fr. ii. (1895) $130=$ pinnata, Linn.

latealata, Porta \& Rigo, in Atti Accad. Agiati, ix. 1891 (1892) 9; Willk. Suppl. Prodr. Fl. Hisp. (1893) 296. - Hisp.

pinetorum, Pau, Not. Bot. Fl. Espan. i. (188\%) 21 ; Willk. l. c. 295. - Hisp.

Reverchoni, Debeaux, ex Willk. l. c. 332.-Hisp. Rollii, Terrac ex Chiosenda, in Bull. Soc. Bot. Ital. (1892) 406. 一 Ital.

vinetorum, Pau, Not. Bot. F1 Espan.i.(18s7) $21=$ amara, Linn.?

IBERVILLEA, Greene, in Erythea, iii. (1895) $75=$ Maximowiczia, Cogn, (Cucurb.)

Lindheimeri, Greene, 1. co = M. Lindheimeri, Cogn. Sonorae, Greene, 1. C. = M. Sonorae, S. Wats. tripartita, Greene, 1. c. = M. tripartita, $\operatorname{Cog} n$.

IBOGA, J. Braun \& K. Schum, in Ber. deutsch. Schutzegeb, ii. (1889) 15\%. APOCYNEAE.

Vateriana, 7. Braun \& $K$. Schum, l.c. - Kamerun.
ICACINA, A. Juss. (Olacin.). - Ind. Kew. 1. 1203. Guessfeldtii. Aschers, in Engl. \& Prantl, Natiirl. Pfanzenfan. iii. 5 (1893) 250. - Loango.

Poeppigiana, Valeton, Crit. overs. Olacin. (1886) 187 = Mappia Poeppigiana, Baill.

ICACOREA, Aubl. = Ardisia, Sw. (Myrsin.)

borbonica, Cordem. Fl. Ile Réunion (1895) $442(=$ Badula borbonica, A. DC.). - Ins. Borbon.

crassa, Cordem. 1. c. 443 (= B. crassa, A. DC. $=$ A. insularis, Baker.

decumbens, Cordem. 1. c. 444. - Ins, Borbon granmisticta, Cordem. 1. c. 443. - Ins. Borbon. insularis, Cordem. 1. c。 = A. insularis, Baker. collifolia, Cordem, 1. c. (1895) 444 (= Badula os alifolia, A. DC.). - Ins. Mascar.

paniculata, Sudworth, in Gard and For. vi. (1893) 324; Sarg. N. Am. Sylva, v. 153, t, $240=$ A. Pickeringia, Nutt.

ICHNOGARPUS, R. Br. (Apocyn.). - Ind. Kew, i. 1204 .

affinis, K. Schum, in Engl. \& Prantl, Natürl, Pflanzenfam, iv. $2(1895) 173=$ ovatifolius. $A . D C$.

Morlae, Eggers, in Bot. Centralbl. liii. (1893) 305. Ecuad.

pruinosus, O. G. Petersen, in Bot. Tidskr. xviii. (1893) 264, t. 18. - Hab. ?

ICHTHYOMEThiA. P. Br. = Piscidia, Linn. (Legum.)

Piscipula, Kuntze, Rev. Gen. (1891) $191=$ P. Erythrina, Linn.

Piscipula, Hitchc, in Gard. and For. iv. (1891) 472 ; Sarg. N. Am. Sylva, iii. 53 t. $117=$ P. Erythrina, Limzz.

ICHTHYOTHERE, Mart. (Compos.). - Ind. Kew. i. 1204.

ovata, S. Moore, in Trans. Linn. Soc. Ser. II. iv. (1895) 38\%. - Bras.

IDOTHEA, Kunth $=$ Drimia, Jacq. (Liliac.). altissima, Kuntze, Rev. Gen. (1891) 712 = Urginea altissima, Baker.

Batcri, Kuntze, 1. c。= D. Barteri, Baker.

Burchellii, Kuntze, 1. c. = D. Burchelli, Baker.

concolor, Kuntze, 1. C. = D. concolor, Baker.

Cowanii, Kuntze, 1. c. = D. Cowanii, Ridl.

laxiflora, Kuntze, 1. c. = D. laxiflora, Baker.

rigidifolia, Kuntze, 1. $\mathrm{c}_{\mathrm{o}}=\mathrm{D}$. rigidifolia, Baker.

robusta, Kuntze, 1. c. = D. robusta, Baker.

IGUANURA, Blume (Palm.). - Ind, Kew. i. 1204.

ambigua, Becc. Malesia, iii. (1886) 125. - Borneo.

bicornis, Becc.l.c. 18S. - Penins. Mal.

corniculata, Becc. l. c. 187. - Penins, Mal.

brevipes, Hook. f. Fl. Brit. Ind. vi. (1892) 416. Perak.

diffusa, Becc. Malesia, iii. (1886) 123. - Perak.

elegans, Berc.l. c. 123. - Borneo.

macrostachya, Becc. l. c. 101. - Borneo.

malaccensis, Becc. l. c. 123. - Penins. Mal.

palmuncula, Becc. l. c. 126. - Borneo.

parvula, Becc. in Hook. f. Fl. Brit. Ind. vi. (1892 417. - Perak

polymorpha, Becc. Malesia, iii. (1886) 189.Perak.

ILEOSTYLUS, Van Tiegh. in Bull. Soc. Bot. Fr xli. (1894) 489, et xlii. (1895) $25=$ Loranthus Linn.

Kirkii, Van Tiegh. 1. c. $489=$ L. Kirkii, $\operatorname{Van}$ Tiegh.

micranthus, Van Tiegh. 1. C. $25=$ L. micranthus, Hook. $f$.

ILEX, [Tourn.] Linn. (Ilicin.) - Ind. Kew. i. 1205. amygdalifolia, Rusby, in Mem. Torrey Bot. Club, iii. 3 (1893) 15. - Boliv.

Berteroi, Loes, ex Urb. in Bot. Fahrb. xv, (1892) 320. - Ins. S. Doming.

boliviana, Britton, ex Rusby, in Mem. Torrey Bot. Club, iii. 3 (1893) 15. - Boliv

californica, T. S. Brandeg, in Gard. and For. vii. (1894) 414. - Calif 
ILEX

amelliaefolia, Carr, in Rev. Hortic. lix. (1887) 234 = I. Aquifolium, Linn.

capitellata, Pierre, Fl. For. Cochinch. Fasc. 18 (1893) t. 278 B. - Cochinch.

caroliniana, Trelease; in Trans. Acad. Sci St. Louis, v. (1892) 347 (= Cassine caroliniana, Walt.). - Am. bor.

ciliata, Hort. ex Koehne, Deutsche Dendrol. (1893) 369 et 582 , ad calc. $=$ I. Aquifolium, Linn.

condorensis, Pierre, Fl. For. Cochinch. Fasc. 18 (1393) t. 279 A. - Cochinch.

Congonha, Mart. ex Valeton, Crit. overs. Olacin (1856) 199, in syn. = Villaresia Congonha, Miers corallina, Franch. in Bull. Soc. Bot. Fr, xxxiii (1886) 448. - China occ.

cubana, Loes, ex Urb. in Bot. Fahrb. xv, (1893) 314. - Cuba

dubia, Britton, Stern of Pogg. Prelim. Catal. (1883) 11: Trelease. ex Kochne, Deutsche Dendrol. (1893) 374 (= Prinos dubins, G. Don). - Am. bor.

Dugesii, Fernald, in Coult. Bot. Gaz. xx. (1895) 533. - Mexic

epiphytica, King, in fourn. As. Soc. Beng. lxiv. (1895) II. 134. - Perak.

eugeniaefolia, Pierre, Fl. For. Cochinch. Fasc. 18 (1893) t. 278 B. - Cochinch

excavata, Pierre, l. c.t. 278 A. - Cochinch.

fabrilis, Pierre, l. c. t. 280 A. - Cochinch.

ficoidea, Hemsl.ex Forb. et Hemsl. in Fourn. Linn. Soc. xxiii. (1886) 116. - Ins. Hongkong.

Fischeri, Hort, ex Carr. in Rev. Hortic. lix. (1887 $43=$ I. Aquifolium, Linn.

glomerata, King, in fourn. As. Soc. Beng. lxiv. (1895) II. 135. - Perak

guianensis, Kuntze, Rev. Gen, (I891) $113=\mathrm{I}$ Macoucoua, Pers.

Harmandiana, Pierre, Fl. For. Cochinch. Fasc. Is (1893) t. 277. - Laos.

hexandra, Bello, Estud. Fl. Porto-Rico, iv. (1886) 38. - Ins. Puerto Rico.

Hookeri, King, in Fourn. As. Soc. Beng. 1v. (1S87) I1. 266 t. 14. - Sikkim.

hypaneura, Loes, in Bot. Falmb. xv. (1893) 321. Cuba.

integrifolia. Hort, ex Gard. Kew, i. Polypet. (1894) 63 = integra, Thunb.

Jelskii, Zahlbr. in Diss. math-phlys. Acad. litt. Cracov. xxix. (1894) 223. - Peruv.

Krugiana, Loes. ex Urb. in Bot. Fahrb. xv. (1893) 317. - Ins. Antill.

Lindenii, Loes. ex Urb. l. c. 323. - Cuba.

longipes, Chapm. ex Trelease, $m$ Trans. Acad. Sci. St. Louis, v. (1889) $346(=$ Nemopantlies canadensis Gattinger). - Am. bor.

macrocarpa, Oliver, in Hook. Icon. pl, xviii. (18S8) t. 1787. - China.

mitis, Radlk. in Act. Congr. bot. Anvers (1887) $172=$ Sideroxylon mite, Linn

monticola, A. Gray, ex Diech, Neuh. offorte Nat Arboret. (1892-93) 19. - Am. bor.

Peragua, Trelease, in Trans. Acad. Sci. St. Louis, v. (1892) 346 in obs. = caroliniana, Trelease

prinifolia, Muehlb. Cat. pl. Am. sept. (1813) 17, ex Dippel, Handb. Laubholzk. ii. (1892) $515=$ Nemopanthes lucida, C. Koch.

racemosa, Oliver, in Hook. Icon. pl. xix. (1859) t. 1863. - China.

revoluta, Stapf, l. c. xxiii. (1893) t. 2263 ; te in Trans. Lim Soc. Ser. II. iv. (1894) 134. - Borneo.

Riedlaei, Loes. ex Urb. in Bot. fahrb. xv. (189:3). Ins. Antill.

rubra, S. Wats. in Proc. Am. Acad. xxi. (1886) 422. - Mexic.

sikkimensis, King, in foum. As. Soc. Beng. Iv. (1887) 11.265 t. 13. - Sikkim.

Thorelii, Pierre, Fl. For. Cochinch. Fasc. 18 (1893) t. 280 B. - Cochinch.

tonkinensis, Pierre, l. c. sub t. 2\%8, in obs. Tonkin.

triflora, T. S. Brandeg. in Gard. and For. vii. (1894) 414. - Calif.

Urbaniana, Loes. ex Urb. in Bot. Fahrb. xv. (1893) 316. - Ins. Puerto Rico.

vacciniifolia, Stapf; in Trans, Linn. Soc. Ser. II. iv. (1894) 140. - Borneo.

\section{ILEX}

Wrighti, Trclease, in Trans, Acad. Sci. St. Louis, v. (1892) $349=$ lanceolata, Chapm.

Wrightii, Loes. ex Urb. in Bot. Fahrb. xv. (1893) 328. - Cuba.

yunnanensis, Franch.Pl. Delar, i. (1889) 128. Yunnan.

II.ICIODES, (-oides) Dum.-Courset $=$ Nemopanthes, Rafin. (Ilicin.).

anadense, Kuntze, Rev, Gen. (1891) $113=\mathrm{N}$. canadensis, $D C$.

mucronata, Britton, in Mem. Torrey Bot. Club, v. (1894) $21 \%=\mathrm{N}$. canadensis, $D C$.

ILLICIUM, Linn. (Magnol.). - Ind. Kew. i. 1208. evenium, King, in fourn. As, Soc. Beng. 1viii. (1889) 1. 374. - Malaya.

manipurense, Watt. ex King, in Ann. Bot. Gard. Calc. iii. 11. (1891) 200, t. 40 B. - Ind

Simonsii, Maxim, ist Bull. Acad. sci.St.Pétersb.xxxii.

1888) 480 ; Watt. l. c. 201 t. 39 B. - Reg. Himal. Tashiroi, Maxim, l. c. 479. - Japon.

verum, Hook. $f$ in Bot.Mag. (1888) t. 7005.-China.

ILLIGERA Blume(Combret.).-Ind. Kew, i. 1208. villosa, C. B. Clarke, in fourn. Linn. Soc. xxv. (1889) $22, \mathrm{t}, 9 .-$ Ind angl.

ILLIPE, F. Muell. = Bassia Koen. (Sapot.)

bulyracea, Engl. Bot. Jahrb. xii. (1890) 509= B. butyracea, Roxb,

Cocca, Engl. 1. c. = B. Cocca. Scheff.

cuncata, Engl, 1. c。 = B. cuneata, Bl.

elongata, Eng1. 1. c. - B. elongata. Miq

Erskineana, Engl. ex Boerl. Fl. Ned. Indiè, ii. 1 (1891) $310=$ B. Erakineana, F. Muell

fulva, Engl. Bot. Jahrb. xii. (1890) $509=$ Dasyaulus fulvus, Thw.

fusca, Engl.l. c. 510. - Borneo

Hollvungii, K. Schum. Fl. Kais. Wilh. Land (1889) 107 ( Burckella Hollnungi, Pierre $)=$ B. Hollrungii, $K$. Schum.

insignis, Engl. Bot. Jahrb. xii. (1890) $509=$ B. insignis, Radlk.

Korthalsii, Engl. 1. c. = B. Korthalsii. Pierre

latifolia, Engl. 1. c. = B. latifolia, Roxb.

Macleyana, Pierre, Not. Bot. Sapot. (1890) 16, cum cit. falsa = Bureavella Macleyana, Pierre.

May, Boerl. Handb. Fl. Ned. Indië, ii. I. (1891) 310 (= Burckella May, Pierre) = B. May, Becc.

Mottleyana, Engl. Bot. Jahrb. xii. (1890) $509=$ B. Mottleyana, De Vriese.

neriffolia, Engl. 1. c $=$ Dasyaulus nerifolius, Thw. obovata, Pierre, Not, bot. Sapot. (1890) $4=B$. obovata, Forst.

pallida, Engl. Bot. Jahrb. xii. (1890) $509=$ B. pallida, Burch.

ILYSANTHES, Rafin. (Scrophu1.). - Ind. Kew, i. 1208

ciliata, Kuntze, Rev, Gen. (1891) $461=$ = Bonnaya brachiata, Link \& Otto.

rulleodes, Kuntze, 1. c. = B. reptans, Spreng.

IMANTOPHYLLUM, Benth. \& Hook, f. = IMATOPHYLLUM Hook, = Clivia, Lindl. (Amaryll.). atrosanguinenm, Williams, Catal. (1888) $20=\mathrm{C}$. miniata, Regel.

IMBRICARIA, Comm. (Sapot.), - Ind. Kew.i. 1208

gigantea, Pierre, ex Baill. in Bull. Soc. Linn. Paris, ii. (1891) 919, in cbs. - Hab. ?

Pierrei, Baill. l. c. - Ins. Maurit.

sechellarum, Oliver, in Hook. Icon. pl. xxiv. (1894) t. 2:15. - Ins. Sechell

IMHOFIA, Heist. Desc, nov. gen. Brunsv. (1753) 19. 20 = Nerine, Herb. (Amaryll.).

amabilis, curvifolia, elegans, evmbescens. excellens, filifolia flexuosa, humilis, lucida, marginata. Mitchamiae, Moorei, pudica, sarniensis, Spofforthiae, undulata, Kuntze, Rev.Gen. (1891) $704=$ homonyma ommia Nerines.

Camii X, Kuntze, 1. c. = N. Camii, Bakr.
IMHOFIA :

Duparquetiana, Baill. in Bull. Soc. Linn. Paris, ii (1894) 1132; Baker, in Gard. Chron, (1894) ii. 624. - Afr. austr.

Fierberti 'X, Kuntze. Rev. Gen. (1891) \%04 - Hybr artef.

Meadewobankii X, Kuntze, 1. c. = N. Meadowbankii, Baker.

O'Brienii Х, Kuntze, 1. c. = N. O'Brienii, Baker

IMPATIENS, Riv, ex Linn. (Geran,), - Ind, Kew, i. 1209 .

affinis, Warb. in Bot. Fahrb. xxii. (1895) 45 et 52 in obs. - Afr. trop. Occ.

assurgens, Baker, in Kew Bull. (1895) 64.-Afr. centr. or

auricoma, Baill. in Bull. Soc. Linn. Paris, 1. (1S86) 596. - Ins. Comor.

auricoma, Poisson, in Le fardin (1893) 53 ; et (1894) 9 fig. 3; Hook. f. in Bot. Mag. (1894) 738 [al praec. ?] - Ins. Comor.

Bakeri, Warb̆. in Bot. Fahrb. xxii. (1895) 49, in obs. - Madag.

Baumannii, Warb. l. c. 52. - Afr, trop. occ.

bisaccata, Warb. l. c. 5. - Madag

chaetodonta, Franch. Pl. Delav. (1889) 155. - Yunnan.

corchorifolia, Franch, in Bull, Soc, Bot, Fr, xxyiii. (1886) 448, - China.

Cornucopia; Franch. Pl. Delar. (1889) 121. - Yunnan.

Delavayi, Franch, in Bull. Soc. Bot. Fr. xxxiii. (1886) 445. - China occ.

delicatula, Baill. in Bull. Soc. Limn. Paris, i. (1886) 599 ; et Hist. pl. Madag., Atlas (1891) t. 173. Madag.

digitata, Warb. in Engl. Pflantrenze. Ost-Afy, C (1895) 252, t. 26. - Afr. trop. or.

dimorphophylla, Franch, in Bull. Soc. Bot. Fr. xxxiii. (18s6) 446. - China occ

divaricata, Franch, l. c, 447. - China occ

dorstenioides, Warb. in Bot. Jahrb. xxii. (1895) 49, in obs. = Trimorphocarpum dorstenioides Baker.

ecalcarata, Collett \& Hemsl. in fourn. Limn. Soc xxvii. (1890) 30, t. 4. - Burma

Ehlersii Schweinf. ex Engl, in Abh Preuss. Akad. Wiss. 1891 ii. (1892) 294 nomen; et in Hoelnel, Zum Rudolph See, Append. (1892) 14. - Afr. trop. or.

Eminii, Warb. in Engl. Pflanzenw. Ost-Afr. C (1895) 254. - Atr. trop. or.

filipes, Baill. in Bull. Soc. Linn. Pavis, i. (1886) 594 - Madag.

Fischeri, Warb, in Engl. Pfanzonu. Ost-Afr. C (1895) 254. - Afr. trop. or.

fissicornis, Maxim, in Act. Hort. Petrop. xi. (1889) 8\%. - China

furcillata, Hemsl, ex Forb. \& Hemsl, in fourn, Linn. Soc. xxiii. (1886) 101. - Corea.

gomphophylla, Baker, in Kew Bull. (1895) 64. Afr. centr. or

hamata. Warb. in Bot. Fahrb. xxii. (1895) 52. Afr. trop. or

Hawkeri, W. Bull, ex Gard. Chron.(1886) i, 761, fie 168; et ex Illustr. Hortic, xxxiv. (1887) 9, t. 2. Ins. Maris austr.

Herzogii, K. Schmo, in Bot. Falvb. ix. (1888) 204 - N. Guin.

Hildebrandti, Baill, in Bull. Soc. Linn. Paris, (1886) 595. - Madag.

Hochstetteri, Warb, in Engl, Es Piantl, Natïrl. Pfanzenfam. iii. 5 (1895) 391. - Afr, trop.

Holstii, Engl, \& Warb, ex Engl, in Abh. Preuss. Akad. Wiss. (1894) 46 et 53 ; et in Engl. Pfanzenz. Ost-Afy. C. (1895) 254. - Afr. trop.

Joquinii, Warb. in Bot. Fahrb. xiii. (1891) 337. Oceania.

kamerunensis, Warb. l. c. xxii.(1895) 51. - Kame run.

Lantziana. Baill. in Bull. Soc. Linn. Paris, i. (1886) 595. -- Madag.

macradenia, Baill. l. c.; et Hist.pl. Madag, Atlas (1S91) t. 172. - Mada.

manaharensis, Baill. l. c.595. - Madas.

mirabilis, Hook. f. in Bot. Mag. (1891) t. T195.Ins. Langkawi. 


\section{IMPATIENS :}

mana, Engl. \& Warb. ex Engl. in Abl. Preuss. Akad. Wiss. (1894) 68; et in Engl. Pfanzenw. Ost-Afr. C (1895) 254. - Afr. trop. or.

notolopha, Maxim. in Act. Hort. Petrop. xi. (1889) ()1 - China

odontopetala, Maxim. l. c. 90. - China.

papilionacea, Warb in Engl. Pfanzenw. Ost-Afr. C $1895) 253$. - Afr. trop. or.

platyceras, Maxim. in Act. Hort. Pctrop. xi. (18S9) 89. - China.

plebeja, Hemsl. ex Forb. \& Hemsl. in Fourn. Linn. Soc. xxiii. (1886) 101. - Corea.

Potanini, Maxim. in Act. Hort. Petrop. xi. (1889) $90 .-$ China.

Preussii, Warb. in Bot, falhb. xxii (1895) 50.-Kamerun.

procridoides, Warb. in Engl. Pflanzenw. Ost-Afr. C (18.5) 254. - Afr. trop. or.

procumbens, Franch in Bull. Soc. Bot. Fro xxxiii. (1886) 447. - China.

raphidothrix, Warb. in Engl. Pfanzenw. Ost-Afr. C (1895) 253. - A Afr: trop. or.

recurvicornis, Maxim. in Act. Hort. Petrop. xi. (1859) is. - China.

rhaphidithix, Warb. ex Engl. in Abh. Preuss. Akad. Wiss. (1894) 55 = raphidothrix, $W a r b$.

Ródicasi, L. Lind. in Iliustr. Hortic. xxxvi. (1889) 25, t. 528. - Java.

rostellata, Franch. in Bull. Soc. Philom. Paris, Sér. II. viii. 1885 (1886) 209. - Tibet.

rubro-maculata, Warb. in Engl, Pfanzenw. Ost-Afr.

C (1895) 253. - Afr. trop. or.

ruassorensis, $W$ arb. l. c. 254. - Afr, trop. or

sacculata, Warb: in Bot.fahb.xxii. (1895) 53. Madag

salicifolia, Baill. Hist. pl. Madag., Atlas (1891)t. 170 [an Baker?]. - Madag.

hirensis, Baker f. in Trans. Limn. Soc. Ser. II, iv. (1894) 7. - Afr. trop.

Sodenii, Engl. \& Warb. ex Engl, in Abh. Preuss. Akad. Wiss. (1894) 55; et in Engl. Pfanzenw. Ost. Afr. C (1895) 253. - Afr. trop. Or.

Stairsii, Warb. l.c. 254, - Afr, trop. or.

Stuhlmannii, Warb, $l, c$, - Afr. trop. or.

swertioides, Warb. in Bot. Fahrb. xxii. (1895) 49. Angola.

tawetensis, $U^{7}$ arb. in Engl. Pfanzenw. Ost-Afr. C (1895) 253. - Afr. trop. or.

trichochila, Warb. l. c. - Afr. trop. or.

trichoclada, Warb. ex Engl. in Abh. Preiss. Akad. Wiss. (1894) 55; [sphalm.? an I. trichochila, Warb. ?]. - Afr. trop. or.

tubulosa, Hentsl. ex Forb. E Hemst. in founn. Linn. Soc, xxiii. (1886) 102, - Corea.

unenensis, Warb. in Engl, Pfanzenw. Ost-Afr. C (1895) 255. - Afr. trop. or.

li rimosa, Franch. in Bull. Soc. Bot.Fr. xxxiii.(1886) 418. - China.

tluourensis, Warb. in Bot. Fahrb. xxii. (1895) 50. Afr. trop. or

vittata, Frxncir. in Nour. Arch. Mus. Paris, Sér. II. viii. (1886) 209. - China occ.

Volkensii, Warb. in Engl. Pfanzenw. Ost-Afr. C $1895) 253$ \&. 26. - Afr. trop. or.

yunnanensis, Franch, in Bull. Soc. Bot. Fr. xxxiii. (1886) 445. - China occ.

Zenkeri, Warb. in Bot. Fahrb. xxii. (1895) 51. Kamerun

Zo!lingeri, Kuntze, Rev. Gen. (1891) 76 (= I. radicans, Zoll. \& Mor.). - Java.

IMPERATA, Cyrillo (Gramin.). - Ind. Kew, $1: 1(1)$

brevifolia, Vasey, in Bul1. Torrey Bot, Club, xiii. (1886) 26; et in I)C. Monog. Phan. vi. (1889) 97 $=\mathrm{I}$. Hookeri, Rupr.

constricta, Hitchcock, in Missouri Bot. Gard. Rep. iv. (1893) $140=$ Saccharum constrictum, H. B. \& $K$

aculatoria, Baill. Hist des pl. xii. (1894) $198=$ jaculatoria, Roem. Es Schult.

minutiflora, Hack. in DC. Monog. Phan. vi. (1889) 100. - Peruvia.

tenuis, Hack. in DC. 1. c. 689. - Bras.
INGARVILLEA, Juss (Bignon.). - Ind. Kew. i. 1211 .

Berezovskii, Batalin, in Act. Hort. Petrop. xiv. (1895) 181. - China.

Bonvaloti, Bureau et Franch. in Morot, Fonm, de Bot. v. (1891) 141. - Tibet.

Delavayi, Burean \& Franch. l. c. 138; et in Rei. Hortic. (1893) 544 cum ic.; Gurtenfl. (1894) 2 t. 1398. - China.

grandiflora, Bureau et Franch. l. c. 138. - China.

lutea, Bureau et Franch.l.c 137. - Yunnan.

Potanini, Batalin, in Act. Hort. Petrop. xi. (1891) 492 ; et xiv. (1895) 180. - China.

Principis, Bureau et Franch. in Morot, Fourn. de Bot. v. (1891) 136. - Tibet.

variabilis, Batalin, in Act. Hort. Petrop. xii. (1892) $17 \%$; et xiv. (1895) 180. - China.

INDIGOFERA, Linn. (Legumin.), - Ind. Kew. i. 1211

acutifolia, Schinz, in Verh. Bot. Ver. Brand. xxx. (1888) 163. - Afr. austro-occ. extratrop.

alboglandulosa, Engl. in Abh. Preuss. Akad. Wiss. ii. 1891 (1892) 258. - Abyss.

aspuragoides, Taub. in Engl. Pfanzenw. Ost-Afr. C (1895) 210, - Afr. trop. or.

Bergii, Vatke, ex Engl. $n$ Abh. Preuss, Akad. Wiss. (1894) 38. - Afr. trop.

brachybotrys, Baker, in fourn. Linn. Soc. xxv. 1890) 309. - Madag.

Charlieriana, Schinz, in Verh. Bot. Ver. Brand. xxx. (1888) 165. - Afr. austro-occ. extratrop.

chaetodonta. Franch. Pl. Delav. (1889) 155. China occ

cinerascens, Franch. l. c. 153.-China occ,

Delavayi, Franch.l.c. $154-$ Yunnan.

coronillacfolia. Hort. ex Gard. Kew, i. Polypet. (1894) $119=$ I. Gerardiana, R. Grah.

demissa, Taub. in Engl. Pfanzenw. Ost-Afr. C 1895) 209. - Afr, trop. or.

desmodioides, Baker, in fourn. Linn, Soc, xxii 1887) 463. - Madag.

desmodioides, Baker, in Kew Bull. (1894) 331.-Arabia.

dimorphophylla, Schinz, in Verh. Bot. Ver. Brand. xxx. (1888) 164, - Afr, austro-occ, extratrop.

drepanocarpa, Taub. in Engl. Pfanzenw. Ost-Afr. C (1895) 209. - Afr. trop. or

Hofmanniana, Schinz, in Verh. Bot. Ver. Brand xxx. (1888) 162. - Afr. austro-occ. extratrop.

Holstii, Taub. ex Engl. in Abh. Prenss. Akad. Wiss. 1894) 18 et 62. - Afr. trop.

lanurinosa, Taub. ex Engl. l. c. 17. - Afr. trop.

longebarbata, Engl. l. c. 1891. ii. (1892) 257. Abyss.

longiflora, Taub in Engl. Pflanzenne, Ost-Afr. C (1895) 210. - Afr. trop.or.

microcharoides, Taub. l. c. 209. - Afr. trop or. mollis, Franch Pl. Delav (I889) 156 - Yunnan. Oliveri. Schweint. ex Engl, in Abh, Preuss. Akad. Wiss. 1891 (1892) 259, nomen; et in Hoehnel, Zum Rudolph See, App. (1892) 13. - Air. trop. or.

ormocarpoides, Baker, in fourn. Limn. Soc. xxii. 1887) 464. - Madag.

Palmeri, S. Wats, in Proc, Am, Akad. xxii. (1887) 404. - Mexic.

Pechuelii, Kantze, in fahrb. Bot. Gart. Bcrt. iv. 1886) 263. - Afr. austro-occ. extratrop.

pendula, Franch. Pl. Delav. (18S9 156. - Yunnan.

polysphaera, Baker, in Kow Bull. (1895) 65. Afr, trop. centr. or.

reticulata, Franch. Pl. Delav. (1889) I53. Yunnan.

reticulata, Koehne, Deutsche Dendrol. (1893) 335.$\mathrm{Hab}$.

Roylei, Hort, ex Koehne, 1. c. = Gerardiana, R. Grat.

Roylii, Hort. ex Dippel, Handb. Laubholzk. iii. (1893) $692=$ praec

saxicola, Engl. Bot. Fahrb. x. (1889) 28. - Afr. austro-occ. extratrop.

caberrima, Schinz, in Verh. Bot. Ver. Brand. xxx. 1888) 163. - Afr. austro-occ, extratrop.

carciesii, S. Elliot, in fourn. Linn. Soc. xxx. (1894) 76 , - Sierra Leone.

sensitiva, Franch.Pl. Delav. (1889) 157. - Yunnan.

sericophylla, Franch. l. c: - Yunnan.

\section{INDIGOFERA}

Sofa, S. Elliot, in foum. Linn. Soc. xxx. (1894) 76 . - Sierra Leone.

tritoidea, Baker, in Kew Bull. (1895) 214. - Reg. Somal.

Volkensii, Taub. in Engl. PAanzenw, Ost-Afr. C (1895) 210. - Afr. trop. or.

INGA, Scop. (Legumin.).-Ind. Kew. i. \214.

boliviana, Britton, in Bull. Torrey Bot. Club, xvii. (1890) 9. - Bolivia,

bullata. F. Muell, in Proc. Linn. Soc. N. S. Wales, Ser. II. v. (June 1890) 20, in obs. = Affonsea bullata, Benth.

comosa. F. Muell. 1. c. = A. juglandifolia. A. St. $\mathrm{Hil}$

juglandifolia, F. Mue11. 1. c. = A. juglandifolia, $A$. St. Hil.

Pittieri, M. Mich。in Bull. Herb. Boiss. ii. (1894) 446 t. 13. - Costarica.

INGENHOUSIA, Kuntze, Rev Gen. (1891) $348=$ INGENHOUZIA, Bert. = Rhetinodendron, Meissn. (Compos.)

Berteroi, Kuntze, 1. c. $=$ R. Berteroi, Hemsl.

INTSIA, Thou. = Afzelia, Sm. (Legumin.).

africana, Kuntze, Rev. Gen.(1891) $192=$ A. africana, $S m$

attenuata, Kuntze, 1. c. = A, attenuata, Klotzsch.

bijuga, Kuntze, 1. c. = A. bijuga, A. Gray.

bracteata, Kuntze, 1. c. = A. bracteata, Vog.

cuanzensis, Kuntze, 1. c. = seq.

Petersiana, Kuntze, 1. c. = A. quanzensis, Welv.

quanzensis, Kuntze, ex Engl. in Abh. Preuss.

Akad. Wiss. (1894) $33=\mathbf{A}$. quanzensis, Welw.

rctusa, Kuntze, Rev.Gen. (1891) $192=$ = A. retusa Kurz.

rhombodea, Kuntze, 1. c. = A. rhomboidea, Wele,

INULA, Linn (Compos.) - - Ind. Kew, i, 1219

altissima, Camus, Catal. pl. Fr. Er Suisse, (1888) $(=$ Conyza altissima, Debeaux \& Naudin). - Gall.

aromatica, Freyn \& Sint. in Bull. Herb. Boiss. iii (1895) 345. - Armen.

attica, Halácsy, in Oest. Bot. Zeitschr. xl. (1890) 466. - Graecia.

Bakeriana, O. Hoffm. in Engl. Pfanzenw. Ost-Afr. C (1895) 411 (= Bojeria s'estita, Baker). - Ins. Maurit. crassifolia, Collelt of Hemsl. in fourn. Lim. Soc xxviii. (1890) 72, t. 12. - Ind. or.

crassineriis, Bcrb, in Oest. Bot. Zeitschr, xxxvi. (1856) 104, nomen ; et in Bot. Jahrb. viii. (1857) 228. - Hung.

denticulata, Borb. 1. c. xxxviii. (1888) 325.-Hung fruticosa, Sch. Bip. (in Schimp. Pl. Abyss. ii n. 664) ex Engl, in Abh. Preuss. Akad. Wiss. 1891 (1882) $432=$ arbuscula, Delile.

glanca, C. Winkl. in Act. Hort. Petrop. xi. (1890) 276. - Turkest

Gombczewskyi, C. Winkl. l. c xiv. (IS95) 149. Turkest.

macedonica, Hausskn. in Mitth. Thïr. Bot. Ver. N. Folge, vii. (1895) 34. - Graecia.

ménesiensis $X$ Simonk. in Oest. Bot. Zeitschr. xxxix, (1889) 13. - Hung.

methanaea, Hausskn. in Nym. Consp. Fl. Eur. Suppl. ii. I. (1889) 176; et in Mitth. Thiir. Bot. Ver. N Folge, viii. (1895) 33. - Graecia.

microcephala $X$. Borb. in Bot. Jahrb. viii. (1887) 235. - Hung.

Neilreichii, G. Beck, ex Formanek, Krétcna, ii. (1892) 528; pt Fl. Nied.-Oest. ii. II. (1893) 1182: - Morav. pleiocephala X. Borb. in Bot. Jahrb. viii. (1887) 239 - Hung.

orgyalis, Boiss, Fl.Or. Suppl.(188S)291.-Armenia. pseudoconyza, Alboff, in Bull. Herb. Boiss. ii. (1894) 453. - Reg. Cauc.

pseudoensiformis $X$, Borb. in Bot. Jahrb. viii. (1887) 232. - Hung,

pseudoensiformis $X, G$. Beck, Fl, Nied.-Oest. ii. I1. (1893) $1182=$ pseudoensifolia, Borb.

scabridula, Formanek, in Vorh. naturf. Ver. Brumn. xxx. (1892) 59. - Maced.

Schmalhauseni, C. Winkl. in Act. Hort. Petrop. ix 1886) 420. - Turkest. 
INULA :

schugnanica, C. Winkl. in Act. Hort. Petrop. xi. (1890) 2\%6. - Turkest.

sericata X, G. Beck, Fl. Nied.-Oest. ii. 11. (1893) 1182. - Austr.

serrata, Burean \& Franch. in Morot, Fourn. de Bot. v. (1891) 50. - China.

speciosa, O. Hoffin. in Engl. \& Prantl. Natürl. Pfanzenfam. iv, j (1890) 203 (= Bojeria speciosa, DC.). - Madag.

subulata, Baker, in Kew Bull. (1894) 333. - Arabia. valiensis, Tausch, ex G. Beck, Fl. Nied.-Oest. ii. II. (1893) 1182, in syn. = pseudoensifolia, Borb. vindobonensis $\mathrm{X}, \mathrm{G}$. Beck, 1. c. 1185. - Austria.

INULOPSIS, O. Hoffm. in Engl. \& Prantl, Natürl. Pflanzenfam. iv. $5(1890)$ 149. COMPOSITAE.

scaposa, O. Hoffm. l. c. $(=$ Haplopappus scaposus, DC.). - Bras.

IODANTHUS, Torr. \& Gray (Crucif.). - Ind. Kew. i. 1221.

pinnatifidus, Prantl, in Engl. \& Prantl, Natürl. Pflanzenfam. iii. 2 (1891) $183=$ pinnatifidus, Steud.

IODES, Blume (Olacin.). - Ind Kew. i. 1221 reticulata, King. in Fonrn. As. Soc. Beng, 1xiv. (1895) 11. 126. - Perak.

velutina, King, l. c. 127. - Penins. Mal.

IODINA, Hook. \& Arn. (Santal.). - Ind, Kew. i. 1220.

cuneifolia, Baill. Hist. des pl. xi. (1892) $4 \pi 0=$ cuneifolia, Miers.

IONIDIUM, Vent.(Violar,). - Ind. Kew. i. 1221. durum, Baker, in Kew Bull. (1895) 180, - Arabia.

Lehmannii, Hzeron, in Bot. Fahrb. xx. Beibl. n. 57 (1895) - Columb.

nyassense, Engl. Pfanzenw. Ost-Afr. C (1895) 2\% . - Atr. trop. or.

IONOPSIDIUM, Reichb. = Cochlearia, Tourn (Crucif.).

Saziantm, Ball, ex Coss. Comp. Fl. At1. ii, (1887) 263 (= Bivonaea Saviana, Caruel). - Ital.

IONORCHIS, G. Beck, Fl, Nied.-Oest, ii. 1 (1890) $215=$ Limodorum, Sw. (Orchid.).

abortica, G. Beck, l. c. = L. abortivum, Sw.

IOXẎ̇̇ pomifertm, Rafin. ex Koehne, Deutsche Dendrol. (1893) $139=$ M. aurantiaca, Nutt.

IPHIGENIA, Kunth (Liliac.), - Ind. Kew. i. 1629

Oliveri, Engl. Bot. Fahrb̆.xv. (1893) 466. - Afr. trop. or.

paucitlora, Martelli, Fl. Bogos. (1886) 86. - Abyss. somalieusis, C. B. Clarke, in Kew Bull. (1895) 228. - Reg. Somal.

IPHIONA, Cass. (Compos.). - Ind. Kew. i. 1222. mucronata, Aschers. \& Schweinf. [IIl. Fl. Egypte] in Mém. Inst. Égypt. ii. (188\%) $86=$ juniperifolia, Cass.

subulata, Baker, in Kerw Bull. (1894) 333. - - Arabía.

IPOMOEA, Linn. (Convolvul.). - Ind, Kew. i. 1222.

aculeata, Kuntze, Rev. Gen. (1891) $442=$ Convolvulus aculeatus, $\operatorname{Linn}$.

acuminata. Baker, in Kew Bull. (1S94) $72=$ zambesiaca, Britten.

adenioides, Schinz. in Verh. Bot. Ver. Brand. $\mathrm{xxx}$. (1888) 270. - Afr. austro-occ. extratrop.

adumbrata, Rendle \& Britten, in fourn. Bot. xxxii. (1894) 173. - Angola.

agrestis, Hochst. ex Engl in Abh. Preuss. Akad. Wiss. 1891 (1892) 345, in syn. = Evolvulus agrestis, Schweinf.

alata, N.E. Rose, in Contrib. U.S. Nat. Hers, i. (1891) 108, -- Mexic,

\section{IPOMOEA}

Althoffiana, Dammer, ex Engl. in Abh. Prenss. Akad. Wiss. (1894) 58; et in Engl. Pfanzenwe Ost-Afr. C (1895) 333. - Afr. trop. or .

amnicola. Morong, in Ann. N. Y. Acad. Sci, vii, (1893) 170. - Parag.

amplexicaulis, Fernaid, in Conlt. Bot. Gaz. xx. (1895) 5:35. - Mexic.

andongensis, Rendle \& Britten, in fourn. Bot. xxxii. (1894) 171. - Angola.

angustisecta, Engl. Bot. Jahrb. x. (1889) $245=$ Bolusiana, Schinz.

arenicola, Rendle \& Britten, in fourn. Bot. xxxii. (1894) 176. - Angola.

argentaurata, Hallier fo in Bot. Fahrb. xviii. (1S94) 132. - Afr. trop. occ.

argentinica, Peter, in Engl \&f Prantl, Natïr. Pflanzenfam, iv. 3a (1891) :30. - Reg. Argent.

asclepiadea, Hallier fo in Bot. Fahro. xviii. (1894) 142. - Afr. trop.

asperifolia, Hallier f. l. c. 125. - Angola.

Assumptionis, Britton. in Ann. N. Y, Acad Sci, vii. (1893) 170. - Parag.

aspericaulis, Baker, in Kew Bull. (1594) 70. Angola.

auriculata, Hallier fo in Bot. Jahrb. xviii. (1894) $130=$ cordofana, Choisy.

Bakeri, Britten, in Fourn. Bot, xxxi1. (1894) 85 (= I. discolor, Baker). - Afr. centr. or

Barteri, Baker, in Kerv Bull. (1894) 70. - Afr. trop. occ.

bathycolpos, Hallier f. in Bot. Fahrb. xviii. (I894) 144. - Afr. austr.

benguelensis, Baker, in 'Kew Bull. (1894) 69. Angola.

Bernouilliana, Peter, in Engl. \& Prantl, Natitr. Pflanzenfam. iv. 3a (1S91) 30. - Guatem.

bipinnatipartita, Engl. Bot. Fakrb.x. (1889) 246. - Afr. austro-occ, extratrop.

blepharophylla, Hallier f. ex Engl.l.c. xviii. (1894) 125. - Afr. trop.

Bolusiana, Schinz, in Verh. Bot. Ver. Brand. xxx. (1888) 2il. - Afr. austro-occ. extratrop.

Buchanani, Baker, in Kew Bull. (1894) 73. - Afr. trop.

Buchneri, Peter, in Engl. \& Prantl, Natiirl. Pfanzenfant. iv. 3a (1891) 20; et ex Hallier fo, in Bot. fahrb. xviii. (1894) 151. - Angola

bullata, Olizer, in H. Folinst. Killim. Exped.. App. (1886) 343, nomen; et in Trans. Linn. Soc. Ser. II ii. (1887) 343, t. 62. - Afr. trop. or

caespitosa, Hallier f., in Bot. Jahrb. xvi. (1893) 552 = Skinneria caespitosa, Choisy.

caespitosa, Kuntze, Rev. Gen. (1891) $443=$ linifo. lia, Blume.

camerunensis, Taub. in Gartenfl. (1891) 394, t. 1352. - Kamerun.

Carletoni, Holzinger, in Contrib. U. S. Nat. Herb. i. (1892) 211, t. 17. - Am. bor.

Carsoni, Baker, in Kew Bull. (1894) 71. - Afr. centr. or.

cephalantha, Baker, l. c. 69. - Afr. trop. or

chaetocaulos, Hallier f., in Bot. falirb. xviii. (1894) 133. - Afr. trop.

chloroneura, Hallier f., l. c. 132. - Angola.

Choisyana, Wight \& Arn. ex Hallier f. 1. c. 130, in obs. = Argyreia Choisyana, Wight

chrysochaetia, Hallier f., l. c. 133. - Loango

cicatricosa, Baker, in Kew Bull. (1895) 221. - Reg. Somal.

coeru'ea, Bello, ex Stahl, Estud. fl. Puerto-Rico, vi (1888) $158=$ caerulea, Bello

comosperma, Drake, Ill, Ins, Mar. Pacif, Fasc. vii, (1892) 242 (= Calonyction comospernum, Bojer) - Afr. trop.; Ins. Vitiens.

convolvulifolia, Hallier $f_{\text {. }}$, in Bot. Fahrb. xviii. (1894) 126. - Afr. trop. bor -or.

convolvuloides, Hailier f. l. c. 140. - Afr. austr. convolvuloides, Schinz, in Verh. Bot. Ver. Brand. xxx. (1888) 273. - Afr. austro-occ, extratrop. cordatosepala, Britten, in fourn. Bot, xxxii. (1894) $170(=I$. cardiosepala, Meissn.). - Bras

cordobana, Peter, in Engl. \& Pranti, Natiirl. Pfanzenfam, iv. 3a (1891) 31. - Reg. Argent. costaricensis, Kuntze, Rev. Gen. (1891) 443. - Costarica.

\section{IPOMOEA}

repidilormis. Hallierf. in Bot. Fahrb, xviii. (1894, 131. - Afr. trop. or

crispa, Hallier f. 1. c. $143=$ Corvolvulus crispus Thunb.

demissa, Hallier f. l. c. 129. - Afr. trop.

diplocalyx, Baker, in Kew Bull. (1894) 71. - Res Zambes.

discoidesperma, 7. D. Smith, in Coult. Bot. Gat xiv. (1589) 27. - Guatem.

discolor, Baker, in Kew Bull. (1894) $69=\mathrm{I}$. Bakeri, Britten.

Elliottii, Baker, l. c. - - Afr. austr.

elytrocephala, Hallierf. in Bot. Fahrb. xviii. (1894 134.- Afr. trop.

emarginata. Kuntze, Rev. Gen. (1891) $443=$ reniformis, Choisy

Emini, Hallier f. l. c. 150. - Afr, trop.

Engleriana, Dammer, ex Engl. in Abh. Prouss. Akw Wiss. (1894) 41 ; et in Engl. Pfanzenw. Ost-Afr. C (1895) 333. - Afr. trop. or.

eurysepala, Hallier f. in Bot. fahwo xviii. (189t 125. - Kordofan

Fendleriana, Kuntze, Rev. Gen. (1S9l) 443. Venezuela.

fruticosa, Kuntze, l. c. - Venezuela.

fulvicanlis, Boiss, ex Hallier f, in Bot. Jahrb; xviii 1894) $128=$ Aniseia fulvicaulis, Hochst.

gracillima, Peter, in Engl. \& Pranth, Natiurl. Pflun zcnfam. iv. 3a (1891) 30. - Venezuela.

gracillima, Prain, in foum. Linn. Soc. 1xiii. (1894) II. 111. - Burma.

grandiftora, Hallier f. in Bot. Jahrb, xviii. (1894 $15: 3$ = Calonyction grandiflorum, Choisy

Grayi., N. E. Rose, in Contrib. U. S. Nat. Herb. i. 1891) 107, - Mexic

Grisebachiana, Peter, in Engl. \& Prantl, Natiirl. Pflanzenfam. iv. 3a (1891) $30=$ Jacquemontia luxurians, Hallier $f$

Hackeliana, Hallier f. in Bot, fahrb. xviii. (1894) 12. - Afr, austro-occ, extratrop.

Hallieriana, Britten, in fourn. Bot. xxxii. (1894) 170 [sphalm.? Halleriana] $(=$ I. zanuscsiaca, Britten) - Zambesia.

Hanningtonii, Baker, in Kew Bull. (1894) z0. - Afr. trop. or.

Hardwickii, Homsl, in foum, Linn. Soc, xxvi. (1S\%) 160 (= Consolantus. Hardwickii, Spreng. .). - As. et Afr, trop.

hellebarda, Schweinf. ex Hallier $f_{\text {; }}$ in Bot. Jahrt, xviii. (18:4) $142=$ sagittata, Honk

heterosepala, Bulker, in Kew Bull, (1895) 222. Reg. Somal

hewittioides, Hallier f. in Bot. Fahrb. xviii. 189t) 127. - Angola.

Holubii, Baker, in Kew Bull. (1894) 79. - Ree. Zambes.

Holstii, Dammer, ex Engl, in Abh. Prenss. Akud. Wiss. (1894) 17, nomen. - Afr. trop.

huillensis, Baker, in Kew Bull. (1894) 70. - Angola. humifera Rendle of Brittent, in Fourn. Bot. Xuxit. (1894) ]77. - Angola.

hypoxantha, Hallier f. in Bot. Fahrs. xviti. (1894) 128. - Afr. trop.

Hystrix, Hallier f. l.c. 146. - Afr, trop. or.

incomta, Hallier f. l. c.151. - Zanzib.

inconspicua, Baker, in Kew Bull.(1894)71.—Afr. trop. intrapilosa, N. E. Rose, in Gard. and For.'vii. (IS9t) $36 \%$ - Mexic

Jicama, T.S. Brandeg. in Proc. Calif. Acad. Ser. II. ii (1889) 188. - Calif

Kilimandschari, Dammer, in Engl. Pfanzenre. Ost Afr. C.(1895) 332, - Afr. trop. or

Kingii, Prain, in fourn. As. Soc. Beng. lxiii. (189.) II. 110. - Ind, angl

Kirkiana, Britten, in fourn. Bot. xxxii. (1894) 85 ) (= I. shivensis, Baker). - Afr. trop.

Klotzschii, Dammer, in Engl. Pfanzenw. Ost-Afr. C (1895) 332 ( = I. stenophylla, Klotzsch). - Aft. trop. or.

laeta, A. Gray, ex S. Wats, in Proc. Am. Acad, xxi (1887) $439 .-$ Mexic

Lambii, Fernald, in Coult. Bot. Gazo xx, (189.5) 5.35.5. - Mexic.

lapathifolia, Hallier f. in Bot, falmb. xyiii. (1S)t 142. - Afr. trop. austro-or. 


\section{IPOMOEA :}

leonensis, Robinson, in Proc. Am. Acad. xxvi. (1891) 170. - Mexic.

leptocaulos, Hallier fo in Bot. Falrbo xviii. (1894) 126. - Atr. trop. occ.

leptosiphon, S. Wats, in Proc: Am. Aiad, xxiii. (1885) $280 .-$ Mexic.

Lesteri, Baker, in Kcw Bull. (1891) 273, nomen; et (1892) 83. - Afr. trop. occ.

Leucanthemum, Hallier f. in Bot. Fakrb. xviii. (1594) 124 (= Calycanthemun Leucanthemum, Klotzsch), - Afr, trop.

linosepala. Hallier f. l. c. 130. - Angola.

longipes, Engl.l.c.x. (1889) 246. - Afr. austr

lophantha, Hallier f. l. c. xviii. (1894) 134. - Afr. trop. or.

macrantha, Peter, in Engl. of Prantl, Natiirl. Pfanzenfan. iv. 3a (1891) 31. - Guatem.

madrensis, S. Wats, in Proc. Am. Acad. xxiii. (1888) 281. - Mexic

magnifica, Hallier f. in Bot. Falirb. xviii. (1894) 152 - Atr. trop.

Masnusiana, Schiz, in Ver h, Bot.Ver, Brand。xxx. (1058) 272. - Afr. austro-occ, extratrop.

Marlothii, Engl. Bot. Fahrb. x. (1889) 244. - Afr. ausiro-occ, extratrop.

Matthewsiana, Kuntze, Rev.Gen. (1891) 443. Peruvia.

medians, Cordenr, Fl. Ile Rémmon (1895) $4 \%$ is (= Pharbitis medians, Choisy.). - Ins. Borbon.

megalochlamys, Baker, in Kew Bull. (1894) 72. Angola.

microcephala, Hallier f. in Bot. Fahrb, xviii. (1894) 131. - Afr, trcp, or

moeroënsis, Baker, in Kew Bull. (1895) 291. - Afr. trop.

Morongii, Britten, in Amn. N. Y. Acad. Sci. vii. (189:5) 171. - Parag.

Morsoni, Baker, in Kin Bull. (1894) 71. - Sierra Leune.

nana, Collett of Hemsl. in founn. Linn, Soc. xxxi. (1890) 97. - Burma.

Neallyi, Coulter, in Contrib. U. S. Nat. Herb. ii (18\%0) 46 ( = Antirrhinum nanrandiodes, A. Gray). - Texas

nuda, Baker, in Kew Bull. (1894) 72, - Angola.

nuda, Peter, in Engl, \&o Pruntl, Natiurl, Pflanzenfam. iv. Ba (1591) 31 (= Operculina tuberosa, Meissn.), - Guatem.

ootusata, Moric, ex Hallier $\mathrm{f}$. in Bot. Jahrb. xvi (189.3) $542=$ Jacquemontia obtusata, Hallier dontosepala, Baker, in Kcw Bull. (1894) 73. - Air. trop, or,

Oenothcrae, Hallier fo in Bot. Jahrb. xviii. (1894) $125=$ Convolvulus Oenotherae, Vatke.

ophthalmantha, Hallier f. l. c. 141. - Afr. trop.

ornithopoda, Robinson, in Proc. An. Acad. xxvii.

(1893) 183. - Mexic

oxyphylla, Baker, in Kew Bull. (1894) 71. - Angola.

Palmeri, S. Wats. in Proc. Am. Acad. xxiv. (1889) 63. - Mexic

Pearceana, Kuntze, Rev. Gen. (1891) 443. - Peruvia.

pellita, Hallicr f. in Bot. Fahrb. xviii. (1894) 130 . Atr, austr.

perlonga, Robinson, ex Pringle, in Gard. and For. vii. (1894) 153; et in Proc. Am. Acad. xxix. (1894) 319. - Mexic.

pharbitiformis, Bakcr, int Kew IBull. (1895) 291. Atr, trop.

phyllosepala, Baker, 1. c. (1894) $69=$ Hewittia bicolor, Wight \&o Arn.

pinnatifida, Hallier f. in Bot. Jahrb. xvi. (1893) 5ร̃ $=$ pinnatifida, $G$. Don ?

flantaginea, Hallier f. 1. c. xviii. (1894) $147=$ Convolvulus plantagineus, $C / z$ isy.

polytricha, Baker, in Kev Bull. (1894) 71. - Afr. trop. occ:

popahensis, Collett \& Hemsl. in fourn. Limn. Soc. xxxi. (1890) 97. - Burma.

porrecta, Rendle \& Britten, in Fourn. Bot. xxxii. (1894) 172. - Angola.

Pringlei, A. Gray, in Proc. Am. Acad. xxii. (188\%) 307. - Mexic

Protea, Rondle E Eritten, in fourn. Bot. xxxii. (1894) 176. - Angola.

\section{IPOMOEA :}

punctata, Baker, in Kew Bull. (1895) 184. - Arabia. pyramidalis, Hallier $f$. in Bot. Falirb. xviii. (1894) 152. - Angola.

quinquefolia, Hochst ex Hallier f. 1.c. 147. - Abyss. racemigera, F. Muell of Tate, in Trans, et Proc. Roy. Soc. S.. Auistral. xiii. (1890) 108. - Austral. repandula, Baker, in Kev Bull. (1894) 110. Lagos.

Robertsii, Hook.f. in Bot, Mag. (1887) t. 6052. Queensland

rhodocalyx, A. Gray, ex S. Wats, in Proc. Am. Acad. xxii. (1887) 439. - Mexic

rostrata, Peter, in Engl. E Prantl, Natiirl. Pfanzenfam. iv. 3a (1891) 30. - Guatem.

rubro-viridis, Baker, in fourn. Linn. Soc, xxii. (1887) 507 - Madag.

sagittaeformis, Cordem. Fl. Ile Réunion (1895) 4 \%. - Ins. Borbon.

salaziana, Cordem.l. c. (1895) 474. - Ins, Borbon.

Saltiana, Rendle, in fourn, Bot. xxxii. (1894) 178. Abyss.

Schrenkiana, Peter, in Engl. E Prantl, Natürl. Pfanzenfane iv, 3a (1891) 30. - Am. bor.

semisagitta, Griseb. ex Peter, in Engl. \& Prant, Natîrl. Pfanzenfam. iv. 3a (1891) 31 (= Merremia pedata, IIallier f.). - Mesopot.

shirambensis, Baker, in Kew Bull. (1894) 79. Zambes.

shirensis, Baker, in Kew Bull. (1894) $74=$ I. Kirkiana, Britten.

shupangensis, Baker, f. c. 73. - Zambes.

Simonsiana, Rendle, in foum Bot. xxxii. (1894) 178. - Afr. trop.

sindica, Stapf, in Kew Bull. (IS94) 346. - Ind. angl.

sinuata, Kuntze, Rev, Gen. (1891) $442=$ carnosa, $R, B r$

Smitthii, Baker, in Kew Bull. (1894) 73. - Congo.

speciosa, Hallier fo in Bot. Jahrh, xviii. (1894) 143 = sagittata, Lam.

stellaris, Baker, in Kew Bull. (1894) 73. - Afr. trop.

stenophylla, Klotzsch, ex Engl. Pflanzenw. Ost-Afr. A (1895) $23=$ I. Klotzschii, Dammer.

Stocksii, Peter, in Engl. \& Prantl, Natürl. Pfanzonfam. iv. 3a (1891) 31. - Ind, angl.

Stuhlmannii, Dammer, in Engl. Pfanzenw. Ost-Afr. C. (1896) 333 - Afr. trop, or

supersticiosa, Rodr.Vellosia, 1885-86, sec. edic 1891) 61 t. 17. - Bras.

syringaefolia, Baker, in foum. Limn. Soc. xxii. (1887) 507. - Madag.

taborana, Dammer, in Engl. Pfanzenw. Ost-Afr. C (iS95) 333. - Afr. trop. or

tambelensis, Baker, in Kerw Bull. (1894) 72. - Reg. Zambes.

tanganyikensis, Baker, l. c. (1895) 70. - Afr. trop. centr. or.

temuifolia, Kuntze, Rev. Gen. (1891) 446 = quinata, R. Br

texana, Coult, in Contrib. U. S. Nat. Herb, i. (1890) 45. - Texas.

tortugensis, Peter, in Engl. \& Prantl, Natürl. Pflanzenfam. iv. 3a (1891) 31 (= Merremia pentaphylla Hallier f.). - Guatem.

uliginosa, Welw。 ex Rendle, in foum, Bot.xxxii. (1894) 179, in obs. - Angola.

vagans, Baker, in Kew Bull. (1894) 70. - Afr. trop. oce.

velutipes, Welw. ex Rendle, in fourn. Bot. xxxii. 1894) 175. - Angola.

Vogelii, Baker, in Kero Bull. (1894) '11. - Afr. centr. bor.

Wakefieldii, Baker, I.c. 72. - Afr. trop

Walcottiana, f. W. Rose, in Gard. and For, vii. (1894) 366. - Mexic.

Wattii, C. B. Clarke, in fourn, Linn. Soc. xxy. (1889) 49, t. 22. - Kohima.

Welwitschii, Vatke, ex Hallier f. in Bot. Fahrb. xviii, (1894) 146. - Angola,

Woodii, N. E. Br. in Kew Bull. (1894) 101. - Afr. austr.

xanthophylla, Hockst, ex Hallier fo inz Bot. Fahrb. xviii, (1894) 113 (= Morremia xanthophilla, Hallier f.). - Abyss.

\section{IPOMOEA :}

xiphosepala, Baker, in Kew Bull. (1894) 69. - Angrola.

zambesiaca, Baker, l. c. 70. - Reg. Zambes. zambesiaca, Britten, in Journ. Bot. xxxii. (1894) 85 $=\mathrm{I}$. Hallieriana, Britten.

IPO, Pers. = Antiaris, Lesch. (Urtic.)

Eenncttii, Kuntze, Rev. Gen. (1891) $629=$ A. Bennettii, Seem.

imzoxia, Kuntze, 1. c. $=$ A. toxicaria, Lesch.

macrophylla, Kuntze, 1. c. = A. macrophylla, $R . B r$

palembanica, Kuntze. Rev. Gen. (1891) $629=$ A. palembanica, Miq.

rufa, Kuntze, 1. c. = A. rufa, Miq.

IPSEA, Lindl. (Orchid.) - Ind. Kew, i, 1228. malabarica, Hook. f. Fl. Brit. Ind. v. (1890) 812 (= Pachystoma malabaricum, Reichb. f.). Malabar.

Thomsoniana, Pfitz. in Engl. \& Prantl, Natïr. Pflanzenfam, ii, VI. 6 (1888) 154 (= Pachystoma Thomsonianum, Reichb. f.). - Zeyl.

Wrayana, Hook. f. Fl. Brit. Ind. v. (1892) 812 ; et in Hook. Icon. pi. xxi. (1892) to 20S5. - Perak.

IRESINE, P.Br: (Amaranth.), - Ind, Kew。i. 1228.

alternifolia, S. Wats. in Proc. Am. Acad. xxiv. (1889) 72. - Mexic.

Benthamiana, Kuntze, Rev, Gen. (1891) $543=\mathrm{He}-$ banthe parviflora, Benth.

laxa, S. Wats, in Proc. Am. Acad. xxi. (1886) 454.Mexic.

muscodes, Kuntze, Rev. Gen. (1891) $542=$ Alternanthera muscoides, Benth. \& Hook. $f$.

paniculata, Kuntze, 1. c. = celosioides, Linn.

Pringlei, S. Wats. in Proc. Am. Acad. xxv. (1890) 161. - Mexic

radicata, Kuntze, Rev, Gen. (1891) $542=$ Alternanthera radicata, Hook. $f$.

Schaffneri, S. Wats. in Proc. Am. Acad. xxi. (18S6) 43\%. - Mexic

scirpodes, Kuntze, Rev, Gen. (IS91) $542=$ Alternanthera scirpoides, $H o o k$, $f$

subscaposa, Kuntze, 1. $c_{0}=$ A. subscaposa, Hook. $f$.

IRIDORCHIS, Thou. in Nouv. Buil. Soc. Philom. Paris (1809) 314, 9; ex Kuntze, Rev. Gen. (1891) $668=$ Oberonia Lind1. (Orchid .

anceps, angustifolia, anthropophora, aporophylla, bicornis, brachystachya, Brunoniana, caulescens, Clarkei, cylindrica, demissa, ensiformis, Falconeri, ferruginea, forcipata, Gardneriana, gracilis, Griffithiana, $\mathrm{Hel}$ feri, imbricata, iridifolia, fenkinsiana, Lindlcyana, Iobbiana, longibracteata, lanata, maxima, microphylla, miniała, Myosurus, myriantha, obcordata, orbicularis, pachyrhachis, pachystachya, platycaulon. pyrulifera, recurva, rufilabris, Scortechinii,. Scyllae, similis, spathulata, tahitensis, temuis, Thisbe, Titania. Treutleri, truncata, verticillata, Wallichiz, Wightiana, zeylanion, Kuntze, Rev. Gen. (1891) $669=$ homonyma omnia Oberoniae.

equitans. Kuntze, 1. c. = O. brevifolia, Lindl. heliophylla, Kuntze, 1. c. = Malaxis heliophila Reichb.f.

IRIA, Hedw. $f .=$ Fimbristylis. Vahl (Cyper.). obtusifolia, Hitchcock, in Missouri Bot. Gard. Rep. iv. (1893) $141=$ F. obtusifolia, Kunth

IRIARTEA, Ruiz \& Pav. (Palm.), - Ind. Kew. i. fusca, Drude, in Engl. E Prantl, Natiirl. Pfanzenfan. ii. 3 (1887) 60. - Columb.

IRIHA, Kuntze, Rev。Gen. (1891) 75l = IRIA Hedw. $f_{0}=$ Fimbristylis, Vahl (Cyper.)

acicularis, Kuntze, 1. . 753 - F acuminata, Vahl. acuminata, Kuntze, 1. c. $751=\mathrm{F}$. acuminata, Vahl aestivalis, Kuntze, 1. c. = F. aestivalis, Vahl. androgyna, Kuntze, 1. c. $753=\mathrm{F}$. androgyna, $R$. $B r$ angulavis, Kuntze, $1 . \mathrm{c}_{0}=\mathrm{F}$. angularis, Link aphylla, Kuntze, 1.c. (= Abilgaardia aphylla, Kunth $=\mathrm{F}$. bahiensis, Steud. apus, Kuntze, 1. c. = F. Vahlii, Link. 
IRIHA

Arnottiana, Kuntze, Rev. Gen. (1891) $753=$ Fimbristylis Arnottiana, Boeck.

autumnalis, Kuntze, 1. c. $752=\mathrm{F}$, autumnalis, Roem. E Schult

barbata, Kuntze, 1. c. $753=$ F. barbata, Benth. Basteri, Kuntze, 1. c. = F. Barteri, Boeck.

biflora, Kuntze, 1. c. $=$ F. cyperoides, $R$. Br

bispicata, Kuntze. 1. c. = F. bispicata, Nees \& Meyer. bisumbellata, Kuntze, 1. c. $752=$ F. spathacea, Roth caespitosa, Kuntze, 1. c. $753=$ F. caespitosa, Boeck. capillaris, Kuntze. 1. c. = F. capillaris, A. Gray. capitata, Kuntze, 1. c. $=$ F, capitata, $R . B r$.

cardiocarpa, Kuntze, 1. c. = F. cardiocarpa, $F$. Muell.

cinnamometorum, Kuntze, 1. c. = F. cyperoides, R. Br.

compressa, Kuntze, 1. c. = F. compressa, Boeck. consanguinea, Kuntze, 1. c. = F. complanata, Link, corinocarya, Kuntze, $1, c$. $=\mathrm{F}$. corynocarya, $F$. Mull.

crassipes, Kuntze, 1. c. = F. crassipes, Boech. cymosa, Kuntze, 1. c, $=\mathrm{F}$. cymosa. $R, B r$ debilis, Kuntze, 1, $c$, $=$ F. debilis, $F$. Muell. denutata, Kuntze, 1. c. (sphalm. $)=$ F. denudata, R. Br.

depauperata, Kuntze, 1. с. = F. diphylla, Vahl. disticha, Kuntze, 1. c. = F. disticha, Bocck.

Drummondii, Kuntze, 1. c. $=$ F, anomala, Boeck. et castanea, Vahl.

elata, Kuntze, 1. C. $=$ F, denudata, $R . B r$.

Eragrostis, Kuntze, 1. c. = F. Eragrostis, Hance.

falcata, Kuntze, 1. c. $=$ F' junciformis, Kunth.

falcifolia, Kuntze, 1.c. = F. falcifolia, Bocck.

forruginea. Kuntze, 1. c. $752=\mathrm{F}$. ferruginea, Vahl.

filifolia, Kuntze, 1. c. $753=$ F. filifolia, Boeck.

fimbristylodes, Kuntze, 1. c. $=$ F. disticha, Boeck.

furva, Kuntze. 1. c. = F. furva, $R$. Br.

fusca, Kuntze, 1. c. = Abilgaardia fusca, Nees.

globulosa, Kuntze, 1. c. $752=$ Fimbristylis globilosa, Kunth.

glomerata, Kuntze, 1. c. $753=$ F. spathacea, Roth gracilis, Kuntze, 1, c. $=$ F, tenuis, Roem. \& Schult. Hanceana, Kuntze, 1. c. = F. rigidula, Nees.

hawaiensis, Kuntze, 1. c. = F. hawaiensis, Hillebr

Hookeriana, Kuntze, 1. c. $=$ F. Hookeriana, Boeck

insignis, Kuntze. 1. c. $=$ F, insignis, Thou.

guncea, Kuntze, 1. $c .=F$, juncea, $R$. $B r$.

junciformis, Kuntze, 1. c. $752=\mathrm{F}$. junciformis, Kunth.

leptoclada, Kuntze, 1. c. $753=$ F. leptoclada, Benth. leucocolea, Kuntze, 1. c. = F. leucocolea, Benth.

leabostachya, Kuntze, 1. c. = F. leucostachya, Roem. \& Schult.

macrantha, Kuntze, 1. c. = F. macrantha, Boeck.

macrostachya, Kuntze, 1. c. = F, macrostachya Boeck.

Martii, Kuntze, 1. c. = F. bahiensis, Siend.

microcarya, Kuntze, 1. c. $=$ F. microcarya, $F$, Muell.

miliacea, Kuntze, 1. c. $752=$ F. miliacea, Vahl. monandra, Kuntze, 1. с. $753=\mathrm{F}$, argentea, Vahl. monostachya, Kuntze, 1. c. 751, $752=$ F. monostachya, Hassk.

mucronata, Kuntze, 1. c. 753 = F. Barteri, Bocck. Muelleriana, Kuntze, 1. $\mathrm{c}=\mathrm{F}$. monandra, F. Muell. multifolia, Kuntze, 1. c. - F. cymosa, $R$, $\mathrm{Br}$.

Neilsonii, Kuntze, 1. c. = F. Neilsoni, F. Muell.

mutans, Kuntze, 1. c. = F. nutans, Vahl.

obtusangula, Kuntze, 1. c. = F. rara, $R$. $B r$

oxystachya, Kuntze, 1. c. = F. oxystachya, F. Muell.

pauciflora, Kuntze, 1. c. $752=\mathrm{F}$. pauciflora, $R . \mathrm{Br}$.

taupercula, Kuntze, 1. c. $753=$ F. paupercula Boeck.

pentaptera, Kuntze, 1. c. $=$ F. pentaptera, Kunth.

Pierottii, Kuntze, 1. c. $=$ F. Pierotii, Miq.

pilosa, Kuntze, 1. c. =- F. pilosa, Vahl.

platystaclya, Kuntze, 1. c. = F. Schultzii, Boeck.

polymorpha, Kuntze, 1. c. $752=$ F. diphylla, Vahl.

polytrichodes, Kuntze, 1. c. $753=\mathrm{F}$. polytrichoides, $R . B r$.

pterygosperma, Kuntze, 1. c. = F. pterigosperma, R. Br.

punctata. Kuntze, 1. c. $=$ F. punctata, $R$. Br.

pycnocephala, Kuntze, 1. c. = F. pycnocephala Hillebr.
IRIHA : -

quinquangularis, Kuntze, Rev. Gen. (1891) $752=$ Fimbristylis quinquangularis, Kunth. rara, Kuntze, 1, c. $753=$ F。 rara, $R$. Br. retzsa, Kuntze, 1. C. = F. leptoclada, Benth. rhyticarya, Kuntze, 1. c. = F. rhyticarya, F. Muell salbandia, Kuntze, 1. c. = F. salbundia, Kunth. scaberrima, Kuntze, 1. c. $=$ F. scaberrima, Nees. schoenodes, Kuntze, 1. c.752 = F. schoenoides, Vahz. sericea, Kuntze, 1. c. $753=$ F, sericea, $R$. Br solidifolia, Kuntze, 1. c. = F. solidifolia, F. Muell spadicea, Kuntze, 1. c. $752=$ F. spadicea, Vahl. sphaerocephala, Kuntze, 1. с. $753=$ F. monandra, F. Muell.

spiralis, Kuntze, 1. c. = F。 spiralis, $R$. Br. spirostaclya, Kuntze, 1. c. = F. diphylla, Vahl. squarrosa, Kuntze, 1. c. = F. squarrosa, Vahl. strictu, Kuntze, 1. c, = F. Schomburgkiana, Stend. subaristata, Kuntze, 1. c, = F. subaristata, Benth. subbulbosa. Kuntze, 1. c. $=$ F. schoenoides, Vahl. subtetrasfachya. Kiuntze, I $\mathrm{c},=\mathrm{F}$. nigrobrunnea, Tha tenera, Kuntze, 1. c. = F. tenera, Roem. E Schult temicula, Kuntze, 1. c. = F. tenuicula, Boeck. tetragona, Kuntze, 1. c. $=$ F. tetragona, $R$. $B r$. thermalis, Kuntze, I. $\mathrm{c},=\mathrm{F}$, thermalis, $S$. Wats Thomsonii, Kuntze, 1. c。 = F. Thomsoni. Beeck.

Thonningiana, Kuntze, 1. c. = F. Thonningiana Bock.

torta, Kuntze, 1. c. = F. junciformis, Kunth.

triffora, Kuntzc, 1. $c_{0}=\mathrm{F}$. triflora, $K$. Schum.

rigastrocarya, Kunize, 1. C, = F, trigastrocarya, F. Muell.

uliginosa, Kuntze, 1. c. = F, uliginosa. Hochst. umbellata, Kuntze, 1. c. = F. castanea, Vahl. áginata, Kuntze, 1. c. = F. leptoclada, Benth.

Vallii, Kuntze, l: c. = F. Vahlii, Link.

velata, Kuntze, 1. c, = F, squarrosa, Vahl

Xyridis, Kuntze, 1. c. $=$ F. Xyridis, $R$. Br.

IRIS, Tourn, ex Linn. (Irid.), - Ind, Kew. i. 1228 Amasiana, Bornm. ex Hausskn. in Flora (1859) 140 , in syn. $=\mathrm{I}$. Danfordiae, Baker.

athoa, Foster, in Gard. Chron. (1893) i. 711. Graecia

atrofusca, Baker, in Gard. Chron. (1893) i. 384 ; ct in Bot. Mag. (1894) t. 7379 sub I. atropurpurea Baker var, atrofusca, Baker), - Palaest.

atropurpurea, Baker, in Gard. Chron. (1889) i. 330. - Syria.

Bakeriana, Foster, in Bot. Mag. (1859) t. 7084; Baker, Handb. Irid. (1892) 42. - Armenia.

Barnumae, Foster \& Baker, in Gird. Chron. (1888) ii. 182; et in Bot. Mag. (1889) t. 705ั0; Baker, Handb. Irid. (1892) 21. - Armenia.

benacensis, A. Kern. ex Stapf, in Verk. zool.-bot. Ges. Wien (1887) 649; Baker, Handb. Irid. (1892) 35. - Tirol.

Biliotti, Foster, in Gard. Chron. (1887) 738; Baker, Handb. Irid. (1892) 37. - As. Min.

Bismarckiana, Regel, ex Wien, Gartenzeit, 1892) 8ว5., fig. 72; Baker, Handb. Irid. (1892) Is; et in Gard. Chron. (1893) i. 506. - Syria.

Bornmuelleri. Hausskn. in Flora (1889) 140; et in Oest. Bot. Zeitschr. xliv. (1894) 326 = I. Danfordiae, Baker.

bosniaca, G. Beck, ex Nym. Consp. Fl. Eur.. Suppl. (1887) 195; it in Annal. Naturhist. Hofmus. Wicn, v. (1890) 573. - Bosn.?

Burnati, Baker, Handb. Irid. (1812) 33. - Alpes Marit.

cardiopetala. Borbas, in Oest. Bot. Zeitschr. xxxviii. (1888) $325=$ spuria, Linn

caroliniana, S. Wats, in A. Gray, Man. Bot. N.U. St. ed. 6 (1890) 514; et in Proc. Am. Acad. xxv. (1898) 134; Baker, Handb. Irid. (1892) 12.Carolina.

Clarkei, Baker, ex Hook. f. Fl. Brit. Ind. vi. (1892) 275; et Handb. Irid. (1892) 25. - Reg. Himal.

compressa, $[N . E . B r$.$] in Monteiro, Delagoa Bay$ (1891) 171 . - Mossamb.

cretica, Herb. ex Baker, Handb. Irid, (1892) $3=$ cretensis, fanka.

crociformis, Freyn, in Oest. Bot. Zeitschr. xliv. (1894) 326, in syn, = I. Bornmuelleri, Hausskn, cypriana Foster \& Baker, in Gavd. Chron. (ISSS) ii 182; Baker, Handb. Irid. (1892) $3 \%$. - Cyprus,
IRIS :

Delayayi, M. Mict.73, in Rev. Hortic. (1895) 398 fig. 128 et $129 .=8$ unnan.

drepanophylla, Aitch. E Baker, in Trans. Linn. Soc. Ser. II. iii. (1S87) 115; Baker, Handb. Irid. (1892) 46. - As. centr. occ.

Duthiei, Foster, in Gard. Chron. (1887) i, 611

Baker, Handb. Irid. (1892) 25. - Kumaon.

flava, Tornab. Fl. Sicula (1887) 212. - Sicil.

Fosteriana. Aitch. \& Baker, in Trans. Linn. Soc. Ser. II. iii. (1887) 114; Baker, in Bot. Mag. (1892) t. $7215 .-$ Afghan

Gatesii, Foster, in Gard. Chron. (1890) ii. 18, fig. 3: Baker. Handb. Irid. (1892) 18. - Armenia

gilgitensis, Baker, ex Hook. f. Fl. Brit. Ind. vi. (1892) 264; et Handb. Irid. (1892) 34. - Tibet.

graminifolia, Freyn, in Oest. Bot. Zeitschr, xliv (1894) 326. - As. Min.

Grant-Duffii, Baker, Handb. Irid. (1892) 7. Palaest

Griffithii, Baker, l. c. 32, - Afghan

Haussknechtii, Bornm. (Pl. exsicc. Anatol. n. 1864 ex Baker, l.c. 4. - As. Min.

Henryi, Baker. l. c. 6. - China.

Hookeriana, Foster, in Gard. Chron. (1887) i. 611 Buker, in Bot. Mag. (1893) t. '7276. - Reg. Himal

Kingiana, Foster, in Gard. Chron. (1857) i.611 Baker, in Bot. Mag. (1857) t. 6957) = kumaonensis, Wall.

Kochii, A. Kern, ex Stapt, in Verh. zool.bot. Ges Wien (18S7) 649 ; Baker, Handb. Irid. (1892) 35. - Istria.

lazica, Alboff, Prodr. Fl. Colch. (1895) 232. - Reg. Cauc

lineata, Foster, ex Regel, in Gartenfl. xxxvi, (1887) $201, \mathrm{t} .1244=\mathrm{I}$. Suwarowi, Regel.

Lóczyi, Kanitz. Fl, exped. Szechenyi in As. centr. coll. (1891) 58. - As. centr.

lupina, Foster, in Gard. Chron. (1857) i. 738 ; Baker. Handb. Irid. (1892) 19. - Armenia.

Ittea, St. Lager, in Cariot, Etud. des fl. éd. S. ii (1889) $794=$ lutea, Lam

macedonica, Nadii [Charrel] Emp. Ottom. $[\mathrm{Pl}$. de Salon.] (1892) 40, nomen. - Maced.

Mandraliscae, Tineo, ex Tornab. Fl. Sicula (1887) 512. - Sicil.

Mariae, Barbey, in Oest. Bot. Zeitschr.xl. (1891) 206

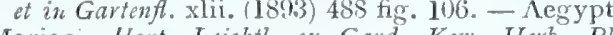
Mariae, I/ort. Leichtl. ex Gard. Kew, Herb. Pl (1895) 241 (an praec. ?), - Hab.

Meda, Stapf, in Bot. Ergeb. Polak Exped. Pers. (1886 20; Baker, in Bot. Mag. (1889) t. 7040. - Persia Mogrridgei Baker, Handb. Irid. (1892) 34.Alpes Marit.

parkor X, Foster, in Gard. Chron. (1895) i. 612. Hybr. artef.

propendens, Lange, in Bot. Tidsskr. (1895) 255. Hab. ?

Robinsonii, Hort. ex Gard. Chron. (1888) ii. $263=$ Robinsoniana, F, Muill.

Sari-nazarens, Foster, ex Gartenft. xlii (1893) 487. - Palaest.

Stocksii. Hemsl. \& Lace, in Journ. Linn. Soc. xxviii. (1891) $320=$ Xiphion Stocksii, Bak。

Suwarowi, Regel, in Act. Hort, Peirop. ix. (1886) 619; et in Gartenf. (1886) 398; Hook. f. in Bnt. Mag. (1888) t. 7029. - Buchara.

Thoroldi, Baker, ex Hemsl, in fourn.Linn. Soc, xxx. (1894), 118; et in Hook. Icont. pl. xxiv. (1894) t 2302. - Tibet.

tigrina, Jacquem. ex Hook. f. Fl. Brit. Ind, vi (1892) 274, in syn. = kumaonensis, Wall.

trojana, A. Kern. ex Stapf, in Verh, zool,-bot. Ges. Wien, (1SS7) 650; Baker, Handb. Irid. (1892) 12 - As. Min.

Van Houtter $\dot{X}$. Hort. Leichtl. ex Baker, Handb. Irid. (1S92) 20. - Hybr. artef.

Wattii, Baker, ex Hook. f. Fl. Brit. Ind, vi. (1892) 273; et Handb. Irid. (I892) 17 [sphalm. Watii]. Ind angl.

IRMISCHIA, Schlect, = Metastelma, $\mathrm{R}, \mathrm{Br}$ (Asclep.)

Paralias, K. Schum. in Eng1. E Prantl, Natür] Pflanzenfam. iv. 2 (1895) $229=$ M. Paralias Decue. 


\section{IRMISCHIA :}

sulerosa, K. Schum, in Enol, \& Prantl, Natürl. Pflanzenfam. iv. 2 (1895) $229=$ Metastelma suberosum, Griseb.

IRVINGIA, Hook. f. (Simarub.). - Ind. Kew. i. 123\%.

gabonensis, Baill. ex Lanen. Pl. util. Colon. Franç. (1886) 812; et in Annal. Inst. bot.-geol. Marseille, i. II. (1893) 1, cum xylogr. - Gabon.

Harmandiana, Pierre, ex Laness. l. c. (1886) 306 nomen. - Cochinch

malayana, Oliver, in Kew Bull.' (1890) 118. Malayd

Oliveri, Pierre, Fl. For. Cochinch. Fasc. 17 (1892) t. 263 B. - Annam.

ISACHNE, R. Br. (Gramin.). - Ind. Kew. i. 1232.

biflora, C. Cordem. in Cordem. F1. Ile Réunion (1895) 115 (= Panicum biflorum, Lam.) = albens, Trin.

Buettneri, Hack., ex Buettn, in Verh. Bot. Ver. Brand. xxxi. (1SS9) 69. - Gabon.

cernua, C. Cordent. ex Cordem. Fl. Ile Rémnion (1895) 115. - Ins. Borbon.

cochinchinensis, Balansa, in Morot, foum, de Bot. iv. (1890) 137. - Cochinch

comata, Munro, ex Hackel, in Hook. Icon. pl. xix. (1889) t. 1866. - Ins. Aneit.

elegans, C. Cordem. ex Cordem. Fl. Ile Réumion (1895 115. - Ins. Borbon.

globosa, Kuntze, Rev. Gen. (1891) $778=$ australis R. $\mathrm{Br}$.

Jardini, Th. Dur. \& Schinz, Consp. Fl. Afr. v 1894 (1895) 739 (= Panian Fardini, Steud.). Guinea.

longifolia, C. Cordem. Fl. Ile Réunion (1895) 115. Ins. Borbon.

pallens, Hillebr. Fl. Haw. Isl. (1888) 504. - Ins. Sandvic.

ISANTHERA, Nees (Gramin.). - Ind. Kew. i. 1233.

lanata, Warb. in Bot. Fahrb. xiii. (1891) 418.Oceania.

parviflora, Ridl. in Trans. Linn. Soc. Ser. II. iit. (1893) 331. - Penins. Mal.

ISANTHUS, Michx (Labiat.). - Ind. Kew. j. 1233.

brachiatus, Britton, Stern \& Poggenb. Prelim. Catal. (1S88) $44=$ coeruleus, Michx.

brachiatus, Kuntze, Rev. Gen.(1891) 520 = praec.

ISATIS, Tourn. ex Linn. (Crucif.). - Ind. Kew, i. 1233.

athoa, Boiss. Fl. Or. Suppl. (18S8) 65. - Graecia. Jullata, Aitch, et Hensl, in Trans, Linn. Soc. Ser. II. iii. (1886) 37. - Turkest.

lanceolata, Stapf, in Denkschr. Akad. Wien (1886) 18. - As. Min

pyramidata, Stapf, l. c. 19.- - As. Min.

stenocarpa, Stapf, l.c.37. - As, occ.

4ranssilzanica, Simonk, in Termesz, Fuzét. x. (1886) 180; et Enum. F1. Transsilv. (1886)- I01= praecox, Kit.

ISCHAEMUM, Linn, (Gramin.). - Ind. Kew. i. $12: 34$.

angustifolium, Hack. ex Olizer, in Hook. Icon. pl. xviii. (1888) t. 1773; et in DC. Monng. Phan. vi. (1SS:) 24 (= Spodiopogon angustifolius, Trin.). As. trop.

aureum, Hack in DC. l. c. 224 (= Spodiopogon aureus, Hook.). - Ins. Loo-Choo.

Beccarii, Hack, in DC. l. c. 24\%. - Borneo.

brachyatherum, Fenzl, ex Hack. in DC. l. c. 239 $(=$ Andropogon brachyatherus, Hochst.). - Afr. trop. or.-lior.

chrysatherum, $K$. Sclimm. cx Engl. in Ab7. Prenss. Alad. Wiss. (1894) 14 et 28. - Afr. trop.

chrysartherus, K. Schum. ex Engl. Pflanzenw. Ost-Afr. A (1895) 13, 31, sphalm. = chrysatherum, K. Schum.

\section{ISCHAEMUN}

commutatum, Hack. in DC. Monog, Phan, vi. (1889) 209. - Zeylan.

cordatum, Hack, ex Warb. in Bot. Fahrb. xiii. (1891) 260 (= Spodiopogon chordatus, Trin.). - As. trop. insul.

eriostachyum, Hack. in DC. Monog. Phan. vi. (1889) 218. - China, Japon.

Feildingianum, Rendle, in fourn. Bot, xxxii, (1894) 101. - Johore.

foliosum, Hack. in DC, Monog. Phan, vi. (18S9) 222, - N. Hibern.. N. Caled.

heterotrichum, Hack. l. c. 220. - Ins. Mascar.

hirtum, Hack in DC. l.c. 228. - Zeylan.

Huegelii, Hack. $2 n$ DC. l. c. 252. - Ind. or.

impressum, Hack in DC. l. c. 210. - As. trop.

koleostachys, Hack. in DC. l. c. 220 (= Andropogon koleostachys. Steud.). - Ins. Borbon.

lutescens, Hack. in DC. l. c.221. - Ins. Sandvic.

magnum, Rendle, in Fourn. Bot, xxxii. (I894) 102

- Penins. Mal.

notatum, Hack. in DC. Monog. Phan. vi. (1889)246 - Ind, or.

petiolare, Hack, in DC. l. c. 238 (= Spodiopogon petiolave, Trin.). - Ind. or.

pilosum, Hack. in DC. l. c. 240 (=S. pilosus, Nees) - Ind. or.

ramosissimum, Hack, in DC. l. c. 249. - As, trop. ? rivale, Hack. in DC. . c. 228. - Zeylan.

spathulatum, C. Corden. ex Corden. Fl. Ilé Réunion (1895) 121. - Ins. Borbon.

sulcatum, Hack, in DC. Monog. Phan. vi. (1889) 248. - Ind. or

tallanum, Rendle, in fourn. Bot. xxxi. (1893) 359. - Sierra Leone.

Turneri, Hack, in DC. Monog. Phan. vi. (1889) 233. - N. Hibern., N. Caled.

ISCHNANTHUS, Van Tiegh. in Bull. Soc. Bot. Fr. xlii. (1895) $260=$ Loranthus, Linn

Ehlersii, Van Tiegh. 1. co = L. Ehlersii, Schweinf. kagehensis, Van Tiegh. 1. c. = L. hagehensis, Engl. Lecardi, Van Tiegh. 1. c. = L. Lecardii, Engl. luluensis, Van Tiegh. 1. c. = L. Iuluensis, Engl. parifloris, Van Tiegh. 1. c. = L. parviflorus, Engl. woodfordioides, Van Tiegh. 1, c. = L. woodfordioides, Schweinf.

ISGHNEA, F. Muell. in Trans. Roy. Soc. Vict. N. S. i. 11. (1889) 13. COMPOSITAE.

elachoglossa, F. Muell. l.c. - N. Guin.

ISGHNOSIPHON, Koen. (Scitam.).--Ind. Kew. i. 1234.

hirsutus, Petersen, in Mart. Fil. Bras, iii. III. (1890) 135. - Bras.

Koernickeanus, Petersen, l.c. 140, - Bras.

Mariae, Eggers, in Bot. Centralbi. 1iii. (1893) 307. t. 2. - Ins. Baloo.

Martianus, Eichl. ex Petersen, in Mart. Fl. Bras. iii. II. (1890) 138. - Bras

pruinosus, Petersen, in Bot. Tidsshr. xviii. (1893) 264 t. 18. - Hab.

secundus, Petersen, in Mart. Fl. Bras. iii. III. (1890) 135. - Bras.

smaragdinus, Eichl. ex Petersen, l. c. 137 (= Calathea smaragdina, Linden). - Bras.

ISEILEMA, Anders, = Anthistiria, Linn. (Gramin.).

anthephoroides, Hack." in DC. Monog. Phan, vi. (1889) 683. - Ind. or.

laxum, Hack. in DC. l. c. 682 (=Iseil. prostratum, Anderss.). - Ind. or.. Zeylan.

prostratum, Kuntze, Rev. Gen. (1891) $7 \% 8=\mathrm{A}$. prostrata, Willd.

ISERTIA, Schreb. (Rubiac.). - Ind. Kew. i. 12:35.

bullata. K. Schum. in Mart. Fl. Bras. vi. VI. (1889) 286. - Bras.

longifolia, $K$. Sclinm. in Vid. Medd, naturh. Foren. (1889) 349 ; et in Mart. l. c. $289(=$ Psychotria longifolia, Hoffmgg). - Bras.

rosea. Spruce, ex K. Schum in Mart. l. c. 284. Bras.
ISNARDIA, Linn, = Ludwigia, Linn. (Onagrar.) arcuata, hirtella, linzfolia, natains, parviflora, pilosa. polycarpa, prostrata, spathulata, Kuntze, Rev. Gen. (1891) 251 = homonyma omnia Ludwigiae. jussienodes, Kuntze, Rev. Gen. (1891) $251=$ L. parviflora, Roxb.

suffruticosa, Kuntze, 1. c. = L. capitata, Michx.

ISOCAULON, Van Tiegh, in Bull. Soc. Bot. Fr. xlii. (1895) $352=$ Loranthus, Linn.

americanum, Van Tiegh. 1, c. = L. americanus, facq.

favo-viride, Van Tiegh. 1. c. = Psittacanthus, flavo-viridis, Eichl.

ISOCHILUS, R. Br. (Orchid.). - Ind. Kew. i. 1235. nilateralis, Robinson, in Proc. Am. Acad. xxix. (1894) 323. - Mexic.

ISOCOMA, Nutt.= Bigelovia, Nutt. (Compos,

acradenia, Greene, in Erythea, ii. (1894) $111=\mathrm{B}$. acradenia, Greene.

arguta, Greene, Man. Bot. San Franc. Bay (1894) 175. - Calif.

coronopifolia, Greene, in Erythea, ii. (1894) $111=$ B. coronopifolia, A. Gray.

Drummondii, Greerie, 1. c. = B. Drummondii, A. Gray.

Hartwegii, Greene, 1. c. = B. Hartwegii, A. Gray. heterophylla, Greene, 1.c. = Linosyris heterophylla, A. Gray.

pluriflora, Greene, 1. c. = B. pluriflora. A. Gray. tridentata, Greene, 1. c. = B. tridentata, Greone.

vencta, Greene, 1. c. = B. veneta. A. Gray.

ISOGLOSSA, Oerst. (Acanth.). - Ind. Kew. i. 1236

Bachmanni, Lindau, in Bot. Falirb. xx. (1894) 57. - Afr. trop. occ.

ciliata, Engl. Bot. Fahrb. x. (1889) 205 (= Rhytiglossa ciliata, Nees). - Afr, austr.

comorensis, Lindak, l. c. xx. (1894) 54. - Ins. Comor.

flava, Lindau, l. c. xxii. (1895) 125 ; et in Engl. Pflanzenw. Ost-Afr. A (1895) 91. - Afr. trop. or. glandulifera, Lindau, l. c. xx. (1894) 54. - Afr. trop. occ

orandiflora, S. Moore, in Trans, Limn. Soc. Ser. II. iv. (1894) 34, in obs. (= Ecteinanthus grandiflorus T. Anders.). - Afr. trop. austro-or.

hypoestiflora, Lindaw, in Bot. Falivb. xx. (1894) 58 - Atr. trop. occ.

xodes, Lindan, l. c. xxii. (1395) 124; et in Engl. Pfanzenw. Ost-Afr. A (1895) 130. - Afr. trop. or.

lactea, Lindan, ex Engl. in Ab\%. Preuss, Akad. Wiss, (1894) 49 . et l. c. xx. (1894) 55. - Afr. trop. or. laxa, Oliver, in $H$. fohnston, The Kitim. Exped. Append. (1886) 344; et in Trans. Linu. Soc Ser. II. ii. (188\%) 345. - Afr. trop.

milanjiensis, S. Moore, l. c. Ser. II. iv. (1894) 33 - Afr. trop

mossambicensis, Lindau, in Engl. Pfanzent. Ost Afr. C. (1895) 372. - Afr. trop. or.

Oerstediana, Lindau, in Bot. Fahrb. xx. (1894) 56. - Afr. trop. or.

origanoides, S. More, in Trans. Linu. Soc. Ser. II iv. (1894) 34 (= Rhytiglossa ciliata, Nees). Afr. austr.

rubescens, Lindau, in Bot. Fahrb. xx. (1894) 57. Afr. trop. or

runssorica, Lindau, l. c. 56. - Afr. trop. or.

violacea, Lindau, l. c. xxii. (1895) 125. - Afr. trop.

Vorkensii, Lindan, l. c. xx. (1894) 55. - Afr. aequat. or.

ISOLEPIS, R. Br. = Scirpus, Linn, ('yper.).

abyssinica, Hochst. ex C. B. Clarke, in Th. Dur. et Schinz, Consp. F1. Afr. v. 18.14 (1895) 605 Fimbristylis exilis. Roem. \& Schult.

andina, Phil. in Anal. Mus. nac. Chile (1891) 79 - Am. austr. occ.

gracillima, Hochst. ex Engl in Abh. Preuss. Akad. Wiss. 1891 (1892) 148, in syn; et ex C. B. Clarke, in Th. Dur, \& Schinz, Consp. Fl. Afr v. $1894(1895) 612=$ S. capillaris, Linn. 
ISOLEPIS :-

humillima, Hochst. ex C. B. Clarke, in Th. Dur. \& Schinz, Consp. Fl. Afr. v. 1894 (1895) $616=$ Bulbostylis striatella, C. B. Clarke.

monostachya, Phil. in Anal. Mus, nac. Chile (1891) 79. - Am. austr. occ.

Norac-Zealandiae, Colenso, in Trans, N. Z. Inst xxi. 1888 (1889) 102. - N. Zel.

oreophrza, Phil. in Anal. Mus. nac. Chile (1891) 79. - Ani. austr. occ.

perpusilla, Nees, ex C. B. Clarke, in Th. Dur. \& Schinz, Consp. Fl. Afr. v. 1894 (1895) $634=$ S. venustulus. Boeck.

praeusta, Nees, ex C. B. Clarke, 1. c. $639=$ Ficinia laevis, Nees.

pubiculmis, Hochst. ex C. B. Clarke, 1. c. 605 (= Isol. pubiculmis, Boeck.) $=$ Fimbristylis exilis Roem. \& Schult.

reticularis, Colenso, in Trans, N. Z. Inst. xviii. 1885 (1886) $27 \%$. N. Zel.

ragosua, Hochst. ex C. B. Clarke. in Th. Dur. \& Schinz, Consp. Fl. Atr. v. 1893 (1895) $618(=$ Isol. rugosa, Boeck.) = S. articulatus, Linn.

subtristachya, Hochst. ex C. B. Clarke, 1. c. $611=$

Bulbostylis barbata, C. B. Clarke.

ISOLOMA, Decne (Gesner.). - Ind, Kew, i 1038 .

Hahnii, Hort. Par. ex Baill, in Bull, Soc. Linn. Paris, i. (1887) 719. - Mexic.

jaliscanum, S. Wats, in Proc. An. Acad. xxv. (1890) 159. - Mexic

ISOMERIS, Nutt. (Capparid.). - Ind, Kew. i. 1238.

aborea, “ Nutt. » ex Greene, Pittonia, i. (June 1888) 200, sphalm. = arborea, Nutt.

ISONEMA, R. Br. (Apocyn.). - Ind. Kew. i. $12: 39$.

Buchholzii, Engl. Bot. Fahrb. vii. (1886) 340. Kamerun.

ISOPETALUM, Sweet = Pelargonium, L'Hérit. (Geran:).

dentatum, Eckl. \& Zeyh, ex Szyszyl. Polyp. Thail Rehmann. (1888) $13=$ P. alchemilloides, Willd.

ISOPOGON, R. Br. (Proteac.) - Ind. Kew.

Dawsoni, R. T. Baker, in Proc. Limn. Soc. N. S. Wales, Ser. II. ix. (Mar, 1895) 658, t. 45, Australia.

Fletcheri, F. Muell. l. c. (Sept. 1894) 151:Austral.

ISOPTERA, Scheffer, ex Burck, Minjak. Tengkawang, Batavia (1886) 27 : et in Ann. Jard. But. vi. (1S87) 222. DIPTEROCARPEAE.

borneensis, Scheff. ll. cc. - Borneo.

ISOPYRUM, Linn. (Ranuncul.), - Ind. Kew. i. 1240.

auriculatum, Franch. in Bull. Soc. Bot. Fr. xxxiii. (1886) 376. - China.

Henryi, Oliver, in Hook. Icon. pl. xviii. (1888) t. 1745. - China.

peltatum, Franch. in Nowv. Arch. Mus. Paris, Sér. II, viii. (1886) 190. - China.

sutchuenense, Franch. in Morot, Fourn. de Bot. viii (1894) 284. - China occ.

thalictroideum. St. Lager, in Cariot, Etud. des fl. éd. 8 , ii. (1889) $23=$ thalictroides, Linn.

trifolinm, Britton, in Bull. Torrey Bot. Club, xviii. (1891) $265=$ Coptis tritolia, Salisb.

vaginatum, Maxim. Fl. Tangut. (1889) 18. China.

ISOSTIGMA, Less. (Compos.). - Ind. Kew. i.

Vailiana, Britton, in Ann. N.Y. Acad. Sci. vii. (1893) 149. - Parag.

ISOTHYLAX. Baill. in Bull. Soc, Linn. Paris, ii. (1890) 877 (gen. vel. sect.?) = Sphaerothylax Bisch. (Podost.),
IRYANTHERA, Warb, in Ber, Deutsch, Bot Ges. xiii. (1895) [84], MYRISTICACEAE.

Hostmanni, Warb. l. c. (= Myristica Hostmanni, Benth.). - Columb.

macrophylla, Warb. l. c. 85 (= M. macrophylla Benth.). - Bras.

ITEA Gronov. ex Linn. (Saxifr.). - Ind, Kew. 1240.

licifolia, Oliver, in Hook. Icon. pl. xvi. (IS86) t. 1538. - China.

parviflora, Hemsl. in Ann. Bot. ix. (1895) 153. Formosa.

riparia, Collett of Hemsl. in Foum. Linn. Soc. xxviii. (1890) 57. - Burma.

ITEIL UMA, Baill. in Bull. Soc, Linn. Paris, it $(1890) 892=$ Sideroxylon, Linn. (Sapot.).

ITOASIA, Kuntze, Rev. Gen. (1891) 590 = Corynaea, Hook. f. (Balanoph.)

crassa, Kuntze, 1. c. = C. crassa. Hook.

Purdiaei, Kuntze, 1.c. = C. Purdiei, Hook. f.

sphaerica, Kuntze, 1. C. = C. sphaerica, Hook. f.

Sprucei, Kuntze, 1, c. = C. Sprucei, Eichl.

IVESIA, Torr. \& Gray = Potentilla, Linn. (Rosac.)

sabulosa, M. E. Jones, in Proc. Calif. Acad. Ser. II. v (1895) 680, in syn. $=\mathrm{P}$. sabulosa, M. E. fones.

sanlotinoides, Greene, Pittonia, i. (Nov. 1887) 99, sphalm. = santolinoides. A. Gray.

Shockleyi, S. Wats, in Proc. Am, Acad, xxiii. (1888) 263. - Calif

IXERIS, Cass. = Lactuca, Tourn. (Compos.)

scaposa, Freyn, in Oest. Bot. Zeitschr. xl. (1890) 45. - Sibiria.

IXIA, Linn. (Irid.). - Ind. Kew. i. 1241

angustifolia. Klatt, in Th. Dur. \& Schinz, Consp. Fl. Afr. v. 1894 (1895) 182 (= Morphixia angustifolia, Klatt ). - Afr, ausir.

brevifolia, Baker, Handb. Irid. (1892) 165. - Afr. austr.

Cooperi, Baker, l. c. 166 (= Morphixia Cooperi, Baker). - Afr, austr.

galaxicides, Klatt, in Th. Dur. \& Schinz, Consp. Fl. Afr, v. 1893 (1895) $184=$ monadelpha, $D$. Delar.

grandiflora, Klatt, in Th. Dur. \& Schinz, 1. c. 181 (= Morphixia grandiflora, Klatt $)=$ monadelpha, D. Delar.

nervosa, Baker, Handb. Irid. (1892) 166_(= Morphixia nevwosa, Baker). - Afr, austr.

purpurea, Klatt, in Th. Dur. \& Schinz, Consp. F1. Afr.v. 1893 (1895) 186 (= Morplixia purpurea, Klatt $)=$ monadelpha, D. Delar

trichorhiza, Baker, Handb. Irid. (1892) 165 (= Morphixia trichorhiza, Baker). - Natal.

Zeyheri, Baker, l. c. 166. - Afr. austr.

IXIOLIRION, Fisch. (Amaryll.). - Ind. Kew. i. 1242 .

macranthum, Hort. ex Baker, Handb. Amaryll. (1888) $132=$ montanum, Herb.

IXONANTHES, Jack (Lineae.). - Ind. Kew. i. 1243.

Hancei, Pierre, ex Laness, Pl. util. Colon, Franc. (18S6) 306. - Cochinch.

IXOPHORUS, Schlecht. = Setaria, Beauv. (Gramin.).

glaucus, Nash, in Bull. Torrey Bot. Club, xxii. (1895) $428=$ S. glauca, Beauv.

italicus, Nash, 1. c. = S. italica, Roem. E Schult

verticillatus, Nash, 1. c. $422=$ S. verticillata, Beauv.

viridis, Nash, 1. c. $423=$ S. viridis, Beanv.

IXORA, Linn. (Rubiac.). - Ind. Kew, i, 1243. abyssinica, assimilis, bidentata. Botwkeri, brachycalyx, canescens, Cooperi, crebrifolia, dolichusepala, edentula,

\section{IXORA :}

gardneriaefolia, Gerrardii, glaucescens, gracilipes, hispida, hispidula, Hookeriana, humilis, indica, involucrata, lanceolata, littorea, longipes, macrosepala, Mannii, mollis, monticola, natalensis, neurocarpa, obovata, Olneriana, opulina, Pseudoamboinica. puberula, rigida, sambucina, silvatica, stenophylla. subcana, subcumeafa, subvelutina, trifiora. Wrightit, Zeyhen', Kuntze, Rev. Gen. (1891) 286-87= homonyma omnia Pavettae.

auminata, Boerl. Handl. Fl. Ned. Indië, ii. I. (1891) $135=$ P. acuminata, Korth

arborescens, Boerl. 1. c. $=$ P. arborescens, Hassk

attcmiata, Kuntze. Rev. Gen.(1891)278 = Webera attenuata, Hook $f$.

baviensis, Drake, in Morot, Fourn. de Bot, ix. (1895) 234. - Tonk

Bluneana, Kuntze, Rev, Gen. (1891) $286=$ Pavetta odorata, Blume.

borbonica, Cordem. Fl. Ile Réunzon (1895) 507 Ins. Borbon.

borneensis, Boerl. Handl. Fl, Ned. Indië, ii. '1. (1891) $35=$ Pavetta borneensis, Miq.

borneensis, Kuntze, Rev, Gen. (1891) $286=$ praec

Buchholzii, Engl. Bot. Fahrb. vii. (1886) 340 . Kamerun.

campaniflora. Kuntze. Rev. Gen. (1991) 278 = Webera campaniflora, Hook. $f$.

canarica, Kuntze, 1, c, = W canarica, Hook, $f$

Candolleana, Kuntze, 1. c. $286=$ Pavetta breviflora, $D C$.

ciliolata, Boerl. Hand1. Fl. Ned. Indië, ii. I. (1891) $135=$ P. ciliolata, Kovth.

ciliolata, Kuntze, Rev. Gen. (1891) $286=$ praec

Clerodendron, Ridl. in Trans. Linn. Soc. Ser. II iii. (1893) 311. - Penins, Mal.

corymbosa, Kuntze, Rev, Gen. (1891) $286=$ Pavetta caffra. Linn.f.

debilis, Drake, in Morot. Fourn. de Bot. ix. (1895) 234. - Tonk.

floribunda, Boerl. Handl. Fl. Ned. Indië, ii i. (1891) $135=$ Pavetta floribunda. Miq.

genipifolia, Kuntze, Rev. Gen.(1891) 286 = P

Baconia, Hiern

Glehnii, Kuntze, 1. c. = P. Gleniei, Thw

gracilis, Kuntze, 1. c. = P. gracilis, Rich

Hiernii, S. Elliot, in fourn. Limn. Soc. xxx. (1894) 82. - Sierra Leone.

hypsophila, Kuntze, Rev. Gen.(1891) $287=\mathrm{P}$ longituba, Miq.

incana, Kuntze, 1. c. $286=$ P. gracilis, Klotzsch.

kavalliana, $K$. Schum. in Engl. Pfanzenw. Ost-Afr. C (1895) 388. - Afr. trop. ör.

keyensis, Warb. un Bot. Fahrb. xiii. (1891) 436. Oceania.

kinabaluensis, Stupf, in Trans. Linn. Soc. Ser. II. iv. (1894) 178. - Borneo.

Korthalsiana, Boerl. Handl. F1. Ned. Indië, ii. ।.

(1891) $135=$ Pavetta Korthalsiana, Miq.

Korthalsii, Kuntze, Rev, Gen. (1891) $286=\mathrm{P}$ oblonga, Korth.

Kurzii, Euntze, 1. c. $278=$ Webera Kurzii Hook. $f$.

leucoxylon, Boerl. Handl, Fl. Ned. Indië, ii. 1. (1891) $135=$ Pavetta leucoxylon, Miq.

leucoxylon, Kuntze, Rev. Gen. (1891) $287=$ praec

longituba. Boerl. Handl. Fl. Ned. Indië, ii. I. (1891) $135=$ Pavetta longituba, Miq.

longituba, Kuntze, Rev Gen. (1891) $287=$ praec

lucents, Kuntze. 1. c. (1891) $278=$ Webera lucens, Hook. $f$.

macrocoma, Kuntze, 1. c. $287=$ W. grandifolia Zoll. E Mor:

macroptera, Boerl. Handl. F1. Ned. Indië, ii. I. (1591) 135 = Pavetta macroptera, Miq.

mollissima, Drake, in Morot. Journ. de Bot. ix. (1895) 234, in obs. = Webera mollissima, Benth.

mucronata, Warb. in Bot. Fam/b. xiii. (1891) 436.N. Gưin.

neglecta, Kuntze, Rev.Gen.(1891) 286 = Pavetta acuminata, Korth.

nilagivica, Kuntze, 1, c, 378 = Webera nilagirica Hook. $f$.

milagivica, Kuntze, 1, c, $286 \doteq$ Pavetta Brunonis Walil. 


\section{IXORA}

dorata, Boerl. Handl. F1. Ned. Indië, ji. I. (1S91) 135 = Pavetta odorata, Blume.

ovata, Boerl.l.c. 136 (= Myonima ovata, Decne). - Timor.

pachyphylla, Baker, in fourn. Linn. Soc. xxii. (1887) 484. - Madag.

paludosa, Boerl. Handl. FI. Ned. Indië, ii, I. (1891) $136=$ Pavetta paludosa, Blume.

paludosa, Kuntze Rev, Gen. (1891) $287=$ praec.

platythyrsa, Baker, in fourn. Linn. Sor. xxv。 (1890) 320. - Madag.

polita, Boerl. Handl, F1. Ned. Indië, ii. L. (1891) $135=$ Pavetta polita, Miq.

Reinwardtii, Kuntze, Rev. Gen. (1891) $286=\mathrm{P}$. montana, Reimw.

veticulata, Boerl. Handl. Fl. Ned. Indië, ii. I. (1891) $135=$ P. reticulata, Blume.

reticulata, Kuntze, Rev. Gen. (1891) 287 = praec

Roxburghii, Kuntze, 1. c. (1891) $286=$ Pavetta indica, Linn.

Singalang, Kuntze, 1. c. = P. calycina, Korth.

siphonantha, Oliver, in Hook. Icon, fl. xxiii. (1892) t. 2236. - Madag.

stellulata, Kuntze, Rev, Gen. (1891) 278 = Webera stellulata, Hook. $f$.

stenophylla, Ridl. in Trans. Limn. Soc. Ser. II. iii. (18963) 311 (= Pavetta stenophylla, Korth.). - As trop.

sumatrana, Kuntze, Rev. Gen. (1891) $286=\mathrm{Pa}$ vetta grandifolia, Korth.

Tey'smanniana, Boerl. Hand1. Fl. Ned. Indië, ii. i. (1891) $135=$ P. Teysmanniana, Miq.

Wallichii, Kuntze, Rev. Gen. (1891) $2: 8=$ Webera Wallichii, Hook。 $f$.

Westi $\times$, J. Hudson, in The Garden, xlii. (1892) 498, t. $886 .-$ Hybr. artef.

IXORHEA, Fenzl, in Verh. zool.-bot. Ges. Wien (1886) 28\%. BORAGINEAE.

Tschundiana, Fenzl, I.c. 288. - Reg. Argent

\section{$J$}

JABOROSA, Juss. (Solan.) - Ind. Kew. i. 1244 araucana. Phil, in Anal. Univ. Chil. xci. (1895) 17 - Araucania.

bipinnatifida, Fr. Meigen, in Bot. Fahrb.xvii. (1893) 270, et xviii. (1894) 454 (= Lonchostigma bipinnatifidm, Phil.). - Chili.

JACARANDA, Juss. (Bignon.).-Ind. Kew. i. 1245. macrocarpa, Burean of K. Sohum. ex K. Schum. in Engl. G Prantl, Natiurl. Pflanzenfam. iv. 3b (1894) 2:34. - Reg. Amazon

JACARATIA, DC. = Jaracatia, Marco.(Passifl.). digitata, Solms, in Mart. Fl. Bras, xiii. III. (1889) 191 (= Carica digitata, Poepp. \& End1.). - Bras. Peruv.

Solmsiz, Urb。 in Bot. Jahrb. xvi。(1898) 158. Kamerun,

JACKSONAGO, Kuntze, Rev. Gen, (1891) $191=$ Wiborgia, Thunb. (Legum.).

cuspidata, flexwosa, fusca, obcordata, sericea, tetraptera, Kuntze, 1. co = lomonyma omnia Wiborgiae.

armata, Kuntze, 1. c。 $=$ W. spinescens, Eckl. E Z $k y r_{2}$

JACKSONIA, R. Br. (Legumin.). - Ind. Kew。 i. 1425

Clarkei, F. Mucll, in Proc. Linn. Soc. N. S. Wales, Ser, II. ii. (Aug. 1ES7) 103. - Austral.

dodecandra, Macmill. Metasp. Minn. (1892) 270= Cleome dodecandra, Michx.

Forrestii, F. Mwell. in Proc. Linn. Soc. N. S. Wales, Ser. II. ii. (Aug. 1887) 194.- Austral.

fcruifolia, Greene, Pittonia, ii. (1891) $375=$ Pclanissa tenuifolia, Torr. E Gray.

Trachisporma, Greene; 1. c. ii. (Sept. 1891) $175=$ P. tra:hysperma, Torr. G Gray,

maiglandulosa, Greene, 1. c. $174==$. uniglandulosa, LC
JACOBAEA, Burm. Thes. Zeyl. (1737) 124, t. 55 = Vicoa, Cass. (Compos.)

cernu, Kuntze, Rev. Gen. (1891) 347 = Vicoa cernua, Dalz.

divaricata, Kuntze, 1. c, = V. divaricata, Benth. of Hook, f.

flexuosa, Kuntze, l. c, = inula flexuosa Boiss.

indica, Kuntze, 1. c. = Vicoa auriculata, Cass.

puticariaeformis, Kuntze, 1. c. = Inula pulicariaeformis, $D C$.

sarana, Kuntze, 1. c. = I. sarana, Boiss.

vestito, Kuntze, 1. c. = Vicoa vestita, Benth. E Hook. $f$.

JACOBAEASTRUM, Mannetti (1\%5l), ex Kuntze, Rev. Gen. (1891) = Euryops, Cass. (Compos.) abrotanifolinm, algoënse, arabicum, Athanasiae, calviscens, Candollei, diversifolinn, Dregeamum, empetri folium, laterifortm, lineare, linifolium, longipes. multifidum, oligoglossum, pectinatum, pinifolium. punctatum, Serra, spathaceum, subcarnosum, subsessile. sulcatnm, tenuissimnm, trifidum, trifurcatum, trilobum, virgineum, Kuntze, 1. c. 347-48=homonyma ommia Euryopsidis.

asparagodes. Kuntze, 1. c. $347=$ E. asparagoides, Less.

JACOBINIA, Moric. (Acanth.). - Ind. Kew. i. 1246.

coccinea, Hiern. in Kew Bull. (1893) 268. - Am, trop.

magnifica, Lindau, in Engl. \& Prantl, Natïl. Pfanzenfam。iv.3b (1895) 351 (=Cyrtanthera magnifica, Nees). - Bras.

Neesiana, Lindau, l.c. (= Sericographis Sellowiana, Nees). - Bras.

ovata, A. Gray, in Proc. Am. Acad. xxi. (1886) 405. - Mexic.

parabolica, Lindau, in Engl. Eo Prantl, Natïr. Pfanzenfam. iv. 3b (1895) $351(=$ Sericographis parabolica, Nees). - Bras.

pauciflora, Lindau, l.c. (= S. paucifora, Nees).Bras.

Pohliana, Lindau, l. c. $(=$ Cyrtanthera Pohliana, Nees). - Bras.

Sellowiana, Lindau, l. c. $(=C$. Sellowiana, Nees $)$ - Bras.

JACQUEMONTIA, Choisy (Convolv.), - Ind, Kew. i. 1240

bifida, Hallier f. in Bot. Farb. xvi. (1893) 543 (= Aniseia Velloziana, Choisy). - Bras.

cumanensis, Kuntze, Rev. Gen. (1891) $441=$ ferruginea, Choisy.

Curtisii, Peter, ex Hallier fo in Bot, fahrb. xvi. (1893) 543. - Florida

Aensiflora, Hallier, f. l, c. - Am. trop.

euricola, Ridl. in fourn. Linn. Soc, xxvii. (1890) 4 7. - Ins. Fernando Nuronha.

floribunda, Hallier f. in Bot. Fahrb. xvi. (1893) (= Convolvulus flovibundus, H. B. \& K.). - Am. austr. fusca, Hallier f.l.c. (= I łomaea fus:a, Meissn.). Am. trop.

racillima, Hallier f. l. c.54l (= Aniseia gracillima, Choisy). - Bras

heterantha, Hallier f.l. .. $543(=$ A. hetcrantha Choisy). - Bras

luxurians, Hallicr f. l. c. (= Ipomoea luxurians, Moric.). - Bras.

Maximiliani, Peter, ex Hallier, l. c, nomen. - Bras. multiflora, Hallicr f.l.c. $(=$ Convolvulus mucronifera,

Choisy pr. p.). - Am, austr.

oaxacana, Hallier f. l. c. - Mexic.

obtusata, Hallier f. 1. c. 542 , in obs. = serrata Meissu.

ovalifolia, Hallier f. l. . . 542; et xviii.(1894) 96 (= Ipomoea ovalifolia, Choisy). - Ins. Sandvic.

Palmeri, S. Wats. in Proc. Am. Acad. xxiv. (1889) 63. - Mexic

paniculata, Hallier f. in Bot. fahrb. xviii. (1894) 95 (= Convoliulus parviflorus, Vahl). - Geront. trop.

paragtayensis, Britton, in Ann. N.Y, Acad. Sci. vii. (1893) 172. - Parag.

polyantha, Hallier fo in Bot. Jahrb. xvi. (1893) 543 = violacea, Choisy.

\section{JACQUEMONTIA}

ulleraria, Hallier f. in Bot. Falirb. xvi. (1893)7543 (= Conro'vulus havanensis, Jacq.). - Ind, occ. rufa, Hallier f.l. c. - Bras.

Selloi, Hallier f.l.c.543 (= Ipomoea Selloi, Meissn.). - Bras.

Smithii, Robinson of Greenm. in Am. Fourn. Sci. Ser. III. I. (1895) 160, - Mexic

solanifolia, Hallier $f$. in Bot falkrb. xvi. (1893) 54\% (= Ipomoea solanifolia, Linn.). - Ind, occ.

spicaetlora, Hallier f. l.c. 54:3 (= Ipomoea spicieftora, Choisy). - Bras.

thomensis. Henriques, in Bolet. Soc. Brot. x. (1892) 143. - Ins. S. Thom

Zollingeri, Hallier f. in Bot. Fahrb, svi. (1893) 54:3 $(=$ Convolvulus Zollingeri, Choisy). - Ins. Saraja.

JACQUINIA, Linn. (Myrsin.), - Ind. Kew, i.

smaragdina, Hort. ex Baill. Hist. des. pl. xi. (1892) $331=$ Deherainia smaragdina, Dccne.

JAEGGIA, Schinz, in Verh. Bot. Ver, Brand, $x x x$. (1888) $253=$ Modecca, Lam. (Passifl.)

repanda, Schinz, 1. c. = M. Paschanthus, Hart.

JAESCHKEA, Kurz (Gentian,), - Ind, Kew. i 1246 .

canaliculata, Knobl. in Bot. Centralb1. 1x. (1894) $387=$ latisepala, C. B. Clarke.

oligosperma, Knobl. 1. C. = gentianoides, Kurz.

JAGERA, Blume (Sapind.). - Ind. Kew. i. 1247. latifolia, Radlk. in Sitzb. Math.Phys. Acad. Muench. Yx. (1890) 264. - N. Guin.

JALISCOA, S. Wats, in Proc. Am. Acad. xxy 1890) 153; O. Hoffm, in En rl, \& Prantl, Natürl. Pflanzenfam, iv. 5 (1893) 388. COMPOSITAE Pringlei, S. Wats, It.co, - Mexic.

JAMBOLIFERA, Linn. = Acronychia, Forst. Rutac.)

acidula, arborea, Baueri, Endlicheri, heteroplyylla, imperforata, laevis, petiolaris, Porteri, retusa, Richii, terandra, trifoliata, Kuntze, Rev. Gen. (1891) 10? = homonyma omnia Acronychiae.

melicopodes, Kuntze, 1. c. = A. melicopoides, $F$. Mull.

JAMBOSA, DC. = Eugenia, Mich. (Myrt.).

baladensis, Niedenzu, in Engl. \& Prantl, Natiirl. Pflanzenfam. iij.7 (1893) 84 (= Caryopliyllus baladensis, Brongn. \& Gris). - N. Caled.

Caryophyllus, Niedenzu, 1. c. $\$ 5(=$ Caryophyllus aromaticus, Linn.) $=$ E. caryophyllata, Thunb.

e'egans, Niedenzu, 1. с. $84\{=$ C. clegans, Brongn. \& Gris). - N. Caled.

mytifolia, Niedenzu, 1. c. = myrtifolia, Sims neurocalyx, Niedenzu, 1. c. = neurocalyx, A. Graty. nutans, Niedenzu, 1. c. $=$ E. nutans, $K$. Schum.

pterocarpa, Niedenzu, 1. c. 85 (= Carjophylhis pterocarpus, Vieill.). - N, Caled.

Schumanniana, Niedenzu, 1. c。 $(=$ E. neurocalyx, K. Schum.). - N. Guin.

JAMESBRITTENIA, Kuntze, Rev. Gen. (1891) 46 = Sutera, Roth (Scrophul.).

dissscta, Kuntze, 1. c. = S. glandulosa, Roth.

JANUSIA. A. Juss. (Malpigh.). - Ind. Kew. i. 1249.

Barbeyi, Chod. in Axch, scicne. phys. et nat. (1890), ex Chod. in Mén. Soc. sci. phys. Gencre, xxxi. 2 n. 3 (1893) 19. - Parag.

JAPARANDIBA, Adans. = Gustavia, Linn. (Myrtac.).

angustifolia, augusta, brasiliana, dubia, fastuosa, longfolia, Pocppigiana. pubescens, Ruiziana, słeciosit. superba, Kuntze, Rev, Gen. (1891).240=homonyma omnia Gustaviae.

antillana, Niedenzu, in Engl, \& Prantl, Natürl. Pflanzenfam. iii.7(1892) $37=\mathrm{G}$. antilana, Miers. gracillima, Niedenzu, 1. c. = G. gracillima, Miers. 
JAPARANDIBA :-

hexapetala, Kuntze, Rev. Gen. (1891) $240=$ Gustavia fastuosa, Willd.

latifolia, Niedenzu, in Engl. \& Prantl, Natïrl. Pflanzenfam. iji. 7 (1892) $37=$ G. latifolia, Miers.

Marcgraviana, Niedenzu, 1. c. = G. Marcgraviana, Miers.

pterocarpa, Niedenzu, 1. c. = G. pterocarpa, Miers.

JARDINEA, Steud. = Thelepogon, Roth (Gramin.

congoërsis, Franch. ex Hack. in DC. Monog. Phan. vi. (1889) 377 , in syn. = Rhytachne congoënsis, Hack.

JASIONE, Linn. (Campanul.). - Ind. Kew. i. 1249.

adpressifolia, Pau, Not. bot. Fl. Espan. i. (1887) 19 Willk. Suppl. Prodr. Fl. Hisp. (1893) 126: - Hisp. atpressifolia, Pau, 1. c. = montana, Linn.

Espadanae, Pau, 1. c. = montana, Linn.

propullulans, Freyn, in Verh. zool.-bot. Ges. Wien xxxviii. (1888) $618=$ supina, Sieb.

JASMINONERIUM, Linn. F1. Zeyl. (1747) 191, ex Kuntze, Rev. Gen. (1891) 414 = Carissa, Linn. (Apocyn.).

acuminatum, africanum, Carandas, cryptophlebium, densiflorum, edule, ervthrocarpum, ferox, grandiflonum, haematocarpum, macrocarpun, madagascariense, oblongifolium, ovatum, pubescens, sechellense, suavissimum, tomentosum, xylopicron, Kuntze, 1. C. 414 = homonyma omnia Carissae.

bispinosum, Kuntze, 1. c. = C. Arduina, Lam

dulce, Kuntze, 1. c. = C, edulis, Valll.

grandifolium, Kuntze, 1. c, = C. grandiflora, A. $D C$.

inerme, Kuntze, 1. c. = C. macrophylla, Waht.

latiflontm, Kuntze, 1. c. = C, laxiflora, Benth.

sulicinum, Kuntze, 1. c, = C. spinarum, Linn.

JASIMINUM, [Tourn.] Linn. (Oleac.). - Ind. Kew. i. 1249

Afu, Gilg, ex Engl. in Abh. Prenss. Akad. Wiss. (1894) 34 ; et in Engl. Pfanzenw. Ost-Afr. C (1895) 308 - Afr. trop. or.

angolense, Baker, in Kew Bull. (1895) 95. -- Angola. asphanodon, Baker, l. c. (1893) 13. - Madas.

Bakeri, S. Elliot, in fourn. Linn. Soc, xxx. (1894) 86. - Sierra-Leone.

begosense, Bccc. ex Martelli, Fl. Bogos. (1886) 51. - Abyss.

brachyscyphum, Baker, in Kew Bull. (1895) 93. Zambes.

brevipes, Baker, l. c. - Angola.

bukobense, Gilg, in Engl. Pfanzenw'. Ost-Afr. C (1895) 308. - Afr. trop. or.

coeruleum, Kuntze, Rev. Gen. (1891) 410. - Ins S. Thom

discolor, Franch, in Nowv. Arch. Mus. Paris, Sér. II x. (1888) 59. - China.

elegans, Knobl. in ỉot. falrb. xvii. (1893) 534. Ins. Nossibe

Eminii, Gilg, in Engl. Pflanzenw. Ost-Afr. C (1895) 309. - Afr. trop. or.

Engleri, Gilg, in Bot. Fahrb. xix. Beibl. n. 47 (1894) 46. - Afr. trop. or

Hildebrandtii, Knobl. in Bot. Fahrb. xvii. (1893) 538. - Afr. trop. or.

Holstii, Gilg, ex Engl. in Abh. Preuss. Akgd. Wiss. (1894) 63; ct in Engl. Pfanzenw. Ost-Afr. C (1895) 309. - Afr. trop. or.

inornatum, Hemsl, in Fourn. Linn. Soc. xxvi, (1890 ou 1859) '78. - China.

italicum, Hort. ex Dippel. Handb. Laubholzk. i. (1889) $146=$ humile, Linn.

Kirkii, Baker. in Kow Bull. (1895) 94. - Zambes.

longipes, Baker, l.c. - Angola.

megalosiphon, Gilg, in Engl. Pfanzenw. Ost-Afr. C (1895; 309. - Afr. trop. or.

Meyeri Johannis, Engl, in Abl. Prouss. Akad. Wiss, 1891 (1892) 334. - Afr, trop. or.

microphyllum, Baker, in Kew Bull. (1895) 93. Angola.

\section{JASMINUM}

niloticum, Gilg, in Engl. Pflanzenw. Ost-Afr, C 1895) 309. - Afr. trop, or

nummularifolium, Baker, in Kew Bull. (I895) 100. - Madag

obovatum, Baker, l. c. 94 - Angola.

obtusifolium, Baker, l. .. 93. - Afr. trop. occ,

octocuspe, Baker, l. . . 110? - Madag.

oleaecarpum, Baker, l. c. 95. - Zambes.

pachyphyllum, Hemsl. in fourn. Linn. Soc, xxvi.

1890) 79, - China.

parvifolium, Knobl. in Bot. fahrb. xvii. (1893) 534. - Ins. Nossibe.

Preussii, Knobl. l. c. 536. - Kamerun

primulinum Hemsl. ex Baker, in Kew Bull. (1895)

109 ; et ex Oliver, in Hook. Icon, $\mathrm{pl}$. xxiv. (1895) t. 2384 - China

rambayense, Kuntze, Rev. Gen. (1891) 410. - Java. Schroeterianum, Schinz, in Verh. Bot. Ver. Brand. xxx. (1888) 256. - Afr. austro-occ, extratrop.

sinense, Hemsl. in fourn. Limn. Soc. xxvi. (1890) 80 - China.

singuliflorum, F. M. Bailey \& F. Muell. ex F. M. Bailey, Syn. Queensl. Fl. Suppl. i. (1886) 38.Austral

Smithii, Baker, in Kew Bull. (1895) 93. - Afr, trop. somaliense, Baker, l.c. 218. - Reg. Somal.

stenodon, Baker, l. c. 94. - Angola,

Steudneri, Schweinf, ex Engl, in Abh. Preuss.

Akad. Wiss, 1891 (1891) 334, in obs."= floribundum, $R . B r$.

tenuifolium, Baker, in Kew Bull. (1895) 95. - Afr. trop.

ternum, Knobl. m Bot. Fahrb. xvii. (1893) 535. Angola Loango.

tomentosum, Knobl.l.c.536. - Zanzib.

triumphans, Hort. ex Dippel, Handb. Laubholzk, i. 1889) 148 = revolutum, Linn.

urophyllum, Hemsl, in foum. Limn. Soc, xxvi. (1890) 81 . China.

Walleri, Baker, in Kew Bull. (1875) 93. - Zambes. Welwitschii, Baker, l. c. 94. - Angola.

JASONIA, Cass (Compos.). - Ind. Kew. i. 1251. amphorata, Rouy, Ill, pl. Europ. ravior. iv, (1895) 12 t. 35. - Ins. Lamped. et Melit.

JATROPHA, Linn. (Euphorb.).- Ind. Kew, i. 1251

acerifolia, Pax, in Bot. Fahrb. xix. (1894) 109.Afr. trop, or,

ancustidens, T. S. Brandeg. in Proc. Calif. Acad. Ser. II. iii. (1891) 172 [an f. angustidens, Muell. Arg. ?]. - Calif.

aspleniitolia, Pax, in Bot. Fahrb. xix. (1894) 108. Reg. Somal.

carpinifolia, Pax, in Eugl. Pfanzenze. Ost-Afr. C (1895) 240. - Afr, trop. or.

heterophylla, Heyze, ex Hook. f. Fl. Brit. Ind. v. (1887) 382, - Deccan.

Hildebrandtii, Pax, in Bot. Fahrb. xix. (1894) 108. - Afr.trop. or.

melanosperma, Pax, l. c. 110. - Afr. trop.

palmatifida, Baker, in Kew Bull. (1895) 227. - Reg. Somal.

Palmeri, S. Wats, in Proc. Am, Acad, xxiv, (1889) 76. - Mexic.

prunifolia, Pax, ex Engl. in Abh. Preuss. Akad. Wiss, (1894) 14; et in Engl. Pfanzenw. Ost-Afr. C (1895) 240. - Afr. trop. or.

Schweinfurthii, Pax, in Bot. Fahrb. xix. (1894) 110 - Afr, trop. centr.

spicata, Fax, l. c. 109. - Afr. trop. or.

Stuhlmannii, Pax, in Engl. Pfanzenzo. Ost-Afr. C (1895) 240. - Afr. trop. or.

tuberosa, Pax, in Bot. Fahrb. xix. (1894) ll1. Afr. trop.

JATUS, Rumpf. Herb. Amboin. iii. (1743) 34. t. 18; Kuntze. Rev. Gen. (1891) $508=$ Tectona Linn. f. (Verben.).

grandis, Kuntze, 1. c. $=$ T. grandis, Linn. $f$.

Hamiltonianus, Kuntze, 1. $\mathrm{c}_{\mathrm{s}}=$ T. Hamiltoniana, Wall.

philippinensis, Kuntze, 1. c. = T. phllippinensis, Benth, \& Hook.f.
JAUMEA, Pers. (Compos.). - Ind. Kew. i. 125?. Itissima, Klatt, ex Schinz, in Bull. Herb. Boiss, iii. (1895) 425. - Angola.

angolensis, O. Hoffm. in Bolet. Soc. Brot, x. (1892) 178. - Angola.

Oliveri, Vatke, ex Kuntze, Rev. Gen. (1891) 348. $\mathrm{Hab}$

tenuifolia, Klatt, in Leopoldina, Heft xxiii. (1887) 146. - Mexic

JAUNDEA, Gilg, in Engl, \& Prant1, Natürl. Pflanzenfam. iii. 3 (1894) 388 , in add. CONNA. RACEAE.

Zenkeri, Gilg, l.c. - Kamerun.

JODANTHUS pinnatifidus, Prantl, in Engl, \& Prantl, Natiirl. Pflanzenfam. iii. 2 (1891) $183=$ Iodanthus pinnatifidus, Sterd.

JOHRENIA, DC. (Umbell.). — Ind. Kew. i. 125:3. Pichleri, Bolss. Fl. Or. Suppl. (1888) 266.Thracia.

platypoda, Aitch. \& Hemsl. in Trans. Linn. Soc. Ser. II. iii. (1886) 71. - Afghan.

Porteri, Post, ex Boiss Fl, Or. Suppl. (1888) 266 et in fourn, Linn. Soc. xxiv. (1588) 431. As. As.

Westii, Post, Pl. Postianae iii. (1892) 9. - Syria.

JOLLYA, Pierre, ex Baill. Hist. des pl. xi. (1892) 298, nomen $=$ Achradotypus, Baill. (Sapot.).

JONORCHIS, G. Beck. Fl. Nied.-Oest, i. (1890) $215=$ Limodorum, Sw. (Orchid.)

abortiva, G. Beck, 1, c. = L. abortivum. Sw

JONTHLASPI, Siegesb = Clypeola, Linn. (Crucif.).

ciliatum, cyclodonteum, dichotonum, echinatum, éleoans, hispidum, lappaceum, Kuntze, Rev. Gen. (1891) 34 = homonyma omnia Clypeolatis.

lannginosum, Kuntze, 1. c. = C. eriocarpa, Cav. microcarpum, Caruel, in Parl. Fl. Ital. ix. (1893) $1051=\mathrm{C}$. microcarpa, Moris.

monospermu. Kuntze, Rev. Gen. (1891) $34=$ C. Jonthlaspi, Limn.

JOSEPHIA, Salisb. = Dryandra, R. Br. (Proteac.)

Arctotidis, armata, Raxteri, bipinnatifida, calopliylla, carduacea, comosa, concinna, conferta, cumeata, fal cata, foliolata, formosa, Fraseri, Hervardiana. 7orrida, Kippistiana, longifolia, mucromulata, nana, nivea, nobilis, obtusa, patens, phumosa, polycephala, praemorsa, Preissii, pteridifolia, pulchella, quercifolia, runcinata, sclerophylla, Serra, Shuttleworthiana, speciosa, squarrosa, tenuifolia. tridentata, vestita, Kuntze, Rev. Gen. (1891) $578=$ homonyma omnir Dryandrae.

carlinodes, Kuntze, 1. c. = D. carlinoides, Meissn cirsiodes, Kuntze, l. c. = D. cirsioides, Meissn. proteodes, Kuntze, 1. C. = D. proteoides, Lindl. senecinifolia, Kuntze, 1. c. $=$ D. seneciifolia, $R . B r$. serratulodes, Kuntze, 1. c。 = D. serratuloides, Meissiz.

stupposa, Kuntze, 1. c. = D. stuposa, Lindl

JOZOSTE, Nees $=$ Actinodaphne, Nees (Laurin.) angustifolia. areolata, borncensis, campamulata, cochinchinensis, concolor, confertiflora. corymbosa, elegans, furfuracea, glabra. glauca, glomerata, gracilis, heterophylla, hirsuta, Hookeri, lanata, leiantha, macrophylla, macroptera, Maingayi, malaccensis, mollis, moluccana, molochina, multiflora, obovale. pauciflora, procera, pruinosa, pubescens, quercina, reticulata, rufescens, Rumphii. salicina, scleroptera. sesquipedalis, Sieboldiana, sikkimensis, speciosu, sphaerocarpa, stonophylla. Kuntze, Rev. Gen. (1891) 569-70 = homonyma omnia generis Actinodaphnes.

heterophylla, Kuntze, 1. c. = A, angustifolia, Nees. longifolia, Kuntze, 1. c. = A, madraspatana, Bedd. Monii, Kuntze. 1. c. = A. molochina, Nies.

Wightiana, Kuntze, l. c。 = A. hirsuta, Hook.f. 
JUSSINIA, Comm. = Eugenia, Linn.(Myrt.). timifolia, Baill Hist, pl. Madag. Atlas (I895) t. :3:39. - Madag.

JUANULLOA, Ruiz \& Pav, (Solan.). - - Ind, Kew. i. 1254

membranacea, Rusby, in Mom. Torrey Bot. Club, iv. (1894) 233. - Bolivia,

pedunculata, Rusby, l. c. 234. - Bolivia.

Sargii, F. D. Smith; in Conlt. Bot. Gaz, xviii. (1893) 5, t. 1. - Guatem.

JUBAEA, H. B. \& K. (Palm.). - Ind. Kew. i, 1254

chilensis, Baill. Hist. des pl. xiii, (1895) $397=$ spectabilis, $H . B . \& K$.

JUGLANS. Linn. (Jugland.), - Ind. Kew. i 1256.

ulata, Carr, ex Dippel, Handb. Laubholzk. ii (1892) $319=$ intermedia, Dippcl.

asplenifolia, Hort. ex Dippel, 1. c. 318 et 58\% = regia, Linn.

disscta, Hort. ex Dippel, 1. c。 = regia, Linn.

fortilis, Hort. ex Dippel, 1. c. = regia, Limn.

frutescens, Hurt. ex Dippel, 1. c. $318=$ regid Linn.

fruticosa, Hort. ex Dippel. 1. c. 318 et 582, ad calc $=$ regia, Linn

mtermedia $\times$, Dippel, 1. c. 318, - Form. hort.

mexicana, S. Wats. in Proc. Am. Acad xrvi. (1891) 152. - Mexic

oralis, Wangenh. Beitr deutsch, holz. Forstw (1887) 24; ex Dippel, Handb. Laubholzk. ii (1892) $335=$ Carya ovata, $C$. Koch.

praematuricns, Hort. ex Dippel, 1. c. $582=$ regia Linn.

pracparturiens, Hort. ex Dippel, 1. c. $318=$ prae salicifolia, Hort. ex Dippel, 1. c. = regia, Limn.

Vilmariniana $\times$, Hort. Lavallee, ex Vilm. in Gard. and For, iv. (1891) 51 ; et ex Dippel, 1. c. $=$ intermedia, Dippel

JULOCROTON, Mart. (Euphorb.). - Ind. Kew. 1. vii. (1893) 222. - Parag.

JUNCELLUS, Kunth (Cyper.). - Ind. Kew. i. 1256

alopecuroides, C. B. Clarke, ex Hook. f. Fl. Brit. Ind. vi. (1893) 595; et in Th. Dur. \& Schints Consp. Fl Afr.v. 1894 (1895) 543 (= Cyperu. alopecuroides, Rottb.). - Geront. trop.

laevigatus, C. B. Clarke. Ul. cc. 596 ; et 549 (= C. lacvigahus, Linn.). - Amphig. trop.

inundatus, C. B. Clarke, $l l$. co. 595 ; et $544(=C$. imurdatus, Roxb.). - Bengal, China.

pustulatus, C. B. Clarke, in Th. Dur. of Schinz Consp. Fl. Afr. v. 1894 (1895) $546(=$ C. pustula turs, Vahl), - Afr. trop.

pygmaeus, C. B. Clarke, in Hook. f. Fl. Brit. Ind. vi. $(18.33) .596$; et 1. c. $546(=$ C. pygmaens, Rottb.) - Amphig. trop.

serotinus, C. B. Clarke, l. c. $594(=$ C. serotinus, Rottb.). - Eur, mer., As, mer. or.

JUNCODES, Moehr. Hort. Priv.(1736) 55; Kuntze, Rev, Gen. (1891) 722 = Luzula, DC. (Juncac.). Alopecurus, antarcticum, arcuatum, boliviense, caespitosum, campestre, canariense, caricinum. Carolinae. elegans, excclsum, Forsteri, Hieronymi, japonicum. fohnstonii, lactoum, lutetm, macusanicnse, niveum. pedemontanum, perwvianum, plumosum, purpurenm, racemosum, rufescens, spadiceum, spicatum, Kuntze, 1. c. $724-25=$ hononyma omnia Luzulae.

chilcnse. Kuntze, 1. c. $724=\mathrm{L}$. campestris, $D C$

Leiboldii, Kuntze, 1. c. = L. Leiboldi, Buchen.

Tuzulinum, Kuntze, 1. co = L. Hostii, Desw.

nemorosum, Kuntze, I. c. = L. albida, $D C$.

modulosum, Kuntze, 1.c. = L. graeca, Kunth.

mutans, Kuntze, 1. c. $=$ L. pediformis. $D C$.

pilosum, Kuntze, 1. c. $=$ L. vernalis, $D C$.

Seuberti, Kuntze, 1. c. = L. elegans, Guthicic

sileaticum, Kuntze, 1. c. = L. maxima, DC.
JUNCOIDES, [Dill.] Adans, = Luzula, DC. (Junc.)

comosum, Sheld. in Minnes. Bot. Stud. i. (1894) $64=\mathrm{L}$. comosa, E. Mcy.

divaricatum, Coville, in Contrib. U. S. Nat. Herb. iv. (1893) 209: Sheld. 1. c. $65=$ L. parviflora, Dese.

giganteum, Sheld. in Minnes. Bot. Stud. i. (1894) $62=$ L. gigantea, Desy.

glabratum, Sheld. 1. c. $63=$ L. glabrata, Dese".

kyperborcum, Sheld. 1. c. : Coville, in Mem. Torrey

Bot. Club, v. (1894) $107=\mathrm{L}$. hyperborea, $R . B r^{\prime}$. mirale, Coville, l.c. $108=\mathrm{L}$. nivalis, Laest.

parifform, Coville, Contrib. U. S. Nat. Herb. iv. (1893) 209 ; theld. 1, c. $63=$ L. parvifiora Desc.

JUNGUS, [Tourn.] Linn. (Junc.), - Ind. Kew. i. 1255

allioides, Franch, in Nont'. Mus, Paris, Sci. II. x. (1887-88) 99; Buchenau, in Bot. Fahrb. xii. (1890) 399. - Tibet.

Balansat, Trab. in Bull, Soc, Bot. Fr. xxxiv. (1887) 397 , in obso = punctorius, $\operatorname{Linn} \mathrm{f}$.

beringensis, Buchenan, in Bot. Fahrb. xii. (1890) 226. - Kamtchatka, Japon

brachyanthus, Trab. in Batt. \& Trab. Fl. de l'Algér. [Monoc.] (1895) 84 = J. Fontanesii. F. Gay.

bracl.ycephalus, Buchenau, 1. c. $268=$ canadensis, 7. Gay.

aesariensis, Coville, in Mem. Torrey Bot. Club, v. (1894) 106 = asper, Engeln.

carpathicus, Simonk. in Termész. Fuzét. x. (1886) $183=$ alpinus, Vill

Clarsonis, Trab, in Batt. \& Trab. Fl. de I'Algér. [Monoc.]. (1895) $84=$ lampocarpos, Ehrh.

Congdoni, S. Wats, in Proc. Am. Acad. xxii. (1887) 480. - Calif.

crassifolius, Buchenau, in Bot. Jahrb, xii. (1890) $326=$ scirpoides, Lam

diastrophanthus, Buchenau, l.c. 309.- Japon.

fallax, Irab, in Batt. \& Trab.Fl, de l'Alger. [Monoc.] (1895) 86. - Algeria.

Fockei, Buchcnau, in Bot。 Fahrb. ii. (1890) 358. N. Holl.

georgianus, Coville, ex Small, in Bull. Torrey Bot. Club, xxii. (1895) 44. - Georgia.

glandulosus, Porta, in Nuov. Giorn. Bot. Ital. xix. (1887) 320. - Ins. Balear.

gymzocarpus, Coville, in Mem. Torrey Bot. Club, v. (1894) $106=$ J. Smithii, Engclm

khasiensis, Buchenau, in Bot. fahrb. xii. (1890) 407. -- Ind. or.

luxurians, Colenso, in Trans. N. Z. Inst. xix. 1886 (18s'7) 269; Buchenau, in Bot, fahrb. xii. (1890) 232. - N. Zel.

luzuliformis, Franch. in Nouv. Arch. Mus, Paris, Sér. II. x. (1887-88) 99; Buchenau, 7. c. 204.Tibet.

macranthus, Buchenau, in Bot. Fahrb. xii. (1890) 398. - China bor.

matritanicus. Trab. in Bull. Soc. Bot. Fr, xxxiv, (1887) $395=$ punctorius, Limn. f.

Maximowiczi. Buchenau, in Bot. Fahrb. xii. (1890) 394. - Japon.

modestus, Buchenau, l. c. 203. - China bor. nematocaulon, Hook. f. Fl. Brit. Ind. vi. (1892) 400 ; et in Hook. Icon pl. xxiii. (1892) t. 2234. Assam.

oreganus, S. Wats. in Proc. Am. Acad. xxiii. (1888) 267 ; Buchenau, in Bot. Fahrb. xii. (1890) 366. Oregon.

paucicapitatus, Buchenau, in Bot. Fahrb. xii. (1890) 307. - Sitcha

polyanthemus, Buchenau, l. c. xxi. (1895) 261. Austral.

Potanini, Buchenau, l. c. xii. (1890) 394. - China bor

Przewalskii, Buchenau, l. c. 401. - China osc.

Regelii, Buchenau, l. c. 414.-Am, bor. occ.

scalovicus $久$, Aschers, \& fraebner, in Ber, deutsch bot. Gesells. xi. (1893) 524, - Germ.

sikkimensis, Hook. f. Fl. Brit. Ind, vi. (1892) 400; et in Hook. Icon. pl. xxiii. (1892) t. 2235. - Reg. Himal.
JUNGUS :

stylosus, C. B. Clarke, Fl. Brit. Ind. vi. (1893) 595. Khasia.

tenageins, S. Lager, in Cariot, Etud. des fl, éd, 8 ii. (1889) 443 = tenageius, Dulac.

Torreyi, Cosille, in Bulll. Torrey Bot, Club, xxii (1895) 303. - Nebraska.

uncialis, Grene, Pittonia, ii. (June 1890) 105. Calif.

validus, Coville, in Bull. Torry Bot. Club, xxii. (1895) 305. - Am, bor.

JUNIPERUS, Tourn, ex Linn, (Conif.). - Ind. Kew. i. 1260 .

facobi, Hort, ex Beissn. Handb. Nadeholzk. (1891) $120=$ chinensis, Linm.

Kanitzii X, Csato, in Magyar. Növenyt. Lapok, x. (1886) 145. - Austria.

Myurus. Hort. ex Beissn. Handb. Nadelholzk (1S91) 117 = phoenicea. Linn.

mutans, Hort. ex Beissn. 1. c. $125=$ virginiana Linn.

oblongo-pendula, Loud. ex Beissn. 1. c. $137=\mathrm{com}-$ munis, Linn.

polymorpha, Hort. ex Beissn. 1. c. $125=$ virginiana. Linn.

Shepherdi, Hort. ex Beissn. 1. c. $122=$ sphaerica, Lindl.

Smithipendula, Hort. ex Beissn. 1. c. $125=$ virginiana. Limm.

tripartita, Hort. ex Beissn. 1. c. $126=$ virginiana Linn.

uralensis, Hort. ex Beissn. 1. c. $138=$ communis, Linn.

utahcusis, "Engelm, » ex Beissn. 1. c. = occidentalis, Hook

utahonsis, Lemmon, in Rep: Calif. Stat. Board. For. 183 = californica, Carr, var.

JURIGHAS, Linn, (1747) ex Kuntze, Rev, Gen. (1891) $144=$ Filicium. Thw. (Burser.).

decipiens, Kuntze, 1. $\mathrm{c} .=\mathrm{F}$. decipiens,

JURINEA, Cass, (Compos.), - Ind, Kew, i. 1261.

aggregata, Freyn \& Sint, ex Freyn, in Bull. Herb. Boiss, iii..(1895) 471, - Armen.

ancistrophylla, Boiss. Fl. Or. Suppl. (1888) 310.Afghan.

Antunowi, C. Winkl, in Act. Hort. Petrap. xi. (1889) 145, t. 3 fig. 4. - Turkest.

baldschuanica. C. Winkl. l. c. xi. (1890) 283.Turkest.

bucharica, C. Winkl. l. c. ix. (1866) 525. Buchara.

bipinnatifida, C. Winkl. l. c. xi. (1890) 322 . Buchara.

cartaliniana, Boiss. Fl, Or. Sutpl. (1888) 311. Reg. Cauc.

coronopitolia, Sommier \& Levier, in Act. Hort. Petrop. xiii. (1893) 48. - Reg. Cauc.

cypria, Boiss, Fl. Or. Suppl. (1888) 311. - Ins. Cypr.

derderioides, C. Winkl, in Act. Hort. Petrop. ix (1886) 525. - - Turkest.

dolomiaea, Boiss. Fl. Or. Suppl. (1888) 311, in obs. (=7. macrocephala, Benth.). - Ind. or.

edulis. Franch, in Morot, Fourn. de Bot. viii. (1894) 337 (= Saussurea edulis, Franch.). - China occ.

Lcvieri, Alboff, in Bull. Herb. Boiss. ii. (1894) 257 ; et Prodr. Fl. Colch. (1895) 145. - Reg. Cauc. maxima, C. Winkl, in Act. Hort, Petrop. xi.. (1890) 336. - Turkest.

mollis, Wettst。 in Sitzb. Akad. Wiss. Wien, xcvii. (1889) 575. - As, centr.

monocephala, Aitch. et Hemsl. in Trans. Linn. Soc Ser. II. iii. (1886) 80. - Persia.

nivea, C. Winkl, in Act. Hort. Petrop. xi. (1890) 321. - Turkest.

pontica, Hausskn. Er Freyn. ox Hausskn. 2n Mitth. Bot. Ver. Fna, (1891) 18. - Pontus.

pumila, Alboff., in Bull. Herb Boiss. 3. (I893) 243 t. 9 ; et ex Sommier \& Levier, in Act. Hort. Petrop. xiii. (1893) 46. - Reg. Cauc. 
JURINEA

Souliei; Franch. in Morot, fourn. de Bot. viii. (1894) 337. - China occ,

transsilvanica. Simonk. Enum. F1. Transsilv. (1886 $344=$ mollis, Reichb.

variabilis, Aitch. \& Hemsl. in Trans. Linn. Soc. Ser. II. iii. (1893) 80 t. 34. - Reg. Afghan.

JUSSIAEA, Hill = Jussieua, Linn. (Onagrar.). - Ind. Kew. i. 1262

Lagunae, Morong, in Ann. N. Y. Acad. Sci, vii. (1893) 111. - Parag.

JUSTAGO, Kuntze, Rev. Gen. (1891) 39 = Gynandropsis. DC. (Capparid.).

clenmodes, Kuntze, 1. C. (= Roeperia cleomoides. F. Muell. $)=$ G. Muelleri, Benth.

JUSTICIA, Houst. ex Linn. (Acanth.). - Ind. Kew, i. 1263 .

acuminata, Lindan, in Engl. \& Prantl, Natürl. Pflanzenfam. iv. 3b (1895) 351 (= Rhigtiglossa acuminata, Nees). - Venez.

aequilabris, Lindan, t. c. $350(=$ Amphiscopia aequilabris, Nees). - Bras.

aethiopica, Martelli, in Nitoo. Giomn. Bot. Ital. xx. (1888) 393. - Afr. trop.

amazonica, Lindau, in Engl. of Prantl, Natirl. Pfanzenfam。iv, 3b (1895) 350 (= Rhytiglossa amazonica, Nees).-- Bras.

Anagallis, Lindan, l. c. 351 (= Dianthera Anagallis, Hems1.). - Mexic.

androsaemifolia, Lindau, l. c. 350 (= Dianthera androsaemifolia, Griseb.). - Ins. S. Doming.

anfractuosa. C. B. Clarke, in fourn. Linn. Soc. xxv. (1889) 54. - Ind. or.

angustata, Warb. in Bot. Fahrb. xiii. (1891) 423. Oceania.

angustifolia, Lindan, in Engl. \& Prantl, Natiirl. Pflanzenfam. iv. 3b (1895) 350 (= Dianthera angustifolia, Benth. \& Hook. ...). - Bras.

arenicola, Engl. Bot. Fahrb. x。 (1889) 264。 - Afr austro-occ. extratrop.

arida, S. Elliot, in foum. Limn. Soc. xxix. (1891) 38. - Madag.

Bailloni. S. Elliot, l. c. - Madag

Bakeri, S. Elliot, l. c. 39. - Madag.

beloperonoides, Lindaut, in Bot. Fahrbo. xxii. (1895) 127. - Afr. trop. or.

Beyrichii, Lindau, in Engl. \& Prantl, Natiirl. EAanzenfam. iv. 3b (1895) 350 (= Amphiscopia Beyrichii, Nees). - Bras.

Buettneri, Lindan, in Bot. Fahrb. xx. (1894) 68. Guin.

campestris, Lindau, in Engl. \& Prantl, Natiurl. Pflanzenfam. iv. 3b (1895) 350 (= Dianthera campestris, Benth. \& Hook. f.). - - Bras.

cardiochlamys, Lindant, in Bot. Fahrb. xix. Beibl. n. 48 (1894) 6. - N. Guin

catharinensis, Lindau, in Bull. Herb. Boiss, iii. (1895) 485. - Bras.

cayennensis, Lindau, in Engl. \& Prantl. Natürl. Pfanzenfam. iv. 3b (1895) $350(=$ Dianthera cayennensis, Griseb.). - Guiana.

caudata, A. Gray, in Proc. Am. Acad. xxi. (1886) 405. - Mexic

Chalmersi, Lindau, in Bot. Fahrb. xix. Beibl. n. 48 (1894) 6. - N. Guin

cydoniifolia, Lindau, in Engl, \& Prantl, Natürt. Pfanzenfam. iv. 3b (1895) 350 (= Adhatoda cydo niaefolia, Nees). - Bras.

dasyclados, Lindau. l.c. $i=$ Dianthera dasyclados, Benth. \& Hook. f.). - Bras.

delicatula, S. Elliot, in fourn. Limn. Soc, xxix. (1891) 39. - Madag,

desertorum, Engl. Bot. Fahrb. x. (1889) 263. Afr, austro-occ. extratrop.

diclipteroides, Lindau, l. c. xx (1894) 65. - Afr trop. or.

diosmophylla, Lindau, in Enst. E Prantl, Natiirl. Pfanzenfan iv. 3b (1895) 349 (= Adhatoda dios mophylla, Nees). - Afr. austr.

distorta, Lindau, i. c. $350(=$ Dianthera distortaBenth. \& Hook. f.). - Bras.

\section{JUSTICIA :}

dumetorum, Morong, in Ann. N. Y. Acad Sci, vii (1893) 193. - Parag.

Emini, Lindau, in Bot. Falirb. xx. (1894) 68. Afr, trop, or.

Engleriana, Lind $c u$, , l. c, 62. - Afr, trop. on

fallax. Lindau, l.c.74. - Guin.

filifolia, Lindau, l. c. 70. - Afr. trop. or

Fischeri, Lindau, l. c. 65. - Afr. trop, or

fruticulosa, Lindanu, l. c. 75. - Afr. centr. bor.

Garckeana, Buethn, in Verh. Bot.Ver. Brond, xxxis (1890) 38. - Congo merid.

genistifolia, Engl. Bot. Fahrb. x. (1889) 264. Afr. austro-occ. extratrop.

Glaziovii, Lindan, in Bull. Herb. Boiss, iii. (1895) 48:3. - Bras.

Gregorii, S. Moove, in fourn. Bot. xxxii. (IS94) 138 - Afr. trop. or.

Guerkeana, Schinz, in Verh. Bot. Ver. Brand. xxxi. (1890) 201. - Afr. austro-occ. extratrop.

hantamensis, Linduru, in Bot. Falirb. xx. (1894) $66^{\circ}$ - Afr. austro-occ.

hereroensis, Engl, 2. c. X. (1889) 264. - - Afr. austro-occ, extratrop.

heterophylla, Lindau. in Engl. \& Prantl, Natürl. Pfanzenfan. iv. 3b (1895) 350 (= Dianthera heterophylla, Benth. \& Hook. f.). - Bras.

hilaris, S. Elliot, in fourn. Linn. Soc. xxix, (1891) 40. - Maday.

Hoepfneri, Lindau, in Bot. Fahrb. xx. (1894) 66. Angola

Hyssopus, I,indau, in Engl. \& Pruntl, Natiurl. Pflanzerfam. iv. 3b (1895) $350(=$ Rhyiıglossa Hyssopus, Nees). 一 Mexic.

insolita, T. S. Brandeg, in Proc. Cullif. Acad. Ser. II. ii. (1889) 195. - Calif

Karschiana, Buttn. in Verho Boto Ver. Brand. xxxij. (1890) 40. - Angola.

Kuntzei, Lindan, in Bull. Herb. Boiss. iii. (1895) 483. - Bolivia.

laevilinguis, Lindau, in Mem. Torrey Bot. Club, iv. (1895) 243; at in Engl. Eo Prantl, Natürl. Pfanzenfam. iv. $3 \mathrm{~b}(1895) 350(=$ Rhy'iglossa laevilinguis, Nees). - Bras.

latiflora, Hemsl, in fourn, Linn. Soc. xxvi. (1890)

245. - China

leikipiensis, S. Moore, in fourn. Bot xxxii. (1894)

137. - Afr. trop. or.

leptocarpa, Lindau, ex Engl. in Abh. Preuss. Akud. Wiss. (1894) 39 ; et in Bot. Fahrb. xx. (1894) 70. - Afr. trop. or,

leptostachya, Hemsl, in fourn. Linzn, Soc xxvi. 1890; 245. - China

leucodermis, Schinz, in Verh Bot. Ver. Brand. xxxi (1890) 202. - Afr. austro-occ. extratrop. linearis, Robinson \& Greenm. in Am. Fourn. Si

Ser. III, 1. (1895) 161. - Mexic.

longecalcarata, Lindau, in Bot. Fahrb. xx. (1894) 73. - Afr. trop. or.

Lorentzinna. Lindau, 1. c. xix. Beibl. n. 48 (1894) $20=$ campestris, Griseb

lucida, Lindau, l. c. 20 (= Leptostachya lucida, Nees). - Bras.

Lushnatii, Lindau, in Engl. \& Prantl, Natiirl. Pfanzenfam. iv. 3b (1895) 350. - Bras.

madagascariensis, Lindau, in Bot. faht b. xx. (I894) 64. - Madag.

malangana, Lindan, l.c. 71. - Angola.

marginata, Lindau, l. c. 73. - Angola.

Martiana, Lindau, in Engl. \& Prantl, Natürl. PAanzenfam.iv.3b (1895) $350(=$ Amphiscopia Martiana, Nees). - Bras.

matammensis, Lindau,l. c. $349(=$ Adhatoda matim mensis, Schweinf.). - Afr. trop.

Melampyrum, S, Moove, in Trans. Limn. Suc., Ser. II. iv. (1894) 32. - Afr. trop.

Meyeniana, Lindau, in Engl. \& Prantl, Nativ\%. Pfanzenfam. jv. 3b (1895) $350(=$ Beloperone Meyeniana, Nees). - Bras.

microphylla, Lindau, in Engl. Pfanzenw. Ost-Afs. C. (1895) 373 (= Adhatuda microphllla, Klotzsch). - Afr. trop.

mossambicensis, Lindau, l.c. $(=$ Dicliplera mossam bicensis, Klotzsch). - Afr. trop.

namaënsis, Schinz, in Verh. Bot, Vor. Brand, xxxi. 1890) 202. - Afr. austro-occ, extratrop.

\section{JUSTICIA :}

nana, Lindau, in Engl. \& Prantl. Natürl. PAanzenfam. iv. $3 \mathrm{~b}(1895) 350(=$ Rhytiglossa nana. Nees). Mexic.

neurantha, Collett \&o Hemsl. in fourn. Limn. So xxviii. (1890) 107. - Burma.

nyassana, Lindau, in Bot. Falhrs. xx. (1894) 66. Alr. trop. or.

plosa, Lindau, in Enol. Es Prantl Natiurl. Pfanzenfam. iv 3b (1895) $350(=$ Adhatoda pilosa. Nees). - Bras.

blonga. Lindau, l.c. (= Dianthera oblunga, Benth $\&$ Hook. f.). - N. Granat.

btusa, Lindau, l. c. $349(=$ Rostellularia obtusa Nees). - As. trop.

obtusifolia, I, indan, int Jot. Zahrb, xix. Beibl. n. 48 (1894) 20 (= Rhytiglossa obtusifolia, Nees). Am. bor.

Palmeri, N.E. Rose, ex Vasey \& N. E. Rose, in Con trib. U.S. Nat. Herb. i. (1890) 75. - Mexic.

parviflora, Lindau, in Engl. \& Prantl, Natürl. Pfanzenfam. iv. 3b (1895) $350(=$ Dianthera parriflora A. Gray). - Am, bor.

Paxiana, Lindau, in Bot. Fahrb. xx. (1894) 63.Afr. trop. occ

Poeppigiana, Lindau, l. c. xix. Beibl. n. 48 (1894) $20(=$ Leptostachya Poeppigiana, Nees). Peruvia.

Poggei, Lindau, l. c. xx. (1894) 61. - Congo,

polymorpha, Schinz, in Verh. Bot. Ver. Brand. xxxi. 1890) 203. - Afr. austro-occ. extratrop.

Pringlei, Robinson, in Proc. Am. Acad, xxvi. (1891) 173. - Mexic.

Pseudorungia, Lindan, in Bot. Fahrb. xx. (1894) $\{3$ Afr. trop. or.

pyomaea, Lindau, in Bull. Herb. Boiss. iii. (189. 484. - Bras.

repens, Lindau, in Engl. \& Prantl, Natiol. Pfanzen fam. iv. 3b (1895) 35l (= Rhytiglossa repens, Nees). - Bras.

riojana, Lindau, in Bot. Fahro. xix. Beibl. n. 48 1594) 19. - Reg. Argent.

Rostellaria, Lindan, l. c. xx. (1894) 74, in obs; tet $i$ Engl, Pfanzenw. Ost-Afr. C (1S\%5) 373. - Afr trop. or.

rostellarioides, Lindan, l. c. 69. - Afr. trop, oce.

Ruiziana, Lindau, in Engl. Go Prantl. Natiirl. PRmzenfam. iv. $3 \mathrm{~b}(1895) \quad 350(=$ Rhytiglossa Rui ziana, Nees). - Peruvia.

Rusbyána, Lindan, in Men. Torrey Bot. Club, iv 1895) 243. - Bolivia.

sansibarensis, Lindau, in Bot. Falurb. xx. (1894) 71. - Zanzibar.

sarmentosa, Lindau, in Engl. \& Prantl, Natiurl. Pflanzenfam.iv. 3b ils95) 351 (= Rhytiglossa say mentosa, Nees). - Bras.

Schenkiana, Lindau, in Bull. Her3. Boiss, iii. (1895 485. - Bras.

Schwackeana, Lindan, l. c. 482. - Bras.

sexsulcata, Lindan, in Bot. Fahrb. xx. (IS94) 67. Afr. trop. occ.

isparensis, Lindan, in Engl. \& Prantl. Nativ? Pfanzenfam. iv. 3b (1895) $350(=$ Rungia sisparensis, T. Anders.). - Ind. or.

speciosa, Lindau, l.c. (= Dianthera speciosa, Benth. \& Hook. f. ). - N. Granat

Steingroeveri, Schinz, ex Lindau, l. c. 349. - Afr. austro-occ. extratrop.

trobilacea, Lindan, l. c.350 (= Amphiscopia stro3ilacea, Nees). - Bras.

suaveolens, Ludau, l. c. $349(=$ Adhatoda suaviolens Nees). - Arabia.

symphyantha, Lindait, l. c. 350 (= Rhytiglossit sympliyantha, Nees). - Bras.

thomensis, Lindan, in Bot. Fohrb. xxii. (1895)

126. - Ins. S. Thom.

togoënsis, Lindan, l. c. xx. (1894) \%2. - Afr. trop. occ

ukambensis, Lindan, l. c. 69. - Aft. trop. or ulugurica. Lindum, l,c. xxii. (1895) 120. - Afr. trop. or.

umbrosa, Lindaw, l. c. xix. Beibl. n. 48 (189.4) 20 = Adhatoda umbrosa, Nees.

Urbaniana, Lindom, l. c. xx. (1894) 64. - Afr. trop. or. 


\section{JUSTIGIA :}

vagans, Collett \& Hemsl. in fourn. Linn. Soc. xxviii (1890) 107. - Burma.

variegata Martelli, in Nuov. Giorn. Bot. Ital. xx. (1888) $39: 3$ (= Adhatoda variegata, Nees). Afr. trop.

velascana, Lindau, in Bull. Herb. Boiss, iii. (1895) 484. - Bolivia.

Thhytei, S. Moore, in Trans. Limn. Soc.Ser. II. iv. (1894) 32. - Afr. trop.

\section{$\mathrm{K}$}

KADSURA, Kaempf. (Magnoliac.). - Ind. Kew. i1. 1 .

Championi, C. B. Clayke, in fourn. Limn. Soc. xxy. (1889) 4. - Hongkong.

chinensis, C. B. Clarke, 1. c. - Hongkong

lanceolata, King, in fourn. As. Soc. Beng. lviii. 1889) II. 376; et in Ann, Gard. Calc, iii. (1891) 223 t. 73b. - Malaya.

Wattii, C. B. Clarke, in fourn. Linn. Soc. xxv (18S9) 4, - Reg. Himal.

KADUA, Cham. et Schlecht. (Rubiac.). - Ind. Kew, ii. 1.

foliosa, Hillebr. Fl. Haw. Isl. (1888) I64. - Ins. Sandvic.

formosa, Hillebr.l. c. 165. - Ins. Sandvic

Knudsenii, Hillebr.l. c. 162. - Ins. Sandvic

littoralis, Hillcbr. l. c. 166. - Ins, Sandvic.

Remyi, Hillobr. l. c. 162. - Ins. Sandvic.

KAEMPFERIA, Linn. (Scitam.). - Ind. Kew ii. 1 .

ethiopica, Solms, ex Engl, in Abh. Preuss, Akad. Wiss. (1894) 45̃. - Afr. trop.

Andersoni, Baker, in Hook, ff Fl. Brit, Ind, vi (1890) 221. - Burma.

atrovirens, $N$. E. Br in Illustr. Hortic, xxxiii. (18S6) 143 t. 610 . - Borneo.

brachystemon, $K$. Schum, ex Engl, an Abh. Preuss. Akad. Wiss. (1894) 30; et in Engl. Pflanzinw. Ost.-Afr. C (1895) 169. - Afr. trop. or.

concinna, Baker in Hook. f. Fl. Brit. Ind. vi. (1890) 221. - Perak.

involucrata, King, ex Baker, l. c, - Reg. Himal

Kirkii, Wittm. \& Perring, in Gartenfl. xlii. (1893) 57 t. $1364=$ Cienkowskya Kirkii, Hook. $f$

parvula, King, ex Baker, in Hook. f. Fl. Brit. Ind. vi. (1890) 223. - Penins. Mal.

pleiantha, K. Schum. in Bot. Fahrb. xv, (1893) 425 - Congo, Angola.

Prainiana, King, ex Baker, in Hook. $f$. Fl, Brit. Ind. vi. (1890) 220. - Penins. Mal.

sikkimensis, King, ex Baker, l. c. 223. - Reg. Himal.

siphonantha, King. ex Baker, l. c. 222. - Ins, Andam.

speciosa, Baker, l. c. 220. - Burma.

KAERNBACH1A, Kuntze, Rev. Gen.(1891) $62=$ Microsemma, Labill. (Ternstrem.)

salicifolia, Kuntze, 1. c. = M. salicifolia, Labill.

KALAHARIA, Baill, Hist, des pl. xi. (1892) 110 Brig. in Encl, \& Prantl, Natiirl. Pflanzenfam. iv.3a (1894) 172. VERBENACEAE.

sprnescens, Guerlie, in Engl. Pflanzenw. Ost-Afr C $(1895) 340=$ Cyclonema spinescens, Oliver.

pimipes, Baill. Hist. des pl. xi.(1892) $111=$ Clerodendron spinescens, Guerke.

KALANCHOË, Adans. (Crassul.). - Ind, Kew ii. 2.

brachycalyx, Baker. in foum. Linn, Soc. xxii. (1857) 470. - Madag.

bracteata, S. Elliot, l. c. xxix. (1891) 15. Madag.

brevicaulis, Bakcr, l. c. xxii. (1887) 470. - Madag carnea, N. E. Br. in Gard. Chron. (1886) i. 298 ; et (1SS7) i. 211 fig. 48 (Calanchoe). Afr. austr.

\section{KALANCHOË :}

Cassiopeja, Dammann, in Monatssch. f. Kakteenk. iii. (1893) 150. - Hab.

deficiens, Aschers. \& Schweinf. Illustr. fl. Ėypte,

(1887) 79 (Calanchœ) $=$ aegyptiaca, $D C$

comphophylla, Baker, in fourn. Linn. Soc. xxii. (1887) 471. - Madar.

Grandidieri, Baill. Hist. pl. Madag. Atlas (1888) t. 57. - Madas.

Holstii, Engl. in Abh. Preuss. Akad. Wiss. (1894) 38; et Pfanzenw, Ost-Afr. C (1895) 189. Afr. or.

integra, Kuntze, Rev, Gen. (1891) $229=$ crenata, Haw.

integrifolia, Baker, in fourn. Limn. Soc, xxii. (1887) 471. - Madag.

lateritia, Engl. in Abh. Preuss, Akad. Wiss. (1894) 19; et Pfanzenw. Ost-Afr. C (1895) 189. - Afu. or. laxiflora, Baker, in foum. Linn. Soc. xxii. (1887) 472. - Madag.

marmorata, Baker, in Gard. Chron. (1892) ii, 300 et in Bot. Mag. (1894) t. 73333 (=K. grandiflora, A. Rich.). - Abyss.

multiflora, Schinz, in Verh. Bot. Ver. Brand. xxx. (1SS8) 173. - Afr austro-occ. extratrop.

ndorensis, Schweinf. ex Engl, in Abh. Preuss. Akad. Wiss. 1891 ii. (1892) 232 nomen; et in Hoelnel, Zum Rudolph See, Append. (1892) 13 [Calanchoe]. - Afr trop or.

Nyilsae, Engl. in Ab7. Preuss, Akad. Wiss. (1894) 38 ; et in Engl. Pfanzenw. Ost-Afr. C (1895) 189. - Afr. or.

obtusa, 17 . cc. 29 et 189. - Afr. or.

pilosa, Baker, in Keq Bull. (1895) 289. - Afr. centr. austro-or.

pubescens, Buker, in Fourn. Linn. Soc. xxii. (1887) 470. - Madag

rosea, C. B. Clarke, in fourn. Limn. Soc. xxv. (1889) 21. - Kohima

Schweinfurthii, Pentig, in Atti Congr. Bot. Genova (1893) 341. - Erithrea.

somaliensis, Baker, in Kew Bull. (1895) 214. - Reg. Somal.

streptantha. Baker, in fourn. Limn. Soc. xxii. (1887) 472. - Madag.

Stuhlmannii, Engl. Pfanzenw. Ost-Afr. C (1895 188. - Afr. or

subpeltata, Baker, in fourn. Linn. Soc. xxii. (1887) 472. - Madag.

sulphurea, Baker, l. c. 471. - Madag

teretifolia, Deflers, in Bull. Soc. Bot. Fr. xl. (1893) 299. - Arabia.

verticillata, S. Elliot, in fourn. Linn. Soc. xxix. (1891) 14. - Madag.

KALBFUSSIA, Sch. Bip. = Leontodon, Linn. (Compos.).

cirtensis, Pomel, ex Batt. \& Trab. Fl. de l'Algér. [Dicot.] (1889) $540=$ L. Mulleri, Ball.

KALLSTROEMIA, Scop. = Tribulus, Linn (Zygophyll.).

angustifolia, Engl, in Engl. \& Prantl, Natürl Pllanzenfam, iil. 4 (1890) $88=\mathrm{T}$ angustifolius, Benth.

bicolor, Engl. 1. c, = T. bicolur, F. Muell.

californica, A. M. Vail, in Bull. Torrey Bot. Club, xxii. $\{1895\} 230=$ T. californicus, S. Wats.

hystrix, Engl. in Engl. \& Prantl, Natürl. Pflanzenfam. iii. 4 (1890) $88=$ T. Hystrix. $R . B r$

macrocarpa, Engl. 1. c. = T. macrocarpa, F. Muell. pentandra, Engl. 1. c. $(=$ Tribulopsis pentandra, R. Br.). - Austral.

ranunculiflora, Engl. l. c. = T. ranunculiflorus, F. Muell.

Solandri, Eng1. 1. c。 = T. Solandri, F. Muell.

KALUHABURUNGHOS, Linn.Fl. Zeyl. (1747) 202, ex Kuntze, Rev. Gen. (1891) 607 = Cleistanthus, Hook, f. (Euphorb.)

acuminatus, angolensis, apodus, Blancoi. Boivinianus, chartaceus, Cunninghamii, Dallachyanus, decurrens, diversifolius, elliptious, ferrugineus, gracilis, Helferi heteropliyllus, hirsutulus, laevis, lanceolatus, lancifolius, macrophyllus, Maingayi, malabaricus, malac-
KALUHABURUNGHOS : -

censis, membranaceus, myrianthus, nitidus, pallidus, paroifolius, patulus, pedicellatus, podocarpus, poly stachyus, robustus, semiopacus, stenophyllus, stipitatus, stipularis, stipulatus, sumatranus, Kuntze, Rev. Gen. (1891) 607 = homonyma omnia Cleistanthi. monoecus, Kuntze, 1. c. = C. monoicus, Muell. Arg. nanopetalus, Kuntze, 1. c. (= Nanopetalum myrian thus, Hassk.). - As. trop.

oblongifolius, Kuntze, 1. c. = C. chartaceus, Muell Arg.

KANAHIA, R. Br. (Asclep.), - Ind. Kew. ii. 3. aniflora, K. Schum, in Eng1. \& Prantl, Natürl Pflanzenfam. iv. $2(1895) 233=$ laniflora, $R . B r$

KARANGOLUM. Kuntze, Rev. Gen. (1891) $272=$ KARA-ANGOLAM, Adans. = Alangium, Lam. (Cornac.)

burbatum, Kuntze, 1. c. = Marlea barbata, R. Br. chinense, Kuntze, 1. c. = M. begonifolia, Roxb.

ebenacem, Kuntze, 1. c. = M. ebenacea, C. B. Clarke.

Faberi, Kuntze, 1. c. = Alangium Faberi, Oliver

Griffithi, Kuntze, 1. c. = Marlea Griffithii C. B. Clarke.

Mohillae, Kuntze, 1. C. = Alangium Mohillae, Tul. nobile, Kuntze, 1, c, = Marlea nobilis, C. B. Clarke. platanifolium, Kuntze, 1. c. = M. platanifolia, Sieb. \& Zucc.

salviaefolium; Kuntze, 1. c. 272 et $273=$ Alangium Lamarckii, Thee.

Siticnse, Kuntze, 1. c, $273=$ Marlea vitiensis, Benth.

Zollingeri, Kuntze, 1. c. = Aiangium Zollingeri, Baill.

KARATAS, Mill. (Bromel.). - Ind. Kew. ii. 3. albo-rosea, Baker, Handb. Bromel. (1889) 4 (= Nidu larium albo-roseum, Griseb.). - Venez.

amazonica, Baker, in Gard. Chron. (1886) i. 814 et Handb. Bromel. (1889) 5. - Am. austr.

ampullacea, Baker, l.c. (= Nidularium ampullaceum Ed. Morr.). - Bras.

Antoineana, Baker, l. c. $6 \Leftrightarrow$. Antoincanum Wawra). - Bras.

carcharodon, Baker, l.c. $12(=$ N. carcharodon, Éd. Morr.). - Bras.

chlorosticta, Baker, l. c. 7 ( = N. chlorostictum, Ed Morr. ). - Bras.

cruenta, Baker, l. c. $10(=N$. cruentum, Regel). Bras.

cyanea, Baker, l. c. $5(=N$. cyaneum, Linden ex Éd. André). - Bras.?

denticulata, Baker, l. c. $4(=N$. denticulatum Regel.). - Bras.

Ferdinando-Coburgi, Baker, l.c. $6(=N$. FordinandoCoburgi, Wawra). - Bras.

Johannis, Baker, l. c. 11 ( $=N$. Fohannis, Carrière) - Bras.?

laciniosa, Lindm. in Kongl. Sv. Vet. Akad. Handl. xxiv. 8 (1891) 18, t. 2 fig. 22-25. - Bras.

leucophoea, Baker, Handb. Bromel. (1889) 7 (= Nidularium leucophoeum, Ed. Morr.). - Hab.?

macrantha, Baker, l. c. 8, in obs. - Bras.

Makoyana, Baker, l. c. 11 (= Nidularium Makoya num, Regel), - Bras.

marmorata, Baker, l. c. 11. - Bras.?

neglecta, Baker, l.c.6. - Bras. ?

Nidus-puellae, Ed. André. in Rev. Hortic. (1S88) $563 ;$ Baker, l.c. 2. - Columb.

Princeps, Baker, l.c. $10(=$ Nidularium Princeps Ed. Morr.). - Bras.

Redoutei. Baker, l. c. 3. - Hab. ?

Regnellii, Baker, l.c. $101=$ Nidularium giganteum Baker). - Bras.

rutilans, Baker, l. c. $9(=$ N. rutilans, Éd. Morr. $)$ - Bras.

sarmentosa, Baker, l. c. $5(=N$. surmentosum, Regel). - Bras.

tristis, Baker, l. c. (=N. triste, Regel). - Bras.

KAREKANDELIA, Kuntze, Rev. Gen. (1891) 234 $=$ KARE-KANDEL, Adans. = Carallia Roxb. (Rhizoph.).

brachiata, Kuntze, 1. c. $236=\mathrm{C}$. integerrima, $D C$. 
KAREKANDELIA :-

caljcina, Kuntze, Rev. Gen. (1891) 235 = Carallia calycina, Benth

celebica, Kuntze, 1. c. = C. celebica, Blume. confinis, Kuntze, 1. c. = C. lanceaefolia, Roxb. cuspidata, Kuntze, 1. $\mathrm{c}_{0}=\mathrm{C}$. cuspidata, Blume. lancenefolia, Kuntze, 1. C. $=$ C. lanceaefolia, Roxb. multiflora, Kuntze, l. c. = C. multiflora, Blime.

KAUKENIA, Kuntze, Rev, Gen. (Is91) $406=$ KAUKEN, Burm. Thes. Zeyl. (1796) $133=$ Mimusops. Linn. (Sapot.)

acuminata, caffra, cuneifolia, dissecta, elata, Elengi, Erythroxybon, floribunda. fruticosa, globosa, hexandra, javcnsis, Kauki, Kirkii. Kummel, lacera, longifolia, Mochisia, multinervis, parvifolia, Roxöurghiana, rufula, subsericea, surinamensis, fimorensis, Kuntze, Rev, Gen. (1891) $406=$ homonis ma omniu Mimusopseos.

Titoralis, Kuntze, 1. c. $=$ M. littoralis, $K u r z$.

Salsmannii, Kuntze, 1. c. = M. Salzmanni, $A . D C$

KAYEA, Wall. (Guttif.), - Ind. Kew ii. 4. caudata, King, in fourn. As. Soc. Beng. lix. (1890) II. 183; Vesque, in DC. Monog. Phan. viii. (1893) 621. - Malaya.

elegans, King. $l l . c c .183$; et 622. - Malaya.

Garciae, Vesque, in DC. Monog. Phan. viii, (1893) 629. (= Vidalia Garciae. F. Vill.). - Ins. Philipp. grandis, King, in fourn. As. Soc, Beng. lix. (1800) II. 182; Vesque, in DC. l. c. 622. - Malaya.

Larnachiana, F. Muell, in Vict. Natural. iii. (Jan 1887) 126 ; et ex Bot. Centralbl. xxx. (1887) 213 ; Vesque, in DC. Monng. Phan. viii. (1893) 625.Austral.

Kunstleri, King, ll.cc. 182; et 620. - Malaya.

Navesii, Vesque, in DC.l.c. 628 (= Vidalia Navesii, F. Vill.). - Ins.

Wrayi, King, in fourn. As. Soc. Beng. lix. (1890) II. 181. - Malaya.

KEDRASTIS, Medic. (Cucurbit.). - Ind. Kew.

Boehmii, Cogn.in Bull.Acad. Belg. Sér. 3, xiv. (1887) 357. - Afr. trop. or

longipedunculata, Cogne ex Schinz, in Bull. Herb. Boiss. iii. (1895) 421. - Natal.

KEENANIA, Hook. f. (Rubiac.). - Ind. Kew. ii. 4 ophiorrhizoides, Drake, in Bull. Mus. Paris, i. (1895) 117 ; et in Morot, fourn. de Bot. ix. (1895) 217 t. 4 - Tonkin.

toonkinensis, Drake, $l l . c c .118$; et 21\%. - Tonkin.

KEERLIA, A. Gray \& Engelm. (Compos.). Ind. Kew. ii. 4

mexicana, A. Gray, ex S. Wats. in Proc. Am. Acad. xxii. (1887) $422 .-$ Mexic.

KELLERONIA, Schinz, in Bull. Herb. Boiss, iii (1895) 400. ZYGOPHYLLEAE.

splendens, Schinz, l. c. t. 9. - Reg. Somal.

KELLOGGIA, Torr. (Rubiac.). — Ind. Kew. ii. 4 chinensis, Franch, in Morot, fourn. de Bot. vi. (1892) 11. - Yunnan.

KENTIA, Blume (Palm.).'-Ind. Kew. ii. 4. clegantissima, Linden, Catal. (1888), ex Gard, Chron. (158s) 11.328 , nomen. - Hab. ?

sapida, Drude, in Engl. E Prantl. Natuirl. Pfanzenfam. ii. 3 (1S87) 73 (= Areca sapida, Soland.).N. Zel.

KENTROPHYLLUM, Neck. = Carthamus Linn. (Compos.)

monspeliensinm. Ces. Passer. \& Gibelli, Comp. Fl. Ital. ii. (1886) $499=$ Carduncellus monspeliensis, All.

pinnatum, Ces., Passer, \& Gibelli, 1. c. $=$ C. pinnatus, $D C$.

tingitanum, Ces., Passer. \& Gibelli, 1. c. = C. caeruleus, Less.

KERMADEGIA. Brongn, \& Gris (Proteac.), Ind. Kew. ii. 5.

\section{KERMADEGIA :}

pimatifida. F. M. Bailey, Cat. Woods Queensl. (Lond. Col Ind. Exhibit. ]886) $69=$ Grevillea pinnatifida, $F, M$. Bailey.

KERNERA. Medic, $=$ Cochlearia, Linn. (Crucif.) alpina, Prantl, in Engl, \& Prantl, Naturl. Pflanzenfam. iii. 2 (1891) $167=$ C. brevicaulis, Facch

KETELEERIA, Carr. (Conif.). - Ind. Kew, ii. 6 Davidiana, Beissn. Handb. Nadelholzk. (1891 4223 figur. 117 (= Abies Davidiana, Franch.). China.

sacra, Beissn. 7. c. 426 (= A, sacra, Arm. David) - China.

KEYSERLINGIA, Brongn. (Legumin.). - Ind kew. ii 6 .

mollis, Boiss. Fl.Or. Suppl. (18S8) 197 (= Edwardsia mollis, Royle!. - Afghan.

KIBARA, Endl. (Monim.). - Ind. Kew. ii, 6. hirsuta, Warb. in Bot. Fahrb. xiii。 (1891) 316. S. Guin.

IIBESSIA, DC. (Melast.), - Ind. Kew. ii. 6. coriacea, $\operatorname{Cog} n$, in Bocrl. Handl. Fl. Nid. Indie, i. II. (1890) 536 ; et in DC. Monog. Phan. viii. (1891) 109. - Borneo.

echinata, Cugn. 11. cc. 536 ; et $1108=$ simplex, Korth.

galeata, $\operatorname{Cog} n$. 77 . co. 537, et 1110 (= Rectomitra galeata, Blume). - Borneo.

gracilis, $\operatorname{Cog} n$. . . c. 1110. - Borneo.

hirtella. Cogn. in Boerl. Handl. Fl. Ned. Tndiè, i. Ir. 1890) 536, nomen; et in DC. Monog. Phan, vii. 1891 $110 \%$ - Borneo.

Liorthalsiana, $\operatorname{Cog} n .7 l . c c .537$; et 1111 (= Rectomitra Korthalsiana, Blume). - Borneo

rostrata, Cogn.l.c. 1111.- Borneo.

tessellata, Stapf, iu Trans, Linn. Soc. Ser. II. iv. (1894) 162. - Bornec.

Teysmanniana, $\operatorname{cog} n$, in DC. Monog. Phan, vii. (1891) 1109. - Borneo.

KIELMEYERA, Murr.(Ternstroem.). - Ind.

Kew ii 6.

bracteosa, Mart. ex Wawra, in Mart. Fl. Bras, xii. (1886) 326 = Bonnetia anceps, Mart.

gracilis, Wawra, in Mart. l.c. 308. - Bras.

longifolia, Mart. ex WVawra, in Mart. 1. c.307 = petiolaris, Mart.

KIERSERA, Nees = Bonnetia, Mart. \& Zucc (Ternstroem.)

anceps, paniculata, sessilis, venulosa, Kuntze, Rev. Gen. (1891) 62 = homonyma omnia Bonnetiae.

KIGELIANTHE, Baill. Hist. des pl. x. (18S8) 50. BIGNONIACEAE

Grevei, Baill. 7.c. - Madag,

Hildebrandtii, K. Schmm in Engl, E Prantl, Natim? Pfanzenfam. iv. 3b (1895) 244. - Madag.

KIGGELARIA. Linn. (Bixin.). - Ind. Kew. ii. 7 grandifolia, Warb, in Engl. Pfanzenw. Ost-Afr. C (1895) 2\%. - Afr. trop. or.

serrata, Warb, ex Enol, in Abh, Preus.s, Akad. Wiss. (1894) 33 ; et l. c. - Afr. trop. or

KINGINDA, Kuntze, Rev. Gen. (1891) $\tau$ = Mitrephora, Blume (Anonac.).

diversifolia, excelsa, grandifora, humilis, macranthe Maingayi, obtusa, polypyrena, Thovelii, tomentosa. Kuntze, 1. c, = homonyma omnia Mitrephorae.

Heyneana, huntze, 1. c. = Melodorum Heyneanum, Thw.

multiflora, Kunlze, 1. c。= Uvaria multiflora Teysm. \& Binn.

KINGELLA, Van Tiegh., in Buil. Soc. Boi. Fr. xlii. (1895) $250=$ Loranthus, Linn.

Scortechinii, Van Tiegh. 1. c. = L. Scortechinii King.
KIRENGESHOMA. Yatabé, in Tokyo Bot. Mag. iv. $(1890) 1$, SAXIFRAGEAE

palmata, Yatabé l.c. 1, t. 18. - Japon.

KLEINIA. Juss, = Jaumea, Pers. (Compos.) arnosa, compositarum, mexicana, Oliveri, peduncularis, Kuntze, Rev. Gen. (1891) $348=$ homonyma omnia Jaumeae.

KLOTZSGHIA, Cham. (Umbellif.). - Ind. Kew. rhizophylla, Ury. in Bot. Fahrb. xvii. (IS93) 508. - Bras.

KNAUTIA, Linn. = Scabiosa, Tourn. (Dipsac.). Breindli, G. Beck, in Ann. Naturh. Hofmus. Wien, ix. (1894) $352=\mathrm{S}$, arvensis, Linn.

budensis, [G. Beck. ?] ex Borb. in Bot. CentralbI. lvii. (1894) 101. - Germ.

byzantina, Fritsch, in Verh. zool.-bot. Ges. Wien, xlv. (1895) 429. - Thrac.

carniolica, G. Beck, in Annal. Naturh. Hofmus,

Wien, ix, (1894) $352=\mathrm{S}$. sylvatica, Linn.

Clementei, G, Beck. 1. co = dalmatica. G. Beck.

cupularis, Janka \& Simonk. ex Simonk. Enum. Fl, Transsilv, (1886). $294=\mathrm{S}$. arvensis, Linn.

dalmatica, G. Beck, in Annal. Naturh. Hofmus,

Wien, ix. (1894) 352. - Dalm.

Fleischmanni, G. Beck, 1. c. 354 (= Trichera Fleischmanni, Nymo.) = S. arvensis. Linn.

illyrica, G. Beck, 1. c. 351. - Litt. Adriat

iutercedens X, G. Beck, 1. c. 353. - Austria

intermedia, Pernh. \& Wettst. in Kern. Sched. F1. Austro-Hung. vi. (1892) n. 2227; et in Oest. Bot. Zeitschr. xliii. (1893) 254. - Austro-Hung

involucrata, Sommier \& Levier, in Act. Hort. Petrop. xiii. (1893) 46. - Reg. Cauc.

montenegrina, G. Beck, in Annal. Naturh. Hofmus. Wien, ix. (1894) $35 \mathrm{l}=$ illyrica, G. Beck.

persicina, Kern. Sched. Fl, Austro-Hung. vi. (1893) 99. - Austria.

Petteri, G. Beck, in Annal, Naturh. Hofmus. Wien. ix. (1894) $352=$ dalmatica. G. Beck.

rigidiuscula, G. Beck, 1. c. 354. [an seq. ?]. = S arvensis, Linm.

rigidiuscula Kern. Sched. Fl, Austro-Hung, vi. (1893) 99 (= Trichera Fleischmanni, Nym. $)_{0}=\mathrm{S}$. arvensis. Linn.

Sendtneri, Bruegg. in Jahresb. Nat. Ges. Graub. xxxi. Beil. (1887-88) $81=\mathrm{S}$, arvensis, Linn. serajevensis, G. Beck, in Annal. Naturh. Hofmus, Wien, ix. (1894) 353 = S. sylvatica, Linn. tergestina, G. Beck, 1. c. $354=\mathrm{S}$. sylvatica, Linn。 traqnicensis, G. Beck, 1. C. = S. arvensis, Linn。 veneta, G. Beck, 1. c. = S. arvensis, Linn.

KNEIFFIA, Spach = Oenothera, Linn..(Onagr.). fruticosa, Raimann, in Engl, \& Prantl, Natürl Pflanzenfam, iii, 7 (1893) $214=$ Oe, fructicosa, Linn.

KNEMA. Lour. = Myristica, Linn

intermedia, Warb, in Ber. Deutsch. bot. Ges, xii. (1895) $[83]=\mathrm{M}$. intermedia, Blume.

retusa, Warb. 1. c. = M. retusa, King

KNIPHOFIA, Moench (Liliac.). — Ind. Kew. ii. 9. ankaratrensis, Baker, in fourn. Linn. Soc. xxv, (1890) 347. - Madar.

citrina, Baker, in Gard. Chron. (1893) ii. 552. Afr. austr.

decaphlebia, Baker, in Bot. Fuhr3. xv. Beibl. n. 35 (1892) 6. - Afr. austro-occ. extratrop.

densiflora, Engl. in Abh. Preuss. Akud. Wiss. 1891 ii. (1S92) 163. - Afr. trop. Or.

drepanophylla, Baker in Bot. Fahro. xv, Beibl. n. 35 (1892) 5. - Afr. austro-occ, extratrop. elegans. Engl. in Abh. Prenss. Akad, Wiss. IS91 ii. (1892) 162 - Afr. trop. or.

Evansii, Baker, un Kew Bull. (1895) 152. - NataI. grandis X, Hort. ex Gumbleton, in Gard. Chron. (1889) ii. 562. - Hybr, artef.

hybrida X. Otto Mann, ex Gumbleton, I. c. Hybr. artef,

Kirkii, Baker, l. c. (1SST) ii. 712. - Afro trop. austro-oc. 


\section{KNIPHOFIA :}

linearifolia, Baker, in Bot. Fahrb. xv. Beibl. n. 35 (1892) 5. - Afr, austro-occ. extratrop.

longicollis, [Hort. Leichllin] Baker, in Gard. Chron. (1S93) i. 682. - Natal.

longistyla, Baker, in Kew Bull. (1893) 158. Zambesia.

maxima X, Hort. ex Gumbleton, in Gard. Chron. (1889) ii. 562. - Hybr. artef.

modesta, Baker, in fourn. Bot. (1889) 43 ; et in Bot.

Mag. (1893) t. 7293. - Afr. austr.

Nelsoni, Mast. in Gard. Chron. (18!2) i. 554 fig. 83. - Afr. austr.

nobilis X, Hort. ex Gumbleton, in Gard. Chron. (1889) ii. 563. - Hybr. artef.

Northiae, Baker, in Fourn. Bot. (1889) 43 ; in Gard. Chron. (1891) ii.66 ; et in But. Mag. (1595) t. 7412 . - Afr. austr

Sandersi $X$. Hort. ex Gumbleton, in Gard. Chron. (1889) ii. 562. - Hybr. artef.

spectabilis $\chi$. Hort, ex Gumbleton, 1. c. - Hybr. artef.

Tysoni. Baker, in fourn. Bot. xxvii. (1889) 43. Afr. austr.

Uraria, Th. Dur. \& Schinz, Consp. Fl. Afr, v. $1893(1895) 294=$ aloides, Moench.

zombensis, Baker, in Kew Bull. (1893) 158. Zambesia.

KNOWLTONIA, Salisb. (Ranuncul.). - Ind. Kew. ii. 9.

brevistylis, Szyszyl. Polyf. Relmann. (1887) \%. Natal.

canescens, Szyszyl. l. c. 8. - Transvaal.

capensis, Huth, in Abh. und Vortr. Gesamtgeb. Naturw. iii. (1890) $69=$ Adonis capensis, Linn.

transvaalensis, Szyszyl. Polyp. Relmamu. (1887) \%. - Transvaal.

KOBRESIA, Willd. (Cyper.). - Ind. Kew, ii. angusta, C. B. Clarke, ex Hook. f. Fl. Brit. Ind. vi. (1894) 695. - Sikkim.

bipartita, Britton in Mem. Torrey Bot. Club, v. (1894) $101=$ caricina, Willd

capillifolia, C. B. Clarke, in Hook. f. Fl. Brit. Ind.vi. (1894)697 (=Elyna capillifolia, Decne).-- Ind.or. curvirostris, C. B. Clarke, ex Hook. f. l. c. 699 (= Hemicarex curata, C. B. Clarke). Sikkim.

Duthiei, C. B. Clarke, ex Hook. f. I. c. 697.Kumaon.

elata, Boeck. Cyper. Nov. ii. (1890) 32. - Tibet.

filicina, C. B. Clarke, ex Hook. f. Fl. Brit, Ind. vi. 696 (= Hemicarex filicina, C. B. Clarke). Reo. Himal.

fissiglumis, C. B. Clarke, ex Hook. f. l. c. - Nepal. foliosa, C. B Clatke, l. c.-Ind. or.

pratensis, Freyn, in Oest. Bot. Zeitschy. xl. (1890) 266. - Sibiria.

pygmaea, C. B. Clarke, ex Hook. f. Fl. Brit. Ind. vi. (1894) 696 (= Hemicarex pygmaed, C. B. Clarke). - Ind. or.

Sargentiana, Hensl. in foum. Linn. Soc. xxx. (1894) 139. - Tibet.

incinoides, C. B, Clarke, ex Hook. f. Fl. Brit. Ind. vi. (1 $\times 94) 698$ (= Carex uncinoides, C. B. Clarke). - Ind. or. Tibet.

vaginosa, C. B. Clarke, ex Hook. f. l. c. 695.Sikkim.

KOCHIA, Rottb. (Chenopod.). - Ind. Kew. ii. 10.

lobostoma, F. Muell. in Vict. Natural. iii. (Nov 1886) $92 .-$ Austral.

sanguinea, Willk. in Oest. Bot. Zeitschr. xi. (1890) 218. - Hisp

spongiocarpa, F. Muell. in Vict. Natural. iii. (Nov. 18S6) 92. - Austral.

KOEHNEAGO, Kuntze, Rev. Gen.(I891) $287=$ Euosmia. Humb. \& Bonpl. (Rubiac,

caripensis, Kuntze, J.c. = E. caripensis, Humb. \& Bonpl.
KOELERA, "Pers, " St Lager, in Cariot, Etud. des fl. é1. 8, ii. (1889) $911=$ Koeleria. Pers (Gramin.)

KOELERIA, Pers. (Gramin.). - Ind. Kew, ii

brevifolia, Rout. ex Barbey, in Bull. Soc. Dauph, xiii. (1886) 554. - Europ.

dasyphylla, Willk. in Oest. Bot. Zeitschr. xl. (1890) 148. - Hisp.

glabra, franka, ex Nym. Consp. Fl. Eur. ii. I. (1889) $235=$ cristata, Pers

longiglumis, Trab. in Bull, Soc. Bot. Fr, xxxiy. 1887) 394; et in Batt. \& Trab. Fl. de 1'Alger. Monoc.] (1895) $194=$ pubescens. Beauv.

mucronata, Trab. 11. cc. = pubescens, Beaui

repens, Freyn, in Oest. Bot. Zeitschr. xliv. (1894) 394 = cristata, Pers.

rigidula, Simonk, in Termész. Füzet. x. (1886) 184 et Enum. F1. Transsilv. (1886) $570=$ cristata, Pers.

KOELLIA, Moench $=$ Pycnanthemum, Michx (Labiat.).

albesccns, Kuntze, Rev, Gen. (1891) $520=$ P. albes cens, Torr. Eo Gray.

aristata, Kuntze, 1. e. = P. aristatum, Michx.

californica, Kuntze, 1. c. $=\mathrm{P}$. californicum, Torr clinopodiodes, Kuntze, 1. c. $=$ P. clinopodioides, Torr. E Gray.

flexuosa, MacMill. Metasp. Minn. (1892) 452; Brit ton, in Mem. Torrey Bot. Club, v. (1894) $279=$ P. linifolium, Pursh.

hyssopifolia, Britton, 1. c. = P. hysopifolitim, Benth. mcana. Baill. Hist. des pl. $\mathrm{x}$. (1892) $31=$ seq.

incana, Kuntze, Rev. Gen. (1891) $520=\mathrm{P}$. incanum, Michx.

lanceolata, Kuntze, 1. c, = P. lanceolatum, Pursh. leptodon, Kuntze, 1. c. = P. leptodon. A. Gray.

montana, Kuntze, 1.c. = P. montanum, [montana Michx.

mutica Britton, ex Small, et Vail, in Mem. Torrey Bot. Club, iv. (1893) $145=$ P. muti ium, Pers. mda, Kuntze, Rev. Gen. (1891) $520=$ P. nudum, Nutt.

pilosa, Baill. Hist. des pl. x. (1892) $31=$ P. pilosum, Nutt.

pilosa, Britton.'in Mem. Torrey Bot. Club, v. (1894) $279=$ praec

pycnanthemodes, Kuntze, Rev. Gen. (1891) $520=\mathrm{P}$ Tullia, Benth.

Torreyi, Kuntze, 1. c. = P. Torre, Benth

verticillata, Kuntze, 1. c. $=\mathrm{P}$, aristatum, Michx virginiana, MacMill. Metasp. Minn. (1892) 454 Britton, in Mem. Torrey Bot. Club, v. (1894) $2 \mathrm{SO}=\mathrm{seq}$

rirginiana, Kuntze, ${ }^{-}$Rev. Gen." (1891) $520=P$. linifolium, Purst

virginicum, Baill. Hist, des pl. x. (1892) $31=$ praec.

KOELPINIA, Pall. (Compos.). - Ind. Kew, ii. 11. latifolia, C. Winkl. in Act. Hort. Petrop. xi. (1890) 284. - Turkest.

macrantha, C. Winkl. l.c.285. - Turkest.

KOELREUTERIA, Laxm. (Sapind.) - Ind. Kew. ii. 11.

bipinnata, Franch, in Bull. Soc. Bot. Fr. xxxiil (1886) 453; et in Rev. Hortic. 1x. (1888) 393, fig. 93. - China.

KOHLERIA, Regel = Isoloma. Decne. (Gesner.) bogotensis, Fritsch, in Engl. \& Prantl, Natürl. Pflanzenfam. iv. 3b (1894) $178=\mathrm{I}$. bogotense Nichols.

Depteana, Fritsch, 1. c. $179=$ I. Deppeanum Hemsl.

digitaliflora, Fritsch, 1. c. $178=$ I. digitaliflorum, Linden \& André.

gigantea $X$, Fritsch, 1. c, - Hybr, artef,

Luciani X. Fritsch 1. c. - Hybr artef.

ocellata, Fritsch, 1. c, = I. ocellatum, Benth. E Hook. $f$.

KOKERA. Adans. = Chamissoa, H. B. \& K (Amarant.).
KOKERA : -

acuminato, Kuntze, Rev. Gen. (1891) $543=$ Chamissoa acuminata, Mart.

Blancheti, Kuntze, 1. C. = C. Blanchetii, Moq.

celosiodes, Kuntze, 1. c. = C. celosioides, Griseb.

paniculata, Kuntze, 1. C. $542=\mathrm{C}$. altissima, $N^{\top} e \mathrm{es}$ \& Mart.

KOLOMIKTA, “ Regel » ez Dippel, Handb. Laubholzk. iii. (1893) 23 sphalm. $=$ KALO MIKTA, Regel = Actinidia, Lindl. (Ternstr.) mandshurica, " Regel » ex Gard. Kew. i. Polypet. (1994) $41=$ A. Kolomikta. Rupr.

KOMAROFFIA. Kuntze, in Act. Hort. Petrop. x. (1857) 144; Prantl, in Engl. \& Prant1, Natuirl. Pflanzenfam. iii. 2 (1891) 274. RANUNCULA$C E A E$.

divaricata, Kuntze, l. c. (= Nigella dizaricata, Franch.). - Turkest.

diversifolia, "Kuntze » ex Engl. \& Prant1, Natürl Pflanzenfam. iii.2(1891)274= divaricata, Kuntze.

KONIGA, R. Br. = Alyssum, Tourn. (Crucif.) fruticosa, Webb, ex Christ, in Bot. Jahrb. ix. (1888) 93. - Ins. Canar.

gracilis, Webb, ex Christ, 1, c. 91 (= Lobularia intermedia, Webb \& Berth.). - Ins. Canar. marginata, Webb, in Bourg. Pl. Canar. exsicc. (1846)] ex Coss. Illustr. Fl. Atlant. i. (1889) 63, t. 43. - Marocc. Ins, Canar.

maritima. Britton, in Mem. Torrey Bot. Club, v, (1894) $175(=$ K. maritima, R. Br. $)=$ A. marimum, Lam.

Vogeliana. Webb, ex Christ, in Bot. Jahrb. ix. 1888) 92 . - Ins, S. Vinc.

KOOMPASSIA, Maing. (Legumin.). - Ind. Kew. ii. 12 .

Beccariana, Taub. in Ber. Deutsch.bot. Ges, x. (1892) 641. - Borneo.

excelsa, Taub. l. c.; et in Engl. Es Prantl. Natürl. Pfanzenfam. iii. 3 (1892) $155(=$ Abauria excolsa Becc.). - Borneo.

KOON, Gaertn. = Pachygona, Miers (Menisp.). oleosus, Pjerre, Fl. For. Cochinch. (1895) t. 328 b = Pistacia oleosa, Lour.

KOPSIA, Dennst. $=$ Orobanche. Tourn

cochinchinensis, Kuntze, Rev. Gen. (1891) 415. Cochinch

nana, Freyn, ex Freyn \& Brandis, in Verh, zoolbot. Ges. Wien, xxxviii. (1888) $623=0$, nana, $N o \dot{c}$

KORTHALSIA. Blume (Palm.). - Ind. Kew。ii. 13

Scortechinii, Becc. in Hook. f. Fl. Brit. Ind. vi. (1893) 475. - Perak.

tenuissima, Becc. Malesia, ii. (1886) 275, in obs, Penins. Mal.

KOSARIA, Forsk. = Dorstenia, Linn. (Urtic.). cuspidata, Schweinf, ex Penzig, in Atti Congr. bot. Genova (1893) $331=$ D. cuspidata, Hockst.

palmata, Schweinf. ex Engl. in Bot. Jahrb. $\mathrm{xx}$. (1894) $147=$ D. palmata, Engl.

KOSTELETZKYA, Presl (Malv.).- Ind. Kew. 11. 13.

althacifolia, Rusby, in Mem. Torrey Bot. Club, v. (1894) $224=$ virginica, Presl.

Buettneri, Guerke, ex Butin. in Verh. Bot. Ver. Brand. xxxi. (1889) 92, - Congo.

flava, E. G. Baker, ex S. Elliot, in Fourn. Linn. Soc. xxx. (1894) 74. - Sierra Leone.

stellata, Fernald, en Coult. Bot. Gaz. xx. (I895) 532. - Mexic.

Thurberi, A. Gray, in Proc. Am. Acad. xxii. (1887) 314. - Am. bor. occ

KRAMERIA, Loef. (Polygal.). - Ind. Kew. ii. 13. bicolor, S. Wats. in Proc. An, Acad xxi. (1886) 417. - Mexic. 
KRAUNIA, Rafin. = Wistaria, Nutt, (Legumin.) australis, Greene, Pittonia, ii. (Sept. 1891) $175=$ W. australis, F, Muell.

brachybotrys, Greene, 1. c. = W. brachybotrys Siebold.

chinensis, Greene, $1 \mathrm{c}$. = W. chinensis, Siebold.

foribunda, Taub. in Engl, \& Prantl. Naturl. Pflanzenfam. iii. 3 (1894) $271=$ W. floribunda, $W$ illd.

frutescens, Greene, Pittonia, ii. (Sept. 1891) 175 $(=K$. frutescens, Rafin. $)=$ W. frutescens, Poir

megasperma, Greene, 1. c. = W. megasperma, $F$ Muell.

KREBSIA, Harv. = Gomphocarpes, R. Br (Asclep.).

arinata, Schlechter, in Journ. Bot. xxriii. (1887) 269. - Afr. austr.

corniculata, Schlechter, in Bot, Jahrb. xx. Beibl. n. $51(1895) 40=$ G. corniculatus. D. Dietr.

stenoglossa, Schlechter, in Journ. Bot, xxiii. (1887) 270 , in obs, ; et 1. c. - Afr. austr.

KRUGIA, Urban, in Ber. Deutsch. bot. Gesells.xi. (1893) 375. MYRTACEAE.

elliptica, Urban, 1. c: $376(=$ Marlierea elliptica, Griseb.) = ferruginea, Urban.

ferruginca, Urban, in Bot. Fahrb, xix. (1895) 604 (= Myrcia ferruginea, DC.). - Ins. Antill.

KRUGELLA. Pierre, Not, bot. Sapot. (1S91) 50. SAPOTACEAE.

Hartii, Pierre, l. c. 52. - Ins. Trinit.

KRYNITZKIA, Fisch. \& Mey. (Boragin.). -

Ind. Kew. ii. 14.
echinoides, M. E. Fones, in Proc. Calif. Acad. Ser. II. v. (1895) 709. - Utah.

Grayi, Vasey et N.E. Rose, in Proc. U. S. Nat. Mus. xi. (188S) 596. - Calif.

micrantha, T. S. Brandeg. in Proc. Calif. Acad. Ser. II. ii. (1SS9) $187=$ micrantha, A. Gray.

peninsularis, N. E. Rose, ex Vasey \& N. E. Rose. in Contrib. U. S. Nat. Herb. i. (1890) 85, - Calif. inf.

racemosa, T. S. Brandeg, in I'roc. Calif. Acad. Ser. II. ii. (1889) 187 = racemosa, Grcene.

utahensis, A. Gray, Syn. Fl. N. Am. ed. 2, ii 1 (1886) 427 (= Cryptanthe utahensis, Greene.) - Utah.

KUENCKELIA, Heim, Rech. Diptéroc, (1892) 92 $=$ KUNCKELIA. Heim = Vateria, Linn. (Diptéroc.).

KUHNIASTERA, Kuntze, Rev. Gen. (1891) $192=$ KUHNISTERA, Lam. = Petalostemon, Michx. (Legumin.).

agastachya, candida, carnea, compacta, decumbens, cmarginata, exilis, flacescens, foliosa, gracilis, grisea, ornata, rosea, Searlsiae, tenuifolia, villosa, Kuntze l. c. = homonyma omnia Petalostemonos.

compacta, Kuntze, 1. c. = P. macrostachyus, Torr phleodes, Kuntze, 1. c. $=$ P. phleoides, Torr. $G$ Gray.

pimata, Kuntze, 1. c. = P. corymbosus, Michx

KUHNisterA, Lam. = Petalostemon, Michx, (Legumin.).

Frayi, Nash, in Bull, Torrey Bot. Club, sxii (1895) $149=\mathrm{P}$. Feayi, Chapm.

multiflora. Heller, in Mem. Torrey Bot. Club, v. (1894) $197=$ P. multiflorus, Nutt.

occidentalis, Heller, in Trans. N. Y. Acad. Sci. xiv. (1895) $33=\mathrm{P}$. candidus, Mich $x$.

pulcherrima, Heller, in Cantrib. Herb. Frankl. and Marsh. Coll. i. (1895) 50 t. 2 [Bot. Expl. S Texas $]=$ P. virgatum, Schee?e.

purpurea, Macmill. Metasp. Minn. (1892) $329=$ P. violaceus, Michx.

KUMLIENIA, Greene. (Ranunc.). - Ind. Kew. ii. 15.

Cooleyae, Greene, in Erythea, ii. (1894) $193(=R a$ nuncu'us Cooleyae, N. E. Rose).

hystricola, Greene, in Bull. Calif. Acad. i. (1SS6) 387. - Calif.
KUNCKELIA, Heim, in Bull. Soc. Bot. Fr, xxxix. (1892) 153; et Recherch. Diptéroc. (1892) 39 [Kuenckelia $]=$ Stemonoporus, Thw. (Diptéroc.)

reticulata, Heim. 11. cc. $=$ S. reticulatus, $T h w$ 。

KUNTHIA, Dennst.= Garuga, Roxb. (Burser.). foribunda, jai'anica, mollis, pinnata, Kuntze, Rey. Gen. (1891) 107 = homonyma omnia Garugae

KUNZEA, Spreng. = Purshia, DC. (Rosac.) glandulosa. Greene, Pittonia, ii. (Sept, 1892) 299 $=$ P. glandulosa, Curran.

KURRIMIA. Wall. (Celastr.), 一 Ind, Kew, ii. 15 gracilis, Vidal, Revis $\mathrm{Pl}$. Vasc. Filipp, (1886) 89. - Ins. Philippin.

luzonica, Vidal, l. c. 88. - Ins. Philipp.

KURZAMRA, Kuntze, Rev, Gen. (1S91) $520=$ Soliera, Clos (Labiat.)

pulchella, Kuntze, 1. c. $521=\mathrm{S}$. pulchella, Clos.

KURZIA, King, ex Hook, f, Fl. Brit. Ind. v. (1888) 479 et 547 , in obs. = Hulletia, King (Urtic.)

KURZINDA, Kuntze, Rev. Gen. (189l) $938=$ Apteron, Kurz (Rhamn.).

Iancelatum, Kuntze, $\mathrm{c}=\mathrm{A}$ lanceolatum, Kurz.

KYDIA, Roxb. (Malv.). - Ind. Kew. ii. 15

rasiliensis, Rodr. Pl. nov. fard. bot. Rio, iii. (1893) 2t. 1. - Bras.

KYLLINGA, Rottb. (Cyper.). - Ind. Kew. ii 15

blepharinota, Hochst. ex Engl. in Abh. Preuss Akad. Wiss. 1891 (1892) 145, in syn. (Kyllingia) $=$ triceps, Rottb.

cartilaginea, $K$. Schum, ex Engl. in Abh. Preuss, Akad. Wiss. (1894) 2S; et in Engl. Pfanzenw. Ost Afr. C (1895) 123 (Kyllingia). - Afr. trop or. chrysantha, K. Schum, in Engl. Pflanzenw. Ost-Afr C (1895) 123 (Kyllingia). - Afr, trop. or. eximia, C. B. Clarke, in Th. Dur, E Schinz, Consp Fl. Afr. v. 1894 (1895) 529. - Reg. Somal.

flexuosa, Boeck, Cyper. Nor. ii. (1890) 1 (Kyllingia) - Ins. Jamaica

microstyla, C. B. Clarke, in Kew Bull. (1895) 229 - Reg. Somal.

oblonga, C. B. Clarke, in Th. Dur. of Schinz, Consp. Fl. Afr. v. 1894 (1895) 530. - Afr. trop. or. planiceps, C. B. Clarke, l. c. 531. - Congo.

sirpina, Reichb. ex C. B. Clarke, 1. c. $615=$ Scirpus cubensis, Poepp. \&o Kunth.

teres, C. B. Clarke, 1. c, 533. - Congo.

Schimperi, Hochst. [in Schimp. Pl. Abyss, ed Hohenack, n. 2201], ex Engl, in Abh. Preuss Akad. Wiss, 1891 (1892) 145, in syn。 = triceps, Rottb.

\section{$\mathbf{I}$}

LABATIA. Mart. (Sapot.). - Ind. Kew. ii. 16. Beaurepairei, Engl. Bot. Fahrb, xii. (1890) 515 (= Lucuma Beaurepairei, Glaziou \& Raunk.). - Bras. ciliolata, Engl. l. c. - Bras. austr.

glomorata, Radlk. ex Engl. \& Prantl, Natürl. Pflan renfam. iv. i. (1890) 142 (an L.glomorata, Pohl ?) - Bras.

lanceolata, Engl. l. c. - Pohl.

tovarensis, Engl. Bot. Falirb. xii. (1890). 515. Columb.

LABISIA, Lindl. (Myrsin.). - Ind. Kew. ii. 17 alata, N. E. Br. in Illustr. Hortic. xxxiv.(I886) 123, t. 605 . $\rightarrow$ Ind, or.

Malouana, L. Linden \& Rodigas, b. c. 102, in obs.Hab. ?

pothoina, Hort. Linden, ex Gard. Chros. (1888) is 328, nomen. - Hab.

smaragdina, $\dot{L}$. Linden \& Rodigas, in Illustr. Hortic xxxix. (1S92) 91, t. 560. - Borneo.
LABORDEA, Benth, = Labordia, Gaudich. (Lo-

glabra, Hillebr. Fl. Haw. Isl. (1888) 291. - Ins. Sandvic.

Grayana, Hillebr. 1. c, 291. - Ins. Sandvic. lephocarpa, Hillebr, 1. c. 289. —Ins. Sandvic.

triflora, Hillebr, 1. c. 293. - Ins. Sandvic.

LABOURDONNAISIA, Boj. (Sapot.). - Ind. Kew. ii. 17.

costata, Pierre, Not. bot. Sapot. (1890) 10, in obs - Hab.

madagascariensis, Pierre, ex Baill. in Bull. Soc. Lim. Paris, ii. (1891) 917. - Madag.

LABRAMIA, A, DC. (Legumin.). - Ind. Kew ii. 17 .

coriacea, Baill. in Bull. Soc. Linn. Paris, ii. (1891) 908. - Madag. ?

LABURNUM, Linn. (Legumin.). - Ind. Kew ii. 17

biflornm, Hort. ex Gard. Kew, i. Polypet. (1S94) $107=$ alpinum, F. S. Presl, var.

iutermedium, Hort. ex Dippel, Handb. Laubholzk iii. (1893). $673=\mathrm{L}$. Watereri, Dippel.

faquinianum, Hort. Dieck, ex Nenheit. Nat. Arboret. Dieck。(1892-93) $\mathbf{1 9}=$ Cytisus Jacqurnianus, Wettst.

Linneanu, Hort, 1, c. $=$ C. Linneanus, $W$ ettst.

serotinum, Hort. ex Dippel, Handb. Laubholzk iii. (1893) 673, in syn. = L. Watereri, Dippel.

Watereri X, Briq. Etud. Cytis. Alpes Marit. (1894) $124=\operatorname{seq}$

Watereri $X$, Dippel, Handb. Laubholzk, iii. (1893) $673=$ Cytisus Watereri, Wettst.

LACCOSPERMA, G. Mann \& $\mathrm{H}$. Wendl. Ancistrophyllum, G. Mann \& H. Wendl (Palm.)

laevis, Kuntze, Rev. Gen. (1891) 729 (= L. laere, G. Mann \& H. Wendl.). - Afr. trop.

opaca, Kuntze; 1. c. $(=L$. opacum, G. Mann \& H. Wend1.). - Afr. trop.

secundiflora, Kuntze, 1. c. = A, secundiflorum, $G$. Mann \& $H . W$ wndl.

LACHENALIA, Jacq. (Liliac。), - Ind. Kew. ii. 18

Bachmanni, Baker, in Bot. Fahrb. xv. Beibl. n. 35 (1892). 8. - Afr. austr.

Cami. Hort, ex Reuthe, in Gartenfl, xxxviii. (1889) 156. - Form. hort.

Comesi X, Sprenger, 1. c. x1. (1891) 358, fig. 7\%. Hybr. artef.

lilacina. Hort. ex Reuthe, 1. co xxxviii. (1889) $15 \%$. - Form. hort.

Massoni, Baker, in fourn. Bot, xxiv. (1886) 336. Afr. austro-occ. extratrop

polyphylla, Baker, in Bot. Fahrb. xv. Beibl.n. 35 (1892) 7.-Afr. austr.

Regeliana X. Sprenger, in Gartenfl. xl, (1891) 356, tig. 76. - Hybr. artef.

succulenta, Masson, ex Baker, in foum. Bot. xxiv, (1886) 336. - Afr, austr.

undulata, Masson, ex Baker, l. c. - Afr. austr.

LACHNAEA, Linn. (Thymelaeac.). - Ind. Kew. ii. 18.

flamentosa, Gilg, in Engl, \& Prantl, Natürl. Pflanzenfam. iii. 6 a (1894) $240=$ buxifolia, Lam. funicaulis, Schinz, in Bull. Herb. Boiss. iii. (1895) 408. - Afr, austr.

LACHNOGA ULON, Kunth (Eriocaul.). - Ind. Kew ii. 19 .

anceps, Morong, in Bull, Torrey Bot. Club, xviii. (1891) $360=$ L. Michauxii, Kmnth.

LACHNOSTYLIS, oppositifolia. Hochst. [in Schimp. Pl. Abyss. ii. n. 123] ex Engl. in Abh. Preuss. Akad. Wiss, 1891 (1892) 330, in syn $=$ Nuxia. dentata, $R . B r$.

ternifolia, Hochst. ex Engl. 1. co = N. congesta, R. Br 
LACINIARIA, Hill = Liatris, Schreb. (Compos.). acidota, Boypinii, Chapmanii, cylindracea, elegans, Garberi, gracilis, graminifolia, pauciflora, punctata, pyenostachya, spicata, tenuifolia, Kuntze, Rev. Gen. (1891) $349=$ homonyma omnia Liatridis.

LACTARIA, Rumph. = Ochrosia, Juss. (Apocyn.). elliptica, Kuntze, Rev, Gen. (1891) $415=\mathrm{O}$. elliptica, Labill.

Kilneri, Kuntze, 1。 c. = O. Kilneri, F. Muell. maculata, Kuntze, 1.c. = O. borbonica, F. F. Gmel. mariannensis, Kuntze, 1. c. $=0$, mariannensis, A. $D C$.

Moorei, Kuntze, 1. c. = O. Moorei, F, Muell.

oppositifolia, Kuntze, 1. $c_{0}=$ Cerbera oppositifolia, Lam.

parriffora, Kuntze, 1. c. = Ochrosia elliptica, Labill.

sandwiccnsis, Kuntze, 1. c. = O. sandwicensis, A. Gray.

LACTUCA, [Tourn.] Linn. (Compos.), - Ind. Kew, ii. I?

alatipes, Collett \& Hemsl, in fourn. Limn. Soc. xsviii. (1890). 79. - Ind. or.

amagawaensis, Makino, in Tokyo Bot. Mag, vi. (1892) 56. - Japon.

atropurpurea, Franch. in Morot, Journ. de Bot, ix (1895) $294=$ grandiflora, Franch.

contracta. Velen, ex Nym. Consp. Fl. Eur. Suppl. ii. (1889) 188; Bornm, in Bot. Centralbl, xxxvi. (1888) $89=$ chondrillaeflora, Boreau

elata. Honsl. ex Forb. E Hemsl, in fourn. Linn. Soc xxiii. (1888) 481: - China.

elegans, Franch. in Morot, fourn. de Bot. ix. (1895) 262. - China:

Faberia, Franch. 1. c. $294=$ Faberia sinensis, Hemisl.

Forsteniana, Bocrl. Hundl. Fl. Ned. Indië, ii. ।. (1891) 245, nomen. - Ins. Celeb.

grandiflora, Franch, tn Morot, Fourn. de Bot. ix (1895) 260 (= L. atropurpurea, Franch.). Yunnan.

Hemsleyi, Franch. 1. c. 293, in obs.= Prenanthes Faberii, Hemsl.

hirsuta, Franch. l. c. 258. - Yunnan.

Hochstetteri, Sch. Bip. [in Schmmp. Pl. Abjss. i n. 1287, ex Engl, in Ab\%. Preuss, Akad. WViss. 1891 (1892) 454. (= Pyrrhopappus Hochstetteri, A Rich.). - Aby'ss.

khasiana, Franch. in Morot, Journ, de Bot. ix. (1895) 292, in obs. = Prenanthes khasiana, C. B. Clarke.

Kanitziana, Martelli, ex Boerl. Fl. Ned. Indid, ii. . . (1891) 245, nomen. - Borneo.

laevigata, Boiss. Fl. Or. Suppl. (1888) $322(=\mathrm{Mul}$. gedium laevigatum, DC.). - Afghan.

likiangensis, Franch, in Morot, Fourn. de Bot, ix. (1895) 259. - Yunnan.

longirostra, Aitcli. \& Hemsï. in Trans, Linn. Soc Ser. II. iii. (1886) 82. - Afghan.

Iuzonica, Vidal, Rci', Pl. Vasc. Filip. (18S6) 165. Ins. Philipp.

Mutsumurae, Makino. in Tokyo Bot. Mag. vi. (1892) 56. - Japon.

nana, Baker, in Kere Bull. (1893) 17. - Afr, trop. melanantha, Franch in Morot, foutn. de Bot. ix. (1895) 201. - Yunnan.

napifera, Franch. l.c.292. - Yunnan.

numidica, Batt. n Batt. E Trab. Fl. de l'Algér. [Dicot.] (1889) 553; et Append. ii. 14; it in Bull. Soc. Bot. Fro xxxvi. (1889) 403. - Alceria. ochrolenca, Franch. in Morot, Journ de Bot. ix. (1895) 293 , in obs. = P'renanthes ochroleuca, Homsl.

oligocephala, Borm un Mitth. Tliür. Bot. Ver. N. Folre, vi. (1894) 55(= Zollikoforia oligocephata, Hausskn. \& Bornm.). - Oriens.

polypodiifolia, Franch, in Morot, fourn, de Bot. ix. (1895) 265. - Yunnan

rostrata, Boerl. Handl F1. Ned. Indië, ii. 1 (1892) $245=$ Prenanthes rostrata, Blume.

rostrata, Kuntze, Rev, Gen. (1891) $349=$ graciliflora, $D C$

Schulzeana, Buettn。 in Verh, Bot. Ver. Brand. xxxi. (1889) 72. - Angola.

\section{LACTUGA :}

Souliei, Franch. in Morot, fourn. de Bot. ix. (1895) 257. - China

spicata, Hitchcock, in Trans. St. Louis Acad. Sci, v. (1892) $506=$ leucophaea, A. Gray.

spicata. Kuntze, Rev. Gen. (1891) 349. = alpina, Benth, \& Hook. f.

taliiensis, Franch, in Morot, fourn. de Bot. ix. (1895) 263. - Yunnan.

Tatarinowiz. Franch. 1.c.293 in obs. = Prenanthes Tatarinowii, Maxim.

thibetica, Franch. l.c. - China

triflora, Hemsl, ex Forb. \& Hemsl, in fourn. Limn. Soc. xxii. (1888) 485. - China.

villosa, Britton, Stern \& Pogg. Prelim. Catal. (1888) 31 = acuminata, Spreng.

Welwitschii, S. Elliot, in fourn. Limn. Soc, xxix. (1891) 30, - Madag., Angola.

yunnanensis, Franch, in Morot, Fourn. de Bot. ix. (1895) 264. - Yunnan.

LADANUM, Dill = Galeopsis, Tourn. $($ Labiat. $)$. dubium. Kuntze, Rev. Gen. (1891) $521=$ G. Ladanum, Linn.

Tetrahit, Kuntze, 1. c. = G. Tetrahit, Linn.

LADENBERGIA, Klotzsch (Rubiac.). - Ind. Kew. ii. 21 .

discolor, K. Schum, in Mart. Fl. Bras, vi. vi. (1889) 146. - Peruvia.

graciliflora, $K$. Schum, l. c. 145. - Peruvia.

pedunculata. K. Schum, 1. c. $146=$ Cinchona pedunculata, Karst.

physophora, Spruce, ex K. Schum. 1. c. 151, in syn. = Remijia physophora, Bcntir.

LAELIA, Lindl. (Orchid.), - Ind. Kew。ii. 21 Anoldiana $\times$. Hort. ex Gard. Chron. (1891) i. 740 et $742=$ Laelio-Cattleya Arnoldiana, Rolfe.

Batemanniana X, Reich. f. 1. c. (1886) ii. 263. Hybr, artef.

Euterpe $\times$, Reichb. f. 1. c. (1\$88) ii.533. - Hybr, artef.

exoniensis $X$, Veitch. Man. Orch. Pl. ii. (1887) 95 et Orchid Alb. x. (1893) t. 443 (= Cattleya exoniensis. - Hybr. artef.

Eyermaniana, Reichb. f. in Gard. Chron. (1888) ii. 91 (an Hybr, spont: ?) - Mexic

felix, Veitch, Man Orch. Pl. ii. (1887) $96=$ Cattleya felix, Reichb. $f$.

Finckeniana X, O'Brien, in Gard. Chron. (1893) i. 194 ; et (1893) ii. 805 fig. 123 et 806 . - Hybr. spont.

Gouldiana, Reichb. f. in Gard. Chron. (IS88) i. 41 ; et Orchid Alb, t. $3 \pi 1$. - Mexic.

Hormiana $\times$, Reichb. f. 1. c. 770; et ex Lindenia, iv. (1888) 8. - Hybr. artef.

juvenilis $\times$, Bleu, in Journ. des Orchid. i. (1890) 230 ; L. Linden, in Lindenia, ix. (1893) 65 t. 415. - Hybr. artef.

lilacina, Philbrich, ex Vcitch, Man. Orch. Pl. ii. (1857) 89; Rolfe, in Gard. Chron. (1890) ii. 241. - Bras.

Lindleyana, Veitch, Man. Orch. Pl. ii. (1887, 73 $(=$ L. Lindleyana, Nichols. $)=$ Cattleya Lindleyana, Reichb. $f$.

lobata, Veitch, 1. c. 74 , cum icone $=$ C. lobata, Lindl.

Measuresiana, Williams, Orch, Grow. Man, ed. 6 (1886?) add. : Warn. \& Williams, Orchid Alb. v. (1886) t. 207 ; et vii. (1888) t. $306=$ LaelioCattleya Schilleriana, Rolfe.

Oweniae X, L. Linden, in Lindenia, viii. (1892) 79 t. $374 .-$ Hybr, artef.

Oveniana X, Hort. ex O'Rrien, in Gard. Chron. (1893) i. 682. - Hybr. artef.

pachystele X, Reichb. f. I. c. (1888) ii. 596 (an Hybr. spont. ?). - Hab.?

porphyritis $X$, Reichb. f. 1. c. (1886) i. 72, - Hybr. artef.

Reichenbachiana, Wendl. E Kraenzl. in Reichb. $f$. Xen. Orchid. iii. 6 (1892) 9\% t. 254 i. fig. 1-\%. $\mathrm{Hab}$.

Russellima, Hort. ex Williams, Orch. Grow. Man. ed. 6, $366=$ purpurata, Lindl. et Paxt.
LAELIA :

Timora Y, Hort. ex N. E. Br. in Gard. Chron. (1887) ii. 428 [sphalm Timoraxx]. - Hybr, artet. Tresederiana X, Reichb. f. 1. c. (1888) i. 136 . Hybr. artef.

triophthalma, Veitch, Man. Orch. P1. ii. (1887) 97 $=$ Cattleya triophthalma, Reichb. $f$

vitellina X, Hort. ex O'Brien, 1. c. (1893) i. 365 fig. 53, - Hylr, artef.

LAELIO-CATTLEYA $\times$, Rolfe, in Journ. Linn. Soc. xxiv, (1887) 168 (Orchid.).

albanensis X, Rolfe, in Gard. Chron. (1893) ii. 584. - Hybr. artef,

amanda $X$, Rolfe, 1. C. (1889) i. 802 ; et ii. 78. Hybr, artef.

Amesiana v, Rolfe, in Journ. Linn. Soc. xxiv. (1887) 168 ; et 1. c. (1889) ii. 78 . - Hybr. artef.

Andreana $\times$, Maron, in Rev. Hortic. 1svii. (1895) 401. - Hybr, artef.

Arnoldiana $\times$. Rolfe, in Journ. des Orchid. ii. (1891) 134; et in Lindenia, vii. (1891) 25 t. 299 . - Hybr. artef.

Aurora, Rolfe, in Gard. Chron. (1889) ii. 380 ; et (1890) i. 8.- Hybr. artet.

bclla $\times$, Rolfe, in Journ. Linn. Soc, xxiv. (1887) 169 ; et 1. c. (1888) i. 361 et (1889) ii. 78. Hybr. arief.

blesensis, Hort, ex Warn. \& Williams, Orchid Alb. xi. (1895?) t. 519. - Hybr. artef.

broomficldiensis $\times$, Hort, ex Gard. Chrcn. (1894) ii. 223. - Hybr, artef.

Brymeriana, J. O'Brien, 1. c. (1895) ii. 338. Hybr, artet,

callistoglossa $\times$, Rolfe, in Journ. Linn. Soc. xxiv. (1887) 168 ; et in Gard. Chron, (1889) ii. 78 (= Laelia callistoglossa, Reichb。 f.). - Hybr. artef.

caloglossa $\times$, Rolfe, 1. c. (1889) ii, 79. - Hybr. artef.

Canhamiana $\times$, Rolfe, in Journ. Linn. Soc, xxiv. (1887) 169 ; et 1. c. (1889) ii. 79 (= Laelia Cankamiana, Reichb. f.). - Hybr. artef.

Cassandra X, Rolfe, in Gard. Chron. (1888) ii. 596 ; (1889) i. 491; (1889) ii. 79 ; et (1890) ii. 529 (= Cattleya Cassandra, Rolfe). - Hybr. artef.

Cassiope $\times$. Rolfe, 1. c. (1889) ii. 620 ; (18:0) i. 8 ; et (1892) i. 88. - Hybr, artef.

Cawwenberghei $X, L$. Linden, in Lindenia, ix. (1893) 91 t. 428. - Hybr. artef.

corbeillensis $X$, Hort. Maron, ex Rev. Hortic. 1xvi. (1894) 52\%. - Hybr. artef.

croomfieldiensis $X$. Hort. 1. c, 1xvi1. (1895) 63 (an broomfieldiensis $\rangle$, Hort. ?). - Hybr. artef.

decia X, Hort. ex Gard. Chron. (1894) ii. 699 fig. 89. - Hybr. artef.

Digbyana-Mossiae X, Rolfe, 1. c. (1889) i. 742; et (1889) ii. 79. - Hybr, artef.

Dominiana X, Rolfe, 1. c. (1889) ii. 79. - Hybr. artef.

Dormaniana $\times$, Rolfe, 1. c. (1889) i. 555 ; et (1889) ii. 79 (= Cattleya Dormaniana, Reichb. f.). Hybr. artef.

elegans $\times$, Rolfe, I. c. (1889) i. 619 ; (1889) ii. 79 ; et (1890) ii. 241 (= Cattleya elegans, Morr.). Hybr. artef.

eximia X. Hort. ex Gard. Chron. (189') i. 800 ; Rolfe, in Lindenia, ix. (1893) 7 t. 386. - Hybr. artef.

exoniensis $Y$, Rolfe, in Journ. Linn. Soc. xxiv. (1887) 169 ; et l. c. (1889) i. 619 ; (1889) ii. 155 $\left(=\right.$ Cattleya exoniensis, Reichb. $\left.\mathrm{f}_{0}\right)$. - Hybr. artef.

fausta $\times$. Rolfe, 1. c. (1889) i. 619 et (1889) ii. 155 (= Cattleya farstic, Reichb. f). - Hybr. artef.

folix $\times$, Rolfe, in Journ. Linn. Soc. xxiv, (1887) 169 ; et J. c. (1889) i. $619 ;(1889)$ ii. 155 (= Cat leya felix, Reichb. f.). - Hybr. artef.

Hormiana X, Rolfe, in Gard. Chron. (1889) ii. 155 ; et (1890) ii. 241 (= Laelia Hormana Reichb. f.). - Hybr, artef. 
LAELIO-CATTLEYA :-

Linden $X$, Hort. ex $L$. Linden, in Lindenia, $x$. (1894) 33, t. 44\% - Hybr. artef.

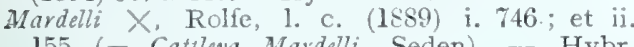
155 (= Cattleya Mardelli, Seden). - Hybr. artef.

Maynardii $\times$.Hort. ex Rev. Hortic. 1xii. (1890) 294 et ex Gard. Chron. (1893) i. 715 . fig. 108. Hybr, artef.

Mylamiana X, Rolfe, in Journ. Linn. Soc, xxiv. (1887) 169 ; et in Gard. Chron. (1889) ii. 155; (1890) ii. 241 (= Laelia Mylamiana, Reichb. f.). - Hybr. artef.

pachystele $\times$. Reichb. f. 1. c. (1888) ii. 596; et (1889) $\mathrm{ii}_{\text {. }}$ 79. - Hybr. artef

Pallas X. Hort ex O'Brien, 1. c. (1890) i. 8. Hybr. artef.

Philbrickiana $X$. Rolfe, in Journ. Linn. Soc, xxiv. (1887) 169 ; et 1. c. (1889) ii. 155 ; (1890) ii. 242 (= Laelia Pnilbrickiana, Reichb. f.). - Hybr. artef.

porphyritis $\times$, Rolfe, 1. c. (1889) ii. 155; (1890) ii. $242(=$ L. porphyritis, Reichb. f.) - Hybr. artef.

Sallieri $\times$ Maron, in Rev. Hortic, 1xvii. (1895) 511. - Hybron, artef.

Sayana, L. Linden, in Journ. des Orchid. v. (1894) 220 ; et in Lindenia, x. (1894) 65, t. 463. - Hybr. artef́

Schilleritna $\times$, Rolfe, in Gard. Chron. (1887) ii. 155; (1890) ii: 241 et 653 (= Laelia Schilleviana, Reichb. f.). - Hybr, axtef.

Schulziana $\times, \bar{L}$. Linden, in Lindenia, xi. (1995) 21, t. 489. - Hybr. artef.

Sedeni $\times$, Rolfe, in Gard. Chron. (1889) ii. 155; et (1890) ii. 653 (= Laclia Sedeni, Reichb. f.). Hybr. artef.

Stcheguleffiana X, Hort. ex Rev. Hortic. 1xvi. (1894) $89=$ seq

Stchegolowiana X. Hort. ex Gard. Chron. (1893) ii. $756 .-$ Hybr, artef.

stella $\times$, Rolfe. 1. c. (1889) ii. 322. - Hybr. artef.

Timora X. Rolfe. 1. c. (1889) ii. 155 (= Latia Timora, N. E. Br.). - Hybr. artef.

Tresederiana X, Rolfe, 1. c. (1889) ii. $155(=L$. Tresederiana, Reichb. f.). - - Hybr artef.

trionophthalua $\times$, Rolfe, 1. c. (1889) i. 802 ; et ii. 155 (= L. trionophthalma, Veitch), - Hybr. 155 artef.

triophthalma X. Rolfe, 1. c. (1890) ii. 653 (= Cattleya triophthalma, Reichb. f.). = praec

Varjenewskyana. L. Linden, in Lindenia, x. (1894) 71, t. 466. - Hybr. artef.

Veitchiana $\times$, Rolfe, in Journ. Linn. Soc, xxiv, (1887) 169; et in Gard. Chron. (1889) i. 802; et ii. 155; (1890) ii. $653(=$ Cattleya Veitchiana, Dominy), - Hybr. artef.

Victoria X, Rolfe, 1. c. (1888) ii. 578; et (1889) ii. 156 et 560 ( $=$ Laelia Victoria, Veitch). Hybr, artef.

Welsiana X. Hort. ex Rev: Hortic. 1xvii. (1895) 63. - Hybr. artef.

Zenobra X, Rolfe, in Gard. Chron. (1889) i. 802: et ii. 156 (三 Cattleya Zenobia Rolfe.). - Hybr. artef.

LAGAROSIPHON. Harv. (Hydrochar.). - Ind. Kew. ii, 22 .

crispus, Rendle, in fourn. Linn. Soc. xxx. (1895). 380 , t. 3 fig. 17. - Afr. trop. or.

densus, Rendle, l. c. xxii. (1886) 235. - Madag.

hydrilloides, Rendle, l. c. xxx. (1895) 381 t. 32 fig. 1-7. - Afr. trop. or.

Nyassae, Ridl. l. c. xxii. (1886) 234. - Afr. trop.

Nyassae, Guerke, in Engl. Pfanzenw. Ost-Afr. C (1895). 95. - Afr. urop. or.

rubellus, Ridl. in fourn. Linn. Soc. xxii. (1886) 234 [rubella]. - Angola.

tenuis, Rendle, l. c. xxx. (1895) 380, t 31, fig. 1-7. - Afr. trop. or.

LAGASGEA, Cav. (Compos.). - Ind. Kew. ji. 23. glandulosa, Fernald, in Coult. Bot. Gaz. xx. (1895) 534. - Mexic.

parvifolia, Klatt, in Annal. Naturh. Hofmus. Wien, ix. (1894) 360. - Venezuela.
LAGENANTHUS, Gilg, in Engl. et Prantl, Natürl. Pflanzenfam. iv. 2 (1895) 99. GENTIANFAE.

princeps, Gilg, l.c. $i=$ Schlimia Princeps, Regel $)$. - N. Granat

LAGENARIA, Ser. (Cucurlit.). - Ind, Kew. ii. 23.

Lagenaria. Cockerell, in Bull. Torrey Bot. Club, xix. (1892) 95 = vulgaris, Seringe.

vernucosa, Hort. ex Gartenfl. xxxix. (1890) $106=$ vulgaris, Seringe.

virginalis, Hort. ex Gard. Chron. (1892) i. 85 fig. $16=$ vulgaris, Seringe.

LAGENOCARPUS, Nees (Cyper.). - Ind, Kew ii. 23.

campestris, Kuntze, Rev。Gen. (1891) $754=$ Cryptangium campestre, Boeck.

densifolius, Kuntze, 1. c. = C. Minarum, Bocck.

humilis, Kuntze, 1. c. $=$ C. humile, Boeck.

junciformis, Kuntze, 1. c. = C. junciforme, Bock

Kuntzeanus, Kuntze, 1. c. = C. Kuntzeanum, Boeck.

leptocladus, Kuntze, 1. c. = C. leptocladum, Boeck Minarlm, Kuntze, 1.c. $=$ C. Minarum, Bock.

polyphyllus, Kuntze, 1. c. = C. polyphyllum, Boeck. stellatus, Kuntze, 1. c. - Bras.

strictus, Kuntze, 1. c. = Cryptangium uliginosum Schrad.

tenuifolius, Kuntze, 1. c. = C. tenuifolius, Boeck. triquetrus, Kuntze, 1, co = C. triquetrum, Boeck.

uliginosus, Kuntze, 1. co = C. uliginosum, Schrad.

LAGENOPHORA, Cass. (Compos.). - Ind. Kew. ii. 23.

Harioti, Franch, in Miss, scient. Cah Horn, v. Bot. (1889) (= L. Commersonii, Hariot). - Am. austr. strangulata, Colenso, in Trans. N.Z. Inst, xxii. 1889 (1890) $471 .-\mathrm{N}$. Zel.

LAGERSTROEMIA, Linn. (Lythrar.). - Ind. Kew, ii, 23.

angustifolia, Pierre, ex Laness. Pl. util. Colon. France. (1886) 323. - Cochinch.

Batitinan, Vidal, Revis. Pl. Vasc. Fillp. (1886). 139. - Ins. Philipp.

cochinchinensis, Pterre, ex Laness. Pl, wtil. Colon. Franç. (1886) 321. - Cochinch.

crispa, Pierre, l.c. 322. - Cochinch.

Koehneana, K. Schum. in K. Schmm. of Hollr, Fl Kais, Will. Land (1889) 85. - N. Guin.

nervosa, Pierre, ex Laness. Pl, util. Colon. Franc. (1886) 322. - Cochinc.

paniculata, Vidal, Revis. P1. Vasc. Filip. (1886) $140=$ Pterocalymna paniculata, Turcz.

petiolaris, Pierre, ex Laness, Pl. util. Colon. Franc. (1886) 321. - Cochinch.

LAGETTA, Juss. (Thymel.) - Ind. Kew。 ii. 23 Wrightiana, Krug \& Urban, in Bot. Falirb. Xv. (1893) 350. - Cuba.

LAGGERA, Sch.-Bip. (Compos.). - Ind. Kew. ii. 23 .

falcata, Kuntze, Rev. Gen..(1891) 350 = flava, Benth. \& Hook. f.

stenoptera, O. Hoffm. ex Schinz, in Bull. Herb̆. Boiss. i. (1893) 76. - Afr, austro-occ. extratrop.

Volkensii, O. Hoffm. in Engl. PAanzenw. Ost-Afr. C (1895) 408, - Afr, trop. or

LAGOA, Th. Dur. Ind. Gen. Phan. (1887) 260 Baill. Hist. des pl. x. (1890) 251. ASCLE PIADEAE.

calcarata, Baill. l. c. $(=$ Zygostelna calcaratum, Fourn.). - Brás.

calcaratc, K. Schum. in Engl. \& Prantl, Natïrl. Pflanzenfam. iv. 2 (1895) $257=$ praec.

LAGOPHYLLA, Nutt. (Compos.). - Ind. Kew ii. 24 .

congesta, Greene, Man. Bot. Saw Franc. Bay (1894) 199. - Calit.
LAGOSERIS, Hoffmgg \& Link = Crepis, Linn. (Compos.)

caspica, Paczosky, Expl.flor, et phyt, stepp. Kalmyks. (1892) 90 [Bull, Soc, Natur. Kiew], - Rossia. runcinata, Boiss. Fl Or. Suppl. (1888) $329(=$ Plerotheca runcinata, Trautv.). - Armenia.

LAGOTIS, J. Gaertn. (Selag.). - Ind. Kew. ii. 24. borealis, Baill. ex Wettst. in Engl. \& Prantl, Natür1. Pflanzenfam. iv, 3b (1891) s7 (= Gymnandra borealis, Pall. $)=$ glauca, $f$. Gaertn.

Gmelini, Baill. ex Wettsto 1. c. $=L$. Gmelini Rupr.) = grlauca, F. Gaertn.

Gregorjevi, Kratssn. in Script. Univ. Petrop. ii. I. (1887-88) 19. - China.

ramalana, Batalin, in 4ct. Hort. Petrop. xiv. (1895) 177. - Tibet.

Stelleri, Baill. ex Wettst. in Eng1. \& Prant1, Natürl. Ptlanzenfam. iv. 3b (1887) $87(=L$. Stelleri, Rupr.) = glauca, 7 . Guertn.

LAGUNAEA, G. Don (Malv.). - Ind. Kew, ii. Schinzii, Guerke, ex Schinz, in Verh. Bot. Ver. Brand, xxx. (1888) 180. - Afr, austro-occ, extratrop.

LAmanonia, Vell. = Belangera, Cambess, (Saxif.).

cuneata, denticulata, glabra, tomentosa, Kuntze, Rev. Gen (1891) $227=$ homonymz omnia Belancerae. grandistipularis. Taub. in Bot. Jahrb, xv. Beibl. n. $34(1892) 16=$ Belangera grandistipularis, Taub.

LAMIAGANTHUS, Kuntze, Rev, Gen, (1891) 492: Lindau, in Engl, \& Prantl, Natiirl. Pfianzerfam, iv. 3b (1895) 303. ACANTHACEAE.

viscosus, Kintze, $l l$.cc. - Java.

LAMIUM, [Tourn.] Linn. (Labiat.). - Ind. Kew

balcanicum, Velen. in Sitz. Buehm. Ges. Wiss. (1892-93) 54. - Bulo.

holsaticum $\times$, Prahl, Krit. Fl, Prov. Schlesv.-Holst. ii. (1890) 169. - Holsat.

pallidiflorım, G. Beck, in Annal, Naturh. Hofmus. Wien, ii. (1887) $144=$ maculatum, Linn.

pelasgicum, Heldr, ex Charrel, in Oest. Bot. Zeitschr. xlii. (1892) 381, nomen. - Maced.

scardicum. Wettst, in Luerss. Bibl. Bot. Heft xxvi. (1892) 8:- - Albania.

setidens. Frem, in Oest. Bot. Zeitschr.xli. (1891) 58. - As. Min.

sibivicum, Cordem. Fl. Ile Réunion (1895) $488=$ Leonurus sibiricus, Linn.

LAMOUROUXIA H. B. \& K. (Scrophul.).. Ind. Kew. i1. 26.

brevifolia, Robinson \& Greenm, in Am. Journ. Sc Ser.III.i. (1895) 170, sphalm. = breviflora, Benth。 coccinea, A. Gray, in Proc. Am. Acad. xxi. (1886) $404=$ viscosa, $H, B \cdot G K$

exserta, Robinson of Greemn. in Am. Foum. Sci Ser. III. 1. (1895) 171.) - Mexic

gracilis, Robinson \& Greenm. 1. c. 174. - Mexic hyssopifolia, A. Gray, in Proc. Am. Acad. xxi. (18s6) 404. - Mexic

integerrima. $\mathcal{F}$. D. Smith, in Coult. Bot. Gaz, xiii. (1588) 189. - Guatem

integerrima, f. D. Smith, ex Robinson Ef Grcenm. in Am. Foun. Soi. Ser. IlI. 1. (1825) 173.Mexic.

longifolia, Robinson \& Greenm. 1. c. $1 \% 0=$ longiflora, Benth

Nilsonii, Rubinson \& Greenm. l. c. 17t. - Mexic. Pringlei, Robinson \& Greenm. in Gard. and For viii. (1895) 273 et 275 fig. 39 ; et lo c. 170. Mexic.

Smithii, Robinson \& Greenm. l. c. 172. - Mexic

LAMPAYA, Phil, ex Murillo, P1。 médic. Chili 1889) 163, nomen; et in Anal. Mus. Nac. Chile (1891) 58.VERBENACEAE.

medicinalis, Phil. l. c. (1891) t. 2. fig. 5. - Chili officinalis, Phit. ex Murvillo. Pl. médic. Chili (1889) 163 , nomen [an praec. ?]. - Chili. 
LAMPROCOCCUS, Beer = Aechmea, Ruiz \& Pav. (Bromel.).

brachycaulis, Éd. Morren, ex Baker, Handb. Bromel. $(1889) 53=\mathrm{A}$. brachycaulis, Baker.

seciosus, Hort. Bull, ex Gard. Chron. (1893) i. 414. - Hab.

LAMPROCONUS, Lem. = Pitcairnia, L'Hérit. (Bromel.).

qurantiacus, Ed, Morren, ex Baker, Handb. Bromel. (1889) 114, in syn, = Pitcairnia densiflora, Brongn.

LAMPROPHYLLUM, Miers = Rheedia, Linn. (Guttif).

- Gardnerianum, Miers, ex Encl. in Mart. F1. Bras. xii. I. (1888) $462(=$ L. Gardnerianum, Triana \& Planch.) $=$ R. Gardneriana, Planch. \& Triana.

LANDESIA, Kuntze, Rev, Gen. (1891) 546 err typ. $=$ LONDESIA, Fisch. \& Mey. = Ghenolea. Thunb. (Chenop.)

LANDOLPHIA, Beauv. (Apocyn.). - Ind. Kew. ii. 27.

angustifolia. K. Schum. ex Engl, in Abh. Prouss. 4kud. Wiss. (1894) 34; et in Engl. Pfanzenw. Ost-Afr. C (1895) 315. - Afr. trop. or

bracteata, Dewerre, in Annal. Soc. scient. Brux. xix. (18:5) sep. 31 . - Afr trop. occ.

comorensis, K. Schum. ex Engl. in Abh. Prouss. Akad. Wiss. (1894) $37=$ florida, Benth.

crassipes, $K$. Schum. in Bot. Fahrb. xv. (1892) 409, in obs. ; et in Engl. E Prantl, Natürl. Pfanzenfam. iv. 2 (1895) 130 (= Vahea crassipes, Radlk.). Madag.

gumnifera, K. Schum. ll.cc. (= Vahea gumunifcra, Poir.). - Madag.

Lecontei, Deweire, in Annal. Soc. scient. Brux. xix. (1845) sep. 25. - Congo gall.

lucida, $K$. Schum. in Engl. \& Prant, Natïr. Pfanzcnfam, iv. 2 (1895) 130. - Congo.

madagascariensis, K. Schum, in Bot. Fahrb. xv. (1892) 406, in obs. (= Vahea madagascariensis, Boj.). - Madag.

Monteiroi, [N.E. Br. $2 n]$ Monteiro, Delagoa Bay. 1891) 160. - Mossamb.

parvifolia, K. Schum, in Engl. Pflanzene. Ost-Afr. A (1895) 50; et in Engl. Go Prantl, Natirl. Pfanzenfam. iv. 2 (1895) 129. - Angola.

Thollonii, Dewevre, in Amal. Soc, scient. Brux. xix. (1895) sep. 50. - Congo gall.

tomentosa, Dewère, 1. c. 41 (= Vahea tomentosa, Leprieur) $=$ L. Heudelotii, $A . D C$

LANDUKIA, Planch, in DC. Monog. Phan. v. (188\%) $446=$ Vitis, [Tourn.] Linn. (Ampelid.).

Landuk, Planch. 1. c. $447=$ V. Landuk, Miq.

LANIUM, Lindl. (Orchid.). - Ind. Kew. ii. 2S. Berkeleyi, Rolfe, in Kew Bull. (1894) 392. - Bras.

LANKESTERIA, Lindl. (Acanth.). - Ind. Kew. ii. 28

loatangana, Lindau, in Engl. \& Prantl, Natürl. Pflanzenfam.iv. 3b (1895) 311 (= Ruellia batangana, J. Braun \& K. Schum.). - Afr. trop. occ.

LANTANA, Linn (Verben.). - Ind, Kew. ii. 28. amoena, Ridl. in fourn. Linn. Soe. xxvii. (1890) $5 \%$. - Ins. Fernando Noronha.

Chamissonis, Briq. in Eigl. \& Prantl, Natürl. Pflanzenfam.iv.3a (1894) 151 (= Ricdelia Chamissonis, Schau.). - Bras.

concinna, Baker, in Kew Bull. (1895) 223. - Reg, Somal.

spicata. Benth. E Hook. f. ex Kuntre, Rer. Gen. (1891) 504. - Reg. Argent.

LANTHORUS, Presl = Loranthus, Linn

Blumeanus, Van Tiegh, in Bull. Soc. Bot. Fr, xli. (1894) 488. - Java, Borneo.

Cuningii, Van Tiegh. 1. c. 488. - Ins. Philipp.

macrostachys, Van Tiegh. 1. c。=.L. macrostachys, Korth

\section{LANTHORUS:-}

pentasepalus, Van Tiegh, in Bull. Soc. Bot. Fr, xli. (1894) $488=\mathrm{L}$. pentasepalus, Roxb.

pentapetalus, Van Tiegh. 1. c. = L. pentasepalus, Van Tiegh. polycarpus, Van Tiegh. I. c. = L. polycarpus,
Wall.

LAPEYROUSIA, Pourr. (Irid.). - Ind. Kew. ii. 30

Barklyi, Baker. Handb. Irid. (1892) 171. - Afr. austro-occ. extratrop.

Burchellii, Baker, l. c:- Afr, austr.

caudata, Schinz, in Verh, Bot, Ver. Brand, xxxi. (1890) 213; Baker, l. c. 172. - Afr. austro-occ. extratrop.

coerulea, Schinz, l. c. 212; Baker, l. c. 168. Afr. austro-occ. extratrop.

congesta, Rendle, in fourn, Linn. Soc. xxx.(1895) 403. - Afr, trop. cr.

grandiflora, $[N . E . B r . i n]$ Monteiro, Delagoa Bay (1891) 171. - Reg. Mossamb

holostachya, Baker, in Kew Bull. (1894) 391. - Afr. trop.

homoidea, Klatt, in Th, Du. E Schinz, Consp, Fl Afr.v. 51893 (1894) 191 (= Gladiolus tissifolius, Jacq.). -- Afr. austr.

leptostachya, Baker, Handb. Irid. (1892) 170.Nata!.

Pappei, Baker, l. c. - Afr. austr.

Sandersoni, Baker.l.c. 169. - Transvaal.

Welwitschij, Baker, l, c, 168. - Angola.

LAPHAMIA, A. Gray (Compos.). - Ind. Kew. ii. 30 ; O. Hoffm, in Engl, et Prantl, Natür. Pflanzenfam. iv. 5 (1890) $25 \%$.

congesta, M. E. Fones, in Proc. Calif. Acad. Ser, II v. (1895) 703. - Arizona.

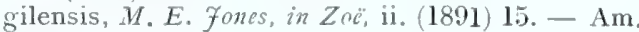
bor. OCC.

gracilis, $M$. E. fones, in Proc. Calif. Acad. Ser. II. v. (1895) 703. - Arizona.

Toumeyi, Robinson \& Greenm, in Am. Fourn. Sci. Ser. III. 1. (1895) 176. - Am. bor.

LAPLAGEA, H. B. \& K. (Ternstroem.), - Ind. Kew, ii. 30.

camelliodes, Kuntze, Rev. Gen. (1891) 6?, sphalm. = camenioides, Sond.

Courtyana, Kuntze, 1. c. = Curtyana, A. Rich.

¿ulcania, Kuntze, 1. c., sphalm. = vuicanica, Korth.

LAPORTEA, Gaudich. (Urtic,). - Ind. Kew. ii. 30 .

armata, Warb. in Bot. Fahrb. xiii. (1891) 293.N. Guin,

sessilithora, Warb. l. c. 292. - N. Guin.

LAPPA, [Tourr.] Rupp. = Arctium, Linn. (Compos.).

Ritschliana X. Aschers. in Ber. Deutsch, bot. Ges. ix. (1891) [99]. - Eur. centr.

subracenosa $\times$, Simonk, Enum, Fl. Transs. (18S6) 340. - Transsilv.

LAPPULA, Monch = Echinospermum, Sw (Borag.).

affinis, Guerke in Engl. \& Prantl, Natürl. Pflànzenfam. iv. 3a (1893) $10 \%=\mathrm{E}$. affine, $K a r$. Kir.

anisacantha, Guerke 1. c. $107=\mathrm{E}$. anisacanthum. Turcz.

barbata, Guerke, 1. c. = E. barbatum, Lehm

brachycentra, Guerke, I. c. = E. brachycentrum, Ledeb.

Bungei, Guerke, 1. c. = E. Bungei, Boiss.

capensis, Guerke, 1.c. = E. capense, $D C$

ciliata, Greene, Pittonia, ii. (Sept, 1891) $182=$ E. ciliatum, A. Gray.

consangwinea, Guerke in Engl. \& Prantl, Natürl. Pflanzenfam.iv. 3a $(1893) 107=\mathrm{E}$. consanguineum, Fisch. \& Mey.
LAPPULA : -

cynoglossoides, Guerke, in Engl. \& Prantl, Natürl. Pflanzenfam.iv. 3a (1893) $107=$ E. cynoglossoides, I,elini.

deflexa, Caruel, in Parl. Fl. Ital. vi. (1886) $859=$ E. deflexum, Lihm.

deflexa, Garcke, in Engl. \& Prantl, Natürl. Pflanzenfam. iv. 3a (1893) $107=$ praec.

deflexa, Greene, Pittonia, ii. (Sept. 1891) $182=$ deflexa, Caruel.

diffusa, Greene, Pittonia, ii. (Sept. 1891) $182=$ E. diffusum, Lehm.

diploloma, Guerke, in Engl. \& Prantl, Natürl. Pflanzenfam, iv. 3a (1893) $107=\mathrm{E}$. diploloma Fisch. \& Mcy.

chinophora, Kuntze, in Act. Hort. Petrop. x, (188\%) $214=\mathrm{E}$. Redowskii, Lelm.

floribunda, Greene, Pittonia, ii. (Sept. 1891) 182 $=$ E. floribundum. Lehm.

heteracantha, Guerke, in Engl. \& Prantl, Natürl. Pflanzenfam. iv. 3a $(1893) 107=\mathrm{E}$. heteracan. thum, Ledeb.

hispida. Greene, Pittonia, ii. (Sept, 1891) 1S2 = E. hispidum, A. Gray.

macrantha, Guerke, in Engl. \& Prantl, Natürl. Pflanzenfam. iv. 3a (1893) $107=$ E. macranthum, Ledeb.

marginala, Guerke, 1. c. $107=$ E. marginatum, Lelm

mexicana, Greene, Pittonia, ii. (Sept. 1891) $182=$ E. mexicanum, Hemsl.

microcarpa, Guerke, in Engl. \& Prantl, Natürl. Pflanzenfam. iv. 3a (1893) $107=$ E. microcarpum, Ledeb

mana Caruel in Parl. F1. Ital. vi. (1886) $\mathrm{S61}=$ Eritrichium nanum, Schrad.

nervosa, Greene. Pittonia, ii. (Sept. 1891) $182=$ E. californicum, A. Gray

patula, Aschers, ex Guerke, in Engl. \& Prantl Natürl. Pflanzenfam. iv. 3a (1893) $107=\mathrm{E}$. patulum, Lehm

pilosa, Hitchcock, Spring Fl. Manhattan (1894) 30 $=\mathrm{E}$, Redowskii, Lehm.

pinetorum, Greene, Pittonia, ii. (Sept. 1891) $182=$ E. pinetorum, Greene.

Redowski, Greene, 1: c. = E. Redowskii, Lelhm.

Redowski, Guerke, in Engl, \& Prantl, Natürl.

Pflanzenfam, iv. 3a $(1893) 107=$ praec.

rupestris, Guerke, 1. c。 = E. rupestre, Schrenk.

scssilifiora: Guerke, 1, c. = E. sessilifiorum, Boiss.

sinaica, Aschers, ex Schweinf. [Illustr. Fl. Eqypte] in Mém. Inst. Égypt. ii. (1887) $111=$ $\mathrm{E}$. sinaicum. A. DC

spinocarpa, Aschers. ex Kuntze, in Act. Hort. Petrop.x. (1887) $215=\mathrm{E}$. Vahlianum, Lehm.

stricta. Guerke, in Engl. \& Prantl, Natürl. Pflanzenfam. iv. 3a (1893) $107=$ E. strictum. Ledeb.

stylosa, Guerke, 1. c. = E. microcarpum, Ledeb.

temis, Guerke, 1. c. = E. tenue, Ledeb.

texana. Britton, in Mem. Torrey Bot Club, v $(1894) 273=$ E. Redowskii, Lelkm

tuberculosa, Guerke, in Engl. \& Prantl, Natürl. Pflanzenfam. iv. 3a (1893) $10 \%=\mathrm{E}$. Vahlianum. Lelin.

ursina, Greene, Pittonia, ii. (Sept. 1891) $182=\mathrm{E}$ ursinum, Greene.

virginiana, Greene, 1. c. = E. virginianum, Lehm.

LAPSANA, Linn. (Compos.). - Ind. Kew. ii. 31. cancellata, Borb. in Oest. Bot. Zeitschr. xliii. (1893) 69, in obs. - Austria.

Freyni, Borb. 1. c = intermedia, Bieb.

glandulosa, Freyn \& Sint. 1. c. xlii. (1892) $266=$ intermedia, Bics.

LARIX, Tourn. ex Adans, (Conif.), - Ins. Kew. ii. 31.

amurensis, Hort. ex Beissner, Handb. Nadelholzk. (1891) 328 = dahurica. Turcz.

Larix, Kern. \& Wettst. in Kern. Sched. Fl, AustroHung. vi. (1893) $104=$ seq.

Larix, Sudw. in Gard. and For. ix. (1S91) $166=$ curopaea, $D C$. 
LARIX

Potanini, Batalin. in Act. Hort. Petrop. xii. (1894) 385. - Tibet.

LARREA, Cav. (Zygophyll.). - Ind, Kew. ii. 32. tridentat a Coult in Contrib. U. S. Nat. Herb, iv. (1893) $75=$ mexicana, Moric.

LASEGUEA. A. DC. (Apocyn.).-Ind. Kew, ii. 32.

bracteata, K. Schum, in Engl. E Pruntl, Natiurl. Pfanzenfam. iv. 2 (1895) 171. - Bras.

Mandoni, Britton, ex Rusby, in Mem. Torrey Bot. Club, iv. (1895) 220. - Bolivia.

LASERPITIUM, Linn. (Umbell.). - Ind. Kew. i1. 32

dauciforme, Schmall, ex Akinfieve, in Bull. Soc. géogr. Cauc, (1892) 207; et in Ber. Dentscl. bot. Gesells. x. (1892) 289. - Reg. Cauc.

glaucum, Post, Pl. Postianae, ii. (1891) 10. Syria.

LASIANTHERA, Beauv. (Olacin.), - Ind. Kew. ii. 34 .

amazonica, Rodr. [Herb. Mus. bot. Amaz, n. 337]. Vellosia, 1885-88, Sec. ediç. (1891) 12, t. 7 A. Bras. bor.

umbellata, King, in fourn. As. Soc. Beng. Ixiv. (1895) II. 11\%, - Perak.

LASIANTHUS, Jack (Rubiac.), - Ind. Kew. ii. 34.

euneurus, Stapf, in Trans. Linn. Soc. Ser. II. iv (1894) 185. - Borneo.

glomeriflorus, $K$. Schum, in Engl. Pflanzenw. OstAfr. A (1895) 92, nomen. - Atr. trop.

kilimandscharicus, $K$. Schtm. l. c. C (1895) 393. - Afr. trop. or.

kinabaluensis, Slapf, in Trans, Linn. Soc. Ser. II. iv. (1894) 184. - Borneo.

macrocalyx, K. Schum. in Engl. Pfanzonw. Ost-Afr. A (1895) 130. - Afr. trop.

membranaceus, Stapf, in Trans. Linn. Soc. Ser. II. iv. (1894) 184. - Borneo.

rotundatus, Stapf, l. c. 185. - Borneo.

trichophlebus, Hemsl. ex Forb. \& Hemsl. in foum. Linn. Soc. xxiii. (1888) 388. - China.

umbellata, Kuntze, Rev. Gen. (1891) 290. - Java.

LASIANTHUS, Linn. = Gordonia, Ellis (Ternstroem.).

acuminatus, ellipticus. excelsus, Maingayi, obtusus, pubescens, pyramidalis, spcciosus, zeylanicus, Kuntze, Rev. Gen. (1891) $63=$ homonyma omnia Gordoniae.

axillaris, Kuntze, 1. $c_{*}=\mathrm{G}$. anomala, Spreng.

pyramidalis, Kuntze, 1. c. $=$ G. Lasianthus, Linn.

LASIOCHLOA, Kunth (Gramin.). - Ind. Kew. ii. 35 .

alopecuroides, Hack. ex Schinz, in Bull. Herb. Boiss. iii, (1895) 393. - Natal.

LASIOCOCGA. Hook, f. Icon. pl. xvi. (1887) t. 1587; et F1. Brit, Ind. v. (1887) 456. EUPHOR$B I A C E A E$

symphilliaefolia, Hook. f. ll. cc. - Reg. Himal.

LASIOCORYS, Benth. (Labiat.). - Ind. Kew. ii.

Pèchuellii, Kuntze, in fahrb. Bot. Gart. Berl, iv. (1886) 271. - Afr. austro-occ. extratrop.

LASIODISGUS, Hook.f. (Rhamn.). - - Ind. Kew. ii. 35

Pervillei, Baill. Hist. pl. Madag., Atlas (1894) t. 290. - Madag.

LASIOSIPHON, Fresen. (Thymel.). - Ind. Kew. ii. 36.

Baroni, Baker, in fourn. Linm. Soc. xxv. (1890) 342. - Madag,

djuricus, Gilg, in Bot. Jahrb, xix. (1894) $269=$ Gnidia djurica, Gilg.

\section{LASIOSIPHON}

Emini, Engl. \& Gilg, ex Gilg, in Bot. Jahrb. ii (1894) $269=$ Gnidia Emini, Engl. \& Gilg.

Fischeri, Engl. \& Gilg, ex Gilg, I. c. = G. Fischeri, Fung. \& Gilg.

genistifolius, Engl. \& Gilg, ex Gilg, 1. c. $268=$ G. genistitolia, Engl. \& Gilg.

Hildebrandtii, S. Elliot, in fown. Linn. Soc. xxix. 1891) 47. - Madas.

Hildebrandiii. Vatke, ex Eng]. in Abh. Preuss. Akad. Wiss. 1891 (1892) $310=$ G. Vatkeana. Engl. \& Gilg.

Hoepfnerianus, Vatke, ex Gilg, in Bot. Jahrb, xix. (1894) $268=$ G. Hoepfneria, Gilg.

Kraussii, Engl, in Abh. Preuss, Akad. Wiss. 1891 (1822) $310 \stackrel{\circ}{=}$. djurica. Gilg.

lampranthus, Gilg, in Bot. Jahrb. xix. (1894) $265=$ G. lamprantha. Gilg.

Oliceri. Vatke, ex Gilg. 1. c. $264=$ G. Oliveriana, Engl. of Gilg.

polyanthes, Gilg, 1. c. $265=$ G. polyantha, Gilg.

rhamnifolius, Baker, in fourn. I.inn. Soc, xxy (1890) 343. - Madag.

saxatilis, S. Elliot, l. c. xxix. (1891) 46. - Madag

Stuhlmanni, Gilg, in Bot. Jahrb, xix. (1894) 267. in syn. = G, Stuhlmanni, Gilg.

Vatkei, Engl. Bot. Jahrb. xvii. (1893) 167, in obs, $=$ G. Vatkeana, Engl. \& Gilg.

usinjensis, Gilg, 1. c. xix. (1894) 269, in syn. = G. usinjensis, Gilg.

LASIORHIZA, Lag. = Leuceria Lag. (Compos.) Barrasiana, canescens, concinna, coquimbensis, fragrans, Gayana, glabra, glabriuscula, integrifolia, Landbeckii, modesta, multifida, nutans, Remy, Poeppigii. polyclados, salina, tenerifolia, tenuisecta, thermarum. Kuntze, Rev. Gen. (1891) $350=$ homonyma ommia (Chabraeae $=$ ) Leuceriae.

anoena, candidissima, Cerberoana, coerulescens, congesta, eriochlaena, floribunda, foliosa, Garciana, Menana, Meyeniana, multiflora, Neaei, oligocephala, paniculata, peduncularis, scrobiculata, tenuis, Kuntze, 1. c. $350=$ homonyma onnia Leuceriae.

aianthodes, Kuntze, 1. c. = L. acanthoides, D. Don.

glandulosa, Kuntze, 1. c. = L. glandulosa, $D$ : Don. hieraciodes, Kuntze, 1. c. = L. hieracioides, Cass Philippiana, Kuntze, 1. c. = L. glandulosa, Phil,

pulchella, Kuntze, 1. c. = L. pulchella, D. Don.

seneciodes, Kuntze, 1. c, = L. senecioides, Hook. \& Arn.

LASIOSTELMA, Benth. (Asclep.). - Ind. Kew ii. 36 .

i1. 36.
Benthami, K. Schum. in Engl. \& Prantl, Natiirl. Pfanienfam. iv. 2(1895) 29\%. - Natal.

LASTARRIAEA, Remy (Polygon.), - Ind. Kew. ii. 36.

linearis, Phil. ex Parry, in Proc. Dacenp. Acad. Sci. v. (1886) 36 ; et in Anal. Univ. Chili, xci. (1895) 501 - Chili

stricta, Phil. ll. cc. 501 et 36 . - Chili.

LASTHENIA, Cav. (Compos.). - Ind. Kew. ii 36

Burkei, Greene, Man. Bot. San Franc, Bay (1894) 204. - Calif.

carnosa, Greene, l. c. 205.-Calif.
chrysantha, Greene. l. c. 204.-Calif

chrysostoma, Greene, l. c. 205. - Calif.

conjugens, Greene, Pittonia, i. (Oct. 1888) 221 ; t l.c. 204. - Calif.

Fremonti, Greene l. c. - Calif.

gracilis, Greene, l. c. 206. - Calif.

hirsutula, Greene, l. c. - Calif.

macrantha, Greene, l. c. 205. - Calif.

microglossa, Greene, Man. Bot. San Franc. Bay (1894) 205. - Calif.

platycarpha, Greene, l. c. - Calif.

tenella, Greene, l. o. 205. - Calif.

uliginosa, Greene, l. c. - Calif.

Volkmanni, Phil. in Gartenfl. xxxviii. (1889) 369 t. 1302, fig. 1. - Chili.
LATANIA, Comm. (Palm.), - Ind. Kew, ii. $36^{3}$ borbonica, Hort. ex W. Wats, in Gard. Chron. 1886) i. $75=$ Livistona chinensis, Mart.

LATHRAEA, Linn. (Orobanch.). - Ind. Kew ii. 37.

purpurea, Cumnins, ex King, in fourn. As. Soc. Beng. 1xiv. (1895) II. 137. - Reg. Himal.

staminea, Janka, in Magyar. Növenyt. Lapok; $x$ (1886) $148=$ squamaria, Linn.

LATHYRUS, [Tourn.]. Linn. (Legumin.). - Ind Kew ii 37 .

Alfredi, T. G. White, in Bull. Torrey Bot. Chub, xxi (1894) $44 \%$ - Calif.

alpestris, Taub. in Engl. \& Prantl, Natürl. PAanzent fam. iii. 3(1894) 354 (= Orobus alpestris, Waldst. $\&$ Kit.) = canescens, Gren. \& Godr.

arizonicus, Britton, in Bull. Torrey Bot. Club xxi. (1894) 454.-Arizona.

armenus, Celak. in Oest. Bot. Zeitschr. xxxviii. (1S8s) 85 (= Orobus armenus, Boiss. \& Huet). - Armenia.

asphodeloides, St. Lager, in Cariot, Etud, des fl. éd. 8. ii. (1889) $209(=0$. asphodeloides. Gouan $)=$ pannonicus, Garke.

Bauhini, Genty, in Bull. Soc. Dauph. Sér, 2. iii. (1892) $90=$ canescens, Gren. \& Godr.

bijugatus, T. G. White, in Bull. Torrey Bot. Club. xxi. (1894) 457. - Idaho.

brachypterus, Colak, in Oest. Bot. Zeitschr. xxxvii (1888) 47. - As. Min.

canescens, Taub, in Engl. \& Prantl, Natïrl. Pflanzenfam. iii. 3 (1894) $354(=$ Orobus canescens Linn. f.) $=$ canescens, Gren. \& Godr.

cicerimus, St Lager, in Cariot, Etud. des fl. éd. 8 ii. (1889) $206=$ L. Cicer, Lim.

cinctus, S. Wats. in Proc. Am. Acad. xxiii. (1889) 263. - Calif.

criaceus, T. G. White, in Bull. Torrey Bot. Club xxi. (1894) 452. - Utah.

cyanens, Celak. in Oest. Bot. Zeitschr, xxxviii.(1888) $46(=$ Orobus cyaneus, Stev. $)=$ cyaneus, $C, K$ och.

Dinklagei, Engl. Bot. fahwb. xx. (1S94) 94. - Afr. trop. occ.

elegans, Porta \& Rigo, ex Porta, in Atti Accal. Agiati, ix. (1891) extr. 23; Willk. Suppl. Prodr. Fl. Hisp. (1893) 240 - Hisp.

Emodi, Fritsch, in Sitzungsb. Akad, Wiss. Wien civ. (1895) 516 (= L. lutews, Baker). - Reg Himal.

filiformis, Celak, in Oest. Bot. Zeitschr. xxxviii. (1888) 47 (= O. canescens, Boiss.). - Thracia.

fliformis, Genty in Bull Soc. Dauph. Sér. 2. iii. (1892) 91 (=Orobus filiformis Lam.) = canescens, Linn. $f$.

gracillimus, Reiche, in Bot. Falvb. xxi. (1895) 47 nomen. - Chili.

graminifolius, T. G. White, in Bull. Torrey 'Bot Club, xxi. 1894) $454=$ palustr s, Linn.

hyorophilus, Taub, in Engl. PAanzenw. Ost-Afr. C (1895) 219, - Afr. trop. or.

Jepsonii, Greene, Pittonia, ii. (Dec. 1890) 158; Man. Bot. San Franc. Bay (1S:4) 8.5. - Calif.

kilimandscharicus, Taub. in Engl. Pfanzenw. OstAfr. C (1895) 219. - Afr. trop. or

laetiflorus, Grecne, in Erythea, i. (1893) 105 ; "ct th Bull. Torrey Bot. Club, xxi. (1894) 451 - Calif.

laerigatus, Fritsch, in Sitzungsb. Akad. Wiss. Wien, civ. (1895) $517(=$ Orobus laevigatus Waldst. \& Kit. $)=$ montanus, Bernh.

laxiflorus, Kuntze, in Act. Hort. Petrop. x. (1887) 185 (= Orobus laxiflorus, Desf.) = hirsutus, Linn.

Layardi, Ball, ex Boiss, Fl. Or. Suppl. (1888) 195.Persia.

Libani, Fritsch, in Sitzmgsh. Akad. Wiss. Wien, (1895) 517 (== Orobus grandiflorus. Boiss.) Syria.

longipes, T. G. White, in Bull, Torrey Bot. Club, xxi. (1894) 453, - Mexic.

macrorrhizus, St. Lager, in Cariot, Etud. des fl. éd. 8 , ii. (1889) $208=$ montanus, Berrh

nissolius, St. Lager, 1. c. $204=$ L. Nissolia, Limn numidicus, Batt. in Bull. Soc. Boh. Fr. xxxiv. (1S87) 388 ; et in Batt. \& Trab. Fl. de l'Algér. [Dicot. (1889) 279. - Algreria. 


\section{LATHYRUS}

Fultallit, S. IVats, in Proc. Am, Acad xxi, (1880) 45) - Am. bor. occ

boratns, T. G. White, in Bull, Torrey Bot. Club, xxi. (1894) $455=$ nevadensis, S. Wats.

occidentalis, Fritsch, in Sitzungsb. Akad, Wiss, Wien, civ. (1895) 499, in obs. et $517=$ montanus, Bernll

oregonensis, T. G. White, in Bull. Torrey Bot. Chub, xxi. (1894) 456. - Oregon.

panciflorus, Fernald, in Conlt. Bot. Gaz, xix. (1894) 3335. - Orecron.

puberulus, White?, cx Grene, Man. Bot. San Franc. Baty, (1894) 85. - Calif.

rigidus, $T$. G. While, in Bull. Torrey Bot. Chub, xxi. (1894) 45.5. - Oregon

Schimper:, Engl. in Abh. Prouss. Akad. Wiss. 1891 ii. (1892) 265. - Abyss.

Sibthorpii, Baker, in Gard. Chron. (1890) i. 704. Reg. Byzant.

spathulatus, Celak. in Oest. Bot. Zeitschr. xxxviii. (1888) 6.- As. Min

subrillosus, Aitch. \& Hemsl. in Trans. Linn. Soc. Ser. II. iii. (1888) $59(=$ Orobus subrillosus, Ledeb.) = Vicia subvillosa, Boiss.

transsilianicus, Fritsch, in Sitzungsb. Akad. Wiss. IVien, civ. (1895) $517(=$ Orobus transsilvanicus, Spreng. $=$ montanus, Bernh

Tromolsianus, Pau, Not, bot. F1. Espan. iv. (1891) 29 [cf. Bull. Soc. Bot. Fr. (1892) Bibl. 9y-100] $=O$. canescens, Limn. $f$.

utahensis, M. E. Fones, in Proc. Calif. Acad. Ser. II. v. (1895) 6\%8. - Utah.

variabilis, Celak. in Oest, Bot. Zeitschr. xxxvii (1888) 47 (= Orobus variabilis, Boiss, \& Kotschy). - Cilicia.

Tarius, Cesati, Passer.\& Gibelli, Comp. Fl. Ital. ii. $(1886) 690$ = pannonicus, Garcke.

violaceus, Greene, in Erythca, 1. (1893) 105; et's in Bull. Torrey Bot. Chib, xxi.(1894) 451. - Calif

LATOUREA, Benth, \& Hook. f. = LATOURIA Blume = Dendrobium, Sw. (Orchid.).

oncidiochila, Kracnal: in Oest. Bot. Zeitschr. xliv. (1894) 336. - N. Guin.

LATUA, Phil. (Solan.). - Ind. Kew. ii. 39.

pubiflora, Baill. Hist, des pl.'ix. (1888) $334=$ venenata, Phil.

LAUGERIA, Vahl (Rubiac.), - Ind. Kew, ii. 39 densiflora, Hitchcock, in Missouri Bot. Gard. Rep iv. [Pl. of Baham.] (1893) 93 = densifiora Benth. \& Hook.f.

LAUNAEA, Cass. (Compos.). - Ind. Kew. ii. 39 Mlabra, Franch, in Nonv. Arch. Mus, Paris, Sér. II. x. (1887-88) 42, - China occ.

goraeënsis, O. Hoffm, in Engl. \& Prantl, Natürl. Pflanzenfam.iv. 5 (1893) $370(=$ Brachyramphu. goraeënsis, DC. $=$ Lactuca goracënsis, Sch Bip. lampsanoides, Franch. in Nouv. Arch. Mus. Paris, Sér. II. x. (1887-88) 42, - Tibet.

I.AUNAYA, Kuntze, Rev. Gen. (1891) $350=$ Launea, Cass. (Compos, )

acanthodes, Kuntze, 1. c. - Persia.

angustifolius, Kuntze, 1. c. (= Zollikoferia arabica, Boiss.). - Arabia, Afr. bor.

Cassiniana, Kuntze, 1. c. - Aegyt. ; Arabia.

fallax, Kuntze, 1. c. - Aegypt.; Persia, Afghan.

massavensis, Kuntze, 1. c, - Afr. bor; Arabia.

polychada, Kuntze, 1. c.-Persia; Beluchist.

prmila, Kuntze, 1. c. - Hispan. : Arabia.

resedifulia, Kuntze, 1, c. = Sonchus chondrilloides Desf.

stenocephala, Kuntze, 1. c. - Beluchist.

Stocksiana, Kuntze, 1. c. - Beluchist.

tenuiloba, Kuntze, 1. c. - Syria; Arabia.

LAURENTIA, Michx. (Campanu1.). - Ind. Kew. ii. 39

ovatifolia, Robinson, in Proc.Am.Acad.xxvi. (1891) 166. - Mexic.

I.AURIDIA, Eckl. \& Zeyh. = Elaeodendron, Jacq. (Celastr.).
LAURIDIA :-

multiflora, Engl. Bot. Jahrb. x. (1889) 38. - Afr. austro-occ, extratrop.

LAUROCERASUS, [Tourn.] M. Roem.= Prunus, Linn. (Rosac.).

colchica, Hort. ex Dippel, Handb. Laubholzk iii. (1893) $649=$ P. Laurocerasus, Limn.

myrtifolia, Hort. ex Dippel, 1. c. 650 et $736=$ P. lusitanica, Linn.

LAUTEMBERGIA, Baill. = Alchornea, Sw, (Euphorb.).

coriacea, Pax, in Engl. \& Pranti, Natürl. Pflanzenfam. iii. $5(1890) 56=$ A. coriacea, Mrtll. Arg.

LAVANDULA, Tourn, ex Linn. (Labiat.). Ind. Kew. ii, 43.

Allardi $X, F$. Hy, in Bull. Herb. Boiss, iii. Append. I. (1895) 16. - Gall.

azrigerana, Mailho, in Bull. Soc. Bot. Rochel. (1889) $42=\mathrm{L}$. Spica, Cav.

bipinnata, Kuntze, Rev. Gen. (1891) $521=\mathrm{L}$. Burmanni, Benth

Burnati $X$, Briq. Lab. Alp. Marit, iii. (1895) 468. - Gall. mer.

foliosa, Christ, in Bot, fahro. ix. (18s8) 130. - Ins. Canar.

hybrida, Reverchon, ex Briq. Lab. Alp. Marit. iii. (1895) $469=$ L. Spica, Cav.

macra, Baker, in Kew Bull. (1894) 339. - Arabia.

LAVATERA, Linn. (Malv.). - Ind. Kew. ii. 43. Davaei, Pereira Continho, in Bolet. Soc. Brot. xi. (1893) 122. - Lusit,

microphylla, Baker, $f$. in fourn, Bot. xxviii. (1890) 211. - Marocco

pscudo-trimestris, Rouy, ex Pereira Continho, in Bolet. Soc. Brot. xị. (1893) 127, in obs。= trimestris, Linn.

Rigoi, Porta, in Nuoc. Giom. Bot. Ital. xix. (1887) 300. - Ins. Balear.

stenopetala, Coss. \& Durieu, [in Bourg, Pl. Algír. exsicc. (1856)] ex Batt. et Trab. Fl. de l'Algér. [Dicot.] (1885) 113 ; Coss. Ill. Fl. Alg. ii. (1893) 8 t. 100. - Algeria.

LAVAUXIA. Spach = Oenothera, Linn. (Onagrar.)

brachycarpa, Britton, in Mem. Torrey Bot. Club, v. (1894) $235=$ Oe. brachycarpa, Britton.

triloba, Raim. in Engl. \& Prantl. Natürl. Pflanzenfam. iii. 7 (1893) $215=$ Oe triloba, Nutt.

LAVIDIA, Phil. in Anal. Univ, Chil. lxxxv. (1894) S37. COMPOSITAE

caespitosa, Phil. l. c. - Potag.

LAVIGERIA, Pierre, Fl. For. Cochinch. Fasc. 17 (1892) sub t. 267. OLACINEAE

macrocarpa, Pierre, l. c. (- Icacina nacrocarpa. Oliver). - Ins. Fernando-Po.

salutaris, Pierre, l. c. - Congo gall.

LAVOISIERA, DC. (Melast.). - Ind. Kew. ii. 44 angustifolia, Cogn. in Mart. Fl. Bras, xiv. IV (1888) $5 \% 5 .-$ Bras.

caparaoënsis, Schwacke \& Cogn. ex Schwacke, in Bot. Fahb. xii. Beibl. n. 28 (1890) 10 ; et in DC. Monog. Phan. vii. (1891) 95. - Bras.

minor, $\operatorname{Cog} n$, l. c. 94 - Bras.

paulensis, Cogn. l. c. 89. - Bras

Schwackeana, Glaziou, ex Cogn. l. c. 90. - Bras.

uliginosa. Cogn. l. c.8E. - Bras.

LAWEA berberifolia "Lindl. " ex Dippel, Handb. Laubholzk. iii. (1893) 601, sphalm. (= Lowed berberifolia, Lindl.) = Rosa berberifolia, Pall.

LAWIA, Griff. ex Tul. = Terniola, Tul. (Podost.). Dalzcllia, Kuntze, Rev. Gen. (1891) $56 \%=\mathrm{T}$. Lawii, Wedd.

foliosa, Kuntze, 1, c. = T. foliosa, $W c d d$.

pedunculosus, Kuntze, 1. c. = T. pedunculosa, Wedd. ramosissima, Kuntze, 1. c $=$ T. ramosissima, Wedd.
LAYIA. Hook. \& Arn. (Compos.). - Ind. Kew, ii hispida, Greene, Pittonia, ii. (Nov. 1889)20. - Calif.

LAZAROLUS, Medic. = Pyrus, Tourn. (Rosac.). Pollverit. "Medic. " ex Gard. Kew, i. Polypet. (1894) $17 \%(=$ L. Pollveria, Medic. $)=$ Pyrus auricularia, $K n o o p$.

LEANDRA. Raddi (Melast.), - Ind. Kew. ii. 45. acuminata, $\operatorname{Cog} n$. in Mart. Pl. Bras. xiv. Iv. (1886) 143. - Bras.

arutiflora, $\operatorname{Cogn}$. l. c. 162 (= Clidemia acutiflora, Naud.). - Bras.

adenothrix, Cogn.l. c. 165. - Bras.

alpestris, $\operatorname{Cog} n$. l. c. 128 (= Clidemia alpestris, Gardn.). - Bras.

alterninervia, Cogn.l.c. 115. - Bras.

anisophylla, Cogzr, l, c. 186 (= Clidemia anisophylla. DC.). - Guiana.

aptera. $\operatorname{Cogn}$. l. $c .12 \%(=$ C. aptera, DC $)$. - Bras. aristigera, $\operatorname{Cog} n$. l. c. 185 (= Oxymeris aristigera Triana). - Bras. Peruv.

aspera, Cogn. in DC. Monog. Phan. vii. (1891) 655. - Bras.

atrata, Cogn. in Mart. Fl. Bras. xiv. Iv. (1886) 189 - Bras.

atropurpurea, Cogn. l. c. $106 .-$ Bras.

atroviridis, Cogn, in DC. Monog. Phan. vii. (1891) 644. - Bras.

attenuata, $\operatorname{Cog} n$. l. c.617. - Bras.

aurea, Cogn. in Mart. Fl. Bras. xiv. Iv. (18S6) 142 (= Clidenia aurea, Cham.). - Bras.

australis, Cogn.l. . 104 (=C. australis, Cham.).Bras.

Balansaei, $\operatorname{Cog} n$. l. c. 106. - Parag.

barbinervis, Cogn.l.c. 159(= Oxymeris barbinervis, Cham.). - Bras,

Bergiana, Cogn. l. c. 89:- Bras,

Blanchetiana, $\log n$. l. c. 122. - Bras.

Boissieriana, Cogn. in Mart. Fl. Bras, xiv. IV. (1886) 184. - Peruvia.

boliviensis, Cogn. ex Rusby, in Mem. Torrey Bot. Clnb, iii. 3 (1 593 ) 29. - Bolivia.

Brackenridgrei, Cogn.l. c. 179 (= Oxymeris Brackenridgei, Trian.). - Bras.

breviflora, $\log _{n}$. l. c. 182. - Bras.

calvescens, Cogn. l. c. 170 (= Oxymeris calvescens, Triana). - Bras.

cancellata, Cogn.l. c. 103. - Bras

carassana, Cogn. l. c. 120 (= Clidemia carassana, DC ) - Bras.

cardiophylla, Cogn.l. c. 99. - Bras.

catharinensis, Cogn. in DC, Monog. Phan, vii. (1891) 118s. - Bras.

chaetocalyx, Cogn. in Mart. Fl. Bras. xiv. :V. (18s6) 168 (= Clidemia chaetocalyx, A. Gray). - Bras. chaetodon, $\operatorname{Cog} n$. l. c. 178 (= C. chutetodon, Naud.). - Am. trop.

ciliolata, Cogn. in DC. Monog. Phan. v1i. (1891) 663. - Bras.

cinerea, Cogn. in Mart. Fl. Bras. xiv. IV. (1856) 71 (= Clidemia cinerea, Griseb.). - Cuba.

cinnamomea, Cogn.l.c. $77(=$ Oxymeris cinnamonea, Triana). - N. Granat.

circumscissa, Cogn.l.c.154. - Bras

confusa, Cogn.l. c. 119. - Bras.

cordifolia, Cogn. l. c. $98(=$ Clidemia cordifolia Naud.). - Bras.

cordigera, Cogn. l. c. $166(=$ Oxymeris cordigera, Triana). - Bras.

coriacea, $\operatorname{Cog} n$. l. c. 608 . - Bras

cornioides, Cogn. l. c. $761=$ Oxymeris comioides, Triana). - Mexic.

costaricensis, Cogn. in DC. Monog. Phan. vii. (1891) 658; ct ex Th. Dur of Pitt. in Bull. Soc. Bot. Belg, xxx. 1891 (1892) 248. - Costarica.

crenata, $\operatorname{Cogn}$. in Mart. Fl. Bras. xiv. IV. (1886) 137 (= Clidemia crenata. Don). - Bras.

cuneata, $\operatorname{Cog} n$. l. c. $161(=C$. cuneatu, Naud.).- Bras.

cuspidata, $\operatorname{Cog} n$. l. c. 175 (= Oxymoris cuspidata, Triana). - Bras.

dasytricha, Cogn.l. c. 113 (= Clidemia dasytricha, A. Gray). - Bras.

debilis, Cogn.l.c.174 (=C.debilis, Naud.). - Bras، 
LEANDRA :-

deflexa, Coon in Mart. Fl, Bras, xiv. IV.'(1886) 168 (= Oxymeris deflexa. Triana) - Bras

dendroides, $\operatorname{Cognz}$. ᄂ. c. 190 (= O. dendroides, Triana). - Bras.

dentata. Cogn. in DC. Monog. Phan. vii. (1891) 662. - Bras.

dichotoma, Cogn, in Mart. Fl. Bras, xiv. IV. (1886) 200 (=Clidemia dichotoma, D. Don). - Am, trop. diffusa. $\operatorname{Cog} n$. . . c. 146. - Bras.

dispar, Cogn.l. c. 117 (= Clidemia dispar, Naud.). - Bras.

divaricata, Cogn. I.c. $196(=$ C. divaricata. Naud.). - Afr. trop.

dolichanta, Cogn.l.c. 105 (=C.dolichantha, Naud.). - Bras.

dolichodons, $\operatorname{Cogn}$. l. c. 176. - Bras.

echinata, Cogn. l: c. 60\%. - Bras.

Eggersiana, Cogn. in DC. Monog. Phan. vii. (1891)

641. - Ins. Jamaica.

Eichleri, Cogn. in Mart. Fl. Bras,-xiv. Iv. (1886) 140. - Bias.

erinacea, Cogn. l. c. 98. - Bras.

eriocalyx, Cogn. in DC. Monog. Phan, vii. (1891) 642. - Bras

erostrata, Cogn. in Mart. Fl. Bras, xiv. IV. (18S6) 139 (=Clidemiz crostrata DC.) - Bras.. Bolivia. fallax, Cogn.l.c. $125(=C$. fallax, Cham.).-Bras. fastigiata, $\log _{n 2}$. l. c. 154. - Bras.

Fendleri, Cogn. l. c. 145. - Venezuela.

flavescens, Cogn. in DC. Monog. Phan, vii, (1S91) 631. - Bras.

floribunda, Cogn. in Mart. Fl. Bras, xiv. IV. (1886) 135 (= Oxymeris floribunda, Triana). - Bras.

fluminensis, Cogn.l.c. 169. - Bras.

foveolata, Cogn.l. c. 100 (= Clidemia foveolata, DC.). - Bras.

fragilis, $\operatorname{Cog} n$. . . c. 88. - Bras.

Francavillana, Cogn.l.c. 197. - Bras.

Freyreissii, Cogn. l. c. 190. - Bras.

fulva, Cogn. in DC. Monog. Phan. vii. (1891) 658. - Costarica.

Gardneriana, Cogn. in Mart. Fl, Bras, xiv. IV, (1886) 96. - Bras.

glabrata, Cogn.l.c.172 (= Clidemia glabrata, Bunbury). - Bras.

glandulifera. Cogn. l. c.207 $(=$ Oxymeris glandulifera. Triana). - Bras.

Glazioviana, $\operatorname{cog}$ n.l.c. 86. - Bras.

gracilis, Cogn. l. c. 163. - Bras.

grandifolia, $\operatorname{cogn}$. in DC. Monog. Phan. vii. (1891) 690 ; et ex Th. Dur. of Pitt, in Bull. Soc. Bot. Belg. xxx. 1891 (1892) 250. - Costarica

Grayana, Cogn. l. c.665 - Bras.

Herincquiana, Cogn. in Mart. Fl. Bras, xiv. IV. (1886) 129. - Paras.

heterobasis, $\operatorname{Cogn}$.l. c. 193 - Bras.

hirtella, Cogn. l. c. 187. - Bras.

horrida, Cogn. in DC. Monog. Phan. vii. (IS91) 1188. - Biras.

inaequalifolia, $\operatorname{Cog} n$. in Mart. Fl. Bras. xiv IV. (1886) 206 (=Clidemia inaequalifolia, DC.).-Bras.

intermedia, $\operatorname{Cogn}$. l. c. 193 (= Oxymeris intermedia, Triana). - Bras.

ionopogon. Cogn.l. c.129 (=O. ionopogon, Triana). - Bras.

Itatiaiae, $\operatorname{Cog} n$. l. c. $173(=0$. Itatiaiae, Wawra),

laevigata, Cogn. l. c. $177(=0$. lavvigata, Triana). - Bras

lancifolia, $\operatorname{Cog} n$. . . . . 145. - Bras.

lacunosa, Cogn.l.c. 138. - Bras.

lasiopetala, Cogn. ex Th. Dur. E Pitt. in Bull. Soc. Bot. Belg. xxx. 1891 (1892) 249. - Costarica.

lasiostachya. Cogn. in Mart. Fl. Bras. xiv. IV. (1866) 172. - Bras

laxa, Cogn. in DC. Monog. Phan. vii. (1891) 642. Bras.

Lehmannii, Cogn. in Bot. Fahrb. viii. (18s7) 20; et l. c. 657. - Columb.

limbata, Cogn. in Mart. Fl. Bras, xiv. IV. (1886) 180. - Bras.

Lindeniana, Cogn. l. c. 136. - Bras

linearifolia, $\operatorname{Cog} n$. l. c. 149. - Bras.

longibarbis, Cogn. l. c. $107(=$ Clidemia longibarbis, DC ). - Bras.

\section{LEANDRA: -}

longicoma, Cogn. in Mart. Fl. Bras, xiv, IV. (1886) 202. - Bras.

longisetosa, Cogn.l. c. 181. - Bras

longistyla, $\operatorname{Cog}$. . . c. 80. - Bras.

lutea, Cogn. l. c. 152. - Bras

macropora, Cogn. l. c. 171 (= Oxymeris macropora, Triana). - Bras.

melanodesma, Cog 3 . I. c. 72 et 115 (= Clidemia me lanodesma, Naud.). - Am. trop.

membranifolia, Cogn. in DC. Monog. Phan, vii. (1891). 682 - Bras.

mexicana, Cogn. in Mart. Fl. Bras, xiv. IV. (1886) 57 (= Clidenia mexicana, $\operatorname{Cogn}$.). - Mexic. Guatem.

miconiastrum, $\operatorname{Cogn}$. l. c. $147(=$ C. miconiasimum, Naud.). - Bras.

micropetala Cogn, l. c. $205(=$ C. micropetala Naud.). - Bras.

microphylla, Cogn. in DC. Monog. Phan. vii. (1891) 6.55. - Bras.

mollis, Cogn, in Mart. Fl. Bras, xiv. IV. (I‘86) 126 - Bras.

Mosenii. Cogn. l. c. 114. - Bras.

Mouraei, $\operatorname{Cogn}$ in DC. Monog. Phan. vii. (1891) 663. - Bras.

multiplinervis, Cogn. in Mart. Fl. Bras, xiv. IV (1886) 180 (= Clidemia multiplincrvis, Naud.). Am. trop.

multisetosa, Cogn, in DC. Monog. Phan. vii. (1891) 632. - Bras.

nervosa, Cogn, in Mart. Fl. Bras, xiv, IV. (18S6) 73 (=Clidemia venosa, Naud.). - Peruv., Ecuad neurotricha, $\operatorname{Cogn}$. . c. 160. - Bras.

Nianga, Cogn.l. c.96 (=Clidenia Nianga, DC. $)$.Bras,

niangaeformis, Cogn. l. c. 93. - Bras.

Niederleinii, Cogn. in 1)C. Monog. Phan. vii. (1891) 1188. - Reg. Arcent.

nutans, Cogn. in DC. Monog. Phan. vii. (1891) 676 - Bras.

oblongifolia, Cogn. l. c. $649^{\circ}$ - Bras

oligochaeta, Cogn, in Mart. Fl. Bras. xiv, IV. (1886) 101 (= Clideniza oligochaeta, Cham.). - Bras.

organensis, Cogn. in DC. Monog. Phan. vii.(1891) 659. - Bras.

organensis, $\operatorname{Cogn}, 1$. c. $622=$ therezopolitana, $\operatorname{Cog} n$ ossaeoides, Cogn. in Mart.Fl. Bras, xiv. Iv. (1886) 75. (= Clidemia ossaeoides, Naud.), - Venez.

ovata, Cogw. l. c. 134. - Bras.

pallida, Cogn. l. c. 167. - Bras.

papillata, $\operatorname{Cog} n$. l. c. 108. - Bras.

paraguayensis, Cogn. l. c. 208 (= Oxymeris para guayensis, Triana). Paras.

parvifolia, $\operatorname{Cogn}$. in Mart. Fl. Bras, xiv. IV. (1886) 150. - Bras.

pectinata, Cogm. . . . 78. - Bras.

penduliflora, $\operatorname{Cog} n$. i.c. 176 (=Clidemia penduliflora Naud.). - Bras.

pennipilis, $\operatorname{Cog} n$, l. c. 144 (= Oxymeris pemipilis, Triana). - Bras.

Pickeringii, Cogn. l. c. $183(=0$. Pickeringii Triana). - Bras.

pilosissima, Cogn. l. c. 130. - Bras.

polychaeta, Cogn. in DC. Monog. Phan. vii. (1891) 1186. - Bras

polystachya, Cogn, in Mart. Fl. Bras. xiv. IV. (1886) 132 (= Clidemia polystachya, Naud.). - Bras.

pubescens. $\operatorname{Cog} n$. l. c. 188 (= Oxymeris pubescens, Triana). - Bras.

pulchra, $\operatorname{Cogn}$. l. c. 163. - Bras.

pulverulenta, $\operatorname{Cogn}$. 1. c. $138=$ Grayana, $\operatorname{Cog} n$.

pulverulenta, Cogn, l. c. $208(=$ Oxymeris pulveru

Ienta, Triana). - Guian. gall.

purpurascens, Cogn.l.c.110i=Clidemia purpura scens, DC.). - Bras.

pustulata, Cogn, in DC. Monog. Phan, vii. (1891) 636. - Bras.

quinquedentata, Cogn, in Mart, Fl. Bras, xiv. IV (1886) 156 (= Oxymeris quinquedentata, DC.). Bras.

quinquenodis, $\operatorname{Cog} n$. l. . . $157(=0$. quinquenodis, DC.). - Bras.

refracta, Cogn.l. c 186. - Bras.

Regnellii, Cogn. l. c. $116(=$ Oxymeris Regnellii, Triana). - Bras.

\section{LEANDRA}

etropila, Cogn. in Mart. Fl. Bras, xiv. IV. (1886) 195. - Bras. Peruvia.

reversa, Cogn. l. . 198 (= Oxymeris reversa, Triana). - Bras.

Thamnifolia, Cogn. l. c. 194 (= Clidemia rhamnifolia,

Naud.) - Bras.

rhodopogon, Cogne.l.c. 109 (= C. rhodopogon, DC.).

ribesiaeflora, Cogn. l. c. 121 (= C. ribesiaeflora, Cham.). - Bras

Riedeliana, Cogn. l. c. 164 (= Oxymeris Riedeliana.

Triana). - Bras.

rigida, $\operatorname{Cog} 7$. l. c. 134. - Bras.

rubida, Cogn. in DC. Monog. Phan. vii. (1891) 679. - Bras.

rufescens, Cogn. in Mart. Fl. Bras, xiv. IV. (1886) 204 (= Tschudya rufescens, DC.). - Bras. Guiana

salicina, Cogn."2. c. 150 (= Melastona salicina, Sw ). - Bras.

Schwackei, $\operatorname{Cog} n$. l. c. 610. - Bras.

secunda, Cogn. l. c. $199(=$ Oxyneris secunda,

Triana). - Bras., Peruv.

secundiflora, Cogn.l. c. 195 (= Clidemia secundzflora, DC.). - Bras. Peruv.

sessiliflora, $\operatorname{Cog} n$. . . . .610. - Bras.

sessilifolia, $\operatorname{Cogn}$. l. c. $75(=$ Oxymeris sessilifolia,

Triana). - N. Granat.

simplicicaulis, Cogn. l.c. 14I (= Clidemia simplicicoutlis, Naud.j. - Bras.

solenifera, Cogn. l. c. 192 (= Melastoma. solenifera, Triana). - Am. trop.

strigilliflora, $\operatorname{Cogn}$. l. c. 126 (= Clidemia strigilliflora, Naud.). - Bras.

Saldanhaei, Cogn. in DC. Monog. Phan. vii. (1891) 666. - Bras.

Schenckii, Cogiz. l. c. 636. - Bras

sphaerocarpa, Cogn. . . c. 676. - Bras

stellulata, Gogn. ex Britton, in Bull. Torrey Bot. Chub, xvii. (1890) 58; et in DC. Monog. Phan. vii. (1891) 660. - Bolivia.

sublanata, Cogn. in Mart. Fl. Bras, xiv, IV. (1886) 118. - Bras

subtrinervis, Cogn。 in DC Monog. Phan。vii. (1891) 67\%. - Bras.

subseriata, Cogn its Mart. Fl. Bras, xiv. IV. (1886) 73 (= Clidemia subscriata, Naud.). - Am. trop.

sulfurea, $\operatorname{Cog} n$. l. c. $153(=$ C. sulfurea, Naud.).Bras.

sylvatica, Cogn.l. c. 131. - Bras.

tetrarona, Cogn. in DC. Monog. Phan, vii. (1891) 635. - Bras

tetraptera, Cogn, in Mart. Fl. Bras, xiv. Iv.(1886) 111. - Bras.

tetraquetra, Cogn. l. c.'112(=Clidemia tetraquetra, Cham.). - Bras.

ternata. Cogn. l. c. 142. - Bras.

therezopolitana, Cogn. in DC. Monog. Phan. vii. (1891) 1186. - Bras.

tomentosa, $\operatorname{logn}$. in Mart. Fl. Bras. xiv. IV. (188s) 609. - Bras.

trauninensis, Cogn, in DC. Monog, Phan, vii. (1891) 666. - Bras.

tristis, Cogn. l. c. 1187 . Bras.

Ulaei, Cogn. l.c. 1186. - Bras

Urbaniana, Cogn. in Mart. Fl. Bras. xiv. IV. (1886) 148 - Bras.

urophylla, Cogn. l. c. 184 (= Oxymeris urophylla, Triana). - Bras.

velutina, Cogn. l. c, 155 (="Clidemia vehtina, Naud. - Bras.

verticillata, Cogn. l. c. $203(=$ Tschudya verticillata, DC.). - Guian. gall.

vesiculosa, $\log n$, l. c. loss. - Bras.

viscosa, Cogn. 7. c. 133. - Bras.

Warmingiana, $\operatorname{Cog} \eta . l$. c. 102.-Bras.

xanthocoma, Cogn.l.c.124 (= Clidemiat xanthocoma,

Naud,). - Bras.

santholasia, Cogn. l. c. $94(=$ C. xantholasia, DC - Bras.

xanthopogon, $\operatorname{Cogn}$. l. c. $123(=$ C. xamthopogon

Naud.). - Bras.

xanthostachys, $\operatorname{Cog}$ \%. l.c. 93. - Bras. 
LEAVEN WORTHIA, Torr. (Crucif。) - - Ind. Kew. ii. 45 .

miflora, Britton, in Mem. Torrey Bot. Club, v. (1894) 171 = Michauxii, Torr.

LEBECKIA, Thunb. (Legumin.). - Ind. Kew, ii. 45.

inflata, Baker, in Hook, Icon. ploxvi. (1887) t. 1576. - Afr, austr.

longipes, Bohls, in Hook. l.c. t. 1552. - Afr. austr. retamoides, Baill. Hist. pl. Madag., Atlas (1885) t. $44 \mathrm{C}$ - Madag

Wrightii, Bolus, in Hook. Icon. pl. xvi. (1887) sub t. 1552. - Afr, austr.

LEGANORCHIS, Blume (Orchid.). - Ind. Kew. ii. 46.

malaccensis, Ridl. in Trans. Limn. Suc. Ser. II. iii. (1893) 371. - Penins. Mal.

LECANOSPERMA. Rusby, in Bu11. Torrey Bot. Club, xx. (1893) 430. RUBIACEAE.

lycioides, Rusby, l.c. 431 , t. 148. - Bolivia.

LEGHEA, Kalm (Cistin.), - Ind. Kew, ij, 46. divaricata, Shuttlew. ex Britton, in Bull. Torrey Bot. Clut, xxi.(1894) 249. - Florida.

intermedia. Leggett, ex Britton \& Hollick, in Rep. Geol. Surv. New Jersey ii. (1889) $54=$ Leggettii, Britton \& Hollcck

Legrettii, Britton \& Hollick, ex Britton, Stcrn \& Poggenb. Prelin. Catal. (1888) 6. - Am. bor.

mavitima, Leggett, ex Britton \& Hollick, in Rep. Geol. Surv. New Jersey, ii. (1889) $56=$ thymifolia, Michx.

stricta, Lrggett, ex Britton, in Bull. Torrey Bot. Club, xxi. (1894) 251.- Am. bor

Iripetala, Britton, 1. c. $252=$ Skinneri, Benth.

LECONTEA, A. Rich. (Rubiac.), - Ind. Kew. ji.

farinosa, Baker, in fourn. Linn. Soi. xxii. (1887) 486. - Madag.

LECOQUIA, Caruel, İpit. F1. Eur. ii. (1894) 261 $=$ Lecokia, DC. (Umbell.).

LEDOCARPUM, DC. = Balbisia, Cav.(Geran.). microphyllum. Phil. in Anal. Mus. nac. Chite (1891) 11. - Am. austr. occ.

LEEA, Royen, ex Linn. (Ampelid.). - Ind. Kew. ii. 47.

cuspidifera, Baker, in foum. Linn. Soc, xxii. (1887) 461. - Madag.

Naumanni, Engl. Bot. Fahrb. vii. (1886) 466. Melanesia.

LEERSIA, Soland. (Gramin.). - Ind. Kew. ii. 48.

japonica, Makino, in Tokyo Bot. Mag.vi. (1892) 48. - Japon.

oryzoidea, "Linn. ) ex St. Lager, in Cariot, Etud, des fl. éd. S ii. (1889) $899=$ oryzoides, Sm.

LEFEBURIA, A. Rich. (Umbell.), - Ind, Kew. benguelensis, Welw, ex Engt. in Abh. Prenss, Akad. Wiss. 1891 (1892) 322. - Angola.

longipedicellata, Engl. Pflanzenw. Ost-Afr. C (1895) 300. - Afr. trop. Or.

Stuhlmannii, Engl.l.c. - Afr. trop. or.

Upingtoniae, Schinz, in Bull. Herb. Boiss, ii. (1894) 206. - Afr. austro-occ. extratrop.

Welwitschii, Enst. in Engl. en A6\%. Prenss. Akad. Wiss. 1891 ; 1892) 322. - Argola.

LEFROVIA, Franch. in Morot, Journ. de Bot, ii. (1888) 378. COMPOSITAE.

rhaponticoides, Franch.l.c.-Bolivia.

IEGOUSIA, Durande, ex Hedw. = Specularia, Heist. (Campanul.).

lijbridd, Gérard, in Rev. bot.(1890) 168 [sphalm. Legouxia] $=$ S. hylorida, $A . D C$.
LEGGOUZIA, Delarbre = LEGOUSIA, Durande $=$ Specularia. Heist. (Campanul.).

biflora, Britton, in Mem. Torrey Bot. Club, v. (1894):09= S. biflora, $A$. Gray.

coloradoense, Heller, in Contrib. Herb. Frankl. and Marsh. Coll. i. [Bot. Explor. S. Texas] (1895 $99=\mathrm{S}$. Lindheimeri, Vatke.

leptocarpa, Britton, 1. c. = S. leptocarpa. A. Gray. perfoliata, Britton, in Mem. Torrey Bot. Club, y. (1893) $309=$ S. perfoliata. A. DC.

LEHMANIELLA, Gilg, in Engl. \& Pranti Natürl. Pflanzenfam, ii. 2(1895) 101. GENTIA $N E A E$

acuminata, Gilg. l. c. - Columbia vol. Ecuad. ?

LEIOCHILUS, Knowles \& Westc = Leochilus Knowles \& Westc. (Orchid.)

labiatus, Kuntze, Rev, Gen.(1891) $656=$ L. cochlearis, Lindl.

LEIOLUMA, Baill. Hist. des pl. xi. (1892) $285=$ Lucuma, Molina (Sapot.).

pubens, Baill, 1. c. = L. pubens, Mart. \& Miq.

LEIOPHYLLUM, Hedw. f. (Ericac.). - Ind Kew, ii. 49 .

fyrolaefiorum, Dippel, Handb. Laubholzk, i. (1889) $436=$ Tolmiea occidentalis, Hook

LEIPHAIMOS, Schlecht. \& Cham = Voyria Aubl. (Gentian.).

angustiloba, Gilg, in Engl. \& Prantl, Natürl. Pflanzenfam. iv. 2 (1895) $104=$ V. angustiloba Spruce.

aphylla, Gilg, 1. c. = V. aphylla, Pers.

azurea. Gilg, 1. c. 105. - Venez.

clavata. Gilg. 1. c. = V. clavata, Splitg.

corymbosa, Gilg, 1. e. = V. corymbosa, Splitg.

flarescens, Gilg, 1. c. = V. flavescens, Griseb.

lencantha, Gilg. 1. c. = V. leucantha, Miq.

nivea, Gilg, 1. $\mathrm{c}_{0}=\mathrm{V}$, nivea, Miq.

muda, Gilg, 1. c. = V. nuda, Splitg.

obconica, Gilg, 1. c. = V. obconica. Progel.

platypetala. Gilg, 1. c。 = V. platypetala. Baker.

primuloides, Gilo, 1. C, $=$ V.primuloides, Baker.

Spruceana, Gilg, 1. c. $105=$ V. Spruceana, Benth.

sulphurea, Gilg. 1. c. = V. sulphurea, Prog.

trinitonsis, Gilg, 1. c. = V. trinitensis, Griseb.

LEITGEBIA, Eichl. (Violar.). - Ind. Kew, ii.

im-Thurniana, Oliver, in Trans. Linm. Soc. Ser. II ii. (1887) 271, t. 37; Oliver, ex im Thurn, in Timehri, v. (J886) 189. - Guian. ang1.

LEMNA, Linn. (Lemnac.). - Ind. Kew. ii. 50 disperma. Hegelm. in Bot fahrb. xxi. (1895) 290. Austral.

LEMURORGHIS, Kraenzl. in Bot. Jahrb. xvii (1893) 58. ORCHIDEAE.

madagascariensis, Kraenzl. i. c.58. - Madag.

LENS, [Tourn.] Linn. (Legumin.). - Ind. Kew. ii. 51.

Linticula, Batt. in Bull. Soc. Bot. Fr, xxxiv. (1887) $388=\mathrm{L}$. Lenticula, Alef

villosa, Batt. in Batt. \& Trab. F1. de l'Algér. [Dicot.] 1889) $27 \%$ (=Errum rillosum. Pomel) - Alger.

LENTISCUS, Linn.= Pistacia, Linn. (Anacard) atlantica, Kuntze, Rev. Gen. (1891) $152=\mathbf{P}$ atlantica, Desf.

chinensis, Kuntze, 1. c. $153=$ P. chinensis, Bunge

Kakrasinghee, Kuntze, 1. C. $152=$ P. Khinjuk Stocks.

mexicana, Kuntze, 1. c. $153=$ P. mexicana, $H$ $B$. \& $K$.

musica, Kunize, 1. c = P. mutica, Fisch. \& Mey.

Tercbintlus, Kuntze, 1. c. $=$ P. Terebinthus Linn

vera, Kuntze, 1. co = P, vera, Limn。
LENZIA, Phil. (Amarant.). - Ind. Kew, ii. 51. vernonioides, Sch. Bip.ex Phit. in Anal. Unit. Chit. xci. (1892) 414. - Chili.

LEONITIS, Spach = Leonotis, R. Br. (Labiat.). malacophylla, Guerke, in Bot. Jahrb, xxii. (1895) 142. - Natal.

mollissima. Guerke, 1. c. 141. - Afr. trop.

Schinzii. Guerke, 1. c. $143-$ Afr. austro-oce

LEONOTIS, R. Br.(Labiat.). - Ind, Kew, ji, 51 Backmannii Guerke in Bot, Jahrb, xxii, (1895) 143. - Transv., Natal.

decadonta, Guerke, 1. c. 144. - Afr. trop. or.

latifolia, Guerke, 1. c. 143. - Natal.

laxifolia. MacOwan, in Kew Bull. (1893) 13. Afr. austr.

LEONTICE, ${ }_{\infty}^{\varepsilon}$ Linn. (Berberid.). - Ind. Kew. ii. 51 .

alpina, Haláczy, in Denkschr. Akad. Wien, Ixi. (1894) 493 = altaica, Pall

LEONTODON, Linn. (Compos.). - Ind, Kew. ii.

ciliatus, Terrac, in Ann. Ist. bot. Roma, iv, 1889-90 (1891) 174 - Apargia citiata, Presl $)=$ Preslii, $D C$.

clavatus, Sacrorsky \& Schneider, Fl. Centrallkarpat (1891) 254 : et ex Pötfuzetek (1892) $141=\mathrm{L}$. Taraxaci, Loisel.

Djurdjurae, Coss. \& Durieu, ex Batt. \& Trab. Fl. de l'Algér. [Dicot.] (1889) 541. - Algeria.

Ehrenbergii, Hort. Kew. ex Gard. Kew, Herb. Pl. (1895) 259 (= Hemitepis Ehrembergii, Kuntze). Hab.

Haussnechtii, Uechtr. ex Hausskn。 in Mitth. Bot. Ver. Fcna, v. (1887) 87. - Graecia.

hispanicum, Batt. in Batt. \& 'Trab. Fl. de l'Algér, [Dicot.] (1889) $540=$ hispanicus, Poir.

lcontodontoides, Batt. in Batt. \& Trab. 1. c. $539(=$ Millina leontodontoides, Cass.) $=$ fasciculatus, Nym.

medius, Simonk, in Bot. Centralbl. xlix. (1892) 268 (= Apargia media, Host) = pyrenaicus, Gouan.

mudicanle, Porter, in Mem. Torrey Bot. Club, v (1894) $348=$ hirtus, Linn.

Reboudianum, Batt. in Batt. E Trab. Fl. de l'Algér. [Dicot.] (1889) 540 (= Fidelia Reboudiana, Pomel). - Algeria.

Rererchoni, Freyn, ex Willk. Suppl. Prodr. F1. Hisp. (1893) 109; et in Bull. Herb. Boiss. i. (1893) $547=$ pyrenaicus, Goman.

Salzmanni. Batt, in Batt. \& Trab. F1. de l'Algér. [Dicot.] (1889) $540=$ Salzmanni, Ball.

tingitanum, Batt. in Batt. \& Trab. Fi. de I'Algér [Dicot.] (1889) $539=$ tingitanus, Ball.

uberosum, Batt. 1. c. = tuberosus, Linn.

LEONTOPODIUM, R. Br. (Compos.). - Ind. Kew. ii. 53.

linearifolium, Britton, in Bull. Torrey Bot. Club, xix. (1892) $148=$ linearifolium, Benth. \& Hook. f. Mariae, F. Muell. in Trans. Roy. Soc, Vict. New Ser. I. ii.( 1889) 8, in syn. = Anaphalis Mariae. F. Muell

sinense. Irmsl. ex Forb. \& Hemsl, in foum. Linn. Soc. xxiii. (1888) 424. t. 12. - China.

Stracheyi, C. B. Clarke, ex Hemsl. l. c. xxx. (1894) 136 - Reg. Himal., Tibet.

LEOPOLDIA, Parl. = Muscari, Mill. (Liliac.) maritima, Ostermeyer, in Verh. zool.-bot. Ges. Wien, xl. (1890) 299, in obs. = maritima, Parl. Spreitzenhoferi, Heldr. ex Ostermeyer, 1. c. Creta.

LEPACHYS, Rafin.(Compos.), - Ind. Kew, ii. 54. mexicana, S. Wats, in Proc. Am. Acad. xxiii. (18ss) 277. - Mexic.

LEPANTHES, Sw. (Orchid.), - Ind. Kew. ii. 54 Blumenawii, Prodr. Vellosia, 1885-88, Sec. ediç. (1891) 117. - Bras. bor. 
LEPANTHES :

carunculigera, Reichb. f. in Flora. 1xix. (1886) 557. - N. Granat.

costata, Reichb.f. l.c. - N. Granat.

cryptantha, Rodr. Vellosia, 1885-88, Sec. ediç. (1891) 120. - Bras. bor,

dasyphylla, Reichb. f. in Flora, 1xix, (1887) 557. N. Granat.

densiflora, Rodr. Vellosia, 1885-88, Sec, ediç (1891) 119. - Bras. bor

funerea, Rodr. l. c. 118. - Bras. bor.

gracilis, Rolfe, in Kew Bull. (1892) 208. - Hab. ?

Pilosella, Reicht. f. in Flora, Ixix. (1886) 556. - N. Granat.

plurifolia, Rodr. Vellosia, 1885-88 Sec. ediç. (1891) 118. - Bras. bor

quartzicola, Rodr. l. c. 119. - Bras, bor.

tracheia, Reichb. f. in Flora, 1xix. (1886) 557.Nov, Gran.

yauaperyensis, Rodr. Vellosia, 1885-88, Sec, ediç, (1891) 117. - Bras, bor.

LEPARGYRAEA, Steud. = LEPARGYREA, Rafin. = Elaeagnus, Linn

argentea Greene, in Pittonia, ii. (Dec. 1892) 122 $=$ Shepherdia argentea, Nutt.

canadensis, Greene, 1. c, = S. canadensis, Nutt.

roturdifolia, Greene, 1. c. = S. rotundifolia, Parry.

LEPERIZA, Herb. = Urceolina, Reichb. (Amaryll.).

miniata, Kuntze, Rev, Gen, (189i) $704=\mathrm{U}$. miniata, Benth. \& Hook. $f$.

urceolata, Kuntze, 1. $c_{0}=$ U. pendula, Herb.

LePiaglaiA, Pierre, Fl. For. Cochinch. Fasc, 21 (1895) sub t. $334=$ Aglaia, Lour. (Meliac.) pyramidata, Pierre, 1. c. = A. pyramidata, Pierre.

LEPIDAGATHIS, Willd. (Acanth.). - Ind. Kew. ii. 55 .

Andersoniana, Lindane, in Bot. Fakrb. xx. (1894) 16. - Afr. trop. or.

Caput-Medusae. S. Moore, in Engl. \& Prantl. Natiirl. Pfanzenfam. iv. 3b (1895) 313. - Afr. centr.

cephalotes, Kuntze, Rev. Gen. (1891) $492=$ hyalina, Nees.

Schweinfurthii, Lindau, in Bot. Fahrb. xx. (1894) 16. - Afr. centr. bor.

thymifolia, Colett. \& Hemst, in fourn. Linn. Soc. xxviii. (1890) 106. - Burma.

LEPIDARIA, Van Tiegh. in Bull. Soc. Bot. Fr xlii. $(1895) 439=$ Loranthus, Linn.

bicarinata, Van Tiegh. 1. c. 440.- Borneo,

biflora, Van Tiegh. 1. c. 441. - Ins. Philipp.

Forbesii, Van Tiegh. 1. c. $440=$ L. Forbesii King.

macrophylla, Van Tiegh. 1, c. - Borneo.

quadriflora, Van Tiegh. 1. c. 441. - Ins. Philipp. raginata, Van Tiegh. 1. c. — 440. - Borneo.

LEPIDIUM, Linn. (Crucif.). - Ind. Kew. ii, 56. arbuscula, Hillebr. Fl. Haw. Isl. (1888) 10. - Ins. Sandvic.

heterophyllum, M. E. Jones, in Zoë, iii. (1893) 284 $=$ integrifolium Nutt. var. heterophyllum, $S$. Wats

iberideun, Rouy \& Jouc. F1. de Fr, ii. (1895) $88=$ = graminifolium, Linn.

Jaredi, T.S. Brandeg. in Zoë, iv. (1894) 398; et in A. Gray \&o S. Wals. Syn. Fl. N. Am. i. 1. (1895) 124. - Calif.

Kirkii, Petrie, in Trans, N. Z. Inst. xxii, 1889 (1890) 439. - N. Zel.

lasiophyllum, T.S. Brandeg, in Proc. Culif. Acad. Ser. II. i. (1889) 207, sphalm = lasiocarpum Nutt.

Matau, Petrie, in Trans. N. Z. Inst. xix. 1886 (1887) 323. - N. Zel.

matritense, Pau, Not. bot. Fl. Espanr. i. (1887) 8. Hisp.

medium, Greene, in Erythea, iii. (1895) $36(=L$. intermedium, A. Gray). - Am. bor. occ.

\section{LEPIDIUM}

Merralli, F. Muell. in Vict. Natural. vii. (Dec. 1890) 114; et ex in Bot. Centralbl. xly. (1891) 124. Austral.

myrianthum, Phit, in Anal, Mus, nac. Chile, (1891) 5. - Chile.

oahuense, Hillebr. Fl. Haw. IsI. (1888) $10=$ owahiense, Cham. \& Schlecht.

ubtusatum, T. Kirk, in Tran

1891 (1892) 423. - N. Zel.

occidentale, Howell, in Erythea, iii. (1895) $32=$ Menziesii, $D C$.

orcganum, Greene, Fl. Francisc. (1891) 274 pr. p. = strictum, Rattan

oreanum, Howell [Pacif. Coast Pl. Coll. (1887)] ex

Greene, 1. c. pr. p. = dictyotum, A. Gray.

Palmeri, S. Wats. in Proc. Am. Acad. xxiv. (1889) 39. - Calif. austr

Pichleri, Boiss. Fl. Or. Suppi. (1888) 63. - Persia. Rahmeri, Phit. in Anal. Mus. nac. Chile. (1891) 5. Am. austr. occ.

Remyi, Drake, Fl. Polyn, Franç. (1890) 106. -- Ins. Sandvic.

Reverchoni, Debeaux, ex Willk. Suppl. Prodr. Fl. Hisp. (1893) 332. - Hisp.

rosulatum, Tornab. Fl. Sicul. (1887) 122. - Sicil.

scopulorum, M. E. Fones, in Proc. Calif. Acad. Ser. II. v.( 1895) 625, Robinson, in A. Gray et S. Wats, in Syn. F1. N. Am. New ed. i. 1. (1895) $125(=L$. heterophyllum. S. Wats.). - Am. bor occ.

utahense, M. E. Jones, in Zoë, iv. (1893) 226 = integrifolium, Nutt.

LEPIDOLOPHA, C. Winkl, in Act. Hort. Petrop. xiii. (1894) 236. COMPOSITAE.

Komarowi, C. Winkl.l. co - Turkest.

LEPIDOPETALUM, Blume = Ratonia, DC. (Sapind.).

hebecladum, Radlk, in Sitz. math.-phys, Akad. Muench.xx. (1890) 269. - N. Guin.

subdichotomum, Radlk, l. c. - N. Guin

xylocarpum, Radlk. l.c. - N. Guin.

LEPIDOSPARTUM, A. Gray (Compos.). - Ind, Kew. ii. 58.

latisquamum, S. Wats, in Proc. Am. Acad. xxv. (1890) 133. - Nevada.

striatum. Corille, in Proc.biol. Soc. Wash. vii. (1892) i3; et in Contrib. U. S. Nat. Herb. iv. (1893) 140, t. 11. - Calif.

LEPIDOSPERMA, Labill. (Cyper.), - - Ind. Kew. 1i, 58. Consp. Fl. Afr. v. $1894(1895) 662=$ Tetraria Rottboellii, C. B. Clarke.

LEPIDOTRICHUM, Velen. \& Bornm. in Oest Bot. Zeitschr. xxxix. (1889) 324; et in Bull. Soc. Dauph. Sér. II. i. (1890) 28, CRUCIFERAE.

Uechtritzianum, Velen.l. c. (1889) 324. - Bulg.

LEPIDOTURUS, Baill. (Euphorb.). - Ind. Kew. ii. 59. ilmifolius, Baill. Hist. pl. Madag., Atlas (1891) t. 201. - Madag.

LEPIGONUM, Wahlbg. = Spergularia, J. \& C. Presl. (Caryoph.)

tenue, Greene, Pittonia, i. (July 1887) 63. Calif.

LEPILAENA, J. Drum. (Naiad.). — Ind. Kew, ii. 59.

monandra, Petrie, in N.Zel. Fourn. Sc. i, (1891) 70 nomen. $-\mathrm{N}$. Zel.

LEPIONOPSIS, Valeton, in Annal. Jard. Bot Buitenz, xiii. 2 (1895) 252. APOCYNEAE. ternatensis, Valeton, l. c. 253, t. 28. - Ins. Ternat.
LEPISANTHES. Blume, (Sapind.). - Ind, Kew. ii 60 ,

cambodiana, Pierre, Fl, For. Cochinch. Fasc, 2I (1895) t. $326, \mathrm{~B}=$ tetrophylla, Radlh

canescens, «Radlk. » ex Pierre. 1. c. t. 325, B sphalm $(=$ Hemigyrosa caneecens, Thw. $)=$ tetraphylla Radlk.

mekongensis, Pierre, l. c. t. 326, - - Cochinch.

LEPISMIUM. Pfeiff. = Rhipsalis, Gaertn. (Cact.)

cavernosum, Lindb. ex K. Schum, in Mart. Fl. Bras. iv II. (1890) $289=\mathrm{R}$ cavernosa, $\mathrm{L} i n d b$.

dissimile, G. A. Lindberg, in Gartenfl. xxxix, (1890) 148, fig. 37 et 38 ; et ex Illustr. Hort, xxxix. (1890) 148 , fig. $338 .=\mathrm{R}$. dissimilis, $K$. Schum

LEPISTEMON, Blume (Convolv.). - Ind. Kew ii. 60 .

asterostigma, K. Schun, in Bot. Fahrb. ix. (1888) 217. - N. Guin.

binectariform, Kuntze, Rev. Gen. (1891) $446=$ L Wallichii, Choisy.

leiocalyx, Stapf, in Kere Bull. (1895) 113. - Ind. or. lignosum, Dammer, ex Engl. in Abh. Prenss. Akad. Wiss. (1894) 53; et in Engl. Pfauzenw. Ost-Afr. C (1895) 331 - Afr trop or.

Wallichit, Prain, in Journ. Soc. As. Beng. lxiii (1894) 11.111 = flavescens, Bhme.

LEPISTEIMONOPSIS. Dammer, in Engl. Pflanzenw. Ost.-Afr. C (1895) 331. CONVOLVULA$C E A E$.

Volkensii, Dammer, l. c. - Afr, trop. or.

LEPTAGTINIA, Hook. f. (Rubiac.). - Ind. Kew, ii. 60

Laurentiana. Deweure, in Bull. Soc. Bot. Belg. xxxiii. 21894 (1895) 102, nomen; et xxxiv. 2 (1895) 95. - Congo occ.

Leopoldi II, Buettno, in Verh. Bot. Ver. Brand. xxsi. (1889) 75 , - Congo.

LEPTALEUM, DC. (Crucif,), 一 Ind, Kew. ii. 60. hamatum, Hemsl. \& Lace, in fourn. Linn. Soc xxviii. (1891) t. 321. - Belutch. brit.

LEPTASPIS, R. Br. (Gramin.)。 - Ind. Kew. ii.

conchifera, Hack, in Bolet. Soc, Brot, v. (1887) 211, t. G fig. A. - Angola.

LEPTOCARPYDION, Hochst. = Triodia, R. Br (Gramin.)

plumosum, Hochst. ex Th. Dur, \& Schinz, Consp, Fl. Afr.v. $1894(1895) 877=$ T. plumosa, Benth.

LEPTOCHLAENA, Spreng.

Leptolaena, Thou. (Chlaenac.)

Bernieriana, “ Baill. » ex Engl. \& Prantl, Natürl. Pflanzenfam. iii. 6 (1893) $174=$ L. Bernieri, Baill.

ferruginea, «S. Elliot, » ex Engl. \& Prant1, 1. c - Madag.

parviflora, «S. Elliot, » ex Engl. \& Prantl, 1. c. = L. parviflora, S. Elliot.

nurbinata, “Baker, ») ex Engl. \& Prantl, 1. c. = L. turbinata, Baker.

LEPTOGHLOA, Beauv.(Gramin.). - Ind. Kew ii. 60 .

albemarlensis, Robinson of Greenm. in Am. Fourn. Sci.Ser. IIl. 1. (1895) 145. - Ins. Galapag.

bifinnata, Herb. Berol, ex Baill. Herb. Boiss. il 1893) 1075 = Eragrostis cynosuroides, Roem. \& Schult.

falcata, Hack. ex Schinz, l. c. iii. (1895) 3S6. - Afr. austr.

mexicana, Scribuer, in Bull. Torrey Bot. Club (1S91) 313. - Mexic

Nealleyi, Vasey ex Coville, in Contrib. U. S. Nat. Herb. ii. (1894) 534 - Texas.

plectostachya, K. Schmm. in Engl. Pfanzenw. Ost Afr. C (1895) 112. - Afr. trop. or

yemensis, Scliveint. ex Penzig, in Atti Congr. bol. Genova (1893) 366, nomen. - Erithrea. 
LEPTOCHLORIS, Munro, ex Kuntzt;, Rev, Gen. (1S91) 771 = Chloris, Sw. (Gramin.)

crinita, Munro, ex Kuntze, 1. c. = C. crinita, Lag.

LEPTODERIIS, Wight. (Rubiac.), - Ind. Kew. ii. 62.

crassifolia, Collett of Hemsl, in Fourn. Limn. Soc. xxviii. (1890) 67. - Ind. or.

diffusa, Ejatalin, in Act. Hort. Petrop. xiii. (1894) 373 - China.

umbellata, Batalin, I. c. 374. - China.

vestita, Hemsl. ex Forb. \& Hemsl, in fourn. Linn. Soc, xxiiı. (1888) 390. - China.

LEPTODESMIA, Benth. (Legumin.). - Ind. Kew, ii. 62.

Bojeriana, Baker, in Journ. Linn. Soc. xxii. (1887) 465 , in obs, = Hallia ? Bojeriana, Baill.

pulchella, Yatabé, in Tokyo Bot. Mag. iv. (Oct. 1890) 2, t. 12. - Japon.

LEPTOGLOTTIS, DC. = Schrankia, Willd. (Legumin.).

ancinita, Rydberg, Fl. Nebraska, (1895) $=\mathrm{S}$. uncinata, Willd.

LEPTOLAENA, Thou. (Chlaenac.). - Ind. Kew. ii. 63 .

Bernieri, Baill, in Bull. Soc. Limn. Paris, i, (1886) 564: et Hist. pl. Madag., Atlas (1888) t. 88.Madag.

cuspidata, Baker, in fourn. Linn. Soc, xxy. (1889) 297. - Madag.

parviflora, S. Elliot, in Foum. Linn. Soc. xxix. (1891) 6. - Madag.

rubella, S. Elliot, l. c. 7. - Madag.

¿EPTOLEPIS, Boeck. Cyp. Nov, i. (1888) 31 CYPERACEAE.

tibetica, Boeck. l. c. - Tibet.

LEPTOMISGHUS, Drake, in Bull. Mus. Paris, i. (1895) 117; et in Morot, Journ. de Bot. ix. (189.5) 208. RUBIACEAE

primuloides, Drake, ll. cc. 117 et 209, t. 4. - Tonk.

EEPTONYGHIA, Turcz. (Stercul.). - Ind. Kew. ii. 63.

heteroclita, K. Schum. in Engl. \& Prantl, Natürl. Pflanzenfam. iii. 6 (1890) 86 = glabra, Turc\%.

LEPTORC.HIS, Thou, in Nouv, Bull, Soc. Philom. (1809) ]4/9, ex Kuntze, Rev. Gen. (1891) $669=$ Liparis, Rich.(Orchid.).

aby'ssinica, acuminata, acutissima, affinis, alata, arnoglossophylla, auriculata, aurita, barbata, Beccarii, Beddomei, bicornis, biloba, bistriata, bituberculata, bootanensis, Bowkeri, brachyglottis, brachystalix. caespitosa, campestris, campylostalix, capensis, Cathicartii, clacigera, Clypeulum, compressa; condylobulbon. connata, cordifolia, cremulata, crispifolia, Cuningii. cuspidata. Dalyollii decurrens, deftexa. delicatula, Dendrochitum, Diodon, disepala, distans, disticha, Dolabelia, Duthiei, Eggersii, elata, elegans, elliptica. ferminginca, flaccida, flavescents, Forbesii, Gamblet, glossula, gracilis, grandiflora, Griffithii, grossa, guincensis, Guingangae, habenarine, hawaiensis, japonica, foi'is-Plunii, Kappleri, Krameri, lacerata, lancifolia, latifolia, liliifolua, longa, longicaulis, lancifolia, latifolia, linifolar, longa, longicautis, Alanni, minima, nuntana, neviosa, nouroglossa, obs cura, ochracea, odontostoma, odorata, olivacea, Fachy puss, pallida, Parishii, parva, parviflora, pectinata, perpusilla, plantaginea, platyphylla, platyrachis, plicata, polycardia, Prainii, fulchella, puncticulata, purpurascens, pusilla, ramosa, refloxa, resupinata, veroluta, Ridleyi, rostrata, rupestris, Sandersiana. Slachyuras, stenoglossa, Stricklandiana, temuifolia, Thawaitesii, foria, tricallosa, triloba, Trimonii. venosa. vestita, viridiffora, viridipurpurea, Wageneri, IValkoriae, Welnitschii, Wightiana, Wrayi, xunthina. Kuntze, 1. c. 671 = homonyma ommia Liparidis.

\section{LEPTORCHIS : -}

atropurpurea. Kuntze, Rev, Gen, (1891) $671=\mathrm{Li}$ paris repens, Ridl.

coelogviodes, Kuntze, 1.c. = L. coelogynoides, F. Muell.

commutata, Kuntze, 1. co = L. cordifolia, Hook. $f$. cordifolia, Kuntze. 1. c. = L. nepalensis, Lindl.

flavileptis, Thou, ex Bull. Herb. Boiss. ii. (1894) $459=I$. flavescens, $L$ ind $l$.

Gerardii, Kuntze, Rev. Gen. (1S91) $669=$ L. Gerrardii, Reichb. $f$.

Lindleyana, Kuntze, 1. c. = L, atropurpurea. Lindl.

Loesclii, MacMill. Metasp. Minn. (1893) $173=\mathrm{L}$. Loeselii, A. Rich.

omithorhynchos, Kuntze, Rev. Gen. (1891) $669=$ L. ornithorrhynchos, Ridl.

tradescantiacfolia, Kuntze, 1. c. $=$ L. tradescantifolia, Lindl.

Wendlandii, Kuntze, 1. c. = L. Wendlandi, Reichb.f.

LEPTORHOEO, C. B. Clarke, (Commelin). Ind. Kew. ii. 64 [Leptorhoës]

floribunda, Baill. Hist. des pl. xii.. (1895) $218=$ filiformis, C. B. Clarke.

tenuifolia, N. E. Rose, in Contrib.U.S. Nat. Herb. i. (1891) 113. - Mexic.

LEPTOSIPHONIUM, F. Mrell. Descr, notes Papuan Pl. vii. (1886) 32. ACAN THACEAE. Stricklandi, F, Muell. l.c. - N. Guin.

LEPTOSPERMUM, Forst. (Myrt.). - Ind. Kew. ii. 64.

Wocroonaran, F.M. Bailey, Rep. Exped. Bellenden Ker. (1889) 40. - Austral.

LEPTOSTACHYA, Mitch. = Phryma, Linn. (Verben.).

carolincnsis, Kuntze, Rev. Gen, (1891) $508=$ P. leptostachya, Linz.

leptostachya, MacMill. Metasp. Minn. (1893) $442=$ P. leptostachya, Limn.

LEPTOSYNE. DC. (Compos.), - Ind. Kew, ii. assecto T S. Brandes, in Proc. Calif. Acad. Ser. II. ii. (1889) $176=$ dissecta, A. Gray.

mexicana, A. Gray, ex S. Wats, in Proc. Am. Acad. xxii. (1857) 429. - Mexic.

parthenioides, T. S. Brandeg. in Proc. Calif. Acad. Ser. II. ii. (1889) 176 i= L. parthenioides, A. Gray). = Coreocarpus parthenioides, Benth.

pinnata, Robinson, in Proc, Am. Acad, xxvii. (1893) 176. - Mexic.

Pringlei, Robinson of Groenm, in Am. Fourn. Soi. Ser. III. 1. (1895) 155. - Mexic.

LEPTOTAENIA, Nutt. = Ferula, Tourn. (Umbell.).

anomala, Coult. \& N. E. Rose, Revis. N. Am. Umbellif, (1888) 53. - Calif.

Eutoni. Coult. \& N.E. Rose, 1. c, - Utah.

purpurea, Coult. \& N. E. Rose, 1. c. - Am. bor.

Watsoni, Coult. \& N. E. Rose, 1. c. - Am. bor. occ.

LEPTOTES, Lindl. = Tetramiera, Lindl. (Orchid.)

minuta, Rolfe, in Gard. Chron. (1889) ii, $323=\mathrm{T}$. minuta, Rolfe.

LEPYRODICLIS, Fenzl = Arenaria, Rupp. (Caryoph.)

cerastoides, Stapf, in Denkschr. Akad. Wicn. ii. (1886) 19 (an L. ccrastoides, Kar. \& Kir. ?). As. vice.

paniculata, Stapf, l. c. - As. occ.

quadridentata, Maxim. Fl. Tangut. (1889) 84.China.

LEPYROXIS canadensis, Beauv, ex Fourn. Gram. Mexic, 1881 (1886) 92, in syn, = Agrostis mexicana, Limn.
LERCHEA, Hall. Comm. Gott. (1751) 223, ex Kuntze, Rev. Gen, (1891) $549=$ Suaeda. Forsk. (Chenopod.).

baccata, calceoliformis, corniculata, heterocarpa, hetcrom phylla, hortensis, linifolia, maritima, microphylla. microsperma, monoica, physophora, pterantha, Fermiculata, Kuntze, 1. c. = homonyma omnia Suadae.

LESGHENAULTIA, R. Br。(Gooden.). - Ind. Kew, ii. 66.

striata, F. Muell. ex Bot. Centralbl. xlv, (1891) 123, sphalm. = stricta, F. Muell.

LESPEDEZA, Michx. (Legumin.). - Ind. Kew. ii. 67.

capillipes, Franch. Pl. Delav. (1890) 165. Yunnan.

Delavayi Franch. l. c.; et in Rev. Hortic. (1890) 225, fig. 70. - Ynnnan.

fasciculiflora, Franch. l.c. 169. - Yunnan.

frutescens, Britton, in Mem. Torrey Bot. Club, v. (1894) $205=$ violacea, Pers.

hirtella. Franch. Pl. Delav. (1890) 167. - Yuman. intermedia, Britton, in Trans. N. Y. Acad. Sci. xii. (1893) $63=$ violacea, Pers.

Prainii, Collett of Hemsl, in foum. Limn. Soc, xxviii. (1890) 46. - Burma.

racemosa, Dippel, Handb. Laubholzk. iii. (1893) 720. - Japon. Corea.

sericophylla, Collett \& Hemst. in fourn. Linn. Soc. xxvii. (1890) 45. -

trigonoclada, Franch. Pl. Delav. (1890) 167. Yunnan.

virginica, Britton, in Trans. N. Y. Acad. Sci. xii. 1893) $64=$ sessiliflora, Michx.

yunnanensis, Franch. Pl. Delav。(1890) 166. Yunnan.

LESQUERElLA, S. Wats, in Proc. Am. Acad. xxiii. (1888) $250=$ Vesicaria, Tourn. (Crucif.). alpina, S. Wats, I. c. $251=$ V. alpina, Nutt.

angustifolia, S. Wats, 1. c. $253=\mathrm{V}$. angustifolia, Nutt.

arctica, S. Wats, I, c. $255=$ V. arctica, Richards, argontca, S. Wats, 1. $.252=$ V. argentea, Schauer. argentaa, MacMill. Metasp. Minn. (1892) $203=$ V. ludoriciana, $D C$.

argyrea, S. Wats, in Proc. Am. Acad. xxiii. (ISS8) $251=$ V. argyrea, A. Gray.

cincrea, S. Wats, 1. c. 255. - Arizona.

densifora, S. Wats, 1. c. $251=\mathrm{V}$. densiflora, A. Gray. Douglusii, S. Wats, 1. c. 25̌5. - Am. bor. occ.

Engelmanni, S. Wats, 1. c. $254=$ V. Engelmanni, A. Gray,

Fendlcri, S. Wats, 1, c. $255=$ V. Fendleri \& stenophylla, A. Gray.

globosa, S. Wats, 1. c. $252=$ V. globosa, Peri.

Gordoni, S. Wats, 1, c. 253 - V. Gordoni, A. Gray. grandiflora, S. Wats, 1. c. $250=$ V. grandiflora Hook.

gracilis, S. Wats, 1. c. $253=\mathrm{V}$. gracilis, Hook. $f$.

Kingii, S. Wats, 1. c, $251=$ V. Kingii, S, Wats.

lasiocarpa, S. Wats, 1. c. $251=\mathrm{V}$. lasiocarpa, A, Gray.

Lescurii, S. Wats. 1. c. 250 (= Alyssum Lescurii, A. Gray). - Tennessee.

Lindhoimeri, S. Wats, 1. c. $253=$ V. Lindheimeri, A. Gray.

Indoviciana, S. Wats, in Proc. Am. Acad, xxiii, (1888) $252=\mathrm{V}$. ludoviciana, $D C$.

mendocina, Kurtz, in Revista Museo La Plata, v. (1883) 284 [Sert. Cordobensem 6] $=\mathrm{V}$. mendocina. Phit.

montana, S. Wats, in Proc. Am. Acad, xxii, (1888) $25 \mathrm{l}=\mathrm{V}$. montana, A. Gray.

monteridensis, $\mathrm{S}$. Wats, $\mathrm{l}$. $\mathrm{c},\llcorner=\mathrm{V}$. montevidensis, Eichl.

Nuttallii, S. Wats, 1. c. $252=$ V. Nuttallii, Torr. Ef Gray.

occidentalis, S. Wats, 1. c. $251=\mathrm{V}$. occidentalis, S. Wats.

pallida, S. Wats, 1. c. $253=$ V. pallida, Nutt.

Palmeri, S. Wats, 1. c, $252=\mathrm{V}$. repanda, Nutt. repanda, S. Wats, 1. c. $254=$ V. repanda, $N^{\top}$ utt. purpurea, S. Wats, 1. c. $253=$ V. purpurea, $A$. Gray. 
LESQUERELLA :

recurvata, S. Wats, 1. c. $253=$ V. recurvata, S. Wats.

Schaffneri, S. Wats, 1. c. $254=$ V. Schaffneri, S. Wats.

Wurdii, S. Wats, 1. c. 252 et 255. - Arizona.

LESSERTIA, DC. (Legumin.). - Ind. Kew. ii. 67.

emarginata, Schinz, in Verh. Bot. Ver. Brand. xxx. (1888) 166. - Afr. austro-occ. extratrop.

incana, Schinz, l. c. 167. - Afr. austro-occ. extratrop.

LESSINGIA, Cham. (Compos.). - Ind. Kew. ii. 67.

Lemmoni, A. Gray, in Proc. Am. Acad.xxi. (18s6) 412. - Arizona

tenuis, Coville, in Contrib. U.S. Nat. Herb, iv. (1893) 124. - Calif.

LETHIA indica, « DC. » ex Forb. \& Hemsl. in Journ. Linn. Soc, xxiii. (IS86) 96. sphalm. = Sethia indica, $D C$

LETO, Phil, in Anal. Mus, nac. Chile (1891) 33. COMPOSITAE.

tenuifolia, Phil. l. c. t. I fig. 3. - Chili.

LETTSOMIA, R. Br. (Convolv.). - Ind, Kew, ii. $6 \mathrm{~s}$.

aggregata, Prain, in Journ. As, Soc. Beng. Ixiii. 1894) 11. 92, in obs. = aggregata. Roxb.

confusa, Prain, l. c. 96. - Burma.

Curtisii, Prain, l. c. 100. - Penins. Mal.

Kunstleri, Prain, l. c. - Malaya.

laxiflora, Prain, l. c. 92. - Burma.

longifolia, Collett \& Hemst. in foum, Limn. Sor xxviii. (1890) 95. - Burma.

Mastersii, Prain, in fourn. As. Soc. Beng, lxiii. 1894) 11. 98. - Assam, Burma.

pallida, Prain, l. c. 97 (= Argyreia pallida, Choisy). - Burma.

Ridleyi, Prain, l. c. 98. - Penins. Mal.

LEUCADENDRON. Linn. = Protea, Linn. attenuatum, buxifolium, crinitum, ellipticum, Gueinzii, lineare, molle, nutans, pedunculatum, penicillatum, puberum, reflexum, Rochetianum, spathulatum, tomentosum, Euntze, Rev. Gen. (1891) 578-79=homonyma ommia, Leucospermi

formosum, Kuntze, 1. c. = I'rotea formosa, R. Br.

heterophillum, Kuntze, 1. c. = Leucospermum diffusum. $R \cdot B r$.

Mundtii, Kuntze, 1. c. = L. Mundii, Meissn.

totta, Kuntze, 1. c. $=$ L. tottum, R. Br.

truncatum, Kuntze, 1. co = L. Zeyheri, Meissn.

LEUGAENA, Benth, (Legumin.). - Ind. Kew,

Greggii, S. Wats. in Proc. Am. Acad. xxiii. (1888) 272. - Mexic.

lanceolata, S. Wats, l. c. xxi. (1886) 42\%. - Mexic.

LEUCANTHEMUM, Burm. Dec. Pl. Afr. (1738) $161 / 2758$ f. 1 (non f. 2), ex Kuntze, Rev, Gen. (1891) $351=$ Osmitopsis, Cass. (Compos.).

astericodes, Kuntze, 1. c. $=$ O. astericoides, Cass.

LEUCANTHEMUM, [Tourn.] Linn. = Chrysan themum, Tourn. (Compus.).

chloroticum, Kern, \& Murb, ex Murb, in Lunds Univ. Arsskrift, xxvii, v. (1892) 109. - Herceg. fissum, Timb.-Lagr. ex Galiss. in Bull. Soc bot. Rochel. xi. $(1889)=$ C. graminifolium, Linn.

intersitum X, Hausskn, in Mitth. Thur. Bot. Ver. N. Folge, vi. (1894) 25. - Graecia.

laciniatum, Huter, ex Porta et Rigo in Nuov. Giorn. Bot. Ital. ii. () 268; et in Ann. Ist. Bot. Roma, iv. (1891) 159. - Italia.

lawatum, Nym. Consp. Fl. Eur. Suppl. II. i. (1889) $169=$ C. ceratophylloides, All.

lobulatum, Levier, ex Levier \& Sommier, in Nuov. Giorn. Bot. Ital. xxiii. (1891) 258. - Italia.

nanum, St Lager, in Cariot. Etud. des $\mathrm{f}$. éd. 8. ii. (1889) $481=\mathrm{C}$.

\section{LEUCANTHEMUM : -}

ccitanicum, Sudre, in Rev, de Bot. Toul. (Janv. 1894) [sp. collect.], ex Bull. Sos. Bot. Fr. xlii. (1895) 199. - Gall.

LEUGAS, Burm. (Labiat.), - Ind, Kew. ii. 70 abyssinzica, Briq. in Bot. Jahrb. xix. (IS94) 193, in obs. = Lasiocorys abyssinica, Benth.

altissima, Engl. l. c. x. (1889) 268. - Afr. austroocc, extratrol:

bracteosa, Guerke, l. c. xxii. (1895) 139, - Afr. trop. argyropliylla, Briq. 1, c, xix. (1894) 193, in obs, $=$ Lasiocorys argyrophylla, Vatke.

bukobensis, Guerke, l. co xxii. (1895) I39. - Afr. trop.

capensis, Engl. 1. c. x. (1889) $268=$ Lasiocorys capensis, Benth.

Coleae, Baker, in Kew Bull. (1895) 226. - Reg. Somal.

Collettii, Prain, in fonm. As. Soc. Beng. lix. (1890) ii. 313. - Burma.

Fleckii, Guerke, in Bot. Fahrb. xxii. (1895) 140. Afr. austro-occ. extratrop

Holstii, Guerke, ex Engl. in Abh. Preuss. Akad. Wiss, (1894) 51, 62, 65; et in Pfanzenw. OstAfr. C (1895) 342, - Afr. trop. or.

Jamesii, Baker, in Kew Bull. (1895) 225. - Reg. Somal.

macrophylla, Vatke, in Abh. Prenss. Akad. Wiss, (1894) 38. -

micrantha, Guevke, in Bot. Falirb. xxii. (1895) 136. - Afr. trop

milanjiana, Guerke, l. c. 141.-Afr. trop. or

Nyassae, Guevkc, l c. 137. - Afr. trop. or.

orbicularis, Guerke, in Engl. Pfanzenw. Ost-Afr. C (1895) 343. - Afr. trop. or

paucijuga, Baker, in Kew Bull. (1895) 226. - Reg. Somal.

Poggeana, Briq. in Bot. Fahrb. xix. (1894) 193.Congr mer.

Schweinfurthii, Guerke, l. c. xxii. (1895) 136. Afr. centr. bor.

stachydiformis, Briq. 1. c. xix. (1894) 193, in obs. = Lasiocorys stachydiformis, Hochst.

stenophylla, Guerke, l. c. xxii. (1895) 138.-Zanzib.

Stormsii, Guerke l. c. 140. - Afr. trop.

thymoides, Baker, in Kew Bull. (1895) 226. - Reg. Somal.

tomentosa, Guerke, in Engl. Pfanzenw. Ost-Afr. C (1895) 343. - Atr. trop. or.

villosa, Guerke, l. c. 137. - Sansib.

usagarensis, Guerke, in Bot. Fahrb. xxii. (1895) 138. - Afr. trop. or.

Volkensii, Guerke, in Engl. Pfanzenw. Ost-Afr. C (18:5) 342. - Afr. trop. or.

Welwitschii, Guerke, in Bot. Fahb. xxii. (1895) 141. - Angola.

LEUGERIA, Lag. (Compos). - Ind. Kew. ii 70 . arhilleifolia, Ball, in foum. Linn. Soc. xxvii. (1S91) 495 (= Leuchaeria achilleifolia, Hook, et Arn.). -Patagon.

anthemidifolia, Phil. in Anal. Univ. Chil. 1xxxvii. (1894) 102. - Chili.

apiifolia, Phit. l. c. 111.-Chili.

araucana, Phil. l. c. $105 .-$ Chili

aurita, Phil. l. c. 106. - Chili.

Barrasiana, Fr. Meigen, in Bot. Jahrb. xviii. (1894 439 (= Chabraea Barrasiana. J. Gay). - Chili.

Contrayerba. Kurtz, in Bol. Acad. nac. cienc. Cordobu xiii. (1893) 201; et in Verh. Bot. Ver. Brand. xxxv. (1894) 112. - Reg. Argent.

debilis, Phil. in Anal. Univ. Chil. 1xxxvii. (1894) 107. - Chili.

discolor, Phil, l. c. - Chili.

fuegina, Phil. l. c.98. - Am, austr. ccc,

clabrata, Phil. l. c. 103. - Am, austr. oco.

Hahnii, Franch. Miss. scient. Cap Horn. v. [Bot.] (1889) 349 t. 3. - Reg. Mavell.

Ibari, Phil, in Anal. Univ. Chil. Ixxxvii. (1894) 99 - Am. austr. occ.

lepida, Phil. l. c. 110. - Am. austr. occ.

longifolia, Phil. l. c. 106. - Am. austr. occ

leucomalla, Phil.l. c. 100, - Am. austr. occ.

magna, Phil. l. c. 108. - Am. austr. occ.

nivea, Phil. l.c. 104. - Am. austr. occ.

\section{LEUCERIA}

nudicaulis, Phil. in Anal. Univ. Chil. 1xxxvii.(1894) 100. - Am. austr. occ

pauciflora, Phil. l.c. 109. - Am. austr. occ. popelana, Phil. l.c. 101.-Am. austr. occ. racemosa, Phil.l.c. 111. - Am. austr. occ. sonchoides, Plizl. l. c, 104, - Am, austr. occ stricta, Phil. 7. c. 109. - Am. austr. occ.

tenerifolia, Phil.l.c.102. - Am. austr. occ

LEUGOBARLERIA, Lindau, in Engl. \& Prant , Natürl. Pflanzenfam. iv. 3b (1895) 353. $A C A N=$ THACEAE

nivea, Lindau, l. c. 354.- - Reg. Somal.

polyacantha, Lindau, l. c.-Reg. Somal.

Robecchii, Lindau, l. c. - Reg. Somal., Arabia.

LEUCOBOTRYS, Van Tiegh, in Bull. Soc. Bot. Fr. xIi. (1894) $503=$ Loranthus, Linn.

adpressa, Van Tiegh. 1. c.504.- Tonk.

inflata, Van Tiegh. 1. c. 503. - Tonk.

pilosa, Van Tiegh. 1. c. 545 . - Ins. Subawa.

LEUGOCALANTHE, Rodr. Hort. Flumin. (1891) 49; K. Schum in Engl, \& Prantl, Natürl, Pflanzenfam. iv. 3b (1895) 242, in obs. BIGNONIA$C E A E$

aromatica, Rodr.l. c. $4 \%$, t. \%.- Bras

LEUCOGORYNW, Lind1. (Liliac.). - Ind. Kew. ii. il.

uniflora, Greene, Pittonia, ii. (May 1890) $57=$ Triteleia uniflora, Lindl.

LEUGOLENA, Ridl, in Journ, Linn. Soc, xxvii 1891) 340. ORCHIDEAE

ornata, Ridl.l.c.t. 43. - Malacca.

LEUCONOCARPUS riparius, Spruce, ex Vesque in DC. Monog. Phan. vii. (1893) $241=$ Moronobea riparia, Planch. \& Triana.

LEUCONOTIS, Jack. (Apocyn.). - Ind. Kew. ii 72,

tenuifolia, Engl. Bot. Fahrb. vii. (1886) 4\%0. - N Brit

LEUCONYMPHAEA, Ludw. = Nymphaea Linn.

alba, amazonum, ampla, blanda, elegans, flava. Gardneriana, gigantea, gracilis, famesoniana, lasiophylla. Lotus, mexicana, oxypetala, Parkerana, sansebariensis, stellala, tetragona, tuberosa, inssilagifolia, undulata, Kuntze. Rev. Gen. (1891) 11-12= homonyma onnia Nymphaeae.

Berneriana, Kuntze, 1. co = N. stellata, Willd,

candida, Kuntze, $1 c_{.}=\mathbb{N}_{\text {, alba, Linn }}$

coerulea, Kuntze, 1. $\mathrm{c}_{n}=\mathrm{N}$. stellata, Willd.

emirnensis, Kuntze, 1, c. $=$ N. stellata, Willd.

Gondotiana, Kuntze, l. c. = N, amazunum, Mart. \& Zucc.

intermedia, Kuntze, 1. c. - Burma.

odorata, MacMill. Metasp. Minn. (1892) 228 [odorata] $=\mathrm{N}$. odorata, Soland.

reniformis, Kuntze, Rev. Gen. (1891) $11-12=\mathrm{N}$. odorata, Solund.

reniformts, MacMill. Metasp. Minn. (1893) $228=$

mbra. Kuntze, Rev. Gen. (1891) 11-12 = N. Lotus. Linn.

LEUCOPHAE, Webb \& Berth. = Sideritis Linn. (Labiat.)

Dendrochahorra, Christ, in Bot. Jahrb. ix. (1885) $1.38=\mathrm{S}$. Dendrochahorra, C. Bolle

discolor. Wedd, ex Christ, 1.c. $137=\mathrm{S}$. discolor C. Bolle

eriocephala, Webb, es Christ, 1. c. $139=\mathrm{S}$. dasysnaphala, $W e b b$

infernalis, Christ, 1, c. $140=\mathrm{S}$. infernalis, C. Bolle.

marmorca, Christ, 1. c. $139=$ S. marmorea, C. Bolle.

nervosa, Christ, 1. c. - Ins. Teneriffa.

stricta, Webb, ex Christ, I. c. = S. candicans, Webb. 
LEUCOPHYTA, R. Br. = Calocephalus, R. Br. (Compos.)

citrea, Dittrichii, Drummondii, Francisii, lactea, multiflora, platycephala, Sonderi. Kuntze, Rev. Gen. (1891) $352=$ homonyma ommia Calocephali. nertodes, Kuntze, I. $_{0}=\mathrm{C}$. aeruoides, Benth. angianthodes, Kuntze, 1. c. $=\mathrm{C}$. angianthoides, Benth.

Lessingii, F, Muell. in Vict. Natural. ix. (April 1873\%. - Austral.

IEUCOPOGON, R. Br. (Epacrid.) - - Ind. Kew, heterophyllus, Colenso, in Trans, N.Z. Inst, xx. 1887 (1888) 198. - N. Zel.

LEUCORCHIS. Blume = Didymoplexis, Griff (Orchid.).

micradenia, Benth. \& Hook f. ex Drake, I11. Ins. Mar, Pacif, Fasc. 7 (1892) $313(=$ Epiphanes micradenia, Reichb. f.). - Ins. Vitiens.

LEUCOSALPA, S. Elliot, in Journ. Limn. Soc, xxix. (1891) 35. SCROPHULARIEAE madagascariensis, S. Elliot, l. c. B6. - Madag.

LEUCOSCEPTRUM, Sm. (Labiat.). - Ind. sinense, Hemsl. in Fourn. Linn. Soc. xxvi. (1891) 310. - China

LEUCOTHOË, D. Don (Ericac.). - Ind, Kew. ii. opulifolia, Dippel, Handb. Laubholzk. i. (1889) 353, fig. $234=$ Lyonia populifolia, K. Kock. stenophylla, Loesen. in Flora, 1xxii. (1889) 78. Bras.

LEUZIA. « DC. » St. Lager, in Cariot, Etud. des fl. éd. 8 ii. (1889) $436=$ Leuzea, DC. (Compos.).

LEVYA, Bureau, ex Baill. Hist. des pl. x. (1888) 28. BIGNONIACEAE.

nicaraguensis, Bureau, l. c. 29. - Nicaragua.

LEWISIA, Pursh. (Portul,), - Ind, Kew, ii. 75. Kelloggii, K. Brandeg. in Proc. Calif. Acad. Ser. II iv. (1894) 88, t. 4. - Calif.

LEYCESTERIA, Wall. (Caprifol.). - Ind. Kew. ii. 75.

stipulata. Fritsch, in Engl, \& Prantl, Natürl. Pflanzenfam. iv. 4 (1891) 169; et in Verh. zool.bot. Ges. Wien, xlv. (1895) 57 , t. $4=$ Pentapyxis stipulata, Hook. $f$.

LHOTZKYA, Schau. (Myrt.). - - Ind, Kew, ii. 75. Smeatoniana, F. Muell, in Austral. Fourn. Pharm, ii. (Jun. 1887) 5 ; ct in Bot. Centralbl. xxx. (1887) 326. - Austral.

LIABUM, Adans. (Compos.). - Ind. Kew. ii. 75. angustissimum, A. Gray, in Proi, Am. Acad. xxii. 1887) 432. - Mexic

bolivianum, Klatt, in Annal. Naturh. Hofmus, Wien, ix. (1894) 362. - Bolivia.

cervinum, Robinson, in Proc. Am. Acad. xxix. (1894) 317. - Mexic.

columbianum, Klatt, in Bot. Fahrb. viii. (1887) 47. Columb.

corymbosum, Klati, in Annal. Naturh. Hofmus. Wien, ix. (1894) 36\%. - Bolivia.

ecuadoriense, Hirron。 in Bot. Fahrb. xix. (1894) 60. - Ecuad

hastatum, Britton, in Bull. Torrey Bot. Club, xix. (1892) 263. - Bolivia.

Klattii, Robinson \& Greenm. in Am. Foum. Sci, Ser. 3 1. (1 $\vdash 95)$ 156. - Mexic.

Lehmanni, Hieron. in Bot. Fahrb. xix. (1894) 61. Ecuad.

liaboides, Hieron, 1. c. 63, in obs. = lyratum A. Gray.

Liebmanni, Klatt, in Leopoldina. Heft xxiii. (1887) 146. - Mexic.

\section{LIABUM}

longiradiatum, Hieron. in Bot. Fahrb. xxi. (1895) 354. - Ecuad.

niveum, Hieron. l. c. xix. (1894) 62. - Columb.

ovatum, Britton, in Bull. Torrey Bot. Club, xix.

$(1892 ; 263=$ ovatum. Ball.

Palmeri, A. Gray, in Proc. Am. Acad. xxi, (1887) 432. - Mexic.

platylepis, Sch. Bip. ex Klatt, in Leopoldina, Heft xxiii. (1887) 146. - Mexic.

polyanthum, Klatt, ex Th. Dur. \& Pitt. in Bull. Soc. Bot. Belg. xxxi. 1892 (1893) 209. - Costarica.

Rusbyi, Britton, in Bull. Torrey Bot. Club, xix, (1892) 263. - Bolivia.

Stuebelii, Hieron. in Bot. Fakrb, xxi. (1895) 353. Ecuad.

vulcanicum, Klatt, viii. (1887) 47. - Columb.

LIATRIS, Schreb, (Compos.), - Ind. Kew, ii, 75. Helleri, Porter, in Bull. Torrey Bot. Club, xviii. (1891) 14\%. - Am. bor. occ.

magnifica, Hort. ex Gard. Kew, Herb. Pl. (1895) 203. - Am. bor.

LIBERTIA, Spreng. (Irid.). - Ind. Kew. ii. 76. azurea. Hort. ex Baker. Handb. Irid. (1892) $118=$ Orthosanthes multiflorus, Sweet.

LIBoGEDRUS, Endl. (Crnif), - Ind. Kew. ii. T7. i. 1. (1889) 32; Beissn. Handb. Nadelholzh. (1891) i. 1.. (1889) $32 ;$ :
31. - N. Guin.

LICANIA, Aubl. (Rosac.). - Ind. Kew. ii. 77. Gardneri, guzianensis, longistyla, pallida, platypus, Salzmannii, Sprucei, tomentosa, utilis, Kuntze, Rev.Gen. (1891) 217 = homonyma omnia Moquileae.

affinis, Fritsch, in Annal. Naturh. Hofmus. Wicn, iv. (1889) 50 ; Kuntze, l, c. - Ind. occ.

apetala, Fritsch, 1. c. $54=$ Moquilea floribunda, Benth.

apetala, Kuntze, 1. c. (1891) $217=$ praec.

bracteosa, Fritsch, 1. c. = M. licaniaeflora, Sagot.

Britteniana, Fritsch, in Oest Bot, Zeitschr. xlii (1892) 6. - Am. austr.

compacta, Fritsch, in Annal. Naturh. Hofmus. Wien, iv. (1888) 52. - Guian. brit.

cymosa, Fritsch, l. c, 47, - Bras.

erensis, Fritsch, l, c.58. - Bras.

Gardneri. Fritsch, 1. c. $56=$ Moquilea Gardneri Hook. $f$.

gracilis, Taub. in Bot. Fahrb. xv. Beibl. n. 34 (1892) 8. - Bras.

Hookevi, Fritsch, in Annal, Naturh. Hofmus Wien. iv. (1889) 56 = Moquilea pallida, Hook. $f$.

Hostmanni, Fritsch, l. c. 42. - Surin.

laxiflora, Fritsch, l. c. 46. - Guian. brit.

longistyla, Fritsch, 1, c. $56=$ Moquilea longistyla Hook. f.

membranacea, Sagot, ex Laness. Pl. util. Colon. Franç. (1886) 130; et ex Fritsch. 1. c. $48=$ incana, $A u b l$.

minutifflora, Fritsch, 1. c. $54=$ Moquilea minutiflora, Sagot.

obtusifolia, Fritsch, 1. c. $53=$ M. parviflora, Blume.

octandra, Kuntze, Rev, Gen. (1891) $21 \%=\mathrm{M}$. Turiuva, Hook. f.

organensis, Fritsch, in Annal. Naturh. Hofmus. Wien. iv. (1889) $59=$ M. organensis, Miers

pallida, Britton, in Bull. Torrey Bot. Club̆, xvii. (1890) 9. - Bolivia

platypus, Fritsch, in Annal. Naturh. Hofmus. Wien, iv. (1889) $53=$ Moquilea platypus, Hemsl.

Poeppigii, Fritsch, l.c. 49. - Bras.

Salzmanni, Fritsch, 1. c. $^{-}=$M. Salzmanni, Hook. f.

Sprucei, Fritsch, 1. с. $55=$ M. Sprucei, Hook. $f$.

tomentosa, Fritsch. 1. c. $52=$ M. tomentosa, Benth.

utilis, Fritsch, 1. c. $56=$ M. utilis, Hook. $f$.
LICHTENSTEIN.IA, Wendl, = Loranthus, Linn. elegans, Van Tiegh, in Bull. Soc. Bot. Fr. xlii. (1895) $254=$ Lor. elegans, Cham. \& Schlecht.

speciosa. Van Tiegh. 1. c. = Lor. speciosus. Diely.

LICUALA, Thunb. (Palm.). - Ind. Kew. ii. 7 . arbuscula, Becc. Malesia, iii. (1856) 79. Borneo.

bidentata, Beco. . . c. 80. - Borneo.

bintulensis, Becc. l.c.75. - Borneo.

borneensis, Becc. l. c. 85 t. 6. - Borneo.

cordata, Becc.l. c.84-Borneo.

ferruginea, Becc. in Hook. f. Fl. Brit. Ind. vi (1892) 432, - Penins. Mal.

Fordiana, Becc. Malesia, iir. (1889) 198. China.

furcata, Becc.l.c. Borneo.

Kingiana, Becc. Malesia, iii. (1889) 193. - Penins. Mal.

Kersteniana, Hort. ex Rev. Hortic. 1xvii. (1895) 249. - Hab. ?

Kunstleri, Becc. in Hook. f. Fl. Brit. Ind. vi. (1892) 433. - Perak.

malajana, Becc, Malesia, iii. (1889) 19\%. - Penins. mal.

mattanensis, Becc.l. c. 86 t. 7. - Borneo.

modesta, Bccc. l, c. 195. - Penins. Mal.

olivifera, Becc. l. c. 78. - Borneo.

orbicularis, Becc. l. c. 83. - Borneo.

petiolulata, Bccc. l. c. 77. - Borneo.

pusilla, Becc. l. c. 194. - Borneo

sarawakensis, Becc.l. c. 81 . - Borneo

Scortechini, Becc. l. c. 192. - Penins. Mal.

spathellifera, Becc. l. c. 76. - Borneo.

spicata, Becc. l. c. $88 \mathrm{t}$. 8. - Borneo.

Veitchii, W. Wats, in Gard. Chron. (1886) i. 139 nomen: Hook. f. in Bot. Mag. (1888) t. 7053. Borneo.

LIGARIA, Van Tiegh. in Bull. Soc. Bot. Fr, xlii. (1895) $345=$ Loranthus, Linn

coronata, Van Tiegh. 1. c. 348

cuncifolia, Van Tiegh. 1. c, $347=\mathrm{L}$. cuneifolius Ruiz \& Pav.

enarginata, Van Tiegh. 1. c.348. - Peruv.

lanceolata, Van Tiegh 1. c. - Chili.

Orbignyana, Van Tiegh. 1. c. - Bolivia, Feruv.

viscoides, Van Tiegh. 1. c. = L. viscoides, Poepp.

LIGHTFOOTIA, L'Hérit. (Campanul.). - Ind. Kew. ii. 78 .

arabidifolia, Engl. Bot. Fahrb. xix. Beibl. n. 47 (1894) 53. - Afr. trop. or.

glomerata, Engl. l. c 52. - Afr. trop. or.

Sodeni, Engl. l.c. - Afr. trop. or.

LIGIA, Fasano = Thymelaea, Tourn.

Glaziovii, Warm. in Vidensk. Selsk. Skr, 6 Raekke, naturw. og mathemo iv. (1888) 465 t. 22 f. 11-16 et t. 23. - Bras.

LIGUSTICUM, Linn. (Umbellif.). - Ind. Kew. ii. 79 .

acuminatum, Franch. in Bull. Soc. Philom. Paris, Sér VIII. vi. (1894) 131. - Yunnan.

acutifolium, T. Kirk, in Trans. N.Z. Inst. xxiii. 1890 (1891) 429-30, nomen; et in fourn. Bot. xxix. (1891) $237 .-\mathrm{N}, \mathrm{Zel}$.

alpinum, F. Kurtz, in Bot. Jahrb. xix. (1894) 464 = Pachypleurum alpinum, Ledeb.

angelicaefolium, Franch, in Bull. Soc. Philom. Paris, Sér. viii. vi. (1894) 133. - Yunnan.

Arafae, Alboff, in Bull. Herb. Boiss. ii. (1894) 250 t. 8. - Reg. Cauc.

brachylobum, Franch. in Bull. Soc. Philom. Paris, Sér. VIII. vi. (1894) 134. - Yunnan.

caradense, Britton, in Mem. Torrey Bot. Club, v (1894) $240=$ seq.

canadense, Vail, ex Small \& Vail, in Mem. Torrey Bot. Club, iv. (1893) 120 [canadensis] = actaeifolium, Michx

Canbyi, Coult. of N.E. Rose, Rev. N. A. Umbell. (1888) 87. - Montana 


\section{LIGUSTIGUM :}

Carvifolia, Caruel, in Parl. Fl. Ital. viii. (1889) 339 $=$ Selinum Carvifolia, Linn.

daucoides, Franch. in Bull. Soc. Philom, Paris, Sér. VIII, vi. (1894) 135 (= Trachydium daucoides, Franch.). - Yunnan.

Delavayi, Franch. l. c. 131. - Yunnan.

Eastwoodae, N. E. Rose, ex Eastwood. in Zoë. iv. (1893) 17; Coult. Eo N. E. Rose, in Contrib. U. S. Nat. Herb, iii. 5 (1895) 320 t. 13. - Colorado

ferulaceum, Franch. in Bull. Soc. Philom. Paris, Sér. VIII. vi. (1894) 135, in obs. - China.

glaucescens, Franch.l.c. 134. - Yunnan.

Grayi, Coult. \& N. E. Rose, Revis, N. A. Umbell. (1888) 88. - Am. bor. occ

Huteri, Porta, in Nuor. Giom. Bot. Ital. xix. (1887) 306. - Ins. Balear.

involucratum, Franch, in Bull. Soc. Philom. Paris, Ser. VIII. vi. (1894) 136. - Yunnan.

Macouni, Conlt. \& N. E. Rose, in Contrib. U.S. Nat. Herb. i. (1893) 289, t. 23. - Alaska.

mucronatum, Hort. Kev ex Gard. Kew Herb. Pl. (1895) 263 (= Neogaya mucronata, Schrenk). Sibiria.

multivittatum, Franch. in Bull. Soc. Philom, Paris, Ser. VIII. vi. (1894) 133. - Yunnan.

physospermifolium, Alboff, Prodr. Fl, Colch. (1895) 109. - Reg. Cauc.

Porteri, Coult, \& N. E. Rose, Rev. N. Am. Umbell. (1888) 86. - Am. bor. ncc.

pteridophyllum, Franch. ex Oliver, in Hook. Icont. pl. xx. (1891) sub t. 1958 , in obs; et in Bull. Soc. Philom. Paris, Sér. VIII, vi. (1894) 132. Yunnan.

shikokianum, Makino, in Tokyo Bot. Matg. vi. (1892) 51. - Japon.

sinense, Oliver, in Hook. Icon. ploxx (1891) to 1958. - China.

tenuifolium, Franch. in Bull. Soc. Philom. Paris. Sér. VIII. iii. (1894) 136 (= Selinum tenuifolinm. Wall.). - Yunnan.

verticillatum, Coult. E N . E. Rose, ex N. E. Rose, in Contrib. U. S. Nat. Herb. iii. 5 (1895) 320 t. 12 (- Angelicn revticillata, Hook.). - Am. bor.

Wallichii, Franch, in Bull. Soc. Philom. Paris, Sér. VIII. vi. (1894) 136 (= Selinun striatum, Benth.). - Yunnan.

LIGUSTRINA, Rupr, = Syringa, Linn. (Oleac.). pekinensis, Regel, ex Dippel. Handb. Laubholzk. i. $(1889) 119=\mathrm{S}$. pekinensis, Rupr.

LIGUSTRUM, [Tourn.] Linn. (Oleac.), - Ind. Kew, ii. 81.

decidulum, Hemsl. in Fourn. Linn. Soc. xxvi. (1890) 90. - China.

Henryi, Hemsl. l. c. - China,

magnoliaefolium, Hort. ex Dippel, Handb. Laubholzk. i. (1889) $129=$ lucidum, Ait.

multiflorum, Hort. ex Baill. in Buil. Soc, Linn, Paris, ii. (1890) 880 , in obs. = Baillonia spicata Baill.

ovatum, Hort. ex Dippel, Handb. Laubholzk. i. (1889) $128=$ japonicum, Thunb.

Regelianum, Hort. Lemoine, ex Dippel, 1. c, $133=$ L. Ibota. Sieb. \& Zucc.

strongylophyllum, Hemsl. in fourn. Linn. Soc xxvi. (1889) 93. - China.

LilaEOPSIS, Greene, Pittonia, ii. (Sept. 1891) $192=$ Grantzia Nutt. (Umbell.).

lineata, Greene, l. c. $=$ C. lineata, Nutt.

LiLIASTRuM, Ludw. = Paradisea, Mazz. (Liliac.).

liliforme, Kuntze, Rev. Gen. (1891) $712=$ P. Liliastrum, Bertol.

LILIUM, Tourn: ex Linn. (Liliac.). - Ind. Kew.

ii. 81.
Bakerianum, Collett \& Hemsl. in fourn. Linn. Soc. xxviii. (1890) 138. - Burma.

Biondii, Baroni, in Nuov. Giorn. Bot. Ital. Ser. II. ii. (1895) 337. - China.

\section{LILIUM}

chinense, Baroni, in Nuor. Gionn, Bot, Ital. Ser. II ji (1895) 333, - China.

claptonense, Hort. Low ex Hook f. Fil Brit. Ind. vi. (1890) 351 , in syn. = primulinum. Baker.

dahurictm, Hort, ex Reuthe, in Gartenfl, xli. (1891; $4 \pi 6$ = dauricum, Ker-Gavel.

Dalhansoni $\times$. Hort. ex Garden (1893) t. 927 ; et ex Gartenfl. xliii. (1894) 24. - Hybr, artef.

Delavayi, Franch. in Morot, Fourn. de Bot.vi. (1892) 314. - China occ

Duchartrei. Franch, in Nowv. Arch. Mus. Paris, Sér. 1I. x. (1887-88) 96. - Tibet.

elegans $X$, T. S. Ware, in Gartenfl. (1891) xli. 475 - Hybr. artef.

Fargesii, Franch, in Morot, Fourn, de Bot. vi. (1892) 317. - China occ.

formosum, Franch. l. c.313. - China scc.

Henryi, Baker, in Gard, Chron. (1888) ii. 660 ; (1890) ii. 380 cum xylogr, et in Bot. Mag. (1891) t. $717 \%$ - China centr.

lankogense, Franch. in Morot, fourn. de Bot. vi. (1892) $31 \%$. - China occ.

Lowii, Baker, in Bot. Matg. (1892) t. 7232 ; in Garden (1892) i. 219, t. 953; et ex Gard. Chron. (1893) ii. 120. fig. 29 (= L. nepalense, Collett \& Hemsl.). - Ind. or.

mirabile, Franch. in Morot, fourn. de Bot. vì. (1892) 310. - China.

myriophyllum, Franch. l. o.313. - China occ.

neilgherrense, Collett \& Hemsl. in Fourn. Linn. Soc xxviii. (1890) $138=$ primulinum, Baker.

nepalense, Collett \& Hemsl. 1. c. t. $32=$ Lowii, Baker.

ochraceum, Franch. in Morot, Fourn. de Bot, vi. (1892) 319. - China occ.

papilliferum, Franch.l. c.316. - China occ.

parviflom, Holzinger, in Contrib. U. S. Nat.

Mus. iii. 4 (1895) $253=$ columbianum, Hanson.

primulinum, Baker, in Hook. f. Fl. Brit. Ind. vi. (1892) 351; et in Bot. Mag. (1892) t. 7227. -. Ind.

onguineo-putpureum, G. Beck, in Annal. Naturhist.

Hofmus. Wien, V. (1890) $569=$ carniolicum, Hofmus. Wien, v. (1890) $569=$ carniolicum,
Berni..

stylosum, Klotzsch, ex. Hook. f. Fl. Brit. Ind. vi. (1892) 351, in syn. = polyphyllum, D. Don

sulphureum, Baker, ex Hook, f. Fl. Brit. Ind, vi. (1892) 351; et in Bot. Mag. (1892) t. $725 \%$ Burma.

sutchuenense, Franch. in Morot, fourn. de Bot. vi. (1892) 318. - China

taliense, Franch. l. c. 319. - China occ.

yunnanense, Franch. l. c. 314. - Yunnan.

LIMACIA, Lour. (Menisperm.). - Ind. Kew, ii. 88.

Kunstleri, King, in fourn. As. Soc. Beng. 1viii. (1889) ii. 383.- - Penins. Mal

sagittata, Oliver, in Hook. Icon, pl, xviii, (1888) t. 1749, - China.

LIMEUM, Linn. (Ficoid.), - Ind. Kew, ii. 88.

fenestratum, Heimerl, in Eng1. \& Prantl, Natürl. Pflanzenfam, iii, lb (1889) $9=$ Semonvillaea fenestrata, Fenzl.

glaberrimum, Pax. in Bot. Fahrb. xix. (1894) 132 - Afr. austro-occ. extratrop.

ptcrocarpum, Heimerl, in Engl. \& Prantl. Natürl, Pflanzenfam. iii. 1b (1889) $9=$ Semonvillaea pterocarpa, f. Gay.

LIMNANTHEMUM, S. Gmel. (Gentian.). Ind. Kew, ii 85 .

andicum, Britton, in Trans. N. Y. Acad. Sci. ix. (1889) $12=$ trachyspermum, A. Gray.

LIMNODEA, Dewey, ex Coult, in Contrib. U. S. Nat. Herb. i. (1594) $518=$ Thurberia, Benth. (Gramin.).

arkansana, Dewey, 1. $\mathrm{c}_{\mathrm{o}}=\mathrm{T}$. arkansana, Benth,
LIMNOBIUM, Rich. (Hydrochar.). - Ind. Kew. Spongia, Baill. Hist. des pl. xiii. (1895) $192=\mathrm{L}$. Spongia, Stend.

LIMNOPEUCE, Adans. = Hippuris, Linn. Haluras

whlaris, "Vaillant » ex Greene, Man. Bot. San Franc. Bay (1894) $138=$ H. vulgaris, Linn.

LIMNOSIPANEA, Hook, f, (Rubiac.). - Ind Kew. ii. 84 .

cythraeoides, K. Schum, in Mart. Fl. Bras, vi, VI. (1889) 253.3 = Sipanea erythraeoides, Cham

LIMODORUM, [Tourn.] Linn. (Orchiđ.). - Ind.

graninifolium, Ham. ex Hook, f. Fl. Brit. Ind. (1890) $85 \%=$ Arundina bambusifolia, Lindl. parviflorum, Nash, in Bull. Torrey Bot. Club, xxil. (1895) $158=$ Calopogon parviflorus, Lindl. stiatum, Reinw. ex Hook. f. Fl. Brit. Ind. (1890) $8 \check{4} 4=$ Calanthe angustifolia. Lindl. Trabutianum, Batt. in Bull. Soc. Bot. Fr. xxxiii. (1886) 297 ; et in Batt. o Trab. Fl. d'Algér. (1886) 15, t. 10; et Fl. de l'Algér. [Monoc.] (1895) 33.Algéria.

LIMODORUM, Ludw. Def. (1737) 120, ex Kuntze Rev. Gen. (1891) 671 = Epipactis, Adans。 e Cephalanthera, Reichb. (Orchid.)

acuminatum, Kuntze, 1.c. = Ceph. ensifolia, Rich athense $\times$, Kuntze, 1. c, - Belo.

Austinae, Kuntze, 1. c. = Ceph. Austinae, Benth \& Hook. f.

chloidophyllum, Kuntze, 1. c. = Ceph. chloidophylla Reichb. $f$.

mcullatum, Kuntze, 1. c. = Ceph. cucullata, Boiss. \& Heldr.

erectum, Kuntze, 1. c. $=$ Ceph, pallens, Rich.

falc.tum, Kuntze, 1. c. = Ceph. falcata, Blume.

gigantenm, Kuntze, 1. c. = Epipactis Royleana Lindl.

grandiflorum, Kuntze, 1. c. = Cephalanthera ensifolia, Rich.

latifolum, Kuntze, 1. c, = Epipactis latifolia, All

longibracteatum, Kuntze, 1. c. = Cephalanthera longibracteata, Blume.

longifoliun, Kuntze, 1. c. $=$ Ceph. ensifolia, Rich

microphyllum, Kuntze, 1. c。 = Epipactis microphylla, Sw.

oreganum, Kuntze 1.c. = Cephalanthera oregana, Keichh. $f$.

palustre, Kuntze, 1. c. = Epipactis palustris Crantz.

papillosum, Kuntze, 1.c. = Epip. papillosa. Franch. Roylcanum, Kuntze, 1, c. = Epip, Royleana, Lindl. nubiginosum, Kuntze, 1. c. = Epip. atrorubens, Schult.

nubrum, Kuntze, 1. c. = Cephalanthéra, rubra Rich.

Deciostm X, Kuntze, 1, c, - Belo.

Thunbergii, Kuntze, 1. c. = Epipactis Thunbergit A. Gray.

veratrifolium, Kuntze, 1. c. = Epip. consimilis, D. Don

violacoun, Kuntze, 1, c. = Epip. latifolia, All.

LIMONIASTRUM, Moench (Plumbar.). - Ind

Kew. ii. S6
Fcei, Batt. in Batt. et Trab. Fl. de l'Algér. [Dicot.] (1889) 726 = Bubania Feei, Girard.

LIMONIODES, Kuntze, Rev. Gen. (1891) $394=$ LIMONOIDES, Sieg. = Limoniastrum Moench, (Plumbag.). monopetalum, Kuntze, culatum, Moench.

Guyonianum, Kuntze, 1. c. = L. Guyonianum, Durieus.

LIMONIUM, Moeht, = Statice, Tourn, (Plumbag.).

alutaceun, anceps, arabicum, artioulatum, oustrate. axillare, bicolor, Billardieri, Bourgeani, brasillense. Bronneri, cabulicum, cacsium, callicomm, ancellatum 


\section{LIMONIUM:}

camosum, chrysacomun, Companyonis, confusum, congestum, corculum, corinthiacum, corynbulosum, cosyrense, cumanum, dalmaticum, decipiens, decumbens, dclicatulum, dichotomum, dictyocladum, diffusunn, Dregeanum, duriusculim, effusum, elatum, cmarginalum, eximium, fermaceum, flexuosum, Franchetii, fruticuns, furfuraceum, Girardiannm, globulariaefolium, globuliferum, Gougetianum, grewiacfolnum, Griffthii, gummiforum, Humboldtii, iconicum, incamum, insigne. Fovibarba, Kaufmannianum, Kranssianum, latifolizm, leptolobum, leptopliyllum. Tcptostaclunum, linifolium, lychnidifolium, macrophyllum, macroptenum, macrorhabdon, macrorhizon, mimutum, minutiflorum, mucronatum, myrianthum, mudum, oboratum, occidentale, ochranthum, ocynifolium, ornatum. otolepis, osalifolium, papillatum, pectinatum, pedicellatum, perfoliatum, planosum, Preanxii, pruinosum, psitocladon, puberwinn, pycnanthum. roseum, raticolum, salicorniaiea, salsuginosum, roseum, rapicolum, salicornatea, salsuginosum, Sibthorpianum, Sieberi, spathulatum, speciosum, spicatum, Stocksii, suffruticosum, tenellum, Thoutinit, tomenteitum, trigonodes, tuberculatum, tubiflorum, Wrightii, Kuntze, Rev, Gen. (1891) $394-96=$ homonyma ommia Statices.

arborescens, Kuntze. 1. c. $395=\mathrm{S}$. fruticans, $W e b b$. Bchon, Kuntze, 1, c. = S. Limonium, Linn Besserianum, Kuntze, 1. c. = S. tatarica. Linn. Bonducellii, Kuntze, 1. c. = S. Bonducelli, Lestib. brassicifulium, Kuntze, 1. c, = S. brassicaefolia, Webb \&o Berth.

carolinianm, Britton, in Mem. Torrey Bot. Club, v. (1894) $255=\mathrm{S}$. caroliniana, W alt

Cossonianum, Kuntze, Rev. Gen. (1891) $395=$

S. corymbulosa, $\Lambda^{\top} y m$.

densiftorm, Kuntze, I. C. $=$ S. oleaefolia, Scop. desertorm, Kuntze, 1. c. = S. tatarica, Lm.

Dodartii, Kuntze, 1..$=S$ S. auriculaefolia, $V a h l$. Dubyi, Kuntze, 1. c. = S. Dubyei, Grert. \& Godr.

Dufouri, Kuntze, 1. c. = S. Dufnurei, Girard.

Durieui, Kuntze, 1. c. = S. Duriaei, Girard.

Gmelinii, Kuntze, 1. c. $=$ S. Gmelini, Koch.

graecum, Kuntze, 1. c. = S. rorida, Sibth. \& Sm.

Guaicuru, Kuntze, 1, c. = S, chilensis, Phil.

japonicum, Iruntze, 1. C. = S. australis, Spreng.

lobatum, Kuntze, 1. $\mathrm{c}_{\mathrm{n}}=\mathrm{S}$. Thouini, Viv.

Meyeri, Kuntze, 1. c. = S. Limonium, Limn. et Gmelini, Koch.

myosurodes, Kuntze, 1. c. = S. myosuroides, Regel. Owerinit, Kuntze, 1. c. $396=\mathrm{S}$. Owerini, Boiss.

peruvianum, Kuntze, 1. c. - Peruvia.

rariflorum, Kuntze, 1. c. $395=\mathrm{s}=\mathrm{S}$. Limonium, Linn. sedodes, Kuntze, 1. c. $396=\mathrm{S}$. sedoides, Regel.

sinense, Kuntze, 1. c. $=\mathrm{S}$. australis, Sfreng.

Sewerzowii, Kuntze, 1. c. = S. Sewerzowi, Regel.

Sutarowii, Kuntze, 1. c. = S. Suwarowi, Regel.

LIMOSELLA, Linn. (Scrophul.). - Ind. Kew.

ciliata, Colenso, in Trans. N. Z. Inst. xxi. 1888) (1889) 96. - N. Zel.

IINANTHUS, Benth. = Gilia, Ruiz \& Pav, (Polemon.)

acicularis, Greene, Pittonia, ii. (Aur. 1892) 259; et Man. Bot. San Franc. Bay (1894) 250. - Calif. ambigus, Greene 11. сc. 256; et 249)= G. ambigua, Ratian.

androsaccus, Greene, 11. cc. 258 ; et $250=\mathrm{G}$. andrasacea, Steud.

aureus, Greene, 1. c. $257=\mathrm{G}$, aurea, Nutt.

bellus, Greene, 1. c. $256=\mathrm{G}$. bella, A. Gray.

bicolor, Greene, 1. c. $260=\mathrm{G}$. tenella, Bonth.

Bigdovii, Greene, 1. c. 25:3 = G. Bigelovii. 1. Gray.

Bolanderi, Greene, 1. c. $255=$ G. Bolanderi, A. Gray.

breviculus, Greene, 1. c. $259=\mathrm{G}$. brevicula, A. Gray. ciliatus, Greene, 1. c. $260=\mathrm{G}$. ciliata, Benth

demissus, Greene, I. c. $257:=\mathrm{G}$ : demissa, $A$ Gray.

dianlhiflorus, Greene, 1. c. $254=$ Fenzlia dianthiAora, Benth.

flipes, Greene, 1. c. $255=$ Gilia filipes, Bcnth.

grandiflorus, Greene, 1. c. 250 (= Leptosiphon grandiflorus, Benth.). = G. densiflora, Benth.

\section{LINANTHUS: -}

Harkmessiz, Greene, Pittonia, ii. (Aug. 1892) $255=$ G. Harknessii, Curran.

fomesii, Greene, 1. c. $254=\mathrm{G}$. Jonesii, $A$, Gray.

Lemmoni, Greene, 1. c. $257=$ G. Lemmoni, A Gray.

liniflons, Greene, 1 c, $249=\mathrm{G}$. liniflora, Benth.

7utcolus, Greene, in Erythea, iii. (1895) 121.

Calif.

montanus, Greene, 1. c. 120. - Am. bor. occ.

neglectus, Greene, 1. c. 24. - Calif.

mdatus, Greene, 1. c, 120. - Calif

Parryae. Greene, Pittonia, ii. (Aug. 1892) $256=$ G. Parryae, A. Gray.

parviflorns, Greene, 1. c. 258 (= Leptosiphon parviflorus, Benth.). = G. micrantha, Stend.

phrarnaceoides, Greene, 1. c. $254=\mathrm{G}$. pharnaceoides, Benth.

pusillus, Greene, 1. c. $255=\mathrm{G}$. pusilla. Benth.

Rattani, Greene, 1. c. $25 \% \equiv$ G. Rattani, $A$. Gray.

osaceus, Greene, 1. c. 259; et Man. Bot. San Franc. Bay (1894) $250=$ G. micrantha, Benth. sermalatus, Greene, in Erythea, iii. (1895) 120. Calif.

LINARIA, Tourn. ex Linn. (Scrophul.). - Ind. Kew. ii. 86 .

aragonensis, Loscos, Trat. pl. Arag. Suppl. 6 (1886 ?) 34; Willk. Illustr. Fl. Hzsp. ii. (1887) 35, t. 111 ; et Suppl. Prodr. Fl. Hisp: (1893) 176. Hisp

auriculata, St. Lager, in Cariot, Etud des fl. éd. S ii. (1889) $622=\mathrm{L}$. Elatine, $M$ ill.

baborensis, Batt. in Batt. \& Trab. Fi. de l'Algér. [Dicot.] (1889) $642=$ pinifolia, Poir

Badali, Wiilk, Illustr. Fl. Hisp. ii. (1892) 33, t. 110; et Suppl. Prodr. Fl. Hisp. (1893) 176. Hisp.

Blanca, Pat, Not. Bot. Fl. Espan. ii. (1889) 10 ; Willh. Suppl. Prodr. Fl. Hisp. (1893) 173. - Hisp. Brebissonii X, Corbière, Nouv. F1. Normand (1893) 427. - Gall. occ.

Camusi $\times$. Héribaud. in Bull. Herb. Boiss. App. iv. (1894) 27. - Gall.

Cossoni, Barratte, in Coss. Ill. Fil. Atlant. ii. (1887) 89, t. 155; Bonmier \& Barratte, Cal. rase. pl. Tunis (1886) 317. - Tunetia.

Doumetii, Coss. ex Batt in Bath. E Trab. Fl. de l'Algér. Dicot. (1889) 640; Bonnet \&o Barratte. Explor. Tunis. Illustr. bot. (1895) t. 12, fig. 1-8. Afr. bor

euxin', Volen, in Bot. Centralbl. xxxvi. (1888) 1.5. - Bulve

fallax, Coss ex Batt. \& Trab. Fl, de l'Algér. i. [Dicot.] (1889) 640; Coss. I7l. Fl, Atlant. ii (1887) 87, t 154. - Algéria.

Fontanesii, Coss. ex Batt. \& Trab. i. (1889) $641=$ L. Cossoni, Barratte.

fragrans, Porta \& Rigo, in Atti Accad. Agiati ix: 1891 (1892) 52, Willk. Suppl. Prodr. Fl. Hisp. 1893) 174. - Hisp.

gobantesiana, Coincy, in Bull. Herb. Boiss. iii, (1595) 27.- Hisp.

Thedexifolia, St. Lager, in Cariot, Etud. des fl. éd. 8, ii. (1889) 622 (=L. hederaefolia, Steud,). $=$ L. Elatine, Mill.

Hevibaudi $X, G$. Camus, in Bull. Herb. Boiss. i. Append. i. (1893) 42. - Gall,

heterophylla, Bolle, in Bot. Fahrb. xiv. (1892) 248 (= Antirrhinum heterophyllum. Schousb.). - Ins. Canar.

Linaria, Karst. Deutsch1. FI. (1880-83) 947; Wettst. in Engl. \& Prantl, Natürl. Pflanzenfam. iv. 3b (1891) $59=$ L. vulgaris, Mill.

Pancicii, Janka, ex Nym. Consp. Fl. Eur. ii. I. (1890) 232 = macedonica, Griseb.

patula. Baker, in Kew Bull. (1895) 222. - Reg. Somal.

Pelliceriana, St Lager, in Cariot, Étud, des ft. éd. 8, ii. (1889) $621=\mathrm{L}$. Pelisseriana, Mill.

Perezii, Nym. Consp. Fl. Eur., Suppl. ii. 1 (1890) 234. - His?

Reverchoni, Wittrock, in Act. Hort. Berg. i. 4 (1891) 11. cum ic.; Willk. Suppl. Prodr. Fl. Hisp. (1893) 173. - Hisp.
LINARIA : -

Rodriouezil Porta, in Nuo\%, Giorn. Bot. Ital xix. (1887) 313. - Ins. Balear

sofiana, Velen. in Sitzungs. Boehm. Ges. Wiss. (1887) 453 = italica, Trevir.

subrotunda. St Lager, in Cariot, Etud. des fl. éd. 8, ii. $(1889) 622=$ spuria, Mill.

LINDENBERGIA, Lehm. (Borag.). - Ind. Kew. ii. 8 .

indica, Kuntze, Rev, Gen. (1891) $462=$ polyantha, Rople.

ruderalis, Kuntze, 1, c. = urticaefolia, Lehm.

sinaica, Terrac. in Ann. Ist. Bot. Roma, v. (1894) 103 = sinaica, Benth.

LINDERA, Thunb. (Laurin.). - Ind. Kew. ii 89

cercidifolia, Hensl. in fourn. Linn. Soc. xxvi. (1891) 38\%. - China.

citriodora, Hemsl. 7. c. - Japon., Ins. Loo Choo. communis. Hentsl. l.c. - China.

fragrans, Oliver, in Hook. Icon, ph. xviii. (1888) t. 1788. - China.

fruticosa, Hemst. in fourn. Linn. Soc. xxvi. (1891) 388. - China,

grandifolia, Stapf, in Trans, Linn. Soc. Ser. II. iv. (1894) 220. - Borneo.

latifolia, Hook. f. Fl. Brit. Ind. v. (1886) 183. Reg. Himal

Laureola, Collett \& Henst. in foum. Linn. Soc. xxviii. (1890) 119. - Burma.

malaccensts, Hook. f. Fl. Brit. Ind. v. (1SS6) 183. - Penins Mal., Borneo.

megaphylla, Henst. in fourn. Linn. Soc. xxvi. (1891) 389. - China.

Meissneri, Hook. f. Fl. Brit. Ind. v. (1886) 182.Reg. Himal,

obovata, Franch. in Now. Arch. Mus, Paris, Sér. II. x. (1887-88) 76. - Tibet.

Oldhami, Hemsl. in fonrn. Linn. Soc. xxvi. (1891) 390. - Formosa.

populifolia, Hemsl. l. c. - China.

puberula. Franch. in Now. Archiv. Mus. Paris, Sér. II. x. (1888) 77. - Tibet.

reflexa, Hemsl. in fourn. Linn. Soc. xxvi. (1891) 391. - China.

sinensis, Hemsl. l. c. 392. - China.

Tzumu, Hemsl. . . . - China.

LINDERNIA, All. = Vandellia, Linn. $($ Scro phul.).

angustifolia, Wettst. in Engl. \& Prantl, Natürl. Pflanzenfam, iv. 3b (1891) $73=$ V. angustifolia, Benth.

diffusa. Wettst. 1, c. $=\mathrm{V}$, diffusa, Linn.

clata, Wettst. 1. c. = V. elata, Benth

gratioloides, Lloyd \& Fouc. F1. Ouest Fr. éd. (1886) $246=$ Ilysanthes riparia, Rafin.

Jirsuta, Wettst. in Encl. \& Prantl, Natür1. Pflanzenfam. iv. $3 \mathrm{~b}$ (1891) $73=\mathrm{V}$. hirsuta, Buch Ham.

Hookeri, Wettst. 1. c. $80=$ V. Hookeri, C. B. Clarke.

lobelioides, Engl. Pflanzenw. Ost-Afr. C (1895) 357 $=\mathrm{V}$. lobelioides, Oliwer.

mollis, Wettst, in En:rl, \& Prantl, Natürl. Pflanzenfam.iv. 3b (1891) $73=$ V. mollis, Benth.

molluginoides, Wettst. 1, c. $80=\mathrm{V}$. molluginoides, Benth.

nummulariaefolia, Wettst, l. c. = V. nummularifolia, D. Don.

pedunculata, Wettst. 1. c. $=$ V. pedunculata Benth.

scabra. Wettst. in Engl. \& Prantl, Natïr1. Pflanzenfam iv. 3b (1891) $80=$ V. scabra, Benth.

sessiliflora, Wettst. 1. $\mathrm{c}_{\mathrm{n}}=\mathrm{V}$. sessiliflora, Benth.

Stuhlmannii, Engl. Pflanzenw. Ost-Afr. C (1895) 357. - Afr. trop. or.

IINDELOFIA, Lehm, (Borag.). - Ind. Kew. ongiflora, Baill. Hist. des pl. x. (1890) 379; Gürke in Engl. \& Prantl, Natürt. Pflanzenfam. iv ?a (1894) 103 = spectabilis, Lehm. 
IINDNERIA, Th. Dur. \& Lubbers, in Bull. Soc Bot. Fr. xxxvi. (1859) p. ccxvi = Pseudogaltonia, Kuntze (Liliac.)

fibrillosa, Th. Dur. \& Lubbers, 1. c. t. 18: Baker in Gard. Chron. (1890) ii. $240=$ P. Pechuelii, Kuntze.

Pechuelii. Th. Dur, \& Schinz, Consp. Fl. Afr. v. 1893 (1895) $376=$ P. Pechuelii, Krntze.

LINGOUM, Rumpf $=$ Pterocarpus, Linn (Legum.).

acuminatum, echinatum, exinaceum, esculentum, indicum, luccns, macrocarpum. Marsupinm, melliferum, Rohrii, rufescens, santalinum, sericerm, simplicifolium, tino torium, willosum, violaceum, Kuntze, Rev。'Gen. (1891) 193 = homonyma ommia Pterocarpi.

acuminatum, Kuntze, 1. c. = P. ancylocalyx, Benth officinale. Kuntze, 1. $c_{0}=$ P. Draco, Linn.

pubescens, Kunize, l. $c_{0}=$ P. Amphymenium, $D C$.

LINKIA, Cav. = Persoonia, Sm. (Proteac.).

acerosa, acicularis, angulata, angustiflora, arborea, articulata, brachystylis. Caleyi, Chamaepence. Chamaepitys, comata confertiflora curnifolia, Cumninzghamii, currifolia, disdena, elliptica, falcata, fastigiata, ferruginea, graminea, Gunni, hakeaeformis hirsuta, juniperina, lcdifolia, linearis, longifolia, lucida, Marginata, media, microcarpa, Mitchellii, mollis, mutans, oblongata. pinifolia, prostrata. quinquenervis, reroluta, rigida, nudis, rufiflora, sac cata, salicina, Sandersiana, scabra, scabrellut. sericea. striata, sulcata, temifolia, - teritifolia, tortifolia. trinervis, virgata, Kuntze, Rev. Gen. (1891) 579 = liomonyma omnia Persooniae.

dillwyniodes, Kuntze, 1. c. = P. dillwynioides, Mcissu.

myrtillodes, Kuntze, 1. c. = P. myrtilloides, Sieber. oxycocodes, Kuntze, I c. = P. oxycocoides. Sicbor. Toro, Kuntze, 1. c. = P. Toru, A. Cunn.

LINOGIERA, Sw, (Oleac.). - Ind. Kew, ii, 90, africana, Knobl. in Bot. Centralbl. Ixi. (1894) 122 Abyss.

axillaris, Knobl. l. c. 87 et $153(=$ Chionanthus axillavis. Benth. \& T. Muell.). - Austral.

Blumeana, Knob/. l. c." (= Ch. glomerata, Blume $)$. - Sumatra.

callophylla, Knobl.l.c. $(=\mathrm{Ch}$ callophilla, Blume $)$. - Malaya.

caribaea, Knobl. 1. c. $(=C h$. caribaea, Jacq. $)$. = glomerata. Pohl.

caudata, Collett \& Hemsl. in fourn. Linn. Soc. xxviii. (1890) 84. - Burma.

coriacca, Cordem. Fl. Ile Rémion (1895) 458.Ins. Borbon.

coriacea, Vidal, Revis. Pl. Vasc. Filip. (1886) 1s1. - Ins, Philipp.

cuspidata, Knobl. in Bot. Centralbl. 1xi. (1894) (= Chionanthus cuspidata, Blume). - Ins. Celebes.

cyanocarpa, Cordem. Fl. Ile Rémuion (1895) 457 . Ins. Borbon.

diversifolia, Knobl, in Bot. Centralbl. 1xi. (1S94( (= Chionanthus diversifolia, Miq.). - Sumatra.

domingensis, Knobl. 1. c. (= Ch. domingensis, Lam.1. $=$ glomerata, Pohl.

Dussii, Knobl. l. c. $(=$ Mayetea Dussii, Krug \& Urban). - Ins. Antill.

litorea, Knobl. l. c. $(=$ Ch. littorea, Miq.). Sumatra.

elliptica, Knobl. l. c. (= Chionanthus elliptica, Blume). - Malaya.

laxiflora, Knobl.l. c. $(=$ ( Ch. laxiftora, Blume) Borneo

macrocarpa, Knobl.1.c. (= Ch.macrocarpa, Blume). = insignis, C. B. Clarke.

Männii, Solered. in Sitzungsb. Bot. Ver. Mucnch. (1891) extr. 9; et ex Knobl, in Bot. Centralbl. xlvi. (1891) 17. - Gabon.

obscura, Cordem. Fl. Ile Rénzion (1895) d.̃. - Ins. Borbon.

picrophloia Knobl. in Bot. Centralbl. 1xi. (1894) $(=$ Chionanthus picrophloia, F. Muell. $)=$ intermedia, Wight.

pluriflora, Knobl. l. c. - Borneo

quadristaminea, Knobl.l.c. (= Chionanhihus qutdristaminea, F. Muell.). - Austral.

\section{LINOGIERA}

amifora, Knobl. in Bot. Centralbl. 1xi. (1894) (= Ch. ramiflora, Roxb.). = macrcphylla, Wall essiliflora, Hemsl. in Ann. Bot. v. (18:1) 504 . Ins. Salom.

spicata, Knobl. $l$. $6 \cdot(=$ Chionanthins spicata. Blume), - Malaya.

sumatrana, Knobl. l. c. 87 et $133(=$ Ch. sumatrana Blume). — Sumatra.

timorensis Knobl.l.c. $(=\mathrm{Ch}$. timorensis, Blume - Timor.

"errucosa Solereder in Sitz Bot Vor. Muench. (1891) extr. 8: et in Bot. Centralbl. xiv. (1891) 399 ; xlvi. 17 (= Vangueria terrucosa, Sieb.).Ins. Maurit.

Welwitschii, Knobl. in Bot. Centralbl, 1.ii. (1895) 129 (= Mayepea Wolwitschii, Knobl.). - Afr. trop. occ.

LrNODES, Ludw. = Radiola, Dill, (Lineae). Radiola, Kuntze, Rev. Gen. (I891) $8 \%=\mathrm{R}$ Linordes, Roth.

LINOSPADIX, Becc. (Palm.). -- Ind. Kew, ii. 90 Forbesii, Ridl. in fourn. Bot. xxiv. (1886) 358, N. Guin.

Hollrungii, Becc. in K. Schum. E Hollr. Fl. Kais. Wilh, Land (1889) 16. - N. Guin.

Micholitzii, Ridl. in Gard. Chron. (1895) ii. 262. N. Guin.

LINOSTOMA, Wall. (Thymel,), - Ind. Kew, ii

albifolium, Rodr. [Herb. Mus. bot. Amaz. n. 63] Vellosia, 1885-88, sec. édic. (1891) 67. t. 20. Bras, bor.

LINOSYRIS, Moehr. Hort. Priv. (1736) 60; ex Kuntze, Rev. Gen.(1891) 687 = Thesium, Linn. (Santal.)

acutissima, alatavica, alpina, amblystachya, angulosa, aphylla, aurea, australis, Basnimiana. Bergeri, Boissieriana, brackyphylla, brasiliensis, capitata, capitellata, capituliffora, carinata, ciliata, commutata, compressa, confinis, corniculata, corymbuligera, cras sifolia, debilis, densiflora, diffusa, divaricata, ebracteata, Ecklonianu, elatior, exul, flexuosa, foliosa. Frisea, funalis, glomeruliflora, gnidiacea, grised. heterophylla. limalensis, hispidula, humifusa, hutmi lis, impressa. intermedia, juncea, juncifolia, Kerne riana, Krebsii, laxiflora, libanotica, lineata, longifolia, macrantha, macrostachya, madagascariensis, maritima, megalismontana, micromeria, microtogon, multicauls, neradensis, nigromontand. pallida, paniculata, Parnassi, parvifolia, phyllos tachya, pinifolia, procumbens, quinquefora, vacemosa, amosa, variflora, refracta, repens, vostrata, rupestris, saxatilis, scabra, scandens, selaginea, spartea, spicata, spimosa, spinulosa, squarrosa, stricta. Szowitsi tauricaula, tenuis, temuissinza, teretifolia. Thunbergiana, triflora, Turczaninowii, virens, virgata, Wightiana, Zeyheri, Kuntze, Rev. Gen (1891) $588=$ homonyma ommia Thesii.

amplexicantis, Kuntze, 1. с. $=$ T. euphorbioides. Berg.

Grevifolia, Kuntze, 1, c. = T. Ieptocaule, Sond. chininsis. Kuntze, 1. $c_{0}=T_{\text {. australe, }} R . B r$. decurrens, Kuntze, l. c. $={ }^{\top} T$. australe, $R \cdot B r$ ericifolia, Kuntze, 1. c. $=$ T. ericaefolium, $A, D C$ cricodes, Kuntze, 1. $\mathrm{c},=\mathrm{T}$, ericoides, $R . B r$ euphlirasiodes. Kuntze, 1, $\mathrm{c}=\mathrm{T}$. euphrasioides, Berg. galiodes, Kuntze, 1. $\mathrm{C}=\mathrm{T}$, galioides, $A, D C$ Linophyllon, Kuntze, 1. c. $587=$ T. bavarum Linophyllon, Kuntze, 1. c. 587 = T. bavarum,
Schrom, intermedium, Schrid. ct divaricatum, fan.

lobeliodes, Kuntze, 1. c. $588 \Rightarrow$ T, lobelioides, $A . D C$ montana, Kuntze, 1. c. $=$ T. bavarum, Sclivante sedifolia, Kuntze, 1 c, $=T$, crassifolium, Send. stellerodes, Kuntze, 1. c. $=$ T. stelleroides, faub. \& Spack.

LINUM, Tourn. ex Linn. (Lineae). - Ind. Kew. ii. 90.

adenophorum, Hausskn. \& Borm, ex Bornm. in Mitth. Thür. Bot. Ver. N. Folge, vi. (1S94) 65. - Oriens.

\section{LINUM :}

Aristidis, Batt. in Bull. Soc. Bot. Fr, xxxii. (1885?) 337; et in 'Batt. \& 'Trab.' Fl. de l'Algér. [Dicot. (1889) $175=$ corymbiferum. Desf.

Boissieri, Aschers, E Sint, ex Boiss. Fl. Or. Suppl. (18sS) 13\%. - As. Min ampanulatum, H
flavum, Linn.

emirnense, Hilsent. E Bojer, ex Baill. in Bull. Soc. Linn. Paris, i. (1886) 598. -- Madag.

floridanum. Trel. in Trans. St. Louis Acad, v. (1886) 13 = virginicum, Linn.

ignosum, Stapf, in Denkschr. Akad. Wien, ii. (1886) 22. - As. Min.

Luschasii, Stapf. l.c.22. - As, Min.

macrosepalum, Stapf, l. c. 42. - As. Min.

Peyroni, Post, Pl. Postianae, iii. (18.2) 6.-Syria. Pringlei, S. Wats. in Proc. Am. Acad xxiii. (I8ss) 269. - Mexic

Reuteri, Boiss. \& Hausskn. ex Boiss. Fl. Or. Suppl. (1858) 139. - Syria.

igidissimum, Post, in foum, Linn. Soc, xxiv. (1883) 424 . - As. occ

sterile, Stapf, in Denlischr. Akad.Wien, ii. (1886) 42. - As. Min.

thracicum, Degen, in Oest. Bot. Zeitschr. xliii. (1893) 55 = flavum, Linn.

Volkensii, Engl. Pfanzenw. Ost-Afr. C (1895) 226.

Vetschkyanum, E. Fiek, in Kneucker, Alloem, Bot. Zeitschir. i. (1895) 233. - Reg. Cauc

LIPARIS, Rich. (Orchid,). - Ind. Kew. ii. 93. cuminata, Hook. f. Fl. Brit. Ind. v. (1890) 696 et in Hook. Icon. pl. xxi. (1890) t. 2007. - Khasia. bambusaefolia, Makino, in Tokyo Bot. MIag. vi. (1892) 48. - Japon

Beccarii, Ridl. in fourn. Limn. Soc, xxii. (1886) 284 - Ind. or. austr.

Beddomei, Ridl. l. c. 268. - Ind. or. austr.

Bernieri, Frappier, ex Corden. Fl. Ile Rétnnion (1895) 185. - Ins. Borbon.

bifolia, Cogn, in Mart. Fl. Bras. iii. Iv. (1895) 289. - Bras.

bifolia, St. Lager, in Cariot, Ltud. des fl. éd. 8 ii. (1859) $814=\mathrm{L}$. Loeselii $A$. Rich.

Cathcartii. Hook, f. in Hook. Iconl. pl. xix. (1889) t. 180S; et Fl. Brit. Ind. v. (189y) 694. - Reg. Himal.

caulescens, Frappier, ex Cordem. Fl. Ile Rónnion 1895) 186. - Ins. Borbun

lavigera, Ridl. in fourn. Linn. Soc. xxii. (1886) 294. - Java.

cordifolia Hook. f in Hook, Icon pl xix. (1889) t. 1811: et Fl. Brit. Ind. v. (1890) 692. - Reg. Himal.

ornicaulis, Makino, in Tokyo Bot. Mag. v. (1891) 213, nomen. - Japon.

Cumingii, Ridl. in Fourn. Limn。,Soc, xxii, (1886) 292. - Malacca.

cuspidata, Ridl. l. c. 266. - Ins, Societ.

Dalzellii. Hook. f. Fl, Brit. Ind.' v. (1890) 698. Concan.

decurrens, Reichb. f. ex Ridl. in foum. Limn. Soc. xxii. (1886) 291 (= Platystylis decurrens, Lind?.). - As, trop.

deflexa, Hook, f. Fl. Brtt. Tnd. v. (1890) 697; et in Hook. Icon. pl. xxi. (1890) t. 2008. - Reg. Himal. delicatula, Hook, f. ll. cc. xix. (1889) t. 1889 ; et $\mathrm{v}$ (1890) 705. - Ind, or.

distans. C. B. Clarke, in fourn. Linn. Soc, Xxv (1889) 71, t. 29; Hook. f. Fl. Brit. Ind. v. (1890) $704 .-$ Assam.

Dolabella, Hook, f. in Hook. Icon. pl. xxi. (1890 t. 2010 ; Hook. f. l. c. vi. (1890) 183. - Khasia Duthiei. Hook, f. ll. cc. x1x. (1889) t. 1857 b ; et vi. 1890) 701. - Reg. Himal.

clerantissima. Hort. ex Ridl. in Journ. Linn. Soc. xxiv, (IS88) $340=$ Microstylis calophylla Reichib. f.

Flammula, Frappier, ex Corden. Fl. Ile Rínnion (1895) 183. - Ins. Borbon.

Forbesii, Ridl, in fourn. Linn. Soc, xxii. (18S6) 283.

fulgens, Rolfe, in Gard. Chron, (1S89) ii. 620:Ins. Philipp. 


\section{LIPARIS}

Gamblei, Hook, f. Icon , pl, xix. (1889) t. 1812! FL Brit. Ind. v. (1890) 693; et in Ann. Bot. Gard. Calc. v. i. (1895) 2, t. 3. - Ind. or.

gracilis, Hook. f. ll. cc. xxi. (1890) t. 2011 ; et vi. (1890) 182. - Perak.

gracilis, Rotfe, in Bolet. Soc. Brot, ix. (1891) 138. Ins. S. Thoma.

Griffithii, Ridl, in foum, Linn.Soc, xxii.(1886) 285; Hook. f. Fl. Brit. Ind, v. (1890) 700.Bootan.

Hookeri, Ridl. l. c. 288. - Khasia.

inconspicua, Makino, in Tokyo Bot. Mag. vi. (1892) 48. - Japon.

japonica, Maxim. int Bull. Acad. sci. Pétersb̆. xxxi (1887) 102. - Japon.

lacerata, Ridl. in fourn. Linn. Soc, xxii. (1886) 284 ct Hook. f. Fl. Brit. Ind. v. (1890) 702. - Borneo

lancifolia, Hook. f. in Hook. Icon. pl. xix. (1889) t. 1855 ; et l. $c .700$. - Khasia.

Layardi, F. Muell, in Wing's Sonth. Sci.Rec. New Ser. i. (Dec. 1885), ex Bot. Centralbl. xxvi. (1886) 87. - N. Caled.

macrantha, Hook. f. in Hook. Icon. pl. xix. (1889) t. 1854; et F1. Brit. Ind. v. (1890) $\% 04=$ distans, C. B. Clarke.

macrantha, Rolfe, ex Hensl, in Ann. Bot, ix. (1895) 156. - Ins. Formos.

macrocarpa, Hook. f. Fl. Brit. Ind. v. (1890) 696. - Reg. Himal,

minuta. Drake, Ill. Ins. Mar. Pacif, Fasc, 7 (1892) 306 ; et Fl. Polyn. Franc. (1892) 209. - Ins. Societ.

nectarina, Frappier, Fl, Ile Rémnion (1895) 184.Ins. Borbon.

obscura, Hook, f. in Hook. Icon. pl. xix. (1889) t. 1886 ; et Fl. Brit. Ind. v. (1890) 702. - Zeyl.

Parishii, Hook. f. l. c. vi. (1890) 182. - Ind. or.

pectinata, Ridl. in fourn, Limn. Soc. xxii. (1886) 27\%. - Ins. Philipp.

perpusilla, Hook, f. in Hook. Icon. pl. xix. (1889) t. 1856 b; et Fl. Brit. Ind. v. (1890) 706.Ind. or.

platyphylla, Ridl. in fourn. Linn. Soc. xxii. (1886) 264 ; et l. c. 695 . - - Ind, or.

platyrachis, Hook. f. Icon. pl. xix. (1889) t. 1890 et l. c. 706. - Reg. Himal.

Prainii. Hook. f. ll. cc. t. 185\%; et 700 . - Assam.

prionotes, Lindl. ex Ridl, in Journ. Linn, Soc, xxii. (1886) 297 , nomen $=$ Sarcochili $\mathrm{sp}$

pnlchella, Hook. fo in Hook. Icon, pl. xix. (1889) t. 1810; et Fl. Brit. Ind. v. (1890) 693. - Khasia.

puncticulata, Ridl. in form. Limn. Soc. xxis. (1886) 119 et 272. - Madag.

punctilabris, Frappier, ex Cordem. Fl. Ile Rémnion (1895) 184. - Ins. Borbon.

pusilla, Ridl. in fourn. Linn. Soc, xxii. (1886) 119 Hook. f. in Hook. Icon. pl. xix. (1889) t. 1856 a, et Fl. Brit. Ind. v. (1890) 701. - Madag.

repens, Ridl. l. c. 279 (= Malaxis atropurpurea, Blume). - Java.

resupinata, Ridl. l. c. 290; in Hook. Icon. pl. xix. (1889) t. 1888 ; Hook, f. Fl. Brit. Ind. v. (1890) 705 ; et vi. (1890) 182. - Reg. Himal.

vobusta, Hook. f. in Hook. Icon. pl. xxi, (1890) t. 2012 ; et 1 . co 182 , in syn. = latifolia Lindl.

scaposa, Frappier, ex Cordem. Fl. Ile Réunion (1895) 183. - Ins. Borbon.

Scortechini, Hook. f. FI. Brit. Ind. v. (1890) 703; et vi. (1890) 182, in syn, ; et in Hook. Icon. pl xxi.(1890) t. $2009=$ latifolia, Lindl.

Simmondsii, F. M. Bailey, in Dept. Agric. Brisbane Bot. Bull. iii. (1891) 18. - Austral.

tenuifolia, Hook. f. in Hook. Icon. pl. xxi. (1890) t. 2013; et Fl. Brit. Ind. vi. (1890) 182. Assam.

Thwaitesii, Hook。 f. ll, cc. v. (1890) 692; e t. 2006. - Zeylan.

torta, Hook, f.ll.cc, xxi.(1890) t, 2014; et vi. (1890) 182. - Khasia.

triloba, Ridl. in foum. Linn. Soc. xxii. (1886) 295 - Ins. Philipp.

Trimenii, Ridl. l. c. xxiv. (1888) 350 ; Hook. f. in Hook. Icon. pl, xix. (1889) t. 1836 ; et Fl. Brit. Ind.v. $(1890 ; 695 .-$ Zeylan.

\section{LIPARIS}

enosa, Ridl, in fourn. Linn. Soc. xxiv. (188S) 350 ; et v. (1890) 695 ; Hook. f. in Hook. Icon. pl. xix. (1889) t. 1836 ; ct Fl. Brit. Ind. v. (1890) 695, Ind. or.

verrucosa, Frappier, ex Cordem. Fl. Ile Réunion. (1895) 185. - Ins. Borbon

rexillifera, Cogn. in Mart. F1. Bras, iii. Iv. (IS95) 289 = elliptica, Reichb. f.

Wrayii, Hook. f. Fl. Brit, Ind, vi, (1890) 181.Perak.

xanthina, Ridl. in fourn. I.imn. Soc, xxii. (1886) 275. - Madag.

zeylanica, "Lodd, " ex Ridl. 1. c. 297. - Nomen omnino delendum, fide cl. Ridl. [Conf. Hook. f. Fl. Brit. Ind. vi. (1890) 183!

LIPOCARPHA, R. Br. (Cyper.). - Ind. Kew. ii. 94.

argentea, Boeck. ex C. B. Clarke, in Th. Dur. \& Schinz, Consp. Fl. Afr, v. 1894 (I895) $649=$ albiceps, Ridl.

atropurpura. Boeck. Cyper. Nov.i.(1888) p. $21=$ pulcherrima, Ridl.

Barteri. C. B. Clarke, in Th. Dur. E Schinz, Const. Fl. Afr. v. 1894 (1895) 650. - Reg. Nigrit.

multibracteata, C. B. Clarke, l, c. - Angola.

Rautanenii, Boeck. ex Schinz, in Verh. Bot. Ver. Brand. xxxi, (1890) $179=$ Scirpus Isolepis, Boeck.

tenera. Boeck. Cyper. Nov. i. (1888) $21=$ pulcherrima, Ridl.

LIPOCHAETA, DC, (Compos.), - Ind, Kew, i. 94.

Aprevaliana, Drake, Ill. Fl. Ins. Mavis Pacif. (1888) \%1, t. 34. - Ins. Sandvic

flexuosa, Drake, l. c.73, t. 36. - Ins. Sandvic.

hastata, Hillebr. Fl. Haw. Isl. (1888) 208. - Ins. Sandvic

peduncularis, Drake, Ill. Fl. Ins. Maris Pacif. (1888) 72, t. 35. - Ins. Sandvic.

LIPOSTOMA, D, Don = Coccocypselum, R. Br. (Rubiac.)

prostratum, K. Schum. in Mart. Fl. Bras, vi. VI. 1889) 275. - Bras.

LIPPIA, Houst. ex Linn. (Verben.). - Ind. Kew. ii. 94 .

aphylla, Phil. in Anal. Univ. Chit. xc. (1895) 623. - Chili.

aprica, Phil. l. c.xci. (1895) 415. - Chili.

barbata, T. S. Brandeg. in Proc. Calif. Acad. Ser. II ii. (1889) 196. - Calif.

boliviana, Rusby, in Mem. Torrey Bot, Club, iv, (1895) 243. - Bolivia.

disepala, Phil. in Anal. Univ, Chil. xc. (1895) 622. - Chili.

fastigiata, T. S. Brandeg. in Proc. Calif. Acad. Ser. II. ii (1889) 196. - Calif

fimbriata, Rusby, in Mem. Torrey Bot, Club, iv. (1895) 244. - Bolivia.

floribunda, Phit. in Anal. Mus, nac. Chile, (1891) 59. - Chile.

Foncki, Phil, in Anal. Univ. Chil. xc. (1895) 620.Chili.

formosa, T. S. Brandeg. in Proc, Calif. Acad. Ser. 1I. iii. (1891) 163. - Calif.

gracilis, Phil. in Anal. Univ. Chil.xc. (1895) 620.Chili.

lantanoides, Coult. in Contrib. U. S. Nat. Herb.ii. (1892) 329 = geminata, $H . B$. \& $K$. ligustrina, Britton, in Trans. N. Y. Acad. Sci. ix. (1889-90) $181=$ lycioides, Steud

litoralis, Phil. in Anal. Univ. Chil. xc. (1895) 624,Chili.

montana, T. S. Brandeg. in Proc. Calif. Acad. Ser. II. iii. (1891) 163. - Calif.

nutans, Robinson of Greenm. in Am. Fomm. Sci Ser. III. I. (1895) 162. - Mexic.

oaxacana, Robinson \& Grenman, l.c. - Mexic.

Palmeri, S. Wats. in Proc. Am. Acad. xxiv. (1889) 67. - Mexic

Recolletae, Morong, in Ann. N. Y. Acad. Scr, vii. (1893) 196. - Parag.

\section{LIPPIA}

salsoloides, Briq. in Engl. \& Prantl. Natürl. Pflanzentam. iv. 3a (1894) $152=$ salsoloides, Benth \& Hook.f.

IIPPOMUELLERA, Kuntze, Rev. Gen. (1891) 579 $=$ Agastachys, R. Br. (Proteac.).

odorata, Kuntze, 1. C. = A. odorata, $R . B r$.

LIRIODENDRON, Linn. (Magnoliac.). - Ind. Kew. ii. 96.

fastigiata, Hort. ex Dippel, Handb. Laubholzk. iii. (1893) 155 et $736=$ L. Tulipifera, Linn.

LIRIOPE, Lour, (Haemodor.), - Ind. Kew. ii. 96. L. graminifolia, Baker) = spicata, Lour. minor, Makino, in Tokyo Bot. Mag. vit. (I893) 32. (= Ophiopogon minor, Royle?).-- Japon.

LISIANTHIUS, P. Br. = Lisianthus, Linn. (Gentian.).

axillaris, Kuntze, Rev. Gen. (1891) $429=$ Leian thus axillaris, Hemsl.

breridentatus, Kuntze, 1. c. $=$ L. brevidentatus, Hensl.

Semanni, Kuntze, 1. c. = L. Seemanni. Griseb.

Skinneri, Kuntze, 1. c. $=$ L. Skinneri, Hems?.

LISIANTHUS, Linn. (Gentian.). - Ind, Kew, ii.

graciliflorus, F. M. Bailey, in Dept. Agric. Brisbane Bot. Bull.v. (1892) 18. - Austral.

im Thurnianus, Oliver, in Trans. Linn. Soc. Ser. II. ii. (1887) 279 [Oliver, ex im Thurn, in Tiwehri, v. (1886) 199]. - Guian. angl.

LISSOCARPA, Benth. (Styrac.). - Ind. Kew, ii.

Benthamii, Baill. Hist. des pl. xi. (1892) $460=\mathrm{seq}$. Benthamii, Guerke, in Engl. \& Prantl. Natiirl. Pfanzenfam. iv. I. (1891) 180; Oliver, in Hook. Icon.pl. xxv. (1895) t 2413. - Bras., Venez.

LISSOCHILUS, R. Br. (Orchid.), 一 Ind, Kew ii. 97.

abyssinicus, Th, Dur. \& Schinz, Consp. Fl. Afr. v J892 (1895) 27 (= Hypodematium abysinicum, A. Rich ). - Abyss.

affinis, Rendle, in fourn. Bot. xxxiii. (1895) 193. -

Afr. trop. or.
Antunesii. Rolfe, in Bolet. Soc. Brot. vii. (1889) $23 \%$. - Angola.

barombensis, Kraensl. in Bot. Fahrb. xvii. (1893) 51. - Kamerun.

brevisepalus, Rendle, in Fourn. Bot. xxxiij. (1895) 195. - Afr. trop, or.

Buettneri, Kraenzl. in Bot. Falirb. xvii. (1893) 53 - Afr. trop.

cornigerus, Rendle, in fourn. Bot, xxxiii. (1895) 194. - Afr. trop. or.

dispersus, Rolfe, in Gard. Chron. (1893) i.684 (= Eulophia disperma, N. E. Tsr.). - Afr. trop. or.

Dybowskii, Godefr.-Leboenf, in L'Orchidophile (1892 300 ; et in Rev. Hortic. Belge. xix. (1893) 47. Congo gall.

Elliotii. Rendle, in fourn Bot. xxxiii. (1895) 169.Afr. trop. or.

gracilior, Rendle, l. c. - Afr trop. or.

Graefei, Kraenzl. in Gard. Chron. (1891) i. 749 et (1893) i. 684, et in Reichb. f. Xen. Orchid. iii. 8 (1894) 125 , t. $272=$ L. Krebsii, Reichb.f.

mediocris, Rendle, in fourn. Bot. xxxiii. (1895) 193. - Afr. trop. or

micranthus, Kraenzl. in Bot. Fahrb, xvii. (1893) 53. - Afr. trop,

milanjianus, Rendle, in Trans, Linn. Soc. Ser. II iv. (1894) 46. - Afr. trop.

monticolus, Rendle, in fourn. Bot. xxxiii. (1895) 172 - Afr. trop. or

papilionaceus, Rendle, l. c. 170. - Afr. trop. or. parvulus, Rendle, l. c. 196. - Afr. trop. or. pulchellus, Rendle, l. c. - Afr. trop. or.

ruwenzoriensis, Rendle, l. c. 170. - Afr. trop. or. saccatus, Rendle, l. c. 172. - Afr. trop, or. 
LISSOGHILUS :

shirensis, Rendle, in fourn. Bot. xxxiii. (1895) 171. - Afr. trop. or.

Stuhlmanni, Kracnzl. in Bot. Fahrb. xix. (1894) 248 - Afr. trop.

Taylori, Ridl. in foum. Bot. xxiv. (1886) 293. Afr. trop. or.

validus, Rendle, l. c. xxxiii. (1895) 19\%. - Afr. trop.

LISTERA, R. Br. (Orchid.). - Ind. Kew. ii. 98 borealis, Morong, in Bull. Torrey Bot. Club, xx (18 3) 30. - Am, bor. art.

shihokiana, Makino, in Tokyo Bot. Mag. vii. (1893) 68. - Japon.

LISTROSTACHYS, Reichb. = Angraecum, Thou (Orchid.).

Althoffi, Th. Dur, \& Schinz, Consp. Fl. Afr. v. $1892(1895) 47=$ A. Althoffii, Kraenzl.

Aschersoni, Th. Dur. \& Schinz, 1. c, $48=\mathrm{A}$ Aschersoni, Kraenzl.

Bakeri, Th. Dur. \& Schinz, 1. c. = A. Bakeri Kraenzl.

Bramii, Th. Dur. \& Schinz, 1.c. = A. cephalotes, Kraenzl.

Bucholziana, Th. Dur. \& Schinz, 1. c. = A. Buchol zianum, Kraenzl.

clavata, Rendle, in Journ. Bot. xxxiii. (1895) 251 - Sierra-Leone.

divitiflora, Kraenzl. in Bot. Jahrb. xxii. (1895) 28 et in Engl. Pflanzenw. Ost-Afr. A (1895) $95 \mathrm{e}$ C (1895) 158. - Afr. trop. or.

Engleriana, Kraenzl. in Bot. Jahrb. xix. (1894) 254 , in obs. = A. Engleriana. Engl.

flijormis, Kraenzl. 1. c. xxi1. (1895) 28. - Afr trop.

forcipata, Kraenzl. 1. c. xix. (1894) 254. - Kamerun.

graminifolia, Kraenz1. 1. c. xxii. (1895) 29 ; et in Engl. Pflanzenw. Ost-Afr. C (1895) 158. - Afr. trop. or.

Metteniae, Kraenzl. in Reichb. f. Xen. Orchid. sii 7 (1893) 122 II. fig. 9-15. - Afr. trop. occ.

palmiformis, Th. Dur, \& Schinz, Consp. Fl. Afr, v. 1892 (1895) $49=$ A. palmiforme, Thou.

tenuifolia. [Engl. ?] Pflanzenw. Ost-Afr. A. (1895) 117. - Quid?

trachypus, Kraenzl, in Bot. Jahrb. xix. (1894) 253. - Kamerun.

urostachya, Kraenzl. 1. c. xxii. (1895) 29 ; et in Engl. Pflanzenw. Ost-Afr. C (1895) 158 - Afr. trop. or.

Zenkeri, Kraenzl. 1. c. xix. (1894) 252. - Afr. trop. occ.

LITHOCARDIUM, Linn. = Cordia, Linn. rag.).

album, acutifolium, adnatum, affine, alliodorum, ambigunm, amplifolium, anabaptistum, angiocarpum, angustifolium, asperum, asterophorum, Aubletii, bantamense, bicolor, bogotense, Boissieri, Bonplandii, brachypodum, brachytrichum, bracteatum, brevispica tum, caffrum, calocephalum, calocomum, calophylhum canescens, cantm, caracasanum, Chamissonianum, convolvuliflorum, corchorifolium, cordifolium, crenatum, crenulatum, crispiflorum, cujabense, cuneiforme, curassavicum, dasycephalum, decandrum, diospyrifolium, discolor, divaricatum, diversifolium, dodecandrum, ellipticum, exaltatum, excelsum, Finlaysonianum, flavescens, foliolosum, fragrantissimum, Fresenii, fulvosum, Galeottianum, Gerascanthus, glabratum, glabrum, glandulosum. grande, grandiflorum, grandifolium, Greggii, Griffithi, guayagulense, guineense, Haenkeanum, hebecarpum, hermanniaefolium, heterophyllum, hirsutum, hispidissimum, hispidum, hypoleucum, insigne, intermedium, laeve, lanceolatum, laxiflorum, leptocaulon, leucocalyx, leucocephalum, leucocomum, leucophlyctis, limum, lineare, longifolium, longipedum, Macleodii, macrocephalum, macrophyllum, macrostachyum, magnoliaefolium, mariquitense, microcephalum, mirandum, moluccanum, monoicum, mucronatum, multispicatum, Myxa. nervosum, niti dum, niveum, nodosum, oaxacanum, obliquum, obovatum, obscurum, obtusum, ochnaceum, octandrum, oilale, oxyphyllum, paniculare, parvifolium, peruvianum, piauhiense, podocephalum, Poeppigii, poliophylla

\section{LITHOCARDIUM :}

polystaihyum, pubescens, reticulasum, vevolutum, riparium, rotatum, Rothi, rotundifolinm. Roxburghi, rufescens, salicifolium, salicinum, scaberrimum, Schamburgkii, Schottianum. Scouleri, Sebestana, Sellowianum, senegalense. sericicalyx, serratum, sessilifolium, silnestre, Sprucei, striatum, suaceolens, subcordatum, subdentatum, subpubescens, sulcatum, superbum, tenuifolium, tetrandrum, tetraphyllum, superbum, tenuifolium, tetrandrum, tetraphyllum, tremulum, trichocladum, trichostemon, truncatum, umbraculiferum, ienosum, verbenaceum, vestitum, villicaule, Kuntze, Rev, Gen.(1891; 976-7\% = homonyma omnia Cordiae.

abyssinicum, Kuntze, 1. c. $976=$ C. Myxa, Linn.

album, Kuntze, 1, c. 438 = C. alba, Roem. \& Schult Andersonii, Kuntze, 1. c. 976, $(=$ Varronia canescens Anderss.). - Ins. Galapag

Blanchetii, Kuntze, 1. $C=C$. Blanchetii, $D C$

Collococca, Kuntze, 1. c. $438=$ C. Colococca, Linn.

corylifolium, Kuntze, 1. c. $976=\mathrm{C}$. alba, Rom. E Schult.

corymbosun, Kuntze, 1. c. $438=$ C. corymbosa, Willd.

cylindrostachym, Kuntze, 1. c. 438 et $97 \pi=\mathrm{C} . \mathrm{cy}-$ lindristachya, Roem. \& Schult

dichntomum, Kuntze, 1. c. $976=$ C. bifurcata, Roem. \& Schult.

elaeagnedes, Kuntze, 1.c. $97 \tau=$ C. elaeagnoides, $D C$ errugineum, Kuntze, 1. c. $438=\mathrm{C}$. ferruginea, Roem. Eo Schult.

farum, Kuntze, 1. c. 977 (= Varronia fara, Anderss.). - Ins. Galapag.

galapagosenum, Kuntze, 1. c. $976(=$ Varronia scaberrima, Anderss.). - Ins. Galapag.

gerascanthodes, Kuntze, 1. c. $977=\mathrm{C}$. gerascanthoides, $H . B$. \& $K$.

globosum, Kuntze, 1. c. $438=$ C. globosa, $H . B$. $\Leftrightarrow K$

guazumifolium, Kuntze, 1. c. $976=$ C. urticifolia, Cham.

Hartwigsiana, Kuntze, 1. c. = C. Hartwissianum, Regel.

Hookerianum, Kuntze, 1. c. = C. linearis, Hook. $f$.

lanatum, Kuntze, 1. c. = C. tomentosa, Roem, \& Schult.

lantanodes, Kuntze, 1. c, = C. lantanoides, Spreng. Leschenaultii, Kuntze, 1. $\mathrm{c}_{\mathrm{s}}=\mathrm{C}$. oblongifolia, Thw. Lockartii. Kuntze, 1. . $438=$ C. Lockartii, Kuntze. macranthum, Kuntze.1.c. = C. paucidentata, Fresen. martinicense, Kuntze, 1. c. = C. martinicensis, Roem. \& Schult.

mezianum, Kuntze, 1. c. $976=\mathrm{C}$. amplifolia, Mez. Muneco, Kuntze, 1. c. = C. Munneco, H. B. \& $K$.

Neowiedianum, Kuntze, l. c. = C. Neowediana, A. DC.

Panicularia, Kuntze, 1. c, $439=$ C. panicularis, Rudge.

parviflorum, Kuntze, 1. c. $976=$ C. serratifolia, H. B. \& $K$

Perrottetii, Kuntze, 1. c. $977=\mathrm{C}$. Perrottetii, A. DC. platyphyllum, Kuntze, 1. c. = C. latifolia, Cham. salviaefolium, Kuntze, 1. c. = C. salvifolia, Fuss.

scabridum, Kuntze, 1. c. $439=$ C. scabrida, Mart

\section{LITHOPHRAGMA, Torr. \& Gray = Tellima} R. Br. (Saxifr.).

rupicola, Greene, in Erythea, iii. (1895) 102. Calif.

scabrella, Grcene, 1. c. = T. scabrella, Greene.

tripartita, Greene, 1. c. = T. tripartita, Greene.

Williamsii, Greene, 1. c。 = Heuchera Williamsii Eaton.

LITHOSANTHES, Blume $=$ Litosanthes, Blume (Rubiac.).

Branniana, Warb. in Bot. Jahrb. xiii. (1891) 441 - N. Guin.

novo-gumeensis, Warb.l. c. 442.- - N. Guin.

LITHOSPERMUM [Tourn.] Linn. (Borag.). Ind. Kew. ji. 98.

calcicola, Robinson, in Proc. Am. Acad. xxvii (1893) 182. - Mexic

arolinense, MacMill. Metasp. Minn. (1893) $438=$ hirtum, Lehm.

\section{LITHOSPERMUM}

glandulosum, Velen, in Sitz. Boelm. Ges. Wiss, (1892-93) 46. - Bulg

Gmelini, Hitchcock, Spring F1. Manhattan (1894) 30. - Am. bor.

revolutum, Robinson, in Proc. Am. Acad, xxvii. (1893) 182. - Mrxic.

tubuliflorum, Greene, Pittonia, i. (Jan. 1888) 155. - Mexic.

LITOSANTHES, Blume (Rubiac.). - Ind. Kew.

\section{ii. 100}

Brauniana, Warb. ex Boerl. Handl.Fl. Ned. Indie, ii. I. (1891) 142. - N. Guin,

novo-guineensis, Warb.l.c.-N. Guin.

LITSAEA, Pers. = Litsea, Lam. (Laurin.).

LITSEA, Lam. (Laurin.). - Ind. Kew, ii, 100

albayana, Vidal, Revis. Pl. Vasc. Filip. (1886) 227. - Ins. Philipp.

albicans, Hook. f. Fl. Brit. Ind. v. (1886) 171

[Litsaea] (= Tetranthera albicans, Kurz). Burma.

angustifolia, Hook.f.l. c. 169 [1 itsaea]. - Ind. or assamica, Hook.f.l.c. 161 lLitsaea] - Reg. Himal. Beddomei, Hook. f. l. c. 17 [Litsaea]. - Deccan. Blumii, Hook. f.l.c. $160 \mid$ Litsaea] $(=L$. ferruginea, Blume). - Malacca, Java.

castanea, Hook. f.l. c. 171 [Litsaea]. - Malacca. cauliflora, Trim. Handb. Fl. Ceyl, ili. (1895) 450 |Litsaea|. - Zeylan.

cauliflora, Stapf, in Trans. Limn. Soc. Ser. II. iv. (1894) 219 [Litsaea]. - Borneo.

chartacea, Hook. f. Fl, Brit. Ind. v. (1886) 170 |Litsaea] (= Tetranthera chartacea, Wall.). Reg. Himal.

confertifolia, Hemsl. in Fourn. Limn. Soc. xxvi. (1891) 379, t. \%.- China.

cordata, Hook. f. Fl. Brit. Ind. v. (1886) $17 \%$ [Litsaea] (= Tetranthera cordata, Jack). - As. trop.

coriacea, Hook. f.l. c. 166 [Litsaea] (= T. coriacea, Heyne). - Deccan.

upularis, Hemsl. in fourn. Limn. Soc. xxvi. (1891) 380 . - China.

Faberi, Hemsl. l. c. 381. - China.

firma, Hook. f. Fl. Brit. Ind. v. (1886) [Litsaea] (= Tetranthera firma, Blume). - As. trop.

Garciae, Vidal, Revis. Pl. Vasc. Filip. (1886) 228. - Ins. Philipp.

geniculata, Mez, in Fahrb. bot. Gart. Berlin, v. (1889) 476 [Litsaea] (= Tetranthera geniculata, Nees). - Virgin., Florida.

glabrata, Hook. f. Fl. Brit. Ind. v. (1886) 174 [Litsaea] ( = T. glabrata, Wall.). - Ind. or. gracilipes, Hemsl. in fourn. Linn. Soc. xxvi. (1891) 387. - China.

gracilipes, Hook. f. Fl. Brit. Ind. v. (ISS6) 159 [Litsaea], - Malacca.

grandis, Hook. f.l. .. 162 [Litsaea] (= Tetranthera firma, Blume). - As. trop

guatemalensis, Mez; in fahrb. bot. Gart. Berlin, v. (1889) 479 [Litsaea]. - Guatem.

Helferi, Hook. f. Fl. Brit. Ind. v. (1886) 1\%2 [Litsaea]. - Tenass.

Hookeriana, Hook.f.l.c. 166 [Litsaea] $(=$ Tetranthera Hookeriana, Meissn.). - Zeylan.

hupeana, Hemsl. in fourn. Linn. Soc. xxvi. (1S91) 382. - China.

iteodaphne, Hook. f. Fl. Brit. Ind. v. (1886) 173 [Litsaea] (= Tetranthera tteodaphne, Thw.). Zeylan.

Kingii, Hook.f.l. c. 156 [Litsaea], - Reg. Himal. Kurzii, King, ex Hook. f. l. c. 164 [Litsaea]. - Ins. Andam.

lancifolia, Hook.f. l. c. 159 [Litsaea] (= Tetranthera lancifolia, Roxb.). - Reg. Himal., Borneo. laurifolia Cordem. F1. Ile Réunion (1895) $304=$ sebifera, fuss.

laxiflora, Hemsl. in foum. Limn. Soc xsvi. (1891) 38.3, t. 8. - China.

leiantha, Hook. f. Fl. Brit. Ind. v. (1886) 1il [Litsaea] (= Tetranthera Teiantha, Kurz). - Ins. Andam. 


\section{IITSEA}

longipes, Hook. f. Fl. Brit. Ind. v. (1886) 172 [Litsdea]. - Tenass.

Maingayi, Hook. f. l. c. 175. - Malacca.

Mannii, King, cx Hook. f. l, c, 180. - Reg. Himal. martabanica, Hook.f.l.c. 164 lLitsaea] (= Tetranthera martabanica, Kurz). - Martab. Tenass.

Meissneri, Hook. f.l. c. 169 [Litsaea] (= L.? klasiana, Meissn.). - Khasia.

membranifolia, Hook. f. l. c. 159. - Res. Himal. mishmiensis, Hook.f.l c. 161 - Reg. Himal.

mollis. Honst. in fourn. Linn. Soc. xxvi. (1891) 383. - China.

myristicaefolia, Hook.f.l. c. 172 [Litsaea] $(=T$ myristicacfolia, Wall.). - Ind or

nitida. Hook. f. l. c. 174 [Litsaea] $(=T$, nitida, Roxb.). - Reg. Himal.

nuculanea, Hook. f. Fl. Brit. Ind. v. (1886) 166 [Litsaea]. - Tenass., Siam.

oblonga, Hook. f. l. c. 168. - Reg. Himal.

oleoides, Hook. f.l. c. 175 [Litsaea] $(=T$. oleoides,

Meissn.). - Reg. Himal.

oreophila, Hook, f. l. c. 1:60 = Lindera Hookeri, Meissn.). - Reg. Himal.

Orizabae, Mez, in fahrb. bot. Gart. Berlin, v. (18S9) 479 (= Persea Orizabae Mart. \& Gal.). - Mexic. Panamonja, Hook. f. Fl. Brit. Ind. v. (1886) 175 [Litsaea\} (= Tetranthera Panamonja. Ham.).Ind. or.

parvifolia. Mez, in fahrb.bot. Gart. Berlin, v. (1889) 481 (= Umbellularia parvifolia, Hemsl.). Mexic.

penangiana, Hook. f. Fl. Brit. Ind. v. (1886) 171. - Penang.

petiolata, Hook. f.l. c. - Penang

Playfairi, Hentsl. in foum. Limn. Soc. xxvi. (1891) 384. - China

pungens, Hemsl. l. c. 384.-China.

Tangoonensis, Hook f. Fl. Brit. Ind. v. (1886) 163 (= Tetranthera rangoonensis, Meissn.). - Burma.

rotundifolia, Henrsl, inz fourn. I,inn. Soc. xxyi. (1891) 385. - China.

salicifolia, Hook. f. Fi. Brit. Ind. v. (1886) 167 [Litsaea] (= Telranthera salicifolia. Roxb.) Ind. or.

semecarpifolia, Hook. f.l. c. 165 [Litsaea] (=Tetranthera semecarpifolia. Wall.). - Ind. or

sericea, Hook.f.l. c. 156 [Litsaea] $(=T$. sericea, Wall.). - Reg. Himal.

sessiliflora, Hook.f.l.c. 160. - Penang.

Stocksii, Hook. f. l. c. 176 (= Tetranthera lanceaefolia. Grah.). - Ind. or.

Thomsonii, Hook. f. l. c. $170(=$ T. Thonsonii, Meissn.). - Ind, or.

undulata, Hook. f. l. c. 185 (= T. ligustrina, Nees). - Zeylan.

rariabilis, Hensl, in fourn. Linn. Soc, xxvi. (1891) 386. - China.

venulosa, Hook. f. Fl. Brit. Ind. v. (1886) 161

[Litsaea] (= Tetranthera venulosa, Meissn.). Deccan.

verticillata, Vidal, Revis, Pl. Vasc. Filip. (1886) 226. - Ins. Philipp.

Wallichii, Hook. f, Fl. Brit. Ind, v, (1886) 160 |Litsaea] (= Lindera nerrosa, Kurz). - Ind. or.

LITTONIA, Hook. (Liliac.). - Ind. Kew. ii. 101. Baudii, Terrac, in Bull. Soc. Bot. Ital. (1892) 425. - Reg. Somal.

Hardegreri, G. Beck, in Paulitschka, Harrar (1888) 451 fig. 8-9. - Reg. Somal.

obscura, Baker, in Kew Bull. (1894) 342. - Arabia.

IITTORELLA, Berg. (Plantag.) - Ind. Kew. ii. 101 .

uniflora, Rusby, in Mem. Torrey Bot. Club, v. (1894) 301 (=L. uniflora, Aschers.) = juncea, Berg.

LIVISTONA, R. Br.(Paim.). - Ind. Kew, ii. 101. Alfredi, F. Muell, in Vict. Natural. ix. (Oct. 1892) 112; et ex Bot. Centralbl. 1iii. (1893) 28. - Austral. Dridei, F. Muell. ex Drude, in Bot. Jahrb. xvi. Beibl. n. 39 (1893) $\mathbf{l l}=$ australis, Mart.

Drudei, Wendl. |conf. W. Wats, in Gard. Chron. (1886) i. 140] (an praec.?).- Hab.?

\section{LIVISTONA}

filamentosa, Hort. Petrop. ex R. Pfister, Beitr. aergl. Anat. Sabalcenblättcr, (1892) 25. - Hab?

Kingiana, Eecc. Malcsia, iii.(1889) 199. - Penins, Mal.

LLOYDIA. Salisb. (Liliac.). - Ind. Kew, ii. 101 ixiolirioides, Baker, ex Oliver, in Hook. Icon. pl. xxiii.(1892) t. 2215. - China.

trisecta, Baker, l. c. t. 2215. - China, Tibet.

LOASA, Adans. (Loas.). - Ind. Kew. ii. 101

canarinoides, Britton, in. Bull. Torrey Bot. Club, xvii. (1890) $281(=$ Illiaria canarinoides, Lenne \& C. Koch). - Bolivia.

carunculata. Urban of Gilg, in Engl. of Prantl, Natïrl Pfanzenfam, iii, 6a (1894) 118 - Bolivia.

chilensis, Ball, in fourn. Lmn. Soc. xxii. (1886) 159 (= Huidobria chilensis, C. Gay). - Chili.

chilensis. Urban \& Gilg, in Engl. \& Prantl, Natürl Pflanzenfam. iii. 6a (1894) $118=$ praec.

fruticosa, Urban \& Gilg, l.c. $(=$ Huidobria fruticosa Phil.). - Chili.

Gayana, Urban \& Gilg. l. c. $117(=L$. sagittata C. Gay). - Chili.

heptamera, Britton, in Bull. Torrey Bot. Club, xvii (1890) 281 ; et in Mem. Torrey Bot. Club, iii. (1893) 36 , in syn. = horruda, Britton.

horrida, Britton, ll. cc. 2; et 36 . - Bolivia.

isnea, Phil, in Anal. Mus, nac. Chile (1891) 24, Chili.

nana, Phil. ex Urban of Gilg, in Engl. \& Prantl. Natür. Pfanzenfam, iil.6a (1894) 117. - Chili. pataronica, Urban \& Gilg, l. c. - Patagon.

petrophila, Urban \& Gilg, ex Kurtz, in Verh Bot.Vur. Brand. xxxy. (1894) 111 ; et l. c. - Reg. Argent. rostrata, Urban. in Mart. Fl. Bras. (1889) 208; ct ex Urban \& Gilg. l.c.118. - Bras.

LOASELLA, Baill, in Bull. Soc, Linn. Paris, i. (1886) $650=$ Sympetaleia. A. Gray. (Loas.).

mpestris, Baill. 1. C. = S. rupestris, S. Wats,

LOBELIA, Adans. = Scaevola, Linn, (Goode niac.)

anblyanthera, angulata. apterantha, atriplicina, atic nuata, auriculata, canescens, Chamissoniana, collaris, coriacea, crassifolia, cunciformis, cylindrocarpa, depauperata, enantophylla, fasicululata. Gaudichaudii, glabra. glandulifera, globulifera, gracilis, hispida, holosericea. Hookerii, humifusa. Inmilis, lancenlata, linearis, longifolia, macrophylla, macrostachya, micrantha, microcarfa, microphylla, mollis. nitida Oldfieldii, oppositifolia, ovalifolia, oxyclona, paludosa, parvifolia, phlebopetala, piliplena, pilosa, platyphylla, porocarya, procera, restiacea, veroluta, sericophylla. spinescens, stenophylla, striata, tomentosa, tortuosa, Kuntze, Rev, Gen. (1891) 377-78 = homonyma ommia Scaevolae.

aemula, Kuntze. 1. c. $378=$ S. saligna, Forst.

anchusifolia, Kuntze, 1. c. = S. anchusaefolia, Benth.

Brooksiana, Kuntze, 1, $c=S$, Brookeana, F. Muell. calcndulacea, Kuntze, 1. c. $=\mathrm{S}$. suaveolens, $R . B r$ Cunninghamii, Kuntze, 1. $\mathrm{C}_{0}=\mathrm{S}$. Cunninghamii $D C$

myrtifolia, Kuntze, 1. c. = S. Groeneri, F. Muell, sericea. Kuntze, 1. с. $377=\mathrm{S}$. Koenigii, Vahl.

thesindes, Kuntze, 1. c = S. thesioides, Benth.

ielutina, Kuntze, 1. c. = S. Koerigii, Vahl.

LOBELIA. Plum, ex Linn, (Lobel.), - Ind. Kew. ii. 102

barbata, Warb. in Bot.? Fahrb, xiii (1891) 444. N. Guin

Baumannii, Engl. in Abh. Prouss. Akad. WViss. (1894) 46 ; ct 7. c. xix. Beibl. n. 47 (1894) 51. Afr. trop. or.

Breyzi, Engl. Pflanzenw. Ost-Afr。C (1895) 402 $(=$ Rapuntiun Breynii, Presl $)=$ L. Breynii, Lam.

cymbalarioides, Engl. Bot Fahrb. xix. Beibl, n, 47 (1894) 50. - Afr, trop. or

Dumii, Greene, Pittonia, i. (May 1889), $297=$ Palmerella debilis, A. Gray.

\section{LOBELIA}

nsifolia, Hitcheoch, an Missouri Bot. Gard. Rep. iv 1893) $\mathrm{I}^{\mathrm{n} 3}(=$ Tupa ensifolia, A. DC. $)$ - Ins. S. Doming.

Gilgii, Engl. Pfanzcnw. Ost-Afr, A (1895) 131.Afr. trop.

Glazioviana, Zahbruckn. in Medd. Naturh. Foren. Kjoeb. (1895) 67. - Bras.

gracilens, A. Gray, in Proc. Anv. Acad. xxi. (18S6) 393. - Mexic

Gregoriana, E, G. Baker, in fourn. Bot. xxxii. (1894) 66. - Afr. trop. or.

Holstii, Engl. Bot. Fahrb. xix. Beibl. n. 47 (1894 51. - Afr. trop. or.

hypolenca, Hillobr. Fl. Haw. Isl. (1888) 238.Ins. Sandvic

kilimandscharica, Engl. Bot. fahrb, xix. Reibl. n. 47 (1894) 52, - Afr. trop. or.

linnaeoides, Petrie, in Trans. N. Z. Inst. xxiii. 1890 (1891) $40 \% .-\mathrm{N}$. ' Lel.

lukwangulensis, Engl. Pfanzenw. Ost-Afr. A (1895) 131. - Afr, trop.

maranguensis, Engl. l. c. C (1895) 401. - Afr. trop. or

Martagon. Hutchoock, in Missouri Bot. Gard. Rep iv. (1893) 103 (= Tupa Martagon, Griseb.). Ind. oce.

minutula, Engl. Bot. Fahrb. xix. Beibl. n. $4 \%$ (1894) 50. - Afr. trop. or.

Molleri, Henviques. in Botet. Soc. Brot. x. (1892) 13\%. - Ins S. Thom

novella, Robinson, in Proc. Am. Acad. xxvi. (1891) 16\%. - Mexic

Nyassae, Engl. Pflanzenu\% Ost-Afr. C (1895) 401.Afr. trop. or.

Palmeri. Greene, Pittonia. i. (May 1889) $297=$ Palmerella tenera, A. Gray.

picta, Robinson of Seaton, in Proc. Am. Acad. xaviii 1893) 112. - Mexic

polvphylla, Fr. Meicen, in Bot. Jahrb, xviii. (1894) $1: 36=$ polyphylla. Hook. \& Arn.

Pringlei, S. Wats, in Proc. Am. Acad. xxv. (1890) 15\%. - Mexic

Rothrockii, Greene, Pittonia, i. (May 1889) $297=$ Palmerella debilis, A. Gray, var.

sublibera, $S$ Wats, in Proc. Am. Acad. xxv. (1890) 157. - Mexic.

Stuhlmanni, Schweinf. ex Engl. Pfanzenw. Ost-Afr. C (1895) 401. - Afr. trop. or.

Tayloriana, E. G. Baker, in fourn. Bot, xxxil (1894) 6\%. - Afr, trop. or.

Telekii. Schweinf. ex Engl, in Abl. Prenss. Akad. Wiss. 1891 (1892) 409, nomen. - Afr. trop. or ulugurensis, Engl. Pfanzenw. Ost-Afr. A (1895) 92 - Afr. trop.

usambarensis, Engl. Bot. Falrb. xix. Beibl. n. 47 1894) 50. - Afr. trop. or.

Volkensii, Engl. l. c. 49 - Afr trop. or.

yuccoides, Hillebr. Fl. Haw. Isl. (1888) 237. Ins. Sandvic

LOBOSTEMON, Lehm. (Borag.). - Ind. Kew.

cryptocephalum, Bakor, in Kew Bull. (1894) 30.Afr. centr. or.

LOBULARIA, Desv. = Alyssum, Tourn. (Crucif.). marginata, Webb, ex Christ, in Bot. Jahrb. ix. (1888) 92. - Ins. Canar.

palmensis, Webb, ex Christ, 1. c. - Ins. Canar.

LOCANDI $[$ A] Adans. = Samadera, Gaertn. (Simarub.)

glandulifera, Pierre, Fl. For. Cochinch. Fasc. 1? (1892) sub t. $262=\mathrm{S}$. glandulifera, $R \circ \times \mathrm{b}$

Harmandii, Pierre, 1. c. t. $261=$ S. Harmandii, Picrre.

indica, Kuntze. Rev. Gen. (1891) $104=$ S. indica, Gaertn.

Iucida, Kuntze, 1. c。 = S. lucida, Planch.

madagascariensis, Kuntze, 1. c. = S. madagascariensis, $A$. Fuss.

mekongensis, Pierre, Fl. For. Cochinch. Fasc. 17 (1892) t. $263=$ S. mekongensis, Pierre. merguensis, Pierre, 1. c. sub t. 262. - Cochinch. pendula, Pierre, 1. $\Leftrightarrow=$ Manangula pendula, Blanco. 
LOCELlA, Van Tiegh. in Bull. Soc. Bot. Fr. xlii. (1895) 261 = Loranthus, Linn

cuneata. Van Tiesh. 1. c. = L. cuneatus. Herne.

goodeniifolia. Van Tiegh. 1. c, = L. goodeniffolius, $D C$.

lobcliifolia, Van Tiegh. 1. c. $=$ L. loheliifolius, $D C$ montana, Van Tiegh. 1. c. = L. montanus, DC.

LOCHNERA, Reichb. = Vinca, Linn. (Apocyn.) lancer, K. Schum, in Engl. \& Prantl, Natürl, Pflanzenfam。iv, 2 (1895) $145=\mathrm{V}$. lancea, Boj.

pusilla, K. Schum. I. c. $=$ V. pusilla, Mur.

LOGKHARTIA, Hook. (Orchid.), - Ind. Kew. ii. 107. cladoniopho
- Hab, ?

LODOIGEA * Comm. (Palm.), - Ind, Kew。 ii. 108.

Sonnerati, Baill. Hist. des pl. xiii. (1895) $323=\mathrm{L}$ Callypyge, Comim.

LOEFLINGIA, Linn. (Caprifol.). - Ind. Kew. ii. 103.

Suharae. Batt, in Batt. \& Trab. Fl, de l'Algér. [Dicot.] (1889) $163=$ hispanica, Limn,

LOESELIA, Linn. (Polemon.). - Ind. Kew. ii. 108

Carionis, Peter, in Engl. Eo Prantl, Natür. Pfanzenfam. iv. 3a (1893) 55. - Guatem.

LOGANIA, R, Br. (Logan,). - Ind. Kew, ii. 108. choretroides, F. Muell. in Vict. Natural. vi. (Nov. 1889) 1!8; et ex Bot. Centralbl. xli. (1890) 28. Austral.

flaviflora, F. Mucll. Il. cc. v. (Mar, 1889) 165; et 461. - Austral.

LOGFIA, Cass. = Filago, Linn, (Compos.).

Willkommii, Pomel, in Bull. Soc. Bot. Fr, xxxv, (1888) 336. - Hisp.

LOLIUM, Linn. (Gramin.). - Ind, Kew. ii, 108.

hybridum X, Hausskn, in Mitth. Bot. Ver. Jena, v, (1887) 32. - Germ.

longighme, St. Lagex, in Cariot, Etud. des fl. éd. S ii. (1889) 955 = temulentum, Linu.

LOMATOPHYJLUM, Willd. (Liliac.). - Ind. Kew. ii. 109.

purpurcum, Th. Dur. \& Schinz, Consp. Fl. Afr.v. 1893 (1895) $325=$ borbonicum, Willd.

LONGHOCARPUS H. B. \& K. (Legumin.). - Ind. Kew. ii. 109.

Glaziovii, Taub. in Flora, 1xxv. (1892) 83. - Bras. lucens, S. Elliot, in Fourn. Linn. Soc. xxx. (1894) 77. - Sierra Leone.

paullinioides, Baker, l. c. xxii. (1887) 466. Madag.

polystachyus, Baker, l. c. xxv. (1890) 313.Madag.

speciosus, Bolus, in Fourn. Linn. Soc, xxv. (1889) 161. - Mossamb., Transvaal.

subulidentatus, Buethn. in Verh. Bot, Ver. Brand. xxxii. (1890) 53. - Congo

Theuszii, Buettn. l. c. 51 [Teusczi]]. - Angola.

LONIGERA, Linn. (Caprifol.). - Ind. Kew. ii, 110.

Amhersti, Dippel, Handb. Laubholzk. i. (1889) 263 fig. $175(=L$. pilosa, Maxim. $)$. - Japon.

belgica, Hort. ex Dippel, 1. c. 442 , ad calc. $=$ L. Periclymenum, Linn.

Bella X Zabel, in Gartenfl, xxxviii. (1889) 525. Hybr. artef.

Braceana, Hemsl. in fourn. Linn. Soc, xxviii. (1890) in obs. - Ind. or.

Bournei, Hemsl.ex Forb. E Hemsl. l.c. xxiii. (1888) 360. - China.

coerulescens, Dippel. Handb. Laubholzk。 i. (1889) 233, fig. 149. - Hybr, artef.

\section{LONICERA}

tinifolia, C. A. Mey.? [Beitr. Pflanzenk. russ. Reichs, v. (1830) 51] ex Dippel, 1, c, $228=\mathrm{L}$. Xylosteum, Linn.

crassifolia, Batalin, in Act. Hort. Petrop. xii. (1892) 172 ; et in Gartenf. xlii. (1893) 332. - China.

deflexicalyx, Batalin. l. c. 173. - China.

emphyllocalyx, Maxim, in Bull. Acad. sci. Pétersb. xxxi. (188\%) 58. - Japon.

flavescens, Dippel, Handb. Laubholzk. i. (1889) 260 , fig. 173. - Columb.

Fortunei, Hort, ex Dippel, 1. c. $225=$ L. Standi. shii, Carr.

fuchsioides, Hensl. e\% Forb. \& Hemsl. in fourn. Linn. Soc. xxiii. (1888) 362, t. 9. - China

fuchsioides. Hort. ex Dippel, Handb. Laubholzk. i. (1889) $214=$ sempervirens, Linn.

gibbifura X. Dippel. 1. c. 23\%, fig. $15 \mathrm{l}(=$ Xylostcm gibbiflorum, Rupr.). - Hybr. artef.

gigantea, Hort, ex Dippel, 1. c. $205=$ etrusca, Sancti.

gynochlamydea, Hemsl. ex Forb. \& Hemsl. in fourn. Linn. Soc, xxiii. (1888) 362. - China.

Halleana, Hort. ex Dippel, IIandb. Laubholzl. i. (1889) 217 et 444 ad calc, = flexuosa. Thunb.

Henryi, Homsl. ex Forb. E Hemst, in Foum. Linn. Soc xxiii, (1888) 359. - China.

heteroloba, Batalin, in Act. Hort. Petrop. xii. (18) 174; et in Gartenfl. xlii. (1893) 333. - China.

Hildebrandtiana, Collett Ê Hemsl, in Fourn. Linn. Soc. xxviii. (1890) 64, t. 11. - Ind. or.

inconspicua, Batalin, in Act. Hort. Petrop. xiv. (1895) 172. - Thibet.

italica, Schm. [Oestr. Baumz. (1794) 106], ex Dippel, Handb. Laubholzk. i. (1889) $202=\mathrm{L}$. Caprifolium, Linn

kamtschatica, Hort, ex Dippel, 1. c. $246=$ orientalis, Lam.

Kesselringi, Regel, in Act. Hort. Petrop. xi. (1800) 310 ; et in Gartenfl. (1891) 124, flo. 41 . Kamtchatka.

Korolkowii, Stapf, in Gard. and, For, vi. (1893) 34 - Turkest.

Kirilowi, Hort. ex Dippel, Handb, Laubholzk. i. (1889) $266=$ coerulea, Limn.

litangensis, Batalin, in Act. Hort. Petrop. xiv. (1895) 173. - Tibet.

macrophylla, Hort. ex Dippel. Handb. Laubholzh. i. (1889) 444, ad calc. = glauca, Hill.

Magnevilleae, Hort. ex Dippel, 1. c. $213=$ sempervirens, Limu.

marylandica, Hort. ex Dippel, 1. c. 444 ad calc. glauca, Hill.

micrantha, Zabel, in Gartonfl. xxxviii. (18S9) 525. As. centr.

minuta, Batalin, in Act. Hort. Pétrop. xiii. (1892) 170 ; et ex Gartenfl. xlii. (1893) 331. - China.

minutiflora X. Zabel, in Gartenfl. xxxviii. (1889) 523. - Hybr. artef.

misera $\times$. Zabel 1. c. - Hybr. artef.

muendeniensis $X$, Rehder, in Gartenfl. xlii. (1893) 102. fig. 19. - Hybr. artef.

muscariensis $\times$, Rehder, 1. c. 100, fig. 18. - Hybr. artef.

Niagaralli, Hort. ex Dippel. Handb. Laubholzk. i. (1889) $226=$ fragrantissima, Car

notha $\times$, Zabel, in Gartenfl. xxxviii. (1889) 525. $\mathrm{Hybr}$. artef.

obscura, Collett \& Hemsl. in Fourn. Linn. Soc. xxviii. (1890) 6:3. - Ind. or.

ovalis, Batalin, in Act. Hort. Petrop. xiv. (189.)) 170. - China

permixta $X$. Zabel, in Gartenf. xxxviii. (IS89) 523. - Hybr artef.

Phyllomachae, Hort. ex Dippel, Handb. Laubholzk. 1. (1889) $247=$ orientalis, Lam.

pileata, Oliver, in Hook. Icon. pl. xvi. (1887) t. 1585 - China.

praeflorens, Batalin, in Act. Hort. Petrop. xii. (1892) 169 ; et in Gartenfl. xlii. (1893) 331. - Mandchuria.

Regeliana, Petzold Eo Kirchn. [im Arboret. Mush. (1864) 433\}; ex Dippel, Handb. Laubholzh. i. (1S89) 220 fig. $140 .-$ As. or. reticulata, Borb. [ubi ?] ex Kuntze, Rev. Gen. (1891)
274 . - [Quid ?].

\section{LONICERA :}

alicifolia $\Varangle$, Zabel, in Gartenfl. xxxviii. (1889) 524. - Hybr. artef.

scabrida, Franch. in Nouv, Arch. Mus, Paris Sér. II. viii. 1885 (1886) 252. - Tibet.

Schmitziana, Roezl [in Cat, Mexic. Pfanz. 1858 ex Dippel. Handb. Laubholak. i. (1889) 247 fig. 159. - Mexic.

segreziensis, Lavallee [Arboret. Segrez. (1878) 142] ex Dippel, l. c. 221. - Reg. Himal.

similis, Hemsl. ex Forb. \& Hemsl. in fourn. Linn. Soc. xxiii. (1859) 366, - China

sinensis, Hort. ex Dippel, Handb. Laubholzk. i. (1889) $224=$ L. Standishii. Carr.

strophicphora, Franch. in Bull. Soc. Philom, Paris, Sér. VII. x. (18sti) 142. - Japon

szechuanica, Batalin, in Act. Hort. Petrop. xi (1895) 172, -- China.

thibetica, Bureau \&. Franch. in Morot. Fourn. de Bo v. (1891) 48. - Tibet.

tongatayamaënsis, Makino, in Tokyo Bot. Mag (1892) 55. - Japon

tragophylla, Hemsl. ex Forb. Er Hemsl. in Fonm, Linn. Soc. xxiii. (1888) 367. - China.

trichosantha. Bureau \& Franch. in Morot. Fourn. de Bot. v. (1891) 48. - Tibet.

miflora, Blume, ex Dippel. Handb. Laubholzk. (1889) $257=$ gracilipes, $\mathrm{Miq}$

vaccinifolia, Hort. ex Dippel, I. c. $282=$ Sympho-

ricarpus montanus, $H . B$. $\&$.

valentina, Pau, Not. bot. Fl. Espan. iii. (1889) 30 nomen; et ex Willk. Suppl. Prodr. Fl. Hisp. (1893) 134. - Hisp.

verna, Hort. ex Dippel, Handb. Laubholzk. (1889) $202=\mathrm{L}$. Caprifolium, Linn.

qulgaris, Roehl. [Deutschl. Fl, ii. (1813) 1:6]; ex Dippel, Handb. Laubholzk. i. (18s9) $228=\mathrm{L}$. Xylosteum. Linn.

xylosteoides. Tausch [in Flora, xxi. (1838) 736], ex Dippe1, 1. c. = L. Xylosteum, Linn.

Youngii, Hort. ex Dippel, 1. c. 215 et 445 , ad calc. = ciliosa, Poir.

Zabelii $\times$, Rehder, in Gartenfl. xlii. (1893) 104. Hybr. artef.

LOPEZIA, Cav. (Caprifol.). - Ind. Kew. ii. 112. angustifolia, Robinson, in Proc. Am. Acad. rxvii. (1893) 168. - Mexic

clavata, T. S. Brandeg. in Proc. Calif. Acad.Ser. If ii. (1889) 157, t. 4. - Calif.

cornuta, S. Wats. in Proc. Am. Acad. xxi. (18s6) 429. - Mexic.

gracilis, S. Wats. 7. c. - Mexic

LOPHIOI A, Ker-Gawl. (Haemodor.).- Ind. Kew.1i. 115

americana, Baill. Hist. des pl. xiii. (1895) $78=\mathrm{seq}$. americana, Coville, in Mem. Torrey Bot: Club: (1894) $118(=\mathrm{L}$, americana, Wood $)=$ aurea Ker-Gavel.

tomentosa, Britton, Stern \& Pogg. Prelim. Catal, (1888) 53 = aurea, $K e v-G u v w l$.

LOPHOPAPPUS, Rusby, in Bull. Torrey Bot Club, xxi. (1894) 487. COMPOSITAE.

foliosus, Rusby, l. c. t. 213 ; et in Mem. Torrey Bot. Club, iv. (1895) 213. - Bolivia.

LOPHOPETALUM, Wight \& Arn. (Celastr.) Ind. Kew. ji, lli3.

Beccarianum, Pierve, Fl. For. Cochinch. Fasc. 20 (18:4, sub t. 307 B. - Borneo.

Duperreanum, Pierre, $l . c . t .307 \mathrm{~A}$, - Cochinch.

LOPHOPHORA. Conlt. in Contrib. U.S. Nat Herb. i1i. (18)4, 131. CACTEAE

Williamsii, Coult. l. c. (= Anhalonium Williamsi Lem.). - Am, bor.

LOPHOPOGON. Hack. in Engl, \& Prantl, Naturt Pflanzenfam. ii. 2 (1887) 26. GRAMINEAE tenax, Balansa, in Norot, Fourt. de Bot. iv. (1890) 83. - Cochinch

tridentatus, Hack. in DC. Monog. Phan, vi. (188?) 254 (= Andropogon tridentatus, Roxb.). - Ind.or. truncatiglumis Hack. 1. c.255 (= Lophopogon truncatiglume, F. Muell.). - Austral. 
LOPHOPYXIS, Hook, f. in Hook. Icon. pl. xviii. (1885) t. 1714 ; et Fl, Brit. Ind. v. (1888) 476. EUPHORBIACEAE.

combretocarpa, Engl. cx Pax, in Engl. \& Prantl, Natiurl. Pfanzenfam. iii. 5 (1893) $25 \%$ (= Treubia cambreticarpa, Pierre). - Ceram.

Maingayi, Hook. f. in Hook. Icon. pl. xviii. (1887) t. 1714. - Malacca.

pentaptera, Engl. in Sitz, Preuss. Akad. Wiss, xviii. (1893, 265 (= Combretopsis pentaptera, K. Schum.). - N. Guin.

Pierrei, Boerl. Handl. Fl. Ned.-Indie, i. 2 (1890) 673. - Ind, bat. (Ceram).

Schumannii, Bocrl. l. c.674.- N. Guin.

LOPHOSTOMA. Meissn. = Linostoma, Wall. (Thymel.).

albifolium, Gilg, in Engl, et Prantl, Natürl. Pflanzenfam. iii. 6a (1894) 232. - Reg. Amaz.

LOPHOTOCARPUS, Th. Dur. Ind. Gen. Phan. (18S8) p, x. ALISMACEAE,

calycinus, 7. G. Smith, in Mcm. Torrey Bot. Chub, v.

(1894) 25 (= Lophocarpus calycimus. M. Micheli).
(1) . T. - Am. bor.

guyanensis, 7. G. Smith, l. c. (= Lophiocarpus guyanensis, M. Micheli). - Reg. trop. amphig.

guyanensis, Th. Dur. \& Schinz, Consp. Fl. Afr.v.

1894 (1895) $48 \%=$ praec.

LORANTHUS, Linn. (Loranth.). - Ind. Kew. ii. 114.

ambiguus, Engl. Bot. Fahrb. xx. (1894) 98. - Zanzibar.

amplexans, Van Tiegh. in Bull. Soc. Bot. Fr. xlii. (1895) 83. - Austral.

angrolensis, Engl. Bot. Fahrb.xx. (1894) 101.Angola.

anguliflorus, Engi. l. c. 10\%. - Angola.

Alnottianus, Wight, ex Hook. f. F1. Brit. Ind. v. (1886) $207=\mathrm{L}$. Wightii. Hook. $f$.

aurantiacus, Engl. Bot. Fahrb. xx. (1894) 124. Zanzibar.

aurantiacus, Engl. in Abh. Prouss. Akad. Wiss, (1894) 26. - Atr. trop.

Batangae, Engl. Bot. Fahrb xx. (1894) 98. - Afr. trop. occ.

Beccarii, King, in foum. As. Soc. Beng. lvi. (1887) II. 98. - Perak.

Braunii, Engl. Bot. Fahrb. xx. (1894) 93. - Afr. trop. occ.

brevipes, Van Ticgh, in Bull. Soc. Bot. Fr. xlii. (1895) 83. - Austral.

brunneus, Engl. Bot. Fahrb. xx. (1894) 88. Angola.

Buchholzii, Engl. l. c. 91. - Afr. trop. occ

Buchneri, Engl. .. c. 114. - Congo.

bukobensis, Engl. l. c. 102. - Afr. trop. or

campestris, Engl. l. c. 95. - Afr. trop, or.

Casuarinae, Ridl. in Trans. Linn. Sec. Ser. II. iii. (1893) 343. - Penins. Mal.

cltidifolius, Engl. Bot. Fahrb. xx. (1894) 123. Atr. trop. or.

centiflorus, Stapt, in Trans. Limn.Soc. Ser. II.jv (1894) 222. - Borneo.

cinereus, Engl. Bot. Fahrb. xx. (1894) 103.Anrola.

cistcides, Wclw. ex Engl. l.c. - Angola.

Collettii, King, ex Collett \& Hemsl. in Fourn. Linn. Soc. xxviii. (1890) 120. - Burma.

constrictiflorus, Engl. Bot. fahrb. xx. (1894) 119 - Afr. trop.

Cornetii. Dewerye, in Bull. Soc.Bot.Bolg, xxxiii. 2 IS94 (1895) 106, nomen; et xxxiv. 2 (1895) 92. Congo.

(rassissimus, Engl. Bot. Fahro. xx: (1894) 122. Afr, trop. or.

crassipetalus. King, in foum. As. Soc. Beng. Ivi. (1857) 11.91. - Perak.

crassus, Hook. f. Fl. Brit. Ind. v. (1886) 217.Penins. Mal.

curvirameus, Engl. Pfanzenw. Ost-Afr。 C (1895) 165. - Atx. trop. or.

Delavayi, Van Ticgh, in Bull. Soc. Bot. Fi, xli. (1894) 535 . - Xunnan.

\section{LORANTHUS}

dependens, Engl. Bot. Fahrb. xx. (1894) 11\%. -

Angola.

dianthus, King of Scortechini, in fown. As. Soc. Beng. lvi. (1887) II. 96. - Perak.

dichrous, Engl. Bot. Fahrb. xx. (1894) 123. - Afr trop. occ.

E djurensis, Engl. l. c. 90. - Afr. centr. bor.

dschallensis, Engl. Pflanzenw. Ost-Afr. C (1895) 166. - Afr. trop. or.

Duthieanus, King, in fourn. As. Soc. Bcng. lvi. 1887) II. 94. - Perak.

Ehlersii, Schweinf. ex Engl. in Abh. Prouss. Akad. Wiss. 1891 ii. (1802) 197 , nomen. - Afr trop. or elegantulus, Engl. Bot. falrb. xx. (1894) 121. Afr. trop. or.

emarginatus, Engl. l. c. 100. - Angola.

Emini, Engl l. c. 113. - Afr. trop.or.

erectus, Engl. l. c. $99 .-$ Afr. trop. or

estipitatus, Stapf, in Trans. Limn. Soc,Ser. II. iv. 1894) 221. - Borneo.

Fauroti, Franch. in Morot, foum. de Bot. i. (1887) 135. - Arab., Afr. trop. or.

Finisterrae, Warb. in Bot. fahrb. xvi. (1893) 20.N. Guin.

Fischeri, Engl. l. c. xx. (1894) 85. - Afr. trop. or. flexilis, Rusby, in Mem. Torrey Bot. Club. iv. (1895) 253. - Bolivia.

fulvus, Engl. Bot. Fahrb. xx. (1894)103. - Angola.

Forbesii, King, in fourn. As. Soc. Beng. 1vi. (1887) 11. 100. - Sumatra.

gabonensis, Engl. Bot. Falıvb. xx. (1894) 127. Afr, trop. occ.

gibberulus, Tate, in Trans, and Proc. Roy. Soc. S. Austral. viii. (1886) 71. - Austral.

Gilgii, Engl. Bot. Fahrb. xx. (1894) 91. - Angola. glomeratus, Engl. l. c. 89. - Angola.

grandifrons, King, in fourn. As. Soc. Bong. Ivi. (1887) II. 93. - Perak

griseus, S. Elliot, in foum. Linn. Soc. xxix. (1891) 46. -- Madar.

Guerichii, Engl. Bot. Fahvb. xix. (1894) 130.-Afr. austro-OCC, extratrop.

Haastii, Van Tiegh. in Bull. Soc. Bot. Fr. xlii. (1895) 24. - N. Zel

Havilandii, Stapf, in Trans. Linn. Soc. Ser. II, iv. (1894) 222, in obs. - Borneo.

Hemsleyamus, King, in Journ. Linn. Soc. xxviii, (1890) 120 = odoratus, Wall.

Henriquesii, Engl. Bot. Fahrb. xx. (1894) 88. Angola.

Hildebrandtii, Engl. l. . . 96. - Afr. trop. or.

hirsutissimus, Engl. l. c. 100.-Afr, trop. or.

Hollrungii, $K$. Schum, in K. Schum. \& Hollr. Fl. Kais. Will. Land (1889) 105. - N. Guin,

Holstii, Engl. Bot, Falirb. xx. (1894) 127. - Afr, trop. or.

inornus, Robinson \& Greenm. in Am. Fonm. Sci. Ser. III. 1 (1895) 163. - Mexic

irangensis, Engl. Bot. Fahrb. xx. (1894) 111. - Afr. trop. or.

intermedius, Wight, ex Hook. f. Fl, Brit. Ind. v. (1886) 205. - Deccan .

kagehensis, Engl. Bot. Fahrb. xx. (1894) 129.Afr. trop. or.

Kayseri, Engl. l. c. 89. - Zanzibar.

kilimandscharicus, Engl. Pfanzenz. Ost-Afr. C. (1895) 166. - Afr. trop. or.

Kingianus, Van Tiegh, in Bull. Soc. Bot. Fr, xlii. (1895) 83. - Austral.

Kingii, Scortech. ex King, in fourn. As. Soc. Beng. lvi. (1887) ॥ 99. - Perak.

Kirkii, Van Ticgh, in Bull. Soc, Bot. Fr, xhii. (1895) 23. - N. Zel.

Kunstleri, King, in Fonm. As. Soc. Beng. 1vi. (188i) 11. 95. - Perak.

laciniatus, Engl. Pflanzenw. Ost-Afr. C (1895) 166. - Afr. trop. or.

lampongus, King, in fourn. As. Soc. Beng. 1vi. (1887) 11. 100. - Sumatra.

Lecardii, Engl. Bot. Fahrb. xx. (1894) 128. Senegamb.

Leschenaultii, Van Ticgh, in Bull. Sor. Bot. Fr. xlii. (1895) 83. - Austral.

Lobbii, Hook. f. Fl. Brit. Ind. v. (1886) 204. Penang.

\section{LORANTHUS}

oranthoideus, Van Ticgh, in Bull. Soc. Bot. Fr. xli. (1894) 70. - Ind. occ.

loniceroides, Pav, ex Van Tiegh,l.c. xlii. (1895̃) 387. - Mexic

Lowii, King, in foum. As. Soc. Beng. 1vi. (1887) II. 98. - Perak.

luluensis, Engl. Bot. fahrb. xx. (1894) 128. Congo.

mabaeoides, Trim, in fourn. Eot. xxvii. (1889) 166. - Zeyl.

Maingayi, Hook.f. Fl. Brit. Ind.v. (1886) 222. Mallacca.

malaccensis, Hook. f. l.c.210. - Malacca.

Mechowii, Engl. Bot. Falurb. xx. (1894) 118. Angola

microphyllus, Engl.l.c.86. - Afr, trop. or.

mirabilis, Van Heurck \& Muell. Arg. ex Van Tiegh. in Bull. Soc. Bot. Fr. xli. (1894) 547, in obs. = Stemmatophyllum Cumingii, Van Tiegh,

Molleri, Engl. Bot. fahrb. xx. (1894) 120. Angola.

mollissimus, Engl.l. c. 119. - Angola.

Mueller:, Van Tiegh. in Bull. Soc. Bot. Fr. xlii. (1895) 83. - Austral.

Muellerianus, Van Tiogh.l.c.-Austral.

mweroënsis, Baker, in Kew Bull. (1895) 292. Afr. trop.

nummulariaefolius, Franch. in Morot, fourn. de Bot. i. (1887) 135, in obs. - Reg. Somal.

ogowensis, Engl. Bot. Fahrb.xx. (1894) 117. - Atr. trop. occ.

Palmeri, S. Wats, in Proc. Am. Acad. xxi.(1886) 438. - Mexic

panganensis, Engl. Hiot. Fahw. xx, (1894) 92. Afr. trop. or.

Parishii, Hook. f. Fl. Brit. Ind. v. (1886) 205. Tenass.

parviflorus, Engl. Bot, falub. xx. (1894) 12\%. Afr. trop. occ

pendulus, Welw. ex Eng1.1.c. $11 \%=$ dependens. Engl.

platyphyllus. King, in fourn. As. Soc. Beng. Ivi. (is87) 11.96. - Perak.

Poggei, Engl. Bot. Fahrb. xx. (1894) 116. - Congo. Preussii, Engl. l. c. 118. - Afr. trop. occ.

productus, King, in fomrn. As. Soc. Beng. Ivi. (138i) II. 91. - Perak.

psilanthus, Hook, f. Fl. Brit. Ind. v. (1886) 222. Reg. Himal.

Ralphii, Van Tiegh, in Bull. Soc. Bot. Fr. xlii. (1895) 23. - N. Zel

Raoulii, Van Tiegh.l. c. 20.- - N.Zel.

rhamnifolius, Engl. Bot. Fahrb. xx. (1894) 87. Afr. trop. or.

sabaënsis, Stapf, in Trans. Limn. Soc. Ser. II. iv. (1894) 222. - Borneo.

Sadebeckii, Engl. Bot. Falw b. xx. (1894) 122. Afr. trop. or.

sansibarensis, Engl. l.c. 121. - Zanzib.

Schelei, Engl.l. c. 105. - Afr. trop. or.

Schweinfurthii, Engl, l, c 124, - Afr. centr, bor.

Scortechinii, King, in Foum. As. Soc. Beng. lvi. (1887) 11.94. - Perak.

Seemennianus, K. Schrm. in K. Schum, \& Holls. Fl. Kais. Wilh. Land (18*9) 106. - N. Guin.

sigensis, Engl, Bot. Fahb. xx. (1894) 101. - Afr. trop. or.

Sonorae, S. Wats, in Proc. Am. Acad. xxiv. (1889) 73. - Mexic.

sordidus, S. Elliot, in fourn. Limn, Soc. xxix. (1891) 46. - Madag.

Soyauxii, Engl. Bot. Fahrb. xx. (1894) 97. - Afr. trop. occ.

Stocksii, Hook. f. Fl. Brit. Ind. v. (1886) 213. Concan

Stuhlmannii, Engl. Bot. Fahrb. xx. (1894) 85. Afr. trop. or.

subulatus, Engl. l. c. 1I2. - Afr. trop, or.

sulfureus, Engl. Pfanzenw. Ost-Afr. C (1895) 165 - Afr. trop. or.

syringifoluus, Engl. Bot. Fahw. xx. (1894) 115. Afr. trop. or.

taborensis, Engl. l. c. 106. - Afr. trop. or

tenuifolius, Van Tiegh. in Bull. Soc. Bot. Fr. xlii. (1895) 83. - Austral. 


\section{LORANTHUS}

errestris, Hook. f. Fl. Brit. Ind. v. (1886) 207.Reg. Himal.

thelocarpus, Hook. f. 1. c. 211. - Penins. Mal.

truncalus, Engl. Bot. Fahrb. xx. (1894) 115. - Afr. trop. occ.

tschintschochensis, Engl.l. c. 116. - Loango.

ugrogensis, Engl. l. c. 96. - Afr. trop. or.

unguiformis, Engl. l. c. 94. - Afr. trop. or

usambarensis, Engl. l. c. 111. - Afr, trop. or.

verrucosus, Engl. l.c. 120. - Afr. centr. hor.

villositlorus, Engl. l. c. 125. - Angola.

vittatus, R. Br. ex Van Tiegh. in Bull. Soc. Bot. Fr. xlii. (1895) 439. - Austral.

Volkensii, Engl. Bot. Fahrb. xx. (1894) 110. - Afr. trop. or.

Welwitschii, Engl. l. c. 87. - Angola.

Wightii, Hook. f. Fl. Brit. Ind. v. (18 6) 20\%. Deccan.

woodfordioides, Schweinf. ex Engl. in Abh. Preuss. Akad. Wiss. 1891. ii. (1892) 198, nomen; et in Pfanzenw. Ost-Afr. A (1895) 129. - Afr. trop. or.

Zenkeri, Engl. Bot. fahrb. xx. (1894) 95. - Afr. trop. occ.

zizyphifolius, Engl.l. c. 92.-Afr. trop. or.

LORETIA, Duv. Jolive = Festuca, Linn. (Gramin.).

delicatula, Willk. Suppl. Prodr. Fl. Hisp. (1893) $24=\mathrm{F}$. delicatula, Link.

gypsophila, Willk. Illustr. F1. Hisp. i. (1885?) 125 t. 86b; et 1. c. = F. gypsophila, Hack.

tenuis, Hack. ex Willk, 1. c. 127, t. 87a $=$ F. tenuis, Nym.

LOREYA. DC. (Melast.). - Ind. Kew. ii. 118 minor. Cogn. in Mart. Fl. Bras. xiv. IV. (1888) 522. - Bras.

LORICARIA, Wedd, = Tafalla. D. Don (Com-

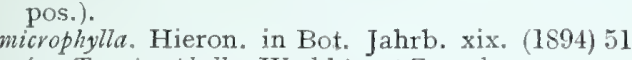
(=T. microphylla, Wedd.). - Ecuad.

reticulosa, Kuntze, Rev. Gen. (1891) $352=$ Baccharis genistelloides, Pers.

scolopendrina, Kuntze, 1. c. = B. scolopendra, Hook.

Stuebelii, Hieron. in Bot. Jahrb. xxi. (1895) 346 . Peruvia.

thujoides. Hieron. 1. c. = Tafalla thyoides, Lam.

thujodes, Kuntze, Rev. Gen. (1891) $352=\mathrm{T}$. thyoides, D. Don.

LOROGL-ORCHIS $X, G$. Camus, in Morot, Journ. de Bot. vi. (1892) 110. ORCHIDEAE.

Lacazei X. G. Camus, 1. c. - Gall.

LOROGLOSSUM, Rich. = Orchis, Linn. (Orchid.).

calcaratum, G Beck, in Annal. Naturhist. Hofmus, Wien. v. $(1890) 576=\mathrm{O}$. caprina, Crantz.

caprinum, G. Beck, 1. c. $574=$ O. caprina, Crantz.

LOTODES, Kuntze, Rev. Gen. (1891) $193=$ LOTOIDES, Siegesb. = Psoralea, Linn, (Legumin.).

acaule, aculeatum, adscendens, andongense, aphyllum, Archeri, argenteum, argophyllum, axillare, azureum, badocanum, balsamicum, Bowieanum, caffrum, californicum, campestre, candicans, canescens, capitatum, carneum, castoreum, cinereum, cuspidatum, cyphocalyx, decumbens, digitatum, divaricatum, drupaceum, erianthum, esculentum, fasciculare, glandulosum, glancinum. Gueinzii, hamatum, hirtum, humile, hypogacum, faubertianum, lachnostachyum, leucanthum, linearifolium, marginatum, Martini, melanocarpum, micranthum, multiugum, Mundtianum, Mutisii, obliquum, obtusifolium, odoratissimum, oligophyllum, Onobrychis, orbiculare, patens, pentaphyllum, physodes, pinnatum. plicatum, plumosum, polyphyllum, polystictum, pustulatum, racemosum, repens, rhonbifolium, rotundifolum, simplex. spicatum, Stachydis, stipulatum, striatum, strobilinum, subacaule, tenax, tenuiflorum, tenuifolium, tenuissimum, Testariae, Thomii, tomentosum, trianthum, uncinatum, velutinum, c'enustum,
LOTODES

virgatum, Zeyheri, Kuntze, Rev. Gen. (1891) 194 =homonyma omma Psoraleae.

americamm, Kuntze, 1. c. $193=$ P. dentata, DC. angustifolium, Kuntze, 1. c. $194=\mathrm{P}$. angustifolia, L'Herit.

biflorum, Kuntze, 1, c, = P. biflora, Harv.

bituminostm. Kuntze, 1, c, $193=\mathrm{P}$. bituminosa Linn.

cephalanthum, Kuntze, 1. c. $194=$ P. badocana, Blanco.

corylifolium, Kuntze, 1. c. $193=$ P. corylifolia, Linn. ellipticum, Kuntze, 1 c. = P. lanceolata, Pursh

floribundum, Kuntze, 1. c. $194=$ P.tenuiflora, Pursh. fruticans, Kuntze, 1. c. = P. bracteata, Berg. parcum, Kuntze, 1. c. = P. adscendens, C. Muell. psoralodes, Kuntze, 1. c. = P. melilotoides, Michx.

restiodes, Kuntze, 1, c。 = P, restioides, Eckl. E Zeyh.

LOTONONIS, Eck1. (Legumin.). - Ind. Kew. ii. 118

filifolia. Bolus, in fourn. Limn. Soc. xxv. (1889) 158 - Transvaal.

foliosa, Bolus, l. c. xxiv, (1887) 1\%3. - Afr. austr.

longiflora, Bolus, l. c. xxiv, (1887) 159. - Atr. austro-occ. extratrop.

Marlothii, Engl. Bot. fahrb. x. (1889) 26. - Afr austr.

namaquensis, Bolus, in foum. Linn. Soc. xxv.j(1889

159. - Afr. austro-occ, extratrop.

LOTUS, [Tourn.] Linn. (Legumin.). - Ind. Kew. ii. 119 .

argensis, Coult. in Contrib. U.S. Nat. Herb. iv. 1893) 83. - Calif.

argyophyllus, Greene, Pittonia, ii. (Dec, 1890) 149 $=$ Hosackia argophylla, A. Gray.

argyraeus, Greene, 1. c, $144=\mathrm{H}$. argyraea, Greenc. balsamiferus, Greene, Man. Bot. San Franc. Bay 1894) $93=$ H. balsamifera, Kell.

Benthami, Greene, Pittonia, ii. (Dec. 1890) 148: et 1. c. = H. cytisoides, Benth.

Biolettii, Greene, Il. cc. ii. (May 1892) 22\%; et 94, Calif.

Bollei, Christ, in Bot, fahrb. ix. (1888) 123. - Ins Capit. Virid.

cedrocensis, Greene, Pittonia, ii. (Dec. 1890) $144=$ Hosackia flexuosa, Greene

chimuamanus, Greene, 1. c. $146=\mathrm{H}$. chihuahuana, S. Wats.

confinis, Greene, in Erythea, i. (1893) 258. - Am bor. occ

crassifolins, Greene, Pittonia, ii. (Dec. 1890) 147 et Man. Bot. San Franc. Bay (1894) 93 Hosackia crassifolia, Benth.

Davidsonii, Greene, in Eryther, i. (I892) 207 (= L sulphureus, Greene). - Calif.

dondroidcus, Greene, Pittonia, ii. (Dec, 1890) 148 (= Syrmatium dendroideum, Greene). - Calif.

denticulatus, Greene, 1. c. 139; et Man. Bot. San Franc. Bay (1894) $91=$ Hosackia denticulata, Drew.

distichus, Greene, 1.c. $149=$ H. disticha, Greene

Douglasii, Greene, 1. c. $=\mathrm{H}$. decumbens, Bonth.

eriophorus, Greene, in Erythea,i. (1893) 207; et Man. San Franc. Bay (1894) 94 (= L. tomentosus, Greene). - Calif.

erythrorhizus, Bolle, in Bot. Fahrb. xiv. (1892) 238 - Ins. Canar.

formosissimus, Greene, Pittonia, ii. (Dec. 1890) 147 et Man. Bot. San Franc. Bay (1894) $92=$ Hosackia gracilis, Benth.

glaber, Greene, 11. cc. 148 et $93=$ H. glabra, Torr.

grandiflorus, Greene, 11 . cc. 145 et $92=\mathrm{H}$. grandiflora, Benth.

guadalupensis, Greene, 1. c. 144 (= H. grandiflora, Greene, non Benth.). - Calif.

hamatus, Greene, 1, c, $150=\mathrm{H}$. micrantha, Nutt.

Haydonii. Greene, 1. c. $149=$ H. Haydoni, Orcutt.

Heermani, Greene, 1. c. ii. (Dec. 1890) 150; et Man. Bot. San Franc. Bay (1894) $94=' \mathrm{H}$ Heermanni, Dur. \& Hilg.

Helleri, Britton, in Bull. Torrey Bot. Club, xvii. (1890) 312; et ex Greene, in Pittonia, ii. (Dec 1890) $138=$ Hosackia Purshiana, Torr. Eo Gray, pr.p.

\section{LOTUS :}

Hillebrandi, Christ, in Bot. Fahrb. ix. (1888) 12\%. - Ins. Canar.

hirtellus, Greene Pittonia, ii. (Dec. 1890) 142 : Man. Bot. San Franc. Bay (1894) 92. - Calif.

hosackioides, Coss. in Roudaire. Rapp. dern. expéd. Chott. 189 ; ex Bonnet in Morot, Journ. de Bot. vii. (1893) $232=$ L. Roudairei, Bonnet. humilis, Greene, Pittonia, ii.(Dec. 1890) $140=$ Hosackia maritima, Greene.

Inumistratus, Greene, 1. c. 139; et Man. Bot. San Franc. Bay $(1894) 91=\mathrm{H}$. brachycarpa, Benth incanus, Greene, 1. c. $147=\mathrm{H}$. incana, Tor

unceus, Greene. 1. c. 148; et Man. Bot. San Fran Bay $(1894) 93=\mathrm{H}$. juncea, Benth.

kabyluzus, Batt, in Batt. \& Trab. F1, de l'Algér. [Dicot.] (1889) $246=$ corniculatus, Linn. lalambensis, Schweinf. ex Penzig, in Atti Congr. Bot. Genova (1893) 339, nomen. - Erithrea.

lathyroides, Greene, Pittonia, ii. (Dec. 1890) 146 Hosackia lathyroides, Dur. \& Hilg.

lencophaeus, Greene, 1. c. 145 ; et Man. Bot. San Franc. Bay (1894) $92=\mathrm{H}$. grandiflora, Benth

lencopliylins, Greene, 1. c. $149=\mathrm{H}$. sericea, Benth.

macranthus, Greene, 1. c. $146=$ Hosackia macrantha, Greene

Mearnsii, Britton, 1. c. $144=$ H. Mearnsii, Britton. mollis, Greene, 1. c. $143=\mathrm{H}$. mollis, Greene.

neo-mexicanus, Greene, l. c. 144. - N. Mexic.

nevadensis, Greene.1. c. 149 (= Syrmatium nevadense,

Greene) $=$ H. decumbens Benth. var.

nevadensis, Coult. in Contrib. U.S. Nat. Herb. iy (1893) 84. - Calif.

niveus, Greene, Pittonia, ii. (Dec. 1890) 145 (= Syrmatium niveum, Greene).- Calif.

mudatus, Greene, 1. c. 148 (= S.matum, Greene). - Ins. Cedros.

mudiflorus, Greene, 1. c. 141; et Man. Bot. San

Franc. Bay (1894) $91=$ Hosackia nudiflora Nutt.

Nuttallianus, Greene, 1. c. $150=\mathrm{H}$. prostrata Nutt.

oblongifolius, Greene, 1. c. $146=\mathrm{H}$. oblongifolia Benth.

ornithopus, Greene. 1. c. $149=\mathrm{H}$. ornithopus Greene.

procumbens, Greene, 1. c, $=\mathrm{H}$. procumbens, Greene.

puberulus, Greene, 1. c. $142=\mathrm{H}$, puberula, Benth rigidus, Greene, 1. C. = H. rigida, Benth.

Roudairei, Ed. Bonnet, in Morot, fourn. de Bot. vii (1893) 232, cum xylogr.; Bonnet \& Baratte. Ill Phanerog. Tunisie, (1895) t. 6 fig. 1-8. - Res Tunet.

rubellus, Greene, Pittonia, ii.(Dec, 1890) 141: et

Man. Bot. San Franc. Bay (1894) $91=$ Hosackia rubella, Nutt.

salsuginosus, Greene, 11. cc. 140 ; et $91=$ H. maritima, Nutt.

stipularis, Greene, 11. cc. 147; et $93=$ H. stipularis, Benth.

stagnalis, Batt. in Batt, et Trab. Fl. de l'Algér. [Dicot.] (1889) $244=$ hispidus, Desf.

sulphureus, Greene, Pittonia, ii. (Sept. (1892) 293 - Calif.

trigosus, Greene, 1. c. (Dec. 1890) 141; et Man. Bot. San Franc. Bay (1894) $92=$ H. strigosa, Nutt.

ubsessilis, Bornm. in Mitth. Thiir. Bot. Verein, N Folge, vi. (1894) 65. - Oriens.

superbus, Bornm.l.c.- Oriens.

tomentellus, Greene, Pittonia, ii (Dec. 1890) 140. Calif.

tomentosus, Greene, 1. c. $150=$ Hosackia tomentosa, Hook. \& Arn.

Torreyi, Greene, 1. c. 146; et Man. Bot. San Franc. Bay $\left(\mathbf{1 8}^{9}\right) 92=\mathbf{H}$. Torreyi, A. Gray.

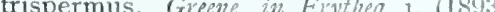
Calif.

Veatchii, Greene, Pittonia, ii. (Dec. 1890) $148=$ Hosackia Veatchii, Greenc.

Watsoni, Greene, 1. c. $149=$ H. Watsoni, Vascy Coult.

Wrightii, Greene, 1. c. $143=\mathrm{H}$. Wrightii. 1 . Gray. 
LOURYA, Banll. in Bull. Soc. Linn. Paris, (1888) i. 743 ; et Hist, des pl, xii. (1894) 525. LILIA$C E A E$.

ampanulata, Baill. ll. co.; Carrierc in Rev. Hortic. (1894) 84 fig. 27 et cum iconc. - Cochinch.

LOUTERIDIUM. S. Wats, in Proc. Am. Acad. xiii. (1888) 283 ; et xxiv. (1889) 85; Lindau, in Engl. \& Prantl, Natürl. Pflanzenfam.iv. 3b. (185) 295. ACANTHACEAE.

Donnell-Smithii, S. Wats. I. c. 284; 7. D. Smith, in Coult. Bot. Gaz. xiv, (1889) 29 t. $7(=$ Neolin dcnia mexicanus, Baill.). - Mexic., Guatem.

LOWIA, Scortech, in Nuov, Giorn. Bot. Ital xviii. (18 6) 308: Petersen, in Engl. \& Prant, Vaturl. Pflanzenfam, ii, 6 (18s8) 10. SCITA$M I N E A E$

borneensis, Baker, in Bot. Mag. (1894) sub t.7351 (=Orchidanthe borneensis, N. E. Br.). - Borneo. lungiflora. Scortech, in Nurt. Giorn. Bot. Ital. xyii 1856) 305 ; Baker, in Houk. f. Fl. Brit. Ind. vi. 1892) $264(=0$. longiflora $\mathrm{N} . \mathrm{E} \cdot \mathrm{Br}$ ). - Perak. maxillarioides, Baker, in Bot.Mag. (1894) t. 7351 (= Protamomum maxillariodes, Ridi.). - Penins. Mal.

LOXANIA, Van Tiegh. in Bull. Soc. Bot. Fr, xlii. (1895) $386^{\circ}=$ Loranthus, Linn

7oniceroides, Van Tiegh. 1.c. $387=\mathrm{L}$. loniceroides Pav.

macrophylla, Van Tiegh. 1. c. = L. microphyllus, Kunth.

LOXANTHERA. Van Tiegh. in Bull. Soc. Bot. Fr. xli. (1894) $260=$ Loranthus, Linn.

Isccarii, Van Tiegh. 1. c. - Borneo.

lampongus, Van Tiegh. xlii. (1894) 449. - Sumatra.

LOXOGALYX, Hemsl, in Journ, Linn. Soc xxvi. (1891)308. LABIATAE.

urticifolius, Hemsl. l. c. 309 t. 5. - China.

LOXODON, Cass. = Chaptalia, Vent. (Compos.) bicolor Kuntze, Rev. Gen. (1891) 369 sphaim. ( Oxydon bicolor, Less.) $=$ C. runcinata, $H . B . \& K$.

LOXOPTERYGIUM. Hook, f. (Anacard.). Ind. Kew. ii. 121

Grisebachii, Ificron. \& Lorentz, in Engl. E Prantl, Natül. Pfanzenfam. iii. 5 (1893) 173. - Reg Argent.

LOXOSTEMON. Hook. f. \& Thoms. (Crucif.). Ind Kew, ii. 121.

Delacayi, Franch, in Bull. Soc, Bot. Fr, xxxiii. (1886) 400. - China occ

LUBINIA, Comm. = Lysimachia, Tourn. $($ Primul.).

mutans, Pax, in Engl. \& Prant1, Natürl. Pflanzenfam. iv. i. (1890) $112=$ L. atropurpurea, Link, Ev Otto.

LUGILIA, Cass. (Compos.) - Ind. Kew, ii, 121. uraucana, Phil. in Anal. Univ. Chil. xc. (1895) 5.Chili.

lioica, Phil. l. c: 6. - Am. austr, oco.

Lehmanni, Hieron. in Bot. fahrb. xix. (1894) 51. Jicuad.

LUGINAEA. DC. (Rubiac.). - Ind. Kew, ii. 122. nervulosa. Slapf, in Trans. Linn. Soc. Ser. II. iv. (18.14) 174. - Borneo.

pentacme, Stapf. l. c. - Borneo

polysperma, K. Schum. in Engl. \& Prant1, Natiirl. Pflanzenfam。iv, 4 (1891) $64=\mathrm{L}$. Morinda, DC.

LUCUMA, Molina (Sapot.). - Ind. Kew ii. 122. Baillonii, Zahlbr. in Oest. Bot. Zeitschr. xxxix. (1889 287; Baill. in Bull. Soc. Linn. Pavis, ii. (1890) 892, - N. Caled.

baladensis, Baill.7.6.896. - N. Caled.

\section{LUCUMA :}

Balansana, Pierre, Not. bot. Sapot. (1890) $22=$ Epiluma pyriformis, Baill.

Beaurepairei, Glaziou Es Raukiaer, ex Raukiaer, in Vidensh. Meddel, naturh. Foren. (1889) 869 [Symb. F1. Bras. centr. xxxi. 7], - Bras.

buchaniaefolia, Pierre, Not. bot. Sapot. (1890) 25 (=Urbanella buchananiacfolia, Pierre). - Columb. crebrifolia, Baill. in Bull. Soc. Linn. Paris, ii. (1891) 898. - N. Caled.

Deplanchei, Baill.. . c. $894(=$ Rhamnoluma novo-caledonica, Baill.). - N. Caled.

discolor, Baill. l. c. 935. - N. Caled.

jacquiniaefolia, Baill. .. o. 897. - N. Caled.

laetevirens, Baill. l. c.894. - N. Caled.

lanceolata, Raukiaer, ex Warm. in Vidensk. Meddel. naturh. Foren. (1889) 870 [Symb. F1. Bras. centr. xxxi. 8]. - Bras.

neo-caledonica, Pierre, Not. bot. Sapot. (1890) 29 (= Poissonella neo-ca?edonica, Pierre) - N. Caled. mevecaledonica, Engl in Engl. \& Prantl, Natürl. Pflanzenfam. iv. $1(1890)$ 142 = seq.

novo-caledonica, Engl. Bot. fahrb. xii. (1890) $526=$ Rhamnoluma novo-caledonica. Baill.). - N. Caled oblonga, Pierre, Not. bot. Sapot. (1890) $25(=U r$ banella oblonga, Pierre). - Ins. Antill.

pinifolia, Baill. [err. cal. Pcucoluma] in Bull. Soc Linn. Paris, ii. (1800) 895 - N Caled

pomifera, Zippel, ex Pierre, Not. bot. Sapot. (1890 15 (= Beauvisagea pomifera, Pierre.). - Hab. ?

pomifera, Peckolt, in Pharm. Fourn. and Trans.

Ser. III. xviii. (May 1888) 952; ct L. Planch. Etud.prod. Sapot.(1888) 81. - Bras.

rubicunda, Pierre, ex Baill. in Bull. Soc. Lim. Paris, ii. (1890) 883. - N. Caled.

Unmackiana, F. M. Bailey, in Dept. Agric. Brisban Bot. Bull.jv. (1891) 12. - Austral.

LUGYA, DC. (Rubiac.). - Ind. Kew. ii, 122 tcrandra, K. Schum. in Engl. \& Prantl, Naturl. Pflanzenfam. iv. $4(1891) 27=$ tuberosa, $D C$.

LUDWIGIA, Linn.(Onagrar.), - Ind, Kew, ii. 122.

Swartziana, Baill.ex Laness. Pl, util. Colon. Franc. (1886) $45 \%$ - Ins. Martinica.

diffusa, Greene, F1. Francisc. (1891) $227=$ Jussieua repens, Linn.

LUEDDEMANNIA, Reichb. f. (Orchid.). - Ind. Kew. ii. 122

triloba, Rolfe, in Kene Bull. (IS!5) 283; et in Gard. Chron. (1895) ii. 713 fig. 118. - Am. austr. andina.

LUEDERITZIA, K. Schum, in Bot, Jahrb, x. (1889) 45. MALVACEAE

pentaptera, $K$. Sclinm. l. $c . l=$ Paconia clathrata Mast.). - Afr. austro-occ.

Pirottae, Terrac, in Bull. Soc. Bot. Ital. (1892) 422. - Reg. Somal.

LUERSSENIA, Kuntze, Rev. Gen. (1891) $268=$ Cuminum, Tourn. (Umbellif.).

Cymmnm, Kuntze, l. c. = C. Cyminum, Limn.

LUETKEA, Bong. - Spiraea, Linn. (Rosac.) caespitosa, Kuntze, Rev. Gen. (189I) 217 = S. caespitosa, Nutt.

caespitosa-elatior, Britton, in Trans. N. Y. Acad Sci. xiv. (1894) $31=\mathrm{S}$, elatior, S. Wals.

Hendersoni, Greene, Pittonia, i1. (May 1892) 219 - Calif.

pectinata, Kuntze. Rev. Gen. (1891) $21 \%=$ S. pectinata, Torr. \& Gray.

unifora, Kuntze, 1. c. (= Eriogynia uniflora, S. Wats.). - Montana.

LUHEA, DC. = Luehea. Willd. (Tiliac.).

Conwcatzii, K. Schum. in Mart. Fl. Bras. xii. IIt (18s6) 154. - Bras.

Eichleri, K. Schum. 1. c, 158.-Bras.

LUINA. Benth. (Compos.). - Ind. Kew, ii. 122.

Piperi. Robinson, in Coult. Bot. Gaz. xvi. (189) 4 ? t. 6, fig. 1-6. - Am. bor.
LUISIA, Gaudich. (Orchid.). - Ind. Kew. ii. 123. Amesiana, Rolfo, in Kew Bull. (1893) 173; Kraenzl. in Reichb. f. Xen. Orchid, iii. 8 (1894) 279. Burma

Beccarii, Reiclb.f. in Bot. Centralbl. xxviii. (1886) 344. - Borneo.

Cantharis, Rolfe, in Kew Bull.(1895) 193. - Burma. filiformis, Hook. f. Fl. Brit. Ind. vi. (1890) 23.Silhet.

Gamblei, Hook. f. l. c. 25; ct in Ann. Bot. Gard. Calc. v. I. (1895) 35 t. 53 . - Ind. or.

Griffithii, Kraenzl, in Reichb, f. Xen, Orchid, iii. 6 (1893) 119, t. $269 \mathrm{fig} .1-9 .(=$ Vanda Griffithit. Lindl.). - Reg Himal.

Grovesii, Hook. f. Fl. Brit. Ind. vi. (1S9(1) 25.Bengal.

micrantha, Hook. f. l. c. 23. - Assam.

striata, Kraenzl. in Reichb, f. Xen. Orchid, iii. 7 1893) 120, in obs. - As. trop.

tristis, Hook. f. Fl. Brit. Ind. vi. (1890) 25. Penans, N. Caled.

tristis, Kuntze, Rev. Gen. (1891) $672=$ teretifolia Gandich.

LUNANIA, Hook. (Saxifr.), - Ind, Kew. ii. 124 cuspidata, Warb. in Engl. \& Prantl, Natiurl. Pflanzenfam. iii. 6a (1S93) 4\%. - Am. austr.

LUNARIA. Tourn, ex Linn. (Crucif.). - Ind. Kew. ii. 124.

pachrrhiza, Borb. in Oest. Bot. Zeitschr. xli. (1891) $422(=$ L. amma, Heuff.). - Hung.

LUPINUS, [Tourn.] Linn. (Legumin.). - Ind. Kew, ii. 125.

adsurgens, Drew, in Bull. Torrey Bot. Club, xvi. (1889) 150; Greene, Fl. Francisc. (1891) $41=$ latifolius,

Bangii, Rusby, in Mcm. Torrey Bot. Chib, iii. 3 (1893) 17. - Bolivia.

canescens. Howell, in Erythea, i. (1S93) 110. - Am. bor. occ.

capitatus, Greene, Pittonia, i. (June 1SSS) 171. - . Arizona.

carnosulus, Grcene, in Bull. Calif. Acad. ii. VI. (1886) 144; et Man. Bot. San Franc. Bay (1894) 104. Calif.

chihuahuensis, S. Wats, in Proc. An. Acad.xxi. (1s86) 423. - Mexic.

Covillei, Grene, in Proi. Acad. Phit. 1892 (1893) $365 .-$ Calif.

Cusickii, S. Wats, in Proc. An. Acad. xxii. (19Si) $46 \%$ - Oregon.

eminens. Greene, in Erythea, i. (1893) 125; et Man. Bot. San Franc. Bay (1894: 106. - Calif.

erminens, S. Wats. in Proc. Am. Acad. xxv. (I890) 146. - Mexic.

eximius, Dary, in Erythea, iii. (1895) 116. - Calif. fallax, Greene, in Erythea, ii. (July 1894) 119 ; et ex. Gard. Chron. (1894) ii. 434. - Calif.

floribundus, Grone, in Proc. Acad. Phil. (1892) 364. Calif.

formosus, Grenc, Man. Bot. San Franc. Bay (1894) 105 ; ot Fl. Francisc. (1894) 42. - Calif.

franciscanus, Greene, Pittonia, i. (July 1887) $64=$ littoralis, Dougl.

gracilentus, Greene, in Proc. Acad. Phil. (1S93) 365. - Calif.

jucundus. Greane, Man. Bot. San Franc. Bay (1894) 106. - Calif

ligulatus, Grcene, Pittonia, i. (Oct. 1S8S) 215. Oregon.

longipes, Grecne, Fl. Francisc (1891) 41. - Am. bor. occ.

malacophyllus, Grene, Pittonia, i. (Oct. 1SSS) 215. - Nevada.

Michenerii, Grene, in Errtiea, ii. (1894) 119.Calif.

mucronulatus, Howell, l. c. i. (1893) 109.-- Oregon. nemoralis, Grone, Fl. Francisc. (1891) 42. Calif.

oreophilus, Phil. in Anal. Mus, nac. Chite (1891) 13. - Chili.

pachylobus, Greene, Pittonia, i (July I8s') 65) ; et Man. Bot. San Franc. Bay (1894) 104:- Calif. 
LUPINUS :

pallidus, T. S. Brandeg. in Zoé, iv. (1893) 203. Calit.

polycarpus, Greene, Pittonia, i. (June 1888) 171 et Man. Bot. San Franc. Bay (18:4) 103. Calif.

propinquus, Greene, in Erythea, i. (1893) 126 ; et l.c. 107. - Calif

saxosus. Howell, l. c. i. (1893) 110. - Am. bor. occ

Shockleyi, S. Wats. in Proc. Am. Acad. xxii. (1887) 470. - Calif.

silvestris, Drew, in Bull. Torrey Bot. Club, xvi. (1889) 150 ; et Fl. Francisc. (1894) $4 \mathbf{l}=$ albicaulis, Dougl.

somaliensis, Baker, in Kerv Bull. (1895) 213. Reg. Somal.

Tidestromii, Greene, in Erythea, iii. (1895) 17. Calif.

tricolor, Greene, 1. c. i. (1893) 126 ; et Man. Bot. San Franc, Bay (1894) 106 = jucundus, Greene. tricolor, Hort, ex Gard. Kew, Herb. Pl. (1895) 281 [an praec.?]. - Form. hort.

umbellatus, Greene, in Bull. Calif. Acad. ii. VI. (1886) 145. - Calif.

LUPSIA, Neck. = Galactites, Moench (Compos.). Durieui, Kuntze, Rev。 Gen. (1891) $352=$ G. Duriaei, Spach.

Galactites, Kuntze, 1. c. = G. tomentosa, Moonch. Hillii, Kuntze, 1, c. $120=\mathrm{G}$. Hillii, F. Muell.

Lehmannii, Hieron. in Bot. Jahrb. xx. Beibl. n. 49 (1895) 41 , in obs. = G. Lehmannii, Hieron.

lupulodes, Kuntze; Rev. Gen。(1891) 118 et $119=$ G. domingensis, Linn

orbicularis, Kuntze, 1. c. $119=$ G. Meyeni, Stend.

LUPULUS, Tourn. ex Mill. = Humulus, Linn.

(Urtic.).
scandens, St. Lager, in Cariot, Étud. des fl. éd. 8, ii. (1889) $733(=$ L. scandens, Lam. $)=$ H. Lupulus, Linn.

LUSSA, Rumpf = Brucea, J. S, Muell. (Simarub.). amarissima, Kuntze, Rev。Gen. (1891) $104=$ B. sumatrana, Roxb.

antidysenterica, Kuntze, 1. c. = B. ferruginea, L'Hérit.

macrpplylla, Kuntze, 1. c. $=$ B. macrophylla, Oliver.

mollis, Kuntze, 1. $\mathrm{c},=$ B. mollis, Wall.

quercifolia, Kuntze, 1. c. = B. quercifolia, Seem.

LUVUNGA, Buch,-Ham. (Rutac.). - Ind. Kew. ii. 126 .

nitida, Pierre, Fl. For. Cochinch. Fasc. 18 (1893) t. 283. - Cochinch.

LUXEMBERGIA, A. St. Hil. (Ochnac.). - Ind Kew. ii. 127.

Schwackeana, Taub. in Bot. fahrb. xvii. (1893) 504. - Bras.

LUZULA, DC. (Junceae). - Ind. Kew, ii, 127. caespitosa, C. Richt. PI. Europ. i. (1890) $187=$ aespitosa, C. Richt.
pediformis, $D C$.

Cheesemani, Buchenau, in Bot. Fakrb. xii. (1890) 146. - N. Zel.

Favrati X, C. Richt. Pl. Europ. i. (1890) 185. Helv.

japonica, Buchenau, in Bot. Falirb. xii. (1890) 82. - Japon.

Johnstoni, Buchenau, l. c. 79. - Afr. trop. or.

subclavata. Colenso, in Trans. N.Z. Inst. xviii. $1885(1886) 276 .-$ N. Zel.

Volkensii, Buchenau, in Bot. Fahrb. xxi. (1895) 192. - Afr. trop. or

LYALLIA, Hook. f. (Caryoph.). - Ind. Kew. ii. 128

andicolá, Phil. in Anal. Mus. nac. Chile (1891) 7 t. 1 fig. 7. - Am. austr. occ.

LYGASTE. Lindl. (Orchid). - - Ind. Kew。 ii. 128. Arnoldiae, Hort. ex Gartenfl. xli. (1892) 183. Hab. ?

\section{LYGASTE}

cinnabarina, Rolfe, in Orcinid. Rev. i. (1893) 303, et in Lindenia, viii. (1893) 23 t. 394 (= Maxillaria cinnabarina, Warscew.). - Peruvia.

Imschootiana $X, \mathbf{L}$. Linden, \& Cogn. in Lindenia, ix. (1893) 55 t. 410 ; in Gard. Chron. (1893) ii. 756 et 775 , fig. 119 ; et in Journ. des Orchid. iv. (1894) 328 fig. 72. - Hybr, artef.

Lindeniana, Hort, ex Kew Bull. (1891) 65. Form, hort.

Luciani $x^{\prime}$, Van Imschoot \& Cogn. in Eindenia, ix. (1893!) 59 t. 412 ; Gard. Chron. (1893) ii. 756 et in Journ. des Orchid. iv. (1894) 361. - Hybr artef.

Lucianiana. Hort. ex Orchid Alb. ii. (1883) $28=$ L. Luciani, Van Imschoot \& Cogn.

Lucieniana, Hort. ex Rev. Hortic. Belg. xx. (1894) $47=L$. Luciani, Van Imschoot \& Cogn

macropogon, Reichb. f. in Gard. Chron. (1888)i. 200. - Costarica.

schoenbrunnensis, Umlauft, in Wien. Mllustr. Gart. Zeit. (1893) 287 ; et ex Gard. Chron. (1894) ii. 118, fig. 18. - Hybr. artef.

LYCHNIS |Tourn.] Linn. (Caryoph.). - Ind Kew, ii. 128

andicola, Brittan, in Bull. Torrey Bot. Club. xvi (1859) 61 (= Silene andicola, Gill.). - Bolivia.

Davidi, Franch. in Nouv. Arch.Mus. Paris, Sér. II viii. 1885 (1886) 204. - Tibet.

glandulosa, Maxim. Fl. Tangit. (1889) 95. - China.

laciniata, St Lager, in Cariot, Étud. des fl. éd, 8 ii. (1889) $113(=$ L. laciniata, Lam. $)=$ L. FlosCuculi, Linn.

mongolica, Maxim. Enum. Fl. Mongol. (1889) 94. - Mongol.

segetalis, St Lager, in Cariot, Etud. des fl. éd. 8, ii (1889) $113=$ L. Githago, Linn.

Taylorae, Robinson of Seaton, in Proc. Am. Acad. xxviii. (1893) 150. - Am. bor.

umbellifera, St Lager, in Cariot, Etud. des flo éd. 8 ii. $(1889) 113(=L$, umbellifera, Lam. $)=$ L. FlosJovis, Desr.

LYCHNODISGUS, Radlk. (Sapind.). - Ind. Kew. ii. 130 .

cerospermus, Radlk, in Engl. \&o Prantl, Natürl. Pflanzenfam. iii. 5 (1890) 344. - Afr. trop. occ.

LYGHNOPHORA, Mart. (Compos.) - Ind. Kew. ii, 130

Itatiaiae, Wauva, Itin. Princ. S. Coburg. ii. (1888) 17. - Bras.

LYCIODES, Kuntze, Rev. Gen. (1891) $406=$ LYCIOIDES, Linn. Hort. Cliff. (1738) $488=$ Bumelia, Sw. (Sapot.)

angustifolium, buxifolium, crenulatum, Dunantii, ferox, Hayesii, laetevirens, lanuginosum, obovatum, obtusifolium, occidentale, parvifolium, persimile, retusum, rotundifolium, Sartorum, spiniflorum, subsessilifforum, tenax, Kuntze, Rev, Gen. (1891) 406-07 = homonzyma omnia Bumeliae.

Candolleanum, Kuntze, 1. c. $406=$ B. spinosa, Linn

myrsinifolium, Kuntze, 1. c. = Sideroxylon obovatum, Lam.

spinosum, Kuntze, 1. c. = B. lycioides, Willd.

LYGIUM, Linn. (Solan.). - Ind. Kew. ii, 130. breanum, Phil, in Anal. Univ. Chil. xci. (1895) 22. - Chili.

carinatum. S. Wats. in Proc. Am. Acad. xxiv. (1889) 65. - Mexic.

cedrosense, Greene, Pittonia i. (Mar. 1889) 268.Calif.

Chanar, Phil. in Anal. Mus. nac. Chile (1891) 68. Am. occ.

crassispina, Phil. in Anal. Univ. Chil. xci. (1895) 25. - Chili.

glandulosissimum. Schinz, in Verh. Bot. Ver. Brand. xxxi. (1890) 183. - Afr, austro-occ. extratrop. Hassei, Greene, Pittonia, i. (Oct. 1888) 222. Calif.
LYCIUM :-

Morongii, Britton, in Ann. N.Y. Acad. Sci. vii (1893) 180. - Parag.

nanum, Phil. in Anal. Univ. Chil. xci. (1895) 25. Chili.

pachyclados. Phil. l. c. 26. - Chili.

peruvianum, Hort. ex Dippel, Handb. Laubholzk. i. (1889) $30=$ obovatum. Miers.

retusum. Robinson \& Fernald, in Proc. Am. Acad. xxx. (1895) 120. - Mexic.

rhadinum, Phil. in Anal. Univ. Chil. xci. (1895) 24. - Chili

phonbifolinm, Dippel, in Dosch \& Scriba, Excursionsfl. Grossh. Hessen (1888) 218; et Handb. Laubholzk, i. (1889) 24; Koohne, Deutsche Dendrol. (1893) $518=$ ovatum, Poir.

sessiliflorum, Phil. in Anal. Univ. Chil. xci. (1895) 22. - Chili

Shockleyi, A. Gray, in Proc. Am. Acad. xxii. (1887) 311. - Am. bor. occ.

umbellatum, 7. N. Rose, in Contrib.U.S. Nat Herb. i. (1890) 74. - Calif.

venosum, Phil. in Anal. Univ. Chit. xci. (1895) 22 - Chili.

Vergarae, Phil. in Anal. Mus, nac. Chile (1891) 67 - Am. austr. occ.

villosum, Schinz, in Verh. Bot. Ver. Brand. xxxi. (1890) 184. - Afr. austro-occ. extratrop.

LYCOPERSIGUM, Hill (Solan.). - Ind. Kew ii. 131

bipinnatifidum, Plit. in Anal. Mus. nac. Chile (1891) 63. - Am, austr. occ

puberulum, Phil. l. c. 64. - Am. austr. occ.

LYCOPUS, Tourn. ex Linn. (Labiat.), - Ind Kew, ii. 132 .

intermedius $\times$. Hausskn. ex Nym. Consp. Fl, Eur ii. I. (1890) 259. - Thessal.

LYCOSERIS, Cass. (Compos.). - Ind. Kew. ii 132

boliviana, Britton, in Bull. Torrey Bot. Club, xix (1892) 266. - Bolivia.

LYGISTUM, P. Br。 = Manettia. Linn. (Rubiac,) acutifolium, barbatum, Beyrichianum, calycosum, ea nescens, ciliatum, congestum, glandulosum, gracile. Guilleminianum, hivtellum, hispidum, ignihm, luteorubrum, marginatum, meridense, microcarpum, mite paniculatum, pedunculatum, pleiodon, racemosum, reclinatum, Tweedieanum, umbellatum, zimapanicum, Kuntze, Rev. Gen. (1891) 287-88 = homonyma omnia Manettiae.

album, Kuntze, 1. c. $387=$ M. Lygistum, Sw,

Bangit, Rusby, in Mem. Torrey Bot. Club, iii 3 (1893) 43. - Bolivia.

pubescens, Kuntze, Rev。Gen. (1891) $288=\mathrm{M}$ luteo-rubra, Benth,

LYONIA, Nutt. (Ericac.). - Ind. Kew. ii, 133. ferraginea, Loesen, in Bull. Herb. Boiss. ii. (1894) $552=$ 'ferruginea, Nutt.

floribunda «C. Koch» ex DippeI, Handb. Laubholzk. i. (1889) 445, ad calc. = Leucothoë floribunda, Nutt.?

LYONSIA, R. Br, (Apocyn.)。-Ind. Kew. ii. 133. diversifolia, Warb. in Bot. Faltrb, xviii. (1894) 204

mollis, Wrarb. l. c. xiii. (1891) 406. - N. Guin pedunculata, Warb. l. c: - N. Guin.

LYPERIA, Benth. (Scrophul.). - Ind. Kew it 133 .

elegantissima, Schinz, in Verh. Bot. Ver. Brand xxxi. (1890) 195. - Afr. austro-occ. extratrop grandiflora, Galpin, in Kew Bull. (1895) 151 . Transvaal.

littoralis, Schinz, in Verh. Bot. V'er. Brand, xxxi. (1890) 192. - Afr. austro-occ, extratrop

LYROGARPA. Hook. \& Harv. (Crucif.), - Ind Kew. ii. 134.

Xanti, T. S. Brandeg. in Proc. Calif. Acad. Ser. II ii. (1889) 127 t. 2,-Calif。 
LYSIANA, Van Tiegh, in Bull. Soc. Bot. Fr xli. (1894) $599=$ Loranthus, Linn

Casuarinae, Van Tiegh. 1. c. 601 ; et xlii. (1895) 86 $=\mathrm{L}$. Casuarinae, $\mathrm{Miq}$.

Exocarpi, Van Tiegh. 11. cc. 603 et $86=$ L. Exocarpi, Behr.

linearifolia, Van Tiegh. Il, $\mathrm{cc},=\mathrm{L}$. linearifolius, Hook. $f$.

Murrayi, Van Tiegh. 11. cc. $=$ L. Murrayi, Tate. vittata, Van Tiegh. 1. c. $86=$ L. vittałus, $R$. $B r$.

LYSILOMA, Benth. (Legumin.). - Ind. Kew。 ii. 134.

candida, T. S. Brandeg. in Proc. Calif. Acad. Ser. II. ii. (1889) 153. - Calif.

formosa, Hitchcock, in Missouri Bot. Gard. Rep. iv. (1893) $83=$ Calliandra formosa, Benth.

Watsoni, F. N. Rose, in Contrib. U. S. Nat. Herb. i. (1891) 99. - Mexic.

L YSIMA GHIA [Tourn.] Linn. (Primul,). - Ind. Kew. ii. 134.

africana, Engl. in Abr. Preuss, Akad. Wiss, (1894) 55 et 59 ; et in Engl. Pflanzenw. Ost-Afr. C (1895) 304. - Afr. trop. nr.

albescens, Franch. in Morot, Fourn. de Bot. ix. (1895) 460 - Yunnan.

auriculata, Hemsl. in fourn. Linn. Soc. xxvi. (1890) 47. - China.

capillipes, Hemsl. l. c. 48. - China.

circaeoides, Hemsl. l. c. 49. - China.

congestiflora, Hemsl. l. c. 50. - China.

crispidens, Hemsl. l. co et t. 1. - China

daphnoides, Hillebr. Fl. Haw. Isl. (1888) 285. Ins. Sandvic.

Delavayi, Franch. in Morot, fourn. de Bot. ix. (1895) 45\%. - Yunnan.

drynarifolia, Franch. l. c. 462. - Yunnan.

Fargesii, Franch. l.c. 463. - China.

Fordiana, Oliver, in Hook. Icon. pl. xx. (1891) t. 1983. - China.

glaucina, Franch. in Morot, fourn.de Bot, ix. (1895) 457. - Yunnan.

grandifolia, Hemsl. in Kew Bull. (1895) 107; et in Hook. Icon. pl. xxv. (1895) t. 2405. - Siam.

Hemsleyi, Franch. in Morot, fourn de Bot. ix. (1895) 461. - Yunnan.

Hemsleyana, Maxim. ex Oliver, in Hook. Icon. pl. xx. (1891) t. 1980. - China.

Henryi, Hensl. in Fourn. Linn. Soc. xxvi. (1889) 52. - China.

heterogenea, Hems1. 1. c. 53, in obs. = heteroganea, Klatt.

hypericoides, Hemsl. l. c. xxix. (1892) 314. China occ.

involucrata, Hemsl. l. c. 315. - China occ.

longipes, Hemsl. l. c. 316. - China occ.

Lydgatei, Hillebr. Fl. Haw. Isl. (1888) 284. - Ins. Sandvic.

miltandra, Franch. in Morot, Fourn. de Bot. ix. (1895) 458. - China.

nigrolineata, Hemsl. in fourn. Linn. Soc. xxix. (1892) 315. - China occ.

omeiensis, Hcmsl.l.c. 314. - China occ.

ophelioides, Hemsl. l. c. xxvi. (1890) 54. - China.

paludicola, Hemsl. l. c. - China.

parvifolia, Hemsl. l. c. 55. - China.

platypetala, Franch. in Nouv. Arch. Mus. Paris, Sèr. II. x. (1887-88) 59. - Tibet.

pterantha, Hemsl. in fourn. Linn. Soc. xxvi. (1889) 56 t. 2. - China.

pumila, Franch. in Morot, Fourn. de Bot. iv. (1890) 460 (= Bernardina pumila, Bando). - China.

Remyi, Hillebr. Fl. Haw. Isl. (1888) 284. - Ins. Sandvic.

rotundifolia, Hillebr. l. c. - Ins. Sandvic.

rubiginosa, Hensl. in fourn. Linn. Soc, xxvi. (1889) 56 ; et in Hook. Icon, plo xx. (1891) t. 1981. China.

simulans, Hemsl. l. c. 57. - China

stenosepala, Hemsl. l. co- China.

Tanakae, Maxim. in Bull. Acad. sci. Pétersb. xxxi. (1887) 66. - Japon.

terrestris, Britton, Stern \& Poggenb. Prelim. Catal. (1888) $34=$ stricta, Ait.

\section{LYSIMACHIA :}

trichopoda, Franch. in Morot, fourn. de Bot. ix. (1895) 464. - Yunnan.

violascens, Franch. in Cat. sem. Hort. Bot. Paris (1891) nomen; et in Morot, fourn. de Bot. ix. (1895) 459. - China.

Volkensii, Engl. PAanzenw. Ost-Afr. C (1895) 304. - Afr. trop. or

yunnanensis, Franch. in Morot, fourn. de Bot. ix. (1895) 462. - Yunnan.

LYSINOTUS, D. Don (Gesneriac.). - Ind. Kew. ii. 135.

ophiorrhizoides, Hemsl. in Fourn. Linn. Soc. xxvi. (1890) 224. - China.

pubescens, C. B. Clarke, l.c. xxv. (1889)58. - Ind.or.

LYSIPOMA, Spreng. = Lysipomia, H. B. \& K (Campanul.).

Bourgoini, Ernst, in Riv. cient. Univ. Venez. (1887) 134. - Venezuela.

LYSIS, Kuntze, Rev. Gen. (1891) $397=$ Apochoris Duby (Primul.).

pentapetala, Kuntze, I. c。 = A. pentapetala, Duby.

LYTANTHUS. Wettst. in Bull. Herb. Boiss, iii. (1895) 271 = Globularia, Tourn. (Selagin.). amygdalifolius, Wettst. 1. c, $272=\mathrm{G}$. amygdalifolia, $W e b b$.

salicinus, Wettst. 1. c. $=$ G. salicina, Lam.

LYTHRUM, Linn. (Lythrar.). - Ind. Kew. ii. 136. adsurgens, Greene, Pittonia, ii. (Nov. 1889) 12; et Man. Bot. San Franc. Bay (1894) 140. - Cálif.

Bryanti, T. S. Brandeg. in Proc. Calif. Acad. Ser. II. ii. (1889) 155. - Calif.

catinense, Tornab. Fl. Sicula (1887) 240. - Sicil.

hyssopifolium, St. Lager, in Cariot, Etud. des ff. éd. 8, ii. (1889) 305 (=L hyssopifolium, Thunb.) $=\mathbf{L}$. Hyssopifolia, Linn.

salicarium, St. Lager, 1. c。 = L. Salicaria, Limn.

Sanfordi, Greene, Pittonia, ii. (Nov, 1889) 12.Calif.

\section{MI}

MABA, Forst. (Eben.). - Ind. Kew。 ii. 137.

caribaea. T. S. Brandeg. in Proc. Calif. Acad. Ser. II. iii. (1891) $151=$ caribaea, Hiern.

Elliotii, Hiern, ex S. Elliot, in fourn. Linn. Soc. xxx. (1894) 85. - Sierra Leone.

Sintenisii, Krug \& Urban, ex Urban, in Bot. Fahrb. xv. (1893) 327. - Ins. Puerto Rico.

MABEA, Aubl. (Euphorb.). - - Ind. Kew. ii. 137. indorum, S. Moore, in Trans. Linn. Soc. Ser. II. iv. (1895) 469. - Bras.

MAGAIREA, DC. (Melast.). - Ind. Kew. ii. $13 \%$. foveolata, Cogn, in Mart. Flo Bras. xiv. IV. (1888) 596. - Bras.

MACAGLIA, Vahl $=$ Aspidosperma, Mart. et Zucc. (Apocyn.)

australus, bicolor, camporum, dasycarpa, decipiens, desmantha, discolor, disperma, excelsa, Gardneri, Gomeziana, Hilariana, macrecarpa, macrophylla, Martii, megalocarpa, melanocalyx, multiflora, nobilis, oblonga, obscura, olivacea, pachyptera, platyphyila, Poliliana, populifolia, pyrifolia, refracta, Spruceana, subiniana, tomentosa, Vargasii, verbascifolia, verruculosa, Kuntze, Rev. Gen. (1891) $416=$ homonyma omnia Aspidospermatis.

Quebracho, Kuntze, 1. c。= A. Quebracho, Blanco.

MAGARANGA; Thoti. (Euphorb.). - Ind. Kew, ii. 138 .

alchorneifolia, Baker, in foum. Linn. Soc. xxv. (1890) 344. - Madag.
MACARANGA:

ankafinensis, Baill. in Bull. Soc. Linn. Paris, ii. (1892) 992. - Madag.

Brandisii, King, ex Hook. f. Fl. Brit. Ind. v. (1887) 453. - Tenass.

clavata, Warb. in Bot. Fahrb. xiii. (1891) 349. N. Guin.

Curtisii, Hook. f. Fl. Brit. Ind.v. (1887) 448. Penang.

cuspidata. Warb. in Bot. Fahrb. xiii. (1891) 351. N. Guin.

densiflora, Warb. l. c. 350,- N. Guin.

ferruginea, Baker, in fourn. Linn. Soc, xxii. (1887) 521. - Madag.

Gamblei, Hook. f. Fl. Brit. Ind. v. (1887) 445. Sikkim.

gmelinaefolia, King, ex Hook. f. l. c.- Reg. Himal.

Hildebrandtii, Baill. in Bull. Soc. Linn. Paris, ii. (1892) 990. - Madag.

Hosei, King, ex Hook.f. Fl. Brit. Ind. v. (1887) 449. - Penins. Mal.

Hullettii, King, ex Hook. f. l. c. 452. - Perak.

Humblotiana, Baill. in Bull. Soc. Linn. Paris, ii. (1892) 990. - Madag.

kilimandscharica, Pax, in Engl. Pfanzenw. Ost-Afr. C (1895) 238. - Afr. trop, or.

Kingii, Hook. f. Fl. Brit. Ind. v. (1887) 451. Penins. Mal.

Lowii, King, ex Hook. f. l. c. 453. - Penins. Mal.

mollis, Pax, in Bot. Fahrb. xix. (1894) 93. - Congo mer.

ovata, Baill. Hist. pl. Madag., Atlas (1890) t. 181 [an Boiv. ?]. - Madag.

perakensis, Hook. f. Fl. Brit. Ind. v. (1887) 447.Perak.

platyphylla, Baker, ex Baill. in Bull. Soc. Linn. Paris, ii. (1892) 991. - Madag.

Poggei, Pax, in Bot. Fahrb. xix. (1894) 94. Congo mer.

Porteana, Ėd. André, in Rev. Hortic. 1x. (1888) 176 fig. 36; W. Wats. in Gard. Chrots. (1894) ii. 284 cum xyl.; Hook.f. in Bot. Mag. (1895) t. 7407. - Ins. Philipp.

Preussii, Pax, in Bot. Fahrb. xix. (1894) 92. Kamerun.

punctata, K. Schum. in K. Schum. \& Hollr. Fl. Kais. With. Land (1889) 80, - N. Guin.

pustulata, King, ex Hook. f. Fl. Brit. Ind. v. (188\%) 445. - Reg. Himal.

quadriglandulosa, Warb. in Bot. fahrb. xiii. (1891) 350. - N. Guin.

racemosa, Baker, in fourn. Linn. Soc. xxii. (1887) 520. - Madag.

riparia, Engl. Bot. Falıb. vii. (1886) 463. - Ins. N. Hannov.

rufibarbis, Warb, l. c xvi, (1893) 21. - N. Guin. saccifera, Pax, l. c. xix. (1894) 93. - Congo.

Schleinitziana, K. Schum. l. c. ix. (1888) 20\%.N. Guin.

Schweinfurthii, Pax, l. c. xix. (1894) 92. - Afr. trop.

MAGARISIA, Thou. (Euphorb.). - Ind. Kew. ii. 138.

emarginata. S. Elliot, in fourn. Linn. Soc. xxix. (1891) 15. - Madag.

MAGFADYENA, A. DC. (Bignon.). - Ind. Kew. ii. 138 .

cynanchoides, Morong, in Amn. N. Y.Acad. Sci. vii. (1893) 187 (= Dolichandra cynanchoides, Cham. \& Schlecht.). - Bras.

mollis, K. Schum. l. c. [an Seem. ?]. - Reg. Argent. dentata, $K$. Schum in Engl. \& Prantl, Natürl. Pftanzenfam. iv. 3b (1894) 227. - Bras.

simplicifolia, F. D. Smith, in Coult. Bot. Gaz. xvi (1891) 198. - Guatem.

undulata, K. Schum. in Engl. \& Prantl, Natürl. Pflanzenfam. iv. 3b (1894) 227. - Bolivia.

MACHAERINA, Vahl = Gladium, R. Br. $(\mathrm{Cy}-$

perac.).
melicoides, Bory, ex C. B. Clarke, in Th. Dur. \& Schinz, Consp. Fl. Afr.v. 1894 (1895) $656=$ Asterochaeta elongata, Kunth. 
MAGHAONIA, Humb. \& Bonpl. (Rubiac.) Ind. Kew. ii. 139.

Pringlei, A. Gray, in Proc. Am. Acad. xxi. (1886) 380. - Mexic

MACHILUS. Nees (Laurin.). - Ind. Kew. ii. 140. Bournei, Hemsl. in fourn. Linn. Soc. xxvi. (1891) 373. - China.

breviflora, Hemsl. l.c. 374 (= Allseodaphne breviflora, Benth.). - Ins. Hongkong.

chinensis, Hemsl. l. $c .(=$ A. chinensis, Champ.). Ins. Hongkong.

Clarkeana, King. ex Hook. f. Fl. Brit. Ind. v. (1886) 137. - Reg. Himal.

edulis, King, ex Hook. f. l. c. 138. - Reg. Himal

Faberi, Hemsl, in fourn. Linn. Soc. xxvi. (1891) 374. - China.

Gamblei, King, ex Hook. f. Fl. Brit. Ind. v. (1886) 138. - Reg. Himal.

Gammieana, King, l. c. 137. - Reg. Himal.

Henryi, Hemsl. in fourn. Linn. Soc. xxvi. (1891) 375. - Hainan.

Kobu, Maxim. in Bull. Acad. Pétersb. xxxi. (1887) 95. - Ins. Boninsima.

Listeri, King, ex Hook, f. Fl. Brit. Ind. v。 (1886) 138. - Reg. Himal.

macrophylla, Hemsl, in fourn. Linn. Soc, xxvi, (1891) 375. - China.

microcarpa, Hemsl. l. c. 374. - China.

Nanmu, Hemsl. l. c. $376 .-$ China.

neurantha. Hemsl. l. c. - China.

Sheareri, Hemsl. i. c. 37\%. - China.

villosa, Hook. f. Fl. Brit. Ind. v. (1886) 140. Reg. Himal.

MAGLEANIA, Hook. (Vaccin.). - Ind. Kew. ii, 140.

Poortmanni, Drake, in Morot, Fourn. de Bot. iii. (1889) 74. - Ecuad.

tuberosa, Niedenzu, in Bot. Jahrb. xi. (1890) 224 (= Thibaudia tuberosa, Leib. [fide $\mathrm{cl}$. Niedenzu].

MACODES, Lind1. (Orchid.). - Ind, Kew. ii. 140. javanica, Hook. f. in Bot. Mag. (1889) t. $7037(=$ Argyrorchis javanica, Blume):- Java.

MACOMARIA $\times$, Rolfe, in Journ. Linn. Soc. xxiv. (1887) 170. ORCHIDEAE.

Veitchii, Rolfe, 1. c. (= Goodyera Veitchii, Hort.). Hybr. artef.

MACPHERSONIA, Blume (Sapind.). - Ind.

Kew. ii. 140,
cauliflora, Radlk. in Sitz. matho-phys. Akad. Muench. xx. (1890) 247, in obs. - Madag.

gracilis, Radll. l. e. [an O. Hoffm. ?]. - Ins. Nossibé.

Hildebrandtii, Radlk. l. c. [an O. Hoffm.?].Madlag.

laevis, Radlk. l. c. 248. - Madag.

macrophylla, Oliver, in Hook. Icon. pl. xxiii. (1892) t. 2243. - Madao.

MACRANTHISIPHON, Bureau, ex K. Schum. in Engl. \& Prantl, Natür1. Pflanzenfam. iv. 3b (1894) 219. BIGNONIACEAE

longiflorum, K. Schum. l.c. (= Bignonia longiflora, Cav.). - Guayaquil.

MACROCALYX, Trew, = Ellisia, Linn. (Hydrophyll.).

bipinnatifida, Coville, in Contrib. U. S. Nat. Herb. iv. (1893) $151=$ Phacelia micrantha, Torr. var. chrysanthemifolius, Kuntze, Rev. Gen. (1891) $434=$ E. chrysanthemifolia, Benth.

membranaceus, Kuntze, 1. c. = E. membranacea, Benth.

micrantha, Coville, in Contrib. U. S. Nat. Herb. iv. (1893) $157=$ Phacelia micrantha, Torr.

Nyctclea, Kuntze, Rev. Gen (1891) $434=$ E. Nyctelea, Linn.

MACROCALYX, Van Tiegh. in Bull. Soc. Bot. Fr. xlii. (1895) $357=$ Loranthus, Linn. (Loranth.).

Holtoni, Van Tiegh. 1. c. (= Psittacanthus Holtoni, Eichl.). - N. Granat.
MACROCARPAEA, Gilg, in Engl. \& Prantl, Natürl. Pflanzenfam. iv. 2 (1895) $94=$ Lisianthus, Linn. (Gentian.)

glabra, Gilg, 1. co. = L. glaber, Linn. $f$.

macrophylla, Gilg, 1. c. = L. macrophyllus, $H . B$. \&o $K$

obtusifolia, Gilg, 1. c, = L. obtusifolius, Griseb. revoluta, Gilg, 1. c. = L. revolutus, Ruiz. \& Pav.

thamnoides, Gilg, l. c. = L. thamnoides, Griseb.

MACROCERATIUM, Reichb. Consp. (1828) 184 Kuntze, Rev. Gen. (1891) $34=$ Andrzeiowskia, Reichb. (Crucif.).

cormutum, Kuntze, 1. c. = A. Cardamine, Reickb.

MACROCHORDION, De Vriese = Aechmea Ruiz \& Pav. (Bromel).

lagenarium, Éd. Morr, ex Mez, in Mart. Fl. Bras. iii. III. (1892) 372 [Macrocordium] = Ae. lagenaria, $\mathrm{Mez}$.

Lamarchei, «Éd. Morr.» ex Baker, Handb. Bromel. (1889) 237 , ad calc. = Ae. bromeliaefolia, Baker.

Lamarckit, Hort, ex Baker, 1. c. 67, sphalm. = Ae. Lamarchei, Éd. Morr

Lindeni, Wittm。 in Bot. Fahrb. xiii. Beibl. n. 29 (1891) 14 [Macrochordium] = Quesnelia Lindeni Ed, Morr.

macracanthum. Regel, in Act. Hort. Pétrop. ix. (1886) 603; et in Gartenfl. xxxv. (1886) 297, fig. $37=$ Ae. conspicuiarmata, Baker.

Van Houtteanum, Wittm. in Bot. Jahrb. xiii. Beibl. n. 29 (1891) 4 = Quesnelia Van Houtteana Ed. Morr.

MACROCLINIUM, Barb. Rodr. ex Pfitz. in Engl. \& Prantl, Natürl. Pflanzenfam. ii. 6 (1889) 220 et Nachtr. 111 = Ornithocephalus, Hook. ? (Orchid.).

MAGRODENDRON, Taub, in Bot. Jahrb, xii Beibl. n. 27 (1890) 19. CUNONIACEAE.

corcovadensis, Taub. l. $c_{0}$ - Bras.

MACRODISCUS, Bureau = Distictis, Mart (Bignon.).

gnaphalantha, Baill. Hist. des pl. x. (1888) $36=$ Bignonia gnaphalantha, $A$. Rich

lactiflora, Bureau, ex Baill. I. $\mathrm{c}=\mathrm{D}$, lactiflora, $D C$.

latiflora. « Baill, » ex K. Schum. in Eng1. \& Prantl, Natürl. Pflanzenfam. iv. 3b (1894) $215=$ praec

MAGROLOBIUMI, Schreb. (Legumin.). - Ind. Kew, ii. 144

Limba, S. Elliot, in fourn. Linn. Soc. xxx. (1894) 77. - Sierra Leone.

Greenei, Greene, in Erythea, ii. (1894) 73 = Aplopappus Greenei, A. Gray.

mollis, Greene, 1. c. = A. mollis, A. Gray.

pygmaeum, Greene, 1. c $=$ A. pygmaeus, $A$. Gray Watsoni, Greene, 1. c. $74 .=$ A. Watsonii, A Gray.

MACROPANAX, Miq. (Aral.). - Ind. Kew, ii 142.

dispermum, Kuntze, Rev. Gen. '(1891) $271=$ oreophilum, Miq.

MAGROPETALUM, Benth. (Asclep.). - Ind Kew. ii. 142.

Benthamii, K. Schum. in Engl. \& Prantl, Natiirl. Pfanzenfam. iv. 2 (1895) 266. - Afr. austr.

MACROPELMA, K. Schum. in Engl. Pflanzenw. Ost-Afr. C (1895) 321; et in Engl. \& Prantl, Natürl. Pflanzenfam. iv. 2 (1895) 213:ASCLEPIA$D E A E$

angustifolium, K. Schum. ll. cc. - Afr. trop. or.

MACROPLEGTRUM Pfitz. in Engl. \& Prantl, Natürl. Pflanzenfam. ii. 6 (1889) 214. ORCH.I$D E A E$

sesquipedale, Pfitz.l.c. fig. 234 (= Angraecum sesquipedale, Thou.). - Afr. trop.
MACRORRHYNCHUS, Lem。= Troximon, Nutt。 (Compos).

elatus. Phil. in Anal. Univ. Chil. Ixxxvii. (1894) 324. - Chili

MAGRoSGePIS, H. B. \& K. (Asclep.). - Ind, Kew. ii. 143 .

pleistantha, 7. D. Smith, in Coult. Bot. Ga? xx. (1895) 543. - Guatem

MAGROSPHYRA, Hook。f。(Rubiac.). - Ind. Kew. ii. 143.

paleacea, K. Schum. in Engl. \& Prant, Natiurl. Pfanzenfam. iv. 4 (1891) '77, in obs. (= Gardenia paleacea, A. Rich.). - Afr. trop.

MAGROTOMIA, DC. (Borag.), 一 Ind. Kéw. ii. 143

Benthami, Boiss. Fl. Or. Suppl. (1888) 352 |Macrotamia]. (= Echium Benthami, Wall.). - Reg. Himal., Afghan.

MACROzAMIA, Miq. (Cycad.). - Ind. Kew。 ii。 144

cylindrica, C. Moore, Handb. Fl. N. S. Wales (1893) - Austral.

Fawcettii, C. Moore, l. c. 380. - Austral.

flexuosa, C. Moore, l. c. - Austral.

heteromera. C, Moore, l. c. - Austral.

Hopii, 'W. Hill, ex F. M. Bailey, Syn. Queensl. Fl. Suppl. i. (1886) 50. - Austral.

Moorei, F. Muell. ex C. Moore, Handb. Fl. N. S, Wales (1893) 379. - Austral.

mountperiensis, F. M. Bailey, Syn. Queensl. Fl. Suppl. i. (1886) 50. - Austral

secunda. C. Moore, Yandb. Fl. N. S. Wales (1893) 379. - Austral.

MAGRozanONIA, Cogn. in Bull. Herb. Boiss. i. (1893) 612 ; Muell. \& Pax, in Engl. \& Prantl, Natürl. Pflanzenfam. iv. 5 (1893) 392 in add. CUCURBITACEAE

macrocarpa, Cogn. ll. cc. (= Zanonia macrocarpa, Blume). - Ins. Sandvic.

MADIA, Molina, (Compos.). - Ind. Kew, ii. 144. corymbosa, Greene, Pittonia, ii. (Sept. 1891) $213=$ corymbosa, $D C$.

exigua, Greene. Erythea, i. (1893) 99; et Man. Bot. San Franc. Bay (1894) 193 = filipes, A. Gray.

hispida, Greene, Pittonia, ii. (Sept. 1891) 217 (= Madaria corymbosa, DC. var.? hispida, DC.).Calif.

madioides, Greene, Man. Bot. San Franc, Bay (1894) $193=$ Nutt.

valida, T. S. Brandeg. in Zoë, iv. (1893) 206. Calif.

MADORIUS, Rumph. Herb. Amboin. vi. (1750) 24, t. 14, ex Kuntze, Rev, Gén. (1891) 421 = Galotropis R. Br. (Asclep.).

Acia, Kuntze, 1. c. = C. Acia, Buch-Ham

giganteus, Kuntze, 1. c. $=$ C. gigantea, $[$ Dryand. in $]$ Aiton.

procerus, Kuntze, 1. c. $=$ C. procera, [Dryand.in] Aiton.

MAERUA, Forsk. (Capparid.). - Ind. Kew. ii

144.
amphilahensis, Terrac, in Ann.Ist. Bot. Roma, v (1894) 114. - Afr, trop. or.

angustifolia, Schinz, in Verh. Bot. Ver. Brand. xxix. (1888) 48. - Afr, austro-occ. extratrop.

caffra, Pax, in Engl. \& Prantl, Natürl. Pftanzenfam. iii. 6 (1891) $234=$ Niebuhria triphylla Wendl. $f$.

calophylla, Gilg, in Engl, Pfunzenw。 Ost-Afr. C (1895) 187. - Afr, or

candata, Pax, in Bot. Fahrb. xiv. (1892) 305. Kamerun.

Emini, Pax, l. c. 30t. - Afr. trop. occ

grandiflora, Pax, l. c. 302. - Afr. trop. or

Guerichii, Pax, in Bot. Falmb. xiv. (1892) 305 in obs; et xix. (1894) 135. - Afr. austro-occ. extra trop. 


\section{MAERUA}

Harmsiana, Gilg, in Engl. Pfanzenv. Ost-Afr. C (1895) 187. - Afr. or.

Hoehnelii, Schweinf. ix Engl, in Abh. Preuss. Akad. Wiss. 1891 ii. (1892) 227, nomen, - Afr. trop, or.

Holstii, Pax, in Engl. Pfanzenw. Ost-Afr. C (1895) 187. - Afr. or

insignis, Pax, ex Engl. in Abr. Preuss. Akad. Wiss, (1894) 30 ; et in Pflanzene. Ost-Afr. C (1895) 187. - Afr. trop. or.

Johannis, Volkens \& Gilg, in Engl. Pfanzenw. OstAfr. C (1895) 18\%. - Afr. or.

juncea, Pax, in Bot. Fahrb. xiv. (1892) 302. - Afr. tro?. austro-or

Timearis, Pax, in Engl. \& Prantl, Natürl. Pflanzenfam. iii. 6 (1891) $234=$ Niebuhria linearis, $D C$.

nuda, S. Elliot, in fourn. Limn. Soc. xxix. (1891) 2. - Madag.

parvifolia, Pax, in Bot. Fahrb. xiv. (1892) 303 in obs ; et xix. (1894) 135. - Afr. austro-occ. extra-

trop. extratrop.

somalensis, Pax, iu Engl. \& Prantl, Natirl. Pfanzenfam. iii. 2 (1891) 235; et in Bot. Fahrb. xiv. (1892) 304. - Reg. Somal.

Stuhlmannii, Pax, l. c. 303. - Afr. trop. or

tomentcsa, Pax, l. c. 305. - Afr. trop. or.

MAESA, Forsk. (Myrsin.). - Ind. Kew. ii. 144. Borjacana. Henriques, in Bolet, Soc. Brot. x. (1892) 138. - Ins. S. Thom.

Hornsheimiana, Warb. in Bot. Fahrb. xiii. (1891) 398. - N. Guin

papuana, Warb.l.c.400. - N. Guin: "

subsessilis, Warb. l. c, 399. - N. Guin

MAESOBOTRYA, Benth. (Euphorb.) - Ind. Kew.ii. 145.

Bertramiana, Buettn. in Verh. Bot, Ver. Brand. xxxi. (1889) 93. - Congo.

MAESOPSIS, Engl. Pflanzenw. Ost-Afr, C (1895) 255. RHAMNEAE.

Eminii, Engl. l. c.; et in Engl. E Prantl, Naturl. Pflanzenfam. iii. 5 (1895) 399. - Afr. trop. or.

Stuhlmannii, Engl. $l l . c c$. - Afr trop. or.

MAFEKINGIA, Baill. Hist. des pl. x. (1890) 303 ; K. Schum, in Engl. \& Prantl, Natürl, Pflanzenfam. iv. 2 (1895) 218. ASCLEPIADEAE

Parquetiana, Baill. $l l . c c .-$ Afr. austr.

MAGNOLIA, Linn. (Magnoliac.).-- Ind. Kew. ii. 145

Delavayi, Franch. Pl. Delav. (1889) 33 t. 9-10. Yunnan.

ferruginea, Hort, ex W. Wats, in Kew Bull. (1S89) 305 = grandiflora, Linn.

foctida, Sarg. in Gard. and For. i. (1889)615; et N. Am. Sylva, i. 3 t. 1 et $2=$ grandiflora, Limn.

Gustavi, King, in Ann. Bot. Gard. Calc. iii. II. 1891) 209 t. 61. - Assam

Hartregii, Hort. ex Gard. Kew, i. Polypet. (1894) 17 = grandiflora, Lim.

Hartwicus, Hort. 1. c. = grandiflora, Linn.var

hybrida $X$, Dippel, Handb. Laubholzk. iii. (1893)

151. - Hybr.artef.

latifolia, Aiton [Hort. Kew. ii. (1789) 251] ex Dippel, 1. c. $145=$ trlauca, Linn.

Lenneana $X$, Hort. ex Koehne, Deutsche Dendrol, (1893) $146 \operatorname{an} M$. Lennei X, Van Houtte?] Hybr. artef.

Maingayi, King, in fourn. As. Soc. Beng. Iviii. (1889) II. 369. - Penins. Mal.

Norbertiana X. Hort. ex Dippel, Handb. Laubholzk. iii. (1893) 152; Koehne, Deutsche Dendrol. (1893) $146=$ hybrida, Dippcl.

Pealiana, King, in Ann. Bot. Gard. Calc. iii. II. (1891) 210 t. 59. - Assam

speciosa, "Cels, » ex Dippel, Handb. Laubholzk. iii. (1893) $152=$ hybrida, Dippel.

stricta. Hort. ex Gard. Kew, i. Polypet. (1894) 17 = grandiflora, Linn.vax.
MAGNOLIA :

tripetala, Trelease, Branner \& Coville, in Branner Rep. Geol. Surv, Ark. $163(=M$. tripetala, Linn. $=$ M. umbrella, Linn.

Thurberi, Hort. ex Gard. Kew, i, Polypet. (1894) 17 $=$ M. Kobus, $D C$.

Watsoni, Hook. f. in Bot. Mag. (1891) t. 715\%. Japon.

Wiesneri, Hort. ex Carr. in Rev. Hortic. Ixii. (1890 406. - Japon?

MAGONIA, Vell. = Ruprechtia, C. A. Mey (Polygon.).

amentacea, apetala, brachysepala, brachystachya, coriacea, corilifolia. Cumingii, excelsa, fagifolia, glauca, Famisonia, laxiflora, Lundii, Martei, mollis. poly. stachya, vamiflora, salicifolia, tenuiflora, trifiora, Vivaru, Kuntze, Rev. Gen. (1891) $553=$ homonyma omnia Ruprechtiae.

carpinodes, Kuntze, 1. c. = R. carpinoides, Meissn costata, Kuntze, 1. c。 = R. Cumingii, Meissn.

MAHEA, Pierre, ex L. Planch. Etud. prod. Sapot. (1888) 26 ; et Not. bot. Sapot. (1890) 8. SAPOTACEAE

glauca, Pierre, l. c. $(=$ Labourdonnaisia glauca, Boj.). -

natalensis, Pierre, l. c.; Baill. in Bull. Soc. Linn. Paris, ii. (J891) 742. - Natal.

MAHERNIA. Linn. (Stercul.). - Ind. Kew, ii. 146.

auricoma, Szyszyl. Polyp. Rehmann.(1887) 51.Natal.

cordata, E. Mey. ex Szyszyl. 1. c. = betonicaefolia, Eckl. \& Zeyh.

Macowanii, Szyszyl. l. c.54. - Natal.

natalensis, Szyszyl.l. . . 52. - Natal.

Rehmannii, Szyszyl.l.c. 55. - Transvaal

MAHOE, Hillebr. F1. Haw. Isl. (1S88) $86=$ Alec tryon, Gaertn. (Sapind.).

MAHONIA, Nutt. = Berberis, Linn. (Berberid.). Fortunei, Hort. ex Dippel, Handb. Laubholzk, iii. (1893) $109=$ B. Fortunei, Lindl.

latifolia, Hort. ex Dippel, 1. c. = B. Aquifolium, Pursh.

Murrayana, Hort. ex Dippel, 1. c. = B. Aquifolium, Pursh.

nepalensis, DC. ex Dippel, 1. c. $112=$ B. nepalensis, Spreng.

Sieboldii “Lavallée. » [Arboret. Segrez. (1870) 16], ex Dippel, 1. c. $11=$ B. nepalensis, Spreng.

trifoliata, Hort. ex Dippel, 1. C. $104=$ B. Schiedeana, Schlecht.

trifurcata, Hort, ex Dippel, 1. c. $113=$ B. trifurca, Forst.

Wagneri, Hort, ex Dippel, 1. c. $107=$ B. pinnata Lag.

MAHYA, Cordem. Fl. Ile Réunion (1895) 490 LABTATAE.

tellata, Cordem. l. c. - Ins, Borbon.

MAIETA, Aubl. (Melastom.). - Ind. Kew, ii. 000 dentata, $\operatorname{Cog} n$. in Mart. Fl. Bras, xiv. IV. (1888) 465 (=Calophysa dentata, Triana). - Peruvia.

tococoidea, Cogn.l.c. (=Calophissa tococoidea, DC. - Bras, , Peruvia.

MAJANA, Rumph. Herb. Amboin, v. (1747) 291, 296, t. 101, f 3, ex Kuntze. Rev. Gen. (1891) 523 = Coleus, Lour. (Labiat.).

acuminata, arabica, bicolor, Blancoi, canina, camosa galeata, glandulosa, grandifolia, inflata, lanuginosa, latifolia, macrophylla, macrostachya, Manni, multiflora, parvifora, puberula, secundiflora, spicata, tenuicaulis, Kuntze, Rev. Gen. (1891) $524=$ homonyma omnia Colei.

amboinica, Kuntze, 1. c. = C. aromaticus, Benth

Benthamiana, Kuntze, 1. c. = C. inflatus. Benth.

Forskalii, Kuntze, 1. c. = C. barbatus. Benth,

paniculata. Kuntze, 1. C. = C. Persoonii. Benth.

pumila, Kuntze, 1. c. = C. acuminatus, Benth。

Richardiana, Kuntze, 1. c. $=\mathrm{C}$. tuberosus, A. Rich.
MAJANA :

scutellariodes, Kuntze, Rev. Gen. (1891) $524=$ Coleus scutellarioides, Benth.

Sugunda, Kuntze, 1. c. = C. aromaticus, Benth.

tuberosa, Kuntze, 1. c. = C. parviflorus, Benth.

Zatarhendi, Kuntze, 1. c. = C. spicatus, Benth.

MAJANTHEMUM, Sieg. Fl. Petrop. (1736) 70 ; ex Kuntze, Rev. Gen. (1891) $981=$ Convallaria Linn. (Liliac.).

majalis, Kuntze, 1. c. = C. majalis, Linn.

MAKOKOA, Baill in Bull. Soc. Linn, Paris, (1886) 619 ; et (1887) $704=$ Octolepis, Oliver (Thymel.).

congolana, Baill. 11. cc. - Congo gall.

MALABAILA, Hoffm. (U'mbellif.). - Ind. Kew ii. 147.

aurantiaca, Alboff. Prodr. Fl. Colch. (1895) 117. Reg. Cauc.

biradiata, Hausskn. ex Nym. Consp. Fl. Eur. Suppl. ii. I. (1889) 138. - Graecia.

Burnatiana, Heldr, in Oest. Bot. Zeitschr. xxxix. (1889) 242. - Graecia.

chrysantha, Alboff, Prodr. Fl. Colch. (1895) 117. Reg. Cauc.

Kirungae, Engl. Pfanzenw. Ost-Afr. A (1895) 134 nomen. - Afr. trop.

parnassica, Heldr, in Oest. Bot. Zeitschr, xxxix. (1889) 243. - Graecia.

porphyrodiscus. Stapf \& Wettst. ex Stapf, in Denkschr. Akad: Wien, ii. (1886) 52, - As. Min Psaridiana, Heldr. in Oest. Bot. Zeitschr. xxix. (1889) 243. - Graecia.

MALACANTHA, Pierre, Not. bot. Sapot. (1891) 60 ; Baill. Hist. des pl, xiii. (1895) 295. SAPO TACEAE.

alnifolia, Pierre, l. c. (1891) 61 (= Chrysophylhum alnifolizm, Baker) - Atr. trop. occ.

Heudelotiana, Pierre, l. c.-Afr. trop. occ.

MALACHE, Trew = Pavonia, Cav. (Malvac $)$. angustifolia, arabica, avenaria, Bojeri, cancellata. castanaefolia, ceratocarpa, clathrata, diuretica, gle chomifolia, grandiflora, grisea, hastata, heterophylla hirsuta, intermixta, Klotschyi, lanceolata, lasiopetala. latifolia, modesta, odorata, paniculata, papilionacea. pellita, propinqua, prostrata, praemorsa, racemiflora, Rosa-campestris, rosea, sagittata, Schimperiana. Schranki, semiserrata, sepium, sessiliflora, sidifolia, speciosa, spinifex. subpandurata, urens, urticifolia velutina, zeylanica, Kuntze, Rev. Gen.(1891)70-71 homonyma omnia Pavoniae.

achanodes, Kuntze, 1. c. = P. achanioides, Griseb. arachnodes, Kuntze, 1. c. = P. arachnoides, Pres?. alba, Kuntze, 1. c. $70=\mathrm{P}$. paniculata, Cav. Burchollii, Kuntze, 1, c. $=$ P. Columella, Cav. cardiosepala, Kuntze, 1, c. $=\mathrm{P}$. varians, Moric. cordifolia, Kuntze, 1. c. = P. Mutisii, $H$. B. \& $K$ corymbosa, Kuntze, 1. c. = P. paniculata, Cav. deltodes, Kuntze, 1. $\mathrm{c}$. = P. deltoidea, Mart.

flava. Kuntze, 1. $c_{0}=$ P. sepium, A. St. Hil. glandulosa, Kuntze. 1. c. = P. glandulosa, Presl. glechomodes, Kuntze, 1. c. = P. glechomoides, A. St. Hil.

hirta, Kuntze, 1. c. = P. glechomoides, A. St. Hil. hivtiflora, Kuntze, 1. c. = P. glandulosa. Presl. involucrata, Kuntze, i, $\mathrm{c}=\mathrm{P}$, sessiliflora, $H, B$ \& $K$.

leptocarpa, Kuntze, 1. c. = P. Typhalaea. Cav.

Luschnathiana, Kuntze, 1. c. = P. microphylla, Casarr.

macrophylla, Kuntze, 1, $\mathrm{c}_{2}=\mathrm{P}$. Kraussiana, Hochst. mexicana, Kuntze, 1. c. = Kosteletzkya mexicana Garcke.

microphylla, Kuntze, 1. c. $71=$ P. Dregei. Garcke. mollis, Kuntze, 1. c. $70=$ P. Mutisii, H. B. \& $K$ muricata, Kuntze, 1. c. $71=$ P. Schrankii, Spreng. mutanda, Kuntze, 1. c. $70=\mathrm{P}$. cordifolia, Wright. Poeppigii, Kuntze, 1. c, $71=$ Hibiscus Poeppigii, Garcke.

polynorpha, Kuntze, 1. c. = P.speciosa, $H . B$. E $K$. 
MALACHE :

repanda, Kuntze, Rev. Gen. (1891) $\% 1=$ Urena repanda, $R o x b$.

rigida, Kuntze. 1. c. = U, rigida, Wall.

scabra, Kuntze, 1. c. = Pavonia paniculata, Cav.

spicata, Kuntze, 1. c. $70=$ P. racemosa, Sw.

stellata, Kuntze, 1. c. $71=$ P. Typhalaea, Cav.

sulfurea, Kuntze, 1. c. = P. cancellata. Cav.

typhalaeodes, Kuntze, 1, c. = P. Typhalaea, Cav

Wrightii, Kuntze, 1. c. = P. lasiopetala, Scheele.

MALACHRA, Linn. (Malv.). - Ind. Kew. il. 148 ruderalis, Guerke, in Mart. Fl. Bras. xii. III. (1891) 460. - Peruvia

MALACOCARPUS, Salm-Dyck = Echinocactus Link \& Otto (Cact.).

Sellowii, K. Schum. in Mart. F1. Bras, iv, II. (1890 238 ; et in Monatsschr. f. Kakteenk. iv. (1893) $160=$ Sellowianus, Salm-Dyck.

tephracanthus. K. Schum. 1. c. $243=$ E. tephracanthus, Link \& Otto.

MALACOCHAETE, Nees = Scirpus. Tourn. (Cyperac.).

aemulans, Arn. ex C. B. Clarke, in Th. Dur. \& Schinz, Consp. F1. Afr. v. 1894 (1895) $620=$ S. corymbosus, Heyne.

MALACODENDRON ovatum, “Cav. » ex Dippel Handb. Laubholzk. iii. (1893) $30=$ Malachodendron ovatum, Cav.

MALACOTHRIX, DC. (Compos.), - Ind. Kew ii. 148 .

foliosa, A. Gray, ex Iyon, in Coult. Bot. Gaz. xi (1886) 335, nomen; et Syn. N.Am. Fl. i. II. (1886) 454. - Calif.

indecora, Greene, in Bull. Calif. Acad. ii. vI. (1886) 152. - Ins. S. Cruz (Calif.).

squalida, Greene, l. c. - Ins. S. Cruz (Calif.).

MALAISIA, Blanco (Urtic.). - Ind. Kew, $\mathrm{ii}_{i} 148$ scandens, K. Schum. in Bot. Jahrb. ix. (1888) 19 (=M. scandens, Planch.) $=$ tortuosa, Blanco.

MALANTHOS, Stapf, in Hook Icon. pl. xxv. (1895 sub t. 2415. Genus omnino delendum [Conf Kew Bull. (1895) 319!.

MALANEA, Aubl. (Rubiac.). - Ind. Kew. ii. 148 grandis, Rusby, in Mem. Torrey Bot. Club, iii. (1893) 43; et iv. (1895) 208, in obs. = Elaeagia grandis, Rusby.

MALAPOENNA, Adans. = Litsea, Lam.(Laurin.) acerina, aciculata, albicans, amara, angulata, angustifolia, assamica, Beddomii, cassiaefolia. castanca, chartacea, chrysocoma, citrata, cordata, coriacea, Cubeba, dealbata, densifolia, diversifolia, elliptica, elongata, ferruginea, firma, fulva, fuscata, glaberrima, glabrata, glaucescens, gracilipes, grandis, guatemalensis, Helferi, Hookeri, Hookeriana, japonica javanica, khasiana, Kingii, Kurzii, laeta, latifolia, leiantha, ligustrina, longifolia, longipes, luzonica, Maingayi, Manni, Meisneri. membranifolia, mishmiensis, myristicifolia, nemoralis, nitida, Noronhae, nuculanaea, obtusa, Orizaba, ovalifolia, Panamonja, parvifolia, penangiana, petiolata, plumbea, polita, Pseudoculitlawan, resinosa, reticulata, robusta, rubra, nugosa, Rumphii, semecarpifolia, sericea, Thomsoni, tomentosa, triplinervia, undulata, venulosa, villosa. Wightiana, Kuntze, Rev. Gen. (1891) 571-73= homonyma omnia Litseze.

accedens, Kuntze, 1. c. $572(=$ Cylicodaphne accedens Meissn.). - Borneo.

ambigua, Kuntze, 1. c. $(=$ Tetranlhera ambigua, Blume) -- Ins. Moluce.

areolata, Kuntze, 1. c. (= T. areolata, Blume).N. Guin.

bancana, Kuntze, 1. c. (= T. bancana, Miq.). Ins. Banca.

bandongana, Kuntze, 1. c. = L. Noronhae, Blume.

Bindoana, Kuntze, 1. c. $571=$ L. Bindoniana, F. Muell.
MALAPOENNA :-

Blumeana, Kuntze, Rev. Gen. (1891) 572 (= Cylucodaphne cuneata, Blume). - Sumatra.

borneensis, Kuntze, 1.c. (= Tetranthera borneensis, Meissn.). - Borneo.

brachystachya. Kuntze, $1, c_{0}=(T$. brachystachya, Blume). - Java.

Brawas, Kuntze, 1. c. (= T. Brawas, Blume).Sumatra.

calicaris, Kuntze, 1. c. 571 (=T. Tangao, Blume), - N. Zel.

caloneura, Kuntze, 1. c. 572 (= T. cakoneura, Miq.). - Java.

chrysophoena, Kuntze, 1. c. $(=T$. chrysophaena, Blume). - Ins. Moluce

chrysopleura, Kuntze, 1. c. $(=T$. chrysopleura, Blume). - Java.

crassifolia, Kuntze, 1. c. (T. crassifolia, Blume). Borneo.

Cupala, Kuntze, 1. c. $571=$ L. lanuginosa, Nees.

cuneata, Kuntze, 1. c. 572 (= Tetranthera cuneata, Blume). - Ins. Celebes.

cuspidata, Kuntze, 1. c. (= T. cuspidata, Blume $)$ Java.

Cylicodaphne, Kuntze, 1.c. (= Cylicodaphne pallida, Blume). - Malaya.

discolor, Kuntze, 1. c。 = L. timoriana, Span.

Doshia, Kuntze, 1. c. = L. oblonga, Meissn.

dubia, Kuntze, 1. c. (= Cylicodafline relutina, Blume). - Java.

flexuosa, Kuntze, 1. c. (= Tetranthera flexuosa, Rlume). - Ins. Moluce.

Forstenii, Kuntze, 1. c. (= T. Forstenii, Blume).Ins. Celebes.

fusca, Kuntze, 1.c. (= Cylicodaphne fusca, Blume $)$. - Sumatra.

fuscuta, Kuntze, 1. c. = L. fuscata, Thw.

fuscescens, Kuntze, 1. c. ( $=$ Cylicodaphne fuscescens, Meissn.j. - Malaya.

gemelliflora. Kuntze, 1.c. (= Tetranthera gemelliflora

Miq.). - Sumatra.

geniculata, Coult in Mem, Torrey Bot. Club, v.(1894) $164=$ L. geniculata, Benth. \& Hook. $f$. glauca, Kuntze, Rev, Gen.(1891) $572=$ L. salicifolia, Hook. $f$

glomerata, Kuntze, 1. c. = L. geniculata, Benth. \& Hook. $f$.

grisea, Kuntze, 1. c. (= Cylicodaphne grisea, Blume). - Sumatra.

hirta, Kuntze, 1. c. (=C. hirta, Blume).- Java. Hookeri, Kuntze, 1. c. = L. oreophila, Hook. $f$. impressa, Kuntze, 1. c. $(=$ Tetranthera impressa,

Blume). - Java.

insignis, Kuntze, 1. c. (= T. insignis, Blume). Sumatra.

intermedia, Kuntze, 1. c. (= T. intermedia, Blume). - Java.

involucrata, Kuntze, 1. c. $571=$ L. zeylanica, C. $\hat{\sigma}$ T. Nees.

Iteodaphne, Kuntze, 1. c. $572=$ L. ovalifolia, Trim?

lancifolia, Kuntze, 1. c. = L. minuta, Reinw.

lucida, Kuntze, 1. c. $(=$ Tetranthera lucida, Hassk. $)$. - Java.

Iucidissima, Kuntze, 1. c, = L. lucida, Blume.

macrantha, Kuntze, 1. c. $5 \% 1=$ L. Sebifera Pers.

macrophylla, Kuntze, 1. c. $572=$ Actinodaphne macrophylla, Nees.

magnifica, Kuntze, 1. c. (= Cylicodaphne magnifica, Miq.). - Sumatra.

mappacea, Kuntze, 1. c. (= Tetranthera mappacea. Blume). - Sumatra.

martabanica, Kuntze, 1, c. (=T.martabanica, Jungh.), - Burma.

Miqueliana, Kuntze, 1. c. (= Lepidadenia mollis, Miq.). - Java?

Mogol, Kuntze, 1. c. (= Tetranthera Mogal, Blume). - Java.

mollis, Kuntze, 1. c. $(=T$. mollis, Miq.). Java?

monopetala, Kuntze, 1. c. $571=$ L. polyantha, Fuss.

Neesiana, Kuntze, 1, c. $(=$ Tetranthera Neesiana. Wall.). - Malacc.
MALAPOENNA :- -

nervosa, Kuntze, Rev. Gen. (1891) $572=$ L. Wallichii, Hook.f.

nigricans, Kuntze, 1. c. 573 (= Tetranthera nigricans Meissn.). - Borneo.

nitens, Kuntze, 1, c. $(=T$. nitens, Blume $)$ Java.

obscura, Kuntze, 1. c. $(=T$. obscura. Blume $)$. N. Guin.

obtusata, Kuntze, 1. c. (=T. obtusata, Nees). -

Java.
oleodes, Kuntze, 1. c. = L. oleoides, Hook. f.

Oliveriana, Kuntze, 1. c. = I, mollis, Oliger.

pallens, Kuntze, 1. c. $572=$ L. umbrosa, Nees.

pallida, Kuntze, 1. c. $573(=$ Tetranthera pallida Blume). - Ins. Celebes.

palmatinervia, Kuntze, 1. c. $571(=T$. palmatinersia Meissn.). - Ins. Fiji

Pantjara, Kuntze, 1. C. (= T. Pantjara, Blume).Java, Sumatra.

penangiana, Kuntze, 1. c. $573=$ L. penangiana Hook. $f$.

polyneura, Kuntze, 1. c. (= Cylicodaphne polynewra Meissn.). - Java.

propinqua, Kuntze, 1. c. (= Tetranthera propingra Blume). - Sumatra.

pulchella, Kuntze, 1. c. = L. zeylanica, C. \& $T$ Nees.

punctata, Kuntze, 1. c. $1=$ Cylicodaphne punctata Blume). - Borneo

rangoonensis, Kuntze, 1. C. (= Tetranthera rangoonen sis. Meissn: ). - Burma.

riparia, Kuntze, 1. c. (= T. riparia, Blume). Ins. Moluce.

rubiginosa, Kuntze, 1. c. (= Cylicodaphne rubiginosa Blume). - Sumatra.

Seemannii, Kuntze, 1.c. (= Tetranthera Seemanni, Meissn.). - Ins. Fiji.

sessiliflora, Kuntze, 1. c. (= Cylicodaphne sessiliflort Meissn.). - Borneo.

sessilis. Kuntze, 1. c. $572=$ L. sessiliflora, Hook. $f$ siamensis, Kuntze, l. c. = I. nuculanea, Hook. $f$.

Sieboldii. Kuntze, 1. c. $=$ L. glauca, Siebold.

sumatrana. Kuntze. 1. c. 573 \% Cylicodaphne suma trana, Miq.). - Sumatra.

tephrophylla, Kuntze, 1. c.(=Lepidadenia tephrophylla Miq.). - Java.

tersa, Kuntze, 1. c. $571=$ L. Sebifera, Pers.

tuberculata, Kuntze, 1. $\mathrm{c}_{0}(=$ Cylicodaphne tuberculata. Blume). - Sumatra.

umbellata, Kuntze, 1. c. = L. hexantha, fuss.

undulata, Kuntze, 1. с. $573=$ L. undulata, Zipp

unita, Kuntze, 1. c. (= Cylicodaphne unita, Blume) - Ins. Moluce

utilis, Kuntze, 1. c. ( $=$ Tetranthera utilis, Meissn.) - Borneo.

varians, Kuntze. 1. c. $(=T$. varians, Blume $)$ Sumatra.

velutina, Kuntze, 1.c. (= T. velutina, Blume).Ind. or.

vestita, Kuntze, 1. c. = L. tomentosa, Blume.

villosa, Kuntze, 1. c. 551 = L. Neesiana, Hems

virens, Kuntze, $1, \mathrm{c},(=$ Tetranthera virens, Nees $)$ - Ins. Penang.

Waitriana, Kuntze, 1, c. (= T. Waitziana, Blume $)$ - Java.

xanthophylla, Kuntze, 1. c. $(=T$, xantophyllir Blume). - Sumatra.

MALAXIS. Soland. ex Sw. (Orchid.).-Ind, Kew ii. 148 .

acutangula, andicola, arachnifera, bancana, biaurita, brachystachya, Burbidgei, calophylla. calycina, caracasana, cardiophylla, carinata, caulescens, Chloro phrys, commelinifolia, cordata, corymbosa. crenulata, crispifolia, cylindrostachya, discolor. disepala, Ehrenbergi, excavata, fastigiata, floridana, furcata, Godefroyi, gracilis, hastilabia. fosephiana, khasiana Iagotis, lancifolia, longisepala, macrostachya, Mainaryi, Massonii, metallica. micrantha, montani. Moritaii, muscifera, myurus, oculata, parvula, polyo don, polyphylla, porphyrea, prbescens, purpurea. rotundata, rupestris. Scottii. segarensis, simillima, stelidostachya, Stocksii, taurina, Ventilabrum, centricosa, Warmingii, nuntze, Rev. Gen.(1891) 6i: - homonyma omnia. Microstylidis. 


\section{MALAXIS :}

densiflora, Rich. \& Galeotti, ex Ridl. in Journ. Linn. Soc. xxiv. (1888) 331, in syn. = Microsty lis macrostachya, Lindl.

platycheila, Kuntze, Rev. Gen. (1891) $673=$ Micr. platychila, Reichb. $f$.

vesupinata, Kuntze, 1. c. = Micr. Rheedii, Reichb. $f$, et versicolor, $L$ indl.

tipulodes, Kuntze, 1. c. = Micr. tipuloides, Lindl.

MALCOMIA, R. Br. (Crucifer.). - Ind. Kew, ii. 149.

auranitica, Post, in fourn. Limn. Soc. xxiv: (1888) 420 [Malcolmia]. - Syria.

bassarana, Petrov. ex Fritsch. in Verh. zool.-bot Ges. Wien, xlv. (1895) 376, in syn. [Malcolmia] = M. Pancicii, Adamov.

ciliaris, Boiss. Fl. Or. Suppl. (1888) 44 [Malcolmia] - Afghan.

Cossoniana, Rouy, in Rouy \& Fouc. F1. de Fr. ii. (1895) 7 , in obs. [Malcolmia] $=$ Sisymbrium malcomioides, Coss. \& Dur.

Doumetiana, Rouy, in Rouy \& Fouc. 1. c. [Malcolmia $]=$ S. Doumetianum, Coss

hybrida $X$, Hausskn. in Mith. Thur. Bot. Ver. N. Folge, iii et iv. (1893) 108 [Malcolmia]. Graecia.

micrantha, Boiss. of Reut. ex Boiss. Fl. Or. Suppl. (1888) 45 [Malcolmia]. - Mesopot.

mana, Pau, Not. Bot. F1. Espan, iji. (1889) 20 $[$ Malcolmia $]=$ Sisymbrium nanum. $D C$.

Pancicii, Adamovic, in Oest. Bot. Zeitschr. xlii (I892) 405 [Malcolmia]. - Serbia.

zachlensis. Post, in fourn, Limn. Soc. xxiv. (1888) 420 [Malcolmia]. - Syria.

MALESHERBIA, Ruiz \& Pav.(Passiflor.). Ind. Kew ii. 149.

breviflora, Phil. ex Harms, in Bot. Fahrb. xv. (1893) 598, in obs. - Am. austr. occ.

densiflora, Phil. in Anal. Mus. nac. Chile (1891) 22. - Am. austr. occ.

Hieronymi, Harms, in Engl. \& Prantl, Naturl. Pfanzenfam. iii. 6a (1893) 68. - Reg. Argent.

pulchra, Phil. in Anal. Mus. nac. Chile (1891) 22 ; et 1. c. 599. - Am. austr. occ.

MALIORTEA, W. Wats, in Gard. Chron. (1886) i. 557, err. typ. = Malortiea, H. Wendl. (Palm.)

MALLINOA, Coult. Bot. Gaz. xx. (1895) 47. COMPOSITAE.

corymbosa, Coult. l. c. t. 5. - Guatem.

MALLOSTOMA, Karst. (Rubiac.). - Ind. Kew. Shannoni, 7. D. Smith, in Coult, Bot. Gaz. xviii.

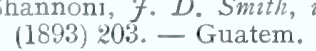

MALLOTUS, Lour. (Euphorb.). 一 Ind. Kew. ii. 150.

anamiticus, Kuntze, Rev, Gen. (1891) 608. - Anam andamanicus, Hook. f. Fl. Brit. Ind. v. (1887) 439 - Ins. Andam.

anisophyllus, Hook.f.l. c. 436. - Malacca, Borneo Beddomei, Hook. f. l. c. 438. - Travanc.

bracteatus, Hook. f. l. c. 436. - Perak.

brevipes, Engl. Pfanzenw. Ost-Afr. A (1895) 18. Quid

Buettneri, Pax, in Bot, Fahrb. xix. (1894) 89.Gabon

Caput-Medusae, Hook. f. Fl. Brit. Ind. v. (1880) 449. - Penins. Mal.

chrysanthus, K. Schum. in K. Schum. \& Hollv. Fl. Kais. Wilh. Land (1889) 78. - N. Guin

Clellandii, Hook. f. Fl. Brit. Ind.v. (1887) 435. Pegu.

columnaris, Warb. in Bot. falnb. xiii. (1891) 349. - N. Guin.

filiformis, Hook. f. Fl. Brit. Ind. v. (1887) 435. Tenass.

Griffithianus, Hook.f.l.c. 433.- Penins. Mal.

Hollrungianus, $K$. Schum. in $K$. Schum. E Holl Fl. Kais. Wilh Land (1889) 79. - N. Guin.

khasianus, Hook. f. Fl. Brit. Ind. v. (1888) 438. Khasia.

\section{MALLOTUS}

Kingii, Hook. 'f. Fl. Brit. Ind. v. (1888; 439. Perak.

Kunstleri, King, ex Hook.f. l. c. 443. - Perak,

Kurzii, Hook. f. l. c. 427. - Ins. Andam.

lancifolius, Hook, $f, l, c .434$. - Penang.

leptostachyus, Hook, f.l.c. 435.-Tenass.

leucodermis, Hook. f.l. c. 441. - Malacca.

Maingayi, Hook. f. l. c. 449. - Penins. Mal.

Playfairii, Hemsl. in fourn. Linn. Soc. xxvi. (1891) 441. - China.

polyneurus, Hook. $f$. Fl. Brit. Ind. v. (1887) 439. - Tenass.

populifolius, Hemsl. in fourn. Linn. Soc. xxvi. \{1891) 441. - China.

puberulus, Hook.f. Fl. Brit. Ind. v. (1887) 435. Perak

vernicosus, Hook.f.l.c.443. - Penins. Mal.

vitifolius, Kuntze, Rev, Gen. (1891) 608.-Cambodia .

Walkerae, Hook. f. l. c. 437. - Zeyl.

Wrayi, King, ex Hook. f. l. c. 433. -- Perak.

MALOPE, Linn. (Malv.). - Ind. Kew. ii. 151. intermedia, Pomel, ex Batt.\& Trab. Fl. de l'Algér. [Dicot.] $(1888) 110=$ malacoides, Linn.

MALOUETIA, A. DC. (Apocyn.). - Ind. Kew. ii. 151.

africana, K. Schum. in Engl. \& Prantl, Natïrl. Pfanzenfam iv. 5 (1895) 18\%. - Afr. trop.

Tamaquarina, K. Schum. 1. c. = M. Tamaquarina. A. $D C$.

MALPERIA, S. Wats, in Proc. Am. Acad. xxiv. (1889) 54 ; O. Hoffm. in Engl. \& Prantl, Natürl. Pflanzenfam. iv. 5 (1893) 388. COMPOSITAE

tenuis, S. Wats. Il. cc. - Calif. austr.

MALPIGHIA, Plum. ex Linn. (Malpigheae.). -

Ind. Kew, ii. 151.
oaxacana, Niedenzu, ex Loesen. in Bull. Herb. Boiss. ii. (1894) 544 t. 20. - Mexic.

MALUS, Tourn. ex Linn. = Pyrus, Tourn. (Rosac.).

chinensis. Hort. ex Gard. Kew, i. „Polypet. (1894) $183=\mathrm{P}$. spectabilis, Ait.

crataegifolia, Koehne, Die Gatt. d. Pomac. (1890) 27 ; et Deutsch. Dendrol. (1893) 257: Dippel, Handb. Laubholzk, iii. (1893) $402=$ P. crataegifolia, Savi.

edulis, Hort. ex Gard. Kew, i. Polypet. (1894) 181 $=\mathrm{P}$. orthocarpa, Nichols.

Halliana, Koehne, 11. cc. 27 et 261 ; Dippel, 1. c. 406. - Japon.

Mengo, Hort. ex Dippel, Handb. Laubholzk. iii. (1893) $406=$ P. Sceboldi, Regel.

Niedzwetzkyana, Dieck, ex Koehne, Deutsche Dendrol. (1893) $259=$ P. Malus, Linn.

orthocarpa, Lavall. ex Gard. Kew, i. Polypet. (1894) $181=\mathrm{P}$, orthocarpa, Nichols.

Parkmanni, Hort ex Koehne, Deutsche Dendrol (1894) $261=$ Halliana, Koehne.

Riversicarnea $\times$, Hort. ex Koehne, 1. c. 260. Hybr. artef.

Ringo, Sieb. [Catal, rais. (1856) 5], ex Dippel, Handb. Laubholzk. iii. (1893) $400=$ P. spectabilis, Ait.

Sieboldi, Regel, [in Gartenfl. ix. (1859) 82], ex Dippe1, 1. c. $406=$ P. Sieboldi, Regel. upsalensis, Hort, ex Dippel, 1. c. $394=$ P. Malus,
Linn.

MALVA, [Tourn.] Linn. (Malv.), - Ind. Kew. ii. 152.

antofagastana, Phil. in Anal. Mus, nac. Chile (1891) 7 = Malvastrum antofagastanum, E. G. Baker diminutiva. Phil. 1. c. $8=$ Malvastrum diminutivum, E. G. Baker.

Duriae, Hort. Kew, ex Gard. Kew, Herb. Pl (1895) $287(=M$, Durieui, Spach ?) = Lavatera mauritanica, Duch.

multicaulis, Schlecht. [in Lechl. Pl. Peruv. n. 1784] ex Britton, in Mem. Torrey Bot. Club, xvi. (1889) 153, in syn. = Malvastrum multicaule, Britton.
MALVA

Papaver, K. Schum, in Engl. \& Prantl, Natürl, Pflanzenfam. iii. 6a (1890) 41 (= M. Papaver Cav.) $=$ Callirhoe Papaver, A. Gray.

Reichei, Phil. in Anal. Univ. Chil. 1xxxii. (1893) $19=$ Malvastrum capitatum, E. G. Baker.

subacaulis, Phil. 1. c. $14=$ M. subacaule. E. G. Baker.

tarapacana, Phil. in Anal. Mus. nac. Chile (1891) 8 . - Am. austr occ.

MALVASTRUM, A Gray (Malv.). - Ind. Kew. ii. 165

Alexandri, E. G Baker, in Fourn. Bot. xxix. (1891) 166. - Afr. austr

alismatifolium, K. Schum. ex Hieron. in Bot. Fahrb. xxi. (1895) 318. - Peruvia.

antofagastranum, E. G. Baker, in fourn. Bot. xxix. (1891) 167 (= Malva antofagastana, Phil.). Chili.

auricomum, Pkil. in Anal. Mus. nac. Chile (1891) 8; E. G. Baker, in Fourn. Bot. xxix. (1891) 365. Chili.

bolivianum, E. G. Baker, l. c. 168. - Bolivia,

Burchellii, E. G. Baker, l. c. 165. - Afr. austr.

capitatum, E. G. Baker, l. c. 168 (= Malva capitata Cav.). - Peruvia, Bolivia.

clandestinum, E. G. Baker, i; c. 363 (= Sida clandestina, Phil.). - Chili.

condensatum, E. G. Baker, l. - Peruvia.

Copelandii, Hieron, in Bot. Fahrb. xx. Beibl. n. 49 (1895) 43. - Peruvia.

decipiens, $K$. Schum, in Mart. Fl. Bras, xii. III (1891) 000 (= Sida decipiens, St Hil. \& Naud.). Bras., Uruguay.

diminutivum, E. G. Baker, in Fourn. Bot. xxxii. (1894) 36 (= Malva diminutiva, Phil.). - Chili. fasciculatum, Greene, Fl. Francisc. (1891) $108=$ M. Thurberi, A. Gray.

Garckeanum, K. Schum. in Mart. Fl. Bras. xii. III. (1891) 267, - Bras., Urug.

interruptum, $K$. Schum l. c. 272.-Argent.

jacens, O. S. Wats. in Proc. Am. Acad. xxi. (1886) 417. - Mexic.

Lobbii, E. G. Baker, in Fourn. Bot. xxix. (1891) 365. - Columbia.

multicaule. Britton, in Bull. Torrey Bot. Club, xvi. 1889) 153 (= Malva multicaulis, Schlecht.). Peruvia.

multiflorum, Greene, Fl. Francisc. (1891) 109. Calif.

nubigena, E. G. Baker, in Fourn. Bot. xxix. (1891) 172 (= Malva nubigena, Wedd.). - Peruvia, Bolivia.

nudum, K. Schum. in Mart. Fl. Bras. xii. III. (1886) 274. - Uruguay, Argent.

obcuneatum, E. G. Baker, in fourn. Bot. xxix. (1891) 363. - Bolivia.

orbiculatum, Greene, Fl. Francisc. (1891) 109.Calif.

Oriastrum, E. G. Baker, in fourn. Bot. xxix. (1891) $172(=$ Malva Oriastrum, Wedd.). - Bolivia.

Pappei, E. G. Baker, 7. c. 166. - Afr. austr. Parryi, Greene, Fl. Francisc (1891) 108. - Calif. parviflorum, Phit. ex E. G. Baker, in Fourn. Bot. xxix. (1891) 363 ; et in Anal. Mus. nac. Chile (1891) 9. - Chili.

Pearcei, E. G. Baker, l. c. 364. - Bolivia

pentandrum, K. Schum. in Mart. Fl. Bras, xii. III: (1891) 273. - Reg. Argent.

Pringlei, E. G. Baker, ex Robinson, in Am. Fourn. Sci.Ser. 1II. 1. (1895) 175. - Mexic.

pygmaeum, E. G. Baker, in fourn. Bot, xxix. (1891) 167 (= Malva pygmaea, Wedd.). - Bolivia.

retusum, E. G. Baker, l.c. $166(=$ Malva retusa, Cav.). - Afr, austr.

rugosum, Phil. l. c. 364; et in Anal. Mus. nac. Chile (1891) 9. - Chili.

Rusbyi, Britton, in Bull. Torrey Bot. Club, xvi. (1888) 64. - Bolivia.

sajanense, Hieron. in Bot. Fahrb. xxi. (1895) 318. - Peruvia, Bolivia.

Schaffneri, S. Wals, in Proc. Am. Acad. xxv. (1890) 143. - Calif.

stipulare, Phil. in Anal. Mus.nac. Chile (1891) 8. Am, austr. occ. 
MALVASTRUM :

Stuebelii, Hieron. in Bot. Fahrb. xxi. (1895) 318. Peruvia.

subacaule, E. G. Baker, in fourn. Bot, xxxii. (1894) 36 (= Malva subacaulis, Phil.). - Chili.

tarapacanum, E. G. Baker, l. c. xxix. (1891) 167 (= Malva tarapacana, Phil.). - Chili.

tenuifolium. E. G. Baker, $l$ c. 169 (= Malva tenufolia, Hook. \& Arn.). - Chili.

trilobatum, E. G. Baker, l. c. 164. - Afr, austr.

Tweedii, E. G. Baker, l. c. 169. - Uruguay.

MALVAVISGUS, Dill. ex Adans. (Malv.). - Ind Kew. ii. 155.

cinereus, E. G. Baker, in Am. Fourn. Sci. Ser. III. 1. (1895) 176 , nomen. - Mexic.

Guerkeanus, Hieron. in Bot. Fahrb. xxi. (1895) 320. - Columb.

Palmeri, E. G. Baker, in Contrib. U. S. Nat. Herb. iii. 5 (1895) 313. - Mexic

Pringlei, E. G. Baher, in Am. Fourn. Sci. Ser. 1II. 1 (1895) 175. - Mexic.

MALVEOPSIS, Presl = Sphaeralcea, A. St. Hil. (Malv.).

acaulis, albens, americana, anthemidifolia, usperrima, borussica, bryoniacfolium, calycina, capensis, Castelnaeana, coccinea, compacta, dissecta, divaricata, exilis, flabellata, grossulariaefolia, humilis, leptophylla, longirostris, Mac Cleanii, macrostachya, Mandoniana, mexicana, Orbigniana, parnassiaefolia, pedicularimelia, peruviana, Phyllanthos, pichinchensis, pinnata, procumbens, racemosa, ribifolia, rotundifolia, setosa, spicata, splendida, stenopetala, stricta, subtriflora, tridactvlites, ulophylla, eirgata, vitifolia, Kuntze, Rev. Gen. (1891) $72=$ homonyma omnia Malvastri. angustifolia, Kuntze, 1. c. = Sphaeralcea angustifolia, G. Don.

arcuata, Greene, Man. Bot. San Franc. Bay (1894) 66. - Calif.

aurantiaca, Kuntze, Rev. Gen. (is91) $72=$ Malvastrum Wrightii, A. Gray.

Copelandii, Hieron, in Bot. Jahrb. xx Beibl. n. 49 (1895) 43, in obs, = Malvastrum Copelandii, Hieron.

ciculata, Kuntze, Rev. Gen. (1891) $72=$ M. Thurberi, A. Gray.

coromandeliana, Morong, in Ann. N. Y. Acad. Sci. vii. (1892) 55 = M. tricuspidatum, A. Gray.

Coulteri, Kuntze. Rev. Gen. (1891) $72=$ Sphaeralcea Coulteri, S. Wats

fragrans, Kuntze, 1. c. = Malvastrum capense, Garcke.

Fremonti, Greene, in Erythea, i. (1893) $171=$ Sphaeralcea Lindheimeri, A. Gray.

hispida, Kuntze, Rev. Gen. (1891) $7_{2}=$ Malvastrum angustum, A. Gray.

lateritia, Morong, in Ann. N. Y. Acad. Sci. vii. (1892) $55=$ M. lateritium, Nichols.

multicaulis, Rusby, in Mem. Torrey Bot. Club, iii. 3 (1893) $9=$ M. multicaule. Britton.

Murroana, Kuntze, Rev. Gen. (1891) $72=$ Sphaeralcea Munroana, Spach.

pedatifida, Kuntze, 1. c. = S. Fendleri, A. Gray,

rosea, Kuntze, 1. c, = S. umbellata, G. Don.

Rusbyi, Rusby, in Mem. Torrey Bot. Club, iii. 3 (1893) $9=$ Malvastrum Rusbyi, Britton.

MAMMEA, Linn. (Guttif.). - Ind. Kew. ii. 156. similis, Goudot, ex Vesque, in DC. Monog. Phan. viii. (1893) 499, in syn. = macrophylla, Planch. E Triana.

MAMMILLARIA, Haw. (Cacteae). - Ind. Kew. ii. 156.

Besleri, “ Link \& Otto » ex Foerst.-Ruempl. Handb. Cacteenk. (1885 ?) 1024, ad calc. sphalm. = Melocactus Besleri, Link \& Otto.

cornimamma, N.E. Br. in Gard. Chron. (1887) ii. 186. - Hab. ?

Gabbii, Engelm. ex Coult. in Contrib. U. S. Nat. Herb. iii. (1894) 109, in syn. - Calif, inf.

Grusoni, Runge, in Gartenfl. xxxviii. (1889). 105, fig. 20. - Mexic.

Halei, T.S. Brandeg, in Proc. Calif. Acad. Ser. II, ii. (1889) 161, t. 6. - Calif.

\section{MAMMILLARIA}

Halei, Coult. ex K. Schum, in Monatsschr. f. Kak= teenk. v. (1895) 89 [an praec. ?]. - Calif.

Neumanni, Regel, ex Foerst-Ruempl. Handb. Cacteenk. (1885 ?) 270 et 1023, ad calc. [Neımanni $]=$ lactescens, Meinsh.

Notesteinit. Britton, in Bull. Torrey Bot. Club, xviii. (1891) $367=$ missouriensis, Sweet.

obscura, Hildm. in Monatsschr. f. Kakteenk. (1891-92) 52, cum xylogr. - Hab.

Pondii, Greene, Pittonia, i. (Mar. 1889) 268. Calif.

purpuracea, S. Wats, in Proc. Am. Acad. xxv. (1890) 150. - Mexic

Purpusii, K. Schum. in Monatsschr. f. Kakteenk. iv. (1894) 165. - Am. bor.

Radleana, K. Schum. l. c. ii. (1892) 104, cum xylogr. - Mexic.

rigidispina, Hildm. ex Quehl. Hall. in Monatsschr f. Kakteenk. iii. (1893) 112, cum xylogr. - Hab. Roseana, T. S. Brandeg. in Zoë, ii. (1891) 19 [Mamillaria]. - Calif.

Schumannii, Hildm. in Monatssclir. f. Kakteenk (1891-92) 101, cum xylogr. (sphalm. 89) et 125 [Schumanni]. - Hab.?

setispina, Engelm. ex Coult. in Contrib. U. S. Nat. Herb. iii. (1894) 106. - Calif. inf.

tuberculosa, ("Engelm. ) ex Foerst.-Ruempl. Handb. Cacteenk. (1885?) 416, sphalm. ( $=M$. tuberculata, Engrelm, $=$ strobiliformis, Scheer.

uberimamma, Mouv. ex Foerst.-Ruempl. l. c. 374. Hab.?

Williamsii, Coult. in Contrib.U.S. Nat. Herb. ii (1891) 129 (= Anhalonium Willramsii, Engelm.). - Am.

MANDEVILLA, Lindl. (Apocyn.). - Ind. Kew ii. 160 .

antennacea, K. Schum. in Engl. \& Prantl. Natürl Pflanzenfam. iv. 2 (1895) $171=$ Echites antennacea, $A, D C$.

auriculata, K. Schum, 1. c. 171 = E. fluminensis, A. $D C$.

Benthamii, K. Schum.1. c. = E. Benthamii, A.DC brachyloba, K. Schum.1. c. = E. brachyloba, Miers bracteata, Kuntze, Rev. Gen. (1891) $414=$ E. brac teata, $H . B . \mathcal{E} K$.

canescens, K. Schum. in Engl. \& Prantl, Natürl. Pflanzenfam. iv. $2(1895) 171=\mathrm{E}$. canescens, Willd.

funiformis, K. Schum. 1. c. = E. funiformis, Vell. javitensis, K. Schum.1. c. = E. javitensis, $H . B$ E $K$

cuyabensis, K. Schum. 1. c. = E. cuyabensis, $A . D C$ leptophylla, K. Schum. 1. c. = E. leptophylla A. $D C$

macrophylla, K. Schum, 1. c. = E. macrophylla $H . B . \& K$.

mollissima, $\mathrm{K}$. Schum. 1. $\mathrm{c}$. $=\mathrm{E}$. mollissima, $H$ B. \& $K$.

scabra, K. Schum. 1. c. = E. scabra, Hoffmgg.

Schumanniara, Loesen. in Bull. Herb. Boiss. ii (1894) 556. - Mexic.

Spruceana, K. Schum. in Engl. \& Prantl, Natiur. Pflanzenfam. iv. 2 (1895) 171 (= Amblyanthera Spruceana, Muell. Arg.). - Bras.

tomentosa, K. Schum. 1. c. = seq

tomentosa, Kuntze, Rev. Gen.(1891) $416=\mathrm{E}$. tomentosa, $V a h l$.

velutina, $K$. Schum, in Engl. \& Prantl, Natuirl. Pfanzenfam.iv. 2 (1895) 171. - Costarica.

MANDRAGORA [Tourn.] Linn. (Solan.). - Ind. Kew. ii. 160

Haussknechtii, Heldr. in Mitth, Geogr. Ges. Fena, iv. (1886) 77. - Graecia.

hybrida $X$, Hausskn. \& Heldr. ex Heldr. 1. c, ; et N. Folge, viii. (1895) 54. - Graecia

MANETTIA, Mutis (Rubiac.). - Ind. Kew. ii. 161.

asperula, Ball, in fourn. Linn. Soc. xxii. (1886) 142. - Columb.

Beyrichiana, K. Schum. in Mart. Fl. Bras. vi. VI. (1889) 181. - Brasil.

canescens, K. Schum.l. c. 178. - Ecuad,

\section{MANETTIA}

congesta, K. Schum, in Mart. F1. Bras. vi. VI. 1889) 177 = albiflora, Schott.

flexuosa, Casar. 1. c. in syn. = albiflora, Schott.

diffusa, Britton, in Bull. Torrey Bot. Chub, xviii (1891) 10\%. - Bolivia

Guilleminiana, K. Schum. in Mart. Fl. Bras. vi. vI, (1889) 181. - Bras.

ignita, K. Schum. 1. c. $170=$ cordifolia, Mart.

lutescens, $K$. Schum.1. c. 186. - Bras.

marginata, K. Schum.l. c. 178. - Venezuela.

meridensis, $K$. Schum.l. c. - Venezuela.

microcarpa, K. Schum. l. c. 179. - Venezuela.

mitis, K. Schum. 1. c. $185=$ fimbriata, Cham. \& Schlecht.

pedunculata, K. Schum. 1. c. $173=$ pseudodiodia, Cham. Eo Schlecht.

pleiodon, K. Schum. l.c. 184. - N. Granat.

scabra, Pohl, ex K. Schum. 1. c. 175 = luteo-rubra, Benth.

Tweedieana, K. Schum. l. c. 169.-- Uruguay,

MANGLIETIA, Blume (Magnoliac.). - Ind. Kew, ii, 161 .

Fordiana. Oliver, in Hook. Icon. pl. xx. (1891) t. 1953. - Ins. Hongkong.

Scortechini, King, in fourn. As, Soc. Beng, lviii. (1889) II. 370. - Ind. or.

MANIHOT, Tourn. ex Adans. (Euphorb.). - Ind. Kew. ii. 162.

Manihot, Cockerell, in Bull. Torrey Bot. Club, xix. (1892) $95=$ utilissima, Pohl.

Pringlei, S. Wats, in Proc. Am. Acad. xxvi. (1891) 148. - Mexic.

MANILTOA, Scheff. (Legumin.). - Ind. Kew.' ii. 162.

Schefferi, K. Schum, in K. Schum. \& Hollr. Fl. Kais. Wilh. Land (1889) $101=$ grandiflora, Scheff.

MANISURIS, Linn. = Rottboellia, Linn. $\mathrm{f}$. (Gramin.).

acuminata, Afzelii, Coelorhachis, compressa, corrugata, cylindrica, digitata, divergens, exaitata, formosa, glandulosa, hirsuta, impressa, latifolia, loricata, mol. licoma, nigrescens, rugosa, Selloana, speciosa, striata, thyrsodea. Kuntze, Rev. Gen. (1891) $779=$ homonyma omnia Rottboelliae.

exaltata, Baill. Hist. des pl. xii. (1894) $199=$ exaltata, Kuntze.

parifera, Hack. in Oest. Bot. Zeitschr. xli. (1891) 48. - Reg. Himal.

rottboelliodes, Kuntze, Rev. Gen. (1891) $779=\mathrm{R}$. ophiuroides, Benth.

MANNIOPHYTON, Muell. Arg. (Euphorb.). Ind. Kew. ii. 163

angustifolium, Baill, in Bull. Soc. Lim. Paris, ii. (1891) 952. - Congo gall,

MANOTES, Soland. ex Planch. (Connac.). - Ind. Kew. ii. 163.

Aschersoniana, Gilg, in Bot. fahrb. xiv. (1892) 334. - Congo.

brevistyla, Gilg, l. c. - Congo.

pruinosa, Gilg, l. c. 332. - Congo

sanguineo-arillata, Gilg, l. c. 333. - Congo.

tomentosa, Gilg, l. c. 332. - Gabon.

MAOUTIA, Wedd. (Urtic.). - Ind. Kew. ii. 168 rugosa, Warb. in Bot. Fahrb. xiii. (1891) 289. N. Guin.

MAPANIA, Aubl. (Cyper.). - Ind. Kew, ii. I6:3 africana, C. B. Clarke, in Th. Dur. \& Schinz, Consp Fl. Afr.v. 1894 (1895) 667, nomen. - Af. trol' occ.

andamanica, C. B. Clarke, ex Hook. f. Fl. Brit. Ind. vi. (1894) 681. - Ins. Andam.

ferruginea, Ridl. in Bolet. Soc. Brot. v. (1S57) 209 fig. 5. - Ins. S. Thom.

Kurzii, C. B. Clarke, ex Hook, f. Fl. Brit. Ind. yi. (1894) 681. - Penins, Mal. 
MAPANIA:

longa, $C, B$. Clarke, ex Hook, f, Fl Brit. Ind. vi (1894) 683. - Penins. Mal., Sumatra.

macrocephala, K. Schum. ex Warb. in Bot. Jahrb. xiii. (1891) $265=$ Hypolytrum macrocephalum, Gaudich.

Mannii, C. B. Clarke, in Th. Dur. Ev Schinz, Consp. Fl. Afr, v. 1894 (1895) 66\%, nomen. - Afr. trop. occ

oblonga, C. B. Clarke, i. c.. nomen. - Afr. trop. occ.

multispicata, C. B. Clarke, ex Hook. f. Fl. Brit. Ind. vi. (1894) 682. - Penins. Mal., Java.

pandanophyllum. K. Schum. in K. Schum. \& Hollr

F1. Kais. Wilh. Land (1889) $25=$ Thoracostachyum hypolytroides, $C$. B. Clarke.

scaberrima, C. B. Clarke, ex Th. Dur. G Schinz, Consp.Fl. Afr. v. 1894 (1895) $667(=$ Hypolytrum scaberrimum, Boeck.), - Gabon

superba, C. B. Clarke, l.c. (= Hypolytrum macranthrım, Boeck.). - Afr. trop. occ

silhetensis, C. B. Clarke, ex Hook. f. Fl. Brit. Ind. v1. (1894) 681. - Ind. or.

tenuiscapa, C. B. Clarke, 1. c. 683. - Ind. or. Sumatra.

Wallichii, C. B. Clarke, l. c. 682.- Penins. Mal. Borneo.

MAPOURIA, Aubl. = Psychotria, Linn. (Rubiac.).

artensis, Beauvisage, Révis, genr. pl. Néo-Caléd. (1894) 8 (= Delpechea artensis, Montr.). - N Caled.

connata, K. Schum. in Engl. \& Prantl, Natürl. Pflanzenfam. iv. 4 (1891) $112=$ Psychotria connata. Wall.

crassa, K. Schum. 1, c. = P. crassa, Benth.

Donarrei, Beauvisage, Révis, genr pl Néo-Caled. (1894) 11 (= Douarrea alba. Montr.). - N. Caléd.

foribunda, Beauvisage, 1. c. $(=$ Delpechea floribunda Montr.). - N. Caled.

fulva, K. Schum. 1. c. = Psychotria fulva, Buch. Hann.

parasitica, K. Schum. 1. c. = P. parasitica, Sw,

parvifolia, K. Schum. 1. c. 111 = P. parvifolia Benth.

sarmentosa, K. Schum. 1. c. = P. sarmentosa, Blume speciosa, Beauvisage, Révis, gen. pl. Néo-Caléd. (1894) 11 (= Donarrea speciosa, Montr.). - N. Caled.

tristis, Muell, Arg. ex Warm. in Vidensk. Meddel. Naturh. Foren. Kjoeb. (1889) 342 (Symb. F1. Bras, centr. xxxiii. (12). - Bras.

MAPPA, A. Juss, = Macaranga, Thou. (Euphorb.).

Porteana, Hurt. ex Éd. André, in Rev. Hort. 1x. (1888) 176, in obs. = Macar. Porteana Ed. André.

MAPPIA, Jacq. (Olacin.). - Ind. Kew. ii. 64. cambodiana, Pierre. Fl. Foy. Cochinch. Fasc I7 (1892) t. 267 b. - Cambodia.

mexicana, Robinson \&o Greenm, in Am. Fourn. Sci. Ser. III. 1. (1895) 150. - Mexic,

pittosporoides, Oliver, in Hook. Icon. pl. xviii. (1888) t. 1762. - China.

MAPROUNEA, Aubl, (Euphorb.). - Ind. Kew ii. 165

obtusa, Pax, in Bot. Fahrb. xix. (1894) 116. - Afr. trop. or.

vaccinioides, Pax, l. c. - Congo,

MARANTA, Plum, ex Linn. (Scitam.). - Ind Kew, ii. 165

albo-lincata, Hort. ex Petersen, in Mart. Fl. Bras. iii. III. (1890) 95 = Calathea ornata, Koern.

asymetrica, Hort, ex Petersen, 1. c. $94=$ C. taeniosa, foriss.

atrata, Hort. ex Illustr. Hortic. xli. (1894) 17\%. Form, hort.

Bachemiana, Hort. ex Petersen, in Mart. Fl. Bras. iii. III. (1890) $115=$ C. Bachemiana, Ed. Morr. bella, Hort. Bull, ex Petersen, 1. c. $127=$ C. bella, Regel.

\section{MARANTA}

bracteosa Petersen, ex Warm, in Vidensk. Meddel. naturh. Foren. (1889) 333 (Symb. Fl, Bras. centr. xxxiii. 903). - Bras.

concolor. Hort, ex Petersen, in Mart. Fl. Bras, iii III. (1890) $126=$ Calathea concolor, Eichl.

coriffolia, Hort. ex Petersen, 1. c. $95=$ C. ornata, Koern.

fascinator, L. Lindint \& Rodigas, in Illustr. Hortic. xli. (1894) 105 t. $\%$ - Bras.

florestina, Hort. 1. c. 177. - Form, hort.

fulgens, Hort. 1. c. - Form. hort

gracilis, Hort. ex Petersen, in Mart. F1. Bras. iii. III. (1890) 149 = noctiflora. Koern

hirsuta, Mart. ex Petersen, 1. c. $135=$ Ischnosiphon hirsutus, Petersen.

conrifera, Hort. Bull. Catal, (1887) 11 = Calathea Makoyana, Ed, Morr

Kegeliana, Hort. ex Petersen, in Mart. Fl. Bras. iii. III. (1890) $115=$ C. Bachemiana. Ed. Morr.

Leopoldi, Hort. ex Gard. Chron. (1892) ii. 160.Form. hort

Lietrei, Hort. ex Petersen, in Mart. Fl. Bras..ii. III. (1890) 111 = Calathea Lietzei, Ed. Morr.

Lindeniana, Wallis [in Linden. Catal. ann. 186 t], ex Petersen, 1. c. $92=$ C. Lindeniana, Ed. Mort.

Louisae, Hort. ex Gard. Chron. (1891) i. 594. Bras.

majestica. L. Linden. in Illustr. Hortic, xli. (1894) 11, in obs. - Form. hort.

Maacelli, Hort ex Petersen, in Mart. Fl. Bras, iii. III. (1890) $118=$ Calathea virginalis, $L$. Lind.

Mariae, Hort. ex Rev. Hort. (1894) 251. - Form. hort.

Massangeana, Hort, Makoy, ex Petersen, in Mart. F1. Bras, iii. III. (1898) $151=$ leuconeura, Ed. Morr.

metallica, Hort. ex Illustr. Hortic. xli. (1894) 17. - Form. hort.

Neuberti. Hort. ex Petersen, in Mart. Fl. Bras, iii. III. (1890) 111 = Calathea Lietzei Ed. Morr.

Openhami, Hort. ex Rev. Hortic. Belge xix. (1893) 258 , sphalm. = seq.

Oppenheimiana, Hort. ex Petersen, in Mart. F1. Bras, iii, III. (1890) $128=$ Calatha Oppenheimiana, Ed. Morr

pacifica. Linden [Catal.], ex Petersen, 1, c, $125=$ C. pacifica, $L$. Linden \&o André.

parvifolia, Petcrsen. ex Warm. in Vidensk. Meddel. Naturh. Foren. (1889) 328 (Symb. Fl. Bras. centr. xxxiii. 898$)$ - - Bras.

Riedeliana, Hort. ex Petersen, en Mart. Fl. Bras. iii. III. (1890) $127=$ Calathea Koernickeana. Regel.

roseo-lincata. Hort. ex Petersen, 1. c. $95=$ C. ornata, Koern.

Sanderana, Hort. ex I. Linden, in Illustr. Hortic. xli. (1894) 11, nomen : et ex Rev. Hortic. (1895) 249 = majestica, L. Lind.

Wioti, Ch. Morr. ex Peeersen, in Mart. Fl. Bras, iii. III. (1890) $130=$ Calathea Wioti, Regel.

MARGELLIA, Baill. in Bull. Soc. Linn. Paris, i. (1886) 625. AMARANTACEAE.

mirabilis, Baill. l. c. - Angola.

MARCETIA, DC. (Melast.). - Ind. Kew. ii. 166. heterophylla, Cogn. in DC. Monog. Phan. vii. (1891) 297 (= Rhexia heterophylla, Hook. \& Arn.). Uruguay.

Schenckii, $\operatorname{Cog} n$. i. c. 291. - Bras

MARGGRAAVIA, Plum, ex Linn. (Ternstroem.), - Ind. K. w. ii. 167

peduncularis, Poepp. ex Rusby, in Mem. Torrey Bot. $C l u b$, iii. 3 (1893) 8 ; et iv. (1895) 205 , in obs. $(=$ Norantea peduncularis, Poepp.). - Bolivia.

Sintenisii, Urban, in fahrb. Bot. Gart. Berlin, iv. (1886) 245. - Ins. Puerto-Rico.

MARESIA, Pomel = Sisymbrium, 'Tourn. (Crucif.).

Doumetiana, Batt. in Batt. \& Trab. Fl. de l'Algér. [Dicot.] (1888) $69=\mathrm{S}$. Doumetianum, Coss.
MARESIA : -

malcolmioides, Batt, in Batt, \& Trab. F1. de l'Algér [Dicot.] (1888) $69=$ Sisymbrium malcomioides, Coss. \& Durieu.

nana, Batt. 1. c. $68=$ S. nanum, $D C$.

MARGARETTA, Oliver (Asclep.). - Ind. Kew ii. 167.

Cornetii, Dewerwre, in Bull. Soc. Bot. Belg. xxxiii. 2 1894 (1895) 103; et xxxiv. 2 (1895) 90. Congo.

Holstii, K. Schum. in Bot. Fahrb. xvii. (1893) 133; et in Abh. Preuss. Akad. Wiss. (1894) 57 et 58. Afr. trop.

distincta, N. E. Br. in Kew Bull. (1895) 255. Afr. trop. austro-or.

orbicularis, N. E. Br. l. c. 256. - Afr. trop. austro-or

Passargei, K. Schum. in Engl. \& Prantl, Natür. Pfanzenfam. iv. 2 (1895) 234 - Afr. trop.

rosea, Britten \& Rendle, in Trans. Linn. Soc Ser. II iv. (1894) 29. - Afr. trop. or.

Whytei, K. Schum. in Engl. Pflanzenw. Ost-Afr.C (1895) $323=$ rosea, Britten \& Rendle.

MARGARITOPSIS, Wright (Rubiac.). - Ind. Kew ii 167

mudiflora, K. Schum. in Engl. \& Prantl, Natürl. Pflanzenfam. iv. 4 (I891) 122. - Cuba

MARGYRIGARPUS, Ruiz \& Pav. (Rosac.). Ind. Kew. ii. 167

cristatus, Britton, in Men. Torrey Bot. Club, iii. 3 (1893) 25. - Bolivia.

MARICA, Ker-Gawl. (Irid.). - Ind. Kew. ii. 168 Martii, Baker, Handb. Irid. (1892) 63. - Bras. occidentalis, Baker, in Gard. Chron. (1892) ii. 150 - Peruvia.

MARILAUNIDIUM, Kuntze, Rev. Gen. (1891) 434 = Nama, Linn. (Hydroph.).

biflorum, Coulteri, demissum, dichotomum, hirsutum, hispidum, Jamaicense, latifolium, Lobbii, origanifolium. Palmeri, Parryi, Rothrockii, rupicolum, sand wicense, Schaffneri, sericeum, stenocarpum, stenophyllum, strictum, subpetiolare, undulatum, Kuntze, 1. c = homonyma omnia Namatis.

aretioides, Coville, in Contrib. U. S. Nat. Herb. iv. (1893) $161=$ Eutoca aretioides, Hook. \& Arn. macranthum, Kuntze, Rev, Gen, (1891) $434=\mathrm{N}$. undulatum, $H . B$. \& $K$. var.

serpyllodes, Kuntze, 1. c. = M. serpylloides, A. Gray

MARIPA, Aubl. (Convolvu1.). - Ind. Kew, ii. 168 paniculata, Barb. Rodr. [Herb. Mus. Bot. Amaz. n. 368] Vellosia, 1885-88. Sec. édic. (1891) 59 t. 27 A. - Bras.

MARISGUS, Gaertn. (Cyperac.). - Ind. Kew. ii 169.

albomarginatus, C. B. Clarke. in Th. Dur. E Schinz, Consp. Fl. Afr. v. 1894 (1895) 584. - Afr. austroor. et austr.

Aster, C. B. Clarke, l. c. - Madag

avenicola, C. B. Clarke, ex Britton, in Bull. Torrey Bot. Club, xvii. (1890) 316, in obs. (= Cyperas Blodgettii, Britton). - Am. bor.

aximensis, C. B. Clarkc, in Th. Dur. \& Schinz, Consp. Fl Afr. v. 1894 (1895) 584. - Guinea.

Bojeri, C. B. Clarcke, l. c. - Madas.

Bolusii, C. B. Clarke, l. c. 585, - Afr. austro-or et austr.

circumclusus, C. B. Clavke, l. c.-Abyss,

bulbosus. C. B. Clarke, ex Hook f. Fl. Brit. Ind. vi. (1893) 620. - Ind. or.

Cooperi, C. B. Clarke, in Th. Dur. \& Schinz, Consp. Fl. Afr. v. 1894 (1895) 586. - Afr. austro-or. et austr.

cupreus, Hochst. ex C. B. Clarke, l. c. 586. Abyss.

dactyliformis, C. B. Clarke, in Trans, Linn. Soc. Ser. II. iv. (1894) 53 (= Cyperus dactyliformis, Boeck.). - Afr, trop, et austr. 


\section{MARISCUS :}

diurensis, $C, B$. Clurke, in Th. Dur. E Schinz. Consp. Fl. Afr. v. 1894 (1895) 586 (= Cyperus diurensis, Boeck.) - Afr. centr et or.

durus C. B. Clarke, l. c. $(=C \text {. durus, Kunth })_{0}-$ Afr. austro-occ. et austr.

detersus, C. B. Clarke, l. c. - Madag.

elatior, C. B. Clurke, l. $c .=$ (C. elatior, Boeck.).Afr, austro-or. et austr.

eurystachys, C. B. Clarke, l. c. $587(=$ C. eurystachys, Ridl.). - Angola.

ferax. C. B. Clarke, ex Hook. f. Fl. Brit. Ind. vi. (1893) 624; et in Th, Dur. \& Schinz, Const. Fl. Afr. v. 1894 (1895) 587 (=C, ferax, Rich.):Reg. trop orb. tot.

foliosus, $C . R$. Clarke, $l, c .588$. - Afr. trop. or.

Grantii, C. B. Clarke, l. o. - Natal.

Gueinzii, C. B. Clarke, i. c. - Afr. austro-or. et austr.

hemisphaericus, C. B. Clarke, l. c. $589(=$ Cyperus hemisphaericus, Boeck.). - Afr. trop.

Hilsenbergii, C. B. Clarke, l. c. - Madag.

Hookerianus, C. B. Clarke, ex Hook. f. Fl. Brit, Ind.vi. (1993) 623. - Sikkim.

liumilis, Nees, ex C. B. Clarke, in Th. Dur. \& Schinz, Consp. Fl. Afr, v, 1894 (1895) $594=$ tabularis, C. B. Clarke.

involutus, C. B. Clarke, l. c. 589. - Afr. austr.

ischnos, C. B. Clarke, in Hook. f. Fl. Brit. Ind. vi. (1893) 623 (= Cyperns ischnos, Schlecht.). - Am. trop. Ind. or.

leptophyllus, C. B. Clarke, in $T$ r. Dur. of Schinz, Consp. Fl. Afr. v. 1894 (1895) 589 (=C. leptophyllus, Hochst.). - Afr. or. et austrc-or

luridus, C. B. Clarke, l. c. - Congo.

luteus, C. B. Clarke, l. c. $589(=$ Cyperus lutens, Boeck.). - Madag.

luzuliformis, C. B. Clarke, l. c. (=C. luzuliformis, Boeck.). - Afr. austro-or. et austr.

macropus, C.B. Clarke, l. c. $590(=$ C. macropus, Boeck.). - Afr. trop.

Marlothii, C.B.Clarke, l.c. (=C. Marlothiz, Boeck.). - Afr, austro-or, et austr.

mollipes, C. B. Clarke, l. c. $(=$ Rynchospora bulbicaulis, Boeck.). - Afr. trop.

Myrmecias, C. B. Clarke, l. c. $(=$ Cyperus Myrmecias, Rill.).. - Angola.

Owani, C. B. Clarke, l.c. (= C. Owani, Boeck.).Afr. trop.

pilosulus, C. B. Clurke, l. c. 591. - Zanzibar.

pseudo-brunneus, C. B. Clarke, l. c. 5. - Ins.

Comor.

pseudo-flavus, C. B. Clarke, l. c. - Afr, trop.

purpurascens, C. B. Clarke, in Kew Bull. (1893) 283 (= Cyperus brunneus, Griseb. pr. p.). - Ins. Antill.

Rehmannianus, C. B. Clarke, $n$ Th. Dur. E Schinz, Consp. Fl. Afr. v. 1894 (1895) 59l (= Cylindrolepis Relimanniana, Boeck.). - Afr. austro-or. et austr.

remotus, C. B. Clarke, l. c. - Congo.

Rohlfsii, C. B. Clarke, l. c. $592(==$ C. Rohlfsii Boeck.). - Abyss.

somaliensis, C. B. Clarke, in Kew Bull. (1895) 229 - Reg. Somal.

Soyauxii, C. B. Clarke, in Th. Dur. \& Schinz, Consp. Fl. Afr.v. 1894 (1895) 593 (= Cyperus Soyauxii, Boeck.). - Gabon.

squarrosus, C. B. Clarke, in Hook. f. Fl. Brit. Ind. vi. (1893) 623; et in Th. Dur. E Schinz, Consp. Fl. Afr.v. 1894 (1895) 594 (= C. squarrosus, linn.). - Ind, or., Afr. trop. or.

strigrosus, C. B. Clarke, in fourn. Linn. Soc: xxx. (is94) 308 ( $=$ C, strigosus, Linn.) - Am. bor.

sul limis, C. B. Clarke, in Th. Dur. E Schinz, Consp Fl. Afr. v. 1894 (1895) $594(==$ C. umbellatus, C. B. Clarke). - Afr. trop.

tabularis, C. B.Clarke, l.c. (=C.tabularis, Schrad.). - Afr. austr.

tanyphyllus C. B. Clarke, l. c. - Afr. trop. or.

Taylori, C. B. Clarke, l. c. - Ins. S. Thom

thomensis. C. B. Clarke, l. c. - Afr. trop. occ.

tomaiophyllus, C. B. Clarke, $l . c:$ - Afr. aequat. or., Madag.

trinervis, C. B. Clarke; t. c. 595. - Congo.

\section{MARISCUS :}

arius, C. B. Clarke, in Th. Dur. \& Schinz, Consp Fl. Afr. v. 1894 (1895) 595. - Madag.

restitus, C. B. Clarke, l. $c .(=$ Cyperus vestitus, Hochst.). - Afr. trop.

MARISCUS, Hall. Enum. stirp. Helv. (1742) 251 52, ex Kuntze, Rev. Gen. (1891) $754=$ Cladium, P. Br. (Cyperac.)

acutus, Kuntze. 1. C. $755=\mathrm{Cl}$. schoenoides, $R, \mathrm{Br}$ affinis, Kuntze, 1. c. = Gahnia Gaudichaudii, Steud.

anceps, Kuntze, 1. c. = Cl. iridifolium, Baker

ancistrophyllus, . Kuntze, 1. c. = Gahnia ancistrophylla, Benth.

anoustifolius: Kuntze, 1. c. (=Vincentia angustifolia, Gaudich.). - Ins. Sandvic.

aristatus, Kuntze, 1. c. = Gahnia aristata, Benth.

arthrophyllus, Kuntze, 1. $\mathrm{c} .=\mathrm{Cl}$. arthrophyllum, F. Mull.

articulatus, Kuntze, l. $\mathrm{c},=\mathrm{Cl}$. àrticulatum R. Br.

asper, Kuntze, 1. c. = Gahnia aspera, F. Muell australis, Kunize, 1. c. $=\mathrm{Cl}$. elynanthoides, F. Muell.

Beechcyi, Kuntze, 1.c. = Gahnia Beecheyi. H.Mann. Cladium, Kuntze, 1, c. = Cl, germanicum, Schrad. congestus, Kuntze, 1. c. = Gahnia globosa, H. Mainn crassus, Kuntze, 1. c. $=$ Cl, riparium, Benth. decompositus, Kuntze, 1. c. = Gahnia Preissii, Nees deustus, Kuntze, 1. c. = G. deusta, Benth

filifolius, Kuntze, 1. c. = Cl. filifolium, Benth. E Hook. $f$.

Filum, Kuntze. 1. c, = Gahnia trifida, Labill.

Gandichandii, Kuntze, 1. c. = G. Gaudichaudii, Stend.

globosus, Kuntze, 1. c. = G. globosa, H. Mann. glomeratus, Kuntze, 1. C. $=\mathrm{Cl}$. glomeratum, $R$. Br insularis, Kuntze, 1, c. = Cl. insulare, Benth.

iridifolins, Kuntzè, 1, $\mathrm{c},=\mathrm{Cl}$. iridifolium, Baker.

javanicus, Kuntze. 1. c. = Gahnia javanica, Mor.

junceus, Kuntze, 1. c. $=\mathrm{Cl}$. junceum, $R . B r$

laniger, Kuntze, 1. c. = Gahnia lanigera, Benth.

lavarum, Kuntze, 1, c, = Cl. iridifolium, Baker

laxus, Kuntze, 1. c, = Cl. laxum, Benth.

leptostaclyus, Kuntze, I. c $=\mathrm{Cl}$. germanicum Schrad.

Mannii, Kuntze, 1. c. = Gahnıa Mannii, Hillebr.

marianus, Kuntze, $1, \mathrm{c},=\mathrm{Cl}$. mariscoides, F. Vill,

mariscodes, Kuntze, 1. c. $=$ Scleria triglomerata Miclix.

melanocarpus, Kuntze, 1. c. = Gahnia melanocarpa R. $\mathrm{Br}$.

Meyenii, Kuntze, 1. c. (= Banmea Meyenii, Kunth). - Ins. Sandvic.

microstachyus Kuntze, 1. c = Gahnia microstachya, Benth.

mironatus, Kuntze, 1. c = G. globosa, H. Mann nudus, Kuntze, 1. c. = Cl. Gunnii, Hook. $f$.

polyphyllus, Kuntze, 1. c. = Gahnia polyphylla Benth.

Preissii, Kuritze, 1. c. = G. Preissii, Nees.

procerus, Kuntze, 1.c. = G. procera, Forst.

psittacrum. Kuntze, 1. c. $=$ G. psittacorum, Labill.

Radula, Kuntze, 1, c. = G. Rađula, Benth

restiodes, Kuntze, 1. c. $(\Rightarrow$ Schoemus restioides, Sw.) - Ind. occ.

riparint, Kuntze, 1, c. $=$ Cl. riparium, Benth.

schoenodes, Kuntze, I. c. = Gahnia schoenoides, Forst.

scirpodens, Kuntze, 1, c. = Cl. scirpoideum, Benth E Hook. $f$

setifolius, Kuntze. 1. c. = Gahnia setifolia, Stend. teretifolius, Kuntze, 1, c. $=$ Cl, teretifolium, $R, B r$ tetragonocaxpus, Kuntze, 1. c. = Gahnia tetragonocarpa, Boeck.

tetraquetrus, Kuntze, $1 \mathrm{c} \cdot=\mathrm{Cl}$. tetraquetrum Hook. f.

trifidus, Kuntze, 1. c, Gahnia trifida, Labill.

tristis, Kuntze, 1. $c_{0}=\mathrm{G}$. tristis, Nees,

zaginalis, Kuntze, 1. co $=\mathrm{Cl}$. vaginale, Benth.

Wichurae, Kuntze, 1. c. = Gahnia tristis, Nees

xanthocarpus, Kuntze, 1. $\mathrm{c}_{i}=\mathrm{G}$. ranthocarpa, Hook. $f$.
MARKHAMIA, Seem. = Dohichandrone, Fënzl (Bignon.).

infundibuliformis, K. Schum, in Engl. \& Prantl Natî̉rl. Pflanzenfam. iv. 3b (1895) 242.-Afr. trop. lanata, K. Schum, 1. c. - Afr. trop. or.

lutec, K. Schum. 1. c. = D. luteum, Seem.

puberula, K. Schum. 1. c. = D. puberulum. Klotzsch.

sansibarica, K. Schum, ex Engl. in Abh. Preuss. Akad. Wiss. (1894) $16=\mathrm{D}$. zanzibaricum, $K l$. stenocarpa. K. Schum. in Eng1. \& Prantl, Natiirl Pflanzenfam, iv. 3b (1895) $242=$ D. stenocarpum, Seem.

tomentosa, K. Schum. ex Engl, in Abh. Preuss. Akad. Wiss. (1894) 34 et 49 ; et 1. c. $=$ D. tomentosum, Benth.

zanzibarica, K. Schum. 1. c. $242=$ sansibarica, $\mathrm{K}$ Schum.

MARLIEREA, Cambess. (Myrt.). - Ind. Kew ji. -170 .

antiscola, Kiaersk. Enum. Myrt. Bras. (1893) 45.Bras.

brachymischa, Kiaersk. l. c. - Bras.

cannifolia, Niedenzu, in Engl, \& Prantl, Natürl. Pflanzenfam. iii. 7 (1893) 76 (=Eugeniopsis cannaefolia, Berg). - Bras.

choriophylla, Kiacrsk. Enum. Myrt. Bras. (1893) 47. - Bras.

Clausseniana, Kiaersk. l.c. $51(=$ Engeniopsis Clausseniana, Berg). - Bras.

edulis, Niedenzu. in Engl. Eo Prantl, Natiirl. Pflanzenfam. iii. 7 (1893) 77 (- Rubachia glomerata. Berg) - Bras

Gardneriana, Niedenzu, l. c. $76(=R$. Gardneriana, Berg). - Bras.

Glazioviana, Kiaersk. Enum. Myrt. Br.ts. (1893) 48. - Bras.

involucrata, Niedenzu, in Engl. \& Prantl. Natitrl Pflanzentam. iii. 7 (1893) 77 (= Rubachia involvcrata, Berg). - Bras.

laevigata, Niedenzu, 1. c. $76(=$ Eugeniopsis laevigata, Berg) - Bras.

laevigata, Kiaersh. Enum. Myrt. Bras. (1893) 51 (=Eugeniopsis laevigata, Berg). - Bras.

Neuriedeana, Niedenzu, in Engl. \& Prantl. Natïrl. Pflanzenfam. iil. 7 (1893) 77 (= Rubachia Nemvicdeana, Berg). - Bras.

obumbrans, Niedenzu, 1. c. $76(=R$. obumbrans Berg). - Bras.

ovata, Niedenzu, l.c. ( = Eugeniopsis orata, Berg) - Bras.

racemosa, Kiaersh. Enum. Myrt. Bras. (1893) 51 (=Eugeniopsis cannaefolia, Berg). - Bras.

Richardiana, Niedenzu, in Engl. \& Prantl, Natür1. Pflanzenfam. iii. 7 (1892) 76 (= E. Richardiana, Berg). - Bras

silvatica, Kiaersk. Enum. Myrt. Bras. (1893) 51 (= E. syleatica, Berg):- Bras.

Sintenisii, Kiaersk. in Bot. Tidskr. xvii. (1889) 252 t. 13a et fig. 2. - Ins. Puerto Rico.

spiciflora, Niedenzu, in Engl. \& Prantl, Natürl. Pflanzenfam. iii. 7 (1893) $7 \%$ (= Rubachia spici. flora, Berg): - Bras

subacuminata, Kiaersk. Enum. Myrt. Bras. (1893) 50. - Bras.

Warmingiana, Kiaersk. 7. c. 44, - Bras.

MARLIERIOPSIS, Kiaersk, in Bot. Tidskr. xvii, (1890) 281: MYRTACEAE

Eggersii, Kiaersh. l. c. 282 t. 11 a et fig. 11 (= Mitranthi Eggersii, Niedenzu). - Ins. Domin.

MARLothiA, Engl. Bot. Jahrb. x。 (1889) 39. RHAMNEAE

spartioides, Engl. l. c. - Afr. austr.

MARRUBIUM, Tourn, ex Linn. (Labiat.). Ind. Kew, ii. 170 .

Aschersonii X, Magnier, ex Nym. Consp. F1, Eur. Suppl. ii. 1. (1889) 253. - Eur.

ballotaeforme, $H$. Braun, in V $\mathrm{crh}$. zool.bet. Ges. Wien, xxxix. (1889) 228. - Persia.

Bornmuélleri, Freyn, in Oest. Bot. Zeitschr. xlii. (1892) 376. - As. Min 


\section{MARRUBIUM}

Sewerzowi, Regel, in Act. Hort. Petrop. ix. (1886) 611 (= Eremostachys Serverzowi, Herder). - As. centr.

virescens $X$, Borb. ex Nym. Consp. Fl. Eur. Suppl. ii. I. (1889) 253. - Croatia.

MARSDENIA, R. Br. (Asclep.). - Ind. Kew. ii. 171.

angolensis, N.E. Er. in Kev Bull. (1895) 258. Angola.

Balansae, Baill.in Bull. Soc. Lim. Paris, ii. (1889) 811. - N. Caled.

barbata, Collett of Hemsl. in fourn. Limn. Soc. xxviii. (1890) 37. - Ind. or.

crinita, Oliter, in Hook. Icon. pl. xx. (1891) t. 1993. - Afr. trop, occ.

cdulis, S. Wats. in Proc. Am. Acad. xxiv. (1889) 60 - Mexic.

Pringkei, S. Wats. l. c. xxy. (1890/158.=-Mexic.

profusa, $N$. E. Br. in Kew Bull. (1895) 258, - Rer. Nigrit.

racemosa, K. Schum。 in Bot. Fahrb. xvii. (1893) 147 Afr. trop.

Selerorum, Loesen, in Finll, Herb. Boiss, ii. (1894) 55\%. - Mexic

sinensis, Hemsl, in fourn. Linn. Soc xxvi. (1889) 113. - China.

speciosa, Baill. in Bull. Soc. Linn. Paris, ii. (1889) 811. - N. Caled.

Taubertiana, K. Schum, in Engl. ct Prantl, Natürl. Pflanzenfam.iv. 2 (1895) 292. - Bras.

verrucosa, Wavb. in Bot. Fahrb, xiii. (1891) 410. N. Guin.

Vieillardi, Baill. in Bull. Soc. Linn. Paris, ii. (1889) 812. - N. Caled.

zambesiaca, Schlechter, in fourn. Bot. xxxiii. (1895) 339. -- Afr. trop. austro-or.

MARShaLLIA, Schreb.(Compos.). - Ind. Kew. 11. 171 .

trimervia [Lesquereux ex] Branner, Trelease \& Coville, in Branner, Rep. Geol. Surv, Ark, iv. 1888 (1891) $196=$ latifolia, Pursh

trineris, Forter, in Mem. Torrey Bot. Club, v (1894) $337=$ praec.

MARSYPIANTHES, Mart. (Labiat.). - Ind. Kew, ii. 172

Chanaedrys, Kuntze, Rev. Gen.(1891) $524=$ hyptoides, Mart.

Chamaedrys, Rusby, in Mem. Torrey Bot. Club, iv. $(1895) 245=$ praec.

MARTIA. Valeton, Crit. overz. Olacin. (1886) 459 = Valetonia. Th. Dur. (Olacin.).

brasiliensis, Valeton,.1.c. - Bras.

MARTiELLA, Van Tiegh. in Bull. Soc. Bot. Fr. xlii. (1895) $168=$ Loranthus, Linn.

Palmeri, Van Tiegh. 1. c. $=$ L. Palmeri, S. Wats.

MARTINELLA. Baill. Hist. des pl. x. (1888) 30 , $\mathrm{K}$. Schum. in Engl. \& Prantl, Natürl. Pflanzenfam. iv. 3b (1894) 216. BIGNONIACEAE.

Martinii, Baill. .l. cc. 31 ; et 216, in adn. (= Bignonia Martinii, DC.). - Am. centr. et austr.

Gollnerii, K. Schum. in Engl. \& Prantl, Natiol. Pfanzenfam.iv. 3b (1894) 216. - Am, austr.

MARTIUSELLA, Pierre, Not. bot. Sapot. (1891) 64; Baill. Hist. des pl. xi.(1892) $296=\mathbf{C h r y -}$ sophyllum, Linn. (Sapot.).

calniensis, Pierre, 1. c. $66=$ Sapota bahiensis, Mart. E Eichl.

Gonocarpa, Pierre, 1. C. = S. gonocarpa, Mart. \& Eichl.

imperialis, Pierre, 1. 'C. = C. imperiale, Bcnth. \& Hook. $f$.

MARTyNIA, Houst. ex Linn. (Pedalin.). - Ind, Kew. ii. 172.

Palmeri, S. Wats, in Proc, Am. Acad, xxiv. (1889) 66. - Calif austr.
MARUMIA, Blanco (Melast.). - Ind. Kew. ii. 172 .

hirsuta, Cogn. in DC. Monog. Phan. vii. (1891) 553. - Borneo.

rhodocarpa, Cogn, in Boerl. Handl. Fl. N'ed. Indië i. II. (1890) 532, nomen; et l. c. $550(=$ M. zeylanica, Triana). - Java, Zeylan.

verrucosa, Cogn. in DC, l. . c. vii. (1891) 549.Malacca.

Warburgii, Cogn, ex Warb. in Bot. Fahrb. xiii, (1891) 393; et l. c. 454 [non Melast. fide cl. Cogrn. in DC. Monog. Phan. App. 1173]. - N. Guin.

MASCAGNIA, Bert. ex Colla = Hiraea, Jacq. (Malperh.)

divaricata. Niedenzu, in Engl. \& Prant1, Natürl. Pflanzenfam. iii. 4 (1890) $55=\mathrm{H}$. divaricata $H . B$ \& $K$.

lilacina, Niedenzu, 1. c. $50=\mathrm{H}$. lilacina, $S$. Wats paraguayensis, Niedenzu, in Bot. Jahrb. xiv. Beibl. n. 30 (1891) 1. - Parag.

prunifolia, Niedenzu, in Engl. \& Prant1, Natür1. Pflanzenfam. iii. 4 (1890) $55=\mathrm{H}$. prunifolia $H . B . \& K$

polybotrya, Niedenzu, 1. c. $55=\mathrm{H}$. polybotrya, fuss.

Seleroriana, Loesen, in Bull. Herb. Boiss. ii. (1894) 549. - Mexic

septentrionalis, Niedenzu, in Engl \& Prantl, Natürl. Pflanzenfam. iii. 4 (1890) $55=\mathrm{H}$. septentrionalis, Fuss.

MASGARENHASIA, A. DC. (Apocyn.). - Ind. Kew ii. 173 .

Gerrardiana, Baker, in fourn. Lim. Soc, xxii. (1887) 504 [Mascarenhaizia]. - Madag.

Fischeri, K. Schum, in Engl. Pflansenw. Ost-Afr. C (1895) 318. - Afr. trop. or.

macrosiphon, Baker, in foum. Linn. Soc. xxii. (1887) 504. - Madag.

micrantha, S. Elliot, ex Baker, l. c. xxv. (1890) 335. - Madag.

rosea, Baker, l. c. - Madag.

speciosa, S. Elliot, l. c. xxix. (1891) 32, - Madag. utilis, Baker, in Hook. Icon. pl. xxiv. (1895) t. 2390. - Madag.

variegata, Britten \& Rendle, in Trans, Limn. Soc. Ser. Il. iv. (1894) 26. - Afr. trop.

MASDEVALLIA, Ruiz \& Pav. (Orchid.). - Ind.

\section{Kew. ii. 173.}

acrochorodonia, Reichb, f. in Gard. Chron. (1886) ii. 526. - Hab.?

astuta, Reichb.f.l.c. (1886) ii. 584. - Costa Rica biflora, Regel, in Act. Hort, Petrop. xi. (1890) 306 et in Gartenfl. xl. (1891) 90. - Columb.

calopterocarpa, Reichb. f. in Flora, lxix. (1886) 560 - N. Granat.

candida, Linden, in Lindenia, ir. (1888) 57 t. 171 $=$ tovarensis, Reichb. $f$.

Cassiope X, Hort. ex Gard. Chron. (1892) i. 749. - Hybr. artef.

chloracra, Reichb. f. in Flora, 1xix. (1886) 560.Hab.?

costaricensis, Rolfe, in Gard. Chron. (1890) ii. 183. - Costa Rica

Courtauldiana $\times$. Hort, ex Gard. Chron. (1889) i. 200. - Hybr, artef.

Culex, Hort, 1. c. (1888) j. 245, 361 et $488=$ Pleurothallis macroblepharis, Reichb. $f$.

demissa, Reichb.f.l.c.(1887) ii. 9.-Costa Rica eclyptrata, Kraenzl. l. c. (1895) ii. 577. - Hab.?

Ellisiana X, Hort. 1. c. (1889) i. 809 ; et ii. 155. Hybr. artef.

falcata $X$, O'Brien, 1. c. (1891) i. 552; et ex Gartenfl. xl. (1891) 359 . - Hybr. artef.

Forgetiana. Kraenzl.l. c.(1895) ii. 484.- Bras.

fulvescens, Rolfe, l. c. (1890) ii. $324 \mathrm{fig} .65$. N. Granat.

Geleniana X, Reichb, f. 1. c. (1887) ii. 586 ; et (1891) ii. 19. - Hybr. artef.

glaphyrantha X, Hort. ex Reichb. f. 1. c. (1886) ii. 648. - Hybr, artef

guttulata, Rolfe, 1. c. (1890) ii. 26\%; et (1895) ii. $324=$ M. Lawrencei, Kracnal.
MASDEVALLIA

haematosticta, Reichb. f. in Flora, lxix. (1886) 559. - N. Granat.

Heathi, Hort. ex Gard. Chron. (1889) i. 810. Hab.?

Henrietta X. Hort. 1. c. (1893) i. 740. - Hybr. artef. heterotepala, Reichb. f. in Flora, ixix.(1886) 561. - N. Granat.

Hincksiana, Reichb. f. in Gard. Chron. (1887) ii. 214. - Hybr artef.

Hubschii, Reichb. f. in Lindenia, iv. (1888) \&, sphalm. = Maxillaria Hubschii, Reichb. $f$.

Lawrencei, Kraenal. in Gard. Chron. (1895) ii. 324. - $\mathrm{Hab}$ ?

Lauchiana, Hort. Sander, ex Gartenfl. xli. (1892) 184. - Hab.?

leontoglossa, Reichb.f.l.c. xxxvi. (1887) 612 fig. 154. - Columb.

Lowii, Rolfe, in Gard. Chron. (1890) i. 416. Columb.

macrochila, Regel, in Act. Hort. Petrop.xi. (1890) 307 ; et in Gartenfl. xl. (1891) 170. - Columb.

Measuresiana X, Rolfe, in Gard. Chron. (1890) ii. 379. - Hybr. artef.

m.eiracyllium. Reichb. f. in Flora, 1xix. (1886) 558. - N. Granat.

microglochin. Reichb. f. l. c. - N. Granat.

mordax. Reichb. f. l. c. 559. - N. Granat.

Mundyana X. Hort. ex Gard. Chron. (1891) ii. 19. - Hybr. artef.

nidifica, Reichb. f. l. c. (18s8) ii. 628, - Hab. ?

O'Brieniana, Rolfe, l. c. (1890) ii. 524; GodefroyLcbouf, L'Orchidophile (1890) 353. - Hab.?

pachyantha, Reichb. $f$. in Flora, 1xix. (1886) 561. - N. Granat.

platycrater, Reichb. f. l. c. 559. - N. Granat.

platyrachis, Rolfe, in Gard. Chron. (1888) ii. $178=$ Pleurothallis platyrachis, Rolfe.

Pourbaisi X, Hort. ex Lindenia, ix. (1893) 9 t. $38 \%$. Hybr. artef.

Pulex, Hort. ex Reichb. f. in Gard. Chron. (1858) i. 488 , sphalm. $(=M:$ Culex, Hort. $)=$ Pleurothallis macroblepharis, Reichb. $f$.

punclata, Rolfe, 1. c. (1888) ii. 323; Hook. f, in Bot. Mag. (1891) t. $7165=$ Scaphosepalum punctatum, Rolfe.

pusilla, Rolfe, in Kow Bull. (1893) 335. - Hab.?

pusiola, Reichb. f. in Gard. Chron. (1887) i. 140. Columb.

Rebecca X, Hort. 1. c. (1893) i. 740. - Hybr. artef. Rolfeana, Kraenzl. l. c.(1891) i. 488.- - Hab.?

sororcula, Rcichb.f.l.c. (1887) ii. 713.-Hab.?

Stella X, Rolfe, 1. c. (1890) ii, 325. - Hybr. artef. striatella, Reichb f.l.c.(1886) ii. 103.-Hab.? strumifera, Reichb. f, in Flora, 1xix. (1886) 560. N. Granat.

trinema, Reichb.f.l. c. 55s. - N. Granat.

Wendlandiana, Reichb. f. l. c. (188\%) i. 174. N. Granat.

yauaperyensis, Barb. Rodr. Vellosia, 1885-88, Sec ediç. (1891) 121. - Bras.

MASSANGEA, Éd, Morr. = Caraguata, Lindl. (Bromel.).

Morreniana, Hort. Linden, ex Baker, in Journ. Bot. xxy. (1887) 172; et Handb. Bғomel. (1889) $151=$ Schlumbergeria Morreniana, Ed. Morr. santoviensis. Hort. Linden, ex Baker, 1. c. (1889) 149. - Bras.

vittata, Ed. Morr, ex Eaker, 1. c. $146=$ Caraguata vittata, Baker.

MASSIA, Balansa, in Morot, Journ, de Bot, iv. (1890) 165. GRAMINEAE

triseta, Balansa, l.c. (= Eviachne triscta, Nees). Cochinch.

MAssonIA, Thunb. (Liliac.). - Ind. Kew, ii.

laeta, Masson, ex Baker, in fourn. Bot. xxiv. (I886) 336. - Afr, austr.

latebrosa, Masson, ex Baker, l. c. - Afr. austr. parvifolia, Baker, in Bot. Fahrb. xv. Beibl. n. 35 (IS92) 8. - Afr. austr

pedunculata, Baker, l. c. - Afr. austr. 
MASTIXIA, Blume (Cornac.). - Ind. Kew. ii. 174.

cambodiana, Pierre, Fl. For. Cochinch. Fasc. 17 (1S92) t. 260b. - Cambod.

MATAYBA, Aubl; = Ratonia, DC. (Sapind.). falcata, Th. Dur. ex Drake, Illustr. Fl. Ins, Maris Pacif. (1890) $\mathbf{1 4 3}=$ Cupania falcata, A. Gray.

stipitata, Th. Dur. ex Drake. l. c. 144; et Fl Polyn. Franc: (1892) 36. - Austral, Ins. Pacif. stipitata, Th. Dur. ex Drake, 1. c. = Ratonia stipitata, Benth.

Storckii, Th. Dur. 1. c. = R. Storckij, Seem.

MATISIA, Humb. \& Bonpl. (Malv.). - Ind. Kew ii. 175

lasiocalyx, $K$ Schum. in Mart. Fl. Bras. xii. III (1886) 239. - Bras.

ochrocalyx, K. Schum. l. c. 238. - Bras.

MATRICARIA, [Tourn.] Linn. (Compos.) - - Ind. Kew. ii. 176.

grandiflora, Britton, in Mem. Torrey Bot. Club, v (1894) $340=$ Chrysanthemum grandiflorum Hook.

matricarioides, Porter, ex Britton, 1, c, $341=$ discoidea, $D C$.

occidentalis, Pomel [ubi ?] ex O. Hoffm. in Engl. \& Prant1, Natürl. Pflanzenfam. iv. 5 (1895) 27\%. Quid.?

occidentalis, Greene, in Bull. Calif. Acad.ii. v1.(1886) 150 ; et Man. Bot. San. Franc. Bay (1894) 208. Calif.

officinarum, Baill. Dict. Bot. iii. (1891) $667=$ Anacyclus officinarum, Hayne.

pinnatifida, Klatt, ex Schinz, in Bull. Hcrb. Boiss.

iii. (1895) 437. - Afr. austro-oec. extratrop.

Raddeana, C. Winkl. in Act. Hort. Petrop. xi. (1s89) 122 t. 3 fig. 2. - Turkest.

spalhipappus, C. Winkl. i. c. x. (1887) 85.Turkest.

zuurbergensis, Oliver, in Hook. Icon. pl. xxiii (1892) t. 2230. - Afr. austr.

MATTHIOLA, R. Br. (Crucif.). - Ind. Kew. ii. 177 .

abortica $\times$. Hausskn. in Mitt. Thür. Bot. Ver. N Folge, iii, et iv. (1893) 105. - Graecia

australis, Rouy \& Fouc. Fl, de Fr. i. (1893) 193 [Mathiola] $=$ sinuata $R . B r$.

Bolleana, Webb, ex Christ, in Bot. Fahrb. ix. (18s8) 88: et xiv. (1892) 231. - Ins. Canar.

circinnata, Kuntze, Rev. Gen. (1891) 935, sphalm. = Malcomia circinnata, Boiss.

exigua, Stapf, in Denkschr. Akad. Wien, ii. (1886) 24. - As. occ.

Jiybrida X. Hausskn. in Mitth. Thür. Bot. Ver. N. Folge, iii. et iv. (1893) 104. - Graecia.

sabauda, Chod. in Bull. Soc. Bot. Fr. xli. (1894) p. ccci.'- Gall.

MATTHIOLA. Plum. ex Linn = Guettarda Linn (Rubiac.).

Angelica, argentea, Blanchetima, bracteata. Burcheilima, calyptrata, comosa, conferta, cordata, crispiflora, dealbata, dependens, dichotoma, elliptica, grandiflora, Hoffmanuseggii. longiflora, macrantha, macrocarpa, membranacea, mollis, ochreata, odorata, prindosa, paniculata, parviflora, parvifolia, platyplylla, platypoda, Pohliana, ramuliflora, reticulata, riabdocalyx, sericea. Spruceana, umbellata, undulata, uruguensis, viscosa, Kuntze, Rev. Gen. (1891) 288 = homonyma omia Guettardae.

arnata, Kuntze, 1. $\mathrm{c}_{0}=$ Chomelia filipes. Benth.

arcmatica, Kuntze, 1. c. = G. aromatica, Poepp. \& Endl.

frondosa, Kuntze 1. c. = Guettarda frondosa, Moritz. myrtodes, Kuntze, 1. c. = G. myrtoides, F. Muell putaminosa, Kuntze, 1.c. = G. putaminosa, F: Mull. speciosa, Kuntze, 1. c. = G. speciosa, Linn.

tenuiflora, Kuntze:-i. c. = Antirrhoea tenuiflora, F. Muell.

viburnodes, Kuntze, 1. c. = G. viburnoides, Chan. \& Schlecht.
MATTUSCHKAEA, Schreb. = Perama, Aubl. (Rubiac).

glabra, Willd. ex K. Schum. in Mart. Fl. Bras. vi, vi (1SSs) 90 , in syn. $=$ P. galioides, Poir

MAUCHIA, Kuntze, Rev, Gen. (1891) $352=$ Bradburia, Torr. \& Gray (Compos.).

hirtella, Kuntze, 1.c. = B. hirtella, Torr. \& Gray,

MAULOUTCHIA, Warb, in Ber, Deutsch, Bot. Gesells. xiii. (1895) $83=$ Myristica Linn Chapelieri, Warb.1. c. = M Chapelieri, Baill.

MAURANDIA, Orteg. (Scrophul.), - Ind. Kew. ii. 178 .

geniculata, Robinson \& Fernald, in Proc. Am, Acad. xxx. (1895) 120. - Mexic.

MAUROCENIA, Linn.= Cassine, Linn. (Celastr.). arguta, Kuntze, Rev. Gen. (1891) $149=$ Turpinia arguta, Scem.

cochinchinensis, Kuntze, 1. c. $150=$ Triceros cochinchinensis. Lour.

heterophylla, Kuntze, 1. c. = Staphylea heterophylla, Ruiz \& Pav.

insignis, Kuntze, 1. c. $149=$ Turpinia insignis, Tul.

occidentalis, Kuntze, 1. c. $150=\mathrm{T}$. occidentalis, G. Don.

pimiata, Kuntze, 1. c. = T. pinnata, Hemsl.

pomifera, Kuntze, 1. c. 147, $149=\mathrm{T}$. pomifera $D C$

Schnziana, Loesen. in Bull. Herb. Boiss. ii. (1894) 194. - Afr, austr.

simplicifolia, Kuntze, Rev. Gen. (1891) $149=$ Turpinia argata, Scem.

phacrocarpa, Kuntze, 1. c. $147,150=$ T. sphaerocarpa; Hassk.

Zollingeri, Kuntze, 1. c. (= Cassine Zollingeri, Kuntze). - Java.

MAVAELIA, Trimen, Handb. Fr, Ceyl. iii. (1895) 419, in obs: = Podostemon, Mickx.

metzgerioides, Trimen, 1. c. - Zeylan.

MAXILlARIA, Ruiz \& Pav. (Orchid.). - Ind. Kew. ii. 178

Amesiana, Hort. ex Gard. Chron. (1891) i. $502,-$ Form, hort.

Endresii, Reichb.f.l.c. (1886) i. 680. - Costa Rica. fucata, Reichb. f, l. c. (1886) ii. 616. - Hab. ?

fuscata, "Reichb. f. » ex 1. c (18s8) 576, sphalm. = fucata, Reichb. $f$.

glumacea, Rolfe, in Kew Bull. (1S92) 210. - Bras.

Huebschii, Reichb. f. iu Gard. Chron. (1888) i. 136. - Hab.?

Lindeniae, Cogn. in fourn. des Orchid. iv. (1894) 362; et in Lindenia, $\mathrm{x}$. (1894) 671. 464. Peruvia.

longisepala. Rolfe, in Gard. Chron. (1890) ii. 94; et Lindenia, vi. $\{1890) 19$ t. 248. - Venezuela.

monantha, Barb. Rodr. Vellosia. 1885-88, Sec. ediç. (1891) 129, - Bras.

mirabilis, Cogn in fourn, des Orchid. iv. (1894) 363 et in Lindenia, ix. (1893) 69 t. 417. - Am. trop.

molitor, Reichb. f. in Gard. Chron. (1887) ii. 242. Hab.?

Mooreana, Rolfe, in Kew. Bull. (1895) 36. - Guatem.

Muelleri, Regel, in Gartenfl. xxxix. (1890) 574; et in Act. Hort. Petrop. xi. (1890) 307. - Columb.

nervosa, Rolfe, ex Britton in Menu. Torrey Bot. Club, iv. (1895) 264. - Bolivia.

parva, Rolfe, in Kew Bull: (1895) 193. - Bras

Sanderiana, Reichb. $f$. in Reichenbachiana, Ser. I. 1 (1887 ?), t. 25; The Garden (1887) ii. 60 t. 686 ; Ed. Andrí, in Rev. Hortic. (1894) 526, cum ic. Peruvia.

sanguinea, Rolfe, in Kew Bull. (1895) 8. - Am. centr.

striata, Rolfe, in Orchid Rev. i. (1893) 266; et in Lindenia, ix. (1893) 31 t. 393. - Hab.

xanthosia, Barb. Rods. Vellosia, 1885-88, Sec. ediç. (1891) 130. - Bras. bor.

\section{MAXILLARIA}

yauaperyensis, Barb. Rodr. Vellosia, 1885-8s, Sec. ediç. (1891) 129. - Bras. bor.

yzabalana, S. Wats, in Proc. Am. Acad. xii. (1888) 286. - Guatem.

MAXIMILIANA, Mart. = ' Cochlospermum, Kunth (Bixin.),

angolensis, Fraseri, Gillivraei, Gossypium, Gregorii, heteroneura. nilotica, orinocensis, Parkeri, tinctoria, Kuntze, Rev, Gen. (1891) $44=$ homonyma omnia Cochlospermi.

Codinae, Kuntze, 1. c. = C. Cadinae. Eichl.

hibiscodes, Kuntze, 1. c. = C. hibiscoides, Kunth

hibiscoides, Millsp. Field Columb. Misc. Bot. Ser I. (IS95) 31. = praec

longirostrata, Barb. Rodr. (Herb. Mus. bot. Amaz n. 9091 Pl. nov. Jard. bot. Rio (1891) 112. Bras. bor.

pauraefolia, Kuntze, Rev. Gen. (1891) $44=$ C. par. keaefolium, Planch.

vitifolia, Krug \& Urban, ex. Urban, in Bot. Jahrb. xv. (1893) $293=$ C. hibiscoides, Kunth.

MAXIMOWASIA, Kuntze, Rev, Gen. (1891) $34=$ Gryptospora, Kar.\& Kir. (Crucif.).

falcata, Kuntze, 1. c. = C. falcata, Kar. \& Kir

MAXIMOWICZIA, $\operatorname{Cog} n$ (Cucurb.). - Ind Kew. ii. 180

Sonorae, S. Wats in Proc. Am. Acad. xxiv. (1889) 51. - Mexic

MAYEPEA, Aubl. = Linociera, Sw. (Oleac.).

arborea, cambodiana, crassifolia, densiflora, elegans, insignis, intermedia, latifolia, laxiflora, leprocarpa. ligustrina. luzonica, malabarica, mandioccana, mi crantha. minutiflora, montana, pauciflora, rostrata Kuntze, Rev. Gen. (1891) 411-12 = homonyma omnia Linocierae.

acuminata, Kuntze, 1. c. = Linociera terniflora Wall.

africana, Knobl. in Bot. Jahrb. xvii. (1893) 529. Angola.

axilliflora, Krug \&-Urban, in Bot. Jahrb. xv. (1893) $345=$ L. axilliflora, Griseb.

bumelioides, Krug \& Urban, 1. c. = L. bumelioides, Griseb.

callophylla, Kuntze, Rev. Gen. (1891) $411=$ Chionanthus callophylla, Blume). - Malaya.

caribaea. Kuntze, 1. c. $411=$ L. compacta, $R . B r$.

cuspidata, Kuntze, 1. c. (= Chionanthus cuspidati Blume). - Ins. Celebes.

diversifolia, Kuntze, 1. c. (=C. diversifolia, Miq.) Sumatra.

domingensis, Krug \& Urban, in Bot. Jahrb. xv (1893) $44=$ Chionanthus domingensis, Lam.

Dussii, Krug \& Urban, 1. c. 347. - Ins. Martinic, clliptica, Kuntze, Rev. Gen. (1891) 411 (= C. elliptica, Blume). - Malaya.

Gilgiana, Volkens, in Engl. Pflanzenw. Ost-Afr. C Add. (1895) 424, nomen. - Afr. trop. or.

glomerata, Kuntze, Rev-Gen. (1891) 411 (= C. glomerata, Blume). - Sumatra.

linocierodes, .Kuntze, 1. c. $711=$ Linociera Wightii, C. B. Clarke.

Mannii, Knobl, in Bot. Jahrb; xvii. (1893) $529=$ L. Mannii, Soland.

nilotica, Knobl. 1. c. $528=$ L. nilotica, Oliver.

odorata, Kuntze, Rev. Gen. (1891) $711=$ L. pur purea, Vahl.

palemb،nica, Kuntze, l. c." = L. pauciflora, C. B Clarke.

Polliana, Kuntze, 1. c. $411=$ L. glomerata, Poht

spicata. Kuntze, 1.c. (=Chionanthris spicata, Blume) - Malaya.

timorensis, Kuntze, 1. c. $(=C$.timorensis, Blume - Malaya.

Verrucosa; Knobl. in Eng1. \& Prantl, Natiirl. Pflanzenfam. iv. 2 (1892) 10; et in Bot. Tahrb. xvii. (1893) $527=\mathrm{L}$, verrucosa, Soland.

Welwitschii, Knob1. 1. c. 580 . - Angola.

zeylanica, Kuntze, Rev. Gen. (ISOJ) $411=$ Lino ciera purpurea, Vaht. 
MAYNA, Aubl = Oncoba, Forst (Bixin.). apeibaefolia, Warb. in Engl. et Prantl, Natürl. Pflanzenfam. iii.6a.(1893) $19=0$. apeibaefolia, Karst. E Triana.

grandifolia, Warb. 1. c. = O. grandifolia. Karst. \& Triana.

pubescens, Warb. 1. c. $=$ O. pubescens, Karst. \& Triana.

suaveolens. Warb. 1, c, = O. suaveolens, Karst. E Triana.

MAYTENUS, Molina (Celastr:). - Ind. Kew。 ii. 181.

Eggersii, Loesen. in Bot. Fahrb. xx. Beibl. n. 49 (1895) 39 - Ecuad.

Jelskii, Zahllr. in Diss. Cl. Math. Phys. Acad. litt. Cracov. xxix. (1S94) 222. - Peruvia.

Glazioviana, Loesen, ex Taub. in Bot. Fahrb. xv. Beibl. n. 38 (1893) 9. - Bras.

longifolia, Reiss. ex Loesent. l. c.9. - Bras.

Muelleri, Schwacke, Addit. Fl. Bras. i. (1886) sub t. 1. - Bras.

Radlkoferiana, Loesen, ex Taub. in Bot. Fahrb.xv, Beibl. n. 38 (1893) 7. - Bras.

Sellowii, Loesen. ex Taub. . c. 8. - Bras

Urbaniana, Loesen. ex Taub. l.c. 10. - Rras.

MAZUS, Lour. (Scrophul.). - Ind. Kew. ji. 181 gracilis, Hemsl. in foum. Limn. Soc. xxvi. (1890) 181. - China.

japonicus, Kuntze, Rev. Gen.(1891) $462=$ rugosus, Lour.

lamifolius, Hemsl. in fourn. Limn. Soc. xxvi. (1890) 181. - China.

procumbens, Hensl. l. c. 182. - China.

pulchellus, Hemsl. l. c. - China.

MEADIA, Catesby $=$ Dodecatheon, Linn. $($ Primul.).

caroliniana, Clevelandii, crenata, Cusickii, Hendersonii. Feffreyi. patula, pauciflora, Kuntze, Rev. Gen. (1S91) 397 = homonyma ommia Dodecatheontis.

MECHOWIA Schinz, in Engl. \& Prantl, Natiirl. Pflanzenfam. iii la (1893) 110 ; et in Bot. Jahrb. xxi. (1895) 186. AMARANTACEAE.

grandiflora, Schinz, $l l . c c$, - Angola.

MECONELLA, Nutt. = Platystigma, Benth.

(Papav.).
denticulata. Greene, in Bu1l. Calif. Acad. ii. V. (1886) 59. - Calif.

MECONOPSIS, Vig. (Papav.). - Ind. Kew. ii. 182.

bella, Prain, in foum. As. Soc. Beng. 1xiii. (1894) II. 82. - Reg. Himal.

hetonicifolia, Franch. Pl. Delav. i. (1889) 42, t. 12. - Yunnan.

chelidonifolia, Burean Es Franch. in Morot, Fourn. de Bot. v. V. (1891) 19. - China occ.

Henrici, Bureau E. Franch. l. c. - China occ.

integrifolia, Franch. in Bull. Soc. Bot. Fr. xxxiii. (1886) 289; et Pl. Delav. i. (1889) 4l (= Cathartia integrifolia, Maxim.). - Yunnan.

punicea, Maxim. Fl. Tangut. (1889) 34. - China,

racemosa, Maxim. l. c. 36.- China.

MECRANIUM, Hook. fo (Melast.). - Ind. Kew. ii. 188

obtusifolinm, Cogn。 in DC.Monog.Phan. vii. (1891) 983. - Cuba.

MEDICA, Tourn, ex Linn. = Medicago, Tourn. (Legumin.).

apiculata, Greene, Man. Bot. San Franc. Bay (1894) $102=$ M. apiculata, Willd.

arabica, Greene, F1. Francisc. (1894) $102=\mathrm{M}$. arabica, $A l l$.

desticulata, Greene, 1. c. = M. denticulata, Willd.

legitima, "Clus, » Greene, 1. c. $101 \approx$ M. sativa, Limn.

Iupulina, Lam. 1. c. = M. Lupulina, Linn.

MEDICAGO, Tourn. ex Linn.(Legumin.). - Ind. Kew. ii. $1 \notin 2$.

\section{MEDICAGO :}

caspia, Grunes ex Boiss. F1. Or, Suppl. (18S8) $16 \%$ (= M. caspica. Jacq. $)=$ denticulata, Willd. cyclocarpa. Hy, in Morot. Journ. de Bot. ix. (1895) ix. (189.5) $431=$ media, Pers.

elongata, Simonk, ex Kern. Sched. Fl. AustroHung, vi. (1893) $4=$ minima, Linn

Loreti, Albert, in Bull. Herb. Boiss. 1. (1893) $13=$ dentículata, Willd.

lilacea $\times . \mathrm{Hy}$, in Morot, Journ. de Bot. ix. (189,5) 432. - Gall.

mixta, Sennh, in Verh, zool-bot, Ges. Wien, xxxviii. (1888) 32; G. Beck, Fl, Nied.-Oest. ii. I. (1892) 839. - Austria.

oligocarpa $\times$,Corbière, Nouv. Fl. Norm. (1893) 150 - Gall. occ

Reynieri, Albert, in Bull. Herb. Boiss. i. (1593), Append. i. $14=$ lappacea. Lan

rhodopea, Velen, in Sitz. Boelnn. Ges. Wiss. (1892-93) 31. - Bulg

rugulosa, Batt. in Batt. \& Trab. Fl. de l'Algrér. [Dicot] $(1889) 239=$ littoralis, Rhode.

Shepardi, Post. ex Boiss. Fl. Or. Suppl. (1888) 163 et in fourn. Linn. Soc. xxiv. (1888) 425. - Syria. spuria X, Hy, in Morot, Journ. de Bot. ix. (1895) 431. - Gall.

tornata, "Willd, " ex Ces., Passer. \& Gibelli, Comp. Fl. Ital, ii. (1886) 723 = muricata, Willd. Urbani. Heldr. ex Boiss. Fl. Or. Suppl. (1888) 165, in syn. = coronata,

MEDINILLA. Gaudich. (Melast.). - Ind. Kew ii. 184 .

amplexicaulis, Baker, in foum. Linn. Soc. xxv. (1890) 316. - Madao.

anomala, Cogn. in DC, Monog. Phan, vii. (18?1) 1185. - N. Guin.

Balls-Headelyi, F. Muell. in Australas. Fourn. Pharm. ii. (April 1887) 125; et in Bot. Centralbl. xxxii. (1887) 213. - Austral.

Beccariana, Cogn. in DC. Monog. Phan. vii. (1891) 600. - Borneo.

cauliflora, Henss. in Kew Bull. (1895) 135, - Ins. Salom.

Chapelieri, Cogn in DC. Monog. Phan, vii. (1891) 587. - Madas.

corallina, $\operatorname{Cog} n .7$. c. 508, - Borneo.

decurrens, Coon $l, 591$ - Borneo.

divaricata, Baker, in fourn. Limn. Soc. xxii. (188i) 478. - Madag.

elongata, Cogn. ex Elliot, l. c. xxix. (1891) 18; et in DC. Monog. Phan vii. (1891) 1185. - Madag.

fasciculata, Coon. in DC. l. c.575. - N. Guin

flagellata, Stapf, in Hook. Icon. pl. xxv. (I895) sub t. 2411. - Borneo.

floribunda, Cogn. in DC. Monog. Phan. vii. (1891) 699. - Sumatra.

Fumblotii, $\operatorname{Cog} n$. l. c.588. — Madag.

hyalantha, Naud. ex Cogn. l. c. 584. - Hab. ?

lasioclados, Stapf, in Trans. Limn. Soc. Ser. II. iv. (1894) 161. - Borneo

linearifolia. Baker, in foum. Linn. Soc. xxi1. (1887) 478. - Madag.

longifolia, Cogn. in DC. Monog. Phan. (1891) 597.N. Guin.

longipedunculata, Cogn. 3. c. 577. - Borneo.

lorata, Stapf, in Hook. Icon. pl. xxv. (1895) t. 2417. - Borneo.

Maidenii, F. Muell. in Wing South. Sci. Record, New Ser. II. (Jan. 1886); et ex Bot. Centralbl. xxvi, (1S86) 20; Cogn, in DC. Monog. Phan. vii. (1S91) $580 .-\mathrm{N}$. Guin.

montana, Cogn. in DC. l. c. vii. (1891) 592. N. Guin.

Mortonii, Hemsl. in Kew Bull. (1894) 211. - Ins. Salom.

Muelleri. Cogn. in DC. Monog. Phan. vii. (1891) 1195. - N. Guin.

nervosa. Cogn. l. c. 594.- Madag.

oblongifolia, Cogn. l. c.589.- - Madag.

pallida, Cogn. l. c. 577. - Sumatra.

quintuplinervis, Cogn. in Boerl. Handb. Fl. Ned. Indie, i. II. (1890) 534, nomen; in Warb. in Bot Falirb. xiii. (1891) 393; et in DC. Monog. Phan. vii. (1891) 574 et $1185 .-$ N. Guin

robusta, Cogn. in DC. l. c. 576. - Borneo.
MEDINILLA :

rubiginosa, Cogn. in DC, Monog. Phan, vii. (1891) 598. - N. Guin.

- sarcorhiza, Cogn. l. c. 587. (= Dissochaeta sarcorhiza, Baill.). - Madaor.

septuplinervia, $\operatorname{Cog} n$. . . c. 576. - Sumatra

serpens. Stapf, in Hook. Icon.pl.xxv. (1895) t. 2411 - Borneo.

stephannstecia, Stapf, in Trans. Limn. Soc. Ser. II. iv. (1894) 160. - Borneo.

subcordata, Cogn, in DC. Monog. Phan. vii. (189I) 589. - Ins. Nossibe.

tetragona, Cogn. l. c. 581. - Madag.

trinervia, Cogn.l. c. 596. - N. Guin.

urophylla, Stapf, in Trans, Linn. Soc. Ser. II. iv. (1894) 160. - Borneo.

Waterhousei, Cign. in DC. Monog. Phan. vii, (1891) 590. - Ins. Vite.

MEDINILLOPSIS, Cogn, in DC. Monog. Phan vii. (1891) 603. MELASTOMACEAE.

Beccariana. Cogn.l. c.-Borneo.

sessiliflora, $\operatorname{Cog} n$. . . c.- Penins, Mal.

MEEHANIA, Britton, ex Small \& Vail, in Mem. Torrey Bot. Club, iv. (1893) 147 ; et in Bull. Torrey. Bot. Club, xxi. (1894) 32 t. 173 = Cedro nella, Riv. (Labiat.).

cordata, Britton, 1l. cc. $=$ C. cordata, Benth.

MEGACARPAEA, DC. (Crucif.) - - Ind. Kew. ii. 185

Delavayi, Franch. in Bull, Soc. Bot. Fr. xxxiii, (1886) 406. - China occ

MEGAGLINIUM, Lindl. (Orchid.), - Ind. Kew. ii. 18.5 .

Clarkei, Rolfe, in Kew Bull. (1891) 198. - Afr, trop. occ.

Imschootianum, Rolfe, l. c. (1895) 8. - Afr. trop. inaequale, Reichb. f. in Flora, lxix. (1886) 553, in syn. = Bulbophyllum inaequale, Reichb. $f$.

leucorhachis, Rolfe, in Kew Bull. (1891) 198. Afr.

minutum, Rolfe, l.c. (1893) 5; Hook. f. in Bol. Mag. (1893) t. 7314. - Sierra Leone.

nummularia, Kraenal. in Gard. Chron. (1894) i. 685. - Kamerun.

oxyodon, Reichb. f. l. c. (1\&88) ii. 91. - Madag.

pusillum, Rolfe, in Kew Bull. (1894) 362. - Afr. trop. or.

scaberulum. Rolfe, in Gard. Cliron. (18S8) ii. 6. Afr. austro-OCC, extratrop.

triste, Rolfe, in Kew Bull. (1894) 362. - Hab. ?

tentaculigerum, Th. Dur. \& Sehinz, Consp. Fl. Afr. v. 1892(1895) 16 (= Bubophyllum tentaculigerum. Reichb. f.). - Kamerun.

MEGADENIA, Maxim. Fl, Tangut, (1889) 76. CRUCIFERAE.

pygmaea, Maxim.l. c. 7\%.-China.

MEGALOTHECA dianthiflora, Welw. ex O. Hcffm. in Bolet. Soc. Brot. x. (1892) 184, in obs.; et in Bot. Jahrb. xv. (1893) $641=$ Erythrocephalum dianthiflorum, $O$. Hoff $m$.

MEGAPHYLLAEA. Hemsl, in Hook. Icon. pl. xviii. (1887) t. 1708. MELIACEAE.

perakensis, Hemsl. l. c. - Perak.

MEGAPTERIUM, Spach = Oenothera, Linn. (Onagr.).

canescens, Britton, in Mem. Torrey Bot. Club, v. (1894) $235=$ Oe. canescens, Torr.

Fremontii, Britton, 1. c. $236=$ Oe. Fremontii, S. Wats.

MEGARRHIZA, Torr. \& Gray = Echinocystis, Torr. (Cucurbit.).

macrocarpa, Rattan, in Bull. Torrey Bot. Club, xiv. (1887) $158=$ E. macrocarpa, Greene. 
MEGASTOMA, Coss. \& Durieu = Eritrichium Schrad. (Borag.).

pusillum, Coss. \& Durieu, ex Bonnet \& Barratte, 111 Phanérog. Tunišie (1895) t. 11 fig. 4-11. - Reg. Tunet.

MEGISTOSTIGMA. Hook. f. Icon. pl. xvi. (1887) t. 1592 ; et F1. Brit Ind.v. (18SS) 46\%. EUPHOR$B I A C E A E$.

malaccense, Hook. f. ll. cc. - Penins. Mal,

MEIBOMIA, Möhring $=$ Desmodium, : Desv. (Legumin.)

acanthoclada, adhaesiva, adscendens, affmis, Alamani, albiflora, ambigua, amplifolia, angustifolia, arenaria, aspera. auricoma axillaris, barbata' batocaulis, biarticulata, brachypodia, brachystacliya, cajanifolia, callilepis, campylodada, canadensis, canescens, capitata, caripensis, candata, Cephalotes; cinerascens, concinna, conferta, cordistipula, cuneata, dusyloba, delicatula, densifori, denudata dependens, diffusa. Dillenii, dimorbha, discolor, dieverifolia, elata, emarginata, erythrinifolia, filiformis, fagellaris, flexwosa, floribunda. floridana, foliosa, formosa. gangetica, Gardnevi, glabella, glabra, gracilis, Grahami, graminea, grandis, Griffithiana, guianensis, gyrans, Hartwegiana, Helleri, heptaphylla, Hilsenbergit, hirsiuta, Jirta, humifusa, illinoensis, juinda, laburnufolia, laevigata, lamprocarpa, laxiflera, leiocarpa, leptoclada, leptopus, limensis, linearifolia, liniata, lutescens, macropodia,- macrostachya; madrensis, malacophylla, mauritiana, megaphylla, mollis, mollicula, monosperma, Muelleri, multicaulis, nemorosa, neomexicanu, neurocarta, nicaraguensis, nitida, mudiflora, obcordata, oblata' oblonga, ochroleuca, Oldhami, orbicularis, orizabana, oxyphylla, pachyrhiza, paleacea, paniculata, Parkinsonii, Parryi, parviflora, parvifolia, pauciflora, physocarpa, platycarpa, plectocarpa, plicata, podocarpa, polystachya, prehensilis, psilocarpa, psilophylla, pulchella, racemifera, racemosa, vadiata, reniformis, reticulata, retincus, retroflexa, rhytidophilla, rigida, Rottleri, rubra, vifescens, Salcinii, sclerophylla, Scorpiurus, scutata, securiformis, sennaarensis, sequax, sericocarpa, sericophylla, serotina, sessilifolia, sinuata, Skinneri, spiralis, striata, stricta, strobilacea. subsecunda, subtilis, tenuifolia, teres, Thwaitesii, tiliaefolia, timorensis, tomentosa, tortwosa, trichostachya, triffora, trifoliastra, triquettra, umbellata, uncinata, varians, velutina, venosa, violacea, viridiflora, viridis, Wade, Wightii, Wislizenii. Wrightii, Kuntze, Rev. Gen. (1891) 195-98 = homonyma omnia Desmodii.

andina, Rusby, in Mem. Torrey Bot. Club, iii. 3 (1893) 21. - Bolivia.

angustifolia, Morong; in Bull. Torrey Bot. Club, xx. (1893) $481=\mathrm{D}$. paniculatum. Torr. E Gray. annua. Kuntze, Rev. Gen. (1891) 197 = D. spirale, $D C$.

arizonica, A. M. Vail, in Bull. Torrey Bot. Club, xix. (1892) $117=\mathrm{D}$. arizonicum, $S$. Wats.

australis, Kuntze, Rev. Gen, (1891) $19 \%=$ D. umbellatum, $D C$

Bakeriana, Kuntze, 1. c. = D. rotundifolium, Baker. bambusetorum, Kuntze, 1. c. = D. Gardneri, Benth.

Bigelowii, Kuntze, 1. c. = D. neo-mexicanum, $A$. Gray.

brevipes, Kuntze, 1. c, = D. cuneatum, Hook

Buergeri, Kuntze, 1. c. $=$ D. polycarpum, $D C$

caffra, Kuntze, 1. c. = D. Dregeanum, Benth.

campylicaulss, Kuntze, 1. c. = D. campylocaulon, F. Muell.

cayennensis, Kuntze, 1. c. = D. barbatum, Benth. o Oerst.

Chamissonis, Kuntze, 1. c. $=$ D. spirale, $D C$.

dasyphylla, Kuntze, 1. c. =- Uraria hamosa, Wall. elegans, Kuntze, 1, c. $198=$ Desmodium tiliaefolium, G. Don.

exigua, Kuntze, 1. c. $=$ D. neo-mexicanum, $A$. Gray. Giesbreglitii, Kuntze, l. c, = D. Ghiesbreghtii, Hcmsl. Godefroyana, Kuntze, 1. c. $196=$ D, Godefroyanum, Kuntze.

grandiflora, Kuntze, 1. c. = D. acuminatum, $D C$. gyrodes, Kuntze, 1. c. = D. gyroides, $D C$. heterocarpa. Kuntze, 1. $\mathrm{c}_{\mathrm{v}}=\mathrm{D}$. polycarpum, $D C$. heterophylla, Kuntze, I. c. $=$ D. heterophyllum, $D C$. Hookeri, Kuntze, 1. c. 197 = D. podocarpum, $D C$.
MEIBOMIA :

Horsfieldii, Kuntze, Rev. Gen, (1891) 198 = Uraria hamosa, Wall.

japonica, Kuntze, 1.c. = Desmodium podocarpum $D C$.

Kurziana. Kuntze, 1 c. $197=$ D. grande, Kurz

lasiocarpa, Kuntze, 1. c. $196=\mathrm{D}$. latifolium, $D C$.

Lindheimeri, A. M. Vail. in Bull. Torrey.Bot. Club, xix. (1892) $111=\mathrm{D}$. Lindheimeri, A M Vait.

lupulina, Kuntze, Rev. Gen. (IS91) $198=$ D. unci natum $D C$.

inarilandica, Kuntze, 1. c. = D. Dillenii, Darl.

Martensii. Kuntze, I. c. $197=\mathrm{D}$. parviflorum Mart. \& Gal.

microphyll.t, Kuntze, 1. c. $198=$ D. parvifolium, Mart.

natalitia, Kuntze, 1. c. = D. gangeticum, DC neglecta, Kuntze, 1,c, $=$ D. villosiun, Homsl. noro-mexicana, A. M. Vail, in Bull. Torrey Bot. Clụb, xix. (1892) $116=\mathrm{D}$. neo-mexicanum, $A$ Gray.

obtusa, A. M. Vaill, I. c, $115=\mathrm{D}$, ciliare; $D C$

ormocarpodes, Kuntze Rev. Gen. (189l) $197=\mathrm{D}$ ormocarpoides. $D C$.

oxybractea, Kuntze, 1. c. $198=$ D. paleaceum Guill. \& Perr.

polygoqpodes, Kuntze, 1. C. = D. polygonoides, Welw Pserdogyrodes, Kuntze, 1. C. $=$ D. gyroides, $D C$.

repanda, Kuntze. 1. c. $19 \%=D$. Scalpe, $D C$. reptans, Kuntze, 1. c. $198=\mathrm{D}$. axillare, $D C$. rhombifolia, A. M. Vail, in Bull. Torrey Bot. Club, xix.-(1892) $113=\mathrm{D}$. rhombifolium, $D C$.

rotundifolia, Kuntze, Rev. Gen, (1891) $197=\mathrm{D}$ rotundifolium, $D C$.

Sonorae, Kuntze, 1. c. $198=$ D. uncinatum, $D C$

stipulacea, Kuntze, 1. C. $=\mathrm{D}$. tortuosum, $D C$

supina, Britton, in Ann. N. Y Acad. Sci. vii. (1892) $83=\mathrm{D}$. incanum, $D C$.

tenella, Kuntze, Rev, Gen. (1891) $198=\mathrm{D}$. spirale, DC.

temuicula, Kuntze, 1. $c_{0}=$ D. spirale, $D C$.

terninialis, Kuntze. 1. c. $=$ D. molie, $D C$.

Treedyi, A. M. Vail, in Bull. Torrey Bot. Club, xix. (1892) $113=$ D. Tweedyi, Britton.

cariffolia, Kuntze, Rev. Gen.(IS91) $197=\mathrm{D}$, incanum, $D C$

cenusta, Kuntze, 1. c. = D. venustum, Stend.

villosa, Kuntze, 1. c. $198=$ D. villosum, $D C$.

zonata, Kuntze, 1. C. = D. ormocarpoides, $D C$.

MEINOCTES, F. Muell, in Trans, and Proc. Roy. Soc. Vict, xxiv. (July 1SS8) 137, in obs., sphalm $=$ Meionectes, $\mathrm{R}$. Br. (Halor.).

MEIOLUMA, Baill. Hist. des pl. xi. (1892) 282 . = Sideroxylon, Linn. (Sapot.).

guianensis, Baill. 1. c. - Guiana.

MELALEUCA, Linn. (Myrtac.). - Ind. Kew. ii 186.

Deanei, F. Muell. in Proc. Linn. Soc. N. S. Wales, Ser. II. i. (Feb. 1887). 1106. - Austral.

quadrifaria, F. Muell, in Wing South. Sc. Record, N.S. ii. (April 1886) - Austral.

seorsiflora, F. Muell, in Austral, fourn. Pharm. (Aug: 1886) 278; et ex Bot. Centralbl. xxviii. (1886) 54. - Austral.

MELAMPODIUM, Linn. (Compos.).- Ind. Kew ii. 188 .

bibracteatum, S. Wats, in Proc. Am. Acad. xxvi. (1891) 140. - Mexic.

brachyglossum, F. D. Smith, in Coult. Bot. Gaz xi1i. (1888) 74. - Guatem.

copiosum, Klatt, in Bot. Falirb̆. viii. (1887) 41. Guatem.

glabrum, S. Wats, in Proc. Am. Acad. xxvi. (1891) 139. - Mexic

Liebmanni, Sch. Bip. ex Klatt, in Leopoldina, Heft xxiii. (1887) 89. - Mexic.

longifolium, Robinson, in Proc. Anr. Acad. xxvii. (1893) 173. - Mexic.

panamense, Klatt, in Bot. Fahirb. viiii. (1SS7) 42. Panama.

sinuatum, T. S. Brandeg. in Proc. Calif. Acäd. Ser. II, iii. (1891) 144. - Calif
MELAMPYRUM, [Tourn.] Linn. (Scrophul.). ‥ Ind Kew, ii. Iss

alpestre, Bruegger, in Jahresb. Naturf. Ges. Graub xxix. (1886) 42 et $132=$ pratense, Limn.

austriacum, G. Beck, Fl. Nied.-Oest, ii. II. (1893) 1071, in syn. = nemorosum, Linn.

decrescens, Celak. $\mathrm{f}$ in Sitzb. Böhm. Ges. Wiss. (1887) $11 \%=$ nemorosum, Linn.

fallax, G. Beck, Fl. Nied.-Oest. ii. I. (1893) 1071 $=$ nemorosum, Linn.

fimbriatum, Vandas, in Oest. Bot. Zeitschr, xxxix. (1889) 52. - Herceg.

Herbichii, Woloszczak, in Spraw Kom. fizyj. Krajow, xxi. (1888) 133; Wet1st, in Engl. \& Prantl, Natül. Pflanzenfan. iv. 3b. (1893) 99. - R Reg. Carpat.

intermedium, Perrier \&o Song, in Bull. Herb. Boiss. ii. (1894) 426. - Sabaud.

moravicum, H. Braun, ex Formanek, Krètenza, iil (1892) 730. - Moravia

scardicum, Wettst. in Luerss. Bibl, Bot. Heft xxvi (1S92) 81 t. 5 fig. 25-30. - Alban

trichocalicinum, Vandas, in Sitz. Boehm. Ges. Wiss. 1889 (1890) 275. - Busnia.

MELANANTHUS, Walp. (Solan.). - Ind. Kew ii. 189

fasciculatus, Solered. in Bot. Centralbl. xlix. (1892) $304=$ dipyrenoides, $W$ alp

MELANCRANIS, Vahl = Ficinia, Schrad. (Cyper.)

acuminata, anceps, argyropus, brevifolia, bulbosa, clandestina, commutata, Ecklonea, elongata, fascicularis, fastigiata, filiformis, gracilis, Kunthiana, laciniata, laevis, lateralis, leiocarpa, lithosperma, monticola. nuda, paradoxa, praemorsa, quinquangularis, repens, secunda, sylvatica, tenuifolia, tribracteatu, tristachya, truncata, Kuntze, Rev. Gen. (1891) $756=120 \mathrm{o}$ my ommia Ficiniae.

Bolusii, Kuntze, I. c. $=$ F. lithosperma, Boeck.

comparbergensis. Kuntze, 1, $\mathrm{c},=\mathrm{F}$. compasbergensis, Drège.

contorta, Küntze, 1. c. = F. stolonifera, Bocck Dregeana, Kuntze, 1. c. = F. pygmaea, Boeck. gracilis, Kuntze, 1. c. = F. gracilis, Schrad.

indica, Kuntze, l. c. = F. setiformis, Schrad, et brevifolia, Nees

xiodes, Kuntze, 1. c. $=\mathrm{F}$. ixioides, Nees.

pallida, Nees, ex Th. Dur. \& Schinz, Consp. Fl

Afr.v, 1892 (1895) $643=$ F, setiformis, Schrad.

trigyna, Kuntze, Rev. Gen. (1891) 756 = scariosa Nees.

Zeyheri, Kuntze, 1.c. = F.gracilis, Schrad

Zeyheri, Kuntze. 1. c $=$ F. Zeyheri, Boeck

MELANDRYUM. Roehl. = Lychnis, Linn. (Caryoph.).

argentimum, Pax, in Bot. Jahrb, xviii. (1893) 23. Reg. Argent.

astrachanicumi, Paczosky, Expl. flor. \& phyt. stepp Kalmylss. [Bull. Soc. Natur. Kiew (1892)] 39 ou 59 - Koss. mer.

Balansae, Boiss F1. Or Suppl. (188s) 109. - As. Min.

glutinosmm. Rouy, in Bu!l. Soc. Bot. Fr. xli. (1894) 327: - Lusit. Hisp.

Hieronymi, Pax, in Bot. Jahrb. xviii. (1893) 22. Reg. Argent.

hybridum X, Bruegrer [ex Killias Die F1. des Un terengad.] in Jahresb. Nat. Ges. Graubünd xxxi. Beil. (1887-88) 27- Helv.

physocalycinmm, Hausskn. \& Bornm. in Mitth. Thür. Bot. Ver. N. Folge, vii. (1895) 6. - Oriens subnemorale $X$, Simonk. in Termész. Fuzét, $x$. (1886, 130. - Transsilv.

Uiscosum, Mariz, in Bolet. Soc:- Brot. v. (18Si) 98 = glutinosum, Rouy.

MELANOGENGHRIS, Neès (Gramin.). - Ind Kew. ii. 190.

monoeca, Kuntze, Rev. Gen. (1S91) 780 = Rothia na Ness.

MELANOCHYLA, Hook. f. (Anacard.). - Ind Kew, ii. 190 .

Beccariana, Oliver, in Hook. Icone pl. xxiv, (1894) t. 2413. - Borneo. 
MELANODISCUS, Radlk. in Th. Dur. Ind. Gen. (1S8S) 75 et in Sitz, math. phys. Cl. Akad. Wiss. Muench.xx. (1890) 285. SAPINDACEAE. africanus, Radlk, $l l . c c .-$ - Afr. trop.

oblongus, Radlk, ex Taub. in Engl. Pfanzenw. OstAfr. C. (1895) 250. - Afr. trop. or

MELANORRHEA, Wall. (Anacard.). - Ind. Kew. ii. 190.

baccifera, Pierre, ex Laness. Pl, util. Colon. Franç. (1886) 308, sphalm, = laccifera, Pierre.

Curtisii, Oliver, in Hook. Icon, pl. xvi. (1886) t. 1513. - Penan:

MELANTHERA, Rohr, (Compos.), - Ind. Kew. ii. 190 .

cinerea, Schweinf. ex Engl. in Abh. Prcuss. Akad. Wiss. 1891 (1892) 434, nomen - Afr. trop. or. Marlothiana, O. Hoffm。 in Bot. Fahrb. x. (1889) $27 \%$. - Afr.austro-occ. extratrop.

MELANTHIUM, Clayt, ex Linn, (Liliac.), - Ind. Kew ii. 190.

hyacinthoides, Herb. Madr. ex Hook. f. Fl. Brit. Ind. vi. (1892) 348 , in syn. = Scilla indica, Baker.

MELASMA, Berg (Scrophul.), - Ind. Kew, ii. 191.

asperrimum, Engl. Pflanzenw. Ost-Afr. C (1895) $358(=$ Alectra asperrima, Benth.). - Abyss.

cordatum, Emgl. l. c. (= Glossostylis cordata, Hochst.), - Afr. trop.

indicum, Wettst, in Engl. \& Prantl, Natürl. Pflanzenfam. iv. 3b. (1891) 91 = Alectra indica, Benth.

orobanchoides, Engl. Pflanzenw. Ost-Afr. C (1895) $359(=$ Alectra orobanchoides, Benth.). - Afr. austr.

pedicularioides, Wettst, in Engl. \& Prantl, Natuirl. Pflanzenfam. 1v. 3b. (1891) 91 (= A. pedicularioides, Baker). - Madag.

spathaceum, Oliver, in Trans, Linn. Soc. Ser. II. ii. (1887) 279 [Oliver, ex im Thurn, in Timehri, v. (1886) 2001. - Guian. angl.

Thomsoni, Wettst. en Engl. \& Prantl. Natürl. Pfanzenfam. iv. 3b. (1891) 91 (= Alcotra Thomsoni, Hook. f.). - Ind. or.

MELASPHAERULA, Ker-Cawl. (Irid.). - Ind. Kew. ii. 191.

ramosa, Klatt, in Th. Dur. \& Schinz, Consp. Fl. Afr.v. 1893 (1895) $20 \%$ = graminea, Ker-Gavol.

MELASTOMA, Burm. ex Linn. (Melast.). Ind. Kew, ii. 191.

Barbeyanum, Cogn。 in Boenl。 Handl. Fl. Ned. Indie. i. II. (1890) 530, nomen; et in DC. Monog. Phan. vii. (1891) 347 - - Java.

Beccarianum, Cognz. $l l . c c .530$; et 356, - Borneo. bifaria, L. C. Rich. ex Cogn, in Mart. F1. Bras. xiv. IV. (1886) $192=$ Leandra solenifera, $\operatorname{Cog} n$. calyptratum, Sieb. [Fl. Martin. n. 108], ex Cogn. in DC: Monog. Phan. vii. (1891) 765. - Ins, Antill. Clarkeanum, Cogn. l.c.346. - Tenass.

cremata. Pavon, ex Cogn. in Mart. Pl. Bras, xiv. Iv. (1886) $137=$ Leandra crenata, Cogn.

Francavilleanum, Cogn, in Boert. Handl. Fl. Ncd. Indië, i. II. (1890) 530, nomen; et in DC. Moneg. Phan. vi.. (1891) 358. - Java.

poupercula, L. C. Rich. ex Cogn, in Mart. F1. Bras. xiv. IV. (1886) $202=$ Leandra agrestis, Ruddi.

MELHANIA, Forsk。(Stercul.), - Ind. Kew, ii. 196

Engleriana, K. Schum, in Abh. Preuss. Akad. Wiss, 1891 (1S92) 393. - Reg. Somal.

griquensis, Bolus; in fourn. Limn. Soc. xxii (1887) 172; K. Schum, in Bot, Fahrb.x. (1889) 41. Afr. austr.

vata, Engl. in Abh. Preuss. Akad. Wiss. 1891 (1892) 303. (= Brotera orata, Cav: $),-$ As, et Afr. trop. Rehmannii, [Rehmanii] Szyszyl. Polyp. Rehmann. (1887) 46. - Transvaal

transvaalensis, Szyszyl. l. c. - Transvaal.
MELIA, Linn. (Meliac.). - Ind. Kew, ii. 197. Volkensii, Guerke, in Engl. Pfanzenw, Ost-Afr. C (1895) 231 . - Afr. trop. or.

MELIADELPHA, Radlk. in Sitz. math.-phys. Cl. Akad. Muench. xx. (1890) 331 , in obs. MELIA$C E A E$.

conferta, Radlk. l. c. 332. - N. Caled.

oceanica, Radlk.l.c.- Polyn.

MELICA, Linn. (Gramin.). - Ind. Kew. ii, 197. argentea, Beal, in Bull. Torrey Bot. Club, xvii. (1890) 153 (= Poa argentea, Howell). - Oregon.

Aschersonit X. M. Schulze, in Mitt. Bot. Ver. Jena, vii. (1889) 38. - Germ.

favescens, Simonk. Enum. F1. Transs. (1886) 577 $=$ ciliata, Linn.

inflata, Vasey, in Contrib. U.S. Nat. Herb. i. (1893) 269. - Calif.

macrantha. Beal, in Bull. Torrey Bot Club, xvii (1890) 153 = Poa macrantha, Wasey.

mexicana, Link, ex Fourn. Gram. Mexic. 1881 (1886) 135 = Buchloë dactyloides, Engelm.

parviflora. Scribn. in Mem. Torrey Bot. Club, v. (1894) 50 ; Vasey, Ill. N. Am. Grass. i. I. (1890) t. $50=$ M. Porteri, Scribn.

Smithii, Vasey, in Bull. Torrey Bot. Club, xv. (1883) 294 (= Avena Smithii, Porter). - Michigan

Teneriffae, Hack. ex Christ, in Bot. Fahrb. ix. (1888) 153. - Teneriffa.

MELICOPE, Forst, (Rutac.). - Ind. Kew. ii. 198.

Broadbentiana, F. M. Bailey, in Dept. Agric. Bris

bane, Bot. Bull. ii. (1891) 9. - Austral.

Chooreechillum, F. M. Bailey, Rep. Exped. Bellendent-Ker (1889) 33. - Austral.

parvula, 7. Buch. in Trans. N. Z. Inst. :xx. 1887 (1888) $255 .-\mathrm{N}$. Zel

pubescens, F. M. Bailey, in Dept. Agric. Brisbane Bot. Bull. iii. (1891) 9. - Austral.

MELICYTUS, Forst. (Violar.). - Ind. Kew. ii 109.

microphyllus, Colenso, in Trans. N.Z. Inst. xix. 1886 (1887) 260 ; xx. 1887 (1888) 189. - N. Zel

MELIENTHA, Pierre, in Bull. Soc. Linn. Paris, i. (1888) 762, et F1. For. Cochinch. Fasc. 17 (1892) t. 264b ; Baill. Hist. des pl. xi. (1892) 457 $O L A C I N E A E$

suavis, Pierre, $l l$. $c c$. - Cambodia.

MELILOTUS, Tourn. (Legumin.) :- Ind. Kew. ii. 199.

hirsuta, Lipski, in Mém. Soc, hist. nat. Kiev, xi. (1891) extr. 21; at in Act. Hort. Petrop. xiii. (1894) 287. - Reg. Cauc

Petitpierriana "Willd. " ex Ces, Pass. \& Gibelli, Comp. FI. Ital. ii. (1886) 718 ( = M. Petitpierreana, Willd.) = officinalis, Desr

Schoenheitianus $X$. Hausskn. in Mitth. Bot. Ver. Jena. viii. (1890) 37. — Europ

MELINIA, Decne- (Asclepiad.), - Ind. Kew. ii 200.

Eichleri, K. Schmm. in Engl. \& Prantl, Natür. Pfanzenfam.iv.2 (1895) 245 (= Kerbera Eichleri, Fourn.). - Mexic.

MELIOSCHINZIA, K. Schum, in K. Schum. \& Hollr. Fl. Kais. Wilh, Land (1889) 62: Boerl. Handl. Fl. Ned. Indië, i. II. (1890) 670. MELIACEAE.

macrophylla, K. Schum. ll.cc. 62 et 671 . - N. Guin.

MELIOSMA, Blume (Sabiac.). - Ind. Kew. ii. rasiliensis, Urban, in Ber. Deutsch. Bot. Gesells.

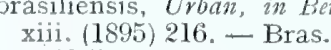

cuneifolia, Franch. in Nour. Archis. Mus. Paris, Sér. II. viii. 1885 (1886) 211. - Tibet

dentata, Urban, in Ber. Deutsch. Bot. Gesells, xiii. (1895) 212 (= Lorenzanea dentata, Liebm.i. Mexic.

Fordii, Hemsl. ex Forb. E Homsi, in fourn. Linn. Soc. xxvii. (1886) 144.- China.
MELIOSMA :

glabrata, Urban, in Ber, Deutsch. Bot. Ges, xiii. (1895) 212 (= Lorenzanca glabrata, Liebm.):Costa Rica

Glaziowii, Urban, ex Warb. in Engl. \& Prantl, Natür. Pfanzenfam. iii. 5 (1895) 372, nomen. Bras,

grandifolium, Urban, in Ber. Deu'scli. Bot. Ges. xiii.(1895) 212 (=Lorenzeana grandifolia, Liebm.). - Mexic.

Herbertii, Rolfe, in Kew Bull. (1893) 244 ; et in Hook. Icon. pl. xxiv. (1894) t. 2305. - Ind. occ.

impressa, Krug \& Urban, ex Warb. in Engl. E Prantl, Natiirl. Pfanzenfam. iii. 5 (1895). 372, nomen. - Haiti.

obtusifolia, Krug of Urban, ex Urban, in Ber. Deutsch. Bot. Gesells. xiii. (1895) 216 (= Atelandra obtusifolia, Bolle). - Ins. Puerto Rico.

Pardonii, Krug \& Urban, l. c. 215. - Ins. Guadalup.

patens, Hemsk. ex Forb. \& Hemsl. in foum. Linn. Soc. xxvii. (1886) 145. - Ins. Hongkong.

Schlimii, Urban, in Ber. Deutsch. Bot. Gesells, xiii. (1895) 217 (=Oligostcmon Schlimii, Turcz.). N. Guin.

Sellowii, Urban, l. c. 212. - Bras.

sinuata, Urban, l. $c_{0}-$ Bras.

MELISSA, Tourn. ex Linn. (Labiat.). - Ind. Kew. ii. 200.

Banmgarteni. Simonk, in Termész. Fuzét. x. (1886) $182=$ Calamintha alpina, Lam.

bolnokensis X. Simonk. Enum. Fl. Transsily: (1986) 445. - Transsilv.

hungarica $X$. Simonk. in Termész. Fuzét. x. (1886) 182 ; et $1 . \mathrm{c} .444=$ Calamintha hungarica, Nym.

fahniana $\times$, Simunk, 1. c. ix. (1885) 25. - Hung.

MELLERA, S. Moore (Acanth.). - Ind. Kew. ii. 201.

nyassana, S. Moore, in fourn. Bot. xxxii. (1894) 133. - Afr. trop, austro-or.

MELLICHAMPIA, A. Gray, ex S. Wats. in Proc. Am. Acad. xxii. (1887) 437. ASCLEPIADEAE rubescens, A. Gray, $l$. $c$.-Mexic.

MELLOA, Bureau (Bignon.). - Ind. Kew, ii. 201 BIGNONIACEAE

populifolia, Britton, in Ann. N. Y. Acad. Sci vii. (1893) $188=$ populifolia, Bureau.

MELOCACTUS [Tourn.] Link \& Otto (Cact.). Ind, Kew, ii, 201

albispinus, Suringar, in Versl. en Medd. Akad. Wetensch. Amst. Ser. III. vi. (1889) 446. - Ins. Aruba. angusticostatus, Suringar, 1. c: ii. (1886) $188=\mathrm{rec}-$ tiusculus, Suringar var.

approximatus, Suringar, l. c. 189. - Ins. Aruba.

arcuatus, Suringar, l.c. vi. (1889) $450(=$ M. Non-

villeanus, Suringar, olim.). - Ins. Aruba.

argenteus, Suringar, l. c. 439. - Ins, Aruba. armatus, Suringar, 7. c. 458. - Ins. Aruba,

Baarscanus, Suringar, l. c 448. - Ins. Aruba.

capillaris, Suringà, l, c. 442.- Ins. Aruba.

compactus, Suringar, l. c. 444. - Ins. Aruba.

contortus, Suringar, l. c. 445. - Ins: Aruba.

cornutus, Suringar, i. c. ii. (1886) 192. - Ins Curaçao.

dilatatus, Suringar, l. c.vi. (1889) 454. - Ins Aruba.

eburneus, Suringair, l. c. 447. - Ins. Aruba. elongatus. Suringar, l.c. 451. - Ins. Aruba. euryacanthus, Suringar, l. c. 447. - Ins. Aruba. extensus, Suvingar, l. c. 442. - Ins. Aruba.

Evertszianus, Suringar, l. c. ii, (1886) 190; et vi. (1889) 448. - Ins. Aruba.

ferox, Suringar, 1. c. 1885 ; et $446=$ ferus, Suringar. ferus, Suringar, 1. c. vi. (1889) $446=$ rubellus, Suringar.

flammeus, Snringar, l. c. 45\% - Ins. Maruba. flavispinus, Suringar, l. c. 453. - Ins. Aruba. flexilis, Suringar. l. c. 453. - Ins. Aruba.

flexus, Suringar, l. c. 441.- Ins. Aruba.

hexacanthus, Suringar, 1.c. i. 1885 (1886) $185=$ rubellus, Suringar, var. 


\section{MELOCACTUS}

humilis, Suringar in Versl eqr Medd. Akad. Wetensch. Amst. Ser. III. vi. (1889) 459. - Venezuela. incurvus, Suringar, $l$. c. 441. - Ins. Aruba. inflatus, Suringar, l. c. 454. - Ins. Aruba.

intermedius, Suringar, l. c. ii. 1885.(1886) 192, Ins. Curaçao.

Koolwijckianus, Suringar, l. c. 184; et vi. (1889) 438. - Ins. Aruba.

lasyacanthus, Hort. ex Sprenger, in. Gartenfl. xli. (1892) 248, nomen. - [Quid ?]

leucacanthus, Suringar, in Versl. en Medd. Akad. Wetensch. Amst. Ser. III. vi. (1889) $454=$ dilatatus Suringar, var?

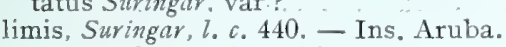

macracanthus. Salm-Dijck, ex Foerst-Ruempl. Handb. Cacteenck. (1885 ?) 442. - Ins. Antill.

martialis, Suringar, in Versl. en Medd. Akad. Wetensch. Amst, Ser. iii VI. (1889) 443. - Ins. Aruba. nanus, Suringar, l. c. 441. - Ins. Aruba.

obliquus, Suringar, l. c. 440. - Ins. Aruba.

obovatus, Suringar, l. c. 453. - Ins. Aruba,

ovatus, Suringar, l. $c .456$, - Ins. Aruba.

parvispinus, Suringar, l. c. ii. (1886) 185̃. - Ins. Bonaire.

patens, Suringar, l. c. Ser. III. ii 1885 (1886) 190 - Ins. Bonaire.

pentacanthus, Suringar, l. c. vi. (1889) 445. - Ins Aruba.

pulvinosus, Suringar, l. c. 458.-Ins, Aruba.

pusillus. Suringar, l. c. ii. 1885 (1886) 102. - Ins. Curaçao.

radiatus, Suringar, l.c. vi. (1889) 446.-Ins. Aruba.

rectiusculus, Suringar, l. c. (1889) 187. - Ins. Aruba.

reticulatus, Suringar, , l. c. vi. (1889) 453. - Ins. Aruba.

reversus, Suringar, l. c. ii. 1885 (18.86) 187. - Ins. Aruba

roseus, Suringar, l. c. vi. (1889) 439. - Ins. Aruba.

rụbellus, Suringar, l. c. ii. (1886) 184 ; et vi. (1889) 448. - Ins. Aruba.

rudis, Suringar, l. c. 442, - Ins. Aruba.

sordidus, Suringar, l. c. 451. - Ins. Aruba.

spatanginus, Suringar, - . c. ii. 1885 (1886) 193. Ins. Curaçao.

stellatus, Suringar, l. c. vi. (1889) 452. - Ins. Aruba.

stramineus, Suringar, l. c. ii. (1886) 185 ; et vi. 448. - Ins. Aruba.

trachycephalus. Suringar, l. c. 455. - Ins. Aruba. trichacanthus. Suringar, l. c. ii. (1886) 186. - Ins. Aruba.

trigonus, Suringar, l. c. vi. (1889) 456. - Ins. Aruba.

uncinatus, Suringar, l. c. 450.- - Ins. Aruba.

MELOCHIA, Dill, ex Linn. (Stercul.). - Ind.

Kew. ii. 202.
Benthami, K. Schum. in Mart. Fl. Bras. xii, In. Benthami, $K$. Schum. in Mart.
(1886) 40. - Bras., Guian.

betsiliensis, Baker, in Fourn. Linn. Soc. xxii. (1887) 451. - Madag.

bracteosa, F. Hoffm. Beitr. Keintn. Fl. Centr. OstAfr. (1889) 13. - Afr. trop.

carthaginensis, Willd. ex K. Schum. in Mart. Fl. Bras. xii. III. (1886) $40=$ M. Benthami, $K$. Schum.

cephalodes, K. Schum. l. c. 45. - Bras.

decandra, "Will." ex K. Schum, 1. c. $31=$ illicioides, K. Schum.

illicioides, $K$. Schum. l.c. - Bras.
littoralis, $K$. Schum. l. c. 44 (= Riedleia littoralis, littoralis. $K$. Schum. l. c. 44 (= Riedleia littoralis,
Poepp. \& Endl.). - Bras. Mororgii, Britton, in Ann. N. Y. Acad. Sci. vii. (1892) 62. - Parag.

paniculata, "Willd. " ex K. Schum, in Mart. Fl,

Bras, xii. III. (1886) $37=$ venosa, Sw.

sorocadensis, K. Schum.l. c. 42. - Bras.

speciosa, S. Wats, in Proc. Am. Acad, xxiv. (1889) 42. - Mexic.

stricta, K.Schum. in .Mart. Fl. Bras. xii. III. (1886) 42. - Bras.

subcordata, Morong, in Ann. N.Y.Acad. Sci. vii. (1892) 62. - Parag.
MELODINUS, Forst. (Apocyn,), - Ind. Kew.ii

202.

786. - N. Caled.

Balansae, Baill. l. c. 785. - N. Caled.

buxifolius, Baill . . . c.787. - N. Caled.

celastroides, Baill. l. c. - N. Caled.

coriaceus, Oliver, in Hook, Icons. pl, xvii. (18s8) t. 1758. - Penang.

inaequilatus, Baill, in Bull. Soc. Linn. Pars, i. (1889) 786. - N. Caled.

Murpe. F. M. Bailey, in Dep. Agxic. Brisbane, Bot. Bull. x. (1895) 23. - Austral.

polyadenus, Baill: in Bull. Soc. Linn. Paris, i. (1889) 786. - N. Caled.

MELODORUIM, Hook. f. \& Thoms. (Anonac.). Ind. Kew. ii, 202.

kinabaluense, Stapf, in Trans. Lim. Soc. Ser. II. iv. (1894) 130. - Borneo.

litseaefolium, King, in fourn. As. Soc. Beng. Ixi. (1S92) II. 103. - Perak.

micranthum. Warb. in Bot. Fahrb. xviii. (1894) 190. - N. Guin.

Oldhami, Hensl. in fourn. Linn. Soc. xxiit. (1886) 27. - Ins. Formosa.

MELOSPERMUM rubro-stamineum, Seortech. ex King, in fourn. As. Soc. Beng. lxiv. (1895) II. 83 in syn. = Walsura multijuga, King.

MELOTHRIA, Linn. (Cucurbit.), - Ind. Kew, ij. 203

acutifolia, Cogn. ex Schinz, in Bull. Herb. Boiss, iii. (1895) 419. - Transvaal.

angustifolia, Cogn. in Bot. Fahrb. xxi. (1895) $20 \%$. - Afr. centr. or.

Donnell-Smithii, Cogn. ex F. D. Smith, in Coult. Bot. Ga\%. xvi. (1891) 9.-Guatem.

Elliotiana, $\operatorname{Cogn}$. ex S. Elliot, in fourn. Linn. Soc. xxix. (1891) 19. - Madag

heterophylla, Boiss. Fl. Or. Suppl. (1888) 243 Boerl. Handl. Fl. Ned. Indië. i. II. (1890) 596 $(=$ Zehneria heterophylla, Thw.). - As. trop. et subtrop.

Marlothii, Cogn. ex Schinz, in Verh. Bot.Ver. Brand. xxx. (1888) 152; et in Bot. Falirb. x. (1889) 270. Afr. austro-occ, extratrop.

membranifolia, Cogn.ex Schinz, in Bull. Herb. Boiss. iii. (1895) 420. - Natal.

papuana, Cogn. in Bull. Acad. Belg. Sér. III. xiv (1887) $355 .-$ N. Guin.

parvifolia, $\log n$. ex Schinz, in Bull. Herb. Boiss, iii, (1895) 420. - Natal.

polycarpa, $\operatorname{Cogn}$. ex S. Elliot, in Fourn. Limn. Soc. xxix. (1891) 20. - Madag.

subpellucida, Cogn. in Bull. Acad. Belg. Sér. III. xiv. (1887) 356. - Austral.

MEMEGXLON, Linn. (Melast.). - Ind. Kew. ii. 204

australe, C. Moore, Handb. F1. N. S. Wales, $208=$ Eugeniae sp.

Bakerianum, Cogn, in DC. Monog. Phan. vii. (1891) 1154. - Madag.

Beccarianum, Cogn, l.c, - Borneo.

Bernierii, $\operatorname{Cog} n$. l. c. 1156. - Madag.

Candolleanum, Cogn. l. c. 1144. - Ins. Andam

cardiophyllum, Cogn. l. c. 1171. - Madag.

Clarkeanum, Cogn. l. c, 1141. - Zeylan.

confertiflorum, Cogn. l.c. 1151. - Borneo

dioicum, Cogn. in Boerl. Handl. Fl. Ned. Indië, i. ii. (1888) 538, nomen; et in DC. Monog. Phan. vii (1891) 1172 (= Lijndenia dioica, Naud.). - Java. discolor, Cogn. l. c. 1149. - Ind. or.

durum, $\operatorname{Cogn} . l, c .2152,-$ Borneo

Englerianum, Cogn.l. c. 1195.-Kamerun.

Helferi, Cogn . l. c. 1166. - Tenass, vel Andam.?

lanceolatum, Cogn. l. c. 1157. - Borneo.

Lijndenia, Kuntze, Rev. Gen.(1891) 247 (= Lijndenia laurina, Zoll. \& Mor.). - Java.

longifolium, Eogn., in DC. Monog. Phan. vii. (1891) 1150. - N. Guin.

malabaricum, Cogiz.l. c.1148, - Ind. or.

molestum, Cogn. l. c. 1169. - Ind. or.
MEMEGYLON :

nigrescens, Engl. Bot. Fahrb. vii. (1886) 338.Kamerun.

nitidulum, Cogn. in DC. Monog. Phan. vii. (1891) 1132. - Guinea.

oblongifolium, Cogn.l. c. 1168. - Madag.

pergamentaceum, $\operatorname{Cogn}$. l.c. 1151. - Borneo.

pulchrum; $\operatorname{Cogn.l.c.1141,-Borneo.~}$

pusilliflorum, Cogn. l.c. 1164. - Ins. Celeb.

rotundatum, Cogn.l. c. - Zeylan.

strychnoides, Baker, in Kew Bull. (I895) 105. - Afr trop. occ.

subreordatum, $\operatorname{logn}$, in DC. Morrog. Phan, vii. (1891) 1164. - Ind. or.

tetrapterum, $\operatorname{Cog} n \cdot e x$ S. Elliot, in fourn. Linn. Sö́ xxix. (1891) 18; et in DC.l. c. 1194. - Madag.

Thwaitesii, Cogn.l. c.1134. - Zeylan.

urceolatum, $\operatorname{Cogn}$. l. c. 1156 (= M. umbellatum,

Thw.). - Zeylan.

violaceum, $\operatorname{Cog} n$. . . c. 1152. - Borneo

zanzibaricum, Taub, in Engl. Pflanzentw. Ost-Afr. C (1895) 296. - Afr. trcp. or.

MEMORA, Miers = Adenocalymma, Mart. (Bignon.).

illamandiflora, Bureau, ex K. Schum. in Eng1. \& Prantl, Natürl, Pflanzenfam. iv. 3b (1894) 225 = Bignonia allamandaeflora, Benth.

axillaris, K. Schum. 1. C. - Bras.

bracteosa, Bureau, ex K. Schum. 1. c. $226=$ Ade nocalymna bracteata, $D C$.

caracasana, K. Schum. 1. c. 225.- Venezuela.

fulgens, Bureau, ex K. Schum. 1. c. 225, - Am austral.

glaberrima, K. Schum. 1. c. = Bignonia glaberrima Cham.

pubescens, K. Schum. 1. c. $226=$ B. fallax, Cham.

valida, K. Schum.. 1. c. 225. - Bras.

MENABEA, Baill. in Bull. Soc. Linn. Paris, ii. (1890) 825. ASCLEFTADEAE

venenata, Baill. l.c. - Madag.

MENDONCIA, Vell. ex Vand. (Acanth.). - Ind Kew. ii. 205 .

Lindavii, Britton, in Mem. Torrey Bot. Club, iv (1895) 241. - Bolivia.

Schwackeana, Lindan, in Bull. Herb. Boiss, iii. (1895) 361. - Bras.

MENTHA, Linn. (Labiat.).- Ind. Kew. ii. 207 acinifolia, Borb. ex .H. Braun, in Verh. zool.-bot. Ges. Wien, xl. (1898) $430=$ verticillata $X$, Linn agraria, H. Braun, 1. c. $470=$ arvensis, Lim. Albae-Carolinae, H. Braun, 1. c. $445=$ arvensis, Linn.

albarracinensis, Pau, Not. Bot. F1.:Espan, i. (1887) 14. - Hisp.

albida, Désegl. \& Th. Dur. ex Briq. Lab. Alp. Marit. i. (1891) 49. in syn. = sylvestris, Limn.

albida. Willd. ex H. Braun, in Verh. zool.-bot

Ges. Wien, xxxix. (1889) 218, in obs.; et xl.

(1890) $395=$ sylvestris, Linn

alpigena, Kern. ex H. Braun, 1. c. $399=$ sylvestris

Linbigua, Wolocz. in Spraw. Kom. fizyj. Krajow xxii. (1888) 11. 207. - Eur.

Amblardii $Y$, Debeaux, in Bull. Soc. Bot. Fr. xxxix. (1892) 154. - Gallia.

amplissima. Strail in Bull. Soc. Bot. Belg. xxvi. $(1887) 133=$ verticillata $\times$, Linn

Andersoniana, H. Braun, in Verh. zool.-bot. Ges Wien, xl. (1890) $484=$ dalmatica $\times$. Tausch. angustata, Opiz, ex $\mathrm{H}$. Braun, 1. c. $422=$ aquatica, Linn.

angustifolia $X$, Corbière, Nouv. Fl. Norm. (1893) 469. - Gall. occ

approximata, Strail, in Bull. Soc. Bot. Belg. xxvi. (1887) $145=$ arvensis, Linn.

approximata,.. H. Braun, in Verh. zonl.-bot. Ges.

Wien, xl. (1890), 452 [an praec.?]= arvensis Linn.

arduennensis, Callay, in Bull. Soc. Dauph. xvi. (1889) 636. - Gall

argutissima. Borb. ex H. Braun, in Verh. zool.-bo Ges. Wien, (1886) $228=$ dalmatioa $X$. Tausch. 


\section{MENTHA}

auryensis, H. Braun, in Verh. zool,-bot. Ges. Wien, xl. (1890) $371=$ villosa $\times$. Huds.

Austiana, H. Braun, in Verh. zool.-bot, Ges. Wien, xl. (1890) $442=$ verticillata $X$, Linn.

Brgutiana, Strail, in Bull. Soc. Bot. Belg. xxvi. (1887) $151=$ arvensis, Linn.

baldensis, H. Braun, in Verh. zool.-bot. Ges. Wien, xl. (1890) $384=$ sylvestris, Limn

balsamifora, $H$. Braun, in Verh. naturf. Ver. Brunn, xxyi. (1888); et 1. c. xxxix. (1889) 43 ; et xl. (1890) $394=$ sylvestris, Linn

Ganatica, H. Braun, l. C. xl. (1890) $403=$ piperita Linn.

Bauhini. "Ten. ") ex Strail, in Bull. Soc. Bot. Belg. xxvi. (1887) $74=$ rotundifolia. Linm.

Beckeri, H. Braun, in Verh. Zool,-bot. Ges. Wien, xl. (1890) $482=$ gentilis, Linn.

belgradensis, H. Braun, 1. c. $443=$ verticillata $X$ Linn.

bihariensis, Borb. in Simonk. Enum. Fl. Transsilv. (1887) 437 ; et H. Braun, Geogr, atq, enum. pl. Comit. Castrif. (1887) 212 ; et in Verh. zool.-bot. Ges. Wiss. Wien, xl. (1890) $48 \%=$ dalmatica $X$. Tausch.

bolzanensis; H. Braun, in Verh. zool.-bot. Ges. Wien, $\mathrm{xl} .(1890) 375=$ villosa $\times$. Huds.

Borbasiana X. Briq. in Bull. Soc. Bot. Genève, y. (1889) 53 = dalmatica $\times$. Tausch.

Borbasiana, H. Braun, in Oest. Bot. Zeitschr. xxxix.(1889) 376, in syn. = arvensis, Linn.

Bommelleri, H. Braun, in Verh. zool.-bot. Ges. Wien, xl. (1890).381.= sylvestris, Linn .

brachystachya, Borb. Arb. Ungar. Naturf, und Aerzte, xx. (1880) 312] ex H. Braun, in Verh. zool.-bot. Ges. Wien, xl. (1890) $410=$ dumetorum $\times$. Schult.

bracteosa, Strail, in Bull. Soc. Bot. Belg. xxvi. (1887) $114=$ verticillata $X$, Linn.

Braini, Oborny, Fl. Mahren, i. (1884) 378; G. Beck, F1. Nied.-Oest, ii. II. (1893) $984=$ dumetorum $\times$, Schult.

brevicomosa, Topitz, ex $H$. Braun \& Topitz, in Deutsche Bot. Monatsschr. xiii. (1895) $171=$ verticillata $\times$, Linn.

bresidentata. Strail, in Bull. Soc. Bot. Belg. xxvi. (1887) $127=$ verticillata $\times$, Linn

breafions, Borbas, ex Briq. in Bull. Soc. Bot. Genève, v. (1889) $91=$ sylvestris, Linn.

brevispicata, Opiz, ex Strail, in Bull. Soc. Bot. Belg. xxvi. (1887) $80=$ sylvestris, Linn.

Brutteleti, Malinv, ex Strail, 1. c, $129=$ revticillata $\times$, Linn.

bulsanensis, H. Braun, ex Ber. Deutsch. Bot. Ges (1891) 164, sphalm. = bolsanensis, H. Braun

calaminthifolia, H Braun, in Verh. zool.-bot. Ges. Wien, xl. (1890) 425 [an praec..?] = aquatica, Linz?.

calaminthacfolia, Dorfler, in Sched. ad cent. xxxi. Herb. norm. (1894) $22=$ aquatica, Linn.

calaminthaefolia. "Host, " ex H. Braun, in Oest. Bot. Zeitschr. xxxvii. (1887) 422 = calaminthoides, $H$, Braunz.

calaminthaeformis, Borb. ex.Briq. in Bull. Soc. Bot. Genève, v. (1889) $55=$ dalmatica $X$ Tausch.

calaminthoides, $\mathrm{H}$. Braun, in Verh. naturf. Ver. Brunn, xxvi. (1887) 119 ; et ex H. Braun, in Verh, zool.-bot. Ges. Wien, x1. (I890) $430=$ rerlicillata $\times$, Linn.

caléescens, H. Braun, 1. c. $480=$ gentilis, Limn.

campicola, H. Braun, 1. c. $456=$ arvensis, Linn.

ardiophyllos, Borb. ex H. Braun, 1. c. $368=$ sylvestris, Limn.

Cornuntiae X, H. Braun, 1. c, 406: G. Beck. Fl, Nied.-Oest. ii. II. (1893) $985=$ dumetorum $X$, Schult.

Ceplaloniae, H. Braun, 1.-c. 493 = M. Pulegium, Linn.

Chaixii, Strail, in Bull. Soc. Bot. Belg. xxvi. (1897) $98=$ aquatica, Linn.

Chrysii. Borb. ex H. Braun. in Verh. zool.-bot. Ges. Wien, xI. $(1890) 481=$ damatica $X$. Tausch.

cinerascens, H. Braun, 1. c, $384=$ dalmatica $\times$, Tausch.

\section{MENTHA}

clinopodiifolia, Hort, ex H. Braun, in Verh. Naturf. Ver.Brunn, xxvi. (1887).121 ; et in Verh. zool. bot. Ges. Wien, xl. (1890) $434=$ ierticillata X, Linn.

caerulescens. Opiz, ex Strail, in Bull. Soc. Bot. Belg. xvi. (1887) $79=$ sylvestris. Linn.

consimilis, Colenso, in Trans. N. Z. Inst. xviii. 1885 (1886) $264=$ M. Cunninghamii, Benth.

crentatifolia, " Opiz, » ex Strail, in Bull. Soc. Bot.

Belo. xxvi. (1887) $123=$ verticillata $X$, Linn.

crenato-dentala, Strail, 1. c. $102=$ aquatica, Linn

cretica, Portenschl, ex H. Braun, in Verh. zool. bot. Ges. Wien, xl. (1890) $390=$ sylvestris, Linn

cyprica, H. Braun, 1. c. xxxix. (1889) $217=$ sylvestris, Linn.

danebialis, Borb. \& H. Braun, 1. c. xl. (1890) 382 $=$ sylvestris, Linn.

densifoliata, Strail, in Bull. Soc. Bot. Belg. xxvi, (1887) $150=$ arvensis, $\operatorname{Linn}$

denticulata, Strail, 1. c, $104=$ aquatica, Linn

distans, H. Braun, ex Formanek, in Verh. Naturf. Ver. Brunn. xxvi. (1887) 205 ; et in Verh. zool. bot. Ges. Wien, xl. (1890) $465=$ arvensis, Limn.

dunensis, Strail, in Bull. Soc. Bot. Belg. xxvi. (1887) 102 = aquatica. Linn.

Durandiona, Strail, 1. c. $124=$ verticillata $\times$, Linn. Durandoana. Malinv, ex Batt. \& Trab Fl. de l'Algér. [Dicot.] (1889) 669; Briq. Lab. Alp. Marit. i. (1891) $72=$ piperita, Linn.

clongata, H. Braun, in Verh. zool.-bot. Ges. Wien, xl. (1890) $424=$ aquatica, $\operatorname{Lin} n$.

Esclifacllevi, H. Braun, 1. c. $439=$ verticillata $\mathrm{X}$ Linn.

exaltata. H. Braun. 1. c. (1890) $417=$ piperita Linn.

Fongliana, $\mathrm{H}$. Braun, 1 c. $484=$ dalmatica $X$. Tausch

flagellifera, Borb. ex H. Braun, 1. c. $409=$ dumetorum $X$. Schult.

flanatica, Borb. ex H. Braun, 1, c. $382=$ sylvestris, Linn

Alexuosa, Strail, in Bull. Soc. Bot. Belg, xxvi (1887) $148=$ arvensis, Linn

florida, H. Bramn, in Verh. zool.-bot. Ges: Wien, xl. (1190) $441=$ arvensis, Linn.

fossicola, H. Braun, 1. c. 457 = arvensis, Linn.

foliticoma, Opiz, ex H. Braun, 1. c. (18s6) $228=$ arvensis, Linn.

Frivaldskiana, Borb. in Termész. Fuzét. xiii. (1890) $78=$ dalmatica $\times$, Tausch

frondosa, Borb. (1879) ex H. Braun, in Verh. zool. bot. Ges. Wien, xl. (1890) $489=$ dalmatica $\times$. Tausch.

gentiliformis, Strail, in Bull. Soc. Bot. Belg. xxvi. (1887) $\mathbf{1 4 4}=$ arvensis, Linn.

Gintliana, "Opiz, » ex H. Braun, in Verh. zool. bot. Ges. Wien, xI. (1890) 459 [err. cal.] = Ginsliana, Opis.

gnaphaliflora, Borb. \& H. Braun, in Oest. Bot. Zeitschr. xxxix. (1889) $376=$ arvensis, Linn.

gracilescens, Opiz, ex Strail, in Bull. Soc. Bot. Belg. xxvi. (1887) $154=$ arvensis, Linn.

grandidentata, Strail, 1. c. 96, = aquatica, Linn.

grazensis, H. Braun, in Verh. zool.-bot. Ges. Wien, xl. (1890) $435=$ verticillata $\times$, Linn. grisella, Briq. in Bull. Soc. Bot. Genève, v. (1889) 93 = sylvestris, Linn.

Hagenbachiana, H. Braun, \& Topitz, in Deutsche Bot. Monatsschr. xiii. (1895) $170=$ dumotorum $\times$. Schult.

haplocalyx; Briq, in Bull. Soc. Bot. Genève; v. $(1889)=$ canadensis, Linn.

hardeggensis. H. Braun in Oest. Bot. Zeitschr. xliii. (1893) $266=$

Haynaldiana, Borb. 1. c. xli. (1891) $60=$ dalmatica $\times$, Tausch

heleogeton, H. Braun, in Verh. zool,-bot. Ges, Wien, xl. (1890) $479=$ gentilis, Linn.

Heleonastes, H. Braun, 1. c. $415=$ verticillata $X$ Linn.

Hsnrici,.Borb. in Oest. Bot. Zeitschr. xli. (1S91) 147, nomen. - Hung.

\section{MTRTA :}

Henffelii, H. Braun, in Verh. zool.-bot. Ges. Wien, xl. $(1890) 404=$ dumetorum $\times$, Schult.

kirtescens, $H$. Braun \& Topitz, in Deutsche Bot. Monatsschr, xiii. (1895) $148=$ piperita, Linn.

lirtiflora, H. Braun, in Verh. zool,-bot. Ges. Wien, xl. (1890) $492=$ M. Pulegium, Linn.

Hollosyana, Borb. in Oest. Bot. Zeitschr. xli. (1891) $146=$ sylvestris, Linn.

hortivaga, H. Braun \& Topitz, in Deutsche Bot. Monatsschr xiii. (1895) $146=$ villosa $\times$. Huds.

Hudsoniana, H. Braun, in Verh. zool.-bot. Ges. Wien, xl. (1890) $402=$ piperita, Linn.

Inmillima, H. Braun, 1. c. $492=$ M. Pulegium, Linn.

ungarica, Borb. in Oest. Bot. Zeitschr. xli. (1891) $318=$ dumetorum $\times$. Schult.

hydrophila, Borb. 1. c. 147 . nomen. - Hung

Hystrix, H. Braun, in Verh. zool,-bot. Ges. Wien, xl. (1890) $426=$ aquatica. Limn.

illyrica, Borb. \& H. Braun, 1. c. $390=$ sylvestris, Linn.

incanescens, H. Braun, 1. c. $377=$ villosa $\times$. Huds. inciso-serrata, Strail, in Bull. Soc. Bot. Belg. xxvi. (1887) 101 ef $168=$ aquatica, Linn.

interrupta, Opiz, ex Strail, 1. c. 112 = verticillata $X$. Linn.

iraziana, Borb, ex H. Braun, in Verh. zool-bot. Ges. Wien, xl. (1890) $485=$ dalmatica $X$. Tausch.

mundata, Opiz, ex Strail, in Bull. Soc. Bot. Belg. xxvi. (1887) $115=$ verticillata $\times$, Linn

isophylla, Borb. ex Pacher, Nachtr. zur Fl. Karnt. (1894) 103. - Form. hort.

fahmiana. H. Braun \& Topitz, in Oest. Bot. Zeitschr. xlv. (1895) 323, nomen. - Austria.

jenensis, H. Braun \& Topitz, in Deutsche Bot. Monatsschr. xiii. (1895) $170=$ dumetornm $\mathrm{X}$. Schult.

jurana, H. Braun, in Verh. zool.-bot. Ges. Wien, xl. (1890) $400=$ sylvestris, Linn.

Furányiana, Borb. in Anal. [Munkalatail medic et nat. scrut. Hung. xxv. (1890) 142; et in Sched. Fl. Austro-Hung. vi. (1893) $52=$ dalmatica $X$, Tausch.

Kitaibeliana, H. Braun. ex Haring, in Verh. zool.bot. Ges. Wien, xxxviii. (1888) 510 ; et xl. (1890) $44 \mathrm{~S}=$ arvensis, Linn.

Kmetiana, H. Braun, 1. c. xl. $473=$ gentilis, Limn. Kotschyana, H. Braun, 1. c. xxxix. (1889) $218=$ sylvestris, $L m n$.

krapinensis, H. Braun, 1. c. x1. (1890) $484=$ dalmatica $X$, Taisch.

hrassoensis, H. Braun, 1. c. $393=$ sylvestris, Linn.

Krockeri, Strail, in Bull. Soc. Bot. Belg. xxvi (1S87) $74=$ rotundifolia, Linn.

Knncii, Borb. Geogr. atq. enum. pl. Comit. Castrif. (1887) $210=$ sylvestris, Limn.

lacerata, "Opiz », ex Strail, in Bull. Soc. Bot. Belg. xxvi. (1887) $87=$ viridis, $\operatorname{Lim}$.

Langiana, Topitz, ex H. Braun, \& Topitz, in Deutsche Bot. Monatsschr. xii. (1894) $148=$ viridis, $L m m$.

late-ovata, Strail, in Bull. Soc, Bot. Belg. xxvi, (1887) $101=$ aquatica, Linn,

latifrons, H. Braun, in Verh. zool.-bot, Ges. Wien, (1890) $378=$ villosa $\times$. Huds

latissima, Strail in Bull. Soc. Bot. Belg. rxvi. (1887) $133=$ verticillala $\times$, Linn

leioneura, Oborny, in Oest. Bot. Zeitschr. xlii. (1892) 186 = sylvestris, Lim.

leiotricha, Borb. 1. c. xli. (1891) 147, nomen. Hung.

leucantha, Borb. ex H. Braun, in Verh. zool.-bot. Ges. Wien, xl. (1890) 381 = sylvestris, Lim.

lcucotricha, Borb. ex H. Braun. 1. c. $408=$ dume tortum $X$, Schult.

levipes, Borb. Geogr. atq. enum. pl. Comit. Castrif. (1887) $212=$ dalmatica $\times$. Tausch.

Libertiana, Strail, in Bull. Soc. Bot, Belg. xxvi. (1887) $119=$ zerticillata $\times$, Linn

ligustrina, H. Braun, in Verh. zool,-bot. Ges. Wien, xl. (1890) $381=$ sylvestris, Lim

imicola, Strail, in Bull. Soc. Bot. Belg. xxvi. (1S8i) $105=$ aquatica, I, inn. 
MENTHA

imnogena, H. Braun, in Verh, zool.-bot, Ges. Wien, xl. (1890) $411=$ dumetorum $\times$, Schult.

limnogeton, H. Braun, ex H. Braun \& Topitz, in Deutsche But. Monatsschr. xiii. (1895) $170=$ dumetorum $\times$, Schult.

limnophila, H. Braun, in Verh, zool.-bot. Ges. Wien, xl. (1890) $406=$ dumetorum $\times$. Schult,

limosa, H. Braun, 1.c. 425 = aquatica, $\operatorname{Linn}$.

lithuanica, H. Braun \& Topitz, in Deutsche Bot. Monatsschr. xiii. (1895) $146=$ villosa $\times$. Huds.

littoralis, Strail, in Bull. Soc, Bot. Belo. xxvi. (1887) 104; et ex H. Braun, in Verh. zool.-bot. Ges. Wien, xl. (1890) $424=$ aquatica, Linn.

Lobliana, H. Braun, 1. c. $415=$ aquatica, Linn.

longibracteata, H. Braun, 1. c. $444=$ arvensis, Linn.

lugosiensis, H. Braun, in Verh. zool.-bot. Ges Wien, xl. (1890) $411=$ dumetorum $\times$. Schult.

macrandria, Borb. ex H. Braun, in Verh. zool.bot. Ges. Wien, xl. (1890) $483=$ dalmatica $\times$ Tausch

macrocephala, Strail, in Bull. Soc. Bot. Belg. xxvi. (1S87) 103 = aquatica, Linn.

macrostemma, Borb. ex H. Braun, in Verh. zool.bot. Ges. Wien, x1. (1890) $397=$ dalmatica $X$, Tausch.

Malinetaldi, Arasse, ex Briq. in Bull. Soc, Bot. Genêve, v. (1889) 78 = viridis, Linn.

Malinataldi X, G. Camus, in Bull. Herb. Boiss. i. Appand. i. (1893) 191 [an praec.?] = carinthiaca $\times$, Host.

Malyi, H. Braun, in Verh. zool.-bot. Ges. Wien, (1890) $3 r 0=$ villosa $\times$, Huds.

marchica, $H$. Braun, 1. c. $405=$ dumetorm $X$, Schult.

marisensis, Simonk. in Termész. Füzet. ix. (1885) $24=$ sylvestris Linn.

mellifuens, H. Braun \& Topitz, in Deutsche Bot. Monatsschr. xiii (1895) $147=$ sylvestris, Limn.

microcephala, Strail, in Bull. Soc. Bot. Belg. xxvi. (1887) 106 et $168=$ aquatica. Linn.

micropliylla, H. Braun. in Verh, zool.-bot. Ges. Wien, x1. (1S90) $492=\mathrm{M}$. Pulegium, Linn

minoriflora; Borb. ex H. Braun, 1. c. $421=$ aquatica, Linn.

minutiflora, Borb. in Bot. Centralbl. xxv. (1886) 239 ; et in Sched. Fl. Austro-Hung. v. (1888) 55 = sylvestris, Linn.

mosoniensis $X, H$. Braun, in Verh. zool.-bot. Ges Wien, xl. (1890) 373 ; G. Beck, Fl. Nied..Oest, ii. II. (1893) $982=$ villosa $\times$. Huds.

Morii, H. Braun \& Topitz. in Deutsche Bot. Monatsschr. xiii. (1894) $169=$ dumetorum $\mathrm{X}$. Schult.

nederheimensis, Strail, in Bull. Soc. Bot. Belg. xxvi. (1887) $95=$ aquatica, Limn.

Veilreichiana, H. Braun, in Verh, zool.-bot. Ges. Wien, xl. (1890) $393=$ sylvestris, Linn.

nemophila, H. Braun, 1. c. $404=$ dumetorum $X$ Schult.

nemorivaga, H. Braun \& Topitz, in Deutsche Bot. Monatsschr. xiii. (1895) $169=$ dumetorum $X$ Schult.

Vicholsoniana, Strail, in Bot. exch. Club. Brit. IsI. Rep. for $(1890) 30 \%=$ sylvestris, Linn.

norica, H. Braun, in Verh. zool.-bot. Ges. Wien, xl. $(1890) 398=$ sylvestris, Linn.

madiceps, Borb, in Termész. Füzet xiii. (1890) 79 ;

H. Braun, 1. c. 414: et in Kern.Sched. Fl. Austro-Hung. vi. (1893) $50=$ verticillata $\lambda$, Linn.

oblongifrons, Borb. ex H. Braun, in Verh. zool.bot. Ges. Wien, x1. (1890) 447 et $451=$ verticillata $X$, Linn.

oblongifolia, Strail, in Bull. Soc. Bot. Belg. xxvi. (1887) 75 et $168=$ rotundifolia, Lins .

obtuse-crenatoserrata, Strail, 1. c. $131=$ verticillata $X$ Linn.

orbiculata, Strail, 1, c, $130=$ verticillata $\times$, Linn.

pachystachya, Timb. \& Marcais, in Bull. Soc. sci.

phys. et nat. Toul. vii. $(1888)=$ rotundifolia, Linn.

pallescins, H. Braun, in Verh. zool.-bot. Ges. Wien. x1. (1890) $391=$ sylvestris, Lim .

Pancicii, H. Braun, 1. c. $489=$ dalmatica $\times$, Tausch.

\section{MENTHA}

pannonica, Borb. ex H. Braun, in Verh. zool.-bot Ges. Wien, xl. (1890) $425=$ dumetorum $\times$ Schult.

panormitana, H. Braun, 1. c, $397=$ sylvestris, Linn,

parietariaefolia, «Beck, " ex Strail, in Bull. Soc. Bot. Belg. xxvi. (1887) 141; K. Richt in Verh. zool.-bot. Ges. Wien, xxxvi. (1886) $226=$ arvensis, Linn.

pauciflora $\times$. Figert, in Deutsche Bot. Monatsschr. vii. (1889) 11 = gentilis, Linn.

Peisonis, H. Braun, in Verh. zool.-bot. Ges. Wien, x1. $(1890) 406=$ dumetorum $\times$. Schult

peracuta. Borb. Geogr. atq. enum. pl. Com. Castref (188\%) 212; et ex H. Braun, 1. c $486=$ dalmatica X, Tausch.

perdentata, H. Braun, 1. c, $472=$ gentilis, Linn.

pergracilis, H. Braun, 1 c, 473 = gentilis. Lim.

petiolata, Wirtgen, ex H. Braun, 1. c. $3: 1=$ sylvestris, Linn.

phyllostachya, Borb. ex H. Braun, 1. c. $488=$ dalmatica $\times$. Tausch.

Piersiana, Borb, in Oest.-Bot. Zeitschr, xl. (1890) $244=$ arvensis. Limn

Pireana, Strail, in Bull. Soc. Bot. Belg. xxvi. (1887) $105=$ aquatica, Limn.

posoniensis, H. Braun, ex H. Braun \& Topitz, in Deutsche Bot. Monatsschr, xiii. (1895) $146=$ villosa $\times$, Huds.

Pseudopiperitu, H. Braun, in Verh. zool.-bot. Ges. Wien, xl. (1890) $420=$ aquatica, Linn.

Pseudostachya, Strail, in Bull. Soc. Bot, Belg, xxvi (1887) $113=$ verticillata $入$, Linn.

pulegiformis, H. Braun, in Verh. zool.-bot. Ges. Wien, xl. (1890) $466=$ arvensis, Linn.

pulverulenta, Strail, in Bull. Soc. Bot. Belg. xxvi (1887) $78=$ villosa $\times$. IIuds.

pycnotricha, Borb. ex H. Braun, in Verh. zool.-bot. Ges. Wien, xl. (1890) $486=$ dalmatica $\times$, Tausch

pyrenaica, $H$. Braun, 1. c. $491=$ carinthiaca $X$ Host.

pyrifolia, H. Braun, 1, c. $420=$ aquatica, Linn.

pyrifolia, A. Kern, Sched. Fl. Austro-Hung, vi (] 893$) 50=$ aquatica, Linn.

quadica, H. Braun, in Oest. Bot. Zeitschr, xliv. (1894) $206=$ carinthaca $\times$, Host.

ramosissima, H. Braun, in Verh. zool.-bot. Ges. Wien, x1. (1890) $491=$ carinthiaca $X$, Host.

ramosissima, Strail, in Bull. Soc. Bot. Belg. xxvi (1887) $97=$ aquatica, Linn.

recedens, H. Braun. in Verh. zool.-bot. Ges. Wien, xl. $(1890) 453=$ arvensis, $\operatorname{Linn}$

Reissekii. H. Braun, in Oest. Bot. Zeitschr. xliv (1894) 112, nomen, et $204=$ carinthiaca $X$, Host retinervis, Borb. ex $\mathrm{H}$. Braun, in Verh. zool.-bot Ges. Wien, x1. (1890) 382 = sylvestris, Limn.

Reverchonii X, Briq. in Bull. Soc. Bot. Genève, v (1S89) $6 \%$ - Creta

rhenana, Topitz, ex H. Braun \& Topitz, in Deutsche Bot. Monatsschr. xiii. (1895) $146=$ villos $\mathrm{X}$ Huds.

rhomboidea, Strail, in Bull. Soc. Bot. Belg. xxvi. (1 87) $118=$ ierticillata $\times$, Linn.

Richtevi, Borb. ex H. Braun, in Verh, zool.-bot. Ges. Wien, $(1890) 385=$ sylvestris, $\operatorname{Linn}$.

rigida, Strail, in Bull. Soc. Bot. Belg. xxvi. (1887) $157=$ arvensis, $\operatorname{Linn}$

Rigoi, H. Braun, in Verh. zool.-bot. Ges. Wien, x1. (1s90) $366=$ villosa $\times$, Huds.

Rocheliana, Borb \& H. Braun, 1, c. $384=$ sylves tris, Linn.

rubescens, Topitz \& H. Braun, in Deutsche Bot. Monatsschr. xiii. (1895) $171=$ verticillata $X$ Linn.

mbicunda, H. Braun \& Topitz, 1. c. 147 = viridis, Linn.

sciaphila, H. Braun, in Verh. zool.-bot. Ges. Wien, x1. $(1890) 432=$ verticillata $\times$. Linn.

sepincola, Holuby, Pf. Temesiner Comit. (18S8) 74 = laciniosa, Schur.

seriata, A. Kern. ex H. Braun, in Verh. zool.-bot. Ges. Wien, xl. (1890) $386=$ sylvestris, Limn.

silvicola, H. Braun. 1. c. $459=$ arvensis, Linn.

similata, Strail, in Bull. Soc. Bot. Belg. xxvi.(1887) $116=$ verticillata $\times$, Linn
MENTHA

Solcana, Strail, in Bull. Soc. Bot. Eelg. xxvi. (1887) $100=$ aquatica, Linn.

sparsiflora, H. Braun, in Verh, naturf. Ver. Brunn. (1887) 203; et in Verh, zool,-bot. Ges. Wien, xl. (1890) $449=$ arvensis, $\operatorname{Linn}$

speciosa, Strail, in Bull. Soc. Bot. Belg. xxvi. (1887) 71 = sylvestis, Linn

sphaerostachya, Haussm. ex $\mathrm{H}$. Braun, in Verh. zool.-bot. Ges. Wien, xl. (1890) $407=$ sylvestris, I.imn.

sphakophylla, H. Braun, ex H. Braun \& Topitz, in Deutsche Bot. Monatsschr. xiii. (1895) $170=$ dumetorum $X$, Schult.

Steffekiana, Borb. \& Waisb, in Oest. Bot. Zeitschr. xlv. $(\mathbf{1 8 9 5}) \mathbf{1 1 0}=$ gentilis, Lim .

stenantha, Borb, ex H. Braun, in Verh, zool-bot. Ges. Wien, xl. (1890) $385=$ sylvestris, Linn.

stenostachya, A. Richt, in Termész. Füzet. xii. (1889) 186 t. $7=$ sylvestris, Linn.

stenotricha, Borb. 1. c. ix. (1883) 34; H. Braun, in Verh. zcol.-bot Ges. Wien, xl. (1890) $393=$ sylvestris, Linn

suaviflora, H. Braun, in Oest. Bot. Zeitschr. xli. (1891) 318; et ex Ber. Deutsch. Bot. Ges. (1891) $156=$ seq.

sarifolia, H. Braun, in Verh. zool.-bot. Ges, Wien, x1. (1890) $486=$ dalmatica $\times$. Tausch.

suavis X. Pau, Not. Bot. Fl. Espan. i. (1887 37 ; et ii. (1889) 14 ; Willk. Suppl. Prodr. F1. Hisp. (1893) 326. - Hisp

subartensis $\times$. Simonk. Enum. Fl. Transsilv. (1886) $438=$ dalmatica $\times$, Tausch

subgentilis, H. Braun, in Verh. zool.-bot. Ges. Wien, xl (1890) $4 \% 2=$ gentilis, Linn.

subincana, H. Braun, 1. c. $367=$ sylvestris, Linn.

sublanata, H. Braun, 1. c. $451=$ arvensis, Linn.

submollis, H. Braun, 1. c. $466=$ carinthiaca $X$ Host.

ubreversa, Simonk. Enum. Fl, Transsilv, (1886) $438=$ dalmatica $\times$. Tausch.

subrotunda, Schur, ex H. Braun, in Verh. zool.bot. Ges. Wien, xl. (1890) $470=$ arvensis, Linn.

subsessilis, Borb. in Oest, Bot. Zeitschr. xxx. (1880) 20, nomen; et Geogr. atq. enum. pl. Comit. Castrif. (1887) $210=$ sylvestris, Linn.

subtomentella. H. Braun, in Verh. zool,-bot. Gès. Wien, x1. (1890) $492=$ M. Pulegium, Limn.

subtomentosa Strail, in Bull. Soc. Bot. Belg. xxvi (1887) $159=$ carinthiaca $\times$, Host

subundulata, Borb. [in Természettud. Közlöny (1891) 500] ex Oest. Bot. Zeitschr. xli. (1891) $413=$ $=$ gentilis, Linn

subviridis, Borb. ex H. Braun, in Verh. zool.bot. Ges. Wien, x1. (1890) $388=$, sylvestris, Limn.

syrmiensis, Borb. ex H. Braun, 1. c. $383=$ sylvestris, Linn.

Szenezyana, Borb. Geogr. atq. enum. pl. Corn. Castrif. (1887) 211 ; et ex H. Braun, 1. c. $368=$ sylvestris, Linn

Szilyana, Borb. in Masy. ory, termd, munk, xxy. (1891) 492 ex Oest. Bot. Zeitsch. xli. (1891) 182 $=$ sylvestris, Limn.

Tauschii, H. Braun, in Holuby, Pfl. Trenesiner Comit. (1888) $74=$ laciniosa. Schur.

tenuicaulis, Strail, in Bull. Soc. Bot. Relg. xxvi. (1887) $150=$ arvensis, Linn.

tlayana, H. Braun, in Verh. zool.-bot. Ges, Wien, x1. (1890) $444=$ arvensis, Limm.

triemarginata, Strail, in Bull. Soc. Bot. Belg. xxvi. (1887) $159=$ carinthiaca $\times$. Host.

rojana, H. Braun, in Verh. zool -bot. Ges. Wien, xl. $(1890) 426$ = aquatica, Linn.

uligmosa, Strail, in Bull. Soc. Bot. Belo. xxyi. (1887) $\mathbf{1 5 5}=$ arvensis, Limm

valdepilosa, H. Braun, in Verh. zool.-bot. Ges Wien, xl. (1890) $431=$ verticillata $X$, Linn.

Van Haesendoncki; Strail; in Bull. Soc. Bot. Belg, xxvi. (1887) $154=$ arvensis, Linn.

veneta. H. Braun, in Verh. zool.-bot. Ges, Wien, xl. $(1890) 366=$ villosa $\times$. Huds.

cerisimilis, -Strail, in Bull. Soc. Bot. Belg', xxvi, (1887) $142=$ arvensis, Limn. 


\section{MENTHA}

inacer, H Braun, in Verh, zool.-bot. Ges. Wien, xI. $(1890) 433=$ verticillata $X$, Linn.

sirgata, H. Braun, 1. c. $48 ?=$ dalmatica $\times$, Tausch

vividescens, Borb. [Bekesvarm. Floraja (1881) 74] ex H. Braun, 1. c. $389=$ sylvestris, Linn

viridior, Borb, [Fl. Comit. Temesiensis (1884) 46]

ex H. Braun, 1. c. $409=$ dumetorum X. Schult

Weinerniana, Opiz, ex Strail, in Bull. Soc. Bot. Belg. xxvi. (1887) 81 ylvestris, Linn.

Wiesbauri, H. Braun, in Verh. zool.-bot. Ges. Wien, xl $(1890) 481=$ dalmatica $\times$. Tausch

abichlicensis, Opiz, ex H. Braun, 1. c. 435 verticillata $X, \operatorname{Linn}$

MENTZELIA, Plum. ex Linn. - Ind. Kew, ii. 210.

affinis, Greene, Pittonia. ii. (June 1890) 103 ; et Man Bot. San Franc. Bay (1894) 141. - Calif.

arborescens, Urban \& Gilg, in Engl. E Prantl, Natürl. Pfanzenfam. iii. 6a (1894) 110.-Mexic

aurea, Baill. ex Urban \& Gilg, l. c. 111 (= Chry sostoma aurea, Lilja). - Calif

bartonioides, Urban \& Gily, 1, c, $110(=$ Acrolasia bartonioides, Presl) = albicaulis, Dough.

cordobensis, Urban \& Gilg, ex F. Kurtz, in Revista Mus. La Plata, v. (1S93) 289. - Reg. Argent.

decapetala, Rusby, in Mem. Torrey Bot. Club, (1894) $229=$ ornata, Torr, \& Gray.

decrpetala, Urban \& Gilo, in Engl. \& Prantl, Natürl. Pflanzenfam. iii. 6a (1894) $111=$ ornata. Torr, of Gray.

Fendleriana, Urban \& Gilg, ex Rusby, in Mem. Torrey Bot. Club, iii. 3 (1893) 34. - Bolivia.

ignea, Urban \& Gilg, in Engl. \& Prantl, Natürl. Pfanzenfam. iii. 6a (1894) 110. - Chili, Peruvia.

Nelsonii, Greene, in Ervthea, iii. (1895) 70. - Wyoming.

nitens, Greene, Fl. Francisc. (1891) 234. - Calif

parvifolia, Urban \& Gilg, ex F. Kurtz, in Revista Mus. La Plata, v. (1893) 289 [Sert. Cordob. 11]. - Reg. Argent.

polyantha, Urban, \& Gilg. in Engl. Es Prantl, Natïrl. Pflanzenfam. iii. 6a (1894) 110. - N. Granat.

reflexa, Conille, in Proc. Biol. Soc. Wash. vii. (1892) 74 ; et in Contrib. U.S. Nat. Herb.iv. (1893) 108 t. 9. - Calif.

Solierii, Urban \& Gilg, in Engl. \& Prantl. Natür. Pflanzenfam. iii. 6a (1894) 110 (= Acrolasia Solierii, C. Gay). - Chili.

MEPHITIDIA, Reinw. = Lasianthus, Jack (Rubiac.).

Balansae, Drake, in Morot, Journ, de Bot. ix. (1895) 238. - Tonk

baviensis, Drake, 1. c. 239. - Tonk.

hispidula, Drake, 1. c. - Tonk.

langkokensis, Drake, 1. c. 240. - Tonk

tonkinensis, Drake, 1. c. - Tonk.

MERANTHERA, Van Tiegh. in Bull. Soc. Bot. Fr xlii. 1895 ) $356=$ Loranthus, Einn

Collum-cycni, Van Tiegh. 1. co (= Psittacanthus Collum-cycni, Eichl.).-Am, trop.

corynocephala, Van Tiegh. 1. C. $(=P$. corynocephalus, Eichl.). - Bras.

eucalyptifolia, Van Tiegh.1.c. = Loranthus eucalyptifolius, $H . B$. \& $K$.

MERGURIALIS [Tourn.] Linn.(Euphorb.). Ind. Kew, ii. 211.

Bichei $X$, Magnier, Scrin fl, select vi. 118 et in Nym. Consp. Fl. Eur. Suppl. ii. (1889) 274. - Gall.

Reverchoni, Rouy, in Le N'aturaliste (1887) 199; et in Bull. Soc. Bot. Fr. xxxiv. (1887) 441; Debeaux Syn.Fl. Gibralt. 185. - Gibralt.

MERENDERA, Ram. 'Liliac.). - Ind. Kew. ii. 212.

atlantica, Chab. in Bull. Soc. Bot. Fr. xxxvi. (1889) 319 , in syn. = filifolia, Cambess.

jordanicola, Regel, in Act. Hort. Petrop. xi. (1891) 476. - Palaest.

\section{MERENDERA}

kurdica, Bornm, in Mitth. Thur, Bot, Ver, N. Folge vii. (1895) 7 , nomen. - Oriens

rhodopea, Velen, in Sit\%. Boehm. Ges. Wiss. 1892 (1893) 66. - Bulg

sobolifera, Hort. ex Baker, in Gard. Chron. (1890)

i. $192=$ Colchicum procurrens, Baker.

MERIANIA, Sw. (Melast.). - Ind. Kew. ii. 214 boliviensis, Cogn. in Bull. Torrey Bot. Club, xvii (1890) 58; et in DC. Monog. Phan. vii. (1891) 428. - Bolivia.

Candollei, $\operatorname{Cogn}$. l. c. 425. - N. Granat.

cordifolia, Cogn. l. c. (= Schwerinia cordifolia Karst.). - N. Granat

dentata, Cogn. l. c. 434. - Bras

excelsa, Cogn。 in Mart. Fl. Bras. xiv. IV. (1886) 28 (= Davya excelsa, Gardn.); et in DC. Monog. Phan. vii. (1891) 435. - Bras.

Glazioviana, $\operatorname{Cog} n . l l . c c .30$; et 434 . - Bras.

Kraenzlini, Cogn. in Bot. Jahrb. viii. (1887) $19=$ nobilis, Triana

Lindenii, Cogn. in DC. Monog. Phan, vii. (1891) 427. - N. Granat.

ongifolia, Cogn,l.c.426 (= Chastenaea longifolia Naud.) - Am austr. occ.

oblongifolia, Cogn. l. c. 429. - Ecuad. vel Peruvia? pergamentacea, Cogn. l. c. 432. - Bras

robusta, $\operatorname{Cog} n$ 。 in Mart. Fl. Bras. xiv. IV. (1888) 605 ; et l. o. 432. - Bras.

Sipolisii, Glaziou of Cogn. in DC. Monog, Phan. vii. (1891) 1182. - Bras.

Spruceana, $\operatorname{Cog} n$.l. c. 426.- Peruvia.

subumbellata, Cogn. l. c. 430 . - Venezuela

Trianae, Cogn, in Bot. Fahrb. viii. (1888) 19; et l. c 424 (= Schwerinia Trianae, Karst.). - N. Granat.

MERIDIANA, Hill. = Gazania, Gaertn. (Compos.) canescens, coronopifolia, heterochaeta, jurineaefolia. Kraussit, Krebsiana, leptophylla, Lichtensteinii. lineariloba, longifolia, longiscapa, mucronata, nivea, Othnnites, oxyloba, Pavonia, pinnata, pygmaea, serrulata, subbipinnata, tenuifolia, uniflora, Kuntze, Rev. Gen. (1891) 353 = homonyma omnia Gazaniae.

arctotodes, Kuntze 1, c. $=\mathrm{G}$, arctotoides, Less,

armeriodes, Kuntze, $1, c_{0}=\mathrm{G}$. armerioides, $D C$.

Echinus, Kuntze, 1. c. $353=\mathrm{G}$. Burchellii, DC.

linearis, Kuntze, 1. c. $=\mathrm{G}$. subulata, $R . B r$.

ringens, Kuntze, 1. c. $352=\mathrm{G}$. rigens, Mocnch

MERIOLIX, Rafin. = Oenothera, Linn. (Onagrar.).

spinulosa, Heller, in Contrib. Herb. Frankl. and Marsh. Coll. i. (1895) 70 [Bot. Expl. S. Tex.] = Oe. spinulosa, Nutt.

MERISMA. Van Tiegh, in Bull. Soc. Bot. Fr. xlii. (1895) $361=$ Loranthus, Linn.

clusiffolia, Van Tiegh. 1. c.=I. clusiifolius, Willd.

MEROSTELA, Pierre, Fl. For, Cochinch. Fasc. 21 (1895) sub t. $334=$ Aglaia, Lour. (Meliac.).

grandis, Pierre, 1. c. = A. grandis, Korth

MERREMIA, Dennst. = Convolvulus, Tourn. (Convolv.)

alatipes, Dammer, ex Engl. in Abh. Preuss. Akad Wiss. (1894) 28 ; et in Pflanzenw. Ost-Afr. C (1895) 330. - Afr. trop. or

ampelophylla, Hallier $\mathrm{f}$, in Bot. Jahrb. xviii. (1894) 115. - Afr. trop. or.

angustifolia, Hallier f. 1. c, xvi. (1893) 552; et xviii. (1896) $117=$ Ipomoea angustifolia, facq. aturensis, Hallier t. in Engl. 1. c. xvi.(1893) $552=$ I. aturensis, G. Don

bipinnatipartita, Hallier f. 1. c. xviii. (1894) $115=$ I. bipinnatipartita, Engl.

calycina, Hallier f. 1. c. xvi. (1893) $552=$ I. calycina, Meissn.

chrysoides, Hallier f. l. c. = I. chrysoides, KerGanl.

cissoides, Hallier f. 1. c. = I. cissoides, Griseb. contorquens, Hallier f. 1. c. = I. contorquens, Cloisy.
MERREMIA : -

Davenporti, Hallier fo in Bot, Jahrb. xvi. (1893) $552=$ I. Davenporti, F. Mull

digitata, Hallier f. 1. c.=Gerardia digitata, Spreng dissecta, Hallier f. 1. c. ; et xviii. (1894) $114=$ Ipomoea dissecta, Pers.

emarginata. Hallier f. 11 . cc. 552 ; et $118=$ I. reniformis, Choisy.

ericoides, Hallier f. 1. c. $552=\mathrm{I}$. ericoides, Meissn gallabatensis. Hallier f. 1. c. = I. gemella, Choisy. glabra. Hallier f. 1. c. ; et xviii. (1894) $116=\mathrm{I}$ glabra, Choisy.

Guerichiana, Hallier f. 1. c. 115 . - Afr. trop.

hastata, Hallier f. 1. c. xvi. (1893) 552; et xviii (1894) $117=$ Convolvulus hastatus, Desr.

hedevaced, Hallier f. 1. c. $118=$ Evolvulus hederaceus, Burm.

maypurensis, Hallier f. 1. c. xvi. (1893) 552. - Bras.

Medium, Hallier f. 1. c. ; et xviii, (1894) $118=$ Aniseia Medium, Choisy.

multisecta, Hallier f. 1. c. 115. - Angola.

palmata, Hallier f. 1. c. 112. - Afr. austro-occ. extratrop.

pedata, Hallier f. 1. c. xvi. (1893) 552 ; et xviii. (1894) 116 = Ipomoea pedata, Hochst. E Steud.

pentaphylla. Hallier f. 11. cc. 552 ; et $115=$ Batatas pentaphylla, Choisy.

pinnata, Hallier f. 11. cc. 552 ; et $116=$ Ipomoea pinnata, Hochst.

potentilloides, Hallier f. 1. c. $552=$ I. potentilloides, Meissn.

pterygocaulos, Hallier f. 11. cc. 552 et $113=$ I. pterygocaulos, Choisy.

quercifolia, Hallier f. 1. c. 114. - Angola.

quinquefolia, Hallier f. 1. c. xvi. (1893) $552=$ I. quinquefolia, Linn.

rhynchorvhiza, Hallier f. 1. co = Ipomoea rhyncorhiza, Dalz.

retusa, Hallier f. 11 . cc. 552 et $117=\mathrm{I}$, retusa, E. Mey. Riedeliana, Hallier f.1. c. $552=$ I. Riedeliana, Oliver. sibivica, Hallier f. 1. c. = I. sibirica, Pers.

spongiosa, Rendle, in Journ. Bot. xxxi. (1894) 179. - Angola.

tomentosa, Hallier f. in Bot. Jahrb. xvi. (1893) 552 $=\mathrm{I}$. tomentosa, Choisy.

tridentata, Hallier f. 1. c. xvi. (1893) 552 ; et xviii. (1894) $116=$ I. tridentata, Roth.

umbellata, Hallier f. 11 . cc. 552 et $114=$ I. umbellata, E. Mey.

vitifolia, Hallier f. 1. c. $552=$ I. vitifolia, Sweet

xanthophylla, Hallier f. 1. c. 552 ; et $113=1$. xanthophylla, Hochst.

MESEMBRYANTHEMUM, Dill, ex Linn. (Ficoid.). - Ind. Kew. ii. 214

abyssinicum, Pax, ex Engl. in Abh. Preuss Akad. Wiss. ii. 1891 (1892) 208 [an $M$. abyssinicum, Regel ?. - Abyss.

Barklyi, N. E. Br. in Hook. Icon. pl. xix. (1889) t. 1820.-Afr. austro-occ, extratrop.

Brownii, Hook. f. in Bot. Mag. (1888) t. 6985 . Afr, austr.

Guerichianum, $P a x$, in Bot. Fahrb. xix. (1894) 1333 - Afr austro-occ. extratrop.

Marlothii, Pax. l. c. x. (1889) 13. - Afr, austroocc. extratrop.

salicornioides, Pax, l. c. xix, (1894) 133. - Afr. austro-occ. extratrop.

MESOGYNE, Engl. Bot. Jahrb. xx. (1894) $11 \%$. URTICEAE

Henriquesii, Engl. l. c. 148. - Ins. S. Thom.

insignis, Engl. in Abh. Preuss: Akad. Wiss. (1894, 44 ; et l. c. - Afr. trop. or.

MESONA, Blume (Iabiat.). - Ind. Kew. ii. 21 procumbens, Hemsl. in Ann. Bot. ix. (1895) 155 t. 7 . - Formosa.

prunelloides, Hemsl. in fourn. Linn. Soc. xxri. (1890) 267. - China.

MESONEPHELIUM, Pierre, Fl. For, Cochinch, Fasc, 21 (1895) sub t. $321=$ Nephelium. Linn. (Sapind.).

cochinchinense, Pierre, 1. c. in syn. - Cochinch. 
MESOPHAERUM, Kuntze, Rev, Gen.(1891) 516, $525-26$, sphalm. $=$ seq.

MESOSPHAERUM, P. Br. = Hyptis, Jacq. (Labiat.)

actinocephalum, adamantium, adpressum, affure, albidum, albipes, alpestre, altheaefolium, altissimum, alutaceum, ammotrophum, angulosum, angustifnlium, araripense, arboreum, aristatum, atrorubens, barbatum. Besckeanum, brachyphyllum, brachystachyzm, brevipes, brunnescens, caespitosum, calidum, calophyllum, calycinum, campanulatum, camporum, canescens, canum, capitatum, caprariaefolium, cardiophyllum, carpinifolium, clavelliferum, coccineum, coeruleum. complicalum, concinnum, confertum, conspersum, coriaceum, corym bosum, crassifolium, crenatum, crinitum, crispatim, cuneatum, cymulosum, densiflorum, densifolium, dictiocalyx, dilatatum, divaricatum, diversifolium, dubium, dyctiodeum, elongatum, Emeroyi, eriocalyx, eviocephalum, eriophyllum, excelsum, expansum, ferrugineum, ferruginosum. floridum, foliosum, fragilifolium, fruticosum, glaucum, glutinosum, gonocephalum, goyazense, halimifolium, heteranthum, heteroplyllum, Hilarii, hirsutum, hispidum, homalophyllum, humile, hypoleucum, imbricatum, inamoenum, incisum, interruptum, involucratum, irregulare, Itatiaiae, laciniatum, lacunosum, lacustre, lagenarium, lamiifolium, lanatum, lanceolatum, laniflorum, lappaceum, latifolium, laurifolium, lavandulaceum, laxiflorum, leptocladum, leucocephalum, leucophyllum, lilacinum, lobatum, longifolium, longipes, lophanthus, Lorentzianum, lucidum, Lundii, lutescens, macranthum, macrocephalum, macrostachyum, malacophyllum, marginatum, marifolium, melanostictum, membranaceum, microphyllum, minutiflorum, Mocinianum, molle, mollissimum, monticolum, multibracteatum, multiflorum, nervosum, nicaraguense, nigrescens. nitidulum, mudicaule, oblongifolium, obtectum, obtusatum, obtusiflorum, obvallatum, odoratum, orbiculare, ovGlifolium, ovatum, paludosum, paniculatum, Parkeri, passerinum, pauciflorum, pectinatum, pedalipes, pedunculare, petiolare, petraeum, pilosum, platanifolium, plumosum, polyanthum, pruinosum, pubescens, Purdiaei, pycnocephalum, racemulosum, vadiatum, ramosum, recurvatum, reflexum, rhabdocalyx, rhytideun, rigidum, rotundifolium, rubicundum, rubiginosum, rugosum, salicimum, salviaefoitum, saxatile. scabrum, selaginifolium, sericeum, Sideritis, simplex, spicigenum, spinulosum, spireaefolium, stellulatum, strictum, suaveolens, subrotundum. subcerticillatum, sylvularum, Tafallae, tephrodes, tetragonum, tomentosum. tricephalum, uliginosum, uncinatum, velutinum; vepretorum, verticillatum, resiculosum, vestitum, viejense, villosum, virgatum, viscidulum, vitifolium, vulcanicum, xanthiocephalum. Kuntze, Rev. Gen. (1891) 516, 525-26= homonyma omnia Hyptidis.

americanum, Kuntze, 1. c. $525=$ H. scoparia, Poit. ammotrichum, Kuntze, 1. c. $=\mathrm{H}$. ammotropha Griseb.

ametlystodes, Kuntze, 1, c. $526=\mathrm{H}$. amethystoides, Benth.

argutum, Kuntze, 1. c. $=$ H. rugosa; Benth. aridum, Kuntze, 1. c. $525=\mathbf{H}$. violacea, Pohl. asterodes, Kuntze, 1. c. = H. asteroides, St. Hil.

Blanchetii, Kuntze, .. c. $=$ H. Blancheti, Benth.

brasiliense. Kuntze, 1. c. $=$ H. Gaudichaudii, Benth.

Claussenii, Kuntze, 1. c. = H. Clausseni, Benth.

cordatum, Kuntze, 1. c. = H. cordata, Pohl.

crîcaulodes, Kuntze, 1. c. sphalm. = H. eriocauloides, A. Rich.

ditassodes, Kuntze, 1. $\mathrm{c} .=\mathrm{H}$. ditassoides, Mart.

fasciculatum, Kuntze, 1. c. 516 (= Clinopodium verticillatum, Vell.). - Bras.

tastigiatum, Kuntze, 1.c. $526=$ Hyptis fasciculata Benth.

glechomodes, Kuntze, 1. c. = H. glechomoides, Weinm.

gratiolifolium, Kuntze, 1. $\mathrm{c} .=\mathrm{H}$, gratiolaefolia St. Hil.

graveolens, Kuntze, 1. c. $=$ H. umbrosa, Salzm.

inodorum, Kuntze, 1. c. $525=$ H. muricata, Schott.

lappulaceum, Kuntze, 1, c. $526=\mathrm{H}$. lappacea, Benth.

latanifolium, Kuntze, 1. с. $525=\mathrm{H}$. lantanaefolia, Poit.

linariodes, Kuntze, 1. c. $526=$ H. linarioides, Pohl. lippiodes, Kuntze, 1. c. = H. lippioides, Pohl.
MESOSPHAERUM : -

longiflorum, Kuntze, Rev. Gen. (1891) $525=\mathrm{H}$. reticulata, Mart.

lythrodes, Kuntze, 1. c. $526=$ H. lythroides, Pohl. marrubiastrum, Kuntze, 1. c. $525=\mathrm{H}$. sinuata, Pohl.

Martinsii. Kuntze, 1. c. $526=\mathrm{H}$. Martiusi, Benth. melissodes, Kuntze, $l_{0} \mathrm{c}_{0}=H_{\text {. melissoides, } H . B}$. \&

melochiodes, Kuntze, 1. co $=$ H. melochioides, St. Hil. menthodorum, Kuntze, 1. c. = H. lophantha, Mart. mutabile. Kuntze, 1. c. = H. spicata, Poit.

oppositifolium, Kuntze, 1. c. $525=\mathrm{H}$. glomerata. Mart

plectranthodes, Kuntze, 1. c, = H. plectranthoides Benth.

pulegiodes, Kuntze, 1. c. $526=\mathrm{H}$. pulegioides, $P$ ohl . pumilhm, Kuntze, 1. c, $525=\mathrm{H}$. communis, St. $H$ il .

rhombodent, Kuntze, 1 c $597-1$ rhomboideum Mart. \& Gal.

salvioides, Zahibr, in Annal. Naturh. Hofmus. Wien, vii. (1892) 9. - Peruvia.

Salzmannit, Kuntze, Rev. Gen. (1891) $527=\mathrm{H}$. Salzmanni, Benth

Sellowii, Kuntze, 1. c。 = H. Selloi. Benth

turnerifolium, Kuntze, 1. c。 = H. turneraefolia, Mart.

Tweedii, Kuntze, 1. c. = H. Tweediei, Benth.

undulatum, Kuntze, 1, c. $525=\mathrm{H}$. fasciculata, Benth.?

urticodes, Kuntze, 1. c. $527 \Rightarrow$ H. urticoides, H. B. \& $K$

vele, Kuntze, 1. c. = H. vilis, Kunth \& Bouché,

verbenifolium, Kuntze, 1 . c. $=H$, verbenaefolia, Mart.

veronicifolium, Kuntze, 1, c。 $=\mathrm{H}$. veronicaefolia, Pohl.

yungasensis, Britton, ex Rusby, in Mem. Torrey Bot. Club iv, (1895) 246. - Bolivia.

MESPILUS, [Tourn.] Linn。= Pyrus, Tourn, etc. (Rosac.).

Carrierei, Hort. ex Gard. Kew, i. Polypet, (1894) 195 = Crataegus Carrierei, Vawvel.

dahurica, Hort. Dieck. Neuheit. Nat. Arboret. Dieck. (1892-93) 21. - Dahuria.

fastigiata, C. Koch, ex Dippel, Handb. Laubholzk. iii. (1893) 459 et 738 , ad calc. = Crataegus monogyna, $f a c q$

integerrimus, Ham. ex Dippel, 1. c. 418; = Cotoneaster affinis, Lindl.

Lalandi, Hort. ex Dippel, 1. c. $421=$ Crataegus Pyracantha, Medio.

stricta, C. Koch, ex Dippel, 459 et '738, in syn。= Crataegus monogyna, facq.

MET APLEXIS, R. Br. (Asclep.). - Ind. Kew, ii. 220

Hemsleyana, oliver, in Hook. Icon. pl. xx. (1891) t. 1970. - China

METASTACHYS, Van Tiegh, in Bull. Soc, Bot. Fr xlii (1895) $164=$ Loranthus, Linn

corymbosa, Van Tiegh.1.c. $165=$ L. corymbosus, Dietr.

denticulata, Vàn Tiegh. 1. c. 166. - Columb.

grandiflorus. Van Tiegh. 1. c. $165=$ L. grandiflorus, Ruiz \& Pav.

secunda, Van Tiegh. 1. c. = L. secundus, Benth.

tholifera, Van Tiegh. 1. c. - Columb.

verticillata, Van Tiegh. 1. c. = L. verticillatus, Ruiz \& Pav.

METASTELMA, R, Br. (Asclep.), - Ind, Kew. ii. 220 .

albiflurum. S. Wats, in Proc. Am, Acad. xxiv. (1889) 60. [albiflora]. - Mexic

brasiliense, $K$. Schum, in Engl. \& Prantl, Natürl. PAlanzenfam. iv, 2 (1895) 241 (= Amphistelma parviflorum, Fourn.). - Bras.

chiapense, A. Gray, in Proc. Am. Acad. xxi. (1S86) 397 , in obs. - Mexic.

filiforme, $K$. Schum, $l$. $c_{0}(=A$. filiforme, Griseb.). - Ins. Antill.

latifolium, F. N. Rose, in Contrib, U. S. Nat. Herb. i. (1891) 106. - Mexic,

\section{METASTELMA}

melananthum, $K$. Schum, in Engl. \& Prantl, $\mathrm{Na}$ tür. Pfauzenfam.iv. 2 (1895) 241 (=Vincetoxicum melanthum, Decne.). - Bras.

multiflorum S. Wats, in Proc. Am. Acad.xxv. (1890) 158. - Mexic

myrianthum, Schlechter, in Oest. Bot. Zeitschr. xlv. (1895) 451. - Bolivia

Pringlei, A. Gray, in Proc. Am. Acad. xxi. (1886)

Schaffneri, A. Gray, l. c. 396, in obs. - Mexic.

METHARME, Ph'1. ex Engl. in Engl. \& Prantl Natürl. Pflanzenfam. iii. 4 (1890) 86: et in Anal. Mus. nac, Chile (1891) 12. ZYGOPHYLLEAE, lanata, Phil. ll. cc. t. 1 fig.2. - Chili.

METRODOREA, A. St. Hil. = Esenbeckia Kunth. (Rutac:)

mollis, Taub. in Bot. Jahrb. xv, Beibl. n. 34 (1892) 5. - Bras.

METRosideros, Banks (Myrtac.). - Ind, Kew. ii. 221

aurata, Colenso, in Trans. N, Z, Inst, xxiii. 1890 (1891) 385. - N. Zel.

Regelii, F. Muell. in Trans. Roy. Soc. Vict. N.S. i. II. (1889) 6. - N. Guin.

speciosa, Colenso in Trans. N. Z. Inst. xxii. 1889 (1890) 463. - N. Zel.

tenuifolia, Colenso, l. c. xxiv, I891 (1892) 387. N. Zel.

METULA, Van Tiegh. in Bull. Soc. Bot Fr, xhii. (1895) 263 = Loranthus, Linn

angolensis, Van Tiegh. 1. c. $264=$ L. angolensis, Engl.

MEYERAFRA, Kuntze, Rev. Gen. (1891) 353 Astephania, Oliver (Compos.).

africana, Kuntze, 1. c. = A. africana, Oliver.

MEZIA, Kuntze, Rev. Gen. (1891) $573=$ Endiandra, R. Br. (Laurin.).

crassiramea, Ita-Uba, navalium, oppositifolia, Sprucei Kuntze, 1. c. homonyma omnia Endiandrae. anacardiodes, Kuntze, 1. c. = Acrodicledium anacardioides, Spruce.

MEZIA. Schwacke, ex Encl, \& Prantl, Natürl. Pflanzenfam. iii. 4 (1890) 58; Niedenzu, in Bot. Jahrb. xiv. Beibl. n. 30 (1891) 3. MALPIGHI ACEAE

Aranjei, Schwacke, $l l . c c .-$ Bras.

MEZIEREA, Gaudich. = Begonia, Linn. Mollevi, C. DC. in Bolet. Soc. Brot. x. (1892) 124 - Ins. S. Thom.

MEZONEURON, Desf. (Legumin.). - Ind. Kew. ii. 223.

andamanicum, Prain, in fourn. As. Soc. Beng, 1xi. (1892) II. 131. - Ins. Andam.

Grevei, Baill. Hist. pl. Madag., Atlas (1886) t. 24 B et C. - Madas.

kauaiense, Hillebr. Fl. Haw. Isl. (1888) 110 (=Caesalpinia kauaiensis, Mann). - Ins. Sandvic.

sinense, Hemsl. in fourn. Linn. Soc. xxiii. (1887 204 ; et in Hook. Icon, pl. xx. (1891) t. 1960. China.

MEZzETTIA, Becc. (Anonac.). - Ind. Kew. ii 223

Curtisii, King, in fourn. As. Soc. Beng. 1xi. (1892) II. 129. - Penang.

Herveyeana, Oliver, in Hook. Icon,pl, xvi.(1SS7) t. 1560, - Malacca.

MICHELIA, Linn. (Magnoliac.). - Ind. Kew, ii 22:3.

compressa, Sarg. For. Fl. Japan. (1894) 11, t. $5=$ Magnolia compressa, Maxim.

Mannii, King, in Ann. Bot. Gard. Calc, iij, II. (1891) 218. t. 70. - Assam. 
MiCHELIA, Linn. [1735, non 1737] = Barringtonia, Forst, (1766) (Myrtac.).

acuminata, acutanoula, angusta, calvptrata, conodea, costata, excelsa, Helferi, Horsfieldii, insignis, intermedia, luzonensis, macrocarpa, macrostachya, neocaledonica, nitida, pterocarpa, Reinwardini, reticulata. serrata, spicata, timorensis, Vriesei, Kuntze, Rev. Gen. (1891) 240-24l = homonyma omnia Barringtoniae.

apiculata. Kuntze, 1. c. (= Butonica apiculata, Miers.). - Madag,

asiatica, Kuntze, 1. c. = Barringtonia speciosa, Limn.

racemosa, Kuntze, 1. c. = B. racemosa, Roxb.

rigida, Kuntze, 1。 c. $241=$ Symplocos rigida, $C$ B. Clarke.

rosata, Kuntze, 1. c. (= Butonica rosata, Miers). Ins. Philipp.

zeylanica. Kuntze, I. c. = Barringtonia ceylanica, Gaertn.

MICONIA, Ruiz \& Pav. (Melastom.). - Ind. Kew ii. 223.

alpestris, $\operatorname{Cog} n$ ex F. D. Smith。 in Conlt, Bot. Gaz. xx. (1895) 288. - Guatem.

altissima, Cogn, in DC. Monog. Phan. vii. (1891) 837. - Bras.

amplexans, $\operatorname{Cog} n$, in Mart. Fl. Bras, xiv. IV. (1887) 256: ct l. c. 749 (= Pogonorhynchus amplexans, Crueg.). - - Ind. occ., Peruvia.

Andreana, Cognz, in Bull. Acad. Belg. Sér. III. xiv (1887) 952; et in DC. Monog. Phan。 vii. (1891) S80. - N. Granat

angustifolia, Cogn. in Mart. Fl. Bras. xiv. IV. (1888) 613 ; ct in DC. . . c. 840 . - Bras.

argyraea, Cogn. in DC. .. . . 838. - Bras.

atrosanguinea, Cogn . in Bot. Fahrb. viri. (1887) 23 et l. c. 760 - Costa Rica.

Augusti, Cogn, in DC. . . c.835. - Bras.

aureoides, Cogno in Mart. Fl. Bras. xiv. IV. (1887) 260 ; et l. c. 762 . - Peruvia.

Bangii, Cogn. ex Rusby, in Mem. Torvey Bot.Club. iii. 3 (1893) 30. - Bolivia.

Barbeyana, Cogn, in DC. Monog. Phan, vii. (1891) 872. - Venezuela

biacuta, Cogno ex Rusby, in Menr. Torrey Bot. Club, iii. 3 (189.3) 31. - Bolivia.

biperulifera, Cogn. in DC. Monor. Phan. vii. (1891) 912; et ex Th. Dur. Eo Pitt. in Bull. Soc. Bot. Belg. xxx, 1891 (1892) 260. - Costa Rica.

Boissieriana, Cogn. in DC. .. c. 734. - Cuba.

boliviana, Cogn. l. c. 001.- Bolivia.

Bourraeana, Cogn. . c. 779. - Mexic.

Brittonii, Cogne ex Britton, in Bull, Torrey Bot. Club, xvii. (1890) 92; et in DC. l. c. 900. - Bolivia. capitellata, Cogn. in DC. . . c. 892. - Ecuad. carassana, Cogn. in Mart. Fl. Bras, xiv. IV. (1887) 346 ; et in DC. l. c. 825. - Bras.

cardiophylla, Cogn。 in Bull. Acad. Belg. Sér. III. xiv. (1887) 960 ; et in DC. l, c, 891. - N. Granat. carnea, Cogn in Bot. Fahwo. viii. (1887) 28: et in DC. l. c. 912. - Costa Rica.

Carioana Cogn, in DC. l. c. 773. - Guatem.

ceramicarpa, Cognz. in Mart. Fl. Bras. xiv. IV (1857) 338 ; ct l. c. 819 (= Clidemia ceramicarpa DC.). - Bras., Gruiana.

chlorocarpa. Cogn. in Bull. Acad. Belg. Sér. III. xiv. (1887) 950; ct in DC. Monog. Phan. vii. (1891) 847. - N. Granat.

cinerea, Cogne, in Mart. Fl. Bras, xiv. IV. (18s7) 290 ; et in DC. l. c. 786 . - Bras.

comosa, Cogn. Il. cc. 408; et 867 . - Peruvia.

conferta, Cosy. hl.cc. 416: et 008 . - Bras.

confusa, Cogn. in DC. Mlonog. Phan. vii. (1891 759. - Cuba.

corymliformis, Cogn, in Bull. Acad. Balg. Sér. III xiv. (1857) O64; ot in DC. l. c. 229. - N. Granat. costaricensis, Cogne in DC. l.c. 887 ; et ex Th. Dur Eo Pitt. in Bull. Soc. Bot. Belg. xxx. 1891 (1892 259. - Costa Rica.

crassinervia, Cogn, in Mart. Fl. Bras, xiv. IV. (1887 391; at in DC. . . c. 85is. - Bras.

decipiens, Cogn in Bull. Acad. Belg. Sér. III. xiv. (1857) 948; ct in DC. 7. c. \$22. - N. Granat densiflora, Cogn. in Boi. Fahro. viii. (1887) 롱 et in DC. . . . 744. - Columb.

\section{MICONIA :}

dichroa, Cogn。 in DC. Monog. Phan, vii. (1891) 1192. - Bras.

dodecandra, Cogn。 in Mart. Fl, Bras, xiv, IV. (188i) 243: et in DC. l. c. 740 et 1190 (= Melastoma dodecandra, Desv.). - Am. trop.

domingensis, Cogn. in DC, Monog. Phan. vii. (1891) 931. - Ins, S. Doming.

Donnell-Smithii, Cogn, ex 7. D. Smith, in Coult. Bot. Ga\%, xx. (1895) 287. - Guatem.

Doriana, Cogn. in Mart. Fl. Bras, xiv. Iv. (1887) 376 ; et in DC. Monog. Phan. vii. (1891) 851 . Bras.

eqensis, Cogn. $l l$. cc. 374 : et 849. - Bras.

Eichlerii, Coon. $l l$ cc. 362 et 849 - Bras.

elaeagnoides, Cogn. 27 . cc. 390 : et 858 . - Bras.

elegans, Cogn. $l l . c c .312$; et 802 . - Bras.

elongata, Cognt. ex Britton, in Bull. Torrey Bot. Chub, xvii. (1890) 91 ; et in DC. $l, c .874$. - Bolivia.

epiphytica, $\operatorname{Cogn}$. in DC. l. c. 934. - N. Granat

eriantha, $\operatorname{Cog} n$. l. c. 845 . - Bras.

eriocalyx, Cognt. in Mart. Fl. Bras, xiv. IV. (1887) xiv. IV. (1887) 342; ct in DC. Monog. Phan. vii. (1891) 823. - Bras., Peruvia

Fendleriana, Cogn. in DC. l. c 822. - Venezuela.

flavescens, Cogn, ex Britton, in Bull. Torrey Bot. Chub, xvii. (1890) 93; et in DC. l. c. 930.Bolivia.

formosa, Cogn. in DC.l.c.842. - Bras.

foveolata, Cogn. in fahrb. Bot. Gart. Berl. iv. (1886) 281 ; et in DC. l. c. 928. - Ins. Porto Rico,

Francavillana, Cogne in Mart Fl, Bras, xix. IV (1887) 237 : et in DC. l. c. 733 - Guian., Bras. gigantea, Cogn. in. DC. Monog. Phan.vii. (1891) 937. - Bras

gilva, Cogn. .. c. 836. - Bras.

Glabrata, $\operatorname{Cog} n$. . l.c.875. - Mexic

clandulifera, Cogn, l. c. 737. - Peruvia.

glandulosa, Kuntze, Rev.Gen. (1891) 244. - Venezuela

Glazioviana, Cogn.in Mart. Fl. Bras, xiv. IV. (1887) 301: et in DC. Monog. Phan. vii.!(1891) 794. Bras.

srandiflora, Cogn, in Bot. Fahrb. viii. (18s7) 25 ; et in DC. $l$ c. 878 . - Columb.

Grayana, Cogn. in DC. l. c. 896 . - Ecuad. vel Peruvia?

guatemalensis, Cogn, ex F. D. Smith, in Coult. Bot. Gaz xvi, (1891)5 et in DC. l. c.758. - Guatem.

guianensis, Cogn. in falirb. Bot. Gart. Berl. iv.

(I886) 280 : in Mart. Fl. Bras. xiv. IV. (1887) 245 ; et in DC. l.o 741 (= Tanonea guyanensis, Aubl.). - Am. austr.

hirta, Cogn. in Mem. Torrey Bot:Club. iii. 3 (1893) 31. - Bolivia.

hirtella, Cogn. u Mart. Fl. Bras. xiv. IV. (1888) 423; et in DC. . C. . 927. - Bras.

hispida, Cogn. Il. cc. 395 ; et $\$ 60$. - Bras.

humilis, Cogn. in DC. Monog. Phan.vii. (1891) 764 . - Am. centr

integrifolia. Cogn.l. c, 936. - Peruvia.

Kraenzlinii, Cogn. in Bot. Falirb. viii. (1887) 22 ct in DC, 7. c. 744.- Columb.

Krugii, Cogn. in DC. Monog. Plian. vii, (1891) 932. - Ins. S. Doming.

laeta, Cogn, in Mart, Fl. Bras, xiv. Iv. (1SSS) 614 et in DC. $., c, 853$. - Bras.

Lehmannii, Cogn. in Bot. Fahrb. viii. (1887) 29 ; ot in DC. l. c. vii. (1891) 915. - Culumb

Liebmanni, Cogn. in DC. l. c. 821. - Mexic

longicaudata. Cogn. l. c. 738. - Venezuela.

longicuspis, $\operatorname{Cog} n$. l. c. $850 .-$ Bras.

longipedunculata, Cogn. in Mart. Fl. Bras. xiv. IV. (1857) 266: et in DC. . c. 768. - Bras.

Langsdorffi, Cogn. Ul. cc. 233 ; et 730 . - Bras.

lurida, $\operatorname{Cog} n$. Il. co. 356; ; et S47. - Bras.

macrotis, Cogn, in DC. Monog. Phan, vii. (1891)

$7491=$ Diplochila macrotis, Griseb.). - Ins.

Trinit. Ecuad.

majalis, Cogn. in Bull. Acad. Belg. Sér. III. xiv. (1887) 953; t in DC. l. c. 886. - N. Granat.

Mandonii, Cogn. ex Britton, in Bull. Torrey Bot. Club, xvii. (1850) 93, nomen; et in DC. l. c. 911. - Bolivia.

martiniconsis, Coon. in DC. l. c. 913. - Ins. Martinic.

\section{MICONIA : -}

Maximowicziana, Cogn. in Mart. Fl. Bras, xiv. Iv (1887) 355 ; et in DC. Monog. Phan. vii. (1891 833. - Bras.

Mendonçaei, Cogn. in DC. l. c. 772. - Bras.

micropetala, Cogn. l. c. 882. - Ecuad.

modesta, Cogn.l. c. 854.- Bras.

Mouraei, Cogn. l. c. 830. - Bras

multiflora, Cogn. ex Britton, in Bull. Torrey Bot. Club, xvii. (1890) 60; et in DC. l. c. 825. Bolivia.

multinervia, Cogn. in Mart. Fl. Bras. xiv. IV. (188\%) 249 ; et in DC. l. c. 761. - Bras.

multinervulosa, Cogn. in DC. Monog. Phan, vii. (1891) 926. - N. Granat

multiplinervia, Cogn. in Bot. Falırb. viii. (18S7) 26 : et in DC. l. c. 892. - Columb.

neurotricha, Cogn. in DC. Monog. Phan. vii. (1891) 8S5. - N. Granat.

nitidissima, $\operatorname{Cog} n$, l. $i, 748$. - Venezuela

nodosa, Cogn. in Bull. Acad. Belg. Sér. III. xiv. (1887) 962 ; et in DC. l. c. 911. - N. Granat.

oblongifolia, Cogn. in Mart. Fl. Bras. xiv. IV. (1887 373 ; et in DC. 6. c. 841. - Bras.

octoscenidium, Cogn. in DC. Monog. Phan, vis, (1891) 871. - Venezuela

octopetala, Cogn. l. c. 754. - Bras.

ovalifolia, $\operatorname{Cog} n$. l. c. $842,-$ Bras,

ovata. Cogn. in Mart. Fl. Bras, xiv. IV. (1887) 281 ; et l. c.782. - Bras.

pachyphylla, Cogn. in fahrb. Bot. Gurt. Berl. iv.

1886) 279: et in DC. Monog. Phan, vii. (1891) 871. - Ins. Porto Rico.

paleacea, Cogn. in DC. . c. 757. - Costa Rica.

parviflora, Cogn. in Mart. Fl. Bras. xiv. IV. (1887)

249 ; st in DC. l.c. 743 (= Diplochila parciflora. Benth.). - Guian., Ind. occ.

parvifolia, Cogn. in DC, Monog, Phan, vii.(1891) 905. - N. Granat.

paupercula, Cogn.l. . .754 $i=$ Octomeris paupercula, Naud ). - Am. austr. occ.

pedicellata, Cogn. l. c. 875 ; et ex Th. Dur. \& Pitt. in Bull. Soc. Bot. Belg. xxxi. 1891 (1892) 258. Am. centr. et austr.

penduliflora, Cogn. in Mart. Fl. Bras, xiv, iv. (1888) 414: et in DC. l. c. 897 . - Bras.

pennipilis, Cogn. $l l . c c .287$; et 785. - Bras.

pergamentacea, Cogn. in Bot. Fahrb. vii. (1887) 24 et in DC. l. c. 873. - Columb.

persicariaetolia, $\operatorname{Cogn}$. ex Britton, in Bull. Torrey Bot. Club, xvii. (1890, 59; at in DC. . c. 768. Bolivia.

peruviana, $\operatorname{Cog} n$. in DC.l. c.909. - Peruvia.

Petroniana, $\operatorname{Cog} n$. \& Sald. ex Cogn. in Mart. Fl. Bras. xiv. IV. (1888) 612; te in DC. l. c.834.Bras.

petropolitana, Cogn. $l l . c c .613 .-$ Bras.

Pittieri, Cogn.in DC. l. c. 1191; et ex Th. Dur. \& Pitt. in Bull. Soc. Bot. Belg. xxx. 1891 (1892) 259. - Costa Rica.

Pohliana, Cogn, in Mart. Fl. Bras. xiv. IV. (18s7) \$50; ot in DC. l. c. 829. - Bras.

polygama, Cogne ex Britton, in Bull. Torrey Bot. Cli5, xvii. (1890) 92; et in DC.l. c, vii. (1891) 901. - Bolivia.

Pseudo-aplostachya, Cogn, in Mart. Fl. Bras, xiv. IV. (1887) 263; et in DC. ..c.767. - Bras.

Pseudo-centrophora, Cogn. in DC. Monog. Phan. vii. (1891) 893: - Ecuad.

Pseudo-nervosa, Cogn, in Mart. Fl. Bras, xiv. IY. 1887) 337; et in DC. .. o. 81\%.-Bras.

Psendo-Petroniana, Cogn. in DC. Monog. Phan. vii. 18:1) 846. - Bras.

Pseudo-Eichlerii, Cogn. l. c. 844. - Bras,

puberula, Cogn. in Mart. Fl. Bras, xiv. IV. (18si 386; et in DC. l. c. 856 . - Peruvia.

pulchra, Cogn. in DC. Monog. Pinan, vii, (1891) 795 - Bras.

quintuplinervia, Cogn, in Bot. Fahrb. viii. (ISs) 26: et in DC. l. c. $\$ 87$. - Columb.

Rabenii, Cogn。 in DC, l. c. 832. - Bras,

Radula, Cogne in Bull. Acad. Bolg. Sér. III. xiv. (1857) 957 ; t t in DC. . c. 859. - Ecuad.

Rerrelii, Cogn. in Mart. Fl. Bras, xiv. IV. (1SSS) 405; et in DC. l. c. 865. - Bras., Peruvia. Regnellii, Cogn. il. cc. 396 ; et 861 . - Bras. 
MICONIA :

resimoides, Cogn.in DC, Monog. Phan.vii. (1891) 926. - Venezuela.

rigidiuscula, Cagn. in Mart. Fl. Bras, xiv. IV. (1888) 398; et in DC. l. c. 862. - Bras.

robusta, $\operatorname{Cogn}$. Il. cc. 270:813. - Bras.

robusta, $\operatorname{Cogn}$. 1. c. $611=$ robustissima, $\operatorname{Cog} n$

robustissima, $\log n$. l. $c$; et in DC. Monog. Phan. vii. (1891) 774. - Bras.

rostrata, Cogn. in DC. Monog. Phan. vii. (1891) 758 (= Octomeris rostrata, Naud.). - Am. austr. occ

Rusbyana, Cogn. ex Britton, in Bull. Torrey Bot. Club, xvii. (1890) 93; et in DC. l. c. $6 \% 1$. Bolivia

Sagotiana, Cogn. in Mart. Fl. Bras. xiv. IV. (1887) 299 ; et in DC. l. c. 791. - Bras., Guian.

Saldanhaei, $\operatorname{Cog} n . l l$. cc. 372; et 841 , — Bras.

sarmentosa, $\operatorname{Cog} n . l l$. cc. 323; et 811. - Guian.

scabra, Cogn. in Bull. Acad. Belg. Sér. III. xiv.

(1887) 956 ; et in DC. l. e. 890 . - Ecuad.

Schlechtendalii, Cogn. in DC. l.c. 804. - Mexic.

Schwackei, Cogn. in Mart. Fl. Bras. xiv. IV. (1887)

342 ; et in DC. l. c.823. - Bras.

scrobiculata, $\operatorname{Cog} n$. $l l$. cc. 334 ; et $\$ 17$. - Bras.

secundifora, $\operatorname{Cog} n . l l . c c .285$; et 784 . - Pras

setoso-ciliata, Cogn. in DC. Monog. Phan. vii. (1891) 843. - Bras.

setulosa, $\operatorname{Cog} n$. l. c. 898. - Peruvia.

Sintenisii, Cogn en fahrb. Bot. Gart Berl, iv. (1886) 281; et l, c. (2):3. - Ins. Porto Rico.

Solmsii, Cogn. in Mart. Fl. Bras, xiv. IV. (1887) 393 et in DC. l. c. 859 . - Venezuela, Ind. occ.

stelligera, $\operatorname{Cog} n$. ll. cc. 276 ; et 778. - Bras., Peruvia.

striata. Cogn. in DC. Monog. Phan. vii. (1891) 765 (= Melastoma striatum, Vahl). - Ind. occ

stricta, Cogn. in Bot. Fahro, viii. (IS87) 27; et in DC l. c. 896 . - Columb.

stylosa, Cogn. in Mart. Fl. Bras, xiv. IV. (1887) 257 et in DC.l. c. 757 . - Bras

subcordata, $\operatorname{Cog} n$. 77 . cc. 244; et 741. - Bras.

subglabra, $\operatorname{Cog} n$. ll. co. 412 ; et 885 . - Peruvia.

suborbicularis, $\operatorname{Cog} n$. in Bull. Acad. Belg. Sér. III. xiv. (1887) 958; et in DC. l. c. 869. - Ecuad.

subvernicosa, Cogn. in Mart. Fl. Bras, xiv. IV. (1887) 374 ; ct in DC. l. c. 85̃l. - Bras.

tetragona, $\operatorname{Cog} n . l l . c c .387$; et 849. - Bras.

theaezans, Cogn. ll. cc. 419; et 923 ( = Melastoma theaezans, Bonpl.). - Am. trop.

tomentella, Cogn. il. cc. 284; et 783. - Guian. bat

Tonduzii, Cogn. in DC. Monog. Phan. vii. (18!1)

1191; et ex Th. Dur. of Pitt. in Buil. Soc. Bot. B.lg. xxx. 1891 (1892) 25\%. - Costa Rica.

tovarensis, Cogn. in DC. l. c. 917. - Venezuela

Traillii, C'gn. in Mart. Fl. Bras, xiv. IV. (1887) 242; et in DC. l. c. 736. - Bras.

Trianaei, Cogn. 11 . cc. 394; et 860. - Bras.

trichodes, Cogn. $l l$. cc. 327 ; et 813 (= Clidemia trichodes, DC.). - Guian. gall.

tschudyoides. Cogn. 11. occ. 32\%; et $813=$ robusta, $\operatorname{Cog} n$.

Tuerckheimii, Cogn. ex F. D. Smith, in Coult, Bot. Gaz, xvi.(1S91) 5; et in DC. Monog Phan. vii. (1891) 762. - Guatem.

umbrosa, Cogn. in Mart. Fl. Bras, xiv, iv. (1887) 315: et in DC. l. c. 804. - Bras.

velutina. L. Linden \& Rodigas, in Illustr. Hortic. xli. (1894) 331, t. 21. - Bras.

verrucosa, Cogne in DC. Monog. Phan, vii. (1891) 920. - N. Granat.

vesicaria, Hort. ex Ed. Andrê, in Rev. Hortic Ixvii. (1895) 250 . - Hab.

violacea, Cogn. in Bot. Fahrb. viii. (18S7) 28 ; et in DC. Monog. Phan vii. (1891) 913. - Columb.

vittata, Cogn. in DC. l. c. 729 (= Clidemia vittata, Linden \& André). - Peruvia.

Warmingiana, Cogn. in Mart, Fl. Bras, xiv. NV. (1857) 282; et in DC. 7. c. 782. - Bras,

MICRAMPELIS, Rafin.= Sicyos, Linn. (Cucurb.). araneosa, Bigelowii, Coulteri, floribunda, gemella, glatinosa, lanata, longispina, milleflora, minima, paniculata, polycarpa, pubescens, torquata, Wrightii, Kuntze, Rev. Gen, (1891) $257=$ homonyma omnia Echinocystis.

\section{MICRAMPEIIS :}

cirropedunculata, J. N. Rose, in Contrib U. S. Nar. Herb. i. (1891) 100. in obs. = Echinopepon cirrhopedunculatum, $N . E$. Rose.

fabacea, Greene, Pittonia, ii. (Dec, 1890) 129; et Man. Bot San Franc. Bay (1894) $144=$ Echinocystis fabacea, Nand.

guadalupensis, Greene, 1. c. = Megarrhiza gruada lupensis, S. Wats.

leptocarpa. Greene, 1. c. (Aug. 1892) 282. - Calif lobata, Greene, 1. c. ii. (Dec.1890) $128=$ Echinocystis lobata, Torr. \& Gray.

macrocarpa, Greene, 1. c $129=$ E. macrocarpa Greene.

macrocarpa, Rusby, in Mem. Torrey Bot. Club, iii 3 (1893) 40 : Micrampelal; et iv. (1893) 207, in obs. (= Echinocystis macrocarpa, Britt.) $=M$ Rusbyi, Greene, - Am. bor.

Marah Greene, Pittonia, ii. (Dec, 1890) 129 et Man. Bot. San Franc. Bay (1894) $14 t=$ Megarrhiza Marah, S. Wats.

oregona, Greene, 1. c. (= Meganhiza oregana, S Wats). = Sicyos oregana, Torr. E. Gray.

Rusbyi, Greene, in Erythea, i. (1893) 138 (= Echinocys (is macrecarpa. Britton). - Am, bor.

Watsoni, Greene, Pittonia, ii. (Dec. 1890) 129 et Man. Bot. San Franc, Bay (1894) 144 [Watsonii] $=$ Echinocystis Watsoni, Cognt.

MICRANTHEMUM, Michx. (Scrophul.). - Ind. Kew. ii. 228.

micranthemoides, Wettst, in Engl. \& Prantl, Natürl Pflanzenfam. iv. $3 \mathrm{~b}(1891) 7 \%=\mathrm{M}$. Nuttallii A. Gray.

MIGRANTHEUM, Desf. (Euphorb.). - Ind. Kew.11. 228. Muell in Vict. Natural, vii (Sept. 1890) 67 . - Austral.

hexandrum, Tate, in Trans, and Proc. Roy. Soc. S Austral. xii. (1889) 28, nomen $=$ demissum. $F$ Muell.

MICRANTHUS, Wendl. = Phaylopsis, Willd, (Acanth.).

angolanis, Kuntze, Rev, Gen, (1891) 493 = P. angolana, S. Moore.

Barteri, Kuntze, 1. c. = P. Barteri, T. Anders

glaudulosus, Lindau, in Bot. Jahrb. xxii. (1895) 115 - Angola.

Hensii, Lindau, 1, c. 114, - Concro.

imbricatus Kuntze, Rev, Gen. (1891) $493=$ P. longifolia, Sims.

lankesterioides, Lindau, in Bot. Jahrb, xx. (1894) 9 - Angola.

longifolizs, Kuntze, Rev, Gen.(1891) $493=$ P. Jongifolia, Sims

microphyllus, Kuntze, 1. c. $=$ P. microphyllus, $T$. Anders.

obliquus, Kuntze. 1. c. = P. obliqua, T. Anders.

Poggei, Lindau, in Bot. Janı b. xvii. (1893) 108. Afr. trop.

rupestris. Kuntze, Rev, Gen, (1891) 403 (= Aetheile ma mpestre, Nees). - Madas.

silvestris, Lindau, in Bot. Jahrb. xvii. (1893) 107. - Afr. trop.

togoënsis, Lindau, 1. c, xx. (1894) 8.- Guinea

MICROGAIAMUS Franch. in Morot, Journ, de Bot iii. (1889) 282. PALMAE

barbinodis, Franch. l. c. - Afr. trop.

MICROCALAMUS, Gamble, in Journ. As. Soc Ben£. lix. (1820) II. 207. PALMAE.

Prainii, Gamble, l. c. t. \%. - Assam.

MICROCEPHALUM, Sch. Bip, ex Klatt, in Leo poldina, Heft xxiii. (1887) $90=$ Gymnolomia H. B. \& K. (Compos.).

Ehrenbergianum, Sch. Bip. 1. c. = G. Ehrenbergiana, Klatt.

Liebmannii, Sch. Bip. 1.c.= G. Liebmannii, Klatt. scricem, Sch. Bip. 1. c. = G. sericea, Klatt.

MICRODONTOCHARIS, Baill, in Bull. Soc. Linn. Paris, II. (1894) $1134=$ Eucharis, Planch. \& Linden (Amaryll.).
MICROGLOSSA, DC. (Compos). - Ind. Kew

Hildebrandtii, O. Hoffm. in Eot. Fahrb. xx. (1894 222. - Afr. trop. or.

blongifolia, O. Hoffm. ex Engl, in Abh. Preuss. Akad. Wiss. (1894) 62; ct l. c. - Afr, trop. or. parvifolia, O. Hoffm. l. c. 223. - Zanzib.

psiadioides, Baker, in foum. Linn. Soc. xxv. (1890) 327. - Madag

pyrifolia, Kuntze, Rev, Gen. (1891) 353 = volubilis. $D C$

\section{MICROGYNOEGIUM, Hook. f. (Chenopod.). -} Ind. Kew ii, 229.

tibeticum, Hook. f. Fl. Brit. Ind. v. (1886) 9 [Mi crogynaecium]; ot in Hook. Icon。pl.xx (1S91) t. 1990. |Conf. Ind. Kew, 1. c.), - Reg. Himal, Tibet.

MICROKOMA, tomiflora, Kuntze, ex Lnness. P1. util. Colon. Franc. (1886) 268, in obs. [Quid ?]

MiGRoLAENA, R. Br. (Gramin.). - Ind. Kew ii. 22\%.

ramosissima, Colenso, in Trans, N.Z. Inst. xxi. $1858(1889) 105 .-\mathrm{N} . Z \mathrm{Zel}$.

MIGROLICIA, D. Don (Melastom.j. - Ind. Kew. ii 229

acuminata, Cogn. in DC. Monog. Phan. vii (1891) 55. - Bras

bryanthoides, Olizer, in Trans. Lim. Soc. Ser. II ii. (1887) 274 t. 39b (Oliver, ex in Thurn, in Ti melivi, v. (1886) 192); Cogn, in DC. Monog. Phan. vii. (1891) 49. - Guian, angl.

glandulifera, $\operatorname{Cog} n$. in DC. l. c. 69. - Bras.

Glazioviana, Cogn. in Mart. Fl. Bras, xiv, Iv (1888) 591 ; ct l. c. 37. - Bras

Mendonçaei, $\operatorname{Cog} n$. ll. cc. 592 : et 59. - Bras.

Schreinerii, Cogn. in DC. Monog. Phan. vii. (1891) 1174. - Bras.

MICROLOMA, R. Br. (Asclep.). - Ind, Kew. ii $2: 30$

namaquense; Bolus, in fourn. Limn. Soc. xxy (1859) 163. - Afr. austro-occ. extratrop.

temuiform, Kuntze, in Jahrb. Bot. Gart, Berlin. iv. (1886) 268 |tenuiftora| = lineare, $R . B r$

tonilifolinum, K. Schum. in Engl, \& Prantl, Naturl. Pflanzenfam. iv. $2(1895) 2 \% 2=$ lineare. R. $\mathrm{Br}$

MICROLONCHUS, Cass. = Centaurea. Linn (Compos.)

spinulosis, Rouy, in Bull. Soc, Bot, Fr. xxxy (1888) 119. - Hisp

MICROLUMA, Baill. Hist. des pI. xi. (1S92) 29 J = Lucuma, Molina (Sapot.)

purviftora, Baill. 1. c. = L. parviflora, Spruce.

MICROMELES, Decne $=$ Pyrus [Tourn.] Linn (Rosac.)

alnifolia, Koehne, in Wiss. Beil. Progr. Falk. Real-Gymn. (1890) 20 : et in Gartenfl. xli. (1892) 282, fio 61 et 62: et in Deutsche Dendrol. (189:3) $25 \%=$ P. alnifolia, Franch

japonica, Koehne, Deutsche Dendrol. (1893) $252=$ P. lanata, D. Don

MIGROMERIA, Benth. (Labiat.). - Ind. Kew ii. 231.

Chamissonis, Greene, Man. Bot. San Franc, Bay (1894) $289=$ M. Douglasii, Benth

Kerneri, Murb in Iunds Uniu. Arsskrift xurii. Y. (1892) 53. - Herceg.

Purtschélleri, Guerke, ex Engl, in Abh. Prouss. Acad. Wiss. 1891 (1892) 365. - Afr. trop. or

pusilla, Phil. in Anal. Unio. Chit. xc. (1so5) 556 [err. typ. pasilla]. - Chili.

Shepardi, Post, in Bull. Herb. Boiss. i. (1893) 40.5. - Syria. 
MICROPHOLIS, Pierre, Not. J3ot. Sapot. (1891) $37=$ Sideroxylon [Dill.] Linn. (Sapot.). angolensis, Pierre, 1. c. 41. - Angola. Burchelliana, Pierre, 1. c. 40. - Bras. calophylloides, Pierre, 1. c, 40. - Guian, gall. chy'ysobtyloides, Pierre, 1, c, 38, - Ins Antil. crassitedicellata. Pierre, 1. co $40=$ Sideroxylon crassipedicellatum, Mart. \& Eichl.

Crnegeriana, Pierre. 1. c. 40. - Ins. Antill.

cylindrocarpa, Pierre, 1. $\mathrm{c},=$ Sideroxylon cylindrocarpum, Poepp. E Endl

entomiaefolia, Pierre, I. c. = Guian, gall.

garciniaefolia. Pierre, 1. c. 38. - Ins. Porto Rico.

Gardneriana, Pierre, 1. с. $37=$ Sideroxylon Gardnerianum, $A, D C$

gruyanensis, Pierre, 1. c. $40=$ S. guianense, $A . D C$ Inurayana, Pierre, 1. c. 39. - Ins. Dominic.

Tinonenra. Pierre, 1. c. - Bras.

Melinoniana, Pierre, 1. c, $40(=$ Stephanoluma rugosa Baill.). - Guan, gall.

polita, Pierre, 1. c. $41=$ Sapota polita, Griseb

portoricensis, Pierre, 1. c. 38. - Ins. Porto Rico.

r'zoosa, Pierre, 1. c, $4 \mathbf{l}=$ Sideroxylon rugosum

Roem. Eo Schult.

Spruceana, Pierre, 1. c. $39=$ S. Spruceanum, Mart. \& Miq.

Urbani, Pierre, 1. c. 38. - Ins. Porto-Rico.

zemulosa, Prerre, 1. c. $40=$ S. venulosum, Mart. \& Fichl.

MICROPLUMERIA, Baill, in Bull, Soc. Linn Paris, i. (1889) 749; et Hist. pl. Madag. Atlas (1888) 187; K. Schum, in Engl. \& Prantl, Natürl. Pflanzenfam. iv. 3 (1895) 154. APOCYNEAE

Sprucei, Buill. $l l . c c$, - Bras

MICROPORA, Hook, f, in Hook, Icon. pl, xvi (1886) t. 1547; et F1. Brit. Ind. v. (1890) 862. LAURINEAE.

Curtisii, Hook. f. ll. cc. (= Hexapora Curtisii, Hook. f.). - Penang.

MICROSACGUS, Blume (Orchid,). - Ind. Kew. ii. 233 .

virens, Hook. f. Fl. Brit. Ind. vi. (1590) 77.Perak, Java, Borneo,

MICROSCHOENUS, C. B. Clarke, ex Hook, f Fl. Brit. Ind vi, (1894) 675. CY PERACEAE.

Duthiei, C. B. Clarke, l.c.-Reg. Himal.

MICROSERIS, D. Don (Compos.). - Ind. Kew. ii. 233 .

anomala, S. Wats, in Proc. Am. Acad. xxii, (1887) 475. - Calif.

brevipes, Phil. in Anal. Univ. Chil. 1xxxvii. (1894) 311. - Chili.

indivisa, Greene, in Erythea, i. (1893) 7; et Man. Bot. San Franc. Bay (1894) 222. - Calif.

intermedia, Greene, l. c. iii. (1895) 100. - Calif.

Parishii, Greene, in Bull. Calif. Acad. ii. v. (1886) 46. - Calif

scapigera, O. Hoffm, in Engl. \& Prantl, Natürl. Pflanzenfam。iv, 5 (1893) $358=$ scapigera, Sch. Bip.

tenella, Greene, Man. Bot. San Franc. Bay (1894) $222=$ tenella, Sch.Bip.

MIGROSTELMA, Baill. Hist. des pl. x. (1890) 286; K. Schum, in Engl. \& Prantl, Natürl. Pflanzenfam, iv。 2 (1895) 304. ASCLEPIA$D E A E$.

MICROSTEPHANUS. N. E. Br, in Kew Bull (1895) 249. ASCLEPIADEAE.

cernuus, N.E.Br. l.c. - Afro trop. or

MIGROSTYLIS, Nutt. (Orchid.). - Ind. Kew, ii. 233.

acutangula, Hook. f. in Hook. Icon.pl. xix, (1889) t. 1835 ; et Fl. Brit. Ind. v. (1890) 688. - Perak. amplexicaulis, F. M. Bailey, in Dept. Agric. Brisbane, Bot. Bull. iii. (1891) 18. - Austral.

\section{MICROSTYLIS :}

andicola, Ridl. in Fourn. Lamn, Soc, xxiv. (1888) 330. - Ecuad.

arachnifera, Ridl. 7.c. 320. - Mexic.

bancana, Ridl. l. c. 343. (= Crepidium Rheedii, Blume). - Ranca.

bella, Reichb. f. in Gard. Chron. (1886) i. 9. - Ins. Sundaic.

brachyrrhynchos, Reichb. $f$. in Flora, 1xxi. (1888) 152. - Mexic.

Burbidgei, Reichb. f. in fourn, Linn, Soc, xxiv. (1888) 336. - Labuan.

calycina, Ridl.l.c.331 (= Dienia calycina, Lindl.). - Mexic.

caracasana, Klotzsch, ex Ridl. l. c. 225. - Columb. crenulata, Ridl. I c. 346; Hook. f. Fl. Brit. Ind.v. (1890) 691. - Ind, or

furcata, Hook. f. in Hook, Icon, pl. xix. (1889) t. $1827 \mathrm{~A}$ e et Fl. Brit. Ind. v, (1890)690. - Perak. gracilis, Ridl. in fourn. Linn. Soc, xxiv. (1888) 321 - Guatem.

Hieronymi, Cogn。 in Mart. Fl. Bras, iii. Iv. (1895) $279(=$ M. rupestris, Griseb.). - Reg. Argent. Javesiae, Reichb. f. in Flora, lxxi.(1888) 152. Mexic.

khasiana, Hook. f. Fl. Brit. Ind. v. (1888) 686 ; et in Hook Icon.plo xix. (1889) t. 1831. - Bengal. abrosa, Reichb. f. in Flora, lxxi. (1888) 15i.Cuba

linguella, Reichb f. l. c. 153. - Mexic.

longisepala, Ridl, in fourn. Limn. Soc. xxiv. (1888) 32\%. - Mexic

macrochila, Rolfe, in Kew Bull. (1895) 6. - Malaya. major, Reichb. f. in Flora, 1xxi. (1888) 153. - Ins. Antill.

Maingayi, Hook. f. in Hook. Icon. pl. xix. (1889) t. 1826 : et Fl. Brit. Ind.v. (1890) 689. - Penang. Mandonii, Reichb. f. in Flora, lxxi. (1888) 152.Bolivia.

Massonii, Ridl. in fourn. Limn. Soc. xxiv, (1888) 323. - Ins. Antill.

Micholitzianus, Kraenzl. in Bot. Falıb. xvii. (1893) 482. - N. Guinea

micrantha, Hook. f. in Hook. Icon. pl. xix. (1889) t. 1834; et Fl. Brit. Ind.v. (1890) 688. - Perak Moritzii, Ridl, in fourn. Linn. Soc. xxiv, (1888) 330. - Venezuela.

muscifera, Ridl. l. c. 333; Hooh. f. Fl. Brit. Ind. v. (1890) 689 (= Dicnia muscifera, Lindi.). Reg. Himal.

ochreata, S. Wats, in Proc. Am. Acad. xxii. (1887) 454. - Mexic

oculata, Reichb. f. in Flora, 1xix. (1886) 554. $\mathrm{Hab}$ ? ?

parvula, Hook. f. in Hook. Icon. pl. xix. (1889) t. $1827 \mathrm{~B}$; et Fl. Brit. Ind. v. (1890) 690 . Perak.

pedicellaris, Reichb. f. in Bot. Centralbl. xxviii. (1886) 345. - N. Guin.

polyodon, Hook, f. Fl. Brit. Ind.v. (1890) 688 ; et in Hook. Icon, pl. xxi. (1890) t. 2002. - Tenass. polyphylla, Ridl. in fourn. Linn. Soc. xxiv. (1888) 339. - N. Caled.

porphyrea, Ridl.l.c. $320(=M$. purpurea, S. Wats, $)$. - Arizona

pratensis, Ridl.l.c. 344 (=M. icrsicolor, Wight). - Ind. or. austr.

Pringlei, S. Wats. in Proc. Am. Acad. xxiix. (1888) 282. - Mexic.

prorepens, Kraenzl. in Bot. Fahrb. xvii. (1893) 48. - Sierra Leone.

resupinata, Drake, III. Ins, Mar. Pacif. (1892) 305 (= Epidendrum resupinatum, Forst.); et F1. Polyn. Franç. (1892) $206=$ M. Rheedii, Lindl. rotundata, Ridl. in Fourn. Linn. Soc. xxiv. (1S88) 322. - Ins, Guadal.

Scottii, Hook.f. Fl. Brit. Ind.v. (1890) 687, Icon. pl. xxi. (1890) t. 2000 ; et in Bot. Mag. (1892) t. 7268. - Pegu, Penins. Mal.

segaarensis, Kraenzl. in Bot. fahrb. vii. (1886 435. - N. Guin.

Stocksii, Hook. f. in Hook, Icon, pl. xix. (1889) t. 1833; et Fl. Brit. Ind. v. (1890) 690. - Malabar.

tenuis, S. Wats. in Proc. Am. Acad. xxvi. (1891) 152. - Mexic
MICROSTYLIS

umbelliflora, Hitchcock, in Missouri Bot. Gard. Rep, iv, (1893) $132=$ umbellulata, Lindl. unifolia, Britton. Stern \& Pogg. Prelim. Catal. (1888) 51 = ophioglossoides, Nutt.

MIGROTAENA, Prain, in Hook. Icon, pl, xix (1889) t. 1872. LABIATAE.

cymosa, Prain, l. co $(=$ Plectranthus Patchouli, C B. Clarke) : et in fourn. Linn. Soc. xxvi. (1891) 306 ; et xxviii. (1890) 110. - Ind. or.

Delavayi. Prain, in Bull. Soc. Bot. Fr. xlii. (1895) 424. - Yunnan.

Griffithii, Prain. in Fourn. As. Soc. Beng. lix. (1890) ii, 310. - Reg. Himal.

moupinensis, Franch. in Bull. Soc. Bot. Fr. xlii. 1895) 426. - Tibet.

robusta, Homsl, in fourn. Linn. Soc, xxvi, (1891) 307. - China

urticifolia, Hemsl. l. c. 308. - China.

MICROTIS, R. Br. (Orchid.), - Ind, Kew, ii. 234 papillosa, Colenso, in Trans, $N, Z$. Inst. xviii. $1885(1886) 269 . \rightarrow \mathrm{N}$. Zel.

MIGROTROPIS, Wall, (Celastr.). - Ind, Kew. ii. 234

pallens, Pierre, Fl, For. Cochinch. Fasc. 20 (1894) t. $305 \mathrm{~b} \quad(=$ Plenrostylia pallens, Pierre $) .-$ Cochinch.

MIDA, R. Cunn ex A. Cunn. = Fusanus, R. Br. (Santal.).

acuminata, Kuntze, Rev, Gen. (1891) $589=$ F. acuminatus $R . B r$.

cignorum, Kuntze, 1. co = F. spicatus, $R . B r$

crassifolia, Kuntze, 1, c $=$ F. crassifolius, $R, B r$. persicaria, Kuntze, 1. c. $=$ F. persicarius, F. Muell.

MIKANIA, Willd. (Compos.). - Ind. Kew. ii. 235. araucana, Phil. in Anal. Univ. Chil. 1xxxvii. (1887) 330. - Araucania.

Carteri, Baker, in Kew Bull. (1895) 106, - Afr. trop. or:

chagalensis, Hieron. in Bot. Fahrb. xix. (1894) 47 . - Ecuad

fragrans, Klatt, in Bot. Falirb. viii. (1887) 36 . Columb.

Lehmanni, Hieron. l. c. xix. (1894) 46. - Columb. nemorosa, Klatt, l.c. viii. (1887) 36. - Columb.

olivacea, Klatt, ex Th.Dur. \& Pitt. in Bull. Soc. Bot. Belg. xxxi. 1892 (18:3) 175 - Costa Rica. punctata, Klatt, l.c. - Costa Rica.

pyramidata, f. D. Smith, in Coult. Bot. Gaz. xiii. (1888) 188. - Guatem.

Stuebelii, Hieron. in Bot. Fahrb. xxi. (1895) 333. Columb.

sylvatica, Klatt, in Bot. Fahrb. viii. (1887) 37. Columb.

Vellosiana, Barb. Rodr. Hort. Flumin, 1893 (1895) 276. - Bras.

MILIUM, Linn. (Gramin.), - Ind. Kew, ii. 286. Treutleri, Kuntze, Rev. Gen. (1891) '780 = Cyathopus sikkimensis, Stapf, et Deyeuxia Treutleri, Stapf [Conf. Hook. Icon. pl. xxiv. (1895) sub t. 2395 et 2396 in obs.]

MILIUSA, Leschen. (Anonac.)。 - Ind. Kew. ii. 237.

longipes, King, in fourn. As. Soc. Beng. 1xi. (1892) II. 124, - Perak

MILlETIA. Wight \& Arn. (Legumin.). - Ind. Kew, ii. 238

Baptistarum, Buettn, in Verh. Bot. Ver. Brand. xxxii. (1\$90) 50. - Congo.

Dorwardi, Collett \& Hemsl, in fourn. Linn. Soc. xxviii. (1890) 40. - Burma.

eurybotrya, Bureau \& Franch. in Morot, Fourn. de Bot. v. (1891) 187. - Tonkin.

gracillima, Hemsl, in Kerv Bull. (1895) 134. - Ins. Salom. 
MILLETIA :

Hookeriana, Taub. in Engl. \& Prantl, Natür. Pflanzenfam. iii. 3 (1894) 271 (= $M$. macrophylla, Hook. f.). - Ins. Fernando-Po.

ichthyochtona, Bureau \& Franch. in Morot, fourn. de Bot.v.(1891) 187. - Tonkin.

Maideniana, F.M. Bailey, in Dept. Agric. Brisbane. Bot. Bull. v. (1892) 12, - Austral.

micans, Taub. in Engl. Pfanzenw. Ost-Afr. C (1895) 212. - Afr. trop. or.

multiflora, Collett \& Hemsl. in Fourn. Linn. Soc. xxviii. (1890) 41, - Burma.

macrophylla. Taub. in Engl. \& Prantl, Natürl. Pflanzenfam. iii. 3. (1894) $271=$ auriculata, Baker.

macrostachya, Collett E Hensl. in fourn. Linn. Soc. xxviii. (1890) 41. - Burma.

pachyloba, Bureau \& Franch, in Morot, fourn. de Bot. v. (1891) 18\%. - Tonkin.

purpurea, Yatabé, in Tokyo Bot. Mag. vi. (1892) 379. t. 12. - Japon.

scabricaulis, Franch. Pl. Delav. i. (1S89) 158. Yunnan.

Stuhlmannii, Taub. in Engl. Pflanzenw. Ost-Afr. C (1-95) 212. - Afr. trop. or

usaramensis, Taub. l. c. - Afr. trop. or.

MILNEA, Roxb. = Aglaia, Lour. (Meliac.). cambodiana, Pierre, Fl. For, Cochinch. Fasc. 21 (I895) sub t. $334=$ A. cambodiana, Pierre

Harmandiana, Pierre, sub t. $333=\mathrm{A}$. Harmandiana, Pierre.

rugosa, Pierre, 1. c. t. $335=$ A. rugosa, Pierre

verrucosa, Pierre, 1. c. 335b. $=\mathrm{A}$. verrucosa, Pierre

MILTONIA, Lindl. (Orchid.). - Ind. Kew. ii. 235.

Bleuana X. Hort. ex -L. Linden \& Rodigas, in Lindenia, iv. (1888) 67, t. 176. - Hybr. artef.

Bleui $X$, God.-Lebcuf, in L'Orchidophile (1889) 45. [an praec.]. - Hybr. artef.

foiceyaña ' $X$, O'Brien, in Gard. Chron. (1893) ii 206. - Bras, ?

Loddigesii, Hort. ex Regel, in Act. Hort. Petrop. xi 1890 (1898) $306=$ flavescens, Reichb. $f$.

Peetersiana, Reichb. $f$. in Gard. Chron. (1886) ii 326. - Hybr. spont. ?

Phalaenopsis, Nichols. Dict. Gard. 1i. (1886) 367 et 369 : Rolfe, in Lindenia, vii. (1891) 95, t. 334 (= Odontoglossum Phalaenopsis, Linden \& Reichb. f.) - N. Granat.

Schroederiana $\times$, O'Brien, in Gard, Chron. (1889) ii 210 (= Odontoglossum Schroederianum, Reichb. f.) - Hybr. artet.

MILTONIOPSIS, Bleui $\times$, God,-Lebouf, in L'orchidophile (1889) 145; Bleu, in Rev. Hortic. Ixii. (1890) $211=$ Miltonia Blewi $X$, God.-Lebœuf

MIMELANTHE, " Greene, » ex Wettst. in Engl. \&, Prantl. Natürl. Pflanzenfam. iv. 3b. (1891) 77 sphalm. = Mimetanthe, Greene (Scrophul.).

MIMoSA, Linn. (Legumin.). - Ind Kew. ii. 239. adenophylla, Taub, in Flora, 1xxv, (1892) 72. Bras.

affinis, Robinson, in Coult. Bot. Guz. xvi. (1891) 341. - Mexic.

Alleniana, Morong, in Ann. N.Y. Acad. Sci. vii (1893) 98. - Parag

bimucronata, Kuntze, Rev. Gen. (1891) $198=$ sepiaria, Benth.

brachystachya, Taub. in Flora, lxxv. (1892) 73.Bras.

delicatula, Baill. Hist.pl. Madag, Atlas (1886) t. 24. - Madag.

dryandroides, Taub, in Flora, Ixxv. (1892) 71. Bras.

hexandra, M. Micheli, in Mém. Soc. Helv. sci. nat. xxx. (1889) n. 7. 91, t. 29. - Parag.

minutifolia, Robinson \& Greenman, in Am. fourn. Sci. Ser. III. 1. (1895) 150. - Mexic.

Morongii, Britton, in Ann. N. Y. Acad. Sci. vii. (1893) 97. - Parag.

myriocephala, Baker, in fourn, Linn. Soc. xxii. (1887) 467. - Madag.

\section{MIMOSA :}

ossibeensis, Balll. Hist. pl. Madag., Atlas (1886) t. $23 \mathrm{~A} \cdot$ - Madag

Palmeri, N.E. Rose, in Contrib.U.S. Nat. Herb. i (1891) 99. - Mexic.

Pittieri, M. Micheli, ex Th. Dur. Es Pitt, in Bull. Soc. Bot. Belg. xxx. 1891 (1892) 294 - Costa Rica.

prolifica, S. Wats, in Proc. Am. Acad, xxi. (1886 45? - Mexic

Pringlei, S. Wats, l. c. - Mexic

plumosa, M. Micheli, in Mém. Soc. Helv. sci. nat. xxx. (1889) n. 7, 91, t. 26. - Parag.

Pseudo-obovata, Taub. in Flora, 1xxv. (1892) 74. Bras.

sesquijugata, F. D. Smith, in Coult. Dot. Gaz. xiii, (1888) 74. - Guatem

Spegoazzinii, Pirotta, in Ann. Ist, Bot. Roma, iii. (1887) 132. - Reg. Argent.

spirocarpa, N.E. Rose, in Contrib. U.S. Nat. Herb. iii. 5 (1895) 316, t. 11. - Calif.

tequilana, S, Wats, in Proc. Am. Acad. xxii. (1887) 409. - Mexic

MIMULOPSIS, Schweinf. (Acanth.). - Ind. Kew ii. 245 .

affinis, Baker, in Fourn, Limn. Soc. xxii, 1887 (1888) 509. - Madag.

bicalcarata, Lindau, in Bot. Fahrb. xvii. (1893) 106. - Kamerun.

Hildebrandtii, Lindau, l. c. xx. (1894) 9. - Madag.

kilimandscharica, Lindau, l. c. 10. - Afr. aequat. or.

runssorica, Lindau. l. c. - Afr. trop. or

sesamoides, S. Moore, in Trans. Linn. Soc. Ser. II. iv. (1894) 30. - Afr. trop.

violacea, Lindau, in Bot. Fahrb. xvii. (1899) 105. Kamerun.

MIMULUS, Linn. (Scrophul.). - Ind. Kew. ii. 245

acaulis, Phil. in Anal. Univ. Chil. xci. (1895) 112. - Chili.

angustatus, Curran, in Proc. Calif. Acad. Ser. II. i. (1888) 259 (= Eunanus angustatus, Greene). Calif.

arvensis, Greene, Pittonia, i. (Mar. 1887) 37; et Man. Bot. San. Franc. Bay (1894)27\%. - Calif

Breweri, Coville, in Coutrib. U. S. Nat. Herb. iv (1893) 171 (= Eunanus Breweri, Greene) $=\mathrm{M}$. rubellus, $A$. Gray.

caespitosus, Greene, in fourn. Bot. xxxiii. (1895) 8 - Calif.

Clarkii, Kellogg, ex Curran, in Proc. Calif. Acad. Ser. II. i. (1888) 259 = angustatus, Curran.

Clevelandi, T. S. Brandeg. in Gard. and For viii (1895) 134 fig. 20; et in Gard. Chron. (1895) i. 518 (= Diplacus Clevelandi, Greene). - Calif.

Congdonii, Robinson, in Proc. Am. Acad. xxvi. (1891) 175. - Calir.

deflexus, S. Wats. l. c. xxiv. (1889) 84. - Calif

dentilobus, Robinson \& Fernald, l. c. xxx. (1895) 120. - Mexic.

auplex, Hort. ex Wettst. in Engl. \& Prantl, Natürl. Pflanzenzenfam. iv. 3b. (1891) 72. - Form. hort.

filicaulis, S. Wats. in Proc. Am. Acad. xxvi. (1891) 125. - Calif.

glareosus, Greene, Pittonia, i. (Mar. 1889) 282; et Man. Bot. San. Franc. Bay (1894) 277. - Calif.

gracilipes, Robinson, in Proc. Am. Acad. xxvi. (1891) 176. - Calif

hybridus $\times$, Hort. ex Wettst. in Engl. \& Prant Natürl. Pflanzenfam. iv. 3b. (1891) 72. - Hybr. artef.

implexus, Greene, in fourn. Bot. xxxiii. (1895) 8. Calif.

Kelloggii, Curran, in Proc. Calif, Acad, Ser. II. i. (1888) $261=$ atropurpureus, Kellogg.

latidens, Greene, Man. Bot. San Franc. Bay (1894) 278. - Calif.

linearis, Wettst. in Engl. \& Prantl, Natürl. Pflanzenfam. iv. $3 \mathrm{~b}$ (1891) $72=\mathrm{M}$. Uvedaliae, Hook. $f$.

marmoratus, Greene, in Erythea, iii. (1895) 73, Calif.

\section{MIMULUS :}

Neuberti, Haage \& Schmidt, ex Wettst. in Engl. \& Prantl, Natürl. Pflanzenfam. iv. 3b (1891) 72 $=$ cupreus, Hook. \& Arn.

pilosus, T, S. Brandeg. in Proc. Calif. Acad. Ser. II. i. (1885) 262: et ii. (1889) 191 (= Herpestis pilosa Bènth. . - Calif.

subrenıformis, Greene, in Erythea, iii. (1895) 6\%. Calif.

ener, Phil, in Anal. Mus, nas, Chile (1891) \%0.-

MIMUSOPS. Linn, (Sapot.), -- Ind, Kew. ii 246

albescens, Baill. Hist. des p1. xi. (1892) $269=\mathrm{La}$ bourdonnaisia albescens. Benth.

angolensis, Engl. Bot. Fahrb. xii. (1890) 523. Angola

Bakeri, Baill. Hist. des pl. xi. (1892) 270; et in Bull. Soc. Linn. Paris, ii. (1891) $942=$ Butyrosper mum? Kirkii, Baker.

Boivinii, Hartog, ex Pierre, Not. bot. Sapot. (1890) 11 (= Semicipium Boinini. Pierre). Madas.

Buchanani, Engl. Pfanzenw. Ost-Afr. C (1895) 307 - Afr. trop, or.

calophylloides, Baill. Hist. des pl. xi. (1892) 303 Cordem. Fl. Ile Réunion (1895) 452 (= Labourdonnaisia calophylloides, Boj.). - Ins. Mascar.

capitata, Baker, in Kew Bull. (1895) 149. - Afr. trop. occ.

coriacea, Baill. in Bull. Soc. Linn. Paris, ii. (1891 92:3 = Labramia coriacea. Baill.

cuneata, Engl. in Abh. Prenss. Akad. Wiss. (1894 36 et 54: et Pflanzenre. Ost-Afr. C (1895) 307 Afr. trop, or.

densiflora. Engl. Pflanzenw. Ost-Afr, C (1895) 307 - Afr. trop.

discolor, Baill. Hist. des pl. xi. (1892) 269 - Atr austr.

dispar, N. E. Br. in Kew Bull. (1895) 107. Natal.

fasciculata, $W a r b$. in Bot. Fahrb. xiii. (1891) 401. N. Guin.

floridana, Engl. Bot. Jahrb, xii. (1890) $525=\mathrm{M}$ Sieberi, $A . D C$

fragans, Engl, in Engl. \& Prantl, Natürl. Pfanzexfam. iv. I. (18.1) 152 (= Fmbricaria fragrans. Baker.). - Reg. Nigrit.

Glaziovii, Raunkiar, ex Warm, in Vidensk. Meddel naturh. Foren. (1889) 863 (Symb. Fl. Bras. centr xxxi. 1). - Bras.

longipes, Baker, in Kew Bull. (1895) 149. - Afr. trop. occ.

maroinata, N.E. Br. l. c. 10\%,- Afr. austr

oleifolia, $N, E, B r . l, c, 109$. - Natal

pachyclada, Baker, l. c. 149. - Afr. trop. occ.

Pancheri, Baill. in Bull. Soc. Linn? Paris, ii, (1891) 907; et Hist. des pl. xi. (1892) 273. N. Caled.

pauciloba, Pierre, ex Baill. l.c. 922. - Jamaic.

Pierrei, Baill. Hist. des pl. (1892) $274=$ seq. ?

Pierrei, Baill. in Bull. Soc. Linn. Paris, ii. (1891) 919. - Ins. Maurit.

Pleeana, Picrre, ex Baill. l. c. 923. - Ind. ooc

vevoluta, Baill. Hist. des pl. xi. (1892) $273=$ revoluta, Hochst.?

Riedeliana, Pierre, ex Baill. in Bull. Soc. Linn. Paris, ii. (1891) 922 ; ct Hist. des pl, xi. (1892) 269 - Am. austr.

sansibarensis, Engl. Pfanzenw. Ost-Afr. C (1895) 307. - Afr. trop. or.

sarcophleia, Baill. Hist. des pl. xi. (1892) 273. Ind. occ.

Schweinfurthii, Baill. in Bull. Soc. Linn. Pavis, ii (1891) 943. - Afr. trop.

Schweinfurthii, Engl. Bot. fahrb̆. xii. (1890) 523 - Afr. centr.

Sideroxylon, Pierre, ex Baill, in Bull, Soc, Limn Paris, ii. (1891) $924(=$ Sapota Sideroxylon Griseb.). - Ind. occ

sulcata, Engl. en Abh. Preuss. Akad. Wiss. (1894) 36 et 54; et Pflanzenw. Ost-Afr.C (1895) 307. - Afr. trop. or.

Welwitschii, Engh, Bot. Fahrb, xii. (1890) 524。Angola. 
MIQUELIA, Meissn. (Olacin.). - Ind, Kew, ii 247 .

caudata, King, in fourn. As. Soc, Beng. 1xiv. (1895) II. 124. - Penins. Mal.

MIQUELINA, Van Tiegh, in Bull. Soc. Bot. Fr. xlii. (1895) $443=$ Loranthus, Linn.

coccinea, Van Tiegh. 1. c. = L. coccineus, Reinw. eremia. Van Tiegh 1. c. = L evenius, Blume.

hypoglauca, Van Tiegh. 1. c. = I, hypoglaucus, Kin.

Kurzii, Van Tiegh. 1. c, - Pegu.

MIRABILIS, Riv, ex Linn. (Nyctagin.), - Ind Kew, ii. $24 \%$

angustifulius, Machill. Metasp. Mimn. (1892) 216 (Calymenia angustifosia, Nutt.)

Bigelovii, A. Gray, in Proc. Am. Acad. xxi. (1886) 413. - Arizona.

ciliata, Fr. Meigen, in Bot. Jahrb, xvii (1893) 237 $=$ Oxybaphus ciliatus, Fhil.

exserta, T. S. Brandeg. in Proc. Calif. Acad. Ser. II. iii. (1891) 165. - Calif.

hirsuta, MacMill, Metasp. Minn. (1893) 217 (hirsutus $=$ oxybaphus hirsutus, Sweet.

lacvis, T. S. Brander, in Proc, Calif, Acad. Ser. II. iii. $(1889) 198=$ seq.

lnevis. Curran, 1. c. Ser. II. i. (1888) 235 (= Oxybapluts laevrs, Benth. $)=$ californica, A. Gray. zyctaginens, MacM11. Metasp. Minn. (1892) $217=$ Allionia nyctaginea, Michix.

orata, Fr. Meigen, in Bot. Jahrb, xviii. (1894) 436 = Oxybaphus ovatus, Vahl.

Watsoniana, Heimerl, in Bot. Fahrb. xi. (1890) 84 - Guatem.

MISANTECA, Cham, \& Schlecht, (Laurin.), Ind. Kew. ii. 248 .

Juergensenii, Mez, in fahrb. Bot. Gart. Berlin, v. (1889) 102. - Mexic

triandra, Mez, 1, c. $103=$ cubensis, Benth

MISGANTHUS, Anderss. (Gramin.). - Ind, Kew. ii. 248.

nepalensis, Hack, in DC, Monog, Phan, vi. (1889) 104 (= Eulalia nepalensis, Trin.). - Ind. or.

nudipes, Hack. l. c. 109 (= Erianthus mipes, Griseb.). - Sikkim.

sacchariflorus, Hack, in Engl. Eo Prantl. Natürl. Pflanzenfam. ii. 2 (1887) 22; et l. c. $102(=I m-$ perata sacchariflora, Maxim.). - As, or.

Tanakae, Makino, in Tokyo Bot. Mag. viii. (1894) 90 , nomen. - Japon.

tinctorius, Hack. in DC, Monog. Phan. vi. (1889) 103 (= Erianthus tinctorius, Sieb.). - Japon.

MISCHOCARPUS, Blume = Ratonia, DC. (Sapind.).

papuanus, Radlk, in Sitzb. Math.-Phys. Acad Muench. xx. (1890) 248. - N. Guin.

paradoxus, Radlk. 1. c. - N. Guin.

MITELLA, Tourn, ex Linn, (Saxifr.). - Ind. Kew, ii 248.

diversifolia, Greene, Pittonia, i. (Feb. 1887) 32; et in West Am. Scientist, iii. (1887) 24. - Calif.

Hallii, Howell, in Erythei, iil. (1895) 33. - Am. bor. occ.

japonica, Makino, in Tokio Bot. Mag, viii. (1894) 44. [an Miq.?]. - Japon.

longiscapa, Makino, l. c. 43; et ix, (1895) 401.Japon.

ovalis, Greene, Pittonia, i. (Feb. 1887) 32; ot in West Am. Scientist, iii. (1887) 25. - Calif.

MITRACARPUS, A. Rich. = Mitracarpum, Zucc. (Rubiac.).

anthospermoides, K. Schum. in Mart. Fl. Bras. vi. VI. (1888) 86. - Bras.

Eichleri, K. Schum. 1 c. - Bras.

frişidus, K. Schum. 1. c. $81=$ Mitracarpum Humboldtianum, Cham. \&o Schlecht.

microspermus, K. Schum. 1. c. \$3. - Am. trop.

paroulus, K. Schum. 1. c. 84 - Bras.
MITRAGYNA, Korth. (Rubiac.). - Ind. Kew. ii. 249

inermis, Kuntze, Rev. Gen.(1891) $228=$ africana, Kunth.

inermis, K. Schum. in Engl. et Prantl, Natürl. Pflanzenfam, iv 4 (1891) 56 , Mitracine $]=$ praec rotundifolia, Kuntze, l. c. 289. - Burma, Ins. Philipp.

stipulosa, Kuntze, 1. c. = macrophylla. Hiern.

tubulosa, Kuntze, $l$. $c .288$. - Ind. or

tubulosa, K. Schum. 1. c. = praec.

MITRANTHES, Berg = Calyptranthus, Sw. (Myrt.).

Eggersii, Niedenzu, in Engl. \& Prantl, Natürl Pflanzenfam. ii. 7 (1893) 72 [Mitranthus] (= Marlieropsis Eggersii, Kiaersk.). - Ins. Domin.

MITREPHORA, Hook, f. \& Thoms, (Anonac.) - Ind. Kew. ii. 250.

Froggattii, F, Muell, in Australas. fourn. Pharm, ii (Jan. 1887) 3; et in Bot. Centralbl. xxx. (1887) 324. - Austral.

macrophylla, Oliver, in Hook. Icon.pl. xvi. (1887) t. 1562. - Penang.

Prainii, King, in fourn. As. Soc. Beng. 1xi. (1892) II. 88. - Ins. Andam.

MITROPHORA, Neck. = Fedia, Gaertn. (Valer.) Cormucopiae, Kuntze, Rev. Gen. (1891) $302=\mathrm{F}$. Cornucopiae, Gaertn.

MIXANDRA, Pierre, ex L. Planch. Etud. prod, Sapot. (1888) 26, et Not. Bot. Sapot. (1890) $2=$ Bassia, Koenio (Sapot.)

butyracea, Pierre, Il. cc. = B. butyracea, Roxb.

MNIOPSIS, Mart. (Podost.). - Ind. Kew. ii. 250. Glazioviana, Warm. Fam. Podost. Ath. 3 (1888) 481. - Bras.

Saldanhana, Warm, l. c. 458 et 481 t. 20. - Bras.

MNIOTHAMUS, Niedenzu, in Engl. \& Prantl, Natiirl. Pflanzenfam. iii. 2a (1S91) 136. BRU NIACEAE.

callunioides, Niedenzu,l.c. $(=$ Berzelia callunioides, Oliver). - Afr, austr.

MOGQUERYSIA, Hua, in Morot, Journ. de Bot. vii. (1893) 259; Warb. in Encl. \& PrantI, Natiirl. Pflanzenfam. iii. 6a (1893) 39. BIXACEAE multiflora, Hua. $l l . c c .26$ ', et 39 , - Afr. trop. occ.

MODEGGA, Linn. (Passifl.). - Ind. Kew, ii. 251. cladosepala, Baker, in foum. Limm. Soc. xzv. (1890) 317. - Madag.

hederaefolia, Baker, l. c. xxii. (1887) 479.-Madag, membranifolia, Baker, l. co xxv, (1890) 317. Madag

MODIOLA, Moench (Malv.). - Ind. Kew. ii. 251. lateritia, K. Schum. in Mart. Fl. Bras, xii. III. (1891) 455 (= Malva lateritia, Hook.). - Am. austr.

MODIOLASTRUM, "K. Schum. in Mart. Fl, Bras. xii. 11.. (1S91) 276. MALVACEAE geranioides, E. G. Baker, in fourn. Bot. xxxi. (1893) $368(=$ Modiola geranioides, Walp.). - Chili.

Jaegrianum, $K$. Schum. in Mart. Fl. Bras, xii. III (1891) 278. - Reg. Argent

malvifolium, K. Schum. l.c.277 (= Modiola malvae folia, Griseb.). - Parag.. Reg. Argent.

MOEHRINGIA, Linn. = Arenaria, Rupp. (Caryophyll.)

frutescens, Panizzi, in Nuov. Giorn. Bot. Ital, xxi. (1889) 4.5. - Ital

sphagnoides, Nym. Consp. Fl. Eur. Suppl. ii.. I (1889) $65=$ Arenaria sphagnoides, Froet. tejedensis, Willk. Suppl. Prodr. F1. Hisp. (1893) $275=\mathrm{A}$. tejedensis. Huter, Porto of Rigo.

MOENCHIA, Ehrh. = Gerastium, Dill. (Caryophyll.).

-dolichotheca, Sommier \& Levier, in Act. Hort. Petrop.xiii. (1893) 40, - Res. Cauc,
MOERENHOUTIA, Blume (Orchid.). - Ind Kew. ii. 252.

heteromorpha, Benth. \& Hook. f. ex Drake, Ill. Ins. Mar. Pacif., Fasc. 7 (1892) 313 (= Phaylopsis hiteromorpha, Reichb. f.). - Ins. Samoa.

MOGHANIA, Jaume St. Hil. = Flemingia, Roxb. Legumin.)

Chappar, Cumingiana, faginea, Grahamiana, guineensis involucrata, lineata, oblongifolia, parviflora, pauciflora, stricta, tuberosa, vestita, Wallichit, Kuntze Rev. Gen. (1891) 199 = homonyma ommia Flemingiae.

macrophylla, Kuntze, 1. c. = F. congesta, Roxb.

Phursia, Kuntze, 1. c. = F. paniculata, Wall.

rhodocarpa, Kuntze, 1. c, = F. congesta, Roxb.

MOGIPHANES. Mart. (Amarant.). - Ind. Kew. ii. 253.

rosea, Morong, in Ann. N.Y.Acad. Sci. vii. (1893) 206. - Parag.

MOHADENIUIM, Pax, in Bot. Jahrb, xix. (1894) 126. EUPHORBIACEAE

coccineum, Pax, l. c. 127. - Afr. trop. or.

MOHAVEA, A. Gray (Scrophu1.). - Ind. Kew. ii, 253.

breviflora, Corille, in Contrib, U, S, Nat, Herb, iv. (1893) 168. - Calit.

viscida, Baill. Hist. des pl. ix. (1888) $438=$ viscida A. Gray.

MOHRIA, Britton, in Gard, and For. vi. (1893) 433-34 et 363 = Halesia, Linn. (Styrac.). carolina, Britton, 1. $\mathrm{c}_{\mathrm{o}}=\mathrm{H}$. tetraptera, Ellis. diptera, Britton, 1. c. = H. diptera, Ellis.

MOHRODENDRON, Britton, in Gard. and For. vi. (1893) $463=$ Halesia, Linn. [non P. Br.] (Styrac.)

carolinum, Britton, 1. c.; et ex Small \& Vail, in Mem. Torrey Bot. Club, iv. (1893) $138=\mathrm{H}$. tetraptera, Ellis.

dipterum, Britton, 1. c. $463=\mathrm{H}$. diptera, Ellis.

MOKOFUA, Kuntze, Rev, Gen.(1891)63= MOKOF, Adans. = Cleyera, Thunb. (Ternstroem.).

alnifolia, andma, brasiliensis, camosa, clusiacolia, congestiflora, crassifolia, cuneifolia, delicatula, dentata, elliptica, enarginata, gedehensis, japonica, laevigata, longipes, meridionalis, micrantha, obovalis, oleaefolia, patens, peduncularis, penangiana, punctata, quinquepartita, Ruiziana, Schomburghiana, Seemanmii, sessiliflora, silvatioa, venosa, verticillata, Kuntze, 1. c. $63-64=$ homonyma onmia Ternstroemiae.

Teperapote, Kuntze, 1. c. $(=$ T. Iineata, DC. $)=$ elliptica, Sw.

MOLINAEA, Comm. ex Juss. = Gupania, Plum. (Sapind.)

laevis, Baill. Hist. pl. Madag, Atlas (1892) t. 242. - Madag.

MOLINAEA, “Schrank » St Lager, in Cariot, Etud. des.fl. éd. 8 ii. (1889) $936=$ Molinia, Schrank. (Gramin.).

MOLINERIA, Parl. = Aira, Linn. (Gramin.). insolucrata, C. Richt. Pl. Europ. i, (1889) 55. ... Lusit., Hisp.

MOLINIA, Schrank. (Gramin.). - Ind. Kew. ii. 253.

Bertim, Hort. ex Carrière, in Rev. Hortic. (1890) $34 \mathrm{~S}=$ caerulea, Moench

MOLLERA, O. Hoffm. in Engl. \& Prantl, Natürl. Pflanzenfam. iv. 5 (1890) 205; et in Bolet. Soc. Brot. x. (1892) 174. COMPOSITAE angolensis, $O . H o f f m . ~ h$.cc. - Angola.

MOLLIA. Mart. (Tiliac.). - Ind, Kew, ii. 253. boliviana, Britton, in Bull. Torrey Bot. Chub, xvi. (1889) $15 \%$. - - Bolivia. 
MOLLINEDIA, Ruiz \& Pav. (Monimiac.). - Ind Kew. ii. 253.

angustifolia, F. M. Bailey, in Dept. Agric. Brisbane Bot. Bull. v. (1892) 23. - Austral.

Macooraia, F. M. Bailey, l. c. - Austral,

subternata, F. M. Bailey, 7. c. 22. - Austra!.

MOLLUGO, Linn. (Ficoid.). - Ind. Kew. ii. 253 caespitosa, S. Elliot, in fourn. Linn. Soc. xxix. (1К91) 25. - Madag.

Cambessedesi, Coult. in Contrib. U. S. Nat. Herb. ii. (1891) $138=$ Glinus Cambessedesii, Fenzl.

decandra, S. Elliot, in fourn. Linn. Soc. xxix. (1891) 24. - Madag.

MOLUGELLA, Linn. (Labiat.). - Ind. Kew, ii. 254.

lanata, Post, Pl. Postianca, ii. (1891) 19. - Syria.

otostegioides, Prain, in fourn. As Soi. Beng. lix. (1891) ii. 311. - Ind. or.

MOMORDICA, [Tourn.] Linn. (Cucurb.). - Ind. Kew. ii. 25i3.

cordata, Cogne in Bot. Fahro. xxi. (1895) 208. Kamerun.

coriacea, Cogn. in K. Schum. E Hollr. Fl. Kais. Wilh. Land (1889) 82. - N. Guin.

dissecta, Baker, in Kew Bull. (1895) 315. - Reg. Somal.

Henriquesii, Cogn. in Bolet. Soc. Brot. vii. (1889) 228. - Zambesia.

heterophylla, " Cogn. » ex Forb. \& Hemsl. in Journ. Linn. Soc. xxiii. (1887) 318 [err. cal.] = Melothria heterophylla, Cogn.

mavtinicensis, Hook. ex Wien. Illustr. Garten-Zeit. (1SS8) 473. - Martinic.

ovata, Cogn. in Boerl. Handl. Fl. Ned. Indië, i. ii (1890) 595. - As. trop.

plinctata, [Engl.?] Pfanzenre. Ost-Afr. A (1895) 109 nomen. - Afr. trop. or.

Schinzii, Cogn. ex Schinz, in Verh. Bot. Ver. Brand. xxx. (18s's) 149. - Afr. austro-occ. extratrop.

MONACHANTHUS, Lindl, = Catasetum, Rich. (Orchid.)

discolor, Barb. Rodr. [Herb. Mus, bot. Amaz. n. 568] in Vellosia, 1885̌-88. Sec. ediç. (1891) 126. - Bras. bor

MONACHOCHLAMYS, Baker (Acanth.). - Ind. Kew. ii. 255.

Boivin1, Baill. in Bull. Soc. Linn. Paris, ii. (1890) 826. - Madag.

madagascarica, Baill. 1. c. = flagellaris, Baker.

madagaskariensis, "Baill. » ex Lindau, in Engl. \& Prantl, Natürl. Pflanzenfam. iv. 3b (1895) 291, sphalm. = madagascarica, Baill.

MONAGHYRON Parl, (Gramin.). - Ind. Kew. ii. 255 .

grandiflorum, Martelli, Fl. Bogos. (1886) 94 (= Tricholaena grandiflora, Hochst.). - Abyss.

MONADENIA, Lindl. = Disa, Berg (Orchid.). bracteata, Th. Dur. \& Schinz, Consp. Fl. Eur. v. $1892(1895) 111=$ D. bracteata, Sw.

cermuc, Th. Dur. \& Schinz, 1. c. = D. cernua, Sw. pygnaca, Th. Dur. \& Schinz, 1. c. = D. pyomaea, Bolus.

reticulata, Th. Dur. \& Schinz, 1. c. $112=$ D. reticulata, Bolus.

rufescens, Th. Dur, \& Schinz, 1, c. = D. rufescens, Siv.

MONANTHES, Haw. (Crassul.). - Ind. Kew. ii.

agriostaphys, Christ, in Bot. fahrb. ix. (1888) 162 (= Petrophyes agriostaphys, Webb). - Ins. Canar. microbotrys, Bolle, l. c. xiv. (1892) 240 (= P. Microbotrys, Webb \& Berth.). - Ins. Canar.

minima, Christ, l. c. ix. (1888) $162(=P$. minima,

Bolle), - Ins. Canar.

muralis, Christ, l. c. $(=$ P. muralis, Webb). Ins. Canar.

\section{MONANTHES :}

pallens, Christ, in Bot. Fahrb. ix. (188s) $162(=P$. pallens, Webb). - Teneriffa.

purpurascens, Christ, l. c. $i=P$. purpurascens, Bolle \& Webb). - Ins. Canar.

tilophila, Christ, l.c. $(=P$. tilophyla, Bolle $)$ - - Ins. Canar.

MONANTHOTAXIS, Baill, in Bull. Soc, Linn, Paris, ii. (1890) 878. ANONACEAE. congoensis, Baill. l. c. 879 , - Congo gall.

MONARDELLA, Benth. (Labiat.). - Ind. Kew. ii. 256.

discolor, Greene, Pittonia, ii. (Nov. IS89) 24. Am. bor. occ.

MONELYTRUM, Hack. ex Schinz, in Verh. Bot Ver. Brand. xxx. (1888) 140. GRAMINEAE. Luederitzianum, Hack. b. c. - Atr, austro-occ extratrop.

MONNIERA, B. Juss. ex P. Br. = Herpestis, Gaertn. f. (Scrophul.)

angulata, arenaria, axillaris, Beccabnnga, caespitosa, depressa, diffusa, fagellaris, floribunda, gracilis, grandifiora, Hamiltoniana, humifusa, imbricata, lanigera, madagascariensis, micromonniera, montevidensis, obovata, pilosa, radicata, repens, reptans, vidensis, obovata, pilosa, radicata, repens, reptans, Kuntze, Rev. Gen. (1891) $46263=$ homonyma omnia Herpestis.

acuminata, Kuntze, 1. $\therefore 463=\mathrm{H}$. nigrescens, Bent7.

bacopodes, Kuntze, 1, c. = H. bacopoides, Benth. calycina, Kuntze, 1. c. $462=$ H. Monnieria, $H$. B. $\& K$.

caprariodes, Kuntze, 1. c. $463=\mathrm{H}$. caprarioides, H. B. \& $K$.

caroliniana, Kuntze, 1. C. = H. amplexicaulis, Pursh.

hesmiariodes, Kuntze, 1. c. $=$ H. herniarioides, Cham.

monnierodes, Kuntze, 1. c. = H. Ranaria, Benth,

Monnicra, Britton, in Mem. Torrey Bot. Club, (1894) 292; et Field Columb. Mus., Bot. Ser. I (1895) $44=H$. Monieria, $H$. B. \& $K$.

myriuphyllodes, Kuntze, Rev. Gen, (1891) $463=\mathrm{H}$. myriophylloides, Benth,

procumbens, Kuntze, 1. c. $=\mathrm{H}$. chamaedryoides, $H$. B. \& $K$

reflexa, Kuntze, 1. c. = Myriophyllum proserpinacoides, Gill.

scabra. Kuntze, 1. c. = Herpestis laxiflora, Benth. semiserrata, Kuntze, 1. c. = H. gratioloides, Benth. serpyllodes. Kuntze, 1. c. $=$ H. serpylloides, Cham. E Schlecht.

stellariodes. Kuntze, 1. c. = H. stellarioides, Cham Trecedii, Kuntze, 1. c. $=$ H. Tweediei. Benth.

MONNIERIA. Linn. (Rutac.), - Ind. Kew. ii crenulata, Small, in Bull. Torrey Bot. Chub, xxii. (1895) 46. - Florida.

MONNINA, Ruiz \& Pav. (Polygal.), —Ind, Kew. Andreana, Chod. in Bull. Herb. Boiss. iii. (1895) 134. - N. Granat.

Autraniana, Chod. l. c. 543. - Bolivia.

boliviana, Chod. l. c. - Bolivia.

boliviensis, A. W. Benu, in Bull. Torrey Bot. Club, xvi. (1889) 20, - Bolivia

Bridgesii, Chod. in Bull. Herb. Boiss. iii. (1895) $54 \%$. Bolivia.

bracteata, Chod.l. c. 153. - Venezuela.

chanduyensis, Chod. l. o. ii. (1894) 166. - Am. austr. occ.

comata, Chod.l. c. 171. - N. Granat.

coriacea, Chod. l. c. 132. - Venezuela.

costaricensis, Chod. ex Th. Dur. Go Pitt. in Bull. Soc. Bot. Belg. xxx. 1891 (1892) 304. - Costa Rica.

Crepini, Chod. cx Th, Dur. \& Pitt. l. c. 302.Costa Rica.
MONNINA:

denticulata, Chod. in Bull. Herb. Boiss, iii. (1895) 135. - Peruvia.

elliptica, Chod. l. c. - N. Granat,

Lechleriana. Chod. l.c. 129. - Peruvia.

Lehmanniana, Chod. l. c.542. - Columb.

longibracteata, Chod. l.c. 130. - Am. austr.

Lorenziana, Chod. l. c. ii. (1894) 168. - Reg. Argent.

Malmeana, Chod. l. c. iii. (1895) 540. - Bras.

Mathusiana, Chod. l. c. - Peruvia.

nitida, Chod. l. c. 130. - I'eruvia.

patula, Chod. l. c. -- Ecuad.

Pavoni, Chod.l. c. 132. - Peruvia.

peruviana, Chod. l. c. 133. - - Peruvia.

Philippiana, Chod. l. c. ii. (1894) 159. - Chili.

piauhensis, Cliod.l. c. iii. (1895) 541. - Bras

Pittieri, Chod. cx Th. Dur. \& Pitt, in Bull. Soc. Bot. Belg. xxx, 1891 (1892) 303. - Costa Rica.

platyphylla, Chod. in Bull. Horb. Boiss. ii. (1S94) 1\%0. - N. Granat.

pulchra, Chod. l. c. iii. (1895) 133. - Ecuad.

Rusbyi, Chod. l. c. ii. (1894) 170. - Bolivia.

Spruceana, Chod. l.c. 16\% - Ecuad.

stipulata, Chod. l. c. 170 - Bolivia.

sylvicola, Chod. ex Th. Dur. \& Pitt. in Bull. Soc. Bot. Belg. xxx. 1891 (1.992) 303. - Costa Rica tenuifolia, Chod. in Bull. Herb. Boiss. iii. (1895) 131 - N. Granat.

MONOGHAETUM, Naud. (Melast.). - Ind. Kew. ii. 258.

angustifolium, Cogn. in DC. Monog. Phan. vii. (1891) 1181. - Mexic.

Candollei, Cogn. . . c. 396. - Mexic

Carazoi, Cogn. l. c. 481; et ex Th. Dur. Ev Pitt. in Bull. Soc. Bot. Belg. xxx. 1891 (1892) 246. Costa Rica.

diffusum. Cogn, ex 7. D. Smith, in Coult. Bot. Gaz. xvi. (1891) 4 ; et in DC. Monog. Phan. vii. (1891) 395. - Guatem

strigosum, Cogn. 1. c. 40\%. - N. Granat.

vulcanicum, $\operatorname{Cog} n$. l.c. 401 ; et ex Th. Dur. \& Pitt. in Bull. Soc. Bot. Belg. xxx. 1891 (1892) 246. - Costa Rica.

MONOCHOSMA, Maxim. (Scrophu1.). - Ind. Kew. ii. 258.

monantha, Hemsl. in fourn. Linn. Soc. xxvi. (1S90) 203. - China.

MONOCOSMIA. Fenzl (Portul.). - Ind. Kew ii. 258

monandra, Baill. Hist. des pl. ix. (1888) $72=$ corrigioloides, Fenzt.

MONODORA, Dunal (Anonac.). - Ind. Kew. ii. 259

borealis, S. Elliot, in foum, Linn. Soc, xxx. (1S94) 72. - Sierra Leone.

MONOLENA. Triana (Melast.). - Ind. Kew. ii. 259. ovata, Cognz in Bull. Acad. Belg. Sér. III. xiv. (1887) 945 ; et in DC. Monog. Phan. vii. (1891) 5.39. - N. Granat.

MONOLEPIS, Schrad. (Chenopod.). - Ind. Kew. ii. 259.

Nuttalliana, Greene, F1. Francisc. (1891) $168=$ trifida. Schrad.

MONOTES, A. DC. (Dipteroc.). - Ind. Kew. ii 260 .

adenophylla, Gilg, in Engl. Pfanzenzu. Ost-Afr. C (1895) 275. - Afr. trop. or.

MONOTROPA, Linn. (Monotrop.). - Ind. Kew ii 260.

glabra, Lange, Haandb. Danske Fl. ed. 4 (IS86-8S) $430 \cdot(=$ H. glabra. Bernh. $)=$ Hypopitys multiflora, $S c o p$.

MONSONIA. Linn. (Geran.). - Ind. Kew. ii. 260 .

Drudeana, Schinz, in Verh. Bot. Ver. Brand. xxxi. (1590) 182. - Afr. austro-occ. extratrop. 


\section{MONSONIA}

gnea, Schinz, in Bull. Herb. Boiss. iii. (1895) 399. - Reg. Somal.

Iuederitziama, Focke of Schnnz, in Verh. Bot. Vev. Brand. Abluandl. xxix, (188S) 60. - Afr. austroocc. extratrop.

parvifolia, Schinz, l. c. - Afr. ausrro-occ. extratrop.

MONTANOA, Cerv. (Compos.), - Ind. Kew. ii. 261.

dumicola, Klatt, ex Th Dur. \& Pitt. in Bull. Soc Bot. Belg. xxxi. 1892 (1893) 200. - Costa Rica. Moritziana, Sch. Bip. ex Kuntze, Rev. Gen. (1891) 336. - Columb.

patens, A. Gray, in Proc. Ann. Acad. xxi. (1886) 3S5. - Mexic

pauciflora, Klatt, in Leopoldina, Heft xxiii. (1887) 90. - Am. austr.

samalensis, Coult. Bot. Gaz. xx. (1895) 49. Guatem.

subtruncata, A. Gray, ex S. Wats, in Proc. Am. Acad. xxii. (1887) 424. - Mexic

MONTIA, Mich. (Portul.). - Ind. Kew; ii. 202. asarifolia. Howell, in Erythea, i. (1893) $39=$ Claytonia asarifolia, Bong.

bulbifora, Howel1, 1. c. = C. bulbifera, A. Gray.

Chamissoi, Greene, Fl. Francisc. (1891) -180 $\doteq$ C. Chamissoi, Ledeb.

dichotoma, Howell, in Erythea, i. (1893) $36=\mathrm{C}$. dichotoma, Nutt.

diffusa. Greene, Fl. Francisc. (1891, $181=$ C. ditfusa, Nutt.

gypsophituides, Howell, in Erythea, i. (1893) $38=$ C. gypsophiloides, Fiscth. \& Mcy.

Halli, Greene, Fl. Francisc. (I891) $180=\mathrm{C}$. Hallii, A. Gray.

linearis, Greene. 1. c. $181=$ C. Hallii, A. Gray.

parviflora, Howell, in Erythea, i. (1893) $38=\mathrm{C}$. parviflora, Dougl.

parvifolia, Greene, Fl. Francisc. (1891) 181; et Man. Bot. San Franc. Bay (1894) $61=$ parvifolia, Moc

perfoliata, Howell, in Erythea, i. (1893) $38=\mathrm{C}$. perfoliata, Donn.

rubra, Howell, l. c. - Am. bor. occ

sibivica, Howell, 1, c. = C. sibirica, Linn.

spathulata, Howell, 1. c. = C. spathulata, Dougl.

tenuifolia, Howell, 1. c. = C. exiona, Torr. \& Gray.

MooREA, Rolfe, in Gard. Chron. (1890) ii. 7. ORCHIDEAE.

irrorata, Rolfe, l. c. ; et (1892) i. 489 fig. 73: Hook. $f$ in Bot. Mag. (1892) t. 7262. - Am. austr. andin.

MOQUILEA, Aub1. (Rosac.). - Ind. Kew. ii. 262. maequalis, Poepp. ex Fritsch, in Annal. Naturh. Hofmus. Wien, v. (1890) 12, in syn. = Conepia amazonica, Fritsch

rufa, Barb. Rodr. Hort. Flumin. 1893 (1895) 165. Biras.

MORAEA, Mill. ex Linn. (Irid.). - Ind. Kew, ii. 262

arenaria, Baker, Handb. Irid. (1892) 52. - Afr, austr.

Baurii, Baker, l. c. 50. - Afr. austr.

Bolusii, Baker, 2. c. 57. - Afr. austro-occ, extratrop.

caponsis, Klatt, in Th. Dur. \& Schinz, Consp. Fl. Afr, v. 18!1:3 (1895) $148=$ edulis, Ker-Gave

Carsoni, Baker, in Kew Bull. (1894) 391. - Afr. trop. austro-or.

cladostachya, Baker, Handb. Irid. (1892) 58. Afr, austr.

Cooperi, Baker, l. c. 54. - Afr. austr

Elliotii, Baker, l. c. 58 ; et in fourn. Bot. xxxix. 1891) 70. - Transvaal.

filicaulis, Baker, l.c.56. - Afr. austr.

glaucopis, Baker, l. c. 59 (= Vieusseuxia glaucopis, DC.). - Afr. austr.

macrochlamys, Baker, l. c. 49. - Afr. austr.

Nartii, Baker, l. c. 63. - Bras.
MORAEA : -

Mechowii, Pax, in Bot. Fahrb.xv. (1893) 151. Angola.

natalensis, Baker, Handb. Irid. (1892) 56. - Nata1. prolongata, Hort. ex Baker, 1. c. 60 , in obs. = iridoides, Linn.

Rogersii, Baker, l. c. 57. - Afr. austr.

serpentina, Baker, l. c. 52. - Afr. austro-occ extratrop.

sicula, Tod. Ind. sem. hort. Panorm. (1887),37; et Hort. Bot, Panorm, t, 34. - Sicil

simulans, Baker, Handb. Irid. (1892) 50, - Afr. austr

spathulata, Klatt, in Th. Dur, \& Schinz, Consp. F1. Afr. v. 1893 (1895) 152 (= Ixia spathulata Linn. f.) = spathacea, Ker-Gawl.

spiralis, Baker. Handb. Irid. (1892) 57. - Afr. austr. Thomsoni, Baker, l. c. - Afr centr, or.

ventricosa, Baker, in Kew Bull. (1895) 73. - Afr trop. centr. or.

Welwitschii, Baker, Handb. Irid."(1892) 51. Angrola.

MORELOSIA, Llav, \& Lex, = Bourreria, P. Br (Borag.)

Andrieuxit, calophylla, cassinifolia, divaricata, domingenzsis, exsucca, formosa, grandiflora, havanensis, lincaris, microphylla, ovata, Radula, recurva, reticulata, revoluta, spathulata, spinifex, tomentosa, virgata, Kuntze, Rev. Gen. (1891) $439=$ homonyma omnia Bourreriae.

Beurera, Kuntze, 1. c. = B. succulenta, facq.

fasciculata, Kuntze, 1. c. = Ehretia fasciculata, H. B. \& $K$.

Guildingiana, Kuntze, 1. c. (= Crematonia Guildingiana, Miers). - Ind. or.

montana, Kuntze, 1. c. = B. cassinifolia, Griseb.

MORETTIA. DC. (Crucif.). - Ind. Kew. ii. 263. Nakkebiana, Hochst. ex Coss. Comp. F1. Atlant. ii. (1887) $128=$ canescens, Boiss.

nana, Hoclist. b. c. - Afr. bor.

MORIGANDIA, DC.(Crucif.). - Ind. Kew, ii.264. cinerea, Coss. Comp. F1. Atlant. ii. (1887) 154, in syn. = Ammosperma cinereum; Hook.

divaricata, Coss. Illustr. Fl. Atlant. i. (1884?) 35 t. 25 ; et l. c. 158. - Algéria.

Tourneuxii, Coss. Ul. co. 36, t. 26; et 159. Algéria.

Winkleri, Regel, in Act. Hort. Petrop, ix. (1886) 612. - Turkest.

MORINA, Tourn. ex Linn. (Dipsac.), - Ind. Kew. ii. 264 .

turcica, Haláczy, in Oest. Bot. Zeitschr. xli. (1891) 409; Degen \& Haláczy, ex Celak. in Bot. Jahrb. xvii. (1893) 396, in obs. = persica, Linn.

MORINDA, Linn. (Rubiac.). - Ind. Kew. ii. 264. Beccariana, Baill. ex K. Schum, in Engl. \& Prantl, Natürl. Pfanzenfam. iv. 4 (1891) 138. - Borneo.

borneensis, Baill. l. c. - - Borneo.

Deplanchei, Baill.l. c.- N. Caled.

hypotephra, F. Muell. in Vict. Natural. vi.(July 1889) 55. - Austral.

pandurifolia, Kuntze, Rev. Gen. (1891) 289. Anam?, Cambod. ?

salomoniensis, Engl. Bot. fahrb. vii. (1886) 478. Ins, Salomon.

tribrachya, K. Schum. in Engl. \& Prant1, Natürl. Pflanzenfam. iv. 4 (1891) 138 = Tribrachya morindiformis, Oliver.

trimera, Hillebr, Fl. Haw. Isl. (1888) 177. - Ins. Sandvic.

MORISONIA, Linn. (Capparid,), - Ind. Kew. ii. 265.

oblongifolia, Britton, in Bull. Torrey Bot. Club, xvi. (1859) 17. - Bolivia.

MORMODES, Lindl. (Orchid.). - Ind. Kew. ii.

Cogniauxii, L. Linden, in fourn. des Orche. v. (1894) 125; et in Lindenia, x. (1894) 27 t. 444. Columb.

\section{MORMODES :}

Lawrenceanum, Rolfe, in Lindenia, vi. (1890) 69 t. 273. - N. Granat.

Rolfeanum, L. Linden, in Lindenia, vii. (1891) 5 t. 289; et in Gard. Chron. (1892) i. 203 fig. 30; Hook. f. in Bot. Mag. (1895) t. 7438. - Peruvia. vernixium, Reichb.f. l. c. (1887) ii. 682. - Guian. angl.

MOROCARPUS. Sieb. \& Zucc. = Debregeasia, Gaudich. (Urtic.).

ceylanicus, Kuntze, Rev. Gen. (I891) $629=\mathrm{D}$ ceylanica, Hook. f.

dentatus, Kuntze, 1. C. = D. dentata, Hook.f.

leucophyllus, Kuntze, 1. $\mathrm{c}=\mathrm{D}$. Wallichiana, $W e d d$.

squamatus, Kuntze, 1. c. = D. squamata, King \& Hook. $f$.

MORONGIA, Britton, in Mem. Torrey Bot. Club, V. (1894) 191 = Schrānckia, Willd.(Legumin.) angustata, Britton, 1, C, = S. angustata. Torr. E Gray.

Roomeriana, Heller, in Contrib. Herb. Frankl. and Marsh. Coll. [Explor. S. Texas] i. (1895) $44=$ S. platycarpa, A. Gray.

uncinata, Britton, izz Menn. Torrey Bot, Clibb, v. (1894) $191=$ S. uncinata, Willd.

MORONOBEA, Aubl. (Guttif.). - - Ind. Kew. ii.

intermedia. Enol ex Oliver in Trans, Linn. Soc. Ser. II if (1857) 271 [Oliver, ex im Thurm, in Timehri, v. (1886) 189]; et in Mart. Fl. Bras. xii. I. (1886) 466. - Guian. angl.

Jenmani, Engl.l. c. 467. - Guian. ang1,

Maconba, Miq. ex Vesque, in DC. Monog. Phan. viii. (1893) 229, in syn. = Symphonia globulifera, Lim.

MORUS, [Tourn.] Linn. (Urtic.). - Ind. Kew. ii.

Cathayana, Hemsl. in foum. Linn. Soc. xxvi. (1891) 456. - China.

Colombassa, Hort. ex Dippel, Handb. Laubholzk. ii. (1892) 10 et $582=$ alba, Linn.

fastigiata, Hort. ex Dippel, 1. c. = alba, Linn. patavia, Audib. ex Dippel, 1. c. [patavina] = alba, Linn.

virginica, Duham. ex Dippel, Handb. Laubholzk. ii. (1892) $14=$ rubra, Lim

MOSENTHINIA, Kuntze, Rev, Gen, (1891) $16=$ Glaucium, Tourn. (Papav.).

Glaucium, Kuntze, 1. c. = G. corniculatum, Curt.

MOSLA, Buch.-Ham, (Labiat.). - Ind. Kew. ii. 267.

Fordi, Maxim. in Bull. Acad. Pétersb. xxxi. (1887) 89. - China.

MOSTUEA, Didr. (Logan.). - Ind. Kew. ii. 26\%. amygdalina, Baker, in Gard. Chron. (1889) ii. 715. - Afr, austr.

Buchholzii, Engl. Bot. Fahrb. vii. (1886) 339.Kamerun.

fuchsiaefolia, Baker, in Kete Bunl. (1895) 96. Angola.

grandiflora, Gilg, ex Engl. in Abr. Preuss. Akad. Wiss. (1894) 51 et 69; et Pfanzenu. Ost-Afr. C (1895) 310. - Afr. trop. or.

microphylla, Gilg, in Engl. Pflanzenw. Ost-Afr. C (1895) 310. - Afr. trop. or

orientalis, Baker, in Kew Bull. (1895) 96 = rubrinervis, Engl.

rubrinervis, Engl. Bot. Fahrb. vii. (1886) 340.Mombassa.

Schumanniana, Gilg, in Bot. Fahrb. xvii. (1893) 560. - Gabon

Walleri, Baker, in Kew Bull. (1895) 96. - Zambesia.

MOTANDRA, A. DC. (Apocyn.). - Ind. Kew. ii. 207. Baill. in Bull. Soc. Limn. Paris, i. (1888:) 760. - Angola. 


\section{MOTANDRA}

Welwitschiana, Baill, in Bull. Soc. Limn. Paris, i. (1888) 760. - Angola.

MOUNTNORRISIA, Szyszyl. in Engl. \& Prantl, Natürl. Pflanzenfam. iii. 6 (1893) $189=$ Anneslea, Wall. (Ternstroem.).

crassipes, Szyszyl. 1. c. = A. crassipes, Hook

fragrans, Szyszyl. 1. c. = A. fragrans, Wall.

MOURERA. Aubl. (Podost.), - Ind. Kew. ii. $26 \pi$ legans, Baill. Hist. des pl. ix. (1888) $260=$ Lonchostephus elegans, Tul.

MoURIRIA, Juss. (Melast.), - Ind. Kew, ii. 267. Chamissoana, Cogne in Mart. Fl. Bras, xiv. IT. (1888) 573 ; et in DC. Monog. Phan, vii. (1891) 1119. - Bras.

Doriana, Sald. ex Cogn, 17 . co. $5 \% 2$ et 1118 . - Bras. dumetosa, Cogn. Il. co. 584 ; et 1127. - Guian. gall. Francavillana, Cogn. $7 l$. cc.576; et 1122. - Guian. gall.

Glazioviana, Cogn. $l l . c c .580$; et 1124. - Bras.

Muelleri, Cogn. in DC. Monog. Phan. vii. (1891) 1118. - Mexic

pauciflora, Spruce [P1. Amaz. 1. 3325] ex Cogn. ll.cc. 581 ; et $1124 .-$ Bras.

penduliflora, Cogn. ll. cc. 578; et 1123. - Guian. gall.

Petroniana, Cogn. \& Saldanha, ex Cogn. ll. cc. 588; et 1129. - Bras.

Regeliana, Cogn. il.cc. 572 ; et 1118. - Bras.

MSUATA, O. Hoffm, in Engl. \& Prantl, Natürl. Pflanzenfam. iv. 5 (1893) 388. COMPOSITAE Buettneri, O. Hoffm. l. c. - Congo.

MUGUNA, Adans. (Legumin.). - Ind. Kew, ii. 268

Andreana, M. Micheli, in Morot, Foum. de Bot. vi. (1892) 146 t. 5 et $6 .-$ N. Granat.

axillaris, Baker, in foum. Limn. Soc. xxii. (1887) 465. - Madag.

Blumei, Burck, in Annal. Fard. Buitenz. xi. (1893) 185. - Java.

ceramensis, Burck, l. c. 184. - Ins. Ceram et Key.

cyanosperma, K. Schum. in K. Schnm. of Hollr. Fl.

Kais. Wilh. Land (1889) 98. - Ins. Molucc. N. Guin.

erecta, Baker, in Kere Bull.'(1895) 65. - Afr. centr. or.

heyensis, Burck, in Annal. Fard. Buit. xi. (1893) 189. - Ins. Key

Kraetkei, Warb. in Bot. Fahrb. xiii. (1891) 329. N. Guin.

lucidula, Burck, in Annal. Fard. Buit. xi. (1893) 190. - Sumatra.

myriaptera, Baker, in foum. Linn. Soc. xxv. (1890) 310. - Madag

pallida, Cordem. Fl. Ile Réunion (1895) 394. - Ins. Borbon.

parvifolia, Burck, in Annal. Fard. Buit. xi. (1893) 188. - Ins. Key.

paucifiora, Blume, ex Burck, 1. c. $188=$ pruriens $D C$

reticulata, Burck, 1. c. 184. - Ins. Celebes.

sempervirens, Hemsl. ex Forb. \& Hensl. in foum. Linn. Soc. xxiii. (1887) 190. - China.

Tjerolang, Blume, ex Burck, in Annal. Jard. Buit. xi. (1893) $190=$ macrophylla. Miq.

urentissima, Blume, ex Burck, 1. c. $185=$ M. Blumei, Burck.

Wertheimii, Burck, l. c. 188 t. 14, fig. 2. - Ins. Key.

MUEHLENBECKIA, Meissn. (Polygon.). - Ind. Kew, ii. 268.

hypogaea, Colenso, in Trans. N.Z. Inst. xxi. 1888 (1889) 98. - N. Zel.

microphylla, Colenso, l. c. xx. 1887 (1888) 204.N. Zel.

muricatula, Colenso, l. c. xxii. 1889 (1890) 482.N. Zel.

paucifolia, Colenso, l. c. xxi. 1888 (1889) 99. - N. Zel.

\section{MUEHLENBECKIA}

rotundata, Plil. in Anal. Univ. Chil. xci. (1895)

493. - Chili.
Stuebelii, Lindan, ex Hieron. in Bot. Fahrb. xxi. (1895) 307 - Columb.

trilobata, Colenso, in Trants. N).Z. Inst. xxi. 1888 (1889) 100. - N. Zel.

truncata, Colenso, l. c. 101. - N. Zel.

MUEHLBERGELLA, Feer, in Bot. Jahrb. xii. (1890) 615 : Schoenl, in Enol \& Prantl, Natuirl. Pflanzenfam, iv. 5 (1894) 394 , in add. = Wah lenbergia, Schrad. (Campanu1.)

Oweriana, Feer, 1. c. (= Edraianthus Owerinianus, Rupr.). - Reg. Cauc.

MUEHLENBERGIA, Schreb. (Gramin.), - Ind Kew, ii. 26s.

acuminata, Vasey, in Coult. Bot, Gaz. xi. (1886) 337; et in Contrib. U. S. Nat. Herb, iii. I (1S92).6\% N. Mexic

Alamosae. Vasey, $7 l$. co. xvi. (1891) 146; et I (1891) 114. - Mexic.

anomalis, Fourn. Gram, Mexic, 1881 (1886) 8? = anomala, Fourn.

argentea, Vasey, ex $S$. Wats, in Proc. Ann. Acad. xxi. (1886) 443, nomen; et in Bull. Torrey Bot. Club, xiii. (1886) 252. - Mexic.

arizonica, Scribn. in Bull. Torrey Bot, Club, xv (1888) 8 t. 76, flg. a; Vasey, in Contrib. U. S. Nat Herb. iii. 1. (1892) 70. - Arizona.

Buckleyana, Scribn. ex Contt. in Contrib. U. S. Nat. Herb. i. (1890) 56 ; Vasey, m Illusir. N. Am. Grass. i. II (1891) t. 12 (= M. texentsis, Buckl.). Texas.

californica, Vasey, zn Bull. Torrey Bot. Chub, xiii (1886) 53; et Illustr. N. An. Grass. ii. (1892) t. 20 - Calif. austr.

dumosa, Scribn. ex Vasey, in Contrib. U. S. Nat. Herb. iii. (1892) $\% 1$; et Illustr. N. Am. Grass. ii (1892) t. 22. - Am bor. austro-occ

elata, Vasey, l. c. i. (1S93) ¿S2. - Mexic.

elongata, Scribn. ix S. Wats, in Proc. Am. Acad. xxi. (18S6) 443, nomen. - Mexic.

Emersleyi, Vasey, in Contrib. U. S. Nat. Herb. Iii. 1 (1892) 66. - Arizona.

filiculmis, Vasey, l.c. i. (1893) 267. - Colorado.

flavida, Vasey, l. c. i. (1892) 282. - Mexic.

grandis, Vasey, l. c.283. - Mexic.

huachucana, Vasey, l.c. iii. 69.- Arizona.

laxiflora, Scribn. in Zoë, iv. (1894) 389. - Calif.

Lemmoni, Scribn. in Contrib. U. S. Nat. Herb. (1892) 70. - Arizona, Texas

longiglumis, Vasey, in Proc. Am. Acad. xxii. (1887) 461, nomen; et in Contrib. U. S. Nat. Herb. (1893) 283, - Mexic

minutiflora. Hitchcock, in Kansas Acad. Soi. (1891) [The Grass. of Kansas| (minutiflorum) 140 (= Dilepyrum minutiflorum, Michx.). - Am. bor.

neo-mexicana, Vasey, in Coult. Bot. Gaz. xi. (1886) 337 ; Illustr. N. Am. Grass. i. II. (1891) t. 13 ; et in Contrib. U.S. Nat. Herb, iii. (1892) ro. Mexic., Arizona.

Palmeri, Vasey, ex S. Wats, in Proc. Am. Acad. xxi. (1886) 443; et in Bull. Torrey Bot. Chub, xiii. (1886) 232. - Mexic.

Parishii, Vasey, in Bull. Torrey Bot. Club, xiii (1886) 53 [err. cal. Parshii]; et Illustr. N. Anu. Grass. ii. (1892) t. 23. - Calif.

parviglumis, Vasey, in Contrib. U. S. Nat. Herb. iii. 1. (1892) 71 et 522, - Texas.

Pringlei, Scribn. ex Vasey, 1. c. iii. 1. (1892) il ; et in Trans. N. Y. Acad. Sci. xiv. (1894) $25=$ neomexicana, Vasey:

racemosa. Britton, Stern \& Pogg. Prelim. Catal. (1888) 67 (= Chloris racemosa, Kunth) = glomerata, Trin.

ramosissima, Vasey, ex S. Wats. in Proc. An. Acad. xxi. (18S6) 443 ; et in Bull. Torrey Bot. Club, xiii. (1886) 232 - Mexic

Reverchoni, Vasey \& Soribn. ex Vasey, in Contrib. U.S. Nat. Herb. iii. 1 (1892) 66. - Texas.

scoparia, Vasey, i. c. i. (1893) 283. - Mexic.

Seatoni, Scribn. ex Seaton, in Proc. Am. Acad. xxviii. (1893) 122. - Mexic.

\section{MUEHLENBERGIA :}

speciosa, Vasey, in Bull. Torrey Bot, Club, xiii. (1886) 232. - Mexic.

temuiflora Britton, Stern \& Pogg. Prelim. Catal. (1888) 67 ; et in Contrib. U. S. Nat. Herb. (1892) $522=\mathrm{M}$. Wllldenowii, Trin.

MUELLERAMRA, Kuntze, Rev. Gen. (1891) $247=$ Pterocladon, Hook. f. (Melastom.)

Sprucei, Kuntze, 1. c. = P. Sprucei, Hook, f.

MUELLERINA, Van Tiegh. in Bull. Soc, Bot. Fr. xlii. (1895) $25=$ Loranthus, Linn.

celcastroides, Van Tiegh. 1. c. = L. celastroides, Sieb. encalyptifolia, Van Tiegh. 1. c. = L. eucalyptifolius, Siez

Raouli, Van Tiegh. 1. c. = I.. Raoulii, Van Tiegh.

MUILLA, S. Wats, (Liliac.). - Ind. Kew。 ii. 269. coronata, Greene, Pittonia, i. (June 1888) 165. Calif.

serotina, Greene, in Erythea, i. (1893) 152. - Calif. transmontana, Greene, Pittonia, i. (July 1857) T3.Am. bor. occ.

MULGEDIUM, Cass. = Lactuca, Tourn. (Compos.)

cuminatum, Conrath \& Freyn, ex Freyn, in Bull. Herb. Boiss. 111. (1895) 476. - Turkest.

ongifolium, C. Winkl, in Act. Hort. Petrop. xi. (1890) 337. - Turkest.

MULINUM, Pers. (Umbellif.). - Ind, Kew. ii. 270

chillanense, Phil. 2n Anal. Univ. Chil. 1xxxv. (1894) 707. - Chili.

clandestinum, Phil. l. c, ros. - Chili.

hirsutum, Phil.l. c. - Chili.

leptactanthum, Phil. l. c. 709. - Chili.

ovalleanum, Phil.l.c. - Chili.

MUNDULA, Benth. (Legumin.). - Ind. Kew; ii. 970

hysterantha. Baker, in fourn. Limn. Soc. xxv. (1890) 309. - Madag.

laxiflora, Baker, l. c. xxii. (1887) 464. - Madag.

MUNROA, Torr. (Gramin.). - Ind. Kew. ii. 270. andina, Phit. in Anal. Mus. nac. Chile (1891) 89.Am. austr. occ.

decumbens, Phil. l.c. 90. - Am. austr. occ.

multiflora, Phil. l. c. - Am. austr. occ.

MUNRONIA, Wight (Meliac.), - Ind. Kew, ii. 270 .

Delavayi, Franch. in Bull. Soc. Bot. Fr. xxxiii (1886) 451. - China.

unifoliolata, Oliver, in Hook. Icon. pl. xviii. (1S8T) t. 1709. - China centr.

yunnanensis, Franch. in Bull. Soc, Bot. Fr, xxxiii. (1886) 463. - China occ.

MUREX, Linn. F1. Zeyl (1747) 205; ex. Kuntze, Rev. Gen, (1891) 481 = Pedalium, Royen (Pedalin.).

Burmanni, Kuntze, 1. c. = P. Murex, Limn.

MURRAYA, Koen. ex Linn. (Rutac). - Ind. Kew. ii. 271.

alata, Drake, in Morot, fourn. de Bot. vi. (1892) 276. — Tonkin.

MURTUGHAS, Linn. Fl. Zeyl. (1741) 221 = Lagerstroemia, Linn. (Lythrar.).

anisoptera, Archeriana, calycina, calyculata, Engleriana, floribunda, hirsuta, hypolenca, indica, lanceolata, madagascariensis, ovalifolia, parviflora, punctata, subcostata, tomentosa, turbinati, vemusta, villosa, Kuntze, Rev. Gen. (1891) 249-50 = homonyma omnia Lagerstroemiae.

Loudonii, Kuntze, 1. c. = L. Loudoni, Teijsm. \&o Binn.

pyriformis, Kuntze, 1. c. $250=$ L. piritormis, Koen. Roettleri, Kuntze, 1. c. = L. Rottleri, C. B. Clarke. speciosa, Kuntze, 1. c. $249=$ L. Flos-reginae, Retz. 
MURUCOA, J. F. Gmel, = MOUROUCOA, Aubl. = Maripa, Aubl. et Lettsomia, Roxb. (Convolv.).

axilliflora, cayennensis, cordifolia, erecta, glabra, nicaraguensis, panamensis, scandens, Kuntze, Rev, Gen. (1891) $446-47$ = homonyma omnia Maripae.

adpressa, atropurpurea, barbata, barbigera, bella, bracteosa. Chalmersii, elliptica, hancorninefolia, hirsutissima, Kurai, Maingayi, mysorensis, peguensis, penangiana, rubens, rubicunda, setosa, sikhimensis, Kuntze, l. c. = homonyma onnia Lettsomiae.

capitata, Kuntze, 1. c. $446=$ Lettsomia strigosa Rox.

Chalmersii, Kuntze, 1. c. $447=$ L. Chalmersii, Benth. \& Hook. f.

Championit, Kuntze, 1. c. = L. Championi, Benth. Es Hook. $f$.

imóricata, Kuntze, 1. c. $446=\mathrm{L}$. aggregata, Roxb. pomacea, Kuntze, 1. $c_{2}=$ Argyreia pomacea, Choisy Thomsonii, Kuntze, 1.c. $447=$ Lettsomia Thom soni, C. B. Clarke.

MUSA, Linn. (Scitam.). - Ind. Kew。 ii. 27?

aphurica, Rumpf, ex Sagot, in Bull, Soc. Bot. Fr. xxxiv. (1887) 329; et ex Rev. Hortic. 1x. (1888) 71 - As. trop.

aurantiaca, G. Mann, ex Baker, in Ann. Bot. vii. (1893) 222; ct in Gard. Chron. (1894) i. 102.- Assam.

Buchanani, Bakcr, l. c. 20\%. - Zambesia.

Champa, Hort. ex Hook. f. F1. Brit. Ind. vi. (1892)

263, in syn. = sapientum, $\operatorname{Linn}$.

Rava, Ridl. in Trans. Linn. Soc. Ser. II. iii. (1893) 385. - Penins. Mal.

giganteu, Kuntze, Rev.Gen. (1891)691. - Sumatra. jabonica, Hort. Veitch. ex Rev. Hcrtic, 1x. (1888) $491=$ M. Basjoo, Sicb. E Zucc.

lasiocarpa, Franch. in Mlorot, foum. de Bot. iii. (1889) 329, cum ic; Baker, in Ann. Bot. vii. (1883) 208. - Yunnan.

malaccensis, Rial. in Trans. Linn. Soc. Ser. II. iii. (1893) 385. - Penins. Mal.

Mannii, H. Wendl. ex Baker, in Hook. f. Fl. Brit. Ind. vi. (1893) 263, in obs; $2 n$ Bot. Mag. (1893) t. 7311 ; et in Am. Bot, vii. (1893) 222. - Assam.

Martini, Hort. ex Carriere, in Rev. Hortic. lxii. (1890) 53 ; et lxvii. (1895) 290. - Teneriffa vel Tonk.

proboscidea, Oliver, in Hook. Icon. pl. xviii. (1888) t. 1777; Baker, in Ann. Bot. vii. (1893) 207. Afr. trop. or,

rosea, Baker, l. c. 221. - Ind. or ?

rubra, Firminger, ex Baker, 1. c. $213=$ sapientum, Linn.

suaveolens, G. Mann, ex Baker, l. c. 222. - Assam.

violacea, How. ex Baker, 1. c. $212=$ sapientum. Linn.

violascens, Ridl. in Trans. Limn. Soc. Ser. II. iii, (189:3) 384. - Penins. Mal.

MUSGARI, Tourn. ex Mill. (Liliac.). - 1nd. Kew.

Ibicaule, Post, Pl Postianae, i. (1890) 13. - Syria, Bouvianum, Heldr, ex Rouy, in Bull. Soc. Bot. Fr. xxxviii. (1891) 135, in obs. - Graecia.

calandrinianum, C. Richt. Pl. Euwop. i. (1890) 228 $(=$ Bclleralia calandriniana, Nym.). - Italia Istria.

Charrelii, Holdr, ex Rouy, in Bull. Soc. Bot. Fr. xxxyiii, (1891) 135, in obs. Halácsy, ex Nadji, Emp. Ottom. [Pl. de Salon.| (1892) 42. - Maced. graminifolium, Heldr. E Holzm. ex Rouy, l. c. Graecia.

Levieri, He'dr. ex Sommier \& Levier, in Nuov. Giom. Bot. Ital. xxiii. (1890) 26\% - Italia.

Maweanum, Hort. Leichtl. ex Baker, in Gard. Chron. (1889) i. 648. - Armenia.

Motelayi, Fouc. in Bull. Soc. sci. nat. Char.-Infér. (IS91) 60 cum ic. - Gall.

segnsianum, Perrier \& Songeon, in Bull. Herb. Boiss. ii. (1894) $436=$ comosum, Mill.

MUUSENIOPSIS, Coult. \& J. N. Rose, Rev. N. Am. Umbell. (1888) 122 ; et in Contrib. U.S. Nat. Herb. iii. 3 (1895) 301. UNBBEL LIFERAE.

\section{MUSENIOPSIS}

acgopodioides, Coult. \& F. N. Rose, Rev. N. An. Unzbell. (1888) 302 (= Smyrnizm aegopodioides, $\mathrm{H}$. B. \& K.?), - Mexic

cordata, Coult. E F. N. Rose, l. c. 304. - Mexic. dissecta, Coult. E. F. N. Rose, l. c. - Mexic peucedanoides, Coult. \& F. N. Rose, l. c. $303(=$ Entophus pencedanoides, Benth. \& Hook, fo). Mexic.

scabrella Coult. E 7. N. Rose, l.c. 304. - Mexic, Schaffneri, Coult. Go 7. N. Rose, l. c. 303. - Mexic. serrata, Coult. \&f F. N. Rose, l. c. 304. - Mexic. tenuifolia, Coult. E F. N. Rose, l.c. 302. (= Eqrlophus temuifolins, S. Wats.). - Am. bor. occ. ternata, Coult. \&. F. N. Rose, l. c. $303(=$ E. ternatus, S. Wats.). - Mexic

texana, Conlt. \&s 7. NT Rose, l. c. 123; et in Contrib. U. S. Nat. Herb, ii. (1891) 146: et iii. 3 (1895) 301 $(=$ Enloplus texanus, Benth.\& Hook. t.).-Texas. tuberosa, Coult. \& F. N. Rose, l. 0. 303. - Calif.

MUSENIUIM. Nutt. (Umbell.). - Ind. Kew, ii. 273.

alpinum, Coult, of F. N. Rose, in Coult. Bot. Gaz. xx. (1895) 260; et in Contrib. U. S. Nat. Herb. iii. 3 (1895) 304. - Mexic.

IMUSGRA VEA, F. Muell, in Proc. Linn. Soc. N. S. Wales, Ser, II. v. (June, 1890) 186. PROTEACEAE

stenostachya, F. Muell. l.c. - Austral.

MUSSAENDA, Burm, ex Linn, (Rubiac.). Ind. Kew. ii. $27 \%$

Bevani, F, Muoll, in Proc. Linn, Soc. N. S. Walcs, Ser. II. ii. (Nov, 1887) 419, t. 6. - N. Gruin. coccinea, Stapf, in Trans, Limn。 Soc. Ser. II. iv. (1894) 170. - Borneo

ferrnginea, $K$. Schmm, in $K$. Schmn. \& Hollr. Fl. Kais, Wilh, Land. (1889) 129. - N. Guin.

Griffithii, Hemssl, in Hook. Icon, pl, xviii, (1887) sub t. 1718 , in obs. (= Acranthera Griffithii, Hook، f.). - Reg. Himal.

hispida, Engl, Bot. Fahrb. viii. (1887) 66. - Congo. kintaensis, King, ex Stapf, in Trans. Limn. Sor. Ser. II. iv, (1894) 172, in obs. - Perak.

Maingayi, Honsl. in Hook. Icon. pl. xviii. (1887) sub t. 1718, in obs. (= Acranthera Maingayi, Hook. f.). - Perak.

mutabilis, Henusl. l. c. t. $1718(=$ A. mutabilis, Hemsl.) - Perak

pilosa, Baker, in Kew Bull. (1895) 105. - Madag.

Soyauxii, Buettn. in Vorh. Bot. Ver. Brand. xxxi. (1889) 81. - Gabon.

MUSSATIA, Bureau, ex Baill. Hist. des pl. x. (1888) 32; K. Schum. in Engl. \& Prantl, Natürl. Pflanzenfam. iv, 3b (1894) 223. BIGNONIA$C E A E$.

Prieurei, Burean, $7 l . c c$. (= Bignonia Prieurei, DC.). Am. austr. trop.

MUTISIA Linn. f. (Compos.). - Ind. Kew。 ii, 26. alata, Hicron. in Bot. Falmb. xix. (1894) 73. Ecuad.

alba, Phil. in Anal. Univ. Chil. 1xxxv, (1894) 823. - Chili.

brachyantha, Phil. l.c. 825. - Chili.

camptosorifolia, Rusby, in Menn. Torrey Bot. Club, iv. (1895) 213. - Bolivia.

cochabambiensis, Hieron. in Bot. Falirb. xix. (1894) 74 , in obs. - Bolivia.

comptoniaefolia, Rusby, in Mem. Torrey Bot. Club, iii. 3 (1893) 65. - Bolivia.

consobrina, Phil. in Anal. Unio. Chil. 1xxxv. (1894) 820. - Chilj.

dentata, Phil. I. c. 819. - Chili.

elegans, Phil. l. c. 822 . - Chili.

eriocephala, Phil. l. c. $-820 .-$ Chili.

intermedia, Hieron. in Bot. Fahrb. xix. (1894) 72. - Ecuad.

Iserni, Phil, in Anal. Univ, Chil. Ixxxiv, (1895) 823. - Bolivia.

Landbecki, Phit. l. c. 825. - Chili.

Lehmanni, Hieron. in Bot. Fahrb. xix. (1894) T3. Ecriad.

\section{MUTTISIA :}

chrocalyx, K. Schum, in Bull. Torrey Bot. Club. xiv. (1891) 233 .

popetana, Phil. in Anal. Univ. Chit. 1xxxv. (1894) 821. - Chili

Stuebelii, Hieron. in Bot, fahrb. xxi. (1895) 36\%.Columb.

versicolor, Phit. in Anal. Univ. Chit. Ixxxv. (1894) 824. - Chili.

MYCETIA, Reinw. - Adenosacme, Wall. (Rubiac.).

acominata, Kuntze, Rev. Gen. (1891) $289=\mathrm{A}$. Lawii, Hook. $f$.

Balansae, Drake, in Morot, Journ. de Bot. ix. (1895) 216. - Tonkin.

holotricha, Kuntze, 1, c, = A. holotricha, Mug.

lanceolata, Kuntze, 1. c. = A. lanceolata, Miq.

longifolia, Kuntze, 1. c. = seq.

longifolia, K. Schum. in Eng1. \& Prantl, Natür1. Pflanzenfam. iv. 4 (I89l) $66=$ A. longifolia, Wall.

macrostachya, Kuntze, 1. c. = A. macrostachya, Hook, $f$

oborata, Kuntze, 1. c. = A. fasciculata, Miq.

stipulata, Kuntze, 1. c. = A. stipulata, Hook. $f$

MYGINDA, Linn. (Celastr.). - Ind. Kew, iis 2ri. cronoclada, Wright, [mss, in Herb. Keve.] ex Kuntze Rev. Ger. (189!) 116. - Cuba

MYONIMA, Comm. ex Juss. (Rubiac.). - Ind Kew. ii. 276.

parciflora, Cordem. Fl. Ile Réunion (1895) $509=$ seq.

parviflora, K. Schum. in Eng1, \& Prantl, Natür1, Pflanzenfam.iv. 4 (1891) $109=$ multiflora Rich.

velutina, Cordem. Fl. Ile Rúunion (1895) 508.Ins. Borbon.

MYOPORUMI, Banks \& Soland. (Myoporin.). Ind. Kew. ii. 276

glabrum, F. Muell. Thivd Suppl. Cers. Austral. Pl. (1886) 6 ; et Descr. and Illustr. of Myoporin. Pl. ii. (1886) t. 70. - Austral

MYOSOTIDIUM, Hook. (Borag.). - Ind. Kew.

Hortensia, Baill. Hist. des pl. x. (1890) $333=$ nobile, Hook.

MYOSOTIS, [Tourn.] Dill. ex Linn. (Borag.). Ind. Kew. ii. 276.

adpressa, Simonk. Enum. F1. Transsilv. (1886) 409 $=$ alpestris, Schmidt.

acnesia, Heldr, ex Nym. Consp. F1. Eur., Suppl. ii. I. (1890) $226=$ pusilla, Loisel.

aequinoctialis, Baker, in Ker Bull. (1894) 29. Afr. trop. or.

bracteata, Rouy, in Bull. Herb. Boiss. i. (1893) 17 $=$ hispida, Schlecht.

Cheesemannii, Petrie, in Trans. N. Z. Inst. xviii. 1885 (1886) 296. - N. Zel.

cognata, Schott, ex Nym. Consp. Fl. Eur., Suppl. ii. I. (1890) $226=$ sylvatica, Hoffm.

Godeti, Coste, in Bull. Soc. Bot. Fr. xxxviii. (1891 268 ; et in Bull. Herb. Boiss. i. App. 1 (1893) $17=$ hispida, Schlecht.

Goyeni, Petrie, in Trans. N.Z, Inst, xxiii. 1890 (1891) $400 .-$ N. Zel.

gracilis, Hort. ex Rev. Hortic. (1894) 214 = sylvatica, Hoffm.

Hamiltonii, Colenso, in Trans, N. Z. Inst. xx. 1887 (18s5) $200 .-$ N. Zel.

macedonica, Velen. \& Charrel, in Sitz. Bochm. Ges. Wiss. (1893) xxxvii. 4\%. - Maced.

macrantha, Hort. Kew ex Gard. Kew, Herb. Pl (1895) 301 (= Exarrhena macrantha, Hook. f.).N. Zel.

macrocalycina, Coss, ex Batt. Eo Trab. Fl. de l'Algér. [Dicot.] (1889) 603. - Afr. bor.

Mathildae, Hausskn. in Mitth. Bot, Thiir. Ver. N. Folge, viii. (1895) 53. - Graecia.

nemorosa, Miégev. in Bull. Soc. Bot. Fr. xl. (1893) 306 = pyrenaica, Pourr. 


\section{MYOSOTIS :}

pratensis, Miégev, in Bull. Soc. Bot. Fr, xl (1S93) $306=$ pyrenaica, Pourr

rhodopea, Veles. in Sitz. Boelzm. Ges. Wiss. (1892) 93 48. - Buly.

scabra, Simonk. Enum. Fl. Transsilv. (1886) $408=$ palustris, With

semperflorens, Hort. ex Gard. Kew, Herb. Pl. (I895) 301. - Form, hort.

subvernicosa, Colenso, in Trans. N.Z. Inst, xxiv. 1891 (1892) 390. - N. Zel.

virginica, Britton, Stern \& Pogg. Prelim. Catal. 1888) $3 \%=$ ovina, Nutt.

MYOSURUS, Linn. (Ranuncul.), - Ind. Kew. ii.

breviscapus, Huth, in Bot. Fahrb. xvi. (1893) 285. - Sicil., Aloer., Calif.

Prenglii, Huth, l.c. - Mexic.

MYRCEUGENIA, Berg = Myrtus, Linn. (Myrt.) apiculata, Niedenzu, in Engl. \& Prantl, Natürl. Pflanzenfam. iii. 7 (1893) $74=$ Eugenia apiculata, $D C$.

MYRGIA, DC. (Myrt.). - Ind. Kew. ii. 276 acuminatissima, Hieron. in Bot. Fahrb. xx. Beibl. п. 42 (1895) 64, in obs. (= Aulonyrcia acuminatissima, Berg). - Bras.

adpresse-pilosa, Kiaersk. Enum. Myrt. Bris. (1893) $75 .-$ Bras.

alloiota, Kiaersh. l. c. 70 (= Aulonyercia alloiota, Berg). - Bras

alpina, Kiaerstr. l. c. $113(=$ Gomidesia Gaudichandiana, Berr). - Bras.

amblyophylla, Kiacrsk. l. c. 76. - Bras.

amethystina, Kiaersk. l. c. 90 ; ot in Engl. Es Prantl, Natiirl. Pfanzenfam. iii. T (1893) 76 (= Aulomyrcia amethystina, Berg). - Bras.

androsaemoides, Krug \& Uróan, ex Urban, in Bot. Fahrb. xix. (1895) $579(=A$. anidrosaemoides, Berg). - Guian.

angustifolia, Niedenzu, in Engl. \& Prantl, Natiurl. Pfanzenfan. iii. 7 (1893) $76(=A$. augustifolia, Berg). - Bras.

Assumptionis, Morong, in Ann. N. Y. Acad. Sci. vii. (1893) 106. - Parao

atramentifera. Barb. Rodr. [Herb. Mus. bot. Amaz. n. 45] Vellosia, 1885-88, Sec. ediç. (1891) 31, t. 1, fig. A. 一 Bras. bor.

atropunctata, Kiaersh. Enum. Myrt. Bras. (1893) 68. - Bras.

Augustana, Kicersh. l. c. 52. - Bras.

ayabambensis, Hieron. in Bot. Fahrb. x:. Beibl. n. 49. (1893) 64. - Ecuad.

bicolor, Kiaersh. Enmm. Myrt. Bras. (1893) 65. - Bras.

bombycina, Kiaersk. l. c. 89 ; Niedenziu, in Engl. \& Prantl, Vatiirl. Pfanzenfant. iii. 7 (1893) 75 (= Ailomyrcia bonbycina, Berg). - Bras.

brasiliensis, Kiaersk, l. c. $102(=$ Gomidesia Schaueviana, Berg). - Bras.

caerulescens, Kiacrsk.l. c. $79=$ Aulonurcia caeru-

lescens, Berg). - Bras.

calumbaënsis, Kiaersk. l. c. $7 \%(=A$. Pohliana, Berg). - Bras.

Candolleana, Kiaersk. l. c. $105 i=$ Gomidesia Candolleana, Berg), - Bras.

coelosepala, Kiaersk. l. c. 81. - Bras.

colpodes, Kiaersk. l. c. 80. - Bras.

crassifolia, Kiaersk. l. c. 89. - Bras.

crocea, Kiaersk. l. c. $105 .-$ Bras.

cubensis, Krug. E Urban, ex Urban, in Bot. fahrb. xix. (1895) 589 ( $=$ Calycorectes cubensis, Griseb.). - Cuba.

cuneata, Niedenzu, in Engl. \& Prantl, Natiirl. PAanzenfam. iii. 7 (1893) 76 (= Aulomyrcia cuneata, Berg). - Venezuela.

cuprea, Kiaersk. Enum. Myrt. Bras. (1893) 95. Bras.

cymosa, Niedenzu, in Engl. \& Prantl, Natürl. Pfanzenfam. iii. 7 (1893) 76 (= Aulomyrcia cymosa, Berg). - Bras.

cymoso-paniculata, Kiaersk. Enum. Myrt. Bras. (1893) 90. - Bras

dermatophylla. Kiacrsk. l. c. 9\%. - Bras.

\section{MYRCIA}

detergens, Hieron. in Bot. Jahrb. xx. Beibl. n. 49 (1895) 63, in obs. = detergens, Miq diaphanosticta, Kiaersk. Emum. Myrt. Bras. (1893) 91. - Bras.

Didrichseniana, Kiaersk. I. G.82 (- Aulomyrciabracteatia, Berg). - Bras.

dolicopetala, Kinersk. l. c. 106 (= Gomidesia Sonderiana, Berg). - Bras.

doloresensis, Hieron. in Bot. Fahrb. xx. Beibl. n. 49 (I895) 63. - Columb

dumosa, Krug \& Urban, ex Urban, in Bot. Fahrb. xix. (1895) 580 (= Aulomyrcia dumosa, Berg). Guiana. Ind. occ.

Dussii, Krug \& Urban, ex Urban, l. c.580. - Ind, OCC.

edulis, Krug of Urban, ex Urban, l. c. 58I ( = Aulomyrcia edulis, Berg). - Guiana, Ind. occ.

emarginata, Niedenzzu, in Engl. \&o Prantl. Natürl. PAlanzenfan. iii. 7 (1893) 76 (= A. emarginata, Berg). - Bras.

estrellensis, Kiaersk. Enum. Myrt. Bras. (1893) 107 (= Gomidesia Riedeliana, Berg). - Bras.

eumecophylla, Niedenzu, in Engl. Es Prantl, Natürl. Pflanzenfam. iii. 7 (1893) 76 (= Aulonyrcia enmecopliylla, Berg). - Bras.

fastigiata, Kiaersk. Enum. Myrt. Bras. (1893) 92. Bras.

Freyreissiana, Kiaersh. l. c. $102(=$ Gomidesiat Freyreissiana, Berg). - Bras.

frontinensis, Hieron. in Bot. Fahrb. xx. Beibl, n. 49 (1895) 63. - Columb.

igantea, Niedenzu, in Engl. \& Prantl, Natür Pfanzenfan, iii. 7 (18n3) 76 (= Aulonnyrcia gigantea, Ber - . - Bras.

romidesoides, Kiarersk. Enum. Myrt. Eras. (1893) 87. - Bras.

glandulosa, Kiaersk. l. c. $83(=$ Au? omyrcia glandu losa, Berg). - Bras.

glaucescens. Kiaersh, 7, c. $83(=A$. glaucescens, Berer). - Bras

Glazioviana, Kigersk l. c. 111. - Bras.

grandiflora, Krug \& Urban, in Bot. Jahrb, xix. (1895) 587, in obs. $=$ seq

grandiflora, Niedenzi, in Enol. \& Prantl. Natiurt. Pflanzenfanr. iii. \% (1893) $7 \%(=$ Aulonzyrcia gran diflora, Berg). - Bras.

grandiglandulosa, Kiaersk. Enum. Myrt. Bras. (1893) 83. - Bras.

Guildingiana, Krug \& Urban, ex Urban, in Bot. Jahrb.xix. (1895) $57=$ Psidium Guildingianum, Griseb.

Gundlachii, Krug \& Urban, ex Urban, l. c. 581. Cuba.

Hartwegiana, Kiaersh. Enum. Myrt. Bras. (1893) 109 (= Gomidesia Hartwegiana, Berg). - Bras.

hepatica,- Kiaersk. l. c.86 (= Aulomyrcia hepatica, Berg). - Bras.

hexasticha, Kiaersk. l. c. 72. - Bras,

Hookeriana, Kiacrsk.l.c. 107 (= Gomidesia Hooke viana, Berg). - Bras.

Hostmanniana, Kiaersk. l. c. $83(=$ Aulomyrcic Hostnanniana, Berg). - Guiana.

ilheosensis, Kiaersk. Enum. Myrt. Bras. (1893) 109 $(=$ Gomidesia Fenzliana, Berg): - Bras.

innovans, Kicersk. l. c. 100.-Bras.

intermedia, Kiaersk. l. c. $90(=$ Aulomyrcia interme dia, Berg). - Bras.

Kunthiana, Kiaersh. l.c. 112 (= Gomidesia Kunthiana, Berg). - Bras.

lamuinosa, Niedenzu, in Enol. \& Prantl, Natürl. Pflanzenfam, iii. 7 (1893) $76=$ lanuginosa

Berg.
laterifolia, Kiaersk. Enum. Myrt. Bras. (1893) 7\%. Bras.

Laureola, Kiacrsk. l. c. S6 (= Aulomyrcia Lawreola, Berg). - Bras.

Lehmannii, Hieron. in Bot. Fahrb. xx. Beibl. n. 49 (1895) 65.-Columb.

lenheirensis, Kiarsh. Enum. Myrt. Bras. (J893) 98 (= Eugeniopsis angustifolia, Berg). - Bras.

lineata, Niedenzu, in Engl. \& Prantl. Natiirl. Pfanzenfam. iii. 7 (1893) 76 (= Aulomyrcia lineata, Berg). - Bras.

longipes, Kiaersk. Enum. Myrt. Bras. (1893) 70 (= A. longipes, Berg). - Bras.

\section{MYRGIA :}

ngipes, Niedenzu, in Engl. \& Prantl, Natuirl. Pflanzenfam. iii. 7 (1893) $76=$ praec

Lundiana, Kiaerste. Emum, Myrt. Bras. (1893) 78 (= Aulomyrcia Vantheriana, Ber:r). - Bras.

magnifolia, Kiaersk. l. c. 107 (= Gonidesia magnifolia, Berg). - Bras.

marahanensis, Kiaersk. l. c. 71 (= Aulonyrcia microntha. Berg). - Bras.

marroqueimadensis, Kiaersk. l. c. 75. - Bras.

martinicensis, Krug \& Urban, ex Krug, in Bot. fahro. xix. (I895) 586. - Ins, Martinic.

melanosepala, Kiaersk. Enum. Myrt. Bras. (1893) 60. - Bras.

melanosticta. Kiaersh. 2. c. 54. - Bras.

membranacea Kiaersh.l. c.71 - Bras.

micropetala, Niedcnztu, in Engl. E Prantl, Natïrl.

Pfanzenfan. iii. 7 (1893) $76(=$ Aulonyrcia micropetala, Berg). - Bras

microstachya, Krug \& Urban, in Bot. Fahrb. xv. (1893) 361. - Jamaica.

minensis, Kiaersk. Enum. Myrt. Bras (IS03) 110

(= Gomidesia Widgreniana. Berg). - Bras.

mischophylla, Kiaersh. l. c. 61. - Bras.

nitida, Kiacrsk. l. c. $102(=$ Gomidesia Chanissoètuna Berg). - Bras.

obovata, Niedenzu, in Engl. Es Prantl, Natïrl. Pfayzenfam. iii. 7 (1893) $761=$ Aulonyrcia obovata, Berg). - Bras

obtecta, Kiaersk. Enum. Myrt. Bras. (1893) $89=$

$(=$ A. oblecta, Berg) $)$ - B Bras.

oreioeca, Kiacrsk. l. c. 94. - Bras.

orthophylla, Kiacrsk.l.c. (= Auloneyrcia orthoplyylla,

Berg). - Bras.

ouropretoensis, Kiaersh. l. c. 113 (= Gomedesio Clanssmiana, Berg). - Bras.

alifolia, Kiaersh. l. c. 84 (= Aulonyrcia ovalifolia, Berg). - Bras

oxyoëntophylla, Kiaersk. l. c. 57. - Bras.

aniculatr, Krug \& Urban, ex Urban, in Bot. Jahrb. xix. (18.95) $577=$ coriacea, $D C$.

paracattensis, Kiaersk. Enum. Myrt. Bras. (1893)

99 (= Aulaunyrcia suffnticosa, Berg). - Bras.

paraënsis, Kiaersle.l. c. $78(=$ A. paraènsis, Ber $r)$. - Bras.

parnahibensis, Kiacrsk. l. c. $89(=$ A. pamahibensis, Bero). - Bras.

Pagani, Krug Eo Urban, ex Urban, in Bot. Fahrb. xix. (1895) 587. - Ins. Porto-Rico.

pauciflora, Niedenzu, in Engl. \& Prantl, Natiurl. Pflanzenfam. iii. T (1893) 76 (= A. pauciflora, Cambess.). - Bras.

pilodes, Kiaersk. Enum. Myrt. Bras. (1893) 67.Bras.

Picardae, Krug of Uroan, ex Urban, in Bot. Fahrb. xv. (1893) 359. - Ins. Haiti.

pilotantha, Kiaersk. Enum. Myrt. Bras. (1893) 67. - Bras.

planipes, Kiaersk. l. c..115 (= Engenia planipes, Hook, \& Arn.). - Bras.

plusiantha, Kuarsk. l. c. 66. - Bras.

Poeppigiana, Hieron. in Bot. Fahrb. xx. Beibl. n. 49 (1895) 65 , in obs, (= Anlonurcia Poeppigiana, Berg). -- Bras.

popayanensis, Hieron. l. c. 62. - Columb.

pulchra. Kiaersk. Enum. Myrt. Bras. (1893) 65 (= Aulomyrcia pulchra, Berg). - Bras.

pyrifolia, Niedenzu, in Engl. \& Prantl, Natiirl. Pfanzenfam. iii. 7 (1893) $76(=$ A. pyrifolia, Berg). - Guian.

pyrrhopilodes, Kiaersh. Enum. Myrt. Bras. (1893) 96. - Bras.

Rabeniana, Kiaersk. l. c. $86 \quad(=$ Aulomyrcia Sonderiana, Berg). - Bras.

racemosa, Kiaersk. l.c. 72 (= A. racemosn, Perg). - Bras.

Ramageana, Krug \& Urban, ex Urban, in Bot. Falivb. xix. (1 \&95) 586. - Ins. S. Lucia.

retusa, Niedenzu, in Engl. E Prantl, Natïrl. Pfanzenfam. iii. 7 (1893) 76 (= Aulomyrcia retusa, Berg). - Bras.

thabdoides, Kiaersk. Enum. MLyrt. Bras. (1893) 99. - Bras.

reticulata, Knng \& U,ban, ex Urban, in Bot. Fahrb. xv. (1S93) 306. - Ins. S. Doming. 


\section{MYRCIA :}

Thoderse. Enmmi. Myyt. Bras. (1893) 75 (= Aulomyrcia lanuginosa, Berg). - Bras.

Richardiana, Kiaerst. l. c. $97(=$ A. Richardiana, Berg). - Bras.

rorida, Kiacrsk. l. c. $79(=$ A. rorida, Berg). Bras.

rosulans, Kiacrsk. l.c. $72(=$ A. rosulans, Berg $)$. Bras.

rotundifolia, Kiacrsh. l. c. $89(=$ A. rotundifolia, Ber( ). - Bras

rugosa, Kiaersk: l. c. 96 (= A. rugosa, Berg). Bras.

Schenckiana, Kiacrsk. l. c. 114. - Bras

sessilifolia, Kiaersk. l. c. 115 (= Gomidesia Regeliana, Berg). - Bras

Sintenisii, Kiacrsh. in Bot. Tidsskr. xvii. (1890) 257 ; ct Enum. Myrt. Bras. (1893) 110 (프 Gomidesia Lindeniana, Bero). - Am, trop.

sparadosticta, Kiaersk. Enum. M1yrt. Bras. (1893) 59. - Bras.

spathulata, Kiaersk. l. c. $72 ;$ Nicdcnzu, in Engl. \& Prantl, Natiirl. Pfanzenfam. iii. 7 (1893) 76 (= Aulomyrcia spathulata, Berg). - Bras.

Springiana, Kiaersk. Emun. Myyt. Bras, (1893) 102 $(=$ Gomidesia Springiana. Berg) - - Bras.

stenocarpa, Kng \& Urban, ex Urban, in Bot. Falnt. xix. (1895) 584. - Ins. Trinit.

stricta, Kiacrsk. Enum. Alyst. Bras. (1893) 99 (=Anlonyrcia stricta, Berg). - Bras.

subobliqua, Niedenzu, in Engl. E Prantl. Natiorl. Pfanzcnfam. 1ii. 7 (1893) $76(=A$. subobliqua, Berg). - Guiana.

subrugosa, Kiaersk. Enum. Myrt. Bras. (1893) 86. - Bras.

subverticillaris, Kiaersk. l. c. 88 (= Aulonyrcia suburticillaris, Ferg). - Bras.

taubatensis, Kiaersk. l. c. $79(=$ A. buxifolia, Berg) . - Bras.

tenuivenosa, Kriacrsk, l. c.84, - Bras.

ticuensis, Elacrsk. l. c. 107.- Bras.

tijucensis, Iriaersk, l. c. 102. - Bras.

vacciniifolia, Niedcnzu, in Engl. \& Prantl, Natïrl. Pfanzenfan, iii, 7 (1893) 76 (= Aulonyrcia vaccimiifolia, Berg). - Rras.

Vittoriana, Kiaersk. Enum. Myrt. Bras. (1893) 102 (= Gomidesia Martiana. Berg). — Bras.

VVarmingiana, Kiacrsk. l. c 104. - Bras.

yungasensis, Rusby, in Mcm. Torrey Bot. Clnb, iii. 311893) 27. - Bolivia.

MYRCIANTHES, Berg = Myrtus, Lin

Krugii. Kiaersk, in Bot. Tidslir. xvii. (1890) 276 t. 00 et fig. $9=$ Eugenia umbellulifera, $K u g$ Ev Urban.

MYRIAGTIS, Less. (Compos.). - Ind. Kew. ii. 2Sl

bellidiformis, F. Muell. in Trans. Roy. Soc. Vict, N. S. i. II. (1889) 12, - N. Guin.

paniculata, Boerl. Handl. Fl Ned. Indië, ii. I. (1891) 2:30. - Jara.

MYRIALEPIS, Becc, in Hook, f. FI. Brit. Ind. vi. (1593) 480. PALMIAE.

Scortechini, Becc. l. c. - Perak.

MYRIANTHUS, Beauv. (Urtic.). - Ind. Kew. gracilis, Engl. Bot. Fahro. xx. (1894) 150. - Afr.

Preussii, Engl. 7. c. 149. - Afr. trop. occ.

MYRICA, Limn. (Myricac.). - Ind. Kew. ji. 281. lentulata, Baill. Hist. pl. Madag., Atlas (1895) t. 308 . - Madas

kilimandscharica, Engl. in Abh. Prouss. Akad. Wiss, ii. 1891 (1892) 188. - Afr. trop. or.

Meyeri Johannis, Engl. l. c. 189. - Afr. trop. or.

peregrina, Kuntze, Rev. Gen. (1891) 638 = asplenifolia, Linn.

pilulifera, Rendle, in Trans. Limn. Soc. Ser. II. iv. (1894) 43. - Afr. trop.

Roraimae, Olicer, in Trans. Linn. Soc. Ser. II ii. (1887) 273, t. 38b|Oliver, ex im Thurn, in Timehri, r. (1886) 1921. - Guian, angl.
IMYRIGA :

rugulosa, Baill. Hist, pl. Madag., Atlas (1894) t. 307. - Madag

spathulata, Baill. l. c. t. 305 et 306. - Madag usambarensis, Engl. Pfanzenw. Ost-Afr. C (is95) 160. - Afr. trop. or.

MYRICARIA, Desv. ('Tamarisc.). - Ind. Kew ii. 281 .

pulcherrima, Batalin, in Act. Hort. Petrop, xi. (1891) 483. - China.

MYRIOGARPA, Benth. (Urtic.). - Ind. Kew

rachystachys, S. Wats, in Proc. Am, Acad, xxvi. (1891) 152. - Mexic.

heterospicata, J. D. Smith, in Coult. Bot. Gaz. xii (1887) $133=$ heterostachya, F. D. Smith.

heterostachya, F. D. Snith, l. c. xiii. (1888) 29. Guatem.

MYRIOGEPHALUS, Benth. (Compos.). - Ind

Dittrichii, F. Muell, in Wing South. Sci. Record, N.S. ii. (May 1886); et ex Bot. Centralbl. xxvii. (1886) $300=$ Calocephalus Dittrichii, F. Muell.

MYRIONEURON, R. Br. (Rubiac.). - Ind. Kew

borneense, Stapf, in Trans. Linn. Soc., Ser. II. iv (1894) 175. - Borneo.

Faberii, Henusl. ex Forb. \& Hemsl. in foum. Lim Soc. xxiii. (1888) 380. - China.

MYRIOPHYLLUM, Ponted, (Haloras.). - - Ind. Kew, ii. 282.

alternifolimm. J. Macoun, in Canad. Record Sci. (Nov. 1894) 148, sphalm. = alterniflorum, DC.

Farwellii, Morong, in Bull. Torrey Bot. Club, xviii (1891) 146. - Am. bor.

humile, Morong, 1. c. 242 (= Purshia Intniles, Rafin.) = ambiguum, Nutt.

intermedium, Baill. [an DC.?] Hist. pl. Madag. Atlas, (1895) t. 369. - Madag

mexicanum, S. Wats, in Proc. Am. Acad. xxv. (1890 148. - Mexic.

pimatum. Britton, Stern \& Poggenb. Prelim. Catal. (1888) $19=$ scabratum, Michx.

MYRIOPTERON, Griff.(Asclep.). - Ind. Kew ii. 282.

extensum, K. Schum. in Engl. \& Prantl, Natürl. Pflanzenfam. iv. 2 (1895) $215=$ paniculatum Griff.

MYRIPNOIS, Bunge (Compos.). - Iud. Kew. ii. 282 .

Maximowiczi, C. Winkl, in Act. Hort. Petrop. xiii. (1893) 12. - China.

MYRISTIGA, Linn. (Myrist.). - Ind. Kew. ii. 282

andamanica, Hook. f. Fl. Brit. Ind. v. (1886) 103. - Ins. Andam.

argentea, Warb. in Bot. Fahrb. xiii. (1891) 311.N. Guin.

Beddomei, King, in Annal. Bot. Gard. Calc. iii. 3 (1891) 291. - ind. or.

bialata, Warb. in Bot. Fahrb, xiii. (1891) 308. N. Guin.

bivalvis, Hook. f. Fl. Erit. Ind. v. (1886) 107.Penins. Mal.

bombycina, King, ex Hook. f. l. c. v. (1890) 861.Reg. Himal.

brachiata, King, in Annal. Bot. Gard. Calc, iii. 3 (1891) 311. - Penins, Mal.

Buchneriana, Warb. in Bot. Fahrb. xiil. (1891) 311. - N. Guin.

canarica, Bedd. ex King, in Annal. Bot. Gard. Calc. iii. 3 (1891) 306. - Canara.

canarioides, King, l. c. 304. - Penins. Mal.

Cantleyi, Hook. f. Fl. Brit. Ind. v. (1886) 110.Penins. Mal.
MYRISTIGA

cinnamomea, King, in Annal, Bot. Gard. Calc. iii. 3 (1891) 292. - Perak.

Clarkeana, King, l. c. 325. - As. trop.

Collettiana, King, l. c. 322. - Penins. Mal.

conferta, King, l. c. 315. - Penins. Mal.

costata, Warb. in Bot. Fahro. xviii. (1894) 191. -

N. Guin.

crassa, King, in Annal. Bot. Gard. Calc. iii. 3 (1891) 293. - Perak

Curtisii, King, l. c. 326. - Penins. Mal

Duthiei, King, ex Hook, f. Fl. Brit. Ind. v. (1890) 861. - Reg. Himal,

faroensis, Hemsl. in Am. Bot. v. (1891) 506. - Ins. Salom.

flocculosa, King, in Annal. Bot. Gard. Calc. iii. 3 (1891) 302. - Perak

Forbesii, King, l. c. 306. - Penins, Mal.

fulva, King, l.c. 297. - Penins. Mal.

Gamblei, King, ex Hook. f. Fl. Brit. Ind. v, (1800) 860. - Ind. or

gigantea, King, in Annal. Bot. Gard. Calc. iii. 3 (1891) 288. - Perak.

Griffithii, Hook. f. Fl. Brit. Ind. v. (1886) 109. Ind or.

Hellwigii, Warb. in Bot. Fahrb. xviii. (1894) 192. - N. Guin.

heterophylla, K. Schum. in K. Schum. E Holl'. Fl. Kais. Wilh. Land (1889) 45. - N. Guin

Kingii, Hook. f. Fl. Brit. Ind. v. (1886) 106. 一 Reg, Himal.

Kunstleri, King, in Annal. Bot. Gavd. Calc. iii. 3 (1891) 314. - Perak

Kurzii, King, cx Hook, f. Fl. Brit. Ind. v. (1890) 860. - Reg. Himal.

Lowiana, King, in Annal. Bot.Gard. Calc, iii. 3 (1891) 293. - Peral:

Maingayi, Hook. f. Fl. Brit. Ind.v. (1886) 104.Malacca.

majuscula, King, in Annal. Bot. Gard. Calc. iii. 3 (1891) 310. - Penins. Mal.

malaccensis, Hook.f. Fl. Brit. Ind. v. (1886) 104. - Malacca.

Miohr, Baill. ex Laness. P1. util. Colon. Franç, (1886) 802, nomen. - Seneg.

Murtoni, Hook. f. Fl. Brit. Ind. v. (18S6) 105. Penins. Mal.

Niohne, Baill. ex Laness, Pl. util. Colon. Franc. (1886) 342. - Seneg.

Niolne, Baill, ex Engl. \& Pranti, Natïrl. Pflanzenfam. iii. $2(1888) 4 \%=$ praec.

oblongifolia. King, in Annal Bot. Gard. Calc. iii. 3 (1891) 313. - Penins. Mal.

paludicola, King, l.c. 313. - Perak.

paradoxa, Schwacke, Addit. Fl. Bras. Fasc. i. (1886) sub t. 2. - Bras.

pendulina, Hook. f. Fl, Brit. Ind.v. (1890) 859. Penins. Mal

polyspherula, Hook.f.l.c. v. (1886) 108. - Ind. or Praini, King, in Annal. Bot. Gard. Calc. iii. 3 (1891) 299. - Ins. Andam.

racemosa, King, l. c. 328. - Penang.

retusa, King. .. c. 330.- Perak.

Ridleyana, King, l. c. 311, - Perak

rubiginosa, King, l. c. 302.- - Penins. Mal.

Schleinitzii, Engl. Bot. Fahrb, vii. (1886) 455. Melanesia.

Scortechinii, King, in Annal. Bot. Gard. Calc. iii. 3 (1891) 317 - Yenins. Mal.; Borneo.

Spanogheana. K. Schum. in Bot. Jahrb. ix. (1887) 200 ; et in K. Schum. \& Hollr. Fl. Kais. Wilh. Land (1889) $200=$ heterophylla, F. Villar.

sphaerula, Hook. f. Fl. Brit. Ind. v. (1890) 859. Malacca.

suavis, King, ist Annal. Bot. Gard. Calo. iii. 3 (1891) 295. - Penins. Mal.

succosa, King, l. c. 301. - Penins. Mal.

tuberculata, K. Sclnumz, in K. Schnmm, \&o Hollr. Fl. Kais. Will. Land (1889) 46. - N. Guin.

Wrayi, King, in Annal. Bot. Gard. Calc. iii. 3 (1891) 315. - Perak.

MYRMECODIA, Jack (Rubiac.). - Ind, Kew. tuberosa, "Becc. " ex Treub, in Annal, Jard, Buitenz. vii. (1888) 19\%. = tuberosa, fack. 
MYRMECODIA :

vivipara, Warb. in Bot. Falkrb. xviii. (1894) 210. N. Guin.

MYRMEDOMA, Becc. (Rubiac.). - Ind. Kew. i1. 284

Naumannii, Warb. in Bot. Fahrb. xviii. (1894) 211. $-\mathrm{N}$. Guis.

MYRMEDONE, Mart. (Melast.). - Ind. Kew. ii.

Beccarii, Hook. f. in Bot. Mag. (I886) t. 6883. Austral. Austral.
lanceolata, Cogn, in Mart. Fl. Bras. xiv. IV. (1888) 468. - Bras.

MYROBALANUS, Breyne = Terminalia, Linn Combret.).

artinophylla, acuminata, adamantinu, argentea, australis, bialata, Biscutella, bursarina. calophylla, Catappa. cicatricosa, circumalata, crenati, diptera, edulis, erythrocarpa, excelsa, exsculpta, fagifolia, flavicans, foetidissima, glabrata, glabrescens, glaucescens, gracilis, grandialata, grandifora, jaíanica, latifolia, latipes, lucida, macroptera, mariana, melanocarpa, microcarpa, modesta, mollis, Muelleri, miriocarpa. nitidissima, oblonga, oblongata, paucifora. petiolaris, phaerocarpa, platyphylla, platyptera, porphyrocarpa. procera, pumila, punctata, pyrifolan, Ruchii, Ricdelii. nubrigemmis, scutifera, sericea, sericocarpa, subsericea, sulcata, Thozetii, tomentella, Vernix, volucris, Kuntze, Rev. Gen. (1891)237 = hononyma omnia Terminaliae.

Benzoé, Kuntze, 1. c. $=$ T. angustifolia, facq. brasilicnsis, Kuntze, 1. c. = T. januarensis, DC. Brownii, Kuntze, 1. c. = T. cycloptera, R. Br. Buceras, Kuntze, 1. c. = T, Buceras, Wight.

Cambessedesii, Kuntze, 1. c。 $=$ T. brasiliensis, Eichl. Commersonii, Kuntze; 1, c. = T. Badamia, DC cuneata, Kuntze, 1. c. $236=$ T. Arjuna, Wight \& Arn.

discolor, Kuntze, 1. c. $237=$ T. discolor, Spreng. Eichleriana, Kuntze, 1. c. $=$ T. guyanensis, Eichl. guianensis, Kuntze, 1. $\mathrm{c}_{\mathrm{s}}=$ T. Tanibouca, Rich. monoptera, Kuntze, l. c. $=$ T. paniculata, Roth obovata, Kuntze, 1. c. = T. obovata, Sterd Pamaea, Kuntze, I. c. = T. Pamea, DC. pterocarpa, Kuntze, l. c. = T. pterocarya, F. M Mull salicifolia, Kuntze, 1. c, = T, salacifolia, Schwoeinf.

MYRODIA, Sw. (Stercul.). - Ind. Kew. ii. 284. guatemalteea, 7. D. Smith, in Coult. Bot. Gaz. xvi. (1891) 2. - Guatem.

MYRosmA, Linn, f. (Scitam.). - Ind. Kew. ii.

nana, Baker, in Gard. Chron. (1894) i. 652. - Bras? milateralis, Th. Dur, \& Schinz, Consp. F1. Afr. v. $1892(1895) 130=$ unilaterale, Benth. \& Hook. $f$.

MYROXYLON, Forst. = Xylosma, Forst. f. (Bixin.).

Benthamii, callopiryllum, ciliatifolium, cinereum, contro versum, Cumingii, digynum, flexusum, fragrans, liatuaiense, integrifolium, intermedium, lanceolatum, latifolium, leprosipes, longifolium, nitidum, ovatum, panamense, prunifolium, racemosum, Salzmanni, Kuntze, Rev. Gen. (1891) $44=$ homonyma omnia Xylosmatos.

amara, Warb. in Engl. \& Prantl, Natürl. Pflanzenfam. iii. 6a (1893) 41 (= Flacourtia amara,

Span.). - Timor.
buxifolium, Krug \& Urban, ex Urban, in Bot. Jahrb. xv. (1893) $300=$ Xylosma buxifolium, A. Gray.

colastrinum. Kuntze, Rev. Gen. (1891) 44 ; Warb. in Engl. \& Prantl, Natürl. Pflanzenfam. iii. 6a (1891) 41 (= Flacourtia celastrina, H. B. \& K.) = X. nitidum, A. Gray.

Closii, Kuntze, Rev. Gen. (1891) $44=$ X. elegans, Planch. \& Triana.

cordatum, Warb. in Engl. \& Prantl, Natïrl. Pflanzenfam. iii. 6a (1893) $4 \mathrm{l}=$ Flacourtia cordata, H. B. \& $K$.
MYROXYLON : -

coriaceum, Kuntze, Rev. Gen. (1891) $44=$ Xylosma nitidum, A. Gray.

elegans, Kuntze, 1. c. ; Warb. in Engl. \& Prantl, Natürl. Pflanzenfam. iii. 6a (1893) $41=$ Flacourtia elegans, Tul.

ellipticum, Kuntze, 1. c. = Xylosma ellipticum, Henisl.

gonicarpum, Kuntze, 1. $\mathrm{c}$, = X. conicarpum, Clos.

Grayi, Warb. 1. c. 41 = Xylosma nitidum, A. Gray. Hillebranthii, Kuntze, Rev. Gen. (1891) $44=\mathrm{X}$. Hillebrandi, Wawra.

infestum, Krug \& Urban, ex Urban, in Bot. Jahrb xv. (1S93) $298=\mathrm{X}$. intestum, Griseb.

lucens, Kuntze, Rev. Gen. (1891) 44=X. Benthami, Griseb.

martinicense, Krug \& Urban, ex Urban, in Bot. Jahrb. xv. (1893) 299. - Ins. Martinic.

molle, Warb, in Enol. \& Prantl, Natürl. Pflanzenfam, iii. $6 \mathrm{a}(1893) 41=$ Xylosma mollis, Triana \& Planch

nitidum, Millsp. Field Columb. Mus. Bot. Ser. I. (1895) 32 [Pl. of Yucat.] = X. nitidum, A. Gray.

obovatum, Warb. in Engl. \& Prantl, Natiirl. Pflanzenfam. iii. 6a (1893) 41 (= Craepaloprimmon obo"atum, Karst. - Columb.

pachyphyllum, Krug \& Urban, ex Urban, in Bot. Jahrb. xv. (1893) 297. - Ins. Porto-Rico.

Palimrus, Kuntze, Rev. Gen. (1891) 44 (= Hisingera Paliurus, Clos). - Hab.

Pringlei, Warb, in Engl. \& Prantl, Naturl. Pflanzenfam. iii. 6a (1893) $41=$ Xylosma Pringlei, Robinsont

pubescens, Warb. 1. c. $41=$ X. pubescens, Griseb.

rubicundun, Warb. 1.c. (= Craepaloprunnuon rubicundun, Karst.), — Venezuela.

schaefferioides, Krug \& Urban, ex Urban, in Bot. Jahrb. xy, (1893) $300=$ Xylosma schaefferioides, A. Gray.

Schwaneckeanum, Krug \& Urban, ex Urban, 1.c. 296. - Ins. Porto Rico.

Semanni, Kuntze, Rev. Gen (1891) $44=$ Xylosma Seemanni. Triana \&o Planch.

senticosum, Warb in Engl. \& Prantl, Natïr1. Pflanzenfam. iii. 6a (1893) $41=\mathrm{X}$. senticosum, Hance. serratum. Krug \& Urban, ex Urban, in Bot. Jahrb. xv. (1893) 295 (= Prockia serrata, Willd.). - Ind. occ.

spicliferum, Kuntze, Rev. Gen. (1891) 44, sphalm.? = Xylosma spiculiferum, Triana \& Planch.

Tweedianum, Kuntze, 1.c. $(=$ Hisingera Treediana Clos). - Bras.

velutinum, Warb. in Engl. \& Prantl, Natür1. Pflanzenfam. iii. 6a (1893) 4 l = Flacourtia velutina, Tul.

MYRRHIDENDRON, Coult \& J. N. Rose, in Coult. Bot. Gaz. xix. (1894) 465. UMBELLIFE$R E A E$.

Donnellsmithii, Coult. \& N. E. Rose, l. c. 466. Costa Rica.

MYRRHIS, [Tourn.] Linn. (Umbell.). - Ind. Kew. ii. 285.

ambigua, Greene, F1. Francisc.(1891) $332=$ Glycosma ambigua, $A$. Gray.

aristata, MacMill, Metasp. Minn. (1892) $398=$ Osmorhiza longistylis, $D C$

brachypoda, Greene, 1. c. $332=$ O. brachypoda Torr

muda, Greene, 1. c. 333; et Man. Bot. San Franc. Bay (1894) $157=0$. nuda, Torr.

Renjifoana, Phil. in Anal. Univ. Chil. 1xxxv. (1894) 725. - Chili.

MYRRHODES, Moehr, = Anthriscus, Bernh. (Umbellif.).

africanum, alpestre, Kotschyi, lamprocarpum, nemorosum, Ruprechtii, tenerrimum, Kuntze, Rev. Gen. (1891) $268=$ homonyma onmia Anthrisci.

Anthriscus, Kuntze, 1. c. = Anthriscus vulgaris, Bernh.

Cerefolium, Kuntze, 1. c. = A. Cerefolium, Hoffm.

elegans, Kuntze, 1. c. $(=$ Cryptotaenia elegans, Webb). - Ins. Canar:
MYRRHODES : -

funariodes, Kuntze, Rev. Gen. (1891)268 = Anthris-

cus fumarioides, Spremg.

silvestre, Kuntze, 1. c. $=$ A. sylvestris, Hoff $m$.

MYRSINE, Linn. (Myrsin.). - Ind. Kew. ii. 285.

rachyclada, Colenso, in Trans. $N$. Z. Inst. xxii. 1889 (1890) 478. - N. Zel.

cyptophlebia, Baker, in Kev Bull. (1894) 149. Ins. Aldabra.

dasyphylla, Stapf, in Trans. Linn. Soc. Ser. II. iv. (IS94) 199. - Borneo.

edulis, [Engl.?] Pflanzenw Ost-Afr. I) (1895) 223 , nomen. [Quid?]. - Afr, trop.

guineensis, Kuntze, Rev, Gen. (1891) $402=$ flori

bunda, $R . B r$.

kauaiensis, Hillebr. Fl. Haw. Isl. (1888) 280.Ins. Sandvic.

Jelskii, Zahlbr. in Annal. Naturh. Hofnus. Wien, ii. (IS92) 3. - Peruvia.

kermadecensis, Cheesem, in Trans. N, Z. Inst, $\mathrm{xx}$. 1887 (1888) 170. nomen; et xxiv. 1891 (1892) 410 . - Ins. Kermad.

lanaiensis, Hill. Fl. Haw. Isl. (1888) 281. - Ins. Sandvic

neo-zealandensis, Colenso, in Trans. N.Z. Inst. xxii. $1889(1890) 479 .-$ N. Zel.

neurophylla, Gilg, in Bot. falirb xix. Beib1. n. 47 (1894) 45 (= M. melanophlaeos, Baker). - Afr. trop. or.

oligophylla, Zahlbr. in Annal. Naturh. Hofmus. Wien, ii. (1893) 2. - Peruvia.

pendula, Colcnso in Trans. $N^{\top}$. Z. Inst, xxi. 1888 (IS89) 94. - N. Zel.

Playfairi, Hcmsl. in foum. In inn. Soc. xxvi. (1889) 61. - China.

rhododendroides, Gilg, in Bot. Falkrb. xix. Beibl. ก. 47. (1894) 44. - Afr. trop. or.

runssorica. Gitg, in Engl. Pfanzente. Ost-Afr. C (1895) 303. - Afr. trop. or.

Vescoi, Drake, Fl. Polyn. Franc. (1892) 119; et Illustr. Ins, Maris Pacif. (1842) 227. - Ins. Societ.

MYRSTIPHYLLUM, P. Br. =Psychotria, Linn. (Rubiac.)

brachiatum, Hitchcock, in Missouri Bot, Gard.

Rep. iv. (1893) $94=$ P. brachiatum, Sw

corymbosum, Hitchcock, 1. c. $=$ P. corymbosum, Sw.

marginatum, Hitchock, 1. c. = P. marginatum, Sw. pubescens, Hitchcock, 1. c. = P. Pubescens, Sw.

undatun, Hitchcock, I. c. $=$ P. undatum, Sw.

MYRTILUMA, Baill. Hist. des p1. xi. (1S92) $283=$ Sideroxylon, Tourn. (Sapot.)

MYRTILLUS, Gilib. = Vaccinium, Linn migra, Lindstrom, in Bot. Notiz. (189.3) 17 ( = M. niger, Gilib.). = V. Myrtillus, Linn

uliginosa, Lindstrom, 1. c.; Kjellm. Fanerog. Vest Eskem. Land $38=$ V, uliginosum, Linn.

MYRTOLEUCODENDRON, Burm. in Rumph. Herb. Amboin. if. (1742) 72 t. 16 et $17=$ Melaleuca, Linn. (Myrtac.).

accrosum, acuminatum, adnatum, alsophilum, angustifolintm. armillare, basicephalum, Baxtert, blacriaefolium, brachystachyum, calycinum, cardiophyllum, ciliosum, concretum, confertum, cordatum, crasssifolium, cucullatum, cuticulare, cymbifolium, decussatum, densum, depauperatum, diosmifolium, dissitiflorum, elachophyllum, eleutherostachyum, ellipticum, erianthum, exaratum, fasciculiflorm, flifolinm, foliolosum, fulgens, genistifolium, gibbosum, glaberrimum, globiferum, glomeratum, hamulosum, holosericerm, Huegelii, hypericifolium, incanum, lasiandrum, lateriflorum, lateritium, laxiflorm, leiocarpun, leiopyxe. leptocladum, linariifolium, linophyllum, longicomnem, macronychimm, megacephalum, micromerum, microphin! lum, mimutifolinm, nodosum, Oldfuldil, pawiftormi, panperiflorum, pentagonum, polycephalum. pulchellum. pustulatum, Radula, scabrum, seriatum, sparsiftorum. spathulatum. squameum, squarrosum, striatum, sub- 
MYRTOLEUCODENDRON : -

mun, tenellum, teretifolnun, thymifolium, trichophyt lun, uncinatum, undulatum, urceolare, vimincum, violaceum, Wilsonii, Kuntze, Rev. Gen. (1891) $241.42=$ homonyma onnia Melaleucae.

acaciodes, Kuntze, I. c. $241=\mathrm{M}$. acacioides $F$. MIuell.

aspalathodes, Kuntze, 1. c. = M. aspalathoides, Schaul.

Gulothamnodes, Kuntze, 1. c. = M. calothamnoides, F. Mncll.

cylindricum, Kuntze, 1. c. = M, armillaris, Sm.

Deanii, Kuntze, 1. $c_{1}=$ M. Deanii, $F$. Mutll.

deltodcum, Kuntze, 1. c. = M. deltoideum, Benth.

ericifolim, Iruntze, 1. c. = M. ericaefolia, Andr.

hakcodes, Kuntze, 1. c. $=$ M. hackeoides, F. Mucll. nesophylhm, Kuntze, I. C. = M. nesophila F. Aluell. parviflorm, Kuntze, 1. c. = M. Preissiana, Schan. polygalodes, Kuntze, 1. c. = M. polygaloides, Schan. pungcus, Kuntze. I. c, = M. pungens, Sihou.

quadrifarium, Kuntze, 1. c. $=$ M. quadrifaria, F. IIucll.

raphiophyllum. Kuntze, 1. c. = M. rhaphiophylla, Schont.

seorsiform, Kuntze, 1. c. = M, seorsiflora, F. MUcll? stypheliodes, Kuntze, 1. c. = M. styphelioides, Sm. thymodcs, Kuntze, 1, c. = M. thymoides, Labill. thyodes, Kuntze, 1. c. = M. thyoides, Turcz.

trichostachytum, Kuntze, 1. c. = M. linariifolia,

iridiflom, Kuntze, 1. c. $241=$ M. Leucadendron, Lmn.

MYRTUS. [Tourn.]. Linn. (Myrt.) - Ind. Kew.

apiculata, Hiaersk. Enum. BIyt. Bras. (1893) 17 (= Blcharocalyx a ficulatus, Berg). - Bras

Beaurepairiana, Kiacrsk. l. c.22. - Bras.

Bergiana, Nicdensu, in Engl. of Pranti, Naturl. Pfanenfam. iii. $\tau$ (1893) $66 \quad(=$ Camponanesia suffruticosa, Berg). - Am, austr. occ

brumnea, Kiacrsh. Emunn. Myrt. Bras. (18.13) $17(=$ Blcpharocalyx brumens, Berg). - Bras.

corynantha, Kitcersk.7. c. 18 - Firas.

emarginatr. Willd, ex Krug \& Urban, in Bot. Jahrb, xix. (1895) $666=$ Eugenia umbellulifera, Krug \& Urban.

epipastica, F. Muell. in Vict, Natural. ix. (May 18!2) 5, nomen. - Austral

exaltata, F. MI, Bavlcy, in Dept. Agric. Brisbane Bot. Bull. viii. (189:3) Ti. - Austral.

flavida, Stapf, in Hook. Icon pl, xxiii. (1894) t. 2290. - Borneo.

fulvescens, Kiacrsk. Enmm. Myrt. Bras. (1893) 24 (= Engenia fulvescens, DC. .). - Bras.

Glazioriana, Kiaersk. l. c. 23. - Bras.

heteroclita, Niedcnzu, in Engl, \& Prantl, Natiurl. Pfanzanfam. iii, 7 (1893) 67 (=Eugenia heteroclitan, Tussac). - Ins S. Doming.

longipes, Kuarsk, Enum. Miyt. Bras, (1893) $18(=$ Bicpharocalyx longipes, Bergy). - Bras.

MIetrosideros, F. M. Bailey, Syn. Quecnsl. Fl. Suppl. iii. (1890) 27. - Austral.

monusperma. F. Muell, in Vict. Natural. ix. (May 1892) 9; ct in Bot. Contralbl. li. (1892) 89. Austral.

neo-caledonica, Nicdenzu, in Engl. \& Prantl, Na-

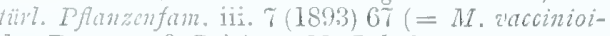
tes, Brongn. \& Gris). - N. Caled.

Reinhardtiana, Kiacrsk. Enum. MIyrt. Bras. (1893) 18 ( = Blepharocalyx cancscons, Berg). - Bras.

Sintenisi1, Kriacrse. in Bot. Tilsskr. xvii. (1890) 285 (= Enguia a Sintenisit, Krug \& Urban). - Ins. Porto Rico

Stahlii, Kiaersk. I. c. 286 t. 7 A et fig. 12 $(=E$ Stuhlii, Krug \& Urban). - Ins. Porto Rico. stictophylla, Kiaersk. Enun. Myrt. Bras. (1893) 20. - Bras.

stenophylla, Oliner, in Trans. Limn, Soc, Ser. II. ii. (1857) 273. t. 392 (Oliver, cx im Thurn, in Timehri, v. (1856) 273). - Guian. angl.

velutina, Kiaersh. l. c. $25 ?=$ Pseudocaryopliyllus a'clutimuls, Bergi, - Bras.

IVarmingiana, Kiaersk. l. c. 19. - Bras.

Widgreni. Kiacrsk. l. c. $18(=$ Blef harocalyx Widgreni, Berg). - Bras.
MYSTAGIDIUM, Lindl, (Orchid.), - Ind, Kew. ii. 290.

aphylhum, Cordem. F1. Ile Réunion (1895) $219=$ Angraecum aphyllum, Thon.

arachnanthus, Th. Dur. E Schinz. Consp. Fl. Afr. v. 1892 (1895) 51 (= Acranthus arachnanthus, Reichb. f.). - Ins. Comor.

Calccolus, Cordem. Fl. Ile Réunion (1895) $220=$ Angraecum Calceolus, Thou.

carpophomm, Cordem. F1. Ile Réunion, (1895) 221 $=$ A. carpophorum, Thou

comorense, Th. Dur. E Sclinz, Consp. Fl, Afr, v. $1892(1895) 52(=$ Aeranthus comorcnsis, Reichb. f.) - Ins. Comor.

dauphinense, Rolfo, ex S. Elliot, in fourn. Limn. Soc. xxix. (1891) 55, - Madag

dentiens, Th, Dur, \& Schinz, Const. Fl. Afr, v, 1892 (1895) 52 (=Aeranthus dentiens, Reichb. f.). - Ins. Comor.

distichum, Pfitz. in Eng1. \& Prantl, Natür1. Pflanfam. ii. 6 (1859) $216=$ Angraecum distichum Lindl.

dolabriforme, Rolfe, in Bolet. Soc. Brot. ix. (1891)

14l. - Afr. trop. occ.

erythropollinium. Th. Dur. \& Sininz, Consp. Fl. Afr. v. $1892(1895) 52(=$ Aeranthus erythropollinius Reichb.f). - Afr. trop.

exile, Th. Dur. of Schinz, l.c. (= Microcoelia exilis. Lindl.). - Madag.

Gilpinac, Th. Dur. \& Schinz, 1. c. = Anrraecum Gilpinae, Reichb. $f$

gladiator, Th. Dur. E. Schinz, l. c. $531=$ Aeranthus gladiator, Reichb. f.). - Ins. Comur

globulosum, Th. Dur. \& Schinz, l. c. $(=$ Gussonia globulosa, Ridi,), - Abyss.

Grandidieranum, Th. Dur. E Schinz, l.c. $(=A c-$ ranthus Grandidieranus, Reichb. f.). - Ins. Cemor. longicorm, Th. Dur. \& Schinz, 1. c. $53=$ filicorne Lindl.

longifolium, Kracnzt. in Bot. fahrt, xvii. (1893) 57. - Afr. trop. or.

mauritianum, Th. Dur. \& Schinz, Consp. Fl. Afr. v. $1892(1845) 53=$ Angraecum gladiifolium, Thout.

Meirax, Bolus, in fourn. Limn. Soc. Xxv. (1889) 181 (=Acranlhus Meirax, Reichb. f.).--Afr. austr. or. micranthum, Th. Dur, \& Schinz, Cunsp. Fl. Afrov. 1892 (1895) $54=$ Angraecum micranthum, Lindl. muscicolum, Th. Dur. E Schinz, l. c. 54 (= Aeranthus muscicolus, Reichb. f.). - Angola.

ophioplectron, Th, Dur. G Schinz, l.c. $(=A$. ophio plectron, Reichb. f.). - Madag.

phalaenophorum, Th. Dur. E Schinz, l.c.l=Aer. phalaenophorus, Reichb. f.). - Madag.

physophorum, Th. Dur, \& Schinz, 1. c. = Angiaecum physophorum, Reichb. $f$.

productum, Kratenzt. in Bot. Falirb. xxi. (1895) 30 - Kamer.

adicosum, Th. Dur. \& Schinz, Consp. Fl. Afr, v. 1892 (1895) $54=$ Angraecum Guyonianum. Reichb.f.

rutilum, Th. Dur. \& Schinz, l.c. (=Aeranthus rutilus, Reichb. f.). - Ins. Comor.

trichoplectrum, Th. Dur. \& Schinz, l.c. (= Aer. trifurcus, Reichb. f.). - Ins. Comor.

viride, Ridl. in foum. Linn. Soc. xxii, (18S6) 122. Madag.

xanthopollinium, Th. Dur. E. Schinz, Consp. Fl. Afr. v. 1892 (1895) 55 (= Acvanthus xanthopollinius, Reichb. f... - Angola.

\section{$\mathbb{N}$}

NACHTIGALIA, Schinz, ex Engl. Bot. Jahrb, xix (1894) 133, nomen $=$ Phaeoptilon, Radlk (Nyctagin.)

protectorata, Schinz, 1. c。 = P. spinescens, Radlk.

NAGEIA, Gaertn, = Podocarpus, L'Hérit. (Conif.).

acutifolia, affinis, anara, andina, angustifolia, appres-
NAGEIA : -

sa, argotaenia, aristulata, chilina, caesia, coriacea, corrugata, costalis, Cumingii, curroifolza, discolor, elongata, eurhyncha, falcata, falciformis, ferruginea, flagelliformis, glomerata, gnidioides, Hallii, insignis, japonica, koraiana, laeta, Lambertii, leptostachya, macrophylla, macrostachya, madagascariensis, Mannii, Meyeriana, neglecta, neriifolia, nivalis, NovaeCaledoniae, nubigena, olcifolia, parrifolia. palembaszica, Purdicana, salicifolia, Sellowii, spicata, Sprucei, tennifolia, theretiacfolia, Totara, usta. Vicillardii, vitichsis, Kuntze, Rev, Gen. (1891) $798-800=$ homonyma onnia Podocarpi,

chinensis, Kuntze, 1. c。 $800=$ P. macrophylla, $D$. Don.

Endlicheriana, Kuntze, 1. c. $=$ P. neriifolia, $D$. Don.

ensifolia, Kuntze, 1. c. = P. elata, $R$. $B r$.

excelsa, Kuntze, 1. c $=P$ spinulosa, $R$. $B r$.

msignis, Kuntze, 1. c. $=$ P. argotaenia, Hance.

Kirkiana, Kuntze, 1. c. = P. angustifolius, $K$ irk

latifolia, Kuntze, 1. co = P. Thunbergii, Hook,

montana, Kuntze, 1. c. = P. taxifolia, H. B. \& $K$.

Nagi, Kuntze. 1. c. $\tau 98=$ P. Nageia, $R . B r$.

Pancheri, Kuntze, 1. c. $8000^{\circ}=$ P. pectinata, Panch.

polyslacliya, Kuntze, 1. c. = P. neriifolia, D. Don.

taxodes, Kuntze, 1. c. = Dacrydium taxioides, Brongn. \& Gris.

tonuifolia, Kuntze, 1. c. $800=$ Podocarpus tenuifolia, Parl.

Tcysmannii, Kuntze, 1. c. = P. Teysmanni, Miq. valdiviana, Kuntze, 1. c. = P. andina, Pocpp.

Wallichiana, Kuntze, 1. c, = P. latifolia, Wall.

NAJAS, Linn. (Najad.). - Ind. Kew, ii. 291. gracilis, Morong, in Mcm. Torrey Bot. Club, iii. II. (1893) 61, [an N. gracillina, A. Br.?]. - Am. bor.

guadalupensis, Morong, l. c. $60(=$ Caulinia guadalupensis, Spreng.). - Am. bor.

interrupta, K. Schnn, in Engl. PAanzenw. Ost-Afr. C (184.) 94. - Afr. trop. or.

microcarpa, C. Bolle, ex Christ, in Bot. Fahrb. ix. (1888) 153. - Ins. Canar.

microcarpa, K. Schun, in Mart. Fl. Bras, iii, III. (1824) $72 \%$ - Bras.

microdon, Morong, in Bot. Gaz. x. (1885) 255 an N. microdon, A. Br.?] = guadalupensis, Morong. protinata, Magnus, in Aschers. \& Schweinf. in Mém. Inst. égypt. [Illustr. Fl. Egypt.] ii. (1887) $145=$ horrida, $A, B r$.

Schweinfurthii, Magnus, in Ber. Dentsch, Bot. Gesells, xii. (1894) 220. - Afr. trop. bor.

NALLOGIA, Baill. in Bull. Soc. Linn. Paris, ii. (1892) $985=$ Cihampereia, Griff. (Thymel.).

Gaudichaudiana, Baill. 1. c, = C. Gaudichaudiana, Van Tiegh.

NAMA, Linn. (Hydrophyl1.), - Ind. Kew. ii. 292. affinis, caroliniana, cormmbosa, clegans, extraxillaris, tiflora, nigricaulis, paludosa, spinosa, Kuntze, Rer. Gen. (1891) $435=$ homonyma omnia Hydroleae.

densa, Lemmon, in Bull. Torrey Bot. Clüb, xvi. (18s9) 222. - Calif

glandulosa, Petor, in Engl. \& Prantl, Natiurl. Pfanzenfam. iv. Ba (1893) 69. [glandulosum] - Mexic. orrata. Britton, in Mem. Torrey Bot. Club, v. (1894) $2 \tau^{2}=$ Hydrolea ovata Nutt.

quadrivalvis, Kuntze, Rev. Gen. (1891) $435=\mathrm{J}=\mathrm{H}$. caroliniana, Michx.

NANI, Adans. Fam, des pl. ii. $88(1763)=$ NANIA, Miq. = Metrosideros, Banlis. (Myrtac.)

albiflora, angutstifolia, ciliata, Colensoi, comosa, diffusa, florida, hypericifolia, hucida, macropus, nervulosa, nitida, operculata, robusta, nubra. sandens, stipularis, suberosa, tetrapetala, tomentosa, Kuntze, Rev. Gen. (1891) 242 = homonyma omia Metrosidereos.

buxifolia, Kuntze, 1. c, = Cloëzia buxifolia, Brongn. \& Gris

canescens, Kuntze, 1. c. $=$ C. canescens, Brongn。 E Gris. 
NANI :-

chrysantha, Kuntze, Rev. Gen. (1891) $242=$ Xanthostemon chrysanthus, F. Muell.

collina, Kuntze, 1. c. = Metrosideros villosa, $S_{m}$.

Deplanihei, Kuntze, 1. c. (= Fremya Deplanchei, Brongn. \& Gris). - N. Caled.

elegans. Kuntze, 1. c. $(=F$. elegans, Brongn. \& Gris). - N. Caled.

flava, Kuntze, 1. c. ( $=$ F. flara, Brongn. \& Gris). - N. Caled.

floribunda, Kuntze, 1. c. = Cloëzia floribunda Brongn. \& Gris.

glomulifera, Kuntze, 1. c. = Syncarpia laurifolia, Tin.

Grisii, Kuntze, 1. c. = Cloëzia Deplanchei, Brongn. \& Gris.

gunmifera, Kuntze, $1 \mathrm{c}_{2}=$ Spermolepis yummifera, Brongn. E Gris.

Teptoclada, Kuntze, 1. c. sphalm. [leptopetala] $=$ Syncarpia leptopetala, F. Muell.

ligustrina, Kuntze, 1. c. = Cloëzia ligustrina, Brongn. E Gris.

obor'ata, Kuntze, 1. c. = Metrosideros villosa, Sm.

faradoxa, Kuntze, 1. c. = Xanthostemon parado-

xus, F, Muell.

rubiginosa, Kuntze, l. c. = Spermolepis rubiginosa, Brongn. \& Gris.

migosa, Kuntze, 1. C. = Metrosideros villosa, Sm.

sessilifolia. Kuntze, 1. c. = Cloëzia sessilifolia Brongn. \& Gris.

t.rnifolia. Kuntze, 1. c. = Lysicarpus ternifolius, F. Muell.

Vieillardii, Kuntze, 1. c. (= Fremy'a Vieillardii, Brongn. \& Gris). - N. Caled.

NANODES, Lindl. = Epidendrum, Linn. (Orchid.).

Mathewsii, Rolfe, in Illustr. Hortic. xxxix. (1892) 43, in obs. = E. Mathewsii, Rcichb. $f$.

NANOSTELMA. Baill. Hist. des pl。x. (1890) 247. ASCLEPIADEAE

congolana, Baill. l. c. 248; K. Schum, in Engl. \& Prantl. Natürl. Pflanzenfant. iv. I. (1893) 248 [congolanum]. - Congo gall,

NAPEANTHUS, Gardn. (Gesnerac.)。 - Ind. Kew. ii. 292.

andina, Rusby, ex F. D. Smith, in Coult. Bot. Gaz. $\mathrm{xx}$ (1895) 6. - Bolivia.

apodemus, f. D. Smith, l. c. - Costa Rica.

NAPOLEONA, Beauv. (Myrt,). - Ind. Kew. ii. 292.

Miersii, Hook. f. in Bot. Mag. (1891) t. 7199. Afr. trop. occ

NARGISSUS, [Tourn.] Linn. (Amaryll.) - - Ind. Kew, ii. 293.

albulus, Levier, in Termész. Fizzet, x. (1886) 45. Eur.

anceps, Rouy, in Bull. Soc. Bot. Fr. xli. (189t) 327 $=\mathrm{N}$. Pseudo-Narcissus, Linn.

Backhousei X, Hort. ex Baker, Handb. Amaryll. (18s8) 12. - Hybr, artef.

Bakeri, C. Richt. Pl. Europ. i. (1890) 245. - I usit.

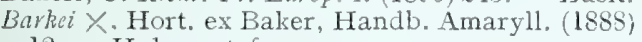
12. - Hybr. artef.

Burbidgei K, Hort. ex Baker, 1. c. - Hybr. artef. Buxtoni X, C. Richt. Pl. Europ. i. (1890) 245. Lusit.

cyclaminus, Baker, in Bot. Mag. (188̃) t. 6950 (= Ajax cyclaminus, Haw.). - Lusit

Fenzii X, Sprenger, in Gartenfl. xl. (1891) $428 \mathrm{fig}$. 84. - Hybr, artef.

Grenieri X, C. Richt. Pl. Europ. i. (1890) 245. Gall. mer.

hedraianthus, Colm. Enum. F1. Penins. v. (1889) SU $=\mathrm{N}$. Bulbocodium, Linn.

Humei $\times$, Hort. ex Baker, Handb. Amaryll. (1888) 12. - Hybr. artef.

fohnstoni, Baker, 1. c. 214 ad calc. $=$ N. PseudoNarcisstus, Limn

Leda X. Hort. ex Gard. Chron. (185\%) i. 832. Hybr. artef.

\section{NARCISSUS :}

Margaritae X, Sprenger, in Gartenfl. xl. (1891) 491 fig. 91. - Hybr. artef.

pallens, Freyn, ex Willk. Suppl. Prodr, Fl. Hist. (189:3) 39, - Hisp.

scaberulus, Henriques, in Bolet. Soc. Brot, vi. (1SS8) 45, cum icon, ; et ex Gard. Chron. (1888) ii, 2.6. Lusit.

Princeps $\times$, Hort, ex Gartenfl. xlv, (1886) 263, Form. hort.

Stella, Hort. 1. c. 264. - Form. hort.

Taiti X. Henriques, in Bolet. Soc. Brot, v. (1887)

170 t. b; Willk. Suppl. Prodr.fl. Hisp. (1893) 323. - Hisp.

Victoricte X. Sprenger, in Gartenfl, xli. (1891) 453, fig. 86. - Hybr, artef.

NARDOPHYLLUM, ¿Hook。 \& Arn. (Compos.). Candollei, Fr. Meigen, in Bot. Fahrb. xviii. (1894) 432 (= Dolichogyne Candollei, Remy). - Reg. Argent.

paniculatum, Phil. in Anal, Univ. Chil. 1xxxvii, (1894) 87. - Chili.

parvifolium, Phil.l.c. 434. - Chili.

scoparium, Phil.l.c. - Chili.

NARDOSTAGHYS, DC. (Valerian.). - Ind. Kew。 ii, 294

chinensis, Batalin, in Act. Hort. Peirop. xiii. (1894) 376. - China.

NARDURUS, Reichb. = Festuca, Tourn. (Gramin.)

cynosuroides, Trab, in Batt. \& Trab. Fl. de I'Algér. [Monoc.] (18:5) $234=$ F. cynosuroides, Desf.

NARTHEGIUM, Mochr. (Liliac.)。 - Ind, Kew.

Reverchoni, Celak. in Oest. Bot. Zeilschr. xxxvii. (1887) 154. - Cors.

NARTHEX, Falc, = Ferula, Tourn. (Umbell.). Poluki, Stapf, in Verh. zool.-bot. Ges. Wien, xxxviii. (1888) 70. - Persia.

NASSAUVIA, Comm. (Compos.). - Ind. Kew. ii. araucana, Phil. in Anal. Univ. Chil. 1xxxriii. (1894) S3. -- Araucan.

argentea, Phil. l. C. 82. - Am. austr.

brevifolia, Phil. l. c. 85. - Am. austr.

glabrata, Phil. l. c. 82. - Am. austr.

humilis, Phil. l. c. ST. - Am. austr.

intermedia, Phil. l. c. 83.-Am. austr.

Lagascae, Fr. Meigen, in Bot. Fahrb. xviii. (1894) 441 (= Caloptilinn Lagascae, Hook. \& Arn.). Am. austr.

lanigera, Pliit. in Anal. Unio, Chil. lxxxvii. (1894) 87. - Am. austr.

latifolia, Fr. Meigen in Bot. Fakrb, xviii. (1894) 443 (= Panargynum latifolinm, Phil.). - Am. austr. patula, Phil. in Anal. Univo. Chil. lxxxvii. (1894) 84. - Am. austr.

rosulata, Ball, in fourn. Linn. Soc, xxvii. (1891) 493 = Acanthophyllume rosulatum. Hook.). - Pataron. sericea, Phil. in Anal. Univ. Chil. Ixxxvii. (1894) 86. - Chili

spinosa, Phil. l. c. 81. - Am. austr.

NASTANTHUS, Miers = Boopis. Juss. (Compos.) Miersii, Phil, in Anal, Univ. Chil, lxxxy. (1894) $81 \%$, in obs. = Boopis Miersii, Fr. Meigen.

NASTURTIUM, Linn. (Crucif.). - Ind. Kew. ii. 290.

amplexicaule, arbuscula, Armoracia, Aucheri, bipinnatifidum, bitinatunn, bonariense, brevicaule, capitatum, Carrerasii, chalepense, Chichicara, chilense, curdatum, coronopifolinm, crassifolinm, crenatifolinm, dictyonm divaricatum, exinaceum, fastigiatum, Jlavm, flexuo sum, fulcosum, Fremontii, glastifolium, graminifolimn, groeshandicun, hirtellunn, hirtum, humefisum, inte-

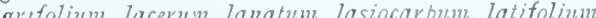
latites, leptopotalum, lineare, linifolium, lyratum majus, Menziesit, montanum, my rocarpum, namzm,

\section{NASTURTIUN :}

nebrodense, nitidum, oblusum, olenacenn, oxycarpum, pedicellosum, perfoliatum, persicum, phlebobetalum. pinnatifidum, propinquum, pubescens, fumilum, racemosum, Ramburei, rotundum, Serra, sordidum, spathatatum, spicutum, spinescens, spinosun, strongylophyllum, subulatum, suffouticosum, trifurcum, IV rightii,

Kuntze, Rev. Gen.(1891) 93\% = homonyma omnid Lepidii.

afghunicun, Kuntze, 1. c. = L. affghanicum, Boiss.

alyssodes, Kuntze, 1. c = L, alyssoides, $A$ Griry. ancricamm, Kuntze, 1, c, - Senebiera pinnatifida, DC.

barbareaefolium, Franch. in Bull. Soc. Bot. Fr. wxxiii. (1888) 396. - China

bracteatum, S. Wats, in Proc. Am. Acad. xxvi 1891) 131. - Mexic.

calicotrichum, Kuntze, Rev, Gen, 1891) $937=$ Lepidium nebrodense, Guss.

capillipes $X$, Nym. Consp. Fl. Eur. Suppl. ii. I (1889) 23 (= Roripa capillipes. Burb.). Hung

Coxi, Phil. in Anal. Unio. Chil. 1xxxi. (1893) 182. - Chuli.

Cammingiammu, Kuntze, Rev, Gen. (1891) $937=$ Lepidium Cumingianum, Fisch. \& Mey.

dictyotum, Greme, Fl. Francisc. (1891) 268. Calif.

dubium, Kuntze, Rev, Gen. (1891) $937=$ Lepidium Humboldtii, $D C$.

erythrocanle X, Nym. Consp. Fl. Eur. Suppl. ii, I (1889) 23 (= Roripa erythrocaulis, Borb.). Hung

ustylis, Benth. ex Kuntze, Rev. Gen. (1891) $21=$ Cardamine eustylis, F, Muell.

Gerardi X, Fouc. \& Rouy, Fl. de Fr. i. (1893) 206 - Gall., Germ.

hastatum, Phil. in Anal. Univ. Chil. 1xxxi。(1893) 180. - Chili.

Henryi, Olizer, in Hook. Icon, pl. xviii. (1887 t. 1719. - China centr.

heteropliyllum, Kuntze, Rev, Gen. (1891) $937=$ Lepidium hirtum, Sm

hungaricum, $X, N y m$. Consp. F1. Eur. ii. :. (1889) 23 (= Roripa hungarica, Borb.). - - Hung.

Hyi X, Fouc. \& Rouy, Fl, de Fr. i. (18:3) 206. Gall.

incismm, Kuntze, Rev. Gen. (1891) 937 = Lepidium incisum, Roth.

insipidum, Reverch. ex Fouc. \& Rouy Fl, de Fr. i. (189:3) $204=$ officinale, R. $B 3^{\prime}$.

kurdicum, Boiss. Eo Hausshn. ex Boiss. Fl. Or. Suppl. (1888) 35. - Persia.

laxum, S. Wats, in Proc. Ame. Acad xxiv, (1889) 39. - Calif. austr.

ligerimum ' $\mathrm{X}, \mathrm{Hy}$, in Bull. Herb. Boiss, ii, App. iv (1894) 11. - Gall.

Marié 火, Fouc. \& Rouy, Fl. de Fr. 1. (1893) 20\% - Gall.

micranthm, Phil. in Anal. Univ. Chil. 1xxxi. (1893) $178=$ flaccidum, Chan

microstyhum, Kuntze, Rev. Gen. (1891) 9:37 = Lepi dium nebrodense, Girss.

millefolium, Baker, in fourn. Linn. Soc. xxii. (185\%) 444. - Maday

monoplocodes, Kuntze, Rev. Gen. (1S91) $037=$ Lepidium monoplocoides, F. Muell.

montanum, Braegg. Fahresb. Nat. Ges, Granbind. xxxi. Beil. (1857-88) 10. - Helv.

Nasturtium, Cockerell, in Bull. Torrey Bot. Club, xix. (1892) $95=$ officinale, $R, B$

meo-gradense X, Nym. Consp. Fl. Eur. Suppl. ii. (1889) 23 (= Roripa neogradensis, Borb.). Hung.

neozelandicum, Kuntze, Rev. Gen. (1S91) 93\%= Lepidium incısum, Roth.

occidentale, Griene, Fl. Frincisc. (1801) 265. Calif.

owahiense, Kuntze, Rev. Gen. (IS9I) 9:: $:$ = Lepi dium owaihiense, Cham. Es Schlect.

oxyotzm, Kuntze, 1. c. = L. humifusum, Reg.

patens, Phil. in Aink. Uniz. Chil. 1xxxi. (1593) 178 - Chili.

fetrophilum. Kuntze, Rev. Gen. (1S!1) :97 = Lep:dium nebrodense, Guss. 


\section{NASTURTIUM :}

Phitinfianum, Kuntze, Rev. Gen.(1891) $937=$ Lepidium suffruticosum, Phil.

wens, Kuntze, 1. c. = L. Draba, Linn.

wtirnm, Kuntze l, c. = L, sativum, Linn.

siifolimn, Phil. in Anal. Univ. Chil. 1xxxi。 (1893) $179=$ officinale, $R, B r$

symbriodes, Kuntze, Rev, Gen, (1891) $937=$ Lepidium sisymbrioides $\mathrm{Hook}_{\mathrm{f}} \mathrm{f}$

stenophyllum $\times$-Nym. Consp. Fl. Eur. Suppl. ii. 1. (1889) 23 (= Rorza stenophylla, Borb.). - Hung. stenophyllum, Phil. in Anal. Unir. Chil. Ixxxi. (1893) 177 - Chili.

shlatum, Kuntze, Rev. Gen.(1891) 937 = Lepidium nebrodense, Guss.?

suglobosum $\times$, Nym. Consp. Fl. Eur. Suppl, ii. I. (1889) 23 (= Roripa subglobosa, Borb.). - Hung. tibeticum, Maxim, Fl. Tangut. (1889) 54. - China. irginicum, Kuntze, Rev. Gen. (1891) $937=$ Lepidium virginicum, Linn.

NATHUSIA, Hochst. = Schrebera, Roxb. Oleac.)

americana, Zahlbr. in Annal. Naturh. Hofmus, Wien, vii. (1892) 4. - Peruvia,

golungonsis, Kuntze, Rev, Gen. (189i) $412=\mathrm{S}$. golungensis, Welw

Holstii. Engl. \& Gilg, ex Engl. in Abh. Preuss. Akad. Wiss (1894) 68, et in Eng1. Pflanzenw. Ost-Afr. C (1895) 308. - Afr. trop. or.

suieteniodes, Kuntze, Rev, Gen. (1891) 41\%= Schrebera swietenioides, Roxb.

trichoclada, Kuntze, 1. c, = S, trichoclada, Welw.

NATSIA TUM, Buch.(Oleac.). - Ind. Kew. ii. $29 \%$. inense, Oliver, in Hook. Icon. pl. xix. (1889) t. 1900. - China.

NAUGLEA, Linn. (Rubiac.), - Ind. Kew. ii. 297. Chalmersii, F. Muell. Desir. Notes Papuan Pl. viii. (1886) $44-$ N. Guin,

cuspidata, Baker, in fourn. Limn. Soc. xxv, (1890) 319. - Madag.

Gordoniana, $F, M$. Bailey, in Dept. Agric. Brisbane Bot. Bull. x. (1895) 22. - Austral.

sinensis, Olicer, zn Hook, Iconl. pl. xx. (1891) t. 1956. - China.

NAUDINIELLA, Krasser, in Engl. \& Prantl, Natürl. Pflanzenfam. iii. 7 (1893) 195. IIELASTO 11 ACEAE.

fraterna, Krasser, l. c. $(=$ Astronia fraterna, A. Gray). - Ins. Tahit.

Glabra, Krasser, l. c: $(=$ A. glabra, Triana). - Ins. Societ

samoensis, Krasser, l.c. $(=$ A. samoensis, $\mathrm{S}$. Moore $)$. Ins. Samoa.

NAUMANNIA. Warb. in Bot. Jahrb。 xiii. (1891) 4.52. ZINGFBERACEAH

insignis, Warb. l.c. - N. Guin.

NAVARRETIA, Ruiz \& Pav。= Gilia, Ruiz \& Pav. (Polemon.).

achilleafolia, agregata, andicola, androsacea, aristella aurca, bella, Bolanderi, Brandegei, brevicula, caes pitosa, californica, campanulata, capillaris, capitata, ciliata, conresta, crassifolia, debilis, demissa, densifora, densifolia, depressa, dichotoma, diffusa, filifoliar, filiformis, floccosa, floribunda, foetida, GavenaGlutinosa, gossypifora, grandiflora, Gunnisonit, dutteta, Ilareardii Haydenii, ibcridifolia, incisa, inconspicura. Foncsii, laciniata, lamuginosa, latiftora. latifolia, leptomeria, leptotes, lincaris, linifora, lutesantifolia, leptomeria, leptotes, lincaris, minifora, humesfora, multicanlis, mulliflora, mudicanlis, Nitutalia. Orcuttui. Parryae, pinualifida, polycladon, panild, Fungons, pusilla, Rattanii, vigidula, spicata, siduothirsa, suómuda, tenclla, tencrima, tenuifloja, temufolia Thurberi, tricolor, vuldiricnsis, virgata, IT atsonii, Wrightii, Kuntze, Rev. Gen. (1S9l) 433 = homonyma omnia Giliae

Giflora, Tiuntze, Rev. Gen. (1891) 4333 = Phlox uiflora, Ruiz \&o Pai
NAVARRETIA : -

Brewer, Greene, Pittonia, i. (Nov. 1887) $137=$ Gilia Bręweri, A. Grav.

dianthiflora, Kuntze, Rèv. Gen. (1891) $433=\mathrm{G}$. dianthoides, Endl.

diraricata, Greene, Pittonia, i. (Nov, 1887) $136=$ G. divaricata, Torr.

diversifolia, Kuntze, Rev, Gen. (1891) 433 = Collomia diversifolia Greene.

effusa, Kuntze, 1. c. = Gilia Dunnii, Kollogg.

critrichodes, Kuntze, 1. c. = Collomia eritrichoides Griseb.

crythraeodes, Kuntze, 1. c, = C, erythraeoides, Griseb.

filicaulis, Greene, Pittonia, i. (Nov, 185i) $1334=$ Gilia filicaulis, Tort

foliacea, Greene, 1. c. 138. - Calif.

giliodes, Kuntze, Rev. Gen. (1891) 443 = Collomia gilioides, Benth.

gracilis, Kuntze, 1. c. = C. gracilis, Dougl,

Gunnisonii, Kuntze, 1.c. = Gilia Gunnisoni, Torr. Es Gray.

hamata, Greene, Pittonia, i. (Nov, 1887) 138, Am. bor.

hamuta, Greene, 1. c. 139 pr. p. = leptantha Greone.

Harcknessii, Kuntze, Rev. Gen, (1891) $443=$ Gilia Harknessii, Curran.

Haydenii, Kuntze, 1. $\mathrm{c}_{\mathrm{s}}=\mathrm{G}$. Haydeni, A. Gray.

hetcrodoxa, Greene, Pittonia, i. (Nov. 1887) $134=$ G. heterodoxa, Grene.

ibcridifolia, B. B. Smyth, Check List pl. Kansas, (1892) $18=\mathrm{G}$, iberidifolia, Benth.

inconspicua, Kuntze, Rev. Gen. (1891) 443 = G parviflora, Spreng.

Lemmonii, Kuntze, 1. c. = G. Lemmoni, A. Gray.

leptantha, Greene, Pittonia, i. (Mar. 1889) 283 Calif.

longiflora, Kuntze, Rev, Gen. (1891) $432=$ Collomia longiftora, A. Gray.

lutea, Kuntze. 1. c. 433 = Gilia micrantha, Steud.

Matthewsi, Coville, in Contrib. U. S. Nat. Herb. iv. (1893) 153 (= Loesclia Matthewsii, A. Gray). - Am. austr. occ

mellita, Greene, Pittonia, i. (Nov, 1887) $134=$ Gilia mellita, Greme.

millefolia, Kuntze. Rev。 Gen. (1891) $433=\mathrm{G}$ Nevini, A. Gray.

mitracarpa, Greene, Pittonia, i. (Nov. 1887) 135. - Calit

nigellaeformis, Greene, 1. c. 132. - Calif.

parciflora, Kuntze, Rev. Gen. (1891) 433 = Gilia Bigelovii, A. Gray.

parvula, Greene, Pittonia, i. (Nov, 1887) $134=\mathrm{G}$ parvula, Greene.

poninsularis, Greene, 1, c. 136. - Calif.

Philippiana, Kuntze, Rev. Gen. (1891) $434=$ Gilia grlutinosa, Phil.

pinmata, Kuntze, 1. co = Collomia Cavanillesii Hook. \& Arn.

prolifera, Greene, Pittonia, i. (1887) 135. - Calit prostratu, Greene, 1. c. $130=$ Gilia prostrata, $A$ Gray.

pumila, B. B. Smyth, Check List pI, Kansas, (1S9:) $18=\mathrm{G}$. pumila, Nutt.

rubra, Kuntze, Rev, Gen. (1891) $433=$ G. coronopifolia, Pers.

setiloba, Coville, in Contrib. U. S, Nat, Herb. iv. 1893) 153. - Calif.

stenosiphon, Kuntze, Rev. Gen. (1891) $434=$ Collomia stenosiphon, Kunze.

subuligera, Greene, Pittonia, i. (Mar. 1887) 13\%.Calif.

tagetina, Greene, 1. c. - Calif.

NAXIANDRA, Krasser, in Engl. \& Prant1, Natur]. Pflanzenfam. iii. 7 (I893) 197 . MLELASTO IIACEAE.

coriacea, Krasser, l. c. - Borneo.

NAZIA, Adans。 = Tragus, Hall, (Gramin.). occidentalis, Scribn, in Zoë, iv。 (1894) $386=\mathrm{T}$ occidentalis. Nees.

racomosa, Kuntze, Rev. Gen. (1891) 780; Baill. Hıst, des pl. xii. (1894) 332; Cordem. F1. Ile Réunion (1895) $120=$ T, racemosus, Hall.
NEAMYZA, Van Tiegh. in Bull. Soc. Bot. Fr, xlii. (1895) $25=$ Loranthus, Linn

Fieldii, Van Tienh.1.C. = L. Fieldis, Buchanan.

NEBELIA, Neck, (Bruniac.). - Ind. Kew. ii 290

angulata, Kuntze, Rev.Gen. (1891) 23:3 (= Berardia angulata, Sond.). - Afr. austr.

aspera, Kuntze, l.c. $(=B$. aspera, Sond. $)$ - - Afr. austr.

Dregeana, Kuntze, l. c. (= B. Dregeana, Sond. $).$ Afr. austr.

fragariodes, Kuntze, l.c. (= B. fragarioides, Sond.). - Afr. austr

laevis, Kuntze, l. c. (= B. lacis, E. Mey.). - Afr. austr.

microphylla, Kuntze, l.c. (=B. microphylla, Sond.). - Afr, austr.

Sonderiana, Kuntze, l. c. - Afr, austr.

sphaerocephala, Kuntze, l.c. $(=$ B. sphacerocephala,

Sond. - Afr, austr.

NECKERIA, Scop.= Gorydalis, Vent. (Papav.) aurea, Millsp. in Bull. West Va. Agric. Exp. Sta. ii. $(1892) 327=\mathrm{C}$ aurea, Willd.

flavula, Millsp, 1. c, = C. flavula. Raf.

curvisiliqua, Rydbers, in Bot. Surv. Nebraslia, iii. (1894) $24=$ C. curvisiliqua, Engelm.

nicrantha, MacMill. Metasp. Minn. (1892) $255=$ C. micrantha, S. Wats. \& Coult.

NECTANDRA, Roland (Laurin.) - Ind. Kew.

\section{iil 2 .}

acutifolia, Mez, in Jahrb. Bot. Gart. Berl, v. (18s9) $409=$ berchemiaefolia, Meinsh

anomala, Mez, l. c. 401. - Bras.

baccans, Mez, l. c. 414 (= Mespilodapline baccans Klotzsch \& Karst.). - Columb.

Brittonii, Mez, l c. 435 - - Bolivia.

Catesbyana, Sarg. in Gard. and For. ii. (1889) 448; et in Bull. Torrey Bot. Club, (1889) $310=$ Willdenowana, Nees.

caucana, Mcz, in fahrb. Bot, Gard. Berl. v. (1889) 420. - Columb.

claiophora, Barb, Rodr. [Herb. Mus. Bot. Amaz. n. 646] Vellosiar, 1885-88 Sec, ediç. (1891) 64 t. 18 , - Bras, bor.

debilis, Mez, in fahrb. Bot. Gart. Berl. v. (1889) 446. - Venezuela.

dominicana, Mez, l.c. 3999(= Oreodaphne dominicana

Meissn.). - Ins, Dominic.

elongata, $M c z$, l. c. 444.- Peruvia.

Glaziovii, Mcz, l. c. 412 . - Bras.

globosit, Mez,1. c, $415=$ sanguinea, Roland

granatensis, $M e z$, l. c. 463. - Columb.

Heydeana, Mez \& F. D. Smith, in Coult, Bot. Gaz.xix. (1894) 262, t. 25. - Guatem.

impressa, Mez, in falub. Bot. Gart. Berl. v. (1889) 439. - Bras

Jelskii, Meś, l. c. - Peruvia

Krugii, Mcz, l. c. $422(=N$, discolor, Griseb.). Ind. occ.

laevis, Mez, l. c. 45.5 - - Peruvia.

latifolia, Mez, 1. C. 454 = polita, Nees.

laxa, Mez, l.c.400 (=Synandrodaphne laxa, Meissn.). - Columb.

lineatifolia, Mez, 1 c. $424=$ amazonum, Nees. martinicnusis, Mez.1. c, $4591=$ Lauvus martinicons

Jacq.). = sanguinea, Roland.

maynensis, Mez, l. c. 428. -- Perlivia.

nitida, Mez, l, c. 461. - Mexic

panamensis, Mez, l. c. 4433. - Panama.

Pearcei, Mez, l. c. 444. - Peruvia.

Pichurini, Mez, 1. c, $449=$ cuspidata, Nees.

purpurea, Mez, 1. C. $443=$ polita, Necs.

reticulata, Mez, 1. C. $404=$ villosa, Nees Er Mart

sanguinea, Hitch. Missouri Bot. Gard. Rep. jv (1893) $125=$ Willdenowiana, $\lambda^{\dagger}$ ees.

Sintenisii, Mez, in fahrb. Bot. Gart. Berl. v. (1889) 419. - Ind, occ.

sinuata, Mez, l. c. 403. - Guatem.

surinamensis, Mcz,. . c. 454. - Guian, bat,

Trianae, Me\%, l. c. 439. - Columb

truxillensis, MIez, l. c. 427, - Venezuela.

Tweediei, Mcz, l. c. 446 (= Oreodaphne Tweediei, Meissn.,. - Am. austr. 
NEGTANDRA :-

umbrosa, Mez, in falirb. Bot. Gart. Berl, v. (18s9) 462. (= Ceramocarpium unbrosim, Nees). - Bras. velutina, Mez, l. 6. 401.-Columb.

NEEA, Ruiz \& Pav, (Nyctagin.). - Ind, Kew, ii. 300

psychotrioides, F. D. Smith, in Conlt. Bot. Gatz, xvi. (1891) 199. - Guatem.

Wiesneri, Heimerl. in Bot. Fahrb. xi. (1890) 89. Columb., Venezuela.

NEGUNDO, Moench (Sapind.). - Ind. Kew. ij. 300 .

Negundo, Karst. Deutschl. Fl. (1880-8.) 596; Sudworth, in Gard. and For. iv, $(1891,160=$ Acer Negundo. Linn.

nikoënse, Nichols. ex Gard. Kew, i. Polypet. (1894) $93=$ A. nikoënse, Maxim.

NEILLIA, D. Don (Rosac.): - Ind. Kew. ii. 300. affinis, Hensl, in fourn. Linn. Soc. xxix. (1S92) 304. - China occ.

gracilis, Franch.Pl. Delar'。 i. (1890) 204.-Yunnan.

alternans, M. E. Fones, in $Z_{00}$, iv. (1893) $43=$ monogyna. Greene.

capitatu, Greene, Pittonia, ii. (Dec, 188s)) $28=$ opulifolia, Benth. \& Hook. f. var.

longiracemosa, Hemsl. in foumt. Linn. Soc. xxix. 1892) 304. - China occ.

malvacea, Greene, Pittonia, ii. (Dec, 1889) 30. Am. bor. occ.

monogyna, Greene, 1. c. $29=\mathrm{N}$. Torreyi, S. Wats. sinensis, Oliver, in Hook. Icon, pl. xvi. (1886) t. 1540. - China centr.

thibetica, Burean \& Franch. in Morot, fourn. de Bot. v (1891) 45. - Tibet.

NELANAREGUM, Adans, = Naregamia, Wight. \& Arn. (Melast.)

alatum, Kuntze, Rev. Gen. (1891) $110=$ Nar. alatum, Wight \&u Arn.

NELSONIA, R. Br. (Acanth.).-Ind. Kew. ii. 301. brunellodes, Kuntze, Rev. Gen. (1891) $493=$ campestris, $R, B r$.

NELUMBO, [Tourn.] Adans. = Nelumbium, Juss. (Nymph.)

Nelumbo, Karst. Deutsch1. F1. (1880-83) $553=\mathrm{N}$. speciosum, IVilld. NEMACLADUS, Nutt. (Campanul.). - - Ind.
Kew. ii.301.

oppositifolius, Robinson, in Proc. Am. Acad. xxvi. (1891) 168. - Mexic.

NEMAL UMA, Baill. Hist. des p1. xi. (1892) $293=$ Ghrysophyllum, Linn, (Sapot.).

NEMASTYLIS, Nutt. (Irid.). - Ind. Kew, ii. 301 .

bracteolata, Baker, Handb. Irid. (1892) 114 (=Chlcmydostylis bractcolata. Baker). - Bolivia.

brevicaulis, Baker, Handb. Irid. (1892) 113. Bolivia.

brunnea, S. Wats. in Proc. Am. Acad. xxy. (1890) $162 ;$ Baker. 7. c. 112. - Mexic

Dugesii, S. Wats. l. c. xxiv. (1889) 86 ; Baker, l. c. - Mexic.

flava, Robinson, 1. c. xxix. (1894) $323=$ N. Dugesii, S. Wats.

grandiflora, Benth ex Baker, Handb. Irid. (1892) 113 (= Gelasine grandiflora, Herb.). - Ecuad.

Pearcei, Baker, l. c. 114.- Peruvia.

Pringlei, S. Wats, in Proc. Am. Acad. xxiv. (1889) 85 ; Baker, l. c. 112. - Mexic.

purruchucana, Benth. ex Baker, Handb. Irid. (1889) 114 (= Gelasine purruchucana, Herb.). - Peruvia. silphurea, Baker, l. c. 113. - Bras.

versicolor, S. Wats. in Proc. Am. Acad. xxii. (18si) 456. - Mexic.

NEMESIA. Vent. (Scrophul.). Ind. Kew。ii. 302. albiffora, N. E. Br. in Kew Buhl. (1895) 28, - Natal.
NEMOPANTHES, Rafin. = Nemopanthus, Rafin. (Ilicin.

canadensis, Gattinger, Tennessee F1. 31, nomen = N. fascicularis, Rafin.

ilicifolia, Hort, ex Dippel, Handb. Laubholzk, ii (1892) 503; Koehne, Deutsche Dendrol. (1893 $370=$ Ilex dipyrena, $W$ all

lacida, Hort. ex Koehne, 1. c. $372=$ mucronata Trel.

mucronata. Trel. in Proc. Am. Acad. Sci. St-Louis $\because$ (1S:2) 349 ; Baill, Hist. des pl, xi. (1892) 2:00 = Nemopanthus fascizularis, Rafin.

NEMOPHILA. Nutt. (Hydrophyll.). - Ind, Kew ii. 30 ?

intermedia, Biolsti, in Erytha, iij.(1895) 141. Calif.

membranacea, Greene, Man. Bot. San Frane. Bay (1894) 252 . - Calif.

spatulata, Couille, in Contrib. U. S. Nat. Herb. iv. (1893) 156. - Calif.

NEMOSERIS, Greene, Pittonia, ii. (Sept. 1891).192 = Rafinesquia. Nutt. (Compos.

califomica, Greene, 1. c. 193; et Man. Bot. San Franc. Bay $(1894) 220=\mathrm{R}$. californica, Nut. nco-mexicana, Greene, 1. c. = R. neo-mexicana A. Gray.

NENGA, H. Wendl. (Palm.), - Ind. Kew. ii, 303. macrocarya, Scortechini, ex Becc. Malcsio, iii. (1889) 180. - Penins. Mal.

NEOBARONIA, Baker = Phylloxylon. Baill. (Legumin.).

xiphoclada, Baker, in Journ. Linn. Soc. xxv. (1890) 313. - Madas.

xylophylloides, Taub. in Eng1. \& Prantl, Natür1. Pflanzenfam. iii. 3 (1894) 48. - Madag.

NEOBENTHAMIA, Rolfe, in Bot. Mag. (1892) t. 7221 ; et in Gard. Chron. (1894) ii. 27\%, fig. 3.7 . ORCHIDEAE.

gracilis, Rolfe, $l l$. co. - Afr. trop. or

NEOBOLUSIA, Schlechter, in Bot. Jahrb. xx. Beibl. 12. 50 (1895) 5. ORCHIDEAE

Tysoni, Schlchter, l.c. $(=$ Brachycorythis Tysoni, Bclus). - Afr, austr.

NEOBOUTONIA, Muell. Arg. (Euphorb.). Ind, Kew. ii, 303.

canescens, Pax, in Bot. Fahrb. xix. (1894) 91 ; et in Abh. Preuss. Akad. Wiss. (1894) 601. - Afr. trop. or et centr. bor.

musculiformis, K. Schum. in Engl. \& Prantl, NatürI. Pflanzenfam. iv.2(1595) $126=$ tuberculata, Blime.

NEOCOLLETTIA. Hemsl, in Journ. Linn. Soc xxviii. (18!0) 44, t. 6 ; Taub, in Engl, \& Prantl Vatirl. Pflanzenfam, iii. 3 (1894) 384 . LEGU MINOSAE.

gracilis, Henst. $l l . c c$. - Burma.

NEODRYAS, Reichb. f. (Orchid.). - Ind. Kew. ii. 303.

Sacciana, L. Linden \& Cogn. in fourn. des Orchid. iv. (1893) 73. - Bolivia.

NEODYPSIS, Baill. in Bull, Soc. Linn. Paris, ii. (1894) 1172; et Hist. des pl. xiii. (1895) 371. PALMAE.

Lastelliana, Baill. ll. co. - Madag.

NEOGLAZIOVIA, Mez, in Mart. Fl. Bras, iii. III. (1894) 426; Baill. Hist. des p1. xiii. (1895) 112. BROMELIACEAE.

variegata, Mez, ll. cc. 427 ; et 11 "2 (= Dyckia Glaziovii, Baker). - Bras.

NEOGOEZIA. Hemsl, in Kew Bull. (1894) 3504; et in Hook. Icon. pl: xxv. (1895) t. 2424; Ccult. \& J. N. Rose, in Contrib. U. S. Nat. Herb. ii. 3 (1895) 305. UMBELLIFERAE

gracilipes, Henrsl. $17 . c c, 355$ et t. $2424=$ Orco myrhis gracilipes, Hemsl.). - Mexic.

\section{NEOGOEZIA :}

minor, Hennsl. in Kew. Bull. (1894) 355; at in IIow. Icon.pl. xxv. (1895) t. 2425. - Mexic.

planipetala, Homsl. \%. c. 35. $(=0$. planifetale

Hemsl.). - Mexi .

NEOJOBERTIA. Baill. Hist. des p1, x. (188s) 30 K. Schum. in Engl. \& Prantl, Natürl. Pflanzen fam. iv. 3b (1894) 227. BIG VONIACEAE

lrasiliensis, Baill.ll.cc. - Bras.

NEOLINDENIA. Baill, in Bull. Soc, Linn. Paris ii. (1S90) 851; Lindau, in Engl. \& Prantl, Natïrl. Ptlanzenfam. iv. 3b (1895) 395. ACANTHA $C E A E$.

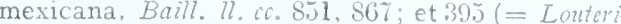
dium moxicanum, S. Wats.). - Mexic.

NEOLUEDERITZIA, Schinz, in Bull. Herlo. Boiss, ii. (1894) 190. ZYGOPHYLLEAE. sericocarpa, Schinz, l. c. 171, t. 2, fig. a, 1 Afr. austro-occ, extratrop.

NEOMACFADYA, Baill. Hist, des p1. x. (1sis 26. BIGNONIACEAE. podopogon, Baill. l. c. (= Macfadyena podopogon,
Griseb.). - Cuba.

NEOMACFADYENA, "Baill. » ex K. Schum, in Engl. \& Prantl, Natix-1. Pflanzenfam. iv. 3b (1894) $227=$ Neomacfadya Baill. (Bignon.).

NEOMUELLERA, Briq, in Bot. Jahrb, xix. (1894) 180. I ABIATAE.

Welwitschij, Briq. l. c. - Angola.

NEONELSONIA, Coult. \& J. N. Rose, in Con trib. U. S. Nat. Herb. iii. 3 (1895) 306. U11 BELLIFERAE.

ovata. Coult. \& $7 . N$. Rose, l. c: 307, t. 9. - Mexic

NEOPHLOGA, Baill. in Bull. Soc. Linn. Paris i1. 1894) 1173 ; et Hist. des pl. xiii. (1895) 3\%2 $P A L M A E$.

Commersoniana, Baill. ll. cc. (= Hyopliorbe Conmersoniana, Mart.). - Madag.

TEOPHyLuM, Van Tiegh. in Bull. Soc. But. Fr. xli. (1894) $508=$ Loranthus, Linn. acutifolim, Van Tiegh. 1. c. 509.- N. Caled Beaudouni, Van Tiegh. 1. c. 548. - N. Caled. Balansa, Van Tiegh. 1. c, 510. - N. Caled. bicolor, Van Tiegh. 1. c. - N. Caled. grandifolium, Van Tiegh. 1. c. - N. Caled. lanceolatnm, Van Tiegh, 1. c. 509. - N. Caled. lutifolium. Van Tiegh. 1. c. 510. - N. Caled. lutem, Van Tiegh. 1. c.50\%. - N. Caled. Pancheri, Van Tiegh. 1. c. - N. Caled. rotundifolimn, Van Tiegh. 1. C. - N. Caled. rubrum, Van Tiesh. 1. C. - N. Caled. scondens, Van Tiegh. l. C. - N. Caled. temiflorm, Van Tiegh. 1. C. - N. Caled. Vieillardi, Van Tiegh. 1. C. - N. Caled.

NEOPRINGLEA. S. Wats, in Proc. Am. Acad. xxvi. (1S91) 134. CELASTRACEAE. integrifolia, S. Wats, l. c. 135. - Mexic.

NEOSPARTON, Griseb.(Verben.). - Ind. Kew ii. 303 .

striatum, Phil. in Anal. Mus. nac. Chile (1861) 60 - Chil 1

NEOSYRIS. Greene, in Erythea, i.i. (1895) 115 Bigelowia, DC. (Compos.).

fuliginea, Greene. 1. c. = B. fuliginea, A. Grat

hypolenca, Greene, 1. c, = B. hypolenca, A. Gray.

NEOTTIA, Linn. (Orchid.). - Ind Kem, ii. $30 \%$ Bigelowii, Ehrenbirgii, grandiflora, Mertinsiana, miti-

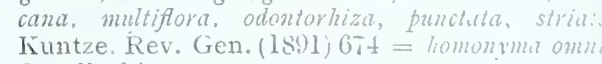

Corallorhizae

Corallorhiza, Kuntze, l. C, $=$ C. innata, $R$. Br. robunchoidar, St Lager, in AIorot. Juurn. cle Hith riji. $(189 t) 8 t=\mathbb{N}$. Nidus-Aris, $R$ 
NEPENTHES, Lim. (Nepenth.). - Ind. Kew. i1 S(0)

Amesiana X. Veitch, in Gard. Chron. (1893) ii 756 ; et ex Kew Bull. Add. Ser. IV. (1895) 271 Hybr, artef.

Burkeii X. Hort. Veitch, ex Gard. Chron. (1889) ii. 492 et 493 fig. 69. - Hybr, artef.

Curtisii, Mast. l. c. (1887) ii. 681 et 689 fig. 139; et (1859) ii. 660 et 661 fig. 90 ; et in Bot. Mag. (1890) 1. 7138; Illustr. Hortic. Xxv. (1888) 65 t. 59. - Burneo.

cylindrica $\times$. Hort. Veitch. 1. c. (1887) ii. 521 fig. 103 ; et (1889) i 81. - Hybr. artef.

Dicksoniana $\times$. Lindsay, 1. c. (1888) ii. 541 et 543 fig. 78; et in Gartenf. xxxviii. (1889) 464 fig. 73. - Hybr. artef.

Elgeworthii, Reichb. f. ex G. Beck, in Wien. Ill Gartenzeit. (May 1895) $183=$ N. Edwardsiana, Low.

cdinemsis X. Lindsay, in Gard. Chron. (1888) i. 470. - Hybr. artef.

excelsior $X$, Williams, in The Garden (188.5) it 463 ; G. Beck, in Wien. Ill. Gartenzeit. (1895) 147. - Hybr, artef

fallax, G. Beck, l. c. (May 1895) 191. - Borneo.

Hibberdii $X$. Williams, 1. c. 218 - Hybr. artef.

hispida, G. Beck, l. c. (May 1895) 18\% - Borneo.

Hookerae, Hort. ex G. Beck, l.c. (June 1895) 222.Form. hort.

Kookeriana "Hort. Low » (err. cal. Hookeriana) ex Becc. Malesia, iii. (1886) $3=N$. Rafflesiana, fack.

longinodis, G. Beck, in Wien. I11. Gartenzeit. (May 1S95) 190 = gracilis, Korth

mixta X. Veitch, in Gard. Chron. (1893) i. 46 fig. 9. - Hybr. artef.

Torthisii $\times$. Veitch, 1. c. (1822) ii. $561=$ mixta, Veitch.

O'Esrieniana, L. Jinden \& Rodigas, in Illustr. Hortic, xxxvii. (1890) $109=$ rufescens, Veitch.

Paradisae, X, Hort. ex G. Beck, in Wien, Ill. Gartenzeit (June 1895) 222. - Hybr. artef.

ufescens X. Veitch, ex Gard. Chron. (1888) ii. 609

fig. 95. - Hybr. artef.

singalana, Becc. Malesia, iii. (1886) 12 t. $2=$ sanguinea. Lind.

Smilesii, Hennsl. in Kew Bull. (1895) 116. - Siam. Smithii, G.Beck, in Wien. Ill. Gartenzeit. (May 1895) ISs. - Borneo.

stcciosa, Hurt. ex G. Beck, 1. c. 2060 = distilla toria, Linnt.

spuria, G. Beck, l. c. 187. - Borneo.

stenophylla, Mast. in Gard. Chron. (1890) ii. 240 et (1892) i. 402 fir. 58) - Borneo.

Treubiana, Warob. in Bot. Fahro, xiii. (1891) 313 - N. Guin.

ittata. Hort. ex G. Beck, in Wien. Ill. Gartenzeit. April 1895$) 150=$ ampullacea, $W$. Fack

NEPETA, Riv, ex Linn, (Labiat.) - Ind. Kew.

Amani, Post, in Bull. Herb. Boiss. i (1853) 29 et 111. - Syria.

Bellevii, Prain, in Foum, As. Soc. B.ng. Ix. (1891) ii. 204. - Afghan.

allichroa. Hausskn, \& Brig. in Mitth. Bot, Ver. fena viii (1s90) 21 - Persia.

Ehlersii, Schweinf. ex Engl. in Abh. Prouss. Akud. Wiss. $18 \% 1$ (18\%2) 368, nomen. - Afr. trop. or.

fixuost, Macdill. Metasp. Minn. (1892) 452 sphalm. (= Origumum flexuosum, TValt.). = Pycnanthemum linifulium. Pursh.

Fordii, Hemst. in foum. Linn. Soc, xxvi. (1891)

259. - China

289. - China Stern ä Pugre. Prel m. Catal. (1888) 43; Baill. Hist. des pl. xi. (1892) 30 ; Greene, Man. Bot. San, Franc Jay (1891) 20) X. Glechoma, Benth

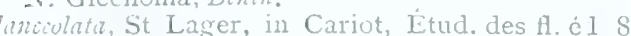
ii. (1889) 66:) = grandiflora, Vill.

Hemsleyana, Otiser, ex Prain, in fourn. As. Soc. Bcng. lix. (18!10) II. 305. - Rer. Himal.

moldariar. Baili. Hist. des pl. xi. (1892, $30=$ Dorycnium moldavicum, Linn.

pharica. Prain, in foun. As. Soc. Bong. 1ix. (1890) II. 306, - Belut:hist.

\section{NEPETA}

rigida, G. Beck, Fl. Nied. Oest. ii. II. (1S93) $1004(=$ Glechoma rigida A Kern.) = N Glechoma Benth. Sewerzowii, Regel, in Trans. Lmn. Soc. Ser. II, iii. 1886) 96. - Turkest.

Shepardi, Post, in Journ. Linn. Soc, xxiv. (188s) $439=$ Micromeria Shepardi, Post.

subintegra, Maxim. in Bull. Acad. Pétersb. xxxi. (1887) 90. - Mongolia.

Wettsteinii, H. Braun, in Verh, zool.bot. Ges. Wien, xxxix. $(1859) 226$. - Persia.

NEPHELAPHYLLUM, Blune (Orchid.). Ind. Kew. ii. 307. f. Fl. Brit. Ind. vi. (1890) 192. - Penins. Mal.

latilabre, Ridi. ex Staff, in Trans. Linn. Soc., Ser. II. iv. (1894) 238. - Borneo.

nudum, Hook. f. Fl. Brit. Ind. vi. (1890) 192 Penins. Mal.

NEPHELIUM, Linn. (Sapind.), - Ind. Kew. ii.

basaccense, Pierre, Fl, For, Cochinch. Fasc, 20 (1894) sub t. 319 b. = bassacense, Pierre.

bassacense, Pierve, l.c. [basaccense, in text.]. Cochinch.

cochinchinense, Pierre, l. c. Fasc, 21 (1895) sub t. $321 \mathrm{a}(=$ Xerospermum cochinchinense, Pierre, 1. c. t. 321). - Cochinch.

Lauteriana, F. M. Bailey, in Dept. Agric. Brisbane Bot. Bull. iv. (1891) 8. - Austral.

oppositifolium, Corden. Fl. Ile Réunion (1895) 379 (= Stadminnia oppositifolia, Puir.). - Ins. Borbon.

Thorelii, Picrre, Fl. For. Cochinch., Fasc. 20 (1894) sub t. $320 \mathrm{~A}$, in syn. (= Gnemidiscus Thorelii, Pierre). - Cochinch

NEPHRADENIA, Decne (Asclep.), - Ind. Kew ii. $30 \%$.

fruticosa, f.D. Snith, in Con't. Bot. Gaz.xvi. (1891) 196. - Guatem

NEPHROPHYLLIDIUM, Gilg, in Eng1. \& Prantl, Natürl. PHanzenfam. 1v. 2 (1895) 105. GENTIANEAE.

Crista-galli, Gilg, l. c. fig. 47 (= Menyanthes Cristagalli, Griseb.). - Am. bor. occ.

NEPHTHYTIS, Sch эtt (Aroił.). - Ind. Kew. ii icturata, N.E. Lr. in Gard. Chron. (1887) i. 476 ; et ex Gartenfl. xxxvii. (1888) $184 \mathrm{fig}$. 40. Congro.

NEPTUNIA, Lour. (Legumin.). - Ind. Kew. ii $50 \mathrm{~s}$

irgata, Trelease, ex Branner \& Coville, in Ann Rep. Geol. Surv, Arkans, for 1888 i. (1891) 178 lutea, Benth.

INERAUDIA, Gandich. (Urtic.). - Ind. Kew. ii 305.

hahoolawensis, Hillebr. Fl. Haw, Is?. (18S8) 416. Ins. Sandvic.

NERINE, Herb. (Amaryll.). - Ind. Kew. ii. 308 appendiculata, Buker, in Gard. Chron. (1894) ii. 336. - Hab.

Elwessi, Hort. Leichtl. l. c. (1S36) i. 42. - Form. hort.

insignis, Hort. Lcichtl. l.c. 41. - Form hort

laticoma, Th. Dur. \& Schinz, Consp. Fl. Afr. v. $1893(1895) 250=1$ lucida, Herb.

Lansellii $\times$ Hort. O'Brien, ex Baker Handb. Bromel. (ISSS) 104 - Hybr. artef.

Moorei, Leichtl. l. c. (1886) ii. 681. - Hab.?

mutcabilis $\times$, O'Brien, 1. c. $(18933)$ i. 130; Bois, in Rev. Hortic. 1xv. (1893) 384. - Hybr. artef.

profust, Hort. ex Baker, Handb. Amaryll. (1888) $100=$ sarnicnsis, $H u_{0 .}$

Strichlandi X, Hort. ex Gard. Chron. (1894) ii. 690 - Hybr, artef.
NERTERA, Banks \& Soland, (Rubiac.), - Ind Kew. Ii, 309.

sinensis, Hemsl. ex Forb. \& Hemsl. in fourn. Linn Soc. xxiii. (1885) 391, t, 10. - China.

NESAEA, Comm. (Lythrar.). - Ind. Kew. ii. 308 kilimandscharica, Koehne, in Engl. Pfanzenw. OstAfr. C (1895) 286. - Atr. trop, or.

Luederitzii, Koehne, ex Schinz, in Verh. Bot. $V \mathrm{or}$ Brand. xxx. (1888) 251. - Afr. austro-ccc. extratrop.

mucronata, Koehme, ex Schinz, l. c. 248. - Afr austro-occ, extratrop.

Schinzii, Kochne, ex Schinz, l. c. 250. - Afr. austroocc. extratrop.

Stuhlmannii, Koehne, in Engl. Pfanzenw. Ost-Afr. C (1895) 286. - Afr. trop. or.

triflora, Baill. [an H. B, \& $K$. ?] Hist. pl. Madag. Atlas (1894) t. 359. - Madag.

Volkensii, Koehne, in Engl, Pfanzenw. Ost-Afr. C (1895) 286. - Afr. trop. or.

NESLIA, Desv. (Crucif.), - Ind. Kew. ii. 309) thracica, Velen. in Oest. Bot. Zeitschr. xli. (1891) 122 et $3 \pi$. - - Bulg.

NESOGORDONIA, Baill, in Bull. Soc. Linn. Paris, i. (1886) 555. TER T'STROEMIACEAE. Bernieri, Baill. l. c. 555 et 563. - Madag.

NESOLUMA, Baill. in Bull. Soc. Linn. Paris, ii. (1891) 964; et Hist. des pl. xi. (1892) $279=$ Ghrysophyllum, Linn, (Sapot.)

polynesiacum, Baill. 11. cc. = C. polynesiacum Hillebr.

NESTLERA, Spreng. (Compos.). - Ind. Kew. ii. corymbosa, Bolus, in Hook, Iconz. pl. xxiv. (1894) t $23^{\circ} 4$, - Atr, austr.

t 23:4. - Atr. austr.
irrata, N. E. Br. in Kew Bull. (1895) 25. - Natal.

NESTRONIA, Rafin. = Buckleya, Torr. (Santal).

distichophylla, Kuntze, Rev. Gen.(1891) $589=$ B distichophylla, Torr.

quadriata, Kuntze, 1. c. = B. lanceolata, Miq umbellata, Kuntze, 1. c., sphalm. = B. unbellulata Rafin.). - Am. bor.

NEUMANNIA. Brongn. = Pitcairnia, L'Hérit. (Bromel.).

aruata, Ed. André, in Rev. Hortic. 1viii. (18,96) 103 cum icon. = P. arcuata, Ed. André.

Lindeni, Ed. Morr. ex Baker. Handb. Bromel (1859) 112, in syn. = P. Lindeni, Baker.

NEUMANNIA, A. Rich. = Aphloia, Benn Bixin.)

deltoidec, Warb, in Engl. \& Prantl, Natürl, Pflanzenfam. iii 6a (1893) $43=$ Prockia deltoidea Lam.

madagascaricnsis, Warb.1.c. = A. madagascariensis, Clos

minima, Warb. 1. c. = A. minima, Baker

NEURACHNE, R, Br. (Gramin.). - Ind. Kew 11.310

Muelleri, Hack. in Oest. Bot. Zeitsciar. xlv. (18!5) 329. - Austral.

NEUROLAENA, R. Br. (Compos.), - Ind. Kew. ii. 310 .

Lieomanni, Sch. Bip., ex Klatt, in Leopoldina, Heft xxiii. (1887) 146, in syn. = S. Liebmannii Klatt.

pedicellata, Sch. Bip. 1. c. = pedicellata, Klatt.

temifolia. Sch. Bip, ex Klatt, 1. c. = Jaumea tenuifolia, Klatt.

NEUROLOBIUM, Baill, in Bull. Soc. Linn Paris, i. (1888) 749; et Hist. des pl.x. (1888) 191: K Schum, in Ens1. \& Prantl, Natiirl Pflanzenfam. iv. 2(1895) 154. APOCYNEAE. cymosum. Baill. n. cc. - Bras. 
NEUROPELTIS, Wall. (Convolv.). - Ind. Kew, ii. 311 .

Maingayi, Peter, ex Hallier $\mathrm{f}$, in Bot. Jahrb. xvi. (1893) 500, in obs. = Lettsomia Maingayi, C. B. Clarke?

NEUROTHECA, Salisb. (Gentian.). - Ind. Kew. i1. 311

loeselioides, Baill. Hist des p1.x. (1888) $138(=\mathrm{Oc}$ topleura loeselioides, Benth.) = loeselioides, Oliver [Conf. Ind. Kew. ii. 311].

NEWGASTLIA, F. Muell, (Verben.), - Ind. Kew. ii. 311.

Dixoni, F. Muell. \& Tate, in Trans. and Proc. Roy. Soc. S. Austral. x. (1888) 81; F. Muell. in Bot. Centralbl. xxxiii. (1888) 119.-Austr.

NEUWIEDIA, Blume, (Orchid.), - Ind. Kew, ii. 311.

calanthoides, Ridl. in foum. Bot. xxiv. (1886) 355 t. 271. - N. Guin

Curtisi, Rolfe, in Fourn. Linn. Soc. xxv. (1889) 232; Hook. f. Fl. Brit. Ind. v. (1890) 175. - As. trop.

Lindleyi, Rolfe, Il. cc. 233 ; et 175; Hook. f. in Bot. Mag. (1894) t. 7365. - Penang, Borneo.

NEWTONIA, Baill, in Bull. Soc. Linn. Paris, i (1888) 721; Taub, in Engl. \& Prantl, Natürl. Pflanzenfam. iii. 3 (1894) 385. LEGUMINOSAE. insignis, Baill. ll. cc. - Afr. trop. occ.

NEWTONIA, O. Hoffm, in Engl. \& Prantl, Natürl. Pflanzenfam. iv. 5 (i895) 285 et $391=$ Antune sia, O. Hoffm. (Compos.)

angolensis, O. Hoffm. 1. C. - Angola.

NHANDIROBA, Barrère = Fevillea. Linn. (Cucurb.).

albiflora, Kuntze, Rev. Gen. (1891) $257=$ F. albifiora, Cogn.

cordifolia, Kuntze, 1. c, = F. cordifolia. I im deltodea, Kuntze, 1. c. = F. deltoidea, Cogn. Karstenii, Kuntze, 1. c. = F. Karstenii. Cogn. Moovei. Kuntze, 1. c. = F. Moorei, Hook. f.

trilobata, Kuntze, 1. c。 = F. trilobata, Lims

NICODEMIA, Ten. (Logan.). - Ind. Kew. ii. 311.

Baroniana, Oliver, in Hook. Icont. pl. xxiii. (1892) t. 2238. - Madas.

grandifolia, S. Elliot, in fourn. Limn. Soc. xxix. (1891) 34. - Madag.

Hermanniana, Cordem. Fl. Ile Rémnion (IS95) 469. Ins. Borbon.

Isleana, Cordem. l. c. 468. - Ins. Borbon

rufescens, Solered. in Bot. Fahrb. xvii. (1893) 558. - Madag.

NICOTEBA, Lindau, in Bot. Jahrb. xviii. (1894) $56=$ Justicia. Houtt. (Acanth.).

Betonica, Lindau, 1. c: = J. Betonica, Limn

fittonioides, Lindau, in Eng1. \& Prantl, Natürl. Pflanzenfam. iv. 3b (1895) $329=\mathrm{J}$. fittonioides, S. Moore.

7ancoolata. Lindau, in Bot. Jahrb. xx. (1894) 38, Afr. centr. bor.

marginata, Lindau, 1. c. xxii. (1895) 119. - Kamerun

nilgherrensis, Lindau, 1. c. xviii. (1894) $56=\mathrm{J}$. nilgherrensis, $W$ all

trinervia, Lindau, 1. c. = J. trinervia, $V a h l$.

trinervis, Lindau, in Engl. \& Prantl, Natürl. Pflanzenfam. iv. 3b (1895) $329=$ praec.

icrsicolor, Lindau, 1. c. xxii. (1895) 118. - Angola.

NIGOTIANA. Linn. (Solan.), - Ind. Kew. ii. 311. brachysolen, Phil. in Anal. Mus, nac. Chile (I891) 62. - Am, austr.

breviloba, feffrey, in Kew Bull. (1894) 102. - Chili. cardiophylla, Phil, in Anal. Univ. Chil. xc. (1895) 7\%2. - Chili.

caudigera, Phil. l. c. 764, - Chili.

Collae, Phil. 1. c. 765 (= Bouchetia crecta, DC.). Texas, Mexic.

\section{NICOTIANA :}

colossea, Éd. André, in Rev. Hortic. (1888) 511 ; et (1891) 75 et 210; Godefr.-Lebouf, in Le Jardin (1889) 274, cum ic. ; Gard. Chron. (1891) i. 84, fig. $25=$ tomentosa, Ruiz. \&s Par.

copiapina, Phil, in Anal. Univ, Chil xc. (1895) $771=$ Berteroana, Hort

coquimbana, Phil. l. c. 76\%, - Chili

flexuosa, Feffrey, in Kew Bull. (1894) 101. - Urugulay.

Greeneana, $7 . N$. Rose, ex Vasey of $7 . N$. Rose, in Contrib. U.S. Nat. Herb. i. (1590) 18. - Calit.

heterophylla, Phil. in Anal. Univ. Chil. xc. (1895) 767. - Chili.

linearis, Phil. l. c. 766. - Chili,

longibracteata, Phil. in Anal. Mus. nac. Chile (189!) 62 . Chili.

mendocina, Phil. in Anal. Unir. Chit. xc, (1895) 769. - Chili.

modesta, Phil. l. c. 765. - Chili.

oligantha Phil. l. c.767. - Chili

parvula, Phil. l. c. 768. - Chili.

uspallabensis, Phil. l.c. 7\%o.- Chili.

NIDORELLA, Cass. (Compos.). - Ind. Kew. ii

ligulata, S. Ellint, in fourn. Linn. Soc. xxix. (1891 28. - Madas:

pedunculata, Oliver, in F. L. fames, Unkn Horn of Afr. Append. (188S) 319. - Reg. Somal

NIDULARIUM, Lem. = Karatas, Adans. (Bro mel.).

agavaefolium, Hort. es Baker, Handb. Bromel

(1889) 4 = K. denticulata, Baker.

Benckeri, Hort. ex Rev, Hortic. Belg, xil. (ISSS) 110. - Form. hort.

bracteatum, Mez, in Mart. Fl. Bras, iii. III. (1891) 224 = Aechmea billbergioides, Baker.

Chantrieri Y. Hort, ex Ed André, in Rev. Hortic. Ixvii. (1895) 45, cum ic, - Hybr artef.

compactum, Mez, in Mart, Fl. Bras, iii. III. (1891) $2: 35 .-$ Bras.

concentricum, Mez, 1, c. $239=\mathrm{K}$. acanthocrater Baker.

digeneum $\times, G$. Beck, in Wien. Ill. Gartenzeit. (1893) 121 t. 1. - Hybr. artef.

emergens, Mez, in Mart. Fl. Bras, iii, I1 (1894) 621 , in obs. - Bras.

eximium. Hort. ex Baker, Handb. Bromel. (1839) $11=\mathrm{K}$. spertabilis, Antoine.

fragrans, Hort. ex Baker, 1. c. $47=$ Aechmea aligusta, Baker.

guyanense, A. Brongn. ex Baker, 1. c. 91, in syn. $=\mathrm{K}$. Morreniana, Antoine.

latifolium, Hort. ex Baker, 1. c. $69=$ Ae. viridis, Buker.

longebracteatum, Mez, in Mart. Fl. Bras, iii. 1m. (1891) 239. - Bras.

1macracant7ium, Regel, in Gartenfl. xxxy. (1886)297, fig. 34. - Bras.

Makoyanum, Regel, J.c. xxxvi. (1887) 650; et in Act. Hort. Petrop. x. (1887) 368. - Am. trop Makoyanm, Hort, ex Baker, Handb, Bromel, (1859) 6 (an praec. ?] = K. neglecta, Bake.

Marechuli, Hort. ex Baker, 1. c. $9=\mathrm{K}$. fuluens, Antoinc?

marnoratum, Éd. Morr. ex Baker, 1. c. 11.Bras. ?

Morrenianm, Hort. ex Baker, 1. c. 9, in syn. = K. Morreniana, Antoine

neolectum, Hort. ex Baker, 1. c. $6=\mathrm{K}$. neslecta Baker.

pauciforum, Lindm, in Svensk. Akad. Handl. xxiv. n. viii. 17, t. 1, fig. $8-18=$ Aechmea billbergioides, Baker.

Paximum, Mez, in Gartenfl, xliv, (1895) 207 t. $1415 .-$ Bras

porpliyrum, Mez, in Mart. H1. Bras, iii. 11. (1891) $219=$ Aechmea purpurea, Bakcr

pubisepalum, Mez, 1. c. 246 et 621 , in obs. $=\mathrm{Ae}$. Burchelli, Baker.

pulcevulentum, Ed. Morr. ex Balier, Handb. Bromel. (IS89) 9 , in syn. = K. Morreniana, Antoine.

mbous, Mez, in Mart. F1. B3ras, iii, 11. (1S91) 219 - Bras.
NIDULARIUM :

spectabile, Hort. ex Baker, Handb. Bromel. (1889) $10=$ Karatas princeps, Buker

striatum, Catal. Bull. (18s8) 8; IConf. Gard. Chron. (1888) ii. 273; et (1890) ii. 183; Rey. Hort. Belg. xvii. (1891) 204, cum xylogr.]. Bras.

IVawreanum, Mez, in Mart. F1. Bras, iii. 11. (1891) $45=$ K, amazonica, Baker, var.

NIDUS, Riv, Icon, pl. (1760) 3 t. 7 , ex Kuntze, Rev. Gen. (1891) $674=$ Neottia, Linn. (Orchid.). islirodes, Kuntze, 1. c. = Neottia listeroides, Lindl. micranthus, Kuntze, 1. c. = N. micrantha, Lindl.

NIEBUHRIA, DC. (Capparid.). - Ind. Kew. ii. mucronata, Kuntze, Rev. Gen.(1891) 38 (= Crataera mucronata, Kuntze, Rev. Gen. (1891) 38

NIEDENZUA, Pax, in Bot. Jahrb, xix, (1994) $106=$ Adenochlaena, Baill. (Euphorb.

cordata, Pax, 1. c. 107 (= A. lemocehrala, Baill.). Ins. Comor.

NIGELLA. | Tourn.| Linn. (Ranuncul.), - Ind. Kew. ii. 314 .

Huthii, Brand, in Holios, xiii. (1895) 26 et 191 Ins. Samos.

intermedia, Rouy \& Fouc. Fl, de Fr. i. (1893) 122 in obs. = hispanica, Lim.

Tauberti, Brand, in Helios, xiii. (1895) 27 et 192. Afr. bcr.

NIGRINA, Linn.= Melasma, Berg (Scrophu1.). ovatum, Kuntze, Rev. Gen. (1891) 46: = M. ovatum, E. Mey.

physalodes. Kuntze, 1. c: = M. hispidum. Benth.

Thinanthodes, Kuntze, 1. c. = M. rhinanthoides, Benth.

NIGRITELLA, Rich. = Habenaria, Willd. (Orchid.).

Moritziana X. Brueore ex Nym. Consp. Fl, Eur. Suppl. ii. I. (1889) 292. - Helv.

nubra, C. Richt, Pl. Europ. i. (1890) 278; Wettst. ex Pacher, Nachtr. Fl. Karnt. (1894) 34. - Alp. Carpath.

NISSOLIA, Jacq. (Legumin.), - Ind, Kew, ii 315

confertiflora, S. Wats. in Proc. An. Acad. xxi. (1856) 424. - Mexic.

setosa, T. S. Brandeg. in Proc. Callf. Acad. Ser. II. iii, (1891) 127. - Calif.

NOAEA, Moq. (Chenop.). - Ind. Kew. ii. 315 mucronata. Aschers. \& Schweinf. Illustr. F1. Egypt. [Mém. Inst. égypt. ii, (lo87) $131=$ spinosissima, $12 c q$.

NOCCAEA, Kuntze, Rev. Gen. (1801) 35\% = NOCCA, Cav. = Lagascea, Cav. (Compos.) angustifolia, Kuntze, $1, c_{0}=\mathrm{L}$. angustifolia, $D C$. biflora, Kuntze. 1. $c_{.}=$L. biflora, Hensh decipicns, Kuntze, 1.c. = L. decipiens, Fenzl. heteropappus, Kuntze, 1. c. = L. heteropappus, Hennsl.

Iociniana, Kuntze, 1. c. = L. Moçiniana, DC.

NOCGAEA, Moench (Crucif.), - - Ind. Kew, ii. 316 affinis, Rouy \& Fouc. Fl. de Fr. ii. (1895) $90=$ alpina, Reich

crassifolia, Rouy \& Fouc. 1. c. 91 et $92=$ Capsella procumbens, Reicht.

diffusa, Rouy \& Fouc.

Reichb

maritima, Rouy \& Fouc. 1. c. = C. procumbens, Reichb.

pauciflora, Rouy \& Fouc. 1. c. 92, in obs. = C. pauciflora, Koch

Prostii, Rouy \& Fouc. 1. c. 92 et 93 (= Hutchinsid Prostii, J. Gay) $=$ C. panciflora, $K$.

Revelicri, Rouy \& Fonc. 1. C. 91 et $9: 3=$ C. procum 


\section{NOCGAEA :}

(1892) 21 et $93=$ Capsella procumbens, Reichb

Fournctortii, Rouy \& Fouc, 1. c. 9l et 92 = C. prombens, Reichb.

TOITTIETIA, « H. B. \& K. » ex Barb, Rodr. Hort. Flumin. $1893(1895) 21$, sphalm. = Noisettia, H. B. \& K. (Violar.)

NOLANA. Limn, (Convolv.). - Incl. Kew. ii, 316. alloa, Phil, in Anal. Univ. Chil. xci. (1895) 32.

Am. austr.

Carrera, Phil.l.c.31 - Am. austr.

debilis, Phil. l. c. 29. - Am. austr.

Seminniflora, Phil. l. c. 2\%. - Am. austr.

lencantha, Phil. l. c. 34. - Am. austr.

linearifulia, Phil. l.c. 요. - Am. austr.

napiformis. Phil. l. c.30. - Am, austr.

Navarri, Phil. l.c. - Am. austr.

ochrocarpa, Phil. l. c. 33. - Am. austr.

parviflora, Phil. l. c. 34. - Am, austr.

parvifolia, Phil. l.c. 35. - Am. austr.

pterosperma, Phil. l. i. 27. - Am, austr.

rupestris, Phil. l.c. 28. - Am. austr.

sessiliflora, Phil.l.c. 32. - Am, aust.

stans, Phil. I.c.31. - Am. austr.

NOLINA, Michx (Liliac,), - Ind. Kew, ii, 316. Beldingi, T. S. Brondeg, in Zö̈, i. (1890) 305. Calif. T. S. Brandeg. in Proc. Calif. Acad. Bigelowi, T. S. Brandeg. in Proc, Calit, Acad.
Ser, II. ii. (1889) $208=\mathrm{N}$. Birelovii, S. Wats. Brittoniana, Nash, in Bull. Torrey Bot. Club, xxii. (1895) 158. - Florida

NOLLETrA, Cass, (Compos.), - Ind. Kew, ii. 316. arenosa, O. Hoffur ex Schind, in Bull. Herb. Boiss. i. (1893) 76; et cx Engl, Bot. Fahrb. xix. (1894) 25l. - Afr. austro-occ. extratrop.

Costata, Klatt, ex Schinz, in Bull. Herb. Boiss, iii. (1895) 430. - Afr, austro-occ, extratrop.

NOMOGHARIS, Franch. in Morot, Journ, de Bot, iii. (1889) 113, Baill. Hist. des pl. xiii. (1894) 580. LILIACEAE.

pardanthina, Franch. $l l, c c$. - China.

NOMOPHILA. Blume (Acanth.). - Ind. Kew. ii. 316

gracillima, Schinz, in Verh. Bot. Ver. Brand, xxxi, (1890) 196. - Afr. austro-occ. extratıop.

NOXATELIA, Aubl, = Lasianthus, Jacq. (Rubiac.)

acuminata, africana, andananica, apiocarpa, appressa, attemuala, Biermanii, Bluneana, capitala, capitulata, chinemsis. chrysoneura, chrysophylla, ciliata. constricta, crinita, iyanocarpa, dichotoma, elliptica. firma Gardueri, glabrescens, Griffithii, Helferi. hexandra. Hookeri, inconsficua. Fachiana, Kurail, hetandra, Hookeri, inconspicuar. Fachiana, Kurzi, laterigatu, lancifolia, latifolia, longzcauda, longifonta mucronulata, obliqua, oblongifolia, obociata, abscura, uligantha. opata, ralcmbanua, parifolia, pancifora,

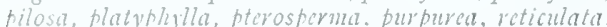
velosa, Rhinoccrotis, vhizophylla, vigida, vufa, sik-

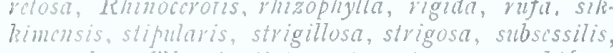
centaculata. Theraitesii, tomentosa, truncata, tubifera, E'arians, imosa, ipulosa, Walkeriana, IVightiana, Kuntze, Rev. Gen.(1S)1) $200-91=$ homonymo omnia Lasianthi.

aculala, Kuntze, 1. c. $291=\mathrm{L}$. mucronatus, $M I \mathrm{kq}$. africant, Kuntze, 1.c. = Triainolepis africana. Hook. $f$.

amazonica. Kiuntze, l. c. = Psychotria amazonica 3lüll. Arg.

borbonica, Kunize, 1, c, $290=$ I'sathura borbonica. 7. F. Gmel.

calaractamm, Kuntze. 1. c. $291=$ Psychotria cataractarum, Ahuell, Arg.

cinnamomodos, Kuntze, I. c. = L. reticulatus. Elume.

dinsiffora, Kuntze, 1. $c_{0}=\mathrm{L}$. densifolius, Miq.

grandifolia, Funtze, $\therefore c .=$ l'sychotria grandifolia, Hoffung.
NONATELIA: - - Rer. Gen, (1891) $291=$ Triainolepis Hildebrandtii, Vatkc.

inaequalis, Kuntze, 1. co = Lasianthus cyanocar pus, fack.

macrothyrsa, Kuntze, 1. c, = Psychotria macrothyrsa, Mutcll. Arg.

megalophylla, Kuntze, 1, c. $=$ P. megalophylla Muell. Ars

myrtifolia. Kuntze, 1. c. $290=$ Psathura myrtifolia, A. Rich.

nitida, Kuntze, 1. c. 291 = Lasianthus strigosus, IVight.

sechellarum, Kuntze, I, c, 200 = Psathura sechel larum. Buker.

sessiliffora, Kuntze, 1. c. (= Octavia sessilifiora. DC.). - Guian.

Silestris, Kuntze, 1. co = Lasianthus sylvestris, Blentic.

Sprucei, Kuntze, 1. $0=$ Psychotria Sprucei IIucll Arg.

stercatoria, Kuntze, 1. c, = L. stercorarius, Bhume. fermifolia, Kuntze, 1, c. = Psathura terniflora, A. Rich.

umbellak, Kuntze, 1. c. = Lasianthus umbellatus, Kuntze.

Wallisiana, Kuntze, 1, c. $291=$ Psychotria Willisiana, Alucll. Arg.

NONNEA, Medic. (Borag.). - Ind. Kew ii. $31 \%$ affinis, Hausskn, in Mitth. Bot, Vor. Fona, ix. (1891) 19. - Persia

anomala, Hausstin. \& Bormm. l. c. - As. Min. commutata, Petrozic, Addit. Fl. Serb. (1885) 130. Serbia.

'csicariat, Willk. Suppl. Prodr. F1. Hisp. (1893) $164=$ violacea $A . D C$

NOPAL silwestre, Thierry, ex Foerst.-Ruempl. Handb. Cacteenk. (1885 ?) $929=$ Opuntia Hex nandezii. $D C$

NORMAnBya, F. Muell。= Ptychosperma Labill. (Palm.

australis, Batill. Hist. des plo xiii. (1895) $364(=$ Saguerus ansivalis, Wendl. \& Drude). - Austral.

NORONHIA, Stadm. (Oleac.). - Ind. Kew, ii 31 \%

livaricata, S. Elliot, in foun, Limn. Soc, xxix. (1891) 32. - Madag.

NORTHEA, Hook, f. (Sapot.). - Ind. Kew, ii Hornci, Pierre, Not, bot. Sapot. (1890) $14=$ seychellana, Hook, f.

NORYSCA, Spach = Hypericum, Tourn. $(\mathrm{Hy}-$ peric.)

Katmiana, C. Koch, ex Dippel, Handb. Laubholzk. iii. $(1893) 5 \mathrm{l}=\mathrm{H}$. Kalmianum, Lim

urata, C. hoch, ex Dippel, 1. c. $46=\mathrm{H}$. patulum Thimb.

NOTAPHOEBE, "Blume " ex Fax, in Engl, \& Prantl, Natírl. Pflanzenfam, iji.2 21889$) 116=$ HOTHAPHOEBE, Blume = Alseodaphne Nees (Laurin.).

alpigenu, Pax, 1. c. = Persea alpigena, Spreng.

borbonica, Pax, 1. C. $=$ P, carolinensis, Nees

cubensis, Pax, 1. c. $=$ P, cubensis, Meissn.

NOTHOCALAIS, Greene, in Bull. Calif. Acad. Ser. II. ii. (1886) $54=$ Microseris, D. Don (Compos.)

cuspidala, Greene, in Bull. Calif. Acad. Ser. II. ii. (1886) 5.5 = Troximon cuspidatum, Pursh.

Sulksdorfi, Greene, 1. c, 54. - Washingt.

troximondes, Greene, 1. c. $54=$ Microseris troximoides, A, Gray.

NOTHOCELASTRUS, Blume, ex Iiuntze, Rey, Ge11. (1891) 113, in syn. = Celastrus alpestri, Blume, ex Kuntze, l. co $=$ C. alpestris Bhin
NOTHOCHILUS, Radik, in Sitz, math.-phys, Cl. bayer, Aliad, Wiss, xix.(1889) 216. SCROPHLiLARINEAE

coccineus, Radlk. 1. c. 21\%. - Bras,

NOTHOPANAX, Miq. = Panax, Linn. (Aral.). Bastardicnus, Harms, in Engl, \& Prantl, Natürl. Pflanzenfam. iii. $8(1894) 47=\mathrm{P}$. Bastardianum, Decne.

dicersifolius. Harms, 1. c. $48=$ Acanthopanax diversifolius, Henlsl

Edgerlcyi, Harms, 1. c. $=$ P. Edqerleyi, Hook f.

integrifolius, Harms, 1. c. = Panax integrifolium, Coleinso

Iincaris, Harms, 1. c. $=$ P. lineare, Hook $f$.

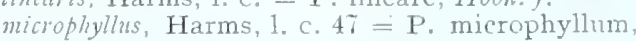
Colcuso.

NOTHOSAERUA, Wight (Amarant.), - Inl, Kew, ii. 318 .

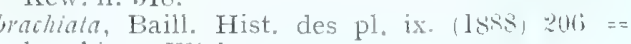
brachiata, Wight.

NOTICASTRUM, DC $=$ Aster, Tourn. (Compos.). glandulosum. Phil, in Anal, Univ, Chil, lxxrrii (1894) 409. - Am. austr.

lencopappun, Phil. 1. c. 408. - Am. austr

Sunfurgi, Phil. 1. c. 409. - Am, austr.

NOTOGERAS, R. Br. (Crucif.). - Ind. Kew, ii. 310.

bicome, Caruel, ex Aschers. \& Schweinf. Mllustr. Fl. Egypt. [Mém. Inst。 égypt, ii. (1887)] $39(=$ $N$. bicome, Amo $=$ cảnariense, $R . B r$.

NOTONIA DC, (Compos) - - Ind, Kew, i3, 319) vestita, Collett of Hemsl. in foum. Linn. Soc: xxriii (1800) 55. - Burma.

NOTOTHIXOS, Oliver (Loranth.). - Ind. Kew ii. 319

malayanus, Oliver, in Hook. Icon. pl, xvi. (1886) t. 1519. - Penang.

NOTOTHLASPI, Hook. fo (Crucif.), - Ind Kew. ii. 319.

Hookeri, 7. Buch, in Trans. N. Z. Inst, xx. 1887 (1888) 255 , t. 13. - N. Zel.

NOTOTRIGHUM Hillebr. Fl. Haw. Isl. (18ss 372. ANIARAN TACEAE.

humile, Hollebr, 2. c, 373. - Ins. Sandwic

sandwicense, Hillebr. l. c, $3 \pi 3 r(=$ Ptilotus sandwi censis, A. Gray). - Ins. Sandwic.

viride. Hillebr. l. c. 3r3. - Ins, Sandwic.

NOTYLIA, Lindl. (Orchid.). - Ind, Kew. ii. 319. brevis, Rolfe, in Kew Bull. (1895) 194 - Am, austr. Bungerothii, Reichb, fo in Gard. Chron. (1887) ii. 38. - Am. aequat

guatemalensis, S. Wats. nn T. Brigham, Gualcm. Append. (1887) 429, nomen: et in Proc. Am. Acad. xxil. (188i) 4\%\% - Guatem.

xiphophorus, Reichb, f, in Flora, lxix. (1886) 55\%. - Am. austr.

yauaperyensis, Barb. Rody. Vollosia, 1855-88, Sec ediç, (1891) 131. - Bras, bor.

NOUELIA, Franch. in Morot, Journ. de Bot. ii. (1888) 66. COMPOSITAE.

insionis, Franch, l. o ' et in Rey. Hortic. 1xi. (1889) 2.29, fig. 60. - China occ.

NUMMULARIA, Gron, = Steironema, Rafin (Primul.).

ciliata, Kuntze, Rev. Gen. (1891) $398=$ S. ciliatum, Rafin.

lanciolata, Kuntze, 1. c. = S. heterophyllum, Rafin. longifolia, Kuntze, 1. c, = S. Iongifolium, Rafin. radicans, Kuntze, 1.c. $=$ S. radicans, $A$. Gray. thyrsiffora, Kuntze, l. c, = Lysimachia thyrsiflora Limn.

NUNNLZHAROA, Ruiz \& Pav。= Chamaedorea Willd. (Palm.)

affinis, altcrnans, amazonica, Andreana, Arcnbergiana. 
NUNNEZHAROA : -

atrocivens, aurantiaca. Bartlingiana, bifurcata, brachyclada, bracteata, brevifrons, Casperiana. cataractarim, concolor, conocarpa, costaricana, Deckeriana, elatior, elegans, Ernesti-Augusti, fenestrata, ficiorirens, formosa, glanca, glaucifolia, graminifolia, humilis, Klotzschiana, lanceolata, lepidota, Lindeniana, linearis; macrospadix, Martiana, membranacea, microphylla, montana, oblongata, oreophila, Pacaya, paradoxa, pauciflora, pochutlensis, pygmaea. radicalis, resinifera, Sartorii, Schiedeana, Tepejilote, IVallisii, Ku-tze, Rev, Gen, 71891 ) 730-31 = homonyma omnia Chamaedoreae.

amabilis, Kuntze. 1. c. 731 - Hab

biloba, Kuntze, 1. c. $=$ C. Bartlingiana, $H$. Wendl.?

Chonta, Kuntze, 1. c. $=$ Juania australis, Drude.

corallina, Kuntze, 1. c. (= Morenia corallina, Karst.) - N. Granat.

corallocarpa. Kuntze, 1. c. $(=M$. corallocarpa, Hort.). - N, Granat.

Demaniana, Kuntze, 1. c. 731. - Hab. ?

desmoncodes, Kuntze, 1. c. $730=$ C. desmoncoides, H. Wendl.

ebrunea, Kuntze, 1 c. 731. - Hab.?

flexnosa, Kuntze, 1. c. = C. Martiana, $H$. Wendl.

humilis, Kuntze, 1. c. - Hab. ?

integrifolia, Kuntze, 1. c. 730 (= Morenia integrifolia, Trail). - Bras.

Karvinskiana, Kuntze, 1. c. = C. elatior, Mart.

latifrons, Kuntze, 1. C. $731=$ C. Arenbergiana, H. Wendl.?

Liboniana, Kuntze, 1. c. - Hab.?

Licbmannii, Kuntze, 1. c, $730=$ C. Liebmanni, Mart.

lunata, Kuntze, $\mathrm{I}, \mathrm{c} .=\mathrm{C}$. oblongata, Mart. mexicana, Kuntze, - 1. c. $731=$ C. Sartorii, Liebm.

Morestia, Kuntze, 1. c. $730=$ C. gracilis, Willd.

oaxacensis, Klintze, 1. c. = C. montana, Liebm.

pinnatifrons, Kuntze, 1. c. = C. gracilis, Willd .

Poeppigiana, Kuntze, 1. c. (= Morenia Poeppigiana

Mart. . - Peruvia.

polita, Kuntze, 1. c. 731. - Hab.?

pulchella, Kuntze, 1. c. = C. pulchella, Licbm.?

regia, Kuntze, $1 . c_{\text {. }}=$ C. desmoncoides, $H$. $W_{\text {endl.? }}$ ?

repens, Kuntze, 1. c. = C. desmoncoides, H. Wendl.?

rigida, Kuntze 1. c. - Hab. ?

robusta, Kuntze, 1, c, $=$ C, robusta, Hort.

simplicifrons, Kuntze, $1_{\text {. }}$. $=\mathrm{C}$. Ernesti-Augusti H. Wendl.

speciosa, Kuntze, 1. c. = C. Schiedeana, Mart.

velutina, Kuntze, 1. c. = C. lepidota, $H . W$ wndl.

Verschaffcltii, Kuntze, 1, c, $=$ C. Verschaffelti, Hort.

Warscewicziana, Kuntze, 1. c. = C. Warscewiczii, $H$. Wendl.

Wendlandiana, Kuntze, 1. с. $730=$ C. Wendlandi, H. Wendl.

Wobstiana, Kuntze, 1, c. $731=$ C. Wobstiana, Linden.

NUPHAR, Sibth. \& Sm. (Nymph.), - Ind. Kew ii. 320 .

juranum, Magnin, in Bonnier, Rev. gén. de Bot. V. (1893) 25\%, nomen ; et in Ann. Soc. Bot, Lyon. xix. (1893-94) 1894 [Compt-rend. 5]. - Reg Jurass

rubrodiscum, Morong, in Conlt. Bot. Gaz. xi.(1886) 16\%. - Am. bor.

NUXIA, Comm, ex Linn. (Logan:). - Ind. Kew.

brachyphylla, Baker, in fourn. Linn. Soc. xxii. (188\%) 506. - Madag.

brachyscypha, Baker, l. c. xxv. (1590) 334. Madas.

coriacea, Sulcred. in Bot. Fahrb. xvii. (1893) 557. Madag.

gracilis, Engl. Bot. Fahrb. x. (1889) 243. - Afr. austr.

Holstii, Gilg, in Engl. Pfañonw. Ost-Afr. C (1895) 312. - Afr. trop. Or.

sambesina, Gilg, l. c. - Afr. trop. or,
NUXIA

sphacrocephala, Baker, in Journ. Linn. Soc, xxii (188\%) $505=$ Buddleia sphaerocephala, Buker. terminalioides, Baker, l. c. - Madag.

usambarensis, Gilg, ex Engl. in Abh. Prenss. Akad.

Wiss. (1894) 63; et in Engl. Pfanzonw. Ost-Afr. C (1895) 312. - Afr, trop. or.

Volkensii, Gilg, in Engl. Pfanzenw, Ost-Afr. C (1895) 312. - Afr. trop. or.

NYMANIMA, Kuntze, Rev, Gen. (1801) r01 = Freesia, Klatt, (Irid.)

Leichtlinii, Kuntze, 1. c. = F. Leichtlini, Klatt.

refracta, Kuntze, l,c. = F. refracta, Klatt.

NYMPHAEA, [Tourn.] Linn.(Nymph.). - Ind,

\section{Kew, ii, 321}

Andreana X. Hort. Latour-Marliac, ex Éd. André. in Rev. Hortic. lxvii. (1895) 5\%0. - Hybr. artef

Airera X, Hort. Latour-Marliac, ex Ld. André, 1. c. 569. - Hybr, artef.

capensis, Baill. Hist.pl. Madag., Atlas (1888) t. 52. - Afr. austr., Madas.

eburnea $\times$, Hort. Latour-Marliac, ex Éd. André in Rev. Hortic, Ixvii. (1895) 259 et 571 . - Hybr. artef.

Fletcheri, Lawson, in Trans. Roy. Soc. Canada, iv, (1S88) $119=$ Nuphar rubrodiscum, Morong.

fulva X, Hort. Latour-Marliac, ex Ed. André, in Rev. Hortic. 1xvii. (1895) 570. - Hybr, artef.

kezunsis $\times$, Hort. ex W. Wats. in Gard. Chron. (1887) ii. 366; et ex Hook. f. in Bot. Mag. (1888) t. 6988. - Hybr artef.

Leydekeri X, Hort. Latour-Marliac, ex Éd. André, in Rev. Hortic, lxvii. (1895) 570 . - Hybr. artef

lucida X. Hort. Latour-Marliac, ex Ed. André, 1. c. - Hybr, artef.

Marliacea, Hort, Latour-Marliac, ex, Gard. Chron. (1888) i. 564 ; Ed. André, in Rev, Hortic. 1xvii. (1895) $570=$ tuberosa, Pyne.

O'Marana X, Hort. ex Gard. Tr. viii. (1895) 96. Hybr, artef.

polysepala, Grecne, Man. Bot. San Franc. Bay (1894) S. - Calif.

Reichardiana, F. Hoffm. Beitr. Kenntn. Fl. Centr, Ost-Afr. (1889) 7 . - Afr. trop.

marodisca. Greene, in Bull. Torrey Bot. Club, xv. (1888) 84 = Nuphar rubrodiscum, Morong.

sansibariensis. "Caspary » ex Kuntze, Rev. Gen. (1891) 12 = zanzibariensis, Caspary.

Seignenxii $\times$, Hort. Latour-Marliac ex Éd. André, in Rev. Hortic, Ixvii. (1895) 258. - Hybr. artef.

Voalefoka, Latour-Marliac, ex Gard. Chron. (1888)

ii. $236=$ stellata, $W$ illd.

NYMPHAEA, Ludw. = Nuphar, Sibth. \& Sm. (Nymphaeac.).

japonica, Kuntze, Rev. Gen. (1891) $12=$ Nuph. japonicum, $D C$.

polysepala, Kuntze, 1. c. = Nuph. polysepalum, Engelm.

NYMPHODES, Ludw. = Limnanthemum, S. P. Gmel. (Gentian.).

aurantiacum, crenatum, cristatum, exigunm, exiliflorum, Forbesianum, geminatum, Grayumum, Humboldtiamum, Hydrophyllum, lacunosum, microphyilum, minimun, parvifolimn. Thunbergianmm, Kuntze, Rev. Gen. (1891) $429=$ homonyma omnia Limnanthemi.

aquaticum, Kuntze, 1. c. = L. trachyspermum, $A$. Gray.

Echloniana, Kuntze, 1. c. = L. indicum, Thw.

hydrocharodos, Kuntze, 1. c. = L. hydrocharoides, F. Muell.

indrcum, Kuntze, 1, c. = L. cristatum, Griseb.

orbiculatum, Kuntze, 1. $\mathrm{c}_{\mathrm{s}}=\mathrm{L}$. indicum, Thw

peltatum, Kuntze, 1. c. = L. nymphoides Hoffmgg \& Link ct peltatum, S. P. Gnucl.

Thmborgianm, Kuntze, 1. c. = L. indicum, Thw.
NYSSA, Gronov, ex Linn. (Corn.). - Ind. Kew. ii. 322 .

aquatica. Coult. \& Evans, in Coult. Bot. Gaz. xv (1890) 91 = multiflora, Wangent.

sinensis, Oliver, in Hook, Icon.pl. xx. (1891) t. 1064. - China.

\section{0}

OAXACANIA, Robinson \& Greenm, in Am. Journ. Sci. Ser. III. 1. (1895) 151. CONPOSI-

malvaefolia, Robinson \& Grconn, l. c. - Mexic.

OBERONIA, Lindl. (Orchid.). - Ind. Kew. ij

biaurita, Hook. f. in Hook. Icon.pl, xxiv, (1894) t. 231\%. - Ind. or

Browneana, Thw, ex Hook. f. Fl, Brit. Ind. (1888) 680, in syn. = zeylanica, Hook. $f$.

ciliolata, Hook. fo in Hook. Icon, pl, xxiv. (189.) t. 2317 ; ot l. c. vi.(1890) 181. - Penins. Mal.

Clarkei, Hook. f. Il. cc. xviii. (1888) t. 1779; et

(1888) 676. - Khasia.

equitans, Drake, Ill. Ins, Mar, Pacif, Fasc, 7 (1892)

305 (= Epidendrum cquitans, Forst.). - Ins. Societat.

equitans, Frappier, ex Cordem. Fl. Ile Réunion (1895) $178=$ praec

Falconeri, Hook. f. in Hook. Icon, pl, xviii. (1888) t. 1780 ; et Fl. Brit. Ind. v, (18s8) 678. - Reg. Himal.

ferruginea, Pavish, ex Hook. f. l. c. 679. - Tenass. gracilis, Hook. f. l. c. 685. - Perak.

Hamadryas, Ridl. in fourn. Bot. xxiv. (1886) 322 - N. Guin.

Helferi, Hook, f, in Hook. Icon. pl. xviii. (188s) t. 1779 ; ct Fl. Brit. Ind. v. (1888)679. - Tenass. heliophila, Benth. of Hock. f. ex Drake, Ill. Ins. Mar. Pacif, Fasc. 7 (1892) $305(=$ Malaxis helio phila, Benth. \& Hook. f.). - Ins. Vitiens. et Samoens.

hexaptera, F. Muell. Descr. Notes Papun Pl. viii. (18s6) 49. - N. Guin.

insectifera, Hook. f. in Hook. Icon. pl. xxi. (1890) t. 2004; et Fl. Brit. Ind. vi. (1890) 180.Perals.

Jenkinsiana, Griff. ex Hook. f.l. c. v. (188S) $676(=$ Malaxis Fenkinsiana, Reichb, f.). - Ind. or.

maxima, Parish, ex Hook. f. lo c. 677. Tenass.

Mannii, Hook. f. in Hook. Icon. pl. xxi. (1890) t. 2003 ; et l. c. vi. (1890) 180. - Silhet.

orbicularis, Hook. f. l. c. - Reg. Himal.

pachyrachis, Reichb. f. ex Hook, f. l. e. 681. Reo. Himal.

pusilla, F. M. Bailey, Rep. Bellenden-Ker Exped. 1859) 62. - Austral.

rosea, Hook. f. in Hook. Icon. pl. xxi. (1890) t. 2005

ct Fl. Brit. Ind. v. (1888) 683. - Perak.

Scortechini, Hook. f. l. c. - Perak.

Thwaitesii, Hook. f. l. c.678. - Zeylan

Treutleri, Hook. f. in Hook. Icon. pl. xviii. (18ss) t. 1786 ; ct l. c. 683 . - Reg. Himal.

Wallichii, Hook, f. l. c. 681. - Silhet.

zeylanica, Hook.f. in Hook. Icon. pl. xviii. (1888)

t. 1782 ; et l. c. 680, - Zeylan.

OBOLARIA, Siegesb. Prim. F1. Petr. (1736) 79, ex Kuntze, Rev. Gen. (1891) $275=$ Linnaea Gronov. (Caprifol.).

bcrealis, Kuntze, 1. c. = L. borealis, Lim.

OGHANOSTAGHYS. Mast. (Olacin.). - Ind. Kew ii 3023.

bancana, Valcton, Crit. overz. Olacin. (1S86) $104(=$ Petalinia bancana. Becc.). - Sumatra.

OGHNA, Linn. (Ochnac.), - Ind. Kew. ii, 32t. ucuminata, affuis, amplexionulis, anceps, angulata aquatica, axillaris, Bhanchetiana, cillopliglla, carain- 


\section{OCHNA : -}

and cassinifolia, custaneafolia, coccinea, condupliata confertiflora, congesta, crassifolia. cuspidata, dependens, elongata, Fieldingiana, floribunda, gigantophylla, glaberrima, glaucescens, grandiflora, grandifolia, hexasperma, hamilis, ilicifolia, inundata, fuergensit, lanceolata, lawrifolia, longifolia, lucens, lucidula, Magdalenae, Manni, membranacea, mexicana, microdonta, Miersii, multiflora, nana, nervosa, obtusifolia, odora, oleaefolia. ocialis, parviflora, parvifolia, pendula, persenefolia, polita, polyantha, pubescens, pulchella, pycnostachys, pyrifolia, reticuata, recoluta, rotundifolia, salicifolia, Sellowiz. semiservata, spectabilis, squantosa, stipulaced, suagied lons, subscandens, sumatranu, Vasicae, Vogelit Kuntze, Rev. Gen. (1891) $106=$ hononyma ommia Gomphiae.

alboserrata, Engl. Bot. Fahrb, xvii. (1893) 75. Afr. trop.

alternifolia, Kuntze, Rev, Gen. (1891) $106=$ Gomphia aiternifolia, $A$. Rich.

andravinensis, Baill. in Bull. Soc. Linn. Paris, i. (1886) 578 ; et Hist. pl. Madag., Atlas (1890) t. 148. - Madag

angustifolia., Kuntze, Rev. Gen. (1891) $106=$ Gomphia anoustitolia $V a h$.

Aschersoniana. Schinz, in Verh, Bot, Ver, Brand. xxix. (1888) 61. - Afr. austro-occ. extratrop. Bakeriana, Kuntze, Rev, Gen. (1891) $106=$ Gomphia lanceolata, Baker.

Bernieri, Baill, in Bull. Soc. Limn. Pavis, i. (1880) 588 ; et Hist. pl. Madag., Atlas (1890) t. 149. Madar.

Boiviniana, Bctll. l. c. 589. - Madag.

brachypoda, Baill. l. c.588. - Madas.

Carvalhi, Engl. Pflanzenw. Ost-Afr. C (1895) 273.Afr, trop. or

caudata. Kuntze, Rev, Gen. (1891) 106 (= Ouratea caudata, Engl.). - Am. trop.

comorensis, Baill. in Bull. Soc. Linn. Paris, i. 1886) 589. - Ins. Comor.

crassinervia, Kuntze, Rev. Gen.(1891) 106 (= Ouratea crassinervia, Engl.) - - Am. trop.

ferruginea, Engl. Bot. Fahrb. xvi1. (1893) 76. - Afr. trop

ferruginea, Kuntze, Rev. Gen. (1891) 106 (= Ourateat fermuginea. Engl.). - dm. trop.

Fischeri, Engl. Bot. Fahrb. xvii. (I892) 78. Afr. trop.

globosa, Kuntze, Rev. Gen. (1891) 106 (= Ourated globosa, Engl.). - Am. trop.

glaberrina, Kuntze, 1. c. = Gomphia glaberrima, Beatuv.

guatenalensis, Kuntze, 1. c. (= Ouratea guatemalensis, Eng1.). - Guatem.

Hildebrandti, Engl, in Abh. Preuss. Akad. Wiss. (1894) 25; et PHanzenw. Ost-Afr. A (1895) 14 et $15=$ ciliata, Lam. var.

Hildebrandti, Kuntze, Rev. Gen. (1891) 106 (= Ouratea Hildebrandtii, Baill.). - Madas.

Ioffmanni Ottonis, Engl. Bot. Fahrb. xvii. (1893) 78. - Atr. trop.

Holstii. Engl. in Abh. Preuss. Akad. Wiss. (1804) 6!) : ot Pflunzmw, Ost-Afr, C (1895) 273. - Afr trop. or.

Humblotiana, Baill, in Bull. Sec. Limn. Paris, i, (18s6) 589; et Hist. pl. Madag., Atlas (1890) t. 150. - Madag.

IImmbloti, Kuntze, Rev. Gen. (1891) 106 (= Ouraton Humblotii, Baill.). - Madas.

macrantha. Baker, in foum. Limn. Sor, xxii. (1887) 45\% - Maday.

macrocarpa, Engl. Bot. Fahro, xvii, (1893) 7\%. Atr, trop, or.

macrophylla, Kuntze, Rev. Gen. (18:1) $106=$ Gom phia reticulata, Beaut

micropetala, Hochst. ex Marlelli, Fl. Begos, (1S86 13. - Abyss.

mitida, Kuntze, Rev. Gen. (1891) $106=$ Gomphia nilida, St

obovata. Buill. in Bull. Soc. Linn. Paris, i. (1886) 589 - Madar.

opaca, Kuntze, Rev. Gen (1891) $1061=$ Curated opaca. Engl.). - Am. trop.

vata, F. Hoffm. Beitr. Kenntn. Fl. Contr. Ost-Afr. (1S.s?) 19. - Afr. trop.

\section{OCHNA}

parviflora, Baill. Hist. pl. Madag., Atlas (1890)

t. 151. - Madag.

parvifolia, Baill. in Eull. Soc. Linn. Paris, i. (1886) 589. - Madag.

patens, Kuntze, Rev.Gen. (1891) $106(=$ Ourated patens, Engl.). - Am. trop.

Pervilleana, Baill, in Bull. Soc. Limn. Paris, j. (1886) 589 ; et Hist. pl. Madag., Atlas (18901) t. 147. - Madas.

pisiformis, Kuntze, Rev. Gen. (1891) $106(=$ Ouratea pissiformis, Engl.). - Am. trop.

polyggyna, Kuntze, 1. c. $(=0$. polygyna, Engl.).Am. trop.

prunifolia, Engl. Pfluzzenw. Ost-Afr. C (1895) 273. - Afr. trop. or

purpureo-custata, Engl. c. - Afr. trop, or.

quangensis, Buctun. in Verh. Bot. Ver. Brand. xxxii. (1890) 49. - Congo.

rapunmicnsis, Kuntze, Rev. Gen, (1891) 106 sphalm = Gomphia rupununiensis, Klobrsch.

Rehmannii, Szyszjl. Pl. Rehmanns, ii. (1888) 28. Transvaal.

Riedeliana, Kuntze, Rev. Gen. (1891) 100 ( $=$ Ouratea Riedelliana, Engl.). - Am. trop.

rigida, Kuntze, 1.c. (= O. rigida, Engl..).-Am. trop. Roramae, Kuntze, 1. c. $(=0$. Roraimate, Engl. $)$ Am. trop.

Schweinfurthiana, F. Hoffm。Beitr. Kenmu, Fl. Centr. Ost-Afr. (1889) 19. - Afr, trop.

Sprucema, Kuntze, Rev. Gen.(1891) 106 (= Ouratea Spruccana, Engl.). - Am. trop.

Stuhlmannii, Engl. Bot. Fahrb. xvii, (1893) 7\%. Atr. trop.

superba, Kuntze, Rev. Gen. (1891) 106 (=_Ouratea superba, Engl.). - Am. trop,

tenuifolia, Kuntze, 1.c. (=O.tenuifolia, Engl.).-Am. trop,

vacciniodes, Kuntze, 1. c. = Gomphia vaccinioides, Engl.

verruculosa, Kuntze, 1. c. (= Ouratex ereruculosa, Engl.). - Am. trop.

Wclwitschii, Rolfe, in Bolet. Soc. Brot. xi. (1893) \&4 $=$ O. Atzelii, R. Br

OCHRATELLUS, Pierre, ex L. Planch. Étud. prod. Sapot. (1888) 20, sphalm. = Ochrothal lus, Pierre (Sapot.).

OCHROCARPOS, Thou."(Guttif.). - Ind, Kew ii. 324. (1893) 525 [Ochrocarpus] (= Mannea angustifolia, Planch. \& Triana). - Madag.

eugenioides, Baill. Hist. pl. Madag., Atlas (1894) t. 354 lan seq. ?], - Madas.

engenioides, Vesque, in DC. Monog. Phan. viii. 1893) 524 (- Manmea engeniordes, Planch. et Triana). - Madag.

excelsus, Vesque. l. c. $525(=11$. excelsa, Planch. \& Triana). - Java.

pachyphyllus, K. Sclum, in $K$ Sclmm. E Hollr. Fl. Kais. Wilh. Land (1889) 51. -- N. Guin.

parvifolius, S. Elliot, in fown. Limn. Soc, xxix. (1891) 5. - Madag.

essiliflorus, Vesque, in DC. Monog. Phan. viii. (1893) 524 [Ochrocarpus] (= MIammea sessiliftora, Planch. \& Triana). - Madag.

OCHRONERUM. Baill. in Bull. Soc. Linn. Paris, i. (1889) 774; et Hist. des pl. x. (1888) 199; K. Schum. in Engl. \& Prantl. Natiirl. Pflanzenfam iv, 2(1895) 175. APOCY ${ }^{\top} E A E$

Humblotii, Baill. ll.co. - Madagr.

ochrosia, Juss. (Apocyn.), - Ind. Kew, i: 324. ommutata, K. Schumb. in Engl. Ev Prantl, Nationl. Pfanzenfam. iv. 2 (1895) 156. - N. Guin.

compta, K. Sclizm ? c 156- - Ins. Sandric.

glomerata, Valeton, in Annal. Fard. Bot. Buitenz. xiii. $2(1695) 233 .-$ N. Guin

Mc Dowalliana, F.M. Bailey, in Dept. Agric. Brisbane Bot. Bull. vii. (1893) 65. - Austral.

eppositifolia, K. Schum. in Engl. \& Prantl, Naturrl. Pflanzentam. iv. 2 (1895) $156=$ Cerbera oppositifolia Lom.

\section{OCHROSIA}

tahitensis, Baill. ex Laness. Pl. util. Colon. Franc. (1886) 865, nomen. - Ins. Tahit,

OCHROTHALI. US, Pierre, in L. Planch. Thès. Sapot. (1888 ?) 26 ; Baill. Hist. des pl. xi. (1892) 298 = Ghrysophyllum, Linn. (Sapot.).

sessilifolius, Pierre, $1, \mathrm{c},-\mathrm{N}$. Caled

OCHTHOGHARIS. Blume (Melast.). - Ind. Kew.

\section{ii. 324.}

ovata, Cogn. in Boevl. Handl. Fl, Ned. Indiè, i 11. (1890) 53! nomen; et in DC. Monog. Phan. vii. (1891) 481. - Borneo.

parviflora, $\operatorname{Cog} n . l l . c c,-$ Borneo.

OGIMUM, Linn. (Labiat.). - Ind. Kew, ii. 324 calycosum, Hochst. ex Briq, in Bot, Jahrb. xis. (1894) $161=$ comigerum, Hochst.

camporum, Guerke, in Engl. Pflanzenw. Ost-Afr. C (1895) 350. - Afr. trop. or.

comigerum, Hochst. ex Briq. in Bot. Fahrb. xix (1894) 161. - Afr. austro-occ. extratrop.

Exsul, Collett \& Hemsl. in fourn. Linn. Soc. xxviii. (1890) 112. - Burma.

fimbriatum, Briq. in Bot. Fahrb. xix. (1894) 161. Angola.

Fischeri, Guevke, l. c. - Afr. trop. or

glossophyllum, Briq. l. c. 162. - Afr. trop. austro-ucc.

kilimandscharicum, Guerke, in Engl. Pfanzenw. OstAfr. C (1895) 349. - Afr trop. or.

Iinearifolium, Briq. in Bot. Fahrb. xix. (1894) 162, - Angola.

modestum, Briq. l. c. - Angula.

Pogseanum, Briq. i. c. 163. - Angola

Schweinfurthii, Briq. in Bot. Fahrb. xix. (18)4) 160. - Afr. trop. centr.

scoparium, Guerke in Engl. Pfanzenw. Ost-Afr. C (1895) 350. - Afr. trop. or.

siphonanthum, Briq. in Bull. Herb. Boiss. ii. (1894) 121. - Madag.

staminosum, Baker, in Keru Bull. (1895) 224. - Regr. Somal.

Stuhlmanni, Guerke, in Bot. Fahrb. xix. (1894) 196. - Afr. trop, or.

tomentosum, Oliver, in Hook. Icon. pl. xxi. (1886) t. 1539 ; et in F. L. Fames, Unkn. Horn of Afr. Append. (1888) 322.-Reg. Somal.

trichodon, Baker, ex Guerke, in Engl. Pflanzenw. OstAfr. C (1895) 350. - Afr. trop. or.

verticillifolium, Baker, in Kew Bull. (1895) 224. Reg. Somal.

OCOTEA, Aubl. (Laurin.). - Ind. Kew. ii. 326. aciphylla, Me\%, in Fahrb. Bot. Gart. Berl. v. (188\%) $243(=$ Oreodaphne aciphylla, Nees). - Bras. acutangula, Mez,l.c. $330\left(=\right.$ Or. acutangula, Mi ${ }_{1}$.) - Bras

acutifolia, Mez, l.c. $310(=$ Or. acutifolia, Nees). Am. austr.

adenotrachelium, Mez, l. c. 304 (= Or. adenotrache limm, Nees). - Bras.

alnifolia, Miz, l.c. 351 (= Or. alnifolia, Meissn.). Columb.

amazonica, $M c z, l . c .359(=O r$, amazonica, Meissn.). - Bras.

aniboides, MLez, l. c. $36 \tau$ (=Or. Riedeli, Meissn.) - Bras

Arechavaletae. Mez, l. c. 34?.-Urung. -

argentea, Mez, l. c. 346 (= Mespilodupline Sprucei Meissn.). - Bras

aurantiodora, Mez, l. c. $295(=$ M. aurantiodora Meissn.). - Columb. Peruvia

bahiensis, Mez, l. c. 235 (= M. bahiensis, Meissn.) - Bras.

balanocarpa. Mez, l. c. 388 $\{=$ M. balanocarpa Nees). - Peruvia.

barcellensis, Mez, l.c. 337 (= Nectandrabarcellensis, Meissn.). - Bras

Benthamiana, Mez; l. c. $263(\equiv$ N. crassifolia Benth.). - Columb.

Bernoulliana, Mez, l. c. 275.-Guatem.

Beyrichii, Mez, l. c. 274 (= Oreodaplne Beyrichii, Nees). - Bras. 
OCOTEA

Blanchetii, Mez, in Fahrb. Bot. Gart. Berl.v. (18s9) 355 (= Oreodaphe Blanchetii, Meissn.). - Bras.

Boissieriana, Mez, l. c. $353(=0$. Blanchetii

Meissn.). - Bras.

borbonica, Cordem. Fl. Ile Rúmion (1895) 303 (= Mespilodaphne borbonica, Meissn.).- Ins. Borbon.

brachybotra, Mez, in falirb. Bot. Gurt. Berl. v,

(1859) 332 (= Oreodapline brachybotra, Meissn.).Bras.

bracteosa, Mez, l. c. $356(=$ O. bract.osa, Meissn.). - Bras.

caesia, Mez, l.c. 287 (= Persea iordata, Meissn.).Bras.

calophylla, Mez, l.c. 298 (= Pleurothyrium velutimum, Meissn.). - Columb.

canaliculata, Mez,l.c.361 (= Oreodaphue cayemnensis,

Meissn.). - Am. austr.

caracasana, Mez,l. c. 292 (= O. caracasana, Nees). - Venezuela.

Catesbyana, Sarg. Sylv. N. Am. vii. (1895) 11 t. 303 $=$ Nectandra Willdenowiana, Meissiz.

caudata, Mez, in Fahrb. Bot. Gart. Berl. v. (1889) 378 (= Oreodaphne caudata, Nees). - Guian. ang1.

ceanothifolia, Mez, l.c. 365 (= Mespilodaphne ceanothifolia, Nees). - Bras.

celastroides, Mez, l. c. 275 (= Oreodapline celastroides, Meissn.). - Venezuela.

cernua, Mez, l. c. $277(=0$. cerma, Nees $)$ - Am. centr., Ind. occ.

cissiflora, Mez, l. c. 259. - Columb.

citritolia, Mez, l. c. 280. - Bras.

citrosmioides, Mez, l. c. 349 (= Oreodaphne citros. mioides, Nees). - Bras.

clavigera, $M e z, l, c .239$. - Ins. Guadal.

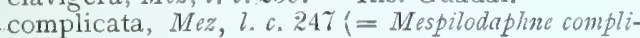
cata, Meissn.). - Bras.

confertiflora, Mez, l. c. $37_{4}(=$ Oreodaphne confertiflora, Meissn.). - Bras.

cordata, Mez, l. c. 313 (= Mespilodaphne cordata,

Meissn.). - Bras.

corymbosa, Mez, l. c. 321 (= M. corymbosa Meissn.). - Bras.

costulata, Mez, l. c. 244 (= Oreodaphne Neesiana, Meissn.). - Guian angl.

crassifolia, Mez, l. c. 336 (= 0 . crassifolia, Nees). - Guian. angl.

cuneifolia, Mez, l. c. 259. - Peruvia.

cuprea, Me\%, l. c. 299 (= Oreodapline cuprea, Meissn.). - Peruvia.

cupularis, Corden. Fl. Tle Rémion (1895) 303 $i=$ Mespilodaphne cupularts, Meissn.). - Ins. Borbon.

daphnifolia, Mez, l. c. 307 (= Oreodaphne daphnifolia, Meissn.). - Bras.

debilis, Mez, l. c. $370^{\circ}(=$ Goeppertia caudata, Meissn.) - Bras.

declinata, Me\%, in falrb. Bot. Gart. Berl. v. (1889) 352 (= Oreodapline declinata, Meissn.). - Bras.

Dendrodaphne, Mez, l. c. 238 (= Dendrodaphne macrophylla, Beurl.). - Am. centr.

densifura, Mez, l. c. 301 (= Persea densiflora, Meissn.). - Bras.

discolor, Mes, l. c. $263(=$ Nectandra discolor. Meissn ). - Columb.

dispersa, Mez, 1. c. $357=$ confusa, Meissn.

divaricata, Mez, l..c. 385 (= Camphoromoea dicaricata, Nees). - Bras.

domatiata, Mez, ex Taub. in Bot. Fahrb. xvii. (1893) 520. - Bras.

effusa, Hemsl.l. c. 272i= Oreodaphne effusa, Meissn.). - Mexic.

Eggersiana, Mez, l. c. 363. - Ind. occ.

Eichleri, Mez, l. c. 377. - Bras.

elegans, Mez, l. c. 253. - Bras.

endlicheriopsis, Mez, l.c. 300. - Guian. gall.

Endresiana, Mez, l.c. 257. - Costa Rica

ensifolia, Taub. in Bot. Fahrb. xvii. (1893) 520. Bras.

fallax, Mer, in fahrb. Bot. Gart. Berl.v. (1889) 310 (= Oreodaphne fallax. Miq.). - Guian. bat.

fasciculata, Mez, l., c. 248 (= Mespilodaphne fasciculata, Meissn.). - Am. austr.

ferruginea. Mez, l. c. $265(=$ Pleurothyrium forngineum. Meissn.). - Peruvia.

\section{OGOTEA}

loribunda, Mez, in fahrb. Bot. Gart. Berl.v. (1889) 325 (= Strychnodaphne floribunda, Griseb.) Ind. occ.

florulenta, Mez, l. c. $3091=$ Oreodaphne florulenta,

Meissn.). - Bras.

foeniculacea, Mez, l. c. 266. - Ind. occ.

frondosa, Mez, l. c. 256 (= Oreodaphme frondos' Meissn.). - Bras.

falcata, Mez, l. c. 388. - Ins. Guadal.

foetens, Baill in Eng1. \& Prantl, Natïrl. Pflanzenfam. iii. 2 (1889) $116=$ foetens, Benth. \& Hook.f

Gardneri, Mcz, in fahrb. Bot. Gart. Berl. v. (1889) 338 (= Mespilodaphne Gardneri, Meissn.). Bras.

glauca, Mez, l. c. 362 (= M. glauca, Meissn.).Bras

glaucina, Mez, l. c. 349 (= Oreodaphne glancina Meissn.). - Bras.

globifera, Mez, l. c. 228. - Guian, gall.

Glaziovii, Mez, l. c. 281. - Bras.

ylomerata, Mez, l. c. 294 (= Oreodaphne glomerata Mez). - Am. trop.

gracilis, Mez, l. c. 327 (=0. gracilis, Meissn.). Guian. angl.

grandifolia, Mez, l.c.290 (= o. grandifolia, Nees) - Peruvia.

grandis, Mez, l. c. 336. - Bras.

Grisebachiana, Mez, in Verh. Bot. Ver. Prov.

Brand. (1886) $6=$ canaliculata, $M e z$

guyanensis, Aubl.l.c. v. (1889) 296 (= Orcodaphn guyanensis, Nees). - Am. trop.

Hemsleyana, Mez, in Falırô. Bot. Gart. Berl. v (1889) 302. - Guian angl.

Hilariana, Mez, l. c.311. - Bras.

Hookeriana, Mez, l. c. 368. - Bras.

hypoglauca, Mes, l.c.285 (= Persea scrobiculatu Meissn.). - Bras.

Imrayana, Mez, l. c. 274, - Ind, occ,

insignis, Mez, l. c. 265 - - Bras.

insularis, $M e z, l$. c. 371 (=Phoebe insularis, Meissn.) - Ins. Cocos.

Jacobinae, Mez, l. c. 355 (= Oreodaphne facobinae, Meissn.). - Bras.

Jacquini, Mez, l. c. $242(=0$. Facquini, Meissn.) - Ins. Martinic.

Jelskii, Me\%, l.c. 261. - Peruvia

Karsteniana, Mez, l. c. 257 (=Aydendron glaucum, Klotzsch \& Karst.). - Columb.

Kunthiana, Mez, l. c. 291 (= A. acipliyllum, Nees) - Guian. gall.

lanata, Mez, l. c. 254 (= Mespilodaphne lanata Meissn.). - Bras.

lancifolia, Mcz, l.c. (= Oreodaplme lancıfolia, Nees $)$ - Bras.

Langsdorffi, Mez, l. c. 312 (= O. Langsdorffi, Meissn.). - Bras.

laxa, Mez, l. c. 381 (= Camphoromoea laxa, Nees). - Bras.

laxiflora, Mez, l. c. $371(=$ Mespilodaphne laxiflora, Meissn.). - Bras.

leptobotra, Mez, l. c. 376 (= Oreodaphne leplobotra, Nees). - Am. austr.-occ.

Leucoxylon, Mez, l. c. $329(=0$. Lencoxylon, Nees), - Ind. occ.

Lindbergii, Mez, l. c. $386(=$ Camphoromoea oralifolia, Meissn.). - Bras.

litsaeifolia, Mer, l. c. $334(=$ C. litsaeifolia, Meissn.). - Bras.

L'Herminieri, Mez, l. c. 273. - Ind. occ.

macrocalyx, Mcz, l.c. $36 \%$ (= Goeppertia macrocalyx, Meissn.). - Bras.

macrophylla, Mez, l. c. 293 (= Oreodaphne macrophylla, Meissn.). - Bras.

macropoda, $M e z$, i, c. 348 (= Persea macropoda H. B. \& K.) - Am. austr

Mandonii, Mez, l. c. 311. - Bolivia.

marowynensis, Mez, l. c. 380 (= Camphorontoed surinamensis, Meissn.). - Guiån. bat

Martiana, Mez, l. c. 324 (= Oreodaphne Martiana, Messin. pr. p.). - Bras.

Martiniana, Mez, l. c. $345(=0$. Martiniana, Nees). - Guian. gall.

martinicensis, $\mathrm{Mez}, l . c .270$. - Ind, occ.

matensis. Mez, l. $c .373$. - Bras.

maynensis, Mc\%, l. с. 359 - Peruvia.

\section{OCOTEA}

megaphylla, Mez, in Fahrb. Bot. Gart. Berl.v. (1889 :387 (= Oreodaphne megaphylla, Meissn.). - Bras. Meyendorffiana, Mez. I. c. 314 (= Mespilodaplme Meyendorffina, Meissn.). - Bras.

micans, Mez, l. c. 297 - Columb.

microbutrys, Mez, l. c. 341 (= Oreodaphne microbotrys, Meissn.). - Bras.

montana, Mez, l. c. 319 (= Mespilodathe montana, Meissn.). - Bras.

moschata, Mez, l. c. $269(=M$. moschata, Meissn.) - Ins. Porto Rico.

Mosenii, Mcz, l. c. 373. - Bras.

multiglandulosa, Mez, l. c 280 (= Oreodaphne

Poeppigiana, Nees). - Peruvia.

myriantha, Mez, l.c. $332(=0$. myriantha, Meissn.)

- Venezuela, Bras.

Nemodaphne, Mez, l.c. $2 \% 0(=$ Nemodaphmecuncata, Meissn.). - Ind. occ.

nicaraguensis, Mez, l. c. 239. - Nicarag.

nitidula, Me\%, l. c. 251 (= Mespilodaphe nitidulu.

Meissn.). - Bras.

notata, Mez, l.c. 339 (= M. notata, Meissn.).-

Bras.

Nummularia, Mez, l. c. $313 !=$ M. Nummuluria,

Meissn.). - Bras.

nutans, Mez,l. c. $362(=$ M. nutans, Meissn.).Bras.

oblonga, Mez, l. c. $367(=$ M. oblonga, Meissn.).Ind. occ., Guian. gall.

obovata, Mez, l. c. 366 (= Oreodaphme oboiatu, Meissn.). - Venezuela.

odorata. Mez, l. c.255 (= O. odorata, Meissn.).Bras.

opaca, Mez, l. c. 246. - Bras.

organensis, Mez. l. c. 321 (= Mespilodaphne organensis, Meissn.). - Bras.

ovalifolia, Mez, l. c. $261,(=$ Oreodaphne sublanuginosa, Nees). - Peruvia.

pallida, Mez, l. c. 282 (= O. pallida, Meissn.).- Bras.

pauciflora, Mez, l. c. $370(=0$. pauciflora, Nees - Bras.

persicifolia, Mez \& F. D. Smith, in Coult. Bot. Gaz. xx. (1895) 10. - Guatem.

Petalanthera, Mez, in Fahrb. Bot. Gart. Berl. (1889) 358 (= Oreodaphne Petalanthera, Meissn.) - Peruvia.

phillyraeoides, Mer, l. c. 315 ( = Mespitodaphime phillyracoides, Meissn.). - Bras.

pomaderrioides, Mez, l. c. 302 (= Oreodaplnue pomaderroides, Meissn. .. - Bras,

portoricensis, $M_{e \%}, l$ c. 364 . - Ins. Porto Rico.

pretiosa, Mez, l.c. 250 (= Mespilodaphne pretiosa, Nees). - Bras

prolifera, Mez, l. c. 276 (= Mespilodaphne prolifera. Nees). - Bras.

pubescens, Mez, l.c. 384 (= Oreodaphne pubcscens Nees). - Bras.

punctulata, Mez, l. c. 379. - Guian. angl. et gall.

Regeliana, Mez, l.c.283(=O.Regeliana, Meissn.). - Bras.

reticulata. Me\%, l. c. 308. - Bras.

rhynchophylla, Mez, l.c. 241 (= Nectandra $\%$ rn. chophylla, Meissn.). - Guian. angl.

Riedelii, Me\%, l. c. 3533 (= Mespilodaphne Riedelii, Meissn.), - Bras.

rigida, Mez. l. c. 284 (=- Oreodapline rigiả, Meissn. - Bras.

Rodiei, Me\%, l. c. 236 (= Ncctandra Rodivi. R

Schomb.). - Guian. angl.

rubra, Mez, l. c. 258. - Guian. sall.

rubriflora, Mez. l.c. 270. - Mexic

rubrinervis, Mez, l. c. 351. - Panama.

rufa, Mez, l. c. $300 .-$ Columb.

Rusbyana, Mez, \%.c, 303.- Peruvia, Bolivia.

Salvini, Mez, l.c. 264. - Guatem.

Sassafras, Mez, l.c.247 $=$ Mespilodaphne Sassafra:

Meissn.). - Bras.

Schomburgkiana, Nez, h. c. 337 Oreodaphm Siliomburghiana, Nees). - Guian, bat.

Schottii, Mez, l. c. 324 (=0. Sihottii, Meissn.).Bras.

Schwackeana, Mez, l. c. 305. - Bras.

semicompleta, Me\%, l. c. 318 (= Orcodaphe semicompleta, Nees). - Bras. 


\section{OCOTEA}

pathulata, Ale\%, mir Fahro. Bot. Gurt. Berl. v. (18S9) ?is. - Ind,

spectabilis, ILez, $l, c .373$ (= Orcodaphne spectabilis, Meissn.). - Am. austr.

Spixiana, Icz, l, c. $260(=0$. Spixiana, Nees). Bras.

splendens, MIez, l, c. 28:2 (=0. splendens, Meissn.). - Guian. gall.

staminea, $71 \%$ s. l. c. 240 (=0. frugans, Mieissn.). Ind.

Sprucei, Mez, l. c 3233 (= Mespilodaphne Sprucei, ILeissn.). - Bras.

Stuebelii, HIcz, l. c. 245. - Columb.

subalpina, .7Lez, l. 0.375 (= Oreodaphne subalpina, MIeissn.). - Bras.

sularacemosa, MIez, l. c, 360, - Bras.

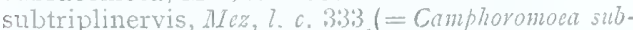
triplincreis, Nees). - Bras.

ylvatica, Mez, l. c. 320 (= Oreodaphne sylertica Meissn.). - Bras.

arapotana, NIcz, l. c. $304(=0$. turapotana, MIeissn.). - Peruvia.

Teleiandra, Mez, l.c.382 (=0. Telitandra, Meissn. $)$ Bras.

tenuiflora, MIo\%, l. c. 383 (= Camphoromoca temut flora, Meissn.). - Bras

tovarensis Mez, l, c, 205 (= Oreodaphne tovarcusis, Klotzsch \& Karst.). - Venezuela.

trichantha, Baker, in Fourn. Linn. Soc, xxii. (188j) 515. - Madag.

undulata, Mer, in fahrb. Bot. Gart. Berl. vo (1889) 278 (= Oreodaphine mudulata, Meissn.). - Bras.

Urbaniana, MLez, l. c. 262. 一 Bras.

urophylla, Mes, l.c. 377 i=Oreodaplene wropliylla, Yeissn. - - Guian, ancrl.

usambarensis, Engl. in Abh. Prouss. Akad. Wiss. (1894) 51 et 54 ; et Pflanzenw. Ost-Afr. C. (1895) 182. - Afr. trop. or.

accinioides, Mez, in fahrb. Bot. Gart. Berl.v. (1889) 252. - Bras.

vacinans, $7 l e r, l \cdot c, 245(=$ Mespilodaphne raginans, i.eissn.). - Venezuela.

Velloziana, Miz, l. . . 347 (= Oreodaphue Vollozianu, Meissn.). - Bras.

veraguensis, MIcz, l.c. $240(=$ Sassafridium veraguchse, Meissn.). - Am. centr.

vernicosa, Mez, l. c. 321. - Guian. yall.

verruculosa, Mcz, l. c. 308 (= Oreodaphe verruculosa Areissn.). - Bras.

viburnoides, MLE, l. c. $322(=$ Persea vibumoides, Mleissn.). - Bras.

Wrightii, Ilez, l.c.267 (= Acrodiclidium Wrightii, Meissn.). - Ind. occ.

OGTOLEPIS, Oliver (Thymel.),-- Ind. Kew, ii. 327. congolana. Warb. in Engl. E Prantl, Natiirl. Pfhne anfam, iii. Úa (1893) 56 (= Makokoa congolana. Baill.). - Congo gall.

OGTOMELES, Miq. (Datisc.). - Ind. Kew. ii. Joluccana, Warb, in Bot. fahrb. xiii. (1891) 38ti. As. \& Oceania trop.

OCTOMERIA, R. Br. (Orchid.). - Ind. Kew, ii.

ulba, Wall. ex Huols. f. Fl. Brit. Ind. v. (1890) 290 = Lria alla, I indl.

Wercatu, Wall. ex Hook, f, 1. c. = E. excavata, Lindl.

Scegeriana, Kracnal. in Reichb. f. Xen, Orchid. iii. 6 (185) 101 t. $25 \pi$. I fig. 1-6. - Bras.

supra-glauca, Rolfe, in Gard. Chron. (1887) ii. 7lli.

anthina, Barb. Rodr. Villosia, 1S8a-sS, Sec, édic (1851) 121. - Bras. bor

Wawrae, Rcichb. f.cx Wonira, Itin. Princ. S. Cuburg. ii. (1888) 156. - Bras.

-auaperyensis, Barb. Rodr. Vellosia, 1885-8s. Sec. edic. (1891) 1:0. - Bras bor.

oGTOTROPIS. Bedd. (Rubiac.). - Ind. Kew, ii terminalis, C. B. Clarke, in foum timn. Soi. Xxy $(1,8,9), 33$ t. 17. - Finrma.
OCYMASTRUM, Seruier = Centranthus, DC (Valer.)

angustifolinn, Calcitrapa, juncunn, longiflorum, macrosiphon, neradchse, rubrum, Sibthorpii, Kuntze, Rev. Gen. (1891) 302.03 = homonyma omnia Centranthi

trincrve, Kuntze, 1. c, $303=$ C. nervosus, Moris.

ODINA, Roxb. (Anacard.), - Ind. Kew. ii. 329.

alata, Engl. Bol. Fahrb. xv (189.3) 105. - Afr. trop. or.

cinerea, Engl. l. c. 104. - Reg: Somal.

cuneifoliolata, Engl. l. c. 105. - Reg. Somal.

fulva, Engl. l. c. 102. - Afr. trop, or

humilis, F. Hoffm. Beitr. Kenntn. Fl. Centr. Ost-Afr. (1889) 24. - Afr. centr. or.

nigritana, S. Elliot, in fourn. Limn. Soc. xxx. (1894) 75. - Sierra Leone.

obcordata, Engl, Bot. Fahrb, xv, (1893) 105. Reg. Somal.

Schimperi, F.Hoffn. Beitr. Konntn. Fl. Centr. Ost-Afr. (1889) 24. - Afr. trop. or.

Stuhlmannii, Engl, Pfanzcmu", Ost-Afr. C (1895) 244. - Afr. trop: or.

tomentosa, Engl. Bot, fahrb. xv. (1893) 102. Afr, trop. or.

ODONTADENIA, Benth. (Apocyn.). - Ind. Kew. $11,329$.

Cururu, K. Schnm, in Engl. \& Prantl, Naiürl, Pfanzenfann iv, 2 (1895) $169(=$ Anisolobus Cuvuru, Muell, Arg.) - Bras,

glandulosa, K. Schum. l. c. - Peruvia.

grandiffora, K. Schum. 1. c. = speciosa, Benth.

Salzmannii, K. Schun. l.c. (= Anisolobus Salzmannii, A. DC.). - Bras.

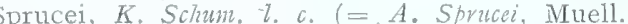
Arg.). - Reg. Amaz.

Zuccariniana, $K$. Schum. l. c. $(=$ Anisclobus hebecarpus, Muell. Arg.). - Bras.

odontella, Van Tiegh, in Bull. Soc. Bot. Fr. xlii. (1895) $260=$ Loranthus, Linn

Deflersii, Van Tiegh. 1. c. - Arabia.

kilimandscharica, Van Tiegh 1. c. = L. kilimandscharicus, Engl.

Schimperi, Van Tiegh. 1. c. = L. Schimperi, Hochst.

Volkcnsii, Van Tiegh. 1. c. = L. Volkensii, Engl.

ODONTITES [Riv.] Hall. = Bartsia, Linn. (Scrophul.)

atlantica, Coss. ex Batt. \& Trab. Fl, de l'Algér. [Dicot.] (1889) 6i57 $=$ discolor, Pomel.

Djurdinwae, Coss, ex Batt. \& Trab. 1. c. = violacea, Ponel.

longifolia, Corbière, Nouv. F1. Norm. (1893) 436 $=$ B. verna, Reichb. $f$.

Odontites, Wettst. in Engl. \& Prantl, Natürl. Pflanzenfam. iv. 3b (1891) $102=\mathrm{B}$. Odontites, Huds.

ODONTOGHILUS, Blume (Orchid,). - Ind.

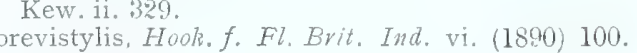
- Perak.

calcaratus, Hook. f. l. c. 99. - Perak.

Clarkei, Hook.f. l. c. 100, - Reg. Himal.

crispus, Hook. f. l. c. $99 \mathrm{i}=$ Anoectochilus crispus, Lindl.). - Reg. Himal.

Elwesii, C. B. Clarke, ex Hook. f. l. c. 100. - Reg. Himal.

macranthus, Hook. f. l. c. 98. - Perak.

pectinatus, Hnok. f. i. c. 99. - Perak

pumilus, Hook. f.l.c. - Reg. Himal.

sandvicensis, Benth. E Hook, f. cx Drake, Inl. Ins. Mar. Pacif, Fasc. 7 (1892) 312 (= Anoectochilus sandvicensis, Lind1.). - Ins. Sandvic.

ODONTOGLOSSUM. H B. \& K. (Orchid.). Ind Kew, ii, 329

aspidorhinum, F.C. Lehm, in Gard. Chron, (1895) ii. 356. - Columb.

auriculatum, Rolfe, in Kew Bull. (1892) 140. - Am. Birgmani X. L. Linden, in Lindenia, vi. (1890) 95 t. 286 . - Hybr. spont?

Boddaertianum, Rcichb. f. in Gurd. Chron. (188s) i. 296 ; et (1885) ii. 328. - Venezuela.

\section{ODONTOG LOSSUM :}

Brandtii, Kracnzl. \& Wittn. in Gartenff. xxxviii. (1859) 378 . - Hab.

chactostoma $\times$. Hort. ex O'Brien, in Gard. Chron. (1S86) i. $76=$ chaetostroma X, Reichb. f.

Clacsianum $\times$. L. Linden, in Lindenia vi, (1300) 65. t. 271. - Venezuela.

dellense $X$, O'Brien, in Gard. Chron. (1891) i. 520 . - Hybr. artef.

dicranophomm $\lambda$. Reichb. f. 1. c. (18S8) i. $330 \mathrm{et}$ 360. - Hybr. spont.

Duvivierianum, Reichb. f. l. e. (1888) 352; ch in Lindenia, v. (1S89) 55, t. 218. - Hybr. spont?

Edithiae, Warner, Select Orch. P1. Ser. 3 t. 25 = crispum, Lindl.

elegantius, Reicho.f. in Gard. Chron. (1888) i. 200 . - Hybr. spont.

Glonerianm, L. Linden, in Lindenia, iv. (1888) 17. t. $151=$ odoratum, Lindl

Godseffamm $\times$, Rolfe, in Gard. Chron. (1894) ii. 72S. - Hybr. artef.

guttatum, Rolfe, in Kew Bull. (1892) 140. - N. Granat.

Halli-xanthm $X, \mathrm{~L}$. Linden, in Lindenia $\mathrm{x} .(1894)$ 73 t. 467. - Hybr. artef.

Harryanum, Ruchb. f. in Gard. Chron. (1886) ii 486. - Hab. ?

hariengtense $X, \mathrm{~L}$. Linden, in Journ. des Orchid. v. (1894) 7 ; et in Lindenia, x. (1894) 95 t. 478. - Hybr. artef.

Harzyanum, Reichb. in Gard. Chron. (1886) ii. 486; et (1887) ii. 169 fig. 41 ; Reichenbachia. Ser. 1, ii. (1889) t. 49 ; et ex Orchid. Alb. viii (1889) t. 366. - Columb.

Hennisii, Rolfe. l. c. (1894) ii. 10̃8. - Ecuad.

Hrubyanum, Reicho. f. l. c. (1888) ii, 234. Peruvia.

Hunnewellianum, Rolfe, l. c. (1889) ii. 67. - N. Granat.

Imschootranum X. Rolfe, 1. c. (I891) ii. $758 .-$ Hybr. spont.

Josephinae, Williams, Orchid Alb, iv. (1885) sub t. 174, in nota, et t.188. - N. Granat.

Kraenzlinii, O'Brien, in Gard. Chron. (1893) i. 442 - Columb.

latinaculatum, Hort. Linden, ex Lindenia, iv. (1888) 5 t. $145=$ crispum, Lindl.

Ieroyanum X. Hort. God.-Lebouf, ex Rev. Hortic. (1890) 167; et in L'Orchidophile (1891) 112: Reichenbachia Ser, 2, ii. t. 37 ; et in Gard. Chron. (1891) ii. 19 et (1892) ii. $11=$ Wilckanum X, Reichb. f.

Lucianum, Reichb. $f$, in Lindenia, ii. (1886) 37 t. 65̃ in Gard. Chron. (1886) ii. 712; ct in Illustr. Hortic xxxiv (1887) 23 t. \%. - Venezuela.

majale, Reichb. $f$. in Flora, Ixix. (18S6) 550. - Am centr.

Noezlamm, Hort. Linden, ex Gard. Chron. (1890) 60 ? : et ex Orchid Alb. xi. (1891?) t. $509=\mathrm{Co}$ chlioda Noezliana. Rolfe.

Owenianum, Rolfe, in Gard. Cluron. (1891) ii. 178. - Hab.?

platycheilum, Rolfe, l. o. (1892) ii. 35. - Am. centr.

vlyuchanthum $\times$, Reichb. f. 1. c. (1887) i. 380.Hab. ?

Schlesingerianum $X, L$. Linden, in Lindenia, v. (1889) 99 t. 240. - Hab.

tenue, Cogn. in fourn. des Orchid. vi. (1895) 266. Venezuela.

Thompsontanum X. Garnier, I. c. iv. (1893) I 19; L Linden, in Lindenia, ix. (1893) 11 t. 388. Hybr. artef.

Warocquedmm, J. et I. Linden, in Lindenia, iv. 1888) 75 t. $180=$ crispum, Lindl.

Wattianum, Rolfe, wn Gard. Chron. (1890) ii. 354.-$\mathrm{Hab}$

Wendlandianum $\times$, Rolfe, 1. c. (1889) i. 6. - N. Graniat.

Youngi, Gower, in The Garden, xxxvii. (1890) 84 Orchid Alb. ix. (1891) t, 406. - Mexic.

ODONTONEMA, Nees = Thyrsacanthus, Nees (Acanth.)

amplexicanle. bracteolatum, callistachynum, cuspidatum, dissitiformm. Flagollum, Hookerianum, interruptum, 
ODONTONEMA : -

Iongifolinm, nitidum, pantasmense, mubrum, rutilans, Schomburgkiamum, sessite strictum, variegatum, Kuntze, Rev. Gen. (1891) $494=$ homonyma onnia Thyrsacanthi.

barleriodes, Kuntze, 1. c. = T. barlerioides, Nees.

foliobracteatum, Kuntze, 1. c. = T. foliaceo-bracteatus, Oerst.

fuchsiodes, Kuntze, 1. c. = T. fuchsioides, Nees.

lilacinum, Kuntze. 1. c. $=\mathrm{T}$. callistachys, N'ees.

paniculatum, Lindau, in Eng-1. \& Prantl, Natürl. Pflanzenfam. iv, 3b (1895) $335=$ Schaueria, paniculata, Nees.

nbiforme, Kuntze, Rev, Gen. (1891) $494=\mathrm{T}$ tubaeformis, Nees.

ODONTONEMELLA, Lindau, in Bot. Jahrb. xviii. (1894) 56; et in Engl. \& Prant1, Natiirl. Pflanzenfam. iv. 3b (1995) $336=$ Eranthemum, Linn. et Dianthera, Gronov. (Acanth.).

indica, Lindau, 11. cc. = Eranthemum indicum, C. B. Clarke.

leptostachya, Lindau, 1. c. $336=$ Dianthera Wallichii, Benth. E. Hook.f.

ODONTOSPERMUM, Neck, (Compos.). - Ind. Kew, i1. 331. maritimum, C. Bolle, in Bot. fahrb. xiv. (1892) 243. - Ins. Canar.

pygmaeum. O. Hoffm. in Engl. \& Prantl, Natïrl. Pflanzenfan. iv. 5 (1890) 209 - Algeria.

ODONTOSTELMA, Rendle, in Journ, Bot xxxii. (1894) 161. ASCLEPIADEAE.

Welwitschii, Rendle, l.c. t. 344. - Angola.

OEDEMATOPUS, Planch. \& Triana = Havetiopsis, Planch. (Guttif.).

polyandrus, Vesque, in DC. Monog. Phan. viii. 1893) 164. - Columb.

OEDINA, Van Tiegh, in Bull, Soc, Fr. xlii. (1895) $249=$ Loranthus, Linn

erecta, Van Tiegh. 1, c. = L, erectus, Engt.

OEGROE, Phil. in Anal. Mus, nac. Chile (1891) 32. COMPOSITAE.

spinosa, Phil. l. c. t. 1 fig. 5. - Chili.

OENANTHE, [Tourn.] Linn. (Umbell.). - Ind,

Kew, ii,
Foucaudi, Tesser, in Bull. Assoc. Pyren. éch. pl. i. (1891) ex Bull. Soc. Bot. Fr, xl. (1893) bibl. 175 - Gall.

Pringlei, Conlt. \& F. N. Rose, in Contrib. U.S. Nat. Herb. iii. 3 (1895) 307. - Mexic.

psychrophila, Ball, in foum. Linn. Soc. xxii. (1885) 38.--Peruvia.

OENOGARPUS, Mart.(Palm.).-Ind. Kew. ii.332. dulis, Hort. ex W. Wats. in Gard. Chron. (1Es7) ii. 15\%. - Demerara.

OENOTHERA, Linn. (Onagrar.). - Ind, Kew. ii. 332.

angelorum, 'S. Wats. in Proc. Am. Acad: xxiv. (1889) 49. - Calif. anstr.

arguta, Grocne, Fl. Francisc. (1891) 212, - Calif.

californica, Greene, Pittonja,.i. (Apri1 1889) $290=$ leptocarpa, Greene.

campestris, Greene, Fl. Francisc. (1891) 216; et Man. Bot. San Franc. Bay (1894) 133 (= Oe. dentata, S. Wats; nec Cav.). - Calif.

coccinea, Britton, in Bull. Torrey Bot. Club, xvii. (1890) 213. - Bolivia.

crassiuscula, Grecne, Pittonia, i. (April 1889) 290. - Calif.

decorticans, Greene, Fl. Francisc. (1891) $217=$ gauraeflora, Torr. \& Gray.

depressa, Greene, Pittona, ii. (Sept, 1891) 216. Am. bor. occ.

elongata, Rusby, in Mem. Torrey Bot. Chub, iii. 3 (1893) 33. - Bolivia.

glabrescens, Plith. in Anat. Univ. Chit. lxxxiv. (1894) 631. - Chili

\section{OENOTHERA :-}

hirsuta, Fr. Mleigen, in Bot. Fahrb. xvii. (1893) 291 ; et xviii. (1894) 435. 44:3 et 464. - Chili.

hirtella, Greene, Fl. Francisc. (1891) 215; et Man. Bot. San Franc. Bay (189t) 133. - Calif.

Ibari, Phil. in Anal. Univ. Chil. lxxxiv. (1894) 6333, - Chili.

idahoensis, A. F. Mtulford, in Conlt. Bot. Gaz. xix. (1894) 117. - Idaho.

Jepsonii, Greene, Fl. Francisc. (1891) 211. - Calif. leptocarpa, Greene, Pittonia, i. (May 1889) 30? (= Eulobus californicus, Nutt.). - Calit.

magallanica, Fhit, in Anal. Univ. Chit. lxxxiv. (1894) 633. - Chilj

nitıda, Greene, Pittonica, i. (July 1887) 70. - Calif ovata, Curran, in Proc. Calif. Acad. Ser. II. (1888) 255. - Calif.

ovata, C. H. Shinn, in West Am. Scicntist. (1S91)

208 [an praec. ?]. - Calif.

picensis, Phil. in Anal. iluts, nac. Chile (1891) 22, - Am. austr. occ.

rutila, Davids. in Erythea, ii. (1894) 61. - Calif.

sceptrostigma, T. S. Brandeg. in Proc. Calif. Acad. Ser. II. ii. (1859) 156. - Calif.

Stuebelii; Hieron. in Bot. Fahrb xxi. (1895) 327. Ecuad.

tenuissima, M. E. Fones, in Proc. Calif. Acad. Ser. II. v. (1895) 683. - Utah.

valdiviana, Phit. in Anal. Univ. Chil. 1xxxiv. (1894) 634. - Chili.

xylocarpa, Corille, in Contrib. U. S. Nat. Herb. iv. (1893) 105, t. S. - Calif.

OEONIA, Lindl. = Aeonia, Lindl. (Orchid,

Elliotii, Rolfe, ex S. Elliot; in Journ. Linn. Soc. xxir. (1891) 55, t. 11. - Madag.

rostris, Cordem F1. Ile Réunion (1895) 217 (= Beclardia erostris, Frappier). - Ins. Borbon. oncidiffora, Kraenz1, in Bot. Jahrb, xvit. (1893) 56 - Madag.

zolucris, Th. Dur. \& Schinz, Consp. F1. Afr. y. $1892(1895) 51(=$ Epidendrum volucre: Thou. $)=$ Aeonia Auberti, Lindl.

OFTIA, Adans. (Myopor.). - Ind. Kew. ii. 335 . fasmimunu, Wettst, in Eng1. \& Prantl. Natirl. Pflanzenfam. iv. 3b (1895) $360=$ africana, Bocq.

OLAX, Linn. (Olaciń.), - Ind, Kew, ii. 335. andronensis, Baker, in fourn. Linn. Soc. xxv. (1889) 306. - Madag

Aschersoniana, Buettn. in Verh. Bot, Ver. Brand. xxxii. (1890) 46. - Congo.

seminifera, Valeton, Crit, overz, Olacin. (1886) 116. - Borneo.

verruculosa, Engl. Bot. Fahrb. xvii. (1893) 69.Afr. trop.

OLDENLANDIA, Linn, (Rubiac.). - Ind. Kew. ii. 336 .

ascedens, acutangula, ampliftora, angustifolia, barbata. Beddomei, bracteosa, buxifolia, cabitellata capituligera, carnosa, cilicanlis, cinereovindis, congesta, consanguinea, cyanescens, cymosit, effusa, clegans, erenia, fruticosa, Gardneri, glabra, Griffithii, Helferi, hirsutissina, inamoena, iodoneura, laevigata, lancea; latifolia, Laresoniare, Lessertiana, lineata, macrae, macrostemon, Maingayi, membranacea, nodnlosa, obscura, ovata, paradoxa, Parryi, pinifolia, prosirata, pruinosa, quinquenervia, radicans, recuria, rigida, migosa, scabra, scandens. stylosa, tenelliflora, Thomsonii, Throaitesii, travancorica, Uncinella, Vachellii, verticillaris, viscida, xanthochroa, Kuntze, Rev. Gen. (1801). 292-93 = homonyma omnia Hedyotidis

alpestris, K. Schum. in Engl. Pfanzenw. Ost-Afr. C (1895) 375. - Afr. trop. or

amatymbica, Kuntze, Rev. Gen. (1891) 292. Afr. austr.

arborea, K. Schum. in Eng1. \& Prantl Natürl, Pflanzenfam.iv. 4 (1891) $26=$ Hedyotis arborea, Roxb. Aurcuhria, K. Schum. 1. c. $25=\mathrm{H}$. Auricularia, Limn.

brachyloba, Kuntze, Rev. Gen. (1891) 292. - Afr. austr.

Cephalotes, Kinntze, l.c. - Afr. austr.

chlorophylla, Kmtze, l. c. - Atr. austr.

\section{OLDENLANDIA}

hlorophylla, K. Schum. in Engt. \& Pranth, Natior. Pflazzenfan. iv. 4 (1891) $26(=H$. chlorophylla Hochst.). - Natal.

cernlea. Kuntze, Rev. Gen. (1891) $292=$ Hedyotis caerulea, Wight \& Arn.

comnata, Kuntze, 1. c. = H. coronata, Woll.

Comnata, K. Schum. in Engl. \& Prantl, Natürl. Pflanzenfam. iv. 4 (1891) $25=\mathrm{H}$. merguiensis Benth. \& Hook. f.

delicatula, K. Schum. in Engl. Pfanzenw, Ost-Afn. C. (1895) 3\%5. - Afr. trop. or.

echinulosa, $K$. Schum, lo - Afr, trop. or.

divaricata, Engl. Bot. fahrb: x. (1889) 269. - Afr

austro-occ. extratrop.

filicaulis, $K$. Schum
(18s9) 271 - Bras.

ruticosa, K. Schum. in Engl, \& Prantl, Natijrl. Pflanzenfam. iv, 4 (1S91)20 = Hedyotis fruticosa, Linn.

geminiflora, Kuntze, Rev. Gon。(1891) 292. - Afr. austr.

glabella, Kuntze, 1. c. = Hedyotis nitida, Wight Es Arn.

Grayi, K. Schum, in Engl. \& Prantl, Natürl. Pflanzenfam.iv, 4(1891) $26=$ H. Grayi. Hook.f. hirtula. Kuntze, Rev. Gen. (1891) 292. - Afr austr.

Holstii, K. Schum, ex Engl, in Abh. Prenss. Akad. Wiss. (1894) 62; et in Engl. Pfanzenzu. Ost-Afr. C (1895) 376. - Afr, trop, or

Hookeri, K. Schum, in Engl, \& Prantl, Natiirl. Pflanzenfam, iv, 4 (1891) $25=$ Hedyotis leptopetala, Hook. $f$.

Horneriana, Kuntze, Rev. Gen. (1891) $292=\mathrm{H}$. barbata, Korth.

hymenocapsa, K. Schum. in Engl. Pfantemw. Ost Afr, C (1895) 375. - Afr. trop. or.

inconstans, Pomel, ex Batt. ist Batt. et Trab. Fl. de l'Algér' [Dicot.] (1889) 388. - Algeria.

Fohnstoni, K. Schum. ex Engl. in Abh. Preuss. Akad. Wiss. 1891 (1892) $397=$ Hedyotis Johnstoni, Oliver.

Lazesoniae, K. Schum, in Engl. \& Prantl, Natürl. Pflanzenfam. iv. 4 (1891) $26=\mathrm{H}$. Lawsoniae, Wight \& Avn

Leptopetalnm, K. Schum. 1. c. $25=\mathrm{H}$. leptopetala Hook.f.

loganiodes, Kuntze, Rev. Gen. (1891) 292 = Hedyotis loganioides, Ben! $! h$.

longifolia, K. Schum. in Engl, Pflanzenw. Ost-Afr. C (1895) $376=$ virgata, DC.

longituba, G. Beck, in Paulitschke, Harrar, App. (18s8) 461, fig 2. - Afr, trop. or.

macrodonta, Baker, in Kerv Bull. (1895) 67. - . Afr. centr. or.

Maingayi, K. Schum. in Engl. \& Prant1, Natürl, Pflanzenfam. iv. 4 (1891) $26=$ Hedyotis MLaingayi, Hook.f.

monocephala, Kuntze, Rev. Gen. (1891) $292=\mathrm{He}$ dyotis monocephala, $R$. Br.

natalensis, Kuntze, l. c. - Afr. austr.

Oliveriana, K. Schum. ex Engl. in Abh. Prouss Akad. Wiss. 1891 (1892) 397. - Afr. trop. or.

pinifolic, K. Schum: in Engl. \& Prantl, Natüx1. Pflanzenfam. iv. 4 (1891) 25 = Hedyotis pini folia, Wall.

Pringlei, Robinson, in Proc. An. Acad. xxvii. (1893) 169. - Mexic.

psychotrioides, F, Muell. in Vict. Natural. (July 1889) 54. -- Austral.

purpurascens, Kuntze, Rev. Gen. (1891) 2019? Hedyotis purpurea, Bedd.

pygmaea, Kuntze, 1. c. $=$ H. caerulea, IVight Arn.

quadrangularis, Kuntze, 1. c. = H. tetrangulari Walp.

rhamnoidea, K. Schum, in Engl. Pfanzenu. Ost-Aft A (1895̃) 131. - Afr. trop.

rupicola, Kuntze, Rev', Gen, (1891) 293.-- Afr. austr.

rotata, Búker, in Kew Bull. (1895) 216. - Re Somal.

rugosa, K. Schum, in Engl, \& Prantl, Natürl. Pflanzenfam. iv, 4 (1591) $25=$ Hedyotis rusosa Korth. 


\section{OLDENLANDIA :}

candens, K. Schum. in Engl. \& Prant1, Natür1. Pflanzenfam.iv. (1891) $26=$ Hedyotis scandens Roxb.

Schweinfurthii, Terrac, in Ann. Ist. Bot. Roma, v. (1894) 107. - Afr. trop. or.

serpyllifolia, Cordem. F1. Ile Réminion 1895) 502 = trinervis, Retz.

ctifera, K. Schum, in Engl. Pflanzenw. Ost-Afr. C (1895) $376=$ caffra, Eckl. \& Zeyh.

silvatica, K. Schum. l. c. - Afr. trop.

sphaerocarpa, K. Schum. ex Engl. in Abh. Preuss. Akad. Wiss. (1894) 37. - Afr. trop. or.

stricta, Kuntze, Rev.Gen.(1891) $292=$ O. Heynii, G. Don.

subdivaricata, Drake. in Morot, Fourn. de Bot. ix. (1895) 211. - Tonk.

swertiodes, Kuntze, Rev. Gen. (1891) $292=0$. swertioides, Hook.

tenella, Kuntze, l.c. - Afr. austr.

temipes, Kuntze. 1. c. = Hedyotis tenuipes, Hemsl. tenuis, K. Schun. in Mart. Fl. Bras, vi. vI. (1889) 27i3. - Bras.

thesifotia, K. Schum. 1. c. $269=$ Hedyotis thesiifolia, A. St Hit.

thymifolia, Kuntze, Rev.Gen. (1891) 292. - Afr. austr.

Eaginata, K. Schum, in Engl. \& Prantl, Natürl. Pflanzenfam. iv. 4 (1891) $25=\mathrm{H}$. vaginata Blume.

stita, Drake, in Morot, Journ. de Bot. ix. (1895) $211=H$. vestita, $R$. B

OLEA, [Tourn.] Linn, (Oleac.). - Ind. Kew. ii. afanica, Knob!. in Bot. Centralbl, 1xi. (1895) 134 = maritima. Wall.

Woodiana, Knobl. in Bot. Fahro, xvii. (1893) 532 - Natal.

OLEARIA, Moench (Compos.). - Ind. Kew. ii. :3:38.

alpina, f. Buchanan, in Trans. N. Z. Inst. xix. 1886 (1887) 215. - N. Zel.

chathamica, T. Kivk, l. c. xxiii. 1890 (189) 444 (O. operina, Hook. f. Handb. N.Z.Fl.731).Ins. Chatham.

ernbescens, Dippel, Handb. Laubholzk, i. (1889) 290 = Eurybia erubescens, DC.

erythropappa, Colenso, in Trans. N. Z. Inst. xxii. $1889(1890) 468 .-$ N. Zel.

fasciculifolia, Colenso, l, c. xxv, 1892 (1893) 330.N. Zel.

fragrantissima, Petrie, l. c. xxiii. 1890 (1891) 398

- N Zel.

fulvida, Archer, ex Kuntze, Rev. Gen. (1891) 315, nomen. - N. Zel.

Hillii, Colenso, in Trans. N. Z. Inst. xx. 1887 (1888) 194. - N. Zel.

Kcrnotii, F. Muell. in Trans. Roy. Soc. Vict. New Ser. I. ii. (1889) 10, in syn. = Aster Kernotii F. IItuell.

monticola, F. M. Bailey, in Dept. Agric. Brisbane Bot. Bull. x. (1895) 39. - N. Guin.

multiflora, Colenso, in Trans. N. Z. Inst. xxvii. 1894 (1895) 387. - N. Zel.

odorata, Petrie, l. c. xxiii. 1890 (1891) 399. N. Zel.

ramuliflora, Colenso, l, c. xxii. 1889 (1890) 467. N. Zel.

rigida, Colenso, l. c."xx. 1887 (1888) 194. - N. Zel. rusposa, Archer, ex Kuntre, Rev, Gen。 (1891) 315 nomen. - N. Zel.

suavis, Cheesent, in Trans, N.Z. Insl, xxiv, 1891 (1892) 409. - N.Zel.

suborbiculata, Colenso, l. c. xviii, 1885 (1886) 26. N. Zel.

uniflora, Colenso, l. c. xxii, 1889 (1890) 469. - N Zel.

anthophylla, Colenso, l. c. xx. 1887 (18S8) 193.N. Zel.

OLIGOBOTRYA, Baker, in Hook. Icon. pl. xvi. (1586) t. 153\% LILIACEAE.

Henryi, Baker, l. co-China.
OLIGOGARPUS, Less. (Compos.). - Ind. Kew. ii. 1338 .

acanthospermus, Bolus, in Hook. Icon.pl.xvi. (1886) t. 1535 (=Xenismia acanthosperma, DC.). - Afr. austro-occ. extratrop.

OLIGOGYNIUM, Eng1. = Nephthytis. Schott (Aroid.).

constrictum, Encl. Bot. Jahrb. xv。(1893) $453=\mathrm{N}$. constricta, N.E.Br.

Gravenreuthii, Engl. 1, c. - Kamerun.

libericm, Engl. 1. c. = N. liberica, N. E. Br.

OLIGONEMA, S. Wats, in Proc. Am. Acad. xxvi. (1891) 138; O. Hoffm. in Engl. \& Prantl, Natiirl. Pflanzenfam iv, 5 (1894) 389. COM. POSITAE

heterophylla. S. Wats. Il.cc.-Mexic

OLINIA, Thunb. [Thymel.), - Ind. Kew, ii. 339. macrantha, Eno1.? Pflanzenw. Ost-Afr. A (1895) I23 [spha]m.?] = micrantha, Decke.?

usambarensis, Gilg, ex Engl, in Abh. Preuss. Akad. Wiss. (1894) 63; ct in Bot. Fahro. xix. (1894) $27 \%$. - Afr, trop. or

Volkensii, Gitg, ex Engl. Pfanzenw. Ost-Afr. C (1895) 285. - Afr. trop. or.

OLIVERELLA, Van Tie h. in Bull. Soc. Bot. Fr. xlii. (1895) $259=$ Loranthus, Linn.

campestris, Van Tiegh. 1. c. = L. campestris, Engl. Hildebrandii, Van Tiegh. 1. c. = I. Hildebrandti, Engl.

nubro-zividis, Van Tiegh. 1. c. = L. rubro-viridis, Oliv

Saclenxii, Van Tiegh. 1. c. - Afr, trop, or

OLIVERODOXA, Kuntze, Rev, Gen, 1891) $692=$ Riedelia, Oliver (Scitam.)

curviflora, Kuntze, 1. C. $692=\mathrm{R}$, curvitlora, Olizer

OMALANTHUS, Juss. = Homalanthus, A. Juss. (Euphorb.).

populners, Kuntze, Rev. Gen. (1S91) $679=\mathrm{H}$. Leschenaultianus, $A$. fuss.

OMALOCLINE, Cass. = Grepis, Linn. (Compos.). granatensis, Willk. Illustr. Fl. Hisp ii, (1886-02) i 47, t. 178. - Hisp.

OMENTARIA, Salisb. = Tulbaghia, Linn. (Liliac:

acutilob̆a, aequinoctialis, alliaceu, capensis, Dregenna, hypoxidea, violacea, Kuntze, Rev. Gen. (1891) 713 = homonyma omsia Tulbaghiae.

OMPHALANDRIA, P. Br. = Omphalea, Linn. (Euphorb.)

brasiliensis, commutata, diandra, frondosa, hypoleuca, triandra, trichotoma, Kuntze, Rev. Gen. (1891) 609 = homonyma omnia Omphaleae.

oppositifolia, Kuntze, 1, c, = O. biglandulosa, Baill.

OMPHALEA. Linn. (Euphorb.), - Ind, Kew. ii. 340 .

Queenslandiae, F. M. Bailey, Rep. Exped. BellendenKer (1889) 58. - Austral.

OMPHALOGARPUM, Beauv. (Sapot.). - Ind. Kew. ii. 341

Radtkoferi, Baill. in Bull. Soc. Linn. Paris, i. (I886) 580 ; L. Planch. Etud. prodr. Sapot. (1888) 60. Afr. trop. occ.

OMPHALODES, Tourn, ex Moench (Borag.).Ind. Kew. ii. 341 .

acuminata, Robinson, in Proc. Am. Acad. xxvi. (1891) 170. - Mexic

cordata, Hemst. in Fourn. Linn. Soc. xxvi. (1890) 148. - China.

Kuzinskyanae, Willh. in Oest. Bot. Zeitschr. xxxix. (1889) 318. - Lusit.

Lojkae, Sommier \& Levier, in Act. Hort. Petrop. xii. (1892) 157. - Reg. Cauc.

mexicana, S. Wats. in Proc. Am. Acad. xxv. (1890) 158. - Mexic

\section{OMPHALODES}

moupinensis, Franch, in Now, Anch. Mus. Paris, Ser. 11. x. (1887) 64. - Tibet.

OMPHALOGONUS, Baill. in Bull. Soc. Linn Paris. i. (1889) 812 ; et Hist. des pl. x. (1889) $300 ; \mathrm{K}$. Schum. in Eng1. \& Pranti, Natürl. Pflanzenfam.iv.2(1895)221. ASCLEPIADEAE calophyllus, Baill. Il.cc. - Zanzib.

OMPHALOPAPPUS, O. Hoffm, in Engl. \& Prantl, Natiir1, Pflanzenfam.iv, 5 (1890) 234; et in Bolet, Soc. Brot.x. (18:2) 176. COMPOSI$T A E$.

Newtoni, O. Hoffm. $l l . c c .-$ Angola.

ONAGRA, [Tourn.] Adans. = Oenothera, Linn, (Onagrar.)

Braunii X, G. Beck, Fl. Nied.-Oest. ii. 1. (1892) $695=$ Oe. Braunii, Docll

muricata. G. Beck, 1, c. = Oe. muricata, Murr

Oakesiana, Britton, in Mem. Torrey Bot. Club, v. (1894) $233=$ Oe. Oakesiana, Robinson.

ONCELLA, Van Tiegh, in Bull. Soc. Bot. Fr. xlii. (1895) 251 = Loranthus. Linn

ambigua, Van Tiegh. 1. c. = L. ambiguus, Engl,

Sucleuxii, Van Tiegh. 1. c.-Zanzib.

ONGIDIUM, Sw. (Orchid.). - Ind. Kew. ii. 341. Braunii, Regel, in Act. Hort. Petrop, ix. (1886) 620 ct in Gartenfl xxxy. (1886) 621 t. 1235. - Hab.? brevilabrum, Rolfe, in Kew Bull. (1894) 158. Hab.?

chrysops, Reichb. f. in Gavd. Chron. (1888) i. 104. - Hab.

chrysorhapis, Reichb.f.l.c.72. - Bras,

cristatum, Rolfe, in Kew Bull. (1892) 210; et in Lintdenia, x. (1894) 41 t. 451. - Bras.

detortum, Reichb. f. in Gard. Chron. (188s) i. 392 $-\mathrm{Hab}$.

fallens, Reichb. f. in Floya, 1xix. (1SS6) 549.-Hab. Gravesianum, Rolfe, in Gard. Chron.(1892) i. 650 fig. 94. - Bras.

Hookeri, Rolfe, l. c. (1887) i. 520. - Bras.

inops, $\operatorname{Cog} n$, \& Rolfe, in Journ. des Orchid, ii 1893) 346 ; et iv. (1893) $74=$ bryolophotum Reiclib.f.

Larkinianum. Gower, in Garden. xxxvii. (1890) 325 et Orchid Alb. ix. (1891) t. 405. - Bras.

Leopoldi, " Rolfe », ex God.-Lebouf, L'Orchidophile $(1890) 353=$ seq.

Leopoldianum, Rolfe, in Gard. Chron. (1890) ii, 556 ; et in Lindenia, vi.71t. 274. - Reg. Andina lepturum, Reich. f. l. c. (1886) i. 40. - Bolivia

Lucasianum, Rolfe, in Kew Bull. (1894) 185. Hab.?

luteum. Rolfe, l. c. (1893) 172.- - Hab?

Mantinii $X$, God.-Lebouf, in L'Orchidophile (1888) 4\% cum ic. ; et ex Gard. Chron. (1888) i. 335 [Hybr. spon+. ?]. - Bras.

méndax, Reichb. fo in Flora, lxix. (18S6) 549. Hab.?

oloricolle, Reichb. f. l. c. 1xxi. (1888) 15l. - Hab. orthostates, Ridl. ex Oliver, in Trans. Linn. Soc. Ser. II. ii. (1887) 283 t. 47 Oliver, ex in Thum, in Timehri, v. (1\$\$6) 204). - Guian. angl.

orthotis, Reichb. f, in Illustr. Hortic, xxxv, (188s 91 t. 69. - Hab. ?

panduratum, Rolfe, in Kew Bull. (1895) 9. Columb.

pardoglossum, Reichb. f. in Gard. Chron. (1886) i. $516 .-\mathrm{Hab}$. ?

platybulbon, Regel, in Act. Hort. Petrop. xi. (1891) $475 .-$ Bras.

Pollettianum, Reichb. f. in Gard. Chron. (1886) ii 326 [Hybr. spont. ?]. -- Hab. ?

robustissimum, Reichb. f. l. c. (1888) ii. 352.Bras.

Rolfeanum, Sander, l.c. (1892) ii, 34 - Columb.

Rusbyi, Rolfe, ex Britton, in Mem. Torrey Bot. Club, iv. (1895) 265. - Bolivia.

Saintlegerianum, Rolfe, in Gard. Chron. (1892) ii 582 , et (1893) i. 194 et 227. - Bras.

Sanderianum, Rolfe, in Kew Bull. (1893) 33\%. Peruvia. 
ONCIDIUM : -

Schmidtianum, Reichb. f. in Flora, 1xix. (1886) 649. - Hab. ?

zonatum. Cogn. in fourn. des Orchid. iv. (1893) 74 - Columbia.

ONCINOTIS, Benth. (Apocyn.). - Ind. Kew. ii. 345 .

gracilis, Stapf, in Kew Bull. (1894) 124; et in Hook Icon. pl. xxiv. (1894) t. 2346. - Lagos.

melanocephala, $K$. Schum. in Abh. Prenss. Akad. Wiss. (1894) 34; et in Engl. Pfanzenve. Ost-Afr. C (1895) 319. - Afr. trop. or.

ONGOBA, Forsk. (Bixin.). - Ind, Kew, ii. 345. fissistyla, Warb, in Engl. Pfanzenw. Ost-Afr. (1895) $27 \%$ - Afr. trop, or.

lairina, Warb, in Engl. of Prantl, Natürl. Pfanzenfam. iii. 6a (1893) 18. - Afr. trop.

macrophylla, Warb. l.c. $(=$ Chlania macrophylla Klotzsch) - Afr. trop.

Poggei, Guerke, in Bot. Fahrb. xviii. (1894) 163.Congo.

Stuhlmanni, Guerke, l. c. 16t. - Afr. trop. or

ONCOCALYX, Van Tiegh. in Bull. Soc. Bot. Fr. xlii. (1895) $258=$ Loranthus, Linn.

Welwitschii, Van Tiegh. 1. c. = L. Welwitschii Engl.

ONCOSTEMMA, K. Schum. in Bot. Jahrb. xvii. (1S93) 148. ASCLEPIADEAE.

cuspidatum, K. Schum. l. c. - Ins. S. Thom.

ONCOSTEMUM, A. Juss. (Myrsin.). - Ind. Kew. ii. 347

botryoides, Baker, in fourn. Limn. Soc. xxii. (1887) 502. - Madag.

flexuosum, Baker, l. c. - Madag.

microsphaerum, Baker, l. c. 501. - Madag.

nervosum, Baker, l. c. xxv. (1890) 333. - Madag.

polytrichum. Baker, l. c. xxii. (1887) 501. - Madag.

vacciniifolium, Baker, l. c. 502. - Madag.

ONCOTHECA, Baill. in Bull. Soc. Linn. Paris, ii (1891) 931; et Hist. des pl. xi. (1892) 220 ILICINEAE.

Balansae, Baill. $l l . c c .-\mathrm{N}$. Caled

ONOBRYCHIS, Linn. (Legumin.). - Ind. Kew ii. 346 .

Bornmuelleri, Freyn, in Oest. Bol. Zeitschr xli. (1891) 9; et in Bull. Herb. Boiss iij, (1895) 189. As. Min

calcarea, Vandas, ex Velen. 1\%. Bulg. (1891) 154. Bulg.

caloptera, Aitch. \& Baker, in Trans. Linn. Soc. Ser. II. iii. (1886) 58. - Turkest.

fallax, Freyn \& Sint. ox Freyn, in Oest. Bot. Zeitschr. xlii. (1892) 81. - Armen.

insignis, Freyn of Bornm。 ex Freyn, $l$. c. - As. Min kurdica, Post, Pl. Postianae, iv. (1892) $6-$ Syria marginata, G. Beck, ex Stapf, in Denkschr. Akad. Wien. $(1886)$ ii. 75. - As. Min.

megalobotrys, Aitch. E Baker, in Trans, Linn. Soc. Ser. II. iii. (1886) 58. - As. centr.

pentelica, Hausskn. in Mitt. Bot. Ver. Fena, v. (1887) 71. - Graecia.

pindicola, Hausskn. l. c. - Graecia.

pulvillus, Trautv. in Act. Hort. Petrop. ix. (1S86) 452. - Turkest

pseudomadritensis, Batt. in Batt. \& Trab. Fl. de l'Algér. [Dicot.] (1889) $292=$ argentea, Boiss scardica, Halácry, in Denkschr. Akad. Wien, lxi 1894) 236. - Graecia.

stenostachya, Freyn, in Oest. Bot. Zeitschr. xl, (1890) 446. - As. Min.

transsilvanica, Simonk. in Termész. Füzét. x. (1S86) 180; et Enum. Fl. Transsilv. (18-6) $191=$ montana, Pers.

xanthina, Freyn \& Bormm. in Oest. Bot. Zeitschr. xl. $(18: 0) 445$ (= Hedysartm xanthinum, Freyn). - As. Min.
ONONIS, Linn. (Legumin.). - Ind. Kew, ii. 348 austriaca, G. Beck, un Verh.zool.-bot. Ges. Wien, xli (1891) 794: et Fl. Nied-Oest. ii. I. (1892) 835.Austria.

Christii, Bolle, in Bot. Fahrb. xiv. (1892) 23\%.Ins. Canar.

cirtenssis, Batt. in Batt, \& 'Trab. Fl, de l'Algér. [Dicot.] (1889) 21s; et in Bull. Soc. Bot. Fr. xxxviii. (1891) $38=$ hirta, Desf.

Clausoniana, Batt, 1. c. $218=$ O. Natrix, Linn

Thomsoni, Ball, ex Oliver, in Hook. Icon. pl. xix. (1889) t. 1829. - Marocc

ONOPORDON, Linn. (Compos.). - Ind. Kew. ii. 349 .

Boissieri, Freyn \& Sint. ex Freyn, in Bull. Herb. Boiss, iii. (1895) 470 . - Ins. Crur.

Espinae, Coss. in Compt,-rend. Acad. Sci. Paris, xcviii. (1884) 468; Ill. Fl. Atlant, ii. (1893) rI t. 143; Rouy, in Morat, fourn. de Bot. vii. (1893) 163. - Tunetia

humile, Loscos, ex Pau, Not. Bot. Fl. Espan. ii. (1889) 6. - Hisp.

micropterum, Pan, l. c. 5. - Hisp

ONOSERIS, DC. (Compos.). - Ind. Kew. ii. 350 , glandulosa, Hieron. in Bot. fahrb. xxi. (1895) 366. - Peruy

lanata, Phil. in Anal. Mus, nac. Chile (1891) $32 \mathrm{t} .2$ fig. 1. - Am. austr. occ

paniculata, Klatt ex Th. Dur. \& Pitt. in Bull. Soi. Bot. Belg. xxxi. $1892(1893) 214(=$ Isotypus onose roides, $\mathrm{H}$. B. \& $\mathrm{K}$.) - Costa Rica.

spathulata, Phil. in Anal. Mus, nac. Chite (1891) 31. - Am. austr.-oce.

Stuebelii, Hieron. in Bot. Fahrb. xxi. (1895)366. Peruvia.

Trianae, Hieron. l. c. xix. (1894) 69.-Columb.

Warscewiczii, Hievon. l. c. 70. - Ecuad

ONOSERIS, Willd. Sp.pl. iii. (1804) 1702) pr.p $=$ Lycoseris, Cass, (Compos.).

bracteata, grandis, latifolia, squarrosa, triplinereia, Kuntze, Rev. Gen. (1891) $354=$ homonyma onniw Lycoseridis.

altissima, Kuntze, l.c. $(=$ Centroclinium altissimum Poep. \& Endl.). - Peruvia.

trinervis, Kuntze, l. . $(=$ Diazenxis trinervis, D. Don). - Peruvia.

ONOSMA, Linn. (Borag.), - Ind. Kew, ii. 350

austriacum, G. Beck, ex Ber, Deutsch. Bot. Gesells, x. (1893) 104. - Austria.

Bormmelleri $X$, Hausskn. \& Eornm. in Mitt. Bot. Ver. Jena, ix. (1891) 19. - As. Min.

bracteosum, Hausskn. E Bornm. l. c. - As. Min.

bulgaricum, Velen. in Sitzb. Boehm, Ges. Wiss. 1889 (1890) ii. 54 ; et Fl. Bulg. (18.1) 398. Bulg.

burmanicum, Collett of Hemsl. in Fourn. Linn. Soc. xxviii. (1890) 94. - Burma.

echivideum, St Lager, in Carıot, Etud. des f. éd. 8 ii. (1889) $612=$ echioides, Linn.

Mattirolii, Baldacci, in Bull. Herb. Boiss. iii. (1895) 226. - Albania.

paniculatum. Bureau \& Franch. in Morot, Fourt. do Bot. v. (1891) 104. - China occ

pyramidale, Hook. f. in Bot. Mag. (1888) t. 6987 [pyramidalis]. - Reg. Himal.

tridentinum. Wettst. in Kern. Sched. Fl. AustroHung. iv. (18S6) $64=$ echioides, Linn.

tubiflorum, Velen. in Sitzb. Boehm. Ges. Wiss. 1889 (18901) 1i. 54 ; et Fl. Bulg. (1891) 398. - Bulg.

OOSTERDYKIA, Burm. = Gunonia, Linn. (Saxit.).

Balansae, Kuntze, Rev. Ger. (1891) $227=\mathrm{C}$. Balansae, Brongn. \& Gris.

Lenormandii, Kuntze, 1. c, = C. Lenormandi, Vieill. macrophylla Kuntze, 1. c. = C. macrophylla, Brongn. \& Gris.

pulchella, Kuntze, 1. c, = C. pulchella, Brongn. \& Gris.

purpural, Kuntze, 1. c. = C. purpurea, Brongn. \& Gris.
OOSTERDYKIA :

implicifolia, Kuntze, Rev. Gen. (1891) $227=\mathrm{Cu}-$ nonia Balansae, Brongn. E. Gris.

Vieillardii, Kuntze, 1. c. - C. Vieillardi, Brongn. 6

OPERCULINA, Silva Manso = Ipomoea, Linn (Convolv.).

codonantha, Hallier fo in Bot. Jahrb. xvi. (1893) 550 $=\mathrm{I}$. codonantha, Benth.

kentrocanlos, Hallier f. 1. c. xviii. (1894) $119=\mathrm{I}$ tuberosa, Rich

Paroni, Hallier f. 1. c. xvi. (1893) 550 = I. Pavonii, Choisy.

peltata, Hallier f. xvi. (1892) 549; et xviii. (1894) $119=$ I. peltata, Chois

populifolia, Hallier f. 1. c. 550 , nomen. - Cuba.

triquetra, Hallier f. 1.c. xviii. (1894) $120=\mathrm{I}$, triquetra, Rocmu. E. Scliult.

Turpethum. Peter, in Engl. \& Prant1, Natiir Pflanzenfam. iv. $3 a$ (1821) $32=-$ I. Turpethum R. Br.

Untricosa, Peter, 1. C. = = I. ventricosa, G. Don iolacea, Barb. Rodr. [Herb. Mus, bot. Amaz. n. 645] Vellosia, I885-88, Sec, edic. (1891) 60 t. 26b. - Bras.

OPHELIA. D. Don = Swertia, Linn. $($ Gentian.$)$ Tashirol, Maxim. in Buil. Acad. Pétersb. xxxi. (1887) 68, - Ins. Kiusiu.

OPHIOCARYON, Schomb. (Sabiac.). - Ind Kew ii $35^{\circ}$.

heterophyllum, Urban, in Ber. Deutsch. Bot. Ges xii. (1895) 221. - Guian.

paradoxum, Urban. 1, c. = paradoxum, Schomb.

OPHIOGAULON, Hook, f. (Passiflor.). - Ind. Kew. ij. 352.

lanceolatum, Engl. Bot. Fahrb. xiv. (1892) 386 ; et xv. (1893) 563. - Congo.

Poggei, Engl. 7l. cc. 386, et 567. - Congo.

Rowlandi, Baker, in Kev Bull. (1895) 16. - Atr. trop. occ.

Schweinfurthii, Engl. Bot. Fahrb. xv. (1893) 569. Afr. trop.

OPHIOPOGON, Ker-Gaw]. (Haemodor.). - Ind. Kew. ii. 352.

brevifolius, Royle, ex Hook. f. Fl. Brit. Ind. vi. (1892) 324 , in syn. = Theropogon pallidus, Maxim.

Clarkei, Hook. f. l. c. 268. - Reg. Himal.

clavatus, C. H. Wright, ex Otizer, in Hook, Icon, pl. xxiv. (1895) t. 2382; et in Kew Bull. (1895) 116 - China.

dracaenoides, Hook. Fl. Brit. Ind. vi. (1892) 268 (= Flueggal dracaenoides, Baker). - Reg. Himal. faburae, R. Schulze, in Bot. Jahrb. xvii. (1893) 377 , sphalm. = O. Jaburan, Lodd.

Griffithii, Hook.f. Fl. Brit. Ind. vi. (1892) 270.Assam

kansuensis, Batalin, in Act. Hort. Petrof. xiii. (I89:3) 103. - China

micranthus, Hook. f. Fl. Brit. Ind. vi. (1892) 269 - Assam

reptans, Hook.f. l. c. 268. - Ind. or.

OPHIORHIZA, Linn (Rubiac.). - Ind. Kew, ii. amplifolia, Drake, in Morot, fourn de Bot. ix. (1895) 213. - Tonk.

baviensis, Drake, l. c. - Tonk.

glauco-rosea. Drake, l.c. 214. - Tonk

inflata, Maxim. in Bull. Acad. Pétersb. xxxii. (18ss) 488. - Ins. Ya Jama.

leptobotrya, Drike, in Morot, foum. de Bot. ix. (1895) 214. - Tonk.

micrantha, Drake, l.c. - Tonls.

rupestris, Hemsl. in Kequ Bull. (1S?4) 212, - Ins, Salom.

subrubescens, Drake, in Morot, Fourn, de Bot, ix. (IS95) 215. - Tonk

Tashiroi. Maxim. in Bull. Acad. Pétorst. xxxii, 1888) 489. - Ins. Ya Jama.

tristis, Drake, in Morot, fourn. de Bot. ix. (1895) 215. - Tonk. 
OPHIURUS, Gae1 tn. f. (Gramin.). - Ind Kew inltatus, Inuntze, Rev. Gen. (1891) $780=$ corymbosus, Gaertn. f.

OPHRYS, Linn. (Orchid.). - Ind. Kew, ii. 3554 . Aschersoni $X$. Nanteuil, in Bull. Soc. Bot. Fr. xxxiv. (IS8 i) 423. - Gall

Barrae Y G. Camus, in Morot. Journ, de Bot. vii. (1853) 159. - Gall.

Botteroni $X$. Chod. [Notice sur Polyg. d'Eur. et d'Or. (1887) in notal in Bull. Soc. Bot. Genève ง. (1889) 187. - Jurass.

cnsifolic, Pav, ex Ridl. in Journ, Linn. Soc, xxix. (1858) 306 , in syn, $=$ fastigiata Reichb. f.

Ficalhonng Guimaraes, in Bolet. Soc, Brot. $\mathrm{v}$ (18Si) $39=$ tenthredinifera, IVilld.

gibbosa X, G. Beck, F1. Nied.-Oest. i. (1890) 1!l' - Austria.

Migoutiana X, H. Gay, in Mém. Assoc. Franç avanc. sci. Paris (1888) 502, cum ic, - Algéria.

Nonfelii $\times$ G. Camus, in Morot, Journ. de Bot. vii. (1893) 158. - Gall.

Pscuda-fusca X. Albert \& G. Camus, in Bull. Soc Bot. Fr, xxxviii. (1891) 392 ; et in Morot, Journ. de Bot. vii,"(1893) 158. - Gall. mer.

Reichenbachiana X.M. Schulze, in Mitth. Bot. Ver. Jena, vii. (1889) 29. - Eur.

Saratoi $\backslash$. G. Camus, in Morot, Journ, de Bot. vii. (1893) 159. - Gall.

triorchis, St Lager, in Cariot, Etud. des fl. éd. \& ii. (18S9) $815=$ Flerminium Monorchis. Linn

OPIIIA. Roxb. (Olacin.). - Ind, Kew. ii. 355. congolana, Baill. in Bunl. Soc. Linn. Paris, ii. (1890 872. - Congo-gall.

tomentella, Engl. Pflanzenw. Ost-Afr. C (1895) 168 - Eng1.

OPIISMENUS. Beauv. (Gramin.). - Ind. Kew ii. 355

Bakeri, Schinz, in Th. Dir. \& Schinz, Consp. Fl. Afr. v. 1894 (1895) 771 = bromoides, Baker.

Benthami, C. Cordem. F1. Ile Réunion, (1895) 118 $=$ Panium Benthami, Benth.

Junghuhnii, Boorl. in Amnal. Fard. Buitenz. viii. (1589) 63. -

simplex, K. Schum. ex Engl. in Abh. Prouss. Akad Wiss. (I894) 48. - Afr. trop.

OPOPANAX, Koch (Umbell,), - Ind, Kew. ii 356.

horridum, Miq. ex Dippel. Hand. Laubholzk. iii (IS93) $238=$ Fatsia horrida, Benth. \& Hook. $f$. syriacum, Boiss. Fl. Or. Suppl. (1888)2\%1. - Syria.

OPULASTER, Medic, = Neillia, D, Don (Rosac.) amurensis, Kuntze, Rev. Gen.!1891) 949 (= Physocarpa armurensis, Maxim.). - As. or.

capitatus, Greene, Man, Bot. San Franc. Bay (1894) $112=\mathrm{seq}$

capitatus, Kuntze. Rev. Gen. (1891) $949=$ Neillia opulifolia, Benth. \& Hook. f.

ficxuosus, Kuntze, 1. c. = Stephanandra flexuosa Sicb. \& Zucc.

gracilis, Kuntze, 1. c. = St. gracilis, Franch. E Sarat. IIancamus, Kuntze, 1 c. = St. chinensis, Hance.

maleacons, Greenc, in Erythea, ii. (1894) 194; Lei-

berg, in Bull. Torrey Bot. Club, xxil. (1895) $2 \% 1=\mathrm{seq}$

maliaccus, Kuntze, Rev. Gen. (1893) $949=$ Neillia malracea. Grom:

monogymus. Greene, in Erythea, ii. (1894) $194=$ seci.

monogynus, Kuntze, Rev. Gen. (1891) $949=$ Neillia Torreyi, S. IV als.

opulifolius, Kuntze, 1. c. = N. opulifolia, Buth. \& Hook. $f$.

sincmsis, Kuntze, 1. c. $=\mathrm{N}$. sinensis, Olicer.

Tanakac. Kuntze, 1.c. = Stephanandra Tanakae,

Franch. \& Sard.

thyrsiflorus, Kuntze, 1. c. = Neillia thyrsiflora, $D$. Don.

OPUNTIA. Tourn, ex Linn. (Cact.), - Ind. Kew.

\section{OPUNTIA}

Airampo, Phit. in Anal. Unir, Chit. 1xxxv. (1894) 492. - Chili.

Alcahes, IV ber, in Bull. Mus, Hist, nat. Paris, i. (1895) 321. - Calif.

Alfayucca, "Karw. " ex Foerst.-Ruempl. Handb. Cacteenk. (1885 ?) 938, sphalm. (= O. Alfagay ucca, Karw.) $=$ O. Amyclea, Ton.

bernardina. Engelm. cx Parish, in Bull. Torrey Bot. Club, xix. (189\%) 92. - Calif.

Chella, Weber, in Bull. Mus. Hist. nat, Paris, i. (1895) 320. - Calif. infér.

Geissei, Phil. in Anal. Univ. Chil. 1xxxy. (1894) 492. - Chili.

heteromorpha, Phil. in Anal. Mus. nac. Chile (1S91) 28. - Am. austr. occ.

inamoena, $K$. Schum. in HIart. Fl. Bras. iv. II. (1890) 306. - Bras

invicta. T.S. Brandeg. in Proc. Calif. Acad. Ser. Ir ii. (1889) 163. - Calif.

lennina, Harge Es Schmidt, ex Foerst-Rucmpl. Handb. Cacleent. (1885) ?) 974, fio. 133. - Chili.

leucophaea, Phil. in Anal. MIus. nac. Chile (1891) 27. - Am. austr.-OcC.

Maihuen, Gay, ex Foerst.-Ruempl. Handb, Cacteenk. (1885 ?) $996=$ Peirescia Poeppigii, SalmDyck.

molesta, T. S. Brandeg. in Proc. Calif. Acad. Ser. II. ii. (1889) 164. - Calif.

Piccolomini. Hort. ex Gartenfl. xxxvi. (1887) 39. Form hort.

Rahmeri, Phil. in Anal. Mus. nac. Chile (1891) 27. - Am. austr. occ.

rotundifolia, T.S. Brandeg, in Zö̈, ii. (1891) 21. Calif.

tarapacana, Phil. in Anal. Mus. nac. Chile (1891) 27. - Am. austr. occ.

tetracantha, Tonmey, in Gard. and For. ix. (1893) 432. - Arizona.

tuberiformis, Phil, in Anal. Mus, nac. Chile (1891) 28. - Am. austr. OcC.

versicolor, Engelm. ex Toumey, in Gard. and For. viii. (1895) 325, 326. -

ORANIA, Zipp. (Palm.).-Ind. Kew. ii, 358. nivea, Hort, Linden, ex W. Wats, in Gard. Chron, (1887) ii. 15\%. - N. Guin.

ORBIGNIA, Mart. (Palm.). - Ind, Kew, ii, 35s exelsa, Barb. Rodr. Pl. nowo. Fard.bot. Rio, i (1801) 32 t. ix, fig. b, 1-9. - Bras.

sabulosa, Barb. Rodr. 7. c. 110. - Bras

speciosa, Barb, Rodr. l. c. 32 t. 9 b, fig. 1-9. Bras.

ORCHAENACTIS, «Coville »ex O. Hoffm. in Engl \& Prantl, Natürl. Pflanzentam. iv. 5 (1893) 391 sphalm. = Orochaenactis, Coville (Compos.).

ORCHI-ACERAS X.G. Camus, in Morot, Journ, de Bot. vi. (1892) 10\%. ORCHIDEAE

Bergoni X, G. Camus, 1. C. (= Orihis Bergoni, de Nanteuil). - Gall.

puria X, G. Camus, 1. c. 108 (= Orchis spuria, Reichb.). - Gall.

IVeddellii $\Varangle$, G. Camus, 1. c. - Gall.

ORCHIASTRUM, Lem. = Lachenalia, Jacq. (Liliac.).

forrifolium, Greene, Man. Bot. San Franc. Bay (1894) $306=$ Spiranthes porrifolia, Lindl.

Romansoffiamm, Greene, 1. c. = S. Romanzoffiana, Cham. E. Schlecht.

ORGHIDANTHA, N. E. Br. in Gard. Chron. (1886) ij. 519; Petersen, in Engl. \& Pranti, Natiirl. Pflanzenfam. ii. 5 (IS88) 10. MIUSACEAE.

borneensis, $N$. E. Br. Il. cc. (= Lowia bornconsis, Balker). - Borneo.

ORCHI-GYMNADENIA $X, G$. Camus, in Morot, Journ: de Bot. vi. (1892) 479 , in obs. ORCHIDEAE.

Hemacliana X, G. Camus, 1. c. (= Orchis Heinzeliana. Reichb.). - Gall.
ORCHI-GYMNADENIA : -

Lebrunii X. G. Camus, in Bull. Soc. Bot. Fr. xxxviii. (1891) 35l; et in Morot, Journ. de Bot. vi. (1892) 492; et Atlas, t. 38. - Gall.

Legrandiana X, G. Camus, 1. c. 478 (= Gymnadenia Legrandiana, G. Camus). - Gall.

Regelii X, G. Camus, 1. c. (= Orchis Regelii, G. Camus). - Gall.

sorippensis $\times$. G. Camus, 1. c. 47\%, et Atlas, t. 25.Gall.

ORCHIODES, Trew. in Act. Phys, Med. Caes. Leop, Nat. Cur. iil. (1736) 406 t. 6 f. 7 ; ex Kuntze, Rev. Gen. (1891) $674=$ Goodyera, R. Br. (Orchid.)

bifidum, celebicum, coloratum, cordatum, foliosum, fumctum, fuscum, grande, Tispidum, macrophyllum, nudum, paroiflorum, procerum, pubescens, pusillum, recuram, repens, reticulatum, rubicundum, Schlechtendalianum. secundiformm, z'elutinum, wiridiforum, viscosmm, wittatum, Waitriamum, Kuntze, Rev. Gen, (IS91) 6.1 = homonyma omnia Goodyerae.

biflorm. Kuntze, 1. c. (= Georchis biffora, Lindl.). - Reg. Himal.

calvum, Kuntze, 1, c. $(=$ G. calva, Lindl.). - Jar'd.

decipiens, Kuntze, 1. c, = Goodyera Menziesii, Lindl.

discolor, Kuntze, 1. c, = Haemaria discolor, Lindl.

clongatun, Kuntze, 1, с. = Hetaeria elongata Lindl.

marginatum, Kuntze, 1. c, = Goodyera repens, $R$.

occultum, Kuntze, 1. c. = Platylepis goodyeroides A. Rich.

polygonodes, Kuntze, 1.c.= Goodyera polygonoides, F. Mucll.

quercilobum, Kuntze, 1. c. = Physurus querceticola, Lindl.

cosupinatm, Kuntze, 1. c. = Goodyera repens, $R$. $B$ r.

ubregulare, Kuntze, 1. c. (= Georchis subregularis, Reich. f.). - N. Caled.

esselatum, Kuntze, 1. c. = Goodyera repens. $R$. $B 1$

ORCHIPEDA, Blume = Voacanga, Thou. (Apocyn.).

papuana, F. Muell. Descr. Notes Papuan Pl. vii. (1886) :30.- N. Guin.

ORCHI-PLATANTHERA $\quad \times, G$. Camus, in Morot, Journ. de Bot. vi. (1892) 474. ORCHI$D E A E$.

Checalticriana, G. Camus, 1. c.; et Atlas, t. 34. Gall.

ORCHIS, [Tourn.] Linn. (Orchid.). - Ind, Kew ii. 359 .

adulterina $X, G$. Camus, in Morot, Journ. de Bot. vi. (1892) 32. - Gall.

alatoides $X$ Fleury in Bull. Soc, Bot. Fr. xxiy. (1887) 163 et $18 \%$; G. Camus, in Morot, 1. c. 406. - Gall.

altissima, Ham. ex Hook, f, F1. Brit. Ind. vi. (1890) $13 T=O$. Suzannae, R. Br.

Arbostii $\lambda, G$. Camus, in Bull. Soc. Bot. Fr. xxrviii (1891) 53 :et, in Morot, Journ. de Bot. vi. (1892) 35 L. - Gall.

balcanica, Velcn, in Sit\%. Boehm. Gess, Wiss. 1889 (1890) ii. 53. - Bulg.

Barlae X, G. Camus, in Morot. Journ. de Bot, vi. (1892) 406 (= Scrapias Barlae, C. Richt.). Gall.

Bergoni $x^{\prime}$, Nanteuil, in Bull. Soc. Bot. Fr, xxxiv 1S57) $422=$ Orchi-Aceras Bergoni $\times$. G. Camus Bonnicriana $X, G$. Camus, Vade-mecum herb. paris, Suppl. (1890) et Morot, Journ. de Bot. vi. 1892) 416; et Atlas, t. 29 et 29 bis, - Gall.

Bomemamiae, "Aschers. ) ex Batt. \& Trab. Fl. de l'Algér. [Monoc.] (1895) 27. sphalm. = O. Bornemanni $X$, Aschers.

Bornemanniana $X$, "Aschers. » ex Nym. Consp. F1. Eur. Suppl. ii. I. $(1890)$ 292, sphalm. $=0$. Borncmanni $\times$, Aschers. 
ORGHIS

psriaca, G. Beck, in Annal. Vaturh. Hofmus. Wien, ii. (1887) 53 t. 1 fig. 1-3; et v. (1898) 57 = latifolia, Linn.

Boudieri $X, G$. Camus, in Buil, Soc. Bot. Fr. xxxviii. (1891) 285; et xlii. (1895็) 506: G. Ca mus, in Morot, Journ. de Bot. vi. (1S92) 252. Gall.

Calvellii, Terrac. in Ann. Ist. Bot. Roma, iv, 1889-90 (1891) 47. - Italia mer

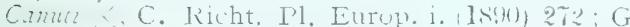
Camus, in Morot, Journ, de Bot. vi. (1892) 349 - Gall.

capitata $\times$. G. Camus, 1. c. 33. - Gall.

carzca X, G. Camus, l. c. 419 ; et Atlas, t. 33:Gall.

Chatini X, G. Camus, in Bull. Soc. Bot. Fr. xxxvi (1859) 341. et in MIorot, Journ. de Bot. vi. (1892 413. - Gall

Cherallieviana $\times$, G. Camus, 1. c. xxxviii. (1891) $156=$ Orchiplatanthera Chevailierana, G. Camus. lat'ata, Heyne, ex Hook, f. Fl. Brit. Ind vi. (1890) 150 , in syn. = Habenaria marginata Colebr.

complicata X, G. Camus, in Morot, Journ, de Bot. vi. (1892) 34. - Pyren.

cyclochila, Maxim in Bull. Acad, Pétersb. xxxi. (1887) 104 (= Hitbencaria iyclochila, Franch. \& Sav.). - Japon.

Debearxii X, G. Camus, in Morot, Journ. de Bot. vi. (1892) 34 et 350 . - Cors.

dccipiens X, G. Camus, 1. c. 412. - Gall.

Eichenfeldtii X, G. Beck, F1. Nied.-Oest, i. (1890) 202. - Austria.

Erdingeri $x$, Sennholz, in Sitz. zool,-bot. Ges, Wien, xli. (1891) Sitzb. 41 ; et in Oest. Bot. Zeitschr, xli. (1891) 381 (= Platanthera Erdint gevi, A. Kern.). - Austria.

erythrantha X, G. Beck, Fl. Nied.-Oest. i. '(1890) 201. - Austria.

Franchetii $\times$, G. Camus, in Bull. Soc. Bot. Fr. xxxiv. (18Si) 243 t. 3, et in Morot, Journ, de Bot. vi. (1892) 415. - Gall.

Grenieri X, G. Camus, 1. c. 410, - Gall

guestphatica X. C. Richt. PI. Europ. i. (1890) 273. - Germ. occ.

Henviques $\times$, Guimaraes, in Bolet, Soc, Brot. v. (1887) 71. - Lusit.

influenza $\times$. Sennholz, in Verh. zool-bot. Ges. Wien, xli. (1891), Sitzb. 40; et in Oest. Bot. Zeitschr. xli. (1891) 381. - Austria.

integrata, G. Camus, in Morot, Journ. de Bot. vi. (1892) $157=$ incarnata, Limn.

intermedia X, Gadeceau, in Mém. Soc, sci. nat. de l'Ouest, ii. (1892) 4 t. 1, fig. 6a et 6b; G. Camus, 1. c. 408. - Gall.

intuta X, G. Beck, F1. Nied.-Oest. i. (1890;205 $(=$ O. Regeliana, C. Richt.). - Austria.

feanperti $X, G$. Camus \& Luizet, in Camus, Vademecum herb. paris. Suppl. (1890), ex Morot, Journ. de Bot. vi. (1892) 416 ; et Atlas, t. 27. Gall

Kisslingii $\times, \mathrm{G}$. Beck, in Verh. zool.-bot. Ges. Wien, xxxviii. (1888) 768; et Fl. Nied.-Oest. i. (1890) 203. - Austria.

Langei X, C. Richt, P1. Europ. i. (1890) 273. Hisp.

Leguei X, G. Camus, in Morot, Journ. de Bot, vi. (1892) 420; et Atlas, t. 32. - Gall.

lewcantha, Ham, ex Hook, f. FI. Brit. Ind, vi (1890) 161, in syn. = Habenaria constricta, Hook, f.

Loeselii, MacMill. Metasp. Minn. (1892) 173, sphalm. = Liparis Loeselii, $A$, Rich.

Luizetiana X, G. Camus, in Morot. Journ. de Bot. ii. (1888) 93 ; et vi. (1892) 415 ; et in Bull. Soc. Bot. Fr. xxxvi. (1889) 341. - Gall.

monticanla X.C. Richt. in Verh, zool.-bot, Ges.

Wien. xxxviii. (1888) 220. - Austria.

uglecta $\times, G$. Camus, Vade-mecum herb. paris. Suppl. (1890) et in Morot. Journ, de Bot. vi (1892) 419. - Gall.

Paulianu $\times$, Malinv, in Bull, Soc. Bot, Fr, xxxyi. (1S89) p. cclxvii. t. 1 ; et in Morot, 1, c. 354 . Gall.

\section{ORCHIS}

pentecostalis, Wellst. \& Semnholz, in Oest. Bot. Zeitschr. xxxix. (18S9) 321; et in Bot. Centralbl. xli, (1890) St. - Austria

Peryetii X. C. Richt. Pl. Europ, i. (1890) 272: G. Camus, in Morot, Journ, de Bot. vi. (1892) 351. - Gall.

pseudo-conopsea, Parmentier, in Bull. Ser, hist. nat. Autun, vii. (1S94) $343=$ conopsea, Linn.

purpurea X, G. Camus, in Morot, Journ. de Bot. vi. (1892) 32. - Gall.

Regeliana X, C. Richt. P1. Europ. i. (1890) 205 = intuta $\times$. G. Beck.

Regelii X. G. Camus, in Bull. Soc. Bot. Fr. xxxvi. (I889) P. 22S; et in Morot, Journ. de Bot, iv. (1890) 2: et vi. (1892) 478. - Helv., Gall.

Roborowskii. Maxim. in Bull. Aand Pétersb. xxxi. 1887) 104. - Reg. Tangut.

Rouyana X, G. Camus, Vade-merum herb, paris. Supp1. (1890), et in Morot, Journ, de Bot. vi. 1892) 416; et Atlas, t. 28. - Gall,

Sauzaiana $\times$, G. Camus, in Bull, Soc. Bot, Fr, xxxvii. (1891) 217; in Morot, 1. c. 419; et Atlas, t. 32. - Gall.

Schulzei X, C. Richt. P1. Europ, i. (1890) 274 ; G. Camus, 1. c. 417. - Gall,, Germ.

Schulzii X. Hausskn. [ubi?] ex Nym. Consp. FI, Europ. Suppl, ii. I. (1890) 292. - Germ.

Skorpili, Velen, in Oest. Bot. Zeitschr. xxxii. (1886) 257 : in Sitz. Boehm. Ges. Wiss, (1887) 461 ; et Fl. Bulg. (1S91) $523=$ O. Morio, Linn .

peciosissima, Wettst. \& Sennholz, in Oest. Bot. Zeitschr. xxxix. (1889) 319: et in Bot. Centralbl. xli. (1890) 84; G. Beck, Fl. Nied.-Oest, i. (1890) $203=$ pentecostalis, Wettst. \& Senzinolz.

stylosanthes, Ham ex Hook, f. Fl, Brit. Ind vi.

(1890) 143 in syn. = Habenaria commelinifolia. Vall.

Surannae, Heyne, ex Hook. f. 1. c. 164, in syn. = H. galeandra, Bcuth.

Széchenyiana, Reichb.f. ex Konitz, Pl. exped. Szechenyi in As, centr. coll. (1891) 58, t. 61 fig. 1-4 [Növenyt. Gysytesele Eredmanyei, 1891]. - As.

Timbaliana X, G. Camus, in Morot, Jourr. de Bot. ii. (1888) 349, t. 9; et vi. (1892) 352. - Gall.

Tominasini $X, G$. Camus. 1. c. vi. (1892) 35 . Gaill.

Vilmsii X. G. Camus, 1. c. 35.5; et Atlas.t 23, Gall.

viride-fusca. Alboff, Prodr. F1. Colch, (1895) 229, Reg. Cauc.

Weddeli X, C. Richt. P1. Europ, i. (1890) 273 [an seq.?]. - Gall.

Weddellii $\times$. Franch. in Bull. Soc. Bot. Fr, xxxiy.

(1SST) 242 t. 3; G. Camus, in Morot, Journ, de Bot, vi (1892) 414. - Gall,

Wilmsii X. C. Richt. Pl. Europ. i. (1S90)'273. Westphal.

ORCHI-SERAPIAS $\times, G$, Camus, in Morot Journ. de Bot. vi. (1894) 31. ORCHIDEAE. adulterina $\times$, G. Camus, 1. c, 32, - Gall. Barlae X, G. Camus, I. C. 33. - Alp. Marit. capitatc $\times$, G. Camus, 1. c. - Gall. complicata $X, G$. Camus, 1. c. 3t. - Gall. Debeanxii X, G. Camus, 1. c. - Cors.

Nouletii $\times$, G. Camus, 1. c. $31-$ Gall.

purpurea X. G. Camus, 1. c. $32(=$ Serapias purpurea, Doumenjon). - Gall.

Tommasini $X, G$. Camus, 1. c. $35(=$ S. Tommasini, Kern.): - Eur. mer.

ORGUTTIA, Vasey, in Bull. Torrey Bot. Club, xiii. (1856) 219 t. 60 ; et in West Am. Scientist, iii. (1886) 4, cum ic.; Hack. in Eng1. \& Prant1, Natür]. Pflanzenfam. iii. 2 (1887) 65. GRAMINEAE. californica, Vasey, l.c. 219; et Illustr. N. An. Grass. ii. (1892) t. 49, - Calif.

Greenei, Vasey, $l l, c c, x v i,(1891) 146$; et t. 50. Guatem.

ORELLANA, Ludw, = Bixa, Lim

mericana, Kuntze, Rev: Gen. (1891) $4 t=\mathrm{B}$ Orellana, Lims.
OREOBOLUS, R. Br. (Cyper,). - Ind. Kew, ii

rrulati, Colenso, in Trans. N. Z. Inst. xxii. 1889 (1S90) $492=$ stricta, Bergg.

OREOBROMA. Howell, in Errthea, i. (1893) $31=$ Calandrinia, H. B. \& K. pr. p. et Lewisia Pursh (Portul.)

brachycalyx, Howell, 1. c. 3I = Lewisia brachyca lyx, Engetm.

biana, Howell,

Cotyledon, Howell,

Cotwledoun Howell, 1, o. = C. Cotyledon. S. Wats.

Hotrallii, Howell, I. c. $=$ C. Howellii, S. Wats.

Leana, Howell, 1. c. $31=$ C. Leana, Porter.

neiradensis, Howell, 1. c. $3: 3=$ C. nevadensis, $A$ Gray.

oppositifolia, Howell, l, c. $32=$ C. oppositifolia,

pygmaca, Howell, 1. c. = Talinum pygmaeum, $A$ Gray.

riphyllat Howell, 1. c. $33=$ Claytonia triphylla Wats.

2reedyi, Howell, 1, c, $32=$ Calandrinia Tweedyi, A. Gray.

OREOGARYA, Greene, in Pittrnia, i. (July 1889) 57; Guerke, in Eng1. \& Prantl, Natürl. Pflanzentam. iv. 3a (1894) 109. BORAGINEAE.

fulvocanescens, Greene, l. c. $(=$ Krynitzkia fulloce nascens, A. Gray), - Am. bor. occ.

glomerata, Greme, i.c. (= K. glomerata, A. Gray) Am. bor. oce.

holoptera, Greene, l.c. (=K. holoptera, A. Gray). - Am. bor. Occ.

leucophaea, Greene, l. $\quad \Leftrightarrow K$ le leucobliaed, A. Gray). - Am. bor. occ.

Palmeri, Greene, b. c. (= K, Palmeri, A. Gray). Am. bor. oce.

sericea, Grene, l. . . ( $=K$. sericed, A, Gray). Am. bor. occ.

setosissima, Greene, l. c. - Am. bor. occ.

suffruticosa, Greene, l. c. $57(=K$. Famesii, A. Gray). - Am. bor. occ

irigata, Greene, l. c. $48 i=K$. virgata, A, Gray) Am. b

OREOCHARIS, Benth. (Gesner.) - Ind. Kew. ii. 363

aurantiaca, Baill, in Bull. Soc. Limn, Paris, i, (188s) 716. - Yunnan.

Delavayi, Baill. l. c. 715. - Yunnan.

Henryana, Oliver

1944, - China,

$(1890)$

OREOGHLOA, Link (Gramin.). - Ind. Kew. ii. 363

sesteriondes, C. Richt. P1. Europ. i. (1889) is = pedemontana, Boiss.

OREODAPHNE, Nees \& Mart. = Ocotea. Aubl. (Laurin.).

diospyrifolia, Mez, in Jahrb. Bot. Gart. Berl. v. (1889) 374 (= Oreodaphne diospyrifolia, Meissn.). Am. austr.

OREODOXA, Willd. (Palm.). - Ind. Kew. ii, granatensis, Hort, Bull. [Conf. W. Wats, in Gard. Chron. (I887) ii. 304; Nichols. Dict. Gard, ii. 521] - N. Granat.

OREOGRASTIS, K. Schum. in EngI. Pflanzenw Ost-Afr. C (1895) 127. CYPERACEAE.

Emini, $K$. Schunb, l. c. - Afr. trop. or.

OREOPANAX, Decne. \& Planch. (Aral.). - Ind.

\section{Kew, 11,364}

eriocephalus, Harms,

Beibl. 67 - Ecuad.

jaliscana. S. Wats, in Proc. Am. Acad. xxy. (1890) 151. - ilexic

Jelskii, Zallbr. in Diss, Cl. Mlath. Phys. Aadd. litt. Cracov. xxix. (1894) 227. - Peruvia.

Lehmannii, Harms,
Beibl. 66. - Ecuad. 


\section{OREOPANAX : -}

membranaceus, Rusby, in Nem. Torrey Bot. Chub, iii. 3 (1893) 42. - Rolivia.

microcephalus, Harms, in Bot. Fahrb. xx. (1895) 68. - Columb.

oligocarpum, F. D. Smith, in Conlt. Bot. Gaz, xvi. 1891) 194. - Am. centr.

Rusbyi, Britton, in Bull. Torrey Bot. Chub, xviii. (1891) 38. - Bolivia

Sanderianum, Hemsl, in Gard. Chron. (1892) i. 718 et (1893) i. 442. - Am. centr.

Taubertianum, F. D. Smith, in Coult. Bot. Gaz xix. (1S94) 4. - Gliatem.

OREORGHIS, Lindl. (Orchid.). - Ind. Kew. ii. 364.

indica, Hook, f. Fl. Brit. Ind, v, (1890) r09.Reg. Himal.

OREOSTYLIDIUM, Berggr. (Stylid.), - Ind. Kew. ii. 365.

affine. Colinso, in Trans. N. Z. Inst. xx. 188 r (1888) 197. - N. Zel.

OREOSYGE, Hook. f. (Cucurb.), 一 Ind. Kew. ii.

Holstii, Cogn, ex Eng1, in Abh. Preuss, Akad. Wiss. (1894) 61, nomen; et Pflanzenw. Ost-Afr. A (189.) $107=$ triangularis, Cogn.

triangularis, Cogn. in Bot falhro. xxi. (1895) 207. - Usambara.

ORESTIA, Ridl. in Journ. Linn. Soc. xxiv. (188i) 197: et in Bolet. Soc. Brot. v. (1887) 201. ORCHIDEAE.

elegans, Ridl. $l l . c c$. - Ins. S. Thom

ORIASTRUM, Poepp. \& Endl. = Ghaenactis, (Compos,) albicaule, Phil.

dioicum, Phil. 1. c. (= Egara dioica, Remy). Chili.

Gayi, Phil. 1. c. 18. - Chili.

glabriusculzm, Phil. 1. c. 16, - Chili.

gossypimum, Phil. 1. c. 19. - Chili

mana, Phil. 1. c. 22, - Chili.

lencocephatum, Phil. 1. c. 16. - Chili.

nivale, Phil. 1. c. 21. -- Chili.

pentacaenoides, Phil. 1. c. 22. - Chili.

pareiflornm, Phil. 1. c. 18. - Chili.

polynallunn, Phil.1. c. J7. - Chili.

uncinatum, Phil. 1. c. 23. - Chili.

ORIGANUMI, Tourn, ex Linn. (Labiat.), - Ind. Kew, ii, 366

aciculare, aesticum, albicans, bracteatum, bracteostm, Broussonctii, capitatum, capitellatum, cappadocicum, carnosum, cephalotes, ciliatum, cilicicum, cimicinum. comptum, docussatum, diffusum, Funkii, granatense. Herba-barona, hirsutum, hirtum, longifionum, Loscosii, maroccamun, Mastichina, mombranacem, nitidum. Pipcrella, sabulicolum. Serpyllum, striatum, syriacum, tomentosum, valentimum, villosim, Webbia mum, W clwoitschii, aygis, Kuntze, Rev. Gen. (1891) $528=$ homonyma ommis Thymi

amanum, Post, in Bunl. Herb. Boiss. iii. (1895) 161 - Syria.

barconse, Simonk, in Termész. Füzetek, x, (1886) $182=$ vulgare, Limn.

Bowii, Kuntze, Rev. Gen. (Is91) $528=$ Thymus Serpyllum, Limn.

caespititimn, Kuntze, 1. $c_{0}=$ T. Serpyllum, Limn Dayi, Post, in Bull. Herb. Boiss, i. (189:3) 405. Syria.

Themale, Kuntze. Rev. Gen. (1891) $528=$ Thymus hyemalis, Lange.

integym, Kuntze, 1. c. = T. Billardieri, Boiss. fankae, Kuntze, 1. c. = T. Serpyllum, Linn. micromeriodes, Kuntze, 1, c, = T. micromerioides Ronty.

Munbyanum, Kuntze; 1. $\mathrm{c},=\mathrm{T}$, ciliatus, Benth

origanodes, Kuntze, 1. $\mathrm{c}_{0}=\mathrm{T}$, origanoides, $W_{e} b \mathrm{~b}$ \& Benth.

Richardi, Kuntze, 1. c. = majoricum, Cambess.

\section{ORIGANUIN :}

Gtwejodes, Kuntze, Rev. Gen. (1891) $528=$ Thymus satureioides, Coss. \& $\mathrm{Bal}$.

semiglaucum, Boiss. \& Reut. ex Briq. Lab. Alp. Marit. iii. (1895) $484=$ vulgare, Limn.

serpyllodes, Kuntze, Rev. Gen. (1891) 528 = Thymus serpylloides, Bory.

silvestre, Kuntze, 1 c. $=$ T. sylvestris, Hoffngg. \& Link

tencriodes, Kuntze, 1. c. $=$ T, teucrioides, Boiss, \& Sprunn.

Thymus, Kuntze, 1. c。= T. vulgaris, Linn.

ORITES, R. Br. (Proteac.). - Ind, Kew. ii. 366. fragrans, F. M. Bailey, Bellenden-Ker, (1889) 56.Austral.
Aust.

ORLAYA, Hoffm. = Daucus, Tourn, (Umbell.). Dancorlaya, Murb. in Lunds Univ. Arsskrift xxvii. V. (1892) 119. - Herceg.

ORMOGARPUM, Beauv, (Legumin.). - Ind. Kew. ii. 367

Buchholzii, Engl. Bot. Fahrb. vii. (1S86) 336. Iamerun.

ORLEANESIA, Barb. Rodr. (Orchid.) - Ind. Kew. ii. 367.

yauaperyensis, Barb. Rodr. Vellosia, 1885-88, Sec. ediç. (1891) 124, - Bras. bor.

ORMOSIA, Jacks. (Legumin). - Ind, Kew, ii. 367.

Balansae, Drake, in Morot, Fourn. de Bot.v. (1891) 213. - Tonk.

Fordiana, Oliver, in Hook. Icon. pl. xxy. (1895) 422 . - China

ORNITHIDIUM, Salisb. (Orchid.). - Ind, Kew. fragrans, Rolfe, in Kow Bull. (1894) 15\% - Hab.? imbricatum, Wall. ex Hook. f. F1. Brit. Ind. (1890) $846=$ Pholidota imbricata, Reichb. f. nanum, Rolfe, in Kew Bull. (1894) 395. - Ind. occ. ochraceum, Reichb.f. in Gajd. Chron.(1887) i. 209. - N. Granat.

ORNITHOCEPHALUS, Hook. (Orchid.). - Ind.

\section{Kew. i1. 366}

Pottsiae, S. Wats. in T. Brighan. Guatem, Append, (1887) 429, nomen; ct in Proc. Am. Acad. xxii. (1887) 478. - Guatem

stenoglottis, Reichb. f. in Flora, lxix. (1886) 551. Hab.?

ORNITHOGALUM, [Tourn.] Linn. (Liliac.). -Ind. Kew. ii. 363 .

amboënse, Schinz, in Verh. Bot. Ver. Brand. xxxi. (1890) 220. - Afr. austro-occ, extratrop.

apertiflorum, Baker, in Gard. Chron. (1889) ii. 38. $\mathrm{Hab}$.

Aserni, Velen, in Sitzb. Boehm. Ges. Wiss. (1893) xxxvii. 63. - Bulo

bosniacm, G. Beck, in Annal. Naturh. Hofmus, Wien, ii. (188\%) $48=$ tenuifolium, Gilss.

brutium, Terrac. in Ann. Ist. Bot. Roma, iv. 1889-90 1891) 17 t. 1. - Italia mer.

indicum, Koenig, ex Hook. f. F1. Brit. Ind. vi.(1892) 334. in syn. = Chlorophytum arundinaceum, Balker.

miniatum, Schin\%, in Bull. Herb. Boiss. ii. (1894) 223. - Afr. austr.

natalense, Baker, in Kew Bull. (1893)210. - Natal.

orbelicum, Velen. in Sit\%. Boelm. Ges. Wiss. 1889

1890, ii, 57: in Oest. Bot. Zeitschr. xt. (1890) 437 ; et Fl. Eutg. (1891) 552. - Bulg.

pulchrum, Schinz, in Verh. Bot, Ver. Brand. xxxi. (1890) 221. - Afr. austro-occ. extratrop.

reflexum, Freyn \&o Sint. in Oest. Bot. Zeitschr. xliv. (1894) 391. - As, Min

Reverchoni, Lange, in Willk. Ill. Fl. Hisp, ii. (1886-92) 117 t. 158; t in Suppl. Prodr. Fl. Hist. (1893) 53. - Hisp.

Saundersiae, Baker, in Gard. Chron. (1894) ii. 452. - Afr. austr.

\section{ORNITHOGALUM}

Sckmalhauscni, Alboff in Bull Soc. Hort, Odessa (1891) extr, 15, ex Bull. Herb. Boiss, i. (1893) 260 , in syn. $=$ O. Balansae, Boiss

Schlecterianum, Schinz, in Bull. Herb. Boiss, ii (1894) 223. - Afr. austr.

Shorpili, Velen, in Sitz. Hoehm. Ges, Wiss. (185: 463 ; et Fl. Bulg. $550=$ oligophylium, C. B Clarke.

sordidum, Baker, in Kev Bull. (1895) 228. - Reg. Somal.

speciosum, Baker, in fourn. Bot. xxix. (1891) 72. Afr. austro-occ. extratrop.

subcucullatum, Rony \&o Coincy, in Bull. Soc. Bot. Fr. xxxvii. (1890) 16\%. - Hisp.

trichophyllum, Baker, in Bot. Falirb. xv. Beibl. 11. 35 (1892) \% - Afr, austr.

ORNITHOGLOSSUM, Salisb. (Liliac.). - Ind, Kew. Ii. 370 .

platycheilum, Weathers, in Gard. Chron. (1892) i. $587 \mathrm{fig}$. et 84. - Hab. ?

ORNITHOPODIUM, Linn, 1735 = Ornithopus Linn. (Legumin.)

coriandrimum, ebracteatum, isthmocarpum. micranthum, perpusillum, satirum, Kuntze, Rev. Gen. (1891 $199-200=$ homonyma omnia Ornithopi.

ORNITHOPUS, Linn. (Legumin.). - Ind. Kew 11,37

Hormolotus, Oliver, in Johnston, Kilimanjaro Exped. (1886) 339 nomen, - Afr. trop. or.

minor, Tornab. Fl. Sicula, (1887)212, - Sicil

OROBANCHE, [Tourn.] Linn. (Orobanch.). Ind. Kew. ii. 371

acmula, G. Beck, in Luerss. Bibl. Bot. Heft. xix. (1890) $102=$ aegyptiaca, Pers.

angustiflora, G. Beck, in Luerss. Pibl. Bot. Heft xix, $(1890) 96=0$. Muteli, F. Schultz.

artemisiophya, St Lager, in Cariot, Etud. des fl. éd. 8, II. (1889) 652 = loricata, Reichb.

Borbasiana, G. Beck, in Luerss. Bibl. Bot. Heft. xix. (1890) 173. - Croatia.

bulbosa, G. Beck, 1. c. 83 fig. $7=$ Aphyllon tuberosum, A. Gray

contauropliya, St Lager, in Cariot, Etud. des fl. éd. 8, II. (1889) $649=$ major, Lim

chilensis, G. Beck, in Luerss, Bibl, Bot. Heft xix. (1890) 82. - Chili.

Cooperi, G. Beck, 1. c. $81=$ Aphyllon Ludovicia num, $A$. Gray.

cyamophya, St Lager, in Cariot, Etud, des fl. éd. S II. (1889) $648=$ speciosa, Forsi.

cchinopophya, St Lager, 1. c. $650=$ major, Linn.

cmarginata, G. Beck, in Luerss, B: b1. Bot. Heft xix. (1890) $98=0$. Muteli, $F$. Schulz

cryngiophya. St Lager, in Cariot, Etud. des fl. éd. 8, ii. (1859) $651=$ amethystea, Thuill.

fastigiatu, G. Beck, 1. c. $102=$ aegyptiaca Pers.

galiophya, St Lager, in Cariot, Etud. des fl. éd. 8 ii. (1889) $648=$ caryophyllacea $S m$.

Grayana, G. Beck, in Lucrss. Bibl. Bot. Heft xix. 1890) 79. - Am. bor. occ.

habrocaulon, G. Beck, in Annal. Naturh, Hofmus Wien, ii (1887) $147=0$. Laserpitii-sileris, Reut

Haussknechtii, G. Beck, in Luerss. Bibl. Bot. Heft xix. (1890) $103=$ aegyptiaca, Pers

hederifixa, St Lager, in Cariot, Etud. des fl. éd. 8 ii. (1889) $65 \mathrm{l}=$ O. Hederae, Dusy.

Hookevi. G. Beck, in Luerss. Bibl. Bot. Heft xix. (1890) $85=$ Boschniakia Hookeri, Walp

Hydrocotylei, Colenso, in Trans. N. Z. Inst. xxi. 1888 (1889) $41 .-N$. Zel.

interjecta, G. Beck, in Luerss, Bibl. Bot. Heft xix (1890) $98=$ O. Muteli, $F$. Schulz.

icterica, Pau, Not. Bot. Fl. Espan. iii. (1889) 5 Willk. Suppl. Prodr. Fl. Hisp. (1893) 18?. Hisp.

lascropliya, St Lager, in Cariot, Étud. des fl. ćd. S ii. (1889) $650=0$. Laserpitii-sileris, Reut. 


\section{OROBANCHE}

latisquamosa, Batt. in Batt. Eo Trab. Fl. de l'Algér. [Dicot.] (1889) 659 (- Boulardia latisquana, F. Schultz). - Algeria.

malloantha. G Beck, in Luerss. Biblioth. Bot. Hett xix. $\{1890\} 98=$ O. Muteli, F. Schultz.

medicaginifixa, St Lager, in Cariot, Etud, des fl. éd. 8, ii. (1889) $649=1$ lutea. Baumg.

monoclonos, G. Beck, in Luerss, Biblioth. Bot. Heft xix. (1890) $89=$ ramosa, Linn.

oxyloba. G. Beck, l. c. $48(=$ Phelypaea oxyloba, Reut.). - As. Min.

Pancicii, G. Beck, in Annal. Naturh. Hofmus. Wien, ii. (1857) 148, t. vi. fig. 8-11; et l. c. 223.-Serbia.

panormitana, G. Beck, in Luerss. Biblioth. Bot. Heft xix. (1890) $97=0$ Muteli, F. Schultz

parasitica, Fischei, ex G. Beck, 1. c. 101 = aegyptiaca, Pers.

pencedanophya, St Lager, in Cariot, Etud, des fl. éd, 8, ii. (1889) 652 = alsatica, Kirschl.

picridophya, St Lagcr, 1. c, $65 \mathrm{I}=\mathrm{O}$. Picridis, F. Schultz.

polyclonos, G. Beck, in Luerss. Biblioth. Bot. Heft xix. (1890) 88 = ramosa, Linn.

proboscistyla. G. Beck, l. c. $89=$ ramosa, Linn.

Promuntarii, G. Beck, 1. c. $\mathscr{T}$ i $=$ O. Muteli, F. Schultz

pulchella. G. Beck, in Luerss. Biblioth. Bot. Heft xix. (1890) $102=$ aegyptiaca, Pers.

rectiflora, G. Beck, 1. c. $198=$ aegyptiaca, Pers.

Recrerchoni, Lance, ex Willk, Suppl. Prodr. Fl.

Hisp, (1893) 187 = mauritanica, G. Beck.

salsa, Kuntze, in Act. Hort. Pétrop, x. (188i) 225 (= Phelypaca salsa, C. A. Mey). - As. bor. et occ.

salrifixa, St Lager, in Cariot, Etud. des fl。 éd. S, ii. $(1889) 000=$ O. Salviae, F. Schultz.

sarothamnophya, St Lager, 1. c. 647 = major, Linn. scabiosifixa, St Lager, 1. c. $649=$ reticulata, Wall.

Schweinfurthi, G. Beck, in Luerss. Biblioth. Bot. Heft, xix, (1890) 94. - Afr. bor.

sinaica, G. Beck, 1. c. $97=$ O. Muteli, F. Sckultz. spissa, G. Beck, 1. c. $96=0$. Muteli, F. Schaltz. stenosiphon, G. Beck, 1. c. $96=$ - O. Muteli, F. Schultz. tarapacana, Phil. in Anal. Mus, nac, Chile (1891) 69. - Am. austr.

tencriophya, St I.ager, in Carint, Etud. des fl. éd. 8, ii. (1889) $648=0$. Teucrii, Holand.

thymopliya, St Lager, 1. c. $648=2 \mathrm{lba}$, Steph

tricholoba, G. Beck, in Luerss. Biblioth. Bot. Heft xix. (1890) 103 = aegyptiaca, Pers.

trifolifixa. St Lager, in Cariot, Etud. des fl. éd. 8, ii. (1889) $650=$ minor, Sutt.

trinacria, G. Beck, in Luerss. Biblioth. Bot. Heft xix. (1890) 102 = aegyptiaca, Pers.

OROBUS, [Tourn.] Linn. = Lathyrus, Tourn. (Legumin.).

Bauhini, Genty, in Bull. Soc: Dauph. éch. pl. Sér, If, iii. (1892) $91=$ L. Bauhini, Genty.

accidentalis, Fritsch, in Sitzb. Alkad. Wîss. Wien, civ. (1895) 499 = L. ochraceus, Kittel.

Skorpili. Velen. in Sitzb. Boehm. Ges. Wiss. 1889 (1890) ii. 32; et Fl. Bulg. (1891) 158. - Bulg.

viftorus, G. Beck, ex Stapf, in Denkschä. Akad. Wien, ii. (1886) 76.-As. Min

OROGHAENAGTIS, Coville, in Contrib. U.S. Nat. Herb: iv. (1893) 134; O. Hoffm. in Engl. \& Prantl, Natürl. Pflanzenfam. iv. 5 (1893) 39 [sphalm. Orchaenactis]. COMPOSITAE.

thysanocarpha, Corille, l.c. $(=$ Chaenactis thiysanocarpha, A. Gray). - Calif.

OROGENIA, S. Wats. (Umbell.). - Ind. Kew. ii. 376

fusiformis, S. Wats, in Proc. An. Acad, xxij. (1887) 474. - Calif.

OROPHEA, Blume (Anonac.). - Ind. Kew, ii. 370. cuneiformis, King, in fourn. As. Soc. Beng, lxi. (1892) II. \&4. - Perak.

gracilis, King, l.c. 83. - Perak

hastata, King, l. c. - Perak.

\section{OROPHEA :}

hirsuta, King, in fourn. As. Soc, Beng. Ixi. (1892) II. 82. - Perak.

maculata. Scortech. ex King, l, c. -.. Perak.

setosa, King, l. c. 80.-Perak.

ORPHIUM. E. Mey. (Gentian.), - Ind. Kew, ii,

376.

fruticosum. Kuntze, Rev. Gen. (1891) 432, sphalm. $=$ frutescens, E. Mey.

ORTGIESIA, Regel (Bromel.). - Ind, Kew ii.

Legrelliana. Baker, Handb. Bromel. (1889) 19 (= Hohenbergia Legrelliana, Baker\}. - Urug.

ORTHAEA, Klotzsch (Vaccin.), - Ind, Kew, ii. 377

abbreviata, Drake, in Morot, Fourn. de Bot. iii. (1889) 75. - Ecuad.

cordata, Oliver, in Hook. Icon. pl. xxv. (1895) t. 2412. - Columb.

ORTHANTHERA, Wight (Asclep.). - Ind. Kew

albida. Schinz, in Verh. Bot. Ver. Brand. xxx. (1888) 265. - Afr. austro.-occ. extratrop.

Browniana, Schinz, l. c. 264. - Afr. austro.-occ. extratrop.

jasminiflora, Schinz, l. c, 265, in obs. $(=$ Barrouid iasminiflora, Decne.). - Afr. austr.

jasminiflora, K. Schum. in Engl. \& Prantl, Natür1. Pflanzenfam. iv. 2(1895) $266=$ praec

ORTHOGARPUS, Nutt. (Scrophul.). - Ind versicolor, Greene, Man. Bot. San Franc. Bay (1894 283. - Calif.

ORTHOGERAS. R. Br. (Orchid.). - Ind. Kew Caput-serpentis, Colenso, in Trans. N. Z. Inst. xxii. $1889(1890) 490 .-\mathrm{N}$. Zel.

rubrum, Colenso, l. c. xviii. 1885 (1886) 273. N. Zel.

ORTHORRHIZA, Stapf, in Denkschr. Akad. Wien (1886) 38: Prantl, in Engl. \& Prantl, Natuirl. Pflanzenfam. iii. 2 (1891) 205ั. CRUCIFERAE.

persica, Stapf, $l l . c o .(=$ Chorispora stricta, DC. $)$. - Persia.

ORTHOSIPHON, Benth. (Labiat.). - Ind. Kew.

adornatus, Briq. in Bot. Fahrb. xix. (1894) 176. -

Afr. trop. occ.

calaminthoides, Buker. in Kew Bull. (1895) 225. Afr.

Cameroni, Baker. l. c. 72. - Afr. trop.

cladotrichos. Guerke, in Engl. Pflanzenw. Ost-Afr.

C (1895) 349. - Afr trop. or

comosum, Baker, in Kew Bull. (1895) 184. Arabia.

debilis, Hemsl. in foum. Limn. Soc. xxvi. (I891) 267 - China.

grandiflorum, Terrac, in Bull. Soc. Bot. Ital. (1892) 424. - Reg. Somal.

heterochrous, Briq. in Bot. Fahwo. xix. (1894) 173. - Congo.

iodocalyx, Briq.l.c. 174. - Congo.

menthaefolius, Briq. l. c. 176. - Angola.

molle, Baker, in Kew Bull. (1895) 275. - Afr. trop.

Parishii, Prain, iu fourn. As. Soc. Beng. lix. (1890) I1. 295. - Tenass

retinervis, Briq. in Bot. Fahrb. xix. (1894) 175. Congo.

roseus, Briq. 7. c. 174. - Afr, trop.

scabridus, Briq. l. c. 175. - Angola.

Schinzianus, Brig. l. c. 173. - Afr, austro-occ. extratrop.

sinensis, Hemsl. in fourn. Limn. Soc. xxvi. (1891) 268. - China.

Stuhlmannii, Guerke, in Engl. Pfanzenv. Ost-Afr.

C (1895) 349. - Afr. trop. or.
ORTHOSIPHON

tuberosus, Briq. in Bot, Fahyb. xix. (1894) 17\%. Angola.

tubulascens, Brig. l. c, 174. - Anorola.

usambarensis, Guerke, in Abh. Prenss, Akad. Wiss. (1894) 62 ; et in Engl. Pfanzente. Ost-Afr. C (1895 349. - Afr. trop. or.

villosus, Briq. nn Bot. Falhrb. xix. (1894) 17\%. Angola.

violaceus, Briq. l. c. 178. - Angrola.

Welwitschii, Rolfe, in Bolet. Soc. Brot. xi. (1893) $88^{\prime}$ - Angola.

ORYCTINA, Van Tiegh, in Bull, Soc, Bot. Fr, xlii. (1895) $168=$ Loranthus, Linn

scabrida, Van Tiegh. 1. c. 169 (= Oryctantus scabridus, Eichl.). - Am. bor.

ORYZA, Linn. (Gramin.).- Ind. Kew.ii. 378.

leersioides, Baill. in Bull. Soc. Linn. Paris,ii. (1892) 1062 = Potamophila leersioides, Benth.

Meyeriana, Baill. Hist. des pl. xii. (1894) 166 (= Padia Meyeriana, Zoll, \& Mor.). = sativa, Linn.

parviflora, Baill. in Bull. Soc. Linn. Paris, il. (is92) $106: 3=$ Potamophila parviflora, $R . B r$ prehensilis, Baill. 1. C. = P. prehensilis, Benth.

ORYZOPSIS. Michx (Gramin.). - Ind. Kew, ii

379. aduca, Beal, in Conlt. Bot. Gaz.xv. (1890) $111(=$ Stipa caduca, Scribn.). - Montana.

coerulescens, Trab. in Batt. \& Trab. Fl. de l'Algér. [Monoc.] (1895) $167=$ coerulescens. Hack.

Hendersoni, Vasey, in Contrib. U. S. Nat. Herb. (1893) 267. - Am. bor

uncea, Britton, Stern \& Poggenb. Prelim. Catal. (1888) $67=$ canadensis, Torr

membranacea, Vascy, Grass. Southwest. i. II. (1891) t 10; et in Contrib. U. S. Nat. Herb. iii. I. (1891) 56 (= Stipa membranacea, Pursh). Am. bor.

miliacea, Benth. \& Hook. f. ex Aschers. Eo Schweinf. in Mem.Inst. égypt. [Ill. Fl. Egypt.|(1Ss7) 169 (= Piptatheram miliacenm, Coss.), - Eur. Sibir.

miliacen, C. Richt. Pl. Europ. i. (1890) 33; G. Beck, F1. Nied.-Oest, i. (1890) 5l; Trab. in Batt \& Trab. Fl. de l'Algér. [Monoc.] (1895) $167=$ praec.

mongolica, Beal, in Coult. Bot. Gaz. xv. (1890) 111 (= Stipa monoolica. Turcz.). - Mongol.

obtusa, Slapf, ex Oliver, in Hook. Icon. pl. xxiv. $(1895)$ t. 2393 . - China.

paradoxa, Trab. in Batt. \& Trab. Fl, de l'Algér. [Dicot.] (1805) 167 paradoxa, Nutt.

Pringlei, Beal, in Coult. Bot. Gaz. xv. (1890) 11. = Stipa Prinolei, Scribn.). - Mexic.

pubiflora, Scribne ex Seaton, in Proc. Ann. Acad. xxviii. (1893) 12: (= Urachne pubiflora, Trin. \& Rupr.). - Mexic

purpurea, C. Richt. Pl. Europ.i. (1890) 34$\}=U$ purpurea, Steud.). - Pyren.

Richardsonii, Beal, in Coult. Bot. Gaz. xv, (1890 111 (= Stipa Richardsonii, Link). - Am. bor

virescens, G. Beck, Fl. Nied.-Oest. i. (1840) $51=$ Urachne virescens, Trin.) = paradoxa, Nutt. var. Wehberi, Vasey, in Bull. Torrey Bot. Club, xv. (1890) 49; et Ill. N. Am. Grass (1892) t. 18, in Contrib. U. S. Nat. Herb. iii. (1892) 55. Calit.

OSBEGKIA, Linn. (Melast.). - Ind. Kew ii. 379 Afzelii, Cogn. Isphalm. Hook. f.| in DC. Monog Phan. vii. (1891) 330 et 1178 (= Antherotoma Af zelii, Hook. f.). - Sierra-Leone.

Brazzaei, $\operatorname{Cog} n$. . . c. 335 . - Congo gall.

Buettneriana, Cogn. ex Buetn. in Verh Bot. Ver Brand. xxxi. (1889) 95 ; et l. c. 332. - Gabon, Congo gall,

Buraeavi, Cogn, in DC. Monog, Phan, vii. (1891) 335̄. - Congo gall.

cinerea, $\operatorname{Cog} n$, l. c. $11 \%$ - Tonk

cochinchinensis, $\operatorname{Cog} n$. l. c. 331. - Cochinch.

congolensis, Cogn. ex Buettn. in Terh. Bot. Ver Brand. xxxi, (1889) 95 ; et l. c. 314. - Congo. 


\section{OSBEGKIA :}

dionychoides, Cogn. ex S. Elliot, in fourn. Linn. Soc. xxix. (1891) 17; et in DC. Monog. Phan. vii (1891) 1178. - Madag

Elliotii, Cogn. $7 l$. cc. - - Madas.

hirsuta. $\operatorname{Cogn}$. l. c. - Angola.

madagascariensis, Cogn. l. c. 328. - Madag.

Nandini, Engl. Bot. Jahrb, xvii. (1893) 168, in obs.

$=\mathrm{O}$. Antherotome, Naud.

papuana, $\operatorname{Cog} n$, in Boerl. Handl. Fl. Ned. Indie, i, 11. (1890) 530, nomen; et in DC. Monog. Phan. vii. (1891) 332. - N. Guin.

saigonensis, Kuntze, Rev, Gen. (1891) 247.-Corhinch.

sublaevia, Cogn. in DC. Monog. Phan。vii. (1891) 321. - Ind. or

Welwitschii, Cogn. l. c. 333. - Angola.

zambesiensis, Cogn. in Bolet. Soc. Brot. vii. (1889) 226 ; ct l. c. 236. - Zambesia.

OSBERTIA, Greene, in Erythea, iii. (1895) $14=$ Erigeron, Linn. (Compos.)

Heleniastrum: Greene, 1. co = E. Heleniastrum, Greene.

stolonifera, Greene, 1, c. = Aplopappus stoloniferus, $D C$

OSERYA, Tul. \& Wedd, (Podostem.). - Ind. Kew, ii, 380 .

flagelliformis, Baill. in Bull. Soc. Linn. Paris, i. (1886) 647 (= Derillea flagelliformis, Tul. \& Wedd.). - Bras.

OSKAMPIA, Baill. in Bull. Soc. Linn. Paris, ii $(1890) 859=$ Nonnea. Medic. (Borag.)

flavescens, Baill. 1. c. $=$ N. flavescens, Fisch. \& Mey.

OSMANTHUS, Lour. (Oleac.). - Ind. Kew. ii. 380.

Delavayi, Baill, in Bull. Soc. Limn, Paris, i. (1886) 613. - Yunnan.

Fordi, Hemsl. in Foum. Limn. Soc. xxvi. (1889) 89. - China.

licifolius, Hort. ex Dippel, Handb. Laubholzk. i, (1889) 140 = Olea aquifolia, Sieb. E Zuco.

marginatus, Hemsl. ex Knobl. in Bot. Centralbl. 1xi. (1895) 83, in obs $=$ marginatus, Benth. \& Hook. $f$.

myrtifolius, Hort. Veitch. ex Dippel, Handb. Laubholzk. i. (1889) $\mathbf{1 4 1}=$ Olea aquifolia, Sieb. \& Zucc

rotundifolins, Hort. ex Dippel, 1. $c_{1}=$ O. aquifolia Sieb. \&o Zuco.

sandwicensis, Knobl, in Bot. Centralbl. 1xi. (1895 $82=$ sandwicensis, Benth. \& Hook. $f$.

OSMARONIA, Greene, Pittonia, ii. (Sept. 1891 $189=$ Nuttalia, Torr. \& Gray. [non Alior. (Rosac.).

cerasiformis, Greene, 1. c. 191 ; et Man. Bot. San Franc. Bay (1894) $110=\mathrm{N}$. cerasiformis, Torr \& Gray.

OSMELIA, Thw. (Samyd.). - Ind. Kew. ii. 380 aniculala, Warb. in Engl. \& Prantl. Natürl. Pflanzenfam. iii. 6a (1893) $49=$ O. Gardneri. Thw.

OSMOHYDROPHORA, Barb, Rodr. Vellosia. 1885-88, Sec edic, (1891) 49; K. Schum, in Engl. \& Prantl, Natürl. Pflanzenfam. iv, 3b (1895) 252, in obs.BIGNONIACEAE.

nocturna, Barb. Rodr. ll. cc. - Bras.

OSMORHIZA, Rafin. (Umbell.), - Ind. Kew. ii 381.

ambigua, Conlt. E F. N. Rose, Rev. N. Am. Umbell. 1888) 119 (= Glycosma ambigum, A. Gray).im. bor. occ.

Claytoni, Britton, Stern \& Poggenb. Prelim. Catal. (1888) $21=$ brevistylis, $D C$.

depauperata. Phil. in Anal. Univ. Chil. 1xxxv. (1S94) 926. - Chili.
OSMOXYLON, Miq. (Aral.), - Ind. Kew. 11. 381 Miquelii, Boerl. in Annal. Fard. Buit. vi. (1887) $125 .-\mathrm{N}$. Guin

OSSAEA, DC. (Melast.). - Ind. Kew. ii. 381. capillaris, Cogn. in Mart. Fl. Bras, xiv. IV. (1888) 550 ; et in DC. Monog. Phan. vii. (1891) 1053 (= Clidemia capillaris, Don). - Peruvia.

caudata, Cogn。 in DC, Monog. Phan. vii. (1891) 1066. - Ecuad

ciliata, $\operatorname{Cogn}$. , , c. $1067(=$ Octopleura ciliata, Triana) - Ins. Trinit.

congestiflora, Coon, in Mart. Fl. Bras, xiv. IV. (1888) 353 ; et l. . . $1054(=$ Oxymeris congestiflora Triana). - Bras.

cuneata, Cogn. ll. co. 550 ; et 1053. - Bras.

diversifolia, Cogn. l. c. 550 ; in Bull. Acad. Belg. Sér. III. xiv. (1889) 968 ; th in DC Monog. Phan. vii. (1891) 1064 (= Octopleura diversifolia, Triana). - Columb.

dizersifolia, Kuntze, Rev, Gen. (1891) $24 \mathrm{~S}=$ praec. fragilis, Cogn. in Mart. Fl. Bras. xiv. IV. (1888 551 ; ct in DC. Monog. Phan. vii. (1891) 1053. Bras.

humilis, Cogn. $7 l$. cc. 552; et 1054. - Bras.

Krugiana, Cogn. [in Sintenis, Pl. Portoric. n. 4642] in DC. Monog. Phan, vii. (1891) 1048. - Ins. Porto Rico.

macrophylla, Cogn.l. c. 1064 (= Octoplenra macrophylla, Triana). - Ins. Cocos.

quinquenervia, $\operatorname{Cogn}$. l. c. $(=$ Octoplenta aninquenevvia, Triana). - Ins. Tumaco, Cocos et PortoBello.

quinquonervia, Kuntze, Rev.Gen.(1891)24S = praec.

robusta, Cogn, in DC. Monog. Phan, vii. (1891) 1065 (= Octopleura robusta, Cogn.). - Am, austr.

rubescens, Cogn. T. c. $106 \%$ (= Oct. rubescons, Triana). - N. Granat.

sanguines, Cogn. in Mart. Fl. Bras, xiv. iv. (1888) 549; et 7. c. 105\%.- - Bras.

tetragona, Cogn. ex Th. Dur \& Pitt. in Bull. Soc. Bot. Belo, xxx, 1891 (1892) 264. - Costa Rica.

Trianaei, Cogn. in DC, Monog. Phan. vii. (1891) 1057. - Cuba.

Warmingiana, Cogn. in Mart, Fl. Bras, xiv, IV, (1888) 544 ; et in Vidensk. Meddel. naturh. Foren. (1889) 895 (Symb. Fl. Bras. centr. xxxii. 44): et l. c. 1050. - Bras.

OSTEOCARPUS, Phil. (Solan.). - Ind. Kew. ii.

brevifolius, Phil. in Anal. Uniw. Chil. xci. (1895) 40. - Chili.

clavatus, Phil. l, c. 41.-Chili.

foliolosus, Phil. l. c. - Chili.

lepidophyllus, Phil. l. c. 42. - Chili

spathulatus, Phil. $l, c, 41$. - Chili.

OSTEOMELES, Lindl. Rosac.).- - Ind. Kew. ji. 381

pernettyoides, Britton, in Bull. Torrey Bot. Club, xvii. (1890) 11 = pernettyoides, Decne.

OSTEOPHLOEUM, Warb. in Ber. Deutsch. Bot. Ges. xiii. (1895) 89. MYRISTICACEAE

platyspermum, Warb.l.c. $(=$ Myristica platysperma, Spruce). - Bras.

OSTEOSPERMUM, Linn.(Compos.). - Ind. Kew. ji. 381

montanum, Klatt, ex Schinz, in Bull. Herb. Boiss, iii. (1895) 432. - Afr, austro-occ. extratrop.

odoratum, Klatt, l. c. 433. - Afr. austro-occ. extratrop.

psammophilum, Klatt, l.c. 434. - Afr. austro-occ. extratrop.

tanaetifolium, Macovean, (Herb. Austro-Afr.n. 1382), ex Oliver, in Hook. Icon. pl. xix. (1889) t. 1839. Afr. austr.

OSTERDAMIA, Neck。=Zoysia. Willd. (Compos.) Matrella, Kuntze, Rev, Gen.(1891) $781=Z$. pungens, Willd.

sinica, Kuntze, 1. $c_{.}=Z$. sinica, Hance

temifolia, Kuntze, 1. c $=Z$. tenuifolia, Willd.
OSTODES, Blume (Euphorb.). - Ind. Kew。ii. 38 .

appendiculatus, Hook. f. Fl. Brit. Ind. v. (1887) 401. - Perak

muricata, Hook. f.l. c. - Perak.

OSTREARIA, Baill. [ubi?] ex Niedenzu, in Eng1, \& Prantl, Nitürl, Pflanzenfam, iii. 2a (1891) 130. HAMAMELIDEAE

australina, Baill. l. c.-Austr.

OSTRYA, Mich. ex Linn, (Cupulif,), - Ind, Kew. ii. 382

japonica, Sarg. in Gard, and For. v. (1893) 383 ; et Forest F1. Japan, (1894) 66 t. $22=$ virginica, Willd.?

Knowltonii, Sarg. l.c. vii. (1894) 115. - Am. bor.

Ostrya, MacMill. Metasp. Minn. (1892) $187=$ virginica, Willd.

virginiana, Britton, Stern \& Poggenb. Prelim. Catal. (1888) $49=$ virginica, Willd.

OSYRICERAS, Blume (Orchid.). - Ind. Kew. ii. 382

purpurascens, Fitzger. Austral. Orchids, v. II. (1895?) tab. (= Bulbophyllum purpurascons, Bailey). Austral.

OSYRIDOCARPOS, A. DC. (Santal.) - Ind. Kew. ii. 38\%.

Kirkii. Engl. Bot, Falvb, xix, Beib1. n. 47 (1894) 30 [Osyridocarpus]. - - Afr. trop. or.

scandens, Engl.l. c. 29. - Afr, trop. or

OSYRIS, Linn. (Santal.). - Ind. Kew. ii. 382

rigidissima, Engl. in Abh. Prewss, Akad. Wiss. 1891 ii. (1892) 199. - Reg. Somal.

tenuifolia, Engl. Pflanzenw. Ost-Afr. C (1895) 167. - Afr. trop. ox.

OTAGANTHUS, Lindl. (Acanth.). - Ind. Kew. ii. 382.

platychilus, Tanb, in Bot, Falurb. xi! Beibl, n, 28 (1890) 15. - Bras.

OTHONNA, Linn, (Compos.). - Ind. Kew. ii.

glauca, Klatt, ex Schinz, in Bull. Herb. Boiss. iii. (1895) 439. - Afr. austro-occ. extratrop.

disticha, N.E. Br. in Kew Bull. (1895) 16. - Afr. austr.

graveolens, O. Hoffm. in Bull. Herb. Boiss. i. (1893) 88 ; et in Engl. E Prantl, Natür. Pflanzenfam. iv. 5 (1893) 303. - Afr. austro-occ. extratrop.

lamulosa, Silhinz, in Bull. Herb. Boiss. iii. (1895) 439. - Afr. austro-occ. ex1ratrop

Lessingii, Klatt, in Amal. Naturh. Hofmus. Wien, ix. (1894) 368. - Afr. austr.

rosea, Klatt, c\% Schinz, in Bull. Herb. Boiss, ii (1895) 424. - Afr, austro-occ. extratrop.

Whyteana, Britten, in Trans. Linn. Soc. Ser. IL. iv. (1894) 21. - Afr. trop.

OTOCARPUM, Willk. Ill, F1, Hisp, ii. (1886-92) 145 t. 186 ; et Suppl. Prodr. Fl. Hisp. (1893) 83 sphalm. = OTOSPERMUM, Willk. = Matricaria, |Tourn.| Linn. (Compos.).

OTOGHILUS, Lind1, (Orchid.), - Ind, Kew, ii 384.

fragrans, Nichols. Dict. Gard. ii. (1886) 534. Reg. Himal.

OTOLEPIS, Turcz. = Capura, Blanco $(\mathrm{Sa}-$ pind.).

amplifolia, Pierre, F1. For. Cochinch. Fasc. 21 (1895) sub t. $331=$ Otophora amplifolia Pierre.

cambodiana, Pierre, 1. c. sub t, $330=0$. cambodiana, Pierre.

furcata, Pierre, 1, c. = O. furcata, Pierre.

nodosa, Pierre, 1. c. sub t. $331=0$. nodosa Pierre. 
OTOPAPPUS, Benth. (Compos.) - Ind, Kew ii. 384.

acuminatus. S. Wats, in Proc. Am. Acad. xxvi (18:1) 140. - Mexic.

alternifolius. Robinson, l. c. 165. - Mexic.

Aschenbornii, Klatt, in Annal. Naturh. Hofmus. Wien, ix. (1894) $362(=$ Verbesina Humboldtii, Klatt). - Mexic.

oaxacanus, Klatt, l. c. $(=V$. oaxacana, DC. $)$. Mexic.

olivaceus, Klatt, l. c. $(=V$. olivacea, Klatt $)$ Mexic.

perymenioides, Klatt, l. c. $(=V$. perymenioides, Sch. Bip. ex Klatt). - Am. austr.

Robinsonii. Klatt, 1. c。= V. alternifolia, Robinson

OTOPHORA, Blume (Sapind.). - Ind. Kew. ii. 384.

amplifolia, Pierre. Fl. For. Cochinch. Fasc. 21 (1895) t. 331. - Cochinch.

cambodiana, Pierre, l.c.t. 330. - Cochinch

furcata, Pierre, l. c. - Cochinch.

nodosa, Pierre, l. c. t. 331 - Coohinch.

pycnostachys, $K$. Schum. in Engl. Pfianzenw. OstAfr. C (1895) 393. - Afr. trop. or.

OTOSTEGIA. Benth. (Labiat.), - Ind, Kew, ii. 384

microphylla, Aschers, \& Schweinf, in Mém. Inst. égypt. ii. (188\%) [Illustr. Fl. Égypt.] $122=0$ Schimperi, Boiss.

OTTELIA, Pers. (Hydrochar.), - Ind. Kew. ii. 384.

plantaginea, Welw. ex Ridl. in foum. Linn. Soc. xxii. (1886) 238. - Angola.

vesiculata, Ridl. l. c. 237.-Angola.

OUBANGUIA, Baill. in Bull. Soc. Linn. Paris, ii. (1890) 869. TIL I ACEAE.

africana, Baill. l.c. - Congo gall.

OURATEA, Aubl. = Gomphia, Schreb. (Ochnac.). affinis, Engl, in Bot Jahrb. xvii. (1893) 79, in obs. Gilg, in Eno1. \& Prantl. Natïrl. Pflanzentam. iii. 6 (1893) $143=$ G. affinis, Hook. $f$

amplexicaulis, Baill, in Bull. Soc, Linn. Paris,

(1896) 587; et Hist. pl. Madag., Atlas (1890) t. 144 ; Gilg, 1. c. $=\mathrm{G}$. amplexicaulis, $O$. Hoffm. anceps. Baill: 1. c. = G. anceps, Baker.

angulata, Baill. 1. c ; Gilg, in Engl. \& Prantl, Natürl. Pflanzenfam. 1ii. 6 (1893) $142=\mathrm{G}$. angulata, $D C$

angustifolia, Baill. ex Laness. PI. util. Colon. Franç. (1586) 667 ; Gilg, 1. c. = G. angustitolia, Vahl:

calophylla, Eng1. Bot. Jahrb, xvii. (1893) 79, in obs, = G. calophylla, Hook.f.

comorensis, Engl. 1. c. 81. - Ins. Comor.

congesta, Engl. in Engl. \& Prantl, Natürl. Pflanzenfam. iii. 6 (1893) $142=$ Gomphia congesta, Oliver.

corymbosa, Engl. Bot. Jahrb. xvii. (1893) 80. Afr. trop.

arspidata, Eng1. ex Gilg, in Eng1. \& Prantl, Natürl. Pflanzenfam. iii. 6 (1893) 142= Gomphia cuspidata, St Hit.

deltoidea, Gilg. 1. c. = G. deltoidea, Baker.

dependesus, Baill. in Bull. Soc. Linn. Paris, 1. (1886) 587 ; et Hist. pl. Madag., Atlas (1890) t. 145 ; Gilo. in Encl, \& Prantl, Natürl, Pflanzenfam. iii. 6 (1893) $142=\mathrm{G}$. dependens, $D C$.

angata, Eng1. Bot. Jahrb. xvii. (1893) 80, in obs. = Gata, Engl. Bot. Jahr
$=$. elongata, Oliver.

glaberima, Engl. in Engl. \& Pranti, Natuirl. Pflanzenfam. iii. 6 (1893) 143 = G. glaberrima, Beau.

Hildebrandtii, Baill. in Bull. Soc. Linn. Paris, i. (1886) 587. - Madag.

Humblotii, Baill. 1. c. - Madag.

laevigata, Baill. 1. c. 584 ; et Hist. p1. Madag., Atlas (1890) t. $144=$ Ochna laevigata, $V a h l$

lanceolata, Baill. in Bu11. Soc. Linn. Paris, i. (1886) 587; Gilg, in Eng1. \& Prantl, Natürl. Pflanzentam. iii. 6 (1893) $142=$ Gomphia lanceolata, Baher.
OURATEA : -

Mannii, Eng1. Bot. Jahrb, xvii. (1893) 80, in obs. = Gomphia Mannii, Oliver.

obtusifolia, Gilg, in Engl. \& Prant1, Natiirl. Pflanzenfam. iii. 6 (1893) $142=\mathrm{G}$. obtusifolia, $D C$.

odora, Engl. 1. c. = G. odora, Poepp.

parviflora, Engl. 1. c. = G parviflora, $D C$.

persenefolia, Baill. in Bull. Soc. Linn. Paris, i. 1886) $587=\mathrm{G}$. perseaefolia, Bakir.?

podogyna. J. D. Smith, in Coult. Bot. Gaz, xvii. (1893) 2. - Guatem.

reticulata, Engl. Bot. Jahrb. xvii. (1893) 79 , in obs. = Gomphia reticulata, Beaur.

rigida, Engl. ex Gilg, in Engl. \& Prantl, Natürl. Pflanzenfam, iii. 6 (1893) 141. - Guian.

sumatrana, Gilg, 1. c. $142=$ Gomphia sumatrana, fack.

Vogelii, Eng1. ex Gilg, 1. c. = G. Vogelii, Hook. $f$.

OURISIA, Comm. ex Juss. (Scrophui.), - Ind. Kew. ii. 385 .

calycina, Culenso, in Trans. N.Z. Inst. xxi. 1888 1889) $97 .-$ N. Zel.

montana, f. Buch.l.c. xix. 1886 (1857) 214 t. 14. - N. Zel.

prorepens, Petrie, l. c. xxv. $1892(1893) 272 .-\mathrm{N}$

OUROUPARIA, Aubl. = Uncaria, Schreb. (Rubiac.).

africana, K. Schum, in Engl. \& Prantl, Natürl. Pflanzenfam, iv. 4 (1891) 57 = africana, Baill. Bermayszi, K. Schum. in K. Schum. \& Hollr. Fl. Kais. Wilh. Land (1889) 12S. - N. Guin.

ferrea, $K$. Schum. 1. C. = Uncaria ferrea, $D C$

sclerophylla, K. Schum. 1. c. $127=$ U. sclerophylla, Roxb.

OVIDIA, Meissn. (Thymel.). - Ind. Kew, ii, 386 anomala, Gilg, in Engl \& Prantl, Natuirl. Pflanzenfam. iil. 6 (1894) $239=0$. Humboldtii Meissn.

OVIEDA, Linn. Glerodendron, Linn. (Verben.) aculeata, Hitchcock, in Missouri Bot. Gard. Rep. iv. $(1893) 118=$ C. aculeatum, Griseb

OXALIS, Linn. (Geran.). - Ind. Kew. ii. 386.

aberrans, K. Reiche, in Bot. Fahrb. xvili. (1895) 28:3. - Chili.

adenocaulos, Phil. in Anal, Univ. Chil. 1xxxii 1893) 914. - Chili

Agassizi, 7. N. Rose, in Contrib. U. S, Nat. Herb. i. (1892) 136. - Ins. Galapag.

albiflora, F. Muell. in Vict. Natural. viii. (Feb. 1892) 164, nomen (= Biopliytum albiflorum, $\mathrm{F}$ Muell.). - N. Guin.

alfalfalis, Phit. $2 n$ Anal. Unim.Chn. 1xxxii.(1S93) 9:2. - Chili.

andina, Britton, in Bull. Torrey Bot. Club, xvi. (1889 159. - Bolivia.

araucana, $K$. Reiche, in Bot. Fahrb. xviii. (1894) 302. - Araucania.

areolata, Tanb. in Bot. Fahrõ. xvii. (1893) 504.Bras.

atacamensis, $K$. Reiche, in Bot. Fahrb. xviii. (1894) 286 ( = O. trichocalyx, Phil.). - Chili

binervis, Regel, in Act. Hort. Petrop. xi. (1890) 312 - Hab.?

Bojeriana, Bailt. in Bull. Soc. Linn. Paris, i. (1889) 597. - Madag.

boliviana, Britton, in Bull. Torrey Bot. Club, xvi. (1889) 159 - Bolivia.

Borchersi, Phil, in Anal. Univ. Chit. Ixxxii. (1893) 905. - Chil.

Breana, Phil. l. c. 1096. - Chili.

breviramulosa, Rusby, in Mem. Torvey Bot. Chü, iii. 11. (1893) 13. - Bolivia.

brevis, Phil, in Anal. Univ. Chil. 1xxxii. (1893) 906 = tarapacana, Phil

Bulbocastanum, Phil. l. c. 1095. - Chili.

caripensis, Hieron. in Bot. Fahrb. xx. Beibl. n. 49 . 1895) 32. - Columb.

catharinensis, $N$ E. Br. in Gard. Chron. (1887) i. 140. - Bras.

\section{OXALIS}

haetocalyx, Phil. in Anal. Univ. Chil. 1xxxii. (1893) 914. - Chili.

Chamaecrista, Baill. in Bull. Soc, Linn, Paris, i. 1886) 597. - Madag.

clematodes, F. D. Smith, in Coult. Bot, xviii. (1893) 198. - Guatem

Commersonii, Baill. in Bull. Sac. Limn. Paris, i. (1886) 598; et Hist. pl. Madag., Atlas (1889) t. 115 - Madag

Cornetii, Deverye, in Bull. Soc. Bot. Belg. xxxiii, 2 1894 (1895) 98, nomen. - Congo.

Darapskyi, Phil. in Anal. Univ. Chil. 1xxxii. (1893) 1096. - Chili

delicatula, Phil. l. c. 906. - Chili.

dimidiata, F. D. Smith, in Conlt. Bot. Ga\%. xv. (1890) 27 - Guatem.

Fluehmanni, Phit, in Anal. Uniz. Chit. 1xxxii. (1893) 901. - Chili.

Gilliesii, Phil. i. c. - Chili.

grandis, Small. in Bull. Torrey Bot. Club, xxi. (1894) $475 \mathrm{t}, 223$. - Am bor.

Hildebrandtii, Baill, in Bull, Soc. Linn, Paris, i. 1886) 597; et Hist. pl. Madag., Atlas (1889) t. 114. - Madag.

Hirthii, Phil. in Anal. Uni\%. Chil. 1xxxii. (1893) 1103. - Chili.

hypsophila, Phit.l. c. 903.-Chili.

illapelina, Phil. l. c. 1097. - Chili.

Inesitae, Phil. l, c. 1103 - Chili

Landbecki, Phil. ., c. 904. - Chili.

leptocaulos, Phil. l. c. 902. - Chili.

leucophylla, Phit.l. c. $9 ! 1$. - Chili.

madrensis, S. Wats. in Proc. Am. Acad. xxv. (1890)

144. - Calif.

Mariae, Szyszyl.Pl. Relmann. ii.(1888) 18.Transvaal.

microphylla. Phil. in Anal. Univ, Chil. 1xxxii. (1893) $903=$ exigua, Phil. [in Linnaea, xxxiii. 35 ?.

Mimosella, Baill. in Bull. Soc. Linn. Paris, i. (1886)

597; et Hist. pl. Madag., Atlas (1895) t. 113. Madag

mollis, S. Elliot, in fourn. Linn. Soc, xxix. (1891) 8 . - Madag.

oligotricha, Baker, in Kew Bull.(1890)64.--Afr. trop. ovalleana, Phil. in Anal. Univ. Chit. 1xxxii. (189:3 910. - Chili.

paniculata, $K$. Reiche, in Bot. Fahrb. xviii, (1894) 287. - Chili.

papuana, F. Muell. in Vict. Natural. ix. (Nov, 1892) 112; et in Bot. Centralbl. 1iii. (1893) 27. N. Guin.

Peraltae, Phil. in Anal. Univ. Chil. lxxxii. (1893) 909. - Chili.

pumila, Phil. l. c. 90\%. - Chili.

recurad, Trelease, in Mem. Bost. Soc. iv. (1888) 89 $=$ grandis, Small.

San Romani, Phil. in Anal. Univ. Chil. Ixxxii. (1893) $112=$ puberula, Phil

semiloba, $[N, E, B r]$ in Monteiro, Delagoa Bay

(1891) 165. - Afr. trop.

sylvicola, Rial. in fourn. Linn. Soc, xxvii. (1890) 25. - Ins. Fernando Noronha.

tarapacana, Phil. in Anal. Mus.nac. Chile (1891) 11. - Am. austr. occ.

thelyoxys, Focke, in Abh. Naturw. Ver. Brem. x. (1889) 516. - Cuba.

thyrsoidea, $K$. Reiche, in Bot. Fahrb. xvii,. (1894 287. - Chili.

torcana, Phil in Anal. Univ. Chil. Ixxxii. (1893) 905. - Chili.

trichophylla, Baker, in Kew Bull. (1895) 63. - Afr. trop. or

yungasensis, Rusby, in Mem. Torrey Bot. Club, iii. 3 (1893) 12. - Bolivia.

OXYANTHERA; Brongn. = Thelasia, Blume Orchid.)

decurva, Hook, ff Icon ph xxii. (1892) t. 2157 .

Penins. Mal.

elata, Hook. f. l. c. - Penins. Mral.

OXYANTHUS, L'Hérit. (Nyctag:), - Ind. Kew.

Monteiroae, N. E. Br. in Kew Bull. (1892) 125. Afr. trop. austro-or. 
OXYBAPHUS, L'Hérit. (Nyctag.). - Ind. Kew.

Bodini, Holzinger, in Contrib. U. S. Nat. Herb. i. $1893) 287$ t. 21. - Color.

dichotomus, Phil. in Anal. Univ. Chil. xci. (1895) 274. - Chili

San-Romani, Phil.l. c. 275. - Chili.

OXXGOGGUS, Tourn, ex Adans, (Vaccin.). Ind, Kew. ii. 392.

Oxycoccus. MacMill. in Bull. Torrey Bot. Club, xix. $(1892) 15=$ palustris, Pers.

OXYDECTES, Linn。 = Groton, Linn。(Euphorb.). abaitensis, aberrans, adamantina, adenocalyx, adenodonia, adenophora, adenophilla, adipata, adpressa, adspersa, agoënsis, agraria, agrophila, alagoënsis, albella, albida, alnifolia, althacacfolia, amabilis, amazonica, andina, angolensis, angustifrons, anisata, anisodonta, antisyphilitica, arguranthema, argyrata, argyrodaphne, arnhemica, aromatica, aspervima, astrogyna, Astroites, atronfu, axillaris, bahiensis, Bailloniana, balsamea, barbata, Benthamiana, betacea. Betulaster, betulina. bicolor, bidentata, bifurcata. Billbergiana, birmanica, Blanchetiana Boissievi, Boiviniand Bojeriana boliviensis, Boutoniana, bracteata, Bridgesii. Burchellii, buxifoliu, Cajucara, caldensis, californica, callicarpifolia, calocephala, calycina, campestris, caperoniaefolia, capitata, carinata, Caryophillus, Cascarilla, Getingana, candata, ceanothifolia, ceavensis, celtidifolia, cerina, cerinodentata, chaetocalyx, chatophora, chamaedryfolia, Chapelievi, chapodensis, chilensis, chlorocalyx, chlorolenca, chrysoclada, Chrysodaphne, ciliatoglandulosa, cincta, cincrella, citrifolia, cladotricha, Clausseniana, clavuligera, cneorifolia, coelococca, comata, comosa, compressa, consanguinea, constricta, Corchoropsis, cordiacfolia, coriacea, corricntesiana, Cortesiana, corylifolia, costaricensis, costata, Cotoneaster, craspedotricha, crenata, cubana, Cumingii, cuneata, debilis, decipiens, desertormm, dichotoma, dichroa, dioica, discolor, Draca, Draconotsis, Ehrenbergii, Eichleri, Elliotii, elliptica. Eluteria, eremophila, erioclada, eriostachya, erythrochila, exuberans, fallax, farinosa, fastuosa, ferruginea, ferruginella, flaiens, floribunda, flosculosa, fragilis, fragrans, Francasilleana, Francoana, Fraseri, Frieseana, Frionis, fruticulosa, fulva, Funckiana fusca Garcheana, Gardneri, Gardneriana, Gaudichandi,, Gibsoniana, glabella, glabrescens. glandulosa, ghutinosa, glyptosperma, gnidiacea, Gnaphalii, gossypifolia, Goudotii, gnyazensis, gracilescens. gracilipes, gracilis, gratissima, greweiaefolia, Griffthii, Grisebuchiana, Guildingii, Hancei, Hasskarliana hecatonandra, Helichnysunn, hemiargyrea. heterocalyx, heterocarpa, heterochroa, heterodoxa, heteroneura, heterotricha, Hialmarsonii, Hilarii, Hoffmannii, Holtonii. homolepida, Horminum, hor vidula, humilis, hypoleuca, incona, incerta, incisa, indivisa, insularis, intercedens, Itacolumi, jacobinensis, Fatropha, Fennyana, Fosephina, Foufra, Fulop. sidium, juncea, Korthalsii, lachnocarpa, lachnoclada, lachnostachya, lavevifoha, laevigata, lagoënsis, lanata, Langsdorffi, lamuginosa. Lapanus, Laseguci, lasiantha, lourifolia, laxiflora, Lechleri, leiophylla, leftobotrys, leptophylla. Leptopus, leptostachya, lew cophlebia, leucophylla, Liebmannit, Lindeniana Lindheimeriana, linearifolia, linearis, lobata, longifolia, longrnervia, lucida, lurida, Luziana, luzoniensis, macrocalyx, macrodonta, magdalenensis, malabarica, Malambo, naritima, Martii, mauritiana, medians, Medusae, megalobotrys, megalocalyx. megapontica. melanolenca, membranacea, menthodora, metallica, mexicana. micans, microcarpa, migrans, miradorensis, mollis, monanthogyna, Mongue, monteridensis, Moonii, morifolia, Mubango, mucronifolia, multicostata, muricata, musicapa. Mutisiana, myriantha, myricifolia, Myrsinites, neomexicana, Newtiledii, migroviridis, nilotica, nitrariacfolia, nivea, mobilis, Noronhae, Novi-Fribursii, mudata. nummularia, mummulariaefolia, oblongifolia, occidentalis, odontodenia, Oerstedtiana, oligantha, olivacea, Orbignyana. organensis, origanifolia, orinocensis, oralifolia, oxypetala oxyphylla, pachysepala, palanostigma, pallida, pallidula, paludosa, panamensis, panduriformis, pani cainta, pannssa, paraensis, pardina, parvifolia,

\section{OXYDECTES :}

parvula, pauciflora, pancistaminea, Pantiniana, Paulina, pautperula, Payeriana, pedicellata, pedunculata, pellita, peltophora, penninervis, peraffinis, pervestita, petraea, pilosa, pimelea, piptocalyx, polycarpa Pomaderris, populifolia, Pottsii, praetervisa, procumbens, Pseudo-Populus, pubescens, pulchella, pulchra. pulegiodora, punctata, puncticulata, pungens, Purdiaei, pycnadenia, pycnantha, pycnocephala, pyrifolia, quadrisetosa, ramiflora, veftexifolia, refracta, Regeliana. Regnelliana, repens, veticulata, Rheedii, rhexiaefolia vivularis, robusta, rosmarinifolia, Rudolphiana, rufoargentea, Ruiziana, Sagraeana, sahutaris, Sampatik santolina, sapiifolia, scaberrima scabiosa, scabra, Schiedeana, Schimperiana, Schultesii, sclerocalyx, Scouleri, Sellowii, seminuda, semivestita, serpyllifolia, serrata, serratifolia, siderophylla, sincorensis, Soliman, Sonderiana. Sonorae, soratensis, sordida, speciosa, Spica, spiralis, Spruceana, squamigera squamulosa staminosa, stenophylla, stenospala, stenotricha, stipulacea. Stoechadis, strigosa, stylosa, suaveslens, suavis, subacuta, subagraria, subcomosa, subcompressa, suberosa, subferraginea, subfragilis, subincana, sublepidota, sublucida, sublyrata, subrillosa, sumatrana, surinamensis, sylvatica. Tamberlikiz tarapotensis. Tartonraira, teincensis, tonella temuissima, terminalis, tetradenia, Teucridium, texensis, thermarum, Thouarsiana, thurifera thymelina, Tiglinm, tiliaefolia, tomentella, Torreyana, trianoularis, trichotoma, tricolor, tridentata, triglauldulata, trigonocarpa, Tulasnei, Turrialva, mumbratilis, Urucurana uriguayensis, varicata, Vauthierana, Velame, Velloziana, velutina, vepreto rum, Verreauxii, vestita, villosa, viminalis, vivens, sirgultosa, Virletiana, vulneraria, Wallichii, War mingii, Welwitschiana, Widgroniana, Wilsonii, xalapensis, ypanemensis, yunguensis, zambesica, Kuntze, Rev. Gen. (1891) 610-14 = homonyma ommia Crotonis.

abutilodes, Kuntze, 1. c. $610=$ Croton abutiloides, $H . B . \& H$.

almodea, Kuntze, 1, $\mathrm{c}_{2}=\mathrm{C}$, alnoidens, Bailt.

cmbanivulensis, Kuntze, 1, c. $611=\mathrm{C}$. ambanivoulensis, Baill.

ardisiodes. Kuntze, 1. c. $614=$ C. ardisioides, Hook. $f$.

argyrophyllodes, Kuntze, 1. c. $611=$ C. argyrophylloides, Muell. Avg.

atrata, Kuntze, 1. c. = C. versicolor, Mull. Arg.

Berlandieri, Kuntze, 1. c. $611=$ C. humilis, Limn.

Bernieri, Kuntze, 1. c. $610=$ C. Berniera. Baill.

bixodes. Kuntze, 1. C, $=$ C. bixoides. Vahl.

Blancoana, Kuntze, 1, c, $=$ C. Tiglium, Linn.

Bocquillonii, Kuntze, 1. c, $611=$ C. Bocquilloni Baill.

Bonplandiana, Kuntze, 1. c. $610=$ C. Persicaria Baill.

brevispicata, Kantze, 1. c. $609=$ C. brachybotryus, Muell. Arg.

ascarillodes, Kuntze, 1. c. $610=$ C. cascarilloides, Geisl.

cassiniodes, Kuntze, 1. c。 = C. cassinioides, Lam.

denticulata, Kuntzc, 1. c. $609=$ C. rhodostachyus, Muell. Arg.

draconodes, Kuntze, 1, c, $611=$ C. draconoides, Muell Arg.

dracunculodes, Kuntze, 1. c. $610=$ C: dracunculoides, Baill.

echiodes, Kuntze, 1. c. = C. eshioides, Baill.

ericodes, Kuntze, 1. c. $611=$ C, ericoiderts, Baill.

riocladodes, Kuntze, 1. c, $610=$ C. eriocladoides Muell, Arg.

rythroxylodes, Kuntze, 1. c. = C. erythroxyloides Muell. Arg.

fothergilliaefolia, Kuntze, 1. c. $611=$ C. fothergillaetolius, Baill.

Glazioni, Kuntze, 1. C. $613=$ C. Glaziovii, Muell. Arg.

glechomifolia, Kuntze, 1. c. $611=$ C. glechomaefolius, Muell. Arg.

gnaphaliodes, Kuntze, 1. c. $610=$ C. gnaphaloides,Schrad.

grangeriodes, Kuntze, 1. c. = C. grangerioides, $B \circ$.
OXYDECTES: -

grequiodes, Kuntze, Rev. Gen. (1891) $610=$ Croton grewioides, Baill.

guyancusis, Kuntze, 1. c. $=$ C. guyanensis. Aubl. Hadrianii, Kuntze, 1. c. = C. Hadriani, Baill.

helicodes, Kuntze, 1. c。 = C. helicoideus, Muell. Arg.

Heptalon, Kuntze, 1, c. = C. Berlandiera, Muell. Arg.

Hostmannii, Kuntze. 1. c. = C. Hostmanni. Miq. inversa, Kuntze, 1. c. = C. piauhiensis, Muell. Arg.

Isabellii, Kuntze, 1. c, $612=$ C. Isabelli, Baill.

Isertii, Kuntze, 1, $\dot{\mathrm{C}}_{1}=\mathrm{C}$. Iserti, Geisl.

famesoni, Kuntze, 1, c, $610=$ C. Jamesoni, Muell. Arg

japirensis, Kuntze, 1. co = C. laurifolius, Spach.

fardinii, Kuntze, 1. c. $612=\mathrm{C}$ Jardini, Muell. Arg.

jatrophifolia, Kuntze, 1. c. $610=$ C. jatrophaefolius, Muell. Arg.

Kalkmannii, Kuntze, 1. c. = C. Kalkmanni, Mwell. Arg.

Klaensei, Kuntze, 1. c. $613=$ C. Klaenzei, Muell. Arg.

Klotzschii, Kuntze, 1. c. $612=$ C. Klotzschianus, Thw.

laccifera, Kuntze, 1. c. $610=$ C. aromaticus, Miq. nacrobothrya, Kuntze, 1. Co = C. macrobothrys, Baill.

macrostachyo, Kuntze, 1. C. = C. macrostachys, Hochst.

Mandonii, Kuntze, 1. c. = C. Marıdonis, Muell. Arg.

maturensis, Kuntze, 1. c. $612=$ C. matourensis. A $u b l$.

Meisneri, Kuntze, 1. c. $=$ C. Meissncri, Mitell. Arg.

microstachya, Kuntze, 1. c. $610=$ C. microstachys, Baill.

Miqueliana, Kuntze, 1. c. = C. aromaticus, Miq. mepetifolia, Kuntze, 1. Cs = C. nepetaefolius, Baill. Paranae, Kuntze, 1. c. = C. Tiglium, Linn.

Pavoni, Kuntze, 1. c. = C. Pavonis, Muell. Arg. persimilis, Kuntze, 1. c. $612=$ C. Joufra, Roxb. phebaliodes, Kuntze, 1. c. = C. phebalioides, Muell. Arg.

plagiographa, Kuntze, 1. c. $613=$ C. plagiographis, Muell. Arg.

Pohliana, Kuntze, 1. c. = C. horridulus, Baill.

polyandra, Kuntze, 1. c. $609=$ C. brasiliensis, Muell. Arg.

pulegiodes, Kuntze, 1. c. $614=$ C. pulegiodorus, Britl.

riginifolia. Kuntze, 1. c. $610=$ C. rivinaefolius, $H$. B. \& $K$

roettlcrifolia, Kuntze, 1. c. = C. rottleraefolius, Baill.

Roxburghiuna, Kuntze, 1. c. = C. dioicus, Roxb, salviaefolia, Kuntze, l, $c_{0}=\mathrm{C}$. rhamnifolius, $H$. $B . \& K$.

Schlechtendaliana, Kuntze, 1. c. = C. fragilis, Schlecht.

Sellowiana, Kuntze, 1. c. $609=$ C. sphaerogynus, Balll.

sidifolia, Kuntze, 1. C. $613=$ C. sidaefolius, Lame.

stignatosa, Kuntze, 1. C. $610=$ C. phebalioiles, Muell. Arg.

subfloccosa, Kuntze, 1 c, $609=$ C. Lundianus, Muell. Arg.

Thwaitesiana Kuntze, 1. c. $613=$ C. Klotzschianus, Thw.

timandrodes, Kuntze, L. c. = C. timandroides, Muell. Arg,

omentosa, Kuntze, 1. c. 613 et $614=$ C. crassifolius, Geisl.

aticifolia, Kuntze. 1. c, $613=$ C. vrticaefolius, Lam.

vacoiniodes, Kuntze, L $_{\text {c }}$. $=\mathrm{C}_{\text {: }}$ vaccinioides, $A$. Rich.

Vaillantíi, Kuntze, 1。c. = C. Vaillanti, Geisl.

verbenifolia, Kuntze, 1. c. = C. verbenaefolius, Muell. Arg.

zeylanica, Kuntze, 1. c. $=$ C. reticulatus, Thunb.

Zippeliana, Kuntze, 1. Co = C. muricatus, Zipp. 
OXYGONUM, Burch.(Polygon.). - Ind. Kew. ii, 392.

atriplicifolium, Martelli; Fl. Bogos, (1886) 69 (= Ceratogonum atriplicifolnum, Meissn.). - A Abyss.

elongatum, Dammer, ex Engl. in Abh. Preuss. Akad. Wiss. (1894) 41; et in Engl. Pflanzenv. Ost-Afr. C (1895) 170. - Afr. trop. or.

salicifolium, Dammer, $l l$. cc. 41 ; et 175 . - Afr. trop. or.

Stuhlmannii, Dammer, l. c. 171. - Afr. trop. or.

OXYGRAPHIS, Bunge (Ranuncul.). - Ind. Kew. ii. 392.

Andersoni, Freyn, in Flora, lxx. (1887) $140(=R a-$ nunculus Andersoni, A. Gray). - Am. bor. occ.

breviscapa, Prantl, in Bot. Fahrb, ix. (1888) $2631=$ $R$ breviscapus, DC.). - Peruv.

Chamissonis, Freyn, in Flora, lxx. (1887) 141 (= R. Chamissonis, Schlecht.). - Am. austr.

Cymbalaria, Prantl, in Bot. Fahrb̆. ix. (1888) 263 (=R. Cymbalaria, Pursh). - Reg. bor. temp.

Delavayi. Franch, in Bull. Soc liot. Fr. xxxiii. (1886) 374. - China.

nubigena, Prantl, in Bot. Fahrb. ix. (1888) 262 (= Ramunculus nubigenus, Kunth). - Peruv.

plumbaginifolia, Prantl, l.c. $(=\bar{R}$. plunbaginifolins, Murr.). - Sibir.

tridentata, Prantl, i.c. (= R. tridentatus, Kunth). Am. austr.

vulgaris, Freyn, in Flora, 1xxi. (1887) 141: et in Deutsche Bot. Monatsschr. xiii. (1895) $92(=R$. glacialis, Linn.). - Reg. bor. \& arct.

OXYMERIS, DC. (Melast.). - Ind. Kew. ii. 392. dolichodons, Cham, ex Cogn, in Mart. Fl, Bras, xiy. IV. (1886) 177 = Leandra dolichodons, $\operatorname{Cog} n$.

OXYMITRA, Hook f. (Rubiac.). - Ind. Kew. ii. 393.

calycina, King, in foum. As. Soc. Beng. Ixi. (1892) 1I. 99. - Penins. Mal.

macrantha, Hemsi. in Kew Bull. (1895) 132; et in Hook. Icon. pl. xxiv. (1895) t. 2399 et 2400 . Ins. Salom.

OXYPETALUM, R. Br. (Asclep.). - Ind. Kew. ii. 393.
andinum, Phil. in Anal. Univ. Chil. xc. (1895) 204.
- Chili.

angustifolium, Phil.l. c. 202. - Chili,

Glaziovianum, Loesen. in Flora, 1xxii. (1889) 78. Bras.

Kuntzei, Schlechter, in Oest. Bot. Zeitschr.xlv. (1895) 453. - Reg. Argent.

Moelleri, Phit. in Anal. Univ. Chil. xc. (1895) 202 - Chili.

paraguayense, Schlechter, in Oest. Bot. Zeitschr. xlv. (1895) 454. - Parag.

parviflorum, Kuntze, Rev. Gen. (1891) 420, sphalm. = parvifolium, Phil.

parvifolium, Phil, in Anal. Univ. Chil. xc. (1895) 203. - Chili.

OXYPOLIS, Rafin. = Peucedanum, Tourn. (Umbell.).

filiformis, Britton, in Mem. Torrey Bot. Club, v. (1894) $239=$ Oenanthe filiformis, Walt.

vigidus, Britton, 1. c. $=$ Sium rigidum, Linn

OXYRIA. Hill (Polygon.). - Ind Kew. ii. 394 sinensis, Hemsl, in fourn. Linn. Soc. xxix. (1892) 317 t. 83. - China occ.

OXYS, Tourn. ex Adans. = Oxalis, Linn. (Geran.). oregana, Greene, Man. Bot. San Franc. Bay (1894) $71=$ Oxalis oregana, Nutt.

OXYSTELMA, R. Br. (Asclep.). - Ind. Kew. ii. 394.

Gilliesii, K. Schum, in Engl. \& Prantl, Natürl. Pfanzenfam。 iv. 2 (1895) 229 (= Philibertia Gilliesii, Hook. \& Arn.). - Am. austr.

Secamone, K. Schum. 1. c. = alpina, Decne.

solanoides, $K$ Schum. l. c. ( = Philibertia solanoides, H. B. \& K.). - Peruvia.

\section{OXYSTELMA : -}

violacea, K. Schum. in Engl. of Prantl, Natiirl. Pfanzenfam. iv. 2(1895) 229. - Chili.

OXYTENANTHERA, Munro (Gramin.). - Ind. Kew. ii. 394.

brachythyrsus, K. Schum. Fl. Kais. Wilh. Land (1889) 23. - N. Guin.

macrothyrsus, $K$. Schum, in Engl. Pfanzenw. OstAfr. C (1895) 11\%. - Atr. trop. or.

OXYTHECA, Nutt. (Polygon.). - Ind. Kew. ii. 394

hirtiflora, Greene, F1. Francisc, (1891) 153; et Man. Bot. San Franc. Bay $(1894) 48=$ Eriogonum hirtiflorum, A. Gray.

spergulina, Greene, 1. C. (1891) $153=$ Reddingiana, M. E. fones.

OXYTROPIS, DC. (Legumin.). - Ind. Kew, ii. cutirostris, M. E. fones, in Proc. Cahlf. Acad. Ser II. v. (1895) 677 (= Astragalus acutirostris,
Ser S. Wats.). - Calif.

Beketowii. Krassn. in Script. Hort. Univ. Petrop, ii. I. (1887-88) 15. - China.

dinarica, Murb. in Lunds Univ. Arsskrift. xxvii. V. (18?2) $143=$ campestris, Linn.

Foucaudi, Gillot, ex Bull. Soc. Bot. Fr. xlii. (1895) 51\%. - Pyren.

graeca, Hansskn, in Mitti, Bot. Ver. Fena, N. Folge, v. (1893) 84. - Graecia.

Halácsyana, Heldr. ex Hanssskn. l.c. 85. - Graecia. japonica, Mnxim. in Bull. Acad. Petersb. xxxi. (1887) 27. - Japon.

micans, Freyn of Sint. in Bull. Heib. Boiss, iii. (I895) 186. - Armenia.

nothoxys, M. E fones, in Proc. Calif. Acad. Ser. II v. $(1895) 677$ (= Astragalits nothoxy's, A. Gray). - Arizona.

prenju, G. Beck, in Annal. Naturh. Hofmus. Wien, ii. (1887) $122=0$. Halleri, Bunge.

Sintenisii, Freyn, in Oest. Bot. Zeitschr. xliv. (1894) 65. - As, Min.

sylinchanensis, Franch, in Morot, Fourn, de Bot. iy, (1890) 304. - China

Tatrae, Borb. in Dest. Bot. Zeitschr. xliii, (1893) 362. nomen, - Hung.

trichophora, Franch. in Morot, fourn. de Bot. iv, 1809) 303. - China.

tyrolensis, Fritsch, in Verh. zool.-bot, Ges. Wien, xxxix. (1889) $592=$ Astragalus tyrolensis, Sieb. yunnanensis, Franch. Pl. Delav. i. (1890) 163. Yunnan.

OYEDAEA, DC. (Compos.)。 - Ind. Kew, ii. 397. boliviana, Britton, in Bull. Torrey Bot. Club, xix. (1892) 149. - Bolivia

Pearcei, Rusby, in Mem. Torrey Bot, Club, iii. 3 (1893) 59. - Bolivia.

\section{$\mathbf{P}$}

PAGHIRA, Aubl, (Malv.). - Ind. Kew. ii. 397. obtusa, Spruce, ex K. Schum. in Mart.Fl. Bras, xii. III. (1886) 222. - Bras.

PACHITES, Lind1. (Orchid.). - Ind. Kew. ii. 397.

Bodkini, Bohus, Icon. Orchid. Austro-Afr, i. 1 (1892) t. 26. - Afr. austro-occ. extratrop.

PACHYACRIS, capensis, Schlechter, in Journ. Bot. xxxiii. (1895) 358, in obs, = Asclepias Tysoniana, Schlechter.

PAGHYanthus, A. Rich. (Melast.). - Ind. Kew. ii, 397.

corymbiferus, $\operatorname{Cogn}$. in DC. Monog. Phan. vij. (1891) 951 (=Chalybaea corymbifera, Natid.). N. Granat.
PACHYGENTRIA. Blume (Melast.). - Ind. macrorhiza, Becc. Malesıa, ii. (1886) 237 t. 56 f, 1-2; macrorhiza, Becc. Malesza, ii. (1886) 237 t. 56 f. 1-2;
Cogn. in DC. Monog. Phan. vii. (1891) $607 .-$
Borneo.

Maidenii, F. Muell. in Wing's South Sci, Record, New Ser. 1I. (Jan, 1886); et in Bot. Centralbl. xxvi. (1886) 20, in syn. = Medinilla Maidenii, F. Irull

microsperma, Becc. Malesia, ii. (1886) 238 t. 58 fig. 1-9; Cogn. in DC. Monog. Phan. vii. (1891) 609. microstyla, Becc. $7 l . c c .239$; et 606. - Borneo.

PACHYCHLAMYS brachyptera, Dyer, ex Brandis, in Journ. Linn. Soc, xxxi, (1895) 77, in syn.
$=$ Shorea brachyptera, Heim.

PAGHYGLADON, Hook. f. (Crucif.). - Ind.

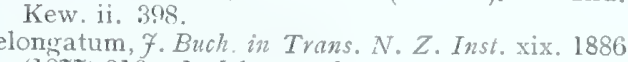
(1877) 216 t. 14 [elongata]. - N. Zel,

PAGHYGORNIA, Hook. $f$ (Chenop.), - Ind.

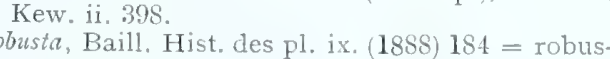
ta, Hook. $f$.

PACHYLOPHUS, Spach = Oenothera, Linn (Onagrar.)

caespitosi, Raimann, in Engl. \& Prantl, Natürl. Ptlanzenfam. iii. 7 (1893) $215=0$. caespitosa Nutt.

PAGHYNOGARPUS, Hook. f. (Dipterocarp.).Ind. Kew. ii. 398.

ruminatus, Brandis, in Fourn. Linn. Soc xxxi. (1895) 136 (= Vatica ruminatit. Burck). - Siam. Stapfianus, King, in foum. As. Soc. Beng. lxii. (1893) II. 136 ; Brandis, l. c. 136. - Perak.

vermucosus, Brandis, 1. $\mathrm{c}$, = seq

verrucosus, Heim, Recherch. Dipteroc, (1892) 107 (= Vatica verrucosa, Burck). - Borneo.

Wallichii. King, in fourn. As. Soc. Beng, lxii. (1893) II. 135; Brandis, in foum. Linn. Soc xxxi. (1895) 136. - As. trop.

PACHYPODIUM, Lindl. (Apocyn.).--Ind. Kew. ii. 399 .

brevicaule, Boker, in fourn. Linn. Soc. xxii. (1887) 503. - Madag.

cactipes, K. Schum, in Engl. \& Prantl, Natiurl. Pflanzenfam. iv. 2 (1895) 178. - Madag.

densiflorum, Baker, in fourn. Limn. Soc, xxii. (1887) 503. - Madag.

giganteum. Engl. Bot. Fahrb, xix. (1894) 147.Afr, austro-occ, extratrop.

Saundersii, N. E. Br. in Kew Bull. (1892) 126. Afr. austr.

PAGHYRHIZUS, Rich. ex DC. (Legumin.). Ind. Kew. ij. 3:99.

bulbosus, Britton, in Bull. Torrey Bot. Club, xix. (1859) $324=$ bulbosus, Kurz.

PACHYSANDRA. Michx (Euphorb.). - Ind.

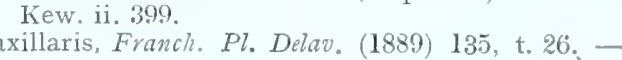
Yunnan.

PACHYSTELA, Pierre = Sideroxylon, Linn. (Sapot.).

brevipes, Baill. in Bull. Soc. Linn. Paris, ii, (1891) 947 , in obs. = S. brevipes, Baker.

Sacleuxii, Pierre, ex Baill.1, c. $946=$ S. Sacleuxii Baill.

PACHYSTIGMA, Hochst. = Fadogia. Schweinf (Rubiac.)。

ancylanthum, K. Schum, in Engl. Pflanzenw. OstAfr. C (1895) $387=$ F. ancylantha, Schweinf. decussatum, K. Schum. 1. c. - Afr. trop. or.

decussatum, K. Schum. 1. C. - Afr. trop. Or.
fuchisioides, K. Schum. 1. c. $=$ F. fuchsioides, Welw.

triphylhm. K. Schum.1. c. = F, triphylla, Baker.

Zeyheri, K. Schum. 1. c. = F. Zeyheri, Sond. 
PACHYSTIMA, «Rafin, » = Pachistima, Rafin, (Celastr

my'sinites, "Rafin. " ex Hamb. Garten und Blumen-Zeit. (1888) $559=$ Myginda myrtifolia, $\lambda^{\top} u t t$

PACHYSTOMA, Blume (Orchid.). - Ind. Kew.

Holtzei, F. Muell, in Vict. Natural. viii. (Mar. 1892 $180(=$ Enlophia Holtzei, F. Muell.). - Austral,

PAGHYSTYLUS, K. Schum. Fl. Kais. Wilh. Land (1889) 133. RUBIACEAE

Guelcherianus, K. Schum. l. c. : et in Engl. E Prantl, Nation. Pfanzenfam. iv. 4 (1891) 109.Aenningsianus, Warb. in Bot. Fahrb. xiii. (1891) 43\%. - N. Guin.

PADUS, Linn. = Prunus, Tourn. (Rosac.).

bracteata, Hort. Gall. ex Dippel, Handb. Laubholzk, iii. (1893) $647=$ Pr. Padus, Linm monstrosa, Hort. Gall. ex Dippel, 1. c. $621=\mathrm{Pr}$ Mahaleb. Lim.

PAEDERIA, Linn. (Rubiac.). - Ind. Kew.ii, 400 argenter. K. Schum. in Engl, \& Prantl, Natül. Pflanzenfam. iv. 4 (1891) $125=$ Lecontea arcrentea, A. Rich.

foetens, $K$. Schum. l. c. $(=$ Siphomeris foetens Hiern). - Afr. trop.

olens. K. Schum. 1. c. = Lygodisodea foetida Ruiz of Pai.

PAEONIA, [Toum.] Linn. (Ranuncul.). - Ind. Iiew, ii. 400 .

algeriensis. Chab. in Bull. Soc. Bot. Fr. xxxyi. (18s9) 18. - Algersa.

angustata, Rouy \& Fouc. Fl de Fr. i. (1893) 145 $=$ peregrina, 11 ill.

atlantica. Kraike cx Trab̉. in Bull. Soc. Bot. Fr. xxxri. (1889) 6\%. - Algeria

Delavayi, Franch. l. c. xxxiii. (1886) 382; Huth, in Bot. fahrb. xiv. (1892) 273. - China.

leiocarta, Rouy \& Fouc. Fl, de Fr, i. (1893) 145= peregrina, Mill.

lutea. Delaiciz', ex Franch, in Bull. Soc. Bot. Fr. xxxizi. (1886) 382; Huth, in Bot. Fahrb. xiv. (1892) 272. - China.

mascula, G. Beck. Fl. Nied,-Oest. i, (1890) $393=$ corallina, Rets.

oratifolia. Rouy \& Fouc. F1 de Fr. i. (1893) $144=$ orallina, Rets.

PAEPALANTHUS, Mart. (Eriocaul.). - Ind. Iiew. ii. 401

Beckii, Saj'szyl. ex Wawra, Itin. Princ. Saxo-Coburg. ii. (1888) 9\% - Bras.

Roraimae. Olicer, in Trans. Linn. Soc., Ser. II. ii. (188i) 286 , t. 49b Olizer, ox in Thum, in Timckri, v. (1886) 208), - Guian. ang1.

PAGAEA, Griseb. (Gentian.). - Ind. Kew. ii. 402 nemorosa. Gilg, in Engl. \& Prantl, Natiorl. Pfanamfan. iv. 2(1895) 102. - Am. austr.

pumila, Gilg, I. c. (= Brachycodon pumilus, Progel $)$. - IBras.

PAGEREA Iluoker, Pierre, ex Laness. Pl. util. Colon. Franç. (1886) 283, nomen. - Cochinch.

PAHUdi, Miq. (Legumin,). - Ind, Kew is 40:3. ochinchinensis, Picre, cx Laness, Pl. wit. Colon. Franc. (1886) 287. - Cochinch.

macrocarpa, Pierre, l. c.- - Cochinch

PAJANELIA, DC. (Bignon.). - Ind. Kew. ii, $40:$

longifolia, K. Schum. in Engl. \& Prant1, Naturrl. Pflanzenfam. iv. 3b (1895) $244=$ multijuga, $D C$.

PALAFOXIA, Lag. (Compos.). - Ind, Kew, ii. arenaria. T. S. Brandeg. in Proc. Calif. Acnd. Ser II. ii. (1889) 178. - Calif.
PALALA, Rumph, Herb. Amboin. ii. (1741) $28=$ Myristica. Linn.

amygdalina. andamanica, ardisiaefolia, argentea, aruana, attenuata, bancana, bialata. Biouliyba, bivalvis, Buchneriana, calophylla, canariformis, Cantleyi, capitellata, carinata, castancaefolia, cinerea, cuspidata, debilis, diversifolia, elliptica, elongata, eugeniaefolia, Farquhariana, fatua, fragrans, furfuracea, Gardneri, geminata, gibbosa, glabra, glaucescens, Globularia gordoniaefolia, gracilis, grandifolia, Griffithi, guatemalensis, ountteriaefolia, heterophylla, Hookeriana, hypargyraea, hypoleuca, hyposticta. iners, insipida, intermedia, inutilis, Irya, iteophylla, Kingii, laevigata, lancifolia, laurifolia, laurina, Lemanniana, lepidota, litoralis, longifolia, macrocarpa, macrocoma, macrophylla, macrothyrsa, madagascariensis, magnifica, Maingayi, malabarica, malaccensis, Mandaharan, numbranacea, mexicana, micrantha, Mocoa, mollissima, Murtonii, nyrmecophila, nesophila, Otoba, panamensis, peltata, pendulina, perwviana, platysperma. polysphaerula, punctata, Radja, rugulosa, Schleinitzii, scbifera, sessilis, simiarum, sphacrula, spicata. Sprucei, subglobosa, subsessitis, succedanea, superba, surinamensis, sylvestris, tingens, tomentosa, tubcrculata, tubiflora, uarpensis, valida, renosa, Wallichii. Kuntze, Rev, Gen. (1891) $567=$ homonyma ommia Myristicae. calocarpa, Kuntze, 1. c, = M. elliptica, Wall.

Commersonii, Kuntze, 1. c. $=$ M. Commersoni, Blitnle.

corticosa, Kuntze, 1. c. = M. glaucescens, Hook.f. E Thoms.

glomerata, Kuntze, 1. c。 = M. Horsfieldia, Blnme. Hostmanni, Kuntze, 1. Co = M. Hostmanni, Benth. Iryaghedi, Kuntze. I. c. = M. Horsfieldia, Blame. Leucuxylon, Kuntze, 1. c. = M. leucoxyla, Miq. lnanica, Kuntze. 1. C. = M. bracteata. A. DC morindifotia, Kuntze, 1. c. = M. fatua, Houtt.

palcmbanica, Kuntze, 1. c. = M. glaucescens, Hook. f. \& Thoms.

paniculata, Kuntze, 1. c. = M. Farquhariana, Wall. parifolia, Kuntze, 1. C. = M. parviflora, Roxb. Paconii, Kuntze, 1. C. = M. Pavonis, A.DC. philippensis, Kuntze, 1. co = M. philippensis, Lam. pinniformis, Kuntze, 1, c. = M. pinnaeformis, Zipp. subcordata, Kuntze, 1. c, = M. fatua, Houtt. sublanceolata, Kuntze, 1.c. = M. iners, Blume sycocarpa, Kuntze, 1. c. = M. elliptica, Wall. Teysmanmi, Kuntze, 1. C. = M. Teysmanni, Miq. thcodora, Kuntze, 1. c. = M. theiodora, Spruce.

PALAQUIUM, Blanco = Dichopsis, Thw. (Sapot.). canaliculatum, Eng1. Bot. Jahrb. xii. (1890) $511=$ Isonandra canaliculata, Thw.

ellipticum, Engl.1.c, = Bassia elliptica, Dol\% fuloosericemm, Engl. 1. c. - Borneo.

grande, Engl. l. c. = Dichopsis grandis, Thw.

Helfori, Engl. 1. C. = D. Helleri, C. B. Clarko.

hexandrum, Engl. 1. C。= Isonandra hexandra, Griff

lacrifolium, Eng1. 1. c. = I. laevifolia. Thw.

lanciolatum, Engl. 1. c, = I. lanceolata $T$ hw.

luzonicnse, Vidal, Revis, P1. Vasc. Filip. (18S6) 176. - Ins. Philipp.

Maingayi, Engl. Bot. Jahrb. xii. (1890) $511=$ Dichopsis Maingayi, C. B. Clarke.

Nadeaudi, Drake, Fl. Polyn. Franc. (1891) 120; et Ill. Ins. Mar. Pacif. (1892) 2\%9 (= Mimusops decussata, Nadeaud). - Ins. Societ.

obovatum, Engl. Bot. Jahrb. xii. (1890) $511=$ Isonandra obovata, Griff.

Ottelanderi, Koerd. \& Valet, Boomsoort. van Java, 1. (1894) 146. - Java.

pauciflorum, Engl. I. c. = I. pauciflora, Thw.

petiolare, Eng1. 1. c, = Dichopsis petiolaris, Thw. polyanthm, Engl. 1. c. = Bassia polyantha, $W$ all. rubens, Eng1. 1. c. = Dichopsis rubens, C. $B$. Clarke.

rubiginosum, Eng1. 1. c. = Isonandra rubiginosa, Ther

Thwaitesii, Trim. Handb. F1. Ceyl. iii. (1895) 84. Zeylan.

PALENIA. Phil. in Ana1. Univ. Chil, xc. (1805) 7. CO.11POSITAE

Delfini, Phil.l.c. - Chili.
PALICOUREA. Aubl. (Rubiac.), - Ind. Kew. ii. 403.

coriacea, K Schum. in Engl. et Prantl, Natürl. Pflanzenfam, iv. 4 (1891) $115=$ xanthophylla Muell. Arg.

discolor. Hort ex Hook, f. in Bot. Mag. (1888) t. 7001, in syn = nicotianaefolia, Cham. et Schlecht.

insularis, Ridl. in fourn. Linn. Soc. xxvii, (1890) 41. - Ins. Fernando Noronha.

megalophylla, K. Schum, in Engl. \& Prantl, Naturl. Pflanzenfam. iv. 4 (1891) $115=$ Psychotria megalophylla, Muell. Arg.

pentandra, K. Schum. 1. C. = Pal. Pavetta, DC.

Spruceana, K. Schum. 1. c. = Psychotria Sprucei, Muell. Arg.

PALISOTA, Reichb. (Commel.), - Ind, Kew. ii. 404 congolana, Hua, in Bull. Soc.Bot. Fr. xlii (I894) p. lii. - Afr. trop. occ.

plaoiocarpa, Hua, l. c. - Afr. trop. occ.

Tholloni, Hua, l c.-Congo gall.

PALIURUS, Tourn. ex Linn. (Rhamn.). - Ind. Kew. ii. 404 .

hirsutus, Honzst. in Kew Bnll. (1894) 388. - China. orientalis, Honsl. l. c. 387. - China.

PALLASIA, Scop = Crypsis, Ait. (Gramin.). aculeata, Kuntze, Rev. Gen. (1891) 781. = C. aculeata, Aiton.

PALMERELLA, A. Gray (Campanu1.). - Ind, Kew ii. 405 .

tenera, A. Gray, ex S. Wats, in Proc. Am. Acad. xxii. (1887) 433. - Mexic

PALMIJUNCUS, Rumph. Herb. Amboin. v. (1747) 95-119, ex Kuntze, Rev, Gen, (1891) $1731=$ Calamus, Linn. (Palm.).

acanthospathus, africanus, amplectens, andamanious, arborescens, arucnsis, asporrimus, Asliyanus, australis, Blancol, caesius, ciliarss, collinus, concinnus, coronarius, deerratus, delicatulus, densus, depressiusculus, Diepenzorstii, diocus, elegans, epetiolaris, cquestris, erectus, cxilis, farinosus, flabellatus, floribundus, gracilis, graminosus, grandis, Griffithianus, Guruba, Helferianus, heteracanthus, horrens. Huge lianus, hypoleucus, insignis, internuptus, javenesis, kentiaeformis, lacrigatus, latifoline, leptospadix. Iindenii, litoralis, longisetus, macropterus, Manan, manillensis, Navgaritae, marginatus, melanacanthus, molanoloma, Meycnianus, micracanthus, micranthus. mollis, Muclleri, Nicolai, nifidus, nivalis, opacus, ornatus, Oxleyanus, pachystemonus, palustris, papuanus, paradoxus, petraeus, philippensis, pisicarpus, platyspathus, plicatus, plumosus, polygamus, pulcher, pygmaeus, quinquencruius, radiatus, ramosissimus, reflexus, refractus, Riedelianus, rivalis, rudentum, Rungdung. schistoacanthus, Scipionum, servulatus. siphonospathus, spectabilis, subangulatus, simphysipus. tenuis, tetradactylus, thysanolepis, triqueter, unifarius, Veitchii, vestitus, viminalis, Walkeri, Kuntze, Rev. Gen. (1891) 733-34= homonyma omnia Calami.

accedens, Kuntze, 1. c. = Daemonorops Draco, Blumie.

adsporsus, Kuntze, 1. c. $733=$ D. adspersus, Blume.

amarus, Kuntze, 1. c. = Calamus tenuis, Roxb. ?

amboinensis, Kuntze, 1. $c_{0}=$ Daemonorops calapparius, Blume.

aureus, Kuntze, 1. $c_{1}=$ Calamus ornatus, Blume. barbatus, Kuntze, 1. c. $732=$ Daemonorops barbatus, Mart.

borneensis, Kuntze, 1. c. $733=$ Calamus javensis Blume.

brevifrons, Kuntze 1. c. = C. Blancoi, Kunth.

calapparius, Kuntze, 1. c. $731=$ Daemonorops calapparius, Blume.

culocarpus, Kuntze, 1. c. $733=$ D. calicarpus, Mart

calolcpis, Kuntze, 1. c. = Calamus melanoloma Mart.

caryotodes, Kuntze, 1. c. = C, caryotoides, A. Cunn. 
PALMIJUNCUS :

cochleatus, Kuntze, Rev. Gen. (189I) $733=$ Daemonorops cochleatus, Teijsm. 'E Binn.

crinitus, Kuntze, 1. c. = D. crinitus, Blume.

discolor. Kuntze, 1. c. = Calamus siphonospathus, Mart.?

Draco, Kuntze, 1. c. $732=$ Daemonorops Draco, Blume.

elongatus, Kuntze, 1. c. $733=\mathrm{D}$. elongatus, Blume. extensus, Kuntze, 1. c. = Calamus palustris, Griff. fasciculatus, Kuntze 1 c. = C. viminalis, Reinw.

Fenandezii, Kuntze, I.c. $=$ C. Oxleyanus, Teysm. E Bins.

fissus, Kuntze, 1. c. = Daemonorops fissus, Blume.

flagellum, Kuntze, 1. c. = Calamus polygamus, Roxb.

Gaudichaudii, Kuntze, 1. c. = Daemonorops Gaudichaudii, Mart.

geniculatus, Kuntze, 1. c. = D. geniculatus, Mart.

glaucescens, Kuntze, 1. c. = Calamus caesius, Blume.

gracilipes, Kuntze, 1. c。= Daemonorops, longipes Miq.

grandis, Kuntze, 1. c. = D. grandis, Mart.

Haenkeanus, Kuntze, 1. c. = Calamus mollis, Blanco.

Heliotropium, Kuntze, 1. c. = C. tenuis, Roxb.

heterodeus, Kuntze, 1. c. = C. Reinwardtii, Mart,

nirsutus, Kuntze, 1. c. = Daemonorops Hystrix. Mart.

Jumilis, Kuntze, 1. c. = Calamus latifolius, Roxb.

hygrophilus, Kuntze, 1. $c_{0}=$ Daemonorops hygrophilus, Mart.

Hystrix, Kuntze, 1. c. = D. Hystrix, Mart.

inemis, Kuntze, 1.c. = Calamus latifolius, Roxb.

intermedius, Kuntze, 1. c. = Daemonorops intermedius, Mart.

fonkinsianus, Kuntze, 1. c. = D. Jenkinsianus Mart.

Korthalsii, Kuntze, 1. c. = D. Korthalsii, Blume.

leptopis, Kuntze, 1. c. $733=$ D. leptopus, Mart.

Levisianus, Kuntze, 1. c. = D. Lewisianus, Mart.

macroacanthus, Kuntze, 1. c. = Calamus latifolius, Roxb.

macrocarpus, Kuntze, 1. c. $=$ C. erectus, Roxb.

malaccensis, Kuntze, 1. $c_{2}=$ Daemonorops malaccensis, Mart.

manicatus, Kuntze, 1. c. = D. crinitus, Blume.

maximus, Kuntze, 1. c. = Calamus manillensis $H$. Wendl.

melanolepis, Kuntze, 1. c. = C. Huegelianus, Mart

mirabilis, Kuntze, 1. c. = Daemonorops mirabilis, Mart.

mishmeensis, Kuntze, 1. c. = Calamus floribundus, Griff.

monoecus, Kuntze, 1. c. = C. Rotang, Linn,

montanus, Kuntze, 1. c. = C. acanthospathus, Griff

monticolus, Kuntze, 1. c, = Daemonorops monticolus, Mart.

Newmanni, Kuntze, 1.c. = Calamus Newmannii Hort.

niger, Kuntze, 1. c. $132=$ Daemonorops niger, Blume.

mutantiflorus, Kuntze, 1. c. = D. Jenkinsianus, Mart.

ovodeus, Kuntze, 1.c, = Calamus ovcideus, Thw.

palembanicus, Kuntze, 1. c. = Daemonorops palem banicus, Blame.

pallens, Kuntze, 1, c. = Calamus Reinwardtii, Mart.

penicellatus, Kuntze, 1, c. = C. javensis, Blume.

periacanthus, Kuntze, 1. c. = Daemonorops periacanthus, Miq.

petiolaris. Kuntze, 1. c. = D. petiolaris. Mart.

platyacanthus, Kuntze, 1. c. = Calamus oblongus, Reinw.

Pseudorotang, Kuntze, 1. c. $=\mathrm{C}$. viminalis, Willd radicalis, Kuntze, 1. c. = radicalis, $H$. Wendl. \& Drude

Rheedii, Kuntze, 1. c. = C. Rheedei, Griff.

rhombodeus, Kuntze. 1. C. $=$ C. rhomboideus, Blume.

Royleanus, Kuntze, 1. c. = C. tenuis, Roxb.

ruber, Kuntze, 1. c. = Daemonorops Draco, Biume.
PALMIJUNCUS: -

schizospathus, Kuntze, Rev. Gen. (1891) $733=\mathrm{Ca}$ lamus erectus, Roxb.

tetrastichus, Kuntze, 1. C。= C. javensis, Bhme. tigrinus, Kuntze, 1. c. = C. longisetus, Griff. trichrous, Kuntze, 1. c。 = Daemonorops trichous, Miq.

usitatus, Kuntze, 1, c. = D. Gaudichaudi, Mart. verticillatus, Kuntze, i. c. $=$ D. verticillatis, Mart. Wightii, Kuntze, 1. c. = C. Huegelianus, Mart. zebrimus, Kuntze, l, c. $=$ C. zebrinus, Beco

PALMIFOLIA, [UM] Trew = Zamia, Linn. (Cycad.).

angustifolium, Chigua. debile, Fischeri, furfuraceum, integrifolium, Kiclexii, latifolium, Loddigesii, medium, multifoliatum, muricatum, Ottonis, Poeppigia num, Pseudoparasiticum, pumilum, pygmaeum, Skinneri, spartoum, tenue, Kuntze, Rev. Gen. (1891) $\mathrm{S} 03$ = homonyma omnia Zamiae.

angustissimum, Kuntze, I. c. $=Z$. angustifolia,

facq.
bolivianum, Kuntze, 1, c, $=Z$, boliviana, $D C$.

floridanum, Kuntze, 1. c. $=Z$. angustifolia, facq.

Galeottii, Kuntze, 1. c. $=$ Centrozamia mexicana, Brongn.

mexicanum, Kuntze, 1. c. = Zamia Loddigesii Miq.

strictum, Kuntze, 1. c. = Z. angustifolia, facq.

Yatesii, Kuntze, 1. c. $=Z$. angustifolia, facq.

PANARGYRUM, D. Don = Nassauvia Juss. (Compos.).

acerorm, Phil, in Anal. Univ, Chil. 1xxxvii. (1894) 97. - Chili.

laxum, Phil. 1. c. 一 Chili.

pectinatum, Phil. 1. c. 96. - Chili

subspinosum, Phil. 1. c. 9s.-Chili.

PANAX, I.inn. (Arab.). - Ind. Kew. ii. 404. affine, Cortem. Fl. Ile Rérnion (1895) 437. - Ins. Borbon

compactum, Hort.? ex Barb. Rodr. Hort. Flumin. $1893(1895) 243 .-\mathrm{Hab}$.

crispatum, Hort. Bull, Catal. (1888) 9 ; et ex Gard. Chron. (1888) ii. 273. - Bras.

Davidi, Franch. in N'our'. Arch. Mus. Paris, Sér. II. viii. 1885 (1886) 248. 一 Tibet.

gomphophylium, Baker, in fourn. Linn. Soc. xxii. (1887) 480 [gomphophylla]. - Madag.

Hermanni, Cordem. Fl. Ile Rémion (1895) 437 Ins. Borbon.

integrifolium, Colenso, in Trans. $N$, Z. Inst. $x x$ 1887 (1888) 192 [integrifolial. - N. Zel.

lepidum, Hort. Bull, Catal. (1888) 9; et ex Gard. Chron. (1888) ii.273. - Bras.

Macdowalli, F. Muell. in Wing South. Sci. Record, New Ser. (April 1886). extr. 4. - Austral.

nitidum, Hort. Bull. Catal. (1888) 9; et ex Gard. Chron. (1888) ii. 273 - Bras.

ornatum, Hort. Bull. ll. cc. - Bras.

plumatum, Hort. ex Barb. Rodr. Hort. Flumin. 1893 (1895) 243. - Hab. ?

repandum, Cordem. Fl. Ile Rémnion (1895) 436 (= Polyscias repanda, Baker). - Ins. Borbon.

Victoriae, Hort. ex Barb. Rodr. Hort. Flumin. 1892 (1895) 243. - Hab. ?

PANCOVIA, Willd, = Erioglossum, Blume (Sapind.).

Delavayi, Franch, in Bull. Soc. Bot. Fr. xxxiii. (1886) 461 (= Sapindus Delavayi, Radlk.). China occ.

Teckeli, Claudel, in Ann. Inst. Colon, Marseille, ii. (1895) n. 11. 45. - Afr. trop. Occ

PANGRATIUM, Dill. ex Linn. (Amary11.). Ind. Kew. ii. 406

Saharae, Coss. ex Batt. E Trab. Fl. de l'Algérie [Monoc.] (1895) 46. - Algéria.

PANDANUS, Rumph. ex Linn. (Pandan.). - Ind. Kew, ii. 407.

Augustianus, L. Linden of Rodigas, in Illustr. Hortic. xxxiii. (1886) 15\%, t. 612, - N. Guin.

\section{PANDANUS :}

Baptisti, Hort. ex Wien. Illustr. Gartenzeit (1893) 306 ; Rev. Hortic. Belg. xix. (1893) 167, fig. 35̃. - Hab.

Barterianus, Rendle, in foum. Bot. xxxii. (1894) 32.4 (Barteriana). - Ins. Fernando-Po.

ceramensis, Hort, ex Gard. Chron. (1888) ii. 63l = labyrinthicus, Kurz.

ceramicus, Hort. 1. c. = praec.

Danchelmannianus, K. Schum. in K. Schum. E Holly Fl. Kais. Wilh, Land (1889) 17. - N. Guin.

dyckioides, Baker, in Fourn. Limn. Soc, xxii. (1887) 527. - Madas.

Grusonianus, L. Linden \&o Rodigas, in Illustr. Hortic. xxxiv. (1887) 35, t. 12, - Ins. Amirant. Hombronia, F. Muell. in Vict. Natural, vii. Lerr. typ. viii] (Jan. 1891) 143; et ex Bot. Cenivalbl. xlv. (1891) 123 (= Hombronia edulis, Gaudich,). Austral.

Kerchovei, L. Linden \& Rodigas, in Illustr. Hortic xxxiii. (1886) 95 t. 590, - Ins. Amirant.

Kirkii, Rendle, in fourn. Bot. xxxii. (1894) 326.Zanzibar.

Krauclianus, K. Schum. in K. Schum. \& Hollv. Fl. Kais. Wilh. Land (1889) 18. -. N. Guin

Livingstonianus, Rendle, in fourn. Bot, xxxii. (1894) 336. - Zambesia

myriocarpus, Baker, in Fontun. Linn. Soc. xxv. (1890) 347. - Madag.

nemorosus, Cordem. Fl. Ile Rémion (1895) 149 (= P. syluestris, Bory). - Ins. Borbon.

odorifer, Kuntze, Rev. Gen. (1391) $737=$ cdoratissimus, Linn. $f$

rabaiensis, Rendle, in Fourn. Bot. xxxii. (1894) 325 et nn fourn. Linn. Soc, xxx. (1895) 432, t. 34 fig. 1-6. - Afr. trop. or. [Mombassa].

sparganioides, Baker, in foum. Bot. xxv. (1890) 347. - Madag.

thomensis, Solms, in Bolet. Soc. Brol.v. (1887) 206 t. E. - Ins. S. Thom.

Thurstoni, Wright, in Kew Bull. (1894) 34S. - Ins. Fiji.

Welwitschii, Rendle, in Fourn. Bot. xxxii. (1894) 324. v. 347. - Angola.

PANDERIA, Fisch. \& Mey. (Chenopod.). - Ind Kew。 ii. 409 .

pilsoa, Hook. f. \& Thoms. ex Hook, f. Fl. Brit Ind. v. (1886) 11 = Kochia odontoptera, Schrenk, et indica, Wight.

PANDOREA, Spach = Tecoma. Juss. $($ Bignon. $)$ austro-caledonica, Bureau, ex Baill. Hist, des pl. x. (1888) 40; K. Schum, in Eng1. \& Prantl, Natürl. Pflanzenfam iv, $3 b(1894) 230=\mathrm{T}$, austrocaledonica, Bureau.

ceramica, "Baill. » ex K. Schum. 1. c. = T. cera. mensis, Teijsm. EN Binn.

jasminoides, K. Schum, 1. C. = T. jasminoides, K. Schum.

Ricasoliana, «Baill, » ex K. Schum. 1. $c$, = T. Ri casoliana, Tanf

PANGIUM, Reinw, (Bixin.) - - Ind. Kew. ii. 409 Naumanni. Warb. in Engl. Eo Prantl, Natiirl. Pflanzenfam, ii. 6a (1893) 23.- N. Guin.

PANICASTRELLA, Moench = Echinaria, Desf (Cramin.).

capitata, Baill. Hist. des p1. xii. (1894) $232=$ capitata. Moench

PANICULARIA. Fabr. = Glyceria. $\mathrm{R}, \mathrm{Br}$ (Gramin).

acutiflora, aquatica, australasica, canadensis, distans, dives, clongata, fuitans, Fordeana, glauéescens, latispicea, magellanica, nervata, pallida, pauciflora, procumbens, ramigera, remota, syrtica Kuntze Rev. Gen. (1891) 782-83 = homonyma omnia Glyceriae.

Fendleviana, Kuntze, 1.c. $7821=$ Atropis californica Munro). - Am. bor. occ

latifolia, Kuntze, 1. c. = Catabrosa latifolia, Plill. Nuttalliana, Kuntze, 1. c. $(=$ Poa temifolia, Nutt. $)$

- Am. bor. Occ.

obtusa, Kuntze, 1. c, = Poa obtusa, Muhl. 
PANICULARIA : -

cabrella, Kuntze, Rev. Gen. (1891) 782 = Poa scabrella, Benth.

zcmuifoliu, Kuntze, 1 c。 = Catabrosa tennifulia, f. Prish.

Thurberiana, Kuntze, 1. c, = Poa pauciflora, Benth. americuna, MacMill. Metasp. Minn. (1892) $81=$ Glyceria aquatica, Wuthlenb. var.

angustata, Scribn, in Mem. Torrey Bot. Club, v. (1\$94) $54=\mathrm{G}$. angustata, Fries,

brevifolia, Porter, in Bull. Torrey Bot. Club, xx. (1843) $205=$ G. acutiflora, Tor

laxa, Scribn. 1. c. xxi. (18:4) $37=$ G. laxa, Scribn. maritina, Scribn. in Mem. Torrey Bot. Club, v.

(18:94) $54==$ G. maritima, Mert \& Koch.

PANICUM, Linn. (Gramin.). - Ind. Kew. ii. 409. adenophorum, $K$. Schmm, in Engl. Pfanzenw. OstAfr. C (1895) 103. - Afr. trop. or.

aequiglume, Hackel \& Arechav. in Anal. Mus, nac. 110nterid. ii. (1894) 111. - Urug.

alburellereum, $K$. Sclann. ex Engl. in Abh. Preuss. Aknd. Wiss. (1894) 36; et in Engl. Pfanzenw. OstAfr.C (1895) 101. - Afr. trop. or.

amoenum, Balcinsa, in Mlorot, fourn. de Bot, iv. $(18.0) 142 .--$ Cochinch.

arrectum, Hack. ex Th. Dur. \& Schinz. Consp. Fl. Afr. v. J894 (le95) 74l (= P. subquadriparam, Nees). - Afr, austr.

arundinitolium, Schweinf. in Bull. Herb. Botss. II. App. ii. (1894) 20. - Eritrea.

atrotuscum, Hack. ex S. Elliot, in fourn. Limn. Soc. xxix. (18.91) 6:3. - Madag.

basisetum, Franch. in Bull. Soc hist, nat. Autunz. riii. (1895) 3533 (= Setaria basiseta, Th. Dur. \& Schinz). - Afr. trop.

bambusoides, Spegaza. ex Arechar, in Anat. Mlus. nat. Monterid. ii. (1894) 128 t. 9 et 10. - Urug.

Buirinianum, Th. Dut. E Schinz, Consp. Fl Afr 1894 (1895) it: ( = Hymenache Boirinianum, Steud.). - Ins. Nossibe.

bureale, Nash, in Bull. Torroy Bot. Club, xxii. (1895) 421 - Am bor.

Bergi, Arechar. in Anal, Mus, nac. Monterd. i (1894) 14i. - Uruguay,

brachyoum, Hacks, ix Sching, in Vork Bot, Vor. Brand. xxx. (1888) 14\%. - Afr. austro occ. extratrop.

Bradypus, Bory, ex Th. Dur. \& Schinz, Consp. F1. Afr. เ. $1894(1895) 734$, in syn. = Zoysia pungens, Willh.

Buckleyanum, Vasey, in Contrib, U. S. Nat. Herb. (1594) 499. - Am. bor.

cambugiense, Batinnsa, in Morot, fourm. de Bot. is 18\%0) 142. - Cochinch.

capillarioides, Vasey, in Contrib. U.S. Nal, Horb. i. (1890, 54: ii. (1894) 507, et iii. (1892) 333. Texas.

chusquevides, Hack. in Bull. Harb. Boiss. iii. (1895) $3 i \overline{6}$ - Natal

Gliatissimum, Buckl. in Bull. U. S. Depl. Aoric Dia' Bot. viii. (1n89) 28 ; at in Contrib. U. S. Nat. Herb. iii. (1892, 29 - Texas

(inereum, Hillibr. Fl. IIaw, Isl. (1888) 500, - Ins. Sandric

cuntusum, C. Cordent. Fl. Ile Réunion (1895) 118. Ins. Burbun.

crinitum, Ilack. cx Th. Dur. E S Schinz, Consp. Fl. Afr. $T .1894$ (1895) 744, nomen. - Afr. trop.

decempedale, Kuntze, Rev. Gon.(1891) 783. - Rew I Iimal.

deltoideum, Hack. cx S. Elliot, in foum. Linn. Soc. xxix, (1891) 64. - Maclaw.

dissitiflorum, Vasey, ex S. Whats in Proc, Ann Acad. xxiv (1889) 80; [an Steud.?] et ex Scribn. in Zoë, iv. (1894) 387. - Mexic.

dorsisetum, Hack. ex T\%. Dur. E Sclinz, Consp Fl. Afr. v, 1894 (189.5) 748 , nomen. - Transvaal.

Drummondii, Vascy, in Contrib. U.S. Nat. Herb. ii. (1s!14) 499. - Am, bor

Echinuchloa, Th. Dur. E. Schinz, l. c. [an P. Echinockloa, Steud. ?] (= Echinochloa diraricata. Anderss.) - Miossamb.

filiculme, Hack. ex Schnz. in Bull. Herb. Boiss, iii. (18,5) 3.1\% - Natal.

\section{PANIGUM :}

fliferum. "Garcke » ex Sagorski \& Schneid. Fl. Centralkarp. index; (1891) p. 37, sphalm. = filiturme, Garcke.

filipes, Scribn. in Contrib. Herb. Frankl, i. (1895) 13. [Bot Explor. S. Texas]. - Texas.

fexile. Scribn. in Bull. Torrey Bot. Club, xx. (1893) $475=$ diffusum. Pursh

gabunense, Hack. ex Butin. in Verh, Bot. Ver. Brand. xxxi. (1889) 70. - Gabon.

glanduliferum $K$. Schum, in Abh. Naturw. Ver Brent, ix. (1889) 401. - Madag.

glomeratum, Hack, ex Schinz, in Verh. Bot. Ver Brand. xxx. (1888) 141. - Afr, austro-occ. extratrop.

Gussonii, C. Richt, Pl, Euroh, i. (1S90) 26. - Ins. Ischia.

Hallii, Vasey, in Contrib. U. S. Nat. Herb. ii. (1894 508. - Am. bor

Havardii, Vasey, in Bull. Torrey Bot Chb, xix. (1887) 95 ; et in Contrib. U.S. Nat.Herb. ir. (1894) 509 ; et iij. (1892) 36. - Texas.

Hildebrandtii, Hack, ex Th. Dur. G Schinz, Consp. Fl. Afr. v, 1894 (1895) 750, nomen. - Ins. Nussibe.

hippothrix, K. Schum. ex Engl, in Abh. Prouss. Akad. Wiss. (1894) 22; et in Engl. Pfanzenw, Ost-Afr. C (1895) 103. - Afr. trop. or.

imbricatum, Hillebr. Fl. Haw. Ist. (1888) 501. Ins. Sandvic

incisum, Munro, ex C. B. Clarke, in fourn. Linn. Soc. xxv. (1889) 84 t. 33. - - Ind or

Joorii, Vasey, in Bull. U. S. Dept. Aglic. Div. Bot viii. (1889) 32: et in Contrib. U. S. Nat. Herb iii. (1892) 31. - Am. bor.

laevifolium, Hack, in Bull. Herb. Boiss, iii. (1895) 37s. - Transvaal.

lasiocoleum, $K$. Schun, cx Engl. in Abh. Prenss. Alad. Wiss. (1894) 14, 23 et 3.5, nomen. - Afr. trop.

leucacranthum, K. Schum. in Engl. Pfanzenw. Ost Afr. C (1895) 102. - Afr. trop. or.

luridum, Hack ex S. Elizot, in Foum. Limn. Soc xxix. (1891) 64. - Madar.

macrostachyum, Hochst, ex Th, Dur \& Schinz, Consp. H1. Afr. v. $1894(1895) 763$, in syn. = sanguinale, Lim.

Marlothii, Hack. in Bot. Fahro. xi. (1820) 398. Atr. austr

melanotylum, Hack. l. c. - Afr, austr.

milanjianum Rendle, in Trans. Linn. Soc. Ser. II. iv. (1894) 56. - Afr. trop.

minus, Nash, in 13ull. Torrey Bot. Club, xxii. (1895) $421=$ diffusum, Pursh

mitopus, K. Schum, in Engl, Pfanzenw. Ost-Afr. C (1895) 103. - Afr. trop. or.

montanum, Poit. ex Fourn. Gram. Mexic. 1881 $(1886) 30=$ pallens, $S w$.

monticola, Hillcbr. Fl. Haw. Isl. (I88s) 500. - Ins. Sandvic.

mossambicense, Hack, in Bolot. Soc. Brot. vi. (1888) 140; et ex Th. Dur. \& Schinz, Consp. Fit. Afr, v. 1894 (1895) 755, nomen, - Mossamb.

Munruanum, Balansa, in Morot, foum. de Bot. iv. (18!0) 140. - Cochinch

najadum, Hack. of Arechar. in Anal. Mus. nac. Monterid. ii. (1894) 123 t. 7bis et 8. - Uruguay.

Nealleyi, Vascy, in Bull. Torrey Bot Club xii. (1886) 25. - Texas.

nigritanum, Hack, ex Th, Dur. \& Schinz, Consp. Fl. Afr. v. 1894 (is95) 756, nomen. - Afr. trop.

itidum. Hack, \& Arechar in Anal Jins nos. Montevid. ii. (18:14) 131.-Urueuay.

nudicaule. Vasey, in Bull. U. S. Dept. Agric. Div Bot. viii. (1889) 31. - Florida

oblongum, Hack. ex Tonduz, in Bull. Herb. Boiss. iii (18\%5) 450, nomen, - Costa Rica.

oplismenoides, Hack. in Bolet. Soc. Brot. vi. (1888) 141. - Mossamb.

oryzetorum, Balansa, in Morot, foum. de Bot. iv. (1890) 141 - Cochinch.

ononbiense, Balansa, l. c. 142.-Cochinch.

oxyanthrm, Steud. ex Th. Dur. \& Schinz, Consp. Fl, Afr. v. 1894 (1895) ' 640 , in syn. = anabaptistum. Stoud.

\section{PANICUMI}

Palmeri, Vasey, in Contrib. U. S. Nat. Herb. i. (1893) 281. - Mexic.

paucispicatum, Morong, in Ann. N. Y. Acad. Sci. vii. (1893) 26\%. - Parag.

pectinatum, Rendle, in Trans. Linn. Soc., Ser. II. iv. (1894) 54. - Afr. trop.

pedicellatum, Vasey, in Bull.U.S. Nat. Dept. Agric. Div. Bot. viii. (1889) 28 ; et in Contrib. U. S. Nat. Herb ii. (1894) 5 \%, iii. (1892) 29. - Texas.

pertense, Boevl. in Ann. Fard. Buitenz, viii. (1889) 51 (= Digitaria pertensis, Buese). - Ins. Banca. platynotum, K. Schum, in Engl. Pfanzcnw. Ost-Afr. C (1895) 101. - Afr. trop. or.

platyphyllum, Munro, ex Bull. U. S. Dept Agric. Div. Bot. viii. (1883) 25; et Contrib. U. S. Nat. Herb. iii. (1892) 27. - Texas.

Porterianum, Nash, in Bull. Torrey Bot. Club, xxii. (1895) $420 \quad(=P$. latifolium, Walt. $)$ - Am. bor.

Prenticeanum. F. M. Bailey, Syn. Queensl, Fl. Suppl.jii. (1890) 8\%. - Austral.

Pseudo-Ischaemum. Boerl. in Ann. Fard. Butenz. viii. (1889) 52 (= Digitavia Pscudo-Ischaemum, Buese). - Java.

psilostachyum, Hochst. ex Th, Dur. \& Schinz, Consp. Fl. Afr. v. 1894 (1895) 768, nomen. Abyss.

pubivaginatum, $K$. Scium, in Engl. Pflanzenw. OstAfr.C (1895) 102. -- Afr. trop. or.

amosum, Arechav, in Anal. Mus, nac. Monterid. ii, (1S94) 111 t. 7. - Uruguay

ramosissimum, C. Corden. Fl. Ile Rúnnion (1895) 117. - Ins, Burbon.

Reverchoni, Vasey, in Bull. U. S. Dept. Agric. Dir. Bot. viii. (1889) 25; et in Coutrib. U. S. Nat. Herb. ii. (1894) 503, iii. (1S92) 26. - Texas

Richardi, C. Curdem. Fl. Ile Réunion (1895) 118. Ins. Borbon

Ridleyi, Hack. ex Rill, in Trans. Linn. Soc. Ser. II. iii. 1893) 400. - Penins. Mal.

scalarum, Schwcinf. in Bull. Hero. Boiss. ii. App. II. (1894) 20. - Arab., Erithrea.

Schinzi, Hack. ex Schinz, in Verh. Bot. Vor. Brand. xxx. (1858) 142. - Afr, austro-occ. extratrop.

Schweinfurthii, Hack. in Th. Dur. Es Schinz. Consp Fl. Afr. v. 1894 (1895) 764, nomen. - Afr centr. bor.

scoparium, S. Wats, in A. Gray, Man. N. Am. Bot. ed. $6(1890) 63 \%=$ Scribnerianum, Nash.

Scottii, Hack. ox S. Elliot, in Fourn. Linn, Soc. xxix. (1891) 63. - Madas

Scribnerianum, Nash, in Bull. Torrey Bot. Club, xxii. (1895) 421. - Am. bor.

setarioides, C. Corden. Fl. Tle Rémnion (1895) 116 - Ins. Borbon.

sparsiflorum, Vasey, in Bull. U. S. Dept. Agric. Di: Bot. viii. (1889) 36 ; ct in Contrib. U. S. Nat Herb. i1. (1894) 505, et iii. (1892) 34. - Am. bor. (pars austr.)

sphagnicolum, Nash, in Bull. Torrey Bot. Club, xxii. (18:5) $42:$ - Florida.

Stuhlmanni, K. Schum. in Engl. Pfanzenwe. Ost-Afr. (18!5) 102. - Afr. trop. or.

subalbidum. Hochst. ex Th. Dur. \& Schinz, Consp. Fl. Atr. v. 1894 (1895) 740 , in syn. = albidulum, Steud

subspicatum, Vasey, in Bull. U. S. Dept, Agric. Div. Bor. viii. (1889)25; et in Contrib. U. S. Nat. Herb. ii. (1894) 503, et iii. (1892) 26: - Texas.

supervacuum, C. B. Clarke, in fomm. Linn. Soc. xxiv. (1888) 407. - Bengal,

terminale, C. Cordem. Fl. Ile Rúmion (1895) 117. Ins. Borbon.

tonkinense, Baransa, in Morot, fourn. de Bot. iv. 1890) 140. - Cochinch.

trachycladus, K. Schum, in Engl. Pflanzenw. OstAfr. A (1895) 108, sphalm. = trichocladum, Hack.

trichocladum, Hack. ex Engl. in Abl. Preuss. Akad. Wiss. 1891 ii. (1892) 119, nomen. - Afr. trop. or. tylanthum, Hack. ex Engl.l.c. 118. - Afr. trop. or. urochloides. Boerl. in Am, fard. Buitenz. viii. (1889) 62 (= Digitaria wrochloides, Buese). - Java. vicinum, F.M. Bailey. Syn. Quensl. Fl. Suppl. iii. (1800) 82. - Austral 


\section{PANICUM : -}

Wilcoxianum, Vasey, in Bull. U. S. Dept. Agric. Div. Bot. viii. (1889) 32 ; et in Contrib. U. S. Nat. Herb. iii. (1892) 31. - Nebraska.

xantholeucum, Hack, ex Schinz, in Verh. Bot. Ver. Brand.xxx. (1888) 141. - Afr. austro-occ. extratrop.

PANOPSIS, Salisb.(Proteac,), - Ind. Kew. ii. 421. polystachya, Kuntze, Rev。Gen. (1891) 579. - N. Granat.

PAPAPAVER, Mcclatchie, in Erythea, ii. (1894) 79 , err. typ. = Papaver, Tourn

PAPAVER, Tourn. ex Linn. (Papav.). - Ind. Kew, ii, 421.

acrochaetum, Bornm. in Mitth. Thiur. Bot. Ver. N. Folge, vii. (1895) 6. - Oriens.

Anthemani $X$, Rouy, in Rouy \& Fouc. Fl. de Fr. i. (1893) 153. - Hybr, spont.

atlanticum, «Ball » ex Cosson, Ill, Fl. Atlant. i. (1882?) 11 t. 6; et Comp. Fl. Atlant, ii. (1883) $64=$ rupifragum, Boiss

californicum, A. Gray, in Proc. Am. Acad. xxii. (1887) 323. - Calif.

cràssifolium, Greene, Man. Bot. San Franc. Bay (1894) 9. - Calif

decipiens, Rouy \& Fouc. Fl. de Fr. i. (1893) $162=$ alpinum, Lmm.

Godroni X, Rouy, 1. c. 153, in obs. - Hybr. spont. guerlekense, Stapf, in Denkschr. Akad. Wien, ii. (1886) 15. - As. Min.

heterophyllum, Greene, Pittonia, i. (June 1888) 168 et Man. Bot. San Franc. Bay (1894) 9 (= Meconopsis heterophylla, Benth.). - Calif

inexpertum X.G. Beck, F1. Nied.-Oest. ii. I. (1892) 434. - Austria.

Lemmoni, Greene, Pittonia, i. (June 1888) 168 ; et Man. Bot. San. Franc. Bay (1894) 9. - Calif.

Pollaki, Kern. ex Wien. Illustr. Gartenzeit. (1888) 272. - Persia.

rhodopeum, Velen, in Sitzb. Bochm。Ges. Wiss. 1893 (1894) n. 37, 5. - Bulg.

rhopalothece, Stapf, in Denksckr. Akad. Wien, ii. (1886) 17 - As. Min

rumelicum, Velen. in Sitzb. Boehm. Ges, Wiss. 1889 (1890) ii. 39; et Fl. Bulg. (1891) 17. - Bulg.

Vesianii $X$, Rouy, in Rouy \& Fouc. Fl. de Fr. i (1893) - Hybr. spont.

Virchowii, Aschers, \& Sint. ex Boiss. Fl. Or. Suppl. 1888) 23. - As. Min.

PAPAYA, Tourn, = Carica, Linn. (Passifl.). candicans, erythrocarpa, glandulosa, gossypifolia, heterophylla, peltata, Kuntze, Rev. Gen. (1891) 253 = homonyma omnia Caricae.

aurantiaca, Kuntze, 1. c. (= Vasconcellea aurantiaca, Regel). - N. Granat.

Bourgeaui, Kuntze, 1. c. = C. Bourgeauii, Solms.

cestriflor, Kuntze, 1. c. (=Vasconcellea cestriftora A. DC.). - N. Granat

chilensis, Kuntze, 1. c. $(=V$. chilensis, Planch. $)$ - Chili.

cubensis, Kuntze, 1. c. = Carica cubensis, Solms.

cundinamarcensis, Kuntze, 1. c. = C. candanamarcensis, Hook. $f$.

Goudotiana, Kuntze, 1. c. (=Vasconcellea Goudotiana, Triana \& Planch.). - N. Granat.

anccolata, Kuntze, 1. c. = Carica lanceolata Benth \& Hook. $f$.

Manihot, Kuntze, 1. c. (= Vasconcellea Manihot, Triana \& Planch.). - N. Granat.

paniculata, Kuntze, 1. c. = C. paniculata Spruce. parviflora, Kuntze, 1. c. (= Vasconcellea parviflora, A. DC.). - Peruv.

platanifolia, Kuntze, 1. c. = C. platanifolia, Solms. pubescens, Kuntze, 1. c. = C. pubescens, Lemé \& C. Koch.

quercifolia, Kuntze, 1. c. = C.quercifolia, Benth. of Hook. f.

Rochefortii, Kuntze, 1. c. = C. Rochefortii, Solms.

PAPHINIA, Lind1. = Lycaste, Lindl. (Orchid.) Lindeniana, Reichb. f. in Flora, 1xx. (1887) 497; et in Lindenia, iii. (1-87) 23 t. 106. - Venezuela.
PAPHIOPEDILUM, Pfitzer. Entwurf, Naturl. anordn. Orchid. (1887) 95 = Cypripedium Linn. (Orchid.)

barbatum, Pfitz in Pringsh, Jahrb. Wiss. Bot xix. (1888) $159=$ C. barbatum, Lindl.

Boxaliz, Pfitz. in Engl. \& Prantl, Natürl. Pflanzenfam. ii. 6 (1888) $84=$ C. Boxallii, Reichb. $f$.

candatum, Pfitz, in Pringsh, Jahrb. Wiss, Bot xix. (1880) $164=$ Selenipedium caudatum, Reichb. f.

concolor, Pfitz, in Engl. et Prantl, Natürl. Pflanzenfam. ii. 6 (1888) $84=$ C. concolor. Batem.

insigne, Pfitz, in Pringsh. Jahrb. Wiss. Bot. xix. 1888) $159=\mathrm{C}$. insigne, Wall.

javanicum, Pfitz. 1. C. $165=\mathrm{C}$. javanicum Blinne.

laevigatum. Pfitz. in Engl. \& Prantl, Natürl. Pflanzenfam. ii. 6 (1888) $84=$ C. philippinense, Reichb. $f$.

Lawerenceanum, Pfitz. in Pringsh. Jahrb. Wiss. Bot. ii. 6 (1888) $164=$ C. Lawrenceanum, Reichb. longifolizm, Pfitz. 1. c. $159=$ Selenipedium longifolium, Reichb. f.

Sedeni X.Pfitz.1. c. $144=$ S. Sedeni x, Reichb。 $\mathrm{f}$

Spiceriannm, Pfitz. 1.c. = C. Spicerianum, Reichb. $f$.

venustrm, Pfitz. 1. C. $165=\mathrm{C}$. venustum, Wall.

PAPPEA, Eckl, \& Zeyh. (Sapind.). - Ind. Kew. ii. 422 .

Radlkoferi, Schweinf. ex Penzig, in Atti Congr, bot. Genova (1893) 336. - Erithrea.

Schumanniana, Schinz, in Verh. Bot. Ver. Brand. xxx. (1888) 156. - Afr, austro-occ, extratrop.

PAPYRIUS, Lam. = Broussonetia, L'Hèrit. (Urtic.).

Kampferi, Kuntze, Rev. Gen. (1891) $629=$ B. Kaempferi, Sicbold.

Karinoki, Kuntze, 1. C. = B. Kazinoki, Siebold.

pafyrifera, Kuntze, I. c. = B. papyrifera, Vent.

PARABARLERIA, Baill, in Bull, Soc, Linn, Paris, ii. (1890) 837; et Hist des pl, x. (1891) 455 , in obs. - ACANTHACEAE

Boivini, Baill. $l l . c c$. - Afr. trop, or.

PARABIGNONIA, Bureau, ex K. Schum, in Engt, \& Prantl, Natürl. Pflanzenfam. iv. 3b (1894) $229=$ Tecoma, Juss. (Bignon.).

Maximiliani, Bureau, 1. c. $=$ T. Maximiliani, Mart

PARABOUCHETIA, Baill, in Bull. Soc. Linn. Paris, i. (1887) 662, Wettst. in Engl. \& Prantl Natürl. Pflanzentam. iv. 3b (1891) 34. SOLA $N E A E$

brasiliensis, Baill. $l l . c c .-$ Bras.

PARAGARYUM Boiss. (Borag.), - Ind, Kew. ii. 423 .

Boissieri. Schweinf. ex Aschers. Eo Schweinf. in [Suppl. Illustr, Fl, Egypte] Mém.Inst, égypt, ii. (1889) 768. - Aegypt.

papillosum, Guerke, in Engl. \& Prantl,- Natür. Pfanzenfam.iv.3a (1893) 105 (= Omphalodes papil losa, DC.). - Arabia.

velutinum, Post, Pl. Postianae, iv. (1892) 10, et in Bull. Herb. Boiss, i. (1893) 26. - Syria.

PARAGOLEA, Baill. in Bull. Soc. Linn. Paris, i. (1887) 692 ; et Hist. des p1. x. (1887) 57, K. Schum. in Engl. \& Prantl, Natürl, Pflanzenfam. iv. $3 \mathrm{~b}$ (1895) 246. BIGNONIACEAE

Boivini, Baill. l. c. 692. - Madag.

Grevei, Baill. ll.cc.692; et 246. - Madag.

PARAdISEA, Mazzuc. (Liliac.), - Ind. Kew. ii. 423.

minor, C. H. Wright, in Kev Bull. (1895) 118. Yunnan.

PARAGONIA, Bureau, ex K. Schum. in Engl, \& Prantl, Natürl. Pfianzenfam. iv. 3b (1894) 218 = Tabebuia, Gomez (Bignon.).

pyramidata, Bureau, l. c. $=\mathrm{T}$. pyramidata, $D C$.
PARAHOPEA, Heim Rech. Diptéroc. (1892) $66=$ Shorea, Roxb. (Dipteroc.).

Balangeran, Heim, 1. c. (= Hopea Balangeran. Korth.). - Malaya.

PARALABATIA. Pierre, Not. bot. Sapot. (1890) 23: Baill. Hist, des pl. xi. (1892) $289=$ Pou teria, Aubl. (Sapot.)

dictyoneura, Pierre, 1. c. = P. dictyoneura, Radll

PARA LST ONIA, Baill. in Bull. Soc. Linn. Paris . (1888) 750. et Hist. des pl. x. (1888) 185; K Schum, in Engl. \& Prantl, Natiirl. Pflanzenfam iv. 2 (1895) 139. APOCYNEAE. clusiaceá, Baill. $l l . c c$. - Ins. Philipp,

PARALYXIA. Baill, in Bull, Soc Linn, Paris i. (1888) 758; et Hist. des pl. x. (1888) 189 ; K. Schum, in Engl. \& Prantl, Natürl. Pflanzenfam. iv. 2 (1895) 155. APOCYNEAE

Schomburgkii, Baill. ll.cc. - Guian.

PARAMANSOA, Baill. Hist. des pl. x. (1888 27; K. Schum, in Engl. \& Prantl, Natürl Pflanzenfam. iv. 3b (1894) 223. BIGNONIACEAE.

Grossourdyana, Baill. ll cc. - Venezuela

PARAmeria Benth. (Apocyn.). - Ind. Kew ii. 423

barbatc, K. Schum. in Engl, \& Prantl, Natürl. Pflanzenfam. iv, 2 (1895) $162=$ glandulifera, Wall.

densiflora, Oliver, in Hook. Icon. pl. xvi. (1886) t. 1520. - Penang

Pierrei, Baill, Hist. des pl.x. (1888) 167 - Cambodia.

PARANEPhelium, Miq. (Sapnid.). - Ind Kew. ii. 423 .

muricatum, Pierre, Fl. For. Cochnnch, Fasc, 21 (1895) sub t. 328 ( = Delpya muricata, Pierre, 1. c. t. 328 B). - Cochinch.

PARANOMUS, Salisb。 \& Knight $=$ Nivenia R. Br. (1810) (Proteac)

capitatus, concavus.. crithmifolins, Dregei, Lagopus, marginatus, medius, mollissimns, parrifolins, Scet tram, spathulatus, spicatus, Kuntze, Rev. Gen. (1891) 580 = homonyma omnia Niveniae.

candicans, Kuntze, 1. co = Serruria albicans Roem. Ê Schult.

PARASGOPOLIA, Baill. Hist. des pl. ix (1888) 338 : Wettst, in Engl. \& Prantl, Natürl, Pflanzenfam. iv. sb (1891) 38. SOLANEAE.

acapulcensis, Baill. $l l . c c$. - Mexic.

PARASHOREA, Kurz = Shorea, Roxb. (Diptéroc.).

plicata, Brandis, in foum. Linn. Linn. Soc. xxxi. (1895) 104. - Ins. Philipp.

Warburgii, Brandis, l. c. 105. - Ins. Philipp.

PARASYSTASIA, Baill. Hist. des pl. x。 (1891) 460 ; Lindau, in Enç1. \& Prantl, Natürl, P.flan zenfam. iv. 3b (1895) 325. ACANTH ACEAE

somalensis, Baill. l.c. 46l (= Barteria somalensis, Franch.). - Reg. Somal.

PARATHESIS, Hook. f。 (Myrsin.). - Ind. Kery ii. 424

calophylla, F. D. Smith, in Conit. Bot. Gaz. xviii. (1893) 205. - Guatem

macrophylla, Britton, ex Rusby, in Mem. Torrey Bot. Club, iv. (1895) $217=$ Ardisia ferruginea. $H . B . \& K$.

micranthera, F. D. Smith, in Coult. Bot.Gaz, xviii. (1893) 4 et 205 [err. cal. micrantha) (= Ardisid micrantha, J. D. Smith, olim), - Guatem.

pleurobotryosa, f. D. Smith, l. c. xvi. (1891) 195 - Guatem.

sessilifolia, F. D. Smith, l. c. - Guatem. 
PARATROPHIS, Blume (Urtic.). - Ind. Kew. ii. 424

nthropophagorum. Benth. \& Hook. f. ex Drake, Int Ins. Jur. Pacif. Fasc. 7 (1892) 296 (= Trophis anthropophagorum, Seem.). - Ins. Vitiens.

Smithii, Checsen, in Trans. N, Z. Inst. xx. 1887 (18s8) $148 .-$ N. Zel

ahitensis, Benth. E Hook. f. ex Drake, Ill. Ins. 1Tar. Pacif. Fasc. 7 (1892) 296; et Fl. Polyn. Franc. (1892) 193 (=Uromorus tahitensis, Bureau). - Ins. Pacif.

IARATROPIA, DC. = Heptapleurum, Gaertn

(Arab.). Barb. Rodr. Hort, Flìmin. 1893 (1895) 244. - Hab.

PARIETARIA, [Tourn.] Linn. (Urtic.). - Ind. Kew. ii. 42.).

macrophylla, Robinson of Grocnm. in Am. Founn. Sci. Ser. 1II. 1. (1895) 165.-Mexic.

persica, Stapf, in Deukschr. Akad. Wien, ii. (1886) 4. - Persia.

thymifolia, Stapf, l. c. - As. occ.

PARINARI, Aubl. = Parinarium, Aubl. (Rosac.). Chapelievi, Baill. Hist. pl. Madag,, Atlas (1886 t. 12 = P. Chapelieri, Baill.

PARINARIUM, Aubl. (Rosac.). - Ind. Kew. ii. 426.

Benna, S. Elliot, in fourn. Linn. Soc. xxx. (1894) \%8. - Sierra Leone.

Boivini, Fritsch, in Annal. Natur, Hofmus. Wien, v (18n(i) 14. - Madag.

emirnense, Baker, in foum. Linn. Soc, xxii. (1887) 469. - Madag.

gabinense, Engl. Bot. Fahrb. xvii. (1893) 8\%. Afr. trop.

guyanense, Fritsch, in Annal. Naturh. Hofmus. Wient, v. (1890) 14. - Guian. bat.

Holstii, Engl. Pfanzenzw. Ost-Afr. C.-Add. (1895) 423. - Afr. trop. or.

Hostmanni, Fritsch, in Annal. Naturh. Hofnuls. IVien, v. (1890) 13. - Surin.

polystachymm, Poepp. ex Fritsch, 1, c. 12, in syn. = Couepia amazonica, Fritsch.

salicifolium, Engl. in Abh. Preuss. Akad. Wiss, (1894) 54 ; et Pflanzenw. Ost-Afr。C (1895) 191 $=$ P. Holstii, Engl.

PARIS, [Ruepp.] Linn. (Liliac.). - Ind. Kew, ii. 426.

chinensis, Franch, in Nouv. Arch. Mus. Paris, Sér. II. x. (1888) 9\%. - Tibet.

in perialis, Jacquem. ex Hook. f. Fl. Brit. Ind. vi. (1892) 362, in syn. = polyphylla, Smith

japonica, Franch. in Mém. Soc. Phit. Paris (1889 291. - Japon.

quadrifolius, Himpel, F1. Elsass-Lothr. (1891) 273 $=$ quadrifolia. Linn.

thibetica, Franch. in Nonv. Archiv. Mus, Paris Sér. II. x. (1887-88) 184. - Tibet.

yunnanensis, Franch. in Mém. Soc. Phil. Paris (1889) 200. - Yunnan

PARITIUM, A. Juss。= Hibiscus Linn. (Malvac.) Paoui. Baill, ex Laness. P1, util. Colon. Franc (1886) 668. - N. Caled.

PARKINSONIA. Plum, ex Linn. (Legumin.). Ind. Kew, ii. 427.

florida, T. S. Brandeg. in Proc. Calif. Acad. Ser. II. ii. (1889) $152=$ florida, S. Wats.

PARNASSIA. [Tourn.] Linn. (Saxifr.), - Ind. Kew. ii. 427.

Bornmuelleri, Freyn, in Oest. Bot. Zeitschr. xliv. (1894) 08. - Persia.

califormica, Greene. Pittonia, ii. (June 1890) 102 ; et Man. Bot. San Franc. Bay (1894) $123=$ palustris, Linn.

Davidi, Franch. in Nour. Arch. Mus. Paris, Sér. II. viii. 185.5 (1886) 237. - China occ.

\section{PARNASSIA :}

Faberi, Oliver, in Hook. Icon. pl. xviii. (1888)

t. $17 \% 8$. - China.

viridiflora, Batalin, in Act. Hort. Petrop. xii. (1892)

168. - China.

PARONYGHIA, [Tourn.] Linn. (Illecebr.). Ind. Kew. ii. 427.

argyroloba, Stapf, in Denkschr. Akad. Wien, ii.

(1886) 12. - As. Min.

caespitosa, Stapf, i. c. 22, - As. Min.

Hieronymi, Pax, in Bot. Fahrb. xviii. (1894) 34. Reg. Argent.

microphylla, Phil. in Anal. Mus.nac. Chile (1891) 26. - Am austr. occ

monandra, T. S. Brandeg. in Proc, Calif. Acad. Ser. II. iii. (1891) 115. - Calif

orthoclada. Webb, ex Christ, in Bot. Jahrb. ix. (1888) $103=$ canariensis, fuss

pusilla. Greene, Pittonia, i. (May 1889) 302 ; et F1. Francisc. (1891) $131=$ Herniaria cinerea, $D C$.

Rouyana, Coincy, in Morot, foum. de Bot. viii, (1894) 65. - Hisp

somaliensis, Baker, in Kew Bull. (1895) 226. Reg. Somal.

subandina, Phil, in Anal. Univ. Chil. Ixxxv. (1894) 233. - Chili.

Wilkinsoni, S. Wats. in Proc, Am. Acad. xxi.(1886) 454. - Mexic

PAROPSIA, Noronha, ex Thon.(Passifl.). - Ind. Kew. ii. 428.

Brazzaeana, Baill. in Eull. Soc. Iinn, Paris, i. (1886) 611. - Congo gall.

laevigata, Warb. in Engl. \& Prantl, Natiml. Pfanz¿cmfan. 1ii.6a (1893) 27 (= Smathmannia lacit grata, Soland.). - Atr. trop.

pubescens, Warb.l.c. $(=$ S. pubescens, Soland.).Afr. trop.

reticulata, Engl. Bot. Fahrb. xiv. (1892) 391 ; et xv. (1893) 586. - Angola.

PAROPSIOPSIS, Eng1. Bot. Jahrb, xiv, (1892) 391 ; et xv. (1893) 586: Warb. in Eng1. \& Prantl, Natiirl. Pflanzenfam, iii. 6a (1893) 27. PASSI. FLOREAE.

africana, Engl. ll. cc. - Gabon.

PAROSELA, Cav = Dalea, Linn. (Legumin.) anrea, Britton, in Mem. Torrey Bot. Club, v. (1894) $\mathbf{1 9 6}=$ Psoralea aurea, Poir.

Dalea, Britton, 1.c. = Dalea alopecuroides, Willd domingensis, Millsp. Field Columb. Mus. Bot. Ser. I. (1895) 21 [Parosella] = Dalea domingen sis, $D C$.

enncandra, Britton, in Mem. Torrey Bot. Club, v. (1894) $\mathbf{1 9 6}=\mathrm{D}$. enneandra, Nutt.

Hallii, Heller, in Contrib. Herb. Frankl. (1895) 49 [Bot. Expl. S. Texas] = D. Hallii A. Gray.

lanata, Britton, in Mem. Torrey Bot. Club, v. (1894) $196=$ D. lanata, Spreng.

nana, Heller, in Contrib. Herb. Frankl. i. (1895) 49 [Bot. Explor. S. Texas] = D. nana, Torr.

pogonathera, Heller, 1. C. = D. pogonathera, A. Gray.

PARQUETINA, Baill, in Bull. Soc. Linn. Paris, ii. (1889) 806 [sphalm. 86 ; et Hist. des pl. x. (1890) 295; K. Schum. in Engl. \& Prantl, Natuirl. Pflanzenfam. iv. 2 (1895) 218. ASCLEPIADEAE.

gabonica, Baill. $l l . c c$. (sphalm. D. gabonica).Gabon

PARRASIA, Greene, in Erythea, iii. (1895) $75=$ Greggia, A. Gray (Crucif.).

camporum, Greene, 1. $\mathrm{c}_{\mathrm{s}}=\mathrm{G}$. camporum, A. Gray. linearifola, Greene, 1. $c_{0}=\mathrm{G}$. linearifolia, S. Wats

PARRYA, R. Br. (Crucif.). - Ind. Kew. ii. 428. arabidiflora, Nichols. Dict. Gard. iii, 25. - Sibiria. Beketowi, Krassn. in Script. bot. Hort. Univ. Petrop. ii. 1 (1887-85) 12 . China.
PARRYA : -

ciliaris, Bureau Ef Franch. in Morot, fonrm. de Bot. v. (1891) 20, - China occ. eurycarpa, Maxim. Fl. Tangut. (1889) 56. - China. Mcnziesii, Greene, F1. Francisc. (1891) $253=$ Cheiranthus Menziesii, S. Wats.

madcaulis, F. Kurtz, in Bot. Jahrb. xix. (1894) 454 = Matthiola nudicaulis, Trauty.

prolifera, Maxim. Fl. Tangut. (1889) 56. - China. siliquosa, Krassn. in Script. bot. Hort. Univ. Petrop. ii. 1 (1887-88) 12. - China.

villosa, Maxim. Fl. Tangut (1889)55. - China.

PARSONSIA, P. Br. = Cuphea. P. Br. (Lythrar.) micropetala, Hitchcock, in Missouri Bot. Gard. Rep.iv. (1893) 87 = C. platycentra, Benth.

petiolata, Rusby, in Mem. Torrey Bot. Club, v. (1894) $2: 31=$ C. petiolata, Koelne.

adicans, Hitchcock, in Missouri Bot. Gard. Rep. iv. (1892) $S 7=$ C. Parsonsia, $R \cdot B r$

PARSONSIA, R. Br. (Apocyn.), - Ind. Kew. ii. $4^{\circ} \mathrm{S}$

affinis, Baill. in Bull. Soc. Linn. Paris, i. (1888) 766. - N. Caled.

angustifolia, Baill. l. c. - N. Caled.

Balansae, Baill. l. c. 765 et $767,-\mathrm{N}$. Caled.

brachycarpa, Baill.l.c.766. - N. Caled.

carnea, Panch. ex Baill. l. c. - N. Caled.

catalpaecarpa, Baill. l. c. 768. - N. Caled.

curvisepala, K. Schum. in Bot. Falnb. ix. (I8s8) 215. - N. Guin.

crebriflora, Baill. in Bull. Soc. Linn. Paris,i. (1888) 767. - N. Caled.

esculenta, Panch. ex Baill, l. c.767. - N. Caled.

flexilis, Baill. l. c. 766. - N. Caled.

flexuosa, Baill. l. c. 765. - N. Caled.

lifuana, Baill. l. c.767. - N. Caled.

linearis, Baill. l. c. 766. - N. Caled.

Galeottiana, Baill. 1. c, ii. (1890) $813=$ Thenardia Galeottiana, Baill.

javanic r, K. Schum. in Eng1. \& Prantl, Natür Pflanzenfam. iv. 2(1895) $184=$ spiralis, Wall. macrocarpa, Baill. in Bull. Soc. Linn. Paris, (1888) 767. - N. Caled.

populifolia, Baill. l.c.-N. Caled

pubercula, Baill. l. c. 765. - N. Caled.

ochracea, Colenso, in Trans. N. Z. Inst. xxii. 1889 (1890) $480 .-$ N. Zel.

reflexa, Baill. in Bull. Soc. Linn. Paris, i. (1888) 765. - N. Caled.

rigida, Baill. l. c. 766.- N. Caled.

Vieillardi, Baill. l. c.768. - N. Caled.

PARTHENIUM, Linn. (Compos.), - Ind. Kew. ii. 428

repens, Eggert. Catal.pl. St Louis (1891) 16. - Am. bor.

PARTHENOCISSUS, Planch, iu DC, Monog. Phan. v. (1887) $447=$ Vitis, [Tourn.] Linn. (Ampelid.).

anamallayana, Planch. 1. c. $452=\mathrm{V}$. anamallayana Bedd.

cuspidifera, Planch. 1. c, $451=$ V. cuspidifera, Miq.

Kimalayana, Planch. 1. c. $450=$ V. himalayana, Brandis.

neilgherviensis, Planch. 1. c. $450=\mathrm{V}$. neilgherriensis, Wight.

quinquefolia, Planch. 1. c. $448=$ V. hederacea, Ehrh.

semicordata, Planch. 1. c. $451=$ V. semicordata, Wall.

Thomsoni, Planch. 1. c. $453=\mathrm{V}$. Thomsoni, M. Lavs, tricuspidata, Planch. 1. c. $452=\mathrm{V}$. inconstans, Niq.

Jitacea, A. S. Hitchcock, Spring. Fl. Manhattan (1894) 26. - Am. bor,

PARVATIA, Decne (Berberid.) , - Ind. Kew. ii. 429

chinensis, Franch. in Morot, Fourn. de. Bot.v. (1891) 281. - China. 
PASACCARDOA, Kuntze, Rev, Gen. (1891) $354=$ Phyllactinia, Benth. (Compos.).

Grantii, Kuntze, 1. c. = P. Grantii, Benth.

PASANIA, Oerst. $=$ Quercus, Tourn. (Cupulif.). Beccariana, Prantl, in Engl. \& Prantl, Natürl. Pflanzenfam. iii, l (1888) $55=\mathrm{Q}$. Beccariana Benth.

javensis, Prantl, 1. $c_{0}=$ Q . javensis, Miq.

Reinwardtii, Prantl, 1. c. = Q. Reinwardtii, Korth

Teysmannii, Prantl, 1. c. $=$ Q. Teysmannii, Bhme.

PASCHIRA, G. Kuntze; in Bot. Centralbl. xly. (1891) 201 = Pachira, Aubl. (Malv.).

PASPALUM, Linn. (Gramin,), - Ind. Kew, ii. 429.

anemotum, Ridl, in fourn. Linn. Soc, xxyii. (1890) 68. - Ins. Fernando Noronha.

Arechavaletae, Hack. ex Arechav. in Anal. Mus, nac. Montevid. i. (1894) 86. - Urug

Buckleyanum, Vasey, in Bull. Torrey Bot. Chub, xiii. 1886) 167 ; et ex Coult. in Contrib. U. S. Nat. Herb. ii. (1894) 498. - Texas.

Chaffanjonii, Maury, in Morot, foum. de Bot. iii. (1889) 159 fig. 5. - Am, austr. trop.

conjugatum, C. Corden. ex F. Corden. Fl. Ile Rére nion (1895) 114. - Ins. Borbon.

culiacanum, Vasey, in Contrib. U. S. Nat. Herb. i. (1893) 281. - Mexic.

dentatosulcatum, Arechav, in Anal. Mus, nac. Montevid. i. (1894) 88. - Urug.

Drummondii. Vasey, in Contrib. U. S. Nat. Herb. iii. (1892) 18 ( = Dimorphostachys Drummondii, Fourn.). - Florida, Texas,

Elliottii, S. Wats, in A. Gray, Man, N. Am. Bot ed. $6(1890) 629=$ paspaloides, Scribu.

enode, Hack. ex Arechav. in Anal. Mus. nac. Montevid. i. (1894) 87. - Urug.

Galmarra, F. M. Bailey, in Dept. Agric. Brisbane Bot. Bull. ix. (1894) 12. - Austral.

giganteum, Baldw. ex Vasey, in Bull. Torrey Bot. Club, xiii. (1886) 166 ; et in Contrib. U.S. Nat. Herb. iii. (1892) 20. - Florida.

giganteum, Arechav. in Anal. Mus. nac. Montevid. i. (1894) 70. - Urug.

gnenoarum, Arechav. l. c. 56. - Urug.

Hackelianum, Sodiro, Gram. Echator. [Anal Univ Quito, 1889|4, nomen. - Ecuad.

ibarrense, Sodiro, l. c. - Ecuad.

inops, Vasey, in Contrib. U. S. Herb. i. (1893) 281. - Mexic.

intermedium, Munvo, ex Morong, in Ann. N.Y. Acad. Sci. vii. (1893) 258. - Parag.

lamprocaryon, $K$. Schum. in Engl. Pflanzenw. Ost. Afr. C (1895) 100 - Afr, trop, or.

Larranagai, Arechav. in Anal. Mus, nac. Montevid. i. (1894) 68 t. 2. - Urug.

monostachys, V.asey, ex Coult. in Contrib. U. S.

Nat. Herb. ii. (1894) 498, sphalm. = seq.

monostachyum, Vasey, l. c, iii. (1892) 17, et ii. (1894) 49\%. - Am, bor.

paspaloides, Scribn. in Mem: Torrey Bot. Club, v. (1894) 29 (= Digitaria paspaloides, Michx) $=\mathrm{P}$. Waltherianum, Schlecht.

paucispicatum, Vasey, in Contrib. U. S. Nat. Herb. i. (1893) 281. - Mexic.

phonoliticum, Ridl. in fourn. Linn. Soc. xxvii. (1890) 68 t. 4. - Ins. Fernando Noronha.

Pittieri, Hack. ex Tonduz, in Bull. Herb. Boiss. iii. (1895) 464, nomen. - Costa Rica.

polystachyum, Kuntze, Rev, Gen. (1891) $786=$ saccharoides, Nees.

proliferum, Arechav. in Anal. Mus.nac. Montevid. i. (1894) 72. - Urug.

pubescens, F. M. Bailey, Rep. Exped. Bellenden-Ker, (1889) 69. - Galmarra.

saltense, Arechav. in Anal. Mus. nac. Montevid. i. (1894) 59. - Urug.

simplex, Morong, in ann. N. Y. Acad. Sci. vii. (1893) 259. - Parag.

Sodiroanum, Hack, ex Sodiro, Gram, Ecuator. [Anal. Univ. Quito, 1889] 3, nomen. - Ecuad.

suffinum; Sieb. ex Th. Dur. \& Schinz, Consp. Fl.

Irr. v. 1894 (1895) 737, in syn. = heteropodium,
ild.

\section{PASPALUM : -}

uruguayense, Arechav. in Anal. Mus, nac. Monterid

i. (1894) 60 t. 1. - Urug.

PASSERINA, Linn. (Thymel.),-Ind. Kew, ii. 433. segobricensis, Pau, Not. bot. fl. Espan. i. (1887) 25.
- Hisp.

PASSIFLORA, Linn. (Passifl.). - Ind. Kew. ii.

allantophylla, Mast. ex F. D. Smith, in Coult. Bot. Gaz. xvi. (1891) 7, - Guatem

amalocarpa, Barb. Rodr. [Herb. Mus. bot. Amaz. n. 964] in Vellosia. 1885-S8, Sec. ediç. (1891) 25 t. 12. - Bras. bor.

ampullacea, Harms, in Enol. \& Prantl, Natirl. Pflanzenfam. iii. 6a (1893) $91=$ Tacsonia am. pullacea, Mast.

Barbosae, Barb. Rodr. Vellosia 1885-88, Sec. ediç. (1891) 27 t. 13a; et Hort. Flumin. 1893 (1895) 184. - Bras. bor.

Barclayi, Drake, Ill. Fl. Ins. Mar, Pacif. (1890) 175 (= Disemma Barclayi, Seem.) - Ins. Vitiens.

Brighami, S. Wats, ex W. T. Brigham, Guatem. 1887) 428, nomen; et in Proc. Am. Acad. xxii. (1887) 473. - Mexic

cabedelensis, Barb. Rodr. Vellosia] 1885-88, Sec. ediç. (1891) 30. - Bras. bor.

choconiana, S. Wats, ex W. T. Brigham, Guatem (1887) 428, nomen; et in Proc. Am. Acad. xxii. (1887) 474. - Guatem.

cisnana, Harms, in Bot. Fahrb, xviii. Beibl. n. 46 (1894) 5. - Ecuad.

clypeophylla, Mast. ex F. D. Smith, in Coult. Bot. Gaz, xvi. (1891)7. - Guatem.

cumbalensis, Harms, in Bot. Fahrb. xviii. Beibl. n. 46 (1894) 13 (= Tacsonia cumbalensis, Karst.). - Ectiad.

cupiformis, Mast. in Hook. Icon. pl. xviii. (1888) t. 1768. - China.

cuspidifolia, Harms, in Eral. \& Prantl, Natuirl. Pfanzenfam. iii.6a (1893) 72; et in Bot. Fahro. xviii. Beibl. n. 46 (1894) 3. - N. Granat.

Decaisneana $X$, Nichols. Dict. Gard. iii. 30. Hybr. artef.

diethophylla, Mast. ex 7. D. Smith, in Coult. Bot. Ga\%. xvi. (1891) 8. - Guatem.

Eggersii, Harms, in Bot. Falnrb. xviii. Beibl. n. 46 (1894) 7. - Guatem

Engleriana, Harms, in Engl. \& Prantl, Natïr. Pfanzenfam. iii. 6a (1893) \%2; et in Bot. Fahrb. xviij. Beibl. n. 46 (1894) 2. - N. Granat.

esclavensis, Ramirex, in Informe Excurs. Ajusco, (1894) 35. - Mexico

fimbristipula, Harms, in Bot. Fahrb. xviii. Beibl n. 46 (1894) 11. - Am. trop.

gigantifolia, Harms, in Engl. Eo Prantl, Natürl. Pfanzenfam. iii.6a (1893) 88; et in Bot. Fahrb. xviii. Beibl. n. 46 (1894) 1. - Ecuad.

gracilens, Harms, 1. co = Tacsonia gracilens, A. Gray.

guatemalensis, S. Wats. ex W. T. Brigham, Guatem. (1887) 428; et in Proc. Am. Acad. xxii. (1887) 473. - Guatem.

hexagonocarpa, Barb. Rodr. [Herb. Mus.bot. Amaz. n. 304] in Vellosia 1885-88, Sec. ediç. (1891) 24 t. 9. - Bras. bor.

Hieronymi, Harms, in Bot. Fahrb. xviii, Beibl. n. 46 (1894) 12. - Ecuad.

Hollrungii, $K$. Schum. l. c. ix. (1888) 211 ; et xv (1893) 81 - N. Guin.

hydrophila, Barb. Rodr. [Hewb. Mus. bot. Amaz. n. 195] Vellosia, 1885-88, Sec. ediç. (1891) 26 t. 13. - Bras

involucellata, Harms, in Bot. Fahrb. xviii. Beibl. n. 46 (1894) 6. - Ecuad.

iodocarpa, Barb. Rodr. Pl. nov. fard. bot. Rio, i. (1891) 3 t. 2 : et Hort. Flumin. 1893 (1895) 184. Bras

Jenmani, Mast. in Hook. Icon. pl. xxiii. (1893) t. 2270. - Guian. brit.

kewensis X. Hort. ex Le Jardin (IS88) 201 ; et Gard. and For. (1888) 293. - Hybr. artef.

Mastersiana, Harms, in Engl. \& Prant?. Nativl. Pflanzenfam. iii. 6a (1893) 89 ; et in Bot. fahrb. xvii. Beibl. n. 46 (1S94) 8. - Ecuad.

\section{PASSIFLORA}

muralis, Barb. Rodr, Vellosia, 18S5̆-S\&, Sec, edic (1891) 29 t. 13b. - Bras. bor.

nephrodes, Rusby, in Bull. Torrey Bot. Club, xvii. (1890) 282. - Bolivia.

ornitheura, Mast. ex F. D. Smuth, in Coult. Bot. Gaz. xvi. (1891) 8. - Guatem.

Palmeri, F. N. Rose, in Contrib. U.S. Nat. Herb. 1892) 131, t. 14. - Ins. Carmen.

perpera, Mast, in Hook, lcon, pl. xviii. (1SSS) sul t. 1768. - Khasia

picroderma, Barb. Rodr. Pl. nov. Fard. bot. Rio, i 1891) t. 1; et Hort. Flumin. 1893 (1895) 185.Bras.

porphyretica, Mast. ex F. D. Smith, in Coult. Bot. Gaz, xx. (1895) 538, t. 36. - Guatem.

praeacuta, Mast. in Bot. Fahrb. viii. (1SST) 220.Columb

Pringlei, Robinson \& Greenm. in An, foum. Sci. Ser. III. 1. (1895) 151. - Mexic.

prolata, Mast. in Bot fahrb. viii. (188\%) 219.Guatem.

retipetala, Mast. in Kew Bull. (1893) 12. - Guian. angl.

rhodantha, Harms, ex Hieron. in Bot. Fahro. xxi. (1895) 324. - Ecuad.

Rusbyi, Rusby, in Bull. Torrey Bot.Clnb, xviii. (1890) 282. - Bolivia.

salmonea, Harms, in Bot. Fahrb. xviii. Beibl. n. 46 (1894) 11. - N. Granat

securiclata, Mast. in Kew Bull. (1893) 12. - Guian. brit.

tolimana, Harms, in Bot. Fahrb. xviil. Beibl. n. 46 (1894) 9. - Am. austr.

transversa, Mast. ex F. D. Smith, in Coult, Bot Gaz. xvi. (1891) 7. - Guatem

trinifolia, Mast. in Bot. Fahrb. viii. (1887) 217. Guatem

trisulca, Mast. l. c. 218. - Columb.

tryphostemmatoides, Harms. l. c. xviii. Beibl n. 46 (1894) 6. - Am. trop.

umbilicata, Harms, in Engl. \& Prantl, Natür. Pflanzenfam. iii. ba (1893) $9 \mathrm{l}=$ Tacsonia umbilicata, Griseb.

Watsoniana, Mast. in Gard. Chron. (1886) ii. 648, fio. 127; in the Garden (1888) 195; Rodigas, in Illustr. Hortic. xxxvi. (1889) 9, t. 524. - Bras.

PASTINACA, Linn, = Peucedanum, Tourn. (Umbellif.)

corsica, Caruel, in Parl. Fl. Ital. viii. (I889) 260. - Corsica.

dentata Freyn \& Sint in Oest. Bot. Zeitschr, xliv. (1894) 103. - As. Min.

grisea, Stapf \& Wettst. ex Stapf, in Denksch, Akad.

Wien, ii. (1886) 52. - As. Min,

Polaki, Stapf \& Wettst. 1. c. - As. Min.

Trysia, Stapf \& Wettst 1. c. 27. - As. Min.

vainans, Velen. in Sitzb. Boehm. Ges. Wiss. 1892 (1893) 380. - Bulg.

PATAGONIA miraflorensis, Rusby, in Mem. Torrey Bot. Club, iii. 3 (1893) $21=$ Adesmia miraflorensis, Remy.

PATAGONICA, Linn. = Patagonula, Linn. (Borag.).

americana, Kuntze, Rev. Gen. (1891) $439=\mathbf{P}$. americana, Iim.

bakiensis, Kuntze, 1. c $=\mathrm{P}$. bahiensis, Moric

Glaziovii, Mez, ex Taub. in Bot. Jahrb. xii. Beibl. n. $27(1890) 1 \%$ - Bras.

PATAGONIUM, Schrank = Adesmia. DE. (Legumin.)

Aegiceras, angustifolium, aphyllum, apricum, arachni. pes, araucanum, arboreum, argenteun, aroyropliyllum, arvense, asperum, atacamense, axillare, balsamicum, bicolor, brachycarpum, bracteatum, calocarpun, ca nescens, capricornu, chillanense, ciliatum, cineroum, Closii, corymbosum, cuneatum, curvifolinm, Davilas. decumbens, dentatum, denticulatum, denudatum. deserticolnm, dichotomum. Echinus, elatum. degans, elongatum, emarginatum, erennophilum, erinacenn, exile, filicaule, filifolium, frigidum, Gayanm, Germainii, Giliesit, glandulosum, glaucum, glaucescens, 


\section{PATAGONIUM :}

glomerulum, ghutinosum, gracile, graveolens, hursukwn, hispidulum, horridum, humifusum, humile Hystrix, incanum, inconspicunm, Kingi, lanatum, latifolium, laxum, leiocarpum, leptacanthum, longipes, longiseinn, Loudonii, Macrostachyum, Meyenianum, micranthum, microplyllum, montanum, mucronatum. multicuspe, muricatum, obcordatum, obovatum, obscuxum, odontophyllum, oligophylhum, oresigenum, oxaldophyllum, papposum, parviflonum, parvifolium, parvinlum, panciflortmin, Pearcei, pedicellatum, pinifolinm, propinquam, prostratum, psilocarpum, pulchrum, pumilunn, prunctatum, pungens, quadrijugum, vadicans, radicifolizun, ramosissimum, retrofractum, retusum, Schneideri, sericentm, sessiliforam, Simonsii, Smith ine, spinosissimun, stipulacerm. subterranewm, trijugum, triste, ulicinum, uspallatense, Valdesia, vesicarium, viscosum, Volkmannii, Kuntze, Rey. Gen. (1891) $200-01$ = homonyma onnia Adesmiae. boroniodes, Kuntze, 1. c. = A. boronioides, Hook. $f$ coronillodes, Kuntze, 1. c. = A. coronilloides, Gill dendrodes, Kuntze, 1. c, = A. dendroidea, Phit.

genistodes, Kuntze, 1. $c_{1}=$ A. grenistoides, Presl.

glabrinscnhmm, Kuntze, 1. с. $200=$ A. glabriuscula Vog

grandifolinm, Kuntze, 1. c. = A. grandifloxa, Ginl. Linddsbckiti, Kunize, 1. Co = A. Landbecki, Phil. lotodes, Kuntze, 1. $c_{0}=$ A. lotoides, Hook. $f$.

monospermun. Kuntze, 1. c, $=$ A. monosperma Clos.

Ononidis, Kuntze, 1. c. = A. Onononis, Griseb.

phyzlodern, Kuntze, 1. c, = A. phylloidea, Clos.

trifoliatum, Kuntze, 1. c. $201=$ A. trifoliata, Phil.

riscidum, Kuntze, 1. c. = A. mucronata, Hook. \& Arne.

PATEFSONIA, R. Kr. (Irid.). - Ind. Kew. ii 438.

borneensis Stapf, in Trans, Linn. Soc. Ser. II. iv. (1894) 242, t. 20 A. 1-6. - Borneo

Lowii, Stapf, l. c. 241, t. 20 B, fig. 7-9. - Borneo.

PATOSIA, Buchenau, in Bot. Jahrb. xii. (1890) 63. FUNCEAE.

clandestina, Buchenau, l.c. 44 (= Rostkovia clandestina, Phil.). - Chili.

PATRINIA, Juss. (Valerian.). - Ind. Kew. i: 438

angustifolia, Hemsl. ex Forb. E Hemsl, in foum Linn. Soc. xxiii. (1888) 396. - China.

saniculaefolia, Hemsl. l. c. 397. - China.

PATRISIA, Rich. = Ryania, Vahl (Bixin.)

acuminata, canescens, Mansoana, Riedeliana, Sago fiana. Kuntze, Rev, Gen. (1891) 45 = homonyma ommia Ryaniae.

chocoënsis Warb, in Eng1. \& Prantl, Natürl. Pflanzenfam. iii. 6a (1893) $50=\mathrm{R}$. chocoënsis Planch. E Triana.

PATTALIAS, S. Wats, in Proc. Am. Acad. xxiv (1889) 60 ; $\mathrm{K}$. Schum, in Engl, \& Prantl, Natürl. Pflanzenfam. iv. 2 (1895) 255. ASCLE PIADEAE.

angustifolius, $K$. Schum. l. c. $(=$ Melinis angusti folia, A. Gray). - Arizona.

Palmeri, S. Wats, in Proc. An. Acad.xxiv. (1889) 60. - Mexic

PAULLINIA, Linn. (Sapind.). - Ind, Kew, ii 4:38:

boliviana, Radlk。 ex Rusby, in Mem. Torrey Bot. Club. iv. (1895) 206. - Bolivia.

hymenobracteata, Radlk. ex f. D. Sinith, in Coult. Bot. Gaz. xx. (1895) 282. - Guatem.

pseudota, Radlk. ex Warm. in Vidensk. Meddel. Naturh. Foren. (1890) 242 (Symb. Fl. Bras. centr. xxxvi1). - Bras.

scarlatina, Radlk, ex F. D. Snith, in Coult. Bot. Grz. xvi. (1891) 193. - Guatem.

sonorensis, S. Wats, in Proc. Am. Acad. xxiv. (1889: 45. - Mexic.

ortuosa, T. S. Brandeg. in Zoë, ii. (1891) 74 ; et in Proc. Calif. Acad. Ser. II. iii. (1891) $123=$ Cardiospermum tortuosum, Benth.
PAULOMAGNUSIA, Kuntze. Rev. Gen. (1891) $702=$ Micranthus, Eckl. (Irid.).

alopecurodes, Kuntze, l. c. = M. alopecuroideus, Eckl.

spicata, Kuntze, !. c. = Watsonia punctata, KerGawl.

PAULO-WILHELMIA, Hochst. (Acanth.). Ind. Kew. ii. 440.

Tabra, Lindan, in Bot. Fahrb. xxii. (1895) 115. Kamerun

sclerochiton, Lindau, in Bot. Fahrb xvii, (1893) 105 ; et in Engl. \& Prantl, Natïl. Pfanzenfam. iv. 3b (1895) 30 (= Ruellia sclerochiton, S. Moore) - Afr. trop.

togoënsis, Lindan, l. c. 105. - Afr. trop.

PAULOWNIA, Sieb. \& Zucc, (Scrophul.). Ind. Kew. ii. 440

Fortunei, Hemsl. in fourn. Linn. Soc. xxvi. (1890) 180; et in Gard. Chron. (1899! i. 448. - China.

grandifolia, Hort. ex Wettst. in Engl. \& Prantl, Natürl. Pflanzenfam. iv. 3b (1891) 67, in obs. = imperialis, Sieb. \&. Zucc.

tomentosa, Baill. Hist. des pl. ix. (1888) $434=$ imperialis, Sieb. \& Zucc.

PAURIDIA, Haw. (Amaryll.). - Ind. Kew. ii.

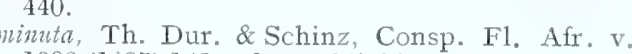
1892 (1895) 142 = hypoxidioides. Hav.
imnta, Th.

PAVETTA, Linn. (Rubiac.). - Ind. Kew。 ii, 440. blepharosepala, $K$. Schum. in Engl. Pfanzenzw. OstAfr. C (1895) 388. - Afr. trop. or

borbonica, Hort. ex Cordem. F1. Ile Réunion. (1895) 507 = Ixora borbonica, Cordcm

corynostylis, K. Schum. in Engl. Pflanzenw. OstAfr. C. (1895) 388. - Afr. trop. or.

crassipes, K. Schnmm. l. c. 389. - Afr, trop. or.

disarticulata, Galpin, in Kew Bull. (1895) 145. Transvaal.

Holstii, K. Schum. ex Engl。 in Abh. Prenss. Akad. Wiss. (1894) 45 ; et in Engl. Pfanzenw. Ost-Afr. C (1895) 389. - Afr. trop, or.

humilis. Boorl. Handl. Fl. Ned. Indic, ii. I. (1891) 136, nomen. - Malacca.

involucrata, $K$. Schum. ex Engl. in Abh. Preuss. Akad. Wiss. (1894) 45 et 51, nomen; et in Engl. Pfanzenw. Ost-Afr. A (1895) 94. - Afr. trop.

kerenensis, Beec. ex Martelli, Fl. Bogos. (1886) 43. Abyss.

Klotzschiana, K. Schum. in Engl. Pflanzenw. OstAfr. C (1895) 388. - Afr. trop. or.

limbata, Stapf, in Trans. Linn, Soc. Ser. II, iv, (1894) 179. - Borneo.

olivaceo-nigra, K. Schum. in Abh. Prenss. Akad. Wiss. (1894) 51; et in Engl. Pfanzenz, Ost-Afr. C. (1895) 388. - Afr. trop. or.

refractifolia, K. Schum. l. c. 388. - Afro trop or.

Schumanniana, F. Hoffm, ex K. Schum. l.c.389. Afr, trop. or.

sepium, K. Schum. l.c. - Afr. trop. or.

stenosepala, K. Schum. in Abh. Preuss. Akad. Wiss. (1894) 26 ; et l. $c .388$. - Afr. trop. or.

teitana, K. Schum. l. c. 389. - Afr. trop. or.

trichanta, Baker, in Kew Bull. (1893) 148. - Ins. Aldabra.

PAVIA, Boerh. ex Mill. = Aesculus, Linn. (Sapind.).

coriacea, Hort. ex Dippel, Handb. Laubholzk. ii. (1892) $403=$ A. Pavia, Linn.

pendula, Hort. ex Gard. Kew, i. Polypet. (1894) 85 = A. Pavia, Linn

pubescens, Hort. ex Dippel, Handb. Laubholzk, ii. (1892) $403=$ A. Pavia, Linn.

pumila, Hort. ex Gard. Kew, i. Polypet. (1894) $85=$ A. Pavia, Linn.

vubicunda, «Lodd. » ex Dippel, Handb. Laubholzk. ii. (1892) $398=$ A. carnea, Hayne

PAVIEASIA, Pierre, Fl. For. Cochinch. Fasc. 20 (1894) sub t. 317 in text. SAPINDACEAE.

namensis, Pierre, $l_{0} \delta_{0}(=$ Sapindus anamensis,

Pierre), - Tonk
PA VONIA. Cass, (Malv. .) - Ind. Kew. ii, 441

argentina, Guerke, in Mart. Fl. Bras. xii. III. (1892) 508. - Reg. Argent.

Aschersoniana, Guerke, l. c. 518, - Bras.

bahamensis, Hitchoock, in Missouri Bot. Gard. Rep. iv. (1893) 63. - Ins. Baham.

bahiensis, Guerke, in Mart. Fl. Bras, xii. III. (1892) 525. - Bras.

Balansae, Guerke, l. c. 507. - Parag.

calyculina, Frapp. ex Cordem. Fl. Ile Réunion (1895) $327=$ Sida calycina, $\mathrm{Car}$

cordifolia, Hieron, in Bot. Jahrb. xx. Beibl, n. 49 $45(1895)=$ Pavonia Kunthii, Guerke.

cristata, Schinz, ex Guerke, in Bull. Herb. Boiss. iii. (1895) 407. - Reg. Somal.

Engleriana, Guerke, in Mart. Fl. Bras, xii. II. (1892) 497. - Bras.

erythrolema, Gutrke, l.c. 523. - Bras.

fraterna, Cordem. Fl. Ile Rénnion (1895) 328. - Ins. Borbon.

Garckeana, Guerke, in Mart. Fl. Bras, xii. III. (1892) 496. - Bras.

Glazioviana, Guerke, l. c. 524. - Bras.

Hieronymi, Guerke, l. c. - Reg. Argent.

kilimandscharica, Guerke, in Bot. Fahrb. xix. Beibl. n. 47 (1894) 40. - Afr. trop. or.

Kunthii, Guerke, in Mart. Fl. Bras, xii. III. (1892) 510 . - Bras., N. Granat.

longipedunculata, Guevke, l. c. 425. - Bras.

mascrostyla, Guerke, l. c. 521. - Bras.

malacophylla, Britton, in Bull. Torrey Bot. Club, xvi. (1859) 154! = Lopimia malacofhylla, Nees \& Mart.). - Am. austr.

melanommata, Robinson \& Seaton, in Proc. Am. Acad. xxviii. (1893) 104. - Mexic.

Morongii, S. Moove, in Ann. N. Y. Acad. Sci. vii. 1892) 58. - Parag.

peruviana, Guevke. in MIrt. Fl. Bras, xii, III. (1892) 48\%. - Peruvia

Pohlii, Guerke, l.c. 51\% - Bras

Rehmannii, Szyszyl. Polypet. Rehmann. (1887) 37 $=$ clathrata, Mast.

Riedelii, Guerke, in Mart. Fl. Bras, xii. III. (1892) 493. - Bras.

Schumanniana, Guerke, ex Schinz, in Verh. Bot. Ver. Brand. xxx. (1888) 174. - Afr. austro-occ, extratrop.

Selloi, Guerke, in Mart, Fl, Bras, xii. III. (1892) 530. - Bras.

semiserrata, Guerke, l. c. 527 (= Lebretonia semiserata, DC.). - Bras,

spinistipula, Guerke. l. c. 513. - Bras.

Urbaniana, Guerke, l. c. 501. - Urug.

Warmingiana, Guerke, l. c. 488. - Bras.

PAVONIA, Ruiz = Laurelia, Juss. (Monim.)

Norozelandiae, Kuntze, Rev, Gen, (1891) $568=\mathrm{L}$ Novae-Zelandiae, A.Cunn

sempervivens, Kuntze, 1. c, = L. aromatica, fuss.

columbiana, Kuntze, 1. c. $(=$ Billia columbiuna Planch. \& Triana). - N. Granat.

octandra, Kuntze, l. c. = A. Pavia, Linn.

pallida, Kuntze, 1.c. $=$ A. glabra, Willd.

PAXIA, Gilg, in Bot. Jahrb. xiv. (1892) 320 ; et in Engl. \& Prantl. Natürl. Pflanzenfam. iii. (1891) 70. CONNARACEAE

scandens, Gilg, $l l . c c .320$; et $70 .-$ Gabon

PAXIODENDRON, Engl. Pflanzenw. Ost-Afr C (1895) 182. LAURINEAE.

usambarense, Engl. l.c. - Afr. trop. or.

PAYENA, A. DC. (Sapot.). - Ind, Kew. ii. 443.

Beccarii. Engl. Bot. Fahrb. xii. (1890) 508. Borneo.

parvifolia, Engl. l. c. - Borneo.

PAYPAYROLA, Aubl. (Violar.). - Ind. Kew. ii. 443.

Glazioviana, Taub, in Bot. Fahrb. xv. Beibl. n. 34 (1892) 2. - Bras. 
PAWIA, (Pavia) Linn. = Aesculus, Linn. (Sapind.).

californica, chinensis, dissimilis, ghıbra, Hippocastanum, indica, mexicana, octandra, pallida, Parryi, parviflora, punduana, rubicunda, turbinata. Kuntze, Rev. Gen. (1891) 146 = homonyma omnia Aesculi.

PECHUELIA. Kuntze, in Jahrb. Bot. Gart. Berl, iv. (1886) $270=$ Selago, Linn. (Selagin.)

alopecuroides, Kuntze, $1 . c_{0}=\mathrm{S}$. alopecuroides, Rolfe.

PECHUEL-LOESGHEA, O. Hoffm, in Bot. Jabrb. x. (1889) 274 ; et in Engl. \& Prantl, SITAE.

Leubnitziae, $O$. Hoffm. $l l . c c$. - Afr. austro-occ. extratrop.

PECKIA, Vell. = Cybianthus, Mart. (Myrsin.). moustifolia, Boissieri, coriacea. cuspidata densicoma, densiflora. detergens, fusca, glabra, longifolia, macrophylla, meridensis, microbotrys, nitida, obotiata, penduliflora, peritvicna, Pricurii, subspicata, Kuntze, Rev. Gen. (1891) $402=$ homonyma ommia $\mathrm{Cy}$ bianthi.

cybianthodes, Kuntze, 1. c. = C. philippinensis, Hock. f.

guianensis, Kuntze, 1. c. = C. guyanensis, Miq.

surinamensis, Kuntze, 1. C. = C. myrianthos, Miq.

PEGTINARIA, Hack. in Engl. \& Prantl, Natürl. Pflanzenfam. ii. 2 (1887) 26. GRAMINEAE.

PECTIS, Linn. (Compos.). - Ind. Kew. ii. 443. aquatica, S. Wats. in Proc. Am. Acad. xxiii. (1888) 279. - Mexic.

Bennettii, Klatt, in Leopoldina, Heft xxv. (1889) 108. - Prom. S. Lucae.

bracteata, S. Wats. in Proc. Am. Acad. xxv. (1890) 155. - Mexic.

caespitosa, Klatt, in Bot. Fahrb. viii. (1887) 46. Columb.

graveolens, Klatt, l.c. - Columb.

Palmeri, S. Wats, in Proc. Am, Acad. xxiv. (1889) 58. - Mexic

stenophylla, A. Gray, l. c. xxi. (1886) 393. Mexic.

PEDDIEA, Harv. (Thyme1.). - Ind. Kew, ii, 444.

Fischeri, Engl. in Abh. Prenss. Akad. Wiss. 1891 (1892) 310; et in Engl. \& Prantl, Nativr. Pfanzenfam. iii. 6a (1894) 226. - Afr. centr. or.

involucrata, Baill. [an Baker? ] Hist. pl. Madag., Atlas (1894) t. 319. - Madag.

longiflora, Engl. \& Gilg. in Bot. Falirb. xix. (1894) 25\%. - Afr. trop. occ.

longipedicellata, Gilg, l. c. 256. - Afr. trop.

Volkensii, Gilg, l. c. xix. Beibl. n. 47 (1894) 41 . Afr, trop, or.

Zenkeri, Gilg, l. c. xix. (1894) 256. - Afr. trop. occ.

PEDICELLARIA, Schranck = Gynandropsis, DC. (Capparid.)

Lehmannii, Hieron, in Bot. Jahrb, xx, Beibl. n. 49 (1895) 20. - Columb.

triphylla, Pax, in Engl. \& Prantl, Natürl. Pflanzenfam. iii. 2 (1891) $224=$ Cleome serrata, facq.

PEDICELLIA, Lour. = Ratonia, DC. ? (Sapind.). grandis, Pierre, Fl. For. Cochinch. Fasc. 21 (1895) t. 324a. - Cochinch.

Loureivi, Pierre, 1. c. t. 323a, - Cochinch.

pentopetala, Pierre, 1. c. sub t, 314 , in obs. $=\mathrm{Cu}-$ pania pentapetala, Wight \& Am.

sundaica, Pierre, 1. c. t. $323 \mathrm{~b}=\mathrm{C}$. Lessertiana, Cambess.

PEDICULARIS, [Tourn.] Linn. (Scrophul.). Ind. Kew. ii. 444.

affinis $X$. Steininger, in Bot. Centralbl. xxix. (1887) 156. - Helv.

\section{PEDIGULARIS}

lbiflora, Prain, in fourn. As. Soc, Beng. lviii 1859) II. 273 ; ct inn Annal. Bot. Gard. Calc. jii. (1890) 156, t. 17 C. D. - Reg. Himal.

Alopecuros, Franch, ex Maxim, in Bull. Acad. Fétersb, xxxii. (1888) 548. - Yunnan.

anas, Maxim.7. c.578, - China.

apodochila, Maxim.. . c. 611.-Xunnan.

atrorubens $X$. Naegeli, ex Steininger, in Bot. Centralbl. xxx. (1887) 26. - Helv, Tirol.

axillaris, Franch. ex Maxinn. in Bull. Acad. Pétersb. xxxii. (1888) 555. - Yunnan.

batangensis, Bureau \& Franch. in Morot, Fourn, de Bot. v. (1891) 106. - China occ.

Baumgarteni, Simonk. in Termész. Füzet. x. (1\&86) 182; et Ennm? Fl. Transsilv, (1886) 431. Transsilv.

bidentata, Maxim, in Bull. Acad. Pétersb, xxxii. (1888) 533. - China

binaria, Maxim. l. . .579. - Szechuen.

birostris, Burean \& Franth. in Morot, fourn de Bot v. (1891) 10\% - China occ

Bohatschini X. Steininger, in Bot. Centralbl. xxix. (1887) 155. - Tirol

Borodowskii, Palibin, in Act. Hort. Petrop. xiy. 1895) 134. $\rightarrow$ Mongol.

bosniaca, G. Beck, in Annal. Naturh. Hofmus. Wien, ii. (1887) 139 = leucodon, Griseb.

carpatica, Andraë, in Oest. Bot. Zeitschr, (1893) 109 - Reg. Carpath.

cephalantha, Franch, ex Maxim. in Bull, Acad Pétersb. xxxii. (1888) 540. - Yunnan.

chumbica, Prain, in foum. As. Soc. Beng. lviii (1889) II. 259 ; et in Annal. Bot. Gard. Calc. iii. 1890) 144, t. 22 B. - Reg. Himal.

collata, Prain, $l l, c c .266$; et $17 \%$, t. 31 C. - Reg. Himal.

Collettii, Prain, l.c. 278; at in Annal. Bot. Gard. Calc. iii. (1890) 154, t. 15 A. - Burma.

omptoniaefolia, Franchs, ex Maxim, in Butl. Acad. Pútersb. xxxii. (188S) 586; et in Amal. Bot. Gard. Calc. iii. (1890) 166, t. 15 B. - Burma, Yunnan confertiflora, Prain, in Fourn. As. Soc. Beng. lviii. (1889) II. 258; et in Annal. Bot. Gard. Calc. iii (1890) 142, t. 27 A-D. - Reg. Himal.

conifera, Maxim. ex Hemsh. in foum, Limn. Soc xxvi. (1890) 206, - China.

corymbosa, Prainn, in fourn. As. Soc, Beng. 1viii. (1889) II. 277: et in Annal. Bot.Gard. Calc, iii (1890) 152, t. 14 B. - Burma.

craspedotricha, Maxim. in Bull. Acad. Petersb. xxxii, (1888) 540. - China.

crenata, Maxim. l. c. 559. - Yunnan.

cristata, Maxim, l, c.547. - China.

Daltoni, Prain, in fotrn. As. Soc. Beng. Iviii. (1889) II. 270 ; et in Annal. Bot. Gard. Calc. iii. (1890 121, t. 6 A. B. - Reg. Himal.

Davidi, Franch. in Nouv. Archiv. Mus. Paris, Sér. II. X. (1887-88) 67. - Tibet.

debilis, Franch ex Maxim. in Bull. Acad. Pétersb. xxxii. (1888) 549. - Yunnan.

Delavayí. Franch. ex Maxim. 7. c. 531. - Yunnan

delphinata $\times$, Steininger, in Bot. Centralbl. xxix. (1887) 216. - Gall. or.

deltoidea, Franch. ex Maxin. in Bull. Acad. Pétersb. xxxii. (1888) 604, - Yunnan.

densispica, Franch. ex Maxim. .. c. 594. - Yunnan

diffusa, Prann, in fourn. As. Soc. Beng. 1xii. (1893) II. 7, t. 1. - Reg. Himal.

eburnata, Robinson \& Seaton, in Proc. Am. Acad. xxviii, (1893) 114。 - Mexic.

arubescins $X$, Steininger. in Bot. Centralbl. xxix (1887) 155. - Tirol.

fallax, G. Beck, in Annal. Naturh. Hofmus. Wien ii. (1887) 139 = leucodon, Griseb

filicitolia, Henusl. in Fourn. Linn. Soc, xxvi. (1890) 208. - China.

Filicula, Franch. in Bull. Acad. Pétsrsb. xxxii. (1888) 573. - Yunnan

flaccida, Prain, in Kew Bull. (1893) 157 ; et in Fourn. As. Beng. 1xii. (1893) II. 8, t. 2. - China.

fragilis, Prain ex Maxim, in Bull. Acad. Petersb. xxxii. (1888) 582: in fourn. As. Soc. Beng. lviii. (1889) II. 263 ; et in Annal. Bot. Gavd. Calco iii. (1890) 178, t. 31 A. - Reg. Assam.

Franchetiana, Maxime. l. c. 553. - China

\section{PEDIGULARIS :}

Gammieana. Prain, in foumz. As. Soc. Beng. lviii, (1889) II. 260; et in Annal. Bot. Gard. Calc. iii. (1890) 162, t. 22 C. - Reg. Himal.

Garckeana, Prain, ex Maxim. in Bull. Acad. Pétersb. xxxii. (1888; 582 ; in fourn. As. Soc. Beng. lviii. (1889) II. 267: et in Annal. Bot. Gard. Calc. iii. (1890) 122, t. 5 A. - Reg. Himal.

Gibbera, Prain, $77, c c .262$; et 174, t. 29 B, - Reo. Himal.

goniantha. Burean E Franch. in Morot, Fourn. de Bot. v. (1891) 128 - China oce Grisebachii, Wettst. in Luerss. Biblioth. Bot. Heft xxvi. (1892) 78. - Albania.

gruina, Franch, ex Maxinz, in Bull. Acad. Pitersb. xxxii. (1888) 536: Prain, in Annal. Bot. Gard. Calc. iii. (1890) 149, t, 10 A. - Yunnan.

syrorhyncha, Franch。 ex Maxim. l. c. 545. China.

Hemsleyana, Prain, in Hook. Iconr.pl. xxiii. (1892) t. 2210. - China

Henryi, Maxim. in Bull. Acad. Pétersb. xxxii. (1888) 560. - China.

Heydei, Prain, in fourn. As. Soc. Beng. 1viii. (1889) II. 258: et in Amal. Bot. Gavd. Calc, iii. (1890) 140 , t. 27 E. - Reg. Himal

hirtella. Franch, ex Hemsl. in foum. Iinn. Soc.

xxvi. (1890) 209. - Yunnan

incarnatoides $X$. Steininger, in Bot. Centralbl. xxix. (1887) $15 \%$ - Eur.

ingens, Maxim, in Bull. Acad. Pétersb. xxxii. (18s8) 565. - China.

instar, Prain, ex Maxim. lo co; in fourn. As. Soc. Beng. 1viii. (1889) II. 257; at in Annal. Bot. Gard. Calc, iii. (1890) 135, t. 26 D, E. - Reo. Himal.

Jankae, Steininger, in Oest. Bot. Zeitschr. xxxvi. (1886) 189. - - Hung.

jurana, Steininger, in Bull, Soc. sci. nat. Neuchatel, xix. (1891) 149. - Helv.

Kingii, Prain, in Bull. Acad. Pétersó. xxxii. (1888) 602; in Fourn. As. Soc. Beng, Iviii, (1889) II. 264 et in Annal. Bot. Gizrd. Calc. jii. (1890) 179, t. 28 A. - Reg. Himal.

leiandra, Franch. ex Hemsl. in Fonrn. Linn. Soc. xxvi. (1890) 211. - China.

likiangensis, Franch. ex Maxinn, in Bull. Acad. Pétersb. xxxii. (1888, 597. - Yunnan.

lineata, Franch. l.c. - Yunnan.

longicaulis, Franch. l. c.577. - Yunnan.

longipes, Maxim. l. c. 554. - China.

longipetiolata, Franch. l.c. 54I. - Yunnan

lutescens, Franch. l. c.605. - Yunnan.

lyrata, Prain, ex Maxim. l. c. 606; in Fourn. As. Soc. Beng. lviii. (1889) II. 264: et in Annal. Bot. Gavd. Calc. iii. (1890) 165, t. 31 B. - Reg. Himal.

macilenta, Franch.ex Hemsl in Fourn. Linn. Soc. xxvi. (1890) 212. - China.

macrosiphon. Franch, in Nour. Archiv. MIus. Paris, Sér. II. x. 1887 (1888) 66. - Tibet.

Maximowiczii, Krasn. in Script. bot. Hort. Univ. Petrop. ii. I. (1887-88) 18. - China.

melampyriflora, Franch, ex Hensl. in foum. Linn. Soc. xxvi. (1890) 212. - Yunnan.

melampyrifolia, Franch. ex Maxim. in Bull. Acad. Pétersb, xxxii. (1858) 603, sphalm. = praec microchila, Franch. l. c.595. - Yunnan.

microphyton, Burean \& Franch. in Morot, fourn. de Bot. v. (1891) 107. - China occ.

moupinensis, Franch, in Nouv. Archiv. Mus. Paris. Sér. II. x. 1889 (1888) 67. - China.

nepalensis, Prain, in fourn. As. Soc. Beng. lviii.

(1889) II. 268; et in Annal. Bot. Gard. Calc, jii. (1890) 124, t. 6 E. - Reg. Himal.

nipponica, Makino, in Tokyo Bot. Mag. ix。 (1895) 72. - Japon,

ockrolenca, Duthie, ex Maxim. in Bull. Acad. Pétersb. xxxii. (1888) $530=$ macrantha, Klotzsch. odontophora, Prain, in founn. As. Soc. Beng, lviii. (1889) II. 275; et in Amal. Bot. Gard. Calc. iii. (1890) 155, t. 10 D. - Reg. Himal.

oligantha, Franch. ex Maxinn. in Bull. Acad. Pétersb. xxxii. (1888) 530. - Yunnan.

Oliveriana, Prain, in fourn. As. Soc. Beng. lviii. (I889) II. 257; et in Annat. Bot. Gard. Calc. iii, (1890) 135, t. 22 H. - Reg. Himal, 


\section{PEDIGULARIS :}

Phiocephala, Mlaximn in Bull. Acad. Pétersb xxxi 1888) 530, Prain, in Annal. Bot. Gard. Calc, iii 1890) 172, t. 33 A. - Reg. Himal.

rbelica, Fanka, ex Pancic, Nov. elcm. Fl, Princ. Bulg. (1856) 34. - Bulg.

Brycarpa, Franch. cx Maxim, in Bull. Acad. Pétersb. xxxiii. (1888) 530. - China.

Pantlingii, Prain, in fourn. As. Soc. Beng. lviii. 1859) II. 2 2 3 : et in Annal. Bot. Gavd. Calc. iii. 1890) 148 , t. 16 B. - Reg. Himal.

Penzigi $\times$, Steininger, in Bot. Centralbl. xxix. 1s8i) 186. - Afr. centr.

plicata, Maxim. in Bull. Acad. Pétersb. xxxii. (is88) 5.98. - China

polyphylla, Franch.ex Maxim. l.c. 543. - Yunnan. Potanini, Maxim. l. c. 5\%0. - China.

Prainiana, Maxim. l.c.567; Prain, in Annal. Bot. Gurd. Calc iii. (1890) 162, t. 11 B.-Reo. Himal.

princeps, Franch. in Morot, fourn. de Bot. v. (1891) 129. - China occ.

Provoti, Franch. . . C. iv. (1889) 318. - China bor.

Psendo-asplenifolia $X$, Steiniger, in Bot. Centralbl. xxix. (1887) 157. - Helv.

pyomaea, Maxinn, in Bull. Acad. Pétersb. xxxiz. (1888) 595. - Tibet.

recurva, Maxim. 7. c. 563. - China.

Regeliana, Prain. in fourn, As. Soc. Beng. lviii. 1889) II. 274; et in Annal. Bot. Gard. Calc. iii. 1894) 169 t. 10 C. - Reg. Himal.

rhyschodonta, Burean Eo Franch, in Morot. Foun'n. de Bot.v. (18:1) 108; Prain, in. Hook. Icon. pl. xxii. (1892) t. 2209. - China.

rex, C. B. Clarke, ex Maxim. in Bull. Acad. Pétersb. kxii. (1888) 589; et in Amal. Bot. Gard. Calc. iii. 1894) 167 t. $30 \mathrm{~A}$ - Himal., Yunnan rioida. Franch ex Maxim. l. C. 58\%. - Yunnan.

rhodotricha, Maxim. l. c. 566. - China.

rupicola, Franch.l.c.599. - Yunnan.

salviaeflora, Franch. ex Hensl. in foum. Linn. Soc xxvi. (1890) 215. - China.

scardica, G. Beck, in Ann, Naturh. Hofmus. Wien, ii. (188\%) 138 t. 3 fig. $1=$ P. Friederici-Augusti, Tomm.

schizocalyx, Steiniger, in Bot. Centralbl. xxix (1887) $249=$ comosa, $\operatorname{Linn}$.

Scullyana, Prain, ex Maxim. in Bull. Acad. Pétersto. xxxi1. (1588) 529; in foum. Linn. Soc. xxvi. (1890) 268, et in Amal, Bot. Gard. Calc. iii. (1894) 127 t. 9 A-C. - Reg. Himal.

semitorta, Maxim. in Bull. Acad. Pétersb. xxxii. (1888) 566. - China.

sigmoidea, Franch.l.c. 535. - Yunnan.

stenantha, Franch. in Bull. Soc. Philom. Paris,

Sèr. VIII. iii. (1891) 149. - Tibet.

strobilacea, Franch. ex Hemsh, in fourn. Linn. Soc. xxvi. (1890) 216. - China.

superba, Franch. ex Maxim. in Bull. Acad. Pétersb. xxxii. (18's') 588. - Yurnan.

Ezetschuanica, Maxim.l.c.601.-China.

Tartarinowi, "Maxim.» ex Hemsl, in Journ. Lin11. Soc, xxvi.(1890) 21\%, sphalm. = P. Tatarinowi. Mlaxim

tasienensis, Burean \& Franch. in Morot, foum. de Bot. v. (1891) 108. - China occ

Tenorenna, Huter, Porta \& Rigo, ex Steininger, in Bot. Centralb1. xxix. (1887) 314 , in syn, = petiolaris, Ten.

tenuicaulis, Prain, in fourn. As. Soc. Beng. lviii. (1889) II. 259; et in Annal. Bot. Gard. Calc. iii. 1890) 144, t. 18 C-E - Reg. Himal.

tenuisecta. Franch. ex Maxim, in Bult. Acad. Pétersb. xxxii. (1888) 558. - Yunnan.

torta, Maxim. l.c. 538. - China.

tsangchanensis, Franch.l.c. 71. - Yunnan.

vagans, Hemsl. in Foum. Linn. Soc. xxvi. (1890) 18; et in Hook. Icone plo xx. (1891) t. 1928. China.

verbenaefolia, Franch. l. c. 549. - Yunnan.

Viali, Franch. ex Hemsl. in fourn. Linn. Soc, xxvi. (1890) 219. - China

villosula, Franch. ex Hemsl. l. c. 220. - China.

Wolfi X, M. Besse, ex Wolf. in Ber, Schweiz. Bot. Gesells. Heft ii. (1892) 37. - Helv.

yunnanensis, Franch. ex Maxim, in Bull. Acad. Pétersb. xxxii. (1888) 572. - Yunnan.
PFDILANTHUS, Neck. (Euphorb.) - Ind. Kew. ii. 447

lycioides, Baker. in fourn. Linn. Soc. xxii. (1887) 516. - Madas

macradenius, F. D. Smith, in Contt. Bot.Gaz, xix, (1894) 263. - Guatem.

pectinatus, Baker, in fourn. Limn。Soc: xxy, (1890) 344. - Madag.

Pringlei, Robinson, in Proc. Am. Acad. xxix. (1894) 322. - Mexic

tomentellus, Robinson \& Greenm. in Am. Fourn. Sci. Ser. III. 1. (1895) 164. - Mexic

PEIRESKIA, Stend, = Pereskia, Plum. (Cact. $)$. calandrinizfolia. Hort, ex K. Schum. in Engl. \& Prantl, Natürl. Pflanzenfam. iii. 6a (1894) 206 = P. calandrinaefolia, Hort. Ber.

cruenta, Hort. ex K. Schum, in Mart. Fl. Bras. iv. II. $(1890) 312=$ P. Bleo, $D C$

anceolata, Hort. Berol. ex K. Schum, in Engl. \& Prantl, Natürl. Pflanzenfam. iii. 6a (1894) 206 $=$ P. lanceolata, Herb. Berol.

spathulata, Hort. Berol. 1. C. = P. spathulata, Otto.

PELAPHOIDES rotundzflord Banks \& Soland. (Mss.). ex Cheesem. in Trans. N. Z. Inst, xix. 1886 (1887) $237=$ Coprosma spatulata, $A$. Cunn.

PELARGoniUM, L'Hérit. (Geran.). - Ind. Kew. ii. 448 .

Barklyi, S. Elliot, in fourn. Bot. xxix. (1891) 68.Afr. austro-occ, extratrop.

dispar, N.E. Br, in Kew Bull。 (1895) 144.Natal.

Fischeri, Engl, in Abh. Prouss, Akad. Wiss. 1891 ii. (1892) 276. - Afr. trop

rramineum, Bohus, in fourn. Linn. Soc, xxv, (1889) 158. - Afr, austr.

leptopodium, Bolus, l. c. 15t. - Afr. austr.

MacOwanii, Bolus, l. c. - Afr. austr.

madagascariense, Baker, l. c. xxii. (1887) 454.Madag.

mossambicense, Engl. Pfanzenw. Ost-Afr. C (1895) 225. - Afr, trop. or.

Rehmannis, Szyszyl. Polypet. Rehmann: (1888) 9.Transvaal,

saxifragoides, N. E. Br. in Gard. Chron. (1890) if, 154. - Hab.

Tysonii, Szyszyl.Polypet.Relmann. (1888) $8(\Longleftrightarrow$ Geranium citiatum, Cav.). - Afr. austr.

usambarense, Engl. in Abh. Prenss. Akad. Wiss. (1894) 61 ; et Pflanzenw. Ost. Afv. C (1895) 225. Afr. trop. or.

PELEA, A. Gray = Melicope, Forst. (Rutac.) barbigera, Hillebr. Fl. Haw. Isl. (1888) $70=\mathrm{M}$. barbigera, A. Gray.

cinerea, Hillebr. 1. c. = M. cinerea, A. Gray. elliptica, Hillebr. 1. c. $69=$ M. elliptica, A. Gray.

Kmadsenii, Hillebr. 1. c. 70. -- Ins. Sandvic.

Lydgatei, Hillebr. 1. c, 65. - Ins. Sandvic.

macropus, Hillebr. 1. c. 65. - Ins. Sandvic

Mannii, Hillebr. 1. c. 66. - Ins. Sandvic.

molokaiensis, Hillebr. 1. c. 65. - Ins. Sandvic.

pallida, Hillebr. 1. c. 68. - Ins. Sandvic.

parvifolia, Hillebr. 1. c. 65. - Ins. Sandvic.

PELECYPHORA, Ehrenb. (Cact.). - Ind. Kew. ii. 456.

pectinata, K. Schum, in Engl. Go Prantl, Natürl. Pfanzenfam. iii.6a (1894; 195. - Mexic.

PELEXIA, [Poit.] Rich. (Orchid.). - Ind. Kew. ii. 456 .

aphylla, Ridl.ex Oliver, in Trans. Linn. Soc. Ser. II. ii. (1887) 284 t. 48b (Oliver, ex im Thurn, in Timehri, v. (1886) 205) = Spiranthes aphylla $\operatorname{cog} n$.

Glazioviana, Cogn. in Mart. Fl. Bras, iii. IV. (1895) 15 t. 34 . - Bras.

maculata, Rolfe, in Kew Bull. (1893) 7. - Hab. ?

clivacea, Rolfe, l. c. (1890) 200. - Andes ?

saccata, Roife, l.c. (1895) 195. - Guatem.

Travassosii, Rolfe, in Gard. Chron. (1892) 1. 330. Hiras.

Wendlandiana, Kraenzl. l.c. (1892) i. 426. - Hab.?
PELIOSANTHES, Andr. (Haemodor.) - Ind Kew, ii, 456

albida, Baker, in Bot. Mag. (1890) t. 7110 ; Hook. f. Fl. Brit. Ind. vi. (1892) 267. - Penang.

Bakeri, Hook. f. l. c. - Reg. Himal.

longiflora, "Steud. " ex Hook. f. 1. c. 266, in syn. Wight.

PELIOSTOMUM, E. Mey. (Scrophul.). - Ind Kew, ii. 456.

calycinum, N. E. Br, in Kew Bull. (1894) 390. Transvaal.

Marlothii, Engl. Bot. Fahrb. x. (1889) 251. - Afr. austr.

oppositifolium, Engl. l. c. xix. (1894) 149. - Afr. austr. occ.

PELLACALYX, Korth. (Rhizophor.), - Ind Kew ii, $456^{\circ}$.

Saccardianus, Scortech. in Hook. Icon. pl. xvi. (1886) t. 1546.

PELLETIERA, A. St Hil. = Asterolinon Hoffm. \& Link (Primul.)

trimum, Pax, in Engl. \& Prantl, Natür1. Pflanzenfam. iv. I. (1890) $113=$ A. trinum, Lando.

PELLIONIA, Gaudich, (Urtic.), - Ind. Kew ii. 456 .

acaulis, Hook. f. Fl. Brit. Ind. v. (1888) 562.Penang.

bulbifera, Hook. f. l. c. 560. - Tenass.

burmanica, Hook f.l. c.561. - Tenass.

Dareananana, Hort. ex Gard. Chron. (1895) ii. 643 = Daveauana, N.E. Br.

nigrescens, Warb. in Bot. Fahrb. xiii. (1891) 291. - N. Guin.

PELTANDRA, Rafin. (Aroid.). - Ind. Kew. ii. 456.

sagittaefolia, Morong, in Mem. Torrey Bot. Club v. (1894) $102=$ sagittaefolia, Rafin.

PELTARIA, Jacq. (Crucif.). - Ind. Kew. ij. 456 marginata, Hausskn. in Mitt. Thür. Bot. Ver. N. Folge, i1i et IV. (1893) 111 = Ptilotrichum emar ginatum, Boiss.

isatoides, Barb. in Bull. Soc. Vaud. sci, nat. xxi. (1885) 219; et Karpathos (1895) 94 t. 1. - Ins. Karpathos.

PELTIPHYLLUM, Engl. in Engl. \& Prantl, Natürl. Ptlanzenfam. iii. 2a (1891) 61. SAXI FRAGEAE.

peltatum, Engl. l.c. (= Saxifraga peltata, Torr.). - Calif.

PELTODON, Pohl (Labiat.), - Ind. Kew, ii, 457. comaroides, Briq. in Bull. Soc. Bot. Genìve, v. (1889) 110. - Parag.

PELTOPHORUM, Walp. (Legumin.). - Ind. Kew, ii. 457

aubirm, Taub. in Engl. \& Prant1, Natür1. Pflanzenfam, iii. 3 (1892) 176; Britton, in Ann. N. Y. Acad. Sci. vii. (1892) $88=$ Vogelianum, Walp. massaiense, Taub. in Engl. Pfanzenw. Ost-Afr. C (1895) 202. - Afr. or.

PELTostigma. Walp. (Rubiac.). - Ind. Kew 11.457

pentaphyllum, F. D. Smith. in Coult. Bot. Gaz xix.(1894) 1. - Guatem.

PELUCHA, S. Wats, in Proc. Am. Acad. xxiv. (1889) 55 ; O. Hoffm, in Eng1. \& Prantl, Natïrl. Pflanzenfam, iv. 5 (1893) 390. COMPOSITAE. trifida, S. Wats. Il. cc. - Calit.

PENAEA, Linn. (Penaeac). - Ind. Kew. ii. 457 ericifolia, Gilg, in Bot. Fahrb, xviii. (1894) 520; et in Engl. et Prantl, Naturl. Pfanzenfam. ii.. 6a (1894) 2I? - Afr, austr. 
PENNISETUM, Rich. (Gramin.). - Ind. Kew. ii. 459

densiflorum, Th. Dur. \& Schinz, Consp. Fl. Afr.v. 1894 (1895) 778 (= Eriochata densiftora, Fig. \& De Not.) - Kordofan.

depauperatum. Schweinf. in Bull. Herb. Boiss. ii. App. II. (1894) 26. - Arabia

flexispica, $K$. Schum. in Engl. Pfianzente. Ost-Afr. C (1895) 105. - Afr. trop. or.

laxum, Hochst. ex Engl. in Abh. Prenss. Akad. Wiss, ji. 1891 (1892) 126, nomen. - Afr. trop. or

longisetzm, K. Schum. in Engl. Pflanzenw. Ost Afr. C (1895) $105=$ Setaria longiseta, Benuv

nemorum, Arechav. in Anal. Mus, nac. Montevid. iii. $(1895) 221=$ nervosum. Trin.

nigricans, Th. Dur. et Schinz. Consp. Fl. Afr. v. 1894 (1895) $781=$ nigricans, Trin.

nigritarum, Th. Dur. \& Schinz, 1.c. (= Penicillarid nigritarum, Schlecht.). - Seneg.

Notarisii. Th. Dur. \& Schinz, 1. c. (= Eriochatet reversa, Fig. \& De Not.). - Nubia.

nitens, Hack. in Bolet. Soc. Brot. vi. (1888) 142 T7. Dur. E Schinz, l. c. 781. (= G1mnotrix nitons, Fig. \& De Not.). - Mossamb.

nubicum, K. Schum, ex Engl. in Abh. Preuss, Akad. Wiss. (1894) 58; et Pflanzenw. Ost-Afr A $(1895) .99=1$ longisetum, $K$. Schum.

Parisi, Trab. in Bull. Soc. Bot. Fr. xxxiv. (18S7) 391: Batt. \& Trab. F1. de 1'Algér. [Monoc.] (1895) $136=$ orientale, Rich.

pumilum, Hack. ex Engl. in Abh. Prenss. Akad. Wiss. 1891 II. (1892) 124. - Afr. trop. or.

reversum, Hack. ex Bucttn. in Verh. Bot. Ver. Brand. xxxi. (1889) 68. - Congo.

Rueppliamum, Hort, ez Gartenfl. xliv, (1895) 137 et $179=$ P. Ruppellii, Stend.

secundiflorum, Th. Dur. Eo Schinz, Consp. Fl. Afr. v. 1894 (1S95) 784 (= Eriochaeta secundiflore Fig. \& De Not.). - Nubia.

sphacelatum, Th. Dur. \& Schinz, l.c. (= Gymnotrix sphacelata, Nees). - Afr. austr.

spicatum, Koern. ex Aschers. \& Schweinf. Ill. Fl. Égypt. [Mém. Inst. égypt.]. (1887) 162; et ex Schinz. in Bull. Herb. Boiss. 1i. (1894) 227 = spicatum, Roem. \& Schult.

tenuifolium, Hack.ex Schinz, l. c. iii. (1895) 380. Transvaal.

tristachyum, Arechav, in Anal.-Mus. nac. Montevid. i. (1894) 219 , t. $13=$ tristachyum, Spreng.

uliginosum, Hack. ex Engl. in Abh. Prenss. Akad. Wiss. 1891 ii. (1892) 123. - Afr. trop. or.

unisetrm, Jacks, ex Th. Dur. \& Schinz, Consp, F1. Afr.v. 1894 (1895) $786=$ unisetum, Benth.

PENTACAENA, Bartl, (Illecebr.). - Ind. Kew. ji. 459 .

andina, Phil. in Anal. Mus, nac, Chile (1891) 26. Chili.

PENTACE, Hassk. (Tiliac.). - Ind. Kew, ii. 459. borneensis, Pierre, Fl. For. Cochinch. Fasc. 10 (1888) sub t. 151. - Borneo.

Curtisii, King, in fourn. As. Soc. Beng. Ix. (1891) II. 103. - Penang.

eximia, King, l. c. - - Perak.

floribunda, King, l.c. 102. - Perak.

Griffithii, King. l. c. 104 . - Tenass.

Hookeriana, King, l. c. 101. - Perak.

Kunstleri, King, l.c. - Perak.

macrophylla, King, l. c. 104. - Perak.

perakensis, King, l. c. 101.- Perak.

Scortechinii, King, l. c. 104. - Perak.

strychnoidea, King, l. c. 105. - Perak.

PENTACHAETA, Nutt. (Compos.), - Ind. Kew. ii. 459 .

Orcutti, A. Gray, in Proc. Am. Acad. xxii. (1887) 309. - Calif. inf.

PENTACME, A. DC. = Shorea, Roxb.(Dipteroc.). malayana, King, in Journ. As. Soc. Beng. lxii. (1893) Ir. 10\%. - Malaya.

pancinervis, Brandis, in Journ. Linn. Soc, xxxi. (1895) 73. - Ins. Philipp.
PENTADIPLANDRA, Baill. in Bu11. Soc. Linn. Paris, i. (1886) 6II. TILIACEAE.

Brazzeana, Baill.l. c. - Congo gall.

PENTAGONIA, Benth. (Rubiac.). - Ind. Kew. ii. 459 .

spathicalyx, $K$. Schum, in Mart. Fl. Bras, vi, VI. (1859) 302. - Bras.

PENTAGONIA, Moehr, = Specularia, Heist. (Campanul.)

biflora, falcata, hybrida, leptocarpa, perfoliata, Kuntze, Rev. Gen. (1891) $381=$ homonyma onnia Speculariae.

con, Kuntze, 1. c. = S. pentagonia, A. DC.

coloradensis, Kuntze, 1. C. = S. Lindhdimeri, Vatke.

PENTAGONOCARPOS, Mich, = Kosteletzkya, Presl (Malvac).

adoënsis, altheaefolius, cordatus, Conlteri, digitatus, Grantii, hastatus, hispidus, madagascariensis, paniculatus, pentacarpus, pentaspermus. sagittatus, relutinus, virglnicus, Kuntze, Rev. Gen. (1891) $73=$ homonyma omnia Kosteletzkeae.

Bakerianus, Kuntze, 1. c. = K. hispida, Baker

macrotis, Kuntze, l. c. = Pavonia macrotis, Baker.

PENTANISIA, Harv. (Rubiac.), - Ind. Kew. ii. 460

longituba, Olizer, in F. L. Fames, Unkn. Horn of Afr., Append. (1888) 319. - Afr. or.

monogyna [Engl.] Pflanzenw. Ost-Afr. A (1895) 42, nomen. - Afr, trop.

veronicoides, K. Schum. in Eng1. \& Prantl, Natürl. Pflanzenfam. iv. 4 (1891) $90=$ Holocarpa veronicoides, Baker.

PENTAPANAX, Seem. (Aral.). - - Ind, Kew. ii. 460.

Willmottii, F. Muell, in Australas, fourn, Pharm. ii. (April (1887) 125; et Bot. Centralbl, xxxii, (1887) 214. - Austral.

PENTAPHALANGIUM, Warb. in Bot. Jahrb. xiii. (18)1) 382; Encl. in Engl. \& Prantl, Natürl. Pflanzenfam. iii. 6 (1893) 240. GUTTIFERIAE

crassinerve, Warb. $l l . c c .-\mathrm{N}$. Guin

PENTAPHRAGMA, Wall. (Campanul.). - Ind. Kew. ii. 460 .

aurantiaca, Stapf, in Trans. Linn. Soc. Ser. II. iv. (1894) 188. - Borneo.

PENTAPOGON, R. Br. (Gramin.). - Ind. Kew. ii. 461

quadrifidum, Baill. Hist. des p1. xii. (1894) $280=$ P. Billardieri, $R, B r$.

PENTARHAPHIA, Lindl. (Gesner.). - Ind. Kew. ii. 461.

Sloanei, Hitchcock, in Missouri, Bot. Gard. Rep. iv. (1893) 114 [Pentaraphia] $=$ P. Sloanei Hanst.

PENTARRHAPHIS, H. B. \& K. (Gramin.). Ind. Kew. ii. 461.

Fournieriana, "Vasey " Hack. \& Scribn. in Bull Torrey Bot. Club, xvii. (1890) 229. - Mexic.

geminata, Hack. \& Scribn. 1. c. $231=$ Fournieriana, Hack. et Scribn.

paupercula, Hack. E Scribn. l. c. 233 (= Polyschistes paupercula; J. \& C. Presl). - Ins. Luzon.

PENTARRHINUM, E. Mey. (Asclep.). - Ind. Kew. ii. 461

coriaceum, Schlechter, in fourn. Bot. xxxii. (1894) 357. - Natal.

fasciculatum, $K$. Schum. in Engl. Pfanzenw. OstAfr. C (1895) 323. - Afr. trop. or.

tylophoroides, K. Schum, in Engl. \& Prantl, Natiirl. Pfanzenfan. iv. 2 (1895) 244. - Afr. austr.
PENTAS, Benth. (Rubiac.). - Ind. Kew. ii. 461. confertifolia, Baker, in Kev Bill. (1895) 67. - Afr.

elata, $K$. Schum. in Engl. Pflananw, Ost-Afr. C (1895; 377. - Afr. trop or.

glabrescens, Baker, in Kev Bull. (1895) 215. Reg. Somal.

hirtiflora, Baker, in Fourn. Linn. Soc. xxii (1887) 482. - Madag.

involucrata, Bakev, in Kerv Bull. (1895) 67. - Reg. Somal.

lanceolata, K. Schum, in Engl. et Prantl. Natür1. Pflanzenfam. iv. 4 (1891) 29= carnea. Benth. longiflora, Oliver, in $H$. Fohnst. Kilim. Exped. Append. (1886) 341 nomen; et in Trans. Lim. Soc. Ser. II, ii (1887) 335. - Afr. trop. or. longituba. K. Schnm, ex Engl. in Abh. Preuss. Akad. Wiss. (1894) 57; et in Engl. Pfanzenzo. Ost-Afr. C (1895) 377. - Afr. trop.

modesta, Baker, in Kevv Bull. (189.̃) 200. - Afr. trop.

monbassana, Hierne ex Olizer, in Trans, I imn Soc.

Ser. II, iii. (1887) 335. - Afr. trop.

pauciflora, Baker, in Kew Bull. (189.5) 215. Reg. Somal.

Schimperi, Hochst. ex Engl. Pflanzenw. Ost-Afr. A $(1895) 92=$ P. Schimperi, Vatke?

speciosa, Baker, in Kew Bull. (1895) 67. - Afr. trop.

Warburgiana, K. Schum, in Engl. Es Prantl. Nalim . Pfanzenfam. iv. 4 (1891) 29. - Afr. trop. occ.

PENTATRICHIA, Klatt, in Bull. Herb. Boiss iii. (1895) 436. COMPOSITAE

petrosa, Klatt, l.c. 437 T 10. - Afr. austro-occ

PENTATROPIS, R. Br. (Asclep.). - Ind. Kew.

officinalis, Hentsl. in fourn. Linn, Soc. xxvi. (1890) 110. - China.

PENTOPETIA, Decne (Asclep.). - Ind. Kew. ii 467

natalensis, Schlechter, in fourn. Bot. xxxi1. (1894) 257. - Afr. austr.

PENTSTEMON, Mitch. (Scrophul). - Ind Kew: ii. 452 .

arenarius, Greene, Pittonia, i. (Mar. 1889) 282.Nevada.

canescens, Brition, in Mem. Torrey Bot. Club, y. (1894) 291. - Am. bor.

Davidsonii. Greene, Pittonia, ii. (July 1892) 241. Calif.

ellipticus, Coult. Eo Fisher, in Coult. Bot. Gaz. xviii. (1893) 302. - Idaho.

fasciculatus, A. Gray, in Proc. Am, Acad. xxi. (1886) 403. - Mexic.

fruticiformis, Conille, in Contrib. U. S. Nat. Herb. iv. (1893) 170. - Calif.

fruticosus, Greene, Pittonia, ii. (July 1892) $239=$ P. Menziesii, Hook.

guadalupensis, Heller, in Contrib. Herb. Frankl. [Bot. Expl.S. Texas] (1895) 92 t. \%. - Texas.

Haydeni, S. Wats. ex Coult. in Bot. Ga\%, xvi. (1891) 311. - Am. bor.

leucanthus, Greene, Pittonia, i. (July 1886) 72.Calif.

linearifolius, Coult. E Fisher, in Coult. Bot. Guz. xviii. (1893) 302. - Idaho.

Moffatii, Eastwood, in Zoë, iv. (1893) 9. Colorado.

montanus, Greene, Pittonia, ii. (July 1892) 240.Am. bor.

Pentstemon, MacMill, in Bul1. Torrey Bot. Club, xix. (1892) 15; Britton, in Mem. Torrey Bot. Club, v. (1891) $201=$ pubescens, Solander.

Pringlei, S. Wats. in Proc. Am, Acad. xxiii, (ISSs) 281. - Mexic.

rotundifolius, A. Gray, l. c. xxii. (185\%) $30 \%$; Dequar, in Gard. Chron. (18S8) ii. 264 fig. 31. Meric

Shockleyi, S. Wats. l. c. xxiii. (18S8) 265. Nevada. 


\section{PENTSTEMON}

Smallii, Heller, in Bull. Torrey Bot. Club, xxi. (1894) 25 et 304. - Am, bor.

sonomensis, Greene, Pittonia, ii. (Sept. 1891) 218: et MIan. Bot. San Franc. Bay (1894) 274. Calif.

triflorus, Heller, in Contrib. Herb. Frankl. Bot. Exp. S. Texas] i. (1895) 92 t. 8. - Texas.

Tweedyi, Canby \& F. N. Rose, in Coult. Bot. Gaz. xv. (1S90) 66, [Penstemon]. - Montana.

ntahensis, Eastwood, in Zoë, iv. (1893) 124. Utah.

PEPEROMIA. Ruiz \& Pav, (Piperac.). - Ind. Kew. ii. 468

albidiflord, C. DC. in Morot, fourn. de Bot. iv. (1890) 399. - N. Granat.

Andrei, C. DC. . . c. 398. - N. Granat,

armadana, C. DC. l. c. 399 - N. Granat.

Bachmannii, C. DC. in Bot. falrz. xix. (1894) 227. - Afr. antstro-oce.

Bangii, C. DC. in Bull. Torrcy Bot. Club, xix. (1892) 49. - Bolivia.

brachytricha, Baker, in fourn. Limn. Soc. xxv. (1890) 342. - Madag.

barbana, C. DC. ex Th. Dur. \& Pitt. in Bull. Soc. Bot. Belg. xxix, 2 (1890) T0; et xxx. (1891) 233. - Costa Rica.

borucana, C. DC. l. c. 232. - Costa Rica.

Brittonii, C. DC in Bull, Torrey Bot. Club, xix. (1892) 254. - Bolivia.

breeana, C. DC. in Bot. Farhb. xix. (1894) 22\% Kamerun.

caespitosa, C. DC. in Morot, foum. de Bot. iv, (1890) 399. - Ecuad.

calvicaulis, C. DC ex Th, Dur \& Pitt in Bull Soc. Biot. Belg. xxx. (1891) 231. - Costa Rica. hrysocarpa, C. DC. l. c. xxix. 2 (1890) 70 ; et xxx. (1891) $22 \%$ - - Costa Rica.

cobana, C. DC. ex F. D. Smith, in Coult. Bot. Gas xix. (1894) 268. - Guatem.

confusa, Hook. f. Fl. Brit. Ind, v. (1886) 98. Zeylan.

Cooperi, C. DC. ex Th. Dur. \& Pitt. in Bull. Sod Bot. Belg. xxx. (1891) 226. - Costa Rica.

costaricensis, C. DC. l. c. 228. - Costa Rica.

dauleana, C. DC. in Morot, fourn. de Bot, iv. (1890) 399. - Ecuad.

Dryadum, C. DC. in Bot. Fahrb. xix. (1894) 229. Madag.

Durandi, C, DC. ex Th, Dur. E Pitt. in Bull. Soc Bot. Belg. Xxx. (1891) 285. - Costa Rica.

Dusenii, C. DC. in Bot. Falirb. xix. (1894) 229. Kamerun

enervis, F. Muell, in Vict. Natural. viii. (Nov. 1891) 109; et in Bot. Centralbl. xlix. (1892) 362. Austral.

vlandulosa, C. DC, in Morot. Fourn. de Bot, iv 1890) 398. - Ecuad.

gracillima, S. Wats, in Proc. Am. Acad. xxii. (1887) 448. - Mexic

guatemalensis, C. DC. cx F. D. Smith, in Coult. Bot Gaz. xix. (1894) 10. - Guatem.

Heydei, C. DC. l. c. 9. - Guatem.

Hildebrandtii, Vatke, ex C. DC. in Bot, fahrb. xix (1894) 228. - Madag.

Holstii, C. DC. in Abh, Prenss. Akad. Wiss. (1894) 37; et in Bot. Fahrb. xix. (1894) 226. - Afr. trop. or.

Imerinae, C. DC. in Bot. Falnb. xix. (1894) 228. Madag

inquilina, Hemsl. in Gard. Chron. (1892) ii. 428. Mexic.

jaliscana, S. Wats. in Proc. Am. Acad. xxvi. (1891) 145. - Mexic.

kamerunana, C. DC. in Bot. Falirb. xix. (1894) 228. - Kamerun.

lencostachya, C. DC. in Morot, fourn. de Bot. iv. (1890) 398. - N. Granat.

ligustrina, Hillebr. Fl. Haw. Isl. (1888) 426. - Ins. Sandvic.

Luxii, C. DC. $e x$ F. D. Smith。 in Conlt. Bot. Gaz. xix. (1894) 260. - Guatem.

macrophylla, C. DC. . . c. 8.- Guatem.

malaccensis, Ridl, in Keto Bull. (1895) 185. - Malacca.

\section{PEPEROMIA :}

mascarena, C. DC, in Abh. Prouss. Akad. Wiss. (1894) 47, nomen. - Ins. Mascar.

metallica. L. Linden \& Rodigas, in Illustr. Hortic. xxxix. (1892) 79 t. 557. - Peruvia.

Molleri, C. DC. in Bolet. Soc. Brot. x. (1892) 154. Ins, S. Thom.

muricatulata. Colenso, in Trans. N. Z. Inst. xxvii. 1894 (1895) 393. - N. Zel

Novae-Zelandiae, Colenso, l. c. 394. - N. Zel.

nudicaulis, C. DC. in Bull. Torrey Bot. Club, xix. 1892) 49. - Bolivia.

palmana, C. DC. ex Th. Dur. E Schinz, in Bull. Soc. Bot. Belg. xxix. 2 (1890) 71; et xxx. (1891) 233. - Costa Rica.

pandiana, C. DC. in Morot, fourn. de Bot, iv, (1890) 398. - N. Granat. Ecuad.

parvula, Hillebr. Fl. Haw. Isl. (1888) 426. - Ins. Sandvic

Pittieri, C. DC. ex Th. Dur. \& Pitt. in Bull. Soc Bot. Belg. Xxx. (1891) 235. - Costa Rica.

pleistostachya, Hillebr. Fl. Haw. Isl. (1888) 426. Ins. Sandvic.

poasana, C. DC. ex Th. Dur. \& Pitt. in Bull. Soc Bot. Belg, xxx. (1891) 224. - Costa Rica

Preussii, C DC. in Bot. Fahrb. xix. (1894) 226. Kamerun,

Pseudo-pubescens, C. DC. in Bull. Torrey Bot. Chub, xxi。 (1894) 160. - Bolivia.

psilophylla, C. DC. . c. 161. - Bolivia.

psilostachya, C. DC. ex M. Micheli, in Mom. Soc Helv. sci. nat, xxxii. (1893) n. 2, 9 t. 54 fig. 6-9 - Parag.

pululaguana, C. DC. in Morot. Fourn. de Bot. iv. (1890) 399. - Ecuad.

Rehmannii, C. DC. in Bot. fahrb. xix. (1895) 227 - Transvaal.

Rusbyi; C. DC. in Bull. Torrey Bot.Club, xix. (1892) 49. - Bolivia.

San-Felipensis, C. DC. ex F. D. Smith, in Coult. Bot. Gaz. xix. (1894) 9. - Guatem.

Santa-Rosana, C. DC. .. c. 10.- Guatem.

Schmidtii, C. DC. in Bot. fahrb. xix. (1894) 229 - Ins. Comor.

scutellata, C. DC. ex Th. Dur. E Pitt. in Bull. Soc Bot. Belg. Xxx. (1891) 230. - Costa Rica.

silvicola, C. DC. in Bot. Fahrb. xix. (1894) 230. Madag.

Siziana. C. DC. ex F. D. Smith, in Coult. Bot. Gaz. xix. (1894) 9. - Guatem.

stenophylla, C. DC. ex Th。Dur. \& Pitt. in Bull. Soc. Bot. Belg. xxx. (1891) 228. - Costa Rica.

Stuebelii, C. DC. in Bull. Torrey Bot. Chub, xix (1892) 255. - Bolivia.

Stuhlmannii, C. DC. in Bot. Falk r. xix. (1892) 225. Afr. trop. or.

truncicola, C. DC. l. c. - Madag.

thomeana, C. DC, in Botet. Soc. Brot. x. (1892) 154 - Ins, S. Thom.

Thomsoni, Hook. f. Fl. Brit. Ind. v. (1886) 9\%. Reg. Himal, ? Zeylan.

Tonduzii, C. DC. ex Th. Dur. \& Pitt. in Bull. Soc. Bot. Belg. Xxix. 2 (1890) 70, et xxx. (1891) 229. - Costa Rica.

vaccinifolia, C. DC, in Bot. Fahrb. xix. (1894) 226. - Kamerun

vinasiana, C.DC. ex Th, Dur. E Pitt. in Bull. Soc. Bot. Belg. xxx, (1891) 231. - Costa Rica.

violaefolia, C. DC. ex 7. Smith, in Conlt. Bot. Gaz. xix. (1894) 8. - Guatem.

Zenkeri, C, DC., in Bot. Falkb. xix. (1894) 226. Kamerun.

PEPINIA, Brogn. = Pitcairnia, L'Hérit.(Bromel.). incarnata, Ed. Morr. ex Baker, Handb. Bromel (1889) 116 , in syn. = P. incarnata, Baker.

recurvata, Ed. Morr. ex Baker, 1. c. $110=$ P recurvata, $K$. Koch.

subjuncta, Baker, 1. c. 116. - Guian. gall.

PEPLIDIUM, Delile (Scrophul.), - Ind. Kew. ii. 466.
martimum, Wettst. in Engl. \& Prantl, Natürl. Planzenfam. iv. 3b (1891) $78=$ humifusum,
Plation, Wetts. in Delito.
PEPONIA, Nand. (Cucurb.) - Ind. Kew ii, 467 bracteata, Cogn. in Bolet. Soc. Brot. x. (1892) 119 - Ins. S. Thom

kilimandscharica, Cogn. ex Engl. in Ab\%. Prenss. Akad. Wiss. 1891 (1892) 406 et (1894) 34 et $64 ;$ el in Bot. Fahrb. xxi. (1895) 210... Afr. trop. or. parviflora, Cogn.l. c. 209. - Afr, trop. or.

trilobata, Engl. Pfanzenw. Ost-Afr. C (1895) 399. Afr. trop. or

umbellata, Cogn. ex Engl. in Ab\%. Prenss. Akad Wiss. (1894) 61; et in Bot. Fahrb. xxi. (1895) 210. - Afr. trop. or.

usambarensis, Engl, in Abh. Preuss, Akad. Wiss. (1894) 61; et Pflanzenw. Ost-Afr. C (1895) 399.Afr. trop. or.

PERAMIUM, Salisb. = Goodyera, R. Br. (Orchid.)

giganteum, Coult. in Contrib. U.S. Nat. Herb, ii (1894) $424=$ Epipactis Royleana, Lindl.

Menziesii, Morong, in Mem. Torrey Bot. Club. v. (1894) $124=$ Goodyera Menziesii, Lindl.

pubescens, C. C. Curtiss, ex Small \& Vail, i. c. iv. (1893) 155; et in Bull. Torrey Bot. Club, xx. (1893) $189=\mathrm{G}$. pubescens, $R$. Br.

PERAXILLA, Van Tiegh. in Bull. Soc. Bot. Fr, xli. (1894)300; etxlii. (1895) $26=$ Loranthus Linn. Colensoi, Van Tiegh. 1. c. $300=$ L. Colensok, Hook. $f$.

decussata, Van Tiegh. 1. c. $26=$ L. decussatus, Kivk

Haastii, Tan Tiegh. 1. c. (= Pevella Haastii, Van Tiegh.). - Austral.

punctata, Van Tiegh. 1. c. (= Perella punctata. Van Tiegh.). - Austral.

tetrasepala, Van Tiegh. 1, c. $300=$ Loranthus tetrasepalus, Linn. $f$.

uniflora, Van Tiegh. 1. c. (= Perella uniflora, Van Tiegh.). - Hab.?

PERDICESEA, Provencher (ubi?) ex Delam. Renauld \& Card. Fl. Miquelonensis (1888) 21 = Mitchella, Linn. (Rubiac.)

repens, Provencher, 1. c. = M. repens, Linn.

PEREBEA, Aubl. (Urtic.). - Ind. Kew ii. 468. Markhamiana. Benth. ex Hook. f. in Trans. Limn. Soc. Ser. II, ii. (1886) 211, in nota. - Darien.

PERELLA, Van Tiegh. in Bull. Soc. Bot. Fr. xvii. (1895) $434=$ Loranthus, Linn.

Haastii, Van Tiegh, 1. c. - Austral.

punctata, Van Tiegh. 1. c. - Austral.

tetrasepala, Van Tiegh, 1. c. $=$ Loranthus tetrasepalus, Linn, $f$.

miflora, Van Tiegh. 1. c. - Hab.

PEREZIA, Lag. (Compos.). - Ind. Kew. ii. 469.

brachylepis, Phil. in Anal. Univ. Chil, Ixxxvii. (1894) 299. - Chili.

capitata, S. Wats. in Proc. Am. Acad.xxv. (1890) 156. - Mexic.

collina, S. Wats. l. c. xxvi. (1891) 144, - Mexic. glomerata, Rusby, in Mem Torrey. Bot. Club. iv. (1895) 214. - Bolivia.

grandifolia, S. Wats. in Proc. Am. Acad. xxv. (1890) 156. - Mexic.

Mandoni, Rusby, in Mem. Torrey Bot. Club, iii. 3 (1893) 66. - Bolivia,

michoacana, Robinson, in Proc. Am. Acad. xxvii. (1893) 179. - Mexic.

montana, F. N. Rose, in Contrib. U. S. Nat. Herb. i. (1891) 105 t. 8. - Mexic.

Palmeri, S. Wats. in Proc. Am. Acad. xxiv. (1889) 58. - Calif. austr.

paniculata, A. Gray, l.c.xxi. (1886) 393. - Mexic. pilifera, Kurtz, in Verh. Bot. Ver. Brand. xxxv. (1894) $112=$ pilifera, Hook. E Amn.

spathulata, Phil. in Anal. Univ. Chil. Ixxxvii. (1894) 300. - Chili.

vernonioides, A. Gray. in Proc. Am, Acad. xxil. (1887) 433. - Mexic.

PEREZIOPSIS, Coult. Bot. Gaz. xx. (1895) 52. COMPOSITAE.

Donnell-Smithii, Coult.l. c. 53 t. 6. - Guatem. 
PERFOLIATA, Burm. = Hermas, Linn. (Umbell.

capitata, Kuntze, Rev. Gen, (1891) $269=$ H. capitata, Linis. $f$.

ciliata, Kuntze, 1. c. = H. ciliata, Linn. $f$.

gigantea. Kuntze, 1. c. = H. gigantea, Lim. $f$.

quinquedentata. Kuntze. 1. c. = H. quinquedentata.

Limrs. $f$.

rillosa, Kuntze, 1. c. = H. depauperata, Linn.f.

PERGUL $\Omega$ RIA, Linn. (Asclep.). - Ind. Kew. ii. 46 ).

africana, N. E, Br, in Kew Bull. (1895) 259.Afr. trop.

PERIANDRA, Mart. (Legumin.). - Ind. Kew ii. 469 .

mediterranea, Taub. in Engl. Eo Prantl, Natürl. Pfanzenfam. iii. 3 (1894) 359. - Bras.

parviflora, M. Micheli, in Bull. Horb. Boiss, ii (1S94) 444, t. 14. - Guatem.

PERIANTHOMEGA, Bureau, ex Baill. Hist des pl. x. (1888) 33; K. Schum, in Engl. \& Pranil, Natürl. Pflanzenfam. jii. 3b. (1S94) 225 BIGNONIACEAE

Vellozii, Bureau, in Warm. Symb. Fl. Bras, centr. xl. (1893) 1228 (= Bignonia perianthomega, Vell.). Bras.

PERIANTHOPODUS, Silva Manso= Cayaponia Silva Manso (Cucurb.).

globulosus, Baill. ex Laness. P1. util. Colon. Franç. (1886) 829. - Seneg

PERIANTHOSTELIMA. Baill. Hist. des pl. x. (1890) 247; K. Schum. in Engl. \& Prantl, Natürl. Pflanzenfam.iv. 2(1895) 249. ASCLEPIA$D E A E$.

PERICHLAENA. Baili. Hist. des p1. x. (1SSS) 50 $\mathrm{K}$. Schum. in Engl, \& Prantl, Natiirl. Pflanzen fam. 1v. 3b. (1ธ94) 232. BIGNOATACEAE.

Richardi, Baill. 7l. cc. - Madas.

PERIEILEMA, Benth. \& Hook. f. = Pereilema Presl (Gramin.)

ciliatum. Fourn. Gram. Mexic. 1881 (1886) $93=$ Pereilema ciliatum. Fourn.

cirratum, Fourn. 1. c. in syn. = P. crinitum, Prest setarioides, Fourn. 1. c = P. setarioides, Fourn.

PERIESTES, Baill. in Bull. Soc. Linn. Paris, ii (18y0) 833; et Hist, des pl, x. (1891) 463. Lin dau, in Engl. \& Prantl, Natürl. Pflanzenfam. iv. 3b (1895) 333. ACANTHACEAE.

Haroni, Baill. Il. cc. - Madag.

comorensis, Lindau, l.c. (= Hypoestes comorensis, Baker), - Ins. Comor.

PERIGLOSSUM, Decne = Cordylogyne, E Mey. (Asclep.).

Kaessnerianum, Schlechter, in Bot. Jahrb, xx. Beibl. n. 51 (1895) 40. - Afr. austr.

PERILLA, Linn. (Labiat.). - Ind. Kew, ii. 470 frutescens, Britton, in Mem. Torrey Bot. Club. v (1894) $277=$ ocimoides Linn.

PERYMENIOPSIS, Sch. Bip. ex Klatt, in Leopoldina, Heft xxiii. (188\%) 90 , in syn. = Gymnolomia, H. B. et K. (Compos.).

perfoliata, Sch. Bip. 1. c. = G decurrens, Klatt.

PERINERION, Baill. in Bull. Soc. Linn. Paris, i. (1S8S) 758; et Hist. des pl. x. (1888) 210 ; K. Schum. in Engl. et Prantl, Natürl. Pflanzenfam. iv. 2 (1895) 174. APOCYNEAE.

Welwischii, Baill. $l l . c c$. - Angola.

PERIOMPHALE, Bail1. in Bul1. Soc. Linn. Paris, i. (1888) 731; et Hist. des pl. x. (1888) 85. GESNERACEAE.

Balansae, Baill. l. c.732. - N. Caled.

Pancheri, Baill. l. c. - N. Caled.
PERIPLOGA, Tourn, ex Linn. (Asclep.). - Ind. Kew, ii, 471 .

latifolia, K. Schum. in Engl. Pflanzenzw. Ost-Afr. C (1895) 321 - Afr. trop. or.

Preussii, K. Schum. in Bot. Fahrb. xvii. (1893) 11 . - Afr. trop.

visciformis, $K$. Schum. in Engl. E Prantl, Natïrl. Pflanzenfam, iv. 2(1895) 216 (= Socotora aphylla, Balf. f.). - Afr. trop. or.

PERISTERIA, Hook. (Orchid.). - Ind. Kew. ii. 471 .

aspersa, Rolfe, in Lindenia, vi. (1890) 57 t. 267. Columb.

laeta, Reichb.f. in Gard. Chron. (1888) ii. 616. $\mathrm{Hab}$ ?

Lindeni, Rolfe, in Lindenia, vii. (1891) 83 t. 328 et in Illustr. Hortic xxxix. (1892) 121. - Hab.

Rossiana, Reichb. f. in Gard. Chron. (18s9) i. 8. $\mathrm{Hab}$.

PERISTETHIUM, Van Tierh. in Bull. Soc. Bot. Fr. xlii. (1895) $175=$ Loranthus, Linn.

leptostachynm, Van Tiegh. 1. c. = L. leptostachys, H. B. \& $K$.

PERISTROPHE, Nees (Acanth.). -- Ind. Kew. ii, 471 .

Doriae, Terrac. in Ann. Ist. Bot. Roma, v. (1894) 102. - Afr. trop or.

keyensis. Warb. in Bot. Fahrb, xiii. (1891) 422. N. Guin.

PERISTYLUS, Blume = Habenaria. R. Br. (Orchid.)

hispidulus, Rendle, in Journ. Linn. Soc. xxx. (1891) 398 [hispidula] $=$ Brachycorythis pubescens, Harv.

PERITYLE, Benth. (Compos.), - Ind. Kew. ii. 472. aurea, $F . N$. Rose, in Contrib. U. S. Nat. Herb. i. (1890) 84. - Calif. inf.

crassifolia, T. S. Brandeg. in Proc. Calif. Acad, Ser. II. iii. (1891) 147. - Calıf.

Brandegeana, F. N. Rose, in Coult. Bot. Gaz. xv. (1890) 114. - Am. bor. Occ

cuneata, T. S. Brandeg. in Zoë, i. (1890) 54.-Calif. deltoidea, S. Wals. in Proc. Am. Acad. xxiv. (1889) 57. - Calif. austr.

effusa. F. N. Rose, in Contrib. U. S. Nat. Herb. i. (1891) 104. - Mexic

Greenei, F. N. Rose, in Coult. Bot. Gaz. xv. (1890) 117. - Calif. austr.

jaliscana, A. Gray, ex $S$. Wats, in Proc. Am. Acad. xxii. (1857) 431. - Mexic.

Lloydii, Robinson E. Fernald, l. c. xxx. (1895) 118 - Mexic

microcephala, A.Gray, l.c.xxi. (1886) 391.-Mexic. minutissima, F. N. Rose, ex T.S. Brandeg. in Proc. Calif. Acad. Ser. II. 1ii. (1891) 148, nomen.Calif.

Palmeri, S. Wats. in Proc. Am. Acad.xxiv. (1889) 5\%. - Mexic.

Rothrockii, F. N. Rose, in Coult. Bot. Gaz. xv. (1890) 114. - Calif.

rotundifolia, T. S. Brandeg. in Zoë, iv. (1893) 210 $=$ P. Fitchii, Torr

socorrosensis. F. N. Rose, in Coult. Bot. Gaz.xv, 1890) 118. - Calif.

Vaseyi, Coult, in Cuntrib. U. S. Nat. Herb. i. (1890) 42, et ii. (1892) 227 t. 3. - Texas.

PERLARIUS, Rumpf, Herb. iv. (1744) 120 t. 56 (non 122 t. 57); Kuntze, Rev. Gen, (1891) 629 = Pipturus, Wedd. (Urtic.).

argentus, asper. mollissimus, platyphyllus, repandus, otundifolius, Kuntze, 1. c. $629-30=$ homonyma omnia Pipturi.

albidus, Kuntze, 1. c. $630=$ Pipt. Gaudichaudianus, Wedd

incamus, Kuntze, 1. c. $629=$ Pipt. velutinus, $W e d d$.

PERNETTYA, Gaudich. (Ericac.). - Ind. Kew. ii. $47 \%$.

andina, Fr. Meigen, in Bot. Fahrb. xvii. (1893) 264 et 292, et xviii. (1894) 440 et 464. - Chili.
PERNETTYA:

brasiliensis, Niedenzu, in Bot. Jahrb. xi. (18S9) 191 - Gaultheria myrtilloides Chann. \&o Schlecht. Hookeri, Niedenzu. 1. c. $190=$ G. microphylla, Hook. macrostigma. Colensu, in Trans, N. Z. Inst. xxi. $1888(1889) 92 .-\mathrm{N}$. Zel.

myrtyllifolia, "Griseb. " ex Phil. in Anal. Univ. Chil, xc. (1895) 197, sphalm = myrtilloides, Griseb. nana, Colcuso, in Trans, N. Z. Inst, xxiii. 1890 (1891) 389. - N. Zel.

Palenae, Phil. in Anal. Univ. Chil. xc. (1895) 195. - Chili.

parvifolia, Phil. l. c. 194. - Chili.

promaucana, Phil. i. c. 195. - Chili.

speciosa, Hort, ex Dippel, Handb. Laubholzk. i. (1889) $349=$ phillyreaefolia, $D C$.

PEROCARPA, Feer, in Bot. Jahrb. xii. (1890) 619 Peracarpa, Hook, f. \& Thoms. (Campanul.). carnosa, Feer, 1. c. $620=$ P. carnosa, Hook. f. E Thoms.

circaeoides, Feer, 1. c. 621 t. 7 et $8(=$ Campanula circaeoides, F. Schmidt). - Japon

PEROTIS. Ait. (Gramin.). - Ind. Kew. ii. 473. indica, K. Schum, in Abh. Preuss. Akad. Wiss. (1894) 2\% et 24; et in Engl. Pflanzenw. Ost.-Atr. C $(1895) 99=$ latifolia, Ait.

PERRALDERIA, Coss. = Grantia, Boiss. (Compos.).

purpurascens, Coss, ex Batt. \& Trab. Fl, de l'Algér. [Dicot.] (1890) 430 - Algeria.

PERROTETTIA, H. B. \& K. (Celastr.). - Ind. $\mathrm{Kew}$. ii. 473 .

alpestris, Loesen. in Engl. \& Prantl, Nasurl. Pfanzenfam, iii. 5 (1892)220. - Malaya.

arborescens, Loesen, l. c. - Austral.

philippinensis, Loesen, l. c. - Ins. Philipp.

PERSEA, Plum. ex Linn. (Laurin.). - Ind. Kew. ii, 473

breviflora, Pax, in Engl. Ex Prantl, Natilrl. Pfanzenfam, iii. 2(1889) $115 i=$ Alseodaphne breviflora. Benth.). - China.

caerulea, Mez, in Jahrb. Bot. Gart. Berlin, v. (1889) 171 = laevigata, $H$. B. et $K$.

Chamissonis, Mez, l. c. 168. - Mexic.

chinensis, Pax, in Engl. \& Prantl, Nativn. Pfanzenfam, iii.2(1889) 115 (= Alseodaphne chinensis Champ.). - Hongkong.

cordata, Mez, in Jahrb. Bot. Gart. Berl. v. (1889) $\mathbf{1 6 5}=$ pyrifolia, Nees.

corymbosa, Mez, l. c. 158. - Peruvia.

ferruginea, $\mathrm{Mez}, 1$. c. 154 (= Laumus fernginea, Ruiz \& Pav.). - Peruvia.

floccosa, Mez, l. c. 148. - Mexic

glaberrima, Mez, i. c. 144. - Ind.

grandis, Me\%, l.c. 160. - Peruvia.

Haenkeana, Mez, l, c. 174. - Peruvia.

Humboldti, Mez. 1. c. $158=$ Persea ferruginea Meissn.

humilis. Nash, in Bull. Torrey Bot. Chub, xxii. (1895) 15\%. - Florida.

hypoleuca, Mez, in Jahrb. Bot. Gart. Berl. v. (1889) $174=$ cubensis, Meissn.

intermedia, Phil. in Anal. Univ. Chil. xcl. (1895) 502. - Chili.

Jenmani, Mez, in fahrb. Bot. Gart. Berl. v. (1889) 162. - Guian. angl.

Krugii, Mez, l. c. 162. - Ins. Porto Rico.

lanata, Mez, 1.c. $164=$ fuliginosa, Meissn.

lanceolata, Mez, l. c. 150 - Bras.

Liebmanni, Mez, l. c. 100. - Mexic,

nitens, Mez, l. c. 146. - Guian. angl.

Persea, Cockerell, in Bull. Torrey Bot. Club, xix. (1892) 95 = gratissima, Gaertn. $f$.

pubescens, Sarg. Sylv. N. Am. vii. (1895) '7 t. 30?

= carolinensis, Nees.

scoparia, Mez, Arb. Bot. Gart. Breslau I. (1892) 115. - Bolivía.

stricta, Mez, in fahrb. Bot. Gart. Berl. v. (18s?) 141. - Peruvia.

Urbaniana, Mez, l. c 143. - Ins, Jamaic.

vestita, Mez, l. c. 154.-Bolivia. 
PERSICA, [Tourn.]. Mill. = Prunus, Linn. (Rosac.).

atropurpurea, Hort. ex Gard. Kew, i. Polypet. (1894) $131=$ Pr, persica, Stokes

Simoni. Lavall. 1. C. $=$ Pr. Simonii, Carr.

PERTYA. Sch. Bip. (Compos.). - Ind. Kew. ii. 475.

sinensis; Oliver, in Hook. Icon, pl. xxiil. (1892) t. 2214. - China.

PERVINCA, Tourn, ex Adans. = Vinca, Linn. (Apocyn.).

medic, Caruel, in Parl. Fl. Ital. vi. (1886) $709=$ V. media, Hoffngg \& Link.

PERYMENIUM, Schrad. (Compos.). - Ind. Kew. ii. 475.

album, S. Wats, in Proc. Ann. Acad. xxv. (1890) 154. - Mexic.

asperifolium, Sch. Bip. ex Klatt, in Leopoldina, Heft xxiii. (1887) 143. - Mexic.

jaliscense, Robinson of Greenm. in Am. Fourn. Sci. Ser. III 1. (1895) 155. - Mexic.

microcephalum, Sch. Bip. ex Klatt, in Leopoldina, Heft xxiii. (1887) 143. - Mexic.

pellitum, Klatt. F.c. - Mexic,

Sartori, Sch. Bip. ex Klatt, 1. c, 144, in syn. = Otopappus verbesinoides, Benth.

PETAGNAEA, Caruel, Epit. Fl. Eur. ii. (1894) 257 = Petagnia, Guss. (Umbell.).

PETALACTELLA, N. E. Br, in Kew Bull. (1894) 100: et in Hook. Icon. pl. xxiv, (1894) t. 2352. CUMPOSIT AE.

Woodii, N. E. Br. ll. cc. - Afr. austr.

PETALODISCUS, Baill. = Savia, Willd. (Euphorb.).

mimosoïdes, Pax, in Engl. \& Prantl, Natürl, Pflanzenfam. iii. 5 (1890); $15=\mathrm{S}$. mimosoïdes, Baill.

oblongifolius, Pax, 1. $\mathrm{c}$. = S, oblongifolia, Baill. pulchilla, Pax, 1. c。 = S. pulchella, Baill.

PETALOSTEMON, Michx (Legumin.). - Ind. Kew. ii. $4 \% 6$.

compactus, Swezey, Nebr. Flow, Pl. (1891.) $6=$ macrostachyus, Torr.

glandulosus, Coult. \& Fisher, in Coult. Bot. Gaz. xviii. (1893) 2:19. - Texas.

Reverchoni, S. Wats, in Proc. Am. Acad. xxi. (1886) 449. - Texas

sabinalis, S. Wats. l. c. 448. - Texas.

PETASITES. [Tourn.] Linn. (Compos.). - Ind. Kew. ii. 477.

nivalis, Greene, Pittonia, ii. (Novi. 1889) 18. - Am bcr. occ.

PETASTOMA, Bureau, in Warm. Symb. Fl, Bras. centr。xl. (1893) 1215. BIGNONIACEAE. formosum, Bureau, l.c. - Bras.

Leucopogon, Bureau, l.c. (= Panterpa Leucopogon Miers). - Bras.

PETESIODES, Jacq. = Wallenia, Sw. (Myrsin.) clusiacfolimm, Kuntze, Rev. Gen. (1891) $402=\mathrm{W}$. clusiifolia, Griseb.

menoralis, Kuntze, 1. c. $=$ W. nemoralis, Mart.

venosum, Kuntze, 1. c. = W. venosa, Griseb.

PETRADOSIA, Greene in Erythea, iii. (1895) $13=$ Solidago (Vaill.) Linn. (Compos.).

pumila, Greene, 1. c. = S. pumila, Torr. \& Gray.

PETRAeOViteX, Oliver (Verben.). - Ind. Kew, ii. 477.

pubescens, Warb. in Bot. Fahrb. xiii. (1891) 427. - N. Guin.

Riedelii, F. Muell. in Bot.Centralbl. 1. (1892) 195 [an Oliver?] - N. Guin.
PETROCOPTIS, A. Br. = Lychnis, Tourn. (Caryoph.).

26 t. 79. - Hisp.

PETROGOSMEA Oliver, in Hook. Icon. pl. xviii. (1887). t. 1716. GESNERACEAE

grandiflora, Hemsl. in Kew Bull. (1895) 115, et in Hook. Icon. pl. xxv. (1895) t. 2410. - China. ionantha, Baill. in Bull. Soc. Linn. Paris, ii. (1894) 1148 = Saintpauhlia ionantha, Wendl. sinensis, Oliver, in Hook. Icon. pl. xviii (1887) t. 1716, - China centr.

PETROPHILA. R. Br, (Proteac.). - Ind. Kew. ii. 478.

Shirleyae, F. M. Bailey, in Dept, Agric. Brisbane Bot. Bull. [ii] (1891) 17. - Austral.

PETROPHYES. Webb \& Berth. = Monanthes, Haw. (Crassul.).

pallens, Webb, ex Christ, in Bot. Jahrb. ix. (1888) 115. - Ins, Canar

PETROSELINUM, Hoffm, = Carum, Linn. (Umbell.).

anatolicum, Freyn \& Sint. in Oest. Bot. Zeitsch. xliv. (1894) 99. - As. Min.

PETRosimonia, Bunge (Chenopod.). - Ind. Kex, 11, 479

triandra, Rechinger, in Verh. zool.-bot. Ges. Wien, xxxix. (1889) $244=$ P. Volvox, Bunge.

PETUNGA, DC. (Rubiac.). - Ind. Kew. ii. 479 acemosa, K. Schum. in Engl. \& Prantl, Natiirl. Pflanzenfam. iv. 4 (1891) $80=$ P. Roxbur ghii, $D C$.

PETUNIA, Juss, (Solan.), - Ind. Kew。 ii. 479 , xillaris, Britton, Stern \& Poggenb. Prelim. Catal. (1888). 38 = nyctaginiflora, Fuss.

PEUGEDANUM, [Tourn.] Linn. (Umbell.), Ind. Kew, ii. 479

abyssinicum, Defers, in Bull. Soc. Bot. Fr. xlii. (1895) 304. - Arabia.

aculeolatum, Engl. Bot. Fahrb. xix. Beibl. n. 4' (I894) 42. - Afr. trop. or.

aegopodioides, Seidel, in Isis, (1888) $86^{\circ}(=$ Physospermum aegopodioides. Boiss.). - Macedon.

aegopoides, Formanek, in Verh. naturf. Ver. Brunn. xxx. (1892) $81=$ P. aegopodiodes, Boiss.

aequiradium, Velen, in Sitz. Bochm. Ges. Wiss. 1889 (1890) ii. 36; et Fl. Bulg. (1891) 205. - Bulg.

Anethum, Baill. Trait. bot. méd. (1884) 1045 ; Cordem. Fl. Ile Réunion, (1895) $4355=$ graveolens, Benth.

Angelica, Caruel, in Parl. F1. Ital. viii. (1889) 281 $=$ Angelica sylvestris, Linn.

angelicaefolium, Engl. Bot. Fahrb. xix. Beibl.n. 47 (1894) 44 , in obs. (= Carum? angelicaefolium, Baker). - Madag.

arevsianum, Deflers, in Bull. Soc. Bot. Fr. xlii. (1895) 305. - Arabia.

Austinae, Coult. \& F. N. Rose, in Coult. Bot. Gaz. xiii. (1888) 268: et Re\%. N. Am. Unbell. (1888) 66. - Calif.

Bojerianum. Baker, in fourn. Linn. Soc. xxv. (1890) 319. - Madag.

Brandegei, Coult. \& F. N. Rose, in Coult. Bot. Gaz. xiii. (1888) 210 ; et Rev. N. Am. Umbell. (1888) 72. - Calif.

calcareum, Alboff, Prodr. Fl. Colch. (1895) 114. Reg. Cauc.

californicum, Coult. \& J. N. Rose, in Coult. Bot. Gaz. xiii. (1888) $14 \%$ = parvifolium, Torr. \& Gray.

Canbyi, Coult, \& F. N. Rose, in Coult. Bot. Gaz. xiii. (1888) 78; et Rev, N.Am. Unbell. (1888) 56. - Am. loc. occ

circumdatum, S. Wats. in Proc. Am. Acad. xxii. (1887) 474. - Oregon.

Conrathi, Freyn, in Bull, Herb. Boiss. iii. (1895) $305 .-$ As. Occ.

\section{PEUGEDANUM :}

Cous, S. Wats. in Proc, Am. Acad. xxi. (1886) 45.3. - Oregon.

Cusickii, S. Wats, l. E. - Oregon

decumbens, Maxim. in Bull. Acad. Pétersb. xxxi.

(1887) 52 (= Angelica decumbens, Franch.). Yunnan

Delavayi, Franch. in Bull. Soc. Philom. Paris, Sér. VIII. vi. (1894) 143. - Yunnan

Donnellii, Coult. \& 7. N. Rose, in Coult. Bot. Gaz. xiii. (1888) 143. et Rev. N. Am. Unbell. (1888) 65. - Oregon.

Eminii, Engt. Pfanzenve. Ost.-Afr. C (1895) 300. Afr. trop. or.

eurycarpum, Coult. \& F. N. Rose, Rev. N. Am. Umbell. (18S8) 61. - Am, bor, occ.

evittatum, Coult. \& F. N. Rose, in Coult. Bot. Ga\%. xiv. (1889) $27 \%$ - Am. bor. occ.

fallax. Freyn \& Sint. in Oest. Bot, Zeitschr. xliv. (1894) $102=$ tomentellum, Freyn \& Sint.

Grayi, Coult. E F. N. Rose, in Coult. Bot. Gaz. xiii, (1888) 209 ; et Rev.N.Am. Umbell. (1888) 60) (= P. millefolinm, S. Wats.) - Am. bor. occ.

Hassei, Coult. \&. F. N. Rose, in Coult, Bot. Gar, riv. 1889) 276. - Calif.

Hendersoni, Coult. \& F. N. Rose, l. c. xi1i. (1888) 210; et Rev N.Am. Umbell. (1888) 56. - Oregon.

heterophyllum, Franch, in Bull. Soc. Philom, Paris, Sér. VIII. v. (1894) 141. - Yunnan

intermedium, Simonk. Enum. Fl. Transsitv. (1886) 265 (= Petroselinum intermedium, Schur). Transsilv.

kauaiense, Hillebr. Fl. Haw, Isl. (1888) 145. - Ins. Sandvic.

Kersteni1, Engl. Bot. Fahrb. xix. Beibl. n. 47 (1894) 43. - Afr. trop. or.

Kingii, S. Wats, in Proc. Am. Acud, xxii. (1887) $474(=P$. graveolens, S. Wats. $)$ - Am. bor. occ, lapidosum, M. E. Fones, in Zoë, ii. (1891) 246. Utah.

Lemmoni, Conlt. \& F. N. Rose, in Coult. Bot. Gaz. xiv. (1889) 27\%. -- Arizona.

macilentum, Franch. in Bull. Soc. Philom. Paris. Sér. VIII. vi. (1894) 142. - Yunnan.

madrense, S. Wats, in Proc, Am. Acad. xxv, (1890) 151. - Mexic.

Martindalei, Coult. \& f. N. Rose, in Coult. Bot. Gaz. xiii. (1888) 142; et Rev. N. Am. Umbell. (1888) 66. - Oregon.

microcarpum, Howell, ex Coult. \& F. N. Rose, l. c. 65. - Oregon.

mohavense, Coult, \& 7. N. Rose, l. c. 62, - Calif multivittatum, Maxim. in Bull. Acad. Pétersb. xxxi. (1887) 52. - Japon.

oreganum, Coult. \& F. N. Rose, Rev. N. Am. Um bell. (1888) 64. - Oregon.

Parishii, Coult. Eo 7. N. Rose, in Coult. Bot. Gaz. xiii. (1888) 209: et $l, \bar{c} .68$. - Calif.

pimpinelloides, Boiss. \& Haussin. ex Boiss. Fl. Or. Suppl. (1888) 268. - As. Min.

Plummerae, Coult \&f F. N. Rose, in Coult. Bot. Gaz. xiv. (1889) 278. - Calif.

Pringlei, Coult. \& J. N. Rose, 1. c. xiii. (1888) 209 = dasycarpum, Torr. \& Gray.

runssoricum, Engl. Bot. Fahrb. xix. Beibl. n. 47 (1894) 44. - Afr. trop. or.

robustum, Fepson, in Erythea, i. (1893) 9; Greene Man. Bot. San Franc. Bay (1894) 156. - Calif. salmoniflorum, Coult. \& F. N. Rose, ex Holsinger. in Contríb. U. S. Nat. Herb. iii. 4 (1895) 228. Idaho.

Sandbergii, Coult. \& F. N. Rose, in Coult. Bot. Gaz. xiii. (1888) 79; et Rev. N. Am. Umbell. (1888) 65 . - Am. bor. occ

sandwicense, Hillebr. Fl. Haw. Isl. (1888) 144. Ins. Sandvic

serbicum, Petrov. Addit. Fl. Agri Nyssani (1885) 89. - Serb.

thracicum, Velen. in Sitz. Boekm. Ges. Wiss, 1892 (1893) $379(=P$. vitizugum, Velen ). - Bulo.

tomentellum, Freyn Eo Sint. in Oest. Bot. Zeitschr. xliv. (1894) 101. - As. Min.

Torreyi, Coult. \& F. N. Rose, in Coult. Bot. Gaz. xiv. (1889) 277 . - Calif.

Vaseyi, Coult. $\hat{0}$ 7. N. Rose, l. c. 144 ; et Rev. $N$. Am. Umbell. (18s8) 67. - Calif. 


\section{PEUCEDANUM}

Volkensii, Engl. Bot. Fahrh. xix. Beibl. n. 47 (1894) 43. - Atr. trop. or.

Watsoni, Coult. \& F. N. Rose, in Coult. Bot. Gaz. xiii. (1888) 209 ; et Rev. N. Am. Umbell. (1888) 57. - Am. bor. occ

xantholeucum, Freyn \& Sint. ex Freyn, in Oest. Bot. Zeitschr. xlii. (1592) 122. - Armen.

PEUCELUMA, Baill. in Bull. Soc, Linn. Paris, ì (1890) 895 ; et Hist. des pl. xi. (1890) $286=$ Lucuma, Molina (Sapot.)

pinifolia, Baill. 1. $\mathrm{c}=$ L. pinifolia, Baill

PFAFFIA, Mart. (Amarant.). - Ind. Kew. ii. 482 cinerea, Kunce, Rei, Gen, (1891) 544. - Hab.? denutata, Kuntze, l. c. 543.-Bras.

eriantha, Kuntze, 1. c. I Hebanthe virgata, Mart,

helichrysodes, Kuntze, l. c. 544. - Bras.

iresinodes. Kuntze, 1. c. $543=$ Gomphrena iresinoides, Moq.

Ianata, Kuntze, 1 c. 5 $44=$ tomentosa, Mart.

paniculata. ISuntze, 1. c. 542,543= Hebanthe paniculata, Mart

pulverulenta, Kuntze, 1. c. $543=\mathrm{H}$. pulverulenta, II art.

reticulata Kuntze, 1. c. = Gomphrena reticulata Seub.

sericea, Kintze, 1. c. = G. sericea, Mart.

spicata, Kuntze, 1. c. = Hebanthe spicata, Mart.

PFEIFFERAGO, Kuntze, Rev. Gen. (1891) $227=$ Codia, Forst. (Saxifr.).

ferruginea. Kuntze, 1. C. = C. ferruginea, Brongn. \& Gris.

floribusda, Kuntze, 1. c. = C. floribunda. Brongn. \& Gris.

montana, K.untze. 1. c. = Callicoma Billardieri D. Don.

obcordata, Kuntze, 1. c. = Codia obcordata, Brongn. E Gris.

spathulata, Kuntze, 1. c. = C. spathulata, Brongn \& Gxis.

PHACA, Linn. = Astragalus, Linn. (Legumin.) brachycarpa, Britton, in Mem. Torrey Bot. Club, v. $(1894) 200=$ A. caespitosus, A. Gray.

canadensis, MacMill. Metasp. Minn. (1892) $325=$ A. canadensis, Linn.

caryocarpus, MacMill. 1. c. $326=$ A. caryocarpus, Ker-Gavl.

compacta, Phil. in Anal. Mus. nac. Chile (1891) 14. - Am. austr. ooc

cryptantha, Phil. 1. c. - Am, austr. occ

diminutiva. Phil. 1. C. - Am. austr. occ

gracilis, MacMill. Metasp. Minn. (1892) $325=$ Astragalus gracilis, Nutt.

hypoglottis, MacMill. 1. c. $324=$ A. hypoglottis, Linn.

plattensis, MacMill. 1. c. $325=$ A. plattensis, Nutt.

viridis, Britton, in Mem. Torrey Bot. Club, v. (1894) $201=$ A. kentrophyta, A. Gray.

PHACELIA, Juss. (Hydrophy1.). - Ind. Kew. ii. 483

Arthuri, Greene, Pittonia, i. (Oct. 1888) 224; et Man. Bot. San Franc. Fiay (1894) 255. - Calif.

cedrosensis, F. N. Rose, in Contrib. U. S. Nat. Herb. i. (1890) 18. - Galif.

Coviliei, S. Wats, in A. Gray, Man. N. Am, Bot. ed. 6 (1890) 360. - Am. bor.

dubia, Trelease, ex Trelease, Branner \& Coville, in Ann. Rep. Geol. Surv. Arkans. for 1888, iv. (1891) 205: Small, in Bull. Torrey Bot. Club, xxi. (1894) $303=$ parviflora, Pursh.

Eisenii, T.S.Brandeg. in Zoë, ii. (1891) 252.-Am. bor. occ.

foliosa, Phil. in Anal. Mus, nac. Chile (1891) 53. Am. austr.

glechomaefolia, A Gray, Syn. Fl. N. Am. ii. I. [Suppl.] (1886) 41\%. - Culorado.

heterosperma, Parish. in Coult. Bot. Gaz, xiii. (1888) 37. - Calif.

hirtuosa, A Gray, in Proc. Am. Acad. xxii. (1887) 310. - Calif
PHACELIA

dahaensis, L. F. Henderson, in Bull. Torrey Bot. Club, xxi. (1895) 4S. - Idaho.

imbricata, Greene, inz Erythea, i. (1893) 127; et Man. Bot. San Franc. Bay (1894) 253. - Calif. inconspicua, Greene. l. c. iii. (1895) 24. - Nevada. leptostachya, Greene, I. c. ii. (1894) 190. - Calif. leucantha, Lemmon, ex Greene, Pittonia, i. (June 1888) 175. - Calif.

linectris, Holzinger, in Contrib. U. S. Nat. Herb. iii. (1895) 242 (= Hydrophyllum lineare, Pursh) $=\mathrm{P}$. Menziesii. Torr

magellanica, Coville, 1. c. iv. (1893) $159=$ circinnata, facq.

nematostyla, Robinson, in Proc. Am. Acad. xxvii. (1893) 181. - Mexic

nemoralis, Greene, Pittonia, i. (Nov. 1887) $141 ; e$ Man. Bot. San Frane. Bay (1894) 253. - Calif.

mudicaulis, Eastwood, in Zoë, iv. (1893) 123 et 296 $=$ demissa, A. Gray.

Paimeri, Vasey of F. N. Rose, in Proc. U. S. Nat. Mus. xi. (1888) 532 - Calif.

parviflora, Phil. in Anal. Univ. Chil.xc. (1895) 226. - Chili.

pauciflora, S. Wats. in Proc. Am. Acad. xxiv, (1889) 61. - Calif, austr.

perityloides, Coville, in Proc. Biol. Soc. Wash, vii. (1892) 75: et in Contrib. U.S. Nat. Herb. iv. (1893) 160, t. 15 . - Calif.

pinetorum, M. E. Fones, in Zoè, iv. (1893) 279. Am. bor. occ.

rugulosa, Lemmon, ex Greene, Pittonia, i. (June 1888) 175. - Calif.

rupicola, Robinson E Fernald. in Proc. Am. Acad. xxx. (1895) 119. - Mexic.

scabrella, Greene, Pittonia, i. (Mar, 1887) 35. Calif.

scariosa, T. S. Brandeg. in Proc. Calif. Acad. Ser. II , ii. (1889) 185. - Calif.

setigera, Phil. in Anal. Mus, nac. Chile (1891) 54. - Am. austr.

splendens, Eastwood, in Zoë, iv. (1893) 9. Colorado.

suaveolens, Greene, Piitonia, i. (Oct. 1888) 223 ; et Man. Bot. San Franc. Bay (1894) 255. - Calif.

thermalis, Greene, in Erythea, iij. (1895) 66. - Calif umbrosa, Greene, l. c. ii. (1894) 191. - Calif.

verna, Hovell, l. c. iii. (1895) 35.- Oregon

villosa, Phil. in Anal. Univ. Chit. xc. (1895) 225. Chili.

PHAGELLARIA Benth. (Santal.), - Ind. Kew. ii 484 .

caulescens. Collett \& Hemsl. in fourn. Limn. Soc. xxviii. (1890) 122, t. 17: - Burma.

Wattii, Hook. f. Fl. Brit. Ind. v. (18S6) 236. Ind. or.

PHAEANTHUS, Hook. $£ . \&$ Thoms. (Anon.). Ind. Kew. ii. 484.

andamanensis, King, in fourn. As. Soc. Beng. lxi. (1892) ii. 122. - Ins. Andam.

lucidus, Oliver, in Hook. Icon. pl. xvi. (1887) t. 1561. - Penang.

PHAEDRANASSA, Herb. (Amary11.). - Ind. Kew. ii. 484

veutricosa, Baker, in Bot. Jahrb. viii. (1887) $210=$ chloracea, Herb.

PHAENICAULTS Menziesii, Greene, in Bull. Torrey Bot. Club, xiii. (1886) $143=$ Phoenicaulis Menziesii, Steud.

PHAEOPAPPUS, Boiss. = Centaurea, Linn.

(Compos.).
depressus, Boiss. F1. Or. Suppl. (1888)211.-Persia.

Freyni, Sint, ex Freyn, in Oest. Bot. Zeitschr. xlii. (1892; 235. - Armenia.

insignis, Boiss. Fl.Or. Supp1. (1888)312. - As, occ. imuloides, Boiss, 1. c. 312, in obs. = Centaurea inuloides, Fisch.

longispinus, Post, P1. Postianae, ii. (1891) 14.As, occ.

macrocephalus, Freyn \& Sint. in Oest. Bot. Zeitschr. xliv. (18.44) 220 - As. Min.
PHAEOPTILUM, Radik. (Nyctag.). - Ind. Kew

ii. 48

Heimerli, Engl. Bot. Fahrb, xix. (1894) 133 [Phaeoptilon]. - Afr, austro-occ. extratrop.

PHAgNaLON, Cass. (Compos.), - Ind. Kew, ii. 485.

aegyptiacum, Boiss. Fl. Or. Suppl. (1888) 296.Desert. Aegypt.-Arab.

Barbeyanum, Aschers, \& Schweinf. in Mém. Inst. égypt. [Illustr. Fl, Egypt.] iii. (188\%) 87.-Aegypt linifolium, Post, Pl. Postianae, i. (1891) 12. As. occ.

methanaeum, Hausskn. in Mitth. Bot, Ver. Fena, v. 1887) 85, et N. Folge, vii. (1895) 30. - Graecia.

PHAIOCALANTHE $\Varangle$, Rolfe, in Journ. Linn. SOc. xxiv. (1887) 168. ORCHIDEAE

irrorata X, Rolfe, 1. c, ; et in Gard. Chron. (1888) 1. 136, in obs. (= Phajus irroratus, Reichb. $f$ ) - Hybr. artef.

Sedeniana $\times$, Reichb, f. 1. c. $(=P$. Sedenianns. Veitch). - Hybr. artef.

PHAIUS, Lour. (Orchid.). - - Ind. Kew. ii. 486. amabilis X, O'Brien, in Gard, Chron. (1893) i. 226 [Phajus]. - Hybr. artef.

andidissimus, N. E. Br. in Ker Bull. (1889) 101. - Burma.

Cooksoni X, Hort, ex Gard. Chron. (1890) i. 388 et 389 fig. 57 ; et (1891) i. 456 ; Orchid Alb. x (1894) t. 478. - Hybr. artef.

Humbloti, Reichb. f. in Rev. Hortic. 1xiii. (1891) 204 cum jc. |Phajus|. - Ins. Comor.

Incarvillei. Kuntze, Rev. Gen. (1891) 675 [Phajus $=$ P. Wallichii, Lindl.

longibracteatus, Frappier, ex Cordem. Fl. Ile Réumion (1895) 226 [Phajus]. - Ins. Mascar.

Marshallianus, N. E. Br. in Ket Bull. (1889) 101. - Hab

nanus, Hook. f. Fl. Brit. Ind. vi. (1890) 192; et in Hook. Icon. pl. xxii. (1893) t. 2088. - Bengal

Owenianus X. Hort. ex Gard. Chron. (1894) i. T83, fig. 102. - Hybr. artef.

philippinensis, N.E. Br, l. c. (1889) ii. 239. [Phajus]. - Ins. Philipp.

Roeblingii, O'Brien, l. c. (1895) i. 358. - Reg. Himal.

roseus, Rolfe, in Kew Bull. (1893) 6. [Phajus]. Burma.

Sedenianus × Reichb. f. in Gard. Chron. (18sశ) i. 174; Veich., 1. c. (1888) 136. - Hybr. artef.

PHALAENOPSIS. Blume (Orchid.) - Ind. Kew. ii. 436.

alboviolacea, Ridl, in Trans. Linn. Soc. Ser. II. iii.'(1893) 373. - Penins. Mal.

Amphitrita Y O'Brien, in Gard. Chron. (1892) i. 619. - Hybr. artef.

Barrti, King, ex Hook. f. Century Ind. Orchids (1895) 38 , in syn. = Phalaenopsis tetraspis, Reichb. $f$.

Buyssoniana, Reichb. f. in Gard. Chron. (1888) ii. 395 ; et in Bot. Mag. (189l) t. $7196=$ P. Esmeralda, Reichb. $f$.

casta X. Hort. ex Gard. Chron. (1890) i. 227. Hybr. artef

Cynthia X, Hort. ex Rolfe, 1. c. 132 et $22 \%$. Hybr. artef.

denticulata, 'Reichb, f. in Lindenia, iii. (1887) 66 ; et l.c. (1888) i. 296 , - Hab.?

Foestermannii, Reickb. l. c. (1887) i. 244. - Hab.

fugax, Kraenzl. l. c. (1893) ii. 360.- - Hab.?

gloriosa, Reichb. f. l. c. (1888) i. 554. - Hab.

Harriettae $X$, Rolfe, 1. c. (1887) ii. 8 fig. 1. Hybr.artef.

Kunstleri, Hook. f. Fl. Brit. Ind. vi. (1890) 30.Perak.

Leda X, Reichb. f. in Gard. Chron. (18s8) i. 45i. - Hybr. artef.

leucorhoda X, Hort. 1. c. i. (1890) 227. - Hybr. artef.

Lindeni, Loker, in fourn. des Orchid. vi. (1895) 10:3. - Hab.?

Micholitzi. Hort. ex Gartenfl. xli. (1892) Is4. - Hab. 


\section{PHALAENOPSIS :}

muscicola, Ridl. in Trans. Linn. Soc. Ser. II. iii. (1893) 373. - Penins. Mal.

Reonieriana, Reichb.f. in Gard. Chron. (1887) ii. 746. - Siam

Rothschildiana X, Reichb. f. 1. c. (1887) i.606.Hybr, arter.

Ruckeriana, Hort, ex Orchid Alb. vi. (1887) sub 4. 266 , in syn. $=$ Thrixspermum unguiculatum Reichb.f.

PHALANGIUM, [Tourn.] Adans.=- Anthericum Linn. (Liliac.)

Frascri, "Nutt.? ) cf. MacMill. Metasp. Minn. (1892) 151, sphalm. = Camasia Fraseri, Torr crotinum, Engelm. ex Baker, in Bot. Jahrb. Xv. Beibl. n. 35 (1892) $9=$ Anthericum serotinum Baker.

PHALANGIUM, Moehr. Hort. Priv. ex Kuntze Rev. Gen. (1891) $713=$ Bulbine, Linn. (Li liac.)

anmunm, bisulcatum, bulbosum, densiflonn, favosum, flifolium, frutescens, latifolium, laxiflorum, longiflifolium, frutescens, latifoin, minimu, narcissifolium, nutans, praemorscapum, minimum, narcissifolim, nutans, praemorsum, pugioniforme, postratum, semuarbatin, Tunto

asprodelodes, Kuntze, 1. $\mathrm{C}_{*}=\mathrm{B}$. asphodeloides,

Spreng.
argineodes, Kuntze, 1. C. $=$ R. urgineoides, Baker.

PHALARIDANTHA, St Lager, in Cariot, Etud. des ff. éd. 8 ii. (1889) 900 = Phalaris, Linn. (Gramin.).

armdinaceo, St Lager, 1. c. = P.arundinacea, Linn. Robinsiana, St Lager, 1. c. in obs. - Ins. Juan Fernandez.

PHALARIS, Linn. (Gramin.). - Ind. Kew. ii. 487 hispanica, Coincy, in Morot, fourn. de Bot, viii. (1894) 207. - Hisp.

Lemmoni, Vasey, in Contrib. U. S. Nat. Herb. iii. (1892) 42 ; et Ill. N. Am. Grass. ii. (1892) t. 5.Calif. Arizona.

PHALRRIA, Jack (Thyme1.). - Ind, Kew, ii. 488. acuminata, Gitg, in Engl. \& Prantl, Natiurl. Pflanzenfam, iii. 6a (1894) 225 (= Drimyspermum acuminatum, Seem.). - Ins. Fiji.

lanceolata, Gilg, l. c. $(=$ D. lanceolatum, A. Gray). - Ins. Fiji.

montana, Gilg, l. c. (= D. montanum, Seem.).Ins. Fiji.

pubiflora, Gilg, l. c. (=D. pubiflorum. Seem.).Ins. Fiji.

subcordata, Gilg, l.c. $(=$ D. subcordatum, Seem.). - Ins. Fiji.

PHALODAI.IS, Herb. = Cypella, Herb. (Irid.). gigantea, Kuntze, Rev. Gen. (1891) 702 = C. gigantea, Klatt.

gracilis, Kuntze, 1. C. = C. gracilis, Baker.

Herbertii, Kuntze, 1. c. = C. Herbertí, Herb.

paludosa, Kuntze, 1. C. = C. paludosa, Klatt.

porwoiana, Kuntze, I. c. = C. peruviana, Baker.

pusilla, Kuntze, 1. . = C. pusilla, Benth. E Hook. $f$.

PHARBITIS. Choisy = Ipomoea, Linn. (Convolv.

cissoides, Peter, in Engl. \& Prant1, Natür1. Pflanzenfam. iv. $3 a$ (1891) $32=$ I. cissoides. Griseb. dichroa. Hochst. ex Hallier $f$ in Bot. Jahrb. xviii. (1894) $136=\mathrm{I}$. dichroa. Hochst.

falkioides, Peter, in Engl. \& Prantl, Natürl. Pflanzenfam, iv, 3a (1891) 32 = I talkioides, Griseb. jamaicensis, Peter, 1.c. = I. jamaicensis, G. Don. leptoloma, Peter, 1. c. = I. leptotoma, Torr.

pinnata, Peter, 1. c. = I. pinnata, Hochst.

PHARMACUM, Rumpf, ex Kuntze, Rev, Gen. (Is91) 248 = Astronia. Noronha (Melastom.) Beccarianum, calycinum, Candolleanum, confertiflorum, Cumingianum, fraternum. Hollrungii, ovalifolium. papuanum, Pickeringii, pileolatum, pulchrum, robustum, Rolfei, samoënse, smilacifolium, Storckii, sub-
PHARMACUM : -

cordatum, tomentosum, Kuntze, Rev. Gen.(1891) 953-54 = homonyma ommia Astroniae.

glabrun, Kuntze, 1. c. = A. Forsteri, Naud intermediun, Kuntze, 1. c. = A. spectabilis, Blume macrophyllum, Kuntze, 1. c. = A. macrophylla, Blume.

papetarium, Kuntze, 1. c。 = A. papetaria, Blume.

parviflora, Kuntze, 1. c. = A. parviflora, Triana.

PHARNAGEUM, Linn. (Ficoid.). - Ind. Kew. 31. 489 .

obovatum, Bolus, in Fourn. Limn. Soc.xxv. (1889) 162. - Afr. austr

PHASEOLODES, Kuntze, Rev. Ge1l (1891) $201=$ Millettia, Wight \& Arn. (Legumin.).

aboënse, argenteum, atropurpureum, Brandisianum, canun, caudatum, Chanpionii, cinerenm, coeruleum, cognatum, drasticum, erianthum, extensum, ferrugineum, fruticosum. glaucescens, gracile, japonicum, leiogynum, macrophyllum. Maingayi, Mannii, megaspermum, monticolum, nitidum, nudiftorum, ovalifolium, pacliycarpum, pendulum, piscidia, pubinerve, pulchrum, racemosum, reticulatum, rhodanthum, rostratum, nubiginosum, sericeum, sericoscmum, splendens, tetrapterum, Thonningii, uropinyllum, versicolor, xylocarpum, Zollingerianum, Kuntze, 1. c. (1891) 201-02 = homonyma ommia Millettiae.

brachy3otrys, Kuntze, 1. c. $201=$ Wistaria brachybotrys, Sieb. \& $Z$ utco.

floribundum, Kuntze 1. C. = W. chinensis, DC frutescens, Kuntze, 1. c. = W. speciosa, Nutt grande, Kuntze, 1. c. $202=$ Millettia caffra, Meissn Hookerianum, Kuntze, 1. c. = M. macrophylla, Benth.

speciosum, Kuntze, 1. c. $201=$ M. speciosa, Champ. splendissimm, Kuntze, 1. c. $202=$ M. splendidissimum, Bhume.

Sutterlandii. Kuntze, 1. c. $202=$ M. Sutherlandii Hara.

PHASEOLUS, [Tourn.] Linn. (Legumin.). - lnd. Kew. ii. 490 .

diffusus, S. Elliot, in fourn. Linn. Soc. xxix. (1891) 12. - Madag.

Esperanzae, Seaton, in Proc. Am. Acad. xxviii (1893) 118. - Mexic.

massaiensis, Taub. in Engl. Pflanzenw. Ast.-Afr. C (1895) 223. - Afr. trop. or

montanus, T. S. Brandeg. in Proc. Calif. Acad. Ser. II. iii. (1891) 130, - Calif

novo-guineensis, Warb. in Bot. Fahrb. xviii. (1894) 194. - N. Guin

polystachyus, Britton, Stern \& Poggenb. Prelim. Catal. (1888) $15=$ perennis, $W$ alt.

Schimperi, Taub. ex Engl. in Abh. Preuss. Akad. Wiss. 1891, ii. (1892) 26\%. - Abyss.

umbellatus, Britton, in Mem. Torvey Bot. Chib. v. (1889) 209. - Am. bor.

PHAYLOPSIS, Willd. (Acanth.). - Ind. Kew. ii. $49)^{\circ}$

imbricata, Cordem. F1. Ile Réunion (1895) $496=$ parviflora, Willd.

PHELLINE, Labill. (Rutac.). - Ind. Kew. ii. $4) 3$

Balansae, Baill. in Bull. Soc. Linn. Paris, ii. (1891) 937. - N. Caled.

brachyphylla, Baill. 7. c.938. - N. Caled.

confertifolia, Baill. l. c. 937. - N. Caled.

erubescens, Baill. l. c. 939. - N. Caled.

floribunda, Baill. l. c. 938. - N. Caled.

macrophylla, Baill. l. c. - N. Caled.

microcarpa, Baill.l.c. - N. Caled.

robusta, Baill. l. c. 939. - N. Caled.

wagapensis, Baill. l. c.937. - N. Caled.

PHEL YPAEA, Tourn. ex Linn. (Orobanch.). Ind. Kew. ii. 493.

albifloy, Lojac. ex G. Beck, in Luerss. Bibl. Bot. Heft xix, (1890) 97 (Phelipaea) = Orobanche Muteli, F. Schultz.

fulgida, Pomel, ex Batt. \& Trab. Fl. de l'Algér. [Dicot.] (189') $658=0$. Muteli, F. Schultz.
PHELYPAEA :

libanotica, Schreeinf. ex Boiss. Fl. Or. Suppl. (188S) 357. [Phelipaea]. - Syria.

Melongenae. Noë, ex G. Beck, in Luerss. Biblioth. Bot. Heft xix. (1892) 101 [Phelipaea] = Orobanche aegyptiaca, Pers.

Millefolit, Corbière, Nouv, F1. Norm. (1893) 442 $(=P$. Millefolii, Nym. $)=0$. ramosa, Limn.

Pareyssi, Boiss. Fl. Or. Suppl. (I888) $35 \%(=0$. Pareyssi, G. Beck) =O. purpurea, facq.

tenuiflora, G. Beck, in Luerss, Biblioth. Bot, Heft xix. (1892) $97=$ O. Muteli, F. Solultz.

PHENAX, Willd. (Urtic.). - Ind. Kew. ii. 494. pallida, Rusby, in Mem. Torrey Bot. Chub, iv. (1895)
259. - Bolivia.

PHEROTRIGHIS, Decne (Asclep.).-Ind. Kew. ii. 494

Balbisii, A. Gray, in Proc. Am. Acad. xxi. (1886) 400 (= Asclepias villosa, Balbis).- - Mexic

leptogenia, Robinson, in Proc. Am. Acad.xxix. (1894) 319. - Mexic

Schaffneri, A. Gray, l, c, xxi. (1886) 400. - Mexic. villosa, $\mathbf{K}$. Schum. in Engl. \& Prantl, Natürl. Pflanzenfam. iv. $2(1895) 303=$ P. Balbisii, Decne.

PHIALOCARPUS, Deflers, 'n Bull. Soc. Bot. Fr xlii. (1895) 304. CUCURBI TACEAE.

glomeruliflorus, Deflers, l. c.- Arabia.

PHIALODISGUS, Radik. (Sapind.), - Ind. Kew. ii. 494

plurijugatus, Radle. in Sitz. Math.-Phys. Akad. Muench. xx. (1890) 263. - Angola.

PHILADELPHUS, [Riv.] Linn. (Saxifr.). - Ind. Kew. ii. 494.

columbarius, Hort. ex Dippel, Handb. Laubholzk. iii. (1893) $342=$ Gordonianus, Lindl.

columbiensis, Hort. ex Gard. Kew. i. Polypet. 1894) $280=$ grandiflorus, Willd.

Coulteri, S. Wats. in Proc. Am. Acad. xxii. (1887) 472 ; et in Gard. and For. i. (1888) $232 \mathrm{fig}$. 40 . Mexic

Falconeri, Hort. ex Gard. Kew, i. Polypet. (1894) 225 ; et ex Sarg. in Gard. and For. viii. (1895) 494. - Hab.?

Godohokeri, Hort. Koehne, Deutsche Dendrol. (1893) 184, sphalm. (= P. Godohokeri, Hort. $)=$ laxus, Schrad.

japonious, Hort. ex Gard. Kew, i. Polypet. (1894) $227=\mathrm{P}$, Satsumi, Sieb.

Kochianus, Koehne, Deutsche Dendrol. (1893) 188. Japon.

Lemoinei $Y$, Hort. ex Wien. I11. Garten-Zeit. (1888) 124; Dippel, Handb. Laubholzk. iii. (1893) $34 \mathrm{l}$ fig. 179. - Hybr. artet.

pulchellus, Hort. ex Gard. Kew, i. Polypet. (1894) 227 (pulchella $)=$ P. Satsumi, Sieb

thyrsiflorus, Hort. 1. C. = P. Lewisii, Pursh.

umbellatus, Hort. ex Koehne, Deutsche Dendrol. (1893) 181. - Hab.?

Yokohamae, Hort. ex Dippel, Handb. Laubholzk. iii. (1893) $343=$ Gordonianus, Lindl.

PHILGAMIA hibbertioides, Baill. Hist. pl. Madag. Atlas (1894) t. 265. - Madag.

PHILIBERTIA, H. B. \& K. (Asclep.). - Ind. Kew. 11. 495.

bicolor, A. Gray, in Proc. Am. Acad. xxi. (1886) $395=$ elegans, Hemsl.

biloba, A. Gray, 1. c. = cynanchoides, B. Gray. campanulata, Nicholds, Dict. Gard. iii. (1886) 96. Peruvia.

clausa, K. Schum. in Eno1. \& Prantl, Natürl. Pflanzenfam. iv. 2 (1895) $229=$ viminalis, A. Gray. elegans, A. Gray, Syn. Fl. N.Am. ii. I. (1886) 87 in obs. ; te in Proc. Am. Acad. xxi. (1886) 395. Am. bor.

Ervendberoii, A. Gray, in Proc. Am. Acad. xxi. (1886) 395. - Mexic

Fendleri, A. Gray, l. c. Venezuela.

Gardneri, K. Schum. in Engl. \& Prantl, Natiorl Pfanzenfam. iv. 2 (1895) 229 (= Sarcostemma Gardneri, Fourn.). - Bras. 


\section{PHILIBERTIA :}

hypoleuca, Schlechter, in Oest. Bot. Zeitschr. xiv. 1895) 450. - Bolivia.

linearis, T. S. Brandeg. in Proc. Calif. Acad. Ser. II. ii. (1889) $183=$ linearis, A. Gray.

Palmeri, A. Gray, in Proc. An. Acad. xxi. (1886) 394. - Mexic.

refracta, 7. D. Smith, in Coult. Bot. Gaz, xviii (1893) 207. - Guatem.

viridiflora, Britton, \& Rusby, in Trans. N. Y. Acad. sci. vii. (1887) 11. - Texas, Mexic.

PHILIPPIA, Klotzsch (Ericac.). - Ind. Kew. ii 495.

adenophylla, Bakor, in fourn. Limn. Soc, xxv (1890) 332. - Madag

benguelensis, Welw ex Engl, in Abh. Prenss. Akad. Wiss. 1891 (1892) 328 , in syn. [an seq. ?] = Salaxis benguelensis. Engl.

benguellensis, Welw. ex Britten, in Trans. Lim. Soc. Ser. II. iv. (1894) 24. - Afr. trup.

capitata, Baker, in fourn. Limn. Soc. xxii. (1887) 499. - Madas.

cryptoclada, Baker, l. c. - Madag.

hispida, Baker, l. c. - Madag.

Holstii, Engl. in Abh. Preuss. Akad. Wiss. (Is94) 59 ; el in Engl. Pfanzenw. Ost-Afr. C (1895) 302 - Afr. trop. or.

intricata, Cordem. Fl. Ile Réunion (1895) 441. Ins. Borbon.

Johnstonii, Schweinf. ex Engl. Pflanzinw. Ost-Afr. C (1895) 302. - Afr. trop. or.

leucoclada, Baker. in fourn. Limn. Soc. xxv, (1890) 332. - Madag.

milanjiensis, Britten, \& Rendle, in Trans, Limn. Soc. Ser. II. iv. (1894) 24. - Afr. trop.

minutifolia, Baker, in fourn. Linn. Soc. xxii. (1887) 500. - Madag.

myriadenia, Baker, l. c. xxv. (1890) 332. - Madag.

pilosa, Baker, l. c. 332. - Madag.

scyphostigma, Cordem. Fl. Ile Rémion (1895) 441. - Ins. Borbon.

senescens, Baker, in foum. Linn. Soc. xxv. (1890) 332. - Madag.

Stuhlmannii, Engl. Pfanzenw. Ost.-Afr. C (1895) 302. - Afr, trop. or,

thomensis, Henriques, in Bolet. Soc. Brot. x. (1S92) 137. - Ins. S. Thom

trichoclada, Baker, in fourn. Linn. Soc. xxii. (1887) 500. - Madag.

trimera, Engl. Pfanzenw. Ost.-Afr. C (1895) 302 t. 33 fig. a-h. - Afr. trop. or.

tristis, Bohus, in fourn. Linn. Soc xxiv. (1887) 187 - Afr. austr.

PHILIPPIAMRA. Kuntze, Rev. Gen. (1891) $58=$ Silvaea. Phil. (Portul.)

amarantodes, Knntze, 1. c, = S. amarantoides, Phil. celosiodes, Kuntze, 1. c. = S. celosioides, Phil. corrigiolodes, Kuntze, 1. c. = S. corrigioloides, Phil. pachyphylla, Kuntze, 1. c. = S. pachyphylla, Phil.

PHILLIPSIA, Rolfe, in Kew Bull. (1895) 223. $A C A N T H A C E A E$

fruticulosa, Rolfe. l. c. - Reg. Somal.

PHILLYROPHYLLUM, O. Hoffm. in Eng1. \& Prantl, Natürl. Pflanzenfam. iv. 5 (1890) 268; et ex Schinz. in Bull. Herb. Boiss. i. (1893) 78. [Philyrophyllum], COMPOSI TAE.

Schinzii, O. Hoffm. ll. cc. - Afr. austro-occ. extratrop.

PHILODENDRON, Schott (Aroid.). - Ind. Kew. 11. 495.

Andreanum, Devans, in Rev. Hortic. Iviii. (1886) 36 cum ic. ; et Rev. Hortic. Belge, xiii. (1887) 274 fig. 30. - N. Granat.

Corsinianum $X$, Hort. ex Bull. Soc. Tosc. Ortic. (1888) 211. - Hybr. artef.

Devansayeanum, L. Linden, in Illustr. Hortic. xlii. (1895) 376 t. 48. - Peruvia.

grandidens, Hort. ex Rev. Hortic. Belge, xiii.(1887) 274 = Andreanum, Devans.

notabile, Hort. Bull, ex Gard. Chron. (1893) i. 414. - Form. hort.
PHILOMEDA, Noronha = Gomphia, Schreb. (Ochnac.)

oborata. Boivin, ex Baill, in Bull. Soc. Linn. Paris, i. (1886) 589, ir syn. = Ochna obovata Baill.

pareifolia, Boivin, ex Baill. 1. c. = O. parvifolia Baill.

PHILOPODIUM rigidnn, Hort. ex Kew Bull. (1889) $102=$ Muehlenbeckia adpressa, Morsn.

PHINAEA, Benth. (Gesnerac.). - - Ind, Kew. ii rubida, Fritsch, in Engl. \& Prantl, Natürl, Pfanzenfam. iv. 3b (1894) 173; Nichols. Dict. Gard, iil. (1886) 99 (= Niphaea crenata, Karst.). - Am. austr.

PHLEUM. Linn. (Gramin.). - Ind. Kew. ii. 498. bulbosum, C. Richt, P1. Europ. i. (1889) $37=$ tenue Schrad.

Brueggeri X, C. Richt. 1.c. - Hely. crypsoideum, Rouy, in Bull. Soc. Bot. Fr. xxxix. (1892) $269=$ Maillea Urvillei, Part. sardoum, Haik. ex Franch. l. c. 274. - Sardinia. subalpinum, Bruegg, in fahresb. Naturf. Ges. Graub. xxxi. Beil. (1887-88) 195.- - Helv.

PHLOGA, Noronha (Palm.). - Ind, Kew. ii. 498 microphoenix, Baill in Bull. Soc. Imnn. Paris, ii. (18\%5) 1185. - Madag.

Scottiana, Becc. e\% S. Elliot m fourn. Iinn. Soc xxix. (1891) 61. - Madag.

PHLOGELLA. Baill. in Bull. Soc. Linn. Paris ii. (1894) 1175; Hist. des p1. xii. (1895) 372 ii. (1894) 11

PAL MAE.
Humblotiana, Baill. l.c. - Ins. Comor.

PHLOMIS. Linn. (Labiat.). - Ind. Kew. ii. 498 albiflora, Henst. in Fourn. Linn, Soc xxvi. (1891) 304. - China,

betonicifolia, Regcl, in Act. Hort. Petrop. ix. (1886) 580. - Turkest.

bucharica, Regel, l. c. 579 t. 10. fig. 2. - Buchara. gracilis, Hemsl. in fourn. Limn. Soc. xxvi. (1890) 305. - China.

hissarica, Regel, in Act. Hort. Petrop. ix. (1886) 594 t. 10, fig. 17. - Turkest.

javanica, Prain, in Ann. Bot. Gard. Calo.. iii. (1891) 231 (= Leonurus javanicus, Blume). Java.

Maximowizii, Regel, in Act. Hort. Petrop. ix. (1886) 594 t. 10. fig. 18. - Mandschuria.

oblongifolia, Prain, in Ann. Bot. Gard. Calc. iii. 2 (1891) 231. (= Leonurus oblongifolins, Blume). Java.

Ostrowskiana, Regel, in Act. Hort. Petrop. ix. (1886) 595 t. 10, fig. 19. - Turkest.

platystegia, Post, in Bull. Herb. Boiss, i. (1893) $40 \%$. - Syria.

setifera, Bureau of Frunch. in Morot, fourn. de Bot. v. (1891) 149. - China,

tatsienensis, Bureau of Franch. \%. c. - China.

PHLOX, Linn. (Polemon.). - Ind. Kew. ii. 500 albomarginata, $M$. E. fones, in $Z$ oë, iv. (1894) 367. - Am. bor. occ

austromontana, Coville, in Contrib. U. S. Nat. Herb. iv. (1893) 151. - Calif.

dolichantha, A. Gray, in Proc. Am. Acad. xxii. (1887) 310 . - Calif.

gracilis, Greene, Pittonia, i. (Nov. 1887) 141; et Man. Bot. San Franc. Bay (1894) $251=$ Gilia gracilis, Dougl.

Kelseyi, Britton, in Bull. Torrey Bot. Club, xix. (1892) 225. - Am. loc.

PHOEBE, Nees (Laurin.). - Ind. Kew. ii 500. amoena, Mez, in Fahirb. Bot. Gart. Berl. v. (1889) 207 (= Oreodaphne amoena, Nees). - Bras., Reg. Argent.

amplexicaulis, $M e z, l . c .216(=$ Persea amplexicaulis Cham. \& Schlecht.), - Mexic.

amplifolia, Mez \& F. D. Smith, in Coult. Bot. Gaz. xix. (1894) 261. t. 24. - Guatem.

\section{PHOEB :}

Barbeyana, Mez, in Fahrb. Bot. Gart. Berl. v. (1889) 209. - Mexic

Benthamiana, Mez, l. c. 195 (= Persea Hartwegii

Hemsl.) - Mexic

betazensis, Me\%, l.c. 192. - Mexic

Bourgeauviana, Mez, l.c. 194. - Mex

brasiliensis, Me\%, 1. c. 199. - Bras.

Ehrenbergii, Me\%, l. c. 201. - Mexic.

erythropus, Mez, 1. c. 189 = Persea erythropus, Nees \& Mart.

estrellensis, Mez, l. c. $198(=$ Oreodaphne estrellensis, Meissn.). - Bras.

Galeottiana, Mez, 1. c. $200=$ Ocotea subtriplinervia, Honsl.

Glaziovii, Mez, l. c. 216. - Bras.

Grisebachiana, Me\%, l. c. $215(=P$. cinnamomifolia,

Rich.) - Cuba.

Haussknechtii, Me\%, l. c. 186. - Bras

Jelicterifolia, Mez, 1. c. 193 = Ocotea helicterifolia. Hemsl.

heteranthera, Mez, 1, c, $185=$ Ruiziana, Nees.

indica, Pax, in Engl, Eo Prantl, Nativl. Pfanzenfam. iii. $2(1889) 115$ (= Persea indica, Spreng.pr.p.) - Ins. Canar.

Mathewsii, Me\%, in Fahrb. Bot. Gart, Berl, v. $\{1889$

217. - Peruvia.

microneura, Mez, 1. c. $204=$ Persea microneura, Ueissin.

mollis, Mez, l. c. 192. - Mexic

nectandroides, Me\%, l. c. 194. - Mexic.

pachypoda, Mez, 1. c. $196=$ Persea pachypoda pallescens, Mez, l. c. 218. - Mexic.

patens, Mez, l. c. $204(=$ Mespilodaphne patens, Meissn.). - Bras.

pauciftora, Me\%, ex Tanb, in Bot. Fahrb. xvii. (1893) 520. - Bras.

porosa, Mez, in fahrb. Bot. Gart. Berl.v. (1889) 205 (= Oreodaphne porosa, Nees \& Mart.). Am. austr.

porphyria, Mez, 1. c. $199=$ Nectandra porphyria Griseb.

purpurea, Mez, l. c. 196.-Guatem

psychotrioides, Mez, 1, c. $191=$ Ocotea psychotrioides, $H$. B. \& $K$

Riedelii, Mez, 1. c. $197=$ Persea Riedelii, Meissn. semecarpifolia, Mez, l. c. 217 (= Oreodaphne seme carpifolia, Meissn.). - Am. austr.

stenophylla, Mez, 1. C. $190=$ Persea stenophylla Meissn.

subsessilis, Mez, 1, c. $183=\mathrm{P}$. subsessilis, Meissn. tampicensis, Mez. l. c. 200. - Mexic

tavoyana, Hook. f. Fl. Brit. Ind. v. (1886) 143. Tenass.

tetragona, Mez, in Fahrb. Bot. Gart. Berl. v. (188? 184 (= Oreodaphne tetragona, Meissn.). - Bras. triplinervis, Mez, I. c. $211=$ peruviana; Meissn.

vesiculosa, Mez, l. c. 206 (= Oreodaphne resiculosa Nees). - Bras.

PHOENICANTHEMUM, Van Tiegh, in Bull Soc. Bot. Fr. xli. (1894) 502 et $544=$ Loranthus, Linn.

Balansae, Van Tiegh. 1. c. 503 (= Dithecina Balansae, Van Tiegh.). - N. Caled.

Bennettianum, Van Tiegh. 1. c. $544=$ Loranthus Bennettianus, Miq.

coccinerm, Van Tiegh. 1. c. $502=$ L. coccineus, facq.

Hookerianum, Van Tiegh. 1. c. $502=$ L. Hookerianus, Wight \& Arn.

intermedium, Van Tiegh. 1. c. = L. intermedius, Wight.

Kingii, Van Tiegh. 1. c. 544. - Ins. Andam.

ligustrinum, Van Tiegh. 1. c. $502=$ L. ligus. trinus, $W$ all.

obtusatum, Van Tiegh. 1. c. 502 et $544=$ L. obtusatus, Wall.

PHOENIX, Linn. (Palm.). - Ind. Kew. ji. jol.

erecta Hort, ex Sauvag, in Rev, Hortic. lxvi. I894) $495=$ canariensis, Hort.

macrocarpa, Hort. ex Sauvag. 1. c. = canariensis, Hort.

Marioposae $\times$, Hort. 1. c. - Hybr. artef. 


\section{PHOENIX}

melanocarpa. Nondd. in Rev. Hortic. (1893) 563, (1894) 494 fig. 183 et 184 ; et ex Gard.' Chronl. (1893) ii. 299. - Hab.

robusta, Hook. f. Fl. Brit. Ind, vi. (1892) 427. Roebelinit. O'Brien, in Gard, Chron, (1889) ii. 4 i5 et 758 , fig. $68=$ humilis, Royle var.

PHOLIDIA, R, Br. (Myopor.). - Ind, Kew, ii. $50 \%$

alternifolia, Baill. ex Wettst. in Eng1. \& Prantl Natürl. Pflanzenfam, iv. 3b (189\%) $359=$ Eremophila alternifolia, $R, 3 r$

Brownii. Baill, 1. c. = E. Brownii F. Muoll.

Drummondii, Baill. 1. c. $=$ E. Drummondii, $F$ Miuell.

eriocalyx, Baill, l, c. $=$ E, eriocalyx, F, Muell. Forreslii, Baill. 1. c. $=$ E. Forrestii, F. Muell Fraseri, Baill. 1. $c_{1}=$ E. Fraseri, F. Mull. Gibsonit, Baill. 1, с. = E. Gibsonii, F, Muell. Gilesii. Baill. 1. co = E. Gilesii, F. Mucll. Hughiesii, Baill. 1. c. = E. Hurghesii, F. Muell leucophylla, Baill. 1. c. = E. leucophylla, F. Muell. Macdonellii, Baill. 1. c, = E. Nacdonellii, F. Muell. MIackinlayi, Baill. 1. c. = E. Mackinlayi, F. Muell. maculata. Baill, 1. c. = E. maculata, F. Muell IIilchellit. Baill. 1. c. = E. Mitchellii, F. Muell. oppositifolia, Baill. 1. c. = E. oppositifolia. $R . B r$ Pantoni, Baili. 1. c. = E. Pantoni, F. Mucll. rotundifolia. Baill, 1, $\mathrm{c},=\mathrm{E}$. rotundifolia, F. Muell. Sturtii, Baill, l. $c_{1}=$ E. Sturtii, R. Br。

PHOLIDOCARPUS, Blume (Palm.). - Ind Kew ii 50\%. macrocarpa, Becc. Malesia, iii. (1886) 92, t. 9, 1-3. - Penins. Mal.

mucronata, Becc. i. c. 91, t. 9, 4-5. - Sumatra?

sumatrana, Becc.l. c. 92, t. 10. - Sumatra.

PHOLIDOTA, Lindl. (Orchid.). - Ind. Kew. ii 50 ?.

assamica, Hort. Sand. ex Regel, in Gartenfl, xxxix, (1890) 607, nomen, - Ind, or.

Convallariae, Hook. f. in Hook. Icon. pl. xix. (1889) t. 1880 ; et Fl. Brit. Ind. v. $(1890) \& 46(=$ Coelogyne Convallariae, Reichb. f.). - Ind. or.

Griffithis, Hook.f. ll.cc. t. 1881 ; et 845 . - RegHimal.

Lagardi, Rolfe, in Kew Bull. (1893) 6. - Burma.

Laucheana, Kraenzl. in Reichb. f. Xen. Orchid. iii. 6 (1892) 106, t. 259, fig. 6-13. - Hab. ?

micrantha, Hook, f. Fl. Brit. Ind. v. (1890) 847 sphalm, = parviflora, Hook. $f$.

obovata, Hook, f. l. c. 845. - Ind. or.

parviflora, Hook. f. in Hook. Icon. pl. xix. (1889) t. 189l. - Ferak.

protracta, Hook. f. l. c. t. 1877 ; et Fl. Brit. Ind. v 18!0) 845 . - Ind. or

repens, Rolfe, in Kew Bull. (1891) 199. - Ind. or.

sesquitorta. Kracnzl. in Reichb, f. Xen. Orchid. iii. 6 (1893) 114, t. 266 i, fig. 1-7. - Borneo.

PHORADENDRON, Nutt. (Loranth.). - Ind. Kew. 11. 502.

Brittonianum, Rusby, in Mem. Torrey Bot, Club, iv. 1895) 254 - Bolivia.

Diguetianum, Van Tiggh, in Bull. Mus, Paris, i. (1895) 31. - Calif. infer.

bovatifolium, Morong, in Ann. N. Y. Acad. sci. vii (189:3) 216. - Parag

Roraimae, Olicer, in Trans, Limn, Soc. Ser. II ii. (1887) 281; (Oliver, ex im Thum, in Timeliri, $\mathrm{v}$. (1886) 201). - Guian. ang1

hacolulense, Loescn, in Bull Herb. Boiss, ii. (1894) 536. - Mexic

PHORIMIUM, Forst. (Liliac.), - Ind. Kew. ii. 503. Hookeri, Gunn, in Bot. Mag. (1888) t. 6973. - N Zel.

PHOTINIA, Lindl. (Rosac.). - Ind. Kew, ii. 503 dentata, Hort. ex Gard. Kew, i. Polypet. (1894) 21 = serrulata, Lindl.

\section{PHOTINIA}

deflexa, Hemsl. in Ann. Bot. ix. (1895) 153.Formosa

elliptica, Nichols. Dict. Gard. iii. (1886) $108=$ Eriobotrya elliptica, Lindl.

foliolosa, Koehne. Deutsche Dendrol. (189) $19=$ Pyrus foliolosa, Wall.

japonica, Benth. \& Hook.f. ex Aschers. \& Schweinf in Mém. Inst. égypt. [Illustr. Fl. Égypt.] (1887) $73=$ Eriobotrya japonica, Lindl

variabilis, Hemsl. ex Forb. \& Hemsl. in fourn. Linn. Soc. xxiii. (1887) 263. - Japon, China.

Wrightiana, Maxim. in Bull. Acad. Pétersb. xxxii. (1888) 486. - Japon.

PHRAGMANTHERA, Van Tiegh. in Bull. Soc Bot. Fr. xlii. (1895) 261 = Loranthus, Linn. cinerea, Van Tiegh. 1. c. $262=$ L. cinereus, Engl. cistoides, Van Tiegh. 1. C. = L. cistuides, Welw fulc'a, Van Tiegh. 1. c. = L. fulvus Engl.

PHRAGMITES, Trin. (Gramin.) - Ind. Kew. ii. 502.

dioica, Hook, in Engl. E Prantl, Natürl. Pfanzenfam. ii. 2 (1887) 68. - Am. austr.

Loscosii, Willk. Suppl. Prodr. Fl. Hisp. (1S93) 13. - Hisp.

Phragmites, Karst. Deutsch1. FI. (1880-83) 3is: Britton, Stern \& Pogg. Prelim. Catal. (1888) 69 $=$ communis, Trin.

PHREATIA, Lindl. (Orchid.). - Ind. Kew. ii. 503

albiflora, Ridl. in fourn. Bot. xxiv. (1886) 326. N. Guin.

formosana, Rolfe, ex Hemsl. in Ann. Bot. ix. (1895) 156. - Formosa.

Listeri, Rolfe, in fourn. Limn. Soc. xxv. (1800) 358 Ins. Christmas.

nana. Hook. f. Fl. Brit. Ind. V. (1890) S11; et in Hook. Icon. pl. xxi. (1892) t. 2084. - Perak.

parvula, Benth. ex Hook, f. l. c. v. (1890) sil ( Octarrliena paroula, Thw.). - Zeyl.

papuana, Ridl, in fourn. Bot. xxiv. (1886) 32\%.N. Guin.

PHRODUS, Miers (Solan.). - Ind. Kew. ii. 504. breviflorus, Phil. in Anal. Univ. Chil. xci. (1895) 20. - Chili.

pestulus. Phil. 1. c. $20=$ seq.

pendulus, Wettst, in Engl. \& Prantl, Natürl. Pfanfan. iv. 3b (1891) 14 (= Rhopalostigma pendulum, Phil.). - Chili.

thymifolius, Phil. 1. c. $20=$ P. Bridgesii, Miers.

PHRYGANOCYDIA, Mart. = Macfadyena, A, DC. (Bignon.)

Coito, Warm. Symb. Fl. Bras, centr, x1, (1893) $1226=$ M. Coito, Miers.

corymbosa, Burean, ex K. Schum, in Engl. \& Prantl, Natürl. Pfanzenfan. iv. 3b (is94) 224. - Am. austr

PHRYGILANTHUS, Eichl. = Loranthus, Linn. aphyllus, Fr. Meigen, in Bot. Jahrb. xvii. (1893) $228=$ aphyllus, Eichl.

Berteroi, Van Tiegh, in Bull. Soc. Bot. Fr, xlii. (189)5) $178=$ Loranthus Berteroi, Hook. \& Arn.

heterophyllus, Van Tiegh. l. c. = L. heterophyllus, Ruiz of Pai.

vadicans, Fr. Meigen, in Bot. Jahrb. xvi. (1893) 229 ; et xviii. (1894) 441 et $165=$ L. radicans Phil.

PHRYNIUM, Loefl. (Scitam.). - Ind. Kew. ii. 504

Cadellianum. King, ex Hook. f. Fl. Brit. Inn. vi. (1892) 260. - Ins, Andam.

Griffithii, Baker, in Hook. f. l. c. - Malacca.

jucundun, Hort. ex Rev, Hort. Beig. xiv. (1SSS) 16 = variegatum, Hort.

macrocephalum, K. Schnm. Fl. Kais. Wilh. Land 1889) 30. - N. Guin.

plicatım, Hort, ex Petersen, in Mart. Fl. Bras, iii. II. (1800) $94=$ Calathea flavescens, Lind

\section{PHRYNIUM :}

tapirorum, Ridl. in Trans, Linn. Soc. Ser. II. iii. (1893) 382.-- Penins. Mal

textile, Ridl. in fourn. Bot. xxv. (188\%) 133. Angola.

thyrsiflorm, Hort. ex Petersen, in Mart. Fl. Bras. iii. III. $(1860) 160=$ Ctenanthe setosa, Eichl.

variegatum. N. E. Br. in Illustr. Hortic. xxxiii. (1886) 125 t. 606. - Hab.

PHTHEIROSPERMUM. Bunge (Scrophul.). Ind Kew ii. 505

tenuisectum, Burcau \& Franch. in Morot, Fourn. de Bot. v. (1891) 129; Prain, in Hook. Icon. pl. xxiii. (1892) t. 2211. - Reg. Himal., Tibet.

PHTHIRUSA, Mart. = Loranthus, Linn.

loranthoidea, Van Tiegh. in Bull. Soc. Bot. Fr, xli. (1894) 70, in obs. = L. loranthoideus, Van Tiegh.

PHUCAGROSTIS, Cavolini = Cymodocea, Kon. (Naiad.)

isoctifolia, Kuntze, Rev. Gen (I891) 744 [Phycagrostis $=\mathrm{C}$. isoëtifolia, Aschers

manatorum, Kuntze, 1. c. = C. manatorum, Aschers. nodosa, Kuntze, 1. C. $=\mathrm{C}$. aequorea, $K o n$.

serrulata, Kuntze, 1. c. = C. serrulata, Aschers. \& Magnus.

PHUS glabra, Macoun, in Erythea, i. (1893) 144 ferr. typ.] = Rhus glabra, Lim.

PHYLAGIUIM, Benn. (Legumin.), - Ind. Kew. 11. 505 .

majus, Collett \&f Henrsl. in Fourn. Linn. Soc. xxviii 1890) 44 t. 7. - Burma.

PHYLICA Linn. (Rhamn.), - Ind. Kew, ii. 50弓. eucocephala. Cordem. Fl. Ile Réunion (1895) 414 (= Blaeria leucocephala, Berg). - Ins. Borbon.

PHYLLAGTIS, Pers. (Valerian.), - Ind. Kew. ii. 506

mapirensis, Britton, in Bull. Torrey Bot. Club, xviii. (1891) 263. - Bolivia.

PHYLLAGATHIS, Blume (Melast.) - Ind. Kew, ii. 506.

elliptica. Slapf. in Hook. Icon. pl. xxiii. (1894) 2279. - Borneo.

hirsuta, Cogn. in Illustr. Hortic. xli. (1894) 41 t. 3. - Borneo.

tonkinensis, Stapf, in Ann. Bot. vi. (1S92) 316.Tonkin.

uniflora, Stapf, in Hook. Icon. pl. xxiii. (1894) t. 2280. - Borneo.

PHYLLANTHUS, Linn, (Euphorb.). '- Ind. Kew. ii. 506.
lbizzioides, Hook. f. Fl. Brit. Ind. v. (1887) 289. albizzioides,
- Burma.

Boehmii, Pax, ine Bot. Fahrb.xv. (1893) 525. - Afr. trop. or.

Brandegei, Millsp, in Proc. Calif. Acad. Ser. II, ii. (1889) 218. - Calif.

Braunii, Pax, in Bot. Fahrb. xv. (1893) 525. Afr. trop. occ.

brevipes, Hook. f. Fl. Brit. Ind. v. (1887) 297. Rer. Himal.

capillariformis, Vathe of Pax, ex Pax, in Bot. fahrb. xv. (1893) 523 - Afr. trop. or.

capilliformis, Pax \& Vatke, ex Engl. in Abh. Preuss. Akad. Wiss. (1894) 20; et in Engl. Pfanzenw. Ost-Afr. A (1895) is [an praec.?] - Afr. trop.

chacoensis, Morong, in Ann. N. Y. Acad. sci. vii (1893) 218. - Parag.

Chamaepeuce, Ridl. in Trans. Linn. Soc. Ser. II iii. (1893) 345. - Penins. Mal.

ciliato-glandulosus, Millsp. in Proc. Calif. Acad. Ser II. ii. (1889) 219. - Calif.

Clarkei. Hook. f. Fl. Brit. Ind. v. (1887) 29\%. Reg. Himal.

columnaris, Warb. in Bot. Fahrb. xiii. (1891) 356 - N. Guin. 


\section{PHYLLANTHUS}

cryptophilus, S. Elliot, $2 n$ fourn. Linn. Soc. xxix. (1891) 48 (= Monarda iryptophila, Juss.). Madag.

cupuliformis. Warb. in Z3ot. fahrb. xiii. (1891) 356. N. Guin.

Dinklagei, $P$ ax, l. c. xix. (1894) 77. - Gabon. elongatus, Klotzsch, ex Gard, Chron. (1S94)i. 526. [an Steud.?] - Bras.

Engleri, Pax, in Engl. Pfanzenv. Ost-Afr. C (i895) 236. - Afr trop. or

Finschii, K. Schum. in Bot. Fahrb. ix. (1887) 205. N. Guin.

Fischeri, Pax, l. c. xix. (1894) 77. - Afr. trop. or.

gigantifolius, Vidal, Rev. Pl. Vase. Filip. (1886) 236. - Ins. Philipp.

gomphocarpus, Hook. f. Fl. Brit. Ind. v. (1887) 301 . - Perak.

Hellwigii, Warb. in Bot. Fahrb. xviii. (1894) 198 - N. Guin.

Hildebrandtii, Pax, l. c. xv. (1893) 526. - Reg. Somal.

humilis, Pax, l. c. x. (1889) 35ั. - Afr. austr.

Humblotianus, Baill. Hist. pl. Madag. Atlas, (1892) t. 221. - Madag.

humilis, Pax, in Bot. Fahrb. x. (1888) 34. - Afr. austr.

hypospodius, F. Muell. in Vict. Natural. viii. (Mar. 1892) 177; et in Bot. Centralbl. 1. (1892) 125. Austral.

keyensis, Warb. in Bot. Fahrb. xiii. (1891) 355. -

N. Guin.
Kunstleri, Hook.f. Fl. Brit. Ind. v. (1887) 292.Penang.

lalambensis, Schweinf. ex Penzig, in Atti Congr. Bol. Genova (1893) 360, nomen. - Erithrea.

leucanthus, Pax, in Bot. Fahrb. xv. (I893) 524. Afr trop. or.

macranthus, Pax, l. c. xix. (1894) 77. - Mossamb. macropus, Hook. f. Fl. Brit. Ind. v. (1887) 287. Reg. Himal.

meruensis, Pax, in Bot. Fahrb. xv. (1893) 526.Afr. trop. or.

minutiflorus, F. Muell \& Tate, in Trans. \& Proc. Roy. Soc. S. Austral, xiii: (June 1890) $98=$ rhytidospermus, Muell. Arg.

missionis, Hook. f. Fl. Brit. Ind. v. (1887) 297. Deccan.

nanus, Hook, f. l, c. 298. - Burma.

oblongifolius, Pax, in Forschungsr. Gazelle Bot. [Siphon.] 48; et in Engl. E Prantl, Natiirl. Pflanzenfam. iir. 5 (1890) 19. - Malaya

paniculatus, Oliver, in Hock. Icon. pl. xxiv. (1895) t. 2372. - Ins. Salom.

pectinatus, Hook. f. Fi. Brit. Ind. v. (1887) 290. Ind. or.

pedunculatus, Warb. in Bot. Fahrb. xiii. (1891) $35 \%$. - N. Guin.

pomiferus, Hook. f. Fl. Brit. Ind. v. (1887) 289. Burma.

Prainianus, Collett \& Hemsl. in fourn. Limn. Soc. sxviii. (1890) 123. - Burma.

Pringlei, S. Wats. in Proc. Am. Acad. xxvi. (1891) 147. - Mexic.

scabrifolius, Hook. f. Fl. Brit. Ind. v. (I887) 299. - Concan.

sessilis. Warb. in Bot. Fahrb. xiii. (1891) 357. N. Guin.

Stuhlmanii, Pax, in Engl. Pfanzenw. Ost-Afr. c. (1895) 236. - Afr. trop. or.

suffrutescens, Pax, in Bot. Fahrb. xv. (1893) 523 - Afr. trop. or.

vergens, Baill. Hist. pl. Madag., Atlas (1892) t. 225 - Madag.

Volkensii, Engl. Pfanzenv. Ost-Afr. C (1895) 236. - Afr. trop. or

PHYLLARTHRON, DC. (Bignon.). - Ind. Kew. ii. 512 .

articulatum, K. Schum. in Engl. \& Pranti, Natürl. Pflanzenfam, iv. 5 (1895) $251=$ Noronhaeanum, $D C$.

madagascariensis, K. Schum. l. c. $3 \mathrm{~b}$ (1895) 250 (= Arthrophyllum madagascariense, Boj.). Madag.
PHYLLIS, Linn. (Rubiac.). - Ind. Kew. ii. 512 iscosa, Christ, in Bot. Fahrb. ix. (1887) 144. Teneriffa.

PHYLLOBOEA, Benth. (Gesner.). - Ind. Kew. ii. 512 .

sinensis, Oliver, in Hook: Icon. pl. xviii. (1887) t. 1721. - China centr.

PHYLLOCACTUS, Link (Cact.). - Ind Kew.$$
\text { ii. } 51: 2 \text {. }
$$

Campmanni, Hook. ex Gartenfi. xxxvi. (1887) 39. Form, hort.

Fransii. Hort. Germ. ex Hildm. in Gartenfl. xli (1892) 225 t. 1370 fig. 1. - Hybr. artef.

Gaertneri, K. Schum, in Ruempl. et $K$. Schnm. Dic Sukkulent. (1892) $147 \mathrm{fig}$. 80 ; et in Monatsschr. $f$. Kakteenk. iv. (1894) 105. - Bras,

Pommer Eschei X. Hildm. in Gartenfl. xli. (1892) 225 t. 1370 fig. 2. - Hybr. artef.

Russellianus, K. Schum. in Ruempl. \& $K$. Schunn. Di Sukkulent. (1892) $147 \mathrm{fig} .79$. - Bras.

Thomasianus, $K$ Schum. in Monatsschr, $f$ Kaktenk. . (1895) 6 cum ic. - Am. trop.

PHYLLOCHLAMYS, Bureat (Urtic.). - Ind. Kew. ii. 513.

Wallichii, King, ex Hook. f. Fl. Brit. Ind. v. (18s8) 489. - Penang.

PHYLLOGLINIUM, Baill, in Bull. Soc. Linn. Paris, ii. (1890) 870 ; Warb. in Eng1. \& Prant1 Naturl. Pflanzenfam. iii. 6a (1893) 38. BIXI NEAE.

paradoxum, Baill. $l l . c c,-$ Congo.

Soyauxianum, Baill. ex Warb. l. c. 38. - Afr trop. occ.

PHYLLOCTENIUM, Baill, in Bull. Soc. Linn. Paris, i. (1887) 692; et Hist, des pl. x. (1888) 57 K. Schum. in Engl. \& Prantl, Natïrl. Pflanzen. fam. iv. 3b (1895) 247. BIGNONIACEAE.

Bernieri, Baill. ll. cc. - Madag.

PHYLLODES, Lour. = Phrynium. Loefl. (Scitam.).

aemulum, affine, albicans, allonia, altissimum, amplissimum, applicatum, argyraeum, Baraquiniz, Bachemianum, barbatum, bellum, blandum, brachystachyum. brasiliense, brevipes, chimboracense, chrysanthum, chrysoleucum, cinereum, coloratum, comosum, concolor, confertum, crocatum, densum, diccphalum, Eichleri, eximium, exscapum, fasciatum, grandis, grandiflorum guianense, hieroglyphicun, inocephalum, insigne, fagorianum. Kummerianum, lanatum, laterale, Legrellianum, leopardinum, leucostachys, Lietzei, Lindbergii, Lindenianun, longibracteatum, longifolium, macilentum, Mannii, Mansonis, mxximum, mediopictum, metallicum, micans, microcephalum, mirabile, modestum, monophyllum, Myrosma, nigro costatum; nitens, nobilis, oblongum, Oppenheimianum, ornatum, ovatum, pachystachyum, pacificum, peravianum, picturatum, princeps, propinquum, pulchellum, pumilum, Rossii, rotondifolium, rufibarbum, Sellowii. smaragdinum, stramineum, strobiliferam, taeniosum, trifasciatum, tuberosum, tubispathum, umbrosum, undulatum, varians, variegatum, Veitchianum, velutimum, vestilum, villosum, violaceum, virgatum, virginale, vittatum, Wallisii. Warscewiczii, Wiotiana, zebrinum, zingiberinum, Kuntze, Rev. Gen. (18\%1) $692-97$ = homonyma ommia Calatheae.

Achiro, Kuntze, 1. c. $696=$ C. capitata, Lindl.

Ackemannii, Kuntze, 1. c. = C. Ackermanni, Koern.

adenocarpum, K. Schum. in Bot. Jahrb. xv, (1892) 442. - Afr. trop. Occ.

angustifolium, Kuntze, Rev. Gen. (1891) $695=$ Phrynium angustifolium, Lodd.

Arrabidae, Kuntze, 1. c. $696=$ Calathea Arrabida. Koern

arrectum, Kuntze, 1. c. = C. arrecta, Lindl. E André.

baccatum, K. Schum. in Bot. Jahrb. xv. (1892) 442. Afr. trop.
PHYLLODES :

bisubulatum, K. Schum. in Bolet, Soc. Brot. xi. (1893) 83. - Angola,

brachystachyum, K. Schum. 1. C. = Phrynium brachystachyum, Benth.

capitatum, Kuntze, Rev. Gen. (1891) $694=$ P. capitatum, Willd.

culindricum, Kuntze, 1. c. $696=$ Calathea grandifolia, Lindl.

densiflorm, Kuntze, 1. c. $695=$ Phrynium densiflorum, Blume.

fasciculatum, Kuntze 1. $\mathrm{c}=\mathrm{P}$. fasciculatum. Floran.

flexnosun, Kuntze, 1. c. = P. flexuosum, Benth

flexusim, K. Schum. in Bot. Jahrb. xv. (1893) 445 $=$ praec

Glaziovii, Kuntze, Rev. Gen. (1891) $696=$ Calathea Glaziovi, Benth.

Grisebachianum, Kuntze, 1. c. = C. macrostachya, Griseb.

Hookeri, Kuntze, 1. c. = C. colorata, Benth. Es Hook. $f$.

imbricatum. Kuntze, 1. c. $695=$ Phrynium imbrican tum, Roxb.

laxifolium, Kuntze, 1. c. = P. latifolium, Blume.

leiogonium, K. Schum. in Bot. Jahrb. xv. (1892) 442. - Afr. trop.

littorale, Kuntze, Rev. Gen. (1891) 695 = Calathea littoralis, Koern.

luteum, Kuntze, l. c. = C. discolor, G. F. W. Mey. Mackoyanum, Kuntze, 1. c. = C. Makoyana, Ed. Morr.

macrophyllum, K. Schum. in Bot. Jahrb. xv. (1893) 444. - Afr. trop. occ.

macrostachyum, Kuntze, Rev. Gen. (1891) $695=$ Phrynium macrostachyum. Wall

macrostachyum, K. Schum. in Bot. Jahrb. xv. (1892) $445=$ praec

Mandiocae, Kuntze, Rev. Gen. (1891) 696 = Calathea Mandioccae, Koern.

maximum, Kuntze, 1. c. $695=$ Phrynium maximum, Blume.

molle, Kuntze, 1. c. = P. villosum, Benth.

monophyllum, K. Schum, in Bot. Jahrb. xv. (1892) 440. - Afr, trop occ.

monostachyum, Kuntze, Rev. Gen. (1891) $695=$ Phrynium macrostachyum, Wall.

Neorviedii, Kuntze, 1. c. = Calathea Neowiedii, Lodd. obliqum, Kuntze, 1. c. = Phrynium obliquum, Lodd.

oxycarpum, K. Schum. in Bot. Jahrb. xv. (1892) 443. - Afr. trop. occ.

Pavoniamm, Kuntze, Rev. Gen. (1891) $695=$ Calathea pavonina, C. Koch \& Linden.

Blutyphyllum, Kuntze, 1. c. $696=$ C. latifolia, Klotzsch.

prionogonium K. Schum. in Bot. Jahrb. xv. (1892) 441. - Kamerun.

pubigerum, Kuntze, Rev. Gen. (1891) 695 = Phrynium pubigerum, Blume.

pubinerve, Kuntze, 1. $\mathrm{c}=\mathrm{P}$. pubinerve, Blume.

roseopictum, Kuntze, 1. c. = Calathea rosea-picta, Regel.

Ruizianum, Kuntze, 1. c. $696=$ C. capitata, Lindl. spicatum, Kuntze, 1. c. $695=$ Phrynium spicatum Roxb.

stenophyllmm, Kuntze, 1, c. $696=$ Calathea augustifnlia, Koern.

stmatranum, Kuntze. 1. c. $695=$ Phrynium sumatranum, Miq.

textile, Th. Dur. \& Schinz. Consp. F1. Afr. $1892(1895) 133=\mathrm{P}$. textile, Ridl.

truncatum, Kuntze, Rev. Gen. (1891) $696=$ Calathea orbiculata, Lodd.

villosum, K. Schum. in Bot. Jahrb. xv. (1893) 445 Th. Dur, \& Schinz, Consp. Fl. Afr. v. 1893 (1895) $133=$ Phrynium villosum. Hook. $f$

virgatum, Kuntze, Rev. Gen. (1891) $696=$ Clinogyne virgata, Benth. \& Hook. $f$.

Widgrenii, Kuntze, 1.c. = Calathea Widgreni, Koern.

PHYLlORCHIS, Thou, in Nouv. Bull. Soc, Phi lom. (1809) 314/9; ex Kuntze. Rev Gen. (1891) $675=$ Bulbophyllum, Thou. (Orchid.). adenopetala, affinis, albida, alcicomis, Alopecurus, 


\section{PHYLIORCHIS :}

Andersonii, angustifotia, antennifera. apoda, Argy copus, aristatu, aurantiaca, aurata, aurea, auricoma. Baileyi, barbigera, Baronii, Beccarii, óicolor, bifat ria, biseta, Blepharistes, Bowkettae, bracteolata, brecipes, cacspitosa, calamaria, candida; capillipes, capitata curdata canliftora, cermua, Cheiri, chinen sis, chloroplera, cilicta, cirriata, clavigera, cochleata. comata, comosa, conchifora, concinna. conferta, corisconsis, crassifolia, crassipes, crocea, Cumingii, cuprea. cylindracea. Dayana, Dearei, distans, clegans, Elisize, elongata, enblephara, exaltata. exigua. falcipetala, favescens. flavida, fusca, fuscopurpurea, gamosctala, geraìnsis, gibbosa, gladiata, Globulus, grandifiora, gravida, Gymnopus, Hildebrandtii, livisuta. hivta. hymenantha, imbricata, inaequalis, iner's, interiexta, javanica. Kingii, lasiantha, lasiochila, laxiflora, lemuniscata, leopurdina, leptantha, leptosepala. Zichengstrume, limzato. Lindlevana. Lobbii, Lundiana, lupulina, mucrantha, maculosa Mannii, maxillavis, Medusae. megalantha, megalonyx, membranacea, membranifolia. merguensis, meridensis, micrantha, micropetala, microtepala. mimutissima, mischmeensis, modesta, moniliformis, monticola, mucronata, mucronifolia, multifora, mutabiles, Napelli, nasuta, nematopoda, obtusa, occlusa, odorata, odoratissinza, nematopoda, obtusa, occlusa, odorata, odoratisstima, cca, parciflora, pariula, patens, pavimenta, PenicitTium. petivlaris, pileata, Pipio, polyrhiza, Prenticel, protracta, psittacoglossa, Psychoon, Punilio, punctata, hurpurascens, pygmaen, quadriseta, radiata, vecurva, Reinzwardtii, repens, reptans, veticulata, Rhizophorae, rostriceps, rufilabra. vufina saltatoria, Sceptrun. Schefferi, Schmidtiana, secunda, setigera, scycheliarum, Sicyoumlbon, Silleniana, sordida, stenobutbon, striata, striatella, suavissina, sulcata, tenella, tenuicaulis, tcmuiflora, Thompsonit, Thwaitesii, tortuosa, tremula, triadenia, triflora, tripetala, tristis, unguiculata, aniflora, vermicularis, violacea, virens, vittata. Wrayi, xylophylla, Kuntze, Rev. Gen. (1891) $675-78=$ homonyma omnia Bulbophylli. acutiflora, Kuntze, 1. c. = Cirrhopetalum acutiflorum, Hook.

biflora, Kuntze, 1. $c,=$ Bulbophyllum bifarium, Hook. $f$.

Blunei, Kuntze, 1. c, $676=$ B. cuspidilingua, Reichb. $f$.

bootanensis, Kuntze, c. $6 \pi=$ Cirrhopetalum bootanense, Griff.

Bufo, Kuntze, $1 \mathrm{c}$. = Megaclinium Bufo, Lindl.

Bulbophylli, Kuntze, 1. c. $676=$ Bulbophyllum Griffithii, Reichb. $f$

catspitosa, Kuntze, 1. c. $675=$ B. caespitosum, Thott.

clarata, Kuntze, 1. c. = B. clavatum, Thou.

Collettii, Kuntze, 1. c. $67 \%$ = Cirrhopetalum Collettii, Hens?.

Commersonii, Kuntze, 1. c. $675=$ Bulbophyllum Commersonii, Thou.

colubrima, Kuntze, 1, c. $67 \%=$ Mesaclinium colubrinum, Reichb. $f$.

cormuta, Kuntze. 1. c. $=$ Cirrhopetalum cornutum, Lindl.

densa, Kuntze, 1. c. $6 \%$ = Bulbophyllum densum, Thou.

Diphyes, Kuntze, 1. c. $676=$ B. capitatum. Lindl. Elaidum, Kuntze, 1. c. $677=$ B, elaidium, Lindl. clata, Kuntze, 1. c. = Cirrhopetalum elatum, Hook. $f$.

Elliae, Kuntze, 1. c. $676=$ C. Wightii, Thw.

crecta, Kuntze, 1. c. = Bulbophyllum erectum, Thou.

falcata, Kuntze, 1. c. $6 \tilde{\sigma}$ = Megaclinium falcatum, Lindl.

fimbriata, Kuntze, 1. c. = Cirrhöpetalum fimbriatum, Lindl.

Gamblei, Kuntze, 1. c, = C. Gamblei. Hook. f.

gracilis, Kuntze, 1. c. $675=$ Bulbophyllum Thouarsii. Steud.

guthlata, Kuntze, 1. c. $677=$ Cirrhopetalum guttulatum, Hook.

Helenae, Kuntze, 1. c. $6 \tau 6=$ C. cornutum, Lindl.

Herininostachys, Kuntze, 1. c. $67 \tau=$ Bulbophyllum herminiostachys, Reichb. $f$

Hookeri, Kuntze, 1. c. $676=$ Cirrhopetalum Thom soni, Hook.
PHYLLORCHIS :

incurera Kuntze, Rev, Geu, (1891) 675 = Bulbophyllum incurvum, Thou.

foschii, Kuntze, 1. c. $67 \%==$ B. aurantiacum Hook. f.

kaitiensis, Kuntze. 1. $\mathrm{c}_{\mathrm{.}}=$ Cirrhopetalum neilgherense, Wiglit.

Tongiffora, Kuntze, 1. c. $675=$ C. Thouarsii, Lindl. longiscapa, Kuntze, 1. c. $6 \pi \%=$ C. longiscapum, Teijsm. \& Binn

Macraei, Kuntze, 1. c. = C. Wighti, Thw.

maxina, Kuntze, 1. c. = Megaclinium maximum, Lindl.

nimuta, Kuntze, 1. c, $675=$ Bulbophyllum minutum, Thous.

monantha, Kuntze, 1. c. $676=$ B. uniforum, Griff.

nilgherensis, Kuntze, 1. c. $67 \%=\mathrm{B}$. neilgherrense Wight.

mutans, Kuntze, 1. с. $675=$ B. nutans, Reichb.

occulta, Kuntze, 1. c, = B. occultum, Thou.

ornatissima, Kuntze, l. c. $67 \%=$ Cirrhopetalum ornatissimum, Reichb. f.

Othonis, Kuntze, 1. c. $676^{\circ}=$ C. nutans, Lindl.

oxyptera, Kuntze, l. c $67 \%=$ Megaclinium oxypterum, Lindl.

pachyrhachis. Kuntze, 1. c. = Bulbophyllum.pachyrrhachis, Griseb.

pendula. Kuntze, 1. c. $6 \pi 5=$ B. pendulum, Thow.

picturata. Kuntze, 1. c. = Cirrhopetalum picturaturm, Lodd.

prismatica, Kuntze, 1. c. = Bulbophyllum prismaticum, Thou.

purpurca, Kuntze, 1. c. $676=$ B. Careyanum. Spreng.

pusilla. Kuntze, 1. c. $6 \tau 5=$ B. pusillum, Thou.

refracta, Kuntze, l.c. $677=$ Cirrhopetalum refractum, Zoll.

Reichenbachii, Kuntze, 1. c. $676=$ Bulbophyllum gracile, Parish of Reichb. $f$.

etusiuscula, Kuntze, 1. c. $677=$ Cirrhopetalum retusiusculum, Reichb. $f$.

Ridleyana, Kuntze, 1. c. $=676=\mathrm{C}$. concinnum, Hooh. f.

Rolfei, Kuntze, 1. c. $677=$ C. parvulum, Hook. $f$.

Roxburghii, Kuntze, 1. C. $=$ C. Roxburyhii, Lindl

sessilis, Kuntze, 1. c. $676=$ Bulbuphyllum clandestinum, Lindl.

Shepherdii, Kuntze, 1. c. $67 \%$ = B. Shepherdi, $F$. Muell.

simillnna. Kuntze, 1, c. = Cirrhopetalum simillimum, Reichb. $f$.

tacniophylla, Kuntze, 1. c. = C. taeniophyllum, Parish \& Reichb.

Thonsonii, Kuntze, I. C. = Bulbophyllum Thomsoni, Ridl.

Trimenii, Kuntze, 1. c. $6 i 6=$ B. purpureum, Thw.

umbellata, Kuntze, 1. c. $675=$ Cirrhopetalum Thouarsii, Lindl.

vaginata, Kuntze, 1, c. $677=$ C. vaginatum, Lindt. Eariegata, Kuntze, 1. c. $675=$ Bulbophyllum variesratum, Thou.

elutina, Kuntze, 1. c. $677=$ Megaclinium velutinum, Lindl.

viridiflora, Kuntze, 1. c. = Cirrhopetalum viridiflorum, Hook. f.

Wallichii, Kuntze, I. c. $676=$ C. Wallichii, $f$ Grah.

Weddellii, Kuntze, 1. c. $678=$ Bulbophyllum Weddelii, Reichb. f.

Wightii, Kuntze, 1. c. $676=$ Cirrhopetalum grandiflorum, Wight.

PHYLLODESMIS, Van Tiegh. in Bull. Soc. Bot. Fr. xlii. (1895) $255=$ Loranthus, Linn. coriacea, Van Tiegh. 1. c. 256. - Yunnan. Delavayi, Van Tiegh. 1. c. 255. - Yunnan. paucifolia, Van Tiegh. 1. c, 256. - Yunnan.

PHYLlogonum, Coville, in Contrib. U. S. Nat. Herb. iv. (1893) 190. POL Y GONEAE.

luteolum, Coville, l. c. t. 21. - Calif.

PHYLLONOMA, Willd. (Saxifr.). - Ind. Kew. ii. 513 .

integerrima. Britton, in Bull. Torrey Bot. Club, xvii. (1890) $11=$ Dulongia integerrima, Turcz.
PHYLLONOIMA :-

laticarpii, Engl. in Engl. \& Prantl, Natürl. Pflanzenfam. iii. 2a (1891) 88, sphalm.? = Dulongia latifoiia, Turcz.

PHYLLOSTACHYS, Sieb. \& Zucc. (Gramin.) - Ind. Kew. ii. 514.

heteroclada, Oliver, in Hook. Icon. pl. xxiii. (1894 t. 2288. - China.

PHYLLOSTEGIA, Benth. (Labiat.). - Ind. Kew, ii. 514.

ambigua, Hillobr. Fl. Haw. Is?. (18s8) 350. - Ins. Sandvic.

hispida, Hillebr. l. c. 353. - Ins. Sandvic,

Knudsenii, Hillcbr. l. c. 354, ... Ins. Sandvic.

linearifolia, Drake, l. c. (1886) 46 t. 20. - Ins. Sandvic.

PHYLLOSTEPHANUS, Van Tierh, in Bull Soc. Bot. Fr. xlii. (1895) $358=$ Loranthus Linn.

Andreanus, Van Tiegh. 1. c. - Ecuad.

Engelsii, Van Tiegh. 1. c. - Columb.

PHYLLOSTYLON, Capan. (Urtic.). - Ind Kew ii. 514

rhamnoides, Taub. in Oest. Bot. Zeitsch. xl. (1890) 409. - Bras.

PHYLLOXYLON, Baill. (Legumin.). - Ind. Kew. ii. 514.

ensifolium. Baill. Hist. Hl. Madag., Atlas (1886) t. 44. - Madag.

PHYSALIS, Linn. (Solan.). - Ind. Kew. ii. 514 ambigua, Brition, in Mem. Torrey Bot. Club, v. (1894) 28\% - Am. bor.

arenicola, Kearney, in Bull. Torrey Bot. Club, xxi. (1894) 48.̆. - Florida. cinerascens, A.S. Hitchcock, Spring Fl, Manhattan, (1394) 32. - Am, bor

comata, Rydbcrg, in Bull. Torrey Bot. Club, xxii. (1895) 306. - Am. hor.

digitalifolia, Britton, in Mem. Torrey Bot. Club, v. (1894) $288=$ hederaefolia, A. Gray.

Francheti, Mast. in Gard. Chron (1894) ii. 434 et 441 , fig. 57 ; et ex Gartenfl. xliv. (1895) 458. Japon.

Greenei, Vasey \&. F. N. Rose, in Contrib. U. S. Nat. Herb. i. (1890) 10. - Calit

macrophysa, Rydberg, in Bull. Torrey Bot. Club, xxii. (1895) 308. - Am bor.

microphysa, A. Gray, in Proc. Am. Acad. xxi. (1886) 402, - Mexic

pedunculata. Greene, Pittonia, i. (Mar. 1859) 268 $=$ P. Greenei, Vasey E f. N. Rose.

subulata, Rydberg, in Bull. Torrey Bot. Chub, xxii. (1895) 306. - Mexic.

versicolor, Rydberg, l. c. 307. - Am. bor.

viscida, Ridl, in Fourn. Limn. Soc, xxvii. (1890) 49 - Ins. Fernando Noronha.

PHYSALODES, Boehmer, in Ludwig. Defin. (1760) 42, ex Kuntze, Rev. Gen. (1891) $452=$ Nicandra, Adans. (Solan.)

pernviamum, Kuntze, 1. c, =N. physaloides, Gaertn. Physalodes, Britton, in Mem. Torrey Bot. Club, v. (1892) $287=\mathrm{N}$. physaloides, Gaertn.

PHYSALOIDES, Moench = Withania, Pauq (Solan.).

physaloides, Britton, ex Small \& Vail, in Mem. Torrey Bot Club, iv, (1893) $142=$ Nicandra physaloides, Gaertn.

PHYSARIA, A. Gray (Crucif.). - Ind. Kew. ii. 516.

argentea, MacMill. Metasp. Minn. (1892) $263=$ Vesicaria Ludoviciana, $D C$

montana, Greene, FI. Francisc. (1891) $249=$ Vesicaria montana. A. Gray. 
PHYSIDIUM. Schrad, = Angelonia, Humb. \& Bonpl. (Scrophul.).

cornigerum, Nichols. Dict. Gard iii. (1S86) $116=$ A. cornigera, Hook.

Gardneri, Nichols. 1. c. = A. Gardneri, Hook.

PHYSOCARPUS. Rafin. = Neillia, D. Don $($ Ro. sac.).

capitatus, Kuntze, Rev. Gen. (1891) $219=\mathrm{N}$. opulifolia, Benth. Eo Hook. f.

Hexuosus, Kuntze, 1.c. = Stephanandra flexuosa, Sieb. \& Zucc.

gracilis, Kuntze, 1. c. = S. gracilis, Franch. \& Sav Hancernus, Kuntze, 1. c. $218=\mathrm{S}$. chinensis, Hance. malraceus, Kuntze, 1, c, $219=$ N. malvacea, Greene. monogynus, Kuntze, 1. c. 218, Coult. in Contrib.

U. S. Nat. Herb. ii. (1891) $104=$ N. Torreyi, S. Wats.

sinensis, Kuatze, 1. c. $=$ N. sinensis, Hook. f.

Tanakae, Kuntze, 1. c. 219 = Stephanandra Tanakae, Franch. \& Sav.

thyrsiflorus, Kuntze, 1, c. $218=$ Neillia thyrsiflora D. Don.

opulifolius, Maxim. ex Koehne, Deutsch. Dendrol. (189:3) 209 = Spiraea opulifolia, Linn.

PHYSOPTYCHIS, Boiss. = Vesicaria, Tourn. (Crucif.).

graphaiodes, Prantl, in Engl. \& Prantl, Natürl.

Pflanzenfam. iii. 2 (1891) 196 = gnaphalodes, Boiss.

Haussknechtii, Bornm, in Mitth. Thür Bot. Ver. N. Folge, vi. (1894) 65. - Oriens.

PHYSOSIPHON, Lindl. (Orchid.). - Ind. Kew.

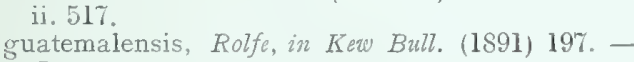
Guatem.

Lindleyi, Rolfe, l. c. (1893) 61. - Mexic.

PHYSOSTEGIA. Benth. (Labiat.). - Ind. Kew ii. 517 .

denticulata, Britton, in Mem. Torrey Bot. Club. v. (1894) $284=$ Dracocephalum denticulatum, Ait.

PHYSOSTELMA, Wight (Asclep.). - Ind. Kew ii. 517 .

carnosa, Collett of Hemsl. in fourn. Linn. Soc. xxviii. (1890) 88. - Burma.

PHYSOSTIGMA, Balf. (Legumin.). - Ind. Kew ii. 517

mesoponticum, Taub. in Ber. Deutsch. Bot. Ges. xii. (1894) 81. - Afr. or. germ.

PHYSURUS, Rich, (Orchid.). - Ind. Kew, ii.

humilis, Cogn, in Mart. Fl. Bras, ii. IV. (1895j 232 t. 55, fig. 1. Bras.

Lindleyanus. Cogn. i. c. 238 t. 55, fig. 2. Bras.

Peterianus, $\operatorname{Cogn}$. l. c. 22\% t. 52, fig. $1(=$. roseus, Reichb. f.). - Guin. bat.

PHYTEUMA. Linn. (Campanul.). - Ind. Kew. ii. 517 .

Huteri. Murr, in Oest. Bot. Zeitschr. xxxix. (1889) 47, et in Progr. Oberrealschule Innsbruck (1890-91) 56. - Tirul.

italicum, Avv.-Touv. in Bull. Soc. Dauph. xiv. (1S87) 584. - Ital

Khekii, Murr, in Oest. Bot. Zeitschr. xliii. (1893) 224; et in Dcutsche Bot. Monatsschr, xii. (1894) 98. - Tirol.

Murrianum, Borb, ex Murr, in Progr. OberRealsch. Innsbruck (1890-91) 56; et ex Ber. Deutsch. Bot. Ges. x. (1892) 125. - Tirol.

obtusifolium, Freyn, in Oest. Bor.Zeitschr. xli. (1891) 56. - Bosnia.

Pseudo-orbiculare, Freyn, in Verh. zool.-bot. Ges. xxxviii. (1888) $618=$ obtusifolium, Freyn.

rumelicum, Orph. \& Janka, ex Buser, in Bull. Herb. Boiss. ii. (1894) 520, in syn. (= Diosphacra ckalcidica, Buser). - Graecia

trichocalycinum, Caruel, in Parl. Fl. Ital. viii. (1888) $63=$ Podanthum trichocalycinum, Boiss.
PHYTOLACGA, Tourn, ex Linn. (Phytol.). Ind. Kew, ii 519

Japonica, Makino, in Tokyo Bot. Mar. vi. (1892) 49 - Japon.

polyandra. Batalin, in Act. Hort. Petrop, xiii. (1893) 99. - China.

volubilis, Heimerl, in Engl. \& Frantl, Natirrl. Pfane zenfan, iii. Ib (1889) Il (= Ercilla volubilis, A. Juss.). - Am. austr. occ

PIARANTUS, R. Br. (Asclep.). - Ind. Kew. ii 519

comptus, N. E. Br. in Hook. Icon. pl. xx. (1S90) t. 8924, b, - Afr, austr.

grivanus, N.E.Br. l.c.t. 1924 a. - Afr. austr.

PIAROPUS, Rafin.=Eichhornia, Kunth(Ponted ) crassipes, Britton, in Ann. N. Y. Acad. sci. vii. (1893) $241=$ crassipes, Rafin.

PIGEA, Link (Conif.). - Ind. Kew. ii. 519 acicularis, Maxim. ex Beissn. Handu. Nadelholzh. (1891) $3801=$ P. japonicu, Regel). -- Japon. utissima. Hort ex Beissn. 1. c. 342 et $358=$ alba, Link et excelsa, Link

alpestris, Bruegg. ex Stein, in Gartenfl. xxxvii (1887) 346. - Hely.

bicolor. Hort. ex Beissn. Handb. Nadelholzk, 1891) $380=$ polita Carr.

canadensis, Britton, Stern \& Pogg. Prelim. Cata?. 1888) 71; Koehne, Deutsche Dendrol. (1893) 23 $=$ alba, $\operatorname{Link}$.

commutata, Hort. ex Beissn. Handb. Nadelholzk. (1891) $346=$ pungers, Engelm

Cranstoni. Hort ex Beissn. 1. c. $360=$ excelsa, Link

elegantissima, Hort. ex Beissn. 1. c. $367=$ excelsa Link.

funedonenzis, Hort, ex Beissn. 1. c. = excelsa, Link glauca, Hort. ex Beissn. 1. c. $342=$ alba, Link.

Gregoryana, Hort. ex Beissn. 1. c. $364=$ excelsa, Link.

hondoënsis, Mayr. ex Koehne, Deutsche Dendrol. (1893) 24. - Ins. Hondo.

Mariana, Britton, Stern \& Pogg. Prelim. Catal. 18s8) 71; Saro in Gard, and For. ii. '1889) 496: Koehne, Deutsche Dendrol. (1893) $23=$ nigra, Link.

Mariana, Kuntze, Rev.Gen.(1891) $800=$ nigra Link.

Maxtelli, Hort. ex Beissn. Handb. Nadelholzk. (1891) $366=$ excelsa, Link.

amorica. Pancic ex Stein, in Gartenfl. xxxvi. (1-87) 13 fig. 4 et 5; Eichl. in Engl. \& Prantl Natürl. Pflanzenfam. iii. I (1889) 79: Wettst. in Sitzungsb. Akad. Wiss. Wien. xcix. (1890) $5.33=\mathrm{P}$. Omorika, Mast.

Parsonsiana, Barron, ex Beissn. Handb. Nadelholzk (1891) $473=$ Abies concolor, Lindl. G Gard.

Remonti, Hort. ex Beissn. 1. c. $363=$ excelsa, Linh

sitkaënsis, Mayr. ex Beissn. 1. c. $390=$ sitchensis, Trautv. Eo Mey.

temuifolia. Hort ex Beissn. l. c. $4.33 \%$ = Abies pectinata, $D C$.

Thumbergii, Koehne, Deutsche Dendrol. (1893) 22 in obs. = Abies Thunbergii, Lamb.

Torano, Koehne, 1. c. $22=$ polita, Carr

viminalis, Hort. ex Beissn. Handb. Nadelholzk. (1891) $360=$ excelsa, $\operatorname{Link}$

Yezomonii, Hort, ex Beissn. 1. c, $338=$ ajanensis, Fisch.

PICHLERIA, Stapf \& Wettst. in Denkschr. Akad. Wien, ii. (1886) 56 UMBELLIFERAE cruciata, Stapf \& Wettst. l.c. 56. - As. Min. pallidiflora, Stapf हo Wettst. l.c.-As. Min

PICHONIA, Pierre, Not. bot. Sapot. (1890) 22. SAPOT ACEAE.

Balansana, Pierre, l. c. (1890) 23.- N. Caled

elliptica, Pierre, l. c. - N. Caled.

PIGRAMNIA, Sw. (Simarub.). - Ind. Kew. ii.

quaternaria, F. D. Smith, in Coult. Bot. Gaz. xx. (18.5) 3. - Am. centr.
PICRIDIUM. Desf. (Compos.). - Ind. Kew. ii 520

Sonsp. Fl. Eur. Suppl, ii. (1889) 203 - intermedium Sch. Bip.

PICRIS. Linn. (Ccmpos.). - Ind. Kew. ii. 521. Balansae, Batt. in Batt. Eo Trab. Fl. de l'Aloèr. [Dicot] (1890) $545(=$ Helminttia Balansa Coss. \& Durieu). - Afr. bor.

racemosa, Batt. l. c. 544 (= Deckera racena, Pomel) - Alreria.

Saharae, Batt. l. c. 542 (= Spitzelia Saharae, Coss.) Afr. bor.

PICROGARDIA, Radlk, in Sitz. Akad. Muench $\mathrm{xx}$. (1890) 344, in obs. SIMARUBEAE.

resinosa, Radlk. l. c. $345,-\mathrm{N}$. Caled.

PICRODENDRON, Planch. (Simarub.). - Ind Kew. ii. 521.

baccatum, Krug \&o Urban, ex Urban, in Bot. fahrb. xv. (1892) 30s (= fuglans baccata, Linn. - Ind. occ.

PICRORHIZA, Royle (Scrophul,). - Ind. Kew ii. 522 .

Lindleyana, Wettst, in Engl. \& Prantl, Natuir Pflanzenfam. iv. 3b (1891) $84=$ Lindleyana Stered.

PIERIS, D. Don (Ericac.). - Ind. Kew. ii. 522 nana, Makino, in Tokyo Bot. Mag. viii. (1894) 213. - Japon.

Swinhoei, Hemsl, in fourn. Limn, Soc xxvi. (1890) 17. - China.

PIERREA, Hance, in Bull. Soc. Linn. Paris, ii (1891) 958; et Recherch. Diptéroc. (1892) 78 DIPTEROCARPEAE

pachycarpa, Heim, 1. c. 958. - Borneo ?

ponangiana. Heim, ex King, in Journ. As. Soc. Beng. 1xii. (1893) II. 133, in syn. ; et ex Brandis in Journ. Linn. Soc. xxxi. (I895) 110 , in syn. = Balanocarpus Heimii, King.

PIGEUM, Laness. P1. util. Colon. Franc. (1886) 284, sphalm. = Pygreum, Gaertn. (Rosac.).

PILEA, Lindl. (Urtic.). - Ind. Kew, ii. 523 crassifolia, Stapf, in Trans. Linn. Soc. Ser. II. (1894) 228. - Borneo.

Clarkei, Huok, f. Fil. Brit, Ind. v (18881,5): - -

Reg. Himal.

cordifolia, Hook. f. l. c. 558. - Ind. or

costaricensis, f. D. Smith, in Conlt. Bot. Gaz. xx. (1895) 294. - Costa Rica.

rasciata, Franch. in Nouv. Archur, Mus. Paris, Sér. II. x. (1887-88) 81. - Tibet.

fruticosa, Hook. f. Fl. Brit. Ind. v. (1888) 558 . Perak.

glabra, S. Wats. in Proc. An. Acad. xxivi. (1891) 152. - Mexic

Holstii, Engl. in Abr. Preuss, Akad. Wiss. (1894) 50 ; et in Engl. Pfanzenw. Ost-Afr. C (1895) 163. - Afr. trop. or.

irrorata. F. D. Smith, in Coult. Bot. Ga\%. xix. (18,4) 11. - Guatem.

Johniana, Stapf, in Trans. Linn. Soc., Ser. II, iv (1894) 227. - Borneo.

Johnstoni, Oliver, in H. Fohnston, Kilinn. Exped. App. (1886) 346, nomen; et in Trans. Linn. Soc. Ser. II. ii. (1887) 349. - Afr. trop. or.

lancifolia, Hook. f. Fl. Brit. Ind. v. (1888) 5.3.) Khasia.

longipes, Engl. Pfanzente. Ost-Afr. C (1895) 16:3. - Afr. trop. or.

macropoda, Baker, in foum. Linn. Soc. xxil. (18ST) 524. - Madag

minuta, C. B. Clarke, l. c. xxv. (1889) 66. - Ind. or

obliqua, Hook. f. Fl. Brit. Ind. v. (ls8s).558. Reg. Himal.

pansamalana, 7. D. Smith, in Coult. Bot. Gaz. xix. (1894) 10. - Guatem.

pleuroneura, F. D. Smith. l. c. 12. - Guatem.

Pseudo-verticillata, Cordem. Fl. Ile Rúunion (18!95 265. - Ins, Borbon. 


\section{PILEA}

pterocaulis, Stapf, in Trans. Lim. Soc., Ser. II. iv. (1894) 227. - Borneo.

quichensis, F. D. Smith, in Coult. Bot. Gaz. xix. (1894) 12. - Guatem.

riparia, F. D. Smith. l.c. 11. - Guatem.

senarifolia, 7. D. Smith, l. c. 12.- Guatem.

usambarensis, Engl. in Abl. Preuss. Akad. Wiss.

(1894) 50 ; et in Engl. Pfanzenw. Ost-Afr. C (1895)

163. - Afr. trop. or.

veronicifolia, Engl.l. c, 164.-Afr. trop. or.

PILOCARPUS, Vahl (Rutac.). - Ind. Kew. ii.

List.

microphyllus, Stapf, in Kew Bull. (1894) 5; et in Hook. Icon. pl. xxiv. (1894) t. 2331. - Bras.

PILOCEREUS, Lem. = Cereus, Mill. (Cact.) Ackemumni $\times$. Hort. ex K. Schum, in Engl. \& Prantl, Natur1. Pflanzenfam. iii. 6a (1894) 183. - Hybr. artef.

albispinus, Salm-Dyck, ex Foerst.-Ruemp1. Handb. Cacteenk. (1885 ?) 649. - Afr。 dustr.

auratus, Labouret, ex Foerst.-Ruempl. 1. c. 650.Peruvia.

barbatus, Reb. ex Foerst.-Ruempl. 1. c. - Hab. ?

Bruennowii, Haage, ex Foerst.-Ruempl. Handb. Cacteenk. (1885?) 651 fig. 86; et in Hamb. Gart. und Blumen-Zeit. (1885) 85, cum ic. - Bolivia.

Brunnowianus, Hort, ex Rev. Hort. lxvii. (1895) $451=$ praec

Brunnowii, “ Haage » ex Nichols. Dict. Gard, iii. (1886) $127=$ P. Bruennowii, Haage.

crenatus $X$, Hort. ex $\mathrm{K}$. Schum. in Eng1. \& Prant1, Naturl. Pflanzenfam. iii. 6a (1894) 183. - Hybr. artef.

crenulatus, Salm.-Dyck, ex Foerst.-Ruempl. Handb. Cacteenk. (18-5?) 655. - Am. austr., Antill.

euphorbioides, Ruempl. in Foerst.-Ruempl. 1. c. 658 $=$ Cereus euphorb oides, Haw.

exerens, K. Schum. in Engl. \& Prantl, Natürl. Pflanzenfam. îi. 6a (1894) $180=$ Cereus virens, $D C$.

flavicomus, Salm-Dyck, ex Foerst.-Ruempl. Handb. Cacteenk. (1885?) 658 ( $=$ C. flavicomus, SalmDyck). - Hab.?

Ghiesbrechtii, Hort, ex Foerst.-Ruempl. 1. c. 661. - Mexic

giganteus, Lemaire, ex Foerst.-Ruemp1. 1. c. 662 fig. 88 ( = Coreus giganteus, Engelm.). - Calif.

Harage, Poselger, ex Foerst.-Ruemp1. 1. c. 665. Bolivia.

Hoppenstedtii, Roezl, ex Foerst.-Ruempl. 1. c. 667 ; et ex Hamb. Gart. und Blumen-Zeit. (1888) 8, cum ic - Mexic.

Hoogendorpii, Ortg. ex K. Schum. in Engl. \& Prantl, Natürl. Pflanzenfam. iii. 6a (1894) 181, nomen $=$ P. Hoppenstedtii, Roezl.

Kanaleri, Haage, ex Foerst.-Ruempl. Handb. Cacteenk. (1885 ?) 671. - Hab,

lanuginosus, Ruempl. in Foerst.-Ruempl. 1. c. 6\%2; K. Schum, in Engl, \& Prantl, Natürl, Pflanzenfam. 1ii. 6a. (1894) $181=$ Cereus lanuginosus, Mill.

lateribarbatus, Pfeiffer, ex Foerst.-Ruempl. Handb. Cacteenk. (1885 ?) $672(=P$. Colmmna, Lemaire). - Mexic.

lutescens, Salm-Dyck, ex Foerst.-Ruempl, 1. c. 675. - Hab.

Mclocactus, K. Schum. in Monatsschr. f. Kakteenk. iii. (1893) 20, cum xylogr. - Bras.

pasacanus, Weber, ex Foerst.-Ruempl. Handb. Cacteenk. (1885 ?) 678. - Am. austr. temp.

pentaëdrophorus, Cons. ex Foerst.-Ruemp1. l. c. 679 $(=$ Cereus pentacidrophorus, Labouret $)$. - Bras.

phyllanthoides X, Hort, ex K. Schum, in Engl. \& Prantl, Natürl, Pflanzenfam. iii. 6a (1894) 183 - Hybr. artef.

polyptichus, Lemaire, ex Foerst. Ruempl. Handb. Cacteenk. (1885 ?) 680. - Hab.

repandus, K. Schum, in Engl. \& Prantl, Natürl. Pflanzenfam. i.i. 6a (1894) $181=$ C. repandus, Nitll.

Royeni, Haworth, ex Foerst.-Ruempl. Handb. Cacteenk. (1885 ?) 682 (= Coveus Royeni, Haw.). - Ind. occ.
PILOCEREUS :-

Russeliamus, Hort. Berol. ex Foerst.-Ruempl. Handb. Cacteenk. (1885 ?) 682. - Venezuela.

Sargentianus, Orcutt, ex K. Schum. in Monatsschr.f. Kakteenk. v. (1893) 86. - Calif

strictus, DC ex Foerst.-Ruempl. Handb. Cacteenk. 1885 ?) 687 (= Cereus strictus, Willd.). - Am austr.

Terscheckii, Parm, ex Foerst.-Ruemp1. 1. c. 688 (= Cereus fulvispinus, Salm-Dyck). - Reg. Argent.

Thurberi, Engelm. ex Foerst.-Ruempi. 1. c. 689. Mexic.

trichacantus, Hort. Berol. ex Foerst.-Ruempl. 1. c. $675(=$ Cereus Pfoifferi, Parm.).- Am. austr

Verhoinei, Hort. ex Foerst.-Ruempl. 1. c. 690. Hab. ?

virens, Foerst.-Ruempl. ex K. Schum, in Engl. \& Prantl, Natürl. Pflanzenfam. iii. 6a (1894) 180 in obs. = virens, Lem.

PILOSTIGMA, Van Tiegh. in Buil. Suc. Bot, Fr. xl. (1894) 488 et $540=$ Loranthus. Linn.

brevipes, Van Tiegh. 1. c. = L. brevipes, Van Ticgh.

Muelleri, Van Tiegh. 1. c. = L. Muelleri, Van Tiegh.

sanguineun, Van Tiegh. 1. c. $489=\mathrm{L}$. sanguineus, F. Muell

PIMELAEA, Kuntze, Rev, Gen. (1891) $974=$ Pimelea, Banks \& Soland. (Myrsin.).

crecta, siuntze, 1. c. sphalm. = Pimelandra erecta C. B. Clarke.

PIMELEA, Banks \& Soland. (Thymel.). - Ind. Kew. ii. 526 .

angulata, Colenso, in Trans. N. Z. Inst, xviii. 1885 (1856) 265. - N. Zel.

bicolor, Colenso. l. c. xxii. 1889 (1890) 485. - N Zel.

dichotoma, Colenso, l. c. - N. Zel

heterophylla, Colesıso, l. c. 486. - N. Zel.

Husseyana. F. Muell. in Trans. Roy. Soc. S. Austral. xix. (1895) 81, nomen. - Austral.

lanceolata, Colenso, in Trans. N.Z. Inst. xxii. 1889 (1890) 483. - N. Zel.

microphylla, Colenso, l. c.484. - N. Zel.

polycephala, Coleniso, l. c. 486. - N. Zel.

rugulosa, Colenso, l. c. xxi. Is88 (1S89) 102. N. Zel.

similis, Colenso, l. c. xxii. 1889 (1890) 483.N. Zel.

stylosa, Colenso, l. c. xx. 1887 (1888) 205. N. Zel.

Suteri, T. Kirk, l. c. xxvi. 1893 (1894) 259. N. Ze!

Treyvaudi, F. Mitell. in Vict. Natural. xi. (May I894) 2, nomen. - Austral.

PIMELEODENDRON, Hassk. (Euphorb.). borneense, Warb. in Bot. fahrb. xvisi. (1894) 199.

borneense, Warb. in Bot. falrb. xvis..
papuanum, Warb. l. c. 198. - N. Guin.

PIMENTA, Lindl. (Myrt.). - Ind. Kew. i1. 527. Pimenta, Cockerell, in Bull. Torrey Bot. Club, xix. (1892) $95=$ officinalis, Lindl.

PIMPINELLA, [Riv.] Linn. (Umbell.). - Ind. Kew. ii. 527.

andina, Phil. in Anal. Univ. Chil. lxxxv. ;1894) 721. - Am. austr. occ

araucana, Phìl. l. c. 723. - Araucania.

Battandieri, Chabert, in Bull. Soc. Bot. Fr. xxxvi (1889) 24. - Algeria.

camptotricha, Penzig, in Atti Congr. bot. Genovd (1893) 343. - Erithrea.

cervariaefolia, Freyn of Sint. in Bull. Herb. Boiss. iii. (1895) 303. - Armenia.

cypria, Boiss. Fl. Or. Suppl. (1888) 253. - Ins. Cypr.

depauperata, Post, in fourn. Linn. Soc. xxiv. (1888) 427. - Syria.

Djurdjurae, Chabert, in Bull. Soc. Bot. Fr. xxxvi. (1889) 25. - Algeria.

\section{PIMPINELLA :}

flaccida, C. B. Clarke, in fourn, I inn. Soc, xxy. (1889) 28, t. 15. - Kohima

huillensis, Welw. ex Engl. in Abh. Preass. Akad. Wiss. 1891 (1892) 319. - Angola.

intermedia $\times$. Figert, in Deutsche Bot. Monatsschr. vii. (1889) 85; G. Beck, Fl. Nied,-Oest, ii. I 1892) 626. - Eur centr.

kllimandscharica, Engl. Bot. Fahrb, xix. Beibl. n. 47 (1894) 42 . - Afr. trop. or.

macrophylla, Phil. in Anal. Univ. Chil. Ixxxv. (1894) 722. - Am. austr. occ.

mexicana, S. Wats. un Proc. An. Acad.xxvi. (1891) 164. - Mexic

moabitica, Post, in Bull. Herb. Boiss. iii. (1895) 156. - Syria.

Moelleri, Phil. in Anal. Univ. Chil. 1xxxv. (1894) 790. - Am. austr. occ.

Navarri, Phil. l. c. 721. - Am. austr, occ.

Parishi, Coult. \& J. N. Rose, in Coult. Bot. Gaz xii. (1887) $157=$ Eulophus Parishi1, Coult. \& 7. N. Rose.

peteroana, Phil. in Anal. Univ. Chil. Ixxxv. (1S94) 723. - Am. austr. occ.

spinzosa, "Gaertn. » ex Dippel, Handb. Laubholzk. jii. (1893) 55l, sphalm. = Poterium spinosum Linn.

Vidali. Phil. in Anal. Univ. Chil. 1xxxv. (1894) 724. - Am. austr. occ.

Volkensii, Engl. Pfanzenw. Ost-Afr. C (1895) 299. - Afr. trop. or.

Welwitschii, Engl. in Abh. Preuss. Akad. Wiss. 1891 (1892) 319. - Angola.

PINALIA, Buch.-Ham. = Eria, Lindl. (Orchid.). abbreviata, acervata, acridostachya, acuminata, acutifolia, albidotomentosa, amica, andamanica, anmulata, aporina, appendiculata, articulata, bambusifolia, barbata, bicolor, bicristata, bifalcis, biflora, bipunctata, braccata, brachystachya, bractescens, calamifolia. canaliculata, capitellata, carinata, ciliata, clavicaulis, compressa, concolor, confusa, crassicaulis, Curtisit. dasyphylla, Dasypus, Dayana, ebulbis, elata, clongata, erecta, Eriopsidobulbon, excaricata, exilis, extinctoria, ferox, ferruginea. Fitzalani. Anovescens, floribunda, foliosa, fragrans, fusca, gracilis, graminifolia, hirta, ividifolia, javensis, Kingii, lancifolia, latifolia, leptocarpa, Lindlyci. lineata, lobata, longifolia, Maingayi, marginata, Matthewsi, merguensis, micrantha, microphylla, monostachya, monticala, mucronata, multiflora, muscicola, mysorensis, nana, nutans, obesa, obliqua, ornata, pachystachya, paniculata, pannea, Parishii, pauciflora, pellipes, Pleurothallis, polystachya, polyura, profusa, pubescens, putvinata pumila, pusilla, pygmaea, recurvatu, Reinwardtii, reticosa, retroflexa, retusa, rigida, ringens, robusta, rosea, rostriftora, rubiginosa, rufinula, saccifera, scabrilinguis, sclerophylla, Scortechinii, sicaria, sinica, sonkaris, stellata, stricta, striolata, sulcata, sumatrana, Thwaitesii, tomentosa, tricolor, truncata, tuberosa, ustulata valida. velutina, restita, vittata, oulpina, Kuntze, Rev. Gen. (1891) 678-79 = homonyma omnia Eriae.

Andersonii, Kuntze, 1. c. $679=$ E. Andersonii, Hook. $f$.

aporodes, Kuntze, 1. c. $678=\mathrm{E}$. aporoides, Lindl. biophylla, Kuntze, 1. c. 679 , sphalm. = leiophylla, Lindl.

cauligera, Kuntze, 1. c. = Phreatia cauligera, Reichb. $f$.

hyacinthodes, Kuntze, i. c. $678=\mathrm{E}$. hyacinthoides, Lindl.

Ferdoniana, Kuntze, 1. c. $679=\mathrm{E}$. Lichenora, Linal. laxiflora, Kuntze, 1. c. $678=$ Phreatia laxiflora, Lindl.

leiophylla, Kuntze, 1. c. 679 [err. typ. biophylla] $=$ E. leiophylla, Lindl.

lencantha, Kuntze, 1. c. = E. alba, Lindl.

limenophyllax. Kuntze, 1. c. $678=\mathrm{E}$. limenophylax, Reichb.f.

Lobbii, Kuntze, 1. c. $679=$ E. elongata, Lindl. microchilos, Kuntze, l. c. = E. Dalzelli, Lindl. myristiciformis, Kuntze, 1. c. = E. myristicaeformis, Hook

nilgherensis, Kuntze, 1. c. = E. pauciflora, Wight. obligantha, Kuntze, 1. c. = E. oligantha, Hook. $f$. 
PINAIIA :-

obliterata, Kuntze, Rev. Gen. (1891) 6r8 = Eria oblitterata, Reichb. $f$.

oreopliyllax, Euntze, 1. c. $679=$ Phreatia oreophylax, Reichb. $f$.

perpusilla, Kuntze, 1. c. = P. perpusilla. Reichb. $f$ prorepens, Kuntze, 1. c. = P. prorepens. Reichb. $f$. pulchella, Kuntze, 1. c. = Eria Griffithii, Reichb. $f$. rigida, Kuntze, 1. c. = E. pulchella, Lindl. Rimannii, Kuntze. 1. c. = E. Rimanni, Reichb. $f$. rilgosa, Kuntze. 1 c. = E. stellata, Lindl.

PINANGA. Blume (Palm.). - Ind. Kew. ii. 529. angustisecta, Beco. Malesia, iii. (1886) 119.Borneo.

auricuiata, Becc. l. c. 134. - - Korneo.

brevipes, Becc. l. c. 121. - Borneo.

calamifrons, Becc. l. c. 132. - Borneo

canina, Becc. l. c. 135. - Borneo.

crassipes, Beco. 7. c. 120. - Borneo.

curvata, Becc. l.c. 128 (= Areca curvata, Griff.). Penins. Mal.

decora, L. Linden \& Rodigas, Cat. pl. Hort. Contin. (1885: 61, n. 119] in. Illustr. Hort. xxxiv. (1886) 171. t. 614. - Borneo.

densiflora, Becc. Malesia, iii. (1886) 116 . - Sumatra.

Duperreana, Pierre, ex Becc. l.c. 144. - Cambodia. globosa, Hort. ex Nichols. Dict. Gard. iii. (1886) $130=$ Calyptrocalyx spicatus, Blume.

gracilis, Hook. f. ex C. B. Clarke, in fourn. Linn Soc. xxv. (1889) 80 (= Areca gracilis, Roxb.) = gracilis, Bhume.

Griffithii, Becc. Malesia, iii, (1886) 117. - Khasia, Assam.

Hookeriana, Becc. l. c. 141. - Khasia.

hymenospatha, Fiook. $f$. Fl. Brit. Ind. vi. (1892) 411. - Burma.

lepida, Bull, Catal. (1888) 9; et ex Gard. Chron. (1888) ii. 273. - Ind, or.

ligulata, Becc. Malesia, iii. (1886) 129. - Borneo.

Manii, Becc l.c. (1889) 178. - Ins. Nicob.

mirabilis, Becc. i. c. (1886) 126. - Borneo.

pectinata, Becc, in Hook. f. Fl. Brit. Ind. vi. (1892) 410. - Perak.

perakensis, Becc. Malesia, iii. (1889) 175. - Penins. Mal.

philippinensis, Becc. l. c. 180. - Ins. Philipp.

polymorpha, Becc. l. c. 172. - Penins. Mal.

rivularis, Becc. l. c. (1886) 130. - Burma.

Iobusta, Beco, in Hook. f. Fl. Brit. Ind. vi. [1892) 408. - Penins. Mal.

rubricaulis, L. Linden. Catal. pl. Hort. Contin. (1885) 61, n. 117; W. Wats, in Gard. Chron. (1893) i. $260=$ Cyrtostachys Renda, Bhume.

Sanderiana, W. Bull, [1885], ex Becc. Malesia, iii. (1889) 170

Scortechini, Becc. l. c. 170. - Penins. Mal

simplicifrons, Becc. l. c. (1883) 124 (= Ptychosperma simplicifrons, Miq.). - Sumatra.

Smithii. Hort. ex Hook. f. in Bot. Mag. (1894) sub t. 7345 , in syn. $=$ Ptychosperma elegans, Blume. spectabilis, Bull, Catal. (1886); ex Becc. Malesia, iii. (1886) 115 ; W. Wats. in Gard. Chron. (1893) i. 260. - Hab.

stricta, Becc. l.c. 133. - Borneo.

stylosa, Becc. l. c. (1889) 177 . - Sumatra.

subruminata, Becc.l.c. 174. - Penins. Mal.

tomentella, Becc. l.c. (1886) 126. - Borneo.

variegata, Becc.l.c. 127. - Borneo.

Von Mohli, Hort. Linden, (1890); |cf. W. Wats. in Gard. Chron. (1893) i. 260]. - Hab. ?

PINAROPAPPUS, Less. (Compos.). - Ind. Kew, ii. 529.
junceus, A. Gray, in Proc. Am. Acad. xxii. (188') junceus, A. Gray.
307. - Mexic.

PINEDA, Ruiz \& Pav. = Banara, Aubl. (Samyd.). Lehnannit, Hieron. in Bot. Jahrb. xx. Beibl. n. 49 (1895) 58, - Ecuad.

PINELliA, Tenore (Aroid.). - Ind. Kew. ii. 529. integrifolia, N. E. Br. in Hook. Icon. pl. xix. (1889) t. 1875 . - China.
PINGUIGULA, Tourn. ex Linn. (Lentibul.). Ind. Kew. ii. 529,

Arveti, Genzty, in Morot, Fourn. de Bot. v. (1891) 250 (= P. variegata, Arv-Touv., non Turcz.). - Gall.

bicolor, Woloszczak, in Oest. Bot. Zeitschr, xxxvii. (1887) 80. - Hung

magellanica, Commers. ex Franch. Miss scient. Cap Horn, v. (Phan.) (1889) 35.3 = antarctica,

parvifolia, Robinson, in Proc. Am. Acad, xxix. (1894) 320. - Mexic.

ramosa, Miyoschi, ex Yatabé. in Tokyo Bot. Mag. iv. (1890) n. 43 t. 11. - Japon.

Reuteri. Genty, in Morot, Foum. de Bot. v. (1891) 229, t. 3. - Reg. Jurass

PINUS, [Tourn.] Linn. (Conif.). -- Ind. Kew. ii.

Apacheca, Lemmon, in Erythea, ii. (1894) 103 t. 3. - Arizona.

atteniata, Lemmon, [in Mining and Scientif. Press. (Jan. 1892)] in Gard. and For. v. (1892; 65= tuberculata, Gord.

Corteana, Hort. ex Beissn. Handb. Nadelholzk. (1891) $222=P$. Pinaster, Soland

digenea $X, G$. Beck, in Annal. Naturh. Hofmus. Wien, iii. (1888) $7 \%$ : et Fl. Nied.-Oest. i. I. (1890) 4.- Austria.

digenea $X$, Wettst. in Oest. Bot. Zeitschr. xxxix. (1889) $108=$ P. Wettsteinii, Fritsch.

Donnell-Smithii, Mast, ex 7. D. Smith in Coult. Bot. Ga\%. xvi. (1891) 199, et xviii. (1893) 13, t. 2. - Guatem

haguenensis, “Loud. » ex Beissn. Handb. Nadelholzk. (189I) 228 = silvestris, Linn.

latifolia, H. Mayr. in Gard. and For ii. (1889) 496 cum xylogr.; Beissn. Handb. Nadelkolzk. (1891) 259; Koehne, Deutsche Dendrol. (1893) 36. Arizona.

Lumholtzii, Robinson of Fernald, in Proc. Am. Acad. xxx. (1895) 122. - Mexic.

Mayri, Zabel, in Forstl. Bl. (1891) 250, ex Gartenfl. xli. (1892) 40 = parviflora, Sieb. \&. Zucc.

peloponmesiaca, Hort. ex Beissn. Handb. Nadelholzk. (1891) $441=$ Abies cephalonica, Link.

permixta X, G. Beck, in Verh. zool.-bot. Ges.

Wien, xxxviii. (1888) 766 ; et F1. Nied.-Oest. i. (1890) 6. - Austria.

Pserdopumila, G. Beck; Fl. Nied.-Oest. i. (1890) 5 $=$ montana, Mill

Wettsteinii $\times$, Fritsch, in Oest. Bot. Zeitschr. xxxix. (1889) 153; G. Beck, Fl. Nied.-Oest. i. 1890) 5. - Austria.

PIPER, Linn. (Piperac.). - Ind. Kew, ii. 534.

albescens C. DC. in Morot, fourn. de Bot. iv. (1890) 398. - N. Granat

Andreanum, C. DC. l.c.39\%. - N. Granat.

anisotis, Hook, f. Fl. Brit. Ind. v. (1886) 86. Reg. Himal.

Bangii, C. DC. in Bull. Torrey Bot. Club. xix. (1892) 354. - Bolivia.

Biolleyi, C. DC. ex Th. Dur. \& Pitt. in Bull. Soo Bot. Belg. xxx. (1891) 210. - Custa Rica

borucanum, C. DC. l. c. 219. - Costa Rica

calvirameum, C. DC. l. c. 200. - Costa Rica.

carrilloanum, C. DC. l. c: 209. - Costa Rica.

carizalanum, C. DC. in Morot, fourn. de Bot. iv.

(1890) 397. - Am. austr.

cascajalanum. C. DC. l. c. 398. - Ecuad.

chrysostachyum, C. DC. ex Th. Dur. Eo Piti. in Bull. Soc. Bot. Belg. xxx. (1891) 207. - Costa Rica.

cinerascens, C. DC. ex M. Micheli, in Mém. Soc. sci. phys. Genève, xxxii. (1893) n. 2, 7, t. 51 fig. 1-5. - Paraguay.

coilostachyum, C. DC. ex Th. Dur. E Pitt. in Bull. Soc. Bot. Belg. xxx. (1891) 212 . - Costa Rica.

corrugatum, Kuntze, Rev.Gen. (1891) 565. - Costa Rica.

daguanum, C. DC. in Bot. Fahrb. x. (1888). 288.Columb.

discophorum, C. DC. ex Th. Dur. E Pitt. in Bull. Soc. Bot. Belg. xxx. (1891):01. - Costa Rica

\section{PIPER}

Donnell-Smithii, C. DC in 7. D. Smith, Enmm, ti Guatem. ii. (1891) 95, nomen: et in Coult Bot. Gaz. xix. (1894) 239. - Guatem.

dryadum, C. DC. ex Th. Dur. E Pitt, in Bull. Soc. Bot. Belg. xxx. (1891) 221. - Costa Rica

emirnense, Baker, in fourn. Linn. Soc. xxii. (188i) 5l4. - Madag

fimbriulatum, C. DC . ex T\%, Dur Es Pitt in Bull Soc. Bot. Belg. xxx. (1891) 207. - Costa Rica flavidum, C. DC. in F. D. Smith. Enum. pl. Guatem. ii. (1891) 66, nomen; et in Coult. Bot. Gaz. xix. (1894) 258 - Guatem

fulvescens, C. DC. in Mém. Soc, sci. phys. Genére

xxxii. (1893) n. 2, 7 t. 53. - Paraguay.

Gaudichaudianum, Kunth, ex C. DC i c 6 .

Bras., Paraguay.

gibbosum, C. DC. ex Th. Dur. \& Pitt. in Bull. Sor

Bot. Belg. xxx. (1891) 212. -- Costa Rica.

Goudotii, C. DC. in Bot. Fahrb. x. (1888) 287, Columb.

guayranum, C. DC. in Morot, fourn. de Bot. iv (1890) 397. - Venezuela.

hainanense, Hemsl. in fourn. Linn. Sac. xxvi. (1891) 365. - China.

Hancei, Maxim. in Bull. Acad. Pétersb. xxxi. (1887) 94 (= Chavica leptostachya, Hance). China.

Heydei, C. DC. ex F. D. Smith, in Coult. Bot. Ga\%. xix. (1894) 6. - Guatem.

jaliscanum, S. Wats, in Proc. Am. Acad. xxvi. (1891) 145. - Mexic

leptonema, Hook. f. Fl. Brit. Ind, v. (1886) 91. As. trop.

longistylosum, C. DC. in Bull. Torray Bot. Club, xxi. (1894) 161. - Bolivia

Luxii, C, DC. ex F. D. Smith, in Conlt. Bot. Ga\%. xix. (1894) 5. - Guatem.

Maingayi, Hook. f. Fl. Brit. Ind. v. (1886) 80.Ind. or

mapirense, C. DC. in Bull. Torrey Bot. Club, xix. (1892) 47. - Bolivia

Mestoni, F. M. Bailey, Rep. Exped.Bellenden-Ker (1889) 54, - Austral.

Molleri, C. DC. in Bolet. Soc. Brot. x. (1892) 153. - Ins. S. Thom.

mollicomum, Kunth, ex C. DC, in Mém. Soc. sci. phys. Genève, xxxii. (1893) n. II, 7. - Am. trop. nemorense, C. DC. 2x Th. Dur. \& Pitt. in Bull Soc. Bot. Belg. xxx. (1891) 222. - Costa Rica neurostachyum, C. DC. l. c. 213. - Costa Rica, novo-guineense, Warb. in Bot. Fahrb. xiij. (1891) 284 . - N, Guin

nudibracteatum, C. DC. l. c. x. (1888) 288.Columb.

nudifolium, C. DC. ex Th. Dur. Eo Pitt. in Bull

Soc. Bot. Belg. xxx. (1891) 205. - Costa Rica.

otophorum, C. DC. l. c. 220. - Costa Rica.

oxyphyllum, C. DC. in Bull. Torrey Bot. Chb, xix. (1892) 48. - Bolivia.

pachyphyllum, Hook. f. Fl. Brit. Ind. v. (IS86) 80. - Malacca.

peltaphyllum, C, DC. ex Th. Dur. E P itt. in Bull. Soc. Bot. Belg, xxx. (1891) 220. - Costa Rica. pendulum, Warb. in Bot. Fahrb. xiii. (1891) 283. - N. Guin

petiolatum, Hook. f. Fl. Brit. Ind. v. (1886) 84.Reg. Himal.

pitanum, C. DC. in Morot, fourn. de Bot.iv. (1890) 397. - N. Granat.

Pittieri, C. DC. ex Th. Dur. \& Pitt. in Bull. Soc Bot. Belg. xxix. 2 (1890) 69 ; et xxx. (1891) 204 - Costa Rica.

poasanum, C. DC. l. c. 206. - Costa Rica.

Postelsianum, Maxim. in Bull. Acad. Pétersb. xxxi. (1887) 93. - China, Ins. Iiukiu.

Pseudo-sylvaticum, C. DC. in Bolet, Soc. Brot. x. (1892) 153. - Ins. S. Thom.

psilocladum, C. DC. ex Th. Dur. \& Pitt. in Bull. Soc. Bot. Belg. xxx. (1891) 211, - Costa Rica. psilophyllum, C. DC. in Bull. Torrey Bot. Clut, xix. (1892) 47. - Bolivia.

quinquenervium, Warb. in Bot. Fahrb. xiii. (1891)

$284 .-N$. Guin.
rubronodosum, Nichols. Dict. Gard. iii. (1886) 148 . - N. Granat. 


\section{PIPER :}

rubro-venosum, Hort. ex Rodigas, in Illustr. Hortic. xxxiv. (1887) 91, t. 33 : ct ex Gurd. Chron. (1888) ii. 328 - N. Guin.

Rueckeri $K$ Schum, in $K$. Schum, \& Hollr. Fl. Kais. Wilh, Land (1889) 36. - N. Guin.

rufescens, C. DC. ox Th. Dur. \& Pitt. in Bull. Soc. Bot. Belg. xxx. (1891) 218. - Costa Rica.

Rusbyi, C. DC. in Bull. Torrey Bot. Club, xix. (1892) 47. - Bolivia.

thytidocarpum, Hook. f. Fl. Brit. Ind. v. (1886) 92. - Reg. Himal.

salinasanum, C. DC. ex Th. Duv. \& Pitt. in Bull. Soc. Bot. Bclg. xxx. (18\%1) 214. - Costa Rica. santa-rosanum. C. DC. in 7. D. Smith, Enum. pl. Guaten. ii. (1891) 96, nomen; et in Coult. Bot. Ga\% xix (1894) 258, - Guatem.

savanense, C. DC. in Bot. Fahrb. x. (18S8) 286. Columb.

Schmidtii, Hook. f. Fl. Bvit. Ind. v. (1886; 89. Reg. Himal.

sclerocladum, C, DC, in Bot. Falirb. xix. (1894) 224. - Afr. trop. occ.

sepicola, C. DC ex Th. Dur. \& Pitt. in Bull. Soc. Bot. Belg. xxx. (1891) 202. - Costa Rica.

sublineatum, Kuntre, Re\%. Gen. (1891) 565. Costa Rica.

subsessilifolium, $C$ DC. Cx Th Dur. \&o Pitt. in Bull. Soc. Bot. Belg. xxx. (1891) 216. - Costa Rica.

tablazosense, C. DC. in Bot. Fahrb. x. (1888) 288 - Costa Rica.

terrabanum, C. DC, ex Th. Dur. \& Pitt, in Bull. Soc. Bol. Belg. xzx. (1891) 217. - Costa Rica.

Thomsoni, Hook. f. Fl. Brit. Ind. v. (1886) 87 . Reg. Himal.

Tuerckheimii, C. DC. in F. D. Snith, Enum. pl. Guatem. ii. (1891) 96, nomen; et in Coult. Bot. Gaz, xix. (1894) 258. - Guatem.

umbricola $C$. DC ex Th Dur, \& Pitt, in Bull.

Soc. Bot. Belg. xxx. (1891) 215. - Costa Rica

uspantanense, C. DC. ex F. D. Smith, in Coult. Bot. Ga\%.xix. (1894) 6. - Guatem.

vallicolum, C. DC. ex Th. Dur. Es Pilt. in Bull. Soc. Bot, Belg, xxx. (1891) 222. - Costa Rica. variabile, C. DC, in 7. D. Snirh, Enum.pl. Guaten. ii. (1891) 66, nomen; et in Coult. Bot. Ga\%. xix. (1894) 259. - Guatem.

Volkensii, C. DC. in Bot. Fahrb. xix. (1894) 225 - Afr. trop. or.

yzabalanum, C. DC. ex F. D. Smith, in Coult. Lot. Ga\%.xix. (1894) 7. - Guatem.

PIPTADENIA, Benth. (Legumin.). - Ind. Kew ii. 542 .

Buchanani, Baker, in Kew Bull. (1894) 354. Afr. trop.

leptoclada, Baker, in fourn. Linn. Soc.xxii. (1887) 467. - Madas.

novo-guineensis, Warb. ex Taub. in Engl. E Prantl Natiin. Pfanzenfan. iii. 3 (1892) 122.- N. Guin. Schumanniana, Taub. in Flora, lxxy. (1892) 75. Bras.

Schweinfurthii, Vatke, ex Enol. in Abh. Preuss. Akad. Wiss. (1894) 44; et in Encl. Pflanzenw. Ost-Afr. A (1895) $82=$ P. Buchanani, Baker.

PIPTANTHUS. Sweet (Legumin.), - Ind. Kew. ii. 542 .

tomentosus, Franch. in Rev. Hortic. lix. (1887) 474; et Pl. Delav. (1890) 150. - China.

PIPTOCALYX, Torr. = Krynitzkia, Fisch. \& Mey. (Borag.).

dichotomus, Greene, Pittonia, i. (July ISS7) $60=$ K. dichotoma, Greene.

PIPTOGARPHA, R. Br. (Compos.). - Ind Kew. ii. 543 .

costaricensis, Klatt, ex Th. Dur. Eo Pitt. in Bull. Soc. Bot. Belg. xxxi. 1892 (1893) 184. - Costa Rica.

Leubnitziae, Kuntze, in falurb. Bot. Gart. Berl. iv. (1856) 265. - Afr. austromocc. extratrop.

sexangularis. Klatt, Beibl. zun Leopoldina (1895) extr. 1 - Costa Rica.
PIPTOMERIS, Turcz. = Jacksonia, R. Br. (Lesumin.)

alata, angulata, capitata, carduacea, Clarkei, compressa, cupulifera, densiflora, floribunda, foliosa, Forrestii, furcellata, hakeoides, horrida, Lehmanni, ncmatoclada, odontoclada. pteroclada racemosa, ramosissima, restioides, rhadinclada, rhadinoclona, scoparia, sericea, spinosa. Stackhousei, Sternbergima, stricte, thesioides, umbellata, relutina, vernicosa, Greene. in Erythea, i. (1893) 114-15 = homonyma omnia Jacksoniae.

dilatata, Greens, 1. c. 114 [sphalm. dilalata] $=\mathrm{J}$. dilatata, Benth.

purpurascens, Greene, 1. c. 115 [sphalm. purpurascens] $=\mathrm{J}$. purpuascens, F. Muell.

PIPTOSPATHA, N. E. Br. (Aroid.). - Ind. Kew. ii. 543 .

Ridleyi. N. E. Br. ex Hook. f. in Bot. Mag. (1894) t. 7410 . - Penins. Mal.

PIPTOTHRIX, A. Gray, in Proc. Am. Acad. xxi. (1886) 383. COMPOSITAE.

Palmeri, A. Gray, l.c.-Mexic.

pubens, A. Gray, l. c. - Mexic.

PIPTURUS, Wedd, (Urtic.). - Ind. Kew. ii 54:).

melastomatifolius, K. Schum. in K. Schnm. Er Hollr Fl. Kais, Wilh, Land (1889) 3\%. - N. Guin.

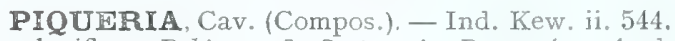
laxiflora, Robinson \& Seaton, in Proc. Am. Acad. xxviii. (1893) 107. - Mexic.

Pringlei, Robinson E Seaton. l. c. - Mexic,

PIRARDA, Adans. = Ethulia, Linn. (Compos.). conyzodes, Kuntze, Rev. Gen. (1891) $355=$ E conyzoides, Limn.

megacephala, Kuntze. 1. c. = E. conyzoides, Linn.

PIRATINERA, Aubl. = Brosimum, Sw. (Urtic.). spuria, Baill. ex Laness. P1. util, Colon Franç. (1886) $452=$ B. spurium, Sw.

PIREA, Th. Dur. Ind. Gen. Phan. (1888) 494; Prantl, in Engl, \& Prantl, Natiirl. Pflanzenfam. iii. 2 (1891) 183. CRUCIFERAE.

Olgae, Th. Dur. ex Prantl, l. c. $(=$ Dictyosperma Olgae, Regel). - As. centr.

PIRIQUETA, Aubl. (Turner.), - Ind. Kew. ii.

544. Urban. in Bot. Falkrb. xv. (1893) 629,

PIRONNEAVA, Gaudich. = Aechmea. Ruiz \& Pav. (Bromel.)

floribunda, Wittm. in Bot. Jahrb. xii. Beibl. n. 29 (1891) $14=$ A. floribunda, Mart.

Morongii, Rolfe, ex Morong \& Britton, in Ann. N. Y. Acad. sci. vii. (1893) I15. - Parag.

PISGIDIA, Linn. (Legumin.). - Ind. Kew. ii. 544.

mollis, 7. N. Rose, in Contrib, U. S. Nat. Herb. i. (1891) 98. - Mexic

Piscipula, Sarg. in Gard. and For. iv. (1891) 436 $=$ H. Erythrina, Limn

PISONIA. Plum. ex Linn. (Nyctag.). - Ind. Kew. ii. 544. Heimerl, ex Warm. in Vidensk. Meddel. Naturh. Foren. (1890) 159 (Symö. Fl. Bras, centr. xxxy, 960). - Bras.

artensis, Montrouzier, [ubi ?] ex Heimerl, in Engl. \& Prantl, Natïrl. Pfanzenfan, iii. 1b (1889) 29. - Ins. Art.

grandifolia, Warb. in Bot. Fahrb. xiii. (1891) 303. - N. Guin.

macranthocarpa, f. D. Snith, in Coult. Bot. Gaz. xx. (1S95) 293. - Guatem.

membranacea, $K$. Schnm, in K. Schum, \& Hollr. Fr. Kais. Will. Land (1889) 43. - N, Guin. Muelleriana, Warb. in Bot. Fahrb. xiii. (1891) 204. - N. Guin.

rostrata Warb. l.c. - N. Guin.

\section{PISONIA :}

platystemon. Heimerl, ex Warm. in Vidensk. Mcddel. Naturh. Foren. (1890) 161 (Symb. Fl. Bras. centr. xxxv, 962), - Bras.

Riedeliana Fischer, ex Wirera, ll. cc. (1891) 162 ; et 963 - Bras.

sandwicensis, Hillebr. Fl. Haw. Isl. (18S8) 369.Ins. Sandvic

Warmingii, Heimerl, ex Warm. in Vidensk. Meddel. Naturh. Foren (1890) 162 (Symb. Fl. Bras, centr. xxxy. 963). - Bras.

PISTAGIA, Linn. (Anacard.). - Ind. Kew. ii. 545 coccinea, Collett \& Hennsl. in fourn. Linn. Soc xxviii. (1s90) 36. - Burma.

falcata, Becc. ex Martelli. Fl. Bogos. (1886) 24. Abyss.

weinmannifolia, Poiss. ex Franch. in Bull. Soc. Bot. Fr. xxxiii. (1886) 467. - Yunnan.

PITCAIRNIA, L'Hérit. (Bromel.). - Ind. Kew.

alborubra, Baker, Handb. Bromel. (1889) 102. - N. Granat.

Altensteinii $\times$, Hort. ex Baker, 1, c. 111. - Hybr. artef.

amazonica, Baker, l.c. 117. - Bras.

anthericoides, Mez, in Mart. Fl. Bras, iii. III. (1894) 441. - Bras.

arcuata, Ed. André, in Rev. Hortic. lx. (1888) 565; Baker, Handb. Bromel. (1889) 111. - N. Granat.

armata. Maury, in Morot, Fourn, de Bot. iii. (188?) 270 fig. 13. - Am. austr.

brachysperma, Ed. André, in Rev. Hortic. 1x. (1S8S 564 : et 1xi. (1889) 22 t. 8; Baker, Handb. Bromel. (1889) 105. - Columb.

brachystachya, Baker, l. c. 105. - Am. trop.

Brongniartiana, Ed. André, in Rev'. Hortic. lx. (1888) 565 ; et 1xi. (1889) 28 t. 9 d. ; Baker, l. c. 110. - Columbia.

Burchelli, Mez, in Fl. Bras, iii. III. (1894) 436. Bras.

Caldasiana, Baker, Handb. Bromel. (1889) 100. Bras.

camptocalyx. Éd. André, in Rev. Hortic. 1x. (1888) 564 ; et lxi. (1889) 19 t. 8c; Baker, l. c. 96. Columbia.

canaliculata, Baker, l. c. 99 - Bras.

caracasana, Baker, l. c. 103. - Venezuela.

carinata, Mez, in Mart. Fl. Bras. iii. III. (1894) 448. - Bras.

Carioana, Wittn , in Bot, fahrb. xiv. Beibl, n, 32 (1891) 4. - Guatem

Claussenii, Mez, in Mart. Fl. Bras, iii. III. (I894) 454. - Bras

corallina X. Hort. ex Baker, Handh. Bromel. (1889) 111. - Hybr. artef.

Darblayana Sallier, in Le Jardin (18S8) 201; et ex Rev. Hortic, 1xii. (1890) 33 fig. 10. - Hybr. artef.

dendroidea, Éd. André, in Rev. Hovtic. 1x. (1888) 564 ; et 1xi. (1889) 26 t. 9a: Baker, Handb. Bromel. (1889) 104. - Columb.

Devansayana, Ed. André, Bromel. Andrean. (Is89) 25 t. $8 \mathrm{~g} ;$ Baker, l. c. $93 .-$ Ecuad.

Dietrichiana, Wittm. in Bot. Falwo. xiii Beibl. n. 29 (1891) 15 . - Bras.

dykioides, Baker, Handb. Bromel. (1889) 118. Bolivia.

echinotricha, Baker, ex Ed. André, Bronel. Andrean. (1889) 33, in syn.; Baker l. c. 119 (= Puya echinotricha, Éd. André). - Ecuad.

ensifolia, Mez, in Mart. Fl. Bras, iii. IIr. (1894) 436 Bras.

Glaziovii, Baker, Handb. Bromel. (1889) 92. - Bras.

Goudotiana, Ed. André, in Rev. Hortic, 1x. (18S8) 564; et 1xi. (1889) 27 t. 9e; Baker, l. c. 108.Columb.

graminifolia, Hort. ex Baker, 1. c. = integrifolia Ker.

Gravisiana, Wittm. in Bot. fahrb.xl. (1889) 56 ; Baker, l.c. 114. - Columb.

Guaritermae, Ed. André, in Rev. Hortic. 1x. (1888) 564 ; et 1x1. (18s9) 23, t. S f. ; Baker, l. c. 112 . Columb.

guyanensis, Baker, l. c. 120. - Guian. ang1. 
PITCAIRNIA :

hypoleuca, Mez, in Mart. Fl. Bras, iii. IIr. (1894) 438. - Bras.

incarnata, Baker, Handb. Bromel. (1889) 116. Guian. gall.

intermedia, Hort. ex Baker, 1. c. 94, in syn. = alta, Hassk.

jaliscana. S. Wats. in Proc. An. Acad. xxii. (1887) 456 ; et in Gard. and For, i. (1888) 195. Mexic.

Klotzschiana, Baker, Handb. Bromel. (1889) 106. Venezuela.

Lamarchiana, Ed. Morr. ex Baker, l. c. 11l.Am. trop.

lancifolia, Mez, in Mart. Fl. Bras. iii. III. (189t) 447. - Bras

laxissima, Baker. Handb. Bromel. (1889) 101. Ecuad.

leiolema. Hort. ex Baker, 1. c. 96, in syn. = muscosa, Mast.

Leprieurii, Baker. .. c. 117.-Guian. gall

L'Herminieri, Hort. ex Baker, 1. c. 185, in syn. = fulcens, Decne.

Lindeni, Baker, l. c. 112 - - Hab.

longicauda, Hornem, ex Mez, in Mart. Fl. Bras, iii. III. (1894) 445. - Bras.

lutea, Hort. Linden, ex Baker, Handb. Bromel. (1889) 104. - Hab.

macranthera, Ed. Andvé, in Rev. Hortic. 1x. (1888) 565 ; et Bromel. Andreanae (1889) 29, t. 9 f. Baker, Handb. Bromel. (1SS9) 110. - Columbia.

macrobotrya, Ed. André, ll. cc. 564 ; et 24, t. $9 \mathrm{c}$ Baker, l. c. 104. - Columbia.

megastachya, Baker, l. c. 120 (= Puya Roezli, Éd. Morr.). - Peruvia.

membranifolia, Baker, l. c. 109. - Costa Rica.

nigra, Éd. André, in Rez'. Hortic. 1x. (1888) 565 ; et Bromel. Andreanae (1889) 30 ; Baker, l. c. 113. Columbia, Ecuad

odontopoda, Baker, l. c. 93. - Peruvia.

Palmeri, S. Wats. in Proc. Am. Acad. xxii. (1887) 456 ; et in Gard. and For, i. (1888) 209 et 211 flg. 38. - Mexic. pastoensis, Baker, Handb. Bromel. (1889) 122. -
Columb.

Pearcei, Baker. l. c. 120. - Peruvia.

Philippii, Baker, l. c. 122 (= Puya paniculata Phil.). - Chili.

platypetala, Mez, in Mart. Fl. Bras. iii. III. (1894) 438 - Bras.

Plumieri, Baker, Handb. Bromel. (1889) 107 (= Brocchinia Plumieri, Griseb.). - Ins. Domin.

Poeppigiana, Mez, in Mart. Fl. Bras, iii. III. (1894) 461. - Peruvia.

polyanthoides, Brongn. ex Baker, Handb. Bromel. (1889) $110=$ recurvata, $K$. Koch.

Poortmanni, Éd. André, in Rev. Hortic, 1x. (1888) 564 ; et Bromel. Andreanae (1889) 26, t. 9 b; Baker, l. c. 103. - Columb.

pruinosa, Mez, in Mart. Fl. Bras, iii. III. (1894) 454. - Bras.

puberula, Mez. \& F. D. Smith, in Coult. Bot. Gaz. xix. (1894) 264. - Guatem.

quetamensis, Baker, Handb. Bromel. (1889) 121 (= Puya quetamensis, Ed. André). - N. Granat.

reflexiflora, Ed. André, in Rev. Hortic. 1x. (1888) 564 ; et Bromel. Andreanae (1889) 18 t. 8 b ; Baker, l. c. 105. - Ecuad., Venezuela.

Roezlii, Éd. André, in Rev. Hortic. Ix. (1888) 564 = Devansayana, Éd. André.

rubiginosa, Baker, Handb. Bromel. (1889) 116. Guian. gall.

Rusbyi, Baker, l. c. 122. - Bolivia.

Sanctae-crucis, Baker, i. c. 120. - Bolivia.

Schiedeana, Bakır, l. c. 95. - Mexic.

Schlimii, Baker, l. c. 100. - Venezuela

Selloana, Baker, l. c. - Bras.

semijuncta, Baker, l. c. 117.- Guian, gall

Shimneri, Hort. ex Baker, 1. c. 94, in syn. = alta Hassk.

speciosissima, Hort. ex Baker, 1. c. 114. in syn. = undulata, Scheidw.

sphaerocephala, Baker. l. c. 123. - Chili.

spinosa. Gillies, ex Baker, 1. c. 136, in syn. = Dyckia Gilliesii, Baker.

\section{PITCAIRNA}

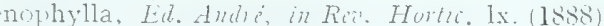
564: et Bromel Andreanae (1889) 2l, t. 8 d Baker, l. c. 95 . - Columbia.

stenothyrsa, Baker. l. c. 122, - Bolivia.

stricta, Ed. André, Bromel. Andreanae, 1889) 31 Baker, l. c. 107. - Columbia.

sulphurea, Ed. André, in Rev. Hortic, 1x. (isss) 565 ; et . . c. - Columb.

tarapotensis, Baker, Handb. Bromel. (1889) 102. Peruvia.

Trianae, Ed. Andri, in Rer. Hortic. Ix. (1888) 564 et Bromel. Andreanae (1889) 17. t. 8 a ; Baker,. 108. - Columbia.

Turckheimii, F. D. Smith, in Conlt, Bot. Gaz, xii . (1S88) 190 et 300 t. 24 ; Baker. l. c. 97. - Guatem a aupensis Baker, l. c. 93. - Bras.

venusta, Baker, l. c. 123 (= Puya Eenusta, Phil.).Chili.

Weddelliana, Buker, l. c. 122. - Bolivia.

PITHEGOCTENIUM, Mart. (Bignon.). - Ind. Kew ii $\overline{2} \%$.

Carolinae, Nichols. Dict. Gard. iii. (1886) 152. $\mathrm{Hab}$.

echinatum, K. Schum. in Engl. \& Prantl, Natürl. Pfanzenfam.iv.3b (1894)218 = P. Aubletri, Splitg.

Glaziovii, Bureau, ex K. Schum. l. c. - Bras.

PITHEGOLOBIUM, Mart. (Legumin.). - Ind. Kew, ii. J47.
cle, Vidal, Revis. Pl. Vasc. Filip. (1886) $121=$ Mimosa Acle, Blanco.

Balansae, Oliqer, in Hook. Icon. pl. xx. (1891) t. 1976. - Tonkin.

flexicaule, Coult, in Contrib. U. S. Nat. Herb, ii (1891) 101. - Texas.

flexicaule, Coult. l. c. - Texas.

kubaryanum, Warb. in Bot. Fahrb. xiii. (1891) 335. - N. Guin

insigne, M. Micheli. ex 7. D. Snith, in Coult. Bot, Ga\%, xx. (1895) 283. - Am. centr.

laxiflorum, Rusby, in Mem. Torrey Bot. Club, iii. (1893) 24. - Bolivia

Lovellae. F. M. Builey, in Dept. Agric. Brisbane Bot. Bull. viii. (189:3) 74. - Austral.

mexicanum, f. N. Rose, in Contrib. U. S. Nat. Herb. i. (1891) 100. - Mexic.

Sonorae, S. Wats. in Proc. Am. Acad. xxiv. (1889) 49. - Mexic

Stuhlmannii, Taub. in Engl. Pfanzenw. Ost-Afr. C 1895) 193. - Afr. or

texense, Coult. in Contrib.U. S. Nat. Herb. i. (1890) 37. - Texas

PITTIERA, Cogn, ex Th. Dur. \& Pitt. in Bull Soc. Bot. Belg. xxx. 1891 (1892) 271 ; Muell. \& Pax, in Engl, \& Prantl, Natürl. Pflanzenfam. iv. 5 (1894) 393, in add. CUCURBITACEAE.

longipedunculata, Cogn. ll. cc. - Costa Rica.

rilobata, Cogn. ex 7. D. Smith, iu Coult. Bot. Gaz. xx. (1895) 239. - Guatem.

PITTOSPORUMI, Banks (Pittospor.). - Ind. Kew. ii. 528

bicrurium, Th. Dur. Es Schinz, in Nowv. Mém. Acad Belg. liii. (1896) 65. - Congo.

capitatum, Baker, in fourn. Linn. Soc. xxv. (1889) 294. - Madag.

Fairchildi, Cheesem, in Trans. N. Z. Inst. xx. $188^{\circ}$ (1888) $147,-$ N. Zel

glomeratum, Hillebr. Fl. Haw, Isl. (1888) 23. Ins. Sándvic.

Galai, K. Schum. in K. Schun. \& Hollr. Fl. Kais. Wilh. Land (1889) 71. - N. Guin.

hawaiiense, Hillebr, l.c. 26. - Ins. Sandvic

heterophyllum, Franch, in Bull. Soc. Bot. Fr. xxxiii. (1886) 415. - China occ.

Humblotianum, Baill. Hist. pl. Madag., Atlas 1889) t. 112. - Madag.

insigne, Hillebr. Fl. How. Isl. (1888) 26 - Ins. Sandvic

kauaiense, Hillebr, l. c. 25. - Ins. Sandvic

lanceolatum Cordem. Fl. Ile Rémion (1895) 419 (= Senacia lanceolata, Lam.). - Ins. Borbon.

pachyphyllum, Baker, in fourn. Linn. Soc, xxii (1887) 444. - Madag.

\section{PITTOSPORUM}

Pervillei. Baill. Hist. pl. Madag., Atlas (1889)

t. 111. - Mada

quinquevalvatum. Warb. in Bot. fahrb. xiii. (1891) 20. - N. Guin

Phiferum, Honnsh, in Kere Bull. (1894) 344. - Ins. Philipp.

vernicosum, Baker, in fourn. Linn. Soc xxii. (1887) 445. - Madas.

Wingii. F. Muell. in South. Sci. Rec. (March 1885), ex F. M. Bailey, Syn. Queens?. Fl. Supp1. i. (IS86) 4. - Austral.

yunnanense, Franch, inz Buill Soc Bot. Fr. xxxiii. (1886) 415. - - China oce.

PITURAN'THOS, Viv. (Umbeli.). --. Ind. Kew. Korollsowi, Schinz in Bunt. Htorb. Bo ii. $(1894)$ 211 (= Deierra Korolkowi, Rerel \& Schmalh.). Turkest.

Rohlfsianus, Schinz. l. c. 209 et 210. - Atr. bor. tortuosus, Benth. \& Hook. f. ex Aschers. \& Schweinf. in Mim. Inst. igypt. [Illusty Fl. Egypt.] ii. (188\%) $80(=$ Deverra tortuosa, DC. $)$. - Aegypt.

triradiatus, Aschers. \& Schweinf. l. $i=D$, trira diata. Hochst.). - Arabia.

PITYROPHYLLUM, Beer $=$ Tillandsia, Linn (Bromel.)

Andreanum, Ed. Morr. ex Éd. André, in Rev. Hortic. 1x. (1888) 567, in syn. = Tillandsia Andréana, Ed. Morr.

PLAGOdiscus, Radlk. (Sapind.). - Ind. Kew.

pseudostipularis, Radlk, in Sitz. Akad. Muench. xx, (1890) 242. - Afr. trop. occ.

tristis, Colenso, in Trans. N. Z Inst xviii 1885 (1886) $271 .-$ N. Zel.

PLACUS, Lour = Blumea. DC. (Compos.) angustifolius, balsamifer, barbatus, Belangerianus, bifoliatus, chinensis, crinitus, Alexuosus, gaviepinus glomeratus, hieracifolius, facquemontii, Kingii, lacerus, laciniatus, macrophyllus, malabaricus, membranaceus, natalensis, neilgherensis, nodifloris, obovatus, oxyodontus, procerus, sericans, sikkimensis, subcapitatus, timorensis, vimineus, wirens. Kuntze. Rev. Gen. (1891) 356-57 = homonyma omnia Blumeae.

acrocephalus, Kuntze, 1. c. = Conyza acrocephala, Miq.

acutatus, Kuntze, 1. c. = Blumea laciniata, DC

Bovei, Kuntze, 1. c. = B. abyssinica. Sch. Bip.

Clarkei, Kuntze, 1. $\mathrm{C}=\mathrm{B}$, elonorata, $D C$

foresiana, Kuntze, 1. c. = Conyza floresiana, Sch. Bip.

humifusa, Kuntze, 1. c. = C. humifusa, Miq. annginosus, Kuntze, 1. c.= Blumea NIalcolmii, Hook.f

Milnei, Kuntze, 1. c, = B. densiflora, DC mollis, Kuntze, 1, c. = B. Wiohtiana, $D C$. obliquus, Kuntze, 1. C. = B. amplectens, $D C$. subracemosa, Kuntze, 1, c. = Conyza subracemosa, Miq.

sumbavensis, Kuntze, 1. c. = C. sumbavensis, Miq. ternatensis, Kuntze, 1. c. = C. ternatensis, Miq.

Zollingeriana, Kuntze, 1. c. =C. Zollingeriana, Turcz.

PLAGIANTHUS, Forst. (Malv.). - Ind. Kew ii. 550 .

densiflorus, E. G. Baker, in foum. Bot. xxx. (1892) 72. - Austral.

Helmsii, F. Muell. \& Tate, Elder Exped. Diagn. Nero Pl. (1893) [1]; et in Bot. Centralbl. 1v. (1893) 316. - Austral.

PLAGIOBOTHRYS, Fisch, \& Mey. (Boragin.) califormicus, Greene in Bull, Calif. Acad. 11. (1887) 407 (= Echidiocarya califormica, A. Gray) = P. Cooperi, A. Gray.

californicus, Greene, Pittonia, ii. (May 1892) $231=$ campestris, Greene.

campestris, Greme, l. c. ii. iAug. 1892) 282: et Man. Bot. San Franc. Bay (1894) $260(=$ P. californicus, Greene, pr. p.). - Calif. 


\section{PLAGIOBOTHRYS}

(Feb. 1886) 21. -

Princlei, Grene, l, c. 21 (= Echidtocarya arizonica A. Gray). - Am bor. ocr.

PLAGIOCHEILUS. Arn. (Compos.). - Ind. Kew: ii. 551.

rectus, Rusby in MLon. Torrey Bot. Club, iv. (1895) 212. - Bolivia.

PLAGIOSPERMUM, Oliver, in Hook. Icon. pl. xvi. (IS86) t. 1526. CEI.ASTRINEAE.

sinense, Oliver, l.c.-China.

PLAGIOSPERMUM, Fierre, Fl. For, Cochinch. Fasc. 17 (1892) t. $260 a=$ Styrax, (Styrac.). Benzoin, Pierre, 1. c. = S. Benzoin, Dryand.

PLANCHONELLA, Pierre, Not. bot. Sapot. (1890) 35 = Sideroxylon, Linn. (Sapot.)

argentea, assamica, attonata, australis. bancana, borneensis, cambodiana, chrysophylla, costata, dongnaicnsis, elongioides, fermoinea, grandifolia, Hookeri, Howeana, indica, javensis, lanceolata, laurifolia, longgensis, maritima, nodosa. oborata, parvifolia, Cetitiana, sandwicensis, spathulata, tomentosa,

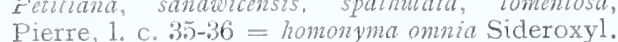
dictyoneura. Pierre, 1. c. $35 .-\mathrm{N}$. Caled. inguaformis, Pierre, 1. c. $36 .-\mathrm{N}$. Caled microphylla, Pierre, 1. c. - N. Caled.

oborata, Pierre, 1. c. $35=$ Sersalisia obovata, Benth.

Pancheri, Pierre, 1. c. - N. Caled.

Pavieana, Pierre, 1. c, 36. - Laos.

vividis, Pierre, 1. c. - N. Caled.

Wakeve, Pierre, 1, c. - N. Caled.

PLANERA, J. F. Gmel. (Urtic.). - Ind. Kew Keakei, “C. Koch » ex Dippel, Handb. Laubholzk, ii, (1892) $40=$ Zelkova acuminata Plinch

Verschaffelti, Hort. ex Dippel, 1. c. 589, ad calc. $=$ Z. japonica, Difpel

PLANTAGO, [Tourn.] Linn. (Plantag.)- - Ind. Kew. ii. 551 .

albida, Phil. in Anal. Univ, Chil. xci. (1895) 269 - Chili.

amphibola, Plit. l. c, 253. - - Chili.

angustitolia, Phil. l. c.258. - Chili

armerifolia. Phil. l. c. 263. - Chili.

Aschersonii, Bolle, in Bot. Fahrb. xiv. (1891) 251 - Ins. Canar.

atlantica, Batt, in Bull. Soc. Bot. Fr. xxxvi. (18s9) 224: et in Batt. E Trab. Fl. de l'Algér. [Dicot. (1890) 744. - Algeria.

Boissieri, Hunsskn. E Bormm. ex Bormm. in Mitth. Thiur. Bot. Ver. N. Folge, vi. (1894) 60.- Oriens.

brachyantha, Phil. in Anal. Unin. Chil. xci.(1895) 270. - Chili.

calbucana, Phit. l, c. 252, - Chili.

californica. Greene, Man, Bot. San Franc. Bay (1894) 236. - Calif

cantagullensis, A. Zahlbr. ex Wawra, Itin. Princ. Sax.-Coburg. ii. (1888) 56. - Bras.

collivubens, Miéger. in Bull. Soc. Bot. Fr. xxxviii. (1891) p. xxxy. - Pyren. gall.

dasyphylla, Colenso, in Trans. N.Z. Inst. xxiv. 1891 (1892) 393. - N. Zel.

disticha, Phil. in Anal. Univ. Chil. xci. (1895) 272 - Chili.

dolichophylla, Phil. l. c. 262. - Chili.

Fischeri, Engl. Bot. Falirb. xix. Beibl. n. 47 (1894)

48. - Afr. trop. or.

Glabriuscula, Phil. l. c. 288. - Chili.

uraeca, Halacsy, in Verh. zool.-bot. Ges. Wicn, xxxviii. (1888) 761. - Graecia.

heterophylla, Phil. in Anal. Univ. Chil. xci. (1895) 265. - Chili.

Julieti, Phil. l. c.262. - Chili.

laevigata, Phil. l. c. 260. - Chili,

lunarensis, Phil. l. c. 266. - Chili

macrosperma, Plit. l. c. 269. - Chili.

\section{PLANTAGO}

Monnieri, Giraudias, in Lucante, Rev, de Bot. iv. (1885-86) 287, in Bull. Soc, étud. sci. Angers $11890) 114$, nomen $=$ media. Lam.

Olizanka, Phil. in Anal. Univ. Chil. xci. (1895) 270 - Chili.

ovata, Phil.l. . 25l. - Chili

pachyrrhiza, Phil. l. c. 265. - Chili

pachystachys, Phil. l. c. 248. - Chili.

picta, Colenso, in Trans. N.Z. Inst, xxii. 1889 (1890) 481. - N. Zel.

Pugae. Phil. in Anal. Univ. Chit. xci. (1895) 250. - Chili.

reniformis, G. Beck, in Annal. Naturh. Hofmus.

Wien. ii. (1S87) 149. t. 2, fig. 1-2. - Bosnia.

rosulata. Batt. in Batt. \& Trab. Fl. de l'Algér.

[Dicot.] (1890) $74: 3=$ P. Coronopis, Limn.

sphacrostachya, A. Kern. Sched FI. Austro-Hung

iv. (1886) $7 \mathrm{i}=$ lanceolata, Limn. var.

stenopetaia, Phil. in Anal, Univ. Chil. xci. (1895) 271. - Chili.

uniflora, Phit. in Anal. Mus, nac. Chite (1891)71. Am. austr, occ.

Tweedyi, A. Gray, Syn. Fl. N. Am. ii. I. reprint (1886) 390. - Am. bor. occ

Vidal1, Phil. in Anal. Unio. Chil. xci. (1895) 264. - Chili.

PLASO, Adans = Butea, Koen. (Legumin.). monosperma, Kuntze, Rev. Gen.(1891) $202=$ B. frondosa, Roxb.

PLATANTHERA, Rich. = Habenaria, Willd. (Orchid.)

algeriensis, Batt. \& Trab. in Bull. Soc. Bot. Fr. xxxix. (1892) 75, xli. (1894) 516 t. 6; et Fl. de l'Algér. [Monoc.] (1895) 31. - Algeria.

arachnoidea, Engl. in Abh. Preuss. Akad. Wiss, 1891 (1892) 179 (= Peristylus arachnoideus, A Rich.). - Abyss.

Brachycorythis, Schlechter, in Bot. Jahrb. xx. Beibl. n. 50 (1895) $12=$ Brachycorythis pubescens Haw.

Bulbinella, Schlechter, 1. c. = Schizochilus Bulbinella, Bolns.

Gerrardi, Schlechter, 1. c. = S. Gerrardi, Bolus

Inspidula, Gilg, in Engl. Pflanzenw. Ost-Afr. 1895) 151 (= Peristylus hispidulus, Rendle). Air. trop.

unterrupta, Maxim. in Bull. Acad. Pétersb, xxxi, (1887) 106. - Ins. Kiusiu

Lefeburiana, Engl, in Abh. Preuss. Akad. Wiss, I89] [1892) 179 (= Peristylus Lefeburianus, A. Rich.). - Abyss.

Mac Owaniana, Schlechter, in Bot. Jahrb, xx. Beibl. n. 50 (I895) 12 = Brachycorythis Mac Owaniana, Reichb. $f$

matalensis. Schlechter, l.c. xx. Beibl. n. 50 (1890) $6=$ Hermininm natalense. Reichb. $f$

vata, Schlechter, 1. c. 12 = Brachycorythis ovata Lindl.

Petitiana. Engl. in Abh. Preuss. Akad. Wiss. 1891 (1892) 179 (= Peristylus Petitianus, A. Rich.). - Abyss.

Prenssii, Kraenzl. in Bot. Jahrb. xvii. (1893) 63. Kamerun.

Quartiniana, Engl, in Ab\%. Prenss. Akad. Wiss. 1891 (1892) $179(=P$. Quartinianus. A. Rich.).-Abyss. satyroides, "Reichb. ) ex Lipsky, in Act. Hort. Petrop. xiii. (1894) 338, in obs. sphalm. = satyrioides, Reicht

tenuior, Schlechter, in Bot. Jahrb. xx. Beibl. n. 50 (1895) 12 = Brachycorythis tenuior, Reichb. $f$

tricruvis, Hochst ex Kraenzl in Bot. Jahrb, xvi. (1893) $194=$ Habenaria tricruris, Reichb. f.

tridentata. Engl. in Abh. Preuss. Akad. Wiss. 1891 (1892) 179 (= Peristylus tridentatus, Hook. f.).Kamerun.

unalaschcensis, F. Kurtz, in Bot. Jahrb, xix, (1894) $40 \mathrm{~S}=$ Habenaria unalaschcensis, S. Wats.

ussuriensis, Maxim. in Bull. Acad. Pétorsb̆. xxxi. (1887) 107. - Mandshuria, Japon.

Volkensiana, Kraenzl. in Bot. Jahrb. xxii. (1895) 17. - Afr. trop. or.

Zeyheri, Schlechter, in Bot. Jahrb. xx. Beibl n. 50 (1895) $12=$ Schizochilus Zeyheri, Sond.
PLATANUS, [Tourn.]. Linn. (Platan.). - Ind. Kew, ii. 556

insularis. Kotschy, ex Koehne, Deutsche Dendrol. (1893) $206=$ orientalis, Limn.

pyramidalis. Bolle, ex Koehne, 1. c. = orientalis Linn.

pyramidalis, Hort. ex Dippel, Handb. Laubholzk. iii (1893) $279=$ occidentalis, Linn.

Sitifolia, "Spach, » ex Dippel, 1. c. 276 et 741 ad calc, $=$ orientalis, Linn.

PLATYCAPNOS, Bernh. = Fumaria, Linn. Echeandice. Pau, Not. Bot. Fl, Espan. ii. (1889) 6 et iv. (1891) (1893) 312. - Hisp.

PLATYGLINIS, Benth. (Orchid.). - Ind. Kew. ii. $55 \%$

corrugata, Ridl. ex Stapf, in Trans. Iim. Soc. Ser. II. iv. (1894) 233. - Borneo.

gracilis, Hook. f. Fl. Brit. Ind. v. (1890) 708; et in Hook. Icon. pl. xxi. (1880) t. 2016. - Perak.

Kingii, Hook. f. ll. cc. 708 et t. 2015. - Perak.

grandiflora, Ridl. ex Stapf, in Trans. Linn. Soo. Ser. II, iv. (1894) 233. - Borneo.

stachyodes, Ridl. ex Stapf, l. c. 234. - Borneo.

PLATYDESMA, H. Mann (Rutac.). - Ind. Kew, ii. 557 .

auriculaefolia, Hillebr. Fl. Haw. Isl. (1888) 72 (= Pelea auriculaefolia, A. Gray). - Ins. Sandvic. cornuta, Hillebr. l. c. - Ins. Sandvic.

rostrata, Hillebr. l. c. - Ins. Sandvic.

PLATYKELEBA, N. E, Br, in Kew Bull. Soc. (1895) 250. ASCLEPIADEAE.

insignis, N.E.Br.l. C. - Madag.

PLATYLEPIS, A. Juss. (Orchid.). - Ind. Kew ii. 557

angolensis, Th. Dur. \& Schinz. Consp. F1. Afr. v $1892(1895) 58=$ glandulosa, Reich6. $f$.

occulta, Cordem. Fl. Ile Réunion (1895) $261=$ goodyeroides. A. Rich.

PLATYLUMA, Baill. Hist. des p1. xi. (1892) $283=$ Sideroxylon, Linn. (Sapot.).

calophylloides, Baill. 1. c. 284. - Guian.

PLATYMISGIUM, Vog. (Legumin.). - Ind. Kew.ii. 558 .

cordatum, Tanb. in Flora, 1xxv. (1892) 84. - Bras. piliferum; Taub. $l$ c. 85 . - Bras.

PLATYMITIUM Warb, in Engl. Pflanzenw, Ost-Afi. C (1895) 279. BIXINEAE.

loranthifolium, Warb. . . c. t. 3. - Afr. trop. or.

PLATYPHOLIS, Maxim. in Bull. Acad. Pétersb. xxxi. $(1887), 88, O R O B A N C H E A E$.

Bonınsimae, Maxim. l. c. - Ins. Boninsima.

PLATYSTEMON, Benth. (Papav.). - Ind. Kew. ii. 558

crinitus, Greene, Pittonia, ii. (Nov. 1889) 13. Calif.

denticulatus, Greone, Fl. Francisc. (1891) $283(=$ Meconella denticulata, Greene). - Calif.

linearis, M. K. Curran, in Proc. Calif. Acad. Ser. II. i. (1888) 242 ; et Man. Bot. San. Franc. Bay (1894) 10 = Platystigma linearis, Benth.

oreganus, M. K. Curran, l. c. = Platystigma oreganum, Benth. et Hook. f.

Torreyi. Greene, F1. Francisc. (1891) 283; et Man. Bot. San Franc. Bay (1894) 10 = Platystigma californicum. Boland.

PLATYSTIGMA, Benth. (Papav.). - Ind, Kew. 11. 558 .

denticulatum, Greene, in Bull. Torrey Bot. Club, xiii. $(1886)$ 218 = Platystemon denticulatum, Greene. 
PLATystoma, Benth. \& Hook. f. = Platostoma, Beauv. (Labiat.)

Buettnerianum, Briq. in Bot. Jahrb. xix. (1894)

166. - Congo occ

flaccidum, Briq. 1. c. 165. - Afr. trop.

PLATYSTYLIS, Lindl. = Liparis. Rich. (Orchid.).

alata, Blume, ex Ridl. in Journ. Linn. Soc. xxii. (1886) $291=\mathrm{L}$. decumbens, Reivhb. $f$.

PLEcospermuM, Tréc. (Urtic.). - Ind. Kew, ii. 559

andamanicum, King, ex Hook, f. Fl. Brit. Ind. (1888) 491. - Tenass, Ins. Andam.

laurifolium, Baill. Hist. pl. Madag., Atlas (1894) t. 294a. - Madag.

PLEGTANeiA, Thou. (Apocyn.), - Ind. Kew. ii. 559.

Hildebrandtii, K. Schumn. in Engl. \& Prantl, Na tiirl. Pflanzenfam. iv. 2 (1895) 144. - Madag.

Pervillei, K. Schum, l. c. - Madag.

PLECTOCOMiA, Mart. (Palm.). - Ind. Kew, ii. 5.59

Griffithii, Becc. in Hook, fo Fl. Brit. Ind. vi. (1893) 478. - Malacca.

maxima, Kuntze, Rev. Gen. (1891) $734=$ elongata, Mart. \& Blume.

montana, Hook. f. \& Thoms, ex Honk, f. Fl. Brit Ind. vi. (1893) 478, in syn. = himalayana, Griff.

PleECTOCOMIOPSIS, Becc in Hook. f. Fl. Brit. Ind. vi. (1893) 479. PALMAE.

geminiflorus, Becc. in Hook. f. l co $(=$ Calamus geminiflorus, Griff.). - Penins. Mal.

paradoxus, Beco. in Hook. f. l. c. 488 (= C. paradoxus, Kurz). - Martab.

Wrayi, Becc. in Hook. f. l. c. - Perak

PLEGTRANTHUS, L'Hérit. (Labiat.). - Ind. Kew. ii. 559.

albidus, Baker, in fourn. Linn. Soc. xxv. (1890) 341. - Madeg.

albus, Guerke, in Bot. Fahrb. xix. (1894) 202.Afr, trop. or.

betonicaefolius, Baker, in Kew Bull. (1895) 72. Afr. trop.

Brandisii, Prain, in fourn. As. Soc. Beng. lix. (1890) II. 296. - Burma.

Burnati, Briq. in Bull. Herb. Boiss. ii. (1894) 124. - Madag.

cardiaphyllus, Homsl, in foum, Linn. Soc, xxvi. (1890) 269. - China.

carnosifolius, Hemsl. l.c, 270. - China.

crenatus, Guerke, in Bot. Fahrb. xix. (1894) 208. Afr. trop. or.

cyaneus, Guerke, in Abh. Preuss. Akad. Wiss. (1894) 37 et $65 ;$; et l. $c$. - Afr. trop. or.

densus, N. E. Br. in Kew Bull. (1894) 12. - Afr. trop. or.

elegans, Britten, in Trans. Lmn. Soc. Ser. II. iv, (1894) 36. - Afr. trop.

Emini, Guerke, in Bot. Fahrb. xix. (1894) 207. Afr. trop. or.

esculentus, N. E. Br. in Kew Bull. (1894) 12.Natal.

Fischeri, Guerke, in Bot. Fahrb. xix. (1894) 200. Afr. tiop. or.

flaccidus, Guerke, in Abh. Prenss. Akad. Wiss. (1894) 18 ; et l. c. 206 (= Coleus flaccidus, Vatke). - Afr. trop.

floribundus, N. E. Br. in Kew Bull. (1894) 12. Natal.

Henryi. Hemsl. in foum. Linn. Soc. xxvi. (1890) 271. - China.

herbaceus, Briq. in Bot. Fahrb. xix. (1894) 179. Angola.

hereroensis, Engl. l. c. x. (1888) 267. - Afr. austroocc. extratrop.

Holstii, Guerke, ex Engl. in Abh. Preuss. Akad. Wiss. (1894) 62 ; et l. c. xix. (1894) 204. - Afr. trop. or.

hoslundioides, S. Elliot, in fourn. Linn. Soc. xxix. (1891) 44. - Madag.

\section{PLECTRANTHUS}

hylophilus, Gur ke. in Bot. Fahrb. xix. (1894) 283. Kamerun.

kamerunensis, Guerke, l.c. 202. - Kamerun.

Kurzii, Prain, in Fourn. As. Soc. Beng. lix. (1890)

II. 一 Sikkim.

Malinvaldi, Briq. in Bull. Herb. Boiss, ii. (1894) 125. - Abyss.

melanocarpus, Guerke, in Bot. Fahrb. xix. (1894) 210. - Afr. trop. or

minimus, Guerke, l. c. 205. - Afr. trop. occ.

miserabilis, Briq. l. c. 180. - Conoo.

modestus, Baker, in Kew Bull. (1895) 72. - Afr. trop.

monticola, Guerke, in Engl. Pfanzenw. Ost-Afr. A (1895) 130 , nomen. - Afr. trop.

nervosus, Hemsl. in Fourn. Limn. Soc. xxvi. (1890) 272. - China.

nudipes, Hemsl. l. c. - China.

orbicularis, Guerke, in Abh. Preuss. Akad. Wiss. (1894) 21; et in Bot. Fahrb. xix. (1894) 203. Afr. trop. or.

parvus, Oliver, in $H$. folnston, The Kitim. Exped. Append. (1836) 345, nomen; et in Trans. Linn. Soc. Ser. II, ii. (1887) 347. - Afr. trop.

pharicus, Prain, in fourn. As. Soc. Beng. lix. (1891) II. 297. - Reg. Himal.

pratensis, Guerke, in Bot. Fahrb. xix. (1894) 201. Afr. trop. or.

primulinus, Bakcr, in Kere Bull. (1895) 292. - Afr. trop. austro-or.

prostratus, Guerke, in Bot. Fahrb. xix. (1894) 206 - Afr. trop.

quarridentatus, Schweinf. ex Penzig, in Atti Congr. Bot. Genora (1893) 356, nomen. - Erithrea.

racemosus, Hemsl. in fourn. Linn. Soc. xxvi. (1890) 273. - China.

rubescens, Hemsl. l. c. - China.

sanguineus, Britten, in Trans. Limn. Soc., Ser. II iv. (1894) 36. - Afr, trop.

subacaulis, Baker, in Kew Bull. (1895) 73. - Afr.

trop.
sylvestris, Guerke, in Bot. Fahrb. xix. (1894) 205. Afr. trop. or.

Tatei, Hemsl. in fourn. Linn. Soc. xxvi (1890) 274 - China.

tetragonus, Guerke, ex Engl. in Abh. Preuss. Akad. Wiss. (1894) 37 ; et in Bot. Fahrb. xix. (1894) 209. - Afr. trop.

usambarensis, Guerke, 17 . cc. 65: et 207. - Afr. trop. or.

violaceus, Guerke, $7 l . c c .53$ : et 201. - Afr. trop. or

Websteri, Hemsl. in fourn. Linn. Soc. xxvi. (1890 275. - China.

Zenkeri, Guerke, in Bot. Fahrb. xix. (1891) 199.Kamerun.

PLECTRITIS, DC. = Valerianella, Tourn (Valerian.).

samolifolia, Fr. Meigen, in Bot. Jahrb. xvii, (1893) 276, et xviii. (1894) 400 et $461=$ Betekea samolifolia, $D C$.

PLECTRONIA, Linn. (Rubiac.). - Ind. Kew. ii, 560.

barbata, Benth. \& Hook. f. ex Hemsl. in fourn. Linn. Soc. Xxx. (1894) 181 (= Canthium barbatum Seem.). - Ins. Sandvic.

barbata, K. Schum, in Engl, \& Prantl, Naturl Pflanzenfam, iv. 4 (I891) 92 ; Drake, Fl Polyn. Franç. (1892) 93 (= Chiococca barbata, Forst.) - Ins. Pacif.

blepharocephala, K. Schmm. ex Engl. in Abh. Preuss.

Akad. Wiss. (1894) 61, nomen. - Afr. trop.
bogosensis, Martelli, Fl. Bogos. (1886) 42. Abyss.

caudatiflora, $K$. Schum, in Engl, Es Prantl, Natïrt. Pfanzenfam.iv. 4 (1891) 92 (= Canthium candatiflorum, Hiern). - Afr. trop.

coprosmoides. K. Schum. l. c. $(=C$. coprosmoides, F. Muell.) - Austral.

cuspidi-stipulata, K. Schum. ex Engl. in Abh. Preuss. Akad. Wiss. (1894) 53, nomen. - Afr. trop.

Diplodiscus, $K$. Schum. in Engl. Pfanzenw. Ost-Afr. C (1895) 385. - Afr. trop.

\section{PLECTRONIA :}

foetida, K. Schum. in Engl. Pfanzenwe. Ost-Afr. C (1895):386 (= Canthimn foetidum, Hiern). - Afr trop.

glabriflora, K. Schunn. in Bolet. Soc, Brot. x. (189?) 129 ; et l. c. $(=$ C. glabriflorum, Hiern $) .-\mathrm{Afr}$ trop. $\mathrm{Occ}$

glauca, K. Schum, in Engl. Pflanzenw. Ost-Afr. C (1895) 386 (=C. glaucum, Hiern). - Afr. trop. or. et alustro-or.

Henriquesiana, K. Schmm. in Bolet. Soc. Brot. (1892) 128. - Ins. S. Thom

hispida, K. Schnme in Engl. Pfanzenw. Ost-Afr. C (1895) 386 (= Canthium hispidum, Benth.). - Afr. trop. oce.

horrida, $K$ Schum, in Engl. E Prantl, Natiurl. Pfanzenfam. iv. 4 (1891) $92(=$ C. horridum, Blume - Java.

Korthalsii, K. Schum. l. c. (= C. umbellatum, Korth $)$

- Borneo.

livida, $K$. Schum. in Engl. Pfanzenu, Ost-Afr. C (1895) $386(=$ C. lividum, Hiern). - Afr. trop. micrantha, Baker, in fourn. Linn. Soc. xxii. (1887) 483. - Madag.

neglecta, K. Schun . cx Engl. in Abh. Preuss. Akad. Wiss. 1891 (1892) 399 (= Canthizm neglectum, Hiern). - Abyss.

nitens, K. Schum. in Engl. Pfanzenue. Ost-Afr. C (1895) 385 ( = C. nitens, Hiern). - Afr. trop.

odorata, Benth. \& Hook. f. ex Hillebr. Fl. Haw. Isl. (1888) 175. - Ins. Sandvic.

parvifolia, K. Schum, in Engl. \& Prantl, Natiurl. Pfanzenfam, iv. 4 (1891) 92 (= Canthium parvifolium. Roxb.). - Ind. or

setiflora K. Schum. in Engl. Pflanzenw. Ost-Afr. C (1895) $385(=C$. setiflorum, Hiern). - Afr. trop. sordida, K. Schum. l. c. 386. - Afr. trop. or

Soyauxii, K. Schnm. in Engl. \&o Prantl, Natürl. Pfanzenfam. iv. 4 (1891) 92. - Gabon.

subcordata, K. Schum. in Engl. Pfanzenw. Ost-Afr, C $(1895) 386(=$ Canthium subcordatum, DC.). Afr. trop.

syringaefolia, Baker, in fourn. Linn. Soc. xxy. (1890) 321. - Madag.

syringodora, $K$. Schum. in Engl. Pflanzenw. Ost-Afr. C (1895) 386. - Afr. trop. or.

umbellata, Kuntze, Rev. Gen. (1891) $293=$ umbellata, Benth. \& Hook. $f$.

umbellata, K. Schum. in Engl. \& Prantl, Natürl, Pflanzenfam. iv. 4 (1891) 92 (= Canthium umbellatum, Bart].) = P. Villarii, Vidal.

Vatkeand, K. Schum. ex Engl. in Abh. Preuss, Akad. Wiss. 1891 (1892) 399; et Pflanzenze. Ost-Afr. A (1895) 106 (= Canthium Vatkeamu, Hiern). Abyss.

vulgaris, K. Schum. l. c. (1895) 386. - Afr. trop. or. zanzibarica, Vatke, ex Engl. in Ab\%. Preuss. Akad. Wiss. (1894) $26 \quad(=$ Canihium zanzibaricum. Klotzsch). Zanzib.

PLEIOCARPA, Benth. (Apocyn.). - Ind. Kew ii. 561 .

bicarpellata, Stapf, in Kew Bull. (1894) 21. - Afr. trop. occ.

PLEIOCERAS, Baill, in Bull. Soc. Linn. Paris, i. (1888) 759 ; et Hist. des pl. x. (1888) 201 K. Schum. in Engl. \& Prantl, Natürl. Pflanzenfam. iv. 2 (1895) 186. APOCYNEAE

Barteri, Baill. Il. cc. - Lagos.

PLEIOGHITON, Naud.(Melast.). - Ind. Kew ii. 561

Glaziovianum, Cogn. in Mart. Fl. Bras. xiv. IV (1888) 426. - Bras

micranthum, Cogn. in DC. Monog. Phan, vii. (1891) 950. - Bras.

parvifolium, Cogn. l.c. 949. - Bras

roseum, Cogn. l. c. 950.- Bras

setulosum, Cogn. in Mart. Fl. Bras, xiv. IV. (1888) 426. - Bras.

PLEIONE, D. Don = Coleogyne, Lindl. (Orchid.). anceps, asperata, barbata, bilamellata, brachyplera. brevifolia, breviscapa, carnea, caulescens, corniculata. corrugata, corymbosa, Croockewitii, Cimingii, Day- 


\section{I'LEIONI}

ana, clata, fimbriata, faccida, farida, Foerstermannii, fuliginosa. fuscescens, Gardneriana, glandulosa, Goweri graminifolia, Griffthis, Hookeriana, Huettmeriana, incrassata, lactea, lentiginosa, iongibrac tenla, longifolia, longipes, macrobulbon, Maingayi, Massangonn, micrantha, miniata, nitida, occultata, ochracea odoratissima, pandurata, Parishii. plantaginea, prolifora, psittacina, purpurascens, Reichenbachiand. rigida, Rossiana, Rumphii, Schilleviana. simplex, Sonderiana, sparsa, speciosa, stenochila, sumareotens, testacea, Thuniana, tomentosa. Treulleri, suavelens, testacea, Thuniana, tomentosa. Treulleri, Gen. $\langle 1891) 679-81=$ homonyma omma Coelogynes chinensis, Kuntze, 1. c. $680=$ C. fimbriata, Lindl. Cycroche, Kuntze, 1. c. = C. Cycnoche, Par. E Reichb. f.

neriosa. Kuntze, 1. c. = C. corrugata. Wight.

Rochussenii, Kuntze, 1. c. $=$ C. Rochusseni, $D$ Vriese.

speciosissimu, Kuntze, 1. c. $681=$ C. cristata, Lind! sulfurea. Kuntze 1.C. = C. sulphurea, Reichb. $f$.

triflicatula, Kuntze, 1. c. = C. fuliginosa, Lodd.

PLEIOTAXIS, Steetz (Compos.). - Ind. Kew. ii, 561.

affinis, O. Hoffnn, in Bot. Fahro. xv. (18:3) 538. Congo, Angola.

Antunesii, O. Hoffnz l. c 539. - Angola.

eximia, O Hoffm.l.c. Angola. Congo.

linearifolia, O. Hoffm. l. c. 538. - Angola.

Newtoni, O. Hofm. .. c.537. - Angola.

pulcherrima. Klatt, in Annal. Naturh. Hoffmus,

Wien, vii. $(1892) 104=$ eximia, O. Hoffm.

racemosa, O. Hoffn. in Bot. Fahrb. xv. (1895) 540 . - Afr. trop. or.

rugosa, O. Hoffm. in Bolet. Soc. Brot. x. (1892) 183 et l. c. 5.38. - Angola.

PIEONOTOMA, Miers = Bignonia, Linn, stichadeninum, K. Schum. in Engl. \& Prantl, Natürl. Pflanzenfam. iv. 3b (1894) 226. - Bras.

PLERANDRA, A. Cunn, (Aral.).-Ind. Kew, ii.

Graeffei, "Seem » ex Gartenf. xxxvi. (1887) 71, sphalm, = P. Grayi, Scent.

Stahliana, Worb. in Bot. fahrb. xviii. (1894) 203. N. Guin

PLETHIANDPA, Hook, f. (Melastrom.). - Ind.

Thew. ii. 562.
cuneata, Stapf, in Hook. Icon. pl. xxv. (1895) sul t. 2418. - Borneo.

Hookeri, Stapf, in Trans, Linn. Soc. Ser. II. iv (I894) I633; ct 7. c. t. 2418 . - Bormeo.

rejangensis, Stapf, l. c. sub t. 2418. - Borneo

sessilis, Stapf, l.c. - Borneo.

PLEURIPETALUM, “ Becc. » ex Th. Dur. Ind. Gen. Phan. (1838) 49:3, sphalm. = Eburopeta lum Becc. (Anonac.).

PLEUROGYNA, Eschsch. (Gentian.). -- Ind Kew. ii. 563.

diffusa. MIIaxim, $2 n$ Bull. Acad. Pétersb, xxxii. (1888) 510 [Pleurogyna]. - Tibet.

PLEUROLOBUS, Jaume St Hil. = Desmodium Desv. (Legumin.)

canadensis, MacMill. Metasp. Minn. (1892) $319=$ D. canadense, $D C$.

canescens, NiacMill. 1. $\mathrm{c},=\mathrm{D}$. canescens, $D C$

grandiflorus, MacMill. 1. c. $321=\mathrm{D}$. acuminatum; $D C$

Dillenii, MacMill. 1. c. = D. Dillenij, Darl.

mudiflorus, MacMill. 1. c. $=$ D. nudiflorum, $D C$.

paniculatus, MacMill. 1. c. $320=$ D. paniculatum, $D C$.

PLEUROPHORA, Don (Lythrar.). - Ind. Kew ii. E63.
aspera, Phil. in Anal. Univ. Chil. 1xxxiv. (1894) 752.
- Chili.

Paulseni : Fr. Phil. ex Phil. l.c. \%51. - Chili.

uncinata, Phil. l.c.752. - Chili.
PLEUROPHYLLUIM, Hook. f. (Compos.). Ind. Kew. ii. 564.

Gilliesianum, T. Kirl, in Trans. N. Z. Inst. xxii. $1890(1891) 435=$ P. Hookeri, F. Buch .

Hookerianum, T. Kirk, 1. c. t. 39 et 40 , sphalm. = P. Hookeri. F. Buth.

splendens, Mart. ex K. Schum. in Mart. Fl. Bras. vi. VI. (1889) 31\%, in syn, = Warscewiczia coccinea, Klotzsich.

PLEUROSPERMUM, Hoffm. (Umbell.), - Ind. Kew. ii. 564 .

Davidi, Franch, in Now Archiv. Muss. Paris, Sér. II. viii. 1885 (1886) 247 . - Tibet.

decurrens, Franch. in Bull. Soc. Philom. Paris, Sér. V1II. vi. (1894) 138. - Yunnan.

foetens, Franch. l.c. 140. - Yunnan.

Franchetianum, Hensl. in foum. Linn. Soc xxix. (1892) 307 ; et in Hook. Icon. pl. xxiii. (1892) t. 2\%44. - China occ.

nanum, Franch, in Bull. Soc. Philon. Paris, Sér. VIII. vi. (1894) 110. - China.

Pulszliyi Kanitz, Pl, exped. Szichenyi, in As, centr. coll. (1891) 25. - As. centr.

Szechenyi. Kanitz, l.c. - As. centr.

yunnanense, Franch, in Bull. Soc. Phitom. Paris, Sér. VIII. vi. (1894) 137. -- Yunnan.

PLEUROSTAGHYS, Brongn. (Cyper.). - Ind.

Kew, ii. 564.
angustifolia, Boeck. Cyper, Nov. i1. (1890) 18. Bras.

Muelleri, Bucck.l.c. 19. - Bras,

paniculata. Boeck. l. c. 20. - Bras.

Rabenii, Bocck. l. c. 19. - Bras.

Ulei, Bocck. l.c. - Bras.

PLEUROSTELMA, Baill. Hist. des p1. x. (1890) 266; K. Schum. in Eng1. \& Prantl, Natürl. Pflanzenfam. iv. 2 (1895) 248. ASCLEPIA$D E A E$.

africanum, Schlechter, in fourn. Bot. xxxiii. (1895) t. 351. - Afr. trop. or

Grevei, Buill. Hist. des pl. x. (1890) $266:$ K. Schum, in Engl. \& Prantl, Natiirl, Pfanzenfam, iv.2 (1895) 218. - Madag.

PLEUROSTYLIA, Wight \& Arn. (Celastr.). Ind. Kew. ii. 564.

capensis, Loesen. in Engl. \& Prantl, Natürl. Pfanzenfam. iii. 5 (1892) $216 \quad(=$ Cathastrum capense, flurcz, - Afr, austr.

capensis, Oliver, in Hook. Icon. pl. xxiii. (1894) t. $229 \%=$ praec

cochinchinensis, Pierre, Fl. For. Cochinoch., Fasc. 20 (1894) sub t. 305 in text. - Cochinch.

pallens, Pierre, l.c. t. 3unb in text $(=$ Microtropis pullens, Pierre). - Cochinch.

Wightii, Pierre, 1. c. t. $305 \mathrm{~b}$, sphalm. = cochinchinensis, Pierre.

PLIUROTHALLIS, R, Br. (Orchid.). - Ind. Kew, ii. 564 .

albiflora, Barb. Rodr. Vellosia, 1885-88, Sec. ediç. (1891) 116. - Bras. bor.

astrophora, Reichb. f. ex Kraenzl, in Reichb. f. Xen. Orchid. iii. 5 (1892) 85246 ii, fig. 8-9. - Hab. ? Autraniana, Kraenzl. in Bull. Herb. Boiss. iii. (1895) 359, - Hab ?

Barbareana. O'Brien, in Gard. Chron. (1888) i. 245 , in obs. sphalm. = Barberiana, Reichb. f. ?

Blaisdellii, S. Wats. in Proc. Am. Acad. xxiii. (1888) 284. - Guatem.

Brighami. S. Wats, l. c. 285. - Guatem.

cardiophylax, Reichb. f. in Flora, lxxi. (1888) 154. - Hab. ?

choconiana, S. Wats in Proc. Am. Acad. xxiii. (18s8) 285. - Guatem.

colossus, Kraenzl, ex de Kerch. Le livre des Orchid. (1894) 376. - Columb.

cryptoceras, Reichb. f: in Flora, lxix. (1886) 554 - Bras.

densifolia, Rolfe, ex Britton, in Mem. Torrey Bot. Club., iv. (1895) 260. - Bólivia.

glossopogon. Hort. ex Gard. Chron. (188') i. $47 \%$. $=$ insignis, Rolfe.

\section{PLEUROTHALLIS :}

inflata, Rolfe, in Kew Bull. (1894) 154. - Columb. insignis, Rolfe, in Gard. Chron. (1887) i. 577. (= P glossopogon, Hort.). - Hab. ?

Josephensis, Barb. Rodr. Vellosia, 1885-88, Sec. ediç. (1891; 11\%. - Bras, bor.

lonchophylla, Reichb. f. in Flora. 1xix. (1886) 555. - Hab. ?

longisepala, Barb. Rodr. Vellosia, 1885-88, Sec. edic. (1891) 115. - Bras. hor.

maculata, Rolfe, in Kew Bull. ii. (1888) [maculatus], et (1893) 334. - Bras

minutiflora, S. Wats. in Proc. Am. Acad. xxiii. (1888) 286. - Guatem.

parva, Rolfe, in Kew Bull. (1895) 33. - Bras. pergracilis, Rolfe, l. c. (1893) 334. - Am. centr.

pernambucensis, Rolfe. l.c. (1894) 361. - Bras.

Pfavii, Reichb. f. in Flora, Ixix. (1886) 555. - Am. centr.

platyrachis, Rolfe, in Fourn. Bot. (1890) 135, in nota et in Bot. Mag, (1890) t. 7129), - Costa Rica.

platysemos, Rcichb. f. in Flora, 1xix. (1886) 555. Am. trop

puberula, Rolfe, in Kew Bull. (1893) 169. - Hab.?

punctulata, Rolfe, in Gard. Chron. (1888) ii. 756. N. Granat.

Regeliana, Reichb. f. in Gartenfl. vxxv. (l886) 50. Bras.

rhombipetala, Rolfe, in Kew Bull. (1893) 4; et in Gard. Chron. (1893) i. 290. - Venezuela.

rhomboglossa, Rcichb. f. in Flora, lxxi. (1888) 154. - N. Granat.

rotundifolia, Rolfe, in Kew Bull. (1895) 191. Jamaica.

scabridula, Rolfe, ex Rusby, in Mem. Torrey Bot. Club, iv. (1895) 260. - Bolivia.

scoparum, Reichb, f. in Flora, lxxi. (1888) 153. Ecuad.

stenosepala, Rolfe, in Kew Bull. (1892) 208. Hab.?

subulata, Rolfe l. c. (1S92) 13\%. - Hab.?

Talpinaria, Reichb. f. in Flora, 1xix. (1886) $554(=$ Talpinaria bivalvis, Karst.), - Columb.

teretifolia, Rolfe, in Gard. Chron. (1892) ii. 521. Bras.

uncinata, W. Favecelt, in fourn. Bot. xxxiii. (1895) 12. - Jamaica.

unistriata, Rolfe, in Kev Bull. (1893) 334. Ha'b. ?

Wendlandiana, Reichb. f. in Flora, 1xxi. (1888) 153. - N. Granat.

yauaperyensis, Barb. Rods'.Vellosia 1885-88, Sec. ediç. (1891) 116. - Bras. bor.

yungasensis, Rolfe, ex Rusby, in Mom. Torrey Bot. Club, iv, (1895) ₹59. - Bolivia.

PLEUROTHYPIUM, Nees (Laurin.). - Ind. Kew, ii. 567

panurense, Mez, in Falurb. Bot. Gart. Berl. v. (1889) $469(=$ Noctandra pannurensis, Meissn.). - Ecuad.

PLICOSEPAIUS, Van Tiegh. in Bull. Soc. Bot. Fr. xli. (1894) 504 et $540=$ Loranthus, Linn. curviflorus, Van Tiegh. 1. c. = L. curviflorus, Bezth.

Fauroti, Van Tiegh. 1. c. = L. Fauroti, Franch.

undulatus, Van Tiegh. 1. c. = L. undulatus, Meyer. PLOCOGLOTTIS, Blume (Orchid.). - Ind. Kew.
ii. 568.

porphyrophylla, Ridl, in Trans. Linn. Soc. Ser. II. iii. (1893) 368. - Penins. Mal.

PLoGosperma, Benth. (Logan.). - Ind. Kew ii, 568 .

macrophyllum, Baill. ex Soleved. in Engl. E Prantl. Natiirl. Pfanzenfan. iv. 2 (1895) 50. - Mexic.

PLUGHFA, Cass. (Compos.), - lnd. Kew. ii. 568 conocephala, F. Muell: in Trans. Proc. Roy Soc. Vict. xxiv. (July 1888) 135 (= Eurybia conociephula F. Muell.). - Austral.

decussata, Klatt, in Bot. Fahrb. viii. (1887) 39. Columb. 


\section{PLUCHEA}

foetida, Britton, Stern \& Pogg. Prelim. Catal. (1888) $28=$ bifrons. $D C$

laxa, Baker, in Kev Bull. (1895) 182. - Arabia.

mollis, Baker, l.c. Arabia.

nitens, O. Hoffm. in Bot. fahro. xx. (1894) 226. Afr. or.

phagnaloides, Hochst. [in Schimp. P1. Abyss. ii. n. 685] ex Engl. in Abh. Preuss. Akad. Wiss. 1891 (1892) 425 (=P. phanaloides, Sch. Bip.) = scoparum, Sch. Bip.

pteropoda. Hemsl. ex Forb. \& Hemsl. in fourn. Linn. Soc. xxiii. (1888) 422 t. 11. - China.

sericea, Coville, in Contrib. U. S. Nat. Herb. iv. (1893) 128 (= Tessaria borealis, A. Gray). Am. bor.

PLUMERIA, Tourn. ex Linn. (Apocyn.). - Ind. Kew. ii. 569.

Jamesoni, K. Schum, in Engl. \& Prantl, Natürl. Pfanzenfam. iv. 2 (1895) 136 [Plumera]. Ecuad.

POA, Linn. (Gramin,), - Ind, Kew, ii. 570 argentea, Howell, in Bull. Torrey Bot. Club, xv. (1888) 11 ; Vasey, Illustr. N. Am. Grass. ii. (1893) t. 72. - Oregon.

arida, Vasey, in Contriōo U.S. Nat. Herb. i. (1893) 270. - Am. bor.

balearica, Porta, in Nuov. Giorn. Bot. Ital. xix. (1887) 354. - Ins. Balear.

Bigelovii, Vasey \& Scribn. Descr. Catal. Grass. (1885) 81 ; et in Contrib. U. S. Nat. Herb. i. (1893) 270. - N. Mexic.

orennia, C. Richt. Pl. Europ. i. (1889) $85=$ violacea, Bell.

brizaeformis, Trab, in Batt. \& Trab. Fl. de l'Algér. [Monoc.] (1895) $207=$ bulbosa, Linn.

Buckleyana, Nash, in Bull. Torrey Bot. Club, xxii. (1895) 465 (=P. tenuifolia, Buckl.). - Am bor. capillipes, Somm. \& Levier, in Act. Hort. Petrop. xiii. (1893) 52. - Reg. Cauc.

Chapmanniana, Scribn. in Bull. Torrey Bot. Club, xxi. (1894) 38. - Am. bor.

Commersoni, Franch. Miss. scient. Cap Horn, v. [Bot. (1886) 385. - Am. austr.

confinis, Vasey, Illustr. N. Am Grass, ii. (1893) t. 75 ; et in Contrib. U S. Nat. Herb. i. (1893) 270. - Alaska.

cucullata, Hack: ex Sodiro, Gram. Ecuat. [Anal. Univ. Quito, 1889] 9, nomen. - Ecuad.

Cusickii, Vasey, in Contrib. U. S. Nat. Herb. i. 1893) 271. - Oregon.

dura, Simonk. Enum. F1. Transsilv. (1886) $578=$ Cynosurus durus, Linn.

dipsacea, Petrie, in Trans. N.Z. Inst. xxvi. 1893 (1894) $271 .-$ N. Ze1.

Djurjurae, Trab. in Batt. \& Trab. F1. de l'Algér. [Monoc.] (1895) $208=$ alpina, Linn.

Fendleriana, Vasey, Illustr, N. An. Grass. ii. (1893) t. 74 (= Eragrostis Fendleriana, Steud.). - Am. bor. austro-occ.

festucoides, M. E. Fones, in Proc. Calif. Acad. Ser. II. v. (1895) 723. - Utah.

Figerti $\times$, Gerhardt, in Deutsche Bot. Monatsschr. x. (1892) 152. - Germ.

filifolia. Vasey, in Contrib. U.S. Nat. Herb. i. (1893) 271 ; et iii. (1895) 262. - Idaho.

gracillima, Vasey, l. c. 272. - Am. bor.

Grayana, Vasey, l. c. - Calif.

Hamiltonii, T. Kirk, in Trans. N. Z. Inst, xxvii. 1894 (I895) 353. - N. Zel.

hispidula, Vasey, in Contrib. U.S. Nat. Herb. i. (1893) 272. - Am. bor.

Howellii, Vasey \& Scribn. in Vasey, Illustr. N. Am. Grass. ii. (1893) t. 78; et l. c. 272. - Oregon, Calif.

hypsophila, Phil. in Anal. Mus.nac. Chile (1891) 87 - Chili.

jemtlandica, C. Richt. Pl. Europ. i. (1889) 84. Suecia.

Jurani, Genty, in Magnier, Scrin. fl. select. v. (1886) 103. - Jurass.

Kelloggii, Vasey, Illustr. N. Am. Grass. ii. (1893) t. 79; et in Contrib. U.S. Nat. Herb. i. (1893) 272. - Calif
POA

leioclada, Hack, ex Sodiro, Gram. Enuat. [Anal. Uniw. Quito, 1889] 9, nomen. - Ecuad.

Lettermani, Vasey, in Contrib. U.S. Nat. Herb. i (1893) 273. - Colorado.

longeradiata, Hillebr. Fl. Haw. Isl. (1888) 526. Ins. Sandvic.

lucida, Vasey, in Contrib. U. S. Nat. Herb, i. (1893) 273. - Colorado.

Macounii, Vasey, in Macoun, Catal. Canad. Pl. iv. (1888) 225. - Canada.

macrantha, Vasey, in Bull. Torrey Bot. Club, xv, (1885) 11; et Illustr. N. Am. Grass, ii. (1893) t. 80. - Calif., Washingt.

Maniototo, Petrie, in Trans. N. Z. Inst. xxii. 1889 (1890) 443. - N. Zel.

menachensis, Schreinuf. in Bull. Herb. Boiss. ii. App. II, (1894) 43. - Arabia.

montana, C. Cordem. Fl. Ile Réunion (1895) 127 Ins, Borbon.

nana, Phil. in Anal. Mus. nac. Chile (1891) 87. Chili.

nervosa, Vasey, Illustr. N. Am. Grass. ii. (1893) t. 81 ; et in Contrib. U. S. Nat. Herb. i. (1893) 274 (= Festuca nervosa, Hook.), = Am. bor. occ occidentalis, Vasey, l. c. 274. - Am. bor.

Orcuttiana, Vasey, in West Am. Scientist, iii. (1887) 165; et in Contrib. U.S. Nat. Herb. i. (1893) 275. - Calif.

oresigena, Phil. in Anal. Mus.nac. Chile (1891) $8 \%$. - Chili.

Pattersoni, Vasey, in Contrib. U. S. Nat. Herb. i. (1893) 275. - Colorado

pollinensis, Terrac. in Ann. Ist. Bot. Roma, iv. 1889.

90 (1891) 37. t. 2. - Ital. mer

Pringlei, Scribst, ex Vasey, in Contrib. U.S, Nat. Herb. i. (1893) 275. - Am. bor. austro-occ,

polonica, Blocki, in Oest. Bot. Zeitschr. xxxvii. (1887) 156. - Eur. centr. or.

Pseudopratensis, Beyer, in Wiss, Beil. Progr. Andreas-Realgymn. Berl. (1891), ex Oest. Bot. Zeitschr, xli. (1891) $177=$ pratensis, $\operatorname{Linn}$.

pumila, Phit. in Anal. MIus. nac. Chile (1891) 87 . Chili.

quitensis, Hack. ex Sodiro, Gram. Ecuat. [Anal. Univ. Quito, 1889| 9. - Ecuad.

reflexa, Vasey \& Scribn. ex Vasey, in Contrib. U.S. Nat. Herb. (1893) 276. - Am, bor. occ.

Rehmanni, C. Richt. Pl. Europ. i. (1889) $83=$ caesia, Smith.

rupestris, Vasey, in Bull. Torrey Bot. Club, xiv, (1887) 94. - Am. bor

Sandbergii, Vasey, in Contrib, U.S. Nat. Herb. i. (1893) 276; et iii. (1895) 263. - Am. bor. austro-occ.

Sheldoni, Vasey, l. c. 276. - Colorado.

Sodiroana, Hack. ex Sodiro, Gram. Ecuator. [Anal. Univ. Quito, 1889] 9. - Ecuad.

subaristata, Soribn. ex Macoun, Catal. Canad. Pl. iv. (1888) 227. - Canada.

texana, Vasey, in Contrib. U.S. Nat. Herb. ii. (1890) $60(=$ Sieglingia Wrightii, Vasey), - Am. bor.

Thurberiana, Vasey, Illustr. N. Am. Grass. ii. (1893) t. 84 (= Panicularia Thurberiana. Kuntze). - Calif.

trachyphylla, Hack. ex Sodivo, Gram. Ecuat. [Anal. Univ. Quito, 1889] 9. - Ecuad.

Tracyi, Vasey, in Bull. Torrey Bot. Club, xv. (1888) 49 ; et in Contrib. U. S. Nat. Herb. i. (1893) 276. - N. Mexic.

tuberifera, Makino, in Tokyo Bot. Mag. vi. (1892) 48. - Japon.

unilateralis, Scribn. ex Vasey, Illustr. N. Am. Grass. ii. (1893) t. 85. - Calif.

ursina, Velen. Beitr. Fl. Bulg. (1886) 45 ; in Abb. Boehm. Ges. Wiss, 1888 (1889) i. 72, et Fl. Bulg. (189I) $624=$ alpina, Linn.

Wolfii, Scribn. in Bull. Torrey Bot. Club, xxi. (1894) 228. - Illinois.

POAGYNUM, Baill. in Bull. Soc. Linn. Paris, i. (1888) 757 ; et Hist. des pl. x. (1888) 208; K. Schum. in Engl. \& Prantl, Natürl. Pflanzenfam. iv. 1 (1895) 179. APOCYNEAE.

pictum, Baill.ll.cc. (= Apocynum pictum, Schrank), - Songar
PODANDRA, Baill. Hist. des pl. x. (1890) 265 K. Schum. in Engl. \& Prantl, Natürl. Pflanzenfam. iv, 2 (1895) 248. ASCLEPIADEAE.

boliviana, Baill. ll.cc. - Bolivia.

PODANTHES, Haw. = Stapelia. Linn. (Asclep.) geminata, Nichols. Dict, Gard. iii. (1886) $172=$ Piaranthus geminatus, $N$.E. Br

PODANTHUM, Buiss, = Phyteuma, Linn. (Campanul.).

aurasiacum. Batt. \& Trab, in Bull. Soc, Bot. Fr. xxxix. (1892) 346, nomen, et p. Lx cum ic.; e Atl. F1. de l'Algér. (1895) 19, t. 12. - Algeria. grandiflorum, Velen. Fl. Bulg. (1891) 373, - Bulg. supimu, Wettst. in Sitzungsb. Akad. Wiss, Wien, xcviii. 1889 (1889) 37\%. - As. Min.

PODISTERA, S. Wats. in Proc. Am. Acad. xxii (1887) 475. UMBELLIFERAE

nevadensis, S. Wats.l.c. $(=$ Cymopterus nevadensis A. Gray). - Calif.

PODOCARPUS, Labill. = Phyllocladus, Rich. (Conif.).
pophylla, Kuntze, Rev. Gen. (1891) $802=\mathrm{Ph}$ hypophylla, Kuntze, Re
hypophylla, Hook. $f$.

trichomanodes, Kuntze, 1. c. = Ph. trichomanoides D. Don.

PODOGARPUS. [L'Hérit.] Pers. (Conif.). - Ind. Kew. ii. 578. - N. Zel.

milanjiana, Rendle, in Trans. Limn. Soc., Ser. II. iv. (1894) 61. - Afr. trop.

montana, Colenso, in Trans. N. Z. Inst, xxvi, 1894 (1895) $395 .-\mathrm{N}$. Zel.

pectinata, Hort. ex Rev. Hortic. 1xvii. (1895) 249 nomen. - Reg. Andina.

pruinosa, Eckl. \& Zeyh. ex Th. Dur. \& Schinz, Consp. Fl. Afr. v. 1894 (1895) 954 = pruinosa E. Mey.

Sciadopitys, Hort. ex Beissn., Handb. Nadelholzk (1891) $181=$ Cephalotaxus pedunculata, Siøo. \&

PODOCHILUS, Blume (Orchied.). - Ind. Kew

cicularis, Hook. f. Fl. Brit. Ind. vi. (1890) 82.Penins. Mal.

khasianus, Hook. f. l. c. 81. - Ind. or.

longicalcaratus, Rolfe, in Kew Bull. (1894) 186. Borneo.

unciferus, Hook. f. Fl. Brit. Ind. vi. (1890) 81. As, trop.

Podochrosia, Baill in Bull. Soc, Linn Paris, i. (1888) 750 ; et Hist. des pl. x. (1888) 193: K. Schum, in Engl, \& Prant1, Natür1. Pflanzenfam. iv, 2(1895) 158. APOCYNEAE.

Balansae, Baill. $l l, c c .-N$. Caled.

PoDoGoGGus, Mann \& H. Wendl. (Palm.), Ind. Kew. ii. 579

acaulis, Hua, in Bull. Muséum Paris, i. (1895) 315. - Congo gall.

PODOCYTISUS, Boiss. \& Heldr. = Laburnum Linn. (Legumin.)

americanus, Hort ex Gard. Kew, i. Polypet. (1894) $107=$ L. caramanicum, Benth. E. Hook.f.

PODOGYINIUM, Taub, in Eng1. Pflanzenw. Ost Afr. A (1895) 92, nomen. LEGUMINOSAE capparidaceum, Taub.l.c. - Afr. trop. or.

PODOLUMA, Baill. Hist. des pl. xi. (1892) 290 = Lucuma, Molina (Sapot.).

PODOON, Baill. in Bull. Soc. Linn. Paris, i. (18s7 682 et (1889) 793; Heimerl, in Engl. \& Prant? TOLACCACEAE

Delavayi, Baill. Ul. co.; Franch. Pl. Delav, $\{1890)$ 146 t. 32-35. - Yunnan. 
PODOPHYLLUM Linn. (Berberid.). - Ind. Kew, ii. 580 .

Delavayi, Franch. in Bull. Muséum Paris, i. (1895) 63. - Yunnan

japonicum, T. Ito, ex Maxim. in Bull. Acad. Pétersb. xxxi. (1887) 14 ; et in foum. Linn. Soc, xxii. (1887) 434 (= Ranzania japonica, T. Ito). - Japon.

pleianthum. Hance, in Gard. Chron. (1889) ii. 298, fig. 44. - China.

PODORUNGIA, Baill. Hist. des pl. x. (1890) 443 Lindar, in Engl, et Prantl, Natïrl. Pflanzenfam. iv. 36. (1895) 341. ACANTHACEAE.

Lantzei, Baill. $7 l . c c$. - M Madag,

PODOSPERMUM, DC, = Scorzonera, Linn (Compos.)

pindicolum, Hausskn, in Mitth. Bot. Ver, Jena, y. (1887) 86: Nym. Consp. Fl. Eur. Suppl. ii. 1. (1889) 204. - Graecia.

PODOSTELMA. K. Schum. in Bot. Jahrb, xvii (1893) 133; K. Schum. in Engl. \& Prantl, Natürl, Pflanzenfam. iv. 2(1895) 234. ASCLEPIA$D E A E$.

Schimperi, K. Schum.ll.cc. (= Astephania Schimperi, Vatke) - Afr. trop. or

Schimperianum, K. Schum. 1. c. 155, sphalm. = praec.

PODOSTEMoN, Michx (Podostem.). - Ind Kew. ii. 580.
distichus, Warm. Fam. Podost. Afh. iii. (1888) 12 t. 19, fig. 5-7 (Lacis disticha, Cham.) = P. Chamissois, $T u$.

Galyonis, Warm l.c. t. 17 - Bras.

metzgerioides, Trimen, Handb. Fl. Ceyl. iii. (1893) 419. - Zeylan.

Muelleri, Warm. Fan, Podost. Afh. iii. (1888) 3 t. 16 et $1 \%$ - Bras.

olivaceum, Warm. 1. c. Afh. iv. (1891) 35, fig. :31-35 $=$ olivaceum, Gardn

Schenkii, Warm. l. c. Afh iii. (1888) 9, - Bras.

Tholloni, Baill. in Bull. Soc. Linn. Paris, ii. $(1890$ 877. - Congo gall

POGGEA, Guerke, ex Warb, in Engl, \& Prantl, Natiirl. Pflanzenfam, iii. 6a (1893) 16: et in Bot. Jahrb. xviii. (1894) 162. BIXINEAE.

alata, Guerke, il. co. - Congo.

POGGEOPHYTON, Pax, in Bot, Jahrb, xix (1894) 88. EUPHORBIACEAE.

aculeatum, Pax, l. c. (1894) 89. - Congo mer.

POGOINA, "Griff. » ex B. Grant, Orchids of Burma, (1895) 355, sphalm。 = Pogonia, Griff. (Orchid.).

POGONANTHER A, Blume (Melast.). - Ind, Kew. ii. 591

pauciflora, Becc. Malesia, ii. (1886) 241. - Sumatra. robusta, Becc. l. c. 240. - Borneo.

POGONIA, Juss. (Orchid.), - Ind. Kew. ii. 582. macroglossa, Hook.f. Fl. Brat. Ind. vi. (1890) 120 - Reg. Himal.

mexicana, S. Wats, in Proc. An, Acad, xxvi. (1891) 154. - Mexic

microstyloides, Reichb. f. in Flora, 1xix. (1886) 547 - N. Granat.

modesta, Cogne. in Mart. Fl. Bras. iii. IV. (1893) 133 (= Psilochilus modesta, Barb. Rodr.). - Bras.

Rodriguesii, Cognt. l. c. 121 (= Pogonia gracilis, Barb. Rodr.). - Bras

simplex, Th. Dur, \& Schinz, Consp. Fl. Afr, y. $1892(1895) 59=$ simplex, Reichb. $f$.

striata, Ridl.in Trans. Linn, Soc. Ser. II. iii. (1893) 377. - Penins. Mal.

trianthophora, Britton, Stern \& Pogg. Prelim. Catal. (1888) $52=$ pendula, Lindl.

POGONIOPSIS, Reichb. f. (Orchid.). - Ind. Kew. ii. 582 .

Schenkii, Cognz, in Mart. Fl Bras. iii. IV. (1893) 136. - Bras.
POGONOPUS, Klotzsch (Rubiac.). - Ind. Kew, aracasensis, Nichols. Dict. Gard. iii. (1886) $175=$ exsertus. Oerst

exsertus, K. Schum. in Eng1. \& Prantl, Natürl. Pflanzenfam. iv. 4 (1891) 21 = exsertus, Oerst. speciosus, $K$. Schum. l.c.l= Macrocnemutm speciosum, Jacq.). - Am. austr. et centr. tubulosus, K. Schum. in Mart. Fl. Bras, vi, VI, (1889) 266 (=Calycophyllum tubulosum, DC.). -
Bras.

POGOSTEMON, Desf. (Labiat.). - Ind. Kew. ii. 583.

benghalense, Kuntze, Rev. Gen.(1891) $529=$ plectrantoides, Desf.

Benthamianum, Kuntze, 1 c. 530 = Dysophylla verticillata, Benth.

cruciatum, Kuntze, 1, c, = D. cruciata, Benth.

erectum, Kuntze, 1. c. $=$ D. erecta, Dal\%.

janthinum, Kanitz, Növényt. Gyijt. Evd. Gróf Szechersyi (1891) 46, nomen. - China.

japonicum, Kuntze, Rev. Gen. (1891) $530=$ Dysophylla japonica, Miq.

lineare, Kuntze, 1. c. = D, linearis, Benth.

myosurodes, Kuntze, 1. c. = D. myosuroides, Benth pentagonum, Kuntze, 1. c. [sp. coll.]. -- Ind. or. quadrifolium, Kuntze, 1. C. sphalm. = Dysodia porophylloides, A. Gray.

stellatum, Kuntze, 1. c. $429=$ D. stellata. Benth

Wattii, C. B. Clarke, in fourn. Linn. Soc. xxv. (1889) 59. - Kohima.

POIKILAGANTHUS, Lindau, in Bot. Jahrb. xviii. 1894, 57 ; et in Engl. \& Prantl, Natürl. Pflanzenfam. iv, 3b (1895) 342. ACANTHACEAE

Hexuosus, Lindan, $l i$. oc. (= Adhatoda flexnosa, Nees). - Bras.

Gilliesii, Lindan, $u$. cc. (=A. Gilliesii, Nees $)$. Reg. Argent.

humilis, Lindau, in Bull. Herb. Boiss, iii. (1895) 481. - Bras.

macranthus, Lind «u, l. c. - Guatem.

Moritzianus, Lindau, in Bot. Fahro. xviii. (1894) 57 ; et in Engl. of Prantl, Natiirl. Pflanzenfam, iv. 3b (1895) 342 (= Adhatoda Moritziana, Nees). Columb.

Tweedianus, Lindan, $l l . c c . x v i i i . ~(1894) 40$ et xix. BeibI. n. 48 (1894) 19 (= A. Tweediana, Nees). - Reg. Argent.

POISSONELLA, Pierre, Not. bot. Sapot. (1890) 29 = Lucuma Molina (Sapot.).

Baillon, Pierre, 1. c. - Hab. ?

neo-caledonica. Pierre, 1. c. = L. neo-caledonica, Pierre.

POLANISIA, Rafin $=$ Gleome, Linn. (Capparid.). bororensis, Pax, ex Gilg, in Engl. Pflanzenw, OstAfr. C (1895) $184=\mathrm{C}$. bororensis, Oliver.

dodecandra, Britton, Stern \& Pogg. Prelim. Catal. (1888) 6 = C. graveolens, Rafin.

hivta, Pax, in Bot. Jahrb. x. (1889) $14=$ C. hirta, Oliver.

Kelleriana, Schinz, in Bull, Herb. Boiss iii. (1895) 395. - Reg. Somal.

Petersiana, Pax, in Bot. Jahrb. xix. (1894) 134 (= Dianthera Petersiana, Klotzsch). - Mossamb. suffruticosa, Pax, 1, c. - Afr. austro-occ. extratrop,

POLEMONIUM. [Tourn] Linn. (Polemon.). -

Ind. Kew. ii. 584 .
Brandegei, Greene, Pittonia, i. (Nov. 1887) 126 (= Gilia Brandegei, A. Gray). - Am. bor, occ.

filicinum, Greene, l.c. 124. - N. Mexic.

occidentale, Greene, l. c. ii. (May 1890) 75. - Am. bor. occ.

panciflorum, S. Wats. in Proc, Am. Acad. xxiii. (1888) 280. - Mexic

Van Bruntiae, Britton, in Bull. Torrey Bot. Chwb, xix. (1892) 224, t. 131, - Am. bor.

POLIOMINTFLA, A. Gray (Labiat.). - Ind, Kew. ii. 000 .

bicolor, S. Wats.' in Proc. Am. Acad. xxv. (1890) 160. - Mexic
POLIOTHYRSIS, Oliver, in Hook. Icon. pl. xix. (1889) t. 1885. BIXINEAE.

sinensis, Hook.f.l. c. - China.

POLLIA, Thunb, (Commelin.). - Ind, Kew. ii. 585

cyanocarpa, K. Schunn. in Engl, Pfanzente. Ost-Afr. A (1895) 91, nomen. - Afr, trop, or.

POLlinia, Trin. (Gramin.), - Ind, Kew, ii 585.

aurea, Cordem. Fl. Ile Rérnion (1895) $123=$ aurea Benth.

collina, Bulansa, in Morot, Fourn. de Bot. iv. (1890), 81. - Cochinch.

debilis, Balansa, l. c. 82, - Cochinch.

fimbriata, Hack, in DC. Monog. Phan, vi. (1889) 164. - Ind or

gracillima, Hack. in DC. . c. 179. = Ins. Tahit

grata, Hack. in DC. l.c. 175. - As. trop.

hirtifolia, Hack. l. c. 165. - Ind. or.

mollis, Hack. l. c. 161 (= Evianthus mollis, Griseb). - Reg. Himal.

monostachya, Balansa, in Morot, Fourn. de Bot. iv. (1890) 81. - Cochinch.

pallens, Hack. in DC. Monog. Phan. vi. (1889) 156. - Ind. or., Yunnan.

phaeothrix, Hack.7.c, 168 (= Erianthus Cumingic F. Muell.). - Ind, or., Zeylan

quadrinervis, Hack, l. c. 158. - Ind. or., China.

Ridleyi, Hack. in Oest. Bot, Zeitschr. xli. (1891 7. - Penins. Mal.

rufispica, Hack, in DC. Monog, Phan. vi. (1889) 171 (= Andropogon rufispica, Steud.). - Java.

speciosa, Hack. l. c. 159. - China.

Thwaitesii, Hack. l. c. 163. - Zeylan,

velutina, Hack. l. c, 169. - Ind. or.

POLYACHYRUS, Lag. (Compos.). - Ind. Kew. foliosus, Phil. in Bot. Fahrb. viii. (1887) 72. Chili.

calderensis, Phil.l.c.76. - Chili.

glabratus, Phil. l.c. 73. - Chili.

nivalis, Phil. l. c. 75 . - Chili.

San Romani, Piril.l c. 76. - Chili.

tarapacanus, Phil, l.c. 74. - Chili

tenuifolius, Phil.. . c. $\%$. - Chili.

POLYALThia. Blume (Anon.). - Ind kew ii. 586 .

Armitiana, F. Muell.Sec. Cens. Austral. Pl. (1889) 5 [Quid ?].

Beccarii, King, in fourn. As. Soc. Beng. 1xi. (1892) ii. 65 . - Perak.

bullata, King, l. c. 64. - Penins. Mal.

clavigera, King, l. c. 60.- Malaya.

congregata, King, l. c.61. - Perak

dumosa, King, l. c. 52. - Perak.

glomerata, King, l.c.61. - Malaya

Hookeriana, King, l. c. 57. - Malacca, Perak.

hypogaea, King, l. c. 62. - Perak.

Kunstleri, King, l. c. 55 . - Perak.

lateriflora, King, l. c. $58(=$ Guatteria lateriflora Miq.). - Malaya

macrantha, King, l. c. 54. - Perak.

macropoda, King, l. c. 60. - Perak

oblonga, King, l.c:65. - Perak.

pachyphylla, King, l. . 66. - Perak.

papuana, Warb. in Bot. Fakrb. xviii. (1894) 191. S. Guin.

pycnantha, King, in fourn. As. Soc. Beng. 1x. (1892) ii. 68. - Malacca,

pulchra, King, l. c. 55. - Perak.

Schefferi Stapf, in Kew Bull. (1892) 195. - Java.

Scortechinii, King, in fourn. As. Soc. Beng. Ix (1892) II. 56. -- Perak.

sumatrana, King, l. c.53 $(=$ Guatteria sumatrana Miq.). - Sumatra.

POL YGARDIA, Juss, (Celastr.). - Ind. Kew. 'ii. $58 \%$.

Baroniana, Oliver, in Hook, Icon, pl. xxiii. (1892) t 2237. - Madag.

centralis, Baker, in Kerw Bull. (1894) 354. - Madag 
POLYGARENA, Benth. (Scrophul.). - Ind. Kew. ii. 587. discolor, Schinz, in Verh. Bot. V
(1890) 191. - Afr, centr. austr.

POLYCARPA, Kuntze, Rev. Gen. (1891) $50=$ Polycarpon, Loefl. (Caryoph.).

urabica, aristata, breviflora, caespitosa, carnosa, corymbosa diffusa, divaricata, fragilis, Gayi, glabrifolia, involucrata, linearifolia, longiflora, prostrata, Smithii, spicata, spirostylis, stellata, synandra, violacea, Kuntze, 1.c. 51 = homonyma omnia Polycarpaeae.

Balfouriana, Kuntze, 1. c. = Polycarpaea divaricata, Balf. $f$.

depressa, Kuntze, 1. c. = Polycarpon depressum,

Nutt.
filifolia, Kuntze. 1. c = Polycarpaea filifolia, $W e b b$. lancifolia, Kuntze, 1. c. = P. lancifolia, Christ.

nivea. Kuntze, 1. c. = P. microphylla, Cav.

repens, Kuntze, 1. c. = Polycarpon Loefflingiae, Benth. E. Hook. $f$

Robbaivea, Kuntze, 1. c. = Polycarpaea prostrata Decne.

succulenta, Kuntze, 1.c. = Polycarpon succulentum,

7. Gay.
tenuis, Kuntze, 1. c. = Polycarpaea tenuis, $W \iota b b$.

POLYCARPA, Linden = Idesia, Maxim. (Bixin.). australis, Britton, in Ann. N. Y. Acad. sci. vii. (1892) 53. - Parag.

POLYGARPAEA, Lam. (Caryoph.), $\rightarrow$ Ind, Kew .

ii. 587 . akkensis, $P$ ax, in Bot. fohrb. xvi1. (1893) $592(=$
Robbairea akkensis, Aschers., - Marocc. filifolia, Webb, ex Christ, in Bot. Fahrb. ix. (1888) 103. - Teneriffa

lancifolia, Christ, l. c. 104.-. Ins. Canar.

platyphylla, Pax, in Bot. Fahrb. xvii. (1893) 590. Liberia.

Poggei, Pax, l. c. 591. - Angola.

tenuis, Webb, ex Christ, in Bot. Fahrb. ix. (1888) 103. - Ins. Canar.

POLYGARPON, Loefl. (Caryoph.). - Ind. Kew. ii. 587.

colomense, Porta, in Nuov. Gionn. Bot. Ital. xix. (1887) 305. - Ins. Balear.

prostratum, Pax, in Engl. \& Prantl, Natirl. Pfanzenfam. iii. 1b (1889) 87 (= Robbairea prostrata. Forsk.). - Afr. bor.; Oriens.

rupicolum, Pomel, ex Batt. \& Trab. Fl. de l'Algér [Dicot.] (1888) $162=$ peploides, $D C$.

POLYCLINE, Oliver, in Hook. Icon, pl. xxiii. (1894) t. 2293. COMPOSITAE.

psyllioides, Oliver, l.c. - Afr. trop. or

gracilis, Oliver, in Hook. f. Icon. pl. (1894) sub t: 2293. - Afr. trop. or

Stuhlmannii, O. Hoffm. in Bot. Fahrb. xx. (1894) 233. - Afr. trop. or.

POLYGYGNIS, Reichb. f. (Orchid.). - Ind. Kew. ii. 588.

Lehmanni, Rolfe, in Kew Bull. (1894) 365. - N. Granat.

POLYDRAGMA. Hook. f. in Hook. Icon pl. xviii. (1887) t. 1701 : et Fl. Brit. Ind. v. (188\%) 45\%. EUPHORBIACEAE.

mallotiformis, Hook. f. ll.cc. - Penins. Mal.

POLYGALA, [Tourn.] Linn; (Polygal.): - Ind, acicularis, S. Wats. in Proc. Am. Acad. xxi. (1886) 445. - Mexic.

acuminata, Willd. ex Chod. in Mém. Soc. Phys. Genève, xxxi. n. 2 (1893) 46. - Peruvia, Chili. aethiopica, Chod. l. c. 330.- - Abyss.

africana, Chod. $l$ c. 168. - Angola.

albida, Schinz, in Verh. Bot. Ver. Brand.xxix. (1888) 53. - Afr, austr.

Albowiana, Chod, in Bull. Herb. Boiss. iii. (1895) 123. - Mexic:

Alfredi, Chod. in Mém. Soc. Phys. Genève, xxxi. n. 2 (1893) $172(=P$. gracilis, A. W. Benn.). - Bras. Alopecurus; Chod. l. c. 227-- Bras.

\section{POLYGALA}

amboniensis, Guerke, in Abh. Prouss. Akad. Wiss. (1894) 14 et 22; et in Engl. Pfanzenw. Ost-Afr. C (1895) 234.-Afr, trop: or

andensis, Chod. in Mém. Soc. Phys. Genève, xxxi n. 2 (1893) 25. - Peruvia.

andicola, Phil. in Anal. Univ. Chil. 1xxxi. (1893) 495. - Chili.

andina, A. W. Bennett, ex Bretton, in Bull. Torrey Bot. Club, xvi. (1889) 19, - Bolivia

Andreana, Chod. in Bull. Herb. Boiss, iii. (1895) 121 - Reg. Andina.

antillensis, Chod, in Mém. Soc. Phys. Genève, xxxi. n. 2 (1893) 38. - Ins. Martinic

aphrodisiaca, Guerke, in Engl. Pflanzenz\%. Ost-Afr. B (1895) 514, et C (1895).234. - Afr. trop. or.

apopetala, T. S. Brandeg. in Proc. Calif. Acad. Ser. II. 3i. (1889) 130 t. 3. - Calif.

argentinensis, Chod. in Mém. Soc. Phys. Genère, xxxi.n. 2 (1893) 2\%1. - Reg. Argent.

Arizonae, Chod. l. c. 108. - Arizona.

Aschersoniana, Chod. in Bull. Herb. Boiss. iii. (1895) 548. - Cyrenaica.

Autranii, Chod. in Mim. Soc. Phys. Genève, xxxi. n. 280. - Bras.

bahiensis, Chod. . c. 49. - Bras.

Baikiesi, Chod, l. c. 334. - Reg. Nigrit.

Barbeyana, Chod.l.c.16. - Mexic.

Bennetti, Chod.l. c. xxx.n. 8 (1889) 113, t. 32, fig. 2 et xxxi. n. 2 (1893) 7. - Parag., Bras.

Berlandieri, S. Wats, in Proc. An, Acad, xxi. 1886) 416. - Mexic

birmanica. Chod. in Bull. Herb. Boiss. iii. (1895) 126. - Burma.

Blancheti, Chod. in Min. Soc. Phys. Genire, xxxi. n. 2 (1893) 88. - Bras

Bojeri, Chod. . . c. 365. - Madag.

bosniaca, Murb. in Lunds Univ. Arsskrift, xxvii. v. (1802) 165 = supina, Schreb.

brevidata, Chod. in Mén. Sac. Phys, Genève, xxxi. n. 2 (1893) 234. - Venezuela

bukobensis, Guerke, in Engl. Pfanzenw. Ost-Afr. C (1895) 233. = Afr. trop. centr.

butyracea, Heck. in Bull. Snc. géogr. Marseille. [Végét. util. Afr. trop.] (1889) 4, t. 1; et in Hook. Icon. pl. xxiv. (1894) t. 2410. - Afr. trop. occ.

calcicola, Chod. l. c. 336. - Reg. Somal.

carpatica, Wolos\%. in Spraw. Közl. fizy. Krajow. xxii. (1888) II. 216. - Reg. Carpat.

carphoides, Chod. in Mém. Soc. Phys. Genève, xxxi. n. 2 (1893) 158. - Bras

chloroptera, Chod. 2. C. 375. - Natal.

Chodatiana, A.W. Bennett, in fourn. Bot. xxxiii (1895) 109. - Reg. Argent.

Chuiti, Chod, in Mém. Soc. Phys. Genève, xxx, n, 8 (1889) 105, t. 29, fig. 1: - Parag.

columbica, Chod. l. c. xxxi. n.2 (1893) 29. Venezuela,

confusa, Macowan, in. Fourn. Limn. Soc. xxy. (1890) 385. - Afr. austr.

cordobensis, A.W. Bennett, in foum. Bot. xxxiii (1895) 109. - Reg. Argent.

costaricensis, Chod. ex Th. Dur. of Pitt. in Bull. Soc Bot. Belg. xxx. 1891 (1892) 298; et in Mém. Soc. Phys. Genève, xxxi. n. 2 (1893) 30. - Costa Rica. crinita, Chod in Mém, Soc. Pliys. Genève, xxxi.n. 1893) 156. - Mexic

croatica, Chod. l. c. 468; et in Bull. Herb. Boiss. i (1893) 356. - Croatia.

cubensis, Chod. in Mém. Soc. Phys. Genève, xxxi, n. 2 (1893) 62. - Cuba.

deflorata. Chod. l. c. 23. - Peruvia.

desertorum, T.S. Brandeg, in Proc. Calif. Acad. Ser. II. ii. (1889) 130, - Calif.

dhotarica, Baker, in Kew Bull. (1895) 181. Arabia.

dichotoma, Chod. in Mém. Soc. Phys. Genive, xxxi n. 2 (1893) 77. - Bras.

Duparciana, Chod. l. c. 409. - Am. austr.

Durandi, Chod. ex Th. Dur. G Pitt. in Bull. Soc. Bot. Belg. xxx. 1891 (1892) 300 ; et l. c. $27 .-$ Costa Rica.

durbanensis, Chod. in Mém. Soc. Pliys. Genère, xxxi. n. 2, 401. - Natal.

Ehlersii, Guerke, in Bot. Fahrb. xix. Beibl.n. 47 (1894) 36. - Afr. trop. or.

\section{POLYGALA}

erubescens, Chod. in Mém. Soc. Phys. Genève. xxxi n. 2 (1893) 398. - Afr. austr.

exasperata, Chod. l. c. 253,- Bras.

extraaxillaris, Chod. l. c. xxx. n. 8 (1889) 103; t. 28, fig. 1. - Parag

fallax, Chod. l. c. 104. - Parag.

fallax, Hemsl. ex Forb. E Hemsl. in fourn. Linn Soc. xxiii. (1886) 59. - China.

Fendleri, Chod. in Mém. Soc. Phys. Genève, xxxi. 11. $2(1893)$ 167. - Venezuela.

filicaulis, Baill. in Bull. Soc. Limn. Paris, i. (1886) 608. - Madag.

Fischeri, Guerke, in Bot. Fahrb. xiv. (1892) 310 . Afr. trop. or.

flabellata, Shuttlew. ex Chod. in Mém. Soc. Phys. Genive, xxxi. n. 2(1893) 53. - Florida.

formosa, $A . W$. Bennett, ex Britton, in Bull. Torrey Bot.Club, xvi. (1837) 19. - Bolivia,

Francheti. Chod. in Mém. Soc. Phys. Genève, xxxi. n. 2 (1893) 276. - Bras.

Funckii. Chod. l. c. 224. - Venezuela

Gagnebiniana, Chod.l. c. 321. - Zanzib.

Galeottii, Chod.l.c. 28 [err.cal. Galleotii].-Mexic.

Galmeri, Chod. l.c. 48. - Venezuela

Galpini, Hook.f. in Bot. Mag. (1895) t. 7439. Afr. austr.

genistopsis, Chod. in Mém. Soc. Phys. Genéve, xxxi. n. 2 (1893) 405. - Afr. austr.

gigantea, Chod.l.c. 75. - Peruvia.

glaucescens, Royle, ex Chod. in Bull. Herb. Boiss. iii. (1895) 126 (= Senecardium glaucescens, Hassk.). - Ind. or.

Glaziovii, Chod. in Mém. Soc, Phys. Geneve, xxxi. n. 2 (1890) 276 [Glaziowii]. - Bras.

gracillima, S. Wats. in Proc. Am. Acad. xxii. (1887) 398. -- Mexic.

Graebiana, Chod in Mém. Soc. Phys. Genève. xxx. n. 2(1889) 110, t. 30, fig. 2. - Parag

Grandidieri, Baill. in Bull. Soc. Linn. Paris, i. (1886) 607 ; Chod. l.c. xxxi.n. 2 (I893) 364. - Madas.

grandis, Hort. ex Gartenfl. xxxvi. (1887) $241=$ latifolia, Ker-Gawl.

Greveana. Baill. in Bull. Soc. Linn. Pavis. i. (1886) 607 ; Chod. in Mém. Soc. Phys. Genéve, xxxi.n. 2 (1893) 330. - Madag.

grisea, A. W. Bennett, in fourn, Bot. xxxiii. (1895) 109. - Reg. Argent.

Guerichiana, Engl. Bot. Fahrb. xix. (1894) 141.-Afr. austro-occ. extratrop.

guatemalensis, A.W. Bennett, in foum. Bot. xxxiii. (1895) 108. - Guatem.

gymnoclada, Mac Owan, in fourn. Linn. Soc. xxv, (1890) 385. - Afr. austr.

Harveyana, Chod. un Mém. Soc. Phus. Genève, xxxi. 11. $2(1893) 412$. - Afr. austr.

heteroptera, A.W. Bennett, ex Kuntze, Rev. Gen. (1891) 47 (= Heterosamara birmanica, Kuntze). Burma.

Hieronymi, Chod. in Mén. Soc. Phys. Genève, xxxi. n. 2 (1893) 302. - Reg. Argent.

Hildebrandtii, Baill, in Bull. Soc. Limn. Paris, i. (1886) 607 ; Chod. l. c. 487. - Madag.

hongkongensis, Hemsl. ex Forb. \& Hemsl. in fourn. Limn. Soc. xxißi. (1886) 60, t. 2. fig. 1-6; Chod. l. c. 350 . - Ins. Hongkozg.

houtboshiana, Chod. in Mém. Soc. Pleys. Genère, xxxi. n. 2 (1893) 408. - Transvaal.

Huberiana, Chod. in Bull. Herb. Boiss, iii. (1895) 122. - N. Granat.

insignis. Klotzsch. ex Chod. in Mém. Soc. Phys. Genive, xxxi. n. 2 (1893) 81. - Bras. mer.

insubrica, Gremli, Neue Beitr. Fl. Schw v. (1890) 22 = nicaeensis, Risso

Jablotzkiana, Fisch. \& Mey. ex Boiss. Fl. or. Suppl. (1888) 75 : Chod, in Mém. Soc. Phys. Genicie, xxxi. n. 2 (1893) $476 .-$ Persia.

jamaicensis, Chod. l. c. 11. - Jamaica.

juncoides, Chod. l. c 210. - Bras.

juniperoides, Chod. l. c. 254. - Bras.

kalaxariensis, Schinz, in Verh. Bot. Ver. Brand xxix. (1888) 52. - Afr, austr.

kaxalariensis, "Schinz) ex Chod. in Mém. Soc. Phys. Genève, xxxi. n. 2(1893) $365=$ praec. kilimandscharica, "Chod." ex Engl. in Abh. Preuss. Akad. Wiss. (1894) $61=$ seq. 


\section{POLYGALA :-}

kilimandjarica, Chod. in Mém. Soc. Phys. Genève, xxxi, n. 2 (1893) 320. - Afr. aequat. or.

Klotzschii, Chod. l. . xxx. n. $8(1889) 114$, in obs. et xxxi. n. 2(1893) 6 (= Acanthocladus brasiliensis, Klotzsch). - Bras.

Krugii, Chod. l. c. xxxi。n. 2 (1893) 63. - Ins, Bahamas.

Kurtzii, A.W. Bennett, in foum. Bot. xxxiii. (1895) 110. - Reg. Argent.

Lecardi, Chod. in Mém. Soc. Phys, Genève, xxxi. n. 2 (1893) 222 . - Sudan. gall.

Lentiana, Guerke, in Engl. Pfanzenw. Ost-Afr. C (1895), 233. - Afr. trop. or.

leptocaulis, Baker, in Fourn. Linn. Soc. xxii. (1887) 445. - Madag.

leptolopha, Chod. iz Mém. Soc. Phys. Genève, xxxi. n. 2 (1893) 147 ( = P. adenophylla, A. W. Bennett) - Bras.

leptosperma, Chod. l.c. 17. - Mexic

leucocarpa, Chod. l. c. 400. - Afr. austro-()cc.

Lindeni, Chod, l. c. 44. - Venezuela.

liniflora, Boj. ex Chod. l. c. 367. - Afr. trop or

Livingstoniana, Clood.l.c. 339 - Transvaal.

lusitanica, Welw.ex Chod. l.c. 441. - Lusit.

lycopodioides, Chod. l. c. $251(=P$. bryoides

A. W. Bennett) - Bras.

lysimachiaefolia, Chod.l. c.377. - Natal

Malmeana, Chod. in Bull. Herb. Boiss. iii. (1895 J4. - Bras.

Mariesii, Hemsl. ex Forb. Eo Hemisl. in fourn. Linn Soc xxiii. (1886) 61, t. 2 b, fig. 7-13. - China.

Mathusiana, Chod. in Mém. Soc. Phys. Genère, xxxi. n. 2 (1893) 231. - Peruvia.

maxima, Guerke, in Engl. Pfanzente. Ost-Afr. C $1895)$ 233. - Afr. trop. or

Michelii, Chod, in Mém. Soc. Pliys. Geneve, xxx. n. (1889) 113, t. 31, fig. 2. - Parag.

michoacana. Robinson of Seaton, in Proc. Am. Acad. xxviii. (1893) 103. - Mexic

modesta, Guerke, in Bot. Fahrb. xix. Beibl. n. 47 1894) 35. - Afr trop. or

nicaraguensis, Chod. in Mém.Soc. Phys. Genève, xxxi. n. 2 (1893) 54. - Nicaragua.

nilotica, Chod. l. c. 369. - Afr. tiop.

nitens, Chod. l. c. S4. - Bras.

mubuca, Hochst. ex Chod. 1. c. $343=$ erioptera, $D C$

obtusissima, Hochst ex Chod. l. c. 322. - Abyss.

opaca, Chod. l. c. 82. - Bras.

Ophiura, Chod. 7. c. 376. - Afr. austro-or

orientalis. Chod. l. c. 324. - Ind. or.

Orobus, Chod.l.c.51.- Bras.

orthocarpa, Chod. l.c. xxx. n. 8 (1S89) 108, t. 30, fig. 1. - Parag.

oxyantha, Phil, in Anal. Univ. Chil. Ixxxi. (1893) 495. - Chili.

oxyrhynchos, Chod. in Mém. Soc. Phys. Genzive. xxxi. n. 2 (1893) 167. - Parag.

panamensis, Chod. l.c. 35. - Panama.

parietaria, Chod.l. c. 50. - Bras.

parvula, Phil. in Anal. Univ, Chil. 1xxxi. (1893) 496. - Chili.

patagonica, Phil. l.c.497. - Patag.

Pavoni, Chod, in Mém. Soc. Phys. Genive, xxxi.n. 2 (1893) 14, - Mexic.

Peplis, Baill, in Bull. Soc. Linn. Paris, i. (1886) 608: Chod. .. c. 341. - Madag.

petraea, Chod. in Mém. Suc. Phys. Goncre, xxxi.n. 2 (1893) 346. - Ukamba

Philippiana, Chod. l. c.300. - Reg. Argent

phlebotaenia, Chod. l. c. 4. - Cuba

piauhiensis, Chod. l. c. 60. - Bras.

Poggei, Guerke, in Bot. Fahrb. xiv. (1892) 309. Afr. trop.

praetervisa, Chod. in Mem. Soc. Phys. Genive, xxxi. n. 2 (1893) 140. - Am. bor.

Pringlei, S. Wats, in Proc. Am. Acad, xxv. (1890) 142. - Mexic.

producta, N.E. Br. in Kev Bull. (1895) 142.Afr. austr.

Pseudocelosioides, Chod. in Mém. Soc. Phys. Genève, xxxi. n. 2 (1893) 237. - Bras.

Pseudocoriacea, C7.od. l. c. 257. - Bras.

Pseudohebeclada, Chod. 2. c. 66. - Bras.

Pseudojuncea. Chod, l.c.211.-Bras.

Pseudosericea, Chod. i. c. 241. - Parag

\section{POLYGALA :}

seudovariabilis, Chod. in Mém. Soc. Phys. Genève, xxxi. n. 2(I893) 181. - Bras.

pterolopha. Chod, l. c.301. -

pulchra. Chod. l. c. 100.- Java.

pygmaea, Guerke. in Engl. Pfianzenw. Ost-Afr. C (1895) 234. - Afr, trop. or.

Radlkoferi, Chod. in Mém. Soc. Phys. Genève, xxxi. n. 2 (1893) 160. - Bras.

recognita, Chod. l. c. 428. - Afr. austr

Regnelli, Chod. in Bull. Herb. Boiss. ii. (1895) 548 - Bras.

Rehmanni, Chod. in Mém. Soc. Pkys. Genève, xxxi. n. 2 (1893) 362. - Transvaal.

retusa, Hochst, ex Chod. 1. c. $342=$ erioptera, $D C$.

rivinifolia, Chod. l. c. 24.- Mexic

rostrata, Chod.l. c.244. - Bras.

Ruiziana, Chod. l. c. 145. - Peruvia.

Sadebeckiana, Guerke, in Engl. Pfanzenw. Ost-Afr.

C (1895) 233. - Afr. trop. or.

salicina, Chod. in Mém. Soc Phys. Genève xxxi, ¿ (1893) 83. - Bras

Sanctae Luciae, Chod. l. c. 36. - Ins. S. Luciae. sansibarensis, Guerke, in Engl. Pfanzenw. Ost-Afr. C. (1895) 233. - Afr. trop. or.

Schimperi, Vatke, ex Engl, in Abhrindl. Preuss, Akad. Wiss. 1891 (1892) 281. nomen: Chod ir Mém. Soc. Phys. Genève, xxxi. n. 2 (1893) 349. - 1 byss. Schinziana, Chod. l.c. 364 . - Afr. austro-occ extratrop

Schweinfurthii, Chod. l. c. 338. - Afr. trop.

scnparioides, Chod. l. c. 285. - Arizona.

senegambica, Chod. l.c. 334. - Senegambia.

Serpentaria, Eckl. ex Chod.l. c. Afr. austr.

singalensis, Chod. l. c. 314. - Zeylan

somaliensis, Baker, in Kew Bull. (1895) 211.

Reg. Somal.

spicata, Chod. in Mém. Soc, Phys. Genère, xxxi, n. 2 (1893) 221. - Angola.

Stanleyana, Chod. l. c. 340. - Angola

Steudneri, Chod.l.c. 390.-

stipulata, Chod. l. c. 89. - Guian. Bat.

Stuhlmannii, Gürke, in Engl. Pfanzenw. Ost-Afr. C (1895) 234. - Afr. trop. or

subulata, S. Wats. in Proc. Calif. Acad. Wiss, xxvi. (1891) 132. - Mexic

tenuissima, Chod. in Bull. Herb. Boiss. iii. (1895)

153. - Reg. Argent.

Tepperi, F. Muell, in Vict. Natural. vii. (July 1890) 38 ; et in Bot. Centralbl. xliii. (1890) $276=$ chinensis, Linn.

Thurmanniana, Chod. in Mém. Soc. Phys. Genève, xxxi. n. 2(1893) 346. - Arabia.

tonkinensis, Chod. l.c.97. - Tonkin.

timoutoides, Chod, l. c. xxx, n. 8 (1889) 112, t

31, fig. 2. - Parag.

Torreyi, Chod.l. c.xxxi. n. 2(1893) 194.-Am. bor.

tovariensis, Chod. l. c. 32. - Venezuela.

transvaalensis, Chod.l. c. 374.- Transvaal.

tricholopha, Chod. l. c. 98. - Ind. or.

tuberculata, Chod, i. c. 242 - Bras.

Tweedyi, Britton. in Mém. Torrey Bot. Club, ii. (1891) 143. - Texas

ukambica, Chod. in Mém. Soc Phys. Genève, xxxi.

n. 2 (1893) 329. - Afr. or.

ukirensis, Guerke, in Bot. Falırb. xiv. (1892) 310. Afr. trop. or

Urbani, Chod. in Mém. Soc. Phys. Genive, xxxi. n. 2 (1893) 58. - Bras.

usambarensis, Guerke, in Abh. Preuss. Akad. Wiss. (1894) 64 ; et in Engl. Pflanzenw. Ost-Afr. C (1895) 283. - Afr trop, or

Vauthieri, Chod, in Mém. Soc. Phys. Genève, xxxi. n. 2 (1893) 65. - Bras.

Villa-Rica, Chod. l. c. xxx. n. S (1889) 106, t. 29, fig. 2, et xxxi. n. 2 (1893) 286. - Parac.

viminalis, Guerke, in Engl. Pfanzenve. Ost-Afr. C (1895) 234. - Afr, trop, or

Vogtii, Chod. in Mem. Soc. Phys. Geneve, xxxi. n. 2 (1893) 144. - Mexic

Volkensii. Guerke, in Engl. Pflanzenw. Ost-Afr. C (1895) 234. - Afr. trop. or

wadibomica, Chod, in Mém. Soc. Phys. Genève, xxxi. (1893) 320. - Afr. or

Warburgii, Chod, ex Warb. in Bot. Fahrb. xiii. (1891) 346. - N. Guin.

\section{POLYGALA :}

Watsoni, Chod, in Mém. Soc. Phys. Geneve, xxxi. n. 2 (1893) 285. - Mexic

Weddelliana, Chod.l. c. 159. - Parag.

Weddelliana Chod. l.c. 207. - Bras.

Welwitschii, Chod.l. c. 340.- Angola.

Wrightii, Chod. l. c. 67. - Cuba.

xyloclada, Chod. l. c. 48. - B-as.

yemenica, Chod. l.c. 32\%. - Arabia.

POLYGONATUM, [Tourn.] Adans. (Liliac.). Ind. Kew. ji. 594

agglutinatum, Hua, in Morot, fourn. de Bot. vi. (1892) 448 - China.

amabile, Yatabé, in Tokyo Bot. Mag. vi. (1892) 279, t. 7; et Icon. Fl. Fapon. i. (1893) 233, t. 57. Japon.

anomalum, Hua, in Morot, Fourn. de Bot, vi. (1892) 420. - China

curvistylum, Hua, l. c. 424, - China.

cyrtonema, Hua, l. c. 393. - China.

Franchetii, Hua, l.c. 392. - China.

nodosum, Hua, l. c. 394. - China.

Delavayi, Hua, l. c. 422. - Yunnan.

erythrocarpum, Hua, l. c. 424. - China.

Fargesi, Hua, l, c. 446. - China, Reg. Himal

fuscum, Hua l. c. 444. - China.

kasuense, Maxim. ex Batalin, in Act. Hort. Petrop. xi. (1891) 493. - China.

Kingianum, Collett of Hemsl. in Fourn. Linn. Soc xxviii. (1890) 28 t. 21; Hook, f. Fl. Brit. Ind. vi. (1892) 322. - Burma

mixtum X C. Richt. P1. Europ. i. (1890) 233. Helv.

platyphyllum, Franch, in Morot. Fourn. de Bot, iv. 1889) 318 - China bor

Prattii, Baker, in Hook. Icon. pl, xxiii. (1892) t. 2217. - China.

pumilum, Hua, in Morot. Fourn. de Bot. vi. (1892) 423 [pumilium]. - China.

Skorpili, Velen, in Sitz. Boehm. Ges. Wiss. (1893) $6 \mathrm{I}$. - Buldr.

Souliei, Hua, in Morot, fourn. de Bot. vi. (1892) 427. - China.

trinerve, Hua, l. c. 445 . - China.

POLYGONELLA, Michx (Polygon.). - Ind. Kew. ii. 594

americana, Small, in Mém. Torrey Bol. Club, v. (1894) $141=$ ericoides, Engelm. \& Gray.

POLYGONIFOLIA, Mappus = Corrigiola, Linn. (Illecebr.).

capensis, Kuntze, Rev. Gen. (1891) 535 = C. capensis, Willd.

deltodea, Kuntze, 1. c. = Monocosmia corrigioloides, Fonzl.

latifolia, Kuntze, 1. c. = Corrigiola latifolia, C. Gay: litoralis, Kuntze. 1. c. = C. Iittoralis, Limn.

propinqua, Kuntze, 1. c, = propinqua, C. Gay.

squamosa, Kuntze, 1. c. = Corrigiola squamosa, Hook. \& Am

telephifolia, Kuntze, 1. c。 = C. littoralis, Limn

POLYGONUM, [Tourn.] Linn, (Polygon.). Ind. Kew. ii. 594

acanthophyllum, Lixdau, in Bot. Fahrb. xix. Beibl. n. 48 (1894) 12. - Reg. Argent.

arachnoideum, Klotzsch, ex Hook. f. Fl. Brit. Ind. v. (1886) $35=$ lanigerum, $R . B r$.

araucanum, Phil. in Anal. Univ. Chil. xci. (1895) 489. - Chili.

auriculatum, Hook. f. \& Thoms. ex Hook. f. Fl. Brit. Ind. v. (1886) $47=$ strigosum, $R . B r$.

axillare, Kuntze, Rev. Gen. (1891) $559=$ Muehlenbeckia dxillaris, $W$ alp.

Banca, Herb. Ham. ex Hook, f. Fi. Brit. Ind. v, (1886) $36=$ minus, Huds

Bettfreudianum, Lindau, in Bot. Fahrb. xix. Beibl. n. 48 (1894) 11. - Reg. Argent.

Bisculatium, Herb. Ham. ex Hook. f. Fl. Brit. Ind. v. $(1886) 39=$ flaccidum, Meissn.

Bishirae, Ham. ex Hook, f. 1. c. 37 = stagninum. Ham.

borealc, Small, in Bull. Torrey Bot. Club, xxi. (1894) $479=$ aviculare, $\operatorname{Lin} n$ 
POLYGONUM :

Buchanani, Dammer, in Engl. Pfanzenw. Ost-Afr. C (1895) 170. - Afr. trop. or.

Caballeroi, Phil. in Anal. Univ. Chil. xci. (1895) 491. - Chili.

cordobense, Lindau, in Bot. Fahrb. xix. Beibl, n. 48 (I894) 10. - Reg. Argent

cynanchoides, Hemsl. in fourn. Linn. Soc. xxvi. (1891) 338. - China

Delfini, Phil. in Anal. Univ. Chit. xc. (1895) 490. - Chili.

dissitiflorum, Hemsl. in fourn. Linn. Soc. xxvi. (1891) 338. - China

Dombeyanum, Kuntze, Rev. Gen. (1891) $559=$ Muehlenbeckia peruviana, Meissn.

emersum, Britton, in Trans. N. Y. Acad. Sci.viii. (1889) 73; Small, Monog. N. Am. Polygon. [Mem. Bot. Columb: Coll. i.] (1895) $44=$ P. Muehlenbergii, S. Wats.

ephiedrodes, Kuntze, Rev. Gen. (1891) $559=$ Muehlenbeckia ephedroides, Hook. $f$.

erythropus, Dammer, in Engl. Pfanzenw. Ost-Afr. C (1895) 170. - Afr. trop. or.

exsertum, Small, in Bull. Torrey Bot. Club, xxi, (1894) 172; et Monog. N. Am. Polygon. [Mem. Bot. Columb. Coll. i.] (1895) 112 t. 43. - Am. bor.

flexuosum, Kuntze, Rev. Gen. (1891) $559=$ Muehlenbeckia adpressa, Meissn.

florulentum, Kuntze, 1. c. = M. Cunninghami, F. Muell.

fluviatile, Herb. Ham. ex Hook, f. Fl. Brit. Ind, v. (1886) 37 = barbatum, Linn

fusiforme, Greene, in Erythea, i. (1893) 259. - Am. bor. occ.

galapagense, Caruel, in Rendic. Acad. Lincei, v. (1889) 624. - Ins. Galapag.

Gilesii, Hemsl. in Hook. Icon. pl. xviii. (1888) t. 1756. - Afghan.

glareosum, Phil. in Anal. Univ. Chil. xc. (1895) 490. - Chili.

Goyalpara, Herb. Ham. ex Hook, f. Fl. Brit. Ind. v. (1886i) 37 = stagninum, Ham .

gracile. Herb. Ham. ex Hook. f, 1, c. $38=$ P. Posumbu, Ham.

graclllimum, Kuntze, Rev. Gen. (1891) $559=$ Muehlenbeckia gracillima, Meissn.

gracilipes, Hemsl. in fourn. Linn. Soc, xxvi. (1891) 340. - China.

Griffithii, Hook.f. Fl, Brit. Ind.v。 (1886) 54..Reg. Himal.

guttuliferum, Miq. ex Hook. fo Fl. Brid. Ind. v. (1886) 42 = alatum, Ham.

hastulatum, Kuntze, Rev. Gen. (1891) $559=$ Muehlenbeckia chilensis, Meissn.

herniarioides, Herb. Strach. \& Winterb. ex Hook. f. F1. Brit. Ind. v. (1886) $28=$ plebejum, $R . B r$.

hirsutum, Herb. Ham. ex Hook. f. 1. C. $36=$ viscosum, Ham.

hypostictum, Miq. ex Hook. f.l. c. $36=$ minus, $H u d s$. Kelloggii, Greene, Fl. Francisc. (1891) 134. - Calif.

leptobotrys, Kuntze, Rev. Gen. (1891) $559=$ Muehlenbeckia leptobotrys, Meissn.

longipes, $H^{r} a$ alácsy \&o Charvel [Nadji] in Oest. Bot. Zeitschr. xl. (1890) 164. - Maced.

longistylum, Small, in Bull. Torrey Bot. Club, xxi. (1894) 165 ; et Monog. N. Am. Polygon. [Mem. Bot. Columb. Coll. i.] (1895) 78, t. 26, - Am. bor.

Marmoramae, Herb. Ham. ex Hook. f. Fl. Brit. Ind. v. (1886) 37 = barbatum, Linn.

Metzianum, Miq. ex Hook, f. 1. c. $42=$ alatum, Ham. mexicanum, Small, in Bull. Torrey Bot. Club, xix. (1892) 356 : et Monog. N. Am. Polygon. [Mem. Bot. Columb. Coll. i.] (1895) 60. - Mexic.

micranthemum, Franch. ex Hook. f Fl. Brit. Ind. v. (1886) $28=$ plebejum, R. Br.

microspermum, Small, in Bull. Torrey Bot. Club, xix. (1892) 366 ; et Monog. N. Am. Polygon. [Mem. Bot. Columb. Coll. i.] (1895) 124 t. 49. - Am. bor microspermum, Sheld. in Minnes. Bot. Stud. i. (1894) $70=$ P. Engelmanni, Greene.

Myosurus, Franch, in Nouv. Arch. Mus. Paris, Sér. II . ₹. (1888) 73. - China. occ.

Newberryi, Small, in Bull. Torrey Bot. Club, xxi. (1894) 170, t. 194 ; et Monog. N. Am. Polygon. [Mem. Bot. Columb. Coll. i.] (1895) 36, t. 5. Am. bor.

\section{POLYGONUM}

Nuttallii, Small, Monog. N.Am. Polygon. [Mem. Bot. Columb. Coll. i.] (1889) 132, t. 53. - Am. bor. occ.

opelousanum, Riddell, ex Small, in Bull. Torrey Bot. Club, xxix. (1892) 354 ; et Monog. N. Am. Folygon. [Mem. Bot. Columb. Coll. i.] (1895) 78. t. 16. Am. bor.

pergracile, Hemsl. in fourn. Limn. Soc. xxvi. (1891) 344 [pergracilis]. - China.

phytolaccaefolium, Meissn. ex Small, in Bull. Torrey Bot. Chub, xix. (1892) 361. - Calif.

pilosum. Hemsl. in fourn. Linn. Soc. xxvi. (1891) 345 (= Koenigia pilosa, Maxim.). - China. pinetorum, Hemsl. l. c. - China.

praetermissum, Hook, f. Fl. Brit. Ind. v. (1886) 47 - Ind. or., Tasmania.

Pringlei, Small. in Bull. Torrey Bot. Club, xix. (1892) 257; et Monog. N. Am. Polygon. [Mem. Bot. Columb. Coll. i.] (1895) 58, t. 16. - Am. bor.

radicans, Hemsl, in fourn. Linn. Soc, xxvi. (1891) 347. - China.

Rapte, Herb. Ham. ex Hook. f. Fl. Brit. Ind. v. 1886) 38 = serrulatum, Lag.

rhyticarium, Kuntze, Rev, Gen. (1891) $559=$ Muehlenbeckia rhytocarya, F. Mwell.

rigidulum. Sheld. in Minnes. Bot. Stud. i. (1894 14, t. 1. - Am. bor.

rupestre, Kuntze, Rev. Gen. (1891) $559=$ Muehlenbeckia rupestris, $W e d d$.

sagittifolium, Kuntze, 1. c. = M. saggittifolia, Meissn. sawatchense, Small, in Bull. Torrey Bot. Chub, xx. (1893) 213; et in Monog. N. Am. Polygon. i. (1895) 120, t. 47. - Am. bor. occ.

Schimperi, Vathe, ex Engl. in Abh. Pyeuss. Akad. Wiss, 1891 ii. (1892) 202. - Afr. trop. or

spergulariaeforme. Meissn. ex Small, in Bull. Torrey Bot. Clшb, xix. (1892) 366. - Am. bor. occ. tatarioum, Wall. ex Hook. f. Fl. Brit. Ind. v. (1886) $52=$ tortuosum, Don

tiliaefolium, Kuntze, Rev. Gen. (1891) $559=$ Muehlenbeckia tiliaefolia. Wedd.

Tuerckheimii, Vatke, ex Small, in Bull Torrey Bot. Club, xix. (1892) 370, in syn. = Meisnerianum, Cham. \& Schlecht.

urophyllum, Barean \& Franch. in Morot, fourn. de Bot. v. (1891) 150. - China occ.

valdivianum, Phil, in Anal. Univ. Chil. xc. (1895) 488. - Chili.

varians, Kuntze, Rev. Gen。(1891) $559=$ Muehlenbeckia varians, Meissn.

Watsoni, Small, Monog. N. Am. Polygon. [Mem. Bot. Columb. Coll. i.] (1895) 138, t. 56. Am. bor.

Znccarinii, Small, l. c. 158, t. 66. - Am. bor.

POLYLEPIS, Ruiz \& Pav.(Rosac.). - Ind. Kew. ii. 599 .

Besseri, Fieron. in Bot. Fahrb. xxi. (1895) 312 (= $P$. villosa, Rusby), - Bolivia.

Lehmannii, Hieron. l. c. xx. Beibl. n. 49 (1895) 29. - Columb. vel Ecuad.

Pauta, Hieron. l. c. xxi. (1895) 313. - Ecuad.

reticulata, Hieron. l.c.312. - Ecuad.

Stuebelii, Hieron. l. c. 313. - Ecuad.

villosa, Rusby, in Mem. Torrey Bot. Club, iii. (1893) $25=$ P. Besseri, Hieron.

POLYMNIA, Linn. (Compos.). - Ind. Kew. ii, 600 .

Liebmanni, Sch. Bip. ex Klatt, in Leopoldina, Heft xxiii. (1887) 89. - Mexic

oaxacana, Sch. Bip. l.c. - Mexic.

quichensis, Coult. Bot. Gaz. xx. (1895) 48. Guatem.

tarapacana, Phil. in Anal. Mus.nac. Chile (1891) 21. - Chili.

Pol yosma, Blume (Saxifr.). - Ind. Kew. ii. 600. bracteosum, Stapf, in Trans. Linn. Soc., Ser. II. iv. (1894) 148. - Borneo

Hookeri, Stapf, in Hook. Icon, plo xxiii. (IS94 t. 2296. - Borneo.

reducta, F. Muell, in Vict. Natural. ix. (June 1892) 42 ; et in Bot. Centralbl. 1i. (1892) 252. Austral.
POLYOSMA :

rigidiuscula, F. Muell, of F. M. Bailey, in Dept. Agric, Brisbane Bot. Bull, i. (1890) 4. - Austral.

POLYPARA, Lour. = Houttuynia, Thunb. (Piperac,

cordata, Kuntze, Rev. Gen, (1891) 565 = H. cor. data, Thunb.

POLYPETALIA speciosa, Hort. ex Gard. Kew, i. Polypet. (1894) $135=$ Prunus italica, Borkh.

POLYPOGON, Desf. (Gramin.) - - Ind. Kew, ii. canadense, Fourn. Gram. Mexic. 1881 (1886) $92=$ Agrostis mexicana, Limn.

majus. Hackel, ex Batt. Go Trab. Fl. de l'Algér. [Monoc.] (1895) 153 (= P. algeriense, Gandog.). - Alreria.

tarapacanum, Phil. in Anal. Mus. nac. Chile (1891) 82. - Chili.

POL YPOMPHOLYX, Lehm. (Lentibul.). - Ind. Kew. ii. 601

Holtzei, F. Muell. in Vict. Natural. ix. (Mar, 1993) 176 ; et ex Bot. Centralbl. liv. (1893) 93 , in syn. $=$ Utricularia Holtzei, F. Muell.

POLYPORANDRA, Becc. (Icacin.). - Ind. Kew. ii. 601.

Hansemanni, Engl. Bot. Fahrb. xvi, Beibl. n. 39 (1893) 13. - N. Guin,

POLYPTERIS, Nutt. (Compos.). - Ind. Kew. ii.

latifolia, Hemsl. in Biol. Centr.-Am. iv. (1886) 59. - Mexic.

sphacelata, Trelease, ex Branner \& Coville, in Ann. Rep. Geol. Surv. Arkans, for 1888, i. (1891) 197 = Hookeriana, A. Gray.

POL YRRHIZA, Pfitz, in Engl. \& Prantl. Natîrl. Pflanzenfam. ii. 6 (1889) 215. ORCHIDEAE. funalis, Pfitz.l.c. (= Aeranthus funalis, Lind1.). Jamaica.

POLYSGIAS, Forst. (Umbell.). - Ind. Kew. ii. 601 .

aculeata, Harms, in Engl. \& Prantl, Natürl. Pfanzenfam. iii. 8 (1894) 45 (= Cuphocarpus aculeatus, Decne). - Madag

amplifolia, Harms, l. c. (= Panax amplifolium, Baker). - Madag.

Anisum, Harms, l. . . (= P. Anisum, DC.). - Ins. Moluce.

austro-caledonica, Harms, l.c. $(=P$, austro-caledonica, Baill.). - N. Caled.

Balansae, Harms, l. c. (= P. Balansae, Baill.) , N. Caled.

cissiflora, Harms, l. c. $(=$ P. cissiflonm, Baker $)$ Madag.

confertifolia. Harms, $l$. o. $(=P$. confertifolizm Baker), - Madag.

Cumingii, Harms, l. c. $\quad(=P$. Cumingianum Rolfe). - Ins. Philipp.

dioica, Harms, l. c. (= Cussonia dioica, Vieill.). N. Caled.

elegans, Harms, l.c. $i=$ Panax elegans, C. Moore \& F. Muell.). - Austral.

farinosa, Harms, in Engl. E Prantl, Natiirl. Pfanzenfam. ii1. (1894) 45 (=Aralia.farinosa, Del. - Abyss.

fruticosa, Harms, l. c. $45(=$ Panax fruticosum Linn.). - As, et Ocean. trop.

gomphophylla, Harms, l. i. $(=$ P. gomphophyl lum, Baker). - Madas

inermis, Harns, l. c. $l=$ Cuphocarpus inermis Baker). - Madar.

Kissodendron, Harms, l. i. $(=$ Panax cissodendron C. Moore \& F. Muell.), - Austral.

Macgillivrayi, Harms, l. c. $(=$ P. Maggillieraei, Benth.). - Austral.

madagascariensis, Harms, l.c. $44(=$ Maralia madagascariensis, DC.). - Madag

microbotrys, Harms, l. c. $(=$ Panax microbotrys. Baill.). - N. Caled. 


\section{POLYSCIAS :}

Dollis, Harms, in Engl, Es Prant, Natiml. Pfanzentfan iii, $S(1894)(=P$, molle, Benth. $)$ - Austral. multibracteata, Horms, l. c. $(=$ Panax multibracteatum, Baker). - Madag.

multijuga, Harns.. . c. $(=\dot{P}$. multijugum, Benth. \& Hook. f.). - Ins, Fiji.

Murrayi, Harms, l.c.(= P. Murrayi, F. Muell.).Austral.

myriophylla, Harms, l.c. (=P. myriophyllam, Baill.).

obtusa, Harms, l. c. (= P. obtusum, Blume). Java.

ornifolia, Harms, l.c. (= P. ovalifolium, Baker). Madag.

Pancheri. Harms, l.c. (= P. Pancheri, Baill.). N. Caled.

pentamera, Harms, l.c. $(=P$. pentamera, Baker $)$. - Madag.

pulchella, Harms, l.c. $(=$ P. pulchellum, Baill.). N. Caled.

Rumphiana, Harms, l. c. $(=P$. pinnatum, Lam. - Archiv. Mal.

sambucifolius, Harns, l. c. $(=P$. sambucifolium, Sieber). - Austral.

samoënsis, Harms, $l, c,(=P$, samoënse, A. Gray $)$. - Ins. Samoens.

Stuhlmanni, Harms, ex Engl. Pfanzenw. Ost-Afr. A (1895) 130 , nomen. - Afr. trop. or.

suboricularis, Harms, in Engl. \& Prantl, Natiurl. Pfanzenfan. iii. 8 (1894) 45, - N. Caled.

tahitensis, Harms, l, c. $(=$ Panax talitense, Nadeaud). - Ins, Tahit.

tripinnata, Harns, l. c. $44(\doteq$ P. tripinnatum Baker): - Madag.

Weinmanniae, Harms, l. c. $(=$ P.W cimmanniae, Baill.). - N. Caled,

xanthoxyloides, Harms, l. c. $(=P$. xanthoxyloides, Baker). - Madag.

POLYSPHAERIA, Hook, f. (Rubiac.), - Ind Kew. ii. 601.

neriifolia. K. Schum, in Engl. Pfanzenve. Ost-Afr. C (1895) 383. - Afr. trop, or

POLYSTACHYA, Hook. f, (Orchid.), - Ind. Kew. ii. 601 .

acutifolia, Lindl. ex Kuntre, Rer. Gen. (1891) 639 (= Dendrorchis aculifolia Kuntze). - [Quid?

albescens, Ridl. in Bolet. Soc. Brot.v. (1887) 199. Ins. S. Thom.

albo-violacea, Kracnzl. in Bot. Fahrb. xvii. (1893) 50. - Afr. trop

Beciarii, "Reichb, f.» ex Martelli, F1. Bogos. (1886) $80=$ Beccariana, Reichb.

Buchanani, Rolfe, m Kew Bull. (1893) 33ĩ. - Zambesia.

bulbophylloides, Rolfe, l. c. (1891) 199. - Afr. trop. or.

caespitifica, Kracnzl. ex Engl.in Abh. Prenss. Akad. Wiss. (1894) 47; in Engl, Pfanzonv. Ost-Afr.C (1895) 155; et in Bot. Fahrb. xxii. (1895) 21. Afr, trop, or.

cucullata, Th. Dur. \& Schinz, Consp. Fl. Afr. V. $1892(1895) 34=$ grandiflora, Lindl

disticha, Rolfe, in Bolet. Soc. Brot. ix. (1891) 139. Ins. S. Thome.

Dusenii, Kraenzl. in Bot. Fahrb. xix. (1894) 251.

Kamerun.

Elliotii, Rendle, in foum. Bot. xxxiii. (1895) 198.Afr. trop. or

expansa, Ridl. in Bolet. Soc. Brot.v. (18S7) 198. - Afr. trop. occ.

farinosa, Kracnsl. in Bot. Zahrb. xvii. (1893) 51.Kamerun.

glaberrima, Schlechter, in Bot, fahrb. xx. Beibl. n. 50 (1895) 11. - Afr. austr.

gracilenta, Kraenzl. \%. c. xix. (1894, 251. - Afr. trop. or

imbricata, Roife, in Kew Bull. (1893) 172. - Zambesia.

Kirkii, Rolfe, l. c. (1895) 283. - Afr. trop. or.

Laurenceana, Kraenzl. 2n Gard. Chron. (18931 ii. 150. - Zambesia.

minima, Rendle, in fourn. Bot. xxxiı. (1895) 198. Afr. trop. or.

\section{POLYSTACHYA}

igrescens, Rendle, in Fourn. Bot, xxxiii. (1895) 201. - Afr. trop. or.

polychaete, Kraenzl. in Bot. Fahrb. xvii. (189:3) 50. - Kamerun

Preussii, Kraenzl. l. c. 51. - Kamerun

Rivae, Schweinf, in Bull. Herb. Boiss. it. App. II (1894) 88. - Eritrea.

ruwenzoriensis, Rendle, in fourn. Bot. xxxiii. (1895) 199. - Afr. trop. or

Sheora, Kranzl, ex Enol, in Abh. Prenss, Akad. Wiss (1894) 57 ; in Engl. Pfanzenw. Ost-Afr. C (1895) 155; et in Bot. Fahrb. xxii. (1895) 22. - Usambara simplex, Rendle, in foum. Bot. xxxiii. (1895) 199 - Afr, trop, or.

spatella, Kraenzl, in Bot. Fahrb. xix. (1894) 25l. Afr. trop. or.

stauroglossa, Kraensl. in Engl. Pfanzenw. Ost-Afr. C (1895) 155; et l. c. xxii. (1895) 22. - Afr trop. or.

Stuhlmannii, Kraenzl. ll. cc. - Afr, trop, or.

Tayloriana, Rendle, in fourn. Linn. Soc. xxx. (1895) 385. - Afr. trop. or.

tenuissima, Kraenzl. in Bot. Fahrb. xix. (1894) 250 - Kamerun.

transvaalensis, Schlechter, l.c. xx. Beibl. n. 50 (1895) 28. - Transvaal.

villosa, Rolfe, in Kew Bull.(1894) 393. - Zambesia zambesiaca, Rolfe, l. c. (1895) 192. - Zambesia.

POLY'TOGA, R. Br.(Gramin.). - Ind. Kew, ii.

Cookei, Stapf, in Hook. Icon, pl. xxiv, (1894) t. 23:3: - Ind, or.

POLYTRIAS, Hack. in Engl. \& Prantl, Natürl. Pflanzenfam, ii. 2(1887) 24. GRAMINEAE. anaura, Kuntze, Rev. Gen. (1891) $788=$ praemorsa, Hach

diversiflora, Baill. Hist. des pl. xii. (1894) $319=$ praemorsa, Hack.

praemorsa, Hack, in Engl. \& Prantl. Natiurl. Pfanzenfam. ii. 2(1887) 24; et in DC. Monog. Phan.vi. (1889) 189 (= Pollinia praemorsa, Nees), - Java.

POL YXENA, Kunth (Liliac.), - Ind. Kew. il. 602.

Bakeri, Th. Dur. \& Schinz, Consp. Fl. Afr. v. 1898 (1895) 366 (= Massonia pygmuea, Schlecht.). Afr. austr.

haemanthoides, Baker, in Hook. Icon. pl. xviii. (1888) t. 172\%. - Afr. austr.

odorata, Nichols. Dict. Gard. iii. (1886) 196. - Afr. austr.

POMADERRIS, Labill. (Rubiac.). - Ind. Kew. ii. 602

amoena, Colenso, in Trans. N. Z. Inst. xviii. 188. (1886) 258. - N. Zel.

mollis, Colenso, l. c. xxv. 1892 (1893) 327. - N. Zel

POMA TOSTOMA, Stapf, in Hook. Icon. pl. xxv (1895) sub t. 3420. MELASTOMACEAE, angustifolium. Stapf, l. c. t. 2420. - Borneo. inaequalis, Stapf, l. c. t. 2421. - Borneo phyllagathoides, Stapf, l. c. - Borneo. sertuliferum, Stapf, l. c. t. 2420. - Borneo.

POMAZOTA, Ridl, in Trans. Linn. Soc, Ser. II. iii, (1893) 308. RUBIACEAE.

sylvestris, Ridl. l. c. - Penins. Mal.

POMMERESGHIA, Wittm. in Gartenfl. xliv. (1895) 131. ZINGIBERACEAE

Lackneri, Wittm. . c., fig. 35. - Ind, or.

PONGAMIA, Vent. (Legumın.). - Ind. Kew. ii. 604

dehiscens, Koevd. E Valet. Boomsoort. van fav'a, ii. (1895) 96. - Java

PONGATIUM, Juss. = Sphenoclea, Gaertn (Campanul.).

zeylanicum, Kuntze, Rev, Gen. (1891) $381=$ S. zeylanica. Gaertii.
PONGELION, Fl. For. Cochinch. Fasc. 19 (1893) sub t. 294, in text. = Ailanthus, Desf. (Simarub:?

calycimum, Pierre, $1 . \mathrm{c}_{0}=\mathrm{A}$. calycinus, Pierre

excelsum, Pierre, 1. c sub t, $295 \mathrm{~A}=\mathrm{A}$. excelsus Roxb.

Fawvelianum, Pierre, 1. c. sub t. $295 \mathrm{~B}=\mathrm{A}$. Fauvelianus, Pierre.

glandulosum, Pierre, 1. c. sub t. $294=$ A. glanduIosus, Desf.

mberbiflorm, Pierre, 1.c. $=$ A imberbiflorus, F. Muell.

malabaricum, Pierre, 1. C. $=$ A. malabaricus, $D C$. moluccanum, Pierre, 1. c. sub t. $294=$ A. moluccanus, $D C$.

PONGONIA, "Griff, » ex Grant. Orchids of Burma (1895) 351. sphalm. = Pogonia, Griff. (Orchid.)

PONTHIEVA, R. Br. (Orchid.). - Ind. Kew. ii. 604.

dicliptera, Reichb. f. in Flora, 1xix. (1886) 548. N. Granat.

grandiflora, Reichb. f. in Gard. Chron. (1888) i. 264. - Ecuad.

phaenoleuca, Cogn, in Mart. Fl. Bras, iii. IV. (1895 273 (= Calorchis phaenoleuca, Barb, Rodr.). Bras.

Sprucei, Cogn. l. c. 274, t. 66, fig. 3. - Bras.

POORTMANNIA, Drake, in Bull. Soc, Philom Paris, Sér. VIII. iv. (1892) 128. SOLANEAE. peciosa, Drake, l. c. 129. - Ecuad.

POPoWIA, Endl. (Anonac.), - Ind. Kew. ii. 60\%. usca, King, in foum. As. Soc. Beng. 1xi. (1892) II. 94. - Perak.

Hookeri, King, l. c. 97. - Ind. or

Kurzii, King, l.c. 96 ( $=$ P. macrophylla, Hook, f. \& Thoms.). - As. trop.

micrantha, Baker, in fourn. Linn. Soc. xxii. (1887) 442. - Madag.

nitida, King, in fourn. As. Soc. Beng. 1xi. (1892) II. 92. - Ins. Andam. et Nicob.

perakensis, King, l.c.94.-Perak

velutina, King, i. c. - Perak.

POPULINA. Baill. Hist. des pl. x. (1890) 443; Lindau, in Engl, \& Prantl, Natürl. Pflanzen. fam. iv, 3b (1895) 344. ACANTHACEAE

Richardi, Baill. ll. cc. - Madag.

POPULUS, Linn. (Salic.). - Ind. Kew, ii. 605.

ambigua X, G. Beck. Fl. Nied.-Oest. 1. (1890) 305. - Austria.

Avembergiana. Hort. ex Dippel, Handb. Laubholzk. ii. (1892) 191 ( = P. Avenbergica, Hort.) = alba, Linn

crispa, Hort. ex Dippel, 1. c. $209=$ laurifolia. Ledeb.

Eugenii, Simon, ex Gartenfl. xxxvi. (188\%) 674; et in Gard. Chron. (1887) ii. 818 (an P. Engenei, Hort. ex C. Koch) = monilifera, Ait.

grandifolia, Hort. ex Wesm. in Bull. Soc. Bot. Belg. xxvi. 1887 (1889) $375=$ heterophylla, Linn.

Fuliana-pendula, Hort. ex Dippel, Handb. Laubholzk. ii. (1892) $192=$ canescens, Sm.

lasiocarpa, Oliver, in Hook. Icon. pl. xx. (1890) t. 1943. - China.

microcarpa, Hook. $f$. E Thoms. ex Hook. f. Fl. Brit. Ind. v. (1888) 639. - Bhotan.

monticola, T. S. Brandeg. in Zoe, i. (1890) 274 . Calif.

Nolestii, Hort. ex Dippel, Handb. Laubholzk. ii, (1892) $199=$ nigra, Linn.

ovata, Hort. ex Dippel, 1. c. 199, sphalm. et 5s: (ad calc.) (Quid ?).

Petrowskiana, Schroed. ex Dippel, 1. c. 200. Koehne, Deutsche Dendrol. (1893) $82=$ canadensis, Moench

Rasumofskyana $X$, "Schroed. " ex Koehne, 1. c. $84=$ seq.

Rasumowskiana, "Schroed. " ex Dippel, Handb. Laubholzk.11. (1892) 204. - Hab.

serotina, Hort. ex Dippel, 1. c, $202=$ angulata. Ait. 
POPULUS :

Steiniana X. Bornm. in Gartenfl. xxxvii. (1888) 173, fig. 37 et 38 ; et in Bot. Centralbl. xxxvi. (1888) 154. - Bulg.

tristis, «Fisch, » ex Dippel, Handb. Laubholzk. ii. (1892) 204; Koehne, Deutsche Dendrol. (1893) 82. - Hab. ?

Viadri X, Ruediger, in Abh. Naturw. Ver. Reg.Bezirk. Frankf. viii. (1889-90), ex Gartenf. xxxix. (1890) 447; Koehne, Deutsche Dendrol. (1893) 84. - Germ.

Woustii, Schroed. ex Dippel, Handb. Laubholzk. ii. (1892) 207 = balsamifera. Linn.

PORANA, Burm. f. (Convolv.). - Ind. Kew, ii. 606.

densiflora, Hallier $f$. ex Engl. in Abr. Prenss. Akad. Wiss. (1894) 26 et 34 ; et in Bot. Fahrb. xviii. (1894)-93. - Afr. trop, or.

sinensis, Hemsl. in fourn. Iinn. Soc. xxvi. (1890) 167. - China.

velutina, Hallier $f$. in Bot. Fahrb. xvi. (1893) 538 (=-Dufourea? velutina, Mart. \& Gal.). - Mexic

PORCELIA, Ruiz \& Pav. (Anonac.). - Ind. Kew ii. 606 .

microcarpa, 7. D. Smith, in Coult. Bot. Gaz, xx. (1895) 1. - Guatem

PORLIERIA. Ruiz \& Pav.(Zygophyll.). - Ind. Kew, ii. 606.

Lorentzii, Engl. in Engl. \& Prantl. Natiurl. Pfanzenfam. iii. 4 (1890) 84.- Reg. Argent.

POROPHYLLUM, Vaill, ex Linn. (Compos.), Ind. Kew. ii. 606

crassifolium, S. Wats, in Proc, Am. Accd, xxiv, (1889) 57. - Mexic.

Pringlei, Robinson, l. c. xxvii. (1893) 178. - Mexic

POROSPERMUM, F, Muell. (Aral.). - Ind. Kew. ii. $60 \%$.

Michieanum, F. M. Bailey, Syn. Queensl. Fl. Suppl. iii. (1890) 31 i= Delarbrea Michieana. F. Muell.) = Michieanum, F. Muell.

PORPHYROCOMA, Scheidw. = Dianthera, Linn. (Acanth.)

lanceolata, Hort, ex Lindau, in Engl. \& Prantl, Natürl. Pflanzenfam.iv. 3b (1895) $342=$ serpens. Lindau.

Pohliana, Lindau, in Bot. Jahrb. xviii. (1894) 40 et 57 ; et 1. c. (= Orthotactus Pohliames, Nees).Bras.

serpens, Lindau, 11. cc, $(=$ Amphiscopia serpens, Nees). - Columb.

PORPHYROSTEMMA,. Benth. (Compos.). Ind. Kew, ii. $60 \%$.

cuanzensis, O. Hoffm, in Bolet. Soc. Brot. x. (1892) 174. - Angola.

PORTEA, C. Koch (Bromel,). - Ind. Kew, ii $60 \%$.

Gardneri, Baker, Handb. Bromel. (1889) 21. - Bras. Glaziovii, Baker, l. c. 22. - Bras.

Legrelliana, Nichols. Dict. Gard. iii. (1886) 202. Bras.

Noettigii, Mez, in Mart. Fl. Bras. iii. II. (1892) $296=$ Aechmea Noettigii, Wawra.

petropolitana, Mez, l. c. $297=$ Ae. petropolitana, Wawra.

tillandsioides, Nichols. Dict, Gard. iii. (1886) 302 - Bras.

PORTERANTHUS, Britton, in Mem. Torrey Bot. Club, iv. (1893) $115=$ Gillenia. Moench (Rosac.).

stipulatus, Britton, 1. c. t. $77=$ G. stipulata, Nutt. trifoliatus, Britton, 1 , c. t. $76=\mathrm{G}$. trifoliata, Moench.

PORTLANDIA; P. Br. (Rubiac.), - Ind. Kew. ii. 607.

pterosperma, S. Wats, in Proc. Am. Acad. xxiv. (1889) 53. - Mexic.
PORTULACA. Linn. (Portul.), 一 Ind. Kew, ii 607

cyclophylla, F. Muell. in Proc. Linn. Soc. N. S. Wales, Ser. II. v. (June 1890) 16. - Austral.

dubia: F. G. O. Tepper, in Trans. and Proc. Roy. Soc. S. Austral. xvii. (1893) 16. - Austral.

Fischeri, Pax, in Bot fahrb. xvii. (1893) 585. Afr. trop. or.

parvula, A. Gray, in Proc. Am. Acad. xxii. (1887) 274. - Am. bor. austro-occ.

POSADAEA, Cogn, in Bull. Acad. Belg, Sér. II. xx. (1890) 476; Muell. \& Pax, in Engl. \& Prantl, Natürl. Pflanzenfam. iv. 5 (1894) 393, in obs. CUCURBITACEAE.

sphaerocarpa, Cogn. $l 7 . c c .477$; et 393.- Columb.

POSOQUeriA, Aubl. (Rubiac.). - Ind. Kew macrantha, Hort. ex Baill. Hist. des pl. xi. (1892) $331=$ Deherainia smaragdina, Decne.

POTAMOGETON. [Tourn,| Linn.(Naiad.).-

\section{Ind. Kew, 11, 609 .}

Aschersonii, A. Bennett, in foum. Bot. xxxi. (1893) 294. - Chili.

aulacophyllus, K. Schum. in Mart. Fl. Bras. iii. III. (1894) 696. - Reg. Argent.

australis, F. Phil. ex Phil. in Anal. Mus, nac. Chite (1891) 95; et in Anal. Univ. Chil. xci. (1895) 525. - Chili.

Bennettii $\times$, Fryer, in Journ. Bot. xxxiii. (1895) I. t. 348. - Brit.

Billupsii X, Fryer, 1, c. xxxi. (1893), 353. t. 337 338. - Brit.

borealis. Kihlm, ex Bot. Notiz. (1887) $84=$ gramineus, Linn.

capensis, Scheele, ox A. Bennett, in Annal. Naturh, Iofmus. Wien, vii. (1892) 287, nomen. - Afr. austr.

coriaceus, Fryer, in fourn. Bot. xxvii. (1889) 8. Germ. Brit.

crassifolins $\times$. Fryer, 1. c. xyviii, (1890) 321. t. 299. - Brit.

Curtissii, Morong, in Bull. Torrey Bot. Club, xiii. (1886) 145. - Florida.

Delavayi, A. Bennett, in fourn. Bot.:xxx. (1892) 22S. - Yunnan

dubius, Tiselius (Potam. Suec. exsicc.n. 19) in Bot. Notiser (1894) 165. - Suecia.

falcatus, Fryer, in Fourn. Bot. xxvii. (1889) 65, t, 286. - Brit

Faxoni, Morong, in Mem. Torrey Bot. Chub, iii. 2 (1893) 22, t. 32. - Am, bor.

Gayii, A. Bennett, in Annal. Naturh. Hofmus. Wien, vii. (1892) 293. - Urug.

millensis, Welw. ex A. Bennett, 1. c. $292=$ java nicus, Hassk.

latifolius, Morong, in Mem. Torrey Bot. Club, iii. $2(1893) 52$, t. $59=$ pectinatus, Linn

limosellifolius, Maxim. ex Korshinsky, in Act. Hort.

Pétrop. xii. (1892) 393. - Sibir.

Lundii $X$, C. Richt, P1. Europ. i. (1890) 13.Suecia.

major, Morong, in Mem. Torrey Hot. Club, iii. II. (1893) $41=$ P. Friesii, Ruprecht

major, Morong, ex MacMill. Metasp. Minn. (1892) 37 , in syn. = rutilus, $W$ olfg.

mexicanus, A. Bennett, in fourn. Bot. xxv. (1887) 289. - Mexic,

Miduhikimo, Makino, ex A. Bennett, l. c. xxx. (1892) 229. - Japon.

montevidensis, A. Bennett, in Amnal. Naturh. Hofmus. Wien, vii. (1892) 293. - Urug.

monticola, Schweinitz, ex A. Bennett, 1. c. 293, in syn. = confervoides, Reichb.

nipponicus, Makino, ex A. Bennett, in fourn. Bot. xxx. (1892) 229. - Japon.

peruvianus, Presl, ex A. Bennett, in Annal. Naturh. Hofmus. Wien, vii. (1892) 292, in syn. $=$ mexicanus, $A$. Bennett.

Phialae, Post, in Bull. Herb. Boiss. i. (1893) 409 $=$ trichoides, Linn.

pumilum, Nutt.' ex A. Bennett, in Annal. Naturh. Hofmus. Wien, vii. (1892) 293, in syn. = I'. Robbinsii, Oakes.
POTAMOGETON :

Purshiamus, Morong, \& MacMill. Metasp. Minn. (1892) 39, in syn. = pauciflorus, Pursh.

reflexus, Herb. Vind. ex A Bennett, in Annal, Naturh. Hofmus. Wien, vii. (1892) $291=$ zosterifolius, Schum

vioularis, Gillot, in Magnier, Scrin. A. select vi. (1887) 118 ; et in Bull. Soc. Dauph. xiv. (1887; 584 = lanceolatus, Smith

sclerocarpus, $K$. Schum. in Mart. Fl. Bras, iii. III. (1894) 688. - Bras.

sibiricus, A. Bennett, in Fourn. Bot. xxviii. (1890) 300. - Sibiria.

spathulaeformis, Morong, in Mem. Torrey Bot. Club, iii. 2 (1892) 26 t. 35. - Am. bor.

stenostachys, $K$. Schum. in Mart. Fl. Eras. iii. III. (1894) 687. - Bras.

suecicus, C. Richt. Pl. Europ. i. (1890) 15. Suecia.

sulcatus, A. Bennetl, in Annal. Naturh. Hofmus. Wien, vii. (1892) 294. - Austral

lenuifolius, - F. Phil. ex Phil. in Anal. Mus, nac. Chile (1891) App. [95]; et in Anal. Univ. Chil. xci. (1895) $521=$ P. Aschersonii, A. Benmett.

Tepperi, A. Bennett, in Fourn. Bot. xxv. (1887) 178. - Austral

Thomasii, (Auct. ?) ex A. Bennett, in Annal, Naturh. Hofmus, Wien, vii. (1892) $286=$ alpinus, Balb.

Tiselii X, C. Richt. P1. Europ. i. (1890) 13. Suecia.

tretocarpus, Maxim. ex A. Bennett, in Journ. Bot. xxix, (1891) 154; et in Annal. Naturh. Hofmus. Wien, vii. (1892) $289=$ mucronatus, Fries.

Ulei, $K$. Sclum, in Mart. Fl. Bras, iii. III. (1894) 690. - Bras.

tricarinatus, F. Muell. \& A. Bennett, ex A. Benm nett, in fourn. Bot. xxx. (1892) 229. - Austral.

varians, Morong, ex Fryer, in Journ. Bot. xxii. 1889) 33, t. 287 et xxy. (1892) 308; Morong, in Mem. Torrey Bot. Club, iii. 2(1893) $26=$ spathulaeformis, Morons.

Wolfgangi, Kihlm. Herb. P1. Mus, Fenn. (1889) et 128; et A. Bennett, in Annal. Naturh. Hofmus. Wien, vii. (1892) $292=$ gracile. Wolfg. Wrightit, Morong, in Bull. Torrey Bot. Club, xiii.

1886) $158=$ lucens, Linn.

POTAMOPITYS, Linn. = Elatine, Linn.

Alsinastrum, ambigua, americana, brachysperma, californica, campylosperma, hexandra. Hydropiper, inaperta, macropoda, major, triandra. Kuntze, Rev. Gen. (1891) $58=$ homonyma omnia Elatines.

POTENTILLA, Linn. (Rosac.), - Ind. Kew, ii 611.

adriatica, Murb. in Lunds Unir. Arsskrift. xxvi1. v. (1892) 134, - Herceg.

adscharica, Sommier of Levier, ex R. Keller, in Bot. fahrb. xiv. (1892) 509. - Reg. Canc.

aetnea, Tornab. Fl. Sicula (1887) 226. - Sicil.

Alberti, Zinm. Beitr. Kenntn. Gatt. Potent. (1889) 33.- - Gall. mer.

ambigens,-Greene, in Erythea, i. (1893) 5. - Color. Andersonii, Greene, Pittonia, i. (Nov, 1887) 104 (= Horkelia parviflora, Nutt.). - Am. bor. occ. Andrzejouskii, Blocki, in Oest. Bot. Zeitschr. xxxviii. (1888) 407. - Galicia

Amtheris $X$, Huter, ex Siegfr. in Ber. Schweiz. Bot. Gesells, iii. (1893) 128. - Helv., Tirol. arizonica, Greene, Pittonia, i. (Nov. 1887) $\perp 04=$ Ivesia pinnatifida, S. Wats.). - Am. bor, occ. armeniaca, Siegfr. [Exsicc. Potent. (1892) n. 648] ex Zimm. in Oest. Bot. Zeitschr, xliii. (189:3) 36 = collina. Wibel.

articulata, Franch. Pl. Delav.(1890) 210.- Yunnan.

Baenitzii, Borb. in Oest. Bot. Zeitsclir, xliii. (1893) 437, nomen. - Silesia.

Baileyi, Greene, Pittonia, i. (Nov.1887) 105 (=Ivesia Baileyi, S. Wats.). - Am. bor. occ.

Battersbyi, Siegfr. ex R. Keller, in Bot. Centralbl. xxxix. (1889) 242 ; et xl. (1889) $203=$ arenaria, Borkh.

bellowensis, Siegfr. [Exsicc, Potent. (1892) n. 万10? ex Oest. Bot. Zeitschr. xliv. (1894) 156. - As. Min. 


\section{POTENTILLA :}

benacensis, Zimm.ex [Siegfr. Exsicc. Potent. (1894) n. 952 b] Oest. Bot. Zeitschr. xliv. (1894) 150, nomen. - Ital., Tirol.

Besseana X. Siegfr. [Exsicc. Potent. (1893) 11. 937] in Ber. Schweiz. Bot. Gesells. iii. (1893) 129: et in Bull. trav. Soc, Murith, Fasc. xxi-xxii. (1894) 119. - Helv

biennis, Greene, Fl. Francisc. (1891) 65; et Man. Bot. San Franc. Bay (1894) 115. - Calif.

bohemica, Blocki, ex Woloszrak, in Spraw. Kom. fizy. Krajow. xxii. (1888) 218; Zimm, Beitr. Kenntn. Gatt. Potent. (1889) 1\%. - Bohem.

Bolanderi, Greene, Pittonia, i. (Nov. 1887) 103 (= Horkelia Bolanderi, A. Gray). - Calif.

bolzanensiformis, Sauter, in Oest. Bot. Zeitschr. xxxviii. (1888) 114. - Tirol.

Borpmuelleri, Borb. Enum. Pl. Comit. Castrif. $(1887-88) 311=$ recta, Linn.

borussica, Uechtr。ex [Siegfr. Exsico. Potent. (1891) n.139| Zimn. Beitr. Kenntn. Gatt. Potent. (1890) 19. - Boruss.

Brandisiana, Siegfr. [Exsicc. Potent. (1892) n. 910] ex Zimm, in Oest. Bot. Zeitschr. xliii. (1893) 36, nomen, = collina, Wibel.

Bronia $X$. Huter, ex A. Kern Sched. Fl. Austrom Hung. iv.(1886) 14. - Tirol.

brevistipula, Dumas, in Rev. d'Auvergne (1891) cum ic. ; et ex Rev, sci. Bourb. v. (1892) 20 = aurea, Linn

Buschakii, Blocki, in Oest. Bot. Zeitschr, xxxv. (1885) 291, et xlii. (1892) 351. - Galicia.

Buseri X. Siegfr. ex R. Keller, in Bot. Centralbl. xl. (1889) 202. - Helv.

calcicola, Blocki, ex [Siegfr, Exsicc, Potent. (1892) n. 328] Zimm. in Oest, Bot, Zeitschr, xliii。 (1893) 36 , nomen. = inclinata, Vill.

californica. Greene, Pittonia, i. (Nov. 1888) 100 ; et Man. Bot. San Franc. Bay (1894) 116 (= Horkelia californica, Cham. \& Schlecht.).- Calif.

Candriani X, Siegfr. in Ber. Schweiz. Bot, Gesells, ii. (1892) 102, et vo (1895) 122. - Helv

capitata, Greene, Pittonia, i. (Nov. 1887) 104 (= Horkelia capitata, Lindl.). - Am. bor. occ.

cardinalis, Hort, ex Zimm. in Oest. Bot. Zeitschr. xli. (1891) $39=$ argyrophylla, Wall.

Chodatiana $\times, \mathrm{Ph}$. Paiche, ex Siegfr. in Ber. Schweiz. Bot. Gesells, iii. (1893) 129. - Helv. chulensis, Siegfr. E Keller, ex Keller, in Bot. Fahrb. xiv. (1892) 504. - Reg. Cauc.

ciliata, Greene, Pittonia, i. (Nov. 1887 103. Calif.

Clevelandi, Greene, l. c. 102. - Am. bor. occ.

confusa X, Prahl, Krit. Fl. Prov. Schlesv.-Holst, ii. (1890) 89 - Germ. bor.

commixta $X$, Hausskn. ex Nym. Consp. Fl. Eur. Suppl. ii. I. (1889) 112; et in Mitth. Thür. Bot. Ver. N. Folge, v. (1893) 96. - Graecia.

Cornati, "Buser » ex Oest. Bot. Zeitschr xliii. (1893) 181. sphalm. = seq

Comazi X, Buser, ex Zimm. Beitr. Kenntn.Gatt, Potent.(1889) 23; M. Besse, in Bull. Soc. trav. Murith. Fasc. $x x i-x x i 1,(1894) 121=$ argentea, Linn.

crassicaulis, Blocki, ex [Siegtr. Exsicc. Potent. (1891) n. 98] Zimm. Beitr. Kenntn. Gati. Potent. (1889) 15. - Podolia.

daucifolia, Greene, Pittonia, i. (Jan. 1888) 160. - Calif. Davidi, Franch, in Nour. Arch. Mus. Paris, Sér. II. viii. (1886) 222, - China occ

decipiens, Greene, Pittonia, i. (Nov, 1887) $106(=$ Ivesia pygmaea, A. Gray). - Calif.

Delavayi, Franch. Pl. Delav. (1890) 215. - Yunnan. Dichtliana, Blocki, ex [Siegfr. Exsicc. Potent. (1890) n. 97] Zimm. Beitr. Kenntn。Gatt. Potent. (1889) 15. - Austria.

dispersa $\times$, Hausskn. ex Nym. Consp. Fl. Eur. Suppl, ii. 1. (1889) 112: et in Mitth. Thür. Bot. Ver. N. Folge, v. (1893) 98. - Graecia

divina, Alboff, in Soc. Imp. Hortic. (Compt.-rend. Sect. Odessa) (1891) extr. 10; et Prodr. Fl. Colch. (1895) 81 , in syn. = Oweriana, Rupr.

Doerfieri, Wettst. in Luerss, Bibl, Bot. Heft xxvi. (1892) 39, t. 2 fig. 17, 20 - Albania.

dolosa X. Hausskn. ex Zimm. Beitr. Kenntn. Gatt. Potent. (1889) 15; et in Mitth. Thür. Bot. Ver. N. Folge, v. (1893) 98. - Graecia, Oriens,

\section{POTENTILLA}

Donnell-Smithii, looke, ex F. D. Smith, in Coult. Bot. Gaz. xvi. (1891) 3. - Guatem.

Douglasi, Greene, in Pittonia, i. (Nov. 1887) 105 (= Horkelia fusca, Lindl.). - Am. bor. occ

elata, Greene, l. c. $(=H$. californica, Cham. \& Schlecht.) - Calit.

eremica, Coville, in Proc. biol. Soc Wash. vii. (1892) 76. - Calif

fallacina, Blocki, ex Zimm. in Oest. Bot. Zeitschr. xli, (1891) 38; et xlii. (1892) 35I = recta, Linn.

Favrati, Zimm, ex Favrat, in Bull. trav. Soc. Murith. Fasc, xiii-xv. (1887) 62: Botan. Kalender (1887) 67 ; et Beitr. Kenntn. Gatt. Potent. (1889) $10=$ P. Tormentilla, Neck.

foliosa, Somm. \& Levier, ex Keller, in Bot. fakrb. xiv. (1892) 500. - Reg. Cauc.

frondosa, Greene, Pittonia, i. (May 1889) 300; et Man. Bot. San Franc. Bay (1894) 116. - Calif.

Gelmiana X, Siegfr. [Exsicc. Potent. (1894) n. 984a] ex Keller, in Bot Centralb1. 1xi. (1895) 288. - Helv., Tirol.

Gibelliana, Siegfr. [Exsicc. Potent. (1894) n, 978] ex Keller, l.c. - Italia.

ginsiensis, Woloszczak, in Köszeg Videken. edenyes Növen. (1891) 64 ; Zinm. in Oest. Bot. Zeitschr. xli. 1891) 381, et xlii. (1892) 289. - Hung.

Goirani, Zimm. Beitr.Kenutn. Gatt. Potent. (1889) 22. - Italia.

Gordoni, Greene, Pittonia, i. (Nov, 1887 ) $106(=$ Horkelia Gordoni, Hook.). - Am. bor. oce.

graja, Beyer, in Wiss. Beil. Progr. Andreas Realgymn. Berl. (1891), ex Oest. Bot. Zeitschr. xli. (1891) $17 \%$ - Germ.

grandiceps, Zimm. Beitr. Kenntn. Gatt. Potent. 1889) 25 = argentea, Lin 32

Gremblichii X, Gandoger, ex Murr. in Deutsche Bot. Monatsschr. ix. (1891) 23. - Europ.

Gremlii, Zimm. Beitr. Kenntn. Gatt. Potent. (1889) 10. - Helv.

haematosticta, Goiran in Giorn Bot. Ital, xxi. (1889) 270 ; xxii. (1890) 537. - Helv.

Halacsyana, Degen, in Oest. Bot. Zeitschr. xli. (1891) 306 et 334. - Ins. Samothr.

Herbichii, Blocki, in Oest. Bot. Zeitschr. xxxv. (1885) 291 ; Zimm. Beitr. Kenntn. Gatt. Potent. (1889) 14 et in Bot. Centralbl. xl. (1889) 243. - Eur. or.

heterosepala, Fritsch, in Bot. Fahrb. xi. (1889) 314. - Am. centr.

Hoolzzi X, Blocki, in |Siegfr. Exsicc. Potent. (1892) n. 322 Oest. Bot. Zeitschr. xlii. (1892) 147 (= P. commutata, Blocki). - Austro-Hung.

Honoratae X, Blocki, ex [Siegfr. 1. c. (1892) n. 939] Zimm. 1. c. xliii. (1893) 36, nomen. - Podolia. Howellii, Greene, Pittonia, i. (Nov. 1887) 104. Oregon.

Huteri $\times$, Siegtr. in Ber. Schweiz. Bot. Gesells. iii. (1893) 128, et in Bull, tav. Soc. Murith. Fasc, xxi-xxii. (1894) 121. - Helv.

intercedens $\%$, Hausskn. ex Nym. Consp. F1. Eur. Suppl. ii. I. (1889) 112; et in Mitth. Thür. Bot Ver. N. Folge. v. (1893) 97. - Graecia.

Faggiana $\times$, Siegfr. ex R. Keller, in Bot. Centralbl. xl. (1889) 199 ; et 1xii, (1895) 35. - Helv. kaeseri $\times$ Sieofr, in Ber. Schweiz. Bot, Gesells. ii. (1892) 102. - Helv.

Karoi, Uechtr. ex Zimm. Beitr. Kenntn. Gatt. Potent. (1889) $18=$ collina, Wibel.

Kelleri X, Siegfr. ex R. Keller, in Bot. Centralbl xl. (1889) 201. - Helv.

Kelloggii, Greene, Pittonia, i. (Nov, 1887) 101 ; et Man. Bot. San Franc. Bay (1894) 116 (= Horkelia Kelloggii, Greene). - Calif.

Kingii, Greene, Pittonia, i. (Nov, 1887) 105 (= Ivesia Kingii, S. Wats.). - Am. bor. occ.

kionaea, Halácsy, in Verh, zool.-bot. Ges. Wient, xxxviii. (1888) 751. - Graecia.

Knappii, Blocki, ex Zimm. Beitr. Kenntn. Gatt. Potent. (1889) 19 ; et in Oest. Bot. Zeitschr, xxxix. (1889) 8. - Galicia

Koernickii, Uechtr. ex Zimm. Beitr. Kenntn. Gatt. Potent. (1889) 19. - Eur.

lasiothrix $\times$, G. Beck, Fl. Nied.-Oest. ii. I. (1892) 759. - Austria.

laxiflora, Drew, in Bull. Torrey Bot. Club, xvi. (1889) 151. - Calif

\section{POTENTILLA}

Lemmoni. Greene, Pittonia, i. (Nov. 1887) 104 (= Ivesia Lemnoni, S. Wats.). - Am. bor, occ.

leopoliensis, Blocki, in Oest. Bot. Zeitschr. xxxvii. (1887) 334; et xlii. (1892) 351; Zimm. Beitr Kenntn. Gatt. Potent. (1889) $\mathbf{1 6}=$ recta Iinn.

lencochaeta, Borb. in Termész. Fuzét. xiv. (1893) $48=$ hirta, Linn

leucopolitanoides, Blocki, in Oest. Bot. Zeitschr. xxxvi. (1886) 103; Zimm. Beitr. Kenntn. Gatt. Potent. (1889) $18=$ collina, Wibel.

leucotricha, Borb. in Oest. Bot. Zeitschr. xxxiv. (1884) 78; Bornm, in Bot. Centralbl. xxxvi. (1888) 59 - Eur. centr. et or.

Levieri. Siegfr. \& Keller, ex R. Keller, in Bot. fahrob. xiv. (1892) 511. - Reg. Cauc.

ligurica $\times$, Siegfr. [Exsicc. Potent. (1894) n. $974 a]$ ex Zimm. in Oest. Bot. Zeitschr. xlv. (1895) 38 nomen. - Italia.

Lindleyi. Greene, Pittonia, i. (Nov. 1887) $10 \mathrm{I}=$ multijuga, Lehm.

longifrons, Borb. in Oest. Bot, Zeitschr. xxxvii. (1887) 404 (= P. longifolia, Borb.). - Hung.

magyarica, Borb. ex H. Braun, l. c. xxxix. (1889) 310. - Hung

mallota, Boiss. Fl. Or. Suppl. (1888) 234. - Persia Mermodi X, Siegfr, ex R. Keller, in Bot. Centralbl. xl. (1889) 243 \& 303 ; Favrat, in Bull. trav. Soc Murith. Fasc. xvi-xviii. (1890) 8. Helv.

micans $\times$, Hausskn. ex Nym. Consp. Fl. Eur. ii. I. (1889) 112 ; et in Mitth. Thür. Bot. Ver. N. Folge, v. (1893) 97. - Graecia.

Micheneri, Greene, in Erythea, i. (1893) 5 ; et Man Bot. San Franc. Bay (1894) 11\%. - Calif.

mirabilis, Siegfr of Moehrlen. ex Siegfr. [Exsicc. Potent. (1894) n. 998] in Ber. Schweiz. Bot. Gesells, v. (1895) 123. - Jurass.

Muirii, Greene, Pittonia, i. (Nov, 1887) 106 (= Ivesia Miurie, S. Wats.). - Am, bor. occ.

monacensis, Woerlein, in Deutsche Bot. Monatsschr. vii. (1889) 8. - Germ.

monticola, Zimm. Beitr. Kenntn. Gatt. Potent. (1889) 31. - Helv.

moupinensis, Franch. in Nouv. Arch. Mus. Paris Sér. II. viii. 1885 (1886) 222. - China occ.

Murithii, Besse, ex Siegfr. [Exsicc. Potent. xi. (1894) n. 960, et vii. (1895) n. 960a in Bull. trav. Soc. Murith. Fasc. xxi-xxii. (1894) 120 ; et in Ber. Schueiz. Bot. Gesells. v. (1895) 124. - Helv

mutinensis, Siegfr. [Exsicc. Potent. (1894) n. 970a] ex Zinm, in Oest, Bot, Zeitschr, xliv, (1894) 156 - Italia.

Nicicii, Adamovic, l. c. xlii. (1892) 406. - Serbia.

Nicolletii, Sheld. in Minnes. Bot. Stud. i. (1891) it = supina, Linn, var. Nicolletii, S. Wats.

nifdaghensis, Zimm. ex Stapf, in Denkschr. Akad. Wien, ii. (1886) 23. - As, Minn.

nubigena, Greene, in Erythed iii. (1895) 36. - Calif. nyssana, Petrov. ex Zimm. Beitr. Kenttn. Gatt Potent. (1889) 15. - Serbia.

okensis X, Petunnikov, ex [Siegfr. Exsicc. Potent (1894) n. 985] Act. Hort. Petrop. xiv. (1895) 17 t. 5 ; Bot. Centralbl. 1xi. (1895) 288 [okaënsis]. - Ross. med.

Paicheana $\times$, Siegfr. in Ber Schweiz. Bot. Gesells. 1i. (1892) 102. - Helv.

pallidioides, M. Besse, ex Siegfr. [Exsicc. Potent. (1893) n.947] l.c. 129; et in Bull. trav. Soc. Murith. Fasc. xxi-xxii. (1894) 119. - Hely.

papuana, Focke, in Abh. Naturw. Ver. Brem, xiii. (1895) 162. - N. Guin.

Parryi, Greene, Pittonia, i. (Nov. 1889) 102 (= Hockelia Parryi, Greene), - Am. bor. occ.

parvula. Hook.f. ex Stapf, in Hook. Iion. pl. xxiii. (1894) t. 2294. - Borneo

pedatoides $\times$. Hausskn. ex Nym. Consp. Fl, Eur. ii. I. (1889) 112; et in Mitth. Thür. Bot. Ver. N. Folge, v. (1893) 97. - Graecia.

Pelivarovicii, Petrov. ex Borb. Enum. Pl. Comit. Castrif. (1887-88) 311, nomen $=$ recta, Limn perincisa, Borb. in Oest. Bot. Zeitschr. xli. (1891) 424, nomen. - Hung.

Peyritschii, Zimm. in Ber. Naturo. Ver. Innsbr. xix. (1891) 37; Siegfr. in Bot. Centralbl. 1xii. (1895) 38. - Helv. 


\section{POTENTILLA :}

Pickeringii, Greene. Pittonia, i. (Nov, 1887) $105(=$ Ivesia Pickeringii, Torr.). - Am. bor. occ,

Piersii X, Siegfr. [Exsiec. Potent. (1892) n. 938 ex Zimm. in Oest. Bot. Zeitschro xliii. (1893) 36. - Hung.

pindicola Hausskn. ex Zimm. Beitr. Kenntn. Gatt Potent. (1889) 15; et in Mitth. Thür. Bot. Ver. N. Folge, y. (1893) $95=$ canescens, Bess. pocutica, Woloszczak, in Spraw Kom. fizyj. Krajow. xxviii. (1888) ii. 218. - Hung.

podolica, Blocki, in Oest. Bot. Zeitschy. xxxv. (1885) 291; Zimm. Beitr. Kenntn. Gatt. Potent. (1889) 17. - Podolia

porphyracea, Santer, in Oest. Bot. Zeitschr. xxxviii. (1888) 113 ; et 8xxix. (1889) 211. - Tirol.

poterioides, Franch. Pl. Delav. (1890) 212. Yunnan.

praecocioides. Sauter, in Oest. Bot. Zeitschr, xxxix. 1889; 211, nomen $\doteq$ collina, Wibcl.

Prinolei, S. Wats, in Proc. Am, Acad, xxiii. (1888) 272. - Mexic

Pseudo-argentea, Blocki, [Siegfr. Exsicc, Potent. (1890) n. 1531 in Zimm. Beitr. Kenntn. Gatt. Potent. (1889) 23. - Galicia.

Psendo-canescens $\times$, Blocki, |Siegfr. Exsicc. Potent. (1890) n. 3331 ex Zimm, in Oest. Bot. Zeitschr. xli. (1891) 39, et xlii. (1892) 351. — Gall., Austro. Hung.

Pseudo-chrysantha, Borb. (in Temesneg. vegyet. (1884) 76 ex Zimm. Beitr. Kenntn. Gatt. Potent. (1889) 29 = chrysantha. Ten.

Pseudo-Herbichii, Blocki, [Siegfr. Exsicc. Potent. (1890) n. 74] ex Zimm. Beitr. Kenntn. Gatt. Potent. (1889) 14. - Galic., Podol.

Pseudo-obscura, Blocki, [Siegfr, l. c. (1;91) n. 73] ex Zimm. l. c. - Galic., Podol.

Pseudo-pallens, Siegfr. [Exsicc. Potent. (1892) n. 946 ex Zimm. in Oest. Bot, Zeitschr. xliii. (189:3) 36, nomen $=$ recta, Linn

Pseudo-rubens, Siegfr. [Exsicc. Potent. vi. (1894) n. 928 a et b] in Ber. Schweiz. Bot. Gesells. ii (1892) 102, et v. (1895) 123, nomen. - Helv.

Psendo-Serpentini X. Waisb. in Oest. Bot. Zeitschr. xliii. (1893) 35\%. - Hung.

puberula, Greene, Pittonia, i. (Nov, 1887) 102.Calif.

purpurascens, Greene, l. c. $105(=$ Horkelia purpenrascens, A. Gray). - Am. bor, occ.

pyenochaeta, Borb. in Termés\%. Fuzét, xiv, (1893) 48. - Hung.

Reineckei X. Sagorski, in Deutsche Bot. Monatschr. ix. (1891) 53. - Thuring.

Roemeri, Siegfr. ex R. Keller, in Bot. Centralbl. x1. 1889) 171, - Transsilv.

rubens, Zimm, ex Sagorski \& Schneid. Fl. Centralkarp. ii. (1891) 137 (= Fragaria rubens, Crantz $=$ opaca, Linn

rubiformis, Czerneaen, ex R. Keller, in Bot, Jahrb. xiv. (1892) 512, in syn. = elatior, Schlecht.

sabulosa, M. E. Fones, in Proc. Calif. Acad. Ser. II. v. (1895) 680. - Am. bor. occ.

Salpichae, “ Blocki ) ex Bot. Centralbl. xl. (1889) 243, sphalm. = P. Sapichae, Blocki.

sanguisorbifolia, Favre \& Wolf, ex Wolf, in Bull. trav. Soc. Murith. Fasc. xvi-xviii. (1890) 33, Helv.

santolinoides, Greene, in Pittonia, i. (Nov, 1887) 106 (= Iresia santolinoides, A. Gray). - Am. bor. occ.

Sapichae, Blocki, in Oest. Bot. Zeitschr. xxxv. (1885) 291; Zimm. Beitr. Kenntn. Gatt. Potent. (1889) 17. - Galic, Podol.

Sauteri, Zimm. l. c. 18. - Tirol.

saxosa, Lemmon, ex Greene, Pittonia, i. (June 18=8) 171. - Calif.

Scholziana X. Callier, in Deutsche Bot. Monatsschr. ix. (1891) 7. - Germ. or.

Schroeteri X, Siegfr, in Ber. Schweiz. Bot. Gesells. ii. (1892) 102 ; Jacc. in Nouv. Mém. Soc. Helv. sci. nat. xxxiv. (I895) 425. - Helv

scopulorum, Greene, in Erythea, i. (1893) 4. Colorado,

semilaciniosa, Borb. [Budapestnek es Kornyeken. Novenyz. (1879) 164] [in Terms, rajzi. Fuzet. 1893], ex Oest. Bot. Zeitschr, xliv。 (1894) 429 $=$ recta, $L i n n$

\section{POTENTILLA}

ericata, Greene, Pittonia, i. (Nov, 1887) 104. (= Horkelic sericata, S. Wats.). - Am. bor, occ. Sibbaldia, F. Kurtz, in Bot. Jahrb. xix. (1894) 375 $=$ P. Sibbaldia, Greissel $)=$ Sibbaldia procum bens, Limn.

Siegfriedii, Zimm. Beitr. Kenntu. Gatt. Potent. (I889) 32. - Helv.

silesiaca, Uechtr ex Zimm. l. c. 19, - Silesia.

Sintenisii, Siegfr. \& $R$. Keller, in Bot. Fahrb. xiy. (1892) 506. - As. Min.

Skofitzii. Blocki, in Oest. Bot Zeitschr. xxxv. (1885) 291 ; Zimm. l. c. 32. - Galicia.

Slendzinskii, Blocki, l. c. xxxviii. (1SS8) 181; Zimm. l. c. 17. - Galicia.

Sommierii, Siegfr. \& Keller, ex R. Keller, in Bot. falorb xiv. (1402) 506 - Reg Cauc.

fahrb. xiv. (1892) 506. - Reg. Cauc.
stenoloba, Grene, in Erythea, iii. (1895) $36(=P$. tenuiloba, Greene, non Jord.). - Calif.

sterilis, C. Richt, in Verh. zool.-bot. Ges. Wien, xxxviii. (1888) Sitz. $97(=P$. sterilis, Garcke $)=$ P. Fragariastrum, Ehr/r.

subcanescens $X$. Waisb. [Kösz. ex Videkénék edenyes növ. nyei (1891) 63] ex Oest. Bot. Zeitschr. xli. (1891) 381 - Hung.

sttunivalis X. Bruegg. ex M. Besse, [Siegfr. Exsicc. Potent. (159:3) n. 254 bl in Bull. trav. Soc. Murith. Fasc xxi-xxii. (1894) $122(=P$. pul cholla, Rruegrg. olim). - Helv.

subsericea, Hautsshn, in Mitth. Thür. Bot. Ver. N. Folge, v. (1893) 94. - Graecia.

sundaica, Kuntze, Rev. Gen. (1891) $219=$ Kleiniana, Wight of Arn.

superargentea, Waisb. [Kösz. es Videkenek edenyes növ. nyei (1891) 63] ex Oest. Bot. Zeitschr. xli. (1891) 381, et xlii. (1893) 289. - Hung.

svanetica, Siegfr. of Kellev, ex Keller in Bot. Fahro. xiv. (1892) 507. - Reg. Cauc.

Tabernaemontani, Aschers, in Abh. Bot. Ver. Prov. Brand. xxxii. (1891) $156=$ verna, Linn.

tenuiloba, Greene, Pittonia, i. (Nov. 1887) 105; et Man. Bot. San Franc. Bay (1894)116 (= Horkelia temailoba, Greene). - Calif.

tenuirugis, Pomel, ex Batt. \& Trab. Fl. de l'Algér. [Dicot.] (IS89) $304=$ hirta, Linn.

thyraica, Blocki, [Siegfr. Exsicc. Potent. (1890) n. 72] ex Zimm. Beit. Kenntn. Gatt. Potent. (1889) 14. - Podolia.

Tilingi, Greene, Pittonia, i. (Nov. 1887) $105=$ tridentata, Soland.

tirolensis, "Zimm. » ex Nym. Consp. Fl. Eur. ii. I. (1890) 362, sphalm. = tiroliensis, Zimm.

tossiensis, Siegfr. [Exsico. Potent. (1894) n. 712].As. Min.

Tollii, Trautw. in Act. Hort. Petrop. x, (1889) 507. - Sibir.

Trefferi $\times$, Siegfr, in Ber. Schweiz. Bot. Ges. ii. (1892) 102; et in Bot. Centralb1. 1xii. (1895) 38; Wilczek, in Bull. Soc. Bot. Fr. xli. 1894 (1895) Sess. extr.p.275. - Helv, Tirol.

tridentina, Gelmi, [Sirgfr. Exsicc. Potent. (1894)n. 9871. - Tirol.

tuberculata, Porta, in Atti Accad. Agiati, ix. (1891) extr. 24: Willk. Suppl. Prodr. Fl, Hisp. (1893) 227 . - Hisp

tuberosa, f. Wolf, [Siegfr. Exsicc. Potent. (1894) n. 914]. - Transsilv.

(uricensis, «Siegfr, » ex Keller, Fl. von Winterthur, i. (1891) 59, sphalm. = turicinensis Siegfr.

Tynieckii $\times$, Blocki, in Oest. Bot. Zeitschr. xxxix. (1889) 49. - Galicia.

umbrosa $X ; \mathrm{Hy}$, in Bull. Herb. Boiss. i. App. I. (1893) 15. - Gall.

umbrosaeformis, Siegfr. \& Alboff, ex Alboff, en Bull. Horb. Boiss. ii. (1894) 640. = Reg. Transcauc. unguiculata, Greene, Pittonia, i. (Nov. 1887) 105. (= Ivesia unguiculata, A. Gray). - Am. bor. occ

utahensis. Greene, Pittonia, i. (Feb. 1888) $162(=$ Ivesia utahensis, S. Wats.). - Utah.

veronensis, Zimm. [Siegfr. Exsicc. Potent. (1894) n.

977]. - Italia.
villosa, G. Beck, in Ann. Naturh. Hofmus. Wien, v. (1887) 116 ; Zimm. ex Sagorski \& Schneid. Fl. Centralkarp. ii. (1891) 138 (= Fragaria villosa Crantz). - Eur. centr.
POTENTILLA : -

vitodurensis, "Siegfr, 》 ex Bot, Centralbl, xi. (1889) 202 et 243 = vitodurinensis, Sicg fr.

Waisbeckevi $X$, Siegfr. [in Waisb. Köszeg Vidékenek. edényes növe nyei (1891) 63] ex Oest. Bot. Zeitschr。 xlii. (1892) 289. - Hung

Webberi, Greene, Pittonia, i. (Nov. 1887) 105 (= Ivesia Webberi, A. Gray), - Am. bor. occ.

Wolffiana X, Siegfr. [Exsicc. Potent. (1891) n. 3:34]. - Transsilv.

Wolfi $\times$, Siegfr. in Ber. Schweiz. Bot. Gesells, ii. (1592) 102. - Helv.

Zapateriana, Pau, Not. Bot. Fl. Espan, iii. (1889) 18; Willk. Suppl. Prodr. Fl. Hisp. (1893) 226. - Hisp.

POTERANTHERA, Bong. (Melast.). - Ind. Kew. ii. 616.

foliosa, Cogn. in DC, Monog. Phan. vii. (1891) 121. - Bras.

gracillima, Cogn.

Naud.). - Bras.

POTERIUM, Linn. (Rosac.). - Ind. Kew, ii. 616. officinale, Benth. G Hook. f. ex Hemsl. \& Forb. in fourn. Linn. Soc. xxiii. (1887) $247=$ officinale, A. Gxay.

rhodopeum, Velen. in Sitz. Bochn. Ges, Wiss. (189293) 27. - Bulg.

POTHOS, Linn. (Aroid.). - Ind. Kew. ii. 617.

aroenteus, Bull. Catal.(1887) 11. - Borneo.

nitens, Bull. l. c. - Malaya.

Curtisii, Hook. f. Fl. Brit. Ind. vi. (1893) 554.Penins. Mal.

Kingii, Hook. f. l. c. 553. - Perak.

Kunstleri, Hook. f. l. c. 554 , - Perak.

lancifolius, Hook. f. l. c. - Perak

latifolius, Hook. f. l. c. - Perak.

macrocephalus, Scortech. ex Hook.f. l. c. 553.Perak.

Maingayi, Hook. f. l. c.554. - Malacca

Wallichii, Hook. f. l. c. 553. - Penins. Mal.

POTHUAVA, Gaudich. = Aechmea, Ruiz \& Pav. (Bromel.).

pycnantha, Hort. ex Baker, Handb. Bromel. (1889) $44=$ Ae. pycnantha, Baker

POTTSIA, Hook. \& Arn. (Apocyn.). - Ind. Kew. ii. 618 .

laxiflora, Kuntze, Rev. Gen. (1891) $416=$ cantonensis, Hook. \& Arr.

POUGHETIA, A. Rich. (Rubiac.), - Ind. Kew. Baumanniana, Buettn. in Verh. Bot, Ver, Brand, xxxi. (1889) 83. - Congo.

PoUTERIA, Aubl. (Sapot.). - Ind. Kew. ii, 619. crassinervia, Eng7. Bot. fakrb. xii. (1890) 514. Bras.

Schenckii, Engl. l. c. - Bras.

Sellowii, Engl. l. c. in obs. (= Lucuma Sellowii, A. DC.). - Bras.

tovarensis, Engl. in Engl. \& Prantl, Natuirl. Pfanlzenfam. iv. 4 (1891) 142. - Am. austr.

POUZOLZIA, Gaudich. (Urtic.). -- Ind. Kew.ii. 619

arabica, Deflers, Voy. au Yémen (1889) 206. Arabia.

frondosa, Kuntze, Rev. Gen. (1891) $630=$ viminea, Wedd.

fuscescens, Kuntze, l. c. - Java.

nivea, S. Wats. in Proc. Am. Acadoxxii. (1887) 453. - Mexic.

Palmeri, S. Wats. l. c. - Mexic.

zeylanica, Kuntze, Rev. Gen. (1891) $631=$ indica, Gaudich.

POZOA, Lag. = Azorella, Lam. (Umbell.).

elegans, Colenso, in Trans. N.Z. Inst. xxii. 1890 (1891) $386=\mathrm{A}$, elegans, Colenso

micradonta. Colenso, 1. c. $387=$ A. microdonta, Colenso. 
PRADOSIA. Liais = Lucuma, Molina (Sapot.). Zactescens, Radlk, in Sitzb. Akad, Muench. xviii. (1888) $407=$ L. glycyphloea, Mart

intescrns, Radlk, in Th. Dur. Ind. Gen. Phan. (1888) 501, sphalm. = lactescens, Radlk.

PRAINEA, King, ex Hook. f. Fl. Brit, Ind. v. (1888) 546. URTICACEAE.

scandens, King, l. c.54\%, - Perak.

PRANGOS, Lindl. (Umbell.), - Ind. Kew, ii. Bungei, i3oiss, Fl. Or. Suppl. (1888) 260. - Persia, Bungei, P3oiss. Fl. Or. Suppl. (1888) 260. - Persia. Akad. Wien (1886) ii. 56. - As. Min.

PRANTLEIA. Mez, in Mart. Fl. Bras, iii. III. (1891) 257. BROMELIACEAE.

Glabra, Mez, l. c. - Bras.

leprosa, Mez, l. c. 259. - Bras.

PRASOPHYLLUM, R, Br, (Orchid.). - Ind,

\section{Kew. if, 620.}

Baueri, Fitzger, Austr. Orchids, iii. II. (1888) cum ic. (= Genoplesim Baneri, R. Br.). - Austral.

Deanianum, Fitzger, l.c. cum ic. - Austral.

Dixoni, F. Muell. in Vict. Natural. ix. (June 1892) 44 ; et ex Bot. Centrabl. 1i. (1892) 253. - Austral. Fitzgeraldi, Dean, ex Tate, in Trans. Roy. Soc. S. Austral. xix. (1895) 82, nomen. - Austral.

Frenchii, F. Miwell. in Vict. Natwral. vi. (Dec, 1889) 126; et in Bot. Centralbl. xli. (1890) 122. Austral.

Laufferianum, Maury, in Morot, Fourn. de Bot. ii. (1888) 302, cum xylogr. - Austral,

pauciflorum, Colenso, in Trans. N. Z. Inst. xviii. 1885 (1886) 273. - N. Zel.

transversum, Fitzger, Austral. Orchids, iv. II. (1891) cum ic. - Austral.

variegatum, Colenso, in Trans. N. Z. Inst, xx. 1887 (1888) 208. - N. Zel.

PRATIA, Gaudich. (Campanul.). - Ind. Kew. ii. 621.

borneensis, Homsl. in Hook. Icon. pl. xvi. (1886) 1532. - Borneo.

nummularia, Kuntze, Rev. Gen. (1891) $381(=P$ mummularia, Benth.) = begonifolia, Lindl.

physaloides, Schoent. in Engl. of Prantl, Natuirl. Pfanzenfam.iv. $5(1889) 69(=$ Colensoa physaloides, Hook. f.). - N. Zel.

PREMNA, Linn. (Verben.). - Ind. Kew. ii. 621. angolensis, Guerke, in Bot. Fahrb. xviii. (1894) 165. - Congo, Angola.

cauliflora, Stapf, in Trans. Limn. Soc., Ser. II. iv. 1894) 215. - Borneo.

formosana, Maxim. in Bull. Acad. Pétersb. xxxi. (1887) 80. - Ins. Formos.

glabra, A. Gray, ex Maxim. ..c. - Japon.

Hildebrandtii, Guerke, in Bot. Falkb. xviii. (1894) 165. - Zanzibar.

Holstii, Guerke, ex Engl. in Abh. Preuss. Akad. Wiss. (1894) 16: et in Engl. Pfanzenzw. Ost-Afr. C (1895) 338. - Afr. trop. or.

ligustroides, ITemsl, in fourn. Limn. Soc, xxvi. (1890) 256. - China,

macroscyphon, Baker, in Bolet. Soc. Brot. x. (1892) 148. - Ins. S. Thom.

nana, Collett \& Hemsl. in fourn. Linnn. Soc. xxviii. (1891) 109. - Burma.

nitida, $K$. Schum. in $K$. Schum. E. Hollr. Fl. Kais. Wilh. Land (1887) 120. - N. Guin.

Schimperi, Engl. in Abh. Preuss, Akad. Wiss, 1891 (1892) 356. - Abyss

staminea, Maxim. in Bull, Acad, Pétersb, xxxi. (1887) 80. - Ins. Liukiu.

Tateana, F. M. Bailey, in Dept. Agric. Brisbane Bot. Bull. iv. (1891) 15. - Austral.

velutina, Guerke, in Engl. Pfanzenw. Ost-Afr. C (1895) 338. - Afr, trop. or.

zanzibarensis, Vatkc, ex Engl, in Abh. Preuss. Akad. Wiss. (1890) 26 et 34 , nomen. - Zanzib.
PRENANTHES, Vaill. ex Jinn. (Compos.). Ind. Kew ii. 622

acerifolia, Matsumma, Cat. Pl. Univ. Tokyo 113 ex Makino, in Tokyo Bot. Mag. vii. (1893) 133 $(=$ Nabalus acerifolins, Maxim. $)$ - Japon.

Faberii, Hemsl. ex Forb. E Hemsl. in fourn. Linn. Soc. xxiii. (1888) 486. - China.

macrophylla, Franch. in Movot, fourn. de Bot, iv. (1889) 307. - China bor.

ochroleuca, Hemsl. in fourn. Linn. Soc. xxiii. (1888) 486 (= Nabalus ochroleucus, Maxim.). - China.

stricta, Greene, Pittonia, ii. (Nov. 1889) 21. - Am. bor. Occ

PRESGOTTIA, Lindl. (Orchid.). - Ind. Kew. ii. 623 .

Glazioviana, Cogn, in Mart. Fl. Bras, iii. IV. (1895) 261. - Bras.

PRESTOEA, Hook. f. (Palm.). - Ind. Kew. ii.

Carderi, Hook. fo in Bot. Mag. (1890) t. 7108. N. Granat

montana, Nichols. Dict. Gard. iii. (1886) 216. Ins. Granat.

trinitensis, Hook. f. in Bot. Mag. (1890) sub t. 7108 , in nota $=$ pubigera, Hook. $f$.

PRestoniA, R. Br. (Apocyn.). - Ind. Kew。 ii. 023.

acutifolia, K. Schnm, in Engl. Eo Prantl. Natürl. PAanzenfam. iv. 2 (1895) 188 (= Hocmadictvon acutifolium, Benth.). - Bras.

ecuadorensis, K. Schum. l.c. - Ecuad.

Gaudichaudii, K. Schum. l.c. (= Haemadictyon Gaudichaudii, A. DC.). - Bras.

Goudotiana, Baill. in Bull. Soc. Linn. Paris, i. (1889) 792. - N. Granat.

longituba, K. Schum. in Engl. \& Prantl, Natürl. Pfanzenfam. iv. 2 (1895) 188. - Costa Rica.

Muelleri, Rusby, in Mom. Torrey Bot. Club, iv. (1895) 217. - Bolivia.

parviflora, Baill. in Bull. Soc. Linn. Paris, ji. (1889) 783 (= Haemadictyon parviflorm, Benth.). - N Granat

venosa, Nichols. Dict. Gard. iii. (1886) 216; Rolfe, in Kequ Bull. (1893) 262 (= Haemadictyon venosum, Lind1.). - Ind. occ., N. Granat.

PREVOSTEA, Choisy = Breweria, R. Br. (Convolv.).

alternifolia, Hallier $f$, in Bot. Jahrb: xviii. (1894) $92(=$ Codonunthus alternifolitus, Planch.). - Afr.

trop.
campanulata, Hallier. f. in Bot, Jahrb, xviii. (1894) 92. - Gabon.

cordata, Hallier, f, 1. c. 93. - Madag.

PRIEURELLA, Pierre, Not. bot. Sapot. (1891) 68 = Ecclinusa, Mart. (Sapot.).

PRIMULA, Linn, fide Kuntze, Rev. Gen.(1891) 398.

Aizoon, albana, altaica, arctica, Aretia, armeniaca, cacspitosa, carnea, chamaejasme, cylindrica, erecta, filiformis, Friesii, globifera, Gmelini, hedreantha, Heerii, hivtella, Hookeriana, imbricata, lactiflora, lanuginosa, longifolia, macrantha, maxima, microphylia, multiscapa, occidentalis, ochotensis, pyrenaica, sarmentosa, Selago, septentrionalis, tapete, triflora, Kuntze, Rev. Gen. (1891) 400 = homonyma omnia Androsaces.

aretiodes, Kuntze, 1. c. = Androsace aretioides, Kern.

brevis, Kuntze, 1.c. = A. alpina, Lam

bryodes, Kuntze, 1. c. = A. bryoides, $D C$

chamaedryodes, Kuntze, 1. c. = Stimpsonia chamaedryoides,

crispidens, Kuntze, 1. c. (= Lysimachiae sp.).China.

curviflora, Kuntze, 1. c. = Dionysia curviflora, Bunge.

Decandollii, Kuntze, 1. c. = Androsace ciliata,

diapensiaefolia, Kuntze, 1. c. = Dionysia diapensiaefolia, Boiss.
PRIMULA : -

Douglasii, Kuntze, Rev, Gen. (1891) $400=$ Douglasia nivalis, Lindl.

drabifolia. Kuntze, 1, $\mathrm{c}_{\mathrm{o}}=$ Dionysia drabaefolia, Bunge.

Dubyana, Kuntze, 1. c。 = Androsace muscoidea, Duby.

Hausmanni, Kuntze, 1. c. = A. Hausmanni, Levb.

helvetica, Kuntze, 1. $c_{0}=$ A. bryoides, $D C$

hirtella, Kuntze, 1. c. = A. alpina, Lam.

Kotschyi, Kuntze, 1. c. = Dionysia Kotschyi, Bunge.

Lehmannii, Kuntze, 1. c. = Androsace Lehmanni, Wall.

linearis, Kuntze, 1. c. = Douglasia arctica, Hook. macrosiphonia, Kuntze, 1. c. = Dionysia caespitosa, Boiss.

Michauxii, Kuntze, 1. c. = D. Michauxii, Boiss.

montana, Kuntze, 1 c. = Douglasia montana, A. Gray.

nana, Kuntze, I. c. $=$ Androsace elongata, Limn. odora, Kuntze, 1. c. = Dionysia odora, Fenzl.

odoratissima, Kuntze, 1. c. = Androsace villosa, Linn.

parviflora, Kuntze, 1. c. = A. rotundifolia, Hardw, patens, Kuntze, 1. c. = A. saxifragaefolia, Bunge Paxianc, Kuntze, 1. c. = A. geraninfolia, Watt. saxifragifolia, Kuntze, 1. C. = A. saxifragaefolia, Bunge.

sempervivodes, Kuntze, 1. c. = A. sempervivoides, facquem.

tapete, Kuntze, 1. c. = A. tapete, Maxim.

tapetodes, Kuntze, 1. c. = Dionysia tapetodes, Bunge.

Wallichiana, Kuntze, 1. c. = Androsace Wiedmanni, Boiss.

Wulfenia. Kuntze, 1. c. = A. hedreantha, Griseb.

PRIMULA, Linn. (Primul.). - Ind. Kew, ii. 624. anisiaca, X. Stapf, in Kern. Sched. F1. AustroHung, iv. (1886) 45; G. Beck. Fl. Nied.-Oest. ii. II. (1893) 914. - Austria.

argutidens, Franch, in Morot, fourn. de Böt. ix. (1895) 451. - China:

austriaca, Wettst. in A. Kern, in Sched. Fl. AustroHung. iv. (1886) 49. - Austria.

baldensis, Goiran, ex Caruel, in Parl. Fl. Ital. viii. (1889) 641 , in syn.$=$ spectabilis, Tratt.

Balfouriana, Watt, ex Pax, in Bot. Fahrb. x. (1889) 175, nomen. - Reg. Himal.

hlattariformis, Franch. in Gard. Chron. (1887) . 5\%. - Yunnan.

bosniaca $X, G$. Beck, ex Fiala, in Wissensch. Mitth. Bosn. und Herceg. i, (1893) 554. Bosnia.

bosniaka, Fiala (Glasnik zemalpm. Bosn. i. Herc. (1891) 3) ex Oest. Bot. Zeitschr. xli. (1891) 414, sphalm. = praec

breviscapa, Franch. in Bull. Muséum Paris, i. (1895) 65. - Yunnan.

Broadheadae, M. E. Fones, in Zoë, iii. (1893) 306. - Idaho.

cadinensis, Porta, in Kolb. Europ. Alpenpflanz. (1890) 234. - Tirol, Lombard.

Caruelii $\times$, Porta, 1. c. 235. - Italia.

chartacea, Franch. in Bull. Muséum Paris, i. (1895) 64. - Yunnan

cinerascens, Franch, in Morot, Fourn. de Bot. ix. (1895) 448, - China.

Cockburniana, Hemsl. in Fourn, Linn. Soc. xxix. (1892) 313. - China occ

cordifolia, Pax, in Bot. Fahrb. x. (1888) 216. Reg. Himal.

coronata, Porta, in Kolb, Europ. Alpenpflanz. (1890) $237=$ daonensis, Leyb,

Cortusa, Sander, ex A. Richt. in Termész. Fuzét, xvii. (1894) 94 = Cortusa Matthioli, Linn.

crenata, Ces., Pass. \& Gibelli, Comp, Fl. Ital. ii. (1886) $408=$ marginata, Curt.

Cusickiana, A. Gray, Syn. Fl. N. Am. ii. I. [Suppl.] (1886) 399. - Oregon.

deorum, Velcn, Fl. Bulg. (1891) 479. - Bulg.

Davidi, Franch. in Bull. Soc. Bot. Fr. xxxiii. (1886) 66 ; et in Nouv. Archiv. Mus. Paris, Sér. II. x. (1887) 56 t. 14 fig. a. - China occ. 


\section{PRIMULA}

danubialis, C. Richt. in Verh. zool.-bot. Ges. Wien, xxxviii. (1888) 219. - Austria.

diantha, Bureau of Franch. in Morot, Fourn. de Bot. v. (1891) 97. - China occ.

Dumoulni X, Stein, ex Pax, in Bot. Jahrb. x. (1889) 232; et in Kolb, Eur. Alpenpflanz. (1890) 239. - Tirol.

exigua, Velen, in Sitz. Boehm. Ges. Wiss. 1888 (1889) 32 (1893) 56 ; et Fl. Bulg. (1891) $478=$ farinosa, Linn.

Faberi, Oliver, in Hook. Icon. pl. xviii. (1888) t. 1789. - Chinā

fallax $X$, C. Richt, in Verh. zool,-bot. Ges. Wien, xxxvii. (1887) 194, - Austria.

Fargesii, Franch, in Morot. Fourn. de Bot. ix. (1895) 452. - China.

Fauriei, Franch, in Bull. Soc. Philom. Paris, Sér. VII. x. (1886) 146. - Japon.

Forbesii, Franch. in Bull. Soc. Bot. Fr. xxxiii. (1886) 64; Hook. f. in Bot. Mag. (1892) t. 7246. - China. gemmifera, Batalin, in Act. Hort. Petrop. xi. (189]) 491. - China.

gracilis $\times$, Stein, in Gartenfl. xxxv. (1886) 240; et in Kolb, Eur. Alpenpfl. (1890) 343, - Form. hort. Griffithii, Pax, in Bot. Jahrb. x. (1888) $213=$ obtusifolia, Royle.

hakusanensis, Franch. in Bull. Soc. Philom. Paris, Sér, VII. x. (1886) 144. - Japon.

Henrici, Bureau \& Franch. in Morot, fourn. de Bot. v. (1891) 98. - China occ,

heterodonta, Franch. in Bull. Soc. Philom. Paris, Sér. VII. x. (18S6) 145. - Japon.

heucherifolia, Franch. sn Bull. Soc. Bot. Fr, xxxiii. (1886) 65 ; et in Nou\%. Arch. Mus. Paris, Sér. II. x. (1887) 55, t. 15, fig. b. - China occ.

incana, $M$. E. Fones. in Prec. Calif. Acad. Ser. II. v. (1895) 306. - Am. bor. occ.

incisa, Franch. in Bull. Soc. Bot. Fr. xxxiii, (1886) 69 ; et in Nouv. Arch. Mus. Paris, Sér. II. x. (1887) 58, t. 15, fig. a. - China occ.

Jaffreyana, King, in fourn. As. Soc. Beng, lv. 1886 (1887) II. 229 t. 10. - Reg. Himal.

furibella $X$, Sünderm, in Oest. Bot. Zeitschr. xxxix. (1889) 156; et in Kolb, Eur. Alpenpfl, (1890) 245 - - Tirol.

dxialensis, Franch, in Morot, fourn, de Bot. ix. (1895) 458. - China.

Kolbeana X, Stein, in Gartenfl. xxxv. (1886) 240. Eur. centr.

Lacei, Hemsl. \&o Watt, in fourn. Limn Soc.xxviii. (1891) 325. - Belutch. brit.

Legueana $\times$, G. Camus, in Bull. Soc. Bot. Fr. xxxvil. (1896) 174. - Gall.

leptopoda, Bureau \& Franch. in Morot. Fourn. de Bot. v, (1891) 97. - China occ.

Loczyi, Kanitz, Pl. exped. Szechényi in As. centr. coll. (1891) 36. - As. centr.

Zongobarda, Porta, ex A. Kern. Sched. Fl. AustroHung. iv. (1886) 50; Caruel, in Parl. Fl. Ital. viii. (1889) $643=$ spectabilis, Tratt.

magiassonica, Porta, ex Pax, in Bot. Jahrb. x. (1889) 232 ; et in Kolb, Eur. Alpenpf. (1890) 247 [magglasonica] = spectabilis, Tratt.

malacoides, Franch in Bull. Soc. Bot. Fr. xxxiii. alacoldes, Franch. in But

(1886) 64, - China occ.
malvacea, Franch. l. c. 65. - China occ.

Matthioli, A. Richt. in Termész. Fuzét. xvii. (1894) $34=$ Cortusa Matthioli Linn.

membranifolia, Franch. in Bull. Soc. Bot. Fr. xxxiii. (1886i) 68. - China occ.

moupinensis, Franch. l. c. 67: et in Now\%. Archiv. Mus. Paris, Sér. II. x. (1887) 57, t. 14, fig. b. Yunnan.

neurocalyx, Franch. in Morot, fourn. de Bot. ix. (1895) 449 . - China.

nipponica, Y atabé, in Tokyo Bot. Mag. iv, (Oct. 1890) 3 t. 13-15; et Icon. Fl. Fap. i. I. (1891) 35, t. 15. Japon.

nutantiflora, Hemsl. in Fourn. Linn. Soc. xxix. (1892) 313. - China occ.

nutans, Delavay, ex Franch. in Bull. Soc. Bot. Fr. xxxiii. (1886) 69. - Yumnan.

Obristii X, Stein, in Gartenfl. xxxv. (1886) 241 [sphalm. Obsistii]; et in Kolb, Eur. Alpenpfl. (1890) 250. - Eur. centr.

\section{PRIMULA}

reodoxa, Franch. 27t Bull. Soc. Bot. Fy, xxxiii (1886) 66 ; ct in Nonv. Archiv. Mus. Paris, Sér. II. x. (1887) 55, t. 15, fig. b. - China occ.

ovalitolia, Franch, $l l$, ce. 67 ; et 57 - China occ.

pannonica X. A. Kern, Sched. Fl. Austro-Hung. iv. (1886) 46 = inflata. A. Kern.

Pantlingii, King, in fourn. As Soc. Beng. 1v. (1887) II. 228. - Sikkim.

Parlatorii, Porta, ex Carnel, in Parl. Fl. Ital, viii. 1889) 642. - Italia.

pellucida, Franch. in Bull. Soc. Bot. Fr, xxxy. (1888) 428. - Yunnan.

Peyritschii X, Stein, in Gartenfl. xxxv. (1886) 241 Pax, in Bot. Jahrb. x. (1889) 229. - Helv.

Poissoni, Franch. in Bull. Soc. Bot. Fr. xxxiii. 1886) 67; Hook.f. in Bot. Mag. (1892) t. 7216. - China.

polyneura, Francir. in Morot, fourn. de Bot. ix. 1895) 448. - China.

Portae X. Huter, ex A. Kern. Sched. Fl. AustroHung. iv. (1886) 53. - Tirol.

Prattii, Hemsl. in foumn. Limn. Soc. xxix. (1892) 3I4. - China occ.

Pseudo-acaulis $X$, Caruel, in Parl. F1. Ital. viir. 1889) 610 (= P. Psendo-acaulis, Schur?). Italia.

pulchella, Franch, in Bull. Soc, Bot. Fy, xxxy. (1888) [P. Stuartii, Franch.]; et in fourn. Linn. Soc. xxvi. (1889) 41. - Yunnan.

pumila, Pax, in Bot. Fahrb. x. (1888) 208 (= P.ni valis, Pall. var, pwnila, Ledeb.). - Fret Behring

purpurascens, G. Beck, Fl. Nied.-Oest. ii. I1. (1893) $914=$ anisiaca, Stapf.

pycnoloba, Bureau E Franch. in Morot, Fourn.d Bot. v. (1891) 99. - China occ.

Reidii, Duthie, in Report Saharamp. Bot. Gard. for 1885 ; in Gard. Chron. (1886) i. 277, in nota, et (1886) ii. 691 fig. 131; Hook. f, in Bot. Mag. $1887)$ t. 6961 - Kumaon

Sanctae Coronae X, G. Beck, Fl. Nied.-Oest. ii. II. (1893) 914. - Austria.

Sertulum, Franch. in Morot, fourn. de Bot. ix. (1895) 451. - China.

similis X; Stein, in Gartenfl. xxxv, (1886) 241, et in Kolb, Eur. Alpenpfl. (1890) 255. - Austria.

sinuata, Franch. in Bull. Muséum Paris, i. (1895) 65. - Yunnan.

Souliei, Franch. in Morot, fourn. de Bot. ix. (1895) 450. - China.

Tanneri, King, in foum. As. Soc Beng. 1v. 1886 (1887) 11. 227 t. 8. - Sikkim.

tenuiloba, Pax, in Bot. Jahrb. x. (1888) $204=$ muscoides, Hook

tongolensis, Franch. in Morot, fourn. de Bot. ix. 1895) 453. - China.

tosaensis, Yatabé, in Tokyo Bot. Mag. iv. (Nov, 1890) 1 t. 44 ; et Icon, Fl. Fap. i. I. (1891) 31 t. 12 - Japon.

ariiflora X, G. Beck, F1. Nied,-Oest, ii. II. (1893 914. - Austria.

Viali, Delaray, ex Franch. in Bull. Soc. Phitom. Paris, Sér. VII. iii. (1891) 848. - Tibet

vinciflora, Franch. in Gard. Chron. 1887) i. 575 fig. 108. - Yunnan.

vittata, Bureau \& Franch. in Morot, fourn. de Bot. v. (1891) 96. - China occ.

vochinensis X, Gusm, in Oest. Bot. Zeitschr. xlini. (1893) 107. - Carinth.

Wettsteinii $\times$, Wiemann, in Verh. zool.-bot. Ges. Wien, xxxvi.(1886) 376 ; G. Beck, F1. Nied.Oest, i1. II. (1893) 918. - Austria.

PRINSEPIA, Royle(Rosac.). - Ind. Kew. ii.6:7 uniflora, Batalin, in Act. Hort. Petrop. xii. (1892) 167; et ex Gartenfl. xli1. (1893) 331. - Mongolia.

PRINTZIA, Cass. (Compos.). - Ind. Kew. ii. $62 \%$ laxa, N. E. Br. in Kew Bull. (1895) 26. - Natal.

PRIONIUM, E. Mey. (Juncac.). - Ind. Kew. ii. 626.
serratum, Baill. Hist. des pl. xii. (1894) $501=\mathrm{P}$. Palmito, E. Mey.
PRIONOSGIAdIUM, S. Wats, in Proc. Am. Acad. xxiii. (1888) 275. UMBELLIFERAE,

linearifolium, Conlt. of $7 . N$. Rose, in Contrib. U. S. Nat. Herb. iii. 3 (1895) 308 (= Cicuta linearifolia, S. Wats.). - Am. bor.

madrense, S. Wats. in Prö. Am. Acad. xxiii. (1888) 275. - Mexic

megacarpum, Coult. Eo F. N. Rose, in Contrib. U.S. Nat. HYerb, iii. 3 (1895) 308. - Mexic

mexicanum, S. Wats, in Proc. Am. Acad. xxiii. (1888) 275. - Mexic.

Pringlei. S. Wats. ..c. 276. - Mexic.

Watsoni, Coult. \&. F. N. Rose, ex S. Wats. l. c. xxy. (1890) $150(=$ Pencedanum mexicanm, S. Wats.) - Mexic.

PRISMATOCARPUS, L'Hérit, (Campanul. . Ind, Kew, ii, 627 acerosus, Schinz, in Bull. Herb, Boiss. ii. (1894) 217.

PRISMATOMERIS, Thw。(Rubiac.), - Ind. Kew. ii. 628. tetrandra, K. Schum, in Engl. \& Prantl, Natïrl.
Pflanzenfam. iv. 4 (1891) $138=$ albiflora, Thw.

PRitchardia, Seem.\& H. Wendl. (Palm, ), Ind. Kew, ii. 628.

aurea, Hort. ex Hook. f. in Rep. Gard. Kew, 1882 (1884) 65 ; et ex Gard. Chron. (1893) i. $332=$ borneensis, Hort.

flamentosa, Hort ex W. Wats, in Kew Bull. iii. (1859) 296 = Washingtonia filifera, $H$. Wendl. grandis, Veitch, Catal. (1885) 54; W. Wats, in Gard, Chron. (1886) i. 139 = Licuala grandis, H. Wendl.

Hillebrandi, Becc. Malesia, iii. (1890) 292. - Ins. Sandvic

lanigera, Becc. l. c. 298. - Ins. Sándvic.

remota, Becc, l. c. 294. - Ins. Sandvic.

Pericularum, H. Wendl. ex Gard. Chron. (1893) i. 332, nomen. - Ins. Pcmotou.

Thurstoni, F. Muell. \& Drude, in Gartenfl.xxxvi. (1857) 486, fig. 123-24; et in Gard. Chron. (1887) ii. 341; Becc. Malesia, iii. (1890) 210. - Ins. Fiji.

PRITZELAGO, Kuntze, Rev. Gen. (1891) $35=$ Hutchinsia, R. Br. (Crucif.).

affinis, Kuntze, 1. c. = H. alpina. [R. Br. in] Ait. alpina, Kuntze, 1. c. = A. alpina. $[R, B r$. in $\mid A i t$. brevicaulis, Kuntze, $1 . c_{.}=H$. alpina, $[R . B r$. in $]$

media, Kuntze, 1 c. = H. media, Beyer, fide Kuntze.

PRIVA, Adans. (Verben.). - Ind. Kew. ii. 628. armata, S. Wats. in Proc. Am, Acad. xxv. (1890) 160. - Mexic.

Orizabae, S. Wats, 7. a. xxiji. (1888) 282,-Mexic.

PROBOSCIDEA. Schmid. = Martynia, Houst. (Pedalin.).

lutea, Stapf, in Engl. \& Prantl, Natürl. Pflanzenfam. iv. 3b (1895) 369 (= Martynia montevidensis, Cham.). - Am. austr.

PROGHNYANTHES, S. Wats. in Proc. Am Acad. xxii. (188\%) 457. AMARYLIIDEAE.

viridescens, S: Wats. l. c. - Mexic.

PROCKIOPSIS, Baill, in Bull. Soc, Linn. Paris, 1886) 573: Warb. in Engl. \& Prantl, Natiirl. Pflanzenfam. iii. 6a (1893) 20. BIXINEAE.

Hildebrandtii, Baill. ll. cc.; et Hist. pl. Madag Atlas (1889) t. 110. - Madag.

PROGRIS, Comm. ex Juss. (Urtic.). - Ind Kew.

obovata, G. Beck, in Annal. Fard. Buitenz. iii. (18ss) 254. - Inst. Stewart.

velutina, Warb. in Bot. fahro. xviii. (1891) 189 N. Guin.

PROMENAEA, Lind1. = Zygopetalum, Hook (Orchid.).

citrina, Hort. Bull, ex Regel, in Act. Hort. Petrop.x. (18S9) 694. - Hab. 
PROSOPIS, Linn, (Legumin.). - Ind, Kew. ii. 630

africana. Taub, in Engl. \& Prantl. Natürl. Pflanzenfam. iii. 3 (1893) 119 (= Coulteria africana Guill. \& Perr.) = oblonga, Benth.

articulata. S. Wats, in Proc. Am. Acad. xxiv. (1889)

48. - Mesac.
Fischeri, Taub. in Engl, Pfanzenw. Ost-Afr. C (1895) 196. - Afr, or,

Palmeri, S. Wats. in Proc. Am. Acad. xxiv. (1889) 48. - Mexic.

stenoloba, Phil. in Anal. Mus, nac. Chile (1891) 20. - Chili.

Tamaruya, Phil. I. c. 21. - Chili.

PROSOPOSTELMA, Baill. Hist. des pl.x. (1890) 247 ; K. Schum. in Engl. \& Prantl, Natürl. Pflanzenfam. iv. 2(1895)22\%. ASCLEPIADEAE.

PRostanthera, Labill. (Labiat.) - Ind. Kew. ii. 630.

chrysocalyx, Briq. in Engl. \& Prantl Natiwr. Pflanzenfam. iv. 3a (1895) 220. - Austra1,

Schultzii, F. Muell, in Trans, Roy. Soc. S. Austral. xix. (1895) 82, nomen. - Austral.

serpyllifolia, Briq. in Engl. \& Prantl, Natürl. Ptianzenfam. iv, 3a (1895) 220 (= Cryphia serpyllifolia, R. Br.). = microphylla, A. Cumn.

PROTAMOMUMI, RidI, in Straits Times (13 Nov 1891), ex Journ. Bot. xxx. (1892) 31; et in Trans Linn. Soc. Ser. II. iii. (1893) 383, t. 66. SCITA IIINEAE.

maxillarioides, Ridl. ll. cc. (= Lowia maxillarioides, Baker). - Penins. Mal.

PROTEA, Lmn. [Gen. p], non Sp. pl. $]=$ Leucadendron, R. Br. (Proteac.).

acuta, aurantiaca, Buekiana, buxifolia, cartilaginea, Dregei, elata, encalyptifolia, florida, glabra, grandiflora, imbricata, lanigera, mitida. ovalis, pedunculata. platysperma, tubbescens, ramosissima, scabra, sessilis spathulata, uliginosa, venosa, verticillutu, liuntze. Rev.Gen. (1891) $580=$ homonyma onnia Leucadendri

brmniodes, Kuntze, 1. c. = L. brunioides, Meissn.

PROTEA, Linn. (Proteac.). - Ind. Kew. ii. 631. Bismarckii, Engl. in Abh. Prizss. Akad. Wiss. 1891 (1892) 196, nomen. - Togo.

ferruginea, Engl. l. c. 19\%, nomen. - Congo mer.

kilimandscharica, Engl. l. c. 195. - Afr. trop. or madiensis, Engl. l. c. 196. in obs. - Afr. trop.

micans, Wclrv.l. c. - - Angola.

Nyasae, Rendle, in Trans. I,inn. Soc. Ser. II. iv. (1894) 39. - Afr. trop.

paludosa, IVelw. in Abh. Preuss. Akad. Wiss. 1891 (1892) 196, in obs. - Angola.

petiolaris, IVelw. l.c. 197. - Angola.

Pogrei, tungl. l.c. - Congo mer

rhodantha, Hook. f. in Bot. Mag. (1893) t. 7331. Transvaal.

Welwitschii. Engl. in Abh. Prenss. Akad. Wiss. 1891 1., (189:2) 196. - Angola.

PROTIUIM, Burm. f. (Burser.).- - Ind. Kew. ii. 634.

bolivianum, Britton, in Bull. Torrcy Bot. Club, xvi. (1889) 189. - Bolivia,

PROTOLIRION, Ridl. in Ann. Bot. ix. (1895) 56 . TRURIDEAE

paradoxum, Ridl. l. c. 57 (= Petrosavia paradoxa, Rid1.), - Penins. Mal.

PROUSTIA, Lagasca (Compos.). - Ind. Kew. ii.

Olvillo, Phil. in Anal. Univ. Chil. 1xxxv. (1894) 838 (=P. reticulata, Phil.). - Chil.

PRUNELLA, Linn. (Labiat.). - Ind, Kew. ii.

integerrima, G. Beck, ex Nym. Consp. F1. Eur. Suppl. ii. I. (1889) $250=$ laciniata, Linn.

\section{PRUNELLA:}

pienina, Ullepitsch, in Oest, 'Bot. Zeitschr. xlii. (1892) 5\%. Hung

spuria $\mathcal{X}$, Stapf, ex Nym. Consp. Fl, Eur. Suppl. ii. I. (1889) 250 . - Tirol.

PRUNOPSIS, Éd. André = Prunus, [Tourn.]

Linn.(Rosac.).
Mume, Ed. André, in Rev. Hortic. 1xviii. (1890) $209=$ Prunus Mume, Sieb. \& Zucc.

PRUNUS, [Tourn.] Linn. (Rosac.). - Ind. Kew.

ii, 635 .

amygdaliformis, Pau, Not. bot. Fl. Espan. i. (1887) $2 \mathrm{l}=$ spinosa, Limn.

baldschuanica, Regel, in Gartenfl. xxxix, (1890) 612 ; et in Act. Hort. Petrop. xi. $(1890) 314 .--$ Buchara.

Besseyi, L. H. Bailcy, in Bull. Cornell. Agr. Exp. State, 1xx. (1891) 70261 ; et in Contrib. U. S. Nat. Herb. iii. (1895) 156. - Nebraska.

bifrons, Fritsch, in Sitzungsb, Akad. Wiss. Wien, ci. (1892) 637. - Reg. Himal.

brachypoda, Batalin, in Act. Hort. Perrop, xiii. (1892) 160 ; et in Gartenfl. xlii. (1893) 330. China.

brahuica, Aitch. \& Hensl, in Trans. Linn. Soc. Ser. II. iii. (1886) 62 (= Amygdalus brahurica, Boiss.). - Beluchist.

Brittoniana, Rusby, in Mem. Torrey Bot. Clnb, iii. 3 (1893) 24. - Bolivia.

brutia, Terrac. in Att. Ist. Incoragg. Napol, i. n. 7 , t. 1: et in Ann. Ist. bot. Roma, iv, 1889-90 (I891) 102. - Italia mer.

californica, Hort. ex Koehne, Deutsche Dendrol. (1893) 312 = acuminata, $W$ illd.

calycosa, Aitch. E Hemsh. in Trans. Limn. Soc. Ser. II. isi. (1886) 61, t. 7. - Turkest.

caudata. Franch, Pl. Delav. (1890) 196 [caudatus]. - Yunnan

cinerascens, Franch. in Nowv. Archiv. Mus. Paris, Sér. II. viii. 1885 (1886)216. - Tibet.

Cocumilio, “ Ten. » ex Dippel, Handb. Laubholzk. iii. (1893) $636=\mathrm{P}$. Cocomilia, Ten.

copallina. Hort. ex Gard. Kew, i. Polypet. (1894) $141=$ P. Capollin, Zuco.

eburnea, Aitch. \& Hemsl. in Trans. Linn. Soc. Ser. II. iii, (1886) 62 (= Amygdalns eburnea, Spach). - Persia

eminenzs X, G. Beck, F1. Nied.-Oest. ii. I. (189:) 821 (= Cerasus intermedia, Hort.). - Austria.

Fenzliana. Fritsch, in Sitzungsb. Akad. Wiss. Wien, ci. (1892) 632, t. 2. - Reg. Cauc.

hirtipes, Hemsl. ex Forb. \& Hemsl. in foum, Linn. Soc. xxiii. (1887) 218. - China.

hortulana, L. H. Bailey, in Gard, and For. v. (1892) 90 ; Sarg. N. Amer. Sylva, iv. 23, t. 151. - Am. bor.

Jacquemonti, Hort. Dieck, Noukeit. Nat. Arboret. Dieck (1892-93) 23. -- Am, bor. occ.

kurdica, Fritsch, in Sitzungsb. Aked. Wiss. Wien, ci. (1892) 628. - Armen.

Laucheana, Bolle, ex Dippel, Handb. Laubholzk. iii. $(1893) 646=$ P. Padus, Linn.

mandschurica, Koehne, Deutsche Dendrol. (1893) 31 \%. - Mandschuria.

Mattrevi X, Zabel, ex Gartenfl. xxxvii. (1888) 124; Koehne, 1. c. 313. - Hybr, artef.

nana, Focke, in Engl. \& Prantl, Natïrl. Pflanzenfam. iii. $3(1391) 54=$ nana, Stokes.

occidentalis, W. S. Lyon, in Bot. Gaz. xi. (1886) 202, 333. - Calif.

orthosepala, Koelne, Dentsche Dendrol. (1893) 311. - Texas

Pattoniana, Hort. ex Gard. Kew, i. Polypet. (1894) $143=$ mollis, $W$ alp.

planteriensis, Simon-Louis, ex Dippel, Handb. Laubholzk. iii. (1893) $634=$ cerasifera, Elwh

praecox, Hort, ex Carr. in Rev. Hortic, 1xiv. (1892) 488, fig. 142 et 143 . - Form. hort.

Salzeri, Zdarek, in Carinthia, 1xvii. (1887) 199 ; et in Verh. zool,-bot. Ges. Wien, xlii. (1892) $17=$ P. Padus, Linn.

Serrula, Franch. Pl. Delav. (1890) 196. - Yunnan.

\section{PRUNUS}

setulosa, Batalin, in Act. Hort. Petrop. xii. (1892) 165 ; et in Gartenf. xlii. (1893) 330. - Reg. Cauc. szechuanaca, Batalin, in Act. Hort. Petrop, xiv. (1895) 167. - China.

thibetica, Franch. in Nouv. Archiv. Mus. Paris Sér. 1I. viii. 1885 (1886) 215. - Tibet

tortuosa, Aitch. \& Hemsl. in Trans. Linn. Soc. Ser. II. iii. (1886) 61 (= Cerasus tortwosa, Boiss.) - Reg. Afghan.

utahensis, Dieck, Catal. (1885), ex Dippel, Handb. Laubholzk. iii. (1893) 634. fig. 259; Koehne, Deutsche Dendrol. (1893) 315. - Utah.

velutina, Batalin. in Act. Hort. Petrop. xiv. (1895) 168. - China

Watsoni, Sarg. in Gard, and For. vii. (1893) 134 $\mathrm{fig}$. 25. - Am. bor.

xerocarpa, Hentsl. in Ann. Bot. ix. (1895) 152. Ins. Formosa.

yunnanensis, Franch. Pl. Delav. (1830) 195. Yunnan.

PRZEWALSKIA. Maxim. (Solan.). - Ind. Kew

Roborowskii, Prain, ex Batalin, in Act. Hort, Petrop. xiii. (1894) 380. - Tibet.

PSACALIUM. Cass. = Senecio, Tourn. (Compos.) strictum, Greene, Pittonia, ii. (May 1892) $228=$ Prenanthes stricta, Greene.

PSAMMISIA, Klotzsch (Vaccin.). - Ind. Kew.

Jessicae, Nichols. Dict. Gard, iii. (1886) 237. Venezuela.

pichinchensis, Hort. ex Nichols. 1. c. = Hookeriana, Klotzsch

symphystemona, 7. D. Smith, in Coult. Bot. Gaz. xx. (1895) 291. - Costa Rica.

PSATHURA, Comm. (Rubiac.). - Ind. Kew. ii. 638

angustifolia, Cordem. Fl. Ile Réunion (1895) 515. Ins. Borbon.

polyantha, Cordem, 1. c. 513. - Ins. Borbon.

PSEPHELLUS, Cass. = Centaurea, Linn. (Compos.)

abchasicus, Alboff, in Soc. imp. hortic. (Compt.rend. Sect. Odessa) (1891) extr. $12=$ heterophyllus, Boiss.

Barbeyi. Alboff, in Bull. Herb. Boiss. i. (1893) 247. - Reg. Cauc

Freynii, Sint. ex Freyn, 1. c. iii. (1895) 472, in syn. Centaurea Freyni, Sint.

PSEUDACACIA, Moench = PSEUDOACACIA Tourn. = Robinia, Linn. (Legumin.).

vulgaris, "Tourn. " Greene, Man. Bot. San Franc. Bay (1894) $88=$ R. Pseudacacia, Linn.

PSEUDALEIA, Thou, = Olax, Linn. (Olacin.). imbricata, Hassk. ex Valeton, Crit. overz. Olacin. (1886) 115, in syn. = O. imbricata, Roxb.

longistylis, Hassk, 1. c. = O. imbricata, Roxb.

PSEUDERANTHEMUM, Rad1k, in Th. Dur. Ind. gen. (1848) 314; Lindau, in Engl. \& Prantl, Natürl. Pflanzenfam. iv. :3b (1895) $330=$ Eranthemum, Linn. pr.p. (Acanth.).

Andersoni, Lindau, 1. c. = E. Andersoni, Mast.

connatum. Lindau, in Bot. Jahrb. xx. (1894) 40. Ins. Comor.

dichotomum, Lindau, 1. c. [dichotoma $]=$ Rhinacanthus communis. Nees

Hildebrandtii, Lindau, 1. c. 39. - Afr, trop. or

Leptunthus, Lindau, in Engl. \& Prantl, Natürl. Pflanzenfam. iv. 3b (1895) $330=$ E. Leptanthus, C. B. Clarke.

Ludovicianum, Lindau, 1. c. = E. Ludovicianum Buettn.

Macgregorii, Lindau, in Bot. Jahrb. xix. Beibl n. 48 (1894) 5. - N. Guin.

malaccense, Lindau, in Engl. \& Prantl, Natürl. Pflanzenfam. iv. 3b (1895) $330=\mathrm{E} 0$. malaccense C. B. Clarke, 
PSEUDERANTHEMUM : -

Muelleri-Fernandi, Lindau, in Bot. Jahrb. xix. Keibl. n. 48 (1894) 4, - N. Guin.

pacificum, Lindau, in Engl, \& Prantl Natürl Pflanzenfam. iv. 3b (1895) $330=$ E. pacificum Engl.

Parishii, Lindau, 1.c. = E. Parishii, C. B. Clarke. Elutinum, Lindau, in Bot. Jahrb, xix. Beibl. n. 48 (18.4) 5. - N. Guin.

PSEUDEVAX, Pomel, in Bull. Soc. Bot. Fr. xxxv, (1888) $334=$ PSEUDEVAX, DC. = Evax Gaertn. (Compos.).

mauritanica, Pomel. 1. c. = E. mauritanica, Batt.

PSEUDOAMPELOPSIS, Planch. in DC. Monog. Phan. v. (1887) 322, nomen = Ampelopsis Planch. (Ampelid.).

PSEUDOBAECKEA, Niedenzu, in Engl. \& Prantl, Natirl. Pflanzenfam. iii. 2a (1891) $136=\mathbf{B r u}$ nia. Linn. pr. p.

capitellata, Niedenzu, 1. c. = B. staavioides, Sond. cordata, Niedenzu, 1. co $_{0}=$ B. racemosa, Brongn. pinifolia, Niedenzu, 1. $\mathrm{c}=\mathrm{B}$. pinifolia, Brongn. squalida, Niedenzu, 1. c. = B, squalida, Sond.

villosa, Niedenzu, 1, c, = B, villosa, E, Mey.

virgata, Niedenzu, 1. c. = B. virgata, Brongn

PSEUDOBARLERIA. T. Anders. = Petalidium, Nees (Acanth.)

canescens, Engl. in Bot. Jahrb. x. (1888) 258. Afr. austro-occ. extratrop.

coccinea, Lindau, in Eng1. \& Prantl, Natürl. Pflanzenfam. iv. 3b (1895) $300=$ Petalidium coccineum, S. Moore.

Currori, Lindau, 1. c. $=$ P. Currori, S, Moore.

Engleriana, Schinz, in Verh. Bot. Ver. Brand, xxxi. (1890) 197. - Afr, austro-occ, extratrop.

glandulosa, Lindau, in Engl. \& Prantl, Natürl. Pflanzenfam, iv. 3b (1895) $299=$ Petalidium glandulosum: S. Moore.

ghutinosa, Engl. in Bot: Jahrb, x. (1888) 259. Afr. austro-occ. extratrop.

halimioides, Lindau, in Engl. \& Prantl, Natürl. Pflanzenfam. iv. 3b (1895) $300=$ Petalidium halimoides, S. Moore

lanata, Engl. Bot. Jahrb. x. (1888) 258. - Afr. austro-occ. extratrop.

latifolia, Schinz, in Verh. Bot. Ver. Brand, xxxi. (1890) 197. - Afr. austro-occ, extratrop.

Lepidagathis, Lindau, in Engl. \& Prantl, Natürl. Pflanzenfam.iv. 3b (1895) $300=$ Petalidium Lepidagathis, S. Moore.

Lindani, Dewèvre. in Bull. Soc. Bot. Belg. xxxiij. 21894 (1895) 104. - Afr, trop. austro-or

finifolia, Lindau, in Engl. \& Prantl, Natürl. Pflanzenfam. iv. 3b (1895) 299 = Petalidium linifolium, T. Anders.

loranthifolia, Lindau, 1. c. $300=$ P. lorantifolium, S. Moore:

oflata, Schinz, in Verh. Bot. Ver. Brand. xxxi. (1890) 198. - Afr. austro-occ. extratrop.

physaloides, Lindau, in Engl. \& Prantl, Natürl. Pflanzenfam. iv. 3b (1895) $299=$ Petalidium physaloides, S. Moore.

mpestris, Lindau, I. c. $300=$ P. rupestre, S. Moore. variabilis. Engl. Bot. Jahrb. x. (1888) 259. Afr. austro-occ. extratrop.

Welzuitschii, Lindau, in Engl. \& Prantl, Natürl Pflanzenfam. iv. 3b (1895) $300=$ Petalidium Welwitschii, S. Moore.

PSEUDOBLEPHARIS, Baill. in Bull. Soc. Linn. Paris, ii. (1890) 836; et Hist. des pl. x. (1891) 457 = Sclerochiton, Harv. (Acanth.)

Boivini, Baill. 1.c. 837. - Madag.

Dusenii, Lindau, in Bot. Jahrb. xx. (1894) 34. Afr, trop. occ.

Grandidieri, Baill, in Bull. Soc, Linn, Paris, ii. (1890) 83\% - Madag.

Holstii, Lindau, ex Engl. in Abh. Preuss, Akad. Wiss. (1894) 26 ; in Bot. Jahrb. xx. (1894) 35 ; et Pflanzenw. Ost-Afr. C (1895) 270. - Zanzib.
PSEUDOBLEPHARIS :-

nitida, Lindau, in Engl. \& Prantl, Natiirl. Pflanzenfam. iv. 3b (1895) $319(=$ Acanthus nitidus, S. Moore). - Angola.

Preissii, Lindau, in Bot. Jahrb. xx. (1894) 34. Afr. trop. occ.

PSEUDOBROMUS, K. Schum. in Engi. Pflanzenw. Ost-Afr. C (1895) 108. GRAMINEAE. silvaticus, $K$. Schum. l. c. - Afr. trop. or.

PSEUDOGEDRELA. Harms, in Bot. Jahrb. xxii. (1895) 153. MIEL IACEAE.

kotschyi, Harms, l. c. $154(=$ Cedrela Kotschyi Schweinf.). - Afr. trop.

PSEUDOGENTRUM, Lindl. (Orchid.), - Ind.

Kew, ii. 639.
sylvicolum, Reichb. f. in Flora, 1xix. (1886) 548, N. Granat.

PSEUDOCHROSIA, Blume (Apocyn.). - Ind. Gew. 11. 639. Bogor. ex Valeton, in Annal. Jard. bot. Buitenz. xiii. 2 (1895) 233, in syn. = Ochrosia giomerata, Valeton.

PSEUDOCLADIA, Pierre, Not. bot. Sapot. (189I) 49; Baill. Hist. des pl. xi. (1892) $291=$ Lucuma, Molina (Sapot.)

laterifora, Pierre, 1. c. $50=$ Lucuma lateriflora, Benth。

Melinoni, Baill. Hist. des pl. xi. (1892) 291. — Hab.?

PSEUDOCONNARUS, Radlk. in Sitzb. Akad Muench, xvi. (1886) 356. CONNARACEAE.

fecundus, Radlk. l. c. (= Connarus fecundus, Baker). - Bras.

PSEUDOGYMOPTERUS, Coult. \& J. N. Rose Rev, N. Am. Umbell. (1888) 74. UMBELLIFE$R A E$

anisatus, Coult. \&. F. N. Rose, l.c. 75 (= Cymopterus anisatus, A. Gray). - Am. bor. occ.

bipinnatus, Coult. \& F. N. Rose, l. c. $(=$ C. bipinnatus, S. Wats.). - Am. bor. occ. montanus, Coult. \& F. N. Rose, l.c. 74 (= Ligusti cum montanum, Benth. \& Hook. f.). - Am. bor. occ.

PSEUDODESMOS riparia, Spruce, ex Engl. in Mart. Fl. Bras. xil. 1. (1888) $466=$ Moronobea riparia, Planch. E Triana.

PSEUDOERNESTIA, Krasser, in Enol. \& Prantl, Natürl. Pfanzenfam. iii. 7 (1893) 149 MELASTOMACEAE

cordifolia, Krasser, l. c. (= Ernestia cordifolict. Berg). - Am. austr: bor.

PSEUdogaLTonia, Kuntze, in Jahrb. Bot. Gart. Berl, iv. (1886) 274 ; et in Engl. \& Prantl, Naturl. Pflanzenfam, ii. 5 (1888) 158, LILIA$C E A E$.

Pechuelii, Kuntze, Il. co. (= Hyacinthus Pechuelii, Kuntze), - Afr, austro-occ, extratrop.

PSEUDOHYDROSME, Engl. Bot. Jahrb, xv, (1893) 455. AROIDEAE.

Buettneri, Engl. l.c. 456. - Afr, trop. occ.

gabunensis, Engl. l. c. 555. - Afr. trop. occ.

PSEUdOLMEDIA, Tréc. (Urtic.). - Ind. Kew, 639

oxyphyllaria. F. D. Smith, in Coult. Bot. Gaz, xx. (1895) 294. - Guatem.

PSEUDOMACODES, Rolfe, in Kew Bull. (1892) 127. ORCHIDEAE.

Cominsii, Rolfe, l. c. 128. - Ins. Salom.

PSEUdOMARSDENIA, Baill. Hist. des pl. $\mathrm{x}$. (1890) 268 ; K. Schum, in Engl. \& Prantl, Natürl. Pflanzenfam, iv. 2 (1895) 285. A SCLEPIA$D E A E$.

Bourgaeana, Baill. ll. co - Mexic.
PSEUDOPANAX, C. Koch (Araliac.). - Ind, Kew, ii. 639.

ferox, T. Kirk, in Gard. Chron. (1890) i. 432. Hab.

racemifertm, Ball, in Journ. Linn. Soc. xxii. (1886) 167 (= Sciadophyllum racemiferum, Miq.). - Am austr.

PSEUDOPHOENIX, H. Wendl. \& Drude, ex Drude, in Eng-1. \& Prantl, Natiirl. Pflanzenfam. iii. 3 (1887) $64 ; \mathrm{H}$. Wendl, in Gard, and For. 1. (1888) 352. PALMAE

Sargenti, H. Wendl. Il. cc, ; et in Gard. Chron. (1888) ii. 408 fig. 56, - Florida.

PSEUDOSANTALUM, Rumpf, Herb, Amb, ii. 54 t. 12, ex Kuntze, Rev. Gen. (1891) $271=$ Osmoxylon, Miq. (Araliac.)

Miquelii, Kuntze, 1. $c_{.}=$O. Miquelii, Boerl

umbelliferum, Kuntze, 1. $\mathrm{c}_{0}=\mathrm{O}$. amboinense, Miq.

PSEUDOSTENOSIPHONIUM, Lindau, in Bot. Jahrb. xviii. (1894) 50; et in Engi. \& Prantl, Natiri. Pflanzenfam. iv. 3b (1895)' $303=$ Strobilanthes, Blume (Acanth.)

cylanicum, Lindau, 11, cc, 50 ; et $303=\mathrm{S}$. zeylanicus, T. Anders.

Gardnerianum, Lindau, 1, c. $52=\mathrm{S}$. Gardneria. nus, T. Anders.

uigrescens, Lindau, 1. c. $=$ S. nigrescens. $T$. Anders.

hamnifotium, Lindau, 1. c. = S. rhamnifolius, T. Anders.

Tcosum, Lindatl, 1, c. $40,52=\mathrm{S}$. viscosa, $T$. Anders.

PSEUDOSTROPHIS, Warb. in Bot. Jahrb, xiii。 (1891: 294. URTICACEAE.

Iaxiffora, Warb. l. c. 295. - N. Guin.

PSEUdotsugA, Carr. (Conif.), - Ind. Kew, 11. 634 .

macrocarpa, Lemmon, Third Rep, Calif. St, Board Forest (1890) 134: H. Mayr. ex Beissn. Handb. Nadelholzk. (1891) $417=$ P. Douglasii, Carr. var. macrocarpa, Engelm.

mucronata, Sudworth, ex Holzinger, in Contrib U. S. Nat. Herb. iii. 4 (1895) $266=$ P. Douglasii, Carr

taxifolia, Britton, in Trans. N. Y. Acad. Sci, viii. (1889) $74=$ P. Douglasii, Carr.

PSEUDOVESICARIA, Boiss. FI. Or. Suppl. (1888, $48=$ Vesicaria, Tourn. ex Adans. (Crucif.).

digitata, Boiss. 1. c. $49=\mathrm{V}$. digitata, C. A. Mey.

PSEVA, Rafin. = Chimaphila, Pursh (Ericac.). japonica, Kuntze, Rev. Gen. (1891) $390=$ C. japonica, Miq.

maculata, Kuntze, 1. c. = C. maculata. Pursh. Menziesiit, Kuntze, 1. c. = C. Menziesii, Spreng. umbellata, Kuntze, 1, c. = C. umbellata, Nutt.

PSIADIA, Jacq. (Compos.) - Ind. Kew, ii. 640. ambigua, Cordem. Fl. Ile Réunion (1895) 530. Ins. Borbon.

amygdalina, Cordem, l.c. 525 (= Conyza anygdalina, Lam.). - Ins. Mascar.

anchusaefolia, Cordem. l. c. $(=C$. anchusaefolia Poir.). - Ins. Mascar.

argentea, Cordem. l. c. 524 (= C. argentea, Lam. - Ins. Mascar.

aspera, Cordem. l.c. (= C. aspera, Bory $)$ - - Ins. Mascar.

callocephala, Cordem. l. c. $523(=$ C. callocephala, Bory). - Ins. Borbon.

cuspidifera, Baker, in foum, Linn. Soc. xxii. (1887) 489. - Madag.

decurrens Klatt, in Bot. Fahrb. xii. Beibl, n. 27 (1890),23. - Madag.

Frappieri, Cordem. Fl. Ile Rémion (1895) 526. Ins. Borbor.

inuloides, O. Hoffm. in Bot, Fahrb, xx. (1894) 22:3. - Afr. aequiat. or. 


\section{PSIADIA}

Insignis, Cordem. Fl. Ile Réunion (1895) '727. - Ins. Borbon.

laurifolia, Cordem.l.c. (= Conyza laurifolia, Lam.). - Ins. Mascar.

lithuspermifolia, Corden. l. c. $524(=$ C. lithospermifolia, Lam.). - Ins. Mascar.

ittoralis, Cordin. I. c. (= Frappicria littoralis Cordem.). - Ins, Borbon.

modesta, Baker, in fourn. Linn. Soc. xxii. (1887) 490. - Madag.

montana, Buill. Dict. encych. sci. méd. Sér. II, xxvii. 712, ex Cordem, Fl. Ile Réunion (1895) 529 (= Frappieria montana, Cordem.). - Ins. Borbon. salaziana, Cordem. Fl. Ile Réunion (1895) 525. Ins. Borbon.

sericea, Cordem. I.c. 524 (= Conyza sericea, Bory). - Ins, Borbon.

scabra, Cordem. l. . . 526. - Ins. Borbon.

stenophylla, Baker, in fown. Linn. Soc xxii. (1887) 490. - Madao.

thermalis, Cordent. Fl. Ile Rémion $529(=$ Frappiertia thernalis, Cordem.). - Ins. Borbon.

tortuosa, Klatt, in Bot. Fahrb. xii. Beibl. (1890) 23. - Madag.

PSIDIUM, Linn. (Myrt.). - Ind. Kew. ii. 640 appendiculatum, Kiaersk, Enum. Myrt, Bras. (1893) 39. - Bras

Brownianum, Niedenzu, in Engl. \& Prantl, Naturl. Pfanzenfam. iii. $T$ (1893) $89=$ Brownianum, Wart.

Eugenii, Kigersk. Enum. Myrt.Bras. (1893) 26. Bras.

ugeniodes, Niedenzu, in Engl. \& Prantl, Natürl. Pflanzenfam. iii. 7 (1893) $69=$ eugenioides, Camb

Friedrichsthalianum, Niedenzu, l. o. (=Calyptropsidum Friedrichsthalianum, Berg). - Guatem.

Gardnarianum, Niedenzu, 1. co = Gardneriana, Birg.

Glaziovianum, Kiaersk. Enum. Myrt. Bras. (1893) 33. - Bras

Kennedyanum, Morong, in Ann. N. Y. Acad. Sci, vii. (1892) 104. - Parag.

lagoënse, Kiaersk. Enum. Myrt. Bras. (1893) 30. Bras.

minutifolinm, Krng Go Urban, ex Urban, in Bot. fahrb. xix. (1894) 569. - Cuba.

ovalifolium, Niedenzu, in Engl. Eo Prantl, Natuirl. Pflangenfam, iii. 7 (1893) 69 (= Mitranthes ovalifolia, Berg), - Bras.

F'ásseanum, Ed. André, in Rev. Hortic. 1xviii. (1890) 2:33, fig, 7l. - Hab.

pulverulentum, Krng \& Urban, ex Urban, in Bot. fahrb, xix. (1894) 567. - Jamaica.

salicifolium, Kuntze, Rev. Gen.(1891) 240 (= Myrtus salicifolia, Willd. $)=$ crenatım, Berg.

Sartorianum, Niedenzu, in Engl. E Prantl, Natiurl. Pfanzenfam. iii. T (1893) $69 \%=$ Mitranthes Sartoriana, Berg). - Mexic.

Schenkiana, Kiaersk. Enum, Myrt. Bras. (1893) 34. - Bras.

Warmingianum, Kiaersk, l.c.28 (= Campomanesia suffruticosa, Berg). - Bras.

Wrightii, Krng \& Urban, ex Urban, in Bot. Falirb. xix. (1894) 570. - Cuba.

PSILA, Phil, in Anal. Mus. nac. Chile (1891) 36. COMPOSITAE.

caespitosa, Phil. l. . i. l fig. 4, - Am, austr. occ.

PSILACTIS, A. Gray (Compos،). - Ind. Kew. ii. (i) 4 .

crispa, T. S. Brandeg. in Proc. Calif. Acad. Ser. II, ii. (1889) 169. - Calif

tenuis, S. Wats. in Proc. Am. Acad. xxvi. (1891) 139. - Mexic

PSILOGARPHUS, Nutt. (Compos.). - Ind. Kew, ii. 641

chilensis, Fr. Meigen, in Bot. Jahrb. xvii. (1893) 281 = Bezanilla chilensis, Remy

elatior, A. Gray, Syn. Fl. N. Am. i. 11. Suppl. (1886) 148. - Am. Lor. OcC.
PSILOCARYA, Torr. = Rynchospora, Vahl (Cyper.).

ritens, Britton, in Bull. Torrey Bot. Club, xv, (1888) $101=$ R. nitens, A. Gray.

PSILOPEGANUM. Hemsl. ex Forb. \& Hemsl. in Journ. Linn. Soc. xxiii, (1886) 103. RUTA$C E A E$

sinense, Hemsl. l. c. t. 3. - China.

PSILOSTAGHYS, Hochst. (Amarant.). - Ind, Kew, ii, 642

Boiviniana, Baill. in Bull. Soc. Limn. Paris, i. (1886) 622. - Zanzib

flipes, Baill. l.c. - Zanzib,

nervulosa, Baill. l.c. [nervulos]. - Afr. trop. or.

PSILOSTROPHE, DC, = Riddellia, Nutt. (Compos.)

Cooperi, Greene, Pittonia, ii. (Sept. 1891) 176 Kuntze, Rev. Gen. (Nov, 189]) $358=$ R. Cooperi, A. Gray.

tagetina, Greene, 1. c.; Kuntze, 1. c. = R. tagetina, Nult.

PSILOTRIGHUM, Blume (Amarant.). - Ind, IKew, ii, 642

africanum, Oliver, in Hook. Icon, pl. xvi, (1886) t. 15 42; ct in Trans. Linn. Soc. Ser. II. ii. (1887) 345. - Afr. trop. or.

humile, Drakc, Ill. Fl. Ins. Pacif. (1892) $270(=$ Nototrichium humile, Hillebr.): - Ins. Sandvic. Schimperi, Engl, in Abh. Preuss. Akad.Wiss. 189 (189:) 207. - Abyss.

iride, Drake, Ill. Fl. Ins, Pacif. (1892) $2 \%$ $(=$ Nototrichum viride, Hillebr. $)$ - Ins. Sandv.

PSILURUS, Trin. (Gramin.). - Ind. Kew. ii. 64 .

aristatus, St. Lager, in Cariot, Etud, des fl. éd. ii. (1889) $908(=$ P. aristatus, Duval-Jouve $)=$ nardoides, Trin.

PSORALEA, Linn. (Legumin.). - Ind. Kew, ii.

collina, Rydberg, Fl. of Nebraska (1895) 54. - Am. bor

Douglasii, Greene, in Erythea, iii. (1895) 99. Calif.

monticola, Greene, l. c. 98. - Calif.

pedunculata, Vail, in Bull. Torrey Bot. Club, xxi. (1891) $114=$ melilotoides, Mich

Purshii, Vail, l.c. 94. - Am. bor.

Reverchoni, S. Wats, in Proc. Am. Acad. xxi. (1886) 447. - Texas.

rigida, Parish, in Bull. Torvey Bot. Chib, xix. (1892) 91. - Calif.

Trianae, Vail, l. c, xxi, (1894) 119 - N. Granat.

Walkingtoni, F. Muell. in Vict. Natural. xii. (Oct 1895) 66 ; et ex Bot. Centralbl. 1xiv. (1895) 364. Austral.

PSOROSPERIMUM, Spach (Hyperic.). - Ind, Kew. ii. 644

albidum, Engl. Bot. Fahrb. xvii. (1893) 83. Angola.

campestre, Engl. 7. c. 84. - Afr, trop. occ:

emarginatum, Baker, in fourn. Linn. Soc. xxii. (1887) 453. - Madag.

malifolium, Baker, l. c. xxv. (1889) 295. - - Madag. membranifolium, Baker, l. c. 296. - Madag.

populifolium, Baker, l. c. xxii. (1887) 453. Madag.

salicifolium, Engl. Bot. fahrb. xvii. (1893) 84. Afr. trop.

Stuhlmannii, Engl. Pflanzenw. Ost-Afr. C (1895) 274. - Afr. trop. or.

verticillatum, S. Elliot, in fourn. Linn. Soc. xxix. (1891) 4. - Madag.

PSYCHOLOBIUM urens, Blume, ex Burck, in Annal. Jard. Buitenz, xi. (1893) 185, in syn. = Mucuna Blumei, Burck.

PSYCHOPSIS, Nutt. ex Greene, Pittonia, ii. (Dec, 1890) 134 = Hosackia, Doug1. (Legumin.)
PSYGHOTRIA, Linn. (Rubiac.). - Ind Kew

albidocalyx, K. Schum. in Abh. Preuss, Akad. Wiss. (1894) 21 et 16 ; et in Engl. Pflanzenw. Ost-Afr. C 1895) 390. - Afr. trop. or.

alsophila, $K$. Schum. $l l . c c, 63$; et 390 . - Afr. trop. amboniana, $K$. Sclum. ll. cc. 26, 28; et 390 . Afr. trop. or.

amicorum, Benth. \& Hook.f. ex Drake, Ill. Fl. Ins. Pacif. (1890) 197 ( = Chasalia amicorum, A. Gray); Hennsl. in fourn. Linn. Soc. xxx. (1894; 181. Ins. Pacif.

albicaulis, S. Elliot, l. c. 83. - Sierra Leone.

apiculata, Warb. in Bot. Fahrb. xiii. (1891) 439. N. Guin.

Aschersoniana, $K$. Schum, in Engl. of Prantl, $\mathrm{Na}$ türl. Pflanzenfam iv, 4 (1891) 114, - Columb.

aurantiaca, $K$. Schun. l.c. (= Grumilea aurantiaca Miq.). - Ind. bat.

Bangii, Rusby, in Mom. Torrey Bot. Club, iii. (1893) 47. - Bolivia.

Beccarii, K. Schumb, in K. Schum。 \& Holly. Fl. Kais. Wilh. Land (1889) 135. - N. Guin.

Boryana, Cordem. Fl. Ile Réunion (1895) 511 = Chusalia Boryana, DC.). - Ins. Borbon.

brachypoda, Britton, in Bull. Torrey Bot. Club, xviii. (1891) 109 (= Mapouria brachypoda, Muell. Arg.) - Bras.

Brackenridgei, K. Schum, in Engl. \& Prantl, Natürl. Pflanzenfam. iv, 4 (1891) $114=\mathrm{P}$. Brackenridgii, A. Gray.

brevicaulis, K. Schum. in Abh. Preuss. Akad. Wiss, (1894) 45 ; et in Engl. Pflanzenw. Ost.Afr. C (1895) 391. - Afr. trop. or.

bukobensis, $K$. Sclimm, l. c. - Afr, trop, or.

chimantha, Britton, in Bull. Torrey Bot. Club,

xviii. (1891) $109=$ P. Luschnathii, Mart.

chondrophylla, Boerl. Handl. Fl. Ned. Indie, ii. I (1891) 139 (= Chasalia chondrophylla, Miq. .. Sumatra.

chrysotricha, Zahlbr. in Annal. Naturh. Hofmus. Wien, ii. (1887) I. - Peruvia.

coaetanea, K. Schnm. in Abh. Preuss. Akad. Wiss. (1894) 45 ; et in Engl. Pfanzenw. Ost-Afr. C (1895 391. - Afr. trop. or

concinna, Oliver, in Trans. Limn, Soc. Ser. II. ii. (1887) 276, t. 42 b [Oliver, ox im Thurn, in Timehri, v. (1886) 196]. - Guian. angl.

congesta, Cordem. Fl. Tle Rémnion (1895) 513. Ins, Borbon.

corallioides, Cordem. l. c. 510. - Ins. Borbon.

crocea, Britton, in Bull. Torrey Bot. Club, xviii. (1891) 110 (= Palicourea crocea, Schlecht.) $=$ subcrocea, Muell. Avg.

densifolia, Stapf, in Trans. Limn. Soc. Ser. II. iv. (1894) 182. - Borneo.

discolor, Rolfe, in Kew Bull. (1893) 258, in obs. Ind. occ.

elachistacantha, K. Schum. in Engl. Pflanzenw. Ost. Afr. A (1895) 92, nomen. - Afr. trop.

falcata, Rusby, in Mem. Torrey Bot. Chub, iii. 3 (1893) 47. - Bolivia.

fimbricalyx, Boerl. Handl. Fl. Ned. Indië, ii: I. (1891) 139 (= Grumilea fimbricalyx, Miq.). Java.

Gavifolia, Rusby, in Mem. Torrey Bot. Chib, iii. (1893) 4ð. - Bolivia.

Franchetiana, Drake, Ill. Fl. Ins, Pacif. (1890) 198, t. 18 (= Uragoga Eranchetiana, Drake). Ins. Tahit.

gaertneroides, Cordem. Fl. Ile Rémnion (1895) 512. Ins. Borbon.

Guerkeana, K. Schum. in Bolet. Soc. Brot. x. (1892) 131. - Ins. S. Thom

guianensis, Rusby, in Mem. Torrey Bot. Club, iii. 3 (1893) 48 = Palicourea guianensis, Aubl.

gyrulosa, Stapf, in Trans. Linn. Soc. Ser. II iv, (1894) 180. - Borneo.

Hasseltiana; Boerl. Handl. Fl. Ned. Indie, ii. I. (1891) 139 (= Chasalia Hasseltiana, Miq.) Java.

Henriquesiana, $K$. Schum. in Bolet. Soc. Brot, x. (1892) ] 32. - Ins. S. Thom.

hirtella, Oliver, in H. Folnston, The Kitim. Exped. Append. (1886) 341, nomen; et in Trans, Linn. Soc. Ser. II. ii. (1887) 336. - Afr. trop. or. 


\section{PSYGHOTRIA}

hypoleuca, K. Schum. in Engl. Pfanzenw. Ost-Afr. C (1895) 391. - Afr. trop. or

Imthurniana, Oliver, in Trans. Linn. Soc. Ser. II. ii. (1887) 276, t. 42 a [Oliver, ex im Thurn, in Timehri, v. (1886) 196]. - Guian, angl.

iteophylla, Stapf, in Trans. Linn. Soc. Ser. II, iv, (1894) 181. - Borneo.

keyensis, Warb. in Bot. fahrboxiii. (1891) 438. N. Guin.

kilimandscharica, $K$. Schum. ex Engl. in Abh, Prenss. Akad. Wiss. 1891 (1892) 400. - Afr. trop. laevis, K. Schum. in Bolet. Soc: Brot. x. (1892) 131 , - Afr. trop. occ.

lamprophylla, K. Schum, in Abh. Prenss. Akad. Wiss. (1894) 54 ; et in Engl. Pflanzenw. Ost-Afr. C (1895) 391. - Afr. trop. or.

Lepiniana, Drake, Ill. Fl. Ins. Pacif. (1890) 198 (= Uragoga Lepiniana, Baill.). - Ins. Tahit.

Limba, S. Elliot, in fourn. Linn. Soc. xxx. (1894) S3. - Sierra Leone.

marchionica, Drake, Ill. Fl. Ins, Pacif. (1890) 198. - Ins. Pacif.

Milnei, K. Schum. in Engl. \& Prantl, Natïrl. Pfanzenfam. iv. 4 (1891) 113 (= Calycosia Milnei, A. Gray). - Ins. Fiji.

Molleri, K. Schum. in Bolet. Soc. Brot. x. (1892) 132. - Ins. S. Thom.

niveo-barbata, Britton, in Bull. Torrey Bot. Clwb, xviii. (1891) 110 (= Mapouria niveo-barbata. Muell. Arg.) - Am. austr.

officinalis, Kuntze, Rev. Gen. (1891) 957, in syn. sphalm. (= Palicourea offcinalis, Mart. $)=$ medica, Muell. Arg.

Parkeri, Baker, in fourn. Linn. Soc. xxii. (1887) 485. - Madag.

porphyroclada, K. Sichum, in Engl. Pfanzenw. OstAfr. C (1895) 390. - Afr. trop. or.

Pseudojapurensis, $K$. Sihzm. in Mart. Fl. Bras. vi. VI. (1889) 400 , in obs. $(=P$. japurensis, Muell Arg. pr. p.). - Bras.

melanosticta, K. Schum. in Abh. Preuss. Akad. Wiss. (1894) 16 et 26, nomen. - Afr. trop.

porphyrantha, K. Schum. l. c. 51, nomen. - Afr. trop.

puberula, K. Schum. in K. Schum. \& Hollv. Fl. Kais. Wilh. Land (1889) 135. - N. Guin.

reducta, Bakea, in fourn. Linn. Soc. xxii. (1887) 484. - Madag.

retiphlebia, Baker, l. c. 485. - Madag.

Schmielei, Warb. in Bot. Fahrb, xiii. (1891) 440 . N. Guin.

Simmondsiana. F. M. Bailey, in Dept, Agric. Brisbane Bot. Bull. ii. (1891) 13. - Austral.

stipularis, Rusby, in Mem. Torrey Bot. Club, iii. 3 (1893) 47 (= Palicourea stipularis, Benth.). Ecuad.

stricta, K. Schum. in K. Schum. \& Hollr. Fl. Kais. Wilh. Land (1892) 134. - N. Guin.

subhirtella, $K$. Schum. in Engl. Pfanzenv. Ost-Afr. C (1895) 390. - Afr. trop. or.

tahitensis, Drake, Ill. Fl. Ins. Pacif. (1890) 199 (= P.asiatica, Nadeaud). - Ins. Tahit

Teysmanniana, Boevl. Handl, Fl. Ned. Indie, ii. I. (1891) 139 (= Grumilea Teysmanniana; Miq.). Ins. Banka.

umbrosa. Britton, in Bull. Torrey Bot, Chub, xviji. (1891) $110 .-\mathrm{Am}$. austr.

velutipes, K. Schum. in Bolet. Soc. Brot. x. (1892) 130. - Ins. S. Thom

Volkensii, K. Schum. in Engl. Pflanzenw. Ost-Afr. C (1895) 390. - Afr, trop. or.

yungasensis, Rusby, in Mem. Torrey Bot. Club, iii. (1893) 46. - Bolivia.

PTAEROXYLON, Eckl. \& Zeyh, (Sapind.).Ind. Kew. ii. 651

bliquum, Radlk. in Sitz. Akad. Wiss, Muench. xx. (1890) 165. - Afr. austr.

PTARMICA, [Tourn.] Neck. = Achillea, Linn. (Compos.).

Barbeyana, Nym. Consp. F1. Eur. Suppl. ii. I. (1889) $166=$ Achillea Barbeyana, Heldr. \& Heimerl.

biserrata, Lange, in Bot. Tidsskr. (1895) 256, in obs. $(=P$. biserrata, DC. $)=$ A. biserrata, Bieb.
PTARMICA : -

alcarea, Nym. Consp. Fl. Eur. Suppl. ii. I. (1889) 167 = Achillea moschata, Wulf.

dacica, Nym.1. c. $166=$ A. oxyloba, Sch. Bip.

discoidea, Lange, in Bot. Tidsskr. (1895) 256. Hab. ?

faborneggi $X$, Nym. Consp. Fl, Eur. Suppl. ii. 1889) $167=$ Achillea faborneggi $X$. Halácsy

Kernevi, Haláczy, in Denkschr. Akad. Wien, 1xi (1894) $243=$ A. Kerneri, Haláczy.

Millii, Nym. Consp. Fl. Eur. Suppl. ii. I. (1889) $166=$ A. umbellata, Sibth, \& Sm

olympica, Heimerl, ex Nym. 1, c. $167=$ A. moschata. Wulf. ?

pindicola, Hausskn. ex Nym. 1. c. - Graecia.

Reichardtiana, Nym. 1. c. = Achillea Reichardtiana, G. Beck

rupestris, Nym. 1. c. $166=$ A. rupestris, Huter.

PTELEA, Linn. (Rutac.), - Ind. Kew, ii, 651. crenulata, Greene, Pittonia, i. (Oct. 1888) 216 ; Man. Bot. San Franc. Bay (1894) 72, - Calif. glauca, Hort. ex Dippel, Handb. Laubholzk. ii. (1892) 354 = trifoliata, Linn.

PTELEOPSIS, Engl. in Abh. Preuss. Akad. Wiss. (1894) 25 et 34 ; et Pflanzenw. Ost-Afr, C (1895) 293. COMBRETACEAE.

variifolia, Engl. II. cc. - Afr, trop, or.

PTERALYXIA, K. Schum, in Engl. \& Prant1, Natürl. Pflanzenfam. iv, 2 (1895) 151. APOCY

NEAE.
macrocarpa, K. Schum. l. . . $(=$ Vallesia macrocarpa, Hildeb.). -.-Ins. Sandvic.

PTERICHIS, Lindi, (Orchid.). - Ind, Kew, ii, 652 .

Widgreni, Cogn. in Mart. Fl. Bras. iii. IV. (1895) 245 (= Acraea Widgreni, Reichb. f.). - Bras.

PTERISANTHES, Blume (Ampelid.). - Ind,

\section{Kew. ii. 652.}

Beccariana, Planch. in DC. Monog. Phan. v. (1887) 418. - Borned.

caudigera. Planch. l.c. 420 (= Embamma candigerum, Griff.), - Ind. or.

Dalhousiae, Planch. l. c. 419. - Ind. or.

eriopoda, Planch. ..0.418 (= Vitis eviopoda, Miq.). - Sumatra.

glabra, Ridl, in Trans, Limn. Soc. Ser. II. iii. (1893) 287. - Penins. Mal

Miquelii. Planch. in DC. Monnog. Phan, v. (1887) $4 \mathbf{1 8}$ (=Vitis araneosa, Miq.). - Sumatra, Borneo. polita, Planch. 1. c. $416=$ polita, M. Lawes.

rufula, Planch. I.c. $41 \%$ (=Vitis rafula, Miq.).Sumatra.

taeniata, Planch. l. c. 419. - Borneo.

PTERNANDRA, Jack (Melastom.). - Ind. Kew. ii. 652

cordifolia, Cogn. in DC. Monog. Phan. vị. (1891) 1105. - Borneo.

discolor, Cogn. l.c, 1194. - Tonkin.

multiflora, Cogrz. i. c. 1104. - Borneo.

Nesopanax, Harms, in Engl. \& Prantl, Natirl. Pfanzenfam. iii. 8 (1894) 29 (= Nesopanax vitiensis, Seem.). - Ins Vjti. PTERNOPETALUM, Franch, in Nouv. Arch.
Mus. Paris, Sér. II. viii. 1885 (1886) 246. UMBELLIFERAE.

Davidi, Franch. . . c. t. 8, fig. B. - Tibet.

PTEROCARPUS, Linn. ${ }^{1} 1747$, non 1763 , fide $\mathrm{cl}$ Kuntze] = Derris, Lour. pr. p. (Leyumin.). acuminatus, amoenus, brachypterus. brevipes, canavensis. chinensis, Cumingii, cuneifolius, discolor, elegans, ellipticus, enalatus, fernugineus, floribundus, glabratus. guianensis, Heyneamus, javanicus, Korthalsianus, laxiflorus, longifolius, lucidus, macrolobus, macropiyllus, Maingayanus, marginatus, micropterus, montanus, multiflorus, negrensis, nobilis, oblongus, paniculatus, parviflorus, polyphylluts, polystachyus, pubinervis, pubipetalus, pyrrothyrsus, robustus, scandens, secundus, Spanogheamus, thyrsiflorus, vestitus.
PTEROCARPUS: -

Wightii, Kuntze, Rev. Gen. (I891) 203-04= homonyma omnia Derreos.

dalbergiodes, Kuntze, 1. c. $203=$ D. dalberoioides, Baker.

Forstenianus, Kuntze, $1 \mathrm{c},=$ D, uliginosa, Benth grandifolius, Kuntze, 1. c. = D. sinuata, Benth. Hanceanus, Kuntze, 1. c. = D. oblonga, Hance. ovalifolius, Kuntze, 1. c. = D. oblonga, Benth. polyarthrus, Kuntze, 1. c. = D. polyanthra, Miq.

teoliatus, Kuntze, 1. c. = D. uliginosa, Benth.

Zollingeri, Kuntze, 1. c. = D. grandifolia

PTERocarpUS, Linn, (Legumin.). - Ind. Kew. ii. 653 .

Buchanani, Schinz, in Bull. Soc. Bot, Geneve, vi. (1891) 66. - Transvaal.

chrysothrix, Taub. in Engl. Pfanzenve. Ost-Afr. C (1895) 218. - Atr. trop. Or.

Michelii, Britton, in Ann. N. Y. Accd. Sci. vii, (1892) 86. - Parag.

papuana, F. Muell. in Austral. Fourn. Pharm, i. (1886) 123 ; et ex Bot. Centralbl. xxvii, (1886) 21. $\rightarrow$ N. Guin.

Soyauxii, Taub. in Hook. Icon. pl, xxiv. (1895) t. 2369. - Afr. trop, occ.

PTERoGARYA, Kunth (Jugland.), - Ind. Kew,

dumosa, Lavallée, ex Dippel, Handb. Laubholzk. ii. (1892) $326=$ fraxinifolia, $C$. Koch

japonica, Hort. ex Dïppel, l. c. 329, fig. 19; Koehne, Dentsche Dendrol. (1893) 74, in obs. - Japon.

macroptera, Batalin, in Act. Hort. Petrop. xiii. (1893) 100. - China.

Paliurus, Batalin, .. c. 101. - China.

pterocarpa, "Kunth » ex Dippel, Handb. Laubholzk. ii. (1892) $326=$ fraxinifolia, C. Koch.

PTEROGAULON, Ell. (Compos.). - Ind. Kew. ii. 653 .

capitatum, Britton, in Ann, N. Y. Acad. Sci, vii. (1893) $144=$ Pluchea capitata, Hook. \&. Arn. redolens, Boerl. Handl. Fl. Ned. Indie, ii. I. (1891) 240 (= Monenteles redolens, Labill.), - Timor. tomentosus, Boevl.l.c. (= M. tomentosa, Sch. Bip.). - Java.

PTERoGelastrus, Meissn. (Celastr.). Ind. Kew. ii. 653

macrostylus, Hochst. ex Szyszyl. P1. Rehm. (1888) 31 = Apodytes dimidiata, E. Mey.

obtusus, Hochst, 1. c. = A. dimidiata, E. Mey.

PTERochrosia, Baill. Hist. des pl. x. (1888) 194; K. Schum. in Engl. \& Prantl, Natürl. Pflanzenfam. iv. 2 (1895) 158. A POCYNEAE. Vieillardii, Baill. i. . . - N. Caled.

PTEROCyMBIUM, R. Br. = Sterculia. Linn campanulatum, Pierre, F1. For. Cochinch. Fasc. 13 (1889) t. 195 A $[$ campanulata $]=\mathrm{S}$. campanulata, Wall.

colunnare, Pierre, I. c, t. 195 b [cohmnaris]. Cochinch.

dongnaiense, Pierre, 1. c. sub t. 193-95, in text. [dongnaiensis $]=\mathrm{S}$. dongnaiensis, Pierre.

tubulatum, Pierre, 1. c. = S. tubulata, Mast.

PTERODISGUS, Hook. (Pedalin.). - Ind. Kew ii. 654 .

angustifolius, Engl. Bot. fahrb. xix. (1894) 155. Afr. trop. or.

brasiliensis, Aschers, in Verh. Bot. Ver. Brand. xxx. (1888) $182=$ aurantiacus, Welw

PTEROGLOSSASPIS, Reichb.f. (Orchid.) Ind Kew ii. 654

Engleriana, Kraenzl, in Bot. Fahrb. xix. (1894) 249 - Afr, trop. or

PTEROLEPIS, Miq. (Melast.). - Ind. Kew, ii. 654.

Oerstedii, Cogn. in Mart. Fl. Bras, xiv. Iv. (18S8)

597 (= P. Arstedii, Cogn. olim). - Am. centr. 
PTEROLOBIUMI, R. Br. (Legumin.). - Ind. Kew. ii. 654 .

punctatum, Hensl. ex Forb. \& Hensl, in fourn. Limn2, Soc xxiii. (1887) 207. - China.

PTEROLOMA, Hochst.= Dipterygium, Decne (Crucit.).

glaucumn, Kuntze; Rev. Gen. (1891) $35=$ D. glaucum, Decne.

PTERONIA, Linn. (Compos.). - Ind. Kew. ii. polygalifolia, O. Hoffn. ex Schinz, in Bull. Herb. Boiss. i. (1893) 73. - Afr. austro-occ, extratrop.

PTERopeTALUM, Pax, in Bot. Jahrb. xiv 1891) 295, cum ic.; et in Engl. \& Prantl, Natuirl. Pflanzenfam. iii. 2 (1891) 229. CAPPARI$D E A E$.

Klingii, Pax, ll. cc. - Togo.

PTERoRHAGHIS, Harms, in Bot. Jahrb, xxii. (1895) 155. MELIACEAE

Zenkeri, Harms. l. c. - Kamerun.

PTERospermadendRon, Amm. = Pterospermum, Schreb. (Stercul.).

Gerifolinm. Blumeanum, cinnamoncum, diversifolinm, fuscun glabrescens, heterophyllum, fackianum, lan

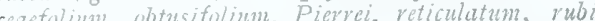

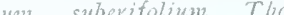

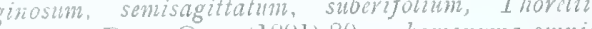
Kuntze, Rev. Gen. (1891) $80=$ homonyma omnia Pterospermi.

grewiacfolimn, Kuntze, 1. c. $=$ P. grewiaefolium, Picree.

insulare Euntze, $1, c_{0}=\mathrm{P}$, insulare, Pierr

involucratum, Kuntze, 1. c. = P. obliquum, Blanco. suigonense, Kuntze, 1. c. = P, saigonense, Pierre. Thorclii, Kuntze, 1. c. = P. Thorelii, Pierre. xylocarbun, Kuntze, 1. $\mathrm{c}_{\mathrm{o}}=$ P. Heyneanum, $W$ all.

PTEROSPERIIUM, Schreb. (Stercul.). - Ind. Kew, ii. 65.5

rrewiaefolium, Pierye, Fl. For. Cochinch. Fasc. 1\% (1888) 7. 181. - Cochinch

insulare, Pievye, t. e. t. 180 b. - Cochinch.

niveum, Vidal, Revis. Pl. Vasc. Filip. (1886) 67. Ins. lhilip.

saigonense, Pierre, ex Laness. Pl. util. Colon. Franc. (1886) 292, nomen; et Fl. For. Cochinzch. Fasc. 12 (1388) t. 180 a. - Cochinch.

suberifolium, Pierye, l. c. sub t. 180 . in obs. Cochinch.

Thorelii, Pierre, l. c. - Cochinch.

PTEROSPUROPSIS, Kell. = Sarcodes, Torr (Monotrop.). sanguinea, Kunt

PTEROSTEMON, Schau. (Rosac.). - Ind. Kew. 11. 6.36 .

rotundifolium, Ramives, in El Estudio, iv. (1893) 453, t. 13 ; et in La Naturaleza. Ser. II. ii. (1894) 41\%, t. 21. - Mexis.

PTEROSTYLIS, R, Br. (Orchid.). - Ind. Kew. 11.600.

auriculata, Colcnso, in Trans. $N, Z$. Inst, xxii. $1889(1890)$ 489. - N. Zel.

depauperata, F. M. Bailey, in Dept. Agric. Brisban Bot, Bull, iv. (1891) 18. - Austral.

Mackibbini, F. Muell. in Vict. Natural. ix. (Oct. 1892) 93 ; et in Bot. Centralbl, xlii. (1892) 347 . Austral.

Oliveri, Petrie, in Trans. N. Z. Inst. xxvi, 189; (1894) $270 .-\mathrm{N}$. Zel.

patens, Colenso, l. c. xviii. 1885 (1886) 270. - N Zel

polyphylla. Colenso, l. c. xxii. 1889 (1840) 489) -

rubella, Colenso, l. c. xviii. 1885 (1886) 271. - N. Zel.

speciosa, Colcrso, 2. c. xxi1. $1889(1890) 488 .-\mathrm{N}$. Zel.
PTEROTROPIA, Hillebr. Fl. Haw. Is1. (1888) 149. ARALIACEAE

dipyrena. Hillebr. l. c. $i=$ Heptapleurum dipyrenum, Mann). - Ins. Sandvic.

gymnocarpa, Hillebr. l. c, 151. - Ins. Sandvic,

auaiensis, Hillebr. l.c. $(=$ Heplapleurum kanaiense, Mann). - Ins. Sandvic.

PTERYGODIUM, Sw. (Orchid.). - Ind. Kew. ii. 657.

alare, Th. Dur. \& Schinz, Consp. Fl. Afr, v. 1892 1895) 116 = platypetalum, Lindl.

hastatum, Bolus, in Fourn. Linn, Soc. xxy, (1889) $17 \%$ tig. 14. - Atr. austr.

PTIRYGOTA, Schott \& Endl. = Sterculia Linn.

Burcavit, Pierre, F1. For. Cochinch. Fasc. 13 1889) sub t. 196, in obs. - Borneo.

Forbesii, F, Muell. in Vict, Natural. iii. (Aug. 1886) 46. - N. Guin.

papuana, Warb. in Bot. Jahrb, xiii. (1891) 376. N. Glin.

PTILEPIDA, Rafin. = Actinella, Nutt. $($ Compos.).

ucaulis, Britton, in Mem. Torrey Bot. Club, v, (1894) $339=$ A. acaulis, Nutt.

limcarifolia, Britton, 1, c. $340=$ A. linearifolia. Torr. \& Gray.

dorata, Britton, 1. c. = A. odorata, A. Gra

scaposa, Britton, 1. c. $=$ A. scaposa, Nutt.

PTILIMNIUM, Rafin. = Discopleura, DC. (Umbell.).

capillaceum. Hollick, in Trans. N. Y Acad, Sci. xiii. (1893) 28 = capillaceum, Rafin.

aciniata, Kuntze, Rev. Gen. (1891) $269=$ D. laciniata, Benth. G Hook. $f$.

Nuttallii, Britton, in Mem. Torrey Bot. Club, v, $(1894) 244=D$. Nuttallii, $D C$

PTILOCALAIS, Greene, in Bull. Calif, Akad. ii. v (1886) $54=$ Microseris, D. Don (Compos.).

gracililoba, Greene, 1. c.; et in Bull. Torrey Bot. Club, xvi. (1889) $150=$ Calais gracililoba, Kell.

major, Greene, 1. c. = Microseris major, A. Gray. mutans, Greene, 1. c. = M. nutans, A. Gray.

PTILOGHAETA. Turcz. (Malpigh.). - Ind. Kew. ii. 657 .

glabra, Niedeuzu, in Bot. Falurb, xiv. Beibl n. 30 (I891) 4. - Bras

PTILORIA, Rafin. = Stephanomeria, Nutt. (Compos.).

canescens, Greene, Pittonia, ii (Dec, 1890) 131; et Man. Bot. San Franc. Bay (1S94) 220 - Calif. cichoriacea, Greene, 1. c. $1: 33$ = Stephanomeria cichoriacea, A. Gray.

coronaria, Greene, 1. c. $132=$ S. Coronaria, Grene.

divaricata, Greene, in Erythea, i. (1893) 224. Calit.

exigna, Greene, Pittonia, ii. (Dec, 1890) 132 = Stephanomeria exigua, Nutt.

lactucina, Greene, 1. c. = S. lactucina, A. Gray.

myrioclada, Greene, 1. c, 138 = S. myrioclada, Eaton.

paniculata, Greene, 1. c. $132=$ S. paniculata, Nutt.

Par'yi, Coville, in Contrib. U. S. Nat. Herb. iv. 1893) $144=\mathrm{S}$. Farryi, $A$. Grat

pentachaeta, Greene, Pittonia, ii. (Dec. 1890) 133 S. pentachaeta, Eaton.

pleurocarpa, Greene, 1. c. 131. - Calit

Schottii, Greene, 1, c. $133=$ Hemiptilium Schottii, A. Grav.

Thurberi, Greene, $1 . c_{0}=$ Stephanomeria Thurberi, A. Gray.

tomentosa, Greene, 1. c. $121=$ S. tomentosa Greene.

virgata, Greene, 1. c. 130 ; et Man. Bot. San Franc. Bay (1894) $230=$ S. virgata, Benth.

Wrightii, Greene, l. c. = S. Wrightii, A. Gray.
PTILOTRICHUM, C. A. Mey. = Alyssum, Tourn. (Crucif.).

Uechtrizianum, Bornm. in Oest. Bot. Zeitschr. xxxviii. (1888) $18=$ Lepidotrichum Uechtritzia num, Velen. \& Bornm.

PTILOTUS, R. Br. (Amarant.). - Ind. Kew. ii 657.

Carlsoni, F. Muell. in Vict. Natural. v. (Oct. 1888) 74. - Austral.

Macleayi, F. Muell. in Proc. Linn. Soc. N.S. Wales, Ser. II. iii. (June 1888) 162. - Austral.

PTYGHANDRA, Scheff。(Palm,). - Ind, Kew. ii. 658 .

Muelleriana, Beco, in Nuov. Giorn. Bot. Itul. xx. (1888) 17\%. - N. Guin

obriensis, Becc. . . c. 178. - N. Guin.

PTYGHOSPERIMA, Labill. (Palm.). - Ind. Kew. ii. 658.

caryotoides, Ridl. in fourn. Bot. xxiv. (1886) 35s. - N. Guin.

litigiosa, Ridl, $\mathrm{I}_{\mathrm{c}} \mathrm{c}_{\mathrm{o}}=$ P. Ridleyi, Beco

Ridleyi, Becc, in Nuor. Giorn. Bot. Ital. xx. (1888) 179 , in obs. ( $=$ P. litigiosa, Ridl.). - N. Guin. Sayeri, Beco. l. c. 178. - N, Guin.

PTYCHOSTYLUS, Van Tiegh, in Bull. Soc. Bot. Fr. xliii. (1895) 389 = Loranthus, Linn.

Deppeanus, Van Tiegh. 1. c. $390=$ L. Deppeanus, Cham. \& Schlecht.

PUCCINELLIA, Parl. = Glyceria, R. Br.(Gra-

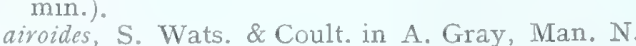
Am. Bot. ed. 6 (1890) $668=$ Glyceria distans, Wahlent.

angustata, Nash, in Bull. Torrey Bot. Club, xxii, (1895) $512=$ G. angustata, Fries.

PUELIA, Franch. in Bull. Soc. Linn. Paris, i. (1887) 674; et in Bull. Soc. Philom. Paris, Sér. VII. xi. (1887) 673. GRAMINEAE.

ciliata, Franch. $2 l . c c$. - Gabon.

PURRARIA, DC. (Legumin.) - Ind. Kew. ii 6 อั

calycina, Franch. Pl. Delav. (1890) 181. - Yunnan.

novo-guineensis, Warb. in Bot. Fahrb. xiii. (1891) $325 .-$ N. Guin.

sericans, K. Schuin, in K. Schum. \& Hollr, Fl. Kais.Wilh. Land (1889) $99=$ phaseoloides, Benth yumnanensis, Franch. Pl. Delav. (1890) 181. Yunnan.

PULASSARIUM, Rumpf, Herb. Amboin. v, (174547) 32 , t. 20, ex Kuntze, Rev. Gen. (1891) 410 = Alyxia, Banks (Apocyn.).

affine, Guxifolium, ceylanioum, coriacenm, disphaerocarpum, fascioulare, glancophyllum, gracile, Halmaheirae, ilicifolium, laurinumn, leucogyne, Lindii, madagascariense, obtusifolium, odoratum, pilosum, podocarpum, pumilum, quinatum, ruscifolinm, scandens, sincnse, spicatum, Spanogheanum, squamulosum, stellatum, Thozetii, thyrsifiorm, Iorresianum, Kuntze, Rev. Gen. (1891) 417 momonyma omnzia Alyxiae.

Alyxiar, Kuntze, 1.c. = A. lucida, Wall.

breviflorim, Kuntze, 1. co (= Gynopogon breviflonm Kurz). - Burma.

brerifolinm, Kuntze, 1. c. = Alyxia breviflora, V'an Heurck of Muell. Avg.

daphnodes, Kuntze, 1. C. = A. daphnoides, A. Cumn. oliviformis, Kuntze, 1, c. = A. olivaeformis, Gaudich.

sulcatum, Kuntze, 1. c. = A. olivaeformis, Gaudich

PULICARIA. Gaertn. (Compos, - Ind. Kew. ii 659.

adenensis, Schweinf. ex Kuntze, Rev. Gen. (1891) 358. - Arabia.

Aylmeri, Baker, in Kew Bull. (1895) 216. - Reg Somal.

iphionoides, Kuntze, Rev. Gen. (1891) 258 = adenensis, Schweinf. 


\section{PULICARIA :}

leucophylla, Baker; in Kew Bull. (1894) 333. Arabia.

suffrutescens, Schreeinf. ex Penzig, in Atti Congr. Bot. Genova (1893) 346, nomen, - Erithrea.

Eizllosa, Kuntze, Rev. Gen. (1891) 358 = Pulicaria Boissieri, Hook. f.

PULMONARIA, [Tourn.] Linn. (Borag.). - Ind. Kew. ii. 660 .

dicica, Simonk. Enum. Fl. Transs. (1886) $406=$ rubra, Schott \& Kotschy.

intermedia X. Palla, ex Ber. Deutsch. Bot. Ges.v. (1887) 131.

Kerneri, Wettst. in Verh. zool.-bot. Ges. Wien, xxaviii. (I-S8) 559, t. 13: Kern, Sched. Fl. Austro-Hung. vi. (1893) 38. - Stiria.

PULSATILLA, [Tourn.] Linn. = Anemone Tourn. (Ranuncul.)

hirsutissima, Britton, in Ann. N. Y. Acad, Sci. vi, (1891) $217=$ A. patens, Linn.

multiceps, Greene, in Erythea, i. (1893) 4. Alaska.

occidentalis, Freyn, in Deutsche Bot. Monatsschr. viii. $(1890) 78=$ Anemone cccidentalis, S. Wats.

Petteri X. G. Beck, Fl. Nied.-Oest. i. (1890) 410. - Austria.

slavia, Reuss, ex Sagorski \& Schneid. Fl. Centralkarp. ii. (1891) 37, sphalm. = slavica, Reuss.

PULTENAEA. Sw. (Legumin.), - Ind. Kew, ii. 661.

Baeuerlenii, F. Muell. in Proc, Linn. Soc. N. S. Wales, Ser. II. i. (Feb. 1887) 1109. - Austral.

PURDIEANTHUS, Gilg, in Engl, \& Prantl, Natürl. Pflanzenfam, iv. 2 (1895) 99), GENTIANEAE.

pulcher, Gilg, l.c. - N. Granat, Columb.

PURPURELLA, Nand, = Tibouchina, Aubl. (Melast.).

cleistoflora, Ule, in Ber. Deutsch. Bot. Gesells. xiii. (1895) 418 , t. 32. - Bras.

hospitı, Krasser, in Engl. \& Prantl, Natürl, Pflanzenfam. iii. 7 (1893) $148=$ Tibouchina hospita, $\operatorname{Cog} n$.

hygrophila, Krasser, $1 . c_{0}=T$. hyorophila, Cogn . minutiflora, Krasser, 1. c. $=$ T. minutiflora, $\operatorname{Cog} n$.

PUSAETHA, Linn. Fl. Zeyl. (174 i) 236 = Entada, Adans. (Legumin.).

abyssinica, acaciaefolia, africana. Dubarquetiana, Kirkii, polyphylla, scandens, sudanica, Kuntze, Rev. Gen. (1821) $204=$ homonyma omnia Entadae.

abyssinica. Taub. in Engl. Pflanzenw. Ost-Afr. C (1895) $196=a b y s s i n i c a$, Kuntze.

Entada, Kuntze, Rev. Gen. (1891) 204 = Entada polystachya, $D C$

Kirkii, Taub, in Engl, Pflanzenw. Ost-Afr. C (1895) $196=$ E. Kirkii, Oliver.

Stuhlmannii, Taub. 1. c. - Afr. trop. or

spicata, Kuntze, Rev. Gen. (1891) $204=$ Entada natalensis, Benth.

Wahlbergii, Kuntze, 1. c. = E. Wahlbergii, Havv,

PUYA, Molina (Bromel.). - Ind. Kew, ii. 663. Achupalla, Hort. Lind. ex Baker, Handb. Bromel, (1889) 126 , in syn $=$ Bonplandiana, Schult. $f$.

aequatorialis, Ed. André, in Rev. Hortic. 1x. (1888) 565 ; et Bromel. Andranae (1889) 36, t. 12a; Baker, l. c. - Ecuad.

boliviensis, Baker, l. c. - Bolivia.

Britoniana, Baker, l. c. 124. - Bolivia.

copiapina, Phil. in Anal. Univ. Chil. xci. (1895) 613. - Chili.

echinotricha, Ed, André, in Rev. Hortic. 1x. (1888) 565 ; et Bromel. Andreanae (1889) 33, t. $11 \mathrm{~b}=$ Pitcairnia echinotricha, Baker.

eryngioides, $E d$. André, $l l . c c .565$; et 32, t. 10 ; Baker, Handh. Bromel. (1889) 125. - Ecuad.

Aloccosa, Éd. Morr. ex Baker, 1. c. in syn. = Pitcairnia floccosa, Regel.

\section{PUYA :}

gigantea, Ed. André, in Tour du Monde, xxxviii. (1879) 332, cum xylogr.; et Rev. Hortic. $1 x$. (1885) $565=$ gigas, Ed. André.

nivalis, Baker, Handb. Bromel. (1889) 124. Columb.

pastensis, Ed. André, in Rev. Hortic, 1x. (IS88) 565 et Bromel. Andreanae (1889) 39, in obs. -Columb. quatameensis. Ed. André, 11. cc. 365; et 38, t. 11 a $=$ Pitcairnią quetamensis, Ed. André.

Thomasiana, Ed. Andrè, $17.6 c .565$; et 35 . t. 1ld;

Baker, Handb. Bromel. (1889) 125. - Columb.

Trianae, Baker. 1. c. 124. - N. Granat.

venusta, Phil, ex Baker. 1. c. (1889) 123, in syn. et in Anal. Univ. Chil. xci. (1895) $613=$ Pitcairnia venusta, Baker.

vestita, Ed. André, in Rev. Hortic. Ix. (1888) 565; at Bromel. Andreanae (1889) 3\%, t. 12b; Baker, l. c 125. - Ecuad.

Weberiana, Godefr, Leboenf, ex Rev. Hortic. 1xiii. 1891) 291. - Hab, ?

PYCNANTHEMUM, Michx (Labiat.). - Ind. Kew. ii. 663

flexuosum, Brittnn, Stern \& Pogg. Prelim. Catal. 1888) $42=$ linifolium. Pursh.

virginianum, Trelease, ex Branner \& Coville, in Ann. Rep. Geol. Surv. Arkans. for 1888 i. (1891) 211 = lanceolatum, $P$ urs $/$.

virginicum, Britton, Stern \& Pogrg. Prelim. Catal. 1888) 42 = lanceolatum, Pursh.

PYGNANTHUS. Warb. in Ber. Deutsch. Bot. Ges, xiii. (1895) 94. MYRISTICEAE.

microcephalus, Warb. in Ber. pharm. Ges. (1892) 226 ; et in Engl. Pfanzenwe. Ost-Afr. B (1895) 271 $(=$ Myristica microcephala, Benth. $)$ - - Afr. trop. Schweinfurthii, Warb. ex Engl. Pfanzenw. Ost-Afr. B (1895) 271 et C. (1895) 180. - Afr. trop.

PYGNARRHENA. Miers (Menisperm.). - Ind. Kew, ii. 663 .

australiana, F. Muell, in Vict. Natural, ii. (Sept. 1886) 61 ; et ex Bot. Centralul. xxix. (1887) 147. Austral.

manillensis, Vidal, Revis. Pl.Vasc. Filip. (1886) 45 - Ins. Philipp.

PYCNOBREGMA, Raill. Hist. des pl. x. (1890) 288; K. Schum in Eng1, \& Prant1, Natiirl. Pflanzenfam. iv. 2 (1895) 304. ASCLEPIADEAE.

Funckii, Baill. ll. $c c,-N$, Granat.

PYGNOCOMA, Benth. (Euphorb.). - Ind. Kew ii. 663 .

littoralis, Pax, in Bot. Fahrb. xix. (1894) 100. Afr. trop. or.

macrantha, Pax, ex Engl. in Abh. Preuss. Akad. Wiss. (1894) 44 ; et ex Engl. Pfanzenze. Osi-Afr. C (1895) 239. - Afr trop or.

rigidifolia, Baill. Hist. pl. Madag., Atlas (1890) t. 178. - Madag

trewioides, Baill. l. c. 180. - Madag.

PYCNOCOMON, Hoffmgg \& Link = Scabiosa Toụrn (Dipsac.).

montanum, Pomel, ex Batt. \& Trab. Fl. de l'Algér. [Dicot.] (1889) 417 , in syn. = $\mathrm{S}$ rutaefolia, Vaht.

PYGNOPHYLLUM, Remy (Caryophyll.). - Ind. Kew. ii. 664

rgentinum, Pax, in Bot. Fahrb, xviii. (1893) 33 - Reg. Argent.

PYGNORHAGHIS, Benth. (Asclep.). - Ind. Kew, ii. 664.

Benthamiana, Baill, Hist. des pl.x. (1890) 278. Malacca.

PYCHNOSTACHYS " Hook. " ex Baill. Hist. des pl. xi. (1892) 69, sphalm. = seq.

PYGNOSTACHYS, Hook. (Labiat,), - Ind. Kew, ii. 664 .

affinis, Guerke, in Engl. Pfanzenw. Ost-Afr. C (1895) 345. - Afr. trop. or.
PYCNOSTACHYS

cyanea, Guerke, in Engl. Pfanzenw. Ost-Afr. C

(1895) 345 . - Afr. trop. or.

Emini, Guerke, in Bot. Fahro. xxii. (1895) 145. Afr, trop. or

Goetzenii, Guerke, in Engl. Pfanzem\%. Ost-Afr. A (1895) 135 [Pychnostachys!. - Afr. trop, or.

Meyeri, Guerke, ex Engl. in Abh. Prenss. Ahad. Wiss. 1891 (1892) 362, et (1894) 53 et 69. - Afr. trop or.

micrantha, Guerke, in Eng7. Pfanzenw. Ost-Afr. C (1895) 345. - Afr. trop. or

niamniamensis, Guerke in Bot falwb xxii (1895) 145. - Afr. trop.

orthodonta, Guerke, in Engl. Pfanzenue. Ost-Afr. C (1895) 345. - Afr. trop. or.

parvifolia, Baker, in Keev Bull. (1895) 72 [parvifolius]. - Afr. trop.

Schweinfurthii, Briq. in Bot. Fahrb. xix. (1894) 191 — Afr. trop.

speciosa, Guerke, in Engl. Pfanzenw. Ost-Afr. C (1895) 345. - Afr. trop. or.

Stuhlmannii, Guerke, l, $c_{0}$ - Afr, trop. or.

verticillata, Baker, in Kew Bull. (1895) il rverticil latus]. - Afr. trop.

Volkensii, Guerke, in Engl. Pfanzenw. Ost-Afr. C (1895) 344. - Afr, trop. or.

PYGNOSTELMA, Bunge (Asclep.). - Ind, Kew ii. 664

lateriflorum, Hemsl. in fourn. Iimn. Soc. xxvi. (1889) 102. - China.

paniculatum, K. Schum. in Engl. \& Prantl, Natürl. Pflanzenfam. iv. 2 (1895) 243 Lpanniculatum] = chinénsis, Bunge.

PYGREUS, Beauv, (Cyper.). - Ind. Kew. 664.

aethiops, C. B. Clarke, in Th. Dur. \& Sching Consp. Fl. Afr. v. 1894 (1895) 534 (= Cytern aetriops, Welw, ) - Afr, trop.

atrobrunneus, C. B. Clarke, l. c. 535. - Madas

atronervatus, C. B. Clarke, l. C. $(=$ Cypertus atronervatus, Boeck.). - Abyss.

atropurpureus, C. B. Clarke, l.c. $(=C$, atropurpureus, Boj.). - Madag.. Ins, Borbon.

betschuanus, C. B. Clarke, l. c. $(=C$. betschuamus, Boeck.). - Afr, austr.

caespitosus, C. B. Clarke, l. c. $(=$ C. caespitosus, Poir.). - Ins. Borbon.

capillifolius, C. B. Clarke, l.c. $(=$ C. capillifolins, A. Rich.). - Afr. trop.

chrysanthus, C. B. Clarke, l. G. (= C. chrysanthus, Boeck.). - Afr. austr.

Cooperi, C. B. Clarke, l. c. - Afr. austr.

cuanzensis, C. B. Clarke, $l . c .536 i=C$. cuanzonsis, Ridl.). - Angola.

divulsus, C. B. Clarke, l. c. $(=C$. dirntsus, Ridl.) - Maday.

elegantulus, C. B. Clarke, l. c. $(=C$. elegantulus, Stend.). - Afr. trop. et austr.

ferrugineus, C. B. Clarke, in Hook. f. Fl. Brit. Ind vi. (1893) 595 ; et ex Th. Dur. \& Schinz, Consp. Fl. Afr. v. 1894 (1895) 536 (= C. ferruginens Poir.). - As., Afr. et Am. trop.

Hildebrandtii, C. B. Clarke. l. c. v. 1894 (1895) 538. - Zanzibar, Mombassa.

lanceolatus, C. B. Clarke, l. c. (= Cyperus lanceolatus, Poir.). - Afr. trop., Madas.

latespicatus, C. B. Clarke, in Hook f. Fl. Brit. Ind. vi. (1893) 690 (= C. -latespicatus, Boeck.). Ind. or.

macranthus, C. B. Clarke, in Th. Dur. E Schinz Consp.Fl. Afr. v. 1894 (1895) 538 (= C. macran thus, Boeck.). - Afr. trop. et austr.

melas, C. B. Clarke, l. c. $(=C$. melas, Ridl. $)$ Angola.

monocephalus, C. B. Clarke, l. c. $(=C$. monocephalus, Baker). - Madag.

nigrescens, C. B. Clarke, in F. Buchan. Nyassaland (18 ) 20 (=C. nigrescens, Steud.). - Afr. trop, nioricans, C. B. Clarke, in Trans. I.mus. Soc. Ser. II. iv. (1894) 53; et 7. c. 539 (= C. nigrivans, Steud.). - Abyss. 


\section{PYCREUS :}

pauper C. B. Clouke in Th. Dur \& Schinz, Const. Fil. Afr v 1894 (1895) 540 (= Cyte us pauper, Hochst.), - Angola, Abyss.

pelophilus, C. B. Clarke, l. c. $(=$ C. pelophilus, Rid1.). - Angola.

Pervillei, C. B.Clarke, l.c. $(=$ C. Pervillei, Boeck. $)$. - Madas.

Rehmannianus, C. B. Clarke, l. C. $542(=C$. Reh mannianus, Boeck.). - Transval.

Smithianus, C. B. Clarke, l. c. $(=$ C. Smuthianus, Ridl.). - Afr. trop.

spissifforus, C. B. Clarke, in Trans. Linn. Soc., Ser. II. iv. (1894) 5i3; et l. c. - Afr. trop. austro-or

stramineus, C. B. Clarke, in Hook. f. Fl. Brit. Ind. vi. (1893) 589 (=C. stamineus, Nees). - Ind. or. Zeylan.

subtrigonus, C. B. Clarke, in Th Dur. E Schin\%, Consp. Fl. Afr. v. 1894 (1895) 542. - Congo.

sulcinux. C. B Clarke, in Hook. f. Fl. Erit. Ind. vi. (1893) 593 ; et ex Th. Dur. Eo Schinz. Consp. Fl. Afr, v. 1894 (1895) $542(=$ Cyperus sulcinux, C. B Clarke). - Orb, vet. weg. trop.

tremulus, C. B. Clarke, in Th. Dur. E Schinz, Const. Fl. Afr. v. $1894(1895) 542(=$ C. tremulus, Poir.) - Afr. trop.

PYGEUM, Gaertn. (Rosac.). - Ind. Kew. ii. (ib).

brevistilum K. Schnm. in K. Schum. \& Holly. Fl. Kais. Wilh. Land (1889) 03. - N. Guin.

nitidum, Pierre, ex Laness. Pl util. Colon. Franc. (1886) 284, nomen. (Pigeum). - Cochinch. oocarpum, Stapf, in Trans. I,inn. Soc. Ser. II. iv. (I8?4) 144. - Borneo.

Parreavii, Pierre, ex Laness. Pl. util. Colon. Franc. (1886) 284, nomen [Pigeum]. - Cochinch.

Tumerianum, F. M. Bailey, in Dept. Agric. Brisbane Bot. Bull. viii. (1893) 74. - Austral.

PYRENAGANTHA, Wight (Olacin.). - Ind. Kew. ii. 664 .

globosa, Engl. Bot. Falub. xvisi. (1594) 80. - Afr. trop, or.

malvaefolia, Engl. in Sitz. Prenss. Akad. Wiss. xviii. (1893) 268. - Afr. trop. or.

vitifolia, Engl. Pfanzenw. Ost-Afr. C (1S95) 24S. Afr. trop. or.

PYRENARIA, Blume (Ternstroem.). - Ind. Kew. ii. 665

Jonquierana. Pierre, ex Laness. Pl. util. Colon. Frani. (1886) 295: et Fl. For, Cochunch. Fasc.8 (1887) t. 120. - Cochinch.

Kunstleri, King, in fourn. As. Soc. Beng. Iix. (1890) II. 200. - Perak

TVrayi, King, l. c. 201. - Perak.

PYRETHRUM, Hill = Chrysanthemum, Tourn (Compos.).

anserinaefolium, Hausskn. \& Bornm. ex Hausslin. in Mitth. Bot. Ver. Jena, ix. (1891) 18. - As. Yiin.

Bornmelleri, Hausskn. \& Bornm. 1. c. - As. Min. defauperatum. Post, in Bull. Herb. Boiss. iii. (1895) 158. - Syria.

Fisherae, Boiss. Fl. Or. Suppl. (1888! $300=$ Tanacetum Fisherae, Aitch. \& Hcms?.

Griffithii, Boiss. 1. c. $299=$ Chrysanthemum Griftithii, C. B. Clarke.

helichrysiflorum, Hausskn. \& Bornm, ex Bornm, in Mith. Thür. Bot. Ver. N. Folge, vi. (1894) 66. - Oriens.

fohnstoni, Boiss. Fl. Or. Suppl. (ISS8) $299=$ Tanacetum Johnstoni, Hemsl.

lcucanthemifolium. Porta, in Atti Accad. Agiati, ix. 1891 (1892) :34. - Hisp.

llarioni, Alboff, in Bull. Herb. Boiss. iii. (1895) 92. - Reg. Cauc

ponticum, Alboff, 1. c. ii. (1894) 4504. - Reg. Cauc. Shepardi, Post, 1. c. iii. (1895) 158, in obs. Syria.

Slarkeanum, Alboff, 1. c. ii. (1894) 454. - Reg. Cauc.
PYROLA, [Tourn.] Linn. (Ericac.). - Ind. Kew.

ii. 667 .

atropurpurea, Franch, in Mlorot, Fourn. de Bot.ix. (1895) 372. - China.

contallariaefolia, Genty, in Bull. Soc. Bot. Fr. xxxvii. (1890) 29 [Pirola] = media, Sw.

PYROSTEGIA, Presl = Bignonia. Tourn. cinerca, Bureau, ex K. Schum. in Engl. \& Prantl, Natül. Pflanzenfam. iv. 3b (1894) 223. - Am. austr

PYRROCOMA, Hook. = Aplopappus. Cass. (Compos.).

apargioides, Greene, in Erythea, ii. (1894) $70=$ A. apargioides, A. Gray.

crocea, Greene, 1, c. $69=$ A. croceus, A. Gray.

Cusickit, Greene. 1. c. $59=$ A. carthamoides, A. Gray var:

elata, Greene, Man. Bot. San Franc. Bay (1894) 173. - Calif.

hirta, Greene, in Erythea, ii. (1S94) $69=$ Aplopappus hirtus, A. Gray.

Howellii. Greene, 1. c. $70=$ A. Howellii, A. Gray.

integrifolia, Greene, 1. c. $69=\mathrm{A}$. integrifolius, Porter.

imuloides. Greene, 1. c. $60=\mathrm{A}$, inuloides, Tory.

Iancoolata, Greene, 1, c $69=$ A. lanceolatus, Torr. E Gray.

subsquarrosa, Greene, 1. c. iii. (1895) 22. Wyoming.

tenuicaulis, Greene, 1, c, ii..(1894) 69 = A. tenuicaulis, D.C. Eaton.

uriflora, Greene, 1. c. $60=$ A. uniflorus, Torr.

PYRUS, [Tourn.] Linn. (Rosac.). - Ind. Kew, ii. 608.

Armud, Hausskn. E Bornm. in Mitth. Bot. Ver. Fona, 1x. (1891) 17. - As. Min.

cathayensis, Hemsl. ex Forb. \& Hemsl, in fourn. Linn. Soc. xxiii. (1857) $256(=$ Cydonia senensis, Thoms.). - China.

Delavayi, Franch. Pl. Delav. (1890) 227, t. 47 [Pirus]. - Yunnan.

Donnell-Smithii, "Mast, » ex Coult. Bot. Gaz, xvi. (1891) 199 (err. cal.) = Pinus Donneli-Smithii, Mast.

flibunda, Nichols, ex Gard. Keve, i. Polypet. (1894) 181 (= Malus floribunda, Sieb.). - Japon.

Halleana. Hort. 1, c. = seq

Halliana, Hort. ex Gard. and For. i. (1888) $152(=$ Malus Halliana, Koehne) $=$ floribunda, Nichols.

iërnsis, I. H. Bailey, in Am. Gard. xii. (1889) 473 f. 7-8; ex Sarg. Silva N. Am. iv. (1892) $72=$ coronaria, Linn.

iowensis, MacMill. Nietasp. Minn. (1892) $284=$ praec.

kansuensis, Botalin, in Act. Hort. Petrop. xiii. (1893) 94. - China.

kohimensis, Watt, ex C. B. Clarke, in fourn. Linn. Soc. xxv. (1889) 20. - Kohima.

lobata, Nichols, ex Gard. Kew, i. Polypet. (1894) 195 $(=$ Crataegus lobata, Bosc $)$. - Reg. Cauc.?

minima, Aug. Ley, in fourn. Bot. xxxiii. (1S95) 84. - Brit.

Miyabei, Sarg. in Gard. and For. vi. (1893) 2l3, et vii. (1894) 14; Dippel. Hanab. Laubhol\%k. iii, (1893) 381 [Pirus]. - Japon.

Myabei, Sarg. Forest Fl. Japan (1894) 40, t. $13=$ praec.

nigra. Sarg, in Gard. and For, iii. (1890) 416; Dippel, Handb. Laubholzk. iii. (IS93) 385, 386 [Pirus] (= Aronia nigra, Dippel). - Am. bor.

ccidentalis, S. Wats. in Proc. Am. Acad. xxiii. (1888) 263. - Calif

orthocarpa, Nichols, ex Gard. Kere, i. Polypet. (1894) 181 (= Malus orthocarpa. Lavall.).- - Japon

Parkmanni, Hort. ex Gard, and For, i. (IS8S) 152 ; Dippel, Handb. Laubholzk, iti. (1893) 406 et 740 , ad calc. [Parkmanii] = floribunda, Nichols.

Polvilla, ( Gmel. » ex Dipfel, 1. c. $359=$ P. Pollveria, Linn.

Prattii, Hemsl. in Kew Bull. (1895) 16. - China

scabrifolia, Franch. Pl. Delav. (1890) 229. Yunnan.
PYRUS :

Pevulata, Hort ex Gard. Kew, i. Polypet. (I \&94) 191 = Pyrus Sorbus, Gaertn.

Soulardi, L. H. Bailey, in Am. Gard, xii. (1891) 17\% (= Malus Soulardi, Britton); Sarg. Sylva N.Am iv. (1892) 72, in obs, = coronaria, Lim.

succica, Garcke, ex Gard, Kew, i. Polypet. (1894)Is7 (= Pyrus suecica, Roehl.) = intermedia, Elırh

Tonorei, Hort, ex Dippel, Handb. Laubholzk. iii. (1893) 399 ; Koehne, Deutsche Dendrol. (1893) $260(=$ Malus spectabilis, Borkh.). - Form. hort. thianschanica, Regel, in Act. Hort. Petrop. xi (1890, 312; et in Gartenfl xl. (1891) 8, fig. $4=$ tianschanica. Franch

Thonsonii, Hort. ex Gard. Kew, i. Polypet. (1894) $189=$ vestita, TVall

transitoria, Batalin, in Act. Hort. Petrop. xiii. (1893) 95. - China.

yunnanensis, Franch, Pl, Delav, (18.70) 2\%S, Yunnan.

PYXIDARIA, Hall. = Vandellia, Linn, (Scrophul.).

cacspitosa, corymbosa, cristacea, cymulosa, diffusa. elata, Ellobum, glandulifera. Hookeri, japonica, latifolia, limosa, minuta, montana, nervosa, nummularifolia, obtusa, pachypoda, pubescens, scapigera, senegalensis, soriana, sphaerocarpa, siachydifolia, subcremulata, subulata, urticifolia, Kuntze, Rev. Gen. (1891) 464-657 = homonyma omnia Vandelliae.

alsinodes, Kuntze, 1, c. $464=\mathrm{V}$, alsinoides, Benth. arridens, Kuntze, 1. c. = V. pedunculata, Benth. cordifolia, Kuntze, 1. c. = V. pedunculata, Benth. hirta, Kuntze, 1. c, = V. mollis, Benth.

lobeliodes, Kuntze, 1. c. = V. lobelioides, Oliver. micrantha, Kuntze, 1, c. $=\mathrm{V}$, ancustifolia, Benthe molluginodes, Kuntze, 1. c. := V. molluginoides, Benth.

oblonga, Kuntze, 1. c. $465=$ Torrenia oblonga, Stend.

obotata, Kuntze, 1. c. = Mazus rugosus, Lour. pusilla, Kuntze, 1. c. $464=$ Vandellia scabra, Benth.

stemodiodes, Kuntze, 1. c. = V. stemodioides, Miq. viscosa, Kuntze, 1. c. = V. hirsuta, Buch. Ham.

\section{Q}

QUAMOCLIT, Tourn. ex Moench = Ipomoea Linn. (Convolv.)

lutea, Hallier f. in Bot. Jahrb. xvi. (1893) $55 \%=$ Ipomoea lutea, Hemsl.

OUAPOYA, Aub1. = Clusia, Linn. (Guttif.) acuminata, Kuntze, Rev. Gen. (1891) 61 = Rengifa acuminata, Planch. \& Triana.

colorans, Klotzsch, ex Engl, in Mart. Fl. Bras. xii. I. (1888) $426=$ Clusia colorans, Engl.

ligulata, Klotzsch, 1. C. $420=$ C. myrianđra, Planch E Triana.

microphylla, Klotzsch, ex Engl. 1. C. $427=$ C. microphylla, Engl.

perwiana, Kuntze, Rev. Gen. (1891) $61=$ Rengifa peruviana, Poepp. \& Endl.

pousta, Klotzsch, ex Engl. in Mart. Fl. Bras, xii I. (1888) $431=$ Clusia Schomburgkiana, Benth.

QUARARIBEA, Aubl. (Malv.). - Ind. Kew. ii

floribunda, $K$. Schum, in Mart. Fl. Bras, xii. III. (1886) $242=$ Myrodia floribunda, St. Hil.). Bras.

pendulifera, K. Schum.l. c. 241. - Bras.

QUEBRACHIA, Griseb. (Anacard.). - Ind. Kew, 11. 671

Laurentzii, « Griseb. ». ex Illustr. Hortic, xxxviii. (1891) 105, in obs, sphalm. = Lorentzii, Griseb. Morongii, Britton, in Ann. N. Y. Acad. sci. vij. (1892) $7 \%$ - Parag. 
oUEKETTIA Lindl. (Orchid.), 一 Ind. Kew, ii. 671.

chrysantha, Barb. Rodr. Veilosia, 1885-88, Sec. ediç. (1891) 130. - Bras, bor.

QUERGUS. [Tourn.] Linn. (Cupulif.). - Ind. Kew, ii. 671 .

abbreviata, Vukot. in Verh. zool.-Bot. Ges. Wien, xxxix. (1889) $199=$ Q. Robur, Linn.

acuminata, Sarg. in Gard, and For. viii. (1895) 93 $=\mathrm{Q}$. Prinos, Linn

Allardi $X, \mathrm{Hy}$, in Bull. Soc. Bot. Fr, xlii. (1895) 558. - Gall.

andegavensis $\mathrm{X}, \mathrm{Hy}, 1 . \mathrm{c} .-\mathrm{Gall}$

agrifolia, Batt. \& Trab. Fl. de l'Algér. [Dicot.] (1890) $825=$ Q. Ilex, Limn

arizonica, Sarg. in Gard. and For. viii. (1895) 89 t. 389. - Arizona.

asiatica, Borb. in Termész. Fiizet, xiii, (1890) 32. As. OcC.

asterotricha, Borb. \& Csató, in Magyar Nöz. Lapok. (1886) 132 - Hung

avellanoides, Vukot. in Verh, zool.-bot. Ges. Wien, xxxix. (18S9) $197=$ Q. Robur, Linn.

bacunensis, Vukot. 1. c. $194=$ O. Robur, Linn.

badensis X, G. Beck, Fl, Nied.-Oest. i. I. (1890) $27 \%$. - Eur. centr.

Balansae, Drake, in Morot, Fourne de Bot.iv. (1890) 152, t. 4, fig. 6. - Tonk.

Banga, Ham. ex Hook. f. Fl. Brit. Ind. v. (18ss 603 , in syn. = lanuginosa, Don,

baviensis, Drake, in Morot, fourn. de Bot. iv. (1890) 150, t. 3 fig. 2. - Tonk

Bedói. Borb̆. in Magyar komopk. Növenyt. (ISS6 54 et 108; et in Termész. Füzet. xiii. (1890) 28 - Hung.

Bedöi X. Simonk. \& Fekete, in Erdész. Lapok, xxvi (1887) 38 : Simonk, Enum. Fl. Transsilv. (1887) $489=$ dacica. Borb.

bellogradensis, Borb. in Termész. Füzet. xiii. (1890) $30=$ Q, Robur, Linn.

Bossebovii $\mathrm{Hy}$, in Bull. Soc. Bot. Fr. xlii. (1895) 559. - Gall.

brevifolia, Sarg. Sylv. N. Am. viii. (1895) 1 1 1, t. $431=$ cinerea Michx.

brcuiloba, Sarg, in Gard, and For, viii. (1395) 93 et Sylv. N.Am. viii. (18\%5) 71, t. $384=0$. Du randi, Buckl.

brevipes, Borb. in Magyar Növenyt. Lapok, x. (1886) $131=$ Q. Robur, Linn

bruttia, Borb, in Oest. Bot. Zeitschr, xxxix. (1889) $376=$ Q. Robur, Limn

budensis $X$, Borb. in Bot. Centralbl. xxxvii. (1S89) 129; Nym. Consp. Fl. Eur. Suppl. ii. I. (1889 278. - Hung.

Budenziana, Borb. in Termész. Füzet. xiii. (1890) $31=Q$. brutia, Ten.

Cantleyana, King, ex Hook, f. Fl. Brit. Ind. v. (1888) 613 ; et in Annal. Bot. Gavd. Calc. ii. (1889) 64, t. 59. - Penins. Mal.

carolineana, Hort, ex Dippel, Handb. Laubholzk. ii. (1892) $85=\mathrm{Q}$. Prinos, Linn

cristanoides, Vukot. in Verh, zool.-bot. Ges. Wien. xxxix. (1889) $198=$ Q. Robar, Linn.

Castellnarnauiana, Vidal. Revis. Pl. Vasc. Filip. (I886) 264. - Ins. Philipp.

Chapmanni, Sarg. in Gard. and For, viii. (1895) 93; et Sylva N. Am. viii. (1895) 4l, 370. - Carolina, Florida.

Clementiana, King, ex Hook.f. Fl. Brit. Ind.v. (1888) 614; et in Annal. Bot. Gard. Calc. ii. (1889) 69. - Penins. Mal.

Collettii, King, 1. c. $49=$ spicata, Smith.

confragosa, King, ex Hook, f. Fl. Brit. Ind. v. (1888) 616 ; et in Annal. Bot. Gard. Calc. ii. (1889) 7\%, t. 71. - Perak

coriifolia, Vukot. in Verh. zool.-bot. Ges. Wien, xxxix. (1889) $196=$ Q. Robur, Linn.

Csatói. Borb. in Magyar Növenyt. Lapok, x. (1886) 133: et in Termész. Füzet。xiii. (1890) $33=$ Q. Robur, Linn.

Curtisii, King, ex Honk.f. Fl. Brit, Ind. v. (1888) 612 ; et in Annal. Bot. Gard. Calc. ii. (1889) 56 , 73, t. 52. - Perak

cyrtocarpa, Drake, in Morot, Fourn. de Bot. iv. (1890) 150 , t. 3, fig. 3. - Tonk.

\section{QUERGUS :}

Q $148(=Q$. Bedoi, Simonk. $)$. - Hung.

de Baryana, Warb. in Bot. fahrb. xiii. (1891) 286 - N. Guin.

devensis. Simonk, in Erdész. Lapok (1887) $415=$ tridactyla, Borb.

digenea $\times$, Borb. in Termész. Füzet. xiii. 7 (1890) 29. - Hung.

digitata, Sudworth, in Gard, and For. v. (1892) 98 ; Sarg. Sylva N. Am. viii. (1895) 147, t. 420 et 421 = falcata, Michx.

Eichleri, Wenzig, in Fumrb. Bot, Gart. Berl. iv. (1886) 236; Hook. f. Fl. Brit. โnd v. (1888) 615 - Sumatra, Perak.

Engelmanni. Greene, West Am. Oaks (1889) 32 t. 15, fig. 2, 3 et t. 17; Sarg. Sylva N. Am, viii. (1895) 83, t. $387=$ oblongitcilia, Torr

erythroneura, Vukot, in Verh, zool.-bot. Ges. Wien. xxxix, (1889) $198=0$. Robur, Limn.

farinosa, Vukot. 1. c. $199=0$, Robut, Limn

Feketei, Simonk. in Erdész. Lapok (1887) 31; et Enum. Fl. Transsilv. (1886) $487=\mathrm{Q}$. Robur, Linn.

Fragnus, A. Longo, in Bollet. Natural. Siena, viii. (18SS) extr. S. - Italia.

grandifrons, King, ex Hook. f. Fl. Brit. Ind. v. (1888) 610 ; et in Annal. Bot. Gard. Calc, ii. (1889) 49 , t. 35. b. - Perak,

grosse-serrata, Kotschy, ex Wenzig, in Jahrb. Bot. Gart. Berl. iv. (1889) $194=$ infectoria, Olivier. Gueraingeri $\times$. Hy, in Bull. Soc. Bot. Fr, xlii. (1895) 5.57. - Gall.

Havilandii, Stapf, in Trans. Limn. Soc, Ser. II. iv. (1894) 231. - Borneo.

hemisphaerica, Drake, in Morot, Fourn. de Bot. iv. (1890) 151, t. 3, fig. 4. - Tonk.

heterophylla, Vukot, in Verh, zool.-bot. Ges. Wien, xxxix. (1889) $195=$ Q. Robur, Limn.

Heuffel, Simonk. in Bot. Centralbl. Ixxvii. (1889) 129 , et in Akad. Math. es Termész. (1800) cum ic. $=$ brutia, Ten.

Hindsiana, "Benth, " ex Dippel, Handb, Laubholzk. ii. (1892) 75, sphalm. $=0$. Hindsii, Benth.

horizontalis, Hort. ex Dippel, 1. c. 62 = Q. Robur, Linn:

hudsonica, Hort. ex Dippel, 1. c. 112 et $3855=$ cuneata, Wangenh.

Jiypophaeas X. "Booth ", ex Koehne. Deutsche Dendrol. (1893) 131. - Hybr. artef.

indica, Drake, in Morot. Journ. de Bot. iv. (1890) $153=$ Castaneopsis indica, $A . D C$.

intercedens X, G. Beck, Fl. Nied.-Oest. i. (1890) 271. - Austria.

irazuensis, Kuntze, Rev. Genz.(1891) 641. - Costa Rica.

Jahnii, Simonk in Akad. Math. es Termész. (18:0) cum ic., ex Oest. Bot, Zeitschr. xl. (1890) 452.Hung.

Kanitziana, Borb. in Erdész. Lapok (1887) 732; in Termész. Fuizct. xiii. (1890) 28. - Hung.

javanica, Drake, in Morot, Journ. de Bot. iv. (1890) $153=$ Castaneopsis javanica, $A . D C$

fenkinsiana, "Benth. " ex Hook. f. Fl. Brit. Ind. v. (1888) 617, sphalm. $=Q$. Jenkinsii, Benth.

kabylica X. Trab. in Bull. Assoc. Franc. avanc. sci., Paris (1888) 506 ; et in Batt. \& Trab. Fl. de l'Algér. [Dicot.] (1899) 822. - Algeria.

Karduchorum. " C. Koch " ex Dippel, Handb. Laubholzk. ii. (1892) $100=Q$. carduchorum C. Koch.

Kunstleri, King, ex Hook. f. Fl. Brit. Ind. v. (1888) 606 ; et in Annal. Bot. Gard. Calc. ii. (1889) 40, t. 31. - Perak, Borneo.

kurdica, Wenzig, in falirb. Bot. Gart. Berl. iv. 1886) 186. - Kurdist.

lacinifolia, Vukot. in Verh. zool.-bot. Ges. Wien, xxxix. (1859) $195=0$. Robur, Linz .

lanuginosa, G. Beck, Fl. Nied.-Oest. i. (1890) 270 $=\mathrm{Q}$. Robur, Linn

leucocarpa, Hook. f. \& Thoms. ex Wenzig, in fahro. Bot. Gart. Berl. iv. (1886) 225. - Bengal.

Listeri, King, in Annal. Bot. Gard. Calc. ii. (1889) 89, t. 82. - Assam.

\section{QUERCUS :}

Louetti, Hort. ex Dippel, Handb. Laubholzk, (1892) $66=$ Q. Robur, Linn

Lowii, King, in Ann. Bot. Gard. Calc. ii, (1889) 28, t. $21 \mathrm{~b}$. - Borneo.

massana, G. Ehrenb, ex Wenziy, in Jahrb. Bot Gart. Berl. iv. (1886; $208=0$. Ehrenbergii, Kotschy.

Mierbeckii, « Durieu » ex Dippel, Handb. Laubholzk. ii.(1892-93) = Q. Mirbeckii, Durien.

magnifica, IIort. ex Dippel, Handb. Laubholzk. i1. (1892) 122 = tinctoria, Burtr.

minor, Sarg, in Gard. and For. ii. (1889) 471; Sylv, N. Am. viii. (1895) 37, t. $36 \%-70=$ obtusiloba, Muhr.

monorensis, Simonk. in Akad. Math. es Termész. (1890), cum ic., ex Oest. Bot. Zeitschr. xl. (1890) $452=$ Q. Bedoi, Borb

monticola, King, in Annal. Bot. Gurd. Calc, ii. (ISSP) 44, t. 37 - Borneo, Sumatra.

nana, Sarg, in Gard, and For.
t. $424=-$ ilicifolia, Wangenh.

Neo-Heuffeli, Borb. in Erde's\%. Lapok (18Si) Hung.

nivea, King, in Annal. Bot. Gard. Cale. ii. (1889) 31 t. 24 b. - Borneo

mumidica $X$ Trab. in Bull. Soc. Bot. Fr. xxxvi. 1889) 58 et 61 . - Algeria.

parvula, Greene, Pittonia, i. (Mar, 188 $40=$ Q. Wislizeni, A. DC.

platanoides, Sudworth. in Rep. Secr. U. S. 189: (1893) 327; Sarg. Sylva N. Am. viii. (1895) 6.3. t. $380=$ bicolor, Willd

pubens, Kotschy, ex Wenzig, in fahrb. Bot. Gart. Berl. iv, (1886) 190. - Syria.

pulchra, King, in Annal. Bot. Gard. Calc, ii. (1889) 85, t. 81. - Borneo.

pusilla, Vukot. in Verh, zool.-bot. Ges, Wien, xxxix. (1889) $196=\mathrm{Q}$. Robur, Linn

ramosa, Hort. ex Dippel, Handb. Laubholzk. ii 1892) 75 et 585 ; Koehne, Deutsche Dendrol (1893) $128=$ alba, Linn.

Rechini X, Hy, in Bull. Soc, Bot. Fr, xlii. (1895) 557. - Gall centr.

reflexa, King, in Hook. f. Fl. Brit. Ind. v. (1888) 616; tet in Annal. Bot. Gard. Calco ii. (1889) 78, t. 72. Penins, Mal.

rhodopea, Velen, in Sitz. Bochm. Ges. Wiss. (1893) xxxvi1. 57. - Bulg.

rubicunda, Hort. ex Dippel, Handb. Laubholzk. ii. (1892) $63=\mathrm{Q}$. Robur, Linn

vufa, Vukot. in Verh. zool.-bot. Ges. Wien, xaxix. (1889) $195=$ O. Robur, Iinm.

rufescens, Hook. f. \& Thoms, ex Hook. f. Fl. Brit. Ind. v. (1888) 620 , in syn. = Castaneopsis Hystrix, A. DC

Scortechinii, King, ex Hook. f. Fl. Brit. Ind. v (1888) 608; et in Annal. Bot. Gard. Calc, ii. (1889) 43, t. 35 a. - Perak

sectifolia. Vukot, in Verh, zool.-bot, Ges. Wien, xxxix. (1*89) $194=$ Q. Robur, Linn.

semilanuginosa, Borb, in Oest. Bot. Zeitschr. xxxvii. (1887) 198; et in Termész. Fuizet. xiii. (1890) 29 - Hung

Sieboldi, Hort. ex Dippel, Handb. Laubholzk. ii (1892) 71; Koehne, Deutsche Dendrol. (1893 $130=$ Q. Robur. Linn

slivonica, Kit. ex Borb. in Erdész. Lapok (1886 $230=$ Q. Farneits, Tenore.

Soleriana, Vidal, Revis, Pl. Vass. Filip. (1886) 261. - Ins. Philipp.

spatulaefolia, Vukot. in Verh, zool.-bot. Ges. Wien, xxxix. (1889) $197=$ Q. Robur. Limn.

speciensis, Hort. ex Dippel, Handb. Laubholzk. ii. (1892) $6 \%=$ Q. Robur. Linn

subcrispa X, Borb. in Termész. Füzet. xiii, 7 (1890) 29. - Hung.

sulcata, Vukot. in Verh. zool.-bot. Ges. Wien, xxxix. (1889) $196=$ Q. Robur, Linn.

superlata, Bort, in Dentsche Bot. Monatsschr. (1885) 164; et in Termész. Fiizet. xiii. 7 (1890) 33. Hung.

svecica, Borb, in Termész. Fuizet, xiii, 7 (1S90) 30; et $33=$ Q. Robur, Linn。 


\section{QUERGUS :}

Szachervana $Y$ Borb, in Erdész. Lapok (1886) 493, et (1887) 679; et in Oest. Bot, Zeitschr. xxxvii. (1887) 143. - Hung.

Szowitzii, Wenzig, in fahrb. Bot. Gart. Berl, iv. (1886) 188. - Reg. Transcauc.

kbajaliana $x$. Simonk, in Erdész. Lapok (1886 567 ; et in Akad. Math. es Termész. (1890) cum ic. - Bosnia

tephrocarpa, Balansa, in Morot, foum. de Bot. iv. (1890) 151, t. 4, fig. 5. - Tonk.

tergestina, Wenzig, in Fahrb. Bot. Gurt. Berl. iv. (1886) 191. - Eur, mer -or.

alracarpa, Vukot. in Verh. zool,-bot. Ges. Wien, wryix (1889) $196=0$. Robur, Linn.

tlemcenensis $\times$, Trab. in Bull. Soc. Bot. Fr. xxxvi. (1889) 58. nomen. - Algeria.

Tiszae X. Simonk. \& Fekete, in Erdész. Lapok, xxvi. (1887) 39; et in Termész. Füzet. xii1. (1890) 30; G. Beck, Fl. Nied.-Oest. I. (1896) 272. - Eur. centr.

Toumeyi, Sarg. in Gard. and For. viii. (1895) 92, fig. 13 et 14 ; et Sylva N. Am. viri. (1895) 93, t. 391. - Am. bor. occ.

Tozzal Hort, ex Dippel, Handb. Laubholzk. ii. $(1892) 62$ et 585 |Tozzael $=$ Q. Robur, Limn

Trabuti $X$. Hy, in Bull. Soc. Bot. Fr, xlii. (1895) 556. - Gall.

tridactyla X, Borb. in Term. Közlöny, xviii. (1886) 353 ; et in Oest. Bot. Zeitschr, xli. (1891) 145 (= O. Kerneri $\times$ Simonk.). - Hung.

truncata, King, ex Hook. f. Fl. Brit. Ind. v. (18SS)

618; et in Annal. Bot. Gavd. Calo. ii. (1889) 84, t. 80 . - Ind. or.

tunkinensis, Drake, in Morot, Fourn, de Bot. iv. (1890) 153, t. 4. fig. 8-10. - Tonk.

(uwbinclla, Greene, West Am. Oaks, i. (1889) 37; et ii. 59, t. 27 pr. p. = undilata, Torr.

ientricosa, Hort. ex Koehne, Deutsche Dendrol. $(1893) 125=\mathrm{Q}$. Aegilops, Linn

renustula. Greene, West Am. Oaks, ii. (1890) 69, t. $32=\mathrm{Q}$. Gambelii, Nutt

Vukotinovici, Borb, in Bot. Centralbl, xxxvii. (1889) 129

TVenzigiana, King, ex Hook. f. Fl. Brit. Ind. v. (1888) 613 ; et in Annal. Bot. Gard. Calc. ii. (1889) (i. t. 58 b. As trop.

VVrayii, King, l. c. 77, t. 104. - Perak.

wanthoclada, Drake, in Morot, Fourn. de Bot. iv. (1890) 149, t. 3, fig. 1. - Tonk.

Zan, Hort. ex Dippel, Handb. Laubholzk, ii. 1892) 93, in syn. = lusitanica, Lam.

Zang, Hort. ex Dippel, 1. c. = praec

QUESNELIA, Gaudich. (Bromel.). - Ind. Kew.

areensis, Mez, in Mart. Fl. Bras. iii. III. (1892) 381 $=$ rufa, Gaudich

Bakeri, Ed. André, in Rev. Hort. 1x. (1888) 564; et Brome7. Andrennae (1889) 16, t. 7; Baker. Handb. Bromel. (1859) 85. - Columbia.

Zlanda, Mez, in Mart. FI. Bras. iii. III. (1892) 383 = strobilispica, Wavera.

cayennensis, Baker, Handb. Bromel. (1889) 85. Guian. gall.

columbiana, Baker, l. c. 87 (= Ronnbergia columbiana, Éd. Morr.). - Columb.

distichanta, Lindm. in Kongl. Svensk, Vet. Akad, Hand1. xxiv, n. 8 (1891) 25, t. 4, fig. $7-10=$ Aechmea brasiliensis, Baker

effusa, Lindm. 1. c. 26, t. 4, fig. 1-6 = Hillbergia marmorata, Baker.

Enderi, Gravis of Wittm. in Gartenfl. xxxvii. (1888) 195, fig. 41-43; Baker, Handb. Bromel. (1889) 86 (= Billbergia Enderi, Regel). - Bras.

Glaziovii, Baker, l. c. 87. - Bras.

humilis, Mez, in Mart. Fl. Bras. iui. III (1922) 386. - Bras

indecora, Mes, $l$ c. 384. - Bras.

Lamarckii, Baker, Handb. Bromel. (1889) 85. Guian.

Selloana, Baker, l.c. - Bras.

Testudo, Lindm. in Kongl. Srensk. Vet. Akad. Handl. xxiv, n. 8 (1891) 24, t. 3, fig. 9-19; Mez. in Mart. Fl. Bras. iii. III. (1892) 380 . - Bras.

\section{QUESNELIA}

illandsioides, Mez, in Mart. FI. Bras, iii. III. (1892) $388=$ Billbergia tillandsioides, Baker.

Wittmackiana, Regel, in Gartenfl. xxxvii. (1888) 497, t, 1281; et in Act. Hort Petrop. x. (1889) 692 ; Baker, Handb. Bromel. (1889) 86. - Bras.

QUIINA, Aubl. (Guttif.). - Ind. Kew. ii. 67S Glaziovii, Engl. in Mart. Fl. Bras. xii. I. (188s) 482. - Bras.

peruviana, Enol. l. c. 481 . - Peruv.

Spruceana, Engl. l. c. - Bras.

QUINARIA, Rafin = Vitis, Tourn. (Ampelid.). quinquefolia, Koehne, in Gartenfl. xli. (1892) 403 et Deutsche Dendrol. (1893) $394=\mathrm{V}$. hederacea, Elirh

radicantissima, Koehne, 1. c. 403, - Form. hort.

tricuspidata, Koehne, 1. c, ; et Deutsche Dendrol (1893) $398=$ Vitis inconstans, Miq.

Veitchii, Koehne, 11. cc. 403 ; et $399=\mathrm{V}$, inconstans, Miq.

QUINCHAMALIUM, Molina (Santal.) - Ind. Kew. ii. 678 .

Stuebelij, Hieron. in Bot. Falzrb. xxi. (1895) 306 - Peruv., Bolivia.

tarapacanum, Phil. in Anal. Mnts, nac. Chite (1891) 75. - Chili

QUINETIA, Cass. (Compos.). - Ind. Kew. ii.

Macgregorii, «F. Muell, s ex Journ. Bot. xxxi. (18.3) 334, sphalm = Quintinia Macgregorii F. Muell.

QUINQUINA, Condam.= Cinchona, Linn. (Rubiac.).

Calisaya, carabayensis, Humboldtiana, lancifolia, Ledgeriana, micrantha, officinalis, orata, succirubra. Kuntze, Rev. Gen. (1891) 294-95 = homonyma ommia Cinchonae.

coccinea, Kuntze, 1. c. $295=\mathrm{C}$. macrocalyx, Pav heterophylla, Kuntze, 1. c. = C. cordifolia, Mutis.

MacIioriana X. Kuntze, 1.c. - Hybr, artef. mixtissima $\times$, Kuntze, ]. c. - Hybr. artef oborata, Kuntze, 1. c. = Cinchona pubescens, Vahl Palton X, Kuntze, 1. c. = C macrocalyx, Par. pubescens, Kuntze, 1. c. = C. cordifolia, Mutis.

QUINTINIA, A. DC. (Saxifr.). - Ind. Kew. ii. 678 .

Macgregorii, F. Mucll, in Vict. Natural, viii. (Feb. 1892) 164, nomen, et ix. (Nov. 1892) 112; ct in Bot. Centralbl. liii. (1893) 27. - N. Guin.

Ouatrefagesii, F. Muell. l.c. vii.(Mar. 1891) 181. - Austral.

QUIVISIA, Comm. (Meliac.). - Ind, Kew, ii, 679 grandifolia, S. Elliot, in fourn. Linn. Soc. xxix. (1891) 10. - Madas.

QUIVISIANTHE, Baill. Hist, pl. Madag., Atlas (1892) t. 251 MEI.IACEAE

Papinae, Baill. l. c. - Madag.

\section{$\mathbf{R}$}

RAGHICALLIS, DC. (Rubiac.). - Ind. Kew. ii.

americana. Hitchcock, in Missouri Bot. Gard. Rep. iv. (1893) $92=$ rupestris, $D C$.

RADINOGION, Ridl, in Bolet. Soc, Brot, v. (1857) 200. ORCHIDEAE.

flexuosum, Ridl. l. c. 200, t. b, fis. a [flexuosa]. Ins. S. Thom.
RADLKOFERELLA, Pierre, Not. Bot. Sapot. (1850) 21 = Lucuma, Molina (Sapot.).

arguacoensium, curvifolia, domingensis, grandiflora, littoralis, marginata, multiglora, pauciflora, serpentaria, sphaerocarta, ralenzulana, venosa, Warmin gii, Pierre, 1. c. = homonyma omnia Lucumae.

Dussiana, Pierre, 1. c. nomen. - Ind. occ.

Eichleri, Pierre, 1. c. = Vitellaria Eichleri, Engl. guadelupensis, Pierre, 1. c. nomen. - Ins. Guadal. inseparabilis, Pierre, 1. c. nomen. - Mexic.

martmicensis, Pierre, 1. conomen. - Ins. Martinic nigrians, Pierre. 1. c. nomen. - Mexic,

nitidula. Pierre, 1. c. = Vitellaria nitidula, Pierre quadrifida. Pierre, 1. c. nomen. - Hab.

Urbani, Pierre, 1. c nomen. - Hab.?

RADLKOFEROTOMA, Kuntze, Rev, Gen. (1891) 358 = Carelia, Less. (Compos.)

cistifolinm, Kuntze, 1. c. = C. cistifolia, Less.

RAFNIA, Thunb. (Legumin.). - Ind. Kew, ii 686

capensis, Schinz, in Bull. Horb. Boiss, ii. (1894) 199 (== Spartium coperne, Linn.), - Afr, austr.

Meyeri, Schinz, l. c.201 (= Rafnia ovata, E. Mey.) - Afr, austr.

ovata, Schinz, i. c. 199 (= Spartium oratum, Berg) - Afr. austr.

Schlechteriana, Schinz, l. c. 197 et 199. - Afr. austr.

RAGALA. Pierre, Not. Bot. Sapot. (1891) 57 Baill. Hist, des pl. xi. (1892) 297. SAPOTA $C E A E$

sanguinolenta, Pierre, Il. co. $(=$ Ecclinusa sanguinolenta, Pierre). - Guian. gall.

RAILLARDELLA, Benth. (Compos.). - Ind. Kew. ii. 680

paniculata, Greene, in Erythen, iii. (1895) 48. Calif.

RAILLARDIA, Gaudich. (Compos.), - Ind. Kew. 11.680. molokaiensis. 71 .
Ins. Sandvic.

RAMISCHIA, Opiz = Pyrola, Tourn. (Ericac.) obtusata, Freyn, in Oest. Bot. Zeitschr. xlv. (1895) 46\%. - Graecia.

RAMISIA. Glaziou, ex Baill, in Bull. Soc, Linn. Paris, i. (1887) 697 ; Oliver, in Hook. Icon. pl. xxv. (1895) t. 2404. NYCTAGINEAE

brasiliensis, Glaziou, ll.cc. - Bras.

RAMIUM, Rumpf, Herb. Amboin. v. (1747) 214 t. 59, f. 1, ex Kuntze, Rev. Gen. (1891) $631=$ Boehmeria, Jacq. (Urtic.)

acuminatum, asperum, auslrale, Blamei, brevirostre. bullatum, catophlebum, caudatum, celtidifolium, compactum, cylindricum, densifiorum, Didymogyne, elongatum, fallax, heterophyllum, hirtum, hispiduhnm, facquinianum, japonicum, Kurzii, Lindenianum, macrophyllum, malabaricin, mollicoma, montico lum, niveum, Pavonit, polystachyum, ramiflorum repens, rigidum, rugulosum, Zollingerianum, Kuntze Rev. Gen. (1891) 632-33 = homonyma omniz Boehmeriae.

ampullaceum, Kuntze, 1. c. $632=$ B. caudata, Sw. denudatum, Kuntze, 1. c. = B. excelsa. Wedd grande, Kuntze, 1. c. = B. stipularis, Wedd. grewiaeflorum, Kuntze, 1. c, $633=$ B. grewiaefolia Presl.

Hamiltonianum, Kuntze, 1. c. = B. platyphylla, D. Don.

Helferi, Kuntze, 1. c. = B. Helferii, Blume. rhyncophyllum, Kuntze, 1. c. = B. rhynchophylla, Wedd.

sedifolim, Kuntze, 1. c, $632=$ B, sidaefolia Wedd.

temue, Kuntze, 1. c. $622=$ B. rugulosa, $W e d d$. 
RAMONA, Greene, Pittonia, ii. (July 1892) 235, et (Sept. 1892) $301=$ Audibertia, Benth. (Labiat.).

7umilis, Greene, in Erythea, i. (1893) 144 ; et in Man. Bot. San Franc. Bay (IS94) $91=\mathrm{A}$. humilis, Benth.

polystachya, Greene, Pittonia, ii. (July 1892) 235 et (Sept. 1892) $302=$ A. polystachia, Benth.

RAMONDA, Caruel, Epit. F1. Europ. ii, (1894) 140 = Ramondia, Rich. (Gesner.).

RANDIA, Houst. ex Linn. (Rubiac.). - Ind, Kew. ii. 631 .

abnormis, Boerl. Handl. Fl. N $N^{\top} e d$. Indiè, ii. I. (1891) 130 (= Gynopachys abnormis, Korth.). Borneo.

acuminata, Boerl. l. 'c. 130 (= Gyn. acuminata, Blime), - Ind. bat.

acuminata, Boerl.l. c. 131 (= Griffithia acuminata. Korth.). - Borneo.

auriculata, K, Schum. in Engl. \& Prantl, Natürl. Pflanzenfam. iv. 4 (1891) $75=$ Anamanthodia auriculata, Hook. $f$.

Barteri, K. Schum. 1. c. = Mitriostigma Barteri, Benth. \& Hook. f.

coffeoides, Drake, Fl. Polyn. Franc. (1892) 00. Polynes.

corymbosa, Boerl. Handl. Fl. Ned. Indie ii. I. (1891) 130 (= Gynopachys corymbosa, Blume). - Ind. bat.

densiflora, BartI. ex K. Schum, in Mart. Fl. Bras. vi. VI. (1889) $343=$ formosa, $K$. Schum.

depauperata, Drake, in Morot, fourn. de Bot. ix. (1895) 21\%, - Tonk

Engleriana, $K$. Schum, in Engl. \& Prantl, Natïrt. Pflanzenfam. iv. 4 (1891) 75; et in Engl. Pflanzenw. Ost-Affr. C (1895) 380, - Afr. trop. or.

euacantha, Boerl. Handl. Fl. Ned. Indië, ii. I. 1891) 131 (= Griffitia emacantha, Korth ). Java, Borneo.

Fischeri, K. Schum, in Engl. Pfanzenw. Ost-Afr. C (1895) 381. - Afr, trop. or.

formosa, K. Schum. in Mart. Fl. Bras. vi. VI. (1889 342. - Bras.

guianensis, Sagot, ex K. Schum. in Mart. Fl. Bras. vi. VI, $(1889) 37 \%=$ Basanacantha spinosa K. Schum.

Gynopachys, Boerl. Handl. Fl. Ned. Indie, ii. I. (1891) 130 (= Gynopachys tomentosa, Blume). Ind. Bat.

Kuhniana, F. Hoffn. \& $K$. Scinun. in Engl. Pfanzenw. Ost-Afr. C (1895) 380, - Afr. trop. or

longiloba, Hemsl, Biol. Centr.-Am. iv. (1886) 101. Ins. Cozumel.

macrosiphon, K. Schumn. ex Engl. in Abh. Frenss. Akad. Wiss. (1894) 28; et in Engl. Pfanzenw. Ost.-Afr, C (1S95) 581.-Afr. trop. or.

obcordata, S. Wats in Froc. Am. Acad. xxiv. (1889) 53. - Mexic.

oxygyna, Bocrl. Handl. Fl. Ned. Indië, ii. 1. (1891) 131 (= Griffithia oxygyza, Korth.). - Sumatra.

oxyodonta, Drake, in Morot. Fourn. de Bot. ix. (1895) 218. - Tonk.

penduliflora, $K$. Schm. in Engl. Pfanzenw. Ost Afr. C (1895) 380. - Afr, trop. or

Pringlei, A. Gray, in Proc. Am. Acad. xxi. (1886) 379 . - Mexic.

pycnantha, Drake, in Morot, Fourn. de Bot. ix. (1895) 218. - Tonk.

Quintasii, K. Schum. in Bolet. Soc. Brot. x. )1892) 127 - Ins. S. Thom

speciosa, K. Schum. in K. Schum. et Hollr. Fl. Kais. Wilh. Land (1889) 130. - N. Guin.

spinuligera, F. Muell. in Viot. Natural. ix. (June 1892) 43; et in Bot. Centralbl. 1i. (1S92) 25\%. Austral.

stenantha, Drake, in Morot, fourn. de Bot. ix. (1895) 219. - Tonk.

Thurberi, S. Wats. in Proc. Am. Acad. xxiv. (1889) 53. - Mexic.

tomentosa, Boerl. Handl. Fl. N'ed.Indiè, ii. I. (1891) 130 (= Gardenia tomentosa, Blume). - Java.

tomentosa. S. Wats. in P'roc. Am. Acad. xxv. (1890) $152=\mathrm{P}$. Watsoni, Robinson.

\section{RANDIA}

tuberculosa, F. M. Bailey, in Dept. Agric. Brisban Bot. Bull. ii. (1S91) 12. - Austral.

Watsoni, Robinson, in Proc. Am. Acad.xxix. (1894) 317. - Mexic.

Zippeliana, Boerl. Handl. Fl. Ned. Indiè, ii. I (1891) 130 (= Gynopachys Zippelzana, Scheff.), N. Guin

RANDoniA, Coss. (Resed.), - Ind. Kew, ii. 682. malensis, Schinz, in Bull. Herb. Boiss, iii. (189:) 398. - Reg. Somal.

RANUNGULUS, [Tourn.] Linn. (Ranuncul.). Ind. Kew. ii. 680 .

abchasicus, Freyn, ex Sonmn. El Leirer, in Bull. Soc. Bot. Ital. (1893) 525 ; et in Oest. Bot. Zeitschr. xliii. (1893) 373. - Reg. Cauc.

aberrans, Phil. ex Britton, in Bull. Torrey Bot. Club, xvii. (1890) 82, nomen. - Am. austr.

abyssinicus, Schube, ex Engl, in Abh. Preuss. Akad. Wiss, 1891, ii. (1892) 219. - Afr. trop. or. acinacilobus, Rouy \& Fouc. F1. de Fr. i. (1893) 89 = flabellatus, Desf.

aconitoides X. Rouy, I11. P1. Eur. rarior. iv. (1895) 25, t. 76. - Helv

acriformis, A. Gray, in Proc. Am. Acad. xxi. (1886) 374. - Am. bor.

acutilobus, Durieu, ex Rony \& Fouc. Fl, de Fr, i. (1S93) $62=$ ololeucos, Lloyd.

alceus, Greene, in Erythea. iii. (is95) 69. - Calif.

alismellus, Greene, Fl. Francisc. (1892) $29 \%=$ alis maefolius, Geyer. var.

allegheniensis, Britton, in Bull. Torrey Bot. Club, xxii. (1S95) 224. - Virginia, Carolina.

alliariaefolius, Simonk, Enum. F1. Transs. (1886) 48 = cassubicus, Linn.

amerophyllus, F. Muell. in Trans. Roy. Soc. Vict. N.S. i. II. (1889) 1. - N. Guin.

ampelophyllus, Somm, Eo Levier, in Bull. Soc. Bot. Ital. (1893) 523, et Sér. II. i. (1894) 9. - Reg. Cauc.

anatolicus, Freyn \& Sint. in Bull. Herb. Boiss. iii. (1895) $34=$ brutius, Ten.

apiopkylus, St. Lager, in Cariot, Étud. des fl. éd. $8(1889) 12=$ sceleraius, Linn.

areolatus, Petrie, in Trans. N.Z. Inst. xxii. 1889 (I890) 439. - N. Zel.

arizonicus, Greene, Pittonia, ii. (May 1890) $60=$ subsagittatus, Grcene.

arizonicus, Lemmon, ex A. Gray, in Proc. Am. Acad. xxi. (1S86) 370. - Arizona.

asarifolius, Diard. ex Rouy \& Fouc. F1. de Fr. i. (1893) $59=$ hederaceus, Lim

astrantiaefolius, Boiss. \& Balansa, in Boiss. Fl. Or. Suppl. (1888) 11. - As. Min.

aurigeranus $\times$, Rouy, in Rouy \& Fouc. Fl. de Fr. 1. -1893$) 101$, in obs. - Gall.

Austinae, Greene, in Erythea, iii. (1895) 44. Calif.

Berggreni, Petrie, in Trans. N. Z. Inst. xix. 1886 (1887) $325 .-\mathrm{N}$. Zel.

Biolettii, Greene, Pittonia, ii. (May 1892) 225. Calif.

Boissieri, Simonk. in Termész. Füzet, xi. (1859) n. $3,4=$ caucasicus, Bieb

Bolanderi, Greene, in Bull. Calif. Acad. ii. V. (1886) 58. - Calif.

Bongardi, Greene, in Erythea, iii. (1895) $54(=R$. recurvatus, Bong, pr. p.) = occidentalis, Nutt.

britannicus, Rouy \& Fouc, F1. de Fr. i. (1893) $69=$ trichophyllus, Chaix.

calandrinioides, Oliver, in Hook, Icon. pl.xix.(1889) t. 1828. - Marocc.

calthaeflorus, Greene, in Erythea, iii. (1895) 45. -

Am. bor. occ.

cavinatus, Simonk. Enum. F1. Transsilv. (1886) 43 $=$ carinatus, Schur.

casaliodes, Kuntze, Rev. Gen. (1891) 3. - Java.

chiclensis, Ball, in fourn. Linn. Soc. xxii. (1885)28. - Peruvia.

cinerascens, Rouy \& Fouc. F1. de Fr. i. (1893) 89 = flabellatus, Desf.

Cooleyae, Vasey, \& F. N. Rose, in Bull. Torrey But. Club, xix. (1892) 239 ; et in Contrib. U.S. Nat. Herb. i. (1893) 289, t. 22. - - Alaska.

\section{RANUNGULUS}

Cooperi, Oliver, in Hook. Icon, pl. xvi. (18S6) t. 1502. - Afr. austr.

Cusickii, M. E. Fones, in Proc. Calif. Acad, Ser. If v. (1895'615. - Am. bor. occ.

dentatus, Freyn, in A. Kern. Sched. F1. Austr. Hung. v. (1888) $4 \%$ = montanus, $W$ illd

dissectus, Rouy \& Fouc, Fl, de Fr. i. (1893) 10.5 = bulbosus, I, inn.

Drummondii, Greene, in Ery/hea, ii, (1894) 192 (= R. Hookeri, Regel). - Am. bor.

dubius, Rouy \& Fouc. Fl. de Fr. i. (1893) $78=$ R Thora. Limn.

ellipticus, Greene, Pittonia, ii. (Dec. 1890) 110 (= R. brevicaulis, Hook,). - Am. bor, occ,

elymaiticus, Boiss. E Hausskn, in Boiss. Fl. Or. Suppl. (1S88) 6. - Persia.

eximius, Greene, in Erythea, xii. (1895) 19. - Am. bor. occ.

extensus, Schube, cx Engl. in Abr. Prenss, Akad. Wiss. 1891 ii. (1892) 218. - Ins. Fernando-Po.

fallax, Strasser, in A. Kern. Sched. Fl. AustroHung, v. (1888) $50=$ auricomus, Limn.

filicantis, Rouy \& Fouc. Fl. de Fr. i. (1893) $69=$ trichophyllus, Chaix.

flabellifolius, Rouy \& Fouc. 1. c. = fluitans, Lam.

Forreri, Greene, Pittonia, i. (Jan. 1888) 154. Mexic.

Freynii, A. Kern. ex Sterneck, in Oest. Bot. Zeitschr. xlv. (1895) 48. - Eur, centr. et merid.

gingkolobus, Somm. \& Levier, in Bull. Soc. Bot Ital. (1893) 524; et Ser. II. i. (1894) 8: d in Act. Hort. Petrop. xiii. (1894) 184. - Reg. Cauc.

gobicus, Maxim. Enum. Pl. Mongol.(1889) 15. Mongol.

Grayanus. Freyn, in Deutsche Bot, Monatsschr. viii. (1890) $179=$ aquatilis, Linn.

Grayi, Britton, in Bull. Toryey Bot. Club, xviii 1891) 265 (= R. pedatifidus, Hook.). - Am. bor.

gymnadenus, Somm. et Levier, in Bull. Soc. Bot. Ital. (1893) 524, et Ser. II. i. (1894) 10; e in Act. Hort. Petrop. xiii. (1894) 181. - Reg. Cauc.

Hartwegi, Greene, in Erythea, iii. (1895) $45=$ alismaefolius, Geyer, var.

Havveyi, Greene, 1. c. ii. (1894) 189 : Britton, in Mem. Torrey Bot. Club, v. (1894) $159=$ aborti vus, Linn. var.

Helenae, Alboff, in Soc, imp. hortic. [Compt.-send. Sect. Odessal (1891) extr. 2; et in Bull. Herb. Boiss. i. (1893) 253. - Reg. Cauc.

hepaticaefolits $\times$, Bruegs. ex Freyn, in Bot. Centralbl. xli. (1820) 133. - Helv

hesperoxys, Greene, in Erythea, ii. (1894) 189. Calif.

involucratus, Maxim. Fl. Tangut. (1889) 15. China.

juniperinus, M. E. Fones, in Proc. Calif. Acad. Ser. II. v. (1895) 615. - Am. bor. occ

Kerneri, Freyn, in A. Kern. Sched. Fl. Austro-Hung. v. (1888) 47, - Tirol.

Kirkii, Petrie, in Trans. N. Z. Inst. xix. 1886 (1887) 323. - N. Zel

lazicus, Boiss. F1. Or. Suppl. (1888) 11, in syn.= R. Huetii, Boiss.

leptorrhynchus, Aitch. \& Hemsl. in Trans. Iinn. Soc. Ser. II. iii. (1886) 29, t. 1. - Afghan.

Lojkae, Somm. \& Levier, in Bull. Soc. Bot. Ital. (1893) 525, et Ser. II. i. (1894) 10 ; et in Act. Hort. Petrop. xiii. (1894) 185. - Reg. Cauc.

longipetiolatus, Colenso, in Trans. N. Z. Inst. xxv. $1892(1893) 325 .-N$. Zel

Lowii, Stapf, in Hook. Icon. pl. xxiij. (1893) t. 2261. - Borneo.

ludovicianus, Greene, in Bull. Calif. Acad. ii. Y. (1886) 58, - Calif

Luizati X. Rouy, in Bull, Soc, Bot. Fr. xl. (1893) 215. - Pyren

Macounii, Brilton, in Trans. N.Y. Acad. Sci. xii. (1892) 2 ; Robinson, Syn. Fl. N. Am. i. I. (1895) 36. - Am. bor.

Marchesinii, Lojac, in Giom. Com, agr, Pal. N. S. xviii. (1886) 79; et Fl. Sicula, i. I. (18S8) 48, et App. t. 8. - Sicil. 


\section{RANUNGULUS}

maximus, Grepte 2 Butl. Torrey Bot. Club, xiv. (1887) ils; et Man. Bot. San Franc. Bay (1894) 3. - Calif.

missouriensis, Greene, in Erythea, iii. (1895) 20. Am. bor

mollis, Rouy \& Fouc. Fl. de Fr. i. (1893) $90=$ flabellatus, Desf.

Muelleri J. Buch in Trans, N., Z. Inst, xix, 1886 1887) $215, \mathrm{t}, 16=\mathrm{R}$. Monroi, Hook.

muricatulus, Colenso, l. c. xxiii. 1890 (1891) 381 - N. Zel.

Novae-Zelandiae, Petrie, l, c. xxvi. 1893 (1894) 266. - N. Zel.

mdicantis, Rouy \& Fonc. F1. de Fr. i. (1893) 73 in obs $=\mathrm{R}$. Ficaria, Linn, var.

orbiculatus, Blanche, in Boiss. Fl. Or. Suppl. (1888) 5. - Syria.

Orphanidis, Boiss. \& Heldr. ex Boiss. l. c. 13. Maced.

ovalifolins, Rouy \& Fouc. F1. de Fr. i. (1893) $89=$ flabellatus, Desf.

petiolaris, E. S. Marshall, in Journ. Bot, xxx. (1892) 289, t. $328=$ R. Flammula, Linu. var.

Pichleri, Freyn, ex Stapf, in Denkschr. Akad. Wicn, (18s6) ii. 23. - As. occ.

flatyphyluss, Simonk. Enum. F1. Transsilv. (1886) $51=$ acris, Limn, var.

Polii, Franch. ex Forb. Es Hemst. in foum. Linn. Soc. xxiii. (1886) 15. - China.

tollinensis, Chiovenda, in Bull. Soc. Bot. Ital 1892) $297=$ montanus, Willd.

Populago. Grecne, in Erythoa, iii. (1895) 19. - Am. bor. occ.

I'orteri, Britton, in Bull. Torvey Bot. Club, xvii. (1890) 310. - Am, bor.

ranunculinus, Rydberg, in Bot. Surv. Nebraska, iii. (1894) 2.3 = R. Nuttallii, A. Gray.

reticulatus, Colcnso, in Trans. N. Z. Inst. xx, 1887 (I888) 188. - N. Zel.

rhodensis. Boiss. Fl. Or. Suppl. (18S8) T. - Ins. Rhod.

rigidulus, Boiss. l. c. 11. = R. Huetii, Boiss

ruahinicus, Colenso, in Trans. N.Z. Inst. xviii. 1885 (18S6) 256. - N. Zel.

uoulosus, Greene, Pittonia, ii. (May 1890) 58. Calif.

Savatieri, Franch. Miss. scicnt. Cap Horn, v. [Phan.] (18s9) 320. - Reg. Magell.

Schweinfurthii, Boiss, Fl. Or. Suppl. (1888) 12. Syria.

Shaftoanus, Boiss. 1. c. $5=$ seq.
Shaftoanus, A. Gray, in Proc. Am, Acad, xxi.

Shaftoantu, A. Gray, in Proc. Am, Acad, xxi.
(1886) $366=$ Oxygraphis Shaftoana, Aitch. E (1886)

Sintenisii, Freyn, in Oest. Bot, Zeitschr. xli. (1891)

362. - Armen.

Sommieri, Alboff, in Bull. Herb. Boiss, j. (1893 245; Somm. E Levier, in Nuon. Giorn. Bot. Ital Ser. II. i. (1894) 9. - Reg. Cauc.

tenorhynchus, Franch. in Nंour. Arch. Mus, Paris Sér. II, viii, 1885 (1886) 189. - Tibet.

subimiatus, Rouy \& Fouc, F1. de Fr, i. (1893) 90 = flabellatus, Desf.

subsagittatus, Greene, Pirtonia, ii. (May 1890) 57. - Am. bor. occ.

Sukstorfi, A. Gray, in Proc. Ann. Acad, xxi. (1880) 371. - Washington.

sychnopetala. Colonso, in Trans, $N$. Z. Inst. xxy. $1892(1893) 324,-$ N. Zel.

tenuis, F. Buth. l. c. xx. 1887 (1888) 255, t. 12 - N. Zel.

Tempskyanus, Freyn of Sint. in Bull. Herb. Boiss. iii. (1895) 35. - Armen.

thasius, Halacsy, in Oest. Bot. Zeitsclir. xlii. (1892) 412. - Ins. Thasos.

tricuspis, Maxim. Fl. Tangut. (1889) 12; et Enum. pl. Mongol. (1889) 16. - Mongol

triternatus, A. Gray, in Proc. Am. Acad xxi. (1886) 370. - Washington.

Turneri, Greene, Pitlonia, ii. (Sept. 1892) 296. Alaska.

uncinatus, Rouy \& Fouc. Fl. de Fr. i. (1893) $90=$ flabellatus, Desf.

vagans, S. Wats, in Proc. Am. Acad. xxvi. (1891) 131. - Mexic.

\section{RANUNCULUS}

Vespertilio, Lojacono, Fl. Sicula, i. I. (1888) 33, t. 3. - Sicil.

itifolius, Boiss. \& Balansa, ex Boiss. Fl. Or. Suppl. (1888) 9. - As. Min.

vitifolius, Lojacono, Fl. Sicula, i. I. (1888) 43. Sicilia.

Volkensii, Engl, Pfanzente. Ost-Afr. C (1895) 181. - Afr. trop. or.

RANZANIA. T. Ito, in Journ. Bot, xxvi. (18s8) 302: Prant1, in Eng1. \& Prantl, Natuirl, Pflanzenfam. iii. 2 (1891) 274. BERBERIDEAE.

japonica, T. Ito, ll. cc. $(=$ Podophyllum japonicum, T. Ito) - Japon.

RAOUIIA, Hook. f. (Compos.), - Ind. Kew. ii. 689

albo-sericea, Colenso, in Trans. N. Z. Inst. xx. 1887 (1888) 195. - N. Zel

RAPHANISTROGARPUS, Baill. in Bull, Soc Lirun. Paris, ii. (1883) 309; Muell. \& Pax, in Eng1. \& Prantl, Natürl. Pflanzenfam. iv. 5 (1889) 25. CUCURBITACEAE.

Boivini, Cogn. ex Engl. Pfanzenw. Ost-Afr. C (1895) 397 (= Monordica Boinini, Baill.). - Afr. trop. or.

RAPHANISTRUM, Tonn, ex $\Lambda$ dans, = Raphanus. Tourn. (Cruc,f.)

microcarpum, Nym. Consp. F1. Eur. Suppl. is. I $(1889) \mathrm{NS}=\mathrm{R}$. microcarpus, Willh.

RAPHANOGARPUS, Hook. f. (Cucurb.). Ind Kew, ii 600

humilis, Cogn. ex Schinz, in Verll. Bot. Ver. Brand. xxx. (IS8S') 149. -- Afr. austro-occ, extratrop.

RAPHANUS, [Tourn.] Linn. (Crucif.). - Ind. Kew. 11. 690.
androides, Rony \& Fouc. Fl. de Fr. ii. (1895) 68 androides, Rouy \& Fouc. Fl.
$=$ R. Raphanistrum, Linn.

rupestris, Porta \& Rigo[Iter, secund. Hisp. (1890) n. 194\}, ex Porta, in Atti Accad. Agiati, ix. (1891) extr. 6; Willk. Suppl. Prodr. F1. Hisp. (1893) 293, in syn. : Rouy, in Deyrolle, Le Naturaliste. Sér. II. xiil. (1891) 248 (= Hutera rupestris, Porta) = Coincya rupestris, Rouy.

PAPHIA, Beauv. (Palm.). - Ind, Kew, ii. 690. Kirkii, [Engl, ? Pflanzenw. Osl-Afr, A (1895̃) 10 Afr, trop.

Monbuttorum, Drude, in Bot. Fahrb. xxi. (1895) 111, 130. - Afr. trop.

RAPHIACME, K. Schum, in Bot. Jahrb. xvii. (1893) 117 ; et in Engl. \& Prantl. Natürl. Pflanzenfam. iv. 5 (1895) 220 = Raphionacme Harv. (Asclep.)

globosa, K. Schum. in Bot. Jahrb. xvii. (1S93) 118 et 1. c. 221. - Angola.

grandifora, K. Schum, in Engl. Pflanzenw. Ost Afr, C (1895) $425=\mathrm{R}$. grandiflora, $N . E . B r$. linearis, K. Schum. in Bot. Jahrb. xvii. (1893) 117 et in Engl. \& Prantl, Natürl. Pflanzenfam. iv 2 (1893) 221. - Angola.

ongifolia, K. Schum. in Engl. Pflanzenw. OstAfr. C $(1895) 425=\mathrm{R}$. longifolia, N.E. $B r$. scandens, K. Schum. in Engl. \& Prantl, Natürl. Pflanzenfam. iv. 2 (1895) $221=\mathrm{R}$. scandens, N.E. $\mathrm{Br}$

RAPHIDOGYSTIS, Hook. f. (Cucurb.). - Ind. kalavensis, Baker, in fourn. Linn. Soc. xxy. (1890) 318. - Madag.

RAPHIONAGME, Harv. (Asclep.). - Ind. Kew. ngolensis, N, E. Br. in Kew Bull. (1895) 248.Angola.

Brownii, S. Elliot, in foum. Linn. Soc. xxx. (1894) 91. - Sierra Leone.

excisa, Schlechter, in foum. Bot. xxxiii. (1895) 301. Afr. trop.

\section{RAPHIONACME :}

Flanagani, Schlechter, th Bot. Fahr. xviii. Beibl. n. 45 (1894) 2. - Afr, austr.

Galpinii, Schlechter, l.c. - Afr. austr.

grandiflora, N.E. Br. in Kew Bull. (1895) 111. Afr. centr. or.

lanceolata, Schin\%, in Verh. Bot. Ver. Brand. xxx. (1888) 263. - Afr. austro-occ. extratrop.

longifolia, N. E. Br. in Kew Bull. (1845) 110. Zambesia.

macrorrhiza, Schlechter, in Bot. Fahrb. xx. Beil]. n. 51 (1895) 10. - Afx. austr.

procumbens, Schlechter, l. c. 11.- Afr. austr.

candens, N. E. Br. in Kew Bull. (1895) $111=$ R. Flanagani, Schlechtor.

splendens, Schlechter, in fourn. Bot. xxxiii. (1895) 301. - Afr, trop.

velutina, Schlechter, in Bot. Fahrb. xx. Beibl. n. 5l (1895) 12. - Afr, austr.

volubilis, Schlechter, in foum. Bot. xxxiii. (1895 302. - Afr. trop.

RAPHIOSTYLES, Bentth. \& Hook. f,=Apodytes E. Mey. (Olacin.)

Poggei, Engl. Bot. Jahrb. xvii. (1893) 73. Kamerun.

Proussii, Eng1. 1. c. 72. - Kamerun.

Stuhlmannii, Engl. 1. c. - Afr. trop.

RAPISTRUM, Tourn, ex Medic, (Crucif.). Ind. Kew. ii. 691 .

Ceratocnemum, Prantl, in Engl. \& Prantl, Natürl. Pflanzenfam. iii. 2 (1891) $181=$ Ceratocnemon rapistroides, Coss. Er Balansa.

RAPONA, Baill, Hist, des pl. x. (1888) 326 Hallier $\mathrm{f}$, in Engl. \& Prantl, Natürl. Pflanzen fam. iv. 3a (1891) 15. CONVULVULACEAE

madagascariensis, Baill. l. c. 328 (= Brewcria tiliaefolia. Baker). - Madag.

RASPALIA, Brongn. (Bruniac). - Ind. Kew. ii. $69 \%$.

affinis, Niedenzu, m Engl. \& Prantl, Natürl. Pfannzenfam. iii. 2a (1891) 135 (= Nebelia affnis, Sweet). - Afr. austr.

Dregeana, Niedenzu, l. c. $(=$ Berardia Dregeana, Sond.). - Afr. austr.

phylicoides, Niedenzu, 1. c. $125=$ phylicoides, Prest.

RAUWOLFIA. Plum. ex Linn. (Apocyn.). Ind Kew ii, 692.

cardiocarpa. K. Schum, in Engl. \& Prantl, Natuirl. Eflanzenfam, iv. 2 (1595) 154. - Gabon.

celastrifolia, Baker, in Fonrn. Linn. Soc. xxv. (1890) 335. - Madag.

chinensis, Hems? in fourn Limn. Soc. xxvi. (1889) 95 (= Ophioxylon chinense. Hemsl.). - China.

clavunculus, $K$. Schmo. in Engl. \& Prantl, Natiorl. Pfanzenfam. iv. 2 (1893) 154. - Madag.

dichotoma, K. Schum. l. c. - Ins. S. Thom

inebrians, $K$. Schum. l. c. ; ct in Engl. Pfanzenw. Ost-Afr. C (1895) 318. - Afr. trop. or

javanica, Koevd. \& Valct. Boomsoort. Ean fac'a, i. (1894) 91. - Java.

macrophylla, Stapf, in Kev Bull. (1894) 20. - Afr, trop. occ.

major, Nichols. Dict. Gard. ii. (1986) 279 [majus]. - Java.

Mannii, Stapf, in Kew Bull. (1894) 21. - Afr. trop. occ.

mombasiana, Stapf, l.c. - Afr. trop. or

monopyrena, $K$. Schum, in Abh. Preuss. Akad. Wiss. (1894) 27; et in Engl. Pfanzenw. Ost-Afr. C (1895) 318. - Afr. trop. or.

obscura, $K$. Schum. in Engl. \& Prantl, Natiurl. Pfanzenfam. iv. 2 (1893) 154. - Congo mer. obrersa. Baill. Hist. des pl. x. (1888) 171, in nota $5=$ serpentina, Benth.

ochrosioides, K. Schum. in Engl. \& Prantl, Natiirl. Pflanzenfam.iv. 2(1893) 154; et in Engl. Pfantzenzw. Ost-Afr. C (1895) 318. - Afr.trpp.or.

parviftora, K. Schum. 1. c. in obs. = Ochrosia sandwicensis, $A . D C$

pleiosiadica, $K$. Schum.l.c. - Ins. S. Thom,

Preussii, K. Schum.l.c. - Kamerun, 


\section{RAUWOLFIA:}

reflexa, Koerd. \& Valet. Boomsoort. van fava, i. (1894) 91. - Java.

reflexa, K. Schum, 1, c. 154 = reflexa, Teijsm. E Binn. rosea, K. Schum. in Engl. Pfanzenw. Ost-Afr. C (1895) 317 . - Afr. trop. or.

serpentina, Baill. Hist. des pl. x. (1888) $170=$ serpentina, Benth.

Stuhlmannii, $K$. Schum, in Engl. Pfanzenw. Ost-Afr. C (18.95) 318. - Afr. trop. or.

trichophylla, Baker, in fourn. Linn. Soc. xxy. (1890) 334. - Madag:

trifoliata. Baill. Hist. des pl. xiii. (1895) $171=$ serpentina, Benth.

verticillata, Baill. 1. c. $170=$ chinensis, Hemsl.

RAVENALA, Adans. (Scitam.). - Ind. Kew. ii. 692

guyanensis, Petersen, in Engl. Eo Prantl, 'Natürl. Pfanzenfum. ii. 5 (1S8S) 7 (= Phenakospermum guyanense, Endl.). - Am. austr. bor.

RAVENIA, Vell. (Rutac.). = Ind. Kew. ii. 693. ruellioides, Oliver, in Trans. Linn. Soc. Ser. II, ij (1887) 272.t.38 (= Oliver, ex im Thum, in Timehri, v. (1886) 191 [err. cal. Revenia]. Guian, angl.

RAVENSARA, Sonner. (Laurin.).- Ind, Kew. ii. 692

parvifolia. S. Elliot, in foum. Iinm. Soc. xxix (1891) 45. - Madag.

RAZOUMOFSKYA, Hoffm. = Arceuthobium Bieb. (Loranth.).

campylopoda, Douglasii, gracilis, minuta, occidentalis, pusilla, robusta, vaginata, ierticilliflora, Kuntze, Rev. Gen. (I891) 587 = homonyma omnia Arceuthobii.

americana, Kuntze, 1. $c_{0}=$ Arceuthobium Oxycedri, Bieb.

cryptopoda, Coville, in Contrib. U. S. Nat. Herb. iv. (1893) $192=$ A. cryptopodum, Engelm.

cupressodes, Kuntze, 1, c. = Dendrophthora cupres soides, Eichl.

diraricata, Coville, in Contrib. U. S. Nat. Herb. iv. (1893) $192=$ Arceuthcbium divaricatum, Engelm. opuntiodes, Kuntze, 1. c. = Dendrophthora opuntioides, Eichl.

REAUMURIA, Linn. (Tamarisc.).- Ind. Kew. eflexa, Lipski, Exc. bot. au delà Mer Casp. (1889)7. - Oriens.

soongarica, Maxim. Fl. Tangut. (1889) 97 : et Enum. Pl. Mongol. (1889) 106 (= Hololachne soongorica, Ehrenb.). - As. centr.

REBOUDIA, Coss. \& Durieu = Erucaria, Gaertn (Crucif.).

microcarpa, Coss. Comp. Fl. Atlant. ii. (1887) 213, in obs. = microcarpa, Boiss.

REBUTIA, K. Schum, in Monatschr. f. Kakteenk. v. (1895) 102. CACTEAE

minuscula, $K$. Schmm. l. c. cum xylogr. - Reg. Argent.

RECHSTEINERA, Regel = Gesneria, Linn. (Gesner.).

aggregata, aurantiaca, Blassii, bulbosa, canescens, caracasana, cardinalis, cochlearis, confertiflora, Cooperi, corruscans, dentata, discolor, Douglasii, elatior, eiliptica, erubescens, faucialis, favescens, gracilis, Hookeri, lateritia, latifolia, macrorhiza, macu lata, magnifica, Marchii, Merckii, pendulinu, polyantha, reflexa, rupicola, rutila, Sceptrum, splendens, stachydifolia, stricta, trifoliata, tuberosa, Vargasii, Vauthieri, Warczewiczii, xanthophylla, Kuntze, Rev Gen. (1891) $474=$ homonyma omnia Gesneriae.

atrosanguinea, Kuntze, 1. c. = G. Lindleyi, Hook.

barbata, Kuntze, 1. c, = Sinningia Carolinae, Benth. \& Hook. f.

chelonodes, Kuntze, 1. c. = Gesneria chelonioides, R. Br.

Gollmeriana, Kuntze, 1. c. = G. Gollmeriana, Hanst.
RECHSTEINERA : -

guazumifolia, Kuntze; Rev, Gen. (1891) 474

Gesneria suazumaefolia, Benth.

Leopoldz, Kuntze, 1. c. = G. Leopoldi, Scheidre.

sceptrodes, Kuntze, 1. c. = G. sceptroides, Hanst.

Schomburgkii, Kuntze, 1. c. = G. Schomburgkiana, Kunth.

Selloi, Kuntze, 1.c. = G. Seliovii, Mart.

Suttonii, Kuntze, 1. c. = G. Suttoni, Booth.

REDFIELDIA, Vasey, in Bull. Torrey Bot. Club, xiv. (1887) 133, t. 70; Hack. in Engl. \& Prantl Naturi. Pflanzenfam. ii. 2 (1887) 97. GRAMI NEAE.

flexuosa, Vasey, $l l, c c,-$ Colorado.

REGELIA, Lindm. in Oefvers. Akad. Holm. (Is90) 542 ; et in Kongl. Svensk. Vet. Akad. Handl. xxiv. a. 8 (1891) 15 = Karatas, Mill. (Bromel.). acanthocrater, Lindm. 11. cc. 543 ; et $21=$ Karatas acanthocrater, Baker.

ampullacea, Lindm. 1. c. = K. ampullacea, Baker.

Binoti, Lindm. 1. c. 543 ou $643=$ Nidularium Binoti. Ed. Morr.

chlorosticta, Lindm. 1. c. $543=$ Karatas chlorosticta, Baker.

coriacea, Lindm. 1. $c=$ K. coriacea. Antoine.

cruenta, Lindm. 1. c. $=\mathrm{K}$, cruenta. Baker.

cyanea, Lindm. 1. c. $542=\mathrm{K}$. cyanea, Baker

denticulata, Lindm. 1. c. $542=\mathrm{K}$. denticulata, Baker.

Fohannis, Lindm. 1 c. $543=\mathrm{K}$. Jchannis, Baker.

Laurenti, Lindm. 1. c. = K. Laurentii, Baker.

Makoyana, Lindm. 1. c. = K. Makoyana, Baker.

Marechali X, Lindm. 1. c. (= Nidularium Mare chali, Hort.). - Hybr. artef.

Morreniana, Lindm. 1. c. = K. Morreniana, Antoine princeps, Lindm. 1. $c_{0}=K$. princeps, Baker.

Regrellii, Lindm. 1. c。 = K, Regnellii, Baker.

sarmentosa, Lindm. 1. c. $542=\mathrm{K}$. sarmentosa, Baker.

spectabilis, Lindm. I. c. $543=\mathrm{K}$. spectabilis, Antoine.

tristis, Lindm. 1. c. $542=\mathrm{K}$. tristis, Baker.

REHMANNIA, Libosch (Scrophul.). - Ind. Kew, ii. 694 .

angulata, Hensl. in foum. Limn. Soc. xxvi. (1890) 193. - China.

Oldhami, Hemsl. l. c. 194; Baker, in Ann. Bot. ix. (1895) 154. - Ins. Formosa.

rupestris, Hemsl. l. c. 195 ; et ex Hook. f. in Bot. Mag. (1891) t. 7191. - China.

REICHARDIA, Roth = Picridium, Desf. $($ Compos.).

dichotoma. Freyn, in Oest. Bot. Zeitschr. xlii, (1892) $267=\mathrm{P}$. dichotomum, Bieb.

RELBUNIUM, Benth. (Rubiac.). - Ind. Kew. ii. 695 .

asperum, $K$. Schum, in Mart.Fl. Bras. vi. VI. (1888) 111. - Bras.

atherodes, K. Schum. 1. c. $107=$ Galium atherodes, Spreng.

bigeminum, K. Schum. 1. c. $106=$ G. bigeminum, Griseb.

buxifolium, K. Schum . l. c. 110. - Bras.

chaetophorm, K. Schum. 1. c. $114=$ Galium chaetophorum, Griseb.

compactum, Rusby. in Mem. Torrey Bot. Club, iii. 3 (1893) 49. - Bolivia.

corymbosum, K. Schum. in Mart. Fl. Bras. vi. VI. (1888) 118. - Bras

croceum, K. Schum.l.c. 116. -- Peruv.

diffusum, $K$. Schum, l. c. 111.-Bras.

diphyllum, K. Schum, l. c. 117. - Bras.

ericoides, K. Schum. 1. c. $109=$ Galium ericoides, Lam.

hirsutum, K. Schum. 1. c. $114=$ G. hirsutum, Ruiz \& Pav.

hirtum, K. Schum, 1. c. $107=$ G. hirtum, Lam.

humile, K. Schum. 1. c. $105=$ G. humile, Cham. \& Schlecht.

Muelleri, K. Schum. l.c. (1889) 406. - Bras.

nitidum, $K$. Schum. l. c. (1S8s) 114. - Bras.

noxium, K. Schum. l. c. 110 (= Rubia noxia, St Hil.), - Bras.

\section{RELBUNIUM :}

rinocense, K. Simm, in Mart. Fl. Bras, vi. VI.

(1888) 112. - Venezuela

ovale. K. Schum: l. o. 115. - Bras

pusillum, K. Sckum..,$c .117$. - Am. austr.

Selloanum, K. Schum. l. c. 115. - Bras.

tuberculosum, Ball, in fourn. Linn. Soc xxii. (1885)

42 (= Rubia tuberculosa. Benth.). - Peruvia.

vaillantioides, K. Schum. in Mart. Fl. Bras, vi. vI. (1888) 115. - Bras.

vile, $K$. Schum l. c. 116, - Bras.

REMIJIA. DC. (Rubiac.). - Ind. Kew. ii. 695.

amazonica, K. Schum. in Mart. Fl. Bras. vi, vI (1889) $153 .-$ Bras.

firmula. $K$. Schnm, in Engl. E Prontl, Natiurl. Pfanzenfam. iv. 4 (1891) 46 (= Ladenbergia fixmula, Mart.). - Am. austr.

hispida, Spruce, ex K. Schum. in Mart. Fl. Bras, vi. v1. (1889) 150. - Venezuela.

involucrata, $K$. Schum. l. c. 150, in obs, ; et in Engl. \& Prantl, Natirl. Pfanzenfam. iv. 4 (1891) 45. N. Granat.

pedunculata, Ed. André, in Rev. Hortic lix. (1887) 417, fig. 84 (= Cinchona pedunculata, Karst.). Columb

physophora, Benth. ex K. Schum. in Mart. Fl. Bras vi. VI. (1889) 151. - Bras.

Roraimae, K. Schum. 1. c. $154=$ Cascarilla Roraimae, Wedd.

REMYA, Hillebr. (Compos.), - Ind. Kew. ii. 695

auaiensis, Hillebr. Fl. Haw. Isl. (1888) 194.Ins. Sandvic.

mauiensis, Hillebr. l. c.-Ins. Sandyic.

RENANTHERA, Lour. (Orchid,). - Ind. Kew. ii. 695 .

angustifolia, Hook. f. Fl. Brit. Ind. vi. (1890) 49.Perak

Edefeldtii, F. Muell. \& Kraenzl. ex Kraenzl. in Oest. Bot. Zeitschr. xliv. (1894) 460. - N. Guin.

Imschootiana, Rolfe, in Kew Bull. (1891) 200. Hab.

Papilio, King of Prain, in fourn. As. Soc. Beng. lxiv. (1895) ii. 328. - Ind. or.

RENEALMIA, Houtt. = Villarsia, Vent. (Gentian.).

albiflora, calthifolia, capitata, lasiosperma, latifolia, ovata, parnassifolia, violifolia, Kuntze, Rev. Gen. (1891) $430=$ homonyma omnia Villarsiae. congestifolia, Kuntze, $1 . c .=\mathrm{V}$. congestiflora,
F. Muell.

exaltata, Kuntze, l. c. $=$ V. reniformis, $R$. Br.

RENEALMIA, Linn. f. (Scitam.), - Ind. Kew.

\section{ii. 696}

chrysotricha, Petersen, in Mart. Fl. Bras. iii. III (1890) 42. - Bras.

circinata, Th. Dur. E Schinz, Consp. Fl. Afr.v. 1892 (1895) 130 (= Ethanizm circinatum, $\mathrm{K}$ Schum.), - Gabon.

gracilis, Petersen, in Mart. Fl. Bras. iii. III. (1890) 47. - Guian. gall.

humilis, Petersen, l. .. 47. - Guian. gall.

mexicana, Klotzsch, ex Petersen, l. c. 45. - Mexic.

RESEDA, Tourn. ex Linn. (Resed.). - Ind. Kew, ii. 696 .

dimerocarpa, Rouy \& Fouc. F1. de Fr. ii. (1S95) 25 I $=$ R. Iuteola, Linn.

epirotica, Formánek. in Verh. Naturf. Ver. Brimn. xxxiii. (1894) 145. - Graecia.

fluminensis, Simonk. in Magyar Nören. Lapok, xii. (1888) 19. - Croatia.

oligomeroides, Schinz, in Bull. Herb. Boiss, iii. (1895) 397. - Reg. Somal.

platystacliya, Rouy \& Fouc. Fl. de Fr. ii. (1895) 242 = alba, Linn.

sphenocleoides, Deflers, in Bull. Soc. Bot. Fr, xlii. (1895) $\div 98$. - Arabia.

tymphaea, Hausskn. in Mitth. Bot. Ver. Fina, v (1888) 10 ; t t N. Folge: v. (1893) 41. - Graecia. 
RESTIARIA, Rumpf = Gommersonia, Forst. \& Rulingia R. Br. (Stercul.)

crispa, echinata, Gaudichaudii, melanopetald, microphylla, et pulchella, Kuntze, Rev. Gen. (1891) 81 = homonyma ommia Commersoniae.

corylifolia, craurophylla, cuneata. densiflora, grandi fova hermanniaefolia, Kampeana, laxophylla, macrantha, madagascariensis, magniflora, parriflora, platycalyx, rotundifolia, rugosa, Kuntze, 1. c. = homonyma omnia Rulingiae.

cygnorum, Kuntze, 1. c. = Rulingia malvaefolia Steetz.

dasypliylla, Kuntze, 1. c, $=$ R. pannosa, $R \cdot B r$.

Fraseri, Kuntze, 1. $\mathrm{c}=\mathrm{R}$. pannosa, $R, B r$.

Leichardti, Kuntze, 1. c. = Commersonia Leichardtii, Benth.

RESTREPIA, H. B. \& K. (Orchid.), - Ind. Kew. ii. 699.

brachypus, Reichti, f. in Flora, 1xix. (1886) 554. N. Granat.

dentata, Rolfe, in Kew Bull. (1892) 208. - Reg. Andina

ecuadorensis, Rolfe, l. c. 138. - Ecuad.

pandurata, Rerchb. f. in Gard. Chron. (1S8S) i. 244 et ex Veitch, Man. Orchid. Pl. v. (1889) 13. N. Granat.

Shuttleworthii, Rolfe, in Kev Bull. (1892) 138. Reg. Andina.

striata, Rolfe, in Gard. Chron. (1891) i. 137 ; th in Bot. Mag. (1892) t. 7233. - N. Granat.

RETAMA. Rafin. = Genista, Tourn. (Legumin.) recutita, Webb, ex C. Bolle, in Bot. Jahrb, xiv. (1892) 236. - Ins. Canar.

RETANILLA. Brongn. (Rhamn.). - Ind. Kew ii. 699 .

Moelleri, Phil, in Anal. Univ. Chil. 1xxxiv. (1893) 5. - Chili.

RETINISPORA, Sieb. \& Zucc. = Thuya, Linn.

(Conif.). (1891) $58=\mathrm{T}$. orientalis. Linn.

glaucescens, Hochst. ex Beissn. 1. c. (1891) $35=$ T. occidentalis, Linn.

Ketelceri, Hort. ex Beissn. 1. c, $95=T$. occidentalis, Linn.

Nobleana, Hort, ex Beissn, 1. c. $94=$ T. occidentalis, Linn.

pygmaea, Hort. ex Beissn. 1. c. $97=$ T. occidentalis, Limn.

Troubetzknana, Hort, ex Gard. Chron. (1890) i. 108; et ex Beissil. 1. c. 05 [Retinospora] = T occidentalis, Limn.

RETINODENDRON, Korth. = Vatica, Linn. (Dipteroc.).

bancanum; King, in Journ. As. Soc. Beng. 1xii. (1893) II. 129, in obs. = V. bancana, Scheff.

Kunstleri, King, 1. c. $129=$ V. Kunstleri, Brandis

moluccamun, Heim, Recherch. Diptéroc. (1892) 104 $=\mathrm{V}$. molucana, Burck

palludum. King, in Jumrn. As, Soc, Beng, lxii. (18.93) II. 128; et in Journ. Linn. Soc xxxi. (1895) $121=$ V. pallida, Dyer.

Scortechini, King, 11. cc, I2S et 121. - Perak.

RETINODENDROPSIS, Heim, in Mem. Assoc. Franç. Pau, 1892 (1893) 475, t. 4. DIPTEROCARPEAE

aspera, Heim, l. c. 470, t. 4. - Borneo.

RHABDIA, Mart. (Boragin.). - Ind. Kew, ii. 700

aquatica, Kuntze, Rev. Gen. (1891) 439 = lycioides, Mart.

REYNOSIA, Griseb. (Rhamn.). - Ind. Kew.ii. 700 .

lnevigata, Sarg. in Gard. and For. iv. (1891) $15=$ latifolia, Griseb.
RHABDOCHLOA, Beauv. = Leptochloa, Beauv. (Gramin.).

bipinnata, Kuntze, Rev. Gen. (1891) $\% 8 S=L$. bipinnata, Hochst.

Burchellii, Kuntze, 1. c. = L. Burchellii, Munro. imbricata, Kuntze, 1. c. = Diplachne imbricata Scribue.

longa, Kuntze, 1. c. = Leptochloa longa, Griseb. folystachya, Kuntze, I. c. = L. polystachya. Benth. rigida, Kuntze. 1. c. = Diplachne rigida. Benth. subdigitata. Kuntze, 1. c. = Leptochlora subdigitata, Trin

uniflora, Kuntze, 1, c. = L. uniflora, Hochst.

RHACHICALLIS, Spach = Rachicallis, DC. (Rubiac.)

americana, Kuntze, Rev, Gen. (1891) 281, in syn. $=$ rupestris, $D C$

mavitima, $\mathrm{K}$. Schum. in Engl. \& Prantl, Natürl. Pflanzenfam, iv. $4(1891) 33=$ rupestris, $D C$.

RHACHIDOSPERMUM, Vasey, in Coult. Bot. Gaz. Xv. (1890) $110=$ Jouvea, Fourn. (Gramin.).

mexicanm, Vasey, I.c. t. 12. - Mexic.

RHACOMA, Adans, = Leuzea, DC. (Compos.) conifermm, Kuntze, Rev. Gen. (1891) $360=\mathrm{L}$ conifera, $D C$.

longifoliam, Kuntze, 1, c. = L. longifolia, Hoffmgg. है Link.

vhaponticodes, Kuntze, 1, c. = Centaurea rhaponticoides, Benth. \& Hook. $f$.

salinum, Kuntze, 1. c. = C. salina, Benth. \& Hook. $f$.

RHACOMA, Linn. = IMyginda, Linn. (Celastr.). decussata, Haill. Hist. pl. Madag., Atlas (1894) t. 284. - Madag.

RHAGADIOLUS, Tourn. ex Scop. (Compos.). Ind. Kew. ii. 701.

papposus, Kuntze, in Act. Hort. Petrop. x. (185i) 205. - Armen. ; Afghan.

Rhagadiolus, Dorfler, in Herb, norm, Sched. ad cent. xxxi. (1894) $19=$ edulis, Gactn.

RHAMNELLA, Miq. = Microrhamnus, A. Gray (Rhamn.),

franguloides. Weberbauer, in Eng1. \& Prantl, Natürl. Pflanzenfam. iii. 5 (1895) $406=$ japonica, Miq.

RHAMNICASTRUM, Link, = Scolopia, Schreb. (Bixin.).

Browni, Kuntze, Rev. Gen. (1891) $45=$ Scolopia Brownii, F. Mnell.

crenatum, Kuntze, 1, c, = S. crenata, Clos.

Ecklonii, Kuntze, 1. c. (= Phoberos Ecklonii, Presl). - Afr. austr.

Mundici, Kuntze, 1. c. (= P. Mundtii, Presl). Afr. austr.

pusillum, Kuntze, 1. c. = Scolopia Gaertneri, Thw.

Rhinanthera, Kuntze, 1. c. = S. Rhinanthera, Clos

spinnsum, Kuntze. 1. c. = S. Roxburyhii, Clos

Zeyheri, Kuntze, 1. c. (= Phoberos Zeyheri Presl). - Afr. austr.

RHAMNIDIUM, Reiss. (Rhamn.), - Ind. Kew. ii. 701 .

ferverm, Sarg. in Gard, and For. iv. (1891) 16: et N. Am. Sylva, ii. (1892) 20, t. $58=$ Condalia ferrea, Griseb.

RHAMNOLUMA. Baill. in Bull. Soc. Linn. Paris. ii. (1890) 894 [err. cal. Rhamo-Moluma]; et Hist. des pl. xi. (1892) $28 \%=$ Lucuma, Molina (Sapot.).

novo-caledonica, Baill. I. c. 288 = L. novo-caledonica, Engl.

RHAMNONEURON, Gilg, in Engl, \& Prantl, Natürl. Pflanzenfam. iii. 6a (1894) 245. THYMELAEACEAE.

Balansae, Gilg, l.c. - Tonk.
RHAMNUS, Tourn. ex Linn. (Rhamn.). - Ind, Kew, ii. 701.

ancricana. Hort. ex Dippel, Handb. Laubholzk. ii. (1892) $526=$ hybrida, L'Herit.

baetica, Reverch. \& Willk. in Oest. Bot. Zeitschy. xli. (1891) 86; et Iliustr. Fl. Hisp. ii. (1886-92) 125, t. 163. - Hisp.

balearica, Willk. Illustr. Fl. Hist. ii, (18s6-92) 4t, t. $117 \mathrm{a}$; et Suppl. Prodr. Fl. Hisp. (1893) 25\%. Hisp.

Billardii, Hort. ex Dippel, Handb. Laubholzk. ii. (1892) $526=$ hybrida, L'Hérit.

boliviana, Rusby, in Mem. Torrey Bot. Club, iii. 3 (1893) 15. - Bolivia.

chincnsis, Hort ex Koehne, Deutsche Dendrol. (1893) $393=$ chlorophora, Decne.

chrysophyllus, Weberbauer, in Engl. E Prantl, Natiorl. Pfanzenfam. iii. 5 (1893) 410 (= Frangula chrysophylla, Reiss.). - Bras.

disperma, Ehrenb. ex Boiss, Fl. Or. Suppl. (18s8) 156. - Desert. Aegypt.Arab.

dumosa, Hort. ex Dippel, Handb. Laubholzk. ii. (1892) $520=$ saxatilis, Limn.

glaucophylla. Somm, in Nuov. Giorn. Bot. Ital. Ser. II. i. (1894) 19, 2 et 3 . - Ital.

granulosa, Weberbauer, in Engl. \& Prantl, Natürl Pflanzenfam. 1ii. I. (1895) 410 [gramlosus] = Ceanothus granulosus, Ruiz of Pav.

heterophylla, Oliver, in Hook. Icon. pi. xviii. (18SS) t. 1759 [heterophyllus]. - China.

Holstii, Engl. in Abh. Prenss. Akad. Wiss. (1894) 69 ; et in Engl. Pfanzcmie. Ost-Afr. C (1895) 255. - Afr. trop. or.

imeretia, Hort. ex Dippel, Handb. Laubholzk, ii. (1892) $525=$ alpina, Linn.

imeretina, Koehne, Dentsche Dondrol. (1893) 393. Reg. Cauc.

imevetina, Hort. ex Dippel, Handb. Laubholzk. il. (1892) $525=$ alpina, Linn.

insularis, Greene, in Bull. Calif. Acad. ii. (1885) 392 et Pittonia, i. (1888) $201=$ crocea. Nutt.

Jelskii, Zahlbr. in Diss, Cl. Math. Phys. Akad. litt. Cracor.xxix. (1894) 223. - Peruvia.

leucodermis, Baker, in Kew Bull. 1895 (1896) 316. Arabia.

myrtifolia, Willh. Illustr. Fl. Hisp. ii. (1886-92) 45, t. 117b; et Suppl. Prodr. Fl. Hisp. (1893) 257. Hisp.

occidentalis, Howell, ex Greene, Pittonta. ii. (Nov. 1889) 15. - Am. bor. occ.

orbiculata, Bormm. in Oest. Bot. Zeitschr, xxxvii. (1887) 225. - Dalm. vel Serb.

Palmeri, S. Wats, in Proc. An. Acad, xxii. (1887) 403. - Mexic.

polymorpha, Weberbauer, in Engl. \& Prantl, Natiirl. Pflanzenfam. jii. 5 (1895) 410 [polymorphus] = sectipetala, Mart.

pubescens. Kuntze, Rev Gen. (1891) $120=$ sectipetala, Mart.

rhodopea, Vclen, Fl. Bulg. (1891) 119; et in Sitz. Boehm. Ges. Wiss. (1893) xxxvii, 19. - Bulg.

rubra, Greene, Pittonia, i. (July 188\%) 63 et $160=$ Purshiana. $D C$.

ruyulosa, Hemsl. ex Forb. E Hemsl. in fourn. Linn. Scc. xxiii. (1886) 129 [rugulosus]. - China.

sphenophylla, Borb. in Erdész. Lapok (1885) 703. - Hung.

tortuosa. Somm. So Levier, in Bull. Soc. Bot. Ital. Ser. II. i. (1894) 26, - Reg. Cauc.

RHAMPHICARPA, Benth. (Scrophul.). - Ind.

\section{Kew. ii. 703.}

angolensis, Engl. Bot. fahrb. xviii. (1894) 74. Angola.

Heuglinit, Hochst. ex Engl. Ptlanzenw. Ost-Afr. C (1895) $361=$ Cycnium Heuglinii, Engl.

Holstii, Engl. in Abh. Prenss. Akad. Wiss. (IS94) 35 ; et Pfanzenw. Ost-Afr. A (1895) 74 (=Cycnium Holstii, Engl.), - Afr. trop.

macrosiphonia, $F$. Micell. in Proc. Limn. Soc. N. S. Wales, Ser. II. vi. (May 1892) 473. Austral.

Medwedewi, Alboff, in Act. Hort. Petrop. xiii. (1893) 435; et in Bull. Herb. Boiss. i. (1893) 248 , t. 6. - Reg. Cauc. 


\section{RHAMPHICARPA}

Meyeri Johannis, Engl, in Abh. Preuss. Akad. Wiss. 1501 (18!2) 382 (= Cycnium Meyeri Johannis, Engl.). - Afr, trop. or.

pratensis, Engl. l. c. (1894) 58, nomen. -- Afr. trop.

stricta. Engl. l. c. 24 et 39 ; ct in Engl. Pfanzcnwe. Ost-Afr. A (1895) $\tau$ ( (= Cycrium strictum, Engl.). - Afr. trop.

RHANTERIUM. Desf. (Compos.). - Ind. Kew. ii. 703

incrassatum, Pomel, ex Batt. \& Trab. Fl. de l'Algér. [Dicot.] (188?) $432=$ adpressum Coss. 6 Duricu.

squarrosun, Coss, \& Durieu, ex Batt. \& Trab. 1. c. $=$ adpressum, Coss, \& Durieu.

RHAPHIDANTHE, H:ern, ex Guerke, in Engl, \& Prant1, Natïrl. Pflanzenfam. iv. I. (1891) 165. EBENACEAE.

obliquifolia, Hiern, l. c. - Afr. trop. occ.

RHAPHIDOPHORA, Hassk. (Aroid.). - Ind. Kew, ii. 703

crassifolia, Hook. f. Fl. Brot. Ind. vì. (1893) 543. Perak

gracilipes, Hook. f. l. c. 545.-Perak.

Hollrungii, Engl, in $\mathrm{K}$. Schum. \& Hollr. Fl. Kais Wilh. Land (1S89) 19. - N. Guin.

Kunstleri, Flook. f. Fl. Brit. Ind. vi. (1S93) 546. Ind. or.

Maingayi, Hook f. l. c. 543. - Malacca.

minor, Hook. f. l. C. 544 - - Penins. Mal.

neo-guineensis, Engl. in K. Schun. E Hollv. Fl Kais. Wîll. Land (18s9) 19. - N. Guin.

Schottii. Flook. f. Fl. Brit. Ind. vi. (1S93) 544. Ind, or.

Scortechinii, Hook. f. l. c. 545. -- Perak.

tetrasperma, Hook. f. Fl. Brit. Ind. vi. (I893) 548. - L'erak.

Wrayi, Hook. f. l. c. 544.-- Perak.

RHAPHIDOPHYLLUM, Benth. = RAPHIDOPHYLLU.I, Hochst. = Sopubia. Buch.-Ham. (Scrophul.).

RHAPHIDOSPORA. Nees $=$ Justicia, Houst

(Acanth.).
campylostemon, Lindau, in Enorl. \& Prantl. Natürl. campylostemon, Lindau, in Engl. \& Prantl. Natürl.
Pflanzenfam. iv, 3b (1895) $390=\mathrm{J}$. campylostemon, T. Anders.

RHAPHIOSTYLIS, Planch. = RAPHIOSTYLES, Benth \& Hook. f. = Apodytes, E. Mey. (Olacin.).

RHAPONTICUM, [Vaill.] Hall. = Centaurea Linn. (Compos.).

integrifolium, C. Winkl. in Act. Hort. Pctrop. ix. (1856) 425. - Buchara.

RHAPTOSTYLUM. Humb. \& Bonpl. = Heisteria. Jacq. (Olac.)

acutum, brasilicnse, cauliform, citrifolium, coccineum, cyanocarpum, densifrons, fexroosum, guianense. Kappieri. laxiforum, longifolium, mücrocarpun, nitidum, oratum, pallidum, purvifolinn. salicifolium, Spruceanum, Kuntze, Rev. Gen.(1891) $112=$ homonyma omnia Heisteriae.

mayteniodes, Kuntze, '1. c. $=\mathrm{H}$. maytenioides. Spruec.

microcalyx, Kuntze, 1.c. $=\mathrm{H}$. microcalyx, Sagot.

RHEEDIA, Linn. (Melast.). - Ind. Kew, ii. 705.

rostrata; Vesque, Epharmos. ii. (1889) 24; et in DC. Nlonog. Phan, viii. (1893) 510. - Bras.

Sagotiana, Engl: in Mart. Fl. Bras. xii. 1. (1SS8) $460=$ macrophylla, Planch. \& Triana.

sessiliflora, Planch. ex Vcsque, in DC. Mlonog. Phan. viii. (1393),50J. - Ins. Jamaic.

\section{RHEEDIA}

Spruceana, Engl, in Mar. Fl Dras, xii. I. (1SS8) 463. - Bras

tenuifolia, Engl.l.c. - Bras

virens, Planch. ex Vesque, in DC. MIonog. Plan. viii. (1893) 511. - Guiana.

RHEUM, Linn, (Pulygon.) - Ind. Kew, ii. 705

Alexandrae, Batalin, in Act. Hort. Petrop. xiii. (1S94) 384 . China.

Bailloni, Hein, in Bull. Soc. Linn. Paris, ii. (IS92) 1015 et 1104 - Hab.

Delavayi, Franch, in Bull. Mus, Paris, i (1005) 212. - Yunnan.

hirsutum, Maxim. ex Franch. 1. c. 213, in obs. = Polygonum acaule, Hook. $f$. E Thom.

kialense, Franch.l.c.212. - China.

strictum, Frunch. l. c. 213. - China.

tibeticum, Maxin. ex Hook. f. Fl. Brit. Ind. v. (18S6) 56, - Reg. Himal., Tibet.

RHEXIA, Linn. (Melast.). - Ind. Kew, ii. 705. aristosa, Britton, in Bull. Torrey Bot. Club, xvii, (1890) 14, t. 99; Cogn. in DC. Monog. Phan. vii. (1891) 1181. - Am. bor. or

floridana, Nash, i. c. xxii. (1895j 150. - Florida.

RHIGOZUM, Burch. (Bignon.). - Ind, Kew. ii. 705.

brevispinosum, Kuntze, in fatrb. Bot. Gart. Benl. brevispinosum, Kuntze, m fatro. Bot. Gart. B
iv. (18s6) 270. - Afr. austro-occ. extratrop. zambesiacum, Baker, in Kow Bull. (1894) 32. Zambesia

RHINACANTHUS. Nees (Acanth.). - Ind. Kew. ncisutus, Kuntze, Rev. Gen. (I891) 474 ; Lindau, in
Engl. \& Prantl, Natiri. Pflanzenfam, iv. 3b (1895) 329 ; et in Engl. Pflanzenw. Ost-Afr. C (1895) $371=$ communis, $\Lambda^{\top}$ ces.

ndorensis, Schweint, ex Engl. in Ab7. Pretss. Akad. Wiss. 1891 (1892) 394, nomen; et in Hoelnel, zum Rudolph See (1892) 7. - Afr, trop. or.

RHINANTHUS, Linn. (Scrophul.). - Ind. Kew. ii. 708 .

dinaricus, Murb. in Lunds Unio. Arsskrift, xxvii. v. (1891) 69. - Hercer.

ellipticus, Hausskn. in Tagebl. Naturf. Vers. Wien (1894) 368. - Germ.

puberulus, Fritsch, in Verh. zool.bot. Ges. Wien, xli, (1891) 74\%. - Austria.

mumelicus, Velen, in Sitz. Boehm, Ges. Wiss. (IS87) 455 ; et Fl. Bulg. (1891) $433=$ major, Ehr/h

serotinus, Oborny. Fl. von Mähren ii. (1886) 435 = major, Ehrh.

RHIPSALIS, Gaertn. (Cact.). - Ind. Kew, ii. \%08.

aculeata, A. Weber, in Rei. Hort. Ixiv (1892) 42S ; et in Monatsschr. f. Kahteenh. iii. (1893) 33. - Reg. Argent.

alata, K. Schum. in Mart. Fl. Bras. iv. II. (1890) $288(=$ Cactus alatus, Sw.). - Am. trop.

anceps, A. Weber, in Rev. Hortic. 1xiv. (1892) 427 ; et in Monatssch . f. Kaktcenk. iii. (1893) 24. Bras.

brevibarbis, K. Schum.in Engl. \& Prantl, Natürl. Pfanzenfam. ii. 6a (1894) 199. - Hab.?

capilliformis, A. IVeber, in Rev. Hortic. 1xiv. (1392) 425 ; et in Monatsschr. $f$. Kaktienk. iii. (1S93) 11. İras.

cavernosa, G. A. Lindb. in Gartenfl. xxxix. (1S90) $153 ;$ K. Schum, in Mart. Fl. Bras. iv. II. (1890) 289. - Bras.

clavata, A. Weber, in Rev. Hortic. 1xiv. (1S92) 429; et in Monatsschr. f. Kaktcenk. iii. (1893) 34. Bras.

comorensis, A. Weber, in Ind. semin. Hort. Paris (189) 1), in Rev. Hortic. 1xiv. (1892) 424; K. Schum. in Monatssch. $f$. Kaktenk. iii. (1893) S. - Ins. Comor.

dissimilis, $K$, Sclum, in Mart. Fl. Bras. iv. II. (1890) 286 : = Lepisminm dissimile, G. A. Lindb.). - Bras.

\section{RHIPSALIS :}

elliptica, G. A. Lindb. ex K. Schum. in Mart. Fl. Zras. iv. II. (1890) 293. - Bras.

erythrocarpa, K. Silim. in Engl. Pfanzenw. Os.

Afr. C (1895) 2S2. - Afr. trop. or.

foribunda, Schott, ex K. Schum, in Mart. F1. Bras

iv. I1. (1890) $274=$ teres, Stcul .

gibberula, $A$. W $c$ bcr, in Rev. IIorlic. lxiv. (1S92) 426 ; in Monatsschr. f. Kaktecnk. iii. (1893) 12. - Bras. gonocarpa, A. TVeber, $7 l$. co. 427 ; et 23. - Bras hadrosoma, G. A. Lindb. in Monatsschr. f. Kakteenk. iii. (15!3) 96. - Bras.

Lindbersiana. K. Schum, in Mart. Fl. Bras, iv, II (1890) 271. - Bras.

linearis, K. Schum. l. c. 290.- Bras,

macropogon. K. Schum. 1. c. $282=$ cavernosa, $G$ A. Lindb.

madagascariensis, A. IV cbon, in Ind. somin. Hort. Paris (18S9), in Rer. Hortic lxiv. (1892) 424; G. A Lind5. in Monatsschr. f. Kakteenk. iii. (1893) Si3, cum ic. - Maday

minutiflora, K. Silum, in Mart. Fl. Bras, iv. Is (1500) 271. - Guian. bat.

Myosurus, $K$. Schum , c. $2 S 1(=$ Lepisminm M10 sorns, Pfeiff.) $=$ R. Myosurus, Foerst.

Neves-Armondii, K. Sihmm. l. c. 2S4.-Bras.

phyllanthus, K. Schum. I. c. $298=$ macrocarpa K. Schum.

pulvinigera, G. A. Lindb. in Gartenfl, xxxviii. (ISS? 182, fig. 33-35: K. Schum. in Mart. Fl. Bras. iv. II. (1890) 273. - Bras.

puniceodiscus, G. A. Lindb. in Gartenfl. xlii. (1893) 233, fig. 49. - Hab.?

ramosissima, K. Schum, in Mlart. Fl. Bras. iv. It. (1890) 290. - Bras.

Regnellii, G. A. Lindb. in Gartenfl. xsxix. (1890) 118, fig. 31 et 32 ; el in Illustr. Hortic. xxxix. (1890) 121, fig. 29, 31, 32; K. Schum, in Mart. Fl. Bras, iv, 11. (I893) 295, t. 58. - Bras.

sansibarica, A. Weber, in Rev. Hortic. lxiv. (189?) 425. - Zanzib.

setulosa, A. Weber, 1. c. 428, in syn. in Monatsschr. f. Kakteenk. iii. (1893) $24=$ dissimilis, $K$ Schinm.

squamulosa, K. Schum. in Mart. Fl. Bras, iv. Ir. (1890) 280 (= Cereus squamulosus, Salm-Dyck). Bras.

suareziana, A. Weber, in Rez'. Horlic. lxiv. (1892) 425 ; et in Monatsschr. f. Kaktenk. iii. (1993) 11. - Madag

Tuglionis, K. Schum. in Monatsschr. f. Kakteenk iv. (1894) 74, sphalm. = R. Saglionis, Otto \& Dietr.

tetraorona, A. Weber, in Rev, Hortic. lxiv. (1892) 429 ; et in Monatsschr. f. Kakteenk. iii. (1893) 34 - Hab. ?

tucumanensis. A. Wejer, ll.cc. 42\%; et 22. - Reg. Argent.

virgata, A. Weber, in Rev. Hortic. 1xiv. (1892) 425. - Bras.

Warmingiana, K. Schum, in Mart. Fl. Bras, iv. II. (1890) 291 ; G. A. Lindb. in Gartenfl. xli. (1892) 8 , fig. 5 et 6. - Bras.

zanzibarica, A. Weber, in Monatschr. $f$. Kakteenk iii. (1893) 11. - Zanzib.

RHIZOTAECHIA, " Radlk. " in Engl. \& Prantl, Natürl. Pflanzenfam. iii. 5 (1895) 347 = Rhyzotoechia, Radlk. (Sapind.).

RHODALSINE, J. Gay = Arenaria. Rupp (Caryophyll.).

Gayana, Webb, ex Christ, in Bot. Jahrb. ix. (1888) $103=$ A. Gayana, Christ.

platypliylla, J. Gay, ex Christ, 1. c. $102=$ A platyphylla, Christ.

RHODAMNIA, Jacq. (Myrtac.). - Ind. Kerv i glabra, Vidal, Revis. Pl. Vasc. Filip. (18S6) I29Ins. Philipp.

RHODIOLA, Linn. = Sedum, Tourn. (Cras-

Scopolii, A. Kern. ex Simonk. Enum. Fl. Transsilv (1Sะ6) 234 - Transsily. 
RHODOCISTUS Spach $=$ Cistus. Tomrm. osbeckiacfolius, Webu, ex Christ, in Bot. Jahrb. ix. (1888) $96=\mathrm{C}$. osbeckiaefolius, Christ.

RIIODOCHLAENA. Spreng. = Rhodolaena Thou. (Chlaenac.).

RHODOCOLEA, Baill, in Bull. Soc. Linn. Paris, (1887) 693 ; et Hist des pl, x. (1888) 57 ; et in Engl. \& Prantl. Natürl. Pflanzenfam. iv. 3b (1895) 249. BIGNONIACEAE.

nobilis, Baill. 17. cc. 693 ; et5s. - Madag.

RHODODENDRON, Linn. (Ericac.), - Ind

denopodum, Franch, in Morot, Fourn. de Bot. ix. (1895) 391. - China.

argyrophyllum, Franch. in Bull. Soc. Bot. Fr. xxxiii. (1886) 231; et in Noute. Arch. Mus. Paris, Sér. II. x. (1857-88) 4S. - China occ.

Armitii. F. M. Bailey, in Dept. Agric. Brisbane Bot. Bull. x. (1895) :39. - N. Guin.

atrovirens, Franch in Bull. Soc. Bot. Fr. xxxiii. (1886) 235, - China occ.

aucubaefolium, Hemsl, in foum. Linn, Soc. xxvi. 1800) 19. - China.

Augustinii, Hemsl. l, c, 19, - China

aureum, Franch. in Morot, fourn. de Bot. ix. (1895) 394. - Yunnan

auriculatum, Hensl. in fourn. Linn. Soc. xxvi, (1889) 20. - China.

blepharocalyx, Franch, in Morot, foum. de Bot. ix. 1895) 396. - China

Bonvaloti, Franch. l. c. v. (1891) 94. - China.

brachyanthum, Franch, in Bull. Soc. Bot. Fr. xxxiii. (1886) 234. - China occ

bullatum, Franch. l. c. xxxiv. (1887) 281. - China

Bureavi, Franch.l. c. - China occ.

calophytum, Franch. l. c. xxxiii. (18S6) 250 ; et in Nour. Arch. Mus. Paris, Sér. II.x. (1887-8S) 45 - Tibet.

canadense. Britton, Stern \& Pogr, Prelim. Catal (1885) 32; Dippel, Handb. Laubholzk. i. (1889) 4ls; Koehne, Deutsehe Dendrol. (1893) 457 (= Rhodora canadensis, Linn.) = R. Rhodora, F. F Gmol.

canescens Porter, in Bull. Torrey Bot, Club, xvi. (1889) $2: 0$ = nudiflorum, Torr. E Gray.

Carringtoniae, F. Matl, in Vict, Natural. iv. (Nov.

1887) 110 ; et in Bot. Centralbl. xxxiii. (1888) 55. - N. Guin.

chartophyllum, Franch. in Morot, Fourn. de Bot. ix. 1895) 398. - Yunnan.

ciliicalyx, Franch, in Bull. Soc, Bot, Fr, xxxiii 1886) 233. - China occ

Clivianum $X$, Hort. ex Ungar. Rosen-Zeit, vii. 6 1904) 24. - Hybr. artef.

conicinnum, Hemsl, in fourn. Linn. Soc. xxvi.(1890) 21. - China.

costulatum, Franch, in Morot, foum, de Bot, ix. 1895) 399. - China

crassifolium, Stapf, in Trans, Linn. Soc. Ser. II. iv. (1894) 195. - Borneo.

crassum, Franch, in Bull. Soc. Bot. Fr, xxxiv. (1887) 282. - China occ.

culminicolum, F. Muell. in Trans. Roy. Soc. Vict. N. S. i. I. (1889) 23. - N. Guin.

cuneifolium, Stapf, in Trans. Linn. Soc. Ser. II.iv. (1894) 198. - Borneo.

dahuricum, "Linn. » ex Dippel, Handb. Laubholzk. i. (1889) 425, fig. $274=$ dauricum, Linn.

Davidi, Franch. in Bull. Soc. Bot. Fr, xxxiii. (1886) 230. - China occ.

Datisi, Hort. ex Koehne, Deutsche Dendrol. (1893) $458=$ sinensis, Sweet.

decorum, Franch, in Bull. Soc. Bot, Fr, xxxiii. (1886) 230 : et in Nour. Arch. Mus, Paris, Sér. II. x. (1887-88) 45. - China occ.

Delavayi, Franch. l. c,231. - China occ

dendrocharis, Franch. l. c. 2333; et in Nowv. Arch. Mus. Paris, Sér. II. x. (1887-88) 51, t. 13, fig. a. - China occ.

discolor, Franch, in Morot, fourn. de Bot. ix. (1895) 391. - China.

\section{RHODODENDRON}

ellipticum, Maxim, in Bull. Acad. Pétcrsb. xxxii (1588) 497. - China.

Faberii, Hemsl, in foum. Linn. Soc. xxvi. (1890) 22. - China.

Fargesii, Franch. in Morot, fourn. de Bot. ix. (1895) B.0. - China.

fasticiatum. Franch, in Bull. Soc. Bot. Fr. xxxiii. (1886) 2:34. - China occ

Fauriae, Franch, in Bull. Soc Philom. Paris, Sér. VII. x. (1S\&6) 145 - Japon.

flavidum, Franch, in Morot, fourn. de Bot. ix. (1895) i3:5. - China

floribundum. Franch, in Bull. Soc. Bot Fr. xxxiii. (ISS6) 232; et in Nouci, Arch. Mus, Paris, Sér. II x. (1887-8S') 49. - China.

Fordi1, Hensl. in Kew Bull (1894) 5. - China.

formosanum, Hensl l. c 183. - Formosa.

fragrans, Franch. in Bull. Soc. Bot. Fr. xxxiv, (1857) $284=$ trichostomum, Franch

olanduliferum, Fronch. l. c. xxxiii. (1856) 231.China 0 ce.

gracilentum, F. Mnell. in Trans. Roy. Soc. Vict. N. S. i. 11. (1889) 22. - N. Guin.

racilipes, Franch, in Morot, fourn. de Bot. ix. (1505) 391. - C

grateulens $\times$ Bull, $C$ al (1S57) ii. - Hybr, artef. hrematodes, Franch, in Bull. Soc. Bot. Fr. xxxiii. (1856) 232. - China occ

Hanceanum, Hemsl. in Fourn. Limn. Soc, xxvi. (18S9) 24. - China.

Hancockii, Hensl, in Kew Bull. (1505) 107; et in Hook, Icon, pl. xxiv. (1895) t. 2381, - China.

Hansemanni, Warb. in Bot. Fahrb. xvi. (1892) 26. - N. Guin

heliolepis, Franch, in Bull. Soc. Bot. Fr, xxxiv. (1857) 283. - China occ.

Hellwigi, Warb. in Bot. Fahrb. xvi. (1892) 5, 26. N. Guin

Herzogii, Warb.l.c. 15, 25. - N. Guin

hypoglaucum, Hemsl. in fourn. Limn. Soc. xxvi. (185.) 25. - China.

intricatum, Franch. in Morot, fourn, de Bot. is. (1845) 395. - China.

irroratum. Franch in Bull. Soc. Bot. Fr, xxxiv, (1857) 280 ; Hook. f. in Bot. Mag. (1894) t. 7361 . - China

kewense $\times$. W. Wats. ex Gard. Chron. (18s8) i. 620 ; The Garden, xlii. (1892) 474, t. 885 . Hybr. artef.

kialense, Franch. in Morot, fourn, de Bot. ix. (1895) $3 ! 12$. - China.

Kotschyi, Simonk. Emmm. Fl. Transs. (1886) 389.Transsilv.

lacteum, Franch.in Bull. Soc. Bot. Fr. xxxiii. (1886) 231. - China occ

lacteum, Stapf, in Trans. Iimn. Soc. Ser. II. iv. (1894) 197. - Borneo.

leptanthum, F. Muell. in Trans Roy. Soc. Vict. N. S. i. 11. (1889) 24, in obs. - N. Guin

Lochae, F, Muell. in Vict. Natural, iii, (Mar. 1887 ) 157 ; in Gard. Chron. (1887) i. 543 ; et in Bot. Centralbl. xxx. (1887) 277. - Austral.

lucidum, Franch. in Morot, fourn. de Bot. ix. (1895) 390. - China.

lutescens, Franch, in Bull. Soc. Bot. Fr. xxxiii. (1886) 235: et in Nowv. Arch. Mus. Paris, Sér. II. x. (1887-88) 235. - China occ.

maculiferum, Franch. in Morot, Fourn. de Bot. ix. (1895) 393. - China.

microphyton, Franch. in Bull. Soc. Bot. Fr. xxxiii. (1886) 235. - China occ,

moupinense, Franch. l. c. 233: et in Nour'. Arch Mus. Paris, Sér. II. x. (1887-S8) 52, t. 12. China occ

neriiflorum, Franch. l. c. 230, - China occ.

nigro-punctatum, Burean \& Franch. in Morot, fourn. de Bot. xxxiv. (1891) 95. - China occ.

occidentale, W. Wats. ex Gard. Chron. (1886) ii 104 fig. $21=$ occidentale, A. Gray.

oleifolium, Franch. in Bull. Soc. Bot. Fr. xxxiii (1886) 235. - China occ.

oreodoxa, Franch. l. c. 230 ; et in Nout. Arch. Mus, Paris, Sér. II. x. (1887-88) 46. - China occ.

pachytrichum, Franch. in Bull. Soc. Bot. Fr, xxxiii. (1886) 231 ; et l. c. 49 - - China occ.

\section{RHODODENDRON :}

entaphyllum, daxim, in Bull. Acad. Pétersb, xxxi. (1887) 64. - Japon.

phaeochiton. F. Muell. in Trans. Roy. Soc. Vict. N. S. i. 11. (1889) 23. - N. Guin.

pittosporaefolium, Hemsl. in fourn. Linn. Soc. xxvi. (1889) 29. - China.

polifolium, Franch. in Morot, foum, de Bot. ix. (1895) 397. - China.

polycladum, Franch. in Bull. Soc. Bot. Fr. xxxiii, (1886) 234. - China occ

polylepis, Franch. l. c.232; et in Nown. Arch. Mus. Paris, Sér. II. x. (1887-83) 50. - China occ.

Potanini, Batalin, in Acl. Hort. Petrop. xi. (1891) 489. - China.

Pratti, Franch, in Morot, Foum, de Bot. ix. (1895) 389. - China.

primulaeflorum, Bureau \& Franch, in Morot, fourn. de Bot.v. (1S91) 95. - China occ.

Principis, Burean \& Franih. l. c. 92. - China

Quadrasianum, Vidal, Revis, Pl. Vasc. Filip. (1886) 170. - Ins. Philipp.

racemosum, Franch, in Bull. Soc. Bot. Fr, xxxiii. (1586) 235; et ex Gard. Chron. (1892) ii. 62; Hook.f. in Bot. Mag. (1893) t. 7301. - China occ.

rigidum, Franch. l. c. 233. - China occ

rosmarinifolium, Dippel, Handb. Laubholzk. i (1889) 421; Koehne, Deutsche Dendrol. (1893) 457 = ledifolium, G. Don.

rosmarinifolium, Vidal, Reilis. Pl. Yasc. Philip. (1886) 172. - Ins. Philipp.

rotundifolinm. Arm. David (As. Soc. North, China Branch. (1871-92) 216), ex Franch, in Bull. Soc. Bot. Fr. xxxiii. (1886) 230 ; et in Nouv. Arch. Mus. Paris. Sér. II. x. (1887-88) 47. - Tibet.

rubiginosum, Franch. in Bull. Soc. Bot. Fr, xxxiv. (1\$87) 282. - China occ

rufescens, Franch. in Morot, fourn. de Bot. ix. (18:5) $39 \%$ - China.

rufum, Batalin, in Act. Hort. Petrop. xi. (I890) 490. - China.

scabrifolium, Franch, in Bull. Soc. Bot. Fr, xxxiii. (1886) 236; Hook.f. in Bot. Mag. (1891) t. 7159. - China

shikokianum, Makino, in Tokyo Bot. Mag. vi. (1892). 53. - Japon.

Smirnowi, Trautr. in Act. Hort. Perrop, ix, (1886) 513: Regel, in Gartenfl. xxxv. (1886) 377, t. 1226 , fig. 2. - Armen.

sonomense, Greene, Pittonia, ii. (Sept. 1891) 172; et Man. Bol. San Franc. Bay (1894) 323. - Calif.

Souliei, Franch. in Morot, Fourn, de Bot. ix. (1895) 393. - China.

spiciferum. Franch. l. c. 400. - Yunnan.

spinuliferum, Franch . . c. 398 - Yunnan

spondylophyllum, F. Muell. in Trans. Roy. Soc. Vict. N. S. i. Ii. (1889) 23. - N. Guin.

stamineum. Franch, in Bull. Soc. Bot. Fr, xxxiii. (1886) 236. - China occ

strigillosum, Franch, l, c. 232; et in Nous. Arch. Mus. Paris, Sér. II. x. (1887-8\$) 49. - China occ.

sulfureum, Franch.l.c xxxiv. (1857) 283. - China. OCC

sutchuenense, Franch. in Morot. Fourn. de Bot. ix. (1895) 392 - China.

taliense, Franch, in Bull. Soc. Bot. Fr, xxxiii. (1886) 232. - China.

Tashiroi, Maxim. in Bull. Acad. Petersb. xxxi. (1887) 64. - Ins. Kiusiu.

tatsienense, Franch, in Morot, fourn, de Bot. ix. (1895) 394. - China

tosaense, Mukino, in Iokyo Bot. Mag. vi. (1S92) 53. - Japon.

trichocladum, Franch. in Bull. Soc. But. Fr. xxxiii. (1886) 234. - China occ.

trichostmum, Franch. in Morot, fourn de Bot. ix. (1895) 396. - Yunnan.

Ungernii, Trautv: in Acl. Hort. Petrop.ix. (1886) 514; Regel, in Gartenfl. xxxv."(1886) 278. fig. 1. Armen. ross.

verticillatum, Vidal., Rev. F1. Vasc. Filip. (1886) $171=\mathrm{R}$. Vidalii, Rolfe.

Viali, Delaray \& Franch; in Morot, fourn. de Bot, ix. (1895) 395. - Yunnan. 
RHODODENDRON

Vidal i, Ro'fe, in foum. Bot. xxiv. (18S6) 348, in obs. $(=R$. Eerticillatum, Vidal). - Ins. Philipp.

Victorianum Y Cuvelier, in Gard. Chron. (1857) i. $387 .=\mathrm{Hybr}$. artet.

TVestlandii, Hemsl. in fourn. Limn. Soc, xxvi. (1889) 31. - China.

yanthinum, Bureau \& Franch. in Morot, fourn. de Bot. v. (IS91) 94. - China occ.

Yelliottii, Warb. in Bot, Fahrb, xvi. (1893) 25.N. Guin

jedoënse. Maxim. ex Regel, in Gurtenfl. xxxy. (1886) 565, t. 1233. - Japon.

runnanense, Franch. in Bull. Soc. Bot. Fr. xxxiii (1SS6) 232 --China occ

Znelleri, Warb, in Bol. Fahrb. xvi. (1892) 15, 34. - N. Guin.

RHODOLAENA, Thou. (Chlaenac.). - Ind.Kew. ii. 712.

Bakeriana. Baill. in Bull. Soc Linn. Paris, i. (1886) 566, et571 : et Hist.pl. Madag., Atlas (1889) t. 103 (= Rhod. altivole, Baker). - Madag.

Ifumblotii, Baill. ll. cc. 566, 571 ; ei t. 104. Madag.

RHODOMYRTUS, Reichb. (Myrt.). - Ind. Kew. 11. T12. baladensis, Niedenzu, in Engl. E Prantl, Natiurl.
Pfanzenfam. iii. 7 (1893) $70(=$ Myrtus baladensis, Brongn. et Gris) - N. Caled.

RIIODOPSIS, Ledeb. = Rosa, Tourn. Lerberifolia. "Ledeb. " ex Dippel, Handb. Laubholzk, iii. (1891) $601=\mathrm{R}$. berberifolia, Pall.

RHodosciadium, S. Wats, in Proc. Am. Acad. xxv. (1890) 151. UMBELLIFERAE.

issectum. Coult \&. F. $N$. Rose, in Contrib. U.S. $\Lambda^{\top} a t . H e r b$. iii. 3 (1895) 30!) - Mexic.

glaucun, Conlt. \& 7. N. Rose, l. e. - Mexic

I'ringlei, S. Wats. in Proc. Am. Am. Acad. xxy. (1890) 151. - Mexic.

RHODOSEPALA, Baker. in Journ. Linn. Soc xxii. (1887) 475. MELASTOMACEAE. crecta, $\operatorname{Cog} n$. in DC. Monog. Phan. vii. (1891) 339. crecta, $\operatorname{Cog} n$.
- Madag.

pauciflora, Baker, in fourn. Linn. Soc. xxii. (1887) $471 ; \operatorname{cogn}$. l. c. $338,-$ Madag.

procumbens, Cogn. l. c. 339; - Madag.

RHODOSPHAERA, Engl. in Engl. \& Prantl, Natürl. Pflanzentam. iii. 5 (1892) 162. AN ONA$C E A E$.

rhodanthema, Engl.l. c. fig. 100 p. - Austral.

RHODOSTACHYS, Phil. (Bromel.). - Ind Kew. ii. 713.
lbo-bracteata, Baker, Handb. Bromel. (1889) 28. albo-bracteata, Baker, Handb. Bromel. (1889)
Chili
argentina. Baker, l. c. 29. - Reg. Argent.

micrantha, Phil. in Anal. Unir. Chil. xci. (1895) 618. - Chili.

Urbaniana, Mez, in Mart. Fl. Bras. iii. II, (1891) 182. - Reg. Argent.

RHOICISSUS, Planch. in DC. Monog. Phan. v. (1857) $463=$ Vitis, [Tourn.] Linn. (Ampelid).

capensis, Planch. 1. c. = V. capensis, Thunb.

cuneifolia. Planch. 1. c. 466 (= Cissus cuneifolia, Eckl \& Zeyh.). - Afr. austr.

drepanophylla, Gilg, in Enghl. Pflanzenw. Ost-Afr. C (1895) 257. - Afr. trop or.

erythrodes, Planch. 1. c. $465=$ Vitis erythrodes, Fres.

Holstii, Engl. in Abh. Preuss. Akad. Wiss. (1894) 61 : et in Engl. Pflanzenw. Ost-Afr. C (1895) 257. - Afr. trop.or.

pauciflora, Planch. in DC. Monog. Phan. v. (1887) $468=$ Cissus pauciflora, Burch.

Revoilii, Planch. 1. c. 469. - Reg. Somal.

rhomboidea, Planch. 1. c. 467 (=Cissus rhomboidea, E. Mey.). - Natal.
RHOICISSUS : -

ansibarensis, Gile, in Abh. Preuss. Akad. WViss. (1895) 53; et in Engl. Pflanzenw. Ost-Afr. C (1595) $25 \%$ - Afr. trop. or.

sericea, Planch. 1. c, $466^{\circ}(=$ Cissus scricen, Eckl. \& Zeyh.) - Afr. austr.

Thunbergii. Planch. 1 c. 469 (= C. Thunbergii,

Eckl. \& Zeyh.). - Afr. austr.

unifoliatu, Planch. 1. c. $470(=$ C. mifoliuta, Harv.). - Afr. austr.

usambarensis, Gilg, in Engl, Pflanzonw. Ost-Afr. C (1895) 257. - Afr, trop. or.

RHOMBONEMA, Schlechter, in Bot. Jahrb. $x$. Beibl. n. 51 (1895) 4l. ASCLEPI.ADEAE.

luridum, Schlechter, l. c. - Afr. austr.

RHUS [Tourn.]. Linn. (Anacard.), - Ind, Kew. is 713.

ambigua, Lazalléei, ex Dippel, Handb. Lanbholzk. ii. (1392) 373. - Japon.

americana, Hort. Batav. ex Dippel, 1. c. $367=$ typhina, Linn.

Bludgettii, Kearncy, in Bull. Torrey Bot. Club, xxi. (1894) 486. - Florida.

borneensis, Stapf, in Trans. Linn. Soc., Ser. II. iv, (1894) 142. - Borneo.

caroliniana, JV. W. Ashe, in Coult. Bot. Gaz. xx. (1895) 548, t. 37. - Carolna.

coccinea, Hort. ex Dippel, Handb. Laubholzk. ii. (1892) $367=$ rlabra, Linu

collina, Engl. in Abh. Preuss, Akad. Wiss, (1894) 25. - Afr. trop.

Delavayi, Franch. in Bull. Soc. Bot. Fr. xxxiii. (1886) 466. - China occ.

Engleriana, Warb. in Bot. Fahrb. xiii. (1891) 363. - N. Guin.

falcata, Prnzig, in Atti Congr. Bot. Genor'a (1893) $\$ 37(=$ Pistacia falcata, Becc.). - Eritrea.

flexicaulis, Baher, in Kew Bul. 1895 (1896) 316 - Arabia.

Grandidieri, Baill. Hist. pl. Madag. Atlas, Fasc, 30 (1892) t. 221. - Madag.

hira, Sudworth, in Bull. Torrey Bot. Club, xix, (1892) $81=$ typhina, Lim.

latifolia, Baill. Hist. pl. Madag., Atlas, Fasc, 30 (189:) t. 23L. - Madag.

Marlothii, Engl. Bot. Fahrb. x. (1SS8) 37. - Afr. austro-occ, extratrop.

myriantha, Baker, in Keqv Bull. (1895) 213. - Reg. Somal.

outeniquensis, Szyszyl. Pl. Rehmann. ii. (1SS8) 52. - Atr, austr.

Palmeri, 7. $N$. Rose, iu Contrib. U. S. Nat. Herb. i. (1891) 65. - Mexic.

Potanini, Maxim. in Act. Hort. Petrop. xi. (1889) 110. - China.

sanguineq, Hort. ex Dippel, Handb. Laubholzk. ii. $(1892): 367=$ glabra, Linn.

somalensis, Engl. in Abh. Preuss. Akad. Wiss. 1891 ii. (1892) 289. - Afr. trop. or

Telopedendron, Baill. Hist. pl. Madag., Atlas, Fasc. 30 (1892) t. 2:32. - Madag.

ve ulosa, Baker. in Fourn. Linn. Soc. xxv. (1890) 309. - Madag.

RHYNGHANTHERA, DC. (Melast.). - Ind. Kew. ii. 716.

humilis, Cogn. in DC. Monog. Phan. vii. (5891) 98. - Bras.

ternata, Cogn. l. c. 105. - Parag

RHYNCHANTHUS, Hok, f, in Bot. Mag. (1886) t 6861. SCITAMINEAE. longifolius, Hook. f.l. c. - Borneo.

RHYNCHOCALYX, Oliver, in Hook. Icon; pl. xxiv. (1894) t. 2348. LYTHRARIEAE.

lawsonioides, Oliver, l. c. - Natal.

RHYNCHOCARPA, Schrad, = Kedrastis, Medic. (Cucurb.)

Courboni, Deflers, in Bull. Soc. Bot. Fr. xxxii (1885) $349=$ Phialocarpus slomerulitorus, Deflers.
RHYNCHOCORIS, Griseb. (Scrophul.). - Ind. liev. ii. 719.

Boissieri, Post, in Bull. IInb. Boiss. i. (1893) 2S. Syria.

intermedia, Alboff, in Soc, imp. hortic. [Compt. rend. Sect. Odessal (1s,1) extr. p 13; et in Bull. Herb. Boiss, i. (1893) 262 = stricta, C. Koch.

RHYNCHODIA, Benth. (Aporyn.), - Ind, Iiew. i⿱. 717.

riynchosperna, K. Schum, in Ens1, \& Prant1, Naturr. PHanzerfam. iv. 2 (1894) $173=\mathrm{R}$. Walli-
chij, Benlh.

RRYNGHORYZA, Baill, in Bull, Soc. Linn Paris, ii. (1892) 1063: et Hist, des pl, xii. (1894) 201. GRAMIN EAE

subulata, Baill. ll. rc. 106 ct 292 (= Oryza subulatu. Nees), - Am, austr.

RHYNCHOSIA, Lour. (Legumin.). - Ind. Kew

calosperma, Warb. in Bot. Fahrb. xiii. (1891) 314 - N. Guin.

chrysadenia, Taub. in Engt. PAanzenu'. Ost-Afr. C (1895) 222. - Afr. trop. or.

chrysantha, Taub. ex Engl. in Abh. Preuss. Akad. Wiss. (1S94) 26, nomen. - Afr. trop.

cinerea, Nash, in Bull. Torrcy Bet. Club, xxii. (1805) 149. - Florida.

comosa, Baker, in Kew Bull. (1894) 99. - Afr trop.

Descampsii, Dewere, in Bull. Soc. Bot. Belg. xxxiii. 2. 1894 (1895( 100. - Afr. trop austro. occ. fagelinides, Taub. ex Engl, in Abh. Preuss, Akad. Wise. (1894) 38 ; et ex Pfanzenw. Ost-Afr. A (1S95) 7\%, nomen. - Afr. trop.

Henryi, Hemsl. ex Forb. \& Hemsl. in Journ. Linn. Soc. $x$ xiii. (188\%) $196,4 \$ ̨ 9=$ Dumasia villosa, $D C$.

hirsuta, Schinz, in Vorh. Bot, Ver, Brand wxy. (18Ss) 16S. - Afr. austro-occ, extratrop.

Holubii, Homsl. in Ann. Bot. v. (1891) 409. Zambesia.

longiflora, Schinz. in Verh. ijot. Ver. Brand. xxx (1888) 169. - Afr. austro-occ. extratrop.

Michauxii, Vail, in Bull. Torrey Bot. Chib, xxii. (1895) 458. - Florida.

nigropunctata, S. Wats, in Proc. An. Acad. xxii (1887) 408. - Mexic.

Pringlei, F. N. Rosa, in Contrib. U. S. Nat. Herb. iii. 5 (1895) 316. - Mexic.

Schenckii, Taub. in Flora, 1xxii. (18S9) 429. Bras.

Torreyi, Vail, in Bull. Torrey Bot. Club, xxii. (1895) 499. - Texas

trichocephala, Baker, in foum. Limn. Soc. xxii. (1887) 465. - Madag.

usambarensis, Taub, in Engl. Pfanzenw. Ost-Afr. C (IS95) 222. - Afr. trop. or

Woodii, Sihinz, in Bull. Herb. Boiss. ji. (1S94) 197. - Natal.

yunnanensis, Franch. Pl. Delav. (1890) 185. Yunnan.

RHYTAGHNE, Desw. (Gramin.). - Ind. Kew. ii 719.

congoënsis, Hack. in DC. Monog. Phan.vi. (1889) 27\%. - Congo gall

gabonensis, Hack. 1. c. 276. - Afr. trop.

princeps, Th. Dur. E Schinz, Consp. Fl. Afr. v. (1895) 700 (= fardinea abjyssinica. Steud.). Abyss.

triseta, Hack. in DC. Monog. Phan. vi, (1S89) 275 - Afr. centr. bor.

RHYTICOCos, Becc. in Malpighia, i. (1856) 350 25:3. PALMAE

amara, Becc. l. 6. 353 (= Cocos amara, Jacq.). occ.

RHYTIDOSOLEN. Van Tiegh, in Bull, Soc, Bot. Fr. xl. (1893) $75=$ Arthrosolen, C. A. Mey.

laxus. Var Tiegh. I. c. $75=$ A. laxus, C.A. Mey 
RHYSOTOECHIA, Radlk. (Sapind,) - Ind. Krew. 11. TS, in Engl. \& Prantl, Natür. Pfanrinfam。 iii. 5 (1895) 34 [Rhizotaechia]. - N Guim.

RIBES. Linn. (Saxifr.). - Ind, Kew. ii, 720,

acerifolium. Howich, in Elytha.7, iii, (1895) 34. Am. hor. occ.

Ahrendsii, Phil. in Anal. Univ, Chil. 1xxxv. (1894) $4 ! 15 .-$ Chili.

amarum, Mac Clatchie, in Erythea, ii. (1894) 79. Calif.

amictum, Grone, Pittonia, i. (July 1S87) 69.Calif.

Darianum, Hort. Gall. ex Dippel, Fandb. Laubholzk, iij. (1893) 294 = sangrineum, Pursh.

Daridi, Franch. in Nouv. Arch. Mus, Paris, Sér. II. viii. (1886) 240, t. 7, fig, $B=$ pachysandroides, Olicior.

Georgianum, Phit. in Anal. Univ. Chit. lsxxv. (1824) 730. - Chili.

hesperium, MacClatchie, in Eryther, ii.(1894) 79. Calif.

heterophyllum, Phit. in Anal. Univ. Chil. lxxxy. (1891) 495. - Chili.

heterotrichum, "Holle s, in Bot. Centralbl. Iiii. (1893) 218. - Hab.

Fiumile. 'Hort. ex Dippel, Handb. Laubholzk, iii, 1893) 301 = alpinum, Lim

interrifolium, Phil, in Anal, Univ, Chil. 1sxxy. (1894) 494. - Chili.

lacarense, Phit. 2. c. 498 et $730-$ Chili.

Loudoni, Hort. ex Dippel, Handb Laubholzk. iii (1893) $295=$ Gordonianum, Lenz.

longeracemosum. Franch, in Nowt. Arch. Mus. Paris, Sér. II. viii. I88. (18S6) 240 - - Tibet.

Marshallii, Greene, in West Am. Scient. Hii, (18S7) 24: et Pittonia, i. (Feb. 1SSi) 31.--Calif.

Mlaximowiczi, Batalin, in Act. Hort. Petrop. xi, 11891) $48 \pi$. - China

micranthum, Phil, in Anal. Unic. Chil. 1xxxy, (1S?4) 49\%. - Chili.

moupinense, Franch. in Nour. Arch. Mhus, Paris, Sér. II. viji. (1886) 240. - China occ

nebularum. Phit. in Anul. Unit. Chit. lxxxv. (189t) 498. - Chiti.

nubigenum Mac Clatchie, in Eryther. ii. (1S24) SO. -

pachysandroides, Olicer, in HOok. Icon. pl. xviii. (1585) t. 1767. - China.

Falenae, Phit. in Anal. Unia'. Clit. 1xxxy. (189t) $4 . \%$. - Chilo.

Palmori, Vascy at F. N. Rose, in Proc. U. S. Nat. Mus, xi. (1888) 529. - Calif.

Pentlandi, Britton, in MIem. Torrey Bot. Chub, iii. 3 (18!3) 213. - Bolivia.

sardoum, Martalli, in Mlalpighia, viii. (1S95) 384, t. $7 .-$ Sardinia.

srotinum, " Lindb. » ex Dippel, Handb. Laubholzk. iii. (1S!3) $50 \tau$ et 743 , ad calc. = aureum, Pttrsh.

Stolpi, Phit. in Anal. Uniz'. Chit. lxxxv. (1894) 496. - Chili.

tripartitum. Maxim. in Act. Hort. Petrop. xi. (1891) 488. - China.

Victoris, Greene, Pittonia, i. (Oct. 18S8) ?24; et 17an. Bot. San Franc. Bay (189t) 12.5. - Calif.

Watsonianum, Koelne, Deutsche Dendrol. (1893) 197. - Washingt.

Wilsonianum, Greene, in Erytlica, iii. (1E95) T0. Calif.

RIBESIODES, Linn. Fl, Zey1. (174 i), n. $403 \mathrm{ex}$ Kuntze, Rev. Gen.(1891) 403 = Embelia, Burm, f. (Myrsin,)

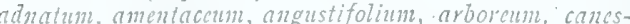
cens, clusiacfolinm, concinnum, coriaconm, dasythyrsum, foribundun, Gamblei, Gardnerianum, Lamfani, longifolinm, lucidum, madagascariense, micranthum, Myrtillus, neviosum, mummulariacfolinm. rutans, oblongifolinm. obor'alum, ov'alum, pacificum, tareifforum, pergamenaccum, philippinse, racentosum, Ribis, robustum. sarmentosum, sessilifto um, restitum. rillosum. viridiflorm, Kantze, Rev. Gen. (1891) $[0.3=$ homonyma omnia Embeliae.
RIBESIODES : -

Gustralianuir, Kuntze, Rev. Gen, (1391) 403 ( = Samara austrationat, $-\mathrm{F}$. Neuell.). - Austral. garciniaefolinm. Kuntze, 1. c. = E. Ribes. Burn. f. Gussicul, Kuntze, 1. c. = E. Jussizei, A. DC macrophyllum, Kuntze, 1. c. = E, coriacea, Wall. Nasughia, Kuntze, 1. c. = E. Nagushia, D. Don.

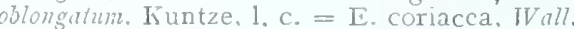
scondens, İuntze, l. c. = I javanica, $A . D C$.

singalchse, Kuntze, 1. C. = E. singalangensis, Scheff.

RICHARDELLA, Pierre, Not. bot. Sapot. (1890) 19 = Lucuma, Molina (Sapot.

Camfechicna, Pierre, 1. с. $20=$ L. Camnechiana, Iinzth

nereosa, Pierre, $1 . c=\mathrm{L}$. nervosa, $A . D C$ Rivicoa, Pierre, 1. c. $19=\mathrm{L}$. Rivicoa, Gacrln, $f$ salicifolia, Pierre, 1. c. = L. salicifolia, Kunth.

Temare, Picree, 1. c. $=$ L. Temare, Kunth

RICHARDIA, Kunth (Aroid). - Ind. Kew. ii. 721 urata. Hort, ex Mottet, in Rev. Horlic. Ixvii. (189.5) 38. - Form. hort

Elliottiana, Hort. ex Mlottet, l. c. - Afr. bor?

Lutwichei, N. E. Bro in Gard, Chron.(1Sy3) i. 568. - Afr trop, austro-or.

Lutwychici, Hort, ex Rev. Hortic. Ixxiii. (189.5) 24?, sphalm, = praec

Pentlandii, R. IVhyte, ex IV. IVats, in Gard. Chron. (1892) ii. 123 et (1894) i. 599 ; et ex Hook. f. in

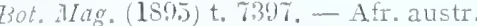

Rehmanni, N. E. Br.ex Krelace, l. c. (1803) ii. 564 er 7ro, fig. 94 (err. cal. Lehmann1); ct is Gartenf. (18:4) 12, fig. 7 (= Zantedeschar Rehnanni, Engl.) - Transvaal.

Relimanniana, "Engl, n ex Hlook. f. in Bot. Mag. $1896)$ subt. 7397 sphalm. = praec

Rhemanni, "Engl. » ex Mottet, in Rev. Hortic. lxvii. (1895) 38, sphalm. =R. Rehmanni, N.E.Br.

RICHARDIA, Houst, ex Linn. = Richardsonia Kunth (Rubiac.)

astroites, Kuntze, Rev. Gen. (1891) $296=$ R. astroites, K. Schum.

coldenioides, Rusby, in Mem. Torrey Bot. Club, iv. (1895) 208. - Bolivia

grandifora, Britton, in Ann. N. Y. Acad. sci. iv. (1893) $132=$ grandiflora, Cham. E Schlecht. redicellata, Kuntze, Rev.Gen,(1891) $296=\mathrm{Ri}$ chardsonia p dicellata, $K$. Schum.

RIGHARDSONIA, Kunth (Rubiac.)。 - Ind. ctroites, $K$ Sclintnz, in Mart. Fl, Bras, vi, VL. (1888) 95. - Bras.

pedicellata, K. Schum. l. c. 97. - I3ras.

RICHEA, Kuntze, Rev. Gen. (1591) 235 = RICHAEIA. Thou, $=$ Weihea, Spreng. $($ Rhizoph. $)$. africana, leptociada, microphylla, oiata, plumosa, zcylanica, Kuntze, Rev. Gen. (1S91) 235 = honronyma omnia TVeiheae.

Afzolia. Kuntze, 1. c. = W. Afzelii, Olicer

phateotricha, Kuntzc, 1 co = W. phaeotricha, Baill

RIGHEA, R Pr. (Epacrid.). - Ind. Kew, ji. 722. gummiflua, Baill. Hist pl. Madagy, Atlas (1891) t. 3:3. - Madiar.

lanceolata, Baill. l. c. t. 324. - Madas

madagascariensis, Baill. l. c. t. 325 . - Madag.

microphylla, Baill. b. c. t. 3:26. - Mradar.

RICHETIA. Heim, in Bull. Soc, Linn. Paris, ii, (1892) (175: ct Recherch. Diptéroc. (1892) 50 = Balanocarpus. Bedd. (Dipteroc.).

acuminata, Baill. 1. c. $979=$ B. acuminatus, Brantis

cortacex, Heim, l. c. 975. - Bernen:

latifolia, Heim, 1. c. $976=$ B. Jatifolia, Brandis. oblongifolia, Heim, 1. c. 979. - Borneo.

penangiana, Heim, 1, c. $980=$ B. penangianus, $K \operatorname{sing}$.

RICIITERAGO, Kuntze, Rev. Gen. (1891) $360=$ Seris, Less. (Compos.).

amplexifolia, Kuntze, 1. c. = S. amplexifolis, Gurdu. discotler, Kuntze, l. c. = S. discoidea, Less.
RICHTERIA, Kar, \& Trir = Chrysanthemum Tourn, (Compos.)

Leonlopodium, C. Winkl. in Act. Hort. Petrop. ix. (IS86) 421. - Turkest.

RICINELLA, Muell. Arg. = Adelia, Linn. $($ Euphorb.).

Vaseyi, Coult. \& Fisher, in Coult. Bot. Gaz. xvii (1502) 351 (= Euphorbia Vaseyi, Coult.). — Texas.

RICINOCARPUS. Burm. Thes. Zeyl. (1737) 203/5, t. 93, f. 1 (non t. 92) p. p. ex Kuntze, Rev. Gen. (1891) $615=$ Acalypha, Linn. (Euphorb.) accedens, acuninatus adenostachyus, adonotrichus, alnifolius, amblyodontus, angatensis, angolensis, angurstifolins, anisodontus. Arcianus, aristatus, arvonsis, australis, Baillonianus, benguelcnsis, Berteroamus, bipartitus, bisctosus, Boiciniamus, boliciensis, Botteriamus, brachyandrus, brachycladus, brachystachyus, bracteatus. Drasiliensis, brevibracteatus, brevicanlis, brecipes, bublatus, californicus, carllosus, cancamus, capillipes, capitatus, carolinianus, carpinifolius, carthagenenensis, Caturus, chorisandrus, ciliatus, cinctus, Claussenii, codnocilyx, consimilis, conspicuns, contermimus, crenatus, cuncatus, cuspidatus, decidurs, dccumbons, denudalus, dcpauperatus, dictyonenкus, digyncius, digynostachyus, dimorphins, distans, diaricatus, direr'sifolins, dumetomm, ellipticus, emirnensis, ercmornm, crythrostachyus, exallatus, fallax, fasciculalus, firmulus. Forsterianus, Fourniceri, fruticosus. fruticulosus, fuscescens, glabratus, slandulosus, grat cilis, grandidentatus, grandis, hatennensis, hederacens, hernandifolius, hetcrodontus, hispidus, indicus, in festus, insulamus, intcgrifolins, irazucnsis, lacvifolins, laerigatus, lagoënsis, lanceolatus, Langianus, languidus, latifolius, laxiflorus, Lepinei, leptocludus, leptopodus, leptorhachis, Lindenianus, Lindhimeri, Livingstonianus, longespicatus, longestipularis, macrodontus, macrostachyus, malabaricus, Mannianus, marginatus, Martianus, melochiacfolins, membranacous, mexicanuls, microcephalus, mollis, monostachyus, multicunlis, nemorum, meocaledonicus, neorranatensis, neomexicanus, nigritianus, obscurus, oliganthus, oligodontus, ornatus, oxyodontus, padifolius, Pancherianus, paroifolius, pariulus, patens, Pickoltii, pedanncularis, persimilis, perwianus, petiolaris, pilosus, platyphyllus, plicatus, Pohlianus, Poiretii, polynorpluts, polystachyus, portorirensis, prunnifolius, pruviens, psilostachyus, pubiflorus, purpurascens, radians, radicans, reflexus, repandus, rhombifolius, Richar dianus, Rudeliamus, vinularis, Ruizianus, salicifoliws, scabrosus, scandens, Schiedeamus, Schlumbergeri, segetalis, seminudus, senensis, senilis, setosus, sidifolius. Sonderianus, Spachianus, spiciftorus, stipulacens, strichus, subtomentosus, subaillosus, tarapotensis, temifolins, tenuiramous, temuis, tomentosus, tricholobus, trilobus, mibracteatus, wrostachyns, qugans, Vahlianus, relamens, fillticaulis, villosus, cirigalus, virginicus, Welwitschianus, zambesious, Zeyheri, Zollingeri, Kuntze, Rev. Gen. (1891) $617=$ ho monyma omnia Acalyphae.

alopecurodes, Kuntze, 1, c. $617=$ Acalypha alopecuroidea, facq.

alternifolint, Kuntze, 1. $\mathrm{c} .=\mathrm{A}$. Hochstetteriana. Muell. Arg.

anemiodes, Kuntze, 1. C. $=A$, ancmioides, $I I . B$. \& $K$.

Blancoanus, Kuntze, 1. c. = A. glandulosa, Blanco. chamaedrifolius, Kuntze, 1. c. = A. reptans, Sw

Claussenii, Kuntze, 1. c. = A. Clausseni, Baill.

communis, Kuntze, 1. c. = A. variabilis, Klotzsich. costariconsis. Kuntze, 1. c. 616. - Costa Rica.

Cunninghamii, Kuntze, 1, c. $617=\mathrm{A}$. Cunninghami, Minell. Arg.

Eckloni, Kuntze, 1. c. = A. Eckloni, Baill.

Grisebachianus, Kuntze, 1. c. $616=$ A. macrostachya. Grises.

Fardini, Kuntze, 1. c. $618=$ A. Jardini, Muell. Arg Liesmannii, Kuntze, 1. c。 = A. Liebmanniana, Muell. Airg.

macrostachyodes, Kuntze, $1, c_{0}=$ A. macrostachyoicles, facq.

Mandonii, Kuntze, 1. c. = A. Mandoni, Muell. Arg. ocymodes. Kuntze, 1. c. $=$ A. ocymoides, H.B. \& $K$. pinilippinensis, Kuntze, 1. c. $67 \%=\mathrm{A}$. tomentosa, Bianco 
RICINOCARPUS : -

phlcodes, Iuntze, Rev. Gen. (1S?1) 618 = Acalyph phleoides, Cav

reticulatus, Kuntze, 1. $\mathrm{c},=\mathrm{A}$, arboren Commz.

roettlerodes. Kuntze, 1. c, = A. rottlercicles, Baill.

samydifolins, Kuntze, 1, c. = A. samydaefolia, Poepp. E Endl.

Schlcchtendulianus, Kuntze, 1. c. = A, Schlechterdahliana, Muell. Arg.

sidifolizs, Kuntze, 1, c = A. sidaefolia, A, Rich

unticifolius, Kuntze, 1. c. = A, urticaefolia, Poir.

IVedellianils. Kuntze, 1. c. $=$ A. brasiliensis, MTucll. Arg.

Wilkesians, Kuntze, 1. c. = A. tricolor, Seem,

RICINUS, [Tourn.] Linn. (Euphorb.). - Ind. Kew. ii. 722.

cambodgensis, Benary, in Gartenfl. xxxvì. (18Si) $102=$ communis, Lim .

zanzibarensis, Hort, ex Illustr. HIortic, xli. (1894) 99 , fig. $19=$ communis, Limin. ?

RIDANIA, Kuntze, Rev. Gen, (1891):60 = RIDAN, Adans. = Actinomeris, Nutt. (Compss.). alba, Kuntze. 1. c. = A. alba. Torr. \& Gray. alternifoliı, Kuntze, 1. c. = A. squarrosa, $N^{\prime} z u t$.

RIDDELliA, Nutt. (Compos.). - Ind. Kew, ii. 722

graphalioides, O. Hoffm. in Bull. Herb. Boiss, iii. (1895) $628=$ arachnoides, $A$. Gray.

RIDLEXINDA, Kuntze, Rev, Gen. (1S91) 6.5 = Isoptera, Burck (Sapot.)

.borneensis, Kuntze, 1. c. = I. borneensis, Burck.

RIEDELIA, Meissn. = Satyria, Ǩ̉lotzsch (Vaccin.).

clonantha, Kuntze, Rev. Gen. (1891) $38 t=$ S, clonantha, Klofzsch.

Fendleriana, Kuntze, 1. c. nomen. - Venezuela.

panurensis, Kuntze, $1 . c_{\text {: }}=\mathrm{S}$. panurensis, Benth. of Hook. $f$.

Warszewiczii, Kuntze, 1. c. = S. Warscewiczii, Klotzsch

RIEDLEIA, Vent. = Melochia, Dill. (Stercul.). argentea, Poepp. ex K. Schum. in Mart. Fl. Bras. xii. III. (1886) $37=M$, venosa, Sw.

RINDERA, Pall. (Boragin.) - Ind, Kew, ii, 724. Bungei, Guerke, in Engl. Eo Prantl. Nalurr. Pfanzenfam. iv. 3a (1S94) $306(=$ Mattia Bungei, Boiss.). - Persia.

cacspitosi, Guerke, 1. c. = caespitosa, Bunge.

lanata, Guerke, 1. c. = lanata, Bus:ge.

Schlumbergeri, Guerke, l.c. $(=$ Matlia SchlumberGeri, Boiss.). - Syria.

RINOREA, Aub1. = Alsodeia. Thou. (Violar.). andina, angustifolia, arborea. ardisiaffora, Aucuparia. bahiensis, bengalensis, braclypetala, castanatefoliar. caudata, cauliftora, cymulosa, dentata, ellibtica, falcata, faciescens, glabra, Gosswpinm, Griffithii, guicanensis, haplobotrys, Homeri, Horsfetldii, ilicifolia, javanica, lanceolata, latifolia, Lindeniana, macrocarpa, Maingayi, Maximiliana, mollis, obtusa, paniculata, paucifora, physiphora, racemosa, Roxonurghit, scssilis, Sprucei, subintegrifolia, ulmifolia, IVallichiand. Wolvoitschii, zeylanica, Kuntze, Rev Gen. (1891) 42 -- homonyma omnia Alsodeiae.

angaifera, Kuntze, l. c. $=$ Alsodeia echinocarpa, Korth.

angustifolia. Baill. in Bull. Soc. Linn. Faris, 1. (1886) 582; Kuntze, Rev. Gen. (1891) $42=\mathrm{A}$. angustifolia, Thou.

arborea, Baill. 1 c. 583 ; Iuntze $1 \mathrm{c}=-1$ arborea, Thou.

ardisiffora, Kuntze, 1, c. = A. ardisiflora, IVelw. aluriculata, Baill. in Bull. Soc. Linn. Paris, i. (18\&6) $58 t=$ A. auriculata, $T u l$.

brachypetala, Kuntze, Rev. Gen. (1891) $42=\mathrm{A}$. brachypetala, Turcz.

Brotemii, Kuntze, 1. c. = A. zeylanica, Thw.

calophylla Baill, Hist. pl. Madag., Atlas (1890) t. $138=$ A. calophylla, $T$ Tul.
RINOREA:

calycina, Baill, in Buil. Soc, Linn. Paris, i. (1886)

583 = Alsodeia calycina, $T u l$.

Gustancoides. Kuntze, Kev, Gen, (1S9I) 42 ; Hiern, Cat. Welw, Afr, Pl, i, $30^{\circ}=$ A. castaneoides, Welaw

canlifora, Kuntze, 1. c. = A. cauliflora, Olizer.

dentala, Kuntze, 1. c. = A. dentata, Bcauv

elliftici, Fiuntze, 1. $c_{0}=$ A, elliptica. Olice

Goudotiana. Baill, in Bull. Soc. I,inn, I'aris,

(1856) 5S2; et Hist. pI. MIadag., Atlas (1890) t. $13+=$ A. Goudotiana. Baill.

Grereana, Baill. 11. cc. 58t; et t. 140. - Madag.

ilicifolit, Kuntze, Rev. Gen. (1891) $42=$ Alsodeia ilicifulia, IVelto

Kuenstierinn. Taub. in Engl. \& Prantl, Natürl. PHanzenfam iii. $6(189.2) 3: 9=$ A. Kuenstleriana Kins.

latifolict, Kuntze, Rer, Gen, (1891) $42=$ A. latitulia. Thon

leucocicha, Baill. in Bull, Soc, Linn, "Paris, i. (IS56) 58:3; et Hist. pl. Madag., Atlas (IS90) t $l+1=\mathrm{A}$ leucocladi. Tul.

Tongifes, Baill. 11. cc. 583 ; et t. $142=$ A. longipes, I iul.

maculata, Baill. 1. c. $583=$ A. maculata, Tul.

Maring yyi, Taul, in Engl. \& Prantl, Natïrl. Pflanzentam, iii, (6 (1s,5) $329=$ A. Maingayi, Itool

monticola. Bail!, in Bull, Soc. Linn. Paris, i. (1S86) $583=$ A. monticola. Tul.

muticu. Baill. 1. c. $=A$ mutica. Tul.

From ura, Kuntze, Rer. Gen. (1891) $42=$ A. guianensis, Eichl.

pamifloy, Baill. in Bull. Soc, Linn. Paris, i. (1SS6) 55:3; et Hist. pl. Madas., Atlas (1890) t. $137=$ A. pauciflora, Thou

pubescens, Baill. 1. c. $583=$ A. pubescens, $T u$.

Rima, Kuntze, Rev. Gen. (1891) $4 \%=$ A. prunifolia. Spreng.

Kutri, Baill, l. c, ; et Hist. pl. Madag., Atlas (1890) t. 130 = A, rubra, Tul.

siliatiar, Isuntze, Rev, Gen. (1891) $42=$ A. sylvatica. Sicm.

spinosa, Baill, in Bull, Soc. Linn. Paris, i. (1886) 583 ; et Hist. pl, Madag., Atlas (1800), t. 1:36= A. spinusa, Borr.

squamosa, Baill. $11 . \mathrm{cc} .583$; et t. $135=\mathrm{A}$. squa mosa, Boin

Eerticillata, Baill. 1. с, $583=$ A. verticillata. Boic virgata, Kuntze, Rev. Gen. (1S91) $42=$ Scyphy!landra vircata, Thi

qiridifera, Baill, 1, c, = Alsodeia viridiflora, Tul

Wrayi, Taub, in Eng1. \& Prantl, Natïrl. Pflanzenfam, iii. 6 (1895) $329=$ A. Wrayi, $K i n g$.

RIOCPEUXIA, Decne (Asclep.), - Ind. Kew, is

\section{4.}

Burchellii, K. Schum. in Engl. \& Prantl, Natiun. Pfanzenfan. iv, 2 (1S95) 27\%. - Afr. austr.

Flanagani, Schlechter, in Bot. Fahrb, xviii. Beibl. n. 45 (18!4) 13. - Afr, austr.

picta, Schlechter, l. c.:4, - Afr. austr.

polyantha, Schlechter, l. c. xxxiij. (1895) 273.Afr. austr.

profusa, $N$ : E. Br. $n$ Kew Bu?. (1895) 260. - Afr. trop. austro-or.

RIVEA, Choisy (Convolv.), - Ind, Kew. ii. 724.

abutiloides, Hallier f., in Bot. Jahrb. xviii. (1894) 158, in obs. (Ipomoea abutiloides, G. Don). Ecuad.

adenioides, Hallier f., l. c. $156(=I$, adenioides, Schinz), - Afr. austro-occ. extratrop.

argyrophylla, Hallier f., 1. c. $157(=I$. argyrophiylla, Vatke). - Afr. trop.

Bernouilliana. Hallier f,, 1. c. 158, in obs. (= I. Bernouilliana, Peter). - Guatem.

bractcata, Hallier f., 1. c. 15s, in obs. (= I. bracteata, Wight). - Ind. or.

corymbosa, Hallier f., 1. c. 157 (= I, Bumami, Choisy). - Am. austr.

decora, Hallier f., l. c. $156(=I$. Hildebrandlii, Vatke). - Afr. trop.

\section{RIVEA :}

Hartmanni, Hallier f. in Bot. Fahrb. xviii. (1804) 156 (= Yponoea Hartmanni, Vatke), - Afr. trop.

kituiensis, Hallier f. l. c. $156(=$ I. kituiensis, Vatke), - Afr, trop.

Lindenii, Hallier f. l. c. 158, in obs. (=I. Lindenii, Mart. \& Galeottj). - Mexic.

nana, Hallier f. l. c. 15\% - Afr. trop. or.

oenotheroides, Hallier f. l. c. 156 (= Comrolvulus oenotheroides, Linn, f, - - Afr, austr.

Pringsheimiana, Dammer, in Engl. PAanzmew, Oste Afr. C (1S95) 334. - Afr. trop. or.

racemosa, Hallicr f. l. c. 158 , in obs. (= Exogoniun raccmosum, Choisy). - Ind. or.

shirensis, Hallier f. l.c. 157 (= Ipomoea shirensis, Oliver). - Afr. trop.

suffruticosa, Hallier f. l. c. $156(=$ I. suffruticosa, Burch.). - Afr, austr.

Urbaniana, Dammer, in Engl. Pfanzenve. Ost-Afr. C (1895) 334. - Afr, trop. or.

RIVINA, Plum, ex Linn. (Phytol.). - Ind, Kew 11.724. Funtze, Rev.Gen.(1801) $557=$ Leden bergia roseoaenea, Lem.

ROBOROWSirIA, Batalin, in Act. Hort. Petrop. Xi13. 1I803) OI. PAPAVERACEAE

mira, Batalin, l. c. - Kashgaria.

ROCHEFOPTIA, Sw. (Borag.). - Ind. Kew. ii

fuscicutata, Guerke, in Engl. \& Prant1, Natürl. Pflanzenfam, iv. 3a (1893) 89 $(=$ Dillostylis fasciculata, Karst. \& Triana). - Columb.

ROCHELIA, Roem. \& Schult. = Echinospermum, Sw. (Borag:

Bungei, 'Trautv, in Act. Hort. Petrop, ix. (18S6) $46 ?$. - Turliest.

ROCHONIA, DC, (Compos.). - Ind. Kew. i 720

senecionoides, Baker, in Fourn. Ilmn, Soc: rxv (1S90) 326. - Madas

RODGERSIA, "A. Gray (Saxifr.). - Ind. Kew. ii 297.

aesculifolia, Butalin, in Act. Hort. Petrop. xili (1893) 96. - China.

pinnata, Franch in Nouv. Arch. Mus. Paris, Sér. II. x. (less) 176 , in obs. (= Astilbe pinnata, Franch.) - China.

RODIGIA, Spreng. (Compos.). - Ind. Kew. ii.

bulgarica, Velen. Fl. Bulg. (1s?1) 362..- Bulg.

gracilis, Freyn of Sint. in Oest. Bot. Zeitsclir. xliv. (1894; 259. - As. Min.

RODRIGUEZIA, Ruiz \& Pav. (Orchid.). - Ind Kew. ii. 727.

anomala, Rolfe, in Gard. Chron. (IS91) i. T2S, fig 145 . - Bras.

Bungerothii, Reichb.f. in Lindenia, iii. (IS87) 65t. 127 ; et l. c. (IS8S) i. 264, et (I888) ii. 328. Venezuela.

Fuerstenbergii, Kracn\%l. l. c. (1890) ii. 746Hab.

inconspicua, Kraenzl, in Bull. Herb̆. Boiss. ii (1595) 650 (= Trichocentrum candidum, Lindl.) - Am. centr.

Lindeni. Cogn. in Fonrn. des Orchid. iii. (1892) In fig. 1. - Bras.

RODRIGUEZIELLA, Kuntze,-Rev, Gen. (19:1) 649 = Thsodorea, Barb. Rodr. (Orchid.)

RODWAYA, F. Muell, in Vict. Natural, vii. (Dec 1890) 116 = Thismia. Griff (Burmann.

thismiacer, F. Mutell. 1. c. $=$ T. Rodwàyi, F. Muell.

ROEMERIs, Medic, (Papav.). - Ind: Kew, ii 727 dodecandra. Stapf, jn Denkschr. Akad. WVien, li. (1886) 295 = orientàlis, 'Boiss. 
ROEPERIA, Spreng. = Ricinocarpos, Desf. (Euphorb.).

Gomescens, glauca, ledifolia, major, marginaia, merit cata, pszoclada rosmarinifolia, speciosa, frichophora,

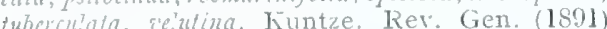
ils = homonyma omnia Ricinocarpeos.

Bowmanii, Kuntze, 1. c. = Ricinocarpos Bow. mani, F. Mlucll.

ROEPEROCHARIS, Reichb, $f_{1}=$ Habenaria. IVilld. (Orchid.)

gleicomis Kraenzl, in Reichb, $f$, Xen, Orchid. iii. 6 (1892) 105, t. $65 \mathrm{~S}$, iv. fig. ]3.15. - Abyss. ccidentalis, Kraenzl, in Bot, Jahrb. xvii. (1893) $6 \%$. - Kamerun

Urǒaniana Kraenzl, in Reichb. f. Xen. Orchid. iii. 6 (1892) 104, t. 258, iii. flg. 9-12. - Abyss.

ROETTLERA, Vahl = Chirita, Don, et Didymocarpus. TVall. (Gesnerac.)

bifolia, brevipes, caliginosa, calia, caerulea, dimidiata, ebuwe fusca glabra. Horsfueldit, humilis, insionis, fuliae Kurzii, lachnensis, macrosiphon, monognis, fulla, Kui, obtusa, primulacea, pumila, sinensis, phylla, Moonii, obtusa, primulacea, pumila, sinensis, speciosa, spectabilis, wricifolia, IV alheri, Zollingeri,
Kuntze, Rev. Gen. (1891) $476-77=$ lomonyma omnia Chiritae.

cuminala albicalyy alternifolia, anoena. Andersonii, angustifolia arematica aurantiaca, bancana, barbiuecarii, bullata, cincrea, conicapsularis, corchorifolia, cordata, corniculata. crinita, detergibilis, demissa, elegans, floccosa, follicularis, gracilipes, hamosa. Hookeri, Humboldtiana, lancoolala, leptocalyx longipes, lyrata, macroplyilla, mada gascarica, mollis, nerrosa, oblonga, otalifolia, paucineraia, pedice?lata, petiularis, platycalyx. platypus, podocarpa, producta, pulchra, punctata, punduana, fygmoea racemosa, repens, replans, reticulosa, rufescens, ruftes seabrimeraia Scheffert semitorta serrata, teris ternata villosa zcylanica, Kuntze, Rev. Gen. (1891) 476-7\% = homonyma omnia Didymocarpi.

alata, Kuntze, 1. c. $476=$ Didymocarpus incana, Benth.

machoreta, Kuntze, 1. c. = Chirita anachoretica, Hance.

barjata. Kuntze, 1. C. $475=\mathrm{C}$. Horsfieldii, $R \cdot \mathrm{Br}$. breapes, Kuntze, 1. c. $476=$ C. brevipes, C. B. Clarke. capsularis, Kuntze, 1. c. = Didymocarpus Blancoi Hass?.

communis, Kuntze, 1 c. - D, zeylanica, $R, B r$. grandifolia, Kuntze, 1. e. = Chirita macrophylla, W all.

Fosephi, Kuntze, 1. c. = C. Hookeri, C. B. Clarke. Kompsöraea, Kuntze, 1 c. = Didymocarpus Koom psoboea,

Jimans, Kuntze, 1. co = Chirita Bilabium, C. B. Clarke.

Miquelii, Kuntze, 1. $\mathrm{c}_{0}=\mathrm{C}$. mollis, Mig.

Mortoni, Kuntze, 1. c. = Didymocarpus Mortoni C. B. Clarke.

oblongifolia, Kuntze, 1.c. $475=$ Chirita-acuminata, $R \cdot B r$

Parabaea, Kuntze, 1. c. = Didymocarpus Paraboea, C. B. Clarke

primulifolia. Kuntze, 1, c, = D. aromaticas, Wall. cerbeniflos, Kuntze, $1 . c .=D$. verbenaeflos, $C . B$. Clarbe.

violodes, Kuntze, 1, C. = D, violoides, C. B. Clarke.

ROEZLIA, regia, Hort ex Éd. André, in Rev. Hortic lix. (1887) 353; ct ex Kew Bull. (1888) 103 = Fourcroya Roezlii, Ed. André

ROGERIA, J. Gay (Pedalin.). - Ind. Kew. ii. jigibbosa, Engl. Bot. Fahrb. x. (1885) 256. - Afr. austro-occ, extratrop.

Gayi, Baill, in Bull. Soc. I.inn. Paris, j. (1887) 668 (=Pterodiscus Guyi, Decne). - Angola.

ROLANDRA Rottb. (Compos.). - Ind. Kew, ii. 728.

fruticosa. Kuntze, Rev. Gen. (1891) $360 i=R$. fru ticosa Rottb.) = argentea, Rotkb.
ROLlandia, Gaudich. (Campanul.). - Ind. Kew, ji. 7?8.

grandifolia, Hillebr. Fl. Haw. Isl. (1838) 245.Ins. Sandvic.

racemosa, Hillebr, l, c. 246 (= Delissea racemosa Mann). - Ins. Sandvic.

ROLLINIA, A. St. Hil. (Anon,), 一 Ind, Kew, ii. i2S.

cordifolia, Szyszyl. in Diss, math.nat. Acad. litt. Cracoo. xxrii. (1894) 140. -- Am. austr.

ROMULEA, Maratti (Irid.). - Ind. Kew. ii. 729.

alpina, Rendle, in Foum. Linn. Soc. xxx. (1895) 401. - Afr. trop. or.

ampanuloides, Harms, in Bot. Fahro. xix. Beibl. n. 47 (1894) 28. -- Afr. trop. or.

Celsii, Khatt, in Th. Dur. of Schinz, Consp. Fl. Afr. v. 1893 (1895) 163. - Afr. austr

citrina, Baker, Handb. Irid. (1892) 100. - Afr. austro-orc, extratrop.

Fischeri, Pax. in Bot. Falub. xv. (1S92) 150. Afr trop. or

sracillima. Baker, IIandb. Irid. (1892) 103. - Afr. austro-occ, extratrop.

monadelpha, I3aker, Handb. Irid. (1892) 104.Afr. austr.

Rouyma, Bati. in Bull. Soc. Bot, Fr, xxxiv. (1887) 390 ; et Fl. de l'Alyér. [Monoc.] (1895) $38=$ R. Linaresii, Parl.

Schlechteriana, Schinz, in Bull. Herb. Boiss, iii. (1895) 395 . - Afr, austr.

nmbellata, Klatt, in Th. Dur. \& Schinz, Consp. Fl. Afr. v, $1893(1895) 167$ (= Trichonema unbellatum, Klatt). - Afr, austr.

RONDELETIA. Linn. (Rubiac.). - Ind. Kew

hispidula. K. Schum, in Engl. \& Prantl, N'atürl. Pflanzenfam, iv. 4 (1891) $35 \%=$ Arachnothrix hispidula, Griseb.). - Ind. occ

rupicola, $K$. Schum in Mart. Fl. Bras, vi. Vr. (18s9) 222. - Bras.

spinosa, K. Schum. ex Loesen. in Bull. Herb. Boiss. iii. (1895) 620. - Mexic.

RORIPA, Scop $=$ Nasturtium, R. Br. (Crucif.). americana. Britton, in Mem. 'Torrey Bot. Club, y. 1S94) $169=\mathrm{N}$. lacustre, A. Gray.

Armoracia, Hitchcock. Spring Fl. Manhattan (1S:4) $18=$ Cochlearia Armoracia, Linn.

arvensis, Rouy \& Fonc. Fl. de Fr. ii. (1895) $194=$ Nasturtium palustre, $D C$

capillipes, $X$. Simonk. Enum. Fl. Transsilv. (1886) $\tau 2=\Lambda^{\top}$. capillipes $X, \Lambda^{\top} y m$.

curisiliqua, Bessey, in Mem. Torrey But. Club, v. (1894) $169=\mathrm{N}$. curvisiliqua, $\lambda^{\prime}$ ut

dictyota, Greene, Man. Bot. San Franc. Bay (1894) 20. - Calif.

erythrocaule $X$, Borb. ex Nym. Consp. Fl. Eur. Stippt. ii. I. (1889t) $22=$ Netsturtium eryttrocalle $X$, Nym.

Gmelini, Rouy \& Fouc. Fl, de Fr, ii. (1895) $195=$ N. amphibium, R. Br.

hispida, Britton, in Mem. Torrey Bot. Club, v. (1894) $169=\mathrm{N}$. hispidum, $D C$

hungaricum $\times$, Borb. ex Nym. Consp. Fl. Eur. Suppl, ii. I. (1889) $22=N$. hungaricum $\%$. Nym.

lyrata, Greene, Man. Bot. San Franc. Bay (1894) $20(=N$. lyratum, Nutt. $)=N$. curvisiliqua,
Nutt.

microcarpa, Rotry \& Fouc. Fl, de Fr. ji. (1895) $190^{\circ}$ $=\mathrm{N}$. pyrenaicum, $R \cdot B r$

Morisoni. G. Beck, Fl. Nied.-Oest. iis. (1892) $465(=N$. Morisonii, Tausch $)=\mathrm{N}$. sylvestre, R. Br.

Nasturtium, G. Beck, 1. c. 463; Rusby, in Mem Torrey Bot. Club, iii. 3 ( 1893$) 5=\mathrm{N}$. officinale, R. $\mathrm{Br}$

Acilreichio Y. G. Heck, 1, c. 465.-Austria.

neogradensis $X$. Borb. ex Nym. Consp. Fl. Eur. Suppl. ii. 1. (1889);22 = Nasturtium neogradenseX,
RORIPA : -

oblusa, Britton, in Mem. Torrey Bot. Club, v. (1894) $169=$ Nasturtium obtusum, Nuth.

palustris, Greene, Man. Bot. San Franc. Bay (1894) $20=\mathrm{N}$, palustre, $D C$.

prolifera. Simonk. Enum. Fl. Transsilv. (1886) 73 $=\mathrm{N}$. brachycarpum, C.A. Mey.

Reichenbachii, Simonk. 1. c. $72(=N$. Reichenbachii, Knaf. $=N$. sylvestre, $R \cdot B r$.

sessiliflora, Hitchcock. Spring FI. Manhattan (1894) $18=\mathrm{N}$, sessiliflorum, $\Lambda^{\top} u t t$.

sinuata, Hitchcock, 1. $c_{0}=\mathrm{N}$. sinuatum, Nutt.

sphacrocarpa, Britton, in Mem. Torrey Bot

Club. vi. (1894) $170=\mathrm{N}$. sphaerocarpum, A. Gray.

stenophylla X, Borb, ex Nym. Consp. Fl. Eur. Suppl. ii. 1. (1889) $22=N$. stenophyllum $X$ Nym.

subglobosa $\times$, Borb. 1. c. $=N^{T}$. subglobosum $\times$ Nym.

tanacelifolia, Heller, Contrib. Frankl, Coll. i. (1895) 40 [Bot. Explor. S. Texas] = N. tunacet1folium, Hook

tenerrima, Greene, in Erythea, iii, i1895) 46. Calif

thracica, Fritsch. in Verh. zonl.-bot. Ges, WVien, xliv. 1894 (1895) $31 \%=$ N. thracucum, Griseb.

Turcaninowi $X$, Simonk. Enum. Fl. Transs. $(1886) 73=\mathrm{N}$. Turczaninowii, Czern.

ROSA, Tourn. ex Linn. (Rosac.). - Ind. Kew, ii. 731

aciphylloides, Crép. ex Cottet \& Castella, Guid. Bot. Cant. Frib. (1891) $114=$ canina, Linn.

acutiformis, Oborny, in A. Kern, Sched. Fl. AustroHung. v. (18S8) 5 = canina, Linn.

adenoclada, $\mathrm{Hy}$, in Bull. Herb. Boiss. iii. App. i. (1895) $9=$ arvensis, Huds

affabilis X. Vukot. in Rad Jugos. Akad. Zagreb. lexxiii. \& (1889) 10. - Austro-Hung.

albida, Kmet, in A. Kern. Sched. Fl. Austro-Hung. v. (1885) 16; Koehne, Deutsche Dendrol. (1893) $290=$ canina, $\operatorname{Lin} n$

algoiensis, Crip. in Bull. Soc. Bot. Belg. xxxiv (1895) 62. - Turkest.

alneriensis, Rouy, ex Willk. Suppl. Prodr. Fl. Hisp. (1893) $224=$ rubiginosa, Linn.

ambigens, Ripart, ex Crép. in Bull. Soc, Bot. Belg. xax. (1891) 101, nomen $=$ Dematraeana, Lagg \& Puget.

anachoretica $\times$, Schmidely, in Bull. Soc. Bot. Genève, vii. (1894) 147; Crép. in Bull. Soc. Bot. Belg. xxxiii. (1894) 141. - Sabaud.

aprica. H. Braun, in Oborny, Fl. von Mähren (1886) 894 ; et in G. Beck \& Syzszyl. Pl. Itin. Cern. \& Alban. lect, = canina, Lim.

arbuscula $X$. "Vilmor, " ex Vukot. in Rau Jugos. Akad, Zagreb. ccxxiv. (1895) 59. Am. bor. ?

aicadiensis, Haláczy, in Denkschr. Akad. Wien, lxi. $(1894) 503=$ canina, $\operatorname{Linn}$.

areitiana $\times$. Cornaz. ex Crép. in Bull. Soc. Bot. Bely- xxviti. (1889) 193. -195. - Helv.

athoens's, Crép. 1. c. xxxi, 2 (1892) 49, in obs. = glutinosa, Sibth. \& Smith.

borcensis, Simonk. Enum Fl. Transsilv. (1886) 212 $=$ tomentosa, Smith.

Batihyranyorum, Borb. Geogr. atq. Enum. pl. Comit. Castrif. (1887-S8) $280=$ canina, Linn.

Dernardi, Moutin, in Bull, Soc. Dauph. xiii. (1886) 547 = rubiginosa, Lim.

Bernetii X. Schmidely, ex Crép. in Bull. Soc. Bot. Belg. xxxiii. (1s!4) 29, in obs. - Helv.

Beyted, Borb, Geogr atq. Enum. pl. Comit. Castrif. (1887-88) $284=$ agrestis. Savi.

bibracensis $X$. Sagorski, in Mitth. Thur. Bot. Ver N. Folge, iii. et iv. (1893) 55. - Eur. centr. Blockiana. Borb. in Oest. Bot. Zeitschr, xxxviii (1888) $72=$ canina, $\operatorname{Linn}$.

Borhekiana, J. B. Kell. \& Formanek, ex Formanek, in Verh naturf. Ver. Brunn, xxxii. (1894) I99= arrestis. Sazi

bourgeonensts, Ozan in Magnier, Scrin. Fl. select.

x. (1891) 189 = canina. I inn.?
brachypetala. Vukot. in Rad Jugos. Acad. Zagreb. lexxiu. $\&(1 S 89) 20=$ canina, Lim. 
ROSA :

Brachtii, H. Braun, \{in Doerfler, Herb. norm Sched. ad Cent. xxxvi. 18947, ex Oest. Bot. Zeitschr. xliv. (IS94) $462=$ canina, Linn.

briacensis, H. Braun, in A. Kern. Sched. Fl, Austro-Hung. v. (1888) $23=$ graveolens, Gren.

Brueggeri $X$, Killias, in Jahresb. Naturf. Ges. Graub. xxxi. Beil. (1885) 58. - Helv.

Brunnoniana, J. B. Kell. in Oest. Bot. Zeitschr xxxvii. (18Si) 208, nomen. = canina, Limn.

bulgarica, Borb. ex $H$. Wagner, in Oest. Bot. Zeitschr. xliv. (1894) 38, nomen. - Bulgo

burmiensis, Cornaz, ex Crép. in Bull. Soc. Bot Belg. xxviii. (1889) 193, 194; et xxxiv. (1895) $104=$ glauca, Vill.

byzantina. Dieck, ex Hamb. Gảrt. und Blum. Zeit. (1S88) 561, nomen ; Koehne. Deutsche Dendrol. (1593) 279 = damascena, Mill.

campicola, H. Braun, in A. Kern. Sched. Fl. Austro-Hung. v. (1888) $16=$ canina, Linm.

corstigena, H. Braun, ex G. Beck, in Annal. Naturh. Hofmus. Wien, ii. (1887) $97=$ arvensis, Huds.

corinianensis $X$. Ozan. in Magnier, Scrin. Fl. select. xi. (1892) 246. - Gáll.

corasifera. J, Kern. ex H. Braun, in G. Beck, F1. Nied.-Oest. ii. I. (1892) 801, in syn. = canina, Limn.

cetica, H. Braun, ex G. Beck, 1. c. $815=$ tomentosa. Smith.

Christii $X$. M. Schulze, in Mitth. Geogr. Ges. Jena, v. (1886) 47: Sagorski, in Deutsche Bot. Monatschr. vil. (1889) 39. - Germ.

Ciesielski, Blocki, in Oest. Bot. Zeitschr, xxxix. (1889) $189=$ canina, Linn.

ciliato-sepala, Blocki, in Bot. Centralbl. xli. (1890) $309=$ canina, $\operatorname{Linn}$

Collettii, Crép. in Bull. Soc. Bot. Belg. xxviii. 2 (1859) 49 ! et in fourn. Linn. Soc. xxviii. (1890) 55, t. 9. - Burma.

congesta, Vukot, in Rad Jugos. Akad. Zagreb. lxxxiii. 8 (1889) $15=$ R. Jundzilli, Bess.?

Coqueberti. Burnat \& Gremli, Révis. group. Oriental. (1887) $47=$ sicula, Tratt. ?

corrugata, Caldesi, in Ces. Passer. \& Gibelli, Consp. Fl. Ital.' (1886) 672, - Italia.

Crameri X, Killias, in Jahresb. Naturf. Ges. Graub. xxxi, Beil. (1888) 59. - Helv.

cuneata, Chastaingt, in Bull. Soc. Bot. Fr. xxxv. (ISS8) 132. nomen = canina, Linn.

decalvata, Crép. ex Formanek, in Oest. Bot. Zeit schr. xxxvi. (1886) $112=$ canira, Lim.

Degeniana. Borb, ex $H$. Wagner, in Oest. Bot. Zeitschr. xliv. (1894) 38 , nomen = tomentosa Sm. [fide cl. Crépin, in sched.].

derelicta, Burnat \& Gremli, Obs. Roses Ital. (1886) 31 ; et Révis, group. Oriental. (188\%) $7 \%=$ Heckeliana, Tratt. ?

Didieri, F. Gerard, in Magnier. Scrin. Fl. select. v. (1886) $100=$ flexuosa, Rau.?

dimorphocarpa, Borb. \& H. Braun, in A. Kern. Sched. Fl. Austro-Hung.v. (1888) $14=$ canina Linn.

ditrichopoda, Kmet, ex H. Braun, in A. Kern. 1. c, $22=$ canina, $\operatorname{Lin} n$.

dolata, H. Braun, in A. Kern. 1. c. $9=$ canina, Linn.

doljensis $X$, Vukot. \& Borb. in Rad Jugos. Akad. Zagreb. 1xxxiii. (1886) extr. ii. 9, et extr. jii. 4 ex A. Kern. 1. c. 4. - Croatia.

dorica, H. Braun \& Halácsy, ex Halácsy, in Verh zool.-bot. Ges. Wien, xxxviii. (1888) $754=$ canina, Linn.

Duftschmidtii, J. B. Keller \& Haselb. Beitr. Rosenfl. Oberoester. (1891) $19=$ R. Jundzillit, Bess.

echinoclada, Boullu, in Magnier, Scrin. Fl. select. xiii. (1894) 320; Pons \& Coste, Herb. Rosar. Fasc. ii. (1895) $14=$ agrestis, Savi.

Engelmanni, S. Wats, in Gard, and For. ii. (1889) 376, fig. 121 ; Dippel, Handb. Laubholzk. iii. (1895) $586=$ acicularis, Lindl.

culanceolata, H. Braun, in A. Kern. Sched. Fl Austro-Hung. v. (1888) 11 = canina, Linn.

fasciculiflora, Boullu, ex St Lager, in Cariot, Etud. des fl. éd. 8 (1892) $245=$ gallica, Linn.
ROSA

faventina, Burn. \& Gremli, Obs. Roses d'Ital. (1886) $27=$ tomentilla, Limn.

flavidifolia, Vukot. in Rad Jugos. Akad. Zagreb. 1xix. 3 (1886) 9; et lxxxiii. 8 (188?) 29, ex A. Kern. Sched, Fl. Austro-Hung. v. (1S8S) 7 = canina. Limn

Floriand, Vukot. 1. c. 1xxxiii. S (1889) $40=$ canina, Linn.

florigera. Bouteill. in Mém. Assoc. Franç. avanc. sci, Paris (1889) 525, nomen = micrantha. Smith

fossicola $X$, Vukot, in Rad Jugros. Akad. Zagreb. 1xxxiii. S (1889) 9-Eur centr.

fraxinoides, H. Braun, in A. Kern. Sched. F]. Austro-Hung.v. (1888) $9=$ canina, Lim.

Fricaldsky, H. Braun, in A. Kern. 1. c. $10=$ glauca, Vill.

fruticulosa X. Borb. \& Vukot, in Rad Jugos,

Akad. Zagreb, Ixxxiii. S (1889) 15. - Eur. centr.

generalis, Chastaingt, in Bull. Soc. Bot. Fr, xxxvii. (IS90) $80=$ canina, Limn

gigantea, Collett, ex Críp, in Bull, Soc. Bot. Bclg. xxvii. 2 (18\&8) 148. et in fourn. Linn. Soc. xxvii. 1890) 56. t. 10; Dippel. Handb. Laubholzh, iii. $1890) 564$; Koehne, Dentsche Dendrol. (1893) 280. - Ind. or.

Gisellae, "Borb. " ex Kcehne, Deutsche Dendrol. (1893) $287=$ R. Gizellae, Borb.

glaberrima Rip ex Boullu, in Cariot, Etud, des fl, éd. 8. $(1889,261=$ canina. Limn.

globulifera, Vukot, in Rad Jugos. Akad, Zagreb, Ixxxiii. $8(1889) 51=$ canina, Linn.

Godefroyae, Carr. in Rev. Hortic. Iviii. (1886) 261; Cochet, Journ. des Roses, x. (1836) $104=$ moschata, Herrm.

gratissima, Greene, F1. Francisc. (1891) $73=$ pisocarpa. A. Gray.

Graretii, Crép. ex Formanek, in Verh. Naturf. Ver. Brunn, xxx. (1892) 82 = glauca, Vill.

Guiccardii, Burnat \& Gremli, Révis. yroup. Oriental. (1887) $78=$ glutinosa, Sibth. \& Smith.

Gussenbaueri, J. B. Keller \& Pacher, in Pacher, Nachtr. Fl. Karnt. (1894) $207=$ tomentosa, Sm.

gypsicola, Blocki, in Bot. Centralbl. xxxix. (1889) $246=$ glauca, Vill.

Hederigae, Blocki, in Oestr. Bot. Zeitschr. xxxvii. (1887) $384=$ tomentosa, Smith.

Herbichiana, Blocki, 1. c, $419==$ canina, Linn

Herbichii, H. Braun, in Spraw Kom. fizij. Krakow. xxi. (18S8) II 43. - Eur. centr.

Hermanni, Burnat \& Gremli, Observ. Ros. Italie (1887) 30 = Strobliana, Burn. E Gremly.

hirta. H. Braun, in Oborny. Fl. von Mähren, ii. (1886) $908=$ canina, Linn.

hispidocarpa $\times$, H. Braun, ex G. Beck, Fl. Nied.. Oestr. ii. I (1892) 776 et 778. - Austria.

hunensis, Conrath, in Oest. Bot. Zeitschr. xxxviii. (1888) $52=$ pimpinellifolia, Linn.

Huteri, H. Braun, ex G. Beck, Pl. Itin. Cern, et Alban. lect. (1888) $117=$ mollis, Smith.

impariserrata, $X$, Beyer, in Wiss. Beil. Progr. Andreas Realgymn.(1891), ex Oest. Bot, Zeitschr, xli. (1891) 177. - Austria.

inianescens, H. Braun, in A. Kern. Sched. F1. Austro-Hung. vi.(1888) $15=$ canina, Linn.

intercedens, H. Braun, in A. Kern. 1. c. v. (I888) 6 = canina, Lims

interjecta, Burnat \& Gremli, Révis. group. Oriental. (1887) 4 = glutinosa, Sibth. Ev Smith.

fanii, Burnat \& Gremli, Obs. Roses Ital. (IS86) 41 ; et Révis. group. Oriental. (1887) $19,46=\mathrm{mi}$ crantha, Smith.

javalambrensis, Pau, Not. Bot. Fl. Espan. i. (1887) 25 = pimpinellifolia, Linn, var.

juncta, Puget, ex H. Braun, in A. Kern. Sched. Fl. Austro-Hung. v. (1S8S) 12 = canina, Linn.

Karstiana, Borb. ex Formanek, in Oest. Bot. Zeitschr. xl. (1890) $103=$ tomentosa, Smith.

Kionae, H. Braun \& Halacsy, ex H. Braun, in Verh. zool.-bot. Ges. Wien, xxxviii. (1888) 752 = glauca, Vill.

Kmetiana, Borb, in Oest. Bot. Zeitschr. xxxvii. (1887) $184=$ canina, Lim
ROSA :

Knappii, Blocki, in Bot. Centralbl. x1. (1889) 197

Kokelii, J. B. Keller \& Pacher, in Pacher, F1. von Kärnten. i. III (1SSi) 296 = rubioinosa, Linn.

Kuncii, Borb. Geogr. atq. Enum. pI. Comit. Cas trif. $(1887) 277=$ stylcsa, $D_{c s}$ ?

lagenarioides $X$, Ozan, in Magnier, Scrin. F1 select. x. (1891) 188, xi. (1892) 248. - Helv.

eopolicnsis. Blocki, in Oest. Bot. Zeitschr. xxxvii. (1887) $113,147,287$ et $269=$ canina, Linn. lexnitzensis, J. B. Keller, in OUorny, F1. von Mäh ren, ii. (1886) 929; G. Beck, Fl. Nied.-Oest. II. (1892) $810=$ micrantha, Smuth

Lichtensteini, Blocki, in Oest. Bot. Zeitschr. xxxviii. (1888) $117=$ micrantha, Smith.

liocladı, Boullu, in Bull. Soc. Dauph. Sér. II. ii (1891) $55=$ canina, Linz

littoralis. Corbière, Nouv. Fl. Normand. (1893) 22. $=$ tomentosa. Sm.

luxemburgiana, Crép. ex Chastaingt, in Bull. Soc. Bot. Fr. xxxvii. (1S90) $\pi 8$, in obs.= canina. Linn.

Maasii X, M. Schulze, in Mitth. Geogr. Ges Jena, v. $3(1886)$ 17. - Germ

macrostylis, Borb. \& nkot. in Rad Jugos. Akad. Zagreb, Ixxxiii. \& (10-9) $46=$ canina, Limm.

Mallardiana, Moutin, in Bull, Soc. Dauph. xyj. (1889) 633 = canina, Limm

massitianensis, Ozan, \& Duffort, in Magnier, Scrin. Fl. select. xi. i 1893) $249=$ stylosa Dese.

Manreri X, M. Schulze, in Mitth. Geogr. Ges. Jena. v. 3 (1885) 21. - Germ

Mayeri, H. Braun, in Oborny, Fl. von Mähren, (1886) S8, ; et in A. Kern. Sched. F1. AustroHung, v. (1886) $5=$ glauca, Vill.

mészköensis, Simonk. Enum. Fl. Transsilv. (1886) $210=$ canina, Lim

micranthiformis, H. Braun, in Spraw kom. fizij. Krakow, xxi. (1888) II. $42=$ rubiginosa, Limi. microtypos, Bort. Eo Vukot, in Rad fuges. Akad. Zagreb. 1xxxiii. 8 (1889) $9=$ Austria.

mirogojana. H. Braun \& Vukot. 1. c. = gallica Linnt

morgana, Borb. ex H. Braun, in Oest. Bot. Zeit schr. xxxix, (1889) $31 \mathrm{I}=$ canina, Lim

multiplex, Hort. ex Koehne, Deutsche Dendrol. (1893) 292. - Form. hort.

Mygindi, H. Braun, in A. Kern. Sched. Fl. AustroHung. v. (1888) $18=$ canina, Lim

myrtyllana. H. Braun, in Bericht Bot. Ver. Landshut (1889) 112 ; et in G. Beck, F1. Nied.-Oest. ji. I (1892) $798=$ canina, Linn

nerinlosa, Gandog. \& Debeaux, in Macnier, Scrin. F1. select. v. (1886) $115=$ canina, Lim. nummulifolia $X$, Vukot. in Rad Jugos. Akad. Zagreb, 1xix. (1889) extr. 13, ex A. Kern. Sched. F1. Austro.-Hung. v. (1888) 3, - Hung.

obversa, Borb. in Oest. Bot. Zeitschr. xli. (1891) 357 $=$ agrestis, Savi.

oetea $\times$, Burnat \& Gremli, Révis. group. Oriental. (1887) 48. - Graecia.

oligantha, Borb. \& Vukot. in Rad fugos. Akad. Zagreb. 1xxxiii. S (1889) 14. - Austria.

oligogyna, Borb \& Vukot. 1.c. $14=$ canina, Limn? oligoseta, Borb. \& Kmet, in Borb. Geogr. atq. Enum.

p1. Comit. Castrif. (1887-88) $283=$ canina Linn

olympica, Burnat \& Gremli, Révis. group. Oriental (1887) $80=$ glutinosa, Sibth. \& Smith.

Oreadis, Cottet, in Cottet \& Castella, Guid. bot. Cant. Frib. (1891) 119 = canina, Lim

pallidiflora, H. Braun, in Verh. zool.-bot. Ges Wien. (1888) 524; et in G. Beck, FI. Nied.-Oest. ii. I (1892) $8=$ tomentosa, Smith.

Parnassi, Sibth. ex Burn.\& Gremli, Révis. group. Oriental. (1887) $72=$ Heckeliana, Tratt

patens, Kmet, ex H. Braun, in A. Kern. Sched. Fl. Austro-Hung, v. (1888) $16=$ canina, Linn.

Penchenati, Gandog. \& Debeaux, in Magnier, Scrin. Fl. select. vii. (138S) $131=$ canina, Lim.

percuriosa $>$, Borb. \& Vukot. in Rad Jugos: Akad. Zagreb, 1xxxiii. 8 (1889) 36. - Austria.

petrophila $X$, Borb. \& H. Braun, in Oestr. Bot. Zeitschr. xxxvi. (1886) $145=$ mollis, Smith。 


\section{ROSA}

Hacidilla, Vulkot, \& Borb, in Rad Jugos. Akad. Zagreb, Ixxxiii, 8 (1S89) $44=$ camna, Linn.

Pliniana, Cornaz, ex Crép. in Bull. Soc. Bot. Belo. xxviii. I. (1889) 193: Schmidely, in Bull. Soc Bot. Genève, vii. (1894) $150=$ montana Chait

pocuticu, Woloszczak [Spraw. kom. fizyjogr, Krakow, xxv. I. 1890 ], ex Oest. Bot. Zeitschr, xli. (1891) $140=$ canina, Linn.

tolonicy H. Bramn in Spraw. Kom. fizyj. Krakow. xxi. (1S8S) II. $4 \overline{3}=$ tomentosa, $S m$.

tratincola, H. Braun, in A. Kern. Sched. Fl, Austro-Hung. (ISSS) n. 1631 ; ct in G. Beck, El. Nied.-Oest. ii. I. $(\mathbf{1 8 9 2}) 786=$ canina, Limn

Fraltii, Hemsl, in Journ. Linn. Soc. xxix (1892) 507 = mactophylla, Lindl.

Tseudocaryophyllacea, Blocki, in Oest. Bot. Zeitschr. xxxix. (Ios') $154=$ tomentosa, Smith.

Pserdoglaberpina, J. B. Keller \& Pacher, in Pacher, Nachtr. Fl. Kärnt. (IS!4) $212=$ canina, Linn.

T sendo-glaucina, II. Bramn, ex G. Beck, in Annal. Naturh. Hofmus. Wien, ii. (1887) $10 \check{3}=$ canina, Limn.

Tsoudo-graieolens, Moutin, ex Boulhu, in Cariot, Etud. des fl. éd. 8 (1889) $277=$ agrestis, Sarit.

Pserdo-rusticana, Crép. ex Rogers, in Journ. Bot. xxvii $(1889) * 4=$ stylosa, Dest

fulchra $\times$, Beyer, in WViss. Be1l. Progr. Andr. Realoymn. Berl. (1891), ex Oest. Bot. Zeitschr. xii. (1891) 1\%\% - Austria

Resmanni, J. B. Keller \& Pacher, in Pacher \& Jaborn. Fl. von Kärnten, iii. (18Si) $419=$ canina Iinn.

riodopetala, Borb. \& Vukot. in Rad Jugos. Akad. Zagreb, 1xxsiii $8(1859) 59=$ canina, Linn。

gidit, H. Braun, ex A. Kern. Sched. Fl. AustroHung. v. (18S8) 5 = canina, Linn.

ricularis, $\mathrm{H}$. Braun \& Borb. in A. Kern, 1. c. $13=$ canina, Linn.

rosusta, F. Gérard, in Magnier, Scrin. F1. select. v. (1886) $100=$ canina, Limn.

Rocheliana, H. Braun, is A. Kern. Sched. Fl Austro-Hung. Y. (1888) $15=$ canina, Linn.

rorida, Cottet, in Cottet \& Castella, Guid. Bot.

Cant Frib. (1891) 125 = canina, Limn

rubiginella. H. Braun, in A. Kern. Sched. Fl Austro-Hung. v. (188S) $24=$ graveolens, Grert.

monlosa, Vukot. in Rad Jugos. Aliad. Zagreb, lxxxiii. 8 (1889) 13 = damascena, Mill.

rupiraga, H. Braun, ex Szyszyl, in Bull. Soc. bot. Fr, x $x$ xvi. (IS89) $120=$ canina, Limn.

armatica, H. Braun, in Spraw. Kom. fizij. Krakow. xxri. (1888) II. $39=$ canina, Linn.

Sunteri, H. Braun, in A. Kern. Sched. Fl. AustroHung. v. (1888) 25 = graveolens, Gren.

Savreana $x$ Boullu, in Bull. Soc, Bot. Lyon, (1887) 3, ex St. Lager, in Cariot, Etud, des fl. ćd. 8 (1SS9) 25̆1, et in Bull. Soc. Dauph. Sér. II ii. (1891) 5ì). - Gall.

syzillacersis Chastaingt, in Bull. Soc. Bot, Fr. wrxy, (1888) 281 = canina, Linn.

schemnitzensis, Fmet. ex H. Braun, in A. Kiern. Sched. Fl. Austro-Hung. v. (1888) $17=$ canina Linn?.

Scheicheri. H. Braun, in G. Beck, Fl. Nied -Oest. ii, 1. $(1892) 773=$ hybrida, Schleich.

Schiossiri, Vukot. \& H. Braun, in Rad Jugos, Akad. Zagreb, 1.xxiii. (1886) extr, $39=$ zalana IViersb.

scopulosa X, Briq. in Bull. Soc. Bot. Genève, vii. (1894) 97. - Gallia.

scotinophilla. Boullu, ex St Lager, in Cariot, Etud. des fl. éd. $8(1889) 270=$ canina, Linn。

sigobricensis, Pau, Not. Bot. Fl. Espan. iii. (1889) 28; TVilik. Suppl. Prodr. Fl. Hisp. (1893) $224=$ R. Pouzini, Trati.

scmibisenrata, H. Braun, in A. Korn. Sched. F1. Austro-Hung. $v$. (188S) $\mathrm{S}=$ canina, Linn.

Ecmiinermis, Borb. \& Vukot, in Rud fugos. Akad. Zncre5.1xxxiii, S (1839) 11. - Austria.
ROSA:

semiscubra; Borb. \& Vukot. in Rad Jugos. Akad. Zagreb, 1xxxiii. $\$$ (1889) $39=$ zalana, $W$ iesb. semisipium, Borb. \& Vukot. 1. c. $36=$ agrestis, Satio

semisimplex. H. Braun, in A. Kern. Sched, Fl. A ustro-Hung. v. (1\$86) $\overline{0}=$ alpina, Linn.

simproniana X. Killias, in Jahresb. Naturf. Ges. Granb, xxxi. Beil. (1888) 59. - Helv,

Sendneri, H. Braun, ex G. Beck, in Annal. Naturh, Hofmus. Wien, ii. (1887) 112 = tomentosa, Sm.

estincnsis, Vukot. in Rad fugos. Akad. Zagrcb, 1xxriii. \& (1889) S. - Austria.

simplex, Hort. ex Hook. f. in Bot. Mag. (1890) sub t. 7119 , in syn. = multiflora, Thunb.

sonomcnsis, Greene, Fl. Francisc. (1891) 72 ;et Man. Bot. San Franc. Bay (1894) 118 = spithamaea, S. IVats.

Soulieana, Crép. in Eull. Soc. Bot. Belg. xxxiv.? (1895) 51, nomen. - China.

stenodonta, H. Braun, in A. Kern. Sched. Fl. Austro-Hung, v. (1836) 4 = alpina, Linn.

Strobliana, Burnat Eo Gremli, Réris. group. Oricntul. (1887) 44 . - Italia.

subalpina, H. Braun ex Sagorski, in Deutsche Bot. Monatsschr. vii. (1889) 165; Sagorski \& Schneider, Fl. Centralkarp. (I891) $15 \mathrm{~s}=$ canina Linn.

subbiscruta, Borb. Geogr. atq. Enum. pl. Comit. Castrif. (1887) 282 = canina, Linn.

subcinnamomed, Borb. ex Vukot. in Rad Jugos. Akad. Zagreb, cxxir. (1845) $62=$ canina Limm.

submo!lis $\times$. Rouy, in Deyrolle, Le Naturaliste Ser. II. x. (1888) 285. - Hybr, spont.

subtristis $\times$, Sagorski, in Deutsche Bot. Monatsschr. vii. (1889) 98. - Germ.

sudetici, H. Braun, in Spraw. Kom. fizij. Krakow. xxi. (18s8) $46=$ tomentosa, $\mathrm{Sn}$.

superba, Chastaingt, in Bull. Soc. Bot. Fr, xxxy. (18SS) $132,28: 3=$ canina. Limn

tenella, Boullu, in Bull. Soc. Dauph. xiii. (1886) 545 ; et ex St. Lager, in Cariot. Etud. dés fl. éd. 8 (1889) $243=$ gallica, Linn.

thiryensis X. Killias; in Jahresb. Naturh. Ges. Graub. xxxi. Beil. (I8S7-S8) 59), - Hely.

Thureci, Burnat \& Gremli, Suppl. Ros. Alp. Marit. (1882) 12, 78; Obs. Ros. Ital. (1886) 48; et Révis. group. Oriental. (IS87) $30=$ glutinosa, Sibth. \& Smith.

thyraica, Blocki, in Pot. Centralbl. xxxix. (18S9) 311 = canina, $\operatorname{Linn}$

tonquinensis, Crép, in Bull. Soc. Bot. Fr. xxv, 2 (1886) 192. - Tonk, China

trigintiperala, Dieck, ex Koehne, Deutsche Dendrol. (189:3) 282. - Form. hort.

Trinacriae, Burnat \& Gremli, Obs, Ros. Ital. (1887) $30,45=$ micrantha, Smith.

twroniccnsis, Chastaingt, in Bull. Soc. Bot. Fr. xxxvii. (1890) 73; et in Mém. Acad. sci, et belles lettres Angers., Nouv, sér. i. (1890-91) $89=$ stylosa, Desu.

Tynieckii, Blocki, in Oest, Bot. Zeitschr, xxxix. (188!) $311=$ canina, Limn.

umbellifcra, Oborny, Fl. von Mähren, ii, (1886) 235 $=$ tomentosa, Smith

umbelliylora, "Swartz » ex H. Braun, in A. Kern. Sched. Fl. Austro-Hung.v (18\&8) 28, sphalm, = umbellifera, $S w$.

Unteykrauteri, J. B. Keller. \& Pacher, in Pacher \& Jaborn. Nachr. Fl. Kärnt. (1895) $189=$ canina Linn.

Eariegata, Boullu, in Bull. Soc. Dauph. xiii. (1\$86) 54.5; et ex St. Lager, in Cariot, Etud. des fl. éd. 2. $8(1889), 246=$ gallica, , inn

Vuruxiana, Moutin, in Bull. Soc. Dauph. xvi. (1839) $634=$ canina, Linn.

vittat., Hort. ex Koehne, Deutsche Dendrol. (1893) 279. - Form, hort.

Vatsoniana, Crép. in Bull. Soc. Bot. Belg, xxvii. 2 (1888) 96 ; Dippel, Handb. Laubholzk. iii. (1895) 556. - Japon.

Weeberi, J. B. Kcller, \& Formanek, ex J. B. Keller, in Oest. Bot. Zeitschr, xxxvi. (1886) $195\lfloor$ Hybr. spont?! - Moravia.
ROSA:-

Wiegnanuii X, M. Schulze, ex Sagorski, in Deut sche Bot. Monatsschr, vii. (IS89) 38. - Germ. Wirtgeni, H. Braun, in A. Kern. Sched. Fl. Austro-Hung. v. (1883) $20=$ tomentella, Lim

Witmannit, H. Braun, in Spraw. Kom. fizij. Kralow. xxi. (1888) II. $4 \mathrm{l}=$ canina, Limn.?

Wormastinyana, Vukot. \& Borb. in Rad Jugos. Akad. Zagreb. 1xxxiii. 8 (1889) $12=$ gallica Linn.

zashonsis, J. B. Keller, ez Formanek, in Verh Naturf. Ver. Brunn, xxxii. (1894) = glutinosa, Sibth. Es Smith.

zoisaeana, Oborny \& H. Braun, in Oborny, Fl. ron Mähren, ii. (1886) $914=$ canina, Limn.

ROSCOEA. Sm. (Scitam.). - Ind. Kew. ii. 740.

longifolia, Baker, in Hook,f. Fl. Brit, Ind, vi, (1890) 208. - Simla.

petiolata, Royle, ex Hook. f. 1. c. 209, in syn. = Cautleya petiolata, Baker [cf. Cur. post.].

tibetica, Batalin, in Act. Hort. Petrop. xiv. (1895) 183. - Tibet.

ROSENBACHIA, Regel, in Act. Hort. Petrop. ix. (1S86) 613, t. 10: Briq. in Engl. \& Prantl, Natürl. Pflanzenfam. iv. :3a (1895) 182, in obs. VERBENACEAE

turkestanica, Regel, l. c. - Turkest.

ROSMARINUS, [Tourn.] Linn. (Labiat.). - Ind. Kew, ii. 740 .

lavandulaceus, Noé, ex Debeaux, in Mém. Assoc. Franc, avanc, sci. Oran (18SS) 312, - Afr, bor.

ROSTKOVIA, Desv. (Juncac.). - Inł. Kew. ii. 740.

ensiformis, Herb. Ham. ex Hook. f. Fl. Brit. Ind. vi. (1892) 396, in syn. = Juncus prismatocarpus, $R . B r$.

ROTALA, Linn. (Lythrar.), - Ind. Kew. ii, 74I. cordifolia, Baker, in fourn. Limn. Soc. xxii. (1887) 478. - Madag.

heteropetala, Kueline, in Bot. Fahrb. xxii. (189\%) 149. - Abyss.

Stuhlmannii, Koehne, in Engl. Pfanzenw. Ost. Afr. C (1895) 285. - Afr, trop. or.

ROTANG, Adans. = Calamus, Linn. (Palm.).

albus, asperrinuts, Blancoi, caesius, Cawa, equestris, graminosus, heteroidens, latispinus, Manan, melanotoma, micracanthizs, ornatus, petraeus, pisicarpirs. rhomboidens, Roy'eanus, rudentum, Scipionum, spectabilis, rerus, viminalss, Baill. Hist. des pl, xiii. (1895) 299-300 = homonyma omnia Calami.

adscendens, Baill. 1. с. $300=$ Daemonorops ascendens, Blume.

barbatus, Baill. 1. c. = D. barbatus, Mart.

crinitus, Baill. 1. $\mathrm{c} .=$ D. crinitus, Blume.

Limnaei, Baill. 1. c. $299=$ Calamus Rotang, Lim. longipes, Baill. 1. c, $300=$ Daemonorops longipes, Miq.

maximus, Baill, 1. c. = Plectocomia elongata, Mart. \& Blume.

niger, Baill. 1. c. $299=$ Daemonorops niger, Btume. palembanicus, Baill. 1. c. $300=$ D. palembanicus, Blume.

periacanthus, Baill. 1, $\mathrm{c}_{0}=\mathrm{D}$. periacanthus, $\mathrm{Miq}$

scandens, Baill. 1: c. $300=$ D. scandens, Blume.

ROTANTHA, Baker, in Journ. Linn. Soc: Xxv. (1890) 31\%. LYTHRARIEAE;

combretoides, Bak:y, l. c. t. 41. - Madar.

ROTHIA, Lam. = Hymenopappus, L'Hérit. (Compos.)

artemisiaefolia, corymbosa. filifolia, flavescens, 'mexicana, temuifolia. Kuntze, Rev. Gen. (1891) $361=$ homsnyma onnia Hymenopappi.

ROTTBOELliA, Linn f. (Gramin.), - Ind. Kew. i: 741 .

acuminata, Hack. in DC. Mlonog. Phan. vi. (1889) 291. - Ind. or.

Afzelii, Haik, in DC l. c. 300, - Sierra Leone. 


\section{ROTTBOELLIA}

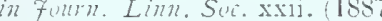

533. - Madag.

caudata, Hack. in DC. Monog. Phan. vi. (1889) 298. - Angola.

Clarkei, Hack. in Oest. Bot. Zeitschr, xli. (1891) 8. Ind. or.

divergens, Hack. in DC. Monog. Phan. vi. (1889) 292 - As. trop.

reminata, Hack, in Oest, Bot, Zeitschr. xli, (1891) 48; Ridl. in Trans. Linn. Soc. Ser. II iii. (1893) 401. - Penins. Mal.

glauca, Hack. l. c. 4\%. - Belutsh

gracillima, Baker, in fourn. Limn. Soc. xxii. (1887) 533. - Madag.

khasiana. Munro, ex Hack. in DC. Monor. Phan. vi. (1889) 302, in syn. = striata, Nees.

papillosa, Th. Dur. of Schinz, Consp. Fl. Afr. v. 1894 (1895) 699 (= Ophinmes papillosus. Hochst.) - Afr. centr. ber.

pratensis, Balansa, in Morot, fourn. de Bot, iv. (1890) 110. - Tonkin

protensa, Hack, in DC. Monog. Phan. vi. (1889) 289 ( = Lodicularia protensa, Nees). - Ind, or.

rariflora, F. M. Bailey, in Dept. Agric. Brisban Bot, Bull. viii. (1893) 86. - Austral.

setifolia, K. Schumn, in Engl, Pflanzenzw. Ost. Afr. C (1895) 96. - Afr. trop. or.

speciosa, Hack. in DC. Monog. Phan. vi. (1859) 282 $(=$ Ischaemun specicsum, Nees). - Ind. or.

thyrsoidea, Hack, in DC. 1. c. $284=\mathrm{R}$. Zea, C. B Clarke.

Zea, C. B. Clarke, in foutn. Linn. Soc, xxv. (1889) 86, t. 35 . - Ind. or

ROTTLERA, Roxb. = Mallotus, Lour.(Euphorb.) anosa, Baill. in Bull. Soc, Linn. Paris, ii. (1894) 1147. - Ind. or. China.

ROT'TLERA, Vahl = Didymocarpus, Wall (Gesner.).

cortuisifolia, Fritsch, in Engl, \& Prantl, Natürl. Pflanzenfam. iv.3b (1894) $148=$ Chirita cortusifolia, Hance.

Kinneari, Fritsch, 1. c. 147 = Didymocarpus Kinneari, F. Muell.

Mannii, Fritsch, in Engl. \& Prantl, Naturl. Pflanzenfam. iv. $3 \mathrm{~b}$ (1894) $140^{\circ}=$ Trachystigma Mannii, C. B. Clarke.

ROUBIEVA. Moq. (Chenopod.). - Ind. Kew. ii. 743.

microcarpa, Phil. in Anal. Univ. Chil. xc. (1895) 423. - Chili.

ROUGHERIA, Planch. (Lineae.). - Ind. Kew. ii. 742 .

contestiana, Pierre, Fl. For. Cochinch. Fasc, 18 (1893) t. 281. - Cochinch.

ROULINIA, Decne (Asclep.). - Ind. Kew. ii. 74:3. acemosa, Kuntze, Rev. Gen. (1891) 422, in syn. K. Schum, in Engl. \& Prantl, Natïrl, Pflanzenfam. iv. 2(1895) $255=$ R. Jacquinii, Decne.

ROUPALA, Aubl. (Proteac.). - Ind. Kew. ii. 743. arvensis, Barb. Rodr. [Herb. Mus. bot. Aniaz. n. 695| Vellosia, 1885-88, Sec, edic. (1891) 67, t. 19 fig. B. - Bras, bor

consimilis, Mez, ex Taub, in Bot. fahrb. xii. Beibl. n. 27 (1890) 11. - Bras.

impressiuscula, Mez, ex Taub. l. c. 12. - Bras

mucronulata, Mez, ex Taub.l.c. - Bras.

tristis, Mez, ex Taub. l. c. 11. - Bras.

yauaperyensis, Barb. Rodr. |Herb. Mus. bot. Amaz. n. 223] Vellosia, 1885-88, Sec. ediç. (1891) 66, t. 19 fig. a. - Bras, bor.

ROUREA, Aubl. (Connar.). - Ind, Kew. ii. 744. amazonica, Radlk, in Sitzb. Math. Phys, Akad. Muench.xvi. (IS86) 375, - Bras.

Bakerana, Britton, in Bull. Torrey Bot. Chub, xvi. (1889) 192. - Bolivia.

camptoneura, Radlk, in Sitab. Math.-Phys. Akad. Muench, xvi. (1886) 375. - Bras.

\section{ROUREA :}

fasciculata. Gilg, in Bot. Fahrob. xiv. (1891) 329.-

Congomer

rudjuana, Gilg, l.c. 323, - Afr, centr, bor.

Mannii, Gilg, l.c - Afr. trop. occ

maxima, Gilg, in Engl. Pflanzesw. Ost-Afr. C (1895) $192(=$ Byrsocarpus maximus. Baker). - Afr. trop. ionticola, Gilg, in Engl. Pflanzenw. Ost-Afr. A (1895) 92, nomen. - Afr, trop.

bliquifoliolata, Gilg, in Bot. Fahrb, xiv, (1892) 328. - Congo

ovalifoliolata. Gilg. in Abh. Preuss. Akad. Wiss, (1894) 25 : et l. c. 327. - Zanzib

ovatifolia, Gitg, in Engl. Pfanzenzw. Ost-Afr. C (1895) 192 (= Byrsocarpus oratifolius, Baker).Afr. trop.

parviflora, Gilg, in Bot. Fahrb. xiv. (1891) 322. Afr trop. or

patentinervis, Radlk, in Sitzb. Pliys,-Math. Akad. Muench. xvi. (1886) 3\%5. - Bras.

Poggeana, Gilg, in Bot. Fahrb. xiv. (1891) 326. Conco.

pseudobaccata, Gilg, l. c. 327. - Afr. trop.

pubescens, Radlk, in Sitzb. Phys.-Math. Akac. Muench. xvi. (1886) 375 (= Connarus pubescens. DC. $=$ revoluta, Planch.

Soyauxii, Gilg, in Bot. Fahrb. xiv. (1891) 324. Gabon.

spadicea, Radlk. in Sitzb. Math.-Phys. Akad, Muench. xvi. (1886) 3\%: - Guian.

splendida, Gilg, in Bot. Fahrb. xiv. (1891) 321. Congo.

subtriplinervis, Radlk, in Sitzb. Math.-Phy's. Wiss. Munch. xx. (1890) 200. - Guian. angl.

unifoliolata, Gilg, in Bot. fahrb. xiv. (1891) 325. Congo.

saramensis, Gilg, in Engl. Pflanzcnw. Ost-Afr. C (1895) 192. - Afr. trop. or.

viridis, Gilg, in Bot. Falirb. xiv. (1891) 327.Congo.

RoYDsIA, Roxb. (Capparid.). - Ind. Kew, ii.

Scortechinii, King, in fourn. As. Soc. Beng. Iviii. (1889) II. 397. - Penins. Mal.

ROYENA, Linn. (Ebenac.). - Ind. Kew. ii, 745 macrocalyx, Guerkc, in Engl. Pfanzenw. Ost-Afr. C (1895) 305 (= Diospyros macrocalyx, Klotzsch). - Afr. trop.

usambarensis, Guerke, ex Encl, in Abh. Preuss. Akad. Wiss. (1894) 34: et in Pflanzenw. OstAfr. A (1895) 73 = macrocalyx, Guerke.

Whyteana, Hiern, in Trans. Linn, Soc. Ser. I1. iv. (1894) 25. - Afr. trop.

ROYLEA. Wall. (Labiat.). - Ind. Kew. ii . 745. cinerea, Baill. Hist. des pl. xi. $(1892(26=$ elegans, Wall.

RUB1A, [Tourn.] Linn. - Ind. Kew. ii. 745.

infundibularis, Hemsl. of Lace, in fourn. Limn. Soc. xxviii. (1891) 324. - Ind., Belutch., Afghan, tetragona, $K$. Schum. in Mart, Fl. Bras, vi. VI. (1888) 120 (= Galium tetragonum, Griseb.). Reg. Argent

RUBUS [Tourn.] Linn. (Rosac.). - Ind. Kew, ii. 746.

ablutus X, G. Beck, Fl. Nied.-Oest. ii. I. (1892) 727. - Austria

acantriophyllnu, Sabransky, in Oest. Bot. Zeitschr. xlii. (1892) 89, in syn。= R. Guentheri, $W$ cihe \& Nees.

acuminatus, Lindeb, [Herb. Rubor. Scand. n. 38] ex Areschoug, in Bol, Notiser (1886) $78=$ corylifolius, Sm.

acutidens, Boulay, in Bull. Soc. Bot. Fr. xlii (1895) $405,415=$ vestitus, Weihe $\&$ Nees

acutifrons, A. Ley, in fourn. Bot. xxxi. (1893) 13. - Brit.

acutus, Lindeb. [Herb. Rubor. Scand. n. 47] ex Areschoug, in Bot. Notiser (1886) $79=$ corylifolius, $S m$.

adenodes, Dichtl, in Dentsche Bot. Monatsschr, iv. (1886) 132. - Austria

\section{RUBUS}

dulterinus, Sabransky, in Oest. Eot. Zeitschr. xlii. 1892) 23. - Reg. Carpat.

aegaeus, L. Farrat, in Barbey, Samos (1892) 41, t. 3 - Ins. Aegea.

aetnens, Tornab. Fl. Sicula (1887) $229=$ australis A. Kcrn.

aetnicus, Tineo ex Nym. Consp. Fl, Eur. Suppl. ii. I. (1889) $107=$ tomentosus, B30rkh.

affinoides $X$ Utsch, in Deutsche Bot. Monatschr. *. (I892) 2. - Germ.

airensis, Schmidely, in Cat. Soc. Helv. 'éch. pl. (1885-86) 8; et in Bull. Soc. Bot. Genève, (1888) $107=$ macrophyllus, Weihe \& Nees.

albiforus, Boul. \& Lucante, in Buil. Sor. Bot. Fr. xlii. (1895) 400, $414=$ macrophyllus, Weihe \& Nees.

allophyllus, Hems?. in Foum, Limn. Soc. xxix (1892) 304. - China occ.

althaeifolius, Simonk. ex Sabransky, in Oest. Bot. Zeitschr, xlii. (1892) 174, in syn。= R. Pseudo Wahlbergii, Sabransky.

americanus. Britton, in Mém. Torrey Bot. Club, 1895) $185=$ triflorus, Richards.

americanus, Hort. ex Gard. Chron. (1887) is. $99=$ villosus, Ait.

Ampelopsis $\times$. Sabransky \& Borb, in Oest. Bot. Zeitschr. xlii. (1892) 5̃. — Reo. Carpat.

amplus, Fritsch, ex Huldacsy, in Verh. zool.-bot. Ges. Wien, xli. (1891) 262 : G. Beck, Fl. Nied.-Oest. ii I. (1892) 727 - Austria.

anglicus, Sabransky, in Deutsche Bot. Monatsschr. x. 1892) 74 . - Brit

anglo-saxonicus, Gelert, ex K. Frider. \& Gelert, in Bot. Tidsskr. xvi. (1886) 81 \& Rés, franç. [16! E. L. Krause, in Prahl, Krit. Flo Pror. Schlesi. Holst. ii. I. (1888) 55. - Eur.

anatolicus, Focke, in Abh, Nat, Ver. Brem, ix (1886)

anonymus X. G. Beck, Fl. Nied.-Oest. ii. I. (189?) 745. - Austria.

Antoni, Borb, in Oest. Bot, Zcitschr. xliii. (1893) 356, nomen, - Hung

appenninus, Erers, in Dentsche Bot, Monatsschr. xiii. (1895) 148. - Italia

appendiculatus, Bonvet, in Bull. Soc. étud, sci. Anger (1889) 146. - Gall, centr.

atrichantherus, E. L. Krause, in Prahl, Krit. Fl. Prov, Schlesv.-Holst, ii. (1890) 61. - Eur, bor.

austrolittoralis, Borb. Enum. pl. Com. Castrif. (188788) 303 , in obs. - Croatia.

Baeumleri, Saüransky, in Oest. Bot. Zeitsch. xlii. (1892) 21. - Reg. Carpat.

Baileyanus. Britton, in Mem. Torrey Bot. Club, v, (1894) $18 \tilde{n}=$ villosus, Aiton.

Bakeri, F. A. Lees, in Bot. Record Club, Manchest. Rep. 1884-86 (1887) $120=$ nitidus, Weine.

balcanus, Borb̈. in Termész. Közlemények, xxiv. (1890) 81. - Eur. or.

bambusarum, Focke, in Hook. Icon. pl. xx. (189I) sub t. 195\%, - China.

Banningii, Utsch, in Deutsche Bot. Monatsschr. iii. (1885) $158=$ elegans, Utsch.

Barthianus, Borb. in Oest. Bot. Zeitschr. xlii, (189:) 289, nomen. - Hung.

Bartrami, “G. Braun » ex Oest. Bot. Zeitschr. (1889) 376, sphalm. = R. Bertramii, G. Brann. Batthyanyanus, Borb. Geogr. atq. Enum。 pl. Comit. Castrif. (1887-88) 326. - Hung

Baumgartneri. H. Brann, in Oest. Bot. Zeilscht. xlv. (1895) 322. - Austria

Beckii, Halacsy, in Verh, zool.-bot. Ges. Wien, xli, (1891) 248. - Austria

Benzonianus X, E. L. Krause, ex Prahl, Krit. F. Prov, Schlesv,-Holst, ii. (1890) 85. - Eur. bor.

Berthae, Borb. Geogy. atq. Enum. pl. Comit. Castrif. (1887-88) 308. - Hun

Bollae, Sabransky, in Oest. Bot, Zeitschr. xxxri. (1886) 289: - Reg. Carpath.

Bollei, Focke, in Ab\%.naturw. Ver. Brem. ix. (1889) 405 , et xii. (1892) 338, t. 3. - Ins. Canar

Borbasii, H. Bramn, in Borb. Geogr. atq. Enmm. pl. Comit. Castrif. (1S8\%-88) 215; et in Termisz. Kozlimenyek, xxiv. (1890) 105. - - Hung. 


\section{RUBUS}

brachyodon, Bw⿱一⿻上丨𣥂 (1890) 98. - Ross.

brachythyrsus, Borb. in Oest. Bot. Zeitschr. xlii. (1892) 362, et xliii.(1893) $361=$ caesius, Linn

brachytrichus, Sabransky, in Oest. Bot. Zeitschr. Xii. (18.91) 412. - Reg. Carpath.

Bramii X, Borb. in Termész. Közlemények, xxiv. (1890) 9\%. - Hung.

Bremon, H. L. Krause, in Bot, Jahrb, xvi. Beibl. n. 37 (1893) 3 [sp. collect. . - Germ.

brevipes, Waisbecker, in Oest. Bot. Zeitschr. xliii. (1893) 354. - Hung.

brovithyrsus, Boulay \& Malbr. Assoc. Rubol, n $246]$ ex Corbière, Nouv. F1. Normand. (1892) 210 - rudis, Weihe \& Necs.

Breyninus, G. Beck, Fl. Nied.-Oest. ii. I (1892) 229 $(=R$. Caflishii, Halácsy). - Austria

britannicus, W. M. Rogers, in fourn. Bot, xxxii, (1894) 48. - Brit.

calophyllus, C. B. Clarke, in foum, Linn, Soc, xxv (1889) 19, t. 7. - Jakpho (Ind. or.)

calvatifolius, Ph. J. Muell. ex Nym. Consp. Fl. Eur. Suppl. ii. I (1889) 108, nomen = R. Koehleri, Weihe \& Nees.

calvescens, Bouvet, in Bull. Soc, étud. sci. Angers (1889) 145, 150 [sp. coll.]. - Gall. centr

canariensis, Focke, in Abh. Naturw. Ver, Bren, ix. (1889) 405; et xij. (1892) 338. t. 4. - Ins. Canar. cuncellatus X. A. Kern. ex Halácsy, in Verh. zool. bot. Gres. Wien, x1i. (1891) 240 ; et in Oest. Bot. Zeitschr. xlii. (1892) $75=$ reticulatus, $A . K \mathrm{crn}$ cardiophorus, Bort, in Oest. Bot, Zeitschr, xli. (1891)

32. - Hung. mit. Castrif. (1887-88) 29 et $328=$ praec

carinthiacus, Halacsy, in Verh. zool.-bot. Ges. Wien, xli. (1891) 354; Pacher, Nachtr. Fl. Kärntn. (1894) 2.22 - Carinth

Caroli, G. Beck, Fl. Nicd.-Oest. ii. I (1892) 738.Austria.

carpaticus, Borb. ex Sabransky, in Verh, zool.-bot. Ges. Wien, xxxv.(1856) 92, et in Oest. Bot. Zeitschr. xxxvii. (1887) 83. - Austria.

Castriferrei, Borb, in Oest. Bot. Zeitschr. xli. (1891) 424, et xlii. (1892) 255. - Hung.

contiformis, K. Frieder, in Bot. Tidsskr. xvi. (1886) 118 et Rés, franç. [26] (sp. coll.). - Scand.

coticus, Halácsy, in Verh. zool.-bot. Ges. Wien, xli. (1891) 244; G. Beck, Fl. Nied.-Oest. ii. I. (1892) $729=$ villicaulis, Koehl.

chagalensis, Hieron, in Bot. Fahrb. xx. Beibl. n. 49 (1895) 2S. - Ecuad.

chaerophyllus, Sagorski \& W. Schullze, ex Sagorski in Deutsche Bot. Monatsschr. xii. (1894) I. - Germ. hiliadenus, Focke, in Hook. Icon。 pl. xx. (1S91) sub t. 195\%. - China.

chinensis, Franch. Pl. Delav.(1890) 207. - Yunnan. chroissepalus, Focke, in Hook. Icon. pl.xx. (1891) t. 1952. - China.

chloroclados, Sabransky, in Oest. Bot. Zeitschr. xli. (1891) 413. - Reg. Carpath.

Ciesielskii, Blocki, l. c. xxxix (1889) 189. - Galicia,

ciliatus, Lindeb. [Herb. Rubor. Scand. n. 50] ex Areschoug, in Bot. Notiser (1S86) 79; K. Frider. \& Gelert, in Bot. Tidsskr. xvi. (1886) 123, et Rés. franc. $[38]=$ corylifolius, $S m$.

cimbricus, Focke, in Abh. Naturw Ver. Brem, ix. (1S86) 334 ; K. Frider, \& Gelert, in Bot. Tidsskr. xvi. (18SS) S3; et Rés. Franc. [16]. - Slesvic. cinercus, Clavaud, in Act. Soc. Linn. Bord. xlii. II. 1S8S) p. Ixix. - Gali, occ.

circipanicus $X, E, L$. Krause, ex Prahl, Krit. Fl. Prov. Schlesv,-Holst, ii. (1S90) 56. Eur, bor.

cistoides, Pam, Not. Bol. Pl. Espan. iii. (1889) 29, nomen. - Hisp.

clypeatus, Sabransky, in Oest. Bot. Zeitschr. xlii. (IS92) $90=$ corylifolius, Sm

Cockburnianus, Hensl. in Foun. Linn. Soc xxix.

(1892) 305. - China. Occ.
cocullutinus. Eicrs, in Diutsche Bot. Mllonatsschr. xiii. (1895) 148. - Italia.

cognatus. N. E. Br. in English Bot. Suppl. edit. B (1892) 101 ; tet in fourn. Bot. xxx. (1892) 302. Brit

\section{RUBUS}

ommixtus, K. Frider. \& Gelert, in Bot. Tidsshr. xvii. (1889) 246. et 330. - Dania.

contiouus, Gelert in K. Frider. \& Gelert, Rub exsici. Daniae, Fasc. 1] in Meddel. Bot. Foren Kjöb. ii. 1887) 35 . et 110. - Dania.

contiguus, E. L. Krause, ex Prahl, Krit. Fl. Pror. Schlesv.-Holst. ii. (1890) 55. [an praec?]. - Slesv.Holst.

Corbierei, Boulay, ex Corbière, Now. Fl. Normand. 1893) 205. - Gall. occ

corifolius, Focke, in J. D. Smith, Enum. pl, Guatem. ii. (1891) $19=$ poliophyllus, Focke

Coronae-Hungariae, Borb, in Oest. Bot, Zeitschr. xlii. (1892) 362 ; et xliii. (1893) 361. - Croat crassipes, Collett of Hemsl. in fourn. Limn. Soc. xxviii. (1890) 68. - Reg. Afghan.

crebrisctus, Boulay \& Corbière, ex Corbière, Nouv. F1. Normand. (1893) $207=$ R. Koehleri, Weine \& Nees

cryptacanthus, Rost. in Ber. Deutsche Bot. Ges. ix. 1591) 1120', nomen. - Europ.

curvidens, f. Liy, in fourn. Bot. xxxii. (1894) 143. - Brit

cyclophyllus, Lindeb. [Herb. Rubor. Scand. n. 48] ex Areschoug, in Bot. Notiser (1886) $19=\mathrm{R}$. Walbergii, Arrhen.

danicus, Focke, in Abhandl. Nat. Ver. Brem. ix. (1886) 321 : K. Frider. \& Gelert, in Bot. Tidsskr. xvi. (1888) \%1, et Rés. Franç. [14] = macrophyllus, Weithe \& Nees.

danubialis, Borb. E Sabransky, in Oest. Bot. Zeitschr. xlii. (1892) 289 (=R. kodrutensis, Sabransky). - Hung

debilis X, G. Beck, Fl, Nied,-Oest. ii. I. (1892) 142. - Austria

Delavayi, Franch. Pl. Delac.(1890) 205. - Yunnan.

Dcmandtii X. Utsch, in Deutsche Bot. Monatsschr. x. (1892) 4. - Germ.

depressus, Boulay of Dioméde, in Bull. Soc. sci. Nat. Nimes, xix. (1891) 78. - Gall.

deronicus, Boulay, in Bull. Soc. Bot. Fr, xlii. (1895) $408,416=$ obscurus, Kall.

devonicnsis, Focke, ex W. M. Rogers, in Journ. Bot. xxx. (1892) $205=$ macrophyllus, Weihe \& Nees.

diclinis, F. Muell, in Trans, Roy. Soc. Vict. N. S 1. II. (1889) 5. - N. Guin.

dictyophyllus, Oliver, in $H$. Folmston, The Kilim. Exped. Append. (1886) 340, nomen; et in Trans. Linn. Soc Ser. II iv, 1887,332 - Afr trop.

ditrichoclados, Borb. Geogr. atq. Enum. pl. Comit Castrif. (1887) 292. - Hung

dobrensis $X$, Simonk. Enum. Fl. Transsilv, (1886) 205. - Transsily.

Rolomiticus X. Holuby, ex Sabransky, in Oest. Bot. Zeitschr. xlii. (1892) 175, - Hung.

domingensis, Focke, in Abh Naturw. Vir. Brem. xi. (1890) 4I1. - Ins. S. Doming

loryades, Sabransky, in Oest. Bot. Zeitschr. xlii 1892) 53, sphalm. = dryades, Sabransky.

donbramicensis, Sabransliy, 1. C. xxxix. (1889) 404 = villicaulis, Koehl.

Dryades, Sabransky, [in Baenitz, Herb. Europ. Lief. liii. 12. 544/3; et in Verh. Ver. Natur.-ic. Heillk. Pressb. 1887], cf. Oest. Bot. Zeitschr. xli. (1891) 423 = rotatus, Sabransky.

dumnoniensis, Bab. in Fourn. Bot. xxviii. (1890) 338. - Angl.

durescens, W. R. Linton, in foum. Bot. xxx. (1892) 70. - Brit.

Durotrigum, R. P. Murvay, in Fourn. Bot. xxx. (1892) 15. - Brit.

çinaceus Celak in Sitzb. Boehm. Ges. Wiss, 1891 1891) i. $46=$ glandulosus, Bell.

Edwardii, Borb. in Oest. Bot. Zeitschr. x1. (1890 247 - Bosnia

egeniflorus, Prog. in Ber. Bot. Vor. Landshut, xi. (1889) 136. - Germ.

coreoinsculus, K. Frider. \& Gelert, in Bot. Tidsski. xvi. (1888) 121, et Rés, franç. [26] = centiformis $K$. Frider. \& Golert.

legans $入$, Utsch, in Deutsche Bot. Monatsschr. iii. (1885) 158. - Germ

eluxatus, L. M. Nemman, in Bot. Notiser (1S8S) 58. - Scand.

\section{RUBUS :}

emophilus \%, Sabransky, in Oest. Bot. Zeitschr. xlii. (1892) 23. - Hung.

erinaceus, Schmidely, in Bull. Soc. Bot. Genève, iv (1888) $158=$ vestitus, Weite of Nees

evioclados $X$, Borb. in Termész. Közleményel xxiv. (1890) 93. - Hung.

Ernesti Bolli, E. L. Krause, ex Prahl. Krit. Fl. Pron. Schl.sv.-Holst. ii. (1890) 5l. - Slesv.-Holst.

erythrandrus, Borb. \& Halácsy. in Oest. Bot. Zeitschr. xlii. (1892) $289(=R$. purpureus, Holuby $=$ thyrscideus, Wimm.

erythrostachys, Sabransky, ex Halácsy, in Verh zool.-bot. Ges. Wien, xli. (1891) 278: G. Beck, Fl. Nied.-Oest. ii. I (1892) $74: 3=$ R. Guentheri Weihe of Nees.

Eugeni X, G. Beck, F1. Nied.-Oest, ii. I (18n? 746. - Austria.

eurythyrsos, Sabransky \& H. Braun, in Oest, Bot. Zeitschr. xxxvii. (1887) $82=$ vinclobonensis Sabransky.

extensus, Schube, ex Engl in Abh, Prens, Akad: Wiss. 1891 (1892) 212 . - Ins, Fernando Po.

extensus, Zahlbr, in Diss, Cl. Math,-Phys. Acad lith. Cracow.xxix (I894) 221. - Peruvia.

Fabryi, A. Richt. in Termész. Fïzet. xii I (1S89) 4 t. I : et in Bot. Centralbl. xxxviii. (1589) 817 ; et in Oest. Bot. Zeitschr. xxxix. (1889) 376. - Hung.

Fargesii, Franche in Morot, foum. de Bot. viii. (1894) $26 \%$ - China occ

fasciatus, Harmand, in Lucante, Rev. de Bot. vi. (1887-88) $\$ 26=$ R. Radula, Weihe.

Favrati, Schmidely, in Bull. Soc. Bot. Genèce, iv. (1888) 145. - Gall. or.

Ferdinandi Muelleri, Focke, in Abh, watww. Ver. Brem. xiii. (1895) 165. - N. Guin.

Fioniae, K. Frider. [Rub. exsicc. Daniae, n. 28] ex Areschong, in Bot Notiser (1886) 81; K. Frider. E Gelert, in Bot. Tidsskr. xvi. (1888) 115, et Rés. franç. $[26]$; E. L. Krause, in Prahl, Krit. Fl. Proi. Schlesi.-Holst. i. (1888) 52. - Eur. bor.

flandricus, Boulay \& de Lesd in Bull. Soc. Bot. Fr. xli1. (1895) $407,416=\mathrm{R}$. Koehleri, Weithe \&o Nees.

flensburuensis, $K$. Frider, in Lange. Handb. Daanske Fl. ed. 4 (1888) 78\%; E. L. Krause, in Prahl, Krit. Fl. Prov. Schlesv.-Holst, li. (1890) 76. - Dania.

florulentus, Focke, in Abh, naturw. Ver. Brem. xi (1890) 411. - Ins. Portor.

flosculosus, Focke, in Hook. Icon.pl. xx. (1891) sub t. 195\% - China.

foliolatus, Halácsy, in Oest. Bot. Zeitschr. xli, (1891) 208; G. Beck, Fl. Nied.-Oest. ii. 1. (1892) 738.Austria.

foliosus, Halácsy, in Verh. zool.-bot: Ges, Wien, xli. (1891) $26.5=$ foliolatus, Halácsy.

Formanckii $\times$. Sabransky, in Oest, Hot. Zeitschr. xxxix.(1889) 404. - Moravia.

Friderichsenii, Lange, Haandb. Danske Fl. ed. 4 (1886-88) 79)4. - Dania.

Friesii, G. Jensen, ex K. Frider. \& Gelert, in Bot. Tidsskt. xvi. (1888) 112, et Rés: franç, [23] = nemorosus, Hayne

fuscidulus, Halaicsy, in Verh. zool.-3ot. Ges, Wicn. xli. (1891) 252. - Austria

Gelertii, K. Frider. in Bot. Tidsskr. xv. (1886) 237 [Gelerti] : et xvi. (I8S8) 80 et 16; Lange, Haandb. Danske Fl. ed, 4 (1886-88) 775 [Gelertii]. - Eur. bor.

genciensis, Schmidely, in Bull. Soc. Bot. Genève iv. (1888) $76=$ thyrsoideus, Wimm.

Gillotii, Boulay, in Bull. Soc. Bot. Fr. xlii. (1895̆) $415=$ hedycarpos, Focke.

ginsiensis. Waisbecker, in Oest, Bot, Zeitschr, xliii. (189.3) 355. - Hung.

Gizella,e, Borb. Googr. atq. Enum, pl. Comit. Castrif. (1887-88) 327 ; et in Oest. Bot. Zeitschr. xli. (1891) 147. - Hung,

glaber, Cordem. Fl. Ile Réunion (1895) 407. - Ins. Borbon.

glanduloso-setosifolius Sagorski, in Doutsche Bot. Monatsschr. xii. (1894)2-Eur. centr.

glottocalyx, G. Beck, Fl. Nied.-Oest. ii. 1. (1892) 739. - Austria.

Goetzenii, Engl. Pfanzenw. Ost-Afr. A. (1895) 134. - Afr. trop. 


\section{RUBUS :}

Göncyanus, Borb. Geogr. atq. Enum. pl, Comit. Castrif. (1887-88) 245. - Hung.

gothicus, K. Frider. E Gelert, in Bot. Tidsskr. xvi, (1888) 134, et Rés. franç. [28]. - Dania.

sraniticolus, Haldicsy, ex Topitz, in Ocst. Bot, Zeitsclir. xlii, (1892;202. - Austria.

graniticus, Sabransky, l. c. 20. - Hung.

Gravet, Boulay, in Bull. Soc. Bot. Fr. xlii. (1895) $408,416=$ obscurus, Kalt.

greinensis, Halácsy, ex Topitz, in Oest. Bot. Zeitschr. xlii. (1892) 202. - Austria.

Gremblichii, Halácsy, l. o. xl. (1890) 433, Austria.

Grossbaueri, G. Beck, Fl. Nied.-Oest. ii. (1892) 731, [Hybr. spont. ?]. - Austria.

hallandicus, L. M. Neuman, in Bot: Notiser (1888) $52=$ corylifol us, Sm

hamatus, Harmand, in Lucante, Rev. de Bot. vi. (1887-88) 326 [Hybr. spont.?]. - Gall.

Hansenii, E. L. Krause, in Prahl, Krit. Fl, Proo, Schlesw.-Holst, i. (1890) 60. - Eur. bor.

Haynaldianus, Borb. Geogr. atq. Enum. pl. Comit. Castrif. (1887) 298. - Hung.

hemimacrophyllus X. E. L. Krause, ex Prahl, Krit. Fl. Prov. Schlesw.-Holst, ii. (1890) 84. - Eur. bor.

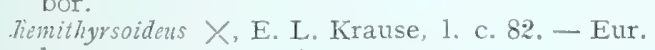
bor.

hennebergensis. Sagorski, in Deutsche Bot. Monatsschiv. v. (1887) 82. - Germ.

Henrici X. Fritsch, ex G. Beck, Fl. Nied.-Oest. ii. 1. (1892) 727. - Austria.

Henryi, Hemsl. \& Kuntze, in fourn. Linn. Soc. xxiii. (1887) 231 ; et in Hook. Icon. plo sviii。 (1887) t. 1705. - China centr.

herbaceus, Pau, Not. Bot. Fl. Espan, iii. (1889) 29, nomen. - Hisp.

hirtiformis, Borb. Geogr. atq. Enum. pl. Comit. Castrif. (1887-88) 297,32\% = R. Castriferrei, Borb.

holerythros, Focke, in fourn. Bot. xxxiii. (1895) 47. - Brit.

Holubyanus, Sabransky, ex Formanek, in Oest. Bot. Zeitschr. xxxvii. (1887) $207=$ oreogeton, Focke.

Holubyanus, Sabransky, in Oest. Bot. Zeitschr. xxxvii. (1887) 207. - Moravia.

huillensis, Welw. ex Engl. Pfanzenw. Ost-Afr. A (1895) 104, et B. 188. - Afr. trop.

Hunfalvyanorum, Bö̌́b. Geogr. atq. Enum. pl. Comit. Castrif. (1887-8s) 290. - Hung.

hupehensis, Oliver, in Hook. Icon。 pl. xix. (1889) t. 1816. - China.

ichangensis, Hemsl. E Kuntze, in foum. Limn. Soc. xxvii. (1887) 231. - China.

imitabilis, K. Frider. [Rub. exsicc. Daniae, Fasc. 1] ex Areschoug, in Bot. Notiser (1886) 81 ; et ex Meddel. Bot. Foren. Kjöb. i. (1886) 214; K. Frider. \& Gelert, in Bot. Tidsshr. xvi. (1888) 111, et Rés. franç. [23] = R. Friesii, fensent.

inermis, Halácsy, ex Topitz, in Oest. Bot. Zeitschr. xlii. (1892) 204. - Austria.

insidiosus, Progel, ex Sabransky, in Deutsche Bot. Monatsschr. viii. (1890) 9. - Germ.

invisus, Britton, in Mem. Torrey Bot. Club, iv. (1893) 115 ; et in Bull. Torrey Bot. Club, xx. (1893) 279 = villosus, Ait

rrovatus, Progel, ex Sabransky, in Deutsche Bot. Monatsschr. viii. (1890) 6. - Eur, or.

Jelskii, Zahlbr. in Diss. Cl. Math.-Phys. Acad. litt. Cracov, xxix. (1894) 220. - Peruvia.

Joannis, G. Beck, Fl. Nied.-Oest. ii. I. (1892) 736. Austria.

Juranyanus, Borb. in Termêsz. Közleminyek, xxiv. (1890) (16. - Hung.

Kampmannii, Schmidely, in Bull. Soc. Bot. Genève, iv. (1888) 76. = thyrsoideus, Wimm

Karsterianus, Borb. in Bot. Centralbl. 1i. (1892) 236, nomen. - Croatia.

Karstianus, Borb. in Termész. Közlemények, xxvi. (1892, 271, ex Oest. Bot. Zeitschr. xliv. (1894) 429 - Hung.

Kelleri, Halácsy, in Oest. Bot. Zeitschr. xl. (1890) 431 ; G. Beck, F7. Nied.-Oest. ii. I. (1892) 725.Austria.

\section{RUBUS}

Kerneri, Borb̆, in Termész. Közleménych, xxiv. (1890) 74; et in Oest. Bot. Zeitschr, xli. (1891) 147. Hung.

Khekii, Holuby, in Dentsche bot. Monatsschr. ix. (1801) 113. - Reg. Carpath.

kodruensis $X$, Simonk, in Termész. Füzet, xii. 1889 (1890) 160. - Hung

köfulvianus, Borb. Gengr, atq. Entm. pl. Comit. Castrif. (1887) 303, 329. - Hung.

kuebensis, G. Beck, Fl. Nied.-Oest. ii, I. (1892) 733. [Hybr. spont. ?. - Austria.

Kuntzeanus, Hemsl, in foum. Limn. Soc, xxiii. 1887) 232. - China.

Lagerbergii. Lindeb. |Herb Rubor. Scand. n. 40| ex Areschour, in Bot. Notiser (1886) 78; K Frider. \& Gelert, in Bot. Tidsskr. xv. (1886) $121=$ corylifolius,, $\mathrm{Sn}$.

lamproleucus X. Borb. \& Sabransky, in Oest. Bot Zeitschr. xli. (1891) 284; G. Beck, Fl. Nied. Oest. ii. II. (1893) 132S, - Austria.

lanceolatus, Waisbecker, Pl, vascul. de Köszeg, éd. ? (1891) 61; Borb. in Oest. Bot. Zeitschr. xlii。 (1892) 289. - Hung.

lasiaxon, Borb. \& Waisbecker, in Oest. Bot. Zeitschr. xliii。 (1893) 361, et xlv, (1895) 145. Hung.

lasiostylus, Focke, in Hook. Iion. pl. xx, (1891) t. 1951 ; et cx Hook. f. in Bot. Mag. (1895) t. 7426. - China.

latifrons. Prog. in Ber. Bot. Ver. Landshut, xi (1889) 135 : et in Ber. Deutsch Bot. Ges. viii. (1890) $[140]=$ irrufatus, P. F. Muell.

Lejolisii, Corbière. Nouv. Fl. Normand. (1893) $209=$ scaber, $W$ eihe \& Nees.

Leyanus, $W$. M. Rogers, in foum. Bot. xxxii. (1894) 375 , in obs., et xxxiii。 (1895) 81. Brit.

Lidforssii, Gelert, in Meddel. bot. Foren. Kjob. ii. (1891) 193; et in Bot. Notiser (1891) 175. Scand., Dania.

Lintoni, Focke, in fourn. Bot. xxv. (1887) 82. Brit.

Lippaianus, Borb. \& Holuby, in Oest. Bot. Zeitschr. xli. (1891) 424 ( $=$ R. coriacens, Holuby). Huns

littoralis, Borb. ex Formanek, 1. c. xxxvii. (1887) $206(=R$. macrogynius, Borb. $)=$ oreogeton, Focke.

longicuspidatus, Boulay \&o Lucante, in Bull. Soc. Bot. Fr, xlii. (1895) 400, 411, - Gall

longiramulus, Sabransky, ex Formanek, in. Oest. Bot. Zeitschr. xxxvii. (1887) 70. - Moravia.

longistylis, Borb. in Magy. orv. Munk. xxv. (1890) 501, ex Oest. Bot, Zeitschr。xli. (1891) $183=$ hirtus, Waldst. E K it.

loppiensis X, Evers, in Deutsche Bot. Monatsschr. xiii. (1895) 148. - Italia.

oropetalus, Franch. Pl. Delav. (1890) 203.Yunnan.

Lowii, Stapf, in Hook. Icon. pl, xxiii. (1894) t. 2288. - Borneo.

lucens, F. Linton, in fourn. Bot. xxv. (1887) 82. Brit.

lusaticus, R. Wagner, in Wiss. Beit.z. 10 faliresb. Realsch. Löbau $f$. Ostern (1886), ex. Ber. Dentsch. Bot. Ges. v. (1887) 94. - Germ. bor.

lusitanieus, R. P. Murray, in Bolet. Soc. Brot.v. (1887) 189. - Lusit.

lutescens, Franch. Pl. Delav. (1890) 206. Yunnan.

Macgregorii, F. Muell. in Trans. Roy. Soc.Vict, N. S. i. II. (1889) 4. - N. Guin.

macrocalyx. Borb. in Termész. Közlemények. xxiv (1890) 93 [an seq. ?]. - Tirol.

macrocalyx, Halácsy, in Oest. Bot. Zeitschr. x1. (1890) 433; G. Beck, Fl. Nied.-Oest. ii. 1. (1892) 73\%. - Austria.

macroclados, Sabransky, in Oest. Bot. Zeitschr. xlii. (1892) 92. - Reg. Carpath.

macrostemonides $X$, Fritsch, in Verh. zool,-bot. Ges. Wien, xxxviii. (1888) 780; G. Beck, F1. Nied, -Oest. ii. (1892) 742, - Austria.

Malgrangiamus, Harmand, in Lucante, Rev. de Bot. vi. (1887-88) $334=$ rhamnifolius, Weine of Nees.

\section{RUBUS :}

malacophyllus, Sabransky, in Oest. Bot. Zeitschr. xxxvir. (IS87) 82, in syn. $=\mathbf{R}$. Guentheri. Weithe \&o Nees.

malifolius, Focke, in Hook. Icon. pl. xx. (1890 t. 1947. - China

Mandersii, Collett \&o Hemst. in Foum Limn. Soc xxviii. (1890) 68. - Reg. Afghan

Marshalli, W. M. Rogers, in Journ. Bot. xarii. (1894) 374 , in obs. $=\mathrm{R}$. Koehleri, Weihe of Nees.

medioximus $x$. Sabransky, in Oest. Bot. Zeitschr. xli. (1891) 379:- Hnng.

melanodermis, Focke, in Fourn. Bot wxy, (1890) 133 et xxxii. (1892) 302 - Brit.

melancxylon. Bab. in Journ. Bot. xxxii. (I8S7) 21, $22=$ melanodermis, Focke

mercicus, E. Bagnall, in fourn. Bot. xxxii。 (1892) 374. - Brit.

microstemon, Celak. Result. d. bot. Durchforschun Böhm。im Jahre 1888 (1859) = glandulosus, Bell.

milliformis, K. Frider. \& Gelert, in Bot. Tidssk1. xvi. (1886) 100, 103, 108 [sp. coll.]. - Eur.

Millspaughii, Britton, in Mem. Torrey Bot. Club, xviii. (1891) 366. - Virginia

minutispinosus, Rost. in Ber. Dentsch. Bot. Ges. ix. (1891) $120(=R \text {. micracanthus, Rost. })_{.}-$ Germ.

mollicellus $\times$. G. Beck, Fl. Nied.-Oest. ii. I. (1892) 734. - Austria.

mollissimus, $W . M$. Rogers, in fourn, Bot, xxxii. 1894) 45. - Brit.

monachus, G. Jensen, ex K. Frider. \& Gelert. in Bot. Tidsslir. xvi..(1888) 88, et Rés. franc. [17 $=$ vestitus, Weihe \& Necs.

montanus, Porter, in Bull. Torrey Bot. Club, xvii. 1890) 15, et xxi. (1894) 120. - Am. bor.-or.

moravicus, Sabransky, in Oest. Bot. Zeitschr, xxxix. (1889) 405. - Moravia

Mortensenii, K. Frider. \& Gelert, in Bot. Tidsskr. xvi. (1888) 120, 123, et Rés. franç. [26] $=$ centiformis, K. Frider. \& Gelert

mucronatus, Lange, Handb. Fl. Dan, ed. 4 (1888) 785 = atrichanthirus, E. L. Krause.

muvicatus, Boulay \& Gillot, in Bull. Soc, Bot. Fr xlii. (1895) $406,416=$ R. Menkei, Weihe of Nees.

Murrii, Fritsch, ex f. Murr, in Progr. Ober-Realsch. in Inssbr. (1890-91), ex Oest. Bot. Zeitschr, xli (1891) 280 - Tirol

racophylhus X, G. Beck, Fl. Nied,-Oest. ii. I. ( $189^{\circ}$ 731. - Austria.

nadasensis $X$, Simonk. in Termész, Füzet。xii. 1889 1890) 160. - Austro-Hung.

nanus, S. Wats. in Proc. Am. Acad. xxvi, (IS91) 162. - Ins, Adscens.

Neumani, Focke, ex K. Frider. E. Gelert, in Bot. Tidsshr. xvi. (1888) 79, et Rés. franç: [16].Slesv.

Newbouldi, Bab. in Foum. Bot. xxiv. (1886) 21. Brit.

nigroviridis, Sabransky, in Verh. Ver. Naturh. Pressb. N. Folge, Heft 7 (1890) 1-15; et in Oest. Bot. Zeitschr. xli. (1891) 247; et xlii. (1892) 22. - Hung

nitens, Sagorshi, in Deutsche Bot. MIonatsschr. v. (1857) 84. - Germ.

Obornyanus, Halácsy, in Verh. zool.-bot. Ges. Wien Xl. (1890) 260 in obs.; G. Beck, Fl. Nied.-Oest. ii. II. (1892) 736. - Austria,

obovatus, G. Brann, ex Areschoug, in Bot. Centralb? xxxvii. (1S89) 268. - Germ.

obtusidens, Boullay \& Diomide ex Cabanes, in Bull. Soc. Nat. Nimes, xix. (1891) 77, nomen Gall

ochrodermis, A. Ley, in fourn. Bot. xxxi. (1893 15. - Brit.

orthosepalus, Halacsy, in Verh, zool.-bot. Ges. Wien. xli. (1891) 243. - Austria.

otophorus, Franch. Pl. Delav. (1890)205. - Yunnan. pachyphyllus, Borb. [FT. Combit. Temesy, 76] Googr. atq. Enum, Pl. Combit. Castrif. (1887-88) 305, in obs. - Austro-Hung.

pajalensis $X$. Samz。 in Bot. Notiser (1890) 184. - 


\section{RUBUS :}

Tor Loulse, in Prahl, Krit. Fl. Prov. Sckilesz2. Holst. ii. (1890) 78. - Schlesw. Holst.

papyraccus $X$. Sabransky, in Oest. Bot. Zeitschr. li. (1891) 376. - Rer. Carpath.

puramethystinus, Borb. ex Formanck, in Vert Naturf. Ver. Brimnn, xxxii. (1894) - Maced.

panciflorus, Halácsy, in Oest. Bot. Zeitschr. xli. (1891) 12 = tectiflorus, Halcásy.

peracanthus, Borb. \& Waisbecker, l. c. xliii. (1893) $356 .-H u n g$.

perdurus, Holuby \& Borbas, ex Sabransky, in Oest. Bot. Zeitschr. xlii. (1892) 21, in obs. (= R. durus Holuby). - Hung

peruvianus, Fritsch, in Diss, Cl. Math.Phys. Acad. litt Cracons xxix, (1S94) 220 -

pileatus, Focke, in Hook. Icont, pl. xx. (1891) sub t. 1952. - China

piliferus, Sagorski, in Deutsche Bot. Monatsschr.v. (1887) 81. - Germ.

pilisiensis $X$, Borb. in Termész. Küzlemények, xxiv. (1890) 94. - Hung.

pinnatisepalus, Hemsl. in foum. Limn. Sor. xxix. (1802) 305 . - China occ

pinetomu. Halácsy, in Verh. zool.-bot. Ges. Wien xli. (1891) 285, in obs. = pseudopsis, Gremli.

Playfairii, Hentst. in fourn. Limn. Soc. xxiii. (18S7) 235. - China.

platyacanthus, Utsch, in Deutsche Bot. Monatsschr. (1592) 3. - Germ.

plusiacanthus, Borb. in Oest. Bot. Zeltschr. xlii. 1892) 289 (= R. Folyacanthus. Gremli). Huner.

podocarpus, Kunt?e, Rer. Gen. (1891) 223. Java.

poliophyllus, Focke, ex F. D. Smith, in Coult. Bot. Gaz. xviii. (1893) 202; ct Enum. Pl. Guatem. iii. (1893) 23. - Guatem

polytrichus, Franch. Pl. Delav. (1890) 203. Yunnan.

polytrichus, A. Kern. ex Borb. in Ternész. Közleminyck, xxiv. (1890) 105. - Hung.

Pomel, Batt. ex Focke, in Abr. naturv. Ver. Bren. si. (1892) 338, 339. - Algeria.

populifolius, Sabransky, in Oest. Bot. Zeitschr. xlii. (1892) 56 = brachyandrus, Gremli.

Porcii, Borb. in Termész. Közlemények, xxiv. (189?) 92. - Hung.

porphyropetalus, Borb. \& Waisbecker, in Oest. Bot. Zeilschr, xlii. (1893) 319. - Hunm.

posoniensis, Sabransky, in Dentsche Bot. Monatsschr. iv. (18S6) 5; et in Verh. zool.bot. Ges. Wien, xxxvi. (1886) 9\%, - Reg. Carpath.

Powelli, W. M. Rogers, in foum. Bot. xxxii. (1894) $4 \%$. - Brit.

Prahlit X, K. Frider. \& Gelert, ex E. L. Krause, in Prahl, Krit. Fl. Prov. Schlesv.-Holst. ii. (18:0) 78. - Slesv.-Holst

Preissmanni, Halacsy, in Verh. zool-bot. Ges. Wien, xli. (1891) 273. - Stiria.

friszaknsis $X$, Simonk. in Termész. Füzet. xii. 1889 (1890) 161. - Hung.

Progelii, Sabransky, in Oest. Bot. Zeitschr. xlii. (1592) $5 \%$ - Hung.

propexus, K. Frider. in Bot. Tidsshr. xvi. (1888) 236, et Rés. franç [31]. — Slesvig.

Pseudo-acer, Makino, in Tokyo Bot. Mag. vi. (1892) 53. - Japon.

Pscudomelanoxylon $X$. Halácsy, in Verh. zool,-bot. Ges. Wien, xli. (1891) 246; G. Beck, Fl. Nied. Oest. ii. 1. (1892) 730. - Austria.

Pseudosericatus, Progel, ex Ber. Deutsch. Bot. Ges. iv. (1886) p. 18S. - Bavaria.

Psendo-venustus, Schmidely, in Bull. Soc, Bot. Genire, iv. (1888) 38, 173, - Sabaund.

Pseudo-Wahlbergii, Sabransky, in Ocst. Bot. Zeitsclir. xlii. (1S92) 174 (= R. Wahlbergii, Sabrans$\mathrm{ky})$. - Reg. Carpath.

pubifrons, Sabransky, l. c. xli. (1S91) 411. - Eur.

Purchasianus, W. M. Rogers, in Fourn. Bot. xxxii. (1894) 374, in obs. - Brit.

pyracanthus, Lange, ex K. Frider. \& Gelert, in Rot. Tidsskr. xvi. (1888) 108 et Rés. franç. [2\%] = milliformis, K. Frider, \& Gelert.

\section{RUBUS :}

quadicus, G. Beck, Fl. Nied.-Oest, ii. 1. (1892) 726 (= R. macrophylius Weihe, subsp. quadious Sabransky) = macrophyllus, Weihe.

quartocestitus X, E. L. Krause, in Prahl, Krit. Fl. Prov. Schlesv.-Holst. ii. (I890) 88. - Slesv.Holst

Radoi, Borb̆. Geogr. atq. Enum, pl. Com. Castrif. (1887-88) 215; et in Termés\%. Közlenények, xxiy. (1890) 96. - Hung.

reflexicalyx, Boulay E Lefère, [Assoc. Rubol, n. 206] ex Corbicre, Nowo. Fl. Normand. (1893) 212 Gall. occ

velains, F. Areschoug, Obs. Gen. Rubus (1886) 156; et in Bot. Notiser (1888) 1 = affinis, Weihe \& Nees.

reni,rons, Sabrancky, in Oest. Bot. Zeitschr. xlii. (1892) 55 = brachyandrus, Gremli

repens, Kuntze, Rev. Gen. (1891) $223=$ R. Dalibarda, Linn

retinervis, Borb. in Termés\%. Közlemények (1892) 271 , ex Oest. Bot. Zeitschr. xlii. (1892) 362 et xiii. (1893) 361. - Hung.

Richteri. Halácsy, l. c. xl. (1890) 434; G, Bcck, Fl. Nied.-Oest. i1. (1892) 740. - Austria.

rigidulus, Schmidely, in Bull. Soc. Bot. Genève, iii. (I8S4) $80,175 \quad(=R$. rigidus, E. Merc.). Eur.

Rogersii, F. Linton, in foum. Bot. xxxii. (1894) 214. - Brit.

rosanthus. Lindeb. [Herb. Rubor. Scand, n, 41-42] ex Areschoug, in Bot. Notiser (1886) $78=$ corylifolius, Sn.

rothomagensis, Boulay, ex Corbière, Nouv, Fl Normand. (1893) $197=$ R. Sprengelii, Weihe of Nees.

rubicundus, W. H. Purchas, in Fourn. Bot. xxxii. (1894) 130. - Brit

rubrisetus, Borb. Geogr. atq. Enum. pl. Comit. Castrif. (1887-88) 329. - Hung.

vugicus X, E. L. Krause, ex Prahl, Krit. Fl. Prov Schlesw,-Holst ii: (1890) 55. - Eur. bor.

runssorensis, Engl. in Engl. Pfanzenw. Ost-Afr. C (1895) 190. - Afr. or.

Rusbyi, Britton, in Bull. Torrey Bot. Cluó. xvis. (1890) 10. - Bolivia.

vussatus, Schwarzer, ex Oest. Bot. Zeitschr, xli. (1891) $423=$ glandulosus. Bell.

sabatimus. Evers, in Deutsche Bot. Monatsschr. xiii. (1895) $37,149=$ ulmifolius, Schott $f$.

sabinus, Evers, l. c. 148. - Italia.

Sabranskyi, Borb, ex Sabransky, in Verh, zool.-bot. Ges. Wien, xxxvi. (1886) 94 ; et Geogr. atq. Enum. pl. Comit. Castrif. (1887-88) 295. - Hung.

Sanioi, Borb. in Termés\%. Közlemények, xxiv. (1890 95. - Boruss.

scepusiensis, Sagorski in Sagorski \& Schneider, Fl. Centralkarp. ii. (1891) $140(=R$. glandulosus, Wahlenb.). - Reg. Carpat.

Scheutzii, Lindeb. [Herb. Rub. Scand. i. n, 32] ex Areschoug, in Bot. Notiser (1886) $38=$ rhamnifolius, Weihe of Nees.

Schmidelyi, Aug. Farrat, in Bull. Soc. Vaud. sci. nat. xxv. (188:) 53. - Helv.

scotophilus, Halácsy, in Verh. zool.-bot. Ges. Wient xli. (1891) 260. - Austria.

scrupeus $X$, Prog. in Ber. Bot. Ver. Landshut si. (1889) 129: Sabransky, in Deutsche Bot. Monatsschr, viii. (1890) 6. - Germ.

sebescnsis $X$, Simonk. in Termész. Füzet, xii. 1889 (1889) 161. - Hung.

segobricensis, Pau, Not. Bot. Fl. Espan. iii. (1889 29, nomen. - Hisp.

selectus, $K$. Frider, ex E. L. Krause, in Prahl, Krit. Fl. Prov. Schlesw.-Holst. i. (1888) 52, - Eur. bor.

Selmeri, Lindeb. [Herb. Rub. Scand, i. n. 33] ex Areschoug, in Bot. Notiser (1886) $76=$ villi caulis. Koehl.

semibifrons $\times$. Sabransky, in Oest. Bot. Zeitschr. xlii. (1892) 175. - Reg. Carpath.

semicaesius, E. L. Krrause, in Prahl, Krit. Fl, Proz'。 Schlesw.-Holst. ii. (1890) 88. - Eux, bor.

semicandicans, Borb. in Oest. Bot. Zeitschr. xlii. (1892) 289 (=R. Laschii, Borb.). - Hung.
RUBUS

semicimbricus X, E. L. Krause, in Prah1, Krit. F1. Prov. Schlesv -Holst. ii. (1890) 82, - Eur. bor. minnereus. Borb. ex Sabransky, in Verh. zool, bot. Ges. Wien, xxxvi. (18S6) 96, in obs, et Geogr. atq. Enum. pl. Comit. Castrif. (1857-8s) $305=$ corylifolius, Sin

semidiscolor $X$. Sabransky, in Ber Deutsch. Bot Ges. (1888) 106 ; et in Oest. Bot. Zeitschr. xlii. (1892) 173. - Reg. Carpath.

semidrejerianus, E. L. Krause, in Prahl, Krit. FI. Pron. Sihlesw.-Holst if (1890 88. - Slesy-Holst. semiegregius $X$, E. L. Krause, 1. c. 82. - Eur. bor semigrabowshianus X. E. L. Krause, 1. C. - Eur bor.

semifissus, E. L. Krause, l.c. 81.- Eur. bor.

semigratus $Y, E, L$. Krause, 1 c. 8t - Eur. bor. semipallidus X. E. L. Krause, 1. C. 85, - Eur. bor. simipliatus X, E. H. L. Krause, 1, c. 82 : et in Abh. Naturw, Ver. Brem. xii. (1891) 156. Eur. bor.

sempyramidalis X. E. L. Krause, 1. c. 85. - Eur. bor.

semiradula Y. E. H. I. Krause, 1. c. 84; et in Abh Naturw. Ver. Brem. xi. (1891) 156. - Eur. bur semisilvaticus X, E. L. Krause, 1. C. - Eur. bor.

semisprengelianus X, E. L. Krause, 1. C. 82. - Eur bor.

semisubereclus X, E. L. Krause, 1, c. 81, - Eur. bor. semitomentosus, Borb. Fl. Comit. Temesv. 76 Geogr, atq. Enum. pl. Comit. Castrif. (1887-88) 304. - Hung.

semirestifus X, E. L. Krause, ex Prahl, Krit. Fl. Prov. Schlesw.-Holst. ii. (1890) 85. - Eur, bor. semivillicaulis, E. L. Krause, l. c. 83. - Eur. bor septimus X. E. L. Krause, 1. c. 51. - Eur. bor.

serpentinus, Th. Dur. in Buil. Soc. Bot. Belg. xxyi 1887 (1889) $364=$ nemorosus, Hayne.

serridens, Boulay \& Diomede, ex Cabanis, in Bulz. Soc. sci, nat. N'imes, xix. (1S9l) $7 \tau$, nomen. Gall.

servulatus, Lindeb. Herb. Rub. Scand. n. 46] ex Areschoug, in Bot. Notiser (1886) 79; et ex K. Frider. \& Gelert, in Bot. Notiser (1886) 79: et ex K. Frider. \& Gelert. in Bot. Tidsskr. xvi. (1886) $126=$ corylifolius, $S m$

setchuenensis, Burean of Franch. in Morot, Foum. de Bot. v. (1891) 46. - China occ

sexius, E. H. L. Krause, in Ber. deutsch. bot. Ges iv. (1886) $80,82=$ suberectus, Anders.

Silvac-Candidae, Evers, in Deutsche Bot. Monatschr, xiii. (1895) 74 et $150=$ ulmifolius, Schott $f$

similatus, K. Frider. ex K. Frider. \& Gelert, in Bot. Tidsskr. xvi. (1883) 121, et Rés. franç. [27] $=$ centiformis, K. Frider. \& Gelert.

simplex, Focke, in Hook. Icon. pl. xx.(1890) t. 1948, - China.

Sommieri, Alboff, in Bull. Herb. Boiss, i. (1893) 245 = Raddeanus, Focke

sozostylus. Focke, in Hook. Icon. pl. xx (1891) sub t. 1952. - China.

spinipes, Hemsl. in foum.. Limn. Soo. xxix. (1892) 306. - China occ

spimulatus, Boulay, in Bull. Soc Bot, Fr, xlii. (1895) 406, 416, in obs, = R. Menkei, Weihe E Nees.

Spitzneri, Sabransky, in Oust. Bot. Zeitsch, xxxix. (1889) 436. - Moravia.

spurius X. Halácsy \& H. Braun, in Verh. zool.bot. Ges. Wien, xli. (1891) 232 : G, Beck, Fl. Nied.-Oest, ii. (1892) 724. - Austria.

squarrosus, Fritsch, in Oest. Bot. Zeitschr. xxxvi. (1886) 259; et in Sitzungsb. Akad Wiss. Wien. xcv. (1S87) 191-94, 215 = australis, A. Kern.

stelliger, Boulay, in Bull. Soc sci. nat. Nimes, xix. 1891) 7\%. - Gall.

stellulatus ×. G. Beck, F1. Nied,-Oest. ii. (1892) 727. - Austria.

stenocarpus, Steud. in Schimp. Pl. Abyss, ii. n. 985] ex En:rl. in Abh. Preuss. Akad. Wiss. 1891 (1892) 220, in syn. = tembensis, Fresen.

stenothyrsanthus, Borb. ex Formanek, in Oest. Bot.

Zeitschr.x1. (1890) 105 [stenothyrsantus] et 383. - Bosnia.

strictus, Boulay \& Diomede, ex Cabanès, in Bull. Soc. sci.nat. Nimes, xix. (1891) \%\%, nomen. - Gall. 
RUBUS :

Briacus, Halácsy. in Oest. Bot. Zeitschr, xli. (1890) 132: G. Beck. Fl. Nied -Oest. ii I (1892) 729. Austria.

subcanus, Boulay, [Assoc. Rubol. n, 905] ex Corbière, Now. Fl. Normand. (1893) 208. - Gall. occ

sublensis, Bonlay Eo Diomede, in Bull. Soc. sii. nat. Nimes, xix. (18 1) 78. - Gall.

subreticulatus X, Borb. \& Sabransky. in Oest. Bot. Zeitschr. xlii. (1892) 54. - Hung

subrudis, Harmand, in Lucante, Rev. de Bot. vi. (1887-88) 325 [Hybr. spont. ?'. - Lotharingia.

mbsenilis, Halácsy, in Oest. Bot. Zeitschr. xli.

(1891) 12. sphalm. = seq

subsessilis, Halacsy, l. c. xli. (1891) 12 [subsenilis]; et in Verh. zool.-bot. Ges. Wien, xli. (1891) 282 ; G. Bcck, Fl. Nied.-Oest. ii. I. (1892) 705. - Austria.

subvestitus, Borb. Googr. atq. Enum. pl. Comit. Castrif. (1887-88) 32S - Austro-Hung.

superbus, Focke, ex F. D. Smith, in Conlt. Bot. Gaz. xviii. (1893) 201; et Enum. Pl. Guatem. ii. (1893) 24. - Guatem.

Szaboi, Borb. Geogr. atq. Enum. pl. Comit. Castrif. (1887-88) 288; Subransky, in Oest. Bot. Zeitschr. xli. (1891) 376. - Austro-Hung.

antiarum, Lindeb. [Herb. Rubor. Scand. n. 191] ex Areschoug, in Bot. Notiser (1886) $3 \%=$ infestus, Weihe.

tectiflorus, Halácsy, in Oest. Bot. Zeitschr, xli. (1891) 207; G. Beck. Fl. Nied.-Oest. ii. I. (1892) 742. Austria

thibetanus, Franch, in Nour. Arch. Mus, Paris, Sér II. viii. 1885 (1886) 221. - Tibet.

thyrsiger, Bab. in foum. Bot. xxiv. (1886) 227. Brit.

Topitzii, Halácsy, ex Topitz, in Oest. Bot. Zeitschr. xlii. (1892) 203. - Austria.

trichomorus, Borb. \& Waisbecker, inz Oest, Boc. Zeitschr. xliii. (1893) 357. - Hung.

trichopus, Boulay, in Bull. Soc. Bot. Fr. xlii. (1895) 409 et 416. - Gall.

trichothamnos $\times$, Dichtl, in Deutsche Bot. Monatsschr. iv. (1886) 131 ; G. Beck, Fl. Nied.-Oest. ii. I. (1892) 730. - Austria.

trichothecus, Waisbecker, in Oest. Bot. Zeitsschr. xliii. (1893) 354. - Hung.

tridentinus $X$, Evers, in Deutsche Bot. Monatsschr. xiii. (1895) 148. - Eur. centr.

trigenius $X$. Fritsch, in Verh, zool.-bot. Ges. Wien, xlv. (1895) 25. - Austria.

trivialis, Bouvet, in Bull. Soc, étud. sci. Angers (1889) 147, 166 [sp. coll.] - Gall, centr.

uncinatus, K. Frider. ex $\overline{\mathrm{K}}$. Frider. \& Gelert, in Bot. Tidsskr. xvi. (1888) 25, in syn. = R. Wahlenberoii, Arrhen.

undulatus, G. Jensen, ex Lange, Haandb. Danske F1. ed. 4 (1886-88) 800, in syn. = corylifolius, Sm.

valentinus, Evers, in Dentsche Bot. Monatsschr, xiii. (1895) 148. - Italia.

valentinus, Pau, Not. Bot. Fl. Espan. i. (1888) 11 ; Willk. Suppl. Prodr. Fl. Hisp. (1893) 226.-- Hisp? alligents, Sabransky, in Oest. Bot. Zeitschr, xlii. (1892) 90. - Reg. Carpath.

vestitifolius, Fritsch, ex Halacsy, in Verh. zool.-bot. Ges. Wien, xli. (1891) 252. - Austria.

viburnifolius, Franch. in Bull. Musénm Paris, i. (1895) 63. - Yunnan.

vindobonensis, Sabransky, in Deutsche Bot. Monatsschr. vii. (1889) 131; G. Beck, Fl. Nitd-Oest. ii. I. (1892) 741. - Austria.

vinodoris, Sabransky, 1. c. viii. (1890) $6=\mathrm{R}$. Guentheri, Weine of Nees.

Volkensii, Engl. Bot. Fahrb. xix. Beibl. n. $4 \%$ (1894) 30. - Afr. trop. or.

Vrabélyianus, A.Kern. ex Formanek, in Oest. Bot. Zeitschr. xxxvii. (1887) 207 [Hybr. spont. ?]. Hung.

Waisbeckeri, Borb. Geogr. atq. Emum, pl. Comit. Castrif. (1887-88) 304.- - Hung.

Warmingii, G. Jensen, ex Lange, Haandb. Danske Fl. ed. 4 (1886-88) 800 ; et ex K. Frider. \& Gelert, in Bot. Tidsskr. xvi. (1888) 122, et Rés, franç. $(27)=$ corylifolius, $S m$.

\section{RUBUS :}

Warmstorfii, Focke, ex Warnst, in Verh. Bot. Ver. Brand. xxxii. (1891) 261. - Boruss.

Wiesbaurii $X$, Sabransky, in Deutsche Bot. Mo natsschr. x. (1892) 72; Borb. in Oest. Bot. Zeitschr. xliii. (1893) 361. - Hung.

Wittingii, Halácsy, in Verh.zool.bot. Ges, Wien, xli. (1891) zil ; Pacher, Nachtr. Fl. Kärtn. (1894 $225,-$ Carinth

xanthocarpus, Bureau of Franch. in Morot, Fourn. de Bot. V. (1891) 46; Regel, in Act. Hort. Petrop. xi. (1891) $47 \%$ - China

Wolnyanus, Borb. De orig. Xanthii spin. Append. 1894) 96 [Conf. Oest. Bot. Zeitschr. xliv. (1894) 398]. - Hung.

RUDBECKIA, Linn, (Compos.), - Ind, Kew. ii. Brittonii, Small, ex Small \& Vail, in Mem. Torrey Bot. Chtb, iv. (1893) 130. - Virginia.

chrysantha, Klatt, in Leopoldina, Heft xxiii. (1887) 143. - Mexic.

RUDGEA, Salisb, (Rubiac.). 一 Ind, Kew. ii.

758 .

citrifolla, K. Schum, in Encl, \& Prantl, Natür1. Pflanzenfam. iv. 4 (1891) $116=$ caribaea Benth.

coriacea, K. Schum. 1. c. = eriantha, Benth.

Lehmannii, K. Schum.l. c. - Columb.

leiocarpa, K. Schum. 1. c. = leiocarpoides, Muenl. Arg.

leusocephala, K. Schum. 1. c. = macrocephala, Benth.

tambillensis, Zahlbr. in Amal. Naturh. Hofmus. Wien, ii. (1857) 2. - Peruvia.

tomentosa, Rusby, in Men. Torrcy Bot. Club, iii. 3 (1893) 48. - Bolivia.

RUELLIA, Plum. ex Linn. (Acanth.). - Ind. Kew ii. 759 .

affinis, Lindau, in Engl. \& Prantl, Natïrl. Pfanzenfam. iv. 3b (1895) 311 (= Dipteracanthus affinis, Nees). - Bras.

amplexicaulis, Lindau, l.c. $(=$ Arrhostoxylum amplexicaule, Nees). - Bras.

angustifolia, Lindau, 1. C. $(=$ Cryphiacanthus angustifolius. Nees) $=$ Tweediana, Griseb.

asperula, Lindau, l. c. (= Stephanophysum asperu lnt, Mart. \& Nees). - Bras.

bahiensis, Morong, in Ann. N. Y. Acad. Sci. vii (1893) 192 (= Dipteracanthus bahiensis, Nees). Bras.

batangana, f. Braun \& $K$. Schnm. in Ber. deutsch. Schutzgeb. ii. (1889) 157. - Afr. trop. occ.

Blanchetiana, Lindau, in Engl. Ex Prantl. Natiin. Pfanzenfam. iv. 3b (1895) 311 (= Dipteracanthus Blanchetianus, Nees). - Bras.

brevicaulis, Lindau, l. c. $310(=$ D. brevicanlis, Nees). - Bras.

bulbifera, Lindau, l. c. 311 (= D. tuberosus, Nees). - Am. trop.

calicosa; Lindau, l. c. $(=D$. calycosus, Nees $)$. Bras.

canescens, Lindau, 1. c. $(=D$. canescens, Nees $)=$ geminiflora, $H . B$. \& $K$

chiquitensis, Baill. in Bull. Soc Linn. Paris, ii. (1890) 853. - Bolivia.

coerulea, Morong, in Ann. N. Y. Acad. sci. vii. (1893) 193. - Parag.

colorata, Baill. in Bull. Soc. Linn. Paris, ii. (1890) 853. - Am. austr. Occ.

confinis, Lindau, in Engl. of Prantl, Nalïrl. Pfanzenfam. iv. 3b (1895) 309 (= Dipteracunthus confinis, Nees). - Bras.

Delavayana, Baill. Hist. des pl. x. (1891) 408. China.

diffusa, Lindau, in Engl. \& Prantl. Natïrl. Pfanzenfam. iv. 3b (1895) 310 (= Siphonacantlurs diffusus. Nees). - Bras.

discifolia, Oliver, in Hook. Tcon. pl. xvi. (1886) t. 1511 ; et in F. L. Fames, Unkn. Horn of Afr. Append. (1888) 321, t. 2. - Reg. Somal.

\section{RUELLIA}

domingensis, Lindall, in Encyl. \& Prant1, Natür1, Planzenfam. iv, 3b (1895) $310=$ domingensis,
Spreng.

erythropus, Lindau, l. c. 311 (= Siphonacanthus erythropus, Nees). - Bras.

euantha, Lindan, in Bull. Herl. Boiss, iii. (1895) 366. - Bolivia.

filicalyx, Lindau, l. c. 362. - Bolivia.

furcata, Lindaw, in Engl. \& Prantl, Natïrl. Pfanzenfam. iv, 3b (1895) 310 (= Dipteracanthus furcacatus, Nees). - Bras.

Garckeana, K. Schum. in Bot. Fahrb. ix. (188\%) 21s. - N. Guin.

glanduloso-punctata, Lindau, in Engl. \& Prantl, Natiirl. Pflanzenfam. iv. 3b (1895) 310 (= Dipteracanthus glanduloso-punctatus. Nees). - Bras.

grandiflora, Lindau, 1. c. (=D. grandiflorus, Nees) = candica, Ruiz \& Pai.

Guppyi, Hemsl. in fourn. Linn. Soc. xxx. (1894) 214, - Ins. Salom.

Humboldtiana, Lindau, in Bull. Herb. Boiss. iii. (1995) 366 (= Stemonacanthis Humboldtianus, Nees). - Am, trop.

humistrata, Lindan, in Engl. \& Frantl. Natürl. Pfanzenfam. iv. 3b (1895) 311 (= Arrliostoxylum repens, Mart.). - Am. trop.

hypericoides, Lindan, in Bot. Fahrb. xix. Beibl. n. 48 (1894) 16 (= Dipteracanthus hypericoides, Nees). - Am. austr.

ibbensis, Lindau, l. 6. xx. (1891) 15. - Afr. centr. bor

incomta, Lindal, in Engl. \& Prantl, Natïrl. Pfanzenfam。iv. 3b (1895) 311 (= Dipteracanthus incomtus, Nees). - Bras.

Kuntzei, Lindan, in Bull. Herb. Boiss. iii. (1895) 365. - Bo!ivia.

lanato-glandulosa, Lindau, in Engl. \& Prantl, $N$ atiirl. Pflanzenfam. iv, 3b (1895) 310 (= Dipteracanthus lanato-glandulosus, Nees). - Bras.

lanceolata, Morong, in Ann. N. Y. Acad. Sci. vii. (1893) 193. - Parag.

longipedunculata, Lindan, in Bull. Herb. Boiss. iii. 1895) $365 .-$ Bolivia.

macrosiphon, Lindau, 1. c. $309=$ lactea, Cav.

Marlothii, Engl. Bot. Fahrb.x. (1888) 257. - Afr. austro-occ, extratrop.

Matagalpae, Lindan, in Bull. Herb. B̉oiss, ii (1895) 364). - Nicarag

mattogrossensis, Lindan, l. c. 362. - Bras.

megachlamys, S. Moore, in fourn. Bot. xxxii. (1894) I34. - Afr. trop. or.

megasphaera, Lindan, in Bull. Herb. Boiss, iii. (1895) 364. - Mexic

microcalyx, Lindau, in Engl. of Prantl, Natiul. Pfanzenfam. iv. 3b (1895) 310 (= Dipteracanthus microcalyx. Nees). - Guian.

microphylla, Lindau, in Bot. Fahrb. xix. Beibl. n. 48 (1894) 16 (=. Arrhostoxylam, microphyllum, Mart ). - Bras.

Morongii, Britton, in Ann. N. Y. Acad. Sci. vij. (1893) 192 (= Cryphiaianthus acaulis, Nees). Bras.

multifolia, Lindau, in Engl, \& Prantl, Natür1. Pflanzenfam.iv. 3b (1895) $310(=$ Dipteracanthus multifolius, Nees $)=$ subdentata, Klotzsch.

Neesiana, Lindan, l.c. $(=D$. Neesiana, Mart. $) .-$ Bras.

Neovedia, Lindan, l.c. $(=D$. Neowedia, Nees).Bras.

panucana, Lindau, in Bull. Hero. Boiss. iii. (1895) 363. - Mexic.

patula, Oliver, in F. L. James, Unkn. Horn of Afr. Append. (1888) 32l = patula, facq.

pedunculosa, Lindau, l.c. (= Arrhostoxylum peduntculosum, Nees). - Peruvia.

porrigens, Lindau, 1. c. (= Dipteracanthus porrigens, Nees) = porrigens, Mart.

praetermissa, Schweinf. ex Lindau, in Bot. Fal.rb. xx. (1894) 15. - Afr. centr. bor.

proxima, I,indau, in Bull. Hirb. Boiss. iii. (1895) 36.5:- Bolivia.

radicans, Lindau, in Engl. \& Prantl, Natïrl. Pfanzonfam. iv. $3 \mathrm{~b}(1895) 311$ (= Stemonacanthus radicans, Nees). - Guian. 


\section{RUELLIA}

rubiginosa, Lindan, in Engl. Eo Prantl, Natiirt. Pfansenfano, iv. 3b (1895) 311 $(=$ Siphonacanthus rubiginosus, Nees), - Bras.

Ruiziana. Lindau, .l.c. (=Stephanophysun Ruiziazum, Nees). - Peruv, Chili.

Schancriana, Lindau, 1. c. $310=$ solitaria. Vell

Sellowiana, Lindau, l. c. 311 (= Stemonacanthus Sellowianus, Nees). - Bras.

essilifolia, Lindinu, l. c. $310=$ Dipteracantinus sessilifolius, Nees). - Bras.

slearcolu, Lindau, 1. c. $311=$ formosa, $A n d r$.

somalensis, Lindau, in Bot. Fahrb. xx. (1894) 14. - Afr. trop. or.

speciosa, Lindau, in Bull. Herb. Boiss, iii. (1895) 36it, in obs. ( $=$ Ophthalmacanthus speciosus, Tees - Mexic.

sectabilis, Nichols. Dict. Gard. iii. (1886) 334. Peruvia

spectabilis, Britton, in Ann. N. Y. Acad. sci. vii. 1593) $192=$ Cryphiacanthus angustifolius,

plendidula, Lindau, in Engl. Es Prantl, Natür. PAlansenfam. iv. 3b (1895) 3il (= Arrhostoxylum splendidulum, Neesj. - Bras

subsessilis, Lindau, l.c. (=A. subsessite, Nees). - Bras

strdanica, Imdan, ex Engl. in Abh. Prouss. Akad. IV iss. (1894) 28, $29:$ et in Bot. Fahrb. xx. (1894) 16, in obs. - Afr. trop.

tetragona, Lindan, in Engl. \& Prantl, Natirl. Pfanzenfann. iv. 3b. (1895) 311. - Am, austr.

thyrsacanthoides, Lindau, $l . c .1=$ Stemonacanthus thyrsacanthoides, Nees). - N. Granat.

Treubiana, Lindau, $l . c .3 \mathrm{I} 0 \mathrm{r}=$ Dipteracanthus vermicosus, Nees). - Java.

turbascensis, Lindau. l. c. 309 $(=$ D. turbascensis, Nees). - N. Granat.

Triedic, T. Anders. ex Morong. in Ann. N. Y Acad. sci. vii. (1893) 192 = Blechum Tweedii Nees.

velascana, Lindau. in Bull. Herb. Boiss, iii. (1895) 363. - Bolivia

vestita, Engl. Bot. Fahro. vii. (1886) 473; et in Forschungsr. Gazelle [Siphon.] (1889) 44. Guinea.

villosa, Lindau, in Engl. Eo Prantl, Natürl. Pfanzenfan. iv. 3b( 1895) 311 (= Siphonacanthus willosus, Nees). - Afr. trop.

Tindex, Lindau, 1. c. $\quad(=$ Dipteracanthus Vindex, Nees $)=$ vindex, Mart

viscidula, Lindau, 1. c. = viscidula, Mart

iscosissima, Lindau, l. $c_{0}(=$ Difteracanthus viscosissimus, Nees). - Bras.

RUELLIOLA, Baill. in Bull. Soc. Limn. Paris, ii. (1890) 852; et Hist. des pl. x. (1891) 427, Lindau, in Engl, \& Prantl, Natürl. Pflanzenfam. iv. 3b. $(189 \%) 30 \%$. ACANTHACEAE.

Grevei, Baill. $l l . c c$. - Madag.

RUGENDASIA, Schiede = Weldenia, Schult, $f$ (Commelin.).

majalis, Ehrenb. ex Hook. f. in Bot. Mag. (1895) t. $7405=$ W. candida, Schult. $f$.

RUIAC, Adans, = Acer, Tourn. (Sapind.). Tcgurdo, Hitchcock, Spring Fl, Manhattan (1894) $6=$ A. Negundo, Linn.

RUMEX, Linn. (Polygon.), - Ind. Kew. ii. 764. albescens, Hillebr. Fl. Haw. Isl. (1888) 378. - Ins. Sandvic

antbigens $\times$. Hausskn. in Mitth, Bot. Ver. Jena, iii. IV. (1885?) 61. - Lurur

angiocarpus, Murb. in Lunds Univ. Arsskrift. xxvii. V. (1892) 46. - Herceg.

rizonicus, Britton, in Trans. N. Y. Acad. Sci, vii. 1859) 73. - Arizona.

Gifo'mis. Rechinger, in Oest. Bot. Zeitschr. xli. (1891) 402 = pratensis, Mert. \& Koch.

Borbasii X. Blocki, 1. c. xxxix. (1889) 155. - Germ. commutatus $X$, Rechinger, in Verh. zool,-bot, Ges, Wien, xlii. (1892) 19. - Tirol.

\section{RUMEX}

confinis X. Hausskn. in Mitth. Bot. Ver. Jena, iii IV. (1885?) 77. - Europ.

Dufftii $\times$. Hausskn. 1. c. 78. - Germ.

dumulosus $X$, Hausskn. 1. c. 67 . - Germ.

erosus, Phil. in Anal. Univ. Chil. xci. (1895) 494 - Chili

erubescens $X$, Hausskn. in Mitth. Bot. Ver. Jena iii. III. (1885 ?) 7\%. - Germ.

fallacinus X, Hausskn, 1. c. 74. - Eur, centr.

fascicularis, Small, in Bull. Torrey Bot. Club, xxii. 1895) $36 \%$ - Florida.

finitimus $X$, Hausskn. in Mitth. Bot. Ver. Jena iii. IV. (1885?) 67.- Germ.

fueginus, Phil. in Anal. Univ. Chil. xci. (1895) 439. - Am. austr.

Geyeri, Trelease, in Missouri Bot. Gard. Rep. iii. (1892) 78, t. $15=$ paucifolius, Nut.

Hcimerli: X, G. Beck, Fl. Nied.-Oest. i. (1890) 318 - Austria

Jiybridus $X$, Hausskn. in Mitth. Bot. Ver. Jena iii. IV. (1885 ?) 69. - Germ.

imundatus X, Simonk. in Termész. Füzet, x. (1886) 183. - Transsily.

Kemeri X. Blocki, in Oest. Bot. Zeitschr. xxxviii (1888) 365. - Galicia

lacustris, Greene, in Erythea, iii. (1895) 63. - Calif.

Lorentzianus, Lindau, in Bot. Fahrb. xix. Beibl. n. 43 (1894) 8. - Reg. Argent

laxiflorus, St. Lager, in Cariot, Etud. des fl. éd. 1889) $709=$ palustris, $S m$

macrophyllus, St. Lager, 1. c. $708=$ R. Hydrolapathum, Huds.

Mezei X, Hausskn, in Mitth. Bot Ver. Jena, iii. IV. (1885?) 60. - Helv

Mureti X. Hausskn. I. c, 73 - Eur. centr

nigricans, Hook. f. Fl. Brit. Ind. v. (1886) 59. Ind. or.

pannonicus $X$. Rechinger, in Oest. Bot. Zeitschr. xli. (1891) 401. - Austria.

platycarpus, Batt. in Batt. \& Trab. Fl. de l'Algér. [Dicot.] (1891) $774=$ bucephalophorus. Lim.

Ruhmeri X. Hausskn. in Mitth. Bot. Ver. Jena

iii. IV. (1885?) 73. - Eur. centr.

Sagorskii X. Hausskn. 1. c. 76. - Germ.

Schmidtii X, Hausskn. 1. c. 66. = Germ.

Schreberi X, Hausskn. 1. c. 74. - Eur. centr.

Schulrei X. Hausskn. 1. c. 68. - Germ.

similatus X, Hausskn. 1. c. 62, - Germ.

Shofitzii X, Blocki, in Oest. Bot. Zeitschr. (1888) 340. - Galicia.

spiralis, Small, in Bull. Torrey Bot, Club, xxii. (1895) 44. - Texas

subalpinus, M. E. Fones, in Proc. Calif. Acad. Ser. ii. V. (1895) 720 [subalpina]. - Utah.

subulatus. Rechinger, in Oest. Bot. Zeitschr. xlii, (1892) $51=$ obtusifolius, Linn.

Weberi $X$, Fischer-Benz, in Prahl, Krit. Fl. Prov. Schlesw.-Holst. ii. (1889-90) 186. - Germ. Bor.

RUMFORDIA, DC. (Compos.). - Ind. Kew. ii. onnata, T. S. Brandeg. in Zoë, iii. (1892) 241, t. 23. - Calif.

RUNGIA, Nees (Acanth.). - Ind Kew. ii. 766. Baumannii, Lindaru, in Bot. Fahrb. xxii. (1895) 120. - Afr. trop. occ.

Buettneri, Lindan, l. c. xx. (1894) 46. - Afr. trop.

coevulea, Warb. 1. c. xiii, (1891) 422 (三 Diclipleve coerulea, Blume $=$ parvifiora, Nees

rosacea, Lindau, l. c. xx. (1894) 46. - Madag.

RUPPIA, Linn.(Naiad.). - Ind. Kew. ii. 766 intermedia, Theden. in Bot. Notiser (1886) 83. Scandin.

lacustris, Macoun, Cat. Canad. Pl. v. $(\mathbf{1 8 9 0}) 27=$ occidentalis, S. Wats.

occidentalis; S. Wats, in Proc. Am. Acad. xxv. (1890) 138. - Columb. brit.

RUSBYA. Britton, in Bull. Torrey Bot. Club, xx, (1893) 67. VACCINIACEAE.

Pearcei, Britton, l. c. 68. - Boliria.

taxifolia. Britton, l. c. - Bolivia.
RUSBYANTHUS, Gilg, in Engl. \& PrantI, Natiurl. PHanzenfam. iv. 2 (1895) 95. GENTIA$N E A E$.

cinchonifolius, Gilg, $l$. c.-Bolivia.

RUSPOLIA, Lindau, in Engl. \& Prantl. Natiirl. Pflanzenfam. iv. 3b (1895) 354. ACANTHACEAE.

pseuderanthemoides, Lindau, l. c.'- Reg. Somal.

RUSSELIA, Jacq. (Scrophul.).-- Ind, Kew, ii.

Tocinea. Wettst. in Engl. \& Prantl, Natürl. Pfanzenfan. iv. 3b (1891) 63; et in Bull. Herb. Boiss. ii. (1894) 562 - Mexic.

racemosa, Wettst. l.c. (= Gomera racemosa, Ruiz \& Pav.). - Peruv.

retrorsa, Greene, Pittonia, i. (June 1888) 176. Mexic.

subcoriacea, Robinson \& Seaton, in Proc. Am. Acad. xxviii. (1893) 113, - Mexic

RUSSOWIA, C. Winkl, in Act. Hort. Pétrop. xi. (1890) 281; O. Hoffm, in Enol. \& Prantl, $\mathrm{Na}$ türl. Pflanzenfam, iv. 5 (1893) 325. COMPO SITAE.

rupinoides, C. Winkl. l. c. 282, t. 1 et 2.Turkest.

RUSTIA, Klołzsch (Rubiac.). - Ind. Kew. ii. \% 68.

angustifolia, K. Schum. in Mart. Fil. Bras. vi. vI. (1889) $262 .-$ Bras.

gracilis, $K$ Schum.l.c. 263. - Bras.

rosea, K. Schum, in Engl, \& Prantl, Natiirl. Pfanzenfam. iv. 4 (1891) 18. - N. Granat

secundiflora, K. Schum. in Mart. Fl. Bras. vi. VI. (1889) 261. - Bras.

RUTA, [Tourn.] Linn. (Rụtac.). - Ind. Kew. ii. erythraea, Aitch. Eo Hemsl. in Trans. Limn. Soc. Ser. II. iii. (1886) $45(=$ Haplophyllum erythraeum, Boiss.). - Afghan.

Gilesii, Hemsl. in Kew Bull. (1894) 4. - Ind. or.

pedicellata, Aitch. \& Hemsl. in Trans. Linn. Soc. Ser. II. ii..(1886) $45(=$ Haplophyllum pedicellatum, Boiss. . - Persia.

pilosa, Kuntze, in Act. Hort. Petrop. x. (1887) 177 (=H. pilosum, Franch.). - Ross. or.

rotundifolia, Aitch. \& Hemsl. in Trans. Limn. Soc. Ser. II. iii. (1886) 45. - Afghan.

RUTTYA, Harv. (Acanth.). - Ind. Kew. ii. 761. fruticosa, Lindau, in Bot. Fahrb. xx. (1894) 45. Afr. trop. or.

RYMANDRA, Salisbury \& Knight = Knightia, R. Br. (Proteac.)

Deplanchei, Kuntze, Rev. Gen. (1891) $580=\mathbf{K}$. Deplanchei, Vieill.

strobilina, Kuntze, l. c. = K. strobilina, $R . B r$.

RYNGHOSPORA, Vah! (Cyper.), - Ind. Kew.

adscendens, C. B. Clarke, in Th. Dur. \& Schinz. Consp. Fl. Afr. v, 1894 (1S95) 65 (= Dichromena candida, Ridl. pr. p.). - Madag

alta, Boeck. Cyp. Noov. ii. (1890) 20 [Rhynchospora]. - Bras.

Arechavaletae, Boeck: l. c. i (1888) 24. - Uruguay; Afr. austro-occ, extratrop.

axillarss, Britton, in Britton, Stern \& Pogr. Prelim. Catal. (1888) 61; et in Bull. Torrey Bot. Club, xv, (1888) 104 [Rhynchospora\} (= Schoenus axillaris, Lam.) = cephalantha, $A$. Gray.

Barteri, C. B. Clarhe, in Th. Dur. of Schinz. Const. Fl. Afr, v. 1894 (1895) 653. - Afr. trop. occ, capillifolia, Boeck. Cyper. No\%. ii. (1890) 22 [Rhynchospora]. - Bras.

columbiensis, Boeck. i c. i. (1888) 29. - Columb. corymbiformis, Britton, in Trans, N. Y. Acad. sci. xi. (1892) 86; et Sp. Scirp. et Rhynch. N.Am. (1S92) 12. - Am. bor.

corymbosa, Britton, l. c: 84. - Parag. 
RYNGHOSPORA :

crymbosa, Hitchcock, in Missour, Bot. Gard, Rep. iv. (189:3) 141 = aurea, Vaht.

crinigera. Boeck. Cyper. Nov. i. (1888) 28 (Rhynchospora]. - Uruguay.

Cruegeriana, Boeck.. . ¿. ii. (1890) 26 [Rhynchospora]. - Ins. Trinit.

Diedrichsenii, Boeck. l. c. 25. - Bras.

Dussiana, Boeck. l. c. 40. - Ins. Martinic.

Eggersiana, Boeck. l. c. 25. - Ins. Jamaic.

elegantula, Manry, ins Morot, fourn. de Bot, iii.

(1889) 209, fig. 10 [Rhynchosporal. - Am. austr. trop.

elongata, Boeck. Cyper. Nov. i. (Iss8) 26 [Rhynchospora]. - Ins. Portoric

erinacea, C. B. Clarke, in Th. Dur. E Schinz, Consp. Fl. Afr, v. 1894 (1895) 65̃ (= Schoenus crinacets, Ridl 1. - Angola.

Fauriei, Franch, in Bull,. Soc. Philom. Paris, Sér. VII. x. (1886) 104 [Rhynchospora]. - Japon.

floribunda, Boeck. Cyper. No\%. ii. (1890) 27 [Rhynchospora]. - Reg. Argent

fuscoides. C. B. Clarks, ex Britton, in Trans. N.Y Acad. sci. xi. (1892) 89; et Sp. Scirp, et Rhynch. N. Am. (1892) 16. - Am. bor. or.

hemicephala, Boeck. Cyper. Nov. i. (188s) 24 [Rhynchosporal. - Bras

Hieronymi. Boeck. l. c. 30. - Reg. Argent.

hyalinolepis, Bocck. l. c. ii. (1890) 23. - Reg, Argent.

infuscata, Boeck. l. c. (1883) 31. -- Columb.

intermedia, Britton, in Truns. N. Y. Acad. sci. xi. (1892) 8\%; et Sp. Scirp: et Rhynch. N. Am, xi (1892) 14 [Rhynchospora]. - Florid., Texas.

leucantha; Bocck. Cyfer, Now. ii. (1890) 22 [Rhynchospora]. - Bras.

Loeforenii. Boeck. l.c. 21. - Bras.

macrocephala, Bock. l. c. 21. - Bras.

maculata, Maury, ex M. Micheli, in Mém. Soc. Helv. sci. mat. xxxi. (1890) n, l, 146, t 43a [Rhynchosporal. - Am. anstr.

malasica, C. B. Clarke, in Hook, f. Fl. Brit. Ind, vi. 1893) 670. - Penins. Mal

Mendoncana, Boeck. Cy'per. Nor, ii. (1890) 23 |Rhynchaspora]. - Bras.

Niederleiniana, Bocck. l. c. i. (1888) 27.-Reg. Argent.

rizabensis, C. B. Clarke, ex Britton, in Trans. A Y. Acad. sci. xi. (1892) 85; et Sp. Scipp. ct Rhynch. N. Am. (1892) 11: et ex F. D. Smith, Enum. pl. Guatem. iii. 1893) 111, nomen |Rhynchospora|. - Mexic., Am. centr.

palustris, Boeck. Cyper. No\%, ii. (1890) 24 [Rhynchosporal. - Bras

panicifolia, Maury, in Morot, fourn. de Bot. ii (1S88) 422 [Rhynchospora]. - Columb.

pauloensis, Bocck. Cyper. Nov. ii. (1890) 24 [Rhynchospora]. - Bras.

praecincta, Maury, ex M. Micheli, in Mém. Soo Hele. sci. nat. xxxi. (1890) n. $1,146, t, 431$ [Rhynchospora]. - Parag.

Prenteloupiana, Boeck. Cyper. Nov. i. (1888) 26 [Rhynchospora]. - Ins. S. Doming.

Pseudolanata, Boeck. l. c. 25. - Cuba.

quadrispicata, Boeck. l. c. 28. - Columb.

qrinquespicata, Boeck. l. c. 29. - Columb.

Schenckiana. Boock. l. c. 22. - Bras.

schoenoides, Britton, in Trans. N. Y. Acad, sci. xi. 1892) 92 ; et Sp. Scirp. et Rhynch. N. Am. 1892) 19 |Rhynchosporal $=$ cyperoides, Mart. setacea, MacMill. Metasp. Minn. (1892) 104 「Rhynchospora] $=$ capillacea, Torr

sikkimensis, C. B. Clarke, in Hook. f. F1. Brit. Ind, vi. (1893) 672. - Sikkim.

sphaerocephala, Boeck. Cyper. Nov. i. (1888) 24 Rhynchospora]: - Bras.

spicaeformis, Hillebr. Fl. Haw. Isl. (1888) 477. Ins. Sandvic.

Stuebelii, Boeck. Cyper. Nov. i. (IS88) 30. -Columb. subtilis, Boeck. . . c. 26.- - Bras.

surinamensis, K. Schum, in Eng1. Pflanzenw. OstAfr. C (1895) 127 |Rhynchospora] = aurea, $V a h l$

Tracyi, Britton, in Trans. N. Y. Acad. sci. xi. 1892) 84 ; et Sp. Scirp. et Rhynch. N. Am. (I892) 11 [Rhynchospora] (= Ceratoschocuns capitatus, Chapm.) $=$ cyperoides, Mart.

\section{RYNCHOSPORA}

Tuerckheimii, C. B. Clarke, ex Britton, in Trans N. Y. Acad. sci. xi. (1892) 85; ; et Sp. Scirp. et Rhynchosp. N. Am。(1592) 12; C. B. Clarke, in F. D. Smith, Enum.pl. Guatem。iii。(1893) 111 nomen [Rhynchospora] - Am. centr.

Urbani, Boeck. Cyper. Nor i. (1888) 26 (Rhynchospora]. - Bras.

Wallichii, K. Schum, in K. Schum. \& Hollr. Fl, Kais. Wilh, Land (1889) $25=$ Wallichiana Kunth.

Widgrenii, Boeck. Cyper. Nov, ii. (1890) 25 |Rhynchospora]. - Bras.

RYPAROSA. Blume (Euphorb.), - Ind, Kew, ii.

\section{iil.}

fasciculata, King, in fourn. As. Soc. Beng. lix. (1890) II. 127. - Malaya

Hullettii, King, l.c. 126. - Malaya

Kingii, King, l. c. 125. - Malaya.

Kunstleri, King, l.c.12\%. - Malaya.

Kurzii, King, l. c, 125 : et in Engl, Eo Prantl, Natiur? Pfanzenfan, iii. 6a (1893) 23, - Ind. or.

Scortechinii, King, l. c. 126. - Malaya.

sumatrana, Warb. in Engl. Eo Prantl, Natiorl. Pfanzenfam, iii, 6a (1893) 23. - Miq.

Wrayi, King, in fourn. As. Soc. Beng. lix. (1890) II. 126. - Malaya.

RYTICARUM, « Becc. » ex Boerl, Handl, Fl. Ned. Indië, i. I. (1890) 215, sphalm.= Ryticaryum Becc. (Palm.)

RYTIDOGARPUS, Cors, Illustr. Fl, Atlant, i (1SS8) 99. CRUCIFERAE.

moricandioides, Coss, l. c. t. 64b, - Marocc

RYTIDOPHYLLUM, Mart, = Rhytidophyllum, Mart. (Gesner.).

stipulare, Urban, ex Bello. Estud. Fl. Puerto Rico vi. (1888) 260. - Ins. Porto Rico.

RYTIDOSTYLIS, Hook. \& Arn。= Elaterium Jacq. (Cucurb.).

carthaginensis, ciliata, cordata, filiformis, glabra, longiflora, quadrifida, quinqueloba, Trianae, trilobata, Kuntze, Rev. Gen. (1891) 258 = homonyma omnia Elaterii.

lastata, Kuntze, 1. c. = Cyclanthera tamnoides, $\operatorname{Cog} n$.

$\mathrm{S}$

SABADILLA, Brandt \& Ratzeb. = Schoenocaulon, A. Gray (Liliac.).

Coulteri, Kuntze, Rev, Gen (1891) 713 = Sc. Conlteri, Baker.

Drummondii, Kuntze, 1. c. = Sc. Drummondii. A. Gray.

dıbia, Kuntze, 1. c. [dubia] = Sc. gracile, A. Gray. intermedia, Kuntze, l. c. = Sc. intermedium. Baker:

SABAL, Adans: (Palm.) - Ind. Kew. ii. 772 Ghiesbrechtii, Hort. ex Pfister, Beitr. vergl. Anat. Sabaleenbl. (1892) 4l. - Hab.

SABAZIA, Cass. (Compos.). - Ind. Kew. ii. 772 glabra, S, Wats, in Proc. Am. Acad. xxiii. (1888) 27\%. - Mexic.

michoacana, Robinson, l. c. xxvii (1893) 173.Mexic.

subnuda, Robinson \& Seaton, l. c. xxviii. (1893) 108 - Mexic.

SABBATIA, Adans, (Gentian.). - Ind. Kew. ii. $7 \% 2$

angustifolia, Britton, in Mem. Torrey Bot. Club, v: (1894) $259=$ brachiata, Ellis.

calycina, Heller, in Bull. Torrey Bot. Club, xxi. (1894) $24=$ calycosa, Pursh.

\section{SABBATIA}

camp.rmulata, Britton, in Mem. Torrey Bot. Club, v (1894) $259=$ gracilis, Salisb.

dichotoma, Trelease, ex Branner \& Coville, in Ann. Rep. Geol. Surv. Arkans. for 1888, i. (1891) $204=$ calycosa, Pursh

Zodecandra, Brıtton, Stern \& Pogo. Prelim. Catal. (1888) $36=$ chloroides, Pursh

Palmeri, A. Gray, ex S. Wats, in Proce Anz. Acad. xxii. (1887) 438. - Mexic.

SABIA, Colebr. (Sabiac.). - Ind, Kew. ii. 772. Swinhoei, Hemsl, ex Forb. \&o Hemsl. in foum. Linn. Soc. xxiii. (1886) 144. - Formosa

yunnanensis, Franch, in Bull. Soc. Bot. Fr, xxxii (1886) 465; et P1. Delav. (1889-90) 14\%, - China

SABICEA, Aubl. (Rubiac.). - Ind. Kew. ii. $77 \%$. acuminata, Baker, in fourn. Linn. Soc, xxv. (1890) 320. - Madag,

arborea, K. Schum. in Engl. Pflanzenw. Ost-Afr. A (1895) 92 - Afr. trop

Henningsiana, Buettn, in Verh. Bot. Ver. Brand. xxxi. (1889) 79. - Gabon.

humilis, S. L. Moore, in Trans, Linn, Soc, Ser, II. IV. (1895) 369. - Bras

ingrata, K. Schum. in Bolet. Soc. Brot. x. (1892) 126. - Ins. S. Thom.

Kolbeana, Buettn. in Verh. Bot. Ver. Brand. xxx (1889) 78. - Congo.

novo-granatensis, K. Schum. in Mart. Fl. Bras, vi VI. (1889) 303, in obs. - N. Granat.

Schumanniana, Buetn, in Verh. Bot. Ver, Brond. xxxi, (1889) 76. - Congo.

speciosa, K. Schum, in Engl. \& Prantl, Natiinl. Pfanzenfam. iv. 4 (1S91) 67. - Kamerun.

SACCHARUM. Linn, (Gramin,), - Ind, Kew. ii. $7 \%$

trorubens, Cuzent \& Pancher, ex Drake, Fl. Polyn. Franç. (1892) $256=$ officinarum, Linn.

fallax, Balansa, in Morot, fourn. de Bot. iv. (1890) 80. - Cochinch.

filiforme, Hack. in DC. Monog. Phan. vi. (1889) 127. - Parag.

fragile, Cuzent \& Pancher, ex Drake, Fl. Polyn. Franç. (1892) $256=$ officinarum, Linn.

glabrum, Cuzent \& Pancher, I. c. = officinarum, Limn.

luzonicum, Hack. in DC. Monog. Phan, vi. (1889) $116=$ officinarum, Linn.

Munroanum, Hack, l, c. 124 (= Eriochrysis pallida, Munro). - Transvaal.

obscurum, Cuzent \& Pancher, ex Drake, FI. Polyn. Franç. (1892) $256=$ officinarum, Limn.

porphyrocomum, Hack, in DC. Monog. Phan, vi. (1889) 120 (=E. porphyrocoma. Hance). - China. purpuratum, Rendle, in Trans, Iinn. Soc. Ser. II. iv. (1894) 56. - Afr, trop, austro-or.

Ridleyi, Hack, in Oest. Bot. Zeitschr. xli. (1891) 6. - Penins. Mal.

rubicundum, Cuzent \& Pancher, ex Drake, FI. Polyn. Franç. (1892) $256=$ officinarum, Lim

SACCOGLOTTIS, Endl. = Sacoglottis, Mart Glaztovii, Urban, in Bot. Jahrb, xvii. (1893) 503.

SAGGOLABIUM, Blume (Orchid.). - Ind. Kew ii. 774

acaule, Hook. f. Fl. Brit. Ind, vi: (1890) 61.Zeylan.

acuminatum, Hook f.l.c. 65. (= Uncifera acminintum, Lindl.). - Penins, Mal.

Archytas, Ridl. in foum. Roy. As. Suc. (Straits Branch) (June 1891) 137. - Ins, Christmas.

bivittatum, Regere, in Gartenf. xxxix. (1890) 60 in Aot. Hort.-Petrop. xi. (1890) 301. - Ind. or calopterum, Kraenzl. in Bot. Fahrb. vii. (1886) 411 - N. Guin.

cephalotes, Hook, f. Fl. Brit. Ind. vi. (1890) 63. Silhet.

cerinum, Reichb. f. in Gard. Chron. (IS88) ii. 206. - Ins Sandvic. 


\section{SACGOLABIUM :}

OL (= Acampe congesta, Lindi.). - Malab., Zeylan. Glavum, Hook.f. l. c. 58; ct in Hook. Icon. pl, xxii. (1893) t. 2131. - Texass

neatum, Gardn. ex Hook. f. 1. c. 71 , in syn. $=$ Cleisostoma maculatum, I inal.

ceminatum "Lindl. " ex Hook. f. 1. c. 55, sphalm. = cemmatum, Lindl.

hainanense, Rolfe, in Kew Bull. (1894) 284. China or.

Helferi, Hook. f. Fl. Brit. Ind. vi. (1890) 57 ; et in Hook. Icon pl. xxii. (1893) t. 2130. - Penins. Ial

inconspicuum, Hook.f.l.c. 56; King, in Amal. Bot. Gard. Calc. v. (1895) 69, t. 49. - Assam.

japonicum, Makino, Ill. Fl. Fapon. i, n. 7 (1891) 3 t. 13. - Japon.

lanatum, Hook.f. Fl. Brit. Ind. vi. (1890) 60; King in Annal. Bot. Gard Calc. v. (1895) 48 t. 7 ? $(=$ Cleisostoma lanatum. LindI.). - Tenass.

Iongicalcaratum, Rolfe, in Kew Bull. (1894) 186. Borneo.

longifolium, Hook. f. Fl, Brit. Ind. vi. (1890) 62 $=$ Vanda longifolia, Lindl.). - Ind. or. China?).

maculatum, Hook.f.l.c. 64 (= Sarcochilus naculatus, Benth.), - Concan, Canara

MIatsuran, Makino, in Tokyo Bol. Mag. vi. (1892) 48. - Japon

microphyton, Frapp. is Corden. Fl. Tle Réunion (1595) 195, - Ins. Borbon.

minimiflorum, Hook.f. Fl. Brit. Ind. vi. (1890) 59; ct in Hook. Icon. pl. xxii. (1893) t. 2135. Perak.

Mooreanum, Rolfe, in Kew Bull. (1893) 64; et ex Hook. f. in Bot. Mag. (1 j95) t. 7428 - N. Guin.

nilagiricum, Hook. f. Fl. Brit. Ind vi. (1890) 60.Ind. or.

btusifolium, Hook. f. l. c. 65 ; et in Hook. Icon. pl. xxii. (1893) t. 2134(= Uncifera obtusifolia, Lindl.). - Reg. Himal.

occidentale, Kraenzl. in Bot. Fahrb. xvii. (1893) 57. - Kamerun.

Pechei, Reichb.f. in Gard. Chron. (1859) i. 447 ; Hook. f. Fl. Brit. Ind. vi. (189') 66, in obs, Penins. Mal.

penangianum, Hook. f.l. c vi. (1890) 57; et in Hook. Icon. pl. xxii. (1893) t. 2129b; King, in Annat. Bot. Gard. Cals. v, (1895) 4\% t 71 - Penins. Bat,

pe:pusillum, Hook. f. Il. cc. 56 ; et t. 2129a. Yenins. Mal.

praemorsum, Hook. f.l. c.62. - Ind. or.

pseudo-distichum, King, \& Pantling, in fourn. As. Soc. Beng. 1xiv. (1805) II, 341. - Ind. or.

rustellatum, Hook, f. Fl. Brit. Ind. vi. (1890) 59; ct in Hook. Icon. pl. xxii. (1893) to.2132. Sikkim.

Eanderianum, Kraenzl. in Reichb. f. Xen. Orchid. iii. $S$ (1894) 134. - As. trop.

saxicolum, Ridl. in Trans, Linn. Soc. Ser. II, iii. (1893) 374. - Penins. Mal.

Sayerianum, F. Muell. \& Kracnzl. in Oest. Bot. Zeitschn. xliv. (1894) 253, xlv. (1895) 180. - N. Guin.

Schleinitzianum, Kracnal. in Bot. Fahrb. vii. (1886) 440 ; et Forschungsr. Gazelle (1886) 21. - N Guin.

Smeeanum, Reichb. f. in Gard. Chron. (1887) ii. 214. - Ins. Sund.

quamatum, Frapp. in Corden. Fl. Ile Rómion, (1895) 165. - Ins. Borbon.

enuicaule, Hook. f. Fl. Brit. Ind. vi. (1890) 64 King, in Annal. Bot. Gard. Calc. v. (1895) 49 t. 74, - Penins. Mal.

IVendlandianm, Kraenzl. in Reichb. f. Xen. Orchid. (1894) 121, t. 269, flg. 10-20= Cleisostoma Wendlandiorum, Reichb. $f$.

Wightianum, Hook. f. Fl. Brit. Ind. vi. (1890) 62 - Ind. or., - Zeylan.

SACCOPETALUM, Benn. (Anon.). - Ind. Kew.

longipes, Vidal, Reris. Pl. Vasc. Filip. (1886) 43 - Ins. Philipp.
SACCUS, Rumpf, Herb. Amboin, i. (1741) 104-05, t. 30.34, ex Kuntze, Rev. Gen. (1801) $633=$ Artocarpus, Forst. (Urtic.)

anisophyllus, biformis, Blumei, bracteatus, callophyllus Chaplasta, Cuningianus, Dadah, Denisonianus, dimorphophyllus, elasticus, Forbesii: glaucescens, glaucus, Gonerianus, hirsutus, integer. Kemando. Kertsou, Kuenstlevi, laevis, Lakoocha, lanceaefolius, lanceolatus, Limpato, Lowii, Maingayi, mariannensis, mollis, nitidus, nobilis, peduncularis, petiolaris, rigidus, Scortechimii, tephrophyllus, tylophyllus, varians, wenenosus, Zollingerianus, Kuntze. Rev. Gen. (1891) 633 = homonyma omnia Artocarpi.

Champeden, Kuntze, 1. c. = A. Polyphema, Pers.

communis, Kuntze, 1, co $=$ A. incisa, Linn, $f$.

clongatus, Kuntze, 1. c. = Sloetia Sideroxylon, Teijsm. \& Binn.

Tieterophyllus, Kuntze, 1. c. $=$ Artocarpus integrifolia, Lim. $f$.

Teijsmanni, Kuntze, I. co = A. Teijsmanni, Miq.

SACLEUXIA. Baill. Hist, des pl. x. (1890) 265 ; K. Schum, in Eng1. \& Prantl, Natürl. Pflanzenfam, iv. 2 (1805) 226. ASCLEPIADEAE.

salicina, Baill. ll. cc. - Zanzib.

SACROPTERYX stipitata, Radlk. in Sitzb. Math. Phys. Akad. Muench. xx. (1890) 259. in obs. sphalm. = Sarcopteryx stipitata, Radlk.

SAGERAEA, Dalz. = Bocagea, A. St. Hil. (Anon.).

Listeri, King, in Annal. Bot. Gard. Calc. iv. (1893) 7. t. 3a. - Penins. Mal

SAGERETIA, Brongn. (Rhamn.). - Ind. Kew ferruginea, Oliver, in Hook. Icon. pl. xviii. (1887) t. 1710. - China centr.

minutiflora in Trans. St. Louis Acad, v. (1889) 367 $=$ S. Michauxii, Britton.

paucicostata, Maxim. in Act. Hort. Petrop. xi. (1889) 1")1. - China.

spinosa, Wettst. in Sitzungsb. zool.-bot. Ges. Wien, xcviii. 1889 (1890) 385, t. 1, fig. 13-15. - As. Min.

SAGINA, Linn. (Caryoph.). - Ind. Kew. ii, 775 arctica, Scheutz'[Pl. vasc. Foniseenses] in K. Svensk Vet. Akad. Handl. xxii. 10 (1885) 93. - Sibiria.

Baungarteni, Simonk. Enum. Fl. Transsilv. (1886) $134=$ S. Linnaei, Presl.

Boydii, Buch. White, in Trans. Bot. Soc. Edinb xvii. (1887) 32-35; et in Fourn. Bot. xxx. (1892) $2 \% 6$, t. 326b. - Scotia.

carnosula, Norm. in Christ. Vidensk.-Selsk. Forhandl. (1893) 000 - Norv

donatioides, F. Mull, in Trans. Roy. Soc. Vict. N. S. i. II. (1889) 3. - N. Guin.

hawaiensis, $P a x$, in Bot. Fahrb. xviii. (1893) 27, in obs. (= S. subu'ata, Hillebr.). - Ins. Sandvic, papuana, Warb. l. c. xvi. (1892) 14, 21. N. Guin.

saginoides, Britton, in Mem. Torrey Bot. Club, v. (1894) $151=$ Spergula saginoides, Linn .

subulata, Hillebr. Fi. Haw. Isl. (1888) $38=$ ha waiensis, $P a x$

truncata, Colenso, in Trans.' $N, Z$. Tnst, xxvii. 1894 (1895) 386. - N. Zel.

SAGITTA, “Plin. ) Adans. == Sagittaria, Rupp. (Alism.).

aquatica, "Pline » St. Lager, in Cariot, Étud. des fi. éd. 8, ii. (1889) $819=$ S. sagittifolia, Linn.

SAGITTARIA, Rupp, ex Linn. (Alism.). - Ind. Kew.i1. 776

ambigua, f. G. Smith, in Missouri Bot. Gard. Rep. vi. (1895) 48, t. 17. - Kansas

demersa, 7. G. Smith, l. c.58, t. 15. - Mexic.

arifolia, Nutt. ex J. G. Smith, 1. c. $32=$ sagittitolia, Linn.

cuneata, Sheldon, in Bull. Torrey Bot. Club, xx. (1893) 283 , t. $159 ; 7 . G$. Smith, l. c. 34, t. 2.Minnesota.
SAGITTARIA :

Engelmanniana, J. G. Smith, in Mem. Torrey Bot. Club, v. (1894) 25; et in Missouri Bot. Gard. Rep. vi. (189.5) $41=$ variabilis, Engelm.

filiformis, f. G. Smith, l. c. vi. (1895) 46, t. 15. - Alabama.

Greggii, f. G. Smith, l. c. 43, t. 12, - Calif. Mexic

isoetiformis, f. G. Smith; l. c. vi. (1895) 115 t. 53. - Florida.

longerostris, J. G. Smith, in Mem. Torrey Bot. Club, v. (1894) 26 ; et 1. c. vi. (1895) $42=$ sagittifolia, Linn.

macrocarpa, f. G. Smith, l. c. 53. t.24. - Carolina

platyphylla, 7. G. Smith, l. c.55, t. $26(=\mathrm{S}$. gra minea, Michx var.). - Am bor.

recurva, Encrelm, ex I'atterson, Check List (1887) 130, nomen $=$ platyphylla, F. G. Smith.

Sanfordii, Greene, Pittonia, ii. (1890) 158; 7. G Smith, in Missouri Bot. Gard. Rep. vi. (1895) 57. - Calif.

subulata, Britton, Stern \& Pogg. Prelim. Catal. (IS88) $58=$ pusilla, $N_{\text {itt }}$.

teres, S. Whats in A. Gray, Man. N. Am. Bot. ed. 6 (1890) 555 : 7. G. Smith, in Missouri Bot. Gard. Rep. vi. (1895) 54 t. 24. - Am. bor. or.

SAGUASTER, Rumpf = Ptychosperma, Labill. (Palm.)

ambigmis, Kuntze, Rev. Gen. (1891) $735=$ Actino. phloeus ambiguus, Becc.

angustifolizs, Kuntze, 1. c. = Coleospadix oninen sis, Becc.

appendiculatus, Kuntze, 1. c. $734=$ Drymophloeus appendiculatus, $\mathrm{Miq}$

bifidus, Kuntze, 1. c. $735=$ D. bifidus, Becc

Capitis-Yorkis, Kuntze, 1.c. = Ptychosperma Capitis-Yorkii, H. Wendl. \& Drude.

Drudei, Kuntze, 1.c. = P. Drudei, $H$. Wendl.

clegans, Kuntze, l. $_{\text {c }}=\mathrm{P}$. elegans, Blume.

gracilis, Kuntze, 1. c. = P. gracilis, Labill.

leprosus, IIuntze 1.c. = Drymophloeus leprosus, Becc.

Macarthuri, Kuntze, 1. c: = Ptychosperma Macarthurii, H. Wendl.

Normanbyi, Kuntze, 1. c. = Areca Normanbyi, F. Muell.

olivifo:mis, Kuntze, 1. c. $734=$ Drymophloeus olivaeformis, Mart.

oninensis, Kuntze, 1. c. $735=$ Coleospadix oninensis, Becc.

pauciflora, Kuntze, 1. c. = Ptychosperma pauciflora, H. Wendl,

perbrevis, Kuntze, 1. c. = Balaka perbrevis, Becc.

Pickeringii. Kuntze, 1. c. = Ptychosperma Pickeringii, $H$. Wendl.

propinquus, Kuntze, 1. c. = Actinophloeus propinquuus, Becc.

punicus, Kuntze, 1. c. = Pinanga ternatensis, Scheff. saxatilis, Kuntze, 1. c. = Drymophloeus saxatilis, Mart.

Semannii, Kuntze, 1. c. = Balaka Seemannii, Becc. tahitensis, Kuntze, 1. c. = Ptychosperma tahitensis, H. Wendl.

vitiensis, Kuntze, 1. c. = P. vitiensis, $H$. Wendl.

SAGUERUS, Rumpf = Arengâ. Mart. (Palm.).

brevipes, Kuntze, Kev. Gen. (1891) $736=$ A. brevipes, Beic.

pinnatus. Kuntze, 1. c. = A. saccharifera, Labill.

undulatifolius, Kuntze, 1. c. = A. undulatifolia, Becc

SAINTPAULIA, Wend1. in Gartenfl, xlii. (1893) 321 . GESNERACEAE

ionantha, Wendl. l.c. fig. 66 t. 1391 : Baill. in Bull. Soc. Linn. Paris, ii. (1893) 1148; Hook. f. in Bot. Mag. (1895) t. 7408. - Afr, trop, or.

SALAGIA, Linn. (Celastr.)..- Ind. Kew, ii. 778. angustifulia, S. Elliot, in fourn. Limn. Soc. xxx. 1894) 75. - Sierra Leone:

camerunensis, Loesen. in Bot. Fahry. xix. (1894) 240. - Afr. trop. occ. 
SALACIA

Chesseana, Pierre, Fl. For. Cochinch. Fasc. 20 (1594) sub t. $312 \mathrm{~B}$ in obs. = Hippocratea Chesseana, Pierre.

dinhensis, Pierre, 1. $\mathrm{c},=\mathrm{H}$. dinhensis, Pierre.

dongnaiensis, Pierre, l c. Fasc. 19 (1893) t. 300B. - Cochinch.

Dusenii, Loesen. un Bot. Fahrb. xix. (1894) 242. -. Kamerun.

erythrocarpa, K. Schum, in K. Schnm. \& Hollr. Fl. Kais. Will, Land (1889) 70. - N. Gtin.

gabunensis, Loesen. in Bot. Fahrb. xix. (1894) 242. - Afr. trop. occ.

Godefroyana, Pierre, Fl. For. Cochinch., Fasc. 19 (1893) t. 300a. - Cochinch

hamputensis, Picrye, l. c. Fasc, 20 (1894) t, 3121 in text. (= Salacia macroplyylla, Pierre, non Miq.). - Cochinch.

laurifolia, Stapf, in Trans. Linn. Soc. Ser. II. iv. (1894) 141. - Borneo.

macropliyllus, Pierre, Fi. For. Cochinc., Fasc. 20 (1894) t. 312b = hamputensis, Pierre.

Viqueliana, Loesent. in Engl. \& Prantl, Natürl. Pfanzenfam. iii. 5 (189:3) $230 i=$ S. marcrophylla. Miq.). - Guian. bat

Naumanni, Engl. Bot. Fahrb. vii. (1886) 464; et in Forschungsr. Guzelle (1586) 36, t. 13. - Ins. Pacif.

noronhioides, Pierve, Fl. For, Cochinch., Fasc 19 (1893) t. 29\%a. - Cochinch.

oliveriana. Loesen. in Bot. Jahrb. xix. (1894) $240=$ S. oblongifolia, Oliver.

pallens, Pierre, Fl. For. Cochinch., Fasc. 19 (1893) t. 298d. - Cambodia.

polyanthomaniaca, Barb. Rodr. [Herb. Mus. bot. Ama\%. n. 647] Vellosia, 1885-\$8, Sec. edic. (1591) 15. t. 8. - Bras. bor

Preussii, Loesen. in fahrb. Bot. xix. (1894) 239. Kamerun.

Regreliana, 7. Braun \& K. Schum, in Ber. Deutsch Schutrg. ii. (1889) 154; Loesen. in Engl. E Prantl, Natiirl. Pfanzenfam. iii. 5 (1893) 230 (Regeliana). - Kamerun.

Rehmannii, Schinz, in Bull. Herb. Boiss. ii. (1894) 195. - Transvaal.

rostrata, Pierre, Fl. For. Cochinch. Fasc. 19 (1893) t, 299a. - Cochinch.

Siputa, S. L. Moore, in Trans. Linn. Soc. Ser. II. iv. (1895) 338. — Bras.

Soyauxii, Locsen. in Bot. fahrb. xix. (1894) 241.Afr. trop. occ.

Stuhlmanniana, Loesen. l. c. - Zanzibar.

typhina, Pierre, Fl. For. Cochinch. Fasc. 19 (1893) t. $297 \mathrm{~b}$ et t. $299 \mathrm{~b}$. - Cochinch.

SALAXIS, Salisb. (Ericac.). - Ind. Kew. ii. 779. benguelensis, Engl. in Abl. Prenss. Akad. Wiss. 1891 (1892) 328 (= Philippia benguelensis, Welw.). - Angola.

SALAZIA. Salisb. (Ericac.), - Ind. Kew. ii. 779. Liebmannii, Klatt, in Leopoldina, Heft xxiii. (1887) 90. - Mexic.

SALDANHAEA, Kuntze, Rev. Gen. (1891) 480 sphalm. = Soldanhaea, Bur. (Bignon.)

Seemanniana, Kuntze, l. c. - Ins. Trinit.

SALICORNIA, |Tourn.] Linn.'(Chenopod.). -

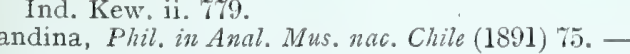
Chili

copiapina, Phil, in Anal. Univ. Chil. xci. (1895) 429. - Chili.

magellanica, Phil. l. c. $430,-$ Chili.

occidentalis, Greene, Fl. Francisc, (1891) 173; et Man. Bot. San Franc. Bay (1894) $57=$ Haplostachys occidentalis, S. Wats.

SALIX, [Tourn.] Linn. (Salic.). - Ind. Kew, ii. 780. Ahlbergi, Behm, in Bot. Notiser (1887) 176. Scand.

algovica $\times$. Hausskn. in Mitth. Thür. Bot. Ver. N. Folge, viii. (1895) 39.-Germ.

Angstroemiana, V. F. Holm, in Bot Notiser (1892) 72. - Scand

\section{SALIX}

Arnelli, Lundstr. in Bot. Notiscr (1888) 26, 31 ;

in Bot. Centraibl. xxxv. (1888) 31. - Sibiria.

Aschersoniana X, Seemen. in Verh. Bot. Ver. Prov.

Brand. xxxvi. (1895) 159. - Germ.

Ausserdorferi X, Huter [in Ausserd. Catal. exsicc.

Tirol. 18\%? ex A. Kern. Sched. Fl. Austro-

Hung. iv. (1886) \%5 - Tirol.

Bcckana X, G. Beck, F1. Nied.-Oest. i. (1890) 292. - Austria.

behringica, Seemen, m Bot. Fahrb, xxi. Beibl.n. $52(1895) 6 .-$ Am arct.

Besseri $X$, Blocki, in Oest. Bot. Zeitschr. xlii. (1892) 350 1. - Austria.

bifax y'. WVoloszczak, 1. c. xxxviii. (1888) 225. Tirol.

Bornmuelleri, Fansskn. in Mitth. Bot. Ver. Fend, ix. (1891) 21. - As. Min.

Boulayi X, F. Gérard, in Rev. de Bot.viii. (1894) 214. - Lothar.

Brownii, Bebb, in Conlt. Bot. Gaz, xiv. (1889) 115 ; et xvi. (1891; 106. - Am. arct.

Buseri $X$. Favrat, in Bull. Soc. Vaud. sci. nat. xxv. (1889) 52; et in Bull. trav. Soc. Murith. Fasc xvi-xvili. (1890) 28. - Helv.

californica, Hort. ex Gartenfl. xxxvi. (1887) 600, $6 \pm t=$ repens, Limn.

calyculata, Hook. f. Fl. Brit. Ind.v. (1888) 635.Reg. Himal,

capnoides X, A. \& J. Kern. ex G. Beck, Fl. Nied.Oest. i. (1890) 29\%. - Austria.

cernua, P. Linton, in fourn. Bot xxxii. (1894) ?02 - Brit.

cinereoides, V.F. Holm, in Bot. Notiser (1892) 71 . Scand.

combinata $X$. Huter, in Verh. zool.-bot. Ges Wien, xli. (1891) 21. - Austria.

commutata, Bebb, in Conlt. Bot. Ga\%. xiii. (1888)

110. - Am. bor. occ.

conjuncta, $B c b \bar{b}$, l. c. - Am. bor. occ.

crentsensis $X, A$. \& J. Kern. Herb. Oest. Weid. Dec. viii. (1869) n. T2।; ex A. Kern. Sched. Fl. Austro-Hung. iv. (1886) S0; G. Beck, Fl. Nied. Oest. i. (1890) 286. - Tirol.

dendroides, $A$. \& F. Kern. $l$ c. 289. - Austria.

eburnea, Dippel, Handb. Laubholzh, ii (1892)291;

Koehne, Deutsche Dendrol.(1893) 99. - Italia mer.

Eichenteldii, Gander, ex C. Richt. in Verh. zool.-bot. Ges. Wicn, xli. (1891) 21. - Austria.

elata X. Blocki, in Oest. Bot. Zeitschr, xlii. (189?) $351 .-$ Austria.

eriocaulos, Lundstr. in Scheutz. Pl. a'ase. Feniss. (1886) n. 679; et in Bot. Ceniralbl. xxxv (1S8S) 31. - Sibir

erythroclados X, Simonk, in Oest. Bot. Zeitschr, xl (1890) 424.- Hung.

eligenes, $E . F$. \& $W$. R. Linton, in foum. Bot. xxxii. (1890) 364 . - Brit.

euryadenia X. Ausserd. ex A. Kern. Sched. Fl Austro-Hung. iv. (1886) 76. - Tirol.

friburgensis, Cottet, in Coltct \& Castclla, Guid. bot. Cant. Frib. (1891) 296; et in Bull. Soc. Murith xixxx. (1892) 8. - Helv.

gemmia X, Buser, ex Jaccard, in Nouv. Mém. Soc. Helv. sci. nat. xxxiv, (1895) 330. - Helv.

glaucella, Belm, in Bot. N'otiser (1887) is3. Scand.

Grenieri X, Corbière, Nouv. Fl. Normand. (1893) 529. - Gall. occ.

hirticeps, V. F. Holm, in Bol. Notiser (1892) 71. Scand.

Hoyeriana, Dieck, ex Dippel, in Gartenfl. xl. (1891) 332; Koehne, Dentsche Dendrol. (1893) 97. Columb. brit.

Indebetoni $X, \mathrm{C}$. Richt, in Verh. zool,-bot. Ges. Wien, xli. (1891) 21, - Suecia

intercedens X.G. Beck, F1. Nied.-Oest. i. (1890) 291. - Austria.

Faccardi $X$. Buser, ex Jaccard, in Nouv. Mém. Soc. Helv, sci nat xxxiv. 1895) $329-$ Helv.

Karelini, Seemen, in Bot. Fahrb. xxi. Beibl. n. 52 (1895) 10. - Turkest

Kerneri $\chi$, Blocki, in Oest, Bot, Zeitschr. xlii. (1892) 351. - Austr. Hung.

Kolulae $X$, Woloszczak, 1. c. xli. (1891) 234. -
SALIX

lagopina, Ausserd. [Catal. exsicc. Tirol. 1873] ex A. Kern. Sched. Fl. Austro-Hung. iv. (18\&6)

longebracleata, Pau, Not, Bot, F1, Espan, ii. (18S? $36=$ incana, Schrank.

longipes. Hook. f. \& Thoms. ex Hook, f. Fl. Brit. Ind. r. (1888) $634=$ S. Serpyllum, Anderss.

ludificans $X, \mathrm{~B}$. White, in Journ. Linn. Soc, xxrii. 1890) 404; et in Journ. Bot. xxx. (1892) 360. Scotia

marchiaca X. Straehler, in Deutsche Bot. Monats. schr, xiii. (1895) 17. - Europ.

I Iargaretac X. Seemen, 1. c. vii. (1889) 124. Eur.

margarita $\times$, . B. White, in journ. Linn. Soc, xxrii. (1890) 441. - Scotia.

Mariana 入. Woloszczak, in Tirol (1888) n. 18; et in Oest. Bot. Zeitschr. xxxviii. (1888) 226, Stiria.

maritima, Hart. ex Dippel. Handb. Laubholzk, ii (1892) 264 = decumbens, Forb.

mexicana, Seemen, in Bot. Fahrb. xxi. Beibl, n. $5 \%$ (1895) 9. - Mexic

microphyta, Franch, in Nour. Arch. MIus. Paris, Sér. II. x. (1888) 83. - Tibet.

missouriensis, Bebb, in Gard, and For. viii. (1895) 373 - Am. bor.

mixta $\times$, Korshinsky, in Act. Hort. Petrop. xii (1892) 391. - As. bor. occ.

Moorei $X$. H. C. Wats, ex B. White, in Journ. Linn. Soc, xxvii. (1890) 438. - Scotia.

moupinensis, Franch. in Nouv. Arch. Mur. Paris,

Sèr. II. x. (1888) S2. - Tibet

neglecta, Cottet, in Cottet \&o Castella, Guid. bot. cant. Frib. (1891) 297 ; et in Bull. trao Soc. Mu rith, Fasc. xix-xx. (1892) 9. - Helv.

Nicholsonii X. Dieck, in Neuheit Offert. fur 1889 90, ex Dippel. Handb. Laubholzk, ii. (1892) 284; Koehne, Deutsche Dendrol. (1893) 104. Am. bor

oenipontana X, A. \& J. Kern. [Herb. Oest. Weid. Dec. vi. (1869) 52।, ex A. Kern. Sched. FI. Austro-Hung. iv. (1886) 79 ; G. Beck. Nied.-Oest. i. (1890) 282. - Tirol.

oligotricha $Y$, Simonk, in Oest. Bot. Zeitschr, x1. (1890) 424. - Austro-Hung-

opaca, Anderss. ex Herder, in Act. Hort, Petrop. xi. (1891) $428=$ stipularis, Sm.

slainensis. $X$, Woloszczak, in Oest. Bot. Zeitschr. xli. (1891) 235. - Gilicia.

Otites, Hort. ex Dippel, Handb. Laubholzk. ii. (1892) 242. = S. Elaeagnos, Scop.

parvifolia, V.F. Holm, in Bot. Notiser (1892) 71. Scand.

Paxii $\times$, Woloszczak, in Oest. Bot. Zeitschr, xli. (IS91) 1333. - Austro-Hung.

pectinata, Hort. ex Dippel, Handb. Laubhoizk. is

(1892) $276=$ nigricans, Sm

perpendens, "Ser. 》 ex Dippel,1. c. 221. sphalm. = propendens, Ser.

Piperi, Bebb, in Gard. and For. viii. (1895) 363. Am. bor.

podolica $X$, Blocki, in Oest. Bot. Zeitschr. xlii. (1892) 351. - Podolia.

rcconditu X. Ausserd. [Catal. exsicc. Tirol. 1874] ex A. Kern. Sched. Fl. Austro-Hung. iv. (1886) 74. - Tirol.

Sacharowi $X$. Schroed. ex Dippel, Handb. Laubholzk, ii. (1892) 291; Koehne, Deutsche Dendrol. (1893) 105. - Hybr, artef.

saskatchevana, Seemen, in Bot. Fahrb. xxi. Beibl. n. 52 (1895) \%. - Am. bor.

Schatilowii. Schroed. ex Dippel, Handb. Laubholzk. ii. (1892) 235. - Ross. centr.

saxetana $\times$. B. White, in Journ. Linn, Soc, xxvil. (1890) 434 ; et in Journ. Bot. xxv. (1892) 361. Scotia.

Schmmanniana $X$, Seemen, in Deutsche Bot. Monatsschr. vii. (1889) 36. - Germ.

scrobigera $X$, Wolozczak, in Oest. Bot. Zeitschr. xxxvi. (1886) 74. - Austria,

semireticulata $X, B$. White, in Journ. Linn. Soc. xxvii. (1890) 444. - Scotia.

semirctusa X. G. Beck, F1. Nied.-Oest. i. (1890) 299. - Austria. 


\section{SALIX :}

Simonk. ex Oest. Bot. Zeitschr. xI.

$(1890)$ 4\% 4. - Austro Huns.

serta $X, B$. White, in Journ, Linn. Soc. xxvii.

(1890) 4:36. - Scotia.

hikoliana, Makino, in Tokyo Bot. Mag. vì. (1892) 49. - Japon

ibuling $\%$ B. White, in Journ. Linn. Soc. xxvii. $(1890,446 .-$ Scotia.

imalatrix $\times$. B. White, 1. c. 439 - Scutia.

sobrina $X, B$. White, 1. c. 440 . - Scotia.

Stephania X, B. White, 1. c. 424. - Scotia

Stoderana $X$, Durrnb. in Jahr.-Katal. Wien. bot. lauschver. (1894) 6. - Hab.

Stmphleri $\times$ Seemen, in Deutsche Bot. Monats schr. vii. (1889) 33. - Germ.

subdola X. B. White, in Journ. Linn. Soc. xxrii. (1890) 354. - Scotia.

superata X, B. White, 1. c. 423. - Scotia.

smotriandra X. G. Beck, Fl. Nied.-Oest. i. (1890) 093. - Austria.

Tatrae, Woloszczak, in G. Beck, l. c. 252. - Austria. Theobaldiana X, Bruegg, in Jahresb.-Naturf. Ges. Graub. xxxi. Reil. (1887-88) 167. - Hely.

Trefferi ${ }^{\circ}$. Huter [Enum. pl. exsicc. ann. 188t] ex 4. hern Sched. Fl. Austro-Hung. iv. (1886) i 7 . - Tirol.

tricolor, V. F. Holm, in Bot. Notiser. (1822) $\pi$. Scand.

Urbaniana, Seencn, in Bot. Fahrb. xxi. Beibl. n. $52(1895)$ 9. - Japon

ariegata, Fronch in Vour', Arch. Mus. Paris, Sér. II. X. (1S88) S2, - Tibet.

ivardi, Bcbb, in Gard, and For. viii. (1895) 363.Am, bor.

IVardiana $X$, B. White, in Journ. Linn. Soc. xxvii. (1890) 403. - Brit.

arostrun, Hook, f. \& Thoms, ex Hook. f. Fl. Brit. Ind. v, (1888) $6: 30$, in syn. = oxycarpa, Anderss.

SALMEA, DC. (Compos,). - Ind. Kew, ii, 787. mikanioides, Britton. in Bull. Torrey Bot. Club, mikanioides, Britten.

ritida, Sch.-Bip. ex Klatt, in Leopoldina, Heft xxiii. (188\%) 145, in syn. = scandens, DC.

Palmeri, S. Wats, in Proc. An. Acad. xxvi. (1891) 1+1. -- Mexic

SALIIIA, Will 1. = Carludovica. Ruiz \& Pav. (Cyclanth.

Inucheana, Hort. Sand. ex Gard. Chron. '1893) i. 44 et $4 \$ 1$, fig. 22 ; et ex Gartenfl. xxxiii. (1894) 345 , fig. 73. - Columb.

SALPIGLOSSIS, Ruiz \& Pav. (Solan.). - Ind. Kew, ii. T8T.
chilensis, Wotst. in Engl. Es Prantl, Natum. Pfanchilensis, Wetst. in Engl. Br Prant, Natur. Pfan T. Gay) - Chili.

linifolia, Wettsl.l, c. $(=$ Leptoglossa linifolia, Benth. \& Hook. f.). - Rer. Argent.

schwenkioides, Wettst. l. c. $(=$ L. schwonkioiltes, Benth. \& Hook. f.). - Peruvia.

tenuis, Wettst. l. c. (= Cyclostigna tonuc, Phil.).Am trop.

SALPINGIA, Raimann, in Eng1. \& Pranti, Natuirl. Pflanzenfam. iii. 7 (1893) $217=$ Oenothera, Linn. (Onagr.).

Hortwegii, Raimann, 1. c. $=$ Oe. Hartwegii, Benth.

SALSOLA, Linn. (Chenopod.). - Ind. Kew. ii. 788. cyclophylla, Baker, in Kew Bull. (1894) 340 . Arabia.

hadramautica. Bakcr, l. c. - Arabia.

leucophylla, Baker, l. c. - Arabia.

oxyanthera, Kuntze, in Act. Hort. Pctrop.x. (1887) 233. - Turkest.

Pachoi, Volkens \& Aschers. [In. Fl. Égypt.] in Mínt. Inst. égypt. ii. (1887) 130. - Aegypt.

Volkensil, Schweinf. \&o Aschers. l. c. - Aegypt.

zygophylla, Batt. E Trab. Fr. de l'Algér. Append. if. (1S90) 15; et in Bull. Soc. Bot. Fr, xxxiv. 1822) 73. - Algeria.
SALVIA, [Tourn.] Linn. (Labiat.). - Ind. Kew.

abyssinica, Hochst. [in Schimp. Pl. Abyss. i.n. 160 ex Enul. in Abh. Preuss, Akad. Wiss. 189I (Is92) $367=$ nudicaulis, Vahl, var.

adulterina $\times$. Hausskn. ex Nym. Consp. Fl. Eur. ii. I. (1889) 248. - Graecia.

alamosana. F. N. Rose, in Contrib. U. S. Nat. Fitb. (1891) 110. - Mexic.

aliena, Greene, Pittonio, i. (Jan 1888) 15\% - Mexic.

alpestris, Iansskn, cx $\Lambda^{\top} y m$. Consp . Fl. Eur. Suppl. ii. 1 (1889) 248. - Graecia.

amasiana, Freyn \&o Bormm. in Oest. Bot. Zeitschr. xli. (1891) 58 - As. Min.

ambigens, Briq. in Bull. Soc. Bot. Genive, v. (1889) $1 \geqslant 0$. - Parar

anisodonta, Hausshn. Eo Briq. ex Hausskn. in Mitt. Bot. Ver. Fena, ix. (1891) 21. - Persia.

Andracjowshii X, Blocki, in Deutsche Bot. Monatsschr. x. (1892) 10\%. - Galicia.

approximata, Briq. in Bull. Soc. Bot, Genicie, v. (1889) 119. - Parag.

approximata, Pan, Not. Bot. Fl. Espan. 1. (1887) 7. - Hisp

Balansare, Briq. in Bull. Soc. Bot. Genève, v. (1889) $117=$ S. Rouyana, Briq.

Bancii, Rusby, in Mem. Torrey Bot Chb, iv. (1895) 246. - Bolivia.

Besseri $x$, Blocki, in Oest Bot. Zeitschr. xlii. $1892) 351 .-$ Austro-Hung

Bornmuelleri, Hausskn, in Mitth. Bot. Vev. Fona, ix (1891) ¿1.-As. occ

brachyodon, Vandas, in Ocst, Bot, Zeitschr, rxxix. 18891179 - Herceo

brevilabra. Franch. in Bull. Soc. Phit. Paris Sér. VIII. iii. (1891) 149. - Tibet.

californica, T. S. Brandeg. in Proc. Calif. Acad. Sér. LI. ii. (1889) 697. - Calif.

cinerarioides, Briq. in Bull. Soc. Bot. Gmirc. v. (18s9) I is. - Parag.

Clecelandi. Greene, Pittonia, ii. (July 1892) $236=$ Audibertia Clevelandi, A. Gray.

mpacta, Kuntze, Rew.Gen. (1891) 530. - Costa Rica.

dranea $X$, Borb, in Termész. Füzet, xiv. (1893) 亏1. - Hung.

Durandiana, Briq. ex Th. Dur. \& Pitt. in Bull. Soc. Bot. Belg, xxx, 1891 (1892) 236 = polystachya, Ortiga.

cytleroplinlla, Hemsl. in Journ. Linn. Soc, xxvi. 1891) $284=$ japonica, Thmo.

Freyniana, Bormm. cx Froyn, in Oest. Bot. Zeitschr. xlii. (1892) 349. - As. Min.

Hegelmaieri, Porti \& Rigo, ex Parta, in Atti Accad. Agiati, ix, (1891) (1892) 56; IVillk. Suppl. Prodr. Fi. Hisp. (189\%) 150. - Hisp.

Goudotii. Briq. in Bull. Herb. Boiss, ii. (1894) 13\%. - Madag

Hildebrandtii, Briq. l. c. 135. - Madag

Issanchon, Hort, ex Rev. Hortic, 1xii. (1890) 229 = splendens, $K \mathrm{Cr}^{\prime}$-Gawl.

Kenneri Y Blocki, in Oest. Bot. Zeitschr. xlii. (1892) 351. - Austro-Hung:

lacophylla. Greene, Pittonia, ii. (July 1892) $236=$ Audibertia nivea, Benth.

lucida, Briq. in Bull. Soc. Bot. Genère, v. (1859) 118. - Parag.

ycioides, A. Gray, in Proc. An. Acad. xxi. (1886) tos. - Mexic.

Laximowicziana, Hensl. in Fourn. Linn. Soc. xxvi. (1890) 285. - China.

mellifera, Greene, Pittonia, ii. (July I892) 236 ; et Ian. Bot. San Franc. Bay (1894) 291 = Audi. bertia stachyoides, Benth

mohavensis, Greene, 1. c. $235=$ A. capitata, $A$. Gray.

namaënsis, Schinz, in Verh. Bot, Ver. Brand, xxxi. 1890) 208. - Afr, austro-occ, extratrop.

musairiensis, Post, in Bull. Herb. Boiss, i. (1893) 406. - Syria.

oblongata, De Not. ex Briq. Lab. Alp. Marit, iii. (1895) 515, in obs. = S. Verbenaca, Linn.

Palmeri, A. Gray, in Proc. Am. Acad. xxi. (1886) 408. - Mexic.

Palmeri, Greene, Pittonia, ii. (July 1892) $236=$ Audibertia Palmeri A. Gray.
SALVIA : -

Pittreri, Briq. ex Th. D:r. \& Pitt. in Bull. Soc. Bot Belg. xxx. 1891 (1892) 23\%. - Costa Rica.

podolica $X$. Blocki, in Oest. Bot. Zeitschr, xlii. (1892) 351. - Austro-Hung.

Prattii, Hemsl. in foum. Linn. Soc, xxix. (1892) 316. - China occ

purpurascens, Post, l. c.xxiv. (1888) 438.- As. occ, (1893) 388. - Buls.

Rouyana, Briq. in Bull. Soc. Bot. Genive, jv. (1888) Add. p. iii. $(=$ S. Balansae, Briq. $)$ - Parag.

rubropunctata, Robinson \& Fornald, in Proc. Am. Acad. xxx. (1895) 121. - Mexic

Rusbyi, Britton, ex Rusbr, in Mem. Torrey Bot. Club, iv. (1895) 246. - Bolivia.

sessilifolia. A. Gray, ex S. Wats. in Proc. Am. Acad. xxii. (1887) 445 - Mexic

Shannoni, f. D. Smith, in Coult. Bot. Gaz. xix. (1893) 256. - Guatem.

sonomensis, Greene. Pittonia, ii. (July 1892) $236=$ Audibertia humilis, Benth.

spathacea. Greene, 1. c, ; et Man. Bot. San Franc. Bay $(1894) 291=$ A. grandiflora, Benth

Steingroeveri, Briq. in Bot. Fahrb. xix. (1894)91. Afr. austro occ. extratrop.

stenodonta, Briq. in Bull. Herb. Boiss, ii. (1894) 135. - Madag.

tananarivensis, Briq. l. c. 136. - Madag.

tatsienensis, Franch. in Bull. Soc. Philon. Paris, Sér. VIII iii. (1891) 150. - Tibet.

Torreri, Greene, Pittonia, i. (Jan, 1888) 156. - Mexic. tricuspis, Franch, in Bull. Soc, Philonk, Paris, Sér. VIII. iii. (1891) 150. - Tibet.

utilis, A. Braun, ex Engl. in Abh. Preuss. Akad. Wiss, 1891 (1892) $367=$ nudicaulis, Vahl.

veronicaefolia, A. Gray, ox S. Wats. in Proc. Am. Acad. xxii. (1887) 444. - Mexic

villicaulis, Borb. IA magyar. komokpuszták növenyoilaga (1856) 88| ex Oest. Bot. Zeitschr. xxxix. (1乏̌9) 234. - Hung.

inlgaris, Briq. Lab. Alp. Marit, iii. (1895) $52 \%=$ pratensis, Linn. subsp.

yoseadensis, Freyn of Bomm. in Oest. Bot. Zeitschr. xlii, (1892) 348. - As, Min.

SALVIACANTHUS, Lindau, in Bot. Jahrb, xx (1894) 75 ; et in Eng1. \& Prant1, Natürl. Pilanzenfam. iv. 3b (1895) 351. ACANTHACEAE.

Preussii. Lindau, ll. co. - Kamernn.

SAMAMA. Rumpf, Herb. Amboin. iii. (1734) 36 , t. 19, ex Kuntze, Rev. Gen. (1891) $296=\mathbf{A n}$ thocephalus, A. Rich. (Rubiac.).

Cadanba, Kuntze, 1. c. = A. morindaefolius, Korth. citrifolia, Kuntze, 1. c. $29 \%=$ A. morindaefolius, Korth

SAMANDURA, Gaertn. (Simarub.). - Ind. Kew.

Harmandiana, Picrre, e\% Laness. Pl, wit. Colon. Franc. (1886) 305 [Samandera). - Cochinch.

Harmundii, Pierre, Fl. For. Cochinch. Fasc. 17 $(189) 2)$ t. $261=$ praec.

indica, Pierre, ex Laness. Pl. util. Colon. Franc. (1886) $305=$ mekongensis. Pierve.

mekongrensis, Pierre, Fl. For. Cochinch. Fasc. 17 (1892) t. 262. - Cochinch.

SAMAROCELTIS, Poiss, in Mém. Assoc. Franc Toulouse, 188\% (1888) $595=$ Phyllostylon Capan. (Urtic.)

rhamnoides, Poiss. 1. c. $=$ P. rhamnoides, Tanb.

SAMBUGUS, Tourn. ex Linn. (Caprifol.), - Ind Kew. ii. 796

arborescens, Hort. ex Koehne, Deutsche Dendrol. (1893) 5:33, in sın. = melanocarpa, A. Gray. aurea, Hort. ex Carr, in Rev. Hortic, 1xiii. (IS9I) $384=$ nigra, Linn.

australasica, Fritsch, in Engl. \& Prantl, Natürl. Pflanzenfam. iv. 4 (1891) $162=$ xanthocarpa, F. Muell.

callicarpa, Greene, Fl. Francisc. (1891) 342; et Man. Bot San Franc. Bay (1894) $163=$ glauca, Nitt? 
SAMBUCUS

Fontenayi, C. Koch, ex Dippel, Handb. Laubholzk. i. (1889) $172=$ glauca, Nutt.

Gautschii, Wettst. in Oest. Bot. Zeitschr. x1, (1890) 230. - Reg. Himal.

maritima, Greene, Pittonia, ii. (Sept 1892) 297 ; et Man. Bot. San Franc. Bay (1894) 163. - Calif.

planteriensis. Hort. Simon-Louis, ex Dippel, Handb. Laubholzk. i. (1889) $169=$ mexicana, Presl. plantievensis, Hort, ex Koehne, Deutsche Dendrol. (1893) $533=$ praec

plumosa, Hort. ex Carr. in Rev. Hortic. lxiii. (1891) $408=$ racemosa, Linu.

SAMERARIA, Desv. = Isatis, Linn. (Crucif.) Dinerdiurae, Coss, Comp. Fl. Atlant. i1. (1887) 296 in syn. = I. Djurdjurae, Coss. \& Duriew.

macrocarpa, Boiss. \& Hausskn. ex Boiss. F1. Or. Suppl. (1888) 64. - Persia.

SAMOLUS, [Tourn.| Linn (Primul.). - Ind. Kew. ii. 796

alyssoides, Heller. in Contr. Herb. Frankl. Coll. [Bot. Expl.S. Texas] i. (1895) 74. t. 3. - Texas.

aquaticus, St. Lager, in Cariot. Etud. de fl. éd. 8, ii, (1889) $5 \%$ is = S. Valerandi, Linn.

bracteolosus, Phil. in Anal. Mus. nac. Chite (1891) 51. - Chili.

SAMPACCA, Rumpf = Michelia, Linn. (Magnol.). Cathcartii, excelsa, Kisopa, lanuginosa, montana, nilagirica, ablonga, parvifolia, punduana. Kuntze, Rev. Gen. (1891) $6=$ homonyma omnia Micheliae.

econymoides, Kuntze, 1. c. = M. Champaca, Linn. longifolia, Kuntze. 1. c, = M. Champaca, Linn. suaveolens, Kuntze, 1. c. = M. Champaca, Linn velutina, Kuntze. 1. с. = M. Tsiampaca, Linn.

SANDERELLA, Kuntze, Rev. Gen. (1891) $649=$ Parlatorea, Barb. Rodr. (Orchid.),

SANDORICUM, Cav, (Meliac.). - Ind. Kew. ii. 67.

Harmandianum, Pierre, ex Laness. Pl. util. Colon. Franc. (1\$86) 310, nomen. - Cochinch.

radiatum. King, in Fourn, As. Soc. Beng. lxiv. (1895) 21. - Penins. Mal.

SANGUISORBA, Rupp. ex Linn. = Poterium Linn. (Rosac.).

annua, Holzinger, in Contrib. U. S. Nat. Herb. iii. (1889) 223. - Am bor.

latifolia, Coville, 1. c. iii. (1895) $339=$ Poterium sitchense. S. Wats.

polygama, G. Beck, Fl. Nied.-Oest. ii. I. (1892) 768 = P. polygamum, Waldst. \& Kit.

Sanguisorba, Britton, in Mem. Torrey Bot. Club. v. (1894) $189=$ P. Sanguisorba, $\operatorname{Lin}$.

SANHILARIA. Baill. Hist. des p]. x. (18\&8) 27 ; K. Schum. in Engl. \& Prantl, Natürl. Pflanzenfam.iv. 3b (1894; 222. BIGNONIACEAE.

brasiliensis, Baill. ll.cc. - Bras.

SANIGULA, [Tourn.] Linn. (Umbell.). - Ind. Kew. ii. 798 .

coerulescens, Franch, in Bull. Soc. Plitlom. Paris, Sér. VIII. vi. (I894) 109. - Yunnan.

divaricata, Greene, in Erythea, iij. (1895) 64. Calif.

gregaria, Bicknell, in Bull. Torrey Bot. Club, xxii. (1595) 354, t. 242. - Am. bor or.

hacquetioides, Franch. in Bull. Soc. Philom, Paris, Sér. VIII. vi. (1894) 110. - Yunnan.

Howellii, Coult. \& 7. N. Rose, in Coult, Bot. Gaz. xiii. (1888) 81 ; et Rev. N. Amn. Umbell. (1888) 104 - Am. bor, occ.

nemoralis, Greene, in Erythea, i. (1893) 6. - Calif. satsumana, Maxim. in Bull. Acad. Pétersb. xxxi. (1887) 47. - Ins. Kiusiu.

saxatilis, Greene, in Erythea, i. (1893) 6; et Man. Bot. San Franc. Bay (1894) 150. - Calif.

septentrionalis, Greene, in Erythea, i. (1893) 6.Am. bor. occ.

\section{SANICULA}

ifoliata, Bickncll, in Bull: Torrey Bot. Club, xxii (1895) 359, t. 244. - Am. bor.

yunnanensis, Franch, in Bull. Soc. Philom, Paris, Sér, VIII. vi.(1894) 108. - Yunnan.

SANOPODIUM Durei, Hort, ex Reichb. in Flora, lxxi. (1688) 156 [sphalm. = Sarcopodium] = Bulbophyllum Dearei, Reicht. $f$.

SANSEVIERIA, Thunb. (Haemudor.). - Ind.

Kew. 11. 798. (1889) 269, fig. 12, - Am. austr.

Kirlii, Baker, in Kew Bull. (1887) 3, 8, fig. 5; et in Bot. Mag. (1894) t. 735\%. - Afr. trop. austro-or. paniculata, Schinz, in Th. Dur. \& Schinz, Consp. Fl. Afr, v. 1892 (1895) 14, - Afr. austr.

subspicata, Baker, in Gard. Cirron. (1889) ii. 436. Mossamb.

Volkensii, Guerke, in Engl. PAlanzonw. Ost-Afr. C (1895) 144. - Afr, trop. or.

SANTALINA, Baili, in Buli. Soc, Linn. Paris, ii, (1890) 843. SANTALACEAE.

madagascariensis, Eaill. l. c. 844, 853. - Madag.

SANTALODES, Linn. = Rourea, Aubl. (Connar.

acuminatum, acutipetalion, caudatum, concolor, cusprdatum, discolor, diversifolium, Doniamum, floridum, frutescens, fulgens, Gardncriamum, glabrum, humile indutum, ligulatum, macrophyllum, Martianum, multiflorum, myrianthum, nitidum. polyphyllum, puberulum, pulchellum, revolutum, rugósum, simile, simplicifolimm, Solanderi, stenopetalum, villosum, Wallichianum, Kuntze, Rev. Gen. (1891) $155=$ homonym omnia Roureae.

Bakeri, Kuntze, 1. c. = Rourea heterophylla, Bocker.

dasyphyllum, Kuntze, 1. c, = Cnestis ramiflora, Griff. fratermm, Kuntze, 1. c. = Rourea induta, Planch. Hcrmanniamm, Kuntze, 1. c. = Rourea santaloides, Wight. \& Arn.

hieterophyllim, Kuntze, 1。 c。= R. heterophylla, Baker.

mimisodes, Kuntze, l. c, $=$ R. mimusoides, Planch. monadelfhum, Kuntze, 1. c. = R. commutata, Planch.

phyllanthodes, Kuntze, 1. c. = R. phyllanthoides, Blume.

Roxbughii, Kuntze, 1. c. = R. Milletii, Planch.

SANTALUM, Linn. (Santal.), - Ind. Kew, ii. 798

Haleakalae, Hillebr. Fl. Haw. Ist. (1888) 390. - Ins. Sandvic.

latifolium, Meurisse, in Bull. Soc. Lim, Paris, ii. (1892) 1026. - Ins. Sandvic.

longifolium, Meurisse, l. c - N. Zel.

Macgregorii, F. Muell. in Bot. Centralbl. 1x. (1894) $227 .-\mathrm{N}$. Guin.

alicifolium, Mcurisse, in Bull. Soc. Linn. Paris, ii. (1892) 1016. - Ins. Sandvic.

SANTIRIA, Blume (Burser.), - Ind. Kew. ii. 798. acuminata, $K$. Schum. in $K$. Schum. \& Hollr. Fl. Kais. Wilh. Land (1889) 64. - N. Guin

balsamifera, Oliver, in Hook. Icon. pl. xvi. (1887) t. 1573 ; Engl. Bot. Jahrb. xi. Beibl. n. 26. (1890) 6 = Santiriopsis balsamifera, Eng

floribunda, King, in fourn. As. Soc. Beng. Ixii. (1893) II. 254. - Perak.

floribunda, K. Schnm in K. Schum. \& Hollr. Fl Kais. Wilh. Land (1889) 63. - N. Guin.

laxa, King, in fourn. As. Soc. Beng. Ixii..(1893) ii 254 (= Cannrum laxum, A.W. Benn.). - Penins Mal.

longifolia, $K$ ing, l. c. 25s. - Perak.

macrocarpa, King, l. c. 256. - Perak

Wrayi, King l. c.259. - Perak.

SANTIRIOPSIS, Engl. Bot. Jahrb. xi. Beibl. n. $26(1890) 6$. BURSERACEAE.

balsamifera, Engl. l. c. $(=$ Santiria balsamifera. Oliver). - Ins. S. Thome.
SANTOLINA. Tourn. ex Linn. (Compos, , - Ind. Kew. ii. 799.

Benthamiana, Pall, Not. Bol. Fl. Espan, iv. (1891) 42 - Hisp.

Benthamiana, Rony, in Bull. Soc. Bot. Fr. xxxviii. (1891) 203 (= S. pectinata Benth.). - Gall. mer.

SANVITA LIA, Gualt. (Compos.).--Ind. Kew, ii tenuis, S. Wats, in Proc, Am, Acad, xxiii. (1888) 277. - Mexic.

SANVITALIOPSIS, Sch. Bip. = Zinnia, Linn. (Compos.)

Liebmanni. Sch. Bip. ex Klatt, in Leopoldina, Heft xxiii. (1887) 89 , in syn. = Z. Liebmanni, Benth. \& Hook.f.

SAPINDUS, Tourn. ex Linn. (Sapind.). - Ind, Kew. ii. 799.

anmensis, Pierre, F1. For, Cochinch. Fasc, 20 (1894) t. $317 b=$ Pavieasia anamensis, Pierm.

Delavayi, Radlk, in Engl. E Prantl, Natürl. Pfanzrnfam. iii. 5. (1893) 315 (= Pancovia Delasayi, Franch.). - China.

marginatus, Hort. Alger. ex Rev. Hortic. Ixvi , (1895) $303=$ utilis, Trab.

oahuensis, Hillebr. Fl. Hav. Isl. (1888) 85. - Ins. Sandvic.

tilis, Trab. $2 n$ Rer. Hortic, Ixvii. (1895) 196. $\mathrm{Hab}$.

SAPIUM R. Br. (Euphorb.). - Ind, Kew. ii. 800 . ornutum, Pax, in Bot. Fahrb. xix. (1894) 114.

Angola,
glandulosum, Morong, in Ann. N. Y. Acad. sci. vii. (I893) $227=$ biglandulosum, Mrell. Arg.

Hildebrandti, Pax, in Bot. Fahrb. xix. (1894) 116. - Madas.

Hookeri, Hort. Calc, ex Hook. f. Fl. Brit. Ind (1888) 470 , in syn. = eugeniaefolium. Ham

Poggei, Pax, in Bot. Fahrb. xix. (1894) 115 Congo mer

rotundifolium, Hemsl. in fourn. Linn. Soc, sxyi. (1891) 445.-China.

sceleratum, Ridl. l. c xxvii. (1890) 60.t. 3. - Ins. Fernando Noronha.

xylocarpum, Pax, in Bot. Fahro. xix. (1894) 115 Congo.

SAPONARIA, Linn. (Caryoph.). - Ind. Ketw, ii. 801.

cypria, Boiss. Fl. Or. Suppl. (1388) 83. - Ins. Cypr. illyrica, Baldacci, in Malpighia, viii. (1894) $81=$ Tunica illyrica, Fisch. \& Mey.

intricata, Freyn, in Bull. Hert. Boiss. iii. (1895) $\%$ - As. Min.

Zapaterii, Pau, Not. Bot. FI. Espan. iv. (1891) 22 = glutinosa, Bieb.

SAPROSMA, Blume (Rubiac.) - Ind. Kew. ii. SO?.

dichotomum, Boerl. Handl. Fl. Ned, Indie, ii. I. 1891) 142 (= Mephitidia dichotomu, Korth.).-

Java.
foetens, K. Schum. in Engl. \& Prantl, Natürl. Ptlanzentam. iv. 4 (1891) $122=$ zeylanicum, Bedd. molle, Boorl. Handl. Fl. Ned. Indie, ii. I. (1891) 142 $=$ Rutidaer mollis, Blume). - Penang.

SARACA, Linn, (Legumin ), - Ind. Kew, ii. 80 ? camboodiensis, Pierre, ex Laness. Pl util. Colon. Franc. (1886) 287, nomen. - Cambodia.

SARACHA. Ruiz \& Pav. (Scrophu1.). - Ind. Kew. ii. 802 .

grandiflora, Robinson \& Greenn. in Am. Fonm Sci. Ser. III. 1. (1895) 161. - Mexic

SARANTHE. Eichl. =Myrosma, Linn.f.(Scitam.)。 Eichleri, Petersen, in Mart. Fl. Bras. iii. II. (1890) 166. - Bras.

membranacea, Petersen, 1. c. 167. - Bras

tenuifolia, Petersen, 1. c. 169. - Bras.

urcoolata, Petersen, 1. c. 167. - Bras

ustutata, Petersen, 1. c. 160̃. - Bras. 
SARARANGA, Hemsl, in Journ. Linn. Soc, xxx. (1894) 216. PANDANACEAE

simuosa, Hensl. l. c. t. 11. - Ins. Salom.

SARCANTHIDIUM. “ Baill. » ex Eng1. \& Prantl, Vaturl. Pflanzenfam. iii. 5 (1893) 245 = Sarcanthidion, Baill. (Olacin.).

SARGANTHUS, Lindl. (Orchid.). - Ind. Kew. 11.803

appendiculatus Hook. f. Fl. Brit. Ind vi. (1890) (i) $[$ =Aerides appendiculatus, Wall.]: in Hook. Icon, 1. xxii. (1893) t. 236; King, in Annal. Bot. Gard. Calc. v. $(1895) 50$, t. 76 . - Ind. or.

auriculatus, Rolfe, in Kew Bull. (1895) 9. - Hab.?

Gilberi, Hook. f. in Hook. Icon. pl. xxxiv. (1894) .334. - Tenass.

lorifolius, Parish, ex Hook. f. Fl. Brit. Ind. vi, (1890) 69; et in Hook. Icon. pl. xxi1. (1893) t. 2130. - Tenass.

praealtus, Reichb, f. Bot. Centralbl. xxviii. (1886) 344. - N. Gu n.

rutilus, Parish, in Grant, Orchids of Buma (1895) 278, nomen. - Burma.

Scortechinit, Hook. f. Fl. Brit. Ind. vi. (1890) 68; ct in Hook. Icon. pl. xxii. (1893) t. 2138. - Perak.

SARCOBATUS, Nees (Chenopod.). - Ind. Kew. 11. $\mathrm{SO}$.

Baileyi. Coville, in Proc. Biol. Soc. Wash. vii. (1892) 77: et in Contrib, U. S. Nat. Herb. iv. (1893) 184. t. 20. - C.alif.

retusus, K. Schum, in K. Schum. E Hollr. Fl. Kais. Wilh. Land (1889) 109. - N. Guin.

SARCOCAULON, Sweet (Geran), - Ind. Kew. ii. 803 .

Marlothii, Engl. Bot. fahwb. x. (1888) 31. - Afr. austro-occ, extratrop.

rioidum, Schinz, in Verth, Bot. Vor. Brand, xxix. (1889) 59. - Afr. austro-occ. extratrop.

SARCOCEPHALUS. Afzel (Rubiac.), - Ind.

Kew, il. 803.

gracilis, Dalla Torre, in Just, Bot, Jahresb. xviii. 1890 (1892) 526. sphaim. = macrocephalus, K. Schum.

macrocephalus, K. Schum. in Engl. \& Prantl, Natürl. PAanzenfam. iv, 4 (1891) 59. - N. Guin. sambucinus, K. Schum. l. c. = esculentus, Afrol.

SARCOCHILUS, R Br.(Orchid.).-- Ind. Kew. aphyllus, Makino, in Tokyo Bot. Mag. vi. (1822) 48.

- Japon.
aureus, Hook. f. Fl. Brit. Ind. vi. (1830) 35 ; King, in Annal. Bot. Gard. Calc. v (1895) 42. t. 64. Perak.

borneensis, Rolfe, in Illustr. Hortic. xxxix. (1892) 99 t. 561. - Borneo.

brachyglottis, Hook. f. Fl. Brit. Ind. vi. (1890) 34 ; King, in Annal. Bot. Gard. Calc. v. (1895) 42, t. 63. - Perak

brachystachys, Hook. f. l. c. vi. (1890) 41. Penang.

caligaris, Ridl. in Trans, Linn, Soc. Ser. II. iii. (1893) 372. - Penins. Mal.

carinatifolius, Ridl. in Foum. Roy. As. Soc. (Straits Branch). (June 1891) 136. - Ins. Christmas.

cladostachys, Hook. f. Fl. Brit. Ind. vi. (1890) 35 ; King, in Amnat. Bot. Gard. Calc. v. (1895) 43, t. 65. - Malaya.

cochinchinensis, Nichols. Dict. Gord. iii. (1886) 360. - Cochinch.

complanatus, Hook, $f$ Fl. Brit. Ind, vi. (1890) 41 (= Limodorum complanatum, Lindl.). - Zeylan.

crassifolius, Rolfe, in Kew Bull. (1894) 396. -

Hab.?
eriochilus, Fitzg. in foun. Bot. xxix, (1891) 153. - Austral.

fliformis, Hook. f. Fl. Brit. Ind. vi. (1890) 39; et in Hook. Icont pl xxii. (1893) t. 2124. - Perak

Fremanii, Nichols. Dict. Gard, iii, (1886) $36 \mathrm{l}=$ S. Freemanii, Reichb. $f$.

\section{SARCOGHILUS}

hirsutus, Hook. f. Fl. Brit. Ind. vi, (1890) 38 ; King, in Annal. Bot. Gard. Calc. v. (1895) 43, t. 67. Perak.

hirtulus, Hook. f. l. c. 39; et in Hook. Icon, pl. xxii. (1893) t. 2121. - Penins. Mal.

leopardinus, Parish \& Reichb. f. ex Hook. $f$. Fl. Iivit. Ind. vi. (189 1) 38 . - Tenass.

luniferus, Benth. ex Hook. f. in Bot. Mag. (18s9) t. 70 (= Thrixpermm luniferum, Reichb. f.). Burma

Mannii, Hook. f. Fl. Brit. Ind. vi. (1890) 36.Ind. or.

merguensis, Hook. f. l. c. 40 ; et in Hook. Icon. pl. xxii. (1893) t. 2125a. - Tenass.

microscopicus, Kraenzl, in Bot. fahrb. xvii. (1593) 487. - Sumatra.

minimifolius, Hook. f. Fl. Brit. Ind. vi. (1890) 37. - Zeylan.

muscosus, Rolfe, in Kew Bull. (1893) \%. - Ins. Andam.

notabilis, Hook. f. Fl. Brit. Ind. vi, (1890) 42 ; et in

Hook Icon pl. xxii. (1893) t. 2126. - Penang.

obtusus, Benth.ex Hook. f. l. c. 36 (= Camuratis obtusa, Lindl.). - Tenass.

papuanus, Kraenzl. in K. Schum. \& Holly. Fl. Kais, With. Land (1889) 34. - N. Guin.

pardalis, Ridl. in Trans, Linn. Soc. Ser. II, iii. (1893) 371. - Penins. Mal.

pauciflorus, Hook. f. Fl. Brit. Ind. vi. (1890) 41.Perak.

platystachys, F. M. Bailey, Syn. Qucensl. Fl. Suppl. i. (1886) 56. - Austral.

psiloglottis, Ridl. in Trans. Linn. Soc. Ser. II. iii. (1893) 372. - Penins. Mal.

pugionifolius, Hook. f. Fl. Brit. Ind. vi. (1890) 196 [pugionifolia]; et in Hook. Icon. pl. xxii (1893) t. 2125b. - Zeylan.

recurvus, Hook. f. $1 l$. co. 39 ; et t. 2122. Perak.

retro-spiculatus, King \& Pantl. in foum. As. Soc. Beng. Ixiv. n. 3 (1855) II. 340. - As. trop.

Roxburghii, Hook. f. l. $36(=$ Camarotis pallida Lindl. . - Ind. or

Scopa, Reichb.f ex Hook. f. l. c. 44. - Perals

Scortechini, Hook.f. I. c. 40. - Perak.

stenoglottis, Hook. f. l. c. 34: King, in Annal. Bot Gard. Calc. v. (139.3) 41 t. 62. - Sumatr (Perak?).

suaveolens, Hook.f.l. . . $33(=$ Aerides suareolens, Roxb.). - Ind. or.

tanyphyllus, Ridl. in Trans, Linn. Soc. Ser, II, iii. (1893) 372. - Penins. Mal.

trichoglottis, Hook. f. Fl. Brit. Ind. vi. (1890) 39 ct in Hook. Icon. pl. xxii. (1890) t, 2123. - Penins Mal.

Trimeni, Hook, f. 1. c. 40, 196, in obs, nomen $=$ viridiflorus, Hook. $f$.

viridiflorus, Hook. l." c. 38 (= Aerides viridiflonus, Thwaites) - Zeylan.

Wightii, Hook. f. l. . . 37 ( $=$ Limodonm pusillum, Willd.). - Ind. or., Zeylan.

SARCOCHLAENA, Spreng:= Sarcolaena. Thou, (Chlaenac.).

codonocllamys, “ Baker », ex K. Schum, in Engl. \& Prantl, Natürl. Pflanzenfam. iii. 6 (1893) 17: = Sarcol. codonochlamys, Baker

SARCOGONUM, G. Don = Muehlenbeckia Meissn. (Polyyon.)

fruticulosum, Rusby, in Mem. Torrey Bot Club iv. (1895) $25 \mathrm{l}=$ M. rupestris, Wedd.

vulcanionn, Rusby, 1. c. $252=$ M. vulcanica, Endl.

SARGOLAENA, Thou. (Chlaenac.). - Ind. Kew.

\section{ii 804}

codonochlamys, Baker, in Kew Bull. (1S93) 11. Madag

diospyroidea, Baill. in Bull. Soc. Limn. Paris, i. (1886) 565 : et Hist. pl. Madag., Atlas (1889 t. 100. - Madag.

Grandidieri, Baill. ll. cc.565 ; ot t. 99. - Madas.

pilosa, Baill, in Bull. Soc, Linn. Paris, i. (1S86) $505=$ Xerochlamys pilosa, Baker.
SARcolobUS, R. Br. (Asclep.). - Ind. Kew. ii. 805 .

ciliolatus, $W$ arb. in Bot. Fa7wb. xiii. (1891) 408. N. Guin.

retusus, $K$. Schum. in Engl. \& Prantl, Natürl. Pfanzonfam. iv. 2. (1895) 285. - N. Gliin.

SARCOPODIUM, Lindl. = Bulbophyllum, Thon. (Orchid).

Godseffamm, Sander, ex Gard. Chron. (1890) ii. so0, nomen, - Hab.?

SARCOPTERYX, Radlk. (Sapind.), - Ind. Kew. ii. 804 .

brachyphylla, Radlk. 2n Sitzb. Math-Phys. Munch. xx. (1890) 265. - N. Guin.

holconeura. Radlk. l. c. 266. - N. Guin.

SARGOSPERMA. Hook. f.(Sapot.), - Ind, Kew. ii. 804 .

pedunculatum, Hensl. in foum. Linn. Soo. xxvi (1890) 68 [pedunculata]. - China.

SARCOSTEMMA, R. Br. (Asclep.). - Ind. Kew: ii. 804 .

acidum, K. Schum. in Engl, \& Prantl, Natürl Pflanzenfam, iv, 2(1895) $256(=\mathrm{S}$. acidum, Voigt) $=$ brevistigma, Wight \& $A$ rnt

carpophylloides, Morong, in Am. N. Y. Acad. Sci. vii. (1893) 165. - Parag

SARCOTHEGA, Blume (Lineae), - Ind. Kew. paniculata, Ridl, in Trans. Iinn. Soc. Ser. II. iii. (1893) 282. - Penins. Mal.

SARCOTHECA, Kuntze, Rev. Gen. (I891) 979 sphalm. = SAROTHECA. Nees = Justicia Linn. (Acanth.)

scabra. Kuntze, 1. c. = Aphelandra pectinata Willd.

SARGENTIA, S. Wats, in Proc. Am. Acad. xxv. $(1890)$ 144. RUT $A C E A E$

Greggii, S. Wats. l. c. - Calif.

Pringlei, S. Wats. l. c. xxvi. (1891) 134. - Mexic

SARIBUS, Rumpf. = Livistona, R. Br. (Palm.). Hasseltii, Hoogendorpii, humnlis, incrmis, Kingiamus. papuamis, rotundifolins, speciosus, Kuntze, Rer. Gen. (1891) $736=$ homonyma ommia Livistonae.

fenkensii, Kuntze, 1. c. = Livistona Jenkinsiana Griff.

Mariae, Kuntze, 1. c. = L. humilis, $R \cdot B r$ ?

SAROTHAMNUS, TVimm. = Cytisus, Linn. (Lerumin.)

Dieckii, Lange, in Danske Vidensk. Selsk. Forh. (1893) $202-$ Hisp.

glancus. St Lager, in Cariot, Étud. des fl. éd. 8, ii (1889) $159=$ Cytisus purgans, Spach.

SARRAGENIA, Linn. (Sarrac.), - Ind, Kew. ij. 806 .

Atkinsoniana $\times$, Hart. ex Nichols, Gard. Dict. iii (1886) 364. - Hybr, artef.

decon $\times$ X. Hort. ex Gard. Chron. (1889) ii. 250. Hybr. artef,

excellens X. Hort. ex Nichols. Gard. Dict, iii. (1886) 363. - Hybr. artef.

exornata $X$. Hort. ex Nichols. 1. c. - Hybr. artef.

exsculta $\times$, Hort, ex Nichols. 1. c. - Hybr, artef.

Fildesi, Hort. ex Nichols. 1. c. 363 = flava, Linn.

illustrata $X$. Hort. ex Nichols. 1. c. 364 : et ex Gard. Chron. (1889) ii. 81. - Hybr. artef.

Maddisoniana X, Hort. ex Nichols. Gard. Dict. iii. (1886) 364; et ex Gartenfl. xxxvi. (1887) 399 : et ex Gard, Chron. (1889) ii. 81 [an seq.?]. - Hybr. artef.

melanorhoda $X$. Hort. ex Nichols. 1. c. 365.Hybr. artef.

Mesoniana $\times$, Hort. ex Gard. Chron. (1889) ii. 81. - Hybr. artef. 
SARRACENIA

Ifitchellacna X Hort. ex Nichols. Gard. Dict. iii. (1886) 365; et ex Gartenfl. xxxvi. (1887) 398 [an praec.?]. - Hybr, artef.

Patersoni X. Hort. ex Nichols. 1. c, ; et ex Gard. Chron. (1889) ii. 81, - Hybr, artef.

Swaniana Y. Hort. ex Nichols, Gard, Dict. iii. (1886) 366. - Hybr. artef.

Iolliana $\times$. Hort. ex Nichols. 1. c. ; ct ex Gartenfl. xxxvi. (1887) 398. - Hybr. artef.

IVrigleyana $X$, Hort. Veitch, ex Gartenfl. xxxvi. (1887) 398, et ex Gard. Chron. (1889) 495. Hybr. artef

SARUMA, Oliver, in Hook. Icon, pl. xix. (188, 9 ) t. IS95. ARISTOLOCHIEAE.

Henryi, Oliver, l.c. - China.

SASSAFRAS, Linn. (Laurin.). - Ind, Kew, ii. 806

Sassafras, Karst. Pharm.-Med. Bot. (1882) 505 Sudworth, in Gard. and For. iv. (1891) 146 = officinale, Nees \& Eberm.

raviifolium, Kuntze, Rev. Gen. (1891) 5 r4 = officinale, Nees \& Eberm.

SATUREJA, Linn. (Labiat.). - Ind. Kew, ii 806.

filiformis, Ces Passer. \& Gibelli. Comp. Fl. Ital. ii. (1886) 302. - Corsica.

garganica. Briq. Lab. Alp. Marit iii. (1895) 421 [Satureia] = graeca, Linn.

olympica, Halácsy, ex Wettst. in Oest. Bot. Zeit schr. xl. (1890) 40, in syn. = pisidica, Wettst.

pisidica, Wettst.l.c. ; et in Sitz. zool.-bot. Ges. Wien xcviii. $1889(1890) 374$ t. 3, fir. 13-16. - As, Min. rumelica, Velen. Fl. Bulg. (1891) 466. - Rumel.

sphaerophylla, Briq. in Bull. Herb. Boiss. ii. (1894) 134 (= Micromeria sfhacropliylla, Baker). Madag.

thynoides, Ces, Passer. \& Gibelli, Comp. F1. Ital, ii. $(1886) 302=$ Micromeria thymoides, De Not

SATYRIUM, Linn, (Orchid.). - Ind. Kew, ii 807 .

chlorocorys, Reichb. f. ex Oliver, in H. Folnston. Kilim. Exped. Append. (1886) 346 : et in Trans. Linn. Soc. Ser. II. ii. (188i) 50, nomen. - Afr. trop.

crassicaule, Rendle, in fourn. Bot. xxxiii. (1895) 29\%. - Afr. trop. occ.

debile, Bolns, in fourn. Linn. Soc. xxv. (1885) 67 - Afr. austr.

emarcidum, Bolus, l. c. - Afr. austr.

gigas, Ridl. l. c. xxi1. (1886) 126. - Madag.

Guthriei, Bolns, Icon. Orchid. Austro-Afr. i. I (1893) t. 21; Rolfe, in Orchid Rev. i. (1893) 269 - Afr. austr.

longebracteatum, Rolfe, in Bolet. Soc. Brot. vii. 1889) 238. - Angola.

Mechowianum, Kraenzl. in Bot. Fahrb. xvii. (1893) 65. - Angola.

microrrhynchum, Schlechter, l. c. xx. Beibl. n. 50 (1895) 14. - Afr. austr.

neglectum, Schlechter, l. c. 15. 39. - Afr. austr.

niloticum, Rendle, in foum. Bot. xxxiii. (1895) 296. - Afr. trop. or

ccellatum, Bolus, Icon. Orchid. Anstro-Afr. i. I (1893) t. 23. - Air. austr. et austro or.

ochroleucum, Bolus, in Fourn. Limn. Soc. xxii. 1S85) 66 - Afr, austr.

pallidiflorum, Schlechter, in Bot. Fahrb. xx. Beibl. n. 50 (1895) 15. - Austr.

paludicola, Schlechter, l. c. 3\%. - Afr. austr.

Princeps, Bolus, in Hook. Icon. pl. xviii. (1888)t 1729 = membranaceum, Sw

Wondii, Schlechter, in Bot. Fahrb, xx. Beibl. n 50. (1S95) 16. - Afr. austr.

SAURAUJA, Willd. (Ternstroem.). - Ind. Kew. ii. 808 .

actinidiifolia, Stapf, in Trans. Limn. Soc. Ser. II. iv. (1894) 135. - Borneo.

amoena, Stapf, l.c. 134. - Borneo.

bifida, Warb. in Bot. Fahrb. xiii. (1891) 380. - N. Guin.

\section{SAURAUJA : -}

bullosa, Wavre in Mart. Fl. Bras, xii. I (1886) 286. - N. Granat.

conferta, Warb. in Bot. Fahrb. xiji. (1891) 379. N. Guin.

Lehmannii, Hieron. 2. c. Beibl, n, 49(189.5) 47. [Sauratia]. - Ecuad.

Oldhami, Hemsl. ex Forb. \& Hens?. in fourn. Lim. Soc. xxiii. (1866) 79. - Formosa.

polyantha, Gitg, in Engl. \& Pranti, Natiur. Pflanzenfam. iii. 6 (1893) 128. [Saurauia]. - CostaRica.

Rusbyi, Brition, in Bull. Torrey Bot. Club, xvi. (1889) 64. - Boliria.

SAUROPUS, Blume (Euphorb.) - Ind. Kew. i1. 809

concinnus, Collett \&o Hemsl. in fourn, Linn, Soc. xxviii. (1890) 12:3 t. 18. - Burma.

forcipatus, Hook, f. Fl. Brit. Ind, v, (1885) 334. Perak.

lanceolatus, Hook. f. l. c. $3333 .-$ Reg. Himal

macrophyllus, Hook. f. l. c. - Reg. Himal.

oblongifolius, Hook, f. l. c. - Reg. Himal.

pubescens, Hook. f. l. c. 3355 . - Rer. Himal.

stipitatus, Hook. f. l. c. 3333. - Reg. Himal,

SAUSSUREA, DC. (Compos.). - Ind, Kew. ii. 810. alatipes. Hemsl-in fourn. Linn. Soc. xxix. (1-92) 30s. - China. occ.

amblyophylla, C. Winkl, in Act. Hort. Petrop, xiii. 1894;244. - Tibet

Aster, Hemsl. in foum, Linn, Soc. xxx. (1594) 115. t. 5. - Tibet.

auriculata, Franch, un Nouv. Arch. Mus. Paris. Sér.

II. x. (1S88) 40, - Tibet.

auriculata, Hemsl. in foum, Linn, Soc, xxix, (I892)

308. - China occ

canescens, C. Winkl. in Act. Hort. Petrop. xi. (1889) 168. - Turkest.

carduiformis, Franch, in Morot, fonm, de Bot. viii.

(1994) 343. - China.

caudata, Franch inz Bull Soc Phil. Paris, Sér.

Vill. iii. (1891) ] 47. - China occ.

chetchozensis, Franch, in Morot, Fourn. de Bot, ii. (1888) 359. - China occ

hondrilloides, C. Winkl. in Act. Hort. Petrop. xi 1889) 169. - Turkest.

ciliaris, Franch, in Morot, foum. de Bot. ii, (1888) 357 - China.

cirsioides, Hemsl, in foum, Linn. Soc xxix, (1892) 309. - China occ

colorata, C. Winkl. in Act. Hort. Petrop. xi. (1889)

167. - Turkest.

conyzoides, Hemsl, in fonrn. Linn. Soc. xxix. (189?) 309 - China occ

corditolia, Hemst. l. c. 312. - China ccc.

dealbata, Collett \& Hemsl. l. c. xxviii. (1890) 76. Afghan.

decurrens, Hemsl. in Hook. Icon. pl. xviii. (1888) t,

1735. - Reg. Afghan.

decurrens, Hemsl. in Foum. Limn. Soc. xxix. (1892) 310. - China occ.

Delavayi, Franch. in Morot, foum, de Bot. ii. (1888) 355. - China occ.

dimorpha, Franch.l.c. viii. (1894) 340. - China

dzeurensis, Franch. l, c. 339. - China occ

edulis, Franch. 1.c. ii. (1888) $337=$ Jurinea edulis, Franch.

eriocephala, Franch. l. c. 329, - China occ

Famintziniana, Krassn, in Script. Univ, Petrop. ii. I. (1887-88) 17. - China.

Fargesii, Franch, in Morot, Fourn. de Bot, viii. (1894) 344. - China occ.

flexuosa, Franch. l. c. 341. - China. occ.

Gilesii, Henusl. in Hook. Iron. pl. xviii. (1888) t. 1736. - Reg. Afghan.

rosseserrata, Franch, in Morot, Foum, de Bot. ii. (1888) $311,354 .-$ China occ

Henryi, Henst, in fourn. Linn. Soc xxix. (1892) 311. - China occ

Koslowi, C. Winkl. in Act. Hort. Petrop. xiii. (1894) 241. - Tibet.

Kuschakewiczii, C. Winkl. l. c. ii. (1889) 170. Turkest.
SAUSSUREA

lamprocarpa, IIcmsl. ex Forb. \& Hemsl, in foum Limn. Soc. xxiii. (1888) 465, -- China.

apatifolia, G. Beck, Fl. Nied.-Oest.

1252 , in $\operatorname{syn} .=$ discolor,$D C$.

Larionowi, C. Winkl. in Act. Hort Petroh xi, (1891 376. - Turliest.

leptophylla, Hemsl. in Hook. Icon. pl. xviii. (18s8 t. 1734. - Reg. Afghan.

likiangensis, Franch. in Morot, foum. de Bot. 18s8) 356 . - China

longifolia, Franch. l. c. 354, - China.

macrota, Franch. i.c. viii. (1894) 343. - China

microcephala, Hemsl. ex Forb. E. Hemsl. in foum Linn. Soc. xxiji. (18S8) 466. - China.

minuta, C. Winkl. in Act. Hort. Petrop. xiii. (1894 243 - China.

mollis, Franch, in Morot, fomm de Bot, viii, (1S94) 353. - China occ.

nobilis, Franch. l. c.3.54. - China occ.

pachyneura, Franch.l.c. - China

pamirica, $C$. IV inlu. in
(18S9) 171. - Turkest.

peduncularis, Franch, in Morot, Foum de Bot.

(ISSS) 35\% - China Occ.

phyllocephala, Collett \& Henst, in foum. Limn. Soc. xxviii. (1890) 76. - Afghan

populifolia, Hensl. l. c. xxix. (1892) 311. - China.

prostrata, C. IVinkl, in Act. Hort. Petrop. ix. (1886) 518. - Turkest.

pulviniformis, C. Winkl. I. c. xi. (1891) 3i. Turkest.

pumila, C. Wink7. l. c. xilii. (1894) 244. - Tibet.

radiata, Franch. in Merot, fonrn. de Bot. ii. (1888)

3.57. - China oce

romuleifolia, Francti. l. c. 339. - China, occ.

rupestris, Homsl. \& Lace, in fourn. Limn. xxviii. (1891) 325. - Belutch. brit

Russowi, C. Winkl. in Act. Hort. Petrop. ix. (1886 423. - Turkest.

saligna, Franch, in Morot, Fourn. de Bot. riji

(1894) 345. - China occ.

Salemanni, C. Winkl, in Aot. Hort. Petrop. 1889) 166. - Turkest.

scabrida, Franch. in Bull. Soc. Phil. Paris, Sér.

VIII. jii. (I891) 146. - China occ.

semilyrata. Bureau of Franch. in Morot, Fourn. de

Bot. v. (1891) 76. - China occ.

Souliei, Franch, in Bull. Soc. Phil. Paris, Sér. VIII. iii. (1891) 14\%. - China occ.

spatulifolia, Franch, in Morot, Fourn, de Bot, ii. (1858) 338. - China occ.

stricta, Franch. l. c. viii. (1894) 342,-China

sutchuenensis, Franch. 7. c. 353. - China occ.

tatsienensis, Franch, in Bull. Soc. Phil. Paris. Sér. VIII. iii. (1891) 148. - China occ

thibetica, Franch. in Mornt, foum. de Bot, viji. (1894) 338. - China. occ.

Thoroldi, Hemsl. in fourn. Limm. Soi. Xxx. (1894)

115 , t. 4, fig. 5-9. - Tibet.

tibetica, C. Winkl. in Act. Hort. Pelrop. xiii. (1894) 242. - Tibet.

vestita, Franch, in Morot, foum. de Bot. ii. (1888) 358. - China occ

villosa, Franch. l. c. 33.5.) - China occ.

virgata, Franch. l. c. 340. - Yunnan.

Woodiana, Hemsl. in fomm. Lim. Soc. xxix. (189?) 312, - China occ.

yesoënsis, Franch. in Bull. Soi. Philon. Paris, Sér. VII. xii. (1888) 88. - Japon.

yunnanensis, Franch. in Morot, Foury. de Bot. ii. (1888) 340. - Yunnan.

SAUSSUREA, Salisb. = Funkia, Spreng. (Liliac.) cocrulea, Kuntze, Rev. Gen. (1S91) $714=$ F, ovata Spreng.

japonica. Kuntze, 1, c. = F. ovata, Sprong.

plantaginea, Kuntze, 1. C. = F. subcordata, Spreng

Sieboldiana, Kuntze, 1. c. = F. Sieboldiana, Hook

SAVASTANA, Schrank = Hierochloë, S. F Gmel. (Crramin.)

alpina, Scribn. in Mem. Torrey Bot, Club, (1894) $34=$ H. alpina, Roem. E Schult. 
SAVASTANA :-

dorata, Scribn. in Mem. Torrey Bot. Club, v. (1894) $34=$ Hierochloë borealis, Roem. \& Sclinglt.

panciflorn, Scribn, 1. с. $353=\mathrm{H}$. pauciftora, $R, \mathrm{Br}$.

SAVIA, Willd. (Euphorb.). - Ind. Kew. ii. S11.

Hildebrandtii, Baill. Hist. pl. Madag. Atlas (1892) t. 209. - Madas

nblongifolia, Baill. l. c. t. 208. - Madag.

revoluta, S. Elliot, in foum, Linn. Soc. xxix. (1891) 45. - Madas.

SAXIFRAGA, Tourn. ex Linn. (Saxirf.), - Ind, Kew, ii. 812.

tliciana, Rouy fo Coincy, Eclog. plo Hisp. (1893) 12 t. 4. - Hisp

Allionii, Terrac. in Bull. Soc, Bot. Ital. (1892) 185. [sp. coll.]. - Eur.

apiculata X. Engl. in Gard. Chron. (1894) i. 5526. fig. 68. - Hybr. artef.?

aplophylloides. Franch.Pl. Delav, (1890) 238.Yunnan.

aurantiaca, Franch. l. c. 236, t. 51b. - Yunnan.

baborensis, Batt. in Bull. Herb. Boiss, i. (1893) 550 ; et Allas Fl. Algér. (1895) 28, t. 20. Algeria.

Blavii, G. Beck, in Annal, Naturh. Hofmus, Wien, ii. $(1887193=$ adscendens, Linn

Boydi $X$, Dewar, in The Garden, xxxviii. (1890) 10. - Hybr. spont

brachyphylla, Franch. Pl. Delav. (1890) 237.China. Occ.

Cucblandi $x$. Hort, ex Stein, in Gartenfl. xxxy. (1886) 306. - Hybr, artef.

californica, Greene, Pittonia, i. (Apr. 1839) 286 : ct Man. Bot. San Franc. Bay (1894) 120. Calif.

Candelabrum, Franch, Pl. Delav. (1890) 232, t. 48. - Yunnan.

cardiophylla, Franch. in Nouv. Arch. Mus. Paris, Sér. II. viii. (1886) 230. - China. occ.

arniolica, Huter, ex A. Kern. Sched. Fl. AustroHung. v. (1888) 52. - Austria.

carpathica, Terrac, in Bull. Soc. Bot, Ital. (1892) 133. - Reg. Carpat, Monten.

caucasica. Somm. E Lcrier, in Bull. Soc. Bot. Ital. (1893) 525 ; et in Act. Hort. Pctrop. xii. (1894) 188. - Reg. Cauc.

cernagorica, Terrac, in Bull. Soc. Bot. Ital. (1892) 134. - Monten.

chrysantha, Franch. Pl. Delav. (1890) 236, t. 50b. - Yumnan.

cintrana, Kuzinsky, ex Willk. in Oest. Bot. Zcitschr. xxxix. (1889) 318. - Lusit.

colchica, Alboff, Prodr. Fl. Colch. (1895) 96. - Reg. Cauc.

columnaris, Schmalh. ex Akinficw, in Bull. Soc. géugr. Canc. (1892) 186 [Fl. Canc. contr. (1894) 21.]. t. 17, fig. 8-18; et in Ber. Dentsch. Bot. Ges. x, (1892.). - Reg. Cauc.

comosa. Britton, in Mem. Torrey Bot. Club, v. (1894) $178=$ foliolosa, $R . B r$

crinalis, Franch. Pl. Delav. (1890) 233. - Yunnan. Davidi, Franch, in Nouv. Arch.Mus. Faris, Sér. II viii. (1886) 229. - Tibet

delphinensis, Ravaud. Guid. bot. Dauph.6e excurs. p. 23 ; et in Bull. Soc. Dauph. xvi. (1889) 634 = pubescens, Pourr.

Dinniki, Schmalh, ex Akinfew, in Bull. Soc. géogr. Cauc. (1892) 185 [Fl. Cauc. centr. (1894) 20]; et in Ber. Deutsch. Bot. Ges, x. (1892) 288, to 18, fig. 6-7. - Reg. Cauc

lrabaeformis, Franch. Pl. Delav. (1890) 235. t. 59b. - Yunnan.

Finglevi X, Hort. ex Gartenfl, xxxix. (1890) 649. Hybr. spont.

flabellifolia, Franch. in Morot, foum. de Bot. viii. 1894) 295. - China. occ.

laucophylla, Franch. Pl. Delav. (1890) 239, t. 53a. - Yunnan.

Grayana. Britton, in Mem. Torrey Bot. Club, v. (1894) $178=$ caroliniana, A. Gray.

Ilaussknechtii X. Stein, in Gartenfl. xxxv. (1886) 306. - Hab?

\section{SAXIFRAGA}

Hochstetteriana, Lange, ex Nym. Consp. Fl. Eur. Suppl. ii. I. (1889) $132=$ granulata, Linn.

Howellii, Greene. Pittonia, ii. (July 1891) 163. Oregon.

Hugucnini, Bruegg. in Gartenfl. xxxv. (1886) 486 t. $1230 \mathrm{~b}=$ aspera, Lmn.

Kerneri X, G. Beck, in Deutsche Bot. Monatsschr vii. (1889) $11 \%$ - Eur, or.

ledifolia, Greene, Pittonia, ji. (June 1890) 101. Calif.

longistyla, Frauch. in Bull. Soc. Philom. Paris, Sér. VIII. iii. (1891) 144. - Tibet.

Mlac Nabiana X,Hort. ex Gartentl. xxxv. (1886) 306 et in Gard. Chron. (1889) ii. 295. [Macna biana]. - Hybr. artef

macrostigma, Franch. Pl Delav, (1890) 240, t. 52a. - Yunnan

madida, Makino, in Tokyo Bot. Mag. vi. (1892) 52. - Japon.

Marshallii, Greene, Pittonia. (Jan. 1888) 159. Calif.

Michauxi, Britton, ex Small \& Vail, in Mem. Torrey Bot. Club, iv. (1894) 118 (= S. lewcanthemifolia. Michx) - Virginia.

micranthifolia, Britton, Stern \& Pogg. Prelim Catal. (1888) $17=$ erosa, Pursh.

montavonicnsis, A. Kern. ex Gartenfl, xxxix. (1890) 649 ; et ex Ber. Dentsch. Bot. Ges, x. (1892) $[126]=$ S. Cotyledon, Limn.

nidifica, Greene, in Erythea, i. (1893) 222. - Calif occidentalis, S. Wats, in Proc. Am. Acad. xxiii (1888) 264. - Am. bor. occ.

oregana, Howell, in Erythea, iii. (1895) 34. - Am. bor occ.

Pachoriana $\%$ Wiesb, in Natur. und Offenbarung, xxxvi, (1891) 762. in Oest. Bot. Zeitschr. (1891 93 ; et ex Pacher, Nachtr. Fl. Karnt. (1894) I45, - Carinth

pallens X, Fritsch, in Verh. zool.-bot. Ges. Wien, xxxiv, (1889) 587. - Austria.

parva. Hentsl. in foum. Linn. Soc, xxx. (1894) 112 - Tibet.

pedata, Hort. ex Gartenfl. xxxy, (1886) 306 [nomen.]. - [Quid?

peplidifolia, Franch. Pl. Delav. (1890) 234. an.

petrophila, Franch.l. c. 237. - Yunnan.

pontica. Alboff, Prodr. Fl. Colch. (1895) 97. - As. Min

Portae, Stein, in Gartenfl. xxxv, (1886) 306. - Ital. mer.

prenja, G. Beck, in Annal. Naturh. Hofmus. Wien ii. (1887) 93 = sedoides, Linn.

Przewalskii, Engl, in Engl. \& Prantl, Natiirl. Pfanzonfam, iii. 2a (1891) 57. - China.

racenzosa Simonk. Enum. FI. Transs, (1886) 247 $=$ hieracifolia. Waldst. \& Kit.

Reyeri $\times$, Huter (Enum. pl. exsicc. Austr. 1873; ex A. Kern. Sched. Fl, Austro-Hung, v. (1888) 52 Pache', Nachtr. Fl. Karnt. (1894) 148. Carinthia.

rhaetica. A. Kern. Sched. Fl. Austro-Hung, iv. (1886) $29=\mathrm{S}$. Hostii, Tausch var

rhodopea, Velen. Fl. Bulg. (1891) 645, - Bulg.

Rigoi, Freyn, ex Porta, in Atti Accad. Agiati, ix. (1891-1892) extr. 26; Willk. Suppl. Prodr. Fl. Hisp. (1893) 209, - Hisp.

Rouyana, Magnier, Scrin。 fl. select. xii. (1893) 286 Willk. Suppl. Prodr. Fi. Hisp. (1893) 329. Hisp.

sanguinea, Franch in Morot, foum de Bot. viii. (1894) 295. - China. occ.

Sartorii, Holdr. ex Boiss. Fl. Or. Suppl. (1888) 348. - Graecia.

scleropoda, Sonm. \& Levier, in Bull. Soc. Bot. Yial. (1893) 526; et in Act. Hort. Petrop. xiii. (1894 186. - Reg. Cauc.

stellariaefolia, Franch. in Nonv, Arch, Mus. Puris, Sér. II. viii. (1886) 231, t. 7 fig. a. - Tibet. subalpina, Bruegg, in Jahresb. Nat. Ges. Graub. xxzi. Beibl. (1887-88) $69=$ stellaris, Linn.

tabularis, Henisl. ex Forb. \& Hemsl. in fourn. Linn. Soc. xxiii. (1887) 269, - China.

trinervia, Franch, in Now, Arch. Mus. Paris, Sér. II. viiì. (1886) 232. - Tibet.

\section{SAXIFRAGA}

Tozetta $X$, Hort, ex Engl, in Engl: \& Prantl, Natürl. Pflanzenfam. iii. 2a (1891) 58. - Hybr. artet.

tsangchanensis, Franch. Pl. Delav. (1878) 233 t. 5la. - Yunnan.

umbellulata, Greene, in Erythea, i. (1893) 222. Calif.

valentina, Willk, ex Herv, in Rev. gén. bot. (1892) 133, cum icc. ; t Suppl. Prodr. Fl. Hisp. (1893) 209. - Hisp

Watanabei, Yatabé, in Tokyo Bot. Mag. vi. (1892) 7 et 43, t. 2 ; et Iconn. Fl. Fapon. i. III. (1S93) 179, t. 44. - Japon,

Willkommii, Kuzinsky, ex Willk, in Oest. Bot. Zeitschr. xxxix. (1889) 318, in syn. = cintrana Kuzinsky.

SAXIFRAGELLA, Eng1, in Eng1. \& Prantl, Natürl. Pflanzenfam. iii. \&a (1891) 61. SAXIFRA. $G E A E$

bicuspidata, Engl. l. c. - Reg: Magell.

SAYERIA. Kraenzl. in Oest. Bot, Zeitschr, xlir (1894) 298. ORCIDEAE

paradoxa, Kraenzl. l.c. - N. Guin

SGABIOSA, [Tourn.] Linn. (Dipsac.) - Ind. Kew: il, 817

balcanica, Velen, ex Nym. Consp. Fl. Eur. Suppl. ii. I. - (1888) 159 ; et Fl. Bulg. (1891) 243. Bulgr

Bretschneideri, Batalin, in Act. Hort. Pctrop. xiv. (1895) 184. - China.

brevipora, Freyn, in Oest. Bot. Zeitschr. xliv. (1894) 145. - As, $\min$.

celtiberica, Pau, Not. Bot. Fl. Espan. iii. (1859) 30, nomen. - Hisp

Correvoniana, Somm. E Levier, in Act. Hort. Petrop. xii. (1892) 152, - Rer Cauc.

Djurdjurae, Chab. in Bull. Soc. Bot. Fr. xxxvi. (1559) 26 ; Debeaux, in Rer, de Bot。 xi. (1893) 177 . - Algeria

dalmatica, Huter \& Kern. ex Freyn \& Brandis, in Verh, zool.-bot, Ges, Wien, xxxviii, (1885) 610 = leucophylla, Borb.

dubia, Velen. Fl. Bulg. (1891) 243. - Bulg.

epirota, Haláczy \& Baldacci, b. c. xlii. 1892 (1893) 577. - Albania.

arinosa, Coss. in Compt.rend. Acad. sci. xcviii. (1884) 468 ; ct Ill. Fl. Atlant. ii. (1893) 58, t. 134 . - Tunetia.

incana, Freyn, ex Freyn \& Brandis. in Verh. zool.-bot. Ges. Wien, xxxviii. (1888) $610=$ leucophylla. Borb.

garganica, Porta \& Rigo, ex Wettst. in Lucrss. Bibl. Bot. Heft xxvi. (1892) 67, t, 4 fig. 1 et 2. Albania.

incanescens, Freyne, ex Conrath, in Oest. Bot. Zeitschr, xxxvii. (1887) 382. - Bosnia

lencoplyylla, Borb. ex Oest. Bot. Zeitschr. xxxviii. (1888) 345 = gramuntia, Linn.

kurdica, Post, Pl. Postianae, iv. (1892) T. - As. Min.

Tucidula X. G。'Beck, Fl. Nied.-Oest, ii. (1893) 1150. - Austria

montana, Batt, in Batt. Eo Trab. Fl. de l'Algér. [Dicot.| (1889) 417 (= Pycnocomon montanum, Pomel) - Algeria

Olgae, Alboff, in Bull. Herb. Boiss. ii. (1894) 453.Reg. Cauc.

psilophylla $\times, G$ Beck, Fl. Nied.-Oest. ii. (1893) 1150. - Austria.

ufescens, Frcyn Eo Sint, in Oest. Bot. Zeitschr. xlii. (1892) 167. - Armen, turc.

silaifolia, Velen. Beitr. Fl. Ost.-Rumel. und Butg. (1886) 19; et Fl. Bulg. (1891) 244. - Bulg.

subalpina, Bruegg. in Jahresb. Nat. Ges. Graub. xxxi، Beil. (1887-88) $82=$ S. Columbaria, Linn. thracica, Velen. Fl. Bulg. (1891) 246. - Bulg

turolensis, Pau, Not. Bot. Fl. Espan. i. (1887) 20 ; et Willk. Suppl. Prodr. Fl. Hisp. (1893) $74=$ tomentosa, Cav

virescens, Freyn, ex Freyn \& Brandis, in Verh. zool.-bot. Ges. Wien, xxxviii. (188s, $610=$ leucophylla, Borb. 
SGAEVOLA: Linn. (Goodenov.), - Ind, Kew. ii.

826.
Beckii, Zahlbr, in Annal, Naturh. Hofmus. Wien, iii. (1888) 281, t. 13 fig. 1. - N. Caled.

cylindrocarpa, Hillebr. Fl. Haw. Isl. (1888) 268. Ins. Sandvic.

novo-guineensis, K. Schum, in Bot. Fahrb. ix. (1887) 222. - N. Guin.

procera, Hillebr. Fl. Haw. Isl. (1888) 268. - Ins, Sandvic.

scandens, F. M. Bailey, Rep. Exped.Bellenden-Ker (1889) 47; et Syn. Qucensl. Fl. Suppl. iii. (1890) 43. - Austral.

SGALESIA Arn. (Compos.). - Ind. Kew, ii, 821. Baurii, Robinson of Greenm. in Am. Fonm. Sci. Ser. III. 1. (1895) 141. - Ins. Galap.

SCALIA, Sims = Podolepis, Labill. (Compos.). aristata, canescens, gracilis, Lessonii, longipedata, microcephala, mutans, pallida, nugata, Kuntze, Rev. Gen (1891) $361=$ homonyma omnia Podolepidis. ä̆achnodea, Kuntze, 1. c. = P. rytidochlamys, $F$. Muell.

capillaris, Knntze, 1. c, = P. Siemssenia, F. Muell.

SCALIGERIA, DC. = Conopodium, Koch $(\mathrm{Um}$ bell.

allioides, Boiss, Fl. Or. Suppl. (1888) $25.5=$ C. allioides, Regel \& Schimalk.

capillifolia, Post, in Journ. Linn. Soc. xxiv. (1888) 428 ; Boiss. 1. C. - Syria.

Hermonis. Post, in Bu\}l. Herb. Boiss. i. (1893) 399. - Syria.

SCANDIX, Tourn. ex Linn. (Umbell.). - Ind. Kew, ii. 821.

eriocarpa, Stapf \& Wettst. ex Stapf, in Denkschn. Akad. Wien, ii. (1886) 29. - As. Min.

SCAPHIUM, Schott \& Endl. = Sterculia, Linn. affine. Pierre, Fl. For. Cochinch. Fasc. 13 (1889) sub t. $193-95$, in text. $=\mathrm{S}$. affinis, Mast.

Beccarianum, Pierre, l. c. t. $195 \mathrm{c}=\mathrm{S}$. Beccariana [Beccarianum], Pievre.

linearicarpum, Pierre, 1. c. sub t. $193-95$, in text. =S. linearicarpa, Mast.

lychnophormm, Pierre, 1. c. sub t. 193-95, in text. = S. lychnophora, Hance.

SGAPHOGHLAMYS, Baker, in Hook. f, Fl. Brit Ind. vi. (1892) 252. SCITAMINEAE.

malaccana, Baker, l. c. - Malacca.

SGAPHOGLOTTIS, Poepp. \& Endl. (Orchid.). - Ind. Kew. ii. 822

longicaulis. S. Wats. in Proc. Am. Acad. xxiii. (1888) 280. - Guatem.

SCAPHOSEPALUM, Pfitz. in Eng1. \& Prantl Naturl. Pflanzenfam. ii. 7 (1S88) 139. ORCHI$D E A E$.

anchoriferum, Rolfe, in foum, Bot. xxviii. (1890) 136 (= Masderallia anchorifera. Reichb. f.); et in Gard. Chron. (1890) i, 709. - Costa-Rica.

antenniferum, Rolfe, in Gard. Chron.(1890) i. 709. - Hab. ?

breve, Rolfe, in foum. Bot. xxviii. (1890) $136(=$ Masdevallia brevis, Keichb. f.). - Guian. brit.

gibberosum, Rolfe, l.c. (= M. gibberosa, Reichb. f.). - N. Granat.

macrodactylon, Rolfe, l. c. $(=M$. macrodactyla, Reichb. f.). - N. Granat.

microdactylum, Rolfe, in Ken Bull. (1893) 335. Hab. ?

ochthodes, Pfitz. in Engl. \& Prantl, Natürl. Pfan zenfam. ii. 6 (1888) 39 (= Masdevallia ochthodes, Reichb, f.). - N. Granat.

pulvinare, Rolfe, in Fourn. Bot. xxviii. (1890) 137

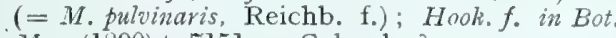
Mag. (1590) t. 7151. - Columb. ?

punctatum, Rolfe, l.c. $(=M$. punctata, Rolfe $)$. N. Granat?

swertiaefolium, Rolfe, l. c. (=M. swertiaefolia, Reichb. f.). - N. Granat.

\section{SCAPHOSEPALUM :}

verrucosum, Pfitz. in Engl, \& Prantl. Natiunt. Pfanzenfan, ii, 6 (1888) 139 (= Plcurothallis zervucosa, Reichb. f. ). - N. Granat.

SCELOCHILUS, Klotzsch (Orchid.). - Ind. riculatus, Reichb. f. in Flora, 1xix. (1886) 551. Am, trop. ncc. Am. trop. Doc, in Kew Bull. (1895) 284. - Am. austr. andina.

variegatus, Cogn. in fourn. des Orchid. vi. (1895) 268: et un Lindenia, xi. (1895) 26. - Columb.

SGHEDONNARDUS. Steud. (Gramin.). - Ind. aniculatus, Ball1. Hist. des pl. xij. (1894) $265=$ seq.

paniculatus, Trelease, Branner \& Coville, ex Branner, in Rep. Geol. Surv. Ark. iv, 1888 (1891) $236=$ texanus. Stend.

SGHEELEA, Karst. (Palm.) - Ind. Kew, ii. 823

amylacea. Barb. Rodr. Pl, nor. Fard. bot. Rro, Fasc. i. (1891) 17, t. 5, 6. - Bras.

excelsa, Barb. Rodr. 1. c. 30, t. 9, fig. a, 1-8; et iv. (1894) 24 = osmantha, Barb. Rodr.

Leandroana, Barb. Rodr. l. c. 19 , t. 5,7 fig. b. - Kras.

osmantha, Burb. Rodr. l. c. Fasc. iv. (1894) 24 (= S. excelsa, Barb. Rodr. - - Bras,

Unguis, Nichols. Dict. Gard .iii. (1886) 385. - Am. trop.

SCHEFFERELLA, Pierre, Not. bot. Sapot. (1890) 4 = Payena, A. DC. (Sapot.).

Bawnu, Pierre, 1. c. $=$ P. Bawun, Scheff.

SCHEFFLERA, Forst. (Aral.). - Ind. Kew, ii. 82.

abyssinica, avensis, Baikici, Barteri, biternatum, Cephalotes, Cumingii, elatum, ellipticum, emaginatum, fimbriatum, heterophyilunu, hypolencum, impressum. insularum, funghuhnianum, Mannii, octophylhum, petiolosum, racemosum, rigidum, rostratum, tomentosum, vemulosun, Wallichianum, Harms, in Engl. \& Prantl, Natiirl, Pflanzenfam. iii. 8 (1894) 36-38 $=$ homonyma omnia Heptapleuri.

actinophylla, Harms, l.c.36 = Britssaia actinophilla, F. Muell.). - Austral.

acuminata; Harms, l. c. $(=$ Sciadophyllun acumina tumn, Poir.). - Peruv.

angulata, Harms, l.c. $(=S$. angulntum, Poir. $)$. Peruv.

aromatica, Harms. l.c. $38(=$ Agalma aromaticum, Seem.) - Java.

Belangeri, Harms, l. c. 3\% (= Sciadophyllum Belangeri, El. March.). - Martinica.

capitata, Harms, l. c. 36 (= Brassaia capitata, C. B. Clarke). - Reg. Himal, , Burm

confusa, Harms, l. c. 37 (= Sciadophylhum confusum, El. March.). - Reg. Amaz.

conica, Harms, l. c. 36 ( $=$ S. conicum, Poir.). Peruv.

coriacea, Harms, l.c. 3 T $(=$ Orcopanax coriacenm, Decne \& Planch. .. - - Guian. brit.

decaphylla, Harms, l.c. $37(=$ Sciadophyllum decaphyllum, Seem.). - Guian. gall.

ferruginea, Harms, l. c. 36 (= S. ferrugineum, Decne). - Peruvia.

glauca, Harms, l. c. 38 (= Heptapleurun elatum, Hiern). - Afr. trop.

Goetzenii, Harms, in Engl. Pflanzenwe. Ost-Afr. A (1895) 134, nomen. - Afr. trop.

Hierniana, Harms, in Engl. of Prantl, Natiirl. Pfanzenfan. iii. 8 (1894) 38 (二 Heptaplenrim scandens, Hiern). - Kamerun.

Hookeriana, Harms, l. c. $(=$ Paratropia alata, Hook. f.). - Kamerun.

Horsfieldii, Harms, l. c. (= Agalma Horsfieldii, Seem.). - Java.

Humblotii, Harms, l. c. - Ins, Comor.

japurensis, Harms. l.c. (= Sciadophyllum japurense, Mart. \& Zucc.). - Bras.
SGHEF FLERA :

Karsteniana, Harms, in Engl. \& Prantl, Natium Pfanzenfam, iii. 8 (1894) 36 (= Sciadophyllum Kat stenianum, El, March.), - Venezuela.

Lehmannii, Harms, in Bot. Fahrb. xx. Beibl. n, 49 (1895) 69 , in obs. (= S, Lehmannii, Harms). Columb.

littoralis, Harms, in Engl. \& Prantl, Natiirl. Pfan. zenfam. iii. 8 (1894) 38 (= Parapanax littoralis. Miq.). - Sumatra,

macrostachya, Harms, l.c.36 $=$ Brassair macrostachya, Seem.), - N, Guin.

Mathewsii, Harms, l. c. $(=$ Sciadophyllum Mathowsii. Seem.). - Peruvia.

parasitica, Harms, l. c. $(=$ Actinomorphe humilis, Miq.). - Java, Sumatra.

patula, Harms, l. c. 37. - Bolivia.

pedicellata, Harmus, l. c. 37 (= Sciadophylhum pedicellatum. Poir.). - Peruvia

pentandra, Harms, l. c. $36(=$ S. pentandrinn, Poir. $)$ - Peruvia.

Planchoniana, Harms, l.c. $(=$ Sciadophyllum Plannchonianum, E. March.., - Ecuad.

polysciadia, Harms, in Engl. Pfanzenzw. Ost.-Afr. C. (1895) 297. - Afr, trop. or.

quindiuensis, Harms, in Engl. \& Prantl, Natïr. Pfanzenfam. iii. 8 (1894) $3 \%$ (= Sciadophyllum quinduense. DC.). - Columb.

rediviva, Harms, l. c. (= Agalma redivirzm, Seem.) - Borneo,

rugosa, Harms, l. c. (= Agalma nugosum, Miq ). Malaya.

samoensis, Harms, l. c. 39 (= Paratropia samocnsis A. Gray). - Ins. Samoens.

Sciadophyllum, Harms, l. c. 37. - Jamaica.

sessilis Harms. l, c. 36 $(=$ Brassaia sessitis, Seem. $)$ - Penins. Mal.

sphaerocoma, Harms, l. c. 37 (= Sciadophyllum sphaerocoma, Benth.). - Ins. Gorgona.

Sprucei, Harms, l. c. $36(=$ S. Sprucei, Seem. ). Peruvia.

stellata, Harms, l. c. $39(=$ Heptapleurum stellatzm Gaertn.). - Zeylan.

Trianae, Harms, . . c. 36 (= Sciadophylhum Trianae, Planch. \& Linden). - N. Granat.

Volkensii, Harms, l. c. iii. 8 (1894) 36, fig. 7. Afr, trop. or.

SGHENGKIA, K. Schum, in Mart. Fl. Bras, vi VI. (1859) 246; et in Engl. \& Prantl, Naturl Pflanzenfam. iv. 4 (1891) 3\% RUBIACEAE

Blumenaviana, K. Schum. ll. cc. 247; et 37. - Bras.

SCHICKENDANTZIA, Pax, in Bot. Jahrb, xi. (1889) 322, 336. AMARY LLIDEAE.

Hieronymi, $P a x$, l. c. - Reg. Argent.

SCHIEGKIA, Meissn. (Rhamn.). - Ind. Kew. ij. 824.

Congesta. Maury, in Morot, Journ. de Bot, iii. (1889 269, fig. $12=$ flavescens, MIaury.

flavescens, Mautry, l.c. - Am. austr. trop.

SGHIEDEA, Cham. \& Schlecht. (Caprifol.). -- Ind. Kew. ii, 824

hawaiiensis, Hillebr. Fl. Haw. Isl. (1888) 33.Ins. Sandvic.

lychnoides, Hillebr. 2. c. 36. - Ins. Sandvic.

Lydgatei, Hillebr. .. c. 34. - Ins. Sandvic.

pubescens, Hillebr. l. c.31 - Ins. Sandvic

salicaria, Hillebr. l. c. 33. - Ins: Sandvic.

SGHIMA, Reinw. (Ternstr.). - Ind. Kew. ii. 824. brevifolia, Baill. ex Stapf, int Hook. Ican pl. xxiii. (1893) t. 2264. - Borneo.

stellata, Pierre, ex Laness. Pl. util. Colon. Frane. (1886) 295 ; et Fl. For. Cochinih. Fasc. S (188i) t. 122, - Cochinch.

SCHIMPERINA. Van Tiegh. in Bull. Soc. Bot. Fr. xlii. (1895) $256=$ Loranthus, Linn.

anroena, Van Tiegh. 1. c. $25 \%=$ L. amoenus, Delile.

platyphylla, Van Tiegh. 1. c. = L. platyphyllus, Hoclist. 
SCHINUS, Linn. (Anacard.), - Ind. Kew, ii. 824.

diversifolia, Rusby, in Men. Torrey Bot. Club. iv. (1890) $2(6.6$ - Bolivia.

CHIVZAFRA, Kuntze, Rev, Gen. (1891) $234=$ Thamnea, Soland. (Bruniac.).

depressa, Kuntze, 1.c. $=\mathrm{T}$. depressa, Olicer.

gracilis, Kuntze, $1 . \mathrm{c}_{0}=\mathrm{T}$, gracilis, Oliver

hirtellit, Kuntze, 1. c. $=$ T hirtella, Oliver.

uniflura, Kuntze, 1. c. = T. uniflora, Soland.

SCHINZIELLA, Gilg, in Engl, \& Prantl, Natürl. Eflanzenfam iv 2 (1895) 74 GENTIANEAE. tetrasona, Gilg, l,c. (= Canscora tetragona, Vatke $)$. - Angola.

SCHISMATOGLADA. Baker (Rubiac.). - Ind. Kew. ii. 825.
tricholarynx, Bakw, in foum. Linn. Soc. xxii. (188i) 480. - Madag.

SCHISMATOGLOTTIS, Zoll, \& Mor. (Aroid.).

brevicuspis, Hook. f. Fl. Brit. Ind. vi. (1893) 537 . - Perak.

brevipes, Hook.f.l. c. 358 - Perah

Kurzii, Hook. f. l. c.539- - Pegu.

minor. Hook, f. l. c. 5338. - Perak.

mutata, Scortech. ex Hook. f.l.c. - Perak.

Scortechini, Hook.f.l.c. 537. - Perak.

SCHISTOGARPAEA, F. Muell, in Vict, NaturaIist. (Nar. 1891) 182. RHAMNEAE.

Johnsoni, F. Mucll. l. c. 1833. - Austral.

SCHISTOGARPHA, Less, (Compos.). - Ind. Liebmannii, Klatt, in Leopoldina, Heft xxiii. (1885) 146. - Mexic.

panicula'a, Klatt, ex Th. Dur. \& Pitt. in Bull. Soc. Bot. Belg, xxxi. 1892 (1593) श10 [Schistocarpa]; ei in fahrb. Hanb. Wiss, Anstult. ix. (1891) extr. 3. - Costa Rica.

pedicellata, Klatt, in Leopoldina, Heft xxiii. (188i) 146. - Mexic

SGHISTOCARYUM. Franch. in Bu1l. Soc. Linn. Paris, ii. (1891) 930. BORAGIVEAE

ciliare, Burean of Franch. in Morot, fourn. do Bot. (1891) 105. - China occ

myosotideum. Franch. in Bull. Soc. Linnt. Paris, ii. (1891) 930. - Yunnan.

oralifolium. Burean \& Franch. in itorot, Fourn. de Bot. v. (1891) 10.5. - China occ.

SCHIZACHYRIUM, Nees = Andropogon, Linn (Gramin.).

tenuiberbe, Munro, ex Hack, in DC. Monog. Phan. vi. (1889) 435, in syn. = A. tenuiberbe, Hack.

SGHIZANDRA, Michx, (Magnoliac.). - Ind.

Rarmorata, Nichols. Dict. Gard. iii. (1886) 383. Borneo.

SGHIZANTHUS, Ruiz \& Pav. (Solan.). - Ind.

albiflorus, Phil, in Anal. Unir. Chil, xci. (1895) 124. - Chili,

angustifolius, Phil. l.c 110. - Chili.

araucanus, Phil, 1. c. $121=$ S. Grahami, Gill.?

Diazi, Phil. 1. c. $122=$ retusus, Hook,

floribundus, Phil.l.c. 1i9. - Chili.

glandulifor, Phil. 1. c. 120 [glandulifera $]=$ alpestris. Porpp.

heterophyllus, Phil. l. c. I25. - Chili.

humilis, Phil. l. c. 118. - Chili.

laciniosus, Phil. l. c. 125. - Chili.

latifolius, Phil. l.c. 123. - Chili.

litoralis, Phil. I c. I18.-Chili.

tenuifolius, Phil. l. c. IIs. - Chili.

tenuis. Phil. l. c. 124. - Chill.
SGHIZOGARPUM. Schrad, (Cucurb.) - - Ind.

Kew, ii. S26.

guatemalense, Cogn. ex F. D. Smith. Enum. pl. Guatem. iii. (1893) 34; et in Coult. Bot. Ga\%. xx. (1895) 290. - Guatem.

Palmeri. Cogn. \& F. N. Rose, in Contrib. U.S, Nat Herb. i. (1891) 100. - Mexic

SCHIZOCASIA, Schott (Aroid.). - Ind. Kew, ii. 820

Regnieri, L. Linden \& Rodig. in Illustr. Hortic xxxiv. (1887) 1\%, t. 6; et ex Gard. Chron. (1888) ii. 328 , nomen. - Siam.

SGHIZOCHILUS, Sond. (Orchid.). - Ind, Kew.

Burchellii, Bolus, in fomm. Linn. Soc.xxv. (1889) 205 (= Brachycorythis Burcholli, Reichb. 1.). Afr. austr.

Gerrardi, Bolus, l.c. (= B. Gevrardi, Reichb. f. $)$ - Afr. austr.

SGHIZOCODON, Sieb. \& Zucc. (Diapens.). Ind. Kew. ii. 826 .

rotunditolius, Maxim, in Bull. Acad. Péter'sb. xxxii, (1888) 497. - Ins, Ya-Yama.

SCHIZODIUM, Lindl. = Disa, Berg. (Orchid.). biflom, Th. Dur, \& Schinz, Consp. FI. Afr. v. $1892(1895) 113=$ D. biflora, $S w$

SCHIZOGLOSSUM, I. Mey. (Asclep.). - Ind Kew. 11. 826.

aemulatum. Schlechter, in fourn. Bot. xxxii. (1894) 258. - Afr. Austr.

altissimum, Schlechter, in Bot. Fahrb. xx. Beibl, n. $51(1855) 13 .-$ Afr, austr.

angustissimum, K. Schm. .. c. xvii. (1893) 123. Afr. trop.

araneiferum, Schlechter, 7 c. xx, Beibl, n. 51. (1895) 13. Afr. austr.

Aschersonianum, Schlichter, in Verh. Bot. Vicr. Brand. xxxv. (1893) 48 . Afr. austr.

atrorubens, Sihlechter, in fourr. Bot. xxxii. (1894) 3.3.3. - Afr, austr.

barbatum, Britton of Rendle, in Trans. Linn. Soc. Ser. II. iv. (1894) 27 . - Atr. trop.

barbatum. Schlechter, in Bot. Falwo. xx, Beibl, n. 51 (1895) 14 - Afr. austr.

Barberae. Schlechter, l. c. xviii. Beibl. 11. 45 (1894) 27. - Afr. austr.

bilamellatum, Schlechtcr, l.c. xx. Beibl, n. 51 (1895) 15. - Afr. austr.

Bolusii, Schlechter, in Verh. Bot. Ver. Brand. xxxv. (1893) 48 - Afr, trop

capitatum, Sihlechter, in Bot. Fahrs. xx. Beibl. 12. 51 (1895) 15. - Afr austr.

carinatum, Schlechter l. c. xviii, Beibl. n. 45 (1894) 3. - Afr. austr.

ciliatum, Schlechter, in fourn. Bot. xxxii. (1895) 354. - Afr. austro-or.

connatum, N. E. Br. in Kew Bull. (1895) 69.-

Afr. centr. or.

debile. Schlochter, in Fourn. Bot.xxxiii. (1895) 305. - Afr. trop. or.

elatum, $K$. Schun. in Bot fahro. xvii. (1S93) 123. - Afr. trop.

elingue, N. E. Br. in Kew Bull. (I895) 149.Natal.

Elliotii, Schlechter, in foum. Bot. xxxiii. (1895) 305. - Afr. trop.

erubescens, Schlechter, l. c. 306:- Afr, trop. or.

excisum, Bolus, l. c. xxxii. (1894) 259. - Afr. austr.

fasciculare, Schlocher, in Bot. Fahrb. xviii. Beibl. n. 45 (1894); et in foum. Bot. xxxii. (1894) $3 \tilde{5} 4$, in obs. (= Aspidoglossum fasciculare, E. Mey.).Afr. austr.

filifolium, Schlechter, 7. c. 4. - Afr. austr.

filipes. Schlechter, l. c. xx. Beibl. n. 51 (1895) 16. Afr, austr.

firmum, $N$ E. $B r:$ in Kew Bull. (1895) 252.Angola.

Flanagani, Schlechter, in Bot. Fahrb. xviii. Beibl, n. $45(1894) 3 .-$ Afr. austr.

\section{SCHIZOGLOSSUM}

flavum. Schlechter, in Fourn. Bot, xxxiii. (1895) 35.) Natal.

Galpini, Schlechter, in Bot. Fahrb. xviii. Beibl, n. 45

(1894) 15. - Afr. austr.

glabrescens, Schlechter, l.c.xx. Beibl. n, 5l (1895) 17. - Afr, austr.

glanduliferum, Schlechter, in fourn. Bot. xxxii.(1894) 25!). - Afr. austr.

grandiflorum, Schlechter, in Bot. Fahrb. xviii. Beibl. n, 45, 1894) 2\%. - Afr, austr.

Guthriej, Schlechter, in Verl Bot. Ver, Brand xxxv. (1896) 49. - Afr., austr.

heterophyllum, Schlechter, in Verh. Bot, Ver. Brand. xxxv. (1893) 5 ; et in Bot. Fahrb. xviri. Beibl. n, 45 (1894) 16 (= Aspitoglossum heterophyllum, E. Mey.). - Afr austr.

Hollandiae, Harv. ex Schlechter, in Bot. Jahrb. xviii: Beibl, n. 45 (1894) $6=$ virens, $E$. Mey.

intermptum, Schlechter, in Engl, \& Prantl, Natürl. Pflanzenfam. iv. 2(1895) 233 = interruptum, Benth. \& Hook.f.

lamellatum. Schlechter, in Verh. Bot. Vor. Brand. xxxv. (1893) 48. - Afr. austr.

linifolium, Schlechter, in Bot. Fahrb. xviii, Beibl. n. 45 (1894) 4. - Afr. austr.

longirostre, Schlechter, in Bot. Fahrb. xx Beibl.n. 51. (1895) 17. - Afr austr.

lunatum, Schlechter, in Verl., Bot. Ver. Brand. xxxv. 1893) 49, - Afr. austr

masaicum, N.E. Br. in Kew Bull. (1895) 252. Afr. trop. or.

multifolium, N. E. Br. l. c. 253. - Afr. trop. austro. or.

nitidum, Schlechter, in Bot. Fahrb. xx. Beibl. n. 51 (1895) 18. - Afr. austr

Nyassae, Britton \&ै Rendle. in Trans. Iinn. Soc. Ser. II. IV. (1894) 26 [err. cal. ? Nyasae.]. - Afr. trop.

oblongum, Schlechter, in fourn. Bot. xxxii. (1894) 260 . - Austr.

orbiculare, Schlechter, in Bot. Fahrb. xx. Beibl. n. 51 (1895) 19. - Afr. austr.

ovalifolium, Schlechter, l. c. sviii. Beibl. n. 45 (1894)5. - Afr. austr.

pachyglossum, Schlechter, in foum. Bot. xxxii. (1894) 354 - Afr. austr.

pallidum, Schlechter, in Bot. Fahrb. xx. Beib1.n. 51 (1895) 19. - Afr. austr.

parvulum, Schlechter, in foum. Bot, xxxii (1894) 354. - Afr. austr.

pedunculatum, Schlechter, in Verh. Bot, Ver. Brand. xxxy. (1893) 50. - Afr, austr.

periglossoides, Schlechter, in Bot. Fahrb. xx. Beibl. n. 51 (1895) 20 - Afr. austr.

pilosum, Silhechter, $l, c$ - Afr, austr.

pulchellum, Schlechtor, b. c, xviii. Beibl, n, 45 (1894) 15. - Atr. austr.

pumilum, Schlechter, l. c. xx. Beibl, n. 51 (1895) 21 - Afr. austr.

pygmaeum, Schlechter, in foum. Bot. xxxii, (1894) 355. - Afr. austr.

quadridens, N. E. Br. in Kew Bull. (1895) 252. Afr. austr.

restioides, Schlechter, in Verh. Bot. Ver. Brand. xxxy. (1893) 50. - Afr. austr.

robustum, Schlechter, in Fourn, Bot. xxxiii. (1985) 267. - Afr. austr.

Schirzianum, Schlechter, in Verh. Bot. Ver. Brand. xxxv, (1893) 51, - Afr, austr.

shirense, N. E. Br. in Kew Bull. (1995) 253. Zambesia.

spathulatum, $K$. Schum, in Bot. Fahrb. xvii. (1893) 120. - Afr, trop.

stenoglossum, Schlechter, l. c. xviii. Beibl, n. 45 (1894) 28. - Afr. austr.

striatum, Schlechtor, in Fourn. Bot. xxxii. (1894) 356 - Afr. austr.

strictum, Schlechter, in Bot. Fahrb. xx. Beibl. 1n.51 $1895)$ 22. - Afr. austr.

tenuissimum, Schlechter, l.c. 23. - Afr. austr.

tomentosum. Schlechter, in fourn. Bot. xxxii. (1894) 261. - Afr. austr.

tricorniculatum, $K$. Schum, in Bot. Fahro. xvii. (1893) 121. - Afr. trop. 


\section{SGHIZOGLOSSUM}

ricuspidatum, Schlechter, in fourn. Iot. xxxiii. (1895) 267. - Afr. austr

tridentatum, Schlechter, in Bot. Fahrb. xviii. Beibl. n. 45 (1894) 5. - Afr. austr.

truncatulum, K. Schum. in Engl. Pfanzenw. Ost-Afr. C (1895) 322. - Afr. trop. Or.

truncatum, Schlechter, in Bot. Fahrb. xviii. Beibl n. 45 (1894) 28. - Afr. austr

tubulosum, Schlechter, l. c. xx. Beibl. n. 51 (1895) 23. - Afr. austr.

umbellatum Schlechter, in Fourn. Bot. xxxii. (1894) 356. - Afr. austr.

umbelluliferum. Schlechter, in Bot. Fahrb. xx. Beibl. n. 51 (1895) 24. - Afr. austr.

venustum, Schlechter, l. c. - Afr. austr.

verticillare, Schlechter, l. c. 25. - Afr. austr.

villosum, Schlechter, l. $c$. xviii. Beibl. n. 45 (1894) 29. - Afr. austr.

violaceum, K. Schum. l. c. xvii. (1893) 122. - Afr. trop.

virgatum, Schlechter, l. c. xviii. Beibl. n. 45 (1894 $6(=$ Lagarinthus virgatus E. Mey.). - Afr. austr.

Wallacei, Schlechter, in Fourn. Bot. xxxiii. (1895) 268. - Afr. austr.

Woodii, Schlechter, in Bot. Fahrb. xx. Beibl. n. 51 1895) 25. - Afr. austr.

SGHIZOLAENA, Thou. (Chlaenac.), - Ind. Kew. ii. 826 .

laurina, Baill. in Bull. Soc. Linn. Paris, i. (1886) 568 et 571 ; et Hist. pl. Madag. Atlas (1889) t. 102. - Madag.

SCHIZONOTUS, Rafin. $=$ Spiraea, (Rosae.) Kuntze, Rev. Gen. (1891) 225 argentea, Linn.

ariaefolius, Greene, Fl. Francisc. (1891) $58=$ ariaefolia, $S m$.

discolor, Koehne, Deutsche Dendrol. (1893) 265 discolor, Rafin.

dumosus, Koehne, 1. c. (1893) 265. - Am. bor.

SGHIZOPEPON, Maxim. (Cucurb.). - Ind. Kew. ii. 827 .

dioicus, $\operatorname{Cog} n$. in Hook. Icon. pl. xxiii. (1892) t, 2224 - China.

SCHIZOPETALUM, DC = Schizopetalon, Sims (Crucif.).

bipinnatifdum, Phil. in Anal. Univ. Chil. Ixxxi. (1893) 192. - Chili.

biseriatum, Phil. 1. c. - Chili.

San Romani, Phil. in Anal. Mus. nac. Ch: '1891) 5 ; et 1. c. 191. - Chili.

tenuifolium, Phil. in Annal. Univ. Chil. lxxxi. (1893) 191. - Chili.

SCHIZOPHRAGMA, Sieb. \& Zucc. (Saxifr.). Ind. Kew. ii. 827 .

integrifolia, Oliver, in Hook. Icon.pl.xx. (1890) t. 1934. - China

SCHIZOPREMNA, Baill. Hist. des. pl. xi. (1892) 119 ; Briq, in Engl. \& Prantl, Natürl. Pflanzenfam iv. 3a. (1894) 166. VERBENACEAE. timorensis, Baill. $l l$. c. 120 ; et 166 . - Timor.

SCHIZOPTERA, Turcz. (Compos.), - Ind. Kew. 11. 827

lyrata, Klatt, in Annal. Naturh. Hofmus. Wien, ix. (1894) 360. -- Mexic.

SCHIZOSCYPHUS, "K. Schum. " ex Taub. in Engl, et Prantl, Natürl, Pflanzenfam, iii. (1892) $130=$ Schizosiphon, K. Schum. (Legum.).

SCHIZOSIPHON, K. Schum, in K. Schum, \& Hollr. Fl. Kais. Wilh. Land (1889) 101 ; Boerl. Fl. Ned. Indië, i-I. (1890)680. LEGUMINOSAE. roseus, $K$. Schum.ll. cc. - N. Guin.
SGHIZOSTACHYUM, Nees (Gramin.). - Ind. Kew, ii. 827.

Warburgii, Hack, ex Warb. in Bot. Fahrb. xiii. (1890) 263. - N. Guin.

SCHIZOSTEPHANUS, Hochst. ex Benth. et Hook, $f_{\text {. }}=$ Vincetoxicum, Moench (Asclep.) alatus. Hochst. ex K. Schum. in Bot. fahrb. xvii. (1893) 139. - Afr. trop.

somaliensis. N. E. Br. in Kew Bull. (1895) 250.Reg. Somal.

SCHIZOTHECA, Lind1. = Atriplex, Tourn. (Chenop.).

hastata. Celak, ex Formanek, Kvétena, ii. (1892) 291 = hastata, Fourn.

littoralis, G. Beck, Fl. Nied.-Oest. i. (1890) $335=$ littoralis, Fourn.

oblongıfolia. Celak. ex Formanek, Kvétena, ii. (1892) $292=$ A. patula, Linn

patula, Celak. 1. c. = A. patula, Limn.

rosea, Celak. 1. c. = A. rosea, Linn.

tartarica, Celak. 1. c. = tatarica, Celak.

SCHIZOZYGIA, Baill, in Bull. Soc, I.inn. Paris, i. (1888) 752 ; K. Schum, in Engl. \& Prantl, Natürl. Pflanzenfam. iv, 2 (1895) 146. APOCYNEAE. coffaeoides, Baill, il. cc. - Zanzib.

SGHKUHRIA, Roth (Compos.). - Ind. Kew. ii. 827

anthemoides, Coult. in J. D. Smith, Enum, pl. Guatem.iv. (1895) $93=$ Hopkirkia, A. Gray. coquimbana, Phil. in Anal. Univ. Chîl. xc. (1895) 29. - Chili.

glomerata, Robinson \& Seaton, in Proc. Am. Acad. xxviii (1893) 109. - Mexic.

platyphylla, Robinson \& Greenm. in Am. Fourn. Sci. Ser. III. 1. (1895) 156. - Mexic.

Pringlei, S. Wats. in Proc. Am. Acad. xxiii. (1888) 278. - Mexic.

HLECHTENDALIA, Will. = Adenophylium, Pers. (Compos.)

lata, Kuntze, Rev. Gen. (1891) $361=$ Dysoancellata, A. Gray,

llum, Kuntze, 1. c. = Adenophyllum Poro'Im. Hemsl.

* *, Kuntze, 1. c. = A. Wrightii, A. Gray. SGhLEGELIA, Miq. (Bignon.). - Ind. Kew. ii.

cornuta, F. D. Smith, in Coult. Bot. Gaz. xviii. (1893) 6. - Guatem.

SCHLEINITZIA, Warb. in Bot. Jahrb. xiii. (189I) 336. LEGUMINOSAE.

microphylla, Warb.l. c. - N. Guin.

SCHLUMBERGERIA, Ed, Morr. (Bromel.), Ind Kew ii 828 .

Lehmanniana; Wittm. in Sot. Jahrb. xi. (1889) 60 = Caraguata Lehmanniana, Baker.

SGHMALHAUSENIA, C. Winkl. in Act. Hort. Petrop. xii. (1892) 281. COMPOSITAE.

eriophora, C. Winkl. l. c. - As. centr.

SCHMIDELIA, Linn. (Sapind.). - Ind. Kew. ii. 828.

insulana, Ridl. in fourn. Linn. Soc. xxvii. (1890) 25. - Ins. Fernando Noronha.

Iasiostemon, G. Beck, in Annal. Naturh. Hofmus. Wien. iii. (1888) 255. - Ins. Stewart.

Rehmanniana, Szyszyl. Pl. Rehmann. ii. (1888) 47. - Natal.

SGHUENOGAULON. A. Gray (Liliac.). - Ind.

.ii. 330 .

te linm, Robinson \&. Greenm. in Am. Fourn. Sci. in th) - Mexic

SC UEDONARDUS paniculatus, Scribn. in Mem. Torrey Bot. Club, v. (1894) 46, sphalm. = Lepturus paniculatis, $N$ utt.
SCHOENOPLECTUS, Palla, in Sitzb, zool.-bot.

Ges. Wien, xxxviii. (1888) $49=$ Scirpus,

「Tourn.] Linn. (Cyper.)

carinatus, Palla, 1. c。 = S, carinatus, Sm.

lacustris, Palla, 1. c $=\mathrm{S}$. lacustris, Linn.

littoralis, $\mathrm{Palla}, \mathrm{l}, \mathrm{c},=\mathrm{S}$, littoralis, Schrad.

mucronatus, Palla, 1. $\mathrm{c}_{n}=\mathrm{S}$. mucronatus, Linn

pungens, Palla, 1. $\mathrm{C}_{0}=\mathrm{S}$. pungens, $V a h l$.

supinus, Palla, 1. c。 $=\mathrm{S}$. supinus, Linn.

Tabernaemontani, Palla, 1. c. $=\mathrm{S}$. Tabernaemontani, C. C. Gmel.

riqueter, Palla, 1, c.; A. Kern. Sched, F1, Austro-

Hung. v. (1888) $90=$ S. triqueter, Linn.

SCHOENOXIPHIUM, Nees (Cyper.). - Ind Kew. ii. $\$ 30$.

Buchanani, C. B. Clarke, in Th, Dier. Es Schinz, Consp. Fl. Afr. v. 1894 (1895) 676, nomen, Natai

SGHOENUS, Linn. (Cyper.).- Ind. Kew. ii. 831 aristatus, Kuntze, Rev. Gen. (1891) $756=$ Tetraria aristata, C. B. Clarke.

capensis, Linn. ex C. B. Clarke, 1, c. $663=\mathrm{T}$ thermalis, C. B. Clarke.

curvulus, F. Muell. in Trans. Roy. Soc. Vict. N. S i. II. (1889) $36 .-$ N. Guin.

deustus. Linn. ex C. B. Clarke, in Th. Dur. \& Schinz, Consp. Fl. Afr. v, 1894 (1895) $664=$ Tetraria ustulata, C. B. Clarke.

discifer. Tate, in Trans, and Proc. Roy. S. Austral. xii. (1889) 131. - Austral.

Dregeanus, Kuntze, Rev. Gen. (1891) $756=$ Tetraria Dregeana, C. B. Clarke.

Hornei, C. B. Clarke, in Th. Dur. of Schinz, Consp. Fl. Afr. v, 1894 (1895) $65 \%$ (= Cyclocampe elongata Benth. . - Ins. Scychell.

ligulatus, Kuntze, Rev. Gen. (1891) $756=$ Tetraria ligulata, C. B. Clarke.

loreus, Kuntze, 1. C. (=Elynanthus loreus, Nees $)=$ T. cuspidata, C, B. Clarke.

microstachyus, Kuntze, 1. c. (=E. microstachyus, Boeck.) = T. fasciata, C. B. Clarke.

natans, Thunb. ex:C. B. Clarke, 1. c. $633=$ Scirpus tenuissimus, Boeck.

pictus, Kuntze, 1. c. = T. picta, C. B. Clarke.

sylvaticus, Kuntze, 1. c. $=$ T. sylvatica, $C . B$ Clarke.

Teneriffae, Vent, ex C. B. Clarke, in Th. Dur. \& Schinz, Consp. Fl. Afr. v. 1894 (1895) $654=$ Rynchospora micrantha, Vahl.

ustulatus, Vahl, ex C. B. Clarke, 1. c. $663=$ Tetraria rottboellioides, C. B. Clarke.

SCHOEPFIA, Schreb. (Olacin.). - Ind. Kew. ii. 832,

californica, T. S. Brandeg. in Proc. Calif. Acad. Ser. II. ii. (1889) 139. - Calif.

Griffithiana, Valeton, Crit. oierz. Olacin.(1886) 128.

- Bengal.
Miersii, Pierre, Fl. For. Cochinch. Fasc. 17 (1892) t. 265b. - Canbodia.

SCHOLLERA, Schreb. = Heteranthera, Ruiz \& Pav. (Ponted.).

callifolia, Kuntze, Rev, Gen, (1891) $719=\mathrm{H}$. callaefolia, Reichb.

dubia, Kuntze, 1. c。 = H. graminea, Vahl.

Kotschyana, Kuntze, I, c. $=$ H. callaefolia, Reichb limosa, Kuntze, 1. c. = H. limosa, Willd.

Potamogeton, Kuntze, 1.c. = H. Potamogeton, Solms, reniformis, Kuntze, 1. c. $=\mathrm{H}$. reniformis, Ruiz \& Pav.

Seubertiana, Kuntze, 1. c. $=$ H. Seubertiana, Solms

spicata, Kuntze, 1. c. = H. spicata, Presl.

zosterifolia, Kuntze, 1. c。 = H. zosteraefolia, Mart

SCHOLLERA, Roth = Oxycoccus, Tourn. (Vaccin $j$

erythrocarpa, Britton, in Mem. Torrey Bot. Club, v. $(1894) 253$ (= S. erythrocarpa, Steud.) $=0$ erythrocarpus, Pers.

macrocarpa, Britton, 1. c. ( $=$ S. macrocarpa, Steud.) $=$ O. macrocarpus, Pers.

Oxycoccus, Britten, in Journ. Bot. xxv. (1887) 233, in obs. $(=S$. Oxycoccos, Roth $)=0$. palustris, Pers. 
SGHOMBURGKIA, Lind1, (Orchid,). - Ind. Kew. ii. 833 .

chionodora, Reichb, f. in Gard. Chron. (1886) i. 73 - Am. centr.

lepidissima, Reichb. f. l. c. (1889) i. 72. - Hab.? Sanderiana, Rolfe, l. c. (1891) i. 202,614.Hab

Thomsoniana, Reichib.f.l.c. (1887) ii. 38, et (1891) i. 615 ; Veitch, Man. Orch, Pl, ii, (1887) 202. Ind. occ

SCHOUTENIA, Korth. (Tiliac.), — Ind, Kew, ii

Butrmanni, Koerd. \& Valet. Boonsoort, san fava. (1894) 215. - Java

glomerata, King, in fourn. As. Soc. Beng. 1x, (1891) ii. 216. - Johore.

hypoleuca Pierre, Fl. For. Cochinch. Fasc. 9 (1888) t. 134. - Cambodia.

Kunstleri, King, in foum, As. Soc, Beng. Ix. (1891) ii. 216. - Penang

Mastersii, King.l. c. 215 (= Chaclocalyx accresccus, Mast.). - Malaya, Borneo.

SCHRANKIA. Willd. (Legumin.) - Ind. Kew. ii. 833 .

Intsia, Trelease, ex Branner \& Corille, in Ann Rep. Geol, Surv. Arkans. for 1888, i. (1889) 178 = uncinata, Willd.

SCHREBERA, Roxb. (Oleac.).-Ind. Kew, ii. 831. Buchanani, Buker, in Kevi Bull. (1895) 95. Zambesia.

SCHREBERA, Thunb. = Hartogia, Linn. -f. chersis, Kuntze, Rev, Gen, (1891) 117 = Agathosmensis, Kuntze, Rev.
ma hispida, Bartl.

SCHRIibERS1A, Pohl = Augusta, Pohl $($ RuIniar.). Kuntze, Rev。Gen. (1891) $298=$ A lanceolata, Pohl.

SCHULTESIA, Mart. (Gentian.), - Ind, Kew. ii. 8.34

mexicana, S. Wats. in Proc. Am, Acad, xxvi. (1891) 144. - Mexic.

seregalensis, Baker, in Kew Bull. (1894) 26. Seneg.

SCHUMANNIA. Kuntze, in Act. Hort. Petrop. x. (1887) 192. UMBELLIFERAE.

furcomanica, Kuntze, 1. c. ; Lipsky, 1. c, xiii. (1894) 368, sphalm. 168 (= Ferula Karelini, Bunge). Turkest.

SGHUURMANSIA, Elume (Violar.). - Ind. Kew. i. 834.

Henningsii. K. Schum, in Bot. Fahrb. ix. (1887) 210. - N. Guin.

SCHWABEA, Endl, (Acanth.). - Ind. Kew, ii. 834

Anisacanthus, Lindau, in Engl, E Prantl, Natuirl. Pfanzenfan. iv. 3D (1895) $346(=$ Fusticia anisacanthus, Schweinf.). - Afr. trop. or.

ecbolioides, Lindau, in Bot. Fahrb. xx. (1894) 58 . - Atr. trop. or

revoluta, Lindau, 7. c. 59. - Afr, trop, or

SGHWAGKAEA, Cogn, in Th. Dur. Ind. gen. Phan. (1888) 132; et in A. DC. Monog. Phan. vii. (1891) 132. MELASTOMACEAE.

cupheoides, Cogn. Il. cc. 132 et 183 (= Pterogastra cuphreoides, Seem.). - Mexic., Am. centr.

SCHWEINFURTHAFRA, Kuntze, Rev, Gen, (1891) 5 = Glyphaea, Hook. f. (Tiliac.)

iateriflora, Kuntze, 1, c. = G. grewioides, Hook. f. tomentosa, Kuntze, l. $\mathrm{c}_{0}=\mathrm{G}$. tomentosa, Mast.

SGHWEINFURTHIA, Al. Br. (Scrophul.). Ind. Kew. ii. 834

latifolia, Baker, in Kew Bull. (1894) 338, nomen; $e t$ in Hook. Icon.pl. xxiv. (1895) t. 2362. -- Arabia.
SCHWENDENERA. K. Schum. in Sitzb. Ges, naturf Freund. Berl, 1886 (1887) 15\% RUBIA $C E A E$

tetrapyxis, K. Schum.l.c. - Bras

SGIADOPHYLLUM, P. Br. (AraI.). - Ind.

arboreun, Hitchcock, in Missouri Bot. Gard. Rep. iv. (1893) $91=\mathrm{S}$. Jacquini, Griseb.

coriaceum, El. March. ex Oliver, in Trans. Linn. Soc. Ser. II. ii. (1887) 275, t. 41 ; Oliver, ex im Thum, in Timehri, v. (1886) 195. - Guian. angl. keptaphylhunt, Hitchcock, in Missouri Bot. Gard. Rep, iv. (1893) 91 = Brownei, Spreng.

Lehmannii, Harms, in Bot. Fahrb. xx. Beibl, n. 49 (1895) c9 (= Scheffera Lehmannii, Harms). Am. centr.

leptoplyzlum, Herb. Kew. ex Hems1, in Kew Bull. (1893) $156=$ Dizygotheca Ieptophylla, Hems? paniculatum. Britton, in Bull. Torrey Bot. Chub, xviii, (1891) 37. - Bolivia,

patulum, Rusby, in Mem. Torrey Bot. Club. iii. 3 (189:3) 41. - Bolivia

SGIAPHILA, Blume (Triurid.). - Ind. Kew, ii. affinis, Bece. Malesia, iii. (1890) 334, t. 39, fig. 1418. - Borneo

andejensis, Becc. l. c. 339 , to 42, fig. 10-14. Borneo.

arfarkiana, Becc. l. c. 336, t. 41, fig. 6-14. Borneo.

caudata, Poulsen, in Vidensk. Middel. Kjob. 1884-86 (1886) 165 ; Lucante, in Rev. de Bot.vi. (1887-88) 197. - Bras.

corniculata, Becc. Malesia, iii.(1890) 336, t. 39. fig. 5-13. - Borneo.

crinita, Becc, l. c. 338, t. 42, fig. 1-9. - - Borneo.

elata, K. Schum, in Mart, Fl, Bras. iii. IIf. (1894) 659. - Bras.

major, Becc. Malesia, iii. (1890) 332, t. 40, fig. 1-11. - Borneo.

papuana. Becc. l.c. 335, t. 41, fig. 1-5. - - N. Guin. papillosa, Becc. l. c. 334, t. 39, fig. 1-4.-- N. Guin. Richardi, Baill. in Bull, Soc.Linn. Paris, ii. (1895) 1189. - Am. trop.

Schwackeana, fobow, in Pringsh. Bot. fahro. xx. (1889) 478. - Bras.

sumatrana, Becc. Malesia, iii. (1890) 333, t. 40, fig. 12-20. - Sumatra.

ȘGILLA, Linn. (Liliac.). - Ind. Kew. ii. 836.

Adlami, Baker, in Gard. Chron. (1891) i, 520.Natal.

Buchanani, Baker, l. c. (1893) i. 568. - Afr. trop. austro-or.

Eckloni, Baker, in Bot. Fahrb. xv, Beibl. n. 35 (1892) 7. - Afr. austr.

edulis, Engl. Bot. Fahrb. xv. (1892) 475. - Afr, trop.

Engleri, Th. Dur, of Schinz, Const. Fl, Afr. v. (1893) 391 (= S. pallidiftora, Engl. . - - Afr. trop. Fischeri, Engl. Pfanzenw. Ost.-Aft, C (1895) 142. - Afr. trop. or.

gabunensis, Baker, in Bot. Fahrb. xv. (1892) 476. - Acillima, Engl. Pfanzenw. Ost-Afr. C (1895) 142. gracillima, Engt.
- Afr. trop.or.

Hildebrandtii, Baker, ix Olicer, in Trans, Linn. Soc. Ser. I1. ii. (1887) 551, nomen, in obs. Madag.

Johnstoni, Bakey: ex Otiver, in H. Fohnston, The Kilim. Njaro Expen: Append, (1886) 347; et in Trans. Linn. Soc. Ser. II. ii, (1887) 35ิ1. - Atr. trop. or.

Ledieni, Engl. in Gartenff. xxxviii. (1889) 153, t. 1394. - Congo.

leucophylla, Baker, in Gard. Chron. (1893) i. 506. Persia.

longipes, Batt. in Batt. \& Trab. Fl. de 1'Algér.

- [Monoc.] (1895) 69 = autumnalis, Linn.

pallidiflora, Engl. Bot. Jahrb。 xv. (I892) $476=\mathrm{S}$. Engleri, Th. Dur. \& Schinz.

Petersii, Engl。 Pflanzenw. Ost-Afr。 C (1895) 142. Afr. trop. or.

Schweinfurthii, Engl, Bot. Falkb. xv. (1892) 475. Afr. trop.
SGILLA

omaliensis, Baker, in Bot. Fahrb. xv. (1892) 476. Reg. Somal.

Tayloriana, Rendle, in Fourn. Limn. Soc. xxx. (1895) 426. - Afr. trop, or.

textilis, Rendle, l. c. 42\% - Afr. trop, or.

uyuiensis, Rendle, l. c. 428. - Afr. trop. or.

Volkensii, Engl. Pfanzenw. Ost-Afr. C (1895) 142 - Afr. trop, or.

yemensis, Defers, Voy. Iémen (1889) 212. - Arabia.

SGINDAPSUS, Schott (Aroid.), - Ind. Kew. ii. perakensis, Hook. f. Fl. Brit. Ind. vi. (1893) 542. - Perak

Scortechinii, Hook. f. l. c. 541. - Perak.

SGIRPUS, [Tourn.] Linn. (Cyper.). - Ind, Kew.

ii. 838.
afflatus, albibracteatus, alboraginatus, albidus, atacamensis, bonaricnsis, capillacents, camiolicus, cellulosus. costulatus, Cunninghamii, debilis, Dombeyanus, emarginatus, fistulosus, fuegiamus, fuscosanguineus, glaucoeirens, gracilis, grandis, Hookeri, japonicus, Lechleri, Liebmannianns, liocarpus, litoralis, macranthus, maculosus, margimulatus, melanocarpus, mendocinus, microcarpus, montevidensis, namus. ochrostachys, olivaccus, pachycarpus, punctatus, Sellowionus, sphacchatus, stolonifor, subarticulatus, subtilis, subriciparus, tenuissimus, tetraquetrus, tricostatus, raldrianus, vicentimus, irititarus, Widgrenii. Kuntze, Rev. Gen.(1891) $757-58=$ homonyma omnia Eleocharitos.

aggregatus, Steud ex C. B. Clarke, in Th. Dur. \& Schinz, Consp. Fl. Afr. v. 1894 \{1895) $644=$ Ficinia tenuitolia, Kunth.

angolensis, C. B. Clarke, ex Th, Du', G.Schinz, l. 617 - Angola.

aphyllus, Boeck. in Bot. Fahrb. vii. (1886) 275. Reg. Argent.

appendiculatus, Kuntze, Rev..Gen. (1891) $757=$ Eleocharis palustris, $R$. $B 3$.

Arechavaletae, Boeck. Cyper.Nor' i. (1888) 18. Uruguay.

arcnicolus, Kuntze, Rev. Gen.(1891) $757=$ Eleocharis montana, Roem. \& Schult.

aristatus, C. Richt, Pl. Europ. i. (1890) $138(=$ Isolepis aristata. Presl). - Hung.

arrhenopogoin, Hochst. ex C. B. Clarke, in Th. Dur. \& Schinz, Consp. Fl. Afr. v. 1894 (1895) $625=$ littoralis, Schrad.

atrosanguineus, Boick, in Bot. Fahrb. vii. (1886) 276. - Afr. trop, or.

aturensis, Maury, in Morot, Fourn, de Bot. iii. (1889) 199, fig. 8. - Am. austr. trop.

Bachmanmianus, Boeck. ex C. B. Clarke, in Th. Dur. \& Schinz, Consp. Fl, Afr. v. 1894 (1895) $634=$ renustulus. Boeck.

Beccarit; Boeck, in Bot, Falzbo vii. (I886) 275. Hab. ?

Boeckelerianus, schreinf. in Bull. Herb. Boiss, App. ii. (1894t50. - Erithrea.

Buettnerianus, Boeck. Cyper. Nor. 1. (1888) 20. Guinea.

Burchelli, C. B. Clarke, in Th. Duw. E Schinz, Consp. Fl. Afr. v. 1894 (1895) 618. - Afr. austr.

Burkei, C. B. Clarke, in Th. Dur. \& Schinz, l. . . Afr. austr. et austro-or.

californicus, Britton, in Trans, N. Y. Acad. Sci. xi. (1892) 79 ; et Sp. Scirp. et Rhynch. N. Am. (1892) 6 = riparius, f. \& C. Presl.

Clarkei. Stapf, in Trans, Limm Soc. Ser. II. iv (1894) 244. - Borneo.

concolor, Maxim. in Bull. Acad. Pétersb. xxxi (1887) 110. - Japon.

cylindricus, Britton, in Trans, N. Y. Acad. Sci. xi. (1892) 79 ; et Sp. Scirp. et Rhynch. N. Am. (1892) $6=$ leptolepis, Chapn.

distichophyllus, Boeck. Cyper. Nov。 i. (1888) 19. Reg. Argent.

Dussii, Boeck. . c. if. (1890) 38. - Ins. Martinic.

erythropodus, Kuntze, Rev。Gen. (1891) 757 = leptolepis, Chapm.

ctuberculata, Kuntze, 1. c. $758=$ leptolepis, Chupm. etuberculata, Kuntze, 1 c. $758=$ leptolepis, Chutpm.
fuirenoides, Maxim. in Bull. Acad. Pétersb. xxxi. (1887) 109. - Japon. 


\section{SGIRPUS :}

fuscus, Roxb. ex C. B. Clarke, in Hook. f. Fl Brit. Ind.vi. (1893) 639, in syn. = Fimbristylis compressa, Boeck.

Gaillardii, Maury, in Horot, fourn. de Bot. iii. (1889) 197, fig. 7. - Am. austr. trop.

globiceps, C. B. Clarke, in Th. Dur: \& Schinz, Consp. Fl. Afr. v. 1894 (18.5) 622. - Afr. austr.

granulato-hirtellus. Boeck, ex Schinz, in Verh. Bot.

Ver. Brand. xxxi. (1890) $179=$ Fimbristylis exilis. Rocm. \& Schult.

griquensium, C. B. Clarke, in Th. Du. Es Sinin\%, Consp. Fl. Afr. v. 1894 (1895) 623. - Afr. austr.

Hallii, Britton, in Trans. N. Y. Acad. sci. ix. (1S89) 11. - Am. bor.

Hieronymi, Boeck. Cyper. Nor. i. (18s8) 18. -Reg. Argent

karroicus, C. B. Clarke, in Th. Dur. E Schinz, Consp. Fl. Afr. v. 1894 (1895) 624. - Afr. austr.

lagoensis, Boeck. Cyper. Nov. ii. (1890) 15. Bras.

Innceaeglumis, C. B. Clarke, in Th. Dur, \& Schinz, Consp. F1. Afr. v. 1894 (1895) $634=$ varius, Boeck.

leuianthus, Boeck. in Verh. Bot. Ver. Brand xxix. (1S88) $46=$ supinus, Linn $_{\text {in }}$

leucocoleus, K. Schum, in Engl. Pfanzenzw. Ost-Afr. C (1895) 125. - Afr. trop.

Loefgrenii, Boeck. Cyper. Nor. ii. (1890) 16. Bras.

loeteflorens, C. B. Clarke, in Th. Dur. E Schinz Consp. Fl. Afr. v. 1894 (1895) 625, nomen. - Afr. austro-occ. extratrop.

longevaginatus, Bock. Cyper. Nov. ii. (Is90) 16. Bras.

macrolepis, Boeck, ex C. B. Clarke, in Th. Dur. \& Schinz, Consp. Fl. Afr. v. 1894 (1895) 614,616 $=$ Bulbostylis Kirkii et Zeyheri, C. B. Clarke.

macrostachys, Boeck. Cyper. Nou. i, (18\$8) 19. Reg. Himal.

melanocephalus, K. Schum. in Engl. Pfanonzw. Ost-Afr. A (1895) 131, nomen. - Afr. trop.

mexicanus, C. B. Clarke, ex Britton, in Trans. N. Y. Acad. sci. xi. (1S92) 77 ; et Sp. Scirp. et Rhynch. N. Am. (1892) $4=$ cyperoides, Hemsl. microstachys, Boeck. Cyper. Nor. ii. (1890) 14. Reg. Argent.

minutissimus, Boeck, in Verh. Bot. Ver. Brand. xxix. (1888) 46 ; et ex C. B. Clarke, in Th. Dur. \& Schinz, Consp. F1. Afr.v. 1894 (1895) $630=$ sororius, C. B. Clarke.

mucronulatus, Kuntze, Rev, Gen. (1891) $758=$ Eleocharis acuta, R. Br

Muelleri, Boeck. Cyper. No\%. ij. (1S90) 14.-Austral. mutatus, Roxb. ex Hook. f. Fl. Brit. Ind. vi. (1893) 627 , in syn. = Eleocharis spiralis, $R . B r$

natalensis, "Boeck. ex C. B. Clarke » in Th. 'Dur. \& Schinz, Consp. F1. Afr, v. 1894 (1895) $623=$ S. Hystrix, Thunb.

Niederleinianus, Boeck. Cyper. Nov, ii. (1890) 16. Reg. Argent.

Novae-Zealandiae, Colenso, in Trans, N. Z. Inst. xviii. 1885 (1886) 27\%. - N. Zel.

pallescens, Boeck. ex C. B. Clarke, in Th. Dur. \& Schinz, Consp. F1. Afr. v. 1894 ; 1895) $633=$ Thouarsianus, Schoult.

Peckii, Britton, in Trans. N. Y. Acad. Sci. xi. (1892) 82 ; et Sp. Scirp. et Rhynch. N. Am. (1892) 9. - Am. bor

pinguiculus. C. B. Clarke, in Th. Dir. \& Schinz, Consp. Fl. Afr. v. 1894 (1895) 629. - Afr. austr. potosinus, Britton, in Trans. N. Y. Acad, sii. xi. (1892) 82 ; et Sp. Scirp. et Rhynch. N.Am. (1892) 9. - Mexic.

pretorianus. Boeck. ex C. B. Clarke, in Th. Dur. \& Schinz, Consp. F1. Afr。 v. 1894 (1895) 613 = Bulbostylis cinnamomea et collina, C. B. Clarke.

Pringlei, Britton, in Bull. Torrey Bot. Club, xy. (1888) 103 t. 30. - Mexic.

Pseudo-setaceus, Dacean, in Bolet. Soc. Brot. ix 1891) 85. t. 1; Trab. in Batt. E Trab. Fl. do l'Algér. [Monoc.] (1895) 99. - Lusit, Algeria purpurascens, Kuntze, Rev. Gen. (1891) $758=$ Eleocharis congesta, D. Don.

radiciflorus, Maury, in Morot, Fourn. de Bot. iji. (1889) 199 fig. 9. - Am. austr. trop.

\section{SCIRPUS :}

. Clarke, in Th. Dnx. Schinz, Consp. Fl. Afr, v. 1894 (1895) 629 in syn, = quinquefarius, Buch-Ham.

Schaffneri, Boeck in Bot. Zahrb. vii, (1886) 275 . Mexic

Sihaffncr, Kuntze, Rev. Gen. (1891) $758=$ Eleo charis cancellatus, S. Wats.

Sihinzianus, Boeck, ex C. B. Clarke, in Th. Dur. \& Schinz, Consp. Fl. Afr.v. 1894 (1895) $61 \mathrm{~s}=$ Burkei, $C, B$, Clarke.

Schinzii, Boeck. in Verh. Bot. Ver. Brand. xxix 18s8) 47 ; et ex C. B. Clarke, in Th. Dur. Schinz, 1. c, 621, in syn. = dioëcus. Boeck.

Schwackeanus, Boeck. Cyper. Nov. ii. (1890) 15. Bras

Sieteri, Kuntze, Rev. Gen. (1891) 75s = Eleocharis variegata. Presl

rorius, C. B. Clarke, in Th. Dur. E Schinz, Consp. Fl. Afr, v. $1894(1805) 630(=I$ solepis sororius Kunth). - Afr. austr.

crnatus, Ham in Hook f. FI. Brit. Ind. vi, (189:3) 656 , in syn. = erectus, $P$ oi

thermalis, Trab. in Batt. \& Trab. Fl. de l'Algér [Monoc.] (1895) $99=$ littoralis, Schrad.

Thomsonii, Kuntze, Rev, Gen. (18.91) $758=\mathrm{Elec}$ charis afflata, Steud.

Torreyamus, Kuntze, 1. c. = E, microcarpa, Torr. trachyspermus, C. B. Clarke, in Th. Dur. \& Schinz, Consp. Fl. Afr. v. 1894 (1095) $6331=$ Isolepis trachysperma, Nees). - Afr. austr.

transiens, K. Schum. ex Engl. in Abh. Preuss. Acad. Wiss. (1894' 38 , nomen. - A fr. trop.

transvadensis, Boeck, ex C. B. Clarke, in Th. Dur. \& Schinz, Consp. Fl. Afr. v. 1894 (1895) $163=$ Bulbostylis cinnamomea, C. B. Clarke.

triangularis, MacMill. Metasp. Minn. (1892) 99 $=$ pungens, $V a h l$.

trispiculatus, Boeck. ex C. B. Clarke, in Th. Dur. \& Schinz, Consp. Fl. Atr. v. $1894(1895) 613=$ Bulbostylis collina, C. B. Clarke.

calidus, Kuntze, Rev. Gen (1891) $758=$ Eleocha ris geniculata, $R$. $B$ r.

varius. Bocch. ex C. B. Clarke, in Th. Dur Eo Schinz, Consp. Fl. Afr. v. 1894 (1895) 634. - Afr. trop. allstro-or.

rividis, Kuntze, Rev. Gen. (1891) 758 = Eleocharis geniculata. R. $B$

Warmingii, Boeck. ex Warm. Lutgoa Santa (1892) 240, cum xylogr. - Bras.

Welwitschii. C. Richt. Pl. Europ. i. (1890) 141.Lusit.

yokuhamensis, Kuntze, Rev. Gen. (1891) $758=$ Eleocharis tetraquetra. Nees.

Zollingeri, Kuntze. 1. C. = E. afflata, Steud.

SCLERANTHUS, Linn.(Illecebr.), 一 Ind. Kew.

fasciculatus, Gillot \& Coste, in Bull. Soc. Bot. Fr. xI. (I893) p. cxxiii. - Gall, mer.

hamatus, Hausskn. Eo Bornm.ex Hausskn, in Mitt. Bot.Ver. Fena, ix. (1891) 17. - As. Min.

imbricatus, G. Beck, in Annal. naturh. Hofmus. Wien, ii. (1887) $66=$ collinus. Horn.

minusculus, F. Muell. in Vict. Natural. vii. (Sept. 1890) 66. - Austral.

pumilus, Gillot \& Coste, in Bull. Soc. Bot. Fr. xxxviii. (1891) p. cxxvii = verticillatus, Tausck. ruscinonensis, Gillot of Coste, l. c. p. cxxvii. Gall.

SCLERIA, Berg. (Cyper.), - Ind. Kew, ii. 845 . Balansae, Maury, ex M. Micheli, in Mém. Soc. Helvsci. nat. xxxi. (1890) n, 1, 148 i. 44b. - Parag.

Baroni, C. B. Clarke, ex Th. Dur. \&o Schinz, Consp. Fl. Afr.v. 1894 (1895) 669, nomen. - Madag. Bojeri, C. B. Clarke, l. c. nomen. - Madag. Buchanani, Boeck. Cyper. Nov. i. (1888) 34.-Afr. trop. or:

Buchanani, Boeck. l. c. 33. - Afr. trop, et austr. Buettneri, Bosck. l c. 36. - Gabon.

canescens, Boeck. l. c. 37. - Ins. Porto Rico.

catophylla, C. B. Clarke, in Th. Dur. E Schinz, Consp. Fl. Afr. v. 1894 (1895) 6\%0. - Afr. trop et subtrop.

\section{SGLERIA}

Clarke, in Th. Dur. \& Schinz, Consp. Fl. Atr, v, 1894 (1895) $669=$ bulbifera, A. Rich.

cubensis, Boek. Cyper. Noo. ii. (1890) 42. Cuba.

Eggersiana, Boeck. l. c. 41 - Cuba.

flaccida, C. B. Clarke, ex Hook. f. Fl. Brit. Ind, vi. (1894) 688. - Ind. or.

fexucsa, Boeck: Cyper. Nov.i. (1888) $33=$ remota, Rid

glabra, Boeck. l.c. 35. - Afr. trop. austro-or. globonux, C. B. Clarke, in Th. Dutr. Ev Schinz, Consp. Fl. Afr. v. 1894 (1895) 671. - Afr. trop. raminifclia, Vasey, in Bull. Torrey Bot. Club. xV. (1S88) 104 . Mexic Bull, Torreg Bot. Chub, sv. (1S88)

Hilsenbergii, Boec
pulchella, Ridl.

keyensis, K. Schum. ex Warb. in Bot. fahrb, xiii. (1890) $267 .-$ N. Guin.

lihasiana, Boeck. Cyper, Nov, ii. (1890) 29. Khasia.

khasiana, C. B. Clarke, cx Hook. f. Fl. Brit. Ind. vi. (1891) 692. - Khasia

Krugiana, Bock. Cyper. Nov. i. (188S) 35. - Ins. Portorico.

Kuntzei, Boeck. .. c.34. - Java.

multispiculata, Boeck. l.c. 36. - Afr. trop. or

multispiculosa, Boeck. l. c., - Afr. trop.

natalensis. Boeck, ex C. B. Clarke. in Th. Dur. है Schinz, Consp. Fl. Afr.v. I894 (1895) 673, nomen. - Natal.

nossibeensis, C. B. Clarke, l. c. nomen. - Ins. Nossibe.

pandanophylla, Kurz, ex C. B. Clarke, in Hook. f. Fl. Brit. Ind. vi. (1894) 714, in syn. = Carex pandanophylla, C. B. Clarke.

Pittieri, Boeck, in Bull. Herö. Boiss. iii. (1895) 7 nomen. - Costa Rica.

Pseudo-Sorghum, K. Schnm, ex Engl. in Abl. Preiss. Akad. Wiss. (1894) 21, nomen. - Afr. trop

psilorrhiza, C. B. Clarke, ex Hook. f. Fl. Brit. Ind. vi. (1894) 691. - Ind. or.

puzzolanea, K. Schum. in Abh. Prouss, Akad. Wiss, (1894) 21 ; et in Engl. Pfanzenथ. Ost-Afr. C (1895) 129. - Afr. trop. or

Rehmanni, C. B. Clarke, in Th. Dur. Es Schinz, Consp. Fl. Afr. v. 1894 (1895) 674, nomen. Transvaal.

Ridleyi, C. B. Clarke, $6 x$ Hook. f. Fl. Brit. Ind. vi. (1894) 686. - Ind. or.

Rinkiana, Boeck. Cyper. Now. ii. (1890) 30. - Ins. Pulo Penang.

salebrosa, C. Spreng. fide Boeck. ex C. B. Clarke in Th. Dur, et Schinz, Consp. Fl. Afr. v. 1894 (1895) $673=$ pergracilis, $K$ unth

scaberrima, Boeck. Cyper. Nov. ii. (1898) 41. - Ins $\mathrm{S}$. Vincent

scabrosa, Maury, ex M. Micheli, in Mém. Soc. Heln sci.nat. xxxi. (1890) n. 1, 148, t. 44.- Parag.

Schenskyana, Boeck. Cyper. Noo, ii. (1898) 31. Bras.

setulosa, Boeck. 1. c. i. (1888) $33=$ Dregeana Kunuth

spinulosa, Boeck, l. c. ii. (1890) 30. - Congo.

Tonduzii, Boeck. ex Tonduz, in Bull. Herb. Boiss, iii.

(1895) 464, nomen. - Costa Rica.

trigonocarpa, Boeck. Cyper. Nov, i. (1888) 37. Bras

Trinitatis, Boeck. l. c. ii. (1890) 31. - Ins. Trinit. ustulata, F. M. Bailey. Syn.Queensl. Fl. Suppl. iil (1898,S1 (=Exocaryasclevioides, Benth.), - Austral.

Vogelii, C. B. Clarke, in Th. Dur. \&o Schinz, Consp. Fl. Afr. v. 1894 (1895) $675(=S$, racemosa, Benth.). - Afr. trop. occ.

Welwitschii, C. B. Clavke, l. $c_{0}(=S$. junciformis, Welw.). - Angola.

Woodii, C. B. Clarke, $l$. C. - Afr, austr. et trop.

SGLEROGARPUS, Jacq. (Compos.), - Ind. Kew. ii.'847. coffeaecola, Klatt, in Ann, naturh. Hofmus
ix. (1894) 360 [coffeaecolus]. - Columb. spatulatus, $\mathcal{F} . N$. Rose, in Contrib. U.S. Nat. Herb. (1891) 103. - Mexic 
SCLEROGARYA, Hochst. (Anacard.). - Ind. Kew. ii. 847.

Schweinfurthiana, Schinz, in Verh. Bot. Ver. Brand. Abhandl. xxix. (1888) 63. - Afr, austro-occ, extratrop.

Schweinfurthi, "Schinz » ex O. Hoffm. in Engl. \& Prantl, Natürl. Pflanzenfam. iii. 5 (1892) $152=$ Schweinfurtiana, Schinz.

SCLEROCHAETIUM, Nees = Tetraria, Beauv. (Cyper.)

dactyloides, Nees, ex C. B.Clarke, in Th. Dur. \& Schinz, Consp. Fl. Afr. v. 1894. (1895) $661=$ T. involucrata, C. B. Clarke,

teres, Nees, ex C. B. Clarke, in Th. Dur. \& Schinz, 1. c. $662=$ T. Rottboellii, C. B. Clarke.

SCLEROCHITON, Harv. (Acanth.) - Ind. Kew. ii. 847 .

stenostachyus, Lindau, in Bot. Fahrb. xx. (1894) 27 - Afr. trop. or.

SGLEROCHLOA, Beauv. (Gramin.). - Ind. Kew. ii. 848 .

filiformis, Tornab. Fl. Sicula (1887) 595, - Sicil.

SGLEROLEPIS, Cass. (Compos.). - Ind. Kew. ii. 848 .

unifora, Britton, Stern \& Pogg. Prelim. Catal. (1888) 25 ; Porter, in Mem. Torrey Bot. Club, v. (1894) 311 = verticillata, Cass.

SCLEROLOBIUM, Vog. (Legumin.). - Ind. Kew. ii. 848 .

Glaziovii, Taub. in Flora, 1xxv. (1892) 80. - Bras.

SCLEROPYRUM, Arn. (Santal,), - Ind. Kew. Maingayi, Hook. f. Fl. Brit. Ind: v. (1886) 235. Penins. Mal.

SCLEROTHEGA, A. DC. (Campanu1,). - Ind.

Kew. ii. 849.
Forsteri, Drake, Ill. Ins. Maris Pacif. (1886) 222 t. 8 ; et Fl. Polyn. Franc. (1892) 114. - Ins. Societ. Closiana, Warb. l. c. $30(=$ Erindaphus Clossianus, Baill.). - Afr.-austr.

maxitima, Warb. l. c. 29 (= Phoberos maritima, Miq.). - Sumatra

SGoliotheCA. Baill, in Bull. Soc. Linn. Paris, i. (1888) 724; et Hist. des pl. x. (1888) 84. GESNERIACEAE

Trianae, Baill. ll.cc. - N. Granat.

SCOLOCHLOA, Mert. \& Koch $=$ Arundo, Tourn. (Gramin.).

anundinacea, MacMill. Metasp. Minn. (1892) $79=$ festucacea, $\operatorname{Link}$.

SCOLOPIA, Schreb. (Bixin.). - Ind. Kew. ii. 849.

borbonia, Warb. in Engl, \& Prantl, Natiirl. Pfanzenfan. iii. 6a (1893) 29. - Ins. Borbon.

cuneata. Warb. i.c. 29; et in Engl. Pflanzenw. OstAfr. C (1895) 278. - Afr. trop. or.

Ecklonii, Warb. 1. c. $29=\mathrm{seq}$

Ecklonii, Szyszyl. Pl. Rehmann.(1887) 19 (= Phoberos Ecklonii, Pres1). - Afr. austr.

Iuzonensis, Warb. in Engl. E Prantl, Natïrl. Pfanzenfam. 1ii. 6a (1893) $30=$ Scolopia Dasyanthera, F. Villar.

Mundtii, Warb. l. c. 29 (= Phoberos Mundtii, Harv. \& Sond.). - Afr, austr.

novo-guineensis, Warb. in Bot. Fahrb. xiii. (1891) 384 ; et l. c. $30 .-\mathrm{N}$. Guin,

phinanthera, Warb. 1. c. $29=$ rhinanthera, Clos.

spinosa, Warb. 1. c. = Roxburghii, Clos.

Zeyheri. Warb. 1. c. $29=$ seq.

Zeyheri, Szyszyl. Pl. Rehmann. (1S8\%) 19 (= Phoberos Zeyheri, Presl). - Afr. austr.

SCOLYMOCEPHALUS, Weinm. = Protea Linn abysinicus, acoulis, acerosus, acuminatus, amplexicaulis, augustatus, auriculatus, barbiger, caffer, calocephalus, canaliculatus. coccineus, compactus, cordatus, echimulatus effusus, elongatus, formosus, fulzus, glaber,

\section{SCOLYMOCEPHALUS : -}

hirtus, incomptus, laevis, lanceolatus, longiflorus, longifolius, loveus, macrocephalus, macrophyllus, mela leucus, mellifer, montanus, mucronifollus, neriifolius, nitidus, obtusifolitus, ovatus, patens, pendulus, pulchellus, reconditus, repens, vevolutus, nupicolus, scaber, scabridus, Scolopendrium, Scolymus, speciosus, tenax, tenuifolius, turbiniflorus, venosus, venulosus, villifer, Kuntze, Rev. Gen. (1891) 581-82 = homonyma omnia Proteae.

coriaceus, Kuntze, 1. c. $581=\mathrm{P}$. punctata. Meissn. cynarodes, Kuntze, 1. c. $=$ P. cynaroides, Linn eximius, Kuntze, $l_{1} c_{0}=$ P. latifolia, $R$. $B r$.

Trumiflorus, Kuntze, 1. c. $=$ P. humilis, $R$. $B$ r

Lepidocarpodendron, Kuntze, 1. c. = P. Lepidocarpon, R. Br.

marginatus, Kuntze, 1. c. $=$ P. melaleuca, $R . B r$. nanus, Kuntze, 1. c. $=$ P. rosacea, Linn.

penicillatus, Kuntze, 1. $\mathrm{c}_{.}=$P. Mundi, Klotzsch. pyrifolius. Kuntze, 1. c. = P. Buekiana, Meissn. Roupelliae, Kuntze, 1. c. = P. Rouppelliae, Meissn. spectabilis, Kuntze, 1. c. $=$ P. Iatifolia, $R$. Br.

SCOPARIA, Linn. (Scrophul.). - Ind. Kew. ii 849

purpurea, Ridl. in Fourn. Limn. Soc. xxvii. (1890) 51. - Ins. Fernando Noronha.

SCOPOLIA, Adans. = Ricotia, Linn. (Crucif.) carnosula, cretica, Lunaria, sinuata, tennifolia, Kuntze Rev. Gen. (1891) $36=$ homonyma ommia Ricotiae.

SGOPOLIA, Jacq. (Scrophu1.). - Ind. Kew. ii. 850.

sinensis, Hemsl.in fourn. Limn. Soc. xxvi. (1890) 176. - China.

SCOPOLINA, Schult. = Scopolia, Jacq. (Solan.). carniolica, japonica, sinensis, tangutica. Kuntze, Rev. Gen. (1891) 452 = homonyma omnia Scopoliae. stemonifolia, Kuntze, 1. c。= Scopolia lurida, Dunal.

SCORIA, Rafin。= Carya, Nutt. (Jugland.). glabra, Kuntze, Rev. Gen. (1891) $6=\mathrm{C}$. porcina Nutt.

minima, MacMill. Metasp. Minn. (1892) $178=$ C. minima, Nutt.

ovata, MacMill. 1. c, = C. alba, Nutt.

SCORTEGHINIA, Hook, f, Fl, Brit, Ind, v (1887) 366 , et in Hook. Icon. pl. xviii. (1887) t 1706. EUPHORBIACEAE.

Kingii, Hook. f. ll.cc. 367, et t. 1706. - Ins. Nicob.

SCORZONELLA, Nutt.= Microseris, D. Don (Compos.)

arguta, Drew, in Bull. Torrey Bot. Club, xvi. (1889) 152. - Calif.

Bolanderi, Greene, in Bull. Calif. Acad. ii. $v$ (1886) 52; et Man. Bot. San Franc. Bay (1894 $223=$ Microseris Bolanderi, A. Gray.

borealis, Greene, Pittonia, ii. (Nov, 1889) $19=$ Leontodon borealis, $D C$.

Hozellii, Greene, in Bull. Calif. Acad. ii. v. (1886) $52=$ Microscris Howellii, A. Gray.

maxima, Bioletti, ex Greene, in Erythea, i. (1893) 69 ; et Man. Bot. San Franc. Bay (1894) 223. - Calif.

megacephala, Greene, in Bull. Calif. Acad. ii. v. (1886) 50. - Am. bor. occ.

montana, Greene, 1. c. 53. - Calif

paludosa, Greene, 1. c. $52(=$ Microseris sylvatica Sch. Bip. var. Stillmani, A. Gray ; et Man. Bot. San Franc. Bay (1894) 223. - Calif,

pratensis, Greene, 1. c. 51 . - Calif.

procera, Greene, 1. c. $50=$ Microseris procera, $A$ Gray.

scapigera, Greene, 1. c. $53=$ Scorzonera scapigera, Forst.

SCORZONERA, |Tourn.] Linn. (Compos.). -

Albertoregelia, C. Winkl. in Act. Hort. Petrop. xi. (1890) 322. - Turkest.

amasiana, Hausskn. E Bornm. ex Hausskn. in Mitt. Bot.Ver. Fena, ix. (1891) 17. - As. Min.

\section{SCORZONERA}

bicolor Freyn so Sint, in Oest. Bot. Zeitschr. xlii. (1892) 266. - Armen. turc.

bracteosa C. Winkl. in Act. Hort. Petrop. xi. (1890) 324. - Buchara.

cana, O. Hoffm. in Engl. \& Prantl, Natürl. Pflanzenfam, iv. 5, (1893) $365=$ Jacquiniana, Boiss. mongolica, Maxim. in Bull. Acad. Pétersb. xxxii. (1888) 492. - Mongolia.

capito, Maxim. I. . . 491. - Mongol.

crispatula, Boiss, ex Willk. Illustr. Fl. Hisp. ii, (1886-92) 83. t. 135. - Hisp.

glabra, C. Winkl. in Act. Hort. Petrop. xi. (1890) 333. - Turkest.

Hissariae, C.Winkl. l.c. xi. (1889) 1\%2. - Buchara. isophylla, Post,Pl. Postianae, iii. (1892) 13. - Syria. facquiniana, G. Beck, Fl, Nied.-Oest. ii. (1893) 1324 = Jacquiniana, Boiss.

kenissaea, Boiss. Fl. Or. Suppl. (1888) 321. - Syria.

leptoclada, Hausskn. \& Bornm. ex Bornm, in Mitth. Bot.Ver. Fena, N. Folge, vi. (1894) 66- - Oriens. Raddeana, C. Winkl. in Act. Hort. Petrop. xi. (1889) 150. t. 3 fig. 1. - Turcom.

rhodantha, Hausskn, in Mitth. Bot, Ver. Fena, v. (1887) 86. - Graecia.

rubriseta, Lipsky, in Mém. Soc. Hist. nat. Kiew, x. (1891) extr. 20; et in Act. Hort. Petrop. xiii. (1894) 315. - Reg. Cauc.

rumelica, Velen, in Sitz. Boehm. Ges. Wiss. (1892-93) 40. - Rumel.

rupicnla, Hausskn, in Mitth. Bot, Ver. Fena, ix. (1891) 17 - As, Min.

Schweinfurthii, Boiss. Fl. Or. Suppl. (1888) 320. Desert. Aegypt.-Arab.

Sintenisii, Freyn, in Oest. Bot. Zeitsizr. xlii. (1892) 267. - Armen. turc.

troodea, Boiss. Fl. Or. Suppl. (1888) 320. - Ins. Cypr.

SCOTTELLIA, Oliver, in Hook. Icon. pl. xxiii. (1893) t. 2265. BIXINEAE.

leonensis, Oliver, l. c. - - Sierra Leone.

SGRIBNERIA, Hack, in Coult. Bot. Gaz. xi. (1886) 105; et in Engl. \& Prant1, Natürl. Pflanzenfam. ii. 2. (1887) 78. GRAMINEAE.

Bolanderi, Hack. ll.cc. t. 5 (= Lepturus Bolanderi, Thurb.). - Calif., Oregon.

SCROFELLA, Maxim. in Bull. Acad. Pétersb. xxxii. (1888) 511. SCROPHULARINEAE.

chinensis, Maxim. l. c. 511 . - China.

SGROPHULARIA, Tourn, ex Linn. (Scrophu1.). - Ind. Kew. ii, 852 .

alaschanica. Batalin, in Act. Hort. Petrop. xiii. (1894) 380. - Mongolia.

antiochia, Post, in Bull. Herb. Boiss, i。 (1893) 27. - Syria.

balcanica, Velen, in Sitzb. Boekm. Ges, Wiss. 1889 (1890) ii. 55 ; et Fl. Bulg. (1891) 421. - Bulg.

Bornmuelleri, Freyn \& Sint. ex Freyn, in Dest. Bot. Zeitschr, xlii. (1892) 348. - As, Min.

bosniaca, G. Beck, in Ann. Naturhist. Hofmus. Wien, ii. (1887) 135 t. 5 fig. 79 = nodosa, Linn. Duriaei, Spach, ex Batt. E Trab. Fl. de l'Algér. [Dicot.] (1890) 632, nomen. - Algeria.

gileadense. Post, in fourn. Linn. Soc. xxiv, (1888) $438,-$ As. occ.

Henryi, Hemsl. l. c. xxvi. (1890) 178. - China

Fanka, Borb, ex Nym. Consp. Fl. Eur. Suppl. ii. I. (1889) 231 = laciniata, Linn.

kansuensis, Batalin, in Act. Hort. Petrop. xiii. (1894) 381. - China.

ningpoensis, Hemsl, in fourn. Limn, Soc. xxvi. (1899) 178. - China.

nusairiensis, Post, in Bull. Herb. Boiss. i. (1893) 27. - Syria.

Peyroni, Post, l. c. 28. - Syria.

pindicola, Hausskn. in Mitth. Bot.Ver. Fena, v. (1887) 88. - Graecia

provincialis, Rouy, in Bull. Soc. Bot. Fr. xxxviii. (1891) 264 [Scrofularia] (=S. lucida, Gren. \& Godr.). - Gall. mer. 
SCROPHULARIA :

Przewalskii, Batalin, in Act. Hort. Petrop. xiii. (1894) 382. - Tibet.

Reuteri, Daveau, in Bolet. Soc. Brot. x. (1892) 169. - Lusit.

Saharae, Batt. \& Trab. Fl. de l'Algér. [Dicot.] (1889) 634; et in Bull. Soc. Bot. Fr. xxxviii, (1891) 296. - Algeria.

Teucrium, Christ, in Bot. Fahrb. ix. (1887) 128. Teneriffa.

SCUTELLARIA, Riv, ex Linn. (Labiat.). - Ind. Kew. ii. 855 .

andamanica, Prain, in Journ. As. Soc. Beng. lix. (1890) II. $307=$ oblonga. Benth.

aurea, Robinson \& Greenm. in Am. Fourn. Sci. Ser. III. 1. (1895) 163. - Mexic.

Brittonii, Porter, in Bull. Torrey Bot. Club, xxi. (1894) 177. - Am. bor.

campestris, Britton, in Mem. Torrey Bot. Club, v. (1894) 283. - Am. bor.

Footeana, A. I. Mulford, in Coult. Bot. Gaz. xix. (1894) 118 . - Am. bor.

formosana, N.E. Br. in Gard. Chron. (1894) ii. 212. - China

Helenae, Alboff, in Bull. Soc. Imp. Hortic. [Compt.-rend. Sect. Odessa (1891)-extr. 14, ex Bull. Herb. Boiss. i. (1893) 261, in syn. = pontica, $C$. Koch.

hercegovinica, Formanek, in Oest. Bot. Zeitschr. xxxviii. (1888) 384: Murb. in Lunds Univ Arsskrift, xxvii. (1892) $65=$ orientalis. Linn.

hispidula, Robinson, in Proc. Am. Acad. xxvi. (1891) 174. - Mexic.

javalambrensis, Pau, Not. Bot. Fl. Espan. ii. (1889) 35 = alpina, Linn

Kingiana, Prain, in fonrn. As. Soc. Beng. lix. (1890) II. 308. - Reg. Himal.

kurdica, Post, Pl. Postianae, iv. (1892) 10. - As.

Min. Ost-Afr. C (1895) 342. - Afr. trop. or.

lutea, F. D. Smith, in Coult. Bot. Gaz. xiii. (1888) 76. - Guatem.

Nicholsoni $\times$, Taub, in Abhandl. Bot. Ver. Prov. Brand. xxvii. (1886) 25, et xxxviii. (1887) 25 t. 2. - Anglia.

nipponica, Makino, in Tokyo Bot. Mag. vi. (1892) 54. - Japon.

obtusifolia, Hemsl. in fourn. Limn. Soc. xxvi. (1890) 296. - China.

orichalcea, f. D. Smith, in Coult. Bot. Gaz. xiv. (1889) 29. - Guatem.

paucifolia, Baker, in Kew Bull. (1895) 292. - Afr. centr. austr.

petiolata, Hemsl. ex Lace \& Prain, in fourn. As.

Soc. Beng. lix. (1890) II. 308 ; et in fourn. Linn. Soc. xxviii. (1891) 326. - Belutchist.

Schweinfurthii, Briq. in Bot. Fahrb. xix. (1894) 194. - Afr. centr. bor. sessilifolia, Hemsl. in Fourn. Linn. Soc. xxvi. (1890)
297. - China.

shikokiana, Makino, in Tokyo Bot. Mag. vi. (1892) 54. - Japan.

stenosiphon, Hemsl, in Foum. Linn. Soc. xxvi. (1890) 297 . - China

strigillosa. Hemsl. l. c. - Chin

suffrutescens, S. Wats. in Proc. Am. Acad. xxv. (1890) 160. - Mexic.

tosaensis, Makino, in Tokyo Bot. Mag. vi. (1892) 54. - Japon.

SGUTIA, Comm. (Rhamn.). - Ind. Kew. ii. 856. obcordata, Baill. Hist, pl. Madag., Atlas (1894) t. 285. - Madag.

SCUTICARIA, Lindl. (Orchid.). - Ind. Kew. ii. 856 .

Keysseriana, Hort, ex Journ. of Hort. ii. (1894) 194, 195, fig. $26=\mathrm{S}$. Steelii, Lindl.

SCYPHANTHUS, [D. Don in] Sweet = Grammatocarpus, Presl (Loaseae).

stenocarpus, Urban \& Gilg, in Engl. \& Prantl, Natürl. Pflanzenfam. iij. 6a (1894) $118=\mathrm{G}$. volubilis, Presl.
SCYPHOCEPHALIUM, Warb. in Ber, Deutsche Bot. Ges, xiii. (1895) 84. MYRISTICACEAE.

chrysothrix, Warb. l. c.; et in Notizbl. Bot. Gart. Berl. (1895) 98. - Kamerun.

Kombo, Warb. ll. cc. (= Myristica Kombo, Baill.). - Gabon.

Mannii, Warb. l. c. 98 (= M. Mannii, Benth.).Afr. trop. occ.

SCYPHOSTEGIA. Stapf, in Trans, Linn. Soc, Ser. II. iv. (1894) 217. MONIMIACEAE.

borneensis. Stapf, l. c.218. - Borneo

SGYPHOSTELMA, Baill. Hist. des pl. x. (18?0) 252; K. Schum. in Engl. \& Prantl, Natürl. Pflanzenfam. iv.2 (1895) 254. ASCLEPIADEAE. granatensis, Baill. ll. co. - N. Granat.

SEBAEA, Soland. ex R. Br. (Gentian.). - Ind. Kew. i1. 857.

acutiloba, Schinz, in Bull. Herb. Boiss, iii. (1895) 412. - Afr. austr.

Barbeyana, Schinz, in Viertelj. Naturf. Ges. Zivich, xxxvii. (1891) 326. - Afr. austr

Evansii, N. E.Br. in Kew Bull. (1895) 27; Oliver, in Hook. Icon。pl. xxiv. (1895) t. 2377. - Afr. austr.

filiformis, Schinz, in Bull. Herb. Doiss, iii. (1895) 412. - Natal.

Grisebachii, Schinz, in Viertelj. Naturforsch. Ges. Ziurich, xxxvi. (1891) 322. - Afr. austr.

linearifolia, Schinz, l. c 321. - Afr. austr.

longicaulis, Schinz, in Bull. Herb. Boiss, ii. (1894) 219. - Afr. austr

microphylla, Knobl. in Bot. Centralbl. 1x. (1894) $324=$ khasiana, C. B. Clarke.

minutiflora, Schinz, in Bull. Herb. Boiss, iii. (1895) 413. - Afr. austr.

Rehmanni, Schinz, in Viertelj. Naturforsch. Ges. Zïrick, xxxvi. (1891) 322. - Transvaal.

repens, Schinz, in Bull. Herb. Boiss. ji. (1894) 219. - Afr. austr.

tabularis, Eckl. ex Schinz, in Viertelj. Naturforsch. Ges, Ziirich, xxxvi. (1891) 319. - Afr. austr.

tetragrona, Vatke, ex Engl, in Abh. Preuss. Akad. Wiss. 1891 (1892) 336. in obs. nomen. - Angola. Welwitschii, Schinz, in Vievtely. Naturforsch. Ges. Ziivich, xxxvi. (1891) 321. - Angola.

Zeyheri, Schinz, l. c. 325.-Afr. austr.

SEBASTIANIA, Spreng. (Euphorb.). - Ind, Kew. ii. 858.

Palmeri, 7. N. Rose, in Contrib. U. S. Nat. Herb. i. (1891) 112. - Mexic

Pringlei, S. Wats. in Proc. Am. Acad. xxvi. (1891) $149^{\circ}$ - Mexic.

Ramirezii, Maury, in La Naturaleza, Ser. II. ii. (1894) 406. - Sonora.

SEBSCHAUERA, Kuntze, Rev. Gen. (1891) $494=$ Sebastiano-Schaueria, Nees (Acanth.). oblongata, Kuntze, 1. c。= S. oblongata, Nees.

SECAMONE, R. Br. (Asclep.). - Ind. Kew. ii. 859.

acuminata, K. Schum, in Engl. Eo Prantl, Natiirl. Pfanzenfam. iv. 2 (1895) 263 (= Toxocarpus acuminatus, Benth.). - Ind. or

crassifolia, K. Schum. l. c. (= Genianthus crassifofolius, Hook. f.). - Penins. Mal.

discolor, K. Schum. \& Vatke, ex K. Schum. in Bot. fahrb. xvii. (1893) 140. - Madag

Elliottii, K. Schum. in B.t. fahrb. xvii. (1893) 141. - Madag.

erythradenia, K. Schmm. l. c. ; et in Engl. E Prantl, Natiurl. Pfanzenfam. iv, 2 (1895) 263. - Afr. trop.

Gerrardi, Havv. ex Sihlechter, in Bot. Fahrb. xviii. Beibl.n. 45 (1894); et in fourn. Bot. xxxiii. (1895) 353. - Afr. austr.

glaberrima, K. Schum, in Bot. Fahrö. xvii. (1893) 142. - Madag.

gracilis, N.E. Br. in Keथ Bull. (1895) 248.Mombasa, Afr. trop. or.

Kirkii, N.E. Br. l. c.- Zanzibar

\section{SECAMONE}

Kleinii, $K$. Schum, in Engl. E Prantl, Natiirl. Pfanzenfam. iv. 2 (1895) 263 i= Toxocarpus Kleinii, Wight et Arn.). - Ind. or.

laurifolia, $K$. Schum. l. c. (= Gonianthus laurifolius, Hook. f.). - Sikkim.

micrandra. K. Schum. in Bot. Fahrb. xvii. (1893) 142. - Afr. trop.

papuana, Warb. l. c. xviii. (1894) 206. - N

platystigma, K. Schum. l.c. xvii. (1893) 143. Angola.

retusa, N. E. Br. in Kew Bull. (1895) 248. Zanzib.

sansibariensis. K. Schum. in Engl. Pfanzenv. OstAfr. C (1895) 325. - Afr. trop. or

Schweinfurthii, $K$. Schum. in Bot. Fahrb. xvii. (1893) 143. - Afr. trop.

stenophylla, $K$. Solum. in Engl. Pfanzenw. Ost-Afr. C (1895) 325. - Afr. trop.

Stuhlmannii, K. Schum.l. c. - Afr. trop. or.

Wightiana, K. Schum. in Engl. E Prantl, Natürl. Pfanzenfam.iv. 2(1895) 263 (= Toxocarpus Wightianus, Hook. \& Arn.). - Ind. or.

zambesiaca, Schlechter, in fourn. Bot. xxxiii. (1895) 303. - Afr. trop. or. SEGURIDACA, Linn. (Polygal.). - Ind. Kew.
ii. 859 .

Engleriana, Chod, $2 n$ Bull. Herb. Boiss, iii. (1895) 545. - Bras.

falcata, Chod. l. c. 547. - Bras.

Fendleri, Chod. l. c.545. - Venezuela.

Gardneri, Chod.l.c. 546. - Bras.

Micheliana, Chod, in F. D. Smith, Enum. pl. Guatem. iv. (1895) 8 ; et l. $c .546$. - Costa Rica.

myrtifolia, Chod.l.c.-Mexic.

rosea, Barb, Rodr. [Herb. Mus. bot, Ama\%, n, 19] in Vellosia, 1885-88, Sec. ediç. (1891) 6, t. 4, fig. a. - Bras. bor

tenuifolia, Chod. in Fiull. Herb. Boiss. iii. (1895)

545. - Ins. Trinit.

Warmingiana, Chod.l. c. 544. - Bras.

SECURINEGA, Comm. ex Juss. (Euphorb.).Ind. Kew. ii. 860 .

keyensis, Warb. in Bot. Fahrb. xiii. (1891) 358, Ins. Key (N, Guin.).

SEDDERA, Hochst, = Breweria, R. Br. (Convolv.

humilis, Haltier fo in Bot. Jahrb, xviii. (1894) 89 . - Afr. trop. or.

latifolia, Hort. ex Terrac, in Ann. Ist. Bot. Roma. v. (1894) $164=$ Breweria latifolia, Terrac.

mucronata, Hallier f. in Bot. Jahrb, xviii. (1894) 88 Convolvulus mucronatus, Engl.

somalensis, Hallier f. 1. c. $90=$ Breweria somalensis, Vatke.

spinescens, Peter, ex Hallier f. I. c. 89. - Afr. trop. or.

suffruticosa, Hallier f. 1. c. $88=$ Breweria suffruticosa, Schin\%.

Welwitschii, Hallier f. 1, c. - Angola.

SEDUM, Tourn. ex Linn. (Crassul.). - Ind. Kew. ii. 860 .

alamosanum, S. Wats. in Proc. Am. Acad. xxv. (1890) 148. - Mexic

Amani, Post, in Bull. Herb. Boiss. i. (1893) 20, 411. - Syria.

andinum, Ball, in fourn. Linn. Soc, xxii. (1885) 38. - Peruvia.

baeticum, Rouy, in Bull. Soc. Bot. Fr. xxxiv. (1857) 441 = hirsutum. All.

brutium, Terrac. in Ann. Ist. Bot. Roma, iv. 1889-90 (1891) 98 , t. 4. - Italia mer.

calcicola, Robinson \&. Greenm. in Am. Fourn. Sci. Ser. III. 1. (1895) 150. - Mexic.

chapalense, S. Wats. in Proc. Am. Acad. xxii. (1887) 411. - Mexic.

chihuahuense, S. Wats. l. co xxiii, (1888) 273.Mexic.

Deserti-hungarici, Simonk. in Oest. Bot. Zeitsclir. xi. (1890) 333. - Hung. 


\section{SEDUM :}

diffusum, S. IVals, in Proc, Am, Aa ad. xxy. (1890)

148. - Mexic.

divergens, Greene, Pittonia, i. (Jan. 1888) 154. Mexic.

erectum. Frcyn, in Bull. Hiró. Boiss, iii. (1895) 302. - As. Min.

filiferum, S. Wats, in Proc. Am. Acal, xxi. (1886) 428. - Mexic.

flipes, Hemsl. cx Forb. \& Hemsl. in Fourn. Linn. Soc. xxiii。(1887) 284, t. 7a, fig, 1-3, China.

Alexuosum, Wettst. in Lucrss. Biblioth. Bot. Heft 26 (1892) 43. - Alban.

madalajaranum, S. Wats, in Proc. Ant Acad xxii, (1887) 411 [guadalajarana]. - Mexic.

jaliscanum. S. Wats. l. co xxv. (1890) 148. Mexic

aralanbrense, Pau, Not. Bot. Fl. Espan. iv. (1891) 38, in syn. = nevadense, Coss

Inmholtzii, Robinson \& Fernuld, in Proc. Am. Acad, xxx. (1895) 116. - Mexic.

macrolepis, Franch. in Nour? Archiv. Muts. Paris, Ser. II. viii, 188.5 (188 i) ?41. - Tibet.

madrense, S. Wats. in Proc. Am. Acad. xxiii. (1888) 273. - Mexic.

Makinoi, Maxim, in Bull. Acad. Petters, xxxii. (1888) 487. - Japon.

Teyeri Johannis, Engl. in Abh. Preuss. Akud. Wiss. ii. 1891 (1892) 229. - Afr. trop. or.

oryzifolium, Makino, Inlustr. Fl. Fapon. i. 8 (1891) 2. t. 50 ; et in Tokyo Bot. Mag. ix. (1895) 261. Japon.

pallescens, Freyn, in Ocst, Bot. Zcitschr. xlv. (1895) 317. - Dahuria.

polonicum, Blocki, in Deutsche Bot. Monatsschr. v. (1857) 66. - Eur. centr. or.

polytrichoides, Hemsl. ex Hemsl. \& Forb. in Fonm. Limn. Soc xxiii. (1887) 286, t. $7 \mathrm{~b}$, fig. 4. China.

Pringlei, S. Wats, in Proc. Am. Acad. xxiii. (1888) $273=$ S. Torreri, Greene

puberulum, S. Wats.l.c. - Mexic.

rodanthum, Bormm. in Mitth: Bot, Ver, fena, v, Folge, vi. (1894) 66. - Oriens.

Stribrnyi, Velen. in Oest. Bot. Zettschr.xlii. (1892) 14. - Bulg.

texanum, F. D. Smith, in Missouri Bot. Gard. Rep. vi. (1895) 114, t. 50. - Texas

Torreri, Grcenc, Pittonia, i. (Feb. 1888) $162(=S$, divergens, Greene). - Mexic.

tosaense, Makino, in Tokyo Bot. Mag. vi. (1892) 52. - Japon.

tricarpum, Makino, Illustr. Fl. Fapon, i. 7 (1891) 3, t. 12. - Japon.

inicolor. S. Wats, in Proce. Ann. Acad, xxi, (1886) 428. - Mexic

Volkensii, Engl. Pfanzenw. Ost-Afr. C (1895) 188. - Afr. or.

SEEMANNIA, Regel (Gesñerac.). - Ind. Kew。 ii. 863.

major, Baill. in Bull. Soc. Linn. Paris, i. (1887) 710. - Bolivia.

purpurascens, Rusby, in Mem. Torrey Bot. Club, iv. (1895) 237. - Bolivia.

ylratica, Baill. in Bull. Soc. Linn. Paris, i. (1857) 708 = ternifolia, Regel.

iniflora, Baill. .. c. 710.- Bolivia.

SEGUIERA, Loef. (Phytol.). - Ind. Kew. ii. 863.

paraguayensis, Morong, in Ann. .V. Y. Acad. sci. vii. (1893) 210. - Parag.

SEGUIERA, Manetti, Virid. Fl. (1751) 81, ex Kuntze, Rev. Gen. (1891) $430=$ Chlora, Ren. (Gentian.)

imperfoliata, Kuntze, 1. c. = C. imperfoliata, Linn. $f$. perfoliata, Kuntze, 1. Co = C. perfoliata, Linn.

SEHIMA, Forsk. = Ischaemum, Linn. (Gramin.). macrostachyum, Hochst. (in Schimp. Pl. Abyss. n. 1705) ex Hack. in A. DC. Nonog. Phan. vi. (1889) 245 , in syn. = I. laxum, $R . B r$.
SEIDELIA, Baill. (Euphorb.). - Ind. Kew, ii.

triandra, Pax, in Bot. Fahrb. x. (1889) $35=\mathrm{S}$. Mer curialis, Baill.

SELAGO, Linn. (Selagin.). - Ind. Kew. ii. 866.

alopecuroides, Rolfe, in fourn. Bot. xxiv, (1886) 175: Kuntze, én fahrb. Bot. Gart. Berl. iv. (1886) 270. - Angola.

densiflora, Rolfo. ex Schinz, in Bull. Herb. Boiss, ii. (1894) 222. - Afr. austr.

Johnstoni, Rolfe, ex Olizer, in Trans. Linn. Soc. Ser. II. ii. (1887) 345. - Afr. trop. or.

milanjiensis, Rolfe, $l . c$. iv. (1894) 35. - Afr. trop.

Nachtigali, Rolfe, ex Schinz, in Vorh. Bot. Ver. Brand. xxxi. (1890) 205. - Afr, austro-occ extratrop.

Thomsoni, Rolfe, ex Oliver, in 7. Thoms. Throush IIasai Land, Aopend. (1887) 351. - Afr. trop. Welwitschii, Rolfe, in foum. Bot, xxiv. (1886) 175 - Afr. trop. occ

Whyteana, Rolfe, in Trans. Linn. Soc., Ser. II. iv. (1894) 35. - Afr. trop.

SELENIPEDILUM, Pfitz. in Engi. \& Prantl, Natürl. Pflanzenfam. ii. $6(1888) 84=$ Selenipe dium, Reichb. f. (Orchid.).

Chica, Pfitzer, 1. c. = S. Chica, Reichb. $t$.

SELENIPEDIUM. Reichb, f, (Orchid.). - Ind. Baconis $X$. Hort. ex Orchid Rev. i. (1893) 358, et iii. (1895) 80 (= Cypripediun Baconis $X$ Kraenzl.). - Hybr. artef.

Brysa X. Hort. 1. c. (= C. Brysa X, Hort.).Hybr. artef.

Glurum $\times$. Nichols. Dict. Gard. iii. (1886) 413 Rolfe, in Lindenia, vii. (1891) 35, t. 304. Hybr, artef.

chlorops X, Reichb. f. in Gard. Chron. (1888) i. 584, in syn. (=C. clilorops, Reichb. f. $)_{2}-$ Hybr arief.

conchiferum $X$, Nichols, 1. c, - Hybr. artef.

Coppininnum $\times$. Hort. ex Orchid Rev. i. (1893) 325 , et iii. (1895) 81 (=Cypripedium Coppinianum $X$ R. H. Meas.). - Hybr. artef.

Dalleannm X. Hort. ex Ed. André, in Rev. Hortic. lxvii. (1895) 164. - Hybr, artef.

Elstcadianum $\times$, Hort. ex Orchid Rev, i. (1893) 358; et iii. (1895) 80 (= Cypripediun Elsteadiamum X. R. L. Meas). - Hybr. artef.

Hardyanum X. Hort. 1. c. ( $=$ C. Hardyannm X. Hort.). - Hybr. artef.

hybridun X. Hort, ex Gard, Chron. (1891: j, 502. - Hybr. artef.

Iemoinierianm $\times$. Hort. ex Orchid Rev. iii. (1895) 79 (= Cypripedium Lemoinierianum $X$ Reichb.f.). - Hybr. artef.

leucorrhodum, Hort. ex Gard. Chron. (1892) i. 211 - Form. hort.

Lindeni, Nichois. Dict. Gard. iii. (1886) 413.-N. Granat.

nitidissimum 入. Reichb. f. in Gard. Chron. (1888 ii. 6, in syn. = Cypripedium nitidissimum, Reichb.f.

Pcrseus X, Hort. ex Orchid Rev. i. (1893) 358 ; et iii. (1895) 80 ( = C. Perseus $\times$, Hort.) $=$ Hybr. artef

reticulatum, Reichb. f. in Lindenia, i. (1885) 25 , t. 10. - Ecuad.

Sanderianum X. Hort. ex Orchid Rev. i. (1893) 16.31, et iii. (1895) 79 (= Cypripedinm Sanderianum X. Reichb. t.). - Hybr. artef.

Sargentianum. Rolfe, $2 n$ Orchid Rev. (1893) et in Gard. Chron. (1894) i. 781, fig. 100; Hook, f. in Bot. Mag. (1895) t. 7446. - Bras.

Schomburgkianum, Desbois, Monog. Cypriped. (1888) $\mathbf{1 4 1}=$ Klotzschianum, Reichb. $f$.

Schroederae \. Nichols. Dict. Gard. iii. (1886) 413 - Hybr. artef.

Stella X, Hort. Sand. ex Orchid Rev. ii. (189t) 110. - Hybr. artef.

Wallisi, J. Linden, in Lindenia, iii. (1887) 73, t. $13 \mathrm{l}=$ Cypripedium Wallisii, Reichb. $f$.

\section{SELENIPEDIUM}

Weidlichianum X, Hort. Sarid. ex Gard. Chron, (1890) 702. - Hybr. artef.

SELINUIM, Linn. (Umbell.). - Ind. Kew. ii. 865. agasylloides, Alboff, in Bull. Herb. Boiss, ii. (1894) 252. t. $S=$ Chymsydia agasylloides, Alboff. Benthamii, F. Kurtz, in Bot. Jahrb. xix. (1894) 382 = Cnidium Benthamii, S. Wats.

Dawsoni, Coult. \& F. N. Rose. in Coult. Bot. Guz xiii. (1888) 114 ; te Rev. N. Am. Unbell. (ISSS) 44 - Am. bor.

eryngiifolium, Greene, Pittonia, ii. (June 1800) 102 ; ct Fl. Francisi. (1892) 326. - Calif.

Gmelini, F. Kurtz, in Bot. Jahrb. xix. (1894) $389=$ Ligusticum Gmelini. Cham. E Schlecht.

Grayi, Coult. \& 7. N. Rose, in Coult. Bot. Gaz. xiii. (1888) 144 ; ct Rev. N.Am. Umbell. (1888) 44; Calit.

Hookeri, S. Wats. ex Coult. Eo f. N. Rose, Revis. N. Am. Unbell. (1888) 45. - Am. bor.

longeradiatum, Maxim. in Bull. Acad. Pétersb. xxxi (1887) 50. - Japon.

SELliERA, Cav. (Goodenov.). - Ind. Kew.. ii 866 .

microphylla, Colenso, in Trans. N. Z. Inst. xxii. $1889(1890) 473 .-$ N. Zel

SELLOA, Spreng. = Gymnosperma, Less. (Compos.),

corymbosa, Kuntze, Rev. Gen. (1891) $362=$ G. corymbosum, $D C$.

eriocarpa, Kuntze, 1. c. = Gutierrezia eriocarpa, A. Gray.

multiflora, Kuntze, 1. c. = Gymnosperma corymbosum, $D C$

scoparia, Kuntze, 1. $c .=G$. corymbosum, $D C$.

SELLOCHARIS, Taub. in Flora, 1xxii. (1889) 521 ; et in Eng1. \& Prant1. Natürl. Pflanzenfam. iii. 3 (1893) 226. LEGUMINOSAE.

paradoxa, Taub.l.c. - Bras.

SEMEGARPUS, Linn. f. (Anacard.). - Ind. Kew. 11, 866.

magnifica, K. Sinum, in K. Schum. fo Hollr. Fl. Kais. With. Land (1889) 65. - N. Guin.

SEMICIPIUM, Pierre, Not. Bot. Sapot. (1890) 10 = Mimusops, Linn. (Sapot.)

Boizinii, Pierre, 1. c. $11=$ M. Boivinii, Havtog.

SEMPEP VIVUM, Rupp. ex Linn. (Crassul.). Ind Kew ii. $86 \%$

adenophorum, Borb. Geogr, atq. Enrm, pl. Conit. Castrif. (1887-88) 238. - Hung.

agriostachys, Kuntze, Rev. Gen. (1891)229[sphalm.?]

= Monanthes agriostaphys, Christ.

Aizoon, Clirist, in Bot. falurb. ix. (1888) 162 (= Greenovia Aizoon, Bolle). - Teneriffa.

Bentejui, Christ, l. o. $160(=$ A 0 oninn Bentejui, Webb). - Ins. Canar.

Berthelotianum, Christ, l. c, 161 (= Ae. Berthclotianum, Bolle). - Teneriffa.

Bethencourtianum, Christ, l.c. $(=$ Ae. Bethencourtianum, Webb). - Ins. Canar.

Bollei, Christ, l.c. 160 (= Aichryson Bollei, Webb), - Ins. Canar.

brachycaulon, Kuntze, Rev, Gen. (1891) 231 (= Petrophyes brachycaulon, Webb \& Berth.). - Ins. Canar.

Castello-Paivae, Christ. in Bot. Fahrb. ix. (1888) 161 (= Aeonium Castello-Paivae, Bolle). - Ins. Canar.

Christii X. Wolf, in Bull, trav. Soc. Murith. Fasc. xvi-xviii. (1890) 29. - Helv.

decorum, Christ, in Bot. Fahrb. ix. (188s) 161 (= Aconium decorum, Webb). - Ins. Canar. diplocyclum, Christ, in Bot. fahrb. ix. (1888) 161 (= Greenowia diplocycla, Webb). - Ins. Canar. cngadinense $X$, Bruegg. [ubi ?] ex Nym. Consp.

Fl. Eur. Suppl, ii. I. (1S89) 129. - Helv.

erration $X$, Bruegg. 1. c. - Helv. 


\section{SEMPER VIVUM :}

Fontanae X.Bruegg-in Jahresb. Nat. Ges. Graub, xxxi. Beil. (1887-88) 67. - Helv

ferreum, Christ, in Bot. Falirb. ix. (188s) 161 (= Greenovia ferrea, Webb). - Ins. Canar.

gracile, Christ, l. c. $(=G$. gracitis, Bolle $)$ Teneriffa.

Heerianum $X$, Bruegg in Jahresb. Nat. Ges. Graub. xxxi. Beil. (188i-88) 67. - Helv

immaculatum, Christ, in Bot. Fahrb. ix. (1888) 160 (=Aichryson immaculatum, Webb). - Ins. Canar.

Laggeri, Schott, ex E. Hallier, in Koch, Syn. Fl. Germ.ed. 3 (1892) 944. - Helv.

leucanthum, Pancic, Nov. elem. Fl. Princ. Butg. (1886) 23. - Bulg

macrolepum, Christ, in Bot. Fahrb. ix, (1888) 161 (= Aconium macrolepum, Webb). - Teneriffa.

Mauriqueorum, Clivist, l. c. $(=A e$. Mauriqueorum, Bolle). - Ins. Canar.

pachycaulon, Christ, l.c. $(=$ Aichryson pachycaulon, Bolle). - Ins. Canar.

palmense, Christ, l. c. $160(=$ A. palmense, TVebb). - Ins. Canar.

palmense, Christ, l. r. $161(=$ Aconium palmense, Webb). - Ins. Canar.

Parlatorei, Christ, l. c. $160(=$ Aichryson Parlatorei, Bolle). - Ins. Canar.

parciflorum, Christ, l. c. $(=$ A. parciflorm, Bolle $)$. - Ins. Canar.

polypharmicum, Christ, l. c. 161 (= Grennorin polypharmica, Webb). - Ins, Canar

Porphyrogennetos, Christ, l. c. 160 (= Aichryson porphyrogennetos, Bolle). - Ins. Canar.

radicescens, Christ, l. c. 161 (= Aichryson radicescens, Webb). - Ins. Canar.

rhaeticum X, Bruegg. in Jahresb. Nat Ges. Graub. xxxi. Beil. (I8S7-S8) 67 [Die Fl, d. Untereng.]. - Helv.

rupifragum, Christ, in Bot. Fahrb. ix. (1888) 161 (=Grenozia rupifraga, Webb). - Teneriffa.

Saundersii, Christ. l. c. (= Aeoninm Sanndersii, Bolle). - Ins. Canar.

sedifolium, Christ, l. c. (= Aichryson sedifolinm, Webb). - Teneriffa.

surcuiosum, Kuntze, Rev. Gen. (1891) $229=$ Monanthes atlantica, Ball

Thomayeri $X$, Corr, in Bull. Soc. Hort. Genève (Dec. 1891) ex Gard. Chron. (1892) i. 104 ; et in Gartenf. xli. (1892) 162. - Hybr. artef.

virgineum, Christ, in Bot. Fahrb. ix. (1888) 161 (= Aeonium virgineum, Webb). - Ins. Canar.

viscatum, Christ, l.c. $(=A$. viscatum, Webb $) .-$ Ins, Canar.

SENAEA, Taub, in Bot. Jahrb. xvii, (1893) 515. GENTIANEAE

coerulea, Taub.l.c.5]6. - Bras.

SENECILLIS, Gaertn. = Senecio. Tourn. (Compos.).

sibirica, Simonk. Enum. fl. Transs. (1886) $143=$ S. Ligularia, Hook, $f$.

SENEGIO, [Tourn.] Linn. (Compos.). - Ind. Kew. ii. 869 .

acerifolius, Klatt, in Anmal. Naturh. Hofmus. Wien, ix. (1894) 363. - Mexic.

acerifolius, C. Winkl. in Act. Hort. Petrop. xiii. (1893) 9. - China.

acetosaefolius, Baker, an fourn. Linn. Sor, xxii. (1887) 496. - Madag

aclonetus, Phil. in Anal. Univ. Chil. Ixxyviii. (1894) 256. - Chili.

Adenotrichia, Nichols. Dict. Gard. iii. (1886) 419 $=$ adenotrichius. $D C$.

admirabilis, Greene, in Erythea, iii. (1895) 23. Colorado.

agnostus, Klatt, in Annal. Naturh: Hofmus, Wien, ix. (1894) 364. - Hab.?

Ahrendsii, Phil. in Anal. Univ. Chil. 1xxxviii. (1894) 267. - Chili.

ainsliaeflorus, Franch. in Morot, Fourn, de Bot, viij. (1894) 361. - China occ.

alabugensis, C. Winkl. in Act. Hort. Petrop. xi. (1890) 320. - Turkest.

\section{SENECIO}

lbiftorus, Phil. in Anal. Mus, nac. Chite (1891) 43 - Chili.

albopunctatis, Bolus, in fourn. Linn. Soc, xxii. 1857) $17 \%$. - Afr. austr.

alfalfalis, Phit in Anal. Univ. Chit. lxxrviii. (1894) 270. - Chili.

alienus, Robinson \& Seaton, in Proc. Am. Aad xxviii. (1893) 110. - Mexic

Alliariaetolius, O. Hoffm. in Bot. Fahto. x. (1888) 280. - Afr. austro-occ. extratrop.

andicola, Phit, in Anal. Univ. Chil. 1xxxviii. (1894) 22. - Chili.

angustatus, Simonk. Enumn. Fl. Transs. (1886) 324 (= Cineraria angusiata, Schur). - Transsilv

anisophyllus, Klatt, in Leopoldina, Heft xxiv (1sss 124. - Mexic.

Antandroi, S, Elliot, in foum, Limn. Soc, xxix. 1891) 30. - Madas.

antipodus, $T$. Kirk, in Trans. $\lambda$. Z. Inst, xxiii $1890(1891)$ 440, nomen. - Ins Antipod.

antirhinifolius, Phil. in Anal. Unif'. Chil. Ixxxviii. 1894) 34. - Chili.

aphanactis, Grecne, Pittonia. i. (Oct. 18S8) 220 ;

Man. Bot. Sun Franc. Bay (1894)212, - Calif.

apricus, Klatt, in Bot. Fahrb. xii. Beibl. n. 27 1S90) 25. - Madas.

apricus, Phil. in Anal. Univ. Chil. Ixxxviii. (1894) 261. - Chile.

arachnanthus, Franch, in Morot, fourn, de Bot. viii. (1894) 355 - Yunnan.

araens, Phil, in Anal. Univ, Chil. 1xxxviii. (1894) 291 = denticulatus, $D C$.

arctiifolius, Baker, in Kew Bull. (1895) 106. Bras.

areolatus, Colenso, in Trans. N. Z. Inst. xxvi. 1893 1894) $317 .-$ N.Zel.

argyreus, Phil. in Anal. Univ. Chil. 1xxxvisi. (1894) 261. - Chili

armeriifolius, Phît. in Anal. Mus. nac. Chile (1891) 43. - Chili.

armerifolius, Franch, in Bull. Soc, Bot. Fr, -xxxix. (1842) 287. - China occ.

arnautorum, Velen. Fl. Bulg. (1888) 45. - Bulg.

ascotanensis, Phil. in Anol. Mus. nai. Chile (1891 41. - Chili.

astephanus, Grcene, Pittonia, i. (June 1888) 174. Calif.

atacamensis, Phil, in Ancl. Mus, nac. Chile (189i) 46. - Chili.

atroviolaceus, Franch, in Bull. Soc, Bot. Fr. xxxix. (1892) 303. - China occ.

auriculatissimus, Britton, in Trans: Limn. Soc. Ser. II. iv. (1894) 21. - Afr. trop.

auriculatus, Steininger in A. Kern. Sched, Fl, Austro-Hung. v. (1888) $73=$ subalpinus, $K o \mathrm{c} /$.

auritus, Wawra, Itin. Princ. Coburg. ii. (1883) 47. - Bras.

Bakeri, S. Elliot, in fomm. Limn. Soc. xxix. (1891) 30. - Madag.

Bangii. Rusby, in Mem. Torrey Bot. Club, iii. 3 1893) 64 . - Bolivia.

Baurii, Oliver, in Hook. Icon. pl.xvi. (1887) t. $15 \% 2$ - Caffraria.

basipinnatus, Baker, in Kew Bu??. (1895) 217. Reg. Somal.

Baxteri X, E. F. Marshall, Bot. Exch. Club Brit. Isles, Rep. for. 1892 (1893) 374 - Brit.

begoniaefolius, Franch. in Morot, fourn. de Bot. viii. (1894) 358. - China occ

Benthamianus, Franch. in Bull. Soc. Bot. Fr. xxxix. (1892) 286. - Sikkim,

bicolor, Ces. Passer. \& Gibelli, Comp. F1. Ital. ii. (1886) $517=$ bicolor, Todaro

bipartitus, Sch. Bip. ex Deflers, Voy. Yémen (1889) 155, nomen. - Arabia.

Blochmanae, Greene, in Erythea, i. (1893) \%. Calif.

boliviensis, Sch. Bip. ex Klatt, in Leopoldina, Heft xxiv, (1888) 127. - Bolivia.

Boninsimae, Yatabe, in Tokyo Bot. Mag. vii. (1893) 1. t. 2.- Japon.

Borchersi, Phil, in Anal. Univ. Chil. 1xxxviii. (1894) 13. - Chili.

bosniacus, G. Beck. in Amal. Naturh. Hofmus Wien, ii. (1887) 163 t. 5, fig. 2-6. - Bosnia.
SENEGIO :

botryodes, C. Winkl, in Act. Hort. Petrop. xiv. (1895) 154. - 'Tibet.

bracteatus, Klatt, in Leopoldina, Heft xxiv, (1888) 125. - Mexic.

bracteolatus, Phil, in Anal. Unie, Chil, lxryviii (1894) 12.-- Chili.

breanus, Phil. l. c. 250. - Chili.

Breweri, Dasy, in Erythea, iii, (1895) 116.Calit.

bucharicus, C. Winkl, in Act. Hort. Petrop. xi. (1890) 335. - Buchara.

buglossus, Phil. in Anal. Univ. Chil, 1xxxviii. (189t) 276. - Chili.

calamitosus, Klatt, in Bot. Fahrb. xii. Beibl. n, 27 (1890) 25. - Madas.

Campanae, Phit. in Anal. Univ. Chil. 1xrxviii. (1888) 248. - Chili.

campanulatus, Sch. Bip. ex Klatt, in Leopoldina. Heft xxiv. (1888) 126. - Bolivia.

campanulatus, Franch, in Buml. Soc. Bot. Fr, xxxix.

(1892) 284. - China. occ.

Caroli, C. Winkl. in Act. Hort. Petrop, xiii. (1893) ॠ. - China

casalpatensis, Ball, in foum. Limn. Soc. xxii. 1885) 47. - Peruvia.

caulanthifolius, Dasy, in Erythea, iii. (189j) 117. - Calif.

cernuus, Phil. in Anal. Mus. nac.Chile (1891) 44 - Chili.

celtibericus, Pau, Not. Bot. Fl. Espan. ii. (1889) 14; Willk. Suppl. Prodr. Fl.Fisp.(1893)87.-Hisp hamomillefolius, Phil. in Anal. Univ. Chil. 1xxxvii (1894) 272. - Chili.

chanaralensis, Phil.l.c.265. - Chili.

chapalensis, S. Wats, in Proc, Am. Acad nxy. (1890) $155 .-$ Mexic

chinotegensis, Klatt, in Leopoldina, Heft xxiv. (1888) $125=$ Gynoxis Oerstedii, Benth

chihuahuensis, S. Wats, in Proc. Am. Acad. xxiil (IS85) 280. - Mexic.

chronotus, Phil. in Anal. Univ. Chil. 1xxxviii. (1S94) 26. - Chili.

chrysanthemoides, Phil. l. c. 269.- Chili

cicatricosus, Baker, in fourn. Linn. Soc. xxii. (1887) 497. - Madas.

cincreus, Velen. Beitr. Fl, Ost-Rum. und Buly (1S86) ex Bot. Centralbl. xxxvi. (1888) $6 \%=$ erucifolius, Limn.

Clarkeanus, Franch. in Bull. Soc. Bot. Fr. xxxix. 1892) 288. - Reg. Himal.

clavifolius, Rusby, in Mem. Torrey Bot. Club, iii, 3

(1893) 64. - Bolivia.

cleistolepis, Phil. in Anal. Unir. Chil, lxxxviii. (1894) 264. - Chili.

cobanensis, Coult. in F. D. Snith, Enum. pl. Guatem. ii. (1891) 42 ; ct in Bot. Gaz. xvi. (1891) 101 - Guatem.

occineus, Klatt, in Bot. Fahb; viii. (1886) 48. Columb.

Coincyi, Rouy, in Bull. Soc. Bot. Fr. xxxvii. (1890) 163; Coincy, Eclog. pl. Hisp. (1893) 16, t. 6 (= Cineraria Coincyi, Willk.). - Hisp.

compactus. Rydberg, in Mem. Torrey Bot. Club, v. (1894) 342, - Am. bor.

concolor, Cordem. FI. Ile Réunion (1895) 5431= Cacalia concolor, Frapp.). - Ins. Borbon.

onipes, Somm. \& Levier, in Nuov. Giorn. Bot. Ital. Ser. II. ii. (1895) 88: - Reg. Cauc

consanguineus, Phil. in Anal. Univ. Chil, Ixxxviii. (1894) 2\%. - Chili.

copiapinus, Phil. l. c. 253, - Chili.

Cordillerae, Phil. i. c. 277. - Chili.

crassifolius, G. Beck, in Annal. Naturh. Hofmus

Wien, ii. (1887) $163(=$ Cineraria crassifolia Kit.) = alpestris, $D C$.

crepidoides, Phil. in Anal. Univ. Chil. Ixxxviii. (1894) 252, - Chili.

ctenophyllus, Plit. in Anal. Mus.nac. Chite (1891) 45. - Chili

cuencanus, Hieron, in Bot. Fahb. xix. (1894)65.Ecuad.

curvidens, Sch, Bip. ex Klatt, in Lepoldina, Heft xxiv. (1888) 127. - Peruvia.

cyaneus, O. Hoffm. in Bot. Faht. xx. (1894) 235. Afr. trop. or. 


\section{SENEGIO}

cyclaminifolius, Franch, in Morot, Fourn, de Bot. viii. (1894) 362. - China occ.

cyclocladus, Baker, in fourn, Limn, Soc. xxii. (1S87) 496. - Madag.

cyclotus, Bureau \& Franch. in Morot, Fourn, de Bot. V. (1891) 74. - China occ

cydoniifolius, $O$. Hoffm. ex Engl. in Abh. Preuss. Akad. Wiss. (1894) 19. 20, 42, nomen. - Afr. trop.

Davidi, Franch. in Nonv. Arch. Mus. Paris, Sér I1. x. (1888) 40. - Tibet.

Davilae, Phil, in Anal. Univ. Chil. Ixxxviii. (IS94) 33. - Chili.

deformis, Klatt, in Leopoldina, Heft xxiii. (1888) 125. - Mexic

Delavayi. Franch. in Bull. Soc. Bot. Fr. xxxix. (1892) 286. - China occ

Delavayi, Franch. in Morot, fourn. de Bot. viii. 1894) 364. - Yunnan.

Delfini, Phil. in Anal. Univ. Chil. lxxxviii. (1894) 275 - Chili.

denticulatus, Engl. in Abh. Preuss. Akad. Wiss. 1891 (1892) 442. - Afr. trop, or.

depilis, Phil. in Anal. Univ. Chil. Ixxxviii. (1894) $291=$ denticulatus, $D C$.

dichotomus, Plitl, in Anal. Mus, nac. Chile (1891) 43. - Chili.

dictionurus, Franch. in Bull. Soc. Bot. Fr, xxxiz. 1892) 294. - China. occ.

digitatus, Phil. in Anal. Mus. nac. Chile (1891) 44. - Chili.

dimorphocarpos, Colenso, in Trans, N. Z. Inst. xxvi. 1893 (1894) 316. - N. Zel

discoideus, Franch. in Bull. Soc. Bot. Fr. xxxix. (1892) 284. - China occ

distinctus, Colenso, in Trans. N. Z. Inst. xxvii, 1894 (1895) 390. - N. Zel.

dodrans, C. Winkl. in Act. Hort. Petrop. xiv. (1895) 15\%. - China.

Domeykoanus, Phil, in Anal. Univ. Chil. Ixxxviii. 1894) 29. - Chili.

Donae-Anae, Phil. l. c.6.- Chili

Donell-Smithii, Coult. in 7. D. Smith, Enum. pl. Guatem. ii, (1891) 42 : et in Bot. Gaz. xvi. (1891) 101. - Guatem.

drepanophyllus. Klatt, iu Bot. Fahrb. xii. Beibl. n. 27. (1S90) 26. - Madag.

duciformis, C. Winkl. in Act. Hort. Petrop. xiv. (1895) 155. - China.

dumosus, Phil. in Anal. Univ, Chil. lxxxviii. (1888) 24. - Chili.

Durandi, Klatt, ex Th. Dur, \&o Pitt, in Bull. Soc. Bot. Belg. xxxi. 1892 (1893) 211. - Costa Rica.

Dux, C, B. Clarke, in fourn. Linn. Soc. xxv. (1889) 40. - Jakpho.

ecuadorensis, Hieron. in Bot. Fahrb. xix. (1894) 68 - Eculad.

ecuadorensis, Klatt, in Annal. Naturh. Hofmus. Wien, ix. (1894) 364. - Ecuad.

Ehrenbergianus, Klatt, in Leopoldina, Heft xxiv. (1888) 125. - Mexic

elamutensis, Franch, in Bull. Soc. Bot. Fr. xxxix, 1892) 292. - Persa.

Englerianus, O. Hoffm. in Bot. Faht. x. (I888) 279. - Afr. austro-occ. extratrop.

erechthithoides, F. Muell, in Trans. Roy. Soc. Vict. N. S. i. II. (1889) 15, - N. Guin.

eriocephalus, Klatt, ex Th. Dur, \& Pitt. in Bull. Soc. Bot. Belg. xxxi. 1892 (1893) 212. - Costa Rica.

eriopodus, Klatt, in Leopoldina, Heft xxiv. (1888) 125. - Mexic

erythropappus, Bureau Eo Franch, in Morot, Fourn. de Bot. v. (1891) 73. - China occ.

euryphyllus, C. Winkl. in Act. Hort. Petrop. xiv. (1895) 156.

Evansi, N. E. Br. in Kew Bull. (1895) 14\%.-

Eversi $\times$, Huter, in Oest. Bot. Zeitschr. xliii. (1893) 151. - Italia.

exilis, Blanche, ex Boiss. Fl. Or. Suppl. (1888) 302. - Syria.

Faberi, Hemsl. ex Forb. E Hemsl. in fourn. Linn. Soc. xxiii. (1888) 452. - China.

\section{SENECIO}

Fargesii, Franch. in Bull. Soc. Bot. Fr. xxxix. (1892) 300. - China occ

Fauriei, Franch in Bull. Sec Phil, Paris, Sér. VII. xii. (1888) 87. - Japon.

Fernandezi, Phil. in Anal. Univ. Chil. 1xxxviii. (1894) 258. - Chili.

Feuillei, Phil. l. c. 264. - Chili.

floccosus, Britton [err. typ.? floscosus] in Bull. Torrey Bot. Club, xix. (1892) 264. Bolivia.

Francheti, C. Winkl. in Act. Hort. Petrop. xi. (1889) 165. - Buchara.

franciscanus, Greene, Pittonia, ii. (Nov. 1889) 19. - Arizona.

Francisci, Phil. in Anal. Univ. Chil. Ixxxviii. (1894) 12. - Chili.

fueginus, Phil.l. c. 26. - Chili.

fulgens, Nichols. Gard. Dict. jii. (1886) 420. Afr. austr.

Fussii, G. Beck, in Annal. Naturh. Hofmus. Wien, ii. (1887) $163=$ campestris, $D C$.

Galpini, Hook. f. in fourn. of Hortic. (1892) 3 ; et in Bot. Mag. (1892) 1. 7239, - Transvaal.

Gannieri, Klatt, in Bot. Jahrb. xii. Beibl. n. 27 (1890) 26 ; et in Annal. Naturh. Hofmus. Wien, vii. (1892) $299=$ erechthitoides, Baker.

Gibbonsii, Grcene, Pittonia, ii. (Nov. 1889) 20. Am. bor, occ

gibraltaricus, Rouy, in Bull. Soc. Bot. Fr, xxxiv. 1887) 140; in Le Naturaliste, Sér. II. ix. (1887) 107: Debeanx, Syn. Fl. Gibraitar (1887) 107.Hisp.

gilvus, Phil. in Anal. Univ. Chil. 1xxxviii. (1894) 16. - Chili.

Goetzenii, O.Hoffm。in Engl. Pfanzenw. Ost-Afr. A (1895) 135, nomen. - Afr. trop.

Goldsacki, Phil. in Anal. Univ. Chit. Ixxxviii. (1894) 249. - Chili.

gomerets, Kuntze, Rev, Gen. (1891) $363=\mathrm{S}$. Steet zii, Bolle.

gossypinus, Baker, in fourn. Limn. Soc. xxv. (1890) 330. - Madag

gracilipes, Robinson \& Greenn. in Am. Fourn. Sci Ser. III. 1. (1895) 156 (= Erechtites polypodioides, Greene). - Am. bor. occ

gracillimus, C. Winkl. in Act. Hort. Petrop. xiii (1893) 5.- Mongol

Grenierii, Klatt, in Bot. Fahrb. xii. Beibl. n. 27 (1890) 26. - Madag.

cuadalajarensis, Robinson, in Proc. Am. Acad.xxvi. (1891) 166. - Mexic.

guayacanensis, Phil. in Anal. Univ. Chil. Ixxxviii. (I894) 281. - Chili.

Gunnisii, Baker, in Kev Bull. (1895) 21\%. - Reg. Somal.

gymnocaulos, Phil, in Anal. Univ. Chrl. Ixxxviii. (1894) 23. - Chili.

Gynura, C. Winkl. in Act. Hort. Petrop. xiv. (1895) 157. - China.

Hallii, Hieron. in Bot. Fahrb. xxi. (1895) 358. Ecuad.

haplogynus, F. Muell. in Trans. Roy. Soc. Vict. N. S. i. II. (1889) 14. - N. Guin.

harazianus, Defers, Voy. au Yémen (1889) 154. Arabia.

Harveianus, Mac Owan, in foum. Linn. Soc. xxv. (1890) 388. - Afr. austr.

Heimerli $X$, Muellner, in Verh. zool.-bot. Ges. Wien, xlv. (1895) 94. - Austria.

helianthoides, Phil. in Anal. Univ. Chil. lxxxviii (1894) 258. - Chili.

Helianthus, Franch. in Bull, Soc. Bot. Fr. xxxix. (1892) 286. - China occ.

heliophytoides, Phil. in Anal. Univ. Chil. 1xxxviii. (1894) 262. - Chili.

Henryi, Hemsl. ex Forb. \& Hensl. in fourn. Linn. Soc. xxiii. (1888) 452. - China.

hesperius, Greene, Pittonia, ii. (July 1891) 166. Oregon.

heterophyllus, Colenso, in Trans. $N . Z$. Inst. xxvii. 1894 (1895) 389 [heterophyllal. - N Zel.

heteroideus, Klatt, in Leopoldina, Heft xxiv. (1888) 125. - Mexic
SENECIO

hibernus, Makino, in Tokyo Bot. Mag. vi. (1892) 55. - Japon.

Hildebrandtii, Baker, in Fourn. Linn. Soc. xxii, (I887) 488. - Madag.

Hillebrandii, Christ, in Bot. Falwb. ix, (1887) 148. - Ins. Canar.

himalayensis, Franch. in Bull. Soc. Bot. Fr. xxxix (1892) 287. - Sikkim

Hirthit, Phil. in Anal. Univ. Chil. Ixxxviii. (1894) 247. - Chili.

Hoffmannii, Klatt, in Leopoldina, Heft xxv. (1889) 106. - Costa Rica.

homogynoides, Klatt, in Annal. Naturh. Hofmus. Wien, ix. (1894) 364. - Bras.

Humblotii. Klatt, in Annal. Naturh. Hofmus. Wien, vii. (1892) 299. - Ins. Comor.

Hyadesii, Franch. Miss. scient. Cap Horn, v [Than.] (1888) 348 t. 2. - Reg. Magell.

hygrophitus, Klatt, in Bot. Jahrb. xii. Beibl. n. 27 (1890) 26 = Cineraria hygrophila, Klatt.

Ibari, Phil. in Annal.Uni?. Chil. 1xxxviii. (1894) 20. - Chili.

iberidifolius, Phil. l. c. 1xxxviii. (1894) 21. Chili.

ilicetorum, A. Davids. in Erythea, ii. (1894) 85. Calif.

Incae, Phil. in Annal. Univ. Chil. 1xxxviii. (1894) 273. - Chili.

innovans, Klatt, in Annal. Natwh. Hofmus. Wien ir. (1894) 365. - Bolivia.

integrifolius, Simonk. Enum. Fl. Transs. (1886) $326=$ Othonna integrifolia, Linn.

involutus, Klatt, in Annal. Naturh. Hofmus, Wien, ix. (1894) 365. - N. Granat.

ionophyllus, Greene, Pittonia, ii. (Nov. 1889) 20.Calif

irregularis, Phil. in Annal. Univ. Chil. Ixxxviii (1894) 273. - Chili.

jaliscana, S. Wats, in Proc. Am. Acad.xxvi. (1891) 143. - Mexic

Jamesii, Hemsl. ex Forb. \& Hemsl. in fourn. Limn Soc. xxiii. (1888) 452. - China.

Jamesonii, Spruce, ex Klatt, in Leopoldina, Heft xxiv. (1888) 127. - Ecuad.

janthophyllus, Franch. in Morot, Fourn. de Bot viii. (1894) 361. - China occ

Jarae, Phil. in Anal. Mus. nac. Crile (1891) 44. Chili.

Johnstonii, Otiver, in folnston, Kilim. Exped. App. (1856) 342, nomen; et in Trans, Linn. Soo. Ser. II. ii. (1887) 340, t. 60. - Afr. trop. or.

Jorquerae, Phil. in Anal. Univ. Chil. Ixxxviii. (1894) $20 .-$ Chili.

jnncalensis, Phil, in Anal. Mus, nac. Chile (1891) 41. -.. Chili.

7usssieui, Klatt, ex Hieron. in Bot. Jahrb. xix. (1894) $69=$ Gynoxys cordifolia, Cass.

kanaitzensis, Franch. in Bull. Soc. Bot. Fr. xxxix. (1892) 298. - China occ.

kansuensis; Franch. l.c. 287. - China occ.

karaguensis, O. Hoffn. in Engl. Pfanzenw. Ost-Afr. C (1895) 417. - Afr, trop. or.

karelinioides, C. Winkl, in Act. Hort. Petrop. xi. (1890) 280. - Turkest.

Kaschkarowi, C. Winkl. l. c. xiv. (1895) 152. China.

kenensis, E. G. Baker, in foum. Bot, xxxii. (1894) 140, - Afr, trop. or

Kerneri $X$, Blocki, ex Nym. Consp. F1. Eur. Suppl. ii. 1. (1889) 165. - Austria.

koualapensis, Franch. in Morot, Fourn. de Bot. viii (1894) 356. - Yunnan.

kukulensis, Wolozszak, in Spraw. Kom. fizij. Krakowei, xxi. (1888) ii. 125. - Eur, centr.

Kurtzi, Phil. in Anal. Univ. Chil. 1xxxviii. (1894) 254. - Chili.

lacarensis, Phil. l. c. 259. - Chili.

lactucinus, Greene, in Erythea, i. (1893) 223. Am. bor. occ

lactucoides. Klatt, in Leopoldina, Heft"xxiv. (1888) $125=$ Erechtites valerianaefolia, $D C$

laetevirens, Phil. in Anal. Univ. Chil. Ixxxviii (1894) 30. - Chili.

lankongensis, Franch. in Bull. Soc. Bot. Fr. xxxis (1892) 301. - China occ. 
SENEGIO

lapathifolius, Franch. in Bull. Soc. Bot. Fy. xxxix (189l) 306. - China occ.

Larranagae, Phil. in Anal. Univ, Chil. 1xxxviii. (1894) 269. - Chili.

latifolius, Mast. in Gard. Chron. (1894) ii. fig. $43=$ laxifolius, Buchanan.

latipes, Franch. in Morot, Foum, de Bot. viii. (1894) 356. - Yunnan.

Lehmanni, Hieron. in Bot. Falnt. xix. (1894)66. Columb.

leptanthus, Phil. in Anal. Univ. Chil.1xxxviii. (1894) 15. - Chili.

leptocaulos, Phil. l. c. 266. - Chili.

leucocephalus, Franch. in Morot, Fourn de Bot. viii. (1894) 360. - China occ.

leucus, Phil. in Anal. Mus, nac.Chile (1891)42.-Chili.

liatroides, C. Winkl. in Act. Hort. Petrop. xiii (1893) 8. - China.

Liebmannii, Buchinger, ex Klatt, in Leopoldina, Heft xxiv. (1888) 125. - Mexic.

limonius, Phil in Anal. Unin, Chil. Ixxxyiii, (1894) 280. - Chili.

Limumae, Makino, in Tokyo Bot. Mag. vi. (1892) 55. - Japon.

longipes, Baker, in Kew Bull. (1895) 217. - Reg. Somal.

Lorentzi, Phil, in Anal. Univ. Chil. 1xxxviii. (1894) 8. - Chili.

Lyallii, Klatt, in Annal. N'aturh. Hofmus. Wien, ix. (1894) 365 . -

Iynceus, Greene, in Eryithea, iii (1895) 22. - Am. bor, occ

Lyoni, A. Gray, ex Lyon, in Coult. Bot. Ga\%. xi. (1886) 335, nomen; et Syn. Fl. N.Am. i. II Suppl. (1886) 454. - Calit.

macer, Phil. in Anal. Unio. Chil. 1xxxviii. (1894 263. - Chili.

Madariagae, Phil, in Anal. Mus, nac. Chile (1891) 45. - Chili.

magellanicus. Phil. in Anal. Univ. Chil. Ixxxviii. (1894) 24. - Chili

Makineanus, Yalabe, in Tokyo Bot. Mag. vi. (1892) 115, t. 3 ; et Icon. Fl. Fapon. i. III. (I894) 183 t. 45. - Japon.

Makinoi, C. Winkl. in Act. Hort. Pctrop. xiii. (1893) 6. - Japon.

maranguensis, O. Hoffn. in Engl. Pflanzenw. Ost Afr. C (1895) 4i8. - Atr. trop. or.

margaritiferus, Klatt, in Bot. Falırb. xii. Beibl. n. 27 (1890) 37. - Madag.

Marlothianus, O. Hoffm. in Bot. Fahrb. x. (1889) 279. - Afr. austro-occ. extratrop.

Maximowiczii, Franch. in Bull. Soc. Bot. Fr. xxxix (1892) 287. - China occ.

melanoccphalus, Franch. l. c, 294. - China occ,

melastomaefolius, Baker, in fourn. Linn. Soc. xxii. (1887) 497. - Madag.

mesogrammoides, O. Hoffm. in Engl. Pfanzenw. Osi-Afr. C (1895) 417. - Afr, trop. or.

Meyeni, Phil. in Anal. Univ. Chil. Ixxxviii. (1894 25. - Chili.

Meyeri-Johannis, Engl, in Abh. Preuss. Akad. Wiss. 1891 (1892) 444. - Afr. trop. or.

microcephalus, Phil. in Anal. Univ. Chil. 1xxxviii (1894) 23. - Chili.

microdontus, Bureau \& Franch, in Morot, Fourn, de Bot. v. (1891) 76. - China occ.

microtis, Phil. in Anal. Univ. Chil. 1xxxviii. (1894) 253. - Chili.

minutifolius, Phil. l. c. 250. - Chili.

mirus, Klatt. in Anal. Mus. Nac. Costarica (1893) 113, nomen; et ex Th. Dur. \& Pitt. in Bull. Soo Bot. Fr, xxxi. 1892 (1893) 213. - Costa Rica.

Moelleri, Phil, in Anal. Univ. Chil. lxxxviii. (1894) :74. - Chili.

mohavensis, A. Gray, Syn. Fl. N. Am. i. II. Suppl. (1886) 454. - Calif,

monocephalus, Baker, in fourn. Limn. Soc. xxii. (1887) 498. - Madag.

montereyanus, S. Wats, in Proc. Am. Acad: xxv, (1890) 155 [Montereyana]. - Mexic.

monticola, Phil. in Anal. Univ. Chil. lxxxviii. (1894) 32. - Chili.

Moritzianus, Klatt, in Leopoldina, Heft xxiv. (1888) 127. - Columb.

\section{SENEGIO}

morrensis, Hieron. in Bot. Fahrb. xxi. (1895) 362. - Peruvia.

mosoynensis, Franch, in Bull. Soc. Bot. Fr, xxxix. 1892) 298. - China occ.

multibracteatus, Phil. in Anal. Unir. Chil. 1xxxviii. (1894) 30. - Chili.

multicorymbosus, Klatt, in Annal. Naturl?. Hofmus, Wien, vii. (18:2) 103. - Angola.

multinervis, Colenso in Trans, $N^{r}$. $Z$. Inst, $\mathrm{xxv}$ 1892 (i893) 330 [multinerve) - N. Zel.

murinus, Phil, in Anal. Univ.Chit. Ixxxviii. (1894) 247. - Chili.

Murrayanus, Wawra, Itin. Princ. Sax.-Coburg. ii. (1888) 48. - Austral

mweroensis, Baker, in Kew Bull (1895) 990. - Afr. centr. austr.

myrianthus, Klatt, in Leopoldina, Heft xxiv. (1888) 12\%. - Bolivia.

myrtifolius, Klatt, in Bot. Fahrb. xii. Beibl. n. 27 (18,0) 27. - Madag.

narensium $C, B$. Clarke, in fourn. Linn. Soc. xxv. (1889) 39. - Ind. or.

nahuelbutanus, Phil. in Anal. Univ. Chil 1xsxvini. (1890) 254. - Chili.

namaquanus, Bolus, in Fourn. Lrinn. Soc. xxiv. (1887) 176. - Afr. austr.

napifolius, Mac Owan, l. c, xxv。 1890) 388. Afr. austr.

narynensis, C. Winkl. in Act. Hort. Petrop. xi. (1890) 31\%. - Turkest.

Navarri, Phil. in Anal. Univ. Chil. lxxxviii. (1894) 11. - Chili.

mapolitamus $X$ Evers, ex Oest, Bot, Zeitschr. liii. (1893) 15๊1, 390. - Italia.

nelumbifolius, Burcau E Franch. in Morot, fourn. de Bot. v. (1891) 74. - China occ

nephelagetus, Franch. in Bull. Soc. Bot. Fr. xxxix, (1892) 285. - Reg. Himal.

nimborum. Franch. in Now, Arch. Mus. Paris, Sér. II. x. (1888) 39. — Tibet.

nobilis, Franch, in Bull' Soc. Bot. Fr. xxxix. (1892) 28\%. - China occ.

novenlepis, Hieron. in Bot. Fahrb. xxi. (1895) 357. - Ecuad.

obesus, Klatt, in Amal. Naturh. Hofmus, Wien, ix. 1894) 366. - Reg. Argent.

blongatus, Franch. in Bull. Soc. Bot. Fr, xxxix. (1892) 286. - Sikkim.

ochroleucus, Phil. in Anal. Univ. Chil. 1xxxviii. (1894) 12. - Chili.

oclonetus, Phil. l. c. 256 - Chiti

odorus, Deficrs, Voy. au Yémen (1889) 158 (= Cacalia odora. Forsk.). - Arabia.

Oerstedtii. Kuntze, Rev. Gen. (1891) $363=$ Gynoxis Oerstedii. Benth.

olivaceus, Klatt, in Annal. Naturw. Hofmus. Wicn, vii. (1892) 299. - Madag.

olivaceus, Phil. in Anal. Unio. Chil. Ixxxviij. (1894) 271. - Chili.

Otaeguianus. Phil.l. c. 246. - Chili.

otophorus, Phil. l. c. 279. - Chili.

ovatus, MacMill. Metasp. Minn. (1892) 555 (=Cacalia ovata, Walp.) == S. Walteri, Sch.Bip.

oxyodon, Phil. in Anal. Mus, nac. Chile (1891) 42. - Chili.

paberensis, Franch, in Bull. Soc. Bot. Fr, xxxix. (1892) 288. - Reg. Himal.

Palenae, Phil. in Anal. Univ.Chil. lxxxviii. (1894) 14. - Chili.

pallescens, Klatt, in Leopoldina, Heft xxv. (1888) 126. - Mexic.

parochetus, Klatt, in Bot. Fahro. xii. Beibl. n. $2 \%$ (1890) 2\%. - Madag.

pendulus, Deflers, Voy au Yémen (1889) $155(=\mathrm{Ca}$ calia ṕendula, Forsk.). - Arabia.

peninsularis, Vasey \&f 7. N. Rose, in Proc. U.S. Nat. Mus. xi. (1888) 531. - Calif.

pentadactylus, Phil, in Anal. Univ. Chil. Ixxxviii. (1894) 260, - Chili

Peraltae, Phil. l. c. 256. - Chili.

peteroanus, Plizl. $l$. c. 28, - Chili.

petrophilus, Klatt, $2 n$ Bot. Fahrb. xii. Beibl. n. 27 (1890) 27. - Madag.

phaenicochaetes, Franch. in Bull. Soc. Bot. Fr. xxxix. (1892) 295, - China occ
SENECIO

Phaedrus, Phil. in Anal. Univ. Chil. 1xxxviii. (1894) 251. - Chili.

phyllocomus, Pluil l, c. 260-Chili.

phyllolepis, Franch, in Morot. Fourn. de Bot, viii (1894) 360. - China occ.

pilotus, Phil. in Anal. Univ. Chil, 1xxxviii. (1894) 292 = denticulatus, $D C$

pindilicensis, Hzeron. in Bot. Fahrb, xix. (1894) 65 - Ecuad.

pinnatifidus, Phil. in Anal. Univ. Chil. 1xxxviii. (1894) 19. - Chili.

Piptocoma, O. Hoffm。 ex Schinz, in Bull. Herb. Boiss. i. (1893) 87. - Afr. austro-occ. extratrop.

plantaginifolius, Franch, in Bull. Soc, Phil. Paris, Sér. VIII. iii. (1891) 145. - Tibet.

platyglossus, Franch, in Bull. Soc. Bot. Fr. xxxix. (1892) 293. - China occ.

platyphylloides, Somm. \& Levier, in Act. Hort. Petrop. xii. (1892) 153. - Reg. Cauc,

pleurocaulis, Franch, in Morot, fourn. de Bot, viii. (1894) $365(=S$, tatsienensis, Franch.) _- China occ.

polygaloides, Phil. in Anal. Univ. Chil. 1xxxviii. (1894) 38. - Chili.

polypodioides, Robinson \& Greonm. in Am. Fourn. Sci. Ser. III 1. (1895) 156 - Mexic

Potanıni, C. Winkl. in Act. Hort. Petrop. xiii. (1893) 5. - China.

primulifolius, Somm. Es Levier. in Nuov. Giorn. Bot. Ital. Ser. II. ii. (1895) 89. - Reg. Callc.

Pringlei, A. Gray, in Proc. Am. Acad. xxii. (1887) 307. - Mexic.

prionites, Mac Owan, in fourn. Linn. Soc. xxv. 1890) 389. - Afr. austr.

promaucanus, Phil. in Anal. Univ. Chil. lxxxviij. (1894) 283. - Chili.

psammophilus, Phil. l. c. 270 ou 271. - Chili.

pteridophyllus, Franch. in Morot, Fourn. de Bot. viii. (1894) 364 - Yunnan.

pubescens, Phil. in Anal. Univ. Chil. Ixxxviii. (1894) 268. - Chili

Puchi, Phil. in Anal. Mus, nac. Chile (1891) 45. Chili.

pulviniformis, Hieron, in Bot. Fahrb. xxi. (1895) 359. - Bolivia.

pumiceus, Colenso, in Trans. $N . Z$. Inst. xxi, 1888 1889) 89. - N. Zel

purpurascens, Klatt, in Leopoldina, Heft xxv. (1888) 126 (= Cacalia purpurascens, Sch. Bip.).-Mexic.

Purtschelleri, Engl. in Abh. Preuss, Akad. Wiss. 1891 (1892) 443, - Afr. trop. or.

Putjatae, C. Winkl. in Act. Hort. Petrop. xiv. (1895) 125. - China.

Rahmeri, Phil. in Anal. Mus. nac. Chile (1891) 42 - Chili.

ranconensis, Sch. Bip. ex Ball, in Journ. Linn, Soc, xxvii. (1891) $490=$ rancoënsis, Sch. 13ip.

ravidus, C. Winkl. in Act. Hort. Petrop. xiii. (1893) 4. - Tibet.

Rawsonianus, Greene, Pittonia, ii. (July 189I) 166. - Calif.

Rehmanni, Bolus, in fourn. Linn. Soc. xxiv. (1887) 177. - Afr. austr.

Reisackii X, Grembl. ex Nym. Consp. Fl. Eur. Suppl, ii. I. (1889) 165. - Tirolia.

Reissianus, Hieron. in Bot. fahrb. xxi. (1895) 356. - Columb.

Remyanus, Phil. in Anal. Univ. Chil. Ixxxviii. (1894) 31. - Chili.

Renjifoanus, Phil.l. c. 10.-Chili.

reniformis, MacMill. Metasp. Minn. (1892) 555 (= Cacalia reniformis, Muehl.) $=\mathrm{S}$. Muehlbergii Sch. Bip.

Rhabdos, C. B. Clarke, in fourn. Limn. Soc. xxy (I889) 40, t. 19. - Ind, or.

rhodanthus, Baker, in fourn. Linn. Soc. xxy. (1590) 3:30. - Madas.

rivularis, Borb. Geogr. atq. Enum, pl, Comit. Castrif. (1887) 190

Robbinsii, Oakes, ex Rusby, in Bull. Torrey Bot. Club, xx. (1S93) 19. - Am. bor. or.

roseus, Klatt, in Annal. Naturh. Hofmus. Wien, ix. (1894) 366. - F'eruvia.

Rosmarinus, Phil. in Anal. Mus, nac. Chile (1S91) 41. - Chili. 


\section{SENECIO}

ruficomns, Frauch iz Bull, Soc But. Fr. xxxix (1892) 298. - China occ.

rufipilus, Franch. in Morot, fourn, de Bot, viii, (18?4) 350 . - China occ.

rumicifolius, Klatt, in Leopoldina, Heft xxiv. (1S8s) $1201=$ Cacalia municifolia, Sch. Bip.). Mexic

rupicolus, Simonk. Enum. F1. Transs. (1886) $324=$ Cineraria rupicola Schur.

agittatus, Hieron. in Bot. Jahrb. xix (1894) 64 (= Cacalia sagittata, Vahl $)=$ Emilia flammea, Cass. Santelicis, Phil. in Anal. Mus. nac. Chile (1891) 45. - Chili.

sarawschanicus, C. Winkl. in Act. Hort. Petrop, xiv. (1895) 153. - Turkest.

sarmentosus, $O$. Hoffm, in Bot. fahrb. xx. (1894) 236. - Afr. trop. or

Schaffneri, Sch. Bip. ex Klatt, in Lcopoldina, Heft xxiv, (1888) 126. - Mexic.

Schinzii, O. Hoffm. ex Schinz, in Bull. Herb. Boiss. i. 11893) 86. - Afr. austro-occ extratrop.

Schoenleini. Fr. Meigcn, in Bot. Fahrb. xvii. (1893) 282, 292, et xviii. (1894) 443,465. - Chili

Schoenemanni, Phil, in Anal. Unia. Chil. lxxxvii. (1894) 21. - Chili.

Schilzeanus, Fr. Meigen, in Bot. Zahrb. xvii. (1893) 282, 292 ; et xviii. (1894) 443, 465. - Chili.

Schweinfurthii. O. Hoffn in Engl. Pfanzenw. OstAfr. C (1895) 417 (= S. Serra, Schweinf.). Afr. trop. or.

scoparius, Phit. in Anal. Univ. Chil. Ixxrviij.(189t) 282. - Chili

scotifolius, Phil. l. c.28-Chili.

sedifoleus, Phil. l. c. \{1895) 28 .

Serra, Schweinf, ex Engl. in Abh. Preuss. Akad. Wiss. 1891 (1892) $446=\mathrm{S}$. Schweinfurthii O. Hoffm

setchuenensis, Franch, in Bull. Sor. Phil Paris, Sér. V1II. iii. (1891) 145. — Tibet.

setulosus, Phil. in Anal. Unir. Chil. Ixxxviii. (1894) 亏. - Chili.

sikkimensis, Franch, in Bull. Soc, Bot. Fr. xxxix, (1892) 285. - Sikkim.

silphioides. Hicron. in Bot. fahrz. xxi, (1895) 361. - Columb.

Simpsoni, Phil. in Anal. Univ. Chil. 1xxxviii, (1894) 25\%. - Chili.

Sinclairi, Hieron. in Bot. Jahrb. xix. (1894) $68=$ Gynoxys Sinclairii, Benth.

Smalli, Britton, ex Small \& Vail, in Mem. Torrey Bot. Club, iv. (1893) 132, et $v \cdot(1894)$ :34)= atreus I.im, var. angustifolius, Britton.

sociorum. Bolus, in foum. Linn. Soc. xx.y. (1857)

175. - Afr. austr.

Sotoanus, Phil. in Anal. Univ. Chil. 1xxxviii. (1894) 9. - Chili.

sotarensis, Hieron.in Bot. Fahrb. xxi. (1895) $360 .-$ Columb.

Souliei, Franch, in Bull. Soc. Phil. Paris, Sèr, VIII. iii. (1891) 165. - Tibet.

Sprucei, Britton, in Bull. Torrey Bot. Club, xix. (1892) 265. - Bolivia.

Sprucei Klat, in Leopoldina, Heft xxiv. (1888) 128. [err. cal. ? Spruccii\}. - Peruvia.

stenoglossus, Franch, in Bull. Soc, Bot. Fr. xxxix. (1892) 305. - China occ

stimopfyllus, Simonk. Enum. Fl. Transsilv. (1886) $325=$ lugens, Richards.

Stirthii, Phil, in Anal. Univ. Chil. 1xxxvi1i. (I894) 247 . - Chiti.

streptanthifolius, Grcone, in Erythea, iii. (1895) 23. - Idaho.

Stuebelii, Hieron. in Bot. Fahrb. xxi. (1895) 356. 357. - Columb.

Stuhlmanni, Klatt, Lcopoldina Heft xaxi. (1895) 10. - Afr. trop.

subauritus, Phil, in Annal. Univ. Chil. Ixxxviii. (1894) 1\%. - Chili.

sublyratus, Phil. l. c. 365 - - Chili.

subspicatus, Burcall \& Franch. in Morol, fourn. de Bot. v. (1891) 75 - China occ.

subvestitus, Howell, in Erythea, iii. (1895) 35. Oregon.

culphirreus, Simonk. Enum. F1. Transs. (1886) 325 = campestris, Retr.

\section{SENECIO}

Sumarae, Deflers, Yoy. au Yimen (1889) 154. Arabia.

Sundti, Phil. in Anal. Univ. Chil. 1xxxviii. (1894) i. - Chili.

syringifolius, $O$. Hoff $m$. in Bot. Fahrh. xx. (1894) 236. - Afr. trop. or.

taliensis, Franch in Morot. Foum de Bot. viii. (1894) 3\%. - Yunnan.

talquinus, Phil, in Anal. Univ, Chil. 1xxxviii. (1894) 35. - Chili.

tarapacanus. Phil. in Anal. Mus.nac. Chile. (1891) 42. - Chili.

tatsiemensis, Bureau \& Franch. in Morot, Jourm. de Bot. v. (1891) 75, Franch. in Bull. Soc. Bot. Fr: $x x x i x,(1892) 293=$ pleurocaulis, Franch.

tchangchanensis, Franch. $l, c, 299$, - China occ.

Telekii, O. Hoffm. in Engl. Pfanzenve. Ost-Afr. (1895) 417 (=Erigeron Telekii, Schweinf.). - Afr. trop. or.

tenuicaulis, Phil. in Anal. Univ. Chl. Ixxxviii. (1894) 11. - Chili.

tenuipes, Franch, in Bull. Soc, Bot. Fr, rxxix. (1892) 998. - China occ.

terefifolius, Less, ex Klatt, in Annal. Naturh. Hofmus. Wien. ix. (1894) 368, in syn. = Othonna Lessingii, Klatt.

comentosus, Cordem. Fl. Ile Réunion $(1895) 543=$ Eupatorium tomen osum, Lam.

tongolensis, Franch. in Bull. Soc, Bot. Fr. xxxix. (1892) 30.5. - China occ

tricuspis, Franch. in Morot, fours, de Bot, viii (1894) 357. - Yunnan

trifurcifolius, Hieron. in Bot. Falrb. xxi. (1895) $358 .-$ Bolivia.

turkestanicus, C. Winkl. in Act. Hort. Petrop. xi. (1890) 279. - Turhest.

(tssilaginea. Kuntze, Rev. Gen. (1891) $36 t=\mathrm{S}$. Kaempferi, $D C$

Tysoni, Mac Owan, in foum. Lim. Soc, xxv. (1890) 389. - Afr. austr.

ukambensis, O. Hoffn. in Bot. Fahr. xx. (1894) 235. - Afr. trop. or.

umbraculifera, S. Wats. in Proc. An. Acad. xxiii. 1888) 279. - Mexic

Vaingaindrani, S. Elliot, in foum. Lim, Soc, xxix. (1891):9. - Madas.

Valderramae, Phil, in Anol. Unit. Chil. Ixxxviii. (1894) 15. - Chili.

valdivianus, Phil. l. c. 255. - Chili.

Valcrima, Oliver, in H. Johnston, Kilim, Exped. Append. (1886) 34\%, nomen = Gynura Valeriana. Olicer.

variabilis, Phil in Anal. Univ, Chit. 1xxxvii. (1894) 976. - Chili.

vellereus, Franch, in Bull, Soc, Bot. Fr. xxxix. (1892) 299. - China occ.

Velenovskyi, Borb. in Oest. Bot. Zeitschr. (1889) 234 $(=S$. cinerens, Velen.). - Bulg.

vernalis, Franch, in Bull. Soc. Bot. Fr. xxxix. (1892) 285. - Sikkim, China occ

vernicosus, Baker, in fourn. Linn. Soc. xxii. (1887) 497. - Madag.

Vespertilio, Franch. in Morot, Fonm, de Bot. viii. 1894) 359. - China occ.

Vidali, Phil. in Anal. Unia, Chit, 1xxxviii. (1894) 18. - Chili.

villiferus, Franch. in Morot, Gourn, de Bot, viii. (1894) 362. - China occ.

virens, Phil. in Anal. Univ. Chil. 1xxxwii. (1894) 259. - Chili.

iridis, Phil, in Anal. Mus, wac. Chile (1891) 43. Chili.

Visianianus, “Papaf, » ex Pacher \& Jabornegrg. Fl. von Karnten (1888) $412=$ Visianus, Papaf

Volkensii. O. Hoffm. in Engl, Pflanzcne. Ost-Atr, C (1895) 418. - Afr. trop. or.

Webbii, Christ, in Bot. Fahrō. ix. (18s7) 147 ( Doronicum Welbii, C. Schultz). - Ins. Canar. Weddellianus, Hicron.' in Bot.' Fahrb. xxi. (1895) $356 .-$ Columb.

Whyteanus, Britten, in Trans, Limn. Soc., Ser. II. iv. (1894) 21. - Afr. trop.

Williamsi, Phil. in Anal. Unï. Chil. 1xxxviii. (1894) ?46. - Chili.

\section{SENECIO}

Wolffi, Simonk, Enum. Fl. Transs, (1886) $325=$ campestris, $D C$

xanthopappus, Klatt, in Annal. Naturh. Hofmus Wien, ix. (1894) 366 ; te in Bot. Fahrb. xxi. (1895) 360. - Hab.?

xanthoxylon, Phil. in Anal. Uniz. Chil. Ixxxviii. (1894) \% - Chili.

yesoensis, Franch. in Bull. Soc. Bot. Fr. xxxix. (1892) 306. - Japon.

yungasensis, Britton, in Bull. Torrey Bot. Club, xis. (1892) 264. - Bolivia.

yunnanensis, Franch in Bull. Soi. Bot Fis xxix. (1892) 303; et in Morot, Fown. de Bot. viii. (1894 (603. - Yunnan

SEPTIMETULA, Van Tiegh, in Bull. Soć. Bot Fr. xlij. (1895) $266=$ Loranthus, Linn.

bukobensis, dschallensis, emarginata, hirsutissima. Macrosolen, regularis, rufescens, sigensis, Van Tiegh. 1, c. = homonyma omia Loranthi.

SEPTULINA, Van Tiegh. in Bull. Soc: Bot. Fr. xlii. (1895) $263=$ Loranthus. Linn. glanca, Van Tiegh. 1. c. = L. glancus, Thunb. ovalis, Van Tiegh. 1. c. = L. Ovalis, E. Mey.

SERAPIAS. Linn. (Orchid.) - Ind. Kew, ii. $\$ 8 \%$ Alberti $X, G$. Camus, in Morot, Journ. de Bot. vi. (18:2) 28:- Gall

Barlae X.C. Richt. P1. Europ. i. (1890) 2:6:Gall. mer.

complicata, G. Camus, in Morot, Journ, de Bot, vi (1892) 34 , in syn. = Orchis complicata, G. Camus

Debeauxii, G. Camus, 1. c. = O. Debeauxii, G Camus.

aigenca $\times, G$. Camus, 1. c. 30.- Gall.

elongata, Toduro, Hort. bot. Panorm. (1886-88) 25, t. .. - Italia.

Grenieri X. C. Richt. Pl. Europ. i. (1890) 25. Gall.

Laramberguei $\times, G$. Camus, in Morot, Journ. de Bot. vi. (1892) 27. Atlas to 6. - Gall.

I.loydii X, C. Richt. Pl. Europ. i. (1890) 27.5.Gall.

meridionalis X.. G. Camus, in Morot, Journ. de Bot. ri. (1892) 29, Atlas, t. 9. - Gall.

Nonletii $X$, Rouy, in Bull. Soc, Bot. Fr. xxxi (1889) 342. - Gall.

parasitica, Pavon. ex Ridl. in Journ. Linn. Soc. xxiv. (1888):3:31, in syn $=$ Microstylis calycina Ridl Timbali
Gall.

SERICOCARPUS, Nees (Compos,). - Ind. Few.

asterodes, Kuntze, Rev. Gen. (1s91) $364=$ seq.

asteroides. Britton. Stern \& Pogr. Prelim. Catal (1888) $26=$ conyzoides, Nees.

bifoliatus. Porter, in Mem. Torrey Bot. Club, v. (1894) $322=$ tortifolius, Necs.

limifolins, Britton, Stern \& Pogg. Prelim. Catal. (1888) 26 = solidagineus, Nees.

tomentellits, Greene, Pittonia, i. (Mar. 1889) $283=$ Aster brickellioides, Grine.

SERICOCOMA, Fenzl (Amarant,) - Ind. Fiew ii. 884 .

Nelsii, Schinz, in Engl. \& Pranll, Naturl. Pfanzen fam. iii. la (1893) 10\%. - Afr。 austro-occ. extratrop.

quadrangula, Engl. Bot. Faho. x. (18S9) 7 - Afr. austro-occ. extratrop.

sericea, Schinz. l. c. xxi. (1895) 181. - Afr. austroocc. extratrop.

sifuarrosa, Sihiz\%, t. c. 18\%. - Afr. austro-occ extratrop.

Zeyheri. Engl. 7. c. x. (IS89) $6 .(=$ Trichinim: Zeyheri. Moq.). - Afr. austr.

SERICOCOMOPSIS. Schinz, in Bot. Jahrb. xxi.

(1895) 184. AMARANTACEAE.
Bainesii, Schinz, l. c. $185(=$ Sericocoma Bainesit, Hook.) - Afr. trop. 


\section{SERICOCOMOPSIS}

Hildebrandtii, Schinz, in Bot. Falyz xxi, (1895) 184 ; et in Engl. Pfanzenw. Osto.tfr. C (1895) 172. - Afr. trop. or

pallida, Schinz, l. c. 155 (= Sericocomur pallida, S, Moore). - Afr. trop. or.

SERICOSTOMA, Stocks (Boragin.). - Ind. Kew. ii. 885 .

rerrucosum, G. Beck, in Panlitschka, Harrar (1888) 457, fig. 3-6. - Arabia.

SERINIA, Rafin, = Krigia, Schreb. (Compos.). gracilis, Kuntze, Rev. Gen. (1891) $664=$ Apogon gracilis, $D C$.

oppositifolia, Kuntze, 1. $c .=$ Krigia virginica, Willd. Wrightii, Kuntze, 1. c. = Apogon Wrightii, A. Gray.

SERIOLA, Linn. $=$ Hypochoeris Linn. (Compos.). caespitosa, Porta, in Nuov. Giorn. Bot. Ital. xix. (1887) 310. - Ins. Balear.

Warionis, Herb. Coss. ex Batt. \& Trab. Fl. de l'Algér. [Dicot.l (1889) 536 , in obs. = Hypochaeris Claryi, Batt.?

SERIS, Willd = Onoseris, DC. (Compos.).

acerifolia, adpressa, annua, Castelnaenna, corymbosa, hastata. hyssopifolia, integrifolia, odorata, reflexa, salicifolia, speciosa, Kuntze, Rev. Gen. (1891) 364 = homonyma omnia Onoseridis.

conspicua, Kuntze, 1. c. = O. Isotypus, Benth.

Cumingii, Kuntze, 1.c, = O. odorata, Hook. \&. Arn ? criocephala, Kuntze, 1. $c_{0}=$ Hieracium erianthum, $H B$. \& $K$

hieraciodes, Kuntze, 1. c. = Onoseris hieracioides, H. B. \& $K$.

purpurea, Kuntze, 1. c. $354,364=0$. purpurata, Willd.

mpestris, Kurtze, 1. c. $364=$ O. Isotypus, Benth.

SERISSA, Comm. ex Juss, (Rubiac,), - Ind, Kew. ii. 885 .

aponica, Dippel, Handb. Laubholzk. i. (1889) 164. $(=$ S. japonica, Thunb. $)=$ foetida, Comm.

SERJANIA, Plum. ex Schum. (Sapind.) - Ind. Kew. ii. 886.

aluligera, Radlk. in Bull. Herb. Boiss. i. (1893) 464. - Peruvia.

areolata, Radlk. Monog. Serj. Suppl. (1886) 87. Bolivia.

chaetocarpa, Radlk. in Engl. \& Prantl. Natiurl. Pflanzenfam. iii. 5 (1893) 302. - Bolivia.

cognata, Baill. Hist. pl. Madag. Atlas (1893) t 248, - Madag.

depauparata, Radlk. Monog. Serj. Suppl. (1886) 92. - Guatem.

didymadenia, Radlk. in Bull. Herb. Boiss. i. (1893) 467. - Bolivia.

dissecta, S. Wats. ex Engl. Monog. Serj. Suppl.

(1856) 138 , in obs, = Cardiospermum dissectum, Radlk.

lamelligera. Rallk. l.c. 123 ; et in Mart. Fl. Bras. xiii. III. (1893) 326. - Bras.

dateritia. Radlk, in Bull. Herb. Boiss. i. (1893) 465. - Guatem.

Palmeri. S. Wats, in Proc. Am. Acad. xxiv. (1889) 45. - Mexic.

pernambucensis, Radlk. in Mart. Fl. Bras, xiii. III. (1893) 233. - Bras.

peruviana, Radlk. Monog. Serj. Suppl. (1886) 154, - Peruvia.

plicata, Millsp. Field Columb. Mus. Bot. Ser. I (1895) 33 = plicata, Radlk

psilophylla, Radlk. ex F. D. Smith. Enum. pl. Guatem. ii. (18:1) Ila ; et in Coult. Bot. Gaz. xvi. (1891) 191. - Guatem.

punctata, Radlk. ex F. D. Smith, l. c. xx. (1895) 281 . - Am. centr.

rachiptera, Radlk. $n$ F. D. Smith, Enum. pl. Guatem. ii. (1891) 1la ; et l. c. xvi. (1891) 192, - Guatem. rufisepala, Radlk. ll. cc. - Guatem.

scatens, Millsp. Field Columb. Mus. Bot. Ser. I. (1893) $33=$ scatens, Radlk.

suborbicularis, Radlk, in Mart. Fl. Bras, xiii. III. (1893) 329. - Bras.

\section{SERJANIA :}

subrotundifolia, Radzk. Monog, Seri, Supt (1886) 118. - Peruvia

truncata, Radlk. in Mart. Fl. Bras. xiii. III. (1893) 331. - Bras.

viridissima, Radlh. in Abhandl. Akad. Mucnch. xri (1886) 81 ; et l.c. $258 .-$ Bras.

SERRASTYLIS, Rolfe, in Kew Bull. (1894) 158 et in Gard. Chron. (1894) ii. 726 fig. 91. ORCHI $D E A E$.

modesta, Rolfe, $l l . c c \cdot-N$. Granat.

SERRATULA, Dill, ex Linn。(Compos.) - - Ind, Kew. ii. 887 .

albarracinensis, Pau, Not. Bot.Fl.Espan. i. (1887) 21, et ii. (1889) 30, Willk. in Oest. Bot. Zeitsein. xli. (1891) 4 : et Illustr. Fl Hisp. ii. (1888-92) 136 t. 171a. - Hisp.

chartacea, C. Winkl. in Act. Hort.Petrop, ix. (1886) 524. - Turkest

decurrens, Pau, Not. Bot. Fl. Espan. iii. (1889) 31 . nomen. - Hisp.

kurdica, Post, Pl. Postianae, iv. (I892) 8. - Syria

lycopifolia, G. Beck, Fl. Nied.-Oest. ii. (1893) 1254 in syn. = heterophylla, Desf

ycopifolia, Wettst. in Sitzb. Akad. Wiss. Wien, xcvii. (1889) $581=$ heterophylla, Desf.

microcephala, Traute in Act. Hort. Petrop. ix (1886) 458. - Turkest.

Sccanei, Willk, in Oest. Bot. Zeitschr, xxxix. (1889) 317: Suppl. Prodr. Fl. Hesp. (1893) 98; Illustr. Fl. Hisp. ii. (1888-92) 104 t. 149. - Hisp.

SERSALISIA, R. Br. = Lucuma, Molina (Sapot.). acuminata, Baill. in Bull, Soc. Lim. Paris, ii, (1891) 945 (= Sebertia acuminata, Pierre). N. Caled.

breripes. Baill. 1. c, 947 = Sideroxylon brevipes, Baker.

cinerea, Pancher, ex Baill, in Bull, Soc, Linn Paris, ii. (1891) 905. (= Sideroxylon sp.). $-\mathrm{N}$ Galed.

SERTULA, Linn,$=$ Melilotus, Tourn,$($ Legumin ${ })$ alba, bicolor, brachystachys, Bungeana. dentata, elegans, indica, infesta, italica, messanensis, neapolitana, officinalis, pallida, polonica, ruthenica, speciosa, suaveolens, sulcata, Kuntze, Rev, Gen. (1891) $205=$ homonyma omnia Meliloti.

altissima, Kuntze, 1. c. = M. officinalis, Lam.

ariensis, Kuntze, 1. c. = M. officinalis, Lam.

Besseriana, Kuntze, 1. c. = M. gracilis, $D C$.

coerulea, Kuntze, 1. c. = Trigonella caerulea, Ser.

macrorhiza, Kuntze, 1. c, = Melilotus officinalis, Lam

SERUNEUM, Rumpf, Herb. Amboin. v. (1747) 423, 426 , t. 156, ex Kuntze, Rev. Gen. (1891) 365 =Wedelia. Jacq. (Compos.).

abysincum, acałulcense, acuminatum, affine, africanum, alagoense, ambigum, asperrimum, biflorum, brachy curpun, calendulaceum, chrysostephanum, Crucianum, Ehrenbergii, elongatum, filipes, Forsterianum, frutescens, Gaudichandii, goyazense, gracile, hispidum, Horsfieldianum, lanceolatum, latifolium, longifolium. Lundii, macrodontum, modestum, molle, mossambicense, natalense, oligocephalum, paludosum, pilosum, polycephalum, populifolium, puberulum, pulchellum, radiosum, reticulatum, scaberrimum, serratum, subvelutinum. Trichostephia, urticifolium, Vauthieri villosum, Kuntze, Rev, Gen. (1891) 365 = homonyma omnia Wedeliae.

buphthalmodes, Kuntze, Rev. Gen. (1891) $361=$ W buphthalmodes, Guseb

canescens, Kuntze, 1. c. = W. Chamissonis. Less.

glabratum, Kuntze, 1. c. $(=$ Wollastonia glabrata DC.). - Ins. Timor.

helianthodes, Kuntze.1.c。 = Zexmenia helianthoides, Benth. \& Hook, $f$.

Hookerianum, Kuntze, 1. c, = Wedelia frutescens, Hook. $f$.

insulare, Kuntze, 1. c. $(=$ Wollastonia insularis, DC.). - Ins, Pacif,

avanicum, Kuntze, 1. co $\left(=\mathbb{W}, \pi^{\prime}\right.$ ana, Turcz. - Java
SERUNEUM : -

moluccarum, Kuntze, Rev, Gen. (1891) 361 (= Wol lastonia moluccanu, DC.). - Ins. Moluce

montanum, Kuntze, 1. c. (= Wollastonia montana, DC.). - Java.

pedinculaium, Kuntze. 1. c。 = W. Schultziana. Miq.

procumbens, Kuntze, 1. c. = Chrysogonum procum bens, Benth. \& Hook.f.

frostratum, Kuntze, 1. C. $\{=$ Wollastonia prostrata, DC.). - Bras

scabrinsculum, Kuntze, 1. c。 = Wedelia biflora, $D C$.

serrulatum, Kuntze, 1. c. ( = Wollastonia sermlata, Miq.). - Sumatra.

spilanthodes, Kuntze, 1. c. $=$ Wedelia spilanthoides, F. Muell.

strigosum, Kuntze, 1. c. = W. Menotriche, Olizes'

strigulosum. Kuntze, 1. c, = W. aristata, Less.

trilobatum. Kuntze, 1, $\mathrm{c}=\mathrm{W}$. carnosa Pers.

Eerbesinodes, Kuntze, 1. C, $=$ W. verbesinoides, F. Muell.

Zollingerianzm, Kuntze, 1. c. (= Wollastonia Zollingeriana, Sch. Bip.). - Ins. Sundaic.

SESAMODES, Ludw. = Astrocarpus, Neck. (Resed.).

canescens, Kuntze, Rev. Gen. (1851) $39=$ A. sesamoides, Colm.

cochlearifolium, Kuntze, 1. c. = A, cochlearifolius, Nym.

minus, Kuntze, 1. $\mathrm{c},=$ A. minor, Lange.

pygmaeum, Kuntze, 1. c. = A. sesamoides, Colm suffruticosum, Kuntze, 1. c。 = A, suffruticosus, Lange.

SESAMUM, Linn, (Pedalin.), - Ind, Kew, ii, 890

angustifolium, Engl. Pfanzenw Ost-Afr. C (1895) 365. - Afr. trop. or

antirrhinoides, Welw. ex Aschers. in Verh. Bot. Ver. Brand. xxx. (1888) 183. - Angola.

foetidum. Afzel. ex Engl. Bot. Jahrb. xix. (1894) 156 = occidentale, Heer \&o Regel.

lamiifolium, Engl, 1. c, x. (1888) $256=$ Ceratotheca lamiifolia, Engl.

macranthum, [Engl.:] Pflanzenv, Ost-Afr. A (1895) 64, nomen. - Afr, trop.

Marlothii, Engl. Bot. Fahrb. x. (1888) 25\%. - Afr. austro-occ. extratrop.

Schenckii, Aschers, ex Schinz, in Verh. Bot, Ver. Brand. xxx. (1888) 184. - Afr. austro-occ. extratrop.

Schinzianum, Aschers, ex Schinz, lo c. 182. - Afr. austro-occ, extratrop.

triphyllum, Welw. ex Aschers, l. c. 185; et (1889) 239. - Afr. austro-occ. extratrop.

SESBANIA, Scop. (Legumin.). - Ind. Kew. ii. 890

Hildebrandtii, Taub. ex Engl, in Abh. Preuss. Akad. Wiss. (1894) 42; et in Engl. Pflanzenw. Ost-Afr. A. (1895) $80=$ speciosa, Taub.

indica, Kuntze, Rev. Gen. (1890) $180=$ aegyptiaca, Poir.

MacOwaniana, Schinz, in Verh. Bot. Ver. Brand. xxx. (1888) 165. - Afr. austro-occ. extratrop. oligosperma, Taub, in Flora, lxxii. (1889) 423 . Bras.

paulensis, Barb. Rodr. Pl. nov. Fard. Bot. Rio, Fasc. ii. (1893) 13, t. 2; et Hort. Flumin. 1893 (1895) 11. - Bras.

speciosa, Taub. ex Engl. in Abh. Preuss. Akad. Wiss. (1894) 21, 42; et in Engl. Pfanzentw. Osl-Afr. C (1895) 213. - Afr. trop. or.

SESELI, Linn. (Umbell.). - Ind. Kew。 ii, 890. athantanthoides, G. Beck, in Annal. Naturhist. Hofmus. Wien, x. (1895) 205 = athamanthoides, C. A. Mey.

calcareum, Alboff, Prodr. Fl. Colch. (1895) 108. Reg. Cauc,

Delavayi, Franch. in Bull. Soe. Phibons. Paris, Sér. Vİl. vi. (1894) 130, - Yunnan.

floribundum, Somm. E Levier, in Nisov. Giorn. Bot. Iıal. Ser. II. 11. (1895) 75. - Reg. Calic. 


\section{SESELI}

inaequale, Torvac, in Ann. Ist. bot. Roma, iv. 1889 90 (1891) 93, t. 3. - Italia mer

pencanum, Phil. in Anal. Univ. Chil. Ixxxy, (1894) 719. - Chili.

resinosum, Freyn of Sint, in Oest. Bot, Zeitschr. xliv. (1894) 100. - As. Min.

rhodopeum, Velen. in Sitzb. Boehm. Ges. Wiss. 1890 (1890) ii. 45 ; Fl. Bulg. (1891) 242; ct in Oest. Bot. Z citschr xli. (1891) 398. - Bulg.

Zubellum, Post, in Bull. Herb. Boiss, iii. (1895) $15 \%$ - Syria.

irescons, G. Beck, in Annal. Naturh. Hofmus. Wien, x. $(1895) 205=$ Silaus carvifolius, $C \cdot A$ $M c y$.

Franch in Bull. Soc. Philom. Paris, Sér. VIII. vi. (1894) 129. - Yunnan.

SESELINIA, G. Beck, in Verh. zool.-bot. Ges Wien, xli. (1891) 797; et F1. Nied.-Oest. il (1892) $637=$ Seseli, Linn. (Umbell.)

ustriaca G. Beck, 11. cc, = Pimpinella Gouani, Benth. \& Hook. $f$.

clata, G. Beck, 1. c. $63 \%=$ Seseli elatum, Limn

SESLERIA, Scop.(Gramin.). - Ind, Kew。 ii

comosa, Velen, in Abh, Boehm. Ges, Wiss, vii. I 1886) $44=$ coerulea, Friv

fallax. G. Beck, in Annal. Naturh. Hofmus. Wien, v. (1890) 559 = argentea, Savi.

hercigovina, G. Beck, 1.c. = argentea, Savi.

Heuferiana, Blocki, in Oest. Bot. Zeitschr, xxxix. 1889) $155=$ coerulea, Friv.

tenzopliylla, G. Beck, in Annal. Naturh. Hofmus, Wien, v. (1890) $659=$ argentea, Savi.

subacaulis, Balansa, ex Th. Dur. \& Schinz, Consp. Fl. Afr. v. 1894 (1895) $8 \% 5=$ Ammochloa subacaulis, Balansa.

cavia. Wettst. in Verh. zool,-bot. Ges. Wien, xxxviii, (1888) 357 ou 557: A. Kern. Sched. FI Austro-Hung. vi. (1893) 107 (= Aira vavia, Jacq.) = coerulea, Friv.

SESSEA, Ruiz \& Pav, (Solan.). - Ind, Kew. ii. Regnellii, Taub. un Bot, fahrb.xv, Beibl, n, 38 (1893) 1s. - Bras.

SESUVIUM. Linn. (Ficoid.). - Ind. Kew. ii. $\$ 92$ distylum, Ridl. in foum. Linn. Soc, xxvii. (1890) 38 - Ins. Fernando Noronha.

maritimum, Britton, Stern \& Pogg. Prelim. Catal 1888) $20=\mathrm{S}$. Portulacastrum, A. Gray.

SETARIA, Beauv. (Gramin.).-Ind. Kew, ii. 892 acromelaena, Th, Dur. \& Schinz, Consp. Fl. Afr. V 1894 (1895) 772 $(=$ Panicum acromelacmum. Hochst.). - Abyss.

atrata, Hack. ex Engl. in Ab\%. Prouss. Akad. Wiss. 1891 ii. (1892) 122, et (1894) 64. - Afr. trop. or bifida. Kuntze, Rev. Gen. (1891) 7\%0, sphalm. = biflora, Hillebr.

basiseta, Th. Dur. \& Schinz, Consp. Fl. Afr. v. 1894 (1895) 772 (= Panicum basisctum. Steud.). - Guinea.

biflora, Hillow. Fl. HIaw. Isl. (1888) 503. - Ins Sandvic.

brachiariaeformis, Th. Duw. Eo Sinin Consh. Fl. Afr. v. 1894 (1895) T5\% (= Panicum brachiariae forme. Steud.). - - Afr. trop. occ.

breviglunis, St Lager, in Cariot, Ltud. des fl. éd. S ii. (1889) 891 = glanca, Beauv.

caespitosa, Hack. \& Arecha', in Anal. Mus, nac Monte\% if (1894) 166.t. 15. -- Urug.

chrysochaeta, Th. Dwr. Eo Sching, Consp. Fl. Afr v. 1894 (189.5) $7 \% 2(=$ Panicun chrysochactum Steud.). - Ins. Borbon.

flava, Fourn. Gram. Mcxic, 1881 (1886) 45 $(=P$ flucum, Nees). - Mexic

Iatiolumis, Vasey, in Bull Torrey Bot Club, xiii. 1886) $229 ; S$. Wats, in Proc. Ant. Acad. xxi. (1886) 442. - Mexic.

megaphylla, Th. Dur. \& Schin\%, Consp. Fi. Afr. v. 1894 (1895) 773 (= Panicum megaphyllum. Steud.) - Guinea.

\section{SETARIA :}

nigrirostris, Th. Dur. \& Schinz, Consp. Fl. Afv, v. 1894 (1895) 774 (= Panioun nigrirostre, Nees). - Abyss, Afr, austr

oligochaete, K. Schum. in Engl. Pfanzenw. Ost-Afr. C (1895) 105. - Afr. trop. or

pauciseta, Vasey, ex S. Wats, in Proc. Am. Acad. xxi. (18S6) 442, nomen; in Bull. Torrey Bot. Club, xiii. (1886) 930 ; et an Contrib. U. S, Nat. Herb, iii. (1892) 39. - Texas.

perennis, Hack, cx Schinz, in Bull. Hcrb. Boiss, ini. (1895) 379. - Transvaal.

perennis, Hall, in B. B. Smyth, Check List pl. Kansas (1892) 26. - Kansas.

phyllomacra, Th, Dur, E Schinz, Cunsp. Fl. Afr. v. 1894 (1895) 774 (= Panicum phyllonacra, Steud.). - Guinea.

plicatilis, Hack. ox Engl. in Abh. Prenss. Akad. Wiss. 1891 (1892) 121 (= Panicun plicatile, Hochst.). - Abyss.

proliseta, Th. Dur. Eo Schinz, Consp. Fl. Afr. v. Princip.

ndimentosa, Th, Dur. \& Schinz, l. c. $(=P$. rudimentosum, Steud.). - Seneg.

transiens, $K$. Schum, in Engl. Pfinzenw', Ost-Afr. C (1895) 105. - Afr. trop. or.

atkeana, K. Schum. in Abh. Naturh. Ver. Brim. ix. (1887) 402. - Madag.

SETILOBUS, Baill. Hist. des pl. x. (1888) 29. BIGNONIACEAE

bracteatus, Baill. l. c. - Bras

simplicifolius, K. Schum, in Engl. \& Prantl, Natürl. Pflanzenfam, iv.3b (1894)221 = truncatus, Duraur.

SEYMERIA, Pursh (Scrophul.). - Ind. Kew. ii.

madagascariensis, Kuntze, Rev, Gen, (1891) 45\% cum cit. talsa. - Madag.

SHERARDIA, Dill. ex, Linn. (Rubiac.), - Ind, Kew, ii. 894 .

agraria, Tomab. Fl. Sicula, (1887) 284. - Sicil

SHOREA, Roxb. (Dipteroc.). - Ind, Kew. ii. $\$ 94$ aptera, Burck, Minjak Tangk. Batavia (1886) 19 ; in Annal. Fard. Buitenz. vi. (1887) 210 t. 22 Brandis, in Founn. Linn. Soc. xxxi. (1895) 78. Borneo.

altopoensis, Picre. Fl. For. Cochinch. Fasc, 15. (1890) t. 232b, et 17. (1892) t, 25\%a:Brandis, is Fourn. Linn. Soc xxxi. (1895) 85. - Cambodia. Bailloni, He1m, in Bull. Soc. Linn. Paris, ik. (1891) $973=$ macroptera, Dyer

Bakeriana, Heim, in Bull. Soc, Linn. Paris, ii. 1891) 974; ct Recherch. Dipteroc. (1892) 47; Bran dis, in fonru. Lim. Soc. xxxi. (1895) 96. - Borneo

Balangeran, Burck, in Annal. Fard. Butcn\%, vi. (188\%) 214 ; Brandis, in foum. Linn. Soc. xxxi. (1895) 86 (= Hopea Balangera, Korth.). - Ind, bat.

barbata. Brandis, in Foum. Linn. Sor. xxxi. (1895) 81. - Malacca.

Beccariana, Burck, in Annal. Fard. Buitcn\%. vi (1887) 213; Brandis, l. c. 8\%. - Borneo

Eeccarii, Dyer, ex Brandis, 1. c. in $\operatorname{syn} .=\mathrm{Bec}$ cariana, Burck.

brachyptera, IIcin, in Bull. Soc. Limn. Paris, ii. (1891) $95 \%$; ct Recherih. Diptiruc (1892) 46 Brandis, l. 6.7\%. - Borneo.

bractcata, Pierre, ex Laness. P1. util. Colon. Franc, (1886) $301=$ siamensis, Miq.

cliata, King, in fonm. As. Soc. Beng. 1xii. (1893) It. l18; Brandis, in foum. Limn. Soc. xxxi.(1895) 82. - Penang.

cambodiana, Pierre, Fl. For. Cochinch. Fasc. 15. 1890) sub t. 229; Brandis, l. c. 89. - Cambodia. chinchinensis, Pierre, l. c. t. $230(=$ S. Talura. Roxb. var. cochinchinensis, Pierre); Brandis, l. c. 84. - Cambodia.

compressa, Burck, Minjak Tangk. Batavia (1886) 26 ; ct in Annal. Fard. Buitenz. vi. (1857) 212, t. \&4; Brandis, l.c. 8\% - Borneo

oriacea. Burck, l. i. 214; Brandis, l. 6. 100. Bones.
SHOREA

ostata, King, in fourn. As. Soc. Beng. 1xii. (1893) ii. 119 ; Brandis, l.c.81. - Penang

Curtisii, Dyer, ex King, l. c. 111 ; Brandis, l. c. 101. - Penang.

dryobalanoides, Dyer, 1 c. $95=$ Faguetiana, Heim.

Dyeri, Heim, in Bull. Linn. Soc, Faris, i1. (1891). 957 = cristata, Brandis

elliptica, Burck, in Annal. Fard. Buiten\%. vi. (1887) 215; Brandis, in fou'n. Linn. Soc. xxxi. (1895) 99. - Borneo

Faguetiana, Hoin, in Bull. Soc, Linn. Paris, ii. (1891) 975; ot Recherech. Diptéroc. (1892) 49 ; Brandis, 7. c. 95. - Borneo.

falcifera, Dyer, ex Brandis, 7. c. 85. - Borneo.

ferruginea, Dyer, ex Brandis, l c.91. - Borneo.

Forbesii, Brandis, l. c. 22, - N. Guin.

Franchetiana, Heim, in Bull. Soc, Linn. Paris, ii (1891) 956 ; et in Mém. Assoc. Franç. Besanç $1892(1893) 459$; Brandis, 1. c. $87=$ Beccariana, Burck.

fusca, Burck, in Annul. Fard. Buitcn\%. vi. (188\%) 207 : Brandis, l.c.83. - Sumatra.

Gala, Baill. Bot.módic. i. (1884)617[Quid.?].-Hab.? gibbosa, Brandis, in foum. Linn. Soc. sxxi. (1895) 99. - Penins. Mal.

glauca, King, in Fourn. As. Soc. Bong. 1xii. (1893) ii. 117 ; Brandis, l. c. 102 . - Penang.

randiflora, Brandis, in foum, Limn Soc rxxi. 1895) 93, - Borneo

Gysbertsiana, Burck, in Minjak Tangh. Balavia 1886) 15; ot in Annal. Fard. Buitenz. vi. (1887) 211 t. 23, 30 fig. 2 ; Brandis, l. c. - Borneo.

Harmandii, Picrre, in Laness. Pl, util. Colon, Franc. (1886) $302:$ Fl. For. Cochinch. Fasc, $15(1890) \mathrm{t}$ 231 ; Brandis, l. c. 85 . - Cochinch.

Havilandi, Brandis, in fourn. Linn. Soc. xxxi. (1895) 82. - Borneo.

Henryana, Picrre, in Laness. Pl. util. Colon. Franc. (1886) 302 ; ct Fl. For. Cochinch. Fasc, 15 (1890), t. 229, et Fasc, 16 (1891) t. 351b : Brandis, $l . c$. 89. - Cochinch.

inappendiculata. Burck, in Amnal. Fard. Buitent. vi. (1887) 206 ; Brandis. l. c. 102. - Borneo.

Kunstleri, King, in fourn. As. Soc. Beng. Ixii. (1893) $116:$ Brandis, l. c.93. - Perak.

macrantha, Brandis, in Fomn. Limn. Soc, xxxi. 1×95) 9\%. - Borneo.

Maranti, Burck, in Annal. Fard. Buiten\%, vi. (188\%) $21 \%$ (= Hopea? Maranti, Miq.); Brandis, l. co. 101. - Ind. bat.

maritima, Picre, in Laness. Pl. util. Colon. Frane. 1886) p. 302 et Fl. For. Cochinch. Fasc. 15. $1890)$ sub. t. 229; Brandis, l. c. 89.-Cochinch. Maxwelliana. King, in fourn. As. Soc. Beng. 1xii. (1893) ii. 114; Brandis, l. c. 86. - Perak.

uchongensis. Pierre, ex Laness. P1. util. Colon. Franc. $(1886$ (3) $301=$ siamensis, .1. iq.

ovata, Dyer, ex Brandis, in foum. Linn. Soc. xxxi 1895) 91. - Borneo

parvistipulata, Heim, in Bull. Soc. Limn. Poris, ii. 1891)974; Brandis, l. c. 95. - Borneo.

pauciflora, King, in fourn. As. Soc, Beng. 1xii. (1S93) II. 110 ; Brandis, . c. 98. - Penang.

philippinensis, Brandis, m fomm. Linn. Soc. xxxi (1895) 88. - Ins. Philipp.

Pierreana, Heim, Recherch. Difteroc. (1592) 48. nomen - Cochinch.

platycarpa. Heim, in Bull. Soc, Linn. Paris, ii. 1891) 956 ; Brandis, in fourn. Linn. Soc. xxxi. (1395) 94. - Borneo

Ridleyana, King, in fou'n. As. Soc. Beng. 1xii. (1893) II. 115 ; Brandis, l. c. 89. - Perak

rivida, Brandis, in Hook. Icon. pl: xxv. (1895) t. 2402 ; et in fourn. Linn. Soc, xxxi. (1895) 102. Penins. Mal.

rugosa. Heim, in Bull. Soc, Limn. Paris, ii. (1891) 973 ; Brandis, l. c. 96 . - Borneo.

scaberrima, Burk, Minjak Tangh. Batavia (1886) 22 ; ot in Annal. Fard. Buitenz. vi. (1887) 208 Brondis, in foum. Iinn. Soc. xxxi. (1895) 78. Borneo.

scrobiculata, Burck, l. c. 207 ; Brandis, 1. c.83.Borneo.

Schumanniana, Gilg, in Bot. Fahrb. xviii. Beibl. n. 45 (1894) 39. - N. Guin. 
SHOREA

scutulata, King, in fourn. As. Soc. Beng. Ixii. (189:3) II. 118 ; Brandis, in fourn. Limn. Soo xxxi. (1895) 83. - Penang.

Singkawang, Burck, in Annal. Fard. Buiten\%. vi. (1887) 219: Brandis, l. c. 87. - Sumatra.

stenoptera. Burck, Minjak Tangk. Batavia (1886)

11 ; et l. c. 209, t. 21; Brandis, l. c. 78 . Borneo

stipulosa, Burck, l. c. 220 (=Vaticu stipulosa, Miq. Brandis, l. c. 96. - Sumatra.

suavis, Pierre, ex Laness, Pl util. Colon. Franc. (1886) $301=$ siamensis. Miq.

Teysmanniana, Dyer, ex Brandis, in fourn. Linn. Soc. xxxi. (1895) 100. - Bangka.

Thiseltoni. King, in Fourn. As. Soc. Beng. 1xii, (1893) 122 ; Brandis, l. c. 77. - Perak.

Thorelii, Pierre, ex Laness, Pl, util. Colon. Franc. 1886, 302; et Fl. For. Cochinch. Fasc, 15 (1890) t. 233 ; Brandis, l. c. $81,-$ Cochinch.

utilis, King, in fourn. As. Soc. Beng. 1xii. (1893) II. 119 ; Brandis, l. c. - Penang.

cerruculosa. Dyer, ex Brandis, in Journ. Linn. Soc. xxxi. (1895) 96 = rugosa, Heim

Vidaliana, Brandis, l. c.83. - Ins. Philipp.

vulgaris, Pierre, ex Laness. Pl. util. Colon. Franc. (1886) 301 ; ot Fl. For. Cochinct. Fase. 15 (1890 t. 232a: Brandis, l. c. S1. - Cochinch.

Warburgii, Gilg, in Bot. Fahrb. xviii. Beibl, n. 45 (1894) 38 ; Brandis, l. c. 98. - Ins. Philipp

SHORTIA, Torr. \& Gray (Diapens.), - Ind. Kew. ii. 895 .

rotundifolia, Makino, in Tokyo Bot. Mag. ix. (1895) 103 (= Schizocodon rotundifolium, Maxim.). Japon.

SHULTZIA, Rafin, = Obolaria, Linn. (Gentian.). virginica, Kuntze, Rev. Gen. (1891) $430=0$. vir ginica, Lim

SHUTERIA. Wight \& Arn. (Legumin.). - Ind, Kew. 11. S94.

SICANA. Naud. (Cucurb.). - Ind. Kew. ii. 895. atropurpurea, Ed. André, in Rev. Hortic. 1xii. (1890 516, et 1xvi. (1894) 108, cum ic. - Uruguay. sphaerica. Hook. f. in Bot. Mag. (1890) t, 7109. Jamaica.

SICKINGIA. Willd. (Rubiac.), - Ind. kew. ii Glaziovii, K. Schum, in Bot. Fahrb. x. (1888) 327 et in Mart. Fl. Brits. vi. vi. (1889) 227. - Bras japurensis, K. Schum.l. c. 229. - Bras.

macrocrater, $K$. Schum. in Bot. Fahrb. x. (1888) 327 ; et l. c. 226. - Reg. Amazon.

Oliveri, K. Schum. ll. cc. 328 ; et 232. — Bras.

paraënsis, K. Schum. $\|$. cc. 328 ; et $292(=\mathrm{Chi}$ marrhis paraensis, Baill.). - Bras.

Pikia, K. Schum. ll. cc. 328 ; et 234 - Bras.

pisoniiformis, K. Schum. 11. cc. 327 ; et $225=$ pisoniaeformis, Baill.

rubra, K. Schum. II. cc. 328; et 233 (= Arariba rubra, Mart.). - Bras

tinctoria, K. Schmm. $7 l$. co. 328 ; et $2281=$ Condaminea tinctoria, DC.). — Bras.

viridiflora, $K$. Schum. ll. cc. 328; et $232(=$ Pinck neya viridiflora, Allem. \& Sald.). - Bras.

xanthostema, $K$. Schum. ll.cc.328; et 229 . - Bras.

SICYOCODON, Feer, in Bot. Jahrb, xii. (1890) 61: = Campanula. [Tourn.] Linn.

macrostylus, Feer, 1. c. = C. macrostyla, Boiss. \& II cldr.

SICYOS, Linn. (Cucurb.). - Ind. Kew. ii. 896. collinus, Robinson Eo Fornald, in Proc. Am. Acad. xxx. (1895) 116. - Mexic.

echinocystoides, Cogn. ex $7 . N$. Rose, in Contrib. U S. Nat. Horb. iii. 5 (1895) 319. - Mexic

hispidus, Hillebr. Fl. Hat? Isl. (1888) 136. - Ins. Sandvic.

laciniatus, Hillebr. l. c. 138. - Ins, Sandvic.

\section{SICYOS}

ongisepalus, Cogn. ex F. D. Smith, in Conlt. Bot. Gaz. xvi, (1891) 11. - Guatem

minimus, S. Wats, in Proc. Am. Acad. xxiii. (1888) 274. - Mexic.

ertuliferus, Cogn, ex Th. Dur. \& Pitt, in Bull. Soc. Bot. Belg. xxx. 1891 ) (189\%) 277 - Costa Rica trigemina, Rusby, in Mem. Torrey Bot. Club, iii. 1893) 38 . - Bolivia

SIDA, Linn. (Malv.), - Ind, Kew, ii. 896.

lamosana, S. Wats. ex F. N. Rose, in Contrib. U. S. Nat. Herb. i. (1891) 93 ; et in Proc. Am. Acad. xxvi. (1891) 133. - Mexic

argentina, K. Schum, in Mart. Fl. Bras, xii. II (1886) 315. - Reg. Argent

Bakeriana, Rusby, ex E. G. Baker, in form. Bot. xxii. (1894) 38. - Bolivia.

Barclayi, E. G. Baker, l. c. xxx. (1892) 236. - San Salvad.

benensis, Britton, in Bull. Torrey Bot. Club, xvi (1889) 153. - Bolivia.

hachapoyensis, E. G. Baku, in Fontm. Bot. xxx. (1892) 324.- Peruv.

chapadensis, K. Schum, in Mart. Fl. Bras, xii, II (1891) 317. - Bras

inerea. E. G. Baker, in Contrib. U. S. Nat. Horb iii. 5 (1895) 311. - Mexic.

dictyocarpa, Griseb. ex K. Schum. in Mlart. Fl. Bras, xii. III. (1891) 314. - Reg. Argent

discolor, E. G. Baker, in foum. Bot, xxx, (1892) 291 [discolora]. - Timor.

Eggersii, E. G. Baker, l. c. 139, 一 Ind. or

Glaziovii, K. Schum, in Mart. Fl. Bras, xii, II (1891) 32\%. - Bras

gorgonea, Lowe, ex E. G. Baker, in Journ, Bot, xxx. (1892) $240=$ rhombifolia, Linn. var

oyazensis, $K$. Schum in Mart. Fl. Bras, xii. II 1891) 316 . - Bras

guianensis, K. Schum. l. c, 305. - Guian. angl et gall

Helleri, f. N. Rose, ex Heller, in Contrib. Herb. Frankl. and Marsch. Coll. [Bot. Expl. S. Texas? 1895) 65. - Texas.

hermaphodita, Rusby, in Mem. Torrey Bot. Club v. (1894) $223=$ S. Napaea, Cav

Hoepfneri, Guerke, ex Schinz, in Bull. Herb. Boiss, iii. (1895) 494. - Afr. austro-occ. extratrop.

Holtzei, F. Mull, in Fomm.Roy. Soc. $N^{\top}, S$. Wales, xxiv. 1890 (1891) 78. - Austral.

Jamesij, E. G. Baker, in foum. de Bot. xxx. (1892) 294. - Ecuad.

Kingii, F. Mull. in Vict. Natural, iii. (Feb. 1887) 138 ; ct ex Bot. Centralbl. xxx. (1887) 243. Austral.

lapaensis, K. Sohum, in Mart. Fl. Bras, xii. II (1886) 302. - Bras.

leprosa, $\pi$. Schum. l. $a, 341(=$ Malia leprosa, Ort. - Am. trop.

odiegensis, E. G. Baker, in Contrib. U. S. Nat. Herb, iii. 5 (1895) 311. - Mexic,

medicaginis, Klotzsch, ex K. Schum. in Mart. Fl. Bras. xii. II. (1891) 313 = serrata, IVilld. montana, K. Schum. l. c. 335. - Reg. Arcent

neo-mexicana. A. Gray, in Proc. Am. Acad xxii. 1887) 296. - Am. bor. occ.

nummularia, E. G. Baker, in Fourn. Bot rxx 1892) 290, - Ins. Pin. [Isle of Pines]

oligandra, K. Schum. in Engl. \& Prantl, Natiurl. Pfanzenfan. iii. 6 (1890) 43 ; et in Mart. Fl. Bras. xiii. III. (1891) 321. - Bolivia.

Palmeri, E. G. Bakev, in fown. Bot. xxx. (1892) $295,-$ Mexic

podopetala, F, Muell. \& Tate, in Trans: and Proc Roy. Soc. S. Austral. xiii. (1890) 107. - Austral

Pseudo-urens, E. G. Baker, in fourn. Bot. xxx. (1892) 294. - Peruv.

purpurascens, Salzm, in Mart. Fl. Bras, xii, iii. (1891) 333. - Bras.

Riedeli, K. Schum. $l, c, 296$. - Bras

savannarum, K. Schmo. l. c. 308. - Guian. angl.

Schweinfurthii, E. G. Baker, in fonrm. Bot. xxx. (1892) 295. - Atr. trop.

Teysmannii, E. G. Baker, l. c 292, - Timor.

Wilkinsoni, F. Mutl, in Vict. Natural, x. Feb. 1894) 166, nomen, - Austral
SIDA

Xanti, A. Gray, in Proc.Ann. Akzd, xxii. (1887) 296. - Calif.

SIDALGEA. A. Gray (Malv.). - Ind. Kew ii. 901 delphinifolia, Greene, Fl. Franc. (1892) $105(=$ Sid delphinifolia, Nutt.). - Calif

Hendersoni, S. Wats in Proc. Am. Acad. xxiii, (1888) 262. - Oreo

Hickmani, Greenc, Pittonia, i. (Nov, 1887) 139 . Calif.

parviflora, Grcene, in Erythea, i. (1893) 148.Calif

pedata, A. Gray, in Proc. An, Acad. xxii, (188i) 288. - Calif

secundiflora, Grecne, Fl. Francisc. (1892) 103 ; Man. Bot. San Franc, Bay (1894) 65. - Calif.

SIDASTRUM, E, G. Baker, in Jomrn, Bot. xxx. (1892) 137. MALV ACEAE

quinquenervium, E. G. Baker, l. $c_{0}(=$ Sida anik quenervia, Duchass.). - Am. trop.

SIDERITIS, Toum, ex Linn. (Labiat.). - Ind, Kew. ii. 901.

aurasiaca, Batt. \& Trab. Fl. de 1'Algér. [Dicot.] (1889) 698 = incana, Linn.

biflora, Porta \& Rigo, ex Porta, in Atti Accad. Agiati, ix. 1891 (1892) 59; Willk. Suppl. Prodr Fi Hisp. (1893) 156. - Hisp.

glandulifera, Post, in Bull. Herb. Boiss, i. (1893) 30 411. - Syria.

javalambrensis, Pan, Not. Bot. Fl. Espan. i. (1887) 26; Willk. l. c. (1893) 155. - Hisp

nusairiensis, Post, in Bull. Herb. Boiss, i. (1893) 29 - Syria.

pycnostachys, Pomel, ex Batt. \& Trab. Fl, de l'Al. gér. [Dicot.] (1890) $699=$ Guyoniana, Boiss. E Reut

Reverchoni, Willh. Suppl. Prodr. Fl. Iisp. (1893) 156. - Hisp.

SIDEROCARPUS, Pierre, ex L. Planch. Etud. prod. Sapot. (1888) 27 ; et Not. bot. Sapot. (1890 31 = Sideroxylon. [Dilt.] Linn. (Sapot.).

Vrieseamus, Pierre, 1, $\mathrm{c}=\mathrm{S}$. Vrieseanum, Picri,

SIDEROXYLON, [Dill.] Linn. (Sapot). - Iid. Kew, ii. 902

amboinense, Boorl. Handl. Fl, Ned. Indië. Ii. I. (1891) 312. - Ins. Molucc

Argan, Baill, in Bull. Soc. Linn, Paris, ii. (1890) $\$ 8 \%$ = Argania Sideroxylon, Rncm. E Schult.

Aylapi Boerl. Handl. Fl. Ncd. Indië, ii. I. (1891)Ind. Bat.

Bakeri, S. Enliot, in foum. Linn. Soc. xxix. (1891) 31. - Madao.

Balanseanum, Baill. in Bull. Soc. Linn. Paris, ii. (1890) $889,-\mathrm{N}$. Caled.

Brousmichii, Baill. l. c. 885. - N. Caled.

burmanicum, Collott of Henst. in foum. Linn. Soc xxviii. (1890) 8\%. - Burma.

ambodianum, Pierre, Not. bot. Sapot. (1891) $36=$ Planchomella cambodiana, Pierre). - Cochinch. riaceum, Baill. in Bull. Soc. Linn. Paris, ii. (1890 892. - N. Caled.

cuneatum, Raunkiaer, ex Wurm. in Videnste. IIcddel. naturh. Forcn. 1889 (1890) [Symb. Fl. Bras. centr. ixxi.] 4. - Bras.

Ictyoneuron, Baill, in Bull, Soc. I imn. Paris, it. (1890) 884. - N. Caled.

longnaiense, Pierre, Not.bot. Sapot. (1891) 36 (= Planchonella dongmaiensis, Pierre). - Cochinch. Eerwah, F. M. Bailley, in Proc. Roy. Soc. Queenst. x. (1894) 52. - Austral.

fastuosum, Baill. in Bull. Soc, Limn. Paris, ii. (1890) $884 .-\mathrm{N}$. Caled.

Fischeri, Engl. Pfantzenw. Ost-Afr. C (1895) 306.Afr. trop. or

floribundum. Cordcm. Fl. Tle Rimion, (1895̃) 45̃l. - Ins. Borbon.

Kaernbachianum, Engl, in Nolizbl, Bot. Gart. Ber?. i. (1895) 102. - N. Guin.

lasianthum, Baill. in Bull. Soc, Linn. Paris, ii. (1890) $88 \%$ - N. Caled. 


\section{SIDEROXYLON}

lasiocladon, Baill, in Bull, Soc. Linn, Parss, it.

(1890) $88 \%$. N Caled.

lauraceum, Baill. l. c. 890 - N. Caled.

laurifolizm, Engl. Bot, Jahrb, xii. (1890) 51\% = S. Richardi, $F$, Mrell.

Lecardi, Baill, in Bull, Soc. I.imn, Paris, ii. (1891) 904. - N. Caled.

leucophyllum, S. Wats, in Proc. Anr. Acad. xxiv, (1889) 59. - Calif. austr.

lifuanum, Baill, in Bull. Soc. Lim, Paris, ii. (1890) 890. - Ins. Lifu.

maritimum, Pierre, Not. bot. Sapot. (1891) 36 (= Planchonella maritina, Pierre). - Cochinch.

microlobum, Baker, in fourn. Limn. Soc, xxv. (1890) 333. - Madag.

microphyllum, S. Elliot, l. c. xxix. (1 191 ) 31. Madag.

novo-guineense, K. Schnm, in Bot. Fahrbo ix. (1887) 214. - N. Guin

Pancher1, Baill, in Bull. Soc. Linn. Paris, ii. (1890) 885. - N. Càled.

papuanum, Boerl. Handl. Fl. Ned. Indië, ii. I. (1891) 312 - N. Guin.

parvifolium, Rannkiacr, ex Warm. in Vidensk. Mcddel. naturh. Foren. 1889 (1890) [Symb. Fl. Bras. contr. xxxi.\} (parvifolia) 4. - Bras.

pedicellatum. Cordem. Fl: Ile Rémion (1845) 451. - Ins. Borbon.

Pervillei, Engl. Bot. Fahrb. xii. (1890) 518. Madag.

petiolare, A. Gray, in Proc. An. Acad. xxii. (1887) 434. - Mexic

Petitianum, Pierre, Not. bot. Sapot. (1891) 36, in syn. (= Planchonella Petitiana, Pierre). $-\mathrm{N}$. Galed.

politum, Pierre, 1. c. 41 (= Sapota polita, Griseb.) - Cuba.

reticulatum. Baill. in Bull. Soc. Linn. Paris, ii. (1890) 891 - N. Caled

reticulatum, Britton, in Ann. N. Y. Acad. sci. vii. (18!3) 156. - Parag.

Sacleuxii, Baill, in Bull, Soc. Linn, Paris, if. (1891) 911.946 - Zanzib.

Sichwackei, Engl, Bot. Jahrb. xii. (1890) $518=$ parvifolium, Raunkiaer.

sphaerocarpum, Baill.-in Bull. Soc. Linn. Paris, ii. (1890) 891. - N. Caled

spathulatum. Hillebr. Fl. Haw. Isl. (1888) 277 (= Planchunella, sp. Pierre). - Ins. Sandvic.

spurium, Cordenn. Fil. Ile Réunion (1895) 450. Ins. Borbon.

imorense, Blume, ex Picrre, Not. bot. Sapot. (1890) 35 (= Planchoncila jacensis, Pierre $)$ - - Ins. Timor.

Vieillardi, Baill, in Bull. Soc. Linn. Paris, ii. (1890) ss6. - N. Galed.

Wakere, Baill. l. c. 882 (= Chrysophyllum Wakere, Panch. \& Sebert) - N. Caled.

Zippelianum, Pierre, ex Boerl. Handl. Fl. Ned. Indic, ii. I. (1891) 312. - Ind. bat.

SIEGESBECKIA, Linn. (Compos,), - Ind. Kew.

repens, Robinson E Grenm. in Am. Foum. Sci. Ser. 11I. 1. (18\%5) 153. - Mexic.

SIEGLINGIA, Bernh= Triodia, R. Br. (Gramin.) acuninata, albescens, ambigua, antarctica, avenacea. Cunninghamii, exigna, filiformis, irritans, microstachyn, mutica, phmosa, procera, pulchella, fungens. Schaffueri, Kuntze, Rev, Gen, (1891) $737=$ homonyma ommia Triodiae.

brasiliensis, Kuntze, Rev, Gen. (1891) (=Uralepis brasilicnsis, Steud.). - Bras.

Bucklcyana, Dewey ex Coult. in Contrib, U. S. Nat. Herb. ii. (1894) 540 . - Texas.

Chapmani. Small, in Bull. Torrey Bot. Club, xxii. (1895) 365. - Am. bor.

congesta, Coult. in Contrib. U.S. Nat. Herb. ii, (1894) 539. - Texas.

Cunninghami, Baill. Hist. des pl. xii. (1894) $230=$ Triodia Cunninghami, Benth.

cragrostoides, Dewey, ex Coult, in Contrib. U. S. Nat. Herb. ii. (1894) 539. - Texas, Florida.
SIEGLINGIA :

flaccida. Kuntze, Rev. Gen. (1891) 739 (= Uralepis flaccida, Doell). - Bras.

flare, Kuntze, 1, $c_{1}=$ Triodia cuprea, facg.

latifolia, Kuntze, 1. Co (= Tricuspis latifolia, Griseb.). - Reg. Argent.

Lindleyana, Kuntze, 1. c。 = Leptochloa Lindleyana, Kunth.

microdon, Kuntze, 1, с。 = Triraphis microdon, Benthe

Mitchelii, Baill. Hist. des pl. xii. (1894) $230=$

seq.
Mitchellii, Kuntze, Rew. Gen. (1891) $789=$ T. Mitchelli, Benth.

Aealleyi, Coult, in Contrib. U.S. Nat. Herb, ii. 1894) $538=$ T. Nealleyi, Vasey

pungens, Baill. Hist, des pl. xii. (1894) $230=\mathrm{T}$ pungens, $R, B r$

purpurea, Kuntze, Rev, Gen, (1891) 789 = Triplasis purpurea, Chapm

seslevioides, Scribn, in Mem. Torrey Bot. Club, y. (1894) 48 = Triodia cuprea, facq

IVrightii, Vasey, in Contrib. U. S. Nat. Herb. i. 1893) 269. - Am. bor, austro-occ

SIEVERSIA, Willd. = Geum, Linn. (Rosac.).

bulgarica, Nym, Consp. Fl. Eur. Suppl. ii. I. (1889) 113. - Bulg., Maced.

pontica. Alboff, in Soc. imp. hort. |Compt.rend Sect. Odessa] (1891) extr. 8. - Reg. Cauc.

haetica $X$, Nym. Consp. Fl, Eur. Suppl, ii. I (1889) 113. - Helv.

speciosa, Alboff, in Trav; Soc. hort. Odessa (1891) ex Prodr. Fl. Colch. (1895) 80, et ex Bull. Herb. Boiss. i. (1893) 244 = Geum speciosum, Alboff.

Sredinskiumum, Krassnoff, in Bull. Soc. Natur. Kharkoff, (1892), ex Bull. Herb. Boiss. i. (1893) $244=$ G. speciosum, Alboff.

SIGMATOSIPHON, Eng1. Bot. Jahrb. xix. (1894) 15o; Stapf. in Engl. \& Prantl, Natürl. Ptlanzen3b (1895) 262. PEDALINEAE

Guerichii, Engl. Il.cc. 151; et 262. - Afr. austroocc. extratrop.

SILAUS, Bernh. (Umbell.). - Ind. Kew. ii. 904

foliosus, Somm. \& Lerier, in Nuor. Giorn. Bot. Ital. Ser. II. ii. (1895) 78. - Reg. Call.

Rocheli, Simonk. Enum. Fl. Transs. (1886) $261=$ Selinum Rochelii, Heuff.

Selinoides, Halácsy, in A. Kern, Sched. Fl. AustroHung, iv. (1856) 37 ; Simonk. Enum. Fl. Trans. silv. (1886) $261=$ Seseli selinoides, facq.

SILENE, Linn. (Caryoph.), - Ind, Kew. ii. 90 .

Acantholimon, Wettst, in Sitzungsb. Akad. Wiss. Wien, xcriii. 1889 (1890) 381. - As. Min.

adenantha, Franch. Pl. Delav. ii. (1889) 84. China occ

Akinfijewi. Schmalh, in Ber. Dentsch. Bot. Ges. x. (1892) 286"; Akinfice, in Bull. Soc. givogr. Cauc. (1892) 90 [Fl. Canc. contr. (1894) 11.]. - Reg.

Alexandri, Hillebr Fl. Haw. Isl. (1888) 28. - Ins. Sandvic

amassiensis, Freyn, in Bu1l. Herb. Boiss. iii. (1895) 99 = filipes, Freyn \& Sint

antiochica, Freyn, in Bull. Herb. Boiss. iii. (1895) 78. - Syria.

asclepiadea, Franch, in Bull. Soc. Bot. Fr. $\mathrm{xxx}$ III (1886) 422 ; et Pl. Delav. (1889) 84. - Yunnan.

asperifolia, Freyn, in Bull. Horb. Boiss. iii. (1895) y7. - As. Min,

Astartes, Blunche, ex Boiss. Fl. Or. Suppl. (188s) 102. - Syria.

avromana, Boiss. \& Hausskn. ex Boiss. l. c. 105. Persia,

Barbeyana, Heldr. ex Boiss. l.c. 107. - Graecia

Berthelstiana, Webb, ex Cluist, in Bot. Fahro. ix. 1888) 100. - Teneriffa.

bernardina, S. Wats. in Proc. Am. Acad. xxir. (1889) 82. - Calif.

Bornmuelleri, Freyn, in Oest. Bot. Zeitschr. xli. (1891) 363. - As. Min.

bosniaca, G. Beck, in Annal. Naturhist. Hofmus. Wien, vi. (1891) $333=$ S. Cucubalus, Wibel.

\section{SILENE}

Bonrgaei, Webb, ex Christ, in Bot. Fahrb. ix (1888) 100 - Ins. Canar.

brachypoda, Rouy, Illustr. pl. Eur. varior. iv. (1895) 26. t. 80, - Gall.

Brotherana, Somm. \& Levier, in Act. Hort. Petrok, xiii. (1893) 36. - Reg. Cauc.

brevistipes, $F, N$. Wrlliams, in fourn. Bot, xxxii (1894) 163. - Teneriffa.

hurmanica, Collett \& Hemsl. in Fourn. Lim. Soc. xxviii. (1891) 23. - Burma.

caespitosa, Bureau \& Franch. in Morot, fourn. d? Bot. v. (1891) 22. - China occ.

capsiriensis, Timb.-Lagr. in Jeanb. \& Timb.-Lagr. Le Capsir 1887 [Bull. Soc. sci. phys. et nat. Toul.] $53=\mathrm{S}$. Cucubalus, Wibel.

cardiopetala, Franch, in Bull. Soc.Bot. Fr, xxxiii, (1886) p. 419 ; et Pl. Delav. (1889) 80, t. 21, Yunnan.

citrina, Boiss. Fl. Or. Suppl. (1888) 101.- - Afghan.

corinthiaca, Boiss. l. c. 96. - Graecia

Correvonianus, Alboff, in Bulb. Herb. Boiss, ini. (1895) 90. - Reg. Cauc.

cryptoneura, Stapf, in Denksihr. Akad. Wien, ii. (1886) 8. - As. Min.

cryptopetala, Hillebr: Fl. Haw, Isl. (1888) 29. Ins. Sandvic.

debilis, Stapf, in. Denkschr。Akad. Wien, ii. (1S86) 14. - As, occ.

Delavayi, Franch, in Bull. Soc. Bot. Fr. xxxiii (1886) 424 ; et Pl. Delav. (1889) 86. - Yunnan.

djimilensis, Boiss. Fl. Or. Suppl. (1888) 103, in syn = saxatilis, Sims.

Engleri, Pax. in Bot. Falwb. xvii. (I893) 586. Abyss.

eremicana, Stapf, in Denkschr. Akad.Wien, ii.(1886) 17. - As. ocd

erysimifolia, Stapf, l. c. - As. occ.

fabarioides, Hansskn, in Nym. Consp. Fl. Europ. Suppl. ii. I. (1889) 51 : et in Mitth. Thiur. Bot, Ver. N. Folge, v. (1893) 47. - Graecia.

filipes, Freyn \& Sint, in Bull. Herb. Boiss. iii. (1895) 98. - As. Min.

Galataea, Boiss. Fl. Or. Suppl. (1888) 102, - Ins. Cypr.

genistifolia, Haldacsy, in Oest. Bot. Zeitschr. xlii. (1892) 369. - Graecia.

glabrescens, Coss.-Ithistr. Fl. Atlant, i. (1890) 133 t. 85 . - Marocc.

crandiflora. Franch in Bull. Soc. Bot. Fr, xxxiii (1886) 42\%; et Pl. Delav, (1859) 90, t. 23. Yunnan.

Hallii. S. Wats. in Proc. Am. Acad, xxi. (18s6) 446 - Am. bor. occ.

Haussknechtii, Heldr. ex Nym. Consp. Fl. Eur. Suppl. ii. I. (1889) 55; Hausskn, in Mitth. Thirr. Bot. Ver. N. Folge, v. (1895) 51. - Graecia.

Hermini, Welw ex Rouy, 1ll. Pl. Eur. rar. iv. (1895) 17 = foetida, Lam.

hifacensis. Rony, Excurs. bot. Espagne 1883 (1884 10, ex IVillk. Illustr. Fl. Hîsp. i. (1885?) 150 ; et Sutpl. Prodr. Fl. Hisp. (1893) 282. - Hisp.

hirticalyx, Boiss, G Hausskn. ex Boiss. Fl. Or. Suppl. (1888) 104. - Persia.

Holzmanni. Heldr. ex Boiss. l. c. 89. - Graecia.

infidelium, Post, ex Bulll. Herb. Boiss, iii. (1895) 154 . - Syria.

intricata, Post. l. c. - Syria

Kerneri, Stapf, in Denkschr. Akad. Wien, ii. (1886) 17. - As. occ

kubanensis, Somm. o Levier, in Act. Hort. Petrop. xiii. (1895) 37. - Reg. Cauc.

Lacaitae. Willk.. Illustr. Fl. Hisp. (1886-9?) 150. t. 89 , in syn.$=$ hifacensis, Rouy.

longistylis, Engelm. ex S. Wats. in Proc. Am. Acad. xxii. (1887) 469. - Calif.

lankongensis, Franch, in Bull. Soc. Bot. Fr. xxxiii (1886) 421 ; et Pl. Delar. (1889) 83. - Yunnan.

lonsitubulosa, Engl. PAanzenw. Ost-Afr. C.(1895) 76. - Afr. trop. or

luisana, S. Wats, in Proc. Am. Acad. xxiii. (1888) 261. - Mexic.

lutea, Franch, in Bull. Soc. Bot. Fr. xxxiii. (1886) 420. - China occ.

macedonica, Formanek, in Verh. Bot. Ges, Brunn xxxii. 1893 (1894) 183. - Maced. 
SILENE

Macounii, S. Wats. in Proc. Ant. Acted xxvi. (1891) 124. - Columb. brit.

macrocarpa, Formanek, in Dultsche Bot. Monatssche. ix. (1891) 68. - Maced.

macronychia, Boiss, Fl. Or. Suppl. (1888) 100.Afghan.

macropoda, Velen. in Sitzb. Boehm. Ges. Wiss, (1886) extr. 8; Nym. Consp. Fl. Eur. Suppl. ii. i. $(1889) 53=$ multicaulis, Guss.

JTanissadjiani. Freyn, in Bull. Herb. Boiss, iii. (1895) 83. - As. Min.

maroccana, Coss, Ill. Fl, Atlant. i. (1890) 130, t. 83. - Marocc.

megalocalyx, Froyn, in Bull. Herb. Boiss. iii. (1895) 82. - Armen.

mekinensis, Coss. Ill. Fl. Atlant, i. (1890) 144, t. 93. - Marocc.

melanantha, Franch, in Bull, Soc. Bot. Fr. xxxiii, (1886) 423 ; ct Pl. Delav. (1889) 86. - Yunnan.

mogadorensis, Coss. Eo Balansa fin Balansa. Pl. Marocc. exsicc. (1867)] in Coss, Ill. Fl. Atlant. i. 1890) 126, t. 80, 81; Batl. \& Trab. Fl. de l'Alger. [Dicot,] (1888) 133 ( $=$ S. candriensis, Otth.). - Marocc.

mongolica, Maxim, Enmm. Pt. Mongol. (1889) 88. Mandschuria.

monantha, Boiss. \& Hausskn. ex Boiss, Fl. Or Suppl. (1888) 99. - Mesopot.

multinervia, S, Wats. in Proc. Am. Acal, xxy. 1898) 126. - Calit

Munbyana, Coss. IIl. Fl. Atlant. i. (1890) 148, in syn. $=$ velutinoides, Pomel.

napuligera, Franch. Pl. Delav. (1889) 8?. - Yunnan.

nurensis, Boiss. E Hausshu. ex Boiss. Fl. Or. Suppl. 11888) 99. - Persia.

oropediorum, Coss. IIl. Fl. Atlant. i. (1890) 189, t. 84. - Algeria.

otodonta, Franch. in Bull. Soc. Bot, Fr. xxxiii. (1886) 427; et Pl. Delaz'. (1889) 89. - Yunnan.

pachyphylla, Haulsskn, ex Nym。Cousp. Fl。 Eur, Suppl.ii. 1. (1889) 55. - Graecia.

pachyrhiza, Franch. in Bull. Soc. Bot. Fr. zxxiii. (1886) 427; et Pl. Delav. (1889) 89. - China occ.

Parrowiana, Boiss. G Haussh. ex Boiss, Fl, Or. Suppl. (1888) 97. - Persia.

parvula, Coss. Iil. Fl. Athent. i. (1890) 137, t. 88, Marocc.

phoenicodonta. Franch. in Bull. Soc. Bot. Fr. xxxiii. (1886) 492; ct Pl. Delav' (1889) 84, China occ.

Pichleri, Stapf, in Denkschr. Akad. Wien, ii. (1886) 15. - As occ.

pindicola, Hanssin. in Mitth. Bot. Ver. Fena, v. (1887) 85: Nym. Consp. Fl. Eur. Suppl. ii. I. (18s9) 53. - Graecia.

platypetala, Burean \& Franch, in Mlorot, fourn. de Bot. v. (189!) 22. - China occ

platyphylla, Franch. iz Eult. Soc. Bot. Fr. xxxiii。 (1886) 419 ; et Pl. Delay. (1889) 81. - Yunnan.

Porteri, Post, ex Boiss. Fl. Or. Suppl. (1885) 104; et in fourn. Limu. Soc. xxiv. (1888) 422. - As. occ.

Potanini, Maxim, in Act, Mort. Petrop, xi, (1889) 66. - China.

Pringlei, S. Wats, in Proc. Anl. Acad, xxiii. (1888) 269. - Mexic.

pteroplenta, Coss. ex Batt. \& Trab. Fl. de l'Algér. [Dicot.] (1888) $134=$ colorata, Poir.

pterosperma, Maxinn, in Act. Hort. Petrop, xi (1889) 67. - China

purpurata, Grecke, Pittonia, ii. (May 1892) 229. Alaska.

rhadinocalyx, Stapf, in Denkschr. Akad. Wien, is. 1886) 8. - As. occ

Rigoi, Boiss. Fl. Or. Suppl. (1888) 94, in syn. = apetala, Willd.

Rouyana, Batt, in Butll. Soc. Bot. Fr Xxxv, (1888) t. 385; Coss. Ill. Fl. Atlant. i. (1890) 14\%, t. 95 - Algeria.

rubicunda. Franch, in Bull. Soc. Bot. Fr. xxxiii. (1886) 417; et Pl. Delav. (1889) 79. - Yunnan.

scaposa, S. Wats, in Proc. Am. Acad. xxviii. (1893) 145. - Oregon.

\section{SILENE}

schizopetala, Bormm. in Mitth. Thür. Bot. Vor. N,

Folge, vii. (1895) 6, nomen. - As. occ.

Schlumbergeri, Boiss. Fl. Oi. Suppl. (1888) 106. Syria.

Schmuckeri, Wettst. in Luterss. Biblioth. bot. Heft xxvi. (1892) 30, t. 2, fig. 6, - Alban.

Schwarzenbergeri, Haldicsy, in Denkschr. Akad. Wien, 1xi. (1894) 47. - Graecia.

scopulorum, Franch: in Bull. Soc. Bot. Fr, xxxiii

(1886) 423 ; et Pl. Delarv, (1889) 85, - Yunnan.

Shockleyi, S. Wats. in Proc. An. Acad. xxy. (1890) 127. - Calif.

simulans, Gieene, Piltonia, i. (July 1887) 63 Calif

Skorpili, Velcn. in Sitzb. Bnelhn. Ges. Wiss, 1890 (1890) i. 39. - Bulg.

subciliata, Robinson, in Proc. Am. Acad, xxix. (1894) 327. - Texas, Louisiana.

subuniflora, Somm. \& Levier, in Act. IIort. Petrop. xiii. (1893; 39. - Reg. Cauc.

Suksdorfii, Robinson, in Conlt. Bot. Guz. xvi. (1S91) 44. t. 6. fig. 9-11. - Am. bor.

Tanakae, Maxim. in Bull. Acad. Pútersb. xxxii (1888) 81. - Japon.

tenuicaulis, Freyn, in Oest. Bot. Zeitschr. xl. (1890) 400. - As. Min.

trachyphylla, Franch. in Bull. Soc, Bot. Fr. xxxiii. (1886) 417 ; et Pl. Delav' (1889) 79. - Yunnan.

vagans, $C, B$. Clavke, in fourn. Limn, Soc, xxv. (1888) 6. - Kohima

virescens, Coss. Ill. Fl Allant. i. (1890) 143, t. 92. - Marocc.

virgata, Stapf, in Denkschr. Akad. Wien, ii. (1886) 15. - As. occ

viscidula, Franch, in Bull. Soc, Bot. Fr xxxiii (1886) 421; ct P\%. Delav. (1889) 83. - China oco.

vittata, Stapf, in Denkschr. Akad. Wien, ii. (1886) 7. - As. occ.

yunnanensis, Franch. in Bull. Soc. Bot. Fr. xxxiii. (1886) 425; et Pl. Delas. (1889) 88. - China occ.

Watsoni, Robinson \& Saton, in Proc. Am. Acad. xxviii, (1893) 143. - Calif.

xylobasis, Frein, in Bull. Herb. Boiss, iii. (1895) 100. - As. Min.

Yanoei, Makino, Illustr. Fl. Fapon。 i. n, ix. (1891) 1, t, 52. - Japon.

yemensis, Defers. Voy. an Irémen. (1889) 11 ?. Arabia.

SILER, Crantz. (Umbell.), - Ind. Kew, ii. 9I2. cordifolium, Boiss. Fl. Or. Suppl. (1888) 263. - is.
yin.

SILIQUAMOMUM, Baill. in Bull. Sixc, Linn. Paris, ii. (1895) 1193. ZINGIBERACEAE. tonkinense, Baill. l. c. - Tonkin.

SILIQUASTRUM, Tourn. = Cercis, Linn. (Legumin.).

covidentale, Greene, Man. Bot. San. Franc, Bay (1894) $84=$ C. occidentalis, Toir.

SILPHIUM, Linn. (Compos.) - Ind. Kew, ii. 912

brachiatum, Galtinger, Teness, Fl. (1887) 54.-Am. bor.

SILVAEA, Phil. (Portub.). - Ind. Kew. ii. 912. fastigiata, Phil. in Anal. Muss. nac, Chile (1891) 26. - Chili.

capitata, Phil. in Anal. Univ. Chit.1xxxv, (1894) 311. - Chili.

SILVIA, Allem = Endiandra, R. Br. (Laurin.) anacardioides, Mez, in Jahrb. Bot. Gart, Berlin, (1889) $108=$ Misanteca anacardioides, Benth. vassitamea, Mez, 1. c, $104=$ M. crassiramea, Benth.

Ita-Uba, Mez, 1. c. $107=$ Endiandra Ita-Uba, Mez. Ita-uba, Pax, in Engl. \& Prantl, Natïrl. Pflanzenfam. iii. 2 (1889) $123=$ praec.

oppositifolia, Mez, in Jahrb. Bot. Gart. Berlin, v, (1889) $110=$ Aydendron oppositifolium. Nees. Sprucei, Mez, 1. c. $109=$ Acrodiclidium Sprucei, Mcissn.
SILVIANTHUS, Hook. f. (Rubiac.). - Ind Kew, ii. 912 .

radiciflorus, C. B. Clarke, in foum. Lim . Soc. xxy. 1859) 32. - Kohima

SIMABA, Aubl. (Simarub.). - Ind. Kew, ii, 912. macrophylla, "Oliver " ex Kuntze, Rev。 Gen (1891) 103, sphalm.? = Simaruba monophylla

SIMARUBA, Aubl, (Simarub.), - Ind, Kew, ii. 913

Berteroana, Krog Eo Urban, ex Urban, in Bot. Fahrb. xv. (1892) 306. - Ins. S. Doming.

Tulae, Urban, in fahrb. Bot. Gavt. Berlin, iv. (1886) 245 ; et in Gartenfl. xxxvi. (1887) 157, to 1298. Ins. Portoric

SIMBULETA, Forsk = Anarrhinum. Desf. (Scrophul.).

abyssinica, bellidifolia, brevifolia, elata. fruticosa, in flora, orientalis. Pechuelii, pedata, prbescerss. Kuntze, Rev. Gen. (1891) $465=$ komonyma omnia Anarrhini.

bellidifolia, Wettst, in Engl. \& Pranth. Natrül. Pflanzenfam. iv, 3b (1891) $60-$ Anarrhinum beklidifolium, Desf.

hirsuta. Kuntze, Rev. Gen. (1891) $465=$ A. Duriminium, Pors

laxiflora, Wettst, in Engl. \& Prantl, Natürl. Pflanzenfam, iv, 3b (1891) $60=\mathrm{A}$. laxiflorum. Boiss. orientale, Wettst. 1. $\mathrm{c}_{0}=$ A. orientale. Benth.

pubescens, Wettst. 1. $c_{2}=$ A. pubescens, Frics.

ieronicodes, Kuntze, Rev, Gen. (1891) $465=$ Linaria veronicoides, A. Rich.

SIMETHI S, Kunth (Liliac.). - Ind. Kew, ii. 91\%. planifolia, Lloyd \& Fonc. Fl, Ouest Fr. éd. 4. (1886) $354(=S$. planifolia, Gren. \& Godr. $)=$

SIMOCHEILUS, Klotzsch (Ericac.) - Ink Kew, ii. 913 .

viscosus, Bolls, in four . Bot. xxxii. (1894) 240, Afr. austr.

SIMONSIA, Kuntze, Rev. Gen. (1891) 980, sphalm. $=$ SIMONISIA, Nees $=$ Beloperone, Nees (Acanth.).

SINAPIDENDRON, Lowe $=$ Brassica, Tourn (Crusif)

Bourgaei, Webb, ex Christ, in Bot. Jahrb. ix. \{1898 89. - Teneriffa.

SINAPIS, Tourn = Brassica, Tourn. (Crusif.) aremensis, Rouy \& Fouc. Fl, de Fr. ii. (1895) 59 $=\mathrm{B}$. Cheiranthus. Vill

Candollei, Runy \& Fouc, 1, c. = B. Cheiranthus, Vill,

corbariensis, Timb. in Lucante, Rev de Bot. $\mathrm{x}$. 1892) $42=$ B. Cheiranthus, Vibt.

pendula, Rouy \& Fouc. Fl. de Fr. ii. (1895) $59=$ B. Cheiranthus, Vill.

pubescens, Nym. Consp. Fl. Eur. Suppl. ii. I. (1889) $28(=$ Evucastrmm pubescens, Willk.). - Hisp. Italia.

pectangularis, Rouy \& Fouc. Fi, de Fr, ii, (1895) 59 $=$ B. Cheiranthus, Vill.

SINCLAIRIA, Hook.\& Arn. = Liabum, Adans, Compos.)

Liebmamm, Klatt, ex Sch. Bip, in Leopoldina, Heft xxiii. (1887) 146, in syn。= Liabum Liebmannii, Klatt.

SINDEGHITES, Oliver, in Hook. Icon pl. xwii. (1388) t. 1772. APOCYNEAE

Henryi, Oliver, l. o. - China.

SINNINGIA. Nees (Gesner.). - Ind. Kew. ji.914 barbata, Nichols. Dict. Gard iii. $(1886) 436=\mathrm{S}$, Carolinae, Benth, \& Hook. f.

concinna, Nichols. l.c. - Bras.

conspicua, Nichols, l. c. - Bras,

hirsita, Nichols. l. 6. - Bras.

Ienziesiana, vichols. l. c. - Hab. 


\section{SINNINGIA :}

pusilla, Baill in Bull, Soc I inn Paris, i. (1888) 772 (= Tapina pusilla, Mart.). - Bras.

spcciosa, Baill. Hist. des pl.x. (1888) $62(=$ Ligeria peciosa, Decne $=$ speciosa, Hicrn.

SIOLMATRA, Baill. (Cucurb.). - Ind. Kew. il. 915.

paraguayensis, Cogn. in Coult. Bot. Gaz, i. (1893) 611. - Parag.

SIPANEA. Aubl. (Rubiac.), - Ind. Kew. ii. 915. unticola. Spruce, ex K. Schum in Mart. Fl, Bras. vi. VI. (1S89) 222, in syn. = Rondeletia rupicola, K. Schum.

veris, S. L. Moove, in Trans. I.im, Soc. Ser. II. iv. (1895) 368. - Bras.

SIPARUNA, Aubl. (Monim.). - Ind. Kew. ii.

Eggersii. Hicron. in Bot. Fahrb. xx. Beibl. n. 49 (1895) 17. - Ecuad.

foetida, Barb. Rodr. [Herb. Mus. Bot. Amaz, n. 686]; Vellosia, 1885-88, Sec. ediç. (1891) 68, t. 21. Bras.

nigra, Rusby, in Men. Torrey Bot. Club, iv. (1895) 252. - Bolivia.

SIPHANTHEMUM, Van Tiegh, in Bull. Soc, Bot. Fr. slii. (1895) $361=$ Psittacanthus, Mart. (Loranth.).

brachynema, Van Tiegh. 1. c. = P. brarhynema, Eichl.

SIPHOBOEA, Baill, in Bull. Soc, Linn. Paris, i. (1888) 722, 733 ; et Hist. des pl. x, (1888) 106 ; Fritsch, in Engl. \& Prantl Natürl. Pflanzen. fam. iv. 3b (18.4) 159. GESNERIACEAE

Commersonii, Baill. $l l$. cc. - Ins, Philipp.

SIPHOGAMPYLUS. Pohl (Campanul.). - Ind. Kew. ii, 915.

andensis, Britton, in Bull. Torrey Bot. Chub, xix. (1892) 373. - Bolivia.

bolivianus, “Zahlbr. » ex Britton, 1. c. = boliviensis, Zuhlbr

boliviensis, Zahlbr. in Annal. Naturh. Hofmus. Wien, vi. (1891) 443 [Syphocampylus]. - Bolivia.

cutervensis, Zahlbr.l.c. 442. - Bolivia.

gloriosus, Britton, in Bull. Torry Bot. Club, xix. (1892) 373. - Bolivia.

sracilis, Britton, l. c. 374. - Bolivia.

ircanus, Britton, l. c. 373. - Bolivia.

Jelskii, Zahlbr. in Annal. Naturh. Hofmus. Wien, vi. (1S91) 440 [Syphocampylus]. - Bolivia.

membranaceus, Brition, in Bull. Torrey Bot. Club, xix $\{1892\} 372 .-$ Bolivia.

radicans, Kuntze, Rcr. Gon. (1891) 381. - Costa Rica.

Rusbyanus, Britton, in Bull. Torrey Bot. Chub, xix. (1892) 372. - Bolivia.

Spruceanus, Zuhlbr. in Annal. Naturh. Hofmus, Wren. vi. (1891) 443 [Syphocampylus]. - Peruvia.

tupaeformis, Zahlbr, l. c. 440); Britton. in Bull. Torrey Bot. Club. xix. (1892) 372. - Bolivia.

urduavensis, Brilton, l. c. 373. - Bolivia.

SIPHOGOLEA. Baill. in Bull. Soc. Linn. Paris, i. (1887) 707-08; et Hist, des p1.x. (1888) 58 ; Bureau \& K. Schum. in Encl. \& Prantl, Naturl. Pflanzenfam. iv. 3b (1895) 249. BIGNONIACEAE.

Boivini, Baill. ll. cc. - Madag.

Hildebrandtii, Baill. ll. cc. - Madacr

rhoifolia, Baill. Il cc. - Madag.

SIPHONERANTHEMUM, Kuntze, Rev. Gen. (1891) $494=$ Eranthemum, Linn. (Acanth.) alatum, atrofurpurtum, bicolor, Conperi, cordatum, cre mulatum, cuspidatum, decurrens, detruncatum, Eldorado, cxacquatum, fasciculatum, focundum, heterophyllum, hispidulum, hypocrateriforme, lanceum, lapathifolium, leptanthum, leptostachyum, macrophyllum, modestum, Moorei, nigritianum, polyncum,

\section{SIPHONERANTHEMUM :-}

praccox, reticulatum, Riedelianum, rosenm, senense, sessile, tenellum, tricolor, tuberculatum, rariabile, verbenaceum, zersicolor, Kuntze, Rev. Gen. (1891) $495-97=$ homonyma omnia Eranthemi.

lilacimu, Kuntze, 1. c. $497=$ E. lilacinum S. Moove [in Herb. Kew. fide Kuntze]. - Parag. Lindenianm, Kuntze, 1. c, 495, $497=$ E. cuspidatum. Nees.

ncrosnm. Kuntze, 1. c. = Daedalacanthus nervosus, T. Anders.

SIPHONODON, Griff. (Celastr.). - Ind. Kew. ii. 917

macrophyllum, Pierre. F1. For. Cochinch. Fasc, 20 (1894) sub t. 312b, in syn. = Salacia hamputensis. Pierve.

pendulum, F. M. Baslley, in Dept. Agric. Brisbane Bot. Bull.iv. (1891) 8. - Austral.

SIPHONOGLOSSA, Oerst. (Acanth.). - Ind Kew. ii. 917

dipteracmina, Heller, in Contrib. Herb. Frankl. and Marsh. Coll. [Bot. Explor. S. Texas.] i. 1895) $95=$ S. Pilosella, Torr

glabrescens, Lindan, ex Loesen, in Bull. Hesb. Boiss, ii. (1894) 564. - Mexic

alcata, Lindau, in Bot, Jahrb. xix. Beibl. n, 48 (1894) $19=$ Jacobinia sulcata, Nees.

ubulosa, Baill. ex Lindau, in Engl. \& Prantl, Natür. Pfanzenfam, iv. 3b (1895) 338. - Afr.austr.

SIPOLISIA, Glaziou, ex Oliver, in Hook. Icon, pl. xxiii. (1894)t. 2281, O. Hoffm. in Engl. \& Prantl, Naturl. Pflanzenfam.iv. 5 (1893) 388. COMPOSITAE.

lanuginosa. Glaziou, ll. cc. - Bras,

SIPHON YGHIA, Torr. \& Gray (Illecebr.). Ind. Kew, ii. 917 .

americana, Baill. Hist. des pl. ix. (1888) $123=$ americana, Torr. \& Gray.

SIRHOOKERA, Kuntze. Rev, Gen, (1891) 68I = Josephia. Wight (Orchid.).

lanceolata. Kuntze, 1. c. = J. lanceolata, Wight.

latifolia, Kuntze, 1. c. = J. latifolia, Wight.

SIRMUELLERA. Kuntze, Rev. Gen. (1891) $581=$ Banksia, Linn. f. (Proteac.).

attemata, Baueri, Baxteri, Caleyi, Candolleana, coccinea, collina. dentata, elegans, Goodii, grandis, Hookeriana, ilicifolia, integrifolia, laevigata, Leman. niana, Lindleyana, media, Menziesii, microstachya, mutans, occidentalis, ornata, petiolaris, prostrata, Prionotes, pulchella, quercifolia, vepens, Sceptrum. serrata, servatifolia, Solandri, speriosa, sphaerocarpa, spinulosa. triscuspis. certicillata, Victoriae, Kuntze, Rev. Gen. (1891,582= homonyma omnia Banksiae.

Brownei, Kuntze, 1. c. = B. Brownii, Baxter.

dryandrodes, Kuntze, 1. C. = B. dryandroides, Baxicr.

ericifolia, Kuntze, 1. c. = B. ericaefolia, Limn. $f$.

litoralis, Kuntze, 1. c. = B. dittoralis, $R, B r$.

Meisncri, Kuntze, 1. C. = B. Meissneri, Lelm.

praemorsa, Kuntze, $1, C_{0}=$ B. marcescens. $R$. Br.

Robur, Kuntze, 1. c. = B. latıfolia, $R \cdot B r$.

serratifolia, Kuntze, 1. $\mathrm{C},=\mathrm{B}$. aemula, $R . \mathrm{Br}$

SISYMBRIUM, [Tourn.] Linn. (Crucif.), - Ind. Kew.ji. 917.

balearicum, Porta, in Nuor. Gionn. Bot. Ital. xix. (1887) 298. - Ins. Balear.

brachycarpum, Plit. in Anal. Mus, nac. Chile (1891) 4. - Chili.

Brandegeanum. Vasey \& $7 . N$. Rose, in Contrib. U. S. Nat. Herb. i (1890) 10. [Brandegeana]. Calif.

caespitosum, Phil, in Anal, Univ. Chil. 1xxxi. (1893) 181. - Chili.

ciliolatum, Phil. l, c, 186, - Chili.

Costei, Four. of Rouy. Fl. do Fr. ii. (1895) $325,326$. - Gall.

crenatum, T. S. Brandeg. in Proc. Calif. Acad. Ser. II. iii. (1891) 111. - Calif.

\section{SISYMBRIUM}

depressum, Phil. in Anul. Mus, nac. Chite (1891) 4

- Chili.

dianthoides, Phil.l.c. 2. - Chili.

elegantissimum, Phit, in Anal. Univ. Chit. Ixxxi

(1893) 189. - Chili.

erodifolium, Phil. l. c. 190. - Chili

exalatum, Robinson of Greenm, in An. Fourn. Sci. Ser. III. 1. (1895) 166. - Mexic.

floridum, Phil, in Anal, Mus. nac. Chile (1891) 3. Chili.

glandulosum, Maxim, Fl. Tangut, 1889) 61 (= Arabis glandulosa, Kar. \& Kir.). - As. centr.

glaucescens, Phil. in Anal. Univ. Chil. Ixxxi. (1893) 190. - Chili

grandiflorum, Post, Pl. Postianae, i. (1890) 3. Syria.

hastifolium, Stapf, in Denkschr. Akad. Wien ii (1836) 31 . - As. occ.

Hochstetterianum, Buchinger, ex Engl, in Abh. Preuss. Akad. Wiss. 1891 (1892) 233. in syn.= S. Irio, Limn

laciniosum, Phil.in Anal. Univ. Chil. 1xxxi. (1893) 187. - Chili.

Lapeyrousianum, Rouy et Fouc. Fl, de Fr. ii. (1895) 23 = pinnatifidum, $D C$

Larranagae, Phil. in Anal. Univ. Chit. 1xxx. (1893) 185. - Chili.

linifolium, Phil. in Anal. Mus.nac. Chile (1891) 2.Am. austr. occ.

longesiliquosum, Willk. Suppl. Prodr. Fl. Hisp. (1893) 332. - Hisp.

longisiliquosum, St Lager, in Cariot, Etud. des fl. éd. 8. ii. (1889) $51=$ S. Columnae, facq. macroloma, Pomel, ex Batt, \& Trab. Fl. de l'Algér. [Dicot.] (1888) $66=\mathrm{S}$. Columnae, facq.

minutiflorum, Fhil. in Anal. Mus: nac. Chite (1891) 3. - Chili.

mollipilum, Maxim. Fl. Tangut. (1889) 62. - China mongolicum, Maxm. l, c. 61 (= Malcolmia mongolica, Maxim.). - As. centr.

monanthos, Boiss. Fl. Or. Suppl. (1888) 42. - Reg Afghan.

multifidum, MacMill. Metasp. Minn. (1892) $258=$ canescens, Nutt.

multiracemosum, S. Wats, in Prac. Am. Acad. xxvi. (1891) 132. - Mexic.

niveum, Phit. in Anal. Univ. Chil. 1xxxi. (1893) 186 - Chili.

pandurifolium, Kuntze, Rev. Gen. (1891) 33, in syn. $(=$ Hesperis paudurifolia, Kuntze). - Venezuela. pazense, Rusby, in Mem Torrey Bot. Club, iii. 3 (1893) 5 lpazensis]. - Bolivia

pimatum, Greene, in Bull. Calif Acad, ii. YII (1S87) $390=$ canescens, $N$ ult.

polyphyllum, Phil. in Anal. Mus. nac. Chile (1891) 2. Chili.

Renteri, Rouy \& Fouc, Fl, de Fr. ii. (1895) $16=$ austriacum, $D C$.

rubescens, Phil. in Anal. Mus. nac. Chile (1891) 3 - Chili.

Rusbyi, Britton, in Bull. Torrey Bot, Club, xvi. (18S9) 16. - Bolivia.

striatum, Boiss. Fl. Or. Suppl. (1888) 42. - Mesopot

Simpsoni, Phil. in Anal. Univ. Chil. 1xxxi. (1893 184. - Chili.

tarapacanum, Phil. in Anal. Mus, nac. Chile (1891) 3. - Chili.

tenuisiliqua, Pomel, ex Batt. \& Trab. de l'Algér [Dicut.] (1888) $67=$ crassifolium, Cav.

te racmoides, Boiss. fo Hausskn. ex Boiss. Fl. Or Suppl. (1883) 43. - Mesopot.

umbelliferum, Phil. in Anal. Univ. Chil. 1xxxi. (1893) 188. - Chili.

SISYRANTHUS, E. Mey.(Asclep.). - Ind. Kew. ii. 920

anceps, Schlechter, in Bot. Fahrb. xx. Beibl. n. 51 (1895) 45. - Afr. austr

rotatus, Schleckter, l. c. 46.-Afr. austr.

schizoglossoides, Schlechter, in fourn. Bot. xxxii. (1894) 357. - Afr. austr.

trichostomus, K. Schum, in Enol. E Prantl, Natürb. Pfanzenfam, iv. 2 (1895) 265 (= S. virgatus, E. Mey, var, trichostomus, Harv. - Afr. Austr. 
:SISYRINGHIUM, Linn. (Irid.). — Ind, Kew, ii. $9: 1$

angustifolium. Phil. in Anal. Univ. Chit. xci. (1855) 625 - Chili.

Balansae, Baker, Handb. Irid. (1892) 133. - Parag.

Balansae, Baker, Hand. Irid. (1892) 133. - (1895) 621. - Chili.

bracteosum, Phil. l. c.631. - Chili.

brevipes, Baker, Handb. Irid. (1892) 130. Peruvia.

Burchellii, Baker, l. c. 123. - Bras.

Coulterianum, Klatt, ex Baker, l. c: 128. - Mexic. demissum, Greene, Pittonia, ii. (May 1890) 69. Arizona.

Elmeri, Greene, 7. c. 106. - Calif.

eleutherostemon, Phil. in Anal. Univ. Chil, xci. (1895) 622. - Chili.

exalatum, Robinson \& Greenm. in Am. Foum, Soi, Ser. III. 1 (1895) 166. - Mexic.

humile, Phil. l. c. 619. - Chili.

illapelinum, Phil.l.c.625. - Chili.

longifolium, Phil. l. c. - Chili.

microspathum, Phil. l. c. 628. - Chili.

Midletoni, Baker, Handb. Irid. (1892) 122. - Patag.

modestum, Steud. Ann. Ist. Bot. Roma, vi. (1895)

62 , in syn. = Ixia Hochstetteriana, Rich.

multiflorum, Phil. in Anal. Univ. Chil. xci. (1895) 628. - Chili.

nanum, Phil. l.c. 621. - Chili.

nudicaule, Phil.l. c.617. - Chili.

oligostachium, Phil. I. c.630. - Chili

palense, Phil. 7.o 618. - Chili

pauciflorum, Phil. l. c.621. - Chili.

pauperculum, Pliz. l. c. 629.-Chili

piligerum. Phil, in Anal. Univ, Chil. xci. (1895) 623. - Chili.

platycaule, Baker, Handb. Irid. (1892) 132. - Parag.

platyphyllum, S. Wats, in Proc. Am. Acad. xxvi.

(1891) 155. - Mexic

polycladum, Robinson \& Greenm, in Am. Fourn. Sci. Ser. IIl. 1. (1895) 166. - Mexic.

Rahmeri, Phil, in Anal. Univ. Chil, xci. (1891) 620, - Chili.

rigidifolium, Baker. Handb. Irid. (1892) 131. -

Bolivia.

sarmentosum, Suksdorf, ex Greene, in Erythea. iii. (1895) 121. - Washington.

stenopetalum, Phil, in Anal. Univ. Chil. xci. (1895) 624. - Chili

stenophyllum. Phil. l. c. - Chili.

Thurowi. Coult. \& Fisher, in Conlt. Bot. Gaz. xvii. (1892) 352; et in Contrib. U. S. Nat. Herb. ii. (1894) 428. - Texas.

valdivianum, Phil, in Anal. Univ. Chil. xci. (1895) 616. - Chili.

Volckmanni, Phil.l. c.619. - Chili.

SITILIAS, Rafin。 = Pyrrhopappus, DC. $($ Com-

pos.).
grandifora, Greene, Pittonia, ii. (Sept. 1891) 180 $=$ P. grandiflorus, Nutt.

multicaulis, Greene, 1. c, $179=$ P. multicaulis, $D C$. panciflora, Greene, 1. c, $180=\mathrm{P}$. pauciflorus, $D C$. Rothrockii, Greene, 1. c. $=$ P. Rothrockii, A. Gray. Sesseana, Greene, 1, c. $=$ P. Sesseanus, $D C$.

:SIUM [Tourn.] Linn. (Umbellif.). - Ind. Kew, ii.

heterophyllum, Greene, Pittonia, ii. (June 1890) 102 ; et Man. Bot. San Franc. Bay (1894) 151.Calif.

ovatum, Yatabe, in Tokyo Bot. Mag. iv. (March 1891) 73 , t. 22 ; et Icon. Fl. Fapon. ii. (1892) 97, t. 27. - Japon.

SKIMMIA, Thunb. (Rutac.). - Ind. Kew. ii. 923. Foremanni $X$ Foremann, ex Gard. Chron, iv (1888) 709, 735. - Hybr. artef.

Eortunei, Mast. in Gard. Chron. (1889) i. 520, 525 , fig. 91, 553; Dippel, Handb. Laubholzk. ii. (1892) 356 (= S. japonica, Hook.). - China.

SLOANEA, Linn, (Tiliac.), - Ind, Kew, ii. 924. chrysocarpa, Poepp. ex K. Schum. in Mart. Fl. Bras. xii. III. (1886) 194, in obs, = Oncoba maynensis, Poepp. \& Endl.
SLOANEA :-

Eichleri. K. Schnm, in Mart. Fl. Bras. xii. III. (1886) 183. - Bras

Forbesii F, Muell in Vict Natural viii, (Febr. 1892) 164, nomen, et ix. (Nov. 1892) 111 ; in fourn. Bot. xxxi. (1893) 323; et in Bot. Centralbl. liii. (1893) 27. - N. Guin.

Garckeana, K. Schum. in Mart. Fl. Bras, xii. III 1886) 177. - Bras

lasiocoma, $K$. Schmm l. c. 184, - Bras

latifolia, $\mathrm{K}$. Schum, 1. c. 173 = corymbiflora, $D C$

Maximowicziana, $K$. Schum. l. c. 192. - Bras.

obtusa, K. Schum, l. c. 181 ( $=$ Dasynema obtusum Splitg.). - Guian. bat.

obtusifolia, $K$. Schum. l. c. $188^{\circ}$ (= Adenoöasiun obtusifolium, Moric.). - Bras.

pentagona, 7. D. Smith, in Coult, Bot. Gaz, xviii. (1893) 1. - Guatem.

Regelii, K. Schum. in Mart. Fl. Bras.xii. III. (1886) 189. 190. - N. Granat.

Schumannii, Warb. in Bot. fahrb. xiii. (1891) 372 - N. Guin.

Sigun, K. Schum, in Engl. \& Prantl, Natiirl. Pfanzenfam. iii. 6 (1890) 5. - Java.

SLoETIA, Teijsm. \& Binn. (Urtic.). - Ind. Kew ii. 924 .

penangiana, Oliver, in Hook. Icon, pl. xvi. (1886) t. 1531; et ex Hook. f. Fl. Brit. Ind. v. (1888) 493. - Penins Mal.

Wallichii, King, ex Hook. f. l. c. ; et in Kew Bull. (1890) 129. -- Penins. Mal. [Java ?]

SMELOWSKIA, C. A. Mey. (Crucif.). - Ind Kew. ii. 924 .

ovalis, M.E. fones, in Proc. Calif. Acad. Ser. II. v. (1895) 624. - Washington.

SMILAGINA. Desf. (Liliac.). - Ind. Kew. ii. 925 oligophylla, Hook. f. Fl. Brit. Ind. vi. (1892) 323 (= Tovaria oligophylla. Baker). - Reg. Himal. tubifera, Batalin, in Act. Hort. Petrop. xiii. (1893) 104. - China.

SMILAX, [Tourn.] Linn, (Liliac.), - Ind, Kew ij. 925 .

aroyraea, L. Linden of Rodigas, in Illustr. Hortic xxxix. (1892) 51; t. 552, et xl. (1893) 39, t. 583 fig. 5 ; et xli. (1894) 12, fig. 1 [argyrea]. Peruv.

anamitica, Kuntze, Rev, Gen. (1891) 715. - Anam. cynodon, Cordem. Fl. Ile Réunion (1895) 150. Ins. Borbon.

ecirrhata, S. Wats, in A. Gray, Man. Bot. North U.S. ed. 6 (1890) $520=$ herbacea, Linn.

flaccida, Wright, in Kev Bull. (1895) 118. - China

Kingii, Hook. f. Fl. Brit. Ind. vi. (1892) 307.Penins. Mal.

longebracteolata, Hook. f. l. c. 305. - Khasia

medicinalis, S. L. Moore, in Trans. Limn. Soc Ser. II. iv. (1895) 496. - Bras. centr.

megacarpa, Morong, in Bull. Torrey Bot. Club, xxi. 1894) 434. - Florida.

megalantha, C. H. Wright, in Kev Bull. (1895) 118 - China.

microphylla, C. H. Wright. l. c. 117. - China

panamensis, Morong, in Bull. Torrey Bot. Club̆, xxi. (1894) 441. - Panama.

quadrangulata, "Muehlb. " ex Dippel, Handb, Laubholzk. i. (1889) 4, sphalm. (= S. quadrangularis, Muehlb.) = rotundifolia, $\operatorname{Linn}$

scobinicaulis, C. H. Wright, in Kew Bull. (1895) $11 \%$. - China.

Smallii, Morong, in Bull. Torrey Bot. Chub, xxi. (1891) 430. - Georgia.

utilis, Wright, in Kew Bull. (1895) 138. - Ins. Salom.

SMITHIA, Ait. (Legumin.). - Ind. Kew. ii. $92 \%$. africana, Taub, in Engl. Pflanzenw. Ost-Afr. C (1895) $215=$ S. Kotschyi, Benth

Carsoni, Baker, in Kev Bull. (1893) 156. - Afr. centr. austr.

recurvifolia, Taub. in Engl. Pfanzenw. Ost-Afr. C (1895) 215; at in Engl. \& Prantl, Natiirl. Pfanzcnfam. iii. 3 (1894) 321. - Afr. centr. or.

\section{SMITHIA :}

rubrofarinacea, Taub. in Engl, PAanzenw. Ost-Aft. C (1895) 216. - Afr, trop. or.

scaberrima, Taub. l. c. 215. - Afr. trop. or

uguenensis, Taub. ex Engl, in Abh. Preuss, Akad. Wiss. (1894) 57 et 60. - Afr. trop.

Volkensii, Taub, in Engl. Pfanzenw, Ost-Afr, C (1895) 215, - Afr. trop. or.

yunnanensis, Franch. Pl. Delar. (1889) 170. China occ.

Welwitschii, Taub. (ubi?) ex Engl. Pfanzenw. OstAfr. 216, in obs. - Afr. trop.

SMITHIANTHA, Kuntze, Rev. Gen. (1891) $97 \%=$ Naegelia, Regel (Gesner.)

Ninabarina, Geroltiana, punctata, secunda, zebrina, Kuntze, Rev. Gen. (1891) 978 = homonyma onnia Naegeliae.

amabilis, Kuntze, I.c. = N. multiflora, Hook.

SOBRALIA, Ruiz \& Pav. (Orchid.). - Ind. Kew 028

Lowii. Rolfe, in Gard. Chron. (1890) ii. 378, N. Granat.

Lucasiana, Hort. ex Journ. of Hort. (1893) 74, 75. fig. 2. - Form. hort

pumila, Rolfe, in Kew Bull. (1893) 337. - Bras.

Veitchii, Hort. ex Journ, of Hortic. (1894) 98, 99 fig. 5. - Form, hort.

xantholeuca, Hort. ex Williams, Orchid Grow. Man. ed. 6 (1885) 576; et Orchid Alb. vi. (1886) t. 250 in Bot. Mag. (1894) t. 7332. - Guatem.

Wilsoniana, Rolfe, in Gard. Chron. (1890) ii. 378. Am. cenir.

yauaperyensis, Barb. Rodr. Vellosia, 1885-88, Sec. ediç. (1891) 131. - Bras. bur.

SODIROA, Ed. André (Bromel.). - Ind. Kew. ii 929.

Andreana. Wittm, in Bot. Fahrb. xi, (1889) 57 Baker, Handb. Bromel. (1889) 142. - Columb.

dissitiflora, Ed. André, in Rev. Hortic. 1x. (188s 565 ; et (1889) 42, t. $13 \mathrm{c}$; Baker, l. c. 142. Columb.

Kalbreyeri, Baker, Handb. Bromel. (1889) 141. Columb.

Pearcei, Baker, in foum. Bot. (1887) 53 ; et l. c. Ecuad.

Sprucei, Ė. André, in Rev. Hortic。 1x. (1888) 565 et 1xi. (1889) 43, t. 13 d; Baker, l. c. 14]. Columb.

SOLANDERA. Kuntze, Rev. Gen. (1891) $452=$ Solandra, Sw. (Solan.)

brachycalyx, Kuntze, 1. c. - Costa Rica.

coriacea, Kuntze, 1. c. - Columb.

SOLANDRA. Sw.(Solan.). - Ind. Kew ii. 929 Selerae, Dammer, ex Loesen. in Bull. Herb. Boiss, iii. (1895) 61\%. - Mexic.

SOLANOA. Greene, Pittonia, ii. (May 1890) 67 ; et Man. Bot. San Franc. Bay (1894) $242=$ Schizonotus, A. Gray (Asclep.)

purpurascens, Greene, 11. cc。 $=$ S. purpurascens, A. Gray.

SOLANOANA, Kuntze, Rev. Gen. (1891) $421=$ Schizonotus, A. Gray (Asclep.).

purpurascens, Kuntze, 1. c. = S. purpurascens, $A$. Gray.

SOLANUM, [Tourn.]. Linn. (Solan.). - Ind. Kew, i1. 929.

aberrans, Phil. in Anal. Univ. Chil. xci. (1895) 15 - Chili.

abutilifolium, Rusby. in Mem, Torrey Bot. Club, (1895) 229. - Bolivia.

albifolium, C. H. Wright, in Kew Bull. (1S94) $12 \%$. - Angola

albotomentosum, C. H. Wright, l.c. 128.- Ansola. aldabrense, $C H$. Wright, l. c. 149.-Ins, Aldabra. amatitlanense, 7. M. Coult. in F. D. Snith, Enum? pl. Guatem. iv. (1895) 110. - Guatem.

amethystimum, Poit. ex Hook. f. in Bot. Mag. (1889) t. $7002=$ pensile, Sindm 


\section{SOLANUM}

antidotum, Danner, in Engl. Pfanzenw. Ost-Afr. C (1895) 355 . - Afr. trop. or.

antiguense, F.M. Conlt. in F. D. Smith, Entm.pl. Guatem.iv. (1895) 187. - Guatem.

aridum, Morong, in Ann. N.Y. Acad, sci. vii. (1893) 173. - Paras

arrazolense, F. M. Coult. in F. D. Smith, Enum. pl. Guatem. 1v. (1895) 110. - Guatem.

barbulatum, Zahlbr. in Annal. Naturh. Hofmus. IVien, vii. (1892) 6. - Peruvia.

Binderianum, Sch. Bip. ex Engl, in Abh, Preuss. Acad. Wiss. 1891 (1892) 372, nomen. - Afr. trop.

Bridgesii, A. DC. in Arch. sc. phys, et natoxv. (18s6) extr. 16. - Chili.

Brittonianum, Morong, in Ann. N.Y.Acad. sci. vii. (1893) 174. - Parag.

botryophorum, Ridl, in fourn. Linn. Soc. xxvii. (1890) 50. - Ins. Fernando Noronha.

bromoënse. Kuntze, Rev. Gen. (1891) 45:3. - Java

campanuliforum, C. H. Wright, in Kew Bull. (1894) 12\% - Angola.

Carvalhoi, Dammer, in Engl. Pfanzenw. Ost-Afr. C (1895) 35̃. - Afr. trop. or.

candiculatum, Phil, in Anal, Univ, Chil, xci. (1895) 12. - Chili,

chrysotrichum, C. H. Wright, in Kew Bull. (1894) 129. - Atr, trop, austro-or.

crumbense, S. L. Moore, in Trans. Linn. Soc. Ser,

II. iv. (1895) 404. - Bras.

crassipes, Phil, in Anal. Unzr. Chil. xci. (1895) 14. - Chili.

cupuliferum, Grente, in Erythea, iii. (1895) 72. Calif.

cutervoanum, Zahlbr. in Annal. Naturh. Hofmus, Wicn, vii. (1892) 7. - Peruvia.

Dallmannianum, Warb. in Bot, farhb. xiii. (1891) 415 . - N. Guin.

Dammanianum, Regel, in Act. Hort. Petrop. xi, (1890) 311; et in Gartcinf. x1. (1891) 20. cum xylogr. 10. - Ecuad.

Donnell-Smithii, F. M. Coult, in F. D. Smith, Enmon. hl. Guatem, ii. (1891) 51; et in Bot. Gaz, xvi. (1891) 144. - Guatem.

Dunali, Phit, in Anal. Unir. Chil. xci. (1895) 12. Chili.

duplosinuatum, Hort, ex Gartenf. xliii. (1894) 96. - Hab.

Englerianum, Dammer, in Engl. Pfanzenw. Ost-Afr. C (1895) 353. - Afr. trop. or.

Fischeri, Dammer, l. c. - Afr. trop. or

Geissei, Phit. in Anal. Univ. Chit. xci, (1895) 16. Chili.

gilioides, Rusby, in Menn. Torrey Bot. Club, iv, (1895) 228. - Bolivia.

glochidiatum, Dammer, in Engl. Pfanzenw. Ost-Afr. C. (1895) 354. - Afr. trop. or

rrandidentatum, Phil. in Anal. Mus. nac. Chite (1891) 64. - Chili.

Grayi, 7. N. Rose, in Contrib, U. S. Nat. Herb. i, $1891)$ 108. - Mexic

Griffithii. Kuntze, Rev. Gen, (1891) 453. - Malaya. Grisebachianum, Kuntze, l. c. - Ins. Trinit.

guatemalense, Hort. ex Gard, and For. v. (1892) 05 = muricatum, Ait.

Handelianum, Morong, in Ann. N. Y. Acad. sci. vii. 1893) 175. - Parag

impar, Warb, in Bot. Fahrb. xiii. (1891) 415. - N. Guin.

inconstans, C. H. Wright, in Kew Bull. (1894) 127 - Ins. Fernando Po.

inelegans, Rusby, in IIcm. Torrey Bot. Club, iv. (1895) 229. - Bolivia.

infundibuliforme. Phil. in Anal. Mus, nac. Chile (1891) 65. - Chili.

Jelskii, Zahlbr. in Annal, Naturh. Hofnus, Wien, vii. (1892) 7.-Peruvia.

kauaiense, Hillebr. Fl. Haw. Isl. (1888) 305. - Ins. Sandvic

Tilinandschari, Dammer, in Engl. Pfanzenve. OstAfr. C (1895) 352. - Afr. trop. or.

kitivuense, Dammcr, l. c. 3553. - Afr. trop. or.

Kunzei, Phil, in Anal. Univ. Chil. xci. (1895) 6. Chil?

Lambii, Fernald, in Coult. Bot. Gaz. xx. (1895) 536. - Mexic.

\section{SOLANUM}

Iucani, F, Aluell, in Vict, Natural, ix. (Mar, 1893 ) 175; et in Bot. Centralbl. liv. (1893) 93. - Austral. Macoorai, F. MI. Bailey, in Dept. Agric. Brisban Bot. Bull. viii. (1893) 80. - Austral.

Maingayi, Kuntze, Re?. Gen.(1891) 453. - Malaya.

Mandonii, A. DC. in Arch, sci. phys, et nat. xv. (1586) extr. 14. - Bolivia.

Mannii. C. H. Wright, in Kew Bull. (1894) 129. Afr. trop. occ.

mazatenangense, F.M. Coult. in F. D. Smith, Emum. pl. Guatem. iv. (1895) 110, nomen. - Guatem.

melastomoides, C. II. Wright, in Kout Bull. (1894) 128. - Reg. Somal.

Miersii Tanb. in Bot. Fahrb. xv. Beibl, n. 38 (1893 16 (= Cliocarpus Gurdneri, Miers). - Bras

Monteiroi, C. H. Wright, in Kew Bull. (1894) 12\%. Angola.

muticum. N. E. Br. l. c. 6: et cx Gartenfl. xliii. (18\%) 171, t. 1401. - Paras.

Naumanni, Engl. Bot. Fulhrb. viii. (1886) 64, - Congo

bliquen, Dammer, in Engl. Pflanzenw. Ost.Afr. C (1895) 354. - Afr. trop. or

ocellatum, Phil, in Anal. Univ. Chil. xci. (1895) 14 - Chili.

olivaeforme, 7. D. Snith, an Conlt. Bot. Gaz, xiv. (1889) 28, xv. (1890) 28, et xvi. (1891) 13, t. 2, Guatem.

pallidum, Rusby, in Mem. Torrey Bot. Club, iv (1895) 228. - Bolivia

Palmeri, Vasey of 7. N. Rose, en Proc, U. S. N'at Mus, xi. (1888) 53\%. - Calif.

pannosum, Phil. in Anal. Univ. Chil. xci. (1895) 9 -Chili.

pauperum, C. H. Wright, in Kew Bull. (1894; 127. - Angola.

Pearcei, Britton, ex Rusby, in Mcm. Torrey-Bot. Club, iv. (1895) 2:27. - Bolivia,

Pearcei, Phil. in Anal. Univ. Chil. xci. (1895) 5. Chili.

phytolaccoides, C. H. Wright, in Kew Bull. (1894) 126. - Abyss.

Pierreanum, Pailleux \& Bois, [Rec. des sci. appliq. 1890| ex André, in Rev. Hortic, 1xii. (1890) 348. Gabon.

pilcomayense, Morong, in Ann. Y. N. Acad, sci vii. (I893) 17\% - Parag.

pitt)sporifolium, Hemsl. in foum. Lim. Soc. xxri (1890) 171. - China.

polyphyllum, Fhil, in Anal. Mus.nac, Chils (1891) 64. - Chili

Pringlei, Robinson \& Grecnm, in An. Fourn. Sci Ser. III. 1. (1845) 160, - Mexic

psilostylum. Danmer, in Engl. Pfanzenw. Ost-Afr. C (1895) 354. - Afr, trop, or

Pugae, Phil. in Anal. Univ. Chil. xci. (1895) \%.Chili.

pulchellum. Phil. in Anal. Mins, nac. Chile (1891 64. - Chili.

quichense, F. M. Conlt. in 7. D. Snith, Enum. pl. Gmatem. iv. (1S95) 111. nomen. - Guatem.

Remyanum, Phil, in Anal. Unia. Chil. xci. (1895 17; et in Mus, nac. Chile (1891) 66 (= S. flevum, Remy). - Chili

Rohrii. C. H. Wright, in Kew Bull. (1894) 128, Abyss.

rupestre, Waisb. in Dest. Bot. Ziitschr. xlv. (1895) 143. - Hung.

Sacciamm, Naud. in Rev. Hortic. 1xiv. (1892) 58 nomen $=$ muricatum, Ait.

salsum, Kuntze, Rev. Gen. (1891) 45\%, - Venezuela. saltiense, S. L Moore, in Trans. Linn. Soc, Ser. II iv, (1895) 404. - Bras

Sanfuegoi, Phit, in Anal, Unir. Chit, xci. (1895) 10. - Chili.

scalare. S. Elliot, in Fourn. Limn. Soc. xxx. (1894) 93. - Sierra Leone.

Schumannianum, Dammer. in Engl. Pfanzenw. OstAfr. C (1895) 352. - Afr. trop. or

septemlobum, Phil. in Anal. Univ. Chil, xci. (1895) 10. - Chili.

setaceum, Danmer, in Engl, Pflanzenw。 Ost-Afr。C (1895) 253. - Afr. trop. or.

tipitato-stellatum, Dammer, in Abh. Preuss. Akad. Wiss. (1894) 63; et in Engl. Pfanzenw. Ost-Afr. C (1895) 353. - Afr. trop. or.

\section{SOLANUM}

Stuhlmannii, Dammer, in Engl. Pfanrenwe. Ost-Afr C (1895) 354. - Afr. trop. or.

styracioides, Rusby. in Mem. Torrey Bot. Club, iv (1895) 230 - Bolivia.

subandinum, Phil, in Anal. Univ. Chil. xci. (1895) 13. - Chili.

subandinum, Fr. Mcigen, in Bot. Fahrb. xvii. (1893) 293, et xviii. (1894) 397, 461. - Chile.

tarapacanum, Phil. in Anul. Mus. nac. Chile (1891 65. - Chili.

tequilense, A. Gray, ex S. Wats. in Proc. Am. Acad. xxii. (1887) 441.-- Mexic

tenuicaule, Phil. in Anal. Unir. Chil. xci, (1895) 13. - Chili.

Thruppii, C. H. Wright, in Kew Bull. (1894) 129. - Reg. Somal.

trepidans, C. H. Wrighit, l. c. 128, - Zambesia. ulugurrnse, Dammer, ex Engl, Pfanzenn. Osi-Afr. A (1895) 130, nomen. fulugurensis]. - Afr. trop. Urbanianum, Dammer, in Engl. Pfanzenze. Ost-Afr. C (1895) :55. - Afr. trop. or

urbanum, Morong, in Ann. $\Lambda^{7} . Y$. Acad sci. vii. (1893) $17 \%$ - Parag

ursinum, Rusby, in Mem. Torrey Bot, Club, iv. (1895) 227. - Bolivia.

usaramense, Dammer, in Engl. Pfanzenw. Ost-Afr. C (1895) 353. - Afr. trop. or.

vagans, C. H. Wright, in Kew Bull. (1894) 12S. Zanzib.

validum, Rusby, in Mem, Torrey Bot. Club, iv. (1895) 2:30. - Bolivia.

vexans, S. L. Moore, in Trans. Linn. Soc. Ser. II iv. (1895) 405. - Bras

villaricense, Morong, in Ann. N. Y. Acad. sci. vii. (1893) 178. - Parag

Volkensii, Dammer, in Engl. PAlanzenw. Ost-Afr. C (1895) 354. - Afr. trop: or

Weddelli, Phit. in Anal. Mus, nac. Chite (1891) 65 - Chili.

Welwitschii. C. H. Wright, in Kew Butl. (1894) 126. - Afr. trop. occ.

Wendlandii, Hook. fo in Bot, Mag. (1887) t. 6914. ... Costa-Rica.

witheringioides, Kuntze, Rev. Gen. (1891) 448 in nota $=$ Saracha Sellowiana, Miers

SOLARIA. Phil. (Liliac.) - Ind, Kew ii. 940. najor, Reiche, in Bot. Fahri, xvi. (1892) 272. Chili.

SOLDANELLA. Limn. (Primul.), - Ind. Kew. ii. 9) 40.

hungarica, Simonk. Enum F1. Transsilv. (1886) 461 ; et in Oest. Bot. Zeitschr, xxxix. (1889) 21! = montana, Willd.

pindicola. Hausskn, in Mitth. Bot. Ver. Fena, v. (1887) E1. - Graecia.

transsilvanica $\times$, Borb. in Pótfüzet. Természettud. Küzlönyh. xii. (1890) 191, ex Oest. Bot. Zeitschr.x!.(1890) 416, et x!i. (1891) 31. - Transsily.

SOLLIROLIA, Gaudich. = Helxine, Req. (Urtic.) repers, Kuntze, Rev, Gen. (1891) $633=$ H. Soleirolii, Req.

SOLENANDRA, Kuntze, Rev, Gen, (1891) $120=$ Stenanthemum, Reiss. (Rhamneae).

coronata, humilis, leucophracta. Waterhousii, Kuntze. Rev. Gen. (1891) $120=$ homonyma ommia.Stenanthemi.

pimelodes, Kuntze, 1. $\mathrm{c}_{0}=\mathrm{S}$. pimeloides, Benth.

pomaderrodes, Kuntze, 1. c. = S. pomaderroides, Reiss.

SOLENANTHUS, Ledeb. (Boragin.). - Ind.

kurdicus, Guerke, in Engl. \& Prantl. Natürl. Pflanzenfam. iv. 3a (1893) $104=$ cerinthoides, Borss.

SOLENOCALYX, Van Tiegh. in Bull. Soc, Bot. Fr. xlii. (1895) $260=$ Loranthus, Linn.

lamprophyllus, Van Tiegh. 1. c. = Psittacanthurs. lamprophyllus, Eichl.

Siphon, Van Tiegh. I. c, = P. Siphon, Eichl. 
SOLENOMELES, Miers (Irid.). - Ind. Kew. ii 941.

Lechleri, Baker. Handb. Irid. (1892) 139 (= Lechlera Sisyrinchinm, Griseb.). - Chili.

SOLENOPHORA, Benth. (Gesnerac.). - Ind, Kew. ii. 941

erubescens. 7. D. Smith. Enum. pl. Gratem, if (1891) 56; et in Coult. Bot. Gaz. xvi. (1891) 197 - Guatem.

SOLENORUELLIA, Baill. Hist. des pl. x. (1891) 445; Lindau, in Engl. \& Prantl. Natürl. Pflanzenfam. iv. 3b (1895) 326. ACANTHACEAE.

Galeottiana, Baill. ll.cc. - Mexic.

SOLENOSTEMON, Thonn. (Labiat.). - Ind. Kew. ii. 941

africanus. [Engl. ?] Pfanzenw. Ost-Afr. A (1895) 116 , nomen [africanum]. -- Afr. trop.

bullatus. Briq. in Bot. fahrb. xix. (1894) 180 . Congo mer.-or.

SOLIDAGO, [Vaill.] Linn. (Compos.). - Ind, Kew. ji. 942.

angustifolia, G. C. Druce, Bot. Exch. Club, Brit. Isles Rep. for $1892(1893)=$ S. virga-aurea, Limn. araucana, Phil. in Anal. Univ. Chil. Ixxxvii. (1894) 431. - Chili.

Earolinima. Britton, Stern \& Poge. Prelim. Catal. (1888) $26=$ tenuifolia, Pursh

floribunda, Phil. in Anul. Univ. Chil. Ixxxvii. (1894) 430. - Chili.

Gattingeri, Chapm. ex Gattinger, Teness. Fl. (1887) 51 = missouriensis, Nutt. var.

Iaxiflora, Phil. in Anal. Untv. Chil. Ixxxvii. (1894) 429. - Chili.

micrantha. Phil. l. c. 432.-Chili

parvula, Phil. l. . . - Chili.

Parryi, Greene, in Erythea, ii. (1894) $57=$ Aplopappus I’arryi, A. Gray.

pataronica, Phil. in Anal. Univ, Chii. 1xxxvii (1894) 433. - Chili.

Purshii. Porter, in Bull. Torvey Bot. Club, xxi. (1894) 311. - Am. bor.

recta. Phil. in Anal. Unio. Chil. 1xxxvii. (1894) 431. - Chili.

rigidiuscula, Porter, $m$ Men,. Torrey Bot. Club. I' (1894) 319. - Am. bor,

roanensis. Porter, in Bull. Torrey Bot. Chub. xix. (1892, 136. - Carolina.

uniligulata, Porter, in Mem. Torrey Bot. Club, v, (1894) $320=$ Bigelovia uniligulata. $D C$.

raldiviana, Phil.in Anal. Univ. Chil. Ixxxvii. (1894) 431. - Chili.

yadkinensis, Small, in Bull. Torrey Bot. Club, xxii. (1890) $368=$ Boottii. Hook.

SOLULUS, Rumpf = Ormocarpum, . Beauv (Legumin.).

bibracteatus, coccinets, elegans, Kivkii. Thurberi, verrucosus, Kuntze, Rev. Gen. (1891) $205=$ homonyma omnia Ormocarpi.

cochinchinensis, Kuntze, 1.c. = Ormocarpum sennoides, $D C$.

coevuleus, Kuntze, 1. c. $=0$. caeruleum, Balf. $f$.

mimosodes, Kuntze, 1. c. $=$ O. mimosoides, S. Moore.

SOMALIA. Oliver, in Hook. Icon. Pl. xvi. (1886) t. 1528, et in F. L. James, Unkn. Horn. of Afr Append. (1888)321, t.3. SCROPHULARINEAE

Bottae, Baill. in Bull. Soc. Linn. Paris, ii. (1890) 838. - Arabia.

diffusa, Oliver, in Hook, Icon. pl. xvi. (1886) t. 1528; et in F. L. Fames, Unkn. Horn of Afr. App. (1888) 321, t. 3. - Reg. Somal.

SOMMERA, Srhlecht. (Rubiac,). - Ind. Kew. ii. abiceoides, K. Schum. in Mart. Fl. Bras. vi. vI (1859) 300. - Bras:

SONCHUS, [Tourn.] Jinn. - Ind. Kew. ii. 944

Dianae, Lacaita, ex Willk. Illustr. Fl. Hisp. ii (1886-92) 16 t, 100; et Suppl. Prodr. Fl. Hisp (1893) 116. - Hisp

\section{SONCHUS :}

Erythraeae, Schareinf, ex Penzig, in Atti Congr. Bot. Genoz'a (1893) 346. - Erithrea.

exauriculatus, O. Hoffm. in Engl. Pfanzonv. OstAfr. C (1895) 421. - Afr. trop. or.

Fischeri, $O$. Hoff $n$. $l . c$, - Afr, trop, or.

Freynianus, Huter, Porta \& Rigo, ex Porta, in Atti Accud. Agiati, ix. 1891 [1892) 43: Willk. Suppl. Prodr. Fl. Hisp. (1893) 114. - Hisp.

gracilis, Phil. in Anal. Univ. Chil. Ixxxvii. (1894) 325. - Chili.

grandifolius, T. Kivk, in fourn, Bot. xxxii. (1894) 184; et in Trans. N.Z. Inst, xxvi. 1893 (1894) 266. - Ins. Chatham.

Haussknechtii X. Bruegg, in Jahresb. Naturf. Ges. Graub. xxxi. Beil. (1887-88) 216. -- Helv

Loscosii, Willk. Suppl. Prodr. Fl. Hisp. (1893) 115. - Hisp.

Lowei, Heer, ex Bolle, in Bot. Fahrb, xiv: (1892) 246. - Ins. Canar.

SONERILA, Roxb. (Melast.), - Ind. Kew, ii. 946. Beccariana, Cogn in Boerl. Handl. Fl. Ned. Indiö, j. II. (1890) 532; et in DC. Monog. Phan. vii. (1891) 508 . - Borneo.

borneensis, $\operatorname{Cog} n$. . ll. cc. - Borneo

cantonensis, Stapf, in Ann. Bot. ii. (1892) 302.China.

Clarkei, Cogn, in DC. Monog. Phan, vii. (1891) 501. - Deccan.

cordifolia, $\operatorname{Cog} n$. l. c. 502. - Zeylan

hirtella, Cogn. l. c. 509. - Borneo.

crassiuscula, Stapf, in Trans, Limn, Soc. Ser. II. iv. (1894) 156. - Borneo.

Hendersoni, Hort ex Corn, in Boerl. Handl. Fl. Ned. Indië, i. 11. (1890) 531, in syn. = margaritacea, Lindl.

hirtella, Cegn. l. c. 532. - Borneo

Impatiens, Becc. ex Cogn.l. c.531, nomen; et in DC. Monog. Phan. vii. (1891) 489. - Borneo.

ntegrifolia, Stapf, in Ann. Bot, vi. (1892) 312.Perak.

kinabaluensis, Stapf, in Trans. Linn. Soc. Ser. II. iv. (1894) 156, - Borneo.

papuana, Cogn. in Boerl. Handl. Fl. Ned. Indie, i. 11. (1890) 532. nomen: et in DC. Monog. Phan. vii. (1891) 511 - - N. Guin.

Parishii, Staff, in Amm.Bot. vi. (1892) 303.Penins, Mal.

parviflora, Cogn, in Boerl. Handl. Fl. Ned. Indie, i 11. (1890) 5i3:. - Borneo.

peperomiaefolia, Oliver, in Hook. Icon. pl. xix. (1889) t. 1814. - China.

pulchella, Stapf. in Trans, Linn. Soc. Ser. II. iv. (1894) 15\%, - Burneo.

purpurascens, Bccc. ex Cogn. in Boevl. Handl. Fl, Ned. Indiê, i. 1. (1890) 531, nomen; ot in DC. Monog. Phan. vii. (1891) 499. - Borneo.

rivularis, $\operatorname{Cog} n$. l. c. vii. (1S91) 1183. - Tonkin.

tonkinensis, Cogn.l.c.1184. - Tonkin.

triflora, Cogn. in Boerl. Handl. Fl. Ned. Indië. i. II. (1890) 531. nomen; et l. c.591. - Borneo

tuberculifera, $\operatorname{Cog} n$. l. c. 532, nomen; et in DC.

Monog. Phan. vii. (1891; 511. - Sumatra.

velutina, Cogn. $l l . c c .532$; et 509. - Borneo.

SONNEA, Greene, Pittonia, i. (Feb. 1887) 22 ; O. Hoffm, in Engl. \& Prantl. Nalürl. Pflanzenfam.iv. 3a (1894) 109. COMPOSITAE.

foliacea, Greene, l. c. i. (Oct, 1ss8) 222. - Nevada.

glomerata. Greene, i. c. i. (Feb. 1887) 22 (= Plagiobothrys glomerata, A. Gray). - Calif.

Harknessii, Greene, l. c, 23. - Calif.

hispida, Greene, l. c. 22 (= Plagiobothrys hispida, A. Gray). - Am. bor. occ.

Jonesii, Greene, l. c. 23 (=P. fonesii, A. Gray).Arr. bor. Occ

Kingii, Greene, l. c. (= P. Kingii, A. Gray), - Am. bor, occ.

SOPHORA, Linn. (Legumin.), - Ind. Kew. ii. 947 chinensis, Hort. ex Dippel, Handb. Laubholzk. iii. (1893) 663, in syn. = violacea, Hort.

Korolkowi, Hort. ex Dipfel; l.c. 662; Koehne, Dintsche Dendrol. (1893) 323. - Mongolia.

\section{SOPHORA}

shikokiana, Makino, in Tokyo Bot. Mag. vi. (1892) 53. - Japon

tomcntosa, Hort, ex Dippel, Handb. Laubholzl: iii. (1893) 663, in syn, = violacea, Hort.

zeylanica, Tyim. Handl. Fl. Ceyl, ii. (1893) 96, t. 30 ; et Plates illustr. Handb. Fl. Ceyl. (1894) t. 30 . - Zeyl.

SOPHROCATTLEYA $\times$. Rolfe, in Journ. Linn, Soc. xxiv. (1887) 169; et in Gard. Chron. (1889) ii. 156. ORCHIDEAE

Batemanniana $X$, Rolfe, 11. cc, $(=$ Laelia Batemanniana, Reichb. f.); Veitch, Man. Orch. Pl. ii, (1887) 92 , cum xylogr. - Hybr. artef.

Calypso X. Rolfe, 1. c. (1890) ii.588. - Hybr artef.

ximia $\times$. Hort. Veitch, ex Journ, of Hort. (1894) 321, fig. 48; et ex Rev, Hortic. 1xvi. (1894) 491 - Hybr, artef.

laeta $X$. Hort. ex Gard. Chron. (18:4) ii. 4\%6, fig,

63 [sphalm. Batenaniana]. - Hybr. artef.

SOPHRONIA. Lindl. = Sophronitis Lindl. (Orchid.

coccinea, Kuntze, Rev. Gen. (1891) $681=$ Sophro. nitis grandiflora, Lendl.

militaris, Kuntze, 1. C. = S. grandiflora, I, indl

pterocarpa, Kuntze, 1. c. = S. pterocarpa, Lindl. Paxt.

violacea, Kuntze, 1. c. = S. violacea, Lindl.

SOPUBIA Buch.-Ham.(Scrophul.). - Ind. Kew. ii. 948 .

angolensis, Engl. Bot. Fahrb. xviii. (1894)6\%.Angola

Buchneri, Engl. l. c. 66. - Angola.

Candei, Terrac, in Eull. Soc. Bot. Ital. (1892) 424. - Reg. Somal.

Eminii, Engl. Pflansenw. Ost-Afr. C (1895) 359.Afr. trop. or.

lanata, Engl. Bot. Fahrb. xviii. (1894) 6\%. - Afr. trop.

latifolia, Engl. 7.c. 66. - Congo mer

parviflora, Engl. l. c. 65. - Afr. centr. bor.

Welwitschii, Engl, Bot, fahrb. xviii. (1894) 66.Angola.

SORANTHE, Salisb. \& Knight = Sorocephalus R. Br. (Proteac.)

diversifolia. Dregei, imberbis, imbricata, lanata. sea brida, setacea, Kuntze, Rev. Gen.(1891) $582=$ homonyma ommia Sorocephali.

phyllicodes, Kuntze, 1. c. = S. phylicoides, Meissn. salsolodes, Kuntze, 1. C. $=\mathrm{S}$. salsoloides, $R, \mathrm{Br}$.

SORBARIA, A. Br. = Spiraea, Linn. (Rosac.).

alpina, Dippel, Handb. Laubholzk. iii. (1893) 50. $=$ S. Pallasii, G. Don.

millefolinm, Focke, in Engl, \& Prant1, Natürl Pflanzenfam. iii. 3 (1888) 16; Dippel, 1. c. 504 fig. $228=\mathrm{S}$. Millefolium, Torr.

SORBUS, [Tourn.] Linn.= Pyrus, Tourn. (Rosac.) auricula, "Pers. » ex Dippel, Handb. Laubholzk. iii. (1893) 371. sphalm. (=S. auriculata, Pers.) $=\mathrm{P}$ pinnatifida, Elr h

coronaria, MacMill. Metasp. Minn. (1892) $284=$ P. coronaria, Limn.

corymbiflora $\times$, Hort. ex Koehne, Deutsche Dendrol. (1893) 248. - Hybr. artef.

cretica, Hort. ex Dippel, Hanḋb. Laubholzk, iij 1893) $376=$ P. Aria, Ehrh.

dulcis, Hort. ex Dippel, 1. c. $367=$ Pyrus auctiparia, Ehrh.

evubescens, A. Kern, ex Dippel, Handb. Laubholzl iii. (1893) $378=$ P. intermedia, Ehr

lanata, Boiss. Fl, Or. Suppl. (18SS) $199=$ P lanata; D. Don.

majestica, Hort. ex Dippel, Handb. Laubholzk. iii. (1893) $374=$ P. Aria, Ehwh.

nepaiensis, Hort. ax Dippel,
Aria, Elirh.

nenillyensis $\times$, Dippel. 1: c. 3\%0. - Hybr. artet.

Nemillyi, Hort. ex Dippel, 1. c. = praec.

quercoides, Hort. ex Dippel. I. C. $=$ P. spuria, $D C$. 


\section{SORBUS :-}

(1891) 54: Koehne, Deutsche Dendrol. (1893) 247, in syn. - Pyrus sambucifolia, Cham. E. Schlecht.

framiorsa, Strobl, in Oest. Bot. Zeitschr, xxxvi. (1886) $239=$ Pyrus praemorsa, Guss.

Sargonti X Dippel. Handb. Laubholzk. iii. (1893) 373. - Hybr, artof.

saturciifolia X. Dippel, 1. c. 370. - Hybr. artef.

suecica, Briq. Fl. du Mont Soudine (1893) 32 ; et in Bull. Soc. Bot. Genève, v. 1893 (1894) $99=$ Pyrus intermedia, Ehrh.

SORGHUM, Linn. (Gramin.)。 - Ind. Kew. ii. 949.

manum, Trab, in Batt. \& Trab. Fl. de l'Algér. [Monoc.] (1895) $128=$ halepense. Coss.

barbatum, Hochst. \& Stend, ex Th. Dur. Eo Schinz: Consp. Fl. Afr. v, 1894 (1895) 846. - Abyss., Arabia.

laxiflorum, F. M. Bailey, Bellenden-Ker Exped. (1889) 70. -- Austral.

SORGUM, Linn. = Sorghum, Linn (Gramin.). abyssinicumz, acutiusculumz, affine, Alopecurus, amethystimum, amplecters. anmulatum, annumm, appendiculatun, arctatum, arenarium, argutum, arrhenobasis, Barteri, bellariense, bicorne, bipennatum, bombycinum, brachystachyum, bracteatum, brevifolizm, Buchneri, Cabanisii, caricosum, carinatum, chrysostachyum, cirratum, conmutatum, condensatum, confine, consanguinerum contortian, Cornucotiae, cubense cynbarium. Delavayi, demissum, diplandrum, distachyum, Elliottii, cucneme, eucomum, exaltatum, exaratum, exile, exothecum, familiave, fastigiatum, filifolinm, filipendulum, finitinum, flavescens, forleolatun, fulvibarbe, gangeticum, Gayanum, Gidarba, glabriusculum, glaucescens, gracilipes, gracile, grandiflorum, Gryllus, Halli,
heteroclitum, Hildebrandtii, hirtiform, hirtifolium,

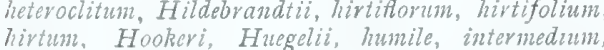
Ischaemum, Iwarancusa, Kuntzeanum, lanigerum, Iaterale, le pidum, leptocladum, leptocomum, lencostaclyum, lithophilunn, lividun, longiberbe, longipes, macrolepis, malacostachym, Mannii, melanocarpum, monatheram, montanum, monticolum, mucronatum, multiplex, Myosurus, Nardus, Newtonii, nodulibarbe, nodulosun, obliquiberbe, oligantum, oryzetorum, papillosum, pertusum, pilosissimum, piptathe"unn, platyphylhum, plumosum, poecilotrichum, Polilianutn, polyatherum, polyptychum, pratense, procertm, prorinciale, Psendoischaemun, pteropechys, pulchellum. pusillum, vefractum, Riedelii, rufum, Ruprechtii, scabriflorum, Schimperi, Schinzii, schirense, Schlmmberveri, Schoenanthus, Schottii, Schwcinfurthii, scoparinun, semiberbe sericeum, serratum, Smithionum, spathifforum, subtile, superciliatum, tenerum, temuberbe, tenute, tornatum, trichochadim, trichosygum. riste, tri:iceum, tubercolatum, umbellatum, urceolatum, cenustum, verticillatzm, vestitun, virginicum, Wrighaii, xanthoblepharis, yunzanense, Zeae, Zollingeri. Iruntze, Rev, Gen. (1891) 790-92 = homonyma omnia Andropogonis.

ciculatum, Kuntze, Rev. Gen。(1891) $791=$ Chry sopogon aciculatus, Trin.

chthistivodes, Kuntze, 1. c. = Andropogon anthistiroides, Hochst.

rocntetm, Kuntze, 1. c. $790=$ A. argyreus, Schult Auchor, Kuntze, 1. c. $791=$ Chrysopogon serrulatus, Trin.

bicolor, Kuntze, 1. c. $790=$ A. dichrous, Steud. Bourgeau, Kuntze, 1. c. $791=$ A. Bourgaei, Hack. campestre, Kuntze, 1, c. $790=$ A. hypogynus, Hack. cimporm, Kuntze, 1. c. $=$ A. campestris, Trin. cerasiaeforme, Kuntze. 1. c. $791=\mathrm{A}$. ceresiaeformis Nees.

iliare, Kuntze, 1. c. $790=$ A. Cymbachne, Hack. comosim, Kuntze, 1. c. = A. coleotrichus, Stcud. rianthodes, Kuntze, 1, c. $=$ A. erianthoides, $F$. inuell.

Glazioui, Kuntze, I. c. = A. Glaziovii, Hack

glomeratum, Kuntze, 1. c. $791=$ A. macrourus $.17 i c h x$.

Mxun, Kuntze, 1, c, 79$)=$ A, apricus, Trin lepton, Kuntze, 1. c. $792=$ A. tener, Kunth.

Licbmannii, Kuntze, 1. co = A. Liebmanni, Hatk. wientale, Kuntze, 1. C. $790=$ A. aristulatus, Hochst.
SORGUM : -

papilipes, Kuntze, Rev, Gen. (1891) $790=$ = Andropogon papillipes, Hochst.

plimosum, Kuntze, 1. c. = Trachypogon polymorphus, Hack.

ude, Kuntze, I. c, $792=$ Arthraxon cuspidatus, Hochst.

saccharodes, Kuntze, I. co= Andropogon saccharoides, $S w$

Salrmannii, Kuntze, 1 c. $790=$ A. imberbis, Hack sanguinarum, Kuntze, 1. c. $792=\mathrm{A}$. sanguinarius, Schreb.

sanguineum, Kuntze, 1. c. '791= A. Psendograya Steud.

servilatum, Kuntze, 1. c. $791=$ Chrysopogon serrulatus, Trin.

villosinn, Kuntze, I. c. = Andropogon Neesi, Kunth zizanodes, Kuntze, l, c. = A. squarrosus, $L$ inn. $f$.

SORIA, Adans = Euclidium, R. Br. (Crucif.) syriaca, Kuntze, Rev. Gen. (1891) $36=\mathrm{E}$. syriacum, $R . B r$.

temilsima, Kuntze, 1. c。 = E, tataricum, DC.

SORINDEIA, Thou. (Anacard.). - Ind. Kew, ii 949

acutifolia, Engl. Bot. Fahrb. xi. Beiblë n. 26 (1890) 6. - Ins, S. Thom.

Afzelii, Engl. l. c. xv, (1892) 107. - Sierra Leone. grandifolia, Engl. l. c. xi. Beibl. n. 26 (1890) 7. Ins. S. Thom.

madagascariensis, Baill. Hist, pl. Madag. Atlas

(1892) t. 230a et b. - Madag.

obtusifoliolata, Engl. Pfanzenw. Ost-Afr. C (1895)

244. - Afr. trop, or

Poggei, Engl. Bot. Fahrb. xv. (1892) 197. - Congo. usambarensis, Engl. in Abh. Preuss. Acad. Wiss, (1894) 44; et Pflanzenw. Ost-Afy. C (1895) 244. Afr. trop. or.

SOROGEA, A. St. Hil. (Urtic.), - Ind, Kew, ii. 949 .

grandifolia, S. L. Moore, in Trans, Limn. Soc. Ser. II. iv. (IS95) 476. - Bras.

SOYAUXIA, Oliver (Passiflor.), - Ind. Kew. ii. labrescens, Engl. Bot. fahrb. xiv. (1891) 390.Gabon.

SPACHEA, A. Juss. (Malpigh.). - Ind, Kew. i1. 950, Kuntze, Rev.Gen. (1891) 88. - Panama.

SPARATTOSPERMA, Mart. (Bignon.). - Ind.

Kew, ii. 951.
loucanthum, K. Schum, in Engl. \& Prantl, Natürl. Pflanzenfam. iv. 3b (1894) 235 [Sparattospermum] = lithotripticum, Mart.

SPARAXIS, Ker-Gawl. (Irid.). - Ind. Kew, ii 951.

lineata, Pax, in Eng1. \& Prantl, Natürl. Pflanzenzenfam. ii. 5 (1888) 155 = Tritonia lineata, Ker

SPARGANIUM, [Tourn.] Linn, - Ind, Kew。 ii. 951

androcladum, Morong, in Bull. Torrey Bot. Club, iv. (1888) 78; et in Macoun, Catal. Canad. Pl. iv. (1888) 70. - Canada.

flaccidum, Meinsh, in Bull. Acad. Petersb, xxxvi. (1895) 37. - Rossia.

Glehnii, Meinsh. l. c. 34. - Sacchalin.

Greenei, Morong, in Bull. Torrey Bot. Club, xv. 1888) $17 \%$ - Calif.

longifolizm, Don, ex Druce, in Journ. Bot. xxvi. 1888) 115, in syn. = affine, Schnirt.

perpusillum, Meinsh. in Bull. Acad. Pétersb̄. xxxvi, (1895) 38. - Rossia.

ratis, Meinsh, in Bull. Soc. Nat. Mose. (1887) S7t: et in Bull. Acad. Pétersb. xxxvi. (1895) 39. Rossia.

septentrionale, Meinsh. $l l . c c$. - Rossia.

simile, Meinsh. in Bull. Acad. Pétersb. xxxvi. (1895) 34. - As, centr.
SPARGANIUM

speirocephalum, Neum, in Meddel. Soc. Fann, et Fl Fenn, xix. (1893) 143. - Fennia.

splendens, Meinsho in Bull. Acad. Pétersb. xxxvi. (1895) 32, - Rossia.

stenophyllum, Maxim, ex Moinsh. in Bull. Soc. Nat Mosc. (1889) 17l; et l. c, 35. - Mandchuria.

subvaginatum, Meinsh, in Bull. Acad. Pétersb, xxxyi. (1895) 34. - Am. bor.

submuticum, Hartm. Skand. Fl, ed. (1889) 108 : Wainio, in Act. Soc. Fann, et Fl. Fenn, viii.n. 4 (1891) 83. - Eur. bor.

SPARTOTHAMNELLA, Briq. in Eng1, \& Prantl, Natürl. Pflanzenfam. iv, $3 a$ (1894) 161 . VERBENACEAE.

juncea, Briq. l. c. (= Sparthothamnus juncous, A. Cunn.). - Austral.

SPARTOCXTISUS, Webb \& Berth. = Cytisus Linn. (Legumin.)

suprambius, Christ, in Bot. Jahrb. ix. (1888) $16 \%$ $\left(=\right.$ Spartium supranubium, Linn, $\left.\hat{t}_{0}\right)$ - Tenerifta

SPATHAGANTHUS, Baill. Hist. des p1. x. (1890 444 ; Lindau, in Engl. \& Prantl. Natürl. Pflanzenfam. iv. 3b (1895) 327. ACANTHACEAE

Donnell-Smithianus, Lindau, in Bull. Herb. Boiss. iii. 371. - Guatem.

Domell-Smithii, Lindau, ex J. D. Smith, in Coult Bot. Gaz. xx. (1895) $293=$ praec

Hahnianus, Baill. Hist. des plox. (1890) 444. Mexic.

Hoffmanni, Lindau, in Bnll. Herb. Boiss, iii. (1895) 370. - Costa Rica.

SPATHANTHIUM, Schott (Aroid.), - Ind, Kew. ii. 952

heterandrum, Baill. Hist. des pl, xiii. (1895) $4 \% 1=$ heterandrum, Benth. \& Hook. f.

SPATHE, P. Br. = Spathelia, Linn. (Simarub.). glabrescens. Kuntze, Rev. Gen. (1891) $104=$ Spathelia glabrescens, Planch.

Thoifolia, Kuntze, l. $\mathrm{C}_{\mathrm{c}}=\mathrm{S}$. rhoifolia, DC

vernicosa, Kuntze, 1. c. $=$ S. vernicosa, Planch.

SPATHIONEMA, Taub. in Engl. Pflanzenw. Ost-Afr. C (1895) 224. LEGUMI OSAE.

kilimandscharicum, Tanb. l. c. 224.-Afr. trop.

SPATHIPHYLLUM, Schott (Aroid.), - Ind. Kew. ii. 953.

pictum, Nichols. Dict. Gard. iij. (1886) $46 \sigma=$ Rhodospatha picta, Nichols. (in App.)

SPATHODEA, Beauv. (Bignon.), - Ind. Kew, ii. 954

Danckelmaniana, Buetn: in Verh. Bot. Ver. Brond. xxxi. (1889) 87. - Gabon.

Danckelmannii, "Buettn, » ex Bureau \& K. Schum. in Engl. \& Prantl, Natürl. Pflanzenfam. iv. 3b (1894) 241, sphalm, = praec.

SPATHOGLOTTIS, Blume (Orchid.). - Ind. Kew, ii. 954 ,

Augustorum, Reichb. f. in Gard. Chron. (1886) i. 0 (1886) ii. 104; et in Bot. Mag. (1888) t. $7013=$ S. Vieillardi, Reichb. $f$.

Bensoni, Hook. f. Fl. Brit. Ind, v. (1890) 814 ; et in Hook, Icon. pi. xxi, (1892) t. 2087. - Parag.

gracilis, Rolfe, ex Hook. $f$. in Bot, Mag. (1894). t. 7366 . - Borneo.

Ericcsoni, Hort. ex Gartenfl. xli. (1892) 184, nomen. [Quid?].

Hollrungii, Kraenzl, in K. Schum, '\& Hollr. Fl. Kais. Wilh. Land (1889) 33. - N. Guin.

Kimballiana, Hort. Sand. ex Gartenfl. xli. (1892) 184; ex Reichenbachia (1894) t. 88; Hook. f. in Bot. Mag. (1895) t. 7443 [Kimbaliana]. - Borneo.

microchilina, Kraenal. in Bot. Fahrb. xvii. (189.3) 484. - Sumatra.

parviflora, Kraenzl. ex Warb. \%. c. xvi. (1892) 13, 18 - N. Guin. 


\section{SPATHOGLOTTIS}

plicata, Ridl, in Journ. Bot. xxiv, (1886) 354, in obs. = plicata, Blume

Portus-Finschii, Kraenzl. in K. Schum, \& Hollv. Fl. Kais. Wilh. Land (1889) 32. - N. Guin.

Regneri, Reichb. f. in Gard. Chron. (1887) 174. Cochinch.

rosea, Nichols. Dict. Gard. iii. (1886) 467. - Ins, Philipp.

stenophylla, Ridl. in fourn. Bol. xxiv. (1886) 354. - N. Guin.

Soutteriana, F. M. Bailey, in Proc. Roy. Soc. Queensl. xi. I. (1895) 15. - Austral.

Wrayi, Hook. f. Fl. Brit. Ind. v. (1890) 812 ; et in Hook. Icon. pl. xxi. (1892) t. 2086. - Perak.

SPATHOLOBUS, Hassk, (Legumin.). - Ind. Kew. ii. 954

parviflorus, Kuntze, Rev. Gen. (1891) $205=\mathrm{S}$, Roxburghii, Benth.

SPATHYEMA, Rafin. = Symplocarpus, Salisb. (Aroid.).

foetidum, Baill. Hist. des pl. xiii. (1895) $508=$ foetida, Rufin.

SPEGULARIA, Heist. (Campanul.). - Ind. Kew. 955

Speculum-Veneris. Caruel, in Parl. Fl. Ital. viii. (1888) $139=\mathrm{S}$. Speculum, A. DC

SPEIRANTHA, Baker (Liliac.), - Ind. Kew, ii. Gardeni, Baill. Hist, des pl. xii. (1894) $524=$ convallarioides, Baker.

SPEIROSTYLA, Baker, in Journ. Linn. Soc: xxv, (1889) 198, STERCULIACEAE.

tiliaefolia, Baker, l. c. t. 4. - Madag.

SPERANSKYA, Baill. (Euphorb.). - Ind. Kew. ii. 955 .

Henryi. Oliver, in Hook. Icon. pl. xvi. (1887) t. 1577 . - China centr.

SPERGULA, Linn. (Caryophyll.). - Ind. Kew. ii. 955 .

flaccida, Aschers, in Verh, Bot. Ver, Brand, xxx. (1889) p. 43. - Afr, bor., As. occ., Afghan. India.

SPERGULARIA, J. et C. Presl (Caryoph.). Ind. Kew. ii. 956 .

angolensis, Phil, in Anal. Univ. Chil. Ixxxii. (1893) 771. - Chil.

aprica, Phil. l.c. 766. - Chili

araucana, Phil. l.c. 764. - Chili.

Borchersi, Phil. i. c. 769. - Chili.

borealis, Robinson, in Proc. Am. Acad. xxxix. (1894) $312(=$ Buda borealis, S. Wats. \& Coult.). - Am.

Clevelandi, Robinson, l. c. 310 (= Tissa Clevelandi, Greene). - Calif.

coquimbensis, Phil, in Anal. Univ, Chil. Ixxxii. (1893) 764. - Chili.

depauperata, Phil. l. c. 765, in obs. (= Arenaria depauperata, C. Gay). - Chili.

fasciculata, Phil. in Anal. Mus. nac. Chile (1891) 6. - Chili.

fruticosa, Phil. in Anal. Univ. Chil. lxxxii. (1893) 767. - Chili.

gracilis, Robinson, in Proc. Am. Acad. xxix. (1894) 311 (二 Lepigonum gracile, S. Wats.). - Am. bor. hybrida X, Hausskn, in Mitth. Thür. Bot. Ver. N. Folge, v. (1893) 59. - Graecia.

Larranagae, Phil. in Anal. Univ. Chil. Ixxxii. (1893) 767. - Chili.

Lebeliana, Rony, in Bull. Herb. Boiss. iii. (1895) 223. - Gall.

longipes, Rouy, l. c. 224. - Gall

macrotheca, Robinson, in Proc. Am. Acad xxix. (1894) 312 (= Lepigonum macrothecum, Fisch. et Mey.) - Calif.

oligantha, Phil. in Anal. Univ. Chil. Ixxxii. (1893)

7\%0. - Chili.

polyantha, Phil. l, c. 765 . - Chili.

\section{SPERGULARIA}

Rengifoi, thit lo c.769. - Chili.

sperguloides, Hausskn, in Mitth. Thiir. Bot. Ver. N. Folge, v. (1893) 58 (= Lepigonum sperguloides, Fisch. \& Mey). - Europ.

tenella, Phil. in Anal. Univ. Chit. 1xxxii. (1893) 766. - Chili.

tenuis, Robinson, in Proc, Ann, Acad. xxix. (1894) 311 (= Lepigonum tenue, Greene.). - Calif.

SPERMAGOGE, Dill. ex Linn. (Rubiac.). - Ind Kew. ii. $95 \%$.

angustifolia, Boerl. Handl. Fl. Ned. Indiè, ii, I. (1891) 144 (= Bigelovia angustifolia, Span.). Ins. Timor.

Baurii. Robinson \& Greenm. in Am. Fourn. sci. Ser. III. 1. (1895) 141 (= Borreria Baurii, Robinson \& Greenm.). - Ins. Galap.

Brownii, Rusby, in Mem. Torrey Bot. Chub, iv. (1895) 208. - Boliv.

galapageia, Robinson \& Greenm. in Am, foum. sci. Ser. III. i. (1895) 141 (= Borreria galapageia Robinson \& Greenm.). - Ins. Galapag.

Jacobsoni, F. M. Banley, in Dept. Agric. Brisbane, Bot. Bull. iii. (1891) 13. - Austral.

megalocarpa, A. Gray, in Proc. Am. Acad. xxi. 1886) 381. - Mexic.

monodon, $K$. Schum, in Engl. \& Prantl, Natiurl. Pflanzesuf.rm. iv. 4 (1891) 144. - Bras.

pacifica, Robinson, et Greenm. in Am. Journ. sci Ser. III. i. (1895) 141 (= Borreria pacifica, Ro binson \& Greenm.). - Ins, Galapag.

Pringlei, S. Wats. in Proc. Am. Acad. xxv. (1890) 152. - Mexic.

pumila, Boerl. Handl. Fl. Ned. Indiö, ii. I. (1891) 144 (= Bigelovia pumila, Span.). - Ins. Timor.

setidens, Boerl. l. . . $(=B$. setidens, Miq. $)$ - Java. sociata, Boerl. l. c. (=B. sociata, Span.), - Ins Timor.

tenuissima, Pohl, ex K. Schum. in Mart. Fl. Bras. vi. VI. (1890) 46, in syn. $(=$ Borreria temus, DC. - Bras

thymocephala. Hitchcock, Missouri Bot. Gard. Rep iv. (1893) 95 (= B. thymocephala, Griseb.). = verticillata, $\operatorname{Linn}$.

uniseta, F.M. Bailey, in Dept. Agric. Brisbane, Bot. Bull. iii. (1891) 13. - Austral.

Zollingeriuna, Boerl. Handl. Fl. Ned. Indië, ii. I. (1891) 144 (= Bigelovia Zollingeriana, Miq.).Java.

SPERMOLEPIS, Rafin. = Apium, Tourn. (Um bell.)-

divaricatus, Britton, in Mem. Torrey Bot. Club, v. 1894) 244 = divaricata, Rafin.

echinatus, Heller, in Contrib. Herb. Frankl, and Marshall Coll, i. [Bot. Expl. S. Texas| (1895) 7? $=$ apium echinatum, Benth. \& Hook. $f$.

SPHAGELE, Benth. (Labiat.). - Ind. Kew. ii 959.

fragrans, Greene, Fittonia, i. (Mar. 1887) 38. Calif.

Grisebachii, F. Kurtz, in Revista Mus. La Plato [Sert. Cordob.] 14 v. (1893) 292. - Reg. Argent.

SPHACOPHYLLUM, Benth. (Compos.). - Ind.

Kew. ii. 959

africanum, O. Hoffm, ex Enol, in Abh. Prenss, Akad $W$ iss. (1894) 58: et Pflanzenw. Ost-Afr.C (1895) 412 (= Astephania africana. Oliver). - Afr. trop. or. Holstii, O. Hoffm. l.c. - Afr. trop. or

Lastii, O. Hoffm. l. c. - Afr. trop. or.

Stuhlmannii, O. Hoffm, l. c. - Afr. trop. or.

SPHACOPSIS, Briq. Lab. Alp. Marit. i. (1891) $184=$ Salvia. Linn. (Labiat.).

verticillata, Briq. 1. c. $=$ S. verticillata, Lim.

SPHAERALGEA, A. St. Hil. (Malv.). - Ind.

Kew. ii. 959.
albiflora, $7 . N$. Rose, in Contrib. U. S. Nat. Herb. i (1890) 81 ; E. G. Baker. in Fourn. Bot. xxxi. (1893) 362. - Calif.

ambigua, A. Gray, in Proc. Ant. Acad. xxii. (188\%) 292. - Am. bor, occ.
SPHAERALGEA :

arenaria, Phil. in Anal. Univ. Chil. 1xxxii. (1893) 11. - Chili.

axillaris, $S$. Wats, in Proc. Am. Acad. xxiv. (1889) 41. - Mexic

californica, F. N. Rose, in Contrib. U. S. Nat. Herb. i. (1890)66; E. G. Baker, in fourn. Bot. xxxi. (1893) 363. - Calif

capitata, Phil. in Anal. Univ. Chil. Ixxxii. (1893) 8. - Chili.

capituliflora, Phil. l. c. 10.-Am. austr. occ.

circinata, Phit. l. c.7.- Am. austr. occ.

Conlteri, T. S. Brandeg, in Proc. Calif, Acad. sci

Ser. II. ii. (1889) $135=$ californica, $7 . N$. Rose

Coulteri, A. Gray, in Proc. Am. Acad. xxii. (18s7) 291. - Arizona

crispa, Hook. ex E. G. Baker, in Fourn. Bot. xxxi. (1893) 363. - Patagonia.

crispifolia, E. G. Baker, l.c. 367 (= Sida crispifolia

Cav.) - Am. austr

fulva, Greene, Pittonia, i. (June 1888) 201. - Ins. Cedros.

grandiflora, Phil. in Anal. Univ. Chil. 1xxxii. (1893) 5. - Chili.

Hainesii, T. S. Brandeg. in Proc. Calif, Acad. Ser. II. ii. (1889) 136. - Calif.

malvastroides, E. G. Baker, in Fourn. Bot. xxxi. (1893) 366. - Afr. austr

Mandoni, E. G. Baker, l. c. 364. - Bolivia.

Orcuttii, F. N. Rose, in Contrib. U. S. Nat. Herb. i. (1893) 290. - Calif.

Palmeri, F. N. Rose, l. c. i. (1890) 23 ; E. G. Baker, in fourn. Bot. xxxi. (1893) 362. - Ins. Guadal. (Calif.).

pannosa, Bolus, in fourn. Limn. Soc. xxv. (1889) 156. - Afr. austr.

pedatifida, A. Gray, in Proc. An. Acad. xxii. (1887) 291 ( $=$ Malvastrum pedatifidum, A. Gray). Texas.

peteroana, Phil. in Anal. Univ. Chil. 1xxxii. (1893) 9. - Chili.

plicata, Phil. l.c.6. - Chili.

prostrata, E. G. Baker, in fourn. Bot. xxxi. (1893)

367 (= Sphaeroma prostratum, Harv.). - Afr.

pulchella, Phil. in Anal. Univ. Chil. (1893) 9.Chili,

Rusbyi, A. Gray, in Proc. Am. Acad. xxii. (1887) 293. - Arizona.

valparadisea, Phil. in Anal, Univ, Chit. 1xxxii. (1893) 12. - Chili.

Vidali, Phil. l. c. 6. - Chili

viridis, Phil. l. . . 8. - Chili.

SPHAERANTHUS, Vaill. ex Linn, (Compos.

\section{- Ind Kew ii 059}

angolensis, O. Hoffm. in Bot. Fahrb. xx. (1894) 228. - Angola.

angustifolizu, Sch. Bip. [in Schimp. Pl. Abyss. ii. n. 525] ex Engl, in Abh. Preuss, Akad. Wiss. 1891 (1892) 422, in syn. = S. Steetzii, Oliver \&

cyathuloides, O. Hoffn. in Bot. Fahrb. xx. (1894) 229. - Afr. trop. or.

Fischeri, O. Hoffm. l. c. 230, - Afr. trop. or.

gomphrenoides, O. Hoffm. l. o. 220. - Afr. trop.

Hildebrandtii, Baker, in fourn. I.im. Soc. $\mathrm{xxv}$. (1890) 326. - Madag.

Stuhlmannii, O. Hoffm. in Bot. Falrb. xx. (1894) 230. - Afr. trop. or.

kambensis, Vathe \& O.Hoffm. ex O. Hoffm. .

228. - Afr. irop. or

SPHAERIUM, Linn. = Goix, Linn. (Gramin.).

giganteum, Kuntze, Rev, Gen. (1891) $793=$ C. Lacryma-Jobi, Linn.

Lacryma, Kuntze, 1. c. = C. Lacryma-Jobi, Lim. tubulosum, Kuntze, 1. c. $79 t=$ C. tubulosa, Hack

SPHAEROCEPHALUS, Linn。= Echinops, Linn. (Compos.).

albicaulis, amplexicaulis, armatus, Aucheri, oannaticus, Bovei, Cephalotes, ceratophorus, chanuecephalus, chantavicus, chorassanicus, commutatus, cornigerus, cyanocephalus, dasyanthus, dichrous, cohinatus, Gaillardotii, 


\section{SPHAEROCEPHALUS}

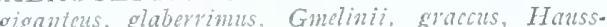
knechtii, licbeletis, Heldrcichii. heteromorphus, hispidus, horridus, humilis, Hussonii. hypoleucus, iticifolins, inermis, integrifolius, jaxarcticus, jesdianus, karataricus, kurdicus, (Boiss. \& Haussk.) leucographus, longifolius, longisectus, macrochaetus, macrophyllus, maracandicus, microcephalus, namus, niceus, ossicus, parciflorus, polygamus, Ritro, ritrodes, robustus, spinosus, strigosus, subglaber, Szowitsii, Toumeforti, tricholepis, ¿aginatus, villosissimus, viscosus, xanthacanthus, Kuntze, Rev. Gen. (1891) $366=$ homonyma omnia Echinopseos.

waltatus, Kuntze, 1, c, = E, exaltatus, Koch.

Griffithianus, Kuntze, 1. C. $=\mathrm{E}$. echinatus, $R \circ \times b$. latifolins, Kuntze. 1. C. = E. dahuricus, Fisch.

multiflorus, Kuntze, 1. c. = E. sphaerocephalus, Linn

polyceras, Kuntze, 1. c. = E. Blancheanus, Boiss. fungens, Kuntze, 1.c. $=$ E. persicus, Stei'

SPHAEROGODON, Benth. (Asclep.). - Ind. Kew, ii, 960.

acutifolizun. K. Schum, in Engl. Pflanzenw. OstAfr. A (1895) 125 [acutifolius j = longipedunculatus, $K$. Schum .

caffrum. Schlechter, in Journ. Bot. xxxiii. (1895) $339=$ obtusifolium, Bentt.

ongipedunculatum, K. Schum, in Engl, Pfanzente. Ost-Afr, C (1895) 326 [longipedunculatus] (= Gymnema longipedunculatum, Schweinf.). - Afr. trop. or.

SPHAEROLOBIUM, Sm. (Legumin.). - Ind. Kew. ii. 960

parviflorum, F. Muell, in Trans. Roy. Soc. Tasm. (1S90) 14. - Austral

SPHAEROMA, Kuntze, Rev. Gen. (1891) $13=$ Sphaeralcea, A. St. Hil. (Malvac.).

Bericroana, bonariense, chilense, choapina, cisplatense, collimm, coquinzarum, crispum, Dregeanum, clegans, Enory, Fendleri, Gayanum, glabratum, hastulatun, Hornschuchianun, Lindheineri, miniatum, mutans, obtusilobum, rupestre, sessiliflorum, velutimum, vitifolimm, Kuntze, Rev. Gen. (1891) $74=$ homonyma omnia Sphaeralceae.

abutilodes, Kuntze, 1. c. = Sphaeralcea abutiloides G. Don.

ambigntm, Kuntze, 1. c, = Sida ambigua, Ten.?

aitaricatum, Kuntze, 1. c. (= Malva diraricata E. Mey). - Afr. austr.

filicaule, Kuntze, 1. c. = Sida diffusa, $H . B$. \& $K$. floridamm, Kuntze, 1. c. - Chili.

incamm. Kuntze, 1. c, = Sida Emoryi, Torr.

pannosum, Kuntze, 1. c. = S. glutinosa, Cav

vizulare, Kuntze, 1. C. = S. acerifolia, Nutt.

calparadiseum, Kuntze, 1. c. = S. obtusiloba, $G$ Don.

Wrightii, Kuntze, 1. c. = S. Emoryi, Tor $\%$

SPHAEROSEPALUM, Baker (Guttif.). - Ind. Kew, ii. 960 .

criaceum, S. Elliot, in fourn. Linn. Soc. xxix. (1S91) 5. - Madag.

SPHAEROSTIGMA, Fisch. \& Mey。=Oenothera Linn. (Onagrar.)

acuminatum, Phil. in Anal. Univ. Chil. Ixxxiv (1894) 629. - Chili.

SPHAEROTHYLAX, Bisch. ex Krauss (Podost.). - Ind. Kew. ii. 961.

abyssinica, Warm. Fam. Podost. iv. (1891) 14, 39 fig. 17 (= Anastrophoea abyssinica, Wedd.); Hook. f. in Hook. Icon. pl. xxiv. (1895) t. 2856.Abyss.

heteromorpha, Baill. in Bull. Soc. Linn. Paris, if. 1890) 876. - Congo gall.

SPHANELLOLEPIS ciliata, "Steud, " ex Cogn. in Mart. Fl. Bras, xiv. IV. (1886) 19, sphalm. (= Sphanellopsis ciliata, Steud.) $=$ Adelobotrys ciliata. Triana.
SPHEDAMNOCARPUS, Planch. (Malpigh.) Ind. Kew ii, 901.

galpliniacfolius, Szyszyl. Polypet. Rehm. (1888)? = Acridocarpus galphimiaefolius, fuss.

pruriens. Szyszyl. 1. C. = A. pruriens, fuss.

Rehmannii. Sryszyl. i. c. 3 [Rehmanii]. - Transvaai.

SPHENANDRA, Benth. (Scrophul.). - Ind. Kew. ii. 961

cinerea, Engl. Bot. Fahrb. x. (1888) 253. - Afr.

SPHENODESME, Jack (Verben.). - Ind, Kew. ii. 961 .

ferrigined, Briq. in Engl, \& Prantl, Natüri. Pflan zenfam. iv. $3 \mathrm{a}(1895)$ I81 $(=S$. ferruginea Wight $)=$ barbata, Schau.

SPHENOSTIGMA, Baker (Irid.), - Ind. Kew, ii, 062

boliviensis, Baker, Handb. Irid. (1892) 10\%. Bolivia.

euryandra, Baker. l. c. 106 (= Herbertia euryandra, Griseb.). - Turkest.

gramineum, S. L. Moove, in Trans, Linn. Soc. Ser. II. iv. (1895) 493. - Bras. centr.

polycephalum. Baker, l, c. 107 Ipolycephala]. Bras.

Spruceanum, Baker, l.c. [Spruceana]. - Ecuad.

SPHINCTANTHUS, Benth. (Rubiac.). - Ind. Kew. ii. 962. maculatus, Spruce, tx K. Schm
vi. VI. (1889) 356 . Bras.

microphyllus, K. Schum. . c, 354.-- Bras.

SPHONDYLIUM, [Tourn.]Adans, = Heracleum Linn. (Umbell.)

alpinum, Caruel, in Parl. Fl. Ital. viii. (1889) 25. $(=S$. alpinum, Scop. $)=\mathrm{H}$. alpinum, Linn.

austriacum, Caruel, 1. c, $254(=S$. austriacum, Scop.) $=$ H. austriacum, Linn

lanatum, Greene, Man, Bot. San Franc. Bay (1894) $157=$ H. lanatum, Michx.

SPHYRANTHERA, Hook, it in Hook, Icon. pl. xviii. (1887) t. 1702 ; et F1. Brit. Ind. v. (1888) 477. EUPHORBIACEAE

capitellata, Hook. f. ll.cc. (= Codiaem lutescens, King). - Ins. Andam.

SPIESIA, Neck. = Oxytropis, DC. (Legumin.). aciphylla, acquipetilla, ajanensis, albana, albiflora, algida, ambigua, ammophila, ampullata, arctobic, argentata. Aucheri. baicalia, bicolor, brachybotrys, brevicanlis. cabulica, caespitosa. campestris, candibreaticatis, cabulica, caespitosa. campestris, candi-
cans, caucasica, caudata, chionobia, chionophylla, chrysocarpa, ciliata, cinerascens, confusa, cuspidata, cyanea, dasypoda, deflexa, densa, dichroantha, didymophysa, dioritica, dubia, eriocarpa, falcata, filiformis, floribunda, foetida, frigida, fruticulosa, Gebleri, glabra, glandulosa, globifiora, gracillima, grandiflosa, Griffithii, gymnogyne, Hallii, heratensis, heteropoda, heterotricha, hirsuta, hirta, hypsophila, Hystrix, inaria, integripetala, intermedia, kansuensis, Kotschyana, Lagopus, Lambertii, lanata, lapponica, lasiopoda, lazica. Lehmanni, leptophylla, leptophysa, leucantha, lencocyanea, lencotricha, longebracteata, longipes, longirostre macrobotrys, macrocarpa, macrosema, : malacophylla, melaleuca, melanocalyx. melanotracha, merkensis, Mixtchsiana. MLeyeri, microfhylla, microsphaera. Middendorfi, mixotricha, mollis, montana, monticola, mugodscharica, multiceps, muricata, myriophylla, nana, nigrescens, nitens, nivea. nutans, ochotensis, ochrantha, ochrocephala, ochrolenca, oligantha, oreophila. oxyphylla, pagobia, Pallasii, Parryi, pellita, persica, physocarpa, pilosa, platonychia, platysema, podocarpa, podoloba, polypliylla, proboscidea, prostrata, pumila, Pumilio, pusilla, pyrenaica, racemosa, recognita, revoluta, rhynchophysa, rosea, rupifraga. samurensis, sawellanica, Schmidtit, Sclivenkii, selegensis, Semenowii, setosa, Sevverzowii, songorica, smidida, splendens, squamilosa, stenopliylla, Stracheyana, strobilacea, submutica, subverticillaris, tartarica, Thomsunii,
SPIESIA :-

tianschanica, tibelica, Tilingii, tragacanthodes, TrantEetteri, trichocalycina, trichophysa, triftora, triphylla. Tschujae, uralensis, raginata. Kuntze, Rev, Gen. (1891:206-07 = homonyma onzia Oxytropidis.

acutirostris, M. E. Jones, in Proc, Calif. Acad. Ser. II. v. (1895) $67 \%$, in obs. = Oxytropis

alpicola, Kuntze, Rev. Gen. (1891) $206=0$. uralensis, $D C$.

alpina, Kuntze, 1, c. $=$ O. uralensis, $D C$. altaica. Kuntze, 1. $c_{0}=\mathrm{O}$. brevirostra, $D C$

arctica. Kuntze, $1 . c_{0}=0$. uralensis. $D C$.

Belli, Britton, ex Macoun, in Canad. Record Sci.

(Nov. 1894) 148. - Am, bor. occ.

bracteosa, Kuntze. Rev, Gen, (1891) $206=0$. oxyphylla, DC

cava, Kuntze, 1. c. = O. cana, Bunge.

chiliophylla, Kuntze, 1. $c_{0}=0$. microphylla, $D C$.

coerulea, Kuntze, 1. $C_{2}=O$. caerulea, $D C$

Gaudini, Kuntze, 1. c. = O. Gaudini, Bunge,

gelida, Kuntze, 1. c. = O. albana, Ster.

glacialis, Kuntze, 1. c. = O. lapponica, Gavd.

Halleri, Kuntze, 1. c. $=0$. uralensis. $D C$

Tumifusa, Kuntze, 1. c, = O. albana, Ster.

inflata, Britton, in Mem. Torrey Bot. Club, v. (1894) $201=0$. podocarpa. A. Gray.

Kasbeki, Kuntze, Rev, Gen. (1891) $206=0$. Kas. becki, Bunoe.

haschemiriana, Kuntze, 1. c. = O. cachemiriana, Cambess.

mandschurica, Kuntze, 1. c. = O. manschurica. Bunge.

Meinshausenii, Kuntze, 1. c. $=0$. Meinshauseni, Schrenk.

nothoxys, M. E. Jones, in Proc. Calif. Acad. Ser. II. v. $(1895) 67 \%$, in syn. $=0$. nothoxys, $M . E$. fones.

Owerini, Kuntze, Rev. Gen. (1891) $206=0$. Owerini. Bunge.

panciflora, Kuntze, 1. c = O. Tschiljae, Bunge.

sulfurea, Kuntze, 1. c. $=$ O. sulphurea, Fisch.

sylvicola, Kuntze, I. $c$. $=0$. sy'vatica, $D C$.

Szovitzii, Kuntze, 1. c. = O. Szovitzii, Boiss.

tattarica. Kuntze, 1. c. = O. tatarica, Cambess.

viscida, Kuntze, 1. c. $=0$. campestris, $D C$.

SPILADOCORYS, Ridl, in Trans, Linn, Soc. Ser. II. iii. (1893) $322=$ Pentasachme, Wall. (Asclep.).

angustifolia, Ridl. 1. $\mathrm{c}=\mathrm{P}$. caudatum, Wall.

SPILANTHES, Jacq. (Compos.). - Ind. Kew. ii. 963

Botterii, S. Wats, in Proc. Am. Acad. xxvi. (1891) 141. - Mexic

disciformis, Robinson, l. c. xxvii, (1893) 176. Mexic.

lateraliflora, Klatt, in Bot. Fahrb. viii. (1886) 43. Guatem.

Lehmanniana, Klatt, l. c. 43. - Columb.

leucophaea. Sch. Bip. ex Klatt, in Lcopoldina, Heft xxiii. (1887) 144. - Mexic.

orizabaensis, Sch.Bip.l.c. - Mexic.

SPINILUMA, Baill. in Bul1. Soc. Linn. Paris, ii. (1891) $943=$ Sideroxylon, Dill. (Sapot).

Oxyacantha, Baill. 1. c. - Abyss.

SPINOVITIS, Romanet $=$ Vitis. Tourn. (Ampel. $)$. Daqidi, Carr, in Rev. Hortic. 1xi. (1889) 312, lxik. (189') 50\%: et 1xiii. (1891) 102, fig. 24-26. China.

Davidiana, «Carr. » ex. Dippe1, Handb. Laubholzk. ii. (1892) 596, ad calc. sphalm. = praec.

SPIRAEA, Linn. (Rosac.), - - Ind. Kew. ii. 964. aemula, "Zabel, " ex Koehne, Deutsche Dendrol. (1893) 219. -

alnifolia, Hort. ex. Zabel, Die strauchig. Spiraeen (1S93) 26 = chamaedryfolia, Linn.

anomala. Batalin, in Act. Hort. Petrop. xiii. (1893) 92. - China.

arbuscula. Greene, in Erythea, iii. (1895) $63=$ betulifolia, Pall. var. 
SPIRAEA : -

argutu, X, Zabel, Die strauchig. Spiraeen (1893) 22: Dippel, Handb. Laubholzk. iii. (1894) 465 . - Hytr. artef

assimilis $\times$, Zabel, 1. c. 74. - Hybr. artef,

aubifolia. Hort. ex Zabel, 1. c. 26; Dippel, Handb. Laubholzk. iii. (1893) $484=$ chamaedryfolia Linn. salicifolia, Linn.

Bermhardi, Hort. Angl. ex Zabel, 1. c. $\forall 7=S$. Bumalda $\times$, Hort.

bethtlemensis, Hort. ex Wenzig, in Flora, 1xxi. (1888) 281, sphalm. (= S, bethleheninnsis, Hort.) = salicifolia, Limn.

Billurdieri, Hort. ex Zabel, Die strauchig. Spiraeen (1S93) $101=\mathrm{S}$. Menziesi, Hook.

blanda $\times$, Zabel, 1. c. 40. - Hybr. artef.

brachystachys $X$. Dippel, Handb. Laubholzk. iii. (1893) 495. - Hybr, artef.

brevipes, Borb. in Magyar Nörenyt. Lapok, xiii. (18:0) 75. - Hung.

Bumalda $\times$. Hort. ex Zabel, Die strauchig. Spiraeen (1893) 66. Dippel, Handb. Laubholzk, iii. (1893) 479; Koehne, Deutsche Dendrol. (189:3) $21^{\circ}$. - Hybr. artef

californica, Hort. Gall, ex Dippel, Handb. Laubholzk, iii. (1893) $490=$ fulvescens, Dippel.

ialifornica, Hort. Germ. ex Dippel. Handb. Laubholzk, iii. (1893) $489=$ macrothyrsa $X$, Dippel.

cinerea $\times, Z$ abel, Die strauchig. Spiraeen (1893) 2:3

Dippel, Handb, Laubholzk, iii. (189:3) 465. Hybr. artef.

concinna $\times$, Zabel, 1. c. $70 .-$ Hybr, artet.

conforta $\times$, Zabel, 1. c. 35. - Hybr. artef.

conspicua $\times$.Zabel. 1. c. 90 ; Koehne, Deutsche Dendrol. (1893) 219. - Hybr. artef.

Constantiae, "Schroed. " ex Zabel, 1. c. 102; Dippel, Handb. Laubholzk, iii. (1893) 486, Kuehne, 1. c. 219. - Hybr. artef.

crispifolia minor. Hort. ex Dippel, 1. c. $480=$ bullata, Maxim

cmeata, Hort. ex Zabel, Die strauchig. Spiraeen (1893) $55=$ canescens, D. Don.

difformis X. Zabel, 1. c. $96,-$ Hybr. artef.

ixpans.n, Hort. ex Zabel, 1. c. $86=$ mbra, Hort.

Jlagelliformis, Hort. ex Zabel, 1. c. 55; Dippel, Handb. Laubholzk iii. (1893) $475=$ canescens, D. Dons.

Fontenaysi X, Hort. Billard. ex Zabel, 1. c. 83 Koehne, Deutsche Dendrol. (189:3) 219. Hybr. artef.

fontenaysiensis. $\times$, Dippel, Handb. Laubholzk. iii. (1893) 490. - Iybr. artef.

Foxii $\times$. Ifort. ex Zabcl, Die strauchig. Spiraeen (1893) 11. - Hybr. artef.

fulvescons X. Dippel, Handb. Laubholzk. iii. (1893) 490. - Hybr. artef.

gemmata $\times$, Zabel, Die strauchig. Spiraeen (1886) 23. - Hybr. artef.

Gieseleriana X.Zabel, 1. c. 28. - Hybr. artef.

grata $\times$ Dippel, Handb. Laubholzk. iii. (1893) 491. - Iybr. artef.

grossularizefolia, Hort. ex Zabel, 1. c. 43 = trilobata, Linin.

Henryi, Hemsl. ex Forb. Ef Hemsl. in fourn, Linn. Soc. xxiii, (1887) 225, t, 6. - China.

hispanica, "Barrelier " ex Zabel, Die strauchig. Spiraeen (1893) $22=$ multiflora, $Z$ abel

inebrians, Hort. ex Zabel, 1. c. $108=$ opulifolia, Maxim.

intermedia $\times$, Hort. Lemoine, ex Zabel, Die strauchig. Spiraeen (1893) 88; Dippel, Handb. Laubholzk. iii. (1893) 493; Koehne, Deutsche Dendrol. (1893) 220. - Hybr, artef.

laxissima, Kockne, Deutsche Dendrol. (1893) 21\% Japon.?

Lemoinei $X$, Zabel, Die strauchig. Spiraeen (1893) 64. - Hybr. artef.

lobata. Zabel, 1. $75=$ betulifolia, Pall.

longifolia $\times$. Dippel, Handb. Laubholzk. iii. (1893) 494. - Hybr. artef.

luxurians. Hort. ex Zabel, Die strauchig. Spiraeen 1893) $5 \%=$ nivea, Hort

lycoctonifolia. Maxim in Bull. Acad. Pétcrsb, xxxi. 1887) 41. - Japon.

macrophylla, Hook. ex Koehne. Deutsche Dendrol. (1893) 217 = japonica, Linn
SPIRAEA

macrothyrsa $X$, Dippel, Handb. Laubholzk. iii. (1893) 489 ; Koehne, Deutsche Dendrol. (1893) 221. - Hybr. artet.

magnifica $\times$. Dippel, 1. c. - - Hybr. artef

Margaritae $\times$ Zabel, Die strauchig. Spiraeen

1893) 71 ; Dippel 1. c. 480; Koehne, Deutsche Dendrol. (1893) 217. -- Hybr. artef.

micropetala X, Zabel, 1. c. 33. - Hybr. artef.

microthyrsa $X$, Z.abel, Die strauchig. Spiraeen (1893) 83. - Hybr. artef.

monbetsusensis, Franch. in Bull, Soc. Philom, Paris,

Ser. VII. xii. (1888) 85. - Japon.

multiflora $\times$, Zabel, 1. c. 20. - Gall.

multijuga, Wenzig, in Flora, 1xxi. (1888) $285=$

Filipendula multijuga, Maxim.). - Japon.

myrtifolia, Hort. ex Dippel, Handb. Laubholzk. iii. (1893) $475=$ canescens, D. Don.

nipponica, Maxim. in Bull. Acad. Pétersb. xxxi. (1886) 40 = bracteata, Zabel

notha $\times$, Zabel, Die strauchig. Spiraeen (1893) 91 Dippel, Handb. Laubholzk. iii. (1893) 491. Hybr, artef.

mudiftora X. Zabel, 1. c. 47. - Hybr. artef.

oxyodon X, Zabel, 1. c. 2\%. - Hybr. artet.

pachysundra, Hort. ex Zabel, 1. c. 94; Dippel,

Handb. Laubholzk. iii. (1893) $489=$ magnitica, Diptel

pachystachys X. Hort. ex Zabel, 1. c. 94. - Hybr. artef.

pallidiflora. Zabel, ex Dippel, Handb Laubholzk. iii. (1893) 487 , in obs. - Hybr, artef.

podolica, Blocki, in Deutsche Bot. Monatsschr, x. (1892) $110=$ media, $F$. Schmidt.?

praecox, Hort. ex Zabel, Die strauchig. Spiraeen 1893) 37: Dippel, Handb. Laubholzk. iii. (1893) $460,474=$ pikoviensis, Bess.

pumila, Hort, ex Zabel, 1. c. 65: Dippel, 1. c. 479 in syn. $=S$. Bumalda $\times$, Hort.

pyramidata, Greene, Pittonia, ii. (May 1892) 221. - Washington.

reflexa $\times$, Hort. ex Dippel, Handb. Laubholzk. iii. (1893) $465=$ cinerea, Dippel.

revitivescenzs $\times$.Zabel, Die strauchig. Spiraeen (1893) 69 ; Dippel, Handb. Laubholzk. iii. (1893) 482 Koehne, Deutsche Dendrol. (1893) 216. - Hybr artef.

rosalba $X$, Dippel, 1. c. 484. - Hybr. artef.

rubella X. Dippel, 1. c. - Hybr. artef.

nubra, Britton, in Bull. Torrey Bot. Club, xviii. (1891) 270 = lobata. facq.

rubra, Hort. ex Zabel, Die strauchig. Spiraeen (1893) 85 ; Dippel, Handb. Laubholzk。 iii. (1893) 2:20. - Hybr. artef

semperforens $X$, Zabel. 11. cc. 86 ; et 492. - Hybr. artef.

spicata $X$, Dippel, Handb. Laubholzk, iii. (1893) 486. - Hybr, artef.

stipularis, Hort. ex.Wenzigr, in Flora, 1xxi. (1888 287 = lobata, Murr

subcordata X, Dippel, Handb. Laubholzk. iii. (1893) 48\%, - Hybr. artef.

superba $\times$, Froeb. ex Zabel; Die strauchig. Spiraeen (1893) 73; Dippel, 1. c. 479 ; Koehne Deutsche Dendrol. (1893) 217. - Hybr, artef. Ienuifolia, Otto, ex Dippel, 1. c. $484=$ alba, Du Roi.

thalictroides, Hort. ex Zabel, Die stranchig. Spiraeen $(1893) 18=$ hypericifolia, Limn.

thibetica, Burcau \& Franch, in Morot, fourn. de Bot. v. (1891) 25. - China occ.

tosaensis, Yatabe, it Tokyo Bot. Mag. vi. (1992) 6. - Japon.

tristis, Zabel, Die strauchig. Spirzecn (1893) 62. Hybr. artef.?

triumphans, Zabel, 1. c. $101=$ S. Menziesii, Hook. velutina, Franch. Pl: Delav. (1890) 201. - Yunnan, virgata, Franch. l. c. 199. - China occ.

virginiana, Britton, in Bull. Torrey Bot. Club, xvii.

(1890) 314. - Virginia.

yunnanensis, Franch.Pl.Delav.(1890)200.-Yunnan.

SPIRAEANTHEMUM, A. Gray (Saxifr.).Ind. Kew. ii. 965 .

Davidsonii, F. Muell, in Australas. Fourn. Pharm. ii. (Mar. 188i) 85; ; et ex Bot. Centralbl. xxx. (1887) 35.5. - Austral.
SPIRANTHES, Rich. (Orchid.). — Ind. Kew。 ii

acaulis, Cogn. in Mart. Fl. Bras, iii. IV. (1835) 221 $=$ picta, Lindl.

Allemanii, Cogn. l.c. 219 (= Sarcoglottis Allcmani, Barb. Rodr. . . Bras.

annur, Lesq. [cf. Trelease. Branner \& Coville, in Branner, Ref. Geol. Surv. Arkans, iv. 1888 (1891) 2221 = cernua, Rich,

aphylla, Cogn. in Mart. Fl. Bras, iii. IF. (1895) 215 (= Pelexia aphylla. Ridl.). - Bras.

atroviridis, Cogn.l. c. $206(=$ Cyclopogon alrosivide, Barb. Rodr.). - Bras.

Bangii, Rolfe, ex Rusby, in Mcm. Torrey Bot. Club, iv. (1895) 265. - Bolivia.

bifida, Ridl. ex Olizer, in Trans. Linn. Suc, Ser. II ii. (1887) 283; [Oliver, ex im Thunn, in Timehri. v. (1886) 205]; Cogn。 in Mart. Fl. Bras, iii. iv, (1895) 200. - Guian angl.

biflora, $\operatorname{Cog} n$. . . c. 2017 (= Serapias biftora, Vell.). Bras

Cogniauxana, Barb. Rodr. ex Cogn fig. 3. - Bras.

clorans, N. E. Br. ex Tonduz. in Bull. Herb. Boiss, iii. (1895) 45:3, nomen. = colorata, $A^{T}$ E. $B r$

eriophora, Robinson \& Greenm. in Am. Fourn. So Ser. III. 1. (1895) 165. - Mexic.

fasciculata, Cognt. in Mort. Fl. Bras, iii. IV. (1895) 22) (= Serapias fasciculata, Vell.). Bras.

Grisebachii, Cognz.l.c. 207 (= S. bicolor, Griseb.) - Antill, Am. austr.

uyanensis, Cogn. I.c. $209=$ Goodyera guyanensis, Lindl.). - Guian.. Ins. Trinit.

aliscana, S. Wats, in Proc. Ann, Acad, xxvi. (1891) 153. - Mexic

leucosticta, Reichb, f. in Gartenfl. xxxiv. (1885) 243 ; et in Flora, lxix. (1886) 548. - Hab.

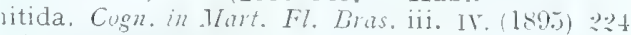
$(=$ Sirapian nitida, Vell.). - Bras.

olivacea, Rolfe, in Kew Bull. (1892) 141. - Peruvia.

orchioides, Hemsl. l.c. (1893) 275 (= Stenorrhynchus orckioides, Rich.). - Am. trop.

paludosa, Cogn. in Mart. Fl. Bras. iii. IV (1895) 202. - Bras

pedicellata, $\operatorname{Cog} n$. . . c 210. - Bras.

praecox, S. Wats, in A. Gray, Man. Bot. North. S. ed. 6 (1890) 503; et in Proc. Ant. Acad. xis (1890) 134. - Am. bor. oc

Pringlei, S. Wats, in Proc. An. Acad. xxvi. (1891) 153. - Mexic.

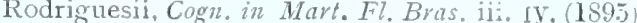
204 (= Cyclopogon trilineata, Barb. Rodr.). Bras.

rubrocalosa, Robinson \& Greenm. in Am. Fourn. Soi. Ser. III. 1. (1895) 165. - Mexic.

suroglossum, Nichols. Dict. Gard, iii. (1886) 479 - Bras.

Schwackei, Cognl, in Mart, FI, Bras, iii. IV (1895) 212, t. 47 fig, 3. - Bras

Ulaei, $\operatorname{Cog} n . \bar{l}$. c. 107 , t. $4 \tilde{\tau}$, fig. 1. -- Bras.

variegata, $\operatorname{Cog} n$. l. c. 193 (= Cyclopogon variegata Barb. Rodr.). - Bras

velata, Robinsun \& Fomald, in Proc. Am. Aculd xix. (1895) 122. - Mexic.

yungasensis, Rolfe, ex Rusby, in Mem. Torrey Bot Club, iv. (1895) 266. - Bolivia.

SPIROLOBIUM, Baill, in Bull, Soc, Linn, Paris, i. 1889) 773: et Hist. des pl. x. (1888) 215. $A P O C Y N E A E$.

cambodianum, Baill. $l l$. cc. $7 \gamma_{4}$; et 215 . - Cambodia.

camóodiense, "K. Schum." in Eng1. \& Prantl. Natürl. Pflanzenfam. iv. 2 (1895) 174, sphalm = cambodranum, Baill.

SPIROPETALUM, Gilg, in Engt. \& Prant1, Natürl. Pflanzenfam, iii. 2 (188S) 70 : et in Bot. Jahrb'. xiv. (1891) 335. COLVNARACEAE odoratum, Gilg, $l l . c c$. - Gabon.

polyanthum, Gilg, in Notizbl. Bot. Gart. Berl. j. (18!5) 69. - Kamerun. 
SPODIOPOGON, Trin. (Gramin.). - Ind, kew. otulifer, Hack in DC. Monog. Phan. vi, (1889) $187(=$ Miscanthus cotulifer, Benth.). - Japon, lnd or

dubrus, Hack, l. c. - Reg. Himal.

moralis, Thw, ex Hack, 1. c. 228, in syn. = Ischaemum rivale, Hack.

SPONDIAS, Linn, (Anacard.). - Ind, Kew, ii mexicana, S. Wats. in Proc. Am. Acad. xxii. (1887) 403. - Mexi

Radlkoferi, F. D. Smith, in Coult. Bot. Gaz. xvi, (1891) 194. - Guatem.

SPONDIOPSIS, Engl. Pflanzenw, Ost-Afr. C (1895) 243. ANACARDIACEAE.

trifoliata, Engl. l.c. - Afr. trop, or,

SPOROBOLUS, R. Br. (Gramin.). - Ind. Kew.

albens, Balunsa, in M1orot. Fourn. de Bot, iv. (1890) 164 , - Tonk.

altissimus, Vascy, ex T. S. Brandeg. in Proc. Calif. Acud. Ser. II. ii. (1889) 212. - Calif.

annuus, Vasey, ex S. Wats. in Proc. Am. Acad. xxi. (1S86) 443, nomen; et in Bull. Torrey Bot. Clute, xiv, (185\%) 9. - Mexic.

avizonicus, Thurber, in Bull. Torrey Bot. Club, xv. (1888) $\mathrm{Q}=$ interruptus, Vascy.

auriculatus, Vasey, in Contrib. U.S. Nat. Herb. iii . (1892) 64 ; II (1894) 518. - Texas.

Bolanderi, Vascy, in Coult. Bot. Gaz, xi. (1886) 337 et l. c. 63. - Oregon.

brevifolius, Scribn, in Mcm. Torrey Bot. Club, y. (1894) 39; Nash, in Bull. Torrey Bot. Club, xxiii. (1895) $464(=\text { Agrostis brevifolia, Nutt. })_{0}$ - Am bor.

Buckleyi, Vasey, Illustr. N. Am. Grass, i. II. (1891) t. 17; et in Contrib. U. S. Nat. Herb. iii. I. (1892) 63. - Am. bor

capillaris. Vasey, in Contrib. U.S. Nat. Herb. i (1893) 284. - Mexic

confusus, Vasey, in Bull. Torrey Bot. Club, xv, (1888) 293 ; et l.c. iii. I. (1892) $64(\approx V$ Vilfa confusa, Fourn.) - Am. bor. oce.

deserticolus, Phil. in Anal. MIns, nac. Chile (1891) 82. - Chili

expansus, Scribn. in Zoë, iv. (1894) 390.-Calit.

filifornis, Rydberg, in Contrib. U. S. Nat. Herb.

iii. $3(1895) 189=$ depauperatus, Scribner.

helvola, Th. Dur. Eo Schinz, Consp. Fl. Afr. v. $1894(1895) 820(=$ Vilfa helvola, Trin.). - Afr. trop., Arabia.

interruptus, Vasey, in Bull. Torrcy Bot. Club; xy (1888) 8; in Contrib. U. S. Nat. Herb. iii. 1 (1891) 61. er Illustr. N. Am, Grass, i. II. (1891) t. is (= Vilfa interrupta, Vasey). - Arizona.

laetevirens, Coss, in Bullh. Soc. Bot. Fr. xxxvi. (1889) 251 ; Batt. É Trab. Fl. de l'Algér. [Monoc.] (1895) 151. - Tunctia.

Julatus, Vasey E Dercey, ex 7. M. Coult in Contrib. U. S. Nat. Herb. i. (1893) 268 ; et ii. (1894) 518 - Texas.

Marlothii, Hack. in Bot. Fahrb. xi..(1889) 401.Afr. austr.

mauritianus, Th Dur. \& Schinz, Consp. Fl. Afr. v. 1894 (1895) 822 (= Vilfa manritiana, Steud.). Ins. Maurit.

Melleri. "Hack. " ex Th. Dur, \& Schinz, 1. sphalm. = Molleri, Hack

micranthus, Th. Dur. Eo Schinz, l.c. 822 (= Triachynum nicranthum, Steud.). - Abyss.

minor, Vasey, in A. Gray, Man. Bot. North. U. S. ed. 6 (1890) 646; in Contrib. U.S. Nat. Herb. iii. L. (1892) 60 ; et in Bull. Torrey Bot. Club, xxv. (1895) 464 = vaginaeflorus, Wood.

mimutus, Engl, in Abh. Preuss. Akad. Wiss, 1891 ii. (1892) 127, in obs. (= Vilfa minutus, Trin.);

Schweinf. ex Terrac, in Ann. Ist. Bot. Roma (1894) $95=$ minutus, Limk

Molleri, Hack. in Bolet. Soc. Brot.v. (1887) 213 t. $g$, fig. b. - Ins. S. Thom.

\section{SPOROBOLUS}

montanus, Engl. in Abh. Prenss, Akad. Whisś. 1891 ii. (1892) 127 ( $=$ Vilfa moniana, Hook. f.). Afr. trop, or

natalensis, Th, Dur, \& Schinz, Consp. Fl. Afr.v. 1894 (1895) \$22 (=Vilfa natalensis, Steud.). Natal.

Nealleyi, Vasey, in Coult. Bot. Gaz, xv. (1888) 49 ; et in Contrib. U.S. Nat. Herb. i, (1890) 57, et iii. $1(1892) 61$. - Texas

nebulosus, Hack. in Bot. Fahwb. xi. (1859) 402. - Afr. austr.

erlectus, Nash, in Bull. Torrey Bot. Club, xxii 1895) 464. - Am. bor.

paniculatus, Th. Dur. of Schinz, Consp. Fl. Afr.v. 1894 (1895) 823 (=Vilfa paniculata, Trin.). Sierra Leone.

pilosus, Vasey, in B. B. Smyth, Check List p1. Kansas (I892) 26, in Conlt. Bot. Gaz, xv。(1888) 49 ; et in Contrib. U. S. Nat. Herb. iii. 1 (1892) $60=$ asper, Kunth

racemosus, Vasey, in Proc. Am. Acad, xxi. (1886) 43, nomen; et in Bull. Torrey Bot. Club, xiv. (18s8) 9. - Mexic.

Rehmanni, Hack ex Schinz, in Bull. Herb. Boiss. iii. (1895) 383. - Transvaal.

rhizomatosus, Th. Dur. \& Schinz, Consp. Fl. Afr. v. $1894(185) 823$ (=Vilfa rhizomatosa. Steud.). - Madag.

Sacatella. Griseb, ex Fourn. Gram. Mexic. 1881 (1886) 101 , in syn. = Vilfa sacatella, Griseb.

setulosus, Terrac. in Ann. Ist. Bot. Roma, v. (1S94) 95 (=Vilfa setulosa, Trin.). - Arabia

Shepherdi, Vasey, is Bull. Torrey Bot. Club, xiv. 1887) 8. - Mexic

subulatus, Hack, ex S. Elliot, in foum, Linn. Soc. xxix. (1891)65. - Madag.

tenellus, Balansa, in Morot, fourn. de Bot. iv. 1890) 164. - Tonk

texanus, Vasey, in Contrib. U. S. Nat. Herb. i. (1890) 57, et iii. (1892) 63. - Texas.

Tournenxii, Coss. in Bull, Soc, Bot. Fr, xxxvi. (1889) 250; Batt. et Trab. Fl. Alger. [Monoc] (1895) 151. - Tunetia.

Wallichii, Munvo, ex Trim, in foum Bot, xxvii. 1889) 171. - Zeyl.

SPRAGUEA, Torr, (Portul.), - Ind. Kew, ii. 970 multicens, Howell, in. Erythea, i. (1893) 39. Oregon,

uda, Howell, 1. c. = Calyptridium nudum, Greene. umbeilata, Coville, Death Vall. Exp. (1893) 282, nomen $=\mathrm{C}$. monospermum, Greene.

SPRUCELLA, Pierre, Not. bot. Sapot. (1890) 27 = Sideroxylon. [Dill.] Linn. (Sapot.).

cyrtobotrya, Pierre, 1. C. = S. cyrtobotryum, Mart.

SPYRIDIUM. Fenzl (Rhamn.), - Ind. Kew, ii. scabridum, Tate, in Trans. Proc. Roy. Soc. S. cabridum, Tate, in Trans. Proc. R
Austral. xii. (1889) 129. - Austral.

SQUAMELLARIA, Becc. Malesia, ii. (1886) 228. $R U B I A C E A E$.

imberbis, Becc. l.c. t. 46, fig. 1-12 (= Myrmecodia imberbis, A. Gray), - Ins. Fiji.

Wilsoni, Becc. l. c. 229, t. 46. fig. 18-24 (= Hydnopliytum Wilsoni, Horne).

STABEROHA, Kunth (Restiac。), - Ind. Kew。 ii. 971.

caricina, Th. Dur. \& Schinz, Consp. Fl. Afr. v. 1894 (1895) $520 \quad(=$ Thammochortus caricinus, Mast.). - Afr。austr.

cernua, Th. Dur. Es Schinz, l. c. (= T. cermus, Kunth). - Afr. austr.

disticha, Th, Dur. E Schinz, l.c. ( $=T$. distichus, Mast.). - Afr. austr.

gracilis, Th. Dur. \& Schinz, l. c. ( $=$ T. gracilis, Mast.). - Afr. austr.

STACHYARRHENA, Hook. f。(Rubiac.), Ind, Kew, ii. 971.

penduliflora, K. Schum, in Mart. Fl. Bras, vi. VI. (1889) $370 .-$ Bras.
STACHYCARPUS, Van Tieot, in Bull. Soc, Bot Fr. xxxviii. (1891) $163=$ Podocarpus [L'Hé rit.] Pers. (Conif.).

andina, Van Tiegh. 1. c. $173=\mathrm{P}$. andina, Poepp ferruginea, Van Tiegh. 1. C. = P. ferruginea, G. Benn.

spicata, Van Tiegh, 1. c. = P. spicata, R. $B r$

taxifolia, Van Tiegh. 1, c, = P. taxifolia, $H, B$ \& $K$

STACHYPHYLLUM, Van Tiegh, in Bull. Soc. Bot, Fr. xlii.(1895) 565 = Antidaphne, Poepp. \& Endl. (Loranth.)

Fendlevi, Van Tiegh. 1.c. - Venezuela.

STACHYS, [Tourn.] Linn. (Labiat.). - Ind. Kew. acuminata. Greene, in Bull. Culif. Acad, ii. VII (1887) 410. - Ins. S. Cruz (Calif.).

adulterina, Hemsl. in fourn. Linn. Soc. xxvi. (1890) 300. - China.

alberecina, J. Neyr. \& Debeaux, in Rev. de Bot. (1891) 263 = italica, Mill.?

ambigua, Britton, in Mem. Torrey Bot. Club, y. (1894) $288=$ hyssopifolia, Michx. var.

andina, Phil. in Anal. Univ. Chil. xc. (1895) 562 (= S. elliptica, Phil.). - Chili.

araucana, Phil. l. .. 563. - Chili.

arenariaeformis, Rouy, in Bull. Soc. Bot. Fr. xxxvii. 1890) 166. - Romania

Baumgaertneri $X$, G. Beck, F1. Nied.-Oest. ii. II. (1893) 1013, - Austria.

bizensis, Schweinf. ex Pentig, in Atti Congr. Bot. Genova (1893) 356, nomen. - Erithrea.

brevidens, Phil. in Anal. Univ. Chil. xc. (1895) 558. - Chili.

cincinnatensis, Kuntze, Rev,Gen.(1891) 531 [an hybr. spont. ?. - Am. bor.

Closi, Phil. in Anal. Univ. Chil. xc. (1895) 561.Chili.

cordifolia, Prain, in fourn. As. Soc. Beng. lix. (1S90) II. 310. - Burma.

costaricensis, Briq. ex Th. Dur. \& Pitt. in Bull. Soc. Bot. Belg. xxx. 1891 (1892) 240. - Costa Rica.

crenata, Phil. in Anal. Univ. Chil. xc. (1895) 562. - Chili.

crenulata, Briq. in Bot. Fahrb. xix. (1894) 192. Afr, austro-occ, extratrop.

digenea $X$, Legué, in Bull. Soc. Bot. Fr. xl. (1893) 213. - Gall.

dinavica, Marb, in Lunds Univ, Arsskrift, xxvii. v. (1892) $61=$ alpina, Linn.

elegans, Formanek, in Verh. Naturf. Ver, Brimm. xxxii. 1893(1894) 171. - Maced.

fragillima, Bornm, in Mitth. Bot. Ver. Fena, $\mathrm{N}$. Folge, vii. (1895) 7, nomen. - Oriens.

Freynii, Hausskn. l. c. Ser. I. v. (1887) 70.Graecia.

glabrata, Phil. in Anal. Univ: Chil. xc. (1895) 559 - Chili.

glabrata, Simonk. Enum. F1. Transsilv. (1886) 450 $=$ recta, Linu.

glandulifera, Post, Pl. Postianae, iv. (1892) 11. As. occ.

Hildebrandtii, Briq. in Bull. Herb. Boiss. ii. (1894) 138. - Madag.

hissarica, Regel, in Act. Hort. Petrop. ix. (1889) 614 - Turkest.

Faniana, Janka, in Magyar Növenyt. Lapok, $x$. (1886) 149, sphalm.= S. Janii, Ces., Passer \& Gibelli

litoralis, Phil. in Anal. Univ. Chil. xc. (1895) 560 - Chili.

longepetiolata $X$, G. Beck, Fl. Nied.-Oest. ii. II 1893) 1013. - Austria.

macrophylla, Alboff, Prodr. Fl. Colch. (1895) 202 - Reg. Cauc.

madagascariensis, Briq. in Bull. Herb. Boiss, ii (1894) 137. - Madag.

Milani, Petrov, ex Magnier, Scrin. fl. select, vi 1887) 117 = spinulosa. Heldr.

nemorivaga, Briq. in Bot. Falirb. xix. (1894) 192 - Angola

obtusifolia, MacOwan, in Kew Bull. (1893) 13.Afr. austr 
STACHYS :

odontophylla, Freyn, in Oest. Bot. Zeitschr. xli. (1591) 59. - As. Min.

pannosa, Phil. in Anal. Univ. Chil. xc. (1895) 564. - Chili.

paradoxa $X$. Rouy, in Bull. Soc. Bot. Fr. xl. (1893) 215. - Gall.

petiolata X, G. Beck, F1. Niel.-Oest, ii. II. (1893) 1013. - Austria.

rupestris, Phil. in Anal. Univ. Chil. xc. (1895) 562 $(=$ S. Meyeniwna, Phil.). - Chili.

Sendmeri, G. Beck, in Annal. Naturh. Hofmus. Wien, ii. (1887) 144, t. 4, fig. 5-7 = pubescens, Vis.

Steingroeveri, Briq. in Bot. Fahrb. xix. (1894) 193. - Afr. austro-occ. extratrop.

stricta, Greene, in Erythea, ii. (1894) 122. - Calif

trichophylla, Baker, in fourn. Linn. Soc. xxv. (1890) 342. - MaJag.

trinervis, Ailch. \& Hemsl. in Trans. Limi. Soc. Ser. II iii. (1886) 97. - Afghan.

turcomanica, Trautr. in Act. Hort. Petrop. ix. (1886) 463. - Turkest.

tubulosa, Macowan, in Kew Bull. (1893) 13. Atr. austr

tymphaea, Hausskn. in Mitth, Bot. Ver. Fena, v. (1585) 70.- Graecia.

relutina, Greeni, in Eyther, ii. (1894) 121. - Calif. venulosa, Grecne, Pittonia, i. (Jan. 1888) 157. Mexic.

zepcensis, Formanck, in Oest. Bot. Zeitschr, xxxviii. (1858) :383. - Bosn

STACHYTARPHETA. Vahl (Verben.). - Ind. Kew, ij. 974.

Nelsonii, Robinson \& Greenm. in An. Fonm. Sci. Ser. III. 1. (1895) 162, - Mexic

STACKHOUSIA, Sm. (Stackhous.). - Ind. Kew ii. 974 .

uniflora, Colenso, in Trans. N. Z. Inst. xviii. 1885 (1886) 258. - N. Zel.

STÄ̈LIA, Cham, \& Schlecht, (Rubiac.), - Ind Kew. ii. 975.

aurea, K. Schum, in Mart. Fl. Bras, vi. VI. (18s8) $7 \%$. - Bras.

capitata, K. Sclium. l.c.72. - Bras.

catechosperma, $K$. Schum. l. c.74. - Bras.

filifolia, Rusby, in Mem. Torrey Bot. Club, iv. (1895) 209. - Bolivia.

lanigera, K. Schum, in Mart. Fl. Bras, vi. vi. (18s8) 73 (= Spermacoce lanigera, Pohl). — Bras.

thymbroides, $K$. Schum. i. c. $7 \tau(=$ Psyllocarpus thymbroides, Mart. \& Zlicc.). - Bras.

restita, K. Schum. l. c.78. - Bras.

virgata, $K$. Schum. l.c. 76 (= Mitracarpum virgahm, Cham. \& Schlecht,). - Bras.

STAHLIANTHUS, Kuntze, Rev. Gen, (1891) 697. SCITAMINEAE.

campanulatus, Kuntze, l.c. - Siam.

STANHOPEA, Frost (Orchid.). - Ind. Kew. ii. 974.

Amesiand, Hort. ex Garden Mag. (1893) 352, cum ic, $=$ S. Lowii, Rolfe.

grandiflora, Nichols, Dict. Gard. iii. (1886) 486.Ins. Trinit.

Lowii, Rolfe, in Kew Bull. (1893) 63; et ex Orchid Rev. i. (1803) 17\%, fig. 12. - N. Granat.

Molliana, Rolfe, in Lindenia, vii. (1891) 89, t. 331.

nigripes, Roife, in Kew Bull. (1894) 364. - Hab.?

Randii, Rolfe, l. c. 363.- Bras.

Spindleriana X, Kraenz1. in Gartenfl, xxxix. (1890) 619, t. 1335. - Hybr. artef.

STANLEYA, Nutt. (Crucif.). - Ind. Kew. ii.

albescens, M. E. fones, in Zoë, ii. (1891) 17. Am. bor. occ,

collina, M. E. fones, l. c. iii. (1893) 284. - Nevada. elata, M. E. fones, l. c. 16. - Am. bor. occ.

pimnata, Britton, in Trans. N. Y Acad. sci. viii, (1888) $62=$ pinnatifida, Nutt.
STAPELIA. I inn. (Asclep.). - Ind. Kew, ii.

affinis, $N$, E. Br. in Hook. Icon, pl. xx. (1890)

ffinis, $N . E . B r$
t. $1912 .-\mathrm{Hab}$.

Arnoti, N. E. Br. l.c. t. 1915. - Afr. austr.

Barklyi, N.E. Br. .. c. t. 1!09. - Afr, austro-occ extratrop.

Desmetiana, N. E Gr. in Gard. Chron. (18s0) ii 684 ; et Hook. l. c. t. 1916. - Afr. austr.

erectifora, N. E. Br. ll. cc. 6.50 ; et t. 1921. Afr. austr.

fuscopurpurea, N.E. Br. in Hook. Icon, pl. xx. (1590) t. 1913. - Hab.

glabricaulis, N.E. Br. l. c. t. 1917. - Afr. austr. horizontalis, N.E. Br. l. c. t. 1907. - Hab.?

intermedia, N. E. Br. l. . . t. 1910 A. - Afr. austr. longidens, N. E. Br. in Gard. Chron. (1S95) ii. 324 - Reg. Mossamb.

Macowani, N.E. Br, in Hook. Icon. pl. xx. (1890) t. 1920, - Afr. austr.

parvipuncta, N.E. Br. l. c. t. 1923. - Afr, austr parvipunctata, « N. E. Br. » ex K. Schum. in Engl. \& Prantl, Natürl. Pflanzenfam. jv. 2 (1895) 278 sphalm. = parvipuncta, $N . E . B r$

vaga, N. E. Br. in Kev Bull. (1895) 265. - Afr. austro-occ, extratrop.

villosa, N. E. Br. in Hook. Icon. pl. xx, (1890) t. 1911. - Afr. austro-occ, extratrop.

virescens, N.E. Br.l.c.t $1910 \mathrm{~b}$. - Afr. austr.

Woodii, NT. E. Br. in Gard. Chron. (1892) i. 554. Natal.

STAPHYLEA, Linn. (Sapind.). - Ind. Kew, ii.

Coulombieri, Ed. André, in Rew. Hortic. lix. (1887) 462; Dippel, Handb. Laubholak. ii. (1892) 476. $\mathrm{Hab}$.

elegans, Zabel, ex Gartenfl. xxxvii. (1888) 499, fig. 113; Dippel, l. c. 472, fig. 225. - Orjens.

holocarpa, Hemsi. in Kew Bull. (1895) 15. - China.

Pringlei, S. Wats, in Proc. Am. Acad. xxv. (1890) 146. - Mexic.

STATHMOSTELMA, K. Schum. in Bot. Jahrb, xvii. (1893) 129; et in Eng1. \& Prant1, Natürl. Pflanzenfam: iv, 2 (1895) 239. ASCLEPIADEAE.

angustatum, K. Schum. in Bot. Fahrb. xvii. (1893) 132 , in obs. ( = Asclepiadis sp., fide N. E. Brown.). - Abyss.

gigantiflorum, K. Schum. l. c. 129. - Afr. trop, globuliflorum, K. Sihum. in Engl. Pfanzenw. Ost Afr. C (1895) 322. - Afr trop. or.

incarnatum, $K$. Schum. in Bot. Fahro. xvii. (1893) 130. - Afr. trop.

Laurentianum, Dewerre, in Bull. Soc. Bot. Belg. xxxiii, 1894 (1895) 102, nomen, et xxxiv. 2 (1895) 87. 'Laurentiana). - Congo.

pauciflorum, K. Schum. in Bot. Fahrb. xvii. (1893) 132, in obs. = Gomphocarpus pauciflorus, Hochist. Es Steud.

pedunculatum, $K$. Schum. l. c. 132, in obs, ; et in Abh. Preuss, Akad. Wiss. (1894) 24 et $411=G$. pedunculatus, Decne). - Afr. austr.

reflexum, Britten \& Rendle, in Trans, Linn. Soc Ser. II. iv. (1894) $27=$ pauciflorum, K. Schum. rhacodes, K. Schum. in Bot. Falirb. xvii. (1893) 131 - Afr, trop.

Welwitschii, Britten \& Rendle, in Trans. Linn. Soc. Ser. II. iv. (1894) 28, in obs. - Afr. trop.

STA TICE, Tourn, ex Linn. (Plumbar.), - Ind. Kew. ii, 978 .

Alberti, Regel, in Act. Hort. Petrop. ix. (1886) 615. -- Turkest.

aragonensis, Debeaux, ex Willk. Suppl. Prodr. Fl. Hisp. (1893) 226 ; et in Rev. de Bot. xii. (1894) 44. - Hisp.

asparagoides, Coss. Es Durieu, [in Bourg. Pl. Alger. exsicc. (1856)', ex Batt. Go Trab. Fl. de l'Algér. [Dicot.] (1890) 727. - Algeria, Marocc

Corculum, Christ, in Bot. Fahrb. ix. (1887) 141. Ins. Canar.

Friderici, Barbey, in Karpathos (1895) 127, t. 13. - Ins. Karpathos.

\section{STATICE :}

Gilesii, Honsl in Hook. Icon. pl. xviii. (1888)

t. 1737. - Giloit.

Heldreichii, Haldesy, in Verm.zonl.-bot. Ges. Wien, (1886) 241, in syn. - Thessal.

Letourneuxii. Coss. ex Batt. in Bull. Soc. Bot. Fr. xxxvii. (1890) 118, in obs, nomen; et in Batt. Es Trab. Fl. de l'Algér. [Dicot.] (1890) 734. Tunet.

Ieucocoleum, Stapf of Weltst. ex Stapf, in Denksclir. Akad. Wicn, ii. (1886) 42. - As. occ

Macphersonii, F. Muell. in Chem. and Drog. Austral. x. (Oct. 1895) 207; et in Bot. Centrulbl. Ixix. (1895) 364. - Austral.

palmyrensis. Post, Pl. Postianae, iii. (1S92) 16. As. occ.

teretifolia, Baker, in Kew Bull. (1894) 334; et in Hook. Icon. pl. xxv. (1895) t. 2355 - Arabia.

Tremolsii, Rouy, in Butl. Soc. Bot. Fr. xli. (1894 325. - Hisp.

tunetana, Barratte, Ill. Fl. Tunisie (1895) t. 15. Reg. Tunet.

xipholepis, Baker, in Kew Bull. (1895) 218. - Res. Somal.

STAUROCHLAMYS. Baker, in Hook. Icon. pl xix. (1889) t. 1825. COMPOSI TAE.

Burchellii, Baker, l. c.- Bras.

STAUROGYNE, Wall. = Ebermaiera, Nees (Acanth.).

Anigozanthus, Beddomei, concinmula, coriacer. eleoans, elongata, fastigiata, glauca, glntinosa, gracilis, Griffithiana, Helferi, hirsuta, humilis, incana, lanceolata. lasiobotrys, longifolia, macrophylla, mandioccana, merguensis, minarm, obtusa, paniculata, pariflora, polybolrya, raeemosa, repens, Riedeliana, setigera, Simonsii, siolonifera, zeronicifolia, zcylanica, Kuntze, Rev. Gen. (1891) 497 = hononyma ommia Ebermaierae.

comosa, Kuntze, 1. c. $=$ Ebermaiera axillaris, Necs. Maclelandii, Kuntze, 1. c. = E. Macclellandii, T. Anders.

Miqueliana, Kuntze, 1. c. = E. humilis, Miq.

thyrsodes, Kuntze, 1. c. = E. thyrsoidea, Nees.

Vauthierana, Kuntze, 1. c. = E. Vauthieriana

STAUROPSIS, Reichb. f. (Orchid.). - Ind. Irew. ii. 982 .

Batemanni, Nichols, Dict. Gard. iii. (1Ss6̉) 493. Ins. Philipp.

undulatus, Benth. ex Honk. f. Fl. Brit. Ind. vi. (1890) 27 (= Vanda undulata, Lindl.); King, in Ann. Bot. Gard. Calc. v. (1895) 36, t. 35. - Reg. Himal.

Warocqueana, Rolfe, in Iindenia, vii, (1891) 65, t. 319. - N. Guin.

STEARODENDRON, Enol. Pflanzenw, Ost-Afr. C (1895) 275 ; et in Notizbl. Bot. Gart. Berl. (IS95) 4\%. GUTTIFERAE.

Stuhlmannit, Engl. ll. cc. - Afr. trop. or.

STEGASTRUM, Van Tiegh. in Bull. Soc. Bot. Fr. xlii. (1895) $447=$ Loranthus, Linn.

alveolatum, Van Tiegh. 1 c. - Ins. Celeb.

Beccarii, Van Tiegh. 1. c. = Loranthus bahajensis, Korth.

lancifoliun, Van Tiegh. 1. c. - Borneo.

STEIRONEMA, Rafin。(Primul.). - Ind. Kew 11. 983.

intermedium, Kearney, in Bull. Torrey Bot. Chub, xxi. (1894) 264, t. 209. - Am. bor.

quadriflorum, Hichcock, in Trans. Si Louis Acad. v. (1892) $506=$ longifolium, A. Gray.

STELECHOCARPUS, Hook. (Anon.). - Ind. Kew. ii. 983 .

grandifolia, Warb. in Bot. Fahrb. xiii. (1S9I) 306. - N. Guin.

nitida, King, in foum. As. Soc. Beng. 1xi. (1892) ii. 5 : et in Annal. Bot. Gard. Calc. iv. (1893) 4, t. 2 . [nitidus]. - Peral.

punctata, King, $7 l$. cc. 4 ; et 4, t. 1. - Peral. 
STELIS. Sw. (Orchid.). - Ind. Kew. ii. 983.

Bangii, Rolfe. ex Rusby, in Men. Torrey Bot. Club, iv. (1805) 260. - Bolivia.

Brittoniana, Rolfe, l. c. 261. - Bolivia

plurispicata, Barb, Rodr. Vellosia, 1887-88, Sec. ediç. (1891) 120. - Bras. bor.

Rusbyi, Rolfe, ex Rusby, in Men. Torrey Bot. Clnb, (1895) 261 - Bolivia.

Toepfferiana, Reichb. $f$. in Flora, 1xix. (1886i) 556. - Dominica.

yauperyensis, Barb. Rodr. Vellosia, 18S5-S8, Sec. ediç. (1591) 120. - Bras. bor.

STELLARIA, Hall. [an Linn.?] = Callitriche, Linn. (Halor.)

s.tgnalis, Kuntze, Rev. Gen. (1891) $234=$ C. stagnalis, Scop

ma, MacMill. Metasp. Minn. (1892) $345=\mathrm{C}$. verna, Linn.

STELLARIA, Linn. (Caryoph.). - Ind. Kew, ii, (1) 84.

arenaria, Maxim.Fl. Tangut. (1889) 11. - China.

axillaris, Phit. in Anal. Univ. Chil. lxxxii. (1893) i62. - Chili.

chlorotica, Timb.-Lagr, in Lucante, Rev. de Bot. x. (1892) $144=$ media, Vill.

cucubaloides, Pau, Not. Bot. Fl. Espan. i. (1887) 14. - Hisp.

Davidi, Hensl. ex Forb. \& Hemsl. in fourn. Linn. Soc. xxiii. (1886) 67 (= Krascheninikowia Davidi, Franch.); Franch. Pl. Delav. (1889) 99. China

decipiens $X$, Hausskn. in Mitth. Bot, Ver. Jena, iii. (1885) 276. - Germ

Delavayi, Franch. Pl. Delar. (1889) 9\%. - China fontinalis, Robinsone, in Proc. Am. Acad. xxix. (1894) ¿\$6 (= Sagina fontinalis, Short \& Perer). - Am. bor.

glochidisperma, Marb. in Lunds Univ. Arsskrift xxvii. V. (1592) $156=$ nemorum, Linn

heterantha, Franch, in Bull. Soc. Bot. Fr. xxxiii, 1886) 435 ; et Fl. Delar. (1889) 101 (= Krascheni. nikowia heterantha, Maxim ). - China.

heterophylla, Hemsl. ex Forb. Er Hemsl. in foum. Limn. Soc. xxiii. (18S6) $68(=K$. heterophylla, Miq.): Franck Pl. Delav. (1889) 101. - China, Japon.

hoterophylla, Yatabe, in Tokyo Bot. Mag. vi. (1892) $13: 3=$ praec

infracta, Maxim, in Act. Hort. Petrop. xi. (1889) 78. - China.

laxa, F. Behm, in Bot. Notis. (18S7). 181. Scandin.

MIaximowicziana, Franch.Pl. Delav.(1889) 101 (= Krascheninikowia Maximowicziana, Franch. \& Sav.). - China.

Maximowicziana, Yatabe, in Tokyo Bot. Mag. vi. (1892) $133=$ praec

montana, F. N. Rose, in Contrib. U. S. Nat. Herb. i. (1891) 93. - Mexic.

oligosperma, Colenso, in Trans. N. Z. Inst. xviii. 1885 (1886) 257. - N. Zel.

pellucida, Colenso, l. c. xxvii. 1894 (1895) 383. N. Zel.

pilosa, Franc7. Pl. Delar. (1889) 99. - China occ.

pilosula, Franch. in Bull. Soc. Philom. Paris, Ser. VII. xii. (1888) $84=$ yezoensis, Maxim.

ponojensis, Arrhen. in Midd. Bot. Foren.-Kjö. (1885.91) 19\%. - Lapp. ross.

raphanorrhiza, Hemsl. ex Forb. \& Hemsl. in Fourn. Linn. Soc. xxiii. (18961) 69; Franch. in Bull. Soc. Bot. Fr. xxxiii. (1886) 435 ; et Pl. Delav. (1889) 101. - China.

rupestris, Hemsl. ex Forb. \& IImsl. l.c. ( = Krascheninikoria rupestris, Turcz.). - China.

upestris, Pax, in Engl. \& Prantl, Natürl. Pflanzenfam, iii, lb $(1859) 80=$ praec

Schimperi. Engl. in Abh, Prouss. Akad. Wiss. 1891 ii. (1S92) 212. - Afr. trop. or.

silvatica, Franch. in Bull. Soc. Bot. Fr. xxxiii. (1886) 435 ; ct Pl. Delav. (IS80) 101 (= Krascheninikowia syleatica, Maxim.). - Reg. Amur.

vicatica, Yatabe, in Tokyo Bot. Mag. vi. (1802) $1: 33=$ praec

\section{STELLARIA : -}

ezoensis, Maxim, in Bull, Acad. Pétersb, xxxi. (1887) 10̃ ; Yatabe, Icon, Pl. Fapon. i. 3 (1894) 167 t. 41. - Japon.

yunnanensis, Franch. Pl. Delav. (1889) 98. Yunnan

STELLASTER. Heister = Gagea, Salisb. (Liliac.). amblyopetalus, bulbifer, chloranthus, chrysanthus, damasconus, Granatelli, Liotardii, minimus, nebrodensis, pusillus, reticulatus, saxatilis, spathaceus, transbaicalensis, Kuntze, Rev, Gen. (1891) 715-16 = homonyma omnia Gageae.

arvensis, Kuntze, 1. c. (1891) $715=\mathrm{G}$, stellaris, Salisb.

bohemicus, Kuntze, 1. c. = G. pygmaea, Salisb

foliolosus, Kuntze, 1. c. = G. foliosa, Schult.

gageodes, Kuntze, 1. c. $=\mathrm{G}$. persica, Boiss

graecus, Kuntze, 1. c. = Lloydia graeca, Endl.

luteus. Kuntze, 1. c. $716=$ Garea fascicularis, Salisb

polycephalus, Kuntze, 1. c. = G. polyphylla, Stev.?

pratensis, Kuntze, 1. c. $715=$ G. bracteolaris, Salisb.

rigidus, Kuntze, 1. c. = G. reticularis, Salisb.

nubroviridis, Kuntze, 1.c. = Lloydia rubro-viridis, Bakror.

triflorus, Kuntze, 1, c, = L, triflora, Baker.

STELLERA, J. G. Gmel. ex Linn. (Thymel.). Ind Kew ii 986.

calycina, cilicica, coridifolia, elliptica, microplylla, nitida, tinctoria, velutina, villosa, viresiens, virgata, Kuntze, Rev, Gen. (1891) 585=homonyma omnia Thymelaeae.

Alberti, Regel, in Act. Hort. Petrop. ix, (1886) 616 ; et in Gartenfl. xxxvi。(188\%) 649, t. 1262. Turkest.

Aucheri, Kuntze, Rev. Gen. (1891) $585=$ Thymelaea Aucheri, Meissn

diveca, Kuntze, 1. $\mathrm{c}_{\text {. }}=$ T. dioica. Alt.

hirsuta, Kuntze, 1. c $=$ Passerina hirsuta, Linn.

incana, Stapf, in Denkschr, Akad. Wien, ii. (1886) 58. - As. min.

lanuginosa, Kuntze, Rev. Gen. (1891) $585=$ Thymelaea canescens, Endl.

Ruizii, Kuntze, 1. c. = T. calycina, Meissn

thesiodes, Kuntze, 1, c, = T. thesoides, Endl.

Thymeliea, Kuntze, 1. c. = T. Sanamunda, Al

Tartonrairae, Kuntze, 1. c. = T. Tartonraira, All.

STELLULARIA, Linn. = Stellaria, Linn. (Caryoph:).

longipes, MacMill. Metasp. Minn. (1892) $222=$ Stellaria longipes, Goldie.

STELMACRYPTON, Baill, in Bu11. Soc Linn. Paris. ii. (1889) 812 ; et Hist. des pl. X. (1890)

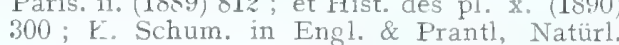
Pflanzenfam.iv. 2(1895)221. ASCLEPIADEAE khasianum, Baill. Il. cc. ( = Pcrtanuma khasiana Kurz). - Khasia; Yunnan.

STELMAGONUM, Baill. Hist. des pl. x. (1890) 287, in Engl, \& Prantl, Naturl. Pflanzenfam. iv. 2. (1895) 304 [Stelmatogronum]. ASCLEPIA $D E A E$.

Hahnianum, Baill. Il. co. - Mexic

STEMMADENIA, Benth. (Apocyn.). - Ind. Kew, 11, 980

bociata, K. Schum, in . Engl. \& Prant1, Natïr] Ptlanzenfam.iv. 2 (1895) $149=$ pubescens Benth.

STEMMATOPHYLLUM, Van Tiegh. in Bull, Soc. Bot. Fr.xli. (1894) $505=$ Loranthus Linn.

acutum, Van Tiegh. 1. c. 546. - Ins. Philipp,

Beccarii, Van Tiegh. I. c. 500. - Borneo.

Cumingii, Van Tiegh. 1. c. 505 . - Ins. Philipp.

luzonense, Van Tiegh. 1. c. $505=$ L. Iuzonensis, Presl.

nodosum, Van Tiegh, 1. c, 506. - Ins. Philipp. irregulare, Van Tierh. 1. c. 546. - Borneo. sessilifolium, Van Tiegh. 1. c. 506. - Ins. Philipp.
STEMODIA, Linn. (Scrophul.). - Inf. Kew: ii.

986

Kingii, F. Muell, in Trans. Roy. Soc, Vict, xxiii. (1886) 5\%. - Austral.

Palmeri, A. Gray, in Proc. Am, Acad. xxi. (1886) 403. - Mexic.

polystachya, T.S. Brandeg. in Proc. Calif. Acad. Ser. II. ii (1889) 191. - Calif.

Schotti, Holzinger, in Contrib. U.S. Nat. Herb. i (1893) 286. - Texas.

STEMODIACRA, P. Br. = Stemodia. Linn. (Scrophul.).

Berteroana, chilensis, debilis. durantifolia, Ehrenbergiana, foliosa, glabra, jorullensis, lanceoiata. lythrifolia, maritima, falustris, peduncularis, pusilla. senegalensis, serrata, stricta, subhastata, suffruticosa, trifoliata, 'iscosa, Kuntze, Rev. Gen. (1891) 460 = homonyma ommia Stemodiae.

bartsiodes, Kuntze, 1. c. = Stemodia bartsioides, Benth.

coenulea, Kuntze, 1. c. = Adenosma caeruleum, R. Br.

gratiolifolia, Kuntze, 1. c. = Stemodia palustris, A. St. Hil

hyptodes, Kuntze 1. c. = S. hyptoides, Cham. \& Schlecht.

linearifolia, Morong, in Ann. N. Y. Acad. sci. vii. (1893) 183. - Parag.

tetragona, Kuntze, Rev. Gen. (1891) $466=\mathrm{S}$. lobelioides, Lelim.

tomentosa, Kuntze, 1. c. = S. lanata, Ruiz \& Par.

certicillata, Kuntze, 1.c. = S..parviflora, Ait.

STEMMODONTIA, Cass. = Wedelia, Jacq (Compos.).

brachycarpa, Morong, in Ann. N. Y. Acad. sci. vii. (1893) $147=$ W. brachycarpa, Baker.

20nota Rusby, in Mem. Torrey Bot. Club, iii. 3 (1893) 58. - Bolivia.

STEMONA, Lour. (Roxburgh.). - Ind, Kew, if.

Curtisii, Hook.f. Fl. Brit. Ind. vi. (1892) 298 ; et in Bot. Mag. (1892) t. 7254, - Penang.

erecta, C. H. Wright, in Lew Bull. (1895) 117 Oliver, in Hook. Icon. pl. xxiv. (1895) t. 2389. China.

javanica, Engl. in Engl. \&o Prantl, N'atïrl. Pflanzenfam i. 5 (1587) 8 (= Roxburghia jaranica, Kunth). - Malaya.

STEMONOPORUS, Thw, = Vateria, Linn (Dipteroc.)

meriosus, Trim. Handb. F1. Ceyl. i. (1893) $135=$ $\mathrm{V}$. nervosa, Thw.

oblongifolus, Pierre, Fl. For. Cochinch. Fasc. 17 (1892) t. 258 1. - Cochinch.

vigidus, Pierre, 1. c. $258 \mathrm{~s}$ - Cochinch.

roseus, Trim. Handb. Fl. Ceyl. i. (1893) $136=$ Vateria rosea, The

STEMONURUS, Blume = Gomphandra, Wall. et Lasianthera, Beauv. (Olacin.),

australianus, Kuntze, Rev. Gen. (1891) $112=$ Brackenridgea australiana, F. Muell.

copitulatus, Kuntze,1. c. = Gomphandra capitulata, Becc.

intermedius, Scortech. ex King, in Journ. As. Soc. Beng. Ixiv. (1895) II. 117, in syn. = Lasianthera umbellata, King.

Maingayi, Valeton, Crit. overz, Olacin. (1886) 236 $=$ L. Maingayi, Mast.

mappiodes, Kuntze, Rev. Gen. (1891) $112=$ Gomphandra mappioides, Valeton.

megacarpus, Hemsl. in Kev Bull. (1895) 133 ; et in Hook. Iion. pl. xxiv. (1895) t. 2398. - Ins. Salom. tomentellus, Valeton, Crit. overz. Olacin. (1886) 237 [tomentella] = Lasianthera lanceolata, Mast.

STENANDRIUM. Nees (Acanth.). - Ind. Kew. 1i. 988

affine, S. L. Moove, in Trans. Linn. Soc. Ser. II. iv. (1895) 426. - Bras. 


\section{STENANDRIUM}

Beeckmannianm $\times$. L. Linden, in Illustr. Hortic. xxxix. (1892) 121. - Hybr. artef.

Boivini, Baill. [ubi ?] ex Lindau. in Engl. of Prantl. Natürl. Pfanzenfam. iv. 3b (1895) 321. - Madag. Goossensianum $X$, L. Linden \& Rodigas, I. c. XI. (1893) 11, - Hybr. artef.

Lindeni, N.E. Br, l.c. xxxviij. (1891) 91, t. 536.Peruvia.

Neesianum, Lindau, in Engl. \& Prantl, Natirl. Pflanzenfam. iv. 3b (1895) 321 (= S. trinerve Nees, var.) - Columb.

pictum, N. E. Br. ex Illustr. Hortic. xxxix. (1892)

121, in obs. (= Eranthemum igneum, Linden). Peruvia.

praecox, S. L. Moore, in Trans, Limn. Soc. Ser. II. iv. (1895) 426. - Bras.

spathulatum, S. L. Moore, l. c. 42\%. - Bras.

STENANTHIUM, Kunth (Liliac.). - Ind. Kew. ii. 988.

gramineum, Morong, in Mem. Torrey Bot. Club, v. (1894) 110 (= S. gramineum, Kunth) = angustifolium, $K$ unth.

STENOCARPUS, R. Br (Proteac.). - Ind. Kew. 11. 988

Grunowii, Zahlbr. in Annal. Naturhist. Hofmus. Wien, iii. (1888) 286, t. 13, fig. 2. - N. Caled.

STENOGLINE, DC. (Compos.). - Ind. Kew. ii. 989.

tomentosula, Klatt, ex Schinz, in Bull. Herb. Boiss. iii. (1895) 434. - Afr, austro-occ. extratrop.

longifolia, Book. f. in Bot. Mag. (1891) t. 7186; W. Wats. in Gard. Chron. (1894) ii. 563 fig. 72. Natal.

STENOGYNE, Benth. (Labiat.). - Ind. Kew. ii. 989.

bifida, Hillebr. Fl. Haw. Isl. (1888) 358. - Ins. Sandvic.

cinerea, Hillebr. l. c. 361. - Ins. Sandvic,

longiflora, Drake, Ill. Fl. Ins. Mar. Pacif. (1886) 265, t. 27. - Ins. Sandvic.

serpens, Hillebr. Fl. Haw. Isl. (1888) 362. - Ins, Sandvic.

vagans, Hillebr. l. c. 362. - Ins. Sandvic.

viridis, Hillebr. l. c. 361. - Ins. Sandvic.

STENOLOBIUM, D. Don = Tecoma, Juss. (Bignon.)

molle, Loesen. in Bull. Herb. Boiss. iii. (1895) 619 $(=$ S. molle, Seem. $)=$ T. mollis, $H . B$. \& $K$.

STENOMERIS, Planch. (Dioscor.). - Ind. Kew. ii. 990.

borneensis, Oliver, in Hook. Icon, pl. xxiv. (1894) t. 2328. - Borneo.

Wallisii, Taub. in Bot. fahrb. z:v. Beibl. n. 38 (1893) 2. - Ins. Philipp.

STENOMESSON, Herb. (Amaryll.). - Ind. Kew. ii. 990 .

panciflorum, Nichols. Dict. Gard. iii. (1886) 498 (= S. pauciflorum, Sweet) = flavum, Herb.

STENOPHRAGMA, Celak. (Crucif.). - Ind.

Kew. ii. 990.
bursifolium, Prant1, in Engl. \& Prant1, Natürl. Pflanzenfam. iii. 2 (1891) $192=$ Sisymbrium bursifolium, Limn.

falcatum, Prantl, ex Engl, in Abh. Preuss. Akad. Wiss. 1891 (1892) $226=$ S. falcatum. Fourn.

pinnatifidum, Prantl, in Eng1. \& Prant1, Natürl. Pflanzenfam. iii. II. (1891) $192=\mathrm{S}$. pinnatifi,dum, $D C$.

salsuginosum, Prantl. in Eng1. \& Prantl, Natürl. Pflanzenfam. iii.2(1891) $192=\mathrm{S}$. salsuginosum, Dall.

STENOPHYLLUS, Rafin = Scirpus, Tourn.

floridanus, Nash, in Bull. Torrey Bot. Club, xxii. (1895) 161. - Florida.

Funckii, Britton, 1, c. xxi. (1894) $30=$ Isolepis Funckii, Britton.
STENOPHYLLUS : -

sphaerolepis, Rusby, in Mem. Torrey Bot. Club, iv. (1895) $270=$ Scirpus sphaerolepis, Boeck.

stenophyllus, Britton, in Bull. Torrey Bot. Club, xxi. 1890$) 30=S$. stenophyllus, Ell.

Warei, Britton, 1. c. (1894) $30=$ I. Warei, Torr,

STENOPTERA, Presl (Orchid.). - Ind. Kew. ii. 990.

actinosophila, Cogn. in Mart. Fl. Bras. iii. IV. (1895) 255, t. $60 \mathrm{fig} .1$ (= Stenorrhynchus actinosophila, Barb. Rodr.). - Bras.

adnata, Ridl. ex Oliver, in Trans. Linn. Soc. Ser. IJ. ii. (1887) 284, t. 48a.; Oliver, ex im Thurn, in Timehri, v. (1886) 205 ; Cogn. in Mart. Fl. Bras. iii. IV. 1895) 251. - Guian. ancl

Lorenzii, $\operatorname{Cog} n$. l. c. 255 . - Bras.

STENORRHYNCHUS, Reichb. = Spiranthes, Rich. (Orchid.)

acianthiformis, Cogn. in Mart. F1. Bras. iii. IV. (1895) 178 (= Pelexia acianthiformis, Reichb. f. \& Warm.). - Bras.

balanophorostachy'us, $\operatorname{Cogn}$. 1, c. 161, t. 48, fig, $4=$ Spiranthes balanophorostachya, Reichb. $f$.

bonariensis, $\operatorname{Cogn}$. 1. c. $164=\mathrm{S}$. bonariensis, Lindl. cuculliger, Cogn.1. c. $175=\mathrm{S}$. cuculligera, Reichb.f. Esmeraldae, Cogn. 1. c. $170=$ S. Esmeraldae, Linden \& Reichb.f.

Glaziorii, Cogn. 1. c. 171. - Bras.

jaliscanta, Nash, in Bull. Torrey Bot. Club, xxii. (1895) $158=$ Spiranthes jaliscana, $S$. Wats.

ongifolius, Cogn. in Mart. F1. Bras. iii. IV. (1895̃) 173. - Bras.

macranthus, Cogn. 1 c. $176=$ Spiranthes macrantha, Reichb. $f$.

oestrifer, Cogn. 1. c. $163=\mathrm{S}$. oestrifera, Reichb. $f$.

paraguayensis, Cugn. 1. c. $162=\mathrm{S}$. paraguayensis Reichä. $f$.

pteryganthus, Cogn. 1. c. $171=$ S. pterygantha, Reichl.f.

rupestris, Cogn. 1.c. $179=$ S. rupestris, Lindl.

saltensis, Cogn. 1. c, $166=$ S. saltensis, Griseb.

Weirit, Cogn. 1. c. $174=\mathrm{S}$. Weirii, Reicht. $f$.

STENOSIPHON, Spach. (Onagrar,). - Ind.Kew ii. 990 .

linifolium, Britton, in Mem. Torrey Bot. Club, v. (1894) $236(=$ S. linifolium, Heynh.) = virgatum Spach.

STENOSPERMATION, Schott (Arold.). - Ind, Kew ii 991

multiovulatum, $\Lambda^{*}$. E. Br. in Gard. Chron. (1894) i $684(=$ S. Spruceanum, Schott, var. multiovulatum, Engl.). - Columb.

STENOSTELMA, Schlechter, in Bot. Jahrb xviji. Beibl.n. 45 (1894) 6. ASCLEPIADEAE. capense, Schlechter, l. c. - Afr. austr.

STENOSTEPHANUS, Nees (Acanth.). - Ind.

Kew. ii 991.
Lindeni, Baill. in Bull. Soc. Linn. Paris, ii. (1890) 855. - Am. austr. occ.

STENOTAENIA, Boiss. = Heracleum, Linn. (Umbell.).

macrocarpa, Freyn \& Sint. ex Freyn, in Oest. Bot. Ze tschr. xlii. (1892) 165. - Armen.

Sintenisii, Freyn, l. c. xliv. (1894) 102, - As. Min

STENOTAPHRUM, Trin. (Gramin.). - Ind Kew.11. 991.

dimidiatum, Kuntze, Rev. Gen. (1891) 794 (=S. dimidiatum, Brongn.) = glabrum, Trin

STENOTUS, Nutt. = Aplopappus, Cass. (Com-

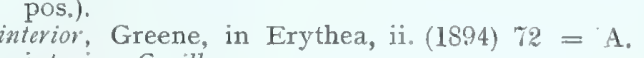
interior, Coville.

lamuinosus, Greene, 1. c. $73=\mathrm{A}$. lanuginosus, $A$. Gray.

stenophyllus, Greene, 1. c. $72=$ A. stenophyllus, A. Gray.
STEPHANIA, Lour. (Menisp.). - Ind. Kew. ii. 991

aculeata, F. M. Bailey, in Dept. Agric. Brisbane Bot. Bull. iii. (1891) 7. - Austral.

africana, Kuntze, Rev. Gen. (1893) 353, sphalm. = Astephania africana, Oliver.

cincinnans, K. Schum. in K. Schum. Es Holls. Fl. Kais. Wilh. Land (1889) 44. - N. Guin.

STEPHANISCUS, Van Tiegh. in Bull. Soc, Bot. Fr. ylii. (1895) $260=$ Loranthus, Linn.

gabonensis, Van Tiegh. 1. c. $261=$ L. ¿abonensis, Engl.

Lecomtei, Van Tiegh. 1. c. ; et in Bull. Mus. Paris, i. (1895) 165. - Afr. trop.

STEPHANODIUM, Poepp. \& Endl. (Chailletiac.). - Ind. Kew. ii. 992

Blanchetianum, Baill. in Mart. Fl. Bras, xii. (1886) 377. - Bras.

estrellense, Baill. l. c. 378. - Bras.

\section{STEPHANODORIA. Greene, in Erythea,} (1895) 12. COMPOSITAE

tomentella, Greene, l.c. $(=$ Xanthocephalun tomentel lum, Robinson). - Am. bor.

STEPHANOLUMA, Baill. Hist. "des pl. xi. (1892) 283 = Sideroxylon, Linn.(Sapot.).

rugosa, Baill. 1. c $=\mathrm{S}$. rugosum, $A . D C$

STEPHANOMERIA, Nutt. (Compos.). - Ind. Kew. ii. 992

tomentosa, Greene, in Bull. Calif. Acad. ii. VI. (1886) 152. - Ins. S. Cruz (Calif.).

STEPHANOSTEGIA, Baill, in Bull. Soc. Linn. Paris, i. (1888) 748; et Hist. des pl. x. (1888) 184: K. Schum. in Engl. \& Prantl, Natürl. Pflanzenfam. iv. 2 (1895) 136. APOCYNEAE.

Hildebrandtii, Baill. ll. cc. - Madag.

STEPHANOTIS, Thou.(Asclep.). - Ind. Kew. ii. 992 .

japonica, Makino, in Tokyo Bot. Mag. vi. (1892) 53. - Japon.

STERGULIA, Linn. (Stercul.), - Ind. Kew, ii 992

appendiculata, $K$. Schum. ex Engl, in Abh. Preuss. Akad. Wiss. (1894) 36 : et in Engl. Pfanzenw. OstAfr. C (1895) 271, t. 29. - Atr. trop. or.

austro-caledonica, Hook. f. in Bot. Mag. (1894) t. 7382. - N. Caled.

Bammleri, K. Schum. in Notizbl. Bot. Gart. Berl. i. (1895) 53, - N. Guin.

Beccariana, Pierre, Fl. For. Cockinch. Fasc. 13 (1889) sub, t. 201, in obs. [Scaphinm Beccarianum, Pierre, 1. c. t $195 \mathrm{cl}$. - Borneo.

cochinchinensis, Pierre, l. c. 12 (1889) 't. 186. Cochinch.

columnaris, Pierre, l. c. Fasc. 13 (1889) sub t. 20?, in obs, - Cochinch.

comorensis. Baill. Hist. pl. Madag., Atlas (1888) t. 65. - Madag.

Conwentzii, K. Schum. in Bot. Fahrb. ix. (1888) 208. - N. Guin.

dongnaiensis, Pierre, Fl. For. Cochinch. Fasc. 13 (1889) t. 202. - Cochinch

Edelfeltii, F. Muell. in Vict. Natural. iii. (Aug. 1886; 47. - N. Guin.

frondosa, Spruce, ex K. Schum. in Mart. F1. Bras. xii. III. (1886) 7 = speciosa, $K$. Schum

gracilipes, Pierre, Fl. For. Cochinch., Fasc. 12 (1888) t. 191B. - Cochinch

Guerichii. K. Schum. ex Engl. in Bot. Fahrb. xix. (1894) I44. - Afr. austro-occ, extratrop.

Harmandii, Pierre, Fl. For. Cochinch. Fasc, 12 (1888) t. 183b. - Cochinch.

Holtzei, F. Muell, in fourn. Roy. Soc. N.S. Wales, xxiv. 1890 (1891) 175; et in Bot. Centralbl. xlv. (1891) 30. - Austral.

hiychnophora, Pierre, Fl. For. Cochinch. Fasc. I3 (1889) t. 200, sphalm. = lychnophora, Hance.

hypochroa, Pierre, l. c. Fasc. 12 (IS85) t. 185. - 


\section{STERCULIA :}

keyensis, W Varb, in Bol Fal, wo xiii. (1S91) 375. -

Kunstleri, King, in foum. As, Soc. Beng. 1x. (1891) 11. 65. - Penins. Mal., Sumatra.

Jissophylla, Pierre, Fl. For. Cochinch., Fasc, 12 1888) t. 188 B. - Cochinch.

IIastersii, Pierre, l.c. t. 183 A. - Cochinch.

Murex, Hemsl. in Kow Bull. (1893) 15e; et in Hook.

Icon. pl. xxiii. (1894) t. 3278. - Transvaal.

oliganthera, F. Muell. in Vict. Natural, iii. (Aug. istio) $49 .-\mathrm{N}$. Caled.

nncinocarpa, F. Muell. \& Forb. l. c. - N. Gtin.

Parkinsoni, F, Muell, in Australas, Fourn. Pham

ii. (Febr, 1887) 43; ct ex Bot, Centralbl. xxxi. (1887) $20 \%-$ N. Brit

pesa, Pierre, Fl. For. Cochinch. Fasc. 1\% (1888) t. 182. - Cochinch.

prurjens, K. Schum, in Mart, Fl. Bras, xii. III, (1886) 8. - Am, austr.

pruriens, K. Schum, in Engl, \& Prantl, Natïrl. Pflanzenfam. iii. 6 (1898) $96=\mathrm{S}$. Ivira, Sw.

quinqueloba, K. Schum. in Bot. Jahrb. xv. (1892)

$135=$ Cola quinqueloba, Garche.

R'x, Mart. ex K. Schum, in Mart, Fl, Bras, xil. III. (1886) 1?, in obs. = Basiloxylon Rex, $K$. Schum.

Shillinglawii, F. Mruell, in Austral. Foum. Pharm. ii. (Feb. 1887) 41 ; ot in Bot. Contralbl. xxxi. (1187) $21,-\mathrm{N}$. Brit.

speciosa, K. Schum, in Mart. Fl. Bras, xii, III. (1886) T. - Bras

stigmarota, Pinne, Fl, For. Cochinch. Fasc. 12 (184's) t. 189. - Cochinch.

subviolacea, $K$ Sclium. in Engl. Pfanzenw. Ost-Afr. C (18:5) 2:1. - Afr, trop. or

Taria, Baill. Hist. pl Madag. Atlas (1888) t. 64. Madag.

Thorelii, Pierre, Fl, For, Cochinch. Fasc, 12 (1888) t. $184 .-$ Cochinch.

translucens, Stapf, in Trans. Linn?. Soc. Ser. II. iv. 18\%4) 136. - Borneo.

STEREOSPERIMUM, Cham. (Bignon), - Ind. Kew ii 094 .

acuminatissimum, $\pi$. Solinm, in Engl. \& Prantl, Natür. Pfanzcnfan iv. 3b (18!5) 243. Kamerun

cinereo-viride, $K$. Sclinum ? c. - Ancrola.

Harmsianum, K. Silnm. l. c. - Afr. centr. bor.

STIERIGMOSTEMON; Bieb, = Sterigma, DC Crucif.

canthocarpun, Kuntze, Rev, Gen. (1891) $36=$ Sterigma acanthocarpum, Fisih. \& $M$ I cy.

aspicum, Kuntze, 1. c. in Act Hort. Petrop. (185i) $169=$ Cheiranthus caspicus, Pall. cutorluplicatum, Kuntze, Rev. Gen. (1891) $36=$ Sterigma contortuplicatum, Boiss.

longistylunl, Kuntze, 1. c。 = S. longistylum, Boiss.

purpurascens, Fiuntze, 1. c. = S. purpurascens, Boiss.

STERIPHE, Phil, (Compos.). - Ind. Kew, ii. 994 cerosa, Phil. in Anal. Unnì. Chil. lxxxvij. (IS94) $678(=$ Grizdelia acerosa, Phil.), - Chili.

Navarri, Phil.l. c.6\% - Chili.

STEUDELAGO, TKuntze, Rev. Gen. (1891) $298=$ Solenandra, Hook, f. (Rubiac.).

ixorodes, Kuntze, 1, c, $=$ S. ixoroides, Hook. $f$

STEUDNERA, C. Koch (Aroid.). - Ind, Kew apitellata, Hook. f. Fl. Brit. Ind. vi. (1893) 521. Burma.

colocasioides, Hook. f. I. c. 520. - Reg. Himal. sesamica, Hook f. l. c. 520. - Assam.

STEVIA, Cav. (Compos.). - Ind. Kew, ii. 995 raccharoides. Fr. Mcigen, in Bot. Fohrb. xvii. (1893) $2 \times 31=$ Nothites baccharoides, DC. . - Chili. Bangii, Rusby, in Mem. Torrey Bot. Chub, iv. (1895) 209. - Bolivia

bicrenata, Klatt, in Bot. Falwo. viii. (1886) 32. Guatem.
STEVIA : -

laxa, Robinson of Seaton, in Proc. Ann. Acad, xxyiii. (1893) 107. - Mexic

madrensis, A. Gray, l. c.xxi. (1S86) 3R2. - Mexic. neglecta, Rusby, in Mem. Torrey Bot. Club, iv. (1895) 209. - Bolivia.

odorata, Hort. Dammer, ex Regel, in Gartenf, xl, (1891) 107 , cum, xylogr. 36. - Hab.

Palmeri, A. Gray, in Proc. Am. Acad. xxi. (1886) 382.-- Mexic.

phlebophylla. A. Gray ex S. Wats. l. c. xxii. (1887) 419. - Mexic.

pinifolia, Phit. in Anal. Mus, nac. Chite (1S91) 37. - Mexic.

Pringlei, S. Wats, in Proc. Am. Acad. xxiii. (18s8) 276. - Mexic.

venosa, A.Gray, l. c. xxi. (1886) 382. - Mexic

STICKMANNIA, Neck. = Dichorisandra, Mihan (Commelin.)

alba, albomarginata, bigoniaefolia, foliosa. Gandichandiana, gracilis, hivtella, inaequalis, incuroa, interrupta, leucophthalmos, mexicana, micans, nosaica, oíalifolia, oxypetala, penduliflora, ferforans, pucta. puberula, pubescins, radicalis, Samdersii, temuior. thyrsiflora. rillosula, Kuntze, Rev. Gen. (1891 $21=$ homonyma ommia Dichorisandrae.

Glaziovi, Taub. in Bot. Jahrb. xv, Beibl. n. 34 1892) $16=$ D. Glaziovii, Taub.

hexandra, Kuntze, Rev, Gen. (18:) $721=$ Dichorisandra Aubletiana, Schult.

mizophora, Kuntze, 1. c. = D. Thizophya, Mart.

STICTOGARDIA, Hallier f, in Bot Jahrb. xviii 18:4) 15?. CON VOLVULACEAE

beraviensis, Halliey f. in Bot. fahrb. xviii. (1894 159 (= Ipomoca heraviensis, Vatke.). - Madag. multiflora, Hallier f. l. c. 160. - Afr, austro-or. tiliaefolia, Hallier f. l. c. 159 (= Rivea tiliafolia, Choisy). - As., Afr, et Amer, trop.

STIGMAPHYLLON, A. Juss, (Malpigh.). Ind. Kew. 11. 996 . ex 7. D. Smith, in Coult. Bot. Gaz. xviii. (1893) 198. - Guatem

Gaz. xvili. (1893) 198. - Guatem.
Lupulus, S. Wats, in Proc. Am. 'Acad, xxi. (1886 461. - Guatem.

trifidum, Niedenzu, in Bot. Falurb. xiv. Beibl. n. 30 (1891) 4. - Bras.

\section{STIGMATOPHYLLUM, Spach = Stigmaphyl} lon, A. Juss. (Malpigh.)

igrescens, Kuntze, Rev, Gen. (1891) $89=$ Banisteria nigrescens, $A$. Fuss.

STILLINGIA. Linn.,(Euphorb.). - Ind. Kew. ji.

icarpellaris, S. Wats, in Proc. Am. Acad. xxi (1886) 455. - Mexic

dentata, Britton \& Rusby, in Trans. N. Y Acad sci. vii. (1887) 14; Coult. in Contrib. U. S. Nat. Herb. ii. (1894) $405=$ Torreyana, S. Wats.

STIPA, Linn. (Gramin.). - Ind, Kew. ii. 998.

Aliciae, Kanitz, Pl. exped. Szechen1i, in As. centr. coll. (1S91) 61 t. $\%$, ji. fig. 4. - China.

arida, M. E. Fones, in Proc. Calif. Acad. Ser. II. v. (1895) 725. - Utah.

avenacioides, Nash, in Bull. Torrey Bot.Club, xxij. (1895) 423. - Florida

caduca, Scribn. ex Vasey, in Contrib. U. S. Nat. Herb. iii. 1 (1892) 54 (= Oryopsis caduca, Beal.). - Montana.

californica, Vasey, ex S. Wats. in Proc. Am. Acad. xxiv. (1889) so, nomen. - Calif.

caucasica, Lipski, in Mem. Soc. hist. nat. Kien, xii (1592) extr. 28 [an seq. ?]. - Ross.

caucasica, Schmalh. in Ber. Deutsch. Bot. Ges. x. 1892) 293 ; ot in Akinfieff, Fl. Caus. centr. (1894) 24. - Reg. Cauc.

charruana, Archaw in Anal. Mus. Nar. BuenosAires iv. (1895) 181, fio. 3.-Urugnay.

olumbiana, Maconn, Catal. Canad. Pl. iv. (1888) 191. - Canad.
STIPA : -

Sodiro Grann. Ecuator (Anal, Univ. Ouito, 1889) 7 , nomen. - Ecuad.

flexuosa, Vasey, in Bull. Torrey Bot. Club, xv. (188s 49 ; et Illustr. N. Am. Grass. i. I. (1890 t. 24. Am. bor. austro-occ

Hackeli, Arechai. in Anal. Mus. Nac. Buenos-Aires, iv. (1891) 179, fig. 11. - UTrug.

Hookeri, Stapf, in foum. Limn. Soc, xxx. (1894) I20. - Tibet.

Hassei, Vasey, in Contrib. U. S. Nat. Herb. i. (1S93) 267. - Calif.

Joannis, Celak. in Formanek, Kétena, i. (185i) 92. - Moravia.

Lasiagrostis, Nichols. Dict. Gard, iii. (1886) 504. Eur.

latifolia, Arechav, in Anal. Mus, Nac. Bupnos-Aires iv. 1895) 181, fig. 4. - Üug.

atifolia, Sodiro, Gram. Ecut. (Anal. Unia'. Quito, 1887) 7, nomen. - Ecuad.

Letourneuxii, Trab. in Bull. Snc. Bot. Fr, xxxyi (1889) 405, Batt. \& Trab, Fl. de l'Algér. [Monoc.] (1895) $165=$ gigantea, Lag.

Lettermani, Vasey, in Bull. Torrey Bot. Club. xiii (1886) 53 . - Idaho.

longitolia, Borb, in Magyar Nözcn. Lapok, x. (1886) 11\%. - Hung.

Macounii, Scribn, in Macoun. Catal. Canad. Pl, v. (1890) $390=\mathrm{S}$. Richardsonii, A. Gray.

pinetorum, M. E. Foncs, in Proc. Calif. Acad. Ser. II. v. (1S.5) 724. - Utah.

Princlei, Scribn ex Vasey, in Contrib. U.S. Nat. Herb. iii. 1 (1892) $5+$ (= Oryzopsis Pringlei, Beal). - Am. bor, austro-occ

rupestris, Phil. in Anal. Mus. nac. Chile (1891) 81 - Chili.

Scribneri, Vasey, Illustr. N. Am. Grass, i. II. (1891) t. 9, - N. Mexic.

Semenowi, Krassn. in Scripta Hort. Univ, Petrop. ii. I. (1887-88) 22. - China

Sodiroana, Hack. \& Sodiro, Gram. Ecuat. (Anal. Univ. Quito, 1889) 7, nomen. - Ecnad.

venusta, Phil. in Anal. Mus, nac. Chile (1891) 81. Am, austro, occ,

Woronini, Krassn. in Scripta Hort. Unir. Petrop. ii. I. (1887-88) 22. - Chira

STIPULICIDA, Michx (Caryophy11.). - Ind. filiformis, Nash, in Bull. Torrey Bot. Club, xxij. (18ษ5) 148 . - Florida.

STISSERA, Linn. = Stapelia, Linn. (Asclep.). acuminala, ambigua, Asterias, atropurpurea, clupeata, comosa, compacta, concinus, conspurcata. deftexa. difecta, dicaricata, fissirostris, flavicomata, fuscata. gemmiftora, glandulifora, glauca, grandiflora, hamata, hircosa, hirsuta, jucenula, lanifera, lepida, lucida. maculosa, marginata, marmorata, Marsonii, mixta, multiflora, mutabilis, nomalis, obliana, orbicularis, pullida, paniculata, patula, pedunculata, picta planiflora, pulchella, pulrinata, quinquencrvis, reflexa, retusa, recoluta, roriftua, rufa, rufescens, nugosa. spectabilis, stellaris, stricta, stygia, tigridia, varicgata, zerrucosa, vetula, Wendlandiana, Kuntze, Rev. Gen. (1891) $421-22=$ homonyma omnia Stapeliae. anguina, Kuntze, 1. c, 421 = Stapelia picta, Donz. aperta, Kuntze, l. c. = Caralluma aperta, $N . E . B r$. articulata, Kuntze, 1. c. = Pectinaria articulata, Haw bisulci, Kuntze, 1. c. = Stapelja variegata, Lim.var. bufonia, Kuntze, 1. c. = S. variegata, Linn, var. caespitos $九$. Kuntze, 1. c. = Duvalia caespitosa, Haz» caudata, Kuntze, 1. c $=$ Brachystelma crispum R. Grals.

ciliata, Kuntze, 1. c. = Diplocyatha ciliata, $N . E$. Bir

concolor, Kuntze, 1. c. = Duvaliae sp.

Curtisti, Kuntze, 1. c. = Stapelia varjegata, Limn. var.

decora, Kuntze, 1. c. $=$ Piaranthus decorus, $N$. E. Br.

depressa, Kuntze, 1. c. = Stapelia patula, Willd.var elegans, Kuntze, 1. c. = Duvalia elegans, Haw. geminata, Kuntze, 1. c。 = Piaranthus serrulatus N. E. Br.

glomerata, Kuntze, 1. c. = Duvalia glomerata,Haw. 
STISSERA : -

hirtella, Kuntze, Rev. Gen. (1891) 421 = Duvalia hirtella, Sweet.

hispidzla, Kuntze, 1. c. = Stapelia glanduliflora, Mass.

inndora, Kuntze, 1. c. = S. variegata, Linn. var. irrorata, Kuntze, 1. c. $=$ S. variegata, Linn. var.

Facquiniana, Kuntze, 1. c. = Duvalia Jacquiniana, Sweet.

lacrigata, Kuntze, 1. C. = D. laevigata, Haw.

laevis, Kuntze, 1. $\mathrm{c} .=$ Stapelia pedunculata, Mass.

mammillaris, Kuntze, 1. c. = Caralluma mammila-

ris, N. E. Br.

mastodes, Kuntze, 1. c. $422=$ Duvalia mastodes, Sweet.

pilifera, Kuntze, 1. c. = Trichocaulon piliferum, N.E. Br.

pruinosa. Kuntze, 1. c: $\Rightarrow$ Caralluma pruinosa, N. E. Br.

pulchra, Kuntze, 1. c. = Stapelia roriflua, facq. radiata, Kuntze, 1. c, = Duvalia radiata, Haw.

ramosa, Kuntze, 1.c. = Caralluma ramosa, N.E. Br veclinata, Kuntze, 1. c. = Duvalia reclinata, Haw. replicata, Kuntze, 1. c. $=$ D. replicata, Sweet.

serrulata, Kuntze, 1. c。 = Piaranthus serrulatus, V. E. Br.

Simsii, Kuntze, 1. c. = Stapelia pedunculata, Mass. sorroria, Kuntze, 1. c. = S. sororja, Mass.

tubercu'ata. Kuntze, 1. c. = Duvalia radiata, Haw.

Woodfordiana, Kuntze, 1. c. = Stapelia picta, Donn.

STIXIS, Lour. = Roydsia, Roxb. (Capparid.) elongata, Baill. in Bull. Soc. Linn. Paris, i. (1887) 655. - Laos.

flaiescens, Baill. 1. c. 654. - Laos.

floribinda, Baill. 1. c. $655=$ Roydsia floribunda, Planch

Hookeri, Baill. 1. c. 6.56, - Cochinch.

mollis, Baill. 1. c. - Cochinch.

obtusifolia, Baill. 1. c. $654=$ Roydsia obtusifolia Hook. f. \& Thoms.

parviflora. Baill. 1. c. 65. = R, parviflora, Griff.

suaveolens, Baill, 1. c. $654=\mathrm{R}$. suaveoleris, Roxb.

STIZOLOBIUM, P. Br. = Mucuna, Adans. (Legumin.).

altissimum, atropurpuroum. Bennettii, bracteatum, capitatum, Championii, coriacenm, fagellipes, giganterm, hirsutum, imbricatum, nucrobotrys, macrocarpunz, macrophylhun, melanocarbum, molle, monospermum, Mutisianum, nireum, noroguineense, platyphyllum, quadrialutum, rostratuni, spurium, stans, Kuntze, Rev. Gen. (1891) $2{ }^{7}{ }^{7}-08^{\prime}=$ homonyma onmia Mucunae.

cyanospermum, Kuntze, 1. c. 208 = M. cyanosperma, K. Schum.

cylindrospernum, Kuntze, 1. c. = Physostigma cylindrospermum, Holmes.

Holtonii, Kuntze, 1. c. :07. - Costa Rica

Funghuhiana, Kuntze, 1. c, 208. - Java.

Kraetkei, Kuntze, 1. c. = M. Kraetkei, Warb.

Psendustizolobinm, Kuntze, 1. c. = M. Macroceratides, $D C$.

sempervivens, Kuntze, 1. c. = M. sempervirens, Hemsl.

STOEBE, Linn. (Compos.) - Ind. Kew. ii. 1001. biotoides. Baker, in fourn. Linn. Soc. xxii. (1887) 494. - Madag.

cryptophylla, Baker, l. c. - Madar.

hilimandscharica, O. Hoffm. in Engl. Pfanzenw. Ost-Afr. C (1895) 411. - Afr. trop. or.

passerinoides, Cordem. FI. Ile Reunion (1895) $534=$ paniculata, Cass.

STOECHADOMENTHA, Linn, Fl, Zeyl. (1747) 194, ex Kuntze, Rev. Gen. (1891) $466=$ Adenosma, R. Br. (Scrophul.).

camphorati, capitata, coevulea, macrophylla, malabarica, microcephala, Muelleri, subrepens, Kuntze, l. c. = homonyma omnia Adenosmatis.

Javanica, Kuntze, 1. c. = A. ovatum, Benth.

STOKESIA, L'Hérit. (Compos.). - Ind. Kew, ii. 1002 .

laevis, Greene, in Erythea, i. (1893) $3=$ cyanea, L'Hirit.
STORMIA, S. L. Moore, in Trans. Linn. Soc. Ser. II. iv. (1895) 300. ANONACEAE.

brasiliensis, S. L. Moore, l. c. (= Hexalobus brasiliensis, A. St. Hil.). - Bras, cent.

STRANVAESIA, Lind1. (Rosac.), - Ind. Kew, inteorifolia Stapf, in Hook. Icon.pl. xxiii. (1894) t. 2295. - Borneo.

STRAUSSIA, A. Gray (Rubiac.).-Ind. Kew. ii. 1002 .

leptocarpa, Hillebr. Fl. Haw. Ist. (1888) 180. Ins. Sandvic.

oncocarpa, Hillebr. l. c. - Ins. Sandvic

STREBLACANTHUS, Kuntze, Rev. Gen. (1891) 497; Lindar, in Eng1. \& Prantl, Naturl. PHanzenfam, iv. 3b (1895) 338. ACANTHACEAE. monospermus, Kuntze, $l l . c c$. - Costa Rica.

STREBLOCHAETA, Hochst. = Danthonia, DC (Gramin.)

Koestlini, "Hochst. » ex Th. Dur. \& Schinz, Consp. Fl. Atr. v. 1894 (1895) 851, in syn. (= S. Costlini, Hochst. $)=$ Danthonia Koestlini, Hochst.

STREBLOSA, Korth. = Psychotria, Linn. (Rubiac.)

urticina, Stapf, in Trans. Linn. Soc. Ser. II. iv. (1894) 182. - Borneo.

STRELITZIA, [Banks] Ait, (Scitam,). - Ind. Kew, ii. 1003.

Niani K, Hort. ex Rev. Hortic. 1x, (188S) 11\%. Hybr. artef.

STREMPELIOPSIS, Benth. (Apocyn.), - Ind. Kew. ii. 1003. pelioides, Benth.

STREPTANTHUS, Nutt. (Crucit.). - Ind.

\section{Kew. ii. 1003}

albidus, Greene, Pittonia, i. (July 18Si) 62 ; et Man Bot. San Franc. Bay (189t) 16. - Calif.

arizonicus, S. Wats, in Proc. Am. Acad. xxv. (1895) 125. - Arizona.

barbatus, S. Wats, l. c. - Am, bor. ouc.

barbiger, Greene, l'ittonia, i. (Oct. 1885) 217 ; Man. Bot. San Franc. Bay (1894) 16. - Calif.

Biolettii, Greene, $l l$. cc. 225 ; et 17. - Calif.

californicus, Greene, Fl. Francisc. (1891) $256=$ Standfordia californica, S. Wats.

campestris, S. Wats. in Proc. Am. Acad. xxv. (1890) 125. - Calif.

Hesperidis, fepson, in Erythea, i. (1893) 14. Calit.

Howellii, M. F. Jones, in Proc, Calif. Acad. Ser. II, v. (18,5) $623=$ Thelypodium Howellii, S. Wats.

inflatus, Greene, Fl Francisc. (1S91) $25 \%=$ Caulanthus inflatus, S. Wats.

Lemmoni, S. Wats, in Proc. Ann. Acad. xxv, (1S90) 125. - Arizona

longirostris, 5. Wats. l. c. 12\%, in obs. (= Arabis longerostris, S. Wats.). - Am. bor. occ

Mildredae, Greene, Fl. Francisc. (1891) 260; et Man. Bot. San Franc. Bay (1894) 16. - Calit

niger, Greene, in Bull. Torrey Bot. Club, xii. (1886) 141 ; et Man. Bot. San Franc. Bay (1894) 16. Calif.

orbiculatus, Greene, Fl. Francisc. (1891) 258 (= S. Broweri, A. Gray, pr. p.). - Calif

Parryi, Grcene, l. c. 25\%. - Calif.

peramoenus, Greene, in Bull. Torrey Bot. Club, xiii. (1886) 142. - Calif.

pulchellus, Greene, Pittonia, ii. (May 1892) 225 ; et Man. Bot. San. Franc. Bay (1894) 17. - Calif. secundus, Greme, Fl. Francisc. (1891) 261 ; at $i .0$. 17. - Calif

suffrutescens, Greente, in Erythea, i. (1893) 147.-

Calif.

versicolor, Greene, l. c. iii. (1895) 99. - Calif.
STREPTOGALYX, Beer (Bromel.) - Ind,

\section{Kew. ii. 1004.}

angustifolius, Mer, in Mart. Fl. Bras, iii. III. (1892) 283. - Bras.

Blanchetii, Baker, Handb. Bromel. (1889) 32. Bras.

floribunda, Mez, in Mart, Fl. Bras, iii, III. (1892) 284 [floribundus| = Aechmea platynema, Baker laxiflora, Baker, Handb. Bromel. (18s9) 31. - Bras longifolia, Baker, l. c. $(=$ Bromilia longifolia. Rudge.). - Guian. gall.

orthopoda, Baker, in Kew Bull. (1892) 198. - Bras. platynema, Lindman, in Kongl. Sv.Vet. Akad. Handl. xxiv. 8 (1891) $37=$ Aechmea platynema, Bakr. podantha, Baker, Handb. Bromel. (1889) $32=$ Portea Glaziovii, Baker.

Poitaei, Baker, l. c.31. - Guian. gall.

STREPTOGARPUS, Lindl. (Gesnerac.). - Ind. Kew. ii. 1004 .

balsaminoides, Engl. Bot, fahrb. xviii. (1894) $\pi$

- Afr. trop. occ.

Bruanti $X$, Hort ex Rer, Hortic. 1xi. (1889) 267. - Hybr. artef.

Dunnii, Mast. in Gard. Chron. (1886) 625: Hookf. in Bot. Mlag. (1856) t. 6903. - Transvaal.

Dycri $X$. W. Wats, in Gard. and For. viii. (18,5) 5. - Hybr. artet.

elongatus, Engl. Bot. Fahrb. xviii. (1894) 76. Afr. rop. occ.

Galpini, Hook. $f$ in fourn. of Hortic. (1891) 388. fig. 76; el in Bot. Mag. (1892) t. 730; W Wats. in Gatrd. Chron. (1892) i. $139 \mathrm{fig} \cdot 24$, Transvaal.

glandulosissimus, Engl. Bot. Falıb. xviii. (1894

78. - Afr. trop. or.

Holstii, Engl. 7. . 7\%. - Afr. trop. or.

kewensis $\chi$, Hort. ex Gard. Chron. (188\%) ii. 240 fig. 61. - H) br. artef.

montanus, Oliver, in H. Fohnston The Kilin. Exped. Append. (1S86) 343 nomen; et in Trans. Linn. Soo Ser, II ii. (1S85) 344. - Afr, trop. or.

rivularis, Engl. Bot. Fahrb. xviii. (1894) 7s. - Afr. trop. or.

saxorum, Engl. l. c. xix. (1894) 154. - Afr. trop. or. Volkensii, Engl. 7.c. 153. - Afr. trop. or.

Watsoni X, Hort. ex Gard. Chron. (1887) ii. 137. 215 fig. 52. - Hybr. artef.

Wendlandii, Hort. Dammann, cx Gartenfl. xli. (1892) 26; W. Wats. in Gard. Chron. (1894) i, 590 ; et ex Hook, f. in Bot. Mag. (1895) t. 7447. - Transvaal.

STREPTOCHAETA, Schrad. (Gramin.). - Ind Kew. i. 1004

Sodiroana, Hack. ex Sodiro, Gram. Euator. (Anal. Unuiv. Quito (1889) j nomen; et in Oest. Bot. Zeitschr.xl. (1890) 111. - Ecuad.

STREPTOGLOXINIA $\times$, Rodigas, in Illustr. Hortic xxxix. (1892) 124. - Gen. hybr. artet. GESNERACEAE.

STREPTOLIRION, Edgew. - Ind. Kew, ii. 1004 .

cordifolium, Kuntze, Rev. Gen. (1891) $722=$ volubile, Edgew.

STREPTOPETALUM, Hochst. (Turneras). Ind. Kew, ii, 1004.

graminifolium, Urban, in Notizbl. bot. Gart. Berl. i. (1895) 31. - Afr. or.

STREPTOPUS, Michx (Liliac.). - Ind. Kew. ii. 1004 .

paniculatus, Baker, in Hook. Icon. pl. xx. (1890) t. 1932. - China.

parviflorus, Franch, in Nonv. Arch. MIus, Paris, Sér. II, x. 1887 (1888) 90. - Tibet.

STRICKL ANDIA, Baker, Handb. Amaryll, (1888) I05. AMARYLLIDEAE.

eucrosioides, Baker, l. c. $(=$ I.eperiza eucrosioides,

Baker). - Ecuad. 
STRIGA, Lour. (Scrophul.). - Ind. Kew。 ii 1004 .

asiatica, Kuntze, Rev. Gen. (1891) 466=densiflora, Benth.

canescens, Engl.Pflanzenw, Ost-Afr. C (1895) 361. - Afr. trop. or.

gesnerioides, Vatke, ex Engl. in Abh. Preuss. Akad. Wiss. (1894) 28, nomen. - Afr. trop.

ansibarensis, Vatke, ex Engl, 1 c. (1894) 28, nomen; Eng1. Pflanzenw. Ost-Afr. A (1895) 13, 74 $=$ pubiflora, Klotzsch.

STROBIDIA, Miq. (Scitam.). - Ind. Kew. ii. $100 \overline{5}$.

conchigera, Kuntze, Rev. Gen. (1891) 698; Baker, in Hook. \pm Fl. Brit. Ind. vi. (1892) 253, in syn. = Alpinia conchifera, Griff.

Mannii, King, ex Baker, in Hook. f. 1. c. 253, in syn. = A. Mannii, Hook. $f_{0}$

oligosperma, Kuntze, Rev. Gen. (1891) 698, in syn. = Alpinia conchifera, Griff.

STROBILANTHES, Blume (Acanth.). - Ind.

\section{Kew ii. luos.}

anamiticus, Kuntze, Rev. Gen, (1891) 498. - Anam.

connatus, Collctt \& Hemsl. in fourn. Linn. Soc. xxviii. (1890) 104 t. 16. - Burma.

Cusia, Kuntze, Rev. Gen. (1891) $499=$ flaccidifolius, Nees.

debilis, Hemsl. in fourn. Linn. Sac. xxvi. (1890) 239. - China.

Dyerianus, Hort. Sander, ex Gard. Chron. (1893) i. 442; et in Rev. Hortic. 1xv. (1893) 201. Ind. or.

Galeopsis, Stapf, in Trans. Limn. Soc. Ser. II. iv. (1894) 215. - Borneo.

gregalis, Collett of Hemsl. in foum. Linn. Soc. xxvii. (1890) 104. - Burma

Henryi, Hemsl. l. c. xxvi. (1890) 240. - China.

hispidula, Baker, l. c. xxii. (1887) 509. - Madag.

integrifolia, Kuntze, Rev. Gen. (1891) $499=$ perfoliatus, T. Anders.

Kinabaluensis, Stapf, in Trans, Limn, Soc. Ser. II. iv. (1894) 214. - Borneo.

latisepalus, Hemsl. in fourn. Linn. Soc. xxvi. (1890) 241. - China

Naumanni, Engl. Bot. Jahrb. vii. (1886) 474 ; et in Forschungsr. Gazelle (1886) 44. - Melanesia.

Nockii, Trim. Handb. Fl. Ceyl. iii. (1895) $31 \mathrm{l}$ t. 70. - Zeylan.

pterygorrhachis, C. B. Clarke, in fourn. Linn. Soc xxv. (1889) 54 t. 25. - Kohima.

recurvus, C. B. Clarke, l. c. 52 t. 24. - Kohima.

reticulatus, Stapf, in Kew Bull. (1894) 347. Ind. or.

urticifolia, Kuntze, Rev. Gen. (1891) $499=$ alatus, Nees.

STROBOPETALUM, N. E. Br, in Kew Bull. (1894) 335 ; K. Schum. in Engl. \& Prantl, Natürl. Pflanzenfam. iv. 2 (1895) 244. ASCLEPIADEAE.

Benti, N. E. Br. Il. cc. 336; et 244. - Arabia.

carnosum, N.E. Br. . c. 390 ; Oliver, in Hook. Icon. pl. xxiv. (1895) t. 2387. - Arabia.

STROGYLODON, Vog. (Legumin. - Ind. Kew ii. 1007 .

Graveniae, Baron \&s Bakr, in Fourn, Bot. xxix. (1891) 74. - Madag.

iderospermum, Corden. Fl. Ile Réminion (1845) 322 [siderospermum]. - Ins, Borbon.

STROMANTHE, Sond. (Scitam.). - Ind, Kew.

ancustifolia, Rusby, in Men. Torrey Bot. Club, iy. (1895) 266. - Bolivia.

papillosa, Petersen, in Mart. Fl. Bras. iii. III. (1890 155. - Bras.

pluriflora, Petersen, ex Warm. in Vidensk. Meddel. naturh. Foren. (1889) 335 (Symb. Al. Bras, centr. xxxi. 905). - Bras.

illosa, Eichl. ex Petersen, in Mart. FI. Bras. iii. III. (1890) $154=$ S. Tonckat, Eichl.
STROMATOCARPUS Kotschoubeyi, Karw. ex Foerst,-Ruempl. Handb. Cacteenk, (1885?) 232 $=$ Anhalonium sulcatum, Salm-Dyck.

STROMBOSIA, Blume (Olacin.). - Ind. Kew. ii. 1007.

lucida, Teysm. E Binn.Crit.overz.Olacin. (1886) 86 - Java.

membranacea, Valeton, . . c. 87. - Java

multiflora, King, in fourn. As. Soc, Beng. lxiv. (1895) 102. - Penins. Mal.

pustulata, Oliver, in Hook. Icon. pl. xxiii. (1894 t. 2299. - Lagos, Sierra Leone.

rotundifolia, King, in Fourn. As. Sor. Bcng. 1xiv. (1895) 103. - Penins. Mal.

STRONGYLOMA, DC. = Nassauvia, Comm. (Compos.).

struthionum, Phil, in Anal. Univ, Chil. Ixxxvii. (1894) 88. - Patag.

STROPHACANTHUS, Lindau, in Eng-1. \& Prantl, Natürl. Pflanzenfam. iv. 3b (1895) 344 $A C A N T H A C E A E$.

coccimus, Lindau, 1. $\mathrm{c}_{0}=$ Dianthera collina, C. $B$. Clarke.

dichotonuts, Lindau, 1. C. = = D. dichotoma, C. B Clarke.

tominalis, Lindau, 1. $\mathrm{c}_{\mathrm{s}}=\mathrm{D}$. terminalis, $C . B$ Clarke.

STROPHANTHUS, DC. (Apocyn.). - Ind. Kew ii. 1007

Aamba, Warb. in Bot. Fahrb. xiii. (1891) 407. 454. - N. Guin.

amboensis, Engl. \& Pax, ex Pax, en Bot. Falirb. xv. (1892) 376; Franch. in Nouv. Arch. Mus. Paris, Sér. III. v. (1893) 289, - Afr. austro-occ. extratrop.

arborcus, Boiv. ex Franch. 1. c. 252, in syn. = Boivini, Baill,

aurantiacus, Blondel, Stroph. comm. Paris (1888) 11, nomen. - Madag. vel Java

Balansae, Franch. in Nouv. Arch. Mus. Paris, Sér. III. v. (1893) 262, t. 17. - Tonkin.

Barteri, Franch. in Morot, Fourn. de Bot. vii. (1893) 323 ; et in Nouv. Arch. Mus. Paris, Sér. III. v, (189.3) 279, t. 11a - Afr. trop. ooc

Boivini, Baill. in Bull. Soc, Linn. Paris, 1. (1888) 757 ; Franch. l. c. 252, t. 7. - Madag.

bracteatus, Franch, in Morot, Fourn. de Bot. vii. (1893) 324; ct l. c. 280, t. 12. - Congo gall.

congoensis, Franch, in Morot, Fourn de Bot, vii. (1893) 302, 324 ; et in Nouv. Arch. Mus. Paris, Sér. III. v. (1895) 288. t. 13. - Congo gall

Courmonti, Sacleux, ex Franch. Il. cc. 300 ou 322, et

286, t. 10. - Afr. trop. or.

ecaudatus, (err. typ. ecandatus) Rolfe, in Bolet. Soc. Brot. xi. (1893) 85. -- Angola.

Emini, Aschers, ex Pax, in Bot. Fahrb. xv. (1892) 366, t. 10 et 11; Franch. in Nowo. Arch. Mus. Paris, Sér. III. v. (1893) $275 .-$ Afr. trop. or.

Fischeri, Aschers. \& $K$. Schum. ex Holmes, in Pharm. Foum. (1893) 868, nomen; et ex Franch. in Morot, fourn. de Bot. vii. (1893) 325. - Afr. trop. or.

gracilis, $K$. Schum. E Pax, ex Pax, in Bot. Fahrb. xv. (1892) 370; Franch. iz Nouv. Arch. Mus Paris, Sér. III, v. (1893) 27\%. - Afr. trop.

ratus, Baill. Hist, des pl. x. (1888) 171 (= Roupellia grata, Hook.). - Afr. trop.

gratus, Franch. in Journ. de Bot. vii. (1893) 321 et in Nouv. Arch. Mus. Paris, Sér. III. v. (1843) $256=$ praec

Grevei, Baill. in Bull. Soc. Linn. Paris, i. (1888) 757 ; Franch. l. c. Sér. III. v. (1893) 254. Madag

intermedius, Pax, in Bot. Fahrb. xv. (1892) 375 Franch, in Nouv. Arch. Mus. Paris, Sér. III.v. (1893) 287. - Angola.

Ledienij, Stein, in Gartenf. xxxvi. (1886) 145, t, 1241; Franch.l.c. 270. - Congo.

Franch. l. c. 270. - Congo. - Reg. Nigrit.

\section{STROPHANTHUS}

minor, Christy, ex Pax, in Bot. Fahrb. xv. (1893) 381, - Reg. Nigrit.

niger, Blondel, Stroph. comm. Paris (1888) 11,nomen. - Hab. ?

ogovensis, Franch. in Morot, fourn, de Bot. vii. 1891 (1893) 324; et in Nowv. Arch. Mus. Paris, Sér. III. v. (1895) 284, t. 15. - Congo gall.

Paroissei, Franch. Il. co. ; et 290, t. 16. Guinea.

parviflorus, Franch. $l l . c c .321$; et 281 , t. $11 \mathrm{~b}$. Angola.

parvifolius, $K$. Schum. in Engl. \& Prantl, Natiirl. Pflanzenfam.iv. 2 (1895) 182. - Angola.

Pierrei, Baill. in Bull. Soc. Linn. Paris, ii. (1894) 1151. - Cochinch.

Preussii, Engl. \& Pax, ex Pax, in Bot. Fahrb. xv. (1892) 369; Franch. in Nowv. Arch. Mus. Paris, Sér. III. v. (1893) 279. - Kamerun.

puberulus, Pax, l. c.378; Franch. l. c. 269. - Ins. Sumbawan.

Rigali, Hort. Paris, ex Pax, l. c. 3S , in obs. Hab.?

scaber, Pax, 1. c. $370=$ gracilis, $K$. Schum. \& Pax.

Schuchardti, Pax, in Bot. Fahrb. xv. (1892) 371 ; Franch, in Nouv. Arch. Mus, Paris, Sér. III, v. (1893) 276. - Angola.

speciosus, Reber, in Der Fortschr. iii. (1887) 299 ; Franch. l, c 287 (= Christya speciosa. Ward \& Haw.) $=$ capensis, $A, D C$.

Tholloni, Franch. in Morot, foum. de Bot. vii. (1893) 299; et l. c. 25\%, t. 8. - Afr. trop. occ

STROPHOSTYLES, Ell. = Phaseolus, Tourn. (Legumin.)

pauciflorus, S. Wats. in A. Gray, Man. Bot. North. U. S. ed. $6(\mathbf{1 8 9 0}) \mathbf{1 4 5}=$ P. pauciflorus, $D C$.

STRUCHIUM, P. Br. = Sparganophorus, Vaill. (Compos.).

sparganophorm, Kuntze, Rev. Gen. (1891) $366=$ S. Vaillantii, Crantz.

STRUTHANTHUS, Mart. - Loranthus, Linn. Selcrorum, Loesen. in Bull. Herb. Boiss. ii. (1894) 536. - Mexic.

STRUTHIOLA, Linn. (Thymelaeac.) - Ind. Kew.ii. 1009 .

amabilis, Gilg, in Engl. Pfanzenw. Ost-Afr. C (1895) 284. - Afr. trop. or.

Bachmanniana, Gilg, in Bot. Fahrb. xis. (1894) 270 ; et in Engl. \& Prantl, Natiirl. PAlanzenfam. iii. 6a (1894) 229. - Afr. austr.

ericina, Gilg, in Bot. Fahrb. xix. (1894) 270. - Afr. trop. or

IIolstii, Engl. 1. c. xvii. (1893) 186, nomen = Gnidia Holstii, Engl.

kilimandscharica, Gilg, in Engl. Pfanzenw. OstAfr. C. (1895) 284. - Afr. trop. or.

Rustiana, Gilg, in Bot. Fahrb. xix. (1894) 270. Afr. austr. et austro-occ.

Stuhlmannii, Gilg, in Engl. Pfanzenw. Ost-Afr.C (1895) 283. - Afr. trop. or.

usambarensis, Engl. Bot. fahrb. xix. (1894) 269. - Afr. trop. or

STRYCHNOS, Linn. (Logan.) - Ind. Kew. ii. 1009 .

aculeata, Soleved. in Bot. Fahrb, xvii. (1893) 544 et in Engl. \& Prantl, Natïrl. Pflanzenfan. iv. 2 (1892) 41. - Afr, trop. occ,

Afzelii, Gilg, in Bot. Fahrb. xvii. (1893) 572. Sierra Leone.

alnifulia, Baker, in Kew Bull. (1895) 150. - Lagos. angolensis, Gilg, in Bot. Fahrb. xvii. (1893) 5\%1. Angola.

Bancroftiana, F.M. Bailey, Rep. Exped. BellendenKer (1889) 49; et Syn. Queensl. Fl. Suppl. iii (1890) 47. - Austral.

Baroni, Baker, in fourn. Linn. Soc. xxii. (1887) 504. - Madag.

Barteri, Solered, in Bot. Fahrb. xvii. (1893) 556 ; Oliver, in Hook. Icon. pl. xxiii. (1894) t. 2284. Afr, trop. occ 


\section{STRYCHNOS}

Buettneri, Gilg, in Bot. Fahrb. xvii. (1893) 5\%4.Afr. trop.

Burtoni, Baker, in Kew Bull. (1895) 98 = S. Quaqua, Gilg.

cerasifera, Gilg, in Engl. Pfanzenw. Ost-Afr. C (1895) 311 . - Afr, trop. or.

chrysocarpa, Baker, in Kew Bull. (1895) 92. - Afr. trop. occ.

cocculoides, Baker, l.c. - Angola.

distichophylla, Gilg, in Engl. Pfanzene. Ost-Afr. C (1895) 310. - Afr. trop. or.

Engleri, Gilg, an Bot. fahrb. xvii. (1893) 568 ; et ex Engl. in Abr. Preiss. Akad. Wiss. (1894) 25, 34, nomen. - Afr. trop.

Fischeri, Gilg', in Bot. Fahrb. xvii. (1893) 565.Afr. trop. or

floribunda, Gilg. l. c. 566. - Reg. Mossamb.

ericetina, Barb. Rodr. [Herb. Mus. Bot. Amaz, n 160] Vellosia, 1885-88, Sec. edic. (1891) 34 t. 3, fig. A. - Bras.

gigantea, Barb. Rodr. ll.cc.t. 4, fig. a. - Bras.

gracillima, Gilg, in Bot. Fahrb. xvii. (1893) 573. Afr. trop.

Guerkeana, Gilg, in Engl. Pflanzenw. Ost.Afr. C (1895) 311. - Afr. trop. or.

guianensis, Baill. Bot, medic. [Phaner.] (1884) 1219. - Guian.

Henningsii, Gilg, in Bot. Fahrb. xi i.(1893) 569. Afr, austro-occ, extratrop.

Henriquesiana, Ḋaker, in Bolet. Soc. Brot. xi. (1893) 86. - Ango!a.

Henriquesiana, Gilg, in Notizbl. Bot. Gart. Berl. i. (1895) 75. - Angola.

Holstii, Gilg, ex Engl. in Abh. Preuss. Akad. Wiss. (1894) 36 ; et in Engl. Pflanzenw. Ost-Afr. C. (1895) 310. - Afr. trop. or

kauichana, Barb. Rodr. [Herb. Mus. Bot. Amaz. n. 202| Vellosia, 1885-88, Sec. edic. (1891) 3\% Bras. bor.

laxa, Soleved. in Bot. Fahrb. xvii. (1893) 554. Reg. Nigrit.

lethalis, Barb. Rodr. [Herb. Mus. Bot Amaz. n. 713] Vellozia, 1885-88, Sec edic. (1891) 39. - Bras. bor.

loandensis, Baker, in Kew Bull. (1895) 97. - Angola.

longecaudata, Gilg, in Bot. Fahvb. xvii. (1893) 570. - Reg. Mossamb.

Iucens, Baker, in Kew Bull. (1895) 9\%. - Angola

macrophylla, Barb. Rodr. Herb. Mus. bot. Amaz. n.

249| Vellosia, 1885-88, Sec, ediç. (1891) 33 t. 11 a.

- Bras. bor.

manacensis, Barb. Rodr. Il. cc. [n. 257] et 37. Bras. bot.

mattogrossensis. S. L. Moove, in Trans. Linn. Soc. Ser. II. iv. (189\%) 392. - Bras.

microcarpa, Baker, in Kew Bull. (1896, 97. Angola.

Moloneyi, Baker, l. c. - Afr. trop. occ.

nigritana, Baker, l. c.-Afr. trop. occ.

Miniungassamba, Gilg, in Notizbl. Bot. Gart. Berl, i. (1895) 77. - Angola.

occidentalis, Solered. in Engl, \& Prantl, Natürl. Pfanzenfam iv. 2 (1892) 40. - Afr, trop. occ.

panganensis, Gilg, in Engl. Pflanzenw. Ost-Afr. C (1895) 311. - Afr. trop. or.

papilosa, Barb. Rodr. [Herb. Mus. bot. Amaz, n. 680] Vellosia, 1885-88, Sec. ediç. (1891) 36 t. 4 fig. b. - Bras

pungens, Soleved. in Bot. Fahro. xvil. (1893) 554: et in Engl. \& Prant, Natiirl. Pfanzenfam. iv. 2 (1892) 40. - Afr. trop.

Quaqua, Gilg, in Bot. Fahró. xvii. (1893) 567.Reg. Mossamb.

rivularia, Barb. Rodr. [Herb. Mus. bot. Amaz. n. 698| Sec. ediç. (1891) Vellosia, 1885-88, 35 t. 2, fig. b et 4 fig. c. - Bras.

Schweinfurthii, Gilg, in Bot. Fahrb. xvii, (1893) 568. - Congo bor

sennensis, Baker, in Kew Bull. (1895) 97.-Zambes, splendens, Gilg, in Bot, fahrb, xvii, (1893) 571. Sierra Leone.

Stuhlmannií, Gilg, l. c. 570. - Afr. trop.

suaveolens, Gilg, l. c. 566 . - Congo. bor.

subscandens, Baker, in Kew Buil. (1893) 96. Angola.

\section{STRYCHNOS}

Thonningii, Soleved, in Engl. \& Prantl, Natiirl. Pfanzenfan iv. 2 (1892) 40 (= S. micrantha, Thw, ) - Zeyl

tomantinensis, Barb. Rodr. [Herb. Mus. bot, Amaz. n. 714] Sec. ediç. (1891) Vellosia, 1885-88, 38. Bras, bor.

Tonga, Gilg, in Bot. Fahro, xvii. (1893) 575. Reg. Mossamb.

triclisjoides, Baker, in Kew. Bull. (1895) 98. - Afr. trop. occ

Urbanii, Barb, Rodr. [Herb. Mus. bot. Amaz, n. 128] Sec. ediç. (1891) 38 t. 4 fig. a. - Bras.

usambarensis, Gilg, ex Engl. in Abr. Preuss. Akad. Wiss. (1894) 36 ; et in Engl. Pfanzenw. Ost-Afr. C (1895) 311 - Afr trop or.

Vogelii, Baker, in Kew. Bull. (1895) 96. - Afr. trop. occ

Volkensii, Gilg, ex Engl. in Abh. Preuss. Akad. Wiss. (1894) 25 ; in Notizbl. Bot. Gart. Berl. i. (I895) 76: et in Engl. Pflanzenw. Ost-Afr. C (1895) 311. - Afr. trop. or.

Wakefueldi, Baker, in Kew Bull. (1895) $98=$ Engleriana, Gilg.

Welwitschii, Gilg, in Bot. Jahrb. xvii. (1893) 573. - Angola.

xerophila, Baker, in Kew Bull. (1895) $98=\mathrm{S}$ Unguacha, $A$ : Rich.

zizyphoides, Baker, l. 0.96, - Afr. trop. or.

STUEBELIA, Pax, in Bot. Jahrb. ix. (1888) 89 $C A P P A R I D E A E$

nitida, Pax, $l$. c. - Columb.

STUHLMANNIA, Taub, in Engl. Pflanzenw, Ost-Afr. C (1895) 201. LEGUMINOSAE.

Moavi, Taub. l. c. - Afr. or.

STYCHOPHYLLUM bryoides, Phil. in Anal. Mus, nac. Chile (1891) 7 , in syn. = Pycnophyllum molle, Remy.

STYLARTHROPUS, Baill. in Bull. Soc. Linn Paris, ii. (1890) 822; et Hist. des pl. x. (1890) 437 = Whitfieldia, Hook. (Acanth.).

Brazzaei, Baill. 1. c. 823. - Congo gall.

Preussii, Lindau, in Bot. Jahrb. xx. (1894) 12. Afr. trop. occ.

Stuhlmanisi, Lindau, 1. c. 11. - Afr. trop̀. or.

tenuiflora, Baill. in Bull. Soc. Linn. Paris, ii. (1890) 823. - Congo gall.

Tholloni, Baill. 1. c. - Congo gall.

STYLIDIUM, Sw. (Stylid.). - Ind. Kew. ii. 1011 Merrallii, F. Muell. in Vict. Naturalist, v. (Oct. 1888) 76 (= Candollea Merrallii. F. Muell.). Austral.

vitiense, Th, Dur, ex Drake, Ill. Fl. Ins. Pacif. (IS86) 184 (= Marlea vitiensis, Benth.). - Ins. Pacif.

STYLOCHITON, Lepr. (Aroid.), - Ind. Kew. ii 1012

angolensis, Engl. Bot, fahँ, xv, (1892) 465. Angola.

maximus, Engl. l. c. 466. - Afr. trop: austro-or.

STYLOCLINE, Nutt. (Compos.). - Ind. Kew, ii 1012 .

arizonica, Coville, in Proc, biol, Soc. Wast. vii. (1892) 79. - Arizona.

STYLOCONUS. Baill. Hist, des pl. xiii. (1895) 75. AMARYLLIDEAE.

canescens, Baill. l.c. (= Blancoa canescens, Baill. $)$. - Austral.

STYLOCORYNE, Cav. = Randia, Houst. (Rubiac:).

campaniflora, K. Schum. in Engl. \& Prantl, Natürl. Pflanzenfam. iv. 4 (1891) $108=\mathrm{R}$. campaniflora, Hook. $f$.

nigrescens, Warb, in Bot. Jahrb. xiii. (1891) 432, in obs. (= Tarenna nigrescens, Warb.). - N. Guin. Wallichii, K. Schum. in Engl. \& Prantl, Natürl. Pflanzenfam. iv. 4 (1891) $108=\mathrm{R}$. Wallichii, Hook. $f$.
STYLONCERUS, Spreng. = Angianthus, WendI. (Compos.).

amplexicaulis, brachypappus, Cunninghamit, demissus, Drummondii, eviocephalus, globifer, microcephalus, Milnei, phyllocephalus, platycephalus, plumiger, Preissianus, pusillus, pygmaeus, strictus, tenellus, tomentosus, Kuntze, Rev. Gen. (1891) $367=$ homonyma omnia Ancianthi.

micropodes, Kuntze, 1. c, = A. micropoides, Benth myosurodes, Kuntze, 1.c. $=$ A. myosuroides, Benth. phyllocalymneus, Kuntze, 1.c. = A. Pleuropappus, Benth.

STYLONEMA, Kuntze. Rev, Gen. (1\&91) $36=$ Syrenia, Andrz. (Crucif.).

bithynzcum, Kuntze, 1, c. = Erysimum cuspidatum, $D C$.

quadrangulum, Kuntze, 1. c. = Syrenia sessiliflora, I dedeb.

STYLOPHORUM, Nutt. (Papav.). - Ind. Kew ii. 1012

lanceolatum, Yatabe, in Tokyo Bot. Mag. vi. (Sept. 1890) 308. - Japon

STYLOSANTHES, Sw. (Legumin.). - Ind. Kew ii. 1013 .

Bangii, Taub, ex Rusby, in Mem. Torrey Bot. Club, iv. (1895) 206. - Boliv,

biflora, Britton, Stern. \& Pogg. Prelim. Catal. (1888) 13; Taub. in Verh. Bot. Ver. Brand. xxxii. $(1890) 25=$ elatior, $S w$

dissitifora, Robmson \& Seaton, in Proc. Am. Acad. xxviii. (1893) 105. - Mexic

hamatr, Taub. in Verh. Bot. Brand. xxxii. (1890) 22 ; et in Bull. Herb. Boiss. iii. (1895) $614=$ procumbens, Sw

mexicanus, Taub. l. c.21.- Mexic

Pohliana, Taub. . c. 29.-Bras.

sundaica, Tawb. l. c.21 (=S.muronata, Miq.). Archip. Sundaic.

sympodialis. Taub. l.c. 19.- Ecuad.

STYPA, «L » ex St Lacer, in Cariot, Etud, des $f$ éd. 8 ii. (1889) $895=$ Stipa, Linn. (Gramin.).

STYPHELIA, Sw. (Epacrid.). - Ind, Kew. ii 1018

ericifolia, F. Muell, Sec. Cenc. Austral. Pl. (1889) 180 (= Pentachondra evicifolia, Hook. f.). Tasman.

Kingiana, F. Muell. in Vict. Natural. x. (Sept. 1893) 78 ; et isz Bot. Centralbl. 1vi. (1893) 124. Austral.

malayica, Drude, in Engl. \& Prantl, Natürl. Pflanzenfam. iv. I (1889) 78 (= Lencopogon malayamus, Jack). - Austral.

Milligani, F. Muell. Sec. Cens. Austral. Pl. (1889) 178; in Papers and Proc. Roy. Soc. Tasm. (189192) 15 ; et in Bot. Centralbl. xlix. (1891) 29 (= Pentachondra verticillata, Hook. f.). - Tasman.

STYRAX, [Tourn,| Limn. (Styrac.). - Ind. Kew. ceramensis, Warb. in Bot. Fahrb. xiii. (1891) 402, $454-$ N. Guin

dealbata, Guerke, in Engl. \& Prantl, Natürl, Pflanzenfam. iv. I. (1891) $178=\mathrm{S}$. Benzoin, Dryand. conterminum, 7. D. Smith, in Coult. Bot. Gaz. xviii. (1893) 5. - Guatem

glabrata, Warb. in Bot. fahrb. xiii. (1891) 482. N. Guin.

guatemalensis, 7. D. Smith; in Coult. Bot. Gaz. xv, (1890) 2\%. - Guatem.

jaliscana, S. Wats, in Proc. Am. Acad. xxvi. (1891) 144. - Mexic.

peruviana, Zahlbr, in Annal. Naturh. Hofmus. Wien, ii. (1842) 4. - Peruv

portoricensis, Knig \& Urban, $2 n$ Bot. Fahrb. xy. (1893) 337. - Ins. Puerto-Rico.

SUAEDA, Forsk. (Chenopod.). - Ind. Kew. ii. 1015

brevifolia, Ptril. in Anal. Univ. Chil. xci, (1895) 432 - Chilî.

cochlearifolia, Woloszczak, ex Stapf, in Denkscht. Akad. Wien, ii. (1886) 7. - As. occ. 


\section{SUAEDA}

Arequine Pittonia, i (Mar. 1839, 264. Coult in Contrib. U. S. Nat. Herb. ii. (1894) 366 $=$ Torreyana, S. Wat

multiflora, Phit. in Anal. Univ. Chil. xci. (1895) 430 , - Chili.

arvifolia, Phil. l, c. 431. - Chili.

tenuifolia, Phil. . c, 432. - Chili.

SUCCISA, Neck. = Scabiosa, Tourn. (Dipsac.). ustralis, Borb. Geogr. atq. Enum. pl. Comit. Castrif. (1887) $187=$ S. australis, Wulf.

Cariateana, Maris, in Bolet. Soc. Brot. viii. (1890) 147. - Lusit

Pefteri, Kern. \& Murb, ex Murb. in Lunds Univ. Arsskrift., xxvii. v. (1892) 112. - Herceg

SUCCISELLA, G. Beck, Fl. Nied.-Oest. ii, II. (1893) $1145=$ Scabiosa, Tourn. (Dipsac.)

inflexa, G. Beck, 1. c. = S. australis, Wuif.

SULLIVANTEA, Torr. \& Gray (Saxifr.). 一 Ind. Kew ii. 1017.

Kew. 11. Coult. Bot. Gaz xvii. (1892) $421=$ Heuchera Hapemani, Coult. \& Fisher.

Sullicantii, Britton, in Mem. Torrey Bot. Club, v. (1894) $1 \pi \mathrm{s}=\mathrm{S}$. Ohionis, Torr. E Gray

SUNAPTEA, Griff, = Vatica, Linn, (Dipteroc.). borneensis, Heim, Recherch. Diptéroc. (1892) 109 $=\mathrm{V}$. borneensis, Burk.

Bureavi, Heim, 1. c. - As, trop.

faginea, Heim, 1. c. $\$ 9=$ Vatica faginea, Dyer.

Teysmannii, Heim, 1. c. $100=$ V. Teysmannii, Burk.

Urbani, Heim, 1. c. 116. - Borneo.

SUNAPTEOPSIS, Heim, Recherch, Diptéroc. (1892) $92=$ Vateria Linn. (Dipteroc

jucunda, Heim, l, c. = V. jucunda, Thw.

SUREGADA, [Roxb.] = Gelonium, Roxb. (Euphorb.

africana, Kuntze, Rev. Gen. (1891) 619 = G. africanum, Mrucll. Arg.

bifaria, Kuntze, 1. c. = G. bifarinm, Roxb.

comorensis. Baill, in Bull. Soc. Linn. Paris, ii. (1891) 978. - Ins. Comor.

Zunccolata, Kuntze, Rev. Gen. (1891) $619=$ Gelonium lanceolatum, Willd.

oxybhylla, Kuntze, I. c. = G. oxyphyllum, Miq.

SURENUS, Rumpf = Cedrela, P. Br. (Meliac.). angustifolia, bogotensis, fussilis, Glaziovii, guianensis, inodora, Kotschyi, montanu, paraguariensis, serrulata, sinensis, Teysmannii, Toona, Velloziana, Kuntze, Rev. Gen.(1891; 111 = homonyma omnia Cedrelae

australis, Kuntze, 1. c. = C. Toona, Roxb,

Brownii, Kuntze, 1. c. = C. odorata, Limn.

febrifuoa, Kuntze, 1. c. = C. Toona, Roxb.

glabra, Kuntze, 1. c. = C. Toona, Roxb.

mexicana, Kuntze, 1. c. = Swietenia humilis, Zuoc.

microcarpa, Kuntze, 1. c, = C. Toona, Roxb.

servata, Kuntze, 1. $\mathrm{c}$. = C. Toona, Roxb.

celutmi, Kuntze, 1. c. = Chickrassia tabularis, $A$.

SURINGARIA. Pierre, in Bull. Soc. Linn. Paris, i. (1886) 6i5. MIYRTACEAE

cambodiana, Pierre, l. c. 636. - Cambod.

SU'FERA, Roth = Chaenostoma, Benth. (Scrophul.).

aithiopica, Kuntze, Rev. Gen. (1891) $467=\mathrm{C}$ aethiopicum, Benth,

affinis, Kuntze, 1, c. $=$ C. affine, Bent7 .

calvcina, Kuntze, 1, c. = C. calycinum, Benth

canpanulata, Kuntze, I. c. = C. campanulatum, Benth.

cephalotes, Kuntze, 1. C. $=$ C. fastigiatum, Benth.

Cordata, Kuntze, 1. c. = C. cordatum, Benth.

cuntcata, Kuntze, 1. c. = C. cuneatum, Benth.

ionudata, Kuntze, 1. c. = C. denudatum, Benth.

foribunda, Kuntze, 1. c. = C. floribundum, Benth.
SUTERA : - -

glabrata, Kuntze, Rev. Gen, (1891) $467=$ Chaem nostoma glabratum, Benth.

halimifolia Kuntze, 1, c. = c. halimifolium, Benth. integrifolia, Kuntze, 1. c. = C. integrifolium, Bmth. laxiflora, Kuntze, 1. c. = C. laxifforum, Benth. linifolia, Kuntze, 1. c. = C. linifolium, Benth. marifolia, Kuntze.1. c. = C. marifolım, Benth. natalensis, Kuntze, 1. c, = C, natalersis, Benth. opfositifolia, Kuntze, 1. c. = C. hispidum, Benth. pauciflora, Kuntze, 1 c. = C pauciflorum, Benth. podunculosa, Kintze, I. c. = C. pedunculosum, Benth.

polyantha, Kuntze, 1. c. = C. polyanthum, Benth. procumbens, Kuntze, 1. C. $=$ C, procumbens, Benth punila, Kuntze, 1. c. = C. pumilum, Bentr racemosa, Kuntze, 1. c. = C. racemosum. Benth. revoluta, Kuntze, 1. c. = C. Tevolutum, Benth. rotundifolia, Kuntze, 1. $\mathrm{C}_{0}=\mathrm{C}$. rotundifolium, Benth subspicata, Kuntze, 1, c. = C. subspicatum, Benth

SUSUM, Blume (Flagellar.).- Ind. Kew. ii. 1017 malayanum: Planch. ex Hook, f. Fl. Brit. Ind. vi. (1892) 391 (= Vevatronia malayana, Miq.). Malaya

SWAINSONA, Salisb. (Legumin.), - Ind. Kew. ii. 1018

atrococcinea, Carriore, in Rev. Hort. (1887) 275 [Swainsonia]. - Form. hort.

Beasleyana, F. Muell. in Chem. and Drug. Austral. (April 188i) 84. - Austral.

cyclocarpa, F. Muell in Vict. Natural, viii. (Jan 1892) 136: et in Bot. Centralb?. xlix. (1892) 350. - Austral.

Forresti, F. Muell, in Vict. Natural, viii. (Jan. 1892) 131, nomen. - Austral.

Kingii, F. Muell. in Trans. and Proc. Roy Soc. Vict. xxiii. (Apríl 1887) 53, - Austral.

salsula, Taub. in Engl. \& Prantl, Natürl. Pflanzenfam. iii. 3 (1894) $281=$ Sphaerophysa salsuJa, $D C$.

SWARTzIA, Schreb. (Legumin.). - Ind, Kew. ii. 1018 .

chrysantha, Barb. Rodr. [Herb. Mus. Bot. Amaz.n. 14:3) Vellosia, 1885-88, Sec, ediç. (1891) I9 t. 7 , C [non t. 9]. - Bras.

SWEERTIA, St. Lager, in Cariot. Etud. des fl. éd. \&. ii. (1889) $58 \%=$ SWEERTIA. Koch = Swertia, Linn. (Gentian.).

SWEETIA, Spreng. (Legumin.). - Ind. Kow. ii. 1019.

fallax, Taub. in Flora, Ixxv. (1892) 82. - Bras.

SWERTIA, Linn. (Gentian.). - Ind. Kew. ii. 1019.

affnis Knob1. in Bot. CentraIb1. 1x. (1894) $394(=$ Ophetia affinis, Wight \& Arn.). - Affinis.

bella, Hennsl. in fourn. Linm. Soc, xxvi. (1890) 138. - China.

bifolia, Batalin, in Act. Hort. Petrop. xiii. (1894) 378. - China.

brachyanthera, Knobl. in Bot. Centralb1. 1x. (1894) $388^{\prime}=$ Pleurogyne brachyanthera, C. B. Clarke. carolinensis, Baill. ex Gilo, in Enol. \& Prantl, Natïrl. Pfanzenfam. iv, 2 (1895) 88 [Sweertia] (= Frasera carolinensis, Walt.). - Carolina.

Clarke, Knobl. in Bot. Centralbl. 1x. (1894) $338=$ Plevrogyna Thomsoni, C. B. Clarke.

coerulescens, Gilg, in Engl, \& Prantl, Natiirl. Pfanzenfanz iv 2 (1895) \&S $(=0$ ophelia coevulescens, Zoll. \& Mor..), - Java.

corymbosa, Knobl. in Bot, Centralb. 1x. (1894) 394 = corymbosa, Wight.

Davidi, Franch. in Nouv. Arch. Mus, Paris, Sér, II. x. (1887-88) 62. - Tibet.

dimorpha, Batalin, in Act. Hort. Petrop. xiii. (1894) 379. - China.

Eminii, Engl. Pfanzenv. Ost-Afr.C (1895) 314. Afr. trop, or

Haussknechtii, Gilg, in Enol. \& Prantl, Natiirl. Pfanzenfan iv, 2 (1895) 88 ( $=$ S. coentlea, Hausskn.) [Sweertia]. - Reg. Himal.

\section{SWERTIA}

kilimandscharica, Engl. in Abh. Prenss. Akad. Wiss. 1891 (1892) 339. - Afr, trop. or.

Lastii, Engl. l. c. 337. - Afr, trop, or.

Lubahniana, Engl. in Abh. Preuss, Akad. Wiss, 1891 (1892) 338, in obs. (= Pleurogyna Lubahniana, Vatke). - Madag:

minor, Knobl. 1. c. = Pleurogyna minor, Benth. \& Hook. $f$.

multicaulis, Engl, ex Gilg, in Engl. \& Prantl. Natiirl. Pflanzenfam.iv. 2 (1895) 88 [Sweertia|. - Abyss.

oculata, Hemst. in fourn. Linn. Soc. xxvi. (1890) 140. - China.

polynectaria, Gilg, in Eng1. \& Prantl, Natür1. Pflanzenfam. iv. 2 (1895) $88=$ decumbens, $V a h l$.

punicea, Hemsl. l. c. - China

purpurascens, Boiss. Fl. Or. Suppl. (1888) $34 \%(=$ Ophelia purpurascens, Don). - Afghan.

Richardi, Engl. in Abh. Preuss. Ahad. Wiss. 1891 (1892 338. - Abyss.

spathulata, Knobl. in Bot. Centralb1. 1x (1894) 388 = Pleurogyna spatulata, Kern.

striata, Collett \&f Hemsl. in fourn. Linn. Soc. xxviii. (1890) 91. - Burma

stricta, Collett \& Hemsl. l. c.-Burma.

tibetica, Batalin, in Act. Hort. Petrop. xiv. (1895) 174. - Tibet.

usambarensis, Engl. in Abh. Preuss. Akad. Wiss. (1894) 59; el Pflanzenw. Ost-Afr. C (1895) 314. Afr. trop. or.

Wattii, C. B. Clarke, in fourn. Linn. Soc. xxv (1889) 47 t. 21, - Jakpho [Ind. or.]

Welwitschii, Engl, in Abh. Preuss. Akad. Wiss. 1891 (1892) 339. - Angola.

SWIETENIA, Jacq. (Meliac.). - Ind. Kew. ii. 1020

macrophyila, King, in Hook, Icon, pl, xvi. (1886) t. 1550. - Honduras.

SYAGRUS, Mart. = Cocos, Linn. (Palm.).

Chavesiana, Barb. Rodr. Herb Mus. bot. Amaz. n. 267] Pl. no\%. Fard. bot. Rio. (1891) $108=\mathrm{C}$ Chavesiana, Barb, Rodr.

SYGOCARPUS, Britton, in Bull. Torrey Bot. Club, xiv, (1887)143. ANACARDIACEAE.

Rusbyi, Britton, l.c. (= Guarea trichilioides, Linn.) - Am. austr.

SYCOPHILA, Welw. ex Van Tiegh. in Bull. Soc Bot. Fr. xli. (1894) 485 = Loranthus, Linn. combrctoides, Welw, 1. c. - Angola.

Mannii, Van Tiegh. 486, 543 (1894) $543=\mathrm{L}$. Mannii, Oliver.

ternata, Van Tiegh. 1. c. - Ins. S. Thom.

SYCOPSIS, Oliver (Hamamel,). - Ind. Kew, ii

1020 .
sinensis, Oliver, in Hook. Icon. pl. xx. (1890) t. 1931. - China.

SYKESIA, Arn. = Gaertnera, Lam. (Logan.), arenaria, calycina, edentata, grisea, hongkongensis, lanceolata, longifolia, macrobotrys, macrostipula, oborata, oxyphylla, paniculata, pendula, phyllosepala, phyllosiachya, rosea, rotundifolia, sphaerocarpa, ternifolia, vaginata, viminea, Zollingeriana, Kuntze, Rev. Gen. (1891) 425-26= homonyma ommia Gaertnerae.

acuminat , Kuntze, 1. c. $325=\mathrm{G}$. Koenigii, Wight. crassifolia, Kuntze, 1. c. = G. crassiflora, Boj. cuneifolia, Kuntze, 1. c. = Chasalia divaricata $D C$.

Funghukniana, Kuntze, 1. c. = Gaertnera Koeningii, Wight.

phanerolebia, Kuntze, 1. c. = G. phanerophlebia Baker.

psychotriodes, Kuntze, 1. c. = G. psychotrioides, Baker.

vaginans, Kuntze, 1. c. = G. Koenigii, Wight.

SYMBEGONIA, Warb. in Eng1. \& Prant1, Natürl. Pflanzenfam iii 6a (1894) 149. BEGONIACEAE fulvo-villosa, $W$ arb. l. c. - N. Guin. 
SYMBOLANTHUS, G. Don = Lisianthus, Linn. (Gentian.)

aniomalus, Gilg, in Eng1. \& Prant1, Natürl. Pflanzenfam. iv. $2(1895) 99=\mathrm{L}$. anomalus, $H . B$. \& $K$.

calygomus, Gilg. 1. c. = L. calygonus, Ruiz \& Pav.

daturoides, Gilg, 1. c. = L. daturoides, Griscb.

Sizebelii, Gilg, 1. c. - Am, austr.

rasculosus, Gilg, 1. c. = L. rasculosus, Griseb.

SYMPETALEIA, A. Gray (Loas.). - Ind. Kew. ii. 1021.

rupestris, A. Gray, ex S. Wats, in Proc. Am. Acad. xxiv, (1859) 50 (= Loasella rupestris, Baill.) T.S. Brandeg, in Proc. Calif. Acad. Ser. II. ii. (1887) 159. - Calif. austr.

SYMPHONIA, Linn,(Guttif.), - Ind, Kew。 ii 1021.

gabonensis, Pierre, ex Vesque, in DC. Monog. Phan. viii. (1893) 231, in syn. = giobulifera, $\operatorname{Lim}$,

Hildebrandtii, E. G. Baker, in fourn. Bot. Xxxii. 1894) 362. - Madag.

microphylla, Benth. E Hook.f. ex-Vesque, in DC. Monog. Phan, viii. (1893) 232 (= Chrysobia microplyylla, Cambess.). - Madag. oligantha, E. G. Baker, in fourn, Bot. xxxii. (1894)
36. - Madag.

SYMPHOREMA, Roxb.(Verben.), 一 Ind, Kew ii. $10 \% 1$.

Cumingianum, Briq, in Engl. \& Prantl, Natiml. Pfanzenfam, iv. 3a (1895) 180. - Ins. Philipp.

SYMPHORIGARPUS, Dill. ex Juss. (Caprifol.) - Ind. Kew. ii. 1021.

antus. Hort. ex Hamb. Gart. und Blumenz. (1888) acutuls, Hort. ex Hamb.
$562=$ mollis, Nutt.

Heyeri, Dippel, Handb. Laubholzk, i. (1889) 281 , fig. 187; Koehne, Deutsche Dendrol. \{1893\} 358 = occidentalis, Hook

pauciflorus, Britton, in Mem. Torrey Bot. Club, v. (1894) 105. - Am. bor.

Symphoricarpos, MacMill, in Bull. Torrey Bot. Club, xix. (1892) $15=$ orbiculatus, Monch.

SYMPHYANDRA, A. DC. (Campanul.). - Ind Kew. ii. 1021.

pangaea, Heldr. E Charrel [Nadji] in Oest. Bot Zeitschr. xlii. (1892) 341. - Maced.

Pangei, Heldr. \& Nadji [Charrel] Emp. Ottom. [P1. de Salon.] (1892) 2! = praec.

sporadum, Haldicsy, in Oest. Bot. Zcilschr.xlv. (1895) 461 , cum xylogr. - Ins. Sporad.

Zangez!ur , Lipsky, in Act. Hort. Petrop, xiii. (1994) 317. - Armen. ross.

SYMPHYOST EMON, Miers (Irid.). - Ind. Kew. acaule, Benth, ex Baker, Handb. Irid. 1892) 138 (= Sisyrinchinum acaule, Klatt). - Bolivia.

SYMPHYTONAMA, Schlechter, in Journ. Bot. xxxii. (1895) 321. . SCLEPIADEAE.

madagascariense Schlechter, l.c. t. 312a.-Madag.

SYMPHYTUM, Tourn, ex Linn. (Borag.). - Ind. Kew. ii. 1022,

ambigunm. Pau, Not. Bot. Fl. Espan. iii. (1889) $32=$ officinale, Limn.

stenophyllww, G. Beck, in Annal, Naturh. Hofmus. Wien, ii. (188T) $132=$ officinale, Limn.

Ullepitschii $X$, Wettst. in A. Kern. Sched. F1.

Austro-Hung. vi. (1893) 87. - Hung.

Wettsteini, Sennh, in Sitzb. zool.-bot. Ges. Wien, xxxviii. (1888) 69 ; et in Bot. Centralbl. xxxv (1888) 60; G. Beck, F1. Nied.-Oest. ii. II. (1893) 964. - Austria.

Zahlbruckneri X, G. Beck. 1. c. 964. - Austria.

SYMPLECTOCHILUS, Lindau, in Bot. Jahrb. xx. (1895) $45=$ Adhatoda, Tourn. (Acanth.). formosissimus, Lindau. 1. c. $=$ A. formosissima, Klotasch.
SXMPLOCOS, Jacq. (Styrac.). - Ind. Kew. ii. 1022 .

ant?llana, Guerke, in Eng-1.\& Prant1: Natür1. Pflanzenfam. iv. I. (1891) $170=$ cubensis, Griseb.

Benthami, Guerke, l. c. $172(=$ S. ciliata, Benth.) - Mexic.

botryantha, Franch. in Nouv. Arch. Mus. Paris

Sér. II. X. (1887-88) 60. - Tibet.

buxifolia, Stapf, nn Trans, Iinn. Soc. Ser. II iv.

(1894) 206. - Borneo,

Clarkei, Gurke, in Engl, \& Prantl, Natiurl. Pfanzenfam. Jv. I. (1891) 170 (= S. acuminata, Bedd.). - Ind. or.

cubensis, Guerke, 1. c. = Lindeniana, Kmg \& Urb.

Curtisii, Oliver, in Hook. Icon, fl, xviii. (1888) t.

175\%. - Penano

deflexa, Stapf, in Trans. Linn. Soc. Ser. II. iv. (1894) 205. - Bornec

fasciculata, Roxb. ex Vesque, in Bull. Soc. Bot. Fr. xlii. (1895) 153. in syn.= Eurya fasciculata, IV all.

guadeloupensis, Krug of Urban. in But. Famb. xv. (1893) 337. - Ins. Guadal.

guianensis, Gucrke, in Engl. E Prant, Natiurl. Pfanzenfam. iv I. (1891) $172(=$ Ciponima guianensis, Aubl.). - Am. trop.

jamaicensis, Krug \&o Urban, in Bot. Fahrb. xy. (1892) 330 . - Jamaica.

Johniana, Stapf, in Trans. Linn. Soc. Ser. II. iv. (18:4) 206. - Borneo.

laeteviridis, Stapf, l. c. 205. - Borneo.

lanata, Krug of Urban, in B t. Fahrb. xv. (1892) 335. - Ins Puerto-Rico.

latifolia, Kimg \& Urban, l. c. 334. -- Ins. PuertoRico.

Lindeniana, Krug of Urban, l. c. - Cuba

luzoniensis, Rolfe, in foum. Bot. xxiv. (1886) 348, in obs. - Ins. Philipp.

Mezii, Zahlbr in Diss. Cl. Math-Plys, Acad. litt. Cracor. xxix. (1894) 230. - Peruvia.

micrantha, Krug \& Urban, in Bot. Fahrb.xv. (1892) 336. - Ins. Puerto.Rico.

montana, Vidal, Revis. P1. Vasc. Filip. (18S6) 179 = Iuzoniensis, Rolfe.

paucistaminea, F. Mucll. \& F. M. Bailey, Syn. Queensl. Fl. Suppl. iii. 1890) 46.- Austral.

polyantha, Krug E Urban, in Bot. Fahrb. xv. (18n2) 333. - Ins. Puerto-Rico.

Pringlei, Robinson, in Proc. Am. Acad. xxvi. (1891) 165. - Mexic

Pseudo-spicata, Vidal, Revis, Pl. Vasc. Filup. (1886) 179. - Ins. Philipp.

sessilifolia, Guerke, in Engl. \& Prantl, Natürl. Pflanzenfam. iv. I. (1891) $170=$ subsessilis Choisy.

Spruceana, Guerke, l. c.-Peruvia.

stricillosa, Krig of Urian, in Bot. fahrb. xv. (1S92) 332. - Cuba.

theaeformis, Guerke, in Eng1. \& Prant1, Natürl. Pflanzenfam, iv. I. (1891) $172=\mathrm{S}$. Alstonia, L'Hérit.

tubulifera. Koug \& Urban, in Bot. fahrb. xv. (1892) 331. - Jamaica.

Villarii, Vidal, Revis. Pl. Vasc. Filtp. (1886) 178. Ins. Philipp.

zizyphoides, Stapf, in Trans. Linn. Soc. Ser. II.

iv. (1894) 205. - Borneo.

SYNADENIUM, Boiss. (Euphorb.). - Ind. Kew. ii. 1024

piscatorium, Pax, in Bot. Fahrb. xix. (1894) 125. Afr. trop. or.

umbellatım, Pax, l. c. 125. - Afr. trop.

Volkensii, Pax, in Engl. Pfanzenw. Ost-Afr. C (1895) 242. - Afr. trop. or.

SYNANDRA, Nutt. (Labiat.). - Ind. Kew. ii. 1024

Irispidula, Baill. Hist. des p1. xi. (1892) 45; Britton, in Mem. Torrey Bot. Club, v. (1894) $285=$ grandiflora, Nutt.

SYNAPTANTHA, K. Schum. in Eng1. \& Prantl, Natürl. Pflanzenfam. iv. 4 (18:1) $24=$ Synaptantha, Iook. f. (Rubiac.).
SXNAPTEA, Kurz = SUNAPTEA, Griff. = Vatica, Linn. (Dipteroc.).

stritricha, Pierre, Fl, For, Cochinch. Fasc, 16 (1891) sub t. 241, sphalm, = seq. astrotricha, Pierre, 1. c. Fasc. 15 (1890) t. $240=$ Vatica astrotricha, Hom.

Dyeri, Pierre, 1. c. t. $241=$ V. Dyeri, Pierre.

faginea, Pierre, 1. c, t. 24\%, $255 \mathrm{y}=\mathrm{V}$. faginea, Dyer.

SYNAPTOLEPIS, Oliver (Thymel.). - Ind Kew. ii. 1024.

Kirkii, Gilg, in Eng1. \& Prant1, Natürl. Pflanzenfam. iij. 6 (1893) 231, fig. 81 f, J. = Oliveriana. fam.

longiflora, Gilg in Bot. Fahrb. xix. (1894) 276. Afr trop. austro-or.

macrocarpa, Gilg, in Engl. Pfanzenw. Ost-Afr. C (18.5) 284, - Afr. trop. or.

Oliveriana, Gilg, in Bot. fahrb. xix. (1894) 276. - Afr. trop. austro or.

pachyphylla, Gilg, in Enol. Pfanzenw. Ost-Afr. C (1895) 284. - Afr. trop. or

SYNCARPIA, Tenore (Myirt.). - Ind. Kew. il 1024

lomulifera, Niedenzu, in Engl. \& Prantl, N'atïrl. Pfanzenfam. 1ii. 7 (1893) $8 S(=S$. lawifolua, Ten.). - Austral.

SYNCEPHALANTHUS, Benth, \& Hook. f. = Syncephalantha, Bartl. (Compos.)

macroshyllus, Klatt, in Leopoldina, Heft xxv. (188?) 108. - Hab.

sanguineus, Klatt, l. c. 106. - Guatem., Costa-Rica.

SYNCHORISTE, Baill. Hist, des p1, x, (18:0) 442: Lindau, in Engl. \& Prant1, Natür1. Pflanzenfam. iv. 3b (1895) 340. ACANTHACEAE. rufopila, i3aill. 27.cc.443; et 340. - Madag.

SYNGLISIA, Benth. (Menisp.). - Ind. Kew. ii. 1024.

delagoensis, N. E. Br, in Kew Bull. (1S92) 196. Afr. trop. austro-or.

leonensis, S. Elliot, in foum. Linn. Soc. xxx. (1894) 72. - Sicrra Leone.

zambesiaca, N.E. Br. in Kew Bull. (1892) 496. Zambesia.

SYNDECHITES, Oliver, in Hook. Icon, pl, xviii. (1888) t 1772. APOCYNEAE.

Henryi, Oliver, l. c. - China.

SYNDICLIS, Hook. f. lcon. pl. xvi. (1886) t. 1515. LAURINEAE

paradoxa, Honk. f. l. co et Fl. Brit. Ind. v. (1886) 127. - Reg. Himal.

SYNEPILAENA, Baill. in Bull. Soc.Linn. Paris, i. (1S88) 725 ; et Hist. des p1. x. (1S88) 81. GESNERACEAE.

granatensis, Baill. $l l$. cc. - N. Granat.

SYNGONIUIM, Schott (Aroid.). - Ind. Kew. ii. 1025 .

Donnell-Smithii, Engl. in F. D. Smith, Enum. Pl. Guatem. ił. (1891) 77. - Guatem.

SYNNEMA, Benth. = Cardanthera, Buch.-Ham. (Acanthac).

africanum, Griffithii, pinnatifidum, Thwaitesii, triftorum, uliginosum, revticillatum, Kuntze, Rev. Gen. (1891) $500=$ homonyma omnia Cardantherae.

bavbigera, Kuntze, 1. c. = C, balsamica, Benth.

SYNPHORANTHERA polystachya, Boj. ex Zahibr. in Annal. Naturh. Hofmus. Wien, vi. (1S91) 442 , in syn. = Dialypetalum floribundum, Benth. \& Hook. $f$

SYNSEPALUM, Baill. Hist. des pl. xi. (1S92) 286, SAPOTACEAE.

dulcificum, Baill.l.c.287 (= Sideroxylon dulcificum, A. DC.). - Afr. trop. occ. 
SYNTHERISMA, Walt, = Panicum, Linn. (Gra-

filiformis, Nash, in Bull. Torrey Bot. Club, xxii. (1895) $420=$ P. filiforme, Linn.

Iincaris, Nash, 1. c. = P. glabrum, Gaud.

sangumalis, Nash, 1. c. = P. sanguinale, Linn,

SYRENIA, Andrz, ex DC. (Crucif.). - Ind. Kew. quadrangula, Kuntze, in Act. Hort. Petrop. x. (1887) $69=$ sessiliflora, Ledeb.

SYRINGA, Linn. (Oleac.). - Ind. Kew. ii. 1026 .

alba, Dietr, ex Dippel, Handb. Laubholzk. (1889) $112=$ vulgaris, Linn

Brctschneideri, Hort. Lemoin. ex Wittm, in Gartenfl, xxxiv, (1895) $499=$ S. Emodi, Wall. correlata, A1.Braun, ex Dippel, Handb. Laubholzk. i. (18s?) $114=$ dubia, Pers.

metensis, Hort. ex Dippel, 1. c $114=$ dubia, Pers. mubra, Lodd. ex Dippel, 1. c. = dubia, Pers.

Salleang, Hort. ex Dippel. 1. c, = dubia. Pers.

sampervirens, Franch, in Bull. Soc. Linn. Paris, i. (18S6) 613. - China occ.

tomentella. Bureur \& Franch. in Morot, fourn. do Bot. v. (1891: 103. - China occ.

mnnanensis, Franch, in Rev. Hortic. 1xiii. (1891) 308. - China occ.

SYRINGODEA, Hook, f. (Irid.). - Ind. Kew. ii. 1026 .

Flanagani, Baker, in Kew Bulll. (1893) 158. - Afr. austr.

SYRMATIUM. Vog. = Hosackia, DougI. (Legu. min.)

argophylhum, cytisoides, decumbens, distichum, Hermanni, junceum, micranthum, nudatum, Ornithopus, procumbouss prostratum, sericenm, Veatchii Greene, in Buil. Acad. Calif. ii. vi. (1886) 148-49= homonyma onmia Hosackiae.

acndroidoum, Greene, 1. c. 146. -- Ins, S. Cruz. (Calif.).

distichumb, Greene, 1.c. $148=$ Hosackia disticha, Greene.

SYSTEMONODAPHNE, Mez, in Jahrb. Bot Gart Berl y (1889) 78: Pax, in Engl. \& Prantl. Natiirl Pflanzenfam. i1i. 2 (1891) 276. LAURI$N E A E$.

geminiflora, Mez, ll. cc. (= Goeppertia geminiflora, MLissn.). - Guian.

SYZYGIUM, Gaertn. = Eugenia, Mich. (Myr-

acutangulum, Niedenzu, in Eng1. \& Prantl, Natür1 Pflanzenfam. iii. 7 (1893) $85=$ E. acutangula, K. Schum.

Euetnerianun, Niedenzu, 1. c. = E. Buettneriana, K. Schum.

oberulatum, Niedenzu. 1. co = E* operculata Roxb.

candricense, Niedenzu, 1. c. $=$ E. sandwicensis, A. Gray.

Smithii, Niedenzu, 1. c, = E. Smithii, Sprong.

SZECFIENYIA, Kanitz, P1. exped. Szechen. in As. centr. collect. (1891) 60. LILIACEAE.

lloydioides, Kanitz, l. c. 60 t. 7, i. fig. 1-3. China.

\section{$\mathrm{T}$}

TABASCINA, Baill. Hist. des p1. x. (1891) 445 Lindau, in Engl. \& Prantl, Natürl. Pflanzenfam. iv. $3 \mathrm{~b}$ (1895) 346. ACANTHACEAE.

Iindeni, Baill, Ul.cc. - Mexic.
TABEBUIA, Gomez (Bionon.), - Ind. Kew, ii 1028

Caraiba. Burean, in Kongl. Vet.Sv. Acad. (1893) 112 [Symb. Fl. Bras, centr. x1.) (= Tecoma Caraiba, Mart.). - Bras.

chrysantha, Nichols, Dict. Gavd. iv, (1887) 1. Venezuela.

Dönnell-Smittii, 7. N. Rose, in Coult, Bot, Gaz. xvii. (1892) 418 t. 26. - Guatem.

globiflora, Emst, in Rev. cient. Univ. Venc\%. (1887) 133. - Venezuela.

longipes, Baker, in Hook. Icon.pl. xviii. (1888) t 1738. - Guian. brit.

nodosa, K. Schum, in Eng-1. \& Prantl, Natürl. Pfanzenfam, iv. $3 \mathrm{~b}(1894) 236=$ nodosa, Griscb.

nbtusifolia, Bureau, in Kongl. Sv. Vet. Acad. (18!3) 113 [Symb. F1. Bras. centr, x1,] = leucoxyla, $D C$.

Palmeri, 7. N. Rose, in Contrib, U. S. Nat, Herb, i. (1891) 109 t. 11. - Mexic.

Roraimae, Oliver. in Trans. Linn. Soc. Ser. II. ii (1887) 286 [Oliver, ex in Thurn, in Timehri, v. (1886) 201.]. - Guian, angl.

serratifolia, Nichols. Dict, Gard. iv. (1887) (= Tecoma serratifolia, G. Don). - Ind. occ.

sernatifolia, Rolfe, in Kew Bull. (1893, $267=$ praec

setulosa, K. Schum. in Engl. \& Prantl, Natürl. Pflanzenfam.iv. 3b (1894) 2:36 (= Tecoma setulosa Griseb.).- Cuba.

spectabilis, Nichols, Dict. Gard, iv. $(1887)(=T$. spectabilis, Planch. \& Linden). - Ind. occ. Venezuela.

trachycarpa, K. Schum. in Engl. Gr Frantl, Natürl. Pfanzenfam. iv. 3b (1894) 236 $(=T$. trachycarpa Griseb.) - Cuba.

TABERNAEMONTANA, Plum, ex Linn, (Apocyn.). - Ind. Kew. ii. 1028,

angolensis, Stapf, in Kew Bull. (1894) 23. -Angola. anguinea, Hemsl. l. c. (1895) 136 ; et in Hook. Icon. pl. xxiv. (1895) t. 2397. - Ins. Salom.

arborea, 7. N. Rose, ex 7. D. Smith, in Coult, Bot. Gaz.xvii. (1893) 206. - Guatem.

brachyantha, Stapf, in Kev Bull. (1894) 22, - Ins. Fernando Po.

contorta, Stapf, l. c. 23. - Afr. trop. occ.

crispiflora, $K$. Schum, in Engl. Eo Prantl, Naturl. Pfanzenfam. iv. 2 (1895) 148. - Gabon.

dipladeniflora, Stupf, in Kew Bull. (1894) 121. Afr. trop. occ.

Donnell-Smithii, F. N. Rose, ex F. D. Smith, in Coult. Bot. Gaz. xviii. (1893) 206. - Guatem.

durissima, Stapf, in Ketv Bull. (1894) 24. - Afr. trop. or.

eglandulosa, Stapf, l. c. - Afr. trop. occ.

elegans, Stapf, l. c. - Afr. trop. occ

Holstii, K: Schum. in Engl. Pfanzenw. Ost-Afr, C (1895) 317. - Afr, trop. or.

inconspicua, Stupf, in Kere Bull. (1894) 120. - Afr. trop. or

longepedunculata, $K$. Schum, in K. Schum. E Hollr. Fl. Kais. Wilh. Land (1889) 113. - N. Guin. nitida, Stapf, in Kew Bull. (1895) 22. - Afr. trop. or. pachysiphon, Stapf, l. c. 22. - Afr. trop. or.

paisavelensis, Loesen. in Bull. Herb. Boiss, ii. (1894) 553. - Mexic.

punctulata, Warb. in Bot. Fahro. xii.. (1891) 406. - N. Guin.

Stapfiana, Britten, in Trans. Limn. Soc. Ser. II. iv, (1894) 25. - Atr. trop.

stenosiphon, Stapf, in Kew Bull. (1895) 23. - Afr.

trop.
usambarensis, K. Schum. ex Engl. in Abh. Preuss. Akad. Wiss. (1894) 36; et in Engl. Eo Prantl, Natürl. Pfanzenfam. iv. 2(1895) 148. - Afr, trop.

Volkensii, K. Schum, in Engl. Pfanzcnw. Ost-Afr. C (1895) 316. - Afr. trop. or

TABERNANTHE, Baill, in Bull. Soc. Linn. Paris, i. (1889) 783, et Hist. des pl. x. (1888) 196. K. Schum in Fncl \& Prantl, Natiirl. Pflanzenfam. iv.2(1895) 146. ACANTHACEAE. Pflanzenfam. iv.2 (1S95) 146. ACANTHACEAE.
Iboga, Baill. l. c.; Oliver, in Hook. Icon. pl, xxiv. (1894) t. 2337. - Afr. trop. occ.
TACAZZEA, Decne (Asclep,). - Ind, Kew, ii 1030.

Barteri. Baill. in Bull. Soc. Linn. Paris, i. (1889) S08 [sphalm. 88]. - Afr. trop. occ.

Brazzaeana, Ba ll. Hist. des pl. x. (1890) 242. in nota 2. - Afr. trop.

conferta, N.E. Br. in Kew Bull. (1895) 247 (Taccazial. - Abyss

Kirkii, N.E. Br. l. c. 248. - Zambesia.

laxiflora, [Engl.?] Pfanzcnw. Ost-Afr. A (1895) 92 nomen. - Afr, trop. or.

Martini, Baill. in Bull. Soc, Limn. Paris, ii. (1889) 808, [sphalm. 88]. - Nubia.

nigritana, N.E. Br. in Kew Bull. (1895) 248 [Taccazia|. - Reg. Nigrit.

pedicellata, K. Schum. is Bot. Fahrb. xvii. (1893) 115. - Afr. trop. or.

Tholloni, Baill. in Bull. Soc. Linn. Paris, i. (18S9) 807, [sphalm. 87]. - Angola.

venosa, Baill. l. c. 808 , sphalm. $88(=$ Periploa wenosa, Hochst.). - Abyss.

verticillata, $K$. Schum. in Bot. fahrb. xvil. (1893) 114. - Afr. trop. occ.

Welwitschii. Baill. in Bull. Soc. Limn. Paris, i. (1889) 807 [sphalm. 87]. 一 Angola.

TACCA, Forst. (Taccac.). - Ind. Kew. ii. 1030 integrifolia, Ham. ex Hook. f. Fl. Brit. Ind. vi (1892) 288, in syn. = laevis, Roxb.

lcontopetalodes, Kuntze, Rev. Gen. (1891) $704=$ pinnatifida, Forst.

TACHIA, Aubl. (Gentian.), - Ind. Kew. ii. 1030. Pavonii, Gilg, in Engl. \& Prantl; Natül. Pfanzen fam. iv. 2 (1895) 93. - Peruvia vel Mexic.?

TAGHIADENUS, Griseb. (Gentian.). - Ind. Kew. ii. 1030

continentalis, Baker, in Kev Bull. (1895) 70. Afr. centr. or.

longifolius, S. Elliot, in foumn. Lmnn. Soc. xxix. (1891) 34. - Madag.

TAGOANTHUS, Baill in Bull. Soc, Linn. Paris, ii. (1890) 832; et Hist. des pl. X. (1890) 426 . Lindau, in Engl: \& Prantl, Natürl. Pflanzenfam. iv. 3b. (1895) 30S. ACANTHACEAE.

Pearcei, Baill. $7 l$. CE. 8333; ct 427 (= Otacantizus Pearcei, Benth.). - Bolivia.

TAGSONIA, Juss. (Bignon.).- - Ind. Kew. ii. 1030 boliviana, Rusby, in Mem. Torrey Bot. Club, iii. (1893) 37 - Boliv.

coactilis, Mast, in Bot. Fahro, viii. (1887) 210. Ecuad.

coccinea, Burb. Rodr. [Herb. Mus, bot. Amaz. n. 164], Vellosia, 1885-88, Sec. ediç. (1891) 23 t. 11. - Bras,

TAENIOPHYLLUM, Blume (Orchid.). - Ind. Kew, ii. 1031

scaberulum, Hook. f. Fl. Brit. Ind. vi. (1890) 77 - Travanc

Paife, Drake, Illustr. Fl. Ins. Pacif. (1886) 311 ; e Fl. Polyn. Franc. (1892) 217. - Ins. Societ. serrula, Hook, f'. Fl. Brit. Ind. vi. (1890) 77. Perak.

TAENIOPLEHRUM, Coult. \& J. N. Rose, in Coult. Bot. Gaz. xiv. (1889) 283. UMBELLIFE$R A E$.

Howellii, Coult. \& F. N. Rose, l. c. 284. - Oregon.

TAFALLAEA, Kuntze, Rev. Gen. (1891) $565=$ TAFALLA, Ruiz \& Pav, = Hedyosmum, Sw (Chloranth.

arborescens, Artocarpus, Bonplandizna, brasiliensis. callososerrata, cumbalensis, Dombeyana, Goudotiana, Grisebachii, integra, Lechleri, mexicana, mutans, parcifolia, Pseudoandromeda, Sprucei, Weddelliana Kuntze, Rev. Gen. (1891) $565=$ homonyma ommia Hedyosmi.

Mandonii, Kuntze, Rev. Gen. (1891) $565=\mathrm{H}$ Mandoni, Solmes.

glabrata, Rusby, in Mem. Torrey Bot. Club, iv, (1895) $252=\mathrm{H}$. glabratum, $H . B . \& K$ 
'TAGETES, Linn. (Compos.). - Ind. Kew. ii 1030.

aristata, Klatt, in Leopoldina, Heft xxv. (1889) 109 - Mexic.

gigantea, Carr. in Rev. Hortic. 1viii. (1889) 107. Bolivia.

lacera, T. S. Brandeg. in Zö̈, i. (1890) 314. - Am. bor. occ.

linifolia, Seaton, in Proc. Am. Acad. xxviii. (1893) 120. - Mexic.

Mandonii, Schult. Bip. ex Klatt, in Leopoldina. Heît xxv. (1S89) 109. - Boliv.

Palmeri, A. Gray, in Proc. Am. Acad. xxi. (18s3) 392. - Mexic.

Pringlei, S. Wats. l. c. xxiii. (1888) 279. - Mexic.

TAINIA, Blume (Orchid.). - Ind. Kew, ii 1032.

cordata, Hook. f. Fl. Brit. Ind. vi. (1890) 193,Reg. Himal.

cordifolia, Hook. f. in Hook. Icon. pl. xix. (1S89) t 1861. - Ins. Formosa.

cordifolia, Hook. f. Century Ind. Orchids (189:) 24 t. 36, sphalm. = cordata, Hook. $f$

hastata, Hook. f. Fl. Brit. Ind. v. (1890) 821; et in Hook. Icon. pl. xxi. (1892) t. $2092=$ Eulophia hastata, Lindl.). - Assam.

Hookeriana, King, in fourn. As. Soc. Beng. lxiv. (1S95) ii. 8. - Penins. Mal.

khasiana, Hook. f. Fl. Brit. Ind. v. (1890) 821 : et in Hook. Icon. pl. xxi. (1892) t. 2090. - Bengal.

latifolia, Benth, ex Hook, f. Fl. Brit. Ind. v. (1890) 820 (= Ania latifolia. Lindl.). - Ind. or.

latilingua, Hook. f. l. c. S27 ; et in Hook. Icon. pl. xxi. (1892) t. 2093. - Perak.

macrantha, Hook. f. in Hook. Icon. pl. xix. (1S89) t. 1860. - China

maculata, Hock, f. Fl. Brit. Ind. v. (1890) 820. Zeyl.

Maingayi, Hook.f.l. c. 822 ; et in Hook. f. Icon. pl. xix. (1889) t. 2094. - Penang.

minor, Hook. f. ll. cc. 821; et t. 6091 . - Reg. Himal.

penangiana, Hook. f. ll. cc. 820 ; et t. 2089. Penang.

promensis, Honk. $f$. in Hook. Icon. pl. xix. (1889) t.

1883; et Fl. Brit. Ind. v. (1890) $\$ 20 .-$ Pegu.

stellata, Pfitz. in Engl. \& Prantl, Natürl. Pfanzenfam. ii. 6 (1888) 153 (= Eria stellata, Lindl.). Java.

TALAUMA, Juss. (Magnoliac.). - Ind. Kew. ii. 1032 .

andamanica, King, in fourn. As. Soo. Beng. Iviii. (1889) ii. 372. - Ins. Andam.

Forbesii, King, l. c.373. - Sumatra.

Kunstleri, King, l. c, - Penins. Mal.

liliffera, Kuntze, Rev. Gen. (1891) $6=$ Magnolia pumila, $A n d r$.

phellocarpa, King, in Ann. Bot. Gard. Calc. iii. II. (1891) 205 t. 47. ter. - Assam.

spongiocarpa, King, l.c. t. 47b. - Burma.

TALIGALEA, Aubl. = Amasonia Linn. $\mathrm{f}$. (Verben.).

angustifolia, calycina, hirta, relutina, Kuntze. Rev. Gen. (1891) $509=$ homonyma omnia Amasoniae.

TALINELLA, Baill, in Bull, Soc, Linn. Paris. i. (1886) 569, Pax, in Eng1. \& Prantl, Naturrl. Pflanzenfam.iii. 1b (1889) 59. POR TULACEAE. Boiviniana. Baill. ll. co. - Madag.

dauphinensis, S. Elliot, in fourn. Linn. Soc. xxix. (1891) 4. - Madag.

TALINUM, Adans. (Portul.). - Ind. Kew. ii. 1032.

brevicaule, S. Wats. in Proc. Am. Acad. xxi. (1886) 446. - Mexic.

coahuilense, S. Wats. in-Proc. An. Acad. xxvi. (1891) 132. - Mexic.

teîtense, Fax \& Vatke, in Bot. Fahrb. xvii. (1893) 585; Engl. Pflanzenw. Ost-Afr, A (1895) 176, nomen. - Afr. trop.
TALISIA, Aubl. (Sapind.): - Ind. Kew. ii. 1032 .

princeps, Oliver, ex Gard. Chron. (1888) 806; et in Hook. Icon. pl. xviii. (1888) t. 1769. Venezuela.

TAMARIX, Linn: (Tamarise.), - Ind. Kew. if. $10: 3 \% 3$.

austro-africana, Schinz, in Bull. Herb. Boiss. ii. (1894) 183. - Afr. austr.

caspica, Hort. Gall. ex Dippel, Handb. Laubholzk. iii. (I893) $9=$ chinensis, Lour

dahurica. "Willd, » ex Dippel, 1. c, 11=davurica. Willd.

kashgarica, Hort. Ienoin, ex Gard. Chron. (1893) i. 414. - As. centr.

Haussknechtiana, Niedenzu, in Ind. lect. Iyc. reg. Hos, Braunsberg. (1894) 5. - Graecia.

japonica, Hort. ex Dippel, Handb. Laubholzk. iii. (1893) $9=$ chinensis, Lour

phaleria, Niedenzu, in Ind. lect. Lyc. reg. Hos. Brannsberg. (1895) 5. - Graecia.

TAMONEA, Krassn. in Engl. \& Prantl, Natürl, Pflanzenfam: iii. 7 (1893) $142=$ Miconia. Ruiz \& Pav. (Melast.)

albicans, andina, argyrophylla, atrata, ciliata, cubensis, epiphytica, fulva, holosericea, humilis, ibaguensis, laevigata, ligustroides, longifolia, macrophylla, minntiflora, nereosa, prasina, mbiginosa, speciosa, stenostachya, theaezans, tomentosa, Krassn. 1. $\mathrm{c}_{1}=1$ iomomyma omnia Miconiae.

TAMUS, Linn. (Dioscor.). - Ind. Kew, ii, 1034.

baccifera, St Lager, in Cariot, Étud, des $\mathrm{fl}$. éd. 8 . ii. (1589) $765=$ communis, Linn.

TANAGETUM, Tourn. ex Linn, (Compos.). Ind. Kew. ii. 1034 .

affune, Simonk. Enum. F1. Transsilv. (1886) $313=$ Chrysanthemum Leucanthemum, Linn

alpinum, Simonk. 1. c. $=$ C. Leucanthemum, Linn.

auriculatum, Simonk. 1. c. = C. Leucanthemum, Linn?.

coromlatum, Simonk. 1. c. $=$ C. Leucanthemum, Linn.

corymbosum, Simonk. 1. c. $312=$ C. corymbosum Linst.

darwasicum, C. Winkl, in Act. Hort, Petrop. xi. (1890) 317. - Turkest.

Gregorjewi, Krassn. in Script, Hort. Univ. Petrop. ii. 1. (1S87-S8) 16 [sp. collect.]. - Ross.

Leucunthmum, Simonk. Enum. F1. Transsilv. (1856) $313=$ Chrysanthemum Leucanthemum, Linn.

macrophyllum, Simonk. 1. c. = C. macrophyllum, $W$ aldst. \& I Iit.

macropodum, Hemsl. E Lace, in fourn. Limn. Soc. sxvili. (18:1) 324. - Belutch, hrit.

myrianthum, Franch, in Bull, Soc. Phit. Paris, Sér. VIII. iii. (1891) 144. - Tibet.

serotinum, Simonk. Enum. F1. Transsilv. (1886) $312=$ Chrysanthemum Leucanthemum, Lim.

Newesskyanum, C. Winkl, in Act. Hort. Petrop. xi (1891) 374. - Turkest.

Pseudachillea, C. TVinkl.l. c. 373. - Turkest. rotundifolinm, Simonk. Enum. F1. Transsilv. (1886) 31: = Chrysanthemum rotundifolium, Waldst. E Kit.

subalpimu, Simonk. Enum. F1. Transsilv. (1886) $31^{*}=$ Chrysanthemum Leucanthemum, Linn

Santolina, C. Winkl. in Act. Hort. Petrop. xi. (1891) 375. - Turkest.

schugnanicum, C. Winkl. l. c. 318. - Turkest.

setaceum, Oliver, in Hook. Icon. pl. xxiv, (1894) sub. t. 2365, in obs. (= Pyrethrum setaceum, Roem. \& Schult.) -

subcorymbosum, Simonk. Enum. F1. Transsilv. (1886) 312 = Chrysanthemum subcorymbosum, Schur. tripinnatitidum, Oliver, in Hook. Icon, pl. xxiv. (1894) t. 2306. - Cachem.
TANARIUS, Rumpf, Herb. Amboin. iii. (1743) 190. 121 ex Kuntze, Rev Gen, (1891) $619=$ Macaranga, Thou. (Euphorb.)

amboinensis, angolensis, Baillonianus, bancanus, bicolor, Brandisii, Chatiniamus, cissifolius, coniferus. cordifolius, coriaceus, cormutus, corymbosus, Cumingii, cuneifolius, cupularis, Curtisii. cuspidatus, denticulatus, depressus, Diepenhorstii, digymus, dirergens. Gambley, giganteus, Grayanus, Griffithianus, Hayveyanus, heterophyllus, Heudelotii, hexandrus, hispidus, Hosei, Hulletti, hypoleucus, indicus, incolucratus. javanicus, Kingii, longestipulatus, Lowii, macrophyllus, Maingayi, Mafpa, mauritianus, membranacens, minutiflorus, monandrus. Mottleyanus, myrianthins, oblongifolizs, obovatus, occidentalis, pachypliyllus, peraliensis, populifolius. prunncsus, pustulatus, Roxburghi, secundus, Seemannii, sinensis, spinosus, stipulosus, strictus, subfalcatus, sumatranus, taitensis, tenuifolius, trichocarpus, trilobus. Vedelianus, velutinus, Kuntze, 1. c. = 7.omonyma ommia Macarangae.

borneensis, Kuntze, 1. c. $620=$ M. trichocarpa Muell. Arg.

boutoniodes, Kuntze, 1. c. = M. boutonioides Baill.

dioecus, Kuntze, 1. c. = M. dioica, Muell. Aro

flexuosus, Kuntze. 1. $\mathrm{c} .=\mathrm{MT}$. indica, Wioht.

glaber, Kuntze, i. c, $619=$ M. Tanarius, MIull Arg.

gmelinifolins, Kuntze, 1. c. = M. gmelinaefolia King.

Helferi, Kuntze, 1. c. = M. minutiflora, Mrell. Arg

Kurzi, Kuntze, 1. с. $620=$ M. membranacea, Kur\%

leptostachyus, Kuntze, 1.c. (Cleidronis cfr.) - N Caled.

megallopiryllus, Kuntze, 1. c. = M. megalophylla, Muell. Arg.

paniculatus, Kuntze, 1. c. = M. denticulata, Muell. Arg.

pelfatus, Kuntre, 1. c. = M. Roxburghii, Wight. hizinodes, Kuntze, 1. c. = M. rhizinoides, Muell Arg.

roettlerodes, Kuntze. 1. c. = M. roetleroides, Baill rugosus, Kuntze, 1. c。= M. megalophylla, Muell. Arg.

Arg.
Teysmanni, Kuntze, 1. c. $=$ M. Teysmanni, Muell Arg.

tomentosus, Kuntze, 1. c. = M. Roxburghii, Wight

Vieillardi, Kuntze, 1. c. = M. Vieillardi, Muell. Arg.

TANULEPIS, Balf. f, in Engl, \& Prant1, Natürl, Pflanzenfam, iv. 2 (1895) 215. ASCLEPIADEAE stenophinla, "Baif. f. " ex K. Schum.1.c.=spheno phylla, Bulf. $f$

TAONABO, Aubl. = Ternstroemia. Mutis.

andina, brasiliensis, Candolleana, carnosa, cernua clusiacfolia, congestiflora, coriacea, crassifolia, cuncifolia, delicatula, elongata, emarginata, flarescens, jatonica, longipes, meridionalis, microcarpa, oleaefolia, patens, Pavoniana, Schomburgkiana, Scortechinil, silzatica, Tapezapote, uimifolia, umbellata, Szyszyl. in Eng1. \& Präntl, Natürl. Pflanzentam. iii. (1895) 188-89 = homonyma onnia Ternstroemiae.

felski, Zahlbr, in Diss. Cl. Math. Phys. Acad. litt. Cracov. xxix. (1894) 224. - Peruvia.

Lehmannii, Hieron. in Bot. Jahrb. xx. Beibl. n. 49 (1895) 48. - Ecuad.

Stuebelii, Hieron. 1. c. xxi. (1895) 320.-Columb.

Wallichana, Szyszyl. in Engl. \& Prantl, Natiirl. Pflanzenfam. iii. 6 (1895) $188=$ Ternstroemia penangiana, Choisy.

TAPAGOMEA, Kuntze, Rev. Gen. (1891) 960 sphalm. = TAPOGOMEA, Aubl. = Cephä̈ lis; Sw. (Rubiac.)

TAPEINANTHUS, Herb. (Amaryll.). - Ind. Kew, 11. 1030 .

ảubius, C.Richt. Pl. Europ. i. (1898) $236(=$ Carregnoa dubia, Perez Lara). - Hisp.

TAPEINIA, Juss. (Irid.), - Ind. Kew. ii. 1036. pumila, Baill. Hist. des pl. xiii. (1895) $149=$ mavellancus, Ker. 
TAPEINOCHILUS, Benth. \& Hook. f. = Tapeimocheilos, Miq. (Scitam.).

ecrutis, K. Schum. in K. Schum. \& Hollr. Fl. Kais. Wilh. Land (1889) 27. - N. Guin.

Hollyungi, K. Schum. 1. c. 26. - N. Guin.

Nazmanni, Warb. in Bot. Jahrb. xiii. (1891) 278 - N. Guin.

piniformis, Warb, 1. c. 277. - N Guin.

fubcscens, Ridl. in Journ Bot, xxiv. (1886; 356. N. Guin.

Tysmanianus, Warb. in Bot. Jahrb. xiii. (1891) 277. - N. Guin.

TAPEINOSTELMA, Schlechter, in Verh. Bot Ver. Brand. xxxv. (1893) 53; K. Schum. in Engl. \& Prantl, Natiirl. Pflanzenfam, 1v. 2 (1895) 267. ASCLEPIADEAE.

caftrum, Schlechter, $l l, c c$. - Afr. austr.

TAPINANTHUS, Blume = Loranthus, Linn globiferus, Mrechowi, Kraussianus, namaquensis, pentigomus, Preussii, pronifolitis, zervucosus. Van Tiegh. in Bull, Soc. Bot. Fr.xlii. (1895) 267=homonyma cmuzia Loranthi.

TAPINOSTEMMA, Van Tiegh. ir Bull. Soc. Bot. Fr. xlii. (1895) $257=$ Loranthus, Linn.

Acaciae, arabicum, gibberulum, nummularifolinm, cenustunt, Van Tiegh. 1. c. = homonyma ommia Loranthi.

TAPIRIRA, Aubl. (Anacard.). - Ind. Kew. ii. 1037.

fasciculata, Loesen, in Flora, lxxii. (1889)76. - Bras.

TAPISGIA, Oliver, in Hook. Icon. pl. $\mathrm{xx}$. (1890) t. 1928; Pax, in Engl. \& Prantl, Natürl. Pflanzenfam, iii. 5 (1893) 262. SAPINDACEAE.

sinensis, Oliver, $l l . c c$. - China.

TAPURA, Aubl. (Chailletiac.), - Ind. Kew, i: 1037

africana, Engl. Pflanzenw. Ost-Afr. C (1895) 235 $=T$, Fischeri, Engl.

cucullata, Spruce, ex Baill. in Mart. F1. Bras. xii. (1886) 373 = guianensis, $A u b l$.

Fischeri, Engl. PAanzenw. Ost-Afr, C addend. (1895) 423. - Afr, trop. or.

TARAITOGENOS, Hassk. (Bixin.). - Ind. Kew, ii. 1037.

Kunstleri, King, in fourn. As. Soc. Beng. lix (1890) II. 122. - Peral

Kurzii, King, l. c. 123. - Burma.

Scortechinii, King, l. c. 122. - Malaya.

tomentosa, King, l, c. - Perak.

TARASA, Phil, in Anal. Mus, nac. Chile (1891) 10. MALVACEAE

Rahmeri, Phil.l.c.t. 1, fig. 1. - Chili.

TARAXAGUM, Linn, (Compos.). - Ind. Kew. 11. 1039. Coss. \& Durieu, ex Batt. et Trab. Fl. de

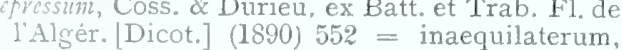
Pomel.

Gregorjzen, Krassnow, in Script, Hort. Univ Petrop, ii. (1887.88) 16 [sp. coll.1. - China.

Gremlii, Appel, ex Naegeli \& Wehrli, in Mitt. Thurgauisch. Naturforsch. Gesellsch. ix. (1890) 150 $=$ officinale. Weber lin Wigg.|.

Haussknechtii, Ueclitr. in Nym. Consp. Fl. Eur. Suppl. ii. I. (1889) 190; et in Mittr. Thitr. Bot. Ver. N. Folge, vii. (1895) 49, - Graecia.

humifusum, Heldr. ex Nym. 1. c. = gymnanthum, $D C$

hyoseridifolium, Are-Towi. \& Marc. d'Aymerie, in Lucante, Rev. de Bot x. (1892) 651. - Gall, mer.

occ. Phit in Anal. Unici. Chiz lyxyvii (1894) 324 - Reg. Magell.

Neyranti, Debeaux, in Lucante, Rev. de Bot. ix. (1891) 255; et in Magnier, Scrin. fl, select. xi. 1892) 259 = obovatum, $D C$

\section{TARAXAGUM}

wirale, Langè, ex Kihlm, in Meddel. Soc. Faun, et Fl. Fenn. (1888-91) 67; et in Bot. Centralbl, xlvi. (1891) 41 = phymatocarpum. J. Vahl.

Taraxacum, Karst. Deutschl. El. (1880-83) 1138 ; MacMill. in Bull. Torrey Bot. Club, xix. (1892) $15=$ officinale, $W$ cber

TARAXIA, Raimann, in Engl. \& Prantl, Natuirl. Pflanzenfam. iij. 7 (1893) $216=$ Oenothera. Linn. (Onagrar.)

gracilifora, Raimann, 1. c. = O. graciliffora, Hook \& Arn.

longiflora, Raimann, 1. c. $=$ O. longiflora, Nutt.

TARENNA, Gaertn. (Rubiac.). - Ind. Kew. ii. 1038

asiatica, Kuntze, Rev. Gen. (1891) $278=$ zeylanica, Gaertn.

nigrescens, Warb. in Bot. Fahrb, xiii. (18:1) 431. N. Guin.

TARIRI, Aubl。= Picramnia, Sw. (Simarub.) Antidesma, Baill. Br.t. médic. [Phan.] (1884) SSO $=\mathrm{P}$. Antidesma. $\mathrm{S} w$.

ciliata, Paiil I. $c_{0}=\mathrm{P}$, ciliata, Mart.

pentandra, Baill.1. c. = P. pentandra, Sw.

TARRIETIA, Blume (Stercul.). - Ind. Kew, ii. $10: 38$.

actinophylla, C. Moore, Handb, Fl, $\mathrm{A}^{\top}$. S. Wales (189:3) 63. - Austral.

Carroni, C. Moore, I. c. = argyrodendron, Benth. cochinchinensis, Pierre, Fl. For. Cochinch. Fasc. 13 (1889) t. 205. - Cochinch.

Curtisii, King, in fourn As. Soc. Beng. 1x. (1891) ii. 7\%. - Penang.

Kunstleri, King, l. c. - - Penang.

perakensis, King, l.c. - Perak.

TAUBERTIA, K. Schum. ex Taub. in Bot. Jahrb. xv. Beibl. n. 3K (1893) 3. MENISPERMACEAE peltata, $K$. Schum. 2. c. 4. - Bras.

TAXILLUS, Van Tiegh. in Full, Soc. Bot. Fr. xlii. (1895) $256=$ Loranthus, Linn

bracteatus, Van Tiegh. 1. c. = L, bracteatus, Heyne. recurius, Van Tiegh. 1. c. $=$ L. recurvus, Wall. tomentosus, Van Tiegh. 1. c. = L. tomentosus, Heyne.

TAXODIUM. Rich. (Conif.), - Ind. Kew. ii. 1039. pyramidatım, Hort, ex Beissn. Handb. Nadelholzk. (189l) $153=$ distichum, Ric/2.

ivens. Hort. ex Beissn. l. c. $155=$ mexicanum, Corry

TAXOTROPHIS, Blume (Urtic.). - Ind. Kew. 11. 1039

ilicifolia, Vidal, Reris. Pl. Vasc. Filip. (1886) 349. Ins. Philip.

TAXUS, [Tourn.] Linn. (Conif.). - Ind. Kew, ii. 1039.

arastonensis, Hort. ex Beissn. Handb. Nadelholzk. (1891) $176=$ baccata, Linn

minor, Britton, ex Small \& Vail, in Mem. Torrey Bot. Club, iv. (1893) 167, et v. (1893-94) $19=$ canadensis. Willd.

TECLEA, Delile = Toddalia, Juss. (Rutac.). unifoliolata, Baill. in Bull. Soc. Linn. Paris, i. (1886) 591. - Ins. Comor.

TECOMA, Juss. (Bignon.). - Ind. Kew. ii, 1039. amazonica, Bureau \& $K$. Schum, in Engl. \& Prantl, Nativl. Pfanzenfam. iv. 3b (1894) 238. - Reg. Amazon.

bipinnata, Collett \& Hemsl. in fourn. Linn. Soc xxviii. (1890) 102. - Burma.

dura, Bureau \& K. Schum. in Engl. E Prantl, Natürl. Pfanzenfam. iv, 3b (1894) 238. - Guian.

evenia, 7. D. Smith, in Coult. Bot. Gaz. xx. (1895) S. - Guatem.
TEGOMA

filicifolia, Nichols, Dict. Gavd. iv. (1857) 13 [filicifolium]. - Ins. Fiji.

hysrida, Hort, ex Dippel, Handb. Laubholzk。 is (1889) $48=$ chinensis, C. Koch

Lapacho, K. Schum. in Engl. Es Prantl, Natürl. Pfinzenfam. iv. 3b (1894) 238 (=T. flavescens, Griscb.). - Reg. Amazon.

obscura, Burean of K. Schum. l. c. - Reg. Amaz.

pratensis, Burcau \& K. Scinm. 7. c. - Reg. Amaz.

Ricasoliana, Tanfan:, in Bull. Soc. Tusc, Ortic. (1887) 17 t. 1-2 ; et in Nuov, Giorn. Bót. Ital. xix. (188i, $103=$ T. Maikenii, S. Wats.

shirensis, Baker, in Kero Bull. (1894) 30. Zambesia.

Smithii $\times$, Hort. ex Gartenf. xliv. (1895) 51, cum xylogr. - Hybr, artef.

villosa Burean of $K$. Schum, in Engl, \&o Prant? Natiirl. Pfanzenfam. iv.3b (1894) 238 (= Bignonia villosa, Vahl). - N. Granat.

TEGOMANTHE. Baill. Hist. des pl, x. (1888) 41 Bureaul \& K. Schum, in Engl. \& Prantl, Natiirl. Pflanzenfamiv 3b(1894)230. BIGNONIACEAE Bureavii Baill. $l l . c c .-$ N. Guin.

TECOMARIA, Spach $=$ Tecoma, Juss. (Bignon.) alata, Bajll. ex K. Schim, in Engl, \& Prantl, Natürl. Pflanzenfam. iv, 3b (1894) $230=\mathrm{T}$. Guarume, DC. [Conf, Baill. Hist, des pl, x. (1888) 4l].

fulva, Baill 1. c. = T. fulva, G. Don.

Nyassae, Baill.1. c. $=$ T. Nyassae, Oliver.

TEINOSOLEN, Hook. (Rubiac.) - - Ind, Kew. ii 1041

Jamesonii, K. Schum. in Engl, Es Prantl, Natiirl. Pflanzenfam.iv. 4 (1891) 27. - Am. austr. occ.

TEKELIA, Adans. Fam. des pl, ii. (1763) 497, ex Kuntze, Rev, Gen. (1891) $702=$ Libertia Spreng. (Irid.).

formosa, Kuntze, 1. c. = L. formosa, R. Grah. grandifora, Kuntze, i. c. = L. grandiflora, Siveet ixiodes, Kuntze, 1, c. = L ixioides, Spreng. micrantha, Kuntze, 1. $\mathrm{c}_{0}=$ L. pulchella, Spreng. paniculala, Kuntze, 1. c. - L. paniculata, Spreng. pulcholla, Kuntze, 1. c. T... = L. pulchella, Spreng. sessiliftora. Kuntze, 1. c, = L. caerulescens, Kunth. tricocca, Kuntze, 1. c. = L. tricncca, Lem.

TELANTHERA, R, Br, (Amarant.). - Ind Kew. ii. $10 \pm 1$

stellata, S. Wats, in Proc. Am. Acad. xxi. (1886) 436 = Alternanthera stellata, Uline \& Bray.

Tuerckheimii, Vatke [fide J. D. Smith] ex Uline \& Bray, in Coult. Bot. Gaz xx. (1895) $161=$ Gomphrena Tuerckheimii, Uline \& Bray.

TELECTADIUM, Baill, in Bull. Soc, Linn. Paris, i1 (1889) 801. ASCLEPIADEAE.

edule, Baill. l. c. - Laos,

TELIS, Linn. = Trigonella, Linn. (Legumin.). aleppica, anguina, arabica, arcuati, astroites, auran tiaca, azurea, Balansae, berythea, calliceras, capitata, cariensis, Cassia, cephalotes, corniculata, crassipes, cretica, cyliszdracea, elliptica, Emodi, falcata, flilipes, Fischeriana, Foerinngraecum, gladiata, gracilis, graeca, grandifora, Griffithii, halophila, hamosa. isthmocarpa, laciniata, lilacina, lunata, macrorhyncha, maritima, monspeliaca, Noüana, occulta, persica, plicuta, polycarpa, polycerata, pubescens, radiata raphanina, vetrorsa, rhytidocarpa, rigida, rostrata Sibthorfii, smyrnea, spicata, spinosa, Spruneriana. stellata strangulata, striata, suavissima, subracemosa, uncata, velutina, Kuntze, Rev. Gen. (1891) $209=$ homonyma omnia Trigonellae.

brahuica, Kuntze, 1. c. $20 \mathrm{~J}=$ T. polycerata, Limn. cachemiriana, Kuntze, 1. c. = T. Emodi, Benth. coelesyriaca, Kuntze, 1. c. = T. caelesyriaca, Boiss. coerulea, Kuntze, 1. c. $=$ T. caerulea, Ser.

Fenzliz, Kuntze, 1. c. $=$ T. Kotschyi, Fenzl.

glomerata, Kuntze, 1. $\mathrm{c}_{0}=\mathrm{T}$. brachycarpa, Moris. hyerosolymitana, Kuintze, 1, $c_{n}=\mathrm{T}$. hierosolymitana Boiss. 
TELIS : -

Kotschyi, Kuntze, Rev. Gen. (1891) $209=$ Trigonella rytidocarpa, Boiss.

incisa, Kuntze, 1. c. = T. polycerata, Linn.

monantha, Kuntze, 1. c. = T. polycerata, Linn.

ornithopadiodes, Kuntze, 1. c. = T. ornithopodioides, $D C$.

orthoceras, Kuntze, 1. c. = T. polycerata, Linn.

ovalis, Kuntze, 1. c. = Medicago ovalis, Urban

procumbens, Kuntze, 1. c. = Trigonella Besseriana, Ser.

TELLIMA, R. Br. (Saxifr.). - Ind. Kew. ii, 1042. nudicaulis, Greene, Pittonia, ii. (July 1891) 162. Am. bor: occ.

Kacemosa, Greene, in Erythea, iii. (1895), 55 (= Heuchera racemosa, S. Wats.

scabrella, Greene, Yittonia, ii. (July 1891) 162, Calif.

tripartita, Greene, in Erythea, i. (1893) 106. - Calif.

TELOTIA, Pierre, in Bull. Soc. Linn. Paris, i. 1888) 754; Prant1, in Engl. \& Prant1, Natür1. Pflanzenfam. iii. 2 (1891) 275. MENISPERMA$C E A E$.

nodiflora, Pierre, $l l . c c$. - Cochinch.

TEMNOLEPIS. Baker, in Journ. Linn. Soc. xxii. (1887) 495. COMPOSITAE.

scrophulariaefolia, Baker, l. c. - Madag.

TEMPLETONIA, R. Br. (Legumin.). - Ind. Kew. ii. l'43.

Battii, F. Muell. in Melb. Chem. and Drug. New Ser. ii. (Febr. 1887) 31 ; et ex Bot. Centralbl. xxx. (1887) 180. - Austral.

TENAGOCHARIS, Hochst. $=$ Butomopsis, Kunth (Alismac.)

lanceolata, Baill. Hist des pl. xii. (1594) $86=$ cordofanus, Hochst.

lanceolata, Th. Dur. \& Schinz, Consp. Fl. Afr. v. 1894 (1895) 489 = praec.

TENARIS, E. Mey, (Asclep.). - Inḍ, Kew. ii. 1043 .

chlorantha, Schlechter, in Bot. Fahrb. xx. Beibl. n. 51 (1895) 44. - Afr. austr.

Volkensiz, K. Schum. in Engl. Pflarizenw. OstAfr. C (1895) $327=$ rostrata, $N^{\top} \cdot E \cdot B r$

TEPHROCACTUS, Lem, = Opuntia, Tourn. (Cact.).

polyacanthus, Lemaire, ex Foerst.-Ruempl. Handb. Cacteenk. (1885?) $915=$ Opuntia platyacantha. Pfeiff.

retrospinus, Lemaire, 1. c. 911 [retrospinosus] $=0$. Parmentieri, Pfeiff.

TEPHROSI.A. Pers. (Legumin.). - Ind. Kew. ii 1043 .

affinis, S. Wats, in Prac. Am. Acad. xxi. (1886) 424 - Mexic.

alpestris, Taub. in Abh. Preuss. Akad. Wiss. (1894) 58, 62 ; et in Engl. Pflanzenw. Ost-Afr. C (1895) 212. - Afr, trop. or.

angustissima, Engl. Bot. Fahrb. x. (1888) 29. Afr. anstr.

cana, T. S. Brandeg. in Proc. Calif. Acad. Ser. II. iii. (1891) 126. - Calif.

Commersonii, S. Elliot, in Journ, Linn, Soc, xxix. (1891) 13 = Galega pumila, Lam.

constricta, S. Wats. in Proc. Am. Acad, xxiv. (1889) 46. - Mexic.

damarensis, Engl. Bot. fahrb. x. (1888) 29. - Afr. austro occ. extratrop.

dura, Baker, in Kew Bull. (1894) 331. -- Arabia.

elata, Defers, Voy. au Yémen (1889) 130. - Arabia.

geminiflora, Baker, in Kew Bull. (1895) 316. Arabia.

grandiflora, Nichols. Dict. Gard. iv. (1887) 17. Afr. austr.

Haussknechtii, Bornm. in Mitth. Thitr. Bot. Ver. N. Folge, vi. (I894) 54. - Arabia.

\section{TEPHROSIA :}

Holstii, Taub. in Engl. Pfanzenzw. Ost-Afr. C (1895) 211. - Afr. trop. or

hypargyrea, Taub. ex Engl. in Abh. Prenss. Akad. Wiss. (1894) 62, nomen. - Afr. trop.

incana, Grah. ex Taub. in Engl. Pflanzenw. OstAfr. A (1895) 15, 21, 53, $74=$ villosa, Pers.

leucoclada, S. Elliot, in fourn. Linnn. Soc. xxix (1891) 13. - Madag.

macrantha. Robinson \& Greenm. ex Pringle, in Gard. and For. vii. (1894) 153, 175. - Mexic.

Meyeri-Johannis, Tanb. ex Engl. in Abla Preuss. Akad. Wiss. 1891 (1892) 260. - Afr, trop. or.

Nyassae, E. G. Baker, in Trinns. Limn. Soc. S. r. II iv. (1894) 9. - Afr. trop.

oraria, Hance, in Fourn. Bot. xxiv. (1886) 17. Ins. Hongkong.

Palmeri, S. Wats, in Proc. Am. Acad. xxiv. (1889) 46. - Mexic.

Purisinae, T. S. Brandeg. nn Proc. Calif. Acad. Ser II. ji. (1889) 149. - Calif.

Schweinfurthii, Deflers, in Bull. Soc. Bot. Fr. xlii. (1895) $302 .-$ Arabia.

talpa, S, Wats, in Proc. Am. Acad. xxii. (1887) 405. - Mexic.

Whyteana, E. G. Baker, in Trans. Linn. Soc. Ser II. iv. (1894) 9. - Afr. trop.

TEREBINTHINA, Rumph, Herb. Amboin, vi (1750) 150, t. 67, fig. 2, ex Kuntze, Rev. Gen. (1891) 477 = Limnophila, R. Br. (Scrophul.) aquatica, Kuntze, 1, c. $468=$ L, polystachya Benth.

aromatica, Kuntze, 1, c, $467=$ L. gratissima, Blume.

balsamea, Kuntze, 1. c. $468=$ L. balsamea, Benth. camphorata, Kuntze, 1. c. = L, diffusa, Benth. cana, Kuntze, 1. c. = L. cana, Griff.

connata, Kuntze, 1. c. = L. hypericifolia, Benth. erecta, Kuntze, 1. c. $467=$ L. erecta, Benth

glabra. Kuntze, 1. c. $468^{\circ}=$ L. Griffithii, Hook. f.

Helferi, Kuntze. 1. c. $=$ L. Helferi. Hook. $f$.

indica, Kuntze, 1. c, $467=\mathrm{L}$. gratioloides, $R . B r$

javanica, Kuntze, l. c. = L. javanica, A. DC.

laxa, Kuntze, 1. c. = L, laxa, Benth

micrantha, Kuntze, 1. C. $468=$ L. micrantha, Benth.

folyantha, Kuntze, 1. c. = L. polyantha Kurz, punctuta, Kuntze, 1. c. = L. conferta, Benth.

pygmaea, Kuntze, 1. c. $467=$ L. pygmaea, Hook。f. racemosa, Kuntze, 1. c. $468=$ L racemosa, Benth rugosa, Kuntze, 1. c. = L. Roxburghii, G. Don . sessiliffora, Kuntze, 1. c. = L. sessiliflora, Blume. tillaeodes, Kuntze, 1. c. = L. tillaeoides, Hook. $f$. villifera, Kuntze, 1. c. $467=$ L. villifera, Miq. wllos, Kuntze, 1, $\mathrm{c},=\mathrm{L}$, villosa, Blume

TERMINALIA, Linn, (Conbret.), - Ind. Kew

ii. 1046

albida, S. Elliot, in foum. Linn. Soc. Xxx. (1894) 79. - Sierra Leone.

Brandisii, Engl. ex Brandis, in Engl. or Prantl. Natïrl. Pfanzenfan. iii, 7 (1893) 118. - Afr. trop. or.

canescens, Radlk, in Th. Dur. Ind, Gen. Phan. (1888) 520; et in Sitzb. Akad. Muench. xx. (1890) 129, in obs (= Alectryon canescens, DC. $)=$ circumalata. F. Muell.

canescens, Engl. Pflanzentv. Ost-Afr. C (1895) 294 - Afr. trop. or.

complanata, K. Schum, in K. Schum. Es Hollr. Fl Kais. Wilh. Land (1889) 83. - N. Guin.

corticosa, Pierre ex Laness. Pl. util. Colon. Frane, (1886) 315. - Cochinch

Darfeuillana, Pierre, l. c. 314. - Cochinch. elegans, Hort. ex Kew Bull. ii. (1888) 117 = Polyscias paniculata, Baker.

Fischeri, Engl. Pfanzenw. Ost-Afr. C (1835) 294, Afr. trop. or

glauca, Pierre, ex Laness. Pl. util. Colon. Franc. (1886) 314, nomen. - Cochinch.

Hildebrandtii, Engl. Pfanzenze. Ost-Afr. C (1895) 294. - Afr, trop, or.

Holstii, Engt. in Abh. Preuss. Akad, Wiss. (1894) 34 ; et l. c. - Afr, trop. or.

\section{TERMINALIA :}

nguovenulosa, Pierre, ex Laness. Pl. utit. Colon. Franc. (1886) 315, nomen. - Cochinch.

Kaernbachii, Warb. in Bot. Fahrb. xviii .(1894) 201.

- N. Gllin.

Kaiseriana, F. Hoffn, Beitr. Kenntn, Fl. Centr, Ost Afr. (1889) 26. - Afr. trop.

kilimandscharica, Engl Pfanzenu. Ost-Afr. C (1895) 294. - Afr, trop. or

nyassensis, Engl. l. c. - Afr. trop. or.

Oliveri. Brandis, in Hook, Iconn. pl. xuiii. (1892) t. 2202. - Burma.

Petersii, Engl. Pfanzenwe.,Ost-Afr. C (1895) 294. Afr. trop. or

porphyrocarpa, Schinz, in Verh. Bot. Ver. Brand. xxx. (1888) 242, - Afr, austro-occ, extra trop.

Rautanenis,

rubiginosa. K. Schum, in K. Schnmm. of Follr. Fl. Kais. Wilh. Land (1889) 84. - N. Guin.

spinosa. Engl. Pfanzenw. Ost-Afr. C. (1895) 294. Afr, trop. or

Stuhlmannii, Engl l. c. - Afr. trop. or

torulosa, F. Hoffm. Beitr. Kemutn, Fl. Centr. Ost Afr. (1889) 27. - Afr, trop. triptera, Stapf, in Kero Bull. (1895) 103. - Ins.
Langlaaui.

TERMINALIS. Rumph, Herb. Amboin. iv. (1744) 79, t. 34; vii. (1755) 40, ex Kuntze, Rev, Gen. (1891) $716=$ Cordyline, Royen (Liliac.).

anstralis, Banksii, floribunda, indevisa, linearifolia, neocaledonica, oxyphylla, Fumilio, rigida, nubra, stricta, Kuntze, Rev. Gen. (1891) $716=$ homonyma omnic Cordylines.

dyacaenodes, Kuntze, 1.c. = Cordyline dracaenoi des, Kunth.

fruticosa, Kuntze, 1. c. = C. terminalis, Kunth.

Marchionae, Kuntze, 1. c. = C. Haageana, C. Koch.

nauritiana, Kuntze, 1. c. = C. macrophylla, C. Koch.

obtecta, Kuntze, 1. c. = C. Baueri, Hook. f.

TERNATEA, Linn. = Clitoria. Linn. (Legum.) amazonum, arborescens, australis, bifora, braclystegia. densiflora, fagellaris, gramdiflora, guianensis, hetero phylla, jazitensis, lasciva, leptostachya, macrophylluz. MLariana, multiflora, nana, polystachya, portobellensis, racemosa, rufescens, Selloi, simplicifolian, Kuntze, Rev. Gen. (1891) 210 =homonyma omnia Clitoriae. rborea, Kuntze, 1. $\mathrm{C}_{\mathrm{e}}=(\mathrm{C}$. arborea, Benth. $)=\mathrm{C}$. Hoffmanseggii, Benth.

Eracteata, Kuntze, 1. c. = C. stipularis, Benth.

Hancianc, Kuntze, 1. c. = C Hanceana, Hemsl.

laurifolia, Kuntze, I. c. = C. cajanifolia, Denth.

pedinculata, Kuntze, 1. c. = C. pedunculata, Boj.

mbbiginosa, Kuntze, 1. c. = C. glycinoides, $D C$.

Scliedeana, Kuntze 1 . c. = Centrosema pubescens, Benth.

TERNSTROEMIA, Mutis (Ternstroem.). - Ind. Kew. ii. 1047

alnifolia, Wawra, zn Mart. Fl. Bras. xii, I. (i886) 275. - Bras.

andina, Wavera, l, c. 27S - N. Granat.

Candolleana, Wawra, l. c. 273. - Bras

laevigata, Wawra, l. c. 281. - Guian, angl.

Lowii, Stapf, in Trans. Limn. Soc. Ser. II. iv: (1894) 132. - Bcrneo.

oleaefolia, Wawra, in Mart. Fl: Bras. xii. I. (1886) 279. - Bras.

Scortechinii, King, in Fourn. As. Soc. Beng. lix. (1890) II. 193. - Malaya.

TESTUDINARIA, Salisb. (Dioscor.). - - Ind Kew. ii, 1048.

Cocolmeca, Procopp, in Bol. Centralb7. xlix. (1892) 201. - Mexic

TETRAGENTRON, Oliver, in Hook. Icon. pl, xix. (1889) t. 1892; Prantl, in Engl. \& Prant1 Natuirl. Pflanzenfam. 1ii. 2 (1891) 273. MAGNOIIACEAE.

sinense, Oliver, $l l . c c$. - China. 
TETRAGERA, Linn. (Dilleniac.). - Ind. Kew. ii. 1049

axillaris, Martelli, in Bece. Malesia, iii. (1886) 151 - Bornea

Billardieri, Martelli, l. c. $152(=T$. enryandra, Labill.). - N. Caled.

Cowleyana, F. M. Bailey, in Dept. Agric. Brisbane Bot. Bull. v. (1892) 7. - Austral.

Empedoclea, Gilg, in Engl. \&o Prantl, Naturt. Jpanzenfann, iii. 6 (1893) 111 (= Empedoclea alnufolia, St Hil.). - Bras.

Everillii, F. Muell. Descr. Notes Papuan Pl, vii. (1886) 25. - N. Guin.

laberrima, Mamelli, in Becc. Matesia, iii. (1886) 150. - Borneo.

rrandis, King, inn fourn. As. Soc. Bong. Iviii. (1889) II. 363. - Penins, Mal.

grandiuscula, F. Muell. Es Tate, in Trans. et Proc. Roy. Soc. S. Austral. xiii. (1890) 108 [grandiuscula|. - Austral.

moluccana Martelli, in Becc. Malesia, iii. (1886) 153 - Ins. Amboin

Radula, Martelli, l. c. - Borneo.

Stuhlmanniana, Gilg, in Engl. Pfinzenz. Ost-Afr. C (1S95) 272. - Afr. trop. or

Teysmannii, Martclli, in Becc. Malesia, iii. (1886) 150. - Ins. Banca.

TETRACERATIUM Kuntze, Rev, Gen. (1891) $36^{\circ}$ = Tetracme, Bunge (Crucif.)

tontorlum, quadricorne, recurvatum, secundum, Stock sii, Kuntze, 1. c. = homonyma omnia generis Tetracmes

TETRACHNE, Nees (Gramin.), - Ind. Kew. li. 1049

aristulata, Hackel of Rendle, ex S. Elliot, in fonm. Bot.xxix. (1891)72. - Afr. austro-occ, extratrop.

TETRAGHONDRA. Petrie, ex Oliver, in Hook Icon. pl, xxii. (1892) t. 2250. BORAGINEAE.

Hamiltonii, Petrie, l.c. $(=$ Tillaea Hamiltonii, $\mathrm{T}$ Kirk), - N. Zel.

TETRACHYRON, Schlecht, = Calea, Linn. $(\mathrm{Com}-$

pos.).
prizabaensis. Sch. Bip. ex Klatt, in Leopoldina Heft xxiii. (1887) 145, in syn. = Calea oriza baensis, Klutt.

TETRACRONIA. Pjerre, Fl. For. Cochinch Fasc. 18 (1893) t. 285a. RUTACEAE. cymosa, Pierre, l. c. - Cochinch.

TETRACUSTELIMA, Baill. Hist. des p1, $x$ (1890) 292. ASCL EPIADEAE.

prostrata, Baill. l. c. 3 (= Lachnostoma prostratum, Decne) - Mexic .

Schaffneri, K. Schum, in Engl. Es Prantl, Natiur. Pfanzenfan. iv. 2 (1895) 304. - Mexic.

TETRADENIA, Briq.(Labiat.).--Ind.Kew.ii.1049. Golldotii, Briq. in Bull. Herb. Boiss。 ii. (1894) 132. - Madao.

Hildebrandtii, Briq. l. c. 134. - Madag.

TETRAENA, Maxim. Enum. pl. Mongol. (1889) 129. ZYGOPHYLLACEAE.

mongolica, Maxim. l. c. 129. - Mongol.

TETRAGASTRIS, Gaertn. = Hedwigia, Sw. (Burser).

balsamifori, Kuntze, Rev. Gen. (1891) $10 \%=\mathrm{H}$ panamensis, Sw

Hostmanni, Kuntze, 1. c. $=$ H. Hostmanni, Engl. panamensis, Kuntze, 1. c. = H. panamensis, Engl.

TETRAGONANTHUS, S. G. Gmel. = Halenia Borkh. (Gentian.)

alatus, breviconis, decumbens, defexus, Dombeyanus, elatus, clongotus, gracilis, inaequalis, longicomis, major multiflorus, nudicaulis, nutans, parvifloris. pancifolins, Palmeri, Perrottetii, pinifolius, plantagineus, Purdieanus. Schicdeanus, Kuntze, Rev. Gen. (1891) $431=$ homonyma onnia Haleniae. Controstennan, Kuntze, 1. c. $=$ H. elliptica, D. Don. comiculatus, Kuntze, 1. c. $=$ H. sibirica, Borckl.
TETRAGONANTHUS :-

Fischeri, Kuntze, Rev. Gen. (1891) 431 = Halenia sibirica, Borckh.

gentianodes. Kuntze, 1. c. $=\mathrm{H}$. gentianoides, $W e d d$. liypericodes, Kuntze, 1.c. = H. hypericoides, Griseb. umbellatus, Kuntze, 1, $\mathrm{c},=\mathrm{H}$. Pavoniana, G. Don.

TETRAGONIA, Linn. (Ficoid.). - Ind. Kew. ii. 1050

limorphantha, Pax, in Bot. Falk b. x. (1888) 12. Afr, austro-occ, extratrop.

horrida, Britton, in Ann. N. Y. Acad. Sci, vii. (1893) 122. - Parag.

macroptera, Pix, in Bot. Fahrb. x. (1888) 11. Afr. austro-occ. extratrop.

Schenkii, Schinz, in Bull. Herb. Boiss. ii. (1894) 204. - Afr. austro-occ. extratrop.

etragonoides, Kuntze, Rev. Gen. (1891) $264=$ T. expansa, Murr.

trigona, Phil, in Anal. Muss. nac. Chile (1891) 24. Chili.

TETRAGONOLOBUS, Scop. = Lotus, Tourn (Leoumin.)

Bironaens. Ces., Passer. \& Gibelli, Comp. Fl. Ital. ii. (1886) $707=$ L. Bivonaeus, Guss,

TETRAGONOTHEGA, Dill, ex Linn, (Compos.), Ind, Kew. ii, 1050.

guatemalensis, Coult. in F. D. Smith, Enum. f7. Guatem. ii. (1891) 38, nomen; et Bot. Gar. xvi. 99. - Guatem.

TETRAMERIUM, Nees (Acanth.). - Ind. Kew. ii. 1051.

costatum. Millsp. Field Colnmb. Muss. Bot. Ser. I. (1895) 47. - Am. bor.

glutinosum, Lindau, ex Loesen, in Bull. Herb. Boiss. ii. (1894) 565. - Mexic.

TETRAMIGRA, Lindl.- (Orchid.), - Ind, Kew. ii. 1051 .

minuta, Rolfe, in Gard.Chron. (1889) i. 526 (= Leptotes minuta, Rolfe.). - Hab. ?

serrulata, Nichols. Dict. Gavd. iv. (1887) $30=$ Leptotes serrulata, Lindl.

TETRAMOLOPIUM, Nees (Compos.). - Ind. Kew. ii. 1051

arenarium, Hillebr. Fl. Haw. Isl. (18S8) 199 (= Vittadisicu arenaria, A. Gray). - Ins. Sandvic.

Chamissonis, Hollebr. l. c. $(=V$. Chamissonis, A. Gray). - Ins. Sandvic.

consanguineum, Hillebr. l.c. $(=V$ V. consangrined, A Gray \%. - Ins. Sandvic.

conyzoides, Filllebr. l. c. $200(=V$. conyzoides, A. Gray). - Ins. Sandvic.

humile, Hillebr. l. c. $198(=$ V. hmmilis, A. Gray $)$. - Ins. Sandvic.

TETRANMMA, Benth. (Scrophul.). - Ind. Kew. ii. 1051

evoluta, F. D. Smith. in Coult. Bot. Gaz. xiv, (1889) 29. -- Guatem.

TETRAPLACUS, Radlk. (Scrophul.). - Ind. Kew. ii. 1053 .

Tauberti, Mes, ex Taub. in Bot. Fahrb. xii. Beibl. n. 27 (1890) 16 (= Otacanthus coenuleus, Lindl. fide Taub.). - Bras.

TETRAPLASAINDRA, A. Gray (Arab.). - Ind. Kew. ii. 1053.

Kaalae Harms, in Engl. \& Prantl, Natiirl. Pfanzenfann. iii. 8 (1894) 30 (= Triplandra Kaalae, Hillebr.) - Ins, Sandvic.

Lydgatei, Harms, l.c. (= T. Lydgatei, Hillebr.).Ins. Sandvic

meiandra, Harms, l. c. $(=$ T. meiandra, Hillebr. $)$. - Ins. Sandvic.

oahuensis, Harms, l. c. 30. - Ins. Sandvic.

TETRAPLEURA, Benth. (Legumin:), - Ind. Kew. ii. 1053 .

tetraptera, Taub. in Bot. Centralbl. xlvii. (1891) $305=\mathrm{T}$. Thonningii, Benth.
TETRAPOGON, Desf. (Gramin.). - Ind. Kew. ii. 1053.

spathaceus, Hack. cx Th. Dur. \& Schinz, Consp. Fl Afr. v. 1894 (1895) 864 (= Chloris spathacea, Hochst.). - Afr. trop. or. et austr.

TETRAPTERIS, Cav. (Malpigh.). - Ind. Kew ii. 1053.

rhodopteron, Oliver, in Trans. Linn. Soc. Ser. II ii. (1887) 272 Coliver, ex im Thurn, in Timelhri, $\mathrm{v}$, (1886) 190.). - Guian. ang1.

TETRARIA, Beauv. (Cyper.). - Ind. Kew, ii. 10.54

aristata, C. B. Clarke, in Th. Dur. \& Schinz, Consp Fl. Afr. v. 1894 (1895) $659(=$ Elynanthus aristatus, Boeck.). - Afr. austr.

Bolusii, C. B. Clarke, J c. 659. - Afr, anstro-or. et austr.

brevicaulis, C. B. Clarke, l. c. - Afr. austr.

Burmanni, C. B. Clarke, l. c. (= Chatospora Bumanni, Spreng.). - Afr. austr.

capillacea, C. B. Clarke, l. c. $(=$ C. capillacea Nees). - Afr. austr.

circinalis. C. B. Clarke, l. c. $(=C$. circinatis, Schrad.), - Afr. austr.

compar, C. B. Clarke, l. c. 660 (= Elynantrius compar. Nees). - Afr. austr.

crinifolia, C B. Clarke, l. c. $(=$ Aulacorriynchus crinifolitu, Nees). - Afr. austr.

cuspidata, C. B. Clarke, l. C. $(=$ Elynanthus cuspidatus, Nees). - Afr. austr.

Dregeana, C. B. Clarke, l. c. $66 \mathrm{I}(=$ E. Dregeanus, Boeck.). - Afr. austr.

eximia, C. B. Clarke, l. c. nomen, - Afr. austr.

fasciata, C. B. Clarke, l. c. $(=$ Elynanthus microsta. chynts, Boeck.). - Afr. austr.

fimbriolata, C. B. Clarke, l. c. (= Chaetospora fimbriolata, Nees). - Afr. austr.

flexmosa, C. B. Clarke, l. c. (=C. flexuosa, Schrad.) - Afr. austr.

involucrata, C. B. Clarke, .l.c. $(=$ Sclerochoetium involucratum, Nees). Afr. austr.

ligulata. C. B. Clarke, l. C. $(=$ Elynanthus ligulatus, Boeck.). - Afr, austr.

Mac Owani, C. B. Clarke, l. c. nomen, - Afr. austr.

nigrovaginata, C. B. Clarke, l. c. 662 (=Cyathocome migrovaginata, Nees). - Afr. austr.

picta, C. B. Clarke, l.c. $(=$ Elynanthus pictus Boeck, ). - Afr. austr.

pleosticha, C. B. Clarke, I. c. nomen, - Afr. austr.

punctoria, C. B. Clarke, l. c. (= Buekia punctoria, Nees). - Afr, austr.

obusta, C. B. Clarke; l. c. (= Chaetospora robusta Kunth). - Afr. austr.

Rottboellii, C. B. Clarke. I. c. (= Iepidosperma Rottbocllii, Schrad.). - Afr. austr.

rottboellioides, C. B. Clarke, l. c. 663 (= Sclerochaetizm angustifolium, Hochst.). - Afr. austr. secans, C. B. Clarke, l. c. nomen. - Afr. austr.

spiralis, C. B. Clarke, l. c. (= Sclerochaetium spirale Hochst.). - Afr. austr.

sylvatica, C. B. Clarke, l. o. (=Elynanthus sylvaticus, Nees). - Afr. austr.

thermalis, C. B. Clarke, l. c. $(=$ Iepidosperma thermale, Schrad.), - Afr. austr.

triangularis, C. B. Clarke, l. C. $(=L$. triangulare Boeck., - Afr. austr.

usambarensis, K. Schunn. in Engl. PAanzento. Ost Afr. C (18\%) 128. - Afr. trop. or.

ustulata, C. B. Clarke, l. c. $664(=$ Elynanthus ustulatus, Nees). - Afr. austr.

Wallichiana, C. B. Clarke, l. c. nomen. - Afr austr.

TETRASTIGMA. Planch, in DC. Monog. Phan. v (1887) 423 = Vitis, [Tourn.] Linn. (Ampelid.) amboinense. Planch. in DC. Monog. Phan. V. (188\%) $443=\mathrm{V}$. amboinensis, Miq.

angustifolizm, Planch. 1. c. 439. - Sumatra. articulatum, Planch. I. $\mathrm{c}$. = Vitis articulata, Mid. bracteolatum, Planch. 1. c. $428=$ V. bracteolata Wall.

campylocarpum, Planch. 1. c. $437=$ V. campylocarpa, Kurz. 
TETRASTIGMA :

capreolatum, Koehne, Deutsche Dendrol. (1893) 401 = serrulatum, Planch.

crassipes, Planch. in DC. Monog. Phan. v. (1887) 426. - Cochinch,

dichotomm, Planch. 1. c. $441=$ Vitis dichotoma .Miq.

dubium, Planch. 1. c. $437=$ V. dubia, Laws,

crubescens, Planch. 1. c. 444. - Tonkin.

Gaudichaudianum, Planch. 1. c. 435. - Cochinch.

glabratum, Planch. 1. C. $430(=$ Cissus glabrato.

Blume). - Java.

olycosmoides, Planch. 1.c. 426. - Zeylan.

Godefroyanum, Planch. 1. c. 436 . - Siam.

Harmandi. Planch. 1. c. $425 .-$ Cochinch.

Hookeri. Planch. 1. c. $428=$ Vitis Hookeri, Lavs.

Typoglaucum, Planch.1. c. 433. - Yunnan.

lanceolarinm, Planch. 1. c. $433=$ Vitis lanceolaria, Wall.

mutabile, Planch. 1. c. $440=$ V. mutabilis, Miq

obtectun, Planch. ex Franch, in Bull. Soc. Bot. Fr. xxxiii. (1886) 458; et 1. c. 434; Franch. P1.

Delav. (1889) $138=$ Cissus obtecta, Wall.).-

Reg. Himal., China mer.

oliviforme, Planch. in DC. Monog. Phan. v. (1887) 438. - Cochinch.

papillosum, Planch. 1. c. 429 (= Cissus papillosa, Blume.). - Java

pupuamum, Planch. 1. c. $442=$ Vitis papuana. $M i q$ pedunculare, Planch. 1 , c. $438=\mathrm{V}$. peduncularis, Wall.

pergamaceum, Planch. 1. c. 431. - Ind batav.

pisicarpum, Planch. 1. c. $441=$ Vitis pisicarpa Miq.

quadridens, Planch. 1. c. 445. - Cochinch.

Raffesiae, Planch. 1, c. $443=$ Vitis Rafflesiae, $M i q$

rannentaceum. Planch. 1. c. 430 (= Cissus glabrata.

Blume ). - Java.

retinervium, Planch. 1.c. 444. - Tonkin.

robustum, Planch. 1. c. 443. - Cambod.

rumicispermum, Planch. 1. c. $429=$ Vitis rumicisperma, Laves.

upestre, Planch. 1. c. 435. - Tonkin.

soariosum, Planch. 1. c, 441 (= Cissus scariosa, Blume). - Java.

serrulatum, Planch. 1. c. $432(=$ C. sermlata,

Roxb.). - Ind. or

subsuberosum, Planch. 1.c. 445. - Cochinch.

tetragynum, Planch, 1. c. $440=$ Vitis tetragyna Miq.

Thomsonianum, Planch. 1. c. 439, in obs. - Silhet.

TETRASTYLIDIUM, Engl. (Olacin.). - Ind. Kew. ii. 1054.

Engleri, Sohwacke, in Bot. Falirb. x. (1888) 291 : et in Engl. E Prantl. Natül. Pfanzenfan. iii. I. (1S89) 235 . - Bras.

TETRAZYGIA, Rich. ex DC, (Melastom.). Ind. Kew. 11. 1054

bicolor, Cogn. in DC. Monog. Phan. vii. (1891) 724 - (= Miconia bicolor. DC.). - Cuba, Baham.

Krugii, Cogn. l. c.719. - Ins. Puerto-Rico.

pallens, Cogn.l.c. 724 (= Miconia pallens, Triana) - Ind. occ.

Stahlii. Cogn. ex Stahl, Estud. Fl, Puerto-Rico, iv (1886) 113 ; in Furhrb. Bot. Gart. Berl. iv. (1886) 279 ; et in DC. Monog. Phan. vii. (1891).719.Ins. Puerto-Rico.

Urbanii, Cogn. $l l$. cc. iv. (1886) 278; et vii. (1891) 719. - Ins. Portoric.

villosa, $\operatorname{Cogn}$. l. c. 721. - Ins. Domin.

TEUCRIUIM, [Tourn.] Linn. (Labiat.). - Ind, Kew. ii. 1055.

ajugaceum, F. M. Bailey \& F. Muell. in F.M. Bailey, Syn. Queensl. Fl. Suppl. ii. (1888) 48. - Austral.

Albarracini, Pau, Not.Bot. F1. Espan. i. (1887) 19 $=$ T. Chamaedrys, Limn.

albo-rubrum, Hemsl. in fourn. Limn. Soc. xxvi. (1891)311. - China

ambiguum, Lange, in Danske Vidensk. Selsk. Forh, (1893) 196.- Hisp.

arisitense $X$. Coste \& Sennen, in Buil. Soc. Bot. Fr. xli. (1892) 584. - Gall.

\section{TEUCRIUM}

aristatum, Perez Lara, in Annal. Soc. Esp. Hist. Nat, xviii. (1889) 90 ; Florul. Gadit. iii. (1886-92) 288; Willk. Illustr. Fl. Hisp. ii. (1886-93) 96 tab. 144. - Hisp.

auraniticum, Post, in fourn, Limn, Soc, xxiv, (188S) 440 - As. occ.

bidentatum. Hemsl. l c. xxvi. (1891) 312. - China. cebennense $\times$ Coste \& Sennen, in Bull. Soc. Bot. Fr. xli. (1894) 582; et in Bull Herb. Boiss, iii. App. i. (1895) 17. - Gall.

Contejeani $\times$. Giraudias, in Bull. Soc étud. sci. Angers (1888) 16; et (1889) 52. - Pyren, gall

corbariense $X$. Coste \& Sennen, in Bull. Soc. Bot. Fr, xli. (1894) 583. - Gall. mer.

Davaeanum, Coss, in Bull. Soc. Bot. Fr. xxxvi. 1889) 102, 105. - Cyrenaica

expansum, Pau, Not. Bot. Fl Espan. ii (1889) 14 Willk. Suppl. Prodr. Fl. Hisp. (1893) 162,-Hisp.

flavovircns, Batt. in Batt. \& Trab. Fl. de l'Algér. [Dicot.] (1889) $714=$ T. Polium, Linn.

floccosum, Coincy, in Morat, fourn. de. Bot. viii 1894) 66 ; et Eclog. alt. Pl. Hisp. (1895) 22 t. . Hisp.

Franchetianum. Rony \& Coincy. in Coincy, Ecloo. Fl. Hisp. (1893) 20 t. S. - Hisp.

Freynii, Reverchon, ex Willk. Suppl. Prodr. Fl. Hisp. (1893) 159. - Hisp

Gautieri X, Fouc, ex Coste \& Sennen, in Bull. Soc. Bot. Fr, xli. (1894) 581, in obs. - Gall.

eucanthum, Phil in Anal. Univ. Chil. xc (1895) 565. - Chili.

Mailhoi X, Giraudias, in Bull. Soc. étud. sci Angers (1890) 56, et (1891) 72. - Pyren. gall

Nashii, Kearney, in Bull. Torrey Bot. Club, xxi. (1894) 484. - Florida.

ninupoense, Hemsl. in foum. Limm. Soc. xxvi, (1891) 313. - China.

nummularifolium, Baker, in Kew Bull. (1895) 185. - Arabia

ornatum, Hents. in fourn. Linn. Soc. xxvi. (1891) 313. - China.

Perryi, "Franch. " ex Briq. in Engl. \& Prant Natiurl, Pflanzenfam. iv. 3a (1895) 213. sphalm. $=$ T. Pernyi, Franch.

pilosum, Aschers. \& Schweinf. Illustr. Fl. Egypte (1887) 189, in add. - Arabia

Reverchoni, Willk. in Oest. Bot. Zeitschr. xli. (1891) 53 ; et Suppl. Prodr. Fl. Hisp. (1893) 160. - Hisp. ruthenense $X$. Coste \& Sennen, in Bu1l. Soc. Bot. Fr. xli. (1894) 586. - Gall. mer.

scindicum, Prain, in fourn. As. Soc. Beng. lix. 1890) 11. 316. - Ind. or.

Townsendii, Vasey of $7 . N$. Rose, in Proc. U.S Nat. Mus, xii. (1890) 146. - Ins. Clarion.

Wattii, Prain, in fourn. As. Soc. Beng. lix, (1890) II. $31 \%$ - Ind or.

Willkommii, Porta, in Nuov. Giom. Bot. Ital. xix. (1887) 3]5. - Ins, Balear

Yebrudi, Pl. Postianae, ii. (1892) 15. - Syria.

yemense, Deflers, Voy. au Yémen. (1889) 190.-Arabia.

THALESIA, Rafin. = Aphyllon, Mitch. (Orobanch.).

fasciculata, Britton, in Mem. Torrey Bot. Club, $v$. (1894) $298=$ A. fasciculatum, A. Gray.

miflora, Britton, 1. c. = A. uniflorum, Torr. \& Gray.

THALIA, Linn. (Scitam.). - Ind. Kew. ii. 1057. caerulea, Ridl. in fourn. Bot. xxv. (1887) 132. Angola.

coarctata, Herb. Vindob. ex Petersen, in Mart. Fl, Bras iii. III. (1890) $168=$ Saranthe cuiabensis, Eichl.

densibracteata, Petersen, l. c. 144. - Bras.

Welwitschii, Ridl. in fourn. Bot. xxv. (1887) 132. - Angola.

THALICTRODES, Amm. = Cimicifuga, Linn. (Ranuncul.).

anericanum, biternatum, cordifolium, clatum,japonicum, ostusilobum, racemosum, Kuntze, Rev. Gen. (1891) 4 = homonyma omnia Cimicifugae.

Cimicifugà, Kuntze, 1. c. = C. foetida, Linn.

simplex, Kuntze, 1. c. - C. foetida, Iim.
THALIGTRUM, Tourn, ex Linn. (Ranuncul.). Ind. Kew. ii, 1057.

arpadinm, Borb. in Termész. Füzet. xvi. (1893(42 $=$ minus, $\operatorname{Lin} n$

bulgaricum, Velen. Fl. Bu'g. (1891) 4 - Bulor. caesium, Blocki, in Oest. Bot. Zeitschy yxrvii (18s8) 286, nomen. - Austria.

caesium, Grene, Fl. Francisc. (1891) 309. - Calif calalaunicum, Pau, Not. Bot. F1. Espan. iv. (1891) $111=$ simplex, Linn.

ceraiense, Matsumura, in Tokyo Bol. Mag. ix. (1895) 276. - Japon

Franch in Morot, Foutrn. de Bot. viii. (1894) 273, - China

crbariense, Timb. in Lucante, Rev. de Bot. x. (1892) $20=$ minus, Limn

corymbulosum, Timb. l. c. 21 - Gall. mer

oriacenm, Small, ex Small \& Vail, in Mem. Torrey Bot. Club, iv. (1893) 98 = dioicum, Linz . var.

crossaeum, Heldreich \& Charrel [Nadji| in Oest. Bot. Zeitschr. xli. (1:91) 374, nomen; et Emp. Ottom. Géogr. bot. [Pl. de Saloniq.l (1892) 7. - Turc.

Delavayi, Franch, in Bull. Sec. Bot. Fr. xxxiii. (1856) 367; et Pl. Delav. (1889) 10; Hook. f. in Bot. Mag. (189i)) t. 7152. - China

dipterocarpum, Franch, 2 . ca. 3us; et 12. - China

gallicum, Rouy et Fouc. Fl. de Fr. i. (1893) 29 [sp. coll.]. - Gall.

grandiflorum, Maxim, in Act. Hort. Petrop. xi. (1889) 11 - China.

grandifolium, S. Wats, in Proc. Am. Acad. xxiii (1888) 26\%. - Mexic

hamatum, Maxim. in Act. Hort. Petrop. xi. (18s9) 16. - China.

hesperium, Greene, Pittonia, ii. (Nov, 1889) 24 ; Man. Bot. San Franc. Bay (1894) $6(=T$. platy carpum, Greene:- - Calif.

ichangense, Lecoyer, ex Oliver, in Hook. Icon. pl. xviii. (1888) t. 1765. - China

integrilobum, Maxinu. in Bull. Acad. Pétersb, xxxii. (1888) 47\%. - Japon.

iodostenon $\times$ “ Borb, s ex Nym, Consp. F1. Eur Suppl. ii. I. (I889) 5, sphalm. = icdosteum $X$ Borb.

Lecoyeri, Franch. Pl. Delav. (1888) 16. - Yunnan. leuconotum, Franch. l. c. 15. - China occ

Limnaeanm, Rouy \& Fouc, F1. de Fr. i. (1893) 35 = flavum, Linn.

longipes, Rouy \& Fouc. 1. c. $22=$ minus, Lim

lugdnonse, Rouy \& Fouc. 1. c. $30=$ gallicum, Rouy \& Fouc

macrorhynchum, Franeh, in Morot, Fourn. de Bot. iv. (1890) 302. - China sept.

microgynum, Lecoyer, ex Oliver, in Hook. I conz. pl. xviii. (1888) t. 1766, - China

macrostylum, Snatl of Heller, in Mesin. Torrey Bot. Club, iii. (18:2) 8. - Carolina.

ligandrum, Maxim, in Act. Hort, Petrop. xi. (1889) 16. - China.

pinnatum, S. Wats, in Proc. Am. Acad. xxiij. (1888) 267. - Mexic.

platycarpum, Greene, Pittonia, i. (June 1888) $166=$ hesperium, Greene.

polygynum, Somm. in Nuov. Giorn. Bot. Ital. xxy. (1893) 46. - Sibiria.

Pringlei, S. Wats, in Proc. Am. Acad. xxv. (1890) 141 - Mexic

reticulatum, Franch, in Bull. Soc. Bot. Fr. xxxiii, (1886) 371; et Pl. Delav. (1889) 17. - China occ.

robustum, Maxim. in Act. Hort. Petrop. xi. (1889) 18. - China.

sabaudum, Rouy \& Fouc. Fl. de Fr. i. 1893) $18=$ minus, Linn.

scabrifolium, Fránch. in Bull. Soc. Bot. Fr. xxxiii (1886) 371; et Pl. Delar'. (1889) 16. - China occ Schleicheri, Rouy \& Fouc. Fl. de Fr. i. (1893) $22=$ minus, Limn.

subfalcatum, Rouy \& Fouc, 1, c. $26=$ minus, Limn subsphaerocarpum, Borb̄. Geogr. atq. Enum. pl. Comit. Castrif. (1887) 240. - Hung.

sultanabádense, Stapf, in Verh. zool.-bot. Ges. Wien, xxxviii. (18S8) 550. - Persia.

tomentellum, Robinson Eo Seaton, in Proc. Am. Acad. xxviii. (1893) 103. - Mexic 


\section{THALICTRUMI :} trichopus, Franch, in Bull. Soc. Bol. Fr, xxxiii.
(1886) 368; et Pl. Deluv. (18S9) 14. - Chiria tripcltatum, Maxim. in Act. Hort. Petrop, xi. (1889) 13. - China

uncatum, Maxim. l.c. 14. - China.

renulosum, Trolease, in Proc. Bost. Soc. Nat. Hist. xxiii. (1886) 302; Macoun, Catal. Canad. Pl. v. (1890) 296. - Am. bor. occ.

Watanabei, Yatabe, in Tokio Bot. Mag. vi, (18?2) 307, t. 9. - Japon.

THALYSIA, Linn, = Zea, Linn, (Gramin.) Mays, Kuntze, Rev. Gen. (1891) T94 = Z. Mays, Lim.

THAMNEA, Soland. (Bruniac,). - Ind Kew. ii.

diosmoides, Oliver, in Hook. Icon. pl, xxiv. (1894) t. 2314. - Afr. austr.

THAMNOSMA, Torr. (Rutac.). - Ind. Kew. ii. .

africanum, Engl. Bol. Falirb. x. (1888) 33. - Afr, austro-occ, extratrop.

Hirschii, Stapf, in Kew Bull. (1895) 315. - Arabia.

TriAPSIA, Linn. (Umbellif.). - Ind. Kew. ii. 1061.

edulis, Nichols. Dict, Gird. iv. (1887) 74. - Ins MIader.

THASPIUM, Linn. (Umbell.). - Ind, Kew. ii 1061.

rifoliatum, Britton, in Mem. Tnrrey Bot. Club, v. (1894) 248 = trifoliatum, $A$, Grat

THEA, Linn. = Camellia. Linn. (Ternstroem.) Dormoyana, Pierre, ex Laness. P1. util. Colon. Franc. (1886) 296; et Fl. For. Cochinch. Fasc. 8 (1857) t. 118. - Cochinch.

drupifera, Pierre, 1. c. sub t. $119=$ Camellia drupifera, Lour.

Edithac, Kuntze. Rev. Gen. (1891) $65=$ C. Edithae Hance

fratema, Kuntze, 1. $c_{0}=$ C. fraterna. Hance.

Greysii, Kuntze, 1. c. = C. Grysii, Hance.

hongkongensis. Pierre, Fl. For. Cochinch. Fasc \& (1887) t. $117=$ C. honglongensis, Secm.

lancoolota, Pierre, 1. c. sub. t. $119=$ C. lanceolata, Scenl.

Iutesccns, Pierre, 1. c. $=$ C. Iutescens, Dyer.

Piqutiana, Pierre, ex Laness, P1. util. Colon. Franç. (1886) 296 : et 1. c. t. 119. - Cochinch.

Quinosaura, Pirre, Fl. For. Cochinch. Fasc. 8 (1887) sub t. 119= Camellia Quinosaura, Seem.

reticulata. Pierre. 1. c. $=$ C. reticulata. Lindl.

rosiflora, Kuntze, Rev, Gen. (1891) $64=$ C. rosaeflora, Hook.

thciformis, Kuntze, 1. co = C. euroides, Lindl.

THAUMATOCARYUM, Baill. in Bull. Suc Linn. Paris, ii. (1890) 839; et Hist. des pl.x. (1890) 38T. BORAGIN'EAE

Hilarii, Buill. ll.cc. - Bras.

THEבACORIS, A. Juss. (Euphorb.). - Ind.Kew ii. 1062 .

membranacea, Pax, in Bolet. Soc. Brot. x. (1892) 158. - Ins. S. Thom

THEGOPHYLLUIM, İ André,Bromel, Andrean. (1S89) 10\%. BROAIELIACEAE.

Poortmanni, Ed. André, l. c. 108. - Ecuad.

Wittmackii, Ed. André, l. c. 107, t. 39b. - Columbis.

THEGOSTELE, Reichb. f. (Orchid.). - Ind, Kew, ii. 1062

maculosa, Ridl. in Trans. Linn. Soc. Ser. II. iii. (1893) 374. - Penins. Mal.

Maingayi, Hook.f. Fl. Brit. Ind. vi. (1890) 20. Mialacea.

quinquefida, Hook, f. l. c. - Malaccea.
THEILEAMEA, Baill, in Bull. Soc, Linn, Paris, i. (1890) 821 ; et Hist, pl. x. (1890) 432, ACAN. THACEAE

rupestris, Baill. $\eta_{0}$ cc. (= Aetheilema mupestris, Nees). - Madag.

THELASIS. Blume (Orchid.). - Ind. Kew. ii, 1062 .

bifolia, Hook, f. Fl. Brit, Ind. vi. (1890) 86.Khasia.

decurva, Hook.f.l. c. st. - Penins. Mal.

elata, Hook. f. l. c. - Perak.

khasiana. Hook. f. l. c. 8\%. - Khasia.

longifolia, Hook. f. l. c, - Khasia.

THELECARPUS, Van Tiegh, in Bull. Soc. Bot Fr, xlii. (1895) $262=$ Loranthus. Linn.

Batangue, Van Tiegh. 1 co = L. Batangae, Engl.

hexasepalus, Van Tiegh. 1. c. 263 ; et in Bull. Mus, Paris, i. (1895) 166. - Congo gall.

Soyauxi, Van Tiegh. 11. cc. =L. Soyauxi, Engl.

Thollonit, Van Tiegh. in Bull. Mus. Paris, i. (1木95) 166. - Congo gall.

THELESPERMA, Less. (Compos.). - Ind. Kew. ii. 1062 .

trifidun, Britton, in Trans. N. Y. Acad. Sci. ix. $(1890) 182=$ filifolium, A. Gray.

THELYGONUM, Linn. (Urtic.). - Ind. Kew. ii. $106^{\circ}$.

macranthum, Franch, in Nowr. Arch. MIus. Paris, Sér. II. x. (1887) 71. - Tibet.

THELYMITRA, Forst. (Orchid.). - Ind. Kew. ii. 1062 .

alba, Colenso, in Trans, N.Z. Inst, xviii. 1855 (1S56) $2 \tau^{2},-\mathrm{N}$ Z Zel

concinna. Colcnso, l. c. xx. 1889 (ISSS) 20T. - N Zel.

cornuta, Colenso, l. c. 206. - N. Zel.

Elizabethae, F. Muell. in Vict. Natural, vii. (Dec. 18.0) 116. - Austral.

fasciculata, Fitzger. Austral. Orchids, xii. II. (1S88) cum jc. - Austral.

fimbriata. Colenso, in Trans. N. Z. Inst. xxii. 1889 (1890) 490, - N. Zel.

nervosa, Colenso, $l_{0} c_{0}$ xx. 1887 (ISS8) 20\%。 - N Zel.

urmalis Fitzger. Austral, Orchids, iji r.. (1SSS) cum ic. - Austral.

THEL YPODIUMI. Endl. (Crucif.). - Ind, Kew. ii. 106 ?

aureum. Eastwood, in Zoë, ii. (1891) 297. - Color. elegans, M. E. fones, in Zoë, iv. (1893) 265. - Am bor. oce.

Honkeri, Greene, Fl. Francisc. (1891) 263 : et Man. Bot. San Franc. Bay (1894) $18=$ Streptanthus flavescens, Hook.

Howellii, S, Wals, in Proc. An. Acud. zxi. (18S6) 445. - Oregon.

lasiophyllum, Greene, in Bull. Torrey Bot. Club, xiii. (1886) 142; ct Man. Bot. San Franc. Bay (1891) 19 (= Turritis lasiophylla, Hook. \& Arn.? Sisymbrium reflexum, Nutt.

Lemmoni, Grecne, in IVest Am. Scicntist, iii. (18S7) 156. - Calif.

proccrum. Greene, Fl. Francisc. (1891) 263; et Man. Bot, San Franc. Bay (1894) 18 = Caulanthus procerus, $S$. Wats.

rigidum, Greene, Pittonia, i. (July 1887) 62 ; et Man. Bot San Franc. Bay (1894) 18. - Calif.

stenopetalum, S. Wats, in Prnc. Am. Acad, xxii. (1887) 468. - Calif.

Vaseyi, Coult. in Contrib. U. S. Nat. Herb. i. (1\$90) 30 ; et is. (1891) 15, t. 1. - Texas.

THEMEDA, Forsk, = Anthistiria, Linn. (Gramin.).

anathera, Hack, in DC. Monog. Phan, vi. (1859) $669=$ A. anathera, Nees.

argucns, Hack. 1. c. $65 \%=\mathrm{A}$. arguens, Willd.

armalinacea, Hack. 1. c. $674=$ A. arundinacea, Roxb.
THEMEDA :-

armendinacer, Ridl, in Trans. Linn. Soc. Ser. II, ii. (1893) 401. - Penins. Mal.

arenacea, Hack, in DC. Monog. Phan. vi. (1887

$677=$ Anthistiria avenacea, F. Muell.

brachyantha. Trab. in Batt, \& Trab. Fl. de l'Aloér. [Monoc. I (1895) $129=T$. Forskalii, Hack

caudata, Hack, in DC. Monog. Phan, vi. (1889) $676=$ Anthistiria caudata, Nees.

ciliata, Hack, 1. c. $66 t=$ A. ciliata, Linn. f. cymbaria, Hack. 1. c. $668=$ A. cymbaria, Roxb. effusa Balansa, in Morot, Journ. de Bot. iv. (1890) 115. - Cochinch.

foliosa, Balansa, 1. c. $116=$ bracteatus, $\dot{W}$ illd.

Forskaliz, Hack. in DC. Monog. Phan. vi. (1889 659. - Orb, vet. reg. trop. \& subtrop.

gigantea, Hack, in DC. Monog. Phan. vi. (1889) $670=$ Anthistiria gigantea, Cav.

Helferi, Hack. 1. c. 665. - Tenass., Ins. Andam. intermodic, Hack. in DC. 1. co = Anthistiria gigantea. Cav.

quidrivalvis. Kuntze, Rev. Gen. (1891) $793=$ A. ciliata, Linn. $f$.

tremula, Hack. 1. c. $667=$ A. tremula, Nees.

sillosa, Hrck, 1. c. $6 \%$ = A. villosa, Poir.

THEMISTOGLESIA, IKlotzsch (Vaccin.). -

Ind. Kew. ii. 1063.
Humboldtiana. Niedenzu, in Bot. Jahrb. xi. (1889) $211=$ Macleania Humboldtiana, KYlotzsch.

THENARDIA, H. B. \& K. (Asclep.). - Ind.Kew. 11. I 6.3

Galeottiana, Baill. in Buil. Soc Linn. Paris, ii. (1890) $\$ 19$. - Mexic.

THEOBROMA, Lin $n$. (Stercul.). - Ind. Kew. ii. 1063 .

grandiforum, K. Schum. in Mart. Fl. Bras, xii, III. (1856) 76 = Guazuma grandiflora, G. Don.

Mariae, K. Schum. 1. c. $71=$ Abroma Mariae, Mlart.

Martii, K. Sihnm. l. c. 78. - Bras.

sylvestris, Baill. Bot médic. [Phan.] (1894) $795=$ Genipa. Merianae, Rich.

THEODORA, Médic. = Schottia, Jacq. $($ Legumin. $)$.

Fischeri, Taub. ex Engl, in Abh. Preuss. Alad. Wiss. (1894) 18, 36; et in Eng-1. Pflanzenw. Ost-Afr. C (1895) 198, - Afr. or.

suakcliensis, Taub. 1. c, 198. - Afr. or.

THEODOREA, Cass. = Saussurea, DC. (Compos.).
Alberti.

, albescons, alpina, americana, avenaria, blanda, bracteata, cana, Candolleana, canescens, Clarkei, colorata, conesta, coronata, daurica, discolor, clata. clegans, ulliptica, elongata, Falconeri, filifolia, Frolovii, Geblcriana, glacialis, glanduligera, gossypiphora, gracilis, graminifolict, grandiflora, Griffithii, hissarica, Hookeri, facea, japonica, kaschigarica, katachaete, Kuschakcurczii, laciniata, lamprocarpa, latifolia, Maximowiczii, Medusa, microcephala, microcephala, nigrescens, nikocnsis, nitponica, obvallata, odoniolepis, paleata, pamirica. pectinata, phaantha, Poljakowii, Przewallaki, pygmaea, Riederi, rigida, robusta, Rovlci, nuncinata, sacra, Salemanni, salicifolia, sa'sa, scaposa, Schultzii. Semenowii, serralit, sordida, stella, Stubendorffi, subulata, Sutghoo, Tanakae, tenuis, trimgulata, tridactyla, triptera, uniflora, ussurienzsis, Yakla, Kuntze, Rev. Gen. (1891) 367-68=homonyma ommia Saussureac. alata, Kuntze, 1. C. == S. japonica, DC.

amurensis, Kuntze, 1. c. = S. eriolepis, Bunge.

Andersoni, Kuntze, 1, c. $=\mathrm{S}$. Andersoni. C. B Clarke.

atkinsonii, Kuntze, 1. c. = S. Atkinsonii, C. B. Clarke.

auriculata, Kuntze, 1. c. $367=$ S. hypoleuca, Spreng.

baikalensis, Kuntze, 1. c. $368=\mathrm{S}$. pycnocephala Ledeb.

brakuica, Kuntze; 1. c. $=\mathrm{S}$. candicans, C. B. Clarke. 
THEODOREA :-

acspitosa, Kuntze, Rev. Gen, (1891) 367 = Saussurea taraxacifolia. Wall.

chondrilloides, Kuntze, 1. c. $368=$ S, chondrilloides, C. Wikkl.

Costhis, Kuntze, 1. c. = S. Lappa, C. B. Clarke

c)noglossifolia, Kuntze, 1. $c=$ S. serrata, $D C$.

Davidi, Kuntze, 1. c. = S. Davidi, Franch.

dillodes, Kuntze, 1, $\mathrm{C}=\mathrm{S}$. deltoides, C. B. Clarke.

denticulata, Kuntze, 1. c. $=$ S. denticulata, $W$ allr.

aiscolor, Kuntze, 1. c. $367=$ S. piptathera, Edgew.

cpilobiodes, Kuntze, 1. c. $368=$ S. epilobioides,

Maxin.

foliosa, Kuntze, 1. $\mathrm{C}_{2}=\mathrm{S}$. foliosa, Ledeb.

fruticulosa, Kuntze 1. $\mathrm{c}=\mathrm{S}$. cana, Ledeb.

gnaflulodes, huntze, 1. c. = S. sorocephala, Hook.f. \& Thoms.

hetcromalla, Kuntze, 1. c. $367=\mathrm{S}$. candicans, $C$ B. Clarke.

integrata, Kuntze, 1. c. $368=$ S. glomerata, Poir intermidia, Kuntze, 1. c. = S. japonica. $D C$.

incolucrata, Kuntze, 1. c. (= Aplotaxis incolucrata Kar. \& Kir.). - As, temp.

iostegia, Kuntze, 1. c. = S. iodostegia, Hance.

negleuicu, Kuntze, 1. $\mathrm{c}_{0}=\mathrm{S}$. denticulata, Ledeb.

papposa, Kuntze, l, c. $=$ S. crassifolia, $D C$.

Poljukowit, Kuntze, 1. $c=S$. Poljakowi, Glehn.

folystickodes, Kuntze, 1. c. = S. polystichoides, Hook.t.

sevmlatades, Kuntze, 1. c. sphalm. = S. serratuloides, Turcz.

siliatica, Kuntze, 1, $c_{0}=$ S. sylvatica, Maxim

Stolicakui, Kuntze, 1. c. = S. Stoliczkae, C. B.Clarke.

Stracheyuna, Kuntze 1. c. = S. foliosa, Hook. f.

tarizzuifolia, Kuntze, 1. c. $36 \%=\mathrm{S}$, erlostemon, IV all.

Thomsonii, Kuntze, 1. c. = S. Thomsoni, C. B. Clurthe.

werneroides, Kuntze, 1, c. $=\mathrm{S}$. wernerioides, $C, B$. Clurke.

THEOPHRASTA, Linn, (Myrsin.), - - Ind. Kew. ii. 1063

Biborrana, caloneura, fulgens, grandis, macrocarpa, pindula, Riedeliana, spatmulata, undulata, Kuntze, Rev. Gen. (1891) $404=$ homonymla ommia Clavijae. Kalbryeri, Kuntze, 1. c. - N. Granat.

taurifolia, Kuntze, 1. c. sphalm. = Clavija Iancifolia, Dest.

pinnata, Hort. ex Gard. Chron. (1888) i. $806=$ Talisea princeps, Olicer.

Ruisiana, Kuntze, Rev. Gen. (1891) $404=$ Clavija vinata, D. Don

sparsifolia, Kuntze, 1. c. I Leonia glycycarpa Ruis \& Pav.

THERIOPHONUM, Blume (Aroid.). - Ind. Kew. ii. 1063. natum. Blumo

THERMOPSIS, R. Br. (Legumin.). - Ind. Kew. argentata, Greene, in Erythea, iii. (1895) 18. - Calif. argentata, Greene, in Erythea, i1i. (1895) 18. - Calif.
gracilis, Howell. l. c. i. (1893) 109. - Am. bor. occ robusta, Howell, i.c. - Calif

velutina, Greene, l. c. iii. (1895) 19. - Calif.

THEROFON, Rafin. [sphalm. THEREFON] = Boykinia, Nutt. (Saxifr.)

conitifolizm, Millsp. in Bu31. West Va Agric Exp. Sta. ii. (1892) $361=$ B. aconitifolia, Nutt.

arım, Greene, Man. Bot. San Franc. Bay (1894)

$121=$ B. occidentalis, Torr. E Gray.

mutjor, Kuntze, Rev. Gen. (1891) $227=\mathrm{B}$. major, 4. Gray.

vccidentale, Kuntze, 1. c. = B. occidentalis, Torr. G Gray.

Richardsonii, Kuntze, 1. c. = B. Richardsonii, $A$. Gray.

THEROGERON, DC. $=$ Minuria, DC. $($ Compos. $)$. Cunminghamii, Kuntze, Rev. Gen. (1891) $369=\mathrm{M}$. Cunninghami, Benth,

leprophyllnim, Kuntze, 1. c. = M. leptophylla, $D C$. suaedifolia, K:nntze, 1. c. = M. suaedifolia, F. Muelt.
THESIUM, Linn. (Santa1.). - Ind, Kew, i1

\section{4}

auriculatum, Vandas, in Sitzb. Boehn, Ges. Wiss. 1889 (1890) ii. 279; et Beitr. Kenutn. Fl. Bosn. und Herceg. (1890) 279. - Eur. or.

bulgaricum, Velent. Fl. Bulg. (1891) 498. - Bulg.

cystoseiroides, Baker, in foum, Linn. Sor. xxii (1885) 516. - Madas.

Dollinerii. Murb. ex V'elen. Fl. Bulg. (1891) 49s; et in Lunds Univ. Arsskrift, xxvii. V. (1892) 43. Bulg.

hybridum X, G. Beck, in Abh. zool,-bot. Ges Wien (1891) 640 ; et Fl. Nied.-Oest. ii. I. (1892) 602. - Austria.

Kemeriamm, Simonk, in Termész. Füzet. x. 1886 183 = divaricatum, fan.

kilimandscharicum, Engl. in Abh. Prenss. Akad. Wiss. 1891. ii. (1892) 200. - Afr. trop. or

mauritanicum, Batt. in Bull. Soc. Bot. Fr, xxxv. (1888) 393 ; et in Batt. E Trab. Fil. de l'Algér. Dicot. 7 (1890) 785. - Algeria.

moesiacum, Velen. Fl. Bulg. (1891) 500, - Buly.

nigricans, Rendle, in Trans. Limn. Soc. Ser. Iİ. iv. (1894) 41. - Afr. trop.

refractum $X$, Bruegg, in Jahresb. Naturf. Ges. Graub, xxix. (1886, n. 105 [Neue und crit. Ptlanzenfam. n. 105 \% , - Hely.

Schweinfurthii, Engl. Pfanzenw. Ost-Afr. C (1895) 16s. - Afr. trop. or.

simplex, Velon. Fi. Bulg. (1891) 499, in obs. Iranssilv.

Stuhlmannii, Engl. l.c. - Afr. trop. or.

subaphyllum, Engl. $l . c_{\text {. }}$ - Afr, trop, or.

ulugurense, Engl. Pflanzenw. Ost-Afr. A (1895) 130, nomen. - Atr. trop. or

Whyteanum, Rendle, in Trans. Linn. Soc. Ser. II. iv. (1894) 42. - Afr. trop.

THESPESIA, Soland. (Malv.). - Ind. Kew. ii. 1066.

Garckeana, F. Hoffm. Beitr. Kenntn. Fl. Centr. OstAfr. (1889) 12. - Afr. trop.

Rehmannii, Sryszyl. Polypet. Retmann. i. (1887) 44 - Natal.

THEVETIA, Linn. (Apocyn.). - Ind. Kew. ii. 1066 .

Gaumeri, Hemsl. in Hook. Icon. pl. (1886) t. 1517 ; et Biol. Cenztr - Anz iv, (I886) 104 - Ins Cozumel. nitida, K. Schum, in Engl. \& Prantl, Natïrl. Pflanzenfam. iv, $2(1895) 159=$ nitida, $A . D C$

paraguayensis, Britton, in Ann. N. Y. Acad. sci. vii. (1893) 158. - Parag.

theretioides, K. Schum. in Engl. \& Prantl, Natürl. Pflanzenfam, iv,2 (1895) $159=$ T. Yccotli, $A$. $D C$.

THINOBIA, Phil. in Anal. Univ. Chil. Ixxxyii. (1894) 399. COMPOSITAE araucana, Phil. l. c. 400. - Chili.

THINOUIA, Planch. \& Triana = Thouinia, Poit. (sapind.)

coriacea, Britton, in Bull. Torrey Bot. Club, xvi. (1889) 191. -- Bolivia.

paraguaiensis, Radlk. in Engl. \& Prantl, Natürl. Pflanzenfam. iii. 5 (1893) $308=$ T. paraguayensis, Britton.

repanda, Radik. 1. c. - Parag.

scpinm, S. Moore, in Trans. Linn. Soc. Ser. II. iv. (1895) 341. - Am. trop.

THISMIA, Griff. (Burmanniac.). - Ind. Kew, ii.

1067.
chrysops, Ridl. in Ann. Bot. ix. (1895) 323:Malacca.

clandestina, F. Mull. in Proc. Roy. Soc. Tasm. 1890 (1891) 235 ; et ex Bot. Centralbl. xlvi. (1891) 141 ( $=$ Sarcosiphon clandestinn, Blume). - Java. clavigera. F. Mucll. Il. co. (= Geometra clazigera, Becc.). - Borneo.

episcopalis, F. Muell. ll.cc. (=G. episcopatis, Becc.). - Borneo.

fumida, Ridl. in fourn. Straiths Branch. Roy. As. Soc. n. 22 (1890) 339. - Penins. Mal.

\section{THISMIA :}

Glaziovii, Poulsen in Kongl. Danske Vidensk. Selsh. Forh. (1890) 24: et ex Bonnier, Rev. gén. de Bot. $1889(1890) 549$ - - Bras

grandiflora, Ridl. in Am. Bot. ix. (1895) 324. Ind. or.

hyalina, Benth. \& Hook, $f$ ex F. Muell, in Proc Roy. Soc. Tasman. 1890 (1891) 234(= Myostome hyalina, Miers). - Bras.

macahensis, Benth. Er Hook. f. ex F. Mutl. l. c.l= Ophiomeris macahensis, Miers). - Bras.

Rodwayi, F. Muell. in Vict. Natural, vii. (Des. $1890) 115$; et in Proc. Roy. Soc. Tasn. 1890 (1891) $232 \mathrm{cum}$ ic。; et ex Bot. Centrabbl xly. (1891) 6.3, 125, 25\%, et xlvi. (1891) 139 et 141. - Austral.

THLADIANTHA. Bunge (Cucurb.).-Ind. Kew ji. 1066

Davidi, Franch. in Nouv. Arch. Mus. Paris, Sér. II viii. (1886) 243. - China occ.

Henryi, Homsl, in fourn. Lim, Soc xxiii (1887 316; Oliver, in Hook. Icon. pl. xxiii, (189?) 2223. - China.

longifolia, $\operatorname{Cog} n$. ‘x Oliee, l. c. xxiii. (1892) t, 22.2. - China.

nudiftora, Hensl. ex Forb. Eo Henst. in fourn, Linn.

Soc. xxiii. (1887) 316 t. 7 . - China.

THLASPI, [Tourn.] Linn. (Crucif.). - Ind. Kew. ii. $106 \%$

atlanticum, Batt. in Batt. \& Trab, Fl. de l'Algerr. Append. 11. (1890) 2 ; et in Bull. Soc. Bot. Fr. xxxix. (1892) 70, cum ic. - Algeria.

cenisiun, Rouy \& Fouc. Fl, de Fr, ii. (1895) $157=$ rotundifolium, Gaudin.

chloraefolium, Hausskn. \& Bormn. in Mitth. Bot Ver. Fena, ix. (1891) 15. - As. mer.

corymbosum, Gremli, Neue Beitr. Fl Schweiz, Heft v. (1890) $\%$ = rotundifolium, Gaudin

Glaudinianun, "Jord. „ex E. Hallier, Syn. Fl. Germ. ed. 3 (1895) 136, sphalm. = Gaudinianum, ford. heterochroum, Boiss. Fl. Or. Suppl. (1888) 58.Eur, or.

imosellifolium, Reut. ex Rouy \& Fouc. F1. de Fr. ii. (1895) $156=$ rotundifolium, Gaudin.

Oliveri, Entgl. in Abh. Prenss, Akad. Wiss. 1891, ii. (1892) 223. - Abyss.

petraenm. Ces., Passer. \& Gibelli, Comp. FI. Ital (1886) $827=$ Hutchiosia petraea, R. Br.

pindicum, Hausskn, in Mitth. Thiur. Bot, Ver. N Folge, iii. IV. (1893) 115. - Graecia.

pimatum, G. Beck, in Sitz. zool.-bot. Ges. Wien (1890) Is; et Fl. Nied.-Oest. ii. I. (1892) $488=$ Hutchinsia petraea, $R, B r$

pinnatum, Fritsch, in Bot. Centralbl. xiii. (1890) 13 $=$ praec

rubellum, Cabanès, in Bull. Soc, sci, nat. Nimes, xix. (1891) $18 \%=$ nubellum, Loret \& Barr.

Salisii, Bruegg, ex Gremli, Neue Beitr. F1. Schw. Heft v. (1>90) $5=$ alpestre, $I_{\text {inn }}$

stenopterum, Conrath of Freyn, in Bull. Herb. Boiss. iii. (1895) 38. - As. Min.

thessalonicum, Charrel [Nadil] in Oest, Bot. Zeitschr. xli. (1801) 375, nomen; et in Emp. Ottom. [Pl. de Saloniq.] (1892) 10. - Maced.

tymphaeum. Hausskn. in Mitth. Thiir. Bot. Ver. N Folge, iii. IV. (1893) 115. - Graecia

umbrosum, Waisbecker, in Oest. Bor. Zeitschr, xliii. (1893) 318, et xliv. (1894) 74. - Austro-Hung.

yunnanensis, Franch. in Bull. Soc. Bot. Fr, xxxiil.

(1888) 407 ; et Pl. Delav. (1889) 67. - Yunnan

THOLLONIA, Baill, in Bull. Soc. Linn. Paris, (1886) 610: Focke, in Engl. \& Prantl, Natuirl Pflanzenfam. iii. 3 (1891) 61. ROSACEAE.

racemosa. Baill. ll. cc. - Congo gall.

THOMANDERSIA, Baill. Hist. des pl xi. (1891) 456 : Lindau, in Engl. \& Prantl, Natürl. Pflan zenfam. iv. 3b (1895) 325. ACANTHACEAE

laurifolia, Baill. Il. ce. ( $=$ Scytanthus laurifolius, T. Anders.). - Afr. trop. occ.

THONNINGIA, Vahl(Balanophor.). - Ind, Kew ii. 1069 .

malagassica, Fanceth, in Trans. Limn. Soc. Ser. II ii. (1886) \%39. - Madag. 
THORACOSPIERAI, Klotzsch = Simocheilus Klotzsch (Ericac.

Lubigira, bicolor, carmea, depressa, glabolla, glabra, hirsutu, hispida, Klotzschiama, multiflora, oblonga, hatens, pubescons, quadrifida, submutica. Kuntze, Rev. Gen. (1801) $390-91=$ homonyma ommia Simocheili.

Irtiulata, Kuntze, 1. c, $390(=$ Syndesmanthus arti matus, Klotzsch). - Afr. austr.

ciliata, Kuntze, 1 . c. $(=S$. ciliatus, Benth. $)$ - - Afr. austr.

discolor. Kuntze, 1. c. (= Anomalanthus discolor Klotzsch). - Afr. austr.

Eiklonia, Kuntze, 1. c, = Simocheilus Ecklonia nus, Benth.

fasciculata, Kuntze. 1. c. = S. rlabellus, Benth.

glauca, Kuntze, 1. c. (= Syndesmanthus glancus Klotzsch). - Afr. Austr.

hivta, Kuntze, 1. c. $391=$ Simocheilus hirsutus Benth.

parviflora, Kuntze, 1. c. 391 (= Codonanthemm parviflorm, Klotzsch), - Afr.austr

panifolia, Kuntze, 1. c. 391 (= Syndesmanthus paut iffolius, Benth.).-Atr, austr.

pubernla, Kuntze, 1. c. (= Codonanthimum puberulum, Klotzsch). - Afr. austr.

cobra. Kuntze. 1. c. 391 (= Syndesnanthus scabor. Klotzsch). - Afr. austr.

squarrosa, Kuntze, 1.c. (= S. squarrosus, Benth.).Afr. austr.

temuis, Kuntze, 1. c. 391 (= Codonanthemun tenue, Benth.). - Afr. austr.

THORACOSTACHYUM, Kurz (Cyper.) - Ind

Few ii. 1069.
hypol! troides, C. B. Clarke, in Hook. f. Fl. Brit. Ind. vi. (1894) 680. - As. et Austral. trop

1HORELDORA, Pierre, Fl, For, Cochinch. (1895) subt. $334=$ Aglaia, Lour. (Anona.)

cochinchinensis, Pierre, 1. c. - Cochinch.

THOTTEA, Rottb. (Aristol.). - Ind. Kew. ii. 1069) tricornis, Maingay, ex Hook.f. Fl. Brit. Ind. v. (1886) 74. - Malacca.

THOUINIA, Poit. (Sapind.). - Ind. Kew, i1. 1069. cuminata, S. Wats. in Proc. Am. Acad. xxv. (1890 145. - Mexic

paragnayensis, Britton, in Ann. N. Y. Acad. sci. vii. (1892) 75. - Paras.

portoricensis, Rallk, in Engl. \& Prantl, Natiur. Pfanzenfan, iii. 5(1893) 311. - Ins. Puerto Rico.

Pringlei, S. Wats, in Proc. Am. Acad. xxv. (1890 145. - Mexic.

stricta, Radlk. in Engl. \&o Prant?, Vatürl. Pfanzen fam. iii. 亏 (1893) 311.-Am. trop.

THOUINIDIUM, Radlk. = Thouinia, Poit. (Sapind.)

hexandrum, Radlk, in Engl, \& Prantl, Natürl. Pflanzenfam. iil. 5 (1893) $314=\mathrm{T}$. hexandra $H . B$. \& $K$.

THRINAX, Linn. f. (Palm.). - Ind. Kew. ii, 1070 Morrisii, H. Wendl. in Gard. Chron. (1891) i. To( fig. 134, et (1892) i. 104, fig. 20, 21. - Ind. occ.

THRINCIA, Roth $=$ Leontodon, Linn. (Compos.) riolonsis, Pau, Not. Bot. F1. Espan. iii. (1889) 32 Hisp.

THRIXSPERIIUM, Lour. = Sarcochilus, R. Br. (Orchid.).

anvenun, brachyglotis, brachystachyum, cladostachyum, emarginatum, fliforme, hirsutum, hirtulum. Hystrix, Mannii, merguense, minimifolinm, minimum, notabile, panciflonm, recurdum, stenoglottis, trichoglottis, wir diflosum, Kuntze, Rev, Gen. (1891) 682 = homonmma ommia Sarcochili.

appondiculatum, Kuntze, 1. c, = Sarcochilus pusillus, Reichb. $f$.

Bcocari, Reichb. fo in Bot. Centralbl. xxviii. 1886 :343. - N. Guin,

clegans, Kuntze, Rev, Gen. (1891) 682 (= Grosourdya elcgans, Reichb, f.). - Malaya.
THRIXSPLRMUM :

indusiatum, Reichb. f. in Gard. Chron. (1886) i, $58.5 .-$ Ins. Sandvic

platyphyllum, Reichb. f. in Bot, Centralbl, xxviii. (1886) 343, - N, Guin

Scorlechini, Kuntze, Rev. Gen, (1891) $682=$ Sarcochilus Scortechini, Hook. $f$.

THRYALLIS, Linn, = Galphimia, CaY. (MaIpish.).

angustufolia, glandulosa, glanca, gracitis, grandiflora. hirsuta, Humboldtiana, latifolia, multicanlis, paniculata, Kuntze, Rev. Gen. (1891) $89=$ homonyma omnia Galphimiae

Cinifolia, Kuntze $1, \mathrm{c}=\mathrm{G}$, anoustifolia, Benth.

THRYALLIS, Mart. (Malpigh.). - Ind. Kew, ii, 1071

Laburnum, S. Moore, in Trans. Linn. Soc. Ser. II. iv. (1895) 324. - Bras

vatifolia, Niedenzu, in Bot. Fahrb. xiv, Beibl. n, 30 (1891) 5. - Bras

THRYOTHAMNUS, Phil, in Anal. Univ. Chil. xc. (18\%5) 618. VERBENACEAE.

junciformis, Phil. l. c. - Chili.

THUNBERGIA, Retz. (Acanth.). - Ind, Kew. ii $10 \% 1$.

Bachmanni, Lindan, in Bot. Fahrb. xvii. (1093) 94. - Afr. austro-occ. extratrop.

bicolor, I.indau, 1. c. xvii. Beibl. n. 41 (1893) $42=$ Wightiana, T. Anders.

borbonica, Lindau, $l, c$. - Ins. Borbon.

brewerioides, Schweinf. ex Engl. in $46 \%$, Prenss. 4 kad. Wiss. 1891 (1892) $38 \%$, nomen; ct in Hochnel, Zum Rudolph Sec, Append. (1892) 6. - Afr. trop. or.

hrysochlamys, Baker, in fourn. Limn, Soc, xxii, (188:) 508 . - Madas.

cordata. Lindan, in Engl. Pfanzenw. Ost-Afy. C (1895) 365. - Afr. trop. or.

Erythraeae, Schaceinf. ex Lindau, in Bot. Fahrb. xx. (1894) 3. - Afr. trop. ol.

fasciculata, Lindan, l. c. xvii. (1893) 9\%. - Afr.trop.

Fischeri, Engl, in Abi. Prenss. Akad. Wiss. 189i (1893) 387 . - Afr. trop. or:

fuscata, T. Andcrs. ex Lindan, in Bot. Fahrb. xvii. Beibl. n. 41 (1893) 40. - Afr. trop.

Gibsoni, S. Moore, in fourn. Bot, xxxii, 1894) 1:31. - Afr. trop. or.

Gregorii, S. Moore, l. c. 13). - Afr, trop. or

Guerkeana, Lindau, in Engt. PAanzenw. Ost-Afr. C (1895) 366. - Afr. trop. or.

hamata, Lindan, ex Engl. in Abh. Preuss. Akud. Wiss. (1894)64: et in Bot. Fahrb. xx. (1894) 2. Afr. trop.

hispida, Lindau, 1. c. xvii. (1893) 93 = Solmsiana, Lindan.

Holstii, Lindau, l. c. 95. - Afr, trop. or.

Hookeriana, Lindau, 1. c. xvii. Beib1. n. 41. (1893) $38=$ T. Kirlii, Hook

kamerunensis, Lindau, . c. xvii. (1S93) 97. - Afr, trop.

longifolia, Lindau, in Bot. Fahrb. xvi1. (1893) 91. Afr. trop.

malangana, Lindan,.,$c .-$ Afr. trop.

manganjensis, Lindau, i. c. 92. - Afr, trop.

Mechowi, Lindau, l. $\iota$. - Afr. trop.

mollis, Lindaw, l. c. xvii. Beibl, n. 41 (1893) 35 nomen, et xx. (1894)2. - Afr. trop.

parva, Roulet, in Bull. Herb. Boiss. ii. (1894) 281 , 282. 316. - $\mathrm{Hab}$.

parrifolia, Lindan, in Brt. Fahy. srui. (1\$93) 90.Afr. trop.

Paulitschkeana, G. Beck, in Paulitschke. Harrar, App. (1888) 459, tig. 12. - Afr. trop.

Petersiana, Lindau, in Bot. Fahwb. xvii. (1893) 89. - Afr. trop.

phytocrmoides. T. Anders, ex Lindan, in Bot. Jahrb. xvii. (1893) 113, in syn, = Afromendoncia phytocrenoides, Gilg.

pondoensis, Lindau, l. c. 93. - Afr. austro-occ. extratrop.

rufescens, Lindal, 7. c. 96. - Afr trop occ.

sessilis, Lindau, l. c. - Afr, trop.

\section{THUNBERGIA}

olmsiana, Lindan, in Engl. Pfanzenw. Ost-Afr. C 1895) 368 , in obs. $(=T$. hispida, Lindau $)$ Madas.

Stuhlmanniana, Lindau, in Bot. Fahro. xvii. (1893) YI. - Afr. trop

subalata, Lindau, l. c. xvii. Beibl. 12. 41 (1893) 41 nomen, et xx. (1894) 3. - Afr, trop.

togoensis, Lindau, l. c. xxii. (1895) 112。 - Afr. trop. occ.

usambarica, Lindau, in Abh. Preuss. Ahad. Wiss 1894) 64 ; et in Bot. Falmb. xvii. (1893) $89 .-$ Afr. trop.

THUNIA, Reichb.f. = Phaius, Lour.(Orchid.).

Brymcriana, Rolfe, in Gartenfl. xli. (1892) IS4 et in Kew Bull. (1894) 156. - Burma.

candidissima, Reichb. f. in Gard. Chron. (18sós ii. $34=$ Phaius candidissima, $N, E, B r$

Mastersiana, Kraenz1. 1. c. (1894) ii. 420. - Penins, Mal.

micalis, Reichb. f. 1. c. (1888) ii. 62, nomen, in obs. $=$ Phaius albus, Lindl.

Veitchi X. Hort, I. c. (1891) i. 740 [an I. Treit chiana X. Reichb.f.?]. - Hybr. artef.

Wimniau, Hort. ex L. Lind, in Lindenia, x. (1894 43. t. $452 .-\mathrm{Hab}$ ?

Wriglcyana, Hort. ex Orchid Alb. vi. (18ssi) sul t. 326, in syn.; Veittch, Man. Orch. Pl. vi. (1890) $20=$ Veitchiana $\times$. Reichb. $f$.

THUROVIA, J. N. Rose, in Contrib. U. S. Nat Herb, iii. (1895) 321. COMPOSITAE.

triflora, $7, N$, Rose, ?., - Texas.

THUSPEINANTHA, Th. Dur, lnd, Gen. Whan (1888) 78 (= TAPEINANTHUS, Boiss.). IA BIATAE.

THUYA, Linn, (Conif.) - Ind. Kew, ii. 10\%

Bodmeri, Hort. ex Beissn. Handb. Nadclholzk 18.1) $42=$ accidentalis, Lim

flabellata. Hort. ex Beissn. 1. c. $42=$ plicata. Don. globosa. Hort. ex Beissn. 1. C. 43 = orcidentalis, Linn.

7ycopodioides, Hort, ex Beissn. 1, c. $44=$ plicata D. Don.

plicatilis, Hort, ex Beissn. 1. c. = plicata, D. Don.

recurva, Hort. ex Beissn, 1. c. $42=$ accidentalis Linn.

recurata, Hort. ex Beissn, 1. c, = occidentalis, Iinn.

semperaurea, Hori. ex Beissn. 1. c. $60=$ orientalis, Lim

THYANA, Ham. = Thouinia, Poit. (Sapind.)

discolor. Hitchcock, in Missouri Bot. Gard. Rep. iv. $(1893) 72=\mathrm{T}$, discolor, Griseb

THYIA, Aschers, = Thuya, Linn. (Conif.).

ccidentalis, "Linn, ex Aschers, \& Schweinf. Illustr. fl. Egypte (1885) $1 \% 9=$ T. occidentalis, Linn.

THYMELAEA, Tourn, ex Scop. (Thyme1,). lnd. Kew, ii. 1073 .

subrepens, Lange, in Danske Vidensk. Selsk. Fork 1893) 193. - Hisp.

THyMUS, Tourn. ex Linn. (Labiat. ). - Ind. Kew,

lbanus, It Broun ex Wertst. in Luerss. Biblioth. Bot. Heft xxvi. (1892) 86. - Alban.

albiflorus, Batt. in Batt. \& Trab. Fl, de l'Algér. [Dicot.], (1889) $673=$ ciliatus, Desf.

Alfredae, Post, Pl. Postianae, iii. (1892) 15. - As. occ.

Antoninae, Rouy \& Coincy, in Bull. Soc. Bot. Fr. xxxyii. (1890) 165: Coincy, Eclog. Pl. Hisp. (1893) 18, t. T; Willk. Suppl. Prodr. Fl. Hisp. (1s93) 145 - Hisp.

arundanus, Willk. in Oest. Bot. Zeitschr. xli. (1891 52: - Hisp.

aureopunctatus, G.Beck, in Annal. Naturh. Hofmus. Wien, ii. (1887) $142=$ T. Serpyllum, Linn. 
THYMUS

acdinsis, H. Braun, ex R. Walz, in Verh. zool.-bot. Ges. Wien, xl, (1890) $559=$ T. Serpyllum

Burinsis, H. Braun, in Oest. Bot. Zeitschr, xli. (189I) $297=T$. Serpyllum, Linn.

Boissieri, Halácsy, in Denkschr. Akad. Wion, Ixi. (1594) 252. - Graecia.

Bvrbasii, Borb. Geogr, atq. Enum. pl. Comit Castrif. (188\%) $215=\mathrm{T}$. Serpyllum, Linn.

Brannii X, Borb. 1. c. 214, 216; G. Beck, F1. Vied.-Oest. ii. II. (1893) 996. - Austria

aloifrons, Borb. \& H. Braun, in Borb. 1. c. $216=$ T. Serpyllum, Lim.

Celakorskyanus, M. Schulae, in Mitth. Bot. Ver. fena, viii. (1890) 39. - Eur. centr.

ciliolatus, Pau, Not. Bot. Fl. Espan, i. (1SSi) 19 Willk. Suppl. Prodr. Fl. Hisp. (1891) 143.Hisp.

dizious, Borb. Symb. Eur, med. (1S90) $76=\mathrm{T}$. Serpyllum, Linn.

dolomiticus, Coste, in Bull. Soc. Bot. Fr. xl. (1893) p. C. $\operatorname{xxx}$ - Gall. mer.

droteansis Batt. 1. c. xxyy (1888) 393 ; et in Batt \& Trab. F1. de l'Alger. [Dicot.] (1889) $671=\mathrm{T}$ Serpyllum, Linn.

ellipticus, F. Braun, in Oest. Bot. Zeitschr. xxxrii (15S3) 157: et in A. Kern. Sched. Fl, AustroHung, vi. (1893) $44=$ T . Serpyllum, Linz .

vidados. Borb. Symb. Thym. Eur, med. (1890) $9: 3=\mathrm{T}$. Serpyllum, Linn

fagellicantis, A. Kern. in. Oest. Bot. Zeitschr. xli. (1891) $29 \%=\mathrm{T}$. Serpyllum, Linn

Giacllą. Borb. [in Pöt. Füizet. Természet. Kïz]. i. (I889) 91 , nomen?, ex Oest. Bot. Zeitschr. rxxix. (1889) $310=$ T. Serpyllum. Lim

Howsmanni, H. Braun, 1. c. xli. (1891) $297=\mathrm{T}$ Serpyllum, Linn.

hetcrophylhus, Batt, in Batt. \& Trab. F1. de l'Algér. [Dicot.] (1889) $671=$ T. Monardi, No

holosericeus, Celak, in Ocst. Bot. Zeitschr. rxxrii. (188\%) 266, in obs. - Ins. Cephal.

humillimus, Celak. 1. c. = hirsutus, Bieb

istriacus, H. Braun, in A. Kern. Sched. Fl. AustroHung. vi. (1893) $42=$ T. Serpyllum, Lim.

furanyanns, Borb. Symb. Eur. med. (1890) 96; et in Oest. Bot. Zeitschr. xli. (1891) 149, et xliii. (1893) $70=\mathrm{T}$. Serpylkum, Lim

kabjlicus, Batt. in Batt. \& Trab. Fl. de l'Algér. [Dicot.] (1889) 672 = lanceolatus, Desf

Korneri, Borb. Symb. Thym. Eur. med. (1890) 74 Pacher, Nachtr. FI. Kärnt. (1894) $108=\mathrm{T}$. Serpyllum, Linn.

leptophyllus, Lange, in Danske Vidensk. Selsk. Forh. 1S93) 198. - Hisp.

lincarifolins, H. Braun, in A. Kern. Sched. F1 Austro-Hung, vi. (1893) $45=\mathrm{T}$. Serpyllum Iinn.

matophyllus, $\mathrm{H}$. Braun, in A. Kern. 1. c. $48=\mathrm{T}$. Serpyllum, Linn.

murcicus. Porta, in Atti Accad. Agiati, ix. (1891) 30; Willk. Suppl. Prodr. Fl. Hisp. (1893) 60. Hisp.

oblongifolins, H. Braun, in Oest. Bot, Zeitschr, xli. (1891) $297=$ T. Serpyllum, Linn.

cmipontanus, H. Braun, 1. c. 296, $297=$ T. Serpyllum, Lim .

Faradoxus X. Rouy, ex Jym. Consp. Fl. Eur. Suppl. ii. I. (1889) 258. - Eur. mer.

pilisiensis, Borb. Symb.Thym. Eur. med. (1890) 94 $=\mathrm{T}$. Serpyllum, Limn.

bolytrichus, A. Kern. ex Borb. in Termész. Közl. xxiv. ii. (1890) 105; et Sched. Fl. Austro-Hung. vi. (1893) $47=$ T. Serpyllum, Linn

Porcii. Borb. in Oest. Bot. Zeitschr. xl. (1890) 462 et xli. (1891) $149=\mathrm{T}$. Serpyllum, Linn.

Portae, Freyn, [in Porta \& Rigo. Iter iii Hisp. (1591) n. 443] in Bull. Herb. Boiss. i. (1893) 547 ; Willk. Suppl. Prodr. Fl. Hisp. (1S93) 147 $=\mathrm{T}$. Antoninae. Coincy.

purvinatus, Celak. in Oest. Bot. Zeitschr. xxxvii. (ISS7) $265=$ hirsutus, Bieb.

quinquecostatns, Colak.l.c. xxxix. (1889) 263.China bor.

Rordoi, Borb. Geogr, atq. Enum. pl. Comit. Castrif. (1887), 215 = T. Serpyllum. Limn.

\section{THYMUS :}

Reuteri, Rony, in Bull. Soc. Bot. Fr. xxrv. (1888) 122, in obs. : IVillk. Suppl. Prodr. Fl. Hisp. (1893) 144; Debeanx, in Lucante, Rer. de Bot. xii. (1895) 359. - Hisp

Sunioi. Burb. Symb. Thym. Eur. med. (1890) 95 $=\mathrm{T}$. Serpyllum, Iim.

cdoides. Celak. in Oest. Bot. Zeitschr, xxxvii. (1887) $266=T$. Serpyllum, I inn

Sintenisii, Celak. 1. c. $268=$ T. Serpyllum, Linn. sparsipilus, Borb. Symb. Thym. Eur. med. 1890 $94=\mathrm{T}$. Serpyllum. Lim

shirsutus, Borb. \& H. Braun, in Borb. Geogr. atq. Enum. pl. Comit. Castrif. (1887) 217 ; et in A. Kern. Sched. Fl. Austro-Hung. vi. (1893) 45 $=\mathrm{T}$. Serpyllum, Lim

sudeticus, Borb. in Termesz. Közl. xxiv. II. (Is90) 103 ; et 1. c. $48=$ T. Serpyllum, Linn

thracicus, Velen, in Oest. Bot. Zeitschr lii (1892) $16=T$. Serpyllum, Lim

alcntimes $X$, Rouy, in Bull. Soc. Bot. Fr. xxxv. 1S85) 123. - Hisp

Vandasii, Volen. in Abh, Boehnn. Ges. Wiss, 1890 (1890) i. 39 ; et Fl. Bulo. (1891) 469. - Bulo.

Webbianus, Rouy, in Bull. Soc. Bot.Fr. xxxy, (18S8) 122. - Hisp.

zygiformis, H. Brann, ex Wettst. in Luerss. Bibl.

Bot. Heft xxvi. (1892) 8\%. - Albania.

THYRSAGANTHUS, Nees (Acanth.). - Ind. hew. i1. 1076. coineus, Regel, in
Lemaireanus, Necs.

eminatus, 7. D. Smith, in Conlt. Bot. Ga\%. xiii. 1888) 7.5. - Guatem.

THYRSODIUM, Salzm. (Anacard.). - Ind. Kew. africanum, Engl.Bot. Falub.xv. (1892) 106. - Congo

THYSANOGARPUS. Hook. (Crucif), - Ind, nchuliferus, Greene, in Bull. Torrey Bot. Club, xiii. (1886) 218. - Ins. S. Cruz. [Calif.] -(1886) 218. - Ins. S. Cruz. [Calif.] 390. - Ins. \& Cruz [Calif.]

THYRSANTHEMA, Neck. = Chaptalia, Vent Compos.

arancusa, dentata, Ehronbergit, exscapa, integrifotia, lyrata, nutans, oblonga, avalis. rotundifolia, runcimata, Scemannii, sinuata, spatulata, Kuntze, Rev. Gen. (1891) $369=$ homonyma omnia Chaptaliae chilinsis, Kuntze, 1. c。 = C. exscapa, Pocpt.

pilosellodes, Kuntze, 1. c. = C. piloselloides, Baker. punila, Kuntze, 1. с. = C. sinuata, Baker. seniflosculare, Kuntze, 1. C. = C. tomentosa, Vent.

tomentosa, Kuntze, 1. c. = C. albicans, Vent.

THYSANOLAENA. Nees (Gramin.). - Ind, maxima, Kuntze, Rev. Gen. (1891) $794=\mathrm{T}$. Agrostis, Nees.

THYSANURUS, O. Hoffm, in Eng1, \& Prantl, Natürl. Pflanzenfan. iv. 5 (1889) 12\%; et in Bolet. Soc. Brot, vii. (1889) 2\%9. COMPOSITAE. angolensis, O. Hoffm. $l l . c c$. - Angola.

TIBOUGHINA, Aubl. (Melast.). - Ind. Kew. ii lata, Cogn. in DC. Monog. Phan. vii. (1S91) 247. Bras.

alba, Cogn. . . c. 210. - Bras

Andreana, Cogn. in Bull. Acad. Belg. Sér. III. xiv. (1887) 936 ; et l. c. 275. - N. Granat.

arthrostemmoides, $\operatorname{Cog} n$. $l l$. cc. 931 ; et $252 .-\mathrm{N}$. Granat.

aspericaulis, Cogn. in DC. Monog. Phan. vii. (IS91) 209. - Bras

bicolor, $\operatorname{Cog} n$. l. c. 265 (= Plerona bicolor, Triana). - Bolivia.

Bourgaeana, $\operatorname{Cogn}$. ex F. D. Smith, in Conlt. Bot. Gaz. xvi. (189I) 4 ; et l. c. 264 ; et ez Th. Du*. \& Pitt. in Bull. Soc. Bot. Belg. xxx, 1891 (1892) 245. - Mexic., Am. centr.

\section{TIBOUCHINA}

Brittoniana, Cosn pre Rusby, in Bull. Torrey kot. Club, xvii. (1890) 55; at in DC. Monog. Phan. vit 1891) 260 . - Bolivia

apitata, $\operatorname{Cog} \pi .71 . c c .54$ : et :551 (= Pleroma capitatum, Triana). - Bolivia

Chamaecistus, Cogn. in DC. Monog. Phan. vil (1891) $267(=P$. Chamuecistus, Triana $)$ - Ins Martinic

chironioides, Cogn. l. c. $26 \pi(=P$. chironioides, Triana). - Ins. Dominica.

ciliaris, Cogn. in Bull. Acad. Belg. Sér. III. xiv. 1887) .932 ; et l. c. $257(=P$. ciliare, Triana). N. Granat.

istoides, Cogne in DC. Monog. Phan, vii. (1891) $266(=P$. cistoides, Triana). - Ins. S. Vinc

citrina. Cogn. I. c. $2531=$ Micranthella citrina, Naud.) - Bolivia.

Cogniauxii, Glazion, ex Cogn, in DC. MLonog. Phan vii. (1891) 1175. - Bras

confertiflora, Cogn. l. c. 253 (= Micranthella confertiflora, Naud.). - Bolivia.

diffusa, Cogn, l. c. $266(=$ Pleroma diffusun, DC. - Ins. Portoric.

echinata, Cogn. l.c. $260(=$ P. cchinatum, Triana) - Peruvia.

erioclada, Cognt. 7. c. 251. - N. Granat

Ferrariana, Cogn, in DC. Monog. Phan, vii, (1801) 1176. - Mexic.

Galeottiana, $\operatorname{Cog}_{n}, l, c, 2581=$ Pleroma Galeottianum Triana ) - Mexic.

Gayana. Cogn. 7. c. $253(=$ P. Gayamm, Triana $)$ - Peruvia

Geitneriana, $\operatorname{Cog} n, l$, c. 255 - Venezuela

glandulosa, Cogn.l.c. 278 (= Pleroma glandulosum Triana). - Guian.

granulosa, Cogn. ex Britton, in Bull. Torrey Bot. Club, xvii. (1890) et l. c. 222.- - Bolivia.

Hieronymi, Cogn. in DC. Monog, Phan. vii. (1891) $1175 .-$ - Bras.

hirsuta, Cogn. in Mart. Fl. Bras xiv. IV. (188s) 601 : et in DC. Monog. Phan. vii. (1891) 237. Bras.

Imperatoris. Sald. \& Cogn. ex Cogn. Ul. co, 598; et 202. - Bras.

lanceolata, Cogne in Bull. Torrey Bot. Clnb, xvii. 1890) 55l; et in DC. Monog. Phan. vii. (1891) 262 - Bolivia

latifolia, Cognt. $l l . c c, 54$ : et $252(=$ Pleroma latifolinm, Triana). - Bolivia.

laxa, Cogn. in Bull. Acad. Belg. Sér. III. xiv. (1887) 933 (=P.laxum, DC.); et in DC. Monog. Phan. vii. (1891) 250. - Ecuad.

lilacina, Cogn , l. c. 212. - Bras.

longifolia, Millsp, Field Columb, Mus. Bot. Ser, I. $(1895) 36=$ longifolia, Baill.

longipilosa, Cognt. in DC. Monrog. Phan. vii. (189l) 1176. - Bras.

longisepala, Cogn. l. c. 259. - Venezuela.

meiodon. Stapf, in Kew Bull. (1895) 104. - Bras. maurocarpa, Cogn. in DC. Monog. Phan. vii. (1891 $260(=$ Pleroma macrocarpum, Triana). - Peruvia. manicata, $\operatorname{Cog} n$. l. c. 220. - Bras.

mexicana, Cogn. l. c. $258(=$ Pleroma mexicannm. DC.). - Mexic.

microphylla, Cogne ex Schwake, in Bot. Fahrb. xii. Beibi. n. 28 (1890) 8, nomen; th in DC. Monog. Plann vii. (1891) 277. - Bras.

monticola, Cogn.l.c. 263 (= Pleroma monticolnn

Triana). - Mexic, Am. centr.

Moritziana, Cogn. l: c. $259(=$ Chatogastra Morit-

ziuna, Klotzsch). - Venezuela.

Mouraei, $\operatorname{Cog} n$. l. c. 236. - Bras.

Naudmiana, $\operatorname{Cog} u$.. . $0.64(=$ Chaetogastra Nandi niana, Decne).-- Mexic

octopetala, Cogn. ex Britton, in Bull. Torrey Bot. Club, xvis. (1890) 57 ; ct 7. c. 273. - Bolivia

Oerstedii, Cogn, in Mart. Fl Bras, xiv, III. (1885) 297; et xiv. IV. (1888) $59 \%$; th in DC. MIonog. Phan. vii. (1891) 269, sphalm. Aerstedii. - Am. centr.

Orbignyana, Cogn,l.c.261 (= Pleroma Orbignyanum, Triana). - Bolivia.

ovata, Cogn. . c. 211. - Bras.

panicularis, Britton, ex Cogn. m Bull. Torrey Bot. Club, xvij. (1890) 54; cr 7.6 .252 (= Pliroma paniculare, Triana). - Bolivia. 


\section{TIBOUCHINA :}

paratropica, Cogne in DC. Monog. Phan. vii. (1891) 257 (= Plcroma paratropicum, Griseb.). - Am. austr.

paulensis, Cogn. 7. c. 229. - Bras.

pendula, Cogn. in Bot. Fahrb. viit. (1886) 18; ot l. c 251. - Ecuad.

Petroniana, Cogn, in Mast. Fl. Bras. xiv. IV. (1888) 598 ; et in DC. Monog. Phan. vii. (1891) 201. Bras.

pilosa, $\operatorname{Cogn}$. Il. ci. 600 : et 216. - Bras

purpurascens, Cogn. in Bull. Torrey Bot. Club rvii. (1890) 50: et m DC. Monog. Phan. vii. (1891) 263 - Bolivia

rufipilis, $\operatorname{Cog} n$. l. c. $250(=$ Pleromu rufipile, Triana) - Mexic

rupestris, Cogn. 7. c. 1176. - Bras.

Rusbyi, Cogzl. in Bull. Torrey Bot. Club. xvii. (1890) 54 ; ct in DC. Monog. Phan, vii. (1891) 249. Bolivia.

scabriuscula, Cogn. l. c. $20.3(=$ Chactogastra seabriuscula, Triana), - Mexic.

Schenckii, Cogn.l. c. 207. - Bras.

Schiedeana, Cogn. l. c. 201 (= Pliroma Schiedermm, Triana), - Mcxic

Schumannii, Cogn. l. c. 256. - Venezuela.

Schwackei, Cogn. l. c. 206. - Bras.

Solmsii, Cogn. l. c. 250. - Peruvia.

stenophylla, Cogn. in Bull. Torrey Bot. Club, xvii. (1890) 56; et in DC. Monog. Phan. (1891):55. Bolivia.

stenopetala, Cogn.l. c.:262(= Pleroma stenopetalum,

Triana). - Peruvia.

strigosa, $\operatorname{Cog} n$. l. c. 266 (= P. strigosum, Triana).

- Ind. occ., Guian ang1.

Trianaei, $\operatorname{Cog} n$. l. c. 261. - Mexic

Ulaei, Cogn. \%. c. 202. - Bras.

Urbanii, Cogn, in Mart. Fl. Bras, xiv. IV. (188s) 602, t. 129, fig. I ; et in DC. Monog. Phan. vii. (1891) $22_{2}$ - Bras.

violacea, $\operatorname{Cog} n$. . . c. 272. - Parag

TIEDEMANNIA, DC. = Peucedanum, Tourn, (Umbell.)

Findlevi Coult, \& J. N. Rose, Revis. N. Am. Umbell. $(1888,48$. - Colorado, N. Mexic

rigida, Coult. \& J. N. Rose, in Coult. Bot. Gaz. xii. (1887) 7 ; etl. c, $47=$ Archemora rigida, $D C$. ternata, Coult. \& J. N. Rose, 11. cc. = A. ternata, Nutt.

TIEGHEMELLA, Pierre, Not. bot. Sapot. (1890) 18. SAPOTACEAE.

africana, Pierre, 7. . . - Gabon

Jollyana, Pierre, in Inst. bot.-giol. colon. Marseille, i. II. (1893) 2 . - Afr. trop.

TIGRIDIA, Juss. (Irid.). - Ind. Kew, ii. 1079. buccifera, S. Wats, in Gard. and For. ii. (1887) 412 ,

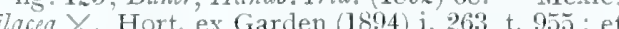
ex Gartenf. xliii. (1894) 639. - Hybr. artef. Meleagris, Nichols. Dict. Gavd. iv. (1886) 39. Mexic.

Pringlei, S. Wats. in Gard. and For. i. (1888) sos's, fig. 61; et ex Baker, in Bot. Mag. (1889) t. 7089. - Mexic.

pulchella, Robinson, in Proc. Am. Acad. xxvii. (1892) 184. - Mexic

TILIA. [Toum.] Linn. (Tiliac.), - Ind. Kew, ii. $106 \%$

aenobarba, Borb. E H. Bram, in Verh, zook-bot. Ges. Wien, xxxviii. (1888) :325, et xxxix. (1889) :363. -

Blcchiana X. Arboret. Zoesch. ex Dippel, Handb. Laubholzk. iii. (1893) 73. - Hybr, artet.

Borbasiana, H. Praun, fin Mathem. es Termesz, Koslem. xxii. (1888)] in Oest, Bot. Zeitschr. xxxviii, (1888) $139=$ cordata, Mill.

Bramii X. Simonk. in Oest. Bot. Zeitschr. xxxvi, (1886) 398. - Austria.

Commliac, H. Braun, 1. c, xlv. (1895) $320=$ vulgaris, Heyne?

chinensis, .Haxim. in Act. Hort, Petrop, xi. (Iss9) 8:3. - China.
TILIA

crostylis, Borb. Geogr. atq. Enum. pl. Comit. Castrif. (1887) $384=$ vulcaris, Heyne

muptera X, Borb, in Oest. Bot. Zeitschr. xli.(1891) 123, - Hung

fivedensis, Herm. ex Borb. 1. c. $4: 3=$ Haynaldiana $\Varangle$ Simonk.

gigantea, Hort. ex Dippel, Handb. Laubholzk. iii. $(1893), 65.67=$ alba. Aiton.

Gizellae, Borb, in Termész. Körl. ri. (1889) 91. Hung

Haynaldiana $\times$, Simonk, in Mag. Nïven. Lapok, xi. (1887) 1 ; et in A. Kern. Sched. F1. AustroHung. v. (1888) 30. - Hün.

Hazslinszkyana, Borb. Geogrr. atq. Enum, pl. Comit. Castrif, (1887) 26.), $325=$ rubra, $D C^{\circ}$

Henryana, Szyszyl. in Hook. Iion. pl. xx. (1890) t. 1927. - China

heggesensis $X$, Simonk, in Mag. Nören. Lapok (188\%) $t=$ furanyanat $X$, Simonk.

Hosteana, Borb, in Oest, Bot, Zeitschr, xxxrii. (1887) 297 = platyphyllos, Scop.

driaca, H. Braun, 1. C. xlıv, (1894) $311=$ dasystyla, Ster

Furanyiana X. Simonk. in Erdész. Lapok, xxy 1886) 570 ; et in A. Kern. Sched. Fl. AustroHung v. (1888) 30. - Eur. centr.

Ledebourit, Borb, in Oest. Bot. Zeitschr. xxxix. 1889) $45=$ dasystyla, Stev.

Ludonicia, Bosc, ex Koehne, Deutsche Dendrol. (1893) 408, nomen = americana, Linn.

morifolia $X$, Simonk. [Potfüzetek (1892) 141] ex Oest. Bot. Zeitschr, xliii. (1893) 67. - Hung.

Oliveri, Szyszyl, in Hook. Icon. pl. xx. (1890) sub t. 1927. - China

paucicostata, Maxim. in Act. Hort. Petrop. xi (1889) 82. - China.

scudobliqua, Simonk, in Mathem, et Term. Közl. xii. (1888) 300 : A. Kern. Sched. Fl. AustroHung. v. (1888) $32=$ vulgaris, Heyne.

Richteri X. Borb. in Bot. Centralbl. xxxvii. (1889) 161; Koehne, Deutsche Dendrol. (1893) 408. Hung.

Steveniana, Borb. in Dentsche Bot. Monatssch. vix. (1889) 3 ( = T rubra, Stev. - Eur.

Hoflarescens, Borb. Geogr. atq. Enum. pl. Comit. Castrif. (1857-88) 264 = rubra, DC.

trichoclados. Borb. in Oest. Bot. Zeitschr, xxxviii 1888) $325=$ platyphyllos, Scop.

Tuan, Szyszyl. in Hook. Icon. pl. xx. $(1890)$ t. 1926 . - China.

Ullipicii, Borb. fin Baenitz, Herb. Europ. (1892) in Oest. Bot. Zeitschr. xlii. (1892) 288, nomen, 487, [ad calc. Ullepitschii]. - Hung.

virescens, Borb. l.c. xli. (1891) 423. [Quid.?

viridis $\times, G$. Beck. F1. Nied,-Oest, ii. I. (1892) 5.33 Koehne, Deutsche Dendrol. (1N93) 490. Austria.

TILLAEA, Mich. (Crassul.). - Ind. Kew. ii. 1080. Bolanderi, Greene, Fl. Francisc, (1891) 183 ; et Man. Bot. San Franc. Bay (1894) 127. Calif.

diffusa, $T$. Kirk, in Trans. N. Z. Inst. xxiv. 1891 (1892) 424. - N. Zel.

multicaulis Petrie, l. o. xix. 1886 (1887) 324. - N Zel.

Novae-Zelandiae, Pctrie, l. c. xxy. $1892(1893) 270$ - N. Zel

viridis, S. Wats, in Proc. Ann. Acad. xxiii. (1588 272 - Mexic

TILOGARPUS, Engl. in Engl. \& Prantl, Natürl Pflanzenfam. iil. 5 (1895) 24\%, OLACINEAE.

papuanus, Engl. l. c. $\quad=$ Lasianthera papuana Becc.). - N. Guin.

TILLANDSIA, Linn. (Bromel.). - Ind. Kew. ii. 1080

achyrostachys, Ed, Morr, ex Baker, Huidb. Bronel. (1889) 171.- Mexic.

adpressa, Ed. Andre, in Rev. Hortic. 1x, (1888) 566 et Bromel. Andreanate (1889) 67 t. 23b. - Ecuad. Alberti X. Ed. André, 1. c. 577. - Hybr, artef.

alta, Baker, Handb. Bromel. (1889) $220(=$ Vriesea alta, Ed. Morr.). - Am. centr.

\section{TILLANDSIA}

amazonica, Baker, in fourn. Bot. xxvi.(1888) 108; et Handb. Bromel. 1S89) 220. - Reg. Amazon.

amethystina, Baker, $7 l$, cc, 106 ; et 218: th Bot. Mag. (1890) t. 7121 . - Bras

Andreana, Ed. Morr. ex Ed. Andre, in Ret. Hortic (1888) 56 ; th Bromel. Andreanae (1889) 85 t. 29b - Columb.

Appuniana. Baker, Handb. Bromel. (1889) 213. Guian. angl.

Araujei, Mez, in Mart, Fl. Bras. iii. IIT. (1894) 600. - Bras

Armadae, Ed. André, in Rev. Hortic. Ix. (18S8) 568; et Bromel, Andranac (1889) 106. - Columb.

arpocalyx, Ed. Andve, $7 l$. cc. $56 \%$; et 101 t. 38. Ecuad.

Aschersoniana, Wittm. in Bot. Fahrb. xi. (1889) 68. - Costa-Rica.

astragaloides, Mez. in Mart. Fl. Bras, iii. III. (1s,t) 601. - Am austr. (Terr. Mission.).

atrichoides, S. Moore, in Trans, Linn, Suc. Ser, ii. IV. $(189,4) 491=$ loliacea, Mart

Bakeriana, Britton, in fourn. Bot.xxvi. (18s8) 170 Baher, Handb. Bromel. (1889) 165. - Bras

bandensis, Baker, 1l. co.234; et 165. - Uruguay.

Barbeyana, Wittm. in Bot. Fahro, xi. (1889) 66.Ecuad.

Barclayana, Baker, in fourn. Bot. xxt. (188i) 239 et Handb. Bromel. (1589) 1\%1. - Ecuad.

Barilleti, Baker. Il. co. xxvi. (1888) 79; et 215 (= Vriesea Barilleti, Ed. Morr.). - Peruria.

Beleana, Ed. Andri, Bromel. Andremar (1889) 6.9 t. 4b. - Columb

Benthamiana, Baker, in fourn. Bot. xxri. (188s) 15. - Mexic

Billbergiae, Baker, l. c. 48. - Mexic.

birittata, Hort. ex Baker, Handb. Bromel. (18s9)

16, in syn, = Cryptanthus bivittatus, Regit.

Blanchetiana, Baker, l. c. 182, - Bras.

boliviensis, Baker, in Mem. Torrey Bot. Club, iv (1895) 26\% - Bolivia.

Botteri, Ed. Morr. ex Baker, Handb. Bromel. (1889) 183. - Mexic.

Bourgaei, Bakcr, in fonrn. Bot. xxv. (188i) 278.Mexic.

brachycephala, Baher, l. c. xxvi. (1888) 40; it Handb. Bromel. (1889) 201. - Peruvia.

brachyphylla, Baker, 77 . cc. 16 ; et 200 - Bras.

brachypoda, Baker, ll. co. xxv. (1887) 23\%.Venezuela.

bracteosa, Klotzsch, ex Baker, Handb. Broni?. (1889) 169. - Ins. S. Doming.

brassicoides, Baker, in fourn. Bot. xxvi. (1888) 12 et Handb. Bromcl. (1889) 189. - Bras.

brevibracteata, Bakcr, $7 l$. cc. xxv. (1887) 346 : et 191 . - Ins. Martinic.

broifolia, Baker, I. c. $239=$ incarnata, $H . B . \& K$. brevispicula, Ed. André, in Rev. Hortic. 1x. (1988) $567=$ Beleana, $E d$. Andre.

Brittoniana, Bakor. Handb. Bromel. (1889) 195.Bolivia.

Brunonis, Ed. André, in Rev. Hortic. 1x. (1588) 568 ; ct Bromel. Andreanae (1859) 92 t. 34. Columb.

Caldasiana, Baker, Handb. Bromet. (1889) 199.Bras.

caracasana, Eaker, in fourn. Bot. xxvi. (18s8) 44 ; ot Handb. Bromul. (1889) 206. - Venezuela.

carinata, Baker, $l l$. cc. 49 ; et $\geqslant 12(=$ Vriesea carinata, Wawra). - Bras.

Carrierei, Ed. André, in Rev. Hortic. 1x. (1888) 568 ; at Bromel. Andranae (1889) 98 t. $30 \mathrm{~b}$. Columb.

caulescens, Brongn, ex Baker, Handb. Brome?. (1889) 168. - Peruria.

chagresiana, Baker, in fourn. Bot. (1888) 109; ct l. c. 22:. - Panama.

chilensis, Baker, Handb. Bromel. (1889) 166. - Chili. chontalensis, Baker, in Fourn. Bot, xxy, (1887) $23 \%$

et $l . c .169$. - Nicaragua

citrina. Baker, l. c. (1889) 224. - Bras

Clausseniana, Baker, l. c. 213. - Bras

Closoni $\times$. Hort, ex Ed. André, in Rer. Hortrc, 1x. (1890) 203. - Hybr. artef.

colmmaris, Ed. Morr, ex Baker, Handb. Bromel. (1889) 208, in syn. = cyanea, Ed. Mor\%. 
TILIA NDSIA :

Conantha, Baker, Handb. Bromel. (1889) 2*8 (= Acanthospora conantha, Spreng.). - Peruvia.

condensata, Baker, l. c. $160^{\circ}$ - Bolivia.

confertiflora, Ed. André, in Re. Hortic. 1x. (1888) 567 ; et Bromel. Andreanae, (1889) 90 t. 26a.Ecuad.

corcovadensis, Britton, in Fourn. Bot. (1888) 172; et Handb. Bromel. (1889) 191. - Bras.

Cornuaulti. Ed. Andre, in Rev. Hortic. Ix. (1888) 568 ; et Bromel. Andreanae (I889) 102 t. 33. Columb.

cornucopia, Bertero, ex Ed. André, 1. c. (1889) 61, in syn = Catopsis nutans, Baker.

Cossoni, Baker, in Fourn. Bot.xxv. (1887) 279; et Handb. Bromet. (1889) 186. - Mexic

crassifolia, Baker, l. c. (1889) 175. - Parag., Bolivia.

crinita, Herb. Willd, ex Baker, 1. c. $160=$ usneoides, Linn.

crocata, Baker, in Fourn. Bot. xxv. (1887) 214; et Handb. Bromel. (1889) 163. - Bras.

Crousseana X. Hort. ex Rev. Hortic, 1x, (1890) 203.

- Hybr. artef.

cryptantha, Baker, in Fourn. Bot. (1888) 142 ; th Handb. Bromel. (1889) 229. - Mexic

cucaënsis, Wittm. in Bot. fahrb. xiv, Beibl. n. 32 (1891) 7. - Guatem.

cylindrica, S. Wats. in Proc. Am. Acad. xxvi. (1891) 155. - Mexic.

dactylifera, Ed. Morr. ex Baker, Handb. Bromel. (1859) 181. - Venezuela.

dasyliriifolia, Baker, in fourn. Bot.xxv. (1887) 304; et Handb. Bromel. (1889) 187. - Hondur.

decipiens, Ed. André, in Rv. Horlic. Ix. (1888, $56 \%$

et Bromel. Andreanas (1889) 68 t. 24a. Ecuad.

decomposita, Baker, Handb. Bromel. (1889) 168. Parag.

decurvata, Baker, l. c. $216(=$ W. recuriata, Baker $)$, - Bras.

denudata, Ed. Andre, in Rev. Hortic. 1x. (1888) 568; et Bromel. Andreanac (1889) 96. - Columb.

didisticha, Baker, in Journ. Bot, xxvi. (1888) $16=$ Lorentziana, Griseb.

discolor. Hort. ex Baker, 1. c. $4=$ Karatas purpurea, Antoine.

Dombcyi, Baker. l. c. 199. - Peruvia.

drepanocarpa. Bakor, in Fourn. Bot. xxvi. (1888) 41 ; et l. c. 202. - Bras.

drepanoclada, Baker, l. c. 188. - Mexic

drepanophylla, Baker, l. c. 176. - Parag.

Dugesii, Baker, in Fourm. Bot. xxv. (1887) 278; et Handb. Bromul. (1889) 185. - Mexic.

dura, Baker, l.c. (1889) 168. - Bras.

Duvaliana, Baker, in Fourn. Bot. xxvi. (1888) 48; et Handb. Bromel. (1889) 213 (=Vriesea Duvaliana, Ed. Morr, 1, - Bras.

Dyeriana, Ed. André, in Rev. Hortic. 1x. (1888) 568: et Bromel. Andranae (1889) 98 t. 32. Ecuad.

Eggersii, Baker, Handb. Bromel. (1889) 170. Ins. S. Doming.

Ehrenbergiana, Klotzsch, ex Baker, l. c. 169 (= Platystachys Ehrenbergii, Beer). - Mexic.

elata, Baker, in fonrt. Bot. xxvi. (1888) 46; et Handb. Bromel. (1889) 209. - Am. trop.

Engleriana, Witm. in Bol. Fahrb. xi. (18s9) 63.Columb.

erectiflora, Ed. Andro, Bronel. Andreanae (1889) 86 t. $26 \mathrm{~b}$. - Ecuad.

erectiflora, Baker, in Fourn. Bot. xxv. (1887) 346 ; et Handb. Bromel. (1889) 191. - Bras.

exserta, Fermald, in Coult. Bot. Goz.xx. (1895) $53 \%$ - Mexic,

fastuosa, Ed. Andre, in Rev. Hortic. 1x. (1888) 568 ; et Bromel. Andreanae (1889) 104, t. 37. Columb.

firmula, Mer, in Mart. Fl, Bras, iii. III. (1894) 603. - Bras.

flabellata, Baher, in fourn. Bot. xxv. (1887) 242; et Handb. Bromel. (18s9) 176. - Guatem.

flagellifera, Ed. Morr. ex Baker, 1. c. (1889) 185, in obs. = violacea. Baker

fuminensis, Mez, in Mart. Fl. Bras. iii. III. (1894) 5!1. - Bras.

\section{TILLANDSIA}

Fournieri, Ed. Morr. ex Baher. Handb. Brome?. (1889) 183. - Mexic

fragrans, Ed. Andre, in Rev. Hortic Ix. (1888) 567 et Bromel. Andreanate (1889) 83 t. $29 a$. Ecuad.

Duratii, Hort, ex Rev. Hortic. lxiv. (1892) 436, tig. 130 et 131. - Uruguay.

Fraseri, Baker, Handb. Bromel. (1889) 18\%. Ecuad.

Funckiana, Baker, l. c. 196. - Venezuela.

Gayi, Baker, l. c. 179. - Peruvia.

Geissei, Phil in Gartenfl. xxxviii. (1889) 3\%0, t. 130\%, fig. 2 ; et ex Rev. Hortic. 1xi. (1889) $388 .-$

geniculata, Ed. Morr. ex Baker, Handb. Bromel. (1889) 190. - Mexic.

Ghiesbreghtii, Baker, l. c. 208, - Mexic.

glaucophylla, Baker, l, c. 183 (1887) 243. - Am. trop.

Glaziovii, El. Morr, ex Bakry, l. c. (1889) 229.Bras.

goniorachis, Baker, in foum. Bot.xxv. (1887) 303 et Handb. Bromel. (1889) 18\%. - Bras.

gradata, Baker, $l l$. cc. xxvi. (1888) 105 ; et 217 . Bras.

graminifolia, Baker, in Journ. Bot. xxv. (188i) 281 = monadelpha, Laker.

grisea, Baker, 1. c. 245 = latifolia, Meyen.

Grisebachiana, Baker, in Foum. Bot. (1888) $143=$ T. tetrantha. Griseb.). - Venezuela.

Grisebachii, Baker, l.c. xxv. (1887) 305 ; ct Handb. Bromel. (1889) 188. - Venezuela.

guadelupensis, Baker, l. c. (1889) 213. - Ins. Guadelup.

guttata, Baker, in fourn. Bot. (18S8) 108 ; et l. o. (1889) 22i (=Vriesed guttata, Ed. André). Bras.

gymnobotrya, Baker, ll. cc. xxv. (1887) 243; et (1889) 181 [sphaln. gymnobotrya]. - Mexic.

gymnophylla, Baker, ll. cc. xxv. (1888) 41 ; ot (1889 201. - Venezuela.

Hartwegiana, Éd. Morr. ex Baker. Handb. Bromel. (1889) 199, in syn. = Benthamiana, Klotzsch

heterandra, Ed. Andre, in Rev. Hortic. Ix. (Is8s $56 \%$; et Bromel. Andrance (1889) 83 t. 27. Columbia

heterophylla, Ed. Morr. ex Baker, Handb. Bromel 1889) $20^{\circ}=$ virginalis, $E d$. Morr.

heterostachys, Baker, in fourn. Bot, xxvi. (1888 106 ; ct Handb. Bromel. (1889) 217. - Bras.

hieroglyphica, Baker, $7 i$. co. 110; el $224(=$ Vriesed hieroglyphica. Ed. Morr.). - Bras.

Hilaireana, Baker, Handb. Bromel. (1889) 199.Bras.

homostachya, Ed. André, in Rev. Hortw. 1x. (188's 567 ; ct Bromel. Andreanae (1889) 00 t. 25a. Ecuad.

Houzeavii, Ed. Morr. ex Baker, Handb. Bromel (1889) $188=$ valenzuelana, $A$. Rich

Humboldtii, Baker, l. c. 203. - Mexic.

imperialis, Ed. Morr, ex Éd. André, Bromel. An dreanae (1889) 96 , in syn. = nigrescens, $E d$ André.

inconspicua, Éd. André, in Rev. Hortic. 1x. (1888 568 ; et Bromel. Andreanae (1889) 74. - Ecuad.

incurvata, Baker, in Fourn. Bot. xxvi. (1888) 49 ; et Handb. Bromel. (1889) 21:3 = Vriesea incurvata, Gaudich.), - Bras.

inflata, Baker, in Bot. Mag. (1886) t. $6882=$ incurvata, Baker.

Itatiaiae, Baker. in foum. Bot. (1888) 110 ; et Handb. Bromel. (1889) 224. - Bras.

Jenmani, Baker, $7 l . c c .545$; et 194. - Guian.

Kalbreyeri, Baker, $l l$. co. xxvi. (1888) 45 ; et 208 . Columb.

Kirchhoffiana, Wittm. in Gartenfl. xxxviii. (1889) 107, fig. 22. - Mexic

Kitteliana X Hort ex Rev, Hortic, 1xii. (1890) 203. - Hybr. artef

Krameri, Baker, Handb. Bromel, (1889) 197. - Bras, lajensis, Ed. André, in Rev. Hortic. 1x. (1888) $56 \%$ ct Bromel. Andreanae (1889) 88 t. 31b. Columb.

lancifolia, Baker, Handb. Bromel. (1889)202. - Bras,

Langsdorffi, Me\%, in Mart. Fl. Bras, iil. III, (1894) 508. - Bras.

\section{TILIANDSIA}

lateritia, Ed. Andri, in Rev. Hontic. 1x. (1888) 566: ch Bronel. Andreanae (1889) 76 t. 21. - Ecuad.

atifolia, Meyer, ex Baker, in foum. Bot. xxv. (18s7) $27 \%$. Peruvia.

leinchlamys, Baker, Handb. Bromel.(1889) 184. Mexic

linenta, É. André, in Rev. Hortic. 1x. (1888) nos: et Bromel. Andreance (1889) 105. - Columb.

longibracteata, Buker, in fourn. Bot. xxvi, (188s) 81; et Handb. Bromel. (1S89) :15. - Venezuela.

longicaulis, Baker, Il. co. 80 ; of 214. - Bras.

longifolia, Baker, i.c. (1889) 185. - Venezuela.

longipetala, Baker, in foum. Bot. xxv. (1888) 14 ? et Handb. Bromel. (1859) 229. - Columb.

Loventzii, "Griseb. " ex Rev. Hortic. 1xiii. (1891)

$1 \%=$ Lorentziana, Griseb.

Lubbersii, Baker, Hundb. Bromel. (1889) $218=$ Vriesea Lubbersii, Ed. Morr. I. - Bras.

lucida, Ed. Morr. ex Baker, l. c. 20\%. - Mexic Guatem.

lutea, Baker, Handb. Bromel. (1889) 198 (= Anoplophytunt luteun, Ed. Morr.). -- Uruguay.

macrochlamys, Baker, in fourn. Bot. (1888) 112: l.c. 180. - Mexic

macropetala, Wawra, in Wien. Ill. Gartenzeit. (18si) 241, cum ic. = vaginalis, $E d$. Mor

macropoda, Baker, Handb. Bromel. (1889) 218. Bras.

magna, Baker, l.c. 210.- - Ins. Martinic

Magnusiana, Wittm, in Bot. Fa7wb. xi. (1889) 66. - Guatem.

Makoyana, Baker, Handb. Bromel. (1889) 189. Mexic.

Iallemonti, Glaziot, ex Mer, in Nart. Fl. Bras, iii. III. (1894) 608. - Bras.

martinicensis; Baker, in foum. Bot. xxvi. (1\&88) 45 : et l. c. 209. - Ins. Martinic.

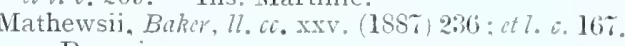
- Peruvia.

megastachya, Baker, 17. cc. xxvi. (1888) to ; et 210 . - Ins. S. Vinc.

meridionalis, Borker, 77. cc. 15; ct 19\%. - Uruguay. micrantha, Baker, 77 . co. xxv. (1887) 303 : et 194.Ins. Trinit.

microxiphion, Eaker, in Bot. Mag. (1893) t. 3320). Uruguay.

monadelpha, Baker, in fourn. Bot. Xxv, (185i) 2S1 it Handb. Bromel. (18s9) 192. - Guian.

monadelpha, Wittm. in Engl. \& Prantl, Natürl. Pflanzenfam. ii. 4 (1888) $5 \%=$ praec.

Moritziana, Klotzsch, ex Baker, Handb. Bromel.

(1889) 174. - Venezuela.

Morreni, Baker, in fourn. Bot. xxv. (1888) 189 ; et 7. c. 226 (= Vriesea Morreni, Wavra) - Bras.

myosura, Griseb. (in Lorent\%, Fl. Argent. exsici. n. 122) ex Baker, Handb. Bromel. (IS89) 163. - Am. austr.

myriantha, Baker, in foum. Bot. xxy. (1885) 24? et Handb. Bromel. (1589; 176. - Venezuela.

nana, Baker, $l$ c 172. - Peruvia.

nigrescens, Ed. Andre, in Rer. Hortic. 1x. (1888) 568 ; et Bromel. Andreana (1859) 96 t. 14b. Columb.

oligantha, Baker, in Fourn. Bot. xxv. (188i) 34. ; et Handb. Bromel. (1889) 215. - Bras.

oranensis, Baker, l. c. (1889) 171. - Reo. Arcent.

orizabensis, Baker, in foum. Bot. xxvi. (1888) 105 t Handb. Bromel. (1889) 217. - Mexic.

oxysepala, Bake, 12 . oc. 141 ; it 228. ruvia.

pachycarpa, Baker, in fourn. Bot. xxv. (1887) 238 . - Ins. Trinit.

pachychlamys, Baker, l. c. xxvi. (1888) 48. Guian. angl.

parabaica, Baker, nl. co. 82; it Handb. Bromel. (1889) 212 (= Vriesed parabata, Wamra). Bras.

paraënsis, Mez, in Mart. Fl. Bras, iii. III. (1894) 586. - Bras

Parkeri, Baker, in fourn. Bot. xxvi. (1888) 42 ; el Handb. Bromel. (1889) 205. - Guian. angl.

Parryi Baker, ll. cc. xxv, (1887) 277 ; it 184.Mexic.

parvispica, Baker, 72, ca. xxv. (1857) 244; 178 Bras. 


\section{TILLANDSIA}

pastelusis, Fa. Andrc in Ro. Hortic, 1x, (1888)568; Bromel. Andrancte (1889) 91 t. 39a. Columb.

Fistuchoffiana, Hort, ex Baker, Handb. Bromel. lss? 220 , in syn. = T. Morreni, Baket

pectinata, Lid. Andri, in Rer. Hortic. 1x. (1888) 56 i Bromel. Andreanac (1889) 85 t. 30 fig. a. : Baker. 204 - Columb

lereziana, Ed, Andri.7l.cc, 56\%: et 80.t. 28. Columb.

1'hilippo-Coburgi, Baker, in foum. Bot.xxv. (1888) 1.38; ot Handb. Bromel. (1889) 2925 (= Vricsea Phlippo-Coburoi, WVawra). - Bras.

hyllostachya, Bakir, l.c. xxv, (1888) 143; et in Bot. Jag (1s89) 20t. - Mexic.

iota, Hort, ex Baker, Handb. Bromel. (1889)215 = splendens, Broirgn

hatypetala, Baler, in Journ. Bot. xxvi. (1888) $47=$ Hamaleana, id Mor\%.

I'latzmanni, Eoker, in form. Bot. xxvi. (1888) 104: HLanab. Brome7. (18S9) 218. - Bras.

lumosa, Baki\%, 7l. cc. 13; ct 196. - Mexic.

nenulata, Bakr, Handb. Broncl. (1889) $230(=$ Vriser pocmulata, Ed, Morr.). - Hab.

I'ohliana. Mez, in Mart. Fl. Bras, iii, III. (189t) $51 \%$ - Bras.

polyphylla, Baker, Handb. Bromel. (1889) 178. Bulivia.

rinclei, S. Wats, in Proc. An. Acad, xxvi. ;1891 15.5. - Mexic

rrodigiosa, Baker. in Fourn. Pot.xxvi.(1888) $140 ;$ et Handb. Bromel. $(1889) 1860=$ Vriesea prodigiosa, Lem. - Mexic.

ulvinata, Ed. Morr. ex Baker, Handb. Bromul. (1889) 190. - Mexic

pyramidata, Ed. André, Bromel. Andreanác (1889) 86. - Columbia.

wadriflora, Baker, Handb. Bromel. (1889) 163.Bolivia.

ramealis, Klotrsch. ex Bakr, l. c, 161. - Ins. S. Thom

ariflora, Ed. Andre, in Rev. Hortic, 1x. (188s) 568 ; et Bromet. Andranae (1889) 95. - Columb.

ctiflora, Ed. André, 1. c. $56 \pi=$ erectiflora, Ed. Ind

curcata, Baker, in Journ. Bot. xxvi. (1888) 106 decurvata, Baker

Kegnelli, .17ez, in Mart. Fl. Bras, iii. III. (1894) 592. - Bras.

Reichenbachii, Baker, Handi.,Bromel. (1889) 166. - Tucuman.

remota, With. in Bot. Fahrb. xiv. Beibl. n. 39 (18.91) 6. - Guatem

Iiestrepeana, Ed. Andri, in Red. Hortic. 1x. (1888) $56 \%$; et Bromel. Andrcanae (1889) 89 t. 28. Columb.

reticulata, Baker, in Gard. Chron. (I887) i. 140; ct Handb. Bromel. (1889) 225 (= Vricsea reticulata Ed. Morr.). - Bras.

Thex X, Hort. cx Res. Hortic, 1xii. (1890) 202. Hybr. artef.

rhodochlamys, Baker, IIandb. Bromel. (1889) 203.IIexic

rhodocincta, Baker, in fourn. Bot. (18s8) 143 Handb. Bromel. (1889) 168. - Guian. angl.

Thomboidea, Ed. Andri, in Rer. Hortic. 1x. (1888) 5)(66: et Bromet. Andreanae (1889) 75 t. 20. Cilim?

rigidula, Baker, in foum. Bot.xxvi. (1888) 44; et Handb. Bromel. (1sst) 207. - Guian. angl.

Riocreuxii, Ed. André, in Rev. Horlic. 1x. (1888 567 ; et Bromet. Andreange (1889) 73 t. 35. Ecuad.

Rudigasiana, Baker, in Fourn. Bot. (1888) 138 ; et H Tundb. Bromel. (1889) 225(= Vriesea Rodigasiana id. Morr.). - Bras.

ropalocarpa, Ed. André, in Rer. Hortic. 1x. (18SS) 506 ; et Bromel. Andranae (1889) 66 t. 23a. Columb

rubella. Baker, in fourn. Bot. xxvi. (1888) 44; et Handb. Bromel. (18S?) 207. - Bolivia.

mbra, Hort, ex Baker, 1. c. (1889) $4=$ Karatas purpurea, Antoinc.

\section{TILLANDSIA}

rupicola, Baker, in fourn. Bot. xxvi. (1888) 13; et

Handb. Bromel. (1889) 196. - Ecuad.

Rusbyi, Baker ? (18s9) 176 - Bolivia.

angunea, Ed. André, in Tour du Monde, xxxviii. $: 367$ = Caraguata sanguinea, Ed. Andrí.

sanguinolenta, Baker, Handb. Bromel. (1889) 226 $1=$ Vriesca sangumolenta, Cogn. \& É1. March.). Columb.

scalaris, Baker, in fourn. Bot. (1888) 108 ; ct Handb. Bromel. (1889) 221. - Bras.

scalarifolia, Baker, ll. co. xxv. (1885) 235 ; et 60.Bolivia.

Schenckiana. Wittm. in Bot. Fahb. xi. (1889) 63 - Columb

Schimperiana, IVittm. ? c.67.-Columb.

Schlechtendalii, (crr. cal. Schlechtendahlii) Baker, in Fourn. Bot. xxvi. (1888) 49; ct IIandb. Bromel. (18s!) 213. - Mexic

Selloana, Buker. 77. cc. 104 ; ct 219. - Bras.

sericea, Hort, ex Baker, 1. c. (18s9) $164=$ xiphioides, $\mathrm{Ker}$.

Sintonisii, Baker, in Journ. Bot, xxvi. (1888) 12; = utriculata, Lim .

soratensis, Bakcr, hl. co. xxv. (188\%) 235; ot 160. Bolivia.

sparsiflora, E. G. Bakcr, 7, c. xxviij. (1890) 306. Am. centr.

sphaerocephala, Baker, in Fourn. Bot. (1888) 141 Handb. Bromel. (1889) 228. - Bolivia

stenostachya, Baker, $7 l$. c6. 109; et 222. - Ins, Trinit.

Stolpi. Phil. in Anal. Univ. Chit. xci. (1895) 614.- Chili.

streptocarpa, Baker, in fourn. Bot.xxv. (1887) 241 ct Handb. Bromcl. (1889) 175. - Parag.

strobilantha, Baker, ll. oc. 168; ot 180.- - Mexic.

strobilifera, Ed. Morr. ex Baker, Handb. Bromel.

(1889) 181. - Mexic

subalata. Ed. Andre in Rev. Hortic 1x. (1888) $56 \%$; et Bromel. Anarcanae (1889) 60 t. 250b. - Columb.

subimbricata, Baker, in Fourn. Bot. (1887) $30 \%$; et

Handb. Bromel. (1889) 185. - Ins. Trinit.

sublaxa, Baker. $7 l . c 0,280$; ch 18T. - Ind, occ

subsecunda, Witm. ex Baker, Handb. Bromel. (1889) 217. - Costa Rica.

Swartzii, Baker, in fonm. Bot. xxvi. (1888) 12; th. c. 191. - Jamaica

tenuispica, Ed. Andre, in Rez'. Hortic. Ix. (1888) 56\%; et Bromel. Andreanae (1889) 11 t. 31 a. - Columb.

Tequendamae, Ed. Andvi, $7 l$. cc. 568 ; et 10.3 t. 36. Columb.

thyrsigera, Ed. Morr. ex Balacr, Handb. Bromel. (1889) 185.- - Mexic

tortilis, Baker, in Journ. Bot. xxv. (185i) $23 \%=$ Ehrenbergiana, Klotzsch.

iricholctis, Baker, 1. c, 231 = Bakeriana, Britton.

trinitensis, Baker, Handb. Bromel. (1889) 211. - Ins. Trinit.

triticea, Burchill, cx Baker, in Fourn. Bot. (1888) 4\%; et l. c. 205. - Bras.

Turneri, Baker, Il. cc. 143 ; ct 173. - Columb.

Tweedieana. Bakcr, 1l. cc. 138; et 228. - Bras.

umbellata, Ed. Andre, in Rev. Hortic, 1viii. (1886)60,

cum ic.; ct Bromel. Andreanac (1889) 97. - Ecuad.

nilateralis, Baker, in Foum. Bot. xxvi. (1888) 105 ;

et Handb. Bromel. (1889) 218. - Bras.

Urbaniana, Wittm. in Bot. Fahrb.xi. (1889) 65.Costa Rica.

valenzuelana, Ed. Andre, in Rev. Hortic. 1x. (1888) 567 ; ot Bromel. Andrcanae (1889) 80 t. 28. Columb.

Veitchii, Baker, Handb. Bromel. (1889) 223 (= Vriesea Veitchii, Ed. Morr.). - Columb.

vernicosa, Baker, in foum. Bot. xxv. (1887) 241; ct 7. c. 175. - Bras.

violacea, Baker, $l l$. cc. $2 \% 9$; ct 185. - Mexic viridiflora, Hort. ex Baker, 1. c. (1889) 214, in syn. = viminalis, Hemsl.

viridifiora, Baker, in foum. Bot. xxvi. (I888) 81 ; it Handb. Bromel. (1889) 214. - Mexic.

viridis, Baker, l. c. $204(=$ Vriesea riridis, Ed Morr.). - Bras.

virginalis, Ed. Morr. ex Gard. Chron. (1888) i. ZI7 fig. 93; Wittn, in Gartenf, xliv, (1895) 398, fig. 87 , 88. - Mexic

\section{TILLANDSIA}

itla! $a$, Hort. ex Balser. Handb. Bromel. (1889) 16, in syn. = Cryptanthus bivittatus, Rogel.

Warmingii, Baker, in Fourn. Bot. xxvi. (1888) 104: et Handb. Bromcl. (1889) 219. - Bras.

Wawrana, Baker, ll. co. 105 ; et 218 [sphalm. Wawranea]. - Bras.?

Weddellii, Bakcr, Handb. Bromel. (1889) 181.Bolivia

Wilsoni, S. Wats, in Proc. Ant, Acad, xxiii. (1888) 460. - Florida.

xyphophylla, Baker, in fourn. Bot. (1888) 204; ot Handb. Bromel. (1889) 204. - Mexic.

yucatana, Baker, ll. cc. 280 ; et 186. - Yucatan.

TIMONIUS, Rumpf. (Rubiac.). - Ind. Kew. ii. 1082.

amboinicus, Bocrt, Handl. Fl. Ned. Indië, ii. I (1891) 133) (= Polyphragnon amboinicum, Miq.). Ins. Amboin

anodon, Boerl. l. c. $(=$ P. anodon, Miq.). - Ins. Amboin.

Bammleri, K. Schm. in Notizb6.Bot. Gart. Bort. i. (1805),56. - N. Guin.

compressicaulis, Boerl. Handl. Fl. Ned. Indie, ii. I. (1891) 1333 ( = Polyphragnon compressicante, Miq.). - Sumatra.

cuneatus, Warb. in Bot. Falrb. xiii. (1891) 433. N. Guin.

Enderianus, $W a r b$. l. c. 434. - N. Guin.

fuscus, Boerl. Handl. Fl. Ncd. Indië, ii. i. (1891) 1333 (= Bobea fusca, Korth. i. - Sumatra.

hydrangiaefolius, Baill. l. c. $(=$ Polyphragmon hidrangcifoliun, Miq.). - Sumatra.

mutabilis, Bocrl. l. c. $132=$ mutabilis, $W a l p$.

novo-guineensis, Warb. in Bot. Fahrb. xiii. (1891) 434. - N. Guin.

ovalis, Boent, Handl, $\mathrm{Fl}$. Ned. Indie, ii. I. (1891) 132 (= Polyphragmon ovale, Korth.). - Borneo.

Pseudocapitatus, Bocrl. l. c. $\{=$ P. Pseudocapitatus, Scheff, ). - Malaya;

splendens, Bocn. T. c. (= P. splondens, Miq.). Sumatra.

trichocaulon, Bocrt. l. c. $(=$ P. trichocaulon, Miq.). - Malaya,

sericeus, K. Schum. Fl. Kais. Wilh. Land (1889) 131: Warb. in Bot. Jahrb. xiii. (1891) $433=$ T. Rumphii, $D C$.

TINA, Roem. \& Schult. = Ratonia, DC. (Sapind.). celutima, Baker, in Journ. Linn. Soc. xxii. (1887) 462. - Madag.

TINANTIA, Schlecht. (Commelin.). - Ind. Kew.

leiocalyx, C. B. Clarke, ex 7. D. Smith, in Coult. Bot. Gaz. xviii. (1893)211, - Guatem.

macrophylla, S. Wats, in Proc. Am. Acad. xxi. (1886) 442. - Mexic.

modesta, T. S. Brandeg. in Proc. Calif. Acad. Ser II. iii. (1889) $175=$ fugax, Scheidw.

TINGUlonga, Rumpf = Protium, Burm. f. (Burser.).

Almacega, altissima, Beandu, Blancheti, brasiliensis, Carana, Copal, crassifolia, dirinricala, clegans, ferruginea, gigantia, grandifolia, guianensis, heptapliglla, Icicariba, insignis, laxiflora, macrophylla, madagascariensis, Martiana, multiflora, nitida, obtusifolia, orata, paniculata. pitosissima. polybotrya, pubescens, reticulata, Riedeliana, serrata, Spruceane, subserrata, temuifolia, trifoliata, cenosa, Warmingiana, Widgronii, Zullingeri, Kuntze, Rev. Gen. 1891) $107-10 \mathrm{~s}=$ homonyma omnia Protii.

Aracuchini, Kuntze, 1. c. $108=$ P. Aracouchili, March

candata, Kuntze, 1, c. $107=$ P. Sagotianum, March. cnneandra, Kuntze, 1. c. = P. decandrum, Marck.

Hostmanni, Kuntze, 1, c. = P. Hostmanni, Engl.

leptostachya, Kuntze, 1. c. 108 (= Icica lcptostachya.). - Mexic.

Mclilons, Kuntze, 1. c. = P. Melinonis, Engl.

Protium, Kuntze, 1. c. = P. javanicum, Burm.

simplicifolia, Kuntze, 1. c. $107=$ P. unifoliolatum, 
TINNEA, Kotschy \& Peyr。(Labiat.). - Ind. Kew. ii. 108.3 .

arabica, Baker, in Kevo Bull. (1894) 339. - Arabia.

Fischeri, Guerke, in Bot. Fahro. xxii. (1895) 128. Afr. trop. or.

gracilis, Guerke, l. c. - Afr, trop.

platyphylla, Briq. in Bot. falkrb. xix. (1894) 194

[Tinnaea]. - Congo mer.

vesiculosa, Guerke, in Bot. farro. xxii. (1895) 129 : it in Engl. Pfanzonw. Ost-Afr. A (1895) 92. Afr. trop. or.

TINOPSIS, Radlk, in Th. Dur. Ind. Gen. Phan. (1888) 78; et in Sitzb. Akad. Muench. xx. (1890, 291. SAPINDACEAE.

apiculata, Radlk, ll. co. - Madag.

TINOSPORA, Miers (Menisperm.), - Ind, Kew.

Hullsii, F. M. Bailey, Syn, Ouensl. Fl. Suppl, iii, (1890) 6 (= Pachygone Hulllsii, F. Muell.).Austral.

TINUS, Burm. = Ardisia. Sw. (Myrsin.).

affinis, ambigut, amplexicaulis, andananica, argatu, Barthesia, bhotanica. bipinnata, borneensis, Gracteata, bracteosa, Brandisiana, brasiliensis, breviftora, brevipedata, calycosa, canaliculata, Capollina, caribaea, caudata, canliftora, celebica, cestrifolia, chinensis, compressa, confinis, coriacea, courtallensis, cubana, Cumingiana, cuspidata, cymosa, demussa, denticulata. depressa, divergens, dubia, durifolia, esculenta, eximia, ferruginea, fortilis, floribunda, foetida, fuliginosa. fusca, fuscopilosa. Gardneri, glandulosa-marginata. grandifolia, Griffithii, Helferiana, Henryi, humilis, Icara, insularis, irasuensis, japonica, jacianica, funghuhniana, khasiana, laevigata, lasvis, Lamponga, lanceolata. lateriflora, laurifolia. lepidota, leptantha, Lhotzkya, Licbmannit, limearifolia, lineata, Lobbiana, longifolia, hurida, luzonensis, macrocaly, macrophylla, maculata, mamillata, marginata, membranacea, micrantha, microphylla, Mlissionis, montana, Moonii, nicaraguensis, nigrescens, nigricans, nigropunctatu, nitidula, mutans, odontophyllu, Olieeri, Oprgrapha, orinocensis, palembanica, paniculata, pancifora, pedunculosa, pellucida, Perrottetiana. petocalyx, philippinensis, Pickeringia, plagioneura, polycephala, porosa, propinqua, Psendojambosa, pterocaulis, pubicalyx, pyramidalis, pyrifolia, quinquangulavis, ramiflora, reclinata, reflexa, revoluta, rhyuchophylla, rigida, rebiginosa, Schomburgkiana, scssitis, Spanogheï, sphenobasis, squamulosa, Storckii, stylosa, subcuncata, sumatrana, sumbarana, surinamensis, tenuiramis, tornatensis, tinifolia, tomentosa, triflora, turbacensis, undulata, verrucosa, virens, Wallichii, Kuntze, Rev. Gen. (1891) 405, 973- $64=$ homonyma omnia Ardisiae.

ucuminata, Kuntze, Rev. Gen. (1891) $973=$ Ardisia Kurzii, C. B. Clarke.

adenanthera, Kuntze, 1. c. $974=$ Parathesis adenanthera, Hook. $f$.

anceps, Kuntze, 1. c. = Ardisia Blumei, $A . D C$. angustifolia, Kuntze, 1. c. $973=$ A. semicrenata, Mart

ardisiodes, Kuntze, 1. c. = A. decipiens, $A, D C$.

attenuata, Kuntze, 1, c, $405=\mathrm{s}$. oxyphylla, $W$ all.

Bakeriana, Kuntze, 1. c. $973=$ A. laurifolia, A. DC.

Balfouriana, Kuntze, 1. c, - Ins. Rodriguez.

borbonica, Kuntze, 1. c. 974 (= Badula borbonica, A. DC.). - Ins. Borbon.

bumelioides, Kuntze, 1. c。 = Ardisia bumelioides, Griseb.

Candolleana, Kuntze, 1. c. $973=$ A. angustifolia. $A$. $D C$.

Clarkeana, Kuntze, 1. c. $973=$ A. zeylanica, C. B. Clarke.

slusiodes, Kuntze, 1. c. $974=$ A. clusioides, Griseb.

complanata, Kuntze, 1. c. = A. colorata, Roxb.

crassa, Kuntze, 1. c. $=$ A. insularis, Baker.

crispa, Kuntze, 1. c. $405=$ A. crenata, Roxb.

cybianthodes, Kuntze, 1. c. $974=\mathrm{A}$, cybianthoides, Miq.

densa, Kuntze, 1. c. = A. crenata, Roxb.

dentata, Kuntze, 1. c, $=$ A. semicrenata. Mart.

diengensis, Kuntze, 1. c. 405. - Java.
TINUS:-

Qistichu, Kuntze, 1. c. = Pimelandra disticha, Benth. \& Hook. $f$

erecta, Kuntze, 1. c. = P. erecta, C. B. Clarke.

erythroxylodes, Kuntze, 1. c. = Ardisia erythroxy loides, Thou.

scalloniodes, Kuntze, 1. c. = A. escallonioides, Schlecht. \& Cham.

enceniaefolia, Kuntze, 1, c, = Pimelandra euoeniaefolia, Benth. \& Hook. f.

Faberi, Kuntze, 1. c. = Ardisia Faberii, Homsl.

Forsterii, Kuntze, 1. c, = A. Forstenii, Scheff.

frangulifolia, Kuntze, 1. c. = A. frangulaefolia, Zipp. \& Sclieff.

Grisebachicura, Kuntze, 1, c, $9: 3=$ A, multiflora Griseb.

guadelupensis, Kuntze, 1. c. $974=\mathrm{A}$. guadalupensis, Duchass.

Dumensis, Kuntze, I. c. 973 = A. acuminata, IVilld.

Hostmannii, Kuntze, 1. c. 9rit = A. Hostmanni. .1Tiq.

jacquiniodes, Kuntze, 1. c. = A. jacquinioides, Griseb.

jambosiodes, Kuntze, 1. c. = A. crassa, C. B. Clurke. Keencuni, Kuntze, 1. c. = A. Keenani, C. B. Clarke Korthalsiana, Kuntze, 1. c, = Pimelandra Wallichii, $A, D C$

Kurzeana, Kuntze, I. c. $9 \% 3=$ P. Griffithii, C. B Clarke.

latifolia, Kuntze, 1. c. = Ardisia Sieberi, Baker ve! guadalupensis, Duchass.

Maingayi, Kuntze, 1, c. = A crassa, C. B. Clarke.

Martiana, Kuntze, 1. c. $974=$ A. latipes, Mart

multiflora. Kuntze, 1. c. = A. insularis, Baker.

myristifolia, Kuntze, 1. c. = A, myristicaefolia Blume.

obovata, Kuntze, 1, c, $973=$ A. Hamiltonii, A. DC orata, Kuntze, 1. c. $9 \tau t=$ A. colorata, Roxb

pachysandra, Kuntze, 1. c.973 = Pimelandra Wallichii, $A . D C$.

paludosa. Kuntze, 1. c. 974 (= Monoporns pahndosus, A. DC. - Madas.

pergamacea, Kuntze, I. c. = Embelia pergamacea A. DC

polysticta, Kuntze, 1. $c_{0}=$ Ardisia crenata; Sims.

primulifolia, Kuntze, 1. c. = A. primulaefolia Gardn. \& Champ.

punctata, Kuntze, 1. c. = A, crenata, Sims .

racomosa, Kuntze, 1. c, = A. Pyrgus, Rocm. \& Schult.

reticulata, Kuntze, 1. c. $975=$ A. insularis, Baker. rhombodea, Kuntze, 1. c. = A. rhomboidea, Wight. semicrenata, Kuntze, I. c. = A. acuminata, Willd. serrata, Kuntze, 1. c, = A. Cavanillesii, Rocm. Schult.

Sicboldii, Kuntze, 1. c. = A. Sieboldi, Miq.

Sprengelii, Kuntze, 1. c. $974=$ A. racemosa, Spreng. simplex. Kuntze, l. c. 405. - Java.

sublurevigata, Kiuntze, 1. c. $974=$ A. Markiana, Miq. thyrsiflora, Kuntze, 1. c. $974=$ A. nerifolia, $W$ all xylosteodes, Kuntze, 1, c. = A. xylosteoides, Griseb. zeylanica, Kuntze, 1. c, $974=\mathrm{A}$. Moonii, C. B. Clarke.

TIPULARIA, Nutt. (Orchid.). - Ind. Kew. ii 1083

mifolia, Britton, Stern \& Pogr. Prelim. Catal. (1888) $5 \mathrm{l}=$ discolor, Nutt.

TIRANIA. Pierre, in Bull. Soc. Linn. Paris, i. (1887) 657; Pax, in Engl. \& Prantl. Natürl. Pflanzenfam. iii. 2 (189I) 236. CAPPARIDEAE purpurea, Pierre, $l l . c 6.658$; et 236. - Cochinch.

TISONIA, Baill. in Bull. Soc. Linn. Paris, i. (1886) 568. TILIACEAE

Bailloni, S, Elliot, in fourn, Linn. Soc. xxix. (1891 3. - Madag

coriacea, S. Elliot, l. c. - Madag.

ficulnea, Baill. in Bull. Soc. Linn. Paris, i. (1886) 568 ; et Hist. pl. Madag. (1889) t. 108. Madag.

glabrata, Baill. l. c. 572. - Madag.

velutina, Baill. l. c. t. 109; et Hist. pl. Madag, Atlas (1889) t. 109. - Madag.
TISSA, Adans. = Spergularia, J. \& C. Pres (Caryophyll.).

campestris, Prantl, in Engl. \& Prantl, Natirl. Pflanzenfam. iii. 1b. (1889) $85=\mathrm{S}$. campestris Willk.

andensis, Britton, in Mem. Torrey Bot. Club, (1894) $152=\mathrm{S}$. media, Presl.

Clecelundi, Greene, Fl, Francisc, (1891) 12- : et Man, Bot. San Franc, Bay (1894) 36. - Calit. quandra, T.S. Brandeg. in Proc. Calif. Acad. Ser.II ii. (1889) 131; Britton, in Bull. Torrey Bot. Club, xvi. (1889) $128=$ Spergularia diandra, Bo

graculis, Britton, I. c. xvii. $(1889,128$ (= Lepigonzum gracile, S. Wäts.). - Calif., Texas.

grandis, Britton, in Ann. N. Y. Acad. sci. vii. (189\%) 53 = Spergularia grandis, Cambess.

gramlis, Fr. Meigen, in Bot. Jahrb. xvii. (1\$4?) 235 , et xviii. (1894) $236=$ praec.

lewcantha, Greene, Pittonia, 1. (May 1889) 301; et Man. Bot. San Franc. Bay (1894) 36. Calif.

macrotheca. T. S. Brandeg. in Proc. Calif. Acau. Ser. II. ii. (1889) 131; Britton, in Bull. Torrey Bot. Club, xvi. (I889) 129 $\Rightarrow$ Spergularia macrotheca, Heyne.

marina, Britton, 1. c. xvi. (1889) $126=$ S. media, Prest.

mexicana, Britton, 1. c. $129=\mathrm{S}$, mexicana. Hemsl. pallida, Greene, ex Britton, 1 c.; et Man. Bot. San Franc. Bay (1894) 360. - Calif.

nora, T. S. Brandeg, in Proc Calif. Acad. Ser. 1I. ii. (1889) 1:13 ; Britton, in Bull, Torrer Bot. Club, xvi. (1889) $127=$ Spergularia rubra, Presl

rubra, Fr. Meigen, in Bot. Jahrb. xvii. (1893) 295 $=$ prae

alina, Britton, in Bull. Torrey Bot. Club. xri. $1889) 127=$ Spergularia media, Presl.

sarsiflora, Greene, in Erythea, iii. (1802) $46,-$ TVymin

Stuebilii, Hieron. in Bot. Jahrb. xxi. (1895) 308. Peruvia.

Talimum. Greene, in Lrythea, i. (1893) 100.Calif.

temuis, Greene, in Bull. Torreyr Bot. Club, rvi (1859) 128 (= Lepigonum tenue, Greene); et Man. Bot. San Franc. Bay (1894) 3i. - Calif.

alida, Greene, in Erythea, i. (l893) 10\%. - Calif. llosa, Britton, in Bull. Torrey Bot. Club, xvi.

(1889) $62,129=$ Spergularia villosa, Cambes

TITHONIA. Desf. (Compos.). - Ind. Ker,

brachypappa, Robinson, in Proc. Am. Acal, xxrii. (1893) 174.-- Mexic.

fruticosa, Canby \& 7. N. Rose. in Contrit. U.S. Vat, Heró. i. (1891) 104 t. 5. - Mexic

glabirima, Kuntze, Rer. Gen. (1891)3i1, sphalm. = Gymnolomia platylepis, A. Gray.

macrophylla. S. Wats, in Proc. Am. Aiad. xxri. (1891) 140. - Mexic

Palmeri, 7. N. Rose, in Contrib. U. S. Nat, Herb. i. (1891) 104, - Mexi

speciosa, Klatt, ex Th. Dur. \& Pitt. in Bull. Sor Bot. Belg. xxxi. 1892 (1893) $203=$ aristata, Benth。

TITHONIA, Lim, = Rivina, Plum, ex Linn. (Phytol.).

humilis, Kuntze, Rer. Gen. (1891) 5.52=R. humilis, Linn.

TITHYMALODES, Ludw, Defin, (173) Kuntze, Rev。Gen. (1891) $620=$ Pedilanthus. Neck. (Euphorb.).

angustifolinm, aphyllum, articulatum, brattoatum, cors dellatum, Fendleri, Finkii, Ghiesbrightiunum. Houlletii, involucratum, linearifolium, macrourpun, padifolinn, retnsum, Kuntze. 1. c. = homonyma omnia Pedilanthi.

myrlifolium, Kuntze, 1. c. = P. tithymaloides Poit

Oerstedtii, Kuntze, 1. c. = P. Oerstedii, Klotzsch E. Garcke.

parasiticum, Kuntze, 1. c. = P. ramosissimus. Boist

Pavonii, Kuntze, 1. $c_{0}=$ P. Pavonis, Boiss 
TI'THYLLUS, Toum, ex Hall. = Euphorbia Linn. Huter, ex Pacher, Fl. von Kärnten (188\%) Koneri. Huter, ex Pacher,
$23 t=$ I. Kerneri, Huter.

villosus. Pacher 1. c. $233=$ E. pilosa, Lim

TOCOCA. Anbl. (Melast.), - Ind. Kew, ii. $1086^{\circ}$ pitata, Trail ox Cogn, in Mart. Fl. Bras. xiv. IV (1888) 615 ; et in DC. Monog. Phan. vii. (IS91) 67. - Bras

Cerruginea, Nichols. Dict. Gard. iv. (1887) 49. Am, austr.

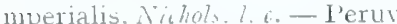

lasiostyla, Cogn. in Mart. Fl. Bras. xiv, IV. (1888) t55; ct in DC. Monog. Phan. vii. (1891) 971 Bras.

Inngisepala, Cogn. 7l.cc. 449 ; et 968. - Bras.

platyuhylla, Cugn, ll,cc, 437; ot 961. - Bras,

Poortmanni. Cogn。 in DC. Monog. Phan. vii. (1891) 971. - Ecrad.

Spruceana, Cogn. l. c. 904. ot in Mart. Fl. Bras. xiv IV. $\left(1888,443 ; e^{\frac{1}{7}}\right.$. c. $964-$ Bras.

subglabrata, Cogn. il. co. 438; et 961. - Bras.

symuhyandra, Cogn, in DC. Jlonog. Phan. vii.

(1891) 963 - N. Granat.

Trajlii, Cogn, in Mart. Fl. Bras, xiv.'TV. (1888) 626; $96 \%$. Bras.

TOCOYENA. Anb1. (Rubiac.). - Ind, Kew, ii. 10s6. formosa, K. Schum. m Mardenia formosa, Cham. \& Schlecht.). Bras.

uianensis, $K$. Schumz. l. c. 346.- Guian. gall.

humoritora, Schum, in Engl \& Prantl, Naturt. Pfanaenfam. iv. 4 (1891) 74(= Gardenia formosa, Cham. \& Schlecht.). - Bras.

Jonophora, Casaretto, ex K. Schum. in Mart. Fl, Bras, vi. VI. (1889) $348=$ brasiliensis, Mart.

Sillona, K. Schum. 1. c. $349=$ Gatdenia Sellowiana, Cham. Ex Schecht.

TODDALIA. Juss. (Rutac.). - Ind. Kew, ii. 1086. cenulata, Engl. Pflanzmu. Ost-Afr. C (I895)228. Afr. trop or.

densiflora, Baker, in fourn. Linn. Soc. xxv. (1889) 303. - Madas

Ellioti, Radlk, ex S. Elliot, l. c, xxix. (1891) 9. IIadas.

uginiafolia, Enol, in Abh. Preuss, Akad. Wiss. 1894) 36: et Pflanzenw. Ost.-Afr. A (1895) 75 = simplicifolia, Engl.

Fischeri, Engl: Pflanamw. Ost-Afr. C (1895) 228.Afr, trop, or.

lomerata, F. II offm, Beitr. Kenntn. Fl. Centr. Ost Afr. (1889) 1s. - Afr. trop.

macrophylla, Baker, m foum. Lim. Suc. xxv. (1889) 303. - Madag.

nitida, Baker, l. $c_{n}$ - Madag

pilosa, Engl. Pfanrena'. Ost-Afr. C (1895) 228. Atr. trup. or

sansibarensis, Engl. . c. - Afr. trop. or.

simplicifolia, Engl. in Abh. Prenss. Akad. Wiss. (1594) 369; et in Engl. Pfanzene. Ost-Afr. C (1895) ¿2s. - Atr. trop. ur.

trichucarpa, Eng7, 2.c. 228. - Afr. trop. or

TUDDAVADDI[A] Zan = Oxalis, Linn. (Geran.) calophylla, casla, dormians, sommians, Kuntze, Rev. Gen. (1891) $96=$ homonyma ommia Oxalidis.

dendrodes, Kuntze, 1. c. $=0$. dendroides, $H, B$. E $K$.

mimosodes, Kuntze, 1. c. $=$ O. mimosoides, $A$. St Hit.

sensitica, Kuntze, 1. c. = Biophytum sensitivum. DC.

TOECHIMA, Radik, (Sapind.). - Ind. Kew. ii, $1086^{\circ}$.

hirsutum, Radlh. in K. Schnm. \& Holl\%. Fl. Kais. Wilh. Land (1889)67; et in Sitzb. Akad. Muench. xx. $(1890) 206$. - N. Guin.

livescens, Radlh. l. c. 266. - Borneo.

subteres, Radlh. l. c. 26\%. - Hab.?
TOFIELdiA, Huds, (Liliac.). - Ind. Kew. ii.

1086.

diverens, Bureau Ef Franch, it Morot, Fourn, de Bot. v. (1891) 15\%. - China.

macilenta, Franch. in Nour. Arch. Mus. Paris, Sér. II. x. (1887) 95 , - Tibet.

guineensis, H. Solnultze, in Bot. Fahrb. xvii. (1893) 330. - Afr. trop.

Moritziana, H. Schultze, l.c. (= Isidrogaloia Moritziana, Klotzsch). - Am. austr.

racemosa, Britton, Stern \& Pogg. Prelim. Catal. (1888) $55=$ pubens, Willd.

chomburrtiana, Olwer, in Trans. Linn. Soc. Ser. II. ii. (1887) 285 t. 49 a (Oliver, ex im Thurn, in Timehri, v, (1886) 206.). - Guian. angl.

thibetica, Franch. in Nout'. Arch. Muss. Paris, Sér. II x. (1888) 95. - China occ.

TOLUIFERA, L. = Myroxylon. Linn. f. (Legumin

permifora, Taub, in Bot. Centralbl: xivii. (1891) 389 $(=T$. perififera, Baill. $)=\mathrm{M}$. peruiferum, Limn. $f$.

pubescens, Taub. 1. c. $(=$ T, pubescens, Baill. $)=\mathrm{M}$. pubescens, $H, B$. \& $K$.

TOLYPANTHUS, Blume = Loranthus, Linn. Gavdneri, Van Tiegh, in Bull. Soc. Bot. Fr. xlii. (1895) $249=\mathrm{L}$. Gardneri, Thw

lageniferus, Van Tiegh. 1. c. xlii. (1893) 249)= L. lageniferus, IVight.

TONDUZIA, Boeck. ex Tonduz, in Bull. Herb. Boiss. iii. (1855) 464, nomen $=$ Durandia, Boeck. (Cyper.).

macrophylla, Boeck. 1.c. = D. macrophylla, Bock

TONNINGIA, Neck. = Cyanotis, D. Don (Commel.)

angusta, axillaris. barbata, capitata, cristata, cucullata, djuwensis, fasciculata, foecunda, geniculata, hirsuta, incerta, Kerliana, kewensis, latata, longifolia, Manuii, nodiflora, papilionacea, parasitica, panciflora, pilosa, tubcrosa, zaga, vaginata, sillosa, vivipara. Wighti, Kuntze, Rev. Gen, (1891) 722-23 = homonyma omnia Cyanotidis,

arachodca, Kuntze, 1. c. $722=\mathrm{C}$. arachnoidea, $C$. F). Clarke.

glaberrina, Kuntze, 1. c。 = C. barbata, D. Don

molncana, Kuntze, 1. c. = C. uniflora, Hassk.

polyrhiza, Kuntze, 1. C. $=$ C. polyrrhiza, Hochst.

geylanira, Kuntze, l. c. = C. ceylanica, C. B. clarkic.

TOPOBEA, Aubl. (Melast.). - Ind. Kew. ii. 1088, Andreana, Cogz. in Bull. Acad. Dilg. Sèr. III. xiv. (1887) 974: et in DC. Monog. Phan. vii. (1891) 1085. - N. Granat

ciliata, Cognz. l. c. 1089. - Ecuad.

Durandiana, Cogn. ex Th. Dur. \& Pith. in Bull. Sof. Bot. Belg. xxx, 1891 (1892) 268. - Costa Rica

Maurofernandeziana, Cogn. in DC. Monog. Phan, vii. (1891) 1193; et l. c 26\% -Costa Rica.

Pittieri, Cogn. ll. cc. 1088 ; ct 268 - Costa Rica.

Regeliana, Cogn. in DC. Monog. Phun. vii. (1891) 1085. - Panama

Trianaei, Cogn. . . c. 1083. - N. Granat

Watsonii, Cogn.l. c. 1089. - Guatem.

TORDYLIUM, Tourn. ex Linn. (Umbell.). Ind, Kew. ii. 1088

pustulosum, Boiss. Fl. Or. Suppl. (1888) 268. As. Min.

TORENIA, Linn, (Scrophul.).-- Ind. Kew, ji.1089. setulosa, Maxim. in Bull. Acad. Pétersb. xxxi. (18Ș

Thonarsi, Kuntze. Rev. Gen, (1891) $468=$ parviflora, Ench.-Ham.

TORICELLIA, DC. (Cornac.). - Ind. Kew. ij. 1089.

angulata, Oliver, in Hook. Icon. pl. xix. (1889) t. is9.3. - China.
TORILIS, Adans.=Caucalis, Linn. (Umbell.) aglochis, Simonk, in Oest. Bot. Zeitschr. x1. (1890) 208; in Termész. Füzet xii. (1890) 4; A. Kern. Sched. Fl. Austro-Hung. vi. (1893) 25. - Hung, Emini, Engl. in Abh. Preuss. Akad Wiss. (1894) 58, 62; et Pflanzenw. Ost-Afr. C (1895) 301, in syn, = gracilis, Engl.

gracilis, Engl. Pflanzenw. Ost-Afr. C (1895) 301. - Afr. trop.

homophylla. Stapf \& Wettst. ex Stapf, in Denkschr. Alsad. Wien, ii. (1S\$6) 28. - As. Min.

Sintenisii, Freyn. in Oest. Bot. Zeitschr. xlii. (1892) 167 = Caucalis Sintenisii, Froy .

TOUNATEA, Aub1. = Swartzia, Schreb. (Legu. min.

acuminata, acutifolia, altema, apetala, aptera, argentea, Benthamiana, bracteosa, Blancheti, calophylla, cardiosperma, caribaea. conferta, corrugata, erocea, cuspidata, dicar'sa, discolor, dodecandra, clegans, criocarpa, Flcningii, floribunda, fugax, grandifolia, Hust manni, latifolia, lanrifolia, laxiflora, leiocalycina, leptopetala, macrocarfa, macrostachya, madagascariensis, Martii, Matthowsi, microcarpa, mollis, multijuga, myrtifolia, oblonga, panamensis, pendula, picta, pilulifera, pinnata, polyphylla, racomosa, pulchra. recurad, rosea, Schomburghii, sericea, Sprucei, tomentosa. Trianae, relutina, Taub. in Bot. Centralbl. xlvii. (1891) 390-91=homonyma omnia Swartziae arborescens, Britton, in Bull. Torrey Bot. Club, xvi. (1889) $325(=$ Pascalia arborescons, Aubl. $)=\mathrm{S}$. triphylla, Willd.

Glazroriand, Taub, in Flora, 1xxii. (1892) 82.Bras.

simplex. Taub, in Bot. Centralbl. xlrii. (1891) 391 $=\mathrm{S}$, grandiflora, Willd.

theïodora, Taub, in Flora, 1xxv, (1892) 81. - Bras.

TORMINARIA, M. Roem. = Pyrus, Tourn. (Rosac.).

latifolia $X$. Dippel, Handb. Laubholzk, iii. (1893) 388 $=$ P. rotundifolia, Moench.

torninalis, Dippel, 1. c. $387=\mathrm{P}$. torminalis, E/rrh.

TORNABENEA. Parl. (Umbell.), - Ind. Kew, ii. 1090 .

msularis, E. H. L. Krause, in Bot. Jahrb. xiv. (1892) $409=$ insularis, Parl.

TOULICIA, Aubl. (Sapind.). - Ind. Kew. ia. 1090 brachyphylla, Radlk. in Sitzb. Matho-Phys. Akad. Muench. xx. (1890) 232. - Venezuela.

TOURNEFORTIA, Linn. (Borag.). - Ind. Kew. ii. 1090, in Anal. Univ. Chil. xc. (1895) $352(=$ aurata, Phit. in Anal. Univ. Chil. xc. (1895) 352
Heliotropinm auratum, Phil.olim), - Chili. ordifolia, Ed. Andri, in Rev. Hortic. lix. (188t) 128 fig. 26, 2\%. - Am. austr.

TOURNESOLIA, Nissol.ex Scop. =TOURNESOL Adans. = Chrozophora, Neck. [1790] (Euphorb.).

Brocchiana, gracilis, obliqua, plicata, senegalensis, tinctoria, revbascifolia, Kuntze, Rev. Gen. (18\%1) 62 = honnonyna omnia Chrozophorae.

obliqua, Franch. in Morot, Journ. de Bot. i. (1887) $135=\mathrm{C}$. obliqua, $A$. fuss.

tinctoria, Baill. Bot. médic. (1884) $932=$ C. tinctoria, Neck.

Warionii, Kuntze, 1. c. = C. Warionis, Coss.

TOUROULIA, Aubl. = Quiina, Aubl. (Guttif.).

decastyla. Radlk. in Sitzb. Math.-Phys. Ahad. Muench. xix. (1889) 218. - Bras.

Jenmani, Oliver, in Hook. Icon. pl. xx. (1891) t, 1998. - Guian. angl.

pteridophylla, Radlk, in Sitzb. Math.-Hhys. Akad. Muench. xix. (1889) 218. - Bras.

TOvomita, Aubl. (Guttif.). - Ind. Kew. ii. 109 ?

acuminata, Enst. in Mart. Fl. Bras, xii. I. (1888) 449. - Bras

bahiensis, Engl. 7. c. 445. - Bras.

breristaminea, Engl.l. c. 446. - Bras. 


\section{TOVOMITA}

ephalostigma, Vesque, Epharmosis, iii. (1889) t. 96 ; at in DC. Monog. Phan viii. (1893) 207 . Guian. gall.

Eggersii, Vesque, $7 l$. cc. 19 ; et 203 . - Ins. Trinit.
elliptica, Engl. in Mart. Fl. Bras. xii. I. (1S88) 453. - Bras.

Glazioviana, Engl.l.c. 445. - Bras.

Goudotiana, Cambess. ex Vesque, in DC. Monog. Phan. viii. (1893) 521. - Madag.

Jenmani, Engl. in Mart. Fl. Bras, xii. I. (1888) 447. - Guian. angl.

Martiana, Engl. l. c. 45\%. - Bras.

martinicensis, Vesque, Epharmosis, ii. (1889) 19 ; et .iii. (1889) t. 103-05; et in DC. Monog. Phan. viii. (1893) 216. - Ins, Martinic

Melinoni, Vesque. $7 l$. cc. 20, t, 100, 101; at $21 \%$ Guian, gall.

obovata, Engl. in Mavt. Fl. Bras, xii. I. (1888) 451 - Bras.

Riedeliana, Engl. l. c. 449. - Bras.

TOVOIITOPSIS, Planch. \& Triana = Chryso chlamys, Poepp. \& Endi. (Guttif.).

Saldanhae, Engl. in Mart. Fl. Bras. xii. I. (1888) $4.7 \%$ - Bras.

Spruceana, Engl. 7. c. 458. - Bras.

TOWNSENDIA, Hook. (Composit.). - Ind. Kev, ii. 1092

exsiapa, Porter, in Mem. Torrey Bot. Club, v. (189t) 321 = sericea, Hook.

montana, M. E. Jones, in Zоë, ii. (1893) $262=$ scapigera, Eaton.

TOXICODENDRON, Linn. = Rhus, Tourn. (Anacard.).

ubyssinicum, acutidens, africanum, albonarginatum, amplum, Andrienxii, angolense, angustifolinm, Aucheri, Bolusii, Burkeanum, ciliatum, copallinum, coriacenn, Coviaria, crenatum, cuneifolium, dentatum, discolor, dissectum, divaricatum, Dregeanum, Ecklonianum, erosum, excisum, glabrum, glaucum, glutinosum, gracillimum, grandidens, grandifolium, Griffthii, Gueinzii, Hindsianum, horridum, hypoleucum, incanum, incismm, insigne, integrifolium, khasianm, Kirkii, Krebsianum, laevigatum, lanceum, laurinum, Lentii, longipes, longispinum, lucidum, macrocarpun, macrophyllum, microphyllum, molle, nysurense, zatalense, nitidum, nodosum, oboüatum, paniculatum, parafforum, pentaphyllum, populifolium, puberulum, pumilum, punjabense, refractum, Rehmamianm, retinorrhoeum, rigidum, rosnarinifolinn, rubifolium, Schiedeanum, scoparium, scytophyllum, semialatum, semiperivens, sinuatum, Sonderi, stenophyllum, succedancum, tenumerie, terebinthifolinm, thyrsifloram, tomentosum, trichocarpum, tridactylun, tridentatum, trilobatum, typhinum, undulatum, villosum, villosissimum, viminale, viticifolium Wallichi, Welwitschii, Zcylicri, Kuntze, Rev. Gen. (I891) 153-54=homonyma omnia Rhois.

Burchellit, Kuntze, 1. c. $153=$ Rhus Burchelli, Sond.

eilostrodes, Kuntze, 1. c: $=$ R. celastroides, Sond. clongata, Kuntze, 1. c. $=$ R. mucronata, Thunb. glawovirens. Kuntze, 1. c. $154=$ R. Zeyheri, Sond. oxyacanthrm, Kuntze, 1. c. = R albida, Schousb.

potentillifolium, Kuntze, 1. c. $=$ R. potentillaefolium, Turc\%.

fyrodes, Kuntze, 1. c. = R. pyroides, Burch

finnatum, "Mill. " ex Dippel, Handb. Laubholzk. ii. (1892) 379, sphalm. = R. venenata, $D C$.

Quartinisnum, Kuntze, Rev, Gen. (1S91) $153=\mathrm{R}$. glaucescens, A.Rich.

quercifolium, "Michx ", ex Dippel, Handb. Laubholzk. ii. (1892) $376=\mathrm{R}$. Toxicodendron, Lim radicans, Kuntze, 1. c. = R. Toxicodendron, Lim . retusum, Kuntze, 1. c. $154=$ R. rufa, Teysm. \& Binn.

sile'estre, Kuntze, 1. c. = R. sylvestris, Sicb. \& Zucc. simarubifolia, Kuntze, 1. c. = R. simarubaefolia A. Gray.

striata, Kuntze, 1. c. $153=$ = R.-juglandifolia, Wall. transelalensis, Kuntze, 1. c = R. transvaalensis Engl.

wernz, Kuntze, 1. c. = R. venenata, $D C$.
TOXOCARPUS Wight. \& Arn. (Asclep.). - Ind. Kew. ii. 1093.

eonensis, S. Elliot, in foum. Linn. Soc, xxx. (1894) 92. - Sierra Leone.

TOXYLON, Rafin. = Maclura. Nutt. (Urtic.). pomifernm. Sarg. in North Am. Sylva, vii. (1895) 89 [Toxylon, Rafin.] = M. aurantiaca Nutt.

TOZZIA, Linn. (Scrophul.), - Ind. Kew. ii. 1093. carpathica, Wolocszcz. in Spraw. Kom. fizyj. Krakow. xxvii, (1892) 216, ex Oest. Bot. Zeitschr. xlii. (1892) 388, nomen, et xliii. (1893) $108=$ alpina, Limn.

TRACHELIOPSIS, Buser, in Bull, Herb. Boiss. ii. (1894) $524=$ TRACHELIOPSIS, Opiz = Campanula, Tourn.

albicans, Buser, 1. c. 531 (= Campanula petraea, Auct. Gall.), - Gall. mér.

petraea, Buser, 1. c. $528=$ C. petraea, Linn.

Postii, Buser, 1. c. 527 t. $19=$ Trachelium Postii, Bois

tubulosa, Pierre, 1. c. $525=$ T. tubulosum, Boiss.

TRACHELIUM. Tourn. ex Linn. (Campanul.). - Ind. Kew. ii. 1092.

halteratum, Bianca, ex Buser, in Bull. Horb. Boiss, ii. (1894) 515. - Sicil.

Postii, Boiss. Fl. Or. Suppl. (1888) 336. - Syria.

TRACHELOSPERMUM, Lem. (Apocyn). -

\section{Ind. Kew, ii. 1093.}

Bowringii, Hemsl. in fourn. Limn. Soc. xxvi. (1889) 99 (= Parcchites Bowningit, Hance). - Ins. Hong Kong

ditaricatum, $\mathbf{K}$. Schum. in Engl. \& Prantl, Natürl. Pflanzenfam, iv, 2 (1895) $173=$ jasminoides Lenn.

lucidum, K. Schum. 1. c. 173 = fragrans, Hook.f.

speciosum, Hort. Berol ex Leonhard, in Bot. Centralbl. xlv. (1891) 99. - Hab.?

stans, A. Gray, in Proc. Am. Acad. xxi. (1886) 394. - Mexic.

TRACHYDIUM, Lindl, (Umbell.). - Ind. Kew. ii. 1093

daucoides, Franch in Nour. Arch. Mus. Paris, Sér. II. viii. 1885 (1886) 245 (= Ligusticum daucoides, Franch.). - Tibet,

Delavayi, Franch. in Bull. Soc. Philom. Paris, Sér. VIII, vi. (1894) 110. - Yunnan.

hispidum, Franch. l. c. 113. - Yunnan.

purpurascens, Franch.l.c. 112. - Xunnan.

rubrinerve, Franch. l. c. - Yunnan.

viridiflorum, Franch.l.c. 111. - Yunnan.

TRACHYLOBIUM, Heyne (Legumin.). - Ins. Kiew. ii, 1094

crrucosum, Engl. Bot. Jahrb. vii. (1886) $457=$ verrucosum, Oliver.

TRACHYMENE, DC. (Umbell.). - Ind. Kew. ii 1094

Croniniana, F. Mucll. in Vict. Natural. xi. (Feb. 1895) 114; et ex Bot. Centralbl. lxii. (1895) $29 \mathrm{t}$. 93 (= Didiscus Croninianes, F. Muell.). - Austr.

Eatoniae, F. Muell. ll.cc. ix. (Aug. 1892) 57; et li. (189:) 35\% - Austral.

elachocarpa, F. Mucll l. c. xi. (Feb. 1895) 144 [elachscarpa]. - Austral.

Maxwelli, F. Muell. l. c. ix. (Aug. 1892) 56; et in Bot. Centralbl. li. (1892) 396 [sphalm. T. Maxwell]. - Austral.

saniculaefolia, Stapf, in Hook. Icon. pl, xxiv. (1894) t. 2308. - Borneo.

TRACHYPHRYNIUM, Benth, (Scitam.). Ind. Kew. ii, 1094 .

Danckelmannianum, 7. Bram of K. Sclinn, in Ber. deutsch. Schutzgeb. i1. (1589) 158. - Afr. trop. occ

Poggeanum, K. Schum. in Bot. Fahrb. xv. (1892) 4:31. - Afr. trop. occ.

Preussianum, K. Schmm. l. c. 430. - Afr. trop. orc. violaceum, Ridl. in foum. Bot, xxv. (1887) 133.Angola.
TRACHYPOGON, Nees (Gramin.). - Ind. Kew, ii. 1094.

secundum, Arechav. in Anal. Mus, nac. Monterideo, iii. (1895) $270(=$ Heteropogon secundum, Presl) - A m. ausir.

ficatus, Kuntze, Rev. Gen. (1891) $794=$ polymorphus, Hack.

TRADESCANTIA, Rupp. ex Linn. (Commelin.) - Ind. Kew. ii. 1095

angustifolia, Robinson, in Proc, Am. Acad, xxvii. (1893) 185. - Mexic

brevifolia, $\tilde{f} . N$. Rose, in Contrib. U. S. Nat. Herb. iii. 5 (1895) 323 t. 16. - Am. bor

guatemalensis, C. B. Clarke, ex F. D. Smith, in Coult Bot. Gaz. xviii. (1893) 210. - Guatem.

montana, Shuttl. ex Small \& Vail, in Mem. Torrey Bot. Club, iv. (1893) $160=$ virginica, Linn.

Palmeri, F. N. Rose, in Contrib. U. S. Nat. Horb. i. (I891) 113. - Mexic.

pilosa, Heyne, ex Hook. f. Fl. Brit. Ind, vi. (189z) 387 , in syn. = Cyanotis pilosa, Schult. $f$.

pinetorum, Grene, in Erythea, i. (1893) 24\% P. tuberosa. Greene, non Roxb.). - Am. bor.

Pringlei, S. Wats, in Proc. An. Acad. xxvi. (1891) 15\%. - Mexic

Reginae, L. Linden \& Rodigas, in Illustr. Hortic. xxxix. (1892) 29, t. 547, et xli. (1894) 13, fig. 2. Peruvia.

subscaposa, 7. D. Snith, in Conlt. Bot. Gaz, xv (1890) 29. - Guatem.

superba, $L$ Linden \& Rodigas, in Illustr. Hortic. xxxix. (1892) 69 t. 555. - Peruvia,

TRAGACANTHA, Tourn. = Astragalus, Tourn. (Legum.)

abbreviata, aboriginorm, abyssinica, acaulis, acicularis, acinacifera, acnophylla, acmotricha, acuta, adsurgens, adunciformis, adusta. aegobroma, ajubensis, alatavica, Alberti, albicans, albicanlis, aliena, alindana, alexan drina, algarbiensis, Alopecias, Alopecurus, Alpanarcae, alpina, altaica, amalecitana, amana, amara, amata, ambigua, amblolepis, Amherstiana, Ammodendron, ammodytes, ammophila, ammotropha, amoena, amphiloga, ampullaria, anacampta, anacardia, anatolica, ancistrocarpa, ancyclea, andalanica, Andersonii, Andrachne, andrachnifolia, angarensis, angulosa, angustata, angistiflora, angustifolia, anisacantha, anmularis, anomala, antabica, Antillbani, apollinea, aprica, Arbuscula, arcuata, arenaria, argaca, arganatica, argurica, argutensis, argyrostachys, avgyrothammus, arida, arizonica, armata, amacantha, asciocalyx, askabadensis, askia, aspadana, aspera, atlantica, atrata, atropatana, atropurpurea, Aucheri, augana, aulacoloba, aurea, Austinae, australis, austriaca, bachtiarica, bactriana, baghensis, baibutensis, baicalensis, bakaliensis, bakunsis, Balansae, barbata, Beckroithii, Benthamiana, berysia, berythea, bethlehemitica, bhotanensis, bicolor, bicuspis, Biebersteinii, biflora, biovnlata, Biservula, bisulcata, Bodeana, Boissieri, Bolanderi, bombycina, Bourgouzi, braihybotrys, brachycalyx, brachycarpa, brachycentra, brachycevas, brachyclada, brachyloba, brachyodonta? brachypteva, Brachypus, brachystachys, brachytropis, brahuica, Brandegei, brazoënsis, brevifolia, brevipes, Breweri, Bruguieri, Buceras, buchtormensis, Buhn seana, Burkeana, cactinalensis, cadmica, caespitosa. calabrica, callichroa, Calliphysa, callistachys, calophylla, calvescens, calycina, calycosa, campestris, camptoceras, camptylantha. campylorhyncha, campylosem., canadensis, cancellata, candidissima, Candotleana, canescens, cana, camoatra, capillipes, Capito, cappadocica, caprina, Caraganae, carduchomu, cariensis, caryocarpa, caryoloba, Casei, castellana, catacampta, cataonica, caudiculosa, iduquensis, Cedreti, cephalantha, cephalonica, cephalotes, cerasocrena. chactodon, chaetoloba, chaetopoda, chalaranthi chartacea, chartostegia, chinensis, chionobia, chiono phila, chlorocyanea, chlorodonta. chlorosphaera, chlorostachys, chlorostegia, chorassanica, chorintensis, Christiana, chrysantha, clisysophylla, chrysoptera, chrysostachys, chrysotricha, chithonocephala, Cicer, cicerella, ciserifolia, ciliolata, cinerea, citrina, clacata, Closiana, cobrensis, codestis, cognata, collina, columnaris, colnteocara, commixta, comosa, compacta, complanata, complicata, compressa, concinna, conden- 


\section{TRAGACANTHA: -}

sasa, confusa, consangainea, iontortuplicata, cordata, ioriacer, cormiculata, Coronilla, corrugata, costata, Coultevi, Cracca, crassa, crassincrvia, crassispina, crenophila, cretacea, cretica, crinita, cruciata, cruenstiflora, cryptantha, cucullaris, cuneifolia, curtipes, umiflora, curitrostris, Cuscutae. cyanea, cylindrica, cymbocarpa, cymbostegis, cypria, cyrtobasis, cysticalyx, dactylocarpa, daenensis, damascena, Darnmbinm, dasyantha, daurica, debilis, declinata, decumbens, dccurvens, deinacantha, demaiendica, densiflora, densifolia, depauperata, dependens, depressa, derbendica, dictyocarpa, dictyoloba. dictyophysa, didynocarpa, didymophysa, dilecta, diluta. Diopogon, diphtheritis, aliphtheroloba, diphysa, dipodura, dipsacea, distans, distorta, dicaricata, Dodtii, dolia, dolichophylla, Doniana, Dorcoceras, Donglasii, drepanophora, Drummondii, drupacea, drusorum, ecbatuma, Echidna, Echinops, Echimus, edulis, effusa, Ehrenbergii, Echinops, Echinus, edulis, effusa, Elwenoergin,
elbrusensis, elegans, elmaluensis, elongata, elymaitica, cmarginata, Enodi, Epiglottis, episcopa, cremophila. Eremothamms, eviacma, erinacea, eviocalyx, eviocephala, crioceras, evionata, eriophylla, eviopoda, eviosphaera, criostyla, erythrolepis, erythrotaenia. escherensis, exscapa, fabaced, falcata, falciforme, Fenzlii, fermsimea, filamentosa, filicanlis, filifolia. filipes, finitima. flaccida, flavescens, Alexa, Acxuosa, foccosa, flovida, fodinarum, foliolosa, follizlaris, Fontanesii, fragifora, fragrans, Fraxinclla, fraxinifolia, Fresenii, Frickii, frigida, fruticosa. gaeobotry's, galactites, galegiformis, Garboncillo, Geblevi. gcminana, geminiflora, geniculata, geocyama, gercnsis, glabriusiula gladiata, glandulifera, glaveosa, glaucacantha, glaucoplivlla, Glaux, globiceps, globiflora, globosa, glomerata, glmmacea, glycyphyllos, Gombo, globosa, glomerata, glumacea, glycyphylos, Gombo, graeca, grammocalyx, Grantii, grateolens, Griffithii, grisea, Gryphus, gudnunensis, Gueldenstedtiae, gunmifcra, gymnoloba, gymnopoda, gyzensis, Haarbachii, 7ucmatocarpa, Halicacabus, Hallii, Halodendron, hamosa, Hancocki, hasbeyana, Hausknechtii, Haydeniana, Heldreichii, hellenica, Hellevi, Helmii, Hemiphaea, heratensis, hermonca, heterodoxa, Heydii, hilaris, himalajana, hirsuta, hirsutissima, hirta, hivticalyx. hispidula. Hohonackeri, hololenia, holopsila, holoplevir, holosemia, Hookeriana, Ilomii, horrida. hostilis, Hueti, humilis, hmmillima, humistrata, hyalolepis, hymenocalyx, hymenocystis, hymenosicgis, hypogaca, hypoglottis, hypolenca, hypsogeton. hyrcana, Hystrix, idaea, iliensis, incana, incurva, infesta, inflata, inflexa, intermedia, iodantha, iodotropis, ischredensis, ispahanica, ispirensis, janthina, fanbentiana, jejuna, jesdiana, fesseni, Fohannis, jubata, juncea, jwenalis, kadshorensis, kahiria, karabaghensis, karakugensis, karputana, karsiana, kentrodes, keratensis, Kesslevi, Keyserlingii, khasinna, kirrindica, koburensis, kohrudica, koschkukensis, Kotschyana, kuhistana, kuldshensis, kurdica. hurrunensis, kurlschnmensis, lactea, laeta, lagocephala, lagonyx. Lagowskii, Lagurus, Lamarckii, lanata, lanceolata, lanigera, lanuginosa, lirica, lasioglottis, lasiopetala, lasiosemia, lasiostyla, 7ateritia, latifolia, leioclada, leioloba, lentiformis, lontiginosa, leontina, lepidantha, leporina, lepsensis, lepta, leptacantha, leptalea, leptocarpa, leptocaulis, lepiocentra, leprophylla, lessertiodes, lencacantha, lencocephala, lencoclada, leucocyana, leucolachna. leucomalla, lewcomclas, leucophaca, loucophylla, lencopsis, lilacina, Lindheineri, linuta, Listoniae, lithophila, litorea, lobophora, lonchocarpa, longicaulis, longicuspis, longiflora, longifolia, longistyla, loliflora, lunata, lupulina, luxurians, lycia, macrobotrys, macrocarpa, macroceplata. macrochlamys, macrodon, macrolob̄a, nacropelmata, nuacropetala, macroplera, macroptila, macropus, macrorrhiza, macroscepa, macrosemia, macrostachys, mucrotropis, macroura, maculata, malaca, malacopliylla, marcotica, Marshalliana, masenderana, mauritanica, maxima, media, megacarpa, megalantha, megalocystis, Megalomera, megalotropis, melalenca, melanoinlyx, melanecarpa, melanocephala, melanodon, melanophrupia, melanostachya, melina, melitenensis, mimbranacea, Horcklinii, meridionalis, mesites, mesogitana, mesoleia, mesoptera, mexicana, Meyori, Mlohanxiana, micracne, micrancislva, micrantholla,

\section{TRAGACANTHA :}

microcephala, mirocystis, microloba, microphysa, microptera, microthamna, miniata, minima, minor, minutissima, misera, Mitchelliana, modesta, mollissima, monadclpha, monanthema, monspessmana, monticola, mossulensis, mucida, mucronata, mucronifolia, multicanlis, multiceps, multijuga, IInuroi, muradica, murina, Muschiana, myriacantha, nana, nanodes, narbonensis, nematodes, neurocarpa, nes'adensis, nicharensis, mitens, nivalis, Noaeana, nothoxys, muclcifera, muda, nummularia, nurensis, obcordata, oblongifolia, obscura, obtusifolia, ocliveata, ochrobia, oclirolenca, odorata, oleifolia, oligophylla, oncotricha, Onobrychis, oocarpa, oocchala, oophora, ophiocarpa, orbiculata, orthantha, orthocarpa, ortholoba, otiponensis, oialis, wiallensis, oxyglottis, oxyodon, oxyphysa, oxyrhyncha, oxysemia, oxytropifolia, pachyacantha, pachystachys, Pallasii, pallescens, Palliseri, Palmeri, pamphylica, pandurata, pamosa, paradoxa, paralitomena, parahurges, paraplesia, Parnassi, Parryi, parva, parviceps, pauciflora. pancijuga, pectinata, peduncularis, pelligera, fellita, pennata, pentaglottis, peregrina, petraca, petropylensis, physocalyx, physodes, Pickeringii, pictus, piestoloba, pinetorum, piptocephala, pisidica, placens, plattensis, platyphylla, platyraphis, platyscmata, platytropis. plebeja, plumosa, podocarpa, podoloba, podosphaera, poecilantha. polaris, polemia, polemoniaca, poliotes, polyantha, polybotrys, polyacantha, polyceras, polyphylla, pontica, porphyracma, porphyrobaphis, porrecta, Prenssii. procera, procumbens, prolixa, prostrata, Prateralskii, pseudaustralis, psendocaspia, psilacantha, psilacma, psilodontia, psilostyla, pterocarpa, ptilodes, prychophylla. pubentissima, puberula, pubiftora, pugionifora, pulchella, pulinata, punctata, purpurascens, Pursclizi, pusilla, pyonocephalda, pycnoloba, pycnostachya, pyrrhotricha, quadrisulcata, quinquefoliolata, raconosa, racemulosa, adiata, radkancusis, raphiodontha, raviflora, Rauvolfi, Reboudii, recognita, redunca, reflexa, refracta, Reinii, remotifora, remotifolia, renotijuga, reptans, retamocarpa, reticulata, Reateriana, rhizantha, rhodochroa, rigidula, Robbinsiz, robusta, rasea, rostrata, nubriflora, rubrostriata, rugosa, mucinata. mpifraga, ruscifolia, rytidocarpa, sabuletorum, saccata, saccocalyx, sachalinensis, saganlugensis, Sahendi, salatavica, salsuginea, samamensis, sancta, sanguinolenta, scaberima. scabrifolia scabriseta, schahrudensis, Schanginiana, Sihclichowii, Schimperi, schirasica, schistocalyx, schizopteva, Schottiana, Schrenhiana, sehurabica, sciadophora, sciurea, sclerocarpa, scleroclada, scleropodia, scleroxylon, scoparia, scopulorum, Scorpius, secunda, seidabadensis, Seidlitrii, Semenovii, semibilocularis, scmitellitus, sericophylla, sericostachya, serotina, sesamea, sesquiflora, setulosa, Sewertzowit, seytunensis, Shortiana, Sibthorpiana, sicula, Sieberi, Sieyersiana, sigmodea, sikkimensis, siliquosa, simplicifolia, singarmisis, sinica, sirinica, sisyrodytes, sitiens, sizasica, skythropa, sofica. Soyeri, Spachiana, sparsa, sparsiflora, speciosa, speirocarpa, splaterantha, sphaerocalyx, sphaerocarpa, sphacrocystis, sphaerophysa, spinella, spinescens, squalida, squarrusa, stenostegia, Steveniana, Stewarti, stipitata, stipulata, Stocksii, straminea striatella, stricta, strictifolia strictispina. strigillosa, strigulosa, strobilifera, stromatodes, subalpina, subbijuga, subcompressa, submitis, subsecunda, subulata, subulifera, succumbens, suffalcata, suidunensis, sulcata, sulfurea, superba, supina, susiana, syrtschensis, tabrisiana, talagonica. talyschemsis, tanaitica, tarijensis, tartarica, tamica, tauricola, Tavernieri, tegetaria, teheranica, tenax, tenera, tenuicantis, tenuifolia, tenuirugis, temuis, tephrodes, tephroloba, testiculata, tetragonocarpa thracica, Thurberi, tibetana, Tigridis, tmolea, tokatensis, tomentosa, torrentum, tortuosa, Toumefortic, trachyacantha, trachytricha, transoxana, Trautvelteri, tribulifolia, trichocarpa, tricholoba, trichopoda, trichoptera, trichostigma, tricolor, tridactylica, triftora, trifoliata, trifoliolata, trigona, trigonocarpa trimestris, triphylla, triradiata, tschujensis, tuberculosa, turbinata, Turczaninowiz, turkestana, tymplivestea, uliginosa, umbellata, uniflora, mifoliolata, unifulta, mijuga, unilatoralis, urmionsis, uraniolimnen, utahensis, utrigera, vaccarmm, vaginans, caginata, Vanillae, s'ariabilis, regeta, z'duchensis, zennsa,
TRAGACANTHA :-

ventorum, ienulosa, vera, ererucosa, versicolor, verlicillaris, vesicaria. vesiculosa, vestita, vexillaris, viciaefolia, villosa, villosissima, virgata, viridis, Vulnerariae, Wagneri, wartoënsis, Webberi, Webbiana, Whitneyi, Wiedemanniana, wolgonsis, Wrighti, xanthotricha, xerophila, xiphocarpa, yuralica, zacharonsis, zachlensis, zanskarensis, zerdana, Kuntze, Rev. Gen. (1821) 942-49= homonyma omria Astragali.

aciphylla, Kuntze, Rev. Gen. (1891) $940=$ AstragaIus acutifolius, Schlecht.

acutifolia. Kuntze, 1. c. = A. Pseudostella, Delile. adunca, Kuntze, 1. с. $942=$ A. Bungeanus, Boiss. aeluropus, Kuntze, 1. C. $=$ A. aeluropus, Bunge. afghana, Kuntze, 1. c. = A. affghanus, Boiss. Agranioti, Kuntze, 1. c. = A. Agraniotii, Orph.

Aitchisoni, Kuntze, 1, c = A. Aitchisoni, Baker.

alicantensis, Kuntze, 1. c. $940=$ A. hispanicus, Coss

alidaghonsis, Kuntze, 1. c. = A. elatus, Boiss. \& Bal. allepica, Kuntze, 1. c. = A. aleppicus, Boiss.

alopecurodes, Kuntze, 1. c. $=$ A. alopecuroides, Linn.

alyssodes, Kuntze, 1. c. = A. alyssoides, Lan.

andina. Kuntze, i. C. (= Phaca Bustillosi, Phil.). Chili.

mgustissima, Kuntze, 1. c. = Astragalus oxypetalus, Bunge.

ankylotes, Kuntze, 1. c, = A. ankylotus, Fisch. \& Mey.

anscrinifolia, Kuntze, 1, c $=\mathrm{A}$. anserinaefolius, Boiss.

anthyllodes, Kuntze, 1. c. = A. anthylloides, Lam. arkalykensis, Kuntze, 1. c. = A. arkalycensis, Bunge. wmenica, Kuntze, 1. c. = A. armeniacus, Bniss.

Arnoceras, Kuntze, 1. c. = A. brachyceras, Ledeb. Arnottiana, Kuntze, 1. c. (= Phaca Amotticna, Gili.). - Chili

aspemila, Kuntze, 1. c. = Astragalus epiglottis, L: $n$ nn

acamensis, Kuntze, 1. c. $(=$ Phaca depauperata, Phil.). - Chili.

bactica. Kuntze, 1. c. $210=$ Astragalus baeticus, Linn.

bayonnensis, Kuntze, 1. c. = A. baionnensis, Loisel. Belangeri, Kuntze, 1. c. = A, tenellus, Bunge.

bella, Kuntze, 1. c. (= Phaca pulchella, Clos). Chili.

beludshistana, Kuntze, 1. c. 943. - Belutchist.

Berteroana, Kuntze, 1. c. 940 (= Phaca canescens, Hook. \& Arn.). - Chili.

Berteroi, Kuntze. 1. c. $943=$ Astragalus Berteri, Colla.

Bienerti, Kuntze, 1. C. = A. Bienerti, Bunge.

bifida, Kuntze, 1. c. = A. multicaulis, Ledeb.

Bigelowii, Kuntze, 1, c. = A. Bigelovii, A. Gray.

bisinflata, Kuntze, 1. c. (= Phaca inflata, Gill.). Chili.

Bourgeanana, Kuntze, 1. c. = Astragalus Bourgaeanus, Coss

Grachypodia, Kuntze, 1. c. = A. lagurus, Willd.

Brackenridgei, Kuntze, 1. c. = A. Braclienbridgei. d. Gray.

bracteosa, Kuntze, 1. c. = A. aksuensis, Bunge.

brevialata, Kuntze, 1. c. ( $=$ Phaca brachyptera, Phil.). - Chili.

bunacantha, Kuntze, 1.c. = Astrasalus bounacanthus, Boiss.

bunophla, Kuntze, 1. c = A. bounophilus, Boiss. \& Hohen.

Bustilosii, Kuntze, 1. c. = B. Bustillosii, Clos.

californica, Kuntze, 1. c. = A. candidissimus, Ledeb.

arinata, Kuntze, 1. c. 943 (= Phaca carinata, Hool.

\& Arn.). - Chili.

caspia, Kuntze, 1. c. = Astragalus caspicus, Bieb. caucasia, Kuntze, 1. c. = A. caucasicus, $P_{\text {an }}$.

ceratodes, Kuntze, 1. c. = A. ceratoides, Bieb.

Chamissonii, Kuntze, 1. C. (= Phaor Chamissonis. Vog. ). - Chili.

Chardini, Kuntze, 1. c. = Astragalus Chardini,

Boiss.
Chaubartii, Kuntze, 1. c. = A. Wulfeni, Koch.

chilensis, Kuntze, 1. C. (= Phaca chilonsis, Nees). Chili. 
TRAGACANTHA : -

choica, Kuntze, Rev. Gen. (1891) $944=$ Astragalus latifolius, Lam.

chordorhiza, Kuntze, 1. c. = A. chordorrhizus, Fisch.

cilicica, Kuntze, 1. c. $941=$ A. cilicius, Boiss,

clandestina, Kuntze, 1. c. (= Phaca clandestina, Phil.), - Chili.

conferta, Kuntze, 1. c. = Astragalus hippocrepides, Benth.

coquimbensis, Kuntze, 1. c. $(=$ Phaca coquimbensis, Hook, \& Arn.). - Chili.

comuta, Kuntze, 1. c. $941=$ Astragalus vimineus, Pall.

Cossonii, Kuntze, I. c. $944=$ A. chlorocyaneus Boiss. \& Reut.

Crotofariae, Kuntze, 1. c. = A. oocarpus, A. Gray.

Cruikshanksii, Kuntze, 1. c. = A. Cruikschankil. Griseb.

aurvicaulis, Kuntze, 1. c. (= Phaca curvicaulis, Clos.). - Chili.

cuspidata, Kuntze, 1. c. = Astragalus schizopterus, Boiss.

iystisodes, Kuntze, 1. c. = A. cystisoides, Bunge.

dasyglossis, Kuntze, 1. c. = A. Hypoglottis, Limn.

decemjuga, Kuntze, 1. co = A. psilacanthus, Boiss.

deluensis, Kuntze, 1.c. = A. yriseus, Boiss.

dendrodes, Kunte, 1. c. = A. dendroides, Kar. \& $K$ ir

demutala, Kuntze, 1. c, $=$ A. microcephalus, Willd.

ebenodes, Kuntze, 1. c. = A. ebenoides, Boiss.

Edmondi, Kuntze, 1. c. $941=$ A. pectinatus, Boiss

eriantha, Kuntze, I. c. = A. gummifer, Labill.

eviocarpa, Kuntze, 1.c. = A. mollis, Bieb.

ervodes, Kuntze, 1. c. $944=$ A. ervoides, Hook. \& Arn.

eubrychiodes, Kuntze, 1. C. = A. eubrychioides, Boiss.

expansa, Kuntze, 1. c. = A. Kotschyanus, Boiss

filaginea, Kuntze, 1. c. = A. gossypinus, Fisch.

fima, Kuntze, 1. c. 941 (= Phaca robusta, Phil.). -

Chili.

Fischeriana, Kuntze, 1. c. $945=$ Astragalus pilodes,

flava, Kuntze, 1. c. (= Phaca flara, Hook. \& Arn.) - Chili.

flaciflova, Kuntze, 1. c. $941=$ Astragalus flavus, vitt.

formosa. Kuntze, 1. c. = A. concinnus, Benth.

Forskalii, Kuntze, 1. c. $945=$ A. Forskahlii, Boiss

frutescens, Kuntze, 1. c. = Brongniartia robinioi des, Kunth.

Gaillardotii, Kuntze, 1. c, = Astragalus Gaillardoti, Boiss.

Gayana. Kuntze, 1. c. $941=$ A. lanuginosus, Clos.

genistodes, Kuntze, 1. c. $945=$ A. genistoides, Boiss.

Germannii, Kuntze, 1, c. = A. Germanii, Phil.

glycyphyllodes, Kuntze, 1. c. = A. Glycyphyllos, Linn.

granatensis, Kuntze, 1. c. $94 \mathrm{I}=\mathrm{A}$. Poterium, Vahl.

grandis, Kuntze, 1. c. (= Phaca macrocarba, Phil. $)$ - Chili.

grata, Kuntze, 1, c. 945 (= P. grata, Clos.). Chili.

Grayi, Kuntze, 1. c. = Astragalus Grayus, Parry.

Hartwegii, Kuntze, 1. c. $941=$ A. Hartwegi, Benth.

Heldreiclii, Kuntze, 1. c. = A, vestitus, Boiss. \& Heldr.

Hendersonii, Kuntze, 1. c. $945=$ A. Hendersoni Baker.

Heydri, Knntze, 1, c. = A. Heydii, Baker.

Hoffmeisteri, Kuntze, 1. c, $94 \mathrm{I}=\mathrm{A}$. adesmiaefo lius, Benth.

hosackiodes, Kuntze, 1. c. $945=$ A. hosackioides, Benth.

hymenocarpa, Kuntze, 1. c. $=$ A. chartaceus, Ledeb.

hymenochlaena, Kuntze, I. c. = A. angustiflorus K. Koch.

iodoshachys, Kuntze, 1. c. = A. jodostachys, Boiss. \& Buhse.

iranica, Kuntze, 1, c. = A. mollis, Biob.

Kapherriana, Kuntze, 1. c. $941=$ A. persicus, Fisch \&. Mey.

karamasica, Kuntze, 1. c. $945=$ A. orthodontus, Bunge.

\section{TRAGACANTHA :-}

kashmirensis, Kuntze, Rev, Gen. (1891) $945=$ Astragalus caschmirensis, Bunge

kellanensis, Kuntze, 1. c = A. kellanensis, Boiss. \& Hausskn.

lagopodes, Kuntze, 1, c. = A. lagopoides, Lam.

lagirodes, Kuntze, 1, c. = A. laguroides, Pall

Landbeckii, Kuntze, 1. c. (=Phaca Landbckii, Phil.). - Chili.

lapponica, Kuntze, 1. c. $941=$ Astragalus arcticus, Bunge.

lasiocrilis, Kuntze, 1.c. = A. pachyacanthus, Bunge.

laxa, Kuntze, 1. c. = A. remotifolius, Boiss. \& Hausskn.

laxiflora, Kuntze, 1. c. = A. bracteosus, Eoiss. E. $N \circ \ddot{e}^{*}$

Laxmannii, Kuntze, 1. c. $946=$ A. adsurjens, Pall. leiocalyx, Kuntze, 1. c. = A. laetus, Bunge.

Lemmonii, Kuntze, 1. c. = A. Lemmonii, A. Gray.

Leontenyx, Kuntze, 1. c. $=$ A. oleifolius, $D C$.

leptothalama, Kuntze, 1. c. $946=$ A. leptothamnus, Boiss.

lessertiodes, Kuntze, 1. c $=$ A, lessertioides, Benth.

libanotica, Kuntze, 1. c. = A. Echinus, DC

longior, Kuntze, 1. c, 941 (= Phaca elongata, Phil.). - Chili.

Lyallii, Kuntze, 1. c. $946=$ Astragalus Lyalli, A. Gray.

lyciodes, Kuntze, 1. C. = A. lycioides, Boiss

macrophysa, Kuntze, 1. c. (= Phaca macrophysa, Phil.), - Chili.

Maxwellii, Kuntze, 1. c. = Astragalus tibetanus, Benth.

medicaginea. Kuntze, 1. c. = A. Kotschyanus, Boiss.

melilotodes, Kuntze, 1. c. = A. melilotoides, Pall.

mesochledensis. Kuntze, 1. c. = A. meschedensis, Bunge.

Michauxiz, Kuntze, 1. c. $941=$ A. olaber, Michx. micrantha, Kuntze, 1. c. = A. Nuttallianus, $D C$. missuriensis, Kuntze, 1. c. $946=$ A. missouriensis Nutt.

Moellendorfii, Kuntze, 1. c。 = A. Moellendorffii, Bunge.

mollis, Kuntze, 1. c. 941 = A. Humboldtii, A. Gray. mongolica, Kuntze, 1. c. $946=$ A. mongholicus, Bunge.

montana, Kuntze, 1. c. $941=$ A. kentrophyta A. Gray.

Mortonii, Kuntze, ].c. $946=$ A. Mortoni. Nutt.

Muellevi, Kuntze, 1. c. $941=$ A. Onobrychis, Limn mugodsharica, Kuntze, 1. c. $946=$ A. mugosaricus, Bunge.

meglecta. Kuntze, 1. c. $941=$ A. Cooperi, A. Gray.

mbigcna, Kuntze, 1. c. 946 (= Phaca mbigena,

E. Mey.). - Chili.

mudata, Kuntze, 1. c. = Astragalus kurdicus, Boiss. mmmulariodes, Kuntze, 1. $\mathrm{c}_{2}=\mathrm{A}$. nummularioides, Desf.

Nuttallii, Kuntze, 1. c. $941=$ A. Menziesii, A. Gray. ochrochlora, Kuntze, 1. c. $946=$ A. ochrochlorus, Boiss. \& Hohen.

Olginii, Kuntze, 1. c. = A. mossulensis, Bnnge.

oligantha, Kuntze, 1. c. (= Phaca oligantha, Phil.). - Chili.

olympica, Kuntze, 1. c. = Astragalus boibutensis, Bunge.

Orbigniana, Kuntze, 1, c. = A. Orbignyanus, Wedd oreodes, Kuntze, 1. $\mathrm{c}_{0}=\mathrm{A}$. oreades, C. A. Mey.

oreophila, Kuntze, 1. c. 947 (= Phaca oreophila, Phil.). - Chili.

ornithopodiodes, Kuntze, 1. c. = Astragalus orni-

thopodioides, Lam.

orobodes, Kuntze, 1 c $=$ A. oroboides, Honzen.

orthodonta, Kuntze, 1. c. = A. karamasicus, Boiss. E Bal.

Owerinii, Kuntze, 1. c. = A. Owerini, Bunge.

pallida, Kuntze, 1. c. = A. drusorum, Boiss.

paphlagonica, Kuntze, 1. c. = A. atropurpureus, Boiss.

parviflora, Kuntze, 1. c. $941=$ A. gracilis, Nutt.

Pattersonii, Kuntze, 1. c. $947=$ A. Pattersoni, $A$. Gray.

Pavillonii, Kuntze, 1. c. $941=\mathrm{A}$. canescens, Bunge. pendulifora, Kuntze, 1. c. = A. alpinus, Linn.
TRAGACANTHA : -

persica, Kuntze, Rev. Gen. (1891) $941=$ Astragalus mesopotamicus, Boiss.

Philippiana, Kuntze, 1. c. (= Phaca amoena, Phil.) - Chili

phlomodes, Kuntze, 1. c. $94 \%=$ Astragalus phlomoides, Boiss.

physalodes, Kuntze, 1. c. = A. physaloides, $D C$.

Pinardii, Kuntze, 1. c. = A. Pinardi, Boiss

Pississi, Kuntze, 1. c. (= Phaca Pisissi, Phil.).Chili.

procerior, Kuntze, 1. c. $941=$ Astragalus Chipidium, Bunge.

prusiana, Kuntze, 1. c, $947=$ A. Boissieri, Fisch.

psilopiera, liuntze, 1. $\mathrm{c}=\mathrm{A}$. genistoides,

psilopus, Kuntze, 1. c. $94 \%=$ A. spartioides, Kar. 6 Kir

psoralodes, Kuntze, 1. c. = A. psoralioides. Willd Pulcifcrac, Kuntze, 1. c. = A. Pulciferi, A. Gray. pungens, Kuntze, 1. c. = A. angustifolius, Lam. purpurea, Kuntze, 1. c. = A. hypoglottis, Linn

pycnorhiza, Kuntze, 1. c. $94 \%=$ A. pycnorrhizus, Wall.

pygmaea, Kuntze, 1. c. $! 41=$ A. Chamaeleuce, A. Gray.

quindeciminga, Kuntze, 1. c. (= Phaca quindeciminga Phil.). - Chili.

Reedii, Kuntze, 1. c. (= P. Reedi, Phil.). - Chili.

reflexistipula. Kuntze, 1. c. $947=$ Astragalus reflexistipulus, Miq.

resupinata, Kuntze, 1. c. = A. fragans, Willd

vigida, Kunt $\%$, 1. c. = A. melanocephalus, Boiss.

Rousseanana, Kuntze, 1. c $=$ A. Roussaeanus, Boiss.

mabarica, Kuntze. 1. c. = A, confusus. Bunge. ramelica, Kuntze, 1. c. = A. veluchensis, Boiss. vupicola, Kuntze, 1. $\mathrm{c}_{\mathrm{a}}=\mathrm{A}$. peregrinus, Vahl. Ruprechtii, Kuntze, 1, c. = A. Ruprechtii, Bunge.

Schmalhausenii, Kuntze, 1. $\mathrm{c}=\mathrm{A}$. Schmalhauseni, Bunge.

scorpiodes, Kuntze, 1. c. = A. scorpioides, Pourr.

scrobiculata, Kuntze, 1. c. = A. gymnolobus, Fisch Segethit, Kuntze, 1. c。 = A. Segethi, Phil.

sengacnensis, Kuntze, 1. c. = A. senganensis, Bunge.

Serenoi, Kuntze, 1. c. $941=$ A. nudus, $S$. Wats

sericea, Kuntze, 1, c. $94 \%=A$. sericoleucus, $A$ Gray.

Serobischir, Kuntze, 1. c. $942=$ A. chrysanthus, Boiss. \& Hohn.

sesamodes, Kuntze, 1, c, = A. sesamoides, Boiss.

Solanderi, Kuntze, 1, c, $210=$ A. Solandri, Lover

Sonorie, Kuntze, 1. c. $948=$ A. arizonicus, A. Gray

Spaldingii, Kuntze, 1. c. = A. Spaldingii, A. Gray.

spartiodes, Kuntze, 1. c. = A. spartioides. Kar. E Kir.

Spruneviana, Kuntze, 1. c, = A. Spruneri, Boiss.

striata, Kuntze, 1. c. (= Phaca striata, Clos). Chili.

subacaulis, Kuntze, 1. c. = Astragalus incertus, Ledeb.

subumbellata, Kuntze, 1. c. = A. hippocrepidis, Benth.

sultanensis, Kuntze, 1, c. = A. bombycinus, Boiss. superisa, Kuntze, 1. C. = A. Candolleanus, Boiss. Szowitsii, Kuntze, 1. c。= A. Szoritsii, Fisch. \& Mey.

talassea, Kuntze, 1. c. = A. talasseris, Boiss. Ex Bal. tobesiensis, Kuntze, 1. c. $942=$ A. cornutus, Bunge. tenella, Kuntze, 1. c. = A. multiflorus, A. Gray

tephrosiodes, Kuntze, 1. C. $948=$ A. tephrosioides, Boiss

thessala, Kuntze, 1. c. = A. Spruneri, Boiss

Thomsonae, Kuntze, 1. c. =A. Thompsonae, S.W ats. tragacanthodes, Kuntze, 1. c. $942=$ A. coluteoides, IVilld.

tribulodes, Kuntze, 1.c. $948=\mathrm{A}$. tribuloides, Willd. trichrou, Kuntze, 1. c. $942=$ A. tricolor, Bunge

trigonellodes, Kuntze, 1. c. $948=$ A. trigonelloides, Boiss.

twhestanica, Kuntze, 1, c. $942=$ A. Dipelta. Bunge. uralensis, Kuntze, 1, c. $=$ A. macropus, Bunge.

uspallatensis, Kuntze, I, c. $949 \quad=$ Phaca uspallatensis, Phil.). - Chili.

usturtensis, Kuntze, 1. c. = Astrogalus ustiurtensis, Bunge.

vaga, Kuntze, 1. c. (= Placaraga, Phil.). - Chili. 
TRAGACANTHA:

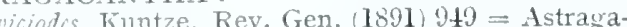
lus vicioides, $R$. Grah.

Volkmamii, Kuntze, 1. c. $=$ A. Volckmanni, Phil.

Watsoniana, Kuntze, l. c. $942=$ A. eriocarpus, $S$ W ats.

IV cddelliana, Kuntze, 1. c. $=$ A. modestus, $W e d d$.

IVulfferii, Truntze, 1, c. $949=$ A. Wulfeni, Koch

Zohrabi, Kuntze, 1. c. = A. lagopoides, Lam.

TRAGIA, Plum, ex Linn. (Euphorb.). - Ind. Kew, ii. 1096 .

brevipes, $P_{a x}$, in Bot. Fahrb. xix. (1894) 103. Afr. trop. or.

Buettneri, Pax, l. c. - Gabon

discolor, Pax, in Engl. \& Prantl, Natiirl. Pfanzenfam. iii. 5 (1890) 65 (=Leptobotrys discolor, Baill.). - Am. bor

glabrescens, Pax, in Bot. Falwb. xix. (1894) 104. Afr. trop. or.

guatemalensis, Lotsy, in Coult. Bot. Gaz.xx. (1895) 35 t. - Guatem.

Klingii, Pax, in Bot. Falhrb. xix. (1894) 105. - Afr. trop. occ.

parvifolia, Pax, l.c. 102. - Afr, trop. or.

Preussii, Pax, l.c. - Kamerun.

subsessilis, Pax, l. c. 101. - Afr. trop, or.

nkambensis, Pax, l. c. 105. - Afr. trop. or.

velutina. $P a x$. l. c. 104. - Afr. trop. or.

Volkensii, Pax, in Engl. Pfunzenw, Ost-Afr. C (1895) 240 . - Afr, trop, or.

TRAGOCEROS, H, B. \& K. (Compos.). - Ind. Kew, ii. $109 \%$.

Mocinianus, A. Gray, in Proc. Am. Acad. xxi. (1886) 38s. - Mexic.

TRAGOPOGON, [Tourn.] Linn. (Compos.) Ind. Kew, ii. 1097

albinerve, Freyn. \& Sint. in Oest. Bot. Zeitschr, xlii. (1892) 266. - Armen. turc

Badali, Willk. Suppl. Prodr. Fl. Hisp. (1893) 112 $=$ crocifolius, Limn.

balcanicam, Velen. ex Nym. Consp. Fl. Eur. Suppl. ii. I. (1889) 203; et Fl. Bulg. (1891) $355=$ crocifolium, Linn.

fibrosum. Freyn \& Sint, ex Freyn, in Bull. Herb. Boiss, iii. (1895) 475. - Armen.

Mlabrum, Nichols, Dict. Gavd, iv, (188i) 66 [glaber]. - Europ

macroceplachm, Pomel, ex Batt. \& Trab. Ft. de l'Algér. [Dicot.] (1889) $549=$ porrifolium, Linn. mirabile $X$, Rouy, in Bull. Soc. Bot. Fr。 xxxvii. (1890) p. xviii [mirabilis]. - Gall.

neglectum X. Hausskn. in Mitt. Bot. Ver. Jena, v. (1887) 26 [neglectus]. — Germ.

rumelicum, Vclenz. in Oest. Bot. Zeitschr. xlii. (1892) 15; et in Abh. Boehn. Ges. Wiss. 1892 (1893) n. xxxvii. 39. - Bulg.

TRAGOPOGONODES, Manetti (1751), ex Küuntze, Rev. Gen. (1891) $370=$ Urospermum, Scop. (Compos.).

Dalochampii, Kuntze, 1. c. $=$ U. Dalechampii, W. F. Schmidt.

Bicrodes, Kuntze, 1. c. = U. picroides, $F, W$. schmialt.

TRAPA, Linn. (Onagrar.) - Ind. Kew, ii. 1099 nlchica, Alboff, in Bull. Herb. Boiss, iii. (1895) 237. - Rer. Caue.

Maximowicii, Korshincky, in Act. Hort. Petrop. xii. (1892) 336. - As, bor.or.

TRAPELLA, Oliver, in Hook, Icom, pl, xvi. (1887) t. 1595; Stapf, in Engl. \& Prantl, Natuirl. PRanzenfam, iv, 3b (1895) 205. PEDALINEAE. sinensis, Olirer, ll.cc. - China.

TRA UNIA, K. Schum. in Notizbl, Bot, Gart. Berl. i. (189.5) 22 ; et in Engl, \& Prantl, Natürl. Pflanzenfam, iv, 2(1895) 257. ASCLEPIADEAE.

albiflora, $K$. Sithm, $l l . c c, 23$; et $2 S \%$ - - Afr. trop.
TRAUTVETTERIA, Fisch. \& Mey. (Ranuncul.). - Ind. Kew, ii. 1099.

arolinensis, Britton, ex A. Murr. \& Vail, in Mem. Torrey Bot. Club, ii. (1890) $42=$ palmata, Fisch. \& Mcy.

TRECHONAETES, Miers (Solan.), 一 Ind. Kew. ii, 1099 .

bipinnatifida, Phil. in Anal. Mus. nac. Chile (1891) 67. - Chili.

floribunda. Phil. l. c. 66. - Chili.

lanigera, Phil. . . c - Chili.

machucana, Phil. l, c. 6\%. - Chili.

parviflora, Phil. l. . 66. - Chili.

TREGUlia, Decne (Urtic.), - Ind, Kew. ii. 1099.

Affona, N. E. Bv. in Kew Bull. (1894) 360 ; et in Hook. Icon . pl xxiv. (1895) t. 2353. - Reg. Nigrit. madagascarica, $N$. E. Br. l.c. - Madag.

obovoidea, N. E. Bi'. l. c. 361 . - Afr. trop. occ.

TREMA, Lour. (Urtic,). - Ind. Kew, ii. 1099 guinensis, Pricmer, in Bot. Fahrb. xvii. (1893) 426 , $469(=$ Celtis guineensis, Schum.). - Afr. trop.

Hochstetteri, Engl, in Abh. Prenss. Akad. Wiss 1891 ii. (1892) 190 ; Pricmer, l. c. 425, $470(=$ Sponia Hochstetteri, Buchinger). - Afr. trop. integrifolia, Baill. Hist. pl. Madag. Atlas (1895) t 292. - Madag.

TREMATANTHERA, F. Muell, in Vict. Natural. iii. (Oct. 1886) $\pi 1$; et ex Bot. Centralbl, xxix. (1S87) 148. TERNSTROEMIEAE

Dufatrii, F. Muell. $l \% . c c_{0} \rightarrow \mathrm{N}$, Guin

TREMATOCARPUS, Zahlbr, in Annal. Naturh Hofmus. Wien, vi. (1891) 430; Hemsl. in Ann. Bot. vi. (1892) 154; et vii. (1893) 289; Stapf, 1. c vii. (1893) 396 = Lobelia, Linn. (Campanul.). macrostachys, Zahlbr. 1. c. $432=$ L. macrostachys Hook. \& Arn.

TRETOGARYA, Maxim. (Boragin.), - Ind Kew. ii. 1100.

ikkimensis, Oliver, in Hook. Icon。 fl, xxiii. (1893) t. 2255. - Reg. Himal.

TREUBELLA, Pierre, Not. Bot. Sapot. (1890) 5 SAPOTACEAE.

macrocarpa, Pierre, $l . c . i=$ Palaquinm macrom carknu, Burck). - Sumatra.

TREUBELLA, Van Tiegh, in Bull, Soc. Bot. Fr. xli. (1894) $265=$ Loranthus, Linn.

amplexans, Van Tiegh. 1.c. xlii. (1895) $87=\mathrm{L}$. amplexans, Van Tiegh.

Forsteriana. Van Tiegh. 1. c. xli. (1894) $266=$ L Forsterianus. Sihult.

glauca, Van Tiegh. 1. c, xlii.(1S95) $436=\mathrm{L}$ slaucus, Van Tiegh.

indica, Van Tiegh. 1. c. xli. (1894) $267=$ L. longiflorus, Desr.

insularm, Van Tiegh. 1. c. xlii, (1895) $435=\mathrm{L}$ insularum, A. Gray.

Mercievi, Van Tiegh. 1. c. - N. Caled.

Muclleriana, Van Tiegh, 1. c. $87=$ Loranthus Muellerianus, Van Tiegh.

sigrata, Van Tiegh.1. c. = L. signatus, Van Ticgh.

triftora, Van Tiegh. 1. c, xll. (1894) $267=\mathrm{L}$. triflorus. Spanz.

vitiensis, Van Tiegh. I. c. $266=$ L. vitiensis, Seem

TREUBIA, Pierre, in Boerl. Handl. F1. Nederl Indië, ii. (1890) 445. SAXIFRAGEAE.

combretocarpa, Pierre, l. c. - Ind, bat, (Ceram).

TREVESIA, Vis. (Aral.). - Ind, Kew. ii. 1100.

barbata, carpophagarm, Geelwinkiana, helleborina, insidiator, Kuntze, Rev, Gen, (1891) $272=$ homonyma omuia Boerlagiodendri, Burck.

Beccarii, Boerl, in Annal. Favd. Bultenz, vi. (1887) 110; et Handl. Fl. Ned. Indië, i, II. (1890) 949. Sumatra.

\section{TREVESIA}

Burckii, Boevl. in Ammul. Fard. Buitonz vi. (1889) 110 ; et Handl. Fl. Ned. Indié, i. II. (1800) $649(=$ Trevesia sundaica, Regel). - Sumatra.

cheirantha, Kuntze, Rev. Gen. (1891) $222=$ Trev. Buxckii, Boerl.

pulcherrima, Kuntze, 1.c. = Eschweileria pulcherrima, Borl.

tahitensis, Drake, Fl. Polyn Franc (1892) 81. Ins. Pacif.

Teysmannii, Kuntze, Rev. Gen. (1891) $272=$ Boerlagiodendron Teysmannii, Harms.

TRIANTFlEMA, Sauv, (Ficoid.). - Ind. Kew. ii. 1101

Camilli, Cordem. Fl. Ill. Rénnion (1895) 291. - Ins. Borbon.

Cussackiana, F. Muell. in Chent, and Drug. Austral. x. (oct. 1895) 207; et ex Bot. Centra7b1. 1xiv. (1895) 364. - Austral.

littoralis, Cordem. Fl. Ill. Réminion (1895) 290.Ins. Borbon.

TRIANTHERA, Wettst, in Engl. \& Prant], Natïrl. Pflanzenfam. iv. 36 (1891) 5. . SCRO PHULARIEAE.

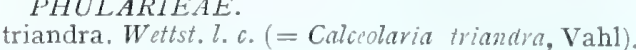
- Peruvia.

TRIARTHRON, Bail, in Bull, Soc, Linn. Paris, ii. (1892) 985; et Hist. des pl, xi. (1892) 4ij) = Loranthus, Linn.

loranthoidenm, Baill. 11. cc. - Am. trop.

TRIAS, Lindl, (Orchid.). - Ind. Kew. ji. 1101 Stocksii, Benth. ex Hook, f. Fl. Brit. Ind. vo (1890) 781. - Deccan.

vitrina, Rolfe, in Kew Bull. (1895) 282. - Tenass.

TRIASPIS, Burch. (Malpigh.). - Ind. Kew, ii. 1101 .

axillaris, Baker, in Fourn. Linn. Soc, xxy. (1889) 302. - Madag.

choregyna, Eaill. Hist. pl. Wadag., Atlas (1894) t. 269. - Madag.

diotostigma, Baill. 7. c. t. 270. - Madag.

Horibunda, Baill. [an O.Hoffm. ?] l. c. t. 268. Madag.

Rehmannii, Szyszy?. Polypet, Rehmamn. ii. (1888) 3. - Transv.

speciosa, Niedenzu, in Engl. Pfanzenw. Ost-Afr. C (1895) 232. - Afr, trop. or.

TRIATHERA, Desv, = Bouteloua, Lag. (Gra-

gracilis, Foum. Gram. Mexic. 1881 (1886) 141. Mexic.

TribULUS, Tourn, ex Linn, (/ygophyil.). Ind. Kew, ii. 1102

erectus, Engl. Bot: Fahrb, x, (1888) 32. - Atr. austro-occ, extratrop.

inermis, Engl. l. c. 32. - Afr. austro-occ. extratrop.

leptophyllus, F. M. Baciley, in Dept. Agric. Brisban Bot. Bull, iii. (1891) S. - Austral.

Pechuelii, Kuntze, in falurb. Bot. Gart. Berl. iv (1886) 262. - Afr. austro-occ, extratrop.

TRIBRAGHYA, Korth. (Rubiac.). - Ind. Kew. ii. 1102.

Beccariana, Boevl, Handl. Fl. Ned, Indie, ii. I. (1891) 137 (= Dibrachya Beccariana, Baill.). Borneo.

TRICALYSIA, A. Rich. (Rubiac.), - Ind. Kew, ii. 1102 .

acocantheroides, K. Schum, in Engl. Pfanzemw. Ost-Afr. C (1895) 382. - Afr. trop. or.

cuneifolia, Baker, in Kew Bull. (1894) 148. - Ins. Aldabra.

Galpinii, Schinz, in Bull. Herb. Boiss. iii. (1895) 416. - Transvaal.

Lastii, K. Schum. in Engl. Pfanzenw' Osf-Afr. C (1895) 382. - Afr, trop. or. 


\section{TRICALYSIA}

singularis, K. Schum, in Engl. E Prantl, Nation Pflanzenfan. iv. 4 (1891) 82 (= Diplospora simgllaris, Korth.). - Ind. or., Malaya.

TRICHERA, Schrad, = Scabiosa, Linn. (Dipsac.). bosniaca, Conrath, in Oest. Bot. Zeitschr. xxxvii. (1887) $38: 3=\mathrm{S}$. arvensis, Lim.

oudensis, A. Kern. ex Simonk. in Bot. Centralbl. lvii. $(1894) 100=$ S. sylvatica, Linn.

dmarica, Murb. in Oest. Bot. Zeitschr, xliv. (1894) $399=$ S. sylvatica, Linn.

neglecta, Conrath, 1. c. xxxvii, (IS87) 383, in obs. $=\mathrm{S}$, arvensis, Linn.

TRICHILIA、P, Br. (Meliac.)。 - Ind. Kew, ii 1104.

Buchanani, C. DC. in Bull. Herb. Boiss. ii. (1894)

580. - Afr. trop. austro-or

Colimana, C. DC. ex F. D. Snith, in Conlt. Bot. Gaz, xix. (1894) 40. - Mexic

Donnell-Smithii, C. DC. ex F. D. Smith, l. c.2.Guatem.

emarginata, S. Elliot, in fonrn. Limn. Soc. xxiz. (1891) 11. - Madag.

cracilis, Loesen. in Flora, 1xxii. (1889) 75. - Bras

Heydeana, C. DC. ex F. D. Smith, in Contt. Bot.

Ga\%. xix. (1894) 3. - Guatem.

Lehmanni, C, DC. in Bull. Herb. Boiss, ii. (1894) 571. - Ins. Jamaica.

levis, C. DC. l. C 573. - Bras.

ovalis, Rusby, in Mem. Torrey Bot. Club. iii. 3 (1893)

14, et jv. (1890) 205, in obs. - Bolivia

Palmeri, C. DC. in Coult. Bot. Gaz. xix. (1894) 38 - Mexio.

peltostylis, Baill. Fist. pl. Madag., Atlas (1892) t. 255. - Madag.

polyclada, C. DC. in Bull. Herb. Boiss. ii. (1894 5\%. - Parag

pterophylla, C.DC.l. c. 581. - Afr. austr.

quadrivalvis, C. DC. ex Schinz, l. c. iii. (1895) 402.

Volkensii, Guerke, in Bot. Falirb. xix. Beibl. n. t7 (1894) 33. - Afr. trop. or.

TRICHINIUM, R. Br. (Amarant.). - Ind. Kew

ii. 1104.
Burtonii, F. M. Bailey, in Dept. Agric. Brisbane Bot. Bull. ii. (iS91) 14. - Austral.

TRICHLORIS, Tourn. (Gramin.). - Ind. Kew, ii. 1105 .

Blinchardiana, Hack, in Engl. \& Prantl, Natürl. Pflanzenfam. ii. 2 (1887) 59, - Am. austro-occ

TRICHOCAULON, N. E. Br. (Asclep.). - Ind. Kew. ii. 1106

cactiformis, N. E. Br, in Hook. Icon, pl, xx, (1890) sub. t. 1905 (= Stapelia cactiformis, Hook.). Atr. austro-occ. extratrop.

officinale, N. E. Br. in Kew Bull. (1895) 264. - Afr. austr.

pedicellatum, Schunz, in Verh. Bot. Ver. Brand. xxx. (1888) 266. - Afr. austro-occ. extratrop.

TRICHOCENTRUM. Poepp. \& Endl. (Orchid.) - Ind. Kew. ii. 1106.

albiflorum, Rolfe, in Kew Bull. (1893) 336. Wexic.

Hartii, Rolfe, l. c. (1894) 395. - Venezuela

Leeanum, Reichb. f. in Flora, lxix. (1886) 550.Am. occ. aequat.?

triquetrum, Rolfe, in Gitrd. Chron. (1891) i. 700; et in Lindenia, vii. (1891)-49, t :311. - Peruvia.

TRICHOGLINE, Cass. (Compos.). - Ind. Kew ii. 1106.

caulescens, Phil. in Anal. Mus. nac. Chile (1891) 31 . - Chili.

corditolia, Baker, in Kew Bull. (1S92) 197. - Bras nivea, Phil. in Anal. Mus, nac. Chile (1891) 31. Chili.

paraguayensis, Baker, in Kow Bull. (1892) 198. Paras.

peruviana, Hieron. in Bot. Fahro. xxi. (1895) 368 - Peruvia.
TRICHOCORONIS, A. Gray (Compos.). - Ind. Kew. ii. $1106^{\circ}$.

riparia, Greene, in Erythea, i. (1893) 42; et Man. Bot. San Franc. Bay (1894) 169 (= Biolcttia riparia, Greene). - Calif.

TRIGHODESMA, R. Br. (Borag,). - Ind. Kew, ii. 1106.

Boissieri, Post, in fourn. Linn. Soc. xxiv. (1888) 436. - Syria.

calycosum, Collett \&o Henst, in fourn. Linn. Soc. xxviii. (1890) 92. - Burma.

randifolium, Baker, in Kew Bull. (1894) 29. - Afr. trop. or.

Hildebrandtii, Gutork, in Engl. \& Prantl, Nation. Pflanzenfam. iv. 3a (1893) 99 ; et in Notizbl. Bot. Gart. Berl. i. (1895) 67. - Reg. Somal.

lanceolatum. Schinz, in Verh. Bot. Ver. Brand. xxx. (1888) 269. - Afr. austro-occ. extratrop

Medusa, Baker, in Kew Bull. (1894) 29. - Angola. pauciflorum. Baker, l. c. - Ins. Hamish

stenosepalum, Baker, l,c. (1895) 221. - Reg. Somal,

TRICHODYPSIS, Baill, in Bull.Soc. Linn. Paris, ii. (1894) 1165; et Hist. des pl. xiii. (1895) 370 . PAIMAE.

Hildebrandtii, Baill. ll.cc. - Madag.

TRICHOGLOTTIS, Blume (Orchid.) - Ind. Kew, ii. 1107.
eontoglossa, Ridl, in fourn. Bot.xxiv, (1886) 355. eontoglossa, $R$

TRIGHOGONIA, Gardn. (Compos.). - Ind. Kew

\section{ii. 1107.}

scabra, Klatt, in falurb. Hanb. Wiss. Anstalt. ix. (1892) 125. - Bras

TRICHOLAENA, Schrad. = Panicum, Linn. (Gramin,).

abbreviata, K. Schum. ex Engl, in Abh. Preuss, Akad. Wiss. (1894) 58. - Afr. trop.

amethystea, Franch. in Bull. Soc. Autun, viii. (1895) 356. - Congo gall.

brevipila, Hack. ex Schinz, in Verh. Bot. Ver, Brand. xxx. (1888) 143. - Afr. austro-occ

congoensis, Franch. in Bull. Soc. Autun, viii. (1895) 355. - Congo gall.

7) regeana. Th. Dur. \& Schinz, Consp. Fl, Afr. v, 1894 (1895) 769. - Natal.

filifolia, Franch. in Bull. Soc. Autun, viii. (1895) $355 .-$ Gabon.

microstacliya, Th. Dur. \& Schinz, Consp. Fl. Afr. v. $(1595)$ \% $(=$ Rhynchelytrum microstachyum. Balf. f.). - Ins. Socotra.

Monachyron, Oliver, in Hook. Icon. pl. xxv. (1895) t. 2374. - Ins. Cap. Virid., Abyss.

meriglumis, Franch, in Bull. Soc, dutum, viii (1895) $35 \%$ - Congo gall

rificoma, Hack. in Bolet. Soc. Brot. vi. (1885) 142; Th. Dur. \& Schinz, Consp. Fl. Afr. v. 1894 (1895) 770. - Reg. Mossamb.

cabrida, K. Schum. in Engl. Pflanzenw. Ost-Afr. C (1895) 104. - Afr. trop. or.

uniglumis, Th. Dur, \& Schinz, Consp. F1. Afr. v. 1894 (1895) 7\%0. - Nubia.

7losa, Th. Dur. \& Schinz, 1. c. (= Monachyron villosum, Parl.). - Ins. Capit. Virid.

Wightii, Hack, ex Schinz, in Verh. Rot. Ver. Brand. xxx. (1888) $143=W$ ightii, Nees \& Arn.

TRICHOLOBUS. Blume (Connar.) - Ind. Kew. ii. 1108 .

africanus, Heckel, in Am. Fac. Sci. Marseille, Fasc. i. (1S91) 16, in obs, - Afr. trop. occ. verruculosus, Kuntze, Reì, Gen. (1891) 155. Cochinch.

TRIGHOPILIA, Lindl. (Orchid.), - Ind. Kew. ii. 1108.

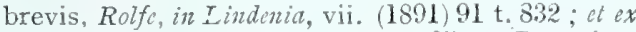
Gard. Chron. (1S95) ii. 641 fig. 105. - Peruvia.

I.ehmanni, Regel, in Act. Hort. Petrop. x. (1887) 371. - Columb.

punctata, Rolfe, in Gard. Chron. (1590) i. 22\%.- Costa Rica.
TRICHOPTERYX, Nees (Gramin.). - Ind. Kew. ii. 1108

arundinàcea, Hack. ex Engl, in Ably. Preuss. Aluad. Wiss. 1891 ii. (1892) 129 (= Tristachya aruzedina cea, Hochst.). - Afr. trop. or.

barbata, Hack. ex Th. Dur. \& Schinz, l. c. $8461=$ T. barbata, Nees).-Abyss., Arabia.

elegans, Hack. ex Engl. in Abl. Preuss. Alad. Wiss. 1891 ii. (1892) 129 (= Loudetia elegans, Hochst.). - Afr. trop. or.

elegantula, Stapf, in Hook, Icon. pl. xxiv. (1S95) t. 2394. - Afr. trop. occ.

grisea, K. Schum. in Engl. Pflanzenw. Ost-Afr. C (1855) 109. - Afr. trop. or.

incompta, Franch. in Bull. Soc. Antun, viii. (1895) 373. - Congo gall.

kagerensis, $K$. Schum. in Engl. Pfanzenw, Ost-Afr. C (1895) 109. - Afr. trop. or.

simplex, Hack. ex Engr. in Abh. Preuss: Akad. Wiss. 1891 ii. (1892) 120, in obs. = simplex, Benth。

omalensis, Engl. l.c. $130(=$ Tristachya somalcnsis, Franch.). - Reg. Somal.

pirathera, K. Sclium. in Engl. Pflanzonw. Ost-Afr. C (1895) 109. - Atr. trop. or.

stipoides. Hack. ex S. Elliot, in fourn. Linn. Soc xxix. (1891) 65 (= Anmdinella stipoides, Hack.). - Madag.

TRICHOSANTHES, Linn. (Cucurb.). - Ind Kew. ii. 1108 .

Holtzei. F. Muell: in Australas. Fourn. Pharm, i. (Dec. 1886) 447 ; et in Bot. Centralbl. xxix. (1887) 275. - Austral.

Muelleri. Cogn, in Bull. Acad. Belg. Sér. III. xiv. (1887) 346 ; et ex F. Mucll. Cens. Austral. Pl. F. Suppl. (1889) 4.- Austral.

shikokiana, Makno, in Tokyo Bot. Mag. vi. (1892) 54. - Japon.

TRICHOSGYPHA. Hook. f. (Anacard.). - Ind. Kew, 11, 1109.

Braunii, Engl. Bot. Falirb. xv. (1892) 111.-Afr trop. occ

Buettneri, Engl. 2. ¿. 162, 113, nomen, in obs. - Afr. trop.

camerunensis, Engl. l.c. 109. - Afr. trop. occ

ferrurinea, Engl. l. c. 112, - Afr. trop. occ

laxiflora, Engl. l. c. 110. - Afr. trop. occ

liberica, Engl. l. c. 108. - Afr. trop. occ.

parviflora, Engl. l. c. - Afr. trop. occ

Preussii, Engl. 7. 0. 110. - Afr. trop. occ.

TRICHOSMA, Lindl. (Orchid.). - Ind. Kew. ii 1110

conaria, Kuntze, Rev. Gen. (1801) 681 = suavis, I.indl.

TRICHOSPORUM. D. DOn = Aeschynanthus Jack. (Gesner.)

cuminatum, amoenum. Andersoni, apiadens, arfakense. Becarii, bracteatuni, brevicalyx, camdatum, cryptansthum, Curtisii, elongatum, fulgens, geminatum, gracile, Griffithii, hians, Hookeri. Horsfildii, javanionm, Kingi, lifidospermum. leptocladum, levipes, Lobbianum, longicanle, longiflorum, macrocalyx, maculatum, Mannii, marmoratum, Matoniae, Motleyi. micranthum, microphyllum, microtrichum, miniatum, oboconiam, oboiatum, parvifolimn, Perrottetii, philitpinense, fodocarpun, rubiginostm, siphonanthum, speciosum, superbum, tetraquctrum, Teysmannianum, tricolor, tubiflorum, vertivillatum, ciridiflorum. Wal lichii. zeylanicum, Zollingeri, Kuntze, Rev. Gen. (1891) $47 \%-78=$ homonyma omnia Aeschynanthi.

Boschianm, Kuntze, 1, c. $47 \%=$ A. Lamponga Miq.

chivitodes, I Iuntze, 1. c. = A. chiritcides, C. B. Clarke.

parasitica, Kuntze, 1. c. $=A$. chiritoides, $C . B$ Clarke.

TRICHOSTELMA, Baill. Hist. des p1. x. (1 88$)^{\circ}$ 28\%: K. Schum, in Engl. \& Prantl, Natürl. PHan287; K. Schum. in Engl. \& Prantl, Naturl. P
zerfam. iv. 2 (1895) 303. A SCI.EPIADEAE. ciliatum, Baill. $11.06 .248 ;$ e: 303. - Mexic. 
TRICHOSTEMA, Gronov, ex Linn, (Labiat.). Ind. Kew, ii. 1110 .

Ind. Kew. 11. I110.
suffrutescens, Kearney, in Bull. Torrey Bot. Club, xxi. (1894) 483. - Florida.

TRICONDYLUS, Salisb. \& Knight = Lomatia R. Br. (Proteac.).

chilesusis, dentata, ilicifolia.ubliqua, polymorpha, simuata, Kuntze, Rev. Gen. (1891) $582=$ homonyma omiia Lomatiae.

Fraseri, Kuntze, 1. c. = L. ilicifolia, $R . B r$.

nigricodes, Kuntze, 1. c. = L. longifolia, $R$. $B r$.

TRICYRTIS. Wall. (Liliac.). - Ind. Kew. ii, 1111 .

macrantha, Maxm. in Bull. Acad. Pélersb. xxxii. (1888) 625, - Japon.

nana, Yatabe, in Tokyo Bot. Mag. vii. (1893) 39 t. 3. - Japon

TRIDAX, Linn. (Compos.). - Ind, Kew, ii. 1111. Ehrenbergii, Sch. Bip. ex Klatt, in Leopoldina, Heft xxiii. (1857) 145. - Mexic.

erecta, A. Gray, in Proc. Am. Acad. xxi. (1886) 390. - Mexic.

Galeottii, Klatl, in Leopoldina, Heft xxiii. (188\%) 145. - Mexic

lanceolata, Klatt, l. c.- Mexic.

leptophylla, A. Gray, in Proc. An. Acad. xxi. (1886) $391 .-$ Mexic.

Iicbnannii, Sch. Bip. ex Klatt, in Leopoldina, Heft xxiil. (1887) 90, in syn. = Salazia Liebmannii, Sch. Bip.

Stuebelii, Hieron. in Bot. Fahrb. xxi. (1895) 351.Ecuad.

tambensis, Hicron. l.c. - Pcruvia,

tenuifolia. 7. N. Rose, in Contrib.U. S. Nat. Herb. iii. 5 (1895):319. - Mexic.

Trianae, Hierom. in Bot. Fahrb. xxi. (1895) 350.Columb.

verticillata, Klatt, in Lcopoldina, Heft xxv, (1889) 10\%. - Bras.

TRIFOLIUM, [Tourn.] Linn. (Legumin.). - Ind. Kew, ii. 1111.

Absadami, Post, in fourn. Limn. Soc. xxiv. (1888) 425. - As. occ

amoenum, Greene, Fl. Francise. (1891) 27; et Man. Bot. San, Franc. Bay (1894) 96. - Calif.

amplectons, Greene, Pittonia, i. (Feb. 1887) $6=$ stenophyllum, Natt.

arizonicum, Grene, in Erythea, iii. (1895) 18. Arizona.

Barbeyi, Gibelli \& Belli, in Atti Accad. Torino, xxii. (1887) 610 t. 8. - Ins. Karpathos.

barbulatum, Freyn \& Sint, ex Freyn, in Oest. Bot. Zeitschr. xliii. (1893) $37 \%=$ aureum, Poll.

blesense, Dodart, ex Gibelli \& Belli, Rev. crit. sp. Trifol. Ital. (1892) 14, in syn. = subterraneum. Iinur.

brachyodon, Celak, in A. Kern. Sched. F1. AustroHung. v. (1888) $1=$ arvense, Linn.

brevidens, Conrath \& Freyn, in Bull. Herb. Boiss. iii. (1895) 17\%. - As. centr.

Candollei, Post, in Fourn, Limn. Soc. xxiv. (188S) 425. - Syria.

capitellatum, Pan, Not. Bot. Fl. Espan. i.(1887) 9, ot iv. (1891)28; Willk. Suppl. Prodr. Fl. Hisp. (1893) 246. - Hisp.

Catalinae, S. Wats, ex T. S. Brandeg, in Zö̈, i. (1890) 134, nomen; et in Proc. Am. Acad. xxv. (1890) 12S. - Calif.

celtibericum, Pau, Not. Bot. F1. Espan. i. (188\%) n. 7, et iv. (1891) 28. Willk. Suppl. Prodr. F1. Hisp (1893) $244=$ montanum, Lim.

chiclense, Ball, in foum. Linn. Soc. xxii. (1889) 35 - Peruvia.

columbinum, Greene, Pitlonia, i. (Feb, 1887) 4 : Man. Bot. San. Franc. Bay (1894 96. - Calif.

costatum, Hochst. ex Engl. in Abh. Preuss. Aliad. Wiss. 1891 (1892) 252, in syn. = bilineatum Fresen.

Delilii, Dalb. ex Gibelli \& Belli, in Malpighia, iii. (1889) 230 = filiforme, Linn,

dirersifolim, Greene, Fl. Francisc. (1891) $33=$ hydrophilum, Greene.

\section{TRIFOLIUM}

dolopium, Heldr. Ef Hochst, ex Gibelli \&o Belli, in Malpighia, iii. (1889) 228. - Graecia.

Durandoi, Pomel, ex Batt. \& Trab. Fl. de l'Algèr. [Dicot.] (1889) $239=$ physodes, Stc\%.

exile, Greene, Pittonia, i. (Feb. 1887) 6. - Am. bor.

flipes, Greene, 1. c. $67=$ pauciflorum, Nutt.

flavulum, Greene, l. c. ii. (May 1892) 223: Man. Bot. San Franc. Bay (1894) 99. - Calif.

franciscanum Greene, Man. Bot. San. Franc. Bay (1894) 100 (= T. stenophyllum, Greene). - Calif.

Grmaniciae, Post, ex Gibelli \& Belli. Rev, crit. sp. Trifol. Ital. (1890) 30, in syn. = physodes, Stev.

glaucescens, Hausskn, in Mitth. Thïr, Bot. Ver. N. Folge, v. (1893) 79. - Syria.

Hanseni, Greene, in Erythea, iii. (1895) 17. - Calif.

Heldreichianum, Hausskn. in Nym. Consp. Fl. Europ. Suppl. ii. I. (1889) 90; et in Mitth. Thïr Bot.Ver. N. Folge, v. (1893) 72. - Graecia.

Hervieri, Freyn, ex Willk. Suppl. Prodr. Fl. Hisp. (1893) 245 ; et in Bull. Herb. Boiss. i. (1893) 543; Debeanx, in Rev. de Bot. xii. (1894) 38. Hisp.

Howellii, S. Wats, in Proc. Am. Acad. xxiii. (18s8) 262. - Oregon

hydrophilum, Greene, Man. Bot. San. Franc. Bay (1894) 100. - Calif.

Johnstoni, Olicer, in H. Folnust. Kilim. Exped. App. (1S86) 339, nomen; et in Trans. Limn. Soc., Ser. II. ii. (188i) 331. - Afr. trop. or

Juliani, Batt. in Bull. Soc. Bot. Fr. (188\%) 387; et int Batt. \& Trab. Fl. de l'Algér. [Dicot.] (1889) 235. (an T. Xatard, DC.?). - Algeria.

kilimandscharicum, Taub. ex Engl, in Abh. Prenss. Akad. Wiss, $1891 \mathrm{ii.}(1892) 254 .-$ Afr. trop. or,

lacerum, Greene, in Erythea, ii. (1894) 182. - Am. bor. occ

laciniatum, Greene, Pittonia, i. (Feb. 1887) \% ; et Man. Bot. San. Franc. Bay (1894) 101. - Calif.

lineare, Greene, Pittonia, i. (Feb. 1887) $6=$ depauperatum, Desv.

Minae, Lojacono, ex Ces., Pass. \& Gibelli. Comp. Fl. Ital. ii. (1886) 714 ; et Fl. Sicula, ii. I. (1891) 91 t. 9 fig. $1=$ phleoides, Pourr.

monoense, Greene, in Erythea, ii. (18.94) 181. Calif.

Morleyanum, Grzene, l. c. iii. (1895) 47. - Calif.

olivaceum, Greene, Pittonia, i. (Feb. 1887) 4; Man. Bot. San. Franc. Bay (1894) 96. - Calif,

orbelicum, Velen, in Abh. Boekm. Ges. Wiss. 1889 (1890) ii. 33 ; et Fl. Bulg. (1891) 140. - Bulg.

oreganum, Howell, in Erythea, i. (1893) 110. - Am. bor, occ.

parvulum, G. Beck, ex Stapf, in Denkschr. Akad. Wicn (1886) ii. 25. - As, occ。

perpusillum, Simonk, in Oest. Bot. Zeitschr. xl. (I890) 333 = ornithopodioides, Sm.

pinetorum, Greene, in Erythea, ii. (1894) $182(T$. involucratum, Greene). - Am, bor. occ.

ponticum, Alboff, in Soc. Imp. hortic. [Comp.-rend. Sect. Odessal (1892) extr. 7. - Reg. Cauc.

productum, Greene, in Erythea, ii.(1894) 181. Calif.

Pseudo-badium, Velen, in Abh, Boehm, Ges. Wiss. 1889 (1890) ii. 33; et Fl. Bulg. (1891) 141 [psedobadium] (= T. badium, Panc. \& Velen.). Bulg.

Pseudo-medium, Hansskn. in Mitt. Bot. Ver. Fena, v. (1887) 70. - Graecia.

guercetorum, Greene, Pittonia, i. (June 1888) $172=$ stenophyllum, Nitt.

Raddeanum, Trantv. in Act. Hort. Petrop. x. (1887) 105. - Dagest.

roscidum, Greene, Fl. Francisc. (1S91) 31 ; et Man. Bot. San Franc. Bay (1894) 98. - Calif.

Rusbyi, Greme, Pittonia, i. (Feb. 1887) 5. - Am bor. occ.

saxicolum, Small, in Bull. Torrey Bot. Chub, xxi. (1894) 302. - Reg. Cauc.

scabrellum, Greene, Pittonia, i. (Jan. 1888) $159=$ tridentatum, Lindl.

Sintenisii, Freyn, in Oest. Bot. Zeitschr. xli, (1891) 404. - As. Min.

stcnopiyllum, Greene, Fl. Francisc. (1891) $34=$ franciscanum, Grecne.
TRIFOLIUM

thessalonicum, Halaicsy of Charrel, ex Halaicsy, in Oest. Bot. Zeitschr. xli. (1891) 370. - Maced.

thionanthum, Hausskn. in Mitth. Bot. Ver. Fena, v (1887) 71 ; Gibelli of Belli, in Malpighia, iii. (1889) 20\%. - Graecia.

triflorm, Greene, Pittonia, i. (Feb. 18si) $5=$ oliganthum, Steud.

turcicum, Velen, in Abh. Boehm. Ges, Wiss. (189293) 23 = scabrum, Linn.

usambarense, Taub. ex Engl. in Abh. Preuss. Akad. Wiss. (1894) 59, nomen; et in Engl. Pflanzenu. Ost-Afr. C (1895) 208. - Afr, trop. or.

Velenowskyi, Vandas, ex Velen. Fl. Bulg. (1891) 143 - Bulg.

virescens, Greve, Pittonia. ii. (May 1892) 223 ; et Man. Bot. San Franc. Bay (1894) 99. - Calif

virginicum, Small, ex Small Ev Vail, in Mem. Torrey Bot. Club, iv. (1893) 112 t. 75. - Virginia

Willkommii, Chabert, in Bull. Herb. Boiss. iii. (1895) 145. - Hisp.

TRIFURCIA, Herb. = Herbertia, Sweet (Irid.). fulchella, Nichols. Dict. Gard. iv. (1887) $89=\mathrm{H}$. pulchella,

TRIGLOCHIN, Riv. ex Linn. (Naiad.). - Ind Kew, ii. 1116.

concinna, Davy, in Erythea, iii. (1895) 117. - Calif.

TRIGONANTHUS pendulus, Korth. ex Hook. f. Fl. Brit. Ind. v. (1890) 826 ; et in Hcok. Icon. pl. xxi. (1892) t. 2100 , in syn. = Ceratostylis pendula. Hook. $f$.

TRIGONELLA, Linn. (Legumin.), - Ind. Kew. ii. 1116 .

laxiflora, Aitch. \& Baker, in Trans. Linn. Soc. Ser. II. iii. (1886) 4\% - Turkest.

Meyeri-Joannis, Taub. ex Engl. in Abh. Preuss. Akad. Wiss, 1891 ii. (1892) 260. - Afr. trop. or. Schlumbergeri, Boiss. Fl. Or. Suppl. (188s) 163.Syria.

TRIGONOPLEURA, Hook. f. Fl. Brit. Ind. v. (1887) 399 ; et in Hook. Icon. pl. xviii. (1888) t. 1753. EUPHORBIACEAE.

malayana, Hook. f. ll.cc.-Penins. Mal.

TRIGONOSCIADIUM, Boiss, = Heracleum, Linn. (Umbell.).

intermedium, Freyn, \& Sint. ex Sint. in Oest. Bot. Zeitschr. xlii. (1892) 123. - Armen.

TRIGONOSTEMON, Blume (Euphorb; - - Ind. Kew. ii, 1118

villosus, Hook. f. Fl. Brit. Ind. v. (1887) 397. Perak.

TRIGONOTIS, Stev. (Boragin.). - Ind. Kew. Haackei, F. Muell. in Trans. Roy. Soc. Vict. N. S. i. II. (1889) 30 . - N. Guin

inoblita, F. Muell.l,, $.31 .-$ N. Guin.

mollis, Hensl. in fourn. Limn. Soc. xxvi. (1890) 153. - China.

TRIGYNAEA, Schlecht. (Anon.), - Ind. Kew, ii. 1118 .

antillana, Rolfe, in Kew Bull. (1893) 285 ; et in fourn. Bot. xxxi. (1893) 351. - Ins. S. Vincent.

TRIGYNEIA, Reichb. = Trigynaea, Schlecht. (Anon.).

botiviensis, Britton, in Bull. Torrey Bot. Club, xvi. (1889) 14. - Bolivia.

TRILEPIDEA, Van Tiegh. in Bull. Soc. Bot. Fr. xlii. (1895) $28=$ Loranthus, Linn.

Adansii, Van Tiegh. 1. c. = L. Adamsii, Chceseman. Ralphii, Van Tiegh.1.c. = L. Ralphii, Van Tiegh.

TRILEPIS, Nees = Kobresia, Willd. (Cyper.). Oliveri, Boeck. Cyper. Nov. i. (1888) $38=$ Eriospora Oliveri, C. B. Clarke. 
TRILEPIS : -

Rehmanniama, Boeck. ex C. B. Clarke, in Th. Dur. \& Schinz, Consp. Fl. Afr. v. 1894 (1895) $676=$ Eriospora Rehmanniana, C. B. Clarke.

setifera. Kuntze, Rev. Gen. (1891) 758 = Trilepis setifera, Ridl.?

TRIMENIA, Seem. (Monim.). - Ind. Kew. ii. 1119.

standifolia, Warb. in Engl. E Prantl, Natürl. Pfanzenfam. iii. 6a (1893) $3 \%$ (= Monospora grandifolia, Hochst.). - Afr, austr.

TRIMEZA. Salisb, (Irid, ), - Ind. Kew, ii, 1119. pathata, Baker, Handb. Irid. (1892) 66 [Trimezia] I= Lansbergia spathata. Klatt), - Bras.

TRIMORPHOPETALUM, Baker, in Journ Linn. Soc. xxii. (1887) 454. GERANIACEAE dorstenioides, Baker, l. c. 455. - Madag

TRINIA, Hoffm. (Umbell.). - Ind. Kew。 i. 1119. osniaca, G. Beck, in Annal. Naturh. Holmus. Wien, $\mathrm{x} .(1895) 200=$ vulgaris, $D C$

TRIODANIS, Ratin. = Specularia, Heist. (Cam-

panul.).
biffora, Greene, Man. Bot. San Franc. Bay (1894) $230=$ S. biflora, Fisch. E Mcy.

TRIODIA, R. Br. (Gramin.). - Ind. Kew. ii. 1120.

antarctica, Petrie, in Trans. N. Z. Inst. xxiii. 1890 (1891) 403 = Deschampsia Chapmani, Petrie.

australis, Petrie, l. c. xxii. 1889 (1890) 442. - N Zel.

Buckleyana, Vasey, in Contrib. U. S. Nat. Herb. ii. (1894) 540, in syn. = Sieglingia Buckleyana, Dewey.

capensis, Th. Dur, E Schinz, Consp. Fl. Afr. v. 1894 (1895) 877 (= Uralepis capensis, Kunth), Afr. austr.

ciliata, Th. Dur. \& Schinz. $l_{0}, c_{0}(=U$. ciliata. Steud.). - Seneg.

Eleusine, Th. Dur. E Schinz, l. c. $(=$ U. Eleusine, Steud.). - Afr. austr.

eragrostoides, Vasey Ef Scribn. ex Coult. in Contrib. U.S. Nat. Herb. ii. (1894) 539 ; et Illustr. N. Amz Grass. i. II. (I891) t. 34 (= Sieglingia eragrostoides, Dewey). - Am. bor. aust.

srandiflora, Vasey l.c.t. $35(=S$. avenacea, Kuntze). - Am. bor. austro-or.

livida, Th. Dur. E Schinz, Conzsp. Fl. Afr. v. 1894 (1895) 877 (=Uralepis livida, Steud.). - Afr. austr.

mollis, Th. Dur. \& Schinz, I.c. (= Leptochloa mollis, Kunth). - Seneg.

Nealleyi, Vasey, in Bull. Torrey Bot. Club.xv. (1888) 49 ; et Illustr. N. Am. Grass, i. II. (IS91) t. $36(=$ Sieglingia Nealleyi, Vasey). - Texas.

pusilla, T. Kirk, ex Petrie, in Trans. N. Z. Inst. xxiii. 1890 (1891) 405 , nomen, - N. Zel.

Vulpiastrum, K. Schum, in Engl. Pflanzenw. OstAfr. C (1895) $113=$ Rhabdochloa Vulpiastrum; De Not.

TRIODON, DC. (Rubiac.). - Ind. Kew. ii. 1120 axum, Spruce, ex K. Schum. in Mart. Fl. Bras vi. VI. (1888) 11 = Borreria dichotoma, Cham. \& Schlecht.

TRIOLAENA, Naud. (Melast.), - Ind. Kew. ii. 1120 .

Barbeyana, Cogn. in DC. Monog. Phan. vii, (1S91) 549. [Triolaena]. - Peruvia.

paleolata. F. D. Smith, in Coult. Bot. Guz. xiii. (1888) 28 ; et l. c. 543. - Guatem.

TRIPETALUM, K. Schum. in K. Schum. \& Hollr. F1, Kais. Wilh. Land(1889) 5l; et in Engl. \& Prantl, Natürl. Pflanzenfam. iii, 6 (1893) 240. GUTTIFERAE.

cymosum, K. Schum. $l l, c c .-N$. Guin.

Stuhlmannii, Harms, in Engl. Pfanzenw. Ost-Afr. C (1865) $280 .-A$ fr. trop. or.
TRIPLARIS, Loetl. (Polygon.), - Ind, Kew, ii. $11: 1$

Macombii, 7. D. Snith, in Cont. Bot. Gut. xix. 1893) $25 \%$ - Guatem

speciosa, Taub. in Bot. Fahrb. xii. Beibl, n. 27 (1890) 14. - Bras.

TRIPLASANDRA, Seem. (Aral.). - Ind. Kew ii. 1121 .

Kaalae, Hillebr. Fl. Haw. Isl. (1888) 154, - Ins. Sandvic.

Lydgatei, Hillebr. l. c. 153. - Ins. Sandvic.

meiandra, Hillebr. l. c. 152. - Ins, Sandvic.

TRIPLATEIA, Bartl. = Hymenella, Moc. \& Sesse, (Caryophyll.).

moehringiodes, Kuntze, Rev. Gen. (1891) $56=\mathrm{H}$ moehringioides, [Moc. \& Sesse] ex DC.

TRlPLEUROSPERMUM, Sch. Bip. = Matrica ria, Tourn. (Compos.)

Theterolepis, Freyn, in Bull. Herb. Boiss, iii. (1895) 349 in syn $=$ C. heterolepis, Freyn \& Sint.

repens. Freyn, 1. c. 350 , in syn. = C. repens, Freyn tenuifolium, Freyn, ex Freyn \& E. Brandis. in Verh. zool.-bot. Ges. Wien, xxxviii. (1888) $613=\mathrm{C}$ uniglandulosum, $\mathrm{V}$ is

TRIPLOCEPHALUM, O. Hoffm. in Bot. Jahrb xx. (1894) 23I ; et in Engl. \& Prantl, Natuirl. Pflanzenfam. iv. 5 (1893) 389. COMPOSITAE

Holstii, O. Hoffm. $l l . c c$. - Afr. trop. or.

TRIPODANDRA, Baill. Hist, pl. Madag. Atlas (1886) t. 50 ; Prantl, in Engl. \& Prantl, Natiirl. Pflanzenfam. iii. 2 (1888) 91. MENISPERMA $C E A E$.

Thouarsiana, Baill. ll.cc. - Madag.

TRIPODANTHUS, Van Tiegh. in Bull. Soc Bot. Fr. xlii. (1895) $178=$ Loranthus, Linn.

acutifolius, Van Tiegh. 1, c. $179=$ L. acutifolius, Ruiz, of Pay.

destructor, Van Tiegh. 1. c. $17 \%=\mathrm{L}$. destructor, $H$. $B . \& K$.

ugenioides, Van Tiegh. 1. c. = L. eugenioides, $H$ B. \& $K$.

Aagellaris, Van Tiegh. 1. c. = L. flagellaris, Cham E Schlecht.

ligustrinus, Van Tiegh. 1. c. = L. ligustrinus, Willd.

suaveolens, Van Tiegh. 1. c. = L. suaveolens, $H . B$. \& $K$

TRIPOGON, Roth (Gramin.). - Ind, Kew, ji 1122

Jacquemontii, Stapf, in Kew Bull. (1892) 85. Ind. Or.

Lisboae, Stapf, l. c. 84. - Ind. or.

TRIPOLIUM, Nees = Aster, Tourn. (Compos.). humile, Phil. in Anal. Univ. Chil. 1xxxvi. (1894) 404. - Chili

Moellevi, Phil. 1. c. 403. - Chili.

diganthum, Phil. 1. c.403. - Chili.

tenuifolium, Phil.1. c. 404. - Chili

TRIPSAGUM, Einn, (Gramin,). 一 Ind, Kew. ii. 1122

floridanum, Porter, ex Vasey, in Contrib. U.S. Nat. Herb. iii. (1892) 6; et in Bull. Torrey Bot. Club, xix. (1592) 130. - Florida.

Lemmoni, Visey, l. c. 130.- Am. bor.

TRIPTERANTHUS, Wall = Burmannia, Linn pusillus, Wall, ex Hook. f. Fl. Brit. Ind. v. (1888) $665=$ Blyxa pusilla, Thw.

TRIPTERIS, Less. (Compos.).-Ind. Kew, ii. 1122 crassifolia, O. Hoffin. in Bot. Fahrb. x. (1888) 280. -- Afr. austro-occ, extratrop.

speciosa, Tarb. l. c. sii. Beibl. n. $27(1890)$ 14.Bras.

Volkensii, O. Hoffn. in Engl. Pfanzenw. Ost-Afr. C (1895) $419 .-\mathrm{Ar}$, trop. or.
TRIPTERODENDRON, Radlk, in Sitz. Matth Phys. Akad. Muench. xx. (1890) 260-290; et in Engl. \& Prantl, Natürl. PHanzenfam. iii. 5 (1895) 342. SAPIND.ACEAE.

filicifolium, Radlk, $l l . c c .-$ Bras.

TRIPTILION, Ruiz \& Pav. (Compos.). - Ind Kew, ii. 112:3.

Berteroi, Phn, in Anal, Univ. Chil, Ixxxvii. (1894) 91 ['Triptilium]. - Chili.

compactum, Phil. l. c. 95.-Chili.

digitatum, Phil.l. c. - Chili.

humile, Phil, $l . c, 91$ - Chili.

pectinatum, Phil.l.c. 92.-Chili

pusillum, Plill.l. c. 96. - Chili.

ramulosum, Phil. l. c. 94. - Chili.

Remyanum, Phil. l. 6.89, - Chili.

TRIRAPHIS, R, Br. (Gramin.)。- Ind. Kew. ii 1123

abyssinica, Nees, ex Engl. in Abh. Prenss. Akad. Wiss. 1891 ii. (1892) 132 [Trirhaphis] (= Danthomia abyssinica, Hochst.). - Afr. trop. or

Elliotii, Rendle, ex S. Elliot, in fourn, Bot, xxix. (1891) 73. - Afr. austro-occ. extratrop.

nana, Hack. in Bot. Fahrb. xi. (1S90) 40.3 (= Diplachne nana, Nees). - Afr. austr.

purpurea, Hach. ex Schin\%, in Verh. Bot. Ver. Brand, xxx. (1888) 146. - Afr. austro-occ, extratrop. ramosissima, Hack, ez Schinz, l. c. 23\% - AfT. austro-occ, extratrop.

Rehmanni, Hock. ex Schinz, in Bull. Hirb. Boiss. iii. (1895) 388. - Afr. austr

Schinzii, Hack. ex Sininz, in Virh. Bot. Ver. Brand. xxx. (1888) 147. - Afr, austro-occ, extratrop.

TRISETUM, Pers, (Gramin.), - Ind, Kew, ii, 1123.

alifornicum, Vasey, in Illustr. N. Am. Grass. ii. 5 (1892) t. 46. - Calif.

Dozei, Franch. Miss, scient. Cap. Horn (1888) 384, t. 9. - Patag

montanum, Vasey, in Bull. Torrey Bot. Club, xiii. (1886) 118. - Am. bor

lasianthum, Perez Lara, in Anal. Soc. Esp. Hist. Nat. xv. (1886) 401; Willk. Suppl. Prodr. Fl. Hisp. (1893) 19. - Hisp.

penusylanicum, Britton, Stern \& Pogs. Prelim. Catal. (1888) $68=$ palustre, Torr

spicatum, Richter, Pl. Europ. i. (1890) 59 = subspicatum, Bean?

TRISTACHYA, Nees (Gramin.).- Ind, Kew. i. 1124

decora, Stapf, in Kow Bull. (1895) 75. - Afr. trop. hispida, K. Schum. in Engl, Pflanzenw, Ost-Afr. C (1895) $109=$ leucothrix, Trin.

inamoena, $K$. Schmo. l. c. - Afr. trop. or.

Rehmanni, Hack. ex Schinz, in Bull. Herb. Boiss. iii. (1895) 584. - Transvaal,

Tholloni, Franch. in Bull. Soc. Autun, viii. (1895) 374. - Congo gall.

TRISTANIA, R. Br. (Myrt.). - Ind. Kew. ii. 1125.

bilocularis, Stapf, in Trans. Linn. Soc. Ser. II. iv. (1894) 152, - Borneo.

Callobuxus, Niedenzu, in Engl. \& Frantl, Natïrl. Pfanzenfan. iii. 7 (1893) $89(=$ Tristaniopsis Callobuxus, Brongn. \& Gris). - X. Caled.

capitellata, Baill. ex Laness. Pl, util. Colon. Franc. (1886) 258, nomen [sphalm.?] = seq.

capitulata, Niedenzu, in Engl. \& Prantl, Natïrl. Pfanzenfam. iii. 7 (1893) 89 (= Tristaniopsis capitulata, Brongn. \& Gris). - N. Caled.

elliptica, Stapf, in Trans. Limn. Soc. Ser. II. iv. 1894) 15̃1 - Borneo.

glauca, Niedenzu, in Enol, \& Prantl, Natürl PHanzenfam. iii. 7 (1893) $89=$ glauca, Panch

Guillaini, Baill. ex Laness. Pl. util. Colon. Franc. (1886) 258 (= Tristaniopsis Guillainil, Vieill.)." N. Caled.

longivalvis, F. Muell. in Wing, Sonth. Sc. Record, N. S. ii. (April. 1886). - Austral.

Vieillardi, Niedenzu, in Engl. Eo Prantl, Natür? Pfanzenfan. iii. \% (1893) $89(=$ Tristaniopsis Vieillardi, Brongn. \& Gris). - N. Caled. 
TRISTANIOPSIS, Brongn. \& Gris = Tristania, R. Br. (Myrt.).

cafitellata, "Brongn. \& Gris " ex Laness. P1. util. Colon. Franç. $(1886)$ 25s, sphalm. = capitulata, Brongn. \& Gris.

TRISTELLATEIA, Thou. (Malpigh.). - Ind. Kew, ii. 1125

emaroinata, Baill. Hist. pl. Madar. Atlas (1894)t. 273. - Madag.

emarginata, Baker, in foum. Linn. Soo. xxii. (1887) 456. - Madas.

Greveana, Baill. Hist. pl. Madag., Atlas (1894) t 271. - Madag.

pluriseta, Baill.l.c.t. 275. - Madag.

Richardi, Baill. ll. cc. t. 274. - Madag

stenoptera, Baker. in foum. Limn. Soc. xxii. (18si) 4.56. - Madas.

TRISTEMMA, Juss. (Melastom.). - Ind. Kew.

ii. 1125. $117 \%$ - Congo.

TRISTIROPSIS, Radlk, in Th. Dur. Ind. Gen, Phan. (1885) 76 ; in Sitzb. Math.-Phys, Akad. Truench. xx. (1890) 76 ; t t in Engl. \& Prantl, Natirl. Pflanzenfam. iij, 5 (1895) 325. SAPIN$D A C E A E$.

acutangula, Radlk. $l l . c c .-$ Ins. Pacif.

ubtusangula, Radli. 7 . co. - Ins. Pacif

TRITHECANTHERA, Van Tiegh, in Bull. Soc Bot. Fr. xli. (1894) 597 = Loranthus, Linn. xiphostachya, Van Tiegh. 1. c. $599(=$ Beccarina xiphostacliya, Van Tiegrh.). - Borneo.

TRITELEIA, Dougl。= Brodiaea, Sm. (Liliac.).

Bridesii, Greene, in Bull. Calif. Acad. ii. VI (1886) $141=\mathrm{B}$. Bridgesii, $S$. Wats.

candida Greene, 1. c 1:39. - Calif.

irocea, Greene, 1.c. $14 i=$ Brodiaea crocea, $S$. IV ats.

gracilis, Greene, 1. C. = B. gracilis, S. Wats,

Hendersoni, Greene, Pittonia, i. (Feb. 1888) $164=$ B. Hendersoni, Howell.

Howellii, Greene, in Bull. Calif, Acad, ii. ri. (1886) $139=$ B. Howellii, S. Wats.

liycinthina, Greene, 1. c. = Milla hyacinthina, Baker.

ixioides, Greene, 1. c. = M. ixiondes, Baker.

Leichtlinii, Nichols. Dict. Gard. iv. (1887) $93=$ Iilla Leichtlinit, Buker.

Lemmonae, Greene, in Bull. Calif. Acad. ii. vi, 141 $=$ Brodiaea Lemmonae, S. Wats

lilacina, Greene, 1. c. 143. - Calif.

ingens, Greene, 1. c, 142. - Calif.

Palmeri, Greene, Pittonia, i. (April 1889) $292=$ Brodiaea Palmeri, S. Wats.

TRITICUM, Linn. (Gramin.). - Ind. Kew。 ii $1120 \%$

alpestre, Bruegg. in Jahresb. Naturf. Ges. Graub. xxxi, Beil. (1887-88) $205=$ caninum, Schreb

burbulatum, Simonk. Enum. Fl. Transsilv. (1886) 5.) $t=$ Agropyron glaucum, Roen. Ev Schult.

Batalini, Krassn. in Scyipt. Hort. Univ. Petrof. ii. I. (1857-85) 21. - China.

bifara, Kuntze, Rev.Gen.(1891) $795=$ Eragrostis coromandelina, Trin.

biunciale, C. Richt. Pl. Europ.i. (1890) 128 i= Acgilops binncialis, Vis.). - Dalm. Graecia.

comosum, C. Richt.l.c. (= Aeg. comosa, Sibth. \& sim.). - Graecia

crassum, Aitch. \& Hemsl. in Trans. Linn. Soc. Ser. II. iii. (18S6) 12\%. - As. centr.

Grenieri X, C. Richt. Pl. Europ. 1. (1890) 129.Gall. mer.

Heldreichii, C. Richt.l.c. 128. - Graecia

Loreti X. C. Richt. 1. c. 129. - Gall. mer.

macrochaetum, C. Richt. l. c. $128(=$ Acgilops macrochaeta, Shuttl. \& Huet). - Gall. mer.

persicum, Aitch. E Honsl. in Trans. Linn. Soc Ser. II. ii. (18\$6) 12\%. - Afghan., Persia.

\section{TRITICUM}

subulatum, Th. Dur. \& Schinz, Consp. Fl. Afr.v 1894 (1895) 939 (=Aegilops subulata, Pomel). Alceria.

uniaristatum, C. Richt. Pl. Europ.i. (1890) 128 (= Acg, miaristata, Vis.). - Dalm., Istria.

varnense, Velen. in Abh. Boehm.Ges. Wiss. (1894) n. xxix. 28. - Bulg.

TIRITOMA. Ker-Gawl. = Kniphofia, Moench (Liliac.).

Canari, Carrière, in Rev. Hort. xl. (1888) $295=\mathbf{K}$. aloides, Moench.

TRITONıA, Ker-Gawl. (Irid.). - Ind. Kew, ii. 1128.

bongensis, Pax, in Bot. Fahrb. xv. (1892) 153; Biker, IIandb. Irid. (1s92) 196. - Afr. centr. bor.

cinnabarina, Pax, l. c. 152. - Ancola

Cooperi, Baker, Hamdb. Irid. (1892) 192. - Afr. austr.

rocosmiflora X. Nichols. Dict. Gard. iv. (1887) 94. - Hybr. artef.

disticha, Baher, Handb. Irid. (1892) 193 (= Tritoni= xia disticha, Klatt). - Afr, austr.

graminifolia, Buker, l.c. 195. - Transvaal.

Krausii, Baker, l, c. 194. - Nata'

mensensis, Schweinf. in Bull. Herb. Boiss, ii. App. ii. 1894) 86. - Eritrea.

Nelsoni, Baker, Handb. Irid. (1892) 195. Transvaal.

pauciflora, Baker, l. c. 193. - Afr, austro-occ. extratrop.

riparia, Corden. Fl. Mll. Rémion (1805) 161. - Ins. Borbon

striata, Klatt, in Th. Dur. \& Schinz, Consp. F1, Afr.v. 1893 (1895) $208=$ Gladiolus striatus, Soland.

Templemanni, Bukcr, Handb. Irid. (1892) 193.Atr. austr.

teretitolia, Baker, l.c. 194. - Natal.

tigrina, Pax, in Bot. Jahrb. xv. (1892) 152. Ancola.

trinervata, Baker, Handb. Irid. (1892) 191. - Afr. austr.

unguiculata, Baker, l. c. 196. - Afr. austr.

ventricosa, Baker, l. c. 192. - Afr. austr

watsonioides, Baker, l. c. 195. - Afr. austr.

Wilsoni, Baker, in Gard. Chron. (1886) ii. 38. - Afr. austr.

TRIUMFETTA, Plum, ex Linn. (Tiliac.), - Ind. Kew. ji. 1128

abysinica, $K$. Schmm. ex Engl. in Bot. Fahrb. xv. 1892) 126 ; et in Abr. Prenss. Akad. Wiss. 1891 ii. (1892) 298. - Abyss.

brachystema, K. Schum. l. c. xv. (1893) 130.Congo mer.

Bradshawii, F. Mucll, in Vict. Natural. viii. (Oct. 1891) 85, nomen; et in Proc. Lim. Soc. N.S. IVales, Ser. II. vi. (May 1892) 460. - Austral.

brevipes, S. Wats. in Proc. Am. Acad. xxii. (1887) 400 - Mexic

buettneriacea, K. Schm. in Bot. Fahrb. xv. (1892) 129. - Afr. centr.

cucullata, Fernald, in Conlt. Bot. Gaz. xx. (1895) 532. - Mexic.

dunalis, Kuntze, Rev.Gen. (1801) 85. - Anam.

heliocarpa, K. Schum. in Bot. Fahrb. xv. (1892) 131. - Congo mer.

insignis, S. Wats, in Proc. Am. Acad.xxii. (1887) 400 - Mexic.

iomalla, K. Schnm. in Bot. Fahrb. xv. (1892) 132.Congo mer.

Jelskii, Zahlbr. in Diss. Cl. Math. Phys. Acad. litt. Cracos, xxix. (1894) 224. - Peruvia.

lepidota, K. Schum. in Bot. Fahrb. xт. (1892) $12 \%$. - Afr. trop.

macrophylla, K. Schum.l. c. 130.- - Afr, trop, or

Mastersii. E. G. Baker, in Trans. Linn. Soc. Ser. II. ir. (1894) 6 - Afr. trop.

micrantha, K. Schmm. in Bot. Fahrb. xv. (1892) 128 . Afr. trop.

Palmeri. S. Wuts. un Prac. Am. Acad, xxii. (1887) $4(0),-$ Mexic

\section{TRIUMFETTA}

seudorhomboidea, Szyszyl. Polyp. Rehmann.i

(1)

scandens, $K$. Schum, in Bot. Fahrb. xт. (1892) 125. - Angola

Sonderiana, Bolus, in fourn. Limn. Soc. xxiv. (1887). $173(=T$. trichocarpa, Sond.). - Afr. austr.

subpalmata, Soland. cx Hents. in foum. Bot. xxrii. (1890) 2. - Austral

Telekii, Schurenf. ex Engl. in Abh. Prentss. Akad. Wiss. 1891, ii (1892) 298, nomen : et in Hochuel, zun Rudolph See, Append. (1892) 15. - Afr. trop. or.

trachystema, $K$. Schum. in Bot. Fahrb. xv. (1892) 130. - Congo mer.

TRIURIS, Miers (Triurid.). - Ind, Kew, ii. 1130. brevistylis, F. D. Smith, in Coult. Bot. Gas. Xvi.
(1591) 14; K. Schnm. in Mart. Fl. Bras. iii. III. (1894) 663. - Guatem., Bras.

major, Ponlsen, in Bot. Tidsstr. xvii. (1890) $296: K$. Schum. in Mart. Fl. Bras, iii. III. (1894) 603.Bras.

TRIXIS, P. Br. (Compos.). - Ind, Kew. î 1130 .

gigas, Wawra, Itin. Princ. Sax. Coburg. ii. (1S88) 50. Bras.

hyposericea, S. Wats. in Proc. Am. Acad. xxv. (1890) 15\%. - Mexic

TROCHERA, Rich = Ehrharta, Thunb. (Gramin.).

acmula aphylla, aienacea, barbinodis, brewifolia, Colensoi,dura, Eckloniana, festucacea, giantea, longiflora, Microlaena, Mncmateia, orata, panicea, paniciformis, pusilla, ramosa, mpestris, stricta, triandra, uniflora. zaricosa, zersicolor, villosa, Kuntze. Rev. Gen. (1891) $975=$ homonyma omnia Ehrhartae auriculata, Kuntze, 1. c. = E. calycina, Su. capensis, Kuntze, 1. c. = E. Mnemateia, Linn. $f$ geniculata, Kuntze, 1. c. = E. calycina, Sm laxiflora Kuntze, 1. c. = E. calycina, $S m$. longiseta, Kuntze, 1. c. = E. longiflora, Sm melicodss, Kuntze, 1. c, = E. melicoides, Thunb. Ottonis, Kuntze, 1. c. = E. longifolia, Sclizad.

TROCHETIA, DC. (Stercul.). - Ind. Kew. ii. 1130

ranulata, Corden. Fl. I7l. Rémion (1895) 318. Ins. Borbon.

TROLLIUS, Linn. (Ranuncul.). - Ind. Kew, ii. 1132

ranunculoides, Hemsl, in fourn. Limn. Soc. xxix. (1892) 301. - China occ

Tatrac, Borb. ex Oest, Bot. Zeitschr. x1i. (1891) $421=$ europaeus, $\operatorname{Lim}$

TROPAEOLUM. Linn. (Geran.). - Ind. Kew. ii. 1132.

argentinum, Buchenau, in Bot. Fahr. xv. (1892) 221 . - Reg. Argent.

bimaculatum, Klotzsch, ex Buchenan, l, c. 217.-Am. centr.

Buchenavianum, Hieron. l. c. xx. Beibl. n. 49 (1895) 33. - Ecuad.

camariense, Hort. ex Kew Bull. iii. (1889) $55=$ aduncum, $S m$,

capillare, Buchenam, in Bot. Fahrb. xv. (1892) 219. - Reg Argent.

Cochabambae, Buchenan, l. c. xxii. (1.95) 161.Bolivia.

Glaziovii, Buchenau, l. c.xv. (1892) 220.-Bras.

Kuntzeanum, Buchonan, l. c. xxii. (1895) 163.Bolivia.

Loichtlinii $\times$, Hort, Leichtl. in Rev. Hortic. Ixvii. (1895) $384 .-$ Hybr. artef.

rectangulum, Buchenan, in Bot. Fahrb. xxii. (1895) 165. - Bolivia.

Seemanni, Buchenan, l. c. XV. (1892) 226. Perur: 
TROPHAEUM, Linn. = Tropaeolum, Linn. (Geran.).

atrosanguincum, artuream, Beuthii, bicolor, bogotense, brachyceras, brasiliense. Bridgesii, Chaixianum, chilense, chrysanthum, ciliatum, cirrhipes, crenatiflorm, crenatum, Deckeriamum, digitatum, dipetalum, cdule, elegans, emarginatum, floribundum, Funckii, Haynianum, Hookerianum, incrassatum, farattii, Klotzschii, Lechlevi, leptophyllum, linearifolium, longifolium. Lechleri, leptophylm, marmoratum, minus, Moritzianum. mucronatnm, mubigenum, oxalianthum, parsiflorum, pentaphyllum, peltophorum, pendulum, peregrinum, pilostm, pinnatum, polyphyllum, pubescens, quinatum, Reineckianum, rhizophorum, speciosum, tenellnm, tenuirostre, trilobum, tuberosum, umbellatum, Wagnerianum. IVarmingianum, Zanderi, Kuntze, Rev, Gen. (1891) $97=$ liomonyma omnia Tropaeoli.

aduncum, Kuntze, 1. c. = T. peregrinum, Linn.

aureum, Kuntze, 1. c. = T. azureum, Miers.

denticulatum, Kuntze, 1. c. = T. denticulatum, Ruiz of Par. [ubi ?] fide cl. Kuntze.

Popelarii, Kuntze, 1. c. = T. albiflorum, Limn.

rlomboderm, Kuntze, 1. c. $=$ T. rhomboideum, Luinn.

tricolor, Kuntze, 1.c. = T. tricolorum, Swect.

TROPIDIA, Lindl, (Orchid.). - Ind. Kew. ii. 1133.

formosana, Rolfe, in Annt. Bot. ix. (1895) 158.Ins. Formosa.

Maingayi, Hook.f. Fl. Brit. Ind. vi. (1890) 93.Penins. Mal.

Reichenbachiana, Kraenzl. in Bot. Falmb. vii. (1886 442 ; et in Forschungsr. Gazelle [Siphonog.] (1889) 25, t. 7, fig. 1. - Ins. Lucepara.

Thwaitesii, Hook. f. Fl. Brit. Ind. vi. (1890) 93.Zeyl.

TROPIDOCARPUM, Hook. (Crucif.). - Ind. Kew. ii. 1133

capparideum, Greene, Pittonia, i. (Oct. 1888) 217; et Man. Bot. San Franc. Bay (1894) 27. - Calif. dubium, Davids. in Erythea, i1. (1894) 179. - Calif

TROUETTIA, Pierre, ex Baill. Hist. des pl, xiii (1895) 295 = Chrysophyllum. Linn. (Sapot.) leptoclada, Pierre, ex Baill. in Bull. Soc. Linn Paris, ii. (1891) 945. - N. Caled.

TROXIMON, [Nutt.] in Fras. (Compos.), - Ind

Kew, ii. 1133.
arizonicum, Grecne, Pittonia, ii. (May 1890) 78. Am. bor. occ.

elatum, Greene, i. c. i. (July (1887) \%1. - Calif.

Marshallii, Greene, l. c. 1. (June 1888) 174. - Calif

plebeium, Greene, l. c, ii. (May 1890) 79. - Calif.

purpurenm, Greene, 1. c. 76 (= Macrorhynclus purpureus, A. Gray) = aurantiacum, Hook.

TRYPHOSTEMMA, Harv. (Passifl.). - Ind

Kew. ii. 1134.
apetalum, E. G. Baker, in Trans, Linn. Soc. Ser. II. iv. (1894) 14. - Afr trop.

heterophyllum, Engl. Bot. Fahrb. xiv, (1891) 388 , in obs, et xv. (1893) $57 \%:=$ Basananthe heterophylla, Schinz). - Afr. austro-occ. extratrop.

lanceolatum, Engl. $i l$. cc. - Afr. trop. or.

littorale, Engl. 11. cc. 389 , et $561=$ Basananthe littoralis, Peyr.

niloticum, Engl. U. cc. - Afr. centr. bor. or.

nummularium, Engl.l. c.58S (= Basananthe Nummularia. Welw.). - Angola

pilosum, Harms, in Engl. Pfanzenw. Ost-Afr. C (1895) $280 .-$ Afr. trop. or.

Schinzianum, Harms, in Engl. \& Prantl, Naturl. Pfanzenfam, iii: 6a (1893) 72, 75 fig. 25a, 26c ct in Engl. Pflansentw. Ost-Afr. C (1895) 281. Afr. trop. or.

trịflorum, Bolus, in Hook. Icon.pl. xix. (1889) t. 1838 [triflora]. - Afr. trop, austro-or.

trilobum, Bolus, ex Schinz, in Bot. Falurb. xv. Beibl. n. 33 (1892) 2, in obs. [triloba]. - Afr. austr.

Volkensii, Hamms, l. e. xix. Beibl. n. 47 (1894) 40 . - Afr trop. or.
TSJERACANARINAM, Adans. (melius-UM) = Cansjera, Juss. (Olacin.)

grossulariodes, Kuntze, Rev, Gen. (1891) $113=\mathrm{C}$ grossularioides, Blanco.

Helferianum, Kuntze, 1. c. = C. Helferiana, Valeton. lancelatrm, Kuntze, 1. c. = C. Rheedii, F. F. Gmel. leptostacliyum, Kuntze, 1. c. = C. leptostachya, Bcnth.

parifiform, Kuntze, 1. c. = C. parvifolia, Kurz.

pentandrum, Kuntze, 1. c. = Antidesma Cumingii, Mzell. Arg.

Rheedii, Kuntze, 1.c. = Cansjera Rheedii, $\mathcal{F} . F$. Gmel.

TSUGA, Carr.(Conif.). - Ind. Kew, ii. 1134 ajanensis, Regel, ex Beissn. Handb. Nadelholzk (1891) $385=$ Picea ajanensis, Fisch

Araragi, Koehne, Deutsche Dendrol.(1893) $10=$ T. Sieboldi, Carr.

dumosa, Eichl, in Engl, \& Prantl, Natürl. Pflanzen. fam. ii. 1 (1887) $80=$ Brunoniana, Carr.

japonica, Shirasawa, in Tokyo Bot. Mag. iz.. (1895) 84; et ex Rev. Hortic. 1xvii. (1895) 274. - Japon.

TUBIFLORA, J. F. Gmel. = Elytraria, Michx (Acanth.)

acaulis. Kuntze, Rev. Gen. (1891) $500=$ E. crenata, Vahl.

pachystachya, Kuntze, 1. c, = E. tridentata, Vahl. squamosa, Kuntze, 1. c. = E. tridentata, Vahl. TUCHIROA, Kuntze, Rev. Gen. (1891) $211=$
TOUCHIROA, Aubl. = Grudia, Schreb. (Legumin.).

acuminata, bracteata, oblonga, oricntalis, senegalensis, zeylanica, Kuntze, 1. c. = homonyma omnia Crudiae.

spicuta, Kuntze, 1.c. = C. Schreberi, F. F. Gnel. tomentosa, Kuntze, 1. c. = C. Parivoa, DC.

TULBAGHIA, Heist. Descr. Brunsv. (1753) 10, ex Kuntze, Rer. Gen. (1891) 718 = Agapanthus. L'Hérit. (Liliac.).

africana, Kuntze, 1. c. = A. umbellatus, L'Hérit. minor, Kuntze, 1. c, = A. umbellatus, L'Hirit.

praecox, Kuntze, 1. c. = A, umbellatus, L'Hértt.

TULBAGHIA, Linn。(Liliac.). - - Ind. Kew. ii, 1135 .

Bragae, Engl. Pfanzcne. Ost-Afr. C (1895) 141. Afr trop. or

natalensis, Baker, in Gard. Chron. (1891) i. 668. Natal.

pauciflora, Baker, in Bot. Falub. xv. Beibl. n. 35 (18.2) 6. - Afr. austr.

TULIPA, Linn. (Liliac.). - Ind. Kew. ii, 1135. aximcnsis, Perr. \& Song. in Bull. Herb. Boiss, ii, (1894) $435=T$. Didieri, ford.?

balcanica, Velen. in Abh. Boehn. Ges. Wiss. 1892 n. 37. (1893) 65. - Bulg.

Baldaccii, Mattei, in Malpighia, vii. (1893) 56. Italia,

Batalini, Regel, in Act. Hort. Petrop. x. (1889) 688; et in Gartenf, xxxviii. (1889) 506, t. 1307 fig. 2. -Buchara.

Boeltgeri, Regel, l. c. x. (1887) 366. - Buchara.

ciliatula, Baker, in Gard. Chron. $(1890)$ i. 640, fig. 106. - As. Min.

concinna, Buker, l. c. (1893) i. 538. - As. occ.

Dammani, Regel, in Act. Hort. Petrop. x. (I889) 688; et in Gartenf. xxxviii. (1889) 314 - Syria.

Leichtlini, Regel, ll. cc. x. (1887) 366 ; et xxxvii. (1888) 93. - As centr.

Marjoletti, Perr. \& Song. in Bull. Herb. Boiss, ii. (1894) 432. - Sabaud.

Maximowiczii, Regel, in Act. Hort. Petrop. x. (1889) 687 ; et in Gartenfl. xxxviii. (1889) 505 t. 1307 fig. 1. - Buchara.

Regeli, Krassn. in Script. Univ. Petrop. ii. (1887-88) 21. - As, centr.

Sintenisii, Baker, in Gard. Chron. (1891) j. 330; et in Bot. Mag. (1891) t. 7193. - Armenia.

Sprengeri, Baker, l. c. (1894) i. 716 ; et in Gartenfl. xliv. (1895) 57, t. 1411، - Armenia.
TUMION, Rafin. ex Greene, Pittonia, ii. (Sept. 1891) $195=$ Torreya, Arn. (Conif.)

californicum, Greene, 1. c. $=\mathrm{T}$. californica, Torn grande, Greene, 1. c. $194=$ T. grandis, Fortunce. muciferum, Greene,1. c. = T. nucifera, Sieb, et Zuce. taxifolinm, Greene, 1. c. = T. taxifolia, Amn.

TUNATEA, Kuntze, Rev.Gen.(1891) $211=$ TOU NATEA, Aubl: = Swartzia, Schreb. (Legumin.).

acuminata, acutifolia, alterna, apetala, aptera, argentea, auriculata, Benthamiana, Blanchetii, brachystachya, bracteosa, calophylla, cardiosperma, caribaea, conferta. corrugata, crocea, cuspidata, dicarpa, discolor, dodecandra, clegans, eviocarpa, floribunda, fugax, grandifolia, Langsdorfi, latifolich, laurifolia, laxiflora, leiocalycina, leptopetala, longifolia, macrocarpa. macrostachya, Martii, microcarpa, mollis, myrtifolia. oblonga, panamensis, pendula, picta, pilulifera, pinnata, polyphylla, raccnosa, recurva, rosea, Schonnburgkii, sericea, Trianae, celutina, Kuntze, Rev. Gen. (1891) 211 = homonyma.omnia Swartziae.

arborescens, Kuntze, 1, c, = S. triphylla, Willd.

Flemingi, Kuntze, 1. c. = S. Flemingi, Raddi.

Hostmannil, Kuntze, 1. c. = S. Hostmanni, Benth

Matthewsii, Kuntze, 1. c, = S. Mathewsii, Benth.

multijuga, Kuntze, 1. c. = S. multijuga, Vog.

Panacoco, Kuntze, 1. c, = S. tomentosa, $D C$.

simplex, Kuntze, 1. $\mathrm{c}_{0}=\mathrm{S}$. grandifiora, Willd.

Sprucei, Kuntze, 1. c. = S. Sprucei, Benth.

TUNICA, Hall, (Caryoph.). - Ind, Kew. ii. 1136.

Davaena, Coss. in Bull. Soc. Bot. Fy. xxxvi. (1889) 103. - Cyren.

filiformis, Post, in Bull. Herb. Boiss, i. (1893) 17 , 411. - Syria.

gracilis, Williams, in fourn. Bot. xxviii. (1890) 196. - Kurdist.

Haynaldiana fanka, ex Nyman, Consp. Fl. Em Suppl. ii. x. (1889) 57; et ex Willians, in fourn Bot. xxviii. (1890) 197 (= Gypsophila Haynal. diana. Janka). - Reg. Banat.

macra, Boiss. E Hausskn; ex Boiss. Fl. Or. Suppl. (1888) 81. - Persia.

Peronini, Boiss. l.c. - As. Min.

phthiotica, Boiss. \&. Heldr. ex Boiss. 7. c. 8.3. Graecia.

rhodopea, Velen, in Abh. Boehm. Ges. Wiss. 1894

n. xxix. (1895) 4 (=T. ochroleuca, Velen.). - Bulg.

TUPA, G. Don = Lobelia, Plum. (Campanu1.) axilliftora, Phil. in Anal. Univ. Chil. xc. (1895) ise - Chili.

Gayana, Phil. 1. c. 190. - Chili.

glaucescens, Phil. 1. c. 187. - Chili.

Kingi Phil.1. c, 189. - Chili.

linearifolia, Phil. 1. c. 190 - Chili.

serrata, Phil. 1. c. 189. - Chili.

TUPISTRA. Ker-Gawl. (Liliac.), - Ind. Kew. ii.

chinensis, Baker, in Hook. Icon. pl. xix. (1889) t. 186\%. - China.

chlorantha, Baill. in Bull. Soc. Linn. Paris, ii. (1893) 1115. - China.

Clarkei, Hook. f. 17. Brit. Ind. vi. (1892) 325. Reg. Himal.

Fargesii, Baill. in Bull. Soc. Linn. Paris, ii. (1893) 1114 (= Campylandra Fargesii, Baill.). - China. tonkinensis, Baill.l.c.1116. - Tonkin.

Wattii, Hook. f. Fl. Brit. Ind. vi. (1892) $325,-$ Reg. Himal.

TURNERA, Plum. ex Linn. (Turnerac.). - Ind. Kew. ii. 1137.

discolor, Urban, in Bot. Fahrb. xvii. (1S93) 506 . Bras.

madacascariensis, Baill. in Bull. Soc. Lim, Paris, i. (1886) 582 (= Piriqueta madagascariensis, Urbán). - Mada

Palmeri, S. Wats, in Proi. Am. Aand. xxii, (1887) 413. - Mexic

revoluta, Urban, in Bot. Fahrb. xvii. (1893) 508. Bras.

setifera, Baill. in Bull. Soc. Linn. Paris, i. (1886) 582. - Madag. 
TuRRAEA, Linn. (Meliac.). - Ind, Kew, ii 1138 .

ambohitsiana, Baill. Hist. Dl. Madag. Atlas (1892) t 253. - Madag.

Bakeriana, Baill. l. c. t. 254c. - Madag.

cumeata. Guerke, inz Engl. Pflanzenw. Ost-Afr. C (1895) 231. - Afr. trop. or.

cuneifolia, Baker, in Fourn. Linn. Soc. xxv. (is89) 305. - Madag.

emetica, Engl. Pfanzenw. Ost-Afr. A (1895) 94, nomen. $\rightarrow$ Afr, trop.

Fischeri, Guckk, in Bot. Fahwb. xiv. (1891) 308. Afr. trop, or

Grandidieri, Baill. Hist. pl. Madag., Atlas (1892) t. 254c. - Madag.

Holstii, Guerke, in Bot. Fahrb. xix. Beibl, n. 47 (1894) 35. - Afr, trop, or.

kilimandscharica, Guerke, in Engl. Pfanzenw. Ost. Afr. C (1895) 230. - Afr. trop.or.

lanceolata, Baill. Hist. pl. Madag., Atlas (1892) t. 252. - Madas.

Iycioides, Buill. 1. c. t. 254d. - Madas.

lycioides, Baker, in Ḱ Bu Bull. (1895) 212. - Reg. Somal.

malifolia, Bakcr, in foum. Lim. Soc. xxv, (1889) 305. - Madag.

obovata, Guerke, in Bot. Fahrb.xiv. (1891) 308.Madag.

parvifolia, Defters, in Bull. Soc. Bot. Fr. xlii. (1895) :301. - Algeria.

Pervillei, Baill. Hist. pl. Madıg., Atlas (1892) t. 252a. - Madag.

Thamnifolia, Baker, in foum. Limn. Soc. xxv. (1889) 305. - Madag.

Thombifolia, Baker, lo c. xxii. (1887) 458. Madas.

Richardi, Baill. Hist. pl. Madag., Atlas, (1892) t. 254. - Madag.

robusta, Guerke, in Bot. Fahrb. xix. Beibl. n. 4 i (1894) 34. - Afr. trop. or.

scabra, Baill. Hist, p. Madag., Atlas (1892) t. 254 b. - Madag.

subcordata, Guerke, in Engl, Pfanzenw. Ost-Afra C (1895) 232. - Afr. trop. or.

usambarensis, Gucrke, l. c. 231. - Afr. trop. or.

venulosa, Baker, in fourn. Linn. Soc, xxii. (1887) 458. - Madas

Volkensii, Guerke, in Bot. Fahrb. xix. Beibl. n. 47 (1894) 34. - Afr. trop. or.

TURRIGERA, Decne (Asclep.). - Ind. Kew, ii 1139.

Lessonii, K. Schun. in Engl. \& Prantl, Natïl. Pfanzenfam.iv. 2(1895) 22\%. 一 Chili.

TURRITIS, Tourn. ex Linn. = Arabis, Linn (Crucif.)

alpina Prantl, in Engl. \& Prantl, Natürl. Pflanzenfam. iii. 2 (Is?i) $192=$ A. brassicaeformis W all .

TYLACHIUM, Lour, fide Gilg, in Notizbl. Bot Gart. Berl. (1895) 63 = Thylachium, Lour (Capparid.).

albo-violaceum, Gilg, ?. c.64. - Afr. trop. or

macrophyllum, Gilg, l. c.63. - Afr. trop.

TYLEGARPUS, Eng1. in Eng1. \& Prant1, Natïr1 Pflanzenfam. iii. 5 (1893) 247. OLACINEAE.

papranus, Engl. l.c. - N. Guin.

TYLLOMA, D. Don = Chaetanthera, Ruiz \& Pav. (Compos.).

albiflonum, Phil. in Anal. Univ, Chil. 1xxxy, (1894) 843. - Chili.

brachyleprs, Phil. 1. c. S42. - Chili.

ciliatum, Phil. 1. c.841. - Chili.

eurylepis, Phil. 1. c, 840 . - Chili.

gnaphalioides, Phil-1. C. 843, - Chili.

mimutum, Phil, in Anal. Mus. nac. Chile (1891) 33. - Chili.

rotundifolinm, Phil. in Anal. Univ. Chil. Ixxxv. (1S94) 843, - Chili.

Stolpi, Phil.1. c. 841. - Chili

styictum, Phil. 1. c. 840 . - Chili.
TYLOPHORA, R. Br. (Asclep.), - Ind. Kew, ii. 1140.

Adalinae, K. Schum. in Engl. \& Prantl, Natiurl. Pfanzenfam. iv. 2 (1895) 286. - Afr, trop.

apiculata, K. Schum, in Engl. Pfanzonw. Ost-Afr. C (1895) 325. - Afr. trop. or.

biglandulosa, $K$. Schum, in Engl. E Prantl, Natür. Pfanzenfam, iv. 2 (1895) 256. - Endl.

cameroonica, N.E. Br. in Ko Bull. (1895) 25\%.Kamerun.

Conspicua, N.E. Br. l. C. - Angola.

cordifolia, Benth, \& Hook. f, ex Kuntze, Rev. Gen. (1891) 424. - China

Flanagani, Schlechter, in Bot. Fahrb. xviii. Beibl. n. 45 (1894) 11. - Afr. austr.

Hellwigii, Warb. in Bot. Fahrb, xiii. (1891) 410 . N. Guin.

Leibiana, F. Muell. in foum. Roy. Soc. N.S. Wales, xxiv. 1890 (1891) 78. - Austral.

longipedunculata, Schlechter, in Journ. Bot. xxxiii. (1895) $338=$ Tylophoropsis heterophylla, $N . E$ $\mathrm{Br}$

oblonga, N. E. Br. in Kew Bull. (1895) 25\%. Sierra Leone.

oculata, $N, E, B r, l, 6.112$ - Ins. Fernando Po.

simiana, Schlechter, in Bot, fahrb. xviii. Beibl. n. 45 (1894) 33. - Afr, austr.

stenoloba, N. E. Br. in Kow Bull. (1895) 257. Afr. trop. or.

tenuipeduncliata, $K$. Schum. in Bot. Fahrb. xvii. (1893) 144. - Afr. trop.

umbellata, Schlechter, l. c. xviii. Beibl. n, 45 (1894) 11. - Afr. austr

Thwaitesii, K. Schum. in Engl. Eo Prantl, Natür. Pflanzenfam. iv. 2 (1895) 286. - Zeylan.

villosa, Benth. E Hook.f. ex Kuntze, Rev. Gent. (1891) 424 (= Vincotoxicum Miquclianum, Kuntze). Ind. bat.

yemensis, Deflers, Voy, au Yémen (1889) $165=$ Tylophoropsis yemensis, $N . E . B r$.

TYLOPHOROPSIS, N. E. Br. in Gard, Chron. (1894) ii. 244; K. Schum. in Engl. \& Prant Natür. Pflanzenfam. iv.2 (1895) 255. ASCLE $P I A D E A E$.

heterophylla, N.E. Br. l. c. 245; Oliver, in Hook Icon. ph. xxiv. (1895) t. 2573 ( $=$ Tylophora heterophylla, Rich.). - Abyss.

yemensis, N. E. Br. l. c. 244 ( $=$ T. yemensis, Deflers). - Arabia

TYNANTHUS, Miers (Bignon.). - Ind. Kew. ii 1141.

guatemalensis, 7. D. Smith, in Coult. Bot. Gaz. xviii, (1893) 6, 209, t. 22, - Guatem.

igneus, Barb. Rodr. [Herb. Mus. bot. Amaz n. 662] Vellosia, 1885̃-88, Sec. ediç. (1891) 51, t. 10.Bras.

TYNNANTHUS, “Miers " ex K. Schum. in Engl, \& Prantl, Natül. Pflanzenfam. iv. 3b (1894) 221 $=$ praec.

TYPHA, Linn. (Typhac.), - Ind. Kew, ii, 1141. aethiopica, Kronfcld, in Verh, zool.-bot. Ges, Wien, xxxix. (I8S9) 162. - Afr, trop. or.

bractcata, Greene, in Bull. Calif. Acad. il. VII. (1887) $413=$ domingensis Pers.

clongata, Dudley, Cayuga F1. (1889) $102=1$ atifolia, Linn.

Maresi, Batt, in Bull. Soc. Bot. Fr. xxxiv. (1887) 389 ; et Batt. \& Trab. Fl. de l'Algér. [Monoc.] (1895) 18 = latifolia, Linn.

spathulaefolia, Kronfeld, in Verh. zool.-bot. Ges, Wien, xxxvii. (1887) Sitzb. 15 = latifolia, Limn。

TYPHONIUM, Schott (Aroid.). - Ind. Kew, ii, 1142 .

brevipes, Hook. f. Fl. Brit. Ind, vi. (1893)511.Reg. Himal.

Millari, F. M. Bailey, in Dept. Agric. Brisbane Bot. Bull. ii. (1891) 20. - Austral.

TYSONIA, Bolus, in Hook. Icon, pl. xx. (1890) t. 1942; Guerke, in Engl. \& Prantl, Natúrl Pflanzenfam. iv. 3a (1894) 106. BORAGINEAE africana, Bolus, ll.co. - Atr. austr.

\section{U}

UAPACA. Baill. (Euphorb, ), - Ind. Kew. ii. 1142. Mole, Pax, in Bot. Fahrb. xix. (1894) 79 Congo.

Teusczii, Pax, l.c. - Angola.

UBOCHEA, Baill. Hist. des pl. xi. (1891) 103 ; Briq. in Eng1. \& Prantl. Naturl. Pflanzenfam. iv. 3a (1894) 155. VERBENACEAE

dichotoma, Baill. ll. cc. - Ins. Capit. Virid.

UCACOU, Adans. = Synedrella, Gaertn. (Compos.).

odiflonm, Hitchcock, in Missouri Bot. Gard. Rep. iv. (1893) $100=$ S. nodiflora, Gaertn.

UEBELINIA, Hochst. (Caryoph.), - Ind. Kew. ii. 1142.

hispida, Pax, in Bot. Fahrb. xvii. (1893) 586. Kamerun.

UECHTRITZIA, Freyn, in Oest. Bot. Zeitschr. xlii. (1892) 240; O. Hoffm. in Engl, \& Prantl, Natiurl. Pflanzenfam. iv, 5 (1893) 391. COMPOSITAE

armena, Freyn \& Sint. cx Freyn, ll. cc. 241, 391. Armen. turc.

ULEX, Linn. (Legumin.). - Ind. Kew. i. 1143. major, St Lacrer, in Cariot, Etud. des fl. éd. 8 , ii. (1889) $158=$ europaens, Limn

minor, St Lager, 1, c. = nanus, Iinn.

ULMARIA, [Tourn.] Hill. = Spiraea, Linn. (Rosac.).

Ulmaria, Barnhort, in Bull. Torrey Bot, Club. xxs (1894) $491=\mathrm{S}$. Ulmaria, Linn.

ULMUS, [Tourn.] Linn. (Urtic.). - Ind. Kew, ii, 1143

adiantifolia, Hort, ex Diprel, Handb. Laubholzk. ii. (1892) $29=$ scabra, Mill.

asperrima, Simonk. Fl. von Grossward. (1890), ex Oest. Bot. Zeitschr. xl. (1890) 424. -Hung

castaneifolia, Hensl. in fourn. Limn. Soc, xxvi. (1891) 446. - China.

cucullata, Hort. ex Dippel, Handb. Laubholzk, ii, (1892) $25=$ campestris, Linn.

Dampieri, Hort. ex Dippel, 1. c. $28=$ scabra, Mill.

fastigiata, Hort. ex Dippel, 1. c. 24, $28=$ campestris, Linn.

glandalosa, “Lindl. » ex Dippel, 1. c. 26, $591=$ glabra, Mill.

intermedia, Hort. ex Dippel, 1. c. $29=$ scabra, Mill.

mommentalis, Rinz, ex Dippe1, 1. c. 29, $590=$ campestris, Linn.

pedunculata, Hook. f. et Thoms. ex Hook. f. FI. Brit, Ind. v. (18s8) 480 , in syn. = Wallichiana, Planch.

Pitteursii, Ch. Morren, ex Dippel. Handb. Laubholzk. ii (1892) 29 = scabra, Mill

Pseudosuberosa, Blocki, in Oest. Bot. Zeitschr, xxxvii. (1887) $130=$ campestris, Linn,

pumila, Hook. f. \& Thoms, ex Hook. f. Fl. Brit, Ind. v. (1888) 481, in syn. = parvifolia, facq. pyramidalis, Hort. ex Dippel, Handb. Laubholzk. ii. (1892) 28,590 = montana, With.

Rosscelsii, Hort. ex Dippel, 1. c. 25, $590=$ campestris, Linn,

tridens, Hort. ex Dippel, 1, c. $29=$ scabra, Mill.

triserrata, Hort ex Dippel, 1, c, $29=$ scabra, Mill.

Verschaffelti, Hort. ex Dippel, 1. c. 39. = Zelkowa japonica, Dippel.

virens, Hort. ex Dippe1, 1. c. 25, 591 = campestris, Linn. 
UMBILICUS, DC $=$ Cotyledon, Tourn. (Crassul.). aetners, Tornab. Fl. Sicula (1887) 249. - Sicil. gendjnamensis, Stapf, in Denkschr. Akad. Wien 1886) ii. 57. - As. occ.

UMBRACULUM, Rumpf, Herb. Amboin, iii. (1743) 124, t. 82, ex Kuntze, Rev. Gen. (1891) $405=$ Aegiceras, Gaertn. (Myrsin.).

co'miculatum, Kuntze, 1. c. = A. majus, Gaerin.

UNCARIA, Burch. = Harpagophytum, DC (Pedal.)

Burchalli, Grandidieri, leptocurpa, peltata, Zeyheri, Kuntze, Rev. Gen. (1821) $481=$ homonyma omnia Harpagophyti.

UNCARIA, Schreb. (Rubiac.). - Ind. Kew, ii. 1145

Bernaysii, F. Wucll, in Australas. Fourn. Pharm. Feb. 1886) 45; et ex Bot. Centralbl, xxvi. (1886) 114. - N. Guin.

UNCARINA, Stapf, in Engl. \& Prantl, Natïrl. Pflanzenfam. iv. 3b (1895) 261. PEDALINEAE.

Didierii, Stapf, l.c. (= Harpagophytum Grandidieri, Baill.). - Madag.

peltata, Stapf, l. c. (= H. peltatum, Baker). Madag.

UNGINIA, Pers. (Cyper.). - Ind. Kew. ii. 1145 capillaris, Colenso, in Trans. N. Z. Inst. xx. 1887 (ISs8) $210=$ riparia, $R$. Br.
(I)

Clarkii, Petrie, l. c. 185. - N. Zel.

disticha, Colenso, in Trans. N. Z. Inst. xx. 188 (1888) $210 .-\mathrm{N}$. Zel.

macrotricha. Franch, Miss, scient. Cap fion, y. [Phan.] (1889) 379 t. 7a. - Patag.

multifolia, Boeck. in Bot. Fahrb. viii. (1887) 207. Columb.

polyneura, Cotenso, in Trans. N. Z. Inst, xix. 1886 (1887) $270 .-\mathrm{N} . \mathrm{Zel}$.

variegata. Colenso, l. c. xx, $188 \pi$ (1888) 211. - N Zel.

UNIFOLIUM, Hall. = Maianthemum, Weber (Liliac.).

amplexicaule, Greene, in Bull. Torrey Bot. Club, xv, 1888; 287 = Smilacina racemosa, Dest.

bifolium. Greene, 1. c.; Millsp. Metasp. Minn. (1892) 152 = Maian themum Convallaria, Weber bifolium, Kuntze, Rev. Gen. (1891) $718=$ praec canadense, Greene, in Bull. Torrey Bot. Club, xv. (1888) 287 = Maianthemum Convallaria, Weber. dilatatum, Greene, Man, Bot, San Franc. Bay (1894) $316=\mathrm{M}$. Convallaria, $W_{\text {eber }}$

litiaceum, Greene, Pittonia, i. (Mar. 1889) $280=$ Smilacina stellata, Desf.

racemosum, Britton, in Trans. N. Y. Acad. Sci, viii, (1889) $74=$ S. racemosa. Desf.

sessilifolium, Britton, in Bull. Torrey Bot. Club, xv, (1888) $287=$ S. sessilifolia, Nutt.

stellatum, Britton, 1. c. = S. stellata, Desf.

trifolium, Britton, 1. $\mathrm{c}_{0}=\mathrm{S}$. trifolia, Desf.

UNIOLA, Linn. (Gramin.), - Ind, Kew, ii. 1146 effusa, Foum. Gram. Mexic. 1881 (1886) 122. Mexic.

laxa, Britton, Stern \& Pogg. Prelim, Catal, (1888) $69=$ gracilis, Michx .

lucens, Fourn. Gram. Mexic. 1881 (1886) 122. Mexic.

longifolia, Scribn. in Bull. Torrey Bot. Club, xxi. (1894) 229. - Am. bor

Muelleri, Fourn. Gram, Mexic. 1881 (1886) 122. Mexic,

Palmeri, Vasey, in Gard. and For. ii. (1889) 401 ou 402 fig. 124 ; et Ill. N. Am. Grass, i. (1893) t. 70. - Mexic.

Pittieri, Hack, in Bull. Herb. Boiss, iii. (J895) 6, nomen. - Costa Rica.

UNJALA, Blume = Heptapleurum, Gaertn. (Aral.).

bifida, Reinw. ex Boerl, in Annal. Jard. Buit. vi. (1887) $116=$ Eschweileria palmata, Zipp.
UNONA, Linn, f. (Anon.). - Ind. Kew, ii, 1146. Ancana, F. M. Bailey, Sym. Queensl. Fl. Sutpl. iii. (1890) J (= Ancana stenopetala, F. Muell.). Austral.

bibracteata, Robinson, in Am. Foumn. Sci. Ser. III, 1, (1895) 175, - Nicaragua,

evecta, Pierre, ex Laness, Pl. atit. Colon, Franc. (1886) 283. - Cochinch.

panamensis, Robinson, in Am. Fourn. Sci. Ser. III 1. (1895) 175, - Panama.

Wrayi, Hemsl, in Hook. Icon. pl. xvi. (1887) t. 1553, - Perak.

URAGOGA, Linn。 = Psychotria, Linn, (Rubiac.) acuminata, alba, horizontalis, justiciodes, laxiflora, serpens, stipulacea, trichocephala, Kuntze, Rev. Gen. (1891) 299-301 = homonyma omnia Psychotriae

abrupta, acutiflora, adenophylla, aeneo-fusca, affinis, Afzelii, agnata, ampla, amplectens, anamallayana, anceps, andamanica, androsaemifolia, anctoclada, angulata, angistata, anisocephala, anisoloba, Ansellii. apiculata, apocynifolia. appendiculata, arborea, arenosa, argentata, aurcola, bahiensis, bantamensis, barbiflora, barcellana, barraensis, Beccarii, Benthamiana, Beskeana, Beyrichiana biaristata biattenuata, bidentata, bifaria, bisulcata, biternata, Blanchetiana. borjensis, brachiata, brachyantha, brachybotrya, brachyceras, brachygyne, brachyloba, Brackenridgei. bracteata, bracteocardia, bracteolata, bracteosa, brasiliensis, Brassii, brevifora, brevipedunculata, braipes, brannea, caloneura, calva, calycosa, calycina, campyloneura, capensis, capitata, carthagenensis, Carronis, casiquiaria, chaenotricha, chlorantha, chlorophylla, chlorotica, comitis, concolor, conferta. conjungens, connata, consanguinea, constricta, contracta, cordata, cordifolia, cornifolia, comigera. cormuta, corymbosa, costaricensis costivenia crassa, crispa, cristata, cujabensis, anneifolia, cymosa, Dalzellii, dasyophthalma, debilis, deflexa, denticulata, dichotoma, diplospharica, divaricata, diversicolor, Doniana, dura, egensis, erratica, erythrocarpa, erythrophylla, estrellana, emmeura, exanulata, excelsa, exserta, extensa, extratropica, ficigemma, flipes, Fitzalani, flavicans, flexuosa, flovibunda, fluminensis, Fockeana, foetida, foliosa, formosa, foveolata, Franquevilleana, fraterna, fulgens, fulva, furcata, gabonica, Gardneri, Gardnerisma, glabrata, glabrescens, glanduliffera, glouca, glaucescens, globosa, glomerata, gracilenta, gracilis, graciliflora, granadestsis, Grayana, grandiflora, grandis, Haenkeana, hancorniaefolia, hastisepala, hebeclada, Helfeviand, heterocephala, hexandra, hirtipes, Hoffinannsegriana, hirsuta, hivta, horvinula, Horsfieldiana, Humboldtiana, humilis, hypargyrea, ignea, inaequifolia, inzfundibularis, insidens, insularum, interjecta, intermedia, imundata, involucellaris, fackii, janeirensis, keyensis, Kolly, konguensis, laciniata, laevis, lagoensis, lanato, Langsdorffiana, lasiophthalma, lasiopus, lasiostylis, latistipula, laxa, leiocarpa, lepidocarpa, leptophylla, lencocarpa, ligularis, linearis, longicollis, longicuspis, longipes, longipetiolata, longistipula, longistipulata, longistylis, lophoclada, lucens, lucida, lupulina, ma crantha, macrophylla, magnoliaefolia, madraspatana, Maingayi, malayana, manillaris, mandiocana, manitlensis, Manni, Mansoana maranhana, Marcoraviz, marginata, mariana, Martiusii, medusula, megacoma, megapontica, melanotricha, mesomorpha, mesotropa, membranifolia, mexicana, micrantha, microcephala, minutiflora, miradorensis, mollis, monocephala, montana, monticola, Moonii, Morae, mucronata, multicolor, multiplex, nomatopoda, nemorosa, nesophila, neurotricha, nicobarica, nigropunctata, nitidella, nitidula, noxia, mubica, mudiflora, nutans, obconica, obfuscata, obliquinervia, obscura, obscurata, obtegens, obtusifotia, octocuspis, oligotricha, opaca, orinocensis, owariensis, pachyneura, pacimonica, padifolia, pallens, paludosa, paniculatir, papantlensis, paradoxa, paraënz sis, pardina, patens, patentinervia, Patrisi, parvula pauciftora, panridiantha, Peckoltiana, pedunculata, penangensis, pentaphthosa, pergamacea, persimilis, Pervillei, philiphensis, phyllacalynma, Pickeringii pilosiuscula, platycocca, platyncura, platyphylla, platypoda, pleiocephala, pluricenia, Poeppigiana, poliostemma, polyantha, polycarpa, polycephala, polyneutra, polytricha. psilogyue, puberula, pubescens, pubi-
URAGOGA :-

gera, pumila, functata, purpurascens, pyramidalis, pyrifolia, quinquecuspis, quinqueradiata, vacemosa, radians, recurva, vefracta, remota, repanda, rettans. reticulata, revoluta, rhinocerotis, rhodolenca, rigida. robusta, rosea, Roxburghii, rubbra, ruelinaefolia, rufescens, rufipes, rugulosa, rupestris, salicifolia, sambucina. santaremica, scabrinscula, Schlechtendaliana, Schmielei, Schomburgkii, Schottiana, Schweinfurthii, sclerophylla, segregata, Sellowiana, semifissa, sessiliftora. sessilifolia, setacea, setigera, silhetensis, silvicolir. sinnilans, sordida, Sororia, Sororiella, Soyaututi. sphaerocephaia, squarrosa, stellaris, stenocalyx, stenoclada, stictophylla, stipulavis, stipulata, stitulosa, stricta, strigosa, subaeneofusia, subcacuminalis, subcrecea, subcuspidata, subfusca, subherbacea, subintegra, subnuda, subobliqua, suborata, subpunctata, subremota, subscandens, subspathacea, subtomentosa, subtriflora, subundulata, succulenta, suffruticosa, sulcata, sumbacana, Suterella syleratica, symelocifolia, tenella, tenevior, tenuifolia, tenuinervis, tephrosantha, tcrminalis ternifolia, tetraphylla, Thwaitesii, tortilis, trachystyla. triantha, trichoclada, tricholoba, trichoneurcl, trichophora, trichostyla, trifida, triphylla, trispicata, truncata, turbinata, turbinella, tylophora, uberabana u iginosa, umbraticola, undata, undulata. urophylla, Vauthieri, vellevea, velutipes, venulosa, verrucosa, verticillata, villosa, virgata, vividis, Vogeliana, Warmngii, Wawrana, Westii, Wightiana, Wrightii, xanthoce hala, xantholoba, xanthophylla, zambesiane. Kuntze, Rev. Gen. (1891) 954-63 = homonymid omnia Psychotriae.

aceransis, Kuntze, Rev. Gen。(1891) 953 = Psychotria obscura, Benth.

aculeoligera, Kuntze, 1. c. = Rudgea angustifolia Muell. Arg.

acutifolia, Kuntze, 1, c. = Psychotria umbellata, Hook. f.

aemulans, Kuntze, 1 c. $(=$ Mapouria aemulans. Muell. Arg.). - Bras

alba, Kuntze, I. c. = Cephaelis alba, Willd alpina, Kuntze, 1. c. = Palicourea alpina, $D C$.

amazonica, Kuntze, 1, c. = Rudoea amazonica, Muell, Arg.

ambigua, Kuntze, 1. c. $954=$ Psychotria Salzmanniana, Mutell. Avg.

amethystina, Kuntze, 1. c. $959=$ Palicourea amethy stina, $D C$.

amicorum, Kuntze, 1. c, = Chasalia amicorum, $A$. Gray.

angusturensis, Kuntze, 1, c. $954=$ Cephaëlis discolor, Polak.

angulosa, Kuntze, 1, c. $299=$ Psychotria angulata, Korth.

angustifolia, Kunize, 1. c. $959=$ P. angustifolia, Poir.

apicata Kuntze, 1, c. $300=$ Palicourea apicata, H. B. \& $K$

abocynacea, Kuntze, 1. с. 959 = Mapouria apocynacea, Muell. Arg.). - Bras.

atoda, Kuntze, 1. c. = Rudgea apoda, Mucll. Arg.

arcuafa, Kuntze, 1. c. $299=$ Psychotria inundata, Benth

aticillata, Kuntze, 1. c. 959 (= Grimilea articulata,

Hiern), - Afr. trop.

Asae, Kuntze, 1. c. 954 = Psychotria gracilis, A. Gray.

Aschersoniana, Kuntze, 1. c. = Rudgea longiflora, Binth.

ustralis, Kuntze, 1. с. (= Mapouria australis, Muell. Arg.). - Bras

xillaris, Kuntze, 1, c. $=$ Cephaëlis axillaris, Si

Bailloniana, Kuntze,1. c. (= Mapouria Burclicllian Muell. Arg.). - Bras.

Bakeriana. Kuntze, 1. c. $955=$ Psychotria ferrug:nea, Baker.

Balfouriana, Kuntze, 1. c. = P. lanceolata, Balf. $f$. barbata, Kuntze 1. c, = P, barbata, Poir

barbinervia, Kuntze, 1. c, = Palicourea barbinervia, $D C$.

Barteri, Kuntze, 1.c. (= Grmilea micrantha, Hiern - Afr. trop.

baviensis, Drake, in Morot, Journ. de Bot. ix. (1895) 236. - Tonkin.

Berteroana, Kuntze, 1. c. = Psychotria Berteriana, $D C$ 
URAGOGA : -

Bisglazioui, Kuntze, Rev. Gen. (1891) $955=$ Psychotria Glaziovij, Muell. Arg.

Boryana. Kuntze, 1. c. $959=$ Chasalia Boryana, $D C$.

Blmmana, Kuntze, 1. c. $955=$ Cephaëlis stipulacea, Blume.

Bolusiana, Kuntze, 1. c, = Rudgea elliptica, Mucl Arg.

Bomplandiana, Kuntze, 1. c, = Palicourea speciosa, IH. B. \& $K$.

brachyandra, 1. c. = Rudgea brachyandra, Muell. Arg.

brachypoda, Kuntze, 1.c. (= Maponria brachyopoda, Muell. Aro.) - Bras.

Grachythere, Kuntze, 1, c. = Psychotria brevicollis, Mucll. Arg.

brevicollis, Kuntze, 1. c. (= Mapouria brevicollis, Muell. Arg.). — Bras

britoguianensis, Kuntze, 1. c. 955 = Psychotria nervosa, Benth.

Brittoniana, Kuntze, 1. c. $=$ P. cordata, A. Gray.

Brouni, Kuntze, 1. c. $959=$ P. Brownei. Spreng.

Burchelliana, Kuntze, 1. c, = Rudgea Burchelliana, Mucll. Arg.

caldasica, Kuntze, 1. c. (= Mapouria cald xsica, Muell. Arg.). - Bras.

callophylla, Kuntze, 1.c. = Palicourea calophylla, $D C$.

culocarpu, Drake, in Morot, Journ. de Bot. ix. (1895) 236 , in syn. $=$ P. calocarpa, King.

Candclariae, Kuntze, 1. c. 955 = Palicourea lanceolata, Benth.

capillacea, Kuntze, 1. c, 959(= Marouria capillaca, Muell. Aro.). - Bras.

capitellata, Kuntze, 1, c. = Psychotria barbiflora, $D C$.

capituliflor $a$, Kuntze, 1. c. (= Maponria capituliflora, Muell. Arg.). - Bras.

Carapichea. Kuntze, 1. c. $955=$ Cephaëlis Patrisii, D. Dictr.

carpintcrensis, Kuntze, 1. c。 = Palicourea intermedia, Oerst.

Carruthersii, Kuntze, 1. c. = Psychotria palicoureoides, Muell. Aro

Carucliana, Kuntze, 1. c. (= Mapouria umbrosa, Muell. Arg.). - Bras,

Casarettoana, Kuntze, 1. c. $959=$ Rudgea Casarettoana, Muell. Arg.

castcllana, Kuntze, 1. c. $(=$ Mapouria castollana, Nuell. Arg. . - Bras.

catharinensis, Kuntze, 1. c. ( $=M$. catharinensis, Muell. Arg.). -- Bras.

cilastrinca, Kuntze; 1. c. = Rudgea celastrinea

iluell. Arg.

clastrodes, Kuntze, 1. c. = Psychotria celastroides, Griseb.

cephalantha, Kuntze. 1. c. (= Mapouria cephalantha, Muell. Arg.). - Bras.

Chamissoi, Kuntze, 1. c. 955 = Rudgea magnoliaefolia, Mucll. Arg.

chinantlensis, Kuntze, 1. c. = Cephaëlis hirsuta Martens of Gal.

chionantha, Kuntze, 1. c. $959=$ Psychotria Luschnathii, Klotzsch.

cinchcnodes, Kuntze, 1. c. 960 (= Maponria cinchonoides, Muell. Ars.). - Bras.

circimata, Kuntze, 1. c. = Palicourea elliptica, H. B. E $K$.

citrifolia, Kuntze, 1. c. $955=$ Rudgea caribaea, Benth.

clavipes, Kuntze, 1. c. $260=$ R. clavipes, $B c n t h$.

coccinea, Kuntze, 1. c. (= Patabea coccinea, Aubl.). Guian.

coerulea, Kuntze, 1. c, $960=$ Palicourea coerulea, Rocm. E. Schult.

coffcodes, Kuntze, 1 c. $955=$ Chasalia divaricata $D C$.

cochoeirensis, Kuntze, 1. c = Rudgea longistipula, .7uell. Avg.

colarensis, Kuntze, 1. c. 960 (= Maponria colarensis, Mitull. Arg.). - Bras.

collina, Kuntze, 1. c. = Psychotria Brownei, Sprong.

colorata, Kuntze, 1. c. = Cephaëlis colorata, Hoffing .
URAGOGA : -

compaginata, Kuntze, Rev. Gen. (1891) $960(=$ Mapouria compaginata, Muell. Arg.). - Bras.

compressistifes, Kuntze, 1. c. 955 = Psychotria clavipes, Muell. Arg.

confertiflora, Kuntze, 1, c. $900=$ P. Korthalsiana, IIIq

ongesta, Kuntze, 1. c. $=$ P. congesta, Hook. $f$.

conocarpa, Kuntze, l, c. = Rudgea conocarpa, Mull. Arg.

corcovadensis, Kuntze, 1. c, 955 = R. calycina, Benth.

Cordillerae, Kuntze, 1. c. = Palicourea alpina, DC. coviacea, Kuntze, 1. c. $960=$ Psychotria coriacea, Poir.

corniculata, Kuntze, 1. c. = Rudgea rorniculata, Benth.

coronata. Kuntze 1. c, = R. coronata, Muell. Arg. corymsifira, Kuntze, 1. c. (= Mapouria corynbifira, Muell. Arg.). - Bras.

cormbulosa. Kuntze, 1. c. = Rudgea corymbulosa, Benth.

Contteriana, Kuntze, 1, c. 955 = R. mucronata, Muell. Arg.

crocea, Kuntze, 1. c. $299=$ Palicourea crocea, Rocm. \& Schult.

cuncata, Kuntze, 1. c. $955=$ Cephaëlis cuneata, Korth.

cupularis, Kuntze, 1. c. $(=$ Mapouvia cupularis, Muell. Ars.). - Bras,

curiflora, Kuntze, 1. c. $299=$ Chasalia curviflora, Tho.

cuspidata, Kuntze, 1. c. $955=$ Psychotria cuspidata, Breden

cuspistifula, Kuntze, 1. c, = Rudgea Blanchetiana, Muell. Arg.

cussareodes, Kuntze, 1. c. 960 (= Mapouria conssareoides, Muell. Arg.). - Bras.

cymosperma, Kuntze, 1, c. = Rudgea cyanosperma, Muell. Arg.

cymuligera, Kuntze, 1. c. (=) Mapomia cjmuligera, Mueli. Arg.). - Bras.

Dallachyana, Kuntze, 1, c. = Psychotria Dallachiana, Benth.

daphodes, Kuntze, 1. C. $=$ P. daphnoides, A.Cunn. decipiens, Kuntze, I, c, - Rudurea decipiens, Muell. Arg.

Delpinoana, Kuntze, 1. c. $955=$ R. tenuitolia, Muell. Arg.

densicostata, Kuntze, 1. c. $960=$ Psychotia densecostata, Muell. Arg

Rensiflora, Kuntze, 1. c. $955=$ Rudgea viburnoides, Benth.

densivenosa, Kuntze, 1. c. $960=$ Psychotria densevenosa, Muell. Aig.

depanperata, Kuntze, 1. c. $=$ Mapouria depauperata, Muell. Arg.). - Bras.

depressoglobosa. Kuntze, 1. c. $955=$ Psychotria pendula, Hook. $f$.

Detoniana, Kuntze, 1. c. $=$ P. Riedeliana, Muell. Arg.

diervillodes, Kuntze, 1. c. $=\mathrm{P}$, diervilloides, $H$. $B$. \& $K$.

discolor, Kuntze, 1. c. = Rudgea discolor, Benth

divergens, Kuntze, 1. c. $300=$ Psychotria divergens, Blume.

domingensis, Kuntze, 1. c. $960=$ Palicourea domingensis, $D C$.

Dyeriana, Kuntze, 1. c. 955 (= Mapouria Netloana, Muell. Arg.). - Bras.

clata, Kuntze, 1. c. = Cephaëlis elata, Sw,

elliptica, Drake, in Morot. Journ. de Bot. ix. (1895) $237=$ Psychotria elliptica, $\mathrm{Ker}$.

elliptica, Kuntze, Rev. Gen. (1891) $300=$ P.commutata, $D C$.

elongata, Kuntze, 1. c. $960=$ P. elongata, Benth.

Eminianu, Kuntze, 1. c. $955=$ P. sulphurea, Schweinf.

Engleriana, Kuntze, 1. c. $\{=$ Mapouria myriantha, Marell. Arg.). - Bras.

eviantha, Kuntze, 1, c. $960=$ Palicourea eriantha $D C$.

evioloba, Kuntze, 1. c. $=$ Rudgea erioloba, Benth.

exythrantha, Kuntze, 1. c. 955 = Palicourea coccinea, $D C$

fastigiata, Kuntze, 1. C. $=$ P. fastigiata, $H . B . \& K$.
URAGOGA:-

ferruginea, Kuntze, Rev, Gen. (1891) 960 (= Mapouria ferruginea, Muell, Arg). - Bras.

fimbriata, Kuntze, 1. c. 955 = Rudgea micrantha Muell. Arg.

fimbriata, Kuntze, 1. c. 983 (= Strempelia guianensis A. Rich.). - Guian.

fimbricalyx, Kuntze, 1. c. 960 (= Grumilea fimbricalyx, Miq.). - Java.

fissistipula, Kuntze, 1. c. = Rudgea fissistipula Muell. Avg,

flavescens, Kunize, 1. $c_{0}=$ Palicourea flavescens, H. B. E $K$.

Forsteriana, Drake, Fl. Polyn. Franç. (1892) $98=$ 'Psychotria Forsteriana, A. Gray.

forsteroniodes, Kuntze, Rev. Gen. (1891) $960=$ P. forsteronioides, Muell. Arg.

fragrans, Kuntze, 1. c。 = Cephaëlis fragans, Hook. E Arm.

Francavillana, Kuntze, 1. c. = Rudgea Francavillana, Muell. Arg.

Franchetiana, Drake, I1l. Fl. Ins. Mar. Pacif. (1886) t. 18 ; et Fl. Polyn. Franc. (1892) 97. - Ins. Pacif.

Franchetiana, Kuntze, Rev. Gen. (1891) $956=$ Psychotria Burchelliana, Muell. Arg.

fuscostipulata, Euntze, 1. c. = P. microcephala Muell. Arg.

Gabrieli, Kuntze, 1. c $=$ P. gabrielis, Mucll. Arg.

Galeottiana, Kuntze, 1. c. = Palicourea Galeottiana, Martens.

galloguianensis, Kuntze, 1, c. $956=$ P. umbellata, $D C$

gardeniodes, Kuntze, 1, c. $960=$ Rudgea gardenioides, Muell. Arg.

Gaudichandii, Kuntze, 1. c, $=$ R. Gaudichandii, Muell. Arg.

gindarussifolia, Kuntze, 1. c, = Psychotria gendarussaefolia, Blume.

glabra, Kuntze, 1. c. = Cephaëlis glabra, Willd.

Glazioni, Kuntze, 1. c. = Rudgea Glaziovii, Mutell. Arg.

Gomeziana, Kuntze, 1, c. = R. Gomeziana, Muell. Arg.

goyazensis, Kuntze, 1.c. = R. goyazensis, Muelt. Ars.

grandifolia, Kuntze, 1. ....5 = Chasalia grandifolia, $D C$.

Greeneana, Kuntze, 1. c. (= Mapouria insignis, Muell. Arg.). - Bras.

Griffithi, K. Schum. in Engl, \& Prantl, Natürl. Pflanzenfam.iv. 4(1891) $120=$ Cephaelis Griffithii, Hook.f.

Griscbachiana, Kuntze, Rev. Gen. (1891) 956 Psychotria coronata, Griseb.

Grumilia, Kuntze, 1. c. $\{=$ Grumilea macrocarpa Hiern). - Afr, trop.

guianensis, Kuntze, 1. C. $983=$ Cephaelis Evea, DC

hebcladodes, Kustze, 1. c. $956=$ Psychotria hebecladoides, Griseb.

Hemsleyana, Kuntze, 1. c. $956=$ P. tomentosa, Hennsl.

herbaca, Kuntze, 1. c. $300=$ Geophila reniformis, Henrsl.

heteromorpha, Kuntze, 1. c. $=$ Psychotria heteromorpha, Korth.

Heurckii, Kuntze, 1. c. = Rudgea Heurckii, Mull. Arg.

Hicrni, Kuntze, 1. c. $956=$ Psychotria virens Hiern.

Hieronymi, Kuntze, 1. c. = P. goyazensis, Muell. Arg.

Hookeri, Kuntze, 1. c, = Coprosma triflora, Benth. E. Hook. f.

Hostmaniana, Kuntze, 1. c. = Rudgea Hostmanniana, Benth.

byacinthiflora, Kuntze, 1, c, = Palicourea hyacinthiflora, Roem. \& Schult.

hygrophilodes, Kuntze, 1. c. = Psychotria hygrophilnides, Benth

Jyptodes, Kuntze, 1. c = P. hyptoides, Beuth

itheotica, Kuntze, 1. c. = Rudgea ilheotica. Muell. Arg.

inhumasensis, Kuntze, 1. c. $956=\mathrm{R}$. loniceroides, Muell. Arg.

insignis, Kuntze, 1. c. = R. insignis, Mutl. Arg. 
URAGOGA :

interrupta, Kuntze, Rev. Gen. (1891) $961=$ Rudgea interrupta, Besth.

inolucrata; Kuntze, 1. c. $956=$ Cephaëlis involucrata, Wild.

irregularis, Kuntze, 1. c. = Rudgea irregularis, Muell. Arg.

ixorodes, Kuntze, 1. c. $=$ Psychotria ixoroides, Bartl.

Facobaschiz, Kuntze,1.c. 950 (= Mapouria Martiana, Muell. Arg.). - Bras.

jacobiniensis, Kuntze, 1. c. $960=$ Rudgea jacobinensis, Muell. Arg

jambosiodes, Kuntze, 1. c. = Psychotria jambosioides, Schlecht.

iapuraguensis, Kuntze, 1. c. 956 (= Mapouria japurensis, Muell. Arg.). - Bras.

japurensis, Kuntze, 1. c. $960=$ Rudgea japurensis, Muell. Arg.

iasminodes, Kuntze, 1, c. $=\mathrm{R}$, jasminioides, Mull. Arg.

fohnstonii, Kuntze, 1. c. 961 = Psychotria Johnsoni, Hook. $f$.

Fosephi, Kuntze, 1. c. $956=$ P. filipes, Hook.f.

Funghumiana, Kuntze, 1. c. $961=\mathrm{P}$. sarmentosa, Blume.

Kerneriana, Kuntze, 1. c. $956=$ Rudgea breviflora, Muell. Arg.

Kingiana, Kuntze, 1. c. $956=$ Psychotria decipiens, Muell. Arg.

Kirkii, Kuntze, 1. c. $961=$ P. Kirkii, Hicm.

Kunthiana, Kuntze, 1. c. $956=$ Cephaèlis salicifolia, $H . B$. \& $K$

Kurziana, Kuntze, 1. c. = Psychotria divergens, Kurz.

lacinulata. Kuntze, 1. c. $961=$ Rudgea lacinulata, Muell. Arg.

Taevifolia, Kuntze, 1. c. (= Maponria luevifolia, Muell. Arg.). - Bras.

lanceaefolia, Kuntze, 1. c. = Rudgea lanceaefolia, Salisb.

lanceolata, Küntze. 1, C. = R. lanceolata, Benth.

Langsdorffi, Kuntze, 1. c. = R. Langsdorffii, Muell. Arg.

lasiorhachis, Kuntze, 1. c. = Palicourea lasiorhachis, Oirst.

latifolia, Kuntze, 1. c. = Psychotria axillaris. Willd, leiocarpodes, Kuntze, 1. c. = Rudgea leiocarpoides,

Muell. Arg.
Lepiniana, Baill. ex Drake, Ill. Fl. Ins. Mar. Pacif. (1886) 19; et Fl. Polyn. Franc. (1892) 96. - Ins. Pacif.

leucophylla. Kuntze, Rev, Gen. (1891) $956=$ Rudgea macrophylla, Benth.

Lesyi, Kuntze, 1. c. = Psychotria parvifolia, Benth. Lindleyana, Kuntze, 1. c. $=$ P. Lindleyana, Muell. Arg.

lineata, Kuntze, 1. c. $300,956=$ Palicourea lineata, Benth.

longiftora, Kuntze, 1. c. $956=\mathrm{P}$. longiftora, $D C$.

longifolia, Kuntze, 1. c, $=\mathrm{P}$. longifolia, $H . B$. \& $K$.

longipedunculata, Kuntze, 1. c. = Psychotria longepedunculata; Manll. Arg.

longivaginalis, Kuntze, 1. c. = P. longevaginalis, Schweinf.

lonicerodes, Kuntze, 1. c. $=$ P. loniceroides, Sieber. Toxensis, Kuntze, 1. c. $956=$ Palicourea calycina, Benth.

Lumdiana, Kuntze, 1, c, $961=$ Rudgea Lundiana, Muell. Arg.

luvida, Kuntze, 1, c. $\Leftrightarrow=$ Mapouria lurida, Muell. Arg.). - Bras.

macrosotrys. Kuntze, 1. c. = Palicourea macrobotrys, Roem. of Schult.

macrocalyx, Kuntze. 1. c. $956=$ Psychotria megalocalyx, Muell. Arg.

macrocarpa. Kuntze, 1. c. $961=$ Palicourea macrocarpa. H. B. \& $K$.

macropoda, Kuntze, 1. c. = Geophila macropoda, $D C$.

Magnisiana, Kuntze, 1. c. 956 (= Maponria pannrensis, Muell. Arg.). - Bras.

major, Kuntze, 1. c. = Rudgea major, Muell, Arg. malaccensis, Kuntze, 1. c. $956=$ Psychotria Griffithii, Hook. $f$.
URAGOGA :

Mannagettaei, Kuntze, Rev. Gen. (1891) $956=$ Psychotria vellerea, Mnell. Arg.

Mapuria, Kuntze, 1. c. $300,983=$ Psychotria nitida Willd.

marchionica, Drake, Ill, Fl. Ins. Mar. Pacif. (1S86) 198; et Fl. Polyn. Franç. (1892) 97. - Ins. Pacif.

Wartensianc Kuntze, Rer Gen. (1891) 956 = Psychotria nicotianaefolia, Martens E Gal.

Martiana, Kuntze, 1. c. $961=$ Rudgea Martiana Muell. Arg.

malogrossensis, Kuntze, 1. c. $950=$ R. cujabensis, Muell. Arg.

medians, Kuntze, 1. c. $961=\mathrm{R}$. medians, MIuell. Arg.

microcarpa, Kuntze, 1. c. (= Maponria microcarpa Muell. Arg.). - Bras

microdesmia, Kuntze, 1. c. $=$ Psychotria microdesma Oerst.

. Miersiana, Kiıntze, 1. c. = Rudgea Miersiana, Benth.

minor, Kuntze, 1. c. $956=\mathrm{R}$. Clausseniana, Benth I'iqudiana. Kuntze, 1. c. = Psychotria oligantha Miq.

mitis, Kuntze, 1. c. $961=$ Palicourea mitis, $D C$

montana, Drake, in Morot, Journ. de Bot. ix. (1895) 237 = Psychotria montana, Blume

Mocniae, Kuntze, Rev, Gen. (1891) 961 = Chasalia Mooniae, Baker

Mooreana, Kuntze, 1. c. $95 \%=$ Rudgea triflora Benth

morindiflora, Kuntze, 1. c, $96 \mathrm{l}=$ Psychotria morindaeffora, $W$ all.

morindodes. Kuntze, 1. c. = P. leucocarpa, Blume. Mulleriana, Kuntze, 1. c. $957=$ P. Martiana, Muell. Arg.

multicostata, Kuntze, 1. с. $961=$ Rudgea multicos tata. Muell. Arg.

muscosa, Kuntze, 1 c。 = Cephaëlis muscosa, Sw.

myriantha, Kuntze, I. c. ( = Mapouria myriantha, Muell. Ars.). - Bras.

myrsinifolia, Kuntze, 1. c. = Rudgea myrsinaefolia, Benth.

Wyrtiphyllum, Kuntze, 1. c. = Psychotria Myrtiphyllum, Sw

Nebrowniana, Kuntze, 1. c. 957 (= Mapouria sessiliflora, Muell. Arg.). - Bras.

nercosa, Kuntze, 1. c. = Palicourea Paretta, $D C$

Nettoana, Kuntze, 1. c. $961=$ Rudgea Nettoana, 11uell. Arg.

Nenwiedii, Kuntze, 1. c. $=$ R. Neirwiedii, Muell. Arg.

nicaraguensis, Kuntze, 1. c. $957=$ Psychotria alba Ruiz of Pav.

nicotianifolia, Kuntze, 1. c, $95 \%=$ P. tabacifolia Muell. Arg.

Nicdenzuna, Kuntze, 1. c. = P. fissistipula, Muell Arg.

migrescens, Kuntze, 1, c: 961 = Palicourea nigrescens, Martens \& Gal.

nilgherensis, Kuntze, 1. c. $950=$ Psychotria elongata, Hook. f.

nicebarbata, Kuntze, 1. c. 961 (= Maponria niveobarbata, Muell. Arg.). - Bras.

nobitis, Kuntze, 1. c. = Rudgea nobilis, Muell. Arg nodosa, Kuntze, 1. c, = R, nodosa, Benth.

norocustellana, Kuntze, 1. c. $957=$ Psychotria castellana, Muell. Arg.

mada, K. Schum, in Engl, \& Prantl, Natür1. Pflanzenfam, iv, 4 (1891) $120=$ P. Gardneriana, Muell. Arg.

Nymannima, Kuntze, Rev, Gen, (1891) $957=$ Rudgea paniculata, Benth.

oblonga, Kuntze, 1. c. = Cephaëlis oblonga, $D C$.

obovala, Kuntze, 1. c. = Palicourea obovata, DC

ochroleuca, Kuntze, 1. c. = Rudgea ochroleuca Muell. Arg.

Oerstedtiana. Kuntze, 1. c. $957=$ Psychotria obovata, Hemsl.

officinalis, Kuntze, 1. c. = P. medica, Muell. Arg. oligantha, Kuntze, 1. c: $961=$ P. oligantha, $D C$. Oliceriana. Kuntze, 1. c. $95 \%=\mathrm{P}$. mandiocana Micell. Arg.

ozalifolia, Kuntze, 1. c. $961=$ Rudgea ovalifolia, Salisb.

ovalis, Kuntze, 1. c. = P. ovalis; Muell. Arg
URAGOGA : -

oxylepis, Kuntze, Rev. Gen. (1891) $941=$ Chasalia oxylepis, Miq.

fachyphylla. Kuntze, 1. c. = Rudgea pachyphylla, Mueli. Arg.

pachysantha, Kuntze, 1. c, = R. pachysantha, Muell. Arg.

palicurodes, Kuntze, 1. c. 962 [sphalm. palecurodes $=$ R. palicouroides. Muell. Arg

Palicurea, Kuntze, 1. c. $300,983=$ Palicourea onianensis, Aubl.

panurensis, Kuntze, 1. c. 96 ? $=$ Rudgea panurensis Muell. Arg.

pararawinensis, Kuntze, 1. c $95 \%=$ Geophila hixta, Korlt?.

parquiodes, Kuntze, 1. c, = Rudgea parquioides, Muell. Arg.

parviflora, Kuntze, 1. c. = Palicourea parviflora, Benth.

parvifolia, Kuntze, 1. c. = Rudgea parvifolia, Muell. Arg.

peduncularis, K. Schum. in Engl. \& Prant], Natürl. Pflanzenfam.iv. 4 (1S91) 120=Cephaëlis peduncularis, Salisb.

pedunculosa, Kuntze, Rev, Gen. (1\$91) $962=$ Palicourea pedunculosa, $D C$

pendula, Kuntze, 1.c. $957=$ Psychotria parasitica. Sw. peraffinis. Kuntze, 1. c. $962(=$ Mapouria peraffinis, Muell. Arg.). - Bras.

petiolaris, Kuntze, 1. $c_{0}=$ Palicourea petiolaris, $H$. B. \& $K$.

Philippiana, Kuntze, 1. c. $957=$ P. Haenkeana, $D C$. phoenica, K. Schum. in Engl. \& Prantl, Natïrl. Ptlanzenfam.iv. $4(1891) 120=$ Palicourea pu. nicea, Ruz \& Pav.

phyllocalymmodes, Kuntze, Rev. Gen. (1891) $962=$ P. phyllocalymmoides, Muell. Arg

picta, Kuntze, 1. c. $957=$ P. calocarpa, $K$ ur\%

pilota, Kuntze, 1. c. 962 [sphalm.?] = P. pilosa, Ruiz \& $P$ av

platypodina, Kuntze, 1. c, $962=$ P. platypoda, $D C$, podocephala, Kuntze, 1. c. $(=$ Mapouria podocephala, Muell. Arg.). - Bras.

Pohliana, Kuntze, 1. c. $\quad(=$ M. Pohliana, Muell. Arg.). - Bras.

Polakolesky, Kuntze, 1. с. $95 \pi$ = Psychotria costaricensis, Polak.

popayensis, Kuntze, 1, c. = Palicourea popayanensis, Benth.

Prantliana, Kuntze, 1. с 957 = Psychotria recurva Hiern.

prunifolia, Kuntze, 1. c. $962=$ P. microcephala, Muell. Arg.

psammophila, Kuntze, 1. c.=Rudgea psammophila Muell. Arg.

Pseudojapurensis, Kuntze, 1. c. 957 = Psychotria japurensis, Muell. Arg.

psychotriafolia, Kuntze, 1. c. = Cephaëlis psychotriaefolia, Seem.

psychotrodes, Kuntze, 1, c. (= Gramilea psychotrioides, DC. . - Afr. trop.

psychophylla, Kuntze, 1.c. (= Mapouria psychophylla, Muell. Arg.). - Bras.

puberulina, isuntze, 1, c. $(=M$. puobrulina, Muell. Arg.). - Bras.

pulchra, Kuntze, 1. c. $300=$ Palicourea pulchra, Griseb.

pulvinigera, Kuntze, 1, c. - Costa Rica ?

purpurea, Kuntze, 1. c. $962=$ Cephaëlis purpurea, Willd.

quadrifolia, Kuntze, 1. c. = Palicourea quadrifolia, $D C$

quinquecornuta, Kuntze, 1. c. $957=$ Rudgea microcephala, Muell. Arg.

Rabeniana, Kuntze, 1. c. 962 (= Mapouria Rabe miana, Muell. Arg.) - Bras.

Reevesii, Kuntze, 1. c, $300=$ Psychotria elliptica, Ker-Gawl.

Reginae, Kuntze, 1. c. $962=$ P. Regina, Muell. Arg

Regatlli, Kuntze, 1. c. = P. Regnellii, Mull. Avg.

retifolia, Kuntze, 1. c. $95 \%=$ Rudgea reticulata, Benth.

Rhinocerotis, Drake, in Morot,Journ. de Bot. ix. (1895) 237, in obs. = Psychotria Rhinocerotis, Reine.

rhytidocarpa, Kuntze, Rev. Gen. (1891) 962 = P. rhytidocarpa, Muell. $A v g$. 
URAGOGA : -

Riedeliana, Kuntze, Rev. Gen. (1891) $963=$ Psy chotria Riedeliana, Muell. Arg.

viparia, Kuntze, 1. .c. = Palicourea crocea, Rocm. \& Sinult.

Rolfscana, Kuntze, 1. c. 957 = Psychotria microcarpa, Mull. Arg.

rostrata, Drake, in Morot, Journ. de Bot. ix. (1895) 38 , in obs. = seq.

rostrata, Kuntze, Rev, Gen, (1891) $300=$ Chasalia rostrata, $\mathrm{Miq}$.

mbribaccata, Kuntze, 1. c. $957=$ Rudgea eriothrocarpa, Muell. Arg.

rudgeodes, Kuntze, 1. c. $962=$ Psychotria rudgeoides. Amell. Aro.

Ruiziana, Kuntze 1. c. $95 \%=$ Palicourea tinctoria, Rocm. E Schult.

Saccardoana, Kuntze, 1. c. = Psychotria Weddelliana, Mucll. Arg.

sarmentosa, Kuntze, 1. c. [sarmentasa] = P. sarmentosa. Blume.

Soliedweilcri, Kuntze, 1. c. 957 = Palicourea gardenioides, Benth. \& Hook. $f$.

Schlechtondali, Kuntze, 1. c. = Psychotria neurothrix, Muell. Arg.

Schomburghiand. Kuntze, 1. c. $962=$ Ruderea Schomburgkiana, Bent?

Simmanniana, Kuntze, 1. c. $9.57=$ Psychotria Rabeniana, Muell. Arg.

Schwechiana, Kuntze, 1. c. $952=$ P. Schuechiana, Mivell. Arg.

slevocalyx, Kuntze, 1. c. (= Mapouria solevocalyx IIuell. Arg.). - Bras.

Selloana, Kuntze, 1. c. =Rudgea Selloana, Muell. Arg

sessilis, Kuntze, 1. c. = R. sessilis, Muell. Arg.

Sieberi, Kuntze, 1. c. $957=$ Psychotria capitata Ruiz \& Par'.

Solnsiana, Kuntze, 1. c. $958=$ P. japurensis, (n. 1589) Muell. Avg.

sotoropolizana, Kuntze, 1. c. $962=$ P. soteropolitana, Muell. Arg.

Sprnoghcania, Kuntze, 1. c. $958=$ P. parviflora, Spanogh.

sathicalyx, K. Schum. in Engl. \& Prantl, Natürl. Pflanzenfam, iv 4 (1598) 120. - Bras.

speciosa. Drake, I11. F1. Ins. Mar. Pacif. (1886) 15 ; et F1. Polyn. Franç. (1892) $97=$ Psychotria speciosa, Forst.

spcciosa, Kuntze, Rev. Gen. (I891) $962=$ Ixora vitiensis, A. Gray.

shateracarpa, Kuntze, 1.c. (= Grumilca sphaerocarta, Hiern.). - Afr. trop

spicata, Kuntze, 1, c. = Psychotria spicata, Muell. Arg.

Spruceanat. Kuntze, 1. c. (= Mapouria Sprucenna, Muell. Arg.). - Bras.

stachyodcs, Kuntze, 1, c. = Psychotria stachyoides, Eenth.

stcnantha, Kuntze, 1. c. = Rudgea stenantha Mucll. Arg.

stcnophylla, Kuntze, 1. c. = Palicourea angustifolia, H. B. \& $K$.

stipulacea, K. Schum. in Eng-1, et Prantl, Natürl. Pflanzenfam. iv. 4 (189l) $120=$ Cephaëlis stipulacea, Blume.

Pricolens, K. Schum, in Engl. Pflanzenw. Ost-Afr C $(1895) 392=$ Cephaëlis suaveolens, Schweinf. subcordata, Kuntze. Rev. Gen. (1891) $962=$ Rudgea subcordata, Mucll. Arg.

subrubra, Kuntze, 1. c。= Palicourea subrubra. Polak.

subrufa, Kuntze, 1. c. = Psychotria Rhinocerotis, Reinn.

Mubessilis, Kuntze, 1. c. $=$ P. subsessilis, Benth.

subspathulata, Kuntze, 1. c. (= Mapouria subspathilata, Muell. Arg.). - Bras.

silfurea, Kuntze, 1. c. = Psychotria sulphurea, Sectin.

slinatrensis, Kuntze, 1. c. $958=\mathrm{P}$. coriacea, Korth.

Suteriana, Kuntze, 1. c. = P. Lindleyana, Muell. Arg.

Swartzit, Kuntze,1. C. $962=$ Cephaëlis Swartzii, $D C$

symplocodes, Kuntze, 1. c. $963=$ Rudgea symplocoides, Muell. Arg.

tobernifolia, Kuntze, 1. c. = Palicourea tabernaefolia. $D C$.
URAGOGA :

ahitensis. Drake, Ill. Fl. Ins. Mar, Pacif. (1886) 17 ; et Fl. Polyn. Franç. (1892) 98. - Ins. Pacif.

Taubertiana Kuntze, Rev Gen (1891) $958=$ Rudgea involucrata, Mucll. Arg.

tenuis, Kuntze, 1. с. 963 (= Mapouria lenuis, Muell Arg, ). - Bras

tetrandra, Kuntze, 1. c. = Cephaèlis Evea, DC.

Tcysmannana, Kuntze, 1. C. $(=$ Grumilea Teysman-

miana, Miq.). - Ins. Banca

Thomsonii, Kuntze, 1. C, $963=$ Psychotria Thomsoni, Hook. $f$.

Thonningii, Kuntze, 1. c. $958=$ P. umbellata Thonn.

thyrsiflora, Kuntze, 1, c. $963=$ Palicourea thyrsiflora, $D C$

tinctoria, Kuntze, 1. c. $958=$ P. parviflora, Willd tingrana, Kuntze, I. c. $963=$ Rudgea tinguana, Muell. Arg.

tinifolia, Kuntze, 1. c. = Palicourea tinifolia, DC tomcntosa, Kuntze, 1. c. $301=$ Psychotria tomentosa Muell. Arg.

tomentosa, K. Schum. in Engl, \& Prantl, Natürl. Pflanzenfam.jv. 4 (1891) $120=$ praec.

tonsa, Kuntze, Rev, Gen. (1891) $958=$ Psychotria elliptica, Ker-Gawl.

tortilis, Kuntze, 1. c, $301=$ P. tortilis, Baill.

travancorica, Kuntze, 1. c. $958=$ = . macrocarpa

Hook. $f$.

Trentoina, Kuntze, 1.c. = Rudgea lasiostylis, Muell. Arg.

triadica, Kuntze, 1. c. 963 (= Mapouria triadica, Muell. Arg.). - Bras.

trichocalyx, Drake, Ill. Fl. Ins. Mar. Pacif, (1886) t. 16 ; et Fl. Polyn. Franç. (1892) $99=$ Calycosia trichocalyx, Drake.

trichogyne, Kuntze, Rev. Gen. (1891) 963 (= Maport via trichogyne, Muell. Arg.). - Bras.

trichophorodes, Kuntze, 1. c. = Psychotria trichophoroides, Muell. Arg.

trichophylla, Kuntze, 1. c. = P. triphylla, Mucll. Avg.

trichotoma, Kuntze, 1. c. = P. trichotoma, Mart. \& Gal.

tricephala, Kuntze, 1. c. (= Mapouria tricophala, Muell. Arg.). - Bras.

Iriflora, Kuntze, 1. c. = Coprosma triflora, Benth. of Hook. $f$.

tristis, Kuntze, 1. c. (= Mapouria tristis, Muell. Arg.). - Bras.

tubulosa, Kuntze, 1. c. $958=$ Rudgea eriantha, Benth.

turrialiensis, Kuntze, 1. c. = Psychotria subsessilis, Benth.

umbellata, Kuntze, I. C. = P. Arrabidae, Muell. Arg. ambellifora, Kuntze, 1. c. (= Grumilea umbellata, Mig.). - Sumatra,

umbelluligera, Kuntze, 1. c, 963 (= Mapouvia umbelluligera, Mucll. Arg.). - Bras,

umbrosa, Kuntze, 1. c. = Rudgea umbrosa, Muell Arg.

Urbanima, Kuntze, 1. c. 958 = Psychotria corym-

bifera. Muell. Arg.

inginata. Kuntze, 1. c. 963 = Palicourea vaginata Benth.

vasivensis, Kuntze, 1. c. (= Mapouria rasivensis, Muell. Arg.). - Bras.

Velhana, Kuntze, 1.c. ( $=$. Velhana, Muell. Arg.). - Bras.

Vellozoana, Kuntze, 1 c. $958=$ Psychotria her bacea, $V$ ell

venosa, Kuntze, 1. c. 963 (= Grmmilea venosa, Hiern). - Afr. trop.

vestita, Kuntze, 1. c. (= Maponria vestita, Muell Arg.). - Bras.

riburnodes, Kuntze, 1. c. = Psychotria viburnoides, $H . B . \& K$.

ziolacea, Kuntze, 1. c. = Geophila violacea, $D C$.

vivens. Kuntze, 1. c, = Psychotria virens, Poctp. \& Endl.

vitoriensis, Kuntze, 1. c. $=$ P. vittoriensis, Muell.

Arg.
Warburgiana, Kuntze, 1. c. $958=$ P. apiculata, Warb.

Watsoniana, Kuntze, 1. c, 958 (= Mapouria crassa, Muell. Arg.). - Bras
URAGOGA : -

Weddeliana, Kuntze, Rev. Gen. (1891) $963=$ Rudgea Weddelliana, Muell. Arg.

Wettsteiniana, Kuntze, 1. c. $958=$ Psychotria brachyandra, Muell. Arg.

Willdenowiana, Kuntze, 1. c. = Cephaëlis violacea, $W$ illd.

Wittmackiana, Kuntze, 1. c. (= Mapouria Langsdorffiana, Muell. Arg.). - Bras.

xanthina, Kuntze, 1. C. $963=$ Palicourea xanthina $D C$

xanthophyllodes, Kuntze, 1. c. (= Mapouria xanthophylloides, Muell. Arg.). - Bras.

ypanemensis, Kuntze, 1. c. = Rudgea ypanemensis, Muell. Arg.

zangebarica, Kuntze, 1. c. = Psychotria zanguebarica, Hiern

zeylanica, Kuntze, 1. c. $958=$ P. stenophylla, Hook.f.

Zollingeriana, Kuntze, 1. c. $963=$ Geophila Zollingeriana, Miq.

zombamontana, Kuntze, 1. c. $958(=$ Grmmilea Kirkii, Hiern). - Afr. trop.

URANDRA, Thw。= Lasianthera, Beauv, (Olacin.)

capitatus, Kuntze, Rev. Gen. (1891) 113 (= Stemomurus capitatus, Becc.). - Borneo.

grandifolia, Kuntze, 1. c. $i=$ S. grandifolius, Becc.) - Borneo.

lanceolata, Kuntze, 1. $c_{0}=$ Lasianthera lanceolata, Mast.

macrocarpa, Engl. in Engl. et Prantl, Natiurl. Pflanzenfam. iii. 5 (1893) $248=$ L. macrocarpa, Miq.

Maingayi, Kuntze, Rev. Gen. (1891) $113=\mathrm{L}$.

Maingayi. Mast.

corpiodes, Kuntze, 1.C. (= Stenronmms scorpioides, Becc.). - Borneo.

secundiflora, Kuntze, 1. c. 112, $113=$ Lasianthera apicalis, Benth. \& Hook.f.

tomentclla, Kuntze, 1, c. $113=$ Gomphandra tomentella, Mast.

umbellata, Kuntze, 1. с. $(=$ Stemonurus umbellatus, Becc.). - Borneo

URARIA, Desv. (Legumin.). - Ind. Kew. ii.1148.

heteropetala, F, M. Bailey, Syn. Oueensl. Fl. Suppl iii. $(\mathbf{1 8 9 0}) 5$ (= Fitzalania heteropetala, F. Muell.). - Austral.

paniculata, C. B. Clarke, in forrn. Limn. Soc. xxv (1889) 15 t. 4. - Kohima.

retroflexa, Drake, in Morot, Fonrn. de Bot. v. (1891) 192. - Tonkin

sinensis, Franch. Pl. Delav. (1890) 172. - Yunnan.

URASPERMUM, Nutt. = Osmorhiza, Rafin. (Umbell.)

aristatum, Kuntze, Rev. Gen. (1891) $270=$ O. 1ongistylis, $D C$.

Berteroi, Kuntze, 1. c. = O. Berterii, $D C$. glabratum, Kuntze. 1. $\mathrm{c}_{\mathrm{s}}=$ O. glabrata, Phil.

mudum, Kuntze, 1. c. = O. nuda, Torm

URBANELLA, Pierre, Not. bot. Sapot. (1890) 25 - Lucuma. Molina (Sapot,)

buchananiacfolia, Pierre, 1. c. $=$ L. buchananiaefolia, Pierre.

cuspidata, Pierre, 1. c, - Bras.

oblonga, Pierre, 1. c. = Lucuma oblonga, Perre.

proccra, Pierre, 1. c. $(\mathbf{l} 890) 25=\mathrm{L}$. procera, Mart.

URBANIA. Phil in Anal. Mus, nac, Chile (1891) 60. VERBENACEAE

eganioides, Phil. l. c. t. I, fig. Ta, b. - Chili.

pappigera, Phil. l. c. t. 1. fig. \%c et d. - Chili.

URBANISOL, Kuntze, Rev, Gen (1891) $370=$ Tithonia, Desf. (Compos.).

aristatus, decurrens, heterophyllus, Thurberi, tubiformis, Kuntze, Rev. Gen. (1891) $371=$ homonyma omnia Tithoniae.

tagetifolius, Kuntze, 1. c. $370=$ T. tagetiflora, Desf. 
URBANODENDRON, Mez, in Jahrb. Bot. Gart Berl. v. (1889) 86; Pax, in Engl. \& Prantl Natürl. Pflanzenfam. iii., 2 (1891) 276. LAURI VEAE.

verrucosum, Mez, $2 l . c c .(=A y d e n d r o n$ vernucosum, Nees). - Bras.

URCEOCHARIS Clibrani X, Mast, in Gard. Chron (1892) ii. 214, fig. 36 ; et ex Gartenfl. xli. (1892) j01. (Amaryth.). - Hybr. artef.

URECHITES, Muell. Arg. (Apocyn.). - Ind Kew. ii. 1149

Neriandra, Rolfe, in Kew Bull. (1893) 262.-Ind.oco.

UREL YTRUM Hack, in Engl, \& Prantl, Natürl Pflanzenfam, ii, 2 (1889) 25, GRAMINEAE.

agropyroides, Hack, in DC. Monrog. Phan. vi. 1889 272 (= Rottbollia agropyroides, Hack.). - Angola digitatum, $K$. Schun, in Engl. Pfanzenv. Ost-Afr. C (1895) 97 [Urelythrum]. - Afr. trop. or.

squarrosum, Hack, in DC. Monog. Phan. vi. (1889) 272 t. 1, fig. 5. - Afr, austr.

URENA, Dill. ex Linn. (Maiv.). - Ind. Kew. ii 1149 .

callifera, C. B. Clarke, in fourn. Linn. Soc. xxv. (1889) 7 t. 3. - Kohima.

cylindrica, Franch. Miss, scient. Cap Horn, v.

[Phan.] (1889) 379 t. 7b. - Reg. Magell.

Hookeri, Guerke, in Bot. Falwb. xvi. (1892) 381. Ind. or.

URERA, Gaudich. (Urtic.). - - Ind, Kew, ii. 1149 Eggersii, Hieron. in Bot. Fahrb. xx. Beibl. n. 49 (1895) 3. - Ecuad.

Hypselodendron. Engl. Pfanzenw. Ost-Afr. A (1895) 130, nomen. - Afr. trop.

tenax, N. E. Br. in Hook. Icon, pl. xriii. (1888) t 1748. - Natal.

URETIA, Kuntze, Rev, Gen. (1891) $544=$ OURET Adans: = Aerva, Forsk. (Amarant.).

congesta, glabrata, lanata. Leubnitziae, leucura, microphylla, Monsonia, Pechnelii, persica, recoluta, sanguinolenta, Wightii, Kuntze, Rev, Gen. (1891) 544 $545=$ homonyma ommia Aervae

sericea, Kuntze, 1. c. = Aerva tomentosa, Lam.

URGINEA, Salisb. (Liliac.). - Ind. Kew. ii. 11 ว0. acinacifolia, Schinz, in Vorh. Bot. Ver. Brand. xxxi. (1890) 220. - Afr, austro-occ, extratrop.

brachystachys, Baker, in Bot. Fahrb. xv. (1892) 474 - Afr. trop. or

Bragae, Engl. Pfanzenv. Ost-Afr. C (1895) 142. Afr. trop. or.

coromandeliana, Hook.f. Fl. Brit. Ind. vi. (1892) 347 (= Scilla coromandeliana, Roxb.) - Coromand.

Eckloni, Baker, in Bot. fahrb. xv. Beibl, n. 35 (1892) 6. - Áfr. austr.

eriospermoides, Baker, in Gard. Chron. (188\%) ii 126. - Afr. austr

macrocentra, Baker, l. c. i. (1887) 702. - Afr. austr. modesta, Baker, in Bot. Fahrb. xv. Beibl. n. 35 (1892) 6. - Afr. austro-occ. extratrop.

noctiflora, Batt. G Trab. in Compt.-rend. Assoc. Franc. Besancon, 1892 (1893) 505 ; et Fl. de l'Algér. [Monoc.] (1895) 250. - Algeria.

Nyasae, Rendle, in Trans. Iimn. Soc. Ser. II. iv. (1894) 50. - Afr. trop.

polyphylla, Hook.f. Fl. Brit. Ind. vi. (1892) 348 (= Ornithogalum polyphyllum, Heyne). - Deccan?

sanguinoa, Schinz, in Verh. Bot. Ver. Brand. xxxi. (1S90) 219. - Afr. austro-occ, extratrop.

Tayloriana, Rendle, in foum. Linn. Soc. xxx. (1895) 424. - Afr. trop. or.

Wightiana, Hook. f. Fl. Brit. Ind. vi. (1892) 347. - Deccan.

UROPAPPUS, Nutt. = Microseris, D. Don (Compos).

Clevelandi, Greene, in Erythea, i. (1893) 137; et Man. Bot. San Franc, Bay (1894) $221=$ Calais Clevclandi, Greene). - Calif.

Kelloggii, Greene, 11, cc. $(=. C$ Kelloggii, Greene $)$. - Calif.
UROPAPPLS : -

leucocarpus, Greene, in Erythea, i. (1893) 260. Calif.

macrochaetus, Greene, 1. c. $137=$ Microseris macrochaeta, Sch. Bip.

UROPEDILUM, Pfitz. in Engl. \& Prantl, Natürl. Pflanzenfam. ii. 6 (1888) 84 , in obs. = UROPEDIUM, Lindl. = Selenipedium, Reichb. f. (Orchid.

UROPHYLLUM, Wall. (Rubiac.), 一 Ind. Kew. ii. 1151 .

chloranthum, Engl. ?] Pfanrenw. Ost-Afr. A (1895) 92, nomen. - Afr, trop.

cyphandrum, Stapf, in Trans. Lim. Soc. Ser, II. iv, (1894) 176. - Borneo.

heteromerum, K. Schum. in K. Schum. \& Hollv. Fl. Kais. Wilt. Land (1889) 130; et in Entol. E Prant, Natür. Pfanzenfam, iv, 4 (1891) 67. - N. Guin hexandrum, Kuntze, Rev.Gen. (1891)301. - Malacca. Holstii, K. Schum, in Engl. Pfanzenf. Ost-Afr. C (1895) 379. - Afr. trop. or.

lineatum. Stapf, in Trans. Linn. Soc., Ser. II. iv (1894) 177. - Borneo.

longidens, Stapf, l.c. 178. - Borneo

salicifolium, Stapf, l. c. 17\%. - Borneo.

subanurum, Stapf, l. c. 175. - Borneo.

UROSPERMUM, Scop. (Compos.). - Ind, Kew. ii. 1151 .

grandiflorum, St Lager, in Cariot, Etud. des fl. éd. 8 (1889) $52 \%$. U. Dalechampii, Desf.

UROSTEPHAN US, Robinson \& Greenm. in Am. Journ. Sci. Ser. III. 1. (1895) 159; K Schum. in Encl. \& Prantl. Natürl. Pflanzenfam. iv. 2 (1895) 306. ASCLEPIADEAE.

gonoloboides, Robinson. Ev Grecnm. ll. cr. - Mexic.

URSINIA, Gaertn.(Compos.), - Ind. Kew. ii. 1153. anethifolia, N.E. Br. in Gard. Chron.(1887) i. 670 (= Sphenogyne anethifolia, Less.). - Afr. austr. anethoides, $\mathrm{V}$. E. Br. l. c. ( $(=S$, anethoides, DC anethoides, 2 .

brachyloba, N.E. Br. l. c. (= S. brachyloba, Kuntze). - Afr. austr.

brachypoda, $N, E, B r$. l. c. $\{=$ S. brachypoda Harv.). - Afr, austr.

calendulaeflora, N. E. Br. 1. c. $=$ calendulaeflora, Benth. \& Hook. $f$.

chanaencloides, N. E. Br. 1. c. = chamaemeloides, $D C$.

hamomillaefolia, N.E. Br. T.c. $(=$ S. chanomillaefolia, DC. . - Afr. austr.

ciliaris, N. E. Br. .. c. (= S. ciliaris, DC. $)$ - Afr. austr.

concolor, N.E. Br. . . c. (= S. conculor, Harv.).Afr. austr.

coronopifolia, $N . E . B r$. l. c. (= S. coronopifolia, Less.). - Afr. austr.

discolor, $N . E . B r$. l. c. (= S. discolor, Less.). Afr. austr.

Dregeana, N.E. Br. l. C. ( $=$ S. Dregeana, DC. $)$ - Afr. austr.

Eckloniana, N.E.Br. l.c. $=$ S. Eckloniana, Sond.). - Afr. austr.

filipes, N.E. Br. l. c. (= S. fllipes, E. Mey.). Afr. austr.

heterodonta, N.E.Br.l.c. (=S, heterodonta, DC. $)$ - Afr. austr.

hispida, N. E. Br, l. c. (= S. hispida, DC.).Afr, austr.

incana, $N . \dot{E}, B r$. l. c. (= S, incana. DC. $)$ - Afr. austr,

leptoglossa, N.E. Br l. c. (= S. leptoglossa, DC.). - Afr, austr

macropoda, N.E. Br.l.c. $(=S$. macropoda, DC. $)$.

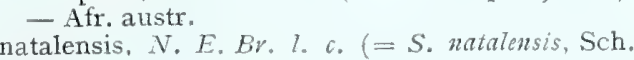
Bip.). - Afr. austr.

mudicaulis, N.E. Br. l.c. (=S. nudicanlis, Less.).

- Afr. austr.

pauciloba. $N . \dot{E}, B r$, l. . . (=S. panciloba, DC. $).-$ Afr. austr.

pulchra, N. E. Br. l. c. ; Nichols: Dict. Gard. iv. (1887) 126. - Afr. austr.

\section{URSINIA :}

punctata, N. E. Br. in Gard. Chron. (1887) i. 670 (= Sphenogyne punctata, Less.). - Afr. austr.

pusilla, N. E. Br.l.c. (= S. pusilla, DC. ). - Atr austr.

quinquepartita, $N . E . B r \cdot l \cdot c \cdot(=S$. quinquepartita DC.). - Afr. anstr.

rigidula, $N$. E. Br. l. c. $(=$ S. rigidula, $\mathrm{DC}$. Afr, austr.

saxatilis, N. E. Br. in Kew Bull. (1894) 355.Transvaal.

scapiformis. N. E. Br, in Gavd. Chron. (1888) i. 670 $(=S$. scapiformis, DC. .). Afr. austr.

sericea, $N . E . B r . l_{.} c_{0}(=$ S. sericea, Less. $)$ - Afr. austr.

subhirsuta, N.E.Br.l.c. $(=\text { S. subhirsutu, DC. })_{0}-$ Afr. austr.

ridentata, N, E $, \mathrm{Br}, 1, \mathrm{C}=$ tridentata, Benth. Hook. $f$.

trifida, $\Lambda^{*}$. E. Br. l. c. $(=$ S. trifida, Less. $)$ - Afr. austr.

trifurca, N.E.Br.l.c. $(=S$, trifurca, Harvi Afr. austr.

tripartita, N.E. Br, l, c. $=$ S. tripartita, DC.).Afr. austr. versicolor, N. E. Br. l. C. $(=S$. versicolor, DC. $) .-$
Afr. austr.

URTICA, [Tourn,] Linn.(Urtic.), - Ind, Kew, ii 1153.

bracteata, Wight, ex Hool. f. Fl Brit. Ind. 1888) 585, in syn. = Pouzolzia caudata, Benn californica, Greene, Pittonia, i. (Mar. 1889) 281; et Man. Bot. San Franc. Bay (1894) 296. - Calif.

Fischeri, Engl. Pfanzenw. Ost-Afr. C (1895̃) 162.Afr, trop. or

panciflora, Hochst. ex Hook. f. Fl. Brit. Ind. (1888) 592, in syn. = Droguetia diffusa, Wedd. sansibarica, Engl. PAlanzenw. Ost-Afr. C (1895) 162 - Afr. trop. or.

siphodon, Stapf, in Denkschr. Akad. Wien, ii. (1886) 3. - As. occ.

URTICASTRUM, Moehr. Hort. Priv. (1736); Heist. Syst. (1748), ex Kuntze, Rev. Gen. (1891) 634 = Laportea. Gaudich. (Urtic.).

alatipes, amplissimum, bulbiform, costatum, decumas num, Gaudichandianm, gigas, Harrey, laxiflonum, microstigma, Milnei, nicaraguense, oleraceum, pelta hm, photinifhylla, Pterostigma, repens, stimulans, Vrieseanm, Kuntze, Rev, Gen. (1891) $635=$ Tomonyma omnia Laporteae.

divaricatum, Kuntze, 1. c. = L. canadensis, Gaudich. eritatum, Kuntze, 1. c. = L. terminalis, Wight mexicanum, Kuntze, 1. c. = L. platycarpa, Wedd morodes, Kuntze, 1. c. = L. moroides, Wedd. simuatum, Kuntze, l. c, = L. stimulans, Miq.

URUPARIA, Rafin.= Uncaria, Schreb. (Rubiac.). acida, africana, attemuta, callopliylla, canescens, cirrhiflora. dasyoneura, ferve.], Gambier, homomalla, jasminiflora, levigata, lanosa, Lobbii, macrophylla, nemorosa, oralifolia, ovata, pedicellata, pilosa, pteropoda, Roxburghiana, sessilifructus, setiloba, Kuntze, Rev. Gen.(1891) $301=$ homonyma omnia Uncariae.

URVILLEA, H. B. \& K. (Sapind.).-Ind. Kew. ii. 1157

dissecta, S. Wats, in Proc. Am. Acad, xxi. (1886) 47. - Mexic.

UTRICULARIA, Linn.(Lentibul.), - Ind. Kew, ii. 1157

hrevicornis, Celak. in Oest. Bot. Zcitschr, xxxyi. 1886) 253 , et xxxvii. (1887) 117, 164, 192.Eur, centr.

bryophila, Ridl. in Ann. Bot.ji. (1888) 305. - Ins. S. Thom.

Campbelliana, Olicer, in Trans. Linn. Soc. Ser. II i. (1857) 280, t. 44b (Oliver, ex im Throm, in Timehri, v. (1886) 200). - Guian. angl.

capilliflora, F, Muell. in fourn. Roy. Suc, N.S. Wales, xxiv. 1890 (1891) 176 ; ct ex Bot. Centralbo xlv: (1891) 31. - Austral.

leistogama, Britton. in Trans. N. Y, Acad. ix. (1859) 12. - Am. bor. 


\section{UTRICULARIA :}

Holtzei, F. Muell, in Vict. Natival. ix. (Mar. 1893) 176; ct in Bot. Centralbl. Liv, (1893) 93. Austral.

involvens, Ridl. in foum. Bot. xxxiii. (1895) 11. Penins. Mal.

Tankae, Volen. ex Nym. Consp. Fl. Eur. Suppl. ii. I. (1859) 259; et Fl. Bulg. (1891) 473. - Bulg.

Kamienskii, F, Muell. in Vict. Natural. ix. (Mar. 1893) 175 ; et ex Bot. Centralbl. liv. (1893) 93. Austral.

littoralis $\times$, Melander, in Bot. Notis. (1887) 175. Srandin

maior. St Lager, in Cariot. Etud. des. fl. éd. 8 18S0) 646 = vulgaris, Lim .

Muelleri, Kamienski, in Bcr. Deutsch. Bot. Ges, xii. 1894) 5. - Austral.

Oliveri, Kamienski, l. c. 4. - Afr. trop.

ophirensis, Ridl. in fourn. Bot. xxxiii. (1895) 10.Malacca.

Singeriana, F. Muell, in Foum, Roy. Soc, N, S. IVales, xxiv. $1889(18.7) \% 6$ - Austral

tortilis, F. Muell. 1. c. = Wallichiana, Wight.

verapazensis, Morong, ex F. D. Smith, in Coult. Bot. Gaz. xviii. (1803) 209. - Guatem.

vulcanica, Colcnso, in Trans. N. Z. Inst. xxvi. 1893 $1894,318 .-\mathrm{N}$ Zel.

TVarmingii, Kamicnski, in Ber. Deutsch. Bot. Ges. xii. (1894) 7. - Bras.

UVA, Burm, = Uvaria, Linn, (Anonac.). acuminata. angolensis, argentea, aurita, bracteata. caffra, Chamae, chinensis, concava, connivens, cristata, cylindrica, dulcis, fusca, glabra, globosa, gracilis, Hamiltonit, hetcropetala, hirsuta, Holtzei, Lobbiana, lucida, luvida, macropoda, Marenteria. mombranacea, micrantha, microcarpa, Nanum, ovata perciflora, pauciovulata, ptychocalyx, rufa. rugosa. cabrida, semecarfifolia, sphenocarpa, subrepanda, smatrana, synsepala, timoriensis, Vogelii, Kuntze. Rev. Gen. (1891) $7=$ homonyma omnia Uvariae brasiliensis, Kuntze, 1. c. = Cymbopetalum brasi liense, Benth.

cordata, Kuntze, 1. c. = Uvaria macrophylla, Roxb. Goetzeana, Kuntze, 1. c: = U. Goezeana, F. Mucll. grandifora, Kuntze, 1. c. = U. purpurea, Blune.

Hasseltii, Kuntze, ]. c. = U. Hasselti, Blume.

hoterophylla, Kuntze, 1. c. - [Quid?].

moluccana, Kuntze, 1. c. = Unona Musaria, Dunat.

oblongifolia, Kuntze, 1, c = Uvaria trioryna, Mart.

Schumacheri, Kuntze, 1. c. = U. cordata, Schum. Thonn.

UVARIA, Linn. (Anonac.). - Ind, Kew. ii. 1159 .

antamanica, King, in foum. As. Soc. Beng. lxi (1892) ii.21. - Perak.

Lukobensis, Engl. Pfanzenv. Ost-Afr. C (1895) i7s.

- Afr. trop. or.

Buchananii, Engl. l. c. 179.-- Afr. trop. or.

chinensis, Hance [ubi ?] ex Kuntze, Rev. Gon. (18:1) S - China.

Curtisii, King. in Fourn. As, Soc. Beng. 1xi. (1892) i. 21. - Perak

İmini, Engl. Pfanzenw. Ost-Afr. C (1895) 179. Afr. trop. or

Iruticosa, Engl. l. c. 178. - Afr. trop. or.

heterophylla, Blume |ubi ?], ex Kuntze, Rew. Gen. (1891) 8. - Hab.?

Holstii, Engl. Pfanzenw. Ost-Afr. C (1895) 178. Atr. trop. or

eploctada, Oliver, in $\mathrm{H}$. Johnston, The Kilim. Exped. Append. (1886) 337, nomen. = seq.

Ieptocladon, Oliner, in Trans. Iinn. Soc. Ser. II, ii. (1887) 327. - Afr, trop. or.

lutescens, $K$. Schum. in KK. Schnm. of Hollr. Fl. Kais. Wilh. Land (18S9) 48. - N. Guin.

neo-guineensis, Engl. Bot. Fahrb. vii. (1-86) 454.N. Guin.

Ridleyi, King, in fourn. As. Soc. Beng. 1xi. (1892) ii. 19 - Perak.

Scortechini, King. l. c. 20. - Perak.

Sofa, S. Elliot, in fourn. Linn. Soc. xxx. (1894) 69 - Sierra Leone.

Stuhlmannii, Engl. Pfanzenw. Ost-Afr. C (1895) 17s. - Afr. trop. or.
UVIFERA, Linn. Hort. Cliff. (1737) 487, ex Kuntze, Rev, Gen. (1s91) $561=$ Coccoloba, Linn. (L'olygon.).

acuminata, aligoënsis, armata, ascendens, barbadensis, Barbeyana. Billbergii, bracteolosa, brasillensis, Candollana, caracasana, cordata, coriacea, costata, Cruegevi, cubensis, Curtisii, cuyabensis, cylindrostachya, declinata, densifrons, Eggersiana, excelsa, excoriata, fagifolia, fallax. fastigiata, favescens, floribunda, geniculata, gracilis, grandiflora, Grisebachiana, ilheensts, jomaicensis, furgensenii, Klotzschiana, Krugii, laeits, latifolia, laurifolia, laxifora, leptostachya, Liebmannii, Lindeniana, longifolia, longipendula, lucidula, manzanillensis, marginata, microneiva, microphylla, Moscnii, nomatostachya, nigrescens, nitida, nodosa, nocogranatensis, nutans, oblonga, obovata, Orizabae, ocata, padiformis, pallida paraënsis. paraguarionsis, parrifolia, peltata, Persicaria, peruriana, pipcricarpa, pirifolia, plantaginea, Plumieri, tolystachya, populifolia, praccox, ramosissima, reflexa, retusa, Riedelii, rosea, rotundifolia, rufescens, rugosa, Ruiziana, Sagotii, salicifolia, Schomburgkii, Schwackiana, scrobiculata, Sintenisii, sparsifolia, sphaerococca, Spruceana, sticticantis, striata, subcordata, Swartzi, tenuifora, tiliacea, Trianaci. Trinitatis, Urbaniana, venosa, verruiulosa, W Warmingi, Wrightii, y'uatana, zebra, Kuntze, Rev. Gen, (1891) $561=$ homonyma ommia Coccolobae.

acrostichades, Kuntze. Rev. Gen. (1891) $561=$ C. acrostichoides, Cham.

Blanchetiana, Kuntze, 1. C. = C. ochreolata, Wedd. crescentifolua, Kuntze, 1. c, = C. crescentiaefolia Chann.

Curtisii, Kuntze, 1. c. = C. lacerifolia, facq.

dioeca, Kuntze, 1. c. $(=C$. dioica, Steud. $)=$ Muehlenbeckia sagittifnlia,

Glazioni, Kuntze, 1. c, = Coccoloba Glaziovii, Lindau.

guyancnsis, Kuntze, 1. c. $=\mathrm{C}$. guianensis, Mcissn.

Humboldti, Kuntze, 1. c。 = C. Humboldtii, Meissn. laurifolia, Kuntze, 1, c. = C. laurifolia, facq. Lelzmanni, Lindau, in Bot. Jahrb xx. Beibl. n. 49 (1895) 7 , in obs. $=$ C. Lehmannii, Lindan. leoganensis, Kuntze, Rev. Gen. (1891) $561=\mathrm{C}$. uvifera, Linn.

leptostachyoides, Kuntze, 1. c。 $=$ C. leptostichyoides, Lindau.

longipcudula, Kuntze, 1. c, = C. Iongependula, Mart. mexicana, Kuntze, 1. $c_{*}=$ C. Schiedeana, Lind obtusifolia, Kuntze, 1. c. = C. microstachya, Willd. pubescens, Kuntze, 1. c. = C. grandifolia, facq. punctata, Kuntze, 1. c. = C. coronata, facq. racemulosa, Kuntze, 1. $\mathrm{c}_{\mathrm{s}}=\mathrm{C}$. racemulosa, Mcissn.

\section{V}

VACCARIA, Medic, = Saponaria, Linn, $(\mathrm{Ca}-$ ryoph.)

tyramidalis, Prahl, Krit. Fl. Prov. Schlesv.-Holst. ii. 11890$) 28=$ S. Vaccaria, Limn.

VACGINIOPSIS, Rusby, in Bull. Torrey Bot. Club, xx. (1893) 433 t. 170 . VACCINIACEAE ovata, Rusby, l. c. 434. - Bolivia.

VAGGINIUM, Linn。(Vaccin.). - Ind, Kew, ii. 1162

acutissimum, F. Muell. in Trans, Roy. Soc. Vict. N. S. j. II, (1889) 15, - N. Guin.

africanum, Britton, in Trans. Linn. Soc. Ser. II. iv. (1894) 23. - Afr. trop.

ambyandrum, F. Muell. in Trans, Roy. Soc. Vict. N. S. i. II. (1889) 19. - N. Guin. amplifolium, F. Muell, l.c. 11. - N. Guin.

atrococcum, Heller, in Bull. Torrey Bot. Club, xxi. (1894) 24 = corymbosum, Lim

barandanum, Vidal, Revis. Pl. Vasc. Filip., (1886) 166. - Ins. Philipp.

benguetense, Vidal, l, c, 168. - Ins. Philipp.

Blumeanum, Niedchzu, in Bot. fahrb, xi. (1889) 200 $(=$ V. floribund:m, Blume).- Java.

\section{VAGGINIUM}

cordifolium Stapf, in Trans. I inn. Soc. Ser. II. iv. (1894) 189. - Borneo.

Cumingianum, Vidal, Revis, Pl. Vasc. Filip. (1886) 167. - Ins. Philipp.

Delavayi, Franch. in Morot, Fourn. de Bot, ix. (1895) 367. - Yunnan.

escallonioides, Drake, l. c. iii. (1889) 76. Ecuad.

Exul, Bohus, in Hook. Icon. pl. xx. (1890) t. 1941.Transvaal.

fragile, Franch. in Morot, foum, de Bot. ix. (1895) 366. - Yunnan.

g'aultherioides, Bigel. in New Engl. Med. Journ. w. 335, ex Dippel, Handb. Laubholzk. i. (188.) 328 = uliginosum, Lim.

Helenae, F. Muell. in Trans. Roy. Soc, Vict. N. S. i. II. (1889) 16. - N. Guin.

Henryi, Henusl. in fourn. Limn. Soc. xxvi. (1890) 15. - China.

indutum, Vidal, Revis.Pl. Vasc. Filip. (1886) 169. Ins. Philipp.

lasiodiscus, Maxim. in Bull. Acad. Petersb. xxxi, (1887) 63. - Japon.

luzoniense, Vidal, Revis. Pl. Vasc. Filip. (1886) 168. - Ins. Philipp.

Macbainii, F. Muell. in Trans. Roy. Soc. Vict. N, S i. II. (1889) 17. - N. Guin.

micrantherum, Stapf, in Trans. Limn. Soc. Ser. II. iv. (1894) 190. - Borneo.

moupinense, Franch. in Nonv. Archiv'. Mus. Paris, Sér. II. x. (1888) 43. - Tibet.

nigrum, Britton, in Mem. Torrey Bot. Club, r. (1894) 252 = pennsyvanicum, Lam.

pachydermum, Stapf, in Trans. Limn. Soc. Ser. II. iv. (1894) 189. - Borneo

parvulifolium, F. Muell. in Trans. Roy. Sor. Vict. N. S, i. II. (1889) 20. - N. Guin.

polyanthum, Kuntze, Rev. Gen. (1891) $385=\mathrm{V}$. Teysmanni, Miq.

pubicalyx, Franch. in Morot, fourn. de Bot, ix. (1895) 369. - Yunnan.

puxophvllum, F. Muell, in Trans, Roy. Soc, Vict. N. S. i. II. (1889) 1\%, in obs. = Agapetes buxifolia, Nutt.

reclinatum, Nicdensu, in Bot. Fahrb. xi. (1890) 224 $(=V$. reflexmm, Hook.). - Bolivia

sabuletrum, Ridl, in Trans. Linn. Soc. Ser, II iii. (1893) 315. - Penins. Mal.

Stanleyi, Schweinf. in Sitzb. Ges. naturf. Fremde Berl. (1892) 173. - Afr trop.

urceclatum, Hemsl. in fourn. Linn. Soc. xxvi. (1889) 16. - China.

Villarii, Vidal, Revis. Pl. Vasc. Filit. (1886) 166. Ins. Philipp.

yumnanense, Franch. in Morot, fourn. de Bot. ix. (1895) 368. - Yunnan.

VAGNERA, Adans. = Smilacina, Desf. (Liliac.) amplexicanlis, Greene, Man. Bot. San. Franc. Bay (1894) $316=$ S. racemosa, Desf.

racemosa, Morong, in Bull. Torrey Bot.-Club, $\mathrm{xx}$. (1893) 480; et in Mem. Torrey Bot. Club, v. (1844) $114=$ S, racemosa, Desf.

sessilifolia, Greene, Man. Bot. San Franc. Bay 18:4) $316=$ S. sessilifolia, Nutt.

stellata, Morong, in Contrib. U. S. Nat. Herb. iii. 1 (1894) 181; et in Mem. Torrey Bot. Club, $v$ (1894) $114=$ S. stellata, Desf.

trifolia, Morong, 1. c. $114=$ S. trifolia, Desf.

VAHEA, Lam. = Landolphia, Beauv. (Apncyn.) Kirkii, Sadeb. in Jahrb. Hamb.Wiss. Anstalt. ix. I. (1891) 226 - L. Kirkii, Dyer.

VAHLIA, Thunb. (Saxifr.). - Ind. Kew. ii. 1164

dichotoma, Kuntze, Rev, Gen. (1891) $227=$ oldenlandivides, Roxb.

digyna, Kuntze, 1. c. $=$ viscosa, Roxb.

VALENTINIA. Heist. = Maianthemum, [Weberl in Wigg. (Liliac.)

bifolia, Baill. Hist. des pl. xii. (1894) 517 = Maianthemum Convallaria [Weber in] Wigg. 
VALERANDIA, Neck. = Orphium, E。 Mey. (Gentian.).

fraticosa, Kuntze, Rev. Gen. (1891) $432=0$ frutescens, E. Mey.

VALERIANA, Tourn, ex Linn. (Valerian.), Ind. Kew. ix. 1164.

aegialitis, Phil. in Anal. Univ. Chil. 1xxxv. (1894) T21. - Chili.

albonervata, Robinson, ex Seaton, in Proc. Am. Acad xxvii (1893) 170. - Mexic

amigut, G. Beck, F1. Nied.-Oest. ii. II. (1893) $1140=$ montana, Limn.

andina, Britton, in Bull. Torrey Bot. Club, xviii. 1891) 264. - Bolivia.

andina, Fr. Meigen, in Bot, Fahrb, xvii. (1893) 276 , 293, et xviii. (1894) 429, 462. - Chili.

apiifolia, A. Gray, c. S. Wats, in Proc. Am. Acad xxii (1887) $41 \%$. - Mexic

araucana, Phil. in Anal. Univ'. Chit. lxxxv. (1894) 744. - Chili.

Gifuga, Simonk. ex Blocki, in Oest. Bot Zeitschr. xlii. (1292) $35 \%=$ tripteris, Linn

boliviana, Britton, in Bull. Torrey But. Chub, xviii. (1891) 263. - Bolivia.

calcarea, Alboff, in Bull. Herb. Boiss. ii. (1894) 452, jii. (1895) 519. - Reg. Cauc

caudata, Phit. in Anal. Univ. Chil. 1xxxy. (1894) 743. - Chili.

ceratophylla, MacMill. Metasp. Minn. (1892) 492 $=$ edulis, Nutt.

Chodatiana, Alboff, in Bull. Herb. Boiss. ii. (1894) $45 \%$ - Reg. Cauc.

columbaria, Phil, in Anal. Univ. Chil. 1xxxv. (1894) 747. - Chili.

crassicaulis, Phil. l.c. 746. - Chili.

crenata, Phil. l. c. 744. - Chili.

Fedtscherkoi, Coincy, Ecl. alt. pl. Hisp. (1895) 15 , in obs. ( $=$ V. longiflora, Regel \& Schmalh.). As, centr.

flagellifera, Batalin, in Act. Hort, Petrop. xiii. (1894) ist. - China.

Glaziuvii, Taub. in Bot. fahrb. xv. Beibl. n. 38 (1843) 10. - Bras

Heyderi, Halacsy, in Verh, zool,-bot. Ges, Wien, xxxviii. (1888) 757. - Graecia.

integrifolia, Phil, in Anal. Univ, Chit. 1xxxv. (1894) $74^{2} .-$ Chili.

kilimandscharica, Engt. Bot. Fahrb. xix. Beibl n. 47 (1894) 48. - Afr. trop. or.

Manduni, Eritton, izs Bull. Torrey Bot. Club, xviii. (1ธ91) $\approx 64$. - Bolivia.

Palmeri, A. Gray, ex S. Wats, in Proc. Am. Acad. xxii. (1887) 417. - Mexic

Pancicir, Halácsy et Baldacci, in Oest. Bot. Zeitschr. xil. (15:1) 408. - Montenegro.

Plin, Ces. Passer, \& Gibelli, Comp. F1. Ital, ii. (18ऽ6) 549. [Sp. collect.]. - Italia.

polemonifolia, Phit, in Anal. Univ. Chil. 1xxxv. (1894) 743. - Chili.

Pugae, Phil. l. c. 746. - Chili.

remota, Bull, in foum, Linn. Soc. xxii. (1885) 42. - Peruvia.

rhomboidea, Greene, Pittonia, i. (Jan. 1888) 154. inexic.

Rusbyi, Britton, in Bull. Torrey Bot. Chub, xviii. (1891) 264. - Bolivia.

Sternbergii, G. Beck, Fl.' Nied.-Oest. ii. II. (L893) $1140=$ montana, Linn.

tangutica, Batalin, in Act. Hort. Petrop. xiii. (1894) 375. - China

Urbani, Phil. in Anal. Mus. nac. Chile (1891) 29. Chili.

gersifolia, Bruegg. in Jahresb. Naturf. Ges. Graub. xxix. 1884-85 (1886) 98, et xxxi. Beil. (1887-88) $80=$ officinalis, $\operatorname{Linn}$

Volkensii, Engl. Pflanzenw. Ost-Afr. C (1895) 395. - Afr. trop. or.

VALERIANELLA, Tourn. ex Hall, (Valerian.), Ind. Kew, ii. 1167

bessarabica, Lipsky, in Soc, Natur. Kiew, xi. II. (1891) 50. - Reg. Cauc.

butgarica, Velen. in Sitzb. Boehm, Ges, Wiss, 1893 (1894) xxxvii. 33 = pontica, Lipsky.

\section{VALERIANELLA :-}

aucasica, Höek, in Engl. \& Prantl, Natïr, Pfanzenfam. iv. 4 (1891) 177 (= Betekea cancasica, Boiss.). - - Reg. Cauc

uxina, Velent in Abh. Boehm. Ges, Wiss. 1894, 1895) n. xxix $16(=V$. pontica, Velen,). - Bulg: Ciocarpa, Kuntze, in Act. Hort. Petrop. x. (1887) $195=$ Dufresnia leiocarpa, $L . C . K o c h$

platycarpa, Trattv. l. c. ix. (1886) 455. - Turkest. Pomeli, Batt. in Batt. \& Trab. Fl. de l'Algér. [Dicot.]. (1889) 406. - Algeria.

pontica, Velen, in Sitzb. Boehm. Ges. Wiss. 1893 (1894) xxxvii. 34 = euxina, Velen.

Willkommi, Freyn, ex Willk. Suppl. Prodr. F1. Hisp. (1893) 71; et in Bull. Herb. Boiss. i. (1893) $546=\mathrm{V}$. Martini, Losc.

VALERIANODES, Medic. = Stachytarpheta, Vahl (Verben.).

acuminatum, albiflonum, bicolor, canescens, contnutatum, crassifolium, glabrum, integrifoliunn, longispicatum, orubicum, pachystachyum, quadrangulum, reticulatum, sanguineum, scaberrimum, spcciosum, villosum, Kuntze, Rev. Gen. (1891) $510=$ homonyma onmia Stachytarphetae.

caycunerssis, Kuntze, 1: $c_{0}=\mathrm{S}$. cajanensis, Vahl.

gesnerodes, Kuntze, 1. c. = S. gesnerioides, Chan.

integrifolinm, Kuntze, 1. c. = S. glauca, Walp

longispicatum, Kuntze, $1 . \mathrm{c}_{0}=\mathrm{S}$. Chamissonis, Walp.

rhombodale, Kuntze, l. c = S. rhomboidalis, Walp.

VALETONIA. Th. Dur. Ind, Gen. Phan. (1888) 64 (= MARTIA, T. Valeton). OLACINEAE.

VALLARIS, Burm, f. (Apocyn.).- Ind, Kew. ii. 1168.

glabra, Kuntze, Rev. Gen. (1891) $417=$ V. Pergulana, Burm.

solanacea, Kuntze, l. c. = V. Heynii, Spreng.

solanacea, K. Schum, in Engl. \& Prantl, Natürl. Pflanzenfam. iv. 2(1895) is6 = praec

VALLESIA, Ruiz \& Pav,(Apocyn.). - Ind. Kew, ii, 1168

laciniata, T. S. Brandeg. isz Proc. Calif. Acad Ser. II. ii. (1889) 182. - Calif

macrocarpa, Hillebr. Fl. Haw. Isl. (1888) 297.Ins. Sandvic.

VALLISNERIA, Mich, ex Linn. (Hydrochar.). Ind. Kew. ii. 1168

caulescens, F. M. Bailey E F. Muell. Syn. Queensl. Fl. Sec. Suppl. (1888) 56. - Austral.

gracilis, F.M. Boiley, Rep. Exped. Bellend. (1889) 62 ; et Syn. Quensh. Fl. Third Suppl. (1890) 70. - Austra1.

VALLOTA, Herb. (Amaryll.) - - Ind. Kew. ii. 1168. sheciosa, Th. Dur. \& Schinz, Consp. Fl. Afr. v. $189: 3(1895) 258=$ purpurea, Herb.

VANGOUVERIA, Ch. Morr. \& Deene,(Borberid.). - Ind. Kew. ii. 1168.

parviflora, Greene, Pittonia, ii. (June 1890) 100; et Man. Bot. San Franc. Bay.(1894) 7. - Calif.

VANDA. Jones (Orchia.). - Ind. Kew. ii. 1168.

Amesiana, Reichb. f. in Gard. Chron. (1887) i, 764 et (1889) i. 233; Williams, Orchid Alb. vii. (1888) t. 296; Hook. f. in Bot. Mag. (1890) t. 7139.Cambodia.

Arbuthnotiana, Kraensl. in Gard, Chron. (1892) i 522; Williams, Orchid Grow. Man. ed. 7 (1894) 740. - Malabar.

Charlesworthtii X; Rolfe, in Orchid Rev, ii. (1894) 322. - Hybr. spont.

Clarkei, N. E. Br. in Kew Bull. (1888) $112=$ Arachnanthe Clarkei, Hook, $f$.

Drakei, Reichb̈. f. in Gard. Chron. (1886) ii. 648. Ins. Sund.

flavobrunnea, Reichb. f. in Flora, 1xix. (1886, 552. - Hab?

Kimballiana, Reichb. f. in Gard. Cliron. (1889) i. 232 (1889) ii, 294, 335, fig. 50; Lindenia, v. (1889) 27, t. 204; Howk. f. in Bot. Mag. (1890) t. 7112. - Hab.?
VANDA :

Lindeni, Reichb. f. in Gard. Chron. (1886) ii, 70; in Lindenia, ii. (1886) 19, t. 56. - Ins. Pacif. Muelleri, Kraenzl. in Oest. Bot. Zeitschr, xliv. (1894) 461. - N. Guin.

obliqua,Wall. ex Hook. f, F1. Brit. Ind.vi.(1890) 61 in syn, = Saccolabium obliquum, Lindl.

pumila, Hook. f. Fl. Brit. Ind. vi. (1890) 53 ; et in Annal. Bot. Gard. Calc. v. (1895) 45. - Reg. Himal.

Roeblingiana, Rolfe, in Kew Bull. (1894) 365.Penins. Mal.

ubulifolia, Reichb, f, in Flora, Ixix (1886) 552 . Hab.

superba, Hort. ex Lindenia, iii. (1887) 83, t. $136=$ V. Boxalli, Reichb. $f$.

itellina, Kraenzl. in Gard. Chron. (1892) ii. 206. $\mathrm{Hab}$ ?

VANDELLIA, Linn. (Scrophul,), - - Ind. Kew. ii 1169

erastoides, Collett of Hemsl. in fourn. Limn. Soc. xxviii. (1890) 100. - Burma.

VANDOPSIS, Pfitz, in Engl \& Prantl, Natürl. Pflanzenfam. ii. 6 (1889) 210. ORCHIDEAE.

Chalmersiana, F. Muell. E Kraenzl. in Oest. Bot. Zeitschr. xliv. (1894) 210. - N. Guin.

gigantea, Pfits. in Engl. \& Prantl, Naturn. Pfanzenfank. ii. 6 (1889) $210 \quad(=$ Stauropsis gigantea. Benth.). - Burma.

lissochiloides, Pfitz.l.c. $(=$ S. lissochiloides, Pfitz. $)$ - Ins. Philipp.

VANGUIERA, Juss, (Rubiac.), 一 Ind. Kew. ii. $116 ?$

acuminatissima, $K$. Schum, in Engl, Pflanzenv. OstAfr. C (1895) 385. - Afr. trop. or.

apiculata, K. Schum, l. c.385. - Afr. trop. or.

glabra, $K$. Schum. l. c. - Afr. trop, or.

loranthifolia, K. Schum. l. c. - Afr. trop. or.

microphylla, K. Schum. l. c. - Afr. trop. or

neglecta, $K$. Schimm. l.c. 384. - Afr. trop. or.

nigrescens, S. Elliot, ex Oliver, in Hook. Icon. pl xxiii. (1894) t. 2283; S. Elliot, in fourn. Linn. Soc. xxx.(1894) 80. - Sierra Leone.

nodulosa, $K$. Schum. in Engl. Pflanzenw. Ost-Afr. A $(1895) 92$ nomen - Afr trop.

Pyrostria, Boerl. Handl. Fl. Ned. Indië, ii. I. (1891) 134 (= Pyrostria spinosa, Miq.). - Java.

tomentosa, K. Schum. in Engl. PAanzenv. Ost-Afr. C 1895) 385. - Afr. trop. or

werncosa, Sieber, ex Solereder, in Bot. Centralbl. xlv. (1891) 398, in syn. = Linocierá verrucosa Solereder.

Volkensii, K. Schunn, in Engl. Pfanzenwe. Ost- Ifr. C (1895) 384. - Afr. trop. or.

VANHOUTTEA, Lem.= Houttea, Decne. (Gesner.

Leptopus, Kuntze, Rev. Gen. (1891) 478 = H. Gardneri, Decne.

salviaefolia, Kuntze, 1. $\mathrm{c}=\mathrm{H}$. salviifolia, Hanst.

VANILLA, Plum. ex Mill. (Orchid.), - Ind. Kew. ii. 1170.

appendiculata, Rolfe, in Kew Fiull. (1895) 178. Guian. angl.

ensifolia, Rolfe, l. c. (1892) 141; S. Moore, in Trans. Lim. Soc. Ser. II. iv. (1895) 479, t. 33, fig. 6. Bras.

Gardneri, Rolfe, l. c. (1895) 177. - Bras,

tolypephora, Ridl. in .Trans. Linn. Soc. Ser. II. iii. (1893) 376. - Penins. Mal.

VANTANEA, Aubl. (Humir.),-Ind. Kew.ii.1170. contracta, Un Bot, fahrb. xy, Beibl, n. 34 (1892) 3 - Bras.

VARANGEVILLEA, Baill. Hist. des pl. xi. (1892) 116; Briq. in Engl. \& Prantl. Natïr. Pflanzenfam. iv. 3a (1895) 178.VERBENACEAE. hispidissima, Baill. ll. at. (= Colea hispidissima, Seem.). - Madag. 
VARTHEMIA, Camel, Epit, FI. Eur, ii. (1894) 227 vartheimia, $D C$.

VASEYANTHUS, Cogn。 in Zoë, i. (1890) 368 , t. 11; Muell, \& Pax in Engl. \& Prantl, Natürl. Pitanzenfam. iv, 5 (1894) 393, in add. CUCURBITACEAE.

Rosei, Cogn. hl.cc. 394. - Calif.

VATERIA, Linn。(Dipteroc.). - Ind, Kew, ii. 1179 .

smmensis, Burck, in Amnal. Jard. Buit, vi. 2 (1887) $184=$ Shorea siamensis, Miq.

VATERIOPSIS, Heim, Recherch. Diptéroc. (1892) 94: et in Bull. Soc. Bot. Fr. xxxix. (1892) 14: = Vateria, Linn. (Dipteroc.).

scychellarum, Heim, 1. c。 = V. seychellarum, Dyer.

VATIGA, Linn. (Dipteroc.). - Ind. Kew, ii. 11 I2. Bantomensis, Burck, in Annal. Jard. Buit, vi. (1887) 231 t. $28=$ grandiflora. Dyer.

Beccariana, Hcimn, in Bull. Soc. Linn. Paris, ii (1891) 955 - - Borneo

Beccarii Drer, ex Brandis, 'in Journ. Linn. Soc. xxxi. (1895) 133, in syn. = V. Urbani, Heim.

borneensis, Burck, in Amal, fard. Buit, vi. (1887) 230. - Borneo.

Burckii, Heim, in Bull, Soc. Linn. Paris, ii, 1891 956 = Cotylelobium Burckii, Heim

Bureavi, Hcim , l, c. 9.5.5. - Borneo.

Caddupir, Buchanan, ex Brandis, in Journ. Limn. Soc. xxxi. (1895) 119, in syn. = chinensis, Linn. celebensis, Brandis, in foum. Limn. Soc. xxxi. (1895) 126. - Ins, Celebes.

cinerea, King, in fourn. As. Soc. Beng. lxii. (1893) ii, 104 - Malaya.

Curtisii, Kring. l. c. 105. - Penang.

Dyeri, King. l.c. 106. - As. trop or.

Dyeri, Pierre, in Laness. Pl. util. Colon. Franc. 1886) $299=$ Synaptea Dyeri. Picre

Forbesiana, Burck, in Annal. Fard. Buit, vi, (188i) 28. - Sumatra

furfuracea, Burck.l, c. - Borneo.

Griffithi, Brandis, in foum. Limn. Soc. xxxi. (1895) 121. - Burma.

Harmandiana, Pierre, in Lnuess. Pl. with. Colon. Framc (1886) 239: et Fl. For. Coclineh. Fasc, 15 (1890) t 209 e et 16 (1891 t. $254 \mathrm{~b}$ - Cochinch

Harmandi. Heim. in Bull. Soc. Linn. Paris, ii (1891) $955=$ Cotylelobium Harmandii, Heim.

Kunstleri, Brandis, in Four \%. Linn. Soc, xxxiii. (1895) 127. - Perak.

lamponga, Burck, in Amurl. Fard. Buit, vi. (188.) 227 t. 29 , fig. 3. - Sumatra.

Lowii, King, in fou'n. As. Soc. Deng. 1xii. (1893) II. 103. - Perak.

moluccana, Burck. in Annal. Fard. Buit. vi. (188: 20 (j) t. 26. - Ins. Moluce

nitens, King in Fourn. As. Soc. Beng. 1xii. (189:3) II. 104. - Penang

obtusa, Burck, in Annal. Jard. Buit. vi. (185i) 228 $=$ Pachynocarpus ruminatus, Brandis var.

popnuna, K. Schum. \& Hollr, in K. Schum, \& Hollr. Fl. Kais, Wilh. Land $(1889,52=$ Schumanniana, Gilg,

pedicellata, Brandis, nn fourn. Lim. Soc. xxxi. (1895) 125. - Borneo.

perakensis, King, in foum. As. Soc. Beng. 1xii. (1893) II. I03, - Peral.

Philastreana. Pierre, in Laness, Pl. util. Colon. Franc, 18s6) 298: et Fl. For. Cochinch. Fasc. 15 (1890) t. 237 ; et 16 (1821) t. $254 \mathrm{c}$ - - Cochinch. reticulata, King, in fourn. As. Sec. Bong. lxii. (1893) II. 106. - Perak.

Ridleyana, Irrandis, in Hook. Icon. pl. xxv. (189.) t. 2401. - Penins. Nal.

ruminati, Burck, in Annal. Jard. Buit, vi. (18s7) 227 t. 29 , fig. $24=$ Pachynocarpus ruminatus Brandis.

Sarawakensis, Irim, in Bull. Soc. Limn. Paris, i1 (1891) 970 ; et Reiherek. Diptiroc. (1892) 109. Borneo.

Schefferi, Brandis, in foumn. Limn. Soc. xxxi.. (1895) IDS (= Dryobalanops Schefferi, Hance). Sumatra.

\section{VATICA}

Ahumanniana, Gilg, in Bol. Fahrb. xviii. Beibl.n. $45(189 t) 38$ - - N, Guin.

Teysmanniana, Burck, in Annal. Fard. Buit. vi. (1887) 230. - Ins. Bangka.

Thorelii, Pirre, Fl. For, Cochinuch, Fasc. 15 (1890) t. 298, ct 16 (1891) t. 254b. - Cambodia.

umbonutat, Burck, in Annal. Jard. Buit, vi. (1887) 232 = Parhynocarpus umbonatus, Hook. $f$.

Urbani, Heim, in Bull. Soc. Linn. Paris, ii. (1891) 956 - Borneo.

revrucosa, Burck, in Annal. Jard. Buit. vi. (188i 232 t. 29, fig. $5=$ Pachynocarpus umbonatus, Brandis.

VAUANTHES, Haw. = Grammanthes, DC (Crassul.)

dichotoma, Kuntze, Rev。 Gen. (1891) 232 = G. gentiancides, $D C$.

VAUQUELINIA, Correa (Rosac.). - Ind. Kew ii. 1li2. Sarg, in Gard, and For. ii. (1889) 400 ; et N. Am. Sylva, ii. (1892) 59, t. $164=$ V. Torreyi, S. Wats.

VAUSA GESIA, Baill. in Bull. Soc. Linn. Paris, ii. (1890) 871. VIOLARIEAE.

africana, Baill. l. c. - Afr, trop.

VAVAEA, Benth. (Meliac.). - Ind. Kew, ii lli: Ins. Fiji.

VEATCHIA. A. Gray (Anacard.). - Ind. Kew, ii $11 \%$ ?

discolor, T. S. Brandeg, in Proc. Calif. Acad. Ser. ii. II. 1889) 140 (= Schinus discolor, Benth.). Calif

VELAEA, DC. = Arracacia, Bancr. (Umbell.). arguta, Coult. \& J. N. Rose, Rev, N. Am. Umbell. (1888) $120=$ A. arguta, Benth. \& Ifook. f.

glanca. Coult. \& J. N. Rose, ex J. N. Rose, in Contrib. U. S. Nat. Herb. iii. 5 (1895) 32: t. 14 - Oregon.

Hartaceg, Coult, \& J. N. Rose, Rer, N, Am Umbell. (1888) $121=$ Arracacia Hartwegi, S. IVals

ITow llit, Coult. \& I. N. Rose, 1. c. 12?. - Oregon. Kelloggii, Coult. \& J. N. Ruse, 1. c. 121 . = Arracacia Kelloggii, S. Wats

Parishii, Coult. \& J. N. Rose, 1. c. - Calif.

vestita. Coult. \& J. X. Rose, 1. c, $122=$ Arracacia vestita, S. II ats.

VELLEIA Sm. (Goodenov.). - Ind. Kew. ii 1173

Salmoniana, $F$, Mtuell, inz Vict. Natural, ix. (Dec. 189:) 127; ct in Bot. Centralbl. 1iii. (1893) 124 [Velleja]. - Austral.

VELLOZIA, Vand. (Amaryll.). - Ind. Kew, ii 1173.

acuminata, Bukw, in Kow Bull. (1895) 228. - Reg. Somal.

aequatorialis, Rendle, in foum. Limn. Soc. xxx. (1895) 409. - Afr. trop. or.

arabica, Baker, in Kew Bull. (1894) 342, et in Hook. Icon. Hl. xxiv, (1895) t. 2364. - Arabia.

humilis, Baker, in foum. Bot. xxvii. (1889) 4. Afr. trop. austro-or., Afr. austr

Schnitgleinia, Martelli, Fl, Boyos. (1880) 8\% = Xerophyta Schnitzleinia, Baker.

splendens, Rendle, in Trans, Lim, Soc, Ser, II , is. (1894) 49. - Afr. trop

villosa, Baker, in foun. Bot. xxrii. (1889) 3. Transvaal.

VELLOZIELLA. Baill, in Bull, Soc, Linn, Paris, 1. (1886) 715. SCROPHULARINEAE,

dracocephaloicles, Baill. l.c. $\ell=$ Digitalis dracocephaloides, Vell.). - Bras.
VELVETIA, Van Tiegh, in Bull, Soc, Bot. Fr. xlii. (1895) $354=$ Loranthus. Linn.

cincta, Van Tregh. 1. c. = L. cinctus, Mart.

VENIDIUM, Less, (Compos.). - Ind. Kew, ii. 1173

calendulaceum, IIort, ex Kew Bul1, (1888) $122=$ fugax, $H a r$.

speciostm, Hort, 1. c. = hirsutum, Har:

VENTILAGO, Gaertn. (Rhamn.), - Ind, Kew. ii. 1174.

ristata, Picrye, Fl. For. Cochinch. Fasc, 20 (1894) t. $314 a,-$ Cochinch

elegans, Honslo in Am. Bot. ix. (1895) 151. Formosa.

fasigera, Pierre, Fl. For. Cochinch. Fasc. 20 (1894) t. 314 d. - Cochinch.

gladjata, Pierre, l. c. t. 31tc, - Cochinch.

Harmandiana, Picre, l. c. t. $313 \mathrm{a}$. - Cochinch.

luzoniensis, Vidal, Revis. Pl. Vasc. Filip. (1886) 90, - Ins. Philipp

microcarpa, K. Schum, in K. Sihnun. \& H Hollr. F7. Kais. Wilh. Land (1889) 72. - N. Guin.

chrocarpa, Picre, Fl. For. Cochinch, Fasc, 20 (1824) t. 314b. - Cochinch.

VEPRECELLA. Naud. (Melast.). - Ind. Kiew. ii. 1174

acuminata, Cogn, in DC. Monog. Phan? vij. (1891) 486. - Madag:

apiculata, $\operatorname{Cog} 3$. \%. c. 483. - Madag.

biformis, Baker, in fourn. Linnn. Soc. xxii, (1Ssi) 477 ; Cogn.l.c. 488. - Madag.

bulbosa, Cogn. in DC. Monog. Phan. rii. (189l) 483. - Madag.

foliosa. $\operatorname{Cog}$ n. . . c. 484. - Madag.

lanceolata, $\operatorname{Cog} 7$. . . c. 488, - Madag.

microphylla, Cogn. l. c. 48.5. - Madag.

oblongifolia, Cogn, 7. c. 487. Madag.

oralifolia, Cogn . . . c. 484. - Madag

pilosula, Cogn. 7. c. 482. - Madar.

riparia, $\operatorname{Cog} \eta_{\text {. }}$. c. 488. - Ins. Nossibe,

rosea, $\operatorname{Cog} \pi$. . . c. 484. - Madar.

tetraptera, Cogyr. . . . 48\%.- - Maday

VERATRUM, [Tourn.] Linn. (Liliac.), - Ind, Kew, ii. 1lit. bosniacum, G. Beck, in Annal, Natu
Wien, ii. (1887) $50=$ album, Limn.

bracteatum. Batalin, in Act. Hort. Petrop. xiii. $0893) 106$. - China

VERBASCUM. Tourn. es Linn. (Scrophul.).Ind. Kew, ii, 11;1.

acaule, alpimem, aureum, Boisseri, brachysepahnm, Cilicia, coronopifolinm, creticum, cyllencum, Daenzeri, floccosum, glindulosum, hetcrophyllum, intermptum, intricaum. lancolatmm, Luciliae, Iyoia, orientale, pedunculusum, persicam, pinetorm, ponticum. pyroliforme, ramosissimum, Surarouimum, Kuntze, Rev. Gen. (1891) 468-69:= homonyma onmia Celsiae.

adspersum, Frey'n \& Sint, ex Freyn, in Oest. Bot. Zeitschr. xliv, (1894) 296. - As. Min.

aintabicum, Post, Pl. Postianac, ii. (1889) 1\%,Syria.

Aliciae, Post, l. c. iii. (1892) 14. - Syria.

ambigens Hausskn. in Mitt. Bot. Ver. Jena, v. (1886) 72. - Graecia

ambracicum $X$, Haláczy, in Denkschr. Akad. Wien, 1xi. (1894) 317. - Graecia.

Andrusi, Post, in Bull. Herb. Boiss. iii, (1895) 161. - Syria.

Antari, Post, Pl. Postinnae, ii. (1891) 17. Syria.

aphyllopodum, Freyn, in Oest. Bot. Zeitschr. xliv. (1894) 264. - As. Min

atlanticum, Batt, in Batt. \& Trab. Fl. de l'Algér. [Dicot.] (1889) 626. - Algeria.

aurantiacum, Coincy, in Morot, foum de Bot. ix. (1895) 332. - Hisp.

adense X, G. Beck. FI. Nied.-Oest, ii. II. (1893) 1032. - Austria.

balcanicum, Velen, Fl. Bulg. (1891) 413. - Bulg

Barbeyi, Post, in foum. Linn. Soc. xxir. (1858), 436. - As. occ 


\section{VERBASGUM}

Barthi, Schur, ex Nym. Consp. Fl. Eur. Suppl. ii. I. (1889) $229=$ nigrum, Linn

Beckexnzm X, G. Beck, Fl. Nied.-Oest. ii. Ir. (1893) 1036. - Austria.

betoxicifolim, Kuntze, Rev. Gen. (1891) 469= Celsia betonicaefolia, Desf.

Bornmuelleri, Velen. in Sitzb. Boehm. Ges. Wiss. 1889. ii. (1890) 38 ; te Fl. Bulg. (1891) 415. - Bulg.

bracteosum, Freyn 'E Sint. ex Freyn, in Oest. Bot.

Zeitschir. xliv. (1894) 294. - As. Min.

breyzimun X, G. Beck, FI. Nied.-Oest. ii. II. (1893) 1033. - Austria.

bulgaricum, Velen. Fl. Bulg. (1891) 408. - Buig.

carinthicutm $X$, Fritsch, in Verh. zool.-bot. Ges. Wien, (1889) Sitzb. 71 ; in Bot. Centralbl. xli. (1890) 82; Pacher, Nachtr. F1. Kärnt. (1894) 119. - Carinth.

caudatum, Freyn ¿े Bomm. ex Freyn, in Oest. Bot. Zeitsinr. xlii. (189:)346. - As. Min.

caudatum, Post, in Bull. Herb. Boiss. iii. (1895) 160 - Syria.

conobitanm X, Hausskn. \& Heldr. in Mitt. Bot.

Ver. Jena, v, (1886) 7\%. - Graecia.

coromaudelicum, Kuntze, Rev. Gen. (1891) $468=$ Celsia coromandelina, Vahl.

crenatum $X$, Borb. ex, Nym. Consp. Fl. Eur. Suppl. ii. 1. (1889) 230. - Croatia,

cylindraceum. Freyn \& Sint. ex Freyn 132 Oest. Bot. Zeitschr, xliv. (1894)295. - As. Min.

Debauxii, Franch, ex Batt. \& Trab. F1. de I'Algér. [Dicot.] (1889) 627, in syn. = kabylianum Dibcull

Decaisneamun, Kuntze, Rev. Gen. (1891) $468=$ Celsia parviflora, Decne.

decorum, Velen. in Sitzb. Boekm. Ges, Wiss, 1889 ii. (1890) 50; et Fl. Bulg. (1891) 41\% - Bulg.

devvichorum $X$, Hausskn. \& Heldr, in Mitt. Bot. Ver. Jena, v. (1886) 72. - As. occ.

divaricatum, Freyn of Sint. ex Freyn, in Oest. Bot. Zeitsilu. xliv. (1894) 265. - As. Min.

Divrikianum, Bomm, in Mitt. Thïr. Bot. Ver. N. Folge, vi. (1894) 66. - Oriens.

eyiocarpun, Freyn \& Sint. ex Freyn, in Oest. But. Zeitschr. xliv. (1894) $297=$ xanthophoeniceum Griseb.

crraticum X, Hausskn. in Mitt. Bot. Ver. Jena, v. 1886) 7\% - Graecia.

fallax, Frcyn \& Sint. ex Freyn, in Oest. Bot. Zeitschr. xliv. (1894) 264. - As. Min.

flaccidum, Frcyn \& Bormm. \%. c. xli. (1891) 57. As. Min.

fimminense X, A. Kern. ex Nym. Consp. Fl. Eur. Suppl. ii. I. (1889) 230. - Croatia, Istria.

Formanekii, Borb. ex Formanek, in Verh. Naturf. Ver. Brimn, xxxi, 1892 (1893) 122. - Bulg.

Friedrichsthaliamm, Kuntze, Rev. Gen. (1891) 468 = Celsia speciosá, Fenzl.

fruticulosum, Post, in Bull. Herb. Boiss. i. (1893) 405. - Syria

gadarense, Post, l. c. 403. - Syria

gileadense, Post, in fourn. Linn. Soc. xxiv. (1888) 426. - As. occ.

glochotrichum, Hausshn. E Heldr, ex Hausshn. in Mitt. Bot. Ver. Fona, v. (1887) 8\%. - Graecia.

grandicalyx $X$. Simonk. in Oest. Bot. Zeitschr. xxxix. (1889) 138. - Hung.

Grisebachianm, Borb. [ubi?] ex Nym. Consp. F1. Eur. Suppl. ii. I. (1889) $229=$ nigrum, Linn.

Halácsyanum, Sint. \& Bormm. ex Halácsy, in Oest. Bot. Zeitschr. xlii. (1892) 374. - Thracia.

Haussknechtii, Heldr, ex Hausskn, in Mitt. Bot. Ver. Fona, v. (1886) 71. - Graecia.

heterophyllum, Velen. in Abh. Bochn. Ges. Wiss. (1888) 21 ; in Nym. Consp. Fl. Eur. Suppl. ii. I. (1889) 229 ; ct Fl. Bulg. (1891) 417. - Bulg:

ibericum, Schmalh. in Ber. Deutsch. Bot. Ges. x. (1892) 290 ; Akinfiew, Fl. Canc. centr. (1894) 23. Reg: Transcauc.

inaequale. Freyn of Sint. ex Freyn, in Oest. Bot. Zeitschr. xliv. (1894) 265 - As. Min.

incanum, Kuntze, Rev. Gerı. (1891) $469=$ Celsia lanceolata, Vent.

infidum X, G. Beck, Fi. Nied-Oest, ii. II. (1893\})

1037. - Austria.

insignitum X, G. Beck, 1. c. 103\% - Austria.

\section{TERBASCUM}

fankae, Velen, in Abh. Boehm. Ges. Wiss, VII. Folge, i. (1886) 33; et Fl. Bulg. (1891) 408, in syn. = pannonicum, Vis. E Pancic.

Jankaeanum, Pancic, Nov. elem. fl. Princ. Bulg. 1886) 32. - Bulg.

furatzkac $\times$, Rechinger, in Oest. Bot. Zeitschr. li. (1891) 338 ; Pacher, Nachtr. Fl. Kärtn. (1894) 120. - Austria.

Fabylianum, Debeaux, in Rev. de Bot. viii. (1390 265 ; et ex Batt. G Trab. Fl. de l'Algér. [Dicot.] (1889) 627. - Algeria.

Karyeteini, Post, Pl. Postianae, ii. (1891) 16. Syria.

Kerneri $x$, Fritsch, in Sitzb. zool.-bot. Ges, Wien, xxxviii. (1588) 251 ; in Bot. Centralbl. xxxiv (1888) 397 ; G. Beck, F1. Nied,-Oest. ii. II. (1893) 103\%. - Austria.

aciniatun, Kuntze, Rev. Gen. (1891) $469=$ Celsia Bernadesii. G. Don.

Letourneuxii. Aschers. fin Letourn. Pl. Aegypt. n 325. cx Barbey, Herb. Lequant. (1887) 182, nomen, ex Aschers. Eo Schwein. [Ill. Fl. Egypte] in Mem. Inst. Egypt. (188\%) 189. - Aegypt.

ancerion $\times$ G. Beck, Fl. Nied-Oest, ii. II. (1893) 1034. - Austria.

lencothrix X, G. Beck, 1. c. 1035. - Austria.

liburnicum $X$, Borb. ex Nym. Consp. Fl. Eur. Suppl. ii. I. (1889) 230. - Eux

Luntii, Baker, in Kew Bull. (1894) 337. - Arabia. macrantherum, Haldicsy, m Oest. Bot. Zeitsclur, xlii. (1892) 373 - Thracia.

macranthum, Post, in Bull. Herb. Boiss. i. (1893) 404. - Syria.

macrocarpun, Kuntze, Rev, Gen.(1891) $469=$ Celsia intricata, Benth.

mardinense, Post, in Bull. Herb. Boiss, iii, (1895) 161. - Syria.

meteoricum, Hausskn. ex Nym. Consp. Fl. Eur. Suppl. ii. I. (1889) 229. - Thessal.

nitidulum. Freyn or Sint. ex Freyn, in Oest. Bot. Zeitschr. xlii. (1892) 34\% - Armen turc.

palmyrense, Post, in Bull. Herb. Boiss. i. (1893) 26. - Syria.

Pancicii X, Bornm, in Oest. Bot. Zeitschr, xxxviii. (1888) 267. - Bulg.

paradoxum $\times$, Hausskn, in Mitt. Bot, Ver. Jena, v. (1886) 72. - Graecia.

phalevenm $\times$. Hausskn. 1. c. - Graeci

Portae, Willk. Illustr. Fl. Hisp.(I886-93) 84, t. I24 - Hisp.

Porteri, Post, Pl. Postianae, ii. (1891) 18. - Syria.

praesigne $X$, G. Beck, Fl, Nied.-Oest. ii. II. (1893) 1037. - Austria.

Psendo-sinuatum $X$. Hausskn, in Mitt. Bot. Ver Jena, v. (1886) 72. - Graecia.

pulchrum, Velen, in Sitzb. Boehm。 Ges. Wiss. (1887) 454; et Fl. Bulg. (1891) 409. - Bulg., Rumel

qulebicum, Post, in foum. Linn. Soc.xxiv. (1888) 437. - As. occ.

rotundifolium, Post, Pl. Postianae, ii. (1889) 16. Syria.

salisburgense $X$. Fritsch, in Verh, zool-bot. Ges Wien, xxxviii. (1888) Sitzb. 23; et in Bot. Centralbl. xxxiv. (1888) 391. - Austria.

saitense, Post, in Bull. Herb. Boiss, i. (1893) 27. Syria.

Sceptrum, Schmalh, in Ber. Deutsch. Bot. Ges. x. (1992) 291; et Fl. Cauc. contr. (1894) 23. - Reg Transcauc.

Schmidtii X. A. Kern, ex Nym. Consp. Fl. Eur. Suppl. ii. i. (1889) 230. - Transsily.

semirigidum $X$, Hausskn, in Mitt. Bot. Ver. Jena v. (1886) 72. - Graecia.

somaliense, Baker, in Keq Bull. (1895̃) 222. — Regr. Somal.

stachydifolium, Freyn \&o Bornm. ex Freyn, in Oest. Bot, Zeitschr, xlii. 1892) 346, - As, Min.

styriacum, Fritsch, l. c, xxxviii. (1888) 262.Styria.

subphlonoides $X$, Hausskn, in Mitt, Bot. Ver Jena, v. (1886) 71. - Graecia.

thessalum $\times$. Hausskn. 1.c. 72. - Graecia

thracicum, Velen. Fl. Bulg. (1891) 410. - Bulg.

tomentosum, Kuntze, Rev. Gen. (1891) 469 (=Celsi tomentosa, Zucc.) = graecum, Heldr. Es Sart.

\section{VERBASCUM :}

tossiense, Freyn of Sint. ex Freyn, in Oest. Bet. Zeitschr. xliv, (1894) 263. - As. Min.

Tounncuxil, "Aschers." ex Aschers, \& Schweint. I11. Fl. Egypt, |Mém. Inst. Égypt.? (1887) 114, sphalm. = V. Letourneuxii, Aschers.

Uechtritzii $X$, Fritze, ex Willk. Suppl. Prodr. F1. Hisp. (1893) 170, nomen. - Hisp.

Warionis, Franch. ex Balt. of Trab. Fl. de l'Algér. [Dicot.] (1889) 62\% - Algeria.

VERBENA, Linn, (Verben.), - Ind. Kew. ii. 1178

gdulterina X, Mausskn. ex Nym. Consp. Fl. Eur. Suppl. ii. I. (1889) 245. - Thessal.

aristigera, S. Moore, in Trans. Limn. Soc. Ser. II iv. (1895) 439. - Bras.

bella, Phil. un Anal. Mus, nac. Chile (1891) 58. Chile.

canadcusis, Britton, in Mem. Torrey Bot. Clin, $(1894) 276=$ Buchnera canadensis, Limm

digitata, Phil. in Anal. Mus, nac. Chile (1891) 59.Chili.

grisea, Robinson \& Gremm. in Am. Fourn. Sci. Ser. III. 1. (1895) 142. - Ins. Galapag

Hystrix, Phil. in An.al. Univ. Chil. xc. (1895) 610 .

illapelina, Phil. 7.6.612, - Chili.

longovina, Phil. l. c. 608. - Chili.

mendocina, Phil. l. c.609. - Chili.

micrantha, Phil. l. c. 615. - Chili.

minutifolia, Phil. . c. 614, - Chili.

Moronvil, Brilton, in Ann. N. Y. Acal, sci. vii. (1S93) 192. - Parag.

neo-mexicana $\times$, Briq. in Engl. \& Prantl, Natïr]. Pflanzenfam. iv. 3a (1894) 148. - N. Mexic

Paulseni, Phil. in Anal. Univ. Chil. xc. (1890) 60\%. - Chili.

quadrangulata, Heller, in Contrib. Herb. Frankl. and Marsh. Coll. [Eot. Expl. S. Texas] i. (1895) 84, t. 6. - Texas.

ramulosa, Phil. in Anal. Univ. Chil. xc. (1895) 6!0. - Chili.

riparia, Rafin. ex Small \& Heller, in Mem. Torrey Bot. Club, iii. (1892) $12=$ urticifolia, Linm

rimelica, Velen, F1, Bulg. (1891) $441=$ officinalis, Limn.

subuligera, Grome, Pittonia, i. (Jan. 1888) 156. Mexic.

hymoides, Phil. ex Ball, nn Fourn, Linn. Soc. xxvii. (1891) 497. - Patas., Chili.

trachea, Phit. in Anal. Univ. Chut. xс. (1895) 609. - Chili.

tridactyia, Phil. in Anal. Mus. \%ac. Chile (1891) 59. - Chili.

triternata, Phil. in Anal. Uniu. Chit. xo. (1895) 615. - Chili.

ulicina, Phil. \%.c. 611. - Chili.

VERBESINA, Lini. (Compos.). - Ind, Kew, ii. 1180

atternifolia, Brilton, ex Kearney, in Bull. Torrey Bot. Club, xx. (1893) 485 = Actinomeris alternifolia, $D C$

aurita, Phil. in Anal. Mns, nac Chile (1891) 48 . Chili.

boliviana, Klatt, in Annal. Naturh. Hofmus. Wien, ix. (1894) 361. - Bolivia.

Bridgesii, Rusby, in Men. Torrey Bot. Club; iv (1895) 212. - Bolivia.

chihuahuensis, A. Gray, in Proc. Am. Acad. xxi. (1886) 389.-Mexic,

cymosa, A. Gray, l, c. 390. - Mexic

Donell-Smithii, Conlt. Bot. Gaz. xx. (1895) 50.Guatem.

erosa, T. S. Brandeg. in Proc. Calif. Acad. Ser. II. iii. (1891) 146. - Calif

hypoglanca, Sch. Bif.ex Klatt, in Leopoldina, Heft xxiii. (1857) 144. - Mexic

leptochaeta, A. Gray, in Proc. Anr. Acad. xxi. (1886) 889. - Mexic.

Liebmanni, Sch. Bip. ex Klath, in Leopoldina, Heft xxiil. (1887) 144. - Mexic

myriocephala, Sch. Bip. ex Klatt, l.c. 144. - Mexic. 


\section{VERTESINA :}

Dobinson \& Seaton, in Proc. Am. Acad. xxvis. (1893) 109. - Mexic.

Palmeri, S. Wals. l. c. xxiv. (1889) 86. - Calif austr.

perymenioides, Sih. Bip. ex Klatt, in Leopoldina, Heft rxiii (1887) 143 - Mexic

platyptera, Sch.Bip.cx Klath, l. c, 144. - Mexic

yotosina, Robinson, in Proc. An. Acad. xxvii. (1893) 175. - Mexic.

Pringlei, Robinson, l.c.-Mexic

resinosa, Klath, in Leopoldina, Heft xxiii. (1887)

144 - Mexic.

Sartorii, Sch. Bip. ex Klatt, 1. c. 143, in syn.= leprosa, Klatt.

candens, Klatt, l. c. Heft xxv。(1889) 100. - Ins Porto Rico.

scaposa, M. E. fones, in Zö̈, ii. (1891) 2 4s. - Utah.

sphaerocephala, A. Gray, ex. S. Wats, in Proc. Am. Acad. xxil. (1887) 428. - Mexic.

tuberosa, Klat, in Amal. Natwr. Hofmus. Wion, ix. (1894) 351, - Mexic.

VERMINIARIA demudata, «Sm, » ex Wien. Illustr. Gartenzeit. (1888) 272, sphalm. = Viminaria denudata, $S m$

VERNONIA. Schreb.(Compos.). - Ind. Kew ii. 1181

Abbotiana, O. Hoffm. in Bot. Fahrb. xx. (1894) 221. - Afr. aequat.-or.

acrocephala, Klatt, in Annal. Naturh. Hofmus, Wicn, vii. (1892) 100. - Angola.

alboviridis, Baker, in foum. Linm. Soc. xxv, (1890) 325. - Madag.

alsodea, Klatt, in Annal. Naturh. Hofmus. Wien, vii. (1892) 295. - Macag.

alsodes, Klatt, l. c. (= Bechium foliosm. Tiatt). Madag

amplexicaulis, Baker, in Ket Bull. (1895) 216. Reg. Somal.

Antinoriana, Acetta, in Nuov, Giom. But. Ital, xxi (1889) 348; in Ammat. Ist. Bot. Roma, vi. (1895) 55, t. 3, fig. 1-3. - Afr. trop, or

Antanossi, S. Elliot, in Fourn. Limn. Soc, xxix (1891) 2\%. - Madas.

Aplinii, Collett \&ै Hemst. l. c. xxviii. (1890) 69.Ind. or.

arbovea, TVelw, ex O. Hoffm, in Bolet. Soc. Brot. x. $(1592) 172$, in obs. = conferta, Benlh.

aristosquamosa, Britton, in Bull. Torrcy Bot. Club. xviii. (1891) 332. - Bolivia.

Bailloni, S. Elliot, in foum. Linn. Soc. xxix. (1891) 26. - Madar.

Bàkerana, Britton, in Bull. Torycy Bot. Club, xvii (1891) 331. - Bolivia.

betonicaefolia, Baker, in founn. Iinn. Soc. xxil 1887) 487. - Madar.

boliviana, Britton, in Bull. Torrcy Bot. Club, xviil. $1891,: 332 .-$ Folivia.

brachycalyx. O. Hoffm. in Engl. Pflanzenw. Ost-Afr. C (1895) 405. - Afr. trop. or

Calvoana, Engl. in Abh. Frouss. Akad. Wiss. 1891 (1502) 415 (= Stengelia Caleana, Hook. ..). Kamerun.

ephalophura, Oliz't, in Hook. Icon. pl. xxil. (189? t. 22.59 . - Maclar.

cistifolia, O. Hoffmo in Engl. Pfanzcnue. Ost. Afr. C (1895) 404. - Atr. trop. or

corifolia, Baker, in fomm. Limn. Soc, xxv. (1890) 325. - Maclas

cryptoceplaala, Boker, in Kew Butl. (1895) ¿16.Reg. Somal.

cuanzensis, TVelw. ex (). Hotim. in Bzolet. Soc Brot. x. (1892) 17t, in ols. = Porphyrostemma cuanzensis, $O$. II f f m

cylindriceps, C. B. Clarke, in foum. Limn. Soi, xxy. (18s9) 35. - Ind.

Drummondi, Shuttlw ex TVerner, in Journ. Cincin. Soc. Nat. Hist. xvi. (1894) 171, ex Heller, Bot. Expl. S. Texas $(1805) 99=\mathrm{V}$. altissima, Vult. var. orandiflora, $A$. Groly.

Jrymaria, Klath, in Annal. Nalurh. Hofmus, Wien, vii. (1892, 100. - Angola.

dumeta. Klat! in Bot. Beibl. ¿. Leopoldina (1895) 1. - Custa-Rica.

\section{VERNONIA}

elaepchroma. Klatt, in Arb. Bot. Mus. Hamb. (1890) I ; et in Fahrb. IIanb. Wiss. Anstalt. ix. (1892) 123. - Hias.

Eminii, O. Hoffm. in Engl. Pfanzenw. Ost-Afr. C (1895) 40 4. - Afr. trop. or.

erythromarula, Klatt, in Annal. Naturh. Hofmus. Wien, vii.(1892) 295 (= Bechium rubricaule, DC.) - Afr. trop.

esculenta, Hemsl. ex Forb. \& Hemsl. in fourn. Limn. Soc. xxiii. (1888) 401, - China.

exserta, Baker, l. c. xxii. (1887) 488. - Madag.

Faradifani, S. Elliot, l. c, xxix, (1891) 2\%. - Madag,

Fischeri, O.Hoffn. in Bot. 7ahrb. xx. (1894) 221 . Afr, trop. or.

gigantea, Trelease, Branner \& Coville, in Ann. Rep. Geol, Surv, Arkans. for 1888, i. (1891) 189 Britton, ex Kearn. in Bull. Torrey Bot. Club, xx. (1893) $485=$ altissima, Nutr.

glomerata, Baker, ex Warm. in Vidensk. Medd. Forh. Kjob. (1890) 185, |Symb. Fl. Bras, centr. xxxvi. 9707. - Bras.

glauca, Britton, in Mem. Torrey Bot. Club, v. (1894) $311=$ glanca, Willd.

Goetzenii, O. Hoffm, in Engl.Pfanzenw. Ost-Afr. A (1895) 135, romen. - Afr trop.

gomphophylla, Baker, in Kew Bull. (1895) 216.Rer. Somal

granienifolia Trelease, Branner \& Coville, ex Brammer, in Rep. Geol. Surv. Arkans, for 1888 1891) 189 = angustifolia, Michx.

grisea, Baker, in foum. Linn. Soc, xxii. (1887) 488. - Madas.

griseola, Baker, ex Warm. in Vidensk. Medl. Forh. Kjob. [Symb. Fl. Bras. centr, xxxvi. 970$\}(1890$ 185. - Bras.

guadulupensis, Heller, in Contr. Herb. Frankl. and Marsh. Coll. [Bot. Explor. S. Texas] (1895) 100 nomen. = fasciculata, Michx

symnoclada, Collett \& Hemsl. in foum, Linn. Soc xxviii. (1890) 70 . - Ind or

herbacea, Rusby, in Mem. Torrey Bot. Club, iv. (1895) $209=$ obovata, Vell.

Heydeana, Coult. Bot. Gaz. xx. (1895) 42.-Guatem, Hildebrandtii, Baker, in foum. Lim. Soc. xxv. (1890) $: 24$. - Madag.

Holstii, O. Hoffm. in Bot. Fahrb. xx. (1894) 220. Afr. trop. or.

huairacajana, Hieron. l. c xix (1894) 43 - Ecuad. insularum, Bonth. G Hook. f. ct Drake, Ill, Fl. Ins Maris Pacif. (1890) $202(=$ Strobocalyx insularum Sch. Bip.). - Ins. Pacif.

iodocalyx, O. Hoffn, in Engl. Pfanzenw. Ost-Afr. C (1895) 403. - Afr. trop. or

Johannis, Volk, ct O. Hoffm. l.c. 405. - Afr. trop.or. enteucephala, Biker, in fourn. I, inn. Soc. xxy. (1890):324. - Madas.

lasiopus, O. Hoffm. in Engl. Pfanzent. Ost-Afr. C (1895) 40:3. - Afr. trop. or

Lastii [O. Hoffm. ?] ex Engl. Pflanzenw. Ost-Afr. A (1895) 5.5, nomen [an $V$ Lentii Volk, \& O. Hoffin. ?. - Afr. trop

Lehmanni, Hicron. in Bot. Fatmb. xix. (1894) 44 . - Columb.

Lenti, Volk. et O. Hoffm, in Engl. Pfanzenw. Ost. Afr. C (1895) 404. - Afr. trop. or

leptanthus, Klatt, in*Anmal. Nalurh. IIoffmus. IVien, vii. (1892) 99. - Angrola

leptolepis, O. Hoffm. in Engl. Pfanzonw. Ost-Afr. C (1805) 405. - Afr. trop. or.

Lenbnitsae, Kuntze, in Jahrb. Bot. Gart. Berl. iv. (1856) $264=$ Piptocarpha Leubnitzae, Kuntze.

lencolepis, Baker, in funm. Linn. Soc. Xxv. (1890) 32:2. - Madag.

Luederitziana, O. Hoffn. in Bolet. Soc. Brot. x. (1892) 171; et ex Schinz, in Bull. Herb. Boiss. i. (IS13) 71 . - Afr. austro-occ, extratrop.

luxensis, Coult, Bot. Gar. xx. (1895) 41. - Guatem. malacophyta, Baker, in fourn. Linn. Soc. xxy (1890) 323. - Madag.

marginata, Trelease, Branner \& Coville, ex Branner, in Rep. Geol, Surv. Arkans, iv. 1888 (1891) 189 Britton, in Mem. Torrey Bot. Club, v (1894) :ill $=$ V. Jamesii, Torr. Eo Gray.

mecistophylla, Baker, in fou'n. Linn. Soc. xxv. (1890) 322. - Madas.

\section{VERNONIA :}

nummulariacfolia, Klatt, ex Schinz, in Bunl Herto. Boiss iii. (1895; 427. - Madag.

bionifolia, O. Hoffm. it Bot. Fahrb. x. (1888) 2\%2 - Afr. austro-occ. extratrop.

obovata, Bocrl. Handl. Fl. Ned. Indie,, ii. I. (1891) $235(=$ Decancuman obovatum, DC. . - Ins. Rawak.

ondongensis, Klatt, ex Schinz, in Bull. Herb. Boiss. iii. (1895) 430. - Afr. austro-occ. extratrop. oocephala, Baker, in Kow Bull. (1895) 68. - Afr. trop. or.

oxyura, O. Hoffm, in Engl, Pfanzenw. Ost-Afr. C (1895) 403. - Afr, trop: or

Palmeri, F. N. Rose, in Contrib. U. S. Nrat. Herb. i. (1891) 101. - Mexic

paucifolia, Rusby, in Mem. Torrey Bot. Club, iil. 3 (1893) 50, et iv. (1895) 209, in obs. = obovata

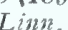

Pechuelii, Kuntre, in Falub. Bot. Gast, Bert. iv (1886) 265. - Afr, austro-occ. extratrop.

Poggeana, O. Hoffn. in Bot fahmb. xx. (1894) 221 - Congo

pogosperma, Klatt, in Annal. Naturh. Hofmus. Wien, vii. (1892) 99. - Angola.

polyantha, Warb. in Bot. Fahrb, xiii. (1891) 44\%.N. Guin

potamophila, Baker, in Annal. Naturh. Hofmus. Wien, vii. (1892) 100. - Angola

pratensis, Klatt, l.c. vii. (1892) $295(=$ Cyanopis madagascariensis, DC.). - Madar.

purpuro-glandulosa, Klatt, in Bot. Jahrb. xii. Beibl. n. 27 (1890) 21 ; et $1 . c_{\text {. }}=$ rhodulepis, Baku.

rampans, Baker, in foum. Limn. Sno. Xxr. (1890). 323, - Madag.

thodopappa, Baker, l. c. xxii. (1887) 48\%. Madag.

rivularis, Klatt, in Bot. Famb. xił. Beibl. 12. 27 1890) 21. - Madag.

rubicunda, Klatt, 1. c. 22 ; et in Annal. Naturh. Hofmus. Wien, vii. (1892) $295=$ V. Hildebrandtii, Bakcr.

Schinzii, O. Hoffme ex Sohinz, in Bull. Hert. Boiss. i. (1893) 72 - Afr. austro-occ, extratrop.

senecionaefolia, Britton, in Bull. Torrey Bot. Club, xviii. (1891) 331. - Bolivia.

Shannoni, Coult. Bot. Gaz. xx. (1895) 44. Guatem.

peiracephala, Baker, in foum. I I inn. Soc. xxv. (1890) 323. - Madag

spiciformis, Klatt, in Annal. Naturh. Hofmus. Wien. vii. (1892) 296. - Madas.

stenoclinoides, Buker, in foum. Linm. Soc. xxii. (1887) 486. - Madag.

stenolepis, Otiver, in H. Fohnston, The Kilin. Exped. App. (1886) 341, nomen; et in Trans. Imm. Soc. Ser. II. ii. (188\%, 237. - Afr. trop or.

Stuebelii, Hieron, in Bot. Fahrb. xxi. (1895) 327.Peruvia.

subaphylla, Baker, in Kew Bull. (1895) 290. - Afr. centr: or.

sublutea, S. Elliot, in fourn. Linn. Soc. xxix. (1891). 26. - Madag.

subuligera, $O$. Hoffn, in Engl. Pfansenz: Ost-Afr. C (1895) 403. - Afr. trop. or.

superba, O. Hoff $n$. l. c. 406. - Afr. trop. or. syringifolia, $O$. Hoff $m . l . c .405$. - Afr. trop. or teitensis, O.Hoffm. l. c. 404. - Afr. trop, or. teucrioides, Welw. ex O. Hoffm. in Bolct. Soc. Brot. 1x. (1892) 171. - Angola,

Teusczii, Klatt, ex Schin\%, in Bull. Herb. Boiss, iii. (1895) 424. - Angrola.

thyrsoidea, Bakey, cxWarm. in Vidensk. Mcdd. Fork. Kjoб. [Symb. Fil. Bras. centr. xxxvi. 970] (189u) 15\%. - Bras.

trichodesma, Baker, in fourn. Limn. Soc, xxt. (1890) 325. - Madag.

usambarensis, $O$. Hoffm, in Bot. Falub. xx. (1894) 220. - Afr, trop. or

verrucosa, Klatt, in Amnal. Naturh. Hofmus. Wien, vii. (1892) 99. - Angrola.

Waketieldii, Oliver, in $H$. folmston, The Iilim. Exped. App. (1886) 341, nomen; ot in Trans. Linn. Soc Ser. II ii. (1887) 336, - Afr. trop. or.

Welwitschii, O.Hoffm. in Bolet. Sac. Brot, x. (1892) 170. - Angola. 


\section{VERNONIA}

Whyteana, Britten, in Trans, Linn. Soc., Ser. II. iv. (1894) 17. - Afr. trop.

yungasensis, Britton. in Bull. Torrcy Bot. Chub, xviii. (1801) 332 . - Bolivia.

VERONICA, [Tourn.] Linn. (Scrophul.). - Ind. Kew. ii. 1187

amphibola $\times$, Hausskn. in Mitth. Thür. Bot. Ver. N. Folge, vi. (1894) 27. - Graecia

areolata, Colenso, in Trans. N.Z. Inst. xxiv. 1891 (1892) $392 .-$ N. Zel.

báesensis, Simonk. in Oest. Bot. Zeitschr. xxxviii. (1888) $10 \%=$ V. Beccabunga, Lim .

balcanica, Velen.Fl,Bulg. (1891) 431 (= V. apen. nina, Velen, et repens, Velen.). - Bulg.

Bornmuelleri, Hausskn. in Mitth. Bot. Ver. Fena, ix. (1891) 20. - As. occ.

Bonarota, Wettst. in Oest. Bot. Zeitschr. xlv. (1895) 22 = Paederota Bonarota, I imn

byzantina, Britton, Stern \& Pogr. Prelim. Catal. (1888) $40=$ V. Tournefortii, C. C. Gmel.

campestris, Schmalh. in Ber. Deutsch. Bot. Ges. $\mathrm{x}$. (1892) 291, t. 16, fig. 12, 14, $16=$ verna Linn.

capreaefolia, Baker, in fourn. Linn. Soc. xxij. (1887) 487. - Madag.

chamaedryoides, Engl. Pfanzenw, Ost-Afr. C (1895) 358. - Afr. trop. or.

commutata, Willk. in Oest. Bot. Zeitschy. xli. (1891) 82; et Suppl. Prodr. Fl. Hisp. (1893) 182. - Hisp compacta, Colenso, in Trans. N. Z. Inst xx. 1887 (1888) 202. - N. Zel.

Cookiana, Colenso, l. c. $201=$ macroura, Hook $f$

Curchillii $X$, Wettst. in Oest. Bot. Zeitschr, xlv (1895) $24=$ Paederota Churchulii $X$, Huter.

dagestanica, Trantr. in Act. Hort. Pctrop. x. (18S7) 124. - Dagest.

Darwiniana, Colenso, in Trans. N.Z. Inst yxu 1892 (1893) 3.32. - N. Zel.

denudata, Alboff, Prodr. Fl. Colch. (1895) 190.Reg. Cauc.

Derwentia, Litlley, ox C. Moove, Handb. Fl. N.S. W ales (1893) 340 - Austral.

Espadanae, Pau, Not. Bot. Fl. Espan, i. (1857) 13, Willk. Suppl. Prodr. Fl. Hisp. (1893) 183. -

Hisp
Fairfieldi, [Hort. Martin.] Hook. f. in Bot. Mag. (1893) t. 7323. - N. Zel.

farinosa, Haussk. in Mitth. Bot.Ver. Fena, ix. (1891) 20. = Persia

flicantis, Halácsy, in Verh. zool-bot. Ges. WVien, xxxviii. (1888) 761, in syn. = prostrata, Lim

filifolia, Lipsky, in Min. Soc. hist. nat. Kierv, xi. (1891) 54; et in Act. Hort. Petrop. xiii. (1894) 32?. - Ross.

Fuhsii, Freyn \& Sint, in Oest, Bot. Zeitschr. xliv (1894) 325 . - As. min.

Godefroyana, Carr. in Rev. Hortic. 1x. (1888) 45 ă Ixii. (1890) 242. - N. Zel.

Gunae, Schweinf. ox Engl. in Abh. Prenss. Akad. Wiss. 1891.1892) 380, nomen. - Abyss.

hirsuta, Colenso, in Trans. N.Z. Inst. xxiv. 1891 1892) 393. - N. Zel

integerrima, G. Beck, in Annal. Naturh. Hofmus. Wien, ii. (1887) $137=$ serpyllifolia, Lim

iatalambrensis, Pau, Not. Bot. Fl. Espan. i. (1887) $22=\mathrm{V}$. Tencrium, Linn

Kovácsi, Borb. Geogr. atq. Enum. pl. Comit. Castrif. (1887) $227=\mathrm{V}$. Anagallis, Linn.

Lendenfeldii, F. Muell, in Trans. Roy. Soc. Vict. N. S. i. Il. (1889) 29. - N. Guin.

lepida, Phil. in Anal. Univ. Chil. xci. (1895) 110. Chili.

Iongiracemosa, Colenso, in Trans, N. Z. Inst. xx. 1887 (1888) 203. - N. Zel.

longistyla, Lange, in Danske Vidensk. Selsk. Forh. (1893) 199. - Hisp

Tuter, Wettst. in Engl. \& Prantl, Natïrl, Pflanzenfam. iv. 3b (1891) 85; et in Oest. Bot. Zeitschr. xlv. (1895) $22=$ Paederota lutea, Scop.

macrocalyx, Colenso, in Trans. N. Z. Inst. xxiv. 1891 (1892) 391. - N. Zel.

magellanica, "Juss, " ex Dippel, Handb. Laubholzk. i. (1889) 448 ad calc, sphalm. = elliptica, Forst. $f$.

\section{VERONICA}

major X, Wettst. in Engl. \& Prantl, Natürl, Pflanzenfam. iv. $3 \mathrm{~b}(\mathbf{1 S 9 0}) 85=V$. Curchillit $X$ Wettst.

mexicana, S. Wats, in Proc. Am. Acad. xxiii. (1888) 282. - Mexic

myrsinoides, Olicer, in $H$. fohnston, Kilim. Exped. App. (1886) 343, nomen; in Hook. Fion. pl. xvi (1886) t. 1509; et in Trans. Linn. Soc. Ser. II. ii 1887) 343. - Afr. trop, or

oligantha, Colenso, in Trans, N. Z. Inst. xxr, 1892 !893) $333 .-\mathrm{N}$ Zel.

Pacheri $X$, Wettst, in Oest. Bot. Zeitschr, xlv 1895) 23. - Carniol.

Parkinsoniana, Colenso, in Trans. $\Lambda^{*}, Z$. Inst, xxi。 ISs8 (1589) 97 - Y.Zel.

poljensis, Murb. in Oest. Bot. Zeitschr. xliii. (1893) $364=$ anagalloides, Guss

pontica, Velen. in Abh. Boehm, Ges. W'iss. 1898 (18!)4) xxxvii. 52. - Bulg.

pontica, Wettst. in Engl. E Drantl, Natiin. Pfanzenfam. iv, 3b (1890) 85 = Paederota lutea Rupr.

frenja, G. Beck, in Annal. Naturh. Hofmus. Wien, ii. (1887) $13 \%, t, 4$, fig. 7 = anstriaca, Limn.

Pseudo-arvensis, Tineo, ex Tornab. Fl. Sicula (188\% 4?6. - Sicil.

pubicarpa, Simonk. Enum. F1, Transsilv: (1886) $422=$ prostrata, Linn

racemifoliata, Perez Lara, Pl. nov. aliq. descr. (1882) 3; Willk. Suppl. Prodr. Fl. Hisp. (1893) 181. Hisp.

rugulosella, Colenso, in Trans. N. Z. Tnst, xxiy. 1891 (1892) 391. - N. Zel.

schizocalyx, Freyz et Sint. in Oest. Bot. Zeitsch xliv. (1594) 324. - As. Min.

senanensis, Maxim. in Bull. Aard. Pitersb. xxxii. 1S88) $515 .-$ Japon.

zechuanica, Batalin, in Act. Hort. Petrop. xiii. (1894) 383. - China.

thracica, Velen, in Abh, Boehm, Ges, IFiss, 1898 (1894) xxxvii, 50. -- Bulgaris

vandellioides, Maxim, in Bull. Acad. Petcrsb. xxxii. (1888) 514. - China.

Velenovskyi, Uechtr. ex Bornm, in Bot. Centralbl. xxxvi. (1888) 125; at in Velen, Fl. Bulg, 1891) 427 - Buls.

venustula, Colenso, in Truns. N.Z. Inst. xxvii. 189. 1895) 393. - N. Zel.

vulcanica, Colenso, 7. c. xx. 1887 (1888) 203.N. Zel.

VERTICILLARIA, Ruiz \& Pav = Rheedia Linn. (Guttif.)

Madruno, Tulasne, ex Vesque, in DC. Monog. Phan. viik. (1893) $508=\mathrm{R}$. acuminata, Flanch. Ev Triana.

rostratu, Miers, ex Engl, in Mart. Fl, Bras. xii. I. 1858) $464=$ R. floribunda, Planch. E Triana

VERTICORDIA, DC. (Myrt.). - Ind, Kew, ii lito.

Rennieana, F. Muell. in Trans. Roy. Soc. South Austral. xvi. (1895) 354. - Austral.

VESICARIA, Tourn. ex Adans, (Crucif.). - Ind. Kew. ii. 1193

tymphaea, Hausskn, in Mitt. Bot. Ver. Fend, v. (188\%) $70 .-$ Graecia.

VESQUELLA, Heim, Recherch. Diptéroc: (1892 $90=$ Stemonoporus, Thw. (Dipteroc.).

acuminata. Heim. Recherch. Dipteroc. (1892) 90 et in Bull. Soc, Bot. Fr. xxxix, (1892) $15 \%=$ Vateria acuminata, Thw.

oblongifolia, Heim, 1l. cc. = Stemonoporus oblongitolia, The

VIBO, Medic. = Emex, Nutt. (Polyson.)

australis, Greene, Man. Bot. San Franc. Bay (1894) $44=\mathrm{E}$, australis, Stcinh.

Centropodium, Kuntze, Rev. Gen. (1891) $562=$ E. australis, Stcinh.
VIBURNUM, Linn. (Caprifol.). - Ind. IKew, ii.

anglicum, Hort, ex Dippel, Handb. I aubholzk,

(1889) $191,199=$ nudum. Limn.

aragonense, Pau, Not, Bot. Fl. Espan. i. (1ssi, 16 $=\mathrm{V}$. Lantana, Lim

A wafuki, Hort. ex Dippel, Handb. Laubholzk, i.

(1859) $199=$ odoratissimum, $K$

wafusci, "Lindl. » ex Dippel, 1. c. = ocloratissi. mum, Ker.

betulifolium, Batalin, (1894) 371. - China

brachybotryum, Ifensl. ex Forb. \& ITemsl. in fourn. Lim. Soc. xxiii. (1S8S) 349. - China.

anadinse, Hort. ex Dippel, Handb. Laubholzk. i. (1889) $182=$ molle 1 ic

Carlesii, Hensl. ex Forb. \& Hensh. in fourn, Linn. Soc. xxiii. (1888) 350. - Corea.

dahuricum, "Pall, " ex Dippel, Handly, Lautholzk. i. $(1889), 198=$ davuricum, $P$ sm.

Davidi, Franch, in Nouv. Aritio Jus Paris, Sér. 11. viii. 1885 (1886) 251. - Tibet.

ferriginewn, Small, ex Small \& Vail, in Mem. Torrey Bot. Club, iv. (1893) 123; et in Bull. Torrey Bot. Club, xxi. (1894) $306=$ prunifolium. Linn. var.

Fortmei, Hort. Gall. ex Dippel, Handb. Laubholzk. i. (1889) $17 \%=$ macrocephalum, Fortumi.

Henryi, Homsl. in foum. Linn. Soc. xxiii. (1888) 353. - China

Jelskii, Zahlbr. in Amal. Nahurh. Hofmus. Wien, vii. (1892) 1. - Peruvia.

kansuense, Batalin, in Act. Hort. Petrop, xiii. (1894) 372. - China.

mexicanm, Hort. cx Dippel, Handb. Laubholzk. i. $(1859) 184=$ molle, Michx.

manum, Hort, ex Dippel, 1. c. 173, 449, ad calc. = V. Opulus, Limn.

mealcnse, Hort, ex Dippel, 1. c, $176=$ Hanceanum. Maxim.

oliganthum, Babulin,
(1894) 372 . China.

propinçuum. Henst. in Forb. Es Henst. in foum. Lim. Soc. xxiij (1888) 35.5. - China.

rhytidophyllum, Hemsl. ex Forb. \& Hemst. l. c. China.

susponsum. Hort, ex Dippel, Handb. Laubholzk, i. $(1889) \%(10=\mathrm{V}$. Sandankwa, Hassh.

utile, Homsl. ex Forb. \& Hemsl. in Fourn. Linn. Soc. xxiii. (1885) 356. - China

Vetteri X, Zabel, in Gartenfl. xxxviii. (1889) 462. Hybr. spont.

VICIA, Tcurn, ex Linn, (Legumin.). - Ind. Kew ii. $119 \%$.

andicola, Phit. in Anat. Univ'. Chit, 1xxxiv. (1894) 270. - Chili.

apiculata, Phil. l, c. 2r4. - Chili

baborensis, Buti. E Trab. in Liall. Soc. Bot. Fr. xxxviji. (18\$1)304. et xxxix. (18:2) 71.-Alyeria californica, Grone, Fl. Francisc (1891) 3. - Calif.

chinensis, Franch.PI. Dem. (184) 1\%T. - Inman. ciliata, Lipsky, in Mim. Soc. hist. nat. Kiew xi. (1891) extr. 2t: et $m$ Act. Hort. Pcrup. xiii. (189t) 293 Alboff, Prodr. Fl. Colch. (1895) 65. - Reg. Cauc. ommutata, Phil. in Anal. Unir. Chil. 1xxxiv. (1894) $270(=V$. Macraei, Clos $),-C h i l i$,

Coxi, Phil.l. c. 2\%5. - Chili

crunta, Coss, ex Batt, in Bull. Soc. Bot. Fr. xrxiv. (185i) $368=$ fulgens, Batt.

dadianorum, Somm. \& Letier, in Act. Hort. Petrop. xiii. (1893) 4\%. - Rer. Cau

dalmatica, A. Kern. Sched. Fl. Austro-Hung. iv. (1886) 2 = tenuifolia, Rolh var.

Darapskyana, Phit. in Anol. Uniu Chit lvxwiv. (1894) 276. - Chili.

dianthes, Phil. l. c. 200.-Chili

diversifolia, Phil.l.c. 26\%. - Ins. Chiloe.

ecirrata, Phil. l. c. 269. - Chili.

elevantissima, Shuttl. ex Rouy, Exc. bot. Esporane en 1851-1882 (1883) 65; et in Le Naturaliste. Sér. II. x. (1sss) 85. - Gall. mer. : Hisp.

Fauriae, Franch. in Bull. Soc. Phit. Paris, Sér. VII. x. (1886) 139, - Japon.

glabrescens. Fritsch, in Verh. zool.-bot. Ges. IVien, 


\section{VICIA :}

glabrescons. A. Kern. Sched. Fl, Austro-Hung. iv.

(1886) 1 = villosa, Roth.

Hassei, S. IVats, in Proc. Am. Acad. xxv. (1890) 129. - Calit

heterophylla, Phil. in Anal. Unit, Chil. lxxxiv, (1824) 268. - Chili.

ucteropus, Freyn, in Oest. Bot Zeitschr. xxxix. (1889) $438=\mathrm{V}$. Cracca, Linn

eptantha, Phil, in Anal, Univ. Chil. Ixxxiv. (1894)

$26 \pi$ - Araucania.

lincaris, Greene, Fl. Francisc. (1891) $3=$ americana, Muhl. var.

usitanica, Freyn, in Bull. Herb. Boiss. i. (1893) 542. - Lusit.

auritenica, Batt. in Bull. Soc. Bot. Fr. xxxvi. (1889) $\mathrm{p}$. cexx. = erviformis, Boiss.

mediocincta, So IVats, in Proc, Am. Acal, xxi (1880) 425. - Mexic

Troorei, Phil. in Anal. Univ. Chit. 1xxxiv. (1894) 2:0. - Chili.

ramosissima, Franch in Morot, fourn. de Bot. iv. (1s:0) 305. - Chira occ

Saffordi Plit at Britton, in Bull. Torrey Bot Ctub, rvii. (1892) 8.2, noment ct in Anal. Univ. Chil. Ixxxiv. (1895) ?66. - Am. austr.

candens, R. P. Mirryay, in fourn. Bot. xxxiii. 1895) 9. - Teneriffa

Schreri, Fruegr, in Jahresb. Nat. Ges. Graub. xxi. Beil. $(1887-88) 45=$ V. Cracca, Linn.

semicincta, Grecne, in Erythuc, iij. (1895) 17.

() regan.

Golisi, Phit, in Anal. Unir. Chil. Ixxxiv. (1894) 267. - Chili.

peciosa, Phil. 7. c. 277. - Chili.

Tenorei, Cos., Passer. Eo Gibclli, Comp. Fl, Ital, ii, (1886) 685. - Italia

tenuikolia, Freyn, in Bunt. Herb. Boiss, iii. (1895) 191. - As, Min.

Thurberi, S. Wats, in Proi. An. Acad. xxy. (1890) 129. - Am. bor. occ.

rariabilis, Freyn of Sint. ce Freyn, in Oest. Bot. Zertsch, xlii. (18v2) 8\%. - Armen

ullensii, Tamb. in Engl. Pflanzena'. Ost-Afr. C 189.5) 219. - Afr. trop. or.

VICOA. Cass, (Compos.), - Ind. Kew, ji. 1198 Albertorerelia, C IVinkl. in Act. Hort. Petrop. xi (18)(0) 277. - Turkest

jatanica, Bocr. Hundl. Fl. .Ted. Indie, ii. I. (1891) 2tl (=? Pegolcttia jacturica, Miq.). - Java.

Pentanema, Aitch. o Homsl. in Trins. Limn, Soc. Ser. II. iri. (1\$86) 75. - Persia.

FIDOTRICUM, Rumpt, Herb. Amboin, i. (1741) 174-75, t. 67, iij, 18t-186, t, 118 , ex Kuntze, Rer ('en. (1891) $407=$ Bassia, Kcien. (Sapot.).

buigracim, caloncumm, Cocca, cmucatum, clongatum, Erspicinum, fulerun, insigne, Korthatsii, latifolium, Lobbii, lungifolinm, malabaricum, microphylum, Tronii, Mottlcyanun, nerifolium, pallidum, Kuntze, . c. = hononyma omnia Bassiae.

uscum, Kuntze, 1. c. (= Illipe fusca, Engl.). Borned

TIEUSSEUXIA, D. Delar, = Moraea, Mill. (Irid.) Klatt, in Th. Dur. \& Schinz, Consp. FI.

Afr. $18.13(1895) 154=$ M. Elliotil, Baher.
Wifotalc, Klatt. 1. C. $15.5=$ M. tripetala, Ker.

VIGNA, Savi (Lewmin.). - Ind. Kew, ii. 1199 byssinica, Tarb. co Engl, in Abr. Prouss. Akad. Wiss. 1891. i1. (18)? 267. - Abyss.

hrachycalyx, Bakor, in fourn. Limn. Soc. xxv. (1890) 310. - Maday

lebanensis, Martelli, Fl. Bogos. (1886) 28. - Abyss.

incana, Tarts. in Engl. Pflanzent', Ost-Afr. C (1895) 22:3. - Atr. trop, or

menedunculata, Taub. l.c. - Atr. trop or

monophylla, Taub. l. c. - Afr. trop. or.

polytricha, Baker, in fourn, Linn. Soc, xxv. (1890) 10. - Mada

Mhens, Kuntze Kev Gen. (1891) 212 = glabra, Saw et retusa, W'ap.

spartioides, Tanb. ex. Engl. in Abh. Prouss. Akad. Wiss. 1s91 it. (18:12) 26\%. - Abyss.

\section{VIGNA}

tenocarpa, [Taub.?] in Engl. Pfanzenw. Ost-Afr. A (1895) 31, nomen. - Afr. trop.

stipulacea, Kuntze, Rev. Gen. (1891) 212=Dolichos stipulaceus, Lam.

strobilophora, Robinson, in Proc. Am. Acad. xxvii. (1893) 16\%, xxix. (1894) 386 ; ct in Gard. and For. vii. (1894) 153. - Mexic

variegata, Deflers, Voy, au Yimen (1889), 132. Arabia.

verticillata, [Taub?] in Engl. Pflanzenw. Ost-Afn. A (1895) 3i, nomen. - Afr. trop.

VIGUIERIA, H. B. \& K. (Compos.). - Ind. Kew ii. 1200

atacamensis. Phil, in Anal. Wus. nac, Chule (1891 48. - Chili.

caleit. Britton, in Bull, Torrey Bot, Club, xix. (1892) $149=$ calva. Benth. E Hook.

glutinosa, Rusby, in Mon. Torry Bot. Club, iv. 1895) 211. - Bolivia.

lanceolata, Britton, in Bull. Torrey Bot. Chub, xix. (1892) 149. - Bolivia

leptocanlis, S. Wats. in Proc. An. Acad. xxvi. (1841) 140. - Mexic

longifes, Coult. in Contrib. U. S. Nat. Herb. (1810) $41=$ Zexmenia hispida, A. Gray.

microphylla, Vasey \& $7 . N$. Rose, in Proc. U.S Nat. Mus. xi. (1888) 535. - Calif

montana. F. N. Rose, in Contrib, U. S. Nat. Herb. i. (1891) 103. - Mexic

Palmeri. A. Gray, ex S. Wats, in Proc. An, Acad. xxii. (1887) 4\%7. - Mexic.

quinqueradiata, $A$. Gray, l. c. - Mexic

pazensis, Rusby, in Mcm. Torrey Bot. Chub, iii. 3 (1893) 59. - Bolivia.

pedunculata, Scaton, in Proc. Am. Acad. xxviii. 1893) 119. - Mexic

Pringlei. Robinson \& Gromm. l. c.xxix. (1894) 388. - Mexic.

Purisimae, 1. S. Brandeg. in Proc. Calif. Acad. Ser, II.ji. (1889) 173. - Calif.

strigosa, Klat, ex Th. Dur. Eo Pitt, in Bull. Soc. Bot. Belg. xxxi, 1892 (1893):04. - Costa Rica.

sylvatica, Klalt, l. c.-Costa Rica.

tenuis, A. Gray, ox S. Wats, in Proc. Am. Acad. xxii. (1887) 4\%6, - Mexic

VILIA, Beauv, = Sporobolus, R. Br. (Gramin.). onfusa, Fourn. Gram. Mexic. 1881 (1886) 101.Mexic.

densiflora. Fourn. 1. c. 98. - Mexic.

Grisebachi, Fourn. 1. c, - Mexic

hamiensis, Schweinf. in Bull. Herb. Boiss. App, ij (1894) 29. - Arabia.

Licbmanni, Fourn. Gram. Mexic, 1881 (1886) 100 . - Mexic.

Mulleri. Fourn. 1. c. 98. - Mexic.

pubcsons, Fourn. 1. c. 102. - Mexic

Sacatella, Fourn. 1. c. 101. - Mexic

VILLAMILLA, Ruiz \& Pav. (Phytolac). - Ind. Kew, ii. 1202.

racemosa, Britton, ex Rusby, in Mten. Torrey Bot. Club, iv. (1895)251. - Boliv.

VILlANOVA, Lag.(Compos.). - Ind. Kew, ii $120 \%$

perpusilla, Phil. in Anal. Mus, nac. Chile (1891) 47. - Chili.

robusta, Phil. l. c.-Chili.

VILLARESIA. Ruiz \& Pav. (Olacin.). - Ind Kew ii, 1202 .

suaveolens, Valeton, Crit. overz. Olacin. (1886) 199 (= Chariessa swareolens, Miq.). - Jara.

VILLARSIA, Vent. (Gentian.). - Ind, Kew. ii. 1203 .

nymphoidea, St. Lager, in Cariot, Etud. des fl. éd. 8, ii. (1889) $581=$ Limnanthemum nymphoides, Hoffing . \& Link

VILLEBRUNEA, Gaudich. (Urtic,). - Ind, Kew. 1i. 1203. in Bot. Fahrb. xiii. (1891) 289.fasciculata,
N. Guin.

\section{VILLEBRUNEA :}

pedunculata, Shirai, in Tokyo Bot. Mag. ix. (1895 158 t. 4. - Japon.

VINCA, Limn. (Apocyn.). - Ind. Kew, ii. 1203.

Haussknechtii, Bormm. Eo Sint. cx Bormm, in Mitth. Thur, Bot.Ver. N. Folge, vi. (1894) 66. - Oriens. mixta, Velen. Fl. Bulg. (1891) 646, in add. = herbacea, Limn.

obtusiflora, Pau, Not. Bot. Fl. Espan, iii. (1889) 20 = media, Hoffngg. G Link.

VINCENTELLA, Pierre, Not. bot. Sapot. (1891) 37 - Sideroxylon, Linn. (Sapot.).

densifiora, Pierre, 1. c. $=$ S. densitlorum, Baker longistyla, Pierre, $1 . c_{0}=$ S. longistylum, Baker revoluta, Pierre, 1. c. $=$ S, revolutum, Baker.

VINCENTIA, Gaudich. = Gladium, P. Br (Cyper.).

ensifolia, Boeck. ex. C. B. Clarke, in Th. Dur. \& Schinz, Consp. F1. Afr. v. $1894(1895) 665=$ C iridifolium, Eaker.

VINGETOXICUM, Moehr. Hort. priv.(1736) 100, fide Kuntze, Rev. Gen. (1891) 422.

abyssinicum, acutum, affure, alatum, aphyllum, auri culatum, boerhaviacfolium, callialata, catense, capillave, candatum [Maxim.], congestum, Dalhousiae, crubescens, excelsum, fimbriatum, floribundum. Fordii, Heydei, insulanum, facquemontianm, ianceolatum, linearifolinm, montevidense, myrtifolinm, mummulariafoliun, psdunculatum, puberulum, Roylei. serpyllifolum, stenophyllum, c'erticillatum, Eivens, Wallichi, Kuntze, Rev, Gen. (1891) 422-25= homonyna omnia Cynanchi.

barbatum, Bolostemmu, biglandulosum, cuffrum, calcaratum, capparidifolinn, chloranthum, cordifo inm, cras sifolium, ouspidatum, Dalzellii, enerre, crectum, exile, forscioulatum, ficxuosum, globiforum, grandiflorum, Holfori, heterophyllum, himalaicum, hissutum, hispidum, longifolium, Jutescens, mollissimum, paniculatum, pauciflorum, Perrottctianum, rotundifolium, rupestre, syliaticum, syringacfolium, tonervimum, temue, Kuntze, 1. c. = homonyma omia Tylophorae.

Adalinae, K. Schum. in Bot. Fahrb. xrii. (1893) 134 - Congo gall.

africanum, Kuntze. Rev, Gen.(1891) $422=$ Cynanchum pilosum, $R . B r$.

angulatum, Kuntze, l, c. 424. - Bras.

arenosum, Kuntzc, l. c, - Bras.

astephanoides, A. Gray, ox S. Wats, in Proc. Am. Acad, xxii. (1887) 435, - Mexic

Baldwinianum, Britton, in Mem. Torrey Bot. Club, v. (1894) $265=$ Gomphocarpus macrophyllus, Ell.

Benthaniamm, Kuntze, Rev. Gen. (1891) $424=$ Tylophora macrophyila, Benth.

biflorm. Kuntze, 1. c.; Heller, in Contr. Herb. Frank1, and Marsh. Coll. [Bot. Expl. S. Texas] i. $(1895)=$ Gonolobus bifforus, Nutt.

Bojerianum, Kuntze, 1. c. (= Cynoctonum Bojerianum. Decne.). - Madag.

capense. Schlechter, in Sot. Jahrb. xx. Beibl. n. 51 (1895) 6 , in syn. $=$ capense, Kuntze.

carolinense, Britton, in Mem. Torrey Bot. Club, v. (1894) $265=$ Cynanchum carolinense, facq.

chiloënse, Kuntze, Rev. Gen. (1891) 424 (= Cynocto mum chiloënse, Decne.). - Chili.

cissodes, Kuntze, 1. c. = Tylophora cissoides, Blume.

Decaisnet, Kuntze, 1. c. $(=$ Orthosia Decaisnet. Fourn.), - Bras.

deltodeum, Kuntze, 1. c. = Cynanchum deltoideum, Hance.

dinnidiatum, Kuntze, 1. c. (= Cynoctonmm dinidiatum, Hassk.). - Java.

discolor, Warb. in Bot. Fahro. xiii. (1891) 409. N. Guin.

Dombeyanum, Kuntze, Rev. Gen. (1891) 424 (二 Cjnoctonum Dombeyanum, Decne.). - Ecuad.

Dregeanum, Kuntze, 1. с. = Cynanchum obtusifolium, Linn. $f$

Eichleri, Kuntze, 1. c. (= Orthosia Eichleri, Fourn.). - Bras. 


\section{VINCETOXICUM :}

(1893) 136. - Mada

Eurychiton, Kuntze, Rev. Gen. (1891) 424 (= Cynoctonum eurychiton, Decne). - Madag.

ferviginerm, Kuntze, 1. c. = Amphistelma ferrugineum, Fourn.

formosantm, Kuntze, 1. с. (=Cynanchi sp.). - Ins. Formosa.

Fournievi, Kuntze, 1. c. = Amphistelma parviflorum, Fours.

hastatum. Kuntze,1.c. = Cynarichum Bungei, Decne. Tirsutum, Britton, in Mem. Torrey Bot. Club, v. (1894) $266=$ Gonolobus hirsutus, Michx.

hirtellum, Oliver, in Trans. Limn. Soc. Ser. II. is. (1887) 279 loliver, ex in Thurn, in Timehri, v. 1886) 1991. - Guian. angl.

hivtulorum, Kuntze, Rev. Gen. (1S91) $424=$ Tylo phora macrantha, Hook. f.

Holstii, $K$. Schum, in Bot. Fahrb. xvii. (1893) 135 - Afr. trop.

hybanthera Kuntze, 1. c. = T, cordifolia, Hook. $f$ irrazudense, Kuntze, 1. $\mathrm{c}=$ T. purpurea, Wall

lave, Kuntze, 1. c. $423=$ Cynanchum ovalifolium, Wight.

Leschenaultii, Kuntze, 1. c. $424=$ Tylophora congesta, Decne.

leucanthum, K. Schum, in Bot. Fahrb. xrii. (1893) 138. - Madag.

lyciodes, Kuntze, 1. c. $424=$ Tylophora lycinides Decne.

madagascariense, $K$. Schum, in Bot, fahrb, xvil. 1893) 138. - Madag.

madagascariense, Kuntze, Rev, Gen, (18.11) $424=$ Tylophora Bojeriana, Decn

Mannii, S. Elliot, in foum. Linm. Soc. xxx. (1894 93. - Afr. trop. occ.

mauritianum, Kuntze, Rev. Gen. (IS91) $424=$ Tylophora laevigata, Decne.

micranthum, Kuntze, l, c. $=$ T. zeylanica, Decne.

Miquelianum, Kuntze, 1. c. = T. villosa, Benth. E Hook. $f$.

mollissimum, Kuntze, 1.c. $=$ T. mollissima, Wall

mucronatum, Kuntze, 1. c. (= Cynoctomun mucronatum, Decne). - Chili.

multiflorm, Kuntze, $1, \mathrm{c}=$ Tylophora 1 phisia, Decne

multiflorm, Kuntze, 1. c. $\{=$ Orthosia multiflora Fourn.). - Bras

muricatum, Kuntze, 1. c. (= Cynoctonum muricatum, Decne.). - Java.

nemonn, Kuntze, 1. с. 425 (=C. nemorosim, Phil.) - Chili.

obliqum, Britton, in Mem. Torrey Bot. Club, v. (1894) $266=$ Cynanchum obliquum, facq.

obovatum, Kuntze, Rev. Gen. (1891) 425 (= Cynoctonum oboratum, Decne.). - Madag.

pachylepis, F. M. Baitev, in Dept. Agric, Brisban Bot. Bull viii. 1893) 79 - Austral.

pachyphyllum, Kuntze, Rev. Gen. (1891) 425 (= Cynostonum pachyphyllum, Decne). - Chili

patagonicum, Kuntze, 1. c. (=C. patagonicum, Phil.) - Patag.

pilosum, Nichols. Dict. Gavd. iv. (1887) 160. - Afr austr.

polyanthun, Kuntze, Rev, Gen. (1891) 424= Tylo phora floribunda, Miq.

polyanthum, K. Schum. in Bot. Fahrb. xvii. (1893) 136. - Afr. trop.

pubescens, Kuntze, Rev, Gen. (1891) $423=$ Cynanchum sinense, $R . B r$

purpurem, Kuntze, 1. C. $424=\mathrm{C}$. roseum, Decne.

Raddeanum, Alboff, Prodr. Fl. Colch. (1895) 170. Reg. Cauc

repandum, Kuntze, Rev. Gen. (1891) 425 (= Cynoctonum repandun, Decne:). - Madag.

Riedelii, Kuntze, 1. c. $(=$ Amplistolma Ricdelii, Fourn.). - Bras.

veticulatum, Heller, in Contr. Herb. Frankl. and Marsh. Coll. [Bot. Expl. S. Texas| i. (1895) 79 $=$ Gonolobus reticulatus, Engeln .

sarcostemmoides, Schweinf. ox Penzig, in Atti Congr. bot. Gerrova (1893) 349, nomen. - Erithrea.

scandens, Somm. \& Levier, in Act. Hort. Petrop. xii. (1892) 158. - Reg. Cauc.

Selloanm, Kuntze, Rev. Gen. (1891) $425=$ Amphistelma Selloanum, Fourn.

\section{VINCETOXICUM}

Lortii, Britton, in Mem. Torrey Bot. Club, v. 1894) $266=$ Gonolobus Shortil. A. Gray keptolobum, Kuntre, Rev, Gen. (1891) 425 Amphistelnza streptolobum, Fourn.). - Bras.

Struthianthus, Kuntze, 1, c, $423=$ Lorostelma Struthianthus, Foum

suberosum, Britton, in Mem. Torrey Bot. Club, v. (1s94) $260=$ Gonolobus suberosus, R. B

thesioides, Freyn, in Oest. Bot. Zeitschir x1, 1890 124 - Sibiria

tomentosum, Kuntze, Rev. Gen, (1891) 425 (= Amphistclna tomeniosum, Fourn.). - Bras.

wberculatum, Kuntze, I, c. = Cynoctonum tubcroulatum, Blume, fide Kuntze.

micatum, Kuntze, Rev, Gen, 1891) 423 = Cynanchum pauciflorum, $R . B r$.

umbrosum, Kuntze, Rev. Gen. (1891) 425 (= Orthosia umbrosa, Fourn.). - Bras.

mululutum, Kuntze, 1. c. $(=$ Cynoctonnm undulatum, Decne.). - Chili.

rocolatum, Kuntze,

Fourn.). - Bras,

niricosum, Kuntze, 1. c. $423=$ Tylophora Wallichii, Hook, $f$.

irescens, $K$. Schmm, in Bot. Fahrb. xvii, (1893) 137. - Madag.

virgatum, Kuntze, Rev, Gen, (1891) $424=$ Guilleminianum, Decn

viride, Kuntze, 1, c. 495 (= Cynoctonum wirke, Phil.). - Chili.

conitorm, Kuntze, 1. c. $424=$ Tylophora asthmatica, Wight \& Am.

Woollsii, Kuntze, 1, $\mathrm{c}=$ T. Woolsii, Binth

Zollingeri, Kuntze, 1. c. $(=$ Cynoctonum Zollingert, Miq.). - Malaya.

VIOLA. Tourn, ex Linn, (Violar.). - Ind. Kew, ii, 1004

acanthophylla, Leyb. ex Reiche, in Bot. Fahrb. xvi. (1893) 442. - Chili.

atnensis, Tornab. Fl. Sicula (1885) 138; et Fl. Aetnea, i.(1889) $132=$ parvula, Tineo

Aizoon, Reiche, in Bot. Fahrb. xvi. (1892) 443. Chili.

albiensis $X$. Sudre, in Lucante, Rev, de Bot, xii. (1894) 19. - Gall.

alichariensis, G. Bech, ine fahr.-Katal. Wien. bot. Tauschier. (1894) 6. - Maced.

Amani, Post, in Bull. Herb. Boiss, i. (1893) 16, 411. - Syria.

ancops $X, C$. Richt. in Sitzb. zool.-bot. WVien, Ges. xli. (1891) 20. - Austria

apennina, Terracc, in Nuov. Giorn. Bot. Ital. xxi. (1889) 327 ; et in Ann. Ist. Bot. Roma, iv. 1889. $90(1891) 77=$ calcarata, Lim .

a) buscula, Phil. in Anal. Univ. Chil. lxxxi.(1893) $491=\mathrm{V}$. Philippii, Leyb

arsenica, G. Beck, in fahr-Katal. Wion. bot. Tauscirev. (1894) 6.- Mared.

atrichocarpa, Borb. in Oest. Bot. Zeitschr, xl. (1890)

$118,16 \pi=$ collina, Bess.

aurata, Phil. in Anal. Unio. Chil. Ixxxi. (1893) 492. - Chili.

banatica, Simonk. Erdély edényes F1. (1887) $112=$ dacica, Borb.

Barceloi, Nym. Consp. Fl. Europ. Suppl. ii. I. (18s9) 45. - Ins. Balear.

Bertoti, Souché, in Bull. Soc. bot. Rochel, (1892), ex Corbière. Nouv. Fl. Norm. (1893) $\pi$ = sylvestris, Lamn,

Bethkeana. Borb. in Oest. bot. Zeitsch. xli. (1891) $422=\mathrm{V}$. Leunisii, Borb

Bethkeana X, Prah1, Krit, F1. Prov. Schlesv.Holst. ii. (1890) 23. - Slesv.-Holst.

Bethkei X, C. Richt, in Verh zool.-bot. Ges. Wien, xxxviii. (1888) 221. - Austria.

bilczensis, Blocki, in Spraw. Kom. fizyy. Kyakon. xxii. (1888) Ir. 213. - Eur. centr.

boliviana, Britlon, in Bull. Torrey Bot. Club, xvi. (1859) 18. - Bolivia

Borchersi, Phil. in Anal. Univ. Chil. lxxxi. (1893) $494=$ frigida, $P$ hil. var

bosniaca, Form. in Oest. Bot. Zeitschr. (1887) 368 : G. Beck, in Annal, Naturh. Hofmus. Wien, x. (1895) $179=$ declinata, Waldst. of $K$ it

\section{VIOLA :}

brachyantha, Slapf, in Denkschr. Akad. It in (1886) 39. - As, Min

Brannii X, Borb. in Hallier, Koch's, Syn deutsch. Fl. ed. 3 (1891) 202. - Austro-Hung.

Bridgesii, Britton, in Bull. Torry Bot. Club, xvi. (1889) 18. - Bolivia.

Burnati $X$, Gremli, F1, anal. Suisse (1\$86) 12t; et Nene Beitr. Fl. Schweiz. v. (1890) 18.Helv.

Caflishii, Woertein, in Ber. Bot. Ver. Landshut, 188889 (1889) 171. - Bavaria

alifornica, Griene, Fl. Francisc. (1891) 3. Calif.

caninaeformis $\times, C$. Richt in Verh, zool -bot, Ges. Wien, xzxviii. (1888) 2\%1. - Austria.

carinthaa $X$, Borb. in Oest. Bot. Zeitschr. xli (1891) 235. - Carinth

carpatica X, Borb. 1. c. xli. (1801) 42\%. - Hun

Celia, G. Beck, ex Borb. 1. c. xlii. (1\$92) 28\% nomen, = leucecras, Borb.

chillanensis, Phil, in Anal. Univ, Chil, 1rxxi, (189;) $347=$ vulcanica, Gill

ochleata, Coincy. in Mlorot. Fourn de Bot.

(1894) 204; el Eilog, alt. Pl. Hisp. (1895) t.?.-

Hisp.

(1893) 196 - Tiro

1893) 196. - Tirol.

ncolor. E. L. Kranse, in Ber. Deutsch. Bol. Ges. 1887) 25 ; Prahl, Krit. Fl. Prov. Schlest.-Holst. il (1890) 22. - Slesv. -Holst.

cuicochensis, Hieron. in Bot. Fahrb. xxi. (1895) 32:3 - Ecuad.

dacica, Borb, in Magyar, Noren. Lapok, xiii. (1890) 79; et ex Oest. Bot. Zeitschr. xli, (1891) i5, $183=$ declinata, Waldst. Go Kit.

damudialis, Borb. 1. c. = elation, Fries

Davidi, Franch. in Noure. Archio'.Mus, Paris, Sér. II viii. (1886) 993 - Tibet.

Gecipiens, Reiche, in Bot. Fahrô. xvi. (1892) 445.Chili.

decora, Formanek, in Verh. Nahurf. Ver. Brünn, xxxii. $1893(1804) 179 .-$ Maced

Delabordii, Hort. ex Kew Bull. (1889) 56. numen.

Delavayi, Franch, in Bull, Soc. Bot, Fr, xxiiii. 1886) 413 ; et Pl. Delar. (1889) i3. - China

deltoidea, Yatabi, in Tokye Bot. Mag. V. (1891), :18 - Japon.

G Camus \& Hariot, in Bull. Sor. Bot, Fr, xxxyiii. (1891) 42\%: - Gall.

Dioszegiana X, Borb. in Magyar Növen. Lapok xiii. (1890) 79; et in Hallier, Koch's Syn. Deutsch, F1. ed. 3 (1892) 191. - Austro Hung.

Mravica, Murr, in Dentsche Bot. Monatsschr. xil. 1894) 3. - Eur centr.

dubia $X$, Wiesb. in Oest. Bot. Zeitschr. xxrvi. 1886) 191. - Austro-Huns.

Eichenfoldii $x$, Halácsy, in Oest. Bot. Zeitschr. xxxix (1889) 181. - Dalm.

Favati. Hausskn. ex Farrat; in Bull. trav. Soc. Murith. Fasc vii-xt, (1887) (1) = odorata, Lim flavida, Buran \& Franch. in Morot, foum, de Bot. v. 1891) 21. - China occ.

Fluehmanni. Phil. in Anal. Univ, Chil, 1xxxi. (1893) 346. - Araucania.

funesta $\times$. C. Richt, in Verh. zonl.-bot. Ges. Wien, xxxviii. (1888) 220. - Austria.

gloggnitzensis $X, C$. Richt. 1. c. xxxvii. (1S87) 197.

- Austria.

Godoyae, Phil. in Anal. Univ. Chil. 1xxxi, (1893) 493. - Chili

Gremblichiix, Murr, in Dentsche Bot. Monatsschr. iv. (1886) 151: Borb, in Hallier, Koch's Sym. Deutsch. Fl. ed, 3 (1892) 18t, - Tirol.

Guitteanae X. Giraudias, in Bull. Soc. Bot. Fr. xii. 1895):37t. - Gall.

Hallieri X, Borb, in Magyar. Növen. Lapok, xii1. 1890) is: et in Hallier, Koch's Syn. Deutsch. F1. ed. 3 (1892) 183. - Hung.

helioscopia, Hillebr. Fl. Haw. Ist. (1888) 17. - Ins. Sandvic

keteracarpa X. Borb. ex C. Richt. in Sitzb. zool. bot. Ges. Wien, xli. (189L) 20. — Scand. 


\section{VIOLA:}

satica If I Krause, in Ber. Deutsch. Bot. Ges. (188i) 25 ; Prahl, Mrit. Fl. Prov. Schlesv. Holst. ii. (1890) 22. - slev.-Holst.

Honkert, Franch, in Bull. Soc. Bot. Fr, xxsii (18S6) 5 = tuberifera. Franch

Howellii, A. Grow, in Proc. Ans, Acad. xxii. (1887) 30 S - Terr. Washingt.

muarica X. Deoen \& Sabransky, in Deutsche Bot. IIonatsschr, (1\&85) 8: G. Beck, F1. Nied.-Oest. ii. I. (1892) 512. - Hung.

Morida $\times$ Wiesb, in Oest. Bot. Zeitsch. xxxvi. (1S86) $192=$ interjecta. Borb.

in C Richter, in Verh. zool-bot. Ges. Wien, xxxviii. (1886) 220. - Austria.

intcreteta, Borb. in Hallier, Koch's Syn. Deutsch. Fl. ed. (1892) 100; G. Beck, Fl. Nied.-Oest. ii 1. (1892)510. - Austria.

Ftertcrta. G. Beck, in Verh, zool.-bot. Ges. Wien, xli. (1891) 64:) : et 1. c. 521. - Austria.

fabornggii ২, Khek, ex Pacher, Nachtr. Fl, Kärnt (1894) 166. - Carinth

kilicnsis x, Prahl, Krit. Fl. Prov. Schlesv--Holst (1890) 24. - Slesv.-Holst

Znomonica Hausskn, in Mitth. Thür. Bot. Ver. Foloe, v. (1593) 44. - Graecia

Zntisibala, Wettst. in Luers. Bibl. Bot. Hett xxvi. $(1892) 2 \tau=$ declinata. Woldst. \& Kit.

eucoceras, Borb. ex f. Murr, in Oest. Bot. Zeitschr. xl. (1890) $134(=V$. meglect $a$ Schm.). - Tirol

Leunisij, Borb. in Oest. Bot.Zeitschr. xli (1891) 422 $=V$. Bethkaura. Borb.). - Hung

Levieri, Pant. ex Camel, Fl. Italiana, ix. (1890) 181 - Ital.

Macloskeyi, F. E. Lloyd, in Erythea, iii, (1895) 74 - Oreron.

Mriulat. Giraudias, in Lucante. Rev, de Bot. (1886) = sylvestris, Lam

agna X. C. Richt. in Sitzb, zool.-bot. Ges. Wien, xli. (1891) 20. - Austria

allingrnsis, Wiesb. in Doubl. Verz. Schles. Tauschver, xxiij. (1885-86i), ex Oest Bot. Zeitschr. Nyvi, $(1886) 190=$ hungarica $入$ Degen \& Sabransky.

usgolitana Y. Prahl, Krit. Fl. Prov. SchlesvHolst. ii. (1890) 24. - Slesv.-Holsat.

Aercurii, Ozph. ex Halacsy in Denkschr. Akad. Wim Ixi. (1894) 497. - Graecia

mornsusteiniensis $X$. Wiesb. ex Murr, xl. (1890) 134: G. Beck, F1. Nied.-Oest. ii. I. (1892) 517 - Tirol.

minutiflora, Phit, in Anal. Univ. Chit. 1xxxi. (1893) 453. - Chils.

mizta $Y$ Sudre, in Lucante, Rev de Bot. xii. (1894) 19. - Gall.

rollis X, A. Kern, ex Wiesb. in Deutsche Bot. Monatsschr (1885) 179: Borb, in Hallier, Koch's Syn. Dentsch, Fl, ed. 33 (1842) 181. - Austria.

moupinensis, Franch. in Bull. Soc. Bot, Fr, xxxiil 1886) 412; at Pl Dilow. (1889) 72. - Yunnan.

ssauvioides. Phit, in Anal. Univ, Chil.1xxxl. (1893) $346-$ Chili

cilveichiant $x$, Borb. in Oest. Bot. Zeitschr. xl (1890) 11\%, 167, 278; et in Hallier, Koch's Syn. Deutsch. Fl. ed, 3 (1892) 185. - Austria.

alretchi Y C Richt in Verh. zool.-Lot. Ges. Wien, xxxviii. (1888) 231 - Austria.

Neumamiana X. Borb.1. c. xli. (1891)20. - Austria

ienensis $\times$, Borb. in Hallier, Koch's Syn. Deutsch F1. (1892) 210. - Tirol,

M2thontona X. Mumr, in Deutsch. bot. Monatsschr. iv (1886) 15l, vii (1894) 93: G. Beck, Fl. Nied.-Oest. ii. I. (18.2) 511 ; et in Oest. Bot. Zeitschr, xliii. (1893) 176. - Austria.

yssitponensis, Rouy, in Magnier, Sctin. fl, select. vi. (1887) $114=$ tricolor, Linnt.

Orophila, Wiesb. in Oest. Bot. Zeitsch

(1886) 191 in obs, = sylvestris, Lanz

alleana, Phil. in Anal. Univ. Chil. 1xxxi. (1893) 4!4. - Chili.

Pacleri X, Wiesb. in Oest. Bot, Zeitschr, xxxvi (1886) 190, et xl. (1890) 134, 16\% : Burb. in Hallier, Koch's Syn, Deutsch. F1, ed. 3 (1892) 185. Tirol.

Faradoxa X, C. Richt. in Verh. zool.-bot. Ges. Wien, xxxviii. (1898) $2 * 0$ - Austria.

\section{VIOLA}

parva, E. Adans. Harturll, Cot. Phaenoy, and. Crypt, Pl. Fitchburg (1885) ex Bull. Torrey Bot. Chub, iii. (1886 85. (Ouid?) - Am. bor.

perrobista, Borb. in Magyar Növen. Lapok, xiii. (1890) 81 ; et in Oest. Bot. Zeitschr. xl. (1890) $245=$ tricolor, Linn

Philippiana, Greene, Pittonia, ii. (Nov. 1889) 14 (= V. chrysantha, Phil.). - Chili.

pinztorum, Greene, I. $c$ a aurea, Kell ?

Pirottae. Chiovenda, in Bull. Soc. Bot. Ital. (1893) 287 = odorata, Linnt.

plantaginea, Webb, ex Christ, in Bot. Fairb. ix. 1888) 96 - Ins. Canar.

Plenigeri. Formanek, in Verh.naturf. Ver. Brunn, xxxiii. 1894 (1895) 158. - Albania.

pluricaulis, Borb. in Oest Bot. Zeitschr. xli. (1891) 422; G. Beck, Fl. Nied.-Oest. ii. I. (1892) $514(=$ V. multicantis ford.) $=$ odorata, Linn.

prenja, G. Beck, in Annal. Naturh. Hofmus. Wien, ii. (1887) 81, t. 4 fig. $1-4=$ odorata, Lisn

Pseudasterias, K. Reiche, in Bot. Fahrb. xvi. (1892) 435. - Chili.

Psendo-mirabilis, Coste, in Bull. Soc. Bot. Fr. xl, (1893) P. cxv, - Gall, mer.

Pscudomontana, Blocki, in Spraw, Kom. Fizyj. Krakow, xxii. (1888) ii, $213=$ elatior. Fvies

Psculosiliaticat $\times$. C. Richt, in Verh. Zool.-bot. Ges. Wien, xxxviii. (1888) 2?1. - Austria.

pubineritis, Rehm. \& Woloszczak, in Oest, Bot Zeitschr, xliii, (1893) $196=$ palustris, Linn.

pulvinata, $K$. Reiche, int Bot. Fahrb. xvi. (1892) 434. - Chili.

radians $X, G$. Beck, F1. Nied,-Oest. ii, I. (1892) 514. - Austria.

reptans, Robinson, in Proc. Am. Acad. xxvii. (1893) 165. - Mexic.

Reverchoni, Willk, ex Coincy. Erlug. pl. alt. Hisp. (1895) sub t. 2 , in syn.; Debeaux, in Lucante, Rev. de Bot. xii. (1895) $345=$ cochleata, Coincy.

rhaetica X, Borb. in Hallier, Koch's Syn. Deutsch. Fl. ed. 3 (1893) 186. - Austria.

robusta, Hillibr. Fl. Haw. Isl. (1885) 16. - Ins. Sandvic

Rossii $\times$. Chiovenda, in Bull, Soc. Bot. Ital. (1893) 207 . - Ital.

Rossii, Hensl. ex Forb. E Hensl. in fourn. Limn. Soc, xxiii. (1886) 54. - China.

roxulanica, Blocki, in Deutsche Bot. Mlonatsschr. v. 1887) 147; ct in Oest. Bot. Zeitschr. xxxviii. (1888) 15. - Eur. centr.or.

Ruprechtiana X. Borb, in Sitzb. zool.-bot. Ges. Wien, xli (1891) 20. - Boruss,

segubricensis, Pau, Not. Bot. Fl. Espan ii. (1889) 9. - Hisp.

serbica, Formanek, in Verh. Naturf. Ver. Briinn. xxxii. 1893 (1894) 179 - Serbia

Shufitziana, Wiesb. in Oestr. Bot. Zeitschr, xxxvi. (1886) 190 ; et in Natur und Offenb. xxxvii. (1891) $500=$ elatior Fries.

Mespicensis X. Prahl. Krit. F1. Prov. Schlesw. Iulst. ii. (18!8) $2 \%$ - Slesv.-Holsat

somalensis, Engl. in Abh. Pretss. Akud. Wiss. 1891 (1892) 308 - Reg. Somal.

Stuebelii, Hicron, in Bot. Fahrb. xxi. (1895) 324. Columb.

suaviftora $\times$, Borb. \& $H$. Braun, in Oest. Bot. Zeitschr. xi. (1890) 26; G. Beck, Fl. Nied.-Oest. ii. I. (1892) 516. - Austria.

subcrenata, Phil, ex Fr. Meigen. in Bot, fahrb. xvii, (1893) 258, nomen. - Chili.

subhivta $\times$, G. Beck, Fl Nied.-Oest. ii. I. (1892) 511. - Austria

subodorata $\times$, Borb. ex Murr, in Oest. Bot. Zeitschr. xl. (1890) 134; et in Deutsche Bot. Monatsschr, xiii. (1894) 92. - Tirol.

subrubescens, Borb, in Natur, und Offenb. xxxvii. (1891) 500 ; et in Oest. Bot. Zeitschr. xli. (1891) 347 ; G. Beck, Fl. Nied. Oest. ii. I. (1892) $519=$ elatior, Fries.

Szilyana, Borb. Geogr, atq. Enum, pl. Comit. Castrif. (1887) 253 ; et in Hallier, Koch's Syn. Deutsch. Fl, ed. $3(1895) 176 ; \mathrm{H}$. Braun, in Uest. 13ot. Zeitschr. xl, (1890) 290 - Stiria.
VIOLA

Tatrae $\times$, Borb, in Magyar Yöven. Lapok, xiii (1890) $81 ; \mathrm{H}$. Braun, in Oest. Bot. Zeitschr. xl. 1890) 243, xlii. (1892) $28 \%=$ tricolor, Linn.

Tenorii, Terrac, in Nuv. Giorn. Bot. Ital, xxi (1889) 326. - Ital.

tonuis X, C. Richt. in Sitzb, zool.-bot. Ges. Wien, xli. (1891) 20. - Scand.

thymifolia, Britton, in Bull. Torrey Bot. Chts, xvi (1889) 18 - - Bolivia.

iroliensis $X$. Borb. in Hallier, Koch's Syn Deutsch. Fl. ed. 3. (1892) 183: in Oest. Bot Zeitschr, xl. (1890) 117, xlv. (1895) 237; Pacher Nachtr. F1. Kärnt. (1894) 169. - Tirol.

tristicha $X$. Waisb. in Oest. Bot. Zeitschr. xly. (1895) 144. - Hung.

tuberifera, Franch. in Bull. Soc. Bot. Fr, xxxiii (1886) 410 ; et Pl, Delav. (1889) 70. - Yunnan.

Uechtritziana $\times$, Borb. in Sitzb, zool.-bot. Ges. Wien, xli. (1891) 20; et in Oest. Bot. Zeitschr. (1891) 33 ; G. Beck, Fl. Nied.-Oest. i. II. (1892) 519. - Austria.

umbrosa, Cesati, ex Chiovenda, in Bull. Soc. Bot Ital. (1893) 287, in syn。 $=$ V. Pirottae, Chiovenda urophylla Franch, in Bull. Soc, Bot. Fr. xxxiii. (1886) 413 ; et Pl, Delar. (1889) 74. - China occ. Vandasii, Velen. Fl. Bulg. add. (1891) 641 ; et ist Sitzb. Bochm. Ges, Wiss, 1893 (1894) xxxvii. 12 - Builg.

alesiaca, Hausskn. ex Favrat, in Bull. trav. Soc. Murith. Fasc, xiii-xv, (1867) $61=$ collina, Bess. audensis $\times$ Hausskn, ex Gremli, Fl, anal, Suisse. (1886, 124. - Helv.

velutina, Envmanek, in Verh. naturf. Ver. Brimn xxx. 1891 (1892) 75, xxxii. 1893 (1894) 17\%, Maced.

Websteri, Hemsl. ex Forb. \& Hemsl. in Fourn. Linn. Soc, xxiii. (1886) 56. - China.

Wettstemii, C. Richt, in Verh, zool,-bot. Ges. Wien, xxxvii. $(188 \pi) 187=$ sylvestris, $\operatorname{Lam}$

Wiesbaurii X, Sabransky, ex Nym. Consp. Fl. Eur. Suppl, ii. I. (1889) 48, - Austria.

VIORNA, Reichb. = Clematis, Dill. (Ranuncul.). cylindrica, Spach, ex Dippel, Handb. Laubholzk. iii. (1893) $181=$ C. cylindrica, Linn.

VIREGTA, Afzel. (Rubiac.). - Ind, Kew. ii. 1210 najor, $K$. Schum, in Engl. Pfanzenw, Ost-Afr. C (1895) 37\% - Afr, trop. or.

VIROLA, Aubl. = Myristica, Linn. (Myrist.). Longata, Warb. in Ber. Deutsch. Bot. Ges, xiii. (1895) $89=$ M. elongata, Benth

VISGAINOA, Greene, Pittonia, i. (Feb. 1888) 163 Engl, in Engl. \& Prantl, Natiurl. Pflanzenfạm iii. 4 (1890) 88. EUPHORBIACEAE

geniculata, Grecne, Il. cc.; T. S. Brandeg. in Proc Calif. Acad. Ser. II. ii. (1889) 1337 (= Shaphyled geniculata, Kell.). - Calif,

VISCARIA, Riv. ex Rupp. = Lychnis, Tourn (Caryoph.).

media, Fries, ex Swanlund, in Bot, Notis. (1886)7. in syn $=\mathrm{L}$. Viscaria, Linn

nvalis, Simonk. Enum. Fl, Transs. (1886) $131=\mathrm{L}$. nivalis, $K$ it.

VISC UM, Tourn, ex Linn. (Loranth.). - Ind. Kew ii. 1211

brevifolium, Engl。Bot, fahrb, xx. (1894) 131. Afr. austr.

clavatum, T. Kirk, in Trans. N.,Z. Inst, xxiv, 1891 (1892) 429 , t. 3\%. - N. Zel.

Fischeri, Engl. Bot. Fahrb. sx. (1s94) 132. - Afr. trop. or.

glomeratum. Baker, in fourn. Linn. Soc. xxii. (1887) 515. - Madag.

Hildebrandtii, Engl. Bot. Fahrb, xx. (1894) 133. Afr. trop.

Holstii, Engl. 1. c.132. - Air. trop. or

MacOwani, Engl. l. c. xix. (1894) 131. - Afr austro-occ, extratrop.

rhipsaloides, Buker, in foum. Linn. Soc. xxii. (1887) 516. - Madag. 


\section{VISCUM :}

Ratenbergii, Buchenau, in Abh. Naturw. Ver. Brem. x. (1889) 376. - Madas

Schimperi, Engl: Bot: Fahn xx. (1894)132. - Abyss. Stuhlmanni, Engl. l. c. - Afr. trop. or.

tenue, Engl.l.c.133. - Afr. trop. or.

vacciniffolium, Baker, in fourn. Linn. Soc. xxv. 1890) 343. - Madag.

VISMIA, Vand. (Hyperic.). - Ind. Kew, ii. 1212 calvescens, Hieron. in Bot. Fahrb. xxi. (1895) $32 ?$. - Columb.

gracilis, Hieron. l. c. xx. Beibl, n. 49 (1895) 52.Columb. v. Ecuad.

Jelskii, Zahlbr, in Diss, Cl. Math. Phys, Acad. litt. Cruco\% xxix. (1894) 2:4, - Peruvia.

Lehmannii. Hieron. in Bot. Fahrb. xx. Beibl. n. 49 1895) 52. - Columb. v. Ecuad.?

Mandurr, Hieron. l. c. 54. - Columb

VITELLARIA, Gaertn. £. = Lucuma, Molina (Sapot.).

campechina, Engl. Bot, Jahrb, xii, (1890) $513=$ L. campechiana, $H$. B. E $K$.

catocladantha, Eng1. 1. c. $514=$ L. catocladantha, Eichl.

Eichleri, Engl: 1. c. 512. - Bras.

glaucophylla, Engl.l. c.513, - Bras.

mammosa, Loes, in Bull. Herb. Boiss, ii. (1894) 564 = Lucuma mammosa. Radlk.

mitidula, Engl. Bot. Jahrb. xii. (1890)512. - Cuba. salicifolia, Engl. 1. c. $514=$ Lucuma salicifolia, $H$. B. fo $K$

tenuifolia, Engl. 1. c. 513. - Cuba

Warmingii, Eng1. 1. c. 512 = Lucuma Warmingii, Eichl.

VITEX, Tourn. ex Linn. (Verben.), - Ind Kew. ii. 1213.

amboniensis, Guerke, in Engl. Pfanzenw. Ost-Afr. C (1895) 340. - Afr. trop. or

angolensis, Guerke, in Bot. Fahrb. xviii. (1894) $16 \%$ - Angola

bracteata, S. Elliot, in fourn. Limn. Soc. xxix. (1891) 42. - Madag.

Buchanani, Baker, ex Guerke, in Engl. Pfanzenw, Ost-Afr. C (1895) 339. - Afr. trop. or.

Buchneri, Guerke, in Bot. Fahro. xviii (1894) 166. - Angola.

camporum, Buttn, in Verh. Bot. Ver. Brand. xxxii. (1890) 35. - Angola.

Carvalhi, Guerke, in Engl. Pflanzenv. Ost-Afr. C (1895) 339. - Afr. trop. or.

cestroides, Baker, in foum, Linn. Soc. xxv. (1890) 341. - Madag.

congesta, Oliver, in Hook. Icon. pl. xxiii. (1892) t. 2240, - Madag

Fischeri, Guerke, in Bot. Fahrb. xviii. (1894) 171. Afr. trop.

flavescens, Rolfe, in Bolet. Soc. Brot. xi. (1893) 87. - Angola.

formosana, Hentsl. in Ann. Bot. ix. (1895) 151.Formosa.

gabunensis, Guerke, in Bot. Fahro. xviii. (1894) 167. - Gabon.

grandifolia, Gueve, l. c. 169. - Gabon

hirsutissima, Baker, in Kew Bull.(1892, 108.-Madag.

Hollrungii, Warb, in Bot. Fahrỏ. xviii.(1894) 208 - N. Guin.

lundensis, Guerke, l. c. 168. - Congo.

Mechowii, Guerke, l. c. 167.:- Angola.

-micrantha, Guerke, l. c. 170. - Afr. trop. occ.

microcalyx, Baker, in fourn. Linn. Soc. xxy. (1899) 341. - Madag.

milanjiensis, Britten, in Trans. Linn. Soc. Ser. II. iv. (1894) 36. - Afr. trop

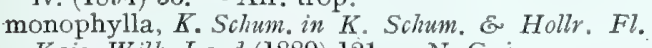
Kais. Wilh. Land (1889) 121. - N. Guin.

mossambicensis, Guerke, in Engl. Pflanzenw. Ost-Afr. C (1895) 340. - Afr. trop. or.

Novae-Pommeraniae, Warb. in Bot. Fahrb, xiii. (1891) 429, xviii. (1893) 208. - N. Guin.

Poggei, Guerke, in Bot. Fahrb. xviii. (1894) 168. Afr. trop. occ.

pyramidata, Robinson, in Proc. Am. Acad. xxix. (1894) 321. - Mexic.

\section{VITEX}

pyramidata, Robinson Eo Pringle, in Gard. and For. vii. (1894) 153. - Mexic

rufescens, Guerke, in Bot. falmb. xviii. (1894) 169 - Angola.

Schweinfurthii, Guerke, l. c 170. - Afr. trop

syringaefolia, Baker, in Kev Bull. (1895) 115. Afr. trop. occ.

tangensis, Guerke, in Engl. Pfanzenv。 Ost-Afr. C (1895) 339. - Afr. trop. or

Teleravina, Baker, in foum. Linn. Soc. xxv. (1890) 340. - Madas.

thyrsiflora, Baker, in Kew Bull. (1895) 152. - Afr trop. occ

tristis, S. Elliot, in Fourn. Linn. Soc. xxix. (1891) 42. - Madag

Volkensii, Guerke, in Enol. Pfanzenw. Ost-Afr.C (1895) 339. - Afr. trop. or.

Welwitschii, Guerke, in Bot. Fahrb. xviii. (1894) 166. - Angola.

VITIS, [Tourn. j Linn. (Ampel,). - Ind. Kew, ii.

cuminata, Carr, in Rev. Hortic. 1xii. (1890) 183.China.

acuminata, Trim.Handb. Fl. Ceyl.i. (1893) 292 (= Cissus acuminata, Thw.). - Zeylan.

angulosa, Rafin. [Am. Man, Grap. Vin. (1830) 16] ex Dippel, Handb. Laubholzk. ii. (1892) $561=$ rotundifolia, Michix.

Apliniana, Collett \& Hensl. in fourn. Linn. Soc xxviii. (1890) 35. - Ind. or.

apodophylla, Baker, in Kev Bull. (i894) 330.Arabia.

artemisiaefolia, Franch. Pl. Delav. (1889) 13\%, in syn. (= Ampelocissus artemisiaefolia, Planch.). China occ.

Baileyana, Munson, ex Bull. Torrey Bot. Clıb, xx. (1893) 500. - Virgin.

Balansaeana, Planch, in DC. Monog. Phan.v. (1887) 612. - Tonkin.

Blancoii, Munson, in Gard. and For. iii. (1890) 474, nomen. - Mexic.

Bourgaeana, Planch. in DC. Monog. Phan. v. (1887) 368. - Mexic.

brevipedunculata, Dippel, Handó. Laubholzk. ii (1892) 564, fig. 267 (= Cissis brevipedunculata, Maxim.). - Japon.

burmanica, Collett \&o Hemsl. in Fourn. Linn. Soc. xxviii. (1890) 35. - Burma.

cardiospermoides, Franch. Pl. Delav. (1889) 140, in syn. (= Ampelopsis cardiospermoides, Planch.).China.

Champini X, Planch. in DC. Monog. Phan. v. (1887) 321. - Texas.

congoensis, Hort. ex Gard. Chron. (1891) i. 116. Congo.

Davidiana, Hort, ex Dippel, Handb. Laubholzk. ii. (1892) $556,564=$ V. Romaneti, Romanet.

Davidiana, Nichols. Dict. Gard. iv, (1887) 187 (= Cissus Davidiana, Carr.). - China.

Delavayana, Franch. Pl. Delav. (1889) 139, in syn. = Ampelopsis Delavayana, Planch.). - China occ.

digitata, Deflers, Voy. au Yémen (1889) 125 (= Cissus digitatus, Lam.). - Arabia.

Doniana, Munson, in Gard. and For. iii. (1890) 473. nomen. - Arkans.

dubia, Becc. ex Martelli, Fl. Bogos. (1886) 19.Abyss.

Foëxeana, Planch. in DC. Monog. Phan. v. (1887) 616. - Texas.

Giradiana, Munson, in Gard. and For. iii. (1890) 473 , nomen. - Calif.

glabrescens, Fritsch, in Verh. zool.-bot. Ges. Wien, xxxix. (1889) 592. - Austria.

glauca, Ccrdem. Fl. Ile Réunion (1895) $410=$ glauca, Wight \&o Arn.

glossopetala, Baker, in Kew Bull. (1894) 344. Madag.

grossedentata, Buettn. in Verk. Bot. Ver. Brand. xxxii. (1890) 44. - Gabon.

Guerkeana, Buettn.l. c. xxxi. (1889) 89. - Congo, Angola.

Henryana, Hemsl.ex Forb. Eo Hemsl. in fourn. Linn Soc. xxiii. (1886) 132. - China.

\section{VITIS}

humilis, N.E. Br. in Hook. Icon, pl, xri. (18S7) t 1565. - Natal.

hypoleuca. Szyszyl. Polypet. Rehmann, ii. (1SSS) 45 (= Cissus hypoletuca, Harv.). - Transvaal.

imerinensis, Baker, in fourn. Linn. Soc. xxv. (1890) 308. - Madag

lanceolata, S. Wats, in Proc, Am. Acad.xxvi, (1886) 462. - Guatem.

letcophlea, S. Elliot, in fourn. Limn. Soc xxix. 1891) 12. - Madag.

Linden1, Nichols. Dict. Gard. iv. (1887) 188, - N. Granat.

Martinelli, Hort. Kew. ex Planch. in DC. Monog. Phan. v. (1887) 375, in obs. (= Ampelocissus Mar= timi. Planch ) - Cochinch.

mauritiana, A. Fuss. ex Planch. l. c. $382 \Leftrightarrow A$. elephantina, Planch.). - Madag.

megabotrya, Collett \& Hemsl. in Fourn, Limn. Soc. xxviii. (1890) 34. - Burma.

morifolia, Baker, in fourm, Linn. Soc, xxy. (1890) 307. - Madag.

Meunsoniana, 7. H. Simson, in Muns. Address 012 Am. Grap. (1886) 5, nomen, ex Planch, in DC. Monog. Phan.v. (1887)615; Munson, in Gard, and For. iii. (1893) 473, 474. - Florida.

nana, Baill. in Bull. Soc. Linn. Paris, ii. (1891) 953. Congo gall.

natalitia, Szyszyl. Polypet.Rehmann. ii. (1888) 4\%. Natal.

novo-mexicana, Lemmon, ex Munson, Nat. Grap.U. S. (1885) 5; et in Address on Am. Grap. (1886) 5 ; Inuevo mexicanal fide Planch. in DC. Monog, Phan.v. (1887) 616. - N. Mexic.

pachyphylla, Corden. Fl. Ile Rénnion, (1895) 412. - Ins. Borbon.

pachyphylla, Hemsl. ex Forb. \& Hemsl. in fourn. Linn. Soc, xxiii. (1886) 132. - China.

pallida, Trim. Syst. Cat. Ceyl. Pl. (1885) 19; et Handb. Fl. Ceyl. i. (1893) 292 (= V. Heyneana, Wall.). - Zeylan.

Planchonii, Franch. Pl. Delav. (1889) 139, in syn. (=Tetrastigma hypoglaucum, Planch.). - Yunnan.

Potanini, Maxim. in Act. Hort. Petrop. xi. (1889) 104. - China.

pycnantha, Collett of Hemsl. in fourn. Linn. Soc. xxviii. (1890) 34. - Burma.

quadrangularis, Cordem. Fl. Ile Réunion, (1895) 411 ; Deflers, Voy. au Yémen (1889) 125 = quadrangularis, Wall.

Regeliana, Hort, ex Dippel, Handb. Laubholzk. ii. (1892) $564=$ brevipedunculata, Dippel.

Retordi, Romanet du Caill. ex Planch. in DC. Monog. Phan. v. (1887) 613. - Tonkin.

rhodotricha, Baker, $7 n$ foum. Iinn. Soc. xxii. (1887) 461. - Madag.

rotundifolia, Deflers, Voy, au Yémen (1889) 125 (= Cissus rotundifolia, Vahl). - Arabia.

rutilans, Carr. in Rev. Hortic. 1xii. (1890) 444, cum ic. - China.

sambucina, Becc. ex Martelli, Fl. Bogos. (1886) 20. - Abyss.

Schumanniana, Kuntre, Rer. Gcn. (1891) 128, 151 - Malacca.

sicyoides, Baker, in Kew Bull. (1893) 243, $249=$ sicyoides, Miq.

Simpsoni, Munson, in Gard. and For. iii. (1890) 473 , nomen. - Florida.

soudanensis, Lécard, ex Planch. in DC. Monog. Phan. vii. (1887) 487, in syn. = caesia, Baker, pr.p.

sphaerophylla, Baker, in fourn. Linn. Soc. xxii (1887) 460.- Madag.

spicigera, Kuntze, in Gartentl. xlii. (1893) $112(=$ Cissus spicigera, Griff.) = macrostachys, $M i$ succulenta, Galpin, in Kew Bubl. (1895) 144. Transvaal.

ulmifolia, Lafon, ex Planch.in DC. Monog. Phan.v. (1887) 405, in obs. - Costa Rica.

umbellata, Hemsl. ex Forb. E Hemsl. in Fourn. Linn. Soc, xxiii. (1886) 137. - Ins. Formosa.

vestita, Franch. Pl. Delav. (1889) 139, in syn. (= Ampelopsis tomentosa, Planch.). - Yunnan.

Virgiliana, Clem. [Ensayo sobre var. Vid. (1879) 53, t. 12], ex Planch, in DC. Monog. Phan. v (1886) $356=$ vinifera, Linn 


\section{VITIS}

Giniana. Munson, in Gard, and For, iii. (1890) $475=$ Baileyana, AIunson.

tiginea, Kuntze, Rev. Gen. (1891) 128, 129, $138=$ repanda, Wight \& Am.

Voanonala. Baker, in Fourn. Linn. Snc. xxii. (1887) 461. - Maday,

ulgavis, Bartr. [Rep. pat. Off. Agric. (1857) 329], ex Dippel, Handb. Laubholzk. ii. (1892) $545=$ $\checkmark$ Labrusca, Linn.

VITTADINIA, A. Rich. (Compos.). - Ind. Kew. 1 to 18

Alinae, F. Huell, in Trans, Roy, Soc. Vict. N. S. i. II. (1889) 11.|Vittadenial. - N. Guin.

macra. F. Muell, l. $c_{*}-\mathrm{N}$, Guin

VIVIANIA. Cav. (Geran.). - Ind. Kew. ii. 1218. aristulata, Fr. Meigen, in Bot. Fahb. xvii. (1893) 249(= Cissarobryn aristulatum, Phil.). - Chili. laxa, Phil. in Anal. Univ. Chil. Ixxxii. (1893) 738. - Chili

ovata, Phll. l. c. 739. - Chili

VLECKIA, Rafin.=Lophanthus, Benth. (Labiat.) amethiodora, Greene, in Mem. Torrey Bot. Club, v (1894) 28\% = Hyssopus anethiodorus, Nutt.

Foenicumu, MacMill. Metasp. Minn. (1892) 449 $=$ Lophanthus anisatus, Benth

articifolia. Holzinger, in Contr. U. S. Nat. Herb iii. $(1895) 246(=$ V. urticaefolit, Rafin. $)=$ L. urticifolius, Benth.

VOACANGA, Thou.(Apocyn.).-Ind. Kew. ii, 1218. africana, Slapf, ex S. Elliot, in foum. Linn. Soc. xxx. (18:4) $87,-$ Sierra Leone.

angustifolia, K. Schum, in Engl. Pfanzenw. Ost-Afr. C (1895) 317. - Afr. trop. or.

Bnehmii, K. Schum. l. co; et in Engl. \& Prantl, Natïrl. Pfanzenfam, iv. 2 (1895) 149. - Afr. centro or.

bracteata, Stapf, in Kew Bull. (1894) 22. - Afr. trop. Occ.

dichotoma, $K$. Schum. in Engl. Pflanzenw. Ost-Afr. C (1895) 31\%. - Afr. trop. or.

diplochlamys. $K$. Schun, in Engl. \& Prantl, Natürl. Pfanzenfan. iv. 2(1895) 149. - Kamerun.

foetida, Baill. Hist. des pl. x. (1888) 171; K. Schum. 1. c. = foetida, Rolfe.

clabra, K. Schun. in Engl. \& Prantl. Natürl. Pfanzenfam, iv, 2 (1895) $149=$ africana, Stapf.

obtusa, K. Schmm. l. c. - Afr. trop.

papuana, K. Schum. 1. c, = Orchipeda papuana, F. Mucll.

puberula, K. Schum. l. c. 149. - Afr. trop. occ

Schweinfurthii, Stapf, in Kew Bull. (1894) 21. Afr. trop.

VOCHYSIA, Juss. (Vochys.). - Ind, Kew ii. 1218. boliviana, Rusby, in Mem. Torrey Bot. Club, iii. III. 1893) \% - Bolivia.

matemalensis. 7. D. Snilh, in Coult, Bot. Gaz. xii. 1887) 131, xiji. (1888) 299, t. 23. - Guatem.

Lehmannii, Hieron. in Bot. Fahr. xx. Beibl. n. 49 (1895) 38. - Columb.

Saldanhana, IVarm. in Vidensk. Meddel. Naturk. Foren. (1889) 877 [Symb. Fl. Bras, centr. xxxil. 66]. - Bras

Schwaclieana, Warm. $l l . c c .-$ Bras.

spathulata, Warm. ll. cc. 876; et 25. - Bras.

VOHEMARIA. Buchenau, in Abh. Naturw. Ver Brem. x. (1889) 372. ASCLEPIADEAE.

Messeri, Buchcnau, l. c. 372, t. 6, fig. 9-12. - Madag.

VOLKAIIERIA, Linn. Syst. ed. $1(1735)=$ Sesa mum. Linn. (Pedal),

alata, angolensis, calycina, laciniata, laniifolia, macrantha, Marlothii, prostrata, Schenkii, Schinziana, tripliylla, Kuntze, Rev. Gen. (1891) $482=$ homo myma onmia Sesami.

antirrhinodes, Kuntze, 1. c. = S. antirrhinoides IV ${ }^{2} 7{ }^{\prime}$.

oricntalis, Kuntze, 1. c, = S. indicum, Linn,

pentaplyylla, Kuntze, 1. c. = S. capense, Burm, $f$. samodes. Kuntze, 1. c. (= Anthadenia sesamoides, Lem.). - Afr. trop.
VOLKENSIA, O. Hoffm. in Bot. Jahrb. xx. (1894) 219 ; et in Encl. \& Prantl, Naturl. PHanzenfam. iv. 5 (1S93) $38 \%$ in add. COMPOSI TAE argentea, $O$. Hoffm. $l_{\text {. cc. }}-$ Afr. trop. or.

VOLKENSIOPHYTON, Lindau, in Bot, Jahrb. xx. (1894) 2\%. ACANTHACEAE.

neuracanthoides, Lindam, l. c., - Afr. trop. or.

VOLVULUS, Medic. = Calystegia, R. Br. (Convolv.).

hederaceus, Krausseanus, marginatus, roseus, siliaticus, Tuguriorum, villosus, Kuntze, Rev. Gen. (1891) $447=$ homonyma onmia Calystegiae.

Hantelmanni, Kuntze, 1. c. $=$ C. Hantelmanni, Phil.

sepinm. Junger, in Oest. Bot, Zeitschr, xl. (1890 $133=\mathrm{C}$. sepium, Lim.

vossIA, Wall, \& Griff. (Gramin.). - Ind. Kew, ii 1219.

cambogiensis, Balansa, in Morot, fourn. de Bot. jy. (1890) 109. - Cochinch.

cuspidata, Baill. Hist. des pl. xii. (18.14) $324=$ procera, Wall.

VOUAPA, Aubl. = Macrolobium, Schreb. (Legumin.)

canaliculata, Taub. in Bot. Centralbl. xlvii. (189I 393 = M. canaliculatum, Spruce.

cocrulea, Taub, in Bot. Jahrb. xix, Beibl, n, 47 (1894) 31 - Afr. trop. or.

discolor. Taub. in Bot. Centralbl, xlvii. (1891) 39 $=$ Macrolobium discolor. Benth.

flexuosa, Taub. 1, c. = M. flexuosum, Spruce.

gracilis, Taub. 1, c = M. gracile, Spruce.

guyanensis, Taub. 1. C. $394=$ M. guyanense, $A u b l$.

latifolia, Taub, 1. c. = M. latifolium, Vogel.

Limba, Taub, in Bot. Jahrb. xix. Beibl. n. 47 (1894

32, in obs. = M. Limba, S. Elliot.

limbata, Taub. in Bot. Centralbl. xlvii. (1891) 393 $=$ M. limbatum, Spruce.

multijuga, Taub, 1. c。= M. multijugum, Benth

pendula, Tattb. 1, $\mathrm{c} .=\mathrm{M}$. pendulum, Willd

stipulacer, Taub, in Engl. \& Prantl, Natürl. Pflanzenfam. iii. 3 (1892) $142=$ M. stipulaceum, Benth.

suaveolens, Taub. in Bot. Centralb1. xlvii. (1891) $394=$ M. suaveolens, spruce.

taxifolia, Taub. 1. c.= M. taxifolium, Spruce.

venulosa, Taub. 1. c. = M. venulosum, Benth.

VOYRIA, Aubl. (Gentian.). - Ind. Kew. ii. 1220. platypetala, Buker, in Kew Bull. (1894) 26. - Afr. trop. occ.

primuloides, Baker, l. c. 25. - Gabon.

VRIESEA, Beer = Tillandsia, Linn. $($ Bromel $)$ aëris-incola. Mez, in Mart. Fl. Bras. iii. III. (1894) $555=$ Catopsis maculata, Ed. Morr.

Alberti $\times$, Éd. André, in Rev. Hortic, xli. (1889) 300 , cum ic - Hybr. artef.

albo-nitens, Nichols. Dict. Gard. iv. (1887) 187. Bras.

alta, Ed. Morr ex Baker, Handb. Bromel. (1889 226 , in syn. = Tillandsia alta, Baker.

amazonica, Mez, in Mart. Fl. Bras. iii. III. (1894) $554=\mathrm{T}$. amazonica, Baker

atra, Mez, 1. C. 543. - Bras.

botafogensis, Mez, 1. c. 536. - Bras

caespitosa, Ed. Morr. ex Baker, Handb. Bromel. (1889) 213 = Tillandsia Schlechtendalii, Baker.

Cappei X. Hort. L. Duval, ex Rev. Hortic. Ixvi (1894) 285. - Hybr. artef

cardinalis X. Hort, L. Duval, 1. c. 1xii. (1890) 358 et in Illustr. Hortic xxxviii. (1891) $39, \mathrm{t}, 525$. Hybr. artef.

citrina, Ed. Morr. ex Baker, Handb. Brome1. (1889) 224, in syn. = Tillandsia citrina, Baker.

Clausseniana, Mez, in Mart. Fl. Pras. iii. IIt. (1894)

$54.5=$ T. Clausseniana, Baker

corcoradensis, $\mathrm{Mez}, 1 . \mathrm{c}, 532=\mathrm{T}$, corcovadensis, Baker.
VRIESEA : -

Crousseana X. Hort. ex Rev. Hort. Belg. xix. (1893)

$258=V$. W armingii, Ed. Morr

crassa, Mez, in Mart. Fl. Bras, iii. III. (1894) 566 - Bras.

crotalophora, Hort. ex Baker, Handb. Bromel. (1889) 215, in syn = Tillandsia Barilleti, Baker densiflora, Mez, in Mart. Fl. Bras, iii. III. (1894) 568. - Bras.

Deransayana X, Hort. L. Duval, ex Rev. Hortic lxvi. (1894) 285. - Hybr. artef,

Duchartrei X, Hort. L. Duval, ], c, 285. - Hybr. artef

fenestrata Y. Hort, ex Rev. Hortic, 1xvi, (1894) 285 , sphalm? = fenestralis, Linden ?

friburgensis, Mez, in Mart. Fl. Bras, iii. III. (1894) 537. - Bras

fulgida $\times$, Hort. ex Rodigas, in Illustr. Hortic. xxxy. (1888) 87, t. 67. - Hybr. artef.

gigantea, Mez, in Mart. Fl. Bras, iii. III. (1894) 566 = Tillandsia gigantea, Baker.

goniorachis, Mez, 1. C. $345=$ T. goriorachis, $M e z$.

gradata, Mez, 1. C. $523=$ T. gradata, Baker.

Gravisiana $X$. Wittm. in Gartenfl. xxxix. (1890) 494. fig. 81; Rev. Hort. Belg. xvi. (1890) 49; cum ic, -- Hybr, artef.

Hillegeeriama, Hort, ex Baker, Handb. Bromel $(1889) 227$, in syn. = Tillandsia regina, $V$ ell.

imperialis, Carrière, in Rev. Hortic. 1x. (1888) $56=$ T. regina, Vell.

nsignis, Hort. Lugd.-Bat, ex Wittm. in Gartenfl. x1 (1891) 476, t. 1362. - Hybr, artef.

Kitteliana X, Wittm. 1. c, xxxix. (1890) 326, fig. 62 - Hybr. artef

leodiensis $\times$. Hort. ex Rev. Hort. Belg. xviii. (1892) 3, cum ic. - Hybr. artef.

Leopoldi X. Witte, in Gartenfl. xl. (1891) 476. Hybr, artef.

Iongicaulis, Mez, in Mart. Fl. Bras. iii. III. (1894) $542=$ Tillandsia longicaulis, Baker

Lubbersii $X$, Hort, ex Rev. Hort. Belg, xix. (1893) 258: - Hybr, artef.

Luschnathi, Mez, in Mart. F1. Bras, iii. III. (1894), 555. - Bras.

macropoda, Mez, 1. c, $554=$ T. macropoda, Baker.

magnifica $X$, Hort. ex Rev. Hort. Belg. xiv. (1888) 136. - Hybr. artef.

I agnusiana $\times$, Kittel \& TVittm, ex Wittm. in Gartenf, xxxviii. (1889) 3 +3.-Hybr. artef.

Mariae X. Ed. André, in Rev, Hortic, lxi. (1889) 301, fig. 74. - Hybr, artef.

Mosenii, Mez, in Mart. F1. Bras, iii. III. (1894) 558 - Bras

Nanoti X, Hort. ex Rev. Hortic. lxvi. (1894) 285. Hybr, artef.

obliqua $\times$. Hort. Ouintus, ex Wittm in Gartenfl. xli. (1892) 201, t. 1369. - Hybr. artef.

oligantha, Mez, in Mart. F1. Bras. iii. III. (1894) $544=$ Tillandsia oligantha, Baker.

pardalina, Mez, 1. c. 523. - Bras.

Pastuchoffana, Glaziou, ex Mez, 1. c, 524 = 'Tillandsia Pastuchoffiana, Hort. ex Baker.

Plenvicii X, Hort. L. Duval, ex Rev. Hortic. Ixvi. (1894) 285.- Hybr. artef.

poemulata, Ed. Morr. ex Baker, Handb. Bromel, (1889) 230 , in syn. = Tillandsia poenulata, Baker.

procera, Mez, in Mart.'Fl. Bras, iii. III. (1894) 539 $=\mathrm{T}$, procera, Mart

procera, Wittm. in Bot, Jahrb, xiii. Beibl. n. 29 (189i) $21=$ praec

purpurascens X, Hort, Bull, ex Gard, Chron, (1893) i. 413. - Hybr. artef.

Quintusiana $X$, Hort. ex Rev. Hort, Belg, xix. (1893) 258. - Bras.

Regnell:, Mez, in Mart. FI. Bras, iii. III. (1894) 54 \%. - Bras.

reticulati, Hort, ex Kew Bull. (18s8) 121 = Tillandsia reticulata, $B$ aker.

Rex X, Hort. L. Duval, ex Rev. Hortic. 1xvi. (1894) 285 ; et in Rev. Hort, Belg. xx. (1894) $217 . \cdots$ Hybr. artet.

oseq, Ed. Morr ex Mez, in Mart. Fl. Bras, iii. III. (18.94) $553=$ Tillandsia platynema, Griseb. ubida Ed. Moŕr. ex Baker, Handb. Bromel. (1889) 215 , nomen $=\mathrm{T}$. oligantha, Baker. 
VRIESEA : -

Rostrum aquilae, Mez, 'in Mart. F1. Bras. iii. IIt. (1894) 518. - Bras

Sinctae-Crucis, S. Moore in Trans. Linn. Soc, Ser. II. 1V. (1895) 491. - Bras.

Schenkiana, Wittm, in Bot. Jahrb, xiii. Beibl. n. 29 (I891) 20. - Bras.

Schlechtendalii. Wittm. 1. c. xi. (1889) 69, xiv. Beibl. n. 32 (1891) $8=$ Tillandsia Schlechtendalii. Baker.

Selloana, Mez, in Mart. Fl, Bras. iii. III. (1894) 547 $=\mathrm{T}$. Selloana, Baker.

squamosa, Éd. Morr. ex Baker, Handb. Bromel. (1889) 212 in obs. $=T$. carinata, Baker.

subsécunda, Wittm. in Bot. Jahrb. xi. (1889) 69. Costa Rica.

thyrsoidea. Mez, in Mart. Fl. Bras iii. III. (1894) 556. - Bras

triligulata, Mez,1. c. 541. - Bras.

Truffantiana, Hort. ex Baker, Handb. Bromel. (1889) $213=$ Tillandsia incurvata, Baker.

Treedieana, Mez, in Mart. Fl. Bras. iii. III. (1894) $561=$ T. Tweedieana, Baker.

milateralis, Mez, in Mart. Fl. Bras, iii. III. (1894) $545=$ T. unilateralis, Baker

rasta, Mez, 1. c, 572. - Bras.

Veitchii. Ed. Morr. ex Baker, Handb. Bromel. (1889) 223, in syn. = Tillandsia Veitchii, Baker.

Weyringeriana $\times$, Wittm, in Gartenfl. xxxix. (1890) 7. - Hybr. artet

Wittmackiana ×. Kittel, in Gärtenfl xxxiii. (1888) 28\%, 553. t. 1283; et ex Gard. Chron. (1888) ii. 565. - Hybr. artef.

VRYDAGZYNEA, Blume (Orchid.). - ind. Kew. ii. 1290 ,

papuana, Reichb. f. in Eot. Centralbl. xxviii. (1886) 345. - N. Guin.

viridiflora, Hook. f. 17. Brit. Ind. vi. (1890) 96 (= Physurus viridiflorus, Lindl.). - Bengal, (Java?).

VUACAPUA, Kuntze, Rev, Gen. (1891) $212=$ VOUACAPOUA, Aubl. = Andira, Lam. (Legum:).

amazomum, cubensis, cujabensis, fraxinifolia, frondosa, gabonica, humilis, laurifolia, nitida, paniculata, par vifolia, Tisonis, vermifuga, Kuntze, Rev. Gen. 1891,212 = homonyma omnia Andirae.

anthelmia, Kuntze, 1, c. = A. anthelminthica, Benth. legalis, Kuntze, 1. c. = A. stipulacea, Benth. sapindodes, Kuntze, 1. co = A. sapindoides, Benth. surinamensis, Kuntze, $1 . c=\mathrm{A}$. retusa, $H . B, \& K$.

VUAPA. Kuntze, Rev. Gen. (1891) $212=$ VOUAPA Aubl. = Macrolobium, Schreb.

acaciaefolia, canaliculata, discolor. flexuosa, florida, gracilis, latifolia, multijuga, pendula, suareolens, stipulacen, taxifolia, vemulosa, Kuntze, Rev. Gen. (1891) 213 = homonyma omnia Macrolobii.

elliptica, Kuntze, 1. c. (= Anthonota elliptica, Desv.). - Am. mer.

guianensis. Kuntze, 1, c. = M. Utea, F. F. Gmel. racemigera, Kuntze, 1. c. $=$ M. pendulum, $W$ illd. unijuga, Kuntze, I. c. = M. limbatum, Spruce.

VULPIA, C. C. Gmel. = Festuca, Tourn. (Gramin.)。

bromoidea, St. Lager, in Cariot, Étud. des fl. éd. 8 ii. (1889) $939=\mathrm{F}$. bromoides, Linn.

ciliata, St. Lager, 1. c. $938=$ F. Myuros, Linn。

exserta, St. Layer, 1. c. = F. sciuroiues, Gmel.

raginata. St. Lager, 1. c. = F. Myuros, I.inn.

\section{$\mathrm{W}$}

WAHLBERGELLA, Fries = Lychnis, Tourn. (Caryoph.).

brachypetala, Freyn, in Oest. Bot. Zeitschr. xlv. (1895) $266=$ L. brachypetala, Schwaegr.

tristis, Freyn, 1. c. xxxix. (1889) $386=$ L. tristis, Bunge.
WAHLENBERGIA, Schrad。 (Campanul.)。Ind. Kew, ji, 1222.

baikalensis, Freyn, in Oest. Bot. Zeitsehr. xl. (1890) 46. - Dahuria.

croatica, Caruel, in Parl. Fl. Ital. viii. (18s8) $39=$ W. Kitaibelii, $A, D C$

ensifolia. Cordem. Fl. Ile Réunion (1895) $498=$ Heterochaenia ensifolia, $A, D C$

kilimandscharica, Engl. in Abh. Preuss. Akad. Wiss. 1891 (1892) 412. - Afr. trop.

Murbeckii X, G. Beck, in Wien. Ill. Gartenzeit. (1893) 293, in syn. (= Hedrainnthus Murbeckii X. Wettst.). - Herceg.

Oliver, Schweinf. ex Engl. in Abh. Preuss, Akad. Wiss. 1891 (1892) 412, nomen. - Afr. trop.

paucidentata, Schinz, in Bull. Herb́.Boiss, iii. (1895) 422. - Natal.

pinifolia, N:E. Br, in Kew Bull. (1895) 148.Natal.

serbica, G. Beck, in Wien. Ill. Gartenzeit. (1893).298, in syn. ( = Hedraianthus serbicus, Wettst.). Serb.

serpyllifolia, G. Beck, ex Nym. Consp. Fl. Eur. suppl. ii. I (1889) 212 = Campanula serpyllitolia Vis.

spinulosa, Engl. Bot. Fahrb. x. (I888) 271. - Afr. austro-occ. extratrop.

virgata, Engl. Pflanzenw. Ost-Afr. C (1895) 400. Afr. trop. or

Wettsteinii, Halácsy \& Baldacci, ex Halácsy, in Oest. Bot, Zeitschr. xli. (1891) 371, in syn. (= Edraianthus Wettsteinii, Halácsy \& Baldaccii). - Montenegro.

WAILESIA, Lindl, = Dipodium. R. Br. (Orchid.) punctata, Nichols. Dict. Gard. iv. C (1887) $151=$ D. punctatum, $R, B r$.

WALDSTEINIA, Wi!ld. (Rosac.)。- Ind. Kew。 ii. 1223 .

ternata, Fritsch, in Oest. Bot. Zeitschr. xxxix. (1889) 449 ; et in Bot. Centralbl. xl. (1889) $168=$ sibirica, Tratt.

WALLERIA, T. Kirk (Liliac.). - Ind. Kew. ii. 1223.

paniculata, Fritsch, in Annal. Naturh. Hofmus. Wien, v. (1890) 493. - Madag.

WALLROTHIA, Spreng. $=$ Seseli, Linn. (Umbell.).

alpina. G. Beck, in Annal. Naturh. Hofmus. Wien, x. (1895) $201=$ tuberosa, Spreng. montana, G. Beck, 1. c. = tuberosa, Spreng.

WALNEWA pulchella, Regel, ex Gard. Chron. (1891) i. 307 , sphalm. = Waluewa pulchella, Regel.

WALSURA. Roxb. (Meliac.). - Ind, Kew, ii. 1224

Candollei, King, in fourn. As. Soc. Beng. Txiv, (1895) U. 84. - Ins. Andam.

multijuga, King, l. c. 83. - As. trop.

WALTHERIA, Linn. (Stercul.), - Ind. Kew, ii 1224

Ackermanniana, $K$. Schum。 in Mart. Fl. Bras, xii. III. (1886) 61. -- Bras.

aspera, K. Schum. l. c. 55. - Bras.

cinerea, A. St Hil. ex K. Schum. 1. c. $56=$ cinerascens, A. St Hil.

collina, $K$. Schum , l. c 63. - Bras.

Glazioviana, $K$. Schum.l.c, - Bras.

mollis, Willd. ex K. Schum. 1. c. $53=$ viscosissima, A. St Hit.

petiolata, K. Schum. l. c.61.-Bras.

Pohliana, K. Schtm: l. c.62. - Bras.

polyantha, $K$. Schum. $l$ o. $60 .-$ - Bras.

prostrata, K. Schum l. c. 56. - Bras.

Selloana, K. Schum.l. . 53. - Bras.

WAL UEWA, Regel, in Act. Hort. Petrop. xi (1890) 309. ORCHIDEAE. pulchella, Regel, l. c. - Bras
WARBURGIA, Engl。 Pflanzenw, Ost-Afr。C (1895) 276; et in Eng1. \& Prantl. Natürl. PHanzenfam. iii. 6 (1895) 318, CINNAMOMEAE.

Stuhlmannii, Engl.ll.cc. - Afr. trop. or

WARSCEWICSZELLA. Reichb. f. = Zygopetalum Hook. (Orchid.).

Lindeni, Hort. ex Journ. of Hort. (1892! i. 419 461 fig. 79 ; et in Journ, des Orchid, vii. (1892) $143 \mathrm{fig}$. $1 \tau=Z$. Lindeni, Rolfe.

WARSCEWICZIA, Klotzsch (Rubiac.). - Ind. Kew, ii. 1225.

cordata, Sprnce, ex K. Schum, in Mart. Fl. Bras. vi VI. (1889) 217 . - Peruv.

longistaminea, $K$. Schm. l. c. 218. - Bras.

Schwackei, $\bar{K}$. Schum, l. c. 219. - Bras.

WASHINGTONIA, H. Wendl. [emend.] (Palm.). - Ind. Kew. ii. 1225.

flamentosa, Gaudichaudii, lanigera, Martii, pacifica, pericularum, remota, Thurstonii, Vuylstekeuna, Kuntze, Rev. Gen. (1891) 737 = homonyma omnia Pritchardiae.

Hildebrandti, Kuntze, 1. c. $=$ P. Hillebrandi Becc

Sonorae, S. Wats in Proc. Am. Acad. xixiv. (1889) 89, xxv. (1890) 136. - Calif。

WATSONAMRA, Kuntze, Rev. Gen. (1891) $302=$ Pentagonia Benth. (Rubiac.).

macrophylla, pinnatifida, spathicalyx, Tinajita, Wendlandii, Kuntze, 1. c. = homonyma omnia Pentauroniae

WATSONIA, Mill. (Irid.).- Ind. Kew. ii. 1225. fulgens, Klatt, in Th. Dur. \& Schinz, Consp. Fl. Afr. v. 1893 (1895) 193 = angusta, Ker-Gawl. juncifolia, Baker, Handb. Irid. (1892) 178 (= Morphixia juncifolia, Baker). - Afr. austr.

lapeyrousioides, Bakey, l: c. - Afr. austr.

lineata, Klatt, in Th. Dux, \& Schinz, Consp. F1. Afr. v. 1893 (1895) $193=$ Tritonia lineata, Kor-Gawl.

pyramidata, Klatt, 1. c. $194=$ rosea, Ker-Gaw?

spicata, Klatt, 1. c. 195 = brevifolia, Ker-Gaw?.

WEBBIA, DC. = Vernonia, Schreb. (Compos.). serratuloides, Sch. Bip. ex Engl. in Abh. Preuss. Akad. Wiss. 1891 (1892) 415, in syn. = V. cylindrica, Sch. Bip.

WEBERA, Schreb = Tarenna, Gaertn. (Rubiac.) albituba, Boerl. Handl. F1. Ned. Indië, ii. I. (1891) $129(=$ Stylocoryna albituba, Miq.). - Sumatra. buruensis, Boer1. 1. c. 130 (= S.buruensis, Miq.). Borneo.

celebica, Boerl. 1.c. (= S. celebica, Miq.). - Ins. Celeb.

coriacea, Boer1. 1. c. $129(=$ S. coriacea, Korth.). Sumatra.

costata, Boerl. 1. c. $129(=$ S. costata, Miq.) Sumatra.

dasypliylla, Boerl. 1. c. $\quad(=$ S. dasyphylla, Miq.).Sumatra.

Forsteriana, Boerl. 1. c. $130(=$ S. Forsteriana, Miq.) . Ins. Celeb.

hirsuta, Miq. ex Boerl. 1. c. $129(=$ S. hirsuta, Korth.). - Java.

Funghuniana, Boer1. 1. c. (= S. Funghuniana, Miq.). - Java ?

lateriflora, Boerl. 1. c. 129 (= S. lateriflora, Span.). - Timor.

Miqucli, Boerl. 1. c. (= S. grandifolia. Miq.). Sumatra.

nigrescens, Boerl.1.c. $130 \doteq$ Tarenna nigrescens, W $\mathrm{W}$ arb.

orophila, Boerl, 1. c. (= Stylocoryna orophila, Miq.). Sumatra.

pacettoides, Boerl, 1. c. 129 (= S. parettoides, Miq.). - Sumatra, Banka.

polycarpa, Boerl. 1. c. (= S. polycarpa; Miq ). Java, Sumatra.

racemosa. Boerl, 1.C. $(=S$. racemosa, Cav. $)$. - Java. saxatitis. S. Elliot, in Journ, Linn. Soc xxix. (1891) 25 - Madag. 
WEBLRA :

tigera, Boerl. Handl. Fl. Ned. Indië, ii. 1. (1891 129 (= Stylocoryna setigeva, Miq.). - Sumatra. Iomentosa, Boerl. 1. c. (= S. tomentosa, Blume). Java.

WEBSTERIA, S. H. Wright, in Bull. Torrey Bot. Club, xiv. (1887) 135, xv. (1888) $99=$ Dulichium. Pers. (Cyper.)

limnophilu, S. H. Wright, 1. Co = Scirpus submersus, Wriglit.

WEDELIA, Jacq. (Compos.). - Ind. Kew. ii. 1226. angolensis, Klatt, in Amal. Naturh. Hofmus. Wien, vii. (1892) 102. - Angola

Glabrata, Boerl. Handl, Fl. Ned. Indie, ii, I. (1891) 242 (= Wollastonia glabrata, DC.). - - Timor, Java.

moluccana, Boevl. l. c. $(=$ Woll. moluccana, DC. $) .-$ Ins. Molucc.

prostrata, Hemsl. ex Forb. G Hemsl. in Fourn. Linn. Soc, xxiii. (ISS8) 434. - China.

quadribracteata, Warb. in Bot. Falkb. xiii. (1891) 449. - N. Guin .

scabriuscula, Engl. Bot. Fahrb. ix. (1887) 2223 ; Boerl. Handl, Fl. Ned. Indië, ii. I. (1891) 241 (= W ollastonia scabriuscula, DC.). - N.Guin , Timor. serrulata, Bocrl. l. c.241 (=Woll. servulata, Miq.). - Sumatra.

Stirlingi, F, Muell. E Tate, in Trans. Roy. Soc. S. Austral. xix. (1895) 81, nomen. - Austral.

strigulosa, Benth. \& Hook. f. ex Drake, Ill. Fl. Ins. Mar. Pacif. (1S90) 207 (= Wollastonia strigulosa. Gaudich.). - Ins. Pacif.

strigulosa, K. Schum, in Bot. Fahrb. ix. (1887) 223, nomen. $\rightarrow$ N. Guin.

Stuebelii, Hieron. l. c. xxi. (1895) 348. - Columb. irilobata, Hitchco in Missouri Bot. Gard. Kep. iv. (189:3) $99=$ carnosa, Pers

Zollingeriana, Boerl. Handl. Fl. Ned. Indie, ii. I. (1891) 242 (= Wollastoniu Zollingeviana, Sch Bip.). - Ind. bat.

WEIGELIA, Pers, = Diervilla, Tourn. (Caprifol.). arborea, Hort. ex Dippel, Handb. Laubholzk. i. (1889) $273=\mathrm{D}$. floribunda, Sieb. Eo Zucc.

arborescens, Hort, ex Dippel, 1. c. = D. floribunda, Sieb. \& Z Zuc .

hybrida, Hort. ex Dippel, 1. c. 272, in syn. = D. hybrida, Dippel.

WEINGAERTNERA, Bernh. = Corynephorus, Beauy, (Gramin.)

articulata, Kuntze, Rev, Gen, (1891) $795=\mathrm{C}$. articulatus, Beawo.

WEINMANNIA, Linn, (Saxifr.), - Ind. Kew, ii, 1227

apetala, F. MI. Bailey, in Dept. Agric, Brisbane Bot. Bull. viii. (1893) 76. - Austral.

auriculifera, Hieron. in Bot. Fahrb. xx, Beibl, n, 49 (1895) 22. - Columb. v. Ecuad

cochensis, Hicron. 7. c. xxi。(1895) 310.- Columb.

Dzieduszyckii, Zahlbr. in Diss. Cl. Mathe-phys Acad, litt, Cracow, xxix, (18:4) 218, - Peruvia.

Ingleriana, Hieron, in Bot. Fahrb. zx. Beibl. n. 49 24. - Columb. v. Ecuad.

Glazioviana, Taub. l. c. xií. Beibl. n. $2 T$ (15:0) Is. - Bras.

guanacasana. Hicron. l. c, xx. Beibl, n. 49 (1895) 25. - Columb

Jeiskii, Zahlor. in Diss, Cl, Math.-phys. Acad. litt. Craco\% xxix. (1894) 218. - Peruvia.

Karsteniana, Saysayl. in Oest. Bot. Zeitschr, xl (1890) 41. - Venezuela.

Lehmannii, Hicron. in Bot, Fahrb. xx. Beibl. n. 49 (1895) 21. - Columb.

leptostachya, Baker, in fourn. Linn. Soc。xxii. (1885) 469. - Madag

luzoniensis, Vidal, Revis. Pl. Vasc. Filip. (1886) 125. - Ins. Philipp.

Mariquitae, Sryszyl. in Oest. Bot.Zeitschiv, xl. (1890) 41. - N. Granat.

nitida, Hieron. in Bot. Fahro. xx. Beibl. n. 49 (1895) 23. - Columb.

popayanensis, Hieron. i. c. 26. - Columb.

\section{WEINMANNIA : -}

stenostachya, Baker, in Keerl Bull. (1895) 103. Madag.

Stuebelii, Hieron. in Bot. Fahrb. xxi. (1895) 329. Ecuad.

Vescoi, Drake, Ill. Fl. Ins. Mar. Pacif. (1886) 35, 164, t. 13; ct Fl. Polyn. Franç. (1892) 61. - Ins. Pacif.

WELDENA longifolia, Pohl, ex K. Schum. in Mart. Fl. Bras. xii. III. (1891) $402=$ Abutilon longifolium, $K$. Schum.

WELWITSGHIELLA, O. Hoffm, in Engl. \& Prantl, Natïrl, Pflanzenfam. iv, 5 (1893) 390. COMPOSITAE.

neriifolia, O. Hoffm. l. c. - Angola.

WENDLANDIA, Bartl. (Rubiac.). - Ind. Kew. ii. 1228

basistaminea, F. Muell, in Vict, Natural. viii. (Mar. 1892) $17 \%$; et ex Bot. Centralbl. 1. (1392) 125. Austral.

buddleacea, F. Muell. Descr. Notes Papuan Pl. viii. (1886) $45,-N$. Guin.

Henryi, Oliver, in Hook. Icon. pl. xviii。 (1887) t. 1712. - China.

montana, K. Schum. in Engl. \& Prantl, Natürl. Pflanzenfam. iv. 4 (1891) $3 \%$ = Notoniana, Wall.

salicitolia, Frazich in Mlorot, fourn. de Bot. ix. (1895) 208. - China, Tonk.

psychotrioides, F. Muell. in Vict. Natural. viii. (Mar. 1892) 178 (= Oldenlandia psychotrioides, F. Muell.). - Austral.

WERNERIA. H. B. \& $\mathrm{K}$ (Compos.). - Ind. Kew. ii. 1238.

acerosifolia, Hicron, in Bot. Fahro. xxi. (1895) 363. - Peruvia.

Antinorii, Arctla, in Nuov. Giom, Bot. Ital. xx. (1889, 348; et in Ann. Ist. Bot. Rona, vi. (1895) 54 t. 3 fig. 4-5. - Afr, trop. or.

decumbens, Hieron. in Bot. falirb. xxi. (1895) 364. - Peruvia.

glaberrima, Phil. in Anal. Mus, nac. Chile (1891) 40. - Chili.

glandulosa, Klatt, in Bot. Fahrb. viii. (1886) 50. Ecuad.

juniperina, Hieronz, l. c. xxi. (1895) 365. - Peruvia. incisa, Phil. in Anal. Mus. nac. Chile (1891) 40. Chili.

Lorentziana, Hicron. in Bot. Fahrb. xxi. (1895) 364. $\perp$ Peruvia.

poposa, Phil, in Anal. Mus, nac. Chile (1891) 40. Chili.

soratensis. Hieron. in Bot. Fahrb. xxi, (1895) 363. - Columb.

Stuebelii, Hieron. l. c. 362. - Peruvia.

Wedelli, Phil, in Anal, Mus, nac. Chile (1891) 40. Chili.

WESTONIA, Spreng. = Rothia, Pers. (Legumin) hirsuta, Kuntze, Rev。Gen. (1891) 213=R. hirsuta, Baker.

indica, Kuntze, 1. c, = R. trifoliata, $D C$

WIBORGIA, Kuntze, Rev. Gen. (1891) $213=$ VIBORQUIA, Ort. = Eysenhardtia, H. B. \& K. (Legumin.)

adenostylis, Kuntze, 1. c。 = E. adenostylis, Baill.

amorphodes, Kuntze, 1. c. $=$ E. amorphoides, $H . B$. \& $K$

spinosa, Kuntze, I. c. = E. spinosa, Engelm.

WIDDRINGTONIA, Endl. = Callitris, Vent. (Conif.).

Whytci, Rendle, in Trans. Linn. Soc. Ser, II. iv. (1894) 60. - Afr. trop.

WIGANDIA, Neck, = Disparago, Gaertn. (Compos.):

Kraussii, lasiocarpa, laxifolia, Kuntze, Rev. Gen. (1891) 371 = homonyma omnia Disparaginis. ericodes, Kuntze, 1. c. = D. ericoides, Gaertn。 seriphiodes, Kuntze, 1. C. $=$ D. seriphioides, $D C$.
WIKSTROEMIA, Endl. (Thymel.). - Ind. Kew. ii. 1230 .

albiflora, Yatabé, in Tokyo Bot. Mag. jv. (July 1891) 217 t. 26 ; et Icon, Fl. Japon. i.2 (1892) 129 t. $35=$ gynopoda. Maxim.

alternifolia, Batalin, in Act. Hort. Pctrop. xiii (1893) 99 [Wickstroemia]. - China.

angustifolia, Hemsl. in fourn. Linn. Soc. xxvi, (1891) 396. [Wickstroemia]. - China.

Balansae, Maury, in Morot, fourn. de Bot. iii. (1889) 227 [Wickstroemia). - Tonkin.

bicornuta, Hillebr. Fl. Haw. Isl. (1888) 387 [Wickstroemia]. - Ins. Sandvic.

canescens, Maxim. in Bull. Acad. Pétersb. xxxi. (1886) 100. - Japon.

foetida, Hillebr. Fl. Hawe. Isl. (1888) 385 (= Daphne foetida, Forst.). - Ins. Sandvic.

Ganpi, Maxim. in Bull. Acad. Pélersb. xxxi. (188\%) 99 [Wickstroemia] (= Passerina Ganpi, Sieb.\& Zucc.). - Japon.

gracilis, Hemisl. ex Hensl. Go Forb. in Fourn. Linn. Soc. xxvi. (1894) 397 [Wickstroemia]. - China.

gynopoda, Maxim. ex Makino, in Tokyo Bot. Mag. vi. (1892) 52 [Wickstroemia], - Japon.

linoides, Hemsl. ex Forb. E Hemsl. in fourn. Linn. Soc. xxvi. (1894) 398. - China

micrantha, Heinsl. l. c. 399. - China.

obovata, Hemsl. l. c. 400. - Ins. Luchu.

stenantha, Hensl, $l, c,-$ China.

villosa, Hillebr. Fl. Haw. Isl. (1888) 386. - Ins. Sandvic.

WILBRANDIA, Silva Manso (Cucurb.), - Ind Kew. ii, 1230. (1887) $354 .-$ Bras.

WILCKIA, Scop. = Malcomia, R. Br. (Crucif.). africana, Halácsy, in Oest. Bot. Zeitschr, xlv. (1895) $215=$ M. africana. R. Br.

angulifolia, Halácsy, 1. c. $176=\mathrm{M}$. angulifolıa, Boiss. \& Orph.

bassarana, Halácsy, 1. c. $174=$ M. bassarana, Petr.

bicolor, Halácsy, 1. c, $172=\mathrm{M}$. bicolor, Boiss. E Heldr

chia, Halácsy, 1. c. $1 \% 6=\mathrm{M}$. chia, $D C$.

confusa, Halácsy, 1. c. $215=\mathrm{M}$. confusa, Boiss.

flexuosa, Halácsy, 1. c. 17: = M. Hexuosa, Sibth. \& Sm

graeca, Halácsy, 1. c. $172=\mathrm{M}$. graeca, Boiss. Ef Sprinn.

illyrica, Halácsy, 1. c. 175. - Dalm

hybrida, Halácsy, 1. c. $176=$ Malcomia hybrida, Hausshn.

hydraea, Halácsy, 1 c. $176=$ M. hydraea, Heldr. E Halacsy.

maritima, Halácsy, 1. c. $176=\mathrm{M}$. maritima, $R . \mathrm{Br}$ muritima, G. Beck, in Annal. Naturh. Hofmus. Wien, x. (1895) $175=$ praec

Pancicii, Halácsy, in Qest. Bot. Zeitschr. xlv. (1895) 177 = Malcomia Pancicii, Adamovic.

parvifiora, Halácsy, I. C. $215=\mathrm{M}$. parriflora, $D C$. serbica, Halácsy, 1. C. $17 \%=$ M. serbica, Pano.

WILDPRETINA, Kuntze, Rev, Gen.(1891) $432=$ Ixanthus, Griseb. Gentian.)

viscosa, Kuntze, 1. c. = I. viscosus, Griseb.

WILKESIA, A. Gray (Compos.). - Ind. Kew, ii. 1031 Grayana, Hillebr. Fl. Haw. Isl. (1888) 220. - Ins Sandvic

WILLARDIA, J. N. Rose, in Contr. U. S. Nat Herb. i (1891) 97 ; Taub. in Eng1. \& Prantl Natürl. Pflanzenfam. iii. 3 (1894) 275. LEGUMINOSAE

mexicana, S. Wats. Ul. cc. 98; et 275 . - Mexic.

WILLDENOWIA, Thunb. (Restiac.). - Ind. Kew, ii, 1231.

Ecklonii, Th. Dur, \& Schinz, Consp. Fl. Afr. v. 1894 (1895) 525 (= Anthochortus Ecklonii, Nees) - Afr, austr. 
WillemetiA, Neck, = Chondrilla, Thunb. (Compos.)

stipitata, Bruegg. in Jahresb. Naturf. Ges. Graub. xxxi. Beil. (1887-88) 108; O. Hoffm, in Engl. \& Prantl, Natürl. Pflanzenfam, iv. 5 (1893) $370=$ C. apargioides, facq.

WILLKOMMIA, Hack, ex Schinz, in Verh. Bot. Ver. Brand. xxx. (1888) 145. GRAMINEAE

annua, Hack. l. c. 146. - Afr. austro-occ, extratrop.

sarmentosa, Hack. l. c. 145. - Afr. austro-occ. extratrop.

WILLOUGHBŸA, Kuntze, Rev. Gen. (1891) $371=$ WILLUGBAEYA. Neck, = Mikania, Willd. (Compos.)

acuminata, amazonica, angularis, angulata, armigera, aspera, attenuata, Badieri, Banisteriae, bogotensis, brachiata, bracteosa, Burchellii, callineura, campanulata, Candolleana, caudata, Charua, chlorolepis, cissampalina, coarctata, conferta, confertissima, cordifolia, coriacea, corydalifalia dentata, discolor, divaricata, evioclada, eviophora, estrellensis. firmula, fulva, Gabrieli, glauca, glomerata, gracilis, Haenkeana, hastata, hastifolia, hemisphaerica, hirsutissima, hispida, Houstonis, Imrayanu, itambana, lagoënsis, lanuginosa, latifolia, laurifolia, laxa, leiolaena, leiostachya, leptotricha, ligustrifolia, 'Lindbergii, Lindleyana, linearifolia, longipes, loxensis, Lundiana, microcephala, microdonta, microlepis, microphylla, multinervia, myriocephala, neurocaula, nigricans, nitiaula, nodosa, nodulosa, nummlaria. obovata. obtusata, officinalis, ovalis, oxylepis, pachylepis, pannosa, parvifolia, pernambucensis, phaeoclados, pilosa, pinnatiloba, Pohliana, populifolia, premnifolia, pteropoda, ramosissima, repanda, reticulata, retifolia, rotunda, nufa, rufescens, Ruiziana, salviacfolia, salzmanniaefolia, sarcodes, scabrida, scandons, Selloi, sericea, sessilifolia, setigera, smilacina, speciosa, Sprucei, stipulacea, strobilifera, subrevticillata, Swartziana, ternifolia, testudinaria, Tlalixcoyan, triangulavis, trichophila, Trinitaria, triphylla, variabilis, verticillata, viminea, vismiaefolia, vitifolia, Warmingii, Kuntze, Rev. Gen. (1891) 371-73 = homonyma omnia Mikaniae.

anbigua, Kuntze, 1. c. $372=$ M. pentstemonoides, DC

argyreia, Kuntze, 1. c. = M. Argyreiae, $D C$.

Andrachne, Kuntze, 1. c. = M. laevis, DC.

argyrostigma, Kuntze, 1. $\mathrm{c}_{0}=\mathbf{M}$. amara, Willd

auriculata, Kuntze, 1. c, = Senecio deltoideus, Less.

Bangii, Rusby, in Mem. Torrey Bot. Club, iii. 3 (1893) 53. - Bolivia.

buddleyaetolia, Kuntze, Rev. Gen. (1891) $372=$ Mikania buddleiaefolia, $D C$.

chagalensis, Hieron. in Bot. Jahrb. xix. (1894) 47, in obs. = M. chagalensis, Hieron

clavellatá, Kuntze, Rev. Gen. (1891) 372=Ophryos. porus Freyreissii, Baker.

complanata, Kuntze, 1. c. = Mikania obovata, $D C$. corymbulosa, Kuntze, 1. c. = Kanimia corymbulosa, Benth. \& Hook. $f$.

diversifolia, Kuntze, 1, c. = Mikania biformis, $D C$,

crithalina, Kuntze, 1. $c_{1}=$ Kanimia erythralina, Benth. \& Hook.f.

flavescens, Kuntze, 1. c. = Mikania nummularia, DC.

Gardneriana, Kuntze, 1. c. $=$ M. microcephala, DC

Glazioui, Kuntze, 1. c. = M. Glaziovii, Baker.

Guaco, Kuntze, 1. c. $=\mathrm{M}$ : amara, Willd.

lasiandra, Kuntze, 1. c. = M. Lasiandrae, $D C$

Lehmannii, Hieron, in Bot. Jahrb. xix. (1894) 47 in obs. = M. Lehmannii, Hieron.

micrantha, Rusby, in Mem. Torrey Bot. Club, iv. (1895) $211=$ M. micrantha, $H . B$. \& $K$.

Moronoa, Kuntze, Rev. Gen. (1891) $372(=$ Corynanthelium Moronoa, Kunze). - Bras.

oblongifolia, Kuntze, 1. c. = Kanimia oblongifolia, Baker.

odorala, Kuntze, 1. c. = Mikania fastuosa, Lem.

parriflora, Kuntze, !. c. = M. amara, Willd.

platyphylla, Kuntze, 1. c. = M. Hookeriana, DC.

polystachya, Kuntze, 1. c. = M. psilostachya, $D C$.

resinosa, Kuntze, 1. c. = Eupatorium sordescens, $D C$.

scabra, Kuntze, 1. c. = Mikania psilostachya, DC.
WILLOUGHBYA:

ipitata, Kuntze, Rev. Gen. (1891) $373=$ Mikania amara, Willd.

strigosa, Kuntze, 1. c. = M. Lasiandrae, DC.

Tafallana, Kuntze, 1, c. = M amara, Willd.

temiflora, Kuntze, 1. c. = Eupatorium patens, Hook. \& Arn.

ternata, Kuntze. 1. c. $372=$ Mikania apiifolia, $D C$ teucriifolia, Kuntze, 1. c. 373= Eupatorium Gaudichaudianum, $D C$

triapsodes, Kuntze, 1, c. = Kanimia thapsoides, Benth. \& Hook.

Vauthierana, Kuntze, 1. c. = Mikania Vauthieriana, Baker

iscosa, Kuntze, 1. c. = Symphyopappus viscosus, Sch. Bip.

WILLUGHBEIA, Roxb. (Apocyn.). - Ind. Kew, ii. $123 \mathrm{i}$

dulcis, Ridl. in Trans. Limn. Soc. Ser. II. iii. (1893) 319. - Penins. Mal.

globosa, Coult. Bot. Ga\%. xx. (1895) 46 |Willughbaeya|. - Guatem.

WILSONIA, R. Br. (Convolv.)。 - Ind. Kew. ii. 1231

ovalifolia, Hallier f. in Bot. Fahrb. xvi. (1893) 532, in obs. - Austral.

sericea, Hallier f. l. c. - Austral.

WIMMERIA, Schlecht. (Celastr.). - Ind. Kew. ii. 1231 .

cyclocarpa, Radlk. ex F. D. Snith, in Coult. Bot. Ga\%. xviii. (1893) 199.-Guatem.

WINGHIA, A. DC. (Apocyn.). - Ind. Kew. ii 1231

glaucescens, K. Schum. in Eng1, \& Prantl, Natirl. Pflanzenfam. iv. 2 (1895) 125 = calophylla A. $D C$.

WINDMANNIA, P. Br, = Weinmannia, Linn, (Saxifr.).

affinis, Balbisiana, Biagiana, bifida, Blumei, Bojeriana, cinerea, comorensis, cordata, crassifolia, crenata, decora, dichotoma, discolor, dryadifolia, clliptica, eviocarpa, fraxinea, glomerata, Hakeana, heteraphylla, hirtella, Horsfieldii, humilis, intermedia, lachnocarpa, Landsbergiana, latifolia, laurina, Lechleviana, lentiscifolia, macrophylla, microthylla, organensis, ovata, parviflora, parvifolia, panlliniaefolia, pinnata, pubescens, racemosa, reticulata, rhodoxylon, Richii, rubifolia, Rutenbergii, samoënsis, serrata, sorbifolia, Spruceana, subsessiliflora, sulcata, sundana, ternata, tinctoria, tomentosa, Trianaea, trichosperma, Kuntze, Rev, Gen, (1891) $228=$ homonyma ommia Weinmanniae.

auviculifera, Hieron, in Bot. Jahrb. xx. Beibl. n. 49 (1895) 22, in obs. = Wein, auriculifera, Hieron. Bangii, Rusby, in Mem. Torrey Bot. Club, iii. 3 (1893) 26. - Bolivia.

Benthamii, Kuntze, Rev. Gen.(1891) $228=$ Geissois Benthamii, F. Muell.

Boirinima, Kuntze, I. c, = Weinmannia tinctoria, Sm

Engleriana, Hieron, in Bot. Jahrb. xx. Beibl, n. 49 (1895) $24=$ Wein. Engleriana, Hieron

fagarodes, Kuntze, 1, c. = Wein. fagaroides, $H$. $B$, \& $K$.

glabra, Kuntze, I. c. = Wein. pinnata, Linn.

Glazioviana, Taub. in Bot. Jahrb, xv. Beib], n, 34 (1893) $16=$ Wein. Glazioviana, Taub.

guanacasana, Hieron. 1. c. xx. Beibl. n. $49(1895)=$ Wein. guanacasana, Hieron.

glianensis, Kuntze, Rev. Gen, (1891) $228=$ Wein guyanensis, Klotschr.

Hildebrandti, Kuntze, 1. c. = Wein. Hildebrantii, Baill.

Lehmannii, Hieron. in Bot. Jahrb, xx. Beibl. n. 49 (1895) 21 , in obs. = Wein. Lehmannii, Hieron. madagascariensis, Kuntze, Rev. Gen. (1891) $228=$ Wein. mauritiana, D. Don.

nitida, Hieron. in Bot. Jahrb. xx. Beibl. n. 49 (1895) $23=$ Wein. nitida, Hieron.

paniculosa, Kuntze, Rev. Gen. (1891) 228 = Ackama Muelleri, Benth.
WINDMANNIA :

popayanensis, Hieron, in Bot. Jahrb. xx. Beibl. n. 49 (1895) 26 , in obs. = Weinmannia popayanensis, Hieron.

Riviniana, Kuntze, Rev, Gen, (1891) $228=$ Wein. tinctoria, $S m$.

WINKLERA, Regel, in Act. Hort, Petrop. ix, 1856) 617 ; Prantl, in Engl. \& Prantl, Natürl. Pflanzenfam. iii. 2 (1891) 206. CRUCIFEREAE。 patrinoides, Regel, $\|$. cc. - Turkest.

WISSADULA, Medic. (Malv.). - Ind. Kew. ii. $123 z$.

andina, Britton, in Bull. Torrey Bot. Club, xvi. (1889) 153. - Bolivia.

Balansae, E. G. Baker, in foum. Bot, xxxi, (1893) 69. - Parag.

decora, S. Moore, in Trans. Lim. Soc. Ser. II. IV. (1895) 312.-Bras

divergens, Hitchcock, in Missour, Bot. Gard. Rep. iv. (1893) $63=$ divergens, Benth

ferruginea, Garcke \&o K. Schum, in Hart, Fl. Bras. xii. III. (1891) 443 (= Sida ferriginea, DC.).Peruvia.

Gymnanthemum, K.Schum. l. c.446.-Reg. Argent. mudiflora, Garcke, in Zeitschr. Naturw. (1890) 123 = stellata, K. Schum.

patens, Gurke, l. c. (= Abutilon patens, A. St Hil.). - Bras

Pringlei, F. N. Rose, in Contr. U.S. Nat. Herb. iii. 5 (1895) 312. - Mexic

stellata, K. Schum. in Mart. Fl, Bras, xii. III. (1892) $446(=$ Sida stellata, Cav.). - Peruv.

WISTARIA, Nutt. (Legumin.). - Ind. Kew. ii. 1232 .

Maideniana, F. M. Bailey, ex C. Moove, Handb. Fl. N. S. Wales (1893) 51\%. - Austral.

WITHANIA, Pauq. (Solan.): - Ind, Kew, ii. 1232.

Holstii, Dammer, in Engl. Pflanzenw. Ost-Afr. C (1895) 351. - Afr. trop. or.

melanocystis, Robinson, in Proc. Am. Acad. xxvi. (1891) 171. - Mexic

WITSENIA, Thunb. (Irid.). - Ind. Kew. ii. 1233. binata, Klatt, ex Th. Dur. E Schinz, Consp. Fl. Afr. v. $1893(1895) 172$ (= Nivenia binata, Klatt). Afr.austr.

WITTMACKANTHUS, Kuntze, Rev。Gen. (1891) $302=$ Pallasia, Klotzsch (Rubiac.)

Stanleyanus, Kuntze, 1. c, = P. Stanleyana, Klotzsch.

WITTMACKIA, Mez, in Mart, F1. Bras, iii. III. (1891) 274 = Aechmea, Ruiz \& Pav.(Bromel.). lingulata, Mez, 1. c. 275 = A. lingulata, Baker. odora, Mez, 1. c. $277=$ A. odora, Baker.

patentissima, Mez, 1. c. $278=$ A. patentissima, Baker.

WITTROGKIA, Lindm. in Kong1. Sv, Vet. Akad. Handl. xxiv. 8 (1891) 20, t. 2 fig, 13-21. BROMEHandl. xxiv.

\section{LIACEAE.}

superba, Lindm.l.c.-Bras,

WOODIA, Schlechter, in Bot. Jahrb. xviii. Beibl. n. 45 (1894) 30. ASCLEPIADEAE.

trifurcata, Schlechter, $l_{0} c_{0}-$ Afr. austr.

trilobata, Schlechter, in fourn. Bot. xxxiii. (1\&95) 38\%. - Afr, trop. or.

n. 45 (1894) 31. - Afr, austr.

WORMIA, Rottb. (Dillen.), - Ind. Kew. ii. 1233.

Kunstleri, King, in forrm. As. Soc. Beng. lviii. (ISS9) II. 366. - Penins. Mal.

longepetiolata, Warb. in Bot. Fahrb. xiii. (1891)

luzoniensis, Vidal, Revis. Pl. Vasc. Filip. (1886) 36.

Macdonaldi, F. Muell, in Vict. Natural. ii. (Mar. 1886) 146 [err. typ. 134]; at ex Bot.Centralbl. xxvi. (1886) $114,-$ N. Guin 


\section{WORMIA :}

meliosmatolia, King, in fourn. As. Soc. Bong. Iviii. (188?) II. 365. - Penins. Mal.

WORMSKIOLDIA, Thonn. (Turner.). - Ind. Kew. ii, 123.

Schinzii, Urban, in Bot. Fahrb. Xv. (1892) 150.Afr. trop. anstro-or.

WRIGHTIA, R. Br. (Apocyn.). - Ind. Kew. ii. 120.

Baccelliana, F, Mlnell, in Vict. Natural. viii. (Mar. 1892) 1\%8; et in Bot. Ceniralbl. 1. (1892) 126. Austral.

Millgar. F. M. Bailey, in Dept. Agric. Brisbane Bot. Bill, vii. (1893) 65. - Austral.

parviflora, Slapf, in Kexe Bull. (1894) 121: et m Hook, Icon. pl. xxiv. (1894) t. 2345. - Afr. trop.

Stuhlmannii, K. Schum, in Engl. Pflunzenw. Ost-Afr. C (18\%5) 319; et in Engl. \& Prantl, Natirl. Pfanzenfan. iv. 2 (1895) 183. - Afr. trop. or.

WULFENIA, Jacq. (Scrophu1.)。 - Ind. Kew。 ii. 1234.

alpina, Greene, in Erythea, ii. (1894) 83 = Synthyris alpina, A. Gray.

cordata, Greene, Man. Bot. San Franc. Bay (1894) $280=S$. renitormis, Benth. var.

Houghtoniana, Greene, in Erythea, ii. (1894) $83=$ S. Houghtoniana, Benth.

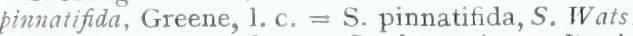
plantaginea, Greene, 1. $c_{1}=\mathrm{S}$, plantaginea, Benth. rotundifolic, Greene, 1. c. $82=\mathrm{S}$, rotundifolia, $A$. Gray.

vubra, Greene, 1. c. $83=$ S. rubra, Benth

WULFFIA, Neck. (Compos.): - Ind. Kew, ii. 1234.

baccata, Kuntze, Rev. Gen. (1891; 373 = stenoglossa, $D C$.

WULL SGHLAEGELIA, Reichb. fo (Orchid.). Ind, Kew. ii. 1234

Ulaei, Cogn。 in Mart. Fl. Bras. iii. IV. (1895) 244 - Bras.

WUNDERLICHIA, Riedel (Compos.), - Ind Kew. ii. 1234.

Crulsiana, Taub. in Cruls, Relat. Commiss. explor. Platanalto centr. Braz. (1894) 365. - Bras.

WURMBEA, Thunb. (Liliac.). - Ind. Kew. ii, 1234 .

spicata, Th. Dur. \& Schinz, Consp. Fl, Afr. v. 1893 (1895) $413=$ capensis, Thunb.

WYETHIA, Nutt, (Compos.), — Ind. Kew, ii.1234. mexicana, S. Wats, in Proc. An, Acad. xxv. (1890) 154. - Mexic.

\section{$x$}

XANTHERANTHEMUM, Lindau, in Bot Jahrb. xviii. (189-4) 54; et in Eng1. \& Prantl, Natuirl. Planzenfam, iv. 3b (1895) 321. ACANTHA. $C E A E$

igneum. Lindau, l.c. (= Chamaeranthemun ignenm, lRegel). - Peruvia.

XANTHIUM. [Tourn.] Linn. (Compos.), - Ind. Kew, ii 1235.

Nigri, Ces. Passer, \& Gibelli, Comp. Fl. Ital, ii (1886) 437 - Italia.

XANTHOCEPHALUM, Willd. (Compos.). Ind. Kew, ii. 1235.

californicum, Greene, Man, Bot. San Franc, Bay (18?4) 1\%1. - Calif.

\section{XANTHOCEPHALUM:}

lucidum, Greene, Pittonia, ii. (Aug. 1842) 282. Calit.

tomentellum; Robinson, in Proc. An. Acad. xxvii (1893) 172. - Mexic

XANTHOCHYMUS, Roxb. = Garcinia, Linn. (Guttif.)

lanceolatus. Thw. ex Vesque, in DC. Monog. Phan. viii. (1893) 311, in syn。 = Garcinia spicata, Hook. $f$, var.

noro-guinecnsis, Warb. in Bot. Jahrb. xiii. (1891) 381: - N. Guinea.

XANTHOPAPPUS, C. Winkl, in Act. Hort. Petrop. xiii, 1893) 10. COMPOSITAE

subacaulis, C. IVinkl. l. c. 11. - China.

XANTHOPHYLLUM, Roxb. (Polygal.). - Ind, Kew. ii. 1236.

andamanicum, King, in Font'n. As. Soc. Beng. lix. (1890) II. 135. - Ins. Andam.

bullatum, King, 7. c. 142. - Malaya.

Curtisii, King, l. c. 138. - Malaya.

Hookerianum, King, l. c. 139. - Malaya.

Kunstleri, King, l. c. - Malaya.

pulchrum, King, l. c. 141. - Malaya.

Scortechinii, King, l. c. 140, - Malaya

sulphureum, King, l.c. 143. - Malaya.

Wrayi, King, l.c. 138. - Malaya.

XANTHOPHYTUM, Reinw, ex Blume (Rubiac.). - Ind. Kew. ii 1236.

Villarii, Vizal, Reris. Pl. Vasc. Filit. (1886) 150.Ins, Philjp

XANTHORRHOEA, Sm. (Junc.). - Ind, Kew, ii. 1236.

Thorntoni, Tate, in Trans. Roy. Soc. S. Austral. xix. (1895) 82, nomen. - Austral.

XANTHOSOMA, Schott (Aroid.). - Ind. Kew. ii. 1236.

maculatum, Nichols, Dict. Gard. iv. (1887) 224. Form. hort

XANTHOSTEMON, F. Muell. (Myrt). - Ind. Kew. ii. 1236.

ciliatum, Niedenzu, in Engl. \& Prantl, Natiirl. Pfanzenfam. iii. 7 (1893) 88 (= Frentya ciliata, Brongn. \& Gris) - N. Caled

elegans, Nicdenzu, i. c. $88(=F$. elegans, Brongn. \& Gris). - N. Caled.

oppositifolius, F. M. Bailey, Cat, indig, and natur. Pl. Queensl.Add. (1890) 109. - Austral.

nuber. Niedenzu, in Engl, \& Prantl, Natürl. Pflan. zenfam iii 7 (1893) $88=$ ruber, Panch. \& Sebert.

Vieillardi, Niedenzu, l. c. (= Fremya Vieillardi, Brongn. \& Gris). - N. Caled.

XANTHOXYLUM, J. F. Gmel, = Zanthoxylum, Linn. (Rutac.)

Fagara, Sarg. in Gard. and For. ij. (1890) 186 ; et in N. Am. Sylv, i. (1892) 73, t. $32=Z$. Fagara, Sarg.

XERAEA Linn. Syst. ed. I (1735)= Gomphrena Linn (Amarant)

acaulis, affinis, agrestis, albiflora, angustifora. aflyolla, arborescens, argentina, Blanchettii, boliviana, brachystylis, Brozimiz, raespitosa, canescons, Clausenii, conferta, conica, cylindrica, debilis, decipiens, decumbens, demissa. desertorum, diffusa, durinscula, elegans, eriophylla. fallax, flaccida, Gardneri, globosa, graminea, Haenkeana, Hilariana, Jumilis, hygrophila, incana, lancifolia, lanigera, leptoclada, lencocephala. Lundii, nacrocephala, macrorhiza, marginata, Martiana, microcephala, mollis, mucronata, nigricans, nitida, oligocephala, pariffora, perennis, pilosa, platandra, Pohlii, prostrata. fulchella, pumila, pungens, pusilla, Regeliana, Riedelii, ridis, scapigera, Sellowiana, sericantha, serrata, Sonorae, tenella, tuberifera, tmbellata, viygata, Kuntze, Rev. Gen. (1891) 543 = homonyma onnia Gomphrenae

argenteosericea, ixuntze, 1. c. $543=$ Hebanthe argenteo-sericea, Benth, of Hook. f.
XERAEA : -

capitata, Kunze. Rev. Gen. (18\%1) $545=$ Gomphrena rupestris, Nees.

celosiodes. Kuntze, 1. $\mathrm{C}_{2}=\mathrm{G}$. celosioides, Mart.

Clausenii, Kuntze, 1. c. $=$ G. Claussenii, Mog.

filagimod s, Kuntze, 1, $\mathrm{c}=\mathrm{G}$. filaginoides, Martens of Gal.

holosericea, Kuntze, 1. c. $543=$ Hebanthe holosericea, Mart.

Maitlandii, Kuntze, 1. c. 54 $=$ Gomphrena Maitlandi, F. Mucll.

Moquinit. Kuntze, 1. c. = G. Moquini, Seub.

paniculata, Kuntze, 1. c. = Hebanthe paniculata Benth. \& Hook. $f$.

phagnalodes, Kuntze, 1. c, = Gomphrena phagnaloides, Griscb.

Pierciz, Kuntze, 1. c. = G. Pearcei, Oliver.

rhodantha, Kuntze, 1. c. = G. rodantha, $M \circ$.

Schlechtendahliana, Kuntze, 1. co = G. Schlechten daliana, Mart.

iaga, Kuntze, 1, с. $543=$ Hebanthe vaga, Benth. \& Hook. f.

E'illosa. Kuntze, 1. c. $545=$ Gomphrena perennis, Lim

XEROCHLAMYS, Baker (Chlaenac.) - Ind. Kew, ii. 1238

pubescers, Baker, in foum. Linn. Soc. xxv. (1889) 296. - Madag.

XEROCHLOA, R. Br. (Gramin.). - Ind. Kew ii. 1238 .

littoralis, Baill, in Bull. Soc. Linn. Parss, ii. (1S92) 1019 (= Kerinozoma littoralis, Steud.). - Java.

XEROCLADIA, Harv. (Legumin.): - Ind. Kew. ii. 1238.

viridiramis, Taub, in Bot. Centralbl. xlvii. (1891) $395=\mathrm{X}$. Zeyheri, Harv

XEROCOGGUS, Oerst. (Rubiac.). - Ind. Kew. ii. 1238

Lindenii, Kuntze, Rev.Gen. (1891) 285. - Mexic.

XEROPHYTA, Juss, = Vellozia. Vand. (Amaryll.) Bakeri, Th. Dur. \& Schinz, Consp. Fl. Afr. v. 1893 (1895) $2 \% 0=$ V. villosa, Baker.

Hildebrandtii Th. Dur. \& Schinz, 1. c. $271=$ Barbacenia Hildebrandtii, $P a x$.

Jumilis, Th. Dur. \& Schinz, 1. c. = Vellczia humilis, Baker.

mollissima, Th. Dur. \& Schinz, 1. c. - Transvaal.

scabrida, Th, Dur. \& Schinz, 1. c. = Barbacenia scabrida, Pax.

tomentosa, Th. Dur. \& Schinz, 1. c. $272=\mathrm{B}$ tomentosa, Pax.

XEROSPERMUM, Blume (Sapind.). - Ind. Kew. ii. 1238.

cochinchinense, Pierre, Fl. For. Cochinch. Fasc. 21 (1895) t. 32la $(=$ Nephelium cochinchinense, Pierre), - Cochinch.

glabratum, Pierre, 1. c. sub t. $322=$ glabrum, Pierre.

glabrum, Pierre, l. c. sub t. 322a. - Cochinch. macrophyllum, Pierre, $l$. $c$. sub t. $321 \mathrm{~b}$. - Cochinch microcarpum, Pierre, l. c. Fasc. 20 (1894) t. 320b, - Cochinch.

Thorelii, Pierre,l.c. t. 320a (= Cnemidesia Thorelii, Pierre). - Cochinch.

XEROTIA. Oliver, in Hook, Icon, pl. xxiv. (1895) t. 2359. CARYOPHYLLEAE

arabica, Oliver, l. c. - Arabia.

XIMENIA. Plum, ex Linn. (Olacin.), - Ind. Kew ii. 1239.

gabonensis, Baill. ex Laness. Pl. util. Colon. Frano (1886) 834. - Gabon

XOLISMA, Rafin. = Andromeda, Linn. (Ericac.) ferrugineum, Nash, in Bull. Torrey Bot. Club, xxii. (1895) 153, in obs. = Lyonia ferruginea, Nutt fructicosum, Nash, 1. c. - Florida.

ligustrina, Britton, in Mem. Torrey Bot. Club. iy (1894) 135 = Lyonia paniculata, Nutt. 
XUAREZIA, Ruiz \& Pav. = Capraria, Tourn. (Scrophul)

frutescens, Kuntze, Rev. Gen. (1891) $469=$ C. saxifragaefolia, Cham. of Schlecht.

7irsuta, Kuntze, 1. C. = C. biflora, Linn

semiserrata, Kuntze, 1. c. = C. semiserrata, Vahl,

XYLANCHE, G. Beck, in Engl, \& Prant1, Naturl Ptlanzenfam. iv.3b (1893) 132. OROBANCHEAE himalaica, G. Beck, l.c. (= Boschniakia himalaica, Hook. f. \& Thoms.). - Reg. Himal.

XYLIA, Benth. (Legumin.). - Ind. Kew, ii. 1240. xylocarpa. Taub. in Bot. Centralbl. xlvii, (1891) 395 = dolabriformis, Benth

XYLOBIUM, Lindl, (Orchid.) - Ind. Kew, ii. 1240

corrugatum, Rolfe, in Gard. Chron. (1889) i. 458 (= Maxillaria corrugata, Lindl.). - Venezuela.

discolor, Nichols. Dict. Gard. iv. (1887) 225. Jamaica.

foveatum, Nichols, l.c. - Guiana.

leontoglossum, Benth. ex Rolfe, in Gard. Chron. (1889) i. 458; et in Bot, Mag. (1889) t. 7085 (= Maxillaria leontoglossa, Reichb. f.). - N. Granat. pallidiflorum. Nichols. Dict. Gard. iv. (1887) 225 Pfizer, in Engl. \& Prantl. Natür. Ffanzenfam. ii. 6 (1888) 163; Rolfe, in Kew Bull. (1893) 278 $(=M$. pallidiflora, Hook. $)$ - Am. trop.

varicosum, Rolfe, in Mem. Torrey Bot. Club, iv. (1895) 262 (= M. varicosu, Reichb. f.), - Bolivia.

XYLON, Linn. = Eriodendron. DC. (Malv.).

Burchellii, Kuntze, Rev. Gen. (1891) \%うั (= Ceiba Burchelliz, K. Schum.). - Bras.

exianthos, Kuntze, l. c。 = Eriodendron leiantherum, $D C$

hypolencum, Kuntze, 1. c. = E. hypoleucum, Spruce

jasminodonm, Kuntze, 1. c. $=$ E. jasminiodorum St Hill.

microphyllum, Kuntze, 1. c. $(=$ Ceiba micropkylla, K. Schum.). - Bras.

pentandrem, Kuntze, l, c = Eriodendron anfractrosum, $D C$.

phaensanthum, Kuntze, 1 c. = E. phaeosanthum, Decme.

pubiflorim, Kuntze, 1. c. $=\mathrm{E}$. pubiflorum, St Hil

Rivieri, Kuntze, 1, c. = E. Rivieri, Decne.

Samauma, Kuntze, 1. c. = E. Samauma, lsart.

XYLOPHYLLOS, Rumpf, Herb. Amboin. vii. (1755) 19 t. 12 ; ex Kuntze, Rev. Gen. (1891) $589=$ Exocarpus, Labill, (Santal.).

abhyllus, Bidwillii, cupressiformis, Gandichaudi, homalocladus, humifusus, latifolius, namus, odoratus, Rolfsianus, spartens, strictus, Kuntze, 1. c. = homonyma omnia Exocarpi.

phyllanthodes, Kuntze, 1. C。 = E. phyllanthoides, Endl.

XYLOPIA, Linn. (Anon.). - Ind. Kew. ii. 1240. Curtisii, King, in foum. As. Soc. Beng. 1xi. (1892) II 116. - Penang.

Eminii, Engl.Pflanzenw。 Ost-Afr。'C (1895) 179.Afr. trop. or.

olivacea, King, in fourn. As. Soc. Beng. lxi. (1892) II. 119. - Penins. Mal.

pyrifolia, Engl. Pfanzenw. Ost-Afr. C (1895) 179. Afr, trop. or.

Ridleyi, King, in fourn. As. Soc. Beng. 1xi. (1892) II. 121. - Penins. Mal.

Scortechinii, King, l. c. 118: et in Annal. Bot. Gard. Calc, iv. I. (1893) 149, Ł. 195. - Penang

s'enopetala, Oliver, in Hook. Icon. pl. xxi. (1887) t. 1563. - Penang.

XYLOPICRUM, P. Br. = Xylopia, Linn.

(Anonac.). aromaticum, barbatum, brasiliense, caudatum, Championii. dicarpum, ellipticum, emarginatum, frutescens, fuscum, grandiftorum, ligustrifotium, * longifolium, magnum, Maingayi, nigricans, nitidum, ochranthum, odoratissimum, parvifolium, Pierrei, polycarpin, pustulatum, rubescens, Spruceanum, Thomsonii, Vie-
XYLOPICRUM :-

lana, Kuntze, Rev. Gen。(1891) $8=$ homonyma omma Xylopiae.

acutzun, Kuntze, 1. c. (= Habralia acuta, Miq.). Java.

A. Sl Hil.

malayanum, Kuntze, 1. c, = X. ferruginea Spruce.

neglectum, Kuntze, 1. c. = X. parviflora, Vallot.

oxyacanthum, Kuntze, $1_{0} \cdot \mathrm{c}_{0}=\mathrm{X}$. oxyantha, Hook. $f$. \& Thoms.

parviflorum, Kuntze, 1, $\mathrm{c}=\mathrm{X}$. Dunaliana, Vallot. Richardii, Kuntze, 1. c. = X. Richardi, Bo

sumatranum, Kuntze, 1. $c_{0}=\mathrm{X}$. malayana, Hook. f. \& Thoms.

trincifolium. Kuntze, $1 \quad c,=X$. trunciflora, Cham. Es Schlecht.

XYLOPLEURUM, Spach = Oenothera Linn (Onagrar.).

roseum, Raimann, in Engl. \& Prantl; Natürl. Pflanzenfam, iii. 7 (1893) $214=0$. rosea, Ait.

speciosum, Raimann, 1. c. = O. speciosa, Nutt

tetrapterum, Raimann, 1, c。= O. tetraptera, Cav.

XYLOSMA, Forst. fo(Bixin.). - Ind, Kew。 ii.1241. celastrimum, H. B. \& K. ex Kuntze, Rev, Gen. (1891) 44, in syn. = Myroxylon citrinum, Kuntze.

Pringlei, Robinson, in Proc. Am. Acad. xxvi. (1891) 164; et xxvii. (1893) 166. - Mexic

quichense, F. D. Smith, in Coult. Bot. Gar. xviii. 1893) 197. - Guatem

XYLOSTEUM, Rupp. = Lonicera, Linn, (Caprifol.)

Philomelae, Hort, ex Dippel, Handb. Laubholzk, i. $(1889) 257=$ L. gracilipes, Miq.

XYLOTHERMIA, Greene, Pittonia, ii. (Sept, 1891) 188 = Pickeringia, Nutt. (Compos.)

Montana, Greene, 1. c.; et Man. Bot. San Franc. Bay $(1894) 10 S=$ P. montana, Nutt.

XYMALOS, Baill. in Bull. Soc. Linn. Paris, i. (1886) 650. BIXINEAE.

monospora, Baill. l. o.; Warb. in Engl. E Prantl, Natiirl. PAanzenfam. jii.6a (1893) 53 (= Xylosma monospora, Harv.). - Atr, austr.

XYRIS, Gronov, ex Linn. (Xyrid.). - Ind. Kew. ii. 1242.

Augusto-Coburgi, Szyszyl. ex G. Beck, Itin. Princ. Sax. Coburg. ii. (1888) 94 t. 14. - Bras.

Bakeri, Alb. Nilsson, in Ofvers, Kongl. Vet. Akad. Förh. Stockh.|Ueb. Afr. Art. Gatt. Xyris\}(1891) 157 ; et in Kongl. Svensk Vet. Akad. Handl. [stud. web. Xyrid.] xxiv. n. 14 (1892) 30. - Madag.

congensis, Bueltn. in Verh.Bot.Ver. Brand, xxxi, (1889) 71. - Congo.

conifera, Chapm. ex H. Ries, in Bull. Torrey Bot. Club, xix. (189:) $40=$ iridifolia, Chapm

cristata, Alb. Nilsson, in Kongl. Suensk Vet. Akad. Handl. [Stud. ueb. Xyrid.] xxiv。 n. 14 (1892) $56 \mathrm{t}$. 3. - Bras

culana, Alb. Nilsson, $2 l . c 0.27$ t. 3 fig. 4. - Cuba.

fascicularis. Chapm, ex H. Ries, in Bull. Torrey Bot. Club, xix. (1892) $39=$ serotina, Chapm.

filitolia, Alb. Nilsson, in Kongl. Svensk Vet. Akad. Handl. [Stid. web. Xyrid.] xxiv. n. 14 (1891) 43 . - Bras.

foliolata, Alb. Nitsson, ll.cc.65. - Angola

fusca, Alb. Nilsson, $l l, c c .57 \mathrm{t}, 3$. - Bras.

glabra, Engelm. ex $\mathrm{H}$. Ries, in Bull. Torrey Bot. Club, xix. (1892) $37=$ flexuosa, Muehl.

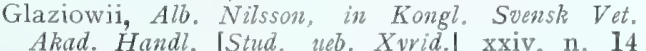
(1892) 61 t. 6 flo. 7. - Bras.

glandulacea, Alb. Nilsson, ll.cc. 50 t. 3. - Bras.

globosa, Alb. Nilsson, $l l$. cc. 57 t. 3.-Venezuela

graminifolia, Chapm. ex H. Ries. in Bull. Torrey Bot. Club, xix. (1892) $40=$ caroliniana, Walt.

Hildebrandtii, Alb. Nilsson, in Ofvers. Kongl. Vet. Akad. Förh. Stockh. UUeb. Afr. Art. Gatt. Xyris] 1891) 155; et in Kongl. Siensk Vet. Akad. Handl. [Stud web. Xyrid.] xxiv, n. 14. (1892) 31. Madag.

\section{XYRIS :}

hevigata, Alb. Nilsson, in Ofuers, Kongl. Vel. Akal. Förh. Stockh. (1\$91) 155; et in Kongl. Svensk Vet. Akad. Handl xxiv. (1892) 50 t. 3. - Bras.

Iongiscapa, Alb. Nilsson, l. c. 59 t. 4 - Bras.

mexicana, S. Wats, in Proc. Am. Acad. xxv。 (1890) 163. - Mexic.

montana, H. Ries, in Bull. Torrey Bot. Club, xix. 1892) 38. - Am. bor

natalensis, Alb. Nilsson, in Ofvers, Kongl. Vet. Akad. Förh. Stockh. (1891) 157; et in Kongl. Svensk Vet. Akad. Handl. [Ueb. Stud, X yrid.] xxiv, n, 14 (1892) 2S. - Afr austr. et austro-or.

neglecta, Alb. Nilsson, in Kongl. Svensh Vet. Akad. Handl. [Stud, web. Xyrid.] xxiv. n. 14 (18!1) 4.5. Bras.

neglecta, Small, in Bull. Torrey Bot. Ciut, xxi. 1894) 300 . - Florida

nigricans, Alb. Vilsson, in Kongl. Syensel Vet. Akad. Handl. [Stud. ueb, Xyvid.] (1891) 60, t. 5, Bras.

milugarensis, Steud. ex Hook, f. Fl. Brit. ind. vi (1892) 365, in syn. = schuenoides, Mart.

nitida, Alb. Nitssont, in Ofwers, Kongl. Vet. Akad. Föhr. Stockh. (1891) 156; et in Kongl. Svensh Vel. Akud, Handl. (1892) 30. - Afr. trop. oc.

obtusiuscula, Alb. Nilsson, li. cc. (IS92) 47 t.2. $X$. asperula, Seub.). - Bras.

partita, Chapm. ex H. Ries, in Bull. Torrey Bot Club, xix. (1892) $39=$ communis, $K$ wnth .

Regnellii, Alb. Nilsson, in Kongl. Svensk Vet. Akad. Handl. Xxiv. n. 14 (1892) 43 t. 2. - Bras.

Rehmanni, Alb. Nilsson, ll. cc. 28. - Transvaal.

rigida, Chapm. ex H. Ries, in Bull. Torrey Bot. Club, xix. (1892) 40 = iridifolia, Chapm.

sirpoides, Chapm. ex H. Ries, 1. c. 36 = flabelliformis, Chapm.

setigera, Oliver, in Trans. Linn. Soc. Ser. II. ii. (1887) 285 t. 50 fig. 1-8 (Oliver, ex im Thurn, in Timehri, v. (1886) 207). - Bras.; Guian. angl.

Seubertii, Alb. Nilsson. in Kongl. Svensh. Vet. Akal. Handl. [Stud. web. Xyrid.] xxiv, n. 14 (1891) 51 t. 4. - Guian. angl.

simulans, Alb. Nilsson, $l l, c c .47$ t. 2, 6. - Bras.

Smalliana, Nash, in Bull. Torrey Bot. Chrb, xxil. (1895) 159 . - Florida.

stenopliylla, Chapm, ex H. Ries, in Bull. Torrey Bot. Club, xix. (1892) $42=$ Baldwiniana Rocm \& Schult.

stenophylla, Alb. Nilsson, in Kongl. Svensk. Vet. Akad. Handl. [Stud, ueb. Xyrid.] xxiv, n, 14 (1891 46 t. 2 fig. $2 \mathrm{a}, 2$ d. - Bras.

straminea, Alb. Nilsson, in Ofiers. Kongl, Vet, Akad. Förh. Stockh. [Ueb. Afr. Art. Gatt. Xyris] (1891) 153 ; et l.c. (1891) 40. - Afr. trop. occ. teres, Alb. Nilsson, ll. cc. xxiv。 n. 14 (1891) 44 t. 1 , fig. $2,2 \mathrm{a}, \mathrm{b} .-$ Bras.

triquetra, Kuntre, Rev。Gen。(1S91) 719. - Ins. Trinit.

Umbilonis, Alb. Nilsson, in Kongl. Suensk Vet. Akud. Handl. [Stud. ubb. Xyrid,] xxiv, n, 14 (1892) 30. - Natal

ustulata, Alb. Nilsson, I. c. 28. - Austral.

witsenioides, Oliver, in Trans. Linn. Soc. Ser. II. ii, (1887) 285 t. 50b. Oliver, ex in Thum, in Timehri. v. (1886) 207]. - Guian, angl.

XYSMALOBIUM, R. Br. (Asclep.). - Ind, Kew ii. 1243 .

angolense, S. Elllot, in fourn. Bot. xxviii. (1890) 365. - Angrola.

bellum, N. E. Br. iji Kew Bull. (1895) 69 - Afr. trop.

Carsoni, N.E. Br.7. c. (1895) 250. - Afr. trop confustrm, S: Elliot, in fown. Bot. xxviii. (1S90) 363. - Natal.

decipiens, N.E.Br, in. Fow Bull. (1S95) 250.Angola.

dissolutum, K. Schum. in Bot. Fahrb. xvii. (1893) 119. - Afr. trop.

ensifolium, Burch. ex S. Elliot, in Journ. Bot. xxviii. (1890) $364=$ undulatum, R. Br.

fraternum. N. E. Br. in Kew Bull. (1895) 252.-

Afr. trop.
fritillarioides, Rondle, in Gown. Bot. xxxii. (1824) 162. - Angola. 


\section{XYSMALOBIUM :}

Gerrardi, S. Elliot, in founn, Bot. xxviii. (1890) 364 . - Natal.

Holubii, S. Elliot, 7. c. 365. - Angola

membraniferum, N. E. Br. in Kez Bull. (1895) 251. - Sierra Leone.

padifolium, S. Elliot, in fonm . Bot. xxviii. (1890) 363 (-Gomphocartus padifolins, Baker), - Afr. austr. parviflorum, Harv, ex S. Elliot, l. c. - Afr. austr. et austro-or.

prismatostigma, K. Schum. in Bot. Fahrb. xvij. (1893) 120. - Afr. trop.

reticulatum, N. E. Br. in Kew Bull. (1895) 251. Afr. trop.

rhomboideum, N.E. Br, l,c. - Angola.

spurium, N. E. Br. l. c. - Zambesia.

stockenstromense, S. Elliot, in fourn. Bot. xxviii. (1890) 364. - Afr, austr.

\section{$\mathbf{Y}$}

YATABEA, Maxim. ex Yatabé, in Tokyo Bot. Mag. v. (1891) 281; et Icon. F1. Japon. i. II. (1893) t. $22=$ Ranzania, $T$. Ito (Berberid.).

japonica. Maxim. 11, cc, = R. japonica, Maxim

YERVAMORA, Ludw, Defin. pl, (1737) 126, ex Kuntze, Rev. Gen. (1891) $545=$ Bosia, Linn. (Amarant.).

canariensis, Kuntze, Rev. Gen. (1891) $545=$ B. Yervamora, Linn.

YPSILANDRA, Franch. in Nouv, Arch. Mus, Paris, Sér. II. X. (1888) 93. LILIACEAE thibetica. Franch. . . 0.94. - Tibet.

YUGCA. Dill, ex Linn.(Liliac.),-Ind, Kew, ii, 1243. australis, Trelease, in Contrib.U, S. Nat. Herb. ii. (1894) 436. - Mexic, Texas.

Carrierei X. Éd. André, in Rev. Hortic. lxxvij, (1895) 81, fig. 21-23. - Hybr. artef.

Eleana, Hort. ex W. Wats. in Kew Bull. (1889) $304=$ guatemalensis, $B a k c r$.

Hanburii Baker, in Kevs Bull (1892) 8; et ex Gard. Chron. (1892) i. 749. - Am, bor. [Mont. Scopul.]

Mazelii, Hort, ex W. Wats. in Kew Bull. (1889) $304=$ guatemalensis, Baker?

valida, T.S. Brandeg. in Proc. Calif. Acad. Ser. II. ii. (1889) 208 t. 11. - Calif.

\section{Z}

ZAA, Baill. in Bull. Soc, Linn. Paris, ii. (1887) 691 ; et Hist. des pl, X. (1888) 58. BIGNONIA$C E A E$

ilicifolia, Baill. $l$. cc. (= Tabebnia ilicifolia, DC.). - Madag

ZACZA TEA. Baill. in Bull. Soc. Linn. Paris, i. (1889) 806 |sphalm. 86]; et Hist. des pl. X. (1890) 295. A SCLEPIADEAE.

angolensis, Baill. Il.co. - Angola.

ZALAGGA. Rumpf (Palm.), - Ind. Kew. ii. 1244. Beccarii, Hook, f. Fl. Brit. Ind, vi. (1893) 4T4. Rangoon.

borneensis, Bccc. Malesia. iii. (1886) 68. - Borneo. dubia, Becc. l.c. - Hab.?

nitida. Bull, Cat. (1886) 9, ex Becc. l.c. in obs. - Afr. trop. occ.

vermicularis, Bccc. l. c. 66. - Borneo

ZALUZANIA, Pers.(Compos.).-Ind.Kew. ii. 1244. discoidea, A. Gray, in Proc. Am. Acad. xxi. (1886) 388 - Mexic.

resinosa, S. Wats. l. co xxv。 (1890) 153. - Mexic.
ZALUZIANSKYA, F. W. Schmidt (Scrophul.) - Ind. Kew. ii. 1245.

Aschersoniana, Silhinz, in Verh Bot Ver. Brand. xxxi. (1890) 190|Zaluzanskia]. - Afr, austro-occ. extratrop.

ZANNIGHELLIA, Mich. ex Linn. (Naiad.). Ind. Kew, ii. 1246

cyclostigna, Clavaud, in Act. Soc, Linn. Bord, xlii. (1888) p. lxvii ; et in Bull. Herb. Boiss. i. App. I. (1893) $20=$ palustris, Limn.

indica, "Cham." ex Morong, in Bull. Torrey Bot Chub, xiii (1886) 159. - Ins. Luchu.

lingulata, Clavaud, in Act. Soc. Linn. Bord. xlii. (1888) p. lxviii ; et in Bull. Herb. Boiss. i. App. I. (1893) $20=$ palustris. Lim

ZANTLDESCHIA, Spreng, = Richardia, Funth (Aroid.).

Lutwychei, Th. Dur. \& Schinz, Consp. Fl. Afr, v. $1894(1895) 477=\mathrm{R}$. Lutwychei, N.E. Br.

ZANTHOXYLUM, Linn, (Rutac.). - Ind. Kew

ii. 1246.

chalybeum, Engt. Pfanzenw. Ost-Afr. C (1895) $22 \%$. - Afr. trop. or

costaricense, J. D. Smith, in Coult. Bot. Gaz. xiii. (1888) $190=$ Z. Limoncello, Planch. \& Oerst.

dimorphophyllum, Henst. in Ann.Bot. ix. (1895) 150. - China.

dissitum, Hemsl. ex Forb. E Hemsl, in fourn. Linn. Soc. xxiii. (1886) 106. - China.

diversifolium, Warb. in Bot. Fahrb. xiii. (1891) 339 $-\mathrm{N}$, Guin.

echinocarpum, Hemsl, in Ann. Bot, ix. (1895) 149. - China.

Fagara,.Sarg, in Gard. and For. iii. (I890) $186=$ Z. Pterota, H. B. \& $K$.

foliolosum, F. D. Snith, in Conlt. Bot. Gaz. xviii. (1893) נ. [Xanthoxylum] ; et Enum. Pl. Guatem. iv. (1895) 17 . - Guatem.

fraxinoides, Hensl. in Amo Bot. ix. (1895) 148. China.

glandulosum, Hillebr. Fl. Hav. Isl. (1888) 74.Ins, Sandvic.

hawaiiense, Hillcbr. . . c. 76. - Ins. Sandvic.

laetum, Drake, in Morot, Fourn. de Bot, vi. (1892) 2\%4. - Tonk.

madagascariense, Baker, in fourn. Linn. Soc xxv. (1889) 303. - Madag

micranthum, Hemsl. in Ann. Bot. ix. (1895) 147. -China.

multijugum, Franch. P7. Delav, i. (1889) 124.China occ

Na deaudi, Drake, Ill. Fl. Ins. Mar. Pacif. (1890) 130: et Fl. Polyn. Franç. (1892) 24. - Ins. Pacif.

oahuense, Hillebr. Fl. Haw. Isl. (1888) 75. - Ins, Sandvic.

olitorium, Engl. Pflanzenw. Ost-Afr. C (1895) $22 \%$. - Air. trop. or.

Piasezkii, Maxim. in Act. Hort. Petrop. xi. (1889) 93. - China.

podocarpum, Hemsl, in foum, Linz?. Soc, xxiii, (1886) 107. - China.

Pringlei, S. Wats. in Proc. Am. Acad. xxvi (1891) 134 [Xanthoxylum]. - Mexic.

rhetsoides, Drake, in Morot, foum, de Bot. vi. (1892) 275. - Tonk.

setosum, Hemsl. ex Forb. \& Hemsl, in fourn. Linn. Soc, xxiii. (1886) 107. - China.

shikokianum, Makino, in Tokyo Bot. Mag. ví. (1892) 51. - Japon.

stenophyllum, Henst. in Ann. Bot. ix. (1895) $14 \%$. - China.

Stuhlmannii, Engl, Pflanzenz. Ost-Afr. C (1895) 227. - Afr. trop. or.

undulatifolium, Henst. in Ann. Bot. ix. (1895) 144. - China.

usitatum, Pierre, ex Laness. Pl. util. Colon. Franc. (1886) 304. - Cochinch.

veneficum, F. M. Bailey, Syn. Queensl. Fl. Suppl, i. (1886) 11. - Austral.
ZAPATERIA, Pau, Not. Bot. Fl. Espan. i. (1887) 17 [conf. Willk. Suppl, Prodr. Fl. Hisp. (1892) 134, in obs. $]=$ Ballota, Linn $_{\text {. }}$ (Labiat.).

ivirsuta, Pau, $1 \mathrm{~L}, \mathrm{CC}_{-} \Rightarrow \mathrm{B}$. hirsuta, Benth.

ZAUSCHNERIA, Presl (Onagrar.). - Ind. Kew. ii. 1248.

cana Greene Pittonia, i (Feb. 1887) 28, - Calif. latifolia, Greene, 1. c. 25; et Man. Bot. San Franc. Bay (1894) 131 = californica, Presl, var. tomentella, Greenc, l.c. 26. - Am. bor. occ villosa, Greene, l, c. 2\%. - Calif.

ZEA, Linn. (Gramin.). - Ind. Kew. ii. 1248. canina, S. Wats. in Proc. Am. Acad. xxvi. (1861) 160. - Mexic.

ZEBRINA, Schnizl. (Commelin。). - Ind. Kew. i: 1248 .

pumila, Grecne, Pittonia, (Jan. 1888) 15\% - Mexic.

ZELKOVA. Spach (Urtic.), - Ind. Kew. ii. 1249. cappinifolia, Dippel, Handb. Laubholzk, ii. (1892) 38: Koehne, Deutsche Dendrol. (1893) $136=$ crenata, $S p a c h$

japonica, Dippel, l. c. 39, fig. 13. - Japon.

Kecki, Dippel, 1. c. 40 ; Koehne, Deutsche Dendrol, (1893) $13 \%$ = acuminata, Planch.

ZENKERELLA, Taub, in Eng1. \& Prant1. Natürl. Pflanzenfam. iii 3 (1894) 386. LEGUMINO $S A E$.

citrina, Taub.l.c. - Kamerun.

ZENOBIA. D. Don (Ericac.)。 - Ind. Kew. ii. 1249 cassinefolia. Pollard, in Bull. Torrey Bot. Club, xxii. $(1895) 231=$ speciosa, D. Don.

pulverulenta, Pollard, 1. c. 232= speciosa, D. Don?

ZEPHYRANTHES Herb. (Amaryll.). - Ind.

\section{Kew, if. 1249.}

albicans, Baker, Handb. Amaryll. (1888) 38 (= Pyrolivion albicans, Herb.). - Peruvia.

Andersoni, Baker, l.c. 37 (= Habranthus Andersoni, Herb.). - Urug.

andicola, Baker, i.c. $36(=H$. andicola, Herb.).Chili

arenicola, T. S. Brandeg, in Proc. Calif. Acad. Ser. II. ii. (1889) 205. - Calif.

Bakeriana, Morong, in Amn. N. Y. Acad. sci. vii (1893) 239. - Parag.

aurea, Baker, Handb. Amaryll. 37 (= Pyrolivion aureum, Herb.). - Peruvia.

boliviensis, Baker, l. c. 38. - Bolivia.

cearensis, Baker, l. . . 36. - Bras.

coerulea, Baker, l. c. $36 \quad(=$ Amaryllis coertlea, Griseb.): - Uruo

entreriana, Pax, in Bot. Fahrb. xi. (1890) 320 (= Amaryllis entreviana, O. Hoffm.). - Parag.

erubescens, S. Wats. in Proc. Am. Acad.xxy. (1890) 162. - Mexic

flammea, Baker, Handb. Amaryll. (1888) $3 \pi(=P y$ volirion flammeum, Herb.). -- Peruvia.

flava, Nichols. Dict. Gard. iv. (I887) $239(=$ Pyrolirion flarum, Herb.). - Peruvia.

Alava, Baker, Handb. Amaryll. (1888) $37=$ praec franciscana, Herb. ex Baker, l. c. 36. - Bras.

gracilifolia, Baker, l. c. $(=$ Habranthits gracilifolins, Herb.). - Urug.

Hieronymi, Pax, in Bot. Fahrb. xi. (1889, 320, 324. - Reg. Argent

lactea, S. Moore, in Trans. Linn. Soc. Ser. II. iv (1895) 495. - Bras.

longistyla, Pax, in Bot. Fahrb. xi. (1889) 320. 323. - Reg. Argent.

macrosiphon, Baker, Handb. Amaryll. (1888) 35. Mexic.

mendocensis, Baker, l. c. 36. - Reg. Argent

pulchella, F. D. Smith, in Missouri Bot, Gard. Rep vi. (1893) 114 t. 52. - Texas.

robusta, Baker, Handb. Amaryll. (1888) 35 (= Ha brantius robustus, Herb.). - Urug.

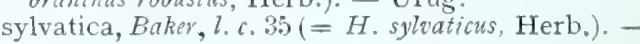
Bras. 


\section{ZEPHYRANTHES}

versicolor, Baker, Handb. Amaryll. (1888) 35 (= Ha branthus versicolor, Herb.). - Bras.

Tauberti, Harms, in Gartenfl. xliv. (1895) 386. Am. Austr.

Wrightii, Baker, Handb. Anaryll. (1888) 82. - Cuba xiphopetala, Baker, in Mem. Torrey Bot. Club, iv (1896) 268. - Bolivia.

ZERUMBET, Wendl. = Alpinia, Linn. (Scitam.) Autrani. Heckel, in Le Naturaliste, Sér. II. riii (1891) $293 \mathrm{fig} .10$. - Congo gall.

ZEUXINE, Lindl. (Orchid.). - Ind. Kew. ii. 1250. abbreviata, Hook.f. Fl. Brit. Ind. vi. (1890) 109; et in Hook. Icon. pl. xxii. (1894) t. 2178 (= Etaeria abbreviata, Lindl.). - Ind. or

affinis, Benth. ex Hook.f. ll. cc. 108 ; et t. $2277(=$ Monochilus affinis, Lindl.). - Ind. or.

cochlearis, Schlechter, in Bot. Fahrb. xx. Beibl. n. 50 (1895) 11. - Afr. austr.

elongata, Rolfe, in Bolet. Soc. Brot. ix. (1891) 142. Ins. Princip.

formosana, Rolfe, ex Hemsl. in Ann. Bot. ix. (1895) 258. - Ins. Form

longifolia, Hook. f. Fl. Brit. Ind. vi. (1890) 109 ; e in Hook. Icon. pl. xxii. (1894) t. 2180 (= Hetacria longifolia, Benth.). - Reg. Himal.

moulmeinensis, Hook.f. li. cc. 109 ; et t. 2179 (= Etaeria moulmeineneis, Parish \& Reichb. f.). Tenass.

plantaginea, Benth. \& Hook. f. ex Drake, Ill. Fl. Ins Mar. Pacif. (1892) 312 (= Monochilus plantagineus, Reichb. f.), - Ins. Pacif.

reniformis, Hook. f. Fl. Brit. Ind. vi. (1890) 107 ; et in Hook. Icon. pl. xxii. (1893) t. 2183. - Perak.

stenophylla, Benth. E Hook. f. ex Drake, Ill. Fl. Ins. Mar. Pacif. (1892) 312 (= Monochilus stenof hyllus Reichb. f.). - Ins. Pacif.

tetraptera, Th. Dur. \& Schinz, Consp. Fl. Afr. v $1892(1895) 57(=M$. tetrapterus, Reichb. f.). Afr, trop. occ.

ZEXMENIA, La Llave (Compos.). - Ind. Kew. ii 1258

dulcis, f. D. Smith, in Coult. Bot. Gaz. xvi. (1891) 99. - Guatem.

fruticosa, F. N. Rose, in Contr. U. S. Nat. Herb. i. (1891) 103. - Mexic.

guatemalensis, F. D. Smith, in Coult. Bot. Gaz, xili (1888) 188. - Guatem.

phyllostegia, Klatt, in Leopoldina, Heft xxv. (1889) 105. - Guatem.

tequilana, A. Gray, ex S. Wats. in Proc. Am. Acad. xxii.(1887) 425. - Mexic.

virgulta, Klatt, ex Th. Dur. E Pitt. in Bull. Soc. Bot. Belg. xxxi. 1892 (1893) 293. - Costa Rica.

ZILLA, Forsk. (Crucif) - Ind. Kew. ii. 1251. spinosa, Prantl, in Engl. \& Prantl, Natürl. Pflanzenfam. iii. 2 (1891) 175 = myagroides, Forsk.

ZIMAPANIA, Engl \& Pax, in Engl. \& Prant, Natürl. Pflanzenfam. iii. 5 (1892) 119. EUPHOR$B I A C E A E$.

Schiedeanum, Engl. \& Pax, l. c. fig. 75. - Mexic.

ZINGIBER, Adans. (Scitam.). - Ind. Kew. ii. 1251.

brevifolium, N. E. Br. in Gard. Chron. (1886) ii. 390. - Ins. Philipp.

Griffithii, Baker, in Hook. f. Fl. Brit. Ind. vi. (1892) 246. - Malacca.

intermedium, Baker, in Hook, f. l. c. - Khasia.

ZINNIA, Linn. (Compos.). - Ind. Kew. ii. 1251

australis, F.M. Bailey, in Dept. Agrio. Brisbane Bot. Bull. iî. (1891) 14. - Austral.

Liebmanni, “Benth. \& Hook. $f$. » ex Klatt, in Leopoldina, Heft xxiii. (1887) 89. - Mexic

Palmeri, A. Gray, ex S. Wats, in Proc. Am. Acad. Palmeri, A. Gray, ex $S$. Wats.

pauciflora, Phil. in Anal. Mus. nac. Chile (1891) 49. - Chile
ZIZANIOPSIS, Doell \& Aschers, = Zizania. Gro nov. (Gramin.)

miliacea, Doell \& Aschers. ex Hack. in Engl. \& Prantl, Natürl. Pflanzenfam. ii. 2 (1887) 40 3aill. Hist. pl. xii. (1893) $293=$ Z . miliacea $\operatorname{Michx}$

ZIZIA, Koch = Carum, Rupp. (Umbell.). Bebbii, Britton, in Mem. Torrey Bot. Club, ii. (1890) 35, et v. (1894) 243. - Am. bor

ZIZIFORUM, Caruel, in Parl. F1. Ital. vi. (1883?) 144; et Epit. Fl. Eur. ii. (1894) 17l=Ziziphora Linn. (Labiat.)

ZIZIPHORA, Iinn. (Labiat.).-Ind. Kew。 ii, 1252. subcapitata. Hausskn. E Bornn. ex Bormm. in Mitth. Thir. Bot. Ver. N. Folge, vi. (1894) 67. - As occ.

rigida, $\mathrm{H}$. Braun, in Verh. zool.-bot. Ges. Wien, xxxix. (1889) 239 = clinopodioides, Bieb.

ZIZYPHUS, Tourn. ex Linn. (Rhamn.). - Ind. Kew. ii. 1252

affinis, Hemsl. in Hook. Icon. pl. xvi. (1886) t. 1544. - Perak.

attoensis, "Pierre 》 ex Weberbauer, in Engl. \& Prantl, Natürl. Pflanzenfam. iii. 5 (1895) $402=$ attopensis, Pierre

attopensis, Pierre, Fl. For. Cochinch. Fasc. 20 (1894) t. 316a. - Cochinch.

cambodianus, Pierre, l. c. t. 315a. - Cochinch.

chloroxylon, Oliver, in Hook. Icon. pl. xix. (1889) t. 1862. - Jamaica.

Chloroxylum, Oliver, in Kew Bull. jii. (1889) 127, cum ic. = praec.

espinosus, Buettn. in Verh. Bot. Ver. Brand xxxii, (1890) 48. - Congo.

Harmandiana, Pierre, Fl. For. Cochinch. Fasc, 20 1894) t. 316b. - Cochinch.

Harmandi, " Pierre », ex Weberbauer, in Engl. \& Pranti, Natürl. Pflanzenfam. iii. 5 (1895) 402, sphalm. = praec

koaensis, Pierre, Fl. For. Cochinch. Fasc. 20 (1894) t. 315b. - Cochinch.

oblongifolius, S. Moore, in Trans. Linn. Soc. Ser. II. iv. (1895) 339. - Bras.

pubescens, Oliver, in $H$. Fohnst. Kilin. Exped. App. (1886) 339, nomen, et in Trans. Linn. Soc. Ser. 11. ii. (1887) 330. - Afr. trop. or.

onorensis, S. Wats, in Proc. Am. Acad. xxv. (1889) 44. - Mexic.

ZOEGEA, Linn. (Compos.). - Ind. Kew. ii. 1253. baldschuanica, C. Winkl, in Act. Hort. Petrop. ix. (1886) 426. - Buchara.

ZOELLERIA, Warb, in Bot. Jahrb. xvi. (1892) 28 Guerke, in Engl. \& Prantl, Natürl. Pflanzenfam. iv, 3a (1895) 131. BORAGINEAE.

procumbens, Warb. $l 7 . c c,-N$. Guin

ZOLLIKOFERIA, DC. = Launaea, Cass. (Compos.).

momala, Batt. in Buil. Soc. Bot. Fr. xl. (1893) 190. - Algeria.

arborescens, Batt. 1. c. xxxv。(1888) 342, 891. - Algeria.

Bornmuellevi, Hausskn. ex Bornm, in Mitth. Thür. Bot. Ver. N. Folge, vi. (1894) 56. - As. occ.

elquiensis, Phil. in Anal. Univ. Chil. 1xxxvii. (1895) $32 \%$ - Chili

oligocephala, Hausskn. \& Bornm. ex Bornm. in Mitth. Thür. Bot, Ver. N. Folge, v. (1894) 55. As. occ.

secunda, Boiss. F1. Or. Suppl. (1888) $923(=$ Microrrhynchus secundus, C. B. Clarke). - Afshan. tapetodes, Boiss. 1. c. 324. - Aghan

tenuiloba, Batt. in Batt \& Trab. FI, de l'Algér.

[Dicot.] (1889) $557=$ mucronata ${ }$ Boiss.

ZOLLINGERIA, Kurz (Sapind.). - Ind. Kew. ii. 1253 .

dongnaiensis, Pierre, in Bull. Soc. Limn Paris, i. (1886) 634; ot Fl. For. Cochinch. Fasc. 21 (1895) t, 325a. - Cochinch.
ZOMBIANA, Baill. Hist. des pl. ix. (1888) 420; Wettst. in Engl. \& Prantl, Natürl. Pflanzenfam. iv. 3b (1895) 360. - MYOPORINEAE.

africana, Baill. $l l . c c$. - Afr. trop. or

ZOSTERA, Linn. (Naiad.). - Ind. Kew, ii. 1254. latifolia, Morong, in Mem. Torrey Bot. Club, iii. II. (1893) $63=$ pacifica, S. Wats

oregana, S. Wats, in Proc. Am. Acad. xxvi. (1891) 131 = marina, Linn

pacifrca, S. Wats, l. . . - Am. bor. occ

ZYGELLA, S. Moore, in Trans. Linn. Soc, Ser, II iv. (1895) 493, t. 34 fig. 1-13. IRIDEAE.

graminea, S. Moore, l. c. 494. - Bras.

ZYGOCACTUS, K. Schum, in Mart. Fl, Bras, iv, II. (1890) $223=$ Epiphyllum, Haw. (Cact.) Altensteinii, K. Schum. 1. C. $225=\mathrm{E}$. truncatum, Hav.

truncatus, K. Schum. I. c. (1890) $224=$ E. truncatum, Haw.

ZYGOCOLAX X, Rolfe, in Gard. Chron. (188\%) i. 765. (Orchid.)

lcopardinum X, Hort. ex Gard. Chron. (1889) i. 809 Veitch, Man, Orch. Pl. ix. (1893) 66; Will. Orch. Grow. Mun, ed. '7 (1894) 758. - Hybr. artef.

Veitchii $Y$. Rolfe, 11, cc, V Veitch, Man. Orch. Pl. ix. (1895) $66(=$ Zygopetalum Veitchii $\times$ Veitch $)$. - Hybr. artef.

ZYGODIA, Benth. (Apocyn.).-Ind, Kew. ii. 1255. kidengensis, $K$. Schum. in Engl. Pflanzenv. Ost-Afr. C (1895) 318. - Afr. trop. or

kindengensis, K. Schum. in EngI. \& Prantl, Natürl. Pflanzenfam. iv. 2 (1895) $164=$ praec

urceolata, Stapf, in Kew Bull. (1894) 122. - Angola.

ZYCONA. Kuntze, Rev. Gen. (1891) 373. COMPOSITAE.

oppositifolia, Kuntze, l. c. - Venezuela

ZYGONERION, Baill. in Bull. Soc. Linn. Paris, i. (1888) 758; et Hist. des pl. $\mathrm{x}$. (1888) 210 ; K Schum. in Engl. \& Prantl, Natiirl. Pflanzenfam. iv. 2 (1895) 174. APOCYNEAE.

Welwitschii, Baill.ll.ce. - Angola

ZYGOPETALUM, Hook. (Orchid.), - Ind. Kew.

Beaumontii, Nichols. Dict. Gard. iv. (1887) 245. -

Bras.

caulescens, Rolfe, in Gard. Chron. (1890) i. 544.Bras,?

citrinum, Nichols. Dict. Gard. iv. (1887) 245; ct l. c. (1888) 94. - Am. bor

Crepeauxi, Carr. in Rev. Hortic. lix. (1887) 420. Bras.

Dormannianum, Nichols. Dict. Gard. iv. (188\%) 245. - N. Granat. ?

fimbriatum, Nichols. l. c. - N. Granat.

Gibeziae, N. E. Br. in Lindenia, iv. (1888) 79 t. 181. - Hab.

graminifolium, Rolfe, in Gard. Chron. (1892) ii. 179; et l. c. viii. (1892) 9 t. 339 ; Veitch. Man. Orch.Pl. ix. (1893) 52. - Bras.

Jorisianum, Rolfe, in Lindenia, v. (1889) 91 t. 237 ; et l. c. (18901) i. 704. - Venezuela.

leopardimm X, Hort. Veitch. ex Reichb. f. in Gard. Chron. (1886) ii. 199, 712 ; Nichols. Dict. Gard, iv. (1887) $246=$ Zygocolax leopardina $X$, Rolfe. leucochilum X, Hort. Veitch. 11. cc. (1892) i. 214 et 246 . -

Lindeniae, Rolfe, in Lind̈enia, vi. (1890) 73 t. 275 et ex Orchid Rev. ii. (1894) 270; Will. Orchid Grow. Man. ed. 7 (1894) 761. - Venezuela.

Lindenii, Rolfe, in Lindenia, viri. (1892) 5 t. 337 ; Veitch. Man. Orch, Pl. iii. (1893) 56. - Hab. lucidum, Rolfe, in Gard. Chron. (1889) i. 799 Guian, angl.

Perrenoudi X, Hort. ex Rev. Hortic. (1894) 191. Hybr. artef.

Sanderianum, Regel, in Gartenfl. xxxvii. (1888) 65\% t. 1287; et in Act. Hort. Petrop. x. (1888) 695. Columb. 
ZYGOPETALUM: -

Veitchii Y. Veitch, in Gard. Chron. (1887) i. $425=$ Zygocolax Veitchii $\times$, Rolfe.

venustum, Ridl. ex Oliver, in Trans. Linn. Soc. Ser. II, ii. (1887) 283, t. 47. - Guian. angl.

Whitei, Rolfe, in Gard. Chron. (1890) i. 354; et in Godefr. Lebcenf, L'Orchidophile (1890) 194. - N. Granat.

ZYGOPHYLLUM, Linn. (Zygophyil.). - Ind. Kew, ii. 1258.

amblyocarpum, Baker, in Kew Bull. (1894) 330. nomen : et in Hook. Icon. pl. xxiv. (1894) t. 2355. - Arabia.

berenicense, Schweinf, Illustr. Fl. Égypte [Mém. Inst. Egypt.ii.] (1887) 56, nomen. - Aegypt.

cinereum, Schin\%, in Bull. Herb. Boiss. ii. (1894) 189. - Afr. austro-occ, extratrop.

densiflorum, Schinz, in Verh, Bot. Ver. Brand, xxxi. (1890) 181. - Afr, austro-occ extratrop.

gobicum, Maxim. Enum, Fl. Mongol. (1889) 125.Mongol.

\section{ZYGOPHYLLUM :-}

incanum, Schinz, in Bull. Hevb. Boiss, iv. (1894) 190. - Afr. austro-occ, extratrop.

Loczyi, Kanitz, Pl. Exped. Szechenyi in As. centr. lect. (1891) 13. - As, centr.

longicapsulare, Schinz, in Verh. Bot. Ver. Brand. xxix. (1888) 55. - Afr. austr-occ extratrop.

longistipulatum, Schinz, l. c. 86. - Afr, austroocc. extratrop

Marlothii, Engl. in Engl. Bot. Jahrb. x. (1888) 32 $=$ Z. Stapfii, Schinz.

paradoxum, Schinz, in Verh. Bot. Ver. Brand. xxx (1888) 155. - Afr, austro occ, extratrop.

rigidum. Schinz, l. c. 55. - Afr. austro-occ, extratrop.

Stapfii, Schinz, l. c. 5\%. - Afr. austro-occ. extratrop.

suffruticosum, Schinz, in Bull. Herb. Boiss. ii. (1894) 188. - Afr. austro-occ. extratrop.

xanthoxylum, Engl. in Engl. \& Prantl, Natish. Pfanzenfam. iii. 4 (1890) 81 (= Sarcozygium xanthoxylum, Bunge). - Mongolia.
ZYGOPHYLLUM : -

anthoxylum, "Engl, » ex Dippel, Handb. Laul holzk. ii. (1893) $358=$ praec.

ZYGORUELLIA, Baill, in Bull. Soc. Linn. Paris, ii. (1890) 820 ; et Hist. des pl, x. (1890) 432 . $A C A N T H A C E A E$

Richardi: Baill. ll. cc. ; Lindau, in Engl. \& Prantl, Natiurl. Pfanzenfam. iv. 3b (1895) 249. - Madag.

ZYGOSTELMA, Fourn. (Asclep.). - Ind. Kew. ii. $125 \%$.

Benthami, Baill. Hist. des pl. x. (1890) 300. Siam.

ZYRPHELIS, Cass. = Mairia. Nees (Compos.) Burchelli, corymbosa, crenata, Ecklonis, foliosa, hirsuta, lasiocarpa, Kuntze, Rev. Gen. (1891) $374=$ homonyma omnia Mairiae.

pilosella, Kuntze, 1.c. = M. perezioides, Nees, 


\section{CURAE POSTERIORES \\ IN INDICEM KEWENSEM}

VEL

\section{ADDENDA ET EMENDANDA \\ POST ANNUM 1895 NOTATA}

$A$

BENJAMIN DAYDON JACKKSON

\section{ORDINA'TA}
a. = adde.
d. $=$ dele.
1. = lege.
p. = pone

\section{A}

1 1' AALIUS, Rumph. ex Lam. Encyc. i. 1 (1793) = Sauropus, Blume (Euphorb.)

\section{ABERIA}

21 1. caffra, Hook. f. ex Harv. Es Sond.

\section{ABIES}

$3^{1}$ a. macrocarpa, Vasey, in Gard. Monthly (Jan. 1876); ex Sargent, in Rep. For. N. Am. (U. S. Census, ix.) $210=$ Pseudotsuga Douglasii.

\section{ABUTILON}

$4^{3}$ 1. albidum, Sweet, (1, c.).

a. arborescens, Noronha, ex Hassk in Hoev, \& De Vriese, Tijdschr, xi. (1844) $215=$ Broussonetiae sp.?

51 1. crispum, Medic. Mati. 29 (cryspum); Sweet.

$5^{2}$ giganteum, Sweet, Hort. Brit. ed. i. 53 ; Presl,

$5^{3}$ polyandrum, G. Don, ... $500=$ seq.

a. polyandrum, Wight, of Arn. Prod... - Ind or.

$6^{1}$ a. spinifex, Scop. Introd. $288=$ Pavonja spinifez.

\section{ACACIA}

$6^{3}$ a. aurea, Noronha, ex Hoev. \& De Vriese, Tijdschr. xi. (1844) $216=$ Burmanniana.

03 1. leiophylla, Benth. 351 = saligna (non Albizzia) prona, Noronha, (1. c.) = Smithia sensitiva?

\section{ACAENA}

$14^{1}$ 1. Huttoni, $R$. Br.ter... $362=$ Poterium Sanguisorba.

\section{ACALYPHA}

$15^{3}$ l. crandis, Benth.

$16^{1}$ a. Maccafeeana, Veitch, Cat. (1878) $25=$ Wilkesiana.

macrostachya, Griseb, Fl. Brit. W. Ind. 4\% Ins. Trinit. (non facq.).

$16^{3} r u b r a$, Nor. fide Hassk. in Tijdschr. Nat. Ges. xi. (1844) $216=$ densiflora.

172 1. ACANTHOCARYA, Pfeiffer, Nom, i. 11 (1871) $=$ seq.

$17^{2}$ a. ACANTHOCARYX, Endl. Gen. 1076 (1840) $=$ ACANTACARYX, Arruda.

\section{ACANTHORHIZA}

191 a. arborea, Drude; cf. Hook. f. Kew Rep. 1882 (1884) 64 - Hab?
$19^{3}$ 1. ACANTHYLLIS, Pomel.

\section{ACER}

2011 barbutum Michx.

californicum, D. Dietr. Syn. P1. ii. $1283=$ Negundo californicum, (loco Torr. \& Gray).

$26^{3}$ manschuricum, Maxim

\section{ACHILLEA}

$23^{3}$ a. oxyloba, DC. Prod. vi. 20. - Europ. serbica, Petr. Addit. Fl. Agr. Nyss. $102=$ ageratifolia.

281 1. ACIDOTON, P. Br. Hist. Jamaic. 335 (1756) (non Sw.) = Securigena, Comm. (Euphorb.)

\section{AGIPHYLLA}

283 1. Traversii, Hook. f. Handb. Fl, N. Zel. 729 F. Mucll.

ACLISIA

$29^{3}$ d. quayaquilensis, (est Acnisti sp.; cf. p. 30)

\section{A CONITUM}

$31^{1}$ 1. lethale, Griff. Not. iv. 73\%. - Ind. or.

$31^{2}$ a. salisburifolium, Griff. in Itin. Not. 306. Ind. or.

ACOSTA, Adans

321 a. spinosa, Scop. Introd. $124=\mathrm{C}$. spinosa.

\section{AGIIINIDIA}

351 1 arguta, Miq. Ann. Mus, Bot. Lugd. Bat. iii 15 ; Franch.

polygama, Miq. (l. c.); Franch.

rufa, Miq. (1. c); Franch.

volubilis, $\mathrm{Miq}$. (l. c.) 16 ; Franch

$37^{1}$ a. ADELAIDA, Buc'hoz, Herb. Col. Amér. t. 74 (1783). (Quid? borbonica, Buc'hoz, l. c, - Maurit

\section{ADINA}

43\% 1. aralioides, Benth. \& Hook. f... $30=$ polycephala 1. trichotoma, Benth. \& Hook. f. (1. c.) $=$ poly cephala.

$43^{3}$ a. ADOCETON, Rafin. in Am. Monthly Mag. i. (1817) $438=$ ADOKETON, Rafin. = Zelanthera, R. Rr.(Illecebr.)

ADDOKETON

$44^{1}$ a. maritimum, Rafin, in Am. Monthly Mag. i. (1817) $438=\mathrm{T}$, frutescens.

saxatile, Rafin. 1. c. $=$ T. frutescens.
ADYSETON

$44^{3}$ a bidentatum, Medic Pflanzeno. 73 - Europ.

1. campestre, Medic, $(1, \mathrm{c})$,74 ; Moench,

a. squamatum, Medic. (1. c.), - Europ.

\section{AELUROPUS}

$47^{2}$ I. villosus, Trin, ex C. A. Mey. Verz. Pfl. Canc, 18.

\section{AEONIA}

473 1. alata, $A$. Rich... xv. (1841) 67 t. 11 .

\section{AEONIUTI}

4731 Berthelotianum, C. Bolle...239. - Ins Canar. Castello-Paivae, Bolle... = S. Paivae. Manriqueorum, C. Bolle,

tabuliforme,

\section{AERANTHES}

481. 1. grandiflora, Lindl. grandiflora, Lindl.

AERANTHUS

481 a, Fischeri, Reichb, in Mitth. Geogr. Geo. Hamb. 1882-83 (1885) 268, nomen:- Afr. trop.

\section{AERIDES}

$48^{2}$ 1. Borrassi, Buch. Ham... = Cymbidium aloifolium.

491 1. quinquevulnera, Lindl... - Ins, Philipp. (non Malaya).

1. Thibautiana, Reichb.f...-Ins. Philipp. (non Polynesia).

AERVA

$49^{3}$ 1. tomentosa, Forsk. Fr. Aeg. Arab. p, 122 ; Lam.

\section{AESCHYNANTHUS}

501 1. lonoiflora, DC. Prod ix. 262.

$50^{2}$ 1. Wallichii, R. Br. in Benn...

AETHEILEMA

$51^{3}$ a. anisophyllum, R. Br. Prod. 478 = Phaylopsis longifolia.

\section{AFZELIA}

$52^{3}$ 1. splendens, Hort. ex Sweet, Hort. Brit. ed. i. 72 ; Loud.

\section{AGANOSMA}

$53^{2}$ 1. Edithre... v, (1865) 227

\section{AGAPANTHUS}

$53^{2}$ a calyciforus Banks \& Soland, ex Hook. f. Fl. N. Zel, j. $56=$ Fuchsia excorticata. 
AGATHOSMA

$54^{3}$ 1. brerifolia, \& bruniodes, Sweet, Hort. Brit. ed. 1 89 ; Lond.

a, desciscens, J, B. Fisher, in Bijdr. Nat. Wetensch. vii. (1832) 22 t. $2=$ bifida

3. GA VE

112 1. Lehnacanensis, (non thuacancnsis).

\section{AGRIMONIA}

601 1. Agrimonoides, I.inn.

AGROPYRON

612 1. violacemm, Rink, Grönl, ed. 2, Add. 11 \% V Vasey, AGROSTIS

63: 1. indica, Norsk... p. $104=$ Sporobolus, etc.

(i4 $4^{3}$ Royleana. Trin, in Mém. Acad Pétersb. Sér. VI. iv. (1845) $371=$ Calamagrostis Royleana.

AIRA

6\%1 1. antartica, Hook... $150=$ Deschampsia antarctica.

$68^{1}$ a. lagopoides, Scop. Introd. $74=$ Aeluropus

\section{AIROPSIS}

691 a. tenella, Coss. \& Dur. Expl. Sc. Algér. 97. Algeria.

\section{AITONIA}

60 a. Nyman]A, Lindb. in Notis. Sällsk. Faun. Fl. Fenn。ix, (1866) 290 in obs.

AJAX

$199^{3}$ a. muticus, J. Gay, in Bull. Soc. Bot. Fr. vii, (1860) $308=\mathrm{N}$. Pseudo-Narcissus.

$72^{2}$ a. ALBONIA, Buc'hoz. Herb. Col. Amér. t. 5 (1783 = Rhus, Tourn. (Anacard.).

peregrina, Buc'hoz, 1. c. = R. succedanea.

72: 1. ALCAEA, Hill... (Malvac.).

\section{ALGHORNEA}

$7.3^{3}$ 1. cordifolia. Muell. Arg... = cordata, Benth.

$76^{2}$ a. ALISMORKIS, Thou. in Nouv, Bull. Soc. Philom.n. 19 (1809) $318 ;=$ Alismorchis Thoul.

\section{ALLANBLAGKIA}

Ti 1. floribunda, Oliver, in fourn. Linn. Soc

\section{ALLIUM}

y2 1 bifolizun Willd

793 flavescens, Poepp... = Nothoscordum striatum glaucum [Desf.]... = A. Scorodoprasum.

8\%2 1. Spuriam, G. Don

\section{ALNUS}

5.1. 1. jncana, Moench, Meth. 424; Medic, Pf. anat. 83.

oblongata, Willd... = glutinosa

\section{ALOE}

861 1. Bainesii, Dyer... 568

Barbarae. Dyer. $568=$ Bainesii

Borviea, Schult. f. (non Bourea).

a. confusa, Todaro, Ind. Sem. Hort. Panorm. (1880) 36. - $\mathrm{Hab}$ ?

$86^{2}$ a. fulgens, Todaro, (l.c.) 37. - Hab.

\section{AISINE}

911 1. biflora, Wahlenb... = Stellaria biflora,

92: a. scandinavica = Stellaria biflora.

a. sedioides, Karst. Pharm. Med. Bot. $533=$ Stellaria petraea.

\section{ALTERNANTHERA}

9.) 1. Achyranthes... lix. (non lxix).

\section{ALYSSUM}

cheirifolium, Berger. I'hyton. 1ii, $125=$
$99^{2}$ a. ALYTOSTYLIS, Mast, in Hook. f. Fl. Brit. Ind. i. 409 in obs. $(18 \% 4)=$ Roydsia Roxb. (Capparid.)

\section{AMARANTHUS}

$101^{1} \mathrm{a}$. flexuosus, Ambrosi, Fl, Tir, Austr, ii, $187=$ viridis.

\section{AMELANCHIER}

$105^{2}$ a. Amelanchier, Karst. Pharm. med. Bot. $784=$ canadensis.

$106^{1}$ a. AMERIX, Rafin. in Am. Monthly Mag. i. (1817) $439=$ Salix, Tourn.

\section{AMMI}

1021 1 cicutarium Willd ex F G, Dietr, Vollst. Lexik. Gaert, II. Nachr, i. 211 ; et...

\section{AMORPHOPHALLUS}

rog3 1. campanulatus, Decne, in Now. Ann. Mus. Par. iii. (1834) 366 ; Blume, Rumphia, i. 139 partim.

$118^{3}$ a. AMPHIBOLIS, Schott \& Kotschy, in Kot schy, Reise Taur. 379 (1858) nomen. = Hyacinthus, Tourn.

coelestis, Schott \& Kotschy, 1.c. = H. azureus.

\section{AMPHICARPAEA}

1111. 1. comosa, Sweét, Hort. Brit. ed, i, 121; G. Don,

$112^{1}$ a. AMPHORKIS, Thou, in Nouv. Bull. Soc. Philom. n. 19 (1809) $316=\mathrm{AMPHOR}$ CHIS, Thou.

\section{AMYGDALUS}

$112^{3}$ a. decipiens, genuina, grandiflora, macrocarpa, mensarum, tenuis, Poit. \& Turp. in Poit, Pomol. Franc. iv,$=$ P. Amygdalus.

\section{AMYRIS}

1132 1. floridana, Nutt... (dele «Wave cx ))

$113^{3}$ 1. pernambuconsis, Arruda... $500=$ Protium heptaphyllum?

$116^{2}$ a. ANAMELIS, Garden, in Linn. Corresp. 340, $599(1821)=$ Fothergilla Murr (Hamamel.)

ANANASSA

$116^{3}$ d. Ananas, Karst. Pharm. Med. Bot. $466=$ Ananas sativas.

\section{ANARRHINUM}

$117^{2}$ 1. canadense, Desf. Fl. Atlant ii. 51 ; et

ANASSER

$17^{8}$ a. Laniti, Blanco, Fl. Filip. ed, 1, 112 ; ed. 2, 81 ; ed. $3,149=$ Wrightia ovata.

\section{ANASTATICA}

$117^{3}$ d. Hierochontis, Medic. (quae sub Euclidio reperies).

]20^a. ANDERSONIA, Koenig, ex R. Br. Prod. $570(1810)=$ Stylidium, Sw

ANDIRA

1208 a. SKolEMORA, Arruda, ex Koster, Trav. 498 (1816).

\section{ANDROPOGON}

1262 l laniger Desf 379 (lanigerum)

$127^{3}$ a. squarrosus, Linn, hb. ex R. Br. Prod. $193=$ Chamaeraphis spinescens.

\section{ANDROSACE}

$128^{3}$ a. erecta, Maxim. in Bull. Acad. Pétersb. xxvii (1881) 499. - China

\section{ANEMOPAEGMA}

$132^{3}$ 1. clematidcum, Griseb. $222=$ Pithecoctenium clematideum.

\section{ANGELICA}

$133^{3}$ 1. Dieffenbachii, Benth. \& Hook, f... (Aciphyllae sp.).

134 a. ANGORKIS, Thou in Nouv Bull. Soc. Philom.n. 19 (1809) $318=$ Angraecum Bory (Orch.)

\section{ANGRAECUM}

$134^{3}$ a. ANGorkis, Thou, in Nouv. Bull. Soc. Phi lom. n. 19 (1809) 318

$135^{1}$ a brachycarpum, Reichb. $f$ in Walp. Ann. iii 573 , in obs. - Afr. trop.

1. distichum, Lindl... $1781=$ Mystacidium distichum.

a. eburneun, S. Moore, in Baker, Fl. Maurit 356 partim $=$ Brongniartianum

Gournenm, Reichb. f. ex S. Moore, in Journ. Bot. xvi.(1878) $137=$ A. Giranae [in Suppl.]

$135^{2}$ a. Kotschyanum, Reichb. f. in Oestr. Bot. Zeitschr. xiv. (1864) 338, - Afr. trop.

1. Kotsitiyi, Reichb, f.. $456=$ praec.

1. luridum, Lindl. in Trans. Hort. Soc. vi. (1826) $86=$ Eulophia lurida

1. pectinatum, Thou...51 = Mystacidium pecti. natum.

1. pellucidum, Lindl... $134=$ M. pellucidum

ANGUILLARIA

$135^{3}$ 1. bahamensis, Gaertn. 1. c. $373=$ Myrsine Heberdenia.

\section{ANISOMELES}

$137^{3}$ 1. furcata, Sweet, Hort. Brit. ed. 1, 315; Loud.

\section{ANISOPHYLLEA}

1381 a flavicans, Hook f. \& Thoms. Fl. Ind. i. 175 in nota. - Ins, Penang.

\section{ANTHEMIS}

$145^{2}$ 1. nigricans, Hort. ex Sweet, Hort. Brit. ed i 243 ;

\section{ANTHERICUM}

$146^{3}$ 1. capillare, F. G. Dietr. Vollst, Lexik. Gaert. I Nachr. i. 254; Spreng.

a. croccum, F. G. Dietr. (1. c.) $255=$ Schoenolirion croceum.

1. dendroides, Stev, in Comm. Soc. Phys. Mosq i. (I808) 43 ; et.

1. fastigiatum, F. G. Dietr. (1. c.) 256 ; Steud

$147^{2}$ 1. niven, F. G. Dietr. (1. c.) ; Spreng.

1481 a. virgatum, F, G. Dietr. (1. c.) $257=$ Nolina georgiana.

\section{ANTHOLYZA}

$149^{2}$ 1. alcthroides, Burm. f... (non alctroides).

$149^{3}$ 1. intermedia, Baker... (1877).

\section{ANTHOXANTHUM}

$150 \%$ 1. amarum, Brot... (dele "f. 1 »)

glauсum, Vahl, ex Poit. Encyc. Suppl. ii. 662 et Roem.

pulchellum, D. Dietr... i. 125 (non 625).

\section{ANTHRISGUS}

$150^{3}$ a, Anthriscus, Karst, Pharm. Med, Bot. $85 \%=$ vulgaris.

\section{ANTHURIUM}

$151^{1}$ 1. candidnm, Bull. = Spathiphyllum candidum N. E. $B r$

\section{$153^{3}$ lin. 1. 1. ANTHYLLIS.}

\section{ANTIRRHINUM}

$155^{\mathrm{I}}$ a. apterum, Vathe, in Oestery. Bot. Zcitschr. xxvi (1875) 96. - Afr. trop.

\section{ANTURA}

$157^{2}$ a. edules, Forsk. (1. c.) p. cvi. = C. edulis

15.3 AOPLA, Lindl, Bot. Reg, sub. t. 1701 (1835) 1573 1. reniformis, Lindl. (Habenariae sp.) $=\mathrm{H}$. er minium reniforme. 
APARGLA

1581 1. danubialis, Scop. Introd. 122 ; F1. Carn.

a. proteiformis, Ambrosi, Fl. Tir. Austr. ii. 564 $=$ hastilis

APERULA

1591 1. pipericarpa, Meissn. (non piporicarpa).

\section{APHELANDRA}

$160^{1}$ a. pulcherrima, R. Bv. Prod. 475, - Ind, occ scabra, R. Br. (1. c.) = pectinata ?

1612 1. APIOS. Corn. ex Medic... (1787) ; Moench, twberosa, Moench, ... = americana.

$163^{3}$ 1. APLOSTEMON, Rafin. in Am. Monthly. Mag. i. (1817) 431 ; et... bracteatum, Rafin. (1. c.) $=\mathrm{S}$. bracteatus. triquetrum, Rafin. $(1, \mathrm{c})=\mathrm{S}$. monander.

\section{APONOGETON}

$165^{2}$ a. Kraussianum, Hochst. ex Krauss, in Flora, xxviii. (1845) 343. - Afr. austr.

APORUM

$165^{3}$ a. incrassatum, Brongn. in Duperr. Voy. Coquille. Phan. 204, t. 42, fig. B. (non Blume). $=$ Eria aporoides.

\section{APPENDICULA}

$166^{1}$ a. manilensis, "Reichb. $f$. in Walp. Ann. i, 791 " in obs. - Ins. Philipp.

manillensis, Miq. Fl. Ind. Bat. iii. $703=$ 1raec.

\section{ARABIS}

$169^{2}$ 1. patens, Sulliv. in Am. Fourn. Sc. Ser. I. xlii. (1841) $49 .-$

ARALIA

1721 a. syana, Veitch, Cat. (1870) 1\% - Ins. Pacif.

\section{ARAUJIA}

1722 1. sericofera (non sericifera)

\section{ARCEUTHOBIUM}

1732 a Pusillum, Peck, in Ann. Rep. N. Y. State Museum Nat. Hist. (Dec. 1875) 112. - Am. bor.

a. verticilliflora, Engelm. in Bot. Calif. ii. 107. - Mexic

\section{ARGFLANGELIGA}

$173^{2}$ a. Archangelica, Karst. Pharm. med. Bot. $843=$ offrcinalis.

ARCTOPHILA

$174^{1}$ a. effusa, Lange, in Adnot. ad Fi. Dan. suppl. 126 (1874); et Consp. Fl. Groenl. 1. 167 (1880). - Groenl.

\section{ARDISIA}

1761 1. excelsa, Ait. $261=$ Myrsine Heberdenia.

$176^{3}$ a. montana, Sieb, ex Miq. Cat. Mus. Bot. Lugd. Bat. 65 nomen; ex Franch, \& Savat, Enum. Pl. fap. i. 305. - Japon.

ARDUNAA, Mill... Linn. Mant. $52(1767)=$

I7\% 1. grandiftora, E. Mey. 1.c. 191 (non 190).

\section{ARECA}

$177^{2}$ 1. Bacaba, Arruda, ... $490=$ Oenocarpus Bacaba.

$1 \pi^{3}$ a. Herbstii, Hort, ex W. Wats, in Gard. Chron. (1884) ii, $426=$ Acanthophoenix crinita.

a. montana, Hort. Cantab. ex R. Grah. in Bot. Mag. sub t. $3874=$ Prestoea montana.

178 Normanbyi, F. Muell... = Ptychosperma Normanbyi.

a. pisifera, Lodd, ex Hook, f. Kew Rep. 1882 (1884) $54=$ Dictyosperma furfuraceum.

a. speciosa, Hort. ex Lem, in Illustr. Hortic xiii. $(1866)$ t. $462-3=$ Hyophorbe amaricaulis.
AREMONIA

$178^{1}$ 1. agrimonoides, DC... Agrimonia Agrimonoides,

\section{ARENARIA}

$178^{3}$ a, Brewerina A. Gray, in Proc, Am. Acad. viii. (1872) 620

$180^{2}$ 1. musciformis, Wall...641 (non 6401).

l. parvifolia, Benth... (non parviflora, quae perperam in mss, Kew, exstat.).

1. scandinavica, Spreng... 402 (non 399).

\section{ARENGA}

$181^{3}$ a. Bonnetti, Hort. Rollis. ex Hook.f. Kew Rep 1882 (1884) 6I. - Ind. or.

\section{ARGANIA}

$182^{2}$ a. TEkELIA, Scop, Introd. $88(177 \%)$

ARISAEMA

$185^{3}$ a. multicarinatum, Wall. ex Royle, Ill. Bot. Himal. 406. - Reg. Himal.

\section{ARISTEA}

186 1. compressa, Buching. ex Krauss. in Flora, xxviii. (1845, 309 nomen; et ex Baker

\section{ARISTIDA}

$187^{1}$ a. Aanuginosi, Burch. Trav. ii. $226=$ vestita, Thunb.

\section{ARISTOLOCHIA}

$188^{3}$ 1. frutescens, Marsh... = A. Sipho (non macrophylla).

1891 1. grandiflora, Arruda... 499; Gomez

\section{ARMENIACA}

$190{ }^{3}$ a. batavica, communis, macrocarpa, mira, mongametia, pracox, tardiflora, Poit. \& Turp. in Poit. Pomol. Franc. $1_{2}=$ P. Armeniaca.

1931 1. AROMADENDRON, Andr. ex Steud. Nom. ed. II. i. $134 \cdot(1840)=$ seq.

$192^{3}$ a. AROMADENDRUM, W. Anders, ex R. Br. Prod. 553 in Adnot. $(1810)=$ Eucalyptus, L'Hérit. (Myrtac.)

\section{ARTEMISIA}

$198^{2}$ 1. pallens, Wall. ex Bess, in Nouv. Mém. Soc Nat. Mosc. iii.o(1834) 85. - Ind, or.

ARTHRATHERUM

$200^{1}$ a. lamuginosum, Burch. Trav, $\mathrm{ii}, 617=$ Arıstida vestita, $T h u n z$

\section{ARTOGARPUS}

2013 1. Dadah, Miq... (nion Dadak).

\section{ARUM}

$202^{3}$ a. divaricatum, Thw. Enum. $334=$ Theriophonum crenatum.

a. Roxburghii, Thw. (1. c.) $432=$ Typhonium Roxburghii.

\section{ARUNDINARIA}

$204^{1}$ a. diversifolia, Kurz, ex Teijsm. \& Binn. Cat. Pl. Bogor. 19 nomen = Fortunei?

Kokantsik, Kurz (1. c.) $=$ Bambusa marmorea.

Kumasosa, Kurz (1, c.) = Bambusa palmata (in Suppl.).

pygmaea, Kurz 1. c. = B. pygmaea?

siamensis, Kurz (1. c.). - Siam.

\section{ARUNDINELLA}

$204^{2}$ a. Pterygostachyul, Nees, ex Steud, nom. ed. II. ii. 42 (1841).

PterigostachYuM, Nees, ex Steud. Syn. Pl. Gram. $413(1855)$.

\section{ARUNDINELLA}

$204^{3}$ 1, setosa, Trin...63 (non 65).

\section{ASGLEPIAS}

$207^{3}$ a. ciliata, [Pers, in] Linn. Syst. Veg. ed. XV. 271; Murr.

\section{ASIMINA}

$210^{1}$ a. virginiana, Poit. \& Turp. in Poit. Pomol Franç. ii。t. $54=$ triloba.

$210^{2}$ a. ASOPHILA, Neck. Elem, ii, $162(1790)=$ Gypsophila, Linn. (Caryoph.).

\section{ASPARAGUS}

2132 a. punjabensis, Stew. Punj. Pl. 233. - Ind. or

$213^{3}$ I sarmentosus, Linn... Afr, austr. (non Ind, or.

a. Satawnar, J. A. Murr. Drugs Sind, $24^{\circ}=\mathrm{ad}^{-}$ scendens.

\section{ASPERULA}

214 $14^{3}$. Fordani, Perr. \& Song, in Bull. Soc. Hist. Nat. Savoie, 1853 (1855) 196 = longiflora.

\section{ASTELIA}

$217^{3}$ 1 albicans, Colenso, ... = spicata.

1. fragrans, Colenso, $\ldots=$ nervosa

\section{ASTER}

2191 a. BRACHYASTER, Ambrosi, Fl, Tir. austr, ii, $379(1857)$

$221^{1}$ 1. Heterochaeta. C. B. Clarke, Comp. Ind. 44.Reg. Himal.

$221^{1}$ a. imbricatus, Harv, in Harv. \& Sond. Fl. Cap. iii. 77. - Afr. austr.

1. imbricatus, Linn... $21=$ Felicia reflexa.

$223^{2}$ 1. scorpioides, Scop. Introd. 130 ; F1. Carn

\section{ASTRAGALUS}

$22 s^{3}$ 1. candidissimus, S. Wats. Bibl. Ind. N. Am. Bot. 191. 一 Calif.

23.33 a linzearis, Edgew, ex Aitch. Cat. Pl. Punjab, $43=$ bakuensis.

2371 a. ramosus, Aitch. Cat. Pl. Punjab, 43, sphalm. = hamosus, Linn.

2381 a. Sprunerianus, Bunge, Astrag. ii. 251 (Index) sphalm。 = Spruneri.

$239^{3}$ 1. wartoënsis, Boiss... (non urtoënsis).

2491 a. ASTRALAGUS, Curran, in Bull. Calif. Acad, i. II. (1885) 152; Greene, (1. c.) 155, sphalm. = Astragalus, Tourn.

\section{ASTROGARYUM}

2402 1. aroenteumn, Hort... = A. Malybo.

a. filare, Hort, Bull. ex Hook. f. Kew, Rep. 1882 (1884) 71. - Hab

a. iriartoides, Willis, ex Regel, in Gartenfl. xxix. (1880) 230 t. 1022 f. 3 (Martinesiae sp ?) $\mathrm{Hab}$ ?

\section{ASYSTASIA}

$242^{1}$ a. quadrangularis, Heyne, ex Trimen, Syst. Cat. Pl. Ceyl. 67, nomen. - Ind. or.

2423 1. ATHALMUM, Neck

\section{ATHAMANTA}

2431 1. Ahinensis Linn = Selinum canadense.

\section{ATHANASIA}

2432 l. capitata, Limn Amoen Acad, vi, 97. - Afr. austr. (i, e. dele «Pl, Afr. Rar. p. $50 »$ )

a. crithmifolia, Scop. Introd. $127=$ parviflora, Thunb.

1. laevigata, Linn. (l.c.) 98 (dele «Pl. Afr. Rar. p. $52 \gg$ ).

a. vigida, Scop. $(1 . \mathrm{c})=$. Pteronia incana.

1. squarrosu, Linn. (1. c.) (dele " Pl. Afr. Rar. p. $52 m$ ).

\section{ATHRIXIA}

2442 1. chaetopoda, F. 14 uth

ATRAGTYLIS

$245^{1}$ 1. lanatus, Scop. Introd. 124 ; Fl. Carn.

2452 1. ATRAPHAX, Scop. Introd. $344(1777)=$ Atraphaxis, Linn.

ATRAPHAXIS

$245^{3}$ I undulata, Scop. Introd. 344: Willd. 
ATRIPLEX

$246^{3}$ 1. holocarpa, F. Muell... = spongiosa.

ATROPIS

:4S: 1, tenuifolia, Thurb... = Poa tenuifolia, Nutt. ATYLOSIA

24:33 1. barbata, Baker...216 = goënsis.

1. goënsis, Dal\%... 186. - Ind. or.

\section{AUBRIETIA}

2492 italica, et Kotschyi, in ordine alphabetico ponuntur.

$242^{3}$ a. ANGUSTA. Ellis, in Linn. Corresp. i. 102$106(182 \mathrm{~L})=$ Gardenia, Ellis (Rubiac.).

\section{AURANTIUM}

$\therefore 1^{2}$ a B Bigarella, conniculatum, coronatum, Poit. \& Turp, in Poit. Pomol. Franc, ii. $=\mathrm{C}$. Aurantium.

\section{AVENA}

2521 1. antarctica, R. Br. Prod, 209 ; Roem. \& Schult. 2522 1. caespitosa, Scop. Introd. 74 ; Kuntze...: : = Deschampsia caespitosa.

a. canina, Scop, $(1, \mathrm{c})=$ Aorostis canina.

$252^{23}$ a. Cupaniana, Ambrosi... $238=$ Aira caryophyllea.

2.,3: 1. Aexnosa, Scop. (1. c.); Mert. \& Koch... = Deschampsia flexuosa.

2.:.' a. Gaudiana, Ambrosi. Tirol. Austr. i. $237=$ Trisetum Cavanillesii.

2.53: 1. montana, Scop. (1. c.); [Weber]... = Aira montana.

$2533^{3}$ 1. arata, Scop. (1. c.); C. C. Gmel... = Lagurus ovatus.

$254^{2}$ a. Spica-renti, Scop. (1. c.) ; = Apera Spicaventi,

1. subspicata, Scop. (1. c.); [Clairv.]... Trisetum subspicatum

AZALEA

2561 a. arborea, Bart. ex Pursh, Fl. Am. Sept. i. 153 $=\mathrm{R}$. arborescens.

$2.56=1$. pontica, Linn, = R. flavum, G. Don.

$256^{3}$ 1. verticillata, Bart... = R. arborescens, Pursh.

\section{AZORELLA}

2.5\% 1. glabra, Wedd... $67=$ diapensoides.

\section{B}

25:3 I. BABIANA, Ker-Gawl. in Bot. Mag. sub t. $539(1801)$; et t. $576(1802)$.

a. crispa, Ker-Gawl. (1. c.) = Tritonia crispa.

fragrans, Ker-Gawl. (1. c) = plicata.

a. mucronata, Ker-Gawl. (l. c.) ; et in...

1. plicata, Ker-Gavel, (l. c.); et t. 576 .

a. plicata, Ker-Gawl. (1. c.) partim= Thunbergii

punicea, Ker-Gawl. (1. c.) = stricta

1. ringens, Ker-Garul. (l. co) ; et in...

rubrocyanea, Ker-Gawl. (1. c.) = stricta.

1. sambucina, Ker-Gawl. (l.c.); et in..

spathacea, Ker-Gawl. (l.c.) ; et t. 638.

stricta, Ker-Gavol. (l. c.) ; et t. 621,637 .

sulphurea, Ker-Gawl. (l.c.) ; et in...

tubata, Ker-Garwl. (l. c. ) ; Eckl.

tubiflora, Ker-Gawe. (l.c.) ; et t. 680

villosa, Ker-Gawl. (l. c. ) ; et t. 583.

villosa, Ker-Gawl. (1, c.); partim = stricta.

\section{BACTRIS}

$.61^{3}$ a. Binoti, Hort. ex Hook. f. Kew Rep, 1882 (1884) 70. nomen. - Hab.

Caraja, Hort. ex Hook. f. l.c. nomen. - Hab.?

\section{BALANITES}

$265)^{1}$ 1. Roxburghii, Planch... ii. (1854) 258. - Ind. or.

\section{BAMBUSA}

$267^{3}$ L. Chino, Franch. \& Sav.

$265^{2}$ 1. senanensis, Franch. \& Sav.. 182, 606 .

$268: 1$. virgata, Trin.

\section{BANISTERIA}

2702 a. rotundifolia, Buc'hoz, Herb. Col. Amerr. t. 28 (Quid?). - Hab.?

\section{BARRINGTONIA}

2751 1. Butonica, Forst $=$ speciosa.

$270^{1}$ a. luzonensis, Rolfe, in fourn. Bot. xxiii. (1885) 213. - Ins. Philipp.

1. Iuzoniensis, Vidal... $113=$ praec.

1. speciosa, Forst... - Ins. Pacif.

$276^{3}$ a. BARTRAMIA, Ellis, in Linn. Corresp. i. $15(1821)=$ Dodecatheon, Linn. (Primul.).

BASILAEA

2772 1. punctata, Mirb. 1. c.; Lam. Illustr. ii. 381 [t. 239 f. 2].

BASSIA

$277^{3}$ a. Maclayana, F. Muell, in Vict. Natural. i. (1885) 168 , nomen, - N. Guin.

BASSIA, Koenig

$273^{3}$ 1. ILLIPE, Gras, in Bull. Soc. Br. Fr. xi, (1864) 83 2773 1. Blancoi, A. DC $\ldots=$ D, latifolia, F, Villar.

2781 1. lanceolata, A. DC... = Dichopsis lanceolata, F. Villar.

oleifera, A. DC $\ldots=$ D. oleifera, $F$. Villar.

\section{BATRACHIUM}

279: 1. Rionii, Nym,.. = R. trichophylla.

\section{BANERA}

2793 a. Ramsaia, W. Anders, ex R. Br. Prod, 553 in adnot. (1810).

\section{BAUHINIA}

$279^{3}$ 1. acuminata, Linn... 375 (non 376).

$281^{2}$ a. timorana, Decne, in Nouv. Ann. Mus. Par. iii. (1834) $466=$ racemosa.

timoriana, Steud $\ldots=$ praec

timoriensis, Baker, in Hook, f. Fl. Brit. Ind. ii. $276=$ timorana.

\section{BEGONIA}

$284^{1}$ a. Chelsoni $\times$, Veitch, Cat. (1871) 14 ; Hort. internedia X. Veitch, Cat. $(1873-74)$; et ex.

BELLEVALIA

$285^{1}$ 1. azurea, Boiss... $=\mathrm{H}$. azureus.

$291^{3}$ 1. BENZOIN, Ludw. Def. 143 (1737); Nees,

\section{BERBERIS}

2921 a. alba, latifoliu, sylvestris, Poit. \& Turp. in Poit Pomol, Franç. ii. = vulgaris.

2922 1. concinna (err typ. oncinna).

$293^{2}$ stenophylla $X$, dele $"=$ Darwinii $»$.

\section{BERGHEMIA}

2931 a. HALAEA, Garden, in Linn. Corresp. i. 378 379 (1821)

$294^{1}$ a. Huxhamia, Garden, (1. c.) 366, 379 (1821).

BERGHAUSIA

$294^{2}$ 1. barbulata, Endl. ex Miq. in Verh. Nederl. Inst. IIl, iv. (1851) 32 (Analect. Bot. Ind. ii. 20) - China ; Malaya,

elata, Arn... - Ind. or.

Emodi, Endl... - Reg. Himal.

pallens, Miq. (1. c.) 33 ; (21). - Ind. or.

tenella, Miq. (1. c.) 34 ; (22) - Ind. or.

BERINGERIA

29t3 1. crispa, Neck. Elem. i. 312; G. Don,...

2952 1. BERMUdiANA, Linn. Syst. ed. I. (1735).

$295^{3}$ a. BERNOULLIA, Neck, Elem, ii, $97(1790)=$ Geum, Linn. (Rosac).

hybrida, Neck. 1. c. = G. rivale.

montana, Neck. 1. $c_{0}=$ G. montanum.

reptans, Neck. 1. c. $=$ G. reptans,

virale, Neck. $1 . c_{0}=G$. rivale.

\section{BETA}

2972 a. atriplicifolia, Rony, in Rev. Sc. Nat. Sér. III. i. (1883) 246. - Hispan.

BETONICA

$298^{1}$ 1. nivea, Stev... = Stachys discolor.

\section{BETULA}

$298^{2}$ a. americana. Buc'hoz, Herb. Col. Amer, t. 36 = nigra?

$298^{3}$ etnensis, Rafin. Specch. Sc. i. 17; ex Call, Life Rafin. 146. - Ital.

glandulosa $\times$, Berl, in Ofvers. Vet. Akad. Förh. xli. (I884) ii. VII. 63. - Groenl.

2991 1. pabyracea, Ait.... = seq.

1. papyrifera, Marsh. Arbustum, 19. - Am. bor.

1. populifolia, Marsh.(l.c.);[Dryand]... - Am. bor.

2992 a. BEVERIA, Collinson, in Linn. Corresp. i. 38 (1821) sphalm. = BEURERIA, Ehret = Galycanthus, Linn.

BIASOLETTIA

3001 a. cynapioides, Karst. Pharm. Med. Bot. $857=$ Carum cylindricum?

\section{BIDENS}

$301^{1}$ a. linifolius, Sch.-Bip. ex Klatt. in Flora, 1xviii. (I885) 203. - Mexic.

$303^{1}$ a. BIGELOWIA, Rafin. in Am, Monthly Mag. i. (1817) $442=$ Arenaria, Rupp. (Caryophyll.)

montana, Rafin. $\left(1 . c_{0}\right)=$ A. montana,

\section{BIGNONIA}

$305^{3}$ l tinctoria Arruda... $497=\mathrm{B}$. Chica

BINECTARIA

$307^{2}$ a. laurifolia, Forsk. (1. c.) p. cx. = I. maxima?

BISGUTELLA

3083 1. verna, Mathieu, F1. Belg. $49=$ laevigata

$313^{3}$ 1. BLUfFIA, Delile... ; Nees, in Delect.. Gram. 61 (1836).

\section{BOEHMERIA}

$316^{3}$ 1 frutescens, Thunb, in Trans, Linn, Soc, ii. 1794) 340 cum. cit. falsa $=$

$317^{2}$ 1. scabrella, Gaudich... 500

3183 1. BOISSIERA, Haenseler, ex Willk. in Bot Zeit. iv. (1846) $313=$

Pumilio, Stapf, ... $9=$ bromoides.

\section{BOMBAX}

$320^{2}$ 1. gossypinum, Linn. Syst. ed. XII. $457=$ Gossypium, Cav. Diss, v. $297=$ praec

1. insigne, Wall... 71 (non 74).

1. mediterraneum, Arruda,... $489=$ Chorisia ventricosa.

3211 a. BONAMYA, Neck, Elem. i. $316(1790=$ Stachys, Tourn. (Labiat.)

$321^{2}$ a. BONINIA, Planch. in Ann. Sc. Nat. Sér. V. xiv. (1871) 309 in nota $=$ Evodia, Forst (Rutac.).

a. glabra, Planch. 1. c. 310 in nota. - China.

a. grisea, Planch. 1. c. - China.

3252 a. BOSSEKIA, Neck, Elem. ii. $91(1790)=$ Rubus, Tourn. (Rosac.).

BOURRERIA

$327^{3}$ a. montana, Wright, in Sauv. F1. Cub. $110=$ cassinifolia.

3293 a, BRACHYASTER, Ambrosi, Fl. Tir. Austr. ii. $379(1857)=$ Aster, Tourn. (Compos.). Bellidiastrum, Ambrosi, 1. c. $380=$ A. Bellidiastrum. 
BRACHYCOR YTHIS

$330^{2}$ 1. tenuior, Reichb. f... - Afr. austr, (non Afr. trop.).

BRAHEA

$333^{2}$ a. glauca, Hort. ex Hook. f. Kew Rep. 1882 (1884) $64=$ Erythea armata.

lucida, Hort, ex Frook. $f$. (l. c.), - Hab.

nobilis, Hort. Rollis. ex Hook. $f$. (l. i. . ). $\mathrm{Hab}$. ?

\section{BRASSICA}

$334^{3}$ 1. SINAPI, Neck. Elem. iii. 80 (1790); Dulac

33.51 a arjensis, Scheele, in Flora, xxvi. (1843) 319 $=$ B. Sinapistrum.

\section{BRAYERA}

3371 1. HAGEA, Pfeiff. Nom, Bot. i. 1544 (1874) cum cit. falsa.

\section{BREWERIA}

3372 a alternifolia, Radlk, in Abh. Nat. Ver. Bremen, viii. (1883) 413, in Adnot. = africana, Benth. \& Hook. $f$.

\section{BRODIAEA}

$340^{1}$ 1. capitata, Greene, in Bull. Calif. Acad. i. IV (1885) $22 \%=$ insularis.

\section{BROMELIA}

$340^{3}$ 1. muricata, Arruda,... $21=$ Ananas sativus. Sagenaria, Arruda,... 14 = Ananas sativus. variegata, Arruda,... $7[=$ Neoglaziovia variegata, Mez].

\section{BROMUS}

3422 1. japonicus, Thumb. Fil. $7 a p .52$ (non 51 )

a. Lloydianus, Nym. Suppl. Syll. $73=$ molliformis.

$343^{1}$ 1. Plukenetii, All... (non Pluckenetii).

a. pseudo-velutinus, Barnard, ex H. C. Watson, in Phytol. iii. (1850) 807 absque descr. = interruptus, Druce.

ve'ulinus, Auct. Ang1, fide H. C. Watson, Phytol. iii. (1850) $808=$ mollis

\section{BROSIMUM}

$344^{2}$ a, utile, Karst. Pharm. Med. Bot. $498=$ B. Galactodendron.

\section{BROWALLIA}

$345^{1}$ a. exaltata, Fourn, in Baill. Dict. Bot. i. $501=$ elata.

BUCHANANIA, Spreng... 1800 ii . (1801)

234.
$349^{2}$ a. LANZAN, Spreng. (1, c.) 235 , in obs,

\section{BUCHNERA}

3501 1. divaricata, Linn. ex Benth, in Hook. Comp. Bot. i. (1835) $371=Z$. pusilla

$350^{2} 1$ palustris, R. Br. Prod. 437 ; Spreng.

\section{BULBOPHYLLUM}

$354^{2}$ a. biflorum, Miq. Fl. Ind, Bat, iii. 646. - Java. $355^{2}$ 1. nutans, Rich. in Mém. Soc. Hist. Nat. Par iv. (1828) 55 = variegatum.

$356^{2}$ a. BULGA, Linn. Syst. ed. $1(1735)=$ Ajuga Linn. (Labiat.).

\section{BUMELIA}

$35 \% 1$ 1. lycioides, Gaertn. f. Fruct. iii. 127, t. 202 (1805).

BUNIUM

$358^{1}$ a. montanum, Koch, Syn. F1. Germ, ed. II. 315 $=$ C. montanum.

$361^{1}$ a. BURCHARDIA, Neck. Elem. ii. 76 (1790) $=$ Psidium, Linn. (Myrtac.).

\section{BURSERA}

$302^{1}$ 1. Delpechiana, Poisson. in C. R. Assoc. Fr. Blois, 1884 (1885) 308. - Mexico.

\section{BYRSONIMA}

$364^{2}$ a. speciosa, Peckolt, in Zeitschr. Allg. Oesterr. A poth. Ver. xxi. (1883) 200, nomen. - Bras.

\section{C}

$369^{3}$ 1. CADIA, Forsk... p. cxi. 90

1. Ellisiana, Baker,... (I883).

pedicellata, Baker, l. c. xxi. (1884)

purpurea, Ait. Hort. Kew. iii. 492

varia, L'Hérit... v. (1795) 22, t. 5.

\section{GAESALPINIA}

$371^{1}$ 1, mimosoides, Lam,.. 462 (non 452)

CAESIA

$371^{2}$ 1. Thunbergit, Kunth, Enum. iv. p. 610.

\section{CAKILE}

$372^{1}$ a. Cakile, Karst. Pharm. Med. Bot. $663=$ maritima.

\section{CALAMAGROSTIS}

$374^{2}$ a. Calamagrostis, Karst. Pharm. Med. Bot. 378 = Stipa Calamagrostis.

\section{CALAMINT'HA}

$375^{3}$ a. Calamintha, Karst. Pharm. Med. Bot. $1002=$ officinalis.

$376^{2}$ a. vutgaris, Karst. (1. c.) $=\mathrm{C}$. Clinopodium.

\section{GALAMUS}

$376^{3}$ a. cochin-chinensis, Hort. ex Hook. $f$. Kew Rep. 188\% (1884) 67. - Cochin China.

$3 \% 1$ l. macropterus, Miq.

$377^{3}$ a, trinervis, Hort. Bull. cf. W. Wats, in Gard. Chron. (1884) ii. 729. - Hab.?

2\%. Nicolai, Hort., Rollis. ex Hook. f. (l.c.) - Hab.?

opacus, G. Mann \& H. Wendl... (= Laccosperma opacum). - Afr. trop.

Oxbyanus, W. Wats, in Gard. Chron. (1884) ii. 729, sphalm, = Oxleyanus

\section{GALANTHE}

$379^{1}$ 1. angustitolia, Lindl. Gen. et Sp. Orch.251 (non 250 ).

1. Ceciliae, Hort. Low, en Reichb. f. in Gard. Chron. (1883) i. 432

cubensis, Linden \& Reichb. $\mathrm{f}$. in Bonplandia, iv. (1856) $322=$ mexicana

1. curculigoides, Wall. Cat. (Hon " Lindl. in »). $379^{2}$ 1. versicolor, Lindl... 42. - Ind. or.

1. vestita, Wall. Cat. (non "Lindl. in »).

\section{CALATHEA}

$380^{1}$ a. guianensis, Klot\%sch, ex Benth. \&. Hook. f. Gen. Pl. iii. 654. - Guiana

$380^{2}$ a. Wioti, Regel, in Gartentl. xxviii. (1879) 298 = Wiotiana.

\section{CALCEOLARIA}

$381^{2}$ a. Logra, Mutis, in Linn. Corresp. ii. 528 (1821).

\section{GALLA}

$384^{3}$ 1. aethiopica, Gaertn... = Richardia africana. ambigua. Salisb... = Richardia africana. pertusa, R. Br. Prod. 327 ; Kunth,

\section{CALLIANDRA}

$385^{3}$ a. macrophylla, Hook. But. Mag. sub t. 5181 sphalm. loco \& Macrophyllae.

a. nitida, Hook. (1. c.) loco \$ Nitidae.

\section{CALLIGARPA}

$386^{2}$ a. Hookeri, C. B. Clarke, in Hook. f. F1. Brit. Ind. iv. 568, in nota $=$ vestita.

\section{CALLISIA}

$387^{3}$ a. gnaphalodes, Linn. P1. Afr. Rar. $23=$ Leysera gnaphalodes.

\section{CALLISTEMMA}

$388^{2}$ 1. hortense, Cass... Suppl. 46 (non 45).

\section{CALLITRIS}

3892 1. articulata, Link, Handb. ii. $473=$

a. articulata, Karst. Pharm. Med. Bot. $319=$ quadrivalvis.

$389^{3}$ 1. cupressiformis, Endl. Syn. Conif, 36 in Syn. -

1. quadrivalvis, Rich. Conif. $46, t, 8, f .1$. -

GALOPHANES

$391^{1}$ a. hyssopifolius, Nees in Limaea, xx. (184\%) 713. - Mexico.

\section{GALOSERIS}

3923 1. rupestris, Benth. 1. c, = O. Isotypus.

$393^{2}$ a, CALOTHERIA, Wight. \& Arn. ex Steud. Syn. Pl. Gram. $199(1855)=$ Pappopho rum. Schreb, (Gramin.)

elegans, Wight. \& Arn. 1. c. $=$ P. elegans.

\section{GAL YGANTHUS}

$394^{2}$ a. Beveria, Collinson, in Linn. Corresp. i. 38 (1821) sphalm.

a Gardenia, Ellis, in Linn, Corresp.i. 86 (1821).

CALYGOTOME

$395^{3}$ 1. villosa... - - Reg. Medit.

$395^{3}$ lin. 28, 1, GALYGOTOME (loco GALIGO TOME)

\section{CALYPTROGYNE}

$397^{2}$ a. elata, H. Wendl.? of. Hook. f. Kev Rep. 1882 (I884) 60. - Hab.

Swartzii, Hook. f. Kew Rep. J882 (1884) 61; Nichols. Dict. Gard. 249. - Ind. occ.

\section{GALYSTEGIA}

$398^{*}$ a. spithamea, R. Br, Prod. $483=$ Convolvulus spithamea.

\section{CALXTHRIX}

$39 S^{3}$ 1. pubescens, Sweet, Hort. Brit. ed. I. 157, nomen; et ex Sond.

1. pulchella, Turcz... = breviseta

\section{CAMARIDIUM}

3991 a. ochroleucum. Lindl... - Guiana. ochroleucum, Lindl. (1. c.) partim =

\section{GAMELLIA}

$400^{1}$ 1. grandiflora, Forsk... = Ruellia longiflora

$400^{2}$ a. CAMMARUM, Hill, Brit. Herb. 47 (1756) = Eranthis, Salisb. (Ranunc.) hyemale. Hill, 1. $\mathrm{c} .=\mathrm{E}$. hyemale

\section{CAMPANULA}

4031 a. groenlandica, Berl in Ofvers, Vet. Akad. Förh. xli. (1885) n. VII. 50. - Groen!

I. rhomboidea, Murr... = Adenophora communis

\section{GAMPHORA}

$407^{3}$ a. Camphora, Karst. Pharm, Med. Bot. $504=$ Cinnamomum Camphora.

\section{CAMPYLOSTACHYS}

4093 1. phylicoides, Sond... xx.

\section{GANNA}

$412^{2}$ a iridiflora X, Carr. in Rev. Hort. (1895) 291.-Hyb. artef.

CANSJERA

$413^{3}$ 1. Rheedii, F. F. Gmel. Syst. ii. 230 (non i.)

\section{GANTHIUM}

$414^{1}$ 1. Gueinzii, Sond... Adausonia, xii. (1878) $18 \%$ $414^{3}$ a. subalatum, Baill.
$-\mathrm{N}$. Caled.

\section{GAPSELLA}

$418^{3}$ 1. spinosa, Medic. Pflanzeng. 85 ; Moench,

GARAGANA

$419^{3}$ a. Caragana, Karst. Pharm. Med. Bot. $699=$ arborescens. 
GARDAMINE

$421^{3}$ 1. longirostris, fanka, in Közlem. Magyar Tudom. Akad. xii. (1876) 164. - Banat.

\section{GARDUUS}

$424^{3}$ Carolorum $\times \ldots=$ Cricus Caroloram $X$.

$426^{3}$ a. simplex, Sweet, Hort. Brit. ed. I. $213=$ Jurinea mollis,

\section{CAREX}

$47^{2}{ }^{2}$ 1. acicularis, Turcy. ex Bess. in Flora, xvii. (1834) Beibl. 26 nomen.

$427^{3}$ 1. anthericoides, Presi,... $204=$ macrocephala.

$428^{1}$ a. arcuata, C. P. Laestad. Bidr. Känned. växtr. Torneo Lappmarks (1860) 26, 43. - Europ. bor.

Arnottiana, Nees, ex Drejer, Symb. Caric. 16. Ceylan.

4292 1. Cheesemanii, Petrié,... = comans, Bergg.

4293 columbiana, Dewey, in Am. Fourn. Sc, xxx (1836) 62, tab, 136, fig. 90. - Am. bor

$429^{3}$ 1. corralensis, Phil.

$430^{3}$ a. disperma, Kunze, ex Carey, in A. Gray, Manual, ed. I. $542=$ rosea

$431^{\lambda}$ 1. epigfjos, Fries, in Bot. Notis. (1843) 105 ; et Summa..

$431^{2}$ 1. Alaccida, Sw, ex Wahlenb, in Vet. Akad. Nya Handl. Stockh. (1803) $149=$

4313 1. gaimardioides, E. Desv... = Scirpus semisubterraneus.

$432^{2}$ a. Halleri, Gunn. Fl, Norv. ii. $103=$ Vahlii

$432^{3}$ a. hyalinolepis, Steud. Syn. P1. Cyp. $235=$ riparia, Curt.

1. hyalinolepis, Stend. in Lechler, Berb. Am, austr. 56. - Peruv

$433^{1}$ a. involuta, Syme, Engl. Bot. ed. III. x. 169. Europ.

$433^{2}$ 1. Kochiana, DC. Cat. Monsp. 89 (non 8),

$434^{2}$ a. longibracteata, Schleicher, Cat. Pl. Helv. ed. IV. (1821). - Helvet.

1. macrocephala, Willd, ex Spren $\alpha$. Syst, iii. 808.

$434^{3}$ a. matvernensis, S. Gibson, in Phytol. i. (1843) $715=$ leporina.

a. melanocephala, Kavel. \& Kivil. in Bull. Soc. Mosc. (1841) 436. - Hab.

melanocephala, Turcz, ex Kunth, Enum. ii. $437=$ Vahlii

Mertensii, Bong. in Mém. Acad. St Pétersb. ii. (1833) 169 ; Presl,

$435^{1}$ 1. Moniezi, Lagrange, (non Timb.).

monostaclya, A. Rich. Tent. Fl. Abyss. ii. 512 = parasitica

$435^{2}$ muricata Cheesem, in Trans. N. Z. Inst. xvi. 1883 (1884) 411 = trachycarpa [in Supp1.].

$436^{1}$ 1. pacifica. Drejer, F1. Excurs. Hafn. (1838) $292=$

1. Parkeri, Petrie,... $332=$ lagopina

parriflora, C. A. Mey, Verz. Pfl. Cauc, 30. Reg. Cauc.

$436^{3}$ a. phaccostachya, Steud. Nom. ed. II. i. sphalm. $=$ seq.

a. phaeostachya, Sm. Engl. Fl. iv. 99. - Europ.

$437 \%$ 1. prolixa, Fries, Novit. Suec. Mant. 3 (1842) $150=$

4372 1. putbescens, Poir... cf. $317=$

rariflora, Sm. Engl. Bot. t. 2516 ; et Engl. Fl. Rasulii, post «rariflora » ponitur

4381 a. Iutilus Humncki, Cat. Pl. Orlécns, 25. Europ.

4391 1. stenolepis, Less. Reise durch Norwegen, 301 = ampullacea

4392 tenuifolius, Poir... cf. $317=$

$439^{3}$ 1. torta, Boott, ex Cavey, in A. Gray, Manual, ed. I. 54 , et ex Tuckern.

1. transilvanica, Schur,... = pallescens.

1. turfosa, Fries, in Bot. Notis. (1843) 104; (1845) 117, fide Summa Veg. $228=$ vulcraris

$440^{2}$ a. vacillans, Drejer, in Hartm. Excurs. F1. ed. I. iii, = salina

vesicaria, W. Boott, in Bot. Calif. ii. 252 = monile.

xanthocarpa, Degland, in Loisel. Fl. Gall. ii. 299. - Europ

\section{CARICA}

$441^{1}$ 1. scandens, Walp. Ann. iv. 868 ; sphalm. = candicans.

\section{CARLINA}

$442^{1}$ a. subfisca. Nym. Consp. $400=$ sulphurea.

$442^{1}$ 1. CARLOTEA, Arruda... (1816) = Hippeastrum? Herb. (Amaryll.).

CARTHAMUS

$444^{3}$ a. carolinensis, Hort. Trian. ex Buc'hoz, Herb. Col. Amer, t. $17=$ Carduncellus caeruleus. $445^{1}$ 1. cyaneus, Hill, Hort. Kew. ed. I. 57 ; Banks,... $445^{1}$ 1. laevis, Hill, Hort. Kew. 57 (1768); ed. II. 57, t. $5(1769)=$ Stokesia cyanea

\section{CARUM}

$445^{3}$ a. montanum, Benth. E Hook. f. ex Archang. Comp. Fl. Ital, 274. - Europ.

\section{CARYOTA}

$447^{1}$ a. Blancui, Hort. Veitch, ex Hook. f. Kerw Rep. 1882 (1884) 61. - Ins. Philipp.

$449^{2}$ a. CASSANDRA, D. Don.

ChamaedaPhNE, Moench, Meth. $45 \%$ (1794).

CASSIA

$450^{1}$ a, babylonica. Schrank, in Hoppe, Bot. Zeit, iv. (1805) $312=$ C. Absus.

4502 1. candenatensis, Dennst... = Dalbergia torta, R. Grak.

$452^{3}$ oborata, Collad... $15=$ obtusa obtusa, Roxb... 757 - Geront. trop.

$453^{2}$ a. pulchra, Rodsch. Bemerk. Kol. Esseq. 42. Guiana.

$454^{2} 1$. venenifera, Rodsch. (1. c.) 43 ; et...

CASTALIA, Salisb... (1805) 71 .

$455^{3}$ a, alba [Wood] in Rees, Cycl, vi. n. $2=\mathrm{N}$. odorata.

1. caerulea [Wood] (1. c.) n. 8; Tratt.

1. Lotus, [Wood] (1. c.) n. 3: Tratt,

a. odorata, [Wood] (1. c.) n. $r=\mathrm{N}$, odorata.

mystica, Salisb... (1805)

pubescens, [Wood] (1. c.) n. $8=\mathrm{N}$. Lotus,

scutifolia, Salisb...(1805)

1. stellata, [Wood] (1. c.) n. 9; Blume,

\section{CASTANEA}

$456^{1}$ a. Castanea, Karst. Pharm. Med, Bot. $495=$ sativa

a. dentata, Borckh. Handb. Forst. Bot. i. 741 $(551)=$ sativa.

$456^{2}$ 1. CASTANOPHORUM RUM) Neck,

\section{CASTILLOA}

$457^{2}$ a. Markhamiana, Markham, Peruv, Bark (1880) 453 = elastica

\section{GATABROSA}

4581 a. antarctica, 7. Buch. Indig. Grasses N. Zeal. t. $41 \mathrm{~B}($ non Hook. f.) - N. Zel.

GATALPA

$458^{2}$ a. Catalpa. Karst. Pharm. Med. Bot. $927=$ bignonioides.

\section{CATAPODIUM}

$558^{3}$ 1. fusiforme Benth... sphalm, = filiforme

a. millaterale, Ledeb. F1. Ross. iv. $347=$ F. tenuiflora.

\section{GATASETUIM}

4591 1. cristatum, Lindl... sub t. 840 ; et t. 966.

\section{GATHA}

$459^{3}$ a. edulis, Forsk... p. cvii.

\section{CATTLEYA}

$461^{1}$ a. Devonzic X. Hort. cf. Proc. Roy. Hort. Soc. iii. (1863) $372=$ Laelia devoniensis

1. devonientis X, Hort. cf. Proc, Roy. Hort. Soc, iv. (1864) $178=$ Laelia devoniensis.

$461^{3}$ 1. Pinellii, Hort. ex Lindl. Bot. Reg. (1844) sub t. 5, n. 9. Bras

\section{GAUCALIS}

4621 1. Carota, Crantz, Umb, Class. 113 ; Huds.

\section{GAUGANTHUS}

$462^{3}$ a. edulis, Forsk. Fl. Aeg. Arab. p. cxi. nomen $=$ arabicus.

\section{CEANOTHUS}

464l 1. bicolor Humb \& Bonpl. ex Roem. \& Schult Syst. v. $300=$

1. buxifolius, Humb. \& Bonpl. ex Roem. E. Schult. Syst. v. 300. -

\section{GENGHRUS}

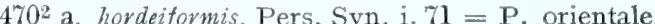

1. orientalis, Willd. ex Trin. Gram. Panic. $69=$

CENTAUREA

$473^{2}$ a ephelidea $X$. Franch, in Bull. Soc, Philom. Sér. VII. vi. (1882) 218. - Gallia.

4741 a, heteroblepharis $X$. Franch. (1.c.) 217-Gallia

$474^{2}$ 1. Jankeana, Simk, in Termész. Füzetek, i. (1877)

a. Kanitziana, Fask $a$, ex Brandza, in Anal. Acad. Romane, Ser. II. iv. (1884) 447, t. 2, Dobrudscha.

$474^{3}$ a. microcentron $X$. Franch. (1. c.) - Gallia.

$475^{2}$ 1. Oliveriana, $D C$ C. $P r, d \ldots$ (non Olivieriana)

1. omphalodes, Coss. \& Dur... nomen = Volutarella omphalodes.

$476^{2}$ 1. Sadleriana, Fanka, in Közlem. Magyar Tudom Akad. xii. (1876) 178 ; et.

$477^{2}$ a. xanthothrix X, Franch. (1. c.) 219. - Gallia.

CENTROCHILUS

$478^{3}$ 1. gracilis, Schau. tab. $13($ non 113$)=$ Habenaria tipuloides.

\section{GEPHA ËLIS}

4802 a, acuminata, Karst. Pharm. Med. Bot. 1196. N. Granat.

\section{GEPHALANTHERA}

$481^{1}$ a. Austinae, Benth. \& Hook. fo Gen. Pl. iii. 619 = oregana.

\section{GEPHALANTHUS}

$481^{1}$ 1. acuminatus, Rafin... $25=$ occidentalis. chinensis, Lam... 678 = Adina globiflora obtusifolia, Rafin... 25 = occidentalis? occidentalis, Lour... $67=$ occidentalis, Linn. orientalis, Blume, $\ldots .38=$ Naucleae $\mathrm{sp}$. orientalis, Linn... $95=$ Nauclea orientalis. orientalis, Roem. \& Schult... = occidentalis?

\section{GERASTIUM}

$484^{1}$ a. Duriaei, Cariot \&o St Lager, Etude des Aleurs, ed. 8, ii. p, 129, ex Rouy \& Fone. Fl. Fr. iii. 221. - Alger.

\section{GERASUS}

$486^{1}$ a. anglica, brevipes, communis, conglobata, Gon douini, longipes, nana, offcinalis, peracida, propera, regalis, sativa, serotina, tenera, Poit. \& Turp. in Poit. Pomol. Franç. ii. $=$ P. Cerasus.

\section{GERATOSTIGMA}

$488^{3}$ 1. plumbaginoides, Bunge,..

\section{CERCIS}

$489^{2}$ a. texensis, Sarg. in Garden \& Forest, iv. (1891) $778=$ occidentalis

\section{CEREUS}

4902 1. ctenoides, Engelm

$491^{1}$ a. gummosus, Engelm. in Zoi, ii. (1891) 20. Calif.

4913 Martinii, Mart. ex Lem. Illustr. Hortic. v. 1853) 17. - Am. austr.

\section{GEROPEGIA}

$493^{3}$ 1. dichotoma, Haw... - Ins. Canar. (non Ind or. errore Stendeliz).

\section{CEROXYLON}

$494^{2}$ 1. andicola, $H . B . K$... 2. t. 1

\section{GHADARA}

$496^{3}$ 1. tenax Forsk ... p. cxiv. velutina, Forsk. $(1$, c.) 106 


\section{GHAILLETIA}

$501^{2}$ a: capitulifera. Spruce, ex Baill. in C. R. Assoc, Fr. Lyon (1874) $479=$ Tapura capitulifera $501^{3}$ 1. gelonioides, Bedd, For. Man. p. lix (1871); Hook. f... $570=$ sumatrana.

$502^{1}$ a. CHALEBUS, Rafin. in Am. Monthly. Mag. i. (1817) 439 = Salix, Tourn.

\section{CHAMAEDORE}

5031 . Corallina, Hooh, f. Kew Rep. 1882 (1884) 58. - Venezuela; N. Granat.

crucifolia, Hort. ex Hook. f. Kew Rep. 1882 (1884) $59=$ glaucifolia ?

Hartwegi, Hort. ex W. Wats, in Gard, Chron. (1885) i. $410=$ Sartorii

latifolia, Hort. ex W. Wats, (1. c.) $=$ Arenbergiana.

$503^{2}$ a. stoloniferá, H. Wendl. ex Hook, f. Kew Rep. 1882 (1884) 59. - Hab. ?

ventricosa, Hort, ex Hook. f. (1. c.) $=$ Ganssia Princeps?

\section{GHAMAERAPHIS}

$504^{3}$ asbera, Nees,

\section{CHAMAEROPS}

$505^{1}$ a. eleacns, Hort ex Hook, f. Kew Rep. 1882 (1884) $64=$ humilis

\section{CHA VICA}

$508^{1}$ a. longa, Karst. Pharm. Med. Bot. $478=$ Piper longum.

\section{CHELONE}

$511^{1}$ a. Sconleri, Dougl. ex Lindl. Bot. Reg. sub t. $127 \%=$ Pentstemon Scouleri

\section{CHENOPODIUN}

$513^{3}$ a. virgatum, Ambrosi, Fl. Tir. austr. ii. $179=$ capitatum.

\section{GHIONACHNE}

$515^{2}$ ?. barbata, Benn. in R. Br.

\section{CHLORAEA}

5191 a oregand Nutt ex Benth. \& Hook, f. Gen. Pl iii. $619=$ Cephalantha oregana.

\section{GHLORIS}

5192 a americana $\mathrm{R}, \mathrm{Br}$. Prod. $173=$ Bouteloua bromoides, juncifolia.

$522^{3}$ a. CHONDROPHORA, Rafin. New Fl. N Am. iv. $79(1836)=$ Bigelowia, DC (Compos.).

\section{CHORIZANTHE}

5242 1. membranacea, Benth... - Calif

$525^{3}$ 1. GHRYSALIDOGARPUS, H. Wendl. in Bot. Zeit. (18\%8) 117 (non 171).

\section{GHRYSANTHENUN}

$526^{1}$ 1. DENDRANTHEMA... (1858) (ncn 185̃5).

$527^{2}$ a. CHRYSASPIS, Desv. F1. Anjou, 338, in Syn $(182 \mathrm{i})$ ) = Trifolium, Linn. (Legum.) campestre, Desv. 1. c. $=$ T. procumbens.

\section{CIMICIFUGA}

$535^{2}$ a. Cimicifuga, Karst. Pharm. Med. Bot. $57 \mathbf{l}=$ foetida.

\section{CINCHONA}

$535^{3}$ a. bogotensis, Mutis, in Linn. Corresp. ii, $530=$ officinalis.

$536^{1}$ gironensis, Mutis, (l.c.) 518, 521 (Al. gen. ?). - N. Granat.

a. Hookeriana, Karst. Pharm. Med. Bot. 1206 = Cascarilla Hookeriana.

$536^{3}$ a. peruviana, Mutis (1. c.) $=$ officinalis.

\section{CINCHONA}

$536^{3}$ a. Purdicana, Karst. (1. c.) $1207=$ Remija Purdieana.

\section{GINNAMOMUN}

$5399^{3}$ a. Cinnamomum, Karst. Pharm. Med. Bot. 503 = zeylanicum.

Culilaban, Karst. (1. c.) $504=$ C. Culilawan.

\section{GIRRHOPETALUM}

$541^{1}$ a. Cumingii, Lindl. l. c. xxix. (1843).

1. delitescens, Rolfe,

\section{GIRSIUM}

$542^{3}$ a. Kornhuberi $\times$, Heimerl, in Verh, zool, bot. Wien, xxxiv. (1884) 95. - Austria.

$543^{2}$ 1. pauciforum, Sweet. Hort. Brit. ed. I. 214 Koch

CISSUS

$545^{2}$ 1. auriculata, Roxb... $411=$ Vitis auriculata

$547^{2}$ 1. tinctoria, Arruda,... 496; Mart...

$550^{2}$ a. CITROPHORUM, Neck. Elem. ii. 401 (1790) = Citrus, Linn. (Rutac.).

\section{GITRULLUS}

5503 a. Rig0CARPUS, Neck. Elem. i. 238 (1790) Citrullus, Karst. Pharm. Med. Bot. $889=$ vulgaris.

\section{GITRUS}

$551^{1}$ a. CitroPHORUM, Neck, Elem. ii. 401 (1790).

1. Aurantium, Linn... 782 (non 78;).

a, Balotina, bicolor, bigena, communis, Poit. \& Turp, in Poit, Pomol. Franç, ii. = C. Medica.

1. decumana, Murr... 580 (non 508).

\section{CLADIUM}

$551^{3}$ elynanthoides, F. MIuell.

$552^{2}$ 1. GLADRASTIS, Rafin. in Cincinnati Literary Gazette, i. 60 (Feb 21. 1824); et Neogenyt. 1 (1825).

fragrans, Rafin. $l l . c c$.

\section{GLEMATIS}

$557^{1}$ a. hedysarifolia, Lindl. Bot. Reg. t. $599=$ Meyeniana.

5581 1. soongarica, Siev, in Pall. N. Nord. Beitr. vii, 331 .

\section{GLEOME}

5591 1. dodecandra, Linn. Sp. Pl. ed. I. 672 ; ed. II.. - Amphig

5591 a. droserifolia, Franch. in Revoii, Comali, ii. = ovalifolia, Deflers.

$559^{2}$ 1. graveolens, Rafin... = dodecandra

a. Hamiltoniana, Miq. in Linnaea, xviii. (1844) 239 , in nota $=$ aculeata.

$562^{3}$ a. CLEYERA, Neck. Elem, iii. 402, Index $(1790)=$ CLEYRIA, Neck.

\section{CLYPEOLA}

$568^{3}$ 1. alliaced, Berger. Phyton. iii. 155 = Peltaria alliacea.

\section{GNIGUS}

$50^{1}$ a. CEPHALANoplos, Neck. Elem. i. 68 (1790).

a. benedictus, Linn. Sp. Pl. $826=$ Carbenia benedicta.

Carolorum X, Jenner. ex Hook. f. Stud. Fl, ed. II. 703. - Scotia.

\section{GOCGOLOBA}

$573^{2}$ a. Moritziana, Klotsch, ex Meissn, in Mart. Fl Bras, v. I. $28=$ Morztzii $=$ ovata

$573^{3}$ a. parvifolia, Schott, in Spreng. Syst. iv. Cur. Post. 405. - Bras

1. vigidu, Meissn.... = parvifolia Schott.

\section{GOGGULUS}

$574^{2}$ 1. flavicans, Wall... = Anisophyllea flavicans.

\section{GOCHLEARIA}

$575^{2}$ 1. longifolia, Medic. Pfanzeng. 70 ; et in Usteri, 1. repanda, Medic. (lll.cc.)

\section{Cocos}

$576^{1}$ a. Blumenaui, Hort. Lind. ex Hook. f. Kcw Rep. 1882 (1884) 72 nomen. - Hab. ?

$576^{\prime}$ a, Butaeei, Hort. (l. c.) . - Hab.

$56^{2}$ a Gaertneri, Hort ex W Wats, in Gard. Clyron. (1885) i, 439. - Hab,

. Normanbyi, M. Hili... = Ptychosperma Normanbyi.

a, pernambucana, Lodd. (l.c.). - Bras.

Sancona, Hook. $f .(l, c)-$. Bras.

$576^{2}$ 1. ventricosa. Arruda, $. .485=$ Acrocomia scelerocarpa.

COELOGLOSSUM

$575^{2}$ a. cernumm, Benth. Fl. Hongk. 362, sphalm. = C. densum = stenostachya.

\section{GOELOGYNE}

$578^{3}$ 1. Cumingii, Iindl. Bot, Reg, (1840) (non 1843). Misc.

$579^{2}$ triplicatula, Reichr. $f_{\ldots} \ldots-$ Burma

\section{COFFEA}

$580^{2}$ l, stenophylla, G. Don... - Afr. trop. (non Abyss.).

coIX

$581^{1}$ 1. exaltata, Fisch. ex Jacq. Ec1. Gram. t. 40 Jacq. ex... 238.

a. gigantea, Hort. ex Jacq. (1. c.) = C. LacrymaJobi.

1. Ma-Yú-ên, Romanet... Sér. III.

$58 \% 1$ a. COLDENELIA, Ellis, in Linn. Corresp. i. $95(1821)=$ Coptis, Salisb. (Ranunc.).

$584^{1}$ a. Collema, W. Anders ex R. Br. Prod. $553(1810)=$ Goodenia. Sm

\section{COLLETIA}

$584^{1}$ a. iguanaea, Scop. Introd. $207=$ Celtis aculeata

$585^{3}$ a. COLOSTEPHANUS, Harv. Gen. S. Afr Pl. ed. I. 41\%, in nota $(1838)=$ Gynanchum, Linn.

a. capensis, Harv. 1. c. = Cyn, capense, Linn. $f$

\section{GOLPODIUM}

$586^{1}$ 1. latifolium, $R$. $B r . ., 285$ (err. typ. I 86 ).

$590^{1}$ a. GOMIES, Buc'hoz, Herb. Col, Amér. t. 3 (178:3) (quid?)

a. barcalis, Buc'Hoz, l, c. - Hab. ?

\section{GOMMELINA}

5921 1. mudiftora, Linn. Sp. Pl, 41.

5931 a. COMMERCONIA, F, MFuell. Fragmenta xi. (1881) 113 , in obs. = Commersonia Forst. (Stercul.)

$593^{1}$ a. COMMERSORCHIS, Thou. Arch. Afr. tab. synop. i. $(1822)=$ Dendrobium, Sw. (Orchid.).

\section{COMMIPHORA}

$593^{2}$ 1. BaLSAMODENDRUM, Kunth.

1. africanum, Engl. [non Endl.].

$594^{1}$ 1. COMPTONIA, L'Hérit. ex Ait. Hort. Kew. iii. $334(1789)$; Banks, ...

1. asplenifolia, Ait. (1. c.) ; Banks (1.c.)

\section{GONNARUS}

5962 1. Rolfei, Vidul,... $106=$ trifoliolatus

a. trifoliolatus, Rolfe, in foum not. xxiii. (1885) 212. - Ins. Philipp.

\section{GONRADIA}

5991 1. hispida, Benth... = P. Sloanei

\section{CONVOLVULUS}

6002 1. gangeticus Iinn $306=$ Cocculus villosus. $603^{3}$ a. macrophylhus, Aitch. Cat. Pl Punjab. 99, sphalm. = microphyllus.

1. manritanicus, Boiss... 122 = elongatus.

1. Mechoacan, Vitman, 


\section{GONVOLVULUS}

$605^{2}$ a. rotundifolius, Schramk, in Hoppe, Bot. Zeit, iv (1805) 30\%. - Hab.

$605^{3}$ simuatus, Petagna, Inst. Bot. ii. $353(1787)=$ Ipomoea carnosa.

\section{CONYZA}

6us? 1. halimifolia, Scop. Introd. 129; Desf...

(i) ${ }^{3}$ 1. ivaefolia, Scop. (l.c.) i I.ess...

\section{COPROSIMA}

(i1 I2 1. concinna, Colenso $\ldots=$ rhamnoides

1. diraricata, A. Cunn... rhamnoides.

a. divaricata, Hook. f. Fl. N.Zel. i, 107, partim. - N. Zel.

Tucida. End1. Prod. Fl. Norfolk. $60=$ Baueri. (ill: 1. pumila, Hook. $\mathrm{f} . .=$ repens.

COPTIS

(i1 $\mathrm{1}^{3}$ a, COLDENELLA, Ellis, in Linn. Corresp. i. 95 (1821).

Fibraurea, J. Colden, in Linn. Corresp. i, $94,98(1821)$

\section{CORALLORPHIZA}

6I:? a. Corallorrhiza, Karst. Pharm. med. Bot. 448 = innata.

1. Macraei, A. Gray,... = striata (non stricta).

6122 1in. 1. 1. CORALLORRHIZA :-

CORBICHONIA

(i1:2 a. decumbens, Scop. Introd. $264=0$. decumbens CORCHORUS

(12: 1 himnilis, Munro, Hort. Agr. 35; et ex Stocks, CORDIA

(101,33 a, curtassarica Auct, ex Fresen, in Mart. F1 Bras, viii. $18=$ curassavica, Roem, et Schult.? CORNUS

619: a. sativa, Poit. \& Turp. In Poit. Pomol. Franç. ii, = sanguinea

\section{CORONOPUS}

6202 a. Coronopus, Karst. Pharm. Med. Pot. $673=$ S. Coronopus.

CORPAEA

6203 a. Euphecarpus, W. Anders, ex R. Br, Prod, 553 (1810).

\section{GORVISARTIA}

$621^{1}$ 1, indica, DC. ex Royle, Illust. Bot. Himal.251, t. 60, f. 1 ;

\section{CORYLUS}

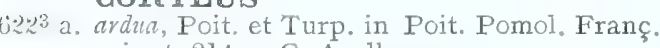
iv. t. $214=$ C. Avellana

1. Hasibani, Sieb... = heterophylla. heterophylla, Fisch... 74. - Japon.

(i: a. sativa, Poit, et Turp. (1. c.), t. $11=$ tubulosa. tetraphylla, Ledeb... = heterophylla.

\section{CORYMBIS}

(i2:3 1. CORYMBORCHIS, Thou. Orch. Afr. tab. (1822).

(is: a. CORYMBORKIS, Thou, in Nouv. Bull. Soc. Philom. n, 19 (1809) $318=$ CorYMBORCHIS, Thou.

\section{COSTUS}

(i2:52 1. spicatus, Scop. Introd, 94 ; Sw.

\section{COTONEASTER}

(i2.,3 a. Cotoneaster, Karst. Pharm. Med. Bot. $785=$ integerrimus.

\section{GOTYLEDON}

(i\%, a Diatostiemon, Salm-Dyck, in Otto Es Dietr. Allg. Garten\%, xxii. (1854) 265 .

GOUEPIA

Pleragine, Arruda, ex Koster, Trav, 499 $(1816)$.

\section{GOUROUPITA}

6291 a. ELSHOLTZIA, Neck. Elem. ii. 256 (1790).

\section{COVELLIA}

6312 1. guttata, Wight,... = F. guttata (1888).

GRANTZIA, Scop.

$6533^{1}$ a. cristata, Scop. Introd. $173=\mathrm{A}$. cristatus.

GREPIS

$641^{3}$ 1. succisaefolia, Tausih, in Flora, xi. (non ix.).

\section{GRINUM}

6422 1. augustum (non angustum).

GROCUS

$644^{3}$ a. appendiculatus, Kern, ex Maw, in Gard. Chron. (1881) ii. 368, in syn. = montenegrinus, $645^{2}$ a. melantherus, Boiss. ex Maw, (1. c.) $749=$ Crewii.

$645^{2}$ 1, monteneorinus, Kerzz... (18S1).

$645^{3}$ a, serbicus, Kern. ex Maw, (1. c.) $368=$ Tomasinianus (vecte Tommasinianus).

$646^{1}$ a. vernts. Berger. Phyton. ii. 159 partim = moesiacus.

a, vernalis, Billb. Econ. Bot. t. $8=$ vernus.

\section{CROSGANDRA}

$646^{2}$ 1. infundibuliformis, R. Br. Prod. 477; Nees,

\section{GROSSOSTYLIS}

$646^{3}$ 1. orandiflora, Brongn of Gris in Bull. Soc. Bot Fr. viii. (1861) 376, et ex Panch et Sebert .

1. multiflora, Brongn. et Gris, (1.c.) $378=$ Haplopetalum multiflorum.

\section{GROTALARIA}

$648^{3}$ 1. latifolia [recte lotifolia], Limn.

6502 a. Stacyana, Wall, in Trans. Med. Phys. Soc. Calc. vii. II. (1835) $228=$ occulta.

$651^{1}$ a. CROTOLARIA, Neck, Elem, iii. 31 (1790) = Grotalaria, Dill. (Legum.).

\section{GROTOI}

6522 a. ciliato-glandulosus, Steud. Nom. ed. II. i. 446 $=$ ciliato-glanduliferus.

$654^{3}$ a, Luzianus, Mull,. Arg. in Mart. Fl. Bras, xi。 II. 218. - Bras.

\section{GRUPINA}

$659^{1}$ a, Crupina, Karst. Pharm. Med. Bot. $1126=$ vulgaris.

CRYPTOPHORANTHUS

6621 1. punctatus,

\section{GUBEBA}

$663^{1}$ a. Cubeba, Karst, Pharm. Med. Bot. $478=$ P. Cubeba.

\section{GUPANIA}

$668^{2}$ 1, revoluta, Rolfe, in fourn. Bot xxiii. (1885) 211 Vidal.

subundulata, Rolfe, (l.c.); Vidal.

6\% $74^{2}$ 1. GUSPARIA, Humb. Tabl. Geogr. ex ej. Voy. Relat. Hist. ii. 672 (err. typ. 172) (1819); et DC

$674^{3}$ febrifuga, Humb. (11. cc.).

$676^{1}$ a. CYANORKIS, Thou, in Nouv, Bull. Soc. Philom.n. 19 (1809) $317=$ CYANORCHIS Thour.

\section{CYBIANTHUS}

$6 \pi^{3}$ a. peruvianus, Miq. in Mart. Fl. Bras. x. 298 in obs. - Peruv.

GYGLEA

$678^{3}$ 1. Burmanni, Miers, ... 41

\section{GYGNOGHES}

$680^{3}$ 1. chiorochilon, Klotzsch, in Allg. Gartenz. vi. (1838) 225; Lindl.

\section{GYDONIA}

$680^{3}$ a. Cydonza, Karst. Pharm. Med. Bot. $783=$ P. Cydonia.

CYLICODAPHNE

$681^{1}$ 1. hucida, Blume... = L. lucida.

\section{GYMBIDIUM}

68211 IRIDORCHIS, Thow, Orch Afr, tab. synop. i. (1822); Blume,

\section{GYNANGHUN}

$684^{1}$ a. africanum, R. Br. Prod. 440 (Cynoctoni sp.) - Atr, austr.

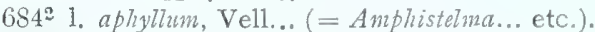
$684^{3}$ a. davuricum, R. Br. (1. c.) $=$ roseum.

$685^{3}$ a. truncatum, R. Br. (1. c.) $=$ pauciflorum

\section{CYNODON}

6862 convergens, F. Muell.

\section{GYNOGLOSSUM}

$687^{1}$ a. cyanemn. Hort. ex Hook, f. in Gard. Chron (I858) $240=$ Myosotidium nobile.

$688^{3}$ a. CYNORKIS, Thou. in Nouv. Bull. Soc Philom. n. 19 (1809) 317 = CYANORCHIS Thou.

\section{CYPERUS}

6922 a elecrans, Schebe ex Rolle, in Usteri, Ann. Bot. x. (1794) 34

$694^{1}$ a. Hochstetteri, Krauss, in Flora,...

$695^{2}$ a. macrostachys, Link, in Schrad. Fourn. Bot, ii. 1799) 310. - Lusitan.

$695^{3}$ a. Meycnianus, Steud. Syn. P1. Cyp. 300 (ind.) err. typ. = Meyerianus

\section{GYPHONEMA}

$701^{1}$ a. Buchanani, Baker, in Journ. Bot. xiv, (18 76$)$ 66 = Apodolirion Buchanani

\section{CYPRIPEDIUM}

7021 Sedeni X, Veitch, Cat. (1874) 16; Gard. Chron, (1873) 1431.

selligerum $\times$.Veitch, Cat. (1878) 22; [Reichb.f.]; cf. ii. p. 1279

Wallisi, Reichb, f. Xenia Orch, ii. $189=$ caudatum.

\section{GYRILLA}

$70: 1$ a fuscata, Rafin Autik, Bot, 8; ex Sargent, Rep. For, N. Am. $37=$ racemiffora.

a, parrifolia, Rafin. (1. c.), ex Sargent (1. c.) = racemiflora.

a, polystachia, Rafin. (1. c.) ex Sargent, (1. c.) $=$ racemiflora.

\section{GYRTANTHUS}

$704^{1}$ a. Guteus, Baker, in Journ, Bot. xiv. (1876) $66=$ Anoiganthus breviflorus.

GYR TANDRA

$703^{2}$ a. peltata, Wawra, in Flora, 1v. (1872) $565=$ Wawrae, Hilleb.

\section{GYTISUS}

\section{1 l. altimus, Linn.}

$706^{2}$ a. Atleyamus, Hort. ex C. Koch, Wochenschr. (1867) $179=$ canariensis, decumbens.

7071 neapolitanus, [Stuart,] in Linn. Corresp. i. 28 $(1821)=$ Medicago arborea

\section{$\mathrm{D}$}

\section{DACI'YLIS}

$708^{3}$ a. calycina, Scop. Introd. $74=$ Schismus marginatus.

\section{DACTYLOGTENIUN}

$709^{1}$ a. verticillatum, Munro, Hort. Agr. 32 =Eleusine verticillata. 
$709^{2}$ a. DACTYLORRHIZA, Neck. Elem. iii. 402, lndex $(1790)=$ DACTYLORHIZA. Neck

DACTYLQSTEMON

7092 angustifolizu, Klotzsch, $\ldots=$ A. angustifolius. brasiliensis, Muell. Arg... = A. Sprengelii communis, Muell. Arg. $=$ A. Sprengelii. glabrescens, Klotzsch, $\cdots=\mathrm{A}$. Sprengelii. glabrescens, Klntzsch, ... = A. Sprengelii.
Hagendorfi, Klotzsch, .. = A. Sprengelii. lasiocarpus, Klotzsch, ... = A. lasiocarpus. obtusatus, Klotzsch,... = A. Sprengelii.

\section{DALBERGIA}

$710^{3}$ 1. alata, Roxb...225 = Derris thyrsiflora.

il1 1 Championii, Thw... 94 = rostrata, R. Grah.

$711^{2}$ Psendo-Sissoo, Miq... 128 = rostrata, $R$. Grah.

$711^{3} \quad$ purpurea, Reinw...53 = Derris elliptica.

purpurea, Wall. Cat. n. $5869=$ cana, $R$. Grah. rostrata, R.Grah,..5867. - Ind. or.; Malaya.

\section{DANTHONIA}

¿15 $5^{3}$ compressa, Peck, in Ind. Ann. Rep. N. York State $C a b$, (1869) 54 ; an eadem ac precedo,? Raouliz, Steud... $246=$ rigida, Raoul.

$716^{2}$ rigida, Raoul, in Ann. Sc. Nat. Sér. III. ii, (1844) 116. - N. Zel.

rigida, Steud... = obtusifolia.

\section{DAPHNE}

71 $i^{2}$ 1. rutestris, Facch. ex Ambrosi, Fl. Tir. Austr. ii. $244,287=$

DARBYA

71822 1. umbellulata, A. Gray,... 389 (non 386).

\section{DARWINIA}

il $8^{3}$ 1. saturejaefolia, Turcz... = brevistyla.

$719^{3}$ a. DASYSPERMUM, Neck. Elem, i. 176 (1790) = Farrago Umbelliferarum.

DASYSTACHYS

7193 a. Drimiopsis, Baker, ex Benth. in Benth. Ef Hook. f. Gen. Pl. iii. p. 789. - Afr, trop. Grantii, Benth.l.c. - Afr. trop.

$720^{2}$ a. DAUBENTONA, Buc'hoz, Herb. Col.Amér. t. $20(1783)=$ Crescentia? Linn. (Bignon.).

7221 a. DAVIL1A, Mutis, in Linn. Corresp. ii. 533 $($ l821 $)$ = Croton ? Linn. (Euphorb.).

DEERINGIA

7242 indica, Zoll. ex Moq. in DC, Prod, xiii. II. 236. - Malaya, Ins. Philipp.

7252 1. DELFECHIA, Montr... = Psychotria, Linn. (Rubiac.).

artensis, Montr... = Mapouria artensis, Beauvis.

floribunda, Montr... = M. floribunda, Beauvis.

7271 a. DELTONEA, Peckolt, in Zeitschr. allg. oesterr. Apoth. Ver. xxi. (1883) 185, nomen, $=$ Theobroma, Linn. (Stercul.).

lactea, Peckolt, 1. C. («luctea $»)=$ T. grandiflorum.

7272 1. DENDRANTHEMA, Des Moul... 1858 (non 1855).

\section{DENDROBIUM}

7272 a. CoMMERsorchis, Thou. Orch. Afr. Tab Synop, i. (1822).

EPIDURKIS, Thou, in Nouv, Bull. Soc. Philom. n. $19(1809) 318$.

PHYLloRkis, Thou, (1. c.) 319

7281. 1. bifalce, Lindl... $237=$ Doritis bifalcis, Reichb. $f$.

brachycarpum, Rich... 282 = Angraecum bra-

7291 1. galeatum. Sw... = Polystachya grandiflora, Lindl.

$729^{3}$ a. lilacinum, Reichb. f. in Gard. Chron. (1865) 674. - Borneo.

\section{DENDROBIUM}

7301 1. manilense, Schau... $430=$ Appendicula manilensis.

$730^{3}$ 1. pumilun, $\mathrm{Sw} . . .=$ P. bulbophylloides, Rolfe.

1. rosium, Sw. . $97=$ Polystachya elastica, Lindl.

$731^{3}$ a, villosulum, Lindl. in Lindl. \& Paxt. Flow. Gard. ii. (1851) 82= Jerdonianum.

\section{DENDROGALAMUS}

$741^{3}$ a. Brandisii, Kurz, For. Fl. Brit, Burma, ii, 560, - Burma.

\section{$732^{2}$ 1. DENDROLOBIUM, Benth.}

7331 a. DENDRORCHIS, Thou, Orch. Afr. Tab. Synop. (1822) = Aërides ? Sw. (Orchid.).

$733^{1}$ a. DENDRORKIS, Thou. in Nouv. Bull. Soc. Philom. n. $19(1809) 318=$ praec.

\section{DERRIS}

$734^{3}$ 1. pinnata. Lour... $432=$ Dalbergiae sp.

\section{DESGHAMPSIA}

7351 1. antarctica, E. Desv... ; Hook. f... - Ins. Antarct.

\section{DESMODIUM}

$736^{3}$ l. dioicunn, DC $. .338=$ confertum floribundum, G. Don... 277 = sambuense.

$737^{2}$ multiforum, $\mathrm{DC} . . .=$ sambuense. sambuense, $D C_{\ldots} . .335$. - - Reg. Himal.

\section{DEUTZIA}

7393 1. staminea, $R$. Br.... n. 3651 ;... (non 365 ).

DIANELLA

$741^{3}$ 1. triandra, Afz. Stirp. Guin. med. $6=$ Palisota thyrsiflora.

\section{DIGHONDRA}

$749^{2}$ a. ESCALLONIA, Mutis, in Linn. Corresp. ii. $532(1821)$.

\section{DICHOPSIS}

$749^{3}$ 1. Krantziana, Pierre, in Bearvis.

a, oblongifolia, Burck, Rapp. Gutta percha, 17

$753^{2}$ a. DICROSPERMA, W. Wats. in Gard. Chron. 18s.i) ii. 362, sphalm. = Dictyosperma, H. Wendl. \& Drude (Palm.)

\section{DIDYIMOGARPUS}

7551 1. albicalyx, C. B. Clurke (non albicaulis).

Hookeri, C. B. Clarke,

$755^{2}$ 1, Lawesii, F, Mruell... $229=$ Boea Lawesii, F. O. Forbes (1889)

polyantha, Veitch, Cat. $(1856-5 \%) 11=$ Streptocarpus polyanthus.

\section{DIDYMOSPERMA}

$756^{1}$ a distichun Hook f. Kew Rep. 1882 (1884) bं = Wallichia disticha.

\section{DIEFEENBACHIA}

$756^{2}$ 1. Bowmanni, Veitch.Cat. (1871) 15 ; Carr...

\section{DILIENIA}

7591 1. Andreana, F. Muell... 175 = Saurauja Andreana (in Suppl.).

DIMERIA

$760^{1}$ d. Ptekyg OstachyoM, Nees (nunc $=$ Arundinella).

$760^{2}$ 1. DIMESIA, Rafin... i。 (1812) 442 ; et (1818).

$760^{2}$ 1. fragrans, Rafin (11. cc.). monticola, Rafin (11. cc.)

\section{DIOSMA}

$765^{3}$ 1. odoratissima, Montin,... 105... (non 104).

\section{DIOSPYROS}

$766^{2}$ bilocularis, Hook. Ic, t. 2336 = Maba Maingayi, Hiern.

7671 1. Embryopteris, Pers... - As. trop. (non Afr.)
76833 1. DIOTOSTEMON, Salm-Dyck,... 265.

\section{DIPLACUS}

$709^{3}$ hachnoideus, Greene, in Bull. Calif. Acad, i. (1885) $210=$ longiflorus

7.01 1. longiforus, Greene, in Bull. Calif. Acad. i. Il (1885) 96 partim. -- Calif.

\section{DIPLADENIA}

$70^{1}$ a. hybrida, Veitch, Cat. (1878) 26. - Hab. DIPLOCHONIUM

$6 \mathrm{ll}^{\mathrm{L}} \mathrm{a}$. Frochstettevi, Stocks, ex Aitch. Cal. Pl. Punjab, $66=$ Orygia decumbens.

$773^{1}$ a. DIPLOPIA, Rafin. in Am. Monthly. Mag. i (1817) 439 = Salix, Tourn.

\section{DIPLOTHEMIUIM}

Fit' a, glaucescens, W. Wats, in Gard Chron (1885) ii. 394, sphalm. = caudescens.

\section{DISPERIS}

is01 a. DRYoRKIS, Thou, in Nouv, Bull. Soc. Philom. n. 19 (1809) 316.

\section{DISSOTIS}

is12 1. votundifolia, Triana..

7S:2 a. DISYNIA, Rafin. in Am. Monthly. Mag, i. (1817) $439=$ Salix , Tour

\section{DODEGATHEON}

is.1a. Bartramia, Ellis, in Linn. Corresp. i. 16 (1821).

\section{DOLICHOS}

$786{ }^{1} 1$ frutescens. Buch.-Ham... = Pueraria Wal lichii.

hexandra, Rnxb... = Dioclea reflexa.

¡862 sesquipedalis, Linn...; Blanco,... = Vigna Catjang

\section{DOLIOCARPUS}

$787^{2}$ a. Skrveria, Neck. Elem, ii. 98 (1790)

\section{DOMBEYA}

$787^{3}$ a. arabica, Baker,... = Glossostemon Bruguieri, DC

DOODIA

7891 1. simplicifolia, Roxb... $366=$ Uraria hamosa

\section{DORYANTHES}

791* a. Larkini, C. Moore, in fourn, Proc. Roy. Soc. N.S. Wales, xviii. (1885) 85. - Austral.

7921 1. DOUARREA, Montr... = Psychotria Linn. (Rubiac.)

alba, Montr... = Mapouria Dourarel.

speciosa, Montr... = M. speciosa.

\section{DRABA}

7931 1. cheirifolia, Berger. Phyton. iii 89. - Hab. ? $794^{2}$ montana, Berger. (1. c.) 105. - Hab.

$795^{1}$ a. spatulata, Berger, (1. c.) $107=$ Alyssum alpestre.

\section{DRACAENA}

$796^{2}$ 1. triandra, Schult Syst. vii. $354=$ Palisota thyrsiflora.

DRIMIA

7983 1. Burchellii, Baker, Ref. Bot. iii. App.

DRIMYS

$792^{2}$ a. insularis, Baill, ex F. Muell. Fragm, ix. 76, nomen $=$ Howiarum

\section{DRYMOPIILOEUS}

8021 Normanbyamus, Benth. \& Hook, f... Ptychosperma Normanbyi.

8022 a. DRYORKIS, Thou. in Nouv. Bull. Soc. Philom. 11, 19 (1809) $316=$ Disperis, Sw (Orchid.). 
DUPONTIA

$804^{2}$ a. Fischeri, Nees, Brown's Verm. Schr. i. (1875) $425=\mathrm{seq}$.

1. Fisheyi, R. Br... 291 (err. typ. 191).

DYPSIS

$805^{3}$ a. Hildebrandtii, Hort. Van Houtte, ex Hook. f. Kew Rep, 1882 (1884) 58, nomen. - Madag.

madagascaricnsis, Hort.; cf. W. Wats. in Gard. Chron. (1885) ii. $394=$ Areca madagascariensis

\section{DYSOXYLUM}

$806^{3}$ 1. malabaricum, Bedd ex Hiern, in Hook. f. Fl. Brit. Ind. i. 548. - Ind. or.

\section{$\mathrm{E}$}

\section{EBERMAIERA}

$807^{3}$ 1. Anigozanthus, Neus,... 16 (non 17)

1. spatulata, Nees, in DC. Prod. xi. 74 (cum cit, falsa) $=$

ECHEVERIA

8091 1. muda, Lindl. in Gard. Chron.

\section{ECHINOGACTUS}

S102 a, ctenoides, Lem. Cact. $5 \%=$ Cereus ctenoides $811^{3}$ a. Orcuttii, Engelm, ex Orcutt. in West Amer. Scientist, ii. (1886) 46, cum ic, - Calif.

EDWARDSIA

\$223 a, hydaspica, Edgew, ex Aitch. Cat. p1. Punjab, 50, in syn. (Quid.?). - Ind. or.

8241 a. EHRETIANA, Collinson, in Linn, Corresp. i. $32(1821)=$ Periploca, Tourn. (Asclep.).

\section{EHRHARTA}

Q241 1. capensis, Thumb...8. - Afr. austr.

erecta, Lam... 34\%. - Afr. austr.

Mnemateia, Linn. f... $209=$ capensis.

panicea, Sm... 32 = erecta.

\section{ELAEOCARPUS}

$826^{1}$ 1. oblongus, Gaertn. Frutct. i. 202, t. 43, f. 3 ; Sm.

\section{ELAPHRIUM}

$82 \% 2$ a. octandrum, Scop. Introd. $225=$ B. tomentosa ELCAJA

8291 1. emetica, M. Roem. Syn. Hesper. $116=$ T. emetica

\section{ELEOGHARIS}

$830^{1}$ 1. dispar, E. Hill = capitata

emarginata, Klotzsch

gracilis, $R$. Br.

nigrescens, Kunth,... - Bras.

8311 1. ELEOGENUS, Nees,

\section{ELETTARIA}

$831^{3}$ a. Matunia. Sm. in Rees, Cyclop. xxxix. sub Elettaria (1819)

8321 1. pallida, Blmme,

\section{ELEUSINE}

832l Ochthucloa, Edgew. in Journ. As. Soc. Beng. xi. (1842) I. 26.

8331 1. ELISARRIENA... = Elissarrhena...

$833^{3}$ a. ELLISIA, Garden, in Linn. Corresp. i. 295 $(1821)=$ Frasera, Walt, (Gentian)

ELLISIA, Garden, in Linn, Corresp. i, 418 ; $43 ;-4 ;(1821)=$ Gelsemium, Juss. (Logan.)

$833^{3}$ a. ELLISIANA, Garden, in Linn. Corresp.i. $364,378(1821)=$ Gelsemium, Juss (Logan).
$834^{1}$ a. ELSHOLTZIA, Neck. Elem. ii. 256 (1790) = Couroupita, Aubl. (Myrtac.).

ENGEPHALARTOS

$838^{3}$ 1. Ghellinckii, Lem. Ill. Hort. xiv. (1867) 80. ENDESPERMUM

$839^{3}$ 1. scandens, Blume... = Dalbergia tamarindifolia.

EPIDENDRUM

$847^{3}$ a. hypoleptum, Reichb. f. in Gard. Chron. (1877) i. 810 , in nota $=$ Pinelia hypolepta.

$850^{2}$ teretifolium, Sw... 121 (non 120).

$851^{2}$ a. EPIDORKIS, Thou, in Nouv. Bull. Soc. Philom.n. 19 (1809) $318=$ Dendrobium, Sw. (Orchid.)

\section{EPILOBIUM}

$852^{1} 1$ canescens, Westendorp, in Bull. Acad. Sc. Brux, iii. (1836) 356-361 ; White,...

\section{EPIPOGUM}

8561 1. Guilfoylii, F. Muell,... 30, ex Benth, F1. Austral. vi. $308=$ nutans

\section{ERAGROSTIS}

8572 1. Brownit [Nees, in] Hook. \& Arn. Bot. Beech. Voy. $253=$ elongata, facq

$857^{3}$ a. elata, Munro, ex Ficalho et Hiern, in Trans, Linn. Soc. Ser. II ii. (18S1) 32. - Afr. trop.

$858^{1}$ a. Eragrostis, Karst. Pharm. Med. Bot. $389=$ minor.

minor, Host, Gram.iv. 15 (1809); Fl. Austr.

$858^{2}$ 1. namaquensis, Nees, Ind. Sem. Vratisl. 1835; ex Linnaea, xi. (1837), Litt. $125=$ interrupta, Beanv.

$858^{3}$ poaeoides, Beauv. Agrost. 162, nomen = minor.

\section{ERANTHEMUM}

$860^{1}$ a. PseuderanthemuM, Radik, in Sitzb. math.Phys. Cl. Alkad. Wiss. Muench. xiii. 1883 (1884) 282.

8592 a. asperum, Hook $\mathrm{f}$ = bicolor.

8503 a, Eldorado, Hort. Williams, ex fust, Bot. Faluresb. 1877 (1879) 935 - - Hab

$860^{1}$ a. punctulatum, Hook. f. Bot. Mag. sub t. 5711 , sphalm. = asperum, bicolor.

$860^{2}$ 1. Zollingerianum, Nees,... Java (non Ins. Philipp.).

ERANTHIS

$860^{2}$ a. CAMnARIUy, Hill, Brit. Herb. 47 (1756)

\section{ERGILLA}

$860^{3}$ 1. spicata, Moq.... $35=$ volubilis

ERIA

8631 1. clavicaulis, Lindl. (non Wall. ex).

$863^{2}$ 1. erecta, ( $n$ on crecta).

\section{ERIACHNE}

S642 1. triseta, $N^{\top}$ ees,... Ind. or. [non Afr. austr.].

\section{ERICA}

$866^{1}$ a. cantabrica, Collins. in Linn. Corresp. i. 69 $(1821)=$ Dabuecia polifolia capillaris, Bartl.

$871^{2}$ 1. simplicifolia, Donn, Hort. Cantab. ed. I. 46 = curviflora, buccinaeformis.

d. simplicifolia, Steud,

8722 Zeyheri, Spring. $f$.

$880^{3}$ 1. ERIOCYLAX, Neck.

\section{ERIOLAENA}

8822 1. quinquelocularis, Wight, Ic. sub t. S82, in obs.; Bedd. Fl. Silv. Anal, t. 5

\section{ERIOPHORUIM}

$883^{1}$ a. lineatum, Benth. \& Hook. f. Gen. P1. iii. 1052 $=$ Scirpus lineatus.

\section{ERIOSTEMON}

885 a. Turczaninonia, F. Muell... = Crowea (non (Correa).
$885^{1}$ a. ERIOSTEMON, Sweet, Hort. Brit. ed. I. 320 , in syn., lapsu = ERIOSTOMUM Hoffmgg. \& Link.

$885^{2}$ a. ERITHRAEA. Neck. Elem. ii. $10(1790)=$ Erythraea, Renealm. (Gentian.).

a. aquatica, aurea, rivalis, pumila, scilloides, verticillata, Neck. 1. c., nomina nuda.

\section{ERODIUM}

887 chumbulense, Munro, Hort. Agr. $35=$ Mon sonia senegalensis

$887^{3}$ 1. malachoides, G. Don, Gen. Syst. i. $724=$ seq. malacoides, Willa.

$888^{3}$ a. ERPORKIS, Thou, in Nouv. Bull. Soc Philom n. 19 (1809) 317 (Orchid.) (Quid. ?).

\section{ERYSIMUM}

8922 1. antarcticum, Verl... $94=$ ochroleucum.

898. ESCAILONIA, Mutis, in Linn. Corresp. ii. 532 $(1821)=$ Dichondra, Forst. (Convolv.)

\section{EUGALYPTUS}

$901^{1}$ a. AkomadendRum, W. Anders, ex R. Br. Prod. 553 (1810).

$902^{3}$ splachnicarpa, Benth. Fl. Austral. iii. 256, in syn. = seq.

splachnicarpon, Hook. Bot. Mag. t. 4036. -

\section{EUCLIDIUM}

$904^{1}$ a. HisRochonTIs, Medic. Pfanzeng, 51 (1792).

\section{EUGENIA}

9051 1. acris, Wicht \& Arn... = Pimenta acris.

$908^{2}$ 1. lucida, Banks, ex Gnertn. Fruct. i. 167, t. 33, fig. 1. - Austral.

9091 a. Michelii, Parodi, Contrib. Fl. Parag. iv. (1879) 122. - Parag.

9062 1. myrtifolia, Sims, Bot. Mag. t 2230; Benth.= paniculata, Banks.

9. 93 1. paniculata, Banks. ex Gaertn. Fruct. i. 167. Austral. paniculata, Lam... - Ins. Borb.

\section{EULOPHIA}

$913^{2}$ a. sumatrana, Blume, Orch. Archip, Ind. 183, in nota; et Miq. Fl. Ind. Bat. iii. 743. Sumatra.

\section{EUONYMUS}

9I $4^{2}$ a Koopmannii, Lauche, in Garten Zeit, ii. (1883) 112 , t. [3], f. $2=$ uanus.

\section{EUPATORIUM}

$915^{1}$ a. KoANuPHYllov, Arruda, ex Koster, Trav. 495 (1816).

9172 grandiflorum, André, in Rev. Horticole (1882) 384, cum tab. - Hab. ?

$920^{3}$ 1. Torreyanum, [Short, in] Transylv. Journ, med. n. 32, viii. (1836) 575; et

921 a. EUPHOCARPUS, Anders. ex R. Br. Prod. $55 \%$, in adnot. $(1810)=$ Corraea, Sm. (Rutac.).

\section{EUPHORBIA}

$923^{1}$ a. cantabrica. Rouy, in Rev. Sc. Nat. Sér. III. i (1883) $24 \%$, in syn. = pilosa

Chamoecise. St Amans, F1. Agen, $188=\mathrm{E}$ Chamaesice.

$925^{1}$ a. grandidens, Goebel, Pflanzensch. i. 41, lapsu = grandicornis.

$925^{2}$ a heptagona, Munro, Hort. Agr.2S nomeñ (quid?) - Ind. or.

9271 a. montana, Rafin, in Am, Monthly Mag. i. (1817 450. - Sicil

\section{EVALLARIA}

$938^{1}$ a. bifolia, Neck. 1. c. = Maianthemum Conval-

a. latifolia, Neek.1. c. = Polygonatum latifolium

a. multiflora, Neck. 1. c. = P. multiflorum 
EVODIA

9391 a. Boninia, Planch. in Ann. Sc. Nat. Sér. V. xiv. (1871) 309 , in nota.

EVOLVULUS

$940^{1}$ 1. gangeticus, Linn... 391, fide herb. = Cocculus villosus.

\section{EXACUM}

$940^{3}$ a. FLOY ERA, Neck. Elem. i. 386 (1790),

\section{F}

glutinosa, Poepp. \& End1... 194 (Eucryphiae sp.).

sinensis, Oliver, in Hook. Ic. t. $1936=$ F. sylvatica var.

FALGaria

$946^{2}$ a. Falcaria, Karst. Pharm. Med. Bot. $835=$ vulgaris.

\section{FEDIA}

$948^{3}$ a. sibirica, Scop. Introd. $137=$ Patrinia sibirica,

\section{FERULA}

$950^{3}$ 1. aurea Link,,$=$ communis

$951^{1}$ 1. foetidissima, Regel \&o Schmalh. in Act. Hort. Petrop. v. (1877) 593. - Turkestan

$991^{1}$ a. Jaeskeana, C. B. Clarke, in Hook. f. Fl. Brit. Ind. ii. 708 (non Vatke). - Reg. Himal.

1. Linkii, Webb et Berth... $160=$ communis.

a. Loscosii, Willk. Ind. sem. Hort. Prag. (1882). $=$ Hispan.

\section{FESTUCA}

$953^{3}$ 1. glomerata, Scop. Introd. 74 ; All.

$954^{2}$ kergwelensis, Hook. f.... = Poa kerguelensis.

$957^{1}$ a. FIBRAUREA, J. Colden, in Linn. Corresp. i. $94,98(1821)=$ Coptis, Salisb. (Ranunc.).

FICARIA

$957^{1}$ a. Ficaria, Karst. Pharm. Med. Bot. $565=$ R. Ficaria

\section{FIGINIA}

9573 1. trichodes, [C. B. Clarke, in $]$ Ind. Kew. -

FIGUS

$958^{3}$ a. burdigalensis, Poit. \& Turp. in Poit. Pomol. Franç. iv.t. $3: 9=$ F. Carica.

FILAGO

$965^{3}$ a. Pseudo-Evax, Rony, in Rev. Sc. Nat. Sér. III. i. (1883) 233. - Hispan.

FIRENSIA

$968^{2}$ a. flavescens, Scop. Introd. $156=$ Cordia flavescens.

$971^{3}$ a. FLOYERA, Neck. Elem. i. $386(1790)=$ Exacum, Linn. (Gentian.)

\section{FOENICULUM}

$972^{1}$ a. Foeniculum, Karst. Pharm. Med. Bot. $837=$ vulgare.

FONTANESIA

$972^{2}$ 1. philliraeoides, Labill. (phillyraeoịdes),

$972^{3}$ a. .FORGEROUXIA, Neck. Elem. iii. 403, 415. Index (1790); Steud... = FORGEROUXA, Neck.

\section{FOSSELINIA}

$973^{3}$ a. Fonthlapsi, Sccp. 1. c. sphalm. = seq.

1. Fonthlaspi, Scop. 1. c. ; All.

\section{FOTHERGILLA}

$.973^{3}$

\section{FOTHERGILLA}

$973^{3}$ a. anamelis, Garden, in Linn. Correst. i. 340 , 599 (1821).

mirajilis, Aubl. 1. c, t. $175=$

\section{FOUQUIERA}

$973^{3}$ a, gigantea Orcutt, in West Amer. Scientist, ii. (18:6) 48. - Calif.

\section{FRAGARIA}

$974^{2}$ a. bargea, campana, florentina, heterophilla, pistillaris, portentosa, Poit. \& Turp. in Poit Pomol. Franc, ii. $=$ vesca.

a, bathonica, caroliniana, grandiflora, Suchiana, Poit. \& Turp. (1. c.) = virginiana.

a. Gillmani, Clinton, in Am. Natural. iii. (1869) 221. - Mexico.

FRANGULA

$975^{2}$ a. Frangula, Karst. Pharm. Med. Bot. $868=$ R. Frangula.

FRASERA

$976^{1}$ a. Ellisia, Garden, in Linn Corresp. i. 295 (1821).

\section{FRAXINUS}

$977^{1}$ l. potamophila, Herd... - Turkestan.

\section{FREYCINETIA}

$978^{2}$ 1. radicans, Gaudich... - Ins. Molucc. (Raurak).

\section{FRITILLARIA}

$980^{2}$ a. Saranna, Stejneger, in Proc. U. S. Nat. Mus. vi. (1883) 63 , nomen $=$ camtschatcensis.

\section{FUCHSIA}

9811 1. coccinea, Curt. Bot. Mag. t. 97; [Soland, in] Ait. Hort. Keres.

1. Kirkii, Hook. f.... i. ed. II. (1871) $92=$ procumbens. $98 \mathbf{1}^{2}$ a. pendulina $\times$, Veitch, Cat. (1856-57) 5.

\section{G}

\section{GAGEA}

$985^{1}$ 1. BoIssIERA, Haenseler, ex Willk. in Bot. Zeit, iv. (1846) 313،

\section{GALEOBDOLON}

$990^{1}$ a. Galeobdolon, Karst. Pharm. Med. Sot. 1010 $=\mathrm{L}$ Galeobdolon.

\section{GALIUM}

$991^{3}$ a Bailloni Brantza, in Anal, Acad. Romane, Sér. II. ii. (1881) 588, 1. - Europ. merid $994^{2}$ a. orbibracteatum, Choub. in St Amans, Fl. Agen.66, t. s.

\section{GARDENIA}

$999^{2}$ a. AUGuSTA, Ellis, in Linn. Corresp. i. 102, 106 (1821)

PorT LANDIA, Ellis 1. c. 122 (1821)

WARNERIA, Ellis 1。 c. 100 (1821)

$1000^{1}$ 1. Manganjae, Hiern, in Oliver, Fl, trop. Afr. iii. 103 = Randia Buchanani, Oliver.

$1000^{3}$ a. GARDENIA, Ellis, in Linn. Corresp. i. $86(1821)=$ Galycanthus, Linn.

GARDENIA, Ellis, in Linn. Corresp. i. $130(1821)=$ Gelsemium, Juss. (Logan.).

GARDENIA, Linn. Corresp. i. 135 (1821) = Kleinhovia, Linn: (Stercul.).

\section{GARRYA}

10012 1. Fadyenii, Hook. Ic. Plant. t. 333 (non Fadyena).

\section{GASTRODIA}

10023 1. javanica, Lindl. Gen, et Sp. Orch, 384 (dele Endl. Gen, 212).

$1003^{1}$ a. GASTRORKIS, Thou. in Nouv. Bull. Soc. Philom. n. 19 (1809) 31\% (Quid ?) Orchid.)

$1004^{2}$ a. GAUNIA, Scop, Introd. 76 (1777) = Gahnia, Forst. (Cyperac.).

\section{GELSEMIUN}

$1007^{2}$ a. ELLISIANA, Garden, in Linn. Corresp. i. 364,378 (1821)

GARDENIA, Ellis, in Linn. Corresp. i. 130 (1821).

\section{GENISTA}

$1010^{3}$ a. ramosissima, Spach, in Ann. Sc. Nat. Sér. III. iii. (1845) 151 = Cytisus canariensis

\section{GENTIANA}

$1012^{3}$ 1. Campellii, Hombr... = cerina. concinna, Hook, f... $=$ cerina

$1013^{3}$ 1. Hookeri, Armst.... = saxosa.

10141 1. Novae-Zelandiae, Armstr.... = montana

$1015^{1} 1$. saxosa, Forst. f. - N. Zel.

\section{GEOFFRAEA}

$1016^{1}$ a. spinosa, Arruda, ex Koster, Trav. $497=$ superba.

GEONOMA

$1016^{2}$ a. chiriquensis, Hort. Lind.; cf. Hook. f. Kev Rep. 1882 (1884) 60. - Hab.

10171 1. Szuartzii, Griseb. = Calyptrogyne Swartzii (Add.).

\section{GERANIUM}

$1017^{3}$ a. album, Myers, in Am. Natural. iv. (1870) 438 = maculatum.

$1020^{1}$ a. malachoides, G. Don, Gen. Syst. i. 724, in Syn. = seq.

1. malacoides, Linn.... = Erodium malacoides.

GETHYLLIS

$1285^{1}$ 1. polyanthera, Soland. ex Britten

\section{GEUM}

$1025^{3}$ a. BerNoulllia, Neck. Elem. ii. 97 (1790)

GIGANTOCHLOA

10271 a. aspera, Kurz, ex Teijsm. \& Binn. Cat. P1. Bogor. $20=$ Oxytenanthera nigrociliata

a. Wallichiara, Kurz l. c. nomen (Quid?). Burma.

$1027^{2}$ a. GigotorCya, Buc'hoz, Herb. Col. Amér. t. 62 (1783) (Quid?).

\section{GIRTANNERIA}

10292 a. Frangula Neck l. c. $=$ R Fran fujuba, Neck. 1. c. = Zizyphus Jujuba。 lineata, Neck. 1. $\mathrm{c}_{\mathrm{i}}=$ Berchemia lineata. micrantha, Neck. 1. c. = Irama micrantha. Nopeca, Neck. 1, c. = Zizyphus Napeca. Oenoplia, Neck. 1. c. = Zizyphus Oenoplia. saxatılis, Neck, 1. $c_{0}=\mathrm{R}$. saxatilis.

Spina-Christi, Neck. 1.c. = Zizyphus SpinaChristi.

theezans, Neck. 1. c. = Sageretia theezans.

\section{GLADIOLUS}

10313 l strictus, facg. (dele t. 260)

10371 a. sulphureus, De Graaf, ex Molkent. in Tuinbouw-Flora, i. (1855) 39. - Transvaal.

\section{GLAUCIUM}

10322 a. Glaucium, Karst. Pharm. Med. Bot. $649=$ flavum.

\section{GLOBBA}

1033 1. coccinea, Hort. Veitch,... = atrosanguinea. GLOSSOGYNE

$1035^{3}$ 1. Kennedyi, R. Br. ter... $259=$ Calotis lappulacea. 
GLYCERIA

10371 a. Langeana, Berl. in Ofvers. Vel. Akad. Förh. xli. (1884) n. VII, 79. - Groenl.

10391 I. GLYCOSMIS (err. typ. GYCOSMIS).

\section{GNAPHALIUN}

10412 1. contortam, Buch. Ham, ex D, Don, Prod. F1. Nep. 1 75 ;

$1044^{3}$ quintuplinerce, Buch. Ham. ex D. Don, (1. c.) 174 ;

\section{GNETUIM}

$1046^{3}$ 1. urens. Blume... 162= G. Thoa.

10483 a. GOMEZIA, Mutis, in Linn. Corresp. ii. $529(1821)=$ GOMOZIA, Mutis $=\mathbf{N e r}-$ tera, Banks et Soland. (Rubiac.)。

\section{GOMPHANDRA}

10491 1. laxiflora, Rolfe, in foum. Bot. xxiii. (1885)

10492 1. polymorpha, Wight, Ill. 103 ; et DC.

\section{GOMPHRENA}

1051 $1^{3}$ 1. Brownii, Moq... = lanata.

$1052^{2}$ rhodantha, Seub, in Mart. Fl. Bras. v I. 220 = rodantha

\section{GONGORA}

$1053^{1}$ saccata, Reichb $f_{\ldots}$. - Bras

\section{GONGROTHAMNUS}

10532 a, multiflorus, Klatt, in Flora, lxviii. (1885) 205. - Ins. Mascar.

\section{GONOLOBUS}

$1054^{2}$ 1. biflorus, Nutt, ex Decne, in DC. Prod. viii. 605 (1844).

\section{GOODENIA}

$1055^{3}$ 1. Collema, W. Anders, ex R. Br. Prod. 553 (1810).

\section{GOODYERA}

$1056^{3}$ a celebica, Blume, Orch. Archip. Ind, 43. Ins. Celebes.

grandis, Blume, Orch. Archip. Ind. 43.Java.

1. Menziesii, Lindl...492 (non 402).

a. taitensis, Biume, l. c. - Ins, Tahiti.

GORDONIA

10571 a. Huxhamia, Garden, in Linn. Corresp. i. $408(1821)$.

a. praelucida, Buc'hoz, Herb. Col. Amér. t. $21=$

\section{GORTERIA}

$105 \%$ rigens, Linn. Am. Acad... = (dele « Pl. Afr. Rar. 23 »).

\section{GOSSYPIUM}

$1058^{2}$ a. Vaupelii, J, Graham, Cat. P1. Bomb. 15. -

$1060^{3}$ a. GRAPHORKIS, Thou, in Nouv, Bull. Soc. Philom. n. $19(1809) 318=$ Limodorum, Sw. (Orchid.).

\section{GREWIA}

$1065^{2}$ pilosa, Lam. [dele « Suppl. 》].

\section{GROSOURDYA}

$1067^{2}$ 1. elcgans, Reichb. f... - Ins. Sunda.

a. Hystrix, Reichb. f. Xenia Orch. ii. $123=$ S. Hystrix.

\section{GROSSULARIA}

$106 \pi^{2}$ 1. diacantha, Mill... = R. Diacantha.

GUAZUMA

$1070^{2}$ 1. tomentosa, $H . B$. \& $K$... 320 (non 32). GUNNERA

$1072^{3}$ 1. strigosa, Colenso,,..$=$ monoica.

\section{GYMNADENIA}

$1074^{1}$ a, conoper, Perard, in Bull. Soc. Bot. Fr. xvii. 1870) $368=\mathrm{G}$. conopsea.

\section{GYMNOCARPOS}

$1076^{1}$ a. deserti, Forsk. l. c. p. 1xiii

\section{GYMNOTRIX}

1078 a. flaccida, Munro ex Aitch. Cat. Punj. Pl. 163 $=\mathrm{P}$. flaccidum

1. purpurascens, Sw. ex Trin. Gram. Panic. $64=$ 10791 a. GYNICIDIA, Neck. Elem. ii. 81 (1790) = Mesembryanthemum, Dill.(Ficoid.)

\section{GYPSOPFILA}

$1080^{3}$ a. AsoPhil A, Neck. Elem. ii. $162(1790)$.

10811 Haynaldiana, Janka, in Közlem. Magyar. Tudom. Akad. xii. (1876) $165=$

\section{$\mathrm{H}$}

\section{HABENARIA}

108221 albida, $R$. Br. Prod. 312, et in Ait.

10823 1. bifolia, $R, B r$. . c. ; et in Ait.

a. Burmanniana, R. Br. I. c. = Bartholina pectinata.

1. ciliaris, R. Br. l.c. ; et in Ait.

10831 1. cristata, $R . B r . l$. c. ; et in Ait.

a. eustachya, Reichb. f. in Ber. Deutsch. Bot. Ger. iii. (1885) 274. - Ind. occ.

$1083^{2}$ 1. fimbriata, R. Br. l. co. ; et in Ait.

$1083^{3}$ a. hispidula, R. Br. 1.c. = parvifolia

1. hyperborea, R. Br. i.c. ; et in Ait.

1. longecalcarata, A. Rich. in Ann. So. Nat. Ser, II. (non III) Xv. (1841) 7l, t. 3

$1084^{1}$ a. monorhiza, Reichb, f. 1. c. = brachyceratitis

$108 \mathbf{x}^{2}$ a. psiloceras, Welw. ex Reichb. $f$. in Flora, 1. (1867) 99. - Afr. trop.

$1084^{3}$ 1. rhodocheila, Hance, 1866 (non 1856).

a. Roxburghii, R. Br. Prod. $312=$ platyphylla. secunda, R. Br. 1. c. = Holothrix secunda. 10851 1. tipuloiles, Benth. in fourn... 355; Benth. \& Hook. f. Gen. Pl. iii. 626 .

$1085^{2}$ 1. viridis, R. Br. l. c. ; et in Ait.

$1085^{2}$ a. HABENORKIS, Thou, in Nouv. Bull. Soc. Philom. n. 19 (1809) 317 = Habenaria Willd. (Orchid.).

HABZELIA

108611 . aromatica, A. DC. $=$ Xylopia aromatica

\section{HAEMADICTYON}

1086² 1. venzosum, Lindl... '70.

\section{HAEMARIA}

1087.1. 1. DicRUPHYLA, (non DichrophyLA).

\section{HAEMATOGARPUS}

10871 a. incusus, Miers, Contrib. iii. $327=$ Thomsoni

$1087^{3}$ 1. HAGEA, Pfeiff. Nom. Bot. i. 1544 (1874) cum cit, falsa = Brayera, Kunth (Rosac.).

$1089^{1}$ a. HALAEA, Garden, Linn. Corresp. i. 378 $379(1821)=$ Berchemia, Neck. (Rhamnac.).

10891 a. HALEA, Linn. Corresp. i. $365(1821)=$ Eupatorium, Tourn. (Compos.).

10891 a. HALEA, Linn. Corresp. i, $365(1821)=$ Schlosseria, Garden (Gen. dub. Palm.).

\section{HALESIA}

10892 a. TetraPteris, Garden, in Linn. Corresp. i. 406 (1821).

HALLERIA

10902 1. elliptica, Thunb. in Nov. Act. Upsal. vi. 1799) 39. - Afr. austr.

\section{HAMMATOLOBIUN}

$1092^{3}$ a graecum, Heldr. ex Boiss, Fl. Or. Suppl. (1888) 171. - Graecia

$1092^{3}$ 1. HANCORNIA, Gomes, Obs... (1808); et in Mem.

a. Ribeirea, Arruda, ex Koster, Trav, 499 (1816).

HAPALOSTEPHIUM

$1093^{1}$ 1. paludosum, pilosum, pyrenaicum, sibirïcum, cf. Sweet, Hort. Brit. ed. I. 210 (1827).

10991 a. HEDERORKIS, Thou. in Nouv, Bull. Soc, Philom. n, 19 (1809) 319 (Quid?) (Orchid.).

\section{HEDYGHIUM}

11001 1. speciosum, Wall... - Ind. or .

11001 1. HEDYOSMOS, Mitch.... = Gunila Linn (Labiat.) (non Ziziphora, Linn. (Rubiac.)).

HEDYSARUM

$1103^{3}$ a. ascendens, Lindl. Bot. Reg. t. $815=$ adscendens, Sw.

11043. 1. dioicum, Buch.-Ham.... = Desmodium confertum.

11062 parviflorum, Spreng... $=$ Desmodium sambuense.

procumbens, Roxb.... = Alysicarpus hamosus, sambuense, D. Don, ... = Desmodium sambuense.

$1107^{3}$ a. virgatum, Cerv, ex Sweet, Hort. Brit. ed. I. $130=$ Desmodium uncinatum.

\section{HELIANTHEMUIM}

$1110^{2}$ a. Helianthemum, Karst Pharm. Med. Bot. 633 $=$ vulgare.

\section{HELIANTHUS}

$1112^{3}$ a. mollis, Buchoz, Herb. Col. Amér. t. 51 (Quid?) - Hab. ?

HELICHRYSUM

$1114^{1}$ a. coralloides, Benth. \&o ITook, f. Gen. Pl. ii. 311. - N. Zel.

a. depressum, Benth. G Lluvel, f. l. c. - N. Zel.

HELICOPHYLLUM

$1117^{2}$ 1. crassifolium, Engl... = H. Lehmanni.

\section{HELIOTROPIUM}

$1120^{2}$ a. deserti, Vatke, in Oest. Bot. Zeitschr. xxv. (1875) $166=$ Verbena supina.

\section{HEMARTHRIA}

$1125^{1}$ a. laxa, Steud. Syn. Pl. Gram. $358=$ Rottboellia compressa.

\section{HEMEROC ALLIS}

112521 . japonica, Thunb. Fl. Jap, $142=$ F, ovata

a. japonica, Thunb, in Trans. Linn, Soc. ii. (1794) $335=$ Funkia Sieboldiana.

11271 1. HEMIMERIS, Linn. Pl, Afr. Rar. 8 (1760) quoad spec, = Diascia, Link \& Otto (Scroph.).

Bonae-spei, Linn. 1. co = D. Bergiana.

HEPATICA

11292 a. Hepatica, Karst. Pharm. Med. Bot. $559=$ A. Hepatica.

HERACLEA

a. capillata, Hill, 1. $\mathrm{e}_{\mathrm{i}}=\mathrm{C}$. capillata

phrygia, Hill, l. c, = C, phrygia.

\section{HERMINIUM}

$1133^{2}$ 1. alpinum, Sweet. Hort. Brit. ed. I. 382; Lindl...

\section{HERNIARIA}

$1134^{2}$ d. eustachya, (ad Habenariam pertinet).

$1134^{3}$ a. nebrodensis, Rafin. in Am. Monthly Mag. i. (1si7) $440 .-$ Sicil 
HESPERIS

$1136^{3}$ 1. fasciculata, Rafin. Specch. Sc. ii. 46-47, ex Call, Life Rafin, 149

$1137^{2}$ a. rupestris, Rafin. (l. $\left.c_{0}\right)$; ex Call (l c.)

HETEROSMILAX

$1141^{2}$ 1. Gaudichaudiana, Maxim. in Bull. Acad. St. Pétersb, xvii. (1876) 176, in obs.: A. DC...

\section{HEVEA}

$1142^{3}$ a. peruviana, Lechl. ex Benth. \& Hook, f, Gen. Pl.

\section{HEXADESMIA}

11431 1. fasciculata, Brongn. (non $A, B r$.)

1. sessilis, Reichb. f... xli (non xlii).

\section{HIBISCUS}

$1147^{3}$ 1. pernambucensis, Arruda,... 487; Bertol.

\section{HIERACIUM}

$1151^{2}$ a. commun Ambrosi, Fl. Tir. austr. ii, $615=$ praealtum.

$1154^{1}$ 1. Heufelii, Janka, in Neilr. Krit. Zusam. Oestr. Hierac. $22=$

$1154^{2}$ a. hypochoerioides, Ambrosi, 1. c. $609=$ Crepis montana.

hypochoerioides. Gibson, in Phytul. i. (1843) 741. - Anglia.

11563 a. Paleya, Ambrosi, (1. c.) $739=$ Crepis albida.

$1157^{2}$ pleiocephalum, Ambrosi, 1. c: $614=$ stoloniflorum.

poeniculaceum, Ambrosi, 1. c. $740=$ Andryala chondrilloides.

\section{HIEROGHLOË}

$1161^{1}$ spp. plurr, lege Trin... sér. VI, v (non V. vi).

1. pauciflora, R. Br...293 (err. typ. 193),

11611 1. HIEROCHONTIS, Medic...=Euclidium, R. Br. (Crucif.)

carniolica, Medic. 1.c. $=$ E. syriacum.

HIMERANTHUS

1. magellanicus, Griseb.... = Jaborosa magellanica.

$1164^{3}$ a. HIPPORCHIS, Thou. in Nouv. Bull, Soc. Philom. n. 19 (1809) 317 (Quid?). (Orchid.).

\section{HIRSCHFELDIA}

$1166^{1}$ incana, Burnat, Fl, Alp: Mar. i. $76=$ Brassica adpressa.

\section{HOLCUS}

11691 a, elatior, Scop. Introd. $76=$ Arrhenatherum elatius.

a. trivialis, R. Br. Prod. $199=$ Chrysupogon ariculatus.

\section{HOLOTHRIX}

$1170^{1}$ 1. aphylla, Reichb. f...-Arab. (non Afr. austr.) $=$ Habenaria aphylla.

\section{HORMIDIUM}

$1174^{3}$ 1. Yygmaeum, Benth. et Hook: fo ex Hemsl. 1. c.

HORNERA, Neck.

$1175^{1}$ a altissima, Neck $1 . \mathrm{c}=\mathrm{M}$. altissima lignosa, Neck. 1. c. = Dolichos Lablab pruriens, Neck. 1. c. = M. pruriens. urens, Neck. 1. c. $=$ M. urens.

\section{HORTONIA}

$1175^{3}$ 1. angustifolia, Trim. Syst. Cat. Ceyl. (1885) 75. - Zeylan.

\section{HOYA}

11772 1. albens, J. Miller, ex Traill, in Trans. Hort. Soc. vil. (182i) 23 = parasitica.

11773-a. Cunninghami-Teijsm. \& Binn. in Tijdschr. Ned. Ind. xxv. (1863) 408 (Cunnighami) = excavata.

11781 1. pilosa, Seem, in Bonplandia, ix. (1861) $25 \%$; et Fl. Vit. 163, nomen $=$ australis
HUERNIA
$1178^{3}$ a. flava, N. E. Br. in Kew Rep. 1876 (1879) 7 , nomen $=$ primulina

\section{HUTCHINSIA}

$1180^{2}$ a. Revelieri, Jord. Diagn. 337 . in obs, = Capsella procumbens.

Tournefortii, Jord. 1. C. 335 in obs. = Capsella procumbens.

$1180^{2}$ a. HUXHAMIA, Garden, ln Linn. Corresp. i. 366, $379(1821)=$ Trillium, Linn (Liliac.).

$1180^{\circ}$ a. HUXHAM1A, Garden, in Linn. Corresp. $378,379(\mathbf{1} 821)=$ Berchemia, Neck. (Rhamnac.).

$1180^{3}$ a. HUXHAMIA, Garden, in Linn. Corresp. i $408(1821)=$ Gordonia, Ellis (Ternstroem.

\section{HYAGINTHUS}

$11 S 0^{3}$ a AMPHIBOLIS, Schott \& Kotschy, in Kotschy, Reise Taur. 379 (I858) nomen

\section{HYDNORA}

$1182^{2}$ 1. bogosensis, Becc.

\section{HYDRANGEA}

$1182^{3}$ ] Hortonsio Sieb 688 = hortensis.

hortensis, Sm...12 - As, or.

HYGROPHILA

11863 a, ringens, R, Br. Prod. $479=$ angustifolia.

\section{HYMENANTHUS}

$1187^{2}$ a. crassifolia, Veitch, Cat. 24 (1877), - N. Zel.

\section{HYMENODICTYON}

$1188^{3}$ a. timorianum, Miq. FI. Ind. Bot. ii, $153=$ timoriense.

\section{HYOPHORBE}

11893. 1. PALMAE loco SOL AN APALMAE.

\section{HYOSPATHE}

$1190^{2}$ a. amaricaulis, Hort. ex Hook. f. Kew Rep. $18 \div 2$ (1884) $59=$ Hyophorbe amaricaulis elata, Hort. ex Hook. f. Kerv Rep. 1882 (1884) 68. - Ins. Celebes.

\section{HYPERIGUM}

11931 a. groenlandicum Berl in Ofvers, Vet, Akad. Förh. xli, (1884) n. VII. $47=$ dovrense

$1193^{2}$ a. hyparcticum, Berl. 1. c. $46=$ nigrescens.

$1194^{3}$ a. vigorosum, Laest. ex Berl. 1. c. $49=$ prenanthoides.

\section{HYPOCHOERIS}

$1196^{2}$ a. alpestris, Facch, ex Ambrosi, Fl, Tir. austr. ii. $559=$ variflora.

\section{HYNOLAENA}

$1197^{3} 1$, aspera, Nees, ex Mast.

\section{HYPOXIS}

$1199^{3}$ 1, simenensis, Hochst. in Flora, (1844) 32 (non simensis).

$1202^{2}$ a. HYSTRINGIUM, Trin, ex Steud. Nom. ed. II. ii. 11 in $\operatorname{syn} .(184)=$ Lasiochloa Kunth (Gramin.)

a. acuminatum, Trin, ex Steud. 1, c. = L. adscendens.

\section{I}

\section{IARAVAEA}

12022 a, aquatica, Scop. Introd, $215=$ Nepsera aquatica.

bivalvis, Scop. I. $\mathrm{c}_{*}=$ Acisanthera brevifolia. siandens, Scop. 1. c。 $=$ AdeIobotrys scandens trivaluis, Scop. 1. c $=$ Acisanthera trivalvis, villosa, Scopi $1, \mathrm{C}_{.}=$Demoscelis villosa
IBEER IS
$1202^{3}$ 1. bursifolia, Berger. Phyton, iii. 23 =

\section{CACOREA}

$1203^{3}$ 1. balomensis, Iam = Myrsine Heberdenia $1203^{3}$ a. paniculata, Sudworth, in Garden and Forest vi. (1893) $324=$ Ardisia Pickeringia.

IGICA

$1204^{2}$ a. Protizm, Karst. Pharm. Med. Bot. $803=$ P. javanicum

ILEX

$1205^{3}$ a, californica, T. S. Brandeg. in Garden and Forest, vii. (1894) 414. - Calif.

$1206^{3}$ a. mitis, Radlk. in Rep. Brit, Assoc. (1885) Aberd ... = capensis

$1207^{2}$ a. triflora, T. S. Brandeg. l. c. 414. - Calif

12082 1. ILLIPE, Gras, in Bu11. Soc. Bot. Fr. xi. 1864) 83 = Bassia, Knenig (Sapot).

a. malabarorm, Gras, 1. c. = B: longiflora.

\section{IMPATIENS}

12092 1. fasciculata, Lam... 363 (non 359).

\section{INDIGOFERA}

$1212^{3}$ a, denudata Schrank, in Hoppe, Bot, Z it iv 1805) 309. - Aegypt.

$1214^{2}$ 1. racemosa, Linn. Amoen. Acad.

\section{INGA}

$1215^{3}$ 1. Bourgoni, Scop.Introd. 298; DC... (Burgoni) $1216^{1}$ 1. cylindrica, Mart... 114 = Entada polysta$1217^{3}$ polystachya, Scop. (1. c.) = Entada polystachya.

\section{IONIDIUM}

$1221^{3}$ a. Marcucii, Bancr. Obs, Pl. Cinch, (1835) 17. - N. Granat.

$1222^{2}$ 1. IOXYLON, Rafin。 in Am. Monthly Mag, ii (1817) 118; et.iv. (1818) $195=$ Maclura Nutt. (Urtic.).

a. fomiferum, Rafin. 1. c. $118=$ M. aurantiaca.

IPOMOEA

12281 1. ternata, facq... - Jamaica.

\section{IREON}

$1228^{3}$ a. parviflora, Scop. Introd. $229=$ Lightfootia oxycoccoides

\section{IRIARTEA}

122921 . gigantea, $\mathrm{H}$. Wend1... $155=$ Socrateae sp. ? Klopstockia, Hort. ex W. Wats, in Gard. Chron. (1885) i, $338=$ Ceroxylon andicolum

nivea, Hort. ex W. Wats, 1. c, ii. $750=$ Ceroxylon, sp

$1229^{2}$ 1. IRIDORCHIS. Thou, Orch. Afr, tab. synop. i. (1822); Blume.

$1229^{2}$ a. IRIDORKIS, Thcu. in Nouv. Bull. Soc. Philom. n. 19 (1809) $319=$ praec.

\section{IRIS}

12302 a erratica Hort ex Baker, in Gard. Chron. (1876) ii. $583=$ Guldenstaedtiana.

foetida, Berger, Phyton. ii. $185=$ foetidissima.

$1231^{3}$ 1. paradoxa, Stev... (1817) (loco 1814).

$1232^{2}$ a Wittmaniana, Hort, ex Baker, in Gard. Chron. (1876) ii. 583 = Guldenstaedtiana.

\section{ISOLEPIS}

$1237^{3}$ a. obliganthus, Steud. in Flora, xii. (1829) 146 = Ficinia filiformis.

a. oliganthes, Nees, in Linnaea, vii. (1832) 503 = Ficinia filiformis.

ISONANDRA

12393 a Percha, Hook. Lond. Journ. Bot. vi. (1847) 610 (Index) = J. Gutta 
ITTNERA

$1240^{3}$ 1. majar, Reichb. Fl. Germ. Excurs. $150=$ ITESEA

$124 I^{R}$ unguiculata, A. Gray,... = P. unguiculata,

\section{$\mathrm{J}$}

$1247^{3}$ a. JADELOTIA, Buchoz, Herb. Col. Amér. t. 42 (1783) Quid?

\section{JASMINUN}

12493 a. Betchei, F. Muell, in Vict. Chem, et Drugg. Sept. (1881). - Ins. Samoa.

\section{JAUMEA}

$1252^{3}$ a. alternifolia, Klatt, in Flora, 1xviii. (1885) 203. - Hab, ?

$1253^{1}$ a. JESSENIA, F. Muell. ex Sond. in Linnaea, xxv. (1852) $519=$ Helipterum, DC. (Compos)

heterocarpa, F. Muell. 1, c. $=\mathrm{H}$. hyalospermum.

$1255^{3}$ a. JONSONIA, Garden, in Linn. Corresp. i. $364(1821)=$ JOHNSONIA, T. Dale $=$ Gallicarpa, Linn. (Verbenac.).

\section{JUNGUS}

12573 1. isoletoides, Nees, ... $244=$

facquini, Sm. Rel. Rudb, $24=$ Schoenus

$1259^{3}$ 1. tenuis,...-Am. bor. (non Austral.).

\section{JUNIPERUS}

126021 audina Nutt . $=$ occidentalis.

$1260^{2}$ 1. australis, Endi... 28 (non 26).

a. canadensis, Burgsdorf, Anleit. $124(1787)=$ caroliniana, Mill.... (Caroliana), =

$1260^{3}$ 1. flagelliformis, Hort... =

Henryana, $R$. Br. Campst... nomen.

a. Hermanni, K. Koch, Dendrol. ii. II. $141=$ occidentalis partim.

Hermanni, Spreng. Syst. III. 908 (non Pers.),

$1261^{2}$ I. pyriformis, [Lindl.?] (non A. Murr.)... california.

1. sabinoides, Endl. Syn. 23 (non 24).

\section{$\mathrm{K}$}

\section{KADSURA}

$I^{1}$ a. Blancoi [Azaola] ex Blanco, Fl, Filip, ed. II. 594. - Ins. Philipp.

\section{KALLSTROEMIA}

$2^{3}$ 1. maxima, Scop. Introd. 212; Wight \& Arn.

\section{KENNEDYA}

$4^{3}$ 1. splendens, Meissn... = Camptosema rubicunda.

\section{KENTIA}

51 1. australis, Hort... = Howea Forsteriana.

a. elegans, Hort. ex Hook. f. Kew Rep. 1882 (1884) $54=$ Veitchia Storckii.

1. robusta, Hort... = Cyphosperma Vieillardi.

\section{KERATOPHORUS}

$5^{3}$ a. Leerii, Burck, Rapp. Gutta-percha, 28. Sumatra.

\section{KIGGELARIA}

I1 1. integrifolia, Jacq... = Royena polyandra

KLEINHOVIA

$77^{3}$ a. GARDENIA, Linn. Corresp. i. 135 (1821),

\section{KNIPHOFIA}

91 1. abyssimica, Schweinf.... 294 (non 249).
93. 1. KOANOPHYLLON, Arruda,... (1816) = Eupatorium, Tourn, (Compos,).

inctoria, Arruda, 1. c. = E, laeve.

\section{KOGHIA}

$10^{2}$ 1. pentatropis, Tate $\ldots=$ decaptera.

\section{KUNDMANNIA}

$15^{2}$ 1. sicula, Scop. Introd. $116 ; D C$.

$15^{3}$ 1. KYDIA,... 51 (non 50$)$

1. calycina, Roxb... iii. 12 (non ii).

\section{KYLLINGA}

$16^{2}$ a. multiceps, Madden, in fourn. As. Soc. Beng. xviii. (1849) 630, nomen. - Reg. Himal.

\section{L}

\section{LACISTEMA}

$19^{3}$ 1. alterum, Spreng... $20=$ Myrica cerifera.

\section{LAELIA}

$21^{3}$ a. devoniensis $\times$, Reichb. $f$. in Gard. Chron. (1877) ii. 424

praestans $\times$. Reichb. $\mathrm{f}$. in $\mathrm{K}$. Koch, Allg. Gartenz. (1857) $536=$

\section{LAGASCEA}

231 1. mollis, Cav... 332 (non 333)

\section{LAGGERA}

$23^{3}$ 1. alata, Sch. Bip. ex Oliver,... xxix (non xxxix).

\section{LAMOUROUXIA}

$26^{3}$ 1. grandiffora Benth. $=$ multifida

1. Gutierrezii, Oerst... (1853). - Costa Rica, Panama (non Venezuela).

1. spathacea, Benth. in DC. Prod. $\mathrm{x}, 539=$ xalapensis.

xalapensis, Benth. (1..c.) partim = exserta (1895).

\section{LANDOLPHIA}

281 a. senegalensis, Kotschy \& Peyr. Pl. Tinn. 31.Afr. trop.

\section{LAN KESTERIA}

282 1. longiflora, Lindl... sub t. 12

\section{LANTANA}

283 a CAMr, Plum, ex Linn. Syst. ed. I. (1735).

a. Lanzan, Spreng; in Schrad, Journ. 1800, II. (1801) 235 , in obs. = Buchanania, Spreng. (Anacard.).

\section{LAPPA}

$30^{3}$ a. Lappa, Karst. Pharm. Med. Bot, $1121=$ A. Lappa.

LAPPULA

$31^{1}$ a. Lappula, Karst. Pharm. Med. Bot. $979=$ E. Lappula,

\section{LARIX}

$31^{3}$ a. Larix, Karst. Pharm. Med. Bot. $326=$ europaea.

\section{LASIOCHLOA}

$35^{1}$ a. HrstringiUM, Trin. ex Steud. Nom, ed. II. ii. 11. in syn. (1840).

\section{LASIOCORYS}

$35^{\mathrm{I}}$ a. argyrophilla, Vatke, in Oest. Bot. Zeitschr. xxv. (1875) 96, = Afr. trop.

$45^{2}$ 1. LEA VENWORTHIA, Torr... iv.

LEDENBERGIA

$46^{2}$ 1. rosea.aenea, Lem.... $590=$ Villamilla roseaaenea.

\section{LEEA}

481. macrophylla, Roxb... 231 (non 251).

1. robusta, Roxb. Hort. Beng. 18 (non 8).

\section{LEERSIA}

$48^{2}$ a. TurRAYA, Wall. Cat. sub n. 8637 (1847).

a. ciliaris, Griff. Notul iii $2=$ hexandra.

a. ciliaris, Griff. Notul. iii. $8=$ Zizania ciliata.

$50^{1}$ a. LeleBA, Rumph. ex Teijsm. \& Binn. Cat. Pl. Bogor. $20(1866)=$ Bambusa, Schreb (Gramin.).

Rumphiana, Kurz, ex Teijsm. et Binn. 1. c. = B. lineata.

\section{LEMNISCOA}

$50^{3}$ a. Parishit, Hook. f. Bot Mag. t. 5961, in obs, $=$ Bulbophyllum lemniscatum, Par.

$50^{3}$ a. LENCYMMAEA, Benth. \& Hook. f. Gen. i. $735(1867)=$ seq.

1. LENGYMMOEA, Presl,

LEONTODON

522 1. Heldreichianus, Boiss. Diag. Ser. II. iii. 88 Fl. Orient.

\section{LEONTOPODIUM}

$53^{2}$ a. Leontopodium Karst. Pharm. Med. Bot. 1074 = alpinum

\section{LEPIDIUN}

$56^{3}$ 1. diandrum, Medic. Pflanzeng. 84 ; et in Usteri,

\section{LEPILAENA}

$59^{3}$ a. buloculata, T. Kirk, in Rep. School Agric Lincoln [n. 3 (1884) 18; repr. in n, 3. Country Journ. ix. (1885) 373; nomen tantum.

\section{LEPTOBAE}

$61^{3}$ a. pubescens, C. B. Clarke, in Hook, f. Fl. Brit. Ind. iv. 368 in nota $=$ multiflora.

LEPTOCHLOA

$62^{1}$ a. bipinnatu, Hochst. in Flora, xxxviii. (1855) 422 = Eragrostis cynosuroides.

bipinnata, Hochst. ex Schweinf. f. Beitr. Fl. Aethiop. 300. - Afr, bor, or.

$63^{3}$ a. LEPTORKIS, Thou, in Nouv. Bull. Soc Philom. n. $19(1809) 317=$ Malaxis ? Sw (Orchid.).

$66^{2}$ 1. LERCHEA, Hall... 1753 (non 1743).

\section{LEUCANT HEMUM}

$70^{1}$ a. tubuliflorum, Tinney, in Am. Natural. i. (1867) $389=$ C. - Leucanthemum.

LEUCOCOCCUS

$71^{2}$ a. vimineus, Wedd. in Arch. Mus. Par. ix. (1856) $104,105=$ Pouzolzia ovalis

$72^{1}$ 1. LEUCOPHAË, Webb \& Berth.

$74^{3}$ a. LEUCYMMAEA, Benth in Hook. Kew Journ. iv. (1852) 287, sphalm, = Lencymmoea Presl (Gen. dub.).

\section{LEVISTICUM}

$75^{1}$ a. Levisticum, Karst. Pharm, Med, Bot. $844=$ officinale.

\section{LIATRIS}

$76^{1}$ 1. fruticosa, Nutt... - Am. bor. oppositifolia, Nutt... - Am. bor

LIBANOTIS, Riv,

$76^{2}$ a. Libanotis, Karst. Pharm. Med. Bot. $842=$ S. Libanotis,

LIGULARIA

791 1. Hodgsoni, Hook... (non Hook. f.).

\section{LIGUSTIGUM}

$79^{3}$ 1. Dieffenbachii, Hook, f... = Angelica Dieffenbachi (Aciphyllae sp.). 


\section{LIGUSTRUM}

802 1 brachystachium, Decne, (non brachystachyum) $80^{3}$ a. japonicum, Thunb. Fl. Fap. 17. t. 1. - Japon.

\section{LIMODORUM}

$85^{1}$ a. Graphorkis, Thou. in Nouv, Bull. Soc. Philom. n. $19(1809) 318$

\section{LIMOSELLA}

862 1. annua, Benth. in DC. Prod. x. 427 (cum cit pre-Linneana)

borealis, Less. Reise durch Norwegen, 299 ; et ex Ledeb...

a. natans, Spreng. ex Drège, in Linnaea, $x x$ (1847) 199 , nomen $=$ aquatica.

palustris, Linn. Mant. ii. 252, in obs. = aquatica.

\section{LINARIA}

$87^{3}$ a. Linaria, Karst. Pharm. Med. Bot. $947=$ vulgaris.

$88^{3}$ 1. speciosa, Ten. Syst. Fl. Neap. $304=$

\section{LINDERA}

892 1. Benzoin, Blume, Mus. Bot. Lugd. Bot. i. 324. a. hypoleuca, Franch. et Sav. Enum. P1 Jap. i. 415 , sphalm. = hypoglauca.

893 1. LINHAREA, Arruda, ex Koster, Trav. 493 (1816).

LINHARIA, Arruda, (1. c.) = praec

\section{LINOSYRIS}

$90^{3}$ a. anacamphthiphylla, Ambrosi, Fl. Tir. Austr. ii. $389=$ Aster Linosyris

tatarica, C. A. Mey. ex Aitch. Cat. P1. Punjab, $72=$ Aster sibiricus?

\section{LIPARIS}

$93^{2}$ 1. angustifolia, Lindl... - Jara.

a. angustifolia, Thw. Enum. Pl. Zeyl. $206=$ obscura (1889)

\section{LIOUIDAMBAR}

$96^{1}$ 1. asplenifolia, Linn... = Myrica asplenifolia.

\section{LITHOSPERMUM}

$99^{2}$ a. Gastoni, Benth. in Hook. Bot. Mag. ii. (1840) 112; in in DC. Prod..

LITSEA

$100^{2}$ a. Malapoenna, Adans. Fam. ii. 447 (1763) $100^{3}$ 1. Bindoniana, F. Muell. Census, 4. (1S82). Austral.

$101^{1}$ a. Ieticulata, Benth. E Hook. f. ex F. Muell. Census, 4 (1882). - Austral.

\section{LITTONIA}

$101^{2}$ a. Keiti, Leichtl, in Garden, xxiv. (1883) 87, in obs. $=$ modesta

LIVISTONA

$101^{3}$ a occidentalis, Hort. ex Hook. f. Kew Rep. 1887 (1884) $64=$ Brahea dulcis.

LOASA

$102^{3}$ a. lateritia, Hook. Bot. Mag. t. $3632=$ Caiophora lateritia.

\section{LOBELIA}

$105^{2}$ a. parvifiora, Scop. Introd. 229 (sphalm.) $=$ parvifolia, Berg.

$105^{3}$ reniformis, Brongn. in Ann. Sc. Nat. Sér. II. iii. (1835) 48 , in obs. sphalm. = Lysipomia reniformis.

$108^{3}$ a. LOGIA, Mutis, in Linn. Corresp. ii. 528 $(1821)=$ Calceolaria, Linn. (Scrophul.).

\section{LONIGERA}

$111^{3}$ a. parviflora, C. Koch, Dendrol, ii. II. 385, sphalm. = parvifolia.

parvifolia, Hayne, Dendrol. Fl. Umg. Berl. 14 = tatarica.

\section{LOPHOSPERMUM}

$113^{3}$ 1. scandens, D. Don,... = N. scandens,

12031 LOUDETIA, Hochst... II. Intell. 30; $\mathrm{A}$. Br. in...

\section{IUGUMA}

1221 1. deliciosa, Planch. E Linden,... 336 (non 836).

$122^{3}$ a. LUdoviCEA, Buc'hoz, Herb. Col. Amér. t. $11(1783)=$ (Quid ?).

gallo-provincialis, Buc'hoz, 1. c. (Quid ?). -

\section{LUISIA}

$124^{1}$ 1, teretifolia, Gaudich, in Freyc. Voy. Bot, 427 (non 426).

\section{LUZU்LA}

$127^{3}$ 1. hyperborea, $R . B r . .283$ (err, typ. 185).

\section{LYGASTE}

$128^{3}$ 1. Deppii (non Deppei).

\section{LYCOPERSICUM}

$131^{3}$ a. Lycopersicum, Karst. Pharm. Med. Bot. 966 = esculentum.

\section{II}

\section{MACLURA}

$140^{2}$ a. IoxyLon, Rafin. in Am. Monthly Mag. ii (1817) 118 ; et iv. (1818) 195

a. aurantiaca Rafin. Med. F1. ii. 268 (1830) = Maclura aurantiaca.

\section{MAERUA}

$144^{3}$ 1. oblono ifolia, $A$. Rich... Abyss, t. 6 (non t. 5 ) ovalifolia, Cambess. in facq. Voy. 23 (non 22).

\section{MAGNOLIA}

$146^{1}$ a. palustris, Garden, in Linn. Corresp. i. 512, $515=$ M. glauca

MAJORANA

$147^{2}$ a. Majorana, Karst. Pharm. Med. Bot. $999=$ O. Majorana.

$148^{3}$ a. MALAPOENNA, Adans. Fam. ii. 447 (1763) = Litsea, Lam. (Laurin.)

\section{MALCOMIA}

$149^{3}$ a. castellana, Rouy, in Rev. Sc. Nat. Sér. III i. (1883) 72. - Hispan.

\section{MALUS}

1521 a. aegra, ambigua, americana, anglica, anisa, apetala apiola, atro-rubra, batavica, britannica, butigliana, Calvilla, canadensis, canicularis, Capucini, Caroli, Castanea, cerea, Colombella Columbina, emetica, Gratiae-portus, gratissima, guttata, hybrida. illecebrosa, fosephinea, leucophaea, marmorea, montalicetia, nana, nigra. normalis, oleosa, passipoma, prasomila, Princeps, pseudocavilla, pumila, punctata pustulifera Rambura, rhotomagensis, Robertiana, Roris, spumosa. Vesperum, violacea, vitrea, zonalis, Poit. \& Turp. in Poit, Pomol, Franc, iv, = P. Malus.

$152^{1}$ a. discordea, viridis, A. Savat, in C. R. Assoc. Fr. Av. Sc. xi. Rochelle, 1882 (1883) 431 $=\mathrm{P}$. Malus.

$152^{2}$ livida, beauvaisiensis, A. Savat. 1. c. $430=$ P. Malus.

microcarpa, glabra, A. Savat. 1, c. $432=$ P. Malus.

santonum, A. Savat. 1. c. $428=$ P. Malus. turbinioides, cylindracea, A. Savat. 1. c. $429=$ P. Malus.

\section{MALVASTRUM}

$155^{3}$ 1. splendidum, Kell... = M. Thurberi.

\section{MAMILLARIA}

$158^{2}$ a. mammillaris, Karst. Pharm. med. Bot. $888=$ simplex.

\section{MANETTIA}

1612 1. pubescens, Cham. \& Schlecht, 1. c. 170, Bras.

MANGIFERA

$161^{3}$ 1. Parih, Miq. (non Parish)

\section{MANIHOT}

$162^{2}$ a. Manihot, Karst. Pharm. med. Bot. $588=$ utilissima.

\section{MAPOURIA}

$164^{1}$ 1. brevicollis, Muell. Arg. . - Bras. Burchelliana, Muell. Arg... - Bras. castellana, Muell. Arg... L- Bras. japurensis, Muell Arg... - Bras. Langsdorffiana, Muell. Arg... - Bras.

a. Luschnathiana, Muell. Arg. in Mart. Fl. Bras. vi. v. 387, sphalm. = M. Luschnatii.

1. mandiocana, Muell. Arg... - Bras.

Martiana, Muell. Arg...-Bras.

microcarpa, Muell. Arg... - Bras. myriantha, Muell. Arg... - Bras. Rabeniana, Muell. Arg... - Bras. Riedeliana, Muell. Arg... - Bras

$164^{2}$ sessiliflora, Muell. Arg... - Bras, xanthophylia, Muell. Arg...-Bras,

\section{MARANTA}

$165^{1}$ a. albo-lineata, Hort, ex Regel, Gartenfl. xxviii. (1879) $295=$ Calathea ornata.

Bachemiana, Hort. ex Regel, (1. c.) $297=$ Calathea Bachemiana.

bella, Hort. Bull, ex Regel, (1. c.) = Calathea bella, Regel.

$165^{2}$ 1. cinerea, Hort... (1872) [non 1892].

a. coriffolia, Hort. ex Regel, Gartenfl. xxviii. (1879) 295 = Calathea ornata

$165^{3}$ Kegeliana, Hort. ex Regel, (1. c.) $=$ Calithea Bachemiana.

Kegcljani, E. Morr. ex Regel, (1. c.) = Calathea bella, Regel.

majestica, Lindèn, ex Regel, (1. c.) $=$ Calathea ornata.

$166^{1}$ orbifolia, Linden. Cat. n. 17 (1862) nomen; et Koern, in Regel, Gartentl. xiii. (1864) $322=$ Calathea rotundifolia.

Ricdeliana, Hort. Paullowsk. ex Regel, Gartenfl. xxviii. (1879) $293=$ Calathea Koernickiana.

roseo-lineata, Hort. ex Regel, Gartenfl, xxviii. (1879) $295=$ Calathea ornata.

$166^{2}$ Wagneri, Hort. Veitch, ex Regel, (1. c.) = Calathea roseo-picta.

\section{MARRUBIUM}

$170^{2}$ a. Aschersoni $\times$, P. Magnus, in Ber. Deutsch. Bot. Ges. ii. (1882) 349. - Ins. Sardoa.

$1 \% 11$ 1. saxatile, Rafin, Specch, Sc, ii. 134-135; ex Call, Life ; Rafin. 150.

\section{MASSOWIA}

1751 1. Gardneri, K. Köch,... = Spathiphyllum candidum.

$175^{3}$ a. MATONIA, Rosc, ex Sm. Life \& Corr, ii. $375(1832)=$ Elettaria? Maton (Scitam.).

$175^{3}$ a. MATONIA, Sm, in Rees, Cyclop. xxxix. sub Elettariâ (1819).

Cardamomum, Steph, \& Church, Med. Bot. ir. t. $106=\mathrm{E}$. Cardamomum

1781 a. MATTONIA, Endl. Gen. 223, in syn. (1837) $=$ MATONIA, Sm. = Elettaria, Maton (Scitam.).

MAXILLARIA

$179^{2}$ 1. floribunda, Lindl. in Benth. Pl. Hartweg. 154. - Peruy.

$180^{2}$ rufescens, Lindl... sub. t. 1802 ; et b. c. t. 1848 
MECONOPSIS

1821 a. glabra, Hook. Ic. Pl. sub t. 732, in syn. sphalm. = heterophylla.

\section{MEDICAGO}

1832 a. lenticulata, Pourr, ex Benth. Cat。 pl. Pyr $100=$ suffruticosa

$184^{1}$ rupestris, Pirona, F1. Forojul. Syll. $41=$ Pironae.

$189^{3}$ a. MELANIX, Rafin. in Am. Monthly Mag. i. 1817) 439 = Salix, Tourn

MELANTHIUM

$191^{2}$ 1. punctatum, Linn... = Androcymbium leucanthum.

\section{MELASTOMA}

$193^{3}$ a. integrifolia, Buc'hoz, Herb. Col. Amér. t. 71 (Quid ?). - Guian.

$196^{3}$ Raussinia, Buchoz, l. c. t. 27. - Hab.

1963 1. MELEAGRINEX, Arruda, $\ldots=$ Sapindus Tourn.

pernambucana, Arruda, 1. c. = S. esculentus.

\section{MELIA}

1971 a. dichotoma, Scop. Introd, $287=$ Diosma cupressina.

hirsuta, Scop. (1. c.) = Diosma oppositifolia.

$197^{2}$ succulenta, Scop. (1. c.) $=$ Diosma succulenta

\section{MELOCACTUS}

$201^{3}$ a. Melocactus, Karst. Pharm. Med. Bot. $888=$ communis

\section{MELOCANNA}

2021 a. Blumei, Kurz, ex Teijsm. \& Binn. Cat. Pl. Bogor. 20. - Java.

brachyclada, Kurz, (l.c.). - - Java. elegantissima, Kurz, (1. c.) = Beesha elegantissima.

1. gracilis, Kurz, (l. c.) ; et ex Munro,

a. Hasskarliana, Kurz, (l.c.). - Java. longespiculata, Kurz, (l.c.). - - Java. serpentina, Kurz, (l.c.). - Java.

tenuispiculata, Kurz, (l.c.). , - Java.

1. Zollingerii, Kurz, (l, c.); et ex Munro,

\section{MESPILUS}

$218^{2}$ a. apyrena, Poit. \& Turp. in Poit. Pomol. Franç. iv, $=$ P, germanica

1. Aucuparia, Scop. Introd. 218; [Web.]

$218^{3}$ macrocarpa, Poit. \& Turp. (1. c.)); DC.

2191 a. portentosa, Poit. \& Turp. (1. c.) = P. germanica.

METROSIDEROS

$221^{3}$ a. demonstrans, Tison。 in C. R. Ass. Fr, v. (1877) 462, - N. Caled.

\section{METROXYLON}

$222^{2}$ a. amicarum, Hook. f. Kew Rep. 1882 (1884) 68 - Ins. Amicor.

$222^{3}$ a. METZLERIA, Sond. in Harv, et Sond. FI. Cap. iii. 532 (1864-65), sphalm. = MEZLERIA, PresI = Lobelia, Plum. (Campan.).

\section{MEUM}

$222^{3}$ a. Meum, Karst. Pharm. Med. Bot. $839=$ athamanticum.

MEZLERIA

2231 1. depressa, Presi,... - Afr. austr.

Dregeana, Sond... - Afr. austr.

\section{MICONIA}

$221_{1}$ a. acalyphoides, Cogn. in DC. Monog, Phan. vii. 1228 (Index), sphalm. = acalephoides.

\section{MICRECHITES}

$228^{2}$ 1. Schrieckii, Rolfe, in fourn. Bot. xxiii. (1885) 214; Vidal.

\section{MICRELIUM}

$228^{2}$ 1. asteroides, Forsk...p. 1xxiv

Tolak, Forsk . 15

$228^{3}$ a. MICROCHITES, Rolfe, in Journ. Bot. xxili. (1885, 214; et op. cit. xxiv. (1886) 59, lapsu $=$ Micrechites, Miq. (Apocyn.).

\section{MIGROGHLOA}

$228^{3}$ a. thomaea, R. Br. Prod. $208=$ Oropetium thomaeum

\section{MIGROULA}

$234^{3}$ 1. Benthami C. B. Clarke,... = tibetica

a. tibetica, Benth. ex Maxim. in Bull. Acad. Pétersb. xxvi. (1880) 502: - Tibet

\section{MIKANIA}

$236^{1}$ a, parniffora, Karst. Pharm. Med。 Bot, $1061=$ amara.

\section{MIMOSA}

$240^{3}$ a. contorta, Buchoz, Herb. Col. Amér.-t. 67 Ouid ?) - - Hab.

$245^{2}$ 1. virginalis, Arruda,...500 = Stryphnodendron Barbatimam.

MITINA

$248^{3}$ 1. lanata, Scop. Introd, 124: Cass.

\section{MITRARIA}

$249^{3}$ 1. Commersonia, J. F. Gmel... = B. speciosa.

\section{MITRASAGME}

$249^{3}$ a. Novae-Zelandiae, Hook. f. Handb. N. Zeal. F1. 737. - N. Zel.

\section{MOEHRINGIA}

$251^{2}$ a. ciliata, Dalla Torre, Atl. Alpenfl. $78=$ A. ciliata.

2561 a. MONANTHEMUM, Scheele, in Flora, xxvi. (1843) $314=$ Morisia, Gay (Crucif.). acaule, Scheele, 1. $c_{0}=$ Morisia hypogaea

\section{MONODORA}

2591 1. Myristica, Dun... - Afr. trop.

\section{MONOSTICHL}

$260^{1}$ 1. Danielli, Horan.: = Thanmatococcus Banielli.

$260^{3}$ a. MONOTHECIUM, Hochst. in Flora, xxvi. (1843) 74 [non 374]. glandulosum, Hochst. l. c.-Afr. trop.

2622 a. MOOREA, Lem. in Ill. Hortic. ii. (1855) Misc. 14 = Cortaderia, Stapf (Gramin argentea, Lem. 1. $\mathrm{C}_{\mathrm{t}}=\mathrm{C}$. argentea, Stapf.

MORENIA

$263^{3}$ 1. pauciflora, Drude... = pauciflora.

MORILANDIA, Neck.

$264^{1}$ a. crenata, Neck. 1. c. $=$ C. crenata.

falcata, Neck, 1. $c_{2}=$ C. falcata.

juniperina, Neck. 1. c. = C. juniperina

obcordata, Neck. 1. c. = C. obcordata.

pulchella, Neck. 1. c. = C. pulchella.

sarmentosa, Neck. 1. c, = sarmentosa.

ternata, Neck. 1. c. = C. polygonifolia.

trifoliata, Neck. 1. c. = C. polygonifolia

$265^{1}$ a. MORISEA, DC. Prod. vi. 90 indidnot. (183\%) $=$ Morisia, Gay (Crucif: $)_{0}$ ?

\section{MORISIA}

$265^{1}$ a. acaulis, J. Gay, ex Colla, in Antologia, xxxiv, (Aprile 1829) 158 , nomen = hypogaea

$265^{-1}$ a. MORISINA, DC Prod. vi. 90, in adnot $(1837)=$ Morisia. Gay (Crucif.. .

\section{MORUS}

$266^{3}$ a. virginiana, Poit, \& Turp. in Poit. Pomol. Franç. ii. - Am. bor.

\section{MOSCHARIA}

$266^{3}$ a. asperidifolia, Forsk: (l.c.) p. Ixxiv. asperifolia, Steud. Nom. ed. 1, 24, in syn. = praec.

\section{MUCUNA}

2682 1. altissima, Scop. Introd, $309 ;$ DC.

a. lignosa, Scop. (1. c.) = Dolichos Jacquini

l. pruriens, Scop. (l. c.) ; $D C$.

urens, Scop. (l. $\left.c_{0}\right) ;$ Medic.

\section{MUSA}

$272^{1}$ 1. paradisiaca, Linn... - As. trop.

\section{MUSCARI}

$272^{3}$ 1. azureum, Fenzl.... $\Rightarrow$ Hyacinthus azureus $272^{3} \quad$ lingulatum, Baker,...6= Hyacinthus azureus

\section{MUSENIUM}

$273^{2}$ 1. tenuifolium, Hook. in Lond. Journ. Bot, vi (1847) $237=$ Peucedanum graveolens.

\section{MYAGRUM}

$275^{1}$ a. foetidum Berger. Phyton, iii. 138 = sativum. prostratrum, Berger. (1. c.) $149=$ Nasturtium sylvestre.

utriculatum, Berger. (1. c.) $35=$

\section{MYOSOTIS}

$276^{3}$ a. albo-sericea, Hook. f. Handb. N. Zeal. Fl. 738. - N. Zel.

\section{MYRGIA}

$278^{3}$ 1. Australasiae, Benth. Fl. Austral. iii. $294=\mathrm{seq}$ australasica, F. Muell...

\section{MXRICA}

$281^{2}$ 1. CoMPtonia, L'Hérit. ex Ait. Hort. Kew, iii 334 (1789); Banks, etc.

altera, DC... $595=$ cerifera

d. australasica (err. cal, vide sub Myrcia).

a. carolinensis, A. Rich. Fl. Cub. Fanerog. ii $231=$ cerifera.

1. carolinensis, Mill... Am. bor.

a. cerifera, Bigelow, Fl. Bost. = carolinensis.

1. heterophyla, Rafin... $9=$ cerifera. Laureola, Tréc... = inodora?

$281^{3}$ luzonica, Vidal,... B. - Ins. Philipp pensylvanica, Hort, $\operatorname{Reg} . . .=$ carolinensis sessilifolia, Rafin... $10=$ carolinensis. verrucosa, Rafin... - Ind. occ.

\section{MYRISTIGA}

$284^{1}$ 1. uaupensis, Spruce (non uapensis)

MYRSINE

$285^{2}$ 1. HeBerdenIA, Banks; ex Vent. Choix, n. 5 verso $(1803)$

$285^{3}$ excelsa, Link, .. $=$ M. Heberdenia.

2861 Heberdenia, Roem. \& Schult... 508, - Ins. Baham.

\section{MYRTUS}

2891 a. nitida. J. F. Gmel. Syst. $792=$ Eugenia lucida, Banks.

$289^{2}$ paniculata, J. F. Gmel. (1. c.) = Eugenia paniculata, Banks.

$290^{2}$ vitiensis, F. Muell. in Proc. Roy. Soc. Tasm 1875 (1876) 165. - Ins. Fiji.

\section{MYSTAGIDIUM}

$290^{3}$ a. distichum, Benth. in fourn, Linn. Soc. xviii (1881) 337..- Afr. trop.

fragrantissimum, Benth. \& Hook. f. Gen. Pl. iii. 584. - Afr. trop.

pectinatum, Benth, (l, c.) $33 \%$ - Madag. Ins, Mascar.

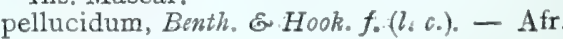




\section{N}

\section{NASTURTIUM}

2961 1. Aschersonianum, Fanka, in Közlem, Magyar Tudom. Akad. xii. (1876) 165. - Europ.

$296^{3}$ a. Nasturtium-aquaticum; Karst. Pharm, med. Bot. $6.5 \% \equiv$ officinale.

1. officinale, $R . B r \ldots 110$ (non 111)

2971 1. sativum, Medic. Pflanzeng. 80; Moen,...

\section{NAUGLEA}

2973 1. glaberrima, Bartl... $344=$ Sarcocephalus glaberrimus.

$298^{1}$ lanceolata, Blume,... 1009. - Java. orientalis, Linn... 243 = Sarcocephalus cordatus, Anthocephalus indicus, etc.

d. orientalis, Willd.

1. palliza, Reinw. ex Miq.... = purpurascens, polycephala, A. Rich... 289 = Uncaria tomentosa.

purpurea, Reinw. ex Miq. Anin. Mis. Bot. Lugd. Bot. iv. $182=$ purpurascens. purpurea, Roxb́... 51. - Ind. or. (non China). rhynchophylla, Miq... $108=$ Uncaria rhynchophylla (cf. Cur. post.)

$298^{2}$ a. surinamensis, Walp. Ann. i. $378=$ Uncaria surinamensis.

1. undulata, Roxb... 508.= Sarcocephalus undulatus.

NEEDHAMIA

$300^{2}$ a. littoralis, Scop. 1. c. $=$ T. cinerea:

NEGUNDO

$300^{3}$ a. Negundo, Karst. Pharm. med. Bot. $596=$ aceroides.

\section{NEILLIA}

$300^{3}$ 1. fallax, Blume.

$301^{1}$ Tanakae, Franch. \& Sav... $121=$ Stephanandra Tanakae.

NELITRIS

$30 \iota^{2}$ 1. vitiensis, A. Gray,... $60=$ Myrtus vitiensis. NELUMBO

$301^{3}$ a. Nelumbo, Karst. Pharm. med. Bot. $553=$ Nelumbium speciosum.

\section{NEPENTHES}

$304^{3}$ 1. Courtii X, Veitch, Cat. (1878) 25; Gard.

3051 Sedeni $\times$, Veitch, Cat. (1871) 17 ; . Veitchii, Veitch, Cat. (1878) 47. lianata.

\section{NEPHELIUM}

$307^{2}$ 1. connatum, F. Muell. in Trans. Phil. Inst. Vict. iii. (1859) 26. - Austral,

$307^{3}$ a. oleaefolium, F. Muell. Native Pl. Victoria, $124=$ Heterodendron oleaefolium.

semiglaucum, F. Muell. (1. c.) $15=$ Cupania semiglauca.

NERTERIA

3091 a. Gomezia. Mutis, in Linn...Corresp. ii. 529 (1821).

NIGANDRA

$311^{2}$ a. Physalodes, Scop. Introd. $188^{\prime \prime}=$ physaloides.

\section{NICOTIANA}

$312^{3}$ 1. plumbaginifolia, Willd. ex Schrank, in Hoppe, vi. (1807)"265; et Enum.

$315^{3}$ a. NOALIIA, Buc'hoz, Herb. Col. Amér. t. 14 (1783) (Quid?)

ncarnata, Buc'hoz, 1. c. - Hab?

NORMANBYA

$317^{3}$ a. Muelleri, Becc. in Ann: Jard. Buitenz. ii (1885) 171 (Index). - Anstral.

NORYSCA

a1 $7^{3}$ a. cernua, Munro, Host. Agr, 10; Voigt,

\section{NOTHOSCORDÜM}

$319^{1}$ a. inodorum, Nichols. Dict. Gard. ii. $447=$ fragrans.

$320^{2}$ a. NUTTALIA, Torr in Ann. Lyc. N. York. ii. (1836) 200 , in nota = Mentzelia, Plum. (Loasac.)

NYCTERINIA

$321^{1}$ 1. rigida, Benth. in DC. Prod. x. 330, sub N. pedunculari,-lapsu $=Z$, divaricata.

$320^{1}$ a. NYMANIA, Lindb, in Notis. Sällsk. Faun. Fl. Eenn. ix. (1868) 290, in obs. [c Trans. Nov. Scand., ] $=$ Aitonia, Thunb. (Sapind.).

capensis, Lindb. 1. c. = A. capensis.

\section{NYMPHAEA}

$321^{3}$ 1. glandulifera, Rodsch. Bemerk. Col. Esseq. 76.

\section{0}

\section{OCHNA}

$324^{2}$ 1. squarrosa, Linn... 731 (non 732).

$324^{3}$ a. OCHTHOCLOA, Edgew. in Journ. As. Soc. Beng, xi. (1842) 1. 26 = Eleusine, Gaertn. (Gramin.).

dactyloides, Edgew. 1. c. $27=\mathrm{E}$. dactylifera.

\section{OCOTEA}

$326^{2}$ a. SENNEBERIA, Neck. Elem. ii. 120 (1790).

ODONTOSTYLES

$331^{2}$ 1. triflora, Breda, 1. c. $=$ B. triflora, Blume.

$335^{2}$ 1. OlSODIX, Rafin. in Am. Monthly Mag. i. (1817) $439=$ Salix, Tourn

OLEA

$3377^{3}$ a. picholina, Poit \& Turp. in Poit. Pomol. Franç. $11=$ europaea.

\section{OLEARIA}

$338^{1}$ 1. Hectori, Petrie, in Trans, N. Z Inst, xvi 1883 (1884) $393=$ fragrantissima (non Hook. f.).

OLINIA

$339^{2}$ a. TePPEA, Delile, in Rochet, Sec. Voy. in Choa, 340 (1846).

ONCOBA

$345^{3}$ I. spinosa, Forsk. (l, c.) p. cxiii. (non 103).

\section{ONOBRYGHIS}

3471 a. hirta, Scop. Introd. $302=$ Lespedeza hirta.

3472 juncea, Scop. (1. c.) = Lespedeza juncea.

1. lineata, Scop. (I. c.); Desv.

a. Onobrychis, Karst.'Pharm. med. Bot. $681=$ sativa.

prostrata, Scop. $(1, \mathrm{c})=$. Indigofera ennea phylla.

1. pumila, Scop. (l. c.); Desv.

\section{ONONIS}

$348^{1}$ a. brachyantha, Rouy, in Rev. Sc. Nitt. Sér. III i. (1883) 81.-Hispan.

\section{OPHRYS}

$354^{3}$ a. Fucus, Berger, Phyton" ii: $65^{\prime \prime}=$ arachnites.

OPLISMEN US, Beauv... t. 68, f. 1 .

$355^{3}$ 1. africanus, Beauv... t. 68, f. 1 .

356! facquini, Kunth, Rév. Gram. i. 44.

$356^{2}$ a. OPODIX, Rafin. in Am. Monthly Mag. i. (1817) $439=$ Salix, Tourn.

\section{OPOPONAX}

$356^{2}$ a. Opoponax, Karst. Pharm. med. Bot. $847=$ $\mathrm{O}$. chironium
OPUINTIA

$358^{1}$ a. Opuntia, Karst. Pharm. med. Bot. $888=$ vul garis.

\section{ORCHIS}

$359^{3}$ a Bornemanniae $\times$. Aschers, in Barbey, F1 Sard. Comp. 183. - Ins. Sardoa.

$360^{1}$ conopea, A. Gras, in Bull. Soc. Bot. Fr. ix. (1862) 334; cf. Pérard, op. cit. xvii. (1870)
$368=$ Gymnadenia conopsea.

3622 l. tipuloides, Linn. $\mathrm{f}_{4 . .} 401=$ Habenaria tipu loides.

\section{OREODOXA}

$364^{2}$ a. granatensis, Hort. Bull. ex Hook. f. Kew Rep. 1882 (1884) 56. - N. Granat.

ventricosa, Hort. ex Hook. f. Kew Rep. 1882 (1884) $59=$ Gaussia Princeps

\section{ORNITHOGALUM}

$360^{1}$ 1. decipiens, Goiran,... Italia.

$370^{2}$ pseudotenuifolium, Goiran,... Italia.

\section{ORNITHOPUS}

$371^{1}$ a. albus, Berger. Phyton. ii. $189=$ perpusillus.

\section{OROBANGHE}

$373^{1}$ a. fragrans, Rafin. in Am. Monthly Mag i. (1817) 440. - Sicil.

$373^{3}$ Ilicis, Mathiew, Fl. Belg. 383 (Quid?). Belgium.

obtusata, Rafin. (l. c.). - Sicil.

\section{ORONTIUM}

$376^{2}$ 1, litiifolium... $=\mathrm{R}$, japonica.

ORTHOPOGON

$377^{3}$ a. albus, Roem. \& Schult. Syst. ii. 890 ; Nees, undulatus. Link. Hort. Reg. Berol. i, $203=$ Op. undulatifolius.

\section{ORYGIA}

$378^{3}$ 1. portulacifolia. Forst.

a. villosa, Forsk. (l. c.) cxiv, - Arab

\section{ORYZA}

$378^{3}$ a. clandestina, A. Br. in Verh. bot. Ver. Brand. ii. $(1860) 195=$

OSTERDAMIA

$382^{2}$ a. Matrella, Neck (1. c.) = Zoysia pungens linifolia, Linn. Pl. Afr. Rar. $25=$ Euryops linifolius.

1. rigens, Linn. (1: c ) $24=$ Gazania rigens.

$392^{2}$ a. OXYDECTES, Linn. Syst. ed. I $(1735)=$ Croton, Linn. (Euphorb.).

OZOTHAMNUS

3971 1. coralloides, Hook. f... $332=\dot{H}$. coralloides $397^{2}$ depressus, Hook. f... $134=\mathrm{H}$. depressum.

\section{$\mathbf{P}$}

\section{PACHIRA}

$397^{3}$ a. RAUSSINIA, Neck. Elem. ii. 419 (I790).

1. Barrigon, Seem... $83=$ Bombax Barrigon. Commersonii. Planch. 'Hort.' Donat. $22=$ Bombax grandiflorum.

a. elegans, Planch. (l. c.) 23. - Hab. imperialis, Planch. (l. c.) - Hab.

1. longifolia, Hook... $4549=$ macrocarpa minor, Hemsl... $124=$ Bombax carolinioides

\section{PAEONIA}

$401^{2}$ a, romanica, Brandza, in Anal. Acad. Romane. Ser. II. ii. (1881) $587, t$. $2=$ decora.

\section{PAEPALANTHUS}

$401^{3}$ 1. compactus, Gardn. (Mon cámpactus). curvifolius, $K$ unth rigidulus, Mart. 
$403^{1}$ 1. PELAQUIUM, Blanco... = Dichopsis, Thw. (Sapotac.).

\section{PALICOUREA}

$403^{3}$ 1. chionantha, DC... = Psychotria Luschnathii. offcinalis, Mart... = Psychotria medica, Muell. Arg.

\section{PALIURUS}

$404^{2}$ a. colnbrina, Scop. Introd. $208=$ Colubrina ferruginosa.

$404^{3}$ a. Palnums, Karst. Pharm. Med. Bot, $870=$ aculeatus.

PALMA

$404^{3}$ a. Aovara, Buc'hoz, Herb. Col. Amér. t. 6 (1783) $=P$. Aioira.

\section{PANAX}

$406^{2}$ a. Schin-seng, Nees, Pl. Med. Suppl. i. « fasc. 5 , t. $15 » ;$ Comp. n. $70=$ P. Ginseng.

\section{PANDANUS}

4092 a. verus, Kurz, in Jour11. Bot. v. (1867) $125=$ odoratissimus.

\section{PANIGUM}

$4]()^{2}$ d. araneosum, etc. (est Penneseti sp, v. ii. p. 458).

$411^{2}$ caesium, Nees, in Hook. Kew Journ. ii. (1850) 97. - Ins. Philipp.

4121 coloratum, Nees, Agrost. Bras. 170, in syn. cum cit. talsa $=$ repens.

1. conglomeratum, Linn... = indicum?

$412^{2}$ curvatum, Limn... 732 (non 730).

4141. Hamiltonii, Kunth, Enum. i. 84, cum cit. falsa.

$417^{1}$ paradoxum. Roth. ex Roem. \& Schult. Syst.

ii. $457=$ abludens.

4181 ramosum, Heyne, ex Roth, Nov. Pl. Sp. $53=$ abludens.

\section{PAPAVER}

4221 1. Roubiaei, Vig. (non Viq.).

rubro-aurantiacum, Sweet, Hort. Brit. ed. I. $15=$

PAPAYA

a. gracilis, Regel, in Gartenflora, xxviii. (1879) 258, t. 986. - Colombia.

Papaya, Karst. Pharm. Med. Bot. $894=$ C. Papaya.

$422^{2}$ a. CAl otheria, Wight \& Arn, ex Steud. Syn. P1. Gram.199 (1855)

PARITA

$42 \mathrm{C}^{3}$ a. panduraeformis, Scop. Introd. $282=$ Hibiscus panduraeformis.

populneus, Scop. (1. c.) = Thespesia populnea.

tiliaceus, Scop. (1. c.) = Hibiscus tiliaceus.

zeylanicus, Scop. (1. c.) = Pavonia zeylanica.

\section{PASPALUM}

$430^{2}$ a. dissectum, Kniphof, Bot. Orig. Cent, xi, n. 74 ; fide Kunth, Enum. Pl. i. 273 = Eleusine coracana.

PASSAEA, Adans.

43.31 a. ormithopoides, Scop. Introd. $310=0$. ornithopodioides.

\section{PASSIFLORA}

$436^{1}$ a. Monnieri, Buc'hoz, Herb. Col. Amér. t. 35. -Hab. ?

4362 Pinardia, Buc'hoz, (1. c.) t. 30. - Hab. ?

Polignacia, Buchoz, (1. c.) t. $38=$ P. Murucuia.

rubra, Buc'hoz, $(1 \mathrm{c})$ t. $12(1783)=$ P: Vespertilio?

\section{PEDILANTHUS}

$44 i^{2}$ 1. cordellatus; Sweet, Hort. Brit. ed. I. 335 ; Stend. PENNISETUM

4582 a. cylindricum, Trin. Gram. Pan. 70 ; et in Mém. Acad. Petersb. Sér. VI. ii. II. (1835) $185=$ typhoideum.

\section{PENNISETUM}

$458^{2}$ 1. cynosuroides, Wall: Cat n. 8653 .

$458^{3}$ a. nepalense, Griseb, in Goett. Nachr. (1868) 302. - Reg. Himal.

1. parviflorum, Trin. Gram. Panic. 65 ; et

PENTAGLOSSUM

$459^{3}$ 1. linifolium, Forsk. (1. c.) p. lix.

\section{PENTSTEMON}

$463^{2}$ 1. Scouleri, Lindl. Bot. Reg. t. $12 \%$.

PERESKIA

$469^{1}$ a. Pereskia, Karst. Pharm. Med. Bot. $888=$ aculeata.

\section{PERIPLOCA}

$471^{1}$ a. Ehretiana, Collinson, in Linn. Corresp. i. 32 (1821).

\section{PERSICA}

$474^{2}$ a accensa, albida ambigua, Bauciana, bullata, cancellaria cerasiana, crispa, cunctabundia, Cursonia, dubia, duplex, flava, fromentina, heteroclita, ispahanensis, mammillata, mammosa, maxima, Merleti, militensis, mirabilis. mucronata, mucronata [bis], nana, narbonensis, Newtonii, oblonga, praccox, prisca, pulchella, veperta, sanguinea, serotina, subcursonia, succedanea, tenera, verrucosa, Poit. \& Turp. in Poit. Pomól. Franç. i. $=$ P. Persica.

\section{PETROSELINUM}

$4^{7791}$ a. Petroselinum, Karst. Pharm. Med. Bot. 831 $=\mathrm{C}$. Petroselinum

\section{PEUGEDANUM}

$480^{1}$ 1. aureum, Spreng... = Ferula communis.

PHACA

$482^{3}$ 1. candidissima, Benth... = A. candidissimus, S. Wats.

chilensis, Nees,

\section{PHAEDRANASSA}

$484^{3}$ 1. chloracea, Herb:

\section{PHALAENOPSIS}

$486^{3}$ 1. Sanderiana, Reichb. f: in Flora, lxv. (1882) 466

$489^{2}$ a. PHARETRANTHUS, Klatt, in Flora 1xviii. (1885) 203. COMPOSITAE.

ferrugineus, Klatt, l. c.204. - lns. Philipp.

$492^{3}$ 1. PHEDIMUS, Rafin. in Am. Monthly Mag. i. (1817) 438 ; et... = Sedum, Tourn. (Crassul.).

a, stellatus, Rafin. I. c, $=\mathrm{S}$. stellatus. unifortu, Rafin. I. c. = S. Cepaea.

\section{PHLEUM}

$498^{2}$ 1. fallax, Janka, in Közlem. Magyar. Tudom. Akad. xii. (1876) $168=$

a. maximim, Pryor, Fl. Herts, $450=$ pratense,

PHOENIX

$501^{3}$ 1. senegalensis, Van Houtte,... (1884).

\section{PHRAGMITES}

$503^{3}$ a. Phragmites, Karst. Pharm. Med. Bot. $379=$ communis.

\section{PHRYNIUM}

$504^{2}$ 1. dichotomum, Koern. in Nouv, Mém. Scc. Nat. Mosc. vî. (1859) $350,35 \mathrm{I}, 360$, tt. $8,9=$ Clinogyne grandis.

$504^{3}$ macrostachyum, Benth. \& Hook. f. Gen. Pl. iii. 654. - Afr. trop.

a. plicatum, Hort, ex Regel, Gartenfl. xxviii. (1879) 293 = Calathea flavescens.

5051 villosum, Benth. \& Hook. f. Gen, Pl. iii. 653 - Afr. trop.

$505^{3}$ a. PHYLANTHUS, Murr. Syst. $707(1774)=$ Phyllanthus, Linn. (Euphorb.)

\section{PHYLLANTHUS}

$510^{1}$ a. mamillosus, Buek, lnd. Cand. iv. 264, sphalm. $=$ ramillosus.

$511^{2}$ roseo-pictus, Hort. ex Garden, x. (187) 261. 1. ruber Spreng.

$513^{3}$ a. PHYLLORKIS, Thou. in Nouv. Bull. Soc. Philom. n. 19 (1809) $319=$ Dendrobium, Sw. (Orchid.).

PICEA

$519^{3}$ a. Abies, Karst. Pharm. Med. Bot. 325=excelsa.

\section{PICRIDIUM}

$521^{1}$ a. picridoides, Karst. Pharm. Med. Bot. $1145=$ vulgare.

PIGRIS

$521^{1}$ 1. autumnalis, Scop. Introd. 122 ; All.

PIGROLEMMA

$522^{1}$ a. Valdivia, G. Plunch. ex Restrepo, Étude du Cídron, 46. - N. Granat.

PILEA

$523^{2} 1$, muitiffora, Wedd.

PILOGYNE

$525^{1}$ a. cerasiformis, Stocks, ex Aitch. Cal.Pl.Punjab. $65=$ Chenolepis cerasiformis.

\section{PIMENTA}

$527^{3}$ a. Pimenta, Karst. Pharm. Med. Bot. $790=$ officinalis.

54 $3^{1}$ 1, PIPTOCALYX, Torr. ex S. Wats. in King, $240(1871)$; et in... $(1874)=$

\section{PISUM}

$546^{1}$ a. botanocolpium, Schrank, in Hoppe, Bot. Zeit. iv. (1805) 312. - Austral.

1. Fomardi, Schrank, in Hoppe, Bot. Zeit. iv. (1805) $309=$ sativum.

\section{PLANTAGO}

$553^{3}$ a. lácuistris, De Cresp. New Lond. F1. 51 ; cf Journ. Bot. xv. (1877) $313=$ P. Coronopus.

PLATANTHERA

556 1. aphylla, Lindl... $290=$

$556^{3}$ tipuloides, Lindl... $285=$ Habenaria tipuloides.

\section{PLATYCAPNOS}

5571 a. grandiflorus, Rouy, in Rév. Sc. Nat. Sér. III. i. (1883) 66. - Hispan

\section{PLECTRONIA}

$560^{3}$ a. Gueinzii, [f. M. Wood, ex] Cooke, in Grevillea, x.' (1882) 124. - Natal.

$561^{1}$ nota PLEGERINA,... sphalm. = PLERAGINA, Arruda = Couepia, Aubl. (Rosac,).

1. odorata, Arruda, 1. c. = C. grandiflora.

rufa, Arruda, 1. c,$=$ C. Witi.

umbrosissima, Arruda, 1. c. (Quid ?) - Bras.

PLEROMA

$562^{2}$ a. monticolum, Triana, ex Polak. in Linnaea, xli. (1877) $555=$ Naudinianum.

\section{PLEUROPHYLLUM}

$564^{1}$ 1. Hombront, Decne... = criniferum

\section{PLEUROTHALLIS}

$566^{1}$ a. Lansbergiana, Regel, Gartenfl. vi. (1856) t. 193. f. d. (err, typ. 190) $=$ Lansbergii.

\section{PLUGHEA}

$568^{3} 1$. Dioscoridis, $D C$.

\section{PLUMBAGO}

$569^{2}$ 1. Larpentae, Lindl... $732=$ Ceratostigma plum. baginoides. 
POA

5r02 a. ambigua, Mathieu, Fl. Belg. 611 (quid?). Belgia.

$573^{2}$ 1. kerguelensis, Hook. f. Fl. Antarct. t. 138; Steud... - Ins. Kerguel.

$575^{1}$ l. quadripedalis, Ehrh.

578' 1. PODOGARPUS, L'Hérit. ex Labill. Pl. Nov. Holl. ii. 71, in adnot. (1806) ; L'Hérit. (1807)

$579^{1}$ E'aldiviana $[$ Nelson] $\ldots=$ andina.

\section{POGONIA}

$582^{2}$ a: Kotschyi, Reichb. fo in Oestr. Bot. Zeitschr. xiv. (1864) 338. - Afr, trop.

1. viridiflava, Reichb. $f$. (non viridiflora).

\section{POGOSTEMON}

5831 1. Cablin, Benth...= Heyneanus.

Patchouly, Pellet... \%. - Ind. or.; Malaya.

POLANISIA

5841 1. bhurtporensis, Munro, Hort. Agr. 35; et ex Wight,

graveolens, Rafin $\ldots=\mathrm{C}$. dodecandra.

viscosa, DC $\ldots=$ C. dodecandra.

\section{POLLINIA}

$585^{3}$ a. Jacquini, Spreng. ex Stend. Syn. Pl. Gram. 45, sub 107. - Hab.?

\section{POLYCEPHALOS}

5881 1. suaveolens, Forsk. (1. c.) p. lxxii.

\section{POLYGALA}

5901 corsica, Bor. in Mém. Soc. Acad. Maine-etLoive, (1857) 87. - Corsica.

POL XGONUIM

$595^{1} 1$. australe, R. Br. Prod. 421 ; A. Rich...

POLYPOGON

$601^{1}$ 1. Adscensionis, Trin. in Mém. Acad. St. Pétersb. Sér. VI. vi. II. (1845) 257. -

\section{POLYSTACHYA}

$602^{1}$ 1. cultriformis, Lindl. ex Spreng... iii... = cultrata.

a. Fischeri, Rcichb. in Mitth. Geogr. Geo. Hamb. 1882-83 (1885) 268, nomen, - Afr. trop. macrantha, Lindl. ex Hook. Bot. Mag. sub t. $3707=$ grandiflora.

$602^{3}$ 1. POLYTROPIA, Presl.

\section{POPULUS}

$605^{3}$ 1. benzoifera, Tausch,... 754

biformis, Rafin. 1. c. $43=$ euphratica.

$606^{1}$ a. longiflora, Fisch. in Otto \& Dietr., Allg. Gartenz. (1841) $403=$

salicifolia, Rafin... $43=$ angustifolia.

suaveolens. Fisch. (1. c.) $404=$

$606^{2}$ a. tristis, Fisch. (1. c.) $402=$ balsamifera?

$607^{3}$ 1. PORTLANDIA, Ellis, in Linn. Corresp. i. $122(1821)=$ Gardenia, Ellis (Rubiac.).

\section{POTAMOGETON}

6092 1 angustatus, Wallm, ex Reichb. Ic. F1. Germ. vii. $16=$

a. Burtoni, Hopkins, ex Syme, Engl. Bot. ed. III. ix. $39=$ decipiens.

$609^{3}$ 1. epihydrum, Rafin... = Claytonii.

flexuosus, Wredow, F1. Mecklenburg, 1. 255 (1811) $=$ praelongus

$610^{1}$ lanceolatus, Eichw,... = rufescens.

a. Liljebladic, Wallm. ex Reichb. (1. c.) $=$ obtusifolius.

1. lonchites, Tuckerm. in Am. Journ. Sc. Ser. I. xlvi. (1843) 38 ; et

6102 paucifolius, Opiz, in Flora, v. (1822) 267 ; Natur. Tausch, n., 10 (1825) 223.

Reichenbachii. Löhr, ex Beurling, in Bot. Notis. (1853) $90=$ pusillus.

$610^{3}$ tenuissimas, Löh, ex Beurling, (1. c.) $=$ pusillus.

\section{POTENTILLA}

$612^{3}$ a, evecta, Karst. Pharm. Med, Bot. $764=\mathrm{P}$. Tormentilla.

$613^{3}$ Keilhani, Sommerf, in Mao. f. Naturvid, II i. (1832) $244=$ Keilhavit

$616^{2}$ unguiculata, Hook. f. in Bot, Mag. t. 6560 - Calif.

$616^{3}$ 1. Weinmannit, Lodd. Bot. Cab. t. 706

\section{POUZOLZIA}

$620^{1}$ 1. ovalis; Miq... - As, trop.

viminea, Wedd...228 = ovalis.

\section{PRATIA}

$621^{1}$ 1. linndeoides, Hook. f. Handb. N. Z. F1, $172=$ Lobelia linnaeoides, Petrie (1891).

PREMNA

6221 a. Perrottetii, C. B. Clarke, in Hook. f. Fl. Brit. Ind. iv. 572, in nota (Quid?). Ind. or.

PRESTOËA

$623^{3}$ a. montana, Hook. f. Kew Rep. 1882 (1884) 56 - Ind, occ.

\section{PRIMULA}

6242 1. altaica, Paxt. Mag. Bot. xvi. (1849) $194=$ vulgaris.

$625^{1}$ a. Dumoutini $\times$, Stein, Ind. Sem. Hort. Vratisl. (1881). - Hab.?

$625^{2}$ gracilis, Stein, (l.c.) , - Hab.

$626^{1}$ Obristii $X$, Stein. (1. c.). - Hab?

6271 Warei, Stein, (l. c. .) - Hab.?

PRINGLEOPHYTUM

6271 1. lanceolatum, A. Gray,... = Berginia virgata

\section{PRITGHARDIA}

6281 a. aurea, Hort. Lind.ex Hook. f. Keथ Rep, 1882 1884) 65. - Hab. ?

\section{PRUNUS}

$635^{3}$ a. ambigua, apiana, apyrena, bifera, Calvellana. catalaunensis, cerasiana, decora, deformis, dolabriformis, durasina, duplex, elliptica, feriarum, formosa, germanica, graphica, helvetica, hiemalis, Fierochuntica,'Hispanica, insignis, lineata, Mauriniana, mirabilis, neustriensis, oleaginosa, pictorum, praedura, provincialis, pseudoclandiana, riomensis, serotina, spectabilis, spontalis, versicolor, virginalis, Poit. et Turp. in Poit. Pomol. Franc. $i_{0}=$ domestica.

angustifolia, brevifolia, cerasifructus, domestica, elegans, elliptica, floribunda, glabra, glomerata inermis, intermedia, Lamottiz, Lloydiz, Lucers, lutescens, praecox, rhamnifructus, spiraeifolia, virgata, A. Savat, in C. R. Assoc, Fr. Av. Sc. xi. Rochelle, 1882 (1883) $434=$ domestica

calycina, divaricata, ericaefora, longicaudata, recta, sputulata, subrotundifolia, A. Savat 1. c. $435=$ domestica?

chlorocarpa, heterocarpa, A. Savat. 1. c. $433=$ domestica ?

6372 vitrea, K. Koch, Die Deutschen Obstgehölze, $165=$ P. Cerasus.

$638^{3}$ a. PSEUDERANTHEMUM, Radlk, in Sitzb. Math.-phys. Cl. Akad. Wiss. Muench, xiii 1883 (1884) 282 = Eranthemum, Linn (Acanthac.).

a. acuminatum, alatum, albiflorum, album, atropurpureum, bicolor, cinnabarinum, Cooperi, cordatum, crenulatum, custidatum, decurrens, detruncatum, diversifolium, exaequatum, faecundum, Haenckeanum, heterophyllum, hispiduhum, hypocrateriforme, lanceum, leptostachyum, modestum, Moorei, nigritianum, palatiferum, paniculatum, racemosum, veticulatum, Richelianum, senense, succifolium, tenellum, tricolor, tubercu latum, variabile, verbenaceum, versicolor, $Z$ ollingerianum, Radlk. 1. c. 286-287, in nota $=$ homonyma omnia Eranthemi.

asperum, Radlk. 1. c. $286=$ E. bicolor, Schrank Blumei, Radlk, 1. c. = E. Andersoni, Mast.

\section{$638^{3}$ a. PSEUDERANTHEMUM}

Blumei, Radlk. in Sitzb Math.-phys. Cl. Akad. Wiss, Muench, xiii, 1883 (1884) 286 = Eranthemum crenulatum, Lindl

Eldorado, Radlk. 1. c. = E. Eldorado, Hort. macrophyllum, Radlk. 1. c, = Anthacanthus microphyllus, Nees.

rosennt, Radll. 1. c. = E, roseum, Lind, of Fournz

tetragonum, Radlk. I. c. = Daedalacanthus tetragonus, T. Anders.

$630^{2}$ a. PSEUDO-ERANTHEMUM, Radlk, in Sitzb. bay. Alad, xiii. (1883) 282, $286=$ praec

\section{PSEUDOTSUGA}

$640^{1}$ 1. jezoènsis, Bertrand, in Arn. Sc. Nat. Sér. V, xx. (1874) p. 89; W. R. Mc Nab,

nobilis, Bertrand, (1. c.) 86; W. R. Mc Nab,

PSIDIUM

$640^{3}$ a. BURCHARDIA, Neck. Elem. ii. 76 (1790),

\section{PSYCHOTRI:}

$646^{1}$ a. cauitellata, Benth of Hook. f. Gen, Pl. ii. 124 (syn. Patabea capitellata, Wawra.)

6471 1. Gardneriana, Mnell. Arg. in Mart. Fl. Bras, vi. V. 235 (non 379). - Bras

$648^{1}$ a. ligularis, Benth, of Hook. f. Gen. Pl, ii., 124. $648^{3}$ 1. obtusifolia, Lam.

$650^{3}$ 1, umbellata, Korth。 in Nederl. Kruide. Arch. ii. II. (1851) 245. - Sumatra.

$651^{2}$ 1. PSYLLOTHAMNUS, Oliver $=$ Sphaerocoma, T. Anders. (Caryoph.)

Beevori Oliver $=S$. Hooker.

PTARMICA

$651^{3}$ 1. oxyloba, DC... = A. oxyloba, $D C$.

PTERANTHUS

$652^{1}$ a, dichotomus, Forsk. (l. c.) p. 1xii. - Arab.

1. PTERigostachy UM, Nees, ... = Arundinella, Raddi (Gramin.)

PTERNIX

6522 a. cynarioides, Rafin. in Am. Monthly. Mag。 i. (1817) $439=$ Cnicus cynarioides

PTEROGARYA

$653^{1}$ a. diechocarpa, Lavall. Arb. Segnez. 67, in nota. - Japon

japonica, Maxim. in Bull. Acad. St. Pétersb. xviii, (1873) 58, in syn. = Juglans regia.

1. sorbifolia, Sieb. \& Zucc... = rhoifolia.

6552 1. PTEROPHORA, Linn. P1. Afr. Rar. 17 (1760); Neck... = Pteronia, Linn. (Compos.).

657 a. PTEROXYLON [Hook, f, in] Harv, Gen. S, Afr. Pl. ed. II. $60(1868)=$ Ptaeroxylon, Eckl. \& Zeyh. (Sapind.).

1. PTERYGOSTACHYUM, Nees,,..$=$ Arundinella, Raddi (Gramin.).

PTYCHOSPERMA

$658^{3}$ 1. Normanbyi, F. Muell...; Becc. in Ann. Fard. Buitenz. ii. (1885) 171 (Index). - Austral.

6591 Normanbyanus, Benth. \& Hook, f. Gen. Pl. iii. 893 , sphalm. = Normanbyi.

PTYCHOTIS

6592 a. saxifraga, Loret \& Barr. F1. Montp. $283=$ C. Bunius.

PULEGIUIM

$659^{3}$ a. Pulegium, Karst. Pharm. Med. Bot. $977=$ M. Pulegium,

PULICARIA

$660^{1}$ a. Pulicaria, Karst. Pharm. Med. Bot. $10 \% 2=$ vulgaris. 
PULSATILLA

$661^{1}$ a. Pulsatilla, Karst. Pharm. Med. Bot. $560=$ A. Pulsatilla.

PUPALIA

$662^{2}$ a. prostrata, R. Br. Prod. 417 , in obs. = Cyathula prostrata.

\section{PYRUS}

$668^{1}$ a. albicans, ambrosiaca, amoena, Angeli, anglica, apyrcna, aquosa, Avdenponti, Arenbergii, Awgusti, aurantzaciun, Aureola. bellveria, bressensis, butyracea, calculosa. Caumontel, cardinalis, Castigatrix Chaptalia cinnabarina, conspersa, crastina, cucurbitiana, cypria, deliciosa, depicta, Descampi, dilecta, dolifera, duplex, Elenchus, exaltata, exquisita, fasciata, femoriformis. Aagellata, fugax, fuscata, fuscata [bis], Germani, guiennensis, Heryana, Mispanica, inculismensis, Lagenaria, lageniformis, lezania, libralis, longipes, Ludovica. maculosa, maculosa [bis], magdalena, maliformis, marchionissa, maxima, montana, moschata, moschatella, neapolitana, nomorum, oleaginosa, olentissima, Driformis, papulata, pastoralis, provincualis, guercifolia, reaclis, remensis, reperta, Robiniana, romana, Ronzilla, vubricata, nufa, Sabina, Salriati, Samsoniana, sanguinolenta, secundaria, seminstulata, splendens, succedanea, suleriensis, tardiflora, tener, unguentula, vallis, vinetorum, virgolensis, viridis, viridis [bis], Poit. \& Turp, in Poit. Pomol. Franc, iii. $=$ communis.

aequalis, A. Savat. in C. R. Assoc. Fr. Av. Sc., xi. Rochelle, 1882 (1883) $425=\mathrm{com}$. munis.

$668^{2}$ cincracea, elongata, ferox, tomentosa, A. Savat. 1. c. $427=$ communis

6621 macrocarpa, subglobosa, rufa, canescens, A. Savat. 1. c. $426=$ communis

macropoda, A. Savat. 1. c. $428=$ communis. Pseudo-chaenomeles, Carr. Rev. Horticole (1882) $236=$ japonica

$660^{3}$ sinensis, Mus. Par. ex Thouin, in Ann. Mus. Hist. Nat. Par. xix. (1812) $145=$ cathayensis, Hemsl.

$670^{1}$ transwersalis, A. Savat. in C. R. Assoc. Fr. Av, Sc, xi. Rochelle, 1882 (1883) $425=$ communis.

\section{Q}

$670^{\circ}$ a. QUADRIA, Mutis, in Linn. Corresp. ii. (1821) $530=$ Vismia, Vand. (Hyperic.),

\section{QUALEA}

$670^{3}$ 1. macropetala, Spruce, ex [Black, in $]$ Lindley Eo Moore, Treas. Bot. ii. 947 (1865). - Hab. ? pulcherrima, Spruce, l.c. - Hab.?

\section{QUERCUS}

6722 1. bambusaefolia, Hance, ex Secm. Bot. Voy. IHerald, 415 , t. 91 ; et ex Miq.

a. Bellota, Colm. \& Boutel, Exam. Arb. Pen。= O. Ilex.

$673^{1}$ 1. conferta, Kit. in Schult. Oester\%. Fl. ii. 619 (1814). - Europ, austr.

$674^{2}$ Fametto, Tenore, Syll. Plant. Vasc. F1. Neapol. $(18: 31)=$ conferta.

\section{R}

$679^{3}$ I. RADERMACHERA, Zoll. \& Mor.

$680^{1}$ lin. 1. insere RADERMACHERA :-

\section{RADIOLA}

6801 a. Radiola, Karst. Pharm. Med. Bot. $606=$ R. Liriodes.
$681^{2}$ a. RAMSAIA, W. Anders, ex R. Br. Prod. 553, in adnot, $(1810)=$ Bauera, Banks. (Saxifr.).

\section{RANUNGULUS}

$684^{2}$ 1. delphinifolius, Torr. in Eaton, Man.ed.II. 395 6851 glabriusculus, Rupr... = auricomus?

$685^{3}$ innominatus, H. C. Wats, Lond. Cat, ed. II. I = tripartitus, $D C$.

686? lacustris, Beck \& Tracy, in Eaton, Man. Bot ed, III 423 (1829:

$686^{3}$ a. Nathorsti, Berl. in Ofvers. Vet. Akad. Förh xli. (I884) n. VII. $20=$ acris.

\section{RAPHANISTRUMI}

6901 1. innocum, Medic. Pflanzeng. $40=$ Raphanus Raphanistrum.

a. Raphanistrum, Karst. Pharm. Med, Bot. 673 Raphanus Raphanistrum.

\section{RAPISTRUIM}

6911 a. bursaefolium, DC $\ldots=$ seq.

a. bursifolium, Berger. etc.

1. Cakile, Berger. (1. c.) $163=$

$692^{3}$ a. RAUSSINIA, Neck. Elem. ii 419 (1790) = Pachira, Aubl. (Malvac.).

\section{RAVENIA}

6932 a. rosea Lebas, in Rev. Hortic, (1880) 179. Bras.

$694^{2}$ a. REGINA, Buc'hoz, Herb. Col。 Amér. t. 66 (1783) [Quid?]

Gallonm, Buc'hoz, 1, c. (Quid?), - Hab. ?

\section{RENEALMIA}

$696^{1}$ a. Mannii, Hook f. in Hook. Ic. Pl. xv, 25 sub t. 1430, - Afr, trop.

RESTIARIA, Lour... $(1 \% 90)=$ Uncaria Schreb. (Rubiac.)

$697^{3}$ 1, cordata, Lour... = Uncaria pedicellata.

\section{RESTREPIA}

6992 1. hypolepta, Reichb. f.., = Pinelia hypolepta

\section{RHAMPHICARPA}

7032 1. Cameroniana... xv, (non xiv.)

$704^{2}$ 1. RHAPHITHAMUS, Miers, RHEXIA

$705^{3}$ a. bogotensis. Mutis, in Linn. Corresp. ii. $527=$ glutinosa.

\section{RHODODENDRON}

\section{$710^{3}$ 1. Blandianum}

Chamaecistus,... = Rhodothamnus Chamaecistus.

711 1. flavum, G. Don,... - Reg. Caucas,

$711^{2} 1$, hirsutiforme $\times$, Gremb.

Lobbii, Veitch, Cat. (1870) 22; Gard. Chron.

$712^{1}$ praccox $X$, Carr. in Rev, Hortic. (1868) 211 cum ic.

\section{RHOPAIOSTIGMA}

7132 1. microphyllum, Phil... = P. microphyllus. pendulum, Phil... = P. pendulus.

RHUS

$713^{3}$ a. Albonia, Buc'hoz, Herb. Col. Amér. t. 57 (1783).

$714^{3}$ Michauxii, Sargent,... = pumila, Michx.

1. Osbeckii, Carr... (1867) [non 1887].

\section{RHYNGHOSIA}

$718^{1}$ a. Rothii, Benth. ex Aitch. Cat. P1. Punjab, 50 = sericea.

$719^{3}$ 1. RIBEIREA, Arruda,... (1816)= Hancornia, Gomes (Apocyn.).

sorbilis, Arruda, 1. c. $=$ H. speciosa.
RIBES
7201 a. albescens, albicans, albo-vivens, auriculatum,
$720^{2}$ carneum, racemosum, Poit. \& Turp. 1. c.) = rubrum.

fiarescens, ianthinum, lobatum, moschatum, purpureo-majus, purpureo-minus, succineum, tubulosum, virente-rotundum, vividi-albescons, viridimajus, viridi-minus, vulgatissima, Poit. \& Turp. in Poit. Pomol. Franç. iii. $=\mathrm{R}$. Grossularia.

$721^{1}$ Munroi, Dougl, in Hook. Comp. Bot. Mag. ij. (1836) 120 , sphalm. = niveum, = gracile.

$724^{1}$ a. RIGOCARPUS, Neck. Elem, i. $238(1790)=$ Gitrullus, Forsk.

\section{ROBINIA}

$725^{3}$ 1. neo-mexicana, A. Gray,... Mont. scopul.

a. pendulina, Sweet, Hort. Brit. ed. I. 125 (Quid?). - Hab.?

RONABEA

7292 1. australis, A. Rich... = Coprosma grandifolia.

\section{RONDELETIA}

7293 a, anomala, Veitch, Cat.(1856-57) 10. - Guatemala?

RORIPA

$730^{3}$ a. Turczaninowii, Simk. in Magy. Növ. Lap. ii. (18'8) $147=\mathrm{N}$. anceps? $D C$.

uliginosa, Simk. (I. c.) nomen (Quid ?).

\section{ROSA}

$731^{1}$ a. affinita, Puget, ex $\mathrm{H}$. Braun, in Abh. Zool Bot. Ges. Wien, xxxv. (1885) $96=$ pilosa. almeriensis, Rouy, in Reo. Sc. Nat. Sér. III. i. (1883) 230. - Hispan.

$731^{2}$ Annoniana, Puget, ex H. Braun, (1. с.) $95=$

$731^{3}$ 1. Biebersteinii, Lindl. in Trans. Hort. Soc. vi. (1826) 89 ; et

7321 a. bohemica, H. Braun, (l. c.) 79 . - Europ. chlorocarpa, Fenzl \& H. Bram, (l. c.) 63. Syria.

$734^{3}$ 1. holikensis, Kmet - Wulfenii.

7351 Hosti, H. Braui, ...) $113=$ Wulfenii.

7351 Hostii, H. Brauis, .. (.) $113=$ Wulfenii.
$735^{2}$ Kerneri, H. Braun, (l. c.) 80 . - Austria.

$735^{3}$ leucadia, H. Bram, (l. c.) 126.-Ins. Graeciae.

$736^{2}$ myrtilloides, $H$. Braun, (l. c.) 125. - Europ.

$736^{3}$ mipponensis, Crép. in Bull. Soc. Bot. Belg. xiv. $(1875)=$ acicularis?

7381 Reussii, H. Braun, (l. c.) 104. - Hungar.

7391 subatrichostylis, H. Braun, (1. c.) $96=$ pilosa. subglabra, H. Braun, (1. c.) $94=$ pilosa.

7392 Tauschiana, H. Braun, (l. c.) 78. - Europ.

$740^{1}$ Woloszczakii, Keller, in Halacsy \& H. Braun, Nachtr. 3. F1. Niederoesterr. $282(1880)=$ pilosa.

\section{ROTTBOELLIA}

${ }^{4} 2^{1}$ a. dimidiata, Linn. f. Suppl. 114; an seq. ?

\section{ROYDSIA}

$745^{1}$ a. ALYTustylis, Mast. in Hook. t. F1. Brit. Ind. i. 409, in obs. (1874).

\section{RUBUS}

$747^{3}$ a. Bosse KIA, Neck. Elem. ii. 91 (1790).

\section{RUDBEGKIA}

7582 1. Neumannii, Steud..." = Newmanni. Newmani. Loud... 584, in syn. = speciosa. Newmanni, Loud... = speciosa

$759^{2}$ a. RUELINGIA, F. Muell. Fragm. xi. 113, in obs. $(188 \mathbf{1})=$ Rulingia, $\mathrm{R} . \mathrm{Br}$. (Stercul.).

RUELLIA

$761^{1}$ a. gangetica, R. Br. Prod. $478=$ Asystasia coromandeliana.

\section{RUPRECHTIA}

$767^{2}$ a, coriacea, Benth. \& Hook. f. Gen. Pl. iii, 105 - Venezuela. 
RUTA

$768^{1}$ a. fimbriata, Rafin. in Am. Monthly Mag. i. (1817) 439 (Quid ?). - Sicil.

$768^{3}$ RUTICA, dele «sphalm. »

\section{RYNGHOSPORA}

$770^{3}$ 1. nivea, Boeck... = Dichromena Reverchoni, H. Wright (in Add.)

77133. 1. RYPARIA, Blume... (Bixin.)

RYPAROSA, Blume... (1825) BIXINEAE. et dele « Gen. dub. Euphorbiacearum, »

\section{S}

SABAL

$772^{1}$ a. Princeps, Hort. Versch, ex Hook. f. Kew Rep. 1882 (1884) 63 nomen. - Hab.

\section{SABICEA}

$772^{3}$ 1. Perrotteti, A. Rich... = Uncaria Perottetii

\section{SAGCHARUM}

$773^{3}$ a. Glaga, Reinw ex Blume, Cat. Gew. Buitenz. $38=$ spontaneum

\section{SAGINA}

776: 1. maritima, G. Don, pat. ex Sm. Engl. Bot. t. 2195 .

\section{SAGITTARIA}

$7 \% 6^{2}$ 1. chinensis, Spreng. Syst. ii. $633=$ sinensis

$776^{3}$ sinensis, Sims, Bot. Mag.t. $1631=$ sagittifolia.

SAGUS

$777^{3}$ a. Sagu, Karst. Pharm. Med. Bot, $412=$ M. Sagu.

\section{SALIX}

$780^{1}$ a. AMERIX, Rafin, in Am. Monthly Mag. i. (1817) 439.

a. Chalebus, Rafin. (1, c.) (1817)

Diplopia, Rafin. (1. c.) (1817).

Disynia, Rafin. (1. c.) (1817).

MELANIX, Rafin. (1. c.) (1817)

1. OIsodix, Rafin. $\left(1, c_{.}\right)$(1817)

a. OpodIX, Rafin. (1. c.) (1817)

1. VIMEN, Rafin. (1 c.) (1817).

7811 1. calostachya, Anderss... = S. Wallichiana Anderss.

7831 ivigtutiana, Lundstr. ex Berl. in Ofvers. Vet. Akad. Förh, xli. (1884) n. VII. 61, 88. Groenl.

SALVIA

$794^{2}$ a. praetermissa, Todaro, Ind. Sem. Hort. Panorm. 1800) $37 .-\mathrm{Hab}$. ?

\section{SANTOLINA}

7991 1. capitata, Linn...

\section{SAPINDUS}

$800^{1}$ a. manatensis, Schuttl. ex Radlk. in Sitzb. Math. Phys. Akad. Muench. viii. (1878) 318. Florida.

\section{SAPONARIA}

$801^{3}$ 1. sicula, Rafin. Specch. Sc. ii. 7 ; ex Call, Life Rafin. 148.

\section{SARGOCEPHALUS}

$803^{2}$ a. Leiohhardtii, F: Muell. Rep. Burdek. Exped. 12 = Morinda citrifolia

SARCOSTEMMA

$805^{1}$ 1. aphyllum, R. Br. Prod. 463; Schult.

$805^{2}$ pyrotechnicum, R. Br. (1. c.); Schult,

$805^{2}$ 1. SARGOSTIGMA, Wight \& Arn... xiv, (1833) 299.

\section{SASSAFRAS}

$806^{2}$ a. Sassafras, Karst. Pharm. Med. Bot. $505=$ officinale.

$806^{3}$ a. SATORKIS, Thou. in Nouv, Bull. Soc, Philom. n.19 (1809) 316; (Orchid.) (Quid?).

\section{SATYRIUM}

8081 a. cormutum, Linn. P1. Afr. Rar. $27=$ Orchis satyroides.

SAURAUJA

$809^{3}$ a. Synarrhena, F. Muell. Fragm. v. 175, in obs. (1866).

\section{SAUSSUREA}

$810^{3}$ 1. Katochaete, Maxim

a. lapatifolia, Karst. Pharm. Med. Bot. $1106=$ alpina.

\section{SCABIOSA}

$820^{1}$ a. TrichOPTERIS, Neck. Elem, i. 110 (1790).

\section{SGAEVOLA}

$820^{3}$ 1. oppositifolia, R, Br, Prod. $583 ;$ Roxb.

\section{SCANDALIDA}

$821^{2}$ a. conjugata, Scop. Introd. $308=\mathrm{L}$. conjugatus, maritima, Scop. (1. c.) = L. siliquosus.

1. siliquosa, Scop. (1, c.) : Medic.

tetragonoloba, Scop. (1, c.) ; Medic.

\section{SGAPHYGLOTTIS}

$822^{2}$ 1. stellata, Lodd.. (1839) [non 1889].

SCHEDONORUS

$823^{3}$ a. laxus, Fries, in Bot. Notis. (1843) $130=$ B. erectus.

steritis, Fries, (1. c.) $131=$ B. sterilis.

tectorum, Fries, $(1, \mathrm{c})=.\mathrm{B}$, tectorum.

\section{SCHEUCHZERIA}

$824^{1}$ a. colyoulata, Scop. Introd. $81,82=$ Tofieldia calyculata.

\section{SCHLEICHERA}

8281 1. trijuga, Willd. Sp. P1. iv, 1096 (non 1396).

$828^{3}$ a. SCHLOSSERIA, Ellis, in Linn. Corresp. i. 130, $159(1821)=$ Styrax, Tourn.

$828^{1}$ a. SCHLOSSERIA, Garden, in Linn. Corresp. i. $365(1821)=($ Palm.) (Quid ?).

SCHOBERA

$829^{2}$ a. angiosperma, Scop. Introd. $158=$ Heliotropium parviflorum.

\section{SCHWEINFURTHIA}

$834^{3}$ a apterum, Vatke, in Oesterr. Bot. Zeitschr. xxv. $(1875) 96=$ Antirrhinum apterum (Cur. Post.).

\section{SCIRPUS}

8382 1. APLOSTEMON, Rafin, in Am, Monthly Mag, i. (1817) 441 : et

$839^{2}$ a. carniolicus, Ambrosi, F1. Tir. Austr. i. $447=$ Eleocharis carniolica

$841^{2}$ 1. lateralis, Retz... 12 (non 11).

8422 obliganthus, Steud.

oliganthus, Steud. Nom. ed. II. ii. $540=$ praec.

$844^{2}$ a. Zanardinii, Ambrosi, (1. c.) $448=$ Eleocharis atropurpurea.

\section{SCLERIA}

$845^{3}$ a. coriacea. Bertol. f. in Mem. Acc. Sc. Bologn. v. $(1854) 476=$ oryzoides

SCLEROPHYLLUM

$848^{3}$ a. coarctatum, Griff, Notul, iii, $8=$ Oryza coarctata.

\section{SCOLOPIA}

$849^{3}$ 1. Rhinanthera, Clos,
SCORODOSMA

$850^{2}$ a. Assa-foetida, Karst. Pharm. Med. Bot. 845, $\$ 46=F$. Assa-foetida.

\section{SGUTELLARIA}

$855^{2}$ a. hirsuta, Short, in Transylv. Journ. Med. viii, (1835) $582=$ pilosa.

$855^{3}$ 1. javanica, fungh.

\section{SEDUM}

$860^{2}$ a. Phedimus, Rafin. in Am. Monthly Mag, i. (1817) 438; et Cat. 15 (1824)

album, Rafin. Cat. Bot. Gard. Lexington (1824) 12, nomen $=$ albidum

SEHIMA

$863^{3}$ 1. Ischamum, Forsk. (1, c.) p. cxxiii

\section{SELENIPEDIUIM}

$865^{2}$ 1. Wallisii, Reichb. f. Xenia Orch, ii. 189; t 18I

\section{SEMPERVIVUM}

$867^{3}$ 1, barbatum, C. Sm, ex Nees, Hor, Phys. Berol. 37 , in nota. - Ins, Canar.

caespitosum, C.Sm. ex Nees, (l. c.) 38 in nota - Ins. Canar.

8681 foliosum, C. Sm. 1, c.) = Smithii.

$868^{2}$ a, hirsutum, Pollini, Fl. Veron. ii. $113=$ hirtum ligulare, Haw. Rev. Pl. Succ, 64, in adnot,

= caespitosum

$868^{3}$ radicescens, Lowe, Man. Fl. Mad. 331 in obs. - Ins. Canar.

8691 a. Smidti, C. Sm. (1. c.) $=$ Smithii.

\section{SENKEBERGIA}

8821 a. bivalvis, Neck. 1. c. $\Rightarrow$ Besleria bivalvis

883 a. SENNEBERIA, Neck, Elem.ii, $120(1790$ $=$ Ocotea, Aubl. (Laurin).

SERIDIA

$885^{1}$ 1. sphaerocephala, Sweet, Hort. Brit, ed, I, 218 Webb,

$890^{1}$ a. SERVERIA, Neck. Elem, ii. 98 (1790) $=$ Doliocarpus, Roland. (Dillen.).

\section{SESUVIUM}

$892^{3}$ 1. pentandrum, Ell. 556.-Am. bor.

\section{SETARIA}

8931 1. effusa, Fourn ... = Panicum sulcatum, $A u b l$. $893^{3}$ Weinmanni, Roem, \& Schulr.

\section{SHOREA}

$894^{3}$ a. Gala, Baill. Bot. Médic. ii. $81 \%(1884)=\mathrm{S}$ Guiso ?

\section{SILAUS}

$904^{2}$ a, Silaus, Karst, Pharm, Med, Bot, $836=$ fla vescens.

SILENE

9071 a. flavescens. Schrank, in Hoppe, Bot. Zeit, iv (1805) $311-\mathrm{Hab}$ ?

$913^{3}$ 1. SINAPI, Neck. Elem. iii. $80(1790)$; Dulac,

\section{SISYMBRIUM}

9173 1. acaule, Sieber. ... 593 = Morisia hypogaea.

$921^{1}$ 1. uniflora, Journ. ... = Braya uniflora.

\section{SISYRINGHIUM}

921" a arizonicum, Rothrock in Coutt. Bot. Gaz, il. (1877) 123. - Arizona.

8222 quadrangulatum, Klatt, in Linnaea, xxxii. (1863) $284-$ Mexic

\section{SIUM}

$922^{3} 1$ Bulbocastanum, Spreng, in Neue Schr. naturf. Ges. Halle, ii. (1813) 31 ; et

9231 ferulaefolium, Spreng. (1. c.); et pencedanoides, Spreng. (1. c.); et 
92:33 1. SKOLEMORA. Arruda,... 1816 = Andira Lam. (Legum.).

pernambucensis. Arruda, 1. $c,=$ A. anthelmintica?

\section{SMILAX}

9271 a, Purhampun, Ruiz, Mem, Raiz de Purhampuy, (1821) $65=$ praec.

SOBRALIA

$928^{3}$ 1. Elisabethae, Rob. Schomb... = S. Liliastrum, Lindl.

SOJA

9291 a. Soja, Karst. Pharm. Med. Bot. $711=$ G. Soja.

\section{SOLANUM}

9303 1 bractostum. Thunb in Act Gorenk. (1812): ex ej. F1. Cap. ii. 57 = Teedia lucida

9322 a. digitatum, Peckolt, inz Zeitschr, allg. oestery. apoth.Ver. xxi (18s3) 186, nomen.-'Bras.

\section{SONCHUS}

$946^{2}$ a. zollikoferioides, Rouy, in Rev. Sc. Nat. Sér. III. i. (1883) 237 - Hispan,

\section{SOPHORA}

$044^{3}$ a, heptaphylla, Arn. in Nov. Act. Nat. Cur x xiii. (1836) 328 - Ind. or

1. heptaphylla, Linn.... 373 (non alior.) = Derris sinuata, Benth.

\section{SORBUS}

$949^{1}$ a. sativa, Ellis, in Linn. Corresp. i. $87=$ Pyrus domestica.

\section{SORGHUM}

$949^{2}$ a. Sorghum, Karst. Pharm. Med. Bot. $367=$ vulgare.

\section{SPANOGHEA}

$951^{1} 1$. connata, F. Muell. in Trans.

\section{SPARGANIUM}

$951^{3}$ 1. pubescens, Poir. Voy, Barb. ii. 254 (err. typ. Poiretii) $=$ Fuirena pubescens.

ramosum, Huds. Fl. Angl. ed. II. 401 ; Curt tenuifolia, Poir. (1. c. err. Poiretii) = Scirpus pubescens.

\section{SPARTIUM}

9522 a. etnensis, Rafin. Speech. Sc. i. 18, ex Call, Life Rafin. 146.

$952^{3}$ scoparium, Linn. P1. Afr. Rar. 13 = Lebeckia sepiaria.

\section{SPATHIPHYLLUM}

95:33 1. commutatum, Schott, ... Ins. Philipp.; Celebes.

1. Gardneri, Schott,... (sp. diversa); of. Massowia Gardneri, C. Koch.

\section{SPERGULA}

$956^{1}$ a. norvegica, Less. Reise durch Norwegen, 294 $=$ Arenaria norvegica.

$950^{2}$ tetraquetra, Neck. Elem. ii. $157=$ Arenaria tetraquetra.

\section{SPIRAEA}

964ํํ 1. banatica. Janka, in Közlem. Magyar Tudom. Akad. xii (1876) $166=$

\section{SPIRANTHES}

$966^{2}$ 1. colorata, Hassk... = Goodyera colorata.

\section{SPONDIAS}

$968^{3}$ I. tubcrosa, Arruda, ... $496=$ venulosa.

\section{SPOROBOLUS}

9693 1. diander, $R$ Br. Prodr. 170, in obs.; Beaw.

\section{STACHYS}

9712 a, BONAMYA, Neck. Elem. i. $316(1790)$

$92^{3}$ 1. lusitanica, Sweet, Hort. Brit. ed. I. 320 Steud... = germanica.

\section{STAPELIA}

$976^{3}$ a erectiflora $N . E . B r$, l. c. nomen - Afr. austr. glabricaulis, N. E. Br. in Kew. Rep. 1878 (1879) 7, nomen. - Afr, austr

$977^{2}$ 1. tsomoensis, N.E.Br.l.c.nomen.- Afr. austr.

$978^{1}$ 1. STAPHYLLAEA, Scop... (1777).

STATIGE

9791 1. caespitosa, Ortega, in Quer, Fl. Esp. vi 334 ; Cav. ... = Armeria caespitosa

\section{STAUROPSIS}

9821 a, violacca, Reichb f. Xenia Orch, ii. $7==$ Pha laenopsis violacea.

\section{STELLARIA}

9862 1. umbrosa, Opiz, ex Rupr. in Flora, xvii. (1834) $710 ;$ Opiz, Seznam...

a. uniflora, Banks et Soland. ex Hook. f, Fl, N. Zel. i. $27=$ Colobanthus Billardieri.

$986^{3}$ a. STELLORKIS, Thon, in Nouv. Bull. Soc Philom. n. 19 (1809) $317=$ Arethusa? Gronov. (Orchid.)

$989^{3}$ lin. 1 1. STENOGLINE : - (non Stenoptera).

\section{STERCULIA}

$993^{2}$ 1. Haynii, Bedd.

Heynii, Mast. in Hook, f. Fl. Brit. Ind, i. 360 , in syn. $=$ pritec.

$996^{2}$ a. STICHORKIS, Thou, in Nouv. Bull. Soc. Philom, n. $19(1809) 318=$ Malaxis ? Sw (Orchid.).

\section{STREPTOGARPUS}

$1004^{1}$ a. Dyeri X, cf. W. Watson, in Gard. \& Forest, viii. (1895) 5. - Hybr, artef.

$1004^{2}$ 1. STREPTOGYNA, Beauv

a. STREPTOGYNE, Poir. in Dict. Sc. Nat. li. $96(182 \%)=$ praec

\section{STRIGA}

$1005^{1}$ a. gesnerioides, Vatke, in Oesterr. Bot. Zeit scht. xxv. (1879) $11=$ orobanchioides.

\section{STROMBOSIA}

$1007^{3}$ 1. philippinensis, Rolfe, in fourn. Bot. xxiri. (1885) 211 ; Vidal

\section{STRYGHNOS}

$1010^{1}$ a. Ignatia, Lindl. Fl. Med. $530=$ S. Ignatii

10102 1. toxifera, Sihomb. ex Lindl. (l. c.); et...

\section{STYLIDIUM}

$1011^{1}$ a. ANDersonIA, Koenig, ex R. Bx. Prod. $5 \%$ (1810)

\section{STYRAX}

10151 a. SCHLosstriA Ellis, in Linn. Corresp. i. $130,159(1821)$

1. angustifolia, Buc'hoz, Herb. Col. Amér. t. 26 (Quid?). - Hah.?

\section{SUAEDA}

$1015^{3}$ 1. heterophylla, Bunge,

1. hortensis, Forsh... 71.

SUCCISA

$1016^{2}$ a. attenuata, Sweet, Hort. Brit. ed. I. $204=$ Cephalaria attenuata.

10163 Succisa. Karst. Pharm. Med, Bot. $1053=$ Scab. Succisa.

\section{SWERTIA}

$1019^{2}$ a. Fraseva, Sm. in Rees, Cyclop. xxxiv. n. 3 = Frasera caroliniana.

\section{SYMPLOCOS}

$1023^{2}$ 1. oblongifolia, Rolfe, in . Fourn. Bot. xxiii. (1885) 214: Vidal

reticulata, C. B. Clarke, in $\mathrm{Hook}, \mathrm{f}$. Fl. Brit Ind. iii. 582, in syn. = Beddomei.
$1024^{2}$ a SYNARRHENA, F, Muell, Fragm, v. 175 in obs. $(1866)=$ Saurauja, Willd. ('Ternstr.).

\section{SYRINGA}

$1026^{1}$ a correlata, R. Br. in Sitzb. Ges. Naturf. Fr. Berl. (1873) $69=$ chinensls. japonica, Decne. in Nouv. Arch. Mus. Par. ciér. II. ii. (1879) 44. - Japon.

1. oblata, [Lindl. in] Gard. Chron. (1859) 868 Fortune, l. c. (1860) 170. - China bor. pelinensis, Rupr.

\section{SYZYGIUM}

$1027^{3}$ 1. lucidum, Gaertn. Fruct. i. $167=$ Eugenia lucida, Banks

panioulatum, Gaertn. (1.c.) = Eugenia paniculata, Banks.

\section{T}

\section{TAENIOPHYLIUM}

$1031^{2}$ a, fornicatum Blume. Tabell, 70 , absque descr. - Hab.?

1. Zollingeri, Reichb. f. Xenia Orch.i. 202; Bonplandia.

\section{TAMONEA}

1034 a. guianensis, Aubl. P1. Gui. 440 (quoad exempl. nonnulla) $=$

\section{TARAXACUM}

10372 a glaucum Boiss \& Haussk ex Rabenh. in Sitzb. Isis (1870) \{reimp.]; et Hedwigia

x. (1871) $22=$ montanum.
$1037^{3}$ Taraxacum, Karst. Pharm. Med. Bot. 1138 $=$ officinale

\section{TARIRI}

$1038^{1}$ a. Antidesma, Baill. Bot. Médic. [Phan.] (1884) $=\mathrm{P}$. Antidesma, Sw

ciliata, Baill. (1. c.) $=$ P. ciliata, Mart.

pentandra, Baill. (1. c.) = P. pentandra, Siv.

\section{TAXANTHEMA}

$1038^{3}$ a. Armeria. Neck. Elem. i. $115=$ Armeria maritima.

$1041^{1}$ a. TEKEL, Adans, Fam. ii. 497 (1763 = seq.

TEKELIA, Scop. Introd. $88(\mathbf{1 7 7 7})=\mathbf{A} \mathbf{r}$ gania, Roem. \& Schult. (Sapot.). spinosa, Scop. Introd. $88=\mathrm{A}$. Sideroxylon.

TELINA

$1041^{3}$ a, canariensis, C. Koch, Dendrol, i. $31=\mathrm{Cy}-$ tisus canariensis.

$1043^{2}$ 1. TEPHEA, Delile,..$=$ Olinia, Thunb. aequipetala, Delilc, $\ldots=0$. Rnchetiana.

\section{TERMINALIA}

$1047^{1}$ 1. mollis, Rolfe, in fourn. Bot, xxiii. (1885) $212 ;$ Vidal

TETRANTHERA

$1051^{3}$ 1. Bindoniana, F. Mull . . = L Rindoniana. caloneura, Miq... (non calonmemira).

$1052^{3}$ Rumphiz; Blume, .. = L. Rumphii.

$1054^{1}$ a. TETRAPTERIS, Garden, in Linn. Corresp, i。 $406(1821)=$ Halesia, Linn. (Styrac.).

THALASSIA

105:2 1. Hemprichii, Aschers. in Sttzb. Ges. Naturf. Fr. $(1870) 83$; et in Neumayer,

\section{THESPESIA}

10661ㅡ. Lampas, Dalz... - As, et Afr, trop

THLASPI

$1068^{1}$ 1. Burselta, Berger. Phyton. iii, $55=$ praec. 


\section{THLASPI}

$1068^{1}$ coronopifolium, Berger. (1. c.) $29=$

$1068^{2}$ Nasturtium, Berger.(1. c.) $43=$

nudicaule, Berger. l. с $2 \gamma=$ Teesdalia nudicaulis.

nudicaule DC $\ldots=T$, nudicaulis, regularis. ruderale, Berger. Phyton. iii. 45; All...

\section{THFINAX}

$1070^{2}$ a. arbores Hort ex Hook, f. Kew Rep. 1882 (1884) $64=$ Acanthorhiza arborea.

. barbadensis, Lodd. ex Mart. Palm. iii. 257. - Ind. occ.

a. clegantissima, Hort. ex Hook. f. Kew Rep. $1882(1884) 66=$ radiata.

trnica, Hort. ex Hook. f. (1. c,) $64=$ Brahea dulcis.

\section{THYMUS}

$1074^{1}$ a. Barrelieri, Rowy, in Rev. Sc. Nat. Sér. IlI. i. (1883) 240. - Hispan.

$1075^{3}$ paradoxws $\times$. Rouy, (1. c.) 242. - Hispan

$1076^{1}$ serbicus, Petr. Addit. Fl. Agr. Nyss. $149=$ T. Serpyllum.

TILIA

$1079^{3}$ a. petiolata, Hook. f. Bot. Mag. sub t. 6737 (1884) lapsu $=$ petiolaris.

\section{TINNEA}

$1083^{1}$ 1. erianthera, Vatke... 539 (species Holmskioldiae). - Afr. trop.

\section{TIPULARIA}

10S32 1. camtschatica, Spreng... $734=$ Habenaria tipuloides.

\section{TITHYMALUS}

$2084^{2}$ a. canariensis, Karst. Pharm. Med. Bot. $587=$ E. canariensis.

$10 \$ 4^{3} \quad$ edulis, Karst. (1. c.) $=$ E. edulis.

10.51 . officinarzm. Karst. (1. c.) $=$ E. officinarum, paluster, Karst. (1. c.) $585=$ palustris.

$1085^{2}$ resiniferus, Karst. (1. c.) $587=$ C. resinifera.

TOLUIFERA, Linn.

$1087^{2}$ a. erythroxyla, Karst. Pharm. Med. Bot. $681=$ Myroxylon peruiferum.

frutescens, Karst. 1. c. = Myrospermum frutescens.

\section{TORENIA}

10891 1. crustacea, R. Br. Prod. 440; Cham. \& Schlecht... - Vandellia crustacea.

a. hexandra, R. Br. Prod. $440=$ V. crustacea.

\section{TORMENTILLA}

$1090^{1}$ a. officinarum, Neck. Elem, ii. $95=$ Potentilla Tormentilla.

TOURNESOLIA

10921 a. tinctoria, Scop.1. c. = C. obliqua.

\section{TOXYLON}

$1093^{2}$ a. aurantiacum, Rafin. Med. Fl. ii. $268=$ M. aurantiaca.

pomiferum, Rafin. Am. Monthly Mag. ii. (1817) 118, ex Sarg.

\section{TRICHOLAENA}

$1107^{3} 1$ arenaria, Nees,... (1835); ex Linnaea, xi. (1837) Litt. $130=$ capensis, Nees, (1. c.); et rosea, Nees, 1. c.) 129; et

tonsa, Nees, (1. c.) 128; et ... = rosea

$1109^{1}$ a. TRICHOPTERIS, Neck. Elem, i. 110 $(1790)=$ Scabiosa, Tourn. (Dipsac.).

\section{TRICHOSPIRA}

$1110^{1} 1$. menthoides, $H . B . K \ldots 28$ (non 23).

TRIDAX

$1111^{2}$ a. imbricatus, Sch.-Bip. ex Klatt, in Flora, 1xviit. (1885) 202. - Mexic.

\section{TRIFOLIUM}

$1111^{1}$ a. ChrYsaspis, Desv. F1. Anjou, 338, in syn. (1827)

$1114^{2}$ 1. multicaule, M. E. Jones,... = monanthum.

\section{TRIGLOCHIN}

$1116^{2}$ 1. maritimum, Linn. Sp. Pl. p. 339 (non 105).

\section{TFILLIUM}

$1119^{1}$ a. HuXmamia, Garden, in Linn, Corresp. i 366,379 (1821).

\section{TRIODIA}

$1120^{2}$ 1. herguelensis, Hork. f... $379=$ Poa kergue lensis.

\section{TROPHIS}

11331 a. brasiliensis, Peckolt, in Zeitschr. Allg. Oesterr. Apoth..Ver. xxi. (1883) 185, nomen.Bras.

\section{TULIPA}

$1135^{2}$ 1. Beccariana, Bicchi,...; in I Giardini, viui. (1860) fasc. 2 (Desc.)

11391 a. TURRAYA, Wall. Cat. sub n. 8637 (1847) = Leersia, Soland. (Gramin.) napalensis, Wall. 1. c. = I. hexandra.

\section{TYNANTHUS}

$1141^{2}$ 1. Goudotiana, (non Gond-).

\section{TYPHA}

$1142^{1}$ 1. minima, Funck, in Hoppe, Bot. Taschenb. (1794) 418 ; (cf. 187); et ex Willd...

\section{U}

\section{ULEX}

$1143^{1}$ 1. intermedims, Cameron, in Gard. Chron. (1848) 157: Le Gall, ... = Gallii.

$1143^{2}$ a. nanus, Lees, Bot. Malvern Hills, $34=$ Gallii.

\section{UNCARTA}

$1145^{1}$ a, RkSTIARIA, Lour, Fl. Cochinch. 639 (1790).

1. acida, Kew. Distr. 82\%/2, ex Hook. f. Fl. Br. Ind $\mathrm{iii}, 31=$ dasyoneura.

a. athemiata, Treub, in Ann. Jard. Bot. Buitenz, iii. (1883) 52, sphalm. ? = attenuata.

1. brevispina, Kew. Distr. 2756, ex Hook. f. Fl Br. Ind. iii. $31=$ dasyoneura.

$1145^{2}$ rhynchophylla, Miq.... 108. - Japon setiloba, Benth. ... Ins. Amboina.

\section{UNONA}

$1147^{1}$ 1. discolor. Steud. Nom. ed. 11. i. 717 in syn. sphalm. = concolor $=$ Xylopia aromatica.

a. farinosa, Dalz. \& Gibs. Bomb, Fl, 3 sphalm. = pannosa.

$114 \tau^{3}$ zeylanica, Dun. (ex Mast.) $=$ Xylopia aromatica (in Cur. Post.)

\section{UROPHYLIUM}

$1151^{1}$ 1. memecyloides, Rolfe, in fourn. Bot. xxiii. (1855) 213 ; Vidal.

\section{UROSPERMUM}

$1151^{2}$ a, echioides, Fraas, Syn. P1. Fl. Class. 198 sphalm. = Picris echioides

1. picrioides, Scop. Introd. 122; F. W. Schmidt, ... - Europ. austr. picroides, F. W. Sctsmidt, ... $275=$ praec.

\section{URTICA.}

$1154^{3} 1$ frutescens, Thunb, in Trans, Linn. Soc ii (1794) 330 in syn. cum cit. falsa $=$ Villebrunnea frutescens.

\section{UTRIGULAFIA}

11581 a. caerutecl, Linn, ex R. Br. Prod, $432=$ cyanea

\section{UVARIA}

$1160^{3}$ 1. Narum,-Blume, Anonac. Fl. Fava, 5 (1823); Wall. Cat. n, 6473 ; et A, DC.

\section{V}

\section{VAGGINIUM}

$1163^{3}$ a. Whitmeei, F. Muell. in Papers Roy. Soo. Tasman. (1875) 103. - Ins. Samoa.

VAHEA

$1164^{1}$ 1. florida, F. Muell. in Wittstein, Org. Const Pl. (1878) 258 ; et

Heudelotii, F. Muell, (1. c.); et

owariensis, F. Muell. (1. C.); e

senegalensis, A. DC. ... $328=\mathrm{I}$. senegalensis (Cur. post.).

\section{VAILIANTIA}

$1164^{2}$ a. crebrifoliata, Chaub. in St. Amans, Fl. Agen.

$1164^{3}$ 1. VALENZUELIA, Mutis,

\section{VALERIANA}

$1166^{\circ}$ a. quadridentata, St Amans, Fl. Agen. 15.

\section{VANCOUVERIA}

$1168^{3}$ 1. chrysantha, Greene,...$=$ hexandra, var.

\section{VANILLA}

$1170^{2}$ 1. lutea, C. Wright, ex Griseb. 1. c. = Wrightii. palmarum, Griseb. Cat. Pl. Cub. $267=$ Wrightii.

VELAGA

$1172^{3}$ 1. xylocarpa, Gaertn

$1173^{1}$ a. VELHEIMIA, Scop. Introd, 85 (1777) sphalm. = Veltheimia

$1173^{3}$ 1. capensis, Scop. Introd. 85 ; [DC.].

a. guineensis, Neck. Elem. iii. $186=$ Sanseviera guineensis

\section{VENTILAGO}

11742 1. madraspatana, Gaertn.

\section{VERBESINA}

$1181^{1}$ 1. scandens, Roxb... $=$ Wedelia scandens.

\section{VERNONIA}

11821 a, aemulans, Vatke, in Oestr. Bot. Zeitschr. xxvii. ( 877 ) 195. - Afr. trop.

$1183^{2}$ 1. demulans, Vatke,... err. typ. = aemulans.

\section{VERONICAA}

$1184^{3}$ a, pyrrhopappus. Sch,-Bip. ex Klatt, in Flora, lxviii. (1885) 203. - Ins. Philipp.

$1190^{1}$ 1. ligustrifolia, R, Cunn.

$1193^{3}$ 1. VETRIX, Rafin. in Am. Monthly Mag. i (1817) 439 ; et. sicula, Rafin. (1. c.)..

\section{VICIA}

$1196^{2}$ a. elegantissima, Shuttlexw. ex Rouy, in Rev. Sc Nat. Sér. III. i. (1883) 229. - Hispan.

$1198^{3}$ a. VICQ-AZIRIA, Buc-hoz, Herb. Col. Amér. t 48 (1783) (Quid).

$1198^{3}$ a. VICTORIA, Buc-hoz, Herb. Col. Amér. t. 75 (1783) (Quid?).

borbonica, Buchoz, 1, c. - Ins. Maurit.

\section{VILLAMILLA}

$1202^{2}$ a. roseoaenea, Benth. G Hook.f. Gen. Pl. iii. 47. - Bras.

203\% 1. VIMEN, Rafin, in Am. Monthly Mag. i. (1817) 439 = Salix, Tourn. 


\section{VIOLA}

$1205^{2}$ 1. begoniaefolia, Benth... $161=$ stipularis.

$1206^{2}$ a erecta, Myers, in Am. Natural. iv. (1870, 438 $=$ Sellirkii.

$1207^{3}$ Maillardi, Souché, in C. R. Assoc. Fr. Blois, $1884(1-85) 288=$ hirta?

VIREA

1:182 1. hispida, Scop. Introd, 122; S. F. Gray,

VISENIA

$1212^{3}$ a. tibiaffolia, Jungh, in Hoev, \& De Vriese. Tijdschr. vii. (1S40) $302=$ Melochia arborea.

1. velutina, Jungh. (1. c.); Turcz.

VISMIA

$1213^{1}$ a. QUADRIA, Mutis, in Linn. Corresp. ii. 530 (1821).

\section{VITIS}

$1215^{3}$ a, densiflora, A. Savat, in C. R. Assoc. Fr. Av Sc. xi. Rochelle, $1882(1883) 436=$ vinifera.

$1216^{1}$ a. Guilelmi, moschata, praecox, Promeryana, tinctoria, Poit. \& Turp. in Poit. Pomol. Franc, iii. = vinifera.

$1216^{2}$ laxiflora, A. Savat. (1. c. $)=$ vinifera.

mensarum, Poit. (1. c.) = vinifera.

VOYRIA

$1220^{2}$ a. Trinitatis, Johow, in Pringsh. Jahrb. xvi, (1885) $448=$ trinitensis

\section{W}

WARIA

$1224^{3}$ 1. zeylanica, Aubl. ... $\mathrm{t}=$ Xylopia aromatica (in Cur. Post.).
$1225^{1}$ a. WARNERIA, Ellis, in Linn. Corresp. i. $100($ I 821$)=$ Gardenia, Ellis (Rubiac.)

$1225^{1}$ a. WARNERIA, Mill. ex Linn. Corresp. i. 114, $121(1821)=$ Watsonia, Mill. (Irid.).

WATSONIA

$1225^{3}$ a. WARNEKIA, Mill. ex Linn. Corresp. i. 114, $121(18: 1)$

\section{WISTARIA}

$1232^{2}$ 1. Consequana, Loud. in Gard. Mag. ii. (1827) $42 \%=$

a. polystachya, K. Koch, Dendrol. i. $6 \approx=$ chinensis.

\section{WITHANIA}

$1232^{2}$ a. origanifolia, Paillieux et Bois, in Bull. Soc Acclim. Sér. IV. i. (1884) $667=$ Salpichroa rhomboidea.

\section{$\mathbf{X}$}

XYLOPIA

$1240^{3}$ a. aromatica, Mart, Fl. Bras, xiii. I. 43 in nota. - Bras.

\section{XYLOSTEON}

$1241^{3}$ a. siculum, Rafin. in Am. monthly Mag. i. (1817) 440.- Sicil。

\section{XYRIS}

12422 1. eriophora, Klotzsch, in R. Schomb. Reise Guiana 3 [1848] $111=$ Isolepis lanata, H.B.K.

\section{Z}

\section{ZANTHOXYLUM}

$124 i^{1}$ a. Fagara. Sargent, in Garden and Forest, iii. (1890) $186=Z$. Limoncello.

$1247^{2}$ a. Hovieanum, F. Muell. Fragm. ix. 77, nomen. = Blackburniana.

ZEA

$1248^{3}$ a. amylacea, amylea-saccharata, everta, indentata, indurata, saccharata, tunicata, Sturtev. ex L H. Bailey, Survival of Unlike, $128=$ Z. Mays.

ZILLA

$1251^{1} 1$. myagroides, Forsk ... 121

a. Myagrum. Forsk. (1. c.) p. 1xix.

ZINGIBER

$1251^{2}$ a. Zingiber, Karst. Pharm. Med. Bot. $471=$ officinale.

ZIZIPHORA

$1252^{2}$ a. intermedia, Lindl. Introd. Bot. ed. 2. 542, sphalm. = media, Link $=$ clinopodioides, Lam.

\section{ZIZYPHUS}

$12533^{1}$ a. Zizyphus. Karst. Pharm. Med. Bot. $870=$ sativa.

$1290^{2}$ 1. LILIUM (non LILIUM).

$1290^{3}$ 1. LIQUIRITIA (non QUIRITIA, err. typ.). NEOTTIA

12932 1. colorata, Blume... = Goodyera colorata,

1294 OREOCNIDE (loco OREOC DE, literis delapsis). 


\section{SEQUUNTUR QUAE}

\section{IN FOO SUPPLEMENTO ADDENDA ET EMENDANDA}

\section{HACTENUS OBSERVAVIMUS}
a. $=$ adde.
d. $=$ dele.
1. = lege.

\section{A}

11 1. AALIUS, Rumph... (1743) (non 1750).

$1^{1}$ a. AAPACA, Metzdorff, in Just, Bot. Jahresb. 1885 (I888) 212, sphalm. = Uapaca, Baill. (Euphorb.).

12 1. ABERIA, Hochst... (non Host).

\section{ABOLBODA}

$\mathrm{I}^{2}$ a. vaginata, Alb. Nillson, in Kongl. Svensk. Vet. Akad. Handl. [Stud. ueber Xyrid.] xxiv. n. 14 (1891) $63=$ brasiliensis, Kunth.

\section{ABUTILON}

$1^{3}$ a. exstipulare, Cordem. Fl. Ile Réunion (1895) 3.5 = exstipulare, G. Don.

hirtum, Cordem. 1. c. $326=$ hirtum, G. Don.

ACACIA

21 a. Bambolah, Karst. Deutsche Fl. ed. 2, ii. (1895) 278 = arabica, Willd.

\section{ACAL YPHA}

$3^{2}$ a. Macafeeana, Veitch, Catal. (1886) 35, nomen. - Hab. ?

\section{ACANTHOPHYLLUM}

$3^{3}$ 1. brevibracteatum... et latifolium... xi. (non xii).

ACER

$3^{2}$ a. album, Hort. ex Handl. Trees Kew, Pt i. [Polypet.] (1894) $87=$ Casycarpum, Ehrh. atheniense, Hort. 1 c. $91=$ Lobelii, Ten. atropurpureum, Hort. 1. c. 93 = palmatum, Thunb.

caucasicum, Hort. 1. c. $89=$ hyrcanum, Fisch. \& $\mathrm{Mey}$.

crispatum, Hort. 1. c. $93=$ palmatum, Thunb. digitatum, Hort. i. c, $95=$ palmatum, Thiñnb.

floridanum, Hort.1. c. $99=$ dasycarpum, Ehrh rubrum, Linn

globosum, Hort. 1. c. $=$ platanoides, Linn., rubrum, Linn

Griffithi, Hort. 1 c. = siklimense, Miq. integrum, Hort. 1. c. $93=$ palmatum, Thunb, lewcophyllum, Hort. 1. c. $99=$ rubrum, Linn.

littorale, Hort. 1. c, $91=$ monspëssulanum, Linn. monspeliense; Hort. 1. c. = monspessulanum, Linn.

pulchrum, Hort. 1. c. $89=$ dasycarpum, Ehrh vugosum, Hort. I. c. $101=$ spicatum, Linn. speciosum, Hort. 1. c. $91=$ macrophyllum, Pursh.

$4^{1}$ virginianum, Hort. 1. c. $99=$ rubrum, Linn. Wieri, Hort. l. c. $89=$ dasycarpum, Ehrh.

\section{ACHILLEA}

$4^{3}$ 1. aromatica...; in in Abh. Boehm. Ges. Wiss. Folge 7, i. (1886) n, viii. 20.

\section{ACHILLEA}

$4^{3}$ 1. Vandasii, Velen, in Sit:. Boehm Ges. Wiss. 1890 (1890) i. 47, et 1892 (1893) 383. - Bulg.

\section{ACOKANTHERA}

$8^{3}$ 1. Ouabaïo, Cathelineau. L'Ouabaïo, 9 ; et in Bull. gén Thérap cxviii. (1889) 1, 7; Lewin..

1. Schimperi, Schweinf. in Boll. Soc Afr. Ttal. x. (1891) 12. - Afr. trop.

ACROSTEPHANUS

$9^{1}$ a. coronatus, Van Tiegh..., et in Bull, Mus. Paris, i. (1895) 166

\section{ADENIA}

1,1 1. globosa, Engl. Bot. Fahrb. xiv. (1891) 382, et

lanceolata, Engl, l c. 478 , et xv..

panduraetormıs, Engl. l.c. 376, et xv...

Schweinfurthii, Eugl. l. c. 37\%, et xv .

\section{ADENOGALYMNA}

$10^{1}$ a. brevidens, S. Moore, in Trans. Linn. Soc. Ser. II. iv. (I895) 420 - - Bras croceum, S. Moore, $l$ c. 419 . - Bras.

\section{ADESMIA}

$10^{3} 1$ Palenae... 283 (non 282)

\section{ADINANDRA}

$11^{3}$ a. bancana, Miq. ex King, in fourn. As. Soc. Beng. 1xix. (1890) II. 132. - Penins. Mal

\section{AEOLANTHUS}

131 a. Poggei, Guerke, in Bot. Falurb. xxii. (1895) 148 - Congo.

\section{AERIDES}

$13^{2}$ a. Dominianum, Hort. Veitch. ex Will, 1. c. 83 - Hybr. artef.

$13^{2}$ 1. AERVA, Forsk... = AERUA, Forsk.

\section{AESCULUS}

$13^{3}$ a. heterophylla, Hort. ex Handl. Trees Kew, Pt i. $\{\text { Polypet. }]^{\prime}(1894) 83=$ A. Hippocastanim, Linn.

incisa, Hort. 1. $c_{0}=$ A. Hippocastanum, Linn. lucida, Hort. 1. c. = A. Hlava, dit.

sinensis, Hort. ex Gard. Chron. (1889) i. 717 tig. $116=\mathrm{A}$. chinensis, Bunge.

\section{AGANISIA}

$14^{1}$ a. alba, im Thurn, in Trans, Linn, Soc. Ser. II ii $(1889): 60$, in obs: $=$ venusta, Rolfe.

venusta, Rolfe, ex Hook. f. in Bot. Mag. (1892) sub t. 72t0. - Guian.

\section{AG $\Omega$ THIS}

$14^{2}$ a. vitiensis, Benttr. E Hook. f. ex Drake, Ill. Fl. Ins. Mar. Pacif. (1892), 353 (= Dammara vitiensis, Seem.). - Ins. Fiji.

\section{AGELAEA}

$14^{3}$ a. paradoxa... et in Bot. Fahrb. xiv. (1891) 318. rubiginusa, Gilg, l.c. 319. - Afr. trop. Schweinfurthii, Gilg, l. c. - Afr. trop.

\section{AGROSTIS}

$15^{3}$ a. Floresii, Sodiro, Gran. Ecuat, [Anal. Univ, Quit. 1889 7.--Ecrad.

Hackeliana, Sodira, l.c. - Ecuad.

\section{AILANTHUS}

$16^{1}$ a. macrophylla, Hort. ex HandI. Trees Kew, P i. [Polypet.] (1894) $53=$ A. glandulosa, Dest. mascula, Hort. 1. c. = A. glandulosa, Desf. purpurascens, Hort. 1. c. = A. glandulosa, Desf. rubra, Hort. 1. c. = A. glandulosa, Desf.

AIRA

$16^{1}$ a. chrysophaena, Porcius, in Anal. Acad. Romane, Ser. II. xiv. (1812) $291=$ Deschampsia caes pitosa, Beawe?

\section{AJUGA}

$16^{2}$ 1. rhodope.7... 1892 (1893) 387 [non (1892) 19], et 1893 (1894) n. xxxvii. 53 = salicifolia Sclireb.

ALBIZZIA

Lucyi, F. Muell. Iconogr. Arstral. Acac. Decad. 13 (1888) 6. - Austral.

$17^{1}$ 1. ALGHEMILLA... (non ALGHIMILLA)

a. glareosa; A, Kern. [ubi? ex Kolb, Alpenpflanzen. (1890) 24, nomen. - Tirol.

ALECTOROLOPHUS

$17^{2}$ aristatus, Gremli, Excurs. F1. Schweiz. ed. 6 (1889) $322=$ Rhinanthus angustifolius, C. C. Gmel.

\section{ALECTRA}

$17^{3}$ a arabica, Deflers, Voy, an Yémen (1889) 179. Arabia.

\section{ALLIUM}

192 1. Hierosolymae, Regel, ex Damm, Catal, xlvi. (1S83) 3 [an A. hierosolymorum, Regel ?]. Palaest.

rhodopeum,... (1890) i. . [non 1890) ii.

Rollii... v (1889)... [non iij. (1889)].

\section{ALOE}

$21^{2}$ a. penduliflora, Baker, in Gard. Chron, (1888) ii. 178. - Zanzib.

ALSINE

221 1. Thomasiana... [Conf. Degen, in Oest. Bot. Zeitschr. xliv, (1894) 438].

\section{ALYSSUM}

$22^{3}$ 1. ponticum... 1893 (1894) n. xxxvii。 10 [non (1892-93) 10

Reiseri... (non Reisserif... 1893 (1694)n。.xxxvii, 9... [non (1892-93) 12].

\section{AMARANTHUS}

231 pycnostachy's, St Lager, in Cariot, Etud. des fl. éd. 8 (1589) $697=$ retroflexus, Linn

\section{AMARYLIIS}

231 1. Tettaui... [non Tettani]. 


\section{AMELANCHIER}

$23^{3}$ a. lancifolic, Hort, ex Handl. Trees Kew, Pt i. [Polypet.] (1894) $217=$ canadensis, Torr. \& Gray.

montana, Hort. 1. c. = alnifolia, Nutt. parrifolia, Hort, 1, c. $217=$ alnifolia, Nutt. pinnata, Hort, 1. c. 191 = Pyrus spuria, $D C$.

stricta, Hort, 1. c. 217 = canadensis, Torr. \& Gray.

\section{AMOMUM}

241 1. macrodons... (non macrodus).

\section{AMORPHA}

$24^{2}$ a. crocea. Hort. ex Handl. Trees Kew, Pt i. [Polypet.] (1894) $117=$ fruticosa, Lirin. dealbata, Hort. 1. $c_{1} \equiv$ frutscosa, Lims, elatior, Hort. 1. c, = fruticosa, Linn. Tudoviciana, Hort. 1. c. = fruticosa, Linn. marginata, Hort. 1. c. = fruticosa, Linn.

$24^{2}$ 1. AMPACUS, Rumph... 1742 (non 1747).

AMPELOPSIS

$2 \tilde{2}^{1}$ a, aconitifolia, Hort, [an? Bunge] ex Handl. Trees Kew, Pt.i. |Polypet.] (1894) $77=$ Vitis heterophylla, Thmb.

AMYGDALUS

$25^{3}$ a. atropurpurea, Hort. ex Handl. Trees, Kew, Pt i. [Polypet.] (1894) $131=$ Prunus persica Stokes.

Simonit, Dieck, 1. c. = P. Simonii, Carr.

ANARRHINUM

$26^{1}$ a. demnatense, Coss, Ill. Fl. Atlant. ii. 84, t. 152 - Reg. Medit.

\section{ANASTREPHIA}

261 1. paucifloscula... (non pauciflosculosa).

\section{ANCHUSA}

$26^{1}$ 1. moesiaca,... 1893 (1894) n. xxxvii. 44 [non 1892-93!

\section{ANDROPOGON}

$26^{3} 1$. bouangensis... (non bonangensis).

$26^{3}$ 1. fragrans... (non elegans).

271 a. Viancini, Franch. in Bull. Soc. hist. nat. Autun. viii, (1895) 231. - Congo gall.

\section{ANGEILICA}

281 a. cureana, Boiss, in Bull. Herb. Boiss. Sér. II iii. (1903) $958=$ koreana, Maxim.

\section{ANGRAEGUIM}

$28^{2}$ 1. Aschersoni... 157 (non 460)

a. Bakeri, Kraenzl. in Mith. deutsch. Schutzegeb. ii. (1889) 159. - Kamerun.

1. cephalotes... 156 (non 4).

$28^{3}$ a. Leonis, Veitch, Man. Orch. Pl. vii, (1891) 134, cum xylogr. (=Aeranthus Leonis, Reichb. f。). - Ins, Comor.

Schumanni, Kraenal. in Mith, deutsch. Schutzegeb. ii. (1889) 159. - Kamerun.

Wittmackii, Kraenzl. l. c. 158. - Kamerun.

ANGUIOA

$22^{2}$ a. Turneri, Williams, Orch. Grow. Man. ed. 7 (1834) 103. - Columb.

\section{ANIBA}

201 a. longifolia, Mez, in Arb. Bot. Gart. Breslau, i. (1S92) 110. - Bras.

293 1, ANIL'a] Ludw... 1737 (non 1837).

\section{NOEGTOCHILUS}

$30^{2}$ a. I3oylei, Hort ox IVill, Orch Grow Man, ed. (1894) 108. - Ind - or

concinnum, Hort. l. c.109:- Assam.

Eldorado, Hort. l. c. - Am. centr.

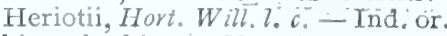

hieroglyphicum, Hort: t. c-Assam.

Turneri, Hort. Will.l. c. 11l. - Java.

zebrinum, Hort. Bull. l.c. - Ind. or.

\section{ANTHEMIS}

$31^{1}$ a. argyrophylla Velen, in Sitzb. Boehm. Ges. Wiss. 1894 (1895) n. xxix. $17=$ Achillea argyrophylla, Halacsy of Gheorgh.

hydruntina, Grozes, in Nuov. Giorn. Bot. Ital. xviii. (1886) 15\%. - Italia.

\section{ANTHOCLEISTA}

$31^{2}$ a. Stuhlmanniana... 580 (non Stuhlmannii... 680 ).

\section{ANTHERIGUM}

$31^{2}$ a sylvestre. S. Moore, in Trans. Linn. Soc. Ser. II. iv. (1895) 503. - Bras.

31: 1. ANTHOSHOREA, Heim... (non Pierre).

\section{ANTHURIUN}

321 1. excelsius... (non excelsior)

Froebelii X, Hort. ex Gartenf. xxxy. (1S86) 52. - Hybr. artef.

Kellermanni $X$, Hort. ex Le Jardin (1893) 43, flg. 15. - Hybr. artef.

Sanderiamm. Hort. Sander, ex Gard. Chron. (1895, i. 594. - Furm. hort.

32 a. ANTIGHEIROSTYLIS, Fitzg. Austral Orch. ii, pars IV. (1891), ORCHIDEAE. apostasioides, Fitzg, l. c. - Austral.

borunastylis, Fitg. l. c. pars iii. (1S88). Austral.

\section{APETAHIA}

$33^{3}$ a. raiateensis, Drake, Ill. Fl. Ins. Mar. Pacif. (1886) 29 t. 9. - Ins. Raiatea.

331 1. APIIANAMIXIS, Blume =..... (non Pierre).

\section{APINAGIA}

$33^{2}$ a. Riedelii, Warm. Fam. Podost. iii. (ISSS) 19 t. $21 \mathrm{fig}$. 11-22 et t. $22 \mathrm{fig}$. 1-11. - Bras.

\section{APODYTES}

$34^{1}$ a. Curtisii, Dyer, ex King, in fourn. As. Soc. Beng. 1xii. (1893) ii. 392. - Penang.

\section{APONOGETON}

$34^{1}$ a. Loriae, Martelli, in Bull t. Soc Bot. Ital. (1895) 57 , nomen. - N. Guin.

\section{ARABIS}

$34^{3}$ a. Doumetii, Coss. Ill. Fl. Atlant. i. (1832) 19 t. 13. - Algeria

parviflora, Porcius, in Anal. Acad. Romaea, Ser. II. ii. (IS83) 102, sub 11.603. - Eur. austr.

\section{ARALIA}

$35^{\mathrm{l}}$ a. ricinifolia, Hort. ex Handl. Trees Kew, Pt i. $[$ Polypet $]$ (1894) $21=$ Acanthopanax ricinifoljum, Seem.

\section{ARCEUTHOBIUM}

$35^{2}$ a. capense, Cordem. Fl. Ile Réunion (1895) $295=$ Viscum c tpense, Linn. $f$.

taenioïdes, Cordem. 1. c. = V. taenioïdes, Conm.

\section{ARENARIA}

$36^{2}$ a. Halacsyj, Baldacci, in Malpighia, v. (1891) 65. - Monteneoro.

$36^{3}$ a. trachyphylla, Lange, in Danske Kongl. Vidensk. Selks. Forh. (1890) 199. - Hisp.

ARIA

$37^{2}$ a dentata, Hort, ex Handl. Trees Kew, Pt i. [Polypet.] (1894) $189=$ Pyrus vestita, Wall.

$37^{2}$ 1. ARICURYROBA, Barb. Rodr... (non ARIKURIROBA).

ARISAEMA

$37^{2}$ 1. Wallichianum, ... = multicarinatum, Wall.

\section{ARISTOLOCHIA}

381 1. moupinensis... (non monpinensis),

\section{ARMENIACA}

381 a, Petzoldii. Hort. ex Handl, Trees Kew, Pt [Polypet] $-(1894), 133=$ Prunus triloba Lindl var.

tomentosa, Hort. 1. co = P. tomentosa, Thuno. triloba, Hort. 1. c. $=$ P. triloba, Lindl

\section{ARRHENATHERUM}

$81^{1}$ a. rumelicum, Velen. in Sitz. Boehm. Ges. Wiss. 1887 (1888) 465. -- Rumel.

\section{ARTEMISIA}

$39^{2}$ a. Roezlii, Huter [ubi?] ex Kolb, Alpenpfanzen (1890) 57. - Hisp.

\section{ARUNDINARIA}

$40^{1}$ a. chrysantha, Mitford, in Gard. Chron. (1894) i 368. - Hab?

khasyana, H. Bean, in Gard. Chron. (1894) i. $301=$ nitida, Hort. Kerv.

Laydeckeri, Hook. f. ox Mitford, in Gard. Cliron. (1894) i, 368، - Hab. ?

\section{ASGLEPIAS}

$40^{2}$ a. cormuta, Cordem. Fl, Ile Réunion (1895) 48 $=$ Gomphocarpus cornutus, Decne.

\section{ASTER}

$43^{2}$ 1. Ottomanum... (1890) i... (non ii.).

\section{ASTRAGALUS}

$45^{3}$ a. Kralikianus, Coss. Ill. Fl. Atlant, ii. (1892) 38, t. $121=$ A. Kralikii. Coss

$46^{2}$ 1. sericans... (non sericeus).

$46^{3}$ a. Vandasii,... $1893(1894)$ n. xxxvii. 24,.. [non $1 \times 92(1893) 34]$

\section{AUBRIETIA}

$48^{2}$ a. Leichtlinii, Hort. ex Wien. Ill. Gartenz, xiii (1888) $325=$ deltoidea, $D C$.

$48^{3}$ a. AURANTIUM, Tourn. = Citrus, Linn. (Rutac.).

$4 S^{3}$ a. e'ariegatum, Hort. ex Barb. Rodr. Hort. Flu min. 1893 (1895) 51. - Form. hort.

$48^{3}$ 1. AUTRANEA... (non AUTRANIA),

AZALEA

$49^{2}$ a. rosaeflura [Dean] in Flor. Mag: $(1880)$ t. 418 - Japon.

\section{B}

BACCHARIS

491 a. patiensis, Hieron. in Bot. Falhrb. xxi. (1895) 345. - Columb.

$50^{3}$ 1. BALIOSPERMUM... (non BALIOSPEREUM).

\section{BAMBUSA}

$50^{3}$ a. ancrustifulia, Mitford, ex Garden, xlvi. (1894 547. - Japon

Castilloni, Hort. ex Rev. Hortic. Iviii. (1886) 513 , fig. 121; et in Gard. Chron. (1894) i. $368=$ Phyllostachys Castillonis, Mitford.

chrysantha, Hort. Marliac, ex Gard. Chron. (1894) i. $368=$ Arundinaria chrysantha, Mitford.

disticha, Mitford, in Garden, xlvi. (1894) 547 (= B. nana, Hort.). - Japon.

Henonis, Hort. ex Gard. Chron. (1S94) i, 368 $=$ Phyllostachys Henonis, Mitford.

Laydckeri. Hort. 1. c. = Arundinaria Laydeleri, Hook. $f$. 
BAMBUSA

$50^{3}$ a marmorea, Mitford, in Garden, xlvi. (1894) 547 (= Arundinaria Kokantsak, Kurz) - Japon. Nagashima, Hort. Marliac, ex Mitford, l. c. - Japon.

pumila, Hort. ex Gard. Chron. (1894) i. 368. Japon.

Weiseneri... (non Wiesneri)

BATRACHIUM

$52^{2}$ a. elegans, Chab. in Bull. Soc. Bot. Fr, xxxvi. (1889) 15 , in syn. = Ranunculus aquatilis, Linn.

$51^{2}$ 1. BARBEYA, Schweinf, in Malpighia, v. (1891) 332 et. oleoides, Schweinf. l. c. t. 24, 25 ; et...

\section{BEGONIA}

$53^{2}$ a. compta, Bull, Catal. (1886) 7. - Bras. cyelophylla, Hook. $f$. in Bot. Mag. (1887) t 6926. - China.

532 1. Eliassi... (non Eliani).

fulgens, Hort. Lemaire, Catal. (1893) n. 123.Bolivia.

Heracleicotyle X, Veitch, Catal. (1895) 48. Hybr, artef.

margaritacea $\times$, Hort. Veitch, Catal. (1895) 3 ; et in Neub. Gart. Mag. (1895) 321, cum fig. - Hybr. artef.

BELLEVALLIA

$54^{2}$ a. Aucheri, “ Baker », ex Bull. Soc. Tosc. Ortic. (1894) $27=$ Hyacinthus Aucheri, Baker.

BELLIS

$54^{2}$ a. Vandasii, Velen. in Sitzü. Boehm. Ges. Wiss. 1888 (1889) 49 ; et...

BENTINGKIA

$54^{3}$ a. nicobarica, Hort. Sand. Catal. (1895) 46. Ins. Nicobar

\section{BERBERIS}

$55^{1}$ a angulizans, Hort ex Handl. Trees Kew, Pt i. [Polypet.] (1894) $27=$ vuigaris, Linn.

coerulescens, Hort. 1. c. $23=$ aristata, $D C$

corallina, Hort. 1. c. $27=$ vulgaris Linn.

elongata, Hort. 1. c. = vulgaris. Linn.

globularis, Hort. 1. c. = vulgaris, Linn.

maxima, Hort. 1. c. = vulgaris, Linn.

pangharengensis, Hort. 1. c. = vulgaris, Linn.

$55^{2}$ 1. rectinervia... (non rectinervis).

\section{BERCHEMIA}

$55^{2}$ a, yemensis, Deflers, Voy. au Yémen (1889) 123. - Arabia.

\section{BERRYA}

$55^{3}$ 1. tahitensis, Drake, Ill. Fl. Ins. Mar. Pacif (1890) $125 ; \varepsilon t .$.

\section{BERSAMA}

561 1. Volkensii, Guerke, in Bot. Fahrb. xix. Beibl 11. 47 (1894) 36 ; et...

\section{BETULA}

$56^{1}$ 1. Raddeana,... ; et in Gartenfl. xxxvii. (1887) 383, fig. 95 .

BICORNELLA

$56^{2}$ a. arabica, Deflers, Voy. au Yémen (1889) 208. Arabia.

\section{BIDENS}

$56^{3}$ 1. orientalis, Velen. in Sitzb. Boehm. Ges. Wiss. 1888 (1889) 48 ; et. .

a. Remyi, Drake, Ill. Fl. Ins. Mar. Pacif. (1888) 78, 210, t. 39 (=Coreopsis Remyi, Drake). Ins. Sandvic.

\section{BILLBERGIA}

$57^{1}$ a. andegavensis $X$, Hort. ex Rev. Hort. lviii (1886) 309. - Hybr. artef.

Gireoudiana $\times$, Wittm. in Gartenfl. xxxvi (1887) 330. - Hybr. artef.

\section{BILLBERGIA}

571 a. Schimperiana... et in Bot. Fahrb. xiii. Beibl. n. $29(1891) 2$

\section{BIOPHYTUM}

$57^{2}$ 1. albiflorum, F. Mull, in Vict. Natural. ix. (Nov 1892); et. .

\section{BLAERIA}

$5 \pi^{3}$ 1. flava, 239 (non 289)

\section{BLAKEA}

$5 \tau^{3}$ 1. Andreana... 959 (non 759).

\section{BLUMENBACHIA}

$58^{3}$ a. acaulis, Phil in Anal. Univ. Chil. lxxv. (1894) 17. - Chili.

mitis, Phil. l. c. 18. - Chili.

nemorosa, Phil. l. c. - Chili

591 a. BOECKELERIA, Th. Dur. Ind Gen. Phan. (1888) $504=$ Decalepis, Wight \& Arn

BOLLEA

$59^{3}$ a. hemixantha, Reichb. f. in Gard. Chron. (1888) ii. $206=$ Zygopetalum hemixanthum, Reicub.f

BORRERIA

$60^{3}$ a. Schumanniana, Taub. ex Ule, in Cruls, Rapp. Comm. expl. plat. centr. Brésil (1894) 351 et in Bot. Jahrb. xxi. (1895) 453. - Bras.

$61^{2}$ 1. BOTRYANTHUS... (non BOTRYANTHES).

$61^{2}$ 1. BOTRYOPHORA... (non BOTRYOSPORA).

\section{BOUGEROSIA}

$61^{2}$ a. penicillata. Deflors, Voy. aw Yémen (1889) 169 - Arabia.

cicatricosa, Deflers, l. c. 170. - Arabia.

\section{BOUGAIN VILLAEA}

$61^{2}$ a. brachycarpa, Heimerl, in Bot. Fahrb. xi. (1889) 88. - Bras.

BOUSSINGAULTIA

$61^{2}$ a. cordata, [Hort.] ex Bull. Soc. Tosc. Ortic. (1895) 207. - Peruv

BRACHYPODIUM

$62^{2}$ 1. ponticum... 1893 (1894) 71 [non 1892 (1893)].

$62^{3}$ 1. BRAMIA, Lam... (non Lour.).

Monniera, Cordem. F1. Ile Réunion (1895) 484 $=B$. Monniera, Drake.

\section{BRASSICA}

$63^{1}$ a. Tinei, Lojac. Fl. Sicula, i. I. (1888) 113. Sicilia.

\section{BRIGKELLIA}

$63^{3}$ 1. lancifolia... Ser. III. 1. (non i.)

\section{BRIDELIA}

$63^{3}$ 1. Fischeri, ... 531 (non 53 ).

BRILLANTAISIA

$63^{3}$ 1. salviiflora... (non salviflora).

\section{BREYNIA}

$63^{3}$ a. turbinata, Cordem. Fl. Ile Réunion (1895) 348 $(=$ Melanthesopsis patens, Muell. Arg.). Ind. or., Ins. Borb.

64프. BROCHONEURA... (non BROCGHONEURA).

\section{BROMUS}

$64^{2}$ a. condensatus. Hack. in Magnier, Scrin. fl. select vii. (1888) $135=$ erectus, Huds.

moesiacus, Velen. Fl. Bulg. (1891) 616. Bulg.

splendens, Velen. in Abhandl. Boehm. Ges. Wiss. vii. Folge, I. (1886) n. 8, 46. - Bulg.
$64^{3}$ 1. BROUSMICHEA... (non BROUSEMTCHEA).

BROWNLOWIA

$65^{1}$ a, kleinhovioidea, King, in fourn. As. Soc. Beng 1x. (1891) II. 9\%. - Perak

macrophylla, King, l. c, 99. - Perak

Scortechinii, Ktng, l. c. 98, - Perak

\section{BRUNELLA}

$65^{1}$ a. hybrida $X$, Giraudias, in Bull. Soc, étud. sci. Angers, xix, 1889 (1890) 113, - Gall. mer.

\section{BUETTNERIA}

$65^{3}$ a. campicola. Taub ex Ule, in Cruls, Rapp, Comm. expl. plat. centr. Brésil (1894) 363; et in Bot. Fahrb. xxi. (1895) 444. - Bras.

BULBOCASTANUM

$66^{1}$ a. mediterraneum, Albert, in Magnier, Scrin $\mathrm{fl}$ select. X. (1891) $190=$ Carum Bulbocastanum, Koch.

\section{BULBOPHYLLUM}

$66^{2}$ a. Cornu-cervi, King, in Fourn. As. Soc. Bent. 1xiv. (1895) ji. 332. - Sikkim.

cylindricum, King, 1. c. $333=$ leptanthum, Hook. f.

ebulbon, King, l. c. - Sikkim

1. Hookerianum... = creonastes, Reichb.

$66^{3}$ a. Leysianum, Burbidge, in fourn. Hort. Soc. Lond. xvir. (1894) Proc. 134, 135, fig. 19 ; et ex Orchid Rev ii. (1894) 294 - Borneo-

Listeri, King, in fourn. As. Soc. Beng. 1xiv. (1895) II. 334. - Bhotan.

saurocephalum, Reichb. $f$. in Gard. Chron. (1886) ii. 262. - Ins. Philipp.

$67^{1}$ 1. Wrayi,... t. 2044,(non 2844).

BULBOSTYLIS

$67^{2}$ a. capillaris, Kunth. fide C. B. Clavke, in Hook. Fl. Brit. Ind, vi. (1893) 652. - Ind. or

junciformıs, C. B. Clarke, ex S. Moore, in Trans. Linn. Soc. Ser. II. iv. (1895).512 $\Rightarrow$ Isolepis junciformis, Kunth). - Am. austr.

\section{BUPLEURUM}

$67^{3}$ a. aricense, Timb in Rev. Soc. Franc. Bot. $x$ (1892) 165 = laricense, Gaut. \& Timb.

1. orbelicum... 47 (non 407 )

a. variabile, Baldacci, in Malpighia, v. (1891) 71 - Montenegro.

\section{BURLINGTONIA}

$68^{1}$ a Farmeri, Hort ex Will. Orch. Grow. Man. ed. 7 (1894) 136. - Hab?

Knowrlesii Hort ex Will 1. c - - Hab.

Leeana, Will. 1. c. = Rodriguezia Leeana, Reichb. $f$.

\section{BURSERA}

681 1. Aracouchii... (non Eraconchii).

$68^{2}$ a. BYTTNERIA, Loefl. = Buettneria, Loefl. (Stercul.)

\section{C}

$68^{2}$ a. CABRALEA, A. Juss. (Meliac.).- Ind. Kew. 1i. 365 .

insignis, C. DC. in Coult. Bot. Ga\%.xix. (1894) 1. - Guatem.

\section{CADABA}

701 1. scandens, $P a x \ldots 301$ (non 361 )...

\section{GALAMAGROSTIS}

11 1. aurea (1889) (non 1884).

a. Curtisit, Vasey, in Coult. Bot. Gaz. xv. (1890) 269 = Ammophila Curtisii, Vasey

\section{CALAMUS}

712 1. Barteri, Becc. (non Drude) 


\section{CALANDRINIA}

i3 a. acuminata, Phit. in Anal. Univ. Chil. lxxyv. 1894; 173. - Chili

gerialitis, F. Phil. ex Plizl. l.c. 184. - Chili. argentea, Phil. l.c. 310. - Chili. arnerifolia, Phil...; ct l. c. 176. - Chili. Bandurriae, Phil. l. c. 316. - Chilr. Barneoudi, Phil. l. c. 174. - Chili. bracteosa, Phit. l. c. 181. - Chili. caesia, F. Phil. ex Phil. l. c. 18\% - Chili. callithrix, Phil. I.c. 317, - Chili. canescens, Phil. l. c. 306. - Chili. capituligera, Phil. l. c. 312. - Chili. caulescens, Phit.l. c. 313. - Chili. copiapensis, [non capiapina] Phil...; et l. c. 191. - Chili.

crassifolia, Phil. l. c. 180.-Chili.

cymosa, Phil. l. c. 192. - Chili

depressa. Phit.l c. 316. - Chili

eritrichioides, Phil. . . . . 315. - - Chili

glandulifera, Phil. \%.c. 188. - Chili.

hispida, Phit. l. c. 310. - Chili

humilis, Phil. . c. 319. - Chili.

involucrata, Phil. l.c. 318 - Chili.

lancifolia, Phit. l. c. 300. - Chili.

laxiflora, Phil. I. c. 183, - Chili.

leucopogon, Phil. l. c. 313. - Chili.

nana, Phil. l. c. 304. - Chili.

nivalis, Phit. l. c. 308. - Chili.

oligantha, Phit.l.c. 188. - Chili.

parviflora, Phil. l. c. $31 \%$ - Chili

pauciflora, Phil. i. c. 193. - Chili.

petiolata, Phil. i. . . 318, - Chili.

phalacra, Phil. l.c.307. - Chili.

polia, Phil. l. c. 306. - Chili.

portulacifolia, Phil.l.c. 178. - Chili,

prolifera, Phil. l.c. 312. - Chili.

Rahmeri, Phil. l. c. 189. - Chili.

rosea, Phit. l. c. 315 . - Chili.

Sanfurgi, Phil. l. c. 309. - Chili.

sanguinea, Phil. . . c. 190, - Chili.

subverticillata, Phil, l. c. 302. - Chili.

tenuifolia, Phil. l. . 189. - Chili. uspallatensis, Phil. l.c. 307. - Chili.

sessiliflora, Phil. l. c. 308.-Chili.

Solisi, Phil. 7. c. 303. - Chili.

stricta, Prill l. c. 194. - Chili.

Tweedyi, A. Gray, in Proc. Am. Acad. xxii. (1887) 277. - Terr. Washington.

vicina, Phil. in Anal. Univ. Chil. Ixxxv. (1894)

301. - Chili.

Vidali, Phil. l. c. 190. - Chili.

Villanuevae, Phil. l. c. 194.-Chili.

Villaroeli, Phil. l. c. 176. - Chili.

viridis, Phil. l. c. 173, - Chili,

\section{GALANTHE}

$\pi 1^{3}$ a, aurora $X$, Veitch, Man. Orch. Pl. vi (1890) 73. - Hybr, artef

721 a. Stevensii, Hort. ex Will. Orch. Grow. Man, ed. 7 (1894) $141=$ Stevensiana, Regnier.

721 a, trulliformis, King \& Pantling, ex King, in fourn. As. Soc. Beng. IXiv, (1895) II. 337. - Sikkim.

\section{GALGEOLARIA}

722 1. glutinosa, Fr, Meigen... xvii. (1893) 292, 289, nomen; et...

\section{GALLIGONUM}

732 1. minimum, Lipsky, in Mém. Soc. Natural. Kiew, xi. (1891) 19; et. ...

GALLIPRORA

$73^{2}$ I. ixioides... (non ixiodes).

\section{CALLITRICHE}

$7^{1}$ a. Ienisulca, Clavaud, in Act. Soc. Linn. Bord. xliv. $1890(1891)$ p. 43. - Gall. occ.

\section{GALOCHORTUS}

65: a pavonacels, Fernati, in Cout. Bot. Ga\%, xix. (1894) 335. - Am. bor.

\section{CALOPHANES}

742 a. repandus, Benth. Eo Hook. f. ex Drake, IIl. Fl. Ins. Mar. Pacif. (1892) 257 (= Chatacanthus repandus, A. Gray). - Ins. Fiji.

\section{GALOPHYLLUM}

$74^{3}$ a. Soulattri, « Burm. » ex F. Mull. in Bot. Centralbl. xliv. (1891) 29, sphalm. = C. Sonalatti, Burm. $f$.

CALYciosia, A. Gray (Rubiac.). - Ind. Kew, ii. 395

trichocalyx, Drake, Ill. Fl. Ins. Mar. Pacif. (1890) 196 ; et Fl. Polyn. Franc. (1`92) $98(=$ Uragoga trichocalyx, Drake). - Ins. Pacif.

\section{CALYPTRANTHES}

751 1. ferruginea... 602 (non 603)

a. glabrescens, Krug \& Urban, in Bot. Fahrb. xix. (1895) 596. - Cuba.

\section{GAMELINA}

$75^{2}$ 1. rumelica... 1887 (1888) 448 [non xli. (1891) 123]

$75^{3}$ 1. CAMIRIUM, Rumph... (non CAMERIUM)

\section{CAMPANULA}

$76^{1}$ a. crucifolia "Feer » ex Barbey, Karpathos (1895) 118, sphalm. = erucifolia, Feer.

1. Dzaaku, (non Dzaakii).

Mykalaea, Barb. E Major, Lydie, Lycie, Carie (1890) 80, t. 5. - As. Min,

Ursaria X, Bruegg. Mitth. Neue u. Krit. Pflanzen. [Jahresb. Naturf. Ges. Graub.] (1886) 49.- Helv.

Velenovskyi... (non Velenowskyi)...; et in Boehm. Ges. Wiss. 1894 (1895) n. xxix $22 \ldots$

velutina... $1890(1890)$ i. 53 |non 1889 (1890) ii. 54]; et Fl. Bulg. 365 . - Bulg.

CAPETHIA, Britton, in Ann. N. Y. Acad. sci. vi. (1892) $234=$ Anemone. Linn (Ranunc.).

integrifolia, Britton, 1. c. = A. integrifolia Humb. \& Bonp?.

Weddellii, Britton, 1. c. $235=(\mathrm{A}$. integrifolia Humb. \& Bonpl.?). - Peruvia.

\section{CAPITANYA}

771 1, otostegioides... (non ostegioides).

1. rogleoides... [an royleoides ?] (non rogieoides).

\section{CAPSELLA}

$78^{2}$ 1. thracica,... 1893 (1894) n. xxxvii. 11... [non 1893 (1893) 11 ].

\section{CARAGANA}

culgaris, Hort. ex Handl. Trees Kew, Pt i. [Polypet.] (1894) $123=$ arborescens, $\operatorname{Lam}$.

CARDAMINE

791 a. alsophila, Phil, in Anal. Univ. Chil. Ixxxi (18.13) 73 = nemophila, Phil

$79^{2}$ 1. Killiasii ×, Bruegg. in Jahresb. Naturf. Ges. Graub. xxix. 1884-85 (1886) 5. - Helv.

1. Seedlitziana... (non Seidlitziana) Skorpili,... 1889 (1890)... [non (1896)].

CARDUUS

$80^{1}$ a. globifer, Velen. Fl, Bulg. (1891) 300 - - Bulg.

$80^{3}$ a. Zapateri, Reverch. \& Debeatx, in Lucante, Rev. Soc. Franc. Bot. xii. (1895) $354=$ pycnocephalus, Linn.

\section{GAREX}

$80^{3}$ 1. alascana, Boeck. in Bot. Fahrb. vii. (1886) 277. - Alasca.

androgyna, L. H. Bailey, in Proc. Am. Acad. xxii. (1887) 101. - Mexic.

Arnelli, Christ, in Scheutz, Pl. vasc. Feniss. (1888) 177. - Sibiria.

atrovirens, Boeck. Cyp. Nov, i. (1888) 52. Reg. Argent.

baritiana, Porcius, in Anal. Acad. Romanae, Ser. II. xiv. (1892) $285=$ transsilvanica, Schur.

Brenneri, Christ, in Schentr, Pl. vasc. Feniss. (1888) 178. - Sibiria.

brunnescens, Boeck. Cyp. Nov.i. (1888) 44. Reg. Argent.

811 1. contracta... (non eontracta).

\section{GAREX}

$81^{1}$ a. Engelmanni, L. H. Bailey, in Proc. An. Acad. xxii. (1887) 132. - Colorado.

Hallii, L. H. Bailey, l.c.82. - Oreoon.

Hendersoni, L.H.Bailey, l.c. 115. - Oregon, Calif.

$81^{3}$ a. inandrensis, Kihlman, ex Hjelt, in Act. Soc. Fenn. v. (1895) 298. - Eur.

inops, L. H. Bailey, in Proc. Am. Acad. xxii. (1887) 126. - Oregon

invisa, L. H. Bailey, l. c. 82, - Calif

Joosi, L. H. Bailey, l. c. 72. - Louisiana.

$82^{1}$ a. mollissima, Christ, in Scheutz, Pl. vasc. Feniss. (1888) 181. - Sibiria

$82^{2}$ a. nova, L. H. Bailey, in fourn. Bot. xxvi. (1888 322. - Am. bor.

orbelica, Velen. Fl. Bulg. (1891) 575. - Bulg.

Pseudobicolor, Boeck. Cyp. Nov.i. (1888) 44. Reg. Himal.

$82^{3}$ a. scaposa, Hook. f. in Bot. Mag. (1887) t. 6940 - China austr.

Sismani,... 1893 (1894) n. xxxvii, 67... Inon 1893 (1893) 67\%.

S31 1. spissa, L. H. Bailey... et in Proc. Am. Acad. xxii. (1 887$) 70 .-$ Calif.

subalpina, Bruegg. Mitth. neue u. Krit. Pflanzenfam. [Jahresb. Naturf. Ges. Graub. (1886) $121=$ limosa, Linn.

$83^{1}$ 1. subnivalis, Arv-Touv ex Favrat, in Bull. Soc. Bot. Genéve, v. 1888 (1889) 8 ; et...

tibetica, Boeck. Cyp. Nov.i. (1888) 46. - Tibet tricolor,... 1890 (1890) i... [non 1889 (1890) ii.] ultra, L. H. Bailey, in Proc. Am. Acad. xxii. (1887) 83. - Arizona.

83ะ 1. Warmingii... 294 (non 244).

$83^{3}$ a. CARINIANA, Casar. = Couratari, Aubl (Myrt.).

Glaziovii, N. Wille, ex Warm. Lagoa Santa (1892) 427, nomen. - Bras.

GARLINA

$83^{3}$ 1. olympica, Formanek... (1891) 128.

\section{CARLOWRIGHTIA}

$83^{1}$ a. hapalcarpa, Robinson \& Greenm in Proc. Am. Acad. xxix. (1894) 390. - Mexic.

\section{CARPODINUS}

$84^{1}$ d. complicata $K$. Schum... (nomen in loco citato deest)

\section{CARTHAMUS}

$84^{2}$ a. dianius, Coincy, Eclog. alt. (1893) 14, t. 15 (= Cardnncellus dianius, Webb). - Hisp.

gracilis, Celak. in Sitz. Boehm. Ges. Wiss. 1885 (1886) 91 - Oriens.

\section{CASEARIA}

$85^{1}$ 1. riparia... 363 (non 364).

\section{CASSIA}

$85^{2}$ a. Campanae, Phil. in Anal. Univ. Chil. lxxxiv. (1894) 439. - Chili.

Closiana Phil 7. c. 440, - Chili.

confusa, Phil. l. c. 438. - Chili.

eremobia, Phil. l. c. 443. - Chili

goyazensis, Taub. ex Ule, in Cruls, Rapp. Comm. expl. Plat. cent. Brésil (1894) 363; et in Bot. fahrb. xxi. (1895) 435. - Bras.

Huidobriana, Phil, in Anal. Univ. Chil 1xxxiv. (1894) 440. - Chili.

oreades, Phil. l. c. 443 . - Chili.

CASTALIA

$85^{3}$ 1. Gibertii... (non Gilbertii).

\section{GATALPA}

$86^{1}$ a. Catalpa, Karst. Pharm. med. bot. (1882) 927 Sarg. N. Am. Sylva, vi. (1894) 86, t. 288 Sudworth,...

\section{CATHCARTIA}

$86^{3}$ a. lyrata, Cummings of Prain, ex Prain, in fourn As. Soc. Beng. lxiv. (1895) ii. 325. - Silhet. polygonoides, Prain, l. c. 326. - Chumbi. 


\section{GATTLEYA}

$87^{1}$ a. amabilis, Hort. ex Will. Orch. Grow. Man, ed, 7 (1894) 152. - Bras.

armainvillierensis $\times$, Hort. ex Rev. Hortic. lxvii. (1895) 359. - Hybr. artef.

Ashtoniana X. Hort. ex Gard. Chron. (1893) ii. 406. - Hybr. artef.

1. Ballantiniana, Reichb. f... (non Balantinia$n i t$... Will, 1. c. 153. -

a. Boissieri, Hort. ex Will. l.c. 154. - N. Granat. crocata, Reichb. fo in Gard. Chron. (1886) ii. $360=$ labiata, Lindl .

Devoniana X, Hort. ex Will. 1. c. 160. Hybr. artef.

Edithiana, Warner, ex Will. l. c, 161. - Bras. foribunda X, Hort, ex W. Wats, in Gard. and For. viii. (1895) 224. - Hybr. spont. ?

fohnstoniana X, Hort. ex Gard. Chron. (1893) ii, 406. - Hybr. artef.

Lowryana... (non Louryana).

Malouana... (non Maloriana).

Nilsoni X, Hort. Sander, ex Regel, in Gartenfl. xxxviii. (1889) 481. - Bras.

Patrocinii, St-Leger, in Citade de Rio (May 1890), ex Orchid Rev. i. (1893) 343. - Bras.

Sedeniana $\times$, Veitch, ex Will. Orch. Grow. Man. ed. 7 (1894) 161. - Bras.

872 a. venosa $X$, Rolfe, in Orchid Rev。 ii. (1894) 132. - Hybr. artef.

veriflora $\times$, Hort. ex Will. Orch. Grow. Man. ed. 7 (1891) 192. - Hybr. artef.

Wellsiana Y, Hort. ex Gard. Chron. (1893) i. 639. - Hybr. artef.

Wendlandii X. Hort. Veitch. ex Gard. Chron. (1894) i. 44\% - Hybr. artef.

$87^{2}$ a. GAUCANTHUS, Forsk. (Malpigh.). - Ind. Kew. i. 462 .

a. squarrosus, Niedenzu, in Bot. Fahrb. xiv. Beibl. n. 30 (1891) 6, et xiv. (1891) 315 (= Triaspis squarrosa, Radlk.). - Reg. Somal.

CAUTLEYA, Baker = CAUTLEA, Royle.

$87^{3}$ a. Cathcarti Baker, in Hook. f. Fl. Brit. Ind. vi. (1890) 208. - Reg. Himal.

lutea, " Royle » (vide Ind. Kew, in loc.). Reg. Himal

petiolata, Baker, 1. c. 209. - Reg. Himal.

robusta, Baker, 1. c. - Reg. Himal.

spicata, Balser, 1. c. - Reg. Himal.

\section{CAVENDISHIA}

$87^{3}$ a. spectabilis, Bull, Catal. (1889) 7.- Columb.

$87^{3}$ a. GAYAPONIA, Silva Manso (Cucurb.). Ind. Kew. j. 463 .

Almeideana, Sald. E Cogn. ex Cogn. in Bull. Acad. Belg. Sér. III. xiv. (1887) 358. - Bras.

boliviensis, Cogn, in Mem. Torrey Bot. Chub, iii, 3 (1893) 39. - Bolivia.

reticulata, Cogn. in Bull. Acad. Belg. Sér. III. xiv. (1887) 360. - Bras.

Saldanhaei, Cogn .l. c. 361. - Bras.

Schenkii, Cogn.l. c. Sér. III. xvi. (1888) 243. - Bras.

\section{GEANOTHUS}

$87^{3}$ a. Andersoni, Parry, in Proc. Davenp. Acad. sci. v. (1889) 172, - Am. bor.

divergens, Parry, l. c. 173. - Am. bor.

foliosus, Parry, l. c. 172. - Am. bor.

intricatus, Parry, $l, c, 168,-\mathrm{Am}$, bor.

Lemmoni, Parry, l. c. 192. - Am. bor.

$88^{1}$ a. radicans, Hort. ex Handl. Trees Kew, Pt i. [Polypet.] (1894) $73=$ thyrsiflorus, Esinsch.

\section{GEGROPIA}

881 1. Bureauiana.... - Guian. gall.

\section{GEDRELA}

$88^{1}$ a. impari-pinnata, C. DC. in Coult. Bot. Gaz. xix. (1894) 4. - Guatem.

\section{GeLASTRUS}

$88^{1}$ a. vitiensis, Benth. E Hook. f. ex Drake, Fl. Polyn. Franc. $(1892) \cdot 31$ (= Catha vitiesis, A. Gray). - Ins. Fiji.

\section{CELOSIA}

$88^{2}$ 1. Schweinfurthiana... 178 (non 17)

CELSIA

882 a. Bottae, Deflers, Voy, an Yémen (1889) 178. Arabia.

\section{GENTAUREA}

$88^{3}$ a. Aschersoniana $\times$. Vetter, in Bull. Soc, Bot. Genève, v. 1888 (1889) 11. - Helv

Barbeyana X, Vetter. 1. c. - Helv.

1. bovina... (non borina)...; et Fl. Bulg. (1891) 329.

a. candida, Velen. l. c. 315. - Bulg.

cyanocephala, Velen, in Abh.Boehm. Ges. Wiss, vii. Folge, i. (1886) n. 8, 26; et Fl. Bulg. (1891) $312 .-$ Bulg

euxina, ... 1890 (1890) i... non ii.), et Fl. Bulg. (1891) 204

Favrati $\times$, Vetter, in Bull. Soc. Bot. Genève, v. 1888 (1889) 11. - Helv.

gracilenta, Velen.Fl。Bulg. (1891) 312. Bulg.

Gyrspergerae $\times$, Favrat, in Bull. Soc. Vaud. sci. nat. xxv. (1889) 54. - Helv.

891 a. kroumirensis, Coss, in Compt.-rend. Acad, sci. Paris, xcviii. (1884) 468; et Ill. Fl. Atlant. ii. (1893) 66, t. 139. - Reg. Tunet.

inuloides, Willk. Suppl. Prodr. Fl. Hisp. (1893) 96. - Hisp.

Loscosii, Willk.Ill. Fl. Hisp. i. (1885 ?) t. 81 ; et l. c. 92. - Hisp.

Mochrleniana X, Vetter, in Bull. Soc. Bot. Genève, 1888 (1889) 11. - Helv.

Nicolai, Baldacci, in Malpighia, v. (1891) 75. Montenegro.

orbelica, Velen. in Sitz. Boehm. Ges. Wiss. 1890 (1890) i. 5 ; et Fl. Bulg. (1891) 310. - Bulg.

Paui Loscos, ex Willk. Ill . Fl. Hisp, ii, 141. t. 174à ; et Suppl. Prodr. Fl. Hisp.94. - Hisp. Pomeliana, Batt. in Bull. Soc. Bot. Fr. xxxv. (1888) 389; et in Batt. \& Trab. Fl. de l'Algér. [Dicot.] 494; Willk. Suppl. Prodr. Fl. Hisp. (1893) 93. - Afr. bor., Hisp.

razgradensis, Velen. in Abh. Boehm. Ges, Wiss. vii. Folge, i. (1886) n. 8, 25, et Fl. Bulg. (1891) 306. - Bulg

Stribrnyi, Velen. l.c. 325. - Bulg.

tartarea,... et Fl. Bulg. (1891) 318.

Vandasii, Velen, in Sitz. Boehm. Ges. Wiss. 1894 (1895) n, xxix, 18 ; et.

varnensis, Velen. Fl. Bulg. (1891) 313. - Bulg.

\section{CENTRANTHUS}

$89^{2}$ a. aurigeranus $\times$, Giraudias, in Bull. Soc, étud. sci. Angers, xix. 1889 (1890) 107. - Gall. mer.

Gillotii $\times$, Giraudias, I. c. - Gall, mer.

$88^{2}$ a. CENTROMAdiA, Greene, Man. Bot. San Franç. Bay (1894) $196=$ Hemizonia, DC. (Compos.)

Fitchii, Greene, 1. c. $197=$ H. Fitchii, A. Gray. maritima, Greene, 1. c. 196. - Calif.

Parryi, Greene, 1. c. $197=$ H. Parryi, Greene. punkens, Greene, 1. c. $196=\mathrm{H}$. pungens, Torr. rudis, Greene, 1. c. 197. - Calif

\section{GENTRONIA}

$82^{2}$ a. tomentosa, Cogn. in Bull. Aoad. Belg. Sér. III. xiv. (1887) 943. - Ecuad.

\section{GERASTIUM}

$90^{1}$ a. busambarense, Lojac. Fl. Sicula, i. I. (1888) $181=$ arvense, $\operatorname{Linn}$.

Gussonei, Todaro, ex Lojac. l.c. 178. - Sicilia. octandrum, Camus, Cat. pl. France (1888) 46 $\doteq$ quaternellum, Fenzl.

orbelicum,... 1890, 1890) i... (non ii.).

CERASUS

$82^{2}$ a. fruticans, Hort. ex Handl. Trees Kew, Pt i. [Polypet.] (1894) $137=$ P. Chamaecerasus, facq.

myrobalanos, Hort. 1. c. 133 = P. cerasifera, Ehrh.
GERATANTHERA

$90^{\circ}$ a. Beaumetzii... ; et in Ie Naturaliste, Sér. II. xiii. (1891) 277 , fig. 1...

\section{CERATOSANTHES}

$90^{3}$ 1. parviflora... 242 (non 232)

\section{GEREUS}

$91^{1}$ a. Huascha, $A$. Weber, in Monatsain. $f$. Kakteenk (189:3) 151. - Reg. Argent.

pasacana, d.Weber, l. c. 165. - Am. austr.

911 1. Palmeri... (non Plmeri).

GEROPEGIA

$91^{2}$ a. sepium, Deflers, Voy. au Yémen (1889) 167. Arabia.

rupicola, Deflers, l. c. - Arabia.

\section{GHAEROPHYLLUM}

$91^{3} 1$. balcanicum... 1893 (1894) n. xxxvii, 30 [non 1892 (1893) 30

gagausorum, Velen. in Abh, Sitz. Boehm. Ges. vii. Folge, i. (1886) n. 8, 17 ; et.

\section{GHAMAEROPS}

$92^{3}$ a. Kwanwortsek, Hort, ex Illustr. Hortic. (1887) 39 , in syn, = flabelliformis, $L^{\prime} H e^{\prime}$ it

\section{GHAMAESARAGHA}

$93^{1}$ a. crenata, Rydberg. in Mem. Torrey Bot. Club, iv, (1893) 308. - Am, bor. austro-occ,

villosa, Rydberg, l.c. in obs. - Mexic.

\section{CHELIDONIUM}

$93^{2}$ a. Dicranostzgma, Prain, in Journ. As. Soc. Beng, Ixiv. (1895) II. $32 \%=$ Dicranostigma lactucoides, Hook.f.

\section{GHENOPODIUM}

$93^{3}$ 1. laxiflorum... (non latifolium)

$94^{2}$ 1. GHLAMYDAGANTHUS, Lindau,... xvii (1893) 107, [non xviii. (1894) 58 ; et in Engl. \& Prantl,...

euphorbioides, Lindan, $\| l . c c .110$, cum ic.; 343 fig. 37.

$94^{3}$ a. CHLOROCHARIS, Rikli, in Pringsh. Jahrb, xxvii. (1895) $564=$ Eleocharis, R. Br. (Cyper.).

Balanscana, Rikli, 1, c =E. Balansaiana, Boeck. capitata, Rikli, $l_{\text {. }} c_{0}=$ E. capitata, $R . B r$. emarginata, Rikli, 1. c. = E. emarginata Klotzsch.

geniculata, Rikli, 1. $\mathrm{c}_{\bullet}=$ E. geniculata, $R . B r$. palustris, Rikli, $1, c_{0}=\mathrm{E}$. palustris, $R . \mathrm{Br}$ subprolifera, Rikli, 1. c. = E. afflata, Steud. tuberculosa, Rikli, 1. c. $=$ E. tuberculosa, $R . B r$ vivipara, Rikli, 1. C. = E. vivipara, Link.

$94^{3}$ a. CHLOROCYPERUS, Rikli, in Pringsh Jahrb. xxvii。 (1895) $563=$ Cy perus, [Mich.]

abyssinicus, Rikli, 1. c. $563=$ Pycreus flavescens, Berav

aegyptiacus, Rikli, 1. c. $564=$ Cyperus aegyptiacus, Gloxin.

articulatus, Rikli, 1. c. $563=$ C. articulatus, Linn.

Barteri, Rikli, 1. c. = C. pustulatus, Vahl,

cimicinus, Rikli, 1.c. (=Cyperus cimicinus, PresI) $=$ Pycrei sp.

confertus, Rikli, 1. c. $564=$ C. confertus, Sw.

Eragrostis,'Rikli, 1. c. 563 (= Pycrei sp.), Geront, trop.

flavescens, Rikli, 1, c. = Pycreus flavescens, Beaw.

grammicus, Rikli, 1. C. ( $=$ Pycrei sp.).-Chili. intermedius, Rikli, l. c. (= Pycrei sp.). - Eur. Iria, Rikli, 1. c, $564=$ Cyperus Iria, Linn. facanini, Rikli, 1. c. $563=$ C. mutans, Vahl. junciformis, Rikli, 1.c. = C. laevigatus, Linn. latispicatus, Rikli, 1. c. $563=$ Pycreus latispicatus, C. B. Clarke.

megapotamicus, Rikli, 1.c. $563=$ P. megapotamicus, Nees. 
CHIOROCYPERUS :- -

melanostachyus, Rikli, in Pringsh. Jahrb. xxvii. (1895) 564 (= Pycrei sp.).-Am. austr Mundlii, [sic] Rikli, 1. c. $563=$ Pycrens Mundtii, Nees.

milagivicus, Rikli, 1. c. $564=$ P. globosus, Reichto.

pannonicus, Rikli, 1. c. $563=$ Cyperus pannonicus, $f a c q$.

Papynus, Rikli, 1. c. = C. Papyrus, Linn.

patuliflorus, Rikli, 1. $\mathrm{C}_{0}=$ Pycreus albo-marginatus, Nees.

pauper, Rikli, 1. $c_{n}=$ P. pauper, C. B. Clarkc.

polystachyus, Rikli, 1. c. = Cyperus polystachyus, Rottl.

rivularis, Rikli, 1. c. 564 (= Pycrei sp.). Am, bor.

\section{GHRYSANTHEMUM}

$95^{3}$ a coronopifolium, Christ, in Bot. Jahrb. ix. (1887) $146=$ coronopitolium, Masf.

marginatum, N. E. Br. in Kew Bull. (1888) 99 (= Pyrethrum marginatum, Miq.). - Japon. nipponicum, Franch ex Dammane in Wien, Ill. Gart. Zeit, xx. (1895) 11, fig. 1. - Japon.

$97^{1}$ a. GHYSIS, Lind1. (Orchid.) - Ind. Kew, i. undulata, Hort, ex Will. Orch. Grow. Man. ed. 7 (1894) 196. - Hab.?

\section{GICHORIUIM}

$97^{2}$ a. Bottae, Deflers, Voy. au Yémen (1899) 159. Arabia

CINERARIA

973 a. stenophylla, Porcius, in Anal. Acad. Romane, Ser. II. xiv. (1892) 136. - Eur.

\section{GIRRHOPETALUN}

(1)2 a. Peyerianum, Kraenzl, in Bot. Farhrb. xvii. (1893) 485 . - Sumatra.

robustnm, Rolfe, in Orchid Rev. i. (1893) 175 ; et ex Gard. Chron. (1895) i. 771, fig. 116. N. Guin

\section{CIRSIUM}

98: a broriscatum $\times$ Eichenf, in Sitzb, zool--bot Ges. Wien, xliii. (1893) 52. - Austro-Hung.

. horridum, Formanek,... 28 = validum, (1896).

a. Kornhuberi X, Heimerl. in Verh. zool.-bot. Ges. Wien, xxxiv, (1885) 95. - Austr.

$98^{3}$ a. Norrisii, Bicknell. in Malpighia, viii. (1891) 392. - Italia.

Sennholzi $\times$, Eichenf. in Sitzb. zool.-bot. Ges. Wien, xliii. (1893) 53. - Austro-Hung.

1. valentinum...; Willk. Suppl. Prodr. Fl. Hisp. 102 .

Velenovskyi... 1890 (1890) i. 268 [nor 1889 (1890) ii.].

viride, Velen. in Abh. Boehm. Ges. Wiss. vii. Folge, i. (1886) n. 8,$23 ; \ldots$

$98^{3}$ a. CISSAMPELOS, Linn. (Menisp.). - Ind. Kew. ii. 544

natalensis, Szyszyl. Polyp. Rehmann. i. (1887) 11. - Natal.

$100^{1}$ a. CISTUS, [Tourn.] Linn. (Cist.). - Ind. Kew, ii. 547.

apricus, arrigens, elegans, fruticans, humilis, microphyllus, platyphylus, rhodanensis, velutinus, Timb. in Rev. Bot. Soc. Franc, x. (1892) 69-70 = homonyma omnia LEDONIAE = C. salvifolius, Linn.

$101^{1}$ a. GITHAREXYLUM, Mill. (Verben,). Ind. Kew, i. 549 .

Berlandieri, S. Wats, in Proc. Am, Acad, xxvi. (1891) 174. - Mexic.

1001 a. CITRIOBATUS, A. Cunn, (Pittospor.). Ind Kew ii. 550

lancifolia, F. M. Bailey, Dept. Agric. Brisbane, Bot. Bull. vii. (1893) 60. - Austral.
$100^{1}$ a. GITRULLUS, Forsk。 (Cucurb.). - Ind. Kew, i. 550 .

ecirrhosus, Cogn. in Abh. Bot. Ver. Brand. xxx. (1889) 151; et in Bot, fahrb. x. (1888) 270. - Afr. austro-occ. extratrop.

$101^{1}$ a. GITRUS, Linn. (Rutac.), - 1nd. Kew。 ii 551.

inodora, F.M. Bailey, Syn. Quensl. Fl. Third Suppl. (1890) 12. - Austral.

$100^{1}$ a. GLADIUM, 'P. Br. (Cyper.). - Ind. Kew. i. 550 .

angustifolium, Benth. \& Hook. f. ex Drake, Ill Fl. Ins. Mar. Pacif. (1892) 334 (=Vincentia angustifolia, Gaudich.); et F1. Polyn. Franç. (1892) 245. - Ins. Sandvic

Durandoi, Chab. in Bull. Soc. Bot. Fr. xxxvi. (1889) 321. - Algeria.

flexuosum, C. B. Clarke, in Th. Dur. E Schinz, Consp. Fl, Afr. v. 1893 (1895) 665 (= Baumea flexuosa, Boeck.). - Ins. Mascar.

latifolium, Benth, \& Hook, f ex Drake, III. F1. Ins. Mar. Pacif. (1892) 334 (= Vincentia latifolia, Kunth.); et F1. Polyn. Franç. (1892) $244=$ iridifolium, Baker.

lavarum, Cordem. Fl. Ile Réunion. (1895) 133 (= Scirpus lavarum, Poir.). - Ins. Borbon.

Meyenii, Benth, ex Hook. f. ex Drake, Ill. Fl. Ins. Mar. Pacif. (1892) 334 (= Baumea Meyenii, Kunth). - Ins. Sandvic.

101' a. CLADOCOLEA, Van Tiegh. in Bull. Soc Bot. Fr. xlii. (1895) $16 \dot{0}=$ Loranthus Linn

Andrienxii, Van Tiegh. 1. c. 167. - Mexic.

Grahami, Van Tiegh. 1.c. 166. = Loranthus Grahami, Oliver.

Oerstedii, Van Tiegh. 1. c, = L. Oerstedii, Oliver.

tehuacanensis, Van Tiegh. 1. c. = L。 tehuaca* nensis, Oliver.

$100^{1}$ a, CL.ADORAPHIS, Franch, in Bull. Soc. Linn. Paris, i. (1887) $673=$ Eragrostis Host (Gramin.)

Duparquetii, Franch. 1. c. = E. spinosa, Thunb.

$100^{1}$ a. GLADOTHRIX, Nutt. (Amarant.). - Ind. Kew. ii. 552

cryptantha, S. Wats, in Proc. Am. Acad. xxvi. (1891) 125. - Calif

$100^{1}$ a. GLADRASTIS, Rafin. (Legumin.). - Ind. Kew, ii. 552

Tashiroi, Yatabe, in Tokyo Bot. Mag. vi. (1892) 345 t. 10. - Japon.

$100^{1}$ a. CLANDESTINA. Tourn. ex Linn, = Lathraea, Linn. (Orobanch.). squamaria, Legrand, F1. du Berry, éd. 1 (1887) $197=$ L. squamaria, Linn.

$100^{1}$ a. GLAOXYLON, A. Juss. (Euphcrb.). Ind. Kew. i. 552 .

atrovirens, Pax, in Bot. Fahrb. xix. (1894) 85. - Afr. trop.

dolichostachyum, Cordem. Fl. Ile Réunion (1895) 341. - Ins. Borbon.

flaccidum, Pax, in Bot. Fahrb. xix. (1894) 86. - Afr.trop,

hispidum, Pax, l. c. 85. - Kamerun.

insigne, Baill, ex Drake, Ill. Fl. Ins. Mar Pacif. (1892) 291. - Ins. Sandvic.

lasiococcum, Pax, in Bot. Fahrb. xix. (1894) 87. - Afr. trop. or.

Molleri, Pax,, , c. 84, - Ins. S. Thom

Schweinfurthii, Pax, l. c. 86. - Afr. trop.

$100^{1}$ a. CLARIONEA, Lag, = Perezia, Lag. (Compos.)

atacamensis, Phil, in Anal. Mus. nac. Chile, i. (1891) 35; et in Anal. Univ. Chil 1xxxvii. (1894) 304. - Chili.
CLARIONEA

$100^{1}$ a caulescens, Phil, in Anal. Univ, Chil. 1xxxvii. (1894) 301. - Chili.

comosa, Phil. 1. c 304. - Chili

nana, Phil. 1. c. 303. - Chili.

spectabilis, Phil. 1. c. - Chili.

\section{CLEMATIS}

$100^{3}$ a campanulata. Hort. ex Handl. Trees Kew, Pt i. [Polypet.] (1894) 7 = campaniflora, B̈rot. Daveyana, Hort. 1. c. $9=$ heracleaefolia, $D C$ Delavayi... (1886) [non 1885].

$101^{1}$ a. latifolia, Hort. ex Handl. Trees Kew, Pt i. [Polypet,] (1894) 9 = integrifolia, Linn. ovalifolia,... (non ovatifolia).

\section{GLEOMODENDRON}

$101^{2}$ 1. somalense... xiv. (1892) 295 [non (1893) 224]

\section{GLERODENDRON}

$101^{3}$ a, fistulosum. Bower, in Proc. Phil. Soc. Glasgowe xviii. (1887) 323, nomen. - Ceylan.

1. micans... 179 (non 180).

a. Powellii, Benth. of Hook. f. ex Drake, Ill. Fl. Ins. Mar. Pacif. (1892) 261 (= Faradaya Powellii, Seem.). - Ins. Pacif.

1021 a. tricholobum, Guerke, in Bot. Fahrb. xviii (1894) 178. - Zanzib., Reg. Mossamb.

\section{GOCGOLOBA}

$104^{3}$ a. lanceolata, Lindau, in Bot. Fahrb. xvii. (1893) 517 - Bras.

$104^{3}$ a. Riedelii, Lindau, l. c. xiii. (1890) 137. - Bras. $105^{1}$ a. Senaei, Lindau, l. . . xvii. (1893) 51\%. - Bras

\section{GOCGULUS}

$105^{1}$ a carolinzanus, Hort. in Gartenf. xxxv. (1886) 404, sphalm. $=$ carolinus, $D C$

COELOGYNE

$105^{3}$ a. Micholitzii, W. Wats. tn Gard. and For. viii (1895) 144. - Hab. ?

\section{GOINOCHLAMYS}

1061 1. Poggeana... 559 (non 558).

$106^{2}$ a. COLEOBOTRYS, Van Tiegh. in Bull. Soc Bot. Fr. xli. (1894) $542=$ Loranthus, Linn.

alata, Van Tiegh. 1. c. 543. - Borneo. acuminata, Van Tiegh. 1. c. 542. - Java. crassisepala, Van Tiegh. 1.c. - Penins. Mal. heterantha, Van Tiegh. 1. c. - Ind. or.

Lobbii, Van Tiegh. 1. c. - Java.

Macklottiana, Van Tiegh.1. c. - Borneo. raphidophora, Van Tiegh. 1. c. - Java. rubra, Van Tiegh. 1. c. = Loobii, Van Tiegh.o? Zollingeri, Van Tiegh. 1. c. - Java.

GOLOBANTHUS

1071 1. Meigeni, Phil. in Anal. Univ. Chil. 1xxxv. (1894) $322 ;$ et...

\section{COLUTEA}

$107^{3}$ a aurantiaca, Hort, ex Handl. Trees Kew, Pt i. [Polypet.] 1894$)=$ arborescens, $\operatorname{Linn}$ crocea, Hort. 1. c. = arborescens, Linn. purpurea, Hort. 1. c. = cruenta, Ait.

\section{COMBRETUM}

$108^{2}$ 1. Raimbaultii . et in Le Naturaliste, Sér.2, xvi. (I894) 236

COMMELINA

$108^{3}$ a. mensensis, Schweinf. in Bull. Herb. Boiss. ii App. 2 (1891) 57, 106. - Erithrea. ussilensis, Schweinf. l. c. 58, - Arabia.

\section{COMMIPHORA}

$108^{3}$ 1. Guerichiana,... xix. (1894) [non 1890].

\section{GONVOLVULUS}

$109^{2}$ 1. Kilimandschari...; et in Bot. Fakrb. xviii. (1894) 109.

$109^{3}$ a. sandvicensis, Benth. \& Hook. f. ex Drake, Ill. Fl.Ins. Mar. Pacif. (1892) 245 (= Facquemontia sandwicensis, A. Gray). - Ins. Sandvic. 


\section{CONYZA}

1092 a. erythrolaena, Klatt, in fahrb. Hamb. Wiss. Anstalt. x. (1893) 125. - Mexic.

$110^{1}$ 1. COPAIBA, Mill... = COPAIFERA (non COPAICA $\ldots=$ COPACFERA)

\section{COPROSMA}

$110^{2}$ a. Nadeaudiana, Drake, Ill. Fl. Ins. Mar. Pacif (1890) 201; et Fl. Polyn. Franc. (1892) 101. - Ins. Pacif.

$110^{2}$ 1. COPTOSAPELTA... (non COPTO SPELTA

\section{CORALLOCARPUS}

$110^{2}$ a. emetocatharticus, Cogn.ex Th. Dur. \& Pitt. in Bull. Soc. Bot. Belg. xxx, 1891 (1892) 279 (= Doyerea emetocathartica, Grossourdy). Am. trop.

\section{GORDIA}

$110^{3}$ a. Bakeri, Britten, in fourn. Bot. xxxiii. (1895) 88 , in nota (= C. obovata, Baker), - Afr. trop.

marchionica, Drake, Ill, Fl. Ins.'Mar, Pacif (1892) 240; et Fl. Polyn. Franc. (1892) 129 - Ins. Pacif

-bovata, Baker... = Bakeri, Britten.

\section{COREOPSIS}

$111^{1}$ a. cordifolia, Drake, Ill. Fl. Ins, Mar, Pacif. (189) 208 ; et.

dichotoma, Drake, l. c. 209 (= Campylotheca dichotoma, Hillebr.). - Ins. Sandvic.

hawaiensis, Drake, 1. c. $=$ Bidens hawaiensis, A. Gray.

Hillebrandiana, Drake, l.c. (= Campylotheca Remyi, Hillebr.). - Ins. Sandvic.

japonica, Hort. Dammann, ex Wien. Ill. Gartenzeit. Xx. (1895) 438, fig. 41. - Japon.

Jardini, Drake, Inl. Fl. Ins. Mar. Pacif. (1890) $209 ;$ et...

molokaiensis, Drake, l. c. $210(=$ Campy lotheca molokaiensis, Hillebr.). - Ins. Sandvic.

petrophiloides, Robinson of Greenm. in Proc. Am. Acad. xxix. (1894) 3r8, - Mexic

polycephala, Benth. \& Hook, f. ex Drake, Ill. FI. Ins. Mar. Pacif. (1890) 217; et Fl. Polyn. Franç. (1892) $108=$ Bidens polycephala, Sch. Bip.

Remyi, Drake, 1. c. $210=$ B. Remyi, Drake. sandwicensis, Benth. \& Hook. f. ex Drake, 1. $\mathrm{C} .=\mathrm{B}$. sandwicensis, Less.

serrulata, Benth. \& Hook. f. ex Drake, 1. c. = B. serrulata, Sch. Bip.

\section{GORNUS}

$111^{2}$ a. citrina, Hort, ex Handl. Trees Kew, Pt i [Polypet.] (1894) $249=$ C. Amomum, Mill.

erythrocarpa, St Lager, in Cariot, Etud. des fl. éd. 8 (1889) $381=\mathrm{C}$. Mas, Linn.

pumila, Hort. ex Handl. Trees Kew, Pti. [Polypet.] (1894) $251=$ C. Mas, Linn. religiana, Hort. 1. c. = macrophylla, Wall. Spaethii, Hort. 1. c. = alba, Linn.

Theleriana, Hort. 1. c. $251=$ macrophylla Wall

Thelicanis, Lebas, [in Rev. Hortic. (1875) fig. $64 \mid 1$. c. $251=$ macrophylla, Wall.

verrucosa, Hort. 1. c. = circinata, L'Hérit.

\section{GORONILLA}

1112-a. pyrenaica, Mailho, ex Giraudias, in Bull. Soc. sci. Angers, xx. 1890 (1891) $69=$ varia Linn.

rupestris, Miégev, in Bull. Soc. Bot. Fr. xxxviii. (1891) p. xxxiv. = minima, Linn

\section{CORYANTHES}

$111^{3}$ a. Wolfii, Lehmann, in Gard. Chron. (1891) is 483 ; et ex Orchid Rey. i. (1893) 264. Ecuad.

\section{CORYDALIS}

1121 a, integra, Barb. E Major, Samos (1892) 30, t. 1 . - Ins. Samos.

1. slivenensis, Velen, in Sitzb. Boehm. Ges. Wiss. 188 7 (1888) 445 ; et.o

\section{Cosmos}

$112^{2}$ a. spectabilis $X$, Hort. ex Rev. Hortic. lxiv. (1892) 372, fig. 114-15. - Hybr. artef.

\section{COTONEASTER}

1123 a. Davidiand Hort ex Handl Trees Kew, Pti [Polypet.] (1894) $213=$ horizontalis, Decne. eriocarpa, Hort. 1. c. $215=$ tomentosa, Lindl. himalayensis, Hort. 1. c. $213=$ frigida, Wall. Hookeriana, Hort. 1, c. = buxifolia, Wall. montana, Hort. 1. c. $215=$ Simonsii, Baker. nevadensis, Hort. 1. c. = Simonsii, Baker. repens, Hort. 1. c. $213=$ buxifolia, $W$ all. sinensis, Hort. 1. c. = lucida, Schlecht. trillosa, Hort. 1. . . = integerrima, Medic Wheeleri, Hort. 1. c. = buxifolia, Wall.

$113^{1}$ a. COUDENBERGIA, Él. March. = Goemansia, Ei. March. (Aral.)

Warmingii, El. March. ex Warm. Lagoa Santa (1892) 269 , nomen $=$ C. Warmingiana, El. March.

\section{COURSETIA}

$113^{2}$ a. mollis, Robinson \& Greenm. in Proc. Am. Acad. xxix. (1894) 384. - Mexic.

\section{COUSINIA}

$113^{2}$ 1. dichacantha, Lipsky. in Mém. Soc. Natural. Kiew, xi. (1891) $12 ;$ et...

CRACCA

$114^{2}$ a. splendens, Monicot \& Miégev. ex Miégev. in Bull. Soc, Bot. Fr, xxxviii. (1891) p. xxxiii. - Pyren. gall.

\section{CRATAEGUS}

$114^{3}$ a, aemula Hort ex Handl, Trees Kew, Pt i. [Polypet.] (1894) 211 = uniflora, Moench.

apiifolia, Hort. 1. c. $205=$ C. Oxyacantha, Linn.

apiifolia, [Loud.] 1. c. $211=$ viridis, Linn aurea, Hort. 1. c. $209=$ punctata, $F a c q$.

Bruantii, Hort. 1. c. $205=$ C. Oxyacantha, Linn.

californica, Hort. 1. c. 207 = pinnatifida, Bunge.

Destefani X, Lojac. Fl. Sicula, i. II. (1891) 205, 310, t. 18, fig. 2. - Sicilia.

fastigiata, Hort. ex Handl. Trees Kew, Pt i. [Polypet.] (1894) $205=$ C. Oxyacantha, Linn.

Lambertiana, Hort. 1, c. $201=$ melanocarpa, M. Bieb.

linearifolia, Hort. 1. c. $197=$ C. Crus-galli, Linn.

Macnabiana, Hort. 1. c. $199=$ C. Douglasii, Lindl

mespilifolia, Hort. 1. c. $203=$ mollis, Scheele. olivaeformis, Hort. 1. c. $195=\mathrm{C}$. Carrierei, Vauvel.

Pinshow, Hort. 1. c 211 = uniflora, Moench spinosissima, Hort. 1. c. $205=$ C. Oxyacantha, Linn.

splendens, Hort. 1. c. $199=$ C. Crus-galli, Linn.

stipulacea, Hort. 1. c. $197=$ C. Crus-galli, Linn.

tartarica, Hort. 1. c. $207=$ pinnatifida, Bunge.

tortuosa, Hort. 1. c. $203=\mathrm{C}$. Oxyacantha, Linn.

urasina, Hort. 1. c. $203=$ C. Oxyacantha, Linn.

$115^{1}$ a. GREMOCARPON, Boiv ex Baill, in Bull. Soc. Linn. Paris, i. (1879) 192 ; et Hist. des pl. vii. (1880) 399. RUBIACEAE. Boivinianum, Baill.1. c. 399. - Ins. Comor.
1151 1. CREMOCARPUS = GREMOGARPON Boiv. (non Boiss.)

Boivinianus... = C. Boivinianum, Baill. (non Bull.).

\section{GREPIS}

$115^{1}$ 1, balcanica, Velen, in Sitzb. Boehm. Ges. Wiss. 1890 (1890) i. 53 ; et ...

a. Baldaccii, Halácsy...; ; et in Malpighia, viii. (1894) 190, - Eur, or

$115^{2}$ a. glabrata, Porcius, in Anal. Acad. Romana Ser. II. xiv. (1892) 15\% - Eur. austr.

nigra, Velen. in Abh. Boehm. Ges. Wiss, vii. Folge i. (1886) n. 8, 28. - Bulg.

1. orbelica, Velen. in Sitzb. Boehm.Ges. Wiss. $1890(1890)$ i. 52 ; et.

racemosa, St. Lager, in Cariot, Etud, des $\mathrm{fl}$ éd. 8 (1889) $499=$ praemorsa, Tausch.

Stribrnyi, Velen. Fl. Bulg. (1891) 333. Bulg.

\section{GRINUM}

$115^{3}$ a. Doriae, Hort. ex Bull. Soc. Tosc. Ortic. (1894) 19. - Abyss.

grandiflorum $X$, Hort. Delenil, ex Rev. Hortic. lxvi, (1894) 147. - Hybr, artef. Kircape X, [E. O. Orpet], in Gard, and For. viii. (1895) 288. - Hybr. artef. yemense, Deflers, Voy. au Yémen (1889) 209. - Arabia.

\section{CRISTARIA}

$115^{3}$ a. australis, Phil. in Anal. Univ. Chil. Ixxxii (1893) 30\% - Chili.

bipinnatifida, Phil. l. c. 319, - Chili.

Borchersi, Phil. l. c. 316. - Chili. carrizalensis, Phil l, c, 319 - Chili.

1. cyanea, Phil...; et l. c. 312, - Chili. divaricata, Phil...; ; t l. c.312. - Chili.

a. flexuosa, Phil, Verz. Antofag. U. Tarap. (1891) 9. - Chili.

glabrata, Phil. in Anal. Univ. Chil. Ixxxii. (1893) 308 , - Chili.

1. grandidentata, Phil...; et l.c. 318. - Chili

a. grandiflora, Phil. l. c. 311. - Chili

hastata, Phil. l. c. 308. - Chili.

hispida, Phil. l.c. 307. - Chili

humilis, Phil. l. c. 310. - Chili.

inconspicua, $F$, Dhil. ex Phil, $7, c, 309,-$ Chili.

Jarae, Phit. Verz. Antofag. U. Tarap, (1891) 9. - Chili.

Larranagae, Phit. in Anal. Univ. Chil. Ixxxii. (1893) 320. - Chili.

oxyptera, Phil. l.c. 305. - Chili

parvula, Phil. I. c. 317. - Chili

patens, Phil. l.c. 316. - Chili.

pilosa, Phil. l. c. 315. - Chili.

1. ranunculifolia, Phil... et l. c. 314. - Chili. saniculifolia, Phil... et l. c. 313, - Chili.

a. setosa, Phil. l.c. 317. - Chili.

Sundti, Phil. l.c. 310. - Chili.

trifida, Phil. l.c. 321. - Chili.

Vidali, Phil. l. c. 306. - Chili.

\section{GROTALARIA}

$116^{3}$ a. squamigera, Defers, Voy. an Yémen (1889) 126. - Arabia.

\section{GROTON}

$116^{3}$ a. Philippsii, Williams, Catal. (1886) 24. Hab. ?

picturatus $X$, [Hort. Chantrier], ex Éd. André, in Rev. Hortic. 1x. (1888) $423=$ Codiaeum variegatum, Blume.

Russelli. [Hort. Low.] ex Gard. Chron. (1893) ii. 629 ; et in Journ. of Hort. xxvii. 493 fig. 71 = Codiaeum variegatum, Blume.

Thomsoni, Hort. ex Gard. Chron. (1893) i. $461=$ Codiaeum variegatum, Blume

Wigmannii, Williams, Catal. (1886) 24. Hab. ?

CRYPTANTHE

1173. laxiflora... [err. cal.] = Cryptocarya laxiflora, Phil. 


\section{GRYPTOGARYA}

1181 1. Burckiana... (non Burckeana).

a. laxiflora, Phil. in Anal. Univ.Chil. xci. (1895)

$118^{2}$ a. Schwackeana, Mez, in Arb. Bot. Gart. Breslau, i. (1892) 107. - Bras

subcorymbosa, Mez, l. c, 106. - Bras.

IIS ${ }^{3}$ 1. CRYPTOPHRAGMIUM... (non GRYPTOPHRAGMIUM).

\section{GUCUMIS}

$118^{3}$ a. Vilmorini, [Hort.] ex Bull. Soc. Tosc. Ortic, xix. (1894) 115, -- Hab. ?

\section{GURCUMA}

1192 a. Kunstleri, Baker, in Hook. f. Fl. Brit. Ind. vi, (1890) 214 [Kuntsleri]. - Pegu.

Kurzii, King, ox Baker, l. c. 216. - Ins, Andam.

GUSCUTA

1192 a. alpicola, Bruegg. Neue u. Krit. Pflanz. [Jahresb. Naturf. Ges. Graub.] (1886) 45. - Helv.

Sarothamni, Bruegg.1, c. $46=$ C. Epithymum, $D C$

1201 1. GYATHOPUS, Stapf, in Hook. Icon. pl. xxiv. (1895) t. 2395. GRAMINEAE (non CYATHOPSIS Brongin. Ev Gris....).

\section{CYATHULA}

$120^{1}$ a triuncinella, Schinz, in Bot. Fahrb. xxi. (1895) 189. - Madag.

\section{CYCAS}

$120^{1}$ a. Duivenbodei, Hort. ex Cat. Comp. Cont. d'Hortic. (1886) 9. - Ins. Molucc. taiwaniana, Carruth. in fourn. Bot. xxxi. (1893) 2, t. 331. - Ins. Formosa.

Wendlandii, Hort. Sander. Cat. (1895) 32. Madag

\section{GYGLAMEN}

1202 1. Pentelici... xviii. Beibl. n. 44 (1894) 1.

\section{CYCNIUM}

$120^{3}$ 1. cameroonianum, Engl... = Rhamphicarpa Cameroniana, Oliver [non ex loco, sed in honorem cl. Cameron nuncupatus].

\section{GYMBIDIUM}

$120^{3}$ a. armainvilliense $X$. Hort. ex Journ. des Orchid. (1894) 9. - Hybr. artef.

inconspicunm, Wall, ex Hook, $f$ in Ann. Bot. Gard. CaIc. v. I. (1895) $46=$ Saccolabium inconspicuum, Hook. $f$.

nipponicum, Rolfe, in Orchid Rev. iii. (1895) 38 (= Bletia nipponica, Franch. \& Sav.). Japon.

$121^{1}$ 1. Winnianum, Hort, ex Veitch, Man. Orch. Pl ix. (1893). 24 ; et.

\section{CYNOGLOSSUM}

$121^{3}$ a. Bottae, Deflers, Voy. au Y'émen (1889) 173. Arabia.

1. paucisetum Borb... (non punctatum) rotatum, Velen... 1893 (1894) xxxvii. 48 [non (I892) 3].

\section{CYPERUS}

1223 a. holostioma, C. B. Clarke, ex Schweinf. in Bull. Herb. Boiss, ii. App. 2 (1894) 103. Erithrea.

\section{CYPHOSTIGMA}

$123^{3}$ a, exertum Scortech, in Nuov, Giorn. Bot. Ital. xviii. (1886) 310 , t. 13. - Penins. Mal.

\section{CYPRIPEDIUM}

$123^{3}$ a. Adrastus X, Hort. ex Gard. Chron. (1892) i. 343. - Hybr, artef. Aeson X, Hort. ex Gard. Chron. (1893) i. 80 - Hybr. artef.

\section{CYPRIPEDIUM}

$123^{3}$ a. albanense, Hort, ex Veitch, Man. Orch. Pl. iv. (1889) 105, in syn. $=$ C. Sedenii $\times$, Reichb. $f$. Allanianum $X$, Hort, ex Orchid Rev, ii. (1894) 22. - Hybr. artef.

Aphrodite X, [Hort. Veitch], Man. Orch. Pl. iv. (1889) 76. - Hybr. artef.

Appletonianum, Hort. ex The Garden, xliii. (1893) $95=$ Hookerae, Reichb. $f$.

Arthurianum X, Reichb. f. ex Lindenia, iii. (1887) 53, t. 121. - Hybr. artef.

Ashtoni $\times$ Hort. ex Gard. Chron. (1895) ii 721. - Hybr. artef

Ashworthiae X, Hort. ex Will. Orch. Grow. Man. ed. 7 (1894) 232. Hybr. artef.

auroreum X, Reichb. fo in Gard. Chron.

(1887) i. 179. - Hybr. artef.

Calupso $\times$ Hort. ex Will. Orch. Grow. Man. ed. 7 (1894) 238. - Hybr, artef.

$124^{2}$ a. cereus $X$, Hort, ex Will. 1. c. 241. - Hybr. artef.

beechense $X$, Hort ex Gard. Chron. (1894) i. 762. - Hybr, artef

Behrensianum $\times$ Hort Sander, ex Orchid Rev. ii. (1894) 111. - Hybr. artef.

Bolerlaerianum X, [Hort. Pauwels], ex Gard. Chron. (1895) ii. 391. - Hybr, artef.

Bosscherianum X, Hort. ex Gard. Chron. 1892) i. 11, sphalm. $=$ C. Debosscheria . num $\times$, Desbois.

Bryani $X$, Hort. ex Gard. Chron. (1892) ii. 138. - Hybr. artef,

Burtonii X, Hort. ex Gard. Chron. (1895) i. 80u. - Hybr, artef.

Carnusianum X, Hort. Veitch. ex Gard. Chron. (1895) ii. 102. - Hybr: artef.

corbeillense $X$. Ch. Maron, in Rev. Hortic. lxv. (1893) 250. - Hybr, artef.

Corndeanii X, Hort. ex Gard. Chron. (1895) i. 627 . - Hybr. artef.

Constableanum X, Hort. ex The Garden, xliii. (1893) 75. - Hybr. artef

Creon X, Hort. ex Will. 1. c. 249. - Hybr. artef.

Diana $\times$, Hort. ex Will. 1. c. 253. - Hybr. artef.

Daviesianum $\times$, Hort. ex Gard. Chron. (1895) i. 82. - Hybr. artef

Debosscherianm $X$, Desbois, in Rev. Hort. Belg. xviii. (1892) 6. - Hybr. artef.

delicatulum $x$, Reichb. $f$, in Gard, Chron. (1887) ii. 55\%. - Hybr. artef.

Donatianum X, [Hort. Sander.] ex Bull. Soc. Tosc. Ortic. xx. (1895) 79. - Hybr. artef. Edwardi $\times$. Hort. ex Gard. Chron. (1893) ii. 132. - Hybr. artef.

excellens $\times$ Hort, ex Orchid Rev, ii. (1894) 275. - Hybr. artef.

festum X, Hort. ex The Garden, xli. (1892) 26. - Hybr. artef.

Fordianum $\times$, Hort. Sander, ex Gard. Chron. (1895) i. 210. - Hybr, artef.

Forelerianum $X$, Hort. Sander. ex Gard. Chron. (1895) i. 337. - Hybr artef.

gloriosum X, Hort. ex Orchid Rev. ii. (1894) 365. - Hybr. artef.

Goweri X, Hort. ex Gard. Chron. (1895) i. 529. - Hybr. artef.

Greyanum X, Hort. ex Gard. Chron. (1893) i. 396. - Hybr, artef.

Huvellianum X. [R. M. Gray] in Orchid Rev, iii. (1895) 15. - Hybr. artef

$124^{3}$ 1. Huybrechtianum,... (non Huybrechtsianum).

Fohnsonianum $\times$, Hort. Sander. ox Gard. Chron. (1892) ii. 744; et in Journ. Hort. Soc. xxvi. 171, fig. 30 . - Hybr. artef.

Laforcadei $X$, Hort. Bauer, ex Godefroy, L'Orchidophile (1886) 122, 181 cum ic.; Veitch, Man. Orch. Pl. iv. (1889) 87. Hybr, artef.

$125^{1}$ a. Leeanum $X$. Hort. ex Will. et Warn, Orchid Alb. v. (1886) t. 223 ; et ex Lindenia, iii. (1887) t. 125. - Hybr, artef.

Macfarlanei X, Kraenzl. in Gard. Chron. (1891) ii. 300; et in Gartenfl. xl. (1891) 534. - Hybr. artef.
CYPRIPEDIUT

$125^{1}$ a. Ledouxiae X, Hort. ex Orchid Rev. i. (1893) 117. - Hybr. artef.

Leopoldianum $\times$, Hort. ex Gard. Chron. (1895) i. 333. - Hybr. artef.

leucorrhodum X, Reichb $f$ in Journ. of Hort. xii. (1886) 129, fig. 121; Orchid Rev. i. (1893) 169, fig. 11; Will. Orch Grow. Man. ed. 7 (1894) 27\%. - Hybr artef.

loochristianum X. Ch. De Bosschere, in Gard. Chron. (1895) i. 100. - Hybr. artef.

Louisae X. Hort, ex Orchid Rev. iii. (1895) 50. - Hybr. artef

Lynchianun $X$, Hort. Sander. ex Gard. Chron. (1893) ii. 692 - Hybr. artef.

macrochilum X. O'Brien, in Gard. Chron. (1891) 343, fig. 40; Will. Orch. Grow. Man. ed.7'(1894) 2\%9. - Hybr. artef

Masonii メ, Hort. ex Gard. Chron. (1895) i 800. - Hybr. Artef

1. Massaianum... (non Massainum)

a. Mauriceanum X, Ch. De Bosschere, in Orchid Rev, i (1893) 118, - Hybr, artef.

Millmani X, Hort. ex Gard. Chron. (1895) i. 800. - Hybr. artef.

Moensii X, Hort. ex Orchid Rev. i. (1893) 98 ; et ii. (1894) 335 (= C. memoria-Moensii Hort.). - Hybr artef.

Morganae Y, Reichb. f, in Gard. Chron (1886) i1. 243; in Illustr. Hortic. (1887) t. 5 ; et in Orchid Alb. vii. (1888) t. 313. $\mathrm{Hybr}$. artef.

Nandi X, Hort. ex Gard. Chron. (1894) ii. 310. - Hybr, artef.

$125^{2}$ a. Orestes $\times$. Veitch, Man, Orch. P1. iv. (1889) 94; Will. Orch. Grow. Man. ed. 7 (1894) 288. - Hybr. artef.

Paulii X. Hurt. ex Orchid Rev. i. (1893) 147. - Hybr. artef.

pendulum X. Hort, ex Gard. Chron. (1895) ii. 192, - Hybr, artef.

platycolor $\times$, Hort. ex Gard. Chron. (1895) ii. 655. - Hybr. artef.

Poyntzianum X, O'Brien, in Gard. Chron. 1894) i. 36; et ex Orchid Rev. ii. (1894) 54. - Hybr. spont.

refulgens $X$. Hort. Ingram. ex Gard. Chron. (1895) i. 210, 338. - Hybr. artef.

Rossianum X, Hort. ex Orchid Rev。 iii (1895) 359. - Hybr. artef.

Sallierii, Godefroy, Les Cypripéd. Part. I (1888), Will. Orch. Grow. Man. ed. 7 (1894) 297; Gard. and For. ii. (1893) 117 [Sallieri]. - Burma

signatum X, Bull, Catal. (1895) 7. - Hybr. artef.

splendens $X$. Hort. ex Lindenia, ii. (1886) t. 69 . - Hybr, artef.

suffusum $X$, Hort. ex Gard. Chron. (1895) i. 210. - Hybr. artef

Thayerianum $X$, Hort. Sander, ex Gard. Chron. (1893) ii. 192. - Hybr. artef

Tryonianum $\times$, Hort. Tate, ex Gard. Chron. (1893) ii. 134. - Hybr, artef.

Uihleinianum $x$, Hort. ex Sander, Catal. (1895) 10 - Hybr. artef.

Umlauftianum $\times$, [Hort. Sander.] ex Gard. Chron. (1893) ii. 70. - Hybr, artef.

Vannerae $X$, Hort, ex Gard. Chron. (1895) i. 402 . - Hybr. artef.

Vigerianum $X$, Hort. Mantin. ex Rev. Hortic. lxvii. (1895) 359 ; et ex Gard. Chron. (1895) ii. 100. - Hybr, artef.

Van Molianum $X$. Hort. Linden, ex Gard. Chron. (1892) i. 502. - Hybr. artef.

Wallaertianum $\times$, Hort, ex Gard. Chron. (1895) ii. 655. - Hybr. artef.

$125^{3}$ a. Wallisii, Will. Orch. Grow. Man.ed. 6 (1885) 261 ; et ed. 7 (1894) 313; in Lindenia, iil. (1887) 73, t. 181; Orchid Alb. viii. (1889) t. 380 . - Ecuad.

warnhamiense $X$, Hort. ex Gard, Chron. (1895) ii. 248. - Hybr. artef.

Watsoniamm $\times$ Hort. Sander, ex Orchid Rev.i. (1893) 244. - Hybr. artef. 


\section{GYPRIPEDIUM}

$125^{3}$ a. Whitelyanum $\times$, Hort. ex Gard. Chron. (1895) ii. 307. - Hybr. artef.

Wiganianum $\times$, Hort. ex Orchid Rev. ii. (1894) 142. - Hybr. artef

\section{GYRTANDRA}

$126^{1}$ a. glauca, Drake, Ill. Fl. Ins. Mar. Pacif. (1892) 253. - Ins. Sandvic.

Vairiae, Lrake, l. c. (1889) 87, 25 i, t. 44; et Fl. Polyn. Franc. (1892) 146. - Ins. Tahit. Vescoi, Drake, l. c. 85,287 , t. 43 . - Ins. Tahit.

vestita, Drake. l. c. 94, 287, t. 48 ; et Fl. Polyn. Franc. (1892) 146. - Ins. Tahit.

CYRTANTHUS

$125^{1}$ a. O'Brieni, Baker, in Gard. Chron. (1894) i. '716. - Afr. austr.

\section{CYTISUS}

$126^{2}$ a. agnipilus, Velen. Fl. Bulg. (1891) 643,-Bulg. Carlieri, Hort, ex Handl. Trees Kew, Pt i. [Polypet.] (1894) 107 = Laburnum anagyroides, Medic.

a. caucasicus, Hort. 1, c, 113 = biflorus, L'Hérit.

1. danubialis... 1890 (1890) i. ... [non (1890) ii.] ganipilus... [err. cal. dele et lege : agnipilus] (conf. supra)

$126^{3}$ medicaginoides, Hort. I. c. $=$ biflorus, L'Hérit. a. quinquefolius, Hort. 1. c. $117=$ sessilifolius, Linn.

\section{D}

1271 a. DACTYLIOPHORA .. (nON DACTYLOPHORA).

DALEA

1272 1. unifoliata... (non unifoliolata)

\section{DAPHNE}

$127^{\circ}$ a. arbuscula, Celak. in Sit\%. Boehm. Ges. Wiss. $1890(1890)$ i. 215. - Hung.

\section{DAPHNOPSIS}

1281 Schwackeana, Taub. in Bot. Fahrb. xii. Beibl. n. 27 (1890) 6 (non 61); et xv. Beibl. n. 38 (1893) 18 (non 8).

Sellowiana, Taub. l, c. xii. Beibl. n. 27 (1890) 7 (non xv...).

sessiliflora, Griseb. ex Taub. l.c. 8 (non xv...).

\section{DAUGUS}

1281 a. drepanensis, Tod. ex Lojac. Fl. Sicula, i. II. (1891) 298. - Sicilia.

\section{DELPHINIUIN}

1292 1. iliense, $H u t h, \ldots 402$ (non 462).

\section{DENDROBIUM}

1293 1. Augustat-Victoriae, Kraenzl... = veratrifolium, Lind'.

burfordiense $X$, Hort. Lawrence, ex Gard. Chron. (1592) ii. 744. - Hybr. artef.

cheltenhamense $X$, Hort. ex The Garden, xliii. (1893) 389. - Hybr. artef.

chlorostele $X$, Reichb. f. in Gard. Chron. (1887) i. 477. - Hybr. artef.

chrysodiscus, Reichb. f. 1. c. (1887) i. 414 ; et... - Hybr. artef.

chrysolabrum... (non chrysolabium).

Cogniauxianum... 281 (non 280).

Donnesiae $\times$, Hort. ex Gard. Chron. (1895) i. 402 ; et ex The Garden (1895) 222, t. 1032, fig. 1. - Hybr. artef.

dulce X, Hort. ex Gard. Chron. (1892) i. 214. - Hybr. artef.

Edithae $\times$. Hort. ex Gard. Chron. (1895) i. 337. - Hybr. artef.

\section{DENDROBIUM}

1293 1. Eriae, F. Muell. Sec. Cens. Austral. Pl. (1889) 186 (= D. eriacoides, F. M. Bailey)。 Austral.

1301 1. galliceanum, Linden, in Lindenia, vi。(1890) 5, t. 241; Will. Orch. Crow. Man. ed.' 1894) 340. - Burma.

Gemma X. Hort. ex Orchid Rev. iii. (1895) 73. - Hybr. artef.

$13 C^{2}$ a. Jofftii... [conf. Tofftii].

Imperatrix, Kraenzl. in Reichenbachia, Fasc, xii. (1895) 11, t. 95. - As. trop.

a. Funo X, Hort. ex Journ. of Hort. xx. (1890) 85, fig. 13; Will.1. c. 344, cum xylogr. Hybr. artef.

utwycheanum $X$, Hort. ex Orchid Rev, ii. (1894) 202. - Hybr. artef.

1302 1. Mettkeanum... (non Meltkeanum).

a. Murrayi $\times$, Hort, ex Orchid. Rev。 iii. (1895) 166. - Hybr. artef

pallens $x$. Hort. Lawrence, ex Will. Orch. Grow. Man. ed. 7 (1894) 354. - Hybr artef

pauciflorum, King \& Pantling, ex King, in fourn. As. Soc. Beng. 1xiv. (1895) II. 332. Sikkim.

porphyrogastrum $\times$, Veitch, Man. Orch. P1 iij. (1888) 90. - Hybr. artef.

$130^{3}$ 1. speciosissimum, Rolfe, in Orchid Rev. iii. Ixvis. (1895) 119, 140; et ex Rev. Hortic. (1895) 415. - Borneo.

Roeblingianum $\times$, Hort. ex Orchid Rev, i. (1893) 211. - Hybr. artef.

Tofftii, F.M. Bailey, Syn. Queensl. Fl. Third Suppl. (1890) 71. - Austral.

Vanneriamum $\times$, Reichb, $f$ in Gard. Chron. (1887) i. 72, - Hybr. artef.

Warburgianum... 281 (non 280).

xanthocentrum $X$, Hort. ex Gard. Chron (1890) i. 88 ; et $(1895)$ i. 82 。 - Hybr artef.

\section{DERRIS}

$131^{2}$ a. polyphylla, Koerd. \& Valet. Boomsoort. van Java, ii. (1895) 89 = Brachypterum poly phyllum, Miq.

\section{DESGHAMPSIA}

$131^{3}$ a. rhenana, Gremli, Excurs, Fl. Schweiz, ed 6 (1889) 451 = caespitosa, Beauv

\section{DEUTZIA}

$132^{2}$ a. californica, Hort. ex Handl. Trees Kew, Pti [Polypet.] (1894) $223=$ crenata, Sieb. \& Zucc.

1312 1. discolor, Maxim...xxxii. (1890) $487=$ hypoleuca, Maxim.

Godohokeri, Hort. ex Handl. Trees Kew, Pt i. [Polypet.] (1894) 225 = Philadelphus hirsutus, Nutt.

a. hypoleuca, Maxim. Dec, pl. Asiat. viii. (1893)

1322 a. japonica, Japon, [Polypet.] (1894) $227=$ Philadelphus Satsumi, Sieb.

pulchella, Hort. 1. c. = P. Satsumi, Sieb.

sanguinea, Hort. 1. c. $225=\mathrm{P}$. grandiflorus, Willd.

\section{DEYEUXIA}

$132^{2}$ a. Royleana, Trim. Cat. Pl. Ceyl. (1885) $108=\mathrm{Ca}$ lamagrostis pilosula, Hook.f. (Suppl. II.).

\section{DIANTHUS}

132: a, aeolicus, Lojac, Fl. Sicula, i. I. (1888) 163. Sicilia.

brachycarpus, Velen. in Abh. Boehm. Ges. Wiss, vii. Folge, I. (1886) 9. - Bulg.

brivatensis $X$, Blanchard, in Le Jardin (1892 174 . - Hybr. artef.

hermaeensis, Coss. Ill. Fl. Atlant. i. (1890) 129, t. 76. - Reg. Tunet

$132^{1}$ a. microcheilus, Williams, in Oest. Bot. Zeitschr. xli. $(1891) 176=$ carpathicus, Borb.

1. Freynii... 1890 (1890) i... [non 1889 (1890) ii....
DIANTHUS

1321 1. Nanteuilii, Burnat... (non Montenilii)... et Malinv. in Bull. Soc. Bot. Fr. xl. (1893) p. 248.

Pancicii, Velen, in Abh, Boehm. Ges. Wiss, vii. Folge, i. (1886) n. 8, 9. - Bulg.

quadrangulus... 1892 (1893) 372... (non 1892 (1893)

a. rumelicus, Velen. in Sit\%. Boehm. Ges. Wiss. 1890 (1890) i, 41 ; et.

DIAPEDIUM, Koen, = Dicliptera, Juss, Acanth.

1332 a. aciminatum, assurgens, baphacum, Beddomei, brachiatum, brasiliense, canescens, capense, caracasanum, ciliare, clavatum, clinopodium, confine, congeshum, cuneatum, effusum, erianthum, Forsterlanum, glabrum, Haenkeamum, heterostegium, Hookerianum, hyalinum. inter. heterostegium, Hookerianum, hyalinum, interruptum, jaranicum, Kurzii, laevigatum, Leonotis, maculatum, mada ascariense, Monitzianum mucronifolinn, multifiorum, ovent, pedun culare, peruvianum, pilosum, cumbens, propinquum, reptans, resupinatum scabrim, sericeum, sexangulare, sparsittorum, speciosum, spicatum, squarrosum, tomentosum trifurcatum, Treedianum, unguiculatum, Kuntze, Rev. Gen. (1891) $484-85=$ homo. nyma omnia Diclipterae.

apiculatum, Kuntze, 1. c. $485=$ Rungia apiculata, Bedd.

Benthamii, Kuntze, 1. c. = R. chinensis, Benth.

Brandisi, Kuntze, 1. c. $484=$ R. Brandisii, C. B. Clarke.

Clarkii, Kuntze, 1. C. $485=$ R. Beddomei C. B. Clarke.

coeruleum, Kuntze, 1. c. $484=$ Dicliptera pubescens, fuss.

crenatum, Kuntze, 1. c. $485=$ Rungia crenata, T. Anders.

cuspidatum, Kuntze, 1. c. $484=$ Dicliptera micranthes, Nees.

diversiforme, Kuntze, 1. c. $485=$ Rungia diversiformis, Nees.

elegans, Kuntze, 1. c. $=$ R. elegans, Dal\%. \& Gibs.

grande, Kuntze, 1, c. $=\mathrm{R}$. grandis, $T$. Anders.

himalayense, Kuntze, 1. $\mathrm{c}_{0}=\mathrm{R}$. himalayensis, C. B. Clarke.

khasianum, Kuntze, 1. c. = R. khasiana, T. Anders.

laetum, Kuntze, 1. c。= R. laeta, C. B. Clarke. latebrosum, Kuntze, 1. c. $484=$ Dicliptera parvibracteata, Nees.

latius, Kuntze, 1. co = Rungia latior, Nees.

linifolium, Kuntze, 1. $\mathrm{c}_{2}=\mathrm{R}$. linifolia, Nees.

longifolium, Kuntze, 1. c. = R. longifolia, Nees.

Mastersii, Kuntze, 1. c. $=$ R. Mastersii, $T$. Anders.

pectinatum, Kuntze, 1. c. = R. parviflora, Nees.

pubinervium, Kuntze, 1. c. $485=$ R. pubinervia, $T$. Anders.

repens, Kuntze, 1. c. $485=$ R. repens, Nees. retortum, Kuntze, 1. c。 = Dicliptera parvibracteata, Ners.

sisparense, Kuntze, 1. c. = Rungia sisparensis, T. Anders.

stoloniferum, Kuntze, l. c. $=\mathrm{R}$. stolonifera, C. B. Clarke.

thlaspiodes, Kuntze, 1. $c_{0}=$ Dicliptera thlaspioides, Nees.

umbellatum, Kuntze, 1. c. $=$ D. micranthes,

verticillare, Kuntze, 1. c。= Hypoestes verticillaris, $R, B r$.

verticillatum, Kuntze, 1. c. $978=$ Dicliptera micranthes, Nees.

Wightianum, Kuntze, 1. c. $485=$ Rungia Wightiana, Nees.

DIGHAELIA

$134^{3}$ 1, elongata... (1894) 35 (non 1884). 
$135^{\circ}$ a DICHOSTYLIS, Rikli, in Pringsh. Jahrb. xxvii (1895) $565=$ Scirpus, Tourn. (Cyperac.).

aristata, Rikli, 1. c. = Cyperus aristatus, Rottb.

hamulosa, Rikli, 1. c. = Scirpus hamulosus, Ster.

1352 a. Micheliana, Rikli, 1. c. = S. Michelianus, Linn.

nitens, Rikli, 1. C. = Rynchospora nitens. A. Gray.

patens, Rikli, 1. c. $=$ Pycreus nitens, Nees

pygmaea, Rikli, 1. c. = Eleocharis Chaetaria, Roem. E. Schult.

\section{DIGLIPTERA}

1352 1. Marlothii... x. (1888) 266 [non (1889) 265].

$135^{3}$ usambarica, ... 47 (non 46 ).

\section{DIGRAEA}

$135^{3}$ a. hamatr, Rolfe, in Mem. Torrey Bot. Chub, iv. 2 (1895) 264. - Boliv.

DIGRANOLEPIS

$135^{3}$ 1. Soyauxii,... vii. (1886) (non 1885).

DIGTYOSPERMA

$136^{1}$ a. fibrosum, C. H. Wright, in Kew Bull. (1894) 35s. - Madag.

136 1. DiDYMiA... = Mariscus, Vahl (Cyper.). DIGITARIA

$136^{3}$ a. vaginata. Magnier, ex Debeaux, in Lucante, Rev, Soc, Franc. Bot, xii. (1895) $303=$ Panicum vaginatum, Sw.

\section{DIGLOSSOPHYLLUMI}

$136^{3}$ a, serrulatum, Wendl, ex Bull. Soc. Tosc. Ortic. xiv. (1889) $337=$ Serenoa serrulata, Hook.f.

\section{DILLENIA}

$136^{3}$ 1. mattanensis... (non mattadensis).

meliosmaefolia, Pierre, ex Gilg, in Engl。 et Prantl, Natïrl. Pflanzenfam. iii. 6 (1893) 123 = meliosmaefolia, Hook. $f$.

membranitolia... (1886) (non 1887),

\section{DINEBRA}

1371 a. guineensis, Franch, in Bull. Soc, hist. nat. Autun, viii. (1895) 376. - Afr. trop. occ.

\section{DIOSMIA}

$137^{2}$ a. Wendlandi, Carriere, in Rev. Hortic. lxiv. 1892) 155. - Afr. austr.

\section{DIPLADENIA}

$138^{3}$ a. carissima, T. Moore, ex Flor. and Pomol. (1869) 169. t. $502=$ Martiana, A. DC.

\section{DIPLOTAXIS}

$139^{2}$ a. maritima, Rouy, Excurs. bot. Espagne, iii. 33; Willk. Suppl. Prodr. Fl. Hisp. (1893) 309. - Hisp.

\section{DISA}

$142^{2}$ a. nervosa, Hort. Kew, ex Gard. Chron. (1894) ii. 308, fig. 41. - Natal.

\section{DISCHISTOCALYX}

$140^{2}$ a. pubescens, Lindau, ex Engl. in Goetzen, Durch Afrika, Append. (1895) 37\%, 382. - Congo or.

\section{DISTERIGMA}

$141^{2}$ I. cuspidatum... xi. (1889) 210 [non (1896) 220]. dendrophilum... 1. c.

$142^{2}$ 1. epacridifolium... 1. c

\section{DONAX}

1423 1. congeusis, ... Xv. (1892) 439.

\section{DODEGATHEON}

$111^{3}$ a. Lemoinei $X$, Hort. ex Wien. Ill. Gart.-Zeit. xiv. (1889) $199=$ D. Meadia, Linn。

\section{DORATOXYLUM}

$142^{2}$ a, apetalum, Radik. in Th. Dur. Ind. Gen. Phan. (1888) $81=$ diversifolium, Benth. \& Hook. $f$.

\section{DORSTENIA}

$143^{1}$ 1. caulescens... xx. (1894) 144

\section{DORYGNIUM}

143 a. diffusum, Fanka, in Magyar Növen. Lapok, x. (1886) 14\%. - Hung.

\section{DRABA}

$143^{3}$ a. cauquenensis, Phil. in Anal. Univ. Chil. Ixxxi (1893) 330. 一 Chili. depilis, Phil. l. c. 331. - Chili.

pectinata, A. Kern. [ubi?] ex Kolb, Alpenpflanzen (1890) 109. - Tirol.

pusilla, F. Phil. ex Phil. in Anal. Univ. Chil. Ixxxi. (1893) 329. - Chili.

1. Saffordi,...; et in Anal. Univ. Chil. 1xxxi. (1893) 331 .

\section{DRACAENA}

$144^{3}$ a. Hibberdii $X$, [Hort. Will.] Flor. Mag. (1876) t. 201. - Hybr. artef

famesii. Hort. ex Gard. Chron. (1893) ii. 629 $=$ Cordyline terminalis.

\section{DURIO}

$146^{1}$ a. Lowianus, Scortech. ex King, in fourn. As. Soc. Beng., lx. (1891) II. 51. - Penins. Mal.

1. testudinarum... (non testudinarius).

Wrayii, King, in fourn. As. Soc. Beng. 1x. (1891) II. 5\%, - Perak.

DUVAUA

$146^{1}$ a. patagonica, Phil. in Ana1. Univ. Chil. 1xxxiv. (1893) 9. - Patag.

\section{DYSOPHYLLA}

$14^{71}$ a. ianthina, Maxim. ex Kanitz, Növenyt. gyujtesek Grof. Széchenyi (1891) $46=$ Pogostemon ianthina, Kanitz.

1. porophylloides... A. Gray (non A. Grag).

\section{E}

\section{EARINA}

1471 1. samoensium,... (non samoensiana).

1471 a. filiformis, Vasey, in Coult. Bot. Gaz.xi. (1886) 117. - Am. bor

\section{EBENUS}

1471 a. Boissieri, Barb. in Bull. Soc. Vaud. sci.nat. xxi. (1885) 221 ; et Lydie, Lycie, Carie (1890 60 t.2. - As. Min.

\section{ECHINARIA}

$149^{2}$ a. spicata, Debeaux, in Rev. de Bot. viii. (1890) 266. - Sicilia.

\section{EGHINOCACTUS}

$149^{2}$ a. Beouini, K. Schum in Monatsschr. f. Kakteenk. (1895) 44. - Mexic

crassihamatus, A. Weber, in Bois, Dict. Hortic. i. (1895 ?) 468. - Mexic

durangensis, Runge, in Hamb. Gart. und Blumenzeit. xlvi. (1890) 231. - Mexic.

Gevardi, A. Weber, in Bois, Dict. Hortic. i. (1895 ?)) $468=$ haematacanthus, Monv.

haematacanthus, Monv. ex A.Weber, l. c. Mexic.

heterochromus, A. Weber, l.c. - Mexic.

Joadii, Hook. f. in Bot. Mag. (1886) t. 6867 . - Uruouay.

Mathsonii, Berge, in Monatsschr. f. Kakteenk. (1893) 45. - Mexic.

phymatothelos, Poselg. in Foerst.-Ruempl Handb. d. Kakteenk. (1886) 602. - Hab.

Saussieri, A. Weber, in Bois, Dict. Hortic. i. (1895?) 468. - Mexic.

Schickendantzii, A. Weber, l. c. 470. - Reg. Argent
ECHINOCACTUS

$149^{2}$ a subniger, Poselg, ex Foerst,-Ruempl. Handb. d. Kakiteenk. (1886) 588. - Mexic.

texensis, Hopfer, ex Regel, in Gartenfl. xxxvii. (1888) 633, t. 1286. - Texas.

ECHINOCEREUS

a. conplomeratus, Mathsson, in Gartenfl. xxxix. (1890) 465. - Mexic.

dubius, Engelm. ex Ruempl. in Foerst.Ruempl. Handb. d. Kakteenk, ed, 2 (1886) 787 = Cereus dubius, Engelm.

glycimorphus, Foerst. in Foerst.-Ruempl. 1. c. $800 .-\mathrm{Hab}$.

mojavensis, Engelm. ex Ruempl. 1. c. $803=$ Cereus mojavensis, Engelm. \& Bigel.

papillosus, Linke, in Foerst.-Ruempl. 1. c. 783. - Нab. ?

paucispinus, Engelm. ex Ruempl. 1. c. $794=$ Cereus paucispinus, Engelm \& Bigel.

Roetteri, Engelm. ex Ruempl. 1. c. $829=$ C. Roetteri, Engelm.

stramineus, Engelm. ex Ruempl. 1. c. $797=$ C. stramineus, Engelm.

twberosus, Poselg. ex Foerst.-Ruempl. 1. c. 783. - Am. bor

\section{EGHINOPS}

$149^{3}$ a byzantinus, Formanek, in Verh. naturf. Ver. Brinn. xxix. 1890 (1891) 129. - Oriens.

1501. a. Raddeanus, Somm \& Levier, in Nuov, Giorn. bnt. Ital. Ser. II. ii. (1895) 90. - Reg. Cauc.

$150^{1}$ 1. thracius... Ges. Wiss. 1890 (1890) i... [non thracicus... Ges. Wiss. (1890) ii.].

\section{ECHITES}

$150^{2}$ a. Sanctae-Crucis, S. Moore, in Trans. Linn. Soc. Ser. II. iv. (1895) 396. - Bras.

1502 a. EELDEA, Th. Dur. Ind. Gen. Phan. (1888) 543 = Candollea, Labill, prop, $M A$ GNOLIACEAE.

\section{EHRHARTA}

$150^{3}$ a. Godefroyi, C. Cordem. in F. Cordem. Fl. Ile Réunion (1895) 123. - Ins. Borbon. penicillata, C. Cordem. l. c. - Ins, Borbon.

EHRETIA

150\% a, Bakeri, Baker, in foumn. Bot. xxxiii. (1895) 88 , in not. - Afr. trop.

$150^{3}$ a. microphylla, Baker, [non Wall.], in Kew Bull. (1894) 29. - Afr. trop. or.

\section{ELAEOCARPUS}

$151^{1}$ a. Hulletii, King, in fourn. As. Soc. Beng. 1x. (1891) ii. 132. - Penins. Mal.

Kunstleri, King, l. c. - Perak.

Mastersii, King, l. c. 139. - Penins. MaI punctatus, King, l. c. - Perak.

salicifollus, King, l. c. 125. - Penins. Mal.

Scortechinit, King, l. c. 124. - Penins. Mal. Wrayi, King, l. c. - Perak.

\section{ELATOSTEMA}

$151^{2}$ a ciliatum Hook, f. ex C. B. Clarke, in fourn. Linn. Soc. xxv. (1889) 67, nomen; et 39 Hook. f. Fl. Brit. Ind. v. 574 (sp. dub.). ind. or

Clarkei, Hook. f. $l l . c c .67$; et 369. - Ind. or.

\section{EIFUTHEROSPERMUM}

$151^{3} \mathrm{a}$. chrysanthum, Somm. \& Levier, in Bull. Soc Bot. Ital. (1895) 43; et in Nuov. Giorn. Bot. Ital. Ser. II. ii. (1895) 74. - Reg. Cauc.

\section{ELIONURUS}

$151^{3}$ a. Brazzae, Franch. in Bull. Soc. hist, nat. Autun, viii. (1895) 323. - Congo gall.

\section{EMBELIA}

$152^{3}$ a demissa, Cordem. Fl. Ile Réunion (1895) 447. - Ins. Borbon.

triquetra, Gordem. l. c. 446. - Ins. Borbon. variabilis, Cordem. l. c. 445. - Ins. Borbon. 
1531 1. ENDACANTHUS... [non ENDECANTHUS

Humblotii. . Fasc. 30 (1892) t. 244 (non 241).

$153^{3}$ a. EPHEDRANTHUS, S. Moore, in Trans. Linn. Soc. Ser, II. iv. (1895) 296. ANOLinn. Soc. parviflorus, S. Moore, l.c.t. 21. - Bras.

\section{EPIDENDRUM}

$153^{3}$ a. Barkeriola, Veitch, Man. Orch. Pl. vi. (1890) 89 (= Barkeria Barkeriola, Reichb. f. Hab.?

Claesianum, [Hort. Lucas], ex Gard. Chron. (1893) i. 64l, nomen. - Hab. ?

Forgetianum, Hort. ex Gard. Chron. (1893) i. 752 . - Hab.?

Kienastii, Reichb. f. in Gard. Chron. (I887) ii. 126. - Mexic

$154^{1}$ a. Matthewsii, Reichb. f. in Gard. Chron. (1886) ii. 458 ; et (1887) ii. 431 . - Peruy.

Watsonianum, Hort. Sander, ex Gard. Chron. (1892) i. 214. - Bras

154: a. EPILAELIA

Hardyana $\times$, Hort. Sander, ex Gard. Chron. (1894) i . 605, 629, fig. 80 ; et ex Orchid Rev. ii. (1894) 364. - Hybr. artef.

$154^{3}$ a. EPIPHRONITIS

Veitchii X, Hort. ex Journ, of Hort. 1xxxiii. (1890) 513, fig. 68; et ex Gard. Chron. (1890) i. 799.- - Hybr. artef.

$155^{1}$ a. EPIPREMUM, Th. Dur. Ind. Gen. Phan, (188s) 446 , err. typ. = Epipremnum, Schott (Aroid.).

\section{EPISGIA}

$155^{1}$ a. maculata, Hook. f. in Bot. Mag. (1890) t. 7131 - Guian. angl.

\section{ERAGROSTIS}

$155^{1}$ a. Brauni1, Schweinf. in Bull. Herb. Boiss. it App. 2 (1894) 41. - Arabia.

Elliottii, S. Wats, in Proc. Am. Acad. xxy. (1890) $140=$ campestris, Trin .

humifusa, C. Cordem. ex f. Cordem. Fl. Ile Réunion (1895) 126. - Ins. Borbon.

155" a. mabiana. Schnveinf. in Bull. Herb. Boiss. ii. App. 2 (1894) 38. - Arabia.

platystachys, Franch. in Bull. Soc. hist. nat. Autun, viii. (1895) 382. - Gabon.

Tholloni, Franch. l. c. 383. - Congo gall.

Tinge-lingua, S. Moore, in Trans. Linn. Soc Ser. II. iv. (1895) $35 \%$ - Bras.

yemensis, Schweinf. in Bull. Herb. Boiss. ii. App. 2 (1894) 41. - Arabia.

\section{ERANTHEMUN}

$155^{3}$ a. congestum, S. Moore, in Trans. Linn. Soc Ser. II. iv. (1895) 428. - Bras.

velutinum, Hort. Bull. Cat. new Pl. (1886) 8:Bras.

\section{ERIA}

$156^{2}$ 1. choneana... (non choniana)

a. fibuliformis, King of Pantling. in fourn. As. Soc. Beng. 1xiv. (1895) II. 336. - Sikkim.

\section{ERIANTHUS}

$156^{3}$ a. longisetosus, T. Anders, ex C. B. Clarke, in fourn. Linn. Soc. xxv. (1889) 85, t. 34. Ind. or.

\section{ERICA}

$156^{3}$ d. flava, Bolus (est Blaeriae species, in loco proprio jam enumeratur).

1571 1. Junonia.... (non Junonis).

\section{ERIGENIA}

$163^{3}$ a. Fitzgeraldi [A. H. S. Lucas] in Vict Natural. viii. (Aug. 1891) 50, err. typ. = Eugenia Fitzgeraldi, F. Muell.

\section{ERIGERON}

1581 a. elegans, Greene, Pittonia, ii. (1891) 173. Calif.

Favrati $\times$, Gremli, Excurs, Fl. Schweiz, ed. 6 (1889) 231, - Helv.

ghabrescens $\times$. Bruegre, in Jahresb. Naturf. Ges. Graub. Fasc, xxiii-xxiv. (1881) 105. - Helv.

parviflorum $\times$, Bruegg. 1. c. - Helv.

$158^{2}$ a. Remyi, Drake, Ill. Fl. Ins. Mar, Pacif. (1888) 65, t. 31 (= Vittadinia Remyi, A. Gray). Ins. Sandvic.

Scribneri, Canby, in Coult. Bot. Gaz. xv. (1890) 150. - Montana.

tenerrimus, Drake, Ill. Fl. Ins. Mar. Pacif. (1888) 67 , t. 32 (= Aster tenerrimus, Less.). - Ins. Sandvic.

FRIOCARPUM

$158^{3}$ a. scabrellum, Greene, in Erythea, ii. (1894) 108. - Calif.

\section{ERIOCAULON}

$158^{3}$ a, decemflorum, Maxim, Dec, pl. Asiat. viii. (1893) \% - China.

dicline, Maxim $l$.

kiusianum, Maxim.l.c.22. - China.

nipponicum, Maxim l. c.9. - Japon

19. Japon.

sikokianum, Maxim. l. c. 16. - Japon.

\section{ERIOCOMA}

1591 a. Lebmanni, Hieron, in Bot, fahrb. xix. (1894) 54. - Columb.

\section{ERODIUM}

$160^{2}$ a. Vetteri, Barb. \& Major, Samos (1892) 36, t. 2. - Ins. Samos.

\section{EROPHILA}

$160^{2}$ a. corsica, Jord. ex Magnier, Scrin. fl. select. $x$. (1891) 13 = vulgaris, $D C$

\section{ERVUM}

$160^{3}$ a. Tenoreanum, Giraudias, in Bull. Soc, étud. sci. Angers, xix. 1889 (1890) 1 C4 = Vicia Tenoreana, Martr.-Donos.

\section{ERYSIMUN}

$161^{1}$ a. Mureti X, Favrat, in Bull. Soc. Vaud. sci. nat. xxv. (1889) 50. - Helv.

\section{ERYTHRAEA}

$161^{3}$ a. Pringleana, Wittr. in Conlt. Bot. Gaz. xvi, (1891) 85. - Mexic.

Schuttlevorthiana, Rouy, in Le Naturaliste, Sér. 2, xiii. (1891) 11, in obs. $=\mathrm{E}$. Centaurium, Linn

turcica, Velen. in Abh. böhm.Ges.Wiss, vii. Folge, i. (1886) n. 8, 31. - Bulg.

\section{ERYTHRINA}

$161^{3}$ a microcarpa, Koerd. \& Valeton, Boomsoort. van fava, ii. (1895) 61. - Java.

\section{ERYTHROXYLUM}

$162^{2}$ a. ampullaceum, Baker, in fourn. Linn. Soc. xxii. (1887) 455. - Madag.

Bangii, Rusby, in Mem. Torrey Bot. Club, iii, 3 (1893) 11. - Bolivia.

durum, S. Moore, in Trans. Linn. Soc. Ser. II. iv. (1895) 322. - Bras.

novo-granatense, Hieron. in Bot. Fahrb. xx. Beibl. n. 49 (1895) 35. - Columb

praecox, S. Moore, in Trans. Linin. Soc. Ser. II. iv. (1895) 321. - Bras.

sparsiflorum, Baker, in fourn. Linn. Soc. xxii. (18877) 455. - Madag.

\section{ESCALLONIA}

$162^{2}$ a. exoniensis, Hort. ex Handl. Trees Kew, Pt i. [Polypet.] (I894) 227. - Form, hort.

Ingrami, Hort. 1. c. 229, in syn. = macrantha, Hook. \& Arn.

\section{ESCHWEILERIA}

1622 a. plecosperma, Th. Dur. ex Drake, Ill. Fl. Ins. Mar. Pacif. (1890) 183 (= Reynoldsia plecosperma, A. Gray). - Ins. Samoa.

sandvicensis, Th. Dutr.l. c. $182 .(=R$. sandvicensis, A. Gray). - Ins. Sandvic.

tahitensis, Th. Dur. l. c. 183 ( = R tahiten sis, Nadeaud). - Ins. Tahit.

EUGALYPTUS

$162^{3}$ 1. Naudiniana, F. Muell, in Austral. Foum. Pharm. (July 1886). - N. Brit.

EUCHARIS

$162^{3}$ a. Clibrani $X$ Hort Clibran, ex Gard Chron. (1892) ii. 138, $214=$ Urceocharis Clibrani $X$ Mast.

1631 a. EUCLASTE, Franch, in Bull, Soc, hist. nat. Autun, viii (1895) 335. GRAMINEAE glumacea, Franch. l. c.336. - Congo gall. Venezuela.

1631 a. EUCYPERUS, Rikli, in Pringsh. Jahrb. xxvii. (1895) $568=$ Cyperus [Mich.] Linn.

alternifolius, Rikii, 1. $\mathrm{c} .=\mathrm{C}$. alternifolius, Linn.

bruneoraginatus, Rikli, l. c. $=$ C. brunneovaginatus, Boeckl.

diffusus, Rikli, 1. $\mathrm{c},=\mathrm{C}$. diffusus, Vaht.

fuscus, Rikli, 1. c. $=$ C. fuscus, Linn.

gracilis, Rikli, 1. c. = C. gracilis, $R$. $B r$. (?)

longifolius, Rikli, 1. C. $=$ C. longifolius, Poir.

longus, Rikli, 1. c. $=$ C. longus, Linn.

Luzulae, Rikli, 1. c. = C. Luzulae, Rottb.

Martianus, Rikli, 1. c. = C. Martianus, Schrad.

pungens, Rikli, 1. C. = C. conglomeratus, Rottb. (?)

Schaffneri, Rikli, 1, c。 = C. Schaffneri, Boeck. textilis, Rikli, 1, c, = C. textilis, Thmnb.

\section{EUGENIA}

1632 1. Argyrocalyx..... 390 (non 391)

a. depauperata, Cordem. Fl. Ile Réunion (1895) 437 - - Ins, Borbon.

Hermanni, Cordem. l.c. (1895) 426. - Ins. Borbon.

heteromorpha, Cordem. l. c. 428. - Ins Borbon.

Holtzeana, F. Muell. Sec, Cens. Austral. Pl. (1889) 101, sphalm. = E. Holtzei, F. Muell.

$164^{1}$ a. mascarensis, Cordem. Fl. Ile Réunion (1895) 429. - Ins. Borbon.

miniata, S. Moore, in Trans. Linn. Soc. Ser. II. iv. (1895) 358. - Bras,

montana, Cordem. Fl. Ile Réunion (1895) 432 - Ins. Borbon.

$164^{2}$ a. platyphylla, Cordem. l. c. - Ins. Borbon

prolixa, S. Moore, in Trans. Linn. Soc. Ser. II iv. (1895) 358. - Bras.

pseudo-verticillata, S. Moore, l. c. 35\%. Bras.

Richardiana, Cordem. Fl. Ile Réunion (1895) 430. - Ins. Borbon.

Sayeri, F. Muell.in Vict. Natur.ix. (May 1892 5 , nomen. - Austral.

sparsa, S. Moore, in Trans. Linn. Soc. Ser. II. iv. (1895) 358. - Bras.

$164^{3}$ 1. stirpiflora ... (1895) (non 1894)

a. urceolata, Cordem. Fl. Ile Réunion (1895) 426. - Ins. Borbon

\section{EULOPHIA}

$165^{1}$ a. coccifera. Fraph ex Cordem. Fl. Ile Réznion (1895) 222. - Ins. Borbon.

165: a. geniculata, King \& Pantling, in fourn. As Soc. Beng. lxxiv. (1895) ii. 337. - Sikkim

1. Holtzei....; i et in Bot. Centralb1. xxxix. (1889) 237.

$165^{3}$ a, versicolor, Frapp, ex Cordem. Fl. Ile Réunion (1895) 221. - Ins. Borbon. 
EULOPHIA

Itj.j3 a. Zeyheri, Hook.f. in Bot. Mag. (1893) t. 7330 $=$ E. bicolor, Reichb. f. \& Sonder $)^{\circ}$ Afr, austr.

\section{EUONYMUS}

166'1 a. tulgaricus, Velen. Fl. Bulg. (1891) 116. Bulg.

citrifolius, Hort ex Handl. Trees Kew, $P t$ i. [Polypet.] (1894) 65.- - Hab.

flavescens, Hort. 1. $\mathrm{c}_{\mathrm{c}}=$ europaeus, Linn.

Liliewrii, Hort, 1, c. $67=$ nanus, Bieb.

macrocarpus, Hort. 1. c. $65=$ atropurpureus, facg.

purpurens, Hort. 1. C. = europaeus, Linn

robustus, Hort. 1. c. = japonicus, Thunb.

\section{EUPATORIUM}

$166^{1}$ 1. brickellioides.... : et in fahrb. Hamb. Wiss. Anstalt, ix. (1892) 123.

a. chapalense, S. Wats, in Proc, Am. Acad. xxvi. (1891) 138. - Mexic.

$166^{2}$ a. cujabense, S. Moore, in Trans. Linn. Soc Ser. II. iv. (1895) 385. - Bras.

Lasseauxii, Hort. ex Gartenfl. xliv. (1895) $625=$ Ageratum Lasseauxii, Carr.

1. malachophyllum.... ; et in fahrb. Hamb. Wiss. Anstalt. ix. (1892) 125 .

\section{EUPHORBIA}

$166^{3}$ a. angustifrons $X$, Borb. in [Magyar homokpusz. Növényv. (1886) 30,96, 101] ex Oest. Bot. Zeitschr. xxxvi. (1886) 400, - Hung:

1671 a. dissimilis, Cordem. Fl. Ile Réunion (1895) 336 - Ins, Borbon.

esuluides, Velen. in Abr. Böhm. Ges. Wiss. vii. Folge, i. (1886) n. 8, 39. - Bulg.

$167^{2}$ a. jaliscensis, Robinson \&o Greenm, in Proc. Am. Acad. xxix. (1894) 392, - Mexic.

1. Normanni, Schmalh. ex Lipski, in Mém.Soc. Natur. Kiew, xi (1891) 57 ; et...

nuda, Velen, Fl. Bulg. (1891) 506. - Bulg.

$167^{3}$ a. perfoliata, Scheutz, Pl. vasc. Fenissens. (1888) 158. - Sibiria.

$168^{1}$ a. variegata, Deflers, Voy, au Yémen (1889) 198. - Arabia.

\section{EUPHRASIA}

$168^{2}$ a. mixta, Gremli, Excurs. Fl. Schweiz. ed. 7 (1893) 318, in obs, = alpina, Lam.

\section{EURYA}

$168^{3}$ a. vitiensis, Hort. Dammann, ex Gartenfl. xxxvi. (1887) 130. - Ins. Fiji.

$169^{1}$ a. EUTHAMIA, Ell. = Solidago, Vaill. (Compos.).

carotiniana, Greene, in Mem. Torrey Bot. Club, v. (1894) $321=$ S. tenuifolia, Pursh leptocephala, Greene, 1. c. $=$ S. leptocephala, Tory. \& Gray.

\section{EVODIA}

1692 a. anisata, Drake, Ill. Fl. Ins. Mar.Pacif. (1890) 130 (= Pelea acuminata, H. Mann). - Ins. Sandvic.

Aubertia, Corden. Fl. Ile Réunion (1895) 367 (= Zanthoxylum Aubertia, DC.). - Ins. Borbon.

auriculata, Drake, Ill. Fl. Ins. Mar. Pacif. (1886) 19,130, t. 4 ; et Fl. Polyn. Franc. (1892) 27 (= Melicope auriculata, Nadeaud). - Ins. Tahit

barbigera, Drake, l.c. (= Melicope barbigera, A. Gray). - Ins. Sandvic.

brachiata, Cordem. Fl. Ile Rémnion (1895) 368. - Ins. Borbon.

brachiata, Drake, Ill. Fl. Ins. Mar. Pacif. (1890) 131; et Fl. Polyn. Franc. (1892) 26. - Ins. Pacif.

cinerea, Drake, l..c. $(=$ Melicope cinerea, A. Gray). - Ins. Sandvic.

clusiaefolia, Drake, l. c. (= Clusia sessilis, Hook \& Arn.). - Ins. Pacif.

elliptica, Drake, l. c. ( Melicope elliptica, A. Gray). - Ins. Sandvic.

\section{EVODIA}

$169^{2}$ a. emarginata, Drake, Ill. Fl. Ins, Mar, Pacif. (1890) 20, 132, t. 5 ; et Fl. Polyn. Franc. (1892) 26. - Ins. Pacif.

kavaiensis, Drake, l. c. $(=$ Pelea kavxiensis, H. Mann). - Ins. Sandvic.

Kundseni, Drake, l. c. $(=$ P. Kundseni, Hillebr.). - Ins, Sandvic.

Lepinei, Baill. ex Drake, 1. c. 22, 113, t. $6=$ brachiata, Drake.

Iydgatei, Drake, l.c. 132 (= Pelea Lydgatei, Hillebr.). - Ins. Sandvic.

macropus, Drake, l. c. $(=$ P. macropus, Hillebr.). - Ins. Sandvic.

Mannii, Drake, l.c. (= P. Mannii, Hillebr.). - Ins. Sandvic.

molokaiensis, Drake, l.c. $(=P$. molokaiensis, Hillebr.). - Ins. Sandvic.

Nadeaudi, Drake, l.c. ; et Fl. Polyn. Franc, (1802) 27. - Ins. Pacif.

nodulosa, Drake, 1. c. 17, t. $3=\mathrm{E}$. Nadeaudi, Drake.

oblongifolia, Drake, l.c. 132 (= Pelea oblongifolia, A. Gray) - Ins. Sandvic.

orbicularis, Drake, l. c. $133(=$ P. orbicularis, Hillebr.) - Ins. Sandvic.

pallida, Drake, l.c. $(=P$. pallida, Hillebr.). - Ins. Sandvic.

parvifolia, Drake, l. c. $(=P$. parvifolia, Hillebr.). - Ins. Sandvic.

rotundifolia, Drake, l. c. $(=P$. rotundifolia, A. Gray), - Ins. Sandvic.

sandvicensis, Drake, l.c. $(=P$. sandvicensis, A. Gray). - Ins. Sandvic

sapotaefolia, Drake, l. c. (= P. sapotaefolia, H. Mann), - Ins. Sandvic.

segregia, Cordem. Fi. Ile Réunion (1895) 368. - Ins. Borbon.

sericea, Drake, I11. F1. Ins. Mar. Pacif. (1886) 15, 132, t. $2=$ E. Nadeaudi, Drake.

simplex, Cordem. Fl. Ile Réunion (1895) 368. - Ins. Borbon.

volcanica, Drake, Ill. Fl. Ins. Mar. Pacif. (1890) 134 (= Pelea volcanica, A. Gray). Ins. Sandvic.

Waialealae, Drake, l. c. [Wailealae] $(=P$. Waialealae, Wawra). - Ins. Sandvic.

\section{EVOLVULUS}

$169^{2}$ a. yemensis, Defers, Voy. au Yémen (1889) 175. - Yemen.

\section{$\mathrm{F}$}

\section{FAGUS}

$170^{1}$ a. rotundifolia, Hort. ex Gard. Chron. (1894) i. $762=$ sylvatica, $\operatorname{Linn}$.

FARAMEA

$170^{2}$ a. coussaroides, S. Moore, in Trans. Linn. Soc. Ser. I1. iv. (1895) 375 . - Bras.

\section{FAUJASIA}

$170^{2}$ a. ambavilloides, Cordem. Fl. Ile Rénnion (1895) 545. - Ins. Borbon.

fontinalis, Cordem. 7. c. 544. - Ins, Borbon.

FERULAGo

$171^{1}$ a. confusa, Velen. Fl. Bulg. (1891) 204. - Bulg. FESTUGA

$171^{1}$ a. saxifraga, Miégev, in Bull. Soc, Bot. Fr. xxxviii. (1891) p. xxxviii = duriuscula, Linn.

singularis, Bordère \& Miégev. l. c. p. xxxvii Pyren, gall.

surculosa, Miégev. 1. c. p. xxxvi $=$ violacea, Gaudin.

\section{FICARIA}

1721 1. pumila, Velen, in Sitz. Boehm. Ges. Wiss 1887 (1888) $438=$ R. Ficaria, Linn. ranunculiflova, "Moench " ex St-Lager, in Cariot, Etud. des fl. éd. 8 (1889) 13, sphalm. $=\mathrm{R}$. Ficaria, Linn

\section{FICINIA}

$172^{2}$ a. varia, Boeck, in Verh. Bot. Ver. Brand, xxxix. (18ะ8) 47. - Afr. austr.

\section{FICUS}

$172^{2}$ a. acidula, King, in Ann. Bot. Gard.i. (1888) 176, t. 223 . - Borneo

araneosa, King, l.c. 136, t. 170. - Penins. Mal.

1. ardisioides... xx. (1894) adde : 171

a. arfakensis, King, in fourn. As. Soc. Beng 1vi. (1887) II. 63; et in Ann. Bot. Gard Calc. i. (1888) 104, t. 133. - N. Guin.

aruensis, King, l. c. 175, t. 176. - Ins, Aru

Beccarii, King, l. c. 102, t. 130, - Borneo

Beddomei, King, l. c. 26, t. 24. - Ind or.

bhotanica, King, l. c. 75, t. 205 b. - Ind. or. brachiata, King,... ; et l. c. 106, t. 136 . Sumatra.

Clarkei, King, l. c. 175, t. 221. - lnd. or. comitis, King, in fourn. As. Soc. Beng. lvi. (1887) II. 63; et l. c. 156, t. 197. - N. Guin. cinerea, Cordem. Fl. Ile Réunion (1895) 272. Ins. Borbon,

condensa, King, in Ann. Bot. Gard. Calc, i. (1888) 113, t. 149. - Borneo

conglobata, King, l. c. 99, t. 123. - Ind. or.

conora, King, in fourn. As. Soc. Beng. lvi. (1887) II. 62; et l. c.. 103, t. 131. - N Guin.

conspicabilis, King, in fourn. As. Soc. Beng. lvi. (1887) II. 61; et l. c. 80, t. 99. - N. Guin.

1. crassipes...; et Syn. Queensl. Fl. Third Suppl. (189.1) 69.

a. cucurbitina, King, l. c. 22, 1. 17. - Borneo, Celebes.

cycloneura, King, l. c. 31, t. 32 (= Urostigma cycloneuron, Miq.). - Sumatra, Borneo.

D'Albertisii, King, in fourn. As. Soc. Beng. 1vi. (1887) II. 64 ; et l. c. 172, t. 216. Sumatra, N. Guin.

$172^{3}$ 1. damarensis... $x_{0}(1888)$ [non $\left.(1856)\right]$.

a. dimorpha, King, in Ann. Bot. Gard. Calc. i. (1888) 111, t. 145 b. - Sumatra.

dumosa, King, l.c. 151, t. 190. - Sumatra

duriuscula, King, l. . . 155, t. 195. - N. Guin.

illiotiana, S. M iore, in Trans. Linn. Soc. Ser. II. iv. (1895) 4 2R. - Bras.

excavata, King, in Ann. Bot. Gard. Calc, i. (1888) 12\%, t, 115 b. - Borneo, Penins. Mal.

flavovenia, Warb. in Bot. Falkb. xx. (1894) 158. - Afr. trop.

Forbesii, King, in Ann. Bot. Gard. Calc. i. (1888) I 1,9, t. 143 . - Sumatra

grandis, King, in fourn. As. Soc. Beng. lvi. (1887) II. 64 ; et l. . . 170, t. 214. - N. Guin.

Hemsleyana, King, l.c. 112, t. 146. - Borneo. Henrici, King, l. c. 174, t. 220. - Sumatra. hypogoea, King, l. c. 100, t. 125. - Sumatra juglandiformis, King, l. c. 28, t. 27. Sumatra.

Kurzii, King, l. c. 47, t. 57. - As. trop.

Lowii, King, l. c. 32, t. 33. - Penius. Mal. lucens, Cordem. Fl. Ile Rémion (1895) 273. Ins. Borbon.

1. mabifolia... (non malifolia).

a. macilenta, King, in Ann. Bot. Gard. Calc. i. (1888) 156, t. 196. - Borneo.

Maclellandi, King, l. c. 52, t. 64. - Pegu macrocarpa, King, l. c. 166, t. 208 (= Pogonotrophe macrocarpa, Miq.). - Ind. or.

mespiloides, King, l. c. 83; t. 105. - N. Guin, Miquelii, King, l. c. 106, t. 137. - As, trop Mooniana, King, l.c. 5\%, t. 69. - Zeylan.

Moseleyana, King, l. c. 144, t. 181. - Ins Key.

natalensis, Krauss, ex Engl. Bot. Fahrb. x. (1888) 5 (=Urostigma natalense, Miq.). Afr. austr.

nigrescens, King, l. c. 78, t. 95 c. - Ind. or obpyramidata, King, l.c. 116, t. 153. - Perak Odoardi, King, l. c. 156, t. 198. - N. Guin. oleaefolia, King, J.c. 160, t. 204 b. - Sumatra. pachyphylla, King, l. c, 32, t. 34. - Borneo pauper, King, l.c. 161, t. 204 a. - N. Guin 


\section{FICUS}

$172^{3}$ a Schefferiana, King, in Ain, Bot. Gard. Calc. i. (1888) 152, t. 192, - Sumatra.

Scortechinii, King, $l, c, 11 \%$, to $14 \%$. Perak,

singalana, King, I. c. 70, t. 91. - Sumatra. soronensis, King, l. c. 161, t. 205 a. N. Guin.

sororia, Cordem. Fl. Ile Réunion (1895) 270. Ins. Borbon.

stipata, King, in Ann. Bot. Gard. Calc. i. (1888) 109, t. 142. - Sumatra.

stolonifera, King, l. c. 104. - Borneo.

Swinhoei, King, l. c. 81, t. 101 c. - Formosa.

Talboti, King, l. c. 51, t. 63, - Canara.

travancórica, King, l. c. 28, t. 26. - Ind. or.

Treubii, King, l. c. 105, t. 134. - Borneo.

1731 1. triangularis... 174 (non 170 ).

a. vaccinioides, Hemsl. \& King, ex King, in Ann. Bot. Gard. Calc. i. (1888) 126, t. 159 a. Formosa.

\section{FLUCGEA}

$174^{2}$ 1. nitida... 77 (non 7 )

\section{FOUQUIERIA}

$175^{3}$ 1. a. columnaris, Kellogg, in Bull. Calif. Acad. i. (1885) 133 ; T. S. Brandeg. in Proc. Calif. Acad. Ser. 2, ii. (1889) 132 (= rdria colnmnaris, Kellogg). - Am. bor.

\section{FRITILLARIA}

$175^{3}$ 1. Stribrnyi. 1893 (1894) n. xxxvii.61 (non [1892-93] 61).

\section{FUCHSIA}

$175^{3} 1$ G Glazioviana 10 (non 16).

a. magniflora, Hort. Williams, Cat. (1885) 9. Form. hort.

Riccartoni, Hort. ex Handl. Trees Kew, Pt i. [Polypet.] (1884) $139=$ Riccartoniana, Hort.

FUIRENA

$175^{3}$ a. Buchanani, Boeck. Cyp. Nov, i. (1888) 20. Afr. trop. or.

\section{G}

\section{GAHNIA}

1762 a articulata F, Muell, Key Syst, Vict. Pl. (1888) 456 (=Cladium articulatum, R. Br.). - Austral.

filum, F. Muell. l.c. $(=$ C. filum, R. Br. $)$ Austral.

glomerata, F. Muell. l. c. $(=$ C. glomeratum,

R. Br.). - Austral

Gunnii, F. Muell.l.c. $(=C$. Ginnii, Hook. f. $)$. - Austral.

juncea, $F$. Muell.l.c. $(=C$. junceum, R. Br. $)$. - Austral.

schoenoides, F. Muell.l.c. $(=C$. schoenoides,

R. Br.). - Austral.

triquetra, F. Muell. l.c. - Austral.

\section{GALACTIA}

$176^{3}$ a. Whitehornii, S. Moore, in Trans. Linn. Soc. Ser. II. iv. (1895) 344. - Bras.

\section{GALANTHUS}

$176^{3}$ a. grandiflorus, Baker, in Gard. Chron. (1893) i. $656(=$ G. maximus, Baker $)$. - Hab. ? umóricus, Hort. Dammann, Cat. (1889) $4=$ nivalis, Linn.

\section{GALIUM}

$177^{3}$ a. mesocarpon, Kern. Sched. F1. Austro-Hung. vi. (1893) $67=$ boreale, Linn.

praecox, Kern. 1. c. $78=$ verum, Linn.

polonicum... 188 (non 189).

rhodopeum... 1893 (1894) [non 1892-93].

\section{GALIUM}

$177^{3}$ a, umbellulutum, Velen, in Sitz. Boehm. Ges. Wiss. $1888(1889) 37=$ anisophyllum. $V i l l$. oriacum, F Gérard, in Maonier, Scrin 1. select. xiii. (1894) 323. - Gall. or.

\section{GASTRODIA}

$179^{1}$ a. Dyeriana, King \&o Pantling, in fourn. As. Soc. Beng. 1xiv. (1895) II. 342. - Sikkim.

\section{GAYLUSSAGIA}

$179^{2}$ a. cinerea, Taub. in Bot. Fahrb. xvii. (1893) 511. - Bras.

\section{GENISTA}

1801 a, daurica, Hort, ex Handl. Trees Kew, Pt ì [T'olypet. $]$ (1894) $115=$ purgans, Boiss. dumetorum Hort, 1, c. $111=$ = tinctoria, Linn

$180^{2}$ a. Oweniana X. Hort. ex Gard. Chror. (1889) i 342. - Hybr. artef.

1. rhodopea... 1893 (1894) n. xxxvii. 20 (non [1892-93] 20)

rumelica... ; et Fl. Bulg. (1891) 125.

a. thyrsiflora, Hort. cx Handl. Trees Kew, Pt [Polypet.] (1894) $111=$ tinctoria, Limn.

\section{GENTIANA}

$180^{3}$ 1. bulgarica... 1887 (1888)... (non 1886) cyananthiflora... (non cynanchiflora)

Favrati, Rittener, in Bull. Soc. Vaud. sci. nat. xxii. (1886) 95 ; et,

$181^{1}$ a. lingulata, Murbo. in Act. Hort. Berg. ii. n. 3 (1892) 22. - Europ.

1. lutescens, Velen. in Sitz. Boelm. Ges. Wiss. $1888(1889) 29$; et ...

\section{GEONOMA}

$181^{3}$ a. Herbstii, Hort. ex The Garden, xxxv. (1889) 463. - Hab ?

intermedia, Hort. Willians, Cat. (1882) 27. Hab. ?

tenuifolia, Hort. ex Ill. Hortic. xlii. (1895) 186. - Peruv.

\section{GERANIUM}

$182^{1}$ a, andinum, Phil. in Anal. Univ. Chil, lxxxii. (1893) 727. - Chili.

caespitosum, Phil. l.c. 730. - Chili

ciliatum, Phil. l. c. 727. - Chili.

hispidum, Phil. l.c. 732. - Chil

Moorei, Phil. l.c. 728. - Chili.

squamosum, Phil. l. c. 733. - Chili.

umbelliforme, Franch. in Bulll. Soc. Bot. Fr. xxxiii. (1886) 443 ; et...

\section{GILIA}

$182^{3}$ 1. Johowi... 266 et 291.

a. Matthewsii, A. Gray, Syn. Fl. N. Am, ed, 2. ii. i. suppl.(1886) 409 (=Loeselia Mattheresii, A. Gray). - Am. bor.

\section{GLADIOLUS}

$183^{1}$ a. armeníacus, F. N. Gerard, in Gard, and For. v. 1892) 318. - Armen.

$183^{2}$ a. Elloni, Hort. ex Wien, Ill. Gartenzeit. xv, (1890) 36. - Afr. austr.

\section{GLAPHYRIA}

$183^{3}$ a. Annae, Stein, in Gartenfl, xxxiv. (1885) 67 in obs. = Leptospermum Annae, Stein.

\section{GLEDISTGHIA}

$184^{1}$ a, macrantha, Hort, ex Handl. Trees Kew. Pt i. [Polypet.] (1894) $129=$ sinensis, $L \mathrm{am}$. macrosperma, Hort, 1. c. $=$ sinensis, Lam.

\section{GLOBULARIA}

$184^{2}$ 1. fuxeensis $\times$, Giraudias, in Bull. Soc. étud. sci. Angers, xviii. 1888 (1889) 53 ; et... Galissieri X, Giraudias, 1. c. 52; et.

\section{GNAPHALIUMI}

$185^{2}$ a. balcanicum, Velen. Fl. Bulg. (1891) 275. Bulg.

sarauentosum, Klatt, in fahrb. Hamb. Wiss. Anstalt. x. (1893) 126. - Mexic.

\section{GNIDIA}

$185^{3}$ 1. dichotoma, Gilg, in Bot. Falirb. xix. (1894) 264 ; et

18631 mecrorrhiza, 260 (non 264).

stenophylla... 258 (non 259).

GODETIA

I $86^{1}$ a. Heucki, Phil, in Anal, Univ, Chil, lxxxiv. (1894) 743. - Chili

\section{GOMPHOGARPUS}

$186^{3}$ l. aureusi. 1\% (nom \%).

involucratus... 19 (non 8).

validus... 20 (non 23)

\section{GOMPHRENA}

1871 a. Mariae, S. Moore, in Trans, Limn. Soc. Ser. II, iv (1895) 444, - Bras.

\section{GONGORA}

$18 i^{1}$ a. Charlesworthii, Rolfe, in Orchid Rev i. (1893) 198; Williams, Orch.Grow.Man.ed.7 (1894) $407 . \mathrm{Hab}$

\section{GOODYERA}

$187^{3}$ a. Dominii $\times$, Hort, ex Williams, Orch. Grow. Man. ed. 7 (1894) 410. - Hybr. artef.

Hemsleyana, King of Pantling, in fourn. A Soc. Beng. 1xiv. (1895) Ir. 342. - Sikkim.

$188^{1}$ 1. Rodigasiana... (non Rodigasciana).

a. Rollissoni, Hort. Gower, ex Williams, Orch. Grow. Man. ed. 6 (1885) 336; ed. 7 (1894) 411. - Malaya

Veitchii Y. Hort. ex Williams, 1. c. 412 Hybr, artef.

\section{GOSSYPIUM}

1881 a. Comesii, Sprenger ex Bull. Soc. Tosc. Ortic. xiv. (188 y) $30 \mathrm{st}$ t. 10, - Hab. ?

GOTHOFREDA

$188^{2}$ a. gracilis, Rusby...; Morong, in Ann, N, Y Acad. sci, vii. (1893)]61.

oblongifolia, Rusby...; Morong, 1. c. 160.

\section{GRAMMATOPHYLLUM}

$188^{2}$ l. Ginilelmi

a. Measuresianum, Sander, in Gard. and For. ii. (1889) 524 ; et ex fourn. of Hort. xxiii. (1891) 342 fig. 69. - Ins. Philipp.

Sanderianum, Hort. ex Gard. Chron. (1893) ii. 15 , sphalm. = speciosum, Blume.

\section{GRAPTOPHYLLUM}

$188^{3}$ a. picturatum, Hort. Bull, Cat. new Pl. (1895) 7 $=$ hortense, Nees.

\section{GREWIA}

1891 a, antidesmaefolia, King in fouriz As Soo Beng. 1x. (1891) II. 113. - Perak.

1. ambongoensis... (non ambongensis)

astropetala... t. 161 (non t. 160)

Bakeriana... 558 (non 559).

a. Boivini, Baill. in Bull. Soc. Linn. Paris, i. (1886) 550 - Madag.

$189^{2}$ 1. chalybaea, Baill. l.c. 55); et...

comorensis,... i. (1886) 558 (non i. 1885)

Richardiana,... 558 (non 358).

trifolia,... 557 (non 587).

\section{GRISELINIA}

$189^{3}$ l. scandens, .. (1892) 391 (non |1893] B98).

GUAREA

$190^{2}$ a, rubricalvx, S. Moore, in Trans. I.imn. Sod Ser, II. iv. (1895) 336. - Bras,

sylvestris, S. Moore, l. 0. 325. - Bras.

GUATTERIA

1902 a, sylvicola, S. Moore, in Trans. Linn. Soc Ser. II. iv. (1895) 298. - Bras.

\section{GUETTARDA}

$190^{2}$ a. hir'suta, Sarg. N. Am. Sylv. v. (189.3) $111=$ speciosa, Linn. 
GUETTARDA

$190^{2}$ a. mattogrossensis, S. Moore, in Trans. Limn. Soc Ser. II. iv. (1895) 372 . - Bras.

\section{GUIDONIA}

$190^{2}$ a gelonioides, Baill, in Bull. Soc. Linn. Paris i. (18S6) 567. - Madag.

grandis, King, in fourn. As. Soc. Beng. Iviii (1889) I1. 205. - Perak.

imbricata, King, l. c. 24 . - Perak.

lucida, Baill in Bull. Soc. Linn. Paris, i.

(1886) $567(=$ Casearia lncida, Tul.). Madag.

multinervis, King, in fourn. As. Soc. Beng Iviii. (1889) II. 205 . - Perak.

nigrescens... 567 (non 561 )

a. Scortechinii, King, in fourn. As, Soc. Beng. lvii. (1889) 11. 204. - Perak.

\section{GUNNERA}

1903 a laxiflora, Phil, in Anal. Univ, Chil. Ixxxiv. 1894) 750. - Chili.

\section{GYMNOSPORIA}

1913 a alaternitolia I oesen in Bot fahrb xvii. (1893 550 (= Catha alaternifolia, Tul.). - Ins Comor

ambonensis, Loesen. l. c. xix. (1894) 231. Afr. trop. or.

arbutifolia, Loesen. 1. c. xvii. (18.13) $547=$ Celastrus arbutifolius, Hochst.

Atkrio, Loesen. 1. $\mathrm{c}=$ Celastrus Atkaio, Rich.

brevipetala, Loesen. l. c.546. - Afr. trop. or Eminiana, Loesen. l. c. 543. - Afr. trop. or Ingleriana, Loesen. . . . 547. - Abyss.

crongmoides, Loesen. 1. c. = Celastrus evonymuides, Welw.

filamentosa, Loesen. l. c. 545. - Afr. trop.

Fischeri, Loesen. l. c. 543. - Afr, trop.

1. gracilipes, Loesen. 1. c. 541 ; et..

a. gracilis, Loesen. l. c. 545.-Zanzib.

Grossularia, Loesen. l. c. $543 \quad\{=$ Catha Grossulariae. Tul.) - Madag.

muillensis, Loesen. 1. c. $548=$ huillensis, Szyszyl.

lancifolia, Loesen. 1. c. = Celastrus lancifolius. Thoms.

laurifolia, Loesen. 1. c. = C. Jaurifolius, A. Rich.

lepidota, Loesen. l. c. 549.-Afr. trop.

leptopus, Loesen. l. c. 548 (= Catha leptopus, Tul.) - Madag.

Iutcola, Loesen.1. c. = luteola, Szyszy?. meruensis, Loesen. l. c. 549. - Afr. trop. mossambiccusiś, Loesen. 1. c. $547=$ Celastrus mossambicensis, Klotzsch

obscura, Loesen. 1. c. $546=$ obscura, Engl.

peduncularis, Loesen. 1. c. $549=$ C. peduncularis. Sond

1. putterlickioides, Loesen. l. c. 544 ; et..

a senegalensis, Loesen. 1. c. $541=$ Celastrus senega'ensis, Lam.

Zeyheri, Loesen. 1. c. $548=$ Zeyheri, Szyszyl

\section{GYPSOPHILA}

192" a chilensis, Phil. in Anal. Univ. Chil. lxxxii. (1893) 761. - Chili.

\section{H}

\section{HABENARIA}

1923 1, arietina "et in Ann. Bot. Gard. Calc. v. I (1895) 64, t. $9 \%$

1931 a. Biermanniana, King \& Pantling, in fonm As. Sor Beng.1xiv. (J895) ii. 343. - Sikkim

Culveri... 14 et 32 .

a. Cumminsiana, King \& Pantling, l. c. Sikkim

1932 1. Helferi,...; et in Ann. Bot. Gard. Calc. v. I. (1895) $66, \mathrm{t} .100$

\section{HABENARIA}

$193^{2}$ 1. latilabris ; ot, c. $6 \%, \mathrm{t}, 101$

Lecardii... (non Lecardi).

Montolivaea... 176 (non 172)

transvaalensis... 6 et 32 .

\section{HATMANTHUS}

$194^{3}$ a. candidus, Hort. Bull. Cat. new Pl. (18:4) 3. Transvaal.

Clarkei X, W. Wats. ex Gard. Chron. (1894) ii 398 . Hybr. artef.

$195^{3}$ a. HANBURYOPHYTON, Bureau, ex Warm. Symb. fl. Bras. centr. xl. (1893) $1226=$ Petastoma, Miers (Bignon.)

xanthinum, Bureau, 1. c, - Bras.

\section{HARPALYGE}

1962 a speciosa Taub, ox Ule, in Cruls, Comm. expl. plat. centr. Brésil (1894) 356; et in Bot. fahvb. xxi. (1896) 435, - Bras.

\section{HARPULLIA}

$196^{3}$ 1. camptoneura...; et in Bot. Fahrb. xiii. (1891) 365

frutescens... ; et Syn. Quecnsl. Fl. Third Suppl. (1890) 17.

HEDERA

$157^{2}$ a. coriacea, Hort. ex Handl. Trees Kew, Pt i. (Polypet.) $247=\mathrm{H}$. Helix, Linn digitata, Hort. 1. c, $245=\mathrm{H}$. Helix, Limn.

1973 a latifolia, Hort. 1, c. $247=\mathrm{H}$. Helix, Linn. marginata, Hort. 1. c. $243=\mathrm{H}$. Helix, Lim minor. Hort. 1. c. $245=\mathrm{H}$. Helix, Linn rhomboidea, Hort. 1. c. $=$ H. Helix, Linn.

\section{HEDYOTIS}

1981 a. psychotrioides, F. Muell. in Vict. Natural. vi. (1889) 54; F, M. Bailey, Syn. Queensl. Fl. Third Suppl. (1890) 33. - Austral.

\section{HEISTERIA}

$198^{2}$ a, rubricalyx, S. Moore, in Trans. Linn. Soc. Ser. II. iv. (1895) 337. - Bras.

\section{HELEOCHARIS}

$198^{3}$ a. alta, Boeck. Cyper, nov, i. (1888) 17. - Java Arechavaletae, Boeck. 1. c. - Üruguay. aurea, Boeck. 1. c. 15. - Mexic. exilis, Boeck 1. c. 16 - Mexic. glauco-virens, Boeck. 1. c. 13. - Bras.

1. Krutzei, Boeck. Cyp. Nov. i. (1S88) 14 (non 1. C. 14)

a. mesopotamica, Boeck. 1. c. 17. - Reg. Argent Niederleinii, Boeck. 1. c. 13. - Reg. Argent. quinquangularis, Boeck. 1. c. 15. - Reg. Argent.

Sintenisii, Boeck. 1. c. 16. - Ins. Portorico Tuerkheimii, Boeck. 1. c. - Guatem. univaginata, Boeck. 1. c. 14. - Chili. viridis, Boeck. 1. c. 17. - Bras. Wrightiana, Boeck. 1. c. 12. - Cuba.

\section{HELIANTHEMUM}

$199^{1}$ a. Aldersonii, Greene, in Erythea, i. (1893) 259. Calif. [err. cal. sub Helianthella indic.].

\section{HELIANTHUS}

$199^{2}$ a. lenticularis, Hort, ex Gartenft. liii. (1894) 104 fig. 25. - Am. bor.

\section{HELIGIA}

$199^{3}$ a Cameronii F. Muell, in Trans. Roy. Soc. Vict. New Ser, I. ii. (1889) 7.=N. Guin.

Whelani...; et Syn. Queensl. Fl. Third Suppl. (1890) 61 .

\section{HELICTERES}

2001 a chapadensis, $S$ Moore, in Trans. Limn. Soc Ser, II. iv. (1895) 316. - Bras. orthotheca, S. Moove, l. c. 31\%.-Bras.
HELLEBORUS

$200^{3}$ 1. siculus, Schiffn, in Bot. Fahrb. xi. (1889.) 116 et.

$200^{3} 1$. HELLWIGIA... 279 et 451 . pulchra... 279 et 451 .

\section{HELONIOPSIS}

$201^{1}$ a. 4 mbellata, Chron. (1887) $i$ 711 , sphalm, = japonica, Maxim.

\section{HEMIGRAPHIS}

$201^{1}$ a colorata, Hort. Bull. Cat. (1885) 14. - Ind or.

$201^{3}$ 1. HENRYA, Hems1...= Neohenrya, Hemsl.

\section{HEPATICA}

$201^{3}$ a. Hepatica, Britton, in Am. N. Y. Acad. sci vi. (1891) $233=$ A. Hepatica, Linn.

\section{HERACLEUM}

2021 1. Bailletianum $=\mathrm{H}$. Sphondylium, Linn

a. carpaticum. Porcius, in Anal. Acad. Romane Ser. II. xiv. (I892) I 9. - Eur. centr.

Freynianum, Somm \&o Levier, in Bull. Soc. Bot. Ital. (1895) 43, nomen: et in Nuov. Giorn. bot. Ital. Ser. I1. ii. (1895) 81. Reg. Cauc.

isopetalum, Maxim. Dec.pl. Asiat. viii. (1893) 2. - Japon.

juranum, Genty, in Magnier, Scrin. A. select. v. (1886) 101 (= H. alpinum, Auct.). Jurass.

micranthum, Borb. Geogr. atq. Enum. p1. Comit. Castrif. (1887) $236=\mathrm{H}$. Sphondylium, Linn.

Mantegazzianum, Somm. Es Levier, in Nuov. Giurn. bot. Ital. Ser, II. ii, (1S95) 79. Res. Cauc.

pachyrhizum, Somm. E Ievier, in Bull. Soc. Bot. Ital. (1895) 43 ; et l. c. 82. - Reg. Cauc.

1. ternatum... ; et Fl. Bulg. (1891) 202.

verticillatum, Pancic, Elem. (1886) 25 ; Velen. Fl. Bulg. (1891) 21 ; et..

HERITIERA

$202^{1}$ a. augustata, Pierre, Fl. For. Cochinch. Fasc. 13 (1889) t. 204. - Cochinch.

\section{HERMANNIA}

2021 1. cristata, Bolus [non Baker].

\section{HERPESTIS}

$202^{3}$ a. acuta, S. Moore, in Trans. Linn. Soc. Ser. II. iv. (1895) 407. - Bras.

parvula, S. Moore, l. c. 406. - Bras,

HESPERIS

203? 1. desertorum... 1893 (1894) n. xxxvii. 7 (non 1892-93) 7

$203^{3}$ a. HETEROCROTON, S. Moore, in Trans. Linn. Soc. Ser. II. iv. (1S95) 461. EUPHOR$B I A C E A E$.

mentiens, S. Moore, l.c. t. 29. - Bras.

\section{HETEROPTERIS}

20411 amplexicaulis. 66 (non 67 )

$204^{2}$ a. nudicaulis, S. Moore, in Trans. Linn. Soc. Ser. II. iv. (1895) 325. - Bras.

\section{HEUCHERA}

204: a rosea Hort, ex Möller, Deutsche Gartenzeit. (1893) 2. - Hybr. artef.

\section{HIBISCUS}

$204^{3}$ a. cernuus, Terrac. in Bull. Soc. Bot. Ital. (1892( 422. - Reg. Somal.

decaspermus, Koerd. Eo Valet. Boomsoort. van 7ava, ii. (1895) 115. - Java.

1. Engleri, K. Schum. in Bot. Fahrb. x. (1880) 47 (non l. c.).

lasiocarpus, S. Wats. in Gard. and For. (1888) 425, fig. 68. - Am. bor.

Mesnyi... : et Fl. For. Cochinch. Fasc. 11 (1888) t. 172. - Cochinch. 


\section{HIER A CIUM}

$206^{2}$ a. Blockit X. Woloszczak, in Spraw Kom. fizyj. Krakow, xxi. (1888) 127. - Hung.

$207^{2}$ 1. Delpinii, Bald. Cenni ed. App. ecc. 75; it ex Malpighia, v. (1891) 76, et vii. (1893) 279 ; et...

2093 a. Montegazzianum, Somm. \& Levier, in Bull, Soc. bot. Ital. (1895) 43, nomen. - Reg. Cauc.

Mureti, Gremii, Excurs. Fl. Schweiz, ed. 6 (1889) 290, ed. 7 (1893) 274. - Helv.

2101 a. paradoxum, Gremli, l. c. ed. 7 (1893) 272. Helv.

pocuticum $\times$, Woloszczak, in Spraw Kom. fizyj. Krakow, xxi. (1888) 129. - Hung.

poecilostictum,... ; et in Act. Hort. Berg. i. 7 (1891) 23 = nigrescens, Willd

$210^{3}$ a. praeteneriforme, Almq. ex Dahlst. l. c. 40. Scand.

Pseudoalbidum, Celak. in Sitzob. Boehm. Ges. Wiss 1885 (1886) 8. - Eur, centr.

Pseudocorymbosum, Gremli, Excurs. Fl. Schweiz, ed. 6 (1889) 292, ed. 7 (1893) 282. - Helv.

Pseudoligusticum, Gremli, l. c. ed. 7 (1893) 277. - Helv.

$211^{1}$ a. Pseudostygium $\times$,Woloszczak, in Spraw Kom fizyj. Krakow, xxi. (1888) 128. - Hung.

Purkynei, Celak. in Sitzb. Boehm. Ges. Wiss. 185.5 (1886) 8. - Eur. centr.

Rehmanni $\times$, Woloszczak, in Spraw Kom. fizyj. Krakow, xxi. (1888) 128. - Hung. ruberuhum, Dahlst. in K. Svensk. Akad. Handl. xxvi. 3 (1894) 233 = rigidum, Hartm. secundum. Freyn, in Velen. Fl. Bulg. (1891) 352. - Bulg.

Skorpili, Freyn, l. c. 339. - Bulg

$211^{3}$ a. splendens $X, A$. Kern. [ubi ?] ex Bruegg. in Jahresb. Naturf. Ges. Graub. xxix. 1884-85 (1886) 87. - Helv.

2121 a. subsimplex, Somm. \& Levier, in Nuov. Giom. bot. Ital. Ser. II. ii. (1895) 94. - Reg Cauc.

svaneticum, Somm. \& Levier, l.c. 92. - Reg. Cauc.

\section{HIPPOGRATEA}

$213^{3}$ 1. Rowlandii... 236 (non 238).

Stuhlmanniana...; et in Bot. Fahrb. xix. (1894) 235.

Volkensii... 237 (non 238).

\section{HIPPOCREPIS}

$213^{3}$ 1. fructicosa... (non fruticosa).

\section{HIPPOMARATHRUM}

$213^{3}$ a. pungens, Lojac. Fl. Sicula, i. II. (1891) $285=$ Cachrys pungens, $\mathscr{F} a n$.

\section{HIPTAGE}

$213^{3}$ d. macrocarpa, parvifolia et pulcherrima (sp. ad HIRAEAMI, transfer.).

\section{HIRAEA}

$214^{1}$ a. nitens, S. Moore, in Trans. Linn. Soc. Ser. II iv. (1895) 328. - Sras.

parvifolia, Niedenzu, in Bot. Fahrb. xiv. Beibl. n. 30 (1891) 2. - Bras.

volubilis, S. Moore, in Trans. Linn. Soc. Ser. II. iv. (1895) 328. - Bras.

\section{HIRSCHFELDIA}

2141 1. consobrina,... (non consobuna).

incana, Burnat, F1. Alp. Marit. i. (1892) 76 = incana, Moench.

\section{HIRTELLA.}

$214^{1}$ a. collina, S. Moore, in Trans. Linn. Soc. Ser. II. iv. (1895) 351. - Bras.

$215^{2}$ a. HOMALOSTACHYS, Boeck. Cyp. Nov. j. (1888) 37 = Carex [Dill.] Linn. (Cyper.). sinensis, Boeck. 1. c. $38=$ C. moupinensis, Franch.

$214^{3}$ 1. HOOKERA, transferetur post HOOKERELLAM in pag. $215^{3}$.
$215^{2}$ HORMOLOTUS, transferetur post HORKELIAM in pag. 216.

\section{HORTENSIA}

$216^{1}$ a. nigra. Carr. in Rev. Hortic. (1880) $180=$ H. Hortensia, $D C$.

\section{HOSAGKIA}

$216^{2}$ a. Mearnsi Britton, in Trans. N. Y. Acad. sci. viii. (1889) $65=$ Lotus Mearnsii, Britton

\section{HLOUSTONIA}

$216^{2}$ 1. J. N. Ruse (non N. E. Rose, passim)

\section{HUFELANDIA}

216 3 a. Tambertiana, Schwacke \& Mez, ex Mez, in Arb. Königl. Bot. Gart. Breslant, i. (1892) 108 - Bras.

2172 1. HUTERA, Porta,... 293 = Goincya, Rouy (Crucif.).

rupestris, ... = C. rupestris, Rouy

HYACINTHELLA

$217^{2}$ a. lencophaea, Velen. Fl. Bulg. (1891) $553=$ Hyacinthus pallens, Roem. \& Schult.

longiloba, Velen. 1. c. 554. - Bulg.

rumelica, Velen. 1. c. - - Rumel.

\section{HYDRILLA}

$218^{1}$ a. verticillata, F. Muell. Key Syst. Vict. Pl. i. (1888) 423. - Austral.

HYDROGOTYLE

2181 a. Candollei, F, Muell. Key Syst. Vict, Pl. i. (18s8) $26 \%$. - Victoria.

\section{HYDROSME}

2182 1. sparsiflora... 461 (non 462).

\section{HYMENOCIARDIA}

\section{$218^{3}$ 1. Poggei... 328 (non 329 )}

\section{HYPEGOUM}

$219^{1} 1$. ponticum...1893 (1894) n. xxxvii. 6.

Pseudo-grandiflorum, Petrov. in Magnier, Scrin. fl. select. vo (1886) 99, - Serbia.

\section{HYPERICUM}

2191 a. apterum, Velen, in Sitz. Boelm. Ges. Wiss. 1887 (1888; 445; et Fl. Bulg. (1891) 104. - Bulg, balcanicum, Velen. l. c. 106--Bulg. Borbasii, Formanek, in Verh. naturf. Ver. Brünn, xxix. 1890 (1891) 143. - Aetolia.

Cuisini, Barbey, in Bull. Soc. Vaud. sci. nat, xxi. (1885) 220; et Karpathos (1895) 99, t. 3. Ins. Karpathos.

2191 1. haplophylloides, Halácsy \& Baldacci, in Verh. zool.bot. Ges. Wien, (1892) 576 ; et in Malpighia, viii. (1894) 166. - Eur. centr.

Kellerii, Baldacci, in Malpighia, ix. (1895) 67. - Ins, Creta

$219^{2}$ 1. Stuebelii... 321 (non 320)

\section{HYPOGHAERIS}

$219^{3}$ 1. cupressorum... (non cupressarum).

a. Pelivanovici, Velen. Fl. Bulg. (1891) 361. Bulg.

thermarum, Phil. in Anal. Univ, Chil. lxxxvii. (1894) 323 . - Chili.

\section{HYPOESTES}

220.1 a. radicans, Deflers, Voy. au Yémen (1889) 183. - Arabia.

\section{HYPOLYTRUM}

$220^{1}$ a. Buchholziänum, Boeck. Cyp. Nov'。 i。 (1888) 22. - Kamerun

heterophyllum, Boeck. l. c. 22. - Kamerun. Kuntzeanum. Bock. l. c. 23. - Panama. microstachyum, Boeck. l. c. - Bras.

\section{HYPTIS}

$220^{2}$ a effusa, S. Moore, in Träns, Linn. Soc. Ser. II iv. (1895) 441. - Bras.

Seemanni... (non Seemannii).

\section{HYPTIS}

2202 a. penaeoides, Taub. ex Ule, in Couls, Comm, Plat. centr. Brésil (1894) 357; et in Bot. Fahrb. xxi. (1896) 450. - Bras,

\section{I}

\section{ILEX}

2.211. eugeniaefolia... t. 278 A (non t. 278 D) excavata,... t. 279 B (non t. 278 A) mitis, Radlk, in Rep. Brit, Assoc. 1885 (1886) 1081, et...

Riedlaei.... adde : 317

$221^{2}$ 1. Wrightii... 322 (non 328).

\section{IMPATIENS}

$221^{3}$ 1.

a. Episcopi, Veitch, Catal. (1886) 12=I. Sultani, Hook. f. var.

Micholitzi, Hort. ex Wien. Ill. Gart,-Zeit. xvii. (1892) 342. - N. Guin.

\section{INGA}

$222^{3}$ a. Sanctae-Annae, S. Moore, in Trans. Linn Soc. Ser. II. iv. (1895) 350. - Bras.

\section{IONIDIUM}

$22: 3$ a: lacteum, S. Moore, in Trans. Linn. Soc. Ser. II. iv. (1895) 307. - Bras.

Lehmannii... xx. Beibl. n. 49 (1895) 57 (non Beibl. 57).

IPHIGENIA

2231 1. Oliveri... 467 (non 466).

\section{IPOMOEA}

$223^{2}$ 1. asperifolia... 128 (non 125).

Brousoni, F. N. Gerard, in Gard. and For. v. (1892) 345 . - Cuba.

crinicalyx, S, Moore, in Trans, Limn, Soc. Ser. II. iv. (1895) 202. - Bras.

$223^{3}$ a. gossypina, Defters, Voy. au Yémen (1889) 174 - Arabia

Hackeliana... 126 (non 12).

Kerberii, Hort ex Bull. Soc. Tosc. Ortic. xix. (1894) 116 fig. 32 (= Quamoclit Kerberii. Fourn. - Am. austr

$224^{1}$ 1. Morongii, Britton [non Bvitten].

$224^{2}$ a. uniflora, Benth. \& Hook. f. ex Drake, IIl. Fl Ins. Mar. Pacif. (1892) $244=$ martinicensis, G. F,W. Mey.

\section{IRIS}

$225^{2}$ a. Agatha $\times$, Hort, ex The Garden, xlvi. (1894) 157. - Hybr. artef.

argentea, Hort. ex Rev. Hortic. 1xiii. (1891) 36, cum ic. = xiphioides, Ehrh.

Cosniae, Hort, ex The Garden, xlvii. (1895) 351. - Hab.

Madonna, Hort. Sprenger, ex Bull. Soc. Tosc Ortic. xvii. (1892) 130. - Arabia

$225^{3}$ a. Skorpili, Velen. Fl. Bulg. (1891) 535. - Bulg. suaveolens, Terrac. in Nuov. Giorn. bot. Ital. Ser. II. i. (1894) 182. - Italia.

Suworowi, Regel, in Gartenfl. xxxy. (1886) 397 et in Bot. Mag. (1888) t. 7029 [Suwarowi - As. centr.

\section{ISA CHNE}

2261 a. filifolia, Franch, in Bull, Soc. hist, nat, Autun , viii. (1895) 340. - Congo gall. nervata, Franch. l.c. - Gabon.

\section{ISCHNOSIPHON}

$226^{2}$ a. arsenteus, S, Moore, in Trans, Linn. Soc. Ser. II. iv. (1895) 485. - Bras. concinnus, S. Moore, l, c. 484. - Bras. nemorosus, $S$. Moore, l. c. 483. - Bras.

$22^{1}$ a. ISOPHYLLUM, Spach = Ascyrum, Linn。 (Hypericin.).

peltatum, Franch, in Ann. Mus. Paris, Sér. II. viii. 1885 (1886) 190 t. 4. - Tibet. 
IXIOLIRION

Sintenisii, Hort. Leichtlin, ex Wien, Ill. Gart. Zert, xvii (1892) 346. - Hab?

ISONANDRA

2.:1 a. polynesica, Benth. \& Hook, f. ex Drake, Ill. Fl. Ins, Mar. Pacif. (1892) 229 (= Chrysophyllum polynesicum, Hillebr.). - Ins. Pacif.

\section{IXONANTHES}

Q2.2 2 a cochinchinensis, Pierre, Fl. For, Cochinch, Fasc. 18 (1893) t. 284 A. - Cochinch.

IXORA

…-3 a. conspicua, Bull, Cat. new Pl. (1886) 8.- Hab. ? salmonea, Bull, Cat, new PI. (1892) 3.Form. hort.

\section{$\mathrm{J}$}

\section{JAGARATIA}

2281 1. Solmsii... (1892) (non 1898).

JACOBINIA

2282 a. stellata, Robinson of Grenm. in Proc. Am. Acad. xxix. (1894) 390. - Mexic.

2283 a. JAEGERIA, H. B. \& K. (Compos.). - Ind. Kew. ii. 1247.

discoidea, Klatt, in fahrb. Hamb. Wiss, Anstalt. x. (1893) 126. - Costa Rica.

"2: ediç. (1891) 124. ORCHIDEAE.

cultrifolia, Rodr. l. c. - Bras. bor.

\section{JASMINUM}

..291 I. elegans... 538 (non 534)

gratissimum, Defers, Voy. an Yémen (1889) 162. - Arabia.

2292 1. parvifolium... 537 (non 531 ).

\section{JULOGROTON}

2:301 a. abutiloides, S. Moore, in Trans. Lim Soc. Ser. II. iv. (1895) 465, - Bras.

elaeagnoides, S. Moore, l.c. 463. - Bras.

lepidus, S. Moore, I. c. 464. - Bras,

\section{JUNCUS}

2:302 1. Fockei... xii (non ii)

a. latifolius, Buchenau, in Bot. Fahrb. xii. (1890) 425. - Am. bor.

niponensis, Buckenau, l.c. 340. - Japon.

1. paucicapitatus... 367 (non 307 ).

\section{JURINEA}

$230^{3}$ a. bulgarica, Velen, in Sitz. Boehm. Ges. Wiss, 1888 (1889) 51 ; et Fl. Bulg. (1891) 302。Bulg.

\section{JUSTIGIA}

$231^{1}$ a. chapadensis, S. Moore, in Trans. Linn. Soc. Ser. II. iv. (1895) 431. - Bras.

$231^{2}$ a. laevilinguis, Lindan, in Bot. Fahrb. xix. Beibl. ก. 48 (1894) $20 ;$ et $\ldots$

Lorentziana. 19 (non 20).

$231^{3}$ a. metallicorum, S. Moore, in Trans. Linn. Soc. Ser. Ir. iv. (1895) 430, - Bras.

Oreadum, S. Moore, l.c. 429. - Bras.

\section{K}

\section{KAEMPFERIA}

2321 a. macrochlamys, Baksv, in Hook. f. Fl. Brit. Ind. vi. (189') 223. - Tenass.

\section{KARATAS}

23:3 a antiacantha X, Hort, ex Gard. Chron. (1888) ii. 474. - Hybr. artef.

\section{KIELMEYERA}

$233^{2}$ a. amplexicaulis, S. Moore, in Trans. Linn. Soc. Ser. II. iv. (1895) 311. - Bras.

\section{KIRENGESHOMA}

$233^{3}$ 1. palmata... et in Icon. $A$. fapon, i. I. (1891) t. 2.

\section{KNIPHOFIA}

$234^{1}$ a. natalensis, Hort, ex The Garden, xxxvi (1889) 459; et in Gard. Chron. (1889) ii. $562-$ Natal.

Sumarae, Deflers, Voy. an Yémen (1889) 210. - Arabia.

Tuckii, [Hort. Leichtlin] Baker, in Gard. Chron. (1893) i. 68. - Afr. austr.

Woodii, A. Campbell, ins The Gorden, xlviii. 1895) 292. - Natal.

KNOWLTONIA

$234^{1}$ a. rotundifolia, Huth, in Abh. and Vortr. Gesamtgeb. Naturw, iii. (1890) 70. - Afr. austr.

\section{KOBRESIA}

$234^{1}$ 1. bipartita, Karst, Deutsch. Fl. ed, 2, i. (1895) 335 ; Britton,

a. brunnescens, Boeck. Cyper. Nov. i. (1888) 45. - Tibet

hyalinolepis, Boeck. l. c. 39. - Tibet

macrantha, Bock. l. c. - Tibet.

\section{KOCHIA}

2341 1. spongiocarpa...; ; et in Icon. Austral. Salsol. Decas $6(1890)$ t. 51

\section{KOELERIA}

$234^{2}$ a intricata, Genty, in Magnier, Scrin. fl, select. viii. $(1888) 153=$ cristata, Pers. nitidula, Velen. Fl. Bulg. (1891) 611. - Bulg., Armen.

KOELLIA

$234^{2}$ ], incana et virginica, Baill... xi. [non $\mathrm{x}$ ].

KONIGA

$234^{3}$ a. insignis, Webb, ex Coss. Illustr. Fl. Atlant i. (1889) 63 t. 43 . - Afr. bor.

KOROLKOWIA

$234^{3}$ a. discolor, Regel, in Gartenfl. xxxy. (1886) 349 ; et in Gard. Chron. (1888) i. $105=$ Fritil= laria Sewerzowii, Regel.

\section{KYLLINGA}

$235^{2}$ a. pellucido-lucida, Boeck. Cyper. Nov. i. (1888) 1. - Reg. Argent.

\section{I}

\section{LACTUGA}

2361 l contracta, Velen.in Abh. Boehm. Ges, Wiss VII. Folge, i. (1886) n. 8, p. 27 ; et..

$236^{\circ}$ a. yemensis, Deflers, Voy, au Yémen (1889) 160. - Arabia.

\section{LADENBERGIA}

236 a. chapadensis, S. Moore, in Trans. Linn. Soc. Ser. II. iv. (1895) 367. - Bras.

\section{LAELIA}

$236^{2}$ a, amoena $\times$. Hort. ex Orchid Rev, ii. (1894) 334. - Hybr. artef

dellensis $X$, Hort. in Gard. Chron. (1889) i. 695. - Hybr, artef

Gottoiana, Hort. ex Gardener's Mag. (1891) 379 (Hybr. spont. ?). - Bras.

$236^{2}$ 1. juvenalis... (non juvenilis).

Lucasiana. Rolfe, in Orchid Rev. i. (1893) 265; Will. Orch. Grow. Man. ed. 7. (I894) 440 - Hab.?

Normanni x, Kraenzl. in Gard. Chron. (1893) i. $98 .-$ Hybr. artef.
LAELIO-CATTLEYA

$236^{2}$ a. amoena $X$, Hort. ex Lindenia, viii. (1892) 65 t. $367=$ Laelia amoena $\times$, Hort.

amplissima $\times$, Hort. ex Journ. des Orchid. (1894) 253. - Hybr. artef.

ascana $X$, Hort. Veitch, ex Will. Orch Grow. Man. ed. 7 (1894) 452, - Hybr. artef.

Darwiniana X, Hort. ex Orchid Rev. Lii. (1895) 293. - Hybr, artef

elsteadensis X. Hort. ex Orchid Rev. iii. (1895) 293. - Hybr. artef.

cumaea $\times$, Hort. Veitch, ex Will. Orch. Grow Man. ed. 7 (1894) 458. - Hybr. artef.

Gottoiana X, Hort. Sander. ex Gard. Chron. (1895) ii. $467=$ Laelia Gottoiana, Hort.

Hardyana X, Hort. in Gard. Chron. (1895) i. 248. - Hybr, artef.

Harrisii $X$, Hort. ex Gard. Chron. (1895) ii. 748. - Hybr. artef.

Hippolyta X, Hort. ex Journ. of Hort. xx. (189) 303 fig. 38 ; Will. Orch. Grow. Man. ed. 7 (1894) 452. - Hybr. artef.

Ingramii $X$, Hort. ex Journ, of Hortic. xxv. (1892) 141 fig. 20. - Hybr. artef.

facobiana X. Hort. ex Rev. Hortic, 1xvii. (1895) 359. - Hybr, artef.

Marriottiana X. Hort, ex Gard. Chron. (1992) i. 503. - Hybr. artef.

Normanni $X$, Hort. Veitch, ex Will. Orch. Grow. Man. ed. 7 (1804) $459=$ Laelia Normanni $\times$, Kraenzl.

Phoebe X, O' Brien, in Gard. Chron. (1892) i. $791 \mathrm{fig} .114$; Gard. Mag. (1892) $268 \mathrm{cum}$ ic 1 .

Pisandra $\times$, Veitch, ex Journ. of Hort. xxvii. (1893) 407 fig. 60 ; Will. Orch. Grow. Man ed. 7 (1894). - Hybr. artef.

Pittiana X. O'Brien, ex Gard. Chron. (1894) i. 264. - Hybr spont. ?

Proserpini $\times$, Rolfe, ex Will. Orch. Grow Man. ed. 7. (1893) 461. - Hybr. artef.

Ridolfana $X$, Hort. ex Bull. Soc. Tose Ortic. (1893) 72 t. 3. - Hybr. artef.

Sanderae X. Hort. ex Orchid Rev。i. (1893) 363. - Hybr. artef.

$236^{3}$ a. Statteriana $\times$, Veitch, ex Gard. Chron. (1893 ii. 631 ; et in Journ. of Hortic. Xxvii. (1894) 463 fig. 67 . - Hybr, artef.

Wellsiae $X$. Hort. Wells, ex Gard. Chron. (1894) ii. 378. - Hybr, artef.

\section{LAGENOPHORA}

$237^{2}$ a. Linearis, Petrie, in Trans. N. Z. Inst. xxv, 1892 (1893) 271. - N. Zel.

\section{LAGGERA}

$237^{2}$ a, arabica, Deflers, Voy, au Yémen (1889) 149 $=$ Conyza arabica, $W_{\text {illd }}$

\section{LAMIUM}

$237^{3}$ a. rumelicum, Velen. F1. Bulg. (1891) 649, in add. = amplexicaule, Linn.

Spachianum, Clem. ex Baldacci, in Malpighia, viii. (1894) $289=$ veronicaefolium, Benth.

\section{LANDOLPHIA}

2381 1. parvifolia K. Schum. in Bot. Jahrb. xv. (1892) 409 ; et.

\section{LANTANA}

2381 a coimbrensis, S, Moore in Trans, Linn. Soo. Ser. II. iv, (1895) 435. - Bras.

scabrida, S. Moore, . . c. 434. - Bras.

\section{LASERPITIUM}

2391 a. platyspermum Somm of Levier in Bull. Soc. Bot. Ital. (1895) 43, nomen; et in Nuov. Giorn. bot. Ital. Ser. II. ii. (1895) 83. Reg. Caucc.

$239^{2}$ a. LA TACE, Phil. in Gartenfl. xxxviii. (1889) $3 i 9, \mathrm{t}, 1302$, fig. 1. LILIACEAE.

Volkmanni, Phil.l. c. - Chili 


\section{LATHYRUS}

2393 1. arizonicus, Britton, in Trans. N. Y. Acad. sci viii. ( 1889$) 65 ;$; $t$...

2401 a. floribundus, Velen. Fl. Bulg. (1891) $156=$ L. Aphaca, Linn

occidentalis, Howell, in Erythea, iii. (1895) 32 - Oregon.

\section{LAVANDULA}

2402 1. canescens, Deflers, Voy. au Yémen (1889) 186 - Arabia.

\section{LAVATERA}

$240^{2}$ a. stenopetala, at Baker $f$. in Fourn. Bot. xxviii, (1890) 211 .

\section{LEAVENWORTHIA}

42:1 a. stylosa, A. Gray, ex Gatting, Teness, Fl. (1887)

torulosa, A. Gray, ex Gatting. 2. c. 23. Am. bor.

\section{LEONOTIS}

$242^{3}$ a malacophylla. Guerke, in Bot. Fahrb. xxii. (1895) 142. - Natal.

mollissima, Guerke l. c. 141. - Afr. trop.

Schinzii, Guerke, l. c. 143. - Afr. austro-occ. extratrop.

\section{LEOPOLDINIA}

- $42^{3}$ a, Laucheana, Hort, Sander, ex Gard. Chron (1892) i. 731, nomen. - Hab.?

\section{LEPIDIUM}

$243^{2}$ 1. Remyi, Drake, Ill. Fl. Ins. Mar. Pacif. (1890) 106... (non Fl. Polyn, Franc...).

\section{LEPISTEMON}

$243^{3}$ 1. asterostigma... 216 (non 217).

\section{LEPTADENIA}

$243^{3}$ a. ephedriformis, Deflers, Voy. au Yémen (1889) 166. - Arabia.

\section{LEPTOCHLOA}

$243^{3}$ a. spicata, Scribn. in Proc. Acad. sci. Phil. (1891) 302. - Am. bor.

\section{LEPTODERMIS}

$244^{1}$ a. pulchella,..., et Icon. Fl. Fap. i. I. t. 8. - Japon.

\section{LEUCERIA}

$245^{2}$ a. fasciata, Klatt, in Bot. Fahrb, viii. (1886) 51 - Ecuad.

$245^{3}$ 1. popebana... (non popelana).

\section{LEUCOIUM}

$245^{3}$ a. transsilvanicum, Porcius, in Anal. Acad. Ro mane, Ser. II, xiv. (1892) 274. - Eur. austr.

$245^{3}$ a. LEUCOPHYSALIS, Rydberg, in Mem. Torrey Bot. Club, iv. (1893) $365=$ Physalis, Linn. (Solan.).

grandiflora, Rydberg, 1. c. $366=\mathrm{P}$, grandiflora, $\mathrm{Hook}$

\section{LEUCOSMIA}

$246^{1}$ a. lanceolata, Benth. \& Hook. f. ex Drake, Ill. Ins. Fl. Mar. Pacif. (1892) 281 (= Drimy spermum lanceolatum, A. Gray). - Ins. Fiji. montana, Benth. \&o Hook. f. ex Drake, $l . c$ (= D. montanum, Seem.). - Ins. Fiji. subcordata, Benth. \& Hook. f. ex Drake, l. c $(=$ D. subcordatum, Seem.). - Ins. Fiji.

\section{LEUCOSYKE}

$246^{1}$ a. corymbulosa, Benth. \& Hook. $f$. Inon Wedd. ex Drake, Ill. Fl. Ins. Mar. Pacif. (1892) 303 (= Missiessya corymbulosa, Wedd.). - Ins. Viti.

\section{LICANIA}

$246^{2}$ 1. gracilipes... (non gracilis)

a. subcordata, Fritsch, in Oest. Bot. Zeitschr. xliv. (1894) I8. - Bras.

\section{LICUALA}

$246^{3}$ a. Kirsteniana, Hort. ex Illustr. Hortic xlii. (1895) 189. - Madag.

LIGEA

$246^{3}$ a. Glaziovii, Warm. Fam. Podost, iii. (1889) 23, t. 22, fig. 11-16, et t. 23. - Bras.

\section{LIGUSTIGUM}

$247^{3}$ a. caucasicum, Somm, et Levier, in Bull. Soc. Bot. Ital. (1895) 43, nomen; et in Nuov. Giorn, bot. Ital. Ser, ii, II. (1×95) 77 . Reg. Cauc.

\section{LIGUSTRUM}

$247^{1}$ 1. medium, Hort. ex Neuh.off. Arbor. Zösch. (1891) 15. - Japon.

\section{LILIUM}

$247^{1}$ a. Beerensi X, Hort. ex The Garden, xlviii. (1895) Il, - Hybr. artef.

$247 \approx$ a. Elisabethae, Hort. Leichtlin, ex Wien. Ill. Gart.-Zeit. xvi. (1891) 198. - Japon.

\section{LIMNANTHES}

$247^{2}$ a. Macounii, Trelease, in Mem. Bost. Soc. Nat. Hist. iv. (1888) 85 (=L. Dougiasii, Macoun) - Ins. Vancouver.

\section{LINARIA}

$248^{2}$ 1. euxina, Velen, in Ab\%. Boehm. Ges. Wiss. VII, Folge, i. $(1886)$ n. 8, p. 34 ; th...

LINDELOFIA

$248^{3}$ a. longifolia, Hort. ex Wien. Ill. Gart.-Zeit. xiii. 1888) $326=$ spectabile, Lehm.?

\section{LIPARIS}

$250^{1}$ a. minutiflora, Rolfe, in Gard. Chron. (1888) i. 75. - Hab. ?

\section{LIPPIA}

$250^{2}$ a. appendiculata, Robinson \& Greenm. in Proc. Am. Acad. xxix. (1894) 391. - Mexic.

jangadensis, S. Moore, in Trans. Linn. Soc. Ser. II. iv. (1895) 435. - Bras.

primulina, S. Moore, l. c. 436. - Bras

\section{LISSOCHILUS}

$250^{3}$ 1, barombensis... 52 (non 51 ).

$251^{1}$ 1. Stuhlmanni... 249 (non 248)

\section{LITHOSPERMUM}

$251^{3}$ l. glandulosum... 1893 (1894) xxxvii. 46 [non (1892-93) 46].

\section{LITSEA}

25:1 a. palmatinervia, Benth \& Hook $f$ ex Drake, Ill. Fl. Ins. Mar. Pacif. (1892) 278 (= Tetranthera palmatinervia, Meissn.). - Ins. Fiji.

Pickeringii, Benth. \& Hook. f. ex Drake, l. c. $(=T$. Pickeringii, A. Gray). - Ins. Fiji. Seemannii, Benth. Eo Hook. f. ex Drake, l. c. (= T.Seemannii. Meissn.). - Ins. Fiji. vitiensis, Benth. \& Hook. f. ex Drake, l. c. $(=$ T. vitiana, Meissn.). - Ins. Fiji

\section{EIVISTONA}

$252^{1}$ a. enervis, Hort. ex Wien. Ill. Gart.-Zeit. xvi (1891) 346, - Hab ?

\section{LOBELIA}

$252^{2}$ a. Deckeni, Schweinf, in Hoehnel, zum Rudolph See, App. (1892) 9. - Afr. trop

Dortmanni, Hort. Dammann, ex Wien. Ill. Gart.-Zeit. xix.(1894) $459=$ L. Erinus Linn.

$252^{3}$ a. Gerardi X, Sauvageau, in Rev. Hortic. Ixv. (1893) 519. - Hybr. artef.

Kerneri, Hort, ex Nagy, in Gartenfl. xxxviii. (1889) 302. - Costa Rica.

Telekii, Schweinf. in Hochnel, zum Rudolph See, App. (1892) $9 ;$; t...
LOGFIA

2531 a. Soyeri, F. Gérard, in Maonier Scrin. $\mathrm{fl}$ select, viii. (1889) $149=$ Filago neglecta, DC.

\section{LONIGERA}

2531 a carpatica Porcius, in Anal. Acad. Romane, Ser. II. xiv. (1892) $110=$ nigra, Linn.

$253^{2}$ a. helvet, ca X. Bruegg, in Jahresb. Naturf. Ges Graub, xxix, 1884-85 (1886) 50, - Helv.

. Korolkowii... vii. (1894) 34 |non vi. (1893) 34$]$. Hildebrandiana... (non Hildebrandtiana). muscaviensis... (non muscariensis).

a. propinqua X. Zabel, in Gartenfl, xxxviii. (1889) 580. - Hybr. artef.

$253^{3}$ a. splendens, J. L. Budd. in Gard, and For. ii 1889) $268=$ tatarica, Linn

\section{LORANTHUS}

$254^{1}$ a. arabicus, Deflers, Voy, au Yemen (1889) 197 - Arabia.

$254^{2}$ a. Dinklasei, Engl. Bot. Fahrb. xx. (1894) 94. Afr, trop.

1. Holstii... 126 (non 12\%)

$255^{3}$ a. ugogensis... 86 (non 96)

\section{LUGUMA}

$256^{2}$ 1. novo-caledonica... 516 (non 526)

\section{LUFFA}

$256^{2}$ a Forskalii, Hort, ex Bull Soc Tosc. Ortic, xviii. (1893) 12, fig. 1. - Arabia.

\section{LUPINUS}

2571 a. Pondii, Greene, in Pittonia, i. (April 1887) 288. - Calif.

\section{LUVUNGA}

$25 \%$ 1. nitida...t. 283 (non 288)

\section{LUZIOLA}

2571 a. pusilla, S. Moore, in Trans. Limn. Soc. Ser. II iv. (1895) 507 t. 37. - Bras.

\section{LYGASTE}

$25 \pi^{1}$ a. ciliata, Veitch, Man. Orch.Pl. ix. (1893) 85 (= Maxillaria ciliata, Ruiz \& Pav.). - Am. trop.

Dyeriana, Hort. Sander in Gard. Chron (1895) ii, 49. - Peruv

$257^{2}$ a. Famesiana, Hort. ex The Garden, xxxv (1889) $502=$ L. Skinneri, Lindl.

Rossiana, Rolfe, in Orchid Rev. i. (1893) 239 - Hab.

\section{LYGHNIS}

2572 a. Lagrangei, Coss. Ill. Fl. Atlant. i. (1890) 12: t. 78 (= Viscaria Lagrangei, Coss.). - Reg. Marocc.

\section{LYGORIS}

$257^{3}$ a. Terracianii, Hort. Dammann, Catal. xliv (1889) 4 = radiata, Herb.

LYONSIA

$257^{3}$ 1. pedunculata; Warb... 407.

\section{LYSIPOMA}

$258^{2}$ a. lycopodioides, Goebel, in Pfanzenbiolog. Schit derung, ii. (1891) 50. - Am. trop.

\section{LYTHRUM}

$258^{2}$ a lineare, Cosini, ex Tornab. FI. Sicula, ii (1891) $229=\mathrm{L}$. Graefferi, Ten.

\section{M}

\section{MABEA}

$258^{2}$ a crenulata, S. Moore, in Trans. Linn. Soc Ser. II. iv. (1895) 470. - Bras. 


\section{MACFADYENA}

$258^{3}$ a bipinnata S Moore, in Trans, Limn. Soc. Ser. II. iv. (1895) 418. - Bras,

pubescens, S. Moore, l. c. - Bras.

\section{2 post MACROLOBIUM, Limba, insere:}

a. MACRONEMA, Nutt. = Aplopappus, Cass. (Compos.)

Greenei, Greene, in Erythea, ii. (1894) $73=$ Aplopappus Greenei, A. Gray.

molle, Greene, 1. c. = A. Greenei, A. Gray.

pygmacum, Greene, 1. c. = A. pygmaeus, A. Gray.

Watsoni, Greene, 1. c. $74=$ A. Watsoni A. Gray.

\section{MADAROSPERMA}

2593 a. oblongum. S. Moore, in Trans. Linn. Soc Ser. II. iv. (1895) 400. - Bras.

\section{MAERUA}

2602 1. Hoehneli1... at in Hoelnel, zum Rudolph Se (1892) 15

MAESA

$260^{1}$ 1. Hernsheimiana... (non Hornsheimiana).

\section{MAGNOLIA}

260? ? spectabilis Hort, ex Handl. Trees Kew, Pt i. [Polypet.] (1894) $15=$ conspicua Salish.

stricta, Hort. 1. c. 17 = grandiflora, Linn

$260^{\circ}$ a. superba, Hort. 1. c. $15=$ conspicua, Salisb. triumphans, Hort. 1. c. = conspicua, Salisb.

MAHONIA

$260^{2}$ a. Moseriana, Moser, ex H. Martinet, in Le Jardin (1895) $128=$ Berberis Aquifolium, Pursh.

\section{MALABAILA}

2603 a vacinans, Velon in Sitzb., Boelim. Ges. Wiss. (1893) ก. xxxvii. 29 (= Pastinaca vaginans, Velen.). - Bulg.

\section{MALUS}

2622 a. Medwietzkyana, Hort. Dieck, ex Gard. Chron (1891) i. 461. - Sibiria

Soulardi, Britton, fide L. H. Bailey, in Am. Gard, xii, (1891) 173 = Pyrus Soulardi L. H. Bailey.

\section{MALVA}

$262^{2}$ a. Duriaei, Hort. Kew. ex Baker f. in fourn. Bot. xxviii. (1890) 340. - Algeria.

$262^{2}$ hastata, Hort. ex Bull. Soc. Tosc. Ortic. xviii. (1893) 108, fig. 15. - Mexic.

2622 a. liocarpa, Phil. in Anal. Univ. Chil. Ixxiii. (1893) 18. - Am. austr. ?

subacaulis, Coss. ex Baker f. in Fourn. Bot. xxviii. (1890) 340. - Marocc.

\section{MALVASTRUIM}

2623 1. sajamense... 319 (non sajanense... 318).

MAMILLARIA

2023 1. furfuracea. S. Wats. in Proc. Am. Acad. iv (1894) 130 (= Anhalonium furfuraceum Couit.) - Am. bor.

2632 Spaethiana, Hort. Spath. Cat. (1894-95), Colurado.

MANISURIS

$263^{3}$ 1. porifera, Hack... (non parifera).

\section{MAPOURIA}

2641 a corumbensis, S. Moore, in Trans. Linn. Soc Ser. II. iv. (1895) 380. - Bras. tomentella, S. Moore, l. c. 381. - Bras.

\section{MARANTA}

$264^{2}$ a. Leoniae, Hort. Sander. ex Gard. Chron. (1893) i. 751 , nomen. - Hab.

longiscapa, S. Moore, in Trans. Linn. Soc. Ser. II. iv. (1895) 486. - Bras.

\section{MARGARANTHUS}

A Mem. Torrey Bot. Club, iv. (1893) 317, - N. Mexic

\section{MARISGUS}

$265^{2}$ a, setiglumis, C. B. Clarke, ex S. Moore, in Trans. Linn. Soc. Ser, II. iv. (1895) 512. - Bras. umbilensis, $C$. Clarke, in Gard. Chron. (1891) ii. 190 (= Cyperus natalensis, Hort. AngI.). - Natal.

\section{MARLIEREA}

$265^{3}$ a cubensis, Krug \& Urb, in Bot, Falirb. xix. (1895) 589 (= Calycorectes cubensis, Griseb.). - Cuba.

Dussii, Krng \& Urb. 7. c. 590. - Ind. oOc.

Guildingiana, Krug \& Urb. l. c. 590 (= Psidium Guildingianum, Griseb.). - Ins, S. Vinc.

\section{MARRUBIUM}

$265^{3}$ 1. Aschersonii X, Magnus, in Ber. Deutsch Bot, Ges. ii. (1884) $349 ; \ldots$ Ross, in Malpighia, v. (1891) 312 ; et..

MARSDENIA

$266^{1}$ a. caulantha, S. Moore, in Trans. Linn. Soc. Ser. II. iv. (I895) 399. - Bras.

\section{MASCAGNIA}

$266^{2}$ 1. Seleriana... (non Seleroriana).

\section{MASDEVALLIA}

$266^{2}$ a. Burbidgeana, Rolfe, in Orchid Rev. i. (1893) 265. - N. Granat

fragrans, Woolward, Monog. Gen. Masdev. (1893) cum icone; et Gard. Chron. (1893) ii. 1152. - Columb.

Macvitiae $\times$, Hort. Thomson, ex Gard. Chron. (1892) ii. 744. - Hybr, artef.

Parksii X, Hort. ex Gard. Chron (1893) i. 636. - Hybr, artef.

$266^{3}$ 1. Pourbaixi... (non Pourbaisi).

a. Rushtoni $\times$, Hort. ex Orchid Rev. i. (1893) 210, - Hybr. artef.

Schroederiana, Hort. Sander, ex Gard. Chron. (1890) ii. 51 ; Fourn. of Hortic. (1890) ii. 557. fig. 74; Woolward, Monog. gen. Mastev. (1893) 143 t. 56. - Peruv.

Shuttryana $\times$, Hort. Lawrence, ex Gard. Chron. (1892) i. 764. - Hybr, artef.

\section{MASSONIA}

$266^{3}$ amyodalina, Baker, in Gard. Chron. (1889) ii. $715,-$ Afr. austr.

\section{MAVAELIA}

2672 1. metzgerioides, .. $=$ Podostemon metzgerioides. Trimen.

MAYEPEA

$267^{3}$ 1. bumeivioides... 344.

domingensis... 344 (non 44)

Welwitschii...550 (non 580).

\section{MAYTENUS}

$268^{1}$ a. Pyraster, Reiss. in Bot. Fahrb. xv, Beibl. n. 38 (1893) 8. - Bras

\section{MAXILLARIA}

$267^{2}$ a Lavrencei Krdenzl in Gard. Chron. (1895) is 324,388 = guttulata, Reich. $f$.

\section{MEDICAGO}

268" a, gaditana, Perez Lara, ex Willk. in Oest. Bot. Zeitschr, xli. (1891) S5. - Hisp.

1. rhodopea... (1893) n. xxxvii. 21 (non 31).

\section{MEDINILLA}

$268^{2}$ a. Baroni, Baker, in fourn. Limn. Soc. xxv. (1890) 317 , in obs. - Madag.

1. divaricata, Baker,...478= M. Baroni, Baker.

\section{MELAMPODIUM}

$269^{2}$ 1. longipilum... (non longifolium),
MELANDRYUM

$269^{3}$ 1. hybriaum $X$, Bruegg. in Jahresb. Naturf. Ges. Graub. xxix. 1884-85 (1886) 10 ; et. .

\section{MELANTHERA}

$270^{1}$ 1. cinerea...; et in Hochnel, zum Rudolph Sec (1892) 10。 -

\section{MELIOSMA}

$270^{3}$ a. yunnanensis, Franch, in Bull. Soc. Bot. Fr xxxiii. (1886) 465. - Yunnan.

\section{MELOCHIA}

$271^{1}$ a. corumbensis, S. Moore, in Trans. Limn, Soc Ser, II. iv, (1895 $31 \%$ - Bras.

\section{MELOTHRIA}

$271^{2}$ a a abyssinica, «Naud, 》ex Bull, Soc. Tosc. Ortic. xviii. (1893) 13 fig. 2 - Abyss.

MEMIORA

$271^{3}$ a. fallax, Bureau, ex Warm. in K. Danske Vidensk. Selsk, Kjoeb. (1893) 105 [Symb F1. Bras. centr. x1, $1220 \mathrm{j}=$ Bignonia fallax, Miers.

fulgens, Bureau, 11. cc. 1 1 6, et 1221 ; et ... magnifica, Bureau, 11. cc. = Adenocalymna magnifica, Miers.

\section{MENTHA}

2722 a. Gorroutei $\times$, Debeaux, in Maonier, Scrin fl. select. xiii, (1894) 326 ; et in Lucante, Rev. de Bot. xii, (1895) 233. - Gall. mer.

$272^{3}$ a. intricata $\times$, Debeaux, in Lucante, Rev, de Bot. xii. (1895) 235. - Gall. mer.

2732 a. Mauponii X. Gadeceau, Matér, étud Menth. Loire-Inf. (1882) 13, 14; et ex Bull. Soc éch. Dauph. xiii. (1886) 551. - Gall. occ.

$273^{3}$ a. sedunensis, Ayasse, ex Jacc. in Mém. Soc Helv, sci, nat. xxxiv, (1895) $437=$ sylvestris, $\operatorname{Linn}$.

varians $X$, Debeaux, in Lucante, Rev, de Bot. xii. (1-95) 235, - Gall.

\section{MERENDERA}

2742 1. rhodopea... 1893 (1894) n. xxxvii, 66 [non (1892-93) 66!.

\section{MERREMIA}

$274^{2}$ 1. angustifolia... (1894) 117 [non (1896) 117]

1. gallabatensis... xvii. (1894) 113

$274^{3}$ 1. MESOGYNE... 147 (non 117).

\section{MESPILUS}

2752 a, tomentosa Castigl, ex Handl. Trees Kew, Pt i. $[$ Polypet.,,$(1894) 211=$ Crataegus tomentosá, Linn

tomentosa, "Mill. » 1. c. $215=$ Cotoneaster tomentosa, Lindl.

$275^{3}$ a. MEZILAURUS, Kuntze, in Bot. Centralbl. 1. (1892) $2 \mathbf{i}=$ Silvia. Fr. Allem. (Laurin.). anacardioides, crassiramea, Ita-Uba, navalium oppositifolia, Sprucei, Taub. ex Mez, in Arb Bot. Gart. Breslau, i. (1892) $112=$ homonyma omnia Silviae.

Lindaviana, Schwacke \& Mez, 1. c. - Bras.

2761 a. MiCHELIA, Th. Dur. Ind. Gen. Phan (1888) $504=$ Lophotocarpus, Th. Dur (Alism.)

\section{MICONIA}

$276^{1}$ a. corallocarpa, S. Moore, in Trans, Linn. Soc Ser. II. iv. (1895) 363. - Bras

\section{MICRA MPELIS}

$277^{2}$ a. gilensis, Britton, in Trans. N. Y.Acad. sci. viii. (1889) 67 = Echinocystis gilensis, A. Gray

\section{MIGROGLOSSA}

$277^{3}$ a. glutinosa, Klatt, in fahrb. Hamb. Wiss. Anstalt. viii. (1891) 288. - Zanzib. 


\section{MICROSTYLIS}

278\% a, Maximowicziana. King \& Pantling, in fourn. As. Soc. Beng. lxiv. (1895) II. 329. - Sikkim.

\section{MILTONIA}

2791 a. Endresit, Nichols. Dict. Gard, ii. (1886) 368 ; Veitch, Man. Orch, Pl, viii, (1892) $101=$ Odontoglossum Warscewiczii, Reichb.

Roezlii, Nichols. 1l. cc. 369 ; et $104=0$. Roezlii, Reichb.

Schroederiana!' Veitch, 1. c. $107=$ Schroederiana, O'Brien.

\section{MIMOSA}

2792 a. pachecensis, S. Moore, in Trans, Linn. Soc. Ser. II. iv. (1895) 349. - Bras,

\section{MIMUSOPS}

2793 l. floridana... 524 (non 525).

\section{MIRABILIS}

$280^{1}$ a. Wrightiana, A. Gray, ex Britton \& Kearn. in Trans. N. Y. Acad. sci xiv. 1894-95 (1895) 28. - Arizona.

MOHRIA

$280^{3}$ a. parviflora, Britton, 1. c. $=\mathrm{H}$. tetraptera, Linn.

MOHRODENDRON

$280^{3}$ a, parriflonm, Britton, 1. c. $=\mathrm{H}$. tetraptera, Linn

\section{MOMORDICA}

$281^{1}$ a. chinensis, Hort. ex Bull. Soc. Tosc. Ortic. xviii. (1893) 14, fig. 1. - China.

enneaphylla, Cogn. in Bull. Acad. Belg. Sér. III. xvi. (1888) 238. - Congo gall.

sinensis, Hort. ex Eull. Soc. Tosc. Ortic. xviii. (1893) $14=$ chinensis, Hort.

Thollonii, Cogn. in Bull. Acad. Belg. Sér. III. xvi. (1888) 238. - Congo gall.

$281^{1}$ a. MONADENIUM, Pax, in Bot. Jahrb, xix (1894) 126. EUPHORBI ACEAE

coccineum, Pax, l. c. 12\% - Afr, trop. or.

\section{MONNIERA}

$281^{2}$ a. Brownii, S. Moore in Trans. Limn. Soc. Ser. II. iv. (1895) 502. - Bras.

\section{MONTBRETIA}

2821 a. crocosmiaeflora $\times$. Hort. Lemoine, ex Rev. Hort. liv. (1882) 124, cum ic.; et ex The Garden (1887) ii. 598 (= Tritonia crocosmiaefora, Hort.). - Hybr. artef.

\section{MONTIA}

2821 1. Chamissonis... (non Chamissoi).

2821 a. MOQUERYSIA, Hua, in Morot, Journ. de Bot. vii. (1893) 259. BIXINEAE

multiflora, Hua, l. c. 260, t. 3. - Afr. trop. occ

MORINDA

2822 1. hypotephra... ; et in Bot. Centralbl. xxxix. (1889) 237.

\section{MORMODES}

$282^{3}$ a. Lawrenceanum, Rolfe, in Lindenia, iii. (1890) 69 , t. 273. - Columb.

platychila, Rolfe, in Gard.Chron. (1887) i. 178. - Hab. ?

punctatum, Rolfe, in Gard. Chron. (1891) ii. $696 ;$ Will. Orch. Grow. Man. ed. 7 (1894) 533. - Hab. ?

vernixium, Reichb. f. in Gard. Chron. (1887) ii. 682. - Guian. brit.

\section{MORRENIA}

$282^{3}$ a. incana, S. Moore, in Trans. Linn. Soc. Ser. II. iv. (1895) $398 .-$ Bras.
$282^{3}$ a. MOSENIA, Lindm, in Konol. Svensk. Vet Akad, Handl xxiy, n. 8 (1891) 27. BROMELIACEAE.

Sicarius, Lindm. 7 . c. t. 5, fig. 1-11. - Bras.

\section{MUEHLBERGELLA}

$284^{2}$ 1. Oweriniana... 616 (non Oweriana... 615).

MUSA

$284^{1}$ a. assamica, G. Mann. ex Baker, in Hook, f. Fl Brit. Tnd. vi. (1892) 263. - Assam.

kewensis Baker, in Gard. Chron. (1895) ii 516 - Hybr, arter.

1. Mannii, H. Wendl... (1892) [non 1893].

\section{MUSCARI}

$284^{1}$ a, bulgaricum, Velen. Fl. Bulg. (1891) 55\%.Bulg.

crossaeum, Heldr cx Nadji, Géogr. bot. Emp. Ottom. [Pl. de Salon.] (1892) 7. - Maced. pyramidatum, Velen. Fl. Bulg. (1891) 556.Bulg.

Skorpili, Velen. ..c. 55\%. - Buly

Vandasii, Velen. . . c. 555. - Bulg.

\section{MYOSOTIS}

$284^{3}$ a. cintra, Hort. Conimbr. ex Bull. Soc. Tose Ortic. xv. (1890) 134, fig. 14; et in Gartenfl. xxxix. (1890) 191, fig. 4\%. - Lusit.

$285^{1}$ 1. rhodopea... (1893) n. xxxyi. 48 [non (1892-93) 48].

\section{MYOSURUS}

$285^{1}$ 1. Pringlei... (non Pringlii)

\section{MYRGXA}

2851 l. ayabambensis. (1895) 64 (non 1893). chapadensis, S. Moore, in Trans. Linn. Soc. Ser. II. iv. (1895) 355. - Bras. collina, S. Moove, l. c. 356 . - Bras

$285^{2}$ a. Govinha, S. Moore, l. c. 354. - Bras.

$285^{3}$ d. verruculata, S. Moore, l. c. 355 . - Bras. microstacliya, Picardae et reticulata Krug \& Urb. sunt Myricae species.

\section{MYRIGA}

$286^{1}$ a. microstachya, Krug \& Urb. in Bot. Fahrb. xv. (1892) 361. - Ins. Jamaic.

Picardae, Krug \& Urb. l. c. 359. - Ins. Haiti reticulata, Krug \& Urb. l. c. 360 . - Ins. S. Doming.

\section{MYRISTICA}

$286^{3}$ a. myrmecophila, Bower, in Proc Phil. Soc. Glasgow, xviii. (1889) 323, nomen. - Zeylan.

\section{MYRMECODIA}

$286^{3}$ a. Beccarii, Hook.f. in Bot. Mag. (1886) t. 6883 - Austral. trop.

\section{MYRTUS}

$288^{1}$ 1. monosperma ... = Eugenia

\section{$\mathbb{N}$}

\section{NARGISSUS}

2891 a. Barri X, Hort. ex Gard. Chron. (1886) 648. - Hybr. artef

intermedius $\times$, Hort. Dammann, Cat. (1893) 5. - Hybr. artef

\section{NARDOSMIA}

$289^{2}$ a. Sahlbergii, Scheutz, Pl. vasc. Feniss. (1888) 122. - Sibiria

\section{NAUGLEA}

2901 1. Gordoniana, F. M.-Bailey, in Bot. Bull. x. (1886 ?) 23. - Austral.

\section{NECKERIA}

$290^{3}$ a. glauca, Millsp, in Bull. West Va. Agric, Exp. Sta. ii. (1892) $327=$ Corydalis glauca, Pursh.

\section{NECKERIA}

$290^{3}$ a sempervivens, Heller, in Bull. Torrey Bot. Club, xx. (1893) $6=$ Corydalis glawca, pursh

\section{NECTANDRA}

$290^{3}$ a bombycina, S. Moore, in Trans. Limn. Soc. Ser. II. iv, (1895) 449. - Bras.

NEEA

2911 a, hermaphrodita, S, Moore in Trans. Linzi. Soc. Ser. II iv. (1895) 442. - Bras.

NEESIA

$291^{1}$ a. ambigua, Becc. Malesia, iii. (1889) 261 t. 30. - Borneo.

glabra, Becc. T. c. 263 t. 31. - Borneo.

piluliflora, Becc. l. c. 267. - Borneo.

purpurascens, Becc. l. c. 264. - Borneo

$291^{3}$ a. NEOHENRYA, Hemsl。in Bull. Torrey Bot. Club, xix, (1892) 97. APOCYNA$C E A E$.

Henrya, Hemsl. in Journ. 'Linn. Soc. xxvi. (1889) 111; et in Hook. Icon. P1, xx. (1891) t. 1971.

Augustiniana, Hemsl. in Bull. Torrey Bot. Club, xix. (1892) 97. - China.

\section{NEPENTHES}

2921 a amabilis X, Hort. Williams, Cat. (1886) 26. - Hybr. artef.

Findlayana $\times$, Hort. Williams, Cat. (1880i) 23, cum fig. - Hybr. artef.

formosa $X$, Hort. Veitch, Cat. (1895) 8. Hybr. artef.

\section{NEPHELIUN}

2922 1. oppositifoliolum... (non oppositifolium).

\section{NERINE}

2922 a Alleni $X$ tort. Allen, ex Gard. Chron. (1895) ii. 526. - Hybr. artef

angustifolia, W. Wats. in Gard. Chron. (1889) ii. 195. - Afr, austr.

pancratioides, Baker, in Gard. Chron. (1891) ii. 576. - Natal.

pumila, Leichtl. in Bull. Soc. Tosc. Ortic, xi. (1890) 73. - $\mathrm{Hab}$ ?

\section{NESAEA}

2923 a pubescens, Koehne, in Bot, Fahrb, xxii'. (1895) 149. - Madag.

1. Schinzii...; et l. c. 151

Stuhlmannii...; et l. c. 150

a. tolypobotrys, Koehne, l. c. 151. - Natal.

\section{NICOTIANA}

2932 1. uspallatensis... (non espallabensis)

NIDULARIUM

2932 a. procerum, Lindm. in Kongl. Svensk. Akad, Handl, xxiv, n. S (1891 16 t. 1 fig. 1-y = Aechmea purpurea, Baker.

\section{NOLLETIA}

294 1. arenosa... 151 (non 251 )

$294^{2}$ a. NOSTOLAGHMA. Th. Dur. Ind. Gen, Phan. (1888) 182. = LACHNOSTOMA Korth.). RUBIACEAE

NOTYLIA

$294^{3}$ a. bisepala, S. Moore, in Trans. Limn, Soc Ser. II. iv. (1895) 478. - Bras.

lyrata, S. Moore, 7.0 .477 , t. $32 .-$ Bras.

\section{NYMPHAEA}

$295^{2}$ a. Robinsoni X. Hort. ex The Garden, xliv. (1893) 29\%. - Hybr. artef

sphaerocaxpa, Hort, ex Gartenfl. xxxviii. (1889) $389=$ alba, Linn.

Trickeri $X$, Hort. ex Gard and For. vi. (1893) 464. - Hybr: artef 


\section{0}

\section{OBERONIA}

$295^{3}$ a falcata, King \&o Tantling, in Fourn. As. Soo. Beng. 1xiv. (1895) ii. 329. - Sikkim.

lobulata, King of Pantling, l. c. 331. Silkim.

longilabris, King \& Pantling, l. c. 330.Sikkim.

micrantha, King \& Pantling, l. c. - Sikkim. parvula, King \& Pantling, l.c. - Bhotan. Prainiana, King \&o Pantling, l. c. 331. Silhet.

\section{OCHNA}

$296 !$ a. comorensis, Engl. Bot. Fahrb. xvii. (1893) 81. - Ins. Comor.

corymbosa, Engl. l.c.80. - Gabon.

\section{OCHROCARPUS}

2962 a. tinctorius, “ Benth. \& Hook. f. » ex Drake, Ill. Fl. Ins. Mar. Pacif. (1890) il6 (= Calysaccion tinctorium, Seem.). - Ins. Pacif,

\section{OCIMUM}

2963 a comosum. Hort. Dammann, ex Wien, Ill. Gart. Zeit. xiv. (1889) 485 fig. 76. - Hab.?

Fischeri, Guevke.. 195.

\section{OCOTEA}

2971 1. ensifolia... 251 (non 250).

\section{OCTOMELES}

2981 1. moluccana.... 385 (non 386).

ODINA

2982 1. fulva... 103 (non I02)

ODONTITES

2982 a. aragonensis, Willk, ex Debeaux, in Lucante, Rcv. de Bot. xii. (1895) 359. - Hisp.

\section{ODONTADENIA}

$298^{2}$ 1. grandiflora, Miers, ex Kuntze, Rev. Gen. (1891) 416; K. Schum...

\section{ODONTOGLOSSUM}

$298^{2}$ a, BLeiclurocderianum X.J.\&L. Lind. in Lindenia, iv. (1888) 69. t. 177. - Hybr. spont.

Bleui X. Hort. ex L'Orchidophile, ix. (1889) 63 (= Miltonia Bleni X, Godef.-Lebœuf). Hybr. artef.

$298^{3}$ a. Cambridgeanum, Hort. ex fourn. of Hort. xvi. (1888) 411, fig. 54; Williams, Orch. Grow. Man, ed. 7 (1894) 543. - Hab.

Grusonianum X. Hort. ex. Lindenia, iv. (1888) $83=$ Andersonianum $\times$, Reichb. $\mathrm{f}$.

Cookianum, Rolfe, an Gard. Chron. (1891) 696 Will. Orch. Grow. Man. ed. 7 (1894) 547 [Hybr. spont, ?]. - N. Granat.?

euastrum, Reichb.f. in Gard. Chron. (1887) ii. 71. - Columb.

1. Lucianianum... (non Lucianum)

a. Masereelianum, Reichb. $f$. in Gard. Chron.. (1888) 1. $618=0$. Sceptrum, Reichb. $f$

ornatum, Hort. ex Wien. Ill. Gart.-Zeit. xvi. (1891) 341. Columb.

Ortgiesianum, Hort. Sander, ex Gartenfl. xl. (1891) 617 , t. 1360; Will. Orch. Grow. Man. ed. 7 (1894) 582. - Hab. ?

Peetersianum X, Hort. in Lindenia, iv. (1888) 83, nomen. - Hybr. spont.

picturatum Hort. ex Wien, Ill. Gart.-Zeit. xvi. (1891) 341. - Hab. ?

Rocbelinianum $\times$, Hort. Sander, ex Gard. Chron. (1893) i. 518. - Hybr. spont.?

rubiginosum $X, I$. Linden, in Lindenia, $x i$. (1895) 7. v. 517. - Hybr. artef.

Seringa, Hort. ex Wien. Ill. Gart.-Zeit. (1891) 341. - Columb.

Staurastrum X, Reichb. f. in Gard: Chron. (1887) i. 313. - [Hybr, spont.]. - Columb.

\section{OENONE}

2991 a. Inthurnij, Goebel, Pflanzenbiolog. Schilderung. ii. (1891) 3\%6. - Am. trop.

latifolia, Goebel, l. c. 375. - Am. trop.

leptophylla, Goebel, l. c. 37\%. - Am. trop.

\section{OLDENLANDIA}

2993 1. psychotrioides...; et in Bot. Centralbl. xxxix. (1889) 236.

OLINIA

$300^{2}$ 1. usambarensis... 278 (non 277)

\section{ONCIDIUM}

$300^{3}$ a articulatum, Rand, ex Fourn, des Orchid, iv. (1893) 95 ; et in Lindenia, v. (1889) 8 dichroneura, Rolfe, in Orchid Rev. iii. (1895) 363. - Péruv.

chrysodipterum, Veitch, Man. Orch. Pl. viii. (1894). - Am. austr.

chrysops, Reichb. f. in Gard. Chron. (1888) i. 104. - $\mathrm{Hab}$ ?

Enderianum, Hort. ex Gard. Chron. (1892) ii. 75 ; et in Kere Bull. Add. Ser. IV. 297 [Hybr. spont. ?] - Bras

lucescens, Reichb. f. in Gard. Chron. (1887) i 799; Williams, Orch. Grow. Man. ed. 7 (1894) 620. - Columb

$301^{1}$ a. unicolor, Rolfe, in Orchid Rev. i. (1893) 266 - Hab.

Wheatleyanum, W. H. Gover, in The Garden, xliv. (1893) 227: Williams, Orch. Grow. Man. ed. 7 (1894) 636. [Hybr, sfont. ?] - Bras.

\section{ONCOCALAMUS}

$30 I^{1}$ a. acanthocremis, Drude, in Bot. Fahrb. xxi. (1895) 133. - Afr. trop.

ONONIS

$301^{2}$ a. Damanti, Lojac. Fl. Sicula, i.II. (1891) 41, 309 Sicilia.

\section{ONOPORDON}

$301^{2}$ a. Gautierl, Rony, in Bull. Soc. Bot. Fr. xxxviii. (1891) p. xvi. - Pyren. gall.

OPHRYS

$302^{1}$ a. pulchra X, G. Camus, in Bull. Soc. Bot. Fr xxxviii. (1891) 43. - Gall.

\section{OPUNTIA}

$302^{2}$ 1. modesta,... (non molesta)

Cholla... (non chella).

a. lucida, Hort, ex Wien. Ill. Gart.-Zeit. xiv. (1889) 146. - Hab?

\section{ORGHIS}

$303^{1} 1$. monticola... (non monticeula).

$303^{1}$ a pyrenaica, Giraudias, in Bull. Soc. étud. sci. Angers (1890) $115=$ Gymnadenia pyre naica, Philippe.

$303^{2}$ a. Regeliana X, Bruegg. ex C. Richt. in Verh. zool.-bot. Ges. Wien, xxxviii. (1888) 230 ; C. Richt...

a. Skorpili, ...xxxvi. (1886) 267 [non xxxii. (1886) 257 .

Stracheyi, Hook. f. Fl. Brit. Ind. vi. (1890) 128; et in Hook. Icon. pl. xxii. (1894) t. 2197. - Reg. Himal.

\section{OREOPANAX}

$303^{3}$ 1. Lehmannii... Beibl. n. 49 (1895) 66 [non (1895) Beibl. 66].

$304^{1}$ a, ORESTIAS, Ridl... (non ORESTIA). [Conf. Journ. Linn. Soc. xxiv, (1888) errata].

\section{ORIASTRUM}

304 a. acerosum, Phil. in Anal. Unir. Chil. Ixxxvii. (1894) 20. - Chili.

\section{ORIGANUM}

$304^{2}$ a. Vetteri, Briq. \& Barbey, in Barbey, Karpathos (1895) 124, t. 13. - Ins. Karpathos.

\section{ORNITHOGALUM}

$304^{2}$ 1, Aseni. (non Aserni).
ORNUS

$304^{3}$ a. Ornus, Karst. Deutsch. Fl. ed. 2, ii. (1895) $624=\mathrm{F}$. Ornus, Linn.

\section{OROBANGHE}

$304^{3}$ a. atropurpurea, $H$. Gay, in Rev de Bot. x. (1892) 718; et xi. (1893) 280. - Cors., Afr. bor.

$305^{1}$ a. pruinosa, Formanek, in Verh. naturf. Ver. Brunn, xxxiii, ] 894 (1895) $139=$ prosgolica, Formanek.

prosgolica, Formanek, l.c. 158. - Epirus.

rhaetica, Bruegg in Fahresb. Naturf. Gos. Graub. xxix 1884-85 (1886) 43.- Helv.

\section{ORTHOSIPHON}

3052 a. depauperatum, Terrac in Bull. Soc. Bot. Ital. (1892) 424. - Reg. Somal.

$3.6^{3}$ a. OTOLEPIS, Turcz = Otophora, Blume [Sapind.] (fide Cl. Kuntze).

alata, cordigera, erythrocalyx, imbricata, pubescens, ramiflora, spectabilis, Kuntze, Rev. Gen. (1891) $44=$ homonyma omnia Otophorae.

amoena, Kuntze, 1.c. = Melicocca amoena Hassk.

fruticosa, Kuntze, 1. c。 = Sapindus fruticosus, Roxb.

\section{OURATEA}

$306^{1}$ a. Orovalis, S. Moore, in Trans. Linn. Soc. Ser. II iv. (1895) 334. - Bras.

purpuripes, $S$. Moore, $l$. c. 332 . - Bras.

rosipes, S. Moove, l. c. 333. - Bras.

simulans, S. Moore, l. c. 334.-Bras,

OXALIS

$307^{3}$ a. Suksdorfii, Trelease, in Mem. Boston Soc. Nat. Hist. iv.' (1888) 89. - Oregon.

\section{OXYPETALUM}

3091 a clavigerum, S. Moore, in Trans, Linn. Soc Ser. II. iv. (1895) 39\%. - Bras.

\section{OXYTROPIS}

3092 a. pentelica, Hausskn, in Mitt. Thur , Bot. Ver.v (I886) 71 ; et N. Folge, v. (1893) 82. Graecia.

\section{$\mathbf{P}$}

PAEONIA

$310^{1}$ a. Bakeri, Lynch, in fourn. Roy. Soc. Hort. xii. (1890) 441, fig. 32. - Oriens.

\section{PALAQUIUM}

$310^{2}$ 1. Ottolanderi... (non Ottelanderi)

\section{PALICOUREA}

$310^{3}$ a. jugosa, Hort. Bull. Cat. new Pl. (1886) 8. Bras.

PANAX

$311^{2}$ a. elegans, F. Muell. \& C. Moore, in C. Moove, Handb. Fl. N. S. Wales (1893) 215. Austral.

\section{PANGRATIUM}

$311^{2} 1$ Saharae, Coss ex Batt. \& Trab. in Bonnier Rev.gén. Bot.ii. (1890) 5 et in Bull. Soc. Bot. Fr. xxxix. (1892) 337 ; et...

\section{PANDANUS}

$311^{3}$ a Dyeri, Hort Sander, ex Gard. Chron. (1892) i. 731. - Austral.

pacificus, Hort. Veitch, ex Gard. Chron. (1892) i. 664. - Ins. Pacif.

Solms-Laubachii, F. Muell. in Bot. Zeit. xly. (1857) 218. - Austral.

\section{PANICUM}

3121 a. amethystinum, Franch. in Mém. Soc. hist. nat. Autun, viii. (1895) 341. - Conyo gall 


\section{PANIGUM}

3121 a. Brazzae, Franch. in Mém. Soc. hist. nat. Autun, viii. (1895) 354. - Congo. gall.

brazzavillense, Franch. l. c. 341.-Congo gall. congoense, Franch.l.c. 342. - Congo gall.

furcellatum, S. Moore, in Trans. Linn. Soc. Ser. II. iv. (1895) $5^{n} 5$ t. 34. - Bras.

Griffonii, Franch. in Bull. Soc. hist. nat. Autun, viii. (1895) 342. - Congo.

mayumbense, Franch. l. c. 343. - Congo.

1. melanostylum... (non melanotylum).

a. ogowense. Franch. in Mém. Soc. hist. nat. Autun, viii. (1895) 344. - Congo.

restioideum, Franch. l. c. 353. - Congo gall.

Tholloni. Franch. l, c. 351. - Congo

PANICULARIA

3121 a. Thurberiana, Kuntze, Rev, Gen. (1891) 783 $=\mathrm{P}$. Thurberiana, Vasey.

\section{PAPAVER}

3131 a, erucifolium, Timb, in Lucante, Rev, de Bot. x. (189:) $36=$ P. Rhoeas, Linn.

glaucum, Hort. Leichtlin, ex Gartenfl. xl. (1891) 608, fig. 116-17. - Armenia.

heterotrichum, Lojac, ex Tornab. F1. Sicula, i. (1888) $57=$ siculum, Guss.

thaticum, Leresche, ex Gremli, Excursionsfl. f. d. Schweiz, ed. 7 (1893) 66. - Helv.

1. rumelicum,... 1887 (1888) $444 ; 1889$ (1890) ii. 29 (nсn 39).

\section{PAPHINIA}

3131 a Randi I. Iinden \& Rodigas, in Lindenia, i. (1885) 65, t. 30 (= Lycaste Randi, Nichols.) $=$ cristata, Lindl.

PAROSELA

$314^{3}$ a. albiflora, A. M. Vail, in Trans. N. Y. Acad. scî. xiv. (1894) $34=$ Dalea albiflora, A. Gray.

formosa, A. M. Vail, 1. c. = D. formosa,

pogonathera, A. M. Vail, 1, c.; Heller,... Torr.

ribescens, A. M. Vail, 1. c. = D. rubescens, S. Wats.

Wislizeni, A. M. Vail, 1. c. = D. Wislizeni A. Gray.

\section{PARSONSIA}

$314^{3}$ a. Wrightii, Kearn, in Trans. N. Y. Acad. sci. xiv. (1894) $37=$ Cuphea Wrightii, A. Gray.

\section{PASSIFLORA}

$315^{2}$ a. dictyophylla... (non diethophylla).

ornithoura... (non ornitheura).

Pfordti $\times$, Hort. Kew, ex The Garden, xxxv. (1889) 572. - Hybr. artef.

Storckii, Benth. \& Hook. f. ex Drake, Ill. Fl. Ins. Mar. Pacif. (1890) 175 (= Disemma Storckii, Seem.). - Ins. Pacif

\section{PATAGONULA}

$316^{1}$ a. Glaziovii, Mez, in Bot. Fahrb. xii. Beibl. n, 27 (189u) 17. - Bras.

\section{PATOSIA}

316' 1. clandestina,... 64 (non 44)

\section{PAVONIA}

$316^{3}$ a. opulifolia, S. Moore, in Trans. Linn. Soc. Ser. II. iv. (1895) 314. - Bras.

\section{PECTIS}

$317^{1}$ a. jangadensis, S. Moove in Trans. Linn. Soc. Ser, II. iv. (1895) 389. - Bras.

\section{PEDICULARIS}

$31^{\prime 2}$ a. Canbyi, A. Gray, Syn. Fl. N. Am. ii. I. Suppl. (1886) 454. - Montana

carpatica. Simonk, in Oest. Bot, Zeitschr. xxxviii. (1888) 221 = foliosa, Linn.

$317^{3}$ a. Jankae, Steininger, in Oest. Bot. Zeitschr. xxxvi. (1886) 189. - Hung.

$318^{1}$ 1. Provosti... (non Provoti).

a. tchangchanensis, Franch. ex Maxim. in Bull. Acad. Pétersb. xxxii. (1888) 571.-China occ.

\section{PENDULINA}

$318^{3}$ a. crassifolia, Lojac. F1. Sicula, i. I. (1888) 118 $=$ Diplotaxis crassifolia, $D C$.

\section{PENNISETUM}

$318^{1}$ a. gabonense, Franch in Bull. Soc hist nat. Autun, viii. (1895) 363. - Congo gall.

indicum, Kuntze, Rev. Gen, (1891) $787=$ ty phoideum, Rich.

nodiflorum, Franch. in Bull. Soc. hist. nat. Autun, viii. (1895) 363. - Congo gall.

purpurascens, Kuntze, Rev. Gen. (1891) $787=$ compressum, $R, B r$.

yemense, Deflers, Voy. au Yémen (1889) 217 typhoideum, Rich.

\section{PENTAGLETHRA}

$319^{1}$ a. africana, Benth. ex Taub. in Engl. \& Prantl, Natïrl. Pfanzenfam. iii. 3 (1892) 125 [Ouid an $P$. macrophylla, Benth. ?]. - Afr, trop. macroloba, Kuntze, Rev, Gen. (1891) $201=$ filamentosa, Benth.

\section{PENTSTEMON}

$319^{3}$ a. Barrettae, A. Gray, Syz. Fl. N. Am. ii. I. Suppl. (1886) 440. - Oregon

đimorphus, Kuntze, Rev. Gen.(1891) 463.Am. bor. occ.

\section{PEPEROMIA}

32011 brieana. (non breeana)

a. Lehmannii, C. DC. in Bot. Fahrb. x。 (1888) 289. - Ecuad.

$320^{2}$ a. palmirensis, C. DC. l. c. 290. - Columb

pavasiana, C. DC. l.c. - Columb?

pinulana, C. DC. l. c. 289. - Guatem.

Stuhlmannii, C. DC... (1894)...(non 1892)

truncicola ... (1894)... (non 1892).

vacciniifolia,.., (non vaccinifolia).

\section{PEPONIA}

$320^{3}$ a. dissecta, Cogn. in Bull. Acad. Belg. Ser. III. xvi. (1888) 234. - Congo gall.

PERAXILLA

$320^{3}$ 1. tetrapetala... 1. c. $300=$ (L. tetrapetalus, Linn. $\left.\hat{\mathbf{x}}_{0}\right)=$ tetrasepala, Van Tiegh. l. c

\section{PEREZIA}

$320^{3}$ a. Pringlei, Robinson of Greenm, in Proc. Am. Acad. xxix. (1894) 388. - Mexic.

\section{PERISTERIA}

$321^{2}$ a. selligera, Reichb. f. in Gard. Chron. (1887) ii. 272. - Guian, ang1.

\section{PEROTIS}

$321^{3}$ 1. indica, Kuntze, Rev, Gen. (1891) 787; K. Schum..

\section{PETASITES}

$322^{1}$ a. Petasites, Karst. Deutsch. Fl. ed. 2, ii. (1889) $641=$ officinalis, Moench

\section{PETROSELINUM}

$479^{1}$ a. Petroselinum, Karst. Deutsch. F1. ed. 2, ii. (1895) 394 = sativum, Hoffm

\section{PEUGEDANUM}

$322^{3}$ a. intermedium, Porcius, in Anal. Acad. Romane, Ser. II. xiv, (1892) 108. - Europ.

1. serbicum ... ; et in Magnier. Scrin. fl. select. viii (1889) 154

\section{PFAFFIA}

$323^{1}$ a. vana, S. Moore, in Trans. Linn. Soc. Ser. II. iv. (1895) 443. - Bras.

\section{PHACELIA}

$323^{2}$ 1, idahoensis... (non idahaensis).
PHACA

$323^{1}$ a. Thurberi, Kearn, in Trans, N Y. Acad, sci. xiv. (1894) $34=$ Astragalus Thurberi, A. Gray.

$323^{2}$ a. PHAENOHOFFMANNIA, Kuntze, Rev. Gen. (1891) 940 = Pleiospora, Hary.

cajanifolia, Kuntze, 1. c. = Pl. cajanifolia, Harv.

PHAGNALON

$323^{3}$ a. harazianum, Deflers, Voy, an Yémen (1889) 150. - Arabia.

PHAIOCALANTHE

$323^{3}$ a. Arnoldiae $\times$. Hort Sander, ex Gard, Chron. (1894) i. 84. - Hybr. artef.

Berryana $\times$, Hort. Sander, ex Gard. Chron. 1895) ii. 655. - Hybr. artef.

PHAIUS

$323^{3}$ a. Cooksonae X, W. Wats. in Orchid Rev. ii. (1895) 220 ; et in Gard, and For. viii. (1895) 274. - Hybr. artef.

Gravesii X, Rob. M. Gray, in Gard. and For. vi. (1893) 169 ; et in Orchid Rev。(1893) 241, fig. 13 (Ph. hybridus, O'Brien, var Gravesii, Hort.). - Hybr, artef.

hybridus X, O'Brien, in Gard. Chron. (1892) i. 619 ; ex Will. Orch. Grow. Man, ed.' (1894) 654. - Hybr. artef.

Marthae $\times$. Hort. Sander, ex Gard. Chron. (1894) i. 343. - Hybro artef.

Oweniae, Hort. Sander, ex Gard. Chron. (1894) i. $539=$ Wallichii, Lindl.

Sanderit, Hort. Sander, ex Gard. Chron. (1892) i. 598. - Hybr. artef.

\section{PHALAENOPSIS}

$323^{3} \mathrm{a}$, alcicornis $X$, Reichb. $f$, in Gard. Chron. (1887) i. 799 |Hybr. spont.]. - Hab. ?

$323^{3}$ 1. Amphitrite...618 (non Amphitrita...619).

a. $f_{\text {fug }} \ldots . . .=$ Sarcochilus unguiculatus, Lindl. $.324^{1}$ a. Vesta X, Hort. Veitch, ex Gard. Chron. (1894) i. 343. - Hybr. artef.

\section{PHASEOLUS}

$324^{2}$ a. Dalzellianus, Kuntze, Rev. Gen. (1891) 202 $(=P$. pauciflorus, Dalz. $)$ - Ind. or.

derasus, Hort. ex Wien, Ill. Gart,-Zeit. xiii. (1888) 126. - Bras.

monospermus, Robinson of Greenm, in Proc. Am. Acad. xxix. (1894) 385. - Mexic

\section{PHILADELPHUS}

$324^{3}$ a igneus Hort ex Handl, Trees Kew, Pt i. [Polypet.] (1894) 225 = grandifforus, Wall.

$325^{1}$ a. PHILIPPIMALVA, Kuntze, Rev. Gen. (1891) 73 = Tetraptera, Phil. (Malv.). parviflora, Kuntze, 1. c. = T. parviflora, $P$ hil

\section{PHILODENDRON}

3251 a Martineti, Hort. Linden, ex Illustr. Hortic. xlii. (1895) 223. - Hab. ?

\section{PHLEUM}

3252 a phleoides, Porcius, in Anal. Acad. Romane, Ser, II. xiv. (1892) 287 = Boehmeri, Wibel.

\section{PHLOMIS}

$325^{2}$ an corace éd. 8 (1889) $680=$ P. Herba-venti, Linn. oblongifolia, Kuntze, Rev. Gen. (1891) 529 (= Leonurus oblongifolins, Blume). - Java.

PHLOX

$325^{2}$ a. atropurpurea, Hort, ex Kolb, Alpenpflanzen (1890) 209, nomen. - Hab. ?

\section{PHOLIDOTA}

$326^{1}$ 1. Lugardi... (non Lagardi), 


\section{PHORADENDRON}

3261 1. thacolulense... (non thacolulense).

\section{PHORMIUT}

"201 a. alpinum, Hort. ex Wien. Ill. Gart.-Zeit. xv. (1890) 448, nomen. - N. Caled. flaccidum. Hort. l. c. nomen, - N. Caled. Hursthonsii, Hort. l. c. nomen. - N. Caled robustum, Hort. l. c, nomen. - N. Caled.

\section{PHTHIRUSA}

3263 a abdita S, Moove in Trans. Linn. Soc. Ser. II. iv. (1894) 450 - Bras.

Bauhinae, S. Moore, l. c. 451. - Bras.

\section{PHYLLANTHUS}

3271 I humilis. (1888) 34, [non (1889) 35]

3271 a. tequilensis, Robinson \& Greenm. in Proc. Am. Acad. xxix. (1894) 392. - Mexic.

\section{PHYLLOSTEGIA}

$328^{3}$ 1. linearifolia, Drake, Ill. Fl. Ins, Mar, Pacif (1886) 47, 264 t. 20. - Ins. Pacif.

\section{PHYSALIS}

$328^{3}$ a. ciliosa, Rydberg, in Mem. Torrey Bot. Club, iv. (1893) 346. - Am. bor. or

hastata, Rydberg, l. c. 363. - Mexic

hederaefolia, Holzinger, in Contrib. U.S. Nat. Herb. i. (1892) $212=$ rotundata, Rydberg.

leptophylla, Robinson of Greenn. in Proc. Am Acad. xxiv. (1894) 389. - Mexic.

rotundata, Rydberg, in Mem. Torrey Bot. Club,

iv. (1893) 352. - Am. bor. occ.

texana, Rydberg, l. c. 339. - Texas.

\section{PHYSURUS}

3091 a. Oreadum, S Moove, in Trans, Linn. Soc. Ser. II. iv. (1895) 479. - Bras.

\section{PILOGYNE}

$330^{2}$ a puctata, Hort Dammann, ex Wien. Ill, Gart Zeit. xiv. (1889) 459, fig. $73=$ Melothria punctata, $\operatorname{Cog} n$.

\section{PILOSELLA}

$330^{2}$ a. acutilis, Norrlin, in Act. Soc. Faun. et Fl. Fenn. xii. 1. 4 (1895) 6\% - Eur. bor. adfixa, Norrlin, 1. c, 34.- Eur. bor. adjuncta, Norrlin, 1. c. 61.-Eur. bor. adtingens, Norrlin, 1. c. ii. n. 4 (1884) 165.Eur. bor.

aeruginascens, Norrlin, 1. c. $129=$ Hieracium Auricula, Linn.

ainolensis, Norrlin, 1. c. xii. n. 4 (1895) '71. Eur. bor.

albicans, Norrlin, 1. c. 8. - Eur. bor. alticeps, Norrlin, 1. c. 24. - Eur. bor. Ambusta, Norrlin, 1. c. 15. - Eur, bor amplectens, Norrlin, 1. c. ii. 4. (1884) $111=$ Hieracium auricula, Limn.

angustella, Norrlin, 1. c, = H. Pilosella, Linn.

aplotea, Norrlin, 1. c. xii. n. 4 (1895) 28.Eur. bor.

aridicola, Norrlin, 1. c. 7. - Eur. bor.

Arrhenii, Norrlin, 1. c. 68. - Eur bor.

asperula, Norrlin, 1. c. ii. n. 4 (1884) 93, 173 $=$ Hieracium Auricula, Linn.

assimilata, Norrlin, 1. c. 151. - Eur. bor.

atrobulbosa, Norrlin, 1. c. xii, n. 4 (1895) 62.Eur. bor.

atroviolascens, Norrlin, 1. c. 41. - Eur. bor, aurutenta, Norrlin, 1. c. 30. - Eur. bor. austerula, Norrlin, 1. c. ii, n. 4 (1881) 146. Eur. bor.

Bonanssonii, Norrlin, 1. c. 33. - Eur, bor. Brachycephala, Norrlin, 1. c. ii, n. 4 (1884) 97= Hieracium auricula, Linn.

calolepidea, Norrlin, 1. c. 49. - Eur. bor Ehaerophylla, Norrlin, 1. c. 48. - Eur. bor,

chrysocephala, Norrlin, ii. n. 4 (1884) $106=$

Hieracium Auricula, Linn.

chrysocephaloides, Norrlin, 1. c, $104=$ H. Auri-

cula, Linn.

\section{PILOSELIA}

$230^{2}$ a clinans, Norrlin, in Act. Soc. Faun. et F1 Fenn. xii. n. 4 (1895) 16. - Eur. bor. coacta, Norrlin, 1. c. 11. - Eur. bor. coalescens, Norrlin, 1. c. ii. n. 4 (1884) $80=$ Hieracium Pilosella, Linn.

cochlearis, Norrlin, 1. c. $100=$ H. auricula, Linn.

colobima, Norrlin, 1. C. xii. n. 4 (1895) 46. Eur bor.

concolor, Norrlin, 1. c. ii. n. 4 (1884) $120=$ Hieracium Auricula, Linn.

congregata, Norrlin, 1. c, xii. n, 4 (1895) 22, Eur. bor.

conspersa, Norrlin, 1. c. ii. n. 4 (1884) $71=$ Hieracium Pilosella, Linn.

conspersiformis, Norrlin, I. c. xii. n. 4 (1895) 16. - Eur. bor.

convexula, Norrlin, 1. c. 17. - Eur. bor. covacodes, Norrlin, 1 c. 55 - Eur bor. cuneolus, Norrlin, 1. c. 18. - Eur bor. curvescens, Norrlin, 1. c. ii, n. 4 (1884) 166.Eur. bor.

cymosa, Norrlin, 1. c. 70. - Eur. bor. denticulifera, Norrlin, 1. c. ii. n. 4 (1884) 167 Eur. bor.

deionsa, Norrlin, 1. c. $156=$ Hieracium glomeratum, Froel.

dimorphoides, Norrlin, 1. c. $133=$ H. dimorphoides, Norrlin.

discolorata, Norrlin, 1. c. $114=$ H. Auricula, Linn

distantilingua, Norrlin, 1. c. xii. n. 4 (1895) 19. - Eur. bor.

dodrantalis, Norrlin, 1. c. 23. - Eur, bor. dubia, Lindeb. ex Norrlin, 1. c. 65 . - Eur. bor

empeda, Norrlin, 1. c. 56. - Eur. bor. erythrocaulis, Norrlin, 1. c. 39. - Eur. bor. erythropoides, Norrlin, 1. c. 42. - Eur. bor. exacuta, Norrlin, 1. c. ii. n. 4 (1884) $65=\mathrm{Hie}$ racium Pilosella, Linn.

ferrea, Norrlin, 1. c. xii. n. 4 (1895) 53. Eur. bor.

fimbrillosa, Norrlin, 1. c. 24. - Eur. bor.

firmicaulis, Norrlin, 1. c. ii. n. 4 (1884) 168. Eur. bor.

fammea, Norrlin, 1. c. 140, in obs. - Eur. bor,

flavella, Norrlin, 1, c. 17. - Eur. bor.

flexipes, Norrlin, 1, c. 15. - Eur. bor.

Alontenta, Norrlin, 1. c. 12. - Eur. bor.

fuliginea, Norrlin, 1. c. 66. - Eur. bor.

galactina Norrlin, 1. c. ii. n. 4 (1884) $154=$ Hieracium glomeratum, Froel.

gorkense, Norrlin, 1. C, xii. n. 4 (1895) 52.Eur. bor.

grisea, Norrlin, 1. c. ii. n. 4 (1884) $155=$ Hieracium glomeratum, Froel.

hadromera, Norrlin, 1. c. xii. n. 4 (1895) 10. Eur. bor.

Hilmae, Norrlin, 1. c, ii, n. 4 (1884) $70=$ Hieracium Pilosella, Linn.

hivticola, Norrlin, 1. c. 139, in obs. - Scand hollolensis, Norrlin, 1. c. $85=$ Hieracium auricula, Limn.

hypopta, Norrlin, 1. c. xii n. 4 (1895) 26. Eur. bor

hypoptella, Norrlin, 1. c. 26. - Eur. bor

illudens, Norrlin, 1. c. 66. - Eur bor.

immigrata, Norrlin, 1. c. 60. - Eur. bor. impallescens, Norrlin, 1. c. 20. - Eur, bor inclinans, Norrlin, 1. c. 32. - Fennia. incrassata, Norrlin, 1, c. ii. n. 4 (1884) 145. Eur. bor.

infecta, Norrlin, 1. c. xii. n. 4 (1895) 20.Eur. bor.

infidula, Norrlin, 1. c. 59. - Eur. bor.

iuterrupta, Norrlin, 1. c. 37 , in syn, = suecica, Fries.

irrubescens, Norrlin, 1. c. 566. - Eur. bor.

jodolepis, Norrlin, 1. c. ii. n. 4 (1884) $82=$ Hieracium Pilosella, Linn.

kavelica, Norrlin, 1. c. $138=$ Hieracium onegense, Norrlin.

Kihlmani, Norrlin, 1, c, xii. n, 4 (1895) 50.Rossia.
PILOSELLA

$330^{2}$ a. ladogensis, Norrlin, in Act. Soc. Faun, et Fl. Fenn. ii, n. 4 (1884) $136=$ Hieracium onegense, Norrlin.

lagarotis, Norrlin, 1. c. xii. n. 4 (1895) 47. Eur. bor.

laticeps, Norrlin, 1. c. ii, n. 4 (1884) $57=$ Hieracium Pilosella, Linn.

laxipes, Norrlin, 1. c. xii. n. 4 (1895) 22.Eur. bor.

lenifolia, Norrlin, 1. c. 78. - Eur. bor.

liridipes, Norrlin, 1, c. 28. - Eur. bor.

lychnea, Norrlin, 1. c. 52. - Ross, bor

Tygaea Norrlin, lo 25 - Eur bor.

lygodes, Norrlin, 1. c. 58. - Eur, bor.

maura, Norrlin, 1. c. 10. - Eur. bor.

melanophaea, Norrlin,"1. c. 52. - Eur. bor.

mollipes, Norrlin, 1. c. ii n.4(1884) $66=$ Hieracium Pilosella, Linn.

neglecta, Norrlin, 1. c. 169. - Eur. bor.

nemophila, Norrlin, 1. c. xii. n. 4 (1895) $46=$ nemoricola, Norrlin.

nemoricola, Norrlin, 1. c. 80, in add. - Eur. bor. nigella, Norrlin, 1. c. ii, n.4 (1884) $112=\mathrm{Hie}-$ racium Auricula, Linn.

obovalis, Norrlin, 1. c. xii. n. 4 (1895) 13:Eur. bor.

obscuripes, Norrlin, 1. c. ii. n. 4 (1884) $73=$ Hieracium Pilosella, Linn.

oenea, Norrlin, 1.c. xii. n. 4(1895) 39.-Eur. bor. onegensis, Norrlin, 1. c. ii, n. 4 (1884) $131=$ Hieracium onegense, Norrlin.

papyrodes, Norrlin, 1. c. xii. n. 4 (1895) 45. Eur. bor.

paroica, Norrlin, 1, c. 34, - Eur. bor.

pericausta, Norrlín, 1. c. 49. - Eur. bor.

phacostigma, Norrlin, 1. c. 41. - Eur. bor.

phlebophylla, Norrlin, 1. c. 38. - Eur. bor.

pinguescens, Norrlin, 1. c. 23. - Eur. bor.

pilipes, Norrlin, 1. c. ii. n. 4 (1884) $141=$ Hieracium pilipes, Sail.

plebeja, Norrlin, 1. c. xii. n. 4 (1895) 78. Eur. bor.

prasinata, Norrlin, 1, c. ii, n. 4 (1884) $78=$ Hieracium Pilosella, Linn.

prasiniza, Norrlin, 1. c. xii. n. 4 (1895) 9.Eur. bor.

pratensis, Norrlin, 1. c. ii. n. 4 (1884) $139=$ Hieracium pratense, Tausch.

privigna, Norrlin, 1. c. xii. n. 4 (1895) 35.Eur. bor.

progenita, Norrlin, 1. c. ii. n. 4 (1884) $87=$ Hieracium Pilosella, Linn.

protuberans, Norrlin, 1. c. xii. n. 4 (1895) 57. - Eur. bor.

pruinosa, Norrlin, 1, c. ii, n, 4 (1884) 57. Eur. bor.

Pseudo-Blyttii, Norrlin, 1. c. ii, n. 4 (1884) 124 $=$ Hieracium Auricula, Linn.

pubescens, Norrlin, 1. c. 169. - Eur. bor.

pulvinata, Norrlin, 1. c. $127=$ Hieracium Auricula, Linn

reflexa, Norrlin, 1. c. xii. n. 4 (1895) 29. Eur. bor.

remotula, Norrlin, 1. c. 14. - Eur. bor.

retractata, Norrlin, 1. c. 7\%, - Fennia.

rhyponta. Norrlin, 1. c. 54. - Eur. bor.

Saelani, Norrlin, 1. c. ii. n. 4 (1884) $121=$ Hieracium Auricula, Linn.

salebrata, Norrlin, 1. c. xii. n. 4 (1895) 9 (= P. salebrosa, Norrlin). - Eur. bor.

salebrosa, Norrlin, 1. c. 9, in syn. = salebrata, Novilin.

septentrionalis, Norrlin, 1. c. ii. n. 4 (1884) $147=$ Hieracium praealtum

sigmoidea, Norrlin, 1. c. $63=\mathrm{H}$. Pilosella, Linn.

signifera, Norrlin, 1. c. xii. n. 4 (1895) 70. Eur. bor

sphacelata, Novilin, 1. c. ii. n. 4 (1884) 162. Eur. bor.

squarrosula, Norrlin, 1. c. xii. n. 4 (1895) 32.Eur. bor.

stemmatina, Norrlin, 1. c. 61. - Eur, bor.

stenomera, Norrlin, 1. c. 57 = irrubescens, Norrlin. 
PILOSELLA

$330^{2}$ a. straminea, Norrlin, in Act. Soc. Faun, et F1 Fenn, ii, n. 4 (1884) $61=$ Hieracium Pilosella, Linn.

subcurvescens, Norrlin, 1. c. xii. n. 4 (1895) 69 - Eur. bor.

subfuscata, Norrlin, 1. c. 61. - Eur. bor. subprasinata, Norrlin, 1. c. 21. - Eur. bor. sutupratensis, Norrlin, 1. c. ii, n. 4 (1884) 102

$=$ Hieracium Auricula, Linn.

subpubens, Norrlin, 1. c. xii. n. 4 (1895) 43. Eur. bor.

subswivensis, Norrlin, 1. c. 45. - Eur. bor. suburnigera, Norrlin, 1. c. 19. - Eur. bor, suivalensis. Norrlin, 1. c. ii. n. 4 (1884) $84=$ Hieracium Pilosella, Linn.

suomensis, Norrlin, 1. c. 163. - Eur. bor. syrjaenorum, Norrlin, 1. c. xii. n. 4 (1895) 74 - Ross. bor

tenebricans, Norrlin, 1. c. 55. - Eur. bor. tenerescens, Norrlin, 1. c. 64. - Eur, bor. tenuilingua, Norrlin, 1. c. ii. n. $4(1884) 75=$ Hieracium Pilosella, Linn.

tenuirhiza, Norrlin, 1. c. xii. n. 4 (1895) 3. Eur. bor.

Thedenii, Norrlin, 1. c. 31. - Suecia. tremipes, Norrlin, 1. c. 7. - Eur. bor. trochocnemia, Norrlin, 1. c. 14. - Eur. bor. urnigera. Norrlin, 1. c. ii. n. 4 (1884) $\% 6=$ Hieracium Pilosella, Linn

valens, Norrlin, 1. c, xii. n. 4 (1895) 8. Eur. bor.

ventricosa, Norrlin, 1. c. ii, n. 4 (1884) $109=$ Hieracium Auricula, Linn.

viridicans, Norrlin, 1. c. xii. n. 4 (1895) 11. Eur. bor.

viridilivens, Norrlin, 1. c. 27. - Eur. bor.

vitilis, Norrlin, 1. c. 29. - Eur. bor.

xanthostigma, Norrlin, 1. c. 42. - Eur. bor.

\section{PINGUICULA}

$331^{2}$ a. variegata. Arv.-Touv, Monog. Pilos. et Hier. Dauph. add. (1880) 54. - Gall.

\section{PINUS}

$331^{2}$ a. pindica, Formanek, in Deutsche Bot, Monatsschr. viii. (1890) 68 [pindicus]. - Thessal.

\section{PIPER}

$331^{2}$ a borbonense, C. DC. in Bot. Fakrb. xix: (1894) 224.

daguanum, C. DC. l. c. x. (1888) 288. Columb.

PISONIA

$332^{3}$ a. rostrata, Warb, in Bot. Fahrb. xiii, (1891) 304 $-\mathrm{N}$. Guin.

\section{PITHECOLOBIUM}

$333^{2}$ a. Kubaryanum, Warb. in Bot. Fahrb. xiii. (1891) 335. - N. Guin.

\section{PLAGIOBOTRYS}

$334^{1}$ a. Jonesil, A. Gray, Sym. Fl. N,Am, ii. [Suppl.] (1886) 43). - Calif.

\section{PLANTAGo}

$334^{1}$ 1. collopubens... (non collipubens)

\section{PLATANTHERA}

3342. 1. natalensis... (1895) [non 1894].

a. subalpina, Bruegg. in Jahresb. Naturf. Ges. Graub. xxix. 1884-85 (1886) $120=$ Habenaria bifolia, $R, B r$.

\section{PLATYCLINIS}

$334^{3}$ a uncata, $N$ E Br. ex Williams, Orch Growe. Man. ed. 7 (1894) 680 (= Dendrachilum uncatum, N. E. Br.). - Ins. Philipp.

\section{PLEGTRANTHUS}

$335^{1}$ a. haciensis, Scliweinf, in Wien, Ill. Gart.-Zeit. xix. (1894) 2. - Arabia.

1. hylophilus... 203 (non 283)

melanocarpus... 200 (non 310).

3352 Schweinfurthii, Sprenger, in Wien. Ill. Gart.Zeit. xix. (1894) 1. - Arabia.

\section{PLEGTRONIA}

$335^{3}$ a. flavida, Benth. Eo Hook, f. ex Drake, Ill. Fl. Ins. Mar. Pacif. (1890) 194 (= Canthium flavidum, Seem.) - Ins. Fiji. sessilifolia, Benth. of Hook. f. ex Drake, l. c. (=C. sessilifolium, A. Gray $),-$ Ins. Fiji.

PLEIONE

$336^{1}$ a. concolor, Hort. ex Williams, Orch. Grow, Man. ed. 7 (1894) 681. - Ind. or.

\section{PLEURANDRA}

$336^{l}$ a. Seemanni, Benth, \& Hook. f. ex Drake, Ill. Fl Ins. Mar, Pacif. (1890) 183 (='Nesopanax witiensis, Seem.). - Ins. Pacif.

\section{PLEUROTHALLIS}

$336^{2}$ a. Banoril Rolfe ex Britton, in Mem. Torrey Bot. Club, iv, 2 (1895) 261. - Bolivia

Brittoniana, Rolfe, l. c. 260, - Bolivia.

Kraenzlini, Hort. Sander, ex Gard. Chron. (1894) ji. 103. - Hab.

$336^{3}$ a. picta, Rolfe, in Gard. Chron. (1887) ii. 431. Guian, angl.

platystachys, Regel, in Gartenfl.xxxvii. (1888) 459. - Bras.

Rusbyi, Rolfe, in Mem. Torrey Bot. Chub, iv. 2 (1895) 260, - Bolivia

scaberula, Rolfe, I. c. - Bolivia.

\section{PLUMBAGO}

3371 a. denticulate St Lager, in Cariot, Étud. des $\mathrm{fl}$. éd. 8 (1889) $690=$ europaea, Linn.

\section{PODAGHAENIUM}

$337^{3}$ a. andinum, Ed. André, in Rev. Hortic. Ixiv. (1892) 414, fig. 122-26. - Columb.

$338^{1}$ a. POGOCHLOA, S. Moore, in Trans. Linn. Soc. Ser. II. iv. (1895) 509* GRAMINEAE brasiliensis, S. Moore, l. c. t. 37. - Bras.

\section{POLYGYCNIS}

3391 1, Lehmanni.... ; et in Gard. Chron. (1895) ii. 245 , cum fig.

POLYGALA

$339^{3}$ a. hygrophiloides, S. Moore, in Trans. Linn. Soc. Ser. II. iv. (1895) 308, - Bras.

\section{POLYGONATUM}

$341^{3}$ a. hybridum $X$, Bruegr in Jahresb. Naturf. Ges. Graub, xxix, 1884-85 (1886) 115. Helv.

intermedium $\times$, Bruegg. 1. c, 116 (= Convallaria intermedia, Boenn.), - Eur. centr.

\section{POLYGONUM}

$34 \mathrm{I}^{1}$ a. convolvuloides $\times$, Bruegg. in Jahresb. Naturf. Ges. Graub. xxix. 1884-85 (1886) 102. Helv.

\section{POLYMERIA}

$341^{2}$ a. occidentalis, F. Muell. Sec. Cens. Austral. Pl. (1889) 160. - Austral.

\section{POLYSTAGHYA}

3421 1. Lawrenceana... (non Laurenceana).

$342^{3}$ 1. POMMERESGHEA...(non POMMERE SCHIA

\section{PORTULACA}

$343^{2}$ a. somalica, N. E. Br. in Gard. Chron. (1886) ii. 134. - Reg. Somal.

\section{POTENTILLA}

$344^{1}$ a. Besseri, Blocki, in Bot. Centralbl. (1889) 202. Helv.

$345^{1}$ a. Pseudopilosa, Porcius, in Anal. Acad. Romane, Ser. II. xiv. (1892) 80. - Europ.

Reverchoni, Siegfr. ex Debeaux, in Lucante, Rev, de Bot, xii. (1895) $350=$ alpestris, Hall. $f$.

\section{POTENTILLA}

$345^{2}$ ], subnivalis $X$, Bruegg, in Jahresb. Naturf. Ges. Graub. xxix。 I884-85 (1886) 17 ; M. Besse,

subternata $\times$, Bruegg. 1. c. - Helv

Tinei, Tod. ex Lojac. Fl. Sicula, i. II. (1895) 197 = parviflora, Dest

varnensis, Velen, in Sitz. Boelim. Ges, Wiss.

1894 (1895) n。 xxix, 13. - Bulg.

\section{POTERIUM}

$345^{3}$ I, rhodopeum... (1894) n. xxxvii. 27 [non (189293) 27].

POTHOS

$345^{3}$ a. nigricans, Hort. ex Catal. Compt. contin. d'hortic. (1886) 8. - Hab.

POUTERIA

$345^{3}$ a. Weddelliana, Pierre, Not. bot. Sapot. (1891) 45. - Guian.

\section{POUZOLZIA}

$345^{3}$ a, arabica, Deflers, Voy, an Yémen (1889) 206, Arabia.

\section{PRASOPHYLLUIM}

$346^{1}$ a. apostasioides, F, Muell. Sec. Cens, Austral. Pl 1889) 190. - Austral

\section{PRESTONIA}

$346^{2}$ a. Evansii, S. Moore, in Trans. Linn. Soc. Ser II. iv. (1895) 395. - Bras.

\section{PRIMULA}

$346^{3}$ a, Churchilii, Gusm. ex Kolb, Alpenpflanz (1890) 236. - Eur. centr.

Cottia, Widmer, in Flora, 1xxii. (1889) '71. Eur. alp. cott.

cridalensis, Gusm, l. c. 237. - Tirol.

3471 a. decipiens, Stein [ubi?] ex Kolb, Alpenpflanz. (1890) 238 - Pedem

deorum, Volen. in Sitz. Boehm. Ges. Wiss. (189(1) 55 ; et Fl. Bulg. (1891) 479. - Bulg.

1. exjoua, Velen, in Abri. Boehm. Ges. Wiss, vii Folge i. (1886) n. 8, p. 38 ; et. .

Laeschkeana, A. Kєrn. [ubi ?] ex Kolb. Alpenzpflanz. (1890) 263. - Reg. Himal.

Lebliana $\times$, Gusm. ex Kolb, Alpenpflanz (1890) 246. - Eur, centr.

$347^{2}$ a. penduliflora, A. Korn. ex Kolb, Alpenfflanz. (1890) 252. - As. centr.

Schmidelyi $\times$. Gremli, Excurs. Fl. Schweiz. ed. 7 (1893) 344. - Helv.

Sturii X, Schutt [ubi ?] ex Kolb, Alpenpflanz. (1890) 256. - Stiria.

1. vockinensis, Gusm. ex Kolb, Alpenpflanz. (1890) 259 ; et...

\section{PRIMULINA}

$347^{2}$ a. sinensis, Hook. f. in Bot. Mag. (189J) t. '7117 $=\mathrm{P}$. Tabacum, Hance.

$348^{1}$ a, PRUMNOPITYS

elegans, Phil... (Ind. Kew. ii. 634) = Podocarpus alpina, $R . B r$

\section{PSIDIUM}

3501 a insulincola S. Moore, in Trans, Linn. Soc Ser. II. iv. (1895) 353. - Bras. tripartitum, S. Moore, l. c. - Bras

\section{PSYGHOTRIA}

$35 \mathrm{~L}^{3}$ a homoplastica, S. Moore in Trans, Linn. Soc Ser. II. iv. (1895) 378, t. 26, - Bras.

Oreadum, S. Moore, l. 6. 376. - Bras. sciaphila, S. Moore, l. o. 379. - Bras.

\section{PTEROSTYLIS}

3521 a pedaloglossa, Fitzg. Austral. Orchids, ii. Part. 3 (1887). - Austral.

PUELIA

$352^{3}$ 1. ciliata... et Bull. Soc. IIist. nat. Autun, viii. (1895) 386 . 
PUELIA

3523 1. occidentalis, Franch. ex Th. Dur. \& Schinz, Consp.Fl. Afr. v. (1895) 545, sphalm. = ciliata, Franch

PULICARIA

$: \because 52^{3}$ a. Ehrenbergiana, Sch. Bip. ex Defers, Voy. au Yémen (1889) 152. - Arabia.

\section{PULMONARIA}

35:3 a dacica, Porcius, in Anal. Acad, Romane, Ser. II. xiv. (1892) 214. - Europ.

PULSATILLA

35.31 a. balkana, Velen. F1. Bulg. (1891) 63\%, in add. - Bulg

Pulsatilla Karst. Deutsch. Fl. ed. 2, ii

(1895) 95 = Anemone Pulsatilla, Linn.

nubra, St Lager, in Cariot, Etud. des $\mathrm{f}$, éd. 8 1889) $14=$ A. Iubra, Lam.

PYRETHRUM

$354^{\prime}$ a glanduliferum, Somm. \& Lerier, in Nuov. Giorn. Bot. Ital, Ser. II. ii. (1895) 87 . Reg. Cauc.

olivieri. Chab, in Bull. Soc. Bot. Fr. xxxviii. (1891) 386. - Algeria.

\section{PYRUS}

$354^{3}$ a. tartarica, Hort. ex Handl. Trees Kew, Pt [Polypet.] (1894) $179=$ baccata, Linn.

\section{$Q$}

\section{QUERCUS}

(3).) 1 a. Chapmani... (non Chapmanni).

352 I. Fragnus, Lonoo in Bull. Natural. Sicil. i. (1856) n. 6; Borzi, in Malpighia, ii. (188889) 267 ; et.

a. Grisebachii, Kotschy, Mattei \& Baldacci, ex Baldacci, in Malpighia, v. (1891) 80, et viii. (1894) 296. - Albania

kabylica X, Trab, in Assoc. Franc. avanc. sci. Paris (1889) 506; Batt. \& Trab. F1, de l'Algér. (1890) 822. - Algeria.

longiglans. Debeaux, in Lucante, Rev. de Bot. xii. (1893) $254 \quad(=$ Q. microcarpa, Lapeyr. $=$ O. Robur, Linn.

$355^{3}$ a. Schochiand $X$. Dieck, Cat. Arbor. Zuesch. (1892) 26. - Hybr. artef.

\section{$\mathrm{R}$}

\section{RADIOLA}

$356^{3}$ a. Radiola, Karst. Deuisch. Fl. ed. 2, ii. (1895) $147=$ R. Linoides, Roth

\section{RANDIA}

(j.). 1. Harveyi, Benth. \& Hook. f. ex Drake, Ill Fl. Ins, Mar. Pacif. (1890) 191 (= Styloco ryne Harveyi. A. Gray); et... - Ins. Fiji. odorata, Benth. of Hook. f. ex Drake, l. c. (= Canthiopsis odorata, Seem.). - Ins. Fiji.

\section{RANUNGULUS}

3573 a. Freynianus, Velen. in Abh. Boehm. Ges. Wiss. 1893 (1894) n. xxxvi1. 3. - Bulg.

3is' a. Meyeri X. Bruegr, in Jahresb. Naturf. Ges. Graub. xxix. 1884-85 (1886) 3.- - Helv. subhirsutus $\times$. Bruegg. 1. c. 2. - Helv

\section{RAPHANISTRUM}

".5 g- a, Raphanistrum, Karst. Deutsch. F1. ed, 2, ii $(1895)=$ Raphanus Rilphanistrum, Linn.

$3 \% \div$ a. RAPHIOLEPIS

integerrima. Hort. ex Handl. Trees Kew, Pt i. [Polypet.] (1894) $217=$ japonica, Sieb.

\section{RAUWOLFIA}

$358^{3}$ a. mollis, S. Moore, in Trans. Limn. Soc. Ser. II iv. (1895) 393. - Bras.

\section{REAUMURIA}

3591 1. reflexa,...; et in Mém. Soc. Natur. Kiew, xi. (1891) 7 ?

3592 a. REIMBOLEA, Debeaux, in Rev, de Bot. viii. (189, $) 266=$ Echinaria, Desf (Gramin.).

spicata, Debeaux, 1. c. = E. spicata, Debeaux.

\section{RENANTHERA}

$359^{3}$ a. striata, Rolfe, in fourn. of Hort. xxiv. (1892) 275, fig. 45; in Bot. Mag. (1892) t. 7233 Williams, Orch. Grow. Man. ed. 7 (1894) 696. - N. Granat.

\section{RENEALMIA}

$359^{3}$ a: follosa, S. Moore, in Trans. Linn. Soc. Ser. II. iv, (1895) 482 - Bras.

Holdenii, S. Moore, l. c. 483. - Bras.

\section{RHAMNUS}

$360^{3}$ a ovalifolia Hort ex Handl Trees Kew Pt [Polypet. $\rceil$ (1894) '71 = hybrida, L'Hérit.

pedunculata, Hort. 1. c. $69=$ californica Escin.

sibirica, Hort. 1. c. $71=$ R. Frangula, Limn

\section{RHEEDIA}

$361^{1}$ a. Guacopary, S. Moore, in Trans. Linn. Soc. Ser. II. iv. (1895) 31\%. - Bras.

\section{RHIPSALIS}

$36 \mathbf{1}^{2}$ a cribrata Ruempl. in Foerst.-Ruempl, Handb. Kakteenk. (1885) $889=$ cribrata, Lem.

\section{RHODODENDRON}

Cat. (1887) 11. - Form hort.

$362^{2}$ 1. Fauriei.,. (non Fauriae)

a. Luscombei X. WV. Watson, in Gard. Chron. (1892) i. 780. - Hybr. artef.

\section{RHODOSPATHA}

$363^{1}$ a. picta, Nichols. Dict. Gard. iii. (1886) 457, in obs, - Am. austr.

RHUS

$363^{2}$ a. Michauxii, Sarg. in Gurd, and For, viii. (1895) 404, fig. 55. - Am. bor

frutescens, Hort. ex Handl. Trees Kew, Pt i. [Polypet.] (1894) $103=$ typhina, Linn.

\section{RHYNGHANTHERA}

$363^{2}$ a. Jeucorrhiza, S Moore, in Trans, Linn. Soc. Ser. II. iv. (1895) 359 [Rhyncanthera]. Bras.

riparia, S. Moore, l. c. 36 ). - Bras

\section{RHYNGHANTHUS}

$363^{2}$ 1. longitlorus... (non longifolius)

\section{RHYNCHOLACIS}

$363^{3}$ a. applanata, Goebel, Pfanzenbiol. Schilderung. ii. (1891) 377. - Bras.

macrocarpa, Tul. ex Goebel, $l, c .378$ - Bras. squamulosa, Tul. ex Gocbel, l. c. 379. - Bras.

\section{RIBES}

$364^{1}$ a. Bridgesii, Hort. ex Handl. Trees Kew, Pt i. [Polypet.] (1894) $237=$ villosum, Gay. curneum. Hort. 1 c. $235=$ sanguineum, Pursh.

Lavollei, Hort, 1. c. 237 = villosum, Gay.

Londonianum, Hort. 1: c. 231 = Gordonianum, Lem.

robustum, Hort. 1. c. 235. - Hab. ?

1. sardoum... (1894) [non 1895]

utahense, Hort, ex Handl. Trees Kew, Pt i. [Polypet.] (1594) 231 = aureum, Pursh.

\section{ROBINIA}

$365^{3}$ a. glomerata, Hort, ex Handi. Trees Kew, Pt i. [Polypet.] (18:4) 123 = Caragana microphylla, Lam.

myrtifolia, Hort. 1. c. $119=\mathrm{R}$. Pseudacacia Linn.

sinensis, Hort. ex Handl. Trees Kew, Pt i Polypet.| (1894) $123=$ Caragana frutescens, $D C$.

\section{ROETTLERA}

$365^{1}$ a. Kinnearii, F. Muell. in Vict. Natural. iji (1887) 159. - Austral

\section{ROLLINIA}

$366^{2}$ a. incurva, $S$, Moore, in Trans, Iinn, Soc Ser. II. iv. (1895) 313 . - Bras.

\section{ROSA}

$366^{3}$ a. affinita, Puget, ex H. Braun, in Verh. zool. bot. Ges. Wien, xxxv, 1885 (1886) $96=$ canina, Linn.

almeriana, Rouy, Excurs, bot. Espagne. ii. (1882-83) 66. - Hisp.

alpiniformis, Haynald, ex Borb. in Magyar Alsad. Termész. Közlem. xvi. (1880) 5:6= alpinoides, Déségl.

amblyphylla, Rip. ex Déségl. in Bull. Soc. bot. Bely. xv. (1876) $380^{\circ}=$ canina, Linn. amurensis, Crép. in Bull. Soc. bot. Belg. xiv. (1875) $6=$ acicularis, Lindl.

annoniana, Puget, ex H. Braun, in Verh. zool.-bot. Ges, Wien, xxxv. (1885) $95=$ canina, Linn.

appennina, Borb. in Magyar Akad. Termész. Közlem. xvi. (1880) 317, $366=$ gallica, Linn.

Aschersoniana, Crép. in Bull. Soc. bot. Belg. xv. $(1876) 5 \mathrm{l}, 53$, in obs. = californica, Cham Eo Schlecht.

asperifolia, Borb. in Magyar Akad. Termész. Közlem. xvi. (1880) 443, $462=$ glauca Vill.?

assurgens, Vukot, in Rad. Jugos. Akad. Zagreb, Ixxxiii. II. (I886) 9, ex A. Kern. Sched. Fl. Austro-Hung. v. (1888) $3=$ hybrida, Sclleich.

Baenitzii, Christ, in Flora, 1x. (1877) 404, in syn.: ex Nym. Consp. F1. Eur, ii. I. (1889) $116=$ pomifera, Herrm.

belgradensis, Pancic, FI. Belgrad. (1865) 130; ed. 2 (1878) 2:31 = rubiginosa, Linn.? Bernardii, Moutin, in Bull. Soc. éch. pl. Dauph. xiii. (1886) $547=$ rubiginosa, I inn. Billotiana, Crèp. in Bull. Soc. bot. Belg. xxi. I. (188:) $89=$ tomentosa, $S m$.

bohemica, H. Braun in Verh. zool.-bot. Ges. Wien, xxxv. (1885) 79; et in A. Kern. Sched. Fl. Austro-Hung. v. (1888) $20=$ canina, $\operatorname{Lin} n$.

borbonica, Hort, Monac. ex Annal. de Gand, ii. (1846) t 42 ; Dippel, Handb. Laubholzk i $1 .\left(18^{\prime}\right) 3$ ) $56: 3=$ chinensis, 7 aca.

budensis, Borb. in Magyar Akad. Termész. Közlem. xvi. $(1880,388,391=$ canina, Limn.

Buziae, Borb. ex H. Braun, in Termésetvizsgalok, xxiii. 75 ; ex A. Kern. Fl. AustroHung, v. (18S8) 12 in obs = canina, I inn. $368^{1}$ a. Camellia Hort. ex Handl. Trees Kew, Pt i. [Polypet.] (1894) I71 = laevigata, Michx. camelliaefolia, Hort. 1. c. = laevigata, Michx. chlorocarpa, Fenzl \& I-I. Braun, ex H. Braun, in Verh. zool,-bot. Ges. Wien, xxxv. (1885) $65=$ phoenicia, Boiss.

cimelium $X$, Kmet, in Oswald, Almanach (1893) 167. - Hung

cistiflora, Hort. ex Handl. Trees Kew, Pt i. i. [Polypet.] (1894) $175=$ spinosissima, Linn.

conjuncta, Crép, in Bull. Soc, bot. Belg. xxi. (1882) $58=$ canina, Linn

Comazi, Gremli, in Neue Beitr. Fl. Schweiz. iv. (1887) 97 = elliptica, Tausch.

cujavica, Spribille, in Bot. Abth. Nat. Ver. Posen, ii. (1895) $5=$ omissa, Déségl. 


\section{ROSA}

$368^{1}$ a. cymelliflora, Borb̆. Ev Vukot. in Oest. Bot. Zeitschr, xxxiv, (1884) 449. - Hung.

dilucida, Déségl, \& Ozanon, in Bull. Soc. éch. pl. Dauph. ix. (1882) $372=$ canina, Linn.

diplacantha, H. Braun, in Verh. zool-bot. Ges. Wien, xxxv. (1885) 114 = glandulosa, Bell.

Dollineriana, J. B. Keller, in Halácsy et $\mathrm{H}$. Braun, Nachtr. Fl. Nied. Oest. (1882) 267 = canina. Linn.

etrusca, Borb. in Magyar Akad. Termész. Közlem. xvi. (1880) $356,366=$ gallıca, Linn.

euvestita, Borb., 1. c. $508,517=$ tomentosa Sm.

fissisepala, Borb., 1. c. $552=$ pimpinellifolia, Linn.

Formánekiana X, J. B. Keller, in Oest. Bot. Zeitschr. xxxy. (1885) 12\%. - Austria.

Gabrielis, F. Gerard, in Magnier, Scrin. fl. select. iv. (1884) 85 = canina, Linn.

gapensis $\times$, Gren. ex DippeI, Handb. Laubholzk. iii. (1895) 595. - Gall.

Gizellae, Borb. in Magyar Akad. Termész, Közlem. xvi. (1880) 479, $486=$ canina, Linn

grupnensis, Wiesb. in Oest. Bot. Zeitschr. xxxvi. (1886) 325, in syn. = inclinat: Kern.

Guentheri, Wiesb. 1. c. 338 = abietina, Gren.

Haussknechtii, Sagorski, Fl. von Naumburg (1885) 21 [Quid?] - Eur. centr.

Haynaldiana, Borb. in Magyar Akad. Termész. Közlem. xvi. (1880) 345, $349=$ arvensis, Huds.?

$367^{2}$ a. Heimerlii, H. Braun in Verh. zool-bot. Ges. Wien, xxxv. (1885) 129. t. 9. - Hung.

Herculis, Borb. in Magyar Akad. Termész. Közlem. xvi. (188') 507, $512=$ tomentosa, Sm.

hivtella, Rip. ex Crép. in Bull. Soc. bot Belg. viii. (1869) 239, 268 ; Cottet \& Castella, Guid, bot. Cant. Frib. (189I) $130=$ canina, Linn.

hirtifolia, H. Braun, in Verh. zool.-bot. Ges. Wien, xxxv. (1885) $109=$ canina, Linn.

hologyna, Borb. in Magyar Akad. Termész. Közlem.xvi. (1880) 346, $353=$ canina, Linn.? (fide cl. Crép.)

Hostii, H. Braun, in Verh zool.-bot Ges. Wien, xxxv. (1885) $115=$ alpina, Linn.

illyrica, Borb. in Magyar Akad. Termész Közlem. xvi. (1880) 532, in syn. = spinosissima, Linn.

Ischiana, Crép. in Bull. Soc. bot. Belg. viii. (1869) 242, 243, 318 nom. nud.; Ces. Passer. \& Gibelli, Comp. Fl. Ital. ii. (1886 670; Burnat \& Gremli, Obs. Ros. Ital. (1887) 33, - Italia.

jenensis, M. Schulze, in Mitt. geogr. Ges. Jena, iii-IV. (1885) $79=$ rubiginosa, Linn

Kerneri, H. Braun, in Verh. zool.bbot. Ges. Wien, xxxv. (1885) 81; G. Beck, F1 Nied.-Oest. ii. I. (1892) $\mathrm{S}^{\prime} \mathrm{l}=$ canina, Linn.?

Kitaibeliz, Borb, in Magyar Akad. Termész. Közlem. xvi. (1880) $507,514=$ tomentosa Sm

Kochiana, Koelme, Deutsche Dindrol. (1893) 293. - Hab.

$36 \%^{3}$ a. lanceolata, Waisb. in Köszeg. Vidékénék edenyes novënyer $(1889) 6 \mathrm{l}=$ canina Linn.

lantoscana, Burnat \& Gremli, Ros. Alp. Marit. Suppl. (1882) $12=$ micrantha, $S m$.

lanuginosa, Ravaud, ex Koehne, Deutsche Dendrol. (1893) $285=$ tomentosa, $\mathrm{Sm}$.

laxifolia, Borb. in Mayryar Akad. Termész. Közlem, xvi. (1880) $421=$ canina, Linn .

laxiphylla, Borb, in Oest. Bot. Zeitschr. xxx. (1880) 1.37; et in Bot. Centralbl. (1880) 286 sphalm. = praec.

leiostyla, Rip. ex Crép. in Bull. Soc. bot. Belg. viii. (1889) $238=$ canina, Linn.

\section{ROSA}

$367^{3}$ a. leucadia, H. Brann, in Verh. zool.-bot, Ges, Wien, xxxv. (1885) 126. - Ins. Leucad.

litoralis X, Borb, in Magyar Akad. Termész. Közlem. xvi. (1880) 346.354 | Hybr, spont?\}. - Croatia.

longisepala, Ravaud, Guid. botan. Dauphiné, 13me excurs. (1894) 17 = pomifera, Herrm. var.

$36 i^{3}$ 1. Maassii... (non Massii).

manternensis, J. B. Keller, in Halácsy et $\mathrm{H}$. Braun, Nachtr. Fl. Nied.-Oest. (1882) 252 $=$ tomentosa, $\mathrm{Sm}$.

micranthoides, J. B. Keller, 1. c. $239=$ micrantha, $S m$.

Mollardiana, (non Mallardiana).

Moutini, Crép. in Bull. Soc. bot. Belg, xxi. (1883) I49; et ex Lager, in Cariot, Etud. des fl. éd. 8 (1889) $280=$ rubiginosa Limn.

muscipula $\times$, Boullu, in Bull. Soc. bot. Lyon, Sér. II, xi. (1884) 75 ; et in Bull, Soc èch. pl. Dauph. xii. (1855) $506=$ gallica, Linn. myrtilloides, H. Braun, in Verh. zoul.-bot. Ges Wien, xxxv。(1885) $125=$ canina, Linn.

Neilreichiz, Wiesb, ex Halácsy et H Braun, Nachtr. Fl. Nied.-Oest. (J88*) \& $6=$ hybrida, Schleich.

nemophila, Déségl. \& Ozanon, in Bull. Soc. éch. pl. Dauph. ix. (1882) $393=$ canina Linn.

nipponenis, Crép. in Bull. Soc. bot. Belg. xiv.

(1875) 7; Dippel, Handb. Laubholzk. iii. $(1 \times 93) 584$, in obs, = acicularis, Lin 37 .

Obornyana, H. Braun, in A. Kern. Sched. Fl. Austro-Hung. ii. (I882) $35=$ canina, Linn oligacantha, Borb. in Magyar Akad. Termész. Közlem. xvi. (1880) 36', $373=$ gallica, Lim

Pacheri, J. B. Keller, in Deutsche Bot. Monatsschr. (1884) 72; et ex Pacher, FI. von Kärnten. (1886) 281 = glauca, Vill.

per-parva, Borb. in Magyar Akad. Termész. Közlem. xvi.(1880) $490=$ micrantha, Sm Petrovicii, Burnat \& Gremli, ex Petrovic, Addit. ad fl. agri Nyss. (1885) 70. - Serbia.

$368^{1}$ a. pisiformis, Hort. ex Handl. Trees Kew, Pt i. [Polypet.] (1894) $173=$ pisocarpa, A. Gray pompuniana, Hort. 1. $\mathrm{c}$. = centifolia, Mill.

platyphylla, Hort. Japon, ex Rev. Hortic. lviii. (1886) $436=$ multiflora, Thunb.

Przewalskit, Regel, [ubi? , ex Koehne, Deutsche Dendrol. (1893) 297, in obs. = macrophylla, Lindl.

Pseudo-cuspidata, Crép. in Bull. Soc, bot. Belg. xi. (1872) 89; et xxi. (1883) $93=$ tomentosa, $\mathrm{Sm}$

Pseudo-montana, R. Keller, in Bot. Centralbl. xlvii. (1891) $323=$ glauca, $V i t l$.

Pseudo-terebinthinacea, Borb. in Magyar Akad. Termész. Közlem, xvi. (1880) $508=$ tomentosa, Sm.

Pseudo-tomentella, H. Braun, in Verh. zool. bot. Ges. Wien, xxxv. (1885) 127, in obs. Eur.

pycnacantha, Borb. 1. c. $450=$ canina, Linn quadica, H. Braun, in Ber. bot. Ver. Landsh.

(1889) 108; G. Beck, Fl. Nied.-Oest. ir. I. (1892) 801 = canina, Limm

querceticola, Déség1, \& A. Kern. ex Borb, in Magyar Akad. Termész. Közlem, xvi. (1850) 387 = canina, Linn.

retinervis, loorb. 1. c. $386,393=$ canina, Linn.

Reussii, H. Braun, in Verh. zool.-bot. Ges. Wien, xxxv, (1885) $104=$ canina, Limn.

rhynchocarpa, Rip. ex Déségl. in Bull. Soc. bot. Belg. xv. (1876) 371 ; Cattet \& Castella, Guid. bot, Cant. Frib. (1891) $129=$ canina, Limn.

Rocheli, Sandor, ex Borb. in Magyar Akad. Termész. Közlem. xvi. (I880) $55 \mathrm{~L}=$ alpina, Linn.

romana, Hort. ex Hándl. Trees Kew, Pt i.

Polypet.] (1S94) $167=$ ferruginea, Vill.

Rosa-mundi, Hort. 1. c. = damascena, Mill.

\section{ROSA}

3681 a. rougeonensis, Ozanon, in Magnier, Scrin. fl. select. X. (1891) 189 ; et ex Lucante, Rev. de Bot. ix. $(1891) 196=$ canina, Linn.

scaniana, Crép, in Bull. Soc, bot. Belg. xxi. (1883) $58=$ canina, Linn

Schmidtii, H. Braun, in Verh. zool, -bot. Ges. Wien, xxxy. (1885) 72: Oborny, Fl, von Mährens (1.886) $216=$ Jundzilli, Bess.?

$368^{2}$ 1. Sendtneri... (non Sendneri)

septicoloides, Crép. in Bull. Soc. bot. Belg. xxi. 1. (1882) 161 = micrantha, $.5 m$.

serbica, Burnat \& Gremli, ex Petrovic, Addit. ad fl. agri Nyss. (1885) 69. - Serbia.

sylvatica, Tausch, in Flora, ii. (1819) 464 Déség1. in Bull. Soc. bot. Belg. xv. (1876) $244=$ gallica, Linn .

Skuftziana, Blocki, ex H. Braun. in Oest. Bot. Zeitschr, xxxvi. (1886) $429=$ canina Iinn

stenomalla, Borb. [ubi ?] ex Ber. Deutsch. Bot. Ges. x. (1892) $[103\}=$ tomentosa Smith

stenosepala $\times$, Christ, Die Rosen d. Schweiz, (1879) 139; Rouy, in Deyrolle, Le Naturaliste, Sér. II, xi. (1889) 10. - Helv.

subatrichostylis, $\mathrm{H}$. Braun, in Verh. zool,-bot. Ges. Wien, xxxv. (1885) $96=$ canina, Linn subdiplicata, Borb. in Oest. Bot. Zeitschr. xxxiii. (1883) 15; et in Bot. Centralbl. xxxviii. (188), (18. - Austria

subglabra, H. Braun, in Verh. zool.-bot. Ges. Wien, xxxv. (1885) $94=$ canina, Linn

subrepens, Vukot. in Rad. Jugos. Akad. Zagreb. lxix. (1884) 17 [Quid. ?], - Hung.

subspoliata, Déségl. \& Ozanon, in Bull. Soc. éch. pl. Dauph. ix. (1882) $377=$ micrantha, Sm.

tardata, Gren. Rev. A. monts Jura (1876) 61 montana, Chaix

Tauschiana, H. Braun, in Verh. zool.-bot. Ges. Wien, xxxv, (1885) $78=$ canina, Linn.

temuiflora, H. Braun, in Verh zool.-bot, Ges, Wien, xxxv. (I885) $116=$ alpina, Linn.

tenuissima, «C. C. Gmel, » ex Dippel, Handb. Laubholzk. iii. (1893) 595, sphalm. (pro mitisima $)=$ pimpinellifolia, Linn.

comentelloides, H. Braun, in Verh. zool,-bot. Ges, Wien, xxxv. (1885) 127 in obs, = R. Pseudo-tomentella, H. Bramm.

3682 1. Unterkreuteri... (non Unterkrauteri)

vagiana. Crép. in Bull. Soc. bot. Belg. xxi, (1882) 57 ; et in Verh. zool.-bot. Ges. Wien. xix. 1870) 513; H. Braun, 1. c. Xxxy. (1885) 93 = canina, Crép

victoria-Hungarorum, Borb in Napi Közlem. xxii. (1882) 10, nomen ; et Enum. pl. Comit Castrif. (1887) $279=$ canina, Linn

Waitziana 火, Tratt. Rosac, Monog. i. (1825) $57=$ gallica, Limn

Woloszczakiz, J. B. Keller ' in Halácsy \& H. Braun, Nachtr. Fl. Niederoest. (1882) 282 ; et in Verh. zool.-bot. Ges. Wien, xxxv. (1885) 91 = canina, Limn.

Zabelii, Crép. in Bull. Soc. bot. Belæ.xxi. I. (1882) 94 ; et ex H. Braun, in Annal. Naturh. Hofmus. Wien; ii. (1887) $113=$ tomentosa, $S m$

zazljensis... (non zasljensis).

zoiseana, H. Braun \& Oborny, in Oest. Bot. Zeitschr. xlii. (1892) 96, nomen. - Austria.

$368^{3}$ 1. ROTANTHA, Baker,... t. 51 = Lawsonia

Linn. (Lythrar.).
combretoides, Baker, 1, c = L. alba, Linn.

\section{RUBUS}

3692 a. acanthoclados, Borb. in Természet. (1878) 322 ex Simonk. Enum, fl. Transsilv, (1886) 204 , in syn. = Idaeus, Lim

acanthodes, Sabransky, in Oest. Bot. Zeitschr xlii. (1892) 89 , in syn, = R. Guentheri, Weine et Nees.

acutifrons, Aug. Ley, in Journ. Bot, xxxi. (1893) $13=$ humifusus, Weike of Nees. 


\section{RUBUS}

$369^{3}$ a. Beckeyi, Halácsy, in Verh. zool.-bot. Ges. Wien, xxxv, (1885) 603; et xli. (1891) 248 - villicaulis, Koehl.

berolinensis, E. H. L. Krause, in Abh. Bot. Ver. Prcv. Brand, xxvi. (1884), $16=$ chlorophyllus, Gremit.

B $7 r_{1}$ a. Burnati, Schmideiy, in Bull. Soc, bot, Genève, iv. (1888) 184. - Helv.

Clusii, Borb, in Evdész. Lapok. (1885) 401; et Geogr, atq. Enum. pl. Comit. Castrif. (1887) 292. - Hung

danicus, Focke, in Abh. Nat. Ver. Brem. ix. 1886) 32.2 = macrophyllus, Weihe

Qebilis $\times$, Halácsy, in Verh. zool.-bot. Ges.

Wien, xxxy, 1885 (1886) 659. - Austria.

decorus, Flalácsy, in A. Kern. Sched. Fl. Austro-Hung. [ed. anni 1883] iii. (1884) 42. - Austria.

dissimulins, Lindeb. in Act. Soc. sci, Gothob. xx. Bih. (1884) 32; Aresch. in Bot. Notiser, xiv. (1886) $78=$ corylifolius, Sm.

empelios, Fccke, in Bot. Ver. Baden, iii. 1894) $152=$ carpinifolius, Weihe

erythrostemon, A. Favrat, in Bull. Soc. Vaud, sci. nat. xvii. (1881) $530=$ obscurus, Kaltenb.

$370^{3}$ 1. foliolosus (non foliosus).

fuscidulus. Halácsy, in Verh. zool.-bot. Ges. Wien, xxxv, 1885 (1886) 666; et xli. (1891) 252 = vestitus, Weihe.

gloggnitzensis $\times$, Halácsy, in A. Kern. Sched. Fl. Austro-Hung. iii. (1884) 40; et in Verh. zool.-bot. Ges. Wien, xxxv. 1885 1886) 660. - Austria.

Griffithiamus, Rogers, in J. E. Griffith, Fl. Angles, and Carnarv. (18,5) $48=$ Borreri, Bell Salt.

$371^{1}$ a. Gussonei, Lojac, F1. Sicula, i. II. (1891) 172 = candicans, Weihe.

Halácsyi $X$, Borb. in Verh, zool.-bot. Ges. Wien, xxxv. I885 (1886) 666 ; et xli. (1891) 251 ; G. Beck, Fl. Nied.-Oest. ii. I. (1892) 732. - Austria.

Harmandii, F, Gérard, in Lucante, Rev. de Bot. viii. (I890) 26, $74=$ orthacanthus, Wimm.?

Heimerlii, Halácsy, in Verh. zool.-bot. Ges. Wien, xxxv. 1885 (1856) 668; et xli. (1891) 282 = orthacanthus, Wimm

inaequalis, Halácsy, l. c. 662; et xli. (1891) 245. - Austria.

incertus $\times$, Halácsy, 1. c. 658. - Austria

Langei, G. Jensen, ex Frederichs, \& Gelert in B.ot. Tidsskr. xvi. (1887) $67=$ villicaulis, Koehl.

laxiflorus, Halácsy, in A Kern. Sched. Fl. Austro-Hung. [ed, anni 1883] iii. (1884) 46. - Ausiria.

1. Iusitanicus... (non lusitanieus)

$371^{3}$ a. melanolasius, Hort. Späth, Catal, (1894-85) , et in Neub. Gart.-Mag. (1894) 177. - Am. bor. occ.

monticolus, Focke, in Hallier-Wohlf.-Koch, Syn. Fl. Germ. i. (1891) $760=$ cunctator, Focke.

nepalensis, Hort. ex Handi. Trees Kew, Pt i. [Polypet.] (1894) $159=$ nobilis, Regel.

obtusiders $X$ Boulay \& Diomède, in Bull. Soc. sci. nat. Nimes, xix. (1891) $7 \%$. Gall. oreteus, Lojac. Fl. Sicula, i. II. (1891) 17t, $310=$ caesius, Linn

orthosepalus, Halacsy, in Verh. zool.-bot. Ges. Wien, xxxv. 1885 (1886) $66 t=$ villicaulis, Koehl.

pauciflorus, Halacsy, in Oest. Bot.Zeitschr, nli. 1891) 12. - Bohem.

$372^{2}$ 1. peramethystenus...65 (non paramethystenus). reconditus, Schmidely, in Bull. Soc. bot, Genève, iv. (1888) 170. - Helv.

Sohnetzleri, A. Favrat, in Bull. Soc, Vaud. sci. nat. xxi. (1881) $119=$ hirtus, Waldst. \& Kit.

siotophilus,. Halácsy, in Verh. zool.-bot. Ges. Wien, xxxv, 1885 (1886) 667 = Koehleri, IVeihe of N'ees.?

\section{RUBUS}

3722 1. scytophyllus, F. Gérard, in Lucante, Rev. de Bot. viii. (1890) 75, in syn。= R. Godroni, P. F. Mruell.

serridens $\times$, Boulay \& Diomède, in Bull. Soc. sci. nat. Nimes (1891) 77. - Gall. mer. strictus, A. Favrat, ex Gremli, Fl, anal. Suisse 11886) 187; , et Excurs. Fl. Schweiz, éd. $6(1889) 149=$ vestitus, Weihe?

subsessitis, Halacsy, in Verh. zool.-bot. Ges. Wien, xli. (1891) 282: et in Oest. Bot. Zeitschr. xli. (1891) 12 [sphalm. subsenilis] = nemorosus, Hayne.

subaculeatus, Borb. in Oest, Bot. Zeitschr. xxsiii. (1883) 151 = Guentheri, Weihe \& Nees.

3731 a, tiliaefolius, J. Harmand, in Lucante, Rev, de Bot.vi. (1887-88) 315, t. 12; et viii. (1890) $75=$ Godroni, $P . F$. Mu:ll.

Vetteri, A. Favrat, ex Fl, anal. Suisse (1886 188; Cottet et Castella, Guid. bot. cant Frib. 1891) 88 = vestitus, Weih

villosulus X, Halácsy, in Verh. zool.-bot. Ges. Wien, xxxv, $1 \succ 85$ (1886) 665. - Austria.

\section{RUDGEA}

$373^{2}$ a. frondosa, S. Moore, in Trans. Linn. Soc Ser. 11. iv. (1895) 381. - Sras

$374^{\mathfrak{1}}$ a. RUEHSSIA, Karst. Deutsch. Fl。 ed, 2, ii, (1895) 609. ASCLEPIADEAE.

estebanensis, Karst.l. o fig. 684.-Am. austr.

\section{RUELLIA}

$373^{3}$ a. Makoyana Hort, Makoy, ex Closon, in Rev. Hort. Belg. (1895) 109, cum ic. - Bras.

\section{RUMEX}

$374^{2}$ a. cordifolins $X$, Bruegg, in Jahresb. Naturf Ges, Graub。 xxix. 1884-85 (1886) 104.Helv.

intercedens $\times$, K. Reching. in Oest. Bot. Zeitschr. xlii. (1892) 19. - Hung.

rhaeticus $\times$, Bruegg, in Jahresb. Naturf. Ges. Graub. xxix. 1884-85 (1886) 103. - Helv.

\section{RUPPIA}

$374^{2}$ a. andina, Phil, in Anal. Univ. Chil. xci. (1894) 525 = maritima, Linn.

\section{RUSBYA}

$374^{2}$ a. boliviana, Britton, in Mem. Torrey Bot. Club, iv. (1893) 215. - Bolivia.

\section{RYPAROSA}

$375^{2}$ a caesia, Kurz ex King in Journ. As. Soc. Beng. lix. (1890) II. $125=$ Kurzii, King.

\section{S}

\section{SACGIA}

$375^{3}$ a. elegans, Naudin, in Rev. Hortic. 1xi. (1889) 35 - Columb., Boliv.

\section{SACCOLABIUM}

$375^{3}$ a, furcatum, Hort ex Williams, Orch. Grow. Man. ed. 7 (1894) 70\%. - Ind. or., Java.

Turneri, Williams, l. c. 703. - Ind, or.

\section{SAGINA}

$376^{2}$ a. pachyrrhiza, Phil. in Anal. Univ. Chil. 1xxxii. (1893) 773. - Chili.

\section{SALDANHAEA}

$377^{1}$ a. myriantha, Bureau, in Vidensk. Medd. Natur. Forh. Kjöb. (1893) 1 4 〔Symb. F1. Bras. (Bignon.) 12]9] = Tecoma myriantha, $D C$

SALIX

$377^{2}$ a. arbusculoides $X$, Bruegg, in Jahresb. Naturf Ges. Graub. xxix. 1884-85 (1886) 111. Helv.

Boulayi $\times$.... viii. (1890) 211 [non viii. (1894) 214].

\section{SALIX}

3772 a. dacica, Porcius, in Anal.Acad. Romane, Ser. II xiv. (1892) 263. - Europ.

davosiana $X$, Bruegg. in Jahresb, Naturf. Ges. Graub. xxix. 1884-85 (1886) 113. -

subcaesia $\times$, Bruegg. 1. c. 114. - Helv.

SALVIA

$378^{3}$ a. Pringlei, Robinson of Greenm. in Proc. Ant. Acad.xxix. (1894) 391, - Mexic

\section{SARANTHE}

$379^{3}$ a. pluriflora, O. G. Petersen, in Vidensk. Medd. naturh. Foren. Kjöb. (1889) 335 [Symb. Fl. Bras. xxxii1. 915]. - Bras.

\section{SARGOGHILUS}

$380^{1}$ a. bimaculatus, King of Pantling, in fourn. As. Soc. Beng. 1xiv. (1895) Ir, 340. - Sikkim.

crepidiformis, King of Pantling, $l$. c. . Sikkim.

Godefroyanus, Benth. \& Hook. f. ex Drake, Ill. Ins. Mar. Pacif. (1892) $310(=$ Thrixspormun Godefroyanum, Reichb. f.). - Ins. Fiji.

Graeffei, Benth, et Hook. f. ex Drake, l. c. (= T. Graeffei, Reichb. f.). - Ins. Samoa.

\section{SARGENTIA}

$38 r^{3}$ a. aricocca, Wendl. ex Bull. Soc. Tosc. Ortic. xiv. (1889) $34 \mathrm{l}$ (= Pseudophoenix Sargenti, H. Wendl.). - Florida.

\section{SARRACENIA}

$380^{3}$ a. Manduiana X, Hort. Pitcher \& Manda, ex Gard. Chron. (1893) i. 455. - Hybr. artef.

\section{SATUREJA}

$381^{1}$ a. olymzica, Halácsy, in Oest. Bot. Zeitschr. x1. (1890) 40 , in syn. = pisidia, Wettst.

pis:dia, Wettst. in Sitzb. Akad. Wiss. Wien, xcviii. I. 1889 (1890) 374; Halácsy, in Oest. Bot. Zeitschr. xl. (1890) 40. - Graecia.

pisidica, Velen. Fl. Bulg. (1891) 466 ; et in Sitz. Boehm. Ges. Wiss. (1894) n。 xxix. 24 = Wiedemanniana, Lall

Wiedemanniana, Lall. [ubi ?] ex Velen.l.c. 24. - Bulg.

\section{SAXIFRAGA}

$382^{1}$ a. blepharophylla, A. Kern。 [ubi ?] ex Kolb. Alpenfanzen (1890) 289. - Stria

1. Engleri, Huter, ex Kolb, l. c. 294 (non Hort.). Gutheriana Х. Hort. ex Kolb, 1. c. $297=$ Guthriana ×. Hort.

$382^{2}$ a. meridionalis, Terrac, in Bull. Soc. Bot. Ital. (1892) 185 = oppositifolia, Linn.

\section{SCABIOSA}

3823 1. balcanica... i et in Sitz. Boehm. Ges, Wiss. 1888 (1889) 40.

Victoriae $X$. Hort, Dammer, ex Wien. Ill. Gart,-Zeit. xiii. (18c8) 437. - Hybr, artef.

\section{SCHISTOCARPHA}

$384^{1}$ 1. paniculata... ; et 2. . (1893) $12 \%$.

\section{SCHIZANTHUS}

$384^{1}$ a. Romani, Phil. in Anal. Univ. Chit.xci. (1895) 126. - Chili

\section{SGHIZOGARPUM}

$384^{2}$ a. parviftorum, Robinson of Greenm in Proc. Am. Acad. xxix. (1894) 386. - Mexic.

\section{SCHIZOGLOSSUM}

$384^{3}$ 1. Nyassae, Britten... (non Britton).

\section{SGILLA}

$386^{2}$ a. antitaurica, J N Gerard, in Gard, and For. (1890) $169=$ sibirica, $A n d r$

laxiflora, Baker, in Gard. Chron. (1891) i. 668 - Afr. austr.

radnensis, Porcius, in Anal. Acad. Romane, Ser. II. xiv. (1892) 276. - Europ. 
SCLERAN'THUS

$38 \% 2$ a aciformis, caniceps, canocethalus (i. e. cephalus), divergens, gemmatus, Hohenackeri, modestus, myriacanthus, Schurii, setipes, spithamaeus, subclavatus, subsessilis, uncinatus, revecundus, Reichb. ex Schur, in Verh. Naturf, Ver. Brünn, xxxiii. (1895) 20c-2(2, nomina nuda = annuus, Linn.

approximifolius, bigeminatus, chlorolencanthus, dodrantalis, elegans, marginatus, neglectus, Reichb. ex Schur, in Verh. Naturf. Ver Brünn, xxxiii. (1895) 199-200, nomina nuda $=$ perennis, Linn.

microcarpus, Schur, 1. c. $201=$ Hohenackeri, Reichb.

\section{SCORODONIA}

$388^{2}$ a. Scorodonia, Karst. Deutsch. Fl, ed. 2, ii. (1895) $593=$ Teucrium Scorodonia, Linn.

\section{SCORZONERA}

$388^{3}$ 1. mongolica.. [transf post S. leptocladam.] rubriseta, Lipsky, in Mém. Soc. Natur. Kiew, xi. (1891) $5 \%$

rumelica... 1893 (1894) n. xxxvii, 40 (non (1892-93) 40).

\section{SCUTELLARIA}

$389^{1}$ a. Pichleri, Velen.Fl. Bulg. (1891) 449. - Bulg.

SEBAEA

$389^{2}$ a. tabularis,... = purpurea, Cham. \& Schlecht. SEDUM

$290^{1}$ a. ponticum, Velen. Fl. Bulg. (1891) 191. - Bulg.

SELENIPEDIUM

- $390^{2}$ a. Finetianum X, Hort. Sander, ex Orchid Rev. iii. (1895) 102. - Hybr. artef.

paulistanum, Rolfe, in Orchid Rev. i. (1893) 239, in obs. (= Cypripedium paulistanum, Barb. Rodr. - Bras.

pulchellum $\times$. Hort. ex Orchid Rev. i. (1893) 166. - Hybr, arfef.

\section{SEMEGARPUS}

$390^{3}$ a vitiensis, Th. Dur ex Drake, Ill. Fl. Ins, Mar. Pacif. (1890) 146 (= Ormocarpus vitiensis, A. Gray). - Ins. Fiji.

\section{SENECIO}

$39,^{2}$ a. Arnautorum, Velen. in Sitwb. Boehm. Ges. Wiss. 1888 (1889) 45; et Fl. Bulg. (1891) 254.-Bulg.

$391^{3}$ a bulgaricus, Velen. $l l . c c .44$ et 256. - Bulg.

$392^{2}$ Heritieri, W. Watson, in Gard. and For. iv. (1S91) 510 , fig. $79{ }^{\circ}=$ Cineraria aurita, Hort:). - Ins. Canar.

$393^{2}$ 1. nephelogetus... (non nephelagetus). peteroanus... (non petersanus).

sagittatus, O. Hoftm. in Engl. \& Prantl, Natürl. Pflanzenfam. iv, 5 (1893) 297 ; Hieron.

$394^{2}$ a. tyrolensis, A. Kern [ubi ?] ex Kolb, Alpenpflanzen (1890) $325=$ abrotanifolius, Lim Wageneri, Degen, in Oest. Bot. Zeitschr. xlir. (1894) 20. - Bulg.

\section{SERRATULA}

$395^{2}$ 1. Seoanei... (non Scoanei).

SESELI

3961 a: validum. Velen. Fl. Bulg. (1891) 213. - Bulg SIDA

$397^{3}$ a. caudatifolia, Robinson \& Greenm. in Proc. Am Acad. xxix. (1894) 382, - Mexic.

\section{SIDEROXYLON}

3982 a. pyrulilerum, Benth. \& Hook f. ex Drake, Ill. Fl. Ins. Mir. Pacif. (1892) 229 (= Sapota pyrulifera, A. Gray). - Ins. Fiji.

sandwicense, Benth. \& Hook. f. ex Drake, l. c 228 (= S. sandwicensis, A. Gray). - Ins. Sandvic.

1. timorense... (non limorense).

vitiense, Bentir of Hook. f. ex Drake, l. c. 229 ( = S. vitiensis, A. Gray). - Ins. Fiji.

\section{SILAUS}

3982 a. Silaus, Karst. Deutsch. F1 ed. 2, ii. (1895) $402=$ flavescens, Bernh

\section{SILENE}

$398^{2}$ a. aloa, Burnat, Fl. Alp. Marit. i. (1892) 212, in obs. = Lychnis dioica, Linn.

Bergiana, Lindman, in Act. Hort. Berg. i. n. 6 (1891) 3. - Hab. ?

3991 a. mentagensis. Coss. Ill. Fl. Atlant. i. (1890) 145, t. 94. - Reg. Maurit.

pindicola... 83 (nun 85).

Pomeli, Batt. In Bull. Soc. bot. Fr. xxxviii. (1891) 219. - Algeria.

Porcari, Tin. ex Lojac. Fl. Sicula, i. I. (1888) 158. - Sicilia.

rubra, Burnat, F1. Alp. Marit. i. (1892) 212, in obs. = Lychnis sylvestris, Schk.

\section{SIPHOCAMPYLUS}

$417^{1}$ a. boliviensis, Zahlbr. in Annal. Naturh. Hofmus. Wien, vi. (1891) 443. - Bolivia. cutervensis, Zahlbr.l.c. 442. - Peruvia.

Jelskii, Zahlbr. l. c. 441. - Peruvia.

meridertsis, Zahlbr. 1. c. $440=$ sessilifolius, Vatke.

Spruceanus, Zahlbr. l.c. 443. - Peruvia

tupaeformis, Zahlbr. l. c. 440 . - Bolivia

\section{SISYRINCHIUM}

$400^{1}$ 1. oligostachyum.... (non oligostachium)

Pringlei, Robinson \& Greenm. in Proc. Am. Acad. xxix. (1894) 394. - Mexic

\section{SKIMMIA}

$401^{1}$ a. Rogersii, Hort. ex Handl. Trees Kew, Pt [Polypet.] (1894) $51=$ japonica, Thunb.

\section{SOBRALIA}

$401^{3}$ a. Amesiana X. Hort. Sander, ex Orchid Rev. iii. (1895) 2(3. - Hybr. artef.

Beyeriana, Hort. Seeger, ex The Garden, xlì. (1891) 324. - Hab. ?

Linden', W. Watson, in Gurd, and For, viii. (1895) 444. - Ecuad

Sanderae, Rolfe, in Gard. Chron. (1890) ii. 494; Williams Orch. Grow. Man. ed. 7 (1894) 714. - Am. centr.

\section{SODIROA}

$401^{3} 1$ dissitiflor (1888) $365^{\circ}$ et Bromel. Andreanae (1889) 42, t. 13 c

Sprucei... (1888) 365; et Bromel. Andrecinae (1889) 43, t. 13 d. (non lxi.)

\section{SOLANUM}

4021 a Duchartrei, Heckel, in Ill, Wien, Gart,-Zeit, xy. (1890) 367. - Afr. trop. occ.

$402^{2}$ a. Mors-elephantum, Hort. Dammann, ex Wien. Ill. Gart.-Zeit. xix. (1894) 29, fig. 7. Afr. trop.

\section{SOLENOGYNE}

4031 a. Emphysopus, F. Muell. Key Syst. Vict. Pl. i, (1885) 310 . - Austral.

\section{SOLIDAGO}

$4 n 3^{1}$ 1. parviflora... (non parvula).

\section{SONCHUS}

$403^{2}$ a. zollikoferioides, Rouy. Excurs. bot. Espagne. ii. (1882-83) 73. - Hisp.

\section{SOPHORA}

$403^{3}$ 1. zeylanica.... = heterophylla, Arn

SORBUS

$403^{3}$ a. argentel, Hort. ex Handi. Trees Kew, Pt i. Polypet.] (1894) $187^{\circ}=$ Pyrus Aria, Polypet.] (1894) $187=$ Pyrus Aria Linn.

discolor, Maxim. ex Gard. Chron: (1891) i. 462. - Sibir. or,

flabellata. Hort, ex Handi. Trees Kew, $\mathrm{Pt}$ i.

[Polypet.] (1894) $185=$ Pyrus Aria, Linn. magnifica, Hort. 1. c. $189=$ P. vestita, Wall.
SORBUS

$403^{3}$ a. quercifolia, Hort ex Handl- Trees Kew Pti. [Polypet.]. (1884) $18 \%=$ Pyrus intermedia, Ehrh.

sulphurea, Hort. 1. c. $186=$ P. Aria, Linn.

\section{SORGHUM}

$404^{2}$ a, Sorghum, Karst. Deutsch, F1. ed. 2, i. (1895) $371=$ vulgare, Pers

\section{SORINDEIA}

$404^{2}$ a. juglandifolia, Engl. Bot. Jahrb. xv, (1893) 108, in obs. sphalm. = grandifolia, Engl.

\section{SPARGANIUM}

$404^{2}$ a. diversifolium, Aschers. in Schr. Naturf. Ges. Danzig, ix. (1895) 335.- Germ.

\section{SPERMOLEPIS}

$4^{n} 5^{2}$ a. tannifera, Heckel \& Schlagd in C-R. Acad. sci. Paris, cxiv, (1892) 1793), in adnot $=$ gummifera, Brongn. E Gris.

\section{SPIRAEA}

4071 a. belloides, Hort. ex Handl, Trees Kew, Pti [Polypet] (1894) 151 = japonica, Thunb. flagellaris. Hort. 1, c. $149=$ canescens, Don.

$407^{2}$ a. rhombifolia, Hort. l. c. = canescens, Don servata, Hort. 1, c, = canescens, Don. Standishii, Hort. 1. c. = canescens Don Thompsoni, Hort, 1. c. $155=\mathrm{S}$. Thunbergii, Sieb o Zucc.

\section{SPOROBOLUS}

$408^{1}$ a. conguensis, Franch. in Bull. Soc. hist. nat. Autun, viii. (1895) 369. - Congo gall. effusus, Franch.l. c. 370 . - Congo gall.

$408^{2}$ a. mayumbensis, Franch. l. c.367. - Congo gall strictus, Franch.l. c. 368. - Congo gall.

\section{STACHYS}

$409^{1}$ a. tuberifera, Naudin, ex Rev. Hortic, lix. (1887) 290 ; et ex Gard. Chron. (1888) i. 211, 13 fig. 1. - China bor.

\section{STANHOPEA}

4091 a. bellaerensis $X$, Hort. ex Gard. Chron. (1895) ii. 100. - Hybr, artef

\section{STAPEIIA}

4092 a albicans, Hort. Sprenger, in Wien. Ill. Gart. Zeit. xix. (1894) 235, fig. $29=$ angulata, Todaro.

Scylla, Hort, ex Wien. Ill. Gavt.-Zeit. xix. (1894) 234, fig. 33. - Hab. ?

\section{STATIC}

$409^{3}$ superba, Hort. Hauge \& Schmidt, ex Gartenfl. xxxvi. (1887) 666, fig. 170. - Hab.

\section{STENOGLOTTIS}

$411^{1}$ a. longifolia, Hook. f. in Bot. Mag. (1891) t. 7186. - Natal.

\section{STEPHANIA}

$411^{3}$ 1. africana... (dele et conf. sub STEPHANIA, Kuntze)

$411^{3}$ a. STEPHANIA. Kuntze(non Lour.) Rev. Gen. (1891) 353 , in obs. Astephania; Oliver. africana, Kuntże, 1. c. = A. africana, Oliver.

\section{STERCULIA}

$412^{1}$ 1. Tavia.... (non Taria).

STEVIA

4121 1. odorata, Hart. Dammanit, Catal. (1890-91) 80, 83 , fig. 53 ; ct.

$415^{3}$ a. STRAILIA. Th. Dur. Ind. Gen. Phan. (1888) 129 (= CERCOPHORA, Miers). $M Y R T A C E A E$.

\section{STREPTOCARPUS}

$413^{3}$ a. Lichterstemensis $X$ Hort ex Wien. Ill Gart. Zeit. xix. (1894) 361, fig, 56,- Hybr. artef, 
STREPTOGARPUS

$413^{3}$ a, multiflorus $X$.Hort. Caing, ex Gard. Chron. (1895)-ii. 211 [multiflora]. - Hybr. artef.

414 1. STRONGYLODON... (non STROGYLO DON.

siderospermum... 392 (non 322)

STROPHANTHUS

4112 1. Barteri... 301 (non 32:3).

bracteatus.... 32 (non 323).

$414^{3}$ 1. ogovensis.... 319 (non 324).

Paroissei... 321) (non 324).

parviforus.... 303 (non 321)

P:errei, Heim, in Bull. Soc. Linn, Paris, ii (1894) 1150. - Cochinch.

\section{STUARTIA}

$415^{2}$ a japonica Hort. ex Handl. Trees Kew, Pt i. [Polypet.] (1894).41 = S. Pseudo-Camellia, iraxim.

SUCCISA

4161 1. Cayraleana, Marez (non Cavialkeana, Maris) Succisa, Karst. Deutsch. Fl. ed. 2. ii. (1895) $632=$ Scabiosa Succisa, Linn .

\section{SUSUMI}

$416^{1}$ a. methelyinzthicum,Maury, in Rev.Hort. Ixi.(1889) 76, fig. $23=$ Susum malayanum, Planch.

\section{SWAINSONA}

416? Ferrandi Hort, ex Rev, Hortic, Ixiv. (I886) 562. - Form. hort.

\section{SWERTIA}

410² a. Clirayta, Karst. Deutsch. Fl. ed, 2, ii. (1895) $602=$ cordata, Wall

$410^{3}$ 1. tibetica... 174 (non 175).

SYMPHORANTHERA

4171 a, polystachza, Boj, ex Zahllbr in Annal, Naturh. Hofmus. Wien, vi. (1^91) $444=$ Dialypetalum floribundum, Benth. \& Hook. $f$

\section{SYMPHORIGARPOS}

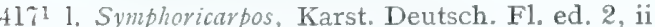
(1895) $764=$ racemosa, Michx.

SYRINGA

Hls' a. japonica, "Decne, ") ex Sarg. in Gard. Chron. (1886) i. 560, fig. 123; et in Gard. and For. ii. (1889) 295, fig. 115. - Japon.

\section{I'}

\section{TABEBUIA}

$418^{2}$ a. aurea, Benth. E Hook. f. ex S. Moore, in Trans. Linn. Soc. Ser. II. iv. (1895) $423(=$ Bignomir aurea, Silva Manso), - Bras.

chapadensis, S. Moore, l. c. 423. - Bras.

\section{TAGHIADENUS}

$418^{3}$ a, radiatus, Hort, ex Wien, Ill Gart.-Zeit. xiv. 1889) 113. sphalm. = carinatus, Griseb.

TAGSONIA

$48^{3}$ a, Smythiana X, Hort. ex Gard. Chron. (1892) ii. 20t, fig. 109. - Hybr. artef.

TAGETES

$419^{1}$ a. scabra, T. S. Brandeg. in Zoe, 1. (1890) 344:Guatem.

TAINIA

Hookeriana, King \& Pantling.... 336 (non King.... 8).

\section{TALINUM}

4191 a. roseum, Hort. Dammann. Cat. (1892) 4. Abyss.

\section{TAMARIX}

$419^{2}$ a. algeriensis, Hort, ex Handl. Trees Kew; Pt i. [Polypet.] (1894) $35=$ gallica, Linn. aphylla, Karst. Deutsch. FI. ed, 2, ii. (1895) = ortentalis, Forsh.

TARASA

4201 a. Alberti, Phil, in Anal, Univ. Chil, 1xxxii. (1893) 321. - Chili

TARENNA

$420^{3}$ a. sambucina, Th. Dutr.'ex Drake, Ill. Ins. Mar. Pacif. (1890) 190 ; et Fl. Polyn. franc. 1892) 89 (= Stylocoryne sambucina, A. Gray), - Ins, Pacif.

TECOMA

$420^{3}$ a. valdiviana, Phil. in Anal. Univ. Chil. xc.(1895) 207. - Chili

\section{TELANTHERA}

$420^{3} \mathrm{a}$. geniculata $S$ Moore in Trans. Linn. Soc. Ser. II. iv. (1895) 443 . - N. Guin.

\section{TEPHROSIA}

$421^{2} 1$. ovaria.... (non oraria)

TEPUALIA

$421^{2}$ a. patagonica, Phil. in Anal. Univ. Chil. Ixxxiv, 750. - Am. austr.

\section{TERMINALIA}

$421^{2}$ a. festinata, S. Moore, in Trans. Linn. Soc. Ser. II. iv. (1895) 352 . - Bras.

\section{TERNSTROEMIA}

$421^{\circ}$ a. Britteniana, F. Muell. in Fourn. Bot. xxix. (1891) 176. - Austral.

\section{TETRAGONIA}

$422^{2}$ a, copiapina, Phil in Anal Univ. Chil. $1 \times x \times 8$. (1894) 169. - Chili.

ovata, Phil. l.c. 168. - Chili.

robusta, Phil.l. c. 169. - Chili.

\section{TETRAPTERIS}

$422^{3}$ a. pilifera, S, Moore, in Trans. Linn. Soc. Ser, II iv. (1595) 326. - Bras.

praecox, S. Mloore, l. c. 327. - Bras

\section{TEUGRIUM}

$423^{3}$ a gracile, Barbey \& Major, Karpathos (1895) 127, t. 10. - Ins. Karpathos.

$423^{3}$ a. Skorpili, Ve'en. in Sitzo. Boehm. Ges. Wiss, 1889 (1890) ii. 39; et Fl. Bulg. (1891) 443. Bulg.

THEVETIA

$425^{2}$ a. Thevetia, Karst. Deutsch. Fl, ed. 2, ii. (1895) $613=$ neriifolia, fuss.

\section{THYMUS}

4271 a. micromeroides, Rouv, in Bull. Soc. bot. Fr. xxxv. (18S8) 122. - Hisp.

$427^{2}$ 1. Vandasii.... 1889 (189 ) ii. $39 \ldots$ (non 1890 (189) i....

TILIA

428! a Beaumontii, Hort. ex Handl. Trees Kew, Pt i. [Polypet.] (1894) $47=$ platyphyllos, Scop laciniata, Hort. 1. c. = platyphyllus, Scop.

\section{TILLAEA}

$428^{2}$ a rencana, Phil, in Anal. Univ. Chil, lxxxv. (1894) 324. - Chili.

\section{TILLANDSIA}

$428^{3}$ a. chrysostachys, Baker, in Bot. Mag. (1886) t. $6900^{\circ}$; in Req'. Hortic. lix. (1887) 166 (= Vriesia chrysostachys, Éd. Morr.). - Peruv.

4293 a leodiensis X. Hort. Veitch. in Gartenfl, xlii. (1893) 340 ; et in Gard. Chron. (1893) i. 580. - Hybr, artef.

Wioti X, Hort, ex Rev. Hortic, 1xii. (189) 203. - Hybr. artef.
$432^{2}$ a, TOLBONIA, Kuntze, Rev. Gen. (1891) 369. COMPOSITAE.

anamitica, Kuntze, l. c. - Anam.

$432^{3}$ a, TOULICIA Aubl

brachyphylla, Radlk. in Kuntze, Rev. Gen. (1891) 145. - Venezuela.

\section{TRADESGANTIA}

$433^{3}$ a. decora, Hort. Bull. Cat. (1892) 3, - Bras. elongata, Hort. Linden, ex Gard. Chron. (1893) i. 474 . - Hab.?

velutina, $L$. Linden, l. c. 475, - Hab.?

\section{TRAGIA}

$435^{1}$ a. affinis, Robinson Er Greenm. in Proc. Am. Acad. xxix. (1894) 393. - Mexic,

\section{TRAGOPOGON}

$436^{1}$ a. balcaricum, Velen, in Sitzb. Bnehm. Ges. Wiss, 1888 (1889) 43 ; et Fl. Bulg. (1891) 355. Bulg.

\section{TRIAS}

$436^{3}$ a. picta, Rolfe, in Gard. Chron. (1888) i: 488 (= Bulboplyllum pictum. Parish \& Reichb. f.) - Burma

\section{TRICHOSPERMUM}

$437^{3}$ a. Kurzii, King, in fourn. As. Soc. Beng. 1x (1891) II. 113 = Bixagrewia nicobarica, Kurz). - Ins. Nicob., Perak.

\section{TRIFOLIUM}

4381 a, amphicarpum, Phil in tnal, Univ Chil. lxxxiv. (1893) 11 - Chili.

axillare, Phil, in Anal. Univ. Chil. 1xxxiv. (1893) 10. - Chili.

balcanicum. Velen...; et in Sitzb. Boehm Ges. Wiss. $1894(1895) \mathrm{n}$. xxix. 7 , in syn, = medium, Linn.

$438^{2}$ a. Lechleri, Phil, in Anal. Univ. Chil. 1xxxiv. (1893) 10. - Chil

radnense, Porcius, in Anal. Acad. Romane, Ser. II. xiv. (1892) 68. - Europ

\section{TRIPLARIS}

$439^{2}$ a. formicosa, S. Hoore, in Trans. Linn. Soc. Ser. II iv. (1s .j) 444, t. 28, fig. 5-6. Bras.

\section{TRITICUM}

$441^{1}$ a. barbulatum, Porcius, in Anal. Acad. Romane, Ser. II. xiv. (1892) 315 (= Agropyron barbulatum, Schur). - Europ.

Pseudocaninum, Porcius, 1. C. $=$ caninum, Linn.

\section{TRITOMA}

$441^{2}$ a. hybrida X. Hort. ex Bull. Tosc. Soc. Ortic. (1891) s1. - Hybr.artef.

\section{TRIXIS}

$440^{3}$ a, radialis, Kuntze, Rev. Gen, (1891) $370=$ radiale, Lag.

\section{TROPAEOLUM}

$42^{3}$ a. Buchenaui, Phil. in Anal. Unw. Chil. 1xxxii, 1893) 8.\%. - Chili.

denticulatum. «Ruiz \& Pav, ), ex Kuntze, Rev. Gen. (1891) $97=$ dipetalum, Ruiz \& Pav.? lepidum, Phil. in Anal. Univ. Chil. Ixxxii. (1893) 889. - Chili.

\section{TROPIDIA}

$441^{1}$ a ctenophora, "Benth. Go Hook f. " ex Drake, Ill. Fl. Ins. Mar. Pacif. (1892) 311 (= Cnemidia ctenophora, Reichb. f.). - Ins. Fiji.

\section{TULIPA}

4t12 L. Dammanni, i... (non Dammani).

Harmonia, Hort. Dammann, Cat. (1893) $5=$ undulatifolia, Boiss.

Levieri, Sprenger, in Bull. Tosc. Soc. Ortic, xix. (1894) 230. - Persia.

libanotica; Regel, in Gartenfl. :xxxvii. (1888) 126. - Syria. 
TULIPA

$441^{2}$ 1. sultanabadensis, Sprenger, in Bull. Soc. Tosc. Ortic. xix. (1894) 23J. - Persia. vitellina $X$. Hort. ex The Garden, xxxvi. (1889) 531. - Hybr. artef.

\section{TUPA}

$441^{3}$ a. axilliflora, Phil. in Anal. Univ. Chil. xc. (1895) 188. - Chili.

Gayana, Phil. l.c. 190. - Chili.

glaucescens, Phil. l. c. 187. - Chili.

Kingi, Phil. l. c. 189. - Chili.

linearifolia, Phil.l. c. 190. - Chili

serrata, Phil.l.c. 189. - Chili.

\section{TURNERA}

$441^{3}$ a. Bernieriana. Baill. [an Tul.?] Hist. pl. Madag. (1890) t. 131. - Madag.

\section{U}

\section{UNGINIA}

$443^{1}$ a. cylindrica, Franch. Miss. scient. Cap Horn. [Phan.] v. (1889) 379, t. 7b. - Patag.

\section{UROPETALUM}

$447^{1}$ a. Becazzeanum, Hort. Dammann, ex Gartenfl. xli. (1892) 611, fig. 127. - Abyss.

\section{UTRICULARIA}

$447^{3}$ a. elachista, Goebel, in Ann. Fard. Buitenz. ix. (1891) 76 . - Ind. or.

longifolia, Hort. Sander, ex The Garden, xli. (1892) 362; et in Gard. Chron. (1893) i. 713, fig. 107. - Guian. brit.

rhyterophylla, Hort. ex Ill. Wien. Gart.-Zeit. (1889) 74 (=U. longifolia, Gardn.). - Bras.

Warburgi, Goebel, in Am. Fard. Buitenz. ix. (1891) 64. - China.

\section{UVARIA}

$448^{\prime}$ a. Hookeri, King, in Ann. Bot. Gard. Calc. iv. I. (1893) 28, t. 22. - Ind. or.

\section{V}

VALLESIA

$449^{2}$ a. inedita, Guib. Trait.drog. simpl.éd.6, ii. (1869) 376. - Bras.

\section{VANDA}

$449^{2}$ a. Dearei, Reichb. f. in Gard, Chron. (18s6) ii. 648. - Ins, Sund.

VANILLA

$449^{3}$ a. cucullata, Kraenzl. ex 7. Braun \& $K$. Schum in Mitth.Deutsch. Schuizgeb.ii. (1889) 161 - Kamerun.

Vanilla, Karst. Deutsch. Fl. ed. 2, i. (1895) $474=$ aromatica, $S w$

\section{VERBASGUM}

4501 l. decorum... 1889 (1890) i. 56 (non 1889) ii (1890).

\section{VERBESINA}

$451^{3}$ a. heterophylla, Klatt, in fahrb. Hamb. Wiss Anstalt. x. 1812 (1893) 127. - Mexic

\section{VICIA}

$454^{1}$ 1. Scheuchzeri, Bruego.... xxix, 1884-85 (1886) 3 ); et xxxi. Beil. (1887-88) 45....

\section{VIGUIERIA}

$454^{2}$ a, drymonia, Klatt, in Bot. Beibl.z. Leopoldina, (1895) 5. - Costa Rica.

\section{VINCETOXIGUM}

$455^{2}$ a. Vincetoxicum, Karst. Deutsch. Fl. ed. 2, it (1895) 607 = officinale, Moench.

\section{VIOLA}

$456^{1}$ 1. intersita... (non intertexta).

VITIS

4572 a. argyrophylla, Carr, ex Rev. Hortic. 1xiv. (1892) 222, sphalm. = aegirophylla, Boiss. canescens, Hort. ex Handl. Trees Kew, Pt i. [Polypet.] (1894) $77=$ cinerea, Engelm. Doaniana, Munson, in Gard and For. iii. (1890) 474. - Am. bor.

Roylei, Hort. ex Handl. Trees Kew, Pt i [Polypet.] (1894) 7\%. = inconstans, Miq

\section{VRIESIA}

$458^{2}$ a. Andreana $\times$ Hort. Duval, ex Illustr. Hortic. xlii. (1895) 21\%. - Hybr. artef.

Aurora $\times$, Hort, Kittel, ex Rev. Hortic. Belg. xx. (1894)28. - Hybr. artef.

Closoni $\times$, Hort. 1. c. - Hybr. artef.

$458^{3}$ a. Elmireana $\times$. Hort. Duval, ex Illustr. Hortic. xlii. (1895) 217. - Hybr. artef. gracilis $\times$, Hort. Kittel, ex Rev. Hortic. Belg. xx. (1894) 28. - Hybr. artef
VRIESIA

$455^{3}$ a. Henrici $X$ Hort Duval ex Illustr. Hortic. xlii. (1895) 217. - Hybr, artef.

Magnisiana X. Kittel \& Wittm, in Gartenfl. xxxviii. (1889) 343, fig. 56-58. - Hybr. artef.

versailliensis $X$, Hort. Truffaut, ex Illustr. Hortic. xxxvi. (1889) 73, t. 87. - Hybr. artef.

Wioti $\times$, Hort. Kittel, ex Rev. Hortic. Belg. xx. (1894) 28. - Hybr. artef.

\section{W}

\section{WISTARIA}

$461^{3}$ a. grandifior, Hort. ex Handl. Trees Kew, Pt i. [Polypet.] (1894) $119=$ multijuga, Van Houtte.

\section{$\mathbf{X}$}

\section{XYRIS}

calostachys, Paulsen, ex Warm in Vidensk. Medd. Foren. Kjöb. (1893) 118 [Symb. Fl. Bras. centr. xl. 12331. - Bras.

trichocephala, Paulsen, Ul.cc. 119 ; et 1234.Bras.

\section{\%}

\section{ZEPHYRANTHES}

465: 1. Tauberti, Harms, in Notizbl. Bot. Gart, Berlin, i. (1895) 81 ; et... = Taubertiana, Harms (1896).

\section{ZINGIBER}

$465^{\mathrm{l}}$ a. Darceyi, Hort. Veitch, Catal. (1897) 13 ; et in The Garden, xxxviii. (1890) 43 [d'Arceyi]. Ins. Pacif.

Zingiber, Karst. Deutsch. Fl, ed. 2, i. (1895) $488 .=$ officinale, Rosc.

\section{ZIZYPHUS}

$465^{2}$ a. Zizyphus, Karst. Deutsch. Fl. ed. 2, ii. (1893) 438 = sativa, Gaertn 


(1)

a d C

(1)

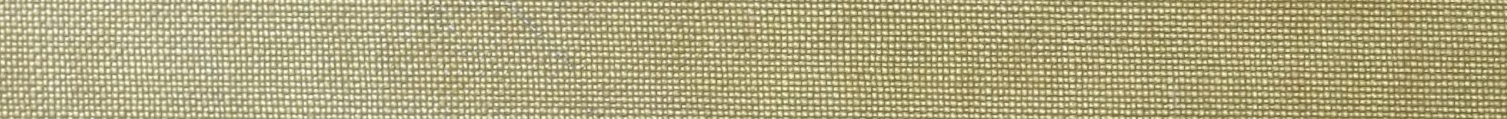

- 